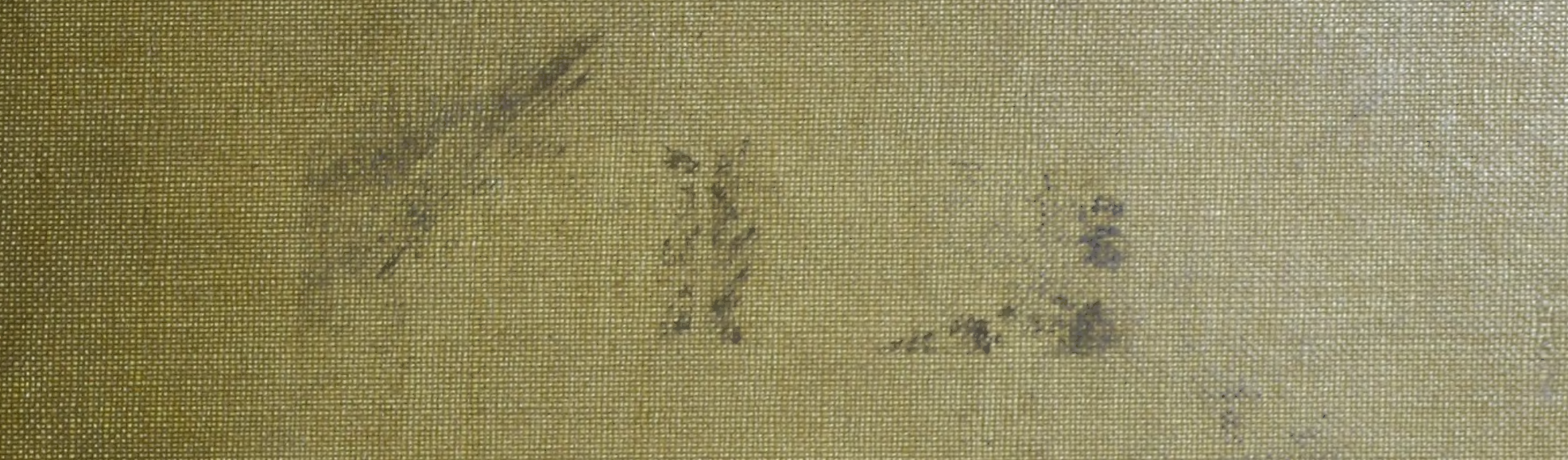

$$
\begin{aligned}
& x^{3}+2=0 \\
& \text { ens }
\end{aligned}
$$

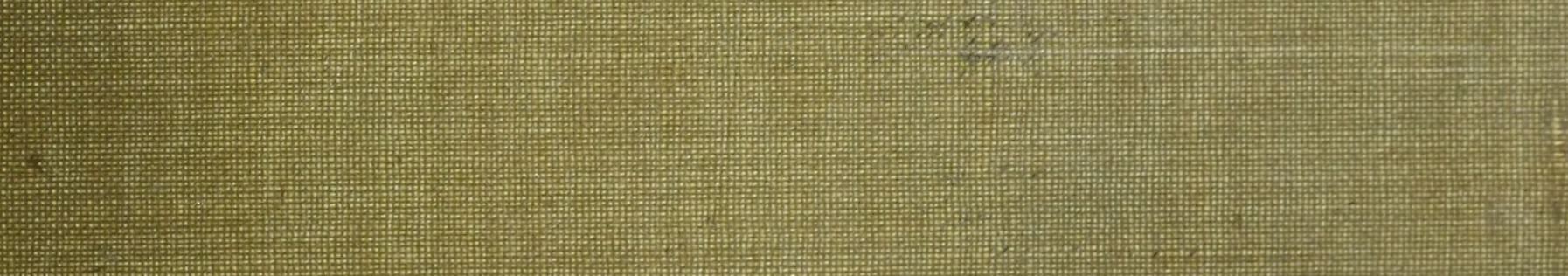

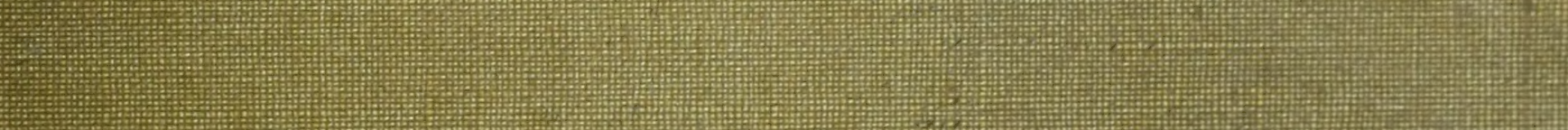

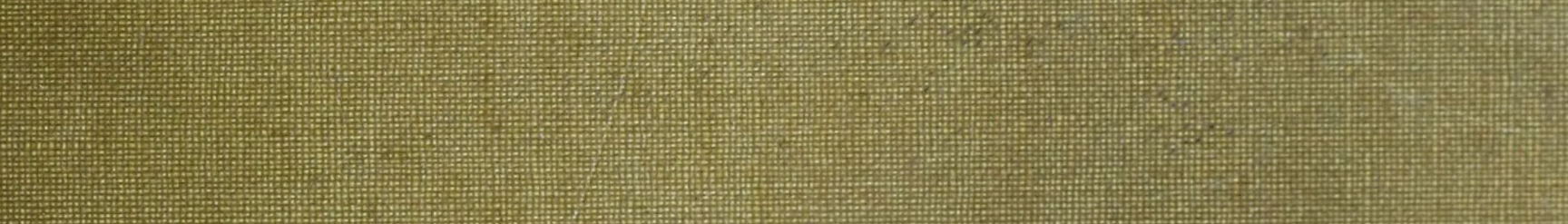

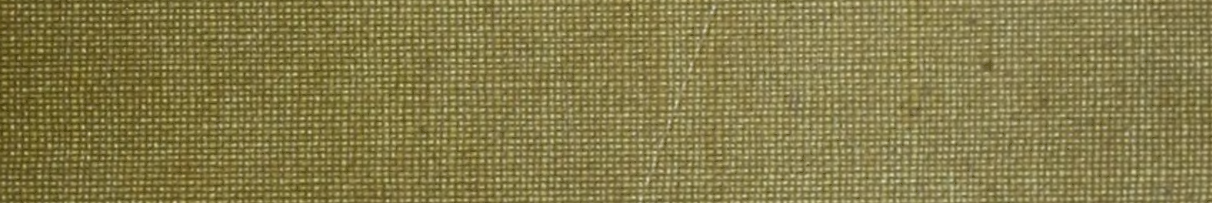

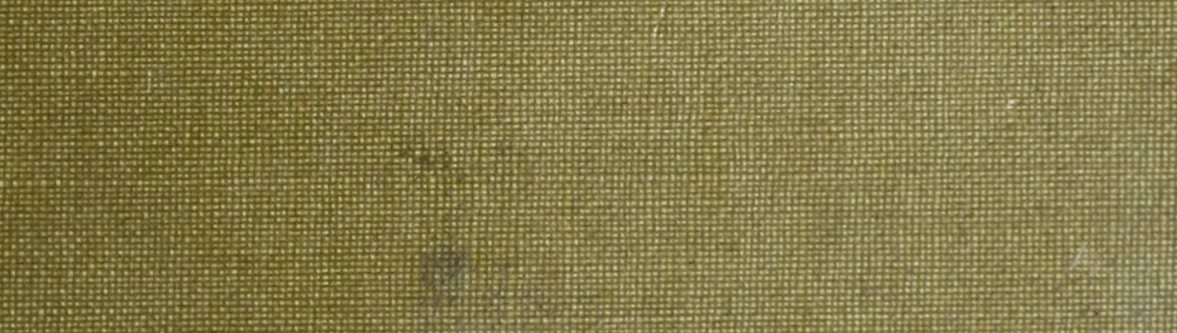




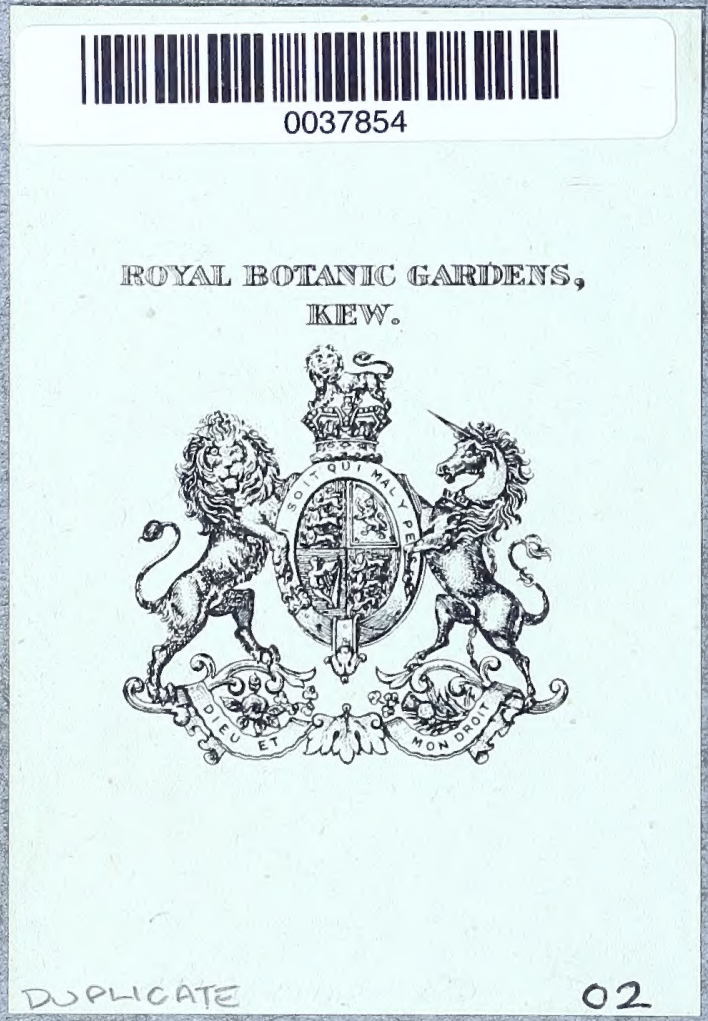




Digitized by the Internet Archive in 2013

http://archive.org/details/indexkewensispla11 hoøk 
INDEX KEWENSIS 


\title{
INDEX KEWENSIS
}

AN ENUMERATION OF THE GENERA AND SPECIES

$\mathrm{OF}$

\section{FLOWERING PLANTS}

FROM THE TIME OF LINNAEUS TO THE YEAR 1885 INCLUSIVE TOGETHER WITH THEIR AUTHORS' NAMES, THE WORKS IN WHICH THEY WERE FIRST PUBLISHED, THEIR NATIVE COUNTRIES AND THEIR SYNONYMS

\author{
COMPILED AT THE EXPENSE OF \\ THE LATE CHARLES ROBERT DARWIN \\ UNDER THE DIRECTION OF JOSEPH D. HOOKER \\ BY \\ B. DAYDON JACKSON
}

VOLUME I

OXFORD

AT THE CLARENDON PRESS

M DCCC XCV 


\section{INDEX KEWENSIS}

\section{PLANTARUM PHANEROGAMARUM}

NOMINA ET SYNONYMA OMNIUM GENERUM ET SPECIERUM

A LINNAEO USQUE AD ANNUM MDCCCLXXXV

COMPLECTENS

NOMINE RECEPTO AUCTORE PATRIA

UNICUIQUE PLANTAE SUBJECTIS

SUMPTIBUS BEATI CAROLI ROBERTI DARWIN

DUCTU ET CONSILIO JOSEPHI D. HOOKER

CONFECIT B. DAYDON JACKSON

TOMUS I

OXONII

E PRELO CLARENDONIANO 


\section{P RE F A C E}

SHORTLY before his death, Mr. DARwin informed me of his intention to $\checkmark$ devote a considerable sum in aid or furtherance of some work of utility to biological science; and to provide for its completion, should this not be accomplished during his lifetime. He further informed me that the difficulties he had experienced in accurately designating the many plants which he had studied, and ascertaining their native countries, had suggested to him the compilation of an Index to the Names and Authorities of all known Flowering Plants and their Countries, as a work of supreme importance to Students of Systematic and Geographical Botany, and to Horticulturists, and as a fitting mode of fulfilling his intentions.

I have only to add that, at his request, I undertook to direct and supervise such a work; and that it is being carried out at the Herbarium of the Royal Gardens, KEw, with the aid of the staff of that establishment.

JOS. D. HOOKER

Royal Gardens, Kew: July, I893. 


\section{MONIT UM}

DAULlO ante quam mortuus est, ostendit mihi vir clarissimus Carolus Robertus Darwin sibi esse in animo pecuniam satis magnam in opus aliquod conferre quod usui foret scientiae biologicae studiosis, eamque pecuniam ita collocare ut quodcunque opus designavisset ad finem perduceretur etiamsi se vivo non potuisset absolvi. Illud praeterea addidit, expertum se, cum tot plantarum naturas exploraret, quam difficile esset nomen proprium unicuique tribuere et patriam indagare, de indice conficiendo cogitasse, qui plantarum omnium phanerogamarum, quotquot cognitae essent, nomina auctores patrias complecteretur: nihil certe maioris pretii fore aut Botanicae systematicae et geographicae studiosis aut hortorum cultoribus, nihil voto suo et consilio convenientius.

Restat ut dicam suscepisse me eius rogatu operis propositi regimen, et id agere hodie in Herbario Horti Regi Kewensis, adiuvantibus eiusdem curatoribus. ut numeris omnibus absolvatur.

JOS. D. HOOKER

Scribebam in Horto Regio Kewensi, m. Julio, a. 1893. 


\section{LONDIN I}

APUD HENRICUM FROWDF

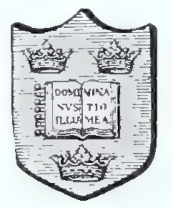

NOVI EBORACI

APUD A. MACMILLAN ET SOCIOS 
INDEX KEWENSIS 


\title{
I VDEX KEWENSIS
}

AN ENUMERATION OF THE GENERA AND SPECIES

OF

\section{FLOWERING PLANTS}

FROM THE TIME OF LINNAEUS TO THE YEAR 1885 INCLUSIVE TOGETHER WITH THEIR AUTHORS' NAMES, THE WORKS IN WHICH THEY WERE FIRST PUBLISHED, THEIR NATIVE COUNTRIES AND THEIR SYNONYMS

\author{
COMPILED AT THE EXPENSE OF \\ THE LATE CHARLES ROBERT DARWIN \\ UNDER THE DIRECTION OF JOSEPH D. HOOKER \\ BY \\ B. DAYDON JACKSON
}

PART 1

OXFORD

AT THE CLARENDON PRESS

M DCCC XCIII 


\section{INDEX KEWENSIS}

\section{PLANTARUM PHANEROGAMARUM}

NOMINA ET SYNONYMA OMNIUM GENERUM ET SPECIERUM

A LINNAEO USQUE AD ANNUM MDCCCLXXXV

COMPLECTENS

NOMINE RECEPTO AUCTORE PATRIA

UNICUIQUE PLANTAE SUBJECTIS

SUMPTIBUS BEATI CAROLI ROBERTI DARWIN

DUCTU ET CONSILIO JOSEPHI D. HOOKER

CONFECIT B. DAYDON JACKSON

FASCICULUS I

OXONII

E PRELO CLARENDONIANO

M DCCC XCIII 


\section{P R E F A C E}

GORTLY before his death, Mr. DARwin informed me of his intention to $\checkmark$ devote a considerable sum in aid or furtherance of some work of utility to biological science; and to provide for its completion, should this not be accomplished during his lifetime. He further informed me that the difficulties he had experienced in accurately designating the many plants which he had studied, and ascertaining their native countries, had suggested to him the compilation of an Index to the Names and Authorities of all known Flowering Plants and their Countries, as a work of supreme importance to Students of Systematic and Geographical Botany, and to Horticulturists, and as a fitting mode of fulfilling his intentions.

I have only to add that, at his request, I undertook to direct and supervise such a work; and that it is being carried out at the HERbarium of the Royal Gardens, KEW, with the aid of the staff of that establishment.

JOS. D. HOOKER 


\section{O N I T U}

DAULlO ante quam mortuus est, ostendit mihi vir clarissimus Carolus Robertus Darwin sibi esse in animo pecuniam satis magnam in opus aliquod conferre quod usui foret scientiae biologicae studiosis, eamque pecuniam ita collocare ut quodcunque opus designavisset ad finem perduceretur etiamsi se vivo non potuisset absolvi. Illud praeterea addidit, expertum se, cum tot plantarum naturas exploraret, quam difficile esset nomen proprium unicuique tribuere et patriam indagare, de indice conficiendo cogitasse, qui plantarum omnium phancrogamarum, quotquot cognitae essent, nomina auctores patrias complecteretur: nihil certe maioris pretii fore aut Botanicae systematicae et geographicae studiosis aut hortorum cultoribus, nihil voto suo et consilio convenientius.

Restat ut dicam suscepisse me eius rogatu operis propositi regimen, et id agere hodie in Herbario Horti Regi Kewensis, adiuvantibus eiusdem curatoribus, ut numeris omnibus absolvatur.

JOS. D. HOOKER 
OXONII

Excudebat Horatius Hart

Typographus academicus 


\title{
I N D EX KE W E N S IS
}

\author{
PLANTARUM PHANEROGAMARUM
}

\section{NOMINA ET SYNONYMA OMNIUM GENERUM ET SPECIERUM}

\author{
A LINNAEO USQUE AD ANNUM M.DCCC.LXXXV
}

\author{
COMPLECTENS
}

\section{AA-ABELMOSCHUS.}

AA, Reichb. f. Xen. Orchid. i. 18 (1858)=Altensteinia, H. B. \& K. (Orchid.). argyrolepis, Reichb. f. 1. c. = Alt. argyrolepis. paleacea, Reichb. f. 1. c. = Alt. paleacea.

AAMA, Hassk. Cat. Hort. Bog. Alt. 171 (1844), sphalm. $=$ ADAMIA, Wall. = Dichroa, Lour. (Saxifr.).

ABACOSA, Alef. in Bonplandia, ix. (1861) 102 $=$ Vicia, Linn. (Legumin.). americana, Alef. 1. c. $104=\mathrm{V}$. americana. canescens, Alef, 1. c. $103=\mathrm{V}$. canescens. dumetorum, Alef. 1. c. $104=$ V. dumetorum Kingii, Alef. 1. c. $103=$ V. Kingii. micrantha, Alef. 1. c. $104=\mathrm{V}$. micrantha. onobrychioides, Alef. 1.c. $103=\mathrm{V}$. onobrychioides. pallida, Alef. $1 . \mathrm{c}_{\mathrm{n}}=\mathrm{V}$. pallida. patagonica, Alef. 1. c. $=$ V. patagonica.

ABALON, Adans. Fam. ii. 511 (err. typ. 512) (1763) $=$ Helonias, Linn. (Liliac.). albiflorum, Rafin. New Fl. Am. i. 33.-Am. bor.

ABALUM, Adans. Fam. $47(1763)=$ praec.

ABAMA, Adans. Fam. ii. 47 (1763)=Narthecium, Moehr. (Liliac.).

anthericoides, Stend. Nom. ed. I. 550, in syn. (1821) $=$ N. ossifragum

glutinosa, Rafin. New F1. Am. i. $36=$ Tofieldia glutinosa.

ossifraga, DC. Fl. Fr. iii. $171=\mathrm{N}$. ossifragam pubens, Rafin. New F1. Am. i. $35=$ Tofieldia pubens. pusilla, Rafin. 1. c. 36.-Am. bor.

scabra, Rafin.1. c. 35 ; F1. Tellur. 28 = Tofieldia pubens.

ABANDION, Adans. Fam. ii, $54(1763)=$ Bulbo codium, Linu. (Liliac.).

ABAPHUS, Rafin. Fl. Tellur. iv. $19(1836)=$ seq.

ABAPUS, Adans. Fam. ii. 57 (1763)=Gethyllis, Linn. (Amaryll.).

spiralis, Rafin. FI. Tellur, iv. $19=\mathrm{G}$. spiralis.

ABASICARPON, Andrz. ex Reichb. in Moessl. Handb. ed. II. $1150(1858)=$ Arabis, Linn. (Crucif.). patulum, Andrz, ex Reichb. 1. c. = Arab, auriculata.

ABASOLOA, La Llave, in Nov. Veg. Desc. fasc. i. 11 (1824). COMPOSITAE, Benth. \& Hook. f. ii. 362. Taboada, La Llave, l. c.-Mexic.

ABATIA, Ruiz \& Pav. Prod. 78. t. 14 (1794). SAMYDACEAE, Benth. \& Hook. f. i. 799.

Graniera, Mand. \& Wedd, ex Benth. \& Hook, f. 1. c.

Myriotriche, Turcz. in Bull. Soc. Nat. Mosc. (1868), I. 554.

RAleighia, Gardn, in Hook. Lond. Journ. Bot. iv. (1845). 97. $+$

\section{ABATIA :-}

americana, Eichl. in Mart. Fl. Bras. xiii. 1. 510.-Bras. brasiliensis, Baill. Adansonia, x. (1872) 245.-Bras. parviflora, Ruiz \& Pav. Syst. i. 136; Prod. t. 14.-

Peruv.; N. Granat.

rugosa, Ruiz \& Pav. ll. cc.-Peruv.

tomentosa, Mart. ex Eichl. in Mart. Fl. Bras. xiii. I. 509.-Bras.

verbascifolia, H. B. \& K. Nov. Gen. et Sp. v. $358=$ parviflora.

ABAURIA, Becc. Malesia, i. (1877) 169. LEGUMINOSAE.

excelsa, Becc. l. c.-Malaya.

ABAZICARPUS, Andrz. ex DC. Syst. ii. 213 (1821)= Arabis, Linn. (Crucif.).

ABBEVILLEA, Berg, in Linnaea, xxvii. 425 (1856)= Campomanesia, Ruiz \& Pav. (Myrtac.)

cerasoides, Berg, in Mart. Fl. Bras, xiv. x. 436.-Bras, chrysophylla, Berg, 1. c. $437=$ Psidium chrysophyllum. eugenioides, Berg, 1. c. 436.-Bras.

Fenzliana, Berg, 1. c. 433 .-Bras.

Gardneriana, Berg, 1. c. 436.-Bras.

Guaviroba, Berg, 1. c. $432=$ C. Guaviroba.

Klotzschiana, Berg, 1. c. 434.-Bras.

Langsdorffiana, Berg, 1. c. 608.--Bras.

Martiana, Berg, 1. c. 435 .-Bras.

maschalantha, Berg, 1. c. 432.-Bras.

neriiflora, Berg, 1. c. 431.-Bras.

phaea, Berg, 1. c. 435.-Bras.

plana, Berg, in Linnaea, xxvii. (1854) 427 (sphalm. = phaea).

punctulata, Berg, in Mart. Fl. Bras. xiv. I. 432.-Bras. recurvata, Berg, 1. c. 438.-Bras.

Regeliana, Berg, 1. c. 608.-Bras.

rufa, Berg, 1. c. $437=$ Psidinm rufum.

nugosa, Berg, 1. c.-Bras.

Schlechtendahliana, Berg, 1. c. 435.-Bras.

Sellowiana, Berg, 1. c. 431.--Bras.

Widgreniana, Berg, in Linnaea, xxxi. (1861-62) 260. -Bras.

ABBOTIA, Rafin. New Fl. Am. i. 36 (1896)=Triglochin, Linn. (Naiad.).

filiformis, Rafin. 1, c. $=\mathrm{T}$. triandrum.

palustris, Rafin. 1. c. $37=\mathrm{T}$. palustre

pumila, Rafin. 1. c. $=$ T. palustre.

ABBOTTIA, F. Muell. Fragm. ix, 181 (1875) $R U B I A C E A E$.

singularis, F. Muell. l. c.-Austral.

ABELIA, R. Br. in Abel, Chin. App. 376 (1818) ii. 4. CAPRIFOLIACEAE, Benth. \& Hook. f. ii. 4. adenotricha, Hance, in fourn. Bot. ix. (1871) 182.China.

biflora, Turcs. in Bull. Soc. Nat. Mosc. (183\%) vir. 152.-China.

chinensis, R. Br. in Abel, Chin. App. 376.-China.
ABELIA :-

coriacea, Hemsl. Diagn. Pl. Nov. 53.-Mexic.

corymbosa, Regel E Schmalh. in Act. Hort. Petrop. $v$ 1877) 608.-As. temp.

Davidi, Hance, in Seem. Journ. Bot. vi. (1868) $32 !$ $=$ biflora.

floribunda, Decne. in Fl. des Serres, Sér. I. ï. (Jany. 1846).-Mexic.

Hanceana, Mart. ex Hance, in Ann. Sc. Nat. Sér. Y v. (1866) $216=$ chinensis.

hirsuta, Walp. Rep. vi. $3=$ speciosa.

rupestris, Lindl, in Journ. Hort. Soc. i. (1816) $63=$ chinensis.

serrata, Sieb. \& Zucc. Fl. Japon. i. 76. t. $34=$ uniflora. spathulata, Sieb. E Zucc. l. c. 77. t. 34.-Japon.

speciosa, Decne, in Fl. des Serres, ii. (1846) sub t. 5. -Mexic.

splendens, Hort. ex C. Koch, Dendrol. ii. I. $20=$ Lonicera caprifolioides.

triflora, R. Br. in Wall. Pl. As. Rar. i. 11. t. 15.Reg. Himal.

uniflora, R. Br. in Wall. l. co-China.

ABELICEA, Reichb. Consp. 84 (1828); Baill. Hist. Pl. vi. $185(1875)=$ Zelkova, Spach (Urtic.).

aquatica, Rafin. New Fl. Am. iii. 41= Planera aquatica. crenata, Baill. Hist. Pl. vi. $181=\mathrm{Z}$. crenata. cretica, Rafin. New Fl. Am. iii. $41=Z$. cretica

Davidii, Buek, Ind. Gen. DC. Prod. iv. 1=Hemiptelea Davidii.

sibirica, Rafin. New F1. Am. iii. $41=Z$. crenata.

ABELMOSCHUS, Medic. Malv. 45 (1787)= Hibiscus Linn. (Malvac.).

achanioides, Turcz. in Bull. Soc. Nat. Mosc xxxi (1858) I. $196=\mathrm{H}$. achanioides.

aculeatus, Walp. Rep. i. $308=\mathrm{H}$. surattensis, cannabinus. acuminatus, C. Muell. in Walp. Ann. vi, 407.-Java. albo-rubens, Benth. Fl. Anstral. i. $209=$ seq.

albo-ruber, F. Muell. Fragm. i. $67=\mathrm{H}$. ficulreus. angulosus, Wight \& Arm. Prod. $53=\mathrm{H}$. angulosus. angustifolius, Hook. \& Arn. in Hook. Bot. Misc. iii.

(1833) $152=\mathrm{H}$. angustifolins. aquaticus, Walp. Rep, i. $811=\mathrm{H}$. roseus. ascendens, Walp. 1. c. $\$ 10=\mathrm{H}$. physaloides. Bammia, Webb, Fragm. Fl. Aethiop. $18=$ H. esculentus. betulifolia, Wall. Cat. p. 87 et $\mathrm{n} .1918=\mathrm{H}$. A belmoschus. cancellatus, Wall. 1. c. p. 87 et n. $1920=\mathrm{H}$. cancellatus. chinensis, Wall. I. c. p. 87 et a. $1916=$ H. Abelmoschus. ciliaris, Walp. Rep. ii. $308=\mathrm{H}$. ciliaris.

cisplatinus, Walp. 1. c. $309=\mathrm{H}$. cisplatinus. congener, Walp. I. c. $\$ 0 \$=\mathrm{H}$. cannabinus. crinitus. Wall. Pl. As. Rar. i. $\$ 9=$ H. cancellatus. cruentus, Wialp. Rep. i. $\$ 10=\mathrm{H}$. cruentus crvptocarpus, Walp. I. c. $=$ H. Abelwoschus. crubensis, Walp. L c $\$ 09=\mathrm{H}$. Abelmoschus. cucurbitacens, Walp. I. c. $\$ 10=$ H. Abelmoschus. decandrus, Medic. Malv, 16 = Pavonia praemorsa. divaricatus, Walp, Rep. i. $\$ 09$ H. divaricalus esculentus, Muench, Metb. $61 \%=$ H. esculentus 


\section{ABELMOSCHUS :}

ficulneoides, Walp. Rep. i. $309=\mathrm{H}$. ficulneoides. ficulneus, Wight. \& Arn. Prod. i. $53=\mathrm{H}$. ficulneus. fusiformis, Wall. Cat. p. 87 et $\mathbf{n}$. $1921=\mathbf{H}$. cancellatus. Genevii, Walp. Rep. i, $310=\mathrm{H}$. liliiflorus.

guineensis, Walp. 1. $\mathrm{c} .=\mathrm{H}$. tiliaceus.

Haenkeanus, Presl, Rel. Haenk. ii. 134.-Ins. Luzon. laxiflorus, Walp. Rep. i. $310=\mathrm{H}$. laxiflorus.

longifolius, Kostel. Allg. Med.-Pharm. Flora, v. 1859 H. Abelmoschus.

maculatus, Bartl. in Linnaea, xii. (1838) Litt. $81=\mathrm{H}$ Bartlingianus.

magnificus, Wall. Cat. p. 87 et n. 1919.-Ind. or.

Manihot, Medic. Malv, $46=\mathrm{H}$. Manihot.

marianus, Presl, Rel. Haenk. ii. 134.-Ins, Marian.

moschatus, Medic. Malv. $46=\mathrm{H}$. Abelmoschus.

multiformis, Wall. Cat. p. 87 et n. 1917.-Ind. or.

officinalis, Endl. ex Heynh. Nom. ii. $1=H$. esculentus. palustris, Walp. Rep. i. $311=$ H. Moscheutos.

panduraeformis, Hassk. in Tijdschr. Nederl. Ind. i.

(1843) $134=\mathrm{H}$. panduraeformis.

pentaphyllus, Voigt, Hort. Suburb. Calc. $119=$ H. pentaphyllus.

persicifolius, WaIp. Rep. i. $308=\mathrm{H}$. persicifolius.

Pseudo-abelmoschus, Blume, Bijdr. $70=\mathrm{H}$. Abel moschus.

pungens, Wall. Cat. p. 87 et n. $1924=\mathrm{H}$. pungens.

quinquelobus, Walp. Rep. i. $310=\mathrm{H}$. quinquelobus.

racemosus, Wall. Cat. p. 87 et n. $1929=$ H. cancellatus.

hodopetalus, F. Muell. Fragm. ii. $113=\mathrm{H}$. rhodopetalus.

roseus, Walp. Rep. i. $311=$ H. Moscheutos.

rostellatus, Walp. 1. c. $308=\mathrm{H}$. rostellatus.

rugosus, Wight \& Arn. Prod. i. $43=$ H. rugosus.

splendens, Walp. Rep, i. $309=\mathrm{H}$. splendens.

strictus, Voigt, Hort. Suburb. Calc. $119=$ H. ficulneus.

sublobatus, Presl, Rel. Haenk. ii. 134.-Ins. Pacif.

tetraphyllus, Wall. Cat.p. 87 et n. $1925=$ H. tetraphyllus.

theiodes, Voigt, Hort. Suburb. Calc. $120=$ H. sul. phureus, Voigt.

tulipaeflorus, Walp. Rep. v. $92=\mathrm{H}$. tulipaeflorus.

venustus, Walp. 1. c. i. $309=\mathrm{H}$. mutabilis.

verrucosus, Walp. 1. c. $308=\mathrm{H}$. cannabinus,

Vriesianus, Hassk, in Hoev. \& De Vriese, Tijdschr. $x$.

(1843) 134 ; xii. (1845) 88.-Malaya.

warreensis, Dalz. in Hook. Kew Journ. iii. (1851) $123=\mathrm{H}$. tetraphyllus.

Zollingeri, C. Muell, in Walp. Ann. vi.407.-Java.

ABENA, Neck. Elem. i. $296(1790)=$ Stachytarpheta, Vahl (Verbenac.)

ABEREMOA, Aubl. P1. Gui. i. 610, t. $245(1775)=$ Duguetia, St. Hil. (Anonac.).

furfuracea, Baill. Hist. Pl, i. 204.-Bras.

guianensis, Aubl. Pl. Gui. i. 610,-Guiana.

lanceolata, Warm. in Kjoeb. Vidensk. Meddel. (1855) 146 ; (1873) 146.-Bras.

longifolia, Baill. Hist. Pl. i. $205=$ D. longifolia.

ABFRIA, Hochst. in Flora, xxvii. (1844) Bes. Beil. 2. BIXINEAE, Benth. \& Hook. f. i. 128.

ATELESTE, Sond. in Linnaea, xxiii. (1850) 9, 10.

abyssinica, Clos, in Ann. Sc. Nat. Sér. IV. viii. (1857)

236. - Afr. trop.

"caffra, Harv. Ẽ Sond. Fl. Cap. ii. Add. 584.-Afr. austr.

edulis, T. Anders. in Journ. Linn. Soc. vii. (1862) $67=$ caffra.

Gardnerii, Clos, in Ann. Sc. Nat. Sér. IV. viii. (1857) 235.-Zeylan.

longispina, Harv. in Harv. E Sond. Fl. Cap. ii. 585. -Afr. austr.

macrocalyx, Oliver, Fl. Trop. Afr. i. 122.-Afr. trop.

mollis, Oliver, $l_{0} c_{0}$-Afr. trop.

tristis, Sond. in Linnaea, xxiii. (1850) 9.-Afr. austr.

verrucosa, Hochst. in Flora, xxvii. (1844) Bes. Beil.2.Abyss.

Zeyheri, Sond. in Linnaea, xxiii. (1850) 10.-Afr, anstr.

ABESINA, Neck. Elem. i. $33(1790)=$ Verbesina, Linn. (Compos.).

ABIES, D. Don, in Loud. Arb. Brit. iv. 2329 (1838)= Picea, Link (Conif.).

ABIES, [Tourn.] Linn. F1. Lapp. 277 (1737); Link, in Linnaea, xष. (1841) 525. CONIFERAE, Benth. \& Hook. f. iii. 441.

Picea, D. Don, in Loud. Arb. Brit. iv. 2293 (1838). ajanensis, Lindl. \& Gord. in Journ. Hort. Soc. v. 1850) $212=$ Picea ajanensis.

\section{ABIES}

alba, Michx. F1. Bor. Am. ii. $207=$ Picea alba alba, Mill. Gard. Dict. ed. VIII. n. $1(1768)=$ pectinata (1805).

Albertiana, A. Murr. in Proc. Hort. Soc. iii. (1863) $149=$ Tsuga Mertensiana.

Alcockiana, Lindl. ex C. Koch, Dendrol. ii. II. $245=$ Picea Alcockiana

Alcoqueana, Gord. Pinet. Supp. \& ('desc. falsa') = praec. amabilis, Forb. Pin. Wob. 125. t. 44.-Am. bor. occ. amabilis, Parl. in DC. Prod. xvi. II. 426, in parte =subalpina.

americana, Mill. Gard. Dict. ed. VIII. n. $6=$ Tsuga canadensis.

Apollinis, Link, in Linnaea, xv. (1841) $528=$ cephalonica.

Araragi, Siebold, in Verh. Batav. Gen, xii. (1830) 12 - Tsuga Sieboldii.

araucana, Poir. Encyc. Suppl, vi. 524 = Araucaria excelsa.

arctica, A. Cunn. ex Gord. Pinet. $11=$ Picea rubra.

arctica, A. Murr. in Journ. Bot. v. (1267) $253=$ Picea alba.

argentea, De Chambr. Traité Prat. Arb. Résin. $17=$ pectinata.

aromatica, Rafin. Atl. Journ. $119=$ balsamea

atlantica, Lindl. \& Gord. in Journ. Hort. Soc. v. (1850) $214=$ Cedrus atlantica

baborensis, Coss. ex Parl. in DC. Prod. xvi. II. $423=$ numidica.

baldensis, Zuccagn, ex Nym. Consp. $674=$ pectinata.

balsamea, Mill. Gard. Dict. ed. VIII. n. 3.-Am. bor.

balsamifera, Michx. Fl. Bor. Am. ii, $207=$ balsamea.

batavorum, Siebold.-Cf. Carr. Conif. ed. II. 229 Cunninghamia sinensis.

bicolor, Maxim. in Bull. Acad. Pétersb. x. (1866) $488=$

Picea Alcockiana.

bifida, Sieb. \& Zucc. F1. Jap. ii. $18=$ firma.

bifolia, A. Murr. Syn. Var. Conif. $29=$ Iasiocarpa.

brachyphylla, Maxim. in Bull. Acad. Pétersb. x. (1866) 488.-Japon.

bracteata, Hook. E' Arn. Bot. Beech. Voy. 394.-Calif. Bridgesii, Kellogg, in Proc. Calif. Acad. ii. (1863) 8= Tsuga Mertensiana.

Brunoniana, Lindl. in Penny Cyclop。 i. $30=\mathrm{T}$. Brunoniana.

californica, Hort. ex Stend. Nom. ed. II. i. $1=$ Pseudotsuga Douglasii.

campylocarpa, A. Murr. in Trans. Bot. Soc. Edinb, vi. (1860) $370=$ magnifica

canadensis, Michx. F1. Bor. Am. ii. 206=Tsuga canadensis.

canadensis, Mill. Gard. Dict. ed.VIII. n. $4=$ Picea alba, candicans, Fisch. ex Endl. Syn. Conif. 96= pectinata. cedroides, Griff. ex Carr. Conif. ed. I. 188=Tsuga Brunoniana.

Cedrus, Poir. Encyc. vi. $510=$ Cedrus Libani.

cephalonica, Link, in Linnaea, xv. (1841)529.-Graecia. chiloënsis, Hort. ex Carr. Conif. ed. I. $222=\mathrm{A}$. Pindrow. chilrowensis, Hort. ex Parl. in DC. Prod. xvi. II. 425 =Webbiana.

chlorocarpa, Purk. ex Nym. Consp. 674 =Picea excelsa. cilicica, Ant. E Kotschy, in Oestr. Wochenschr. (1853) 409.-As. Min.

cilicica, Carr. Conif. ed. I. 229.-As. Min.

cinerea, Borkh. Forstb. i. $398=$ Picea excelsa.

Clanbrassiliana, Hort ex Loud. Encyc. Pl. 804=P. excelsa

coerulea, Lodd. ex Forbes, Pin. Wob. $99=$ P. alba.

coerulescens, Hort. ex C. Koch, Dendrol. ii. II. $242=$ P. rubra.

Columbaria, Desf. Tabl. ed. II. $247=$ Araucaria imbricata.

commutata, Gord. Pinet. ed. II. $5=$ Picea Engelmanni. concolor, Lindl. E Gord. in Fourn. Hort. Soc. v. (1850) 210.-Am. bor. occ.

cupressoides, Poir. Encyc. vi. $524=$ Libocedrustetragona. curvifolia, Salisb. in Trans. Linn. Soc. viii. (1807) 315 $=$ Picea alba.

Dammara, Poir. Encyc. Suppl. v. $35=$ Agathis loranthifolia.

Davidiana, Franch. in Nouv. Mém. Mus. Par. vi. (1884) $96 .-\mathrm{As}_{\text {。 or }}$

decidua, Wall.-Cf. C. Koch, Dendrol. ii. Ix. $253=$ Tsuga Brunoniana.

densa, Griff. Notul. iv. 19.-Cf. Webbiana.

denticulata, Poir. Encyc. vi. $520=$ Picea nigra.

Deodara, Lindl. in Penny Cyclop. i. $34=$ Cedrus Deodara.
ABIES :-

diversifolia, Maxim. in Bull. Acad. Pétersb. xii. (1868) 229 = Tsuga diversifolia.

Douglasii, Lindl. in Penny Cyclop. i. $32=$ Pseudotsuga Douglasii.

Drummondi, Hort. ex Gord. Pinet. ed. I. $16=$ praec. dumosa, Loud. Arb. Brit. iv. 2325 Tsuga Brunoniana.

Eichleri, Lauche, in Berl. Gartenz. i. (1882) $63=$ Veitchii.

elegans, Sm. ex Knight, Syn. Conif. $36=$ Picea excelsa. Engelmanni, Parry, in Trans. Acad. St. Louis, ii. (1868) $212=$ Picea Engelmanni.

eremita, Hort. Gall. ex C. Koch, Dendrol. ii. II. $237=$

Picea excelsa.

erythrocarpa, Purk. ex Nym. Consp. $674=\mathrm{P}$. excelsa.

excelsa, Link, in Abh. Acad. Berl. (1827) $182=$ pectinata.

excelsa, Poir. Encyc, vi. $518=$ P. excelsa

extrema, T. Fries, in Bot. Notiser (1867), $56=\mathrm{P}$. excelsa. falcata, Rafin. Atl. Fourn. 120.-Am. bor.

finedonensis, Hort. ex Gord. Pinet. Suppl. $4=$ P. excelsa Finhonnoskiana, R. Neum. ex Parl. in DC. Prod. xvi II. $431=$ homolepis.

firma, Sieb. \& Zucc. Fl. Fap. ii. 15. t. 107.-Japon.

Fischeri, Lindl. ex Ledeb. Fl. Ross. ii. 172.-Rossia.

Fortunei, A. Murr. Pin. Japan. $49=$ Keteleeria Fortunei.

Fraseri, Lindl. in Penny Cyclop. i. 30.-Am. bor. gigantea, Sm. ex Carr. Conif. ed. II. $327=$ Picea excelsa. glauca, Roezl, ex Gord. Pinet. $149=$ religiosa.

glaucescens, Roezl, Cat. Gr. Conif. Mex. (1858-59) $5=$ religiosa.

Glehni, F. Schmidt, Reisen Amurl. $176=$ Picea Glehnii.

Gmelini, Rupr. in Beitr. Pf. Russ. Reich. ii. $56=$ Larix dahurica.

Gordoniana, Carr. Conif. ed. II. $298=$ grandis.

grandis, Lindl. in Penny Cyclop. i. 30.-Am. bor. occ. Gregoryana, Low, ex Gord. Pinet. Suppl. $4=$ P. excelsa. Griffithiana, Lindl. \& Gord. in Joum. Hort. Soc. v. (1850) $214=$ Larix Griffithii.

Hanburyana, Hort. ex Gord. Pinet. ed. II. 32, 421= Tsuga Sieboldii?

Harryana, McNab, in Proc. Roy. Irish Acad. (1876) $689=$ homolepis.

heterophylla, C. Koch, in Linnaea, xxii. (1849) $295=$ sibirica.

heterophylla, Rafin. Atl. Journ. 119=Tsuga Mertensiana.

hirtella, Lindl. in Penny Cyclop. i. 31 = religiosa.

hispanica, De Chamb. Trait. Prat. Arb. Résin. $339=$ A. Pinsapo.

holophylla, Maxim. in Bull. Acad. Pétersb. x. (1866) 487.-As. temp.

homolepis, Sieb. E Zucc. Fl. Fap. ii. 17.-Japon.

Hookeriana, A. Murr. in Edinb. N. Phil. Journ. N. S i. (Jan.-Apr. 1855). 289=Tsuga Hookeriana.

Hudsonia, Bosc, ex Carr. Conif. ed. I. $200=$ Fraseri.

humilis, La Pyl. in Mém. Soc. Linn. Par. iv. (1826) $437=$ Fraseri.

inverta, R. Sm, ex Gord. Pinet. Suppl, $4=$ P. excelsa.

jezoënsis, Lindl. \& Paxt. Flow. Gard. i. (1850-51) 42. f. $26=$ Keteleeria Fortunei

jezoënsis, Sieb. \& Zucc. Fl. Jap. ii. 19. t. $110=$ Picea Alcockiana.

Kaempferi, Lindl. in Penny Cyclop. i. 34=Pseudolarix Kaempferi.

kamtschatica, Rupr. in Beitr. Pf. Russ. Reich. ii. $57=$ Larix dahurica.

Khutrow, Loud. Encyc. Trees, $1032=$ Picea Morinda.

Kotschyana, Fenzl, ex Tchihat. Asie Min. Bot. i1. 495. -As. Min.

lanceolata, Poir. Encyc. vi. $523=$ Cunninghamia sinensis.

Larix, Poir. Encyc. Suppl. vi. $511=$ Larix europaea. lasiocarpa, Hook. Fl. Bor. Am. ii. 163.-Am. bor. occ. lasiocarpa, Lindl. \& Gord. in Journ. Hort. Soc. v. 1850) 210 - grandis, Lowiana.

laxa, C. Koch, Dendrol. ii. II. $243=$ Picea alba

Ledebourii, Rupr. in Beitr. Pf. Russ, Reich. ii. $56=$ Larix dahurica.

leioclad $a$, Stev. ex Gord. Pinet. $\mathbf{1 5 2}=$ Nordınanniana.

Lemoniana, Booth, ex Gord.1. c. ed. I. $5=$ Picea excelsa

leptolepis, Sieb. \& Zucc. Fl. Japon. 12. t. 103=Larix japonica.

Lindleyana, Roezl, ex Carr. Conif. ed. II. $275=$ religiosa.

Lowiana, A. Murr. Syn. Var. Conif, 27.-Am, bor. occ 


\section{ABIES :}

Luscombeana, Loud. Arb. Brit. iv. 2325=cephalonica. magnifica, A. Murr. in Proc. Roy. Hort. Soc. iii. (1863) 318.-Calif.

Mariana, Mill. Gard. Dict. ed. VIII, n. $5=$ Picea nigra. Mariesii, Mast. in Gard. Chron. xii. (1879) 789,-As. or.

Maximowiczii, R. Neum. Cat. (1865); ex Parl, in DC.

Maximowiczit, R. Neum. Cat. 1865 ); ex
Prod. xvi. II. $431=$ Picea Maximowiczii.

medioxima, Lawson, Pin. Brit. $159=\mathrm{P}$. excelsa.

Menziesii, Lindl. in Penny Cyclop. i. $32=$ Picea Menziesii.

Merkiana, Fisch. ex Parl. in DC. Prod. xvi. II. $418=$ Picea Menziesii.

Mertensiana, Lindl. \& Gord. in Journ. Hort. Soc. v. (1850) $211=$ Tsuga Mertensiana.

metensis, Hort. Par. ex Gord. Pinet. ed. II. $211=$ pectinata.

microcarpa, Lindl. in Penny Cyclop. i. $33=$ Larix microcarpa.

microphylla, Rafin. At7. Fourn. (1820) 119.-Am. bor. microsperma, Lindl. in Gard. Chron. (1861) $22=$ Picea ajanensis.

miniata, Knight, ex Gord. Pinet. ed. II. $8=$ P. excelsa minor, Duham. ex Gord. 1. c. ed. I. $143=$ balsamea.

minor, Gilib. Exerc. Phytol. ii. $412=$ pectinata.

minuta, Poir. Encyc. vi. $523=$ P. rubra

Momi, Siebold, in Verh. Batav. Gen. xii. (1830) $12=$ firma.

montana, Nym. Syll. Suppl. $602=$ P. excelsa.

Morinda, Loud. Encyc. Pl. 1294=P. Morinda.

mucronata, Rafin. Atl. Journ. 120= Pseudotsuga Douglasii.

mucronata, Rauch, ex Carr. Conif. ed. II. $329=$ Picea excelsa.

nephrolepis, Maxim. in Bull. Acad. Pétersb. x. (1866) $486=$ Veitchii.

nigra, Desf. Hist. Arbr, et Arb. ii. $580=$ Picea nigra

nigra, Duroi, Harb. Baumz, ed. Pott, ii. $182=$ P. nigra,

nigra, Engelm. in Am. Journ. Sc. xxxiii. (1838) 330

Picea Engelmanni.

nobilis, Lindl. in Penny Cyclop. i. 30.-Am, bor. occ.

Nordmanniana, Spach, Hist. Vég. Phan. xi. 418.

Reg. Caucas.

Novae-Angliae, C.Koch,Dendrol.ii.II.240=Picea nigra

numidica, De Lannoy, ex Carr. in Rev. Hortic. (1866) 106.-Afr. bor.

obliqua, Bong. ex Gord. Pinet. Supp. $10=$ Pseudotsuga Douglasii.

obliquata, Rafin. ex Gord. 1. c. = praec.

obovata, Lond. Arb. Brit. iv. $2329=$ Picea obovata.

Omorika, Nym. Consp. $673=$ Picea Omorika.

orientalis, Poir. Encyc. vi. $518=$ Picea orientalis.

panachaica, Heldr. ex Parl, in DC. Prod. xvi. II. $422=$ cephalonica.

Parsonsiana, Hort. ex Mast. in Gard. Chron. (1880)

I. $648=$ Lowiana.

parvula, Knight, Syn. Conif. $36=$ Picea excelsa.

Pattoni, Jeffrey, ex Gord. Pinet. Suppl. $6=$ seq.

Pattoniana, Jeffrey, ex A. Murr. in Bot. Exped. Oregon.

Circ. $=$ Tsuga Hookeriana.

pectinata, $D C$. Fl. Fr. iii. 276.--Europ.

pectinata, Gilib. Exerc. Phytol. ii. $411=$ P. excelsa.

pectinata, Poir. Encyc. vi. $523=$ Picea rubra.

peloponnesiaca, Haage, ex Parl. in DC. Prod. xvi. II. $422=$ cephalonica

pendula, Griff. ex Gord. Pinet.Suppl. $7=$ Picea Morinda. pendula, Lindl. \& Gord. in Journ. Hort. Soc. v, (1850) $213=$ Larix microcarpa

Picea, Lindl, in Penny Cyclop. i. $29=$ pectinata

Picea, Mill. Gard. Dict. ed. VIII. n. $2=$ Picea excelsa.

Pichta, Forbes, Pin. Wob. 113. t. $39=$ sibirica.

Pindrow, Spach, Hist. V'́g. Phan. xi. 423.-Reg. Himal.

Pinsapo, Boiss. in Bỉl. Univ. Genive (1838); ex ej. Voy. Bot. Espagne, ii. 584.-Hispan.

polita, Sieb. \& Zucc. Fl. Jap. ii. 20. t. $111=$ Picea polita.

Reginae-Amaliae, Heldr. in Regel, Gartenfl. ix. (1860) 318 = cephalonica.

religiosa, Lindl. in Penny Cyclop. i. 31.-Mexic.

Rinsi, Hort. Par. ex Gord Pinet. Suppl, $50=$ cilicica.

Romania, Loud, ex Steud. Nom. ed. II. i. $1=$ Pinns Laricio.

rubra, Poir. Encyc. vi. $520=$ P. rubra.

sachalinensis, Mast. in Gard. Chron. (1879) I1. 588.As, or.

sacra, Franch. in Nouv. Arch. Mus. Par, vii. (1882) 290 - As. or

Schrenkiana, Lindl. \& Gord. in Journ. Hort. Soc. v, (1850) $212=$ Picen obovata.

\section{ABIES :}

selinusia, Carr. in Fl. des Serres (1859), 69=cilicica. sibirica, Ledeb. Fl. Alt. iv. 202.-Sibir.

sitchensis, Lindl: \& Gord. in Journ. Hort. Soc. 1850) $212=$ Picea Menziesii.

Smithiana, Lindl. in Penny Cyclop. 1. $31=$ P. Morinda. spectabilis, Spach, Hist. Vég. Phan. xi. $422=$ Webbiana spinulosa, Griff. Itin. 259, 265, 275=Picea Morinda.

Standishiana, C. Koch, Dendrol. ii. II. $257=$ Tsuga Douglasii.

subalpina, Engelm. ex L. Ward, in Am. Natural. $x$.

1876) $555=$ lasiocarpa.

subarctica, Nym. Consp. $674=$ Picea excelsa.

sumatrana, Desf. Hort. Par. ed. III. $356=$ Agathis loranthifolia

taxifolia, Desf. 1. $\mathrm{c}$ = pectinata.

taxifolia, Drum. ex Gord. Pinet. $16=$ Pseudotsuga Douglasii.

taxifolia, Jeffr. ex Gord. 1. c. 18=Tsuga Mertensiana. taxifolia, Presl, Epim. Bot. $237^{\circ}=$ Pseudotsuga Donglasii.

taxifolia, Rafin. New Fl. Am. i. 38.-Ara. bor.

Tchugatskoi, Lawson, ex Gord. Pinet. Suppl.50= cilicica.

Thunbergii, Lindl. in Penny Cyclop. i. $34=$ Picea polita.

Tlapalcatuda, Roezl, Cat. Gr. Conif. Mex. (1858-59) $5=$ religiosa.

Torano, Siebold, in Verh. Bat. Gen. xii. (1830) $12=$

Picea polita.

trigona, Rafin. Atl. Journ. (1820) $119=$ Sequoia sempervirens?

Tschonoskiana, Regel, in Ind. Sem. Hort. Petrop. (1865) $32=$ homolepis

Tsuga, Sieb. \& Zucc. F1. Jap. ii. 14. t. $106=$ Tsuga Sieboldi

Veitchii, Lindl. in Gard. Chron. (1861) 23.-Japon.

venusta, C. Koch, Dendrol. ii. II. $210=$ bracteata.

viminalis, Wahlenb. Fl. Suec. $630=$ Picea excelsa

virescens, Hinterh. ex Nym. Consp. $673=\mathrm{P}$, alba.

vulgaris, Poir. Encyc. vi. $514=$ pectinata.

Webbiana, Lindl. in Penny Cyclop. i. 30.-Reg. Himal. Williamsonii, Bridges, ex Gord. Pinet. Suppl. $12=$ Tsuga Mertensiana.

Williamsonii, Newberry, in Williamson, in Pacif. Rail.

Rep. vi. 53. t. $7=$ Tsuga Hookeriana.

ABIGA, St. Lag. in Ann. Soc. Bot. Lyon, vii. 85 (1880) = Ajuga, Linn. (Labiat.)

cistifolia, St. Lag. 1. c. 85, 119= Ajuga Iva.

ABILDGAARDIA, Vahl, Enum, ii. $296(1806)=$ Fimbristylis, Vahl (Cyperac.)

aphylla, Kunth, Enum, ii. $248=\mathrm{F}$. bahiensis

Baeothryon, St. Hil. Voy. $i 1.389=$ F. bahiensis.

barbata, Beauv. Fl. Oware, ii. 47. t. 86. f. 1.-Afr. trop.

brevifolia, Steud. Syn. Pl. Cyp. $72=$ F. setacea.

cinnamometorum, Thw. Enum. Pl. Zeyl. $347=\mathrm{F}$. cyperoides.

compressa, J. \& C. Presl, Rel, Haenk. i. $179=$ F. monostachya.

cyperoides, Nees \& Meyen, in Wight, Contrib, $95=$ F. cyperoides.

Eragrostis, Nees \& Meyen, 1. c. $=$ F. Eragrostis.

fimbristyloides, F. Muell. Fragm. viii. $273=\mathrm{F}$, disticha.

fulvescens, Thw. Enum. P1. Zeyl. $347=\mathrm{F}$. fulvescens.

fusca, F. Muell. Fragm. viii. $273=\mathrm{F}$. cyperoides.

fusca, Nees, in Wight, Contrib. 95.-Reg. Himal.

geminata, Schrad. ex Nees, in Mart. F1. Bras. ii. 1. 71 $=\mathrm{F}$. bahiensis.

indica, Nees, in Linnaea, ix. (1835) $289=\mathrm{F}$. monostachya.

javana, Nees, 1. c. = F. monostachya.

javanica, Steud. Syn. P1. Cyp. $72=$ F juncea

laevigata, Willd. ex Steud. Nom, ed. II. i. $1=$

F. monostachya

lanceolata, Schum. Guin. Pl, $33=\mathrm{F}$. tristachyn

monostachya, Vahl, Enum. ii. $296=$ F. monostachyo. nervosa, J. \&c C. Presl, Rel. Haenk.1. $180=$ F. schoenoides, pauciflora, Kunth, Enum. Pl. ii. 249.-Ins. Molucc. pilosa, Nees, in Linnaea, ix. (1835) 289 -Afr. trop. polycephala, Brongn, in Duperr. Voy. Bot. 176. t. $32=$

Androtrichum polycephalum.

polygama, Spreng. Nov. Prov. 45.-Bras.

polystachya, Spreng. F1. Hal. Mant. $29=$ Pharus angustifolius.

pubescens, J. \& C. Presl, Reliq. Haenk. $180=$ F. exilis. Rottboelliana, Nees, ex Hook, \& Arn. Bot. Beech.

Voy. $272=\mathrm{F}$. monostachya.

schoenoides, R. Br. Prod. $229=\mathrm{F}$. squarrulosa.
ABILDGAARDIA :-

scirpoides, Nees, in Linnaea, ix. (1835) $289=\mathrm{F}$ bahiensis

setacea, Griseb. Cat. P1. Cub. 238.-Cuba.

ternata, Schrad, ex Nees, in Mart. Fl. Bras. ii. I. $71=$

F. bahiensis.

tristachya, Vahl, Enum. ii. $297=$ F. tristachya.

vaginata, R. Br. Prod. i. $229=$ F. Brownii.

ABILDGARDIA, Reichb. Consp. $56(1828)=$ praec.

ABILGAARDIA, Poir. in Dict. Sc. Nat. i. Supui $3(1816)=$ praec.

ABLANIA, Aubl. P1. Gui. i. 585. t. $234(1775)=$

Sloanea, Linn. (Tiliac.)

digitata, Spreng. Syst. iv. Cur. Post. 210.-Mras

guianensis, Aubl. Pl. Gui. i. 585. t. $234=$ S. guianensis.

laurifolia, Pers. Syn. ii. $81=\mathrm{S}$. guianensis.

ABOBRA, Naud, in Rev. Hortic. (1862) 111

BITACEAE, Benth. \& Hook. f, i. 834.

tenuifolia, Naud. l. c.-Bras.

viridiflora, Naud. $l . c_{0}-\mathrm{Am}$. austr.

ABOLA, Adans. Fam. ii. $31 \quad\left(1763^{\circ}=\right.$ Cinma, Linn Gramin.

ABOLA, Lindl. Fol. Orch. (1853). ORCHIDEAE Benth. \& Hook. f. iii. 566.

radiata, Lindl. l. c- -N. Granat.

ABOLARIA, Neck. Elem. i. $105(1790)=$ Globularia Linn. (Selagin.

ABOLBODA, Humb. \& Bonpl. P1. Aequin. ii. 10. 114 (1809). XYRIDEAE, Benth. \& Houk. f. iii. 8t: CHLoERUM, Willd. ex Link, in Spreng. Jahrb. i. II $74(1833)$

PoArchon, Mart ex Seub, in Mart. Fl. Bras, ii t. $223(1855)$

Aubletii, Kunth, Enum. Pl. iv. 28.-Guian.

brasiliensis, Kunth, l. c. 26.-Bras.

grandis, Griseb. in Linnaea, xxi. (1848) 281.-Bras. imberbis, $H . B . \&$ K. Nov. Gen. et Sp. i. 256.-Guian. inermis, Link, ex Steud. Nom. ed. II. i. 2 =iroberbis. Poarchon, Seub. in Mart. Fl. Bras. iii. 1, 223.-Bra. Poeppigii, Kunth, Enum. Pl. iv. 27.-Bras pulchella, Humb. E Bonpl. Pl. Aequin. ii. 110. t. 11 . -Venezuela.

ABROCHIS, Neck. Elem. iii.130 (1790)=Orchis, Tourn

ABROMA, Jacq. Hort. Vind, iii. t. 1 (1776). SIEK

CULIACEAE, Benth. \& Hook. f. i. 224.

AMBROMA, Linn. f. Suppl. 341 (1781)

alata, Blanco, Fl. Filip. ed. I. 605 - Ins. Philipp.

angulata, Lam. Encyc. i. $126=$ angusta.

angulosa, Poir. Encyc. Suppl. 1. $322=$ augusta. augusta, Linn. f. Suppl. 341 (Ambroma). - As. trul.

communis, Blanco, Fl. Filip. ed. I. $606=$ augusta.

denticulata, Miq. Pl. Fungh. 288.-Java.

elongata, Lam. Encyc. i. 127 = angusta.

fastrosa, R. Br. in Ait. Hort. Kew. ed. II. iv. 409.-As.

trop.: Austral.

fastuosa, Gaertn. Fruct. i. 307. t. $64=$ augusta.

fastuosa, Jacq. Hort. Vind. iii. 3. t. 1 =augusta.

javanica, Miq. Fl. Ind. Bat. i. II. 18s.-Java.

Mariae, Mart. in Denkschr. Bayer. Ges. 1ii. '1587-13 297.- Java.

mollis, DC Prod i. 485.-Ins, Molucc.

nitida, Poepp. Eo Endl. Non. Gen. et Sp iii. 73-Chili. obliqua, Presl, Rel. Haenk. ii. 143.--Ins. Phili, :

tomentosa, Steud. Nom. ed. II. i. 2, sphalm.-1

Ambora tomentosa.

Wheleri, Retz. Obs, v, $2 \bar{i}=$ augusta

ABRONIA, Juss. Gen. 448 (1799). NYCT.tGI.TE: . Benth. \& Hook. f. iii. ?

Cycloptera, Natt. ex A. Gray, in Am. Journ. S:

Ser. II $x v(1 \$ 5 \%) 319$.

TrICratus, L'Hérit, ex Willd. Sp. Pl. i. SO $18 \% ?$

arenaria, Mensies, ex Hook. Exot. Fl. t. 193.-Calii.

californica, Raeusch. Nom. ed. III. $191=$ umbellata

Crux-Maltae, Kellogg, in Proc. Calif. Acad. ii. (156s

71. f. 16. - Calif.

Cycloptera, A. Gray, in Am. Goum. Se. Ser. II.

1853) 319.-Texas.

fragrans, Nutt. ex Hook. Kew Gourn. v. (1\$59) $20^{\circ} 1$ Calif.

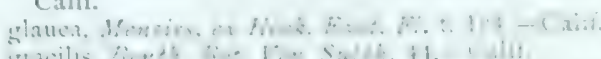

latifolia. Eschsch. in Alim. Acad. Peterso. v. (18:ni 281.-Calif. 


\section{ABRONIA :-}

maritima, Nutt. ex S. Wats. Bot. Calif. ii. 4.-Calif mellifera, Dougl. in Hook. Bot. Mag. t. 2879.-Calif. Menziesii, Dougl. ex Hook. Fl.Bor. Am. ii. 125.-Calif, micrantha, Choisy, in DC. Prod. xili. II. $436=$ A. Cycloptera.

nana, S. Wats. in Proc. Am. Acad. xïv. (1870) 294. -Am. bor. occ.

parviflora, H. B. E K. Nov. Gen. et Sp. ii. 216. t. 128. -N. Granat.

rosea, Hartweg, ex Loud. Hort. Brit. Suppl. iii. $479=$ umbellata?

rotundifolia, Gaertn. f. Fruct. iii. t. $214=$ umbellata.

speciosa, Buckl. in Proc. Acad. Sc. Philad. (1863) 7.-Am. bor, occ.

turbinata, Torr. ex S. Wats. in Bot. King's Exped. 285. t. 31.-Am. bor. occ.

umbellata, Lam. Illustr. i. 469. t. 105.-Calif.

vespertina, Dougl. ex Hook. Fl. Bor. Am. ii. $125=$ mellifera.

villosa, S. Wats. in Am. Naturalist, vii. (1873) 302.Am. bor.

ABROPHAËS, Rafin. Sylva Tellur. 99 (1838) = Fothergilla, Linn. f. (Hamamel.).

mirabilis, Rafin. 1. c. $=$ F. alnifolia.

ABROPHYLLUM, Hook. f. in Benth. Fl. Austral.ii. 437 (1864). SAXIFRAGEAE, Benth. \& Hook.f. i. 647. Brachynema, F. Muell. Fragm. iii. 90. (1862)。

ornans, Hook, f: loc.-Austral.

ABROTANELLA, Cass. in Dict. Sc. Nat. xxxvi. 27 1825). COMPOSITAE, Benth. \& Hook. f. ii. 431. Ceratella, Hook, f. Fl. Antarct. i. 23. t. 18 (1844) Scleroleima, Hook. $f$. in Lond. Journ. Bot. v. (1846) 444. t. 14

TrineuroN, Hook. f. Fl. Antarct. i. 23. t. 17 (1844).

marginata, Cass, in Dict.Sc. Nat. xxxvi. 27 (1825).Ins. Falkl.

forsterioides, Hook. f. Handb. N. Zeal. F'. 139-N Zel.; Austral.

inconspicua, Hook. f. l. c. 140.-N. Zel.

linearifolia, A. Gray, in Proc. Am. Acad. v. (1861) 137.-Fuegio.

linearis, Bergo, in Minneskr. Fisiog. Sällsk. Lund (1877), viII. p. $14 .-\mathrm{N}$. Zel.

nivigena, F. Muell. in Benth. Fl. Austral. iii. 554.Austral.

pusilla, Hook. f. Handb. N. Zeal. Fl. 139.-N. Zel

rhynchocarpa, Balf. $f$. in Phil. Trans. clxviii. (1879) 352 - Ins. Rodr.

rosulata, Hook, f. Handb. N. Zeal. Fl. 139.-N. Zel.

scapigera, F. Muell. ex Benth. Fl. Austral. iii. 554.Austral.

spathulata, Hook. f. Handb. N. Zeal. Fl. 139.-N. Zel.

submarginata, A. Gray, in Proc. Am. Acad. v. (1861) 137.-Reg. Magell.

ABROTANUM, [Tourn.] Linn. Syst. ed. I (1735) = Artemisia, Tourn. (Compos.).

alpestre, ambiguum, brachylobium, congestum, incanescens, pauciflorum, pedunculare, platylobum, pulverulentum, rhodanicum, suave, virgatum, viridulum, xerophilum, Jord. \& Fourr. Brev. Pl, Nov fasc. ii. $69-72=$ Art. Abrotanum.

frutescens, Gilib. Fl. Lituan. i. $173=$ Art. campestris.

ABRUS, Linn. Hort. Cliff. 488 (1737). LEGUMINOSAE, Benth. \& Hook. f. i. 527.

ZaGA, Rafin. Fl. Tellur, ii. 33 (1836).

acutifolius, Blume, ex Miq. Fl. Ind. Bat. i. $160=$ pulchellus.

arboreus, Vell. Fl. Flum. 303 ; vii. t. $99=$ Ormosia nitida. canescens, Welw. in Oliver, Fl. Trop. Afr. ii. 175.-Afr. trop.

cantoniensis, Hance, in Fourn. Bot. vi. (1868) 112.China.

fruticulosus, Wall. Cat.n. 5820.-Ind, or.

laevigatus, E. Mey. Comm. i. 126=pulchellus.

lusorius, Vell. Fl. Flum. 302 ; vii. t. $97^{a}$-Dras.

maculatus, Noronha, in Verh. Batav, Gen. v. (1790),

Art. IV. 7 = precatorius.

melanospermus, Hassk. Cat. PI. Hort. Bog. Alt. $282=$ pulchellus.

minor, Desv. in Ann. Sc. Nat. Sér. I. xi. (1826) $418=$ precatorius.

mollis, Hance, in Fourn. Bot. ix. (1871) 430.-China.

pauciflorus, Desv. in Ann. Sc. Nat. Sér. I. ix. (1826) $418=$ precatorius.

\section{ABRUS}

precatorius, Linn. Syst. ed. XII. 472.-Reg. trop. pulchellus, Wall. Cat. n. 5819.-Ind. or.; Afr. austr squamulosus, E. Mey. Comm. 1. 126=precatorius, tenuiflorus, Benth. in Mart. Fl. Bras. xv. I. 216.-Bras.

ABRYANTHEMUM, Neck. Elem. ii. $82(1790)=$ Mesembryanthemum, Linn. (Ficoid.).

ABSINTHIUM, Tourn. ex Linn. Syst. ed. I (1735)= Artemisia, Tourn. (Compos.).

alpinum, Bess. in Bull. Soc. Nat. Mosc. i. (1829) 240 $=$ Art. lanata.

arborescens, Moench, Meth. $579=$ Art. arborescens.

argenteum, Bess. in Bull. Soc. Nat. Mosc. 1. (1829) 272 $=$ Art. argentea.

bipedale, Gilib. Fl. Lituan. i. $174=$ Art. Absinthium.

boreale, Bess. in Bull. Soc. Nat. Mosc. i. (1829) $265=$

Art. borealis.

campestre, Dulac, Fl. Hautes-Pyr, $502=$ Art. campestris camphoratum, Bess. in Bull. Soc. Nat. Mosc. i. (1829) $230=$ Art. camphorata.

canariense, Bess. 1. c. $229=$ Art. canariensis

candidum, Bieb. ex DC. Prod. vi. $125=$ Art. frigida

cernum, Moench, Meth. $579=$ Art. crithmifolia.

chinense, DC. Prod. vi. 118 sub n. $139=$ Art. chinensis congestum, Lam. Fl. Fr. ii. $46=$ Art. glacialis

corymbosum, DC. Prod. vi. 122. sub n. $161=$ Art camphorata.

dentatum, Bess. in Bull. Soc. Nat. Mosc. i. (1829) 265 $=$ Art. rupestris.

divaricatum, Fisch. ex Bess. 1. c. $263=$ Art. anethifolia.

frigidum, Bess. in Bull. Soc. Nat. Mosc. i. (1829) 251 $=$ Art. frigida

glaciale, Lam. Illustr. iii. 273. t. $695=$ Art. glacialis.

grandiflorum, Bess. in Bull. Soc. Nat. Mosc. i. (1829) $232=$ Art. grandiflora.

grandiflorum, RoehI. ex Steud. Nom. ed, II. i. 2=Art. rupestris.

lagocephalum, Bess. in Bull. Soc. Nat. Mosc. i. (1829) $233=$ Art. lagocephala.

lanatum, Bess. 1. c. $265=$ Art. lanata.

laxum, Lam. Fl. Fr. ii. $46=$ Art. Mutellina.

mollissimum, Bess. in Bull. Soc. Nat. Mosc. i. (1829) $265=$ Art. mollissima

Moxa, Bess. 1. c. $228=$ Art. Moxa.

Mutellina, Roehl. ex Steud. Nom. ed. II. 1. $2=$ Art Mutellina.

nitens, Bess. in Bull. Soc. Nat. Mosc. i. (1829) $235=$ Art. sericea.

officinale, Brot. F1. Lusit. i. $357=$ Art. Absinthium

pedunculare, Stev. in Mém. Soc. Nat. Mosc. iv. (1813) $63=$ Art. splendens.

petrosum, Baumg. Enum. Stirp. Transs. iii. $90=$ Art. Baumgarteni.

ponticum, Bess. Enum. Pl. Volh. $76=$ Art. pontica. rupestre, Schrank, Prim. F1. Salisb. $203=$ Art. rupestris. santonicum, Gueldenst. ex Ledeb. Fl. Ross. ii. $573=$ Art. maritima.

saxatile, Bess. in Bull. Soc. Nat. Mosc. i. (1829) $231=$

Art. camphorata.

sericeum, Bess. 1. c. $237=$ Art. sericea

Sieversianum, Bess. I. c. $259=$ Art. Sieversiana.

spathulatum, Noronha, in Verh. Batav. Gen. v. (1790) Art. IV. $6=$ Dichrocephala latifolia.

spicatum, Baumg. Enum. Stirp. Transs. iii. $90=$ Art. spicata.

splendens, Bess. in Bull. Soc. Nat. Mosc. i. (1829) 238 $=$ Art. splendens.

tanacetifolium, Gaertn. Frnct. ii. $393=$ Art. tanacetifolia.

trifidum, Schrank, Baier. Fl. ii. 362=Art. austriaca.

virescens, Juss, ex Bess. in Bull. Soc. Nat. Mosc. viii.

(1835) $29=$ Art. Jussieana.

virgatum, Turcz. ex Ledeb. Fl. Ross. ii. $597=$ Art. rupestris.

viride, Bess, in Bull. Soc. Nat. Mosc. i. (1829) $249=$ Art. rupestris.

viridiflorum, Bess. 1. c. $246=$ Art. rupestris.

vulgare, Dulac, Fl. Hautes-Pyr. $502=$ Art. vulgaris.

vulgare, Lam. F1. Fr. ii. $45=$ Art. Absinthium.

ABSYNTHIUM, Gaertn. Meyer \& Scherb. Fl. Wett. iii. $196(1801)=$ praec.

ABULFALI, Adans. Fam. ii. $190(1763)=$ Thymbra, Linn. (Labiat.).

ABUMON, Adans. Fam. ii. $54(1763)=$ Agapanthus, L'Hérit. (Liliac.).
ABUTA, [Barr.] Aubl. Pl. Gui. i. 618. t. 250 (1775).

MENISPERM ACEAE, Benth. \& Hook. f. i. 35

Anelasma, Miers, in Ann. Nat. Hist. Ser. II. vii. (1851) 42 .

Batschra, Mutis, ex Thunb. in Nov. Act. Soc. Sc. Upsal. v. (1792) 120. t. 2.

TrICHOA, Pers. Syn. ii. 634 (1807)

acutifolia, Miers, in Ann. E Mag. Nat. Hist. Ser. III. xiv. (1864) 259.-Bras.

amara, Aubl. Pl. Gui. i. $620=$ Aristolochia glaucescens. barbata, Miers, in Ann. E Mag. Nat. Hist. Ser. III. xiv. (1864) 258.-Guiana.

candicans, Rich. ex DC. Syst. i, 543.-Guiana.

Candollei, Triana E Planch. in Ann. Sc. Nat. Sér. IV. xvii. (1862) 47.-Guiana

concolor, Benth. in Journ. Linn. Soc. v. (1861) App. 49 = guianensis.

concolor, Poepp. E Endl. Nov. Gen. et Sp. ii. 64. t. 188.-Am. austr.

Grisebachii, Triana E Planch. in Ann. Sc. Nat. Sér. IV. xvii. (1862) 47.-Bras.

guianensis, Eichl. in Flora, xlvii. (1864) 390,-Guiana. heterophylla, Miers, in Ann. \& Mag. Nat. Hist. Ser. III. xiv. (1864) 258.-Am. austr.

Imene, Eichl. in Flora, xlvii. (1864) 389.-Bras.

macrophylla, Miers, in Ann. E Mag. Nat. Hist. Ser. III xiv. (1864) 258.-Am. austr.

oblonga, Miers, l. c.-Am. austr.

oblongifolia, Miers, $l$. $c$.-Am. anstr.

panurensis, Eichl. in Flora, xlvii. (1864) 390.-Bras.

platyphylla, Mart. ex EichI. in Mart. Fl. Bras. xiii. I.

200 (=Botryopsis platyphylla).-Bras.

racemosa, Triana Eo Planch, in Ann. Sc. Nat. Sér. IV. xvii. (1862) 48.-N. Granat.

rufescens, Aubl. Pl. Gui. i. 618. t. 250.-Guiana.

rufescens, DC. Syst. i. $542=$ Candollei.

rufescens, Griseb. in Journ. Linn. Soc. iii. (1859) $109=$

Grisebachii.

scandens, DC. Syst. i. 542 in syn. $=$ rufescens.

Seemanni, Triana Eo Planch. in Ann. Sc. Nat. Sér. IV. xvii. (1862) 50.-Darien.

Selloana, Eichl. in Floxa, xlvii. (1864) 389.-Bras.

spicata, Triana E Planch. in Ann. Sc. Nat. Sér. II.

xvii. (1682.) 119.-N. Granat.

tomentosa, Sagot, ex Benth. in Journ, Linn. Soc. v. (1861) Suppl. ii. 51 (Coccolobae sp.).-Guian.

umbellata, Sagot, ex Benth. 1. c. = Sciadotaenia cayennensis.

ABUTILAEA, F. Muell. in Linnaea, xxv. (1852) 379 = Abutilon, Tourn. (Malvac.).

cryptantha, F. Muell. 1. c. = A butilon Mitchelli.

ABUTILON, Tourn, ex Adans, Fam, ii. 398 (1763). $M A L V A C E A E$, Benth. \& Hook. f. i. 204.

AbutilaeA, F. Muell. in Linnaea, xxv. (1852) 379.

BELÖ̈RE, Shuttlew, ex Benth. \& Hook. f. Gen. i. (1862) 204 .

BogenHARDEA, Reichb. Nom. 200 (1841)

Herissantia, Medic. Phil. Bot. i. 90 (1789).

LAss, Adans. Fam. ii. 400 (1763).

Prestonia, Scop. Introd. 281 (1777).

acerifolium, G. Don, Gen. Syst. i. $504=$ Sida acerifolia. affine, G. Don, $l_{\text {. }} c$. 503.-Reg. Argent.

albescens, Miq. Pl. Jungh. $285=$ crispum.

albidum, Sweet, Hort. Brit. ed. I. 54.-Ins. Canar.

albidum, Walp. Rep. i. 325.-Mexic.

albidum, Webb \& Berth. Phyt. Canar. i. 39. t. $2=$ fruticosum.

ambiguum, Turcz. in Bull. Soc. Nat. Mosc. xxxi. (185̌8) $205=$ Sida Lindeniana.

americanum, Sweet, Hort. Brit. ed. I. $53=$ indicum.

amplexifolium, G. Don, Gen. Syst. i. 502.-Mexic.

amplum, Benth. Fl. Austral. i. 200.-Austral.

Anderssonianum, Garcke, ex Anderss. Galap. Oar. Vegetat. 280.-Ins. Galap.

Andrieuxii, Hemsl. Diagn. Pl. Nov. 24.-Mexic.

angulatum, Mast. in Oliver, F1. Trop. Afr. i. $183=$ intermedium.

anodoides, St. Hil. E Naud. in Ann. Sc. Nat. Sér.

II. xviii. (1842) 49.-Bras.

arborescens, Medic. Malv. $29=$ indicum

arboreum, Sweet, Hort. Brit. ed. I. 53.-Peruv.

Arnottianum, Walp. Rep. i. $324=$ Sida Arnottiana

asiaticum, G. Don, Gen. Syst. i. 503.-Reg. trop.

asiaticum, Guill. \& Perr. Fl. Seneg. Tent. 1. $67=$ glaucum.

asiaticum, Sweet, Hort. Brit. ed. I. $53=$ indicum

atropurpuream, G. Don, Gen. Syst. i. 502.-Java. 


\section{ABUTILON}

aurantiacum, S. Wats. in Proc. Am. Acad. xx. (1885) 357.-Calif.

aureum, G. Don, in Sweet, Hort. Brit. ed. III, $80=$ Sida aurea.

auritum, Sweet, l. c. ed. I. 53.-Geront. trop

australe, Presl, Bot. Bemerk. 20 ; Garcke, Ind. Sem.

Hort. Berol. (1861) 10.-Austral.

A vicennae, Gaertn. Fruct. ii. 251. t. 135.-Geront. trop.

Bedfordianum, A. St. Hil. in Ann. Sc. Nat. Sér. II xviii. (1842) 48.-Bras.

Behrianum, F. Muell. in Trans. Phil. Soc. Vict. i. (1855) $13=\mathrm{A}$. Avicennae.

benedictum, Bunb. in Proc. Linn. Soc. i. (1841) 109.Bras.

bidentatum, Hochst. ex A. Rich. Tent. Fl. Abyss. i. 68 -Abyss.; Ind. or

blandum, Fenzl, Delect. Sem. Hort. Bot. Vindob. (1858).-Mexic.

californicum, Benth. Bot. Voy. Sulph. $8=$ A. Avicennae. calycinum, Presl, Rel. Haenk. ii. 115.-Peruv. carneum, A. St. Hil. Fl. Bras. Mer. i. 205.-Bras. ceratocarpum, Hook. Bot. Misc. iii. (1833) 154.-Chili. Chapelieri, Baill. in Bull. Soc. Linn. Par. i. (1885) 508.-Madag.

cinereum, Griseb. in Goett. Abh. xxiv. (1879) 45.-Reg. Argent.

circinnatum, G. Don, Gen. Syst. i. 502.-Bras.

cistiflorum, G. Don, l. c. 503.-Java.

coccineum, Hort. ex Regel, Cat. Pl. Hort. Aksakov. (1860) 1, nomen.-Hab. ?

confertiflorum, A. Rich. Ess. Fl. Cub. i. 153.-Cuba.

contractum, Sweet, Hort. Brit. ed. II. $64=$ Sida contracta.

cornutum, Sweet, 1 . c. $65=$ Sida cornuta.

crassifolium, G. Don, Gen. Syst. i. 504.-Ind. oce. crispum, Sweet, Hort. Brit. ed. I. 53.-Reg. trop. cryptopetalum, F. Muell. ex Benth. Fl. Austral. i. 201. -Austral.

Cunninghami, Benth. l. c. 205.-Austral.

cymosum, Triana E Planch. in Ann. Sc. Nat. Sér. IV. xvii. (1862) 185.-Am. trop.

cysticarpum, Hance, in Walp. Ann. ii. $157=$ indicum.

Darwini, Hook. f. Bot. Mag. t. 5917.-Bras.

decarpum, Rafin. New Fl. Am. i. 40.-Am. bor.

deflexum, Moench, Meth. 620.-Hab. ?

densiflorum, Walp. Rep. i. 324.-Chili.

denticulatum, Webb, Fragm. Fl. Aethiop. $51=$ fruticosum.

depauperatum, Hook.f. in Trans. Linn.Soc. xx. (1847) 232. - Ins. Galap.

dianthum, Presl, Reliq. Haenk. ii. 114.-Peruv.

diplotrichum, F. Muell. in Linnaea, xxv. (1852) $380=$ Fraseri.

discissum, Schlecht. in Linnaea, 218.--Reg. Argent.

divaricatum, Turcz. in Bull. Soc. Nat. Mosc. xxxi.

(1858) I. 204.-Mexic.

domingense, Turcz. l. c. 205,-Ins. S. Doming.

elaeocarpoides, Webb, Fragm. Fl. Aethiop. $53=$ ramosum.

elatum, Griseb. Fl. Brit. W. Ind. 79.-Ind. occ. ; Mexic.

elegans, A. St. Hil. Fl. Bras. Mer, i. 207.-Bras.

elegans, Walp. Rep, i. 325 = Sida elegans.

ellipticum, Schlecht. in Linnaea, xi. (1837) 368.Mexic.

elongatum, Moench, Meth. Suppl. $205=$ indicum. erosum, Schlecht. in Linnaea, xi. (1837) 367.-Mexic esculentum, A. St. Hil. Fl. Bras. Mer. i. 240.-Bras.

excelsior, G. Don, Gen. Syst. i. $500=W$ issadula excelsior.

exonemum, F. Muell. Fragm. xi. 63.-Austral.

exstipulare, G. Don, Gen. Syst. i. 503.-Ins. Borbon.

falcatum, St. Hil. E Naud, in Ann. Sc. Nat. Sér. II xviii. (1842) 48.-Bras.

ferrugineum, H. B. \& K. Nov. Gen, et Sp. v. $271=$ Sida ferruginea.

Figarianum, Webb, Fragm. F1.Aethiop. $52=$ graveolens. floribundum, Schlecht. in Linnaea, xi. (1837) 366.Mexic

foetidum, Moench, Meth. Suppl. 206.-Hab.?

Fraseri, Walp. Ann. ii. 158.-Austral.

frutescens, Medic. Malv, $29=$ indicum.

fruticosum, Guill. E Perr. Fl. Seneg. Tent. i. 70.-As. et Afr. trop.

furfurellum, Miq. Fl. Ind. Bat. i. II. 144.-Java.

geminiflorum, H. B. \& K. Nov. Gen. et Sp. v. 274

t. $474=$ ibarrense

geranioides, Benth. Fl. Austral. i. 202.-Austral.

\section{ABUTILON :}

giganteum, Presl, Rel. Haenk. ii. 116.-Am. trop. glaucum, G. Don, Gen. Syst. i. 504.-Afr. trop. glaucum, Sweet, Hort. Brit. ed. I. 54=muticum. glechomaefolium, A. St. Hil. Fl. Bras. Mer, i. 198. t. 411.-Bras.

globiflorum, G. Don, Gen. Syst. i. 502,-Maurit.

Goudotianum, Triana E Planch, in Ann. Sc. Nat.

Sér. IV. xvii. (1862) 184.-N. Granat.

grandiflorum, G. Don, Gen. Syst, i. 504=indicum.

grandifolium, Sweet, Hort. Brit. ed. I. $53=$ molle.

graveolens, Seem. Bot. Voy. Herald, $365=$ indicum.

graveolens, Wight E Arn. Prod. 56.-Geront. trop.

Grevilleanum, Walp. Rep. i. 324.-Chili.

Guichenotianum, Decne. in Herb. Timor. Desc. 106 (1835).-Ins. Timor.

gymnanthemum, Griseb. in Goett. Abh. xxiv. (1879) 47. -Reg. Argent.

Haenkeanum, Presl, Rel. Haenk. ii. 115.-Mexic.

halophilum, F. Muell. in Linnaea, xxv. (1852) $381=$ Fraseri.

hernandioides, Sweet, Hort. Brit. ed. I. $53=$ Sida hemandioides.

heterotrichum, Hochst. ex Mast. in Oliver, Fl. Trop. Afr. i. $187=$ hirtum

hirsutissimum, Moench, Meth. Suppl. 205=indicum,

hirtum, G. Don, Gen. Syst. i. 503.-Reg. trop.

hirtum, Sweet, Hort. Brit. ed. I. $53=$ graveolens.

holosericeum, Scheele, in Linnaea, xxi. (1847) 471.

Texas.

Hulseanum, Torr.ex A. Gray, Pl. Fendl.23,-N. Mexic.

hypoleucum, A. Gray, Pl. Wright. i. 20.-Texas.

ibarrense, H.B. E K. Nov. Gen.et Sp. v.272.-Ecuador

imberbe, G. Don, Gen. Syst. i. $502=$ crispum.

inaequilaterum, A. St. Hil. Fl. Bras. Mer. i. 198. t. 40 . -Bras.

ncanum, Sweet, Hort. Brit. ed. I, 53.-Ins. Sandvic.; Mexic.

indicum, Sweet, l. c. 54.-Geront. trop.

insigne, Planch, in Van Houtte, Fl. des Serres, Sér. I vi. (1850-51) 41-N. Granat

integerrimum, Hook. Bot. Mag. t. 4360.-Mexic

intermedium, Hochst. ex Schweinf. Beitr. Fl. Aethiop. 49.-Geront. trop.

Jacquini, G. Don, Gen. Syst. i. 503.-Am. bor.

Julianae, Endl. Prod. Fl. Norf. 135.-Ins. Norfolc.

Kotschyi, Hochst. in Webb, Fragm. F1. Aethiop. 52= hirtum.

lanatum, Miq. in Linnaea, xxii. (1849) 553.-Bras.

laxiflorum, Guill. \& Perr. F1. Seneg. Tent. i. $66=$

Wissadula rostrata.

leiospermum, Griseb. Fl. Brit. W. Ind. 79.-Ind. occ.

Lemmoni, S. Wats, in Proc. Am. Acad. xx. (1885) 357.-Calif.

lepidum, F. Muell. Fragm. vi. 168=Sida lepida.

Leschenaultianum, Sweet, Hort. Brit. ed. I. $53=$ Wissadula Leschenaultiana.

Leucanthemum, A. St. Hil. Fl. Bras. Mer, i. 200.-Bras. lencopetalum, F. Muell. ex Benth. Fl. Austral. i. 200. -Austral.

lignosum, G. Don, Gen. Syst. i. 501 = Jacquini.

longicuspe, Hochst. ex A. Rich. Fl. Abyss. i. 69.Abyssin.

longilobum, F. Muell. Fragm. ix. 130.-Austral. lucianum, Sweet, Hort. Brit. ed. I. 53.-Ind. occ.

macranthum, Peyr. in Linnaea, xxx. (1859-60) 59.Mexic.

macranthum, A. St. Hil. Fl. Bras. Mer. i. 208.-Bras, macrocarpum, Guill. E Perr. Fl. Seneg. Tent. i. 69Afr. trop.

macrocarpum, St. Hil. \& Naud. in Ann. Sc. Nat. Sér. II. xviï. (1842) 47.-Bras.

macrophyllum, St. Hil. E Naud. l. c.-Bras.

macropodum, Guill. E Perr. Fl. Seneg. Tent. i. 69. t.

14.-Afr. trop.

macrum, F. Muell. Fragm, ix. 59-Austral.

malachroides, St. Hil. E Naud in Ann. Sc. Nat. Sér

II. xviii. (1842) 49.-Bras.

marmoratum, Hort. ex Lem. in Illustr. Hortic. ii. (1856) t. $82=$ Hibiscus narmoratus.

mauritanicum, Medic Malv, $28=$ seg

mauritianum, Sweet, Hort. Brit. ed. I. $53=$ indicum. megapotamicum, St. Hil. E Naud, in Ann. Sc. Nat Sér. II. xviii. (184\%) 49.-An. trop.

melanocarpum, St. Hil. \& Naud. l. C. 48.-Bras. mendocinum, Plit. Sert. Mend. Alt. 6.-Chili.

Menziesii, Seem. Fl. Vit. 15. - Ins. Sandvic.

mexicanum, Presl, Rel. Haenk. ii. 115.-Mexic

\section{ABUTILON}

micranthum, G. Don, Gen. Syst. i. 502, sphalm. macrantbum.

micropetalum, Benth. Fl. Austral. i. 201.-Austral. microphyllum, A. Kich. Fl. Abyss. i. $70=$ fruticosum. microspermum, G. Don, Gen. Syst. i. 501.-Hab. Mitchelli, Benth. Fl. Austral. i. 201.-Austral molle, Sweet, Hort. Brit. ed. II. 65.-Peruv. mollicomum, Sweet, l. c.ed. I. 54.-Hab.?

mollissimum, Sweet, l. c. 58.-Perny.

montanum, A. St. Hil. Fl. Bras. Mer. i. 207.-Bras. mucronulatum, A. Gray, in Proc. Am. Acad. v. (186? $\mathbf{1 7 5}=$ Wissadula mucronulata.

muticum, Sweet, Hort. Brit. ed. II. 65.-Geront. trop. muticum, Webb, Fragm. Fl. Aethiop. $51=$ glaucum.

neilgherrense, Munro, in Wight, Ill. t. 66.-Ind, or.

neurocarpum, Miq. Pl. Fungh. 285. - Java

Newberryi, S. Wats. in Proc. Am. Acad. xi. (1876) 125.-Am. bor.

niveum, Griseb. in Goett. Abh. xix. (1874) 92.-Reg. Argent.

notolophium, A. Gray, in Proc. Am. Acad.v. (1875) 175.-Mexic.

nudiflorum, Sweet, Hort. Brit. ed. I. $53=$ Wissadula nudiflora.

Nuttallii, Torr. E Gray, Fl. N. Am. i. 231.-Am. bor. obtusúm, G. Don, Gen. Syst. i. 501.-Hab.

occidentale, Medic. Malv, $29=$ Gaya subtriloba.

Ochsenii, Phil. in Linnaea, xxviii. (1856) 613.-Chili. orbiculatum, G. Don, Gen. Syst. i. 504.-China otocarpum, F. Muell. in Trans. Phil. Soc. Vict. i. 1855) 13.-Austral.

oxycarpum, F. Muell. Fragm, ii, 12.-Austral.

oxypetalum, Planch. E Linden, in Ann. Sc. Nat. Sér.

IV. xvil. (1862) 184-N. Granat.

oxyphyllum, Presl, Bot. Bemerk. $20=$ polyandrum.

paeoniaeflorum, Walp. Rep. v. 95.-Bras.

Palmeri, A. Gray, in Proc. Am. Acad. viii. (1870) 283. -Am. bor

pannosum, Webb, Fragm. F1. Aethiop, $52=$ glaucum.

paranthemoides, Griseb. in Goett. Abh. xxiv, (1879) 46.--Reg. Argent.

paranthemum, Griseb. l. c.-Reg. Argent.

Parishii, S. Wats. in Proc. Am. Acad. xx. (1885) 357. -Arizona.

parviflorum, A. St. Hil. Fl. Bras. Mer. i. 201-Bras.

parvulum, A. Gray, Pl. Wright. i. 21.-Texas.

patens, A. St. Hil. Fl. Bras. Mer. i. 200.-Bras

panciflorum, A. St. Hil. L. c. 206.-Bras.

pedunculare, H.B. E K.Nov. Gen. et Sp.v. 273.-Bras. peraffine, Shuttl. ex Chapm. Fl. S. U. St. $56=$ Jacquini.

periplocifolium, Sweet, Hort. Brit. ed. I. $53=$ W'issa-

dula rostrata

permolle, Sweet, l. c.-Florida; Cuba.

petiolare, H.B.E K.Nov. Gen.et Sp.v.272.-N. Granat.

pictum, Walp. Rep.i. 324.-Reg. Argent.

planiflorum, C. Koch \& Bouche, in C. Koch, Allg. Gartenz. (1857) 98.-Mexic.

polyandrum, G. Don, Gen. Syst. i..500.-Ind. or.

polyanthon, Sweet, Hort. Brit. ed. I. $53=$ Sida polyantha.

populifolium, Sweet, 1. c. = indicam.

pubescens, Moench, Meth. $620=$ A. Avicennae.

pulchellum, Sweet, Hort. Brit, ed. I. $53=$ seq.

pulchrum, G. Don, Gen. Syst, i., 503=Plagianthus pulchellus.

pyramidale, Turcz. in Bull. Soc. Nat. Mlosc. xxxi. 1858) 1. 203.-N. Granat

racemosum, Schlecht.in Linnaea, xi. (183i) 36\%.-Mexic ramiforum, A. St. Hil. Fl. Bras. Mer. i, 199.-Bras. ramosissimum, Presl, Rel. Haenk, ii. 116.-Mexic. ramosum, G. Don, Gen. Syst. i. $501=$ Sida cordifolia. ramosum, Guill. E Perr. Fl. Seneg. Tent. i. 68.-Geront. trop.

reflexum, Sweet, Hort. Brit. ed. I. 53; Presl, Re Haenk. ii. 114 -Mexic.

Regnellii, Miq. in Linnaea, xxii. (1849) 554.-Bras.

rigidum, G. Don, Gen. Syst. i. 504.-Afr. trop.

rivulare, A. St. Hil. Fl. Bras. Mer. i. 2u2. - Lirs

rufescens, G. Dun, Gen. Syst. i. $502=$ rufinerve

rufescens, Turca. ing Bull. Sor. Nab. Mosc. 1ass.

202 - Mexic.

rafinerve, A. St. Hil. Fl. Bras. A/er. i. 205. t. 42.-Bras. rufinerve, Seem. Bot. Voy. Herald, $S 3=$ cymnsum.

Sellovianum, Regel, in Ann. Sc. Nab. Ser. IV. xii. (185! 379.-Bras

septemlobum, Mig. in Linnaea, xxii. (1519'554.-Bras.

sessiliflorum, Presl, Rol. Hacrk. ii. 118.Mexic. 


\section{ABUTILON :}

sidoides, Dalz, \& Gibs, Bomb. Fl, 18=ramosum

sidoides, Hemsl. Diagn. Pl. Nov. 24.-Mexic.

Sonneratianum, Sweet, Hort. Brit. ed. I. 54.-Afr. austr.

Sonorae, A. Gray, Pl. Wright. ii. 23.-Mexic

sparmannioides, Guill. \& Perr. F1. Seneg. Tent. i. 70 - ramosum.

speciosum, G. Don, Gen. Syst. i. $502=$ Sida speciosa.

spicatum, H. B. \& K. Nov. Gen. et Sp. v. $271=$ Wissadula spicata.

stenopetalum, Garcke, in Bot. Zeit. viii.(1850) 683.N. Granat.

stipulare, Presl, Rel. Haenk. ii. 114.-Luzon.

striatum, Dicks. in Bot. Reg. (1839) Misc. 39.-Bras.

subviscosum, Benth. Fl. Austral. i. 202.-Austral.

sundaicum, G. Don, Gen. Syst. i. 500 (1831).--Java.

terminale, A. St. Hil. Fl. Bras. Mer. i. 203.-Bras.

texense, Torr. \& Gray, F1. N. Am. i. 231 = incanum.

Theophrasti, Medic. Malv. $28=$ A. Avicennae.

Thurberi, A. Gray, Pl. Now. Thurb. 307.Texas, ; Mexic.

thyrsodendron, Griseb. in Goett. Abh. xxiv. (1879) 48 -Reg. Argent.

tiliaefolium, Sweet, Hort. Brit. ed. I. $53=$ A. Avicennae. timoriense, G. Don, Gen. Syst. i. 500 (1831).-Ins. Timor.

tomentosum, Wight \& Arn. Prod. 56=muticum.

tortuosum, Guill. \& Perr. Fl. Seneg. Tent. i. $66=$ graveolens.

trichodum, A. Rich. Ess. Fl. Cub. i. $155=$ crispum. trilobatum, Hemsl. Diagn. Pl. Nov. Mex. 24.-Mexic. triquetrum, Presl, Relig. Haenk, ii. 115.-Mexic. triquetrum, Sweet, Hort. Brit. ed. I. 53.-Ind. occ. truncatum, G. Don, Gen. Syst. i. 503.-Ins. S. Doming. tubulosum, Walp. Ann. ii. 158.-Austral. umbellatum, Sweet, Hort. Brit. ed. I. 53.-Ind. occ. umbelliferum, G. Don, Gen. Syst. i. $501=$ seq. umbelliflorum, A. St. Hit. Fl. Bras. Mer. i. 204,-Bras. uratocarpum, Walp. Rep. i. $324=$ ceratocarpun. velutinum, G. Don, Gen. Syst. i. 504.-Afr. trop. velutinum, A. Gray, Illustr. Gen. P1. Am. Bor. ii. 67 t. $\mathbf{1 2 5}=$ holosericenm.

venosum, Lem. Hortic. Univ. Misc. 1844 ; ex Fl. des Serres, ii. (Mars 1846) t. 5.-Mexic.

verbascoides, Turcz. in Bull. Soc. Nat. Mosc. (1858) I. 202.-Venezuela.

vesicarium, Sweet, Hort. Brit. ed. I. $54=$ A. Avicennae. vexillarium, E. Morr. Belg. Hortic. (1864) 289 =megapotamicum.

virens, St. Hit. E Naud, in Ann. Sc. Nat. Sér. II. xviii. (1842) 48.-Bras.

virgatum, Sweet, Hort. Brit. ed. I. 53.--Hab.?

vitifolium, Presl, Rel. Haenk. ii. 116:-Chili.

Wagenerianum, Regel, Cat. Pl. Hort. Aksakov. (1860)

1, nomen.-Hab.?

wissadifolium, Griseb. in Goett. Abh. xxiv. (1879) 47. -Reg. Argent.

Wrightii, A. Gray, in Bost. Fourn. Nat. Hist. vi. (1850) 162.-Texas.

zanzibaricum, Boj. ex Mast. in Oliver, Fl. Trop. Afr.

i. 186.-Afr。trop.

ABUTUA, Lour. F1. Cochinch. $630(1790)=$ Gnetum, Linn.

africana, Lour. 1. c. 631 (Quid ?).-Afr. or.

indica, Lour. 1. c. $630=\mathrm{G}_{\text {.o }}$ funiculare.

ACACALLIS, Lindl. Fol. Orchid. 1853. ORCHIDEAE, Benth. \& Hook. f. iii. 544.

cyanea, Lindl. $l$. $c_{0}$-Bras.

ACACIA, [Tourn. ] Linn. F1. Zeyl. 217 (1737); Willd. Sp. Pl. iv. 1049 (1805). LEGUMINOSAE, Benth. \& Hook. f. i. 594

Arthrosprion, Hassk. Retzia, i. 212 (1855).

Chitonanthus, Lehm. Pl. Preiss. ii. 368 (1847),

Cuparilla, Drepaphyla, Eburnax, Esclerona,

Gumifera, Hecatandra, Poponax, Senegalia,

Zigmaloba, Rafin. Sylva Tellur. 118-120 (1838)

Farnesia, Gasp. Desc. Nuov, Gen. (1838)

Hoopesia, Buckl. in Proc. Acad. Sc. Philad. 1861

(1862) 433, partim

Phyllodoce, Link, Handb. ii. 132 (1831)

Tetracheilos, Lehm. Pl. Preiss. ii. 868 (1847).

Vachelira, Wight \& Arn. Prod. 272 (1834).

abietina, Willd. Sp. Pl. iv. $1051=$ linifolia.

abstergens, Steud. Nom. ed. II. i. $3=$ concinna.

abyssinica, Hochst, ex Benth. in Hook. Lond. Fourn. Bot. v. (1846) 97.-Abyssin.

\section{ACACIA :-}

acanthocarpa, Willd. Enum. Hort. Berol. $1057=$ Mimosa acanthocarpa.

acanthoclada, F. Muell. Fragm. iii. 127.-Austral acantholoba, Humb. \& Bonpl. ex Willd. Sp. P1. iv $1089=$ Mimosa acantholoba

acanthophora, Steud. Nom. ed. II. i. $3=$ Mimosa acan thocarpa.

acapulcensis, Kunth, Mim. 78. t. 24=Lysiloma acapul censis.

acatlensis, Benth. in Hook. Lond. Fourn. Bot. i. (1842) 513.-Mexic.

acicularis, R. Br. in Ait. Hort. Kew. ed. II. v. $450=$ juniperina.

acicularis, Humb. \& Bonpl. ex Willd. Enum. Hort. Berol. $1056=$ Farnesiana

acinacea,Lindl.in Mitch. Three Exped.ii. 267.-Austral. aciphylla, Benth. in Linnaea, xxvi. (1853-55) 627.Austral.

Acradenia, F. Muell. in Journ. Linn. Soc. iii. (1859) 142 = umbellata.

acuifera, Benth. in Hook. Lond. Fourn. Bot. i. (1842) 496.-Ins. Baham.

aculeaticarpa, Lag. Gen. et Sp. Nov. 16= Mimosa acanthocarpa.

acuminata, Benth. in Hook. Lond. Fourn. Bot. i. (1842) 373.-Austral.

acutangula, Buch.-Ham. ex Wall. Cat. sub n. $5271=$ Pithecolobium angulatum.

acutistipula, Mart. in Flora, xx. (1837) Beibl. ii. 107 = Mimosa acutistipula.

Adansonii, Guill. \& Perr. F1. Seneg. Tent. i. $249=$ arabica.

adenantheroides, Mart. \& Gal. in Bull. Acad. Brux. xii. (1846) $311=$ Mimosa adenantheroides.

adenocarpa, Walp. Rep. i. 924, sphalm. =seq.

adenopa, Hook. '\& Arn. in Hook. Bot. Misc, iii. (1833) $206=\mathrm{A}$. Farnesiana

adenophora, Spreng. Syst. iii. $140=$ decurrens.

adenostylis, Fenzl, in Flora, xxvii. (1844) $312=$ Dichrostachys nutans.

adhaerens, Benth. in Hook. Lond. Fourn. Bot. i. (1842) 517.--Bras.

adiantoides, Spreng. Syst. iii. $146=$ Piptadenia laxa

adnata, F. Muell. in Melb. Chemist (July 1882). Austral.

adstringens, A. Cunn. in G. Don, Gen. Syst. ii. $405=$ falciformis.

adstringens, Mart. Reise Bras. i. 548-Stryphnodendron Barbatimam.

adunca, A. Cunn. ex G. Don, Gen. Syst. ii. $406=$ crassiuscula.

aegyptiaca,Baill.Adansonia, iv. (1863-64)82.-Aegypt affinis, Sweet, Hort. Brit. ed. I. $102=$ dealbata.

alata, R. Br. in Ait. Hort. Kew. ed. II. v. 464.-Austral. alba, Colla, Hort. Rip. App. ii. $339=$ Calliandra portoricensis.

alba, De Vriese, in Miq. Pl. Fungh. 270.-Malaya

alba,Willd. Enum. Hort. Berol. Suppl. $68=1$ encophloea. albescens, Steud. Nom. ed. II. 1. $3=$ tortuosa.

albicans, Kunth, Mim.87.t.27 = Pithecolobiumalbicans

albida, Delile, Fl. Egypt. 286. t. 52. f. 3.-Afr. bor,

albida, Lindl. Bot. Reg. t. $1317=$ tortuosa.

alliacea, Buch.-Ham. in Wall. Cat. n. $5258=$ caesia.

alpina, F. Muell. Frogm. iii. 129.-Austral.

amara, Willd. Sp. P1. iv. 1074=Albizzia amara.

amazonica, Benth. in Trans, Linn. Soc. xxx. (1875)

523.-Am. trop.

ambigua, Hoffmgg. Verz. Pfl. Nachtr. iii. 15.-Afr. trop. ambigua, Vogel, in Linnaea, x. (1835-36)600.-Am.trop amblycarpa, R. Grah. in Wall. Cat. n. $5260=$ pennata.

amblygona, A.Cunn. ex Benth. in Hook. Lond. Foum.

Bot i. (1842) 332.-Austral.

amblyphylla, F. Muell. in Wing, South Sc. Fecord (July 1882).-Austral.

amentacea, $D C$. Prod. ii. 455.-Am. bor.

amentifera, $F$. Muell. in fourn. Linn. Soc. iii. (1859)

141. - Austral

amoena, Sieher, ex Walp. Rep. i. $897=$ rubida.

amoena, Wendl. Comm. Acac. 16. t. 4.-Anstral.

amythethophylla, Steud. ex A. Rich. Fl. Abyss. i. 245. -Abysin.

anceps, DC. Mém. Lég. xii. 446.-Austral.

anceps, Hook. Ic. $\mathrm{Pl}, \mathrm{t}, 167=$ complanata.

aneura, F. Muell. in Linnaea, xxvi. (1853-55) 627.Austral.

Angico, Mart. Mat. Med. Bras. 53=Piptadenia rigida angulata, Desv. Journ. Bot. iii. (1814) $68=$ discolor.

\section{ACACIA}

angulosa, Bertol. Fl. Guatim. $42=$ filicina

angustifolia, Lodd. Bot. Cab. t. $768=$ longifolia.

angustifolia, Meissn. in Lehm. Pl. Preiss. i. $13=$ triquetra. angustifolia, Wendl. Comm. Acac. $34=$ suaveolens. angustiloba, DC. Prod. ii. 470= Piptadenia peregrina. angustisiliqua, Desf. Cat. Hort. Par. ed. III. $300=$ Desmanthus virgatus.

anthelmintica, Baill. Hist. P1. ii, $56=$ Albizzia anthelmintica.

apiculata, Meissn. in Lehm. Pl. Preiss. i. $17=$ subcaerulea.

arabica, Willd. Sp. Pl. iv. 1085.-Afr. ; As. trop.

Arar, Buch.-Ham. in Wall. Cat. n. $5249=\mathrm{A}$. Intsia

arborea, Benth. P1. Hartw. 13=Lysiloma microphylla. arborea, Willd. Sp. P1. iv. $1064=$ Pithecolobium filicifolium.

Arceuthos, Spreng. Syst. iii. $134=$ juniperina.

arcuata, Decne. Herb. Timor. Desc. 133.--Ins. Timor.

arcuata, Sieber, ex Spreng. Syst. iii. $135=$ melanoxylon

arenosa, Willd. Sp. Pl. iv. 1054 (err. typ. 1060) $=$ Mimosa arenosa.

argyrophylla, Hook. ex F. Muell. Pl. Vict. ii. 18= brachybotrya.

arida, A.Cunn.ex G. Don, Gen. Syst. ii. 404-Austra1. armata, $R$. Br, in Ait. Hort. Kerw. ed. II. v. 463.Austral.

armata, Heyne, ex Wall. Cat. n. 2564=A. Farnesiana. armatoides, Hort. ex Walp. Rep. i. $888=$ armata.

Aroma, Gill. in Hook. Bot. Misc. iii. (1833) $206=$ macracantha.

aromatica, Poepp, ex Benth, in Trans, Linn. Soc. xxx. (1875) $502=\mathrm{A}$. Farnesiana

Arrophula, D. Don? in Wall. Cat. n. $5257=$ Albizzia stipulata?

Arrophula, D. Don. Prod. Fl. Nep. $247=$ pennata.

Asak, Willd. Sp. Pl. iv, $1077=$ hamulosa?

asparagoides, A. Cunn. in Field, N. S. Wales, 343. -Austral.

aspera, Lindl. in Mitch. Three Exped.ii. 139.-Austral. asperulacea, F. Muell. in Journ. Linn. Soc. iii. (1859) $123=1$ ycopodifolia

aspidioides, G. F. W. Mey. Prim. Fl. Esseq. 165= Pentaclethra filamentosa.

asplenioides, Nees, in Flora, iv. (1821) $303=$ Calliandra mertensioides.

astringens, A. Cunn. ex G. Don, Gen. Syst. ii. $405=$ penninervis.

ataxacantha, DC. Prod. ii. 459.-Afr. trop.

ataxiphylla, Benth. in Linnaea, xxvi. (1853-55) 605. - Austral.

atomiphylla, Burch. Trav. i. 341 = haematoxylon.

atramentaria, Benth. in Hook. Lond. Fourn. Bot. i.

(1842) 392.-Chili.

Aucheri, Benth. l. c. $499=$ nubica.

aulacocarpa, A. Cunn. ex Benth. L. c. 379.-Austral.

aurea, Noronha, in Verh. Batav. Gen. v. (1790) Art. iv. 5. - Java.

auriculaeformis, A. Cunn. ex Benth. in Hook. Lond. Fourn. Bot. i. (1842) 377.-Austral

auriculata, Buch.-Ham. ex Wall. Cat, sub n. $5237=$ Albizzia stipulata.

auriculata, Charp. ex Fourn. in Bull. Soc. Bot. Fr. xii (1865) $400=$ Albizzia auriculata.

aurita, Schlecht. in Linnaea, xii. (1838) $565=$ Lysiloma aurita.

auronitens, Lindl. Swan River App. 15.-Austral.

Ausfeldi, Regel, Ind. Sem. Hort. Petrop. (1866) 106 Gartenfl. xvi. (1867) $225=$ aspera.

axillaris, Benth. in Hook. Lond. Fourn. Bot. i. (1842) 341. - Tasmania.

Azak, G. Don, Gen. Syst. ii. $412=$ hamulosa?

Bagsteri, Benth. in Hook. Lond. Fourn. Bot. i. (1842) $327 .-$ Austral.

bahamensis, Griseb. F1. Brit. W. Ind. $221=$ Lysiloma latisiliqua.

bahiensis, Benth. in Trans. Linn. Soc. xxx. (1875)

525.-Am. trop.

Balbisii, Spreng. Syst. iii. $140=$ Pithecolobium fragrans,

Bancroftiana Bert ex Colla, Hort Rip, 1; DC. Prod. ii. 473 = Caesalpinia bijuga.

barbinervis, Benth. in Hook. Lond. Fourn. Bot. i. (1842) 326.-Austral.

basaltica, F. Muell. \& Benth. in Journ. Linn. Soc. iii. (1859) $146=$ Albizzia basaltica.

Baveri, Benth. in Hook. Lond. Fourn. Bot. i. (1842) 344.-Austral.

Baxteri, Benth.l. c. 327.-Austral. 


\section{ACACIA :}

Baxteri, Meissn. in Lehm. Pl. Preisso i. $7=$ congesta. beila, Mart. ex Spreng. Syst. iii. 141 = Calliandra bella. Benthamii, Meissn. in Lehm. P1. Preiss. $11=$ cochlearis, Berlandieri, Benth. in Hook. Lond. Fourn. Bot. i. (1842) 522.-Mexic.

Bernieri, Baill, in Bull. Soc. Linn. Par, i. (1883) 363. -Madag.

Berteriana, Balb. ex DC. Prod, ii. $470=$ Pithecolobium fragrans.

Berteriana, Spreng. Syst. iii. 138.-Jamaica.

biceps, Wiild. Sp. Pl. iv. $1075=$ Lencaena glauca.

bidentata, Benth. in Hook. Lond. Fourn. Bot. i. (1842) 333.-Austral.

Bidwilli, Benth. in Linnaea, xxvi. (1853-55) 629.Austral.

biflora, R. Br. in Ait. Hort. Kew. ed. II. v. 463.Austral.

biflora, Paxt. Mag. ix. (1842) 221 = decipiens,

biglandulosa, Meissn. in Lehm. Pl. Preiss. ii. $205=$ pentadenia.

Bilaura, Buch.-Ham. ex Wall. Cat. sub n. $5234=$ odoratissima.

bimucronata, DC, Prod. ii. $469=$ Mimosa sepiaria.

binervata, DC. l. c. 452 . - Austral.

binervosa, DC. Mém. Lég. xii. $448=$ bivenosa.

bivenosa, DC. Prod, ii. 452.-Austral.

Blomei, Ohlend. in Nete Allgem. Gartenz. (1845) 369 $=$ saligna.

Boivini, Baill. in Bull. Soc. Linn. Par. i. (1883) 363.Madag.

bombycina, Benth. ex Paxt. Flow. Gard. ii. (1851-52). $101=$ brachybotrya.

bonariensis, Gill. in Hook. Bot. Misc. iii. (1833) 207. -Reg. Argent.

Bonplandii, Gill, ex Hook. I. c. $205=$ Mimosa Bonplandii.

bossiaeoides, A. Cunn. ex Benth. in Hook. Lond. fuurn. Bot. i. (1842) 323.-Austral.

bossiaeoides, Seem. Eingef. Acac. t. $1=$ glaucoptera.

botrycephala, Desf. Cat. Hort. Par. ed. III. $300=$ discolor.

brachyacantha, Humb. \& Bonpl. ex Willd. Enum. Hort. Berol. $1055=$ Mimosa acanthocarpa.

brachybotrya, Benth. in Hook. Lond. Fourn. Bot. i. (1842) 347.-Anstral.

brachyloba, Willd. Sp. P1. iv. $1071=$ Desmanthus brachylobus.

brachyphylla, Benth, ex Schlecht. in Linnaea, xxvi. (1853-55) 615.-Austral.

brachyptera, Benth. in Hook. Lond. Journ. Bot. i. (1842) $325=$ incurva.

brachystachya, Benth. Fl. Austral. ii. 403.-Austral.

brasiliensis, Spreng. Syst. iii. 142, - Bras.

brevifolia, Benth. Fl. Austral. ii. 395.-Austral.

brevifolia, Lodd. Bot. Cab. t. $1235=$ lunata.

brevipes, A. Cunn. in Bot. Mag. t. $358=$ melanoxylon.

Browuniana, Wendl. in Flora, ii. (1819) $139=$ strigosa

Brownii, Steud. Nom. ed. I. 2 = juniperina.

brunioides, A. Cunn。 ex G. Don, Gen. Syst. ii. 404.Anstral.

Buchananiana, Voigt, Hort. Suburb. Calc. $293=$ pinnata. Burkei, Benth. in Hook. Lond. Fourn. Bot. v. (1816) 98.-Afr, 2ustr.

Burkittii, F. Muell. ex Benth. Fl. Austral, ii. 400Austral.

Burmanniana, DC. Prod. ii. 461.-Ind. or.

buxifolia, A. Cunn. in Field, N.S. Wales, 344.-Austral.

Bynoeana, Benth. in Linnaea, xxvi. (1853-55) 614.Austral.

caduca, Humb. \& Bonpl. ex Willd. Sp. Pl. iv. 1089 = Minosa caduca.

caesia, Roxb, ex"Wall. Cat. n. 5253 A = pennata.

caesia, Wight \& Arn. Prod. 278.-Ind. or.

caesia, Willd. Sp. P1. iv. 1090, ex parte = A. Intsia.

caffra, Willd. l. c. 1078.-Afr. austr.

calamifolia, Sieber, ex Stend. Nom. ed. II. i. $4=$ quadrilateralis.

calamifolia, Sweet, ex Bot. Reg. t. 839.-Austral.

Caleyi, A. Cunn. ex Benth. in Hook. Lond. Journ.

Bot. i. (1842) $347=$ podalyriaefolia.

callicoma, Meissn. in Hook. Lond. Gourn. Bot. ii. (1843) 104.-Afr. austr.

calligera, F. Muell, ex Benth. in Journ. Linn. Soc. iii. (1859) $141=$ Wickhami.

Callistemon, Schlecht, in Linnaea, xii. (1838) $568=$ Calliandra grandiflora.

callosa, Bertol. Pl. Nov, Hort. Bon. i. 9.-Hab. ?

\section{ACACIA :-}

callosa, Spreng. Syst. iii. $138=$ Piptadenia communis

calyculata, A. Cunn. ex Benth. in Hook. Lond. Fourn. Bot. i. (1842) 379.-Austral.

Campbellii, Arn in Nor. Act. Nat. Cur. xviii. 1. (1836) $333=$ planiformis

campylacantha, Hochst. ex A. Rich. Tent. Fl. Abyss. i. $242=$ A. Suma.

campylophylla, Benth. ex Schlecht. in Linnaea, xxvi. (1853-55) 605.-Anstral.

Candolleana, Meissn。 in Lehm, Pl. Preiss. ii. $200=$ Drummondii.

canescens, R. Grah. in Wall, Cat. n. $5256=$ pennata. canescens, Mart. \& Gal, in Bull. Acad. Brux. Xo It

1843) $314=$ Mimosa depauperata.

capensis, Burch. Trav, i. $195=$ horrida.

capensis, Colla, in Mem. Acc. Torin. xxxy. (1831) 175. -Afr. austr.

caracasana, Willd. Sp. Pl. iv, $1068=$ Calliandra caracasana.

carbonaria, Schlecht. in Linnaea, xii. (1838) $571=$ villosa.

cardiophylla, A. Cunn. ex Benth. in Hook. Lond. Fourn. Bot. i. (1842) 385.-Austral.

Caringa, Buch.-Ham. in Wall. Cat. n. $5239=$ Leucaena glauca.

cassioides, Willd. Enum. Hort. Berol. 1051.-Hab. ?

Catechu, Brandis, For. Fl. $186=$ A. Sundra.

Catechu, Wight \& Arn. Prod. $272=$ A. Suma

Catechu, Willd. Sp. Pl. iv, 1079.-Ind, or,

catechuoides, Benth. in Hook. Lond. Journ. Bot. i. 1842) $510=$ A. Catechu.

caudata, DC. Prod. ii. $456=$ Entada polystachya.

Cavenia, Bert. ex Bull. Férussac, xx. (1830) $108=$

A. Farnesiana.

Cebil, Griseb. in Goett. Abh. xix. (1874) 136.-Reg. Argent.

cedroides, Benth. ex Schlecht. in Linnaea, xxvi. (1853-55) 615.-Austral.

celastrifolia, Benth. in Hook. Lond. Journ. Bot. is (1842) $349=$ myrtifolia.

centrophylla, DC. Prod. ii. 465.-Jamaica.

centrota, Spreng. ex DC. 1. c. = praec

Ceratonia, Willd, Sp. PI. iv. 1091= Mimosa Ceratonia. chlorantha, Zucc. in Abh. Akad. Muench. ii. (1832) $347=$ filicina

chordophylla, F. Muell. ex Benth. in Linnaea, xxvi. $(1853-55) 612=$ rigens.

choriophylla, Benth. in Hook. Lond. Fourn. Bot. i. (1842) 495,-Ins. Baham.

chrysantha, $D C$. Prod. ii. 471.-Guiana.

chrysobotrys, Meissn. Ind. Sem. Hort. Basil. (1842) $1=$ spectabilis.

chrysocoma, Miq. in Fl. Ind. Bat. i. I. $6=$ tomentosa.

Chundra, Willd. Sp. P1. iv. $1078=$ A. Catechu.

cibaria, F. Muell. in Melb. Chemist (July 1882),Austral.

ciliata, R. Br. in Ait. Hort. Kew. ed. II. v. 465 = strigosa. ciliata, Humb. E Bonpl. ex Willd. Enum. Hort. Berol. 1055.-Am, austr.

cincinnata, F. Muell. Fragm. xi. 35.-Austral.

Cineraria, Willd. Sp. Pl. iv. $1057=$ Prosopis spicigera.

cinerascens, Sieber, ex DC. Prod. ii. $454=$ glaucescens.

cinerea, Spreng. Syst. iii. $143=$ Dichrostachys cinerea.

Clausseni, Benth. in Hook. Lond. Journ, Bot. i. (1842) $518=$ paniculata .

clavata, Schlecht. in Linnaea, xx. (1847) $662=$ montana

clavigera, E.Mey. Comm. Pl.Afr.Austr.168.-Afr, austr.

Coa, Walp, Ann. iv, 626=A. Koa,

cochlearis, Wendl. Comm. Acac. 15. - Anstral.

cochliacantha, Humb. E Bonpl. ex Willd. Sp. Pl. iv. 1081.-Am. austr.

cochliocarpa, G. Don, Gen. Syst. ii. 422.-Bras.

cochlocarpa, Meissn. in Bot. Zeit. xiii. (1855) 10.Austral.

Colleana, Presl, Rep. Bot. Syst. $183=$ Calliandra portoricensis.

colletioides, A. Cunn.ex Benth. in Hook. Lond. Gourn. Bot. i. (1842) 396.-Austral.

colletioides, F, Muell. Pl. Vict. ii. $5=$ continua.

colubrina, Mart. Herb. Fl。Bras。 107 = Piptadenia colubrina.

comorensis, Baill, in Bull. Soc. Linn. Par. 1. (1883) 363.-Afr, trop.

complanata, A. Cunn. ex Benth. in Hook. Lond. Fourn. Bot. i. (1842) 369 -Austral.

compressa, Schult. ex Colla, Hort. Ripul. App. ii. $993=$ visneoides.
ACACIA :-

concinna, $D C$. Prod. ii. 464. - As. trop.

concinna, Phil, in Anal. Univ. Chil. (1870) II. 170.-

Chili.

concinna, Wall. Cat. n. $5250 \mathrm{D}=$ pennala

concordiana, Loud. Hort. Brit. $402=$ Pithecolobium umbellatum.

conferta, A. Cunn. ex Benth, in Hook. Lond. Fourn.

Bot. i. (1842) 345.-Anstral.

congesta, Benth, l. c. 327.-Austral.

conjunctifolia, F. Muell. Fragm. xi. 68.-Austral.

conspersa, F. Muell. in Fourn. Linn. Soc. iii. (1859)

140.-Austral.

conspicua, A. Cunn. ex G. Don, Gen. Syst. ii. $405=$ vestita.

constricta, Benth. in A. Gray, Pl. Wright. i. 66.N. Mexic.

continua, Benth. Fl. Austral. ii. 322.-Austral.

contorta, DC. Prod, ii. $470=$ Piptadenia contorta.

Cooleyi, Eaton, Man. ed. VI. (1833) 1 =Desmanthus Jamesii.

cordata, Steud. Nom, ed. II. i. 4.-Aastral.

criacea, DC. Mím. Lég. xii. 446.-Austral.

coriaria, Buch.-Ham. ex Wall. Cat. sub n. 5264 B

A. Farnesiana.

cornigera, Willd. Sp. Pl. iv. $1080=$ spadicigera. sphaerocephala.

coronillacfolia, Desf. Tabl. ed. II. 307.-Afr. bor.

costata, Benth. in Hook. Lond. Fourn. Bot. i. (1812)

339.-Austral.

Coulteri, Benth. ex A. Gray, Pl. Wright. i. 66.-N.

Mexic.

Courrantiana, DC. Prod. ii. $465=$ Mimosa acantholoba. crassicarpa, A. Cunn.ex Benth in Hook. Lond. Fourn. Bot. i. (1842) 379.-Austral.

crassifolia, A. Gray, in Mem. Am. Acad. N. S. v. (1855) 317.-Mexic.

crassistipula, Benth. in Hook. Lond. Fourn. Bot. (1842) 326.-Anstral.

crassiuscula, Meissn. in Lehm. Pl. Preiss. i. $16=$ pycnophylla.

crassiuscula, Wendl. Comm. Acac. 31. t. 8.-Austral.

crispala, Benth. ex Schlecht. in Linnaea, xxvi. (185355) 606.-Austral.

cultrata, Ait. ex Steud. Nom. ed. II. i. 4.-Austral.

cultriformis, A. Cunn. ex G. Don, Gen. Syst. ii. 406.Austral.

cumanensis, Humb. \& Bonpl. ex Willd. Sp. P1. iv. $1058=$ Prosopis julifiora.

Cumingii, Benth. in Hook. Lond. Journ. Bot. i. (1842, $525=$ villosa.

cuneata, Benth. in Enum. Pl. Hueg. 42.-Austral

Cunninghamii, Hook. Ic. Pl. t. 165.-Austral.

Cunninghamii, Sweet, Hort. Brit. ed. II. $16 \pm=$ triner-

vata.
curvifolia, Bonpl. Desc. Pl. Malm. 99. t. 40.-Hab.? cuspidata, A. Cunn. ex Benth. in Huok. Lond. Jonm. Bot. i. (1842) $337=$ diffusa.

cuspidata, Schlecht. in Linnaea, xii. (1838) $5 \% 3=$ fili. cina.

cyanophylla, Lindl. Bot. Reg. (1539) Misc. 15.Austral.

cyclophylla, Schlecht. in Linnaea, xx. (181i) $669=$ obliqua.

Cyclops, A. Cunn. ex G. Don, Gen. Syst. ii. 404 Austral.

cyclosperma, DC. Prod. ii. $456=$ Albizzia fulgens.

cycnorum, Benth. in Hook. Lond. Joura. But. i. 15:? $388=$ pulchella.

cycrorum, Hook. Bot. Mag, t. 4653=obscara

cygnorum, Meissn, in Lehm. Pl. Preiss. i. $22=\mathrm{pal}$. chella.

cylindrifiora, Mart. \& Gal. in Bull. Acad. Brux. x. (1843) 311.-Mexic.

cymbacantha, Zacc. ex Benth. in Trans. Lian. Soc. $x \times x$. 1875) $501=$ cochliacantha

cyperophylla, F. Muell. ex Benth. Fl. Aastrab. ii. tou. -Austral.

Daintreana, F. Mfuell. Fragm. iv. $6=$ excelsa.

Dalera, Desv. Joum. Bot. iii. (1s11) 69 Ilichrostachsy cinerea.

Dallachiana, F. Isuell. Fragm. i. 7.-Austral.

daphnifolia, Meissa. in Bot. Zeir xiii. (1855) 11 = microbotrya.

dasyphylla, A. Cunn. ex Benth. in Hook. Lond. Joum. Bot. i. $(1 \$+2) 359$ - limeata.

daviesiacfolia, A. Cunm. ex Lowd. Hort. Eria. fivo.Austral. 


\section{ACACIA :-}

daviesioides, A. Cunn. ex G. Don, Gen. Syst. ii. $402=$ diffusa

dealbata, A. Cunn. in Field, N. S. Wales, $345=$ lunata dealbata, Link, Enum. Hort. Berol. 445.-Austral.

Decaisnei, Steud. Nom. ed. II. i. $4=$ arcuata.

decipiens, R. Br. in Ait. Hort. Kew. ed. II. v. 463.Ind. or. ; Austral

decora, Reichb. Ic. Exot. t. 199.-Austra1.

decurrens, Willd. Sp. Pl. iv. 1072.-Austral.

decussata, Tenore, Cat. Ort. Nap. (1845) $77=$ longifolia.

delibrata, A. Cunn. ex Benth. in Hook. Lond. Fourn. Bot. i. (1842) 374.-Austral.

deltoidea, A.Cunn. ex G.Don, Gen. Syst. ii. 401.Austral.

demostachya, Benth. PI. Hartw. 12 = acapulcensis.

Dempsteri, F. Muell. Fragm. xi. 65.-Austral

densa, Wall. Cat. n. 5262=leucophloea.

densifolia, Benth, in Hook. Lond. Journ. Bot. i. (1842) $360=$ asрега.

denticulosa, F. Muell. Fragm.x. 32.-Austral.

dentifera, Benth. in Maund, Botanist, iv. t. 179.Austral.

denudata, Lehm. Del. Sem. Hort. Hamb. (1842)= pulchella.

depauperata, Mart. ex Steud. Nom. ed. II. i, $4=$ Desmanthus virgatus.

dependens, A. Cunn. ex Benth. in Hook. Lond. Journ. Bot. i. (1842) $372=$ longifolia.

dermatophylla, Benth. Fl. Austral. ii. 346.-Austral.

desmostachya, Benth. Pl. Hartw. 13=Lysiloma acapulcensis.

detinens, Burch. Trav. i. 310.-Afr. austr.

dictyocarpa, Benth. in Linnaea, xxvi.(1853-55) 616 = brachybotrya.

dictyophleba, F. Muell. Fragm. iii. 128.-Austral.

Dietrichiana, F. Muell. in Wing, South Sc. Record, ii (1882) 149.-Austral.

diffusa, Lindl. Bot. Reg. t. 634.-Austral

dilatata, Benth. in Linnaea, xxvi. (1853-55) 608.Austral.

dilatata, Steud. Nom. ed. II. i. 4.-Austral.

dimidiata, Benth. in Hook. Lond. Fourn. Bot. i. (1842) 381.-Austral.

dineura, F. Muell. ex Benth. in Journ. Linn. Soc. iii. (1859) $130=$ binervata.

diptera, Lindl. Swan River App. 15.-Aastral.

diptera, Willd. Enum. Hort. Berol. $1051=$ Prosopis juliflora.

discolor, Whitley, ex Steud. Nom. ed. II. i. 4 = prismatica discolor, Willd. Sp. Pl. iv. 1068.-Austral.

dissitiflora, Benth. in Hook.Lond. Journ. Bot. i. (1842) $371=$ longifolia.

dissoneura, F. Muell. in Wing, South Sc. Record (July 1882)-Austral.

distachya, Moç. \& Sesse, ex DC. Prod. ii. 456=Mimosa distachya.

divaricata, A. Cunn. ex Steud. Nom. ed. II. i. $4=$ dilatata.

divaricata, Willd.Sp.Pl.iv.1070=Lysiloma.Schiedeana divergens, Benth. in Hook. Lond. Fourn. Bot. i. (1842) 331 - Austral.

diversifolia, Schlecht. in Linnaea, xii. (1838) $571=$ Leucaena diversifolia

dodonaeifolia, Willd. Enum. Hort. Berol. Suppl. 68.Austral.

dolabriformis, Colla, Hort. Ripul. $1=$ decipiens.

dolabriformis, A. Cann. in Hook. Ic. Pl. t. $169=$ di midiata.

dolabriformis, Wendl. Acac. $56=$ Daviesia incrassata.

domingensis, Bert. ex DC. Prod. ii. 464=Mimosa do mingensis.

doratoxylon, A. Cunn. in Field, N. S. Wales, 345.Austral.

doratoxylon, Meissn. in Lehm. P1. Preiss. i. $19=$ acuminata.

drepanocarpa, F. Muell. in fourn. Linn. Soc. iii. (1959) 137.-Austral.

Drummondii, Benth. in Lindl. Swan River App.15.Austral.

dumetorum, $D C$. Prod. ii. 458.-Bras.

dumosa, Wight \& Arn. Prod. $274=$ latronum.

dura, Benth. in Linnaea, xxvi. (1853-55) 622.-Austrai. Durandiana, Buckl. in Proc. Acad. Sc. Philad. 1861 (1862) $453=$ Greggii.

dysophylla, Benth. in Hook. Lond. Journ. Bot. i. (184.2) $346=$ undulaefolia.

eburnea, Willd. Sp. Pl. iv. 1081.-Oriens; Ind. or.

\section{ACACIA:-}

echinula, DC. Prod. ii. $449=$ juniperina.

Edgeworthii, T. Anders. in Fourn. Linn. Soc. v. (1860) Suppl. 18.-Ind. or.

edulis, Humb. \& Bonpl. ex Willd. Enum. Hort. Berol. $1056=$ A. Farnesiana.

eglandulosa, DC. Mém. Lég. xii. $445=$ cochlearis

Ehrenbergiana, Hayne, Arzneigew. x. t. 29.-Afr. trop

Ehrenbergii, T. Nees, P1. Offic. t. $334=$ praec.

Ehrenbergii, Steud. Nom. ed. II. i. 5.-Mexic.

elata, A. Cunn. ex Benth. in Hook. Lond. Fourn. Bot.

i. (1842) 383.-Austral.

elata, R. Grah. in Wall. Cat. n. $5233=$ Albizzia procera elegans, Schlecht. in Linnaea, xii. (1838) $569=$ filicina.

elephantina, Burch. Trav. ii. $236=$ Elephantorrhiza Burchelli.

Elephantorrhiza, Burch. ex DC. Prod. ii. $457=$ praec. elliptica, A. Cunn. ex Benth. in Hook. Lond. Journ. Bot. i. (1842) $347=$ bivenosa.

elongata, Sieber, ex DC. Prod. ii. 451.-Austral

emarginata, Wendl. Comm. Acac. $27=$ stricta.

Emoryana, Benth. in Trans. Linn. Soc. xxx. (1875) 522.-Am. bor.

Endlicheri, Meissn. ex Lehm. Pl. Preiss. i. 21 =strigosa. ephedroides, Benth. in Hook. Lond. Fourn. Bot. (1842) 370 -Austral.

eriadenia, Benth. l. c. v. (1846) 98.-Afr. austr.

eriantha, Desv. Fourn. Bot. 1ii. (1814) 68.-Ind. or.?

ericaefolia, Benth. in Hook. Lond. Fourn. Bot.1. (1842)

345.-Austral.

erinacea, Benth. l. c. 360-Austral.

erioclada, Benth. in Linnaea, xxvi. (1853-55) 606.Austral.

evioloba, Edgew. in Journ. As. Soc. Beng. xvi. (1847) $1215=$ Edgeworthii.

evioloba, E. Mey. Comm. Pl. Afr. Austr. i. 171= giraffae, eriophylla, Hort. ex Loud. Encyc. Pl. Suppl. i1. 1532 $=$ viscidula.

erubescens, Welw.ex Oliver, Fl. Trop. Afr.ii. 343.Afr. trop.

erythrantha, Steud. ex A. Rich. Tent. Fl. Abyss. i. 243 =A. Suma.

erythrocephala, A. Cunn. ex Benth. in Hook. Lond. Journ. Bot. i. (1842) $362=$ aspera.

erythropus, Tenore, Ind. Sem. Hort. Nap. (1842) $12=$ Riceana.

esculenta, Mart. \& Gal. in Bull. Acad. Brux. x. II. (1843) $314=$ Leucaena pulverulenta

esculenta, Moc. \& Sesse, ex DC. Prod. ii. $470=$ Leacaena esculenta.

Esterhazia, Mackay, ex Regel, Cat. Pl. Hort. Aksakov. 2.-Austral.

estrophiolata, F. Muell. in Wing, South Sc. Record (July 1882).-Austral.

etbaica, Schweinf. in Linnaea, xxxv. (1867-68) 330 . t. 7, 8.-Afr. trop.

excelsa, Benth. in Mitch. Trop. Austral. 225.-Austral. explanata, Jungh. Reise, 260; ex Miq. F1. Ind. Bat. I. $9=$ letucophloea.

exsudans, Lindl. in Mitch. Three Exped. ii. $214=$ verniciflua.

extensa, Linall. Swan River App. 15.-Austral.

fagonioides, Benth. in Hook. Lond. Journ. Bot. i. (1842) 387 = pulchella.

falcata, Desf. Tabl. ed. II. $207=$ Prosopis juliflora.

falcata, Sieber, ex Steud. Nom. ed. II. 1. $5=$ plagiophylla.

falcata, Willd. Sp. Pl. iv. 1053.-Austral

falcifolia, Hoffmgg. Verz. Pfl. Nachtr. 125, $201=$ procumbens.

falciformis, DC. Prod. ii. $452=$ penninervis.

falcinella, Meissn.in Bot. Zeit. xiii.(1855) 11 = pycnantha.

falcinella, Tausch, in Flora, xix. (1836) 419 -Anstral.

fallax, E. Mey. Comm. Pl. Afr. Austr. i. 169=caffra.

farinosa, Lindl. in Mitch.Three Exped.ii. 146.-Austral.

Farnesiana, Wall. Cat, n. $5264=$ planifrons.

Farnesiana, Willd. Sp. Pl. iv. 1083.-Reg. trop.

fasciculata, R. Br. in Salt, Abyss. App. 65=A. Lahal.

fasciculata, Guill. \& Perr. Fl. Seneg. Tent. i. $252=$ tortilis.

fasciculata, Kunth, Mim.75.t. $23=$ Mimosa fasciculata. fasciculifera, F. Muell. ex Benth. Fl. Austral. ii. 361. -Austral.

ferox, Benth. in Hook. Lond. Fourn. Bot. v. (1846) 97.-Afr. austr.

ferox, Mart. Eم Gal. in Bull. Acad. Brux. x. II. (1843) 312.-Mexic.

ferruginea, $D C$. Prod. ii. 458.-Ind. or.

\section{ACACIA :}

filicina, Willd. Sp. Pl. iv. 1072,-Mexic. filicoma, Mart. in Flora, xx. (1837) Beibl. ii, $109=$
Piptadenia nitida.

filifolia, Benth. in Hook. Lond. Journ. Bot. i. (1842) $369=$ ephedroides.

fimbriata, A. Cunn. ex G. Don, Gen. Syst. ii. $406=$ prominens.

Fistula, Schweinf, in Linnaea, xxxv. $(1867-68) 344=$ A. Seyal.

flaccida, Spreng. Syst. iii. 137.-Bras.

flava, Spreng. ex DC. Prod. ii, $469=$ Piptadenia flava.

flavescens, A. Cunn. ex Benth. in Hook. Lond. Fourn. Bot. i. (1842) 381.-Austral.

flexicaulis, Benth. l. c. 505.-Texas.

flexifolia, A.Cunn. ex Benth. l.c. i. 359.-Austral.

flexuosa, Humb. \& Bonpl. ex Will. Sp. Pl. iv. $1082=$ macracantha.

flexuosa, Lag. Gen. et Sp. Nov. $16=$ Prosopis juliflora. floribunda, Willd. Sp. PL. iv. $1051=$ longifolia.

fluviatilis, Spreng. Syst. v. Ind. $3=$ polyphylla.

foetida, H. B. \& K. Nov. Gen. et Sp. vi. $265=$ Piptadenia foetida.

foliolosa, R. Grah. in Wall. Cat. n. 5241=Albizzia myriophylla.

formosa, Kunth, Mim. 102. t. $32=$ Calliandra formosa.

fragrans, Tenore, Cat. Ort. Nap. 1 = Calliandra caracasana.

Fraseri, Hook. Ic. PI. t. $171=$ podalyriaefolia.

frondosa, Willd. Sp. Pl. iv. 1076=Leucaena glauca.

frutescens, Steud. Nom. ed. II. 1. 5.-Ind. or.

fruticosa, Loud. Hort. Brit. $409=$ frutescens.

fruticosa, Mart. Herb. Fl. Bras. 107=Piptadenia latifolia.

fruticosa, Voigt, Hort. Suburb. Calc. $261=$ Mimosa fruticosa, Roxb.

fulgens, Charp. ex Fourn. in Bull, Soc. Bot. Fr. xix. (1865) $400=$ Albizzia Charpentieri.

fulgens, Labill. Sert. Austr. Caled. 68. t. $67=$ Albizzia fulgens.

furcata, Desv. Journ. Bot. iii. (1814) $67=$ Prosopis juliflora.

furcata, Gill. in Hook. Bot. Misc. iii. (1833) 206.-Am. austr.

furcifera, Lindl. in Mitch. Three Exped. ii. $267=$ armata.

furfuracea, G. Don, Gen. Syst. ii. $405=$ lunata.

galioides, Benth. in Hook. Lond. Fourn. Bot. i. (1842) 344.-Austral.

gemella, Hoffmgg. Verz. Pfl. Nachtr. ii. 40 ; iii. 16. Hab?

genistifolia, Link, Enum. Hort. Berol. ii. $442=$ diffusa.

genistoides, A. Cunn. ex Benth. Fl. Austral. ii. 330.Austral.

Gerrardi, Benth. in Trans. Linn. Soc. xxx. (1875) 508. -Afr. austr.

gigantea, Noronha, in Verh. Batav. Gen. v. (1790) Art. IV. 5=Parkia speciosa.

Gilberti, Meissn. in Lehm. Pl. Preiss. ii. 204.-Austral.

Gilesiana, F. Muell. in Melb. Chemist (July 1882).Austral.

Gilliesii, Steud. Nom. ed. II. i. $5=$ furcata.

Giraffa, Sieber, ex Stend. 1. c. = A. Seyal.

giraffae, Hochst. ex A. Rich. Tent. Fl. Abyss. i. $238=$ stenocarpa

giraffae, Willd. Enum. Hort. Berol. 1054.-Afr. austr.

glabrata, Schlecht. in Linnaea, xii. (1838) $569=$ filicina.

gladiiformis, A. Cunn. ex Benth. in Hook. Lond. Fourn. Bot. i. (1842) 354.-Austral.

glandulosa, Guill. in Ann. Sc. Nat. Sér. II. vii. (1837) $360=$ Leucaena Forsteri.

glandulosa, Willd. Sp. Pl. iv. $1071=$ Desmanthus brachylobus.

glauca, Moench, Meth. $466=$ Leucaena glauca .

glaucescens, Willd. Sp. Pl. iv. 1052.-Austral.

glaucifolia, Baumg. ex Lehm. Pl. Preiss. 1.14 in nota = cultriformis.

glaucophylla, Steud. ex A. Rich. Tent. Fl. Abyss. i. 243.-Afr. trop.

glaucoptera, Benth. in Linnaea, xxvi. (1853-55) 604. -Austral.

glomerosa, Benth. in Hook. Lond. Fourn. Bot. i. (1842) 521.-Am. austr.

glutinosa, F. Muell. Fragm. iv. $6=$ ixiophylla .

Gnidium, Benth. Fl. Austral. ii. 359-Austral.

gonoacantha, Mart. in Flora, xx. (1837) Beibl. ii. 109 = Piptadenia communis. 


\section{ACACIA:-}

gonocarpa, F. Muell. in Fourn. Linn. Soc. iii. (1859) 136.-Austral.

gonoclada, F, Muell. l. c. 140.-Austral.

gonophylla, Benth. in Linnaea, xxvi. (1853-55) 613. - Austral.

gracilis, Mart. \& Gal. in Bull. Acad. Brux. x. II. (1843) $311=$ Calliandra formosa.

graminea, Lehm. Del, Sem. Hort, Hamb. (1842)= extensa.

grandiflora, Willd. Sp. Pl. iv. $1074=$ Calliandra grandiflora.

grandis, Henfr. in Gard. Mag. Bot. iii. (1851) $177=$ pulchella.

grandisiliqua, Benth. in Hook. Lond. Joum. Bot. i. (1842) $518=$ paniculata.

grandistipula, Benth. l. c. 511.-Bras.

granulosa, Labill. Fl. N. Caled. 67 . t. $66=$ Albizzia

granulosa.
grata, Willd. Enum. Hort. Berol. 1056 = Piptadenia macrocarpa.

graveolens, A. Cunn. ex G. Don, Gen. Syst. ii. $404=$ verniciflua.

Greggii, A. Gray, Pl. Wright. i. 65.-N. Mexico.

Gregorii, F. Muell. Fragm. iii. 47.-Austral.

Greveana, Baill. in Bull. Soc. Linn. Par. i. (1883) 364 -Madag.

Guachapele, H. B. \& K. Nov. Gen. et Sp. vi. $281=$ Lysiloma Guachapele.

guadalupensis, DC. Prod. ii. $464=$ riparia

gualparensis, Steud. Nom. ed. II. i. $5=$ Albizzia stipulata.

guatemalensis, Hook. \& Arn. Bot. Beech. Voy. $419=$ Mimosa guatemalensis.

guayaquilensis, Desf. Tabl. Hort. Par. ed. II. $208=$

Mimosa guayaquilensis.

guianensis, Willd. Sp. P1. iv. $1061=$ Stryphnodendron guianense.

Guilandinae, DC. Prod. ii. $465=$ Mimosa obovata.

gummifera, Delile, F1. Aeg. Illustr. $79=$ spirocarpa.

gummifera, Willd. Sp. Pl. iv. 1056.-Afr. bor.

Gunni, Benth, in Hook. Lond. Journ. Bot. i. (1842)

$332=$ vomeriformis.

guttata, Hoffmgg. Vers. Pfl. Nachtr. i. 201, 125,Hab.?

guttulifera, Hoffmgg. l. c. iii. 16= Martinicus

gyrocarpa, Hochst. ex A. Rich. Tent. F1. Abyss. i. 241 $=$ albida.

Habbas, Link, Enum. Hort. Berol. ii. $444=$ Mimosa aspera?

habbasioides, Boj. Hort. Maurit. $116=$ concinna.

hadiensis, DC. Prod. ii. 472.-Arab.

haematomma, Bert. ex DC. Mém. Lég. xii. 448. t. 68 = Calliandra haematomma.

Hacmatoxylon, Willd. Enum. Hort. Berol. 1056.Afr. austr.

hakeoides, A. Cunn. ex Benth. in Hook. Lond. Fourn. Bot. i. (1842) 354.-Austral.

Hamiltoni, Desv, in Ham. Prod. Fl. Ind. Occ. $59=$ Calliandra portoricensis.

hamulosa, Benth. in Hook. Lond. Fourn. Bot. i. (1842) 509.-Arab.

harpophylla, F. Muell. ex Benth. Fl. Austral. ii. 389.

Hartwegi, Benth. P1. Hartw. $13=$ filicina.

Harveyi, Benth. Fl. Austral. ii. 368.-Austral.

hastulata, Sm. in Rees, Cyclop, xxxix, Suppl.Austral.

Hayesii, Benth. in Trans. Linn. Soc. xxx. (1875) 524.Am. trop.

hebecephala, A. Cunn. ex G. Don, Gen. Syst. ii. $408=$ elongata.

hebeclada, DC. Cat. Hort. Monsp. 73 ; Prod. ii. 461.Afr. austr.

hecatophylla, Steud. ex A. Rich. Tent. Fl. Abyss, i. 242. - Afr. trop

hemignosta, F. Muell. in Fourn. Linn. Soc. iii. (1859) 134.-Am. trop.

hemiteles, Benth. in Linnaea, xxvi. (1858-55) $619=$ subcaerulea.

Hemu, Walp. Rep. v. 598 (sphalm. pro A. Nemu).

heteracantha, Burch. Trav. i. 389.-Afr. austr.

heterocarpa, Delile, F1. Aeg. Illustr. $79=$ Prosopis Stephaniana.

heteroclita, Meissn. in Lehm. Pl. Preiss. i. 18.Austral.

heteroneura, Benth. in Linnaca, xxvi. (1853-55) 624 -Anstral.

\section{ACACIA:-} heterophylla, Hook. \& Arn. Bot. Beech. Voy. $81=$
A. Koa.

heterophylla, Willd. Sp. Pl. iv. 1054.-Ins. Mascar.

Hindsii, Benth. in Hook. Lond. Fourn. Bot. i. (1842) 504,-Mexico.

hippuroides, Heward, ex Benth. l. c. 344.-Austral

hirsuta, Schlecht. in Linnaea, xii. (1838) $572=$ filicina hirta, Boj. Hort. Maurit. 115.-Ins. Maurit.

hirta, Mart. \& Gal, in Bull. Acad. Brux. x. II. (1843) $318=$ Mimosa Galeottii.

hirta, Nutt. in Torr. \& Gray, Fl. N. Am. i. $404=$ filicina.

hirtella, E. Mey. Comm. Pl. Afr. Austr. 167.-Afr. austr.

hispidissima, DC. Prod. ii. $455=$ pulchella.

hispidula, Willd. Sp. Pl. iv, 1054.-Austral

Hoffmannseggii, DC. Prod. ii. 471.-Bras.

holocarpa, Benth. Fl. Austral. ii, 408.-Austral.

holosericea, A.Cunn ex G. Don, Gen. Syst ii 407 Austral.

homaloclada, F. Muell. Fragm. xi. 34.-Austral. homalophylla, A. Cunn. ex Benth. in Hook. Lond. Fourn. Bot. i. (1842) 365.-Austral.

homomalla, Wendl. Acac. 49. t. $13=$ glatcescens.

Hookeri, Meissn. in Lebm. Pl. Preiss i. $11=$ ericifolia

Hooperiana, Zipp. ex Miq. Fl. Ind. Bat. i. $10=$ concinna.

horrida, Span. in Linnaea, xv. (1841) $199=$ pennata horrida, Willd. Sp. Pl. iv. 1082.-Afr. austr.

horridula, Meissn. in Lehm. Pl. Preiss. i. 9.-Austral.

hostilis, Mart. Reise, i. $555=$ Mimosa hostilis

Houstoni, Willd. Sp. Pl. iv, $1062=$ Calliandra Houstoni.

Huegelii, Benth. in Enum. Pl. Hueg. 42.-Austral.

Humboldtii, Desv. in Ham. Prod. F1. Ind. Occ. $60=$ macracantha.

humifusa, A. Cunn. ex Benth. in Hook. Lond. Fourn. Bot. i. (1842) 382.-Austral.

humilis, Schlecht. in Linnaea, xii. (1838) $567=$ Calliandra humilis.

Hunteri, Oliver, in Hook. Ic. Pl. t. 1350.-Arab.

hybrida, Lodd. Bot. Cab. t. $1342=$ armata

hypacantha, Hoffmgg. ex Heynh. Nomencl. i. 3, nomen.-Afr. austr.

idiomorpha, A. Cunn. ex Benth. in Hook. Lond. Fourn. Bot. i. (1842) 329.-Austral.

ignorata, C. Koch, in Allo. Gartz. (1858) 195.-Hab. ? imbricata, F. Muell. Fragm. i, 65=lineata,

implexa, Benth. in Hook. Lond. Fourn. Bot. i. (1842) 368.-Austral.

impressa, F. Muell. in Fourn. Linn. Soc. iii. (1859) 133.-Austral

impressa, Lindl. in Bot. Reg. t. $1115=$ penninervis.

incana, Spreng. Syst. iii. $137=$ Mimosa incana.

incrassata, Hook. Ic. Pl, t. $370=$ decipiens.

incurva, Benth. in Hook. Lond. Fourn. Bot. i. (1842) 325.-Austral.

indica, Desv. Journ, Bot. i. (1814) $69=$ Farnesiana.

ingrata, Benth. Fl. Austral. ii. 331.-Austral.

insignis, Hoffmgg. Verz. Pf. 159=Albizzia lophantha. insignis, Mart. \& Gal, in Bull. Acad. Brux, x. If (1843) $313=$ filicina

insularis, A. Rich. Ess. Fl. Cub. 464.-Ind. oce. insularum, Guill. in Ann. Sc. Nat. Sér. II. vii. (1837) $360=$ Leucaena Forsteri.

intermedia, A. Cunn. ex Hook. Bot. Mag. t. $3203=$ longifolia

intermedia, Pasq. in Atti R. Acad. Nap. ix. (1882) 7. -Hab.?

intertexta, Sieber, ex DC. Prod. ii. $454=$ longifolia,

Intsia, Willd. Sp. Pl. iv. $1091=$ caesia.

intsioides, DC. Prod, ii. $464=$ praec.

inundata, Mart. Reise, i. 555=Pithecolobium multiflorum.

irrorata, Sieber, ex Spreng. Syst. iii. 141=dealbata.

Isenbergiana, Schimp. ex A. Rich. Tent. Fl. Abyss. i. $286=$ Albizzia Julibrissin.

iteaphylla, F. Muell, ex Benth. in Linnaea, xxvi. (1858-55) $617=$ neriifolia

ixiophylla, Benth. in Hook. Lond. Fourn. Bot. i. (1842) 364.-Austral.

Jacquemontii, Benth. L. c. 499.-Ind. or.

Jaubertiana, Baill. in Bull. Soc. Linn. Par. i. (18\&\$) 363.-Madas

javanica, $D C$. Prod. ii. 471.-Tava.

Fulibrissin, Willd. Sp. PI. iv. $1065=$ Albizzin Julibrissin.
ACACIA :-

Fulibrissin, Sieber, ex Benth. in Trans. Linn. Soc. $x x x$ (1875) $529=$ paniculata.

julifera, Benth. in Hook. Lond. Fourn. Bot. i. (1842 374,-Austral.

julifera, F. Muell. in Joum. Linn. Soc. ii. (1859) 13 !

juliflora, Willd. Sp. PI. iv, $1076=$ Prosopis juliflora

juncifolia, Benth. in Hook. Lond. Fourn. Bot. i. (1842) 341.-Austral.

juniperina, Willd. Sp. Pl. iv. 1049.-Austral.

Fupunba, Willd. I. c. $1067=$ Pithecolobium trapezi lium.

Jurema, Mart. Reise, ii. 788; Syst. Mat. Med. Fl. Bras. 53.- Bras.

Kalkora, G. Don, in Loud. Hort. Brit. $409=$ Albizzia Julibrissin.

Kantuffa, Bruce, ex Steud. Nom. ed. I. $2=$ Mimosa Kantuffa.

Karroo, Hayne, Arzneigew.x. t. $33=$ horrida

Kempeana, F. Muell. in Melb. Chemist (July, 1882, - Austral.

Kirkii, Oliver, Fl. Trop. Afr. ii. 350.-Afr. trop.

Koa, A. Gray, Bot. U. S. Expl. Exped. i. 480.-Ins. Sandvic.

Kraussiana, Meissn. ex Benth. in Hook. Lond. Fourn. Bot. i. (1842) 515.-Afr. austr

Kunthii, Dehnh. Rivist. Nap. i. 169; ex Walp. Rep. 924.-N. Granat.

lacerans, Benth. in Hook. Lond. Fourn. Bot. i. (1842 511.-Bras.

lachnophylla, F. Muell. in Wing, South. Sc. Record (July, 1882).-Austral.

lacustris, Desf. Cat. Hort. Par. ed. III. $301=$ Neptania oleracea.

laeta, R. Br. in Salt, Abyss. App. 65-Afr. bor. Arab.

laevigata, Humb. \& Bonpl. ex Willd. Sp. Pl. iv. 105 $=$ Prosopis juliflora

laevis, Hort. ex Steud. Nom. ed. II. i. 6=Gleditschia triacanthos.

Lahai, Steud. \& Hochst. ex Benth. in Hook. Lond. Fourn. Bot. i. (1842) 506.-Abyss.

Lambertiana, D. Don, in Bot. Reg. t. $721=$ Calliandra Lambertiana.

lanata, Mart. \& Gal. in Bull. Acad. Brux. x. II. (1843. 315.-Mexico.

Langsdorfii, Benth. in Hook. Lond. Fourn. Bot. i, (1842) 521.-Bras.

lanigera, A. Cunn. in Field, N. S. Wales, 345.Austral.

lanuginosa, Hort. ex Regel, in Gartenfl. (1854) $155=$ pulchella

laricina, Meissn. in Lehm. Pl. Preiss. i. 6.-Austral.

lasiocarpa, Benth. in Enum. Pl. Hueg. $43=$ palchella.

lasiopetala, Oliver, Fl. Trop. Afr. ii. $\$ 46$-Afr trop.

lasiophylla, Benth. in Trans. Linn. Soc. xx. (1575) 527.-Am. trop.

latescens, Benth. in Hook. Lond. Fourn. Bot. i. (1812) 380.-Austral.

latifolia, Benth. l. c. 382.-Austral.

latifolia Desf. Tabl. Hort. Par. ed. II. $207=$ A. melanoxylon.

latifrons, Hort. ex Seem. \& Schmidt, in Flom, rxvii. (1844) $495=$ alata.

latipes, Benth. in Hook. Lond. Fourn. Bot. i. (15t2 334.-Austral.

latisiliqua, Willd. Sp. Pl. iv. $1067=$ Lysiloma lati. siliqua.

latispinosa, Desf. Cat. Hort. Par. ed. III. $299=$ Mimosa latispinosa.

Latrobei, Meissn. in Lehm. Pl. Preiss i. $10=$ acinaceat. latronum, Willd. Sp. Pl. iv. $107 \%$.-Ind. or.

lanrifolia, Willd. I. c. 1058.-Ins. Pacif.

Lawsoni, Ait. er Sterd. Nom. ed. II. i, 6,-Austral.

laxa, Willd. Sp. Pl. iv. $1009=$ Calliandra laxa.

laxiflora, DC. Prod. ii. $455=$ Pithecolobium laxi. florum.

laxophylla, vide lorophylla.

Lebbeck, Willd. Sp. Pl. iv. $1060^{\circ}=$ Albizzis Lebbek.

lebbekoide's, DC. Prod, ii. $1607=$ Albizzin lebbekides. Lcicharditi. Benth. F\%. Atustral. ii. 872 . - Austral.

leiophylla, Benth. in Hook. Lond. Journ. Bot. i. (1st2 $851=$ Albizzia saligna.

lenticellafa, F. Muchl. in Joum. Linn. Soc iii. (1559 $14 i=\mathrm{F}$ arnesiann

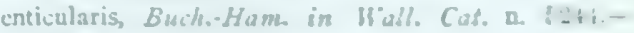
Ind. or. 


\section{ACACIA:-}

lentiscifolia, Desf. Tabl. Hort. Par. ed. II. 208.Mexico.

lentiscifolia, A. Rich. Ess. Fl. Cub. 469.-Cuba.

lepidota, Hook. \& Arn. in Hook. Bot. Misc. iii. (1833) $205=$ Mimosa Bonplandii.

leprosa, Sieber, ex DC. Prod. ii. 450.-Austral.

leptocarpa, A. Cunn. ex Benth. in Hook. Lond. Fourn. Bot. i. (1842) 376.-Austral.

leptoclada, A. Cunn. ex Benth. l. c. 385.-Austral.

leptoneura, Benth. l. c. 341.-Austral.

leptopetala, Benth. in Linnaea, xxvi. (1853-55) 619.Austral.

leptophleba, F. Muell. in Journ. Linn. Soc. iii. (1859) $143=$ anlacocarpa.

leptophylla, DC. Cat. Hort. Monsp. 74=Farnesiana.

leptophylla, F. Muell. Fragm. xix. $9=$ A. Bynoeana.

leptosperma, Bello, in Anal. Soc. Esp. Hist. Nat. x. (1881) 265 . - Ind. occ.

leptospermoides, Benth. in Linnaea, xxvi. (1853-55) 626.-Austral.

leptostachya, Benth. Fl. Austral. ii. 406.-Austral.

leucacantha, Bert. ex Spreng. Syst. iii. $144=$ tortuosa.

leucacantha, Vatke, in Oest. Bot. Zeit. xxx. (1880) 276. -Afr. trop.

leucadendron, A. Cunn. ex Benth, in Hook. Lond. Journ. Bot. i. (1842) $374=$ glaucescens

leucocephala, Link, Enum. Hort. Berol. ii. $444=$ Leucaena glauca.

leucolobia, Sweet, Hort. Brit. ed. II. 165.-Austral.

leucophloea, Willd. Sp. Pl. iv. 1083.-As. trop

leucophylla, Colvill, ex Sweet, Hort. Brit. ed. I. $101=$ holosericea.

leucophylla, Lindl. in Mitch. Three Exped. ii. $13=$ pendula.

ligulata, Ait. ex Steud. Nom, ed. II. i, 6.-Austral. -Cf. seq.

ligulata, A. Cunn. ex Benth. in Hook. Lond. Fourn. Bot. i. (1842) $362=$ salicina.

ligustrina, Meissn. in Lehm. Pl. Preiss, ii. 203.Austral.

limbata, F. Muell. in Fourn. Linn. Soc. iii. (1859) 145.--Austral.

linarioides, Benth. in Hook. Lond. Fourn. Bot. i. (1842) 371.-Austral.

Lindleyi, Meissn. in Lehm. Pl. Preiss. i. 14.-Austral.

linearis, Desv in Ham. Prod. F1. Ind Occ 591= Calliandra portoricensis.

linearis, Sims, Bot. Mag. t. 2156.-Austral.

lineata, A. Cunn. ex G. Don, Gen. Syst. ii. 403.Austral.

lineolata, Benth. ex Schlecht. in Linnaea, xxvi. (1853-55) 626.-Austral

lingvatouana, Baill. in Bull. Soc. Linn. Par. i. (1883) 362.-Madag.

linifolia, Willd. $S p . P l$. iv. 1051.-Austral.

litakunensis, Burch. Trav. ii. 452.-Afr, austr.

littoralis, A. Rich. Ess. Fl. Cub. 467.-Cuba.

lomatocarpa, DC. Prod, ii. $467=$ Albizzia stipulata.

longifolia, Paxt. Mag. Bot. xii. (1846) $269=$ dentifera.

longifolia, Willd. Sp. Pl. iv. 1052.-Austral.

longispicata, Benth. in Mitch. Journ. Trop. Austr. 298 =Cunninghamii.

longissima, Wendl. Comm. Acac. 45.t. $11=$ linearis.

lophantha, Willd. Sp. Pl. iv. $1070=$ Albizzia lo phantha.

lophanthoides, DC. Prod, ii. 457=villosa.

loxocarpa, A. Cunn. ex Benth. in Hook. Lond. Fourn. Bot.i. (1842) 377.-Austral.

loxophylla, Benth. in Linnaea, xxvi. (1853-55) 622.Austral.

lucens, Boj. Hort. Maurit. 116.-Madag.

lucida, Baill. Hist. Pl. ii. $61=$ Albizzia lucida.

Ludwigii, Ohlend, Verz. (1844) 74; Walp. Ann. ii. $453=$ myrtifolia.

Luehmanni, F. Muell. Fragm. xi. 116.-Austral.

lunata, Hort. Prag. ex Stend. Nom. ed. II. i. $6=$ falcinella.

Iunata, Lodd. Bot. Cab. t. $324=$ myrtifolia.

lunata, Sieber, ex DC. Prod. ii. 452.-Austral.

lutea, Leavenw. in Am. Journ. Sc. vii. (1824) $61=$ Neptunia lntea.

lycopodifolia, A. Cunn. in Hook. Ic. Pl. t. 172.Austral.

lycopodioides, Desv. Journ. Bot. iii. (1814) $69=$ Neptunia

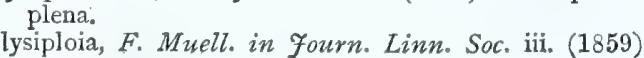
137.-Austral.

\section{ACACIA:}

macocentra, Walp. Rep. i. 876. in syn.-sphalm.-Cf malacocentra.

macracantha, Humb. \& Bonpl. ex Willd. Sp. Pl. iv. 1080.-Am austr.

macracanthoides, Bert. in DC. Prod. ii. $463=$ macra cantha.

macradenia, Benth. in Mitch. Trop. Austral. 360.Austral.

macrocentra, Walp. Rep. iv. 200,--Cf. malacocentra.

macroloba, Willd. Sp. Pl. iv. 1054=Pentaclethra filamentosa.

macrophylla, Bunge, Enum. Pl. Chin. Bor. $20=$ Albizzia Lebbek.

macrostachya, Reichb. ex G. Don, Gen. Syst. ii. 411. -Senegal.

Magdalenae, Bert. ex DC. Prod. ii. $455=$ Calliandra Magdalenae.

Maitlandi, F. Muell. Fragm. iii. $46=$ patens.

malacocentra, Mart. Herb. F1. Bras. $106=$ Mimosa malacocentra,

malacophylla, Benth. in A. Gray, Pl. Wright. i. 64.Mexico.

malacophylla, Steud. ex A. Rich. Tent. F1. Abyss. i. 235 $=$ Albizzia pallida.

mammifera, Schlecht. in Linnaea, xii. (1838) 563.Mexico.

Mangium, Willd. Sp. Pl. iv. 1053.-Ins. Molucc.

maroinata, Buch.-Ham. in Wall. Cat. n. $5243=$ Albizzia stipulata.

marginata, Steud. Nom. ed. I. $\dot{3}=$ Albizzia odoratissima.

marginata, R. Br. in Ait. Hort. Kew. ed. II. iii. $462=$ myrtifolia.

maritima, Benth. in Hook. Lond. Journ. Bot. i. (1842) $384=$ discolor

Martii, Benth. l. c. 519.-Bras.

martinicensis, Presl, Bot. Bemerk. $65=$ paniculata.

maschalocephala, Griseb. Cat. Pl. Cub. 82.-Cuba.

mauroceana, DC. Cat. Hort. Monsp. 74.-Marocco. media, Mart. \& Gal. in Bull. Acad. Brux. x. II. (1843) $316=$ Calliandra angelina

megaladena, Desv. Journ. Bot. iii. (1814) $69=$ pennata. megalantha, F. Muell. in Fourn. Linn. Soc. iii. (1859) 143.-Austral.

megaphylla, F. Muell. 1. c. $117=$ anceps.

Meissneri, Lehm. Del. Sem. Hort. Hamb. (1842). Austral.

melanoceras, Beurling, in Vet. Akad. Handl. Stockh. 1854) 53.-Panama.

melanochaetes, Zoll. in Nat. en Geneesk. Arch. Neel Indie, iii. (1846) $80=$ leucophloea.

melanoxylon, R. Br. in Ait. Hort. Kew. ed. II. v. 462 - Austral.

mellifera, Benth. in Hook. Lond. Fourn. Bot. i. (1842) 507.-Abyss.

metrosideriflora, Schlecht. in Linnaea, xii. (1838) 567 $=$ Calliandra Houstoni.

metrosiderosifolia, Hort. ex Steud. Nom. ed. II. i. $6=$ dodonaeifolia

micracantha, A. Dietr. in Otto \& Dietr. Allg. Gartenz. i. (1833) $83=$ armata.

micracantha, Desv. Journ. Bot. iii. (1814) $69=$ Pithe colobium parvifolium

micradena, Benth. in Hook. Lond. Journ. Bot. i. (1842) $518=$ adhaerens.

micrantha, Benth. in Trans. Linn. Soc. xxx, (1875) 526.-Mexico.

micrantha, Desv. in Ham. Prod. Fl. Ind. Occ. $59=$ seq. microcantha, G. Don, Gen. Syst. ii. $476=$ Pithecolobium parvifolium

microbotrya, Benth. in Hook. Lond. Fourn. Bot. i. (1842) 353.-Austral.

microcarpa, F. Muell. 2nd Gen. Report, 7.Austral.

microcephala, A. Rich. Ess. Fl. Cub. $469=$ paniculata. microcephala, R. Grah. in Wall. Cat. n. $5263=1$ eucophloea.

microcephala, Macfad. Fl. Jamaic. i. 316=macracantha.

microneura, Meissn. in Lehm. Pl. Preiss. i. 19.Austral.

microphylla, Roxb. ex Steud. Nom. ed. II. i. $6=$ Albizzia myriophylla

microphylla, Willd. Sp. Pl. iv. 1073=Piptadenia peregrina

Miersii, Benth. in Hook. Lond. Fourn. Bot. i. (1842)

\section{ACACIA:-}

Mikanii, Benth. in Trans. Linn. Soc. xxx. (1875) 526.Am. trop.

minutifolia, F. Muell. Fragm. viii. 243.-Austral

Mirbeli, Dehnh. Rivist. Nap. i. 168; ex Walp. Rep. i. 922.-Austral.

misera, Vatke, in Oest. Bot. Zeit. xxx. (1880) 275.Afr. trop.

Mitchelli, Benth. in Hook. Lond. Fourn. Bot. i. (1842) 387.-Austral.

modesta, Wall. Pl. As. Rar. ii. 27. t. 130.-Ind. or. moesta, Lindl. Bot. Reg. (1846) t. $67=$ verticillata. mollicula, Mart. E Gal. in Bull. Acad. Brux. x. II. (1843) 313.-Mexico.

mollis, Wall. Pl. As. Rar. ii. 76. t. $177=$ Albizzia Julibrissin.

mollissima, Willd. Enum. Hort. Berol. $1053=$ decurrens.

monacantha, Willd. l. c. 1056.-Bras

moniliformis, Griseb. in Goett. Abh. xix. (1874) 136.Reg. Argent.

montana, Benth. in Hook. Lond. Fourn. Bot. i. (1842) 360.-Austral.

montana, Jungh. in Nat. en Geneesk. Arch. Neerl. Indie, ii. (1845) $35=$ Albizzia montana.

mossambecensis, Bolle, in Peters, Reise Mossamb. Bot. i. $15=$ albida .

mucronata, Willd. Enum. Hort. Berol. Suppl. $68=$ longifolia.

Muelleri,Benth. in Linnaea, xxvi.(1853-55)603 = anceps. multiflora, H. B. \& K. Nov. Gen. et Sp. vi. $277=$ Pithecolobium multiflornm.

multiflora, Spreng. Syst. iii. $142=$ polyantha

multifoliolata, Bertol. Misc. Bot. xvi. 26.-Ins. S. Doming.

multijuga, Meissn. in Hook. Lond. Fourn. Bot. ii. (1843) 105.-Afr, austr

multinervia, DC. Mém. Lég. xii. 445 ; Prod. ii. $250=$ lanigera.

multispicata, Benth. Fl. Austral. ii. 400.-Austral.

muricata, Willd. Sp. $P l$. iv. 1058.-Ind. occ

Murrayana, F. Muell. ex Benth. Fl. Austral. ii. 370. Austral.

myriadenia, Bert. ex Guill. in Ann..Sc. Nat. Sér. II. vii. (1837) $359=$ Serianthes myriadenă.

myriobotrya, Meissn. in Lehm. Pl. Preiss. i. $15=$ microbotrya.

myriophylla, R. Grah. in Wall. Cat. n. 5242=Albizzia myriophylla.

myrtifolia, Willa. Sp. Pl. iv. 1054.-Austral.

natalitia, E. Mey.Comm. Pl. Afr. Austr.167.-Afr.austr.

Neboueb, Baill. Adansonia, iv. (1863-64) 117.-Afr trop.

Nellyrenza, R. Grah. in Wall. Cat. n. $5240=$ amara nematophylla, F. Muell, ex Benth. in Linnaea, xxvi. 1853-55) $612=$ calamifolia.

Nemu, Willd. Sp. Pl. iv. 1065=Albizzia Julibrissin.

neriifolia, A. Cunn. ex Benth. in Hook. Lond. Fourn. Bot. i. (1842) 357.- Austral.

Nernstii, F, Muell. Fragm, iv, 3=amblygona,

nervosa, DC. Mém. Lég. xii. 444.-Austral.

Neuciana, Backl. ex Benth. in Trans. Linn. Soc. xxx. (1875) 592 sphalm. = Pithecolobium brevifolium. neurocarpa, A. Cunn, in Hook. Ic. Pl. t. 168=holosericea.

nigra, Clos, in C. Gay, F1. Chil. ii. $253=$ Calliandra chilensis.

nigrescens, Oliver, Fl. Trop. Afr. ii, 340.-Afr. trop.

nigricans, R. Br. in Ait. Hort. Kew. ed. II. v. 465.Austral.

nilotica, Delile, F1. Aegypt. Illustr. 79 ; Desf. Tabl. Hort. Par. ed. II. $208=$ arabica.

Niopo, H. B. \& K. Nov. Gen. et Sp. vi. $282=$ Piptadenia peregrina.

nitida, Willd. Sp. Pl. iv. $1086=$ Pithecolobium umbellatum.

nitidula, Benth. Fl. Austral. ii. 381.-Austral.

nodifora, Benth. in Linnaea, xxvi. (1853-55) 621. Austral.

nodosa, Willd. Sp. P1. iv. $1016=$ Cassia bacillaris

notabilis, F. Muell. Fragm. i. 6.-Austral.

nubica, Benth. in Hook. Lond. Fourn. Bot. i. (1842) 498.-Nubia.

nudiflora, Willd. $S p$. $P l$. iv, 1058.-Ind, occ.

Nuceiana, Buckl. in Proc. Ac. Sc. Philad. ' 1861 ' (1862) $453=$ Pithecolobium brevifolium.

nutans, Spreng. ex DC.Prod. ii. $429=$ Mimosa leiocarpa? nyssophylla, F. Muell. Fragm. iv. 4=calletioides. 


\section{ACACIA:-}

obliqua, A. Cunn. ex Benth. in Hook. Lond. Fourn. Bot. i. (1842) 334.-Austral

obliqua, Desv. Journ. Bot. iii. (1814) $67=$ suaveolens. obliquifolia, Mart. \& Gal. in Bull. Acad. Brux. x II. (1843) $317=$ Pithecolobium dulce.

obovata, Benth. in Hook. Lond. Fourn. Bot. i. (1842) 329.-Austral.

obscura, A. DC. Not. vi. Pl. Rar. Fard. Gen. 23. t. 3.Austral.

obtusa, Humb. \& Bonpl. ex Willd. Sp. Pl. iv. 1087= macracantha.

obtusata. Sieber, ex DC. Prod. ii. 453.-Austral. obtusifolia, A. Cunn. in Field, New South Wales, $345=$ longifolia

odorata, Desv. Journ. Bot. iii. (1814) $67=$ suaveolens. odoratissima, Buch.-Ham. ex Wall. Cat. n. $5233=$ elata.

odoratissima, Willd. Sp. Pl. iv. $1063=$ Albizzia odora-

tissima.
offiicnalis, Dehnh. Rivist. Nap. i. 170 ; ex Walp. Rep. i. 923.-Tasman.

Oldfieldii, F. Muell. Fragm. iv. $17=$ acuminata.

oleaefolia, A. Cunn. ex G. Don, Gen. Syst. ii. $405=$ lunata.

oligoneura, F. Muell. in Fourn. Linn. Soc. ii. (1859) 139 -Austral.

oligophylla, Hoffmgg. Vers. Pfl.Nachtr. i.201.-Hab.? Oliveri, Vatke, in Oest. Bot. Zeit. xxx. (1880) 274.Afr. trop.

omalophylla $=$ homalophylla.

oncinocarpa, Benth. in Hook. Lond. Fourn, Bot. i. (1842) 378.- - Austral.

oncinophylla, Benth. in Lindl. Swan Riv. App. 15.Austral.

oraria, F. Muell. Fragm. xi. 66.-Austral.

ornithophora, Sweet, Fl. Austral. t. $24=$ armata.

orthocarpa, F. Muell. ex Benth. in Journ. Linn. Soc. iii. (1859) $136=$ xylocarpa.

Oswaldi, F. Muell. Pl. Vict. ii. 27,-Austral.

Oswaldi, F. Muell. Pl. Vict. ii. 27.-Aust.
Ouyrarema, DC. Prod. ii. 469.-Guiana.

ovoidea, Benth. in Hook. Lond. Journ. Bot. i. (1842) $339=$ verticillata.

Oxycedrus, Sieber, ex DC. Prod. ii. 453.-Austral.

oxyclada, F. Muell. ex Benth. Fl. Austral. ii. 341.Austral.

oxyphylla, R. Grah. in Wall. Cat. n. $5252=$ caesia pachycarpa, F. Muell, in Fourn. Linn. Soc. iii. (1859) 139. - Austral.

pachyloma, Mart. Herb. Fl. Bras. n. $1108=$ Calliandra

pallida, F. Muell. in Fourn. Linn. Soc. iii. (1859) 147. -Austral.

pallida, Humb. \& Bonpl. ex Willd. Sp. Pl. iv. $1059=$ Prosopis juliflora.

Palmeri, S. Wats. in Proc. Am. Acad. xvii. (1881-82)

350.-Am. bor. occ

paludosa, Blume, ex Miq. F1. Ind. Bat. i. $14=$ pennata.

paniculaeflora, Stend. in Flora, xxvi. II. (1843) 760 = Mimosa myriadenia.

paniculata, Willd. Sp. Pl. iv. 1074.-Bras.

papulaeformis, Walp. Rep. i. $898=$ bnxifolia

papyrocarpa, Benth. Fl. Austral. ii. 338.-Anstral.

paradoxa, DC. Cat. Hort. Monsp. $74=$ armata.

parvifolia, Hort. ex Stend. Nom. ed. II. i. $7=$ guttata.

parvifolia, Willd. Sp. Pl. iv. $1086=$ Pithecolobium parvifolium.

patens, F. Muell. in Fourn. Linn. Soc. iii. (1859) 120. - Anstral.

patula, Humb. \& Bonpl. ex Willd. Enum. Hort. Berol. 1055.-Am. austr.

pauciflora, A. Rich. Ess. Fl. Cub. 461.-Cuba.

Pawlikoruskyana, Ohlend. in Neue Allg. Gartenz. (1845)

$369=$ myrtifolia

pectinata, Hoffmgg. Verz. Pf. Nachtr. i. $201=$ Hoffmannseggiana.

pectinata, H. B. \& K. Nov. Gen. et Sp. vi. $282=$ Parkia pectinata.

pedicellata, Benth. in Hook. Lond. Fourn. Bot. i. (1842) 522.-Bras.

pedunculata, Roxb. ex Steud. Nom. ed. II. i. $7=$ Parkia biglandulosa?

pedunculata, Willd. Sp. Pl. iv, $1084=$ Farnesiana.

pellacantha, Vog. in Nov. Act. Nat. Cur. xix. Suppl. i. (1843) $19=$ macracantha.

pendula, A. Cunn. ex G. Don, Gen. Syst. ii. 404.Austral.

penicillifera, Lag. Gen. et Sp. Nov, $16=$ filicina.

\section{ACACIA:-}

pennata, Willd. Sp. Pl. iv. 1090.-As. et Afr. trop.

pennatula, Benth. in Hook. Lond. Fourn. Bot. i. (1842) 390.-Mexico.

penninervis, Sieber, ex DC. Prod. ii. 452.-Austral.

pennivenia, Balf.f. in Proc. Roy. Soc. Edinb. xii. (1884)

404.-Ins. Socotra.

pentadenia, Lindl. in Bot. Reg, t. 1521,-Austral

pentaedra, Regel, Gartenfl. (1852) 228, t. $23=$ extensa.

pentagona, Hook. f. in Hook. Nig. F1. $331=$ pennata.

pentaptera, Welw. Apont. $584=$ pennata.

peregrina, Kunth, Mimos. Humb. 96. t. $30=$ Piptadenia colubrina.

peregrina, Willd. Sp. Pl. iv. $1073=$ Piptadenia peregrina.

Perrottetii, Steud. Nom. ed. II. i. $7=$ tortilis.

persica, Sterl. Hort. Nymph. ex Steud. Nom. ed. II. i. $7=$ Prosopis Stephaniana.

personioides, Ait. ex Steud.Nom. ed. II. i. 7.-Austral, Pervillei, Benth. in Trans. Linñ. Soc. xxx. (1875) 521. - Madag

peruviana, Humb. \& Bonpl. ex Willd. Enum. Hort. Berol. 1056.-Peruv.

Petersiana, Bolle, in Peters, Reise Mossamb. Bot. i. 4. -Mossamb.

petiolaris, Lehm. Novit. Pl. Hort. Hamb. (1851) 7;

Linnaea, xxy. (1852) $306=$ pycnantha.

Peuce, F. Muell. Fragm. iii. 151.-Austral.

Pharnesiana, Risso, Fl. Nice, $166=$ Farnesiana

philippinarum, Benth. in Hook. Lond. Joum. Bot. i. (1842) $514=$ concinna.

phlebocarpa, F. Muell. in fourn. Linn. Soc, iii. (1859)

119.-Austral.

phlebophylla, F. Muell. 1st Gen. Rep. 12=longifolia.

piauhiensis, Benth. in Trans. Linn. Soc. xxx. (1875)

523.-Bras.

piligera, A. Cunn. in Hook. Bot. Mag. sub t. $3394=$ undulaefolia.

pilosa, Benth. in Linnaea, xxvi. (1853-55) 607.Austral.

pilosa, Bert. ex DC. Prod. ii. $455=$ Calliandra haematomma?

pinifolia, Benth. in Mitch. Trop. Austral. $342=$ juncifolia.

pinnata, Dalz. \& Gibs. Bomb. Fl. $87=$ pennata.

pinnata, Link, Enum. Hort. Berol. ii. $446=$ tamarindi. folia.

pityoides, F. Muell. in Fourn. Linn. Soc, iii. (1859) 135.-Austral.

plagiophylla, F. Muell. 1. c. $131=$ undulaefolia. plagiophylla, Spreng. Syst. iii. $135=$ falcata.

planifrons, Wight \& Arn. Prod. 276.--Ind. or

platyacantha, Schlecht. in Linnaea, xii. (1838) 565.Mexico.

platycarpa, F. Muell. in Journ. Linn. Soc. iii. (1859) 145 = sericata.

platyloba, Spreng. Syst. iii. 144-N. Granat.

platyloba, Bert. ex DC. Prod. ii. $472=$ Pithecolobium sericiflorum.

platyphylla, Sweet, Hort. Brit. ed. I. 102, nomen.Anstral.

platyptera, Lindl. in Bot. Reg. (1841) Misc. $3=$ alata.

plectocarpa, A. Cunn. ex Benth. in Hook. Lond. Fourn.

Bot. i. (1842) 375.-Austral.

plumosa, Lowe, in Bot. Mag. t. 3366.-Bras.

pluricapitata, Steud. Nom. ed. II. i. 7.-As. trop.

podalyriaefolia, A.Cunn. in G. Don, Gen. Syst. ii. 405.

-Austral.

polyacantha, Willd. Sp. Pl, iv, $1079=\mathbf{A}$. Catecho.

polyantha, Spreng. ex Benth. in Trans. Linn. Soc. xxx.

(1875) $591=$ Pithecolobium multiflorum.

polyantha, Zipp. ex Span. in Linnaea, xv. (1841) $199=$ juncifolia.

polybotrya, Benth. in Hook. Lond. Fourn. Bot. i. (1842) 384-Austral.

polycephala, DC. Prod. ii. $473=$ concinna

polycephala, R. Grah. in Wall. Cat. n. $5255=$ pluricapitata.

polymorpha, Pasq. Cat. Ort. Bot. Nap. 1.-Austral

polyphylla, Clos, in C. Gay, Fl. Chil. ii. 254=Lysiloma

polyphylla.

polyphylla, DC. Cat.Hort. Monsp. 74 ; Prod. ii. 469.-

N. Granat.

polystachya, A. Cunn. ex Benth. in Hook. Lond. Fourn. Bot. i. (1842) 376. - Austral.

portoricensis, Willd. Sp. Pl. iv. $1069=$ Calliandra portoricensis.

praecox, Griseb. in Goett. Abh. xix. 136.-Reg. Argent.

\section{ACACIA:}

praelongata, F. Muell. in Melb. Chemist, iii. (Aug. 1883).-Austral

pravifolia, F. Muell. Fragm. i. 4 =sublanata.

pravissima, F. Muell. 1st Gen. Report, 12.-Austral

Preissiana, Lehm. Del. Sem. Hort. Hamb. (1842)= obscura.

prensans, Lowe, in Bot. Mag, t. 3408= pennata.

prismatica, Hoffmgg. Verz. Pfl. 159.-Hab.?

procera, Willd. Sp. Pl. iv. $1063=$ Albizzia procera.

prominens, A.Cunn. ex G. Don, Gen. Syst. ii. 406.Austral.

prona, Noronha, in Verh. Batav. Gen. v. (1790) Art. iv. 5, nomen.-Java.

propinqua, A. Rich. Ess. Fl. Cub. i. $466=$ Albizzia Lebbek.

prosopoides, Moç. \& Sesse, ex DC. Prod. ii. $460=$ Piptadenia patens.

rosopoma, Schnyder, in Anal. Soc. Cient. Argent. iii 1877) 152.-Reg. Argent

prostrata, Lodd. Bot. Cab. t. $631=$ diffusa.

pruinescens, Kurz, in fourn. As. Soc. Beng. xlv. (1876) II. 296, 298.-Burma.

pruinosa, A. Cunn. ex Benth. in Hook. Lond. Journ. Bot. i. (1842) 383.-Austral.

prunifolia, C. Muell, in Walp. Ann. vii. 937, sphalm. -Cf. pravifolia.

psendoarabica, Blume, ex Miq. in Fl. Ind. Bat. i. 8.N. Guinea.

pseudointsia, Miq. I. c. $12=$ caesia

pseudotrichodes, DC. Prod. ii. 466.-Ins. S. Doming.

psilostachya, DC. 1. c. $457=$ Piptadenia psilostachya.

Psoralea, DC 1. c. $464=$ Mimosa Psoralea

pteridifolia, Benth. in Hook. Lond. Fourn. Bot. i. (1842) 521.-Am. trop

pterigoidea, Seem. in Verh. Gartenb. (1846) $11=$ micro botrya.

pterocarpa, F. Muell. in Journ. Linn. Soc. iii., (1859 $134=$ excelsa.

pterocarpa, Steud. Nom. ed. I. $3=$ Gagnebina tama riscina.

pteroclada, F. Muell. Fragm. iv. $3=$ trigonophylla. pterophylla, Hoffmgg. Verz. Pf. (1824) 202 = pennata. pterygocarpa, Hochst. ex Benth, in Hook. Lond. Journ. Bot. v. (1846) $96=$ nubica

ptychophylla, F. Muell. in fourn. Linn. Soc. iii. (1859 142.-Austral.

pubescens, R. Br. in Ait. Hort. Kew. ed. II. v. 467.Austral.

pabescens, Schlecht. in Linnaea, xii. (1838) 563.Mexico.

pugioniformis, Wendl. Comm. Acac. 38. t. 9.-Austral. pugioniformis, Wendl. in Flora, ii. (1819) $139=$ juniperina.

pulchella, R. Br. in Ait. Hort. Kew. ed. II. v. 464.Austral.

pulcherrima, Willd. Sp. P1. iv. $1061=$ Stryphnodendron floribundum.

pulverulenta, A. Cunn, ex Benth, in Hook. Lond. Journ. Bot. i. (1842) $342=$ calamifolia

pulverulenta, Schlecht. in Linnaea, xii. (1838, $571=$ Lencaena pulverulenta.

punctata, Desf. Cat. Hort. Par, ed. III. $300=$ Neptunia plena.

punctata, Humb. \& Bonpl. ex Willd. Sp. Pl. iv. 10S4 $=$ macracantha.

pungens, Spreng. Syst. iii. $184=$ juniperina

purpurascens, Vatke, in Oest. Bot. Zeit. xxx. (1850 277.-Afr. trop.

purpurea, Bolle, in Peters, Reise Mossamb. Bot. 6. -Afr. trop.

purpurea, Steud. Nom. ed. II. i. $7=$ Inga tergemina.

pycnantba, Benth. in Hook. Lond. Fourn. Bot. i. (104:2 351.-Austral.

pycnophylla, Benth. Fl. Austral. ii. S6S.-Austral. pycnostachya, F. Muell. Pl. Vict. ii. 38.-Austral pyrifolia, DC. Mim. Lf $\mathcal{g}_{\text {. }}$ xii. 447.-Austral.

quadrangularis, Link, Enum. Hort. Berol. ii. 445 Calliandra tetragona.

quadriglandulosa, Mart in Flora, xx. (1S3s); Rcibl. ii $110=$ riparia.

guadrilateralis, DC. Prod ii $451=$ pugioniformis guadrilateralis, Decne. Herb. Tim. $1 \% \bar{r}=$ juncifolia quadrimarginen, F. Muell. Fragm. x. 81.-Austral. quadrisulcata, $F$. Muell. I. c. iii. 12\%.-Austral. Raddiana, Snvi, Sopra Alc. Acrc. Egiz. $1=$ tortilis ramosissima, Benth. in Howk. Lond. Gourn. Bot. (1842) $350^{\circ}$ ex parte.-Austral. 


\section{ACACIA:-}

ramosissima, Benth. in Hook. Lond. Journ. Bot. (1842) 356 ex parte $=$ Harveyi.

reclinata, F. Muell, 1st Gen. Rep. $12=$ leprosa.

recurva, Benth. in Hook. Lond. Fourn. Bot. i. (1842) 519.-Bras.

reficiens, Wazwra \& Peyr. Sert. Benguel. 15. - Afr. trop, reniformis, Benth in Hook. Ic. Pl. t. 1165,-Mexicorestiacea, Benth. in Hook. Lond. Fourn. Bot. i. (1842) 323.-Austral.

reticulata, Willd. Sp. $P l$. iv. 1056,-Afr. austr.

retinervis, Benth. in Hook. Lond. Fourn. Bot. i. (1842) 379.-Austral.

retinodes, Schlecht。 in Linnaea, $\mathrm{xx}$. (1847) $664=$ neriifolia.

retivenea, F. Muell. Fragm. iii. 128.-Austral. retrorsa, Meissn. in Bet. Zeit. (1855) $10=$ sphacelata. revoluta, Kunth, Mimos. Humb. 84 . t. $26=$ Mimosa revoluta.

rhigiophylia, F. Muell. ex Schlecht. Benth. in Linnaea, xxvi. (1853-55) 611.-Austral.

rhodacantha, Desf. Tabl. Hort. Par. ed. II. 208.Hab.?

rhombifolia, Desf. ex Benth. in Trans. Linn. Soc. xxx. (1875) 637.-Hab.?

rhombifolia, Poir, ex Steud. Nom. ed. I. 3.-Ins. Trinit. Riceana, Hensl. in Maund, Botanist, t. 135.-Tasman.

Richii, A. Gray, Bot. U. St. Expl. Exped. i. 482, t. 53. -Ins. Fiji.

rigens, A. Cunn. ex G. Don, Gen. Syst. ii. 403.Austral

rigidula, Benth. in Hook. Lond. Journ. Bot. i. (1842) $504=$ amentacea

riparia, Bert. ex Spreng. Syst. iii. $142=$ polyphylla.

riparia, H. B. \& $K$. Nov. Gen. et Sp. vi. 276. N. Granat.

robusta, Burch.Trav, ii, 442.-Afr. austr.

Roemeriana, Scheele, in Linnaea, xxi. (1848) 456.N. Mexico.

Rohriana, DC. Prod. ii. $457=$ nudifora

rostellifera, Benth. in Hook. Lond. Fourn. Bot. i. (1842) 356.-Austral.

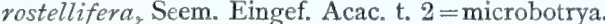

rostrata, Humb. \& Bonpl. ex Willd. Sp. Pl。 iv, 1054 (err. typ. 1060) $=$ Lysiloma rostrata.

rotundata, Benth. in Trans. Linn. Soc. xxx. (1875) 521.-Am. trop.

rotundifolia, Hook. Bot. Mag. t. $4041=$ obliqua.

Rovumae, Oliver, Fl. Trop. Afr. ii. 353.-Afr. trop.

Roxburghii, Kostel. Allg. Med. pharm. Flora, iv. $1367=$ Albizzia myriophylla.

Roxburghii, Wight \& Am. Prod. i. $276=$ planifrons et eburnea?

rubescens, Mart. \& Gal. in Bull. Acad. Brux. x. II. (1843) $315=$ Calliandra laxa.

rubida, A. Cunn. in Field, New South Wales, 344.-Austral.

rufa, Hassk. Cat. Pl. Hort. Bog. 290=Albizzia rufa。 rugata, Buch.-Ham. in Wall. Cat. n. $5251=$ concinna runciformis, A. Cunn。 ex G. Don, Gen. Syst. ii. $404=$ lineata.

rupestris, Stocks, ex Boiss. Fl. Orient. ii. $638=$ A. Senegal rupicola, F. Muell. ex Benth, in Linnaea, xxvi. (185355) 610.-Austral

ruscifolia, A. Cunn. ex G. Don, Gen. Syst. ii. $407=$ verticillata.

rutaefolia, Ait. ex Steud. Nom. ed. II. i. 8.-Austral.

rutaefolia, Link, Enum. Hort. Berol. ii. $444=$ nigricans.

Sabeana, Buckl, in Proc. Ac. Sc. Philad, '1861' (1862) $453=$ Leucaena retusa.

saccharata, Benth. in Hook. Lond. Journ. Bat. i.. (1842) $505=$ albida.

salicina, Lindl. in Mitch. Three Exped. ii. 20.-Austral. saligna, Wendl. Comm. Acac. 26.-Austral.

salinarum, DC. Prod. ii. $456=$ Prosopis juliflora

Saltiana, Steud. Nom. ed. II. i. $8=$ A. Lahai

saltuum, Jungh. in Bot. Zeit. iii. (1845) $703=$ Albizzia montana.

Sandra, Bedd. Fl. Sylv, t. 50=A. Sundra.

sanguinea, Hochst. ex A. Rich. Tent. Fl. Abyss. i. 245 = venosa.

sapindoides, A. Cunn. ex Sweet, Hort. Brit. ed. III. 198 $=$ Pithecolobium pruinosum.

saponaria, Heyne, ex. Benth. in Trans. Linn, Soc. xxx. (1875) $531=$ concinna.

sarmentosa, Desv. Journ. Bot. iii. (1814) $70=$ caesia.

sarmentosa, Griseb. Fl. Brit. W. Ind. $221=$ riparia.

Sassa, Baill. Hist. Pl. ii. 47.-Madag.

\section{ACACIA :-}

scabra, Benth. in Linnaea, xxvi. (1853-55) 605. Austral.

scalpelliformis, Meissn. in Lehm. Pl. Preiss, ii. 200.Austral.

scandens, Benth. in Hook. Lond. Journ. Bot. i. (1842) $517=$ plumosa

scandens, Willd. Sp. P1. iv, $1057=$ Entada scandens. scandens, Willd. Enum. Hert. Berol.1057 = polyphylla. seapuliformis, A. Cunn. in G. Don, Gen. Syst. ii, $405=$ cultriformis.

schinoides, Benth. in Hook. Lond. Journ. Bot. i. (1842) $382=$ pruinosa

Schottii, Torr, in Bot. Mex. Bound, 62-Am, bor. scirpifolia, Meissn. in Bot. Zeit. (1855) 10.-Austral. sclerophylla, Lindl. in Mitch. Three Exped. ii. 139. Austral.

sclerosperma, F. Muell. in Wing, South. Sc. Record, (July, 1882).-Austral.

scleroxyla, Tuss. Fl. Antill. i. t. 21-Ind. occ

secundiflora, Juss. ex DC. Prod. ii. 425 = Entada polystachya.

Seeressa, Roxb. ex Steud. Nom. ed. II. i. $8=$ Albizzia Lebbek.

selenicarpa, Desv. in Ham. Prod. Fl. Ind. Occ. $60=$ albida.

Selloi, Spreng. Syst. iii. $137=$ Calliandra brevipes.

semicordata, Roxb. ex Steud. Nom. ed. II. i. 8.--Ind, or semispinosa, Willd. ex Steud. 1. c. = Mimosa semispinosa.

semitriptera, Mart. ex Steud. l. c.-Bras.

semiverticillata, Knowl. \& Westc. Fl. Cab. ii. (1838)

$27=$ verticillata.

Senegal, Willd. Sp. $P l$. iv. 1077.-Geront. trop.

Sentis, F. Muell. 2nd Gen. Report, 7 (1854).Austral.

sericata, Ait. ex Steud. Nom. ed. II. i, $8=$ seq. ?

sericata, A. Cunn. ex Benth. in Hook. Lond. Fourn.

Bot. i. (1842) 380.-Austral.

sericea, Mart. \& Gal. in Bull. Acad. Brux. x. Ix. (1843) 311 $=$ acatlensis.

sericocephala, Fenzl, in Flora, xxvii. (1844) $312=$ Albizzia amara.

sericophylla, F. Muell. ex Benth. in Journ. Linn. Soc iii. (1859) $122=$ stenophylla

Serra, Benth. in Hook. Lond. Fourn. Bot. i. (1842) 519.-Bras.

sertiformis, A. Cunn. in Bot. Mag. sub to $3394=$ undulaefolia.

sessiliceps, F. Muell. in Melb. Chemist (July, 1882). -Austral.

sessilis, Benth. in Hook. Lond. Journ. Bot. i. (1842) $336=$ sphacelata

setigera, Hook. Ic. Pl. t. $361=$ undulaefolia.

setosa, Dehnh. Rivist. Nap.i. 169 ; ex Walp. Rep. i. 924 - Hab. ?

setosa, Spreng. Syst. iỉ. 137.-Bras.

setulifera, Benth. in Linnaea, xxvi. (1853-55) 625 -Austral.

Seyal, Delile, Fl. Aegypte, 286. t. 52. f. 2.-Aegypt.

Shuttleworthii, Meissn. in Lehm. Pl. Preiss. i. 7.-Austral.

siculiformis, A. Cunn. ex Benth. in Hook. Lond. Fourn Bot. i. (1842) 337.-Austral.

Sieberi, Tausch, ex Steud. Nom. ed. H. i. $8=$ crassius cula.

Sieberiana, DC. Prod. ii. 453.-Senegal.

Sieberiana, Scheele, in Linnaea, xxvii. (1843) $337=$ discolor.

Sieberiana, Tausch, in Flora, xix. (1836) $420=$ crassiuscula.

signata, F. Muell. Fragm. iv. 7.-Austral.

Siliquastrum, Lag. Gen. et Sp. Nov, $16=$ Prosopis juliflora.

similis, Zoll. E Morr. in Nat.en Geneesk. Arch. N. Ind iii. (1846) 81.-Maliaya.

Simsii, A. Cunn, ex Benth. in Hook. Lond. Fourn, Bot i. (1842) 368.-Austral.

Sing, Guill. \& Perr. Tent. FI. Seneg. i. $251=$ Sieberiana. Sixissa, Buch $-\mathrm{Ham}$, in Wall Cat. n. $5265=$ Albizzin Lebbek.

smilacifolia, Field. \& Gardn. Sert. Pl. t. $3=$ urophylla. Smithiana, Roxb. ex Wall. Cat. n. 5237=Albizzia stipulata.

Sobeana, Buckl. Proc. Acad. Nat. Sc. Philad. (1861) 453.-Am. bor.

socotrana, Balf. f. in Proc. Roy. Soc. Edinb. xi. (1882) 511.-Ins. Socotra.

\section{ACACIA:-}

Solandri, Benth. Fl. Austral. ii. 406.-Austral.

somalensis, Vatke, in Oest. Bot. Zeit. xxx. (1880) 274. -Afr. trop.

somnians, Sterler, ex Steud. Nom. ed. II. i. $8 \doteq$ Mimosa somnians.

Sophorae, R. Br. in Ait. Hort. Kew. ed. II. v. $462=$ longifolia.

spadicigera, Cham. \& Schlecht. in Linnaea, v. (1830) 594.-Jamaica.

spathulata, F. Muell. ex Benth. Fl. Austral. ii. 356.Austral.

spathulata, Tausch, in Flora, xix. (1836) $420=$ longifolia.

speciosa, Hort. ex Steud. Nom. ed. II. i. $8=$ Albizzia Iophantha.

speciosa, Willd. Sp. Pl. iv. $1066=$ Albizzia Lebbek.

spectabilis, A. Cunn. ex Benth. in Hook. Lond. Fourn, Bot. i. (1842) 383.-Austral

sphacelata, Benth. l. c. 338--Austral.

sphaerocephala, Cham. \& Schlecht. in Linnaea, v. (1830) 594.-Mexico

spinescens, Benth. in Hoøk. Lond. Fourn. Bot. i. (1842) 323.-Austral.

Spini, Balb. in Spin. Cat. Suppl. (1823) 8.-Ins. Guadaloup.

spinosa, E. Mey. Comm. Pl. Afr. Austr. i. 170=Dichrostachys nutans.

spinosissima, Benth. ex Schlecht. in Linnaea, xxvi. (1853-55) 621-Austral.

spinulosa, Srveet, ex Steud. Nom. ed. II. i. 8.-Austral. spirocarpa, Hochst. ex. A. Rich. Tent. Fl. Abyss. i. 239. -Afr. trop.

spirorbis, Labill. Sert. Austr. Caled. 69. t. 69,-N. Caled.

spondylophylla, F. Muell. Fragm. viii. 243.-Austral. Sprengelii, G. Don, Gen. Syst. ii. $4 \mathbf{1 0}=$ Berteriana.

Sprengeliu, Hook. \&c Arn. in Hook. Bot. Misc. iii. (1833) $205=$ Mimosa incana

squamata, Lindl. Swan Riv. App. 15.-Austral.

squamata, Morr. in Ann. Soc. Gand, iii. (1847) 209. t. $134=$ restiacea.

squarrosa, Mart. ex Benth. in Hook. Lond. Journ. Bot. iii. (1844). $104=$ Calliandra squarrosa.

stellata, Willd. Sp. Pl. iv. 1078.-Arab.

stenocarpa, Hochst. ex A. Rich. Tent. Fl. Abyss. i. 238. - Abyss.

stenophylla, A. Cunn. ex Benth. in Hook. Lond. Fourn. Bot. i. (1842) 386.-Austral.

stenoptera, Benth. l. c. 325.-Austral.

stenostachya, Desv. ex Ham. Prod. Fl. Ind. Occ. 59 $=$ Piptadenia psilostachya.

Stephaniana, Willd. Sp. Pl. iv. 1088=Prosopis Stephaniana.

stereophylla, Meissn. in Lehm. Pl. Preiss. ii. 203.Austral.

stigmatophylla, A.Cunn. ex Benth. in Hook. Lond. Fourn. Bot. i. (1842) 377.-Austral.

stipellata, Schlecht, in Linnaea, xii. (1838) $574=$ filicina.

stipulata, DC. Prod. ii, 469= Albizzia stipulata.

stipuligera, F. Muell. in Fourn. Linn. Soc. 1ii. (1859) 144. - Austral.

stipulosa, F. Muell. l.c. 119.-Austral.

stolonifera, Burch. Trav. ii, 241 = hebeclada.

striata, Humb. \& Bonpl. ex Willd. Sp. Pl. iv. 1089.Am. austr.

striatula, Benth. in Hook. Lond. Fourn. Bot. i. (1842) 336.-Austral.

stricta, Willd. Sp. Pl. iv. 1052-Austral.

strigosa, Lindl. in Mitch. Three Exped, ii. $185=$ aspera.

strigosa, Link, Enum. Hort. Berol. ii. 444.-Austral.

strigosa, Spreng. Syst. iii. $137=$ strigulosa.

strigulosa, Steud. Nom. ed. II. i. 8.--Peruy.

strombulifera, Willd. Sp. Pl. iv. 1055 = Prosopis strombulifera.

strongylophylla, F. Muell. Fragm. viii, 226.-Austral.

Stuartiana, F. Muell. ex Benth. in Linnaea, xxvi. (185355) $609=$ siculiformis

suaresensis, Baill. in Bull. Soc. Linn. Par. i. (1883) 363.-Madag.

suaveolens, Willd. Sp. Pl. iv. 1050.-Austral.

subalata, Vatke, in Oest. Bot. Zeit. xxx. (1880) 276.Afr. trop.

subbinervia, Meissn. ex Lehm. Plant. Preiss. i. $16=$ rostellifera.

subcaerulea, Lindl. in Bot. Reg. t. 1075.-Austral. 


\section{ACACIA:-}

subdimidiata, Splitgerb, in Hoev, \& De, Vr, Tijdschr. ix. (1842) $112=$ Pithecolobinm multiflorum

suberosa, A. Cunn. ex Benth. in Hook. Lond. Fourn. Bot. i. (1842) 499.-Austral.

subfalcata, Meissn. in Bot. Zeit. (1855) $11=$ micro botrya.

subinermis, Berx. ex DC. Prod. ii $463=$ macracantha. sublanata, Benth. in Enum. Pl. Hueg. 42.-Austral. subporosa, F. Muell. Pl. Vict. ix. 24.-Austral. subrhombea, Baill. in Bull. Soc. Linn. Par. i. (1883) 364.-Madag.

subternata, F. Muell. \& Benth. in Fourn. Linn. Soc. iii. (1859) 124.-Austral.

subtilifolia, H. B. \& K. Now. Gen. et Sp. vi. $268=$ Pip tadenia subtilifolia.

subtilinervis, F. Muell. Pl. Vict. ii, 32.-Austral. subtilis, Hoffingg. Verz. Pfl. Nachtr. ii. 43.-Austral. subulata, Bonpl. Fard. Malm. 110. t. 45.-Austral sulcata, R. Br. in Ait. Hort. Kew. ed. II. v. 460.-Austral.

sulcipes, Sieber, ex G. Don, Gen. Syst. ii. $419=$ decurrens

Suma, Buch.-Ham. ex Wall. Cat. sub n. $5227=$ A. Sundra.

Suma, Kurz, ex Brandis. For. Fl. 187.-Ind, or.

Sundra, DC.Prod. ii. 458 -Ind. or

Sundra, Roxb. in Wall. Cat. n. 5227=A. Suma

taitensis, Vatke, in Oest. Bot. Zeit. xxx. (1880) 278.-

Afr, trop.

tamarindifolia, Griseb. Cat. Pl. Cub. $82=$ Mimosa polyancistra.

tamarindifolia, Willd. Sp. Pl. iv. 1092.-Am. austr.

tamariscina, Willd. 1. c. $1062=$ Gagnebina tamariscina taxifolia, A. Cunn. in Field, New South Wales, 344 $=$ trinervata.

taxifolia, Lodd, Bot. Cab. t, $1225=$ Riceana:

taxifolia, Willd. Sp. Pl. iv, 1050_-Cochinch.

Tayloriana, F. Muell. in Wing, South. Sc. Record (July, 1882).-Austral,

tenerrima, Miq. Fl. Ind. Bat, i. 14. t. 1=pennata,

tenuiflora, Willd. Sp. Pl. iv. $1088=$ Mimosa Cabrera.

tenuifolia, F. Muell. in Trans. Phil. Soc. Vict. i. (1855)

37.-Austral

tenuifolia, Willd. Sp. Pl. iv. 1091 = paniculata.

tenuissima, F. Muell. ex Benth. in Journ. Linn. Soc. iii. (1859) $135=$ xylocarpa.

tephroloba, A. Gray, PI. Wright. i. $65=$ Berlandieri.

teretifolia, Benth. in Hook. Lond. Fourn. Bot. i. (1842)

326.-Austral.

tetragona, Willd. Sp. PI. iv. $1069=$ Calliandra tetragona.

tetragonocarpa, Meissn. in Lehm. Pl. Preiss. i. 4.Austral.

tetragonophylla, F. Muell. in Fourn. Linn. Soc. iii. (1859) 121.-Austral.

texensis, Torr. \& Gray, F1. N. Am. i. 404=filicina

thegonocarpa, A. Cunn. ex Sweet, Hort. Brit. ed. III 198 , sphalm. = trigonocarpa.

Thibaudiana, DC. Prod. il. $456=$ Piptadenia moniliformis.

Thosetiana, F. Muell. Fragm, iv. 3=Albizzia Thozetiana.

Tomentilla, Zipp. ex Span. in Linnaea, xv. (1841) 199 = pennata.

tomentosa, Willd. Sp. Pl. iv. 1087.-Ind, or.

torquata, Lag. Gen. et Sp. Nov. 16, n. 206= Prosopis torquata.

tortilis, Hayne, Aroneigen, ix, t. 31-Afr. trop.; Arab. tortuosa, Willd. Sp. Pl. iv. 1083.-Am. austr.

torulosa, Benth. in fourn. Linn. Soc. vii. (1859) 139 -Austral.

translucens, A. Cunn. in Hook. Ic. Pl. t 160Austral.

trapesoidea, DC, ex Steud. Nom, ed. II. i. $8=$ decipiens.

triacantha, Hochst. ex. A. Rich. Tent. Fl. Abyss. i. $244=$ glaucophylla.

triangularis, Benth. Enum. Pl, Hueg, $44=$ biflora.

trichandra, Zucc. Pl. Nov. Fasc. ii. $41=$ Leucaena diversifolia

trichodes, Willd. Sp. Pl. iv. $1063=$ Lencaena trichodes.

trichophylloides, Macfad. Fl. Jamaic. $320=$ Piptadenia peregrina.

trigona, A. DC. Not, viii. PI. Rar. Jard. Gen. $20=$ myrtifolia.

trigonocarpa, A. Cuan. ex Lond. Hort. Brit. $407=$ longifolia.

\section{ACACIA:-}

rigonophylla, Meissn. in Lehm. Pl. Preiss. ii. 199 Austral.

trinervata, Sieber, ex DC. Prod. ii. 451.-Austral:

trinervis, Desv. Fourn. Bot. iii. (1814) 70.-Hab.?

trineura, F. Muell. Pl. Vict, ii. 25.-Austral.

triptera, Benth. in Hook. Lond. Fourn. Bot. i. (1842) 325. - Austral.

triptycha, F. Muell. ex Benth. Fl. Austral. ii. 337.Austral.

triquetra, Benth. in Hook. Lond. Fourn. Bot. i. (1842) 358.- - Austral.

trisperma, Mart. Herb. Fl. Bras, 108=Piptadenia trisperma.

trispinosa, Stokes, Bot. Mat. Med. iii. 168=A. Senegal.

trissoneura, F. Muell. Fragm. iv. $6=$ heteroclita.

tristis, R. Grah. in Bot. Mag. t. $3420=$ armata.

tristis, Welw.ex Oliver, in Fl. Trop. Afr. ii. 349.-

Afr. trop.

truncata, Hort. ex Hoffmgg. Pf. Verz. $34=$ decipiens?

tuberosa, Sterler, Hort. Nymph. ex Steud. Nom. ed. II. i. 8. - Hab.?

tubulifera, Benth. in Hook. Lond. Fourn. Bot. i. (1842) 520.-Peruv.

tucumanensis, Griseb, in Goett. Abh, xix. (1874) 135.Am. austr.

tumida, F. Muell. in Fourn. Linn. Soc. iii. (1859) 144. - Austral.

Tumndra, Steud. Nom. ed. II: i. 8, sphalm.=Sundra. ulicina, Meissn. in Lehm. Pl. Preiss, ii. 202.-Austral. umbellata, A.Cunn ex Benth in Hook. Lond. Fourn. Bot. i. (1842) 378. 一Austral

umbellifera, Kunth, Mimos. Humb. 100. t. $13=$ filicina.

umbraculata, Wight, in Wall. Cat, n. $5245=$ latronum. umbrosa, A. Cunn. ex G. Don, Gen. Syst. ii. $405=$ binervata.

uncifera, Benth. in Mitch. Trop. Austr. 341.-Austral. uncinata, Lodd. Bot. Cab. t. $909=$ undulaefolia.

uncinella, Benth. in Linnaea, xxvi. (1853-55) 613.Austral.

uncinella, DC. ex. Steud. Nom. ed. II. i. $8=$ acanthocarpa.

uncinella, Desf. Cat. Hort. Par, ed, T.IT. 299= Mimosa uncinella.

undulata, Willd. Enum. Hort. Berol. Suppl. $68=$ armata undulaefolia, A.Cunn. ex G. Don, Gen. Syst. ii. 404. - Austral.

ungulata, Desv. Journ. Bot. iii. (1814) $68=$ Calliandra portoricensis.

uniglandulosa, Seem. \& Schmidt, in Flora, xxvii. 1844) 495 = alata.

urophylla, Benth. ex Lindl. in Bot. Reg. (1841), Misc. 24.-Austral.

vaga, Willd. Sp. Pl. iv. 1066-Bras.

Valenzuelana, A. Rich. Ess. Fl. Cub. $462=$ villosa

varians, Benth. in Mitch. Journ. Trop. Austral: $132=$ salicina.

velutina, Benth. in Hook. Lond, Journ. Bot.i. (1842) $512=$ monacantha.

velutina, Bertol. Pl. Nov. Hort. Bonon. ii. 13. t. 4.Ind. occ.

velutina, $D C$. Prod. ii. 459 .--Bras.

venosa, Hochst. ex Benth. in Hook. Lond. Fourn. Bot. v. (1846) 98.-Abyss.

venulosa, Benth. $l: c, 366$-Austral.

venusta, Regel \& Koern. Ind. Sem. Hort. Petrop. (1858). 53.-Hab. ?

venusta, Willd. Enum. Hort. Berol. 1052=Calliandra portoricensis.

vera, Willd. Sp. Pl. iv. $1085=$ arabica.

Vorek, Guill. \& Perr. Tent. Fl. Senog. i. 245. t. $56=\mathrm{A}$.

Senegal.
verniciflua, A. Cunn. in Field, New South Wales, 344.-Austral.

verticillata, Sieber, ex Benth. F1. Austral. i. $332=$ juniperina.

verticillata, Willd. Sp. Pl. iv. 1049.-Austral

verugera, Schweinf, in Linnaea, xxxv. (186 $\tilde{\imath}-68) 340$ t. 9, 10.-Afr. trop.

vespertina, Macfad. Fl. Jamaic.i. $318=$ Calliandra portoricensis.

vestita, Ker-Gawl. in Bot. Reg. t. 698.-Austral,

viarum, Allem. ex Tenore, Cat. Ort. Napol. 77.Bras.

vicioides, Ferr. \& Galin. Voy, Abyss. iii, $119=$ mellifera.
ACACIA:-

Victoriae, Benth. in Mitch. Journ. Trop. Austral. $333=$ sentis.

villosa, Willd. Sp. Pl. iv. 1067.-Jamaica,

viminalis, Ait. ex Steud. Nom. ed. II. i. 8.-Austral.

viminea, Dietr. ex Steud. l. c. 9-Austral.

Vincentis, Griseb. F.. Brit. W. Ind. $222=$ Pitheco-

lobium tortum.

Virchowiana, Vatke \& Hildeb. in Oest. Bot. Zeit. $\mathrm{xxx}$ (1880) 275.-Afr. trop.

virescens, DC. Cat. Hort. Monsp. 74,-Am, austr.

virgata, Gaert. Fruct. ii. 317. t. $148=$ Desmantbus virgatus.

virgata, Lodd. Bot. Cab. t. $1246=$ vernicifus.

virgata, Rafin. Fl. Ludov. 136.-Am, bor.

virgultosa, Vahl, ex: Walp. Rep. i. $929=$ Inga virgultosa.

viridiflora, Kunth, Mimos. Humb. 81. t. $25=$ P'iptadenia subtilifolia.

viridiflora, Tweed. ex Benth. in Hook. Lond. Journ. Bot. iii. (1844) $98=$ Calliandra viridiflora.

viridiramis, Burch. Trav. i. $300=$ Xerocladia Zeyheri, viridis, Baill. in Bull. Soc. Linn. Par. i. (1883) 363.Madag.

viscidula, Benth. in Maund, Botanist, iv, t. $179=$ elongata.

viscidula, A. Cunn. ex Benth. in Hook. Lond. Fourn Bot. i. (1842) 363.-Austral.

visciflua, F. Mucll. Pl. Vict. ii. $24=$ dodonaeifolia.

Visco, Lorentz, ex Griseh. in Goett. Abh. xxiv. (1879) 122. - Reg. Argent.

viscosa, Schrad. ex Wendl. Comm. Acac. 30. t. $7=$ dodonaeifolia.

Visite, Griseb. in Goett. Abh. xix. (1874) 135.-Reg. Argent.

visneoides, Colla, in Linnaea,. iv..(1829) Lit. 56. -Austral.

Vogeliana, Steud. Nom. ed. II. i. $9=$ ambigua.

volubilis, F. Muell. Fragm. x. 98.-Austral.

vomeriformis, A. Cunn. ex. Benth. in Hook. Lond. Fourn. Bot. i. (1842) 332.-Austral.

vilcanica, Korth. Hort. Bogor. ex Flara, xxa. (1\$47) $705=$ Albizzia montana.

Wallichiana, DC. Prod. ii. 458=A. Catechu.

Wattsiana, F. Muell. ex Benth. Fl. Austral. ii. 374.Austral.

Welwitschii, Oliver, Fl. Trop. Afr. ii. 341.-Afr. trop.

Westiana, DC. Prod. ii. $464=$ riparia.

Whanii, F. Muell. ex Benth. Fl. Austral. ii. 386.Austral.

Wickhami, Benth. in Hook. Lond. Fourn. Bot. i. (1842) 379.-Austral.

Wightiana, R. Grah. in Wall. Cat, n. $5259=$ Albizzia amara

Wightii, Baker, ex Benth. in Trans. Linn. Soc. xucx. (1875) 506.-Ind. or.

Wightii, Wight \& Arn. Prod. 274=Albizzia amara,

Wilhelmiana, F. Muell. in Trans. Phil Soc. Victoria, i (1855) $37=$ calamifolia.

Willdenowana, Wend!. Verm. K. Berggart. (1845) $5=$ diptera.

Wrightii, Benth. ex A. Gray, in Pl. Wright. i. 64.Texas.

xanthina, Benth. in Hook. Lond. Joum. Bot. i. 1812 $355=$ bivenosa

xanthophloea, Benth in Trans. Limn. Soc. xxx. (15i5) 511.-Afr. trop.

xiphocarpa, Hochst. ex Benth. in Hook. Lond. Journ. Bot. v. (1846) $96=$ abyssinica.

xylocarpa, A. Cunn. ex Benth. l. c. i. (1S42) 370 -Austral.

xylocarpa, Willd. Sp. Pl. iv. $1055=$ Aylis dolabri. formis.

Zygia, Baill. in Bull. Soc. Linn. Par. i. (1583) 364.Madag.

zygioides, Baill. l. c. 363.-Madag

ACAENA, Linn. Mant ii. $145(17 i 1)-$ ROSACE.AE Bentb. \& Hook. f. i. ti?s.

Axcistrum, Forst. Char. Gen. 3. t. 2. (17it) IAslocirpus, Bunks \& Soland. ex Hook. f. Fl. Antarct. $26 \pm(1$ t \pm )

SPHAERULA, Anders, ex Ilook. f. l. c 208 154

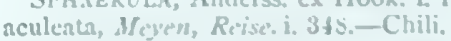

adscendlens, Fohl, Ensm. i $20 \%$. - An. austr. Austral.

affinis, Hook. fo Fl. Antarct, 208. t. $90^{\circ}=$ ausocndens 


\section{ACAENA:-}

agrimonioides, H. B. \& $K$. Nov. Gen. et Sp. vi. 231. -Mexico.

alpina, Poepp. in Nov. Act. Nat. Cur. xix. Suppl. i. 1843) 326.-Chili.

andicola, Gill. ex Walp. Rep. ii. $43=$ pinnatifida.

andina, Phil. in Linnaea, xxviii. (1856) 636.-Chili

antarctica, Hook. f. Fl. Antarct. 269.-Reg. Magell.

argentea, Bert. ex Steud. Nom. ed. II. i, $9=$ Berteriana

argentea, Ruiz \& Pav. Fl. Per. i. 67. t. 103. f. b.Chili.

Behriana, Schlecht. in Linnaea, xx. (1847) $660=$ ovina.

Berteriana, Bernh. ex Steud. Nom. ed. II. i. 9.-Chili.

Buchanani, Hook. f. Handb. New Zeal. Fl. 57.-N Zel.

Cadilla, Hook. f. Fl. Antarct. 269.-Patagonia

caespitosa, Gill in Hook, Bot. Misc. iii. 307 (1833)Chili.

Calcitrapa, Phil. in Linnaea, xxxiii. (1864-65) 67.Chili.

canescens, Phil, Fl. Atac. 18.-Chili.

Closiana, C. Gay, Fl. Chil. ii 298.-Chili.

Coxi, Phil, in Linnaea, xxxiii. (1864-65) 63.-Chili

cnneata, Hook. E A Arn. in Hook. Bot. Misc. iii. 307 $(1833)=$ Reg. Magell.

cylindristachya, Ruiz \& Pav. Fl. Per. i. 68 t. 104. f 2.-Peruv.

decumbens, Menzies, in Hook. f. Fl. Antarct. $9=$ Sanguisorbae.

depressa, T. Kirk, in Trans. N.Z. Inst. ix. (1877) 548 $-N$. Zeland

digitata, Phil. in Anales Univ. Chil. (1862) ii.445.Chili.

echinata, Lehm. PI. Preiss, i. 95=0vina.

elegans, C. Gay, Fl. Chil. ii. 297.-Chili.

elongata, Linn. Mant. ii. 200-Mexico

Eupatoria, Schlecht. in Linnaea, ii. (1827) 30.Uruguay.

exigua, A.Gray, Bot. U.S. Expl. Exped.i. 498-Ins. Sandvic.

glaberrima Phil in Linnaea, xxwiii (1856) $685=$ pumila glabra, 7. Buch. in Trans. N.Z. Inst. iv. (1872) 226 t 14.-N. Zel

Grahamiana, Gill. ex Walp. Rep. ii. $43=a d-$ scendens.

hirsuta, Phil. in Anales Univ. Chil. (1872) 712.Chili.

Huttoni, $R . B r$. [ter.] in Trans. N.Z. Inst. xvi. (1884) 382.-N. Zeland.

incisa, Lindl. Bot. Reg. t. $1271=$ pinnatifida

inermis, Hook. f. Fl. N. Zel. i. 54.-N. Zel.

integerrima, Gill. in Hook. Bot. Misc. iii. (1833) 306. -Chili.

Krausei, Phil. in Anales Univ. Chil. (1862) $711=$ laevigata.

laevigata, Ait. Hort. Kew. ed. II. i. 68.-Reg. Magell.

lappacea, Ruiz \& Pav. Fl. Per. i. 66. t. 103. f. a.Peruv.

latebrosa, Ait. Hort. Kew ed. II. i. 67-Afr, austr

laxiflora, Willd ex Steud. Nom, ed. II i, 9-Am. austr.

leptacantha, Phil. in Linnaea, xxxiii. (1864-65) 66.Chili.

lucida, Vahl, Enum. i. 296.-Ins. Falk1.

lucida, Willd. ex Steud. Nom. ed. II i. $9=$ pinnatifida. macrocephala, Poepp. Fragm. Syn. 25.-Chili. macrorhiza, Hook. f. Fl. Antarct. 265.-N. Granat

macrostemon, Hook. f. in Hook. Lond. Fourn. Bot. vi. (1846) 476, 269.-Chili.

magellanica, Vahl, Enum. i. 297.-Reg. Magell.

microcephala, Schlecht. in Linnaea, xxviii. (1856) 463. -Chili.

microphylla, Hook. f. Fl. N. Zel. i. 55.-N. Zel.

montana, Hook. f. in Hook. Lond. Fourn. Bot. vi. (1846) 276.-Tasman.

montana, Phil. in Linnaea, xxviii. (1856) 686.-Chili. montevidensis, Hook. f. Fl. Antarct. $265=$ A. Eupatoria multifida, A. Dietr. Sp. Pl. i. $619=$ trifida.

multifida, Hook. f. Fl. Antarct. 265.-Patagonia

myriophylla, Lindl. Bot. Reg. t. 1271,-Reg. Argent.

Novae-Zelandiae, T. Kirk, in Trans. N.Z. Inst. ii.

(1871) $177 .-\mathrm{N}, \mathrm{Zel}$

ochreata, Wedd. Chlor. And. ii. 240.-Peruv,

oligacantha, Phil. in Linnaex, xxxiii. (1864-65) 66. Chili.

ovalifolia, Ruiz \& Pav. Fl. Par. i. 67. t. 103.-Am. austr.

\section{ACAENA:}

ovalis, Pers. Syn. i. $142=$ ovalifolia.

ovina, A. Cunn. in Field, New South Wales, 358.Austral.

pectinata, C. Presl, Epim. Bot, 201.-Chili.

pinnatifida, Bert. ex Stend. Nom. ed. II. i. $9=$ cuneata myriophylla

pinnatifida, Hort. ex Stend. 1. c. = A. Berteriana.

pinnatifida, Lindl. Bot. Reg. t. $1271=$ trifida.

pinnatifida, Ruiz \& Pav. Fl. Per. i 68. t. 104.-Chili

Poeppigiana, C. Gay, Fl. Chil. ii. 284.-Chili.

polycarpa, Griseb, in Goett. Abh. xix. (1874) 138.-

Reg. Argent.

poterioides, Willd. ex Steud. Nom. ed. II. i. 9.-Am. austr.

pumila, Phil. in Linnaea, xxxïi. (1864-65) 67.-Chili. pumila, Vahl, Enum. i. 298.-Reg. Magell.

quinquefida, Phil. in Linnaea, xxviii. (1856) 686.CChili. Sanguisorbae, Vahl, Enum. i. 294.-Austral.

sarmentosa, Carmich. in Trans. Linn. Soc. xii. (1818) $502=\mathrm{A}$. Sanguisorbae.

sericea, Facq. f. Ecl. i. 81. t. 55.-Mexico.

splendens, Hook. \& Arn. in Hook. Bot. Misc. iii. (1833) 306.-Chili.

stellaris, Meyen, Reise, i. 348.-Chili.

stricta, Griseb. in Goett. Abh. xix. (1874) 138.-Reg. Argent.

suaveolens, A. Gray, Bot. U. S. Expl. Exped. i. 748, sphalm. = Acacia straveolens

subincisa, Wedd. Chlor. And. ii. 242.-Ecuador

tridactyla, Presl, Epim. Bot. 201.--Mexico.

trifida, Ruiz \& Pav. Fi. Per. i. 67. t. 104. f. c.-Calif.; Peru; Chili.

trifida, Stend. \& Hochst. ex Steud. Nom. ed. II. i. $9=$ Berteriana.

valdiviana, Phil. in Linnaea, xxxiii. (1864-65) 65.Chili.

venulosa, Griseb. in Goett. Abh. vi. (1854) 118.-Reg. Magell.

ACAENOPS, Schrad. ex Stend. Nom. ed. II. 9 (1840) = Dipsacus, Linn.

pilosus, Fourr. in Ann. Soc. Linn. Lyon. N.S. xvi. (1868) $400=\mathrm{D}$. pilosus.

vulgaris, Schrad. ex Steud. Nom. ed. II. i. $9=$ D. pilosus.

ACAJOU, Tourn. ex Adans. Fam. ii. 344 (1763)=seq.

ACAJUBA, Gaertn. Fruct. i. 192. t. 40. $(1788)=$ Anacar dium, Linn

occidentalis, Gaert, 1. c. = Anac. occidentale

ACALYPHA, Linn. Coroll. Gen. 19 (1737). EU PHORBIACEAE, Benth. \& Hook. f. iii. 311.

Calyptrospatha, Klotzsch, ex Baill. Etudes Euph. 440 (1858).

Caturus, Linn. ex Schreb. Gen. Pl. 67 \% (1791).

Cupameni, Adans. Fam. ii. 356 (1763)

Galurus, Spreng, Anleit. ii. II. 364 (1817)

GYMNALYPHA, Griseb, in Bonplandia, vi. (1858) 2.

Linostachys, Klotzsch, ex Schlecht. in Linnaea, xix. (1847) 235

Odonteilema, Turez. in Bull. Soc. Nat. Mosc. xxi. x. (1848) 587 .

Usteria, Dennst. Schluess. Hort. Malab. 31 (1818). abortiva, Hochst. ex Baill. Etud. Gén. Euphorb. $443=$ indica.

accedens, Muell. Arg. in Linnaea, xxiv. (1865-66) 35.-Bras.

acuminata, Benth. in Hook. Kew fourn. vi. (1854) 329. -Bras.

acuminata, Vahl, ex Baill. Adansonia, i. (1860) $267=$ spiciflora."

acuta, Thunb. Fl. Cap. ed. Schult. $546=$ Adenocline acuta.

adenophora, Griseb. in Goett. Nachr. (1865) $175=$ membranacea.

adenostachya, Muell. Arg. in Linnaea, xxxiv. (1865) 21.-Mexico.

adenotricha, A. Rich. Tent. Fl. Abyss, ii. 248.-Abyss. adscendens, Hornem. Hort. Hafn. Suppl. $108=$ chamae drifolia.

affinis, Klotzsch, in Nov. Act. Acad, Nat. Cur. xix. Suppl. i. (1843) $416=$ stipulacea.

agrimonioides, D. Dietr. Syn. v. 377 err. typ. $=$ anemioides.

alnifolia, Poir. Encyc. vi, $203=$ Poiretii.

\section{ACALYPHA:}

alnifolia, Klein, ex Willd. Sp. Pl. iv. 525.-Ind. or

alnifolia, Wall. Cat. n. $7782 \mathrm{~A}=$ capitata.

alopecuroidea, facq. Ic. Rar. iii. 19. t.620; Coll. iii. 196. -Venezuela.

amblyodonta, Muell. Arg. in Mart. Fl. Bras. xi. II. 365.-Bras

amboynensis, Benth. in Hook. Lond. Journ. Bot. ii (1843) $233=$ grandis.

amentacea, Roxb. Fl. Ind. iii. $676=$ fruticosa

andina, Muell. Arg. in Flora, 1v. (1872) 26,--Reg. Andin.

anemioides, H. B. \& K. Nov. Gen. et. Sp. ii. 94.Mexico.

angatensis, Blanco, Fl. Filip. ed. I. 750.--Ins. Philipp.

angolensis, Muell. Arg. in Fourn. Bot. ii. (1864) 335.Afr. trop.

angustata, Sond. in Linnaea, xxiii. (1850) $115=$ peduncularis.

angustifolia, Sw. Prod. Veg. Ind. Occ. 99.--Ins. S Doming.

anisodonta, Muell. Arg. in DC. Prod.xv. II. 819.--Ins, Pacif.

arborea, Comm. ex Poir. Encyc. vi. 205.-Ins. Masc. St. Helen.

Arciana, Muell. Arg. in Mart. Fl. Bras. xi. II. 362.Bras.

aristata, H. B. \& K. Nov. Gen. et Sp. ii. 93.-N. Granat.

arvensis, Poepp. \& Endl.Nov.Gen. \& Sp.iii. 21.-Peruv australis, Linn. Sp. Pl. 1004.--Reg, trop.

Bailloniana, Muell. Arg. in Linnaea, xxxiv. (1865-66) 44.-Afr. trop.

Baroni, Bakex, in fourn. Linn. Soc. xx. (1884) 254 Madag.

benguelensis, Muell. Arg. in Fourn. Bot. ii. (1864) 335.-Afr. trop.

Berteroana, Muell. Arg. in Linnaea, xxxiv. (1865-66) 33.-Porto-Rico

betulaefolia, Sw. Prod. Veg. Ind. Occ. $99=$ scabrosa.

betulina, Retz. Obs. Fasc. v. $30=$ fruticosa.

betulina, Schweinf. P1. quaedam Nilot, $13=$ Cephalo eroton cordofanus.

betulina, Sond. in Linnaea, xxxiii. (1850) $116=\mathrm{gla}$ brata.

betuloides, Klotzsch, ex Baill. in Adansonia, v. (186465) $228=$ variabilis.

betuloides, Pav. ex Klotzsch, in Seem. Bot. Herald, 101 = diversifolia.

Bilbergiana, Klotzsch, 1. c. = diversifolia.

bipartita, Muell. Arg. in Flora, xlvii. (1864) 538.-Afr trop.

bisetosa, Spreng. Syst. iii. 879.-Venezuel

boehmerioides, Miq. Fl. Ind. Bat. Suppl. i. 459.-Ins, Pacif.

Boiviniana, Baill. Adansonia, i. (1860-61) 272.Afr. trop.

boliviensis, Muell. Arg. in Linnaea, xxxiv. (1865-66) 162.-Bolivia.

Botteriana, Muell. Arg. L. c. 46-Mexico.

brachiata, Krauss, in Flora, xxvii. (1845) 83, nomen= tenuis.

brachyandra, Baill. in Adansonia, v. (1864-65) 232 -Bras.

brachyclada, Muell. Arg. in DC. Prod. xv. II. 862.Peruv.

brachystachya, Hornem. Hort. Hafn. ii. 909.-China bracteata, Miq. Fl. Ind. Bat. ii. 406.-Malaya.

brasiliensis, Muell. Arg. in Linnaea, xxxiv. (1865-66) 37. - Bras.

brevibracteata, Muell. Arg. in DC. Prod.xv. Ix. 855.Ins. Pacif.

brevicaulis, Muell. Arg. in Linnaea, xxxiv. (1865-66) 13.-Mexico

brevipes, Muell. Arg. in Mart. Fl. Bras. xi. II. 348.Bras.

brevipes, Rafin. New Fl. Am. i. 44.-Am. bor.

Buchenavii, Muell. Arg. in Bremen, Abh. vii. (1880) 27.-Afr. trop.

bullata, Muell. Arg. in Linnaea, xxxiv. (1865-66) 17. -Peruv.

californica, Benth. Bot. Voy. Sulph. 51.-Calif.

callosa, Benth. Pl. Hartw. 252.-N. Granat.

calyciformis, Wight, ex Wall. Cat. n. $7786=$ brachystachya.

cancana, Muell. Arg. in Flora, xlvii. (1864) 438. -N. Granat.

canescens, Wall. Cat. $\mathrm{n} .7785=$ indica. 


\section{ACALYPHA :-}

capensis, D. Dietr, Syn. v. 378, sphalm. = corensis caperonioides, Baill. Adansonia, iii. $(1862-63) 157=$ peduncularis. capillipes, Muell. Arg. in Linnaea, xxxiv. (1865-66) 40.-Austral.

capitata, Wall. Cat. n. 7783. A, B=fruticosa. capitata, Willd. Sp. Pl. iv. 525.-Ind. or. caroliniana, Blanco, F1. Filip. ed. I. $748=$ indica caroliniana, Ell. Sketch, ii. 645.-Am. bor. caroliniana, Walt. Fl. Carol. 238=virginica. carpinifolia, Poepp. ex Baill. Etud. Gén. Euphorb. $442=$ leptostachya.

carpinifolia, Poir. in Lam. Encyc, vi. 203. (1804).Ins. S. Doming

carthagenensis, Facq. Enum. Pl.Carib. 32.-N. Granat. Caturus, Blume, Bijdr, 629.-Java.

caudata, H. B. \& K. Nov. Gen. et Sp. ii. $95=$ macrostachya.

chamaedrifolia, Muell. Arg. in DC. Prod. xv. Ir. $879=$ reptans.

Chibomboa, Baill. Adansonia, i. (1860-61) 269.-Ins. Comor.

chinensis, Roxb. Fl. Ind. iii. $677=$ australis.

chorisandra, Baill. Adansonia, v. (1864-65) 235.Bras.

ciliata, Forsk. Fl. Aegypt. Arab. 162.-Geront, trop.

ciliata, Wall. Cat. n. $7779 \mathrm{~J}=$ indica.

cincta, Muell. Arg. in Linnaea, xxxiv. (1865-66) 20. -Mexico.

circinnata, A. Gray, ex Seem. List Vit. P]. $11=$ Wilkesiana.

Clausseni, Baill. Adansonia, v. (1864-65) 226.-Bras. codonocalyx, Baill, l. c. i. (1860-61) 271.-Ins. Comor colorata, Spreng. Syst. iii. $879=$ integrifolia.

Commersoniana, Baill. Adansonia, i. (1860-61) $267=$ inregrifolia.

communis, Muell. Arg. in Linnaea, xxxiv. (1865-66 $23=$ variabilis

conferta, Roxb. Fl. Ind. iii. $677=$ brachystachys

consimilis, Muell. Arg. in DC. Prod. xv. II. 807.-Ins.

Pacif.

conspicua, Muell. Arg. l. c. 832,-Mexico

contermina, Muell. Arg. in Linnaea, xxxiv. (1865-66) 46.-Peruv.

corchorifolia, A. Rich. in Sagra, Hist. Cuba, iii. 203.Ind. occ.

corchorifolia, Vahl, ex Baill. Etud. Gén. Euphorb. 443 $=$ fallax.

corchorifolia, Willd. Sp. Pl. iv. $524=$ reptans.

cordata, Drège, ex Baill. Adansonia, iii. (1863) $158=$ Eckloni.

cordata, Thunb. Prod. P1. Cap. $117=$ decumbens.

cordifolia, Hook. f. in Trans. Linn. Soc. xx. (1847)

$186=$ parvula.

cordifolia, Griseb. in Goett. Abh. xix. (1874) 97.-Reg. Argent.

cordifolia, Anderss. Galap. Veg. 103= parvula.

cordobensis, Griseb. in Goett. Abh. xix. (1874) $97=$ seq.

cordoviensis, Muell. Arg. in Fourn. Bot. xii. (1874) 228.-Reg. Argent.

corensis, facq. Enum. Pl. Carib. 32.-Ind, occ.

crassa, Meissn. ex Krauss, in Flora, xxviii. (1845) 83 $=$ peduncularis.

crenata, Hochst. ex A. Rich. Tent. Fl. Abyss, ii. 245. -Afr. trop.

crenulata, Rafin. New Fl. Am. i. $44=$ virginica.

cucullata, Poir. Encyc. Suppl. iv. $683=$ macrostachya.

cuneata, Poepp. \& Endl. Nov. Gen. iii. 22.-Am. austr.

Cunninghami, Muell. Arg, in Linnaea, xxxiv. (186566) 35.-Austral.

cuspidata, facq. Hort. Schoenb. ii. 63. t. 243.-Am. austr.

cylindrica, Roxb. Fl. Ind. iii. $678=$ Poiretii.

decidua, Forsk. Fl. Aegypt. Arab. 161.-Arab.

decumbens, Thunb. Prod. Pl. Cab. 117.-Afr. austr.

densiflora, Blume, Bijdr. 628 = hispida.

dentata, Schum. \& Thonn. Beskr. Guin. Pl. $410=$ Mallotus oppositifolius.

denudata, Muell. Arg. in DC. Prod. xv, II. 819.-Ins Pacif.

depauperata, Muell. Arg. in Linnaed, xxxiv. (1865-66) 160. -Mexico.

Deppeana, Schlecht. in Linnaea, vii. (1832) $385=$ Schiedeana.

\section{ACALYPHA:}

dictyoneura, Muell. Arg. in Linnaea, xxxiv. (1865-66) 12.-Peruv.

diffusa, Anderss. Galap. Veget. $104=$ parvula.

digyneia, Rafin. Fl. Ludov. 112,-Louisian.

digynostachya, Baill. Adansonia, v. (1864-65) 233.Bras.

dimorpha, Muell. Arg. in Mart. Fl. Bras. xi. 11. 354. Bras.

discolor, Boj: Hort. Maurit. $286=$ integrifolia.

discolor, E. Mey, Zwei Pfl. Docum. 129 (n. 20) in Flora, xxviii. (1845) $84=$ decumbens.

distans, Muell. Arg. in DC. Prod. xv. II. 820.-Cuba. divaricata, Baill. in Adansonia, v. (1864-65) $234=$ gracilis.

divaricata, Muell. Arg. in Linnaea, xxxiv. (1865-66) 34.-- Регuv.

divaricata, Rafin. New. Fl. Am. i. 44.-Am. bor.

diversifolia, facq. Hort. Schoenb. ii. 63, t, 244.-Am austr.

domingensis, Spreng. Syst. Veg. iii. $880=$ carpinifolia.

dumetorum, Muell. Arg. in Fourn. Bot. ii. (1864) 334 -Afr. trop.

Dupraeana, Baill. Adansonia, v. (1864-65) $229=$ accedens.

echinata, Rafin..New. Fl. Am. i. 45.-Am, bor.

Eckloni, Baill. Adansonia, iii. (1862-63) 158.-Afr austr.

elegantula, Hochst. ex A. Rich. Tent. F1. Abyss. $246=$ brachystachya.

elliptica, Sw. Prod..Veg. Ind. Occ. 99.-Jamaica

emimensis, Baill. Adansonia, i. (1860-61) 270 . Madag.

eremorum, Muell.Arg.in Flora, xIvii. (1864) 440.Austral.

erythrostachya, Muell..Arg. in Linnaea, xxxiv. (186566) 51.-N. Granat.

estrellana, Baill. Adansonia, v. (1863-64) $237=$ brasiliensis.

exaltata, Baill. l. c. ii. (1861-62) 225.-N. Caled.

fallax, Muell. Arg. in Linnaea, xxxiv. (1865-66) 43.As. trop.

fasciculata, Muell. Arg. l.c. 31.-Ins. Mascar.

filiformis, Poir. Encyc. vi. $205=$ arborea.

filiformis, Klotzsch, ex Schlecht. in Linnaea; xix. 1847) $235=$ Schlechtendaliana

fimbriata, Baill. Adansonia, i. (1860-61) $272=$ Bailloniana et crenata.

fimbriata, Hochst. in A. Rich. Tent. Fl. Abyss. ii. 245. -Abyss.

fimbriata, Schum. \& Thonn. Beskr. Guin. Pl. $409=$ ciliata.

firmula, Muell. Arg. in Linnaea, xxxiv. (1865-66) 21. -Am. centr.

fissa, Herb. Madro ex. Wall. Cat. n. 7786. B.=brachystachya.

flaccida, Hook. f. in Trans. Linn. Soc. xx. (1847) 186 = parvula.

fexuosa, Wight, ex Stend, Nom, ed. II. i. $9=$ lanceolata.

Forsteriana, Muell. Arg. in DC. Prod. xv. 11. 807.Ins. Pacif.

Fournieri, Muell. Arg. in Linnaea, xxxiv. (1865-66) 162.-Mexico.

Frederici, Muell. Arg. in DC. Prod. xv. II. 828Mexico.

fruticosa, Forsk. Fl. Aegypt. Arab. 161.-Geront, trop fruticulosa, Rafin. Fl. Ludov. 112.-Louisiana.

fuscescens, Muell. Arg. in DC. Prod. Xv. II. 821.-Afr. trop.

gemina, Spreng. Syst. iii. $880=$ australis

glabrata, Thunb. Prod. Pl. Cap. 117.-Afr. austr

glabrata, Vahl, ex A. Juss. Tent. Euph. $105=$ Thecacoris madagascariensis.

glandulifolia, Meissn. ex Kranss, in Flora, xxviii. (1845) 83 = peduncularis

glandulosa, Blanco, Fl. Filip. ed, I. 749.-Ins. Philipp.

glandulosa, Cav, in Anal. Hist. Nat. Madr.ii. (1800) 141.-Mexico.

glechomaefolia, A. Rich. F1. Cub. Fanerog. ii. $205=$ reptans.

Goudotiana, Baill. Adansonia, i. (1860-61) 268 arborea.

gracilens, A. Gray, Man. Bot, N. Unit. States, $\$ 90=$ virginica.

gracilipes, Baill. Adansonia, i. $(1860-61) 273=$ integrifolia.

\section{ACALYPHA:-}

gracilis, Spreng. Syst. iv; Cur. Post. 315.-Bras

grandidentata, Muell. Arg. in DC. Prod. xv. II. 823.-

Afr. austr.

grandifolia, Poir. Encyc. vi. $204=$ Claoxylon crassifolium.

grandis, Benh. in Hook. Lond. Fourn. Bot. ii. (184 232.-Malaya.

Hartwegiana, Benth. ex Baill. Etud. Gén. Euphorb. $442=$ diversifolia

bavanensis, Muell. Arg. in Linnaea, xxxiv. (1865-68) 49.-Cuba.

hederacea, Torr. in Bot. Mex. Bound. 200.-N. Mexico hernandifolia, Sw. Prod. Veg Ind. Occ. 99.-Jamaica. heterodonta, Muell. Arg. in Linnaea, xxxiv. (1865-66) 12.-Am. trop.

hirsuta, Hochst, ex A. Rich. Tent. Fl. Abyss. ii. $248=$ villicaulis.

hirsutissima, Willd. Sp. Pl. iv. $528=$ macrostachya.

hirta, Cav. in Anal. Hist. Nat. ii. $(1800) 141=$ phleoides.

hirta, Spreng. Syst. iv ; Cur. Post. $315=$ variabilis.

hispida, Blume, Bijdr. 628 = boehmerioides,

hispida, Burm. f. Fl. Ind. 303. t. 61.-Ind, or

hispida, Wall. Cat. n. 7780. pro parte =fallax.

hispida, Willd. Sp. P1. iv. $523=$ Poireti.

Hochstetteriana, Muell. Arg. in Linnaea, xxxiv. (1865-66) 39.-Afr. trop.

hologyna, Baker, in Fourn. Linn. Soc. xxi. (1885) 44$]$ - Madag.

Hystrix, Balb. ex Spreng. Syst. iii, $883=$ aristata.

indica, Linn. Sp. Pl. 1003.-As. \& Afr. trop.

indica, Vell. Fl. Flum.x. t. $64=$ Poiretii.

infesta, Poepp. \& Endl. Nov. Gen. iii. 22.-Peruv.

infestans, Muell. Arg. in Linnaea, xxxiv. (1865-66)

$23=$ praec

insulana, Muell. Arg. in Flora (1864) 439.-Ins. Pacif. integrifolia, Willd. Sp. Pl. iv. 530.-Ins. Mascar. interrupta, Schlecht. in Linnaea, vii. (1832) $386=$ Bernardia interrupta.

jamaicensis, Rafin. New Fl. Am.46,-Jamaica.

japonica, Houtt. ex Steud. Nom. ed. I. $4=$ Boehmeria spicata.

Jardini, Muell. Arg. in Linnaea, xxxiv. (1865-66) 36 -Ins. Pacif.

Karwinskii, Muell. Arg. in Flora, 1\%. (1872) 41. Am. centr.

Klotzschiana, Muell. Arg. in DC. Prod. xv. 11. $857=$ prunifolia.

Klotzschii, Baill. Adansonia, v. (1864-65) $231=$ longi folia.

Kraussiana, Buching. ex Krauss, in Flora, xxvii. (1845 $84=$ decumbens

laevifolia, Muell. Arg. in DC. Prod. xv. II. 853.-Ins. Pacif.

laevigata, Sw. Prod. 99.-Jamaica.

laevigata, Willd. Sp. Pl. iv. 527 = carpinifolia.

Lagascana, Muell. Arg. in Flora, lv. (1872) 27.-Am. centr.

lagoensis, Muell Arg. in Mart. Fl. Bras. xi. I1. 367. Bras.

lamiifolia, Scheele, in Linnaea, xxv.(1852) 587.-Afr. austr.

lanceolata, Wall. Cat. n. 7789= australis

lanceolata, Willd. Sp. Pl. iv. 524.-Ind. or.

Langiana, Muell. Arg. in Linnaea, xuxiv. (1865-60 159.- Mexico.

languida, E. Mey. \& Sond. in Linnaen, xxiii. (1850) $116=$ petiolaris.

languida, Muell. Arg. in Linnaea, scxir. $1805-60$ 29. - Afr. ausir.

lantanaefolia, Boj. Hort. Maurit. $286^{\circ}=$ reliculata.

latifolia, Muell. Arg, in DC. Prod, xw, 11.817.-Ins. Pacif

laxifora, Muell. Arg. in Linnaea, xxxiv. (1865-60 19.-Ind. occ.

leonensis, Benth. in Hook. Nig. F\%. $501-$ Mareya micrantha.

Lepinei, Muell. Arg. in Linnaea, xxxiv. (1865-68) 1 t. -Ins. Pacif.

leptoclada, Benth. in Bot. Voy. Sulph. 164.-Mexico.

leptopoda, Macll. Ary. in Linmaca, xxxiv. (1865-60 34.-Mexico.

leptorbachis, Mruell. Ang. I. c. 7.-Cuba,

leptostachya, A. Rich, in Sagra, Hist. Cuba, iii. :05 = Iaxillura.

lepostachya, H. B. \& K. Nov. Gen et Sp. ii. $96=$ diversi.

folin.

Lie'bmanni, Muell. Arg. in DC. Prod. xv. 11. \$2: ma \$o! 


\section{ACALYPHA:-}

Liebmanniana, Muell. Arg. in Linnaea, xxxiv. (1865 66) 161.-Mexico.

Lindeniana, Muell, Arg. in DC. Prod. xv. II. 827.Mexico.

Lindheimeri, Muell. Arg. in Linnaea, xxxiv. (1865-66) 47.-Mexico.

Linostachys, Baill.Adansonia, v. (1864-65) $235=$ villosa. Livingstoniana, Muell. Arg, in Flora, xlvii. (1864) 440. -Afr. trop.

longestipularis, Muell.Arg. in Linnaea, xxxiv. (1865-66) 51.--Mexico.

longifolia, Baill. Etud. Gen. Euph. $443=$ cuneata.

longifolia, Klotzsch, ex Baill. Adansonia, v. (1864-65) 231-Bras.

longispicata, Muell. Arg. in Linnaea, xxxiv. (1865-66) 163.-Mexico

Lyallii, Baker, in Fourn. Linn. Soc. xx. (1884) 255.Madag.

macrodonta, Muell. Arg. in Linnaea, xxxiv. (1865 66) 51.-Peruv.

macrophylla, H. B. \& K. Nov. Gen. et Sp. ii. $96=$ macrostachya.

macrosperma, Muell. Arg. in Linnaea, xxxiv. (1865 66) $18=$ membranacea.

macrostachya, Facq. Hort. Schoenb. ii. 63. t. 245.-Am, austr.

macrostachyos, Poir. Encyc.' vi. $208=$ Poiretii.

macrostachyoides, Muell. Arg. in DC. Prod. xv. II. 809. -Mexico.

major, Baill. Adansonia, v. (1864-65) $236=$ Weddelliana.

malabarica, Muell. Arg. in Linnaea, xxxiv. (1865-66) 42.-Ind. or.

Mandoni, Muell. Aro. l. c. 162,-Bolivia

Manniana, Muell. Arg. in Flora, xlvii. (1864) 441.Afr. occ.

Mappa, Willd. Sp. Pl. iv. 526=Macaranga Mappa.

marginata, Spreng. Syst. iii. 879 ---Ind. or.

Martiana, Muell. Arg. in Mart. Fl. Bras. xi. II. 359.Bras.

melochiaefolia, Muell. Arg. in DC. Prod. xv. II. 821. -Mexico.

membranacea, A.Rich.Fl. Cub. Fanerog, ii. 204.-Cuba. mexicana, Muell. Arg. in Linnaea, xxxiv. (1865-66) 41.-Mexico.

micrantha, Benth. in Hook. Nig. Fl. 505=Mareya micrantha.

microcephala, Muell. Arg. in Linnaea, xxxiv. (186566) 160 - - Mexico

microgyne, Poepp. \& Endl. Nov. Gen. iii. $21=$ diversifolia.

microphylla, Klotzsch, in Seem. Bot. Voy. Herald, $278=$ reptans.

microstachya, Benth. Pl. Hartw. $71=$ mollis

mollis, H.B. E K..Nov. Gen. et. Sp. ii. 94.-Mexico

monococca, Engelm. ex A. Gray, Man. Bot. N. U.

States, $390=$ virginica.

monostachya, Benth. PI. Hartw. $\mathbf{1 5}=$ anemioides.

monostachya, Cav, in Anal. Hist. Nat. Madr. ii. (1800)

138.-Mexico.

multicaulis, Muell. Arg. in Linnaea, xxxiv. (1865-66) 53.-Bras.

multipartita, Moench, Meth. Suppl. $122=$ tomentosa. muralis, Zipp. ex Span. in Linnaea, xv. (1841) 350, nomen.-Timor.

nana, Griseb. in Goett. Nachr. (1865) $176=$ reptans

nemorum, Muell. Arg. in Linnaea, xxxiv. (1865-66) 38.-Austral.

neocaledonica, Muell. Arg. in DC. Prod.xv. II. 812.N. Caled.

neogranatensis, Muell. Arg. in Linnaea, xxxiv. (186566) 15.-N. Granat

neomexicana, Muell. Arg. l. c. 19.-N. Mexico.

neptunica, Muell. Arg. in Bremen Abh. vii. (1880) 26. -Afr. trop.

nigritiana, Muell. Arg. in Flora, xlvii. (1864) 440.-. Afr. trop.

obovata, Benth. in Bot. Voy. Sulph. 163. t. $53=$ cuneata. obscura, Muell. Arg. in Linnaea, xxxiv. (1865-66) 163. -Mexica.

obtusa, Thunb. F1. Cap. ed. Schult. $546=$ Leidesia obtusa.

obtusata, Spreng, ex Steud. Nom. ed. II. i. 10. [Adenocline, sp.].-Afr. austr.

ocymoides, H.B. E K. Nov.Gen.et. Sp. ii. 93.-Mexico. odorata, Steud. Nom. ed. II. ii. 696 sphalm. =integrifolia.

\section{ACALYPHA:}

aligantha, Muell. Arg. in Linnaea, xxxiv. (1865-66) 159 - Mexico.

oligodonta, Muell. Arg in DC. Prod. xv. Ir. 831.Mexico.

ornata, Hochst. ex A. Rich. Tent. Fl. Abyss. ii. 247.Abyss.

ostryaefolia, Riddell, Syr. F1. W. St. $33=$ caroliniana. ovalifolia, Baill. Adansonia, i. (1860-61) $269=$ arborea. oxyodonta, Muell.Arg. in Mart. Fl. Bras. xi. II. 367. -Mexico.

padifolia, H.B. \& K. Nov. Gen.et Sp,ii. 97.-Am. austr panamensis, Klotzsch, in Seem. Bot. Voy. Herald, 101 $=$ diversifolia.

Pancheriana, Baill. Adansonia, ii. (1861-62) 225.N. Caled.

paniculata, Miq. Fl. Ind. Bat. i. II. 406. (1859).-Geront, trop.

parvifolia, Muell. Arg. in Linnaea, xxxiv. (1865-66) 161.-Mexico

parvula, Hook. f. in Trans. Linn. Soc. xx. (1847) 185 -Ins. Galap.

Pastoris, DC. ex Willd. Enum. Hort, Berol, $993=$ phleoides.

Pastoris, Schrank, in Denkschr. Bayer. Ges. ii. (1822) $39=$ phleoides.

patens, Muell. Arg.in DC. Prod. Xv.II. 847-Afr. austr. pauciflora, Hornem. Hort. Hafn. ii. $909=$ australis.

Pavoniana, Muell. Arg. in Linnaea, xxxiv. (1865-66 $50=$ arvensis

Peckoltii, Muell. Arg. in Mart. Fl. Bras. xi. II. 365. -Bras.

peduncularis, E. Mey. Zwei Pf. Docum. 136 n. $26=$ Zeyheri.

peduncularis, Meissn. ex Krauss, in Flora, xxviii. (1845) 82.-Afr. austr.

pendula, Wright, ex Griseb. in Goett. Nachr. (1865) $176=$ reptans.

persimilis, Muell. Arg. in Linnaea, xxxiv. (1865-66) 25.-Ind. occ

peruviana, Muell. Arg. l. c. 17.-Peruv.

Pervilleana, Baill. Adansonia, i. (1860-61) $273=$ arborea.

petiolaris, Krauss, in Flora, xxviii. (1845) 83.Afr. austr.

petiolaris, Sond. in Linnaea, xxiii. (1850) $117=$ Sonderiana.

phleoides, Cav. in Anal. Hist. Nat. Madr. ii. (1800) 139.-Mexico

phleoides, Torr. Bot. Mex. Bound. Surv. $199=$ Lindheimeri.

pilifera, Klotzsch, ex Baill.Adansonia, v. (1860-61) $227=$ variabilis

pilosa, Cav. in Anal. Nat. Hist. Madr. ii. (1800) 136.-Am. trop.; Ins. Philipp.

pinnata, Poir. Encyc. vi. 205 = Tragia pinnata.

platyphylla, Muell. Arg. in Linnaea, xxxiv. (1865-66) 6.-Peruv.

plicata, Muell. Arg, in DC. Prod. xv. II. 855.-Bolivia.

Pohliana, Muell Aro in Mart. El Bras xi. II. 360 Bras

Poiretii, Spreng. Syst. iii. 879.-Am.trop.

polymorpha, Muell. Arg. in Fourn. Bot. ii. (1864) 335.-Afr. trop.

polystachya, facq. Hort. Schoenb. ii. 64. t. 246.Peruv, Mexico.

popayanensis, H. B. \& K. Nov. Gen. et Sp. vii. 173= diversifolia.

portoricensis, Muell. Arg。 in Linnaea, xxxiv. (1865-66) 22.-Ind. occ.

Pringlei, S. Wats. in Proc. Am. Acad. xx. (1885).373. -Am. bor.

prunifotia, H. B. \& K. Nov. Gen. et Sp. ii. $92=$ phleoides.

prunifolia, Nees \& Mart. in Nov. Act. Nat. Cur, xi. (1823) 37.-Bras.

pruriens, Nees \& Mart. l. c.36-Bras.

psilostachya, Hochst. ex A. Rich. Tent. Fl. Abyss.ii 246.-Abyss.

pubiflora, Baill. Adansonia, i. (1860-61) 268. Afr. trop.; Madag.

punctata, Meissn. ex Kranss, in Flora, xxvii. (1845) $83=$ peduncularis.

purpurascens, H.B. \& K. Nov. Gen. et. Sp. ii. 97.-

pygmaea, A. Rich. F1. Cub. Fanerog. ii. 205= reptans.

racemosa, Heyne, in Wa11. Cat. n. 7784 $=$ paniculata.

\section{ACALYPHA:}

radians, Torr. in Bot. Mex. Bound. 200,-N. Mexico. radicans, Muell. Arg. in Linnaea, xxxiv. (1865-66) 39. -Bras.

Radula, Baker, in Fourn. Linn. Soc. (1884) 254.Madag.

reflexa, Muelh Arg. in Linnaea, xxxiv. (1865-66) 33. -Peruv.

reniformis, Hook. f. in Trans. Linn. Soc xx. (1847) $187=$ parvula

repanda, Muell. Arg. in Flora, xlvii. (1864) 439 Ins. Pacif.

reptans, Sw. Prod. Veg. Ind. Occ. 99.-Ind. occ reticulata, Muell. Arg. in DC. Prod. xv. Ix. $851=$ arborea.

rhombifolia, Baill. Adansonia, v. (1864-65) $230=$ Poiretii.

Thombifolia, Schlecht. in Linnaea, vii. (1832) 382.Mexico.

rhomboidea, Rafin. New. Fl. Am. i. 45.-Am. bor.

Richardiana, Baill. in Adansonia, i. (1860-61) 268.Madro.

Riedeliana, Baill. l. c. v. (1864-65) 231. - Bras.

rivularis, Seem. List Vit. Pl. 11.-Ins. Fiji.

rottleroides, Baill. Adansonia, i. (1860-61) 270.Madag.

rotundifolia, Vahl, ex Baill. Etud. Gén. Euphorb. 442 = infesta.

rubra, Roxb. in Beatson, Tracts St. Helena Append. $295=$ arborea

rubra, Wight, ex Wall. Cat. n. $7781=$ ciliata.

rubra, Willd. Enum. Hort. Berol. $992=$ phleoides.

Ruiziana, Muell. Arg. in Linnaea, xxxiv. (1865-66) 16.-Peruv.

salicifolia, Muell. Arg. in Flora, xlvii. (1864) 438.Peruv

salviaefolia, Baill. Etud. Gén. Euphorb. 443, nomen.Ins. Mascar.?

samydaefolia, Poepp. E Endl. Nov. Gen. iii. 21. t. 224.-Peruv.

scabra, Vahl, ex Baill. Adansonia, i. (1860-61) $280=$ Claoxylon parviflorum

scabrosa, Sw. Prod. Veg. Ind. Occ. 100.-Jamaica.

scandens, Benth. in Hook. Kew fourn. vi. (1854) 329 -Am. trop.

Schiedeana, Schlecht. in Linnaea, vii. (1832) 384.Mexico.

Schlechtendahliana, Muell. Arg. in Linnaea, xxxiy. (1865-66) 6.-Mexico.

Schlumbergeri, Muell. Arg. in DC. Prod.xv. II. 861.Mexico.

Seemanni, Klotzsch, in Seem. Bot. Voy. Herald, $102=$ macrostachya.

segetalis, Muell. Arg. in Fourn. Bot. ii. (1864) 336.Afr. occ.

seminuda, Muell. Arg. in Mart. Fl. Bras. xi. II. 360.Bras.

senensis, Klotzsch, in Peters, Reise Mossamb. Bot. 96 -Afr. occ.

senilis, Baill. Adansonia, v. (1864-65) 228.-Am. austr. septemloba, Muell. Arg. in Flora, Iv. (1872) 27.Amer. centr.

sericea, Anderss. Galapag. Veget. $103=$ parvula

sessilis, Poir. Encyc. vi. $204=$ australis.

setosa, A. Rich. Fl. Cub. Fanerog. ii. 204-Cuba.

sidaefolia, A. Rich. Tent. Fl. Abyss. ii, 249.-Abyss.

sidaefolia, H. B. \& K. Nov. Gen. et Sp. ii. $95=$ macrostachya.

somalium, Muell. Arg. in Bremen Abh. vii. (1880) $27=$ segetalis.

Sonderiana, Muell. Arg. in Linnaea, xxxiv. (1865-66) 9.-Afr. austr.

Spachiana, Baill. Adansonia, i. (1860-61) 272.Madag.

spicata, Anderss. Galap. Veget. $104=$ parvula.

spicata, Forsk. Fl. Aegypt. Arab. $161=$ indica.

spiciflora, Burm. f. Fl. Ind. 303 (i. e. 203) . t. 61.Madag.

spiciflora, Thou. ex Baill Adansonia, i. (1860-61) $281=$ Claoxylon Linostachys.

spiciflora, Poir. Encyc. vi. $206=$ Claoxylon parviflorum. spicigera, Klotzsch, in Seem. Bot. Voy. Herald, $101=$ diversifolia.

spinescens, Benth. in Hook. Ic. Pl. t. 1291.-Malaya. stenoloba, Muell. Arg. in Flora, lv. (1872) 41.Peruv.

stipulacea, Klotzsch, in Nov, Act. Acad. Nat. Cur. xix. (1843) Suppl. I. 416.-Ins. Molucc. 
ACALYPHA:-

stricta, Poepp. \& Endl. Nov. Gen. iii. 21. t. 225.Peruy.

strobilifera, Hook. f. in Trans. Linn. Soc. xx. (1847) $187=$ parvula.

subtomentosa, Lag. Elench. Hort. Reg. Matr. (1805); Gen. et Sp. Nov. 21.-Mexico.

subvillosa, Muell. Arg. in Mart. Fl. Bras. xi. I1. 341.Bras.

supera, Forsk. F1. Aegypt. Arab. 162=brachystachya.

tarapotensis, Muell. Arg. in DC. Prod. xv. II. 808.Peruv.

tenuicaulis, Baill. Adansonia, v. (1864-65) $234=$ multicaulis.

tenuifolia, Muell. Arg. in DC. Prod. xv. II. 863.Venezuela.

tenuiramea, Muell. Arg. l.c. 858.-Ins. Pacif.

tenuis, Muell. Arg. in Linnaea, xxxiv. (1865-66) 30.-Afr, austr.

tiliaefolia, Poir Encyc vi. 203. (An Euphorbiacea ?).Ins. S. Doming.

tomentosa, Blanco, Fl. Filip. ed. I. 750.-Ins. Philipp.

tomentosa, Boj. Hort. Maurit, $285=$ marginata.

tomentosa, Sw. Prod. Veg. Ind. Occ. 99.-Ins. S. Do-

mingo.
trachyloba, Muell. Arg. in Flora, 1v. (1872) 25.Mexico.

tricholoba, Muell. Arg. in Linnaea, xxxiv. (1865-66). -Mexico.

tricolor, Seem. Fl. Vit. 225, -Ins. Pacif.

triloba, Muell. Arg. in Linnaea, xxxiv. (1865-66) 23. -Mexico.

tristis, Poepp. \& Endl. Nov. Gen, et Sp. iii. $22=$ macrostachya.

ulmifolia, Benth. Pl. Hartw. 252 =diversifolia.

unibracteata, Muell. Arg. in Linnaea, xxxiv. (1865-66) 160.-Mexico.

urophylla, Boiv. ex Baill. Adansonia, i. (1860-61) 273.-Afr. trop.

urostachya, Baill. l. c. v. (1864-65) 229.-Bras.

urticaefolia, Poir. Encyc. vi. 208.-Am. austr.

urticoides, Klotzsch, ex Baill. Adansonia, v. (1864-65) $227=$ communis.

vagans, Cav. in Anal. Hist. Nat. Madr. ii. (1800) 139.-Mexico.

Vahliana, Muell. Arg. in Linnaea, xxxiv. (1865-66) 43.-Afr. trop.

variabilis, Klotzsch, ex Baill. Adansonia, v. (1864-65) 226.-Bras.

Vedeliana, Baill. Adansonia, ii. (1861-62) $224=$ Macíranga Vedeliana

velamea, Baill. l. c. v. (1864-65) $228=$ Bras.

velutina, Hook. f. in Trans. Linn. Soc. xx. (1847) 186 = parvula.

venosa, Poir. Encyc. vi. 204=Leptonema venosum.

vestita, Benth. in Bot. Voy. Sulph. $164=$ cuspidata.

villicaulis, Hochst. ex A. Rich. Tent. Fl. Abyss. ii 248.-Abyss.

villosa, facq. Enum. Pl. Carib. 32.-Ind. occ.

villosa, Vahi, ex Baill. Etud. Gén. Euphorb. $442=$ Poiretii.

virgata, Forst. f. Prod. $67=$ Forsteriana.

virgata, Linn. Pugill. Famaic. Pl. 28 (Am. Acad. v. 410). - Jamaica.

virgata, Vell. Fl. Flum. x. t. $63=$ variabilis.

virgata, Thunb. Fl. Jap. $268=$ anstralis.

virginica, Linn. Sp. Pl. 1003.-Am. bor.

virginica, Wall. Cat, $\mathrm{n}, 7779 \mathrm{G}=$ fallax.

Wallichiana, Mnell. Arg. in DC. Prod. xv. 1r. $802=$ seq.

Wallichii, Thw. Enum. Pl. Zeyl. $271=$ paniculata.

Weddelliana, Baill. Adansonia, v. (1864-65) $232=$ brasiliensis.

Welwitschiana, Muell. Arg. in fourn. Bot. ii. (1864) 334.-Afr, trop.

Wightiana, Muell. Arg. in Linnaea, xxxiv. (1865-66) $43=$ lanceolata

Wilkesiana, Mnell. Arg. in DC. Prod. xv. I1. $817=$ tricolor.

zambesica, Muell. Arg. in Flora, xlvii. (1864) 440.Afr. trop.

Zeyheri, Baill. Adansonia, iii. (1862-63) 156.Afr, anstr.

zeylanica, Rafin. New Fl. Amer, i, 46, nomen.Zeylan.

Zollingeri, Muell. Arg. in Linnaea, xxxiv. (1865-66) 40.- Sumbawa.
ACAMPE, Lindl. Fol. Orch. (1853)

ORCHIDEAE, Benth. \& Hook. f. iii. 579.

Cephalotes, Lindl. l. c. 3.-Ind. or.

congesta, Lindl. l. c. 2,-Ind. or.

dentata, Lindl. l. c. 3.-Ind. or.

excavata, Lindl. $l$. $c .3$. - Ind. or.

Griffithii, Reichb. f. in Flora, 1v. (1872) 277.-Ind. or intermedia, Reichb. in Otto \& Dietr. Allg. Gartenz. xxiv. (1856) 2I7.-Hab. ?

longifolia, Lindl. Fol. Orchid. Acampe, 1.-Ind. or. multiflora, Lindl. l. c.-China.

pachyglossa, Reichb.f. Otia Bot. Hamb. 76; et in Bot Zeit. xxxix. (1881) 449.-Afr, trop.

papillosa, Lindl. Fol. Orch. Acampe, 2.-Ind. or.

Renschiana, Reichb. f. Otia Bot. Hamb. 77 ; et in Bot. Zeit. xxxix. (1881) 449,-Madag.

Wightiana, Lindl. Fol. Orch. Acampe, 2.-Ind. or.

ACAMPTOPAPPUS, A. Gray, in Proc. Am. Acad. viii (1873) $634=$ Aplopappus, Cass, - Compos.) Shockleyi, A. Gray, 1. c. xvii. (1881-82) 208.-Am. bor. sphaerocephalus, A. Gray, 1. c. viii.(1873) 634.-Am. bor

ACANOS, Adans. Fam. ii. $116(1763)=$ Onopordon Linn. (Compos.).

Spina, Scop. Fl. Carn. ed. II. ii. $132=$ O. Acanthium.

ACANTACARYX, Arruda, ex Koster, Tray. Bras. 491 (1816)=Caryocar, Linn. (Ternstroem.)

pinguis, Arruda, ex Koster, 1. c.-Bras.

ACANTHELLA, Hook, fo in Benth, \& Hook. f. Gen. 748 (1867).-MELASTOMACEAE, Benth. \& Hook f. i. 748 .

Sprucei, Hook.f.l.c.-Bras.

ACANTHINOPHyLLUM, Fr. Allem. in Rev, Brazil. (1858) $368=$ Sahagunia, Liebm. (Urtic.)

strepitans, Fr. Allem. 1. c. 369.-Bras.

ACANTHIUM, Hall. Enum. Stirp. Helv. ii. 674 (1742) = Onopordon, Linn. (Compos.)

Onopordon, Gueldenst. Reise Russl. ii. $69=$ O. Acan thium.

ACANTHOBO'TRYA, Eckl. \& Zeyh. Enum. 192 (1836) $=$ Lebeckia, Thunb. (Legumin.).

angustifolia, Eckl. \& Zeyb. 1. c. 194=L. multiflora armata, Eck1. \& Zeyh. 1. c. $193=$ L. microphylla. cinerea, Eckl. \& Zeyh. 1. c. $193=\mathrm{L}$. microphylla. decumbens, Eckl. \& Zeyh. 1. c. $193=$ L. humilis. disticha, Eckl. \& Zeyh. l. c. $193=$ L. disticha.

linearifolia, Benth. in Ann. Wien. Mus. ii. (1838) 142 $=\mathrm{L}$. linearifolia

microphylla, Benth. 1. c. = L. microphylla. pungens, Eckl. \&. Zeyh. Enum. 193=L. pungens. sericea, Eck1. \& Zeyh. 1. c. $193=$ L, microphylla. sessilifolia, Eckl. \& Zeyh. 1. c. $193=$ L. marginata.

ACANTHOCARPEA, Klotzsch, in Peters, Reise Mossamb. Bot. 137. t. $24(1861)=$ Limeum, Linn. (Ficoid.)

scabrida, Klotzsch, 1. c. 139.-Mossamb.

sulcata, Klotzsch, 1. c. 138. t. $24=$ L. linifolium.

ACANTHOCARPUS, Lehm. Pl. Preiss.ii.274 (1847) FUNCACEAE, Benth. \& Hook. f. iii. 864. fimbriatus, F. Muell. Census, 119.-Austral.

Preissii, Lehm. Pl. Preiss, ii. 274.-Austral.

Serra, F. Muell. Census, 119.-Austral.

ACANTHOCARYA, Arruda, ex Endl. Gen. 1076 (1840) = Caryocas, Linn. (Ternstroem.).

ACANTHOCAULON, Klotzsch, in Endl. Gen. Suppl. iv, III. $88(1850)=$ Platygyne, Mercier (Euphorb. pruriens, Klotzsch (sphalm. pruricus), ex Endl. 1. c. $=\mathrm{P}$. urens.

ACANTHOCEPHALUS, Kar. \& Kir. in Bull. Soc. Nat. Mosc. xv. (1842) 127. COMPOSITAE, Benth. \& Hook. f. ii. 510.

Harpachaena, Bunge, Del. Sem. Hort. Dorp. (1845).

Harpocarpus, Endl. Gen. Suppl. iii. 10 (1843) amplexifolius, Kar. \& Kir. in Bull. Soc. Nat. Moso xv. (1842) 128.-Sibir. altaic.

Benthamianus, Regel, Pl. Nov. Fedsch. 47.-Turkestan.
ACANTHOCHITON, Torr in Sitgr, Rep, 170 , 13 (1853). AMARANTACEAE, Benth. \& Hook. f. iii. 29 .

Wrightii, Torr. l. c.-N. Mexico.

ACANTHOCLADIUM, F. Muell. Fragm. ii. 155 (1861) = Helichrysum, Vaill. (Compos.)

Dockerii, F. Muell. 1. c. $156=$ H. Dockerii.

ACANTHOCLADUS, Klotzsch, ex Hassk. in Miq. Ann. Mus. Lugd, Bat. i. 184 (1864). POLYGALEAE, Benth. \& Hook. f. i. 974 .

albicans, A. W. Benn. in Mart. Fl. Bras, xiii. III. 46. -Bras.

brasiliensis, Klotzsch, ex Hassk. in Miq. Ann. Mus. Lugd. Bat. i. 184.-Eras.

microphylla, Griseb. in Goett. Abh. xxiv. (1879) 24.Reg. Argent.

ACANTHODIUM, Delile, F1. Egypte, 241. t. 33 (1812, $=$ Blepharis, Juss. (Acanth.)

angustum, Nees, in DC. Prod. xi. 273.-Afr. austr. capense, Nees, in Linnaea, xv. (1841) 361.-Afr. austr. carduifolium, Nees, in DC. Prod. xi. $278=\mathrm{B}$. carduifolin.

Delilii, Buek, Ind. DC. Prod, iii, $1=\mathrm{B}$, edulis,

dispermum, E. Mey. ex Nees, in DC. Prod, xi. $278=$ Acanthopsis disperma.

diversispinum, Nees, 1. c. 275--Afr. austr.

furcatum, Nees, 1. c. 276.-Afr. austr.

glabrum, Nees, 1. c. 278.-Afr. austr.

glaucum, Nees, 1. c. 277.-Afr. austr.

grossum, Nees, 1. c. 274.-Afr. austr.

grossum, Wight, Ic. t. $1535,1536=\mathrm{B}$. scindica

hirtinervium, Nees, in DC. Prod. xi. 277.-Afr. aust.

hirtum, Hochst. ex Nees, 1. c. $274=$ B. scindica.

Hoffmanseggianum, Nees, 1. c. xi. 277.-Afr. austr.

macrum, Nees, 1.c. 276.-Afr. austr.

marginatum, Nees, 1. c. 275.-Afr. austr.

plumulosum, E. Mey. ex Nees, 1. c. $278=$ Acanthopsis horrida.

procumbens, Nees, in Linnaea, xv. (1841) 362.-Afr. austr.

serrulatum, Nees, in DC. Prod, xi. 275-Afr. austr.

sinuatum, Nees, in Linnaea, $x v$. (1841) 362.-Afr. austr.

spathulare, Nees, in DC. Prod. xi. 277.-Afr. austr.

spicatum, Acerbi, ex Nees, 1. c. $67=$ Nelsonia canescens.

spicatum, Delile, F1. Egypte, 241. t. 33. f。 $3=$ B. edulis.

squarrosum, Nees, in DC. Prod. xi. 275.-Afr. austr.

ACANTHODUS, Rafin. Princ. Somiol. $26(1814)=$ Acanthus, Tourn. (Acanthac.).

ACANTHOGLOSSUM, Blume, Bijdr. 381 (1825) = Pholidota, Lindl. (Orchid.)

nervosum, Blume, 1. c. $382=\mathrm{P}$. nerrosa,

ACANTHOGONUM, Torr. Pacif. Rail, Rep. iv. 132 $(1856)=$ Chorizanthe, R. Br. (Polygon.)

corrugatum, Torr. \& Gray, 1. c. $\nabla . ~ \$ 6 t=$ C. corrugata. rigidum, Torr. 1. c. iv. $133=$ C. rigida.

ACANTHOLEPIS, Less. in Linnaea, vi. (1831; COMPOSITAE, Benth. \& Hook. f. ii. 468 . orientalis, Less. l. c.-As. Min.; Persia.

ACANTHOLINUM, C. Koch, in Linnaea, xi. $1515^{\circ}$ 715 , sphalm. $=$ seq.

ACANTHOLIMON, Boiss, Diagn, Ser. I. vii. 6y (1846). PLUMBAGINEAE, Benth. \& Hook. fo ii. $6: 5$.

acerosum, Boiss, 4 c. Ser I. vii 80-As Min.

acmostegium, Boiss. E Buhse, in Nouv. Mím. Mf. xii. (1860) 182.-Persia.

alatavicum, Bunge, Gatt. Acanthol. 40.-Sibir.

Alberti, Regel, in Act. Hort. Petrop. vi. (15i: 3s!. Turkestan.

androsaceum, Boiss. Diagn. Ser. I. vii. 73.-Oriens.

araxanum, Bunge, Gatt. Acanthot. 38-Persia.

aristulatum, Brunge, l. c, 60,-Persia.

armenum, Boiss. \& Huet, Diagu. Ser. II. ir. 64.Armenia.

nspradanum, Bunge, Gatt. Acanthel. 50- - Persia

assyriacum, Boiss. Diagu. Ser. I. vii. $\$ 1=$ venustum. 


\section{ACANTHOLIMON:}

atropatanum, Bunoe, Gatt, Acanthol. 29,-Persia. auganum, Bunge, l. $c$.-Afghan.

avenaceum, Bunge, l. c. 25.-Persia.

Balansae, Boiss, ex Bunge, 1, c. $36=$ armenum

baltanense, Boiss. \& Haussk. ex Boiss. Fl. Orient. iv 838.-As. Min.

Bodeanum, Bunge, Gatt. Acanthol. 42.-Persia.

brachyphyllum, Boiss. in DC. Prod. xii. 628.Afghan.

brachystachyum, Boiss. ex Bunge, Gatt. Acanthol. 51. -Kurdistan.

bracteatum, Boiss. Diagn. Ser. I. vii. 70.-Armen. Persia.

breviscapum, Boiss. \& Haussk. ex Boiss. Fl. Orient. iv. $840=$ Kotschyi

bromifolium, Boiss. ex Bunge, Gatt. Acanthol. 23.Kurdistan.

cabulicum, Boiss. in DC. Prod. xil. 623.-Afghan. caesareum, Boiss. \& Bal. Diagn. Ser. II. iv. 66.Cappadoc.

calocephalum, Aitch. \& Hemsl. in Fourn. Linn. Soc xviii. (1881) 77.-Afghan.

Calverti, Boiss. Diagn. Ser. II. iv. 65.-Armenia.

caryophyllaceum, Boiss. Diagn. Ser. I. vii. 78.-Kurdistan.

caryophyllaceum, Haussk, ex Bunge, Gatt. Acanthol. $37=$ armenum

cataonicum, Bunge, 1. c. $43=$ lycaonicum.

cephalotum, St. Lag. in Ann. Soc. Bot, Lyon. vii. (1880 $118=\mathrm{A}$. Cephalotes.

Cephalotes, Boiss. in DC. Prod. xii. 622.-Afghan.

curviflorum, Bunge, Gatt. Acanthol.57-Persia.

cymosum, Bunge, l. c. 15.-Persia.

desertorum, Regel, in Act. Hort. Petrop. vi. (1879) 391.-Turkestan

diapensioides, Boiss. in DC. Prod. xii. 624,-Afghan

distachyum, Boiss. l. c. 623.-Afghan.

Echinus, Bunge, Gatt. Acanthol. $46=$ androsaceum.

erythraeum, Bunge, in Act. Hort. Petrop. iii. (1875)

99.-Turkestan.

eschkerense, Boiss. \& Haussk. ex Boiss. Fl. Orient. iv. 844.-Persia

fasciculare, Boiss. in DC. Prod, xii. 626.-Afghan.

Fausti, Trautv. in Act. Hort. Petrop. ii. (1873) 482.Persia.

ferox, Boiss, Diagn. Ser. I. vii. $81=$ A. Scorpius.

Fetisowi, Regel, Dec. Pl. Nov. 8.-Turkest.

festucaceum, Boiss. Diagn. Ser. I. vii. 76.-Persia.

flexuosum, Boiss, ex Bunge, Gatt. Acanthol. 51.-

Persia.

genistoides, Boiss. Diagn. Ser. I. vii. 76.-Persia.

glumaceum, Boiss, $l$. c. 75.-Armenia.

Griffithianum, Boiss, in DC. Prod. xii. 623.-Afghan

gulistanum, Bunge, Gatt. Acanthol. 67.--Persia

Hausknechti, Bunge, 1. c. $37=$ armenum.

heratense, Bunge, l. c. 55.-Afghan.

Hohenackeri, Boiss. Diagn. Ser. I. vii. 75.-Reg Caucas.

Hohenackeri, Ledeb. Fl, Ross. ii., $470=$ glumaceum.

horridum, Bunge, Gatt. Acanthol. 64.-Persia

Huetii, Boiss. Diagn. Ser. II. iv, 65.-Armenia.

Hystrix, Stapf, in Denkschr. Acad. Wien, 1. (1885) 71--Persia.

iconicum, Boiss . E Heldr. ex Boiss. Fl. Orient. iv. 839 -As. Min.

incomptum, Boiss. \& Buhse, in Nouv. Mém. Mosc. xii. (1860) $183=$ A. Scorpius.

Karelini, Bunge, Gatt. Acanthol. 58.-Armenia.

kokandense, Bunge, in Act. Hort. Petrop. iii. (1875) 99. - Turkest.

Kotschyi, Boiss. Diagn. Ser. I. vii. 74.-Cilicia.

kurdicum, Bunge, Gatt. Acanthol, $52=$ brachysta chyum.

Iatifolium, Boiss. Diagn. Ser. II. iv. 61.-Kurdistan.

latifolium, Rupr. Sert. Thiansch. $69=$ Ruprechti.

laxiflorum, Boiss. Fl. Orient. iv. $832=$ venustum.

laxiflorum, Boiss. ex Bunge, Gatt. Acanthol. 28.Syria.

leptostachyum, Aitch. \&o Hemsl. in Fourn. Linn. Soc. xviii. (1881) 76.-Afghan.

lepturoides, Boiss. Diagn. Ser. I. vii. 77.-Reg. Caucas leucacanthum, Boiss. 1. c. $81=\mathrm{A}$. Scorpius.

libanoticum, Boiss. in DC. Prod. xii. 630.-Syria.

Listoniae, Boiss. 1. c. $631=$ acerosum.

longifforum, Boiss. Diagn. Ser. II. iv. 62.-Afghan.

lycaonicum, Boiss. \& Heldr. ex Boiss. in DC. Prod. xii. 627.-As. Min.

\section{ACANTHOLIMON:-}

lycopodioides, Boiss. in DC. Prod. xii. 632.-As. centr.; Kashmir.

Maewskianum, Regel, in Act. Hort. Petrop. vi. (1879) 391.-Samarkand.

melananthum, Boiss. Diagn. Ser. I. vii. 74.-Persia.

Munroanum, Aitch. Hemsl. in Fourn. Linn. Soc.

xviii. (1881) 76.-Afghan

oliganthum, Boiss. Diagn. Ser. I. vii. 77.--Persia

Olivieri, Boiss. l. c. 80.-Persia.

parviflorum, Regel, Pl. Nov. Fedsch. 73.--As. temp.

Peronini, Boiss. Fl. Orient. iv, 842.-Cilicia.

petraeum, Boiss. ex Bunge, Gatt. Acanthol. 28.Kurdistan.

phrygium, Boiss. Diagn. Ser. I. vii. $79=$ acerosum.

Pinardi, Boiss. 1. $\mathrm{c}=$ =acerosum.

polystachyum, Boiss. in DC. Prod. xii. 624,-Afghan. pterostegium, Bunge, Gatt. Acanthol. 15.-Persia. puberulum, Boiss. \& Bal. Diagn. Ser. II. iv. $62=$ androsaceum.

quinquelobum, Bunge, Gatt. Acanthol. 56.-Persia. restiaceum, Bunge, l. c. 22.-Persia

roseum, Boiss. Diagn. Ser. 1. vii. 71.-Persia ; Afghan. rubellum, Boiss. ex Bunge, Gatt. Acanthol, $66=$ roseum.

Ruprechti, Bunge, Gatt. Acanthol. 20.-Turkestan. sahendicum, Boiss. \& Buhse, in Nouv. Mém. Mosc. xii. (1860) 183.-Persia

sarawschanicum, Regel, Pl. Nov. Fedsch. 73.-As. temp.

scabrellum, Boiss. \& Haussk. ex Boiss. Fl. Orient. iv. 845.-Persia.

schahrudicum, Bunge, Gatt. Acanthol. 65.-Persia.

schirazianum, Boiss. Diagn. Ser. I. vii. 72 --Persia. scirpinum, Bunge, Gatt. Acanthol. 22.-Persia. scorpioideum, St. Lag. in Ann. Soc. Bot. Lyon. vii. (1880) $118=$ A. Scorpius.

Scorpius, Boiss. Diagn. Ser. I. vii. 81.-Persia. senganense, Bunge, Gatt. Acanthol. 29.-Persia. setiferum, Bunge, l. c. 68.-Turkestan

splendidum, Bunge, 1. c. $17=$ bracteatum.

Stocksii, Boiss. Diagn. Ser. II. iv. p. 63.-Beluchistan subulatum, Boiss. in DC. Prod. xii. 629.-Afghan

Szovitzii, Boiss. \& Buhse, in Nouv. Mém. Mosc. xii.

(1860) $\mathbf{1 8 4}=$ Karelinii.

talagonicum, Boiss. in DC. Prod. xii. 625.-Persia.

tataricum, Boiss. l. c. 623.-Turkestan.

Tchihatcheffi, Fisch. \& Mey, in Ann. Sc. Nat. Sér. IV. (1854) i. $30=$ acerosum.

tenuiflorum, Boiss. Diagn. Ser. I. vii. 78.-Trans Caucas.

tibeticum, Hook. f. \& Thoms, ex C. B. Clarke, in Hook

f. Fl. Brit. Ind. iii. $479=$ lycopodioides.

tomentellum, Boiss. Diagn. Ser. I. vii. 72.-Persia.

Tournefortii, Boiss. l. c. 74,-Armenia.

tragacanthinum, Boiss, l. c. 81_- Persia.

tragacanthinum, Griff. ex Bunge, Gatt. Acanthol. $64=$ fasciculare.

truncatum, Bunge, $l$. c. 56.-Persia.

ulicinum, Boiss. in DC. Prod. xii. 627,--Syri

venustum, Boiss. Diagn. Ser. I. vii. 80.-As. Min

viscidulum, Boiss. l. c. 71,-Persia.

Wiedemanni, Bunge, Gatt. Acanthol, 45.-Anatolia.

ACANTHOLIPPIA, Griseb. in Goett. Abh. xix. (1874) 244 = Lippia, Linn. (Verben.).

hastulata, Griseb. 1. c. xxiv. (1879) $279=\mathrm{L}$. hastulata salsoloides, Griseb. 1. c. xix. (1874) 244.-Reg. Argent.

ACANTHOLOMA, Gaudich. ex Baill. Adansonia, vi. (1866) 231. t. $\mathrm{i}=$ Pachystroma, Klotzsch (Euphorb.).

spinosum, Baill. 1. c. $237=\mathbf{P}$. ilicifolium

ACANTHOMINTHA, A. Gray, in Syn. FI. N. Am. ii. 365 (1878) —LABIATAE, Benth. \& Hook. f. ii. 1192. ilicifolia, A. Gray, l. c.-Calif.

lanceolata, Curran, in Bull. Calif. Acad.i. (1884) 13.Calif.

ACANTHONEMA, Hook. f. Bot. Mag. t. 5339 (1862). GESNERACEAE, Benth. \& Hook. f. ii. 1021 .

strigosum, Hook. f. l. c.-Afr. trop.

ACANTHONOTUS, Benth. in Hook. Nig. Fl. 293 (1849) = Indigofera, Linn. (Legum.)

echinatus, Benth. I. c. = I. echinata.
ACANTHONYCHIA, Rohrb, in Mart. Fl. Bras, xiv. II 249. t. $56(1872)=$ Pentacaena, Bartl. (Illecebr.). polycnemoides, Rohrb. 1. c. $250=\mathrm{P}$. polycnemoides. ramosissima, Rohrb. 1. c. 249 , to $56=\mathrm{P}$. polycnemoides.

ACANTHOPANAX, Miq. Ann. Mus. Lugd. Bat. i. 10 (1863). ARALIACEAE, Benth. \& Hook. f. i. 939 Kalopanax, Miq. 1. c. (1863).

Plectronia, Lour. Fl. Cochinch. $162(1790)$ aculeatum, Seem. in Fourn. Bot.v. (1867) 238.-As. trop. asperatum, Franch. \& Sav. Enum. Pl. Jap. ii. $378=$ divaricatum.

divaricatum, Seem. in Fourn. Bot. v. (1867) 239.Japon.

innovans, Franch. E Sav. Enum. Pl. Fap.i. 193.-Japon. japonicum, Franch. \& Sav. l. c. ii. 377.-Japon. ricinifolium, Seem. in Fourn. Bot. vi. (1868) 140 -Japon.

sciadophylloides, Franch. \& Sav. Enum. Pl. Fap. ii. 378.- Japon

sepium, Seem. in Journ. Bot. v. (1867) $239=$ aculeatum. sessiliflorum, Seem. $l$. c.-China.

spinosum, Miq. Ann. Mus. Bot. Lugd. Bat. i. 10.Japon.

richodon, Franch. \& Sav. Enum. Pl. Fap. ii. 377.Japon.

ACANTHOPHIPPIUM, Blume, Bijdr. 353. t. 47 (1825). ORCHIDEAE, Benth. \& Hook. f. iii. 512 bicolor, Lindl. Bot. Reg. xx. (1835) 1730.-Zeylan. Curtisii, Reichb. f. in Gard. Chron. N.S. xv. (1881) I. 169.-Malaya.

javanicum, Blume, Bijdr.354.-Tava.

parviflorum, Hassk. Cat. Bog. Alt. 43.-Malaya. ringiflorum, Griff. Notul. iiî. $347=$ sylhetense.

striatum, Lindl. Bot. Reg. (1838) Misc. 41.-Reg. Himal.

sylhetense, Lindl. Gen. et Sp.Orch. 177.-Reg. Himal.

ACANTHOPHOENIX, H. Wendl, in Fl, des Serres. Sér. II. vi. (1865-67) 181.t.1706. PALMEAE, Benth. \& Hook. f. iii. 898 .

Deckenia, H. Wendl, ex Seem. in Gard. Chron. (1870) 561.

erinita, $H$. Wendl. $l . c$-Ins. Mascarens.

rubra, $H$. Wendl. $l$. c. sub t. 1706.-Ins. Mascarens.

ACANTHOPHYLLUM, Hook. \& Arn. in Hook. Comp. Bot. Mag. i. (1835) $37=$ Nassauvia, Juss. (Compos.). axillare, Hook. \& Arn. 1. c. (=Strongyloma glomerulosa).

rosulatum, Hook. \& Am. 1. c. $43=$ N. rosulata.

ACANTHOPHYLLUM, C. A. Mey. Verz. PA. Cauc. 210 (1831). CARYOPHYLLEAE, Benth. \& Hook. f. i. 145 .

Allochrusa, Bunge, in Boiss. Fl. Orient. i, 559 (1867).

JoRdANIA, Boiss. Diagn. Ser. I. viii. 93 (1849).

Alexandrae, Smirn. ex Regel, in Act. Hort. Petrop. v. (1877) 250.-Reg. Amur.

bracteatum, Boiss. Diagn. Ser. I. i. 43.-Persia

Bungei, Trautv. in Act. Hort. Petrop. ii. (1873) 511.Persia.

caespitosum, Boiss. Diagn. Ser. I. i. 42.-Persia.

crassifolium, Boiss. l. c.-Persia.

elatius, Bunge, in Boiss. Fl. Orient. i. 561.-Persia Turkest.

Fontanesii, Boiss. \& Buhse, in Nouv. Mém. Mosc. xii. (1860) 39 = glandulosum

Fontanesii, Boiss. Diagn. Ser. I. i. 41.-.-Persia

glandulosum, Bunge, ex Boiss. Fl. Orient. 1. 565.Persia.

glaucum, Bunge, ex Boíss. 1. c. $566=$ sordidum.

gracile, Bunge, ex Boiss. l. c. 562.-Persia

grandiflorum, Stocks, in Hook. Kew Fourn. iv. (1852) 142-Baluchist.

ypsophiloides, Regel, Pl. Nov. Fedsch. 15.-Turkest. Korolkowi, Regel \& Schmalh. in Act. Hort. Petrop. v. (1877) 249 - Turkest.

laxiflorum, Boiss. Diagn. Ser. II. i. $182=$ Gypsophila erinacea.

macrodon, Edgew. in Hook. Fl. Brit. Ind. i. 216.Ind. or.; Afghan.

microcephalum, Boiss. Diagn. Ser. 1. i, 43.-Persia. mite, Fisch. Eै Mey. in Ann. Sc. Nat. Sér. IV. (1854) i. 35. t. 1.-As. Min. 


\section{ACANTHOPHYLLUM:-}

mucronatum, C. A. Mey. Verz. Pfl. Cauc. 210.Reg. Caucas.

mucronatum, Fenzl, in Ann. Wien. Mus. i. (1836) $37=$ Tournefortii.

paniculatum, Regel \& Herd. in Bull. Soc. Nat. Mosc, xxxix. (1866) I. 539.- Turkest.

pungens, Boiss. Fl. Orient. i. $561=$ spinosum

sordidum, Bunge, ex Boiss. Fl. Orient. i. 565.-Persia. spinosum, Bunge, in Mém. Sav. étr. Pétersb. vii. (1851) $227=$ elatius

spinosum, C. A. Mey. Verz. Pfl. Cauc. 210.-Reg. Caucas.; Sibir.

squarrosum, Boiss. Diagn. Ser. II. i. 81.-Persia.

Stocksianum, Boiss. 1. c. = squarrosum.

Tournefortii, Fenzl, in Ann. Wien. Mus. ii. (1838) 310. - Armenia.

versicolor, Fisch. E Mey. Ind. Sem. Hort. Petrop. iv. 31.-Persia.

verticillatum, C. A. Mey. Verz. Pfl. Cauc. 210.-Armenia.

ACANTHOPHYTON, Less. Syn. Comp. $128(1832)=$ Cichorium, Linn. (Compos.)

spinosum, Less. 1. c. $=$ C. spinosum.

ACANTHOPLEURA, C. Koch, in Bot. Zeit. vii. (1849) 408 = Polylophium, Boiss. (Umbell.)

involucrata, C. Koch, I. c $s=$ P. orientale.

ACANTHOPRASIUM, Spenn. in T. Nees, Gen. Fl. Germ. Gamop. ii. (1843)= Ballota, Linn. (Labiat.). frutescens, Spenn. 1. c. = B. spinosa?

ACANTHOPSIS, Harv. in Hook. Lond. Journ. Bot, i. (1842) 28. ACANTHACEAE, Benth. \& Hook. f. ii. 1089 .

disperma, Harv. l. c.-Afr. austr.

horrida, Nees, in DC. Prod. xi. 278.-Afr. austr.

ACANTHORHIZA, H. Wendl, in Kerch, Palmiers, 230 (1878); Bot. Zeit. (1879) 147. PALMAE, Benth. \& Hook. f. iii. 925.

aculeata, H. Wendl. in Kerch. Palmiers, 230; Illust. Hortic. xxvi. (1879) t. 367.-Mexico.

Chuco, Drude, in Mart. Fl. Bras. ii. II. 554-Bras. Mocinni, Benth. \& Hook. f. Gen. iii. 925.-Mexico. stauracantha, H. Wendl. ex Linden, Cat. n. 87 (1871); Illust. Hortic. xxviii. (1881) $15=$ aculeata.

Wallisi, H. Wendl. ex Regel, in Gartenfl. xxviii. (1879) 163. t. 977. f. 2.-Hab. ?

Warscewiczii, H. Wendl. in Kerch. Palmiers, 230.Panama.

ACANTHOSICYOS, Welw, in Trans. Linn. Soc. xxvii. (1869) 30. CUCURBITACEAE, Benth. \& Hook, f. i. 824

horrida, Welw. l. c. 31.-Afr. trop.

ACANTHOSPERMA, Vell. F1. Flum. viii. t. 152 (1827) =Acicarpha, Juss. (Calycer.).

tittorale, Vell. 1. c. = Acicarpha spathulata.

ACANTHOSPERMUM, Schrank, Pl. Rar. Hort. Monac. t. 53 (1819). COMPOSITAE, Benth. \& Hook. f. ii. 349 .

Centrospermum, H. B. \& K. Nov. Gen. et Sp. iv. 270 . t. $397(1820)$.

Echinomium, Poiteau, ex Cass. in Dict. Sc. Nat. lix. $285(1829)$

ORCYA, Vell. Fl. Flum. 344 (1825)

brasilum, Schrank, Pl. Rar. Hort. Monac, ii. 53.-Bras.

hirsutum, DC. Prod. v. $522=$ brasilum.

hispidum, $D C$. $l . c .522 .-$ Bras.

humile, $D C$. l. c. 522 .-Ind. occ.

xanthioides, DC. 1. c. $521=$ brasilum.

ACANTHOSPORA, Spreng. Anleit. ii. I. 255 (1817); Syst. ii. $25(1830)=$ Tillandgia, Linn. (Bromeliac) conantha, Spreng. Syst. ii. $25=\mathrm{T}$. strobilantha. juncea, Spreng. 1. c. $25=\mathrm{T}$. setacea.

vittata, D. Dietr. Syn. PI. ii. $1056=$ Cryptanthus bivittatus?

ACANTHOSTACHYS, Link, Klotzsch \& Otto, Ic. PI. Rar, i, 21, t. 9 (18+1) BROMELLACEAE, lenth. \& Hook. f. iii. 663 .

strobilacea, Link, Klotssch, \& Otto, l. c. 22. t. 9.-Bras.
ACANTHOSTEMMA, Blume, Rumphia, iv. 29 (1848)=

Hoya, R. Br. (Asclepiad.)

Hasseltii, Blume, 1. c. $=$ H. Hasseltii.

Kuhlii, Blume, l. c. $=\mathrm{H}$. longifolia.

longifolium, Blnme, $\mathrm{l} . \mathrm{c} .=\mathrm{H}$. Rumphii.

pictum, Blume, 1. c. $=$ H. picta.

pruinosum, Blume, 1. c. $30=\mathrm{H}$. pruinosa.

puberum, Blume, 1. c. $29=$ H. pubera.

Rumphii, Blume, 1. c. $29=$ H. Rumphii.

ACANTHOSYRIS, Griseb, in Goett Abh xxiv (1879) 151. SANTALACEAE, Benth. \& Hook. f. iii. 224 .

falcata, Griseb. l. c.-Reg. Argent.

spinescens, Griseb. l. c.-Reg. Argent.

ACANTHOTHECA, DC. Prod, vi, $73(1887)=$ Dimor photheca, Moench (Compos.)

dentata, DC. 1. c. $74=\mathrm{D}$. dentata.

integrifolia, DC. 1. c. $74=\mathrm{D}$. integrifolia

pinnatisecta, DC. 1. c. $73=$ D. pinnata.

ACANTHOXANTHIUM, Fourr, in Ann. Soc.Linn. Lyon. N.S. xvii. (1869) $110=\mathbf{X}$ anthium, Toum. (Compos.) spinosum, Fourr. 1. c. $110=\mathrm{X}$. spinosum

ACANTHUS, Tourn. ex Linn. Syst. ed. I. (1735). ACANTHACEAE, Benth. \& Hook. f. ii. 1090.

Acanthodus, Rafin. Princ. Somiol, 26 (1814).

Cherlopsis, Moq. in Ann. Sc. Nat. Sér. I. xxvi (1832) 230 .

Dilivaria, Juss. Gen. 103 (1789)

ZoNablephis, Rafin. Sylva Tellur. 143 (1838). arboreus, Forsk. Fl. Aegypt. Arab. 115.-Aegypt.

Barteri, T. Anders. in Fourn. Linn. Soc. vii. (1864) 37.-Afr. trop.

capensis, Thunb. Prod. Pl. Cap, 97.-Afr, austr. cardnaceus, Griff. Notul. iv. 138.-Keg. Himal. carduifolius, Linn. f. Suppl. $294=$ Blepharis carduifolia.

ciliaris, Burm. f. Fl. Ind, $139=$ Blepharis boerhaviaefolia.

cristatus, Rottl. ex Nees, in DC. Prod. xi. 256=Lepidagathis cristata

Delilei, Spreng. Syst. iii. $819=$ Blepharis edulis

Dioscoridis, Linn. Cent. ii. 23 (Am. Acad. iv. 321).Syria.

Doloarin, Blanco, Fl. Filip. ed. I. 487=ilicifolius, ebracteatus, Vahl, Symb. Bot. ii. 75. t. 40.-As, trop. edulis, Forsk. F1. Aegypt. Arab. $115=$ Blepharis edulis furcatus, Linn. f. Suppl. $295=$ Blepharis furcata. glaber, E. Mey. ex Nees, in DC. Prod. xi. $278=$ Ble pharis carduifolia.

glaucus, E. Mey. ex Nees, 1. c. $277=$ Blepharis glauca glomeratus, Lam, Encyc. i. $23=$ Blepharis glomerata hirsutus, Boiss. Diagn. Ser. I. iv. 86.-Oriens. hispanicus, Hort. ex Loud. Hort. Brit. $256=$ niger. humilis, Vahl, ex Nees, in DC. Prod. xi. 274 (=Acan thodium sinuatum.

ilicifolius, Linn. Sp. Pl. 639 (err. typ. 939).-As. trop. Austral.

ilicifolius, Lour. F1. Cochinch. $375=$ ebracteatus.

imbricatus, Edgew. in Fourn. As. Soc. Beng. xvi (1847) 217.-Ind. or

integrifolius, E. Mey. ex Nees, in DC. Prod. xi. 276 =Blepharis furcata.

integrifolius, Thunb. Prod. Pl. Cap. $97=$ Blepharis saturaejaefolia.

Kirkii, T. Anders, in Fourn. Linn. Soc. vii. (1864) 37. -Angola.

latifolius, Hort. ex Goeze, in Gard. Chron. (1867) 856, $903=$ mollis

leucostachyus, Wall. Cat. n. 2512.-Ind, or.

longibracteatus, Kurs, in fourn. As. Soc. Beng. xxxix. (1870) Ir. 79.-Burma.

longifolius, Poir. Encyc. Suppl. i. 88.-Europ. austr.

longipetiolatus, Kurz, For. Fl. ii. 241.-Burma.

lusitanicus, Hort. cf. Gard. Chron. (1867) $903=$ mollis.

macer, E. Mey. ex Nees, in DC. Prod. xi. $276=$ Ble pharis furcata.

maderaspatanus, Vahl, ex Nees, in DC. Prod. xi. $26 \%$ Blepharis boerhaviaefolia.

maderaspatensis, Linn. Sp. Pl. 639 (err. typ. 939) = Blepharis molluginifolia.

mollis, Graf \& Noé, ex Nees, in DC. Prod, xi. 270 longifolius.

mollis, Linn. Sp. Pl. 639 (err. typ. 939).-Europ. austr.

\section{ACANTHUS:}

mollis, Riedel, ex Nees, in DC. Prod. xi. $271=$ spinosus montanus, $T$. Anders. in Fourn. Linn. Soc. vii. (1864 37.-Afr. trop.

mucronatus, Heyne, ex C. B. Clarke, in Hook. f. Fl. Br. Ind. iv. $517=$ Lepidagathis spinosa.

niger, Mill. Gard. Dict. ed. VIII. n. 2.-Lusitan

nitidus, S. Moore, in. Fourn. Bot. xviii. (1880, 232. Afr. trop.

pectinatus, Willd. ex Necs, in DC. Prod. xi. $274=$ Blepharis edulis.

polystachyus, Delile, in Caill. Voy, au Méroé, 2, t. 62 . f. 2.-Afr. trop.

procumbens, Herb. Madr. ex Wall. Cat. sub n. 2513 = Blepharis boerhaviaefolia

procumbens, Thunb. Prod. Pl. Cap. 97=Blepharis glomerata?

pungens, Herb. Madr. ex Wall. Cat. n. $2498=$ Lepida gathis pungens.

Raddei, Trautv, in Act. Hort. Petrop. iii. 1I. (1875) $269=$ Dioscoridis.

repandus, Nees, in DC. Prod. xi. 435, sphalm.= Antha canthus repandus.

repens, Vahl, Symb. Bot. ii. $76=$ Blepharis mollugini folia.

rubens, Rafin. Fl. Ludor. 36.-Am. bor.

spathularis, E. Mey. ex Nees, in. DC. Prod. xi. 27\%.Am. bor.

spinosissimus, Desf. Tabl. Hort. Par. $51=$ spinosus.

spinosissimus, Host, Fl. Austr. ii. $218=$ mollis

spinosus, Linn. Sp. Pl. 639 (err. typ. 939)-Europ.

spinosus, Nees, in DC. Prod. xi. $271=$ hirsutus, syriacus

spinulosus, Host, Fl. Austr. ii. $217=$ spinosas.

syriacus, Boiss. Diagn. Ser. I. xi. 135.-Syria.

tetragonus, R. Br. in Salt, Abyss. App. 65 ; Verm. Schr. ed. Nees, iii. 249.-A byss.

verus, Wender, ex Steud. Nom ed. II i. 11- - Hab. ?

volubilis, Wall. Pl. As. Rar. ii. 56. t. 172,-Ind, or.

ACANTHYLLIS, Pomel, Nonv. Mat. Fl. At\}. $179(1874$ =Anthyllis, Riv. (Legum.).

numidica, Pomel, $1 . \mathrm{c}_{n}=$ Anth. numidica.

tragacanthoides, Pomel, 1. c。=Astragalus armatus

ACARNA, All. F1. Pedem. i. $153(1785)=$ Atractylis Linn. (Compos.)

caespitosa, Willd. Sp. Pl. iii.1700=Atractylis caespitosa cancellata, All. Fl. Pedem. i. 153= Atractylis cancellata chinensis, Bunge, Enum. Pl. Chin. Bor. 36=Atractylis ovata.

comosa, Spreng. Syst. iii. $380=$ Atractylis comosa.

cyanoides, Bess. Enum. P1. Volh. $32=$ Jurinea cyanoides. cyanoides, Wibel, Prim. Fl. Werth. $169=$ Jurinea Pol lichii.

gummifera, Willd, Sp. Pl, iii. $1699=$ Carlina gummifera lancea, Willd. 1. c. $1700=$ Atractylis ovata.

macrocephala, Willd. 1. $c_{0}=$ Carlina Fontanesii. macrophylla, Willd. 1. $\mathrm{c}_{\mathrm{n}}=$ = Carlina macrophylla. mollis, Bess. Enum. Pl. Volh. 32 = Jurinea mollis. ovata, Willd. Sp. P]. jii. 1701= Atractylis ovata. rigida, Godet, ex DC. Prod, vi, $674=$ Jurinea longifolia. serratuloides, Spreng. Syst. iii. $379=$ Atractylis serratuloides.

ACARNA, Hill, Veg. Syst. iv. $13(1762)=$ Cnicus,

Linn. (Compos.)

Casabonae, Hill, Hort. Kew, 59 = C. Casabonae

leucographa, Hill, l. c. = Tyrimnus leucographus.

onopyxe, Hill, 1. c. = Cardus Onopyxos.

ACARPHA, Griseb, in Goett. Abb. vi. (1859-55) $125=$ Boopis, Juss. (Calycer.).

australis, Griseb, 1. c. 120 = B. australis.

ACARPHAEA, Hary. \& Gray, ex. A. Gray, in Mem. Am. Acad. iv. (1849) i. (Pl. Fendl.) $98=$ Chaenactis, DC. (Compos.)

artemesiaefolia, Harv. \& Gray, l. c. $=$ C. artemisiaefolia.

ACASTE, Salisb in Truns Hort. Soc i. (1812) 3:2

Babiana, Ker-Giawl. Irich.

pulchra, Salisb. 1. c. $328=$ B. stricta

venusta, Salisb. 1. c. $\$ 22=$ B. rubrucyanea.

ACCA, Berg, in Linnnea, xxvii. (1855) 198 = Psidium. Linn. MIrrtac.)

domingersis. Berg, 1. c. 138.-Ind. oce

peruviana, Berg, I. c. 199.-Pcruv. 
ACCIA, St. Hil. Morphol. $499(1840)=$ Plukenetia, Linn. (Euphorb.).

scandens, St. Hil. 1. c. (=Fragariopsis scandens).

ACCIPITRINA, Riv. ex Rupp. Fl. Jen. ed. Hall. 81 $(\mathbf{1 7 4 5})=$ Sisymbrium, Linn. (Crucif.).

ACCOROMBONA, Endl. Gen. Suppl. i. 1427 (1841) Galega, Linn. (Legum.)

tricolor, Benth. ex Walp. Rep. i. $672=\mathrm{G}$. officinalis.

ACEDILANTHUS, Benth. \& Hook. f. Gen. iii. 835

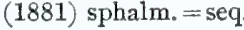

ACELIDANTHUS, Trautv. \& Mey. in Middend. Reise (Fl. Ochot. 94, t. 28) (1847)=Veratrum, Linn (Liliac.).

anticleoides, Trautv. \& Mey. 1. $\mathrm{c} .=\mathrm{V}$. Maackii.

ACENTRA, Phil. Sert. Mendoc. Alt. 3 (1871) VIOLARIEAE.

serrata, Phil. l. c.-Reg. Argent.

ACER, [Tourn.] Linn. Syst. ed. I. (1735). SAPINDA$C E A E$, Benth. \& Hook. f. i. 409.

EuACER, Opiz, Seznam, 42 (1852)

abchasicum, Rupr. Fl. Cauc. 279.-Reg. Caucas.

acuminatum, Wall. ex D. Don, Prod. Fl. Nep. 249. -Reg. Himal

aetnense, Hort. ex C. Koch, Dendrol. $531=$ platanoides. affine, Hoffmgg. ex Walp. Rep. i. $410=$ campestre. affine, Opiz, in Flora, vii. (1824) Beil. i. 83 ; xii. (1829) $547=$ campestre.

Amaliae, Orphan.ex Boiss. Fl. Orient. i. 951.-Graecia. amoenum, Carr. in Rev. Hortic. (1867) $280=$ palmatum.

argutum, Maxim. ex Miq. in Arch. Néerl. ii. (1867) 475.-Japon.

austriacum, Tratt. Arch. Gew. i. t. 36=campestre.

barbatum, Hook. F1. Bor. Am. i. $113=$ glabrum.

barbatum, Michx. Fl. Bor. Am. ii. $252=$ saccharinum.

barbinerve, Maxim. ex Miq. in Arch. Néerl. ii. (1867) 476.-Japon.

bohemicum, Presl, ex Opiz, Seznam, $9=$ campestre.

Boscii, Spach, Hist. Vég. Phan. 111. 88.-Am. bor. ?

Buergerianum, Miq. Ann. Mus. Bot. Lugd. Bat. ii. 88 = palmatum.

Buzimpala, Buch.-Ham. ex D. Don, Prod. Fl. Nep. $249=$ oblongum

caesium, Wall. ex Brand. For. Fl. iii. t. 21.-Reg. Himal.

californicum, D. Dietr. Syn. ii. $1283=$ Negundo aceroides.

californicum, Torr. \& Gray, Fl. N.Am. i. 250.Calif.

Campbellii, Hook. f. \& Thoms., ex Brand. For. Fl. 109.-Reg. Himal.

campestre, Linn. Sp. Pl. 1055.-Europ.; Oriens. canadense, Duham. Arb. i. t. $12=$ pensylvanicum

capillipes, Maxim. ex Miq. in Arch. Néerl. ii. (1867) 477.- Japon.

carolinianum, Walt. F1. Carol. $251=$ rubrum?

carpinifolium, Sieb. E Zucc. in Abh. Akad. Muench. iv. II. (1845) 154.-Japon.

cassiaefolium, Blume, Rumphia, iii. 193. t. 167. B.f. 2 . -Java.

caudatum, Wall. Pl. As. Rar. ii. 4,-Reg. Himal.

cinerascens, Boiss. Diagn. Ser. I. vi. 29.-Persia.

circinnatum, Pursh, Fl. Am. Sept. i. 267.-Amer. bor. circumlobatum, Maxim. in Bull. Acad. Pétersb. xii. (1867) 225.-Japon.

cissifolium, C. Koch, in Miq. Ann. Mus. Bot. Lugd. Bat. i. 252.-Japon.

coccineum, Michx, f. Arb. Am. i. 203=rubrum.

colchicum, Hartwiss, in Loud. Gard. Mag. (1840) 632 $=$ pictum.

Collinsona, Thunb. Diss. Acere, 6.-Hab.?

collinum, Tenore, Syll. $194=$ campestre.

commutatum, J. \& C. Presl, Delic. Prag. $31=$ monspes sulanum.

cordifolium, Moench, Meth. $55=$ tatarium.

coriaceum, Lodd. ex Spach, Hist. Vég. Phan. iii. 107 = polymorphum.

coriaceum, Bosc, ex Tausch, in Flora, xii. (1829) 550 . -Hab.?

crataegifolium, Sieb. \& Zucc. in Abh. Akad. Muench. iv. II. (1845) 155.-Japon.

\section{ACER :}

creticum, Linn. Sp. Pl. ed. II. 1497.--Oriens

creticum, Schmidt, ex Tratt. Arch. Gew. i. t. $45=$ parvifolium.

crispum, Moench, Verz. Ausl. Baeume, 2.-Hab.?

cultratum, Wall. Pl. As. Rar, ii. $4=$ pictum.

dasycarpum, Ehrh. Beitr. iv. 24.-Am. bor.

Dedyle, Maxim. in Bull. Phys. Math. Acad. Sc. Pétersb. xv. (1856) $125=$ spicatum.

diabolicum, Blume, ex Koch, in Miq. Ann. Mus. Bot. Lugd. Bat. i. 251.-Japon.

discolor, Maxim. in Bull. Acad. Sc. Pétersb. xxvi. (1880) 436.-China.

dissectum, Thunb. Fl. Jap. $160=$ palmatum.

distylum, Sieb. E Zucc. in Abh. Akad. Muench. iv. II. (1845) 154,-Japon.

Dittrichii, Opiz, Seznam, $9=$ A. Psendo-Platanus.

Douglasii, Hook. Lond. Journ. Bot. vi. (1846) 77. t. 6 = glabrum.

Drummondii, Hook. \& Arn. in 1. c. i. (1834) $200=$ rubrum.

eriocarpon, Opiz, in Flora, vii. (1824) I. Beil. $83=$ campestre.

eriocarpum, Michx. Fl. Bor. Am. ii. $253=$ dasyearpum.

Fabri, Hance, in Fourn. Bot. xxii. (1884) 76.-China.

Fieberi, Opiz, Seznam, 9.-Bohem.

floridanum, Hort. ex C. Koch, Dendrol, $542=$ dasycarpum.

formosum, Carr. in Rev. Hortic, (1867) 300.-Tapon.

fraxinifolium, Nutt. Gen. Am. i. 253=Negundo aceroides.

fraxinifolium, Rafin. New Fl. Am. i. 48.-Am. bor.

Friederici-Guillelmi, Carr. in Rev. Hortic. (1867) 300 = palmatum.

Ginnale, Maxim. in Bull. Phys. Math. Acad. Sc. Pétersb. xv. $(1856) 126=$ tataricum.

glaucum, Hort. ex C. Koch, Dendrol. $543=$ sanguineum.

glaucum, Marsh, Arbust. $2=$ rubrum?

glabrum, Torr. in Ann. Lyc. New York, ii. (1828) 172. -Am. bor.

granatense, Boiss. Elench. $25=$ opulifolium.

grandidentata, Nutt. ex Torr. E Gray, Fl. N.Am. i. 249.-Am. bor.

Heldreichii, Boiss. \& Heldr. in Boiss. Diagn. Ser. II v. 71.-Graecia.

heterolobum, Opiz, Natural. $\mathrm{jx}_{\mathrm{x}}$ (1825) $114=$ campestre.

heterophyllum, Willd. Berl. Baumz. 10. t. $1=$ creticum.

hispanicum, Pourr. in Mém. Acad. Toul. iii. (1788) $305=$ opulifolium.

Hookeri, Miq. in Arch. Néerl. ii. (1867) 471.-Reg. Himal.

humile, Salisb. Prod. $281=$ creticum.

hybridum, Bosc, Dict. Agr. v. $251=$ pensylvanicum.

hypoleucum, Hort. ex C. Koch, Dendrol. $543=$ rubrum.

hyrcanum, Fisch. \& Mey. Ind. Sem. Hort. Petrop. iv. 31.-Oriens.

ibericum, Bieb. Fl. Taur. Cauc. ii. $447=$ monspessulanum.

illyricum, Jacq. f. in Flora, xii. (1827) $551=$ monspessulanum.

insigne, Boiss. E̋ Buhse, in Nouv. Mém. Mosc. xii. (1860) 46.--Persia.

intermedium, Panc. ex Nym. Consp. $135=$ monspessulanum.

isolobum, Kurz, in Fourn. As. Soc. Beng. xli. (1872) II. 304.-Burma.

italum, Lauth, de Acere, n. 8.--Europ.; Oriens.

japonicum, Thunb. Fl. Fap. 161.-Japon.

javanicum, Jungh. in Hoev. \& De Vr. Tijdschr. viii. (1841) $391=$ niveum.

javanicum, Burm. $f$. Fl. Ind. 221.--Java.

jucundum, Carr. in Rev. Hortic. (1867) 380.-Japon.

laciniatum, Borckh. ex Tratt. Arch. Gew. $35=$ platanoides.

lactescens, Pers. Syn. i. $417=$ platanoides

laetum, C. A. Mey. Verz. Pfl. Cauc. 236.-Oriens

laevigatum, Wall. Pl. As. Rar. ii. 3. t. 104.-Reg. Himal.

laurifolium, D. Don, Prod. Fl. Nep. $249=$ oblongum.

laurinum, Hassk. in Hoev. \& De Vr. Tijdschr. x. (1843) $138=$ niveum

laurinum, Hassk, 1. c. = niveum.

leiocarpon, Opiz, in Flora, vii. (1824) I. Beil. $82=$ campestre.

leptopterum, Guss. ex Nym. Consp. $135=$ opnlifolium.

\section{ACER}

lobatum, Bosc, ex C. Koch, Dendrol. $519=$ Boscii.

lobatum, Rafin. New Fl. Am. i. 48

Lobelii, Tenore, Fl. Nap. v. 29. t. $199=$ platanoides. macrocarpon, Opiz, in Flora, vii. (1824) I. Beil. $82=$ campestre.

macrophyllum, Pursh, Fl. Am. Sept. i. 267.-Am. bor. macropterum, Vis, in Mem. Ist. Venet. ix. (1860) 175; Suppl. $28=$ Visianii.

majus, S. F. Gray, Nat. Arr. Brit. P1. ii. $635=$ A. PseudoPlatanus.

mandshuricum, Maxim. in Bull. Acad. Sc. Pétersb. xii (1868) 228.-Manchur

marsicum, Guss. Pl. Rar, $375=$ campestre

Martini, Jord. Pugill. $52=$ opulifolium.

marucum, Walp. Rep. i. $408=$ campestre.

Maximowiczianum, Miq. in Arch. Néerl. ii. (1867) 478 -Japon.

melliodorum, Opiz, Seznam, $9=$ A. Pseudo-Platanus.

mexicanum, A. Gray, in Proc. Am. Acad. v. (1861) 176.-Mexico.

micranthum, Sieb. \& Zucc, in Abh. Akad. Muench. iv. II. (1845) 155.-Japon.

microcarpon, Masn. ex Opiz, Natural. vi. (1824) 48; in

Flora, vii. (1824) I. $83=$ campestre

microphyllum, Opiz, in Flora, vii. (1824) 1. Beil. 82 ; et Natural, vi. (1824) $48=$ campestre.

molle, Opiz, 1. c. $83=$ campestre.

Mono, Maxim. in Bull. Phys. Math. Acad. Sc. Pétersb. xv. $(1856) 126=$ pictum.

monspessilanum, Linn. Sp. Pl. 1056.-Europ. austr. montanum, Ait. Hort. Kew. ed. II. iii. $435=$ spicatum montanum, Lam. F1. Fr. ii. $553=$ A. Pseudo-Platanus neapolitanum, Tenore, Fl. Nap, ii, 372. t. $100=$ opulifolium.

neglectum, Hoffmgg. ex Walp. Rep. i. $410=\mathrm{Hab}$. ?

neglectum, Lange, in Bot. Tidss. xiii. (1882) 30.-An hybr.?

Negundo, Linn. Sp. Pl. $1056=$ Negundo aceroides. nigrum, Michx. f Arb. Am. ii, 238. t. $16=$ saccharintum. nikoense, Maxim. in Bull. Acad. Sc. Pétersb. xii. (1868) $227=$ Maximowiczianum.

nikoense, Miq. in Arch. Néerl. ii. (1867) 478.-Japon. niveum, Blume, Rumphia, iii. 193.- Java; Ind. or. oblongum, Wall. ex DC. Prod. i. 593.-Reg. Himal. obtusatum, Waldst. \& Kit. ex Willd. Sp. Pl. iv. $984=$ opulifolium.

obtusifolium, Sibth. \& Sm. Fl. Graec. t. $361=$ cre ticum.

Opalus, Mill. Gard. Dict. ed. VIII. n. $8=$ opulifolium. Opizi, Ortm. ex Opiz, Seznam, 9.-Bohem.

opulifolium, Thuil. ex Loud. Hort. Brit. Supp. ii. 606 $=$ A. Pseudo-Platanus.

opulifolium, Vill. Hist. Pl. Dauph. iv. $802=$ Europ. Oriens

orientale, Linn. Syst. ed. X. ii. $1300=$ creticum. ornatum, Carr, in Rev. Hortic. (1867) 300.-Japon. orthopteron, Masn. ex Opiz, Natural. vi. (1824) 49 ; et

Flora, vii. (1824) I. Beil. $82=$ campestre

pallidum, Ait. ex Steud. Nom. ed. II. i. $11=$ dasycarpum palmatifidum, Tausch, ex Steud. 1. c. = platanoides.

palmatisectum, Ortm. ex Celak. Prod. Fl. Boehm. 538 = campestre.

palmatum, Rafin. New Fl. Am. i. $48=$ macrophyllum. palmatum, Thunb. Fl. Fap. 162...Japon.

palmifolium, Borckh. F1. Katzeln. $107=$ saccharinum. parviflorum, Ehrb. Beitr. iv. $25=$ spicatum.

parviflorum, Franch. \& Sav. Enum. Pl. Fap. ii. 321 Japon.

parvifolium, Tausch, in Flora, xii. (1829) 545.-Europ. austr.

pectinatum, Wall. Pl. As. Rar. ii, $4=$ caudatum

pennsylvanicum, Duroi, Diss. $61=$ spicatum.

pensylvanicum, Linn. Sp. Pl. 1055.-Am. bor.

pentapomicum, Stewart, ex Brand. For. Fl. 111.-

Reg. Himal.

pictum, Thunb. Fl. Fap. 162,-Japon

pilosum, Maxim. in Bull. Acad. Sc. Pétersb. xxvi.

(1880) 436.--As. or

pinnatum, Lour. Fl. Cochinch. ii. 649.-Cochinch.

platanifolium, Griff. Itin. Not. 200 (=villosum?).-Reg. Himal.

platanifolium, Stokes, Bot. Mat. Med. ii. $382=$ platanoides.

platanoides, Linn. Sp. Pl. 1055.-Europ.; Oriens.

Platanus, Burm. f. F1. Ind. 221 (=quid ?) -Ind. or. polycarpon, Opiz, Natural. vi. (1824) 49 ; in Flora, vii (1824) I. Beil. $82=$ campestre. 


\section{ACER :}

polymorphum, Sieb. \& Zucc. in Abh. Akad. Muench. iv. II. (1845) $158=$ palmatum

polymorphum, Spach, Hist.V'g. Phan. iii. 107.-Oriens. praecox, Opiz, Seznam, $9=$ campestre

procerum, Salisb. Prod. $280=$ A. Pseudo-Platanus.

Pseudoplatanus, Falk, Beitr. ii. $279=$ platanoides.

Pseudo-Platanus, Linn. Sp. Pl. 1054.-Europ.; Oriens.

pubescens, Franch. in Ann. Sc. Nat. Sér. VI. xv. (1883) 246. - Turkest.

purpurascens, Franch. E Sav. Enum. Pl. Fap. ii. 320 -Japon.

pyenanthum, C. Koch, in Miq. Ann. Mus. Bot. Lugd. Bat. i. 250.-Japon.

quinquelobatum, Wagn. ex Opiz, in Flora, vii. i. (1824) Beil. $83=$ campestre

quinquelobum, C. Koch, Dendrol. $540=$ creticum.

quinquelobum, Gilib. Fl. Lituan, ii. $198=$ A. Pseudo-

Platanus.

rectangulum, Dulac, Fl. Hautes-Pyr. $242=$ monspessulanum.

Reginae-Amaliae, Orphan. ex Boiss. Diagn. Ser. II. i. $109=$ Amaliae.

reticulatum, Champ. ex Benth. in Hook. Kew fourn

iii. (1851) 312.-Hongkong.

Reygassei, Boiss. Diagn. Ser. I. ii. 5, 71=hyrcanum. robustum, Opiz, Seznam, $9=$ campestre?

rotundifolium, Lam. Encyc. ii. $382=$ italum.

rotundum, Dulac, Fl. Hautes-Pyr. $242=$ platanoides

rubrum, Lam. Encyc. ii. $380=$ dasycarpum.

rubrum, Linn. Sp. Pl. 1055, - Am. bor.

rubrum, Wats. Dendrol. Brit. t. $169=$ rubrum.

rufinerve, Sieb. \& Zucc. in Abh. Akad. Muench. iv.

II. (1845) 155 . - Japon.

saccharinum, Linn. Sp. Pl. $1055=$ dasycarpum.

saccharinum, Wangenh. Nordamer. Holzarten (1787)

36. t. 11. f. 26.-Am, bor.

saccharophorum, C. Koch E Fint. Wochenschr. (1859) 349.-Am. bor.

Saira, Hort. ex C. Koch, Dendrol. $541=$ dasycarpum. sanguineum, Carr. in Rev. Hortic. (1867) 280.-Japon sanguineum, Spach, in Ann. Sc. Nat. Sér. II. ii. (1834) $176=$ rubrum.

Sch wedleri, Hort. ex C. Koch, Dendrol. $530=$ platanoides. Semenovii, Regel \& Herd. in Bull. Soc. Nat. Mosc. xxxix. (1866) I. 550,-As. temp.

sempervirens, Linn. Mant, i. $128=$ heterophyllum. sempervirens, Tausch, in Flora, xii. (1829) 550。-Hab. septemlobum, Thunb. Fl. Jap. $162=$ palmatum.

serotinum, Kit. in Linnaea, xxxii. (1863) 552.-Europ. sessilifolium, Sieb, \& Zucc. in Abh. Akad. Muench. iv.

II. (1845) $158=$ palmatum.

Sieboldianum, Miq. Ann. Mus. Bot. Lugd. Bat. ii. 87. -Japon.

sikkimense, Miq. in Arch. Néerl. ii. (1867) 471.-Reg. Himal.

spicatum, Lam. Encyc. ii. 381.-Am. bor.

stachyophyllum, Hiern, in Hook. f. Fl. Brit. Ind. i. 694. -Reg. Himal.

sterculiaceum, Griff. Itin. Notes, $148=$ pictum.

sterculiaceum, Wall. Pl. As. Rar. ii. 3. t. $105=$ villosum. striatum, Du Roi, Harbk. Baumz. i. 8 = spicatum. suberosum, Dum. F1. Belg. Prod. $113=$ campestre.

sylvestre, Wender, in Schr. Nat. Ges. Marb. ii. (1830) $250=$ campestre

syriacum, Boiss. \& Gaill Diagn. Ser. II. v. 72.Syria ; Cyprus.

tataricnm, Linn.Sp. Pl. 1054, - Oriens.

tauricolum, Boiss. \& Balansa, Diagn. Ser. II. v. $72=$ hyrcanum.

Tauschianum, Opiz, Seznam, $9=$ campestre.

tegmentosum, Maxim. in Bull. Phys. Math. Acad. Sc Pitersb. xv. (1856) 125.- Reg. Amur.

ternatum, Moc. \& Sesse, ex DC. Prod. i. 596.-Mexico. tomentosum. Dulac, Fl. Hautes-Pyr, $242=$ opulifolium. Thomsoni, Miq. in Arch. Néerl. ii. (1867) $470=$ villosum. tomentosum, Kit. in Linnaea, xxxii. (1863) $552=$ campestre.

tomentosum, Desf. Cat. Hort. Par. ed. III. $136=$ erio carpum.

Trantvetteri, Medw. ex Trautv, in Act. Hort. Petrop. vii. $(1880) 428$ in obs, $-\mathrm{Hab}$.

tricuspifolium, Stokes, Bot. Mat. Med. ii. $370=$ pensylvanicum

trifidum, Hook. \& Arn. Bot. Beech. Voy, 174,-China trifidum, Thunb. Fl. Jap. $163=$ Lindera triloba.

trifoliatum. Rafin。 Ncw Flo Amo i. 48-Am. bor

trifolium, Dubam, Arb. i. t. 10, f. $8=$ monspessulanum.

\section{ACER:-}

trilobatum, Lam. Encyc. ii. $\mathbf{3 8 2}=$ monspessulanum.

trilobum, Gilib. Fl. Lituan. ii. 198 = campestre.

trilobum, Moench, Meth. $56=$ monspessulanum.

tripartitum, Nutt. ex Torr. \& Gray, Fl. N. Am. i. 248 = glabrum.

truncatum, Bunge, Enum, Pl. Chin. Bor. $10=$ pictum. ukurunduense, Trautv. \& Mey, in Middend. Reise ( $\mathrm{F} 1$ Ochot. 24) = spicatum.

Van-Volxemii, Mast. in Gard. Chron. vii. (1877) 72. -Reg. Caucas.

velutinum, Boiss. Diagn. Ser. I. vi. $28=$ insigne

villosum, J. \& C. Presl, Delic. Prag. $31=\mathrm{A}$. PseudoPlatanus.

villosum, Wall. Pl. As. Rar, ii. 4.-Reg. Himal.

virens, Thunb. Diss. Acere, 8. (err. typ. 5).-Oriens

virgatum, Rafin. New Fl. Am. i. 48.-Am. bor.

virginianum, Mill. ex Steud. Nom. ed. I. 5 = dasycarpum.

Visianii, Nym. Consp. 135.--Servia.

vitifolium, Opiz, ex Tausch, in Flora, xii. (1829) Ir. 549 = platanoides.

Wondračekii, Opiz, Seznam, $9=$ campestre.

ACERANTHUS, Morr. \& Decne. in Ann. Sc. Nat. Sér. II. ii. (1837) 349. t. 14. BERBERIDEAE Jenth. \& Hook. f. i. 44.

diphyllus, Morr. E Decne. I.c. 350,-Japon.

macrophyllus, Blume, ex C. Koch, in Miq. Ann. Mus. Bot. Lugd. Bat. i. 253.-Japon,

sagittatus, Sieb. \& Zucc. in Abh. Akad. Muench. iv. II (1845) $175=$ Epimedium sagitattum.

triphyllus, C. Koch, in Miq. Ann. Mus. Bot. Lugd. Bat. i. 253.--Japon.

ACERAS, R. Br. in Ait. Hort. Kew. ed. IT. v. 191 (1813). ORCHIDEAE, Benth. \& Hook, f. iii. 621. affinis, Boiss. Fl. Orient. v. 56-As. Min.

alpina, Steud. Nom. ed. II. i. $12=$ Herminium alpinum angustifolia, Lindl. in Wall. Cat. n. $7061=$ longicruris. anthropomorpha, Steud. Nom. ed. II. i. $12=$ anthropophora.

anthropophora, R. Br. in Ait. Hort. Kew. ed. II. v. 191. -Europ.

caprina, Lindl. Gen. et Sp. Orch. $282=$ Orchis hircina. densifora, Boiss. Voy. Espagne, ii. $595=$ Habenaria intacta.

Duquesnei, Reichb. f. Ic. Fl. Germ. xiii-xiv, 171= Orchis pyramidalis.

formosa, Lindl. Gen. et $\mathrm{Sp}$. Orch. 282 = Orchis formosa hircina, Lindl. 1. $\mathrm{c}_{\circ}=$ Orchis hircina

intacta, Reichb. f. Ic. FI. Germ, xiii-xiv. $2=$ Habenaria intacta.

lancea, Steud.. Nom. ed. II. i. 12 (=Ophrys lancea).

longibracteata, Reichb. f. Ic. Fl. Germ. xiii et xiv. 3 $=$ Orchis longibracteata.

longicruris, C. Wright, ex A. Gray, in Mem. Am. Acad. N. S. vi. (1858-9) 411,- Japon.
maculata, Gren. in Gren. \& Godr. Fl. Fr. îi. 282 in nota $=$ Habenaria intacta.

pyramidalis, Reichb. f. Ic. Fl. Germ. xiii-xiv. 6 $=$ Orchis pyramidalis.

secundiflora, Lindl, in Bot. Reg. t. $1525=$ Habenaria intacta.

ACERATES, Ell. Sketch, i. $316(1817)=$ Gomphoearpus, $\mathrm{R}$. Br. (Asclepiad.)

angustifolia, Decne. in DC. Prod. viii. 522 = Asclepias stenophylla,

asperula, Decne. 1. c.-Mexico.

atropurpurea, Kellogg, in Proc. Calif. Acad. (1854-59) $65 ;$ repr. $69=\mathrm{G}$. cordifolius.

auriculata, Engelin. ex Torr. in Bot. Mex. Bound. 160. -Am. bor.

bifida, Rusby, ex A. Gray, in Proc. Am. Acad. xx. (1885) 296.-Arizona.

circinalis, Decne. in Ann. Sc. Nat. Sér. II. ix. (1838) 322.-Mexico.

connivens, Decne. in DC. Prod, viii. 521 (= Anantherix connivens)

cordifolia, Benth. Pl. Hartw. $323=$ G. cordifolins

decumbens, Decne. in DC. Prod. viii. 522= Asclepiodora decumbens.

Feayi, Chapm. in Coulter, Bot. Gazette, iii. (1878) 12 -Florida.

gomphocarpoides, Benth. Pl. Hartw. $66=$ Nephradenia neriifolia.

gomphocarpoides, Decne, in Ann. Sc. Nat. Sér, II. ix 1838) 323.- Mexico.

humilis, Benth. Pl. Hartw. 291.-Mexico.
ACERATES :-

incarnata, Decne, in DC. Prod, viii. 523,-Am, bor. lanceolata, Steud. Nom. ed, II, i. $12=$ G. viridiflorus lanuginosa, Decne, in DC. Prod, viii. 523.-Am. bor. latifolia, Torr. \& Frém. in Frém. Rep. Exped. (1845) $317=$ Asclepias eryptoceras

longifolia, Ell. Sketch, i. $317=$ Asclepias longifolius. paniculata, Decne. in DC. Prod。 viii. 521=Asclepiodora viridis.

Schaffneri, Fourn. in Ann. Sc. Nat. Sér. VI. xiv. (1882) 386,-Mexico.

tomentosa, Torr. in Bot. Mex. Boand. $160=\mathrm{G}$. tomen tosus.

vinosa, Fourn. in Ann. Sc. Nat. Sér. VI. xiv. (1882) 387.-Mexico?

viridiflora, Ell. Sketch, $317=\mathrm{G}$. viridiflorus

ACERATIUM, DC. Prod, i.519 (1824)=Elaeocarpus Linn. (Tiliac.)

Calomala, Blanco, Fl. Filip. ed. II. $306=$ E. nitidus. oppositifolium,. DC.. Prod. i. $519=\mathrm{E}$. oppositifolius.

ACEROTIS, Rafin. New Fl. Am. i. $49(1836)=$ Ascle pias, Tourn.

ACETOSA, Tourn. ex Mill. Gard. Dict. ed. VI. $(1752)=$ Rumex, Linn. (Polygon.)

Acetosella, Mill. Gard. Dict. ed, VIII.n. $2=$ R. Acetosella aculeata, Chaz. in. Mill. Dict. Suppl. i. $8=\mathbb{R}$ bucephalophorus

agrestis, Rafin. New FI. Am, iv. $52=\mathrm{R}$. Acetosa alpina, Mill. Gard. Dict. ed. VIII. n. $5=$ R. montanus alpina, Moench, Meth. $357=\mathrm{R}$. alpinus.

amplexicaulis, Rafin. New Fl. Am. iv, $53=$ R. Acetosa angustata, Rafin, $\mathrm{L}, \mathrm{c}=\mathrm{R}$. Acctosa

arifolia, Schur, in Verh. Siebenb. Ver. Naturw. iv. (1853) $64=\mathrm{R}$, arifolius.

bidentula, Rafin. New Fl. Am, iv, $52=\mathrm{R}$. Acetosa bipinnata, Chaz. in Mill. Dict. Suppl. i. 8=R. pictus. bucephalophora, Fourr, in Ann. Soc. Linn. Lyon. N. S. xyii. (1869) $145=\mathrm{R}$. bucephalophorus.

digyna, Mill. Gaxd. Dict. ed. VIII. n. 4 = Oxyria digyna hastata, Moench, Meth. $357=$ R. Acetosella. hastifolia, Schur, Enum. Pl. Transs. $581=$ R. Acetosa hastulata, Rafin. New Fl. Am. iv. $52=\mathrm{R}$. Acetosa, heterophyla, Rafin. 1. $c_{1}=\mathrm{R}$. maximus?

integrifolia, Kafin. l. $c_{\mathrm{A}}=\mathrm{R}$ integrifolia.

intermedia, Fourr. in Ann. Soc. Linn. Lyon. N. S. xvii. (1869) $145=\mathrm{R}$. intermedius.

Lunaria, Mill. Gard. Dict. ed. VIII. n. $6=$ R. Lunaria, luxurians, Chaz, in Mill. Dict. Suppl. i. $8=$ K. Iuxurians. magna, Gilib. Exercit. ii. $445=$ R. Acetosa.

multifda, Chaz, in Mill. Dict. Suppl. i. $8=$ R. multifidus officinalis, Gueldenst, ex Ledeb. FL Ross. iii. $510=\mathbb{K}$. Acetosa.

olitoria, Rafin. New Fl. Am。 iv. $53=\mathrm{R}$. Acetosa

parva, Gilib. Exercit. ii. $446=\mathrm{R}$. Acetosella.

pratensis, Mill. Gard. Dict. ed. VIII. n. $1=\mathrm{R}$. Acetosa repens, S. F. Gray, Nat. Arr Brit, Pl. ii. $276=$ R. Ace tosella.

rosea, Mill. Gard. Dict. ed. VIII. n. $7=$ R. roseus, scutata, Mill. 1. c. n. $3=$ R. scutatus. sterilis, Mill. 1. c. n. $8=\mathrm{R}$. Acetosella.

swbalpina, Schur, Enum. Pl. Transs. $581=$ R. Acetosa. tingitana, Fourr in Ann. Soc. Linn. Lyon, N. S. xъij. (1869) $145=\mathrm{R}$. tingitanus.

tuberosa, Chaz. in Mill. Dict. Suppl. i. $8=\mathrm{R}$, tuberosus

ACETOSELLA, Rapp. Fl. Jen. ed. Hall. $12 \tau(1 ;+5)=$ Rumex, Linn. (Polygon.)

vulgaris, Fours, in Ann, Soc, Linn, Lyon, N. So xvì (1869) $145=\mathrm{R}$. Acetosella.

ACHAEMENES, St. Lag, in Ann. Soc. Bot. Lyon, vii. (1880) $41=$ Achimenes, P. Br. iGesnema.

ACHAETA. Fourn. (Gram. Mex. 109) ex Benth. \& Hook f. Gen, iii, 1153 (1883)= Deyeuxia, Clar. (Gmmin.) geniculata, Foum. 1. c. ex Hemsl. Biol, Centr. Am. Bot. iii. 553.-Mexico

plamosa, Fourn. 1. c. ex Hensl. 1. c. 553.-Mexico.

ACHAETOGERON, A. Grav, in $M \mathrm{~cm}, A \mathrm{~m}, A \mathrm{cat}$

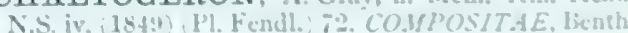
\& Hook, f. ii. 123?

Galeotii, A. Gray. ex Hemsl. Biol. Centr. Am. Bis. ii. 119.-Mexico

Scemannii, A. Gray, ex Hemsl. I. c. 120.-Mexico 


\section{ACHAETOGERON :}

Wislizeni, A. Gray, in Mem. Am. Acad. N.S.iv. (1849) (Pl. Fendl.) 72.-Mexico.

ACHANiA, Sw, Prod. Veg. Ind. Occ. $102(1788)=$ Malvaviscus, Dill. (Malvac.).

ciliata, Spreng. Syst. iii. $100=$ M. ciliatus

coccinea, Salisb. Prod. $385=$ M. arboreus.

concinna, Spreng. Syst. iii. $100=\mathrm{M}$. concinnus

cordata, Nees \& Mart. in Nov. Act. Nat. Cur. xi. (1823) $99=$ M. Balbisii.

floridana, Rafin. New Fl. Am, i. $49=$ Hibiscus floridanus?

Malvaviscus, Sw. Prod.Veg. Ind. Occ. $102=$ M. arboreus. mollis, Ait. Hort. Kew. ii. $459=$ M. mollis pilosa, Sw. Prod. Veg. Ind. Occ. $102=$ M. pilosus. Poeppigii, Spreng. Syst. iii. $100=$ Hibiscus Poeppigii. stylosa, Schrank, in Flora, ii. (1819) 449.-Bras.

tomentosa, Sterler, ex Steud. Nom. ed. II. i. 12.-Hab.?

ACHARIA, Thunb. Prod. Pl. Cap. 14 (1794). PASSIFLOREAE, Benth. \& Hook. f. i. 814 .

tragodes, Thunb. $l$. $c_{0}$ - - Afr. austr.

ACHARITEA, Benth. in Benth. \& Hook. f. Gen ii. $1142(1876)$. VERBENACEAE, Benth. \& Hook. tenuis, Benth. l. c.-Madag.

ACHARITERIUM, Bluff \& Fingerh. F1. Germ. ii. 345 1825) = Filago, Linn. (Compos.

arvense, Bluff \& Fingerh. 1. c. $346=\mathrm{F}$ arvensis,

ACHASMA, Griff. Notul. iii. 426 (1851)=Amomum, Linn. (Scitam.)

macrocheilos, Griff. 1. c. 429.--Ind. or.

megalocheilos, Griff. 1. c. 426.-Ind. or

metriocheilos, Griff. 1. c. 427.--Ind. or

ACHATOCARPUS, Triana, in Ann. Sc. Nat. Sér. IV ix. (1858) 45. AMARANTACEAE, Benth. \& Hook. f. iii. 26 .

nigricans, Triana, l. c. 46,-N. Granat.

praecox, Griseb. in Goett. Abh. xxiv. (1879) 32.-Reg Argent.

spinulosus, Griseb. l. c. 32.-Reg. Argent

ACHETARIA, Cham. \& Schlecht. in Linnaea, ii. (1827) $566=$ Beyrichia, Cham. (Scrophularin.)

Sprengelii, Cham. \& Schlecht. 1. c. $557=$ B. villosa

ACHILLAEA, Linn. Phil. Bot. 29 (1764)= Achillea, Linn. (Compos.)

ACHILLFA, Linn. Syst, ed I (1735), COMPOSITAE, Benth. \& Hook. f. ii. 419.

Ageratoines, Ponted. ex Linn. Class. P1. 527 (1747).

Alitubus, Dulac, Fl. Hautes-Pyr. 499 (1867)

Arthrolepis, Boiss. Diagn. Ser. I. xi. 14 (1849).

Conforata, Caesalp. ex Fourr. in Ann. Soc. Linn.

Lyon. N. S, xvii. (1869) 91.

Mrllefolium, Tourn. ex Adans. Fam. ii, 128 (1763)

Ptarmica, [Tourn.] Rupp. Fl. Jen. ed. Hall. 174 (1745).

abrotanifolia, Hort. ex Steud. Nom. ed. II. i. 12 (= Pyrethrum myriophyllum)

abrotanifolia, Linn. Sp. Pl. $897=$ Tanacetum millefoli atum.

abrotanoides, Vis. Fl. Dalmat. ii. 81. t. 10. f. 1.Europ.

absinthifolia, [Clairv.] Man. Herb. 251=Clavennae.

acuminata, Sch. Bip. in Flora, xxxviii. (1855) 15.Sibiria.

adulterina, Leresch, ex Heimerl, in Denkschr. Acad. Wien, xlviii. (1884) $167=$ obscura.

aegyptiaca, S. G. Gmel. It. ii. 198= Gerberi.

aegyptiaca, Hort. ex Steud. Nom. ed. II. i. $12=$ semipectinata.

aegyptiaca, Linn. Sp. P1. $900=$ Toumefortii. aegyptiaca, Sm. Fl. Graec. ix. $71=$ taygetea.

ageratifolia, Benth. \& Hook. f. Gen. ii. 420.-Graecia. Ageratum, Linn. Sp. Pl. 897.-Earop.

albicaulis, C. A. Mey. Verz. Pfl. Cauc. $76=$ tenuifolia. albida, Willd, Enum. Hort. Berol. Suppl. $61=$ tenuifolia.

aleppica, DC. Prod. vii. 296.-Oriens

alpina, Linn. Sp. Pl. $899=$ Europ.

ambigua, Boiss. Fl. Orient. iii. 255=A. Millefolium.

ambigua, Pollini, Viag. Lag. Garda, $117=$ magna.

\section{ACHILLEA :-}

ambrosiaca, Boiss. Fl. Orient. iii. 276.-Thessal. amoena, C. A. Mey. Verz. PA. Cauc. $76=$ vermicularis anethifolia, Fisch. ex Herd. in Bull. Soc. Nat. Mosc. (1865) I, 404=A. Millefolium.

anglica, G. Don, in Lond. Hort. Brit. $355=$ decolorans.

angustifolia, Salisb. Prod. $204=$ alpina.

anthemoides, Willd. Sp. Pl. iii. 2200.-Hab. ?

arabica, Kotschy: in Sitzb. Acad. Wien. Math. Nat

lii. Abth. I (1866) 255.-Arab.

arborea, Hornem. Hort. Hafn. Suppl. 102=Gonospermum elegans.

argentea, Salisb. Prod. $204=$ Clavennae.

argentea, Lam. Encyc. i. $29=$ Tanacetum argenteum.

armenorum, Boiss. \& Haussk. in Boiss. Fl. Orient. iii 269.-Armen.

asperula, Ces. \& Pass. ex Nym. Consp. $362=$ Anthemis asperula

aspleniifolia, Leresch, ex Sch. Bip. in Oestr. Bot. Wochenschr. vi. (1856) $301=$ Lereschei.

asplenifolia, Vent. Fard. Cels, t. 95.-Am. bor.?

atrata, Linn. Sp. Pl. 899.-Europ.

Aucheri, Boiss, Diagn Ser. I. vi, 87-Persia.

aurea, Lam. Encyc. i. $26=$ Chrysanthemum achilleaefolium.

auriculata, Willd. Sp. Pl. iii. 2203.-Oriens.

baikalensis, Fisch. Hort. Gorenk. ed. II. (1812) 41.Sibir. baikal.

bandana, Buch.-Ham. in Wall. Cat. n. 3291 = Chrysan thellum indicum.

bannatica, Kit. ex DC. Prod. vi. $29=$ crithmifolia.

Barbeyana, Heldr. \& Heimerl, in Denkschr. Acad. Wien, xlviii. (1884) 161.-Graecia.

Bardana, Buch.-Ham. ex DC. Prod. v. 631. sphalm. = bandana.

Barrelierii, Sch. Bip. in Flora, xxxviii. (1855) 15.Europ.

biaristata, Spreng. Syst. iv. Cur. post. $303=$ Anacyclus clavatus.

bicolor, Wender. in Flora, xii. (1829) I. Erg. 25.Europ.?

bipinnata, Linn. Sp. Pl. $900(=$ Pyrethrum myrio phyllum).

biserrata, Bieb. Fl. Taur. Cauc, ii, 334-As. Min.

Bocconii, Koch, Ind. Sem. Hort. Erlang. (1834)= alpina.

Boissieri, Haussk. ex Boiss. Fl. Orient. iii. 272.Persia.

Boissieriana, Heldr. ex Heimerl, in Denkschr. Acad. Wien, xlviii. (1884) $162=$ Barbeyana.

borealis, Bong. Veget. Ins. Sitcha, $149=$ A. Millefolium brachyphylla, Boiss. \& Haussk. in Boiss. Fl. Orient iii, 273 -Mesopot

buglossis, Frivald. in Flora, xix. (1836) $433=$ lingulata callichroa, Boiss. Diagn. Ser. I. vi. 86.-Persia. camphorata, Gilib. Fl. Lituan. i. $217=$ nobilis

camtschatica, Rupr. ex Heimerl, in Denkschr. Acad.

Wien, xlviii. (1884) $189=$ sibirica.

Cancrini, Gruner, in Bull.Soc. Nat. Mosc. xli. (1868) II. 417.--Tauria

capillaris, Poir. Encyc. Suppl. i. $102=$ = setacea

capillata, Lapeyr. Hist. Abr. Pl. Pyr. $534=$ chamaeme lifolia.

capitata, Willd. Tract. Ach. $17=$ Clavennae.

cartilaginea, Ledeb. Ind. Dort, ex Boiss. Fl. Orient. iii. 274.-Europ.; Oriens.

chamaecyparissus, Sch. Bip. in Flora, xxxviii. (1855) 14.-Europ.

chamaecyparyssus, Reichb. f. Ic. FI. Germ. xvi. 64. t $1012=$ praec.

chamaemelifolia, Pourr. in Mém. Acad. Toul. ii. (1788) 305.-Mont. Pyren.

chrysantha, Griseb. ex Boiss. F1. Orient. iii. $265=$ chrysocoma.

chrysocoma, Frivald. in Flora, xviii. (1835) 336.Graecia

cilicica, F. Gay, ex Tchihat. Asie Min. Bot. ii. 270. -As. Min.

claudiopolina, Janka, in Oestr. Bot. Wochenschr. (1854) $403=$ impatiens.

claudiopolitana, Wolff, ex Heimerl, in Denkschr. Acad. Wien, xlviii. (1884) $185=$ impatiens.

Clavennae, Linn. Sp. Pl. 898.-Europ.

Clusiana, Tausch, in Flora, iv. (1821) II. 551.-Enrop. Clusii, Sauter, in Flora, vii. (1824) I. $211=$ Clusiana clypeolata, Sibth. \& Sm. Fl. Graec, t. 893.-Oriens coarctata, Poir. Encyc. Suppl, i. 94=compacta.
ACHILLFA :-

collina, Becker, ex Reichb. Fl. Germ. Excurs. $850=\mathbf{A}$. Millefolium.

collina, Schur, ex Nym. Consp, $367=$ setacea.

commutata, Heimerl, in Flora, 1xvi. (1883) 385.-Europ.

compacta, Lam. Encyc, i. $27=$ magna.

compacta, Willd. Sp. Pl. iii. 2206.-Oriens.

condensata, Miq. Fl. Ind. Bat. ii. 85.-Java.

conferta, DC. Prod. vi. 32.-Oriens

coronopifolia, Willd. Tract. Ach. 18. n. 9.t. 1. f. $2=$ tanacetifolia.

corymbifera, S. G. Gmel. It. i. 137. t. 25. f. 1=nobilis.

crassifolia, Hort. ex Steud. Nom. ed. II. i. $13=$ A. Millefolium.

cretica, Linn. Sp. Pl. 899.-Oriens.

crispa, Lam. ex DC. Prod. vi, $26=$ asplenifolia

cristata, Hort. ex DC. 1. c, $25=$ tanacetifolia.

cristata, Retz. Obs, Fasc, ii. $25=$ falcata?

cristata, Willd. Tract. Ach. n. 4 et 8 ; Sp. Pl. iii. $2192=$ alpina

crithmifolia, Frivald. ex Hampe, in Flora, xx. (1837) I. $229=$ micrantha.

crithmifolia, Waldst. E'Kit. Pl. Rar.Hung. i. 68, t. 66. -Oriens.

crustata, Schur, Enum. Pl. Transs. 329.-Transylv.

cuneata, Sch. Bip. in Linnaea, xix. (1836) $313=$ grandifolia.

cuneatiloba, Boiss. Ẽ Buhse, in Nouv. Mém. Mosc. xii. (1860) 117. t. 10. f. 2.-Persia.

cuneifolia, Lam. Encyc. i. 28=A. Herba-rota.

cuspidata, Wall. Cat. n. $3230=$ A. Millefolium.

cylindrica, Poir. Encyc. Suppl. i. $95=$ nobilis.

damascena, DC. Prod. vii. $296=$ falcata.

decipiens, Vest, in Flora, xii. (1829) I. Erg. $60=$ nobilis.

decolorans, Schrad. in Willd. Enum. Hort. Berol. 913. -Europ.

decumbens, Lam. Encyc. i. 27.-Kamtschat.

dentato-serrata, Heuffel, ex Heimerl, in Denkschr. Acad. Wien, xlviii. (1884) 179.-Europ.

denticulata, Bess. ex Heimerl, 1. c. $188=$ sibirica.

dentifera, DC. Fl. Fr. Suppl. $485=$ tanacetifolia.

dentifera, Reichb. Fl Germ. Exc $230=$ A. Millefolium.

depressa, Fisch. ex Herd. in Bull. Soc. Nat. Mosc. (1865) 1. $405=$ sibirica

depressa, fanka, in Oestr. Bot. Zeitschr. xxiii. (1873) 204.-Balkan.

distans, Waldst. \& Kit. ex Willd. Sp. Pl, iii. $2207=$ tanacetifolia.

diversifolia, Schur, Enum. Pl. Transs. $330=$ crithmifolia.

djimilensis, Boiss. Fl. Orient. iii. $259=$ latiloba.

dracunculoides, Desf. Cat. Hort. Par. ed. III. $180=$ A. Ptarmica.

Dracunculus, Hort. ex Steud. Nom. ed. II. i. $13=$ Artemisia Dracunculus?

dshimilensis, C. Koch, in Linnaea, xxiv. (1851) $324=$ latiloba.

dubia, Fisch. ex Steud. Nom. ed. II. i. 13.-Sibir.

Dumasiana $\times$, Vatke, in Oestr.Bot. Zeitschr.xxii. (1872) 374.--Europ.

elegans, Sch. Bip. in Flora, xxxviii. (1855) 13.Hispan.

erba-rota, 'Auct.' = A. Herba-rota.

eridania, Bertol. Fl. Ital. ix, $407=$ nobilis.

erioclada, DC. Prod. vii. $296=$ cretica.

eriophora, DC. Prod. vi. 31,-.--Persia.

Eupatorium, Bieb. Fl. Taur. Cauc. ii. $337=$ filipendulina.

falcata, Lapeyr. Hist. Abr. Pl. Pyr, $534=$ chamaemelifolia.

falcata, Linn. Sp. Pl. 897.--Oriens.

fasciculata, Burm. f. F1. Cap. Prod. $27=$ Eriocephalus umbellatus.

Feliciana x, Bruegg. in Fahresb. Naturf. Ges. Graub. N. Fol. xxiii-xxiv. (1880) 105.-Europ.

filicifolia, Bieb. Fl. Taur. Cauc. ii. $338=$ filipendulina. fililoba, Freyn, in Flora, lxiv. (1881) 210.-Graecia.

filipendulina, Lam. Encyc. i. 27.-Oriens.

flabellifolia, Boiss. \& Heldr. Diagn. Ser. I. xi, $27=$ Tanacetum flabellifolium.

flabelliformis, Sibth. \& Sm. F1. Graec. ix. $72=$ holosericea.

flava, Hort. ex Steud. Nom. ed. II. i. $13=$ Chrysanthemum achilleaefolium.

flosculosa, Desf. Tab. Hort. Par. 105 (nomen)-Oriens. formosa, Sch. Bip.in Flora, xxxviii. (1855) 13.-As. Min. Fraasii, Sch. Bip. l.c. xxv. (1842) Beibl. i. 159,-Graecia. 
ACHILLEA :-

fragilis, Balb, ex DC. Prod, vi, $23=\mathrm{A}$. Ptarmica. fragrantissima, Sch. Bip. in Flora, xxxviii. (1855) 13. Oriens; Aegypt.

fruticulosa, Willd. ex Ledeb. Fl. Ross. ii. $536=$ Gerberi. Genipi, Murr. App. Med. i. $168=$ moschata. Gerberi, Bieb. Fl. Taur. Cauc. i. $336=$ nobilis. Gerberi, Willd. Sp. Pl. iii. 2196.-Europ.; Caucas. gilva, Moench, Meth. Suppl. 257.-Europ.?

Glavennae, (err. typ.) Schrank, Baier. Fl. ii. $409=$ Clavennae

glomerata, Bieb. Fl. Taur. Cauc. iii. $585=$ compacta. goniocephala, Boiss. E' Bal. in Boiss. Diagn. Ser. II. vi. 98.-As. Min.

gracilis, Rafin. [' Fl. texensis, 12'] Atl. Journ. $177=$ A. Millefolium.

grandiflora, Bieb. Fl. Taur. Cauc. ii. 333.-As. Min

grandifolia, Frivald. in Flora, xix. (1836), II. 433. Oriens.

grandifolia, Bieb. Fl. Taur. Cauc. ii. $444=$ A. Ptarmica. grandis, Fisch. ex Herd, in Bull. Soc. Nat. Mosc. (1865) I. $407=$ A. Ptarmica.

grata, Fenzl, in Tchihat. Asie Min. Bot. ii. $261=$ odorata.

Gussonii, Ces. \& Pass. ex Nym. Consp. $362=$ Anthemis abrotanifolia

Haenkeana, Tausch, in Flora, iv. (1821), $567=$ A. Millefolium.

Halleri, Crantz, Inst. i. $303=$ atrata.

Haussknechtiana, Aschers, in Festschr. Ges. Naturf. Fr. Berl. (1873) $243=$ seq.

Haussknechtii, Boiss. Fl. Orient. iii. 264,-Persia

helvetica, Schleich. ex Gaud. Fl. Helv. v. $368=$ valesiaca?

Herba-rota, All. Fl. Pedem. i. 180.-Europ. merid.

Herba-rotta, Vill. Prosp. Delph. $32=$ praec

heterophylla, Spreng, Nachr. i. Bot. Gart. Halle, 9.sibir.

hispanica, Schrank, Pl. Rar. t. $70=$ nobilis.

holosericea, Sibth. \& Sm. Fl. Graec t. 894.-Graecia

hybrida, Gaud. in Koch, Syn. Fl. Germ. ed. II. 409.Enrop.

imbricata, Ancher, ex DC. Prod. vii. $296=$ aleppica.

imbricata, Vent. Jard. Cels, t. $54=$ membranacea.

impatiens, Linn. Sp. Pl. 898. - Sibir.

impunctata, Vest, in Flora, iii. (1820) 3, $7=$ moschata.

incisa, [Clairv.] Man. Herb. 251,-Europ.

inodora, Linn, Sp, Pl, $900=$ Lonas inodora

intermedia, Schleich. Cat. Pl. (1821) $5=$ A. Millefolium.

ircutiana, Sch. Bip. in Flora, xxxviii. (1855) $15=$ A. Plarmica.

Jaborneggi x, Halacsy, in Oestr. Bot. Zeitschr. xxvii. 1877) 45.-Europ.

Facea, Griseb. Iter, ii. 264. ex Spicil. Fl, Rumel, ii. 216 $=$ chrysocoma.

Jankae, Sch. Bip. ex Nym. Consp. 366.-Europ.

japonica, Sch. Bip. in Zoll. Syst. Verz. Ind. Archip.

125 = sibirica.

kellalensis, Boiss. \& Haussk, in Boiss. Fl. Orient. iii. 263.-Persia,

Kotschyi, Boiss. Diagn. Ser. II. iii, $19=$ odorata

Kracttliana x, Bruegg. in fahresb. Naturf. Ges.Graub. N. Fol, xxiil-xxiv. (1880) 105, nomen-Europ.

Laggeri, Sch.Bip. in Oestr. Bot. Wochenschr. vi. (1856) s00,-Europ.

lanata, Lam. Fl. Fr. iii, $640=$ A. Millefolium.

lanata, Spreng. Cat. Fl. Hal. ex Willd. Enum. Hort. Berol. 915.-Hab. ?

lanulosa. Nutt. in Fourn. Acad. Philad, vii. (1834) 36 $=\mathbf{A}$. Millefolium

latifolia, Salisb. Prod. $204=$ macrophylla.

latiloba, Ledeb. ex Nordm, in Bull. Acad. Sc. Pstersb. ii. (1837) 312 . Caucas.

Ledebourii, Heimerl, in Flora, lxvi. (1883) $989=$ impatiers.

lenensis, Turcz. ex DC. Prod. vii. $295=$ ircutiana.

leptophylla, Bieb. Fl. Taur. Cauc. ii. 395,-Tauria

leptophylla, C. Koch, ex Nym. Consp. $367=$ crithmifolia

Lereschei, Sch. Bip. in Oestr. Bot. Wochenschr. vi (1856) 301.-Europ.

lencanthema, Pers. Syn. ii. $467=$ A. Ptarmica,

ligustica, All. Fl. Pedem. i. 181. t. 52. f. 2.-Europ.; Oriens.

ligustica, Vis, ex Nym. Consp. $867=$ nobilis.

linearis, Steud. Nom. ed. II. i. $13=$ A. Ptarmica,

lingulata, Waldst. \& Kit. Pl. Rar. Hung. i. 2.-Europ. orient.

livea, Scop. Delic. Insub. i. $6=$ moschata.

lobata, Forsh. Fi. Acgypt. Arab. 218.-Aegypt.

\section{ACHILLEA :-}

lucida, Salisb. Prod. $204=$ impatiens.

lycaonica, Boiss. \& Heldr. Diagn. Ser. I. xi. $18=\mathrm{con}$ ferta.

macrocephala, Rupr. Beitr. Pf. Russ. Reiches, ii. (1845) $41=$ A. Ptarmica

macrophylla, Pill. \& Mitterb. It. Poseg. 111. t. $11=$

Chrysanthemum macrophyllum.

macrophylla, Linn. Sp. Pl. 898.-Europ.

macrophylloides, Pand. ex Nym. Consp. $366=\mathrm{A}$. grandifolia.

magna, Haenke, in Jiras. Beob. Riesengeb. $103=\mathrm{A}$ Millefolium.

magna, All. F1. Pedem. i. 184=tanacetifolia

magna, Linn. Sp. Pl. ed. II. 1267.-Europ.

magna, Sibth. \& Sm. Fl. Graec. ii. 194=ligustica.

major, Heimerl, in Denkschr. Acad. Wien, xlviii. 1884) 157.-Europ.

marginata, Turcz. ex Ledeb. Fl. Ross. ii. $532=$ A. Millefolium.

maxima, Fischer, ex Heimerl, in Denkschr. Acad.

Wien, xlviii $(1884)=\mathrm{A}$. Ptarmica

membranacea, DC. Prod. vi. 32.-Oriens.

Michelii, Sch. Bip. in Flora, xxxviii. (1855) 14,Europ.

micrantha, Bieb. Fl. Taur. Cauc. ii. $336=$ pubescens micrantha, Willd.Sp. Pl. iii. 2209.-Soongar; Oriens microloba, DC. Prod. vi. $32=$ teretifolia microphylla, Willd. Sp. Pl. iii. $2210=$ odorata Millefolium, Ledeb. Fi. Alt. iv. $124=$ setacea Millefolium, Linn. Sp. Pl. 899.-Europ.; As.; Am. mollis, Andrz. ex Trautv. in Act. Hort. Petrop. viii 1883) 451, nomen.-Rossia.

mangolica, Fisch, ex Spreng. Nov. Prov. Hort. Hal. et Berol. (1818) i. $3=$ sibirica

monocephala, Boiss. \& Bal. Diagn. Ser. I. v. 110.Cilicia.

montana, Schleich. ex DC. Prod. vi. 21.-Europ

monticola, Martr. Pl. Crit. du Tarn, $31=$ A. Millefolium.

Morisiana, Reichb. Ic. Fl. Germ. xv1, 66, t, $1019=\mathrm{A}$ Herba-rota.

moschata, Facq. Fl. Austriac. v. 45.-Europ.

mucronata, Hort. ex Steud. Nom. ed. II. i. $13=$ heterophylla.

mucronulata, Sch. Bip. in Flora, xxxviii. (1855) 15.

Europ,

multifida, Griseb. Spicil. Fl. Rumel. ii. $212=$ atrata.

multifida, Sch. Bip. in Flora, xxxviii. (1855) 15. Graecia.

multifida, Sprun. ex Nym. Consp. $367=$ setacea. multiflora, Hook. Fl. Bor. Am. i. 318.-Am. bor multiplex, Renar. Fl. Orn. 78=A. Ptarmica.

muricata, Ces. \& Pass. ex Nym. Consp. 362=Anthe mis muricata.

muschensis, C. Koch, in Linnaea, xxv。 (1851) $329=$ vermicularis.

myriophylla, Willd. Enum. Hort. Berol. 916=Tanacetum millefoliatum.

nana, Lam. Fl. Fr. ed. I. ii. $154=$ A. Herba-rota

nana, Linn. Sp. Pl. 899.-Europ.

Neumayeri, Heldr. ex Heimerl, in Denkschr. Acad.

Wien, xlviii (1884) $163=$ Fraasii.

Neilreichii, Kern. in Oestr. Bot.Zeitschr. xxi. (1871) 148 $=$ nobilis.

nitida $\times$, Pers. Syn. ii, $467=$ A. impatiens.

nivea, Sprun. ex Nym. Consp. 365.-Europ.

nobilis, Linn. Sp. Pl. 899 -Europ.; Oriens.

nobilis, Roch. ex Nym. Consp. $367=$ crithmifolia

Novae-Graeciae, Sch. Bip. in Flore (1841), i. 158.Enum.

obscura x, Nees, Ind. Sem. Hort. Bonn. (1831) 1.Europ.

occidentalis, Rafin. ex DC. Yrod. vi. $24=$ A. Mille

folium.

ochrolenca, Eichw, Skizze, $149=$ A. Millefolinm

ochrolenca, Ebrh. Beitr. vii. $166=$ nobilis,

ochroleuca, Waldst. \& Kit. P1. Rar. Hung. i. $38=$ pec tinata.

odorata, Linn. Syst. ed. X. 1225.-Europ.; Oriens.

odorata, Pall. Reise, i. $\mathbf{3 7 9}=$ nobilis

odorata, Wulf. in Jacq. Coll. i. $259=$ setacea.

oligocephala, DC. Prod. vi. 32.-Mesopot.

oravicensis, Kit. \& Kanits, Reliq. Kitrib. 82 , in Verh.

Zool. Bot. Ges. Wien, xiii. (1863) 506.-Europ

ossica, C. Koch, in Linnaea, xxiv. (1851) $929=\mathrm{A}$

Millefolium

oxyodonta, Boiss. Dingn. Ser. I. xi 15.-Persia

\section{ACHILLEA}

oxylepis, Boiss, \& Haussk, in Boiss, Fl. Orient, iii 271.--Persia

oxyloba, Sch. Bip. in Flora, xxxviii. (1855) 15.-Afr. austr.

pallescens, DC. Prod. vii. $296=$ grandifolia

pallescens, Linn. Syst. ed. X, 1225.-Hab.

pallida, Salisb. Prod. $204=$ Tournefortii.

pannonica, Scheele, in Linnaea, xviii. (1835) $471=$

Millefolium.

partheniftora, Fisch. ex Herd. in Bull. Soc. Nat. Mosc (1865) I. $407=$ A. Ptarmica.

partheniifolia, Desf. ex Steud. Nom. ed. II. i. 14 nomen-Hab.?

pauciflora, Lam. Encyc. i. 26, = Tanacetum Vahlii.

pectinata, Lam. Encyc. i. $28=$ odorata.

pectinata, Willd. Sp. Pl. iii. 2197.-Hungar; Tauria.

Peronini, Boiss. Fl. Orient. iii. 261-As. Mín.

peucedanifolia, Griseb. Spicil. Fl. Kumel, ii, $214=$ grandifolia.

phrygia, Boiss, E Bal. Diagn Ser. II vi 99 - As. Min. pilosa, Willd. Sp. Pl. jii. 2196.-Hab.

pinnata, Reichb. f. Ic. Fl. Germ. xvi. 64; Sch. Bip. in Flora, xxxviii. (1855) 14-Europ.

polyphylla, Schleich, ex Koch, Syn. Fl. Germ. ed. II 411 = setacea.

pseudo-tanacetifolia, Wier. ex Reichb. Fl. Germ. xvi.

$69=$ magna.

pseudo-pectinata, Fanka, in Oestr. Bot. Zeitschr. xxii. (1872) 179.-Turcia.

Ptarmica, Linn. Sp. Pl. 898.--Reg. temp. bor.

Ptarmica, Richards. in Frankl. Ist Journ. ed. II. App. $33=$ multiflora

ptarmicoides, Maxim. Prim. Fl. Amur, $154=$ sibi. rica.

pubescens, Sibth. \& Sm. Fl.Graec. t. $895=$ micrantha

pubescens, Linn. Sp. Pl. 897.-Oriens

pubescens, Willd. Sp. Pl. iii. $2206=$ odorata.

pumila, Schar, Enum. Pl. Transs, $330=$ tanacetifolia

punctata, Moench, Meth. $603=$ alpina

punctata, Tenore, ex Fenzl, in Tchibat. Asie Min. Bot. ii. 264 = odorata.

pyrenaica, Sibth. ex DC. Fl. Fr. iv. $211=\mathrm{A}$ Ptarmica.

ramosissima, Moench, Meth. Suppl. $256=$ alpina?

recurvifolia, Lapeyr. Hist. Abr. H1. Pyr. $534=$ chamaemelifolia.

Reichardtiana $\times, G$. Beck, in Sitzb. Zool. Bot. Ges Wien, xxvii. (1878) 44.-Europ

rigida, Wallr. Beitr. Fl. Hercyn. 331.-Europ.

rosea, Desf. Tabl. Hort. Par. ed. I. 105; ed. III. $181=$ asplenifolia.

rosea, Waldst. \& Kit. Pl. Hung. Rer-Hungar

rosmarinifolia, Sch. Bip. in Flora, xxxviii. (1055) 11.Europ. occ.

rubra, Hildebr. ex Steud. Nom. ed. II. i. $11=$ dentifera rupestris, Huter, ex Beck, in Denkschr. Acad. Wien.

xlviii. (1882) 150.-Europ.

salicifolia, Bess. in DC. Prod. vi. $28=$ A. Ptarmica.

salina, Schur, Enum. P1. Transs, $328=$ setacen.

sambucifolia, Desf. Cat. Hort. Par. ed. III. $1 \& 0=$ Chrysantbemum macrophyllum.

sambucina, Thonin, ex DC. Prod. vi. $58=$ Chrysanthemum macrophyllum.

Santolina, Falk, Beitr. ii, 243 - Gerberi.

Santolina, C. A. Mey, Verz. Ph. Cauc. $76=$ teretifolia

Santolina, Hort. ex Willd. Sp. Pl. iii. $2200=$ anche moides.

Santolina, Linn. Sp. Pl. 896. -Oriens.; Afr. bor.

Santolina, Sibth. \& Sm. Fl. Graec. ix. $70=$ cretia.

Santolina, Willd. Tract Ach, ex Steud. Dom, ed. I = tenuifolia

santolinoides, Lag. Gen. et Sp. Nor. 30,-Hispan.

scabra. Host. Fl. Anstr. ii. $512=$ A. Millefolium.

Schkukrii, Spreng. ex Nvm. Consp. $36 \bar{i}^{-}$nobrlis.

Schurii, Sch. Bip. in Oestr. Bot. Wochenschr, vi. (15joi) $300=$ oxvloba.

Seidlii, J, \& C Presl, Fl. Cech, 173=A. Mitlefolium. semipectinata, Desf. Cat. Hort. Par. ed. III (lsat $403=$ auriculats.

senecioniflora, Fist, in Flora, xii. 1829), Ers. i. 54 dentifera.

sericera, Janka, in Linnaca, $x x \times .\left(1859-0^{\circ} 5,59=c\right.$

practa.

scricera. Vis, ex Reichb. Fl. Germ. Exeurs ii, 2a:

C'lavennac.

serrata x. Retz. Ohs. Fase. id. 25. - Sitir.

serraba, Sm, End. Los. 1. $25 \$ 1$ - deculurans 


\section{ACHILIEA :}

serratifolia, Salisb. Prod. $204=$ serrata.

serrulata, Hornem. Hort. Hafn. ii. $835=$ A. Ptarmica. setacea, Waldst. \& Kit. P. Rar. Hung. i. 68. t. 66.Europ.; Oriens.

setacea, Schwein. in Long, Exped. ii. 119=A. Millefolium.

sibirica, Ledeb. Ind. Sem. Hort. Dorpat, (1811); Fl. Ross. ii. 528.-Reg. temp. bor.

sicula, Rafin. Préc. Dec. 40; et in Journ. Bot. ii. (1814) $271=$ ligustica.

Siegfriedi x, Bruegg. in Fahresb. Naturf. Ges. Graub. N. Fol. xxiii-xxiv. (1880) 58.-Europ.

silvatica, Auct. = sylvatica.

simplicicaulis, Boiss. Fl. Orient. ini. $259=$ latiloba.

speciosa, Henckel, Adumbr. PI. Hort. Hal. 1=A.

Ptarmica.

spinosa, Schur, in Verh.Siebenb.Ver. Naturw. x. (1859) 103.- Europ.

spinulifolia, Fenzl, ex Tchihat. Asie Min. Bot. ii. 268. -Taurus.

spinulosa. Schur, ex Heimerl, in Denkschr. Acad. Wien, xlvini. (1884) $185=$ impatiens.

spithamea, Coss. \& Dur. ex Coss. in Ann. Sc. Nat.

Sér. IV. i. (1854) 239.-Algeria.

squarrosa, Ait. Hort. Kew. ed. I. ini. 242 (sp. dubia). - Hab. ?

squarrosa, Hassk. Cat. Pl. Hort. Bogor. $101=$ sibirica.

stricta, Schleich. ex Koch, Syn. F1. Germ. ed. I. $374=$ magna.

subcartilaginea, Heimerl, in Denkschr. Acad. Wien, xlviii. (1884) 188.-Europ

subhirsuta, Gilib. Fl. Lituan. i. $217=$ A. Millefolium.

sudetica, Opiz, in Hesperus (1813), 623, ex ej. Natural.

n. vi. (1824) $49=\mathrm{A}$.' Millefolium

sulphurea, Boiss. Diagn. Ser. I. xi. 17.-Syria.

sylvatica, Becker, Fl, Frankf. i. 295=A. Millefolium.

sylvatica, Tenore, Fl. Nap. iv. $126=$ ligustica.

sylvestris, S. F. Gray, Nat. Arr. ii. $458=$ A. Ptarmica.

Szowitzii, Fisch. \& Mey. ex DC. Prod. vi. $26=$ latiloba.

talagonica, Boiss. Diagn. Ser. I. xi. 17.-Persia.

tanacetifolia, All. Fl. Pedem. i. 188=Europ.; Oriens.

tanacetifolia, Mill. Gard. Dict. ed.VIII. n. $7=$ A. Millefolium?

taurica, Bieb. F1. Taur. Caurc i. $\mathbf{3 3 6}=$ Ieptophylla.

taygetea, Boiss. \& Heldr. Diag. Ser. I. xi. 16.-Oriens.

tenuifolia, Lam. Encyc. i. 26.-Oriens.

tenuifolia, Salisb. Prod. $204=$ A. Millefolium.

tenuis, Schur, Enum. P1. Transs. $329=$ A. Millefolium.

teretifolia, Willd. Sp. Pl. iui. 2198,-Oriens.

Thomasiana, Hall.f. ex Murith, Bot. Val. 49,-Europ.

Thomasii, Thomas, ex Heimerl, in Denkschr. Acad.

Wien, xlviii. (1884) $167=$ praec.

tomentosa, Fraas, ex Nym. Consp. $367=$ holosericea.

tomentosa, Frivald. ex Nym. Consp. $368=$ compacta.

tomentosa, Linn. Sp. Pl. 897._Europ.; Oriens.; As. bor.

tomentosa, Pall. Tnd. Taur. ex Leđeb. F1. Ross. ii. 536 $=$ leptophylla

tomentosa, Pursh, F1. Am. Sept. $563=$ A. Millefolium.

Tournefortii, DC. Prod. vi. 28.-Graecia.

Trautmanni x, Stein, in Oestr. Bot. Zeitschr. xxviii. (1878) 243, nomen; cf. Heimerl, in Denkschr. Acad. Wien, xlviii. (1882) 180.-Europ.

trichophylla, Schrenk, Enum. Pl. Nov. 48.-Soongaria.

trilingulata, Sch. Bip. ex Boiss. F1. Orient. iii. $271=$ aleppica.

tyrolensis, Wender. in Flora, ix. (1826) $353=$ Clavennae.

umbellata, Sibth. E Sm. Prodr. ii. 192.-Graecia.

valesiaca $\times$, Suter, Fl. Helvet. ii. 199.-Europ.

velutina, Desf. Cat. Hort. Par. ed. III. $180=$ compacta.

vermicularis, Trin. in Mém. Acad. Petersb. vi. (1818)

494. t. 13.--Oriens.

vermiculata, DC. Prod. vi. $32=$ vermicularis.

versecensis, Kit. ex Kanitz, Reliq. Kitaib. 82. in Verh.

Zool.-bot. Ges. Wien, xiii. (1863) 506.-Europ.

virgata, Hort. ex DC. Prod. vi. $31=$ tenuifolia.

viridis, Reichb. f. Ic. Fl. Germ. xvi. t. 1012.-Europ.

viscosa, Lam. F1. Fr. ii. $156=$ A. Ageratum.

viscosa, Sch. Bip. in Flora, xxxviii. (1855) 14.-Europ.

Wilhelmsii, C. Koch, in Linnaea, xxiv. (1851) 328.-

Oriens.

Wolffi, Schur, ex Nym. Consp. $365=$ impatiens.

ACHILLEOPSIS, Turcz, in Bull. Soc. Nat. Mosc. xxii. (1849) II, $9=$ =Rulingia, R. Br. (Stercul.).

densiflora, Turcz. l. c. $10=\mathrm{R}$. densiflora.
ACHILlios, St. Lag, in Ann. Soc. Bot. Lyon. vii. (1880) $118=$ Achillea, Linn. (Compos.).

millefoliatus, St. Lag. 1. c.=A. Millefolium.

ACHIMENES, Vahl, Symb. Bot. ii. 71. (1791)= Arta nema, D. Don (Scroph.)

sesamioides, Vahl, 1.c.=Art. sesamoides.

ACHIMIENES, P. Br. Hist. Jamaic. 271. t. 30. f. 1. (1756). GESNERACEAE, Benth. \& Hook. f. ii. 998. Cyrilla, L'Hérit. Stiry. Nov. 147. t. 71 (1784).

DolichodeIRA, Hanst. in Linnaea, xxvi. (1853) 205.

Eucononia, Hanst. 1. c. 201.

GUTHNickiA, Regel, in Flora, xxxii. (1849) 179.

Hout'rea, Heynh. Nom. ii. 306 (1846)

Kon Rnickia, Regel, Ind. Sem. Hort. Petrop. (1857) 48 ; et Gartenfl. (1858) 309.

Locheria, Regel, in Flora, xxxi. (1848) 251.

Mandirola, Decne, in Rev. Hortic. (1848) 468

SCHEeria, Seem. in Bot. Mag. t. 4743 (1853).

Trevirana, Willd. Enum. Hort. Berol. 637 (1809). amabilis, Decne. in Fl. des Serres, Sér. II, ii. (1857) 21. t. $1192=$ Naegelia multiflora.

amoena, Van Houtte, ex Hanst. in Linnaea, xxvii. (1854) 713.-Mexico.

Andrieuxii, DC. Prod. vii. 536.-Mexico.

argyrostigma, Hook. Bot. Mag. t. $4175=$ Koellikeria argyrostigma.

atrosanguinea, Lindl. in Journ. Hort. Soc. iii. (1848) $318=$ foliosa.

autumnalis, Hanst. in Linnaea, xxvii. (1854) 724.Guatemala.

candida, Lindl. in Journ. Hort. Soc. iii. (1848) $317=$ Dicyrta candida.

cardinalis, A. Dietr. in Allg. Gartenz. xv. (1847) 314.-Mexico.

coccinea, Pers. Syn. ii. 165.-Ind, occ.

cochinchinensis, Spreng. Syst. ii. 812 (=Diceros cochinchinensis)

comifera, DC. Prod. vii. 536.-Am. austr.

cordata, Hort. ex Regel, in Flora, xxxii. (1849) $182=$ grandiflora.

cornifera, Walp. Rep. ii. $719=$ comifera.

cupreata, Hook. Bot. Mag. t. $4312=$ Episcia cupreata.

Diceros, Gmel. ex Steud. Nom. ed. I. 7. $273(=$ Dicero cochinchinensis)

divaricata, Poepp. \& Endl. Nov. Gen. et Sp. iii. 9.-Peruv.

erinoides, DC. Prod. vii. 536.-Am. austr. foliosa, Morr. in Ann. Soc. Gand, ii. (1846) 403. t. 91.

Georgeana, Hort. ex Belg. Hortic. x. (1860)66. t. 5. Hab.?

Ghiesbrechtiana, Hort. ex Regel, in Flora, xxxi. (1849) $182=$ grandiflora

Ghiesbrechtii, Lindl. in Journ. Hort. Soc. v. (1850) 193 = grandiflora.

gloxiniaeflora, Forkel, ex Lem. in Fl. des Serres, Sér. I. iv. (1848) $318=$ Gloxinia glabrata.

gracilis, Warcsz. ex Regel, in Flora, xxxi. (1849) $180=$ Dicyrta candida.

grandiflora, DC. Prod. vii. 536.-Mexico.

Haageana, Otto, ex Regel, in Flora, xxxi. (1849) $182=$ longiflora.

heterophylla, DC. Prod. vii. 536.-Bras.

hirsuta, DC. l. C.-Bras.

ichthyostoma, Hanst. in Linnaea, xxxiv. (1865-66) 434.-Bras.

igneseens, Lem. in Fl. des Serres, Sér I. iii. (1847) t. $248=$ heterophylla.

incisa, Klotzsch, ex Oerst. in Vidensk. Selsk. Skr. V. v. (1861) 93.-Guatemala

Faureguia, Warscz. ex. Haage, in Fl. des Serres, Sér. I. v. $(1849)$ t. $536=$ longiflora.

Kleei, Paxt. Mag. Bot. xvi. (1849) $289=$ longiflora.

Knightii, Lem. in Fl. des Serres, Sér. I. iv. (1848) t. 420,-Guatemala.

lanata, Hanst. in Linnaea, xxxiv. (1865-66) 434.Mexico.

Liebmanni, Lem. in Fl. des Serres, Sér. I. iii. (1847) t. 262 ; Misc. 47 B.-Hab.?

longiflora, DC. Prod. vii. 536.-Mexico.

maculata, Walp. Rep. ii. $719=$ foliosa.

maculata, Poepp. \& Endl. Nov. Gen. et Sp. iii. 8. t. 207 A.-Peruy.

magnifica, Lindl. in Gard. Chron. (1856) $116=$ Locheria magnifica.

\section{ACHIMENES :}

Martensiana, Walp. Rep. ii. $719=$ foliosa

misera, Lindl. in Journ. Hort. Soc. iii. (1848) $319=$

Dicyrta Warscewicziana.

mollis, Poepp. \& Endl. Nov. Gen. et Sp. iii. 9.-Chili. multiflora, Gardn. in Hook. Ic. Pl. t. 468.-Bras.

naegelioides, Van Houtte, Fl. des Serres, Sér. II. viii. (1870) 117.-Hab. ?

ocellata, Hook. Bot. Mag. t. 4359.-N. Granat.

panamensis, Hemsl. Biol. Centr. Am. Bot. ii. 475. -Panama.

patens, Benth. Pl. Hartw. 67.-Mexico.

pauciflora, Oerst. in Vidensk. Selsk. Skr. V. v. (1861) 91.-Costa Rica.

pedunculata, Benth. Pl. Hartw. 78.-Mexico.

picta, Benth. in Hook. Bot. Mag. t. $4126=$ Tydaea picta.

purpurea, Pritzel, Ind. Ic. App. 3, sphalm. = seq

pyropaea, Gordon, in Journ. Hort. Soc. ii. (1847) 293. t. 4. f. $I=$ coccinea.

repens, Herb. Madr. ex Benth. in DC. Prod. x. $387=$ Limnophila repens.

rosea, Lindl. Bot. Reg. (1841) 65.-Guatemala.

rupestris, Gardn. in Hook. Ic. P1. t. 480.-Bras.

scabra, Poepp. \& Endl. Nov. Gen, et Sp. iii. 8.Peruv.

Scheerii, Hemsl. Biol. Centr.Am. Bot. ii. 476.Mexico.

Skinneri, Gordon, in Journ. Hort, Soc. ii. (1847) 293. t. 4. $\mathrm{f}, 2=$ hirsuta.

superba, Moritz, ex Hanst. in Linnaea, xxxiv. (186566) 436.-N. Granat.

tenella, DC. Prod. vii. 536.-Mexico,

tenerrima, Poepp. \& Endl. Nov. Gen. et Sp. iii. 9.Peruv.

urticaefolia, Poepp. E Endl. l. c. 8. t. 207. B.-Peruv.

urticaefolia, Warcz. ex Regel, in Flora, xxxii. (1849) 181 = Dicyrta Warszewicziana.

Warszewicziana, Regeh, in Flora, xxxii. (1849) 181.Am. austr.

ACHIMUS, Poir. in Dict. Sc. Nat. v. $51(1827)=$ Streblus, Lour. (Urticac.).

ACHIRANTHES, P. Br. Hist. Jamaic. $180(1756)=$ Achyranthes, Linn. (Amarantac.).

ACHIRIDA, Horan. Prod. Monog. Scitam. 18. t. 2. $(1862)=$ Canna, Linn. (Scitam.).

iridiflora, Horan. 1. c。 = C. iridiflora.

ACHLAENA, Griseb. Cat. PI. Cub. 228 (1866). GRAMINEAE, Benth. \& Hook. f. iii. 1117. piptostachya, Griseb.l. c. 229.-Cuba.

ACHLYS, DC. Syst. ii. 35 (1821). BERBERIDEAE, Benth. \& Hook. f. i. 45.

japonica, Maxim. in Bull. Acad. Pétersb. xii. (1868) 61.-Japon.

triphylla, DC. Syst. ii. 35.-Am. bor.

ACHNA THERUM, Beauv. Agrost. 19. t. 6. f. 7 (1812)= Stipa, Linn. (Gramin.).

argenteum, Beauv, 1. c. $146=\mathrm{S}$. Calamagrostis. bromoides, Beauv. 1. c. $146.20=\mathrm{S}$. Aristella. Calamagrostis, Beauv. 1. c. $146=\mathrm{S}$. Calamagrostis. capense, Beauv, 1. c. $146=$ Danthonia papillosa. conspicunm, Beauv. 1. c. 146. $20=$ Arundo conspicua. Hallerii, Beauv. 1. c. $146=\mathrm{S}$. Calamagrostis.

lanceolatum, Beauv. 1. c. $146.20=$ Calamagrostis lanceolata.

miliaceum, Beauv. 1. c. 146. 20 (=Uxachne parviflora). soboliferum, Beauv. 1. c. $146.20=$ Muehlenbergia sobolifera.

speciosum, Bubani, in Nuov. Giorn. Bot. Ital. v. (1873) \$17, nomen.--Europ.

tenuifolium, Beauv. Agrost. 146.20=Agrostis canina.

ACHNERIA, Beauv. Agrost. $72(1812)=$ Eriachne, R. Br. (Gramin.)

brevifolia, Beauv. 1. c. $73.146=$ E. mucronata. capillaris, Beauv. 1. c. $73.146=\mathrm{E}$. capillaris. mucronata, Beauv. I. c. $70.146=\mathrm{E}$. mucronata obtusa, Beauv. 1. c. 73. $146=$ E. obtusa.

ACHNERIA, Munro, in Harv. Gen. Pl. Cap. ed. II. 449 (1868)

GRAMINEAE, Benth. \& Hook. f, iii. 1158. 
ACHNODON, Link, Hort. Berol. i. $65 \quad(1827)=$ Phleum, Linn. (Gramin.).

arenarius, Link, $1 . \mathrm{c} .=\mathrm{P}$, arenarium

Bellardi, Link, l. c. $=$ P. tenue.

ACHNODONTON, Beauv. Agrost. 24. t. 7. f. 5. $(1812)=$ Phleum, Linn. (Gramin.).

arenarium, Trin. Gr. Unifl. $166=\mathrm{P}$. arenarium.

Bellardi, Beauv. Agrost. $25=\mathrm{P}$. tenue.

tenuis, Beauv. I. c. $=$ P. tenue.

ACHNOPHORA, F. Muell. in Trans. Roy. Soc. S. Austral. vi. (1883) 32. COMPOSITAE.

Tatei, F. Muell. l. c. 38.-Austral.

ACHRAS, Linn. Gen, ed. I. 365 (1737). SAPO TACEAE, Benth. \& Hook. f. ii. 657.

SAPOTA, Gaertn. Fruct. ii. 103. t. 104 (1791).

arnhemica, F. Muell. ex Benth. Fl. Austral. iv. 280 $=$ Sideroxylon arnhemicum.

australis, R. Br. Prod. $530=\mathrm{S}$, australe

Balata, Aubl. Pl. Gui. i. $308=$ Mimusops Kauki.

brasiliensis, Willd. ex Steud. Nom. ed. II. i. $15=$ Chrysophyllum brasiliense.

Brownlessiana, F. Muell. Fragm. vii. $111=$ Sideroxylon Brownlessianum.

Cainito, Ruiz \& Pav, Fl. Per. iii. 18 = Lucuma Cainito. chartacea, F. Muell. ex Benth. Fl. Austral, iv, $281=$ Sideroxylon chartaceum.

costata, Endl. Prod. Fl. Ins. Norf. $49=$ S. costatum.

cotinifolia, F. Muell, in Nuov. Giorn. Bot. iii. (1871)

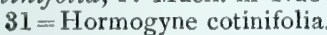

cuneifolia, Poir. Encyc. vi. 534 = Sideroxylon obovatum? dissecta, Linn. f. Suppl. 210 ; Forst. f. Plant. Esc. $43=$ Mimusops Kauki.

elengioides, Bedd. Fl. Sylv. t. $235=$ Sideroxylon tomentosum.

euphlebia, F. Muell. Fragm, vii. $110=$ S. euphlebium. ferruginea, Casar. Stirp. Bras. Dec. vii. $63=$ A. Sapota. glaucescens, Willd. ex Stend. Nom. ed. II. i. $15=$ Lucuma Rivicoa.

Guapeda, Casar. Stirp. Bras. Dec. vii. $61=\mathrm{L}$. laurifolia. Howeana, F. Muell. Fragm. ix. $72=$ Sideroxylon Howeanum.

laurifolia, Casar. Stirp. Bras. Dec. vii., $62=$ Lucuma Casaretti.

laurifolia, F. Muell. ex Benth. Fl. Austral. iv. $282=$ Sideroxylon Richardi.

Lucuma, Blanco, Fl. Filip. ed. I. 237=Lucuma mammosa.

Lucuma, Ruiz \& Pav. Fl. Per. iii, $17=$ L. obovata.

mammosa, Bonpl. ex. Miq. in Mart. Fl. Bras. vii. 64 $=\mathrm{L}$. Bonplandii.

mammosa, Linn. Sp. Pl. ed. II. $469=$ L. mammosa.

mammosa, Sieber, ex A. DC. in DC. Prod, viii. $204=$ Mimusops Kauki

mammosa, Tuss. Fl. Antill, iii. t. $6=$ Bassia Jussiaei.

montana, Poir. Encyc. vi. $533=$ Dipholis montana.

myrsinoides, A. Cunn. ex Benth. Fl. Austral, iv. 283 $=$ Sideroxylon myrsinoides.

nigra, Poir. Encyc. vi. $532=$ Dipholis nigra

obovati, F. Muell. ex Benth. Fl. Austral. iv. $283=$ Sideroxylon Brownii.

octodecemfida, Stokes, Bot. Mat. Med. ii. 294=Mimusops Kauki.

pallida, Poir. Encyc. vi. $533=$ Sideroxylon pallidum. pentagona, Poir. 1. c. $533=$ S. pentagonum.

Pohlmaniana, F. Muell. Fragm. v, 184=Sideroxylon Pohlemanum.

retusa, Dennst. Schlness. Hort. Malab. $30=$ Aglaia edulis.

retusa, Poir. Encyc。 vi, $533=$ Bumelia rctusa.

rotundifolia, Poir. 1. c. $534=$ B. rotundifolia.

salicifolia, Linn. Sp. Pl. ed. II = Dipholis salicifolia.

Sapota, Linn. Sp. Pl. ed, II. 4i0,-Am. austr.

sericea, Schum. \& Thonn. Beskr. Guin. Pl. 176.-Afr.

trop.

serrata, Poir. Encyc, Suppl, v. 36 = Prunus caroliniana sessiliflora, Poir. Encyc, vi. 531,--Ins. Borb.

tomentosa, Bedd. Forest. Man. Bot. $142=$ Sideroxylon tomentosum.

venosa, Mart. Herb. Fl. Bras, $180=$ Lucuma venosa. verrucosa, Stokes, Bot, Mat. Med. ii, 294=A. Sapota ( $)$. vitellina, Tuss. Fl. Antill, iv, $19=$ Lucuma pauciflora *erocarpa, F. Mucll. ex Benth, Fl. Austral, iv. $281=$ Sideroxylon xerocarpum.

Zapota, Linn. Sp. PI. ed, I. app, $1190=$ A. Sapota

Zapotilla, Jacq. ex Nutt. Sylv. Am. iii. $90=$ A. Sapota
ACHROANTHES. Rafin. in Med. Repos. New York, (1808) $352=$ Microstylis, Lindl. (Orchid.).

acuminata, Rafin. New F1. Am. i. $59=$ M. monophylla

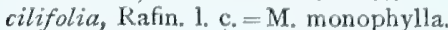

laxiflora, Rafin. 1. c. $58=$ M. ophioglossoides. obtusifolia, Rafin. l. c. = M. ophioglossoides. unifolia, Rafin. in. Med. Repos. New York, v. (1808) $352=\mathrm{M}$. ophioglossoides

ACHROCHLOA, Griseb. Spicil. Fl. Rumel. ii. 446 (1845 = Airochloa, Link (Gramin.)

ACHromolaENA, Cass. in Dict. Sc. Nat. lvi. 222 (1828) = Cassinia, R. Br. (Compos.)

viscosa, Cass. 1. c. $=$ C. quinquefaria.

ACHROOSTACHYS, Benth。 in Journ. Linn. Soc, xix (1881) 134, err. typ. $=$ Athroostachys, Benth. (Gramin.).

ACHRYSUM, A. Gray, in Hook. Kew Journ. iv. (1852) 228 = Calocephalus, R. Br. (Compos,

glomeratum, A. Gray, 1. c. 229 = C. multiflorus.

ACHUDEMIA, Blume, Mus. Bot. Lugd. Bat. ii. 57 t. 20. ' 1852 ' [1856]. URTICACEAE, Benth. \& Hook. f. iii, 385 .

japonica, Maxim. in Bull. Acad. Pétersb. xxii. (1877) 241.-Japon.

javanica, Blume, Mus. Bot. Lugd. Bat. ii. 57. t. 20.-Java

ACHYMUS, Vahl, ex Juss. in Dict. Sc. Nat. i. Suppl. 31 $(1816)=$ Streblus, Lour. (Urticac.)

pallens, Soland. ex Blume, Mus. Bot. Lugd. Bat. ii. $79=\mathrm{S}$. asper

ACH YRACHAENA, Schau. Del. Sem. Hort. Vratisl. (1837) 3, ex Linnaea, xii. (1838) Litt. 87. COM POSITAE, Benth. \& Hook, f. ii. 396.

Lepidostephanus, Bartl. Ind. Sem. Hort. Goett. (1837), ex Linnaea, xii. (1838) Litt. 82.

mollis, Schau. l. c. 3.-Am. bor. occ.

ACHYRANTHES, Linn. Gen. ed. I. 34 (1737) AMARANTACEAE, Benth. \& Hook, f. iii. 35. AMorgine, Rafin. New Fl. Am. iv. 44 (1836) Cadelaria, Rafin. Fl. Tellur. iij. 39 (1836) Centrostachys, Wall. in Roxb. Fl. Ind. ed. Carey, ii, 497 (1835)

Codivalia, Rafin. Fl. Tellur. iii. 40 (1836). ECLOTORIPA, Rafin. 1. c. (1836)

STEIREMIS, Rafin. l.c. (1836).

abyssinica, Nees, in Del. Sem. Hort. Vratisl. (1850) 3. -Abyss.

alba, Eckl. \& Zeyh. ex Moq. in DC. Prod. xiii. II. 311. -Afr. austr.

alopecuroides, Lam. Encyc. i. 548=Aerva javanica. alternifolia, Linn. Mant. i. 50=Digera arvensis. alternifolia, Linn. f. Suppl. 159= Cyathula globosa. alternifolia, Russ. ex Wall. Cat, n. $6887=$ Digera arvensis.

altissima, Jacq. Enum. Pl. Carib. 17=Chamissoa altissima.

amaranthoides, Lam. Encyc. i. 548=Digera arvensis, angustifolia, Benth. in Hook. Nig. Fl. 492-Afr, trop. aquatica, R. Br. Prod. 417.-Ind. or.; Afr. trop. arborescens, $R$. Br. l.c.-Ins. Norfolk. argentea, Lam. Encyc. i. $545=$ aspera. aspera, Jacq. f. Ecl, 109, t. $74=$ crispa. aspera, Linn. Sp. P1. 204.-Geront. trop. aspera, Wall. Cat. $\mathrm{n}, 6924 \mathrm{H}=$ bidentata

atra, Pav. ex Moq. in DC. Prod, xiii. II. $372=$ Telanthera elongata.

atropurpurea, Lam. Encyc. i. $546=$ Pupalia atropùrpurea

australis, R. Br. Prod. 417.-Austral.

avicularis, E. Mey. ex Moq. in DC. Prod, xiii. II. 311 Afr. austr.

axillaris, Willd. Enum. Hort. Berol. 270=Alternanthera spinosa.

baccata, Pav。 ex Moq. in DC. Prod. xiii. Ir. $250=$ Chamissoa altissima.

bengalensis, Lam. Encyc. i. 459 (Sp. dub.) - -Ind. or bidentata, Blume, Bijdr. 5t5.-As trop.

borbonica, Willd, ex Roem. et Schult. Syst. y. 549. Ins. Borbon.

brachiata, Linn. Mant. $50=$ Nothosacrua brachiata. brasiliana, Thouin, ex Moq. in DC. Prod, xiii. 11. 360, $318=$ Altermanthera procumbeus.

\section{ACHYRANTHES}

calceolata, Russ。 ex Wall. Cat. D. $6927=$ Psilotrichum calceolatum.

Calea, Ibantz, in La Natural. iii. (1879) 79. t. 3.Am. centr.

canescens, R. Br. Prod. i. 417.-Austral.

capitata, Forsk. Fl. Aegypt. Arab. 48.-Arab.

capitata, Moq. in DC. Prod. xiii. II. $310=$ involucrata

capituliflora, Bert. in Colla, Hort. Ripul. 4. to 18.-N Granat.

carnosa, Wall. Cat. n. $6931=$ Psilotrichum trichatomura. ciliata, Lam. Encyc. i. 549=T)igera arvensis.

conferta Ruiz, ex Seub. in Mart. F1. Bras. v. I. 223= Guilleminea densa.

cordata, Hochst. in Flora, xxvii (1844) Beil. $6=$ = Psilostachys gnaphalobrya,

corymbosa, Heyne, ex Wall. Cat. n. $6913=$ Celosia polygonoides.

corymbosa, Linn. Sp. Pl. $205=$ Polycarpaea corymbosa, crispa, Desf. ex Poir. Encyc. Suppl. ii. 10.-Am. austs cylindrica, Boj. ex Moq. in DC. Prod. xiii. 11. $328=$ Cyathula cylindrica

debilis, Poir. Encyc. Suppl. ii, $10=$ Cyathula prostrata. decumbens, Forsk. Fl. Aegypt. Arab. 47 = Celosia polygonoides,

cliandra, Roxb. Fl. Ind.ed. Carey, ii. 504.-Zeylan.

dichotoma, Linn. Mant. 51.-Am. bor.

diffusa, Moench, Meth. $315=$ Cyathula prostrata?

Digera, Poir. Encyc. Suppl. i. 2. $11=$ Digera arvensís

dioica, Pav, ex Moq. in DC. Prod, xiii. II. $350=$ Alternanthera flavescens.

echinata, Retz. Obs. Fasc. ii. 12 = Pupalia lappacea

ellipticifolia, Stokes, Bot. Mat. Med, i. $479=$ aspera.

excelsa, Thou. ex Moq. in DC. Prod, xiii. $11.315=$ aspera.

fasciculata, Ehrenb. ex Schweinf. Beitr. Fl. Aethiop. 179.-Afr. trop.

ferruginea, Roxb. Fl. Ind. ed. Carey, ii. $502=$ Psilo trichum ferrugineum.

ficoidea, Lam. Encyc, i. $548=$ Telanthera ficoidea,

filifolia, Willd. ex Roem. et Schult. Syst. ₹. 549.Venezuela

frumentacea, Burm. f. Fl. Cap. Prod. 7.-Afr. austr.

frutescens, Hort. ex Steud, Nom. ed. II. i. 15 = Digera arvensis

fruticosa, Desf. Cat. Hort. Par. ed. III. $76=$ aspera. fruticosa, Lam. Encyc. i. 545.-Ind. or.

gerninata, Schum. \& Thonn. Beskr. Guin. Pl. 38.-A fr trop.

geniculata, Pav, ex Moq. in DC. Prod. xiii. II. $381=$ Telanthera capitulifiora.

glabella, A. Gray, in Proc. Am. Acad. vii. (1868) 200.-Ins. Sandy

globosa, Pers. Syn. i. 259 = Cyathula globosa.

glauca, Heyne, ex Wall. Cat. n. $6927=$ Psilotrichum calceolatum.

globulifera, Boj. ex Mog. in DC. Prod, xiii. 1I. 32y = Cyathula globulifera.

grandifolia, Moq. in DC. Prod. xiii. II. 318.-Tava.

halimifolia, Lam. Encyc. i. $517=$ Telanthera frutescens Heudelotii, Moq. in DC. Prod. xiii. II. $310=$ Pandiaki Heudelotii.

hirtiflora, A. Rich. Fl. Cub. Fanerog. ii. 175.-Cuba. hispida, Moq. in DC. Prod, xiii. II. $312=$ biden. tata.

incana, Fisch. ex Schrank, in Denkschr. Bot. Ges. Re gensb. ii. (1822) 36.-Bras.

incana, Pav, ex Moq. in DC. Prod. xiii. $11.365=$ Telan. thera frutescens.

incana, Roxb. Fl. Ind. i. 671 ; ed. Carey, ii. $495=$ Aersa javanica.

indica, Mill, Gard. Dict, ed, VIII. D, $2=$ aspera.

involucrata, Moq. in DC. Prod, xiii. 11. $310=$ Pandiaha involucrata.

javanica, Mog.l. c. \$12.-Javn.

javanica, P(rs. Sy.1, i. 25!) = Aerra javanica.

lanato, Linn. Sp. Pl. 20t= Aerva lanata.

lancrolata, Klein, in Wall. Cat, n. 64:29 bidentate.

lanceolata, Zoll, \& Mor. ex Mog, in DC. I'rud. xiii. "I $312=$ javanica

Iappacea, Linn. Sp. PI. 20t = Papalin atropurpurea lappacea, Willd. Sp. P'. i. $1192=$ I'upalia lappacea.

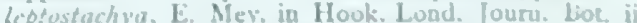

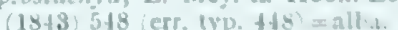

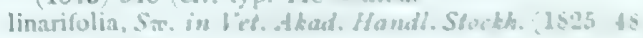
-Ins. Moluce

Linkiana, Kocm. \& Schult, Syst. \$. 345-Chatuissom macrocarpa. 


\section{ACHYRANTHES}

lupulina, Willd, ex Steud. Nom, ed. II, i, 15 = Telanthera lupulina.

mauritiana, Moq. in DC. Prod. xiii. II. 313.-Ins. Maurit.

mollis, Lepr. ex Seub. in Mart. F1. Bras. v. I. $230=$ Cyathula prostrata.

mollis, Schum. E Thonn. Beskr. Guin. Pl. 137.-Afr. trop.

Monsoniae, Pers. Syn. i. $258=$ Aerva Monsoniae.

montana, Klein, ex Wall. Cat. n. $6926=$ Psilotrichum nudum.

Moorcroftiana, Hook. f. Fl. Brit. Ind. v. 8. lapsu, pro Axyridi = Euotia ceratoides

mucronata, Herb. ex Moq. in DC. Prod. xiii. II. $248=$ Allmania albida.

mucronata, Lam. Encyc. i. $547=$ Alternanthera Achyrantha.

muricata, Linn. Sp. P1. ed. II. $295=$ Digera arvensis. mutica, A. Gray, ex H. Mann, in Proc. Am. Acad. vii. (1867) 200.-Ins. Hawaii

natans, Buch.-Ham. ex Wall. Cat. n. $6932=$ aquatica nervosa, Roth, Nov. Pl. Sp. 170.-Ind. or. nivea, Ait. Hort. Kew. i. 286.-Ins. Canar. nivea, Link, in Buch, Beschreib. Canar. $141=$ Alternanthera Achyrantha.

nodiflora, Roxb. Fl. Ind. i. $678=$ Allmania nodiflora.

nodosa, Bert. ex Moq. in DC. Prod, xiii. II. $352=$ Alternanthera argentata.-Am. trop.

nodosa, Vahl, in Schum. E Thonn. Beskr. Guin. Pl. 139.-Afr. trop.

Novae-Brasiliae, Steud. Nom, ed. II, i. $\mathbf{1 5}=$ seq.

novae-brasilianae, Thouin, ex Roem. \& Schult. Syst. v.

$564=$ Alternanthera procumbens.

nuda. Heyne, ex Wall. in Roxb. F1. Ind. ed. Carey, ii. $507=$ Psilotrichum nudum.

obovata, Pav. ex Moq. in DC. Prod. xiii. II. $359=$

Alternanthera Achyrantha.

obovatifolia, Stokes, Bot. Mat. Med. i. $480=$ aspera.

obtusifolia, Lam. Encyc. i. $545=$ aspera.

orbiculata, Heyne, in Roxb. F1. Ind. ed. Carey, ii. $507=$ Pupalia lappacea.

ovata, Ehrenb. ex Schweinf. Beitr. Fl. Aethiop. 135.Afr. trop.

paludosa, Bunb. in Proc. Linn. Soc. i. (1841) $109=$ Telanthera philoxeroides.

paniculata, Forsk. Fl. Aegypt. Arab. $48=$ Celosia caudata.

papposa, Forsk. 1. c. $48=$ Eurotia ceratoides.

patula, Linn. f. Suppl. $160=$ Pupalia lappacea.

persica, Steud. Nom. ed. I. $8=$ Aerva javanica.

picta, Passer. in Bot. Zeit. (1864) 31.-Bras.

pilosa, Pav. ex Moq. in DC. Prod. xiii. II. $352=$ Alternanthera argentata.

piloselloides, Poit. ex Moq. 1. c. $337=$ Gossypianthus lanuginosus.

polygonata, Heyne, ex Wall. Cat. n. $6914=$ Banalia thyrsiflora.

polygonoides, Heyne, ex Wall. 1. c. n. $6926=$ Psilotrichum nudum.

polygonoides, Lam. Encyc. i. 547=Telanthera polygonoides.

polygonoides, Retz. Obs. Fasc. ii. $12=$ Digera arvensis

polygonoides, R. Br. Prod. $416=$ Telanthera poly* gonoides.

polystachya, Forsk. Fl. Aegypt. Arab. 48.-Arab

porphyristachya, Wall. Cat. n. $6925=$ aspera.

porrigens, Jacq. Hort. Schoenb. iii. $54=$ Telanthera porrigens.

prostrata, Linn. Sp. Pl. ed. II. $296=$ Cyathula prostrata.

prostrata, Willd. Sp. P1. i. $1194=$ Cyathula globosa.

pubescens, Roth, Nov. Pl. Sp. $171=$ Aerva Monsonia

pungens, Lam. Encyc i. 546=-Aerva Monsonia.

purpurea, Pav, ex Moq. in DC. Prod. xiii. II. $377=$

Telanthera porrigens.

radicans, Cav. in Ânal. Hist. Nat. Madr. iii. (1801) 27 = Altemanthera Achyrantha.

radicans, Heyne, in Roth, Nov. PI. Sp. $170=$ Aerva

radicans.

repens, Ell. Sketch, i. $309=$ Telanthera polygonoides.

repens, Heyne, in Roth, Nov. Pl. Sp. $167=$ Cyathula

prostrata.
repens, Linn. Sp. Pl. $205=$ Alternanthera Achyrantha.

rivinaefolia, Desf. Cat. Hort. Par. ed. III. (1829) 390,

76.-Hab. ?

rosea, Spreng. Syst. iv. Cur. Post. $103=$ Polycarpaea violacea.

\section{ACHYRANTHES :-}

rotundifotia, Klein, ex Wall. Cat. n. $6936=$ Pupalia orbiculata.

rubrofusca, Wight, Ic. v. t. $1778=$ aspera.

sanguinolenta, Linn. Sp. Pl. ed. II. 294.-Ind. or. sarmentosa, Link, ex Seub. in Mart. F1. Bras. v. I. 241 = Chamissoa macrocarpa.

sarmentosa, Vahl, Symb. Bot. ii. 44.-Ind, or.

scandens, Hook. f. \& Thoms, ex C. B. Clarke, in Journ. Linn. Soc. xv. (1877) $139=$ Stilbanthus scandens.

scandens, Heyne, ex Moq. in DC. Prod. xiii. II. $348=$ Iresine amarantoides.

scandens, Roxb. F1. Ind. i. 676.; ed. Wall. ii. $503=$ Aerva scandens.

scandens, Thonn. ex Moq. in DC. Prod. xiii. II. $331=$ Pupalia atropurpurea.

sequax, Wall. in Roxb. Fl. Ind. ed. Carey, ii. 506= Cyathala tomentosa.

sericea, Heyne, ex Wall. Cat. n. 6390.-Ind. or.

sericea, Koen. in Roxb. Fl. Ind. iii. 675; ed. Carey, ii.

502 = Psilostachys sericea.

serpyllifolia, Poir. Encyc. Suppl. ii. 11=Telanthera serpyllifolia.

sessilis, Steud. Nom. ed. II. i. $16=$ Alternanthera sessilis setacea, Roth, Nov. Pl. Sp. $168=$ Aerva Monsonia

sicula, Roth, Catalect. Bot. i. $39=$ aspera.

spinosa, Desv. Hort. Divion. (1834-36).-Hab.?

spinosa, Hornem. Hort. Hafn. i. $240=$ Alternanthera spinosa.

splendens, Mart. ex Moq. in DC. Prod. xiii. II. 316.Ins. Sandy

stellata, Willd. Sp. Pl. i. $1195=$ Polycarpaea stellata

styracifolia, Lam. Encyc. i, $546=$ Pupalia lappace

tenella, Poit. ex Moq. in DC. Prod. xiii. II. $341=$ Ire sine seтрyllifolia.

tenuifolia, Steud. Nom. ed. II. i. $16=$ aspera?

tenuifolia, Willd. Sp. PI. i. $1196=$ Polycarpaea tenui folia.

ternata, Host, ex Fisch. Mey. \& Lall. Ind. Sem. Hort. Petrop. ix. Suppl. $12=$ Gomphrena decumbens

Thonningii, Schum. in Schum. E Thonn. Beskr. Guin Pl. 137.-Afr. trop.

thyrsiflora, Heyne, ex Wall. Cat. n. $6914=$ Banalia thyrsiflora.

tomentella, Zipp. ex Span. in Linnaea, xv. (1841) 345 . -Malaya.

tomentosa, Roth, Nov. PI.Sp. $167=$ Cyathula tomentosa. triandra, Roxb. Fl. Ind. i. $678=$ Alternanthera sessilis trichotoma, Perr. ex Moq. in DC. Prod. xiii. II. $322=$ aquatica.

uncinata, Willd. ex Roem. \& Schult. Syst. v. $554=$ Cya thula achyranthoides.

uncinulata, Schrad. Ind. Sem. Hort. Goett. (1833) 1.Afr. austr.

velutina, Hook. \& Arn. Bot. Beech. Voy. 68.-Ins, Societ.

Verreauxii, Moq. in DC. Prod, xiii. II. $311=$ alba.

Verschaffeltii, Lem. Illustr. Hortic. $(1846)$ t. $409=$ Iresine Herbstii.

verticillata, Thunb. in Hoffm. Phytogr. Blaetter, i (1803) 26.-Afr. austr.

villosa, Blanco, Fl. Filip. ed. I. 189=Alternanthera nodiflora.

villosa, Forsk. F1. Aegypt. Arab. $48=$ Aerva lanata.

violacea, Spreng. Syst. iv. Cur. Post. $102=$ Polycarpaea violacea.

virgata, [Desf.] Poir. Encyc. Suppl. ii, 10.-Portorico.

virgata, Hort. ex Steud. Nom. ed. II. i. $16=$ Celosia virgata.

virgata, Klein, ex Wall. Cat. n. $6915=$ Banalia thyrsiHora.

Wightiana, Wall. Cat. n. $6928=$ bidentata

ACHYRASTRUM, Neck. Elem. i. $57(1790)=$ Hyoseris, Linn. (Compos.).

ACHYROBACCHARIS, Sch. Bip. in Walp. Rep. ii. $952(1843)=$ Baccharis, Linn. (Compos.).

ACHYROCLINE, Less. Syn. Comp. 332 (1832) COMPOSITAE, Benth. \& Hook. f. ii. 305.

adoensis, Sch. Bip. ex A. Rich. Tent. Fl. Abyss. i. 428. -Abyss.

alata, $D C$. Prod. vi. 221.-Ecuad.

albicans, Griseb. in Goett. Abh. xxiv. (1879) $187=$ satureioides.

argentina, O. Hoffm. in Linnaea, xliii. (1880-82) 135. -Reg. Argent.

\section{ACHYROCLINE :-}

batocana, Oliver \& Hiern, in Oliver, Fl. Trop. Afr. iii. 339.-Afr. trop.

bogotensis, $D C$. Prod. vi. $221 .-\mathrm{N}$. Granat.

candicans, DC. $\mathrm{l}_{\text {. }} \mathrm{c}_{\mathrm{s}}=$ satureioides.

capitata, Baker, in Mart. Fl. Bras. vi. III. 117 -Bras. celosioides, DC. Prod. vi. 221.-Peruv.

citrina, Griseb. in Goett. Abh. xxiv. (1879) $187=$ satureioides.

coquimbense, Klatt, in Linnaea, xlir. (1878-79) 112. -Chile.

disjuncta, Hemsl. Bot. Voy. Challenger, i. II. 128.Ins. Trinit.

flaccida, $D C$. Prod. vi 220 -Bras

flavescens, Griseb. in Goett. Abh. xix. (1874) $181=$ alata. glumacea, Oliver \& Hiern, in Oliver, Fl. Trop. Afr. iii. 340.-Afr. trop.

hirta, Klatt, in Linnaea, xlii. (1878-79) 113.-N Granat.

Hochstetteri, Sch.Bip.ex A. Rich. Tent. Fl. Abyss, i. 428.-Abyss.

latifolia, Wedd. Chlor. And. i. 148.-Boliv.

leptocephala, DC. Prod. vi. 220.-Madag.

luzuloides, Vatke, in Linnaea, xxxix. (1875) 489 ; et in Oestr. Bot. Zeitschr. (1875) 326.-Afr. trop.

madioides, Meyen \& Walp. in Nov. Act. Nat. Cur.xix. Suppl. i. (1843) 275.-Peruv.

mathiolaefolia, DC. Prod. vi. $221=$ satureioides

mollis, Benth. Pl. Hartw. $207=$ satureioides

Moritziana, Klatt, in Linnaea, xlii. (1878-79) 112.-. N. Granat.

pterocaula, DC. Prod. vi. 221 = alata.

rufescens, $D C$. l. c. $220,-\mathrm{N}$. Granat.

rugosa, Gardn. in Hook. Lond. Journ. Bot. vi. (1847) $419=$ Stenocline chionaea.

satureioides, DC. Prod. vi. 220-Am. merid.

satureioides, Gardn. in Hook. Lond. Journ. Bot. vii. (1848) $424=$ Stenocline Gardneri.

Schimperi, Sch. Bip. ex A. Rich. Tent. Fl. Abyss. i. 42S.-Abyss.

sclerochlaena, Sch. Bip. ex Oliver \& Hiern, in Oliver, Fl. Trop. Afr. iii. 341.-Afr, trop.

Steetzii, Vatke, in Oestr. Bot. Zeitschr. xxvii. (1877) 194 = batocana.

tamariscina, Schrank, in Denkschr. Akad. Muench. viii. (1821-22) $170=$ Stoebe fusca.

Trianae, Klatt, in Linnaea, xlii. (1878-79) 113.-N. Granat.

Vargasiana, DC. Prod. vi. $220=$ satureioides.

Vautheriana, DC. 1, c. = alata.

ventosa, Klatt, in Linnaea, xlii. (1878-79) 112.Mexico.

ACHyrocomA, Cass. in Dict. Sc. Nat. v. 57 (1828) = Vernonia, Schreb. (Compos.)

tomentosa, Cass. 1. c. xxvi. $21=\mathrm{V}$. Achyrocoma.

ACHYROCOME, Schrank, in Denkschr. Akad. Muench. viii. (1821-22) $147 \& 170=$ Elytropappus, Sch. Bip. (Compos.).

ambigua, Schrank, 1. c. =E. ambiguus.

ACHY RONIA, Royen, ex Linn. Gen. ed. II. 346 (1742) = Aspalathus, Linn. (Legumin.).

ACHYRONIA, Wendl. Obs. Bot. 39. t. 12. (1798) = Priestleya, DC. (Legum.).

arborea, Spreng. Syst. iii. 285, iv. Cur Post. 271, $287=$ Carmichaelia australis.

villosa, Wendl. Obs. Bot. $39=$ P. Thunbergii?

ACHYRONYCHIA, Torr. \& Gray, in Proc. Am. Acad. vii. (1868) 330. ILLECEBRACEAE, Benth. \& Hook. f. iii. 15.

Cooperi, A. Gray, in Proc. Am. Acad. vii. (1868) 331. -N. Mexico; Calif.

Palmeri, Hook. f. in Benth. \& Hook. f. Gen. iii. $15=$ Parryi.

Parryi, Hemsl. Diag. Pl. Nov. 36.-Mexico.

ACHYROPAPPUS, Bieb. ex Fisch. in DC. Prod. vi $563(1838)=$ Tricholepis, DC. (Compos.).

ACHYROPAPPUS, H. B. \& K. Nov. Gen. et Sp.iv. 257. t. $390(1820)=$ Schkuhria, Roth (Compos.) anthemoides, H. B. \& K. I. c.=Bahia anthemoides. maritimus, Poepp. ex DC. Prod. v. $657=$ Bahia ambrosioides. 


\section{ACHYROPAPPUS :-}

pedatus, Less. Syn. Comp. $289=$ Florestina pedata

schkuhrioides, D. Don, ex Hook. \& Arn. in Hook Lond. Fourn. Bot. iii. (1840) 322.-Hab.?

schkuhrioides, Link \& Otto, Abb. Neuer Gew. Gart. Berl. t. $30=$ Schkuhria senecioides.

Woodhousei, A. Gray, in Proc. Am. Acad. vi. (1864-5) $546=$ Bahia Woodhousei

ACHYROPHORUS, Adans. Fam. ii. $112(1763)=$ Hypochoeris, Linn. (Compos.)

acaulis, Remy, in C. Gay, Fl. Chil. iii. 448.-Chili.

albiflorus, Sch. Bip. in Pollichia, xvi-xvii. (1859) 52.

N. Granat.

alpicolus, Schur, Enum. Pl. Transs. $365=$ H. maculata

ambiguus, DC. Prod. vii. $93=$ H. cretensis

andinus, DC. 1. c. $92=\mathrm{H}$. andina.

angustissimus, Phil. in Linnaea, xxxiii. (1864-65) 127. -Chili.

apargioides, DC. Prod. vii. $94=\mathrm{H}$. apargioides.

araucanus, Phil. in Linnaea, xxviii. (1856) 721.-Chili.

arenarius, DC. Prod. vii. $95=\mathrm{H}$. arenaria.

aurantiacus, DC. 1. c. $93=\mathrm{H}$. grandiflora.

Balbisii, Hornem. Hort. Hafn. Suppl. $91=$ H. Balbisii

barbatus, Sch. Bip. in Pollichia, xvi-xvii. (1859) 48,

N. Granat.

Bipontinae, Sch. Bip. 1. c. $54=$ H. Gardneri.

Boissierianus, Walp. Ann. ii. 956-Creta.

brasiliensis, Sch. Bip. in Nov. Act. Nat. Cur. xxi. I. (1845) $106=\mathrm{H}$. brasiliensis.

brasiliensis, Gardn, in Hook. Lond. Journ. Bot. iv. (1845) $128=\mathrm{H}$. Gardneri.

brevicaulis, Phil. in Linnaea, xxxiii. (1864-65) 127.Chili.

chilensis, Sch. Bip. in Nov, Act. Nat. Cur. xxi. I. 1845) 104.-Chili.

chondrilloides, A. Gray, in Froc. Am. Acad. v. (1845)

$145=\mathrm{H}$. brasiliensis.

chrysanthus, DC. Prod. vii. $94=\mathrm{H}$. chrysantha.

ciliatus, Sch. Bip. in Nov. Act. Nat. Cur. xxi. I. (1845)

$128=\mathrm{H}$, grandiflorus.

clarionoides, Remy, in C. Gay, Fl. Chil, iii. 450.-Chili. coronopifolius, Sch. Bip, in Flora, xxxviii. (1855) 123 -Reg. Magell.

cryptocephalus, Sch. Bip. in Lechl. Berb. Am. Austr. 57.-Peruv.

elatus, Wedd. Chlor. And. i. $223=\mathrm{H}$. elata,

discolor, Godr. in Mém. Acad. Stanislas, Sér. III. [xvii.] $1853(1854), 407$. - Hab. ?

eriolaenus, Sch. Bip. in Lechl. Berb. Am. Austr. 57.Peruv.

foliosus, Phil. Fl. Atac. 29.-Chili.

Gardneri, Sch. Bip. in Pollichia, xvi-xvii. (1859), $64=$ H. Gardneri.

glabrescens, Steud. Nom. ed. II. i. $16=$ H. arenaria

glaucus, Phil. F1. Atac. $29=\mathrm{H}$, andina.

graminifolius, Sch. Bip. ex Walp. Rep. vi. $333=$ tenuifolius.

grandidentatus, Phil. Fl. Atac. 29,-Chili.

grandiflorus, Sch. Bip. in Nov. Act. Nat. Cur. xxi I. (1845) 113.-Sibiria.

grandiflorus, Ledeb. Fl. Ross. ii. $777=\mathrm{H}$. grandiflora helveticus, Hornem. Hort. Hafn. ii. $772=\mathbf{H}$. uniflora. helveticus, Less, Syn. Comp. $130=\mathrm{H}$. helvetica,

hispidus, Hornem. Hort. Hafn. ii. $772=\mathrm{H}$. hispida

Hohenackeri, Sch. Bip. in Lechl. Berb. Am. Austr. 57. -Peruv.

Humboldtii, Sch. Bip. in Pollichia, xvi-xvii. (1859) 52. -N. Granat.

humilis, Phil. in Anales Univ, Chil. (1873) 482.Chili. incanus, Sch. Bip. in Nov. Act. Nat. Cur. xxi. I. (1845) 100.-Am. austr.

Fussieui, Sch. Bip. 1. c. 96.-Chili.

Lechleri, Sch. Bip. in Lechl. Berb. Am. Austr. 54.Chili.

Lessingii, Sch. Bip. 1. c. 98.-Chili.

maculatus, Scop. Fl. Cam. ed II. ii. $116=$ H. maculata Meyenianus, Walp. Rep. vi. $336=$ H. Meyeniana.

microcephalus, Sch. Bip. in Pollichia, xvi-xvii. (1859), $\mathbf{5 9}=\mathrm{H}$. brasiliensis.

microphyllus, Remy, in C. Gay, Fl. Chili. iii. 449,Chili.

minimus, Hornem. Hort. Hafn. ii. $773=\mathrm{H}$. minima.

montanus, Phil. in Linnaea, xxviii. (1856) 720. - Chili.

odoratus, Walp. Rep. vi. 336,-Chili.

oxydontus, DC. Prod. vii, $92=\mathrm{H}$. cretensis.

palustris, Phil. in Anales Univ. Chil. (1865) ii. 317 Chili.

\section{ACHYROPHORUS :-}

petiolaris, DC Prod vii, $94=\mathrm{H}$. petiolaris

pinnatifidus, DC. 1. c. $93=\mathrm{H}$. pinnatifida.

praemorsus, Webb, ex Walp. Rep. vi. $329=$ Webbii

psychrophilus, Wedd. Chlor. And. i. 222.-Chili.

quitensis, Sch. Bip. in Nov. Act. Nat. Cur. xxi. I. (1845)

120.-Ecuad.

radicatus, Scop. Fl. Carn. ed. II. ii. $117=\mathrm{H}$. radicata ramosus, DC. Prod. vii. 92 - - Hab.

Robertia, Sch. Bip. in Nov. Act. Nat. Cur. xxi. I. (1845 127.-Italia.

roseus, Less, in Linnaea, v. (1830) 133. t. 2. f. $5=$

Pinaropappus roseus.

sagittatus, Phil Sert. Mend alt 20-Chili.

Scorzonerae, DC. Prod. vii. $94=\mathrm{H}$. Scorzonerae.

Selloi, Sch. Bip. in Pollichia, xvi-xvii. (1859), $60=\mathrm{H}$ brasiliensis.

serioloides, DC. Prod. vii. $93=\mathrm{H}$. cretensis.

sessiliflorus, DC. 1. c. $95=\mathrm{H}$. sessiliflora.

setosus, Wedd. Chlor. And, i. 220--Peruv.

sonchoides, DC. Prod. vii. $95=\mathrm{H}$. sonchoides.

spathulatus, Remy, in C. Gay, F1. Chil. iii. 447.Chili.

spinuliger, Phil. in Linnaea, xxviii. (1856) 721.-Chili. stenocephala, A. Gray, ex Wedd. Chlor. And. i. 221.Peruv.

taraxacifolius, Sch. Bip. in Nov. Act. Nat. Cur. xxi. I. (1845) $101=\mathrm{H}$. radicata.

taraxacoides, Walp. Rep. vi. 336.-Peruv.

tenerifolius, Remy, in C. Gay, Fl. Chil. iii. 446.Chili.

tenuifolius, DC. Prod. vii. $94=\mathrm{H}$. tenuifolia.

tenuisectus, Sch. Bip. in Pollichia, xvi-xvii. (1859),

$57=$ H. variegata.

thrincioides, Remy, in C. Gay, F1. Chil. iii. 445.-Chili

trichocephalus, Sch. Bip. in Pollichia, xvi-xvii. (1859) $57=\mathrm{H}$. variegata.

uniftorus, F. W. Schmidt, Samml. Phy. Aufz. i. (1795) $284=$ H. uniflora

variegatus, Sch. Bip. in Nov. Act. Nat. Cur. xxi. I (1845) $119=\mathrm{H}$. variegata.

Volckmanni, Phil. in Anales Univ. Chil. (1873) 482.Chili.

Webbii, Sch. Bip. in Nov. Act. Nat. Cur. xxi. I. (1845 97.- Ins. Faik.

ACHYROPSIS, Benth. \& Hook. f. Gen. iii. 36 (1880), AMARANTACEAE, Benth. \& Hook. f. 1. c. acicularis, Benth. \& Hook.f.l. c.-Afr. austr.

alba, Benth. \& Hook. f. l. c.-Air. austr.

leptostachya, Benth. \& Hook.f.l.c.-Afr. austr.

ACHYROSERIS, Sch. Bip. in Nov. Act. Nat. Cur. xxi. I (1845) $165=$ Scorzonera, Linn. (Compos.)

macrospermum, Sch. Bip. 1. c. $=\mathrm{S}$. macrosperma.

ACHYROSPERMUM, Blume, Bijdr。 840 (1826 LABIATAE, Benth. \& Hook, f, ii. 1208

Lamprostachys, Boj. ex Benth. in DC. Prod. xii 457 (1848).

SIPHOTORIS, Boj. ex Benth.l.c. (1848)

aethiopicum, Welw, in Trans. Linn. Soc. xxvii. (1869) 56.-Afr. trop.

densiforum, Blume, Bijdr. 841.-Ins. Malay.

fruticosum, Benth. Lab. Gen. et Sp. 643 \& 745 . Madag.

philippinense, Benth. in DC. Prod. xii. $458=$ densiflorum phlomoides, Blume, Bijdr. 841.-Java.

seychellarum, Baker, Fl. Maurit. 259.-Ins, Seychelles

Wallichianum, Benth. ex Hook. f. Fl. Brit. Ind. iv. 673.- - Reg. Himal.

ACHXROSTEPHUS, Kunze, ex Reichb. Consp. $212^{n}$ (1828). (Compos.)

ACIA, Schreb. Gen. ii. $458(1791)=$ Couepia, Aubl (Rosac.).

amara, Willd, Sp. Pl. iii. $717=$ C. guianensis.

dulcis, Willd. 1. $\mathrm{c}_{\mathrm{o}}=\mathrm{C}$. guianensis

ACIACHNE, Benth, in Hook. Ic. PI. t. 1362 (1881) GRAMINEAE, Bentb. \& Hook, f. iii. 1143. pulvinata, Benth. l. c. -N. Granat.

ACIANTHERA, Scheidw. in Otto \& Dictr. Allgem. Gartenz. X. (1812) 292.= Pleurothallis, R. Br. (Orchid.)

punctata, Suheidw, I. c. = P. Acianthera.
ACIANTHUS, R, Br. Prod, 321 (1810), ORCHY

$D E A E$, Benth. \& Hook, f, iii. 611

atepalus, Reichb. f. in Linnaea, xli. (1877) 56.N. Caled.

bifolius, R. Br. Prod, 322 = Chiloglottis diphylla

caudatus, R. Br.l. c. 321.-Austral.

elegans, Reichb. f. in Linnaea, xli. (1877) 56.N. Caled.

exsertus, R. Br. Prod. 321.-A ustral.

fornicatus, R.Br.l. C.-Austral.

petiolatus, D. Don, Prod. Fl. Nep. $29=$ Liparis nepalensis.

rivularis, A. Cunn. in Hook. Comp. Bot. Mag, ii. (1836 376.-N. Zel

Sinclairii, Hook. f. Fl. N. Zeal. i. 246-N. Zel

viridis, Hook. f. Fl. Tasm. ii. 372.-Austral.

ACIALYPTUS, A. Gray, Bot. U. S. Expl. Exped, 551.t. 67. (1854). MYRTACEAE, Benth, \& Hook f. i. 708 .

Fullagari, F. Muell. Fragm, viii. 15.-Ins. D. Howe.

myrtoides, A. Gray, Bot. U. S. Expl. Exped. i. 551. 67.- Ins. Fiji.

myrtoides, Seem. in Bonplandia, ix. (1861) $206=$ Seemanni.

nitida,Brongn. \& Gris, in Bull. Soc. Bot. Fr, xii. (1865) 186 ; et in Ann. Sc. Nat. Sér. V. iii. $1865 ; 227$. N. Caled.

Seemanni, A. Gray, in Bonplandia, x. (1862) 35.Ins, $\mathrm{Fiji}$.

ACICARPA, Raddi, Agrost. Bras, 31 (1823)= Panicum,

Linn. Gramin.).

sacchariflora, Raddi, 1. c. t. 1. f. $4=$ P. leucophaeum.

ACICARPA, R. Br. in Trans, Linn. Soc. xii. (1818; 13: $=$ seq.

ACICARPHA, Juss, in Ann. Mus. Par. ii. (1803) 34 t. 58. CALYCEREAE, Benth. \& Hook. f. ii. $16^{\circ}$. ACANTHOSPERMA, Vell, Fl, Flum. Ic. viii, I. 152 (1827)

Cryptocarpha, Cass. in Bull. Soc. Philom. (1817 34.

Echinolema, Jacq. f. ex DC. Prod, v. $3(1836$ Sommea, Bory, in. Ann. Gén. Sc. Phys, vi. (1820, 92. t. 87.

bupleuroides, Less. in Linnaea, vi. (1831) $527=$ Boopis bupleuroides.

crassifolia, Miers, in Ann. \& Mag. Nat. Hist. Ser. III. vi. (1860) 402,-Bras.

lanata, Lag, ex Pers. Syn ii. 488,-Mexico.

pinnatifida, Miers, in Ann. \& Mag. Nat. Hist. Ser. III vi. (1860) 404.-Bras.

procumbens, Less. in Linnaea, vi. (1831) 527.Bras.

runcinata, Miers, in Ann. \& Mag. Nat. Hist. Ser. III. vi. $(1860) 404 .-$ Bras.

spathulata, $R, B r$. in Trans. Linn. Soc, xii. (1815 129.-Bras.

tribuloides, $\mathscr{f}$ uss. in Ann. Mus. Par. ii. (1803) 348. t. 58.- -Reg. Argent.

ACICARPHAEA, Walp. Ann. ii. $877(1852)=$ Chaenactis, DC. (Compos.)

artemisiaefolia, Walp. L. c. = C. artemisiaefolia.

ACICLINIUM, Torr. \& Gray, Fl. N. Am, ii. 231 in adnot. $(1841)=$ Bigelowia, DC. $($ Compos.

ACIDANDRA, Mart, ex Spreng. Gen, i. 988 '1580' Zollernia, Mart. (Legumin.)

ACIDANTHERA, Hochst. in Flora, sxvii. (1s: 25. IRIDEAE, Benth. S Hook. f. iii. itv'. SPHAERUSPORA, Klate, in Linnaea, xxrii. 1sci3 725.

Houtruysia. Houtt. Handl. Plantenk. xii. Ats. t. $85(1780)$

nequinoctialis. Baker, in Gourn. Linn. Sor. xvi $15 \%$ 160.-Afr. trop.

bicolor, Hochst, in Flora, xxvii. (184t' 25-Abves brachystachys, Boker, in Yourn. Bos, xiv, isit. YSS.Afr. trop.

brevicollis, Boker, I. 6. 399,-Afr. trop.

exscapa. Baher, ex Bouche Wittm. in Berl. Munatsuth.

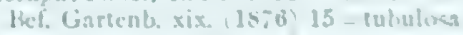

Alexuosin, Baber, ex Busche \& H"ifim. I. r.-All 


\section{ACIDANTHERA :-}

graminifolia, Baker, in Fourn. Bot. xiv. (1876) 338.Afr. trop.

Huttoni, Baker, l. c. 339.-Afr. trop.

platypetala, Baker, l. c.-Afr. austr.

tubulosa, Baker, in Fourn. Linn. Soc, xvi. (1877) 160 Afr, trop.

unicolor, Hochst. ex Baker, l.c.-Abyss.

ACIDOCROTON, Griseb. Fl. Brit. W. Ind. 42 (1864) EUPHORBIACEAE, Benth. \& Hook. f. iii. 291 adelioides, Griseb. l. c. -Ind. occ.

ACIDOTON, Sw. Prod. Veg. Ind. Occ. 83 (1788). EUP HORBIACEAE, Benth, \& Hook. f. iii. 328 . innocuus, Baill. Etud. Gén. Euphorb. 402. t. 18. f. $10-$ 11.--Ind. occ.

urens, Szw. Prod. Veg. Ind. Occ. 83.-Jamaica.

ACILEPIS, D. Don, Prod. Fl. Nep. 169 (1825)= Ver nonia, Schreb. (Compos.).

cirsiifolia, Spreng. Syst. iii. 387 = Pacourina cirsiifolia

lanata, Spreng. ex DC. Prod. vii. $36=$ Dicoma tomentosa.

squarrosa, D. Don, Prod. Fl. Nep. $169=$ V. teres.

ACINAX, Rafin. Fl. Tellur, iv. $53(1836)=$ Costus, Linn. (Scitam.).

ACINETA, Lindl. Bot. Reg. (1843) Misc. 67. ORCHI$D E A E$, Benth. \& Hook. f. iii. 551.

NeIPPERgiA, Morr. in Ann. Soc. Agr. Gand, v. (1849) 375 . น. 282 .

Barkeri, Lindl. in Bot. Reg. (1843) Misc. 68.Mexico.

chrysantha, Lindl. \&o Paxt. Flow. Gard. i. (1850-51) 31.-Am. centr.

cryptodonta, Reichb. $f$. in Bonplandia, ii. (1854) 92.Am. centr.

densa, Lindl. \& Paxt. Flow. Gard. i. 91 (1850-51).Am. centr.

erythroxantha, Reichb. f. in Bonplandia, ii. (1854) 92 -Hab.?

fulva, Klotzsch, in Otto \& Dietr. Allg. Gartenz. (1852) $146=$ Humboldtii

glauca, Linden, ex Lindl. \& Paxt. Flow. Gard. i. (185051) $123=$ Cycnoches Pescatorei.

Hrubyana, Reichb. f. in Gard. Chron. N. S. xviii (1882) II. 102.-N. Granat.

Humboldtii, Lindl. Bot. Reg. (1843) Misc. 68.-Am. centr.

longiscapa, Reichb, f. in Bot. Zeit. x. (1852) $706=$ Lacaena bicolor.

Schilleriana, Reichb. f. in Walp. Ann. vi. 609.Hab. ?

Sella-turcica, Reichb. f. in Bot. Zeit. x. (1852) 705.Am. centr.

sulcata, Reichb. f. in Gard. Chron. N. S. xi. (1879) I. 652.-Ecuador?

superba, Reichb in Walp. Ann. vi. $609=$ Humboldtii

Warscewiczii, Klotzsch, in Otto \& Dietr. Allg. Gartenz. xx. (1852) $145=$ densa.

ACINODENDRUM, Linn. Gen, ed. I. $129(1737)=$ Melastoma, Burm.?

aurea, Rafin. Sylva Tellur. 94.-Hab. ?

cymosa, Rafin. 1. c. = Amphiblema cymosum?

laxiflora, Rafin. I. c.-Hab.?

ACINOLIS, Rafin. Sylva Tellur. 95 (1838)= Melastoma, Burm.

elliptica, Rafin. 1. c. $=$ M. ellipticum?

ACINOS, Rupp. F1. Jen. ed. Hall. 233 (1745); Moench Meth. 407 (1794)=Calamintha, Lam. (Labiat.). acuminatus, Frivald, in Flora, xviii. (1835) $332=\mathrm{C}$ suaveolens.

acutifolizs, Schur, Enum, P1. Transs, $530=$ C alpina.

adscendens, Moench, Meth. Suppl. $138=$ C. patavina. aestivalis, Kito in Linnaea, xxxii. (1863) 432.Europ.

alpinus, Moench, Meth. 407 =C. alpina.

canus, Reichb. Fl. Germ. Excurs. $327=$ C. graveolens.

clinopodiifacie, Gilib. Fl. Lituan. i. $75=$ C. Acinos.

corsicus, G. Don, in Sweet, Hort. Brit. ed. III. 768.Corsica.

diffusus, Boenningh. Prod. F1. Monast. 182.-Europ.
ACINOS :-

erectus, Frivald. in Flora, xviii. (1835) $333=\mathrm{C}$. graveolens.

exiguus, G. Don, ex Steud. Nom. ed. II. i. 17 = C. gra. veolens.

grandiflorus, G. Don, ex Loud. Hort. Brit. $239=\mathrm{C}$. grandiflora.

graveolens, Link, Enum. Hort. Berol. ii. $117=$ C. graveolens.

Herba-barona, G. Don, in Loud. Hort. Brit. $239=$ Thymus Herba-Barona.

heterophyllus, G. Don, 1. c. $=$ C. suaveolens.

incanus, Griseb. Spicil. Fl. Rumel. ii. $123=$ C. maritima.

multiflorus, C. Koch, ex Boiss. Fl. Orient. iv. $579=$ C. umbrosa.

patavinus, Pers. Syn。 ii. 131. (err. typ. 151) =C. alpina.

purpurascens, Pers. l. c. $=$ C. graveolens.

rotundifolius, Frivald. ex Walp. Rep. iii. $730=$ C. alpina.

rotundifotius, Pers. Syn. ii. 131. (err. typ. 151) $=$ C. Nepeta.

suaveolens, G. Don, ex Loud. Hort. Brit. $239=$ C. suaveolens.

thymoides, Moench, Meth. $407=$ C. Acinos.

transsilvanica, Schur, Enum. Pl. Transs. $529=$ C. Nepeta.

villosus, Pers. Syn。 ii. 131. (err. typ. 151) = C. Acinos

vulgaris, Pers. 1. c. $=$ C. Acinos.

ACINOTUM, Reichb. Handb. 260 (1837)= Mathiola, R. Br. (Crucif.).

ACIOA, Aubl. Pl. Gui. ii. 698. t. $280(1775)=$ Couepia, Aubl. (Rosac.)

amara, Steud. Nom. ed. I. $9=$ C. guianensis.

Bellayana, Baill. Adansonia, vii. (1866-67) $224=$ Griffonia Bellayana.

dulcis, Steud. Nom. ed. I. $9=$ C. guianensis.

guianensis, Aubl. Pl, Gui, ii, $698=$ C. guianensis

Icondere, Baill. Adansonia, vii. (1866-67) $223=$ Griffonia Icondere.

pallescens, Baill. 1. c. $224=$ Griffonia pallescens.

Smeathmanni, Baill. l. c. x. (1872) 244.-Afr. trop.

ACIOTIS, D. Don, in Mem. Wern. Soc. iv. (1823) 300 MELASTOMACEAE, Benth. \& Hook. f. i. 744 SPENNERA, Mart. in DC. Prod. iii. 115 (1828). acuminifolia, Triana, in Trans. Linn. Soc. xxviii. (1871) 51.-Am. trop.

acuminifolia, Triana, J. $\mathrm{c}_{2}=$ sphaeranthera, etc. acutiflora, Triana, l. c. 52. pro parte--Am. trop. acutiflora, Triana, 1. c. pro parte =laxa.

aequatorialis, Cogn。 in Mart. Fl. Bras, xiv. III. 464.Bras.

amazonica, $\operatorname{Cog} n$. l. c. 461.-Bras

annua, Triana, in Trans. Linn. Soc. xxviii. (1871) 52. -Am. merid.

aquatica, G. Don, in Loud. Hort. Brit. 174.Guiana.

brachybotria, Triana, in Trans. Linn. Soc. xxviii. (1871) 51.-Bras,

caulialata, Triana, l. c. 52.-Peruv.

circaeifolia, Triana, l. c--Bras.; Guiana.

dichotoma, Cogno in Mart. Fl. Bras. xiv. III. 460.Guiana.

discolor, D. Don, in Mem. Wern. Soc. iv. (1823) 301. -Ins. St. Vincent.

dysophylla, Triana, in Trans. Linn. Soc. xxviii. (1871) 52.-Bras, : Peruv.

ferruginea, Triana, 1. c. $51=$ brachybotria.

fragilis, $\operatorname{Cog} n$. in Mart. Fl. Bras. xiv. III. 475.Guiana.

herbacea, $\operatorname{Cog} n$. l. $c_{0} 468 .-$ Bras.

indecora, Triana, in Trans. Linn. Soc. xxviii. (1871) 52.-Bras.; Guiana

latifolia, $\operatorname{Cog} n$. in Mart. Fl. Bras. xiv. III. 464.Bras.

laxa, $\operatorname{Cog} n$. l. c. 476.-Bras

Levyana, $\operatorname{Cog}$. l. c. $460 .-$ Nicarag.

longifolia, Triana, in Trans. Linn. Soc. xxviii. (1871) 52-Bras.

Martiana, Cogn. in Mart. Fl. Bras. xiv. III. 463.Bras.

paludosa, Triana, in Trans. Linn. Soc. xxviii. (1871) 51.-Bras.

\section{ACIOTIS :-}

pendulifolia, Triana, in Trans. Linn. Soc. xxviii. (1871) 52.-Guiana.

polystachya, Triana, $l . c, 52,-$ Bras.

purpurascens, Triana, $l$. c. 52. t. 3. f. 36.-Am. trop

rostellata, Triana, l. c. 51.-Mexico.

rubricaulis, Triana, l. c. 52 2. t. 3 . f. 36 b.-Bras.

Sieberi, Triana, 1. c. $52=$ Nepsera aquatica.

sileniflora, Triana, $l . c .52$.-Bras.

sphaeranthera, Cogn. in Mart. Fl. Bras. xiv. III. 458. -Peruv.

uliginosa, Triana, in Trans. Linn. Soc. xxviii. (1871) 51.-Venezuela.

viscosa, Triana, $l$. c. 52 -Am. trop.

ACIPETALUM, Turcz. in Bull. Soc. Nat. Mosc, xxi. (1848) I. $577=$ Cambessedesia, DC. (Melast.) lineatum, Turcz. 1. c. $578=$ Pyramia pityrophylla. rugosum, Turcz. 1. c. $=$ C. rugosa.

ACIPHYLLA, Forst. Char. Gen. 135. t. 68 (1776).UMBELLIFERAE, Benth. \& Hook. f. i. 912.

ANisotome, Hook. f. Fl. Antarct. i. 16. t. $8,9(1845)$ Caloscradium, Endl. Gen. Suppl. iv, III. 7 (1850). Gingidium, F. Muell. in Trans. Phil. Inst. Vict. i. (1855) 103.

Colensoi, Hook. f. Handb. N. Zeal. Fl. 92.-N. Zel.

crenulata, Armst. in Trans. N. Z. Inst. xiii. (1881) 336.--N. Zel.

Dobsoni, Hook. f. Handb. N. Zeal. Fl. 93.-N. Zel.

glacialis, F. Muell. ex Benth. Fl. Austral. iii. 375.Anstral.

Hectori, F. Buch, in Trans. N. Z. Inst. xiv. (1882) 346.-N. Zel.

Lyallii, Hook. f. Handb. N. Zeal. Fl. 92.-N. Zel.

Monroi, Hook. f. Fl. N. Zel. ii. 330,-N. Zel.

montana, Armst. in Trans. N. Z. Inst. iv. (1872) 290. $-\mathrm{N}$. Zel.

procumbens, F. Muell. ex Benth. Fl. Austral, iii. 375. -Austral.

simplicifolia, F. Muell. ex Benth. l. c.-Austral.

squarrosa, Forst. Char. Gen. 136.-N. Zel.

Traillii, T. Kirk, in Trans. N. Z. Inst. xvi. (1884) 371. - N. Zel.

Traversii, F. Muell. ex F. Buch, l. c. vii. (1875) 335 . $-\mathrm{N}, \mathrm{Zel}$.

ACIPHyllaEA, A. Gray, in Mem. Am. Ac. N. S. iv. (1849) (Pl. Fendl.) $91=$ Hymenatherum, Cass. (Compos.).

acerosa, A. Gray, 1, c. $=\mathrm{H}$. acerosum.

ACIPHYLLUM, Steud. Nom. ed. II. i. $17(1840)=$ Chorizema, Labill. (Legum.).

ACIS, Salisb. Parad. Lond. sub t. $74(1807)=$ Leucojum, Linn. (Amaryll.)

autumnalis, Salisb. 1. c. = L。 autumnale

Broteri, Jord. \& Fourr. Ic. Pl. Europ. 25 = L. trichophyllum.

grandiflora, Sweet, Brit. Fl. Gard. iii. sub t. $297=\mathrm{L}$. trichophyllum.

hiemalis, M. Roem. Syn. Ensat. $24=$ L. hyemale. hyemalis, Sweet, Brit. Fl. Gard. iii. sub t. $297=$ praec. longifolia, M. Roem. Syn, Ensat. $25=$ L. longifolium. rosea, Sweet, Brit. Fl. Gard. t. $297=$ L. hyemale

oporantha, Jord. \& Fourr. Brev. Pl. Nov. fasc. i. 51 $=\mathrm{L}$. autumnale.

pulchella, Jord. \& Fourr. I. c. $=$ L. autumnale.

roseus, Sweet, ex Loud. Hort. Brit. Supp. iii. $482=$ L. roseum.

trichophylla, Sweet, Brit. Fl. Gard. iii. sub t. $297=$ L. trichophyllum.

ACISANTHERA, P. Br. Hist. Jamaic. 217. t. 22, f. i. (1756). MELASTOMACEAE, Benth. \& Hook, f. i. 739 Anisocentrum, Turcz, in Bull. Soc. Nat. Mosc. xxxv. (1862) I. 322

Dicrananthera, Presl, Symb. Bot. i. 75. t. 50 (1832).

Exodicilis, Rafin. Sylva Tellur. 97 (1838).

Miocarpus, Naud. in Ann. Sc. Nat. Sér. III. ii (1844) 146.

Noterophila, Mart. Nov, Gen, et Sp. iii. 110. t. 254 (1829).

URANTHERA, Naud, in Ann. Sc. Nat Sér. III. ii. (1844) 146. 


\section{ACISANTHERA:-}

adscendens, Wright, in Sauvalle, Cat. Fl. Cub. $52=$ quadrata.

alata, $\operatorname{Cogn}$. in Mart. Fl. Bras. xiv. III. 225.-Bras.

alsinaefolia, Triana, in Trans. Linn. Soc. xxviii. (1871)

34. t. 2. f. 18 h.-Bras.

Beccabunga, Triana, l, c. $33=$ brevifolia.

bivalvis, Cogn . in Mart. Fl. Bras, xiv. 111. $216=$ brevifolia.

Boissieriana, Cogn. l. c. 209.-Bras.

brevifolia, Griseb Fl. Brit. W. Ind. 269.-Ind. occ. ; Bras.

brevifolia, Triana, in Trans. Linn. Soc. xxviii. (1871) $33=$ trivalvis

divaricata, Cogn. in Mart. Fl. Bras. xiv, III. 212.Bras.

fluitans, $\operatorname{Cog} n$. l. c. 214.-Bras.

Glazioviana, $\operatorname{Cogn}$. l. c. 223.-Bras.

hedyotoidea, Triana, in Trans. Linn. Soc. xxviii. (1871) 33.-Bras.

hedyotoidea, Triana, 1. c. pro parte=Salemanni.

inundata, Triana, l. c.-Bras.

limnobios, Triana, l. c. t. 11.-Am. trop.

pellucida, Wright, in Griseb. Cat. Pl. Cub. 104.Cuba.

pulchella, Cogn, in Mart. Fl. Bras. xiv. III. 211.Bras.

punctatissima, Triana, in Trans. Linn. Soc. xxviii. (1871) 34. t. 11. f. 18 c.-Bras.; N. Granat.

quadrata, Fuss. ex Poir. Encyc. Suppl. i. 111.-Jamaica.

recurva, Griseb. in Goett. Abh. ix. (1861) 58.-Bras. ;

Guiana.

recurva, Triana, in Trans, Linn. Soc. xxviii. (1871) 34. t. 2. f. 18 b.-Bras.

Salzmanni, Cogn. in Mart. Fl. Bras, xiv. III. 209.-Bras. tetramera, Triana, in Trans. Linn: Soc, xxviii. (1871) 33.-Bras.

trivalvis, Cogn. in Mart. Fl. Bras, xiv. III, 217.-Bras. variabilis, Triana, in Trans. Linn. Soc. xxviii. (1871) 34. t. 11. f. $18 \mathrm{~g}$.-Bras.

ACISPERMUM, Neck. Elem. i. $34(1790)=$ Coreopsis, Linn. (Compos.)

ACISTOMA, Zipp, ex Span, in Linnaea, xv. (1841) 202 =Woodfordia, Sm. (Lythrar.)

coccineum, Zipp. ex Span. 1. c. =W. floribunda.

ACKAMA, A. Cunn. in Ann. Nat. Hist. ii. (1839) 358. SAXIFRAGEAE, Benth. \& Hook. f i. 653. Muelleri, Benth. Fl. Austral. ii. 444.-Austral. rosaefolia, A. Cunn. in Ann. Nat. Hist. ii. (1839) 358. -N. Zel.

ACLADODEA, Ruiz \& Pav. Prod. 133. t. 29 (1794) Talisia, Aubl. (Sapind.)

pinnata, Ruiz \& Pav. Syst. Veg. $262=$ T. Acladodea.

ACLEIA, DC. Prod. vi. $340(1837)=$ Senecio, Linn. (Compos.).

belbeysia, DC. 1. c. $=\mathrm{S}$. belbeysius.

ACLEISANTHES, A. Gray, in Am. Journ. Sc. Ser. II. Xv. (1853) 259. NYCTAGINEAE, Benth. \& Hook. f, iii, 6 .

Pentacrophys, A. Gray, l. c. 261 (1853)

anisophylla, A. Gray, l. c.-Texas.

Berlandieri, A. Gray, l. c. 260.-Texas.

crassifolia, A. Gray, l. c.-Texas.

longiflora, $A$. Gray, $l$. $c_{0}-\mathrm{N}$. Mexico.

Wrightii. Benth. \& Hook. f.ex Hemsl. Biol. Centr. Am. Bot. iii. 6.-Texas.

ACLINIA, Griff. Notul, iii, 320 (1851)=Dendrobium, Sw. (Orchid.).

ACLISIA, E. Mey. in Presl, Rel. Haenk. i. 137. t. 25 $(1827)=$ Pollia, Thunb. (Commel.)

celebica, Hassk. Commel. Ind. $49=$ P. macrophylla.

Cumingiana, Hassk, 1. c. $47=$ P. macropliylla.

elegans, Hassk, in Miq. Pl. Jungh. 49= P. sorzogonensis.

florida, Hort, Berol. (1837) ex Kunth, Enum. Pl.iv. 47 $=$ Athyrocalpus pallidus.

gigantea, Hassk. Commel. Ind. $46=\mathrm{P}$. sorzogonensis. indica, Wight, Ic, t. $2068=\mathrm{P}$. sorzogonensis.

sorsogonensis, Kunth, Enum. Pl. iv, $74=\mathrm{P}$. indica.

sorsogonensis, E. Mey. in Presl, Rel. Haenk. i. 138. t

$25=\mathrm{P}$, sorzogonensis.

\section{ACLISIA :-}

guayaquilensis, G. Don, Gen. Syst. iv. 461.-Peruv. subumbellata, C. B. Clarke, Commel. et Cyrt. Beng. $30=$ P. subumbellat

Thomsoni, C. B. Clarke, I. c. t. $31=$ Aneilema Thomsoni. Zollingeri, Hassk. Commel. Ind. $51=\mathrm{P}$. Zollingeri.

ACMADENIA, Bartl. \& Wendl. f. Diosm. 59. t. A

(1824). RUTACEAE, Benth. \& Hook. f. i. 289.

alternifolia, Cham in Linnaea, v: (1830) 52.-Afr. austr. assimilis, Sond. in Harv. E' Sond. Fl. Cap. i. 383.Afr. austr.

cassiopoides, Turcz. in Bull Soc. Nat. Mosc. xxxi. 1858) I. $439=$ Macrostylis dubia.

cucullata, E. Mey. ex Harv. \& Sond. Fl. Cap. i. 383. -Afr. austr.

densifolia, Sond. l. c.-Afr, aust

flaccida, Eckl. \& Zeyh. Enum. 105.-Afr. austr. juniperina, Bartl. \& Wendl. f. Diosm. 61.-Afr. austr laevigata, Bartl. \& Wendl.f.l. c. 64.-Afr. austr.

laevigata, E. Mey. ex Harv. \& Sond. Fl. Cap. i. $383=$ assimilis.

Mundiana, Eckl. E Zeyh. Enum. 105.-Afr. austr. muraltioides, Eckl. \& Zeyh. 1. c. $106=$ juniperina.

Niveni, Sond. in Harv. \& Sond. Fl. Cap. i. 380.-Afr. austr.

obtusata, Bart. \& Wendl. f. Diosm. 63.-Afr. austr. obtusata, Eckl. \& Zeyh. ex Harv. \& Sond. F1. Cap i $376=$ Diosma teretifolia

psilopetala, Sond. in Harv. E Sond. l. c. i. 380.-Afr. aust

pungens, Bartl. \& Wendl. f. Diosm. 64.-Afr. austr. pungens, Eckl. \& Zeyh. ex Harv. \& Sond. Hl. Cap. i. $381=$ obtusata.

rosmarinifolia, Bartl. in Linnaea, xvîi. (1844) 355.Afr. austr.

strobilina, E. Mey. ex Harv. \& Sond. Fl. Cap. i. $381=$ tetragona.

tetragona, Bartl. \& Wendl.f. Diosm. 65.-Afr. austr.

tetragona, Eckl. \& Zeyh. Enum. $105=$ laevigata.

ACMANTHERA, Griesb, in Mart. Fl. Bras, xii, I 28 (1858), MALPIGHIACEAE, Benth. \& Hook. f

i. 253.
latifolia, Griseb. l. c. 29.-Bras.

ACMELLA, Rich. in Pers. Syn. ii. $472(1807)=$ Spilanthes, Jacq. (Compos.).

biflora, Spreng. Syst. iii. $591=$ Wedelia biflora.

brachyglossa, Cass, in Dict. Sc. Nat, 1.258=S. Acmella,

brasiliensis, Spreng. Syst. iii. 592=Wedelia paludosa.

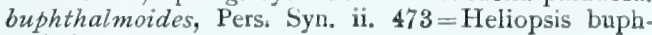
thalmoides.

caulorrhiza, Delile, Cent. Pl. Afr. Méroé, 45.t. iii. f. 7 $=\mathrm{S}$. Acmella.

ciliata, Cass, in Dict. Sc. Nat. xxiv. $331=\mathrm{S}$. ciliata

debilis, Cass, 1. c. $331=\mathrm{S}$. debilis.

fimbriata, Cass. 1. c. $=\mathrm{S}$. fimbriata.

flavicaulis, Kafin. New Fl. Am. i, 52.-Am. bor.

Garcini, Spreng. Syst. iii. $591=$ Anvillea Garcini

globosa, Spreng. 1. c. 592=Zaluzania globosa.

hirta, Lag. Gen. et Sp. Nov, $30=$ Jaegeria hirta

intermedia, Rich, ex Pers. Syu. ii. $472=\mathrm{S}$, intermedia.

lanceolata, Link, ex Spreng. Syst. iii. $444=$ S. Pseudoacmella.

Linnaei, Cass, in Dict. Sc. Nat. xxiv, $330=\mathrm{S}$. Acmella. mauritanica, Rich. ex Pers. Syn. ii. $472=$ S. Acmella. Mutisii, Cass. in Dict. Sc. Nat. xxiv. $331=\mathrm{S}$. Mutisii.

nudicaulis, Rafin. New Fl. Am. i. 52.-Am. bor.

Nuttaliana, Rafin. 1, c. $=\mathrm{S}$, repens,

occidentalis, Nutt. Gen. Am. ii. $171=$ S. repens. occidentalis, Ricb. ex Pers. Syn. ii. $473=$ S. Mutisii parvifolia, Rafin. New Fl. Am. i. 52

repens, Rich. ex. Pers, Syn. ii. $473=$ S. repens.

spilanthoides, Cass. Dict. Sc. Nat, xxiv, $\$ 29=$ Wedelia carnosa.

tenella. Cass. in 1. c. xxiv. $391=\mathrm{S}$. tenella.

trilobata, Spreng. Syst. ii. $591=$ Zaluzania triloba.

uliginosa, Cass. in Dict. Sc. Nat. xxiv. $331=$ S. Acmella.

ACMENA, DC. in Dict. Class. Hist. Nat. xi. 401 (1526)

= Eugenia, Linn. (Myrtac).

bracteoiata. Walp. Rep, ii. $181=\mathrm{E}$, bracteolata

Championi, Benth. in Hook. Kew Journ. Bot. i. (1852) 118.-Hongkong.

chinensis, Planch. Hort. Donat. 84.-China.

claviflora, Walp. Rep. ii. $181=\mathrm{E}$. claviflora,

elliptica, G. Don, ex Steud. Nom. ed. II. i. $17=E$ Smithii.
ACMLNA :-

floribunda, DC in Dict. Class, Hist. Nat. xi 401;

Prod. iii. $262=$ E. Smithii.

Gerrardi, Harv. Gen. S. Afr. Pl. ed. 11. 112.-Afr. austr grata, Walp. Rep. ii. $181=$ E. grata.

inophylla, Wight, Ic. ii. t. $623=\mathrm{E}$. inophylla

Kingii, G. Don, Gen. Syst. ii. $851=$ E. Smithit

lanceolata, Thw. Enum. Pl. Zeyl. 119=E. Wightiana

leptantha, Walp. Rep. ii. $181=\mathrm{E}$. leptantha.

oblata, Walp. 1. $\mathrm{c}_{\mathrm{s}}=\mathrm{E}$. oblata.

parviflora, DC. Prod. iii. $262=$ E. zeylanica

Wightiana, Walp. Rep. ii. $181=\mathrm{E}$. Wightiana.

seylanica, Thw. Enum. Pl. Zeyl. $118=$ E. zeylanica.

ACMISPON, Rafin. Atl. Joum. 144 (1832)= Hosackia

Dougl. (Legumin.)

multiflorum, Rafin. New F1. Am. 1. $53=$ seq.

sericeum, Rafin. Atl. Journ。 $145=\mathrm{H}$. sericea.

ACMOSTIMA, Rafin. Sylva Tellur, 26 (1838)=

Pavetta, Linn. (Rubiac.).

brevifolia, Rafin. 1. $c,=$ P. pentandra.

longifolium, Rafin. 1. c. = P. barbata.

ACNADENA, Rafin. Sylva Tellur. 41 (1838)=Cordia

Linn. (Borag.).

elliptica, Rafin. I. c. $41=$ C. elliptica.

ACNIDA, Linn. Diss. Chen。 32 (1750) (Am. acar) iii. 19). AMARANTACEAE, Benth. \& Hook. f. iii. 2 Monielia, A. Gray, Man. Bot. N. U. States, ed. II $369\left(1856^{\circ}\right)$

altissima, Michx. ex. Moq. in DC. Prod xiii. II. 277 = rusocarpa.

altissima, Ridd. ex Moq. 1. c. = tuberculata?

australis;. A. Gray, in Am. Natural. x. (1876) 489.Am. bor.

cannabina, Chapm. Fl.S. U. St. Suppl. $645=$ australis cannabina, Linn. Sp. Pl. 1027.-Am bor

cuspidata, Bert. ex Spreng. Syst. iii. $903=$ cannabina Ellioti, Rafin. New Fl. Am. i. 54.-Am. bor.

floridana, S. Wats, in Proc. Am. Acad. xvii. (1881 82) 376.-Am. bor.

obtusifolia, Rafin. New Fl. Am, i. 54.Am. bor.

odorata, F. G. Dietr. ex Mog. in DC. Prod. xiii. 11. 278 , nomen - Ilab.?

rhyssocarpa, Steud. Nom. ed. II. i. 17=rusocarpa. ruscocarpa, Willd. Sp. Pl. iv. $768=$ rusocarpa. rusocarpa, Moq. in DC. Prod. xiii. 11. $277=$ tuberculata rusocarpa, Michx. Fl. Bor. Am. ii. 234. t. 50.-Am. bor salicifolia, Rafin. in Am. Monthly Mag.ii. (1817) 43 -Am. bor.

tamariseina, A. Gray, in Am. Natural. x. (1876) 489.Am. bor.

tuberculata, Moq. in DC. Prod. xiii. 11. 27\%.-Am. bor.

ACNISTUS, Schott, in Wien. Zeitschr. (1829) iv

1180, ex Linnaea, vi (1831) Litt. 54, SOLANACEAE.

Benth. \& Hook, f. ii. 894.

CoDochoNIA, Dan, in DC. Prod, xiii. I. 482 (1852).

Lxcioplesium, Miers, in Hook. Lond. Joum. Bor. iv. $(1845) 330$

EPHaila, Huanuca, Kokarus, Pederles, Pli. CulA, Trozelia, Rafin. Sylva Tellar. $54-55,124$ (1838)

aggregatus, Miers, in Hook. Lond. Fourn. Bot. iv. (1845) 341.-Peruv.

arborescens, Schlecht, in Linnaea, vii. (1832) 67. Mexico.

Benthami, Miers, in Hook. Lond. Fourm. Bot. 2v. (1845) 342.-Mexico.

breviflorus, Sendtn. in Mart. Fl. Bras. x. 152.-Bras, caulifiorus, Miers, in Hook. Lond. Journ. Bot iv. (1\$45 $337=$ Miersi.

cauliflorus, Schott, in W"ien. Zeitschr. (1529) iv. $1180 .-$ Bras.

cestroides, Miers, in Hook. Lond. Journ. Bot iv. (1Sf: $343=$ Lycium cestroides.

confertifforus, Miers, in Ann. et Mag. Nab. Hist. Ser. II. iv. 1849'31.-l'eruv.

ellipticus, Hook. f. in Trans. Linn. Soc. xx. (1S50 205.-Ins. Galap.

fasciculatus, Benth. Er Hook. f. Gen. ii. \$94.-Tholis Aloribundus, G. Dun. Gis. Si'si. iv. t61. - Peruy

frutescens, Bolle, in A nal. Soc. Esp. Hisł. . Vab. $x$, 158] 2:9!3.-I'ortu licico.

grandiflorus, Miers, in Hook. Lond. Gourn : : ..

(1s\$5) $\$ 4$ t. - Tenezuela. 


\section{ACNISTUS}

guayaquilensis, G. Don, Gen. Syst. iv. 461.-Peruv, Miersi, Dun. in DC. Prod. xiii. I. 497.--Bras.

parviflorus, Griseb. in Goett. Abh. xix. (1874) 219.Reg. Argent.

Plumieri, Miers, in Hook. Lond. Fourn. Bot. iv. (1845) 340.-Am. austr.

ramiflorus, Miers, l. c. 342.-Ind. occ.

sideroxyloides, G. Don, Gen. Syst. iv. 461-N. Granat. spatulatus, G. Don, l. c.--Peruv.

umbellatus, Miers, in Hook. Lond. Fourn. Bot. iv. (1845) 342.-Peruv.

virgatus, Griseb. in Goett. Abh. xxiv, (1879) 247.Reg. Argent.

ACOELORRHAPHE, H. Wendl, in Bot. Zeit. xxxvii. (1879) 148. PALMAE.

ACOIDIUM, Lindl. Bot. Reg. (1837) sub t. $1951=$ Trichocentrum, Poepp. \& Endl. (Orchid.)

fuscum, Lindl. 1. c. $=\mathbf{T}$. fuscum

ACOKANTHERA, G. Don, Gen. Syst, iv. 485 1837) APOCYNACEAE, Benth. \& Hook, f, ii. 696. ToxicophlaeA, Harv, in Hook. Lond. Journ. Bot. i. $(1842) 24$.

Lamarkii, G. Don, Gen. Syst. iv. 485.-Afr, austr.

lycioides, $G$. Don, $l$. $c_{\text {. }}$-Afr. austr.

pubescens, G. Don, l. c. 486.-Afr. austr.

spectabilis, Hook. f. Bot. Mag. t. 6359.-Afr. austr

venenata, G. Don, Gen. Syst. iv. 485-Afr. austr.

ACOMA, Benth. Bot. Voy. Sulph. 29. t. $17(1844)=$ Coreocarpus, Benth. (Compos.)

dissectum, Benth. 1. c. (=Leptosyne dissecta).

ACOMIS, F. Muell. Fragm. ii. 89 (1860). COMPOSITAE, Benth. \& Hook. f. ii. 317. macra, F. Muell. l. c. iv. 145.-Austral. rutidosea, $F$. Muell. l. c. ii. 89.-Austral.

ACONCEVEIBUM, Miq. F1. Ind. Bat. i. II. 389 1859). EUPHORBIACEAE

trinerve, Miq. $l$. c.-Malaya.

ACONITUM, Tourn. ex Linn. Syst. ed. I. (1735). RANUNCULACEAE, Benth. \& Hook. f. i. 9

Anthora, Hall. in Rupp. Fl. Jen. ed. Hall. 290 (1745).

Cammarum, Fourr. in. Ann. Soc. Linn. Lyon. N. S. xvi. (1868) 327

LyCOCTONUM, Fourr. 1. c. 326

Napellus, Rupp. F1. Jen. ed. Hall. 275 (1745).

Nirbisia, G. Don, Gen. Syst. i. 63 (1831)

abbreviatum, Langsd. ex DC. Prod, i. $61=$ Fischeri.

achranthum, C. A. Mey, in Ledeb. Fl. Alt. ii. 285.Sib. altaic.

acuminatum, Reichb. Uebers. Acon. $46=$ paniculatum. acutum, Reichb. 1. c. $21=\mathrm{A}$. Napellus. aegophonum, Reichb. 1. c. $69=$ A. Lycoctonum. alatum, Wender. in Linnaea, xv. (1841) Litt. $99=\mathrm{A}$. Napellus.

albicans, Host, Fl. Austr, ii. 76,-Europ.

albidum, Bernh. ex Reichb. Uebers. Acon. $31=\mathrm{A}$. Napellus.

album, Ait. Hort. Kew. ii. $246=$ variegatum.

alienum, Reichb. Uebers. Acon. 73. = A. Lycoctonum.

alpinum, Mill. Gard. Dict. ed. VIII. n, 7 =variegatum.

altigaleatum, Hayne, Arzn. Gew. xii. t. $16=$ variegatum.

altissimum, Mill. Gard. Dict. ed. VIII. n. $2=$ A. Lycoctonum.

ambiguum, Reichb. Monog. Acon. t. $23=$ A. Napellus amoenum, Reichb. Uebers. Acon. $23=$ A. Napellus. ampliflorum, Reichb. 1. c. $37=$ A. Napellus. angustifolium, Bernh. ex Reichb. l. c. $29=$ A. Napellus, Anthora, Linn. Sp. Pl.532.-Europ.; Oriens.; As, bor. anthorum, St. Lag. in Ann. Soc. Bot. Lyon, vii. (1880) $119=$ A. Anthora

anthoroideum, DC. Syst. i. $366=$ A. Anthora.

arctophonum, Reichb. Uebers. Acon. $71=$ A. Lycoctonum.

arcuatum, Maxim. Prim. Fl. Amur. 27.-Reg. Amur. Atees, Royle, in Journ. As. Soc. Beng. i. (1832) $459=$ heterophyllum.

atlanticum, Coss. in Bull. Soc. Fr. xxii. (1875) 53, nomen.-Afr. bor.

atrox, Walp. Rep. i. $57=$ ferox

australe, Reichb. Uebers. Acon. $71=$ A. Lycoctonum.

\section{ACONITUM}

austriacum, Tratt. ex Reichb. Monog. Acon, '18' (t. 71) = A. Cammarum.

autumnale, Lindl, in Journ. Hortic. Soc. ii. (1847) 77 $=$ Fischeri.

autumnale, Reichb. Monog. Acon. t. 17. f. $2=\mathrm{A}$. Napellus.

baicalense, Turcz. ex Steud. Nom. ed. II. i. 18.-Sibir. baical.

barbatum, Patr, ex Pers. Syn. ii. 83=A. Lycoctonum.

Banmgarteni, Schur, in Verh. Siebenb. Ver. Naturw. iii. (1852) 84,-Europ.

Bernhardianum, Reichb. Uebers. Acon. $34=$ A. Napellus.

Bernhardianum, Wallr. Sched. Crit. i. 250.t. 2 =variegatum.

Besserianum, Andrz. ex Trautv. in Act. Hort. Petrop. viii. (1883) 58, nomen.-Podolia.

bicolor, Schult. Obs. Bot. $101=$ A. Cammarum

biflorum, Fisch. ex DC. Syst. i. 380.-Sibir. altaic.

boreale, Ser, ex Reichb. Uebers. Acon. $62=$ A. Lycoc tonum.

bracteosum, Bercht. \& Presl, Rostl. i. Ranunculac. 127, nomen.-Europ.

Braunii, Reichb. Uebers. Acon. $29=$ A. Napellus.

Breiterianum, Reichb. 1. c. $54=$ A. Cammarum.

bulbiferum, Reichb. 1. c. $55=$ variegatum.

caeruleum, Dulac, F1. Hautes-Pyr. $223=\mathrm{A}$. Napellus.

callibotryon, Reichb. Monog. Acon. 98. t, 16. f. $2=$ A. Napellus.

Camarum, Schleich. Cat. (1821) $5=$ paniculatum.

Cammarum, Linn. Sp. $P l$. ed. II. 751.--Europ.

Cammarum, Jacq. F1. Austr. v, t. $224=$ variegatum.

camtschaticum, auct, = kamtschaticum.

Candollei, Reichb. ex Steud. Nom. ed. II. i. $18=\mathbf{A}$. Anthora.

canescens, Schleich. ex Reichb. Fl. Germ. Excurs. 741 $=$ A. Napellus.

Carmichaeli, Debeaux, in Act. Linn. Soc. Bord. xxxiii 1879) 87 (Florule du Tientsin, 61) = Fischeri.

cernuum, Baumg. ex Schur, Enum. PI. Transs. $32=\mathbf{A}$. Cammarum.

cernuum, Wulf. ex Koelle, Spicil. 17 = paniculatum.

Chamissonianum, Reichb. Uebers, Acon. $37=\mathrm{A}$ Napellus

chinense, Siebold, ex Paxt. Mag. v. (1838) 3, cum tab.= Fischeri.

chinense, Sieb.ex Sieb. \& Zucc. Fl. Fap. Fam. Nat. 76 [75].-Japon.

ciliare, DC. Syst. i. $378=$ villosum, volubile.

Clairvilleanum $x$, Bruegg. in Fahresb. Naturf. Ges. Graub. II. xxiii,-xxiv. (1881) 82.-Europ.

Clusianum, Reichb. Monog. Acon. $13=$ seq.

Clusii, Reichb. Uebers. Acon. $22=$ A. Napellus.

columbianum, Nutt. in Torr. \& Gray, Fl. N. Am, $34=$ Fischeri.

commutatum, Reichb. Uebers. Acon. $36=$ A. Napellus,

compactum, Reichb. 1. c. $27=\mathrm{A}$. Napellus.

confertum, Reichb. 1. c. $36=$ A. Napellus.

cordatum, Rafin. New Fl. Am. i. 56,-Am. bor,

cordatum, Royle, Illustr. $56=$ heterophyllum

cynoctonum, Reichb. Uebers. Acon. $73=$ A. Lycoctonum.

Decandollii, Reichb. 1. c. $16=$ A. Anthora.

decorum, Reichb. 1. c. $51=$ A. Cammarum

delphinifolium, DC. Syst. i. $380=$ A. Napellus.

delphinifolium, Hort. Prag. ex Steud. Nom, ed, II.

$18=\mathrm{A}$. Lycoctonum

densiflorum, Hoppe, ex Steud. Nom. ed. II. i. $18=\mathbf{A}$ Napellus.

dissectum, D. Don, Prod, F1. Nep. $197=$ A. Napellus.

dissectum, Tausch, ex Reichb. Monog. Acon. t. 47 $=\mathrm{A}$. Lycoctonum.

divergens, Panč. Elem. 18.-Europ.

divergens, Rafin. New Fl. Am. i. 56.-Am. bor.

elatum, Salisb. Prod. $375=$ A. Napellus.

eminens, Koch, ex Reichb. Uebers. Acon. $35=\mathrm{A}$

Napelins.

engadinense $\times$, Bruegg. in Fahresb. Naturf. Ges. Graub. II. xxili-xxiv. (1880) 82.-Europ.

eriostemum, DC. Syst. i. $377=$ A. Cammarum

eulophum, Reichb. Uebers. Acon. 15= A. Anthora.

eustachium, Reichb. 1. c. $24=$ A. Napellus.

exaltatum, Bernh. ex Reichb. 1. c. $51=$ A. Cammarum.

excelsum, Reichb. Monog. Acon. t. 53,-Rossia ; Sibir excelsum, Turcz. Cat. Baikal. n. $70=\mathbf{A}$. Lycoctonum. ferox, Wall. in Ser. Mus. Helv. i. 160.-Reg. Himal

\section{ACONITUM}

ferox, Wall. Cat. n. 4721 A (Pl. As. Rar. t. 41)=A Napellus.

firmum, Reichb. Uebers. Acon. $20=$ A. Napellus.

Fischeri, Reichb.Monog. Acon. t. 22.-As. bor, ; Am bor. flaccidum, Reichb. Uebers. Acon, 39,-Sibir.

flexicaule, Hoppe \& Hornsch. ex Reichb. Monog. t. 38 in syn.= panicalatum

flexuosum, Presl, ex Reichb. 1. c.t. 7 in syn. = variegatum. flexuosum, Rafin. New Fl. Am. i. 55.-Am. bor. formosum, Reichb. Uebers. Acon, $36=$ A. Napellus.

fornicatum, Gilib. Fl. Lituan. ii. $285=$ A. Napellus.

Funckianum, Reichb. Monog. Acon. t. $66=$ A. Napellus.

Funckii, Reichb. Uebers. Acon. $28=$ A. Napellus.

galeatum, Steven, ex Steud. Nom. ed. II. i. $18=$ orientale.

galeriflorum, Stokes, Bot. Mat. Med. iii. $216=\mathbf{A}$. Lycoctonum.

galectonum, Reichb. Uebers. Acon. $67=$ A. Lycoctonum. geraniifolium, Host, Fl. Austr. ii. 76.-Europ. gibbiferum, Reichb. Monog. Acon. t. ]9= paniculatum. gibbosum, Ser. Mus. Helv. i. 141. t. 15. f. 14, $15=$ variegatum.

giganteum, Host, ex Steud. Nom. ed. II. i. $18=\mathbf{A}$. Napellus.

giganteum, Zumag. Fl. Pedem. ii. $345=\mathrm{A}$. Lycoctonum?

glabrum, DC. Syst. i. $379=$ variegatum.

Gmelini, Reichb. Uebers. Acon. 63=A. Lycoctonum.

gracile, Reichb. 1. c. $55=$ variegatum.

grandiflorum, [F isch.] Hort. Gorenk. ed. I. (1808) 77 =biflorum.

grandiflorum, Pall. ; cf. Reichb. Uebers. Acon. $38=\mathbf{A}$. Napellus.

guttatum, Turcz. ex Regel, in Bull. Soc. Nat. Mosc. (1861) II. 114=A. Napellus.

gymnandrum, Maxim, in Bull. Acad. Pétersb. xxiii. (1877) 308.-China.

Hallevi, Reichb. Uebers. Acon. $27=\mathrm{A}$. Napellus. hamatum, Hort. Berol. ex Steud. Nom. ed. II. i. $18=$ variegatum.

hamatum, Reichb. in Cat. Hort. Berol. (1818): Uebers. Acon. $48=$ A. Cammarum.

Hamiltonii, G. Don, Gen. Syst. i. $62=$ A. Napellus.

hebegynum, UC. Syst. i. $376=$ paniculatum.

heterophyllum, Wall. Cat. n. 4722.-Reg. Himal

hians, Host, Fl. Austr. ii. 71.-Europ.

hians, Reichb. F1. Germ. Excurs. $742=$ A. Napellus.

hispidum, DC. Syst, i. 367=A. Lycoctonum.

Hoppeanum, Reichb. Monog. Acon. t. $65=$ A. Napellus. Hoppii, Reichb. Uebers. Acon. $24=$ A. Napellus.

hortense, Hoppe, ex Reichb. Monog. Acon.t. 71 in syn, = A. Cammarum

Hosteanum, Schur, in Verh. Siebenb. Ver, Naturw, ii. 1851) $177=$ A. Lycoctonum

humile, Bernh. ex Reichb. Uebers. Acon. $34=\mathbf{A}$. Napellus

humile, Salisb. Prod. $375=$ paniculatum.

illinitum, Reichb. Uebers. Acon. 54 =variegatum. inclinatum, Sweet, Hort. Brit. ed. II. 9=A. Anthora? intermedium, DC. Syst. i. $374=\mathrm{A}$. Cammarum

intermedium, Gaud. ex Steud. Nom. ed. II. i, $18=$ variegatum.

intermedium, Host, F1. Austr. ii. $69=\mathrm{A}$. Lycoctonum. inunctum, Koch, ex Reichb. Monog. Acon, '6. app.' (Index) $=$ A. Napellus.

italicum, Tratt. ex Reichb. 1. c. t. 7. in syn. = variegatum, Facquini, Reichb. Uebers. Acon. $17=$ A. Anthora. Facquinianum, Host, Fl. Austr. ii. $68=$ A. Lycoctonum. japonicum, Decne, in Rev. Hortic. (1851) 175.-Japon. japonicum, Hort. ex Steud. Nom. ed. II. i. $18=$ variegatum.

japonicum, Thunb. F1. Jap. $231=$ uncinatum.

kamtschaticum, Pall. ex Reichb. Uebers. $39=$ Fischeri Koehleri, Reichb. Uebers. Acon. $30=$ A. Napellus

Koelleanum, Reichb. 1. c. $19=$ A. Napellus.

Kusnezoffil, Reichb. Monog. Acon. t. 21.-As. bor. or

laciniosum, Schleich. ex Steud. Nom. ed. II. i. 18= variegatum.

laetum, Reichb. Uebers. Acon. $21=$ A. Napellus.

laeve, Royle, Illustr. $56=\mathrm{A}$. Lycoctonum.

laevigatum, Schleich, ex Steud. Nom. ed. II. i. $18=$ variegatum.

lagoctonum, Reichb. 'Uebers. Acon. $71=$ A. Lycoctonum.

Lamarckii, Reichb: Monog. Acon. t. 40=A. Lycoctonum.

lasiocarpum, Reichb. Uebers. Acon. 55=variegatum, 


\section{ACONITUM :}

asiostomum, Reichb. Monog. Acon. t. 49-Ross.; Podol.

lasiostomum, Spreng. Syst, ii. $620=$ orientale. laxiflorum, Schleich. Cat. (1821) $5=$ A. Napellus. laxum, Reichb. Illustr. Acon. t. 13 verso = A. Napellus. leptanthum, Reichb. Monog. Acon. t. 64-Rossia. lethale, Griff. Notul. iv. $732=$ palmatum.

leucanthemum, Wender. in Linnaea, v. (1830) Litt. 53 $=$ variegatum.

leucanthum, Reichb. Uebers. Acon. 55.-Hab.?

Lobelianum, Host, Fl. Austr. ii. 74.-Europ.

Lubanskyi, Reichb. Monog. Acon. t. $20=$ F ischeri.

Lubarscii, Heynh. Nom. i. $13=$ praec

luparia, Reichb. Uebers. Acon. $74=$ A. Lycoctonum.

lupicida, Reichb. 1. c. $70=$ A. Lycoctonum.

luridum, Hook. f. \& Thoms. Fl. Ind. i, 55.-Reg. Himal

luridum, Salisb. Prod. $375=$ variegatum.

Lycoctonum, Bess. Enum. PI. Volh. $22=$ orientale.

Lycoctonum, Linn. Sp. Pl. 532.-Europ.; As, bor.

macranthum, Reichb. Uebers. Acon. 51 = variegatum.

macrophyllum, Hort. ex G. Don, in Loud. Hort. Brit. $223=$ orientale

macrorhynchum, Turcz. in Bull. Soc, Nat. Mosc. xv. (1842) 83.-As. temp.

maximum, Pall. ex DC. Syst. i. 380 ; Prod. i. $61=$ Fischeri.

medium, Schrad. Cat. Hort. Goett. ex Reichb. Monog. Acon. $\mathrm{t} .71$ in syn. $=$ A. Cammarum.

meloctonum, Reichb. Uebers. Acon. $65=$ A. Lycoctonum.

Meyeri, Reichb. 1. c. $33=$ A. Napellus

microphyllum, Gaud. ex Steud. Nom. ed. II. i. $19=\mathrm{A}$ Napellus.

microstachyum, Reichb. Uebers. Acon. $36=$ A. Napellus. Mielich hoferi, Reichb. 1. c. $29=$ A. Napellus.

mixtum, Reichb. l, c. $61=$ variegatum.

moldavicum, Hacq. ex Reichb. 1.c. $67=$ A. Lycoctonum. molle, Reichb. 1, c. $47=$ paniculatum.

monanense, Schmidt, ex Reichb. Monog. Acon. t. 51 in obs. $=\mathrm{A}$. Lycoctonum.

monogynum, Forsk. Fl. Aegypt. Arab. p. xxvii=Delphinium Aconiti.

multifidum, Koch, ex Reichb. Monog. Acon, t. $70=$ A.

Napellus.

multifidum, Royle, rllustr. $56=\mathrm{A}$. Napellus.

myoctonum, Reichb. Uebers. Acon. $68=$ A. Lycoctonum.

nanum, Stephan, ex Ledeb. Fl. Ross. i. $70=$ biflorum

napelloides, Sw. ex Reichb. Monog, Acon. t. 69 in syn. $=$ A. Napellas.

Napellus, Linn. Sp. Pl. 532.--Reg. bor. temp

Napellus, Pall. Reise, ii. $528=$ villosum.

Napellus, S. G. Gmel. It. i. $8=$ A. Lycoctonnm.

Napellus, Thunb. Fl. Jap. $231=$ Fischeri.

nasutum, Fisch. ex G. Don, Gen. Syst. i. 61 (1831) 58 =variegatum.

nasutum, Hook. F1. Bor. Am, i. $26=$ Fischeri.

neapolitanum, Tenore, Fl. Nap. iv. $327=$ A. Lycoctonum.

nemorosum, Bieb. ex Reichb. Uebers. Acon. $17=\mathrm{A}$. Anthora.

neomontanum, Baumg. Fl. Transs. ii. $100=$ paniculatum.

neomontanum, Koelle, Spicil. $16=\mathrm{A}$. Napellus. neomontanum, Willd. Sp. Pl. ii. 1236=A. Cammarum. neubergense, DC. Syst. i. $373=$ A. Napellus.

nitidum, Fisch. ex Steud. Nom. ed. II. i, $19=$ barbatum.

nutans, Hort. Helmst. ex Steud. Nom. ed. II. i. $19=$ A. Napellus.

Nuttallii, Sweet, Hort. Brit. ed. II. 584, nomen.-Am. bor.

obscurum, Reichb. ex S. Wats. Bibl. Ind. $2=\mathrm{A}$. Napellus.

obtusifolium. Host, Fl. Austr. ii. 72.-Europ.

ochotense, Reichb. Monog. Acon. t. 18.-Sibir. or

ochranthum, C. A. Mey, in Ledeb. F1. Alt. ii. $285=$ A. Lycoctonum.

ochroleucum, Hort. ex Steud. Nom. ed. II. i. $19=$ A. Lycoctonum.

ochroleucum, Salisb. Prod. $375=$ A. Anthora.

ochroleucum, Willd. Sp. PI. ii. $1233=$ orientale.

oliganthemum, Kern, in Ber. Naturw. Ver. Innsbruck, i. (1870) $119=$ A. Napellus.

oligocarpum, Reichb. Uebers. Acon. 24=A. Napellus. oregonsense, Rafin. New Fl. Am. i. 57.-Oregon.

orientale, Mill. Gard. Dict. ed. VIII, n, 10,-Reg. Caucas.

\section{A CONITUM :}

Ottonianum, Reichb. Uebers. Acon. $54=$ A marum.

ovatum, Lindl. in Bot. Reg. (1840) Misc. $53=$ hetero phyllum?

Pallasii, Reichb. Uebers. Acon. 18=A. Anthora.

pallidum, Nutt. ex Loud. Hort. Brit. Suppl. 482, nomen $=$ Nuttallii.

pallidum, Reichb. Uebers. Acon. $65=\mathrm{A}$. Lycoctonum, palmatifidum, Reichb. l. c. $48=\mathrm{A}$. Cammarum. palmatum, D. Don, Prod. Fl. Nep. 196.-Reg. Himal. paniculatum, Lam. Fl. Fr. iii. 646.-Europ.

paradoxum, Reichb. Monog. Acon. 76. t. 10. f. $3=$ A Napellus.

parviflorum, Reichb. Uebers. Acon. $46=$ paniculatum. parvifolium, Host, Fl. Austr. ii. 70.-Europ.

pauciflorum, Bertol. Misc. xxiv. p. 17. t. $6=\mathrm{A}$ Napellus.

pauciflorum, Host, Fl Austr ii $70=\mathrm{A}$. Lycoctonum.

perniciosum, Reichb. Uebers. Acon. $68=$ A. Lycocto

num.

Phthora, Reichb. 1. c. 71.=A. Lycoctonum

plicatum, Koehler, ex Reichb. 1, c. $29=$ A. Napellus,

productum, Reichb. l. c. t. $38=\mathrm{A}$. Napellus.

pubescens, Moench, Meth. $310=$ A. Napellus.

pubiceps, Rupr. Fl. Caucas. 42,-Reg. Caucas.

pumilum, Schur, Enum. Pl. Transs. $33=$ A. Napellus.

purpureum, Host, Fl. Austr. ii. 74.-Europ.

pygmaeum, Steud. Nom. ed. I. $10=$ A. Napellus.

pyramidale, Mill. Gard. Dict. ed. VIII. n, $6=\mathrm{A}$. Napellus.

pyrenaicum, Hort. ex Steud. Nom, ed. II. i. $20=$ leptanthum.

pyrenaicum, Koelle, Spicil. $24=$ A. Lycoctonum.

pyrenaicum, Linn. Sp. Pl. $532=\mathrm{A}$. Lycoctonum

pyrenaicum, Pall. Reise, ii. $316=\mathrm{A}$. Anthora

Raddeanum, Regel, in Ind. Sem. Hort. Petrop. (1861)

43 ; et Fl. Ussur. 11.-Mantchuria.

ranunculifolium, Reichb. Ic. Fl. Germ. iv. $22=\mathrm{A}$. Lycoctonum.

ranunculoides, Turcz. in Bull. Soc. Nat. Mosc. xv (1842) 78.--Rossia,

reclinatum, A. Gray, in Hook. Lond. Journ. Bot. ii (1843) $118=$ A. Napellus.

recognitum, Reichb. Uebers. Acon, $42=$ volubile

rectum, Bernh. ex Reichb. 1. c. $69=$ A. Lycoctonum.

reflexum, Reichb. 1. c. $43=$ paniculatum.

rhynchanthum, Reichb. 1. c. $56=$ variegatum.

rigidum, Reichb. 1. c. $36=$ A. Napellus.

rostratum, Bernh. Ind, Sem. Hort. Erf. (1815); Reichb.

Uebers. Acon. 56 = variegatum.

rotundifolium, Kar. \& Kir. in Bull. Soc. Nat. Mosc. $\mathrm{xv}$. (1842) $139=\mathrm{A}$. Napellus.

rubellum, Sweet, Hort. Brit. ed. I. $9=$ A. Napellus.

rubicundum, Fisch. ex Steud, Nom. ed. II. i. $20=$ A.

Lycoctonum.

sachalinense, F. Schmidt, Reise Amurland, 107.-Ins. Sachal.

scandens, Muhl. ex Reichb. Uebers. Acon, $38=$ unci natum.

scandens, Rafin. New Fl, Am. i. 55.-Am, bor. Schleicheri, Reichb Uebers. Acon, $35=$ A. Napellus.

Sczukini, Turcz. in Bull. Soc. Nat. Mosc. xiii. (1840 61.--Sibir.

semigaleatum, Pall. ex Reichb. Uebers. Acon. $38=\mathrm{A}$ Napellus.

septentrionale, Koelle, Spicil. $22=\mathrm{A}$. Lycoctonum

sibiricum, Poir. Encyc. Suppl. i. 113 = barbatum.

sinense, Siebold, ex Lindl. \& Paxt. Flow. Gard. i. 17 $=$ Fischeri.

speciosum, Otto, ex DC. Prod. i. $60=$ A. Cammarum. spicatum, Donn, Hort. Cantab. ed. X. $209=$ A. Napellus. Sprengelii, Reichb. Uebers. Acon, $35=\mathrm{A}$. Cammarum. squarrosum, Linn. ex DC. Syst. i. $368=$ barbatum.

squarrosum, Koch, ex Reichb. Uebers. Acon. $29=\mathrm{A}$ Napellus.

Stoerkianum, Reichb. 1. c. $49=$ A. Cammarum. strictissimum, Reichb. 1. c. $69=$ A. Lycoctonum strictum, Bernh. ex DC. Syst. i. $873=\mathrm{A}$. Napellus. strictum, Willd. ex Reichb. Uebers. Acon. $51=$ A. Ly coctonum.

taurericum, Reichb. Monog. Acon. 87. t. $12=$ A Napellus.

tauricum, Wulf, in Jacq. Coll. ii. $112=$ A. Napellus,

Tauschianum, Steud. Nom。ed. II. i. 20-Sibir.

tenuifolium, Reichb. Uebers. Acon. $24=$ A. Napellus.

tenuifolium, Turcz in Bull. Soc. Nat. Mosc. xv. (18t2) $8 \mathbf{8}=$ macrorhynchum.

\section{ACONITUM :-}

tenuisectum, Schur, in Verh. Naturf, Ver. Bruenn, xv. II. (1877) $65=\mathrm{A}$. Lycoctonum?

thelyphonum, Reichb. Uebers. Acon. $73=$ A. Lycocto num.

theriophonum, Reichb, 1. c. $73=$ A. Lycoctonum.

tianschanicum, Rupr. Sert. Tianschan. $38=\mathrm{A}$

Napellus.

tortuosum, Willd. Enum. Hort. Berol. 576.-Silit

toxicarium, Salisb. Prod. $375=\mathrm{A}$. Lycoctonum.

toxicum, Reichb. Uebers. Acon. 43 = paniculatum.

tragoctonum, Reichb. 1. c. $73=$ A. Lycoctonum.

transilvanicum, Lerch, ex Schnr, in Verh. Siebenb.

Ver. Naturw. X. (1859) $165=$ A. Lycoctonum.

Trattinickii, Bess. ex Reichb. Uebers. Acon. 75, nomen -Hab.?

trichocarpum, Reichb. l. c. 29.-Hab.

triste, Fisch. ex Steud. Nom, ed. II. i. $20=$ A. Lycoc tonum.

truncatum, Rafin. New Fl. Am. i. 55.-Am. bor.

tuberosum, Host, Fl. Austr. ii. 72,-Europ.

tuberosum, Patr. ex Reichb. Uebers. Acon, $16=\mathrm{A}$ Anthora.

umbraticolum, Schur, in Verh. Naturf. Ver. Bruenn, xy.

II. $(1877) 65=$ A. Lycoctonum

uncinatum, Hort. ex Steud. Nom. ed. II. i. $20=$ varie gatum.

uncinatum, Linn.Sp. Pl. ed. II. 750,-Am. bor.; Japon uncinatum, Sievers, ex Pall. Nord. Beitr. vii. $229=$ biflorum.

variegatum, Hook. f. \& Thoms. Fl. Ind. $56=$ uncinatum. variegatum, Linn. Sp. Pl. 532.-Europ.

venustum, Reichb. Uebers. Acon. $28=$ A. Navellus.

versicolor, Reichb. 1. c. $50=$ A. Cammarnm.

versicolor, Ster, ex Ledeb. F1. Ross. i. $66=\mathrm{A}$. Anthora villosum, Maxim. Ind. Fl. Pek. in Prim. Fl. Amur. 4 ti = Kusnezoffi.

villosum, Reichb. Uebers, Acon. 39,-Sibir.

virgatum, Reichb. 1. c, $28=\mathrm{A}$. Navellus,

virosum, D. Don, Prod. F1. Nep. $196=$ A. Napellus

volubile, Moench, Meth. Suppl. $110=$ variegatum.

volubile, Koelle, Spicil. 21-Sibir. altaic

volubile, Muhl. Cat. ii. $54=$ uncinatum.

vulgare, DC. Syst. i. $371=$ A. Napellus.

vulparia, Reichb. Uebers. Acon, $70=\mathrm{A}$. Lycoctonum.

Willdenowii, Reichb. 1. c. $35=\mathrm{A}$. Napellus.

Wilemetianum, Delarb. F1. Auv. ed. II. $499=$ panicu-

latum.

Wulfenianum, Reỉchb. ex Stend. Nom. ed. II. i. $20=$

A. Napellus,

zooctonum, Reichb. Uebers. Acon. 65 = A. Lycoctonum.

ACONOGONUM, Reichb. Consp. 162 (1828)= Poly gonum, Linn.

alpinum, Schur, in Verh. Siebenb. Ver. Naturw. iv.

(1853) $64=$ P. alpinum.

ACONTIAS, Schott, Melet. i. $19(1832)=$ Xanthosoma, Schott (Aroid.)

conspurcatus, Schott, Prod. $193=\mathrm{X}$. conspurcatum.

cubensis, Schott, in Bonplandia, vii. (1859) $163=\mathrm{X}$ cubense.

diversifolius, Regel, Ind. Sem. Hort. Petrop. (186a

44; Gartenf. (1866) $68=\mathrm{X}$. platylobum.

hastifolius, Schott, Melet. i. $19=\mathrm{X}$. hastifolium.

helleborifolius, Schott, 1. c. = X. helleborifolium.

Hoffmanni, Schott, Prod. $196=\mathrm{X}$. Hoffmanni.

luridus, G. Don, in Sweet, Hort. Brit. ed. III. $632=$

Caladium luridum.

pentaphyllus, Schott, Syn. $65=\mathrm{X}$. pentaphyllum.

platylobus, Schott, in Ann. Mus. Lugd. Bat. i. $279=$ X. platylobum.

Plumieri, Schott, Syn i. $65=$ X. Plumieri

Riedelianus, Schott, Prod, $192=$ X. Riedelianum,

striatipes, Schott, 1. $\mathrm{c}$ = Caladium striatipes,

variegatus, Kunth, Enum. PL iii. $45=\mathrm{X}$. hellebori folium.

Wendlandii, Schott, in Oestr. Bot. Zcitschr. viii. (18.is

$178=\mathrm{X}$. Hoffmanni.

ACOPHORUM. Gaudich. ex Steud. Nom. ed. II. 20 (1840), nomen. GR.AI/IAEAE?

caerulescens, Gandich, 1. c.-Hab.?

ACORIDIUM, Nees \& Meren, in Nov. Act. Nat. (Cut xix. Suppl. I. (1848) $181=$ Ceratostylis, Blum (Orchid,

tenellum, Necs \& Mcyen, J. $c=$ C. graciliz 
ACORUS, Linn. Gen. ed. I. 104 (1737). AROIDEAE, Benth. \& Hook. f. iii. 999.

americanus, Rafin. New Fl. Am. i. 57=A. Calamus? angustifolius, Schott, in Ann. Mus. Bot. Lugd. Bat. i. $284=$ A. Calamus.

aromaticus, Gilib. Exercit. ii. 507 = A. Calamns,

Belangeri, Schott, in Ann. Mus. Bot. Lugd. Bat. i. 284 =A. Calamus

brasiliensium, Schott, ex Nees, in Mart. FI, Bras. ii 1. $170=$ Scleria hirtella

Calamus, Linn. Sp. Pl. 324.-Reg. bor. temp.

Calamus-aromaticus, [Clairv.] Man. Herb. 104=A. Calamus.

Casia, Bertol. in Mem. Acad. Sci. Bolog. Ser. II. iv. (1864) $310=$ A. Calamus.

cochinchinensis, Schott, Melet. i. 22.-Cochinch.

Commersonii, Schott, in Ann. Mus. Lugd. Bot. i. 284 $=\mathrm{A}$. Calamus

commutatus, Schott, Prod. 578=A. Calamus.

elatus, Salisb. Prod. $263=$ A. Calamus,

europaeus, Dum. F1. Belg. 162=A. Calamus.

flexuosus, Rafin. 'New Fl. Tex. 29'; Atl. Journ. $178=$ A. Calamus.

floridanus, Rafin. New F1. Am. i. $57=$ A. Calamus.

gramineus, [Soland. in] Ait. Hort. Kew. ed. I. i. 474.

-Japon.

Griffithii, Schott, in Oestr. Bot. Zeitschr. (1858) 351 $=$ A. Calamus

humilis, Salisb. Prod. $263=$ A. gramineus.

nilaghirensis, Schott, in Oestr. Bot. Zeitschr. (1859) $101=$ A. Calamns.

odoratus, Lam. F1. Fr. iii. $299=\mathrm{A}$. Calamus.

Palmita, Lichtenst. Reise, ii. 256= Prionium Palmita

pusillus, Siebold, in Verh. Bat. Genoot. xii. (1830) $2=$ gramineus.

spurius, Schott, in Miq. Ann. Mus. Bot. Lugd. Bat. i. $284=$ A. Calamus.

Tatarinowii, Schott, in. Oestr. Bot. Zeitschr. (1859) 101 $=$ A. Calamus.

terrestris, Spreng. Syst. ii. $118=\mathbb{A}$. Calamus

triqueter, Turcz. ex Schott, Prod. $578=$ A. Calamus.

undulatus, Stokes, Bot. Mat. Med. ii. $282=$ A

Calamus.

verzts, Rafin. Med. Fl. i. $26=$ A. Calamus.

ACOSMIA, Benth. in Wall. Cat. n. $644(1829)=$ Gypso phila, Linn. (Caryophyll.)

rupestris, Benth. 1. c. $=\mathrm{G}$. cerastioides.

ACOSMTUM, Schott, in Spreng. Syst. iv. Cur. Post. 406 $(1827)=$ Sweetia, Spreng. (Legumin. $)$.

lentiscifolium, Schott, 1. $\mathrm{c}_{0}=\mathrm{S}$. lentiscifolia.

lentiscifolium, Vog. in Linnaea, xi. (1887) $395=\mathrm{S}$. fruticosa.

ACOSMUS, Desv, in Desf. Cat. Hort. Par, ed. III. 233 (1829) = Aspicarpa, Lag. (Malpig.)

pruriens, Desv. 1. c. = A. hirtella.

ACOSTA, Adans. Fam. ii. $117(1763)=$ Centaurea, Linn. (Compos.).

ACOSTA, DC. Prod. v. $90 \quad(1836)=$ Spiracantha, H. B. \& K. (Compos.).

Rolandrae, DC. 1. $\mathrm{c}_{\mathrm{o}}=\mathrm{S}$. cornifolia.

ACOSTA, Lour. Fl. Cochinch. $276(1790)=$ Agapetes, G. Don (Vaccin.)

spicata, Lour. 1. c. =A. Acosta.

ACOSTA, Ruiz \& Pav. Prod. I (1794)= Moutabea, Aubl. (Polygal.)

aculeata, Ruiz \& Pav. F1. Per. i. 5=M. Acosta.

ACOUROA, Aubl. Pl. Gui, ii. 753. t. $301(\mathbf{1 7 7 5})=$ Ecastaphyllum, Rich. (Legumin.).

violacea, Aubl. 1. c. (= Geoffraea violacea).

ACOURTIA, D. Don, in Trans. Linn. Soc. xvi. (1830) $203=$ Perezia, Lag. (Compos.).

formosa, DC. Prod. vii. $66=\mathrm{P}$. fruticosa

formosa, D. Don, in Trans. Linn. Soc. xvi. (1830) 203 $=$ P. turbinata.

formosa, Hook. \& Arn. Bot, Beech. Voy. 437=P. rigida.

formosa, Sch. Bip. in Seem. Bot. Voy. Herald, t. $56=$ P. patens.

hebeclada, DC. in Deless. Ic. Sel, iv. t. $95=$ P. hebeclada.

\section{ACOURTIA :-}

macrocephala, Sch. Bip, in Seem. Bot. Voy. Herald, t. $55=\mathrm{P}$. turbinata

microcephala, DC. Prod. vii. $66=$ P. microcephala.

moschata, DC. 1. c. = P. moschata

rigida, DC. 1. c. $=$ P. rigida.

Seemanni, Sch. Bip. in Seem. Bot. Voy. Herald, t. 54 $=\mathbf{P}$. Seemannii.

turbinata, DC. Prod. vii. $66=\mathrm{P}$, turbinata.

ACRACHNE, Wight \& Arn. ex Lindl. Introd. Nat Syst. ed. II. 381 (1836)=Eleusine, Gaert. (Gramin.) eleusinoides, Wight \& Arn. ex Steud. Nom. ed. II. $21=$ E. verticillata

verticillata, Wight \& Am. Cf Lind1. Introd. Nat. Syst. ed. II. $381=\mathrm{E}$. verticillata.

ACRADENIA, Kipp. in Proc. Linn. Soc, ii. (1852) 201 ; et Trans. Linn. Soc. xxi. (1855) 207. t. 22 RUTACEAE, Benth. \& Hook. f. i. 292.

Frankliniae, Kipp. ll. cc.-Tasmania

zierioides, Kipp. in Proc. Linn. Soc. ii. (1852) $201=$ Frankliniae.

ACRAEA, Lindl. in Benth. Pl. Hartw. 155 (1845)= Pterichis, Lindl. (Orchid.)

Mandonii, Reichb f. Xenia Orch. iii. 18-Boliv. multiflora, Lind1. Orchid. Linden. 26.-N. Granat. parvifolia, Lindl. in Benth. Pl. Hartw. 155.-Ecuador. triloba, Lindl. in Ann. Nat. Hist. xv. (1845) 386.-Peruv. Widgreni, Reichb. f. Otia Bot. Hamb. 83.-Bras.

ACRANDRA, Berg, in Linnaea, xxvii. (1854) 435; et in Mart. F1. Bras, xiv. I. $459(1857)=$ Campomanesia Ruiz \& Pav. (Myrtac.)

laurifolia, Berg, in Mart. FI. Bras. xiv. I. $459=$ C. lauri folia.

Sellowiana, Berg, 1. c.-Bras.

verrucosa, Berg, 1. c.-Bras.

ACRANTHERA, Arn. ex Meissn. Gen. 162 (115) (1838); et in Ann. Nat. Hist. iii. (1839) 20. $R U$ $B I A C E A E$, Benth. \& Hook. f. ii. 64 .

ANDRotropis, R. Br. in Wall. Cat. n. 8398 (1847 ?) anamallica, Bedd. Ic. Pl. Ind. Or, i. 5.-Ind, or.

grandiflora, Bedd. $l$. c.-Ind, or.

Griffithii, Hook. $f$. Fl. Brit. Ind. iii. 92.-Reg. Himal. Maingayi, Hook. f. l. c.-Moluce.

tomentosa, Hook. f. l. c.-Reg. Himal

uniflora, Kurz, in Journ. As. Soc. Beng. xli. (1872) II. $312=$ Musseenda uniflora.

zeylanica, Arn. in Ann. Nat. Hist. iii. (1839) 21.Zeylan.

ACRATHERUM, Link, Hort. Berol. i. 230 (1827)= Arundinella, Raddi (Gramin.)

fuscatum, Nees, ex Steud. Syn. Pl. Gram. 114= Arund. fuscata.

miliaceum, Link, Hort. Berol. i. $320=$ Arund. ne palensis.

pumilum, Hochst. ex A. Rich. Tent. Fl. Abyss. ii $414=$ Arund. pnmila.

ACRIDOCARPUS, Guill. \& Perr. Tent. F1. Seneg i. 123. t. 29 (1832), MALPIGHIACEAE, Benth. \& Hook. f. i. 256 .

Anomalopteris, G. Don, Gen. Syst. i. 647 (1831) adenophorus, A. Fuss. in Arch. Mus. Par. iii. (1843) 487.-Madag.

angolensis, $A$. $\widetilde{F}$ uss. $l$. $c$. 490,-Afr, tiop.

argyrophyllus, $A$. Fuss. $l$. c. 493.-Madag.

austro-caledonicus, Baill. Adansonia, xi. (1873-76 248. - N. Caled.

Cavanillesii, A. Juss. in Arch. Mus. Par. iii. (1843) t. $\mathbf{1 5}=$ Smeathmanni.

chloropterus, Oliver, Fl. Trop. Afr. i. 279.-Afr. trop.

corymbosus, Hook. f. in Hook. Ic. Pl. t. 774.-Afr. trop.

excelsus, A. Fuss. in Arch. Mus. Par. iii. (1843) 489. - Madag.

galphimiaefolius, A. Fuss. l. c. 491.-Afr. trop.

guineensis, A. Juss. 1. c. t. $15=$ Smeathmanni

Hirundo, S. Moore, in Fourn. Bot. xviii. (1880) 1.Afr. trop.

longifolius, Hook. f. in Hook. Niger Fl. $244=$ Smeathmanni.

natalitius. A. Fuss. in Arch. Mus. Par. iii. (1843) 486. - Natal.
ACRIDOCARPUS :-

orientalis, A. Fuss, in Arch. Mus. Par. iii. (1843) 488 -Natal.

plagiopterus, Guill. E Perr. Tent. Fl. Seneg. i. 123. t. 29. - Senegamb.

pruricus, A. Fuss. in Arch. Mus. Par. iii. (1843) 492. -Natal.

Smeathmanni, Guill. \& Perr. Tent. Fl. Seneg. i. 124. -Afr. trop.

zanzibaricus, A. Fuss. in Arch. Mus. Par. iii. (1843) 485. t. 15.-Zanzibar.

ACRILIA, Griseb. Fl. Brit. W. Ind. 129 (1864)= Trichilia, Linn. (Meliac.).

Sloanei, Griseb. 1. c. = T. terminalis.

ACRIOPSIS, Reinw. ex Blume, Cat. Gew. Buitenz. 97 (1823); Blume, Bijdr. 376 (1825). ORCHIDEAE, Benth. \& Hook, f iii. 586.

densiflora, Lindl. in Bot. Reg. (1847) snb t. 20 -Borneo Griffithii, Reichb. in Bonplandia, ii. (1854) $92=$ javanica. indica, Wight, Ic. v. t. 1748.-Malaya.

javanica, Reinw. ex Blume, Cat. Gew. Buitenz. 97.; Blume, Bijdr. 377-Malaya.

picta, Lindl, in Bot. Reg. (1843) Misc. $69=$ javanica.

ACRIULUS, Ridl. in Journ. Linn. Soc. xx. (1884) 336.

CYPERACEAE

griegifolius, Ridl. l. c.-Madas

madagascariensis, Ridl. l. c.-Madag.

ACROANTHES, Rafin. in Journ. Phys, Ixxxix, 261 $(1819)=$ Microstylis, Lindl. (Orchid.).

ACROCARPIDIUM, Miq. in Versl. en Medel, Kon. Nederl. Inst. ' 1842 ' (1843) 198. t. $2=$ Peperomia, Ruiz \& Pav. (Piperac.)

brevipes, Benth. Bot. Voy. Sulph. $166=$ P. brevipes. cordifolium, Miq. Syst. Pip. $56=\mathbf{P}$. cordifolia. exile, Miq. 1. c. $=\mathrm{P}$. exilis.

guayaquillense, Miq. in Hook. Lond. Journ. Bot. iv. (1845) $411=\mathrm{P}$. guayaquilensis

Guildingianum, Miq. 1. c. $412=$ P. Guildingiana

hispidulum, Miq. Syst. Pip. $54=$ P. hispidula

Famesonianum, Miq. in Hook. Lond. Journ. Bot. iv.

$(1845) \cdot 412=P$. Jamesoniana

majus, Miq. Syst. Pip. $60=$ P. hederacea.

mexicanum, Miq. 1. c. $58=\mathrm{P}$. metapalcoensis.

molle, Miq. in Versl. en Medel. Kon. Nederl. Inst.

' 1842 ' (1843) $199=\mathrm{P}$, mollis.

nummularifolium, Miq. 1. c. $198, \mathrm{t} .2=\mathrm{P}$. nummulari folia.

pulicare, Miq. 1. c. $199=$ P. scandens

repens, Miq. 1. c. $=$ P. scandens.

rotundifolium, Miq. $1, \mathrm{c}_{\mathrm{o}}=\mathrm{P}$. circularis?

scandens, Miq. Syst. Pip. $59=$ P. scandens.

Sellowianum, Miq. 1. c. $55=\mathrm{P}$. hispidula.

serpens, Miq. in Versl. en. Medel. Kon. Nederl. Inst

'1842' (1843) $199=$ Verhuellia serpens.

tenellum, Miq. $1 . \mathrm{c} .=$ P. tenella.

urocarpum, Miq. Syst. Pip. $63=$ P. urocarpa.

urospermum, Schlecht. in Linnaea, xxvii. (1854) 486= praec.?

ACROCARPUS, Nees, in Mart. F1. Bras. ii. 1. 158. t. 16, $17(1842)=$ Cryptangium, Schrad. (Cyperac.).

campestris, Nees, 1. c. $160=$ C. campestre.

densifolius, Nees, 1. c. $159=$ C. densifolium

humilis, Nees, l, c, $161=\mathrm{C}$. humile.

junciformis, Nees, 1. c. =C. junciforme.

minarum, Nees, l. c. $159=$ C. minarum

polyphyllus, Nees, 1. c. $160=\mathrm{C}$. polyphyllum

stellatus, Nees, ex Boeck. in Linnaea, xxxviii. (1874

$422=$ C. stellatum.

ACROCARPUS, Wight, ex Arn. in Mag. Zool. \& Bot.

ii. (1839) 547. LEGUMINOSAE, Benth. \& Hook. f. i. 568 .

combretiflorus, Teysm. \& Binn. in Tijdschr. Nederl. Ind. xxix. (1866) 258.-Malaya.

fraxinifolius, Wight \& Arn. in Mag. Zool. \& Bot. ii. (1839) 547.- - Ind. or.

grandis, Miq. Ann. Mus. Bot. Lugd. Bat. iii. 87.Sumatra.

ACROCENTRON, Cass, in Dict. Sc. Nat, xliv. 37.

$(1826)=$ Centaurea Linn. $($ Compos. $)$

Boissieri, Webb, Iter Hisp. $32=$ C. Boissieri. 


\section{ACROCFNTRON}

collinum, Cass in. Dict. Sc. Nat. xlvii. $37=$ C, collina granatense, Webb, Iter Hisp. 32 =C. granatensis. ornatum, Webb, 1. c. $=\mathrm{C}$. ornata.

tenuifolium, Cass. in Dict. Sc. Nat. 1, $254=$ C. rupestris.

ACROCEPHALUS, Benth. in Bot. Reg. sub tt. 1282, $1300(1829)$. $A B I A T A E$ Benth. \& Hook. f. ii. 1173. axillaris, Benth. in DC. Prod. xii. 48.-Ind. or. Blumei, Benth. in Bot. Reg. sub t. $1300=$ capitatus. caeruleus, Oliver, in Trans. Linn. Soc, xxix. (1875) 135.-Afr. trop.

capitatus, Benth. in Bot. Reg. sub t. 1300.-Ind, or.; China.

cylindraceus, Oliver, in Trans. Linn. Soc. xxix. (1875) 135.-Afr. trop.

lilacinus, Oliver, $l$. $c$-Afr. trop.

scariosus, Benth. in Bot. Reg. sub t. $1282=$ capitatus. verbenaceus, Vatke, in Linnaea, xl. (1876) 178.Afr. trop.

villosus, Benth. in Bot. Reg. sub t. 1300 ; Lab. Gen. et Sp. 23. - Madag.

ACROCHAENE, Lindl. Fol, Orch. (1853), OR CHIDEAE, Benth. \& Hook. f. iii. 507.

punctata, Lindl. l. c. - Ind, or

Rimanni, Reichb. f. in Gard. Chron. N. S. xvii. (1882) 796. -As. trop.

ACROCLINIUM, A. Gray, in Hook. Kew Journ. iv. (1852) $270=$ Helipterum, DC. (Compos.) multicaule, A. Gray, 1. c. $271=\mathrm{H}$, chlorocephalum. phyllocephalum, A. Gray, l. $\mathrm{c}_{2}=$ Podotheca fuscescens roseum, Hook. Bot. Mag. t. $4801=$ H. roseum. rubellum, A. Gray, in Hook. Kew Journ. iv. (1852) 71 $=\mathrm{H}$. rubellum.

ACROCOMIA, Mart. Hist. Nat. Palm. ii. 66. tt. 56, 57 (1823). PALMAE, Benth. \& Hook, f. iii. 943. aculeata, Lodd. ex Mart. 1. c. iii. 286 = sclerocarpa. cubensis, Lodd. ex H. Wendl. Ind. Cycl. Pand. Cycad. 1 = lasiospatha.

fusiformis, Sweet, Hort. Brit. ed. I. $432=$ lasiospatha? glaucophylla, Drude, in Mart. Fl. Bras. iii. II. 392.Bras.

globosa, Lodd. ex Mart. Hist. Nat. Palm. iii. 286.Ins. S. Vincent.

guianensis, Lodd.ex G. Don, in Loud. Hort. Brit. 382, nomen.-Guiana.

horrida, Lodd. ex Mart. Hist. Nat. Palm. iii. 286.-Ins. Trinit.

intumescens, Drude, in Mart. Fl. Bras. iii. II. 391.Bras.

lasiospatha, Mart. in Palm. Orbign. 81.-Ind. occ.

lasiospatha, Wallace, Palms Amaz. 97. t. $37=$ selerocarpa.

mexicana, Karw. ex Mart. Hist. Nat. Palm. iii. 285. t. 138.-Mexico.

minor, Lodd. ex G. Don, in Loud. Hort. Brit. $382=$ lasiospatha?

sclerocarpa, Mart. Hist. Nat. Palm. ii. 66. tt. 56, 57, 100. f. 5-Am. trop.

sphaerocarpa, Desf. Cat. Hort. Par. ed. III. $30=$ sclerocarpa.

tenuifrons, Lodd. ex Mart. Hist. Nat. Palm. iii. 286.Ins. S. Domingo.

Totai, Mart. in Palm. Orbign. 78. t. 9. f. 1_-Boliv. vinifera, Oerst. in Kjoeb. Vidensk. Meddel. (1858) 47. -Nicaragua.

Zapotecis, Karw. ex H. Wendl, in Kerch. Palm. $230=$ mexicana.

ACROCORION, Adans. Fam. ii. 57 (1768)= Galan thus, Linn. (Amaryll.)

ACROCORYNE, Turcz. in Bull. Sor. Nat. Mosc. xxy. (1852) II. 316 = Metastelma, R. Br. (Asclep.).

caribaea, Turcz。 $1 . c_{0}=M$, bahamense.

ACRODICLIDIUML, Nees, Laurin. Disp. Progr. 13 1833) LAURINEAE, Benth. \& Hook, f. iii. 154. Triplomera, Rafin. Sylva Tellur. 134 (1838) anacardioides, Spruce, ex Meissn. in DC. Prod. xv. I. 86.-Bras

brasiliense, Nees, Syst. Laurin. $267=$ Aydendron bra siliense

Camara, Schomb, in Hook. Lond. Fourn. Bot. iii. (1844) 680.-Guiana.

\section{ACRODICLIDIUM}

chrysophyllum Meissn in DC Prod vv I. 87.-Guiana

dominicense, Meissn, l. c. 86. - Ins. Dominic

Gardneri, Meissn. in DC. Prod. xv, 1. 87.-Bras

guianense, Nees, Syst. Laurin.268.-Guiana.

Ita-uba, Meissn. in DC. Prod. xv. 1. 86.-Bras.

jamaicense, Griseb. Fl, Brit. W. Ind. i. 280, ex parte $=$ Wrightii

jamaicense, Nees, Syst. Laurin. 270.-Jamaic.

Kunthianum, Nees, 1. c. $269=$ Aydendron aciphyllum. oppositifolium, Nees, in Linnaea, xxi. (1868) 500,Guiana.

salicifolium, Griseb. Fl. Brit. W. Ind. i. 280,-Ind, occ sericeum, Griseb. l. c. 280,-Ins. Dominic.

Sprucei, Meissn. in DC. Prod. xv. I. 86.-Bras.

Wrightii, Meissn. l. c. 85. - Cuba.

ACRODRYON, Spreng. Syst. i. $365(1825)=$ Cephalanthus, Linn. (Rubiac.)

angustifolius, Spreng. 1. c. $336=\mathrm{C}$. angustifolius.

orientalis, Spreng. l. c. $336=$ C. orientalis.

ACROELYTRUM, Steud. in Flora, xxix. (1846) 20 Lophatherum, Brongn. (Gramin.).

japonicum, Steud. 1. c. $21=\mathrm{L}$, elatum.

ACROGLOCHIN, Schrad. Cat. Hort. Goett. ex Schult. f. Mant. i. 69, 227 (1822). CHENOPODIACEAE, Benth. \& Hook. f. iii. 48.

Blitanthus, Reichb. Cat. Hort. Dresd. (1824)

Lecanocarpus, Nees, PI, Hort. Bonn. 4, t. (1823).

chenopodioides, Schrad. ex Schult. f. Mant. i. 227.Reg. Himal, ; China,

persicarioides, Moq. in DC. Prod. xiii. Ir. 254= chenopodioides.

Schraderiana, Schult. f, ex Moq. 1. c. $=$ chenopodioides

ACROGLYPHE, E. Mey. Zwei PA. Docum. 100 (1843) =Annesorhiza, Cham. \&c Schlecht. (Umbell.) flexuosa, E. Mey. 1. c. $100=$ Ann. hirsuta + montana. hispida, Sond. in Harv. \& Sond. F1. Cap. ii. $546=$ Ann. villosa.

hispidula, E. Mey. Zwei Pfl. Doçum. $74=$ Ann. villosa. runcinata, E. Mey. 1. c. 100.-Afr. austr.

ACROLEPIS, Schrad. in Comm. Gotting. vii. (1832) 142 Ficinia, Schrad. (Cyperac.)

ferruginea, Nees, ex Boeck. in Linnaea, xxxvii. (1871-73) 91.-Afr. anstr.

ramosissima, Boeck. l. c. $89=\mathrm{F}$, ramosissima.

trichodes, Schrad. in Comm. Gotting. vii. (1832) $142=$

F. trichodes.

ACROLOBUS, Klotzsch, in Verh. Akad. Berl. (1856) 236. t. $3=$ Heisteria, Linn. (Olacin.).

parvifolia, Klotzsch, 1. c. 237. t. $3=\mathrm{H}$. parvifolia.

Schoenleinii, Klotzsch, 1. c. 236. t. $3=$ H. parvifolia.

ACROLASIA, Presl, Rel. Haenk. ii. 39. t. 55. $(1831)=$ Mentzelia, Linn. (Loasac.).

bartonioides, Presl, 1. c. 39.=M. albicaulis

Solierii, C. Gay, Fl. Chil. ii, 430.-Chili.

squalida, Hook. f. in Trans. Linn. Soc. Xx. (1851) 222 $=\mathrm{M}$. aspera?

ACROLOPHUS, Cass. in Dict. Sc. Nat. 1. (1827) 253 = Centaurea, Linn. (Compos.).

maculosus, Cass. l. c. $253=$ C. maculosa

Mierghii, Fourr. in Ann. Soc. Linn. Lyon, N. S. xvii. (1869) $97=$ C. paniculata.

paniculatus, Cass. in Dict. Sc. Nat. 1. $253=$ C. paniculata.

ragrusinus, Webb, ex Steud. Nom. ed. II". i. $23=$ C. ragusina.

rigidulus, Fourr. in Ann. Soc. Linn. Iyon, N. S. xvii, (1869) $97=$ C. paniculata.

subalbidus, Fourr. 1. c. = C. maculosa

tenuisectus, Fourr. $\mathrm{l}_{0} \mathrm{c}=\mathrm{C}$. maculosa

ACRONEMA, Falcon. ex Edgew, in Trans. Linn. Soc. xx. (1851) $51=$ Pimpinella, Linn. (Umbellif. tenerum, Edgew. 1. c. $=$ P. tenera.

ACRONIA, Presl, Rel. Haenk。 i. 103 (182\%); Symb. Bot. ii. 9 (1858)=Cryptostylis, R. Br. (Orchid phalangifera, Presl, 11. cc. 104. 10.-Peruy.
ACRONODA, Hassk, Cat. Hort. Bogor, Alt. 208 (1844 $=$ seq.

ACRONODIA, Blume, Bijdr. (1825) $123=$ Elaeo carpus, Linn. (Tiliac.).

punctata, Blume, 1. c. =E. Acronodia

ACRONOZUS, Steud. Nom. ed. II. i. 21 (1840)= praec.

ACRONYCHIA, Forst. Char. Gen. 53. t. $27(1776$

RUTACEAE, Benth. \& Hook. f. i. 302.

Cunto, Adans, Fam. ii. 446 (1763)

Cyminosma, Gaert. Fruct. i. 280. t. $58(1788$.

Dorrienia, Dennst. Schluess. Hort. Malab. 31 (1818

GELA, Lour. Fl. Cochinch. $232(1790$

Huonis, Montrous, in Mém, Acad. Lyon, x. (1860 185.

JAmbolana, Adans. Fam. ií, 508 (1763

Jambolifera, Linn. Diss. Dass. 15 (1747) ; Amoen.

Acad. i. $398(1749)$

Koelpinia, Scop. Introd. 231, et Ind. (1777

SELAS, Spreng. Syst. ii. 216 (1825)

acidula, F. Muell. Fragm. iv. 154.-Austral.

apiculata, Miq. Fl. Ind, Bat. Suppl. 532.-Sunotra.

arborea, Blume, Bijdr. 244.-Java.

Baneri, Schott, Fragm. Bot. 5. t. 3.-Austral

Cunninghamii, Hook. Bot. Mag. t. $3994=$ Medicosma Cunninghamii

Endlicheri, Schott, Fragm. Bot. 3. t. 2-Ins. Norfolc.

Halmaheirae, Miq. Ann. Mus. Bot. Lugd. Bat. iii. 24 . -Malaya,

heterophylla, A. Gray, Bot. U.S. Expl. Exped. i. 333

t. 32.-Ins. Samoz,

Hillii, F. Muell. Fragm, i, $26=$ Baneri.

imperforata, $F$, Muell. $l_{0} c_{0}-$ Austral.

laevis, Forst. Char. Gen. 54. t. 27.-Austral.

laurifolia, Blume, Cat. Gerv. Buitenz. 27. 63; Bijdr.

245.-As. trop.

laurina, F. Muell. 3rd Rep. Veg. Vict. 7 ; Fragm. $27=$ laevis.

melicopoides, F. Muell. Fragm. v. 3.-Anstral

Minahassae, Miq. Ann. Mus. Bot. Lugd. Bat. iii. 245. -Ins. Celebes

oblongifolia, Endl. ex Heynh. Nom. it. 8 = laevis.

ovata, Endl, ex Heynh. 1. c. = Baueri.

pedunculata, Miq. FI. Ind. Bat. Sappl. $532=$ laurifolia petiolaris, A. Gray, Bot. U. S. Expl. Exped. i. 335. t. 33. -Ins. Fiji.

Porteri, Hook. f. Fl. Brit. Ind i. 498.-Malaya.

retusa, A. Gray, Bot. U. S. Expl. Exped. i. 338. t. 34 -Ins. Samoa.

Richii, A. Gray, 2. c. 336. to 33.-Ins. Samoa

simplicifolia, Steud. Nom. ed. II. i. $21=$ Endlicher tetrandra, F. Muell. Fragm. ix, 104. - Austral

trifoliolata, Zoll. \& Mor. in Nat. en Geneesk. Arch.

Neerl. Ind. ii. (1845) 585. - Java.

vestita, F. Muell. Fragm. iv. 155.-A A ustral.

ACROPERA, Lindl. Gen. et Sp. Orch. 172 (1839 Gongora, Ruiz \& Pav. (Orchid.)

armeniaca, Lindl, in Lindl, \& Paxt. Flow. Gard, (1850-51) $94=$ G. armeniaca.

atropurpurea, Hort. ex Heynh. Nom. ii. 8 = G. galeata. Batemanni, Lindl, ex Reichb. f. in Gard. Chron. N. S ii. $(1874)$ I. $322=\mathrm{G}$. galeata,

citrina, Hort. ex Reichb. f. Xenia Orch. i. $51=\mathrm{G}$ galeata.

cornuta, Klotzsch, in Otto \& Dietr. Allg. Gartenz xx (1852) $186=\mathrm{G}$. armeniacs.

favida, Klotzsch, 1. c. xix. (1851) $217=\mathrm{G}$. galcata fuscata, Hort. Belg, ex Heynh. Nom. ii. 8.-Mexico grandiflora, Hort. ex Pasq. Cat. Orto Bot. Napol. \$ nomen.-Hab. ?

Loddigesii, Lindl. Gen, et Sp. Orch. $172=\mathrm{G}$. galeata.

luteola, Hort. ex Heynh. Nom, ii. 8 = fuscata.

pallida, Hort, ex Heynh, 1. c = G. galeata.

purpurea, Hort. ex Heynh. 1. $c=$ G. galean.

sulphurea, Hort. ex Heynh. 1. c. = fuscate.

ACROPET ALUN, A. Juss, in Orb. Dict. vii. 617 (18.99

XEROPLTAlum, Delile = Dombeya, Cav. $($ Ser cul.).

ACROPHYLLUM, benth. in Maund, Bot. ii. 2 . 5 1840 ?) SAXIFR.AGEAE, Benth. \& Hook. C. i. 655 Carycoms, D. Don, in Edinb. N. Phil. Journ. (is (July-Oct. 1830), is. 


\section{ACROPHYLLUM :-}

venosum, Benth in Maund, Bot. ii. t. 95.-Austral. verticillatum, Hook. Bot. Mag. t. $4050=$ venosum

ACROPHyLluM, E. Mey, Zwei Pf. Docum. 140 $(1943)=$ Kiggelaria, DC. (Bixin.)

obtusatum, C. Muell, in Walp. Ann. vii. $233=\mathrm{K}$ africana.

obtusum, E. Mey. Zwei Pf. Docum. $140=\mathrm{K}$. africana.

ACROPODIUM, Desv. in Ann. Sc. Nat. Sér. I. ix. (1826) $408=$ Aspalathus, Linn. (Legumin.

suffruticosum. Desv. 1. $\mathrm{c}$. = Asp. suffruticosa.

ACROPSELION, Spach, Hist, Vég. Phan. xiii. 163 (1846) = ACROSPELION, Bess. =Trisetum, Pers (Gramin.).

ACROPTILION, Endl. Ench. 247 (1841) = seq.

ACROPTILON, Cass, in Dict. Sc. Nat. 1. 464 (1827) = Centaurea, Linn. (Compos.) angustifolium, Cass. 1. c. $466=\mathrm{C}$. Picris obtusifolium, Cass. 1. c. $465=$ C. Picris.

Picris, DC. Prod. vi. $662=$ C. Picris.

repens, DC $1, \mathrm{c}, 663=\mathrm{C}$. Picris

serratum, Cass, in Dict. Sc. Nat. $1,466=\mathrm{C}$. Picris

subdentatum, Cass. 1. c. $465=$ C. Picris.

ACROSANTHES, Eckl. \& Zeyh. Enum. 328 (1837) FICOIDEAE, Benth. \& Hook. f. i. 855.

Didaste, E. Mey. ex Harv. \& Sond. Fl. Cap. ii. 472 (1862).

anceps, Sond. in Harv. E Sond. l. c.-Afr. austr. angustifolia, Eckl. \& Zeyh. Enum. 329.-Afr. anstr. decandra, Fenzl, in Ann. Wien. Mus. ii. (1838) 270 . -Afr. austr.

fistulosa, Eckl. \& Zeyh. Enum. 328.-Afr. austr.

humifusa, Sond. in Harv. \& Sond. Fl. Cap. ii. 472.Afr. austr

teretifolia, Eckl. E Zeyh. Enum. 329.-Afr. austr.

ACROSPELION, Bess, ex Trin. in Mém. Acad. Pétersb. Sér. VI. i. (1831) $59=$ Trisetum, Pers. (Gramin.)

ACROSPIRA, Welw. ex Baker, in Trans. Linn. Soc. Bot. Ser. II. i. (1878) 255. t. 34. LILIACEAE, Benth. \& Hook. f. iii. 787.

asphodeloides, Welw. l. c.-Afr. trop.

ACROSSANTHES, Presl, Bot. Bemerk。22 (1844) = Vismia, Vell. (Hypercin.).

Lhotskyanus, Presl, l, c。 $=$ V. decipiens.

ACROSTEMON, Klotzsch, in Linnaea, xii. (1838) 227 = Grisebachia, Klotzsch (Ericac.)

equisetoides, Klotzsch, 1, c. 228.-Afr. austr.

glandulosus, Rach, 1. c. xxvi. (1853-55) 790.-Afr. austr.

hirsutus, Klotzsch, 1. c。 xii. (1838) 228.-Afr, austr. incanus, Klotzsch, 1. c. $228=\mathrm{G}$. incana.

incurvus, Benth. in DC. Prod. vii. 702.-Afr. austr.

ACROTAPHROS, Steud ex A. Rich. Tent. F1. Abyss. i. 207.t. $38[1847]=$ Ormocarpum, Beauv. (Legum.) bibracteata, Steud. ex A Rich $1 \mathrm{c}=\mathrm{O}$ bibracteatum.

ACROTICHE, Poir. in Dict. Sc. Nat. i. Suppl. 50 (1816) $=$ Acrotriche, R. Br. (Epacrid.)

ACROTOME, Benth. in Endl. Gen. 627 (1838) LABIATAE, Benth. \& Hook. f. ii. 1206. hispida, Benth. in DC. Prod. xii. 436.-Afr. austr. inflata, Benth. l. c.-Afr. austr.

pallescens, Benth. l.c.-Afr. austr.

ACROTREMA, Jack, in Malay Misc. i. (1820) Art. V. p. 36. DILLENIACEAE, Benth. \& Hook. f. i. 13 Anottianum, Wight, Illustr. Ind. Bot. i. 9, t. 3.Ind. or.

bullatum, Thw. Enum. Pl. Zeyl. $20=$ uniflorum costatum, Fack, in Malay Misc. i. (1820) Art. V. p. 36 -Ind. or.; Malaya.

costatum, Wall. Cat. n. $1117 \mathrm{~B}=$ Amottianum.

dissectum, Thw. in Hook. Kew Fourn. viii. (1856) 242 -Zeylan.

\section{ACROTREMA :}

Gardneri, Thw.Enum. Pl. Zeyl. 3.-Zeylan.

intermedium, Thw. l. $c$-Zeylan.

lanceolatum, Hook. Ic. Pl. sub t. 157.-Zeylan.

lyratum, Thw. in Hook. Kew fourn. viii. (1856) 242 Zeylan.

sylvaticum, Thw. Enum. Pl. Zeyl. 2 = uniflorum.

Thwaitesii, Hook. f. \& Thoms. in Hook. Kew Gourn.

viii. (1856) 241. Z Zeyian.

uniflorum, Hook.Ic. Pl. t. 157.-Zeylan.

Walkeri, Wight, ex Thw. Enum. Pl. Zeyl. 3.Zeylan.

Wightianum, Wall. Cat. n. $3669=$ costatum.

ACROTRICHE, R. Br. Prod. 547 (1810). EPACRIDEAE, Benth. \& Hook. f. ii. 614

Froebelia, Regel, Gartenfl, i. (1852) 164, t. 18

affinis, DC. Prod. vii. $757=$ serrulata.

aggregata, R. Br. Prod. 547.-Austral.

aristata, Benth. in Enum. Pl. Hueg. $76=$ Lencopogon cuspidatus.

cordata, R. Br. Prod. $548=$ ovalifolia

depressa, $R . B r . l$. c.-Austral.

divaricata, $R, B r . l, c .547$ - Austral.

fasciculiflora, Benth. Fl. Austral. iv. 229.-Austral.

latifolia, A. Cunn. ex DC. Prod. vii. $757=$ Leucopogon

cordifolius.

Manglesii, Sond, in Lehm. Pl Preiss, i. $326=$ ramiflora

ovalifolia, $R$. Br. Prod. 548.-Austral

patula, Hook. f. Fl. Tasm. i. $253=$ serrulata.

patula, R. Br. Prod. 547.-Austral.

prostrata, F. Muell, in Trans. Vict. Inst. (1855) $40=$ serrulata.

ramiflora, $R$. Br. Prod. 547.-Austral.

ramiflora, Sond, in Linnaea, xxyi. $(1853-55), 251=$

fasciculiflora

serrulata, R. Br. Prod. 547.-Austral

subcordata, DC. Prod. vii. $757=$ ovalifolia.

ACROXIS, Trin. ex Steud. Nom. ed. II. i. $22(1840)=$ Muehlenbergia, Schreb. (Gramin.).

ACROZUS, Spreng. Syst. iv. Cur. Post. 145, 149 (1827) =Elaeocarpus, Linn. (Tiliac.)

punctatus, Spreng. 1. c. =E. Acronodia.

ACRYPHYLLUM, Lindl. Introd. Nat. Syst. ed. 1I. 156 (1836) err. typ. = ARCYPHYLLUM, Ell. = Tephrosia, Lour. (Legum.).

ACTAFA, [Tourn.] Linn. Syst. ed. I (1735). RANUNCULACEAE, Benth. \& Hook, f. i. 9

Christophoriana, Toum. ex Moench, Meth. 276 (1794)

acuminata, Wall. Cat. n. $4726=$ spicata

alba, Mill, Gard. Dict. ed. VIII. n. 2.-Am. bor.

americana, Pursh, F1. Am. Sept. $366=$ alba.

arguta, Nutt. ex Torr. \& Gray, F1. N. Am. i. $35=$ spicata.

aspera, Lour. Fl. Cochinch. 332. = Tetracera sarmentosa brachypetala, var. $a$, DC. Syst. i. $385=$ alba.

brachypetala, var, $\beta$, DC. 1. c. = spicata.

Christophoriana, Gouan, Fl. Monsp. $152=$ spicata

Cimicifuga, Hook. Fl, Bor. Am. i. 26= Cimicifuga elata.

Cimicifuga, Linn. Sp. Pl. 504=Cimicifuga foetida

cordifolia, DC. Syst. i. $383=$ Cimicifuga cordifolia

corymbosa, Stokes, Bot. Mat. Med. iii. $176=$ spicata.

dahurica, Turcz. ex Fisch. \& Mey. Ind. Sem. Hort

Petrop. i. $21=$ Cimicifuga foetida.

davurica, Franch. Pl. David. $23=$ Cimicifuga davurica.

dioica, Walt. Fl. Carol. 152.-Carolina.

erythrocarpa, Fisch. ex Fisch. \& Mey. Ind. Sem. Hort

Petrop. i. $20(1835)=$ spicata.

frigida, Wall. Cat. n. $4725=$ Cimicifuga foetida.

grandis, D. Dietr. Syn. Pl. iii. $233=$ Trantvetteria palmata.

gyrostachya, Wender. Ind. Sem. Hort. Marb. (1840).

Cf. Linnaea, xv. (1841), Litt. $100=$ Trantvetteria palmata.

japonica, Thunb. F1. Jap. 221 = Cimicifuga japonica

longipes, Spach, Hist. Vég. Phan. vii. $388=$ spicata.

macrophylla, Baill. in Bull. Soc. Linn. Par. i. (1879) 224 $=$ Anemopsis macrophylla.

macropoda, Turcz. ex Fisch. \& Mey. fide Ledeb. Fl Ross. i. $73=$ Cimicifuga foetida.

monogyna, Walt. Fl. Carol. $151=$ Cimicifuga racemosa nigra, Gaert Mey, \& Scherb. Fl. Wett ii. $265=$ spicata.

\section{ACTAEA :-}

orthostachya, Wender. Ind. Sem. Hort. Marb. (1840)

-Cf. Linnaea, xv. (1841) Litt. $100=$ Cimicifuga racemosa.

pachypoda, Ell. Sketch, ii. $15=$ alba

palmata, DC. Syst. i. $383=$ Trautvetteria palmata

pentacarpa, Michx. ex Torr. \&c Gray, F1. N Am. i. 39 $=$ Cimicifuga americana.

pentagyna, Walt. Fl. Carol, $151=$ Cimicifuga americana.

podocarpa, DC. Syst. i. $282=$ Cimicifuga americana.

podocarpa, Schlecht. in Linnaea, vi. (1831) $583=$ Cimicifuga foetida.

pterosperma, Turcz. ex Fisch. \& Mey. Ind. Sem. Hort. Petrop. i. 21 = Cimicifuga foetida.

racemosa, Geners, ex Steud. Nom, ed. II i, $22=$ Cimicifuga foetida.

racemosa, Gilib. Fl. Lituan. ii. $226=$ spicata

racemosa, Linn. Sp. Pl. $504=$ Cimicifuga racemosa.

racemosa, Walt. ex steud. Nom. ed. II. i. $22=$ Trautvetteria palmata.

rubra, Bigel. F1. Bost ed. II, $211 \approx$ alba?

rubra, Willd. Enum. Hort. Berol. 561 ; Ledeb. Fl. Alt. ii. $275=$ spicata

simplex, Wormsk. ex Fisch. \& Mey. Ind. Sem. Hort.

Petrop. i. 21 = Cimicifuga foetida.

spicata, Linn.Sp. Pl. 504.-Reg. bor, temp.

ACTAEOGETON, Steud. Nom. ed. II. i. $22(1840)=$ Scirpus, Linn. (Cyperac.).

ACTEGETON, Blume, Bijdr. $1143(1826)=$ Azima, Lam. (Salvador).

sarmentosum, Blume, I. c. $1144=\mathrm{A}$. sarmentosa.

ACTEGITON, Endl. Gen. 1089 (1840), err. typ. = praec.

ACTEPHILA, Blume, Bijdr. 581 (1825). EUPHOR. BIACEAE, Benth. \& Hook. f. iii. 269

Anomospermum, Dalz. in Hook. Kew Joum. iii. 1851) 228

Lithoxylon, Endl. Gen. $1122(1840)$

bantamensis, Miq. Fl. Ind. Bat. i. Ir. $356=$ excelsa. excelsa, Muell. Arg. in Linnaea, xxxii. (1863) 78.Ind. or. ; Malaya.

grandifolia, Baill. Adansonia, vi. (1865-66) 330.Austral.

javanica, Miq. F1. Ind. Bat. i. II. $356=$ excelsa latifolia, Benth. Fl. Austral. vi. 89.-Austral. major, Muell. Arg. in Linnaea, xxxii. (1863) 77.Java.

Mooreana, Baill. Adansonia, vi. (1865-66) 330.Austral.

neilgherrensis, Wight, Ic. t. $1910=$ excelsa

petiolaris, Benth. Fl. Austral. vi. 89.-Austral.

puberula, Kurz, in Fourn. As. Soc Beng. xlii. (1873 II. 236.-Ins. Andaman.

rectinervis, Kurz, in fourn. Bot. xiii. (1875) 329.Ins. Nicobar.

sessilifolia, Benth. Fl. Austral. vi. 90.-Austral.

Thomsoni, Muell. Arg. in Linnaea, xxxiv. (1863) $65=$ excelsa.

zeylanica, Muell. Arg. 1. c. $77=$ excelsa.

ACTIMERIS, Rafin. in Am. Monthly Mag. (1819) 195 =Actinomeris, Nutt. (Compos.).

ACTINANTHUS, Ehrenb. in Linnaea, iv. (1829) 398. UMBELLIFERAE, Benth. \& Hook. f. i. 903. syriacus, Ehrenb. l. c.-As. min.; Syria.

AC'IINEA, Juss, in Ann. Mus. Par. ii. (1803) 425. t. 61 =Cephalophora, Cav. (Compos.) acaulis, Spreng. Syst. iii. $574=$ Actinella acaulis. alternifolia, Spreng. 1. c. =C. heterophylla. biternata, Spreng. 1. c. = Coreopsis biternata. chrysanthemoides, H. B. \& K. Nov. Gen. et Sp. iv. 298. $\mathrm{t}, 411=$ Hymenoxis chrysanthemoides. commutata, Spreng. Syst. iii. $574=$ Calea pinnatifida. heterophylla, Juss. in Ann. Mus. Par. ii. (1803) 425 $=\mathrm{C}$. heterophylla.

integrifolia, H. B. \& K. Nov. Gen. et Sp. iv. 297. t. $410=$ Helenium integrifolium

integrifolia, Torr. in Ann. Lyc. New York, ii. (1828) 213.-Am. bor.

lanata, Steud. Nom. ed. I. $15=$ Bahia lanata

oppositifolia, Spreng. Syst. iii. $574=$ Blainvillea bahiensis. 
ACTINELLA, Nutt. Gen. Am. ii. 173 (1818). COMPOSITAE, Benth. \& Hook, f, ii. 414.

Phrleozera, Buckl. in Proc. Ac. Sc Fhilad. '1861' (1862) 459 .

Picradenia, Hook: Fl. Bor. Am. i. 317. t. 108 (1833).

acaulis, Nutt. Gen. Am. ii. 173.-Am. bor.

argentea, A. Gray, in Mem. Am. Ac. iv. (1849) (Pl. Fendl.) 100.-N. Mexico,

biennis, A. Gray, in Proc. Am. Acad. xiii, (1878) 373 -Am. bor. occ.

Bigelovii, A. Gray, Pl. Wright. ii. 96 , in adnot.Mexico.

Brandegei, T. C. Porter, ex A. Gray, in Proc. Am. Acad. xiii. (1878) 373.-Am. bor. occ.

chrysanthemoides, A. Gray, $l$, c. xix. (1883) 32.Mexico.

Cooperi, A. Gray, l. c. vii. (1868) 359,-Calif.

depressa, Harv. \& Gray, ex Gray, in Mem. Am. Acad. iv. (1849) (Pl. Fendl.) 100.-Am. bor. occ.

glabra, Nutt. in Trans. Am. Phil. Soc. N. So vii. (1841) $379=$ acaulis.

grandiflora, Torr. \& Gray, in Bost. Fourn. Nat. Hist. v. (1847) 110.-Am. bor, occ.

insignis, A. Gray, ex S. Wats. in Proc. Am. Acad. xviii. (1882-83) 109. - Am. bor. occ.

lanata, Nutt, in Trans. Am. Phil. Soc. N. S. vii. (1841) $379=$ acaulis

lanata, Pursh, Fl. Am. Sept, ii. $560=$ Eriophyllum caespitosum.

lanuginosa, Buckl. in Proc. Ac. Sc. Philad. (1862 $459=$ scaposa.

leptoclada, A. Gray, in Pacif. Rail. Rep. iv. 107.Am. bor. oce.

linearifolia, Torr. \& Gray, Fl. N. Am. ii. 383.-Texas.

odorata, A. Gray, in Mem. Am. Acad. iv. (1849) (Pl. Fendl.) 101.-Am. bor. occ.

Palmeri, A. Gray, in Proc. Am. Acad. xix. (1883) 31. -Mexico.

Richardsonii, Nutt. in Trans. Am. Phil. Soc. N. S. vii. (1841) $379=$ biennis.

Rusbyi, A. Gray, in Proc. Am. Acad. xix. (1883) 33.N. Mexico.

scaposa, Nutt. in Trans. Am. Phil. Soc. N. S. vii (1841) $379 .-\mathrm{Am}$. bor. occ

Torreyana, Nutt. l. c. = acaulis.

Vaseyi, A. Gray, in Proc. Am. Acad. xvii. (1881-82 219.-Am. bor. occ.

ACTINELLA, Pers. Syn. ii. $469 \quad(\mathbf{1 8 0 7})=$ Cephalophora, Cav. (Compos.).

heterophylla, Pers. 1. c $\equiv$ C. heterophylla.

ACTINIDIA, Lindl. Introd. Nat. Syst. ed. II. 439 (1836). TERNSTROEMIACEAE, Benth. \& Hook. f. i. 184 .

Kanomikta, Regel, in Bull. Phys. Math. Acad. Pétersb, xv, (1857) 219

TrochostigMA, Sieb. \& Zucc. in Abh. Akad. Wiss, Muench. iii. (1843) 726, t. 2. f. 2.

acuminata, Budisch. ex Trautv. in Act. Hort. Petrop. viii. (1883) 167.-Manchur.

ergruta, Franch. \& Sav. Enum. Pl. Jap. i. $58=$ callosa.

callosa, Lindl. Introd. Nat. Syst. ed. II. $439 .-$ Reg Himal, ; Japon.; Manchur.

Championi, Benth. Fl. Hongk. 26.-China.

chinensis, Planch. in Hook. Lond. Fourn. Bot. vi.

(1847) 303.-China.

cordifolia, Miq. Ann. Mus. Bot. Lugd. Bat. iii. 15.-Japon.

Davidii, Franch. Pl. Davidian. i. 57.-China. eriantha, Benth. in Gourn. Linn. Soc. v. (1861) 55.-
Hab.?

fulvicoma, Hance, in Fourn. Bot. xxiii. (1885) 321.China.

Kolomikta, Maxim. Prim. Fl. Amur. $63=$ callosa.

platyphylla, A. Gray, in Miq. Ann. Mus. Bot. Lugd. Bat. iii. 15. - Japon.

polygama, Franch. ESav.Enum.Pl.Fap. i. 59,-Japon. rufa, Franch. \& Sav. 1. c. $58=$ callosa.

strigosa, Hook. f. \& Thoms. in Gourn. Linn. Soc. $y$ (1861) 55,-Reg. Himal.

suifunensis, Budisch. ex Trautv. in Act. Hort. Petrop. viii. (1883) $167=$ acuminata.

volubilis, Franch. \& Sav. Enum. Fl. Fap. i.59.-Japon.

ACTINOBOI.E, Endl. Gen. Suppl. iii. 70 (1843)=

Graphalode8, A. Gray (Compos.).
ACTINOCARPUS, R. Br. Prod. $342(1810)=$ Dama sonium, Juss. (Alismac.).

australis, Spreng. in Ersch \& Gruber, Encyc. i. $348=$ D, australe.

Damasonizı, Sm, in Rees, Cycl. Suppl. n. 1=D stellatum.

europaeus, Spreng. in Ersch \& Gruber, Encyc. i (1818) $348=\mathrm{D}$, stellatum.

maior, Bercht. \& Presl, Rostl. i. Alismac. $8=\mathrm{D}$. stellatum.

minor, R. Br. Prod. $343=$ D. australe

ACTINOCARYA, Benth. in Benth. \& Hook. f. Gen, ii. $846(1876)$. BORAGINEAE, Benth. \& Hook. f. ii. 846 .

tibetica, Benth. l. c.-Reg. Himal.

ACTINOCHLOA, Willd. ex Beauv. Agrost. 41 (1812); et ex Roem. \& Schult. Syst. ii. (1817) 22. $417=$ Bouteloua, Lag. (Gramin.

barbata, Roem. \& Schult. 1. c. ii. $420=$ B, harbata bromoides, Roem. \& Schult. 1. c. $=$ B. bromoides ciliata, Willd. ex Beauv. Agrost. $41=$ Chloris ciliata gracilis, Willd, ex Roem. \& Schult. Syst. ii. $418=\mathrm{B}$. oligostachya.

hirsuta, Roem. \& Schult. 1. c. $149=$ B. hirsuta.

humilis, Willd. ex Beanv. Agrost, $41=\mathrm{B}$. prostrata

juncifolia, Roem. \& Schult. Syst. ii. $420=$ B. juncifolia.

ovata, Roem. \& Schult. 1. c. = B. ovata.

procumbens, Roem. \& Schult. 1。 c. $417=$ B. tenuis,

prostrata, Roem. \& Schult. 1. c. $419=$ B. prostrata scorpioides, Roem. \& Schult. 1. c. $420=\mathrm{B}$, scor pioides.

simplex, Roem, \& Schult. 1. c. $418=$ B. simplex.

tenuis, Willd, ex Beauv. Agrost. $41=\mathrm{B}$, tenuis.

ACTINOCLADUS, E. Mey. Ind. Sem. Hort. Regiom. 1846)=Capnophyllum, Gaertn. (Umbellif.). cinerascens, E. Mey. 1. c. = C. africanum.

AC'TINOCYCLUS, Klotzsch, in Monatsb. Akad. Berl (1857) $14=$ Pyrola, Tourn. (Ericac.

secundus, Klotzsch, 1. c. = P. secunda.

ACTINODAPHNE, Nees, in Wall. Pl. As. Rar. ii 68 (1831). LAURINEAE, Benth. \& Hook. f. iii. 160.

Iozoste, Nees, 1. c. 63 (1831)

Iozosmene, Lindl. Introd. Nat. Syst. ed. II. 202 (1836).

acuminata, Meissn. in DC. Prod. xv. I. 211.-Japon.

angustifolia, Hook. f. \& Thoms. ex Meissn, in DC Prod. xV. I. $218=$ Hookeri.

angustifolia, Nees, in Wall. Pl. As. Rar. iii. 34.-

Ind. or. ; Malaya.

areolata, Blume, Mus. Bot. Lugd. Bat. i. 344.Java.

Blumii, Nees, Syst. Laurin. $598=$ Litsea ferruginea.

borneensis, Meissn. in DC. Prod. xv. I. 213.-Borneo

Candolleana, Meissn. 1. c. $219=$ speciosa

celebica, Miq. Fl. Ind. Bat. i, 972 -Ins. Celebes.

chinensis, Nees, Syst. Laurin, 600. - China.

cochinchinensis, Meissn. in DC. Prod. xv. I. 216.Cochinch.

concolor, Blume, Mus. Bot. Lugd. Bat. i. $345=$ scleroptera.

concolor, Nees, in Wall. Pl. As. Rar. iii. 31.-Ind. or confertiflora, Meissn. in DC. Prod. xv, I. 216.- Reg Himal.

corymbosa, Blume, Mus. Bot. Lugd. Bat. i. 343.Sumatra.

elegans, Thw. Enum. Pl. Zeyl.256--Zeylan

furfuracea, Blume, Mus. Bot. Lugd. Bat. i. 345.Malaya.

glabra, Blztme, l.c. i. 344.-Java

glauca, Nees, Syst. Laurin. 599.-Zeylan.

glomerata, Nees, l. c. 597 . - Java.

gracilis, Miq. Fl. Ind. Bat. Suppl. 363.-Sumatra.

heterophylla, Blume, Mus. Bot. Lugd. Bat. i. $342=$ angustifolia.

hirsuta, Blume, l. c. 345.-Java.

Hookeri, Meissn. in DC. Prod. xv. I. 218.-Ind. or

javanica, Miq. Fl. Ind. Bat. i. I. 969.-Java.

lanata, Meissn. in DC. Prod. xv. 1. 219.-Ind, or.

lancifolia, Meissn. l. c. 211.-Japon.

macrophylla, Nees, Syst. Laurit. 598,-Java.

macroptera, Miq. Fl. Jnd. Bat. i. I. 970.-Sumatra.

\section{ACTINODAPHNE}

mollis, Blume, Mus. Bot. Lugd. Bat. i. 343

Sumatra.

molochina, Nees, Syst. Laurin.603.-Zeylan.

moluccana, Blume, Mus. Bot. Lugd. Bat. i. 344. Ins. Molucc.

Moonii, Thw. Enum. Pl. Zeyl. $256=$ molochina

multiflora, Benth, in Hook. Lond. Fourn. Bot. ii. 1843

230. - Ins. Fiji

obovata, Blume, Mus. Bot. Lugd. Bat. i. 342.Ind. or.

paucifora, Blume, l. c.-Borneo.

pedunculata, Meissn. in DC. Prod. xv. I. 211.-China,

procera, Nees, Syst. Laurin. 605,-Java,

pruinosa, Nees, in Wall. Pl. As. Rar, ii. 68.-Ind. or.

pubescens, Blume, Mus. Bot. Lugd. Bat. i. $345 .-$ Malaya.

quercina, Blume, l. c. 344.-Java

reticulata, Meissn. in DC. Prod. xvi. 1. 212.-Ind, or.

rufescens, Blume, Mus. Bot. Lugd. Bat. i. 313.-

Malaya.

Rumphii, Blume, L c. 344.-Ins. Molucc.

salicina, Meissn. in DC. Prod. xv, 1. 212.-Ind. or

scleroptera, Miq. Fi. Ind. Bat. i. 1. 972,-Malaya

sesquipedalis, Hook. f. E Thoms. ex Meissn. in DC.

Prod. xy, 1. "216.-Ind, or.

Sieboldiana, Mig. in Zoll. Syst. Verz. Ind. Archip. 114

116.-Japon.

sikkimensis, Meissn. in DC. Prod. xvi. 1. 213.-Jeg Himal.

speciosa, Nees, Syst. Laurin.602.-Zeylan.

sphaerocarpa, Nees, l. c. 605.-Java.

stenophylla, Thw. Enum. Pl. Zeyl. 256.-Zeylar.

Thwaitesii, Meissn. in DC. Prod. xv. I. $212=$ stenophylla.

ACTINODIUM, Schar. ex Schlecht. in Linnaea,

(1835) 311. MYRTACEAE, Benth. \& Hook, f. i. 696.

TripheliA, R. Br. ex Endl, in Enum. Pl. Hueg. 48 (1837)

Cunninghami, Schau. ex Lindl. Introd. Nat. Syst. ed. II. 440.-Austral.

proliferum, Turcz. in Bull. Soc. Nat. Mosc. xxii. (1849 II. $17=$ Cunninghami

ACTINOLEMA, Fenzl, Pugill. Pl. Nov. Syr. 16. t. 12 $(1842)=$ Astrantia, Linn. (Umbellif)

eryngioides, Fenzl, 1. c- Oriens.

macrolema, Boiss. F1. Orient. ii. 831.-Oriens.

ACTINOLEPIS, DC. Prod. $\vee .655$ (1836). CO. POSITAE, Benth. \& Hook. f. ii. 899 .

Hymenoxys, Torr, \& Gray, Fl. N. Am. ii. 380 (1841)

anthemoides, A. Gray, in Bot. Calif. i. 378.-Calif.

coronaria, A. Gray, in Proc. Am.Acad. ix. (1874) 197. -Calif.

lanosa, A. Gray, l. c.-Utah.

Lemmoni, A. Gray, l. c. xvi. (1881) 101.-Calif

multicaulis, $D C$. Prod. v. 656.-Calif.

mutica, A. Gray, in Proc. Am. Acad. ix. (1874) 197. -Calif.

nivea, A. Gray, l. c.-Calif.

tenella, A. Gray, l. c.-Calif.

Wallacei, A. Gray, l. c.-Utah.

ACTINOMERIS, Nutt. Gen. Am. ii. 181 (1818 COMPOSITAE, Benth. \& Hook. f. ii. 373.

Actimeris, Rafin. in Am. Monthly Mag. (1819) 195.

Pterophyton, Cass, in Bull. Soc. Philom. (1818) 76.

RIDAN, Adans. Fam. ii. 180 (1763)

alata, Nutt. Gen. Am. ii. $181=$ Verbesina occidentalis alba, Torr. \& Gray, Fl. N. Am. ii. \$95.-Am. bor.

alternifolia, DC. Prod. v. $572=$ squarros..

Ellioti, Rafin. Nern Fl. Am, i. 61.-Am. bor.

helianthoides, Nutt. Gen. Am. ii. 181.-Am. bor.

heterophylla, Chapm. in Conlt. Bot. Gas. iii. (18;8; 6 -Am. bor.

longifolia, A. Gray, in Smithson. Contrib. v. (1853, Pl. Wright, ii, s9.-Arizuna.

nudicaulis, Nutt, in Trans. Am. Phil. Sor. N. S. vii (18+1) 864 . - Florida

oppositifolia, DC. Prod. ․ $575=$ helianthoides.

opposififulia, Fresen. Ind. Sem. Ilort. Francol. (189ei

squarross.

oyata, Nutt, Gen. Am. ii. 1s1.-Mexico. 


\section{ACTINOMERIS :-}

pauciflora, Nutt, in Am. Fourn. Sc. v. (1822) 301.Florida.

pedunculosa, DC. Prod. v. $576=$ Verbesina Capitaneja procera, Steud. Nom. ed. II. i, $23=$ squarrosa. squarrosa, Nutt. Gen. Am. ii. 181.-Am. bor. occ. squarrosa, Nutt. Gen. Am. 11. 181.-Am. bor. occ. tetragona, DC. Prod. v. 576.-Mexico.

tetraptera, $D C . l . c .575 .-$ Mexico.

Wrightii, A. Gray, in Mem. Am. Acad.iv. (1849) (Pl Fendl.) 85.-N. Mexico.

ACTINOMORPHE, Miq. Comm. Phyt: $102 \cdot(1840)=$ Heptapleurum, Gaertn. (Araliac.).

humilis, Miq. 1. c. $=$ H. parasiticum.

ACTINOPAPPUS, Hook. f, ex A. Gray, in Hook. Kew Journ, iv. (1852) $226=$ Rutidosis, DC. (Compos.)

Drummondii, A. Gray, 1. c. = R. Pumilio

perpusillus, Hook. f, ex A. Gray, 1. c. = R. Pumilio.

ACTINOPHORA, Wall. Cat. n. $1163(1832)=$ Schou tenia, Korth. (Tiliac.).

fragrans, Wall. l. c. $=$ S. ovata.

ACTINOPHYLLUM, Ruiz \& Pav. Prod. 51. t. 8 $(1794)=$ Sciadophyllum, P. Br. (Araliac.). acuminatum, Pav. in Mem. Acad. Med. Madr. (1797) $196=\mathrm{S}$. acuminatum.

angulatum, H. B. \& K. Nov. Gen. et Sp. v, $92=$ S Humboldtianum.

angulatum, Pav. in Mem. Acad. Med. Madr. i. (1797) $194=\mathrm{S}$. angulatum

conicum, Pav. 1. c. $195=\mathrm{S}$. conicum.

digitatum, Wall. ex Steud. Nom. ed. II. i. $23=\mathrm{S}$. digitatum

divaricatum, Blume, Cat. Gew. Buitenz. $42=$ S. divaricatum.

farinosum, Blume, 1. c. $43=\mathrm{S}$. tomentosum

pedicellatum. Pav. in Mem. Acad. Med. Madr. i. (1797) $195=\mathrm{S}$. pedicellatum.

pentandrum, Pav. 1. c. $197=$ S. pentandrum

ACTINORHYTIS, H. Wendl. \& Drude, in Lininaea, xxxix. (1875) 184. PALMAE, Benth. \& Hook. f, iii. 889 .

calapparia, $H$. Wendl. \& Drude, l. c.-Malaya.

ACTINOSCHOENUS, Benth. in Hook. Ic. Pl. xiv. 33. t. 1346 (1881). CYPERACEAE, Benth. \& Hook. f. iii. 1058.

Arthrostylis, Boeck. in Linnaea, xxxvii. (1873) 523.

chinensis, Benth. $l$ : c.-Hongkong.

filiformis, Benth. l. c.-Zeylan.

Thouarsii, Benth. l. c.-Madag

ACTINOSPERMUM, Ell. Sketch, ii. $448(1824)=$ Baldwinia, Nutt. (Compos.)

angustifolium, Torr. \& Gray, F1. N. Am. ii. $389=$ B. multiflora.

multiflorum, Ell. Sketch, ii. $441=$ B. multiflora

ACTINOSPORA, Turcz, ex Fisch. \& Mey. Ind. Sem. Hort. Petrop، i. $21 \quad(1835)=$ Cimicifuga, Linn. (Ranunc.).

dahurica, Turcz. ex Fisch. \& Mey. 1. $\mathrm{c}_{\mathrm{b}}=$ C. davurica. frigida, Fisch. \& Mey. 1. c. = C. frigida.

pterosperma, Walp. Rep。 i. $60=$ C. davurica.

Wallichii, Meissn. Gen. Comm, $4=$ C. foetida.

ACTINOSTEMA, Lindl. Veg. Kingd. 281 (1846) err. typ. = Actinostemon, Mart. (Euphorb.).

ACTINOSTEMMA, Griff. PI. Cantor, 24, t. 3 (1837?) CUCURBITACEAE, Benth. \& Hook. f. i. 838.

Mitrosicyos, Maxim, in Ann. Sc. Nat. Sér. IV xiii (1860) 95 .

Pomasterion, Miq. Ann. Mus. Bot. Lugd. Bat. ii. (1865) 80.

japonicum, Miq. 1. c. iii. $188=$ racemosum.

lobatum, Maxim. in Franch. ô Sav. Enum. Pl. Fap. i. 175 .- Japon

paniculatum, Maxim. ex Cogn. in DC. Monog. Phan. iii. 920.-China.

racemosum, Maxim. ex $\operatorname{Cog} n$. l. c. 922,-China.

\section{A CTINOSTEMMA}

tenerum, Griff. Pl. Cantor, 25. t. 3.-Ind. or.

tenerum, Naud, in Ann. Sc. Nat. Sér. V. (1866) $39=$ lobatum.

ACTINOSTEMON, Mart. ex Klotzsch, in Wiegm. Archiv, vii. (1841) 184. EUPHORBIACEAE, Benth. \& Hook. f. iii. 338 .

Dactylostemon, Klotzsch, 1. c. 181.

acuminatus, Baill. Etud. Gén. Euphorb. 532. t. $5=$ concolor.

angustifolius, Klotzsch, ex Regel, Gartenfl. (1859) 363 = concolor.

caribaeus, Griseb. in Goett. Abh. vii. (1857) 168.Bras.; Ind. occ.

concolor, Muell. Arg. in DC. Prod. xv. II. $1193=$ caribaeus.

cuneatus, Baill. Adansonia, v. (1864-65) 535.-Bras. echinatus, Muell. Arg. in Linnaea, xxxi1. (1863) 107. -Bras.

furcatus, Klotzsch, ex Baill. Etud. Gén. Euph. 532 = caribaens.

grandifolius, Baill. 1. $\mathrm{c}=$ = caribaeus.

imbricatus, Muell. Arg. in Linnaea, xxxiv. (1865-66) 216.-Bras.

Klotzschianus, Baill. Adansonia, v. (1864-65) 334 (= Dactylostemon grandifolius).

lanceolatus, Saldanha, in Baill. l. c. viii. (1867-68 263.-Bras.

lasiocarpoides, Baill. l. c. v. (1864-65) 334.-Bras.

lasiocarpus, Baill. l. c. -Bras.

macrocarpus, Muell. Arg. in Mart. Fl. Bras, xi. II 597.-Bras.

marginatus, Klotzsch, ex Baill. Etud. Gén. Euph. 532 = caribaeus.

multiflorus, Muell. Arg, in Linnaea, xxxii. (1863) 111. -Bras.

oligandrus, Baill. Adansonia, v. (1864-65) 335.Bras.

polymorphus, Muell. Arg. in Linnaea, xxxii. (1863) 108 = caribaeus.

sessilifolius, Klotzsch, Ind. Sem. Hort. Berol. App. (1851) $13=$ caribaeus.

Sprengelii, Baill. Etud. Gén. Euph. 333 (=Dactylostemon Klotzschii).

trachycarpus, Muell. Arg. in Mart. Fl. Bras. xi. II 591.-Bras.

verticillatus, Baill. Adansonia, v. (1864-65) 334.Bras.

ACTINOSTIGMA, Turcz, in Bull. Soc. Nat. Mosc. xxxii. (1859) $259=$ Seringia, J. Gay (Sterculiac.).

lanceolatum, Turcz. 1. c.-Austral

ACTINOSTIGMA, Welw. Apont. $560 \quad(1858)=$ Symphonia, Linn. f. (Gutlif.)

speciosum, Welw. 1. c. =S. globulifera.

ACTINOSTROBUS, Miq. in Lehm. Pl. Preiss. i. 644 (1845) CONIFERAE, Benth. \& Hook. f. iii. 425. acuminatus, Parl. Ind. Sem. Hort. Florent. (1862) 25. -Austral.

pyramidalis, Miq. in Lehm. Pl. Preiss. i. 644.Austral.

A CTINOTUS, Labill. P1. Nov. Holl. i. 67. t. $92(1804)$ UMBELLIFERAE, Benth. \& Hook. f. i. 880, 1008. ERIOCALIA, Sm. Exot. Bot. t. 78, 79 (1806).

Hemiphues, Hook. f. in Hook. Lond. Journ. Bot vi. (1847) 469

Holoтome, Endl. Gen. 766 (1839).

bellidioides, Benth. Fl. Austral, iii. 369.-Austral.

Gibbonsii, F. Muell Fragm, vi 23-Austral.

glomeratus, Benth. Fl. Austral. iii. 369.-Anstral,

Helianthi, Labill. Pl. Nov. Holl. i. 67. t. 92.Austral.

leucocephala, Benth. in Enum. Pl. Hueg. 56.-Austral minor, DC. Prod. iv. 83.-Austral.

Novae-Zealandiae, Petrie, in Trans. N.Z. Inst. xiii. (1881) $324 .-\mathrm{N}$. Zel

omnifertilis, F. Muell. ex Benth Fl. Austral. iii. 368 -Austral.

rhomboideus, Benth. Fl Austral. iii. 368.-Austral.

ACTIPSIS, Rafin. Fl. Tellur. ii. $43(1836)=$ Solidago Linn. (Compos.)

glomerata, Rafin. 1. c. = S. glomerata.

squamosa, Rafin. 1. c. = praec.?
ACTISPERMUM, Rafin. New Fl. Am. i. 61 (1836) (=ACTINOSPERMUM, Ell. $)=$ Baldwinia, Nutt. (Compos.).

ACUAN, Medic. Theod. $62(1786)=$ Desmanthus, Willd. (Legum.).

arboreum. Medic. 1. c.-Hab.

virgatum, Medic. 1. $\mathrm{c}=\mathrm{D}$. virgatus,

ACUBA, Link, Enum. Hort. Berol. ii. 386 (1822), sphalm. = Aucuba, Thunb. (Cornac.).

ACUBALUS, Neck, Elem, ii. $167(1790)=$ Cucubalus, Tourn. (Caryophyll.).

ACUNA, Endl. Gen. $759(1839)=$ seq.

ACUNNA, Ruiz \& Pav. Prod. 69.t. 12 (1794)= Befaria, Mutis (Ericac.)

lanceolata, Cav. ex DC. Prod. vii. $731=$ B. coarctata. lanceolata, Ruiz \& Pav. Syst. Veg. $124=$ B. aestuans, oblonga, Ruiz \& Pav. 1. c. $123=\mathrm{B}$. oblonga.

ACURA, Hill, Veg. Syst. v. 52 (1769) (Compos.).

ACUROA, J. F. Gmel. Syst. $1083(1791)=$ ACOUROA, Aubl. = Ecastaphyllum, P. Br. (Legum.).

ACUSTON, Rafin. Sylva Tellur. 131 (1838)=Farsetia Desv. (Crucif.).

clypeatum, Rafin. 1. c. $131=\mathrm{F}$. clypeata.

lunaroides, Rafin. 1. c. $=$ F. lunarioides.

ACYNOS, Pers, Syn. ii. 131 (1807) (err. typ. '151') $=$ ACINOS, Rupp.=Calamintha, Moench (Labiat.).

ACYNTHA, Medic. Theodora, $76 \quad(1786)=$ Sansevieria, Thunb. (Haemodor.).

guinensis, Medic. 1. c. $=\mathrm{S}$. guineensis.

ADA, Lindl. Fol. Orch. (1853). ORCHIDEAE, Benth. \& Hook. f, iii. 566.

aurantiaca, Lindl. l. c.-N. Granat.

ADAMANTOGETON, Schrad, ex Nees, in Mart. Fl, Bras. ii. I. $165(1842)=$ Lagenocarpus, Nees, (Cyper.).

ADAMBEA, Lam. Encyc. 39 (1783)=Iagerstroemia, Linn. (Lythrar.).

olabra, Lam. 1. c. = L. Flos-reginae

hirsuta, Lam. 1. $\mathrm{c}_{\mathrm{o}}=\mathrm{L}$. hirsuta.

ADAMBOE, Rafin. Fl. Tellur. iv. $73(1836)=$ Argyreia, Lour. (Convolv.).

bicolor, Rafin. 1. c. = A. tiliaefolia

ADAMIA, Wall. Tent. Fl. Nep. 46. t. $36(1824)=$ Dichroa, Lour. (Saxifrag.).

chinensis, Gardn. \& Champ. in Hook. Kew Journ. i. $311(1849)=\mathrm{D}$. febrifuga

cyanea, Wall. Tent. F1. Nep. 46. t. $36=$ D. febri-

fuga.
sylvatica, Meissn. in Walp. Rep. ii. $377=\mathrm{D}$. febrifuga.

versicolor, Fortune, in Lindl. Journ. Hort. Soc. i. (1846) $298=$ D. febrifuga .

ADAMSIA, Fisch. ex Steud. Nom. ed. I. 366, 357, in syn. $(1821)=$ Geum, Linn. (Rosac.)

anemonoides, Fisch. ex Steud. 1. c. $366=\mathrm{G}$. ane monoides.

glacialis, Fisch. ex Steud. 1. c. $366=\mathrm{G}$. glaciale

reptans, Fisch. ex Steud. 1. c. $367=\mathrm{G}$ reptans.

rotundifolia, Fisch. ex Steud. 1. c. $=G$. rotundifolium.

ADAMSIA, Willd. in Mag. Ges, Naturf. Fr. Berl. ii. (1808) $16=$ Puschkinia, Adams (Liliac.).

scilloides, Willd. 1. c. $=\mathbf{P}$. scilloides,

ADANSONIA, Linn. Sp. Pl. 1190 (1753). MALVACEAE, Benth. \& Hook. f. i. 209.

BAOBAB, Adans. Fam。 ii. 399 (1763).

Opteids, Lour. Fl. Cochinch. 412 (1790).

$B a h o b a b$, Linn. Sp. Pl. ed. II. $960=$ digitata.

Baobab, Gaert. Fruct. ii. 253. t. $135=$ digitata. 
ADANSONTA :-

digitata, Linn. Sp. Pl. 1190.-Afr. trop.; Ind. or Gregorii, F. Muell. in Hook. Kew Fourn. ix. (1857) 14 -Austral.

integrifolia, Rafin. Sylva Tellur. $149=$ A. Situla. madagascariensis, Baill. Adansonia, xi. (1873-76) 251 -Madag.

microphylla, A. Rich. F1. Cub. Fanerog. ii. 825, lapsu $=$ Adelia microphylla

pedunculosa, A. Rich. 1. c. lapsu=Adelia pedunculosa Scutula, Steud. Nom. ed. II. i. 24, sphalm.= seq. Situla, Spreng. Syst. iii. 124.-Afr. or.

ADAPHUS, Neck. Elem. ii. $240(1790)=$ Laurus, Tourn.

ADATODA, Rafin. Fl. Tellur. iv. 60 (1836)= Justicia Linn. (Acanth.)

arborea, Rafin. 1. c. $61=$ J. Adhatoda

Betonica, Rafin. 1. $\mathrm{c}=\mathrm{J}$. Betonica.

repens, Rafin. 1. c.-Hab.?

ADELANTHUS, Endl. Gen. 1327. n. 6839 ; Suppl. ii. $30(1841)=$ Pyrenacantha, Wight (Olacin. $)$. grandifiorus, Harv. ex Baill. Adansonia, x. (1872) 271 $=\mathrm{P}$. grandiflora

scandens, Endl. ex Baill. in DC. Prod. xvii. $18=\mathrm{P}$. scandens.

ADELASTER, Lindl.in Proc. Roy. Hort. Soc. i. (1861) 568; Lem. in Illustr. Hortic. t. 320 = Eranthemum Linn.? (Acanthac)

albivenis, Lind1. 1l. cc.-Hab. ?

ADELBERTIA, Meissn. Gen. Pl. 114 (1837)= Meri ania, Sw. (Melast.).

calophylla, Meissu. 1. c. $(=$ Davya calophylla $)$.-Bras.

ADELIA, P. Br. Nat. Hist. Jamaic. $361(1756)=$ Forestiera, Poir. (Oleac.)

acuminata, Michx. Fl. Bor. Am. ii. $225=\mathrm{F}$. acu minata.

cassinioides, Steud. Nom. ed. II. i. $24=$ F. cassinoides ligustrina, Michx. Fl. Bor. Am. ii. 224=F. ligustrina ovata, [Desf.] Hort. Par. ex Pers. Syn. ii. 635.-Am

porulosa, Michx. Fl. Bor. Am. ii. $224=$ F. porulosa.

virgata, Poir. Encyc. Suppl. i. $132=$ Securinega buxifolia.

ADELIA, Linn. Syst. ed. X. (1759) 1298. EUPHOR $B I A C E A E$, Benth. \& Hook, f. iii. 312.

Ricinella, Muell. Arg, in Linnaea, xxxiy. (1865) 153.

Acidoton, Blanco, Fl. Filip. ed. I. $815=$ Sumbavia rottleroides.

Acidoton, Linn. Syst. ed. X. 1298; Pl. Fam. Pugill. 29.-Jamaica ; Cuba.

anomala, Juss. ex Steud. Nom. ed. II. i. $24=$ ovata.

anomala, Poir. Encyc. Suppl. i. $132=$ Erythrococca aculeata.

barbata, Blanco, F1. Filip. ed. II. $561=$ Mallotus ricinoides.

barbinervis, Cham. \& Schlecht. in Linnaea, vi. (1831) 362.-Mexico.

Bernardia, Hlanco, F1. Filip. ed. I. $814=$ Mallotus ricinoides.

Bernardia, Linn. Syst. ed. X. $1298=$ Bernardia dicho toma.

caperoniaefolia, Baill. Adansonia, iv. (1864) $376=$ Bernardia caperoniaefolia.

castanicarpa, Roxb. Fl. Ind. iii. $848=$ Chaetocarpus castanocarpus.

celastrinea, Baill. Adansonia, iv. (1864) $375=$ Bernardia axillaris.

cordifolia, Roxb. Fl. Ind. iii. 849.-Ins. Molucc.

cuneata, Wall. Cat n. $7954=$ Homonoia retusa

dodecandra, Sesse, ex Cav, in Anal. Cienc. Nat. v. (1802) $254=$ Bernardia interrupta.

ferruginea, Poit. ex Baill. Etud. Gén. Euph. $418=$ Bernardia leprosa.

glandulosa, Blanco, Fl. Filip. ed. I. $814=$ Alchornea javensis.

gracilis, Salisb. Prod. $388=$ A. Acidoton.

hirsutissima. Baill. Adansonia, iv. (1864) $372=$ Bernardia peduncularis.

Houlletiana, Baill. 1. c. $378=$ Bernardia axillaris.

javasica, Mig. Fl. Ind. Bat. i. 11. 388.-Java.

\section{ADELIA}

Martii, Spreng. Syst. iii, $147=$ Bernardia axillaris, microphylla, A. Rich. Fl. Cub. Fanerog. ii. 209.Cuba.

monoica, Blanco, F1. Filip. ed. II. 561= Mallotus moluccanus

myrtifolia, Vent. ex Spreng. Syst. iii. 147.-Hab. nereifolia, Heyne, ex Roth, Nov. Pl. Sp. $375=$

Homonola riparia.

oxxacana, Hemsl. Biol. Centr. Am. Bot, iii. 129,Mexico.

papillaris, Blanco, F1. Filip. ed. II. $562=$ Mallotus Zollingeri.

pedunculosa, A. Rich. Fl. Cub. Fanerog, ii. 210.Cuba.

pulchella, Baill. Adansonia, iv, (1864) $374=$ Bernardia pulchella.

resinosa, Blanco, F1. Filip. ed. II. $562=$ Claoxylon Wallichianum

retusa, Wight, Ic. t. $1869=$ Homonoia retusa.

Ricinella, Linn. Syst. ed. X. 1298; Pl. Fam. Pugill. 29. - Ind. occ.

scabrida, Baill. Adansonia, iv. (1864) $373=$ Bernardia axillaris.

scandens, Span. in Hook. Comp. Bot. Mag. i. (1835) 350 , nomen.-Malaya.

spartioides, Baill. Adansonia, v, (1865) $319=$ Bernardia spartioides.

sylvestris, Griseb. in Goett. Nachr. (1865) 174. - Cuba tamanduana, Baill. Adansonia, iv. (1864) $374=$ Bernardia tamanduana.

imoriana, Span. in Hook. Comp. Bot. Mag. i. (1835)

350 , nomen.-Ins. Timor.

riloba, Hemsl. Biol, Centr. Am. Bot. iii. 130.Panama.

ADELIOIDES, R. Br. ex Benth. F1. Austral. i. 59 (1863 $=$ seq.

ADELIOPSIS, Benth, in Benth \& Hook. f Gen i. Add. $436^{\circ}$ (1862), MENISPERMACEAE, Benth. i. I. Add. 436 (1862). MENISPERM
$\&$ Hook. f. Gen. i. I. Add. 436 ; i. 964.

Adelioides, R. Br. ex Benth. Fl. Austral. i. 59 (1863).

decumbens, Benth. 1. c. ; et Fl. Austral. i. 59.Austral.

ADELMANNIA, Reichb. Consp. 110 (1828)= Bor richia, Adans. (Compos.)

ADELOBOTRYS， DC. Prod. iii. 127 (1828) MELASTOMACEAE, Benth. \& Hook, f. i. 750

Sarmentaria, Naud, in Ann. Sc. Nat. Sér. III. xviii. (1852) 140 .

Sphanellopsis, Steud. ex Naud. 1. c. 137.

Xeracina, Rafin. Sylva Tellur. 98 (1838)

adscendens, Triana, in Fourn. Bot. v. (1867) 210.Am. trop.

barbata, Triana, in Trans. Linn. Soc. xxviii. (1871) 68.-Bras.

ciliata, Triana, l. c. 68.-Guiana.

fuscescens, Triana, $l$. c.- N. Granat.

laxiflora, Triana, l. c.-Guiana.

Lindeni, Naud. in Belg. Hortic. xv. (1865) 98.Bras.

rotundifolia, Triana, in Trans. Linn. Soc. xxviii. (1871) 68. - Bras.

scandens, $D C$. Prod. iii. 127.-Gniana.

scandens, Macfad. Fl. Jamaic. ii. $99=$ adscendens.

ADELODA, Rafin. Fl. Tellur. iv. $61(1836)=$ Justicia Linn. (Acanthac.)

integra, Rafin. 1. c.-Hab.

serrata, Rafin. 1, c, = J. serrata.

ADELONEMA; Schott, Prod. Aroid. $316(1860)=$ Homalonema Schott (Aroid.)

erythropus, Schott, 1. c. 317 --Bras

ADELONENGA, Becc. in Ann. Jard. Buitenz, ii. 1885) 82. PALMAE, Benth. \& Hook. f. iii. 885. Geclvinkiana, Becc. l. c,-Malaya. variabilis, Becc. l. ca-Malays

ADELOSA, Blume, Mus. Bot. Lugd. Bat. i. $170^{\circ}$ (1850), VERBEVACEAE, Benth. \& Hook. fo ii. 1153.

microphylla, Blume, b. c,-Madag.
ADELOSTEMMA, Hook. f. in Hook. Ic. Pl. xv. (1883) 22. ASCLEPIADEAE.

gracillimum, Hook. f. l. c.-Burma.

ADELOSTIGMA, Steetz, in Peters, Reise Mossamb. Bot. 428 (1863). COMPOSITAE, Benth. \& Hook. f. ii. 285 .

athrixioides, Steetz, l. c. 430.-Afr, trop.

senegalensis, Benth. in Hook. Ic. Pl. t. I144.-Arr. trop.

ADENACANTHUS, Nees, in Wall. Pl. As. Rar, iii, 75 \& $196(1832)=$ Strobilanthes, Blume (Acanthac acuminatus, Nees, 1. c. iii. $84=$ S. acuminatus. latifolia, Nees, in DC. Prod. xi. 197.-Hab. ?

ADENACHAENA, DC. Prod. vi. $49 \quad(1837)=$ Phy maspermum, Less. (Compos. leptophylla, DC. 1. c. = P. leptophyllum parvifolia, DC. 1, c. = P. parvifolium. pubescens, DC. 1. c. 49.-Afr. austr.

ADENANDRA, Willd. Enum. Hort Berol. 256. (1809). RUTACEAE, Benth. \& Hook. f. i. 290. Glandulifolia, Wendl. Collect. t. 33, 37 (1808 Haenkaea, Usteri, Ann. Bot. vi. (1793) 117. HaEnkeA, F. W. Schmidt, Neue u. Seltne PA. 1 (1793); nomen prius.

OCENIA, F, G Dietr. Lex, Gaert. Nachtr, y, $34^{7}$ (1819)

OCKEA, F. G. Dietr. 1. c. i. 105 (1815)

OCkenia, Steud. Nom. ed. II. 24. (1840)

OKEA, Steud. 1. c. ed. I. $562(1821$

acuminata, Sweet, Hort. Brit, ed. I. $88=a$ moena

alba, Roem. \& Schult. Syst. v. 451.-Afr, aust

alternifolia, Cham. \& Schlecht. in Linnaea, v. (183! 52.-Afr. austr.

amoena, Bartl. \& Wendl.f. Diosm. 80.-Afr. austr. amoena, Link, Enum. Hort. Berol. i. $239=$ fragrans. Bartlingiana, Eckl. \& Zeyh. Enum. $101=$ viscida.

biseriata, E. Mey. ex Bartl. E Wendl. f. Diosm. 75. Afr. austr.

brachyphylla, Schlecht. in Linnaea, vi. (1831) 199.Afr. austr.

calycina, Steud. Nom. ed. II. i. 24.-Afr. austr.

ciliata, Sond. in Harv. E' Sond. Fl. Cap. i. 388.-Afr. austr.

cistoides, Eckl. \& Zeyh. Enum. $100=$ biseriata.

cordata, Link, Enum. Hort. Berol. i. $239=$ Barosma serratifolia.

coriacea, Eckl. \& Zeyh. Enum. 100 ex Sond. in Harv. \& Sond. Fl. Cap. i. $389=$ macrodenia.

coriacea, Bartl. \& Wendl, f. Diosm. $75=$ biseriata

coriacea, Lichtst. in Roem. \& Schult. Syst. $\mathrm{v} .452$. Afr. austr.

crenata, Willd. ex Bartl. \& Wendl. f. Diosm. $82=\mathrm{um}$ bellata.

cuspidata, Eckl. \& Zeyh. Enam. 101 ex Sond. in Harv. \& Sond. Fl. Cap. i. $385=$ obtusata

cuspidata, E. Mey. ex Bartl. \& Wendl. f. Diosm. \&7. -Afr. austr.

fragrans, A. Gonault, in Rev. Hortic. Sér. IV. i. 185:321.-Afr. austr.

fragrans, Eckl. \& Zeyh. Enum. $99=$ serpyllacea. fragrans, Roem. \& Schult. Syst. v. 451 -Afr, anst.

glandulosa, Lichtst. ex Roem. \& Schult. Syst. v. $4 \vdots 0$. umbellata.

gracilis, Eckl. \& Zeyh. Enum. 101.-Afr. austr. hamilis, Eckl. \& Zeyh. l. c. 99.-Afr. austr.

intermedia, Eckl. \& Zeyh. 1. c. $99=$ marginata.

Kraussii, Meissn. in Flora, xxvii, 184t 301 -Alr. austr.

lasiantha, Sond. in Har. E Sond. Fl. Cap. i. $\$ 90$. Afr. austr.

linearis, A. Juss, in Mém. Mns. Par. xii. 1825 ti] uniflora.

linifolia, Bartl, in Linnaca, xvii. (18.18' 359.-Af? anstr.

macradenia, Sond. in Harw. EN Sond. Fl. Cap. i. S8: Afr. auser.

marginata, Eckl. \& Zcyh. Enum. $99=$ linifolia.

marginata, Roem. \& Schult. Syst. v. 45.2 - A muser.

mundiacfolia. Eckl. E Zeyh. Enum. sy. - Afr. nustr.

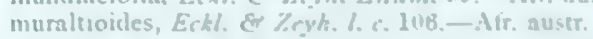
obtusata, Sond. in Hart. Ee Sond. Fl. Cap. I S:5 Afr. austr.

rata, Link, Enum. Hurt. Bcrol, i. 29:1 - amvet 


\section{ADENANDRA :}

pubescens, Sond. in Harv. E Sond. Fl. Cap. i. 385.Afr. austr.

rosmarinifolia, A. Juss. in Mém. Mus. Par. xii. (1825) $471=$ marginata

rotundifolia, Eckl. \& Zeyh. Enum, 101-Afr, austr. "ugosa, Otto, ex Steud. Nom. ed. II. i. $24=$ umbellata. Schmidtiana, Steud. l. c.-Afr. austr.

serpyllacea, Bartl. in Linnaea, xvii. (1843) 359.-Afr. austr.

serratifolia, Link, Enum. Hort. Berol. i. 239= Barosma serratifolia.

speciosa, Link, 1. c. = umbellata

tetragona, Sweet, Hort. Suburb. $45=$ Acmadenia tetragona.

trigona, Eckl. \& Zeyh. Enum. 100.-Afr. austr.

umbellata, Willd. Enum. Hort. Berol. 257.-Afr. austr.

uniflora, E. Mey. \& Drège, in Harv. \& Sond. F1. Cap. i. $391=$ serpyllacea

uniflora, Willd. Enum. Hort. Berol. 256.-Afr. austr.

villosa, Eck1. \& Zeyh. Enum. p. $101=$ pubescens.

villosa, Hort. ex Harv. \& Sond. Fi. Cap. i. $388=$ uniflora.

villosa, Lichtst. ex Roem. \& Schult. Syst. v. $452=$ cuspidata.

viscida, Eckl. E Zeyh. Enum. 101.--Afr. austr

Wendlandiana, Eckl. \& Zeyh. Enum. $100=$ umbellata.

ADFNANTHERA, Royen, ex Linn. Coroli. Gen. 7 (1737). LEGUMINOSAE, Benth. \& Hook. f. i. 590 GonsII, Adans. Fam. ii. 318 (1763).

Pongelion, Adans. Fam. ii. 319 (1763).

abrosperma, F. Muell. Fragm. v. 30.-Austral

aculeata, Roxb. Hort. Beng. 90 ; F1. Ind. ii. $37=$ Prosopis spicigera.

bicolor, Moon, Cat. Pl. Ceyl. 34, ex Thw. Enum. Pl. Zeyl. 98.-Zeylan.; Malaya.

Bonplandiana, H. B. \& K. Nov. Gen. et Sp. vi. $311=$ Entada polystachya.

chrysostachys, Benth. in Hook. Lond. Journ. Bot. iv. (1852) $343=$ Piptadenia chrysostachys.

circinalis, DC. Prod. ii. $446=$ Pithecolobium cly pearia.

falcata, Linn. Diss. Herb. Amb. 14 (Amoen. Acad. iv. 124), - Ins. Molucc.

Falcataria, Linn. Sp. PI. ed. II. $550=$ falcata. Gersenii, Scheff. in Flora, lii. (1869) 307.-Malaya.

glauca, Span. in Hook. Comp. Bot. Mag. i. (1835) 347 , nomen.-Malaya.

Gogo, Blanco, F1. Filip. ed. I. $358=$ Entada scandens.

microsperma, Teijsm. E Binn. in Nat. Tijdschr. Ned. Ind. xxvii. (1864) 58.-Java.

oudhensis, J. L. Stewart, ex Brand. For. Fl. Ind. $168=$ Piptadenia oudhensis.

pavonina, L.inn. Sp. Pl. 384.-As. trop.; Malaya

polita, Miq. Fl. Ind. Bat. i. 47.-Malaya.

scandens, Forst. f. Prod. $33=$ Entada scandens.

scandens, Vieill, in Bull. Soc. Linn. Normand. ix (1865) $340=$ Entada Adenanthera.

tetraptera, Schum. \& Thonn. Beskr. Guin. Pl. $213=$ Tetrapleura Thonningii.

triphysa, Dennst. Schluess. Hort. Malab. $32=$ Ailan thus malabarica.

ADENANTHES, Knight, Prot. 96. (1809) = seq

ADENANTHOS, Labill, P1. Nov. Holl, i. 28. t. 36 (1804). PROTEACEAE, Benth. \& Hook. f. uii. 173. apiculata, R. Br. Prod. Suppl. 9.-Austral.

armata, Meissn. in DC. Prod. xiv. $313=$ pnngens

barbigera, Lindl. Swan Riv. App. 86. n. 182.Austral.

crenata, Willd. ex Spreng. Syst. i. $472=$ cuneata.

cuneata, Labill. Pl. Nov. Hoil. i. 28. t. 36-Austral.

Cunninghamii, Meissn. in Lehm. Pl. Preiss. i. 513.-

Anstral.

Detmoldi, F. Muell. Fragm. viii. 149.-Austral.

Dobsoni, F. Muell. l. c. vi. 204.-Austral.

Drummondii, Meissn. in Lehm. Pl. Preiss. i. $514=$ apiculata.

filifolia, Benth. Fl. Austral. v. 355.-Austral.

flabellifolia, [Salisb. in] Knight, Prot. 96= cuneata.

flavidiflora, $F$. Muell. Fragm. i. 157-Austral.

Forrestii, F. Muell. in Wing, South Sc. Record, ii. (1882) 230.-Austral

linearis, Meissn. in DC. Prod. xiv. 311.-Austral.

\section{ADENANTHOS :}

Meissneri, Lehm. Pl. Preiss. i, 512 ; ii. 248.-Austral. obovata, Labill. Pl. Nov. Holl. i. 29. t. 37.-Austral. procumbens, Meissn. in Lehm. Pl, Preiss. i. 512; ii. 248 = apiculata.

pungens, Meissn. l. c. i. 515-Austral.

sericea, Labill. Pl. Now. Holl. i. 29. t. 38,-Austral

terminalis, $R$, Br. in Trans. Linn. Soc. x. (1810) 152.Austral.

velutina, Meissn. in DC. Prod. xiv. 312.-Anstral

venosa, Meissn. l. c.-Austral

ADENANTHUS, Roem. \& Schult. Syst. iii. 22, 397 $(1818)=$ praec.

ADENARIA, H. B. \& K. Nov, Gen, et Sp. vi. 185. t. 549 (1823). LYTHRARIEAE, Benth. \& Hook. f. i. 777.

floribunda, $H, B . \& \circ, l, c .188$, t. $549,-\mathrm{N}$. Granat

griseleoides, H. B. \& K. 1. c, $\mathbf{1 8 5}=$ floribunda.

lanceolata, Beurling, in Vet. Akad. Handl. Stockh. (1854) 124.-Panama.

parvifolia, Hook. Ic. Pl. t. $166=$ floribunda

purpurata, H. B. \& K. Nov. Gen. et Sp.vi. $185=$ floribunda.

ADENARIUM, Rafin. in Am. Monthly Mag. (1818) 266 = Arenaria, Linn. (Caryophyll.)

marinum, S. F. Gray, Nat. Arr. Brit. Pl. ii. $545=$ Aren. peploides.

maritimum, Rafin. New Fl. Am. i. 62=Aren. peploides.

peploides, Rafin. in Am. Monthly Mag. (1818) $266=$ Aren. peploides.

ADENELEUTEROPHORA, Rodrig. Orch. Nov. ii 170 (1881) ORCHIDEAE. graminifolia, Rodrig.l. c. 171--Bras.

ADENEMA, G. Don, Gen. Syst. iv. $201(1837)=$ Eni costema, Blume (Gentian.)

hyssopifolium, G. Don, I. c, = E. littorale.

ADENESMA, Griseb. in DC. Prod. ix. $65(1845)=$ praec.

ADENIA, Forsk. Fl. Aegypt. Arab。 $77(1775)=$ Modecca, Linn. (Passif.) venenata, Forsh. 1. c.-Arabia.

ADENIA, Torr. F1. New York, ii. t. $122(1843)=$ Pilea, Lindl. (Urtic.)

pumila, Torr. 1. c. = P. pumila.

ADENILEIMA, Reichb. Nom. 159 (1841) = seq

ADENiLEMA, Blume, Bijdr. 1120 (1826)= Neillia, D. Don (Rosac.).

fallax, Blume, 1. c. $1121=\mathrm{N}$. thyrsiflora

ADENILEMMA, Hassk. Cat. Hort. Bogor. Alt. 170 (1844) $=$ praec

ADENIUIM, Roem. \& Schult. Syst. iv. 35 \& 411 (1819) $A P O C Y N A C E A E$, Benth. \& Hook. f. ii. 722. arboreum, Ehrenb. Symb. Phys, 4.-Afr. trop.

Honghel, A. DC. in DC. Prod. viii. 412,-Afr. trop. Honghel, Lindl. Bot. Reg. xxxii. t. $54=$ obesum. multiflorum, Klotzsch, in Peters, Reise Mossamb. Bot. 279.-Afr, trop

namaquanum, Wyley, ex Harv. Thes. Cap. ii. 11. t. $117=$ Pachypodium namaquanum

obesum, Roem. \&o Schult. Syst. iv. 411.-Arab. ; Afr. trop.

speciosum, Fenzl, in Sitzb. Acad. Wien. Math. Nat. li. Abth. II. (1865) 140.-Afr. trop.

ADENOBASIUM, Presl, Symb. Bot. i. 39. t. 27 (1830) =Sloanea, Linn. (Tiliac.)

obtusifolium, Moric. P1. Nouv. 83 . t. $55=\mathrm{S}$, obtusa

salicifolium, Presl, Symb. Bot. i. 40 . t. $27=$ S. mono sperma.

ADENOCALYMMA, Endl. Ench. 347 (1841)=seq.

ADENOCALYMNA, Mart in Meissn. Gen. 300 (208) et in DC. Prod. ix. 199 (1840). BIGNONIACEAE, Benth \& Hook. f. ii. 1036.

Leguminaria, Bur. Monog. Bignon. 42 (1864).

\section{ADFNOCALYMNA :-}

Memora, Miers, in Proc. Roy. Hort. Soc. iii. (1863) 185

PaChyptera, DC. Prod. ix. (1840) 175.

acutissimum, Miers, in Ann. \& Mag. Nat. Hist. Ser.

III. vii. (1861) 395.-Bras,

alliaceum, Miers, 1. c. 394= Bignonia alliacea

brachybotrys, DC. Prod. ix, 203,-Guiana.

bracteatum, DC. i. c. 200.-Bras.

bracteolatum, $D C$. l. c. 200.-Bolivia

divaricatum, Miers, in Ann. \& Mag. Nat. Hist. Ser.

III. vii. (1861) 390.-Bras.

comosum, DC. Prod. ix. 201.-Bras.

coriaceum, DC. l. c. 202-Bras.

flavidum, Miers, in Ann. E Mag. Nat. Hist. Ser. III. vii. (1861) 389.-Bras.

flavum, Mart. ex DC. Prod. ix. 202.-Bras

floribundum, DC. Prod. ix. 201,-Bolivia

grandifolium, Mart. ex DC. L. C. 199.-Bras.

Guillemini, $D C$. l. c. 202.-Bras.

inundatum, Mart. ex DC. l. c. 201.-Bras.

japurense, Mart. ex DC. 1. c. 203.-Bras.

laevigatum, Mart. ex DC. 1. c. $200=$ marginatum.

lanceolatum, Miers, in Ann. \& Mag. Nat. Hist. Ser.

III. vii. (1861) 390.-Bras.

longeracemosum, Mart. ex DC. Prod. ix. 201.-Bras. macranthum, Mart, ex DC. 1. c. 203,-Bras.

macrophyllum, DC. l. c. 199.-Bras.

macrostachyum, Miers, in Proc. Roy. Hort. Soc. iii

(1863) 180.-Bras.

magnificum, Mart. ex DC. Prod. ix. 202.-Bras.

marginatum, DC. l. c. 200.-Bras.

nitidum, Mart. ex $D C$. $l$. c.-Bras.

prasinum, Miers, in Ann. E Mag. Nat. Hist. Ser. III. vii. (1861) 395 - - Bras.

paniculatum, Benth. ex Miers, l. c. 393.--Bras

pliciflorum, Mart. ex DC. Prod. ix, 202,-Bras.

prehensile, Miers, in Ann. \& Mag. Nat. Hist. Ser.

III. vii. (1861) 388.--Bras.

Salzmanni, DC. Prod. ix. 200.--Bras

scabriusculum, Mart. ex DC. l. c. 201.-Bras.

scansile, Miers, in Ann. \& Mag. Nat. Hist. Ser. III vii. (1861) 388--Bras

sepiarium, Mart, ex DC. Prod. ix. $200=$ nitidum.

stridula, Miers, in Ann. \& Mag. Nat. Hist. Ser. IJI vii. (1861) 392.-Bras

subsessilifolium, DC. Prod. ix. 199.-Bras.

veruciferum, Miers, in Ann. \& Mag. Nat. Hist. Ser.

III. vii. (1861) 393,-Bras.

ADENOCALyX, Bert. ex H. B. \& K. Nov. Gen. et Sp vi. $330(1823)=$ COULTERIA, H. B. \& K. = Caesal pinia, Linn. (Legum.).

racemosus, Bert. ex H. B. \& K. 1. $\mathrm{c}=\mathrm{C}$. mollis

remotus, Steud. Nom. ed. II. i. 428, sphalm. = praec.

ADENOCARPUM, D. Don, ex Hook. \& Am. in Hook. Lond. Journ. Bot. iii.(1841) $318=$ ADENOSPERMUM, Hook. \& Ain. = Chrysanthellum, Rich. (Compos.) tuberculatum, D. Don, ex Hook. \& Am. 1. c. = C. indicum

ADENOCARPUS, DC. Fl. Fr. Suppl. 549 (1815). LEGUMINOSAE, Benth. \& Hook. f. i. 481. anagyrifolius, Coss. Eo Bal. in Bull. Soc. Bot. Fr. xx. (1873) 246 ; xxii. (1875) 57, nomen,-Marocc anagyrus, Spreng. Syst. 1ii. 226.-Ins. Canar. anisochilus, Boiss. Diagn. Ser. II. ii. 5.-Hispan benguellensis, Welw. ex Baker, in Oliver, Fl. Trop. Afr. ii. 47.-Afr. trop

Bivonii, Presl, Fl. Sic. i. p. xix. $=$ intermedius.

Boissieri, Webb, Iter Hispan. $53=$ decorticans

cebennensis, Delile, Ind Sem. Hort. Monsp. (1838) =intermedius.

commutatus, Guss. F1. Sic. Prod. ii. $875=$ intermedius

complicatus, J. Gay, ex Gren. \& Godr. Fl. Fr. i. $364=$ intermedius.

decorticans, Boiss, in Bibl. Univ. Genèv. (Feb. 1836). -Hispan.

divaricatus, Sweet, Hort. Brit. ed. I. 112 =intermedius. foliolosus, DC. Fl. Fr. Suppl. 549.-Ins. Canar. frankenioides, Choisy, in DC. Prod. ii. 158=anagyrus. graecus, Griseb. Spicil. F1. Rumel. 1. $10=$ intermedius. grandiflorus, Boiss. in Bibl. Univ. Genèv. (Feb. 1836) -Gallia.

hispanicus, DC. Fl. Fr. Suppl. 549.-Hispan.

intermedius, $D C$. l.. .-Europ.; Oriens. 


\section{ADENOCARPUS :-}

Mannii, Hook. f. in Fourn, Linn. Soc, vii. (1864) 189 -Afr. trop.

parvifolius, DC. F1. Fr. Suppl. $549=$ intermedius. speciosus, Pomel, Nouv. Mat. Fl. Atl. 178.-Afr. bor. telonensis, DC. F1. Fr. Suppl. 549=grandiflorus? umbellatus, Coss. É Dur. in Ann. Sc. Nat. Sér. IV. i 1854) 222, nomen.-Afr, bor.

villosus, Boiss. Diaon. Ser I ii. $14=$ intermedius. viscosus, Webb \& Berth. Phyt. Canar. ii. $32=$ anagyrus. wolgensis, Spreng. Syst. iii. $226=$ Calophaca wol garica.

ADENOCAULON, Hook. Bot. Misc. i. 19. t. 15 (1830). COMPOSITAE, Benth. \& Hook. f. ii. 344. adhaerescens, Maxim. Prim. F1. Amur. 152=bicolor. bicolor, Hook. Bot. Misc. i. (1830) 19. t. 15-As, bor. Himal. ; Am. bor.

chilense, Less. in Linnaea, vi. (1831) 107.-Chili.

himalaicum, Edgew. in Trans. Linn. Soc. xx. (1851) 64 = bicolor.

integrifolium, Nutt. in Trans. Am. Phil. Soc. N. S. vii. (1841) $289=$ bicolor

Lechleri, Sch. Bip. in Flora, xxxviii. (1855) 113.Reg. Magell.

ADENOCHAENA, DC. Prod, vi. 680 (1837)=ADENACANTHA, DC. = Phymospermum, Less. (Compos.)

ADENOCHETON, Fenzl, in Flora, xxvii. (1844) $312=$ Cocculus, Linn. (Menisperm.)

phyllanthoides, Fenzl, 1. c. = C. Leaeba.

ADENOCHETUS, Baill. Etud. Gén. Euph. 653 (1858) = praec.

ADENOCHILUS, Hook. f. Fl. N. Zel. i. 246.t. 56 (1853). ORCHIDEAE, Benth. \& Hook. f. iii. 613 . gracilis, Hook. f.l.c.-N. Zel,

Nortoni, Fitzg. Austral.Orch. i. II. 2.-Austral.

ADENOCHLAENA, Boiss, ex Baill. Etud. Gén Euph. 472 (1858). EUPHORBIACEAE, Benth. \& Hook. f. iii. 307 .

Centrostylis, Baill. Etud. Gén. Euph. 469 (1858). SYMPHYLliA, Baill. 1. c. 473, t. 11 (1858)

Symphyllium, Benth. in Journ. Linn. Soc, xyii. (1878) 228.

calycina, Bedd. For. Man. Bot. 207.-Ind. or.

indica, Bedd. Fl. Sylv. ii. t. 261.-Ind. or.

leucocephala, Baill. Etud. Gén. Euph. $473=$ Cephalocroton leucocephalus.

silhetensis, Benth. in fourn. Linn. Soc. xvii. (1880) 228. - Ind or

zeylanica, Thw. Enum. Pl. Zeyl.270.-Zeylan.

ADENOCLINE, Turcz. in Bull. Soc. Nat. Mosc, xvi. (1843) 59. EUPHORBIACEAE, Benth. \& Hook. f iii. 310 .

Diplostylis, Sond. in Linnaea, xxiii. (1850) 113.

Paranenocline, Muell. Arg. in DC. Prod. xv. II $1141(1866)$

acuta, Baill. Etud. Gén. Euph. 457.-Afr. austr.

humilis, Turcz. in Bull. Soc. Nat. Mose. xvi. (1843) 61.-Afr. austr.

Mercurialis, Turcg. l. c, 60,-Afr, austr.

ovalifolia, Turcs. $l$. c.-Afr, austr.

pauciflora, Turcs. l. c. 61.-Afr. austr.

scrrata, Turc.. l. c. xxv. (1852) II. 180.-Afr. austr.

sessiliflora, Baill. Etud. Gín. Euph. 457.-Afr. austr.

sessilifolia, Turcr. in Bull. Soc. Nat. Mosc. xvi. (1843

61.-Afr. austr.

ADENOCREPIS, Blume, Bijdr。 $579 \quad(1825)=$ Baccaurea, Lour. (Euphorb.)

javanica, Blume, 1. c. = B. javanica.

lanceolata, Muell. Arg. in Linnaea, xxxii. (1863) $82=$ B. lanceolata.

tetrandra, Baill. Etud. Gén. Euph. $601=$ B. tetrandra.

ADENOCHAENA, Steud. Nom. ed. II, i. 25 1510 sphalm。= Adenachaena, DC.

ADENOCYCLUS, Less, in Linnaea, iv. (1829) 337 Oliganthes, Cass. (Compos.)

condensatus, Less, 1. $\mathrm{c}=\mathrm{O}$. coudensata,
ADENODISCUS, Turez. in Bull. Soc. Nat. Mosc, xix. 1846) Ir. $504=$ Belotia, A. Rich. (Tiliac.)

mexicanus, Turcz. 1, c. = B. grewiaefolia

ADENODUS, Lour. Fl. Cochinch. $294(1790)=$ Elaeocarpus, Linn. (Tiliac.)

sylvestris, Lour. $1, \mathrm{c}_{2}=\mathrm{E}$. sylvestris.

ADENOGRAMMA, Reichb, Iconogr. Exot, ii. 3.t 109 (1827). FICOIDEAE, Benth. \& Hook. f. i 858.

Steudelia, Presl, Steud. Nov. Pl. Gen. (1829); et Symb. i. 3. t. $2(1830)$

diffusa, Fenzl, in Ann. Wien. Mus. ii, (1840) 275 (err. typ. 255).-Afr. austr.

galioides, Fenzl, l. c. 277.-Afr. austr.

lampocarpa, E. Mey. ex Fenzl, in Ann. Wien. Mus. ii. (1840) 276. -Afr. austr

Mollugo, Reichb. Iconogr. Exot. ii. 3. t. 109.-Afr, austr.

oppositifolia, Hassk. in Flora, xxxi. (1851) 754.Java.

physocalyx, Fenzl, in Ann. Wien. Mus. ii. (1840) 276. -Afr. austr.

rigida, Sond. in Harv. \& Sond. Fl. Cap. 149.-Afr. austr.

sylvatica, Fensl, in Ann. Wien. Mus. ii. (1840) 275 (err. typ. 255).-Afr. austr.

ADENOGYNA, Rafin. New Fl. Am. i. 62 (1836)= Saxifraga, Linn

sarmentosa, Rafin. 1. c. $63=\mathrm{S}$. sarmentosa

ADENOGYNE, Klotzsch, in Wiegm. Archiv, (1841) 183 = Sebastiania, Spreng. (Euphorb.) angustifolia, Klotzsch, 1. c. $184=\mathrm{S}$. angustifolia. brachyclada, Klotzsch, 1. c. $=\mathrm{S}$. brachyclada. discolor, Klotzsch, 1. c. = Gymnanthes marginata guianensis, Klotzsch, in Schomb. Fauna \& Fi. Guy. $1185=\mathrm{S}$. guyanensis

marginata, Klotzsch, in Wiegm. Archiv, vii. (1841) 184 $=$ Gymnanthes marginata.

mucronata, Klotzsch, 1, c. =S. Schottiana

pachystachya, Klotzsch, 1. c. = S. pachystachys. rotundifolia, Klotzsch, I. c. =S. brevifolia.

serrata, Klotzsch, 1. c. $=$ S. serrata.

ADENOGYNE, Rafin, Fl, Tellur, ii, 67 (1836) Saxifraga, Linn.

ADENOGYNUM, Reichb. f. \& Zoll. in Verh. Natuturk. Ver. Nederl. Indie, i. (1856 23; et in Linnaea, xxviii. (1856) $325=$ Chloradenia, Baill. (Euphorb.) 312.

discolor, Reichb. f. \& Zoll. 11. cc. = C. discolor odontophyllum, Miq. F1. Ind. Bat. i. II. 400.-Java.

ADENOGYRUS, Klotzsch, in App. Ind. Sem. Hort Berol. (1854) $\boldsymbol{l}$; et in Walp. Ann. iv. $226(1857)=$ Scolopia, Schreb. (Bixin

Braunit, Klotzsch, Il. cc.-Hab. ?

ADENOLEPIS, Less. in Linnaea, vi. (1831) $510=$ Cosmos, Cav. (Compos.

calva, Sch. Bip, in Miq. F1. Ned. Ind. ii. $79=$ Cosmos sulphureus,

pulchella, Less. in Linnaea, vi. 510 (1831).-.-Ins Sandvic.

ADENOLINUM, Reichb. Handb. (1837) $306=$ Linum, Linn.

alpicola, Reichb. 1. c. $307=\mathrm{L}$. alpinum.

alpinum, Reichb. 1. c.; et Ic. Fl. Germ. xvi. $65=$ L. alpinum.

angustifolizm, Reichb. 1. c. $307=\mathrm{L}$, angustifolium ausiriaum, Reichb. 1. c. 307 ; et Ic. Fl. Germ. xvi $66=$ L. austriacum.

barbatulum, Reichb. Ic. Fl. Germ. xvi. $73=\mathrm{L}$, an striacum.

barbulatum, Schur, Enum. Pl. Transs. $127=$ L. bar bulatum.

Leonii, Reichb. Ic. Fl. Germ. xvi. $65=$ L. Leonii marginatum, Reichb. Handb. 307 ; et Ic. Fl. Gerın. xvi. $73=\mathrm{L}$, austriacum.

montanum, Reichb. Ic. Fl. Germ. xvi. $65=$ L. montanum.

nervosum, Reichb. Handb. $807=\mathrm{L}$. nervosum.

pallescens, Reichb. I. $c_{0}=L$, pallesicens.
ADENOLINUM:-

perenne, Reichts. Ic. FI. Germ. xvi. $65=\mathrm{L}$, perenne.

provinciale, Fourr, in Ann. Soc. Linn. Lyon, N. S.

(1868) $350=\mathbf{L}$. alpinum.

pyrenaicum, Reichb. Handb. $307=\mathrm{L}$. alpinum.

sibiricum, Reichb. 1. c. $307=\mathrm{L}$. sibiricum.

squamulosum, Reichb. Ic. Fl, Germ.

squamulosum.

Tommasinii, Reichb. 1. c.-Europ.

ADENONCOS. Blume, Bijdr. $381(1825)=$ Sarco chilus, R. Br.? (Orchid.)

virens, Blume, l. co-Java.

ADENONEMA, Bunge, in Mém. Sav, Étrang. Pétersl, ii. (1836) 548; reimpr. Verz. Suppl, Fl. Alt. Stellaria, Linn. (Caryophyll).

petraeum, Bunge, 11. cc. $=\mathrm{S}$. petraea

ADENOON, Dalz, in Hook. Kew Journ, ii. 185 344. COMPOSITAE, Benth. \& Hook. f. ii. 225 . indicum, Dalz. l. c.,-Ind. or.

ADENOPA, Rafin. Fl. Tellnr. iii. $37(1836)=$ Drosera Linn.

anglica, Rafin. 1. c. = D. anglica.

ADENOPAPPUS, Benth. Pl. Hartw, 41 ' 1840 COMPOSITAE, Benth. \& Hook fo ii. 411.

persicaefolius, Benth. l. c.-Mexico.

ADENOPELTIS, Bert. in Bull. Féruss. xxi. (1831) nomen; et ex A. Juss, in Ann. Sc. Nat. Sér. I. xxy (1832) 24. EUPHORBIACEAE, Benth. \& Hook. iii. 338 .

Colliguaya, Bert. l. c.-Chili.

ADENOPETALUM, Klotzsch \& Garcke, in Monatsl, Akad. Berl. 1859 (1860) 250; et Abh. Acad Berl. (1860) $47=$ Euphorbia, Linn.

boerhaaviffolizm, Klotzsch \& Garcke, 11. cc. 250, t" E. boerhavifolia

bracteatum, Klotzsch \& Garcke, II. cc. 48 scabrella.

discolor, Klotzsch \& Garcke. 11. cc. 49 - E discolor.

ellipticum, Klotzsch \& Garcke, in Monatsb. Akad.

Berl. 1859 (1860) $250=$ E. graminea.

ellipticum, Klotzsch \& Garcke, in Abh. Akad. Berl. 1860) $50=\mathrm{E}$. saccharata.

gramineum, Klotzsch \& Garcke, in Monatsb. Akad. Berl. (1859) 250 ; et in Abh. Akad. Berl. (1560 $\$ 7$ E. graminea.

Hoffmanni,. Klotzsch \& Garcke, 11. cc. 250, 47 E. graminea.

irasuense, Klotasch \& Garcke, 11. cc. 250. $50=$ graminea.

mexicanum, Klotzsch \& Garcke, in Abb. Akad. B.rl (1860) $50=\mathrm{E}$. graminea,

Oerstedii, Klotzsch \& Garcke, in Monatst. Akad, Kerl. 1859) 250 ; et in Abh. Akad. Berl. $(1860 ; 40=1$ graminea.

pictum, Klotzsch \& Garcke, 11. cc. $250,47,-\mathrm{Hab}$ ?

pubescens, Klotzsch \& Garcke, 11. cc. 250, $f 9=$ graminea.

sphaerorhisum, Klotzsch \& Garcke, in Monatsb. Akarl. Berl. (1859) 250.-Hab.

subsinuatum, Klotzsch \& Garcke, in Monatib. Akad. Berl. (1859) 250 ; et in Abh. Akad. Berl. '1860) $4 \mathrm{~s}$ $=\mathrm{E}$. graminea

ADENOPETALUM, Turcz, in Bull. Suc. Mat. Mos xxxi. (1858) 1. $416=$ Vitis, Linn. (Ampel.

palmatum, Turcz. 1. c. 417 . - Hab. ?

ADENOPHAEDRA. Muell. Arg in Mart. Fl. Bm xi. II. 385 t 101 1Si\$ ELPBORBICEA Benth \& IIook f iii. \$14.

megalophylla, Muell. Arg. l. c. \$\$6.-Bras.

ADENOPHORA. Fisch, in Mem, Soc, Yat. Mo vi. $(18231$ 165. CAIMPAVCLACEAE, linent. Iluok. I. ii. jei3

FlOERKFA, Spreng. Anleit. ii. 11. 523 1515.

communis, Fisch. I. c. 168.-Eurup.

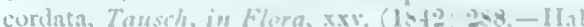

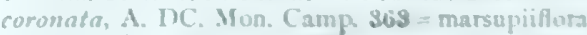

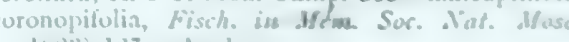

Is:D 167. - As bor

rispala, Turce ex Lesteb. Fl. Russ ii. 849 . corer 


\section{ADFNOPHORA:-}

Tenticulata, Fisch. in Mém. Soc. Nat. Mosc. vi. (1823) 167 = tricuspidata

divaricata, Franch. \& Sav. Enum. Pl. Fap. ii. 423.

Japon.
Fischeri, G. Don, in Loud. Hort. Brit. $75=$ communis

Gmelini, Fisch in Mém. Soc. Nat. Mosc. vi. (1823) 167.-Dahur.

intermedia, Sweet, Hort. Brit. ed. I. $249=$ communis, intermedia, Ledeb. Ind. Sem. Hort. Dorpat. (1824) 1 = coronata.

Isabellae, Hemsl. in Fourn. Bot. xiv. (1876) 207.China.

Lamarkii, Fisch. in Mém. Soc. Nat. Mosc. vi. (1823) 168. - Sibir

latifolia, Fisch. l. c.-Sibir

liliflora, Schur, in Verh. Siebenb. Ver. Naturw. iv. (1853) $48=$ communis

Jitifolia, Ledeb. Cat. Hort. Dorp. (1822); ex A. DC. Prod. vii, $492=$ communis.

marsupiiflora, Fisch. in Mém Soc. Nat. Mosc. vi. (1823) 167.-Dahur.

montana, Turcz. in Bull. Soc. Nat. Mosc, xxi. (1848) II. 484,-Dahur.

nikoensis, Franch, \& Sav, Enum, Pl. Fap. ii.423.Japon.

pereskiaefolia, G. Don, in Loud. Hort. Brit. $74=$ latifolia.

periplocaefolia, A.DC. Mon. Camp. 361.-Sibir.

Pichleri, Vis. Suppl. ex Nym. Consp. 479=Campanula trichocalycina.

polymorpha, Ledeb. Fl. Alt. i. 246 in nota.-Rossia.

pomponiifolia, Fisch. in Mém. Soc. Nat. Mosc. vi, 1823) $167=$ Gmelini.

Rabelaisiana, G. Don, in Loud. Hort. Brit. 75.sibir.

remotiflora, Mig. Ann. Mus. Bot. Lugd. Bat. ii. 193. -Japon.

reticulata, G. Don, in Loud. Hort. Brit. Suppl. 471.Sibir.

sinensis, A. DC. Mon. Camp. 354.-China

stricta, Miq. Ann.Mus. Bot. Lugd.Bat. ii. 192.-Japon.

stylosa, fisch in Mém. Soc. Nat. Mosc. vi. (1823) 168. As. bor

stylosa, Reichb. Iconogr. Exot. 32. t. $45=$ communis.

suaveolens, Reichb. 1. c. 22 . t. $32=$ communis

tetraphylla, Fisch. in Mém. Soc. Nat. Mosc. vi. (1823) $169=$ verticillata

trachelioides, Maxim. Prim. Fl. Amur. 186.-China.

tricuspidata, A. DC. Mon. Camp. $355=$ denticulata.

triphylla, A. DC. l. c. 365--Japon.

verbenaefolia, Bunge, ex Heynh. Nom. ii. 9.-Japon.

verticillata, Fisch. in Mém. Soc. Nat. Mosc. vi. (1823)

167.-Dahur.; Japon.

ADENOPHYLLUM, Pers. Syn, ii. 458 (1807)

COMPOSITAE, Benth. \& Hook. f, ii. 408

Dyssodia, Willd. Enum. Hort. Berol. 900 (1809).

Lebetina, Cass. in Dict. Sc. Nat. xxy. 394 (1822).

SCHLECHTENDAHLIA, Willd. Sp. Pl. iii. 2125 (1803).

WILIDENow A Cav Ic. Pl, i. 61, t. 89 (1791)

capillaceum, DC. Prod. v. $638=$ coccineum.

coccineum, Pers. Syn. ii. 458.--Mexico.

Porophyllum, Hemsl. Biol. Centr. Am. Bot. ii. 218.Mexico.

Wrightii, A. Gray, Pl. Wright. ii. 92.-Mexico.

ADENOPLEA, Radlk. in Bremen, Abh. viii. (1883) $406=$ Buddleia, Houst. (Logan.)

baccata, Radlk. 1. c. $407=$ B. sinuata

sinuata, Radlk. in Ber. Deutsch. Bot. Ges. ii. (1884) $261=$ B. sinuata.

ADENOPLUSIA, Radlk. in Bremen Abh. viii (1883) 461. LOGANIACEAE

xillaris, Radlk. l. c. 462.-Madag.

Wildenowii, Radlk. in Ber. Deutsch.Bot. Ges, ii. (1884) 259.-Madag.

ADENOPODIA, C. Presl, Epimel, Bot. $206(1849)=$ Entada, Adans. (Legum.)

spicata, C. Presl, 1. c. $207=$ E. natalensis.

ADENOPUS, Benth. in Hook. Niger F1. 372 (1849). CUCURBITACEAE, Benth \& Hook, f i 823

abyssinicus, Hook. f. in Oliver, Fl. Trop. Afr. ii. 528 -Afr. trop.

\section{ADENOPUS :-}

brevillorus, Benth, in Hook. Niger Fl. 372,-Afr trop.

Cienkowskii, Schweinf, Rel. Kotschy. 45. t. $30=$ Peponia Cienkowskii.

eglandulosus, Hook. f. in Oliver, Fl. Trop. Afr. ii. 529 - Afr. trop.

longiflorus, Benth. in Hook. Niger Fl. 372.-Afr. trop.

ADENORHOPIUM, Reichb. Consp. 195 (1828)= ADENOROPIUM, Pohl, = Jatropha, Linn. $(\mathrm{Eu}-$ phorb.).

ADENORIMA, Rafin. F1. Tellur. iv. 112 (1836)= Euphorbia, Linn.

punicea, Rafin. 1. c. = E. punicea.

ADENOROPIUM, Pohl, Pl, Bras. Ic. i. 12. t. 9 (1827)= Jatropha, Linn. (Euphorb.)

Berterii, Pohl, 1. c. $14=$ J. Berterii.

divaricatum, Pohl, 1 , c. $14=\mathrm{J}$. divaricata.

divergens, Pohl, 1. c. $15=\mathrm{J}$. Pohliana.

elegans, Pohl, 1. c. $15=$ J. gossypifolia.

ellipticum, Fohl, 1. c. 13. t. $9=$ J. elliptica.

Forskohlii, Pohl, 1. c. $15=\mathrm{J}$. glandulosa.

glaucum, Pohl, 1. c. $15=\mathrm{J}$. glauca.

gossypifolium, Pohl, 1. c. $16=\mathrm{J}$. gossypifolia

hernandiaefolium, Pohl, 1. c. $14=\mathrm{J}$. hernandiaefolia

integerrimum, Pohl, 1. c. $14=\mathrm{J}$. integerrima.

Facquini, Pohl, l. c. $15=\mathrm{J}$. gossypifolia.

luxurians, Pohl, 1. c. $16=\mathrm{J}$. Pohliana

Martiusii, Pohl, 1. c. = J. Martiusii.

mollissimum, Pohl, l. c. $15=\mathrm{J}$. Pohliana.

multifidum, Pohl, 1. c. $16=\mathrm{J}$. multifida

mutabile, Pohl, 1. c. $14=\mathrm{J}$, matabilis.

panduraefolium, Pohl, 1. c. $14=\mathrm{J}$. hastata.

peltatum, Pohl, 1. c. $16=\mathrm{J}$. peltata.

ribifolium, Pohl, I. c. $15=\mathrm{J}$. gossypifolia.

Roxburghii, Kostel. Allg. Med.-pharm. Flora, v. $1750=$

J. glandulifera

spinosum, Pohl, Pl. Bras. Ic. i. $15=\mathrm{J}$. spinosa.

tomentosum, Pohl, 1. c. $16=\mathrm{J}$. tomentosa.

tripartitum, Pohl, 1. c. $15=$ Manihot tripartita

variegatum, Pohl, 1. c. $14=\mathrm{J}$. variegata.

villosum, Pohl, 1. c. 15= J. Pohliana

ADENOSACHMA, A. Juss, in Orb. Dict. xi. 255 (1849) $=$ seq.

ADENOSACME, Wall. Cat. n. 6280-82 (1832) RUBIACEAE, Benth, \& Hook, f. ii. 69.

LAwIA, Wight, in Calc, Journ. Nat. Hist, vii (1847) 14

Mycetia, Reinw. in Syll. Ratisb. ii. (1828) 9

cauliflora, Miq. Fl. Ind. Bat. ii. 215.-Malaya.

fasciculata, Miq. l. c. 216.-Tava.

holotricha, Miq. l. c. 217.-Sumatra.

lanceolata, Miq. l. c 217.-Sumatra.

Lawii, Hook. f. Fl. Brit. Ind. ii. 96.-Ind. or

longifolia, Wall. Cat. n. 6280.-Ind. or.

macrostachya, Hook. f. Fl. Brit. Ind, iii. 96,--Ind. or.

malayana, Wall. Cat. n. $6282=$ longifolia

nepalensis, Wall l c. n $6281=$ longifolia.

oborato, Miq Fl. Ind. Bat ii. $216=$ fasciculata

stipulata, Hook. f. Fl. Brit. Ind. iii. 95.-Ind. or

ADENOSCILLA, Gren. \& Godr. F1. Fr. iii. 187 (1855 = Scilla, Linn. (Liliac.)

bifolia, Gren. \& Godr. 1. c. $=$ S. bifolia

nivalis, J. Gay, ex Baker, in Journ. Linn. Soc. xiii. (1873) $239=\mathrm{S}$. bifolia

unifolia, Texidor, in Rev. Prog. Cienc. xviii. (1869).Cf. Bull. Soc. Bot. Fr. xvi. (1869); Bibl. $222=$ S bifolia?

ADENOSELEN, Spach. Hist. Vég. Phan, x. $23(1841)=$ ADENOSOLEN, DC. = Marasmodes, DC. (Compos.).

ADENOSEPALUM, Fourr. in Ann. Soc. Linn. Lyon, N. S. xvi. (1868) $352=$ Hypericum, Linn. hirsutum, Fourr. 1. c. $353=\mathrm{H}$, hirsutum. montanum, Fourr. $1 \mathrm{c}=\mathrm{H}$. montanum. nummularium, Fourr. 1. $\mathrm{c}_{\mathrm{o}}=\mathrm{H}$. nummularium pulchrum, Fourr. 1. c. $352=\mathrm{H}$. pulchrum. tomentosum, Fourr. 1. $\mathrm{c}=\mathrm{H}$, tomentosum
ADENOSMA, R. Br. Prod. 442 (1810). SCROPHULARINEAE, Benth. \& Hook. f. ii. 949.

Anisan'thera, Griff. Notul. iv, 100 (1854).

Pterostigma, Benth. Scroph. Ind. 20 (1835)

Spathestigma, Hook. \& Arn. Bot. Beech. Voy. 204 (1836)

Brownii, Zipp. ex Span. in Linnaea, xv. (1841) 332, nomen.-Malaya.

caeruleum, R. Br. Prod. 443-As, trop.; Austral.

camphoratum, Hook. f. Fl. Brit. Ind. iv. 264.Zeylan.

capitatum, Benth. ex Hance, in Fourn. Linn. Soc. xiii. (1873) 114.-As. trop.

chenopodiifolia, Spreno. Syst. ii. 829.-Ins. Societ,

chenopodioides, Zipp. ex Span. in Linnaea, xv. (1841) 332, nomen.-Hab.?

cuspidatum, Benth. in Wall. Cat. n. $3852=$ Linden bergia macrostachya.

fragrans, Spreng. Syst. ii. 829.-Ins. Societ.

grandiflorum, Benth. ex Hance, in Fourn. Linn. Soc. xixi. (1874) 114.-China.

hirsutum, Kurz, in Fourn. As. Soc. Beng. xlv. (1876 II. 143.-Ins. Nicobar.

macrophyllum, Benth. in Wall. Cat. n. 3853.-Ind. or. malabaricum, Hook. f. Fl. Brit. Ind. iv. 264,Malabar.

microcephalum, Hook, f. l. c-As. trop.

Muelleri, Benth. Fl. Austral. iv, 485-Anstral.

ovatum, Benth. ex Hook. f. Fl. Brit. Ind. iv. 263.Malaya.

subrepens, Benth. ex Hook. f. l. c.-Zeylan.

triflora, Seem. Fl. Vit, $284=$ Limnophila Roxburghii. villosum, Benth, in Wall. Cat. n, 3851=caeruleum.

ADENOSMA, Nees, in Wall. Pl. As. Rar. iii. 75 (1832) = Cardanthera, Buch.-Ham. (Acanthac.).

affinis, Griff. Notul. iv. $133=$ Strobilanthes Acrocephalus.

africana, T. Anders, in Journ. Linn. Soc. vii. (1864) 21 -Afr. trop.

balsamea, Spreng. Syst. ii. $829=$ C. balsamica.

biplicata, Nees, in Wall. Pl. As. Rar. iii. $79=\mathrm{C}$ avana.

elongata, Blume, Bijdr. $757=$ Ebermaiera elongata

Griffithii, T. Anders. in Journ. Linn. Soc. ix. (1867) 454 $=\mathrm{C}$. Griffithii.

lanceolata, Blume, Bijdr. $757=$ E. lanceolata.

pinnatifida, T. Anders. in Journ. Linn. Soc. ix. (1867 $455=\mathrm{C}$. pinnatifida .

polysperma, Spreng. Syst. ii. $829=$ Hygrophila Serpyllum.

spatulata, Blume, Bijdr. $737=$ Ebermaiera glauca

Thymus, Nees, in Wall. Pl. As. Rar. iii. $79=\mathrm{C}$. balsamica.

triflora, Nees, 1. c. $=$ C. triflora

Thwaitesii, T. Anders. in Thw. Enum. Pl. Zeyl. 224 ; et in Journ. Linn. Soc ix. (1867) $455=\mathrm{C}$. Thwaitesii.

uliginosa, Nees, in R. Br. Verm. Schrift, iii. $298=\mathrm{C}$ uliginosa.

verticillata, Nees, in DC. Prod. xi. $69=$ C. verticillata.

ADENOSOLEN, DC. Prod vi, $136(1837)=$ Maras modes, DC. (Compos.)

tenuifolius, DC. 1. c.-Afr. austr.

ADENOSPERMUM, Hook. \& Arn. in Hook. Journ. Bot. iii. (1841) $318=$ Chrysanthellum, Rich. (Compos.) tuberculatum, Hook. \& Arn. 1. c. = C. indicum.

ADENOSTEGIA, Benth. in Lindl. Syst. Nat. ed. II. 445 (1836) = Cordylanthus, Nutt. (Scrophul.)

rigida, Benth. 1. $\mathrm{c}=\mathrm{C}$. filifolius.

ADENOSTEMA, Desport. in Dict. Sc. Nat, i. 256 (1816) $=$ seq.

ADENOSTEMMA, Forst. Char. Gen. 89. t. 45 (1776). COMPOSITAE, Benth. \& Hook. f. ii. 239 Lavenia, Sw. Prod. Veg. Ind. Occ. 112 (1788). angustifolium, Arn. in Nov. Act. Nat. Cur. xviii. 1836) $347=$ viscosum

aquaticum, D. Don, Prod. F1. Nep. $81=$ viscosum. Berterii, DC. Prod. v. 110.-Ins. S. Doming. biflorum, Less. Syn. Comp. $136=$ Wedelia biflora. brasilianum, Cass. in Dict. Sc. Nat. xxv. 363.-Bras. caffrum, $D C$. Prod. v. 112.-Afr. austr.

decumbens, Don, ex Heynh. Nom. i. $19=$ Beretrii

Dregei, DC. Prod. v. 111.-Afr. austr. 
ADENOSTEMMA :-

elatum, D. Don, Prod. F1. Nep. 181= viscosum. erectum, DC. Prod. v. $113=$ viscosum. erectum, DC. Prod. v. $113=$ viscosum.
fastigiatum, DC. 1 . c. $111=$ viscosum.

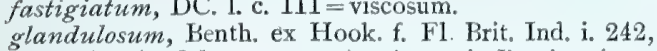
sphalm. (=Odontostemma) = Arenaria Benthami glutinosum, $D C$. Prod. v. 111.-Ins. Sandy. Gymnocoronis, Sch. Bip. ex Baker, in Mart. Fl. Bras. vi. II. $183=$ Gymnocoronis spilanthoides, hirsutum, $D C$. Prod. v. 113.-Java.

hirtiflorum, Benth. Pl. Hartw. 75.-Mexico.

lanceolatum, Miq. Fl. Ind. Bat. ii. 24.-Malaya.

latifolium, D. Don, Prod. F1. Nep. $181=$ viscosum.

leiocarpum, DC. in Wight, Contrib. $9=$ viscosum.

macrophyllum, DC. Prod, v. $113=$ viscosum.

madurense, DC, in Wight, Contrib. $9=$ viscosum.

mauritianum, DC. Prod. v. $110=$ viscosum.

microcephalum, DC. 1. c. $111=$ viscosum

natalense, $D C . l$. c. 112.-Afr. austr.

nitidum, Spreng. Syst. ii. 357, lapsu=Gomortega nitida.

ovatum, Miq. Fl. Ind. Bat. ii. 25.-Malaya.

parviflorum, DC. Prod. ₹. $\mathbf{1 1 1}=$ viscosum

Perrottetii, DC. l. c. 110.-Prom. Virid.

platyphyllum, Cass. in Dict. Sc. Nat. xxv. 363.Peruv.

reticulatum, DC, in Wight, Contrib, $8=$ viscosum.

rivale, Dalz. in Hook. Kew Journ. iii. (1851) $231=$ viscosum.

Roylei, DC. Prod. v. $112=$ viscosum.

rufescens, Sch. Bip. in Zoll. Syst. Verz. Ind. Archip. 120 , nomen.--Malaya.

rugosum, DC. in Deless. Ic. Sel. 4. t. $10=$ viscosum. scaevolifolium, Mart. ex Baker, in Mart. Fl, Bras. vi II. $186=$ suffruticosum

Schimperi, Sch. Bip. ex A. Rich. Tent. Fl. Abyss, i. 382.-Abyss.

suffruticosum, Gardn. in Hook. Lond. Fourn. Bot. vi, (1867) 433.-Bras.

Swartzii, Cass, in Dict. Sc. Nat, xxv, 362,-Ind. occ. ; Ecuador.

tinctorium, Cass. 1. c. $=$ viscosum.

triangulare, DC. Prod. v. $113=$ viscosum.

viscosum, Forst. Char. Gen. 90.-Geront. trop.

ADENOSTEMON, Spreng. Anleit. ii. 788 (1818)=seq.

ADENOSTEMUM, Pers. Syn. i. $467(1805)=$ Gomortega, Ruiz \&e Pav. (Laurin.?).

nitidum, Bert. Merc. Chil. 557; ex Am. Journ. Sc. xix. (1831) $67=$ Cryptocarya Peumus.

nitidum, Pers. Syn, i. $467=$ G. nitida.

ADENOSTEPHANUS, Klotzsch, in Linnaea, xv. (1841) $51=$ Euplassa, Salisb. (Proteac.)

austro-caledonicus, Brongn. \& Gris, in Bull. Soc. Bot. Fr. x. (1863) 229 . - N. Caled.

bahiensis, Meissn. in Mart. Fl. Bras. v. I. 94. t. 36.Bras.

Bleasdalii, Benth. F1. Austral. v. 417.-Austral.

guyanensis, Meissn. in Mart. Fl. Bras. v. I. $95=\mathrm{E}$ meridionalis.

incana, Klotzsch, in Linuaea, xv. (1841) 52.-Bras

inaequalis, Endl. Gen. Suppl. iv. II. 87.-Bras.

laxiflora, Meissn, in Mart. F1. Bras. v. I. 94.-Bras

nitida, Meissn. 1. c.-Bras.

organensis, Endl. Gen. Suppl, iv. II. 87.-Bras.

Sellowii, Klotzsch, in Linnaea, xv. (1841) 52.-Bras.

ADENOSTOMA, Blume, in Flora, viii. (1825) 680, nomen. SCROPHULARINEAE.

ADENOSTOMA, Hook. \& Am. Bot. Beech. Voy. 139, et 388. t. 30 (1832). ROSACEAE, Benth. \& Hook. f. i. 613 .

brevifolium, Nutt. ex Torr. \& Gray, F1. N. Am. i. $430=$ fasciculatum.

fasciculatum, Hook. \& Arn. Bot. Beech. Voy. 139, 338 t. 30.-Calif

sparsifolium, Torr in Emory, Notes Mil. Reconnois. 140 ; Bot. Bound. 63. t. 20,-Calif.; Mexico.

ADENOSTYLES, Cass, in Dict. Sc. Nat. i. Suppl. 59 (1816). COMPOSITAE, Benth. \& Hook. \& ii. 247.

Adenostylium, Reichb. Ic. Fl. Germ, xvi, II. $895(1853)$

\section{ADENOSTYLES :}

albida, Cass. 'Bull. Soc. Philom. 1816;' Dict. Sc

Nat. i. Suppl. 60.-Europ.

albifrons, Reichb. Fl. Germ. Excurs. $278=$ albida

Alliariae, Kern. in Oestr. Bot. Zeitschr. xxi. (1871) 12 -Europ.

alpina, Bluff \& Fing. Comp. Fl. Germ. ii. $829=$ viridis.

alpina, Kern. in Oestr. Bot. Zeitschr.xxi. (1871) 12.-

Europ.

australis, Nym. Consp. $396=$ viridis

candidissima, Cass. in Dict. Sc. Nat. i. Suppl. 60.Europ

dubia, Reichb. f. Ic. Fl. Germ. xvi. Mr.-Europ.

glabra, DC. Prod. v, $203=$ viridis.

hirsuta, Fourr. in Ann. Soc. Linn. Lyon, N. S. xvi 1868) $401=$ albida

hybrida, DC. Prod. v. $204=$ alpina, candidissima, leuco phylla, viridis.

leucophylla, DC. 1. c. vii. $271=$ orientalis.

leucophylla, Reichb. Fl. Germ. Excurs. $278=$ candidissima.

macrophylla, Tenore, Syll. ex Nym. Consp. $396=$ viridis.

Nardosmia, A. Gray, in Proc. Am. Acad. viii. (1873) $631=$ Cacaliopsis Nardosmia.

nebrodensis, Strobl, in Flora, 1xv. (1882) 196.-Sicil,

orientalis, Boiss. Fl. Orient. ii., 155.-Oriens.

Petasites, Bluff \& Fing. Comp. Fl. Germ. ii. $329=$ albida.

pontica, C. Koch, in Linnaea, xiii. (1839) 696.-As Min.

pyrenaica, Lange, in Kjoeb. Vidensk. Meddel. (1861) 64.- Hispan.

viridis, Cass. in Dict. Sc. Nat. i. Suppl. 60.-Enrop

ADENOST'YLES, Benth. \& Hook. f. Gen. iii. 599 (1883) err. typ. $=$ seq.

ADENOSTYLIS, Blume, Bijdr. 414 (1825)=Zeuxine Lindl. (Orchid.)

emarginata, Blume, $1 . \mathrm{c} .=\mathrm{Z}$. sulcata.

integerrima, Blume, $1 . c_{.}=Z$. integerrima

ADENOSTYLIUM, Reichb. f. Ic. Fl. Germ。xvi. 2. $t$ 895 (1853) = Adenostyles, Cass. (Compos. dubium, Reichb. 1. c. = Adenostyles dubia. hybridum, Reichb. 1. c. = Adenostyles viridis.

ADENOTHECA, Welw. ex Baker, in Trans. Linn. Soc Ser. II. i. (1878) 255 = Schizobasis, Baker (Liliac.) aphylla, Welw. ex Baker, l. c, =S. angolensis.

ADENOTRIAS, Jaub. \& Spach, Illustr. Pl. Or. i. (1842) $76=$ Hypericum, Linn

Kotschyi, Jaub. \& Spach, 1. c. 77 (=Triadenia Rus seggeri).-Syria.

phrygia, Jaub. \& Spach, 1. c. $76=$ praec.

ADENOTRICHIA, Lindl. Bot. Reg. t. 1190 (1828)= Senecio, Linn. (Compos.)

amplexicaulis, Lindl. $1_{*} \mathrm{c}_{*}=\mathrm{S}$. adenotrichius senecioides, Fisch. \& Mey. Ind. Sem. Hort. Petrop. i $22=\mathrm{S}$. sinuatilobus

ADENCM, G. Don, Gen. Syst. iv, (1837) $80=$ Ade nium, Roem. \& Schult. (Apocyn.)

ADESMIA, DC. in Ann. Sc. Nat. Sér. I. iv. (1825) 94 LEGUMINOSAE, Benth. \& Hook. f. i. 517.

LoudoniA, Bert. ex Hook. Bot. Misc. iii. (1883) 193.

Patagonium, Schrank, in Muench. Denkschr. (1808) 93 , nomen vetustius.

Streptodesma, A. Gray, in Proc. Am. Acad. ii (1853) 6

Aegiceras, Phil, in Linnaea, xxviii. (1856) 684-Chili. affinis, Hook. f. Fl. Antarct. 257.-Terr. Magell. alpina, Gill. ex Hook. Bot. Misc. iii. (1833) $191=$ trijuga.

angulata, Hook. f. Fl. Antarct. ii. $257=$ incana. angustifolia, Hook. \& Arn. Bot. Beech. Voy. 19.Chili.

aphylla, Clos, in C. Gay, Fl. Chil. ii. 177.-Chili

aprica, Phil. in Anales Univ. Chil. (1872) 697.Chili.

arachnipes, Clos, in C. Gay, Fl. Chil. ii. 158.-Chili

araucana, Phil, in Linnaea, xxviii. (1856) 683,-Chili.

\section{ADESMIA :}

arborea, Bert. Merc. Chil. xii, 559; cf. Bull. Féruss. xx. (1830) 108.-Chili.

arborea, Colla, in Mem. Acc. Torin. xxxvii. (1834) 58 =glutinosa.

argentea, Gill. ex Hook. Bot. Misc. iii. (1833) $191=$ trijuga.

argentea, Meyen, Reise, i. 402, et in Nov. Act. Nat. Cur. xix. Suppl.i. (1843) 22,-Peruy.

argyrophylla, Phil. in Linnaea, xxviii. (1856) 631.Chili.

Arnottiana, Gill. ex Hook. Bot. Misc. iii. (1833) 191 $=$ trijuga.

arvensis, Phil. in Linnaea, xxxiii, (1864-65) 55,-Chili aspera, Gill. in Hook. Bot. Misc iii. (1833) 190 Chili.

atacamensis, Phil. Fl. Atac. 16.-Chili

axillaris, Phil. in Linnaea, xxviii. (1856) 683,-Chili

balsamica, Bert. ex Colla, in Mem. Acc. Torin. xxxvi (1834) 59. t. 10.-Chili.

balsamifera, Hook. Eo Arn. Bot. Beech. Voy. 20.-Chili

Berteroniana, Steud. Nom. ed. II. i. 27 =arborea.

bicolor, DC. in Ann. Sc. Nat. Sér, I. iv. (1825) 95. Reg. Argent.

bijuga, Phil. in Anales Univ. Chil. (1884) reimpr. -Chili.

boronioides, Hook. f. Fl. Antarct. 257-Terr. Magell brachycarpa, Phil. in Linnaea, xxyiii. (1656) 684. Chili.

bracteata, Hook. E Arn. in Hook. Bot. Misc. iii. 1833 193.-Chili.

caespitosa, Gill. ex Hook. 1. c. $191=$ horrida

calocarpa, Phil. in Anales Univ. Chil. (1865) It. 33 . -Chili.

calycina, Vog. in Iinnaea, xii. (1838) 75 = punctata.

candida, Hook. f. Fl. Antarct. 257.-Patag

canescens, Phil. in Anales Univ. Chil. (1872) 703.Chili.

capricornica, Gill. ex Hook. Bot. Misc. iii. (1833) 19! = horrida.

Capricornu, Phil. in Anales Univ. Chil. (1862) 11. 393 : et in Linnaea, xxxiii. (1864-65) 58.-Chili.

Caragana, Griseb. in Goett. Abh. xix. (1874, 119.Reg. Argent.

chillanensis, Phil. in Anales Univ. Chil. (1865) 11. 326. -Chili.

ciliata, Vog. in Linnaea, xii. (1838) 74.-Bras.

cinerea, Clos, in C. Gay, Fl. Chil. ii. 179.-Chili.

Closii, Phil. in Anales Univ. Chil. (1872) 700. Chili.

coluteoides, Gill. in Hook. Bot. Misc. iii. (1833) 190.Reg. Argent.

coluteoides, Phil. in Anales Univ. Chil. (1872) 783.Chili.

compacta, Phil. in Linnaea, xxviii. (1856) 628.Chili.

conferta, Hook. \& Arn. Bot. Beech. Voy. 20,-Chili. coronilloides, Gill. in Hook. Bot. Misc, iii. (1583) 190. -Chili.

corymbosa, Clos, in C. Gay, Fl. Chil. ii. 165.-Chili.

cuneata, Meyen, Reise, i. 402, et in Nov. Act. Cur. xix. Suppl. i. (18t3) 22.-Chili.

curvifolia, Clos, in C. Gay, Fl. Chil. if. 189.-Chili

cytisoides, Griseb. in Goett. Abh. xix. (1871) 119.

Reg. Argent

Davilae, Phive in Anales Univ. Chil (1872) 699.Chili.

decipiens, Steud. Nom. ed. II. i. 27--Chili

decumbens, Phil. in Linnaea, xxviii. (1556) 628.Chili.

dendroidea, Phil to c. 683,-Chili.

dentata, $D C$. in Anm. Sc. Nat. Ser. I. iv, 15:25:95.Chili.

dentata, Gill. ex Hook. Bot. Misc iii. (1538; 18 ! Gilliesii.

denticulata, Clos, in C. Gay, F\%. Chil. ii. 191.-Chili. denticulata. Sterd. Som. ed. 11. i. 27.-Chili.

denudata, Phil in Limnara, xxriii, $(1>6+-65) 30$.

Chili.

deserticula, Phil. in Anales ['nis. Chst. 1565) 18. 3ft -Chili.

dichotoma, Clos, in C. Gay, Fl. Chil. ii. 150,-Chili. dilfusn, Bert. ex Stewd. Dom. ed. 11. i. 2i.-Chili. Doniana, Gill, ex Hook. Bot. Misc iii. 1539, 191 trijuga.

Echinus, Presl, Symb. Bot. ii. 14. 1. 16.-Am. austs.

clata, Clos, in C. Gay. Fl. Chii, ii. 160,-Chili.

cleguns, Clos, l. c. 188.-Chili. 


\section{ADESMIA :}

elongata, Phil. in Linnaea, xxviii. (1856) 633.-Chili. emarginata, Clos, in C. Gay, Fl. Chil. ii. 187.-Chili. eremophila, Phil. Fl. Atac. 15.-Chili.

erinacea, Phil.l.c. 16.-Chili.

exilis, Clos, in C. Gay, Fl. Chil. ii. 150.-Chili. filicaulis, Phil. in Anales Univ. Chil. (1872) 702.Chili.

filifolia, Clos, in C. Gay, Fl. Chil. ii. 157.-Chili. filipes, A. Gray, Bot. U.S. Expl. Exped. i. 425.--Patag. floribunda, G. Don, Gen. Syst. ii. 283.-Mexico.

frigida, Phil. Fl. Atac. 16.-.-Chili.

fruticulosa, G. Don, Gen. Syst. ii. 282-Mexico.

Gayana, Phil. in Linnaea, xxvini. (1856) 634.-Am. austr.

genistoides, Presl, Symb. Bot. ii. 16,-Am, austr.

Germaini, Phil. in Linnaea, xxviii. (1856) 629.-Chili.

Gilliesii, Hook. \& Am. in Hook. Bot. Misc. iii. (1833) 188.-Chili.

glabriuscula, Vog. in Linnaea, x. (1836) $592=$ radicans.

glandulosa, Phil. in Anales Univ. Chil. (1861) 47; et in Linnaea, xxxiii. (1864-65) 57.-Chili.

glauca, Phil. in Linnaea, xxviii. (1856) 682.-Chili. glancescens, Phil. in Anales Univ. Chil. (1872) 707. -Chili.

glomerata, Auct.ex Phil. f. Cat. Pl. Chil. 49 (sp. dub.). -Chili.

glomerula, Clos, in C. Gay, Fl, Chil. ii. 184.-Chili,

glutinosa, Hook. E Arn. Bot. Beech. Voy. 19.-Chili.

gracilis, Meyen, ex Vog. in Nov.Act. Nat. Cur.xix.

Suppl. i. (1843) 25.-Chili.

grandiflora, Gill. in Hook. Bot. Misc. iir. (1833) 190. -Chili

graveolens, Phil. Fl. Atac. 16,--Chili

grisea, Hook. f. Fl. Antarct. 257.-Patag.

hirsuta, Phil. in Anales Univ. Chil. (1872) $706 .-$ Chili.

hispidula, DC. in Ann. Sc. Nat. Sér. I. iv. (1825) 95. -Peruv.

Hookeriana, Gill. ex Hook. Bot. Misc. iị. (1833) 191 $=$ trijuga.

horrida, Gill. in Hook. l. c--Chili.

humifusa, Phil. in Anales Univ. Chil. (1872) 698.Chili.

humilis, Phil. in Linnaea, xxviii. (1856) 682.-Am. austr.

Hystrix, Phil. Fl. Atac. 16.-Chili

incana, Vog. in Linnaea, xii. (1838) 76.-Bras.

inconspicua, Phil.l. c. xxviii. (1856) 631-Chili.

inflexa, Griseb. in Goett. Abh. xix. (1874) 121.-Reg. Argent.

Kingi, Phil.in Anales Univ. Chil. (1872) 706.-Chili.

Lambertiana, Gill, ex Hook. Bot. Misc. iii. (1833) 191 =trijuga.

lanata, Hook. f. Fl. Antarct. 256-Terr. Magell

Landbecki, Phil. in Linnaea, xxxiii. (1864-65) 59.Chili.

latifolia, Vog. l. c. xii. (1838) 74,-Bras

laxa, Clos, in C. Gay, Fl. Chil. ii. 162.-Chili.

leiocarpa, Hook. \& Arn, in Hook. Bot. Misc. iii. (1833) 189.-Chili.

leptacantha, Phil. in Anales Univ. Chil. (1872) 705. -Chili.

longipes, Phil. in Linnaea, xxviii. (1856) 630.-Am. austr.

longiseta, DC. in Ann. Sc. Nat. Sér. I. iv. (1825) 95. -Chili.

lotoides, Hook.f. Fl. Antarct. 225.-Terr, Magell.

Loudonia, Hook. E' Arn. in Hook.Bot. Misc. iii. (1833) 193.-Chili.

macrostachya, Benth. in Mart. Fl. Bras, xv. I. 55.Bras.

Meyeniana, Phil. in Linnaea, xxviii. (1856) 632-Am. austr.

Meyeriana, Walp. Rep. i. $729=$ Aeschynomene micrantha.

micrantha, Phil. Fl. Atac. 15.-Chili

microphylla, Hook. E Arn. Bot. Beech. Voy. 19. t. 9. - Chili.

mimosoides, G. Don, Gen. Syst. ii. 282.-Mexico.

miraflorensis, Remy, in Ann. Sc. Nat. Sér. III. vi. (1846) 357.-Bolivia

monosperma, Clos, in C. Gay, Fl. Chil. ii. 184.Chili.

monosperma, Steud. Nom. ed. II. i. 27.-Chili

montana, Phil. in Linnaea, xxviii. (1856) 629.-Am. austr.

\section{ADESMIA :}

mucronata, Hook \& Arn in Hook, Bot. Misc iii. (1833) 189.-Chili

multicuspis, Clos, in C. Gay, Fl. Chil. ii. 190.-Chili.

muricata, Bert. ex Steud. Nom. ed. II. i. $27=$ decipiens. muricata, DC. in Ann Sc. Nat. Sér. I. iv. (1825) 95.-

Patag.; Chili.

muricata, Gill. ex Hook. Bot. Misc. iii. (1833) $188=$ retrofracta.

obcordata, Clos, in C. Gay, Fl. Chil. ii. 199.-Chili.

obovata, Clos, $l$. $c$.-Chili

obscura. Clos, l. c. 183.-Chili.

odontophylla, Phil. in Anales Univ. Chil. (1865) II. 344,-Chili.

oligophylla, Phil. in Linnaea, xxviii. (1856) 636.Chili.

Onononis, Griseb. in Lechl.Berb. Am. Austr. 55, nomen. -Chili.

oresigena, Phil. in Anales Univ. Chil. (1872) 698.Chili.

oxalidiphylla, Phil. l. c. (1865) Ix. 345,-Chili.

papposa, Bert. ex Steud. Nom. ed. II. i. 27 = angustifolia papposa, DC. in Ann. Sc. Nat. Sér. I. iv. (1825) 95.Chuli.

parvifora, Clos, in C. Gay, Fl. Chil ii. 158.-Chili.

parvifolia, Phil. in Linnaea, xxviii. (1856) 683.Am. austr.

parvula, Phil. in Anales Univ. Chil. (1872) 697.Chili.

pauciflora, Vog. in Nov. Act. Nat. Cur. xix. Suppl. i. 1843) 25.-Chili.

Pearcei, Phil in Anales Univ. Chil. (1872) 704.-Chili.

pedicellata, Hook. \& Arn. in Hook. Bot. Misc. iii. 1833) 191.—Chili

pendula, Bert. ex Steud. Nom. ed. II. i.27 =denticulata, diffusa.

pendula, DC. in Ann. Sc. Nat. Sér. I. iv. (1825) 95.Reg. Argent

phylloidea, Clos, in C. Gay, Fl. Chil. ii. 186.-Chili.

pinifolia, Gill. in Hook. Bot. Misc. iii. (1833) 192.Chili.

polyacantha, Wedd. Chlor. And. ii. 265.-Am. austr propinqua, Clos, in C. Gay, Fl. Chil. ii. 188.-Chili. prostrata, Clos, l. c. 169.-Chili.

psilocarpa, Phil. in Anales Univ. Chil. (1865) II. 345.Chili.

psoraleoides, Vog. in Linnaea, xii. (1838) 80.-Bras.

pugionata, Griseb. in Goett. Abh. xix. (1874) 120 Reg. Argent.

pulchra, Phil. in Linnaea, xxviii. (1856) 632.-Am austr.

pumila, Hook. f. Fl. Antarct. 255.-Patag

punctata, $D C$. in Ann. Sc. Nat. Sér. I. iv. (1825) 95 -Am. austr.

pungens, Clos, in C. Gay, Fl. Chil. ii. 197.-Chili.

pusilla, Phil. Fl. Atac. 15.-Chili.

quadrijuga, Phil. in Anales Univ. Chil. (1872) 705.Chili.

racemosa, Steud. Nom. ed. II. i. $27=$ Aeschynomene micrantha.

radicans, Bert. ex Steud. l. c.-Chili

radicans, Clos, in C. Gay, Fl. Chil. ii. 173.-Chili.

radicifolia, Clos, l. c. 169.-Chili.

ramosissima, Phil. in Linnaea, xxxiii. (1864-65) 56.-Am. austr.

retrofracta, Hook. \& Arn. in Hook. Bot. Misc. iii. 1833) 188.-Chili.

retusa, Griseb. in Goett. Abh. vi. (1855) 119.-Am austr.

rupicola, Wedd. Chlor. And. ii. 266.-Am. austr.

Sckickendanzii, Griseb. in Goett. Abh. xxiv. (1879) 104.-Reg. Argent.

Schneideri, Phil. in Linnaea, xxxiii. (1864-65) 60 Am. anstr.

sericea, Griseb. in Lechl. Berb. Am. Austr. 55, nomen. -Chili.

sessiliflora, Phil. Fl. Atac. 16.-Chili.

Simonsi, Phil. in Anales Univ. Chil. (1872) 701.Chili.

Smithiae, Bert. ex Stend. Nom. ed. II. i. $27=$ muricata Smithiae, DC. in Ann. Sc. Nat. Sér. I. iv. (1825) 95. -Am. austr.

spinosissima, Meyen, Reise, ii. 27 ; et in Nov. Act. Nat. Cur.xix. Suppl.i. (1843) 24.-Chili.

stipulacea, Clos, in C. Gay, Fl. Chil. ii. 164.-Chili. subterranea, Clos, l. c. 192.-Chili.

suffocata, Hook. f. Fl. Antarct. 256-Terr. Magell. tenella, Hook. E Arn. Bot. Beech. Voy. 19,-Chili

\section{ADESMIA :-}

tomentosa, Meyen, in Nov. Act. Nat. Cur. xix. Suppl. i. (1843) 23.-Chili.

tribuloides, Steud. Nom. ed. II. i. 27.-Chili.

trifoliata, Gill. in Hook. Bot. Misc. ii. (1833) 194.Chili.

trifoliata, Phil. in Linnaea, xxviii. (1856) 635.-Am. austr.

trijuga, Gill. in Hook. Bot. Misc. iii. (1833) 191.Chili.

tristis, Vog. in Linnaea, xii. (1838) 77.-Bras

ulicina, Presl, Symb. Bot. ii. 15.-Am. austr.

uspallatensis, Gill. in Hook.Bot. Misc. iii. (1833) 192.-

Chili.

Valdesia, Clos, in C. Gay, Fl. Chit. ii. 174.-Chili.

verrucosa, Meyen, in Nov. Act. Nat. Cur. xix. Suppl. i. (1843) 20.-Chili.

vesicaria, Bert. ex Colla, in Mem. Acc. Torin. xxxvii. (1834) 58 , - Chili.

villosa, Hook. f. Fl. Antarct. 256.-Reg. Magell.

virgata, Bert. ex Steud. Nom. ed. II. i. 27.-Chili.

viscida, Bert. Merc. Chil. xii. 557; Colla, in Mem. Acc.

Torin. xxxvii. (1834) $59=$ mucronata.

viscosa, Gill. in Hook. Bot. Misc. iii. (1833) 192.-Chili.

Volckmanni, Phil. in Linnaea, xxviii. (1856) 619.-Am. austr.

Wallichiana, Gill. ex Hook. Bot. Misc. iii. (1833) 190 = Aeschynomene aspera.

ADHADOTA, Steud. Nom. ed. II. i. 27 (1840) err. typ. $=$ seq.

ADHATODA, Nees, in DC. Prod. xi. 384 (1847). Genus minime retinendum, species fere omnes ad Fusticiam referendae. Vide infra.

ADHATODA, Tourn. ex Medic. in Act. Acad. Theod. Palat. vi. Phys. (1790) 393; Nees, in Wall. Pl. As. Rar, iii, 102 (1832). ACANTHACEAE, Benth. \& Hook, f. ii. 1112.

Carima, Rafin. Fl. Tellur, iv, 62 (1836).

Durernoya, E. Mey. in Drège, Zwei Pfl. Docum. $150(1843)$, nomen.

acuminata, Nees, in DC. Prod. xi. 400,-Abyss.

adenostachya, Nees, l. c. 408.-Bras.

amaranthoides, Nees, 1. c. $400=$ ceylanica

anagalloides, Nees, l. c. 403.-Afr. austr.

Anselliana, Nees, 1, c, $403=$ Dianthera Anselliana.

arenaria, Nees, in Wall. P1. As. Rar. iii. $103=$ Justicia trinervia.

argyrostachya, Nees, 1. c. $102=$ Justicia argyrostachya aspera, Nees, in DC. Prod. xi. 397.-Ins. Philipp. aurantiaca, Regel, Ind. Sem. Hort. Petrop. (1857) 47. - Hab.?

auriculata, Nees, in DC. Prod, xi, 407.-Bras.

bahiensis, Nees, in Mart. Fl. Bras. ix. 148,-Bras.

Beddomei, C. B. Clarke, in Hook. f. Fl. Brit. Ind. 540.- - Ind. or.

Betonica, Nees, in Wall. PI. As. Rar. iii. $103=$ Justicia Betonica,

boerhaaviaefolia, Nees, in DC. Prod. xi. 409.--Madag.

Bojeriana, Nees, l. c. 386,--Madag.

candicans, Nees, 1. c. $396=$ Dianthera candicans.

capensis, Nees, l. c.-Afr. austr.

carthagenensis, Nees, 1. c. $403=$ Beloperone violacea

cheiranthifolia, Nees, l. c. 387.-Afr, austr.

ceylanica, Nees, 1. c. $400=$ Justicia ceylanica

chinensis, Benth. in Hook. Kew Fourn. v. (1853) 134 -Hongkong.

chrysotrichoma, Nees, in DC. Prod. xi. 408,-Bras.

ciliata, Nees, l. c. 396.-Bras.

congrua, Nees, in Mart. Fl. Bras. ix. 147.-Bras.

cuneata, Nees, in DC. Prod xi. 392.-Afr, austr.

cuneifolia, Nees, $l$. c. 405 -Bras.

cydoniaefolia, Nees, in Mart. Fl. Bras. ix, 148.-Bras

decussata, Nees, in DC. Prod. xi. $408=$ Justicia decussata.

diffusa, Benth. in Hook. Niger Fl, $483=$ Justicia insularis.

diosmophylla, Nees, in DC. Prod. xi. 394.-Afr. austr Dipteracanthus, Nees, 1. c. $396=$ Siphonoglossa pilosella.

divaricata, Nees, l. c. 391.-Afr, austr.

divergens, Nees, l. c. 406-Am. merid.

diversiformis, Nees, 1. c. $399=$ Justicia glauca

Eustachyana, Nees, 1. c. $404=$ Beloperone Eustachyana fasciata, Nees, $l$. c. 402.-Afr. austr. 


\section{ADHATODA :}

Felisbertiana, Nees, in DC. Prod, xi. 406.-Bras. flava, Nees, l. c. 401.-Arab.

flexuosa, Nees, in Mart. Fl. Bras. ix. 148.-Bras. formosissima, Kotzsch, in Peters, Reise Mossamb. Bot. 215.-Afr. trop.

furcata, Nees, in DC. Prod. xi. $398=$ Justicia furcata. genistiformis, Nees, l. c. 394.-Bras.

Gilliesii, Nees, l. c. 395.-Reg. Argent.

glandulosa, Nees, l. c. 405.-Bras.

glomerata, Miq. Fl. Ind. Bat. ii. 831.-Malaya.

holosericea, Nees, in Mart. Fl. Bras. ix. 148.-Bras.

Hookeriana, Nees, in DC. Prod. xi. $403=$ Justicia Hookeriana.

Hypericum, Solms, ex Schweinf. Beitr. Fl. Aethiop. 102. -Afr. trop

hyssopifolia, Medic. in Act. Acad. Theod. Palat. vi.

Phys. $(1790) 393=$ Dicliptera ocymoides.

hyssopifolia, Nees, in DC. Prod. xi. 392.-Afr. austr.

incana, Nees, l. c. 393.-Afr. austr.

jalappaefolia, Buchoz, ex Stend. Nom. ed. I. $15=$ Dicliptera ocymoides.

Kotschyi, Nees, in DC. Prod. xi. 397.-Afr. trop.

leptantha, Nees, l. c. 390.-Afr. austr.

leptostachya, Nees, $l$. c. 403.-Arab.

Lindeniana, Nees, l. c. 405,-N. Granat.

lithospermifolia, Nees, l. c. 398.-Peruv.

longiflora, Torr. in Bot. Mex. Bound. 125=Siphonoglossa longiflora.

longifolia, Nees, in DC. Prod. xi. 404.-Ins. Mascar.

lupulina, Nees, $l$. c. 385.-Afr. austr.

Magnolia, Noronha, in Verh. Batav. Gen, v. (1790) ed. I. Art. 4.6.-Malaya.

major, Nees, in DC. Prod. xi. 397.-Abyss.

Martiana, Nees, l. c. 405.-Bras.

matammensis, Schweinf. in Verh. Zool. Bot. Ges. Wien, xviii. (1868) 674,-Afr. trop.

microphylla, Klotzsch, in Peters, Reise Mossamb. Bot. 216.-Afr. trop

minor, Nees, in DC. Prod. xi. 400.-Abyss.

mollissima, Nees, l. c. 391.-Afr. austr.

Moretiana, Miq. Fl. Ind. Bat. ii. 830--Malaya

Moritziana, Nees, in DC. Prod. xi. 388.-N. Granat.

mossambicensis, Klotasch, in Peters, Reise Mossamb.

Bot. 217.-Afr. trop.

natalensis, Nees, in DC. Prod. xi. 391.-Afr. austr.

Neesiana, Nees, 1. c. $397=$ Justicia Neesiana.

nilgerrhensis, Nees, in Wall. P1. As. Rar. iii. $103=$

Justicia nilgerrhensis.

nilgherrica, Nees, in DC. Prod. xi. $386=$ Justicia nilgerrhensis.

nuda, Nees, l. c. 402.-Arab.

odora, Nees, l. c. 399 -Arab.

Orbigniana, Nees, l. c. 404.-Bolivia.

orchioides, Nees, l. c. 393.-Afr. austr.

origanoides, Nees, $l$. c. 407 .- Ind. or.

orixensis, Nees, 1. c. $400=$ Justicia glanca.

pacifica, Oerst. in Kjoeb. Vidensk. Meddel. (1854) 164 $=$ Justicia pacifica.

palustris, Nees, in DC. Prod. xi. 402.-Afr. trop.

paniculata, Benth. in Hook. Niger Fl. 482.-Afr.

trop.

patula, Nees, in DC. Prod. xi. 393.-Afr. austr.

periplocifolia, Nees, l. c. 395.-Venezuela.

petiolaris, Nees, $l$. c. 402 .-Afr. trop.

pilosa, Nees, l. c. 405.-Bras.

plicata, Nees, l. c. 401.-Afr. trop.

protracta, Nees, l. c. 390,-Afr. aust

pubescens, Moench, Meth. $431=$ Gendarussa Adhatoda.

pygmaen, Nees, in DC. Prod. xi. 394.-Afr. austr.

quadrifaria, Nees, 1. c. $396=$ Justicia quadrifaria.

ramosissima, Nees, in Wall. P1. As. Rar. iii. $108=$

Justicia Betonica.

reflexiflora, Nees, in DC. Prod. xi. 398.-Ind. occ

rostellaria, Nees, 1. c. $397=$ Justicia neglecta.

rostrata, Hochst. ex Oliver, in Trans. Linn. Soc. xxix.

1872) $131=$ Asystasia Schimperi.

rostrata, Solms, ex Schweinf. Beitr. Fl. Aethiop. 104 -Afr. trop.

rotundifolia, Nees, in DC. Prod. xi. 391.-Afr. austr.

scabra, Nees, l. c. 407.-Venezuela.

Schimperiana, Hochst. ex Nees, l. c. 388.-Abyss.

sericea, Nees, fide Benth. \& Hook. f. Gen. ii. $1115=$

Jacobinia mexicana.

sisparensis, Benth. in Journ. Linn, Soc. ix. (1867) 518

- Rungia sisparensis

sphaerosperma, Nees, in DC. Prod. xi. 409.-Ind. occ.

\section{ADHATODA}

spicata, Burm. ex Steud. Nom. ed. I. 15, $274=$ Rungia repens.

spicata, Nees, in DC. Prod.xi. 408.-Malaya.

striata, Klotzsch, in Peters, Reise Mossamb. Bot. 216. -Afr. trop.

suaveolens, Nees, in DC. Prod. xi. 401.-Arab.

subserrata, Nees, $l_{0} c_{0} 409$-Ins. Philipp.

sulcala, Nees, l. c. 401-Arab.

tetramera, Bello, in Anal. Soc. Esp. Hist. Nat. x. (1881) 301.-Porto-Rico.

thymifolia, Nees, in DC. Prod. xi. 392-Afr. austr.

tranquebariensis, Nees, 1. c. $399=$ Justicia tranquebariensis.

trinervia, Nees, in Wall. Pl. As. Rar, iii, $103=$ Justicia trinervia.

tristiflora, Teijsm. \& Binn. in Tijdschr. Nederl. Ind. xxix. (1867) 250.--Java.

tristis, Nees, in DC. Prod. xi. 404-Afr. trop

tubulosa, Nees, l. c. 392.-Afr. austr

Tweediana, Nees, l. c. 395.-Bras.

numbrosa, Nees, l. c. 406.-Bras.

variegata, Nees, l. c. 385:-Afr. austr.

vasculosa, Nees, 1. c. $407=$ Justicia vasculosa

Vasica, Nees, in Wall. Pl. As. Rar, iii. 103.As trop.

Velasquezi, Nees, in DC. Prod.xi. 409.-Guatemala ventricosa, Nees, 1. c. $407=$ Justicia ventricosa.

verticillata, Noronha, in Verh. Batav. Gen. v. (1790) ed. I. Art. IV. 6.- Java.

wynaadensis, Nees, in DC. Prod, xi. $406=$ Justicia wynaadensis.

Zollingeriana, Nees, 1. c. xi. 396=Justicia Zollingeriana.

ADHUNIA, Vell. Fl. Flum. 236 (1825); จ. t. 118 (1827)

- Gen. dub.

emarginata, Vell. 11. cc.-Bras.

ADIANTHUM truncatum, Burm. f. Fl. Ind. 235. t. 66. f. $4=$ Acacia decipiens.

ADIANTUM trincatum, Murr. Syst. Veg. $790=$ Acacia decipiens.

ADICEA, Rafin. Cat. $13(1824)=$ Urtica, Tourn glabra, Rafin. 1. c. =U. glabra.

pumila, Rafin. ex Torr. Fl. New York, ii. $223=$ Pilea pumila.

trinervia, Rafin. ex Torr. 1. c, = Pilea pumila.

ADIKE, Rafin. New F1. Am. i. 63 (1836); Fl. Tellur. iii. $48(1836)=$ Pilea, Lindl. (Urtic.)

allophyla, Rafin. Fl. Tellur. iii. $48=$ P. trianthemoides glaberrima, Rafin. New Fl. Am. i. $64=$ P. smilaci folia.

lanceolata, Rafin. 1. c. = P. lanceolata

pumila, Rafin. 1. c. $63=$ P. pumila.

rhomboidea, Rafin. 1. c. $54=$ P. rhombea.

ADINA, Salisb. Parad. Lond. t. 115 (1807). RUBIA$C E A E$, Benth. \& Hook. f. ii. 30.

aralioides, Benth. \& Hook. f. Gen. ii. 30.-Java. cordifolia, Benth. E Hook. f. l. c.-Ind. or.

globiflora, Salisb. Parad. Lond. t. 115 (errore globifera) -China.

Griffithii, Hook. f. Fl. Brit. Ind. iii. 24.-Ind, or. microcephala, Hiern, in Oliver, Fl. Trop. Afr. iii. 40. -Afr. trop.

peduncularis, DC. Prod. iv. $349=$ globiflora

polycephala, Benth. Fl. Hongk. 146.-Ind. or.

racemosa, Miq. Ann. Mus. Bot. Lugd. Bat. iv. 184.China; Japon.

rubella, Hance, in Fourn. Bot. vi. (1868) 114.-China sessilifolia, Benth. \& Hook. f. Gen. ii. 30.-Ind. or. trichotoma, Benth. \& Hook.f.l. c.-Malaya.

ADINANDRA, Jack, in Malay Misc. ii. n. 7. p. 49 (1822). TERNSTROEMIACEAE, Benth. \& Hooh. f. i. 182.

HAENKAEA, Usteri, Anm. Bot, vi. (1798) 117

Sarosanthera, Korth. Verh. Nat. Gesch. Bot. ed. Temminck, 108, t. 16 (1840 ?).

acuminata, Korth. l. c. ed. Temminck, 109.-Sumatra cordata, Choisy, in Mém. Soc. Phys. Gendv, xiv. (1855) 114.

crenulata, T. Anders, in Hook, f. Brit. Ind. Fl. i. 289 -Ind or.

cyrtopoda, Miq. Fl. Ind. Bat. Suppl. i. $478=$ dumosa.

\section{ADINANDRA}

dasyantha, Choisy, in Mém. Soc. Phys. Genèv. xiv. (1855) $180=$ integerrima.

dasyantha, Korth.Verh. Nat.Gesch. Bot.ed. Temminck. 108.-Borneo.

dumosa, Fack, in Malay Misc. ii. (1822) n. 7. p. 50. - Malaya; China.

dumosa, Vidal, Sinops. Filip. t. $12=$ integerrima.

excelsa, Korth. Verh. Nat. Gesch. Bot. ed. Temminck,

10\%. Borneo.

glabra, Miq. Fl. Ind. Bat. Suppl. i. $479=$ dumosa

Griffithii, Dyer, in Hook. f. Fl. Brit. Ind. i. 282 Reg. Himal.

integerrima, T. Anders, ex Dyer, l. c.-Malaya.

Fackiana, Korth. Verh. Nat. Gesch. Bot. ed. Temminck. $106=$ dumosa

javanica, Choisy, in Zoll. Syst. Verz. Ind. Archip. 143.

146.-Java.

Lamponga, Miq. Fl. Ind. Bat. Suppl. i. 479.Sumatra.

lasiopetala, Choisy, in Mém. Soc. Phys. Genev. xiv. (1855) 114.-Zeylan.

leiopetala, Miq. Ann. Mus. Bot. Lugd.Bat. iv, 104.Sumatra.

macrantha, Teijsm. \& Binn. in Tijdschr. Nederl. Ind. xxv. (1863) 421.- Java.

maculosa, T. Anders. ex Dyer, in Hook. f. Fl. Brit. Ind. i. 282.-Malaya.

Mannii, Oliver, Fl. Trop. Afr. i. 170,-Afr. trop.

Millettii, Benth. E Hook. f. ex Hance, in Fourn. Bot.

xvi. (1878) 9.-China.

phlebophylla, Hance, l. c. xiv. (1876) 240.-Cam. bodia.

Sarosanthera, Miq. Fl. Ind. Bat. i. II. 477.-Bomeo.

stylosa, Miq. 1. c. Suppl. $478=$ dumosa.

sylvestris, fack, in Malay Misc. iii. (1822) n. 7 p. iii. - Sumatra.

trichocoryna, Korth. Verh. Nat. Gesch. Bot ed. Tem. minck, 107 = dumosa

villosa, Choisy, in Mem. Soc. Phys. Genèv. xiv. (1855 - Burma.

ADIPE, Rafin. Fl. Tellur. ii. 101 (1836)=Bifrenaria Lind1. (Orchid.) (1843).

fulva, Rafin. 1. c。 $=$ B. racemosa

racemosa, Rafin. 1. c. $=$ B, racemosa.

ADIPERA, Rafin. Sylva Tellur. 129 (1838) = Cassia Tourn. (Legum.).

Herberti, Rafin. 1. c. = C. Herbertiana.

ADISA, Steud. Nom. ed. II. i. 28 (1840), sphalm. =seq.

ADISCA, Blume, Bijdr. (1825) 609=Mallotus, Lour. (Euphorb.)

aczminata, Blume, 1. c. $610=$ M. acuminatus,

albicans, Blume, 1. c. $611=$ Cephalocroton albicans.

floribunda, Blnme, 1. c. $610=$ M. Aloribundus.

subfalcata, Zoll. in Linnaea, xxix. (1857-58) $464=$

Macaranga subfalcata.

subpeltata, Blume, Bijdr. $610=$ M. subpeltatus.

timoriana, Span. Ic. n. 26 ; et in Linpacr, xV. (18\$1

$348=$ M. repandus.

Zippelii, Blnme, Bijdr. $611=$ M. ricinoides.

ADLERIA, Neck. Elem. ii. $642(1790)=$ Eperua, Aubl (Legum.).

ADLUMIA, Rafin. in Med. Repos. New York

(1808) 352. PAPAVERACEAE, Benth. \& Hook. A i. 55 .

BicucullA, Borckb. in Roem. Arch. i. If. $46^{\circ} 17: 7 \%$ nomen prius.

cirrhosa, Rafin. l. c.-Am. bor.

ADNARLA, Rafin. Fl. Ludow, 56,1517 ! VACCl.1\%A. CEAE.

odorata, Rafin.l. c.-Am. bor.

ADNULA, Rafin. Fl. Tellur. ii. st $1 \$ 30^{\circ}-$ Polerta Poit. Orchich.

petiolaris, Rafin. I. $c=$ P. spimnthoides

ADODENIOKON, DC. Prod. vii. $7: 25=$ ser

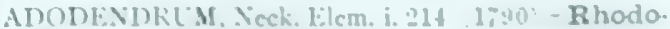
thamnus, Reicbb. Ericac. 
ADOKETON, Rafin. Mus. N. Sc. 1; New FI. Am. i. $65(1836)=$ Telanthera, R. Br. (Chenop.). saxatile, Rafin. 11. $\mathrm{cc} .=\mathrm{T}$. frutescens. uniflorum, Rafin. New Fl. Am. i. 65,-Am. bor.

ADOLIA, Lam. Encyc. i. (1783) 44=Scutia, Comm. (sec. Endl. Gen. Suppl. i. 1424) (Rhamnac.). alba, Lam. 1. c. $45=\mathrm{S}$, indica.

rubra, Lam. 1. c. =S. indica.

ADOLPHIA, Meissn. Gen. 70 (50) (1837). RHAMNEAE, Benth. \& Hook. f. i. 384

californica, S. Wats. in Proc. Am. Acad. xi. (1876) 126. -Calif.

infesta, Meissn, Gen. Pl. 70 (50),-Mexico.

ADONANTHF, Spach, Hist. Vég. Phan. vii. 227 (1839) = Adonis, Linn. (Ranunc.).

pyrenaica, Spach, 1. c. $230=$ Adonis pyrenaica. sibirica, Spach, 1. c. $229=$ Adonis sibirica. vernalis, Spach, 1. c. $228=$ Adonis vernalis.

ADONIASTRUM, Schur, in Verh. Naturf. Ver. Bruenn xv. II. (1877) $27=$ Adonis, Dill. (Ranunc.). vernale, Schur, 1. $\mathrm{c}_{\mathrm{s}}=$ Adonis vernalis.

ADONIGERON, Fourr. in Ann. Soc. Linn. Lyon, N. S xvi. (1868) $404=$ Senecio, Linn. (Compos.).

adonidifolius, Fourr. 1. c. $=$ S. adonidifolius.

ADONT.S, Dill. ex Linn. Syst. ed. 1. (1735). RANUNCULACEAE, Benth. \& Hook, f. i. 5 .

Adonanthe, Spach, Hist. Vég. Phan. vii. 227 (1839).

Adoniastrum, Schur, in Verh. Naturf. Ver. Bruenn, Xv. II. (1877) 27.

Cosmarium, Dulac, Fl. Hautes-Pyr, 215 (1867) aestivalis, Bieb. F1. Taur. Cauc. iii. $378=$ autumnalis. aestivalis, Linn. Sp. Pl. ed. II. 771.-Europ.; Oriens. aestivalis, Link, ex Webb \& Berth. Phyt. Canar, i. 12 $=$ microcarpa.

aethiopica, Thunb. Prod. P1. Cap. $94=$ Knowlionia gracilis.

aleppica, Boiss. in Ann. Sc. Nat. Sér. II. xvi. (1841) $350 .-$ Syria.

ambigua, Gaud. F1. Helv. iii. 518=aestivalis. amurensis, Regel \& Radde, in Bull. Soc. Nat. Mosc (1861) II. 35. t. 2. f. 12.-Manchur.

annua, Linn. Sp. P1. $547=$ aestivalis et autumnalis.

anomala, Wallr. Sched. Crit. $273=$ flammea.

apennina, Linn. Sp. Pl. $548=$ vernalis.

apennina, Pall. Reise, ii. $388=$ wolgensis.

apennina, Schouw, ex DC. Prod. i. $25=$ pyrenaica.

autumnalis, Bieb. Fl. Taur. Cauc. ii. $23=$ aestivalis

autumnalis, Linn. Sp. Pl. ed. II. 771.-Europ.; Oriens.

baetica, Coss. Not. PI. Crit. ii. $25=$ autumnalis

caerulea, Maxim. in Bull. Acad. Pétersb. xxiii. (1877) 306.-China.

capensis, Linn. Sp. Pl. 548=Knowltonia rigida.

capensis, Thunb. Prod. Pl. Cap. 94=Knowltonia gracilis.

caudata, Stev. in Bull. Soc. Nat. Mosc. xxi. (1848) II $271,273=$ flammea.

chaerophylla, Fisch. in DC. Prod. i. $25=$ wolgensis

Chrysocyathus, Hook. f. E Thoms. ex Hook. f. Fl. Brit.

Ind. 15.-Reg. Himal.

citrina, DC. Syst. i. $223=$ flammea

citrina, Hoffm. Fl. Germ. i. $251=$ aestivalis.

coriacea, Poir. Encyc. Suppl. i. $146=$ Knowltonia rigida.

Cupaniana, Guss. Syn. Fl. Sic ii. $36=$ microcarpa.

cyllenea, Boiss. Heldr. E Orph. Diagn. Sér. II. v. 5.Graecia.

daucifolia, Lam. Encyc. i. $46=$ Knowltonia daucifolia. davurica, Reichb. Ic. Crit. Cent. iv. 21. t. $321=$ vernalis.

dentata, Delile, Fl. Egypte, 287.-Europ.; Afr. bor.

dentata, Duby, ex Nym. Consp. $4=$ aestivalis.

distorta, Tenore, Fl. Nap, iv, 337, t. 149-Ital.

eriocalycina, Boiss. Fl. Orient. i. 17.-Armenia,

erosipetala, Stokes, Bot. Mat. Med. iii. $255=$ autumnalis.

filia, Linn. f. SuppI. $271=$ Knowltonia daucifolia .

Hammea, Facq. Fl. Austr. iv. 29. t. 355.-Europ.;

Oriens.
flammea, Schleich. ex Steud. Nom. ed. II. i. $28=$ aestivalis.

Alava, Vill. Cat. Jard. Strasb. $247=$ aestivalis.

\section{ADONIS :}

fulgens, Hochst. in Lorent, Wanderungen, 338.As. Min.

gracilis, Poir. Encyc. Suppl. i. $147=$ Knowltonia gracilis.

Helleborus, Crantz, Stirp. Austr. ed. I. fasc. ii. 82 ; ed. II. $110=$ vernalis

hirsuta, Poir. Encyc. Snppl. i. $147=$ Knowltonia hirsuta.

hybrida, Wolff, ex Nym. Consp. $4=$ wolgensis.

Inglisii, Royle, Illustr. Himal. P1. 53 = aestivalis.

intermedia, Webb \& Berth. Phyt. Canar. 1. $121=$ microcarpa.

ircutiana, Fisch. ex DC. Prod. i. $25=$ vemalis.

laserpitiifolia, Poir. Encyc. Suppl. i. 147=Knowltonia vesicatoria.

maculata, Roth, Enum. Pl. Phan. Germ. ii. 602.Europ.

maculata, Wallr. Sched. Crit. $270=$ aestivalis.

magellanica, Raeusch, Nom. ed. III. $162=$ Hamadryas magellanica.

marginata, Bienert, ex Hook. f. Fl. Brit. Ind. i. 15= scrobiculata.

Marschalliana, Andrz. ex Bess. Enum. Pl. Volh, 47 $=$ wolgensis.

micrantha, DC. Syst. i. $222=$ antumnalis.

microcarpa, $D C$. . . C.-Europ.

miniata, Jacq. Fl. Austr. iv. $28=$ aestivalis.

palaestina, Boiss, Diagn. Ser. I. viii. 1.-Syria

palustris, Raeusch, Nom. ed. III. 162=Ranunculus sceleratus.

parviflora, Fisch. ex DC. Prod. i. 24,-Oriens.

parviflora, Janka, ex Nym. Consp. 4 =vernalis.

perramosa, Schur, Enum. Pl. Transs. $6=$ autumnalis.

persica, Boiss. Diagn. Ser. I. vi. $4=$ dentata.

phoenicea, Bercht. et Presl, Rostl. i. Ranunculac, 42 = autumnalis.

pilosa, Raeusch, Nom. ed. III. 162=Ranunculus pensylvanicus.

polymorpha, Zumag. Fl. Pedem. ii. $362=$ aestivalis, autumnalis.

pratensis, Ledeb. Fl. Ross. i. $24=$ vernalis

Preslii, Tod. ex Nym. Consp. 4 = flammea.

pyrenaica, DC. Fl. Fr. v. 635 -- Europ.

pyrenaica, Hook. fo \& Thoms. Fl. Ind. $26=$ A. Chrysocyathus.

riparia, Rafin. New Fl. Am, i, 66.-Am. bor.

scrobiculata, Boiss. Diagn. Ser. II. i. 6.-Afghan

sibirica, Patrin, ex Ledeb. Ind. Hort. Dorp. Suppl. (1824) 1.-Sibir, altaic.

Sibthorpii, Boiss. Orphan. \& Heldr. in Bull. Congr. Bot. Pétersb. 1869 (1870) 124.-Graecia.

squarrosa, Stev. in Bull. Soc. Nat. Mosc. xxi. (1848) II. $271,2 \% 2=$ aestivalis

vernalis, Asso, Syn. Stirp. Arag. $70=$ dentata.

vernalis, Linn.Sp. Pl. 547.-Europ.; As. bor.

vesicatoria, Linn. f. Suppl. $272=$ Knowltonia vesicatoria.

villosa, Ledeb. Ind. Hort. Dorp. Suppl. (1824) $1=$ wolgensis.

wolgensis, Stev. ex DC. Syst. i. 545.-Europ.; Oriens; As. bor.

ADOPOGON, Neck. Elem. i. $55(\mathbf{1 7 9 0})=$ Krigia, Schreb. (Compos.).

ADORIUM, Rafin. Neogenyt. $3(\mathbf{1 8 2 5})=$ Seseli, Linn. (Umbellif.).

crassifolium, Rafin. 1. c. $=\mathrm{S}$. divaricatum.

ADOXA, Linn. Syst, ed. I. (1735). CAPRIFOLIA $C E A E$, Benth. \& Hook. f. ii. 2.

Muscatella, Adans. Fam. ii. 243 (1763).

Moschatellina, [Tourn.] Hall. Enum. Stirp. Helv. i. 412 (1742).

inodora, Falc. ex Clarke, in Hook. f. FI. Brit. Ind. iii.

$2=$ A. Moschatellina.

moschata, Dulac, Fl. Hautes-Pyr. 462=A. Moschatellina.

Moschatellina, Linn. Sp. Pl. 367.-Europ.; As, bor. Am. bor.

tuberosa, S. F. Gray, Nat. Arr. Brit. Pl. ii. $493=$ A.

Moschatellina

ADRASTAEA, DC. Syst. Veg. i. 424 (1818) DILLENIACEAE, Benth. \& Hook. f. i. 15.

AD RASTEA, Spreng. Syst. ii. 360 (1825)

salicifolia, $D C$. l. c.-Austral.
ADRIANA, Gaudich. in Ann. Ser. Nat. Ser. I. v (1825) 223. EUPHORBIACEAE, Benth. \& Hook f. iii. 306 .

Trachycaryon, Klotzsch, in Lehm. Pl. Preiss. i. 175 (1844).

acerifolia, Hook. in Mitch. Journ. Trop. Austral. 371 = glabrata.

Billardieri, Baill. Etud. Gén. Euph. Atl. 6. t. 2. f. $19=$ quadripartita.

Gaudichaudi, Baill, Adansonia, vi. (1865-66) 31. =tomentosa.

glabrata, Gaudich. in Ann. Sc. Nat. Sér. I. v. (1825 223.--Austral.

heterophylla, Hook. in Mitch. Journ. Trop. Austral. 371 = glabrata.

Hookeri, Muell. Arg. in DC. Prod. xv. II. 891.Austral.

Klotzschii, Muell. Aqg. l. c. 892,--Anstral,

quadripartita, Gaudich. Bot. Voy. Freyc. 489.-Austral. tomentosa, Gaudich. in Ann. Sc. Nat. Sér. I. v. (1825) 223. - Austral.

ADROMIsCHUS, Lem. Jard. Fleur. ii. (1852) Mise. 59 = Cotyledon, Tourn. (Crassul.).

caryophyllaceus, Lem. 1. c. $60=\mathrm{C}$. caryophyllacea. clavifolius, Lem. 1. c. =C. clavifolia.

cristatus, Lem. 1. c. = cristata

cuneatus, Lem. 1, $\mathrm{c},=$ cuneata

hemisphaericus, I.em. 1. c. = C. hemisphaerica.

jasminiflorus, Lem. 1. c.-C. jasminiflora.

maculains, Lem. 1. c. = C. maculata.

mammillaris, Lem. l. c. =C. mammillaris

mucronatus, Lem. 1. c. =C. maculata.

rhombifolius, Lem. 1. $\mathrm{c}_{\mathrm{o}}=\mathrm{C}$. rhombifolia.

robustus, Lem. 1. c. $=$ C. triflora

ADULPA, Endl. Gen. (1836) 119 (err. typ.) = seq.

ADUPLA. Bosc, in Jaume St. Hil. Expos. Fam. Nat. i. $65(1805)=$ Cyperus, Linn.

ADVENTINA, Rafin. New F1. Am. i. 67 (1836), COMPOSITAE.

ciliata, Rafin. 1. c.-Am. bor.

parviflora, Rafin. 1 . c.-Am. bor

ADYSETON, Adans. Fam. ii. $420(1763)=$ Alyssum

Linn. (Crucif.)

alpestre, Sweet, Hort. Brit. ed. I. $467=$ Alyss. alpestre. altaicum, G. Don, in Sweet, 1. c. ed. III. $30=$ Alyss. Fischerianum.

argenteum, Sweet, I. c. ed. I. $467=$ Alyss. argenteum.

atlanticum, G. Don, Gen. Syst. i. $178=$ Alyss, atlanticum.

Bertolonii, Sweet, Hort. Brit. ed. I, $467=$ Alyss. montanum.

calycinum, Scop. F1. Carn. ed. II. ii. $13=$ Alyss. calycinum.

campestre, Moench, Meth. Suppl. 87=Alyss. cam-

pestre.
cuneifolium, Sweet, Hort. Brit.ed.I. $467=$ Alyss, cuneifolium.

dentatum, G. Don, Gen. Syst. i. $1.79=$ Camelina sativa.

diffusum, Sweet, Hort. Brit. ed. I. $467=$ Alyss. montanum.

dubium, G. Don, Gen. Syst. i. $179=$ Alyss. dubium.

edentulum, Link, Enum. Hort. Berol. ii. $157=$ Alyss. gemonense.

Fischerianum, Sweet, Hort. Brit. ed. II, 25=Alyss. canescens.

gemonense, Sweet, 1. c. = Alyss. gemonense

gnaphalodes, G. Don, Gen. Syst. i. $179=$ Vesicaria gnaphalodes

halimifolium, Link, Enum. Hort. Berol. ir. $157=$ Alyss. halimifolium.

hyperboreum, G. Don, Gen. Syst. i. $179=$ Alyss. hyberboreum.

lanigerum, G. Don, 1. c. $178=$ Alyss, lanigerum.

lenense, G. Don, 1. c. = Alyss. lenense.

maritimum, Link, Enum. Hort. Berol. ii. $157=$ Alyss maritimum.

Marschallianum, Sweet, Hort. Brit. ed. II. 25= Alyss. Marschallianum.

montanum, Scop. Fl. Carn. ed. II. ii. 14=Alyss. Wulfenianum.

murale, Sweet, Hort. Brit. ed. I. $467=$ Alyss, argenteum.

mutabile, Moench, Meth. $267=$ Alyss. calycinum. 
ADVSETON :-

nebrodense, Sweet, Hort. Brit. ed. II. $25=$ Alyss. serpyllifolium.

obcordatum, G. Don, Gen. Syst, i. 179=Abyss. obcordatum.

obtusifolium, Sweet, Hort. Brit. ed I. 467=Alyss. alpestre.

orientale, Sweet, 1. c. $467=$ Alyss, orientale.

petalodes, G. Don, Gen. Syst. i. $179=$ Farsetia obovata repens, Sweet, Hort. Brit. ed. II. $25=$ Alyss. alpestre. savranicum, G. Don, Gen. Syst, i. $178=$ Alyss. alpestre. saxatile, Sweet, Hort. Brit. ed. I. $467=$ Alyss, saxatile serpyllifolium, Sweet, 1. c. = Alyss. serpyllifolium. sibiricum, G. Don, Gen. Syst. i. $179=$ Alyss. saxatile. spathulatum, Sweet, Hort. Brit. ed. I. $467=$ Alyss. spathulatum.

spinosum, Link, Enum. Hort. Berol, ii. $157=$ Alyss. spinosum.

tortuosum, Sweet, Hort. Brit. ed. I. $467=$ Alyss. alpestre. vernale, Sweet, I. c. $=$ Alyss. rostratum.

Wulfenianum, Sweet, 1. c. = Alyss. montanum.

ADYSETUM, Link, Enum. Hort. Berol. ii. 157 (1822) $=$ praec.

AECEOCLADES, Duchartre, in Orb. Dict. ix. 170 (1849) err. typ. = OECEOCLADES, Lindl.

AECHMAEA, Brongn. in Ann. Sc. Nat. Sér. II. xv. (1841) $371=$ Aechmea, Ruiz \& Pav. (Bromel.).

AECHMANDRA, Arn. in Hook. Lond. Journ, Bot. iii. (1841) $274=$ Melothria, Linn. (Cucurb.)

Blumeana, M. Roem. Syn. Pepon. $33=$ M. Rumphiana. conocarpa, Dalz. \& Gibs. Bomb. Fl. 100=Corallocarpus conocarpus.

deltoidea, Arn. in Hook. Lond. Journ. Bot. iii. (1841) $274=$ M. zeylanica.

epigaea, Arn. 1. c. = Corallocarpus epigaeus

indica, C. B. Clarke, in Hook. f. Fl. Brit. Ind, ii. 626 $=\mathrm{M}$. indica.

odorata, Hook. f. \&. Thoms. ex Benth. Fl. Hongkong, $124=$ M. odorata.

rostrata, Am. in Hook. Lond. Journ. Bot. iii. (1841) $274=$ Kedrostis rostrata.

velutina, Dalz. \& Gibs. in Bomb. Fl. $200=$ Corallocarpus velutina.

zeylanica, Thw. Enum. PI. Zeyl. $125=$ Cerasiocarpum zeylanicum.

AECHMANTHERA, Nees, in Wall. Pl. As. Rar. iii. 75, 87 (1837). ACANTHACEAE, Benth. \& Hook 75, 87 , 18.

gossypina, Nees, 1. c. $87=$ tomentosa

leiosperma, C. B. Clarke, in Hook. f. Fl. Brit. Ind. iv. 429. - Ind. or.

tomentosa, Nees, in Wall. Pl. As. Rar, iii. 87.-Ind. or. Wallichii, Nees, in DC. Prod. xi, $170=$ tomentosa.

AECHMEA, Ruiz \& Pav. Prod. 47. t. 8 (1794) BROMELIACEAE, Benth. \& Hook, f. iii. 663. ANDROLEPIS, Brongn. ex Houllet, in Rev. Hortic. (1870) 12 .

Canistrum, E. Morr. Belg. Hortic. (1873) 257. t. 15. Disouamia, Lem. Jard. Fleur. iii. (1852-3) t. 269. Echinostachys, Brongn. in Planch. Hort. Donat. 25 (1854).

Eriostax, Rafin. Fl. Tellur. iv, 25 (1836)

HoHENBERGIA, Schult. f. Syst. vii. II. 71, 1251 (1830).

Hoplophytum, E. Morr. Belg. Hortic. (1865) 162. LAMPRococcus, Beer, Bromel. 103 (1857)

MACROCHORdion, De Vriese, in Jaarb. Nederl. Maat. Tuinb. (1853) 14.

Pironneava, Gaudich. Voy. Bonite, Bot. t. 63. (1839-52).

Pothuava, Grudich. 1. c. tt. 116, 117 (1839-52).

angustifolia, Poepp. \& Endl. Nov. Gen. et Sp. îi. $43=$ spicata.

aquilega, Griseb. Fl. Brit. W. Ind. 592.-Ind. occ.

augusta, Baker, in Fourn. Bot. xvii. (1879) 162.Am. trop.

aurantiaca, Boker, l. c. 235,-Am, trop.

Barleei, Baker, in Gard. Chron. xx. (1883) 102.Honduras.

bracteata, Griseb. Fl. Brit. W. Ind. 592,-Ind, occ

brasiliensis, Regel, Gartenfl. (1885) 258.-Bras.

brassicoides, Baker, in fourn. Bot. xx. (1882) 329.Brit, Guian.

\section{AECHMEA :-}

bromeliaefolia, Baker, ex Benth. \&s Hook. f. Gen. iii. 664.-Am, trop.

Burchellii, Baker, in Fourn. Bot. xvii. (1879) 231.Am. trop.

caerulea, E. Morr. Cat. (1871) $1=$ seg.

caerulescens, Hort. ex Baker, in fourn. Bot. xvii. 1879) 227.-Am, trop

calyculata, Baker, in fourn. Bot, xvii. (1879) 232.Am. trop.

capitata, Baker, 1. c. $167=$ exsudans.

coelestis, E. Morr. Fl. des Serres, Sér. II. xi. (1875) 1. t. 2146.-Am. trop.

olumnaris, André, in Illustr. Hortic, xxy. (1878) 50.N. Granat.

comata, Baker, in fourn. Bot. xvii. (1879) 234.Am. trop.

contracta, Baker, l. c.-Am. trop.

corallina, Brongn. ex Beer, Bromel. 106.-Bras.

Cornui, Carr. in Rev. Hortic. (1885) $36=$ nudicaulis.

Cumingii, Baker, in fourn. Bot, xvii. (1879) 227 N. Granat.

cymoso-paniculata, Baker, l. c. 165,-Venezuela.

dactylina, Baker, l. c. 161.--Panama

dichlamydea, Baker, l. c. 133.-Ins. Tobago.

discolor, Morr, in Ann. Soc. Hort. Gand, ii. (1846) 175 . t. $65=$ fulgens.

distans, Griseb. Fl, Brit. W. Ind 592--Ind occ.

distans, Griseb. Pl. Cub. $253=$ Wrightii.

distichantha, Lem. Fard. Fleur. iii. (1853) t. 269.-Bras. exsudans, E. Morr. ex C. H. Morr. in Belg. Hortic xviii. (1878) 303,-Bras.

excavata, Baker, in Fourn. Bot. xvii. (1879) 134.Paraguay.

fasciata, Baker, l. c. 231.-Am. trop.

floribunda, Mart. ex Schult. f. Syst. vii. II. 12\}1.Bras.

fulgens, Bronon in Ann. Sc. Nat. Sér. II xy. (1841) 371.-Guiana.

Furstenbergii, E. Morr. ex C. H. Morr. in Belg. Hortic. xxviii. (1878) $252=$ Streptocalyx Furstenbergi.

Glaziovii, Baker, in Fourn. Bot.xvii. (1879) 133.-Bras.

glomerata, Hook. f. Bot. Mag. t. 5668.-Bras.

Hookeri, Lem. Illustr. Hortic. xi. (1864) Misc. 42.Bras.

Hystrix, E. Morr. ex C. H. Morr. in Belg. Hortic, xxx. (1880) 90 \& 243. - Guiana.

Fenmani, Baker, in Journ. Bot. xx. (1882) $329=$ Melinonii.

Lalindei, Linden \& Rodigas, in Illustr. Hortic. xxx. (1883) t. 481-N. Granat.

laxiflora, Benth in Bot. Voy. Sulph. 173.-Mexico.

Legrelliana, Baker, in Fourn. Bot. xvii. (1879) 236. Am. merid.

Lindeni, E. Morr.ex C. Koch, Wochenschr. viii. (1865) 398.-Bras.

lingulata, Baker, in fourn. Bot. xvii. (1879) 164.Jamaic.

Luddemanniana, Brongn. ex E. Morr. Cat. Bromel (1871) $1=$ caerulescens.

macracantha, Brongn. in Illustr. Hortic. (1880) $59=$ Schiedeana.

Mariae-Reginae, H. Wendl. in Hamb̆. Gartenz. xix. 1863) 32.-Ám. centr.

martinicensis, Baker, in fourn. Bot. xvii. (1879) 132.Ins. Martinic.

melanacantha, De Vriese, in Tuinb. Fl. i. (1855) 356 - Hab.'

Melinonii, Hook. Bot. Mag, t. 5235.-Am. trop.

Mertensii, Schult. f. Syst. vii. II. 1272.-Am, austr.

mexicana, Baker, in Fourn. Bot. xvii. (1879) 165.Mexico.

Meyeri, Baker, 1. c. xviii. (1880) $16=$ aquilega.

micrantha, Brongn. in Ann. Sc. Nat. Sér. II. xv. (1841)

$370=$ Araeococcus micranthus.

mucroniflora, Hook. Bot. Mag. t. 4832.-Guiana

multiceps, Baker, in Fourn. Bot. xviii. (1880) 49.Am. trop.

Noettigii, Wawra, in Oestr. Bot. Zeitschr. xxx. (1880) 117. - Bras.

nudicaulis, Griseb. Fl. Brit. W. Ind. 598.-Am.trop. odora, Baker, in fourn. Bot. xvii. (1879) 226. - Am. troj

organenses, Wawra, in Oestr. But. Keitschr, xxx. 1s, $116=$ floribunda.

ornata, Baker, in Fourn. Bot. xvii. (1879) 162.-Am. trop.

Ortgiesii, Baker, l. c. 236.-Am. trop.

\section{AECHMEA :}

Paniculata, Ruiz \&o Pav, Fl. Per, iii. 37-Peruy

paniculigera, Griseb. Fl. Brit. W. Ind. 593.-Ind. occ

parviflora, Baker, in Fourn. Bot. xvii. (1879) 167.Bras.

patentissima, Baker, l. c. 227.-Am. trop.

pectinata, Baker, l. c. 233.-Am. trop.

petropolitana, Wavra, in Oestr. Bot. Zeitschr. 1880) 116.--Bras.

Pineliana, Baker, in Fourn. Bot. xvii. (1879) 232.Am. trop.

platynema, Baker, l. c. 166.-Bras.

polycephala, Baker, l. c. 164.-Ins. Jamaic

pubescens, Baker, L. c. 135.-Nicarag.

pyramidalis, Benth. in Bot. Voy. Sulph. 173.-Mexico. ramosa, Mart. ex Schult. f. Syst. vii. 11. 1272.-Bras. regularis, Baker, in fourn. Bot. xvii. (1879) 229-Am trop.

Schicdeana, Schlecht, in Linnaea, xviii. (1814) 437.Mexico.

setigera, Mart. ex Schult. f. Syst. vii. It. 12\%3.-Bras.

spectabilis, Brongn. ex Houllet, in Rev. Hortic. 1875 311.-Guatemala.

sphaerocephala, Baker, in Fourn. Bot. xvii. (1879) 162 -Am. trop.

spicata, Mart. ex Schult. f. Syst. vii. II. 1273.-Bras, suaveolens, Knowl. \& Westc. Flor. Cab. iii. (1840) 177 -Bras.

subinermis, Baker, in Foum. Bot. xvii. (1879) 228.Am. trop.

tillandsioides, Baker, l. c. 134.-Bras.

Veitchii, Baker, in Bot. Mag. t. 6329.-N. Granat

viridis, Baker, in Fourn. Bot. xvii. (1879) 235.-Am. austr.

vriesioides, Baker, 1. c. 134=tillandsioides.

Weilbachea, Carr. in Rev. Hortic. (1871) $171=$ seq.

Weilbachii, F. Didr. in Ann. Sc. Nat. Sér. IV. ii. (1854) 375 - - Bras.

Wrightii, Baker, in Fourn. Bot. xvii. (1879) 163.-Cuba

AECHMOLEPIS, Decne, in DC. Prod, viii. (184t) 493. ASCLEPIADEAE, Benth. \& Hook. f. ii. $7+1$. rosmarini.olia, Decne. l. c.-Afr. trop.

AECHMOPHORA, Spreng. ex Stend. Nom. ed. II. (1840) 29= Bromus, Linn. (Gramin. arduensis, Spreng. ex Steud. 1. c. = B. arduensis.

AEDEMONE, Kotschy, in Oestr. Bot.Zeitschr. viii. I 1858 $116=$ Herminiera, Guill. \& Pers. (Legumin mirabilis, Kotschy, 1. c. = H. Elaphroxylon.

AEDMANNIA, Spach, in Orb. Dict. i. (1841) 139, err typ ${ }_{0}=$ OEDMANNIA, Thunb. (Legum.

AFDULA, Noronha, in Verh. Batav, Gen, P. 1790 ed I. Art. 4. 1, nomen.

AEEGIPHILA, Sw. Prod. Veg. Ind. Occ. (1788) 31, en typ. $=$ Aegiphila, Jacq.

AEËRIDIUM, Salisb, in Trans. Hort. Soc. i. (1512 295 = Aërides, Lour. (Orchid.)

odorım, Salisb. 1. c. = Aërides odoratum

AEGELATIS, Roxb. Fl. Ind. ii. 111 , 1832 err. typ.= Aegialitis, R. Br. (Plumbag.

AEGIALEA, Klotzsch, in Walp. Ana, ii. 1852) $1113=$ Pieris, D. Don (Ericac.

AEGIALINA, Schult. Mant. ii. 1\$24) $13,222=$ Koeleria, Pers. (Gramin.)

tenuis, Schult. l. c. $=K$, villoss.

AEGIALINITES, Presl, Bol. Bemerk. (1St $103=$ Aegialitis, R. Br. Plumbas. annulata, Presl, 1. $c_{0}=$ Aegiahtis annulat: rotundifolia, Presl, 1. c. = Aegialitis rotundifolia.

AEGIALITIS, R. Br. Prod. 1\$10: $\left.426 . \quad P L l^{\circ}\right)$ BAGINEAE, Benth. \& Hook. f, ii, ti2t.

Afoldalvites, Presl, Bot. Bemerk. 184t) 108. annulata, Kurz, in Journ. As. Soc. Beng. sivi. 1. 11. 217 - rotundifolia.

annulata. R. Br. Prod. i. t20.-Austral.

rotundifolia, Rorb. F\%. Ind, ii, 111.-Ind, or 
AEGIALITIS, Trin. Fund. Agrost. 127. t. 9. $(1820)=$ Koeleria, Pers. (Gramin.).

tenuis, Trin. $1 . c_{.}=\mathrm{K}$. villosa.

AEGIALOPHILA, Boiss. \& Heldr. Diagn. Ser. I. x. (1849) $105=$ Centaurea, Linn. (Compos.). cretica, Boiss. \& Heldr. 1. c. $106=\mathrm{C}$. pumila. pumila, Boiss. 1. c. $105=$ C. pumila.

AEGIANILITES, C. B. Clarke, in Hook. f. Fl. Brit. Ind. ii.. 479 (1882), err. typ.=Aegialitis, R. Br.

AEGIATILIS, Griff. Not. iv. 207 (1854), err. typ. = praec.

AEGICERAS, Gaertn. Fruct. i. 216. t. 46 (1788). MYRSINEAE, Benth. \& Hook. f. ii. 648.

MalaspinaeA, Presl, Reliq. Haenk. ii. 68. t. 61 (1830).

corniculatum, Blanco, F1. Filip. ed. I. $79=$ majus. ferreum, Blume, Bijdr. $693=$ majus. floridum, Roem. \& Schult. Syst. iv. 512=majus. fragrans, Kon. in Kon. \& Sims, Ann. Bot. i. (1805) $131=$ majus.

majus, Gaertn. Fruct. i. 216. t. 46.--Geront. trop. Malaspinaea, A. DC. Prod. viii. 143=majus. minus, A. DC. 1. c. $412=$ majus.

minus, Gaertn. Fruct. i. 216, t. 46.-Ind. or. nigricans, A. Rich. Voy. Astrol. Bot, ii. 57. t. $21=$ majus.

obcordatum, Steud. Nom. ed. II. i. $29=$ majus.

obovatum, Blume, Bijdr. $693=$ majus.

AEGICON, Adans. Fam. ii.36 (1763)=Triticum, Linn. (Gramin.)

AEGILOPS, Linn. Coroll. Gen. 20 (1737)= Triticum, Linn. Gramin.).

agropiroides, Godr. in Mém. Acad. Montp. (Sect. Médic.) i. (1853) 456.- Syria.

aromatica, Walt. Fl. Carol. $249=$ Ctenium americanum.

Aucheri, Boiss. Diagn. Ser. I. v. $74=$ Agropyron Aucheri.

Augeri, Steud. Syn. Pl. Gram. 355 (err. typ.)= praec.

bicornis, Jaub. \& Spach, Illustr. Pl. Or. iv. $11=\mathrm{T}$. bicorne.

biuncialis, Vis. Fl. Dalm. 1-Europ.

brachyathera, Pomel, Nouv. Mat. Fl. Atl. 389.-Afr.bor caudata, Bertol. Fl. Ital. vi. $622=$ Agropyron Aucheri. caudata, C. A. Mey. Verz. Pfl. Cauc. $26=$ T. Aegylops. caudata, Balb. Elencho, 98 ; Griseb. Spicil. Fl. Rumel. ii. $425=\mathrm{T}$. cylindricum.

caudata, Linn. Sp. Pl. 1051=Agropyron villosum?

ciliaris, Koen. ex Roem. \& Schult. Syst. ii. 772 .Ind. or.

comosa, Sibth. \& Sm. Fl. Graec. 75. t. 94.-Graecia.

connata, Steud. Syn. Pl. Gram. 356.-Graecia

crassa, Boiss. Diagn. Ser. I. vii. 123.-Oriens.

crithodium, Steud. Syn. Pl. Gram. $355=$ = T. monococcum

cylindrica, C. A, Mey. Verz, Pf. Cauc, $26=\mathrm{T}$. Aegylops?

cylindrica, Host, Gram. Austr. ii. 6. t. $7=\mathrm{T}$. cylindricum.

cylindrica, Schur, Enum. PI. Transs. $813=\mathrm{T}$. ovatum.

cylindrica, Sibth. \& Sm. Fl. Graec. t. $95=$ T. caudatum.

divaricata, Jord. \& Fourr. Brev. P1. Nov. Fasc. ii. 129 $=\mathrm{T}$. ovatum.

echinata, Presl, Gram. Sic. $47=\mathrm{T}$. triunciale.

Echinus, Godr. in Mém. Acad. Montp. (Sect. Médic.)

i. (1853) 456.-Gallia?

elongata, Lam. F1. Fr. iii. $632=\mathrm{T}$. triunciale

erigens, Jord. \& Fourr. Brev. Pl. Nov. Fasc. ii. $131=$ T. ovatum.

erratica, Jord. \& Fourr. 1. c. $130=$ T, ovatum.

exaltata, Linn. Mant. ii. App. $575=$ Ophiurus corymbosus.

fluviatilis, Blanco, Fl. Filip. ed. I. 47.-Ins. Philipp.

fragilis, Parl. Fl. Ital. i. $515=\mathrm{T}$. fragile.

geniculata, Roth, Catalect. i. $121=$ T. ovatum.

hordeiformis, Steud. Syn. Pl. Gram. 354.-Mesopotam.

Hystrix, Nutt. Gen. Am, i. 86,-Am. bor.

incurva, Linn. Sp. Pl. $1051=$ Lepturus incurvatus.

incurvata, Linn. Sp. Pl. ed. II. $1490=$ praec.

Kotschyi, Boiss. Diagn. Ser. I. vii. $129=$ T. triunciale.

Larenti, Steud. Syn. Pl. Gram. $354=$ Lorentii.

loliacea, Jaub. \& Spach, Illustr. Pl. Or. iv. $23=$ mutica.
AEGILOPS :-

longearistata, Steud. Syn. Pl. Gram. 356.-Guiana. Lorentii, Hochst. in Lorent, Wanderungen, $326=\mathrm{T}$ ovatum.

macrochaeta, Shuttl. \& Huet, ex Duval, in Bull. Soc. Bot. Fr. xvi. (1869) $384=$ T. ovatum.

macrura, Jaub. \& Spach, Illustr. Pl. Or. iv. $21=$ Agropyron Aucheri.

microstachys, Jord. \& Fourr. Brev. Pl, Nov. Fasc. ii. $132=\mathrm{T}$. ovatum.

muricata, Retz. Obs. ii. $27=$ Ischaemum pectinatum. mutica, Boiss. Diagn. Ser. I. v. 73.-Oriens.

neglecta, Req. ex Bertol. Fl. Ital. i. $787=$ T. triari statum.

nigricans, Jord. \& Fourr. Brev. P1. Nov. Fasc. ii. 128 $=\mathrm{T}$. ovatum.

Notarisii, Clem. in Mem. Acc. Torin. Ser. II. xvi (1857) $335=\mathrm{T}$. ovatum

ovata, Linn. Sp. Pl. $1050=\mathrm{T}$. ovatum

ovata, Roth, in Usteri, Ann. iv. (1793) $41=T$. triari statum.

parvula, Jord. \& Fourr. Brev. Pl. Nov. Fasc. ii. $131=$ T. ovatum.

persica, Boiss. Diagn. Ser. I. vii. $129=$ T. caudatum. platyathera, Jaub. \& Spach, Illustr. Pl. Or. iv. 17.Mesopotam.

procera, Jord. \& Fourr. Brev. P1. Nov. Fasc. ii. $129=$ T. ovatum.

pubiolumis, Ford. \& Fourr. 1. c. $131=$ T. ovatum. saccharina, Walt. F1. Carol. $249=$ Eleusine aegyptiaca singularis, Steud. Syn. Pl. Gram. 354.-Persia. sicula, Jord. \& Fourr. Brev. Pl. Nov. Fasc. ii. 129=T. ovatum.

speltaeformis, Jord, in Ann. Sc. Nat. Sér. IV. iv. (1855) $313=\mathrm{T}$, ovatum

speltoides, Tausch, in Flora, xxxix. (1837) $109=\mathrm{T}$. bicorne.

squarrosa, Willd. Sp. P1. iv. $944=\mathrm{T}$. ventricosum.

squarrosa, Cav. Ic. t. 90 . f. 2 =platyathera

squarrosa, DC. ex Steud. Nom, ed. II. i. $29=$ T. cylindricum.

squarrosa, Linn. Sp. P1. 1051=T. Aegylops.

subulata, Pornel, Nouv. Mat. Fl. Atl. 388.-Afr. bor.

Tauschii, Coss. Notes Crit. $69=$ T. Aegylops

triaristata, Req. ex Bertol. Fl. Ital, i. $789=\mathrm{T}$. triunciale.

triaristata, Willd. Sp. P1. iv. $943=$ T. triaristatum.

tripsacoides, Jaub. \& Spach, Illustr. Pl. Or. ii. 121. $200=$ mutica .

triticoides $\times$, Req. ex Berto1. Fl. Ital. i. 788.-Europ triuncialis, Linn. Sp. PI. 1051=T, triunciale.

truncata, Ledeb. ex Trantv. in Act. Hort. Petrop. ix. (1884) 312, nomen.-Rossia.

uniaristata, Steud. Syn. Pl. Gram. 354.-Graecia.

uniaristata, Vis. Fl. Dalm. iii. 345.-Europ.

vagans, Jord. \& Fourr. Brev. Pl. Nov. Fasc. ii. $130=$ T. ovatum.

ventricosa, Tausch, in Flora, xxxix. (1837) $108=\mathrm{T}$. ventricosum

virescens, Jord. \& Fourr. Brev. PI. Nov. Fasc. ii. $130=$ T. ovatum.

AEGINETIA, Cav. in Anal. Cienc. Nat. iii. (1801) 129 $=$ Bouvardia, Salisb. (Rubiac.)

capitata, R. Grah. in Edinb. N. Phil. Joum. (Jan. 1828) $389=$ Coccocipselum capituliflorum

longiflora, Cav. in Anal. Hist. Nat. iii. (1801) $130=$ Houstonia longiflora.

multiflora, Cav. 1. c. = Bouvardia Cavaníllesii

AEGINETIA, Linn. Syst. ed. I. (1735). $C H A C E A E$, Benth. \& Hook. f. ii. 982.

Centronia, Blume, Bijdr. 776 (1826).

Centronota, DC. ex Meissn. Gen. 303 (213) (1840); et Prod. ix. 286 (1846).

Gasparinia, Endl. Gen. 1408 (1840).

Tronicena, Steud. Nom. ed. II. ii. 721 (1841).

abbreviata, Buch.-Ham. ex Benth. Scroph. Ind. 55= pedunculata.

acaulis, Walp. Rep. iii. 481 = pedunculata.

Centronia, Miq. Fl. Ind. Bat. ii. 713.-Java.

coccinea, Juss, ex Walp. Rep. iii. $481=$ Phelypaea coc-

indica, Linn.Sp. Pl. 632 ; Roxb. Pl. Corom. i. 63. t. 91.-As. trop.

japonica, Sieb. \& Zucc. in Abh. Math. Akad. Muench. iv. III. (1845) $341=$ indica.

pedunculata, Wall. Pl.As. Rar.iii, 13.t.219.-As. trop.
AEGIPHILA, Jacq. Stirp. Am. t. 16 (1763); Obs. Bot. ii. 3. t. 27 (1767). VERBENACEAE, Benth. \& Hook. f. ii. 1151.

Amerina, DC. in Meissn. Gen. 278 (186) (1840).

Brueckia, Klotzsch \& Karst. Ausw. Gew. Venez. 31. t. 10 (1848)

Manabea, Aubl. Pl. Gui. i. 61. t. 23, 25 (1775).

Omphalococca, Willd. ex Roem. \& Schult. Syst. iii Mant. $10(1827)$

arborescens, Vahl, Eclog. i. 15. t. 10.-Am. austr. aurea, Turcs. in Bull. Soc. Nat. Mosc. xxxvi. (1868) II. 218.-Cuba.

Berteriana, Schau. in DC. Prod. xi. 654.-N. Granat. brachiata, Schlechto in Linnaea, vi. (1831) 371.Mexico.

brachiata, Vell. F1. Flum. 38 ; i. t. $93=$ triantha. casseliaeformis, Schau in DC. Prod. xi. 651.-Bras. cestrifolia, Gardn. in Hook. Lond. Fourn. Bot v. (1846) 184.--Bras.

cordata, Poepp. ex DC. Prod. xi. 650,-Peruv.

comifolia, Kunth, in Abh. Akad. Berl. (1831) 215.Bras.

cuspidata, Mart. ex DC. Prod xi 653-Bras.

Deppeana, Steud. Nom. ed. II. i. $29=$ brachiata

diffusa, Andr. Bot. Rep. ix. t. 578.-Ind. occ.

dumosa, Salisb. Prod, $67=$ martinicensis.

elata, Sw. Prod. Veg. Ind. Occ. 31.-Am. trop.

filipes, Mart. \& Schau. in DC. Prod xi. 652.-Bras.

fluminensis, Vell. Fl. Flum. 38 ; i. t. 95.-Bras.

foetida, Sw. Prod. Veg. Ind. Occ. 32.-Tamaic.

glabra, Lam. Illustr. t. 70. f. $1=$ martinicensis.

glomerata, Benth. Bot. Voy. Sulph. 154.-Ecuador.

grandiflora, Hook. Bot. Mag. t. $4230=$ Clerodendron grandiflorum.

grandifolia, Walp. Rep. iv, $121=$ magnifolia

graveolens, Mart. \& Schau. in DC. Prod, xi. 651.Bras.

hirta, Casar. Nov. Stirp. Bras. Decad. 47.-Bras.

Humboldti, Schau. in DC. Prod. xi. 652.-Venezuela.

incana, Turcz, in Bull. Soc. Nat. Mosc. xxxvi. (1863) II. 218. - Cuba

inflexa, Vell. Fl. Flum, 38 ; i. t. 96. (Rnbiacea, sec. Schau. .-Bras.

integrifolia, facq. Hist. Stirp. Am. 15. t. 173. f. 7. $-\mathrm{N}$. Granat

laeta, H. B. \& K.Nov. Gen. et Sp. ii. 249.-N. Granat. laevigata, fuss. in Ann. Mus. Par. vii. (1806) 76.Ind occ.

laevis, Poepp. ex Walp. Rep. iv. 119.-Bras.

laevis, Willd. Sp. $P l$. i. 617.-Guiana.

lanuginosa, Gardn. in Hook. Lond. Journ. Bot. iv. 1845) $134=$ obducta

latifolia, Willd, ex Walp. Rep. iv. 120=Mutisii

laxiflora, Benth. in Ann. Nat. Hist. ii. (1839) 449. Guiana.

Lhotskiana, Cham. in Linnaea, vii. (1832) 112.-Bras. longifolia, Turcz. in Bull. Soc. Nat. Mosc. xxxvi. (1863) II. 218.-N. Granat

Luschnatii, Schau. in DC. Prod. xi. 651.-Bras,

lutea, Lam. Illustr. t. 70, f, $3=$ laevis

macrophylla, Desf. Cat. Hort. Paris. ed. III. $391=$ magnifolia.

macrophylla, H. B. \& $K$. Nov. Gen. et Sp. ii. 251.Am. austr.

macrophylla, Sieber, ex Schau. in DC. Prod. xi. 655 (= Rubiacea, sec. Schat.).-Ins. Trinit.

magnifolia, Steud. Nom. ed. II. i. 29.-Ind. occ.

Manabaea, Sw. Prod. Veg. Ind. Occ. i. $256=$ laevis

martinicensis, facq. Obs. Bot. ii. 3.-Ins. Martinic

mediterranea, Vell. Fl. Flum 38 ; i. t. 94-Bras.

membranacea, Turcz. in Bull. Soc. Nat, Mosc. xxxvi. 1863) II, 219.-Am. trop.

mollis, H.B. \& K. Now. Gen. et Sp. ii. 250.t. 130.Am. austr.

multiflora, Ruiz \& Pav. Fl. Per. i. 50. t. 76.-Peruv.

Mutisii, H. B. \& K. Nov. Gen. et Sp. ii. 250. t. 131.-

A.m. austr.

Nuxia, Willd. Sp. P1. i. $616=$ Nuxia verticillata.

obducta, Vell. Fl. Flum. 39 ; i. t. 97 .-Bras.

obovata, Andr. Bot. Rep. ix. 578.--Ind, occ.

oleifera, Casar. Nov. Stirp. Bras. Decad. 47 =fluminensis.

peruviana, Turcz. in Bull. Soc. Nat. Mosc. xxxvi. (1863) II. 219.-Peruv.

pubescens, Willd. ex Steud. Nom. ed. II. i. $29=$ salutaris.

punctata, Turcz. in Bull. Soc. Nat. Mosc. xxxvi. (1863) II. 219. - Jamaic 


\section{AEGIPHILA :-}

racemosa, Vell. Fl. Flum. 37 ; i. t. $88=$ cuspidata. Riedeliana, Schau. in DC. Prod. xi, 649.-Bras. salutaris, H. B. E K. Nov. Gen. et Sp. ii. 249.-Am. austr.

Sellowiana, Cham. in Linnaea, vii. (1832) 111.Bras.

serrata, Vell. F1. Flum. 38 ; i. t. $92=$ graveolens. splendens, Schau. in DC. Prod. xi. 648.-Bras. stipulata, Vell. Fl. Flum. 37 ; i. t. 90 (Rubiacea, sec. Schau.).-Bras.

straminea, Hoffmgg. Verz. Pf. Nachtr. iii. 18.-Bras. tomentosa, Cham. in Linnaea, vii. (1832) 110.-Bras. triantha, Schau. in DC. Prod. xi. 650.-Bras. trifida, Sw. Prod. Veg. Ind. Occ. 32.-Jamaic. umbellata, Vell. Fl.Flum. 37 ; i. t. 89. (Rubiacea, sec Schat.).-Bras,

verrucosa, Schau, in DC. Prod xi. 650.-N. Granat. verticillata, Vell. Fl. Flum. 37 ; i. t. $91=$ tomentosa. viburnifolia, Fuss. in Ann. Mus. Par. vii. (1806) 76 -Ins. Philipp.

villosa, Vahl, Eclog. i. 16.-Guiana

virgata, Turcz. in Bull. Soc. Nat. Mosc. xxxvi. (1863) II. 220.-Bras

vitelliniflora, Klotesch, ex Walp. Rep. iv, 123.-Hab. ?

AEGIPHXLA, Steud. Nom. ed. II. i. $29=$ Aegiphila, Jacq.

AEGLE, Correa, in Trans. Linn. Soc. v. (1800) 22 RUTACEAE, Benth. \& Hook. f. i. 306.

Belou, Adans. Fam, ii. 408 (1763).

decandra, $F$. Villar, in Blanco, Fl. Philipp. ed III Nov. App. 38. -Ins. Philipp.

Marmelos, Correa, in Trans. Linn. Soc. v. (1800) 223. - Ind. or.

sepiaria, DC. Prod. i. $538=$ Citrus trifoliata.

AEGLE, Dulac, Fl. Hantes-Pyr. $43(1867)=$ Posidonia, Koen. (Naiad.).

fragilis, Dulac, 1. c. $=$ P. fragilis.

AEGOCHLOA, Benth. in Bot. Reg. sub t. 1622 (1833) = Gilia, Ruiz \& Pav. (Polemon.).

atractyloides, Benth. 1. $\mathrm{c} .=\mathrm{G}$. atractyloides.

cotulaefolia, Benth. 1. c. = G. cotulaefolia.

eryngioides, Benth. 1. c. = G. Navarettia.

intertexta, Benth. 1. c. = G. intertexta.

pubescens, Benth. 1. $c_{*}=G$. cotulaefolia.

pungens, Benth. 1. c. $=\mathrm{G}$. squarrosa.

Torreyi, G. Don, Gen. Syst. iv. $246=\mathrm{G}$. pungens.

AEGOMARATHRUM, Steud. Nom. ed. II. i. 30 (1840) Cachrys, Tourn. (Umbell.)

crispum, Steud. 1. $\mathrm{c}_{\mathrm{r}}=\mathrm{C}$. crispa.

pterochlaena, Steud. 1. $c_{0}=$ C. sicula.

siculum, Mor. ex Nym. Consp. $314=$ Hippomarathrum Bocconi.

AEGONYCHON, S. F. Gray, Nat. Arr. Brit. Pl. ii. $354(1821)=$ Lithospermum, Linn. (Borag.) arvense, S. F. Gray, 1. c。=L. arvense,

repens, S. F. Gray, 1. c. = L. purpureo-caeruleum.

AEGOPICRON, Giseke, Prael. $474(1792)=$ AEGO PRICON, Linn. f. = Maprounea, Aubl. (Euphorb.).

AEGOPODION, St. Lag. in Ann. Soc. Bot. Lyon, vii. (1880) $119=$ seq.

AEGOPODIUM, Knaut, ex Linn. Syst. ed. I. (1735). UMBELLIFERAE, Benth. \& Hook, f, i. 893.

Podagraria, Hall. Enum. Stirp. Helv, ii. 427 (1742).

alpestre, Ledeb. Fl. Alt. i. 354--Sibir. altaic. angelicaefolium, Salisb. Prod. $169=$ Ae. Podagraria. Carum, Wibel, Prim. Fi. Werth. $199=$ Carum Carvi. involucratum, Orphan. ex Boiss. F1. Orient. ii, $923=$ Physospermum aegopodioides.

latifolium, Turcz, in Bull. Soc. Nat. Mosc. xvii. (1844) $711=$ A.e. Podagraria.

Podngraria, Linn. Sp. Pl. 265.-Europ.; As. bor. ternatum, Gilib. Fl. Lituan. 1i. 4I=Ae. Podagraria.

AEGOPOGON, Beauv. Agrost. 122. t. 22. f. 4. (1812) partim = Amphipogon, R, Br. (Gramin.)

avenaceus, Beauv. 1. c. $=$ Am. strictus.

debilis, Beauv. 1. c. = Am. debilis.

laguroides, Beauv. 1. c. = Am. laguroides.

\section{AEGOPOGON:-}

pusillus, Spreng. Syst. i. $270=$ Chloris cruciata. strictus, Beauv. Agrost. $122=\mathrm{Am}$. strictus. turbinatus, Beauv. 1. c. $=\mathrm{Am}$. turbinatus.

AEGOPOGON, Beauv. Agrost. 122 (1812) partim; Humb. \& Bonpl. in Willd. Sp. Pl. iv. 899 (1805) Humb. \& Bonpl. in Willd. Sp. Pl. iv. 899
GR AMINEAE, Benth. \& Hook. f. iii. 1121. Hymenothecrum, Lag. Gen. et Sp. Nov. 4 (1816) Schellingia, Steud. in Flora, xxxiii. (1850) 231. t. 1 .

bryophilus, Doell, in Mart. Fl. Bras, ii. III. 239.-Bras. cenchroides, Humb. E Bonpl. ex Willd.Sp. Pl. iv. 899. -Venezuela.

geminiflorus, Humb. E Bonpl. Nov. Gen. et Sp. iv. 133. t. 43.-Am. trop.

multisetus, Steud. Syn. Pl. Gram. $146=$ cenchroides. quinquesetus, Roem. \& Schult. Syst. ii. $805=$ cen chroides.

pusillus, Beauv. Agrost. $122=$ geminiflorus. rigidisetus, Steud. Syn. Pl. Gram. 146.-Texas setifer, Nees, in Linnaea, xix. (1847) 691=cenchroides. submuticus, Rupr.ex Trin. in Mém. Acad. Pétersb. Sér.

VI, v. II. (1840) 3.-Hab.?

tenellus, Trin. Gram. Unifl. $164=$ geminiflorus.

trisetus, Roem. \& Schult. Syst. ii. $805=$ cenchroides. unisetus, Roem. \& Schult. 1. c. = geminiflorus.

AEGOPORDON, Boiss. Diagn. Ser. I. vi. (1845) $112=$ Jurinea, Cass. (Compos.).

berardioides, Boiss. 1. c. 113.--Persia.

AEGOPRICON, Linn. f. Suppl. $413(1789)=$ seq.

AEGOPRICUM, Linn. Pl. Surinam. 15 (1775); (Amoen Acad. viii. 263) = Maprounea, Aubl. (Euphorb.). betulinum, Linn. 1. c. = M. guianensis.

AEGOSERIS, Steud. Nom. ed. II. i. (1840) $30=$ Crepis, Linn. (Compos.)

leontodontoides, Fourr. in Ann. Soc. Linn. Lyon, N. S. xyii. (1869) $103=$ C. leontodontoides.

setosa, Fourr. 1. $\mathrm{c}_{2}=\mathrm{C}$. setosa.

suffreniana, Fourr. 1. c. =C. suffreniana

AEGotoxiCON, Molina, Sagg. Chile, ed. II. 298 (1810) =Aextoxicon, Ruiz \& Pav. (Euphorb.).

AEGOTOXICUM, Endl. Ench. $589(1841)=$ praec.

AEGYLOPS, Honck. Syn. i. 484 (1792) err. typ. $=$ AEGILOPS, Linn. = Triticum, Linn. (Gramia.)

AEIPHANES, Spreng. Anleit. ii. II. 875 (1818) err. typ. =AIPHANES, Willd.= Martinezia, Ruiz \& Pav. (Palm.).

AFLUROPUS, Trin. Fund. Agtost. 143 (1820). GRAMINEAE, Benth. \& Hook. f, iii. 1193. CalothecA, Spreng. Anleit. ii. I. 167 (1817); Syst. i. $347(1825)$.

Chamaedactylis, T. Nees, Gen, Fl. Germ. Monocot. i. n. $66(1840$ ? $)$.

arabicus, Steud. Nom. ed. II, i. 30_-Aegypt.; Abyss. bombycinus, Figar. \& De Not. in Mem. Acc. Torin Ser. II. xii. (1852) 258 =arabicus.

brevifolius, Nees, ex Steud. Nom. ed. II. i。 $30=$ pubescens.

concinnus, Figar. \& De Not. in Mem. Acc. Torin. Ser. II. xii. (i852) $257=$ laevis.

grandiflorus, Munro, in Cat. Kew Distrib. Griffith, \&c 57 , nomen.-Afghan.

hirsutus, Munro, l.c. nomen.-Ind. or

intermedius, Regel, in Bull. Soc. Nat. Mosc. xli. (1868) II. 292.-As. temp.

laevis, Trin. Fund. Agrost. 143.-Oriens,

litoralis, Parl. F1. Ital. i. $461=$ laevis.

mucronatus, Aschers, in Schweinf. Beitr. Fl. Aethiop. $297=$ arabicus

niliacus, Steud. Nom. ed. II. i. 30--Aegypt.

pubescens, Trin. ex Stend. Nom. ed. II. i. 30 Ind. or.

pungens, C. Koch, in Linnaea, xxi. (1848) 408 laevis.

repens, Parl. Fl. Ital. i. $462=$ villosus.

sinaicus, Figar. \& De Not. in Mem. Acc. Torin. Ser.

II. xii. $(1852) 257=$ laevis.

Smithii, Steud. Nom. ed. II. i 30.--Ins. Canar.

villosus, Trin. Fund. Agrost. 1\$3.-Afr. bor.; Graecia.
AENOTHERA, Lam. Encyc. iv, 550 (1796), err, typ. Oenothera, Limn. (Onagr.).

AEOLANTHUS, Mart. Amoen. Bot. Monac. 4. 1825). LABIATAE, Benth. \& Hook. f. ii. 1176. Orollanthus, E. Mey. Comm. Pl. Afr. Austr. ii. 23 (1837).

abyssinicus, Hochst. ex Benth. in DC. Prod. xii. 80.Abyss.

ambustus, Oliver, in Trans. Linn. Soc. xxix. 1875 138.-A fr. trop.

heliotropioides, Oliver, l. c. 137.-Afr. trop.

Livingstonei, C. Koch, Berl. Wochenschr. iii. (1860 183.-Afr. trop.

parvifolius, Benth. in DC. Prod. xii. 80.-Afr. austr.

pinnatifidus, Hochst. ex Benth. l. c.-Abyss.

pubescens, Benth.l. c.-Afr. trop.

repens, Oliver, in Trans. Linn. Soc. xxix. (1855) 1:; -Afr. trop.

suaveolens, G. Don, in Loud. Hort. Brit. 247 = suavis.

suavis, Mart. Amoen. Bot. Monac. 4. t. 2.-Bras. Afr.?

zanzibaricus, 'S. Moore, in Fourn. Bot. xv. (1877) 68 -Afr. trop.

AEOLLANTHUS, Spreng. Syst. ii. $750(1825)=$ praec.

AEONIA, Lindl. Bot. Reg. sub t. 817 (1821). OR. CHIDEAE, Benth. \&C Hook. f. iii. 584

Brachystepis, Thou, ex Pritzel, Ind. Ic. 162 (1855) OEONIA, Lindl. Orch. Scel. 14, err. typ. (1826)

alata, A. Rich. in Ann. Sc. Nat. Sér. II. xvi. (1841) t. 11. - Ind. or

Auberti, Lindl. Bot. Reg. sub t. 817.-Madag.

brachystachya, Lindl. Gen. et Sp. Orch. 245.-Madag. macrostachya, Lindl. l. c. 245.-Madag.

polystachya, Benth. \& Hook. f. Gen. iii. 584.Madag

rosea, Ridl. in Fourn. Linn. Soc. xxi. (1885) 496.Madag.

AEONIUM, Webb. \& Berth. Phyt. Canar. i. 184 (1836), t. 28 = Sempervivum, Linn. (Crassul.)

arboreum, Webb \&c Berth. 1. c. $185=$ S. arboreum.

balsamiferum, Webb \& Berth. 1. c. $192=$ S. balsamiferum.

barbatum, Webb \& Berth. 1. c. $188=$ S. piliferum.

Berthelotianum, Bolle, in Bonplandia, vii. 1859) 239

Bethencourtianum, Webb, ex Bolle, 1. c. 243.-Ins. Canar.

caespitosum, Webb \& Berth. Phyt. Canar. i. $191=$ S. caespitosum

canariense, Webb \& Berth. 1. c. i. $196=$ S. canariense. Castello-Paivae, C. Bolle, in Bonplandia, vii. (185y 240.-Ins. Canar.

ciliatum, Webb \& Berth. Phyt. Canar. i. $195=$ S. ciliatum.

cruentum, Webb \& Berth. 1. c. $186=$ S. cruentum. cuneatum, Webb \& Berth. 1. c. $197=$ S. cuneatum. decorum, Webb, ex C. Bolle, in Bonplandia, vii. (185? 241.-Ins. Canar.

frutescens, Webb \& Berth. Phyt. Canar. i. 198 ? = S. frutescens.

glandulosum, Webb \& Berth, 1, c. $185=$ S. glandu. losum.

glutinosum, Webb \& Berth. 1. c. $185=$ S. gluti. nosum.

Goochiae, Webb, \& Berth. 1, c. $190=$ S. Goochiae.

gorgoneum, J. A. Schmidt, Beitr. Fl. Cap. Verd. Ins, 258.-Ins. Cap. Verd.

Haworthii, Webb \& Berth. Phyt. Canar. i. $1: 03=$ S. Haworthii.

holochrysum, Webb \& Berth. 1. c. $1: 4=$ S. holochrysum.

laxum, Webb \& Berth 1. c. i. 199 ? =S. laxam.

leucoblepharum, Webb, ex A. Kich. Tent. Fl. Abyss i. $314=\$$. chrysanthum.

Lindleyi, Webb \& Burth. Phyt. Canar. i. 18!=s. villosum.

manriqucorum, C. Bolle, in Bonplanclia, vii. lss!

$2+1$. - Ins. Camar.

Meverheimii, C. Bolle, 1. c. 23!.-Ins, Mrader.

Saundersii, C. Bolle, 1. c. :11.- Ins. Canar.

Smithii. Webb \& Berth. Phyt. Canar. i. 157=s Simithii.

strepsicladum, Webb \& Bcrth. 1. $c_{0}=$ S. strepsit

clatum.

abulactorme. Webl \& berth. I. c. $1 \$ 5-\$$. eabelac. luruse. 


\section{AEONIUM :-}

undulatum, Webb \& Berth. Phyt. Canar, i. $197=\mathrm{S}$ undulatum

urbicum, Webb \& Berth. 1. c. $194=$ S. urbicum.

viscatum, Webb, ex C. Bolle, in Bonplandia, vii. (1859) 241.-Ins. Canar.

Webbii, C. Bolle, 1. c. 238.-Ins. Canar.

Youngianum, Webb \& Berth. Phyt. Canar. i. $197=$ S. Youngianum.

AËRA, Aschers, Fl. Brandenb. $830($ (1864)=Aira Linn (Gramin.).

AËRANGIS, Reichb, f. in Flora, xlviii. (1865) $190=$ Angraecum, Thou. (Orchid.).

flabellifolia, Reichb. f. 1. c. 191-Afr trop

Kotschyi, Reichb. f. Otia Bot. Hamb, $78=$ Angr Kotschyi.

AËRANTHES, Lindl. Bot. Reg t. 817 (1824) ORCHIDEAE, iii. 576 .

Arachnitis, Lindl. Bot. Reg. t. 817.-Ins. Mascar. fliformis, Griseb. Fl. Brit. W. Ind. 625.-Ind. oce. grandiflorus, Lindl. Bot. Reg. t. 817.-Madag. grandiflorus, Lindl. Gen. et Sp. Orch. 243, pro parte = A. Arachnitis.

jamaicensis, Reichb. f. ex Griseb. F1. Brit. W. Ind $625=$ Angraecum micranthum.

sesquipedalis, Lindl. Bot. Reg. sub t. $817=$ Angraecum sesquipedale.

AERANTHUS, Bartl. Ord. 57 (1830)= praec.

AËRANTHUS, Reichb. f. in Walp. Ann. vi. 899 (1861) = Mystacidium, Lindl. (Orchid.), \&c.

aciculatus, Reichb f. \& Warm, in Otia Bot. Hamb. 91. -Bras.

arachnanthus, Reichb. fo in Flora, Ixviii. (1885) 539. Ins. Comor.

brachystachyus, Boj. Hort. Maurit. $314=$ Aeonia brachy. stachya.

Calceolus, S. Moore, in Baker, Fl. Maurit. $353=$ Angraecum Calceolus.

comorensis, Reichb. f. in Flora, lxviii. (1885) 540.-Ins. Comor.

Cumowianus, Reichb. f. in Gard. Chron. N. S. xix. (1883) I. 306.-Madag.

dentiens, Reichb, f. in Hlora, Ixviii. (1885) 381,-Ins. Comor.

distichus, Reichb. f. in Walp. Ann. vi. 901=Angraecum distichum.

erythropollinius, Reichb. f. in Flora, xlviii. (1865) 190

-Afr. trop.

expansus, S. Moore, in Baker, Fl. Maurit. 351=Angraecum expansum.

Fasciola, Reichb. f. in Walp. Ann. vi. 902=Angraecum Fasciola.

fiticornis, Reichb. f. 1. c. $900=$ M. filicome.

fragrans, Reichb. f. 1. c. $899=$ Angraecum fragrans.

funalis, Reichb. f. 1. c. $902=$ Angraecum funale

Gerrardi, Reichb. f. in Flora, 1. (1867) 117.-Afr austr.

Gladiator, Reichb. f. 1. c. Ixviii. (1885) 539--Ins. Comor.

gladiifolius, Reichb. f. in Walp. Ann. vi. $900=$ Angraecum gladiifolium.

gracilis, Reichb. E in Flora, 1. (1867) $117=$ M. gracile

Grandidieranus, Reichb. f.1. c. Ixviii. (1885) 381.-Ins. Comor.

Guyonianus, Reichb. f. 1. c. xlviii. (1865) $190=\mathrm{An}$ graecum Guyonianum.

hispidulus, Reichb, f, in Linnaea, xli. (1877) 31.N. Granat.

hymenanthus, Griseb. Cat. Pl. Cub. 264=Dendrophylax hymenanthus.

intermedius, Reichb. f. \& Warm. in Otia Bot. Hamb. 91.-Bras.

jamaicensis, Reichb. f, in Walp. Ann, vi. $901=$ Angraecum micranthum.

Lansbergii, Reichb. f. l. c. = Angraecum Lansbergii.

Lehmanni, Reichb, f. Otia Bot. Hamb, 10.-Hab.?

Leonii, Reichb. in Flora, lxviii. (1885) $380=\mathrm{seq}$

Leonis, Reichb. f. in Gard. Chron. N. S. xxiii. (1885) $726=$ Angraecum Humblotii

Lindenii, Reichb. f. in Walp. Ann, vi. $902=\mathrm{An}$ graecum Lindenii.

macrostachys, Reichb. f. 1. c. $900=$ Aeonia macrostachya.
AERANTHUS:-

Meirax, Reichb. f. in Flora, lxviii. (1885) 540.-Afr. austr.

micranthus, Reichb. f. in Walp. Ann, vi. 90=Angraecum micranthum

Monteverdi, Reichb. f. in Flora, xlviii. (1865) 279.Hab. ?

muscicola, Reichb. f. 1. c. 190.-Afr. trop

neglectus, Reichb. f. \& Warm. in Otia Bot. Hamb. 91. -Bras.

organensis, Reichb, f. in Walp. Ann. vi. $901=$ Angraecum organense.

ornithorrhynchus, Reichb. f. 1. c. 903=Angraecum ornithorrhynchum.

pachyrhyzus, Reichb. f. in Flora, xlviii. (1865) 279. Ind. occ.

parahybunensis, Rodrig. Orch. Nov, ii. 245.-Bras.

pectinatus, Reichb. f. in Walp. Ann. vi, $900=$ Angraecum pectinatum.

phalaenophorus, Reichb. f. in Flora, 1xviii. (1885) 539. -Ins. Comor.

polystachyus, Reichb. f. in Walp. Ann. vi. 901=Aeonia polystachia.

porrectus, Reichb. f. in Flora, xlviii, (1865) 279.Ind. oce.

pusillus, Reichb. f. 1. c. 1. (1867) $117=$ M. pusillum.

rectus, S. Moore, in Baker, F1. Maurit. $351=$ Angraecum rectum.

rutilus, Reichb. f. in Flora, Ixviii. (1885) 540--Ins. Comor

Sallei, Reichb. f. in Walp. Ann. vi. 902.-Ins. S Doming

Schiedei, Reichb. f. I. c. 901=Campylocentron Schiedei.

sesquipedalis, Reichb. in Flora, 1xviii. (1885) $381=$ Angraecum sesquipedale.

spathaceus, Griseb. Cat. P1. Cub. 264.-Cuba.

Thozsarsii, S. Moore, in Baker, Fl. Maurit. $35=$ Angraecum filicornu.

trifurcus, Reichb. f. in Flora, lxviii. (1885) 540.-Ins. Comor.

volucris, Reichb. fo in Walp. Ann, vi. $900=$ Aeonia Auberti.

xanthopollinius, Reichb. 1. c. xlviii. (1865) 190,Afr. trop.

A ËRIDES, Lour. Fl. Cochinch. 525 (1790). ORCHI$D E A E$, Benth. \& Hook. f. iii. 576.

AËERIDIU M, Salisb, in Trans. Hort. Soc i. (1812) 295.

OrXerA, Rafin. Fl. Tellur. iv. 37 (1836).

acuminatissimum, Lindl. Gen. et Sp.Orch. 240,--Java.

affine, Wall. Cat. n. $7316=$ multiflorum.

amplexicaule, Lindl. Gen. et Sp. Orch. 239 = Sarcochilus lilacinus.

ampullaceum, Roxb. Fl. Ind. iii. $476=$ Sarcolabium ampullaceum.

anceps, Lindl. Gen. et Sp. Orch. $242=$ Sarcochilus anceps.

angustifolium, Lindl. 1. c. $241=$ Sarcochilus angusti folius.

appendiculatum, Wall. Cat. n. $7315=$ Sarcanthus appendiculatus.

Arachnites, Lindl. Gen. et Sp. Orch. $238=$ Sarcochilu Arachnites.

Arachnites, Sw. in Schrad. Journ. ii. (1799) $233=$ Arachnanthe moschifera.

Ballantinianum, Reichb. f. in Gard. Cliron. N. S. xxiv. (1885) II. $198=$ suavissimum.

Bernhardianum, Reichb. f. l. c. 650.-Borneo.

bicolor, Reinw. ex LindI. Fol. Orchid. Vanda, $4=$ Vanda furva.

Borassi, Buch.-Ham. ex Sm. in Rees, Cyclop. xxxix.n. 8.- Ind. or

Brockessii, Heynh. Nom. ii. $11=$ crispum.

Broekei, Batem. ex Lindl, in Bot. Reg. (1841) Misc. 55 = crispum.

calceolare, Teijsm. \& Binn. in Tijdschr. Nederl. Ind. xxvii. 1864) 19.-Sumatra.

calceolare, Buch.-Ham. ex Sm. in Rees, Cyclop. xxxix. n. $11=$ Saccolabium calceolare.

carnosum, Griff. Notul. iii. $365=$ Doritis taenialis.

compressum, Lindl. Gen. et Sp. Orch. 240= Dendro colla compressa

coriaceum, Sw. in Schrad. Fourn. (1799) 234.Madag.

cornutum, Roxb. Hort. Beng. 63 ; Lindl. Bot. Reg. t. $1485=$ odoratum
AËRIDES :-

costatum, 'Westk.' ex Steud. Nom. ed. II. i. 30.Ind, or,

crassifolium, Par. \& Reichb. $f$. in Trans. Linn. Soc. xxx. (1874) 145.-Burma.

crispum, Lindl. in Wall. Cat. n. 7319.-Malabar.

cylinxricum, Hook. Bot. Mag. t. $4982=$ A. vandarum cylindricum, Lindl. in Wall. Cat. n. 7317.--Ind. or.

decumbens, Griff. Notul. iii. 365 ; Ic. Pl. Asiat. t. 320 -Burma.

dasypogon, Sm. in Rees, Cyclop. xxxix. n. 10.Nepal.

dasypogon, Hort. ex Batem. in Hook. Bot. Mag. sub t. $5630=$ Sarcanthus erinaceus.

difforme, Wall. ex Lindl. Gen. et Sp. Orch. $242=$ Ornithochilus fuscus.

diurnum, Teijsm. \& Binn, in Tijdschr. Nederl. Ind. xxvii. (1864) 19,-Sumatra.

elongatum, Blume, Bijdr.367.--Java.

emarginatum, Lindl. Gen. et Sp. Orch. $241=$ Sarcochilus emarginatus.

Emericii, Reichb. f. in Gard. Chron, xviii. (1882) II. 586.-Ins. Andam.

expansum, Reichb. f. 1. c. $40=$ falcatum.

falcatum, Lindl. \& P Paxt. Fl. Gard. ii. (1851) 142.Burma.

Farmeri, Boxall, ex Naves, in Blanco, Fl. Philipp. ed. III. Nov. App. 239.-Ins. Philipp.

Fenzlianum, Reichb. f. in Hamb. Gartenz. xvi. (1860) 282,-Ins. Philipp.

Fieldingi, Lodd. ex E. Morr. in Belg. Hortic. (1876) 286. t. 10.-Reg. Himal.

flavidum, Lindl. E Paxt. Flow. Gard. ii. (1851-52 $101=$ suavissimum.

Flos-aëris, Sw. in Schrad. Journ. ii. (1799) $233=$ Sarcochilus Arachnites.

guttatum, Roxb. F1. Ind. iii. $471=$ Rhynchostylis retusa.

Houlletianum, Reichb. f. in Gard. Chron. (1872) 1194. -Cochinch.

Hystrix, Lindl. Gen. et Sp. Orch. $242=$ Sarcochilus Hystrix.

Hystrix, Lindl. in Journ. Linn. Soc. iii. (1859) $42=$ Ornithochilus fuscus.

illustre, Reichb. f. in Gard. Chron. N. S. xviii. (1882) II. $71=$ maculosum.

inflexum, Teijsm. Eै Binn. in Tijdschr. Nederl. Ind. xxiv. (1862) 324.-Malaya.

japonicum, Reichb. f. in Hamb. Gartenz. xix (1863) 210.-Japon.

jucundum, Reichb. f. l. c. xvi. (1860) 281.-Java.

Larpentae, Hort. ex Reichb. $f_{\text {. }}$ in Otto et Dietr. Allg. Gartenz. xxiv. (1856) $219=$ falcatum.

lasiopetala, Willd. Sp. Pl. iv, 130.-Ind, or

latifolium, Thw. Enum. Pl. Zeyl. 429,-Zeylan.

Lawrenciae, Reichb. f. in Gard. Chron. xx. (1883) 460. -As. trop.

Leeanum, Reichb.f.l.c. xv. (1881) 656.-Hab.?

Leonaei, Reichb. f.-Cf. L'Orchidoph. (1885) 301.Burma.

lepidum, Reichb. f. in Gard. Chron. xix. (1883) 466.Ind. or.

Lindleyanum, Wight, Ic. P1. Ind. Or, 1677=crispum.

Lobbii, Hort. ex Lem. Tllustr. Hortic. xv. (1868) t. 559 $=$ multiflorum.

Lobbii, Teijsm. \& Binn. in Tijdschr. Nederl. Ind. xxiv. (1862) 323.-Burma.

McMorlandi, Williams, Man. Orch.66; ed. VI.105.-Ind. or.

macrostachyon, Spreng. Syst. iii. $719=$ Aeonia macrostachya.

maculatum, Buch.-Ham. ex Sm. in Rees, Cyclop. xxxix. n. $9=$ Vanda spathulata.

maculatum, Llanos, Fragm. 93.-Ins. Philipp.

maculosum, Lindl. Bot. Reg. xxxi. (1845) 58. Ind. or.

margaritaceum, Williams, Man.Orch. 66 ; ed. VI. 105. -Ind. or.

marginatum, Reichb. f. in Gard. Chron. N. S. xxiii. (1885) I. 533.-Hab. ?

matutinum, Blume, Bijdr. 366.-Java.

matutinum, Willd. Sp. Pl. iv. $131=$ Renanthera Arachnites.

Mendeli, Hort. ex E. Morr. in Belg. Hortic. (1876) 288 - falcatum

minimum, Lindl. Gen. et Sp. Orch. $241=$ Sarcochilus minimus. 
A ERIDES :-

mitratum, Reichb. f. in Bot. Zeit. xxii. (1864) 415.Ind. or.

multiflorum, Roxb. Fl. Ind. iii. 475.-Ind, or

nobile, Warn. Sel. Orch. Ser. I. t. $11=$ suavissimum. obtusum, Lindl. Gen. et Sp. Orch. $239=$ Sarcochilus obtusus.

odoratum, Lour. Cochinch. 525.-China; Ind. or

odoratum, Reinw. ex Blume, Rumphia, iv. $53=$ suaveolens.

Ortgiesianum, Reichb. f. in Gard. Chron. xxiii. (1885) 501.-Hab. ?

pachyphyllum, Reichb. f. l. c. xiv. (1880) 231.Burma.

pallidum, Blume, Rumphia, iv. 53.-Ins. Timor.

pallidum, Lindl. Gen. et Sp. Orch. $241=$ Sarcochilus pallidus.

pallidum, Roxb. Fl. Ind.iii. 475 (=Camarotis pallida). paniculatum, Ker-Gawl. Bot. Reg. iii. $220=$ Vanda

paniculata.
praemorsum, Willd, Sp. Pl. iv. 130.-Rhynchostylis retusa.

purpurascens, Lindl. Gen. et Sp. Orch. 240,-Java.

pusillum, Lindl. 1. c. $241=$ Sarcochilus pusillus.

quinquevulnera, Lindl. Sert. Orch. 30.-Malaya.

radiatum, Roxb. Fl. Ind. iii, 476.-Ind, or.

radicosum, A. Rich. in Ann. Sc. Nat. Sér. II. xv, (1841) 65.t. 1. f. c.-Ind. or.

Reichenbachii, Linden, in C. Koch \& Fint. Wochenschr. 1858) $61=$ suavissimum

retusum, Sw. in Schrad. Journ. ii. (1799) $233=$ Rhynchostylis retusa.

rigidum, Buch.-Ham. ex Sm. in Rees, Cyclop. xxxix n. 12.-Ind. or

Roebelenii, Reichb. f. in Gard. Chron. xxi. (1884) 510. -Ins. Philipp.

Rohanianum, Reichb. f. 1. c. $206=$ suavissimum.

roseum, Lodd. ex Paxt. Fl. Gard. t. $60=$ multiflorum.

rostratum, Roxb. Fl. Ind. iii. 474 =Sarcochilus purpureus.

Ruckeri, Hort. Donat. ex Lubbers, Cat. Pl. Rar. San Donato (1880) 14.-Hab.?

Sanderianum, Reichb. f. in Gard. Chron. xxii. (1884) 134.-As. trop.

Schroederi, Hort. ex Reichb. f. in Allgem. Gartenz. 1855) $226=$ maculosum.

shibatianum, Boxall, ex Naves, in Blanco, Fl. Philipp. ed. II. Nov. App. 239.-Ins. Philipp. ; sphalm. ?= Thibautianum.

spicatum, D. Don, Prod. F1. Nep. 31=Rhynchostylis retusa.

spurium, Lindl. Gen. et Sp. Orch. 241.--Java.

suaveolens, Blume, Rumphia, iv. 53.-Tava.

suaveolens, Roxb. Fl. Ind. iii. 473.-Ind. or

suavissimum, Lindl, in Journ. Hort. Soc. iv. (1849) 264 -Malacca.

subulatum, Lindl. Gen. et Sp. Orch. $241=$ Sarcochilus subulatus.

Sulingi, Blume, Bijdr. $367=$ Renanthera Sulingi

taeniale, Lindl. Gen. et Sp. Orch. $239=$ Doritis tae nialis.

teres, Lindl. l. c. 240,-Java.

tessellatum, Wight, in Wall. Cat. n. $7318=$ Vanda Roxburghii

testaceum, Lindl. Gen. et Sp. Orch. 238=Vanda parviflora.

Teysmanni, Miq. Choix Pl. Buitenz. t. 18.-Malaya.

Thibautianum, Reichb. f. in Gard. Chron. (1866) 100 -Polynesia.

Thunbergii, Miq. Ann. Mus. Bot. Lugd. Bat. ii. 205.Japon.

timoranum, Miq. Fl. Ind. Bat. iii. 695.-Ins. Timor

trigonum, Klotzsch, in Otto \& Dietr. Allg. Gartenz. xxiii. (1855) $177=$ multiflorum

umbellatum, Wall. Cat. n. $1137 \equiv$ Saccolabium acutifolium.

uncinatum, Teijsm. \& Binn. in Tijdschr. Nederl. Ind.

xxiv. (1862) 324.-Java.
undulatum, Sm. in Rees, Cyclop. xxxix. n. $13=$ Saccolabium praemorsum

vandarum, Reichb. f. in Gard. Chron. (1867) 997.Ind. or.

Veitchi, Hort. ex E. Morr. in Belg. Hortic. (1876) 291 xxxi. (1881) $123-$ multiflorum.

virens, Lindl. Bot. Reg. (1843) Misc. 41.-Hab.?

virjdiflorum, Thr. Enum. Pl. Zeyl.430,-Zeylan.

Wightianum, Lindl. in Wall. Cat, n. $7820=$ Vanda parviflora.

\section{AËRIDES :}

Williamsii, Wam. Sel, Orch. Ser. I, t. $21=$ Fieldingi. Wilsonianum, Hort. ex Gard. Chron. xxiii. (1885) 705 = suavissimum?

Zollingeri, Reichb. f. in Bonplandia, v. (1857) 40.Java.

AËRIDIUM, Pfeiff. Nom. i. 67 (1873)=AEËRIDIUM, Salisb. $=$ Aërides, Lour. (Orchid.).

AËROBION, Kaempf. ex Spreng. Syst. iii. 679 (1826)= Angraecum, Thou. (Orchid.)

aphyllum, Spreng. 1. c. $718=$ Angr, aphyllum. Calceolus, Spreng. 1. c. $717=$ Angr. Calceolus. carinatum, Spreng. 1. c. $718=$ Eulophia virens caulescens, Spreng. 1. c. $717=$ Mystacidium caulescens citratum, Spreng. 1. c. $718=$ Angr. citratum. crassum, Spreng. 1. c. $717=$ Angr. crassum cucullatum, Spreng. 1. c.=Angr. cucullatum. expansum, Spreng. 1. c. $716=$ Angr. expansum filicornu, Spreng. 1. c. = Angr. filicornu. fragrans, Spreng. 1. c. = Angr. fragrans. gladiifolium, Spreng. 1. c。=Angr. gladiifolium gracile, Spreng. 1. c. $717=$ Angr. gracile. implicatum, Spreng. 1. c. $716=$ Angr. implicatum inapertum, Spreng. 1. c. $717=$ Angr. inapertum maculatım, Spreng. 1. c. $718=$ Angr. maculatum. multiflorum, Spreng. 1. c. $717=$ Angr. multiflorum palmiforme, Spreng. 1. c. = Angr. palmiforme. parviflorum, Spreng. 1. c. $718=$ Angr, parviflorum pectinatum, Spreng. 1. c. $717=$ Angr. pectinatum. rectum, Spreng. 1. c. $716=$ Angr. rectum recurvum, Spreng. 1. $\mathrm{c}$ = = Angr. recurvum striatum, Spreng. 1. c. $717=$ Angr, striatum. superbum, Spreng. 1. c. $718=$ Angr. superbum. triquetrum, Spreng, 1. c. $717=$ Angr. triquetrum

AEROKORION, Scop. Ann. iv. Hist. Nat. $96(1770)=$ AEROCORION, Adans. = Galanthus, Tourn (Amaryll.).

AERUA, Juss. Gen. $88 \quad(\mathbf{1 7 8 9})=$ Aerva, Forsk. (Amarant.).

AFRVA, Forsk. Fl. Aegypt. Arab. 170 (1775.) AMA RANTACEAE (Benth. \& Hook. f, iii, 34)

aegyptiaca, I. F. Gmel. Syst. ii. $1026=$ tomentosa ambigua, Moq. in DC. Prod. xiii. II. 302.-Afi. austr bengalensis, Buch.-Ham. ex Wall. Cat. stb n. $6911=$ scandens.

Bovii, Edgew. in Journ. Linn. Soc. vi. (1862) $206=$ tomentosa.

brachiata, Mart. Beitr. Amarant. $83=$ Nothosaerua brachiata.

Burchellii, Moq. in DC. Prod. xiii. II. $302=$ A. leucura. caudata, Boj. Hort. Maurit. 268.-Madag.? chenopodiifolia, Boj. 1. $\mathrm{c} .=$ Nothosaerua brachiata. congesta, Balf. f. ex Baker, Fl. Maurit. 267.-Ins. Mascar.

elegans, Moq. in DC. Prod. xiii. 11. 303.-Arab. floribunda, Wight, Ic. Pl. t. $1776=$ lanata. glabrata, Hook. f. Fl. Brit. Ind. iv. 728.-Ind. or incana, Mart. in Nov. Act. Acad. Nat. Cur. xii. (1826) $291=$ tomentosa.

javanica, Juss, in Ann. Mus. Par, xi. (1808) $131=$ tomentosa.

lanata, fuss. l. c.-As. trop.; Arab.

leucura, Moq. in DC. Prod. xiii. Ir. 302.-Afr. austr.

microphylla, Moq. l.c. 301.-'Mare rubrum.'

Monsonia, Mart. Beitr. Amarant. 83.-Ind. or

nervosa, Mart. l. c.-Ind, or.

ovata, Lhrenb. ex Schweinf. Beitr. Fl. Aethiop, $174=$ tomentosa.

platyphylla, Ehrenb. ex Schweinf. 1. c. = tomentosa.

pubescens, Mart. Beitr. Amarant. 83.-Ind, or.

radicans, Mart. I. c. -Ind. or.

revoluta, Balf. $f$ in Proc. Roy. Soc. Edinb. xii. (1884)

92.-Ins. Socotr.

sanguinea, Hort. ex Moq. in DC. Prod. xili. I. $300=$ sanguinolenta.

sanguinolenta, Blume, Bijdr. 547.-Java.

scandens, Gamble, Trees of Darjeeling = Stilbanthus scandens.

scandens, Wall. Cat. n.6911.-As, et Afr. trop.

sericea, Moq. in DC. Prod. xiii. 11. 304.-Ins.

Sandvic.

setacea, Mart. Beitr. Amarant. $88=$ A. Monsonia

suaveolens, Edgew, in Journ. Linn, Soc. vi. (1562) 207 - tomentosa.

\section{AERVA:-}

imorensis, Moq in DC Prod xiii II 301 - Ins, Timor timoriensis, Zipp. ex Span, in Linnaea, XY. (1841) 345 = sanguinolenta.

tomentosa, Lam. Encyc. i. 46.-As. et. Afr. trop.

toncafolia, Buch.-Ham. ex Wall. Cat, sub n. $6911=$ scandens.

Tondalo, Buch.-Ham. 1. c. $6909=$ lanata.

trichophylla, Ehrenb. ex Schweinf. Beitr. Fl. Aethiop. $174=$ tomentosa

velutina, Moq. in DC. Prod. xiii. II. $301=$ Pupalia lappacea.

villosa, Moq. l. c. 304.-Ins Maurit

viridis, E. Mey. ex Moq. 1. c, =lanata.

Wallichii, Mog. 1. c. $300=$ tomentosa

Wightii, Hook. f. Fl. Brit. Ind. iv. 728.-Ind. or.

AESCHINANTHUS, Endl. Gen. 716 (1838)=Aeschynanthus, Jack (Gesnerac.)

AESCHINOMENE, Nocca in Usteri, Ann. Bot. v. 1793 16 = Aeschynomene, Linn. (Legum.

AESCHRION, Vell. Fl. Flum. 58; i. t. $152(1827)=$ Picraena, LindI. (Simarab.

crenata, Vell. 1l. $\mathrm{cc}=\mathrm{P}$. Vellozii.

AESCHYNANTHUS, Jack, in Trans. Linn. Soc xiv. (1823) 42. GESNERACEAE, Benth. \& Hook. f. ii. 1013 .

RheithrophyluUm, Hassk. Cat. Hort. Bogor. Alt $123(1844)$

Trichosporum, D. Don, in Ediab. Phil. Journ. vii. (1822) 84 (nomen prius).

acuminata, G. Don, Gen. Syst. iv, $657=$ Chirita acuminata.

acuminata, Wall. Cat. n.6397.-Ind. or. ; China

albida, A. DC. Prod, ix. $262=$ purpurascens.

albida, Steud. Nom. ed. II i. 32.-Java.

alba, Hort. ex Hanst. in Mart. Fl, Bras. viii, $418=$ Codonanthe Devosiana.

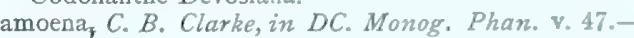
Java,

Andersoni, C. B. Clarke, Comm. et Cyrt. Beng. t. 48 - Burma.

angustifolia, Steud. Nom ed. II i. 32-Jara.

apicidens, Hance, in fourn. Bot. xxi. (1853) 16\%.China.

arfakensis, C. B. Clarke, in DC. Monog. Phan. V. 36 -N. Guin.

atropurpurea, Van Houtte, Hort. Vanhout. Fasc, it $42=$ purpurascens.

atrosanguinea, Van Houtte, Cat. (1851) ex C. B.

Clarke, in DC. Monog. v. 52.-Hab.

Ancklandiae, Low, Sarawak, 382, 386.-Borneo.

Aucklandi, Hort. Low, ex Loud. Hort. Brit. Supp. iii. $484=$ praec.

Beccarii, C. B. Clarke, in DC. Monog. Phan. צ. 47.Sumatra.

Blumei, Mor, ex C. B. Clarke, 1. c. $48=$ A. Lamponga. Boschiana, De Vriese, in Morr. Ann. Soc. Agric. Bot Gand, ii. $(1816) 403=$ A. Lamponga.

bracteata, Benth. Fl. Hongkong, $258=$ acuminata.

bracteata, Wall. Cat, n. 794-Ind. or.

brevicalyx, Miq. Fl. Ind. Bat ii. 720.-Sumatra.

candida, Henders. Cat. (1851) ex C. B. Clarke, in DC

Monog. Phan. v. 52.-Hab. ?

caudata, C. B. Clarke, l. c. 34.-Sumatra.

cevlanica, Gard. in Calc. Fourn. Nat. Hist. vi, Isto

474.-Zeylan.

ceylanica, Wight, Ic. t. $13.17=$ Perrottetii.

chinensis, Gard. \& Champ. in Hook. Kew Journ. i. (1849) $328=$ acuminata

chiritoides, C. B. Clarke, in DC. Monog. Phan. .28 , -Reg. Himal.

conferta, Griff. Priv. Journ. 69, nomen $=$ Lepionotus confertus.

cordifolin, Hook. Bot. May, L 5181-Bameo.

cryptantha, C. B. Clarke, in DC. Munog. Phans. v. 50. -Borneo.

Curtisii, C. B. Clarke, l. . 43. Burneo

discolor. T. Moore, in Part. Fl. Liard. iii. $11552-58$ 55 a purpuraicens.

elongata, C. B. Clarke, in DC. Moneg. Phan. v. $15 .-$ liorneu.

fulgens, Wisll. Cab. n. 79\%,-Ind. or.

geminata, Zoll. E Murr. in Nas. en Generst. Arith Acerl. Inel. ii. (1045:5it.-Jave. 


\section{AESCHYNANTHUS :-}

gracilis, Hort ex Hanst, in Mart. F1. Bras. viii. $418=$ Codonanthe Devosiana.

gracilis, Parish, ex C. B. Clarke, Comm. et Cyrt. Beng. $t$. 48.--Ind. or.

grandiflora, J. Grah. Cat. Pl. Bomb. $146=$ Perrottetii. grandiflora, Spreng. Syst. iv. Cur. Post. 238.Ind, or.

Griffithii, R. Br. in Benn. Pl. Fav, Rar. 115.-Ind. or. hians, C. B. Clarke, in DC. Monog. Phan. v. 51.Borneo.

Hookeri, C. B. Clarke, . c. 21.-Reg. Himal.

Horsfieldii, R. Br. in Benn. Pl. Fav. Rar. 116.-Java.

intermedia, Teijsm. \& Binn. in Tijdschr. Nederl. Ind. xxv. (1863) 414.-Malaya.

javanica, Hook. Bot. Mag. t. 4503.-Java.

Kingii, C. B. Clarke, in DC. Monog. Phan. v. 31.Reg. Himal.

Lamponga, Miq. Fl. Ind. Bat. Suppl. 563.-Sumatra. lepidosperma, C. B. Clarke, in DC. Monog. Phan. v. 35.-Borneo.

leptoclada, C. B. Clarke, l. c. 39.-N. Guin

levipes, C. B. Clarke, l. c. 28.-Assam.

Lobbiana, Hook. Bot. Mag. t. 4260.-Java.

longicaulis, Wall. Cat. n. 888.-Ind. or.

longiflora, Blume, Bijdr. 766.-Malaya.

longiflora, Wall. Cat, n, $795=$ superba.

macrocalyx, C. B. Clarke, in DC. Monog. Phan. v. 46.-Sumatra.

maculata, Lindl. Bot. Reg. (1841) t. 28.-Ind. or.

Mannii, Kurz, ex C. B. Clarke, in DC. Monog. Phan. v. 29 - Ind or

marmorata, F, Moore, in Paxt. Fl. Gard. iii. (1852-53) 56.- Hab. ?

Masoniae, Kurz, ex C. B. Clarke, l. c. 29-Ind, or. micrantha, C. B. Clarke, l. c, 27.-Reg. Himal. microphylla, $C$. B. Clarke, $l$. $c_{\text {. }} 49$.-Ins. Celebes. microtricha, $C . B$. Clarke, $l . c .51$ - $-\mathrm{N}$. Guin. miniata, Lindl. Bot. Reg. N. S. xix t. 61.-Java.

Motleyi, C. B. Clarke, in DC. Monog: Phan. vi 20 Malaya.

Neesii, Zoll. \& Moritzi, Syst. Verz. Zoll. $45=$ pulchra. obconica, C. B. Clarke, in DC. Monog. Phan. v. 50. -Malacca.

oblongifolia, G. Don, Gen. Syst. iv. $657=$ Chirita acuminata.

obovata, C. B. Clarke, in DC.Monog. Phan. v. 47.-Java, barasitica, C. B. Clarke, Comm. et Cyrt. Beng. t. $49=$ Hookeri.

parasitica, Wall. Cat. n. $796=$ grandiflora, pro parte. parvifiora, C. B. Clarke, Comm, et Cyrt. Beng, t. $47=$ micrantha.

parviflora, Spreng.Syst.iv.Cur.Post. $238=$ ramosissima

parvifolia, R. Br. in Benn. Pl. Fav. 115.-Banca.

Paxtonii, Lindl. in Journ. Hort. Soc. iv. (1849) $79=$ bracteata.

Peelii, Hook, f. \& Thoms. Illustr. Himal. Pl. $17=$ bracteata.

Perrottetii, A. DC. in DC. Prod. ix. 261.--Ind. or

Perrottetii, Gardn. in Calc. Journ. Nat. Hist. vi. (1846) $475=$ ceylanica.

philippinensis, C. B. Clarke, in DC. Monog. Phan. v. 39.-Ins. Philipp.

podocarpa, C. B. Clarke, Z. c. 40.-N. Guin.

pulchella, Hort. ex Hanst. in Mart. Fi. Bras, viii. $418=$ Codonanthe Devosiana.

pulchra, G. Don, Gen. Syst. iv. 656.-Malaya.

purpurascens, Hassk. Cat. Pl. Hort. Bogor. Alt. 154.-

Java.

radicans, Fack, in Trans. Linn. Soc xiv. (1823) 43.Malaya.

radicans, Wall. Cat. n. $798=$ Griffithii.

ramosissima, Wall. Cat. n. 799.-Ind. or.

Roxburghii, Paxt. Bot. Dict. ex C. B. Clarke, in DC. Monog, v, 52-Hab?

rubiginosa, Teijsm. E Binn. in Tijdschr. Nederl. Ind. xxv. (1863) 413.-Java.

siphonantha, C. B. Clarke, in DC. Monog. Phan. v. 45. - Borneo.

speciosa, Hook. Bot. Mag. t. 4320.-Java.

splendens, Lindl. \& Paxt. F1. Gard. iii. 169. t. 108= speciosa.

splendida $\times$, Lem. Fard. Fleur. iii. (1853) t. 255.

superba, C. B. Clarke, Comm. et Cyrt. Beng. t. 46.Ind. or.

Szcokhoffii, Hort. Berol. ex C. B. Clarke, in DC Monog. Phan. v. $43=$ pulchra

tetraquetra, C. B. Clarke, l. c. 38.-Sumatra.

\section{AESCHYN ANTHUS :-}

Teysmanniana, Miq. in Bot. Zeit. vi. (1848) 509Java.

tricolor, Hook. Bot. Mag. t. 5031.-Java

tubiflora, C. B. Clarke, in DC. Monog. Phan. v. 36.N. Guin.

verticillata, C. B. Clarke, l. c. 40.-N. Guin.

viridiflora, Teijsm. E Binn. in Tijdschr. Nederl. Ind. xxvii. (1864) 34.-Ins. Celebes.

volubilis, Fack, in Trans. Linn. Soc. xiv. (1823) 42.t 3. f. 3.- Sumatra.

Wallichii, Benn.Pl. Fav. Rar. 116.-Malaya,

Wilsoni, Walker, ex C. B. Clarke, in DC. Monog. v. $26=$ ceylanica

zebrina, Van Houtte [Cat. 1851] ex Walp. Rep. vi. $521=$ marmorata.

seylanica, Walp. Ann. iii. $95=$ ceylanica

Zollingeri, C. B. Clarke, in DC. Monog. Phan. v. 44.Java.

AFSCHYNOMENE, Linn. Gen. ed. I. 350 (1737) LEGUMINOSAE, Benth. \& Hook. f. i. 515.

GAJATI, Rumph. ex Adans. Fam. ii. 328 (1763)

Mantodda, Adans. Fam. ii. $508(1763)$

Macromiscus, Turcz. in Bull. Soc. Nat. Mosc. (1846) II. 507.

Patagonium, E. Mey. Comm. P1. Afr. Austr. 122 (1835).

RoCHEA, Scop. Introd. 296 (1777).

Rueprelia, A. Rich. Tent. Fl. Abyss. i. 203. t. $37(1847)$.

abyssinica, Vatke, in Oest. Bot. Zeitschr. xxix. (1879) $224=$ Ruppellii.

aegyptiaca, Steud. Nom. ed. II. i. $31=$ Seshania aegyp-

acutangula, Welw. ex Baker, in Oliver, Fl. Trop. Afr.

ii. 148.-Afr. trop.

americana, Linn. Sp. Pl. 713.-Ind. occ.; Am.

trop.

aquatica, Steud. Nom. ed. II. i. $31=$ aspera.

arborea, Linn. Sp. Pl. $713=$ Desmodium umbellatum aristata, Jacq. Hort. Schoenb. i. $59=$ Pictetia aristata aspera, $\operatorname{Linn}$. Sp. $P l$. 713.-Geront. trop.

aspera, Wall. Cat. n. $5666=$ indica.

aspera, Muhl. ex Willd. Sp. Pl. iii. $1163=$ hispida

atropurpurea, Span. in Linnaea, xv. (1841) 192.-Ins. Timor.

bispinosa, Jacq. Ic, iii. 13= Sesbania aculeata.

bracteosa, Welw. ex Baker, in Oliver, Fl. Trop. Afr.ii. 150.-Afr. trop.

brasila, Schrank, in Denkschr. Bot. Ges. Regensb. ii. 1822) $63=$ Martiusii

brasiliana, $D C$. Prod. ii. 322.-Bras.

brevifolia, Poir. Encyc. iv. 451.-Madag.

brevipes, Benth. in Mart. Fl. Bras. xv. I. 66.Bras.

Burmanni, Raeusch. Nom. ed. III. 214,-Ind. or.

cachemiriana, Cambess. in Jacquem. Voy. Bot. $40=$ indica.

cannabina, Retz. Obs. Fasc. v. $26=$ Sesbania aculeata. cassioides, Desv. in Ham. Prod. P1. Ind. Occ. $51=$ Histrix.

cassioides, Ruiz \& Pav. ex G. Don, Gen. Syst. ii. 240 = Sesbania cassioides.

ciliata, Vog. in Linnaea, xii. (1838) $84=$ hispida.

coccinea, Linn. f. Suppl. $330=$ Sesbania grandiflora

coluteoides, Less. \& A. Rich. Voy. Astrol. Bot. ii. 87. t

$32=$ Ormocarpum sennoides.

conferta, Benth. in Ann. Nat. Hist. iii. (1839) 433.Guian.

crepita, facq. Fragm. 37.t. 42. f. 2.-Venezuela.

cristata, Vatke, in Oest. Bot. Zeitschr. xxviii. (1878) 215.-Afr. trop.

debilis, Welw. ex Baker, in Oliver, Fl. Trop. Afr. ij. 150.-Afr. trop.

decumbens, Zipp. ex Span. in Linnaea, xv. (1841) 193 = sensitiva.

densiflora, Benth. in Hook. Lond Fourn. Bot. ii. (1840) 56.-Guian

dentata, Lag. Gen. et Sp. Nov. $22=$ Adesmia dentata.

diffusa, Roxb. ex Wight \& Arn. Prod. $215=$ Sesbania procumbens.

diffusa, Klein, ex Willd. Sp. P1. iii. 1164=indica.

dimidiata, Welw. ex Baker, in Oliver, Fl. Trop. Afr. ii. 151.-Afr. trop.

divisa, Nees \& Mart. in Nov. Act. Nat. Cur. xii. (1826) $31=$ americana

Echinus, Vog. in Linnaea, xii. (1838) 92.-Bras.

\section{AESCHYNOMENE :-}

elegans, Cham. Eे Schlecht. in Linnaea, v. (1830) 583. -Mexico.

elongata, Salisb. Prod. $341=$ Sesbania aegyptiaca. erubescens, E. Mey. Comm. Pl. Afr. Austr. i. 123.Afr. austr.

evenia, Wright, in Sauv. Fl. Cub. 27.-Cuba.

falcata, DC. Prod. ii. 322.-Bras.

fascicularis, Cham. E Schlecht. in Linnaea, v. (1830) 584.-Mexic

flipes, Baill. in Bull. Soc. Linn. Par. i. (1884) 415.Madag.

filosa, Mart. ex Benth. in Mart. Fl. Bras. xv. I. 61.-Bras.

fistulosa, Bello, in Anal. Soc. Esp. Hist.Nat.x. (1881) 259.- - Porto Rico.

floribunda, Mart. \& Gal. in Bull. Acad. Brux. X. II. (1843) $186=$ americana.

fluminensis, Vell. Fl. Flum. 310 ; vii. t. 119,-Bras.

frutescens, Poir. in Lam. Encyc. iv. 451=Lespedeza capitata.

fruticulosa, Nees, ex G. Don, Gen. Syst: ii. $282=$ Adesmia fruticulosa.

fulgida, Welw. ex Baker, in Oliver, Fl. Trop. Afr. ii. 149.-Afr. trop.

fusa, Steud. Nom. ed. I. 17, sphalm. = seq.

fusca, Desf. Tabl: Cat. Hort. Par. ed. I., 198.Hab.?

gangetica, Poir. in Lam. Encyc. iv. $453=$ Desmodium gangeticum.

glaberrima, Poir. Encyc. Suppl. iv. $76=$ hispida ?

glabrescens, Welw. ex Baker, in Oliver, Fl. Trop. Afr. ii. 148.-Afr. trop.

glandulosa, Benth. in Miq. Pl. Jungh. $210=$ javanica. glandulosa, Poir. Encyc. Suppl. iv. $76=$ americana. gracilis, Miq. in Linnaea, xviii. (1844) $566=$ paniculata.

gracilis, Vog, 1. c, xii. (1838) $891=$ falcata.

grandiflora, Linn. Sp. Pl. ed. II. $1050=$ Sesbania grandiflora.

guayaquilensis, G. Don, Gen. Syst. ii. 284.-Ecuador. hedysaroides, Mart. E Gal. in Bull. Acad. Brux. x. II. (1843) 180.-Mexic.

herbacea, $A u b l . P l$. Gui. 1i. 775.-Guian.

heterophylla, Lour. Fl. Cochinch. 446.-Cochinch.

Heurckeana, Baker, in Fourn. Linn. Soc. xx. (1881) 130.--Madag.

hirsuta, Vitm. Summa PI. iv. $270=$ Burmanni.

hirsuta, DC. Prod. ii. $322=$ americana.

hirta, Lam. Illustr.t. 629, ex ejusd. Encyc. iv. 450.Ind. or.

hispida, Roxb. ex Steud. Nom. ed. II. i. $31=$ Robinia hispida.

hispida, Willd. Sp. Pl. iii, 1163.-Am. bor.

hispidula, H.B. \& K. Nov. Gen. et Sp. vi. $530,-\mathrm{N}$. Granat.

hispidula, Lag. Gen. et Sp. Nov. 22. n. $297=$ Adesmia hispidula.

Histrix, Poir. Encyc. Suppl. iv. 77.--Guian.

honesta, Nees \& Mart. in Nov. Act. Nat. Cur. xii. (1826) $32=$ sensitiva.

incana, G. F. W. Mey. ex DC. Prod. ii. $332=$ Desmodium incanum.

incana, Vog. in Linnaea, xii. (1838) 90.-Bras.

indica, Burm. f. F1. Ind. $169=$ Sesbania aegyptiaca.

indica, Linn. Sp. Pl.713.-Ind. or.

indica, Wall. Cat. n, 5667 = aspera.

interrupta, Benth. in Hook. Lond. Fourn. Bot. ii (1840) 56 -Guian.

javanica, Miq. Fl. Ind. Bat. i. 275.-Java.

kashmiriana, Baker, in Hook. f. Fl. Brit. Ind. iv 151 $=$ indica.

laevis, Mart. \& Gal. in Bull. Acad. Brux.x. II. (1845) 180.-Mexico.

Lagenaria, Lour. F1. Cochinch. ii. $446=$ aspera.

laevis, Noronha, in Verh. Batav. Gen. v. $(1790)$ ed. I Art. iv. 6.-Malaya.

latifolia, Spreng. Syst. ii. $322=$ Adesmia latifolia.

latisitiquosa, Hill, ex Steud. Nom. ed. II. i. $31=$ Poiretia latisiliquosa.

laxiflora, Boj. ex Baker, in Fourn. Linn. Soc. xx. (1884) 130.-Madag.

leptostachya, Benth. in Mart. Fl. Bras. xv. I. 65. Am. austr.

littoralis, Vog. in Linnaea, xii. (1838) 96.-Bras.

longifolia, Cav. Ic. iv. $8=$ Piscidia longifolia.

longifolia, Orteg. Hort. Matr. Dec. $70=$ Sesbania Cavanillesii. 


\section{AESCHYNOMENE:-}

macropoda, DC. Prod. ii. $320=$ indica.

maculata, Poir. in Lam. Encyc. iv. $452=$ Desmodium gangeticum.

marginata, Benth. in Mart. Fl. Bras. xv. I, 66.-Am. trop.

Martii, Benth. l. c. 62.-Am. trop.

Martiusii, Steud. Nom. ed. II. i. 31.-Bras.

mazangayana, Baill. in Bull. Soc. Linn. Par.i. (1884) 415.-Madag.

micrantha, DC. Prod. ii. 321.-Madag.

microphylla, Desv. ex DC. l. c. 322.-Bras.

mimosoides, Nees, ex G. Don, Gen. Syst. ii. $282=$ Adesmia mimosoides

mimulosa, Blume, ex Miq. Fl. Ind. Bat. i. 276=javanica. miniata, Orteg. Hort. Matr. Dec. $28=$ Piscidia punicea. mimosifolia, Vatke, in Oest. Bot. Zeitschr. xxix. (1879) 224.-Afr. trop.

mollicula, H. B. \& $K$. Nov. Gen. et Sp. vi. 532.Am. austr.

moluccana, Kostel. Allg. Med.-pharm. Flora, iv. 1285. -Molucca.

montana, Span. in Linnaea, xv. (1841) $192=$ indica.

montevidensis, Vog. in Linnaea, xii. (1838) 83.Reg. Argent.

mucronata, Benth. in Hook. Lond. Fourn. Bot. ii. (1840) 56.-Guian

mucronulata, Benth. l. $c$. 56.-Guian.

multiflora, Steud. Nom. ed. II. i. 31.-Ind. or

obovalis, Baill. in Bull. Soc. Linn. Par. i. (1884) 415. -Madag.

oligantha, Welw. ex Baker, in Oliver, Fl. Trop. Afr.

ii. 146.-Afr. trop.

oroboides, Benth. in Mart. Fl. Bras. xv. I. 64.-Am. austr.

paludosa, Roxb. Fl. Ind. iii. $333=$ Sesbania aculeata paniculata, Willd. ex Vog. in Linnaea, xii. (1838) 95 -Bras.

papposa, Lag. Gen. et Sp. Nov, $23=$ Adesmia papposa papulosa, Welw. ex Baker, in Oliver, Fl. Trop. Afr. ii. 146.-Afr. trop.

parviflora, Micheli, in Kjoeb. Vidensk. Meddel. (1875) 66.-Bras.

patagonica, Hort. ex Steud. Nom. ed. II. i. $31=$ Adesmia muricata.

patula, Poir, Encyc. Suppl. iv. $78=$ sensitiva.

pauciflora, Vog. in Linnaea, xii. (1838) 93.-Bras.

paucifolia, Vog. l. c. 94.--Bras.

paucijuga, DC. Prod. ii. $321=$ brasiliana.

picta, Cav. Ic. iv. $7=$ Sesbania aegyptiaca

pilosa, Poir. in Lam. Encyc. iv. 450.-Ind, or.

platycarpa, Benth. in Mart. Fl. Bras, xv. 1. 63.Peruv.

platycarpa, Michx. F1. Bor. Am. ii. $75=$ Sesbania

pleuronervia, DC. Prod. ii. 321.-Ins. S. Doming

pluriarticulata, G. Don, Gen. Syst. ii. 284.-Ecuador

podocarpa, Vog. in Linnaea, xii. (1838) $89=$ falcata.

procumbens, Roxb. F1. Ind. iii. $337=$ Sesbania procum bens.

prostrata, Poir. Encyc. Suppl. iv. $76=$ viscidula.

psezdoacacia, Roxb. ex DC. Prod. ii. $261=$ Robinia Pseudacacia.

psendoviscosa, Blume, ex Miq. Fl. Ind. Bat. i. $276=$ javanica.

puberula, DC. Prod. ii. $321=$ scoparia.

pubescens, Poir. in Lam. Encyc. iv. 450.-Ind, or.

pubescens, Vahl, ex DC. Prod. ii. $265=$ Sesbania pubescens.

pudica, F. G. Dietr. Lexik. Gaertn. i. 136.-Aegypt.

pudica, Zoll. \& Morr. in Nat. en Geneesk. Arch. Neerl.

Ind. iii. (1846) 55, nomen.-Java.

pulchella, Planch. ex Baker, in Oliver, Fl. Trop. Afr. ii. 149.-Afr. trop.

pulchra, Vatke, in Oest. Bot. Zeitschr. xxix. (1879)

250.-Afr. trop.

pumila, Linn. Sp. Pl. ed. II. $1061=$ indica

punctata, Steud. Nom. ed. I. $17=$ indica.

pygmaea, Welw. ex Baker, in Oliver, Fl. Trop. Afr. ii. 148.-Afr. trop.

quadrata, Schum. \& Thonn. Beskr. Gnin. Pl. $356=$ indica.

racemosa, Vog, in Linnaea, xii. (1838) 92.-Bras

remota, Poir. in Lam. Encyc. iv, $452=$ Desmodium Scalpe.

rostrata, Benth. in Mart. Fl. Bras. xv. 1. 60.-Bras.

Roxburghii, Spreng. Syst. iii. $322=$ indica.

rudis, Benth. Pl. Hartw. $116=$ hispidula.

\section{AESCHYNOMENE :-}

Ruppellii, Baker, in Oliver, Fl. Trop. Afr. ii. 149.-

Afr. trop.

scabra, G. Don, Gen. Syst. ii. 284.-Ecuador.

Schimperi, Hochst. ex A. Rich. Tent. Fl. Abyss, i. 202. -Abyss.

Scoparia, H. B. E K.Nov. Gen. et Sp. vi. 532-Peruv. scoparia, Splitgerb. in Hoev. \& De Vriese, Tijdschr.ix. (1842) $107 .-$ Bras.

Selloi, Vog, in Linnaea, xii. (1838) 82.-Bras.

sensitiva, Beauv. F1. Owar. 89 . t. $53=$ indica.

sensitiva, Sw\%.Fl. Ind. Occ. iii. 1276.-Am. trop.

Sesban, Jacq. Collect. ii. $283=$ Sesbania aculeata

Sesban, Linn. Sp. P1. $714=$ Sesbania aegyptiaca.

siifolia, Welw. ex Baker, in Oliver, Fl. Trop. Afr. ii.

151,-Afr. trop.

spicata, Poir. in Lam. Encyc, iv. $452=$ Desmodium supinum.

spinulosa, Roxb. Fl. Ind. iil $333=$ Sesbania aculeata

subviscosa, DC. Prod. ii. $321=$ indica.

sulcata, H. B. \& K. Nov. Gen. et Sp. vi. $530=$ sensitiva.

surattensis, Wight \& Arn. Prod. $219=$ Sesbania acu leata?

Suymenta, Steud. Nom. ed. II. i. $31=$ Sesbania aegyptiaca.

tecta, Vog. in Linnaea, xii. (1838) $87=$ falcata.

tenuirama, Welw. ex Baker, in Oliver, Fl. Trop. Afr. ii. 150.-Afr. trop.

tenuis, Griseb. Cat. Pl. Cub. 72 - Cuba

ternata, Spreng. ex DC. Prod. ii. $314=$ Pictetia ternata.

timoriana, Span. Ic. 62 ; et in Linnaea, xv. (1841) 193 $=$ sensitiva

trachyloba, Miq. Fl. Ind. Bat. i. 276=aspera

tribuloides, Baill. in Bull. Soc. Linn. Par. i. (1884) 414.-Madag.

triflora, Poir. in Lam. Encyc. iv. $451=$ Desmodium triflorum.

triquetra, St. Hil. ex Steud. Nom. ed. II. i. $32=$ Desmodium triquetrum.

trisperma, Klotzsch, in Schomb. Faun. \& Fl. Guy. 1103-Guian.

tuberculata, Griseb. Cat. Pl. Cub. 72.-Cuba.

uliginosa, Roxb. Fl. Ind. iii. $334=$ Sesbania aculeata.

uniflora, E. Mey. Comm. Pl. Afr. Austr. i. 123.-Afr. austr.

versicolor, Wender, in Bot.Zeit. i. (1843) 347.-Mexic villosa, Poir. Encyc. Suppl. iv. 76.-Ins. Porto-Rico.

violacea, Noronha, in Verh. Batav. Gen. v. (1790) ed. I. Art. iv. 5.-Malaya.

virgata, Cav. Ic. iii. $47=$ Coursetia virgata

viscidula, Michx. Fl. Bor. Am. 1i, 75,-Florida.

viscidula, Roxb. ex Willd. Enum. Hort. Berol. $776=$ indica.

viscosa, Vatke, in Bremen Abh. vii. (1882) 247.-Afr.

trop.
Warmingii, Micheli, in Kjoeb. Vidensk. Meddel. (1875) 68.-Bras.

AFSCULUS, Linn. Syst. ed. II. 22 (1740). SAPINDACEAE, Benth. \& Hook, f. i. 398.

Billia, Peyritsch, in Bot. Zeit. xvi. (1858) 153

Calothyrsus, Spach, in Ann. Sc. Nat. Sér. II. i (1834) 62.

Esculus, Linn, Gen. ed. I. 109 (1737)

Hippocastanum, Tourn. ex Rupp. Fl. Jen. ed. Hall. $291(1745)$

Isvpus, Rafin. Fl. Tellur. iv. 73 (1836)

Macrothyrsus, Spach, in Ann. Sc. Nat. Sér. II. ii. (1834) 61 .

Nebropsis, Rafin. Alsog. Am. 68 (1838)

Oesculus, Neck. Elem. ii. 232 (1790)

Ozotis, Rafin. Alsog. Am. 71 (1838).

Pavia, Boerh. ex Mill. Gard. Dict. ed. VI. (1752)

Paviana, Rafin. Fl. Ludov. 87 (1817)

Putźeysia, Planch. \& Linden, in Linden, Cat. n. 22 (1857), 3

alba, Rafin. Alsog. Am.69.-Am. bor.

arguta, Buckl. in Proc. Acad. Phil. (1860) 443.-Am. bor.

asplenifolia, Hort, ex Loud. Encyc. Trees, $124=$ A Hippocastanum.

assamica, Griff. Notul. iv. $540=$ punduana.

barbats, Rafin. Alsog. Am. 70,-Am. bor.

californica, Nutt. in Torr. E Gray, Fl. N.Am. i. 251 Calif.

carnea, Wats. Dendr. Brit. t. $121=$ glabra.

Castanea, Gilib. F1. Lituan, ii, $197=$ A. Iippocastanum.

\section{AESCULUS:-}

chinensis, Bunge, in Mém. Sav.étr. Pétersb, ฉi. (183.

84.-China

discolor, Pursh, F1. Am. Sept. 1. $255=$ flava,

dissimilis, Blume, Rumphia, iil. 195.-Japon.

echinata, Muhl. Cat. PI. Am. Sept. 38=glabra.

flava, Ait. Hort. Kew. i. 494.-Am. bor.

glabra, Willd. Enum. Hort. Berol. 405.-Am. bor.

Hippocastanum, Linn. Sp. Pl. 344.-Turc.

humilis, Lind1. Bot: Reg. t. $1018=$ Ae. Pavia?

hybrida, $D C$. Hort. Monsp. (1818) 75=flava.

indica, Coleb. ex Wall. Cat. n. 1181. - Reg. Himal

intermedia, Steud. Nom, ed. II. i. 32.-Am. bor.

levigata, Rafin. Alsog. Am. 70.-Am. bor.

livida, Steud. Nom. ed. II. i. 32.-Am. bor.

lutea, Wangh. in Schr. Berl. Ges. Naturf. Fr, viii. (1788

133. $\mathrm{t} .6=$ flava

Lyonii, Loud. Arb. Brit. i. $468=$ A. Pavia

macrostachya, Michx. FI. Bor. Am. i, $220=$ parvifora. macrostachys, Pers. Syn. 1. $403=$ parviflora.

Memmingeri, Hort. ex C. Koch, Dendrol. i. $506=$ A

Hippocastanum.

mexicana, Benth. \& Hook. f. ex Hemsl. Biol. Centr.

Am. Bot. i. 213.-Mexic

muricata, Rafin. Alsog. Am.68.-Am. bor.

neglecta, Lindl. Bot. Reg. t. $1009=$ flava.

ochroleuca, Rafin. Alsog. Am.68.-Am. bor.

odorata, F. G. Dietr. Lexik, Gaertn. Nachtr. i. 118 -

Am. bor.

ohioensis, Michx. Arb. For. Am. Sept. iii. $242=$ glabra

pallida, Willd. Enum. Hort. Berol. $406=$ glabra.

Parryi, A. Gray, in Proc. Am. Acad. xvii. (1881-82

200.-Am bor.

parviflora, Walt. Fl. Carol. 128.-Am, bor.

Pavia, Linn. Sp. Pl. 344.-Am, bor.

procera, Salisb. Prod. $280=$ A. Hippocastanum

punduana, Wall. Cat. n. 1189.-Reg. Himal.

rosea, Hort. ex Loud. Encyc. Trees, $127=$ glabra.

rubella, Wender. Ind. Sem. Marb. (1853) 1. et $4=$ glabra?

rubescens, Tausch, in Flora, xxi. (1838) 1. Beibl. $79=\mathrm{A}$

Pavia

rubicunda, Lodd. Bot. Cab. t. 1242=glabra

rubra, Pers. Syn. i. $403=$ A. Pavia.

septenata, Stokes, Bot. Mat. Med. ii. $337=$ A. Hippo-

castanum.

turbinata, Blume, Rumphia, iii. 195.-Japon.

verrucosa, Rafin. Alsog. Am. 69.-Am. bor.

versicolor, Wender. Ind Sem. Hort. Marb. (1853) 4 = A. Pavia?

Watsoniana, D. Dietr. Syn. ii. $1225=$ glabra.

Whitleyi, Hort. ex C. Koch, Dendrol. i. $511=$ A. Pavia.

AETHEILEMA, R. Br. Prod. 478 (1810)=Phaylopsis,

Willd. (Acanth.)

alopecuroides, Spreng. Syst, ii. $826=$ Lepidagathis alo pecuroidea.

anisophyllum, E. Mey. ex Nees, in DC. Prod. xi. $262=$ P. longifolia.

glutinosum, Stend. Nom. ed. II. i. $32=$ P. parviflora

Haenkei, Nees, in Mart. Fl. Bras. ix. $72=$ Lepidagathis alopecuroidea.

imbricatum, R. Br. Prod. i. $478=\mathrm{P}$. longifolia.

javanicum, Hassk. in Hoev. \& De Vriese, Tijdschr. $x$.

1843) 129.-Java.

longifolium, Spreng. Syst. Cur. Post. $236=$ P. longifolia. micranthum, Benth. in Hook Nig. Fl. 450.-Afr. trop. mucronatum, Griff. Notul. iv. $137=$ P. parviflora. parvifiorum, Spreng. Syst. ii. $826=$ P. parviflom. Rothii, Steud. Nom, ed. II, i. $32=$ P. parvillom reniforme, Nees, in Wall. PI. As. Rar. iii. $9 t=P$. parviflora.

rigidum, Bartl. ex Nees, in DC. Prod. xi. $24 \$=$ Barle. riola solanifolia.

rupestre, Nees, 1. c. 262.-Madag.

AETHEOLAENA. Cass, in Dict. Sc. Nat. xlviii. 150 $(1827)=$ Senecio, Linn. (Compos.

involucrata, Cass. I. c. $151=\mathrm{S}$, involucratus.

AETUEONEMA, Reichb. Nom. 199 (1s41)= Gaert nexa Iam. ( Logan.).

AEIIILOPAlPLS, Cass, in Dict. Sc. Nat. 1. 230,1527 Centaurea, Linn. Compos.

Balansac. Buiss Fl. Oricne. iu. Gili =C. Balansac

palcherrimus, Cass, in Dice Sc Nat. li. $52=$ C. pul cherrima. 
AETHEORHIZA, Cass. in Dict. Sc. Nat. xlviii. 425 $(1827)=$ Crepis, Linn. (Compos.). bulbosa, Cass. 1. c. = C. bulbosa.

montana, Willk. in Oest. Bot. Zeitschr. xxv. (1875) $110=$ C. montana

\section{AETHEORRHIZA, Reichb. Consp. $98(1828)=$ praec.}

AETHERIA, Endl. Gen, $214(1837)=$ Hetaeria Blume (Orchid.).

AETHIONEMA, R. Br. in Ait. Hort, Kew, ed. II. iv 80 (1812). CRUCIFERAE, Benth. \& Hook. f. i. 88. Diastrophis, Fisch. \& Mey. Ind. Sem. Hort. Pe trop. ii. 35 (1835)

Disynoma, Rafin. Fl. Tellur. iii. 81 (1836)

Ethionema, Brongn, Enum. Gen. 92 (1843)

EUNOMIA, DC. Syst. ii. 555 (1821).

Oethionema, Knowl. \& Westc. Flor, Cab, i. (1837) 41.

arabicum, Andrz. ex DC. Syst. ii. $560=$ cappadocicum armenum, Boiss. in Ann. Sc. Nat. Sér. II. xvii. (1842) 191.-Ármen.

Balansae, Boiss. Diagn. Ser. II. vi. 20 (=Crenularia glaucescens).

banaticum, Janka, in Linnaea, xxx. (1859-60) $558=$ saxatile.

Beyrichii, Tausch, in Flora, xix (1836) 411-Persia.

Bourgaei, Boiss. Fl. Orient. i. 344.-Syria.

Buxbaumi, DC. Syst. ii. $560=$ cappadocicum.

caespitosum, Boiss. Fl. Orient. i. $343=$ Iberidella caespitosa.

campylopterum, Boiss. $l$. c. 353.-Syria.

capitatum, Boiss. E Balansa, Diagn. Ser. II. v. 43.As. Min.

cappadocicum, Spreng. Nov. Prov. i. 2.-Oriens.

cardiophyllum, Boiss. \& Heldr. Diagn. Ser. I. viii. 43.-As. Min.

chloraefolium, Boiss. Fl. Orient. i. 344.-As. Min.

clandestinum, Delile, in Ann. Sc. Nat. Sér. II. vii.

(1837) 285.-Hab. ?

cordatum, Boiss. Fl. Orient. i. 350.-Oriens.

coridifolium, DC. Syst. ii. 561.-Oriens.

coridifolium, Hort. ex Boiss. Diagn. Ser. I. vili. 43 = puichellum.

cristatum, $D C$. Syst. ii, 560.-Oriens.

diastrophis, Bunge, Del. Sem. Dorp. (1841) 7.Armen.

elongatum, Boiss. Diagn. Ser. I. vi. 17.-Persia

fimbriatum, Boiss, in Ann. Sc. Nat. Sér. II. xvii. (1842) 193.-Persia.

Fischeri, Tausch, in Flora, xix. (1836) 410,-Sibir.

gracile, $D C$. Syst. ii. 559.-Carniol.

graecum, Boiss. E Sprun. Diagn. Ser. I. vi. 16.Graecia.

grandiflorum, Boiss. \& Hohen. l. c. viii. 42.-Persia

heterocarpum, F. Gay, in Fisch. \& Mey. Ind. Sem

Petrop. iv. 1, nomen.-Syria.

heterophyllum, Boiss. Fl. Orient. i. $343=$ Iberidell heterophylla.

iberideum, Boiss. l. c. 1. 351.-Oriens,

lacerum, Boiss. Diagn. Ser. II. v. 45.-Cilicia

leptocarpium, Delile, in Ann. Sc. Nat. Sér. II. vii. (1837) 285.-Hab. ?

lignosum, Boiss. \& Haussk. ex Boiss. Fl. Orient. i. 348. -As. Min.

membranaceum, DC. Syst. ii. 561.--Persia.

monospermum, R. Br. in Ait. Hort. Kew. ed. II. iv. 80.-Hispan.

moricandianum, Boiss. Fl. Orient. i. 351-As. Min.

oppositifolium, Boiss. l. c. 344.-Syria.

ovalifolium, Boiss. l. c. 351-_-Oriens.

polygaloides, DC. Syst. ii. 562.-Ins. Scios.

polygaloides, Ledeb. F1. Ross. i. $209=$ armenum

pulchellum, Boiss. \& Huet, Diagn. Ser. II. v. 43 . -

Oriens.

pyrenaicum, Boutigny, in Bull. Soc. Bot. Fr. iv. (1857)

777.--Mont. Pyren.

rotundifolium, Boiss. Fl. Orient. i. 344.-Reg. Caucas.

rubescens, Boiss. l. c. 343 - -As. Min

sagittatum, Boiss. 1. c. $342=$ Iberidella sagittata

salmasium, Boiss. l. c. 350.-Persia.

saxatile, R. Br. in Ait. Hort. Kew. ed. II. iv, 80,-

Europ. austr.

schistosum, Boiss. E Kotschy, Diagn. Ser. II. v. 42.-

As. Min.

speciosum, Boiss. \& Huet, l. c. 44.-Oriens.

\section{AETHIONEMA :-}

spicatum, Post, in Hook. Ic. Pl. xv. 62, t. 1478,--Syria. stenopterum, Boiss. in Ann. Sc. Nat. Sér. II. xvii,

(1842) 192.-Persia.

stylosum, DC. Syst. ii. 562.- Syria.

subulatum, Boiss. Fl. Orient i. 349.-As, Min.

Szowitzii, Boiss. l. c. 345 .- - Persia.

tenue, Boiss. 1. c. $343=$ Iberidella tenuis.

thesiifolium, Boiss. \& Heldr. Diagn. Ser. I. viii. 44.As. Min.

Thomasianum, F. Gay, in Ann. Sc. Nat. Sér. III. iv. (1845) 81.-Europ.

trinervium, Boiss. F1. Orient. i. $342=$ Iberidella trinervia.

AETHIOPIS, Fourr. in Ann. Soc. Linn. Lyon, N. S. xvii. (1869) $134=$ Salvia, Tourn. (Labiat.).

Sclarea, Fourr. 1. c. = S. Sclarea

vera, Fourr. 1, $\mathrm{c}_{\mathrm{o}}=\mathrm{S}$. Aethiopis.

AETHONIA, D. Don, in Edinb. N. Phil. Journ. (Mar. 1829) $309=$ Tolpis, Adans. (Compos.)

filiformis, D. Don, 1. c. $=\mathrm{T}$. filiformis

fruticosa, D. Don, 1. c. = T. fruticosa.

lagopoda, D. Don, 1. c, = T. lagopoda.

\section{AETHUSA, Linn. Sp. Pl. 256 (1753)}

LIFERAE, Benth. \& Hook. f. i. 907.

Cynapium, Riv. ex Rupp. Fl. Jen. ed. Hall. 28 (1745).

ETHUSA, Linn. Syst. ed. I. (1735)

Ammi, Spreng. in Ges. Naturf. Fr. Berl. Mag. vi (1812) $260=$ Ammi majus.

Bunius, Murr. Syst. Veg. ed. XIII. 236=Carum Bunius.

capillacea, Nutt. ex DC. Prod. iv. 106=Apiastrum angustifolium.

Cicuta, Neck. Delic. Gallo-Belg. i. 146=A. Cynapium. cynapioides,Bieb. Fl. Taur. Cauc. i. $227=\mathrm{A}$. Cynapiun Cynapium, Linn.Sp. Pl. 256.-Europ.; Oriens. cynica, Dulac, Fl. Hautes-Pyr. $353=$ A. Cynapium. divaricata Spreng, in Ges. Naturf. Fr. Berl. Mag, vi.

(1812) $260=$ Apium divaricatum.

elata, Friedl. ex Fisch. Cat. Hort. Gorenk. (1813) 45 $=\mathrm{A}$. Cynapium

fatua, Ait. Hort. Kew. i. 352=Carum verticillatum, leptophylla, Spreng. in Ges. Naturf. Fr. Berl. Mag. vi 1812) $260=$ Apium leptophyllum.

Meum, Murr. Syst. Veg. ed. XIII. $236=$ Meum atha manticum.

micrantha, Opiz, ex Nym. Consp. $297=$ A. Cynapium. montana, Lam. Fl. Fr. iii. $649=$ Carum Bunius.

mutellina, Lam. 1. c. $443=$ Meum mutellina

petroselinifolia, Gilib. Fl. Lituan. ii. $25=$ A. Cynapium.

pinnata, Nutt. ex DC. Prod. iv. $141=$ Cynosciadium pinnatum.

segetalis, Boenn. Prod. F1. Monast. $85=$ A. Cynapium.

tenuifolia, S. F. Gray, Nat. Arr. Brit. P1. ii. $513=$ A

Cynapium.

tenuifolium, Salisb. Prod, $\mathbf{1 6 6}=$ Meum athamanticum toxicaria, Salisb. $1_{n} \mathrm{c}_{\mathrm{v}}=$ A. Cynapium.

AETIA, Adans., Fam. ii. $84(1763)=$ Combretum, Linn.

AEXTOXICON, Ruiz \& Pav. Prod. 131. t. 29 (1794). EUPHORBIACEAE, Benth. \& Hook, f. iii. 285.

AEgotoxicon, Molina, Sagg. Chile. ed. II. 298 (1810)

punctatum, Ruiz \& Pav. Syst. Veg. 260.-Chili.

AFARCA, Rafin. Sylva Tellur. 30 (1838):= Sageretia, Brongn. (Rhamn.).

parviflora, Rafin. I. c. $=$ S. Michauxii.

AFFONSEA, A. St. Hil. Voy. Diam. i. 387 (1833), LEGUMINOSAE, Benth. \& Hook. f. i. 599. bullata, Benth. in Hook. Lond. Fourn. Bot. v. (1846) 77. - Bras.

comosa, Benth. 1. c. 76. t. $1=$ juglandifolia.

densiflora, Benth. l. c.-Bras.

juglandifolia, A.St. Hit. Voy. Diam. i. 385.-Bras.

AFZELIA, J. F. Gmel. Syst. $927(1791)=$ Seymeria, Pursh (Scrophul.).

cassioides, Y. F. Gmel. 1. c. $=$ S. tenuifolia.
AFZFLIA, Sm. in Trans. Linn. Soc. iv. (1798) 221 LEGUMINOSAE, Benth. \& Hook. f. i. 580.

IntSiA, Thou. Gen. Nov. Madag. 22 (1809).

africana, $S m$. l. c.-Afr. trop.

attenuata, Klotzsch, in Peters, Reise Mossamb. Bot. i. 20.--Afr. or. trop.

bijuga, A. Gray, Bot. U. St. Expl. Exped. i. 467.-Ins. Pacif.

bijuga, Spreng. Syst. iv. Cur. Post. $170=$ Erioglossum cauliflorum.

bracteata, Vog. ex Benth. in Hook. Ic. Pl. t. 790.-Afr. trop.

cambodensis, Hance, in Fourn. Bot. xiv. (1876) 258.Cambod.

coriacea, Baker, in Hook. f. Fl. Brit. Ind. ii. 275.Ind. or.

cuanzensis, Oliver, Fl. Trop. Afr. ii. $302=$ quanzensis discolor, Hort. ex Steud. Nom. ed. II. i. 33.-Afr. trop. grandis, Hort. ex Loud. Hort. Brit. $168=$ Erythrophleum guineense.

madagascariensis, Baill. Hist. Pl. ii. $112=$ bijuga,

palembanica, Baker, in Hook.f. Fl. Brit. Ind. ii. 275. -Ind. or.

Pancovia, DC. Prod. ii. $507=$ Erioglossum cauliflorum.

Petersiana, Klotzsch, in Peters, Reise Mossamb. Bot. i. 19 = quanzensis.

quanzensis, Welw. Apont. 586.-Angola.

retusa, Kurz, in Fourn. As. Soc. Beng. xlii. (1873) II. 73.-Malacca.

rhomboidea, Vidal, Phanerog. Cuming. Philipp. 26, 110.--Iñs. Philipp.

splendens, Hort. ex Loud. Hort. Brit. 168=Carapa procera.

AGALINIS, Rafin. New Fl. Am. ii. 61 (1836)=Gerardia, Linn. (Scrophul.

aphylla, Rafin. 1. c. $65=\mathrm{G}$. aphylla

corymbosa, Rafin. 1. c. $63=\mathrm{G}$. Plukenetii.

fasciculata, Rafin. $1 . c_{n}=\mathrm{G}$, purpurea

filifolia, Rafin. l. c. $65=\mathrm{G}$. filifolia.

longifolia, Rafin. 1. c. $62=\mathrm{G}$. aspera?

maritima, Rafin. 1. $c=\mathrm{G}$, maritima.

microphylla, Rafin. 1. c. 65.-Am. bor.

obtusifalia, Rafin. 1. c. $64=$ Aulaya obtusifolia?

palustris, Rafin. 1. c. $62=\mathrm{G}$. purpurea.

perennis, Rafin. 1. c. $63=\mathrm{G}$. linifolia.

Plukeneti, Rafin. 1. c. = G. Plukenetii.

setacea, $\mathrm{Rafin} .1, \mathrm{c}, 64=\mathrm{G}$, setacea.

tenuifolia, Rafin. l, c. $=\mathrm{G}$. tenuifolia,

virgata, Rafin. 1. c. $62=$ Seymeria virgata?

AGALLIS, Phil. in Linnaea, xxxiii. (1864-65) 12 CRUCIFERAE.

montana, Phil. l. c.-Chili.

AGALLOCHUM, Lam. Encyc. i. 48 (1783)=Aquilaria, Lam. (Thymel.)

officinarum, Lam. 1. c. = Aquil. malaccensis

praestantissimum, Lam. 1. c. 48.-As. or.

sylvestre, Lam. 1. c. 49.--Ins. Timor.

AGAlLOSTACHYS, Beer, Bromel. $35(1857)=$ Bro melia, Linn.

antiacantha, Beer, 1. c. $37=$ B. fastuosa.

chrysantha, Beer, 1. c. $38=\mathrm{B}$. chrysantha

Commeliniana, Beer, 1, c, $39=\mathrm{B}$. fastuosa

fastuosa, Beer, l. c. $36=$ B. fastuosa.

laciniosus, C. Koch, Wochenschr. ii. (1859) $140=$ B. laciniosa.

Pinguin, Beer, Bromel. $36=$ B. Pinguin.

sylvestris, Beer, 1. c. $35=\mathrm{B}$, sylvestris.

variegata, Beer, 1. c, $38=$ Billbergia speciosa.

AGALMA, Miq. Fl. Ind. Bat. i. I. $751(1855)=$ Hepta pleurum, Gaert. (Araliac.).

aesculifolium, Seem. in Journ. Bot. ii. (1864) $298=$

Brassaiopsis aculeata.

aromaticum, Seem. 1. c.-Java.

elatum, Seem. l. c. = H. elatum.

glaucum, Seem. 1. c. $299=$ H. glaucum

Griffithii, Seem. 1. c. $=$ H. elatum.

Horsfieldii, Seem. 1. c. 298.-Java.

kavaiense, Seem. Revis. Hederac. $103=\mathrm{H}$. kavaiense.

lucescens, Seem. in Journ. Bot. ii. (1864) $299=\mathrm{H}$. octophyllum.

octophyllum, Seem. 1. c. $298=$ H. octophyllum.

racemosum, Seem. 1. c. $=$ H. racemosum.

redivivum, Seem. 1. c. 299.-Borneo. 
AGALMA :

rostratum, Seem. in Journ. Bot. ii. (1864) $298=\mathrm{H}$. rostratum.

rugosum, Miq. Fl. Ind. Bat. i. I. 752. t. 11.-Malaya

simillimum, Miq. 1. c.-Malaya

tomentosum, Seem. in Joum. Bot. ii. (1864) $298=\mathrm{H}$. impressum.

vitiense, Seem. F1. Vit. 116,-Ins. Fiji.

AGALMA, Steud. Nom.ed. II. i. $33(1840)=$ Sonchus, Tourn. (Compos.).

AGALMANTHUS, Hombr. \& Jacquinot, ex Decne. Pot. Voy. Astrol, et Zel. $7^{8}(1845)=$ Metrosideros, Banks (Myrtac.).

umbellata, Hombr. \& Jacquinot, ex Decne. 1. c. $=$ M. lucida.

AGALMYLA, Blume, Bijdr. 766 (1826). GESNERACEAE, Benth. \& Hook. f. ii. 1014 ORITHAlia, Blume, F1. Jav. Praef. 6 (1828) Orythia, 'Blume,' ex Endl. Gen. Suppl. i. 1408 (1841).

angustifolia, Miq. Fl. Ind. Bat. ii. 723.-Malaya asperifolia, Blume, Bijdr. $767=$ Dichrotrichum asperifolium

Beccarii, C. B. Clarke, in DC. Monog. Phan. v. 57.Sumatra.

longistyla, Carr. in Rev. Hortic. (1873) $271=$ staminea, staminea, Blume, Bijdr. 767.-Java.

tuberculata, Hook. f. Ic. Pl. t. 897.-Borneo.

AGALOMA, Rafin. Fl. Tellur. iv. $116(1836)=\mathbf{E u}$ phorbia, Linn.

angustifolia, Rafin. 1. c. $117=\mathrm{E}$. angustifolia?

corollata, Rafin, 1, $\mathrm{c},=\mathrm{E}$, corollata,

graminifolia, Rafin. 1. c, =E. granulata.

AGANIPPEA, Moc. \& Sesse, ex DC. Prod. vi. 3 1837). COMPOSITAE, Benth. \& Hook. f. ii. 358 . Heliogenes, Benth. Pl. Hartw. 42 (1840).

bellidifiora, Moc. \& Sesse, ex DC. Prod. vi. 3.-Mexic. dentata, $D C$. $l$. $c$. -Mexic

AGANISIA, Lindl. in Bot. Reg. xxv. (1839) Misc. 45; xxvi. t. 32 (1840). ORCHIDEAE, Benth. \& Hook. f. iii. 544.

Koellensteinia, Reichb. f. in Bonplandia, ii (1854) 17 .

caerulea, Reichb. f. in Gard. Chron. N. S. vi. (1876) II. 226. - Bras

cyanea, Relchb. f. in Nov. Act. Nat. Cur. xxxv. II. (1876)

13. t. $4=$ Acacallis cyanea

fimbriata, Reichb. f. in Gard. Chron. N. S. ii. (1874) II. 452.-Guian

lepida, Linden \& Reichb. f. in Nov. Act. Nat. Cur. xxxv. II. (1876) 15. t. 5.-Am. trop

Oliveriana, Reichb. f. in Gard. Chron. N. S. ix. (1878) I. 558.-Bras.

pulchella, Lindl. in Bot. Reg. (1839) Misc. 45; xxvi. (1840) t. 32.-Guian.

AGANON, Rafin. Sylva Tellur. $161 \quad(1838)=$ Calli carpa, Linn. (Verben.).

umbellata, Rafin. 1. c. $=$ C. arborea.

AGANOPE, Miq. Fl. Ind. Bat. i. I. $151(1855)=$ Derris, Lour. (Legumin.)

foribunda, Miq. I. c. = D. thyrsiflora.

marginata, Miq. 1. c. $152=$ D. marginata.

microphylla, Miq. 1. c.-Java.

subavenis, Miq. 1. c. Suppl. i. 299,-Sumatra.

sumatrana, Miq. 1. c. 300.-Sumatra.

AGANOSMA, G. Don, Gen. Syst. iv. 77 (1837) $A P O C Y N A C E A E$, Benth. \& Hook. f. ii. 717

Ganosma, Decne, in DC. Prod.viii. 625 (1844), sphalm. acreminata, G. Don, l. c. = marginata

affinis, G. Don, 1. c. = Ichnocarpus ovatifolius.

Blumei, A. DC. in DC. Prod. viii. 432.-Java,

Blumei, Wight, Ic. t. $1905=$ caryophyllata.

calycina, A. DC. in DC. Prod. viii. 432.-Ind. or.

crryophyllata, G. Don, Gen. Syst. iv. 77.-Ind, or.

concanensis, Hook. Ic. Pl. v. t. $841=$ Parsonsia spiralis conferta, G. Don, in Loud. Encyc. Pl. Suppl. ii. $1312=$ cymosa.

cymosa, G. Don, Gen. Syst. iv. 77.-Ind. or.

\section{AGANOSMA}

Doniana, Wight, Ic. t. $1306=$ cymosa

elegans, G. Don, Gen. Syst. iv, $77=$ cymosa

Edithae, Hance, in Ann. Sc Nat. Sér. V. v. 166 $227=$ Cryptolepis elegans.

euloba, Miq. F1. Ind. Bat. ii. $447=$ acuminata.

gracilis, Hook, f. Fl. Brit. Ind, iii. 664--Reg. Himal,

laevigata, J. Grah. Cat. Bomb. P1. 113 (= Parsonsiae sp. ?). - Ind. or.

laevis, Champ. ex Benth. in Hook. Kew Journ. iy.

(1852) $335=$ Anodendron laeve

macrocarpa, A. DC. in DC. Prod. viii. $434=$ marginata marginata, G. Don, Gen. Syst. iv. 77.-Ind. or.

Roxburghii, G. Don, 1. c. = calycina.

velutina, A. DC. in DC. Prod. viii. 434.-Malaya.

Wallichii, G. Don, Gen. Syst. iv. $77=$ calycina.

AGAPANTHUS, L'Hérit. Sert. Angl. 17 (1788) LILIACEAE. Benth. \& IJook. f, iii. 798.

ABUmon, Adans. Fam. ii. 54 (1763)

Mnuhlia, Dahl, Obs, Syst. Linn, 25 (1787)

africanus, Hoffmgg. Verz. Pf. $35=$ umbellatus.

ensifolius, Willd Sp. Pl ii, 48 = Massonia ensifolia.

medius, Lodd. ex Steud. Nom. ed. II. i. $33=$ umbellatus. minor, Lodd. Bot. Cab. t. $42=$ umbellatus.

multiflorus, Willd. Enum. Hort. Berol. $353=$ um bellatus.

praecox, Willd. 1. $\mathrm{c}_{\mathrm{n}}=$ umbellatus.

tuberosus, Linn. ex [DC. in] Red, Liliac. i. $6=\mathrm{um}$ bellatus.

umbellatus, L'Hérit. Sert. Angl. 18.-Afr. austr.

umbelliferus, Poir. Encyc. Suppl. i. 155 = umbellatus.

variegatus, Hort. ex Stend. Nom. ed. II. i. $33=u m$

bellatus.

AGAPATEA , Stend, in Bot. Zeit. xiv. (1856) $391=$ Distichia, Nees \& Meyen (Juncac.)

filamentosa, Buchen. in Bremen Abh. iv. (1874) $124=$ D. filamentosa.

peruviana, Steud. in Bot. Zeit. xiv. (1856) $390=\mathrm{D}$. muscoides.

AGAPETES, G. Don, Gen. Syst. iii. 862 (1834). VACCINIACEAE, Benth. \& Hook. f. ii. 571. Caligula, Klotzsch, in Linnaea, xxiv. (1851) 28. PAPHIA, Seem. in Journ. Bot. ii. (1864) 77

Acosta, Dun. in DC. Prod. vii. 556=Vaccinitum Acosta acuminata, D. Don, ex G. Don, Gen. Syst, iii. $862=$ Corallobotrys acuminata.

amblyornidis, Becc. Malesia, i. (1878) 208.-Malaya. angulata, Benth. \& Hook. f. Gen. ii. 571.-Ind. or

arborea, Dun. in DC. Prod vii. $555=$ Vaccinium Leschenaultii.

auriculata, Benth. \& Hook. f. Gen. ii. 571--Ind. or

bracteata, Hook. f. ex C. B. Clarke, in Hook. f. Fl. Brit. Ind. iii. 448.-Ind. or.

buxifolia, Nutt. ex Hook. f. Bot. Mag. t. 5012-Reg. Himal.

campanulata, C. B. Clarke, in Hook. f. Fl. Brit. Ind. iii. 449.-Ind, or.

coriacea, G. Don, Gen. Syst. iii. $863=$ Vaccinium Korthalsii.

cuneifolia, G. Don, 1. c. = Vaccinium cuneifolium

discolor, C. B. Clarke, in Hook. f. Fl. Brit. Ind. iii. 448,-Reg. Himal.

elliptica, G. Don, Gen. Syst, iii. $862=$ Vaccinium ellipticum.

foribunda, G. Don, 1. c. = Vaccinium Teysmanni

glabra, C. B. Clarke, in Hook. f. Fl. Brit. Ind. iii. 444.-Ind. or

grandiflora, Benth. \& Hook. f. Gen, ii. 571.-Ind, or.

Griffithii, C B Clarke, in Hook of Fl, Brit. Ind. iii 449.-Reg. Himal.

hirsuta, Klotzsch, in Linnaea, xxiv. (1851) $38=$ setigera.

laurifolia, G. Don, Gen. Syst. iii. $862=$ Vaccinium laurifolium.

linearifolia, C. B. Clarke, in Hook. f. Fl. Brit. Ind. iii. 449.-Reg. Himal.

Lobbii, C. B. Clarke, l. c. 448.-Ind. or.

loranthifora, D. Don, ex G. Don, Gen. Syst. iii. 862.Ind. or.

lucida, G. Don, 1. c. $863=$ Vaccinium lncidum. macrantha, Benth. \& Hook. f. Gen, ii. 571-Ind. or. macrophylla C. $B$. Clarke, in Hook, f. Fl. Brit. Ind. iii. $445 .-$ Reg. Himal

macrostemon, C. B. Clarke, l. c. 443.-Burms.

madagascariensis, Dun. in DC. Prod. vii. 555.Madag.

\section{AGAPETES :-}

meliphagidum, Becc. Malesia, i. (1878) 208.-Malaya. microphylla, Fungh. in Nat. en Geneesk. Arch. Neerl. lnd. ii. (1845) 35.--Tava.

miniata, Benth. \& Hook. f. Gen, ii. 571.-Re Himal

mitrarioides, Hook. f. ex C. B. Clarke, in Hook. f. Fl. Brit. Ind. iii. 447.- Reg. Himal.

myrtoidea, G. Don, Gen. Syst. ixi. $863=$ Vaccinium myrtoides.

Myzomelae, Becc. Malesia, i. (1878) 209.Malaya. nana, Benth. \& Hook. f. Gen. ii. 571 -Reg. Himal. Nuttallii, C. B. Clarke, in Hook. f. Fl. Brit. Ind. ii. 445.-Reg. Himal.

obliqua, Benth. \& Hook. f. Gen. ii. $571=$ setigera. obovata, Benth. \& Hook.l. c. 572.-Reg, Himal. odontocera, Benth. \& Hook. f. 1. c. $571=$ variegata

Parishii, C. B. Clarke, in Hook. f. Fl. Brit. Ind. 445.-Ind. or.

pilifera, Hook. f.ex C. B. Clarke, l.c. 448,-Reg. Hima pulcherrima, Benth. \& Hook. f. Gen. ii. $571=$ variegata. rosea, Fungh. in Nat, en Geneesk. Arch. Neerl. Ind. ii. (1845) 35.-Java?

salicifolia, C. B. Clarke in Hook. f. Fl. Brit. Ind. iii 445.--Reg. Himal.

salicifolia, Gardn. ex Thw. Enum. P1. Zeyl, 170

Vaccinium Leschenaultii.

saligna, Benth. \& Hook. f. Gen. ii. 571-Ind, or

serrata, G. Don, Gen. Syst. ii. $862=$ Vacciniom sorratum

setigera, D. Don, ex G. Don, l. c.-Ind. or.

Sprengelii, G. Don, 1. c. =Vaccinium Donianum

symplocifolia, D. Don, ex G. Don, l. c. =Vaccinium

Leschenaultii.

vaccinacea, Dun, in DC. Prod. vii. $554=$ Vaccinium serratum.

variegata, Dun. 1. c. = setigera

variegata, D. Don, ex G. Don, Gen. Syst. iii. 862.Ind. or.

varingiaefolia, G. Don, l. c. = Vaccinium varingiaefolium.

verticillata, D. Don, ex G. Don, I. c. =setigera.

vulgaris, Jungh. in Nat. en Geneesk. Arcb. Neerl.

Ind, ii. (1845) $34=$ Vaccinium ellipticum.

Wallichiana, Klotzsch, in Linnaea, xxiv. (1851) 38

setigera.

AGARDHIA, Spreng. Syst. i. 4, $17(1825)=$ Qualea Aubl. (Vochys.).

cryptantha, Spreng. 1. c. $17=$ Q. cryptantha.

grandiflora, Spreng. 1. c. =Q. grandiflora?

AGARISTA, DC. Prod. v. $569(1836)=$ Coreopsis Linn. (Compos.)

calliopsidea, DC. 1. c. =C. calliopsidea.

AGARISTA, D. Don, in G. Don, Gen. Syst iii. 837 1834). ERICACEAE, Benth. \& Hook. \&. ii. 586 AMECHANIA, DC. Prad, vii. 578 (1838) anastomosans, G. Don, l. c. iii. 838-N. Granat bracamorensis, G. Don, l.c. $837 .-\mathrm{N}$. Granat. buxifolia, G. Don, 1. c. = Agauria buxifolia. chlorantha, $G$. Don, $l . c .838$.-Bras.

eriophylla, G. Don, l. c.-Bras.

eucalyptoides, G. Don, l. c. 837.-Bras.

ilicifolia, G. Don, l. c. 838 - - Peruv.

Itatiaiae, Wawra, It. Princip. Coburg. i. 78.-Bras

multiflora, G. Don, Gen. Syst. iii. 837.-Bras.

neriifolia, G. Don, l. c. 838.- Bras.

nummularia, G. Don, l. c. 837 .-Bras.

oleifolia, G. Don, l. c. E38.-Bras.

Pistrix, G. Don, l. c.-Bras

Pohlii, G. Don, l. c. 897 -Bras.

pulchella, G. Don, l.c. 835 .-Bras.

pulchra, G. Dons, l. c. 837 .-Bras.

pyrifolia, G. Don, 1. c. $\$ \$ S=$ Agamia salicifolia

salicifolia, G. Don, 1. c. $\$ 9 \pi=$ A gauria salicifolia.

serrulata. G. Don. l. c. \$ss.-Bras.

Sprengelii, G. Don, l. c. \$3;.-Lims.

subrotunda. G. Don, l. c.- lita.

AGASSIZIA, Chav. Monog. Antirrb. $180.111 .1 \leq 8.1$

Galvesia, Domb. Sirophul.

limenssis, Chav, l, $\mathrm{c} \approx \mathrm{G}$. limensis.

AGASSI\%IA, Gmy \& lingelm. in Proc Am. Aca

$1847) 40=$ Gaillardia, Fouger. (Compos.

snareis, A. Gray \& Engelm. L c $50=$ G. simj lex 
AGASSIZIA, Spach, Hist. Vég. Phan. iv. $347(1835)=$ Oenothera, Linn. (Onagrar.)

cheiranthifolia, Spach, 1. c. $348=$ O. Agassizia.

AGASTA, Miers, in Trans. Linn. Soc. Ser. II. i. 59 (1875) =Barringtonia, Forst. (Mytac.) asiatica, Miers, I. c. $61=\mathrm{B}$. speciosa. indica, Miers, 1. c. $63=\mathrm{B}$. speciosa. splendida, Miers, 1 , c. $60=\bar{B}$. speciosa.

AGASTACHYS, R. Br. in Trans. Linn. Soc $\mathrm{x}$ (1811) 158. PROTEACEAE, Benth. \& Hook. f. iii. 175 odorata, R.Br.l.c.-Tasmania.

AGASTIANIS, Rafin. in New Fl. Am. iii. 85 (1836)= Sophora, Linn. (Legum.)

secundiflora, Rafin. 1. c. $86=\mathrm{S}$. secundiflora.

AGASYLLIS, Spreng. in Ges. Naturf. Fr. Berl. Mag. vi. (1812) $259=$ Siler, Scop. $($ Umbellif. $)$

caucasica, Spreng. 1, c. $=$ S. caucasicum.

Galbanum, Spreng. 1. c. = Peacedanum Galbanum. latifolia, Boiss. F1. Orient. ii. $980=\mathrm{S}$. caucasicum. salsa, Spreng. in Ges. Naturf. Fr. Berl. Mag. vi. (1812) $259=$ Pencedanum redivivum

AGATEA, A. Gray, in Proc. Am. Acad. ii. (1852) 323 =Agation, Brongn. (Violar.)

violaris, A. Gray, 1. c. $324=$ Agation violare.

AGATEA, Rich, ex A. Gray, Bot. U. S. Expl. Exped. i $609(\mathbf{1 8 5 4})=$ Haplopetalum, A. Gray (Rbizoph.)

AGATHAEA, Cass. in Bull. Soc. Philom. (1815) 175 Dict. Sc. Nat. i. Suppl. 77. t. $89(1817)=$ Felicia, Cass. (Compos.).

abyssinica, Hochst, ex A. Rich. Tent. F1. Abyss, i. $383=$ F. Richardi.

amelloides, DC. Prod. v. $225=$ Aster rotundifolius.

amoena, Sch. Bip. ex Walp. Rep. ii. $956=$ Aster amoenus.

barbata, DC. Prod. v. $224=$ Aster barbatus.

Bergeriana, DC. 1. c. $223=$ Aster Bergerianus.

brevifolia, DC. 1. c. 225.-Afr. austr.

coelestis, Cass. Opusc. i. $3=$ Aster rotundifolius

corymbosa, Turcz. in Bull. Soc. Nat. Mosc. xxiv. (1851) II. $60=$ Gymnostephium corymbosum.

dentata, A. Rich. Tent. F1. Abyss. i. $384=$ F. Richardi

diffusa, DC. Prod. v. $224=$ Aster demissus

Ecklonis, Nees, Gen. et Sp. Ast. 262 = Aster Ecklonis.

elongata, Nees, 1, c. $266=$ Aster elongatus.

hirta, DC. Prod. v. $224=$ Aster hirtus.

hispida, DC. 1. c. = Aster elongatus.

Kraussii, Sch. Bip. ex Walp. Rep. ii. $95=$ Aster Kraussii.

leiocarpa, DC. Prod. v. 225=Aster Ieiocarpus.

linifolia, G. Don, in Loud. Hort. Brit. $349=$ Euryops linifolius.

microphylla, Cass. in Bull. Soc. Philom. (1817) $183=$ Aster aethiopicus.

natalensis, Sch. Bip. ex Walp. Rep. ii. $956=$ Aster natalensis.

rotundifolia, Nees, Gen. et Sp. Ast. $258=$ Aster rotundifolius.

scabrida, DC. Prod, v. 225= Aster seabridus.

serrata, Nees, Gen. et Sp. Ast. $259=$ Aster serratus.

spathulata, Fisch. Mey. \& Avé-Lall. Ind. Sem. Hort.

Petrop. x. $43=$ Amellus annuus.

spathulata, Kunze, Pugill. Pl. Ined. i. 9=Amellus hispidus.

stricta, DC. Prod. v. $224=$ F . adfinis

strigosa, Nees, Gen. et Sp. Ast. $263=$ Aster strigosus.

tenera, DC. Prod. v. $224=$ Aster tener.

tricolor, Nees, Gen. et Sp. Ast. $267=$ Aster tricolor.

Zeyheri, Nees, 1. c. $260=$ Aster linifolius.

AGATHFIPIS, Choisy, in Mém. Soc. Phys. Genèv. ii. (1824) 85, 89. SELAGINEAE, Benth. \& Hook. f. ii. 1129 .

adunca, E. Mey. Comm. Pl. Afr. Austr. i. 252.-Afr. austr.

angustifolia, Choisy, in Mém. Soc.Phys. Genèv. ii. (1824) 95.-Afr. austr.

brevifolia, E. Mey. Comm. Pl. Afr. Austr. i.253.Afr. austr.

mucronata, E. Mey.l.c.-Afr. austr.

\section{AGATHELPIS :-}

nitida, E. Mey. Comm. Pl. Afr. Austr. i. 252.-Afr. austr.

parvifolia, Choisy, in Mém. Soc. Phys. Genèv.ii. (1824) 95.-Afr. austr.

AGATHIS, Salisb. in Trans. Linn. Soc. viii. (1807) 311 t. 15. CONIFERAE, Benth. \& Hook. f iii. 436. DAMMARA, [Rumph.] Lam. Encyc. ii. 259 (1786). anstralis, Steud. Nom. ed. II. i. 34.-N. Zel. Dammara, Rich. Conif. 83. t. $19=$ loranthifolia. loranthifolia, Salisb. in Trans. Linn. Soc. viii. (1807) 312. t. 15.-Malaya.

AGATHISANTHEMUM, Klotzsch, in Peters, Reise Mossamb. Bot. 294 (1861)=Oldenlandia, Plum. (Rubiac.)

Bojeri, Klotzsch, 1. c. = O. Bojeri.

globosum, Klotzsch, 1. c. = O. globosa.

Petersii, Klotzsch, 1. c. $295=0$ O. Bojeri.

AGATHISANTHES, Blume, Bijdr. 645 (1825)= Nyssa, Linn. (Cornac.)

javanica, Blume, l. c. $=\dot{\mathrm{N}}$. sessiliflora

AGATHOMERIS, Delaun. in Bon Jard. (1805) ex DC. Prod. vi. $157=$ Humea, Sm. (Compos.).

AGATHOPHORA, Bunge (Anabas. Revis. 92); in Mém. Acad. Pétersb. Sér. VII. iv. (1862) n. $11=$ Halogeton, C. A. Mey. (Chenopod.),

alopecuroides, Bunge, 1. c. $=\mathrm{H}$. alopecuroides.

AGATHOPHYLLUM, Juss. Gen. 431 (1789)= Ravensara, Sonner. (Laurin.)

acuminatum, Willd. ex Meissn. in DC. Prod. xv. I. 110 $=\mathrm{R}$. acuminata.

aromaticum, Willd. Sp. PI. ii. $842=\mathrm{R}$, aromatica.

cupulare, Blume, Mus. Bot. Lugd. Bat. i. 340

Mespilodaphne cupularis

cymosum, Meissn. in DC. Prod. xv. I. $111(=$ Mes pilodaphne cymosa).

heteromorphum, Blume, Mus. Bot. Lugd. Bat. i. 340 (= Mespilodaphne heteromorpha)

Lindleyanum, Blume, 1. c. (=Mespilodaphne Lindleyana.

marginatum, Blume, 1. c. (=Mespilodaphne mar ginata).

Neesianum, Blume, 1. c. 339 (=Mespilodaphne mau ritiana)

obtusatum, Blume, 1. c. 340 (=Mespilodaphne heteromorpha).

Persoonianum, Blume, 1. c. 341 (=Mespilodaphne Persooniana).

Ravensara, Mirb. ex Steud. Nom, ed. II. $34=\mathrm{R}$ aromatica.

retusum, Willd. ex Meissn. in DC. Prod. xv. T. $110=$ $R$. retusa.

AGATHOPHYTON, Moq. in DC. Prod. xii.. II. 84, in syn. $(1849)=$ seq.

AGATHOPHYTUM, Moq. in Ann. Sc. Nat. Sér. II i. (1834) 291, t. 10. c. = Chenopodium, Linn. acuminatum, Schur, Enum. Pl. Transs. 879; Index $=$ C. acuminatum.

Bonus-Henricus, Moq. in Ann. Sc. Nat. Sér. II. i.

(1834) $291=$ C. Bonns-Henricus.

crassifolium, Fuss, Fl. Transs, $553=$ C. crassifolium

glaucum, Fuss, 1. c。=C. glaucum.

humifusum, Kitt. Taschenb. ed. II. $264=$ C. crassifolium.

rubrum, Reichb. F1. Sax. 321 = C. rubrum

AGATHOSMA, Willd. Enum. Hort. Berol. 259 1809). RUTACEAE, Benth. \& Hook. f. i. 290. 1809). RUTACEAE, Benth. \& Hoo
BuCCo, Wendl. Coll. t. 2. etc. (1808).

Dichosma, DC. ex Loud. Hort. Brit. 85 (1830) GyMnoNyChIUM, Bartl. in Linnaea, xvii. (1843) $354 . t .11$.

Hartogia, Linn. Syst. ed. X. 939 (1759) (nomen prius).

acerosa, Eck1. \& Zeyh. Enum. 114.-Afr. austr. acuminata, Drège, ex Walp. Ann. i. $155=$ punctata. acuminata, Willd. Enum. Hort. Berol. $260=\mathrm{im}$ bricata.

acutifolia, Sond, in Harv. \& Sond. Fl. Cap. i. 416.Afr. austr.

\section{AGATHOSMA :-}

adenocaulis, Eckl. \& Zeyh. Enum, 115.-Afr. austr. affinis, Sond. in Harv. \& Sond. Fl. Cap. i. 405.-Afr austr.

alaris, Cham. in Linnaea, v. (1830) 53.-Afr. austr ambigua, Sond. in Harv. \& Sond. Fl. Cap.i. 426.-Afr. austr.

ambigua, Sweet, Hort. Brit. ed. I. 89,-Afr. austr

anomala, E. Mey. ex Sond. in Harv. \& Sond. Fl. Cap. i. 408.-Afr, austr.

apiculata, E. Mey. ex Sond. 1. c. $405=$ apiculata.

apiculata, E. Mey, in Bartl. \& Wendl. f. Diosm. $17 \hat{0}=$

Barosma apiculata.

aristata, Presl, Bot. Bemerk. 32.-Afr austr.

asperifolia, Eckl. \& Zeyh. Enum. 111.-Afr. austr.

aulonophila, Eck1. \& Zeyh. 1. c. $115=$ commutata virgata.

barbata, Spreng. Pugill. i. $20=$ Macrostylis lanceolata. barosmaefolia, Eckl. \& Zeyh. Enum. 111.-Afr. austr. barosmoides, Sond. in Harv. \& Sond. Fl. Cap. i. 416. -Afr. austr.

Bartingiana, Eck1. \& Zeyh. Enum. 114=A. Cerefolium, serpyllacea.

berzeliaefolia, Eckl. \& Zeyh. 1. c. $115=$ virgata.

bifida, Bartl. \& Wendl. f. Diosm. $152=$ umbellata

biophylla, Eckl. \& Zeyh. Enum. $110=$ hirta.

bisulca, Bartl. \& Wendl. f. Diosm. 129.-Afr. austr.

blaerioides, Cham. in Linnaea, v. (1830) 55.-Afr. austr.

blaerioides, Eckl. \& Zeyh. Enum. 112=chortophila

brevifolia, Loud. Hort. Brit. $86=$ erecta.

bruniades, Loud. 1. c. ; G. Don, Gen. Syst. i. $787=$ cuspidata

capitata, Sond. in Harv. \& Sond. Fl. Cap. i. 434.-Afr. austr.

cephalotes, E. Mey. ex Sond. 1. c. $406=$ globuliflora Cerefolium, Bartl. \& Wendl. f. Diosm. 159.-Afr. austr. chortophila, Eckl. \& Zeyh. Enum. 116.-Afr. austr.

ciliata, Link, Enum. Hort. Berol, i. 238.-Afr, austr

clavata, Hoffmgg. Verz. Pfl. $36=$ obtusa.

collina, Eckl. \& Zeyh. Enum. 110.-Afr. austr.

commutata, Sond. in Harv. E Sond. Fl. Cap. i. 412.... Afr. austr.

concinna, Hoffmgg. Verz. Pfl. 36.-Afr. austr.

cordata, Hoffmgg. 1. $\mathrm{c}_{2}=$ subcordata.

corymbosa, G. Don, Gen. Syst. i. $789=$ villosa

craspedota, E. Mey. ex Sond. in Harv. \& Sond. Fl. Cap. i. 415.-Afr. austr.

crassifolia, Sond. l. c. 438.-Afr. austr.

cuspidata, Bartl. \& Wendl. f. Diosm, 182-Afr, austr. cyminoides, Eckl. \& Zeyh. Enum. 117=chortophila.

decumbens, Eckl. \& Zeyh. l.c. 116.-Afr. austr.

dioica, Sweet, Hort. Brit. ed. I. $89=$ Barosma lanceolata.

Dregeana, Sond. in Harv. \& Sond. Fl. Cap. i. 410.Afr. austr.

Eckloniana, Schlecht. in Linnaea, v. (1830) 207.-Afr austr.

elata, Sond. in Harv. \& Sond. Fl. Cap. i. 438.-Afr. austr.

elegans, Cham. in Linnaea, v. (1830) 54.-Afr. austr. erecta, Bartl. \& Wendl. f. Diosm. 135.-Afr. austr. eriantha, Steud. Nom ed. II i. $35=$ Schlechtendalii

ericoides, Schlecht. in Linnaea, vi. (1831) 206.-Afr. austr

fastigiata, Eckl. E Zeyh. Enum. 117.-Afr. anstr

filipetala, Eckl. \& Zeyh. l. c. 112.-Afr. austr.

florida, Sond. in Harv. \& Sond. Fl. Cap. i. 424.-Afr. austr.

florulenta, Sond. l. c. 437.-Afr. austr.

foetidissima, Hort. ex Steud. Nom. ed. II. i. $35=$ Barosma foetidissima.

foliosa, Sond. in Harv. \& Sond. Fl. Cap. i. 421.-Afr. austr.

fraudulenta, Sond. l. c. 415-Afr, austr.

geminifolia, Eckl. \& Zeyh. Enum. 115.-Afr. austr.

Gillivrayi, Sond. in Harv. \& Sond. Fl. Cap. i. 437,Afr. austr.

glabra, Eckl. \& Zeyh. Enum. $116=$ serpyllacea.

glabrata, Bartl. \& $\mathcal{E}^{2}$ Wendl. f. Diosm. 165. -Afr. austr. glabrata, E. Mey. ex C. Muell. in Walp. Ann. vii. $513=$ crassifolia

glandulosa, Sond. in Harv. E Sond. Fl. Cap. i. 420.Afr. austr.

glauca, Eckl. \& Zeyh. Enum. $112=$ bisulca.

globulifiora, Presl, Bot. Bemerk. 31.-Afr. austr.

gnidioides, Schlecht. in Linnaea, vi. (1831) 206.-Afr. austr. 


\section{AGATHOSMA}

gonaquensis, Eckl. \& Zeyh. Enum. 110.-Afr. austr. gracilicaulis, Sond. in Harv. \& Sond. Fl. Cap. i. 409 -Afr. austr.

graveolens, Meissn. in Flora, xxvii. (1844) I. $302=$ graveolens,

hirta, Bartl. \& Wendl. f. Diosm. 188.-Afr. austr. hirta, [Ker-Gawl.] in Bot. Reg. t. $369=$ villosa. hirtella, Sond. in Harv. \& Sond. Fl. Cap. i. 430.-Afr. austr.

hispida, Bartl. \&o Wendl f. Diosm. 132-Afr. austr

Hookeri, Sond. in Harv. \&o Sond. Fl. Cap. i. 406.-Afr. austr.

humilis, Sond. $l$. $c$-Afr. austr.

hybrida, Bartl. \& Wendl. f. Diosm. $167=$ rugosa. hyponeura, Eckl. \& Zeyh. Enum. 114=serpyllacea. imbricata, Drège, ex Walp. Ann. i. $155=$ polyphylla. imbricata, Willd. Enum. Hort. Berol. 259,-Afr. austr.

involucrata, Eckl. E Zeyh. Enum. 109.-Afr. austr.

Joubertiana, Schlecht. in Linnaea, vi. (1831) $207 .-$ Afr. anstr.

juncea, Hoffmgg. Verz. Pf. $36=$ imbricata.

juniperifolia, Bartl. in Linnaea, xvii. (1843) 376.Afr, austr.

juniperina, Sond. in Harv. \&s Sond. Fl. Cap. i. 433.Afr. austr.

lanceolata, Spreng. ex Bartl. \& Wendl. f. Diosm. 156 $=$ ciliata.

lancifolia, Eckl. \& Zeyh. Enum. 109.-Afr. austr. lasiophylla, G. Don, Gen. Syst. i. $788=$ villosa.

latifolia, Loud. Hort. Brit. $85=$ Barosma serratifolia.

latipetala, Sond. in Harv. E Sond. Fl. Cap. i. 422.Afr. austr.

laxa, Bartl. \& Wendl, f. Diosm. $162=$ villosa.

lediformis, Eckl. E Zeyh. Enum. 109.-Afr. austr.

leptospermoides, Sond. in Harv. \& Sond. Fl. Cap. i. $405=$ aristata

linifolia, Lichtst. ex Roem. \& Schult. Syst. v. 448,Afr. austr.

lycopodioides, Bartl. \& Wendl. f. Diosm. 148.-Afr. austr.

marifolia, Eckl. \& Zeyh. Enum. 113-Afr. austr.

Martiana, Sond. in Harv. \& Sond. Fl. Cap. i. 416.Afr. austr.

inelaleacoides, Sond. l. c. 431.-Afr. austr.

Meyeriana, Presl, Bot. Bemerk. 32,-Afr. austr.

microphylla, E. Mey. in Bartl. \&o Wendl. f. Diosm. 173.

-Afr. austr.

minuta, Schlecht. in Linnaea, vi. (1831) 206.-Afr. austr.

mollis, Bartl. \& Wendl. f. Diosm. 168=rugosa.

mollis, Eckl. \& Zeyh. ex C. Muell. in Walp. Ann. vii. $514=$ florida.

montana, Schlecht. in Linnaea, vi. (1831) 207.-Afr. austr.

monticola, Sond. in Harv. \& Sond. Fl. Cap. i. 409.Afr. austr.

mucronulata, Sond. l. c. 417.-Afr. anstr.

Mundtii, Cham. in Linnaea, v. (1830) 56.-Afr. austr. myrsinites, G. Don, Gen. Syst. i. $789=$ ciliata. nigra, Eckl. \& Zeyh.Enum. 117.-Afr. austr. nigromontana, Eckl. \& Zeyh. l. c. 111.-Afr. anstr. Niveni, Sond. in Harv. \& Sond. Fl. Cap. i. 413.-Afr. austr.

obtusa, Bartl. \& Wendl.f. Diosm. 169=rugosa.

obtusata, G. Don, Gen. Syst. i, 789 =imbricata.

obtusifolia, Presl, Bot. Bemerk. 31.-Afr. austr.

orbicularis, Bartl. \& Wendl. f. Diosm. 175.-Afr. austr.

Owanii, Harv. \& Sond. ex Harv. Thes. Cap. ii. 42.Afr, austr.

parvifora, Bartl. E Wendl. f. Diosm, 181-Afr, austr.

patens, Hort. ex Barth. \& Wendl. f. Diosm. $159=\mathrm{A}$. Cerefolium.

patentissima, Eckl. \& Zeyh. Enum. $114=$ cuspidata.

patula, Eckl. \& Zeyh. 1. c. $116=$ variabilis.

patula, G. F. W. Mey. ex Bartl. E Wendl. f. Diosm.

134.-Afr. anstr.

pentachotom, E. Mey, ex Sond. in Harv. E Sond. Fl. Cap. i. 405.-Afr, austr.

perforata, G. Don, Gen. Syst. i. 789.-Afr. austr.

pilifera, Schlecht. in Linnaea, vi. (1831) 206.-Afr. austr.

planifolia, Sond. in Harv. \& Sond. Fl. Cap. i. 413.-

plinifoustr.

platypetala, Eckl. S Zeyh. Enum. 116.-Afr. austr.

\section{AGATHOSMA :}

polyphylla, Presi, Bot. Bemerk. 32.-Afr. austr. prolifera, Bartl. \& Wendl. f. Diosm. 185.-Afr. austr. prolifera, Eckl. \& Zeyh. Enum. $114=$ bisulca. propinqua, Sond. in Harv. E Sond. Fl. Cap. i. 423.Afr. austr.

pubescens, G. Don, Gen. Syst. i. $788=$ villosa.

pubescens, Sond. in Harv. E' Sond. Fl. Cap. i. 413.Afr. austr.

pubescens, Willd. Enum. Hort. Berol. 259.-Afr. austr.

pubigera, Sond. in Harv. Es Sond. Fl. Cap. i. 414.Afr. austr.

pulchella, Link, Enum. Hort. Berol. i. $238=$ Barosma pulchella.

punctata, G. Don, Gen. Syst. i. $789=$ ovata.

punctata, Sond. in Harv. E Sond. Fl. Cap. i. 417. -Afr, austr.

recurvifolia, Sond. l. c. 415.-Afr. austr.

reflexa, Link, Enum. Hort. Berol. i. 238.-Afr. austr. robusta, Eckl. E Zeyh. Enum. 110.-Afr. austr.

rubra, Willd. E Lichtst.ex Bartl. E Wendl.f. Diosm.

178.-Afr. austr.

rufescens, G. Don, Gen. Syst. i. $789=$ rubra.

rugosa, Link, Enum. Hort. Berol. i. 238=pubescens.

sabulosa, Sond. in Harv. E Sond. Fl. Cap. i. 406.Afr. austr.

salina, Eckl. \& Zeyh. Enum. $111=$ asperifolia.

Schlechtendalii, Sond. in Harv. Es Sond. Fl. Cap. i. 407.-Afr. austr.

Schlechtendahliana, Eckl. \& Zeyh. Enum. 109= Schlechtendalii.

sedifolia, Schlecht. in Linnaea, vi. (1831) 206.-Afr. austr.

serpyllacea, Lichtst. ex Roem. E Schult. Syst. v. 447 -Afr. austr.

serruriaefolia, Eckl, \& Zeyh. Enum. 109= bifida. speciosa, Hoffmgg. Verz. PA. Nachtr. i. $126=$ laxa.

spicata, Lichtst. ex G. Don, Gen. Syst. i. 788.-Afr. austr.

spinosa, Sond. in Harv. E Sond. Fl. Cap. i. 417.Afr. austr.

squamosa, Bartl. E Wendl.f. Diosm. 141.-Afr. austr. stadensis, Eckl. \& Zeyh. Enum, $113=$ microphylla. stenopetala, Steud. Nom. ed. II. i. $36=$ filipetala. suaveolens, Eckl. \& Zeyh. Enum. $113=$ A. Cerefolium subcordata, Hoffmgg. Verz. Pf. $36,163=$ imbricata? tabularis, Sond. in Harv. E Sond. Fl. Cap. i. 403.Afr, austr.

tenuis, Sond. l. c. 423-Afr. austr.

tenuissima, Otto, ex Bartl. \& Wendl. f. Diosm. 137= erecta.

teretifolia, G. Don, Gen. Syst. i. $787=$ Diosma tere tifolia.

Thunbergiana, Bartl. E Wendl.f. Diosm. 150.-Afr. austr.

Thunbergiana, Schlecht. in Linnaea, vi. (1831) $204=$ ambigua.

Thunbergiana, Sond. in Harv. \& Sond. Fl. Cap. 1. 425 $=$ platypetala.

thymifolia, Hoffmgg. Verz. Pfl. $36=$ acuminata.

thymifolia, Schlecht. in Linnaea, vi. (1831) 205.-Afr. anstr.

thuyoides, Sond. in Harv. \& Sond. Fl. Cap. i. $437=$ glabrata.

thyoides, G. Don, Gen. Syst. i. 787 ; Eckl. \& Zeyh. Enum. 116 = glabrata.

trachyphylla, Eck1. \& Zeyh. 1. c. $110=$ hispida.

umbellata, Sond. in Harv. \& Sond. F1. Cap. i. $408=$ bifida.

variabilis, Sond. l. c. 433.-Afr, austr.

Ventenatiana, Bartl. E Wendl.f. Diosm. 161.-Afr. austr.

vestita, Willd. ex Roem. \& Schult. Syst. v. $447=$ imbricata.

villosa, Willd. Enum. Hort. Berol. 259.-Afr. austr. virgata, Bartl. Eo Wendl. f. Diosm. 139.-Afr. austr.

virgata, E. Mey, ex Sond. in Harv. \& Sond. Fl. Cap. i. $412=$ commutata

virgata, Spreng. ex Bartl. \& Wendl. f. Diosm. $145=$ imbricata.

Wendlandiana, G. Don, Gen. Syst. i. $788=$ erecta.

AgAthotes, D. Don, in Phil. Mag. viii. (1836) 77 Swertia, Linn. (Gentian.)

alata, D. Don, ex G. Don, Gen. Syst. iv. $177=$ S. alata.

Chirayta, D. Don, 1. c. $182=\mathrm{S}$. Chirata.

nervosa, G. Dod, 1. c. $177=$ S. nervosa.
AGATHYRSUS, D. Don, in Edinb. N. Phil. Joum (1828-29) $310=$ Lactuca, Linn. et Sonchus, Tourn (Compos.)

alpinus, D. Don, $\mathrm{I}, \mathrm{c}_{\mathrm{n}}=\mathrm{L}$, alpina

cacaliaefolius, D. Don, 1.c. (= Mulgedium cacaliaefolius).

caeruleus, D. Don, 1. c. $=$ L. alpina

cyaneus, D. Don, 1. c. = L hastata.

floridanus, D. Don, 1. $c_{0}=\mathrm{L}$. leucophaea.

leucophaeus, Beck, Bot. $170=\mathrm{L}$. leucophaea.

macrophyllus, Beck, 1. c. = L, macrophylla.

Plumieri, D. Don, in Edinb. N. Phil. Jour

(1828-29) $310=$ L. Plumieri.

prenanthoides, D. Don, l. c. $=$ L. prenanthoides.

pulchellus, D. Don, 1. $\mathrm{c}_{\mathrm{n}}=\mathrm{L}$. pulchella.

sibiricus, D. Don, 1. c $\simeq$ L. sibirica.

spicatus, D. Don, I. c.-Hab.?

tataricus, D. Don, l. c. $=$ L. tatarica.

AGATHYRUS, Rafin. New Fl. Am. iv. 84 (1836)

ENOXIS, Rafin. = Lactuca, Linn. ? (Compos.)

AGATI, Adans. Fam. ii. 326. (1763)=Sesbania, Per (Legum.)

cannabina, Desv. Journ. Bot. i. (1813) $120=$ S. aculeata. coccinea, Desv. 1. c. t. $4=\mathrm{S}$. grandiflora.

formosa, F. Muell. Fragm. ii. $88=$ S. grandiflora.

grandiflora, Desv. Journ. Bot. i. (1813) 120. t. $4=\mathrm{S}$ grandiflora.

tomentosa, Nutt. ex A. Gray, Bot. U. St. Expl. Exped. i. $409=\mathrm{S}$, tomentosa

virgata, Desv. Journ. Bot. i. (1813) $120=$ Coursetia virgata.

AGATION, Brongn. in Bull. Soc. Bot. Fr. viii. (1861 79. VIOLARIEAE, Benth. \& Hook. f. i. 118 Agatea, A. Gray, in Proc. Am. Acad. ii. (1852) 323 (nomen prius)

Pancheri, Brongn. l. c. 80.-N. Caled

Vieillardii, Brongn. l. c.-N. Caled.

violare, Brongn. l. c.-Ins. Fiji.

AGATOPHYTON, Fourn in Ann. Soc Linn. Lyon, N.S. xvii. (1869) $144=$ AGATHOPHYTUM, Moq. $=$ Chenopodium, Linn.

AGAURIA, Benth. \& Hook. f. Gen, ii. 586 (1876) ERICACEAE, Benth. \& Hook. f. ii. 586

Agarista, D. Don, in G. Don, Gen. Syst, iii. 837 (1834) (quoad spp. Africanae)

buxifolia, Baker, Fl. Maurit. 187, in obs.-Ins. Borb.

polyphylla, Baker, in Fourn. Linn. Soc. xx. (1884, 194.-Madag.

salicifolia, Hook. f. ex Oliver, Fl. Trop. Afr. iii. 483.Afr. trop.

AGAVE, Linn. Hort. Ups. 87 (1748) LIDEAE, Benth. \& Hook. f. iii. 738

Allibertia, Marion, in Rev, Hortic Bonch. Rhon (Nov. 1882), ex Baker, in Gard. Chron. (1883 I. 176 .

BonaparteA, Haw. Syn. Succ. 68 (1812)

LITTAEA, Tagliabre, in Bibl. Ital. i. 106 (1816)

MANFREDA, Salisb. Gen. Pl. Fragm. 78 (1866)

albicans, Facobi, in Hamb. Garteng. xai. (1S65) 250. -Mexic.

Alibertii, Baker, in Gard. Chron. N. S. xix. (1859! I. 176.-Mexic.?

aloides, Facobi, in Hamb. Gartens. xxii. (15806) 265.Hab. ?

aloina, C. Koch, Wochenschr. iii. $180^{\circ}, 97=$ Sartorit altissima, Zumag. Fl. Pedem. ï. $50=$ americana americans, Linu. Sp. Pl. 928 - Am, trop.

amoena, Lem. ex Jacobi, in Hamb. Gartenz. xxi. (1sö $120=$ A. Scolymus.

amurensis, Jacobi, 1. c. xx. (1S64) $54 S=x y$ lonacnotha ananassoides, De Jonghe \& Jacobi, Nachtr. i. \$2

Regeliana.

augustifolia, Haw, Syn. Succ, $\bar{i}^{2}=$ rigida.

angustifolia, IIor. Par, ex Steud. Nom. ed. II. i

$\mathrm{B} \mathrm{t}=$ Furcraea tulkeruso.

angustissima, Engelm. in Trans. Acad. SC. St. Lo: iii. $(18 ; 5)$ S $100 .-$ Mexic.

antillarum. 1)escourt. Antill, iv. 28!, t. 2st=sabali fera.

applanata, Lem. ex Gacubi, in Hanb. Gariend. Xr. 180 !) 550 - Mcxic. 


\section{AGAVE:-}

aspera, Jacq. Enum. Vindob. App. $307=$ Furcraea cubensis.

asperrima, Facobi, in Hamb. Gartenz. xx. (1864) 561. -Texas.

atrovirens, Karw. in Salm-Dyck, Hort. (1834) 302.Mexic.

attenuata, Salm-Dyck, l.c.303.-Mexic

auricantha, Hort. ex Baker, in Gard. Chron. (1877) II. $40=$ A. Scolymus.

australis, Steud. Nom. ed. I. $18=$ Furcraea cubensis.

Banlan, Perr. in Mém. Soc. Linn. Par. iii. (1824) 97.Java.

Beaucarnei, Lem. Illnstr. Hortic. xi. (1864) Misc. $65=$ Kerchovei.

Beauleriana, Jacobi, in Abh. Schles. Gesell. (1869) $150=$ mexicana

Bernhardi, Facobi, Nachtr. i. 38.-Mexic.

Besseriana, De Smet, ex Jacobi, in Hamb. Gartenz. xxi. (1865) $155=$ macroacantha.

Bonnetiana, Peacock, ex Baker, in Gard. Chron. (1877) II. $40=$ ferox

Botterij, Baker, in Bot. Mag. t. 6248.-Mexic.

Bouchei, Facobi, in Hamb. Gartenz.xxi. (1865) 217.Mexic.

brachystachys, Cav. Descr. 453.--Mexic.

bracteosa, S. Wats. ex Engelm, in Gard. Chron. (1882) I. 776. f. 139.-Mexic.; Calif.

Brauniana, Facobi, in Hamb. Gartenz. xxii. (1866) 216.-Mexic.

bromeliaefolia, Salm-Dyck, Hort. (1834) 303.-Mexic. bulbifera, Bonpl.ex Steud. Nom. ed. II. i. $34=$ mexicana bulbifera, Salm-Dyck, Hort. (1834) 8, 303.-Mexic.

caerulescens, Salm-Dyck, ex Jacobi, Monog. $38=$ lophantha.

caespitosa, Tod. Hort. Bot. Panorm. (1877) 32. t. $8=$ Sartorii.

californica, Jacobi, Nachtr. $47=$ falcata.

Canartiana, Jacobi, in Abh. Schles. Gesell. (1869) $147=$ atrovirens.

Candelabrum, Tod. Hort. Bot. Panorm. (1877) 66.t $15=$ rigida

Cantula, Roxb. F1. Ind. 11. $167=$ vivipara.

caribaea, Hort. Kew. ex Baker, in Gard. Chron. (1879) II. 683.--Ind. occ

Celsiana, Jacobi, in Hamb. Gartenz. xxi. (1865) 446 $=$ Celsii.

Celsii, Hook. Bot. Mag. t. 4934.-Mexic

chiapensis, Hort. Belg. ex Jacobi, in Hamb. Gartenz. xxii. (1866) $213=$ polyacantha.

chloracantha, Salm-Dyck, in Otto, Allg. Gartenz. (1834) 50--Mexic.

cinerascens, Jacobi, in Hamb. Gartenz. xx. (1864) 553 = applanata.

coarctata, Jacobi, in Abh. Schles. Gesell. (1869) $147=$ atrovirens.

coccinea, Roezl, ex Facobi, in Hamb. Gartenz. xxi. 1865) 61.-Mexic.

cochlearis, Facobi, Nachtr, ii. 67.-Mexic.

Cohniana, Jacobi, in Hamb. Gartenz. xxii. (1866) 321 = yuccaefolia.

Commelini, Salm-Dyck, Hort. (1834) $301=$ Furcraea Commelyni.

concinna, Baker, in Gard. Chron. (1877) II. 137.Mexic.

concinna, Hort. Angl. ex Baker, 1. c. $717=$ albicans.

conduplicata, facobi \& Bond. in Hamb. Gartenz. xxi. (1865) 562.-Mexic.

Consideranti, Carr. in Rev. Hortic. (Nov. 1875) 429. $\mathrm{f}$. $68=\mathrm{A}$. Victoriae-reginae.

Corderoyi, Versch. ex Baker, in Gard. Chron. (1877) II. 398.-Mexic.

crenata, Jacobi, in Hamb. Gartenz. xxii. (1866) $176=$ A. Scolymus

cubensis, Jacq. Amer. $100=$ Furcraea cubensis,

cucullata, Lem. ex Facobi, in Hamb. Gartenz. xxi. (1865) 124.-Mexico.

cuspidata, Hort. Saunders, ex Baker, in Gard. Chron. 1877 ) II. 137 = flaccida.

cyanophylla, Jacobi, in Hamb. Gartenz. xxii. (1866) $175=$ mexicana.

dasylirioides, Facobi \& Bouché, l. c. xxi. (1865) 344.Guatemal.

dealbata, Lem. ex Jacobi, 1. c. $346=$ dasylirioides

Debaryana, Jacobi, in Abh. Schles. Gesell. (1869) 164 = pruinosa.

Decaisneana, facobi, l. c. 153.--Mexic.

deflexispina, Jacobi, Nachtr. ii. $72=$ atrovirens.

\section{AGAVE :-}

Demeesteriana, Hort. ex Jacobi, Monog. 218=miradorensis.

De-Meesteriana, Facobi, in Hamb. Gartenz. xxii. (1866) 167 -Mexic.

densiflora, Hook. Bot. Mag. t. 5006.-Mexic.

densiflora, Regel, Gartenf. (1863) 274. t. $410=$ rupicola dentata, Hort. ex Baker, in Gard. Chron. (1877) II. $748=$ pruinosa

Deserti, Engelm. in Trans. Acad. Sc. St. Louis, iii, 1875) 310.-Calif.

Desmetiana, Hort, ex Baker, in Gard. Chron. (1877) I. $621=$ horrida

Desmettiana, Jacobi, in Hamb. Gartenz. xxii. (1866) $217=$ miradorensis

drimiaefolia, Hort. Petrop. ex Baker, in Gard, Chron. 1877 ) II. $808=$ undulata

Ehrenbergiana, Baker, 1. c. $620=$ Ehrenbergii.

Ehrenbergii, Facobi, in Hamb. Gartenz. xxi. (1865) 255.-Mexic

echinoides, Jacobi, Nachtr. i. $48=$ striata.

Ellemetiana, C. Koch, Wochenschr. viii. (1865) 103.Mexic.

elongata, Jacobi, in Hamb. Gartenz. xxi. (1865) $168=$ rigida.

ensifera, Jacobi, Nachtr. $14=$ univittata.

ensiformis, Hort. ex Baker, in Gard. Chron. (1877) II. $556=$ striata.

excelsa, Facobi, in Hamb. Gartenø. xxii. (1866) 215. Honduras.

expansa, Jacobi, Nachtr. ii. $26=$ americana

falcata, Engelm. in Trans. Acad. Sc. St. Louis, ini. (1875) 304.-Mexic.

Fenzliana, Facobi, in Hamb. Gartenz. xxii. (1866) 170. -Mexic.

ferox, C. Koch, Wochenschr. iii. (1860) 23.-Mexic

filamentosa, Salm-Dyck, in Bonplandia, vii. (1859) 94 = filifera.

filifera, Salm-Dyck, Hort. (1834) 309.-Mexic.

flaccida, Haw. Syn. Succ. $73=$ rubescens,

flaccida, Facobi, in Hamb. Gartenz, xxii. (1866) 174.Mexic.

flavescens, Salm-Dyck, Hort. Dyck. $8=$ macroacantha. flavovirens, Facobi, in Hamb. Gartenz. xxii. (1866) 270 , $\mathrm{Hab}$.

foetida, Linn. Sp. Pl. 323=Furcraea gigantea

fourcroydes, Lem. Illustr. Hortic. xi. (1864) Misc. $65=$ rigida.

fragrantissima, Facq. Enum. Vindob. App. 309.-Hab.? Fuerstenbergii, Jacobi, Nachtr. ii. $72=$ americana.

funifera, Lem. Illustr. Hortic. xi. (1864), Misc. 65, sub

t. $419=$ Yucca funifera.

Funkiana, C. Koch \& Bouché, in C. Koch, Wochenschr.

iii. (1860) $47=$ lophantha.

Galeottei, Baker, in Gard. Chron. (1877) II. 40.Mexic.

geminiflora, Ker-Gazvl. in Brande, Fourn. Sc. iii. (1817) no. 3.t. 1.-Peruv.

Ghiesbrechtii, C. Koch, Wochenschr.v. (1862) 83, 143.-

Mexic.

gigantea, D. Dietr. Syn. Pl. ii. $1192=$ Furcraea gigantea Gilbeyi, Hort. ef. Gard. Chron. (1873) $1305=$ horrida. glabra, Karw. in M. Roem. Syn. Ensat. 292.-Mexic glaucescens, Hook. Bot. Mag. t. $5333=$ attenuata.

glaucescens, Otto, in M. Roem. Syn. Ensat. 292

Mexic.

Goeppertiana, Facobi, in Hamb. Gartenz. xxii. (1866) 219.-Mexic.

gracilis, Jacobi, Nachtr. ii. $66=$ atrovirens

grandidentata, Hort. Belg. ex Jacobi, in Hamb. Gar tenz, xxii. (1866) $114=$ horrida.

granulosa, Scheidrw. in C. Koch, Wochenschr.iv. (1861) 286.-Mexic.

Guedeneyri, Houllet, in Rev. Hortic. (1875) 466. Mexic.

Gustaviana, Hort. Corderoy, ex Baker, in Gard. Chron

N.S. viii. (1877) II. 201=Maximiliana

guttata, Facobi \& Bouché, in Hamb. Gartenz, xxi. (1865) 561.-Mexic

Haseloffii, Facobi, in Hamb. Gartenz. xxii. (1866) 2:20.-Mexic.

Haworthiana, M. Roem. Syn. Ensat. $290=$ mexicana? Haynaldi, Tod. Hort. Bot. Panorm. i. 88. t. 24.Mexic.?

heteracantha, Hort. ex Jacobi, in Hamb. Gartenz. xxii. (1866) $62=$ lophanta.

heteracantha, Zucc. in Nov. Act. Nat. Cur.xvi. (1833) II. 675 -Mexic.
AGAVE:-

hexapetala, Facq. Enum. Pl. Carib. 18.-Ind, occ

Hookeri, C. Koch, Wochenschr. viii. (1865) $104=$ yuc-

caefolia.
Hookeri, Facobi, in Hamb. Gartenz. xxii. (1866) 168.-Mexic.

Hookeri, Baker, in Bot. Mag. t. $6589=$ Fenzliana.

horizontalis, Facobi, in Abh. Schles. Gesell. (1869) 148, bis.-Mexic.

horrida, Lem. ex Facobi, in Hamb. Gartenz. xx. (1864) 546 - Mexic.

Houlletii, Hort. Par. ex Jacobi, 1. c. xxii. (1866) $268=$ rigida.

Humboldtiana, Facobi, l. c. 264.-Mexic.

humilis, M. Roem. Syn. Ensat. $285=$ brachystachys.

hybrida, Versch. Cat. n. $12(1868-69)=x y l o n a c a n t h a$.

Hystrix, Hort. ex Baker, in Gard. Chron. (1877) II $556=$ striata

inaequidens, C. Koch, Wochenschr. iii. (1860) 28.Mexic.

Inghami, Versch. Cat. n. 16 (1871-72), $11=$ Roeziana.

Ixtli, Karw. in Salm-Dyck, Hort. (1834) $304=$ rigida ixtlioides, Hook. f. Bot. Mag. t. $5893=$ rigida.

Facobiana, Salm-Dyck, in Bonplandia, viii. (1860), $88=$ atrovirens

Facquiniana, Schult. f. Syst. vii. $727=1$ lurida.

Karatto, Mill. Gard. Dict. ed. VIII. n. 6.-Mexic.

Karwinskii, Zucc, in Nov. Act, Nat. Cur, xvi, II (1833) $675=$ rigida.

Kellocki, Jacobi, in Abh. Schles. Gesell. (1869) $165=$ pruinosa.

Keratto, Steud. Nom. ed. II. i. $36=$ Karatto.

Keratto, Salm-Dyck, Hort. Dyck. $304=$ mexicana.

Keratto, Salm-Dyck, in Bonplandia, vii. (1859) 93 $=$ Salmdyckii

Kerchovei, Lem. Illustr. Hortic. xi. (1864) 64.-Mexic kewen'sis, Facobi, in Hamb. Gartenz. xxii. (1866) 218 -Mexic.

Kochii, Jacobi, 1. c. $117=$ xylonacantha.

lamprochlora, Jacobi, in Abh. Schles. Gesell. (1869 $150=$ Smithiana

laticincta, Versch. Cat. n. 12 (1868) 2.-Mexic

latifolia, Karw. in M. Roem. Syn. Ensat. 292,-Mexic

latissima, Jacobi, in Hamb. Gartenz. xx. (1864) $551=$ atrovirens.

Laurentiana, Facobi, l. c. xxii, (1866) 266.-Mexic.

laxa, Hort. Monac. ex Salm-Dyck, Hort. (1834) 8.Am. austr.

Lecheguilla, Torr. Bot. Mex. Bound. $213=$ hetera cantha.

Legrelliana, Jacobi, in Hamb. Gartenz. xxii. (1860 ) 266 = Ehrenbergii. ?

Leguayana, Versch. Cat. n. 12 (1868) $2=$ Ghies brechtii.

Lehmanni, Jacobi, in Abh. Schles. Gesell. (1869) $146=$ atrovirens.

Lemairei, Hort. F. Versch. ex Illustr. Hortic. xi. (1864) Misc. 65.-Hab?

lepida, D. Dietr. Syn. ii. $1192=$ lurida

Lindleyi, facobi, in Abh. Schles. Gesell. (1869) 152 bis.-Mexic.

linearis, Jacobi, in C. Koch, \& Fint. Wochenschr. xii. (1869) $179=$ macroacantha.

lophantha, Schiede, in Linnaea, iv. (1829) 582.Mexic.

lurida, Ait. Hort. Kerw. 1. 472--Mexic.

macrantha, Tod. Hort. Bot. Panorm. ii. 11. t. xxvii. -Mexic.?

macroacantha, Zucc, in Nov. Act. Acad. Nat. Cur. xvi. II. (1833) 676.-Mexic

maculata, Regel, Ind. Sem. Hort. Petrop. (1856) 16.Texas.

maculosa, Hook. Bot. Mag. t. $5122=$ maculata.

madagascariensis, Spreng. Syst. ii. $79=$ Furcraea madagascariensis.

Magni, Desf. Tabl. ed. II. $33=$ mexicana

Maigretiana, Jacobi, in Hamb. Gartenz, xxii. (1866) $121=$ horrida

Malinezii, C. Koch, Wochenschr. v. (1862) $198=$ rudis.

Manguai, Desf. Tabl. Hort. Par. ed. II. $33=$ mexicana. marmorata, Roezl, in Belg. Hortic. (1883) 238.Mexic.

Martiana, C. Koch, Wochenschr. iii. (1860) 38.Mexic.

Maximiliana, Hort. Saunders, ex Baker, in Gard. Chron. (1877) II. 201,-Mexic. 
AGAVE :

megalacantha, Hemsl. Diag. Pl. Nov. Mex. 55.Mexic.

melanacantha, Lem. ex Facobi, in Hamb. Gartenz xxi. (1865) 215,-Mexic

Mescal, Ellem. ex.C. Koch, Wochenschr. viii. (1865) $94=$ A. Scolymus

mexicana, Lam. Encyc. i. 52.-Mexic.

micracantha, Salm-Dyck, in Bonplandia, vii. (1859

93.-Mexic.

Milleri, Haw. Syn. Succ. 71 = americana

miradorensis, Facobi, in Abh. Schles. Gesell. (1869) 156.-Mexic.

mitis, Mart. Del. Sem. Hort. Monac. (1848) 4.-Mexic mitraeformis, Jacobi, in Abh. Schles. Gesell. (1859) $145=$ atrovirens

Muilmanni, facobi, l. c. (1870-71) 76.-Mexic.

Newberyi, Engelm. in Trans. Acad. Sc. St. Louis, iii (1875) 309.-Arizona.

Nissoni, Baker, in Gard. Chron. (1877) I. 528.Mexic.

Noacki, Jacobi, in Hamb. Gartenz, xxi, (1865) $221=$ Sartorii.

oblongata, facobi, in Abh. Schles. Gesell. (1869) 155.Mexic.

obscura, Schiede, in Linnaca, xviii. (1844) 413.Mexic.?

odorata, Pers. Syn. i. $380=$ Furcraea cubensis.

Offoyana, De Smet, ex facobi, in Hamb. Gartenz. xxi. (1865) 214.-Havana.

oligophylla, Baker, in Gard. Chron. (1878) 11. 492.Mexic.?

ornata, Jacobi, in Hamb. Gartenz, xxi. (1865) $59=$ americana.

Ottonis, Jacobi, 1. c. xxii. (1866) $320=$ atrovirens.

Ousselghemiana, Jacobi, in Ain. Schles. Gesell. (1869) 156 = albicans.

pallida, Salisb. Prod, $247=$ virginica.

pallida, Sartorius, ex Facobi, in Hamb. Gartenz. xxi. (1865) 171.- Mexic.

Palmeri, Engelm. in Trans. Acad. Sc. St. Louis, iii $1875) 319$ - Arizona.

Parryi, Engelm. l.c.311.-Arizona, Mexic

parviflora, Torr. Bot. Mex. Bound. 214.-Mexic

paucifolia, Tod. Hort. Bot. Panorm. i. (1877) 77.Mexic.

Peacockii, Croucher, in Gard. Chron. (1873) 1400. t. 283.-Mexic.

pendula, Schnitts. in Zeits. Gartenb. Darmst. (1857) Jun. n. $21=$ Sartorii

perbella, Hort. ex Baker, in Gard. Chron. (1877) 527 $528=$ xylonacantha.

perlucida, Jacobi, in Abh. Schles. Gesell. (1869) 151= Smithiana.

picta, Salm-Dyck, in Bonplandia, vii. (1859) $88=$ americana.

polianthoides, M. Roem. Syn. Ensat. 286.-Mexic.

polyacantha, Haw. Rev. Pl. Succ. 35.-Mexic

polyanthoides, Cham. \& Schlecht. in Linnaea, vi. (1831) $55=$ brachystachys.

polyanthoides, Schiede, ex Schlecht. in Linnaea, xviii. (1844) 413.-Mexic.

polyphylla, C. Koch, Wochenschr. iii. (1860) $38=$ mexicana.

Poselgerii, Salm-Dyck, in Bonplandia, vii. (1859) $92=$ heteracantha.

potatorum, Zucc. in Nov. Act. Nat. Cur. xvi. (1833) I1. 675.-Mexic.

pruinosa, Lem. ex Gacobi, in Hamb. Gartens. xxi. (1865) 449.-Mexic.

pubescens, Regel \& Ortg. in Gartenfi. (1874) 227. t. 804.-Mexic

pugioniformis, Zucc. in Nov. Act. Nat. Cur.xvi. (1833) II. 676.-Mexic.

pulcherrima, Hort. ex C. Koch, Wochenschr. viii. (1865) $104=$ Sartorii.

pulcherrima, Otto, in M. Roem. Syn. Ensat. 292.Mexic.

pulchra, Hort. Monac, in Salm-Dyck, Cat. 8,-Am austr.

pulverulenta, Versch.Cat. (1863).-Sierra Nevada.

punctata, Hort. Berol. ex Kunth, Enum. Pl. ii. 837.Mexic.

quadrata, Lem. Illustr. Hortic. xi. (1864) Misc. 65.-

Mexic.

ramosa, Moench, Meth. $642=$ americana.

recurva, Zucc. in Abh. Akad. Muench, iv. I11. (1845) 22 $=$ striata.

\section{AGAVE:}

Regeliana, Hort. ex Baker, in Gard. Chron. N. S. vii 1877) I. $621=$ horrida.

Regeliana, Facobi, in Hamb. Gartenz. xxii. (1866) 214.-Mexic

regia, Hort. Saunders, ex Baker, in Gard. Chron. N. S. viii. (1877), II. 620.-Mexic.

revoluta, Klatzsch, in Otto \& Dietr. Gartenz. viii. (1840) 274--Mexic,

rigida, Mill. Gard. Dict. ed. VIII. n. 8.-Mexic.

rigidissima, Jacobi, in C. Koch \& Fint. Wochenschr. xii. $(\mathbf{1} 869) 179=$ Kerchovei

Roezliana, Baker, in Gard. Chron. N. S. vii. (1877) I. 528. f. 79.-Mexic.

Rohanii, Hort. Belg. ex Jacobi, in Hamb. Gartenz. xx. (1864) $546=$ Ghiesbrechtii.

rubescens, Salm-Dyck, Hort. (1834) 306.-Mexic

rubrocincta, Jacobi, in Abh. Schles. Gesell. (1869) $153=$ Sartorii

rudis, Lem. ex Facobi, in Hamb. Gartenz. xxi. (1865) 216.-Mexic.

rufocincta, Jacobi, Nachtr. i. $88=$ Sartorii.

Rumphii, Hassk. in Hoev. \& De Vriese, Tijdschr. x. (1843) 121 = vivipara

rupicola, Regel, Gartenfl. vii. (1858) 312.-Mexic

Salmdyckii, Baker, in Gard. Chron. N. S. viii. (1877) II. 490.-Mexic.

Salmiana, Otto, in Otto \& Dietr. Allg. Gartenz. (1842) 51 = atrovirens.

Saponaria, Lindl. Bot. Reg. (1838) Misc. $76=$ brachystachys.

Sartorii, C. Koch, Wochenschr. iii. (1860) 37.-Mexic.

Saundersii, Hook. f. Bot. Mag. t. $5493=$ A. Scolymus

scabra, Salm-Dyck, in Bonplandia, vii. (1859) $89=$ Wislizeni.

schidigera, Lem. in Illustr. Hortic. viii. t. 289, verso 1860) ix. t. 330 .-Mexic.

Schlechtendahlii, Jacobi, in Hamb. Gartenz. xx. (1864) $555=$ atrovirens.

Schnittspahnit, Jacobi, 1. c. xxi. (1865) $120=$ A. Scolymus.

Schottii, Engelm. in Trans. Acad. Sc. St. Louis, iii. 1875) 305 - Mexic

Scolymus, Karw. in Salm-Dyck, Hort. (1834) 307.Mexic.

Seemanniana, facobi, in Abh. Schles. Gesell. (1869) 154.-Guatemal.

serrulata, Karw. in Otto \& Dietr. Allg. Gartenz. 1842) 51.-Mexic.

sessilifora, Hemsl. Diag. Pl. Nov. 55.-Mexic.

Shawii, Engelm. in Trans. Acad. Sc. St. Louis, iii (1875) 314. t. 2-4.-Calif.

sisalana, Perrine, ex Engelm. 1. c. (reimpr. 28) = rigida.

Smithiana, Facobi, in Hamb. Gartenঞ. xxii. (1866) 263.-Mexic.

sobolifera, Salm-Dyck, Hort. (1834) 307, 309,-Ind. occ. : Mexico.

spectabilis, Salisb. Prod, $247=$ americana.

spectabilis, Tod. Hort. Bot. Pan. ii. 4. t. 25. Mexic?

spicata, Cav. in Anal. Cienc. Nat. v. (1802) 261 ; Desc. 454.-Cuba.

spicata, DC. Cat. Hort. Morsp. (1813). $74=$ brachy stachys.

spicata, Guss. Ind. Sem. (1825) ex Kunth, Enum. Pl. y. 831 = yuccaefolia.

spinosa, Steud. Nom. ed. II. i. $37=$ Furcraea tuberosa.

splendens, Facobi, in Abh. Schles. Gesell. (1870-71) 63.-Mexic.

stenophylla, Jacobi, in Hamb. Gartenz. xxii. (1866) $269=$ vivipara

striata, Zucc. in Nov. Act. Nat. Cur. xvi. Ir. (1833) 678.-Mexic.

stricta, Salm.Dyck, in Bonplandia, vii. (1859) $94=$ striata.

subfalcata, Jacobi, in C. Koch \& Fint. Wochenschr, xii. (1869) $179=$ macroacantha.

subinermis, M. Roem. Syn. Ensat. 289.-Bras.

sudburyensis, Hort. Peacock, ex Baker, in Gard. Chron. N. S. viii. $(1877)$ II. $187=$ concinna.

Taylori x, Hort. cf. Gard. Chron. N. S. ii. (1874) 60 et visi. (1877) 621. f 125

Taylorea X, Hort. Veitch, in Rev, Hortic. (1877) $36=$ Taylori.

thuacanensis, Karw, ex Otto in Otto \& Dictr. Allg. Gartenz. (1842) $51=$ atrovirens.

\section{AGAVE}

teoxomuliana, Karw. ex M. Roem. Syn. Ensat. $292=$ bromeliaefolia.

Theometel, Zuccagn. in Roem. Collect. 138.-Mexic.

Thomsoniana, facobi, in Hamb. Gartenz, xxii. (1866) 262.-Mexic

Toneliana, Hort. Peacock, ex Baker, in Gard. Chron $\mathrm{xv}$. (1881) I. 362.-Mexic. ?

triangularis, Jacobi, in C. Koch \& Fint. Wochenschr. xii. $(1869) 178=$ horrida

tuberosa, Mill. Gard. Dict. ed. VIII. n. $4=$ Furcraea tuberosa.

uncinata, Jacobi, in Hamb. Gartenz, xxi. (1865) $165=$ polyacantha.

undulata, Klotzsch, in Otto ô Dietr. Allg. Gartenz. viii. (1840) 274.-Mexic.

univittata, Haw. ex Salm-Dyck, Hort. (1834) 308.-Mexic.

utahensis, Engelm. in Bot. King, Exp. 497.- Ltah et Arizona.

Vandervinneni, Lem. Illustr. Hortic. xi. (1861), Misc. 64.-Mexic.

Vanderdonckii, Hort. ex Baker, in Gard. Chron. N. S. vii. (1877) $1.527=$ xylonacantha.

variegata, Hort, ex Steud. Nom. ed. I. $18=$ americana ariegata, Facobi, in Hamb. Gartenz. xxi. (186j 459.-Mexic.

Vera-Crucis, Haw. Syn. Succ. $72=$ seq

Vera-cruz, Mill, Gard. Dict. ed. VIII, n. $7=$ larida.

Verschaffeltii, Lem. ex Facobi, in Hamb. Gartenz, xxi. 1865) 122 .-Mexic.

Victoriae-Reginae, T. Moore, in Gard. Chron. N. S. iv (1875) II. 485.-Mexic.

virginica, Hort. ex Baker, in Gard. Chron. N. S. xix. 1883) I. $176^{\circ}=$ Alibertii

virginica, Linn. Sp. Pl. 323.-Am, bor.

virginica, Mill. Gard. Dict. ed. VIII. n. 2 =americana.

viridissima, Hort. Peacock, ex Baker, in Gard. Chron. N. S. viii. (1877), II. 137.-Mexic.

vivipara, Arruda, Diss. Pl. Bras. $23=$ Furcraea agave phylla.

vivipara, Linn. Sp. Pl. 323.-Mexic

Wallisii, Facobi, Nachtr. ii. 78.-N. Granat.

Warelliana, Hort. cf. Gard. Chron. N. S. v. (1876), I. 603, et Baker, l. c. viii. (1877) 11. 264.-Mexic. wiesenbergensis, Wittm. in Berl. Gartens. (1885, 14.-Mexic.

Wislizeni, Engelm. in Trans. Acad. Sc. St. Louis, iii. (1875) 320 - Mexic

xalapensis, Roezl, ex Jacobi, in Hamb. Gartenz, xxi. (1865) $61=$ polyacantha.

xylacantha, Hort. cf. Gard. Chron. N. S. vii. (1877) $528=x y l o n a c a n t h 2$.

xylonacantha, Salm-Dyck, in Bonplandia, vii. (1859) 92.-Mexico

yuccaefolia, $D C$. in Red. Lil. t. 328, 329.-Mexic.

Yxtli, Karw, ex G. Don, in. Sweet, Hort. Brit. ed. III. $705=$ rigida.

Zuccarinii, Otto, in Allg. Gartens. x. (1842) 51, nomen. -Mexic. ?

AGDESTIS, Moç. \& Sesse, ex DC. Syst. Veg. i. 543 (1818). PHYTOLACCACEAE, Benth. \& Hook. f. iii. 87 .

clematidea, Mof. \& Sesse, l. c.-Mexic.

teterrima, De Not. Ind. Sem. Bot. Genuens, 1855 $29=$ clematidea

AGELAEA, Soland. ex Flanch. in Linnaea, xxii (1850) 43\%. CONNARACEAE, Benth. \& Hook. f. i. 432 .

HemLavdriva, Hook, $f$ in Trans, Linn. Soc xxiii. (1860) 1\%1. t. 28

ferruginea, Soland. ex Planch. 1. c. $\$ 40=$ Cnestis ferruginea.

glabrifolia, Hance, in Gourn. Bot. xiv. (1876) 257.Cambodia.

Koneri, O. Hoffm. \& Hildebr. ex O. Horfm. Serp. Madag. 15.-Madas.

Lamarckii, Planch, in Linnaca, xxiii. (1550) 135.Afr. trop.

nitida, Soland. ex Phouch. l. c. 487.-Afr. trop. obliqua, Baker, in Obieer, F\%. Trop. Afr. i. 134 -Afr. trop.

pentagyna, Baill. in Bull. Soc. Linn. Par. i. ISEg St = Limarckii.

proriens, Soland. ex Planch. in Linnaea, xxiii. (1950) $140=$ C'nestis corniculata. 


\section{AGELAEA :-}

Thouarsiana, Baill. Adansonia, vii. (1866-67) 240,Madag.

vestita, Hook. f. Fl. Brit. Ind. ii. 46.-Malaya.

villosa, Soland. ex Planch. in Linnaea, xxiii. (1850) 438. - Afr. trop.

Wallichii, Hook. f. Fl. Brit. Ind. ii. 47.-Malaya,

AGENIUM, Nees, in Lindl. Introd. Nat. Syst. ed. II. $447(1836)=$ Andropogon, Linn. (Gramin.). nutans, Nees, 1. c. $=$ A. Neesii.

AGENORA, D. Don, in Edinb. New Phil. Journ. (Mar. 1829) $310=$ Hypochoeris, Linn. (Compos.). laevigata, D. Don, 1. c--H. laevigata.

AGERATINA, Spach, Hist. Vég. Phan. x. $286(1841)=$ Fupatorium, Linn. (Compos.) ageratoides, Spach, $1 . c_{.}=\mathrm{E}$. ageratoides. aromatica, Spach, 1. c. $=\mathrm{E}$. aromaticum cordata, Spach, 1. c. =E. aromaticum.

AGERATIOPSIS, Sch. Bip. ex Benth. \& Hook. f. Gen. ii. $246(1873)=$ Eupatorium, Linn. (Compos.). apiculata, Sch. Bip. ex Baker, in Mart. Fl. Bras. vi. II. $362=\mathrm{E}$. a piculatum.

AGERATIUM, 'Adans,' ex Steud. Nom. ed. II. i. 37 1841) = AGERATUM, Tourn。=Exinus, Linn。 (Scrophul.).

AGERATIUM, Reichb. Consp. 209 (1828), err. typ.= ACERATIUM, DC. = Elaeocarpus, Linn. (Tiliac.)

AGERATOIDES, Ponted. ex Linn. Class. Pl. 527 (1747 $=$ Achillea, Linn. (Compos.).

AGERATUM, Linn. Gen. ed. I. 247 (1737). COMPOSITAE, Benth. \& Hook. f. ii. 241.

Caelestina, Cass. Dict. Sc. Nat. vi. Suppl. 8. t. 93 (1817).

Carei.iA, Adans. Fam. ii. 123 (1763)

Coelestina, Cass, in Bull. Soc. Philom. (Jan. 1817) 10 .

DeCACHAETA, Gardn. in Hook. Lond. Journ. Bot. v. (1846) 462.

Oxylobus, Moç. ex DC. Prod. v. 115 (1836)

adscendens, Sch. Bip. ex Benth. \& Hook. f. Gen. ii. 243.-Mexic.

albidum, Hemsl. Biol. Centr. Am. Bot. ii. 81.Mexic.

album, Stend. Nom, ed. I. 18= conyzoides.

alternifolium, Baker, in Mart. Fl. Bras. vi. II. 195.Bras.

altissimum, Linn. Sp. Pl. $839=$ Eupatorium ageratoides.

angustifolium, Spreng. Syst. iii. $446=$ Calea angustifolia.

aquaticum, Roxb. Hort. Beng. 61; et FI. Ind. iii. 416 $=$ Adenostemma viscosum.

arbutifolium, H. B. \& $K$. Nov. Gen. et Sp. iv. 149.Mexic.

brachystephanum, Regel, Gartenft. iii. (1854) 245. t. 108 f. c.-Caraccas.

caeruleum, Hort. ex Poir. Encyc. Suppl. i. $241=$ conyzoides.

campuloclinioides, Baker, in Mart. Fl. Bras. vi. II. 196.-Bras.

ciliare, Linn. Sp. Pl. 839.-Ind, or. ?

ciliare, Lour. Fl. Cochinch. 484.-Cochinch

coelestinum, Sims, Bot. Mag. t. $1730=$ corymbosum coeruleum, Desf. Tabl. ed. I. $98=$ conyzoides. coeruleum, Sieber, ex Baker, in Mart. Fl. Bras. vi. II. $345=$ Eupatorium macrophyllum.

confertum, Baker, l. c. 196-Bras.

conspicuum, Hort. ex C. Koch \& Fint. Wochenschr.

i. (1858) $33=$ Eupatorium glechonophyllum.

conyzoides, Linn. Sp. Pl. 839.-Reg. trop.

conyzoides, Sieber, ex Steud. Nom. ed. II. i. $37=$ Eupatorium repandum.

cordifolium, Roxb. F1. Ind. iii. $415=$ conyzoides.

corymbosum, Benth. \&. Hook. f. Gen. ii. $242=$ Agrian-

thus corymbosus.

corymbosum, Zucc. ex Pers. Syn. ii. 402.-Mexic.

domingense, Spreng. Syst. iii. 446.-S. Doming.

echioides, Hemsl. Biol. Centr. Am. Bot. ii. 81.-

Mexic.

\section{AGERATUM :-}

febrifugum, Sesse, ex DC. Prod. v. 104=Piqueria trinervia.

glanduliferum, Sch. Bip. ex Benth. \& Hook. f. Gen. ii. 242.-Mexic

guianense, Aubl. Pl. Gui. ii. $800=$ Eupatorium macrophyllum.

heterolepis, Baker, in Mart. Fl. Bras. vi. II. 198.Bras.

hirsutum, Poir. Encyc. Suppl. i. $242=$ seq.

hirtum, Lam. Encyc. i. $54=$ conyzoides.

Houstonianum, Mill. Gard. Dict. ed. VIII. n. 2.Mexic.

humile, Salisb. Prod. $\mathbf{1 8 8}=$ conyzoides.

isocarphoides, Hemsl. Biol. Centr. Am. Bot. ii. 82. -Mexic.

Lasseauxii, Carr. in Rev. Hortic. (1870-71) $90=$ Conoclinium Lasseauxii.

latifolium, Cav. Ic. iv. $33=$ conyzoides

latifolium, Hemsl. Biol. Centr. Am. Bot. ii. 82.Guatemal.

lineare, Cav. Ic. iii. 3. t. $205=$ Palafoxia linearis

littorale, A. Gray, in Proc. Am. Acad. xvi. (1881) 78. - Am. bor.

longifolium, Baker, in Mart. Fl. Bras. vi. II. 197.Bras.

maritimum, H. B. \& K. Nov. Gen. et Sp. iv. $150=$ conyzoides

matricarioides, Less. Syn.Comp. 155.C.Cuba

melissaefolium, DC. Prod. v. 109.-Bras

mexicanum, Sims, Bot. Mag. t. $2524=$ conyzoides

mexicanum, Sweet, Brit. Fl. Gard. i. t. $89=$ brachystephanum.

microcarpum, Hemsl. Biol. Centr. Am. Bot. ii. 82.Costa-Rica.

microcephalum, Hemsl.l. c.-Mexic.

micropappum, Baker, in Mart. Fl. Bras. vi. II. 198.Bras.

microphyllum, Sch. Bip. in Seem. Bot. Voy. Herald, 298.-Mexic

muticum, Griseb. Fl. Brit. W. Ind 356.-Tamaic.

nanum, Hort, ex Sch. Bip. in C. Koch \& Fint Wochenschr. i. (1858), Garten-Nachr. 26 = suffruticosum.

obtusifolium, Lam. Encyc, i. $54=$ conyzoides.

odoratum, Vilm, Fl. Pl. Terre, ed. II $42=$ conyzoides.

paleaceum, Hemsl. Biol. Centr. Am. Bot. ii. 83.Mexic.

paniculatum, Hort. ex Stend. Nom. ed. II. i. $37=$ Eupatorium paniculatum.

pedatum, Ortega, Hort. Matr. $38=$ Florestina pedata.

petiolatum, Hemsl. Biol. Centr. Am. Bot. ii. 83.-

Nicarag.

Pohlianum, Baker, in Mart. Fl. Bras. vi. II. 197.Bras.

punctatum, Facq. Hort. Schoenb. iii. 28. t. 300.Mexic.

punctatum, Ortega, Hort. Matr. $37=$ Stevia Eupatoria. purpureum, Vitm. Summa Pl. iv. 474.-Guian.

purpureum, Moç. \& Sesse, ex DC. Prod.v. $122=$ Stevia viscida.

quadriflorum, Blanco, F1. Filip. ed. I. 624=Elephantopus spicatus.

rubens, Viv. Elench. Pl. Hort. Dinegro, 9,-Hab.

salicifolium, Hemsl. Biol. Centr. Am. Bot. ii. 83,Mexic.

scabriusculum, Hemsl. l. c.-Mexic

scorpioideum, Baker, in Mart. Fl. Bras, vi. II. 197.Am. trop.

sessilifolium, Schau. in Linnaea, xix. (1847) 715.Mexic.

strictum, Hemsl. Biol. Centr. Am. Bot. ii. 83.Mexic.

strictum, Sims, Bot. Mag. t. $2410=$ Adenostemma viscosum.

suffruticosum, Regel, Gartenf. iii. (1854) 389. t. 108.Mexic.

tomentosum, Hemsl. Biol. Centr. Am, Bot. ii. 84.Mexic.

viscosum, Ortega, Hort. Matr. 36=Stevia Iucida, salicifolia.

Wendlandii, Hort. ex Vilm. Fl. Pl. Terre, Suppl. 2.Mexic.

Wrightii, Torr. \& Gray, in Proc. Am. Acad. i. (1848) 46. - Texas.

AGERATUM, Tourn. ex Adans, Fam. ii. 210 (1763)= Erinus, Linn. (Scrophul.).
AGERELLA, Fourr, in Ann. Soc. Linn. Lyon, N. S. xvii. (1869) $129=$ Veronica, Linn. (Scrophul.). acinifolia, Fourr. 1. $\mathrm{c}_{\mathrm{e}}=\mathrm{V}$. acinifolia. arvensis, Fourr. 1. $\mathrm{c}_{\circ}=\mathrm{V}$. arvensis. verna, Fourr. 1. c. $=$ V. verna.

AGERIA, Adans. Fam. ii. $166^{\circ}(1763)=$ Ilex, Linn. acuminata, Rafin. Sylva Tellur. $46=\mathrm{I}$. Macoucoua, Cassena, Rafin. 1. c. $47=$ I. Cassine. geminata, Rafin. 1. c. $48=\mathrm{I}$. Cassine. heterophylla, Rafin. 1. c. =I. Dahoon. mucronata, Rafin. 1. c. 47.-Hab.? obovata, Rafin. 1. c. $48=$ I. Dahoon. opaca, Rafin. 1. c. $47=\mathrm{I}$, opaca. ovalis, Rafin. 1. c. $48=\mathrm{I}$. ovalifolia? palustris, Rafin. 1, c. $47=\mathrm{I}$. Dahoon. retusa, Rafin, l, c. $46=\mathrm{I}$, retusa. uniflora, Rafin. 1. c. $47=\mathrm{I}$. uniflora.

AGGERANTHUS, Wight, Ic. v。 18. t. 1737 (1852)= Eria, Lindl. (Orchid.).

marchantioides, Wight, 1, c. $=$ E. reticulata.

AGIALID, Adans. Fam. ii. 508 (1763)= Balanites, Delile (Simarub.).

AGIHALID, Alp. ex Juss. in Dict. Sc. Nat, i. 297 (1804) = praec.

AGINA, Neck. Elem. ii. $153(1790)=$ Sagina, Linn (Caryophyll.).

AGIRTA, Baill. Etud. Gén. Euph. 463 (1858)= Tragia Linn. (Euphorb.)

Boiviniana, Baill. 1. c. = T. Boiviniana.

AGLAEA, Steud. Nom. ed. I. 19 (1821)= Mela sphaerula, Ker-Gawl. (Irid.).

graminea, Steud. 1. c. = M. graminea.

AGLAIA, Allem, in Nov. Act. Nat. Cur. iv. (1770) $93=$ Cyperus, Tourn.?

AGLAIA, Lour. F1. Cochinch. 173 (1790). MELIA CEAE, Benth. \& Hook. f. i. 334, 994.

Amerina, Noronha, in Verh. Batav. Gen. v. (1790) Art. IV. I.

ARGOPHILUM, Blanco, F1. Filip. 186 (1837).

EUPHORA, Griff. Notul. iv. 547 (1854).

Milnea, Roxb. Fl. Ind, ed. Wall. ii. 430 (1824).

Nemedra, Juss. in Mém. Mus. Par. xix. 223 (1830)

Nyalelia, Dennst. Schluess. Hort. Malab. 30 (1818).

Selbya, M. Roem. Syn. Hesper. 89, 126 (1846).

acminatissima, Teijsm. \& Binn. in Nat. Tijdschr. Ned. Ind. xvii. (1864) 42.-Malaya.

ancolana, Miq. F1. Ind. Bat. Suppl. i. 506=argentea.

andamanica, Hiern, in Hook. Fl. Brit. Ind. i. 555.Ins. Andaman.

angustifolia, Miq. Ann. Mus. Bot. Lugd. Bat. iv. 55.Sumatra.

apiocarpa, Hiern, in Hook. Fl. Brit. Ind. i. 555.Zeylan.

argentea, Blume, Bijdr. 170.-Tava.

aspera, Teijsm. E Binn. in Nat. Tijdschr. Ned. Ind. xxvii. (1864) 42.-Java.

basiphylla, A. Gray, Bot. U. St. Expl. Exped. i. 237.Ins. Fiji.

batjanica, Miq. Ann. Mus. Bot. Lugd. Bat. iv. 46.Malaya.

chittagonga, Miq. 1. c. $44=$ Amoora chittagonga

cordata, Hiern, in Hook. f. Fl. Brit. Ind. i. 557.-

Malacca.

coriacea, Korth. ex Miq. Ann. Mus. Bot. Lugd. Bat. iv. 57.-Borneo.

crassinervia, Kurg, ex Hiern, in Hook. f. Fl. Brit. Ind. i. 556.-Tenasserim.

Cumingiana, Turcz in Bull. Soc. Nat. Mosc. xxxi. (1858) I. $409=$ Hearnia Cumingiana.

decandra, Wall. Cat. n. $1276=$ Amoora decandra. denticulata, Turcz. in Bull. Soc. Nat. Mosc. xxxi. (1858) I. 410.-Luzon.

Diepenhorstii, Miq. Fl. Ind. Bat. Suppl. i. 507.Sumatra.

Dookkoo, Griff. Notul.iv. 505 (=Lansium domesticum?). edulis, A. Gray, Bot. U. St. Expl. Exped. i. 237.Ind. or. ; Fiji.

edulis, Hiern, in Hook, F1. Brit. Ind.iii. $556=$ undulata, minutiflora. 
AGIAIA :-

edulis, Seem. Fl. Vit. $37=$ basiphylla.

elaeagnoidea, Benth. Fl. Austral. i, 383.-Austral.

elliptica, Blume, Bijdr. $171=$ Hearnia elliptica.

eximia, Miq. Fl. Ind. Bat. Suppl. i. $506=$ argentea.

Forstenii, Miq. in Ann. Mus. Bot. Lugd. Bat. iv. 46.-Amboina

Ganggo, Miq. Fl. Ind. Bat. Suppl. i. 506.-Sumatra.

glabrata, Teijsm. \& Binn. in Nat. Tijdschr. Ned. Ind

xxvii. (1864) $42=$ Dysoxylum Halmaheirae.

glabriflora, Hiern, in Hook. f. Fl. Brit. Ind. i. 555.-

Malacca.

grandis, Korth. in Miq. Ann. Mus. Bot. Lugd. Bat. iv. 56.-Borneo.

grata, Wall. ex Voigt, Hort. Suburb. Calc. $136=$ Rox burghiana.

Griffithii, Kurz, in fourn. As. Soc. Beng. xliv. (1875) II. 146.-Malacca

Halmaheirae, Miq. Ann. Mus. Bot. Lugd. Bat. iv. $58=$ Dysoxylum Halmaheirae.

hexandra, Turcz. in Bull. Soc. Nat. Mosc. xxxi. (1858) I. 410.-Luzon.

hypolenca, Miq.Fl. Ind. Bat. Suppl. i. 507.-Sumatra inaequalis, Teijsm. \& Binn. in Nat. Tijdschr. Ned. Ind xxvii. (1864) $305=$ Hearnia elliptica.

khasiana, Hiern, in Hook. f. Fl. Brit. Ind. i. 554.Ind. or.

Korthalsii, Miq. Ann. Mus. Bot. Lugd. Bat. iv. 42.Sumatra.

latifolia, Miq. l. C.-Tava.

laxiflora, Mig. l. c. 52.-Borneo.

lepidota, Miq. Fi. Ind. Bat. Suppl. i. $507=$ Roxburghiana

leptantha, Miq. Ann. Mus. Bot. Lugd. Bat.iv. 51.Sumatra.

littoralis, Miq. l. c. 45,-Nov, Guin.

Llanosiana, C. DC. in DC. Monog. Phan. i. 621.-Ins. Philipp.

longifolia, Teijsm. E Binn. in Tijdschr. Ned. Ind. xxvii. (1864) 42.-Java.

macrobotrys, Turcz. in Bull. Soc. Nat. Mosc. xxxi. (1858) I. 409.-Luzon.

macrophylla, Teijsm. \& Binn. in Tijdschr. Ned. Ind. xxvii. (1864) $42=$ Dysoxylum Halmaheirae.

midnaporensis, Carey, ex Voigt, Hort. Suburb. Calc. 136 = Roxburghiana.

minutiflora, Bedd. Pl. Ind. Or. 1. 44.-Ind. or.

mucronulata, C. DC. in DC. Monog.Phan, i.601.-Tava

multijuga, Seem. Fl. Vit. 37.-Ins. Fiji.

odorata, Lour. Cochinch. 173,-China

odoratissima, Benth. in Hook. Lond. Journ. Bot. ii (1845) 218 = elaeagnoidea.

odoratissima, Blume, Bijdr. $171=$ Diepenhorstii

oligantha, C. DC. in DC. Monog. Phan. i, 603.Ins. Philipp.

oligocarpa, Miq. Ann. Mus. Bot. Lugd. Bat. iv. 45.Sumatra.

oligophylla, Miq. Fl.Ind. Bat. Suppl.i. 507.-Sumatra. ovata, Teijsm. \& Binn. in Nat. Tijdschr. Ned. Ind. xxvii. (1864) $43=$ Hearnia elliptica.

pachyphylla, Miq. Ann.Mus. Bot.Lugd. Bat. iv. 57.Sumatra.

palembanica, Miq. Fl. Ind. Bat. Suppl.i.507.-Borneo

Pamattonis, Miq. in Ann. Mus. Bot. Lugd. Bat. iv. 53 - Borneo.

paniculata, Kurs, in fourn. As. Soc. Beng. xliv. (1875)

II 199 - Ind or.

pedicellaris, C. $D C$. in DC. Monog. Phan. i. 607.Ind. or.

pentaphylla, Kurz, in Miq. Ann. Mus. Bot. Lugd. Bat. iv. $48=$ odorata.

perviridis, Hiern, in Hook. Fl. Brit. Ind. i. 556Ind or.

pirifera, Hance, in Fourn. Bot. xv. (1877) 331.-

China.
polyantha, Bedd. Pl. Ind. Or. i. $44=$ minutiflora.

polyphylla, Miq. Ann. Mus. Bot. Lugd. Bat. iv. 56.Java.

polystachya, Wall, in Roxb. FI. Ind, ii. $429=$ Amoora Rohituka.

pycnocarpa, Miq. Fl. Ind. Bat. Suppl. i. 196.-Sumatra. pyramiclata, Hance, in Fourn. Bot. xv. (1877) 381.C'hina.

pyrrholepis, Miq. Ann. Mus.Bot.Lugd. Bat. iv. 47.Java.

Reinwardtii, Miq. l. c. 51.-Celebes.

Roxburghiana, Kurz, in Journ. As. Soc. Beng. xliv (1875) I1. $147=$ undulata.

\section{AGLATA :-}

Roxburghiana, Miq. Ann. Mus. Bot. Lugd. Bat. iv 41.-As. or.

rufa, Miq. l. c. 49.-Sumatra.

samoënsis, A. Gray, Bot. U. St. Expl. Exped. i. 236.Ins. Navigat.

sexipetala, Griff. Notul. iv. $505=$ edulis.

sipamias, Miq. Fl. Ind. Bat. Suppl. i. $506=$ palem banica.

Spanoghei, Blume, ex Miq. l. c. $197=$ Roxburghiana.

speciosa, Blume, Bijdr. 171.-Java.

speciosa, Teijsm. \& Binn. Cat. Hort. Bogor. $211=$ argentea.

spectabilis, Hort. Calc. ex C. DC. in DC. Monog. Phan. i. $585=$ Amoora spectabilis

subgrisea, Miq. Ann. Mus. Bot. Lugd. Bat. iv. 54.Malaya.

submonophylla, Miq. l. c. 40.-Borneo.

Sulingi, Blume, Bijdr. 170.-Java.

Sulingi, Hassk. Cat. Hort. Bogor. 220=Diepenhor stii.

tenuicaulis, Hiern, in Hook. f. Fl. Brit. Ind. i. 556.Malaya.

Teysmanniana, Miq. Ann. Mus. Bot. Lugd. Bat. iv. 48. - Sumatra.

tomentosa, Teijsm. \& Binn. in Tijdschr. Ned. Ind. xxvii. (1864) $43=$ palembanica

trichostemon, C. DC. in DC. Monog. Phan. i. 608,Borneo.

Turczaninowii, C. DC.. . c. 623.--Ins. Philipp.

undulata, Miq. Ann. Mus. Bot. Lugd. Bat. iv. 44.Ind. or.

Wallichii, Hiern, in Hook. f. Fl. Brit. Ind. i. 555.Ind. or.

Zippelii, Miq. Ann. Mus. Bot. Lugd. Bat. iv. 54.Nov. Guin.

AGLAiOpsis, Miq. Ann. Mus. Bot. Ligd. Bat. iv. $58($ 1868-69) = Hearnia, F. Muell. (Meliac.). lancifolia, Miq. 1. c. $59=\mathbf{H}$. lancifolia.

glaucescens, Miq. 1. c. $58=$ H. glaucescens.

AGLAODENDRON, Remy, in Ann. Sc. Nat. Sér. III xii. (1879) $175=$ Plazia, Ruiz \& Pav. (Compos.) cheiranthifolium, Remy, 1. c. $=$ P. cheiranthifolia.

AGLAODORUM, Schott, Gen. Aroid. t. 58 (1858):=

Aglaonema, Schott (Aroid.)

Griffithii, Schott, 1. c.=Aglaonema palustre.

AGLAONEIMA, Schott, Melet. i. 20 (1829). AROIDEAE, Benth. \& Hook, f. iii. 981.

Aglaodorum, Schott, Gen. Aroid. t. 58 (1858) acutispathum, N.E. Br. in Gard. Chron. N. S. xxiv. (1885) II. 39-China.

commutatum, Schott, Syn. Aroid, $123=$ Scindapsus Cuscuaria.

Cuscuaria, Miq. F1. Ind. Bat. iii. $217=$ Scindapsus Cuscuaria.

fallax, Schott, ex Engl. in DC. Monog. ii. $439=$ simplex.

gracile, Schott, in Ann. Mus. Lugd. Bat. i. $279=$ pictum.

Haenkii, Schott, in Bonplandia, vii. (1859) 30.-Ins. Philipp.

Hookerianum, Schott, l. c.-Ind. or.

integrifolium, Schott, Melet.i. 20.-Malaya

longicuspidatum, Schott, Prod. $304=$ Schottianum.

maculatum, Blume, Rumphia, i. 154.-Ins. Philipp.

malaccense, Schott, in Bonplandia, vii. (1859) $30=$ Schottianum

marantifolium, Blume, Rumphia, i. 153.t. 66.-Malaya.

Mannii, Hook.f. Bot. Mag. t. 5760.-Afr, trop.

modestum, Schott, ex Engl. in DC. Monog. Phan. ii. 442.-Malaya.

nitidum, Kunth, Enum. PI. iii. 56 = integrifolium. oblongifolium, Kunth, 1. c. $55=$ marantifolit:m.

palustre, Teijsm. \&o Binn. in Nat. Tijdschr. Ned. Ind. xxv. (1863) 399.-Malaya.

victum, Kunth, Enum. Pl. iii. 55.-Ind, or.; Malaya. princeps, Kunth, 1. c. = simplex.

propinquzem, Schott, in Ann. Mus. Lugd. Bat. i. $280=$ Schottianum.

pygmaeum, Hassk. in Hoev. \& De Vriese, Tijdschr. ix. $(1842) 161=$ Chamaceladon pygmaeum.

Schottianura, Miq. Fl. Ind. Bat. iii. 216.-Malaya.

simplex, Blume, in Rumphia, i. 152. t. 65.-Java.

subundulatum, Zoll. Syst. Vers. Ind. Arclip. 76.Celebes.
AGLITHEIS, Rafin. F1. Tellur. ii. $17(1836)=$ Allium, Linn. (Liliac.)

carinata, Rafin. 1. c. $18=$ All, carinatum.

tatarica, Rafin, 1. c。=All. tataricum.

ursina, Rafin. 1. c. = All, ursinum.

AGLOTOMA, Rafin. Fl. Tellur, ii. 44 (1836) = Aster Linn. Compos.

multiflora, Rafin. 1. c, = Aster multiflorus.

AGLYCIA, Willd. ex Steud. Nom. ed. II. i. $37(1840)=$ Eriochloa, Kunth (Gramin.

coarctata, Willd. ex Steud. 1. c. = E. polystachya

distachya, Willd. ex Stend. 1. c。=E. distachya.

AGNANTHUS, Vaill, ex Linn. Gen. ed. I. 366 (1737)= Cornutia, Linn. (Verben.)

AGNISTUS, G. Don, in Sweet, Hort. Brit. ed. III. 503 (1839) err. typ. = Acnistus, Schott (Solanac.).

AgNOSTUS, A. Cunn. in Loud. Hort. Brit. Suppl. $580(1832)=$ Stenocarpus, R. Br. (Proteac.).

sinuatus, A. Cunn. 1. c. =S. sinuatus.

AGNUS-CASTUS, [Tourn.] Carr. in Rev. Hortic. xlii (1870-71) $415=$ Vitex, Linn. (Verben.

incisa, Carr. 1. c. = V. Negundo,

Negundo, Carr, 1. c. = V. Negundo.

robusta, Carr. I. c, = seg. ?

vulgaris, Carr. 1. c. $414=$ V. Agnus-castus.

AGONANDRA, Miers, in Ann. Nat. Hist. Ser. II. viil. (1851) 172, nomen. OLACINEAE, Benth. \& Hook f. i. 349

brasiliensis, Benth. \& Hook.f. Gen. i. 349.-Bras excelsa, Griseb. in Goett. Abh. xxiv. (1879) 149.-Am. austr.

AGONIS, Lind1. Swan River App. 10 (1839). MYR TACEAE, Benth. \& Hook. f. i. 703.

Billottia, R. Br. in Joum. Soc. Geogt. i. (1832) 19, angustifolia, Schau. in Lehm. Pl. Preiss. i. $118=$ linearifolia.

conspicua, Schan. 1. c. = linearifolia.

flexuosa, Lindl. Swan River App. 10.-Austral.

floribunda, Turcz. in Bull. Soc. Nat. Mosc. xxii. (1849 II. 20.-Austral.

glabra, Turcz. in Bull. Acad. Pétersb. x. (1852) 334 -Austral.

grandiflora, Benth. Fl. Austral. iii. 100.-Austral.

hypericifolia, Schau. in Lehm. Pl. Preiss, i. 117.Austral.

juniperina, Schau. l. c. 118.-Austral.

linearifolia, Lindl. Swan River App. 10.-Austral. marginata, Schau, in Lehm. Pl. Preiss. i. 117.Austral.

obtusissima, F. Muell. Fragm. xi. 119.-Austral.

parviceps, Schau. in Lehm. Pl. Preiss. i. 119.Austral.

Scortechiniana, F. Muell. Fragm. xi. 118.-Austral. spathulata, Schau. in Lehm. Pl. Preiss. i. 119.Austral.

theaeformis, Schau. 1. c. ii. $223=$ hypericifolia.

undulata, Benth. Fl. Austral. iii. 100.-Austral.

AGONOLOBUS, Reichb. Nom, $183(1 \mathrm{~s} 41)=$ Cheir anthus, Linn. (Crucif.).

AGONOMYRTUS, Schan. ex Reichb. Handb. 253 (1\$3= Leptospermum, Forst. ? (Myrtac.)

AGOPHYLLUM, Neck. Elcm, ii. $227(1790)=$ Z 5 go phyllum, Linn.

AGORRHINUM, Fourr, in Ann. Soc. Linn. Lyon, N. S xvii. (1869) 126= Antirrhinum, Toum. Scrophul. Oruntiums, Fourr. 1. $c=$ Ant. Orontium.

AGOSFRIS, Rafin. Fl. Ludov, $55(181 i)=$ Troximon, Nutt. (Compros.).

cruspidata, Steud. Nom. ed. II, i, $3 \overline{7}=$ T. marginatum. glaucus, Stcud. I. c. = T. glaucum. parsifora, D. Dietr. Syn. Pl. iv. 1982 = T. parviflorum, rosca. D Dicle, l, $c_{0}=\mathrm{T}$. roscum. taraxacifolia, D. Diet. I. c. $=$ T. taraxicifolium. 
A GOSTANA, Bute, ex S. F. Gray, Nat. Arr. Brit. Pl. ii. $526(1821)=$ Bupleurum, Tourn. (Umbell.) divaricata, S. F. Gray, 1. c. $527=$ B. Odontites. divaricata, S. F. Gray, 1. c. $527=$ B. Odontites.
tenuissima, Bute, ex S. F. Gray, 1. c. $526=$ B. tenuissimum.

AGRAPHIS, Link, Handb. 1. $166(1829)=$ Scilla, Linn. (Liliac.)

campanulata, Link, 1. c. $=$ S. hispanica

cernua, Reichb. Fl. Germ. Excurs. $105=$ S. cernua.

nutans, Link, Handb. i. $166=\mathrm{S}$. nutans.

patula, Reichb. Fl. Germ. Excurs. $106=\mathrm{S}$. hispanica serotina, Heynh. Nom. ii, $14=$ Dipcadi serotinum.

AGRAULUS, Beauv. Agrost. 5.t. 4 (1812)=Agrostis, Linn. (Gramin.)

alpinus, Beauv. 1. c. = Agrostis rupestris.

anemagrostoides, Trin. in Spreng. N. Entdeck. ii. $56=$ Agrostis effusa.

caninus, Beauv. Agrost. 5. t. 4. f. $7=$ Agrostis canina flavescens, Panz. ex Steud. Nom. ed. I. 19, $340=$ Festuca varia.

mexicanus, Presi, Reliq. Haenk. i. $236=$ Agrostis tolıcensis.

montanus, Panz. ex Steud. Nom, ed. I. 19=Agrostis

pallidus, S. F. Gray, Nat. Arr. Brit. P1. ii. $149=$ Agrostis pallida.

setaceus, S. F. Gray, 1. c. = Agrostis setacea.

AGRETTA, Eckl, Verz. 23 (1827)=Tritonia, Ker-Gawl (Irid.)

crispa, Eckl. 1. c. $24=$ T. undulata.

grandiflora, Eckl. 23, nomen.-Afr. austr.

pallideflavens, Eckl. 1. c. 24.-Afr. austr

pentandra, Eckl. 1. c. $23=\mathrm{T}$. scillaris.

retusa, Stend. Nom. ed. II. i. 37.-Afr. austr.

stricta, Eckl. Verz. 23, nomen.-Afr. austr.

AGRIANTHUS, Mart. ex DC. Prod. v. 125 (1836) COMPOSITAE, Benth. \& Hook. f. ii. 244. campestris, Mart. l. c.-Bras.

corymbosus, $D C$. l. $c$. vii. 266 .- Bras.

empetrifolius, Mart. l.c. v. 126.-Bras

AGRICOLAEA, Schrank, in Denkschr. Akad. Muench. (1808) $98=$ Clerodendron, Linn. (Verben.). fragrans, Schrank, 1. $\mathrm{c}_{\mathrm{v}}=\mathrm{C}$. fragrans.

AGRIMONIA, Toum. ex Linn. Syst. ed. I. (1735). ROSACEAE. Benth. \& Hook. f. i. 622

Amonia, Nestl. Potent. 17 (1816)

ArEMonia, Neck. Elem. ii. 100 (1790).

Spallanzania, Pollini, Hort. Veron. Pl. Nov. 10 (1816).

acutifolia, Dum, FI, Belg. Prod, $97=$ odorata.

adhaerens, Gilib Fl, Lituan, ii. $185=$ A. Eupatorium

adscenden =, Andra. ex Trautv. in Act. Hort. Petrop, viii. (1883) 311, nomen.-Rossia.

agrimonoides, Linn. Sp. Pl. 448.-Europ.

americana, Luca, ex Wallr. Beitr. Bot. i. $43=$ A. Eupatoria.

Blumei, G. Don, Gen. Syst. ii. 563.-Java; Japon.

bracteata, E. Mey. ex C. A. Mey. in Bull. Sc. Acad.

Pétersb. x. (1842) $349=$ A. Eupatoria.

bracteosa, E. Mey. Zwei Pf. Docum. 51, 142, nomen = A. Eupatoria.

caffra, E. Mey. ex C. A. Mey. in Bull. Sc. Acad.

Pétersb. x. (1842) $349=$ A. Eupatoria.

canescens, Dum. Fl. Belg. Prod. $97=$ odorata.

ceylanica, Wight, Ic. t. $224=$ zeylanica.

conopsea, Tschern. ex C. A. Mey. in Bull. Sc. Acad Pétersb. x. (1842) $346=$ pilosa.

dahurica, Willd. ex Stev. ex DC. Prod. ii. 587= pilosa.

davurica, Schlecht. pat. ex Ledeb. Fl. Ross. ii. $32=$ praec.

decumbens, Linn. f. Suppl. $251=$ Acaena latebrosa

elata, Moench, Meth. $674=$ repens.

elata, Salisb. Prod, $361=$ A. Eupatoria.

Eupatoria, Michx. Fl. Am. Bor, i. $287=$ parviflora.

Eupatoria, Linn. Sp. Pl. 448.-Reg. bor. temp.

Eupatorium, Thw. Enum. P1. Zeyl. $102=$ zeylanica.

eupatoroides, Gueldenst. ex Ledeb. F1. Ross. ii. $31=\mathrm{A}$ Eupatoria.

glabrata, Spreng. ex C. A. Mey. in Bull. Sc. Acad.

Pétersb. x. (1842) $346=$ A. Eupatoria

Goctectiana, Andrz. ex C. A. Mey, 1, c.=A. Eupatoria.

\section{AGRIMONIA :}

graeca, Boiss. \& Heldr. ex Boiss. Fl. Orient. ii. $728=$

A. Eupatoria.

grandis, Andrz. ex C. A. Mey, in Bull. Sc. Acad.

Pétersb. x. $(1842) 343=$ A. Eupatoria.

gryposepala, Wallr. Beitr. Bot. i. $49=$ A. Enpatoria.

hirsuta, Bong. ex C. A. Mey. in Bull. Sc. Acad.

Pétersb. x. (1842) 347.-Bras.

humilis, Wallr. Beitr. Bot. i. 37.-Dalmat

incisa, Torr. E Gray, Fl. N. Am. i. 431.-Am. bor.

inermis, Pers. Syn. i1. $9=$ agrimonoides.

javanica, Jungh. Java, i. 664, ex Miq. F1. Ind. Bat. i. 1. $370=$ Blumei.

lanata, Wall. Cat. n. $709=$ A. Eupatoria.

leucantha, Kunze, Del. Sem. Hort. Lips. (1842).-

Hab.?

major, Uspensky, in Bull. Soc. Nat. Mosc. vii. (1834)

$373=$ odorata?

microcarpa, Wallr. Beitr. Bot. i. $39=$ A. Eupatoria.

minor, Mill. Gard. Dict. ed. VIII. n, $2=$ A. Eupatoria.

nepalensis, D. Don, Prod. F1. Nep. $229=$ A. Eupatoria.

octandra, Luce, Topogr. Nachr. Ins. Oesel, 150.-Ins. Ossil.

odorata, Mill. Gard. Dict. ed. VIII. n. 3.-Europ.

officinalis, Lam. Encyc. i. $62=$ A. Eupatoria.

officinarum, Lam. Fl. Fr, iil. $477=$ A. Eupatoria.

parviflora, [Soland. in] Ait. Hort. Kew. ed. I. ii. 130

-Am. austr.

parziflora, Spreng. Syst. 1i. $461=$ A. Eupatoria.

pilosa, Ledeb. Ind. Hort. Dorp. Suppl. (1823) $1=$ A

Eupatoria.

platycarpa, Wallr. Beitr. Bot, i. $38=$ A. Eupatoria.

procera, Wallr. Beitr. Fl. Hercyn. 203; in Linnaea,

xiv. $(1840) 573=$ odorata

pubescens, Wallr. Beitr. Bot. i. $45=$ A. Enpatoria.

pumila, Muhl. ex Rafin. Fl. Ludov. 134, nomen. -Am. bor.

repens, Eckl. \& Zey. Enum. 264=A. Eupatoria. repens, Linn. Syst. ed. X. 1046.-Hispan. ; As. Min.

repens, Mutel, Fl. Fr. i. 342 =odorata

robusta, Andrz. ex Trautv. in Act. Hort. Petrop. viii. (1883) $311=$ odorata?

rostellata, Wallr. Beitr. Bot. i. $42=$ A. Eupatoria.

serrifolia, Wallr. 1. c. $40=$ A. parviflora.

sessiliflora, Dum. F1. Belg. Prod. $97=$ odorata.

sororia, Fisch. E Mey. ex C. A. Mey. in Bull. Sc.

Acad. Pétersb. x. (1842) 344.-Oriens.

stipularis, Dum. F1. Belg. Prod. $97=$ odorata

striata, Michx. Fl. Bor. Am. i. $887=$ A. Eupatoria.

suaveolens, Hort. ex C. A. Mey. in Bull. Sc. Acad.

Pétersb, x. (1842) $344=$ odorata

suaveolens, Blume, Bijdr. $1113=$ Blumei

suaveolens, Pursh, Fl. Am. Sept. i. $336=$ parviflora.

sulcata, Dulac, F1. Hautes-Pyr. 303=A. Eupatoria

viscidula, Bunge, in Mém. Sav. étr. St. Pélersb. ii. 100

Enum. Pl. Chin. Bor, 26) =A. Eupatoria.

mulgaris, S. F. Gray, Nat. Arr. Brit. Pl. ii. $577=$ A.

Eupatoria.

zeylanica, Moon, Cat. $37=$ Alchemella indica.

AGRIODENDRON, Endl. Gen. $144(183 \%)=$ Aloë, Linn. (Liliac.).

AGRIOPHYLLUNI, Bieb. F1. Taur. Cauc. iii. 6 (1819). CHENOPODIACEAE, Benth. \& Hook. f. iii. 58

arenarium, Bieb. l. c.-As. bor.

arenarium, Bungé, in Mém. Sav.étr. Pétersb. vii. (1851) 456 (Lehm. Rel. 280).-As. temp.

gobicum, Bunge, in Bull. Acad. St. Pétersb. xxv. (1879) 355.-Sibir.

lateriflorum, Moq. in DC. Prod. xiii. II. 139.Armen.

latifolium, Fisch. E Mey. in Bull. Soc. Nat. Mosc. (1839) 170.-Oriens.

minus, Fisch. E Mey. l. c.-Turkest.

mongolicum, Hort. Aven. ex Moq. in DC. Prod. xiii II. $\mathbf{1 3 9}=$ arenarium.

pungens, Link, ex A. Dietr. Sp. Pl. i. $124=$ Corispermum pungens.

squarrosum, Moq. in DC. Prod. xiii. II. $139=$ arenarium.

Tournefortii, Fisch. ex Moq. 1. c. = lateriflorum.

AGRIPHYLLUM, Juss. Gen. 190 (1789)=Berkheya,

Ehrh. (Compos.)

asteroides, Desf. Tabl. Hort. Par. ed. I. $109=\mathrm{B}$. fruticosa.
AGRIPHYLLUM :-

ciliare, Desf. Cat. Hort. Par. ed. III. 186=Collumia ciliaris.

echinatum, Desf. Tabl. Hort. Par. ed. I. $109=$ B. cernua grandiflorum, Desf. Cat. Hort. Par. ed. II. $186=\mathrm{B}$. grandiflora.

incanum, Desf. 1. c. = B. fruticosa

spinosum, Desf. ex Steud. Nom. ed. I. 19, $106=$ B. fruticosa.

AGROCHARIS, Hochst. in Flora, xxvii. (1844) I. 19 = Caucalis, Linn. (Umbell.).

gracilis, Hook. f. in Journ. Linn. Soc. vi. (1860) $9=$ C. melanantha.

melanantha, Hochst. in Flora, xxvii. (1844) I. $19=$ C. melanantha.

AGROPHYLLUM, Neck. Elem. ii. $227(1790)=$ Zygo phyllum, Linn.

AGROPYRON, T. Gaert. in Nov. Comm. Petrop. xiv. (1770) I. 539. GRAMINEAE [Benth, \& Hook. f. iii. 12027

Anthosachne, Steud. Syn. Pl. Gram. 237 (1855).

Braconotia, Godr. I. c. ed. I. iii. 191 (1844)

Costia, Willk. in Bot. Zeit. (1858) 377.

Cremopyrum, Schur, Enum. Pl. Transs. 80` (1866).

Crithopyrum, Hort. Prag. ex Steud. Syn. Pl. Gram. 344 (1855)

Elytrigia, Desv. in Nouv. Bull. Soc. Philom. ii. (1810) 190.

EREMopyrum, Jaub, \& Spach, Illustr. Pl. Or, iv. $26(1850-53)$

Haynaldia, Schur, Enum. Pl. Transs. 807 (1866)

Heteranthelium, Hochst. ex Jaub. \& Spach, Illustr. Pl. Or. iv. 24 (1850),

Roegneria, C. Koch, in Linnaea, xxi. (1848) 413.

Secalidium, Schur, in Verh. Siebenb. Ver. Naturw. iv. (1853) 91.

acutum, C. Koch, in Linnaea, xxi. (1848) $424=$ repens.

acutum, Roem. \& Schult. Syst. ii. 751.-Europ. acutum, Reichb. ex Nym. Consp. 841 = pungens. affine, Reichb. Ic. Fl. Germ. xi. $7=$ acutum. alpinum, Schur, Enum. Pl. Transs. 810.-Europ. altissimum, Schur, 1. c. $809=$ repens.

angustifolium, Schult. Mant. ii. 412.-Sibir. apricum, Opiz, in Lotos, iii. (1853) 63.-Europ. aristatum, Bess. Enum. P1. Volh. $41=$ cristatum. attenuatum, Roem. \& Schult. Syst. ii. 751.-Ecuador. Aucheri, Boiss. Diagn. Ser. I. v. 75.-Oriens.

barbatulum, Schur, in Verh. Siebenb. Ver. Naturw, iv. (1853) $21=$ seq.

barbulatum, Schur, Enum. Pl. Transs. 809.-Europ.

bicorne, Roem. \& Schult. Syst. ii. $760=$ Triticum bicorne.

biforum, Roem. \& Schult. t. c-Syria

biforme, Fig. \& De Not. in Mem. Torin. Ser. II. xii. 1852) $260=$ patulum.

Bourgaei, Boiss. Fl. Orient. v. 669.-Armen.

brachyphyllum, Boiss. \& Haussk. ex Boiss. Fl. Orient, v. 663.-Persia.

brevissimum, Beauv. Agrost. 102 (sphalm. pro laevissimo)=Triticum polonicum.

bromiforme, Schur, Enum. P1. Transs, $808=$ repens

bulbosum, Boiss. Diagn. Ser. I. v. 75.-Persia.

caesium, J. \& C. Presl, Delic. Prag. $213=$ repens.

caespitosum, C. Koch, in Linnaea, xxi. (1848) 424.Armen.

Caldesii, Goran. in Nuov. Giorn. Bot. xii. (1880) 145. -Ital.

campestre, Godr. E Gren. Fl. Fr. iii. 607.-Europ

caninum, Beauv. Agrost. 102.-Europ.

capillare, Beauv. 1. c. = repens.

caudatum, Beauv. 1. c. = villosum

collinum, Opiz, Natural. x. (1825) 248 ; Seznam, $12=$ repens.

concinnum, De Not. ex Parl. Fl. Ital. i. $498=$ pungens. condensatum, Presl, Rel. Haenk. i. 266.-Chili.

crinitum, Link, Hort. Berol. 1. 32.-Hab.?

cristatum, F. Gaert. in Nov. Comm. Petrop. xiv, (1770)

I. 540-Iberia; Tauria; Sibir

cristatum, Beauv. Agrost. 102; Roem. E Schult. Syst. ii. 758.-Hab.?

curvifolium, Lange, in Kjoeb. Vidensk. Meddel. (1860) $55=$ scirpeum.

dasyanthum, Ledeb. in Ind.Sem. Dorpat. (1820) 3.Rossia. 
AGROPYRON :-

dasystachyum, Scrib. in Torrey Bot. Club. x. (1883) 78. -Am. bor

densiflorum, Beauv. Agrost. 102.-Sibir.

desertorum, Schult, Mant. ii. $412=$ sibiricum?

distans, C. Koch, in Linnaea, xxi. (1848) $426=$ Bourgaei.

distichum, Beauv. Agrost. 102.-Afr, austr.

divaricatum, Boiss. \& Bal. in Bull. Soc. Bot. Fr. iv. (1857) 307.-Oriens.

divergens, Nees, ex Steud. Syn. Pl.Gram. 347.-Am. bor.

dumetorum, Trautv. in Act. Hort. Petrop. ix. (1884) 322.-Europ.

elatum, Opiz, Seznam, 12 = cristatum

elongatum, Host, ex Beauv. Agrost. $102=$ rigidum.

elymogenes, Aindt, ex Nym. Consp. $840=$ strictum.

farctum, Boiss. Fl. Orient. v. 665 in syn. = junceum

filiforme, Poir. ex Roem. \& Schult. Syst. ii. 760.-Ins. Borbon.

firmum, J. \& C. Presl, Fl. Cech. $28=$ repens.

geminatum, Schult. Mant. iii $655=$ Eleusine indica.

giganteum, Roem. \& Schult. Syst. ii. $753=$ rigidum.

glaucum, Blanco, ex Nym. Consp. $841=$ repens.

glaucum, Roem. \& Schult. Syst. ii. 752.-Europ.

Halleri, Reichb. Fl. Germ. Excurs. $20=$ Festuca Poa.

hirsutum, Hort. Berol. ex Ledeb. F1. Alt. i. $114=$ cristatum.

hispanicum, Presl, Cyp. et Gram. Sic. $49=$ Festuca Poa hordeaceum, Boiss, Diagn. Ser. I xiii. $67=$ orientale. imbricatum, Roem. \& Schult. Syst. ii. 757.-Rossia.

intermedium, Beauv. Agrost. $102=$ glaucum.

intermedium, Reichb. Fl. Germ. Excurs. $140=$ glaucum junceum, et obtusiflorum.

junceum, Beauv. Agrost. 102.-Europ.

Kotschyanum, Boiss. \& Hohenh. Diagn. Ser. I. xiii. 69 $=$ patulum

laevissimum, Beanv, Agrost. $146=$ Triticum polonicum. lasianthum, Boiss. Diagn. Ser. I. xiii. $68=$ orientale.

laxum, 'Fr.' ex Willk. \& Lange, Prod. i. $109=$ acutum.

lazicum, Boiss. Fl. Orient. v, 661.-As. Min

ligusticum, De Not. in Atti Ottav. Riun. Sc. Ital. 602.-Ital.

ligusticum, Savign. in Flora, xxx. (1847) $569=$ Triticum ligusticum.

littorale, Dum. Obs. Gram. Belg. 97.-Europ.

loliiforme, Schur, Enum. P1. Transs. $808=$ repens.

longearistatum, Boiss. Fl. Orient. y, 660.-Oriens.

longiglume, Hack. ex Stapf, in Denkschr. Acad. Wien, 1. (1885) 11.-Europ.

maritimum, Beauv. Agrost. $102=$ Cutandia maritima mucronatum, Opiz, Seznam, $12=$ glaucum. multiflorum, Beauy. Agrost. $102=$ repens.

muricatum, Eichw. Skizze, 119 = cristatum

muricatum, Schult. Mant. ii. 414.-Sibir.

nubigenum, Nees, ex Steud. Syn. Pl. Gram. 342.-Java. obtusiflorum, Roem. \& Schult. Syst. ii. 753 -Batav.

obtusiusculum, Lange, Handb. ed. II. 48.-Dan, ; Scan.

orientale, Roem. \& Schult. Syst.ii. 757.-Oriens; Afr. bor.

panormitanum, Parl. ex Boiss. Voy. 680 ; Pl. Rar. Sic. Fasc. ii. 20,-Europ.; Oriens.

patulum, Trin. Fund. 152.-Aegypt.

pauciflorum, Schur, in Verh. Siebenb. Ver. Naturw.

x. (1859) 77.-Europ.

pectinatum, Beauv. Agrost. 102.-Austral.; N. Zel pectiniforme, Roem. \& Schult. Syst. ii. 758.-Tauria. peruvianum, Rocm. \& Schult. l. c. 761.-Peruy.

pilosum, Presl, Reliq. Haenk. i. 267.-Mexic.

pilosum, Schu, Enum. Pl. Transs. $809=$ barbulatum.

Pousolsii, Godr. \& Gren. Fl. Fr, iii. 608=glaucum.

prostratum, Beanv. Agrost. $102=$ triticeum.

pseudo-caninum, Schur, in Verh. Siebenb. Ver. Naturw.

iv. (1853) 91 = caninum.

pumilum, Beauv. Agrost. 102 = triticeum

pungens, Reichb. ex Nym. Consp. $840=$ acutum.

pungens, Roem. \& Schult. Syst. ii. 753.-Europ.

pycranthum, Gren. \& Godr, Fl. Fr. iii. $606=$ littorale

Kaegnerii, Boiss. Fl. Orient. v. 662.-Reg. Caucas.

repens, Beauv. Agrost. 102.-Reg. temp.

Richardsoni, Schrad. in Linnaca, xii. (1838) 467 in syn.-Am. bor.

rigidum, Beanv. Agrost. 102.-Europ.

Rothii, Opis, in Lotos, iii. (1853) 64.-Europ.

Ronxii, Gren, \& Duval, in Mím. Soc. Emul, Doubs, III. iv. (1860) 391.-Lurop.

rupestre, Schult. Mant, ii, $\$ 09$.-Hab.

Savignonii, De Not. Prosp. Fl. Ligust. 57.-Liguria.

\section{AGROPYRON}

scabrum, Beauv. Agrost. 102.-Austral.

scirpeum, Presl, Gram. Sic. 49.-Sicilia.

Scribneri, Vasey, in Bull. Torrey, Bot. Club, x. (1883)

128.-Am. bor

secundum, Presl, Rel. Haenk, i. 266.-Chili.

semicostatum, Nees, ex Steud. Syn. Pl. Gram. 346.Affghan.

sepium, Beauv. Agrost. $102=$ repens.

sibiricum, Beauv. l. c.-Europ. or. ; As. occ.

squarrosum, Link, Hort. Berol, i. $82=$ patulum.

stipaefolium, Czern. Consp. P1. Charcov. 70, nomen -Rossia.

striatum, Nees, ex Steud. Syn. P1. Gram. $346=$ Triticum striatum.

strictum, Reichb. in Moessl. Handb. ed. II. iii. 1812,Europ.

strigosum, Boiss. Fl. Orient. v. 661.-Oriens,

subulatum, Roem. \& Schult. Syst. ii. 761.-Aleppo.

Tauri, Boiss. \& Bal. in Bull. Soc. Bot. Fy. iv. (1857) 307.-As. Min.

tenerum, Vasey, in Coult. Bot. Gaz. x. (1885) 258.Am. bor.

tenuiculum, Steud. Nom. ed. II, i. $38=$ Festuca Poa.

Tournefortii, De Not. in Atti Ottav. Riun. Sc. Ital. 602.-Oriens.

Tournefortii, Saviga. in Flora, xxx. (1847) $569=$ Aucheri.

triticeum, F. Gaertn. in Nov. Comm. Petrop. xiv. (1770) I. 539.-Europ. ; As. bor.

truncatum, Fuss, Fl. Transs. 749.-Europ.

unilaterale, Beanv. Agrost. $102=$ Festuca tenuiflora

vaginans, Beauv. Agrost. 102.-Am. merid.

Vaillantianum, Trautv. in Act. Hort. Petrop. ix. (1884) 323.-Europ.

variegatum, Roem. \& Schult. Syst. ii. 759,-Hab.

velutinum, Nees, in Hook. Lond. Fourn. Bot. ii. (1843) 417.- Austral.

villosum, Link, Hort. Berol. i. 31.-Europ.; Oriens.

violaceum, Vasey, Gram. Un. St. 45.-Am. bor.

AGROPYRUM, Roem, \& Schult. Syst. ii. 750 (1817) praec

AGROSINAPIS, Fourr. in Ann. Soc. Linn. Lyon, N. S. xvi. (1868) $329=$ Brassica, Tourn. (Crucif.) arvensis, Fourr. 1. $\mathrm{c}_{\circ}=\mathrm{B}$, arvensis.

AGROSTANA, Hill, Veg. Syst. v. $32(\mathbf{1 7 7 2})=\mathbf{B u}$ pleurum, Linn. ('Tmbell.)

AGROSTEMA, Linn. Syst. ed. I. (1735)= seq.

AGROSTEMma, Linn. Gen. ed. I. $135(1737)=$

Lychnis, Linn. (Caryophyll.

apetala, G. Don, Gen. Syst. i. $416=\mathrm{L}$, apetala.

alpina, Forbes, Hort. Woburn. $104=\mathrm{L}$. alpina.

Banksia, Meerb. Fl. Sel. $28=$ L. coronaria.

brachypetala, Sweet, Hort. Brit. ed. I. $44=\mathrm{L}$. apetala.

Bungeana, D. Don, in Sweet, Fl. Gard. Ser. II, 317

$=\mathrm{L}$. Bungeana.

Coeli-rosea, Linn. Sp. Pl. $436=$ L. Coeli-rosa

Coronaria, Linn. 1. c. $=$ L. Coronaria

corsica, G. Don, Gen. Syst. i. $416=\mathrm{L}$. corsica.

declinis, G. Don, $1 . \mathrm{c}=\mathrm{L}$. diclinis

decumbens, Denson, ex Loud. Hort. Brit. Suppl. i. 580

$=\mathrm{L}$. decumbens.

dioica, Dufour, ex G. Don, Gen. Syst. i, $416=\mathrm{L}$, diclinis.

fimbriata, G. Don, 1. c. $417=\mathrm{L}$. indica.

Flos-cuculi, G. Don, 1. c. = L. Flos-cuculi.

Flos-jovis, Linn. Sp. Pl. $436=$ L. Flos-jovis

Flos-jovis, Pollich, Hist. Pl. Palat. i. $443=\mathrm{L}$, coronaria.

fulgens, Doell, Rhein. Fl. $643=\mathrm{L}$. fulgens.

Githago, Linn. Sp. F1. ed. II. $485=$ L. Githago.

Gitthago, Retz. F1. Scand. $86=$ praec.

gracilis, Boiss. Diagn. Ser. II. i. 80 -As. Min.

grandiflora, Doell, Khein. F1. $643=\mathrm{L}$. coronaria

hirsuta, Gilib. Fl. Lituan. ii. $173=\mathrm{L}$. Githago.

hirsuta, Stokes, Bot. Mat. Med. ii. $559=\mathrm{L}$. Githago.

inflata, G. Don, Gen. Syst, i. $417=\mathrm{L}$. inflata.

involucrata, G. Don, 1. c. $416-\mathrm{L}$. apetala.

laet $a, \mathrm{G}$. Don, 1. c. = Silene laeta.

lusitanica, G. Don, 1. c. $417=\mathrm{L}$. Flos-cuculi

nicaeensis, Pers. Syn. i. $519=\mathrm{L}$ 。 Githago

nivalis, G. Don, Gen. Syst, i. $416=\mathrm{L}$. nivalis.

parviflara, Cay, ex Steud. Nom. ed, I. $19=$ Silune laeta.

perennans, Haw. ex Loud. Hort. Brit. Suppl. i. $580=$

L. Densoni.

pulchra, G, Don, Gen. Syst, i. $41 \hat{\imath}=$ Silene laciniata.
AGROSTEMMA :-

pusilla, Desf. ex Steud. Nom. ed.1I. i. $38=$ L. Coeli-rosa pyrenaica, G. Don, Gen. Syst. i. $417=$ L. pyrenaica. saxatilis, G. Don, in Sweet, Hort. Brit, ed. 111.67 = I saxatilis.

sibirica, G. Don, Gen. Syst. i. $416=\mathrm{L}$. sibirica. suecica, Maund, ex Steud. Nom. ed. II. i. $38=$ L. alpina. sylvestris, G. Don, Gen. Syst. i. $416=\mathrm{L}$. dioica. triflora, G. Don, 1. c. $417=\mathrm{L}$. triflora.

variegata, G. Don, 1. c. $416=\mathrm{L}$. variegata.

AGROSTICULA, Raddi, Agrost. Bras. 33.t. 1.f. 2 (1823 =Sporobolus, R. Br. (Gram.

muralis, Raddi, 1. c. $=\mathrm{S}$. minutiflorus.

AGROSTIS, Linn. Syst. ed. I. (1735); Gen. ed.

19 (1737). GRAMINEAE, Benth. \& Hook. $\mathrm{f}$ iri. 11 4s.

Agraulus, Beauv. Agrost. 5. t. 4 (1812)

AVENA, Hall, ex Scop. Introd. 74 (1777).

Decandolia, Bast. Fl. Maine-et-Loire, 28 (1809).

Nosonema, Rafin. Neogenyt. 4 (1825)

Pereilema, Presi, Reliq. Haenk. i. 233 . t. 37 (1830)

Trichodium, Michx. Fl. Bor. Am. i. 41. t. 8 (180:

Vilfa, Adans. Fam. ii. 495 (1763)

abakanensis, Less. ex Trin. in Mém. Acad. Pétersb. Sé

VI. vi. 1. (1845) $325=$ Michauxii.

aberrans, Steud. Syn. Pl. Gram. 422.-Reg. Magcll

actinoclada, F. Muell. Fragm, vi. $84=$ Sporobolu:

actinoclados.

aculeata, Scop. F1. Carn. ed. II. i. $62=$ Crypsis aculeata acutiflora, Steud. Nom. ed. I. $19=$ Deyeuxia acutiflora. adscendens, Lange, in Kjoeb. Vidensk. Meddel (1860 $33=$ verticillata

aemula, R. Br. Prod. $172=$ Deyeuxia Forsteri.

aenea, Spreng. Syst. Cur. Post. $337=$ Sporobolus aenens.

aenea, Trin. in Mém. Acad. Pètersb. Sér. VI. vi. (1845) 332.-Sitcha.

aequata, Nees, in Hook. Lond. Journ. Bot. ii. (1843

$413=$ Deyeuxia aequala

aequivalvis, Trin. in Mèm. Acad. Pétersb. Sér. TJ.

vi. II. (1845) 362.-Am. bor. occ

affinis, Kunth, Enum. PI. i. $228=$ canina.

affinis, Schult. Mant, ii. $195=$ Sporobolus Muchlenbergii.

africana, Poir. Encyc. Suppl. i. $254=$ Sporobolus capensis.

airaeformis, Steud. Syn. Pl. Gram. 172.-Chili.

airoides, Torr. ex Spreng. Syst. Cur. Post. $31=$ Sporo

bolus airoides.

alba, Kunze, in Flora, xxix. (1846) 678= Reuterii.

alba, Linn. Sp. Pl. 63.-Europ.; As.

albicans, Buckl. in Proc. Ac. Sc. Philad. ' 1862 ' (1863.

$91=$ exarata

albicans, Presl, ex Steud. Nom. ed. I. 19._Hab.

albida, Trin. in Mém. Acad. Pétersb. Sér. VI. vi.

(1845) 344.-Sarepta; Rossia.

algida, [Soland. in] Phipps, Voy. $200=$ Phippsia algida.

alopecuroides, Lam. Illustr. 1. $812=$ Polypogon Bu...

peliensis.

alopecuroides, Link, ex Kunth, Enum, Pl. i. $228=$ efiasa,

alopecuroides, Vahl, ex Kunth, Enum. Pl. i. sol=

Panicum Myurus.

alpestris, Laest. ex Nym. Consp. $802=$ rubra.

alpicola, Hoohst. in Flora, xxxvii. (1855) 284.-Afr. or

alpina, Leyss. F1. Halen. $16=$ canina.

alpina, Willd. Sp, Pl i. $368=$ rupestris.

alpina, Savi [Fl. Pisana, i. 81 ?], ex Steud. Nom. cd. I

$19=$ vulgaris.

alpina, Scop. Fl. Cam. ed. II. i. 60.-Europ.

alpina, Stokes, in With. Bot. Arr. Brit. Pl. ed. II.

$71=$ setacea

altissima, Tuckerm. in Am. Fourn. Sc. xlv. (18:j

$44=$ elata

ambigua, Roem. \& Schult. Syst. ii. $85 t=$ albas.

anatolica, C. Koch, in Limsen, xxi. (15ts) $37:$

verticillata.

andina, Phil. in Anales L'nis. Chil, 18:9: 501.-Chili.

Anemagrostis, Syme, Eng. But. ed. III. xi. $48=$ Aperaz

Spica-venti, et intermpta.

anemegrostoide's, Trin. in Spreng, Nene Entdeck, ii. :

=effus?.

a nomala. Willt. Sp. I'l. i. $370=$ elata.

antarctice, Hook. f. Fl. Antoreb. 3it. t. $192-$ Kes.

Antaret.

Antoniana, Griseb, in Gortt. $46 h$, xxiv, 1siv) 2:19-

licg. Argent.
apetala. Buse, ex Trin. in Mem. Acad. Pecersb. Ser. VI.

vi 11. (1St5) $25 i=$ Muchleubergia diffusa. 


\section{A.GROSTIS :-}

aphanes, Trin. in Mém. Acad. Pétersb. Sér. VI. vi. II. (1845) $346-\ldots$ N. Zembl.

aquatica, Buckl. in Proc. Ac. Sc. Philad. '1862.' (1863) 90.-Am. bor.

aquatica, Pourr. in Mém. Acad. Toul. iii. (1788) $306=$ verticillata.

arachnoidea, Poir. Encyc. Suppl. i. $249=$ Cinna arundi nacea.

arachnoides, Ell. Sketch, i. 134.-Am. bor.

arenaria, Gouan, Illustr. $3=$ Sporobolus pungens, arenaria, Schur, in Oestr. Bot. Zeitschr. ix. (1859) $51=$ canina.

arenosa, Schur, Enum. Pl. Transs. $736=$ canina. argentea, Lam. Fl. Fr. iii. $570=$ Stipa Calamagrostis. aristata, Sincl. ex Steud. Nom. ed. II. i. $39=$ alba. aristulata, C. Muell, in Bot. Zeit. xiv. (1856) 349.Ins. Falkland.

articulata, Brot. F1. Lusit.i. $73=$ Chaeturns fasciculatus arundinacea, Linn. Sp. Pl. $61=$ Deyeuxia sylvatica arundinacea, Presl, in Rel. Haenk. i 238-Peruy. arundinacea, Vill. Hist. Pl. Dauph. ii. $79=$ Calam. agrostis varia.

arvensis, Phil. in Linnaea, xxix. (1857-58) 87.-Chili. aspera, Michx. F1. Am. Bor. i. $53=$ Sporobolus asper aspera, Willd. ex Steud. Nom. ed. II. i. $39=$ Muehlen bergia stipoides.

asperifolia, Trin in Mém. Acad. Pétersb. Sér. VI. vi II. (1845) $317=$ exarata.

asperigluma, Steud. Syn. Pl. Gram. 422.-Chili.

asperula, Phil. in Linnaea, xxix. (1857-58) 87.-Chil atropurpurea, Hort. Hafn, ex Steud. Nom. ed. II. i. $39=$ vulgaris.

atrovirens, Roem. \& Schult. Syst. ii. $361=$ Sporobolus atrovirens.

aucklandica, Hook. f. Fl. Antarct. i. $96=$ Deschampsia caespitosa.

australis, Lam. Encyc. i. 57.-Europ.

australis, Linn. Mant. i. $30=$ Gastridinm australe.

avenacea, J. F. Gmel. Syst. i. $171=$ Deyeuxia Forsteri.

avenoides, Hook. $f$ Handb. Nery Zeal. Fl. 330.-N Zel.

barbata, Buckl. in Proc. Acad. Sc. Philad. '1862.' (1863) $334=$ Sporobolus ramulosus.

barbata, Banks \& Soland. ex Hook. f. Fl. Nov. Zel, i. $293=$ Dichelachne crinita

barbata, Pers. Syn. i. $75=$ Sporobolus virginicus.

Bergiana, Trin. Gram. Unift. 203.-Afr. anstr.

berica, Hort. Madr. ex Steud. Nom. ed. II. i. $39(=$ Urachne parviflora).

Berlandieri, 'Fourn. Mex. Pl. En. Gram. 96', ex Hemsl. Biol. Centr. Am. Bot. iii. 550.-Mexic.

bermudiana, Tuss, ex Kunth, Enum. Pl, i, $259=$ Cynodon Dactylon.

Berteriana, Spreng. ex Steud. Nom. ed. II. $39,143=$ Arundinella martinicensis.

Biebersteiniana, Claus, Beitr. Russ. Reich. viii, $264=$ trichoclada.

Billardieri, R. Br. Prod. $171=$ Deyeuxia Billardieri.

biseta, Spreng. ex Steud. Nom. ed. II. i. $39,143=$ Arundinella indica.

Boeckeleri, Seubert, ex Steud. Syn. P1. Gram. 218 (= Gymnopogon distichophyllus)

borbonica, Steud. l. c. 170 -Ins. Borbon.

borealis, Haitm. Skand. F1. ed. IV, $23=$ canina

Bourgaei, 'Fourn. Mex. Pl. En. Gram. 95', ex Hemsl. Biol. Centr. Am. Bot. iii. 550,-Mexic.

brachyathera, Steud. Syn. Pl. Gram. 422.-Reg. Magell.

brachyphylla, Steud. 1. c. $175=$ Polypogon brachyphyllus.

brachyphylla, Willd. ex Steud. Nom. ed. II. i. $39=$ Sporobolus atrovirens.

brachystachys, Schult. Mant. iii. 569.-Sicilia.

brasiliensis, Spreng. Nov. Prov. $45=$ Reimaria acuta.

brevifolia, Nutt. Gen. Am. i. 44.-Am. bor.

breviglumis, F. Muell. Census, 133.-Austral.

brevis, Knapp, Gram. Brit. $116=$ alba?

bromidioides, Griseb. in Goett. Abh. xxiv. (1879) 293 Reg. Argent

bromoides, Linn. Mant. i. $30=$ Stipa Aristella.

bryoides, Dum. Fl. Belg. 152.-Belgium.

byzantina, Boiss, Diagn. Ser. I. xiii. 46.-Byzantium.

caerulescens, Poir. Encyc. Suppl. i. 258 (=Urachne caerulescens).

caerulescens, vide etiam coerulescens, DC.

caespitosa, Gaudich. in Freyc. Voy. Bot. 407 (=Vilfa Gaudichaudii).

\section{AGROSTIS :}

caespitosa, Hoppe, ex Steud. Nom. ed. II. i. $39=$ rupestris.

caespitosa, Presl, Rel. Haenk. i. $237=$ Preslii

caespitosa, Torr. in Ann. Lyc. N. York, i. (1824) $152=$ Torreyi.

caespitosa, Willd. ex Steud. Nom. ed. II. i. $39=$ Muehlenbergia quadridentata.

caespitosa, Salisb. Prod. 25= Deschampsia caespitosa.

Calamagrostis, Georgi, Besch. Russ. Reich. iii. IV.687 = Calamagrostis lanceolata.

Calamagrostis, Linn. Syst. ed. X, $872=$ Stipa Calamagrostis.

Calamagrostis, Suter, F1. Helv. i. $36=$ Calamagrostis epigeios.

calamagrostoides, Regel, Ind. Sem. Hort. Petrop. (1865) $38=$ Calamagrostis agrostoides.

californica, Trin. Agrost. ii. $113=$ exarata

calycina, Willd. ex Steud. Nom. ed. II. i. 39 ; ii. $530=$ Schismus marginatus.

campestris, Phil. in Linnaea, xxix. (1857-58) 87.Chili.

campyla, Tuckerm. in Am. Fourn. Sc. Ser. II. vi 1848) 231.-Am. bor.

canariensis, Parl. in Webb \& Berth. Phyt. Canar. iii. 391.-Ins. Canar.

Candollei, Parl. Fl. Palerm. i. $68=$ alba.

canescens, Griseb. in Goett. Abh.xix. (1874) 253.-Reg. Argent.

canescens, Salisb. Prod. $25=$ Corynephorus canescens.

canina, Linn. Sp. Pl.62.-Amphig.

canina, Ucria, Hort. Reg. Panom. $57=$ pallida.

capensis, Lam. Encyc. 1.58.-Afr. austr.

capensis, Steud, in Flora, xii. (1829) 467=Bergiana.

capensis, Willd. Sp. Pl. i. $372=$ Sporobolus capensis

capillaris, All. Fl. Pedem. ii. $233=$ canina.

capillaris, Huds. F1. Angl. ed. II. $27=$ alba.

capillaris, Boiss. \& Lange, ex Anderss. in Walp. Ann.

vi. $981=$ truncatula.

capillaris, Desf. Fl. Atlant, i. $69=$ Reuterii.

capillaris, Bieb. Fl. Taur. Cauc. i. $55=$ trichoclada.

capillaris, Linn.Sp.Pl.62; Huds.Fl.Angl. 27.-Europ.

capillaris, Pall. Ind. Taur. ex Bieb. Fl. Taur. Cauc i. $55=$ trichoclada

capillaris, Pourr. ex Nym. Consp. $801=$ olivetorum.

capillaris, Thore, Chlor. $26=$ elegans.

capillaris, Vill. Hist. Pl. Dauph. ii. $73=$ vulgaris

cenisia, De Not. ex Parl. Fl. Ital. i. 189=alpina.

Carmichaeli, Roem. E Schult. Mant. iii.571.-Ins Tristan d'Acugn.

caryophyllea, Salisb. Prod. 25= Aira caryophyllea.

castellana, Boiss. Eै Reut. Diagn. Hisp. 26.-Hispan.

Afr. bor.

chamaecalamus, Trin. in Mém. Acad. Pétersb. Sér. VI. vi. I1. (1845) 365.-Peruv.

Chamissonis, Trin. t. c. 374.-Ins. Paschalis

chilensis, Kunze, ex Trin. l.c. 339.-Chili.

Chinantlae, 'Fourn. Mex. Pl. En. Gram. 96' ex Hemst. Biol. Centr. Am. Bot. iii. 550.-Mexic.

chinensis, Koen. ex Steud. Nom. ed. II. i. $39=$ Leptochloa tenerrima.

chonotica, Phil. in Linnaea, xxix. (1857-58) 87.Chili.

ciliaris, Steud. Syn. PI. Gram. 116=Arundinella anomala.

ciliata, Trin. in Mém. Acad. Pétersb. Sér. VI. vi. II 1845) 373.- Ind. or.

ciliata, Pall. ex Ledeb. Fl. Ross. iv. 404 = Pappophorum boreale.

ciliata, Thunb. F1. Jap. $49=$ Festuca Thunbergii.

ciliata, Willd ex Steud. Nom. ed. II. i. $39=$ Muehlen bergia ciliata.

cimicina, Poir. Encyc. Suppl. i. 258=Panicum cimi cinum

Cinna, Lam. ex Roem. \& Schult. Syst. ii. $373=$ Cinna arundinacea.

Cinna, Retz. Obs. Fasc. v. $18=$ Muehlenbergia mexicana.

clandestina, Spreng. Fl. Hal. Mant. $32=$ Sporobolus asper.

clausa, Phil.in Anales Univ. Chit. (1873) 562.-Chili clausa, Steud. Syn. Pl. Gram. 169.-Mesopot.

clavata, Trin. in Spreng. Neue Entdeck. ii. 55.Kamtschat.

coarctata, Ehrh. ex Hoffm. Fl. Germ. ed. II. i. $37=$ alba. coerulescens, DC. Fl. Fr. Suppl. 250=Piptatherum coerulescens.

cognata, Steud. Syn. Pl. Gram. 421.-Reg. Magell.

\section{AGROSTIS :}

colorata, Willd. ex Steud. Nom. ed. II. i. $40=$ Muehlenbergia elegans.

comosa, Poir. Encyc. Suppl. 1. 257 (=Urachne parvi flora).

complanata, Ait. Hort. Kew. i. $96=$ Chloris petraea. composita, Poir Encyc. Suppl. i. 254,-Carolina. compressa, Willd. in Roem. \& Ust. Mag. iv. (1790) XI. $39=$ alba

compressa, Poir. Encyc Suppl. i. 258.-Carolina.

compressa, Doell, in Mart. Fl. Bras. ii. III. 27.-Bras.

compressa, Torr. Cat. Pl. N. York, $91=$ Sporobolus compressus.

concinna, Tuckerm. in Journ. Am. Sc. Ser. II. xlv. 1843) $43=$ canina

condensata, Willd, ex Steud. Nom. ed. II. i. $40=$ verticillata.

conferta, Nees \& Meyen, in Nov. Act. Nat. Cur. xix. Suppl. $312=$ nana

conferta, Willd. ex Steud. Nom. ed. II. i, $40=$ alba,

conspicua, Roem. \& Schult. Syst. ii. $364=$ Arundo conspicua.

contracta, F. Muell. ex Hook. f. F1. Tasm. ii. $116=$ Deyeuxia scabra.

Cornucopiae, Sm. ex Fraser, Monog. 2.-Am. bor. Cornucopiae, Lam. ex Steud. Nom. ed. II. i. $40=$ laxiflora.

coromandeliana, Roxb. Fl. Ind. ed. Wali. i. 318 (= Vilfa Roxburghiana).-Ind. or.

coromandelina, Retz. Obs. Fasc. iv. $19=$ Sporobolus coromandelinus.

corralensis, Phil. in Linnaea, xxxiii. (1864-65) 286.Chili.

cremenica, Bess, ex Steud. Nom. ed. II. i. 39, $40=$ alba. crinita, Moench, Meth. 178= Polypogon monspeliensis. crinita, R. Br. Prod. i. 170.-Austral.

crinita, Rich. ex. Trin. \& Rupr. in Mém. Acad. Pétersb. Sér. VI. vii. (1849) $4=$ Dichelachne Fors teriana.

cruciata, Linn. Pl. Jam. Pugill. ii. 7 ; Syst. ed. X. $873=$ Chloris cruciata.

cryptandra, Torr, in Ann. Lyc. N. York, i. (1824) 151 $=$ Sporobolus cryptandrus

cuspidata, Willd. ex Steud. Nom. ed. II. i, $40=$ Calamagrostis toluccensis.

cylindrica, $R$. Br. Prod, i. 171-Austral.

dalmatica, Trin in Mém. Acad. Pétersb. Sér, VI, vi. II. (1845) 357.-Europ.

debilis, Poir. Encyc. Suppl. i. $249=$ Deyeuxia Forsteri debilis, Spreng. Syst. i. $262=$ Muehlenbergia debilis.

decipiens, R. Br. Prod. i. $172=$ Deyeuxia scabra.

decipiens, Salzm. ex Steud. Syn. Pl. Gram. $101=$ Eriochloa polystachya.

decumbens, Host, Ic. Gram. iv. t. $54=$ alba.

decumbens, Link, Hort. Berol. i. 80.-Mexic.

delicatula, Pourr. ex Kunth, Enum, Pl. i. 219.Lusitan.

delicatula, Steud.in Lechl. Berb. Am. Austr. 56.-Peruv.

Delislei, Hemsl. in Bot. Challeng. i. Ir. 269.-Ins. Amsterdam.

densa, Bieb. Fl. Taur. Cauc. i. $56=$ verticillata.

densa, F. Muell. Census, 133.-Austral

Desvauxii, Phil. in Linnaea, xxxiii. (1864-65) 288.Chili.

diandra, Hornem, in Syll. Ratisb, i. (1824) $193=$ dianthera.

diandra, Retz. Obs. Fasc. v. $19=$ Sporobolus diander dianthera, Schult. Mant. ii. 571.--Ind, or

diaphora, Trin. in Mém. Acad. Pétersb. Sér. VI. vi. II. (1845) $366=$ Deyenxia quadriseta.

difficilis, Hemsl. Bot. Challeng, i. II. 268. t. 43 . -Ins. Amsterdam.

diffusa, Banks \& Soland. ex Hook. f. Fl. New Zeal. i. 298=Deyeuxia Billardieri.

diffusa, Bess. Prim. F1. Galic. 1. $68=$ verticillata.

diffusa, Host, Ic. Gram, iv. t. $55=$ alba.

diffusa, Mulh. Desc. Gram. 64=Muehlenbergia sylvatica.

digitata, Lam. Encyc. i. 59=Paspalum digitatum.

dispar, Hort. Par. ex Steud. Nom. ed. II. i. 40 (= Urachne parviflora).

dispar, Michx. Fl. Am. Bor. i. 52=elata?

distans, Kunze, Del. Sem. Hort. Lips, $(1847)=$ De yeuxia scabra.

disticha, Schweig. ex Steud. Nom. ed. II. I. 39, $40=$ alba.

distichophylla, Phil. Fl. Atac. 54.-Chili.

distichophylla, Roem. \& Schult. Syst.ii. 354.-Austral. 


\section{AGROSTIS :}

divaricata, Griseb. in Goett. Nachr. (1868) 81.-Ind. or divaricata, Hoffm. Fl. Germ. ed. II. i. $37=$ vulgaris. divaricata, Hort. ex Steud. Nom. ed. II. i. $40=$ Chaeturus fasciculatus.

divaricata, Salzm, ex Ball, in Journ. Linn. Soc. xvi. (1878) $713=$ alba

domingensis, Schult. Mant. iii. $570=$ Sporobolus domingensis.

Dregeana, Steud. Syn. Pl. Gram. 173.-Afr. austr.

dubia, DC. Fl, Fr. iii. $21=$ vulgaris.

dubia, Leers, F1. Herborn. $21=$ canina.

dubia, Auct. ex Steud. Nom. ed. II. i. $40=$ Chaeturus fasciculatus.

dulcis, Hort. Par. ex Poir. Encyc. Suppl. i. 250=alba. dulcis, Sibth. ex Kunth, Enum. Pl. i. $218=$ verticillata. dura, Willd. ex Steud. Nom. ed. II. i. $40=$ Sporobolus virginicus?

Duriaei, Boiss. \& Reut. ex Nym. Consp. $802=$ truncatula.

Ecklonis, Trin. in Mém. Acad. Pétersb. Sér. VI. vi

II. (1845) 364.-Afr. austr.

effusa, Lam. Encyc. i. $59=$ Milium effusum

effusa, Spreng. Syst. i. 260.-Europ.

elata, Trin. in Mém. Acad. Pétersb. Sér. VI, vi. II (1845) 317.-Am. bor.

elatior, Steud. Syn. Pl. Gram. 174.-N. Zel

elegans, Salisb. Prod. $25=$ A. Cornucopiae.

elegans, Roem. \& Schult. Syst. ii. $362=$ Humboldtiana

elegans, Thore, ex Loisel. in Fourn. Bot. ii. (1809) 207.

t. 8.-Europ.

Elliotiana, Schult. Mant. ii. $372=$ arachnoides.

elongata, Lam. Illustr. i. $162=$ Sporobolus indicus.

elongata, Roth, Nov. Sp, $41=$ Sporobolus orientalis

eminens, Griseb. in Goett. Abh. xix. (1874) 254.-Reg.

Argent.

erecta, Spreng. Syst. i. $204=$ Muehlenbergia aristata

exarata, Trin. Gram. Unifl. 205 ; Ic, Gram. iii. t. $27 .-$ Am. bor.

exasperata, Trin. in Mém. Acad. Pétersb. Sér. VI. vi.

II. (1845) $352,-$ Chili.

exigna, Thurb, in S. Wats, Bot. Calif ii 275-Calif

exilis, Loisel. in Mém. Soc. Linn. Par. vi. (1827) $399=$ elegans.

expansa, Poir. ex Steud. Nom. ed. II. i. $40=$ Cinna arundinacea.

falklandica, Hook. f. Fl. Antarct. 373.-Ins. Falkland fascicularis, Sincl. Hort. Gram. Wob. $154=$ canina.

fasciculata, Roem. \& Schult. Syst. ii. 362-Ecuador

fertilis, Steud. Syn. Pl. Gram. $170=$ Sporobolus elongatus.

festucoides, Muhl. ex Kunth, Enum. P1. i. $200=$ Muehlenbergia glomerata.

festucoides, Vill. Prosp. $16=$ alpina.

filifolia, Link, in Schrad. Fourn, ii. (1799) 313.-

Lusitan.

filiformis, Koen. ex Kunth, Enum. Pl, i. 261=Cynodon elongatus. filiformis, Spreng. Fl. Hal. Mant. $32=$ Deyeuxia

filiformis, Vill. Hist, Pl. Dauph. ii. $78=$ alpina

filiformis, Willd. Enum. Hort. Berol. $95=$ Muehlenbergia mexicana.

flabellata, Salsm. ex Steud. Syn. Pl. Gram. 53= Setaria sulcata

fava, O. F. Muell. F1. Dan. t. $751=$ alba.

favescens, Host, Ic. Gram. iv, $52=$ alpina

Ravida, Schur, in Oestr. Bot.Zeitschr. ix.(1859) $48=$ alba

flavidula, Steud. Syn. Pl. Gram.421.-Reg. Magellan.

foliata, Hook. f. Fl. Antarct. 95.-N. Granat.

foliosa, Hort. ex Kunth, Enum. Pl. 1. $207=$ Muehlen

bergia mexicana.

foliosa, Vasey, in Bull. Torrey Bot. Club, x. (1883) 63.-Am. bor.

Fonckii, Phil. in Linnaea, xxxiii. (1864-65) 286.-Chili. Forsteri, Rich. ex Rocm. \& Schult. Syst, ii. $359=$ Deyeuxia Forsteri.

frigida, F. Muell. ex Benth. Fl. Austral. vii. $583=$ Deyeuxia frigida.

frondosa, Guss. Fl. Sic. Prod. i. 58.-Sicilin

frondosa, Poir. Encyc. Suppl. i. $252=$ Muchlenbergia mexicana.

frondosa, 'Tenore, ex Spreng. Pugill. ii, $5=$ vulgaris.

fulva, Griseb. in Goett. Abh. xxiv. (1879) 294-Reg. Argent.

gnditans, $N y m$. Syll. 408,-Lusitan.

gallecica, Hort. ex Steud. Nom. ed. I. 20 ; ed. II. i. 40 = Airopsis agrostiden.

\section{AGROSTIS :}

Gayana, E. Desv. in C. Gay, Fl. Chil. vi. 313.-Chili. gelida, F. Muell, in Trans. Vict. Inst. (1855) $43=$ Muelleri.

gelida, Trin. in Mém. Acad. Pétersb. Sér. VI. vi. II. (1845) 343.-Peruv.

geminata, Trin. Gram. Unift. 207.-Unalasch.

geniculata, Lam. Fl. Fr. iii. $572=$ canina.

Ghiesbreghti,, 'Fourn. Mex. Pl. En. Gram. 97,' ex Hemsl. Biol. Centr. Am. iii, 551.-Mexic.

gigantea, Roth, Tent. F1. Germ. i, $31=$ alba.

glabra, Kunth, Enum. Pl. 1. 226.-Chili.

glabra, Presl, ex Trin. in Mém. Acad. Pétersb. Sér. VI. vi. II. $(1845) 342=$ stricta.

glabrata, Spreng. Syst. i. $262=$ Muehlenbergia glabrata.

glauca, Muhl. Desc. Gram. $76=$ Deyeuxia Nuttaliana

glauca, Steud. Syn. Pl. Gram. 175.-Mexic.

glaucescens, Opiz, ex Steud. Nom. ed. II. i. 40 parvula.

glaucescens, Spreng. Syst. i. $258=$ sicula.

glaucina, Bast. F1. Maine-et-Loire, Suppl. $25=$ vulgaris.

globosa, Poir. Encyc. Suppl. i. 257=Milium globosum. glomerata, Kunth, Enum. Pl. i. 219.-Peruy.

glutinosa, Fisch, ex Kunth, 1. c. $138=$ Melinis minutiflora.

gracilis, Kit. ex Schult. F1. Austr. ed. II. i. 180; et in Linnaea, xxxii. (1863) $306=$ alba

racilis, Willd. ex Stend. Nom, ed. II. i. $40=$ Muehlenbergia gracilis.

gracilis, Salisb. Prod. $25=$ Koeleria cristata.

graeca, Sibth. Fl. Graec. t. 66 (=Urachne parviflora) grandis, Trin. in Mém. Acad. Pétersb. Sér. VI. vi II. $(1845) 316=$ exarata.

groenlandica, Steud. Syn. Pl. Gram. 175.-Groenland.

Gunniana, F. Muell. Census, 133.-Austral.

gynostyla, Steud. Syn. Pl. Gram. 170.-Afr. austr.

Hegetschweileri x, Bruegg. in Fahresb. Naturf. Ges. Graub. II. xxv. (1882) 60.-Europ.

Helenae, Steud. Syn. Pl. Gram. 171.-Ins. S. Helena

herbacea, Steud. 1. c. $224=$ Aira paradoxa.

Hillebrandii, Thurb. ex Boland. in Trans. Calif. Agr. Soc. (1864) $136=$ aequivalvis.

hirsuta, Linn. f. Suppl. 108.-Teneriff

hirtella, Hochst. ex Steud. Syn. Pl. Gram. 173. Abyssin.

hispanica, Boiss. \& Reut. Pugill. $120=$ castellana.

hispida, Brot ex Nym. Consp. $802=$ truncatula.

hispida, Willd. Sp. Pl. i. $370=$ vulgaris

holciformis, Bieb. F1. Taur. Cauc. i. $54=$ Oryzopsis holciformis.

Hornungiana, Schur, in Oestr. Bot. Zeitschr. ix. (1859) $46=$ vulgaris

Humboldtiana, Steud. Nom. ed. II. i. 40.-Quito

humifusa, Roem, \& Schult. Syst. ii. $361=$ Sporobolus humifusus.

humilis, Vasey, in Bull. Torr. Club, x. (1883) 21.Am. bor.

hybrida, Gaud. Agrost. i. $66=$ canina.

hygrometrica, Nees, in Mart. F1. Bras. ii. 404 (=Bro* midium hy grometricum).

hyperborea, Laest. ex Nym. Consp. $802=$ rubra.

implicata, Spreng. Syst. 1. $262=$ Muehlenbergia implicata.

inaequiglumis, Griseb. in Goett. Nachr. (1868) 80.Ind. or.

inconspicua, Kunze, ex C. Gay, Fl. Chil. vi. 315.Chili.

incurvata, Scop. Fl. Carn. ed. II. i. $62=$ Lepturus incurvatus.

indica, Forsk. Fl. Aegypt. Arab. 104. n. $66=$ Sporobolus coromandelinus.

indica, Linn. Sp. Pl. $63=$ Sporobolus indicus.

infirma, Buese, in Mig. Pl. Fungh. 342,-Java.

insignita, Schur, Enum. Fl. Transs. $792=$ alba.

intermedia, Balb. Elench. $85=$ vulgaris

interrupta, Linn. Syst. ed. x. $872=$ Apera interrupta.

intricata, Nees, in Hook. Lond. Journ. Bot. ii. (18t3

$413=$ scabra.

involuta, Muhl. Desc. Gram. 72 = Sporobolus asper.

involuta, Poir. Encyc. Suppl. 1. 252.-Marocc.

jamaicensis, Poir. 1. c. $258=$ Digitaria filiformis.

Jamesoniana, Steud. Syn. Pl. Gram. $16^{\circ} 3=$ Am. merid.

japonica, Steud. l. c. 171.-Japon.

javanica, Burm, ex Kunth, Enum. Pl. i. 512 Ischae. mum muticum.

juncea, Lam. Encyc, i, $60=$ Sporobolus tremulus.

juncea, Michx, H1. Am. Bor, i. 52 = Sporobolus junceus.

\section{AGROSTIS :}

unciformis, Willd. ex Steud. Nom. ed. II, i. $41=$ Deyeuxia junciformis.

Juressi, Link, in Schrad. Fourn. ii. (1799) 312.Lusitan.; Hispan.

Kitaibeli, Schult. Fl. Austr, ed. II. i. $178=$ alba

koelerioides, E. Desv. in C. Gay, Fl. Chil. t. vi. 317.Chili.

Labillardieri, Roem. \& Schult. Syst. ii. $360=$ Deyeuria Billardieri.

lachnantha, Nees, in Ind. Sem. Hort. Bot. Vratish. (1834).-Afr. austr.

Laersii, J. F. Gmel. Syst, ii. $169=$ canina.

lanata, H. B. \& K. Nov. Gen. et Sp. 1. $136=$ Epicampes lanata.

lanceolata, Roem. \& Schult. Syst. ii. $364=$ Calamagrostis lanceolata.

Langei, Nym. Consp. $801=$ vulgaris

lanigera, Desv. Opusc. 61.-Bras.

lasiantha, Phil. in Linnaea, xxix. (1857-58) 87.Chili.

lateriflora, Michx. FI. Bor. Am. i. $53=$ Muehlenbergia mexicana.

latifolia, Trevir. in Goeppert, Beschr. Bot. Gaert, in Breslau, 82 = Cinna arundinacea.

laxa, S. F. Gray, Nat. Arr. Brit. Pl. ii. $147=$ vulgaris. laxa, Schreb. ex Pursh, F1. Am. Sept. 1, $61=$ scabra. laxiflora, Poir. Encyc. Suppl. i. 255.-Am. bor. laxiflora, Richards. Frankl. Voy. App, $3=$ scabra. lazica, Balansa, in Bull. Soc. Bot. Fr, xxi. (1874) 12 -Orjens.

Lechleri, Steud. Syn. Pl. Gram. 422.-Chili.

Leersii, J. F. Gmel. Syst. $1495=$ canina.

lendigera, Poir. Encycl. Suppl. i. $259=$ Gastridium australe.

lenta, Ait. Hort. Kew. i. $96=$ Panicum filiforme.

leptos, Steud. Syn. Pl. Gram, 169.-Louisiana.

leptostachys, Hook. f. Fl. Antarct. 94.-Reg. Antarct,

leptotricha, E. Desv. in C. Gay, Fl. Chil. vi. 316.Chili.

Lessoniana, Steud. Nom. ed. II. i. $41=$ Arundo conspicua.

ligulata, Steud. Syn. Pl. Gram. 173.-Austral.

limonias, Phil. in Linnaea, xxxiii. (1864-65) 287. Chili.

limosa, Schur, in Verh. Siebenb. Ver. Naturv. i (1853) 82 ; et Oestr. Bot. Zeitschr. ix. (1859) $48=$ alba.

Lindeniana, Steud. Syn. Pl. Gram. 171-Colombia.

linearis, Retz. Obs. Fasc. iv. $19=$ Cynodon Dactylon.

lithuanica, Bess. ex Roem. \& Schult Mant. 568, in add. $=$ vulgaris.

litigans, Steud. Syn. Pl. Gram.162.-Lusitan.

littoralis, Lam. Illustr. $161=$ Sporobolus virginicus.

littoralis, With. Arr. Brit. Pl ed. III ii. 129 . $23-$

Polypogon littoralis.

lobata, R. Br. Prod. i. 171= Deyeuxia quadriseta

longiaristata, Herb. Ross. ex Kuntb, Enum. i. 178 Stipa splendens.

longiflora, Willd. ex Steud. Nom. ed. II. 1. $41=$ Cinna arundinacea.

longifolia, Torr. ex A. Gray, Man. Bot. N.U.St.

ed. I. $575=$ Sporobolus asper.

longiseta, Hort. ex Steud. Nom. ed. I. 21, $645=$ Chaeturus fasciculatus.

lusitanica, Stend. Syn. Pl. Gram, 169= castellana.

lutescens, Banks \& Soland. ex Hook, f. Fl. N. Zel. i. $299=$ Arundo conspicua.

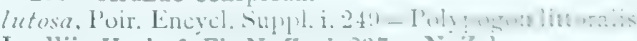
Lyallii, Hook. f. Fl. N. Zeal. 297.-N. Zel magellanica, Lam. Illusir. i. 160.-Reg. Magellan. malaccensis, Willd. ex Kuntb. Einum. Pl. i. $113=$ Isachne pulchella

maritima, Lam. Encyce, i. 61: Jlhustr, i. 101 =alba

maritima, With. Arr. Brit. Pl. ed. III. ii. 182 = Elymus arenarius?

Matrella, Linn. Mant. ii. $185=$ Zovsia pungens.

maxima, Koxb. Fl. Ind, i. 319 = Thysanulaena Agro. stis.

media Carneich, in Trans. Linr. Sec xii. 1810 504. -Ins. Trist. da Cunha.

melanosperma, Lam. Lincyc. i. 5s T"racisme Limenaze melalereca. Trin, in Mem. Acal. St. I'cersb. ii. 1s32 $170=$ nenen.

Mertensii. Trin. in linnarea, \& is35) $3(02-$ - Chili: Linalaschk.

mexicana, Nionth. Ensm. Pl. i. 223.-Mevic

mexicana, Lind. Mrat. $\$ 1=$ Muchlenbergia racxicana 


\section{AGROSTIS :-}

mexicana, Pers. Syn. i. $76=$ Deyeuxia canadensis Meyeni, Trin. in Mém. Acad. Pétersb. Sér. VI. vi. II. (1845) 312-Chili.

Michaelis, Steud. Syn. Pl. Gram. 171.-Ins. Azor.

Michauxii, Trin. Gram. Unifl. $206=$ scabra.

Michauxii, Zuccagn. in Roem. Collect. $123=$ Chaeturus fasciculatus.

micrantha, Steud. Syn. Pl. Gram. 170.-Nepal. microcarpa, Hort. ex Steud, Nom, ed. II, i. 164; ii $4 \mathbf{1}=$ Muehlenbergia debilis

microphylla, Steud. Syn. Pl. Gram. 164=exarata. microsperma, Lag. Elench. $2=$ Muehlenbergia debilis miliacea, Linn. Sp. P1. 61=Piptatherum miliaceum.

Milium-comosum, Poir. Encyc. Suppl. 1. $257=$ Pipta therum miliaceum.

minima, Linn. Sp. P1. $63=$ Mibora verna

minima, Lour. Fl. Cochinch. 50.-Cochinch

minor, F. Muell. ex Benth. Fl. Austral. vii. $582=$ Deyeuxia minor.

minutiflora, Desf. ex Steud. Nom. ed. II. i. $41=$ Sporo bolus minutiflorus

minutiflora, Steud. Syn. Pl. Gram, 170 (=Vilfa indica).

minutissima, Steud. 1. c. $171=$ Sporobolus raminulosus. monandra, Hornem. Hort. Hafn. i. $72(=$ Urachne parviflora).

monostachya, Poir. Encyc. Suppl. i. 256=Panicum amplexicaule.

montana, Krock. F1. Siles. i. $110=$ alpina

montana, R. Br. Prod. i. $171=$ Deyeuxia montana

montevidensis, Spreng. ex Nees, Agrost. Bras. $403=$ Montevid.

monticola, Roem. \& Schult. Syst. ii. 359=Deyeuxia montana.

Montis-aurei, Delarbre, F1. Auverg. 8, ex Poir. Encyc. Suppl. 1. $246=$ Piptatherum multiflorum.

mucronata, Presl, Rel. Haenk. i. 238.-Am. bor. occ mucronata, Spreng. Syst. i. $262=$ Muehlenbergia mucronata.

Muelleri, Benth. Fl. Austral. vii. 576.-Austral

Muelleri, Presl, Bot. Bemerk. $120=$ verticillata.

multicaulis, Hook. f. Fl. Antarct. 95-Ins. Campbell.

multicaulis, Kit. in Linnaea, xxxii. (1863) $306=$ alba.

Munroana, Aitch. \& Hemsl. Journ. Linn. Soc. xix. 1881) $192=$ Calamagrostis Munroana. muricata, Kunth, Enum. Pl. i. 219.-Peruy. muscosa, T. Kirk, im Trans. N. Z. Inst. xiii. (1881) 385.-N. Zel.

Mustaphae, Steud. Syn. Pl. Gram. 169.-Afr. bor. mutabilis, Knapp, Gram. Brit. $28=$ alba. mutabilis, Sibth. Fl. Oxon, $36=$ setacea.

Myuros, Lam. ex Beauv. Agrost. $49=$ Panicum Myurus. nana, Delarbre, Fl. Auverg. ed. II. $664=$ pumila. nana, Kunth, Enum. Pl. i. 266.-Peruv.

nardifolia, Griseb. in Goett. Abh. xix. (1874) 252.Reg. Argent.

nebulosa, Boiss, \& Reut. Diagn, 26-Hispan.

nebulosa, Bourg. ex Reut. \& Lange, in Bull. Soc. Bot. Fr. xi. (1864) 47 = delicatula

Neesii, Trin. in Mém. Acad. Pétersb. Sér. VI. vi. II. (1845) 361.-Afr, austr.

neglecta, Schult. Fl. Austr. ed. II. i. $179=$ alba.

nemoralis, Phil. in Linnaea, xxx, (1859-60) 205Chili.

neogaea, Steud. Syn. Pl. Gram. 171.-N. Zembl.

nerrosa, Nees, ex Trin. in Mém. Acad. Pétersb. Sér. VI. vi. II. (1845) 328.-Ind, or

nevadensis, Boiss. Elench. 87.--Hispan.

nigra, With. Arr. Brit. Pl, ed. III. ii. 131=vulgaris.

nigrescens, Salzm. ex Steud. Nom. ed. II. i. 41 . Bigrescens

nigricans, Poir. Encyc. Suppl. i. $259=$ Milium nigricans. nitens, Guss. Fl. Sic. Prod. i. $50=$ Triplachne nitens. nivalis, F. Muell. in Trans. Vict. Inst. (1.855) $43=$ Deyenxia nivalis.

nivea, Sincl. Hort. Gram. Woburn, $152=$ alba?

nobilis, De Not. ex Parl. F1. Ital. i. $\mathbf{1 8 6}=$ canina. nootkaensis, Trin. in Mém. Acad. Pétersb. Sér. VI. vi. II. $(1845) 326=$ nutkaensis.

Nowae-Hollandiae, Beauv. Agrost. $148=$ Deyeuxia Forsteri.

noveboracensis, Spreng. Syst. i. $260=$ Epicampes lanata. nutans, Poir. Encyc. Supp1. i. $255=$ Ichnanthus pallens. nutans, Spreng. Syst. i. $263=$ Muehlenbergia gracilis. nutkaensis, Kunth, Enum. Pl. i. 222. -Am, bor. occ. obliqua, Auct. ex Trin. Gram. Unif. $196=$ alba.

\section{AGROSTIS :-}

obliqua, Kit. in Linnaea, xxxii. (1863) 306.-Austria obtusata, Auct ex Steud. Nom. ed. II. i. $41=$ Eatonia obtusala.

odorata, Lour. Cochinch, 64.-Cochinch.

oligantha, Roem. \& Schult. Syst. ii. $372=$ panciflora olivetorum, Gren. E Godr. Fl. Fr. iii. 483.-Gallia. oreophila, Trin. in Mém. Acad. Pétersb. Sér. VI. vi II. (1845) 323.-Am. bor.

orientalis, Nees, Agrost. Bras. $393=$ Sporobolus tenacissimus.

oseroensis, Seenus, Reise Istr. (1805) 50 ( = Urachne parviflora)

ovata, Forst. f. Prod. $8=$ Echinopogon ovatus.

owarensis, Roem. \& Schult. Syst. ii. Mant. $199=$ Sporo-

bolus pyramidalis.

pallens, Trin. in Mém. Acad. Pétersb. Sér. VI. vi. II. (1845) 328.-Am. bor

pallida, DC. Fl. Fr. Suppl. 251.-Enrop.

pallida, Schk. Handb. 3; Nachtr. $1=$ canina.

pallida, With. Arr. Brit. Pl. ed. III. ii. 128, t. $22=$

palustris, Huds. Fl. Angl. $27=$ alba

panicea, Lam. Encyc. i. 58; Iilustr. $811=$ Gastridum australe.

panicea, Ait. Hort. Kew. i. $94=$ Polypogon mons peliensis.

panicoides, Lam. Allustr. $162=$ Panicum Lamarckii. paniculata, Hort. Madrit. ex Steud. Nom. ed. II. i. 41 $=$ Muehlenbergiae sp. sec. Trin.

papposa, Gilib. Exercit. ii. $524=$ Stipa Calamagrostis paradisiaca, Steud. Syn. Pl. Gram, $163=$ chilensis paradoxa, Linn. Sp. P1. 62 (=Urachne Linnaei).

paradoxa, R. Br. in Ross, Voy. ed. II. ii, $192=$ Colpodium latifolium.

parviflora, R. Br. Prod. $170=$ scabra

parvula, Schuit. F1. Austr. ed. II. i. $182=$ Sporobolus minutus

patagonica, Phil. in Linnaea, xxix. (1857-58) 87.Patagon.

patens, Trin. in. Mém. Acad. Pétersb. Sér. VI. vi II. (1845) 322,-Chili.

patula, Gaud. Agrost. Helv. i, $80=$ alba

panciflora, Pursh, Fl. Am. Sept. i. 63.-Am. bor.

pauciflora, Schrad. HI. Germ. $3=$ alba.

paucinodis, Hack. in Engl. Bot. Fahrb. vi. (1885) 242 -Reg. Magell.

perennans, Tuckerm. in Am. Fourn. Sc. Ser. II. xly. (1843) 44.-Am. bor.

pernambucensis, Spreng. Syst. i. 258=Panicum rivulare.

peruviana, Spreng. 1. c. $262=$ Muehlenbergia Clomena phleoides, E. Desw. in C. Gay, Fl. Chil. vi. 320.Chili.

phleoides, Willd. ex Steud, Nom. ed. II. i. $41=$ Calam agrostis coarctata.

Pickeringii, Tuckerm. in Am. Fourn. Sc. Ser. II, xlv. (1843) 42.-Am. bor.

pilosa, Schleich. ex Gaud. Agrost. Helv. i. $75=$ Calamagrostis tenella.

pilosa, Less. in Rich. Voy. Astrol. 134. t. 23.-N. Zel. pilosa, Retz. Obs. Fasc. vi, $22=$ Cynodon pilosus. pilosula, Trin. in Mém Acad. Pétersb. Sér. VI. vi II. (1845) 372.-Ind. or

pisidica, Boiss, in Ann. Sc. Nat. Sér. IV ii. (1854) 255 $=$ trichoclada

planifolia, C. Koch, in Linnaea, xxi. (1848) 380.Armen.

plebeia, R. Br. Prod. i. $172=$ Deyeuxia plebeia.

plicata, Lour. Fl. Cochinch. 64.-China.

plumosa, Tenore, Prod. i. $59=$ Panicum Teneriffae

poaeformis, Willd. ex Steud. Nom. ed. II. i. $42=$ Poa subunitlora

polymorpha, Huds. F1. Angl. ed. II. i, $31=$ alba, vulgaris.

Polypogon, Salzm. ex Steud. Syn. Pl. Gram. 178= Muehlenbergia brasiliensis.

polystachya, Bosc, ex Steud. Nom. ed. II. i. $42=$ composita.

Pourretii, Spreng. Syst. i. $260=$ Avena Pourreti.

Pourretii, Willd. in Ges. Naturf. Fr. Berl. Mag. ii.

(1808) $290=$ effusa

praecox, Salisb. Prod. $24=$ Aira praecox

Preslii, Kunth, Enum.Pl. i. 225.-Peruv.

procera, A. Rich. Voy. Astrol. $125=$ Arundo conspicua.

procera, Retz. Obs. iv. 19.-Malabar.

procumbens, Roem. \& Schult. Syst. ii. $371=$ alba.

\section{AGROSTIS :}

prorepens, G. Mey. Korresp. B1. Naturf. Ver. Riga, xxvi. 56 (quid?).-Rossia.

prostrata, Hook, f. Fl. Antarct. 373.-Ins, Falkland. pseudo-arundinacea, Schleich. ex Gaud. Agrost. Hely. i. $92=$ Calamagrostis varia.

pubens, Willd. ex Steud. Nom. ed. II. i. $42=$ Epicampes lanata.

pubescens, S. F. Gray, Nat. Arr. Brit. Pl. ii. 148= alba.

pubescens, H.B. \& K. Nov. Gen. et Sp. i. $136=$ Epicampes pubescens.

pulchella, Guss. Fl. Sic. Prod. i. 58.-Sicilia.

pulchella, Kunth, Gram. i. $70=$ Humboldtiana.

pulchella, Loisel. ex Trin. Gram. Unif. $205=$ elegans. pulchella, Roth, ex Roem. \& Schult. Syst ii. 367= Sporobolus pulchellus.

pumila, Linn. Mant. $31=$ vulgaris

pumila, Steud. Syn. Pl. Gram. 171.-Ins. Adscens. punctata, Lam. Encyc. 1. 58. n. $17=$ Eriochloa poly stachya.

pungens, Muhl Desc. Gram. $72=$ Zoysia pungens

pungens, Pall. 'Ind. Taur.' ex Georgi, Beschr. iii. IV $688=$ Aeluropus litoralis.

pungens, Schreb. Graes. ii. $46=$ Sporobolus pungens.

pungens, Pursh, Fl. Am. Sept. $64=$ Sporobolus virginicus.

purpurascens, Bert. ex Steud. Nom. ed. II. i. 42.-S. Doming.

purpurascens, Sw. Prod. Veg. Ind. Occ. $25=$ Sporobolus purpurascens.

purpurea, Gaud. Agrost. Helv. i. 70=Apera Spicaventi.

pusilla, Dum. Obs. Gram. Belg. 129=canina.

pyramidalis, Rich. ex Steud. Syn. Pl. Gram. 153 (=Vilfa Richardi).-Ind. occ

pyramidata, Lam. Illustr. i. 161 = Sporobolus affinis, pyrenaea, Timb. in Mém. Acad, Toul. Sér. IV. vi (1856) $97=$ alpina.

pyyenaica, Pourr. 1. c. iii. (1788) $306=$ rupestris

quadridentata, Spreng. Syst. i. 263=Muehlenbergia quadridentata.

quadrifida, Labill. Pl. Nov. Holl. i. 20=Pentapogon Billardieri.

quadriseta, R. Br. Prod. i. $171=$ Deyeuxia quadriseta.

quitensis, Spreng. Syst. 1. $262=$ Muehlenbergia elegans. quitensis, Willd. ex Steud. Nom. ed. II. i. $42=$ Muehlenbergia calamagrostidea.

racemosa, Michx. H1. Bor. Am. i. $53=$ Muehlenbergia glomerata.

radiata, Linn. Pl. Jam. Pugill. 7 ; Syst. ed. X. $873=$ Chloris radiata.

ramosa, Poir. Encyc, Suppl. 1. $257=$ Eriochloa annulata. ramosa, Roem. \& Schult. Syst. ii. $364=$ Calamagrostis lanceolata.

ramulosa, Carm, in Trans, Linn. Soc. xii. (1818) $504=$ Carmichaeli.

ramulosa, Roem. \& Schult. Syst. ii. $361=$ Sporobolus ramulosus.

rara, R. Br. Prod. i. $171=$ Dichelachne sciurea

rata, Nees, ex Trin. in Mém. Acad. Pétersb. Sér. VI

vii. (1849) $3=$ Dichelachne sciurea.

Ravennae, Beauv. Agrost. $148=$ Erianthus Ravennae.

refracta, Moench, Meth. Suppl. $60=$ verticillata.

Reinwardtii, Miq. Fl. Ind. Bat, iii. 750.-Malaya.

repens, Sincl. Hort. Gram. Woburn. $148=$ alba.

retrofracta, Willd. Enum. Hort. Berol. $94=$ Deyenxia Forsteri.

Renterii, Boiss. Voy. Espagne, ii. 645.-Hispan

Reygeri, [Honck.] Verz. Aller Gew. Teutschl. $204=$ alpina?

rigescens, Presl, in Rel. Haenk. i. 237.--Peruv.

rigida, Lesson, ex A. Rich. Voy. Astrol. 124=Dichelachne rigida.

rigida, Spreng. Syst. 1. $262=$ Muehlenhergia rigida.

rigida, Willd. ex Steud. Nom. ed. II. i. $42=$ Calamagrostis recta.

rigidula, Steud. Syn. Pl. Gram. 171.-Java.

rigidifolia, Poir. Encyc. Suppl. i. 257 = Panicum rigidifolium.

rivularis, Brot. Fl. Lusit. i. $75=$ verticillata

rosea, Griseb. in Goett. Abh. xix. (1874) 253.-Reg. Argent.

Royleana, Trin. Agrost. ii. 125.-Ind, or.

rubicunda, Bosc, ex Desv. Opusc. $55=$ Cinna arundinacea.

rubra, Auct. ex Steud. Nom. ed. II. i. $42=$ canina. 


\section{AGROSTIS}

rubra, Huds. Fl. Angl. $26=$ Gastridium australe. rubra, Linn. Sp. Pl. 62.-Europ.

rubra, Wahlenb. ex Nym. Consp. 801 =vulgaris. rudis, Roem. \& Schult. Syst. ii. $360=$ Deyeuxia scabra.

rupestris, All. Fl. Pedem. ii. 237.-Europ.; Am. bor. rupestris, Willd. ex Kunth, Gram. i. $70=$ alpina. Ruprechtii, Boiss. Fl. Orient. v. 517.-Caucas. salina, Dum. in Bull. Soc. Bot. Belg. vii. (1868) $366=$ alba.

salmantica, Kunth, Gram. i. 71.--Hispan.

scaberrima, Hassk. Pl. Fav. Rar. 26.-Java.

scabra, R. Br. Prod. $172=$ Deyeuxia scabra.

scabra, Tuckerm. in Am. Fourn. Sc. Ser. II. xlv. (1845)

44.-Am. bor.

scabra, Willd. Sp. Pl. i. 370.-Am. bor.

scabriglumis, Boiss. \& Reut. Pugill. $125=$ alba.

scabriuscula, Buckl. in Proc. As. Sc. Philad. '1862' (1863) $90=$ scabra

Schaffneri, Fourn. Mex. Pl. En. Gram. 94, ex Hemsl. Biol. Centr. Am. Bot. iii. 551.--Mexic.

Schiedeana, Fourn. l. c. 96, ex Hemsl. l. c.-Mexic.

Schiedeana, Trın. in Mém. Acad. Pétersb. Sér. VI. vi. (1845) 327.-Mexic.

Schimperiana, Hochst. ex Steud. Syn. Pl. Gram. 170.Abyss.

Schleicheri, Jord. \& Verłot, in F. Schultz, Arch. Fl. Fr. et Allem. 339, $347=$ alpina.

Schottii, Trin. in Mém. Acad. Pétersb. Sér. VI. vi. (1845) 356.-Gibraltar.

Schultesii, Kunth, Enum. Pl. i. 228.-Pannonia. Schweinitzii, Trin. in Mém. Acad. Pétersb. Sér. VI. vi. (1845) $311=$ elata.

sciurea, R Br. Prod. i. 171=Deyenxia sciurea.

scoparia, Koen. ex Steud. Syn. Pl. Gram. 115 = Panicum semialatum.

Scouleri, Trin. in Mém. Acad. Pétersb. Sér. VI. vi. (1845) 329,-Am. bor. occ.

semibarbata, Trin. 1. c. $378=$ Deyeuxia Forsteri.

sepium, Jacq. Enum. Stirp. Vindob. 12 (=Urachne parviffora).

sericea, Banks \& Soland, ex Hook. f. Fl. Nov. Zel. i. $299=$ Arundo conspicua

sericea, Ell. Sketch, i. $135=$ Muehlenbergia capillaris. serotina, Linn. Mant. $30=$ Diplachne serotina.

serotina, Torr. Fl. Un. St. i. $88=$ Sporobolus serotinus. sesquiflora, E. Desv. in C. Gay, Fl. Chil. vi. 318.Chili.

setacea, Curt. Fl. Lond. vi. t. 12.-Europ.

setacea, Yill. Hist. Pl. Dauph, ii. $76=$ rupestris.

setifolia, Brot. Fl. Lusit. i. $74=$ setacea.

setifolia, Willd. ex Steud. Nom. ed. II. i. $42=$ tenuifolia sctifolia, Hook. f. Handb. New Zeal. Fl. 329.-N. Zel

setifolia, Fourn. Mex. Pl. En. Gram 97; ex Hemsl.

Biol. Centr. Am. Bot. iii. 551.-Mexic.

setosa, Mubl. Descr, Gram. $68=$ Mueblenbergia glomerata.

setosa, Spreng. Syst. i. $262=$ Muehlenbergia debilis.

Sibthorpii, Hort, ex Steud. Nom。 ed. II. i. $42=$ verticillata.

sicula, Guss. ex Stend. Nom. ed. II. i. $42=$ Gastridium muticum.

sicula, Kunth, Rev. Gram. i. 71.-Sicilia,

signata, Schur, in Oestr. Bot. Zeitschr. ix. (1859) $47=$ alba.

simensis, Hochst. ex Steud. Syn. Pl. Gram. 173.Abyss

simulans, Hemsl. in Hook. Ic. Pl. t. 1455.-Ins, Sta. Helena.

sinaica, Boiss. Diagn. Ser. I. xiii. $46=$ alba.

sobolifera, Mubl. ex Willd. Enum. Hort. Berol. $95=$

Muehlenbergia sobolifera.

Solandri, F. Muell, Veg. Chath. Isl. $60=$ Deyeuxia Forsteri.

spicaeformis, Linn. f. Suppl, $108=$ Perotis latifolia

spicata, Thunb. Prod. Pl. Cap. 19 = Sporobolus capensis.

spicata, Vahl, Symb. i. $9=$ Sporobolus spicatus.

Spica-venti, Linn. Sp. Pl. ed. I. $61=$ Apera Spicaventi,

Sporobolus, Spreng. Nov, Prov. $46=$ Sporobolus Sprengelii.

sparia, Roem. \& Schult. Syst. ii. $346=$ Calamagrostis lanceolatn.

stellata, Willd. Sp. Pl. i. $376=$ Cynodon Dactylon.

stipata, Koel, Gram. 77 = Stipa Calamarostis.

stipoides, Spreng. Syst. i. $263=$ Muehlenbergia stipoides,

stolonifera, Host, Gram, iv, t. $56=$ alba.

\section{AGROSTIS :-}

stolonifera, Leers, $\mathrm{Fl}$. Herb. t. 4. f. $6=$ vulgaris

stolonifera, Linn. Sp. Pl. 62.-Europ.

stolonifera, Linn. ex Sm. Fl. Brit. i. $80=$ verticillata.

stolonizans, Bess. in Roem. \& Schult. Mant. 567, add. = alba.

straminea, Hartm. Gram. Scand. $4=a \mathrm{lba}$.

stricta, Buese, in Miq. Pl. Fungh. 341.-Java.

stricta, De Not. ex Parl. Fl. Ital. i. 187.-Italia.

stricta, J. F. Gmel. Syst. $170=$ alba.

stricta, Sincl. Hort. Gram. Woburn, $150=$ canina

stricta, Trin. in Mém. Acad. Pétersb. Sér. VI. vi. (1845)

342.-Chili

stricta, Willd. Sp. Pl. i. 366. - Am. bor

suaveolens, Blytt, in Mag. for Naturvidensk. (1837); sec. Sommerfelt, in Skand. Akad. Handl. (1837) $25=$ Cinna arundinacea.

subaristata, Aitch. \& Hemsl. in Fourn. Linn. Soc. xix. (1882) 192. - Affghan.

subulata, Hook. f. Fl. Antarct. 95.-Ins. Campbell.

sylvatica, Georgi, Beschr. Russ. Reich. iii. $687=$

Calamagrostis sylvatica.

sylvatica, Huds. Fl. Angl. 28 =alba.

sylvatica, Koel. Gram. $92=$ vulgaris.

sylvatica, Torr. Fl. N. Amer. i. $87=$ Muehlenbergia Willdenowii

tabularis, Steud. Nom. ed. II. i. $42=$ Bergiana.

tacubayensis, Fourn. Mex. Pl. En. Gram. 95, ex

Hemsl. Biol. Centr. Am. Bot, iii. 551.-Mexic.

tarda, Drude, in Flora, lx. (18/7) 273.-Tyrolia.

tenacissima, Linn. f. Suppl. 197 = Sporobolus indicus.

tenella, Hoffm. Fl. Germ. ed. II. i. $36=$ vulgaris.

tenella, Poir. Encyc. Suppl. i. $257=$ Airopsis glo bosa.

tenella, Willd. ex Steud. Nom. ed. II. i. 42=Muehlenbergia tenuifolia.

tenella,' Schleich。 ex Gaud. Agrost. Helv, i. $75=$ Calamagrostis tenella.

tenerrima, Trin. Gram. Unifl. $205=$ elegans.

Tenorii, Otto, ex Loud. Hort. Brit. 26.-Italia?

tenuiflora, Willd. Sp. Pl. i. $364=$ Muehlenbergia Willdenowii.

tenuiflora, Steud. Syn. Fl. Gram. $163=$ perennans.

tenuifolia, Curt. Brit. Gr. $42=$ canina

tenuis, Bast. ex Roem. \& Schult. Syst. ii. $277=$ canina.

tenuis, Sibth. Fl. Oxon, 36 = vulgaris.

tenuis, Vasey, in Bull. Torr. Club, x. (1883) 21.Calif.

tenuissima, Spreng. Syst. i $258=$ Sporobolus indicus.

tenuissima, Vest, ex Steud. Nom. ed. II. i. $42=$ Polypogon monspeliensis.

Thunbergii, Steud. Syn. Pl. Gram. 163.-Japon.

thyrsoides, Bosc, ex Steud. Nom. ed. II. i. 42 (=Vilfa fulvescens)

Tillierii, Willd. ex Steud. I. c. = Catabrosa aquatica.

tolucensis, H. B. \& K. Nov. Gen. et Sp. i. 135. Mexic.

toluccensis, Willd. ex Steud. Syn. PI. Gram. 164= virescens.

Torreyana, Schult. Mant. ii. $203=$ compressa

Torreyi, Kunth, Enum. Pl. i. 226.-Am. bor.

transilvanica, Schur, in Oestr. Bot. Zeitschr. ix. (1859) $50=$ canina

tremula, Willd. Sp. P1. i. $372=$ Sporobolus tremulus.

triaristata, Knapp, Gram. Brit. $23=$ Polypogon monspeliensis.

trichantha, Schrank, in Regensb. Bot. Denkschr. ii. (1818) 4.-Labrador.

trichoclada, Griseb. in Ledeb. Fl. Ross. iv. 439.Oriens.

trichoides, Roem. \& Schult. Syst. ii. 361.-Peruv.

trichopodes, Ell. Sketch, i. $135=$ Muehlenbergia trichopodes.

trichotoma, Auct. ex Stend. Nom. ed. II. i. $43=$ alba.

trichotoma, Nees, ex Trin. in Mém. Acad. Pétersb. Sér. VI. vi. (1845) 338-Monte Video.

trichotoma, Kit. in Linnaea, xxxii. (1563) 306.Austria.

tricuspidata, Hack. in Oestr. Bot. Zeitschr. xxvii. (1877) $46=$ canina.

triflora, Hort. Hafn. ex Steud. Nom. ed. II. i $43=$ Chaeturus fasciculatus.

trinervata, Trin. ins Méms. Acad. Pétersb. Sér. VI vi (1845) 347 -Caucas.

trisetoides, Steud. Syn. Pl. Gram. 172.-Chili.

tropica, Beauv. Fl. Oware, ii. 37.-Afr. trop.

\section{AGROSTIS}

trancatula, Parl. Fl. Ital. i, 185.-Europ.

uliginosa, Phil. in Anales Univ. Chil. (1865) I1. 323. -Chili.

umbellata, Colla, in Mem. Acc. Torin. xxxix. (1836) 23.-Chili.

umbellulata, Trin. in Mém. Acad. Pétersb. Sér. VI. vi (1845) 370 - - Afr, austr.

umbrosa, Pers. ex Trin. l.c. 345.-Gallia.

umbrosa, Schur, in Oestr. Bot. Zeitschr. ix. (1859) $47=$ vulgaris

vaginaeflora, Torr. in A. Gray, Man. $576=$ Sporobolus vaginaeflora.

vaginata, Steud. Syn. Pl. Gram. 173.-Ins. Sandvic. valentina, Roem. \& Schult. Syst. ii. 348.-Hispan.

valvata, Steud. Syn. Pl. Gram. 171.-Japon.

varia, Host, Gram. iv. t. 57 ; Fl. Anstr. î. $100=$ alba. varians, Thuil. Fl. Par. ii. $35=$ canina

varians, Trin. in Mém. Acad. Pétersb. Sér. VI. vi. (1845) 314.-Am. bor.; Chili.

velutina, Poir. ex Steud, Nom. ed. II. i. $43=$ Paspalum velutinum.

ventosa, Dulac, Fl. Hautes-Pyr. $74=$ Apera Spicaventi.

ventricosa, Gouan, Hort. Monsp. 39, $547=$ Gastridum australe.

venusta, Trin. in Mém. Acad. Pétersb. Sér. VI, vi. (1845) 340.-Austral.

vernalis, Hort. Dorp. ex Trin. Gram. Unifl. $198=$ alba.

vernalis, Poir. Encyc. Suppl. i. $259=$ Milium vernale.

versicolor, Hoppe, ex Steud. Nom. ed. II. i. $43=$ alpina.

versicolor, Hort. Hafn. ex Trin. Gram. Unifl. 201, 203 =vulgaris.

versicolor, Stev, in Mém. Soc, Nat. Mosc, iii. (1812) $282=$ Catabrosa versicolor

verticillata, Lam. Encyc. i. 59 ; Illustr, n. $831=$ Andro. pogon squarrosus.

verticillata, Thuil. F1. Par, ii. $36=$ vulgaris,

verticillata, Vill. Prosp. 16,-Europ.

vestita, Hochst. ex A. Rich. Tent. Fl. Abyss. ii. 401.Abyss.

Vidali, Phil. in Anales Univ. Chil. (1873) 561.Chili.

Villarsii, Poir. Encyc. Suppl. i. $251=$ verticillata

villosa, A. Spreng. Syst. Suppl. $5=$ Sporobolus ciliatus.

villosa, Poir. ex Steud. Nom, ed. II. i. 43 = Tricholaena insularis.

villosa, Reichb. ex Stend. 1. c. $=$ Sporobolus villosus

villosa, Vill. Hist. PI. Daaph. i. $378=$ Calamagrostis sylvatica.

vinealis, [Honck.] Verz, aller Gew. Tentschl. $205=$ castellana.

vinealis, With. Arr. Brit. Pl. ed. III. ii. $127=$ canina.

vinealis, Schreb. Spicil. $47=$ alba.

violacea, Phil. in Anales Univ. Chit. (1873) 560Chili.

violacea, Thuil. Fl. Par. ii. $35=$ vulgaris.

violaceo-purpurea, Gilib. Exercit, ii. $525=$ canina,

virescens, $H . B$. \& K. Nor. Gen et Sp. i. 135.-Calif. Mexic.

virescens, Rupr. in Bull. Acad. Brux. ix. (1842) $229=$ tolucensis.

virgata, Willd, ex Steud. Nom. ed. II. i. $48=$ Leptochloa tenerrima.

virginica, Forsk. Fl. Aegypt. Arab. $20=$ Sporobolus spicatus.

virginica, Linn. Sp. $\mathrm{Pl} .68=$ Sporobolus virginicus.

virginica, Muhl, ex Stend. Nom. ed. II. i. $43=$ Sporobolus vaginaeflorus.

viridis, Gouan, Hort. Monsp. $546=$ Sporobolus pungens.

viridis, Rafin. in Am. Monthly Mag. (1811) \$50, nomen. -Am. bor

Virletii, Fourn. Mex. Pl. En. Gram. 96, ex Hemsl. Biol. Centr. Am. Bot. iii. 551.-Mexic

vivipara, Bivona, ex Roem. \& Schalt. Syst. ii. 347 in nota $=$ alba

vulgaris, With. Arr. Brit. Pl. ed. IIJ. ii. 132--Reg.

Wallichiana, Steud. Syn. Pl. Gram. 17t.-Reg. Himal. Wilswitschii, Stcud. I. c $168=$ Reuteri.

Wightid, Nees, ex. Sicud. l. c, -Ind. or

Youngii, Hook. f. Handb. New Zeal. F. 330, -N. Zel. Zenkeri, Trin. in Mim. Acud. Ptersb. Ser. VI. vi. 15.5) 968 . - Ind. or.

zeylanica, Átein, ex Steud. Syn. P1. Gram 83.-Zeylao. 
AGROSTISTACHYS, Dalz. in Hook. Kew Journ. ii. (1850) 41. EUPHORBIACEAE, Benth. \& Hook. f. iii. 302 .

SarCOCLINIUM, Wight, Ic. v. 24. t. 1887, 1888, (1852).

africana, Muell. Arg. in Flora, xlvii. (1864) 534.Afr. trop.

Gaudichaudii, Muell. Arg. in Linnaea, xxxix. (186566) 144 . - Ind. or.

Hookeri, Benth. \& Hook. f. Gen. iii. 303.-Zeylan.

indica, Dalz. in Hook. Kew Fourn. Bot. ii. (1850) 41. -Ind. or.

longifolia, Benth. ex Hook. f. Fl. Brit. Ind. vo 407.Canara.

longifolia, Kurz, For. Fl. Brit. Burma, ii. $377=$ Gaudichaudii.

AGROSTOCRINUIM, F. Muell. Fragm. ii. 94 (1860) LILIACEAE, Benth. \& Hook. f. iii. 792. stypandroides, F. Muell. l. c. 95.-Austral.

AGROSTOMIA, Cerv, in La Naturaleza (1870) $345=$ Panicum, Linn. (Gramin.).

aristata, Cerv. l. c.-Mexic

barbata, Cerv. 1. c. $346 .-$ Mexic

mutica, Cerv, 1. c. 345 .-Mexic.

AGROSTOPHYLLUM, Blume, Bijdr. 368 . t. 53 1825). ORCHIDEAE, Benth. \& Hook, f, iii, 517.

Diploconchium, Schan. in Nov. Act. Nat. Cur xix. Suppl. I. (1843) 428. t. 12.

callosum, Reichb. f. in Seem. Fl. Vit. 296,-Reg. Himal.

Hasseltii, Reichb. f. in Bonplandia, v. (1857) 41; et in Walp. Ann. vi. 909.-Ind. or.

javanicum, Blume, Bijdr. 369. t. 53.-Java.

khasiyanum, Griff. in Calc. fourn. Nat. Hist. iv (1844) 376,-Reg. Himal.

longifolium, Reichb̆. f. in Bonplandia, v. (1857) 41.Java.

megalurum, Reichb. fo in Seem: Fl. Vit. 296.-Ins. Samoa.

planicaule, Reichb. f. in Walp. Ann. vi. $909=$ khasiyanum.

AGUAVA, Rafin. Sylva Tellur。 107 (1838)=Myrcia, DC. (Myrtac.).

guianensis, Rafin. 1. c. $=$ M. guianensis.

tomentosa, Rafin. 1. c. = M. tomentosa.

AGYLLA, Phil. in Anales Univ. Chil. (1865) I. $643=$ Cladium, P. Br (Cyperac.)

ensifolia, Phil. 1. c. $=$ C. scirpoideum.

AGYLOPHORA, Neck. Elem. i. $145(1790)=$ Uncaria, Schreb. (Rubiac.)

AGYNAIA, Hassk. in Flora, xxv. (1842); Beibl. $40=$ seq.

AGYNEIA, Linn. Mant. ii. 161 (1771); Vent. Jard. Cels, t. $23(1800)$. EUPHORBIACEAE, Benth. \& Hook. f. iii. 271 .

DiploMorPHA, Griff. Notul. iv. 479 (1854).

affinis, Kurz, ex Teijsm. \& Binn, in Tijdschr. Ned.

Ind. xxvii. (1864) 118 = bacciformis.
bacciformis, A. Fuss. Tent. Euph. 24.-Ind. or. ; Malay.

Berterii, Spreng. Syst. iii. $19=$ Phyllanthus grandifolius.

ciliata, Wall. Cat. n. $7852=$ Trigonostemon semperflorens,

coccinea, [Buch.-Ham. in] Symes, Embassy, ed. II. iii. $317=$ Glochidion coccineum.

flexuosa, Heyne, ex Wall. Cat. n. $7863=$ Glochidion zeylanicum.

glomerulata, Miq. Fl.Ind. Bat. Suppl.447.-Sumatra.

hirsuta, Miq.l.c. i. II. 368.-Malaya.

impubera, Miq. l.c. 367.-Malaya.

impubera, Wall. Cat. n. $7869=$ Glochidion multi. loculare.

impubes, Herb. Madr.? Wall. Cat. n. 7990 partim = Glochidion littorale.

impubes, Linn. Mant. ii. $296=$ Phyllanthus puberus. impubes, Vent. Jard. Cels, 23. t. $23=$ bacciformis. lanceolata, $F_{0}$ G. Dietr. Lexik. Gaertn。 i. 186.Austral.?

latifolia, Moon, Cat. $65=$ Aporosa latifolia.

\section{AGYNEIA :-}

multiflora, Hassk. Cat. Hort. Bog. Alt. 240 (=Phyllanthi, sp.).-Malaya.

multilocularis, Rottl. ex Willd, in Ges. Naturf Freunde, Neue Schr. iv. (1803) 206=Glochidion multiloculare.

obliqua, Willd. Sp. P1. iv. $568=$ Glochidion zeylanicum. ovata, Poir. Encyc. Suppl. i. 243 ; Miq. Fl. Ind. Bat, i. II. $367=$ Sauropus albicans.

phyllanthoides, Spreng. Syst. iii. $19=$ bacciformis

pinnata, Miq. Fl. Ind. Bat. i. II. $368=$ Glochidion obscurum.

pubera, Linn. Mant. ii. $296=$ Phyllanthus puberus.

sinica, Miq. Fl. Ind. Bat, i. II. $368=$ Phyllanthus puberus.

tenera, Zoll. \& Mor. ex Miq. Fl. Ind. Bat. i. II. $365=$ Andrachne anstralis.

tetrandra, Buch.-Ham. in Trans. Linn. Soc. xv. (1826) $125=$ Phyllanthus Hamiltonianus.

tetrandra, Wall. Cat. n. $7852=$ Trigstemon Hookerianus.

AHOUAI, Tourn. ex Adans. Fam. ii. 171 (1763)= Thevetia, Linn. (Apocyn.)

AICHRYSON, Webb \& Berth. Phyt. Canar. i. 180. t. 27 $(1840)=$ Sempervivum, Linn. (Crassul.).

Bethencourtianum, C. Bolle, in Bonplandia, vii. (1859) 243.-Ins. Canar.

Bollei, Webb, ex Bolle, 1. c. - Ins. Canar.

dichotomum, Webb \& Berth. Phyt. Canar. i. 181= S. dichotomum.

pachycaulon, C. Bolle, in Bonplandia, vii. (1859) 244.-Ins. Canar.

palmense, Webb, ex C. Bolle, 1. c. 243.-Ins. Canar. Parlatorei, C. Bolle, I. c. 244.-Ins. Canar.

parviflorum, C. Bolle, 1. c. 243.-Ins. Canar.

porphyrogennetos, C. Bolle, 1. c.--Ins. Canar.

pulchellum, C. A. Mey. ex Fisch. Mey. \& Avé-Lall.

Ind. Sem. Hort. Petrop. ix. 55 - - Hab.?

punctatum, Webb \& Berth. Phyt. Canar. i. $182=\mathrm{S}$, punctatum.

pygmaeum, Webb \& Berth. 1. c. 184.-Ins. Canar.

radicescens, Webb \& Berth. 1. c. $183=$ S. villosum.

sedifolium, Webb, ex C. Bolle, in Bonplandia, vii. (1859) 242.--Ins. Canar.

tortuosum, Webb \& Berth. Phyt. Canar. i. 184=S. tortnosum.

villosum, Webb \& Berth. 1. c. $181=\mathrm{S}$. villosum.

AIDELUS, Spreng. Syst. iv. Cur. Post. $17(1827)=$

Veronica, Tourn. (Scrophul.).

micranthus, Spreng. 1. c.-Nepal.

AIDIA, Lour. F1. Cochinch. 143 (1790). Gen. haud recogn. Cf. Benth. \& Hook. f, ii. 29.

cochinchinensis, Lour. l. c.-Cochinch.

AIGIROS, Rafin. Alsog. Am. 42 (1838)= Populus, Tourn. (Salic.).

heterophylos, Rafin. I. $\mathrm{c}_{\mathrm{s}}=\mathrm{P}$. heterophylla

AIKINIA, R. Br. in Wall. P1. As. Rar. iii. 65. t. 288 $(1832)=$ Epithema, Blume (Gesnerac.)

Brunonis, Wall. Pl. As. Rar。 iil, 66. t. $288=\mathrm{E}$. Brunonis.

carnosa, G. Don, Gen. Syst. iv. $665=$ E. carnosum.

Horsfieldii, R. Br. in Wall. Pl. As。 Rar。 iii. $66=\mathrm{E}$. difforme.

AIKINIA, Salisb. ex A. DC. Monog. Camp. 135, 141 $(1830)=$ Wahlenbergia, Schrad. (Campan.). hederacea, Salisb. ex A. DC. 1. c. =W. hederacea.

AIKINIA, Wall. Pl. As. Rar. iii, t. 273. p. 46 (1832)= Ratzeburgia, Kunth (Gramin.).

elegans, Wall. 1. $c_{0}=\mathrm{R}$. pulcherrima.

AILANTHUS, Desf. in Mém. Acad. Sc. Par. 1786 (1789) 265. t. 8. SIMARUBEAE, Benth. \& Hook. i. 309 .

excelsa, Roxb. Pl. Corom. i, t. 23.-Ind. or.

flavescens, Carr. in Rev. Hortic. (1865) $366=$ Cedrela sinensis. glandulosa, Desf. in Mém. Acad. Sc. Par. 1786. (1789)
265. t. 8.-China.

gracilis, Salisb. Prod. $171=$ Brucea sumatrana.
AILANTHUS :-

imberbiflora, F. Muell. Fragm. iii. 42 '; xix. 44.Austral.

integrifolia, Lam. ex Stend. Nom. ed. II. i. $43=$ moluccana.

japonica, Hort. ex C. Koch, Dendrol. $569=$ glandulosa. malabarica, DC. Prod. ii. 89.-Malabar.

moluccana, $D C$. l. $c$.-Ins. Molucc.

Pongelion, J. F. Gmel. Syst. ii. $726=$ glandulosa.

procera, Salisb. Prod, $171=$ glandulosa.

punctata, F. Mucll. Fragm. iii. $42=$ Pentaceras australis.

rhodoptera, F. Muell. 1. c. 43=glandulosa

AILANTUS, DC. Prod. ii. 88 (1825) = praec.

AILUROSCHIA, Stev, in Bull. Soc. Nat. Mosc. xxix (1856) II. 151 = Astragalus, Tourn. (Legum.). amygdaliger, Stev. 1. c. = Astrag. amygdaliger. diffusa, Stev. l. c. = Astrag. dolichophyllus. galactites, Stev. 1. $\mathrm{c}_{\mathrm{v}}=$ Astrag. galactites. glomeratus, Stev, 1, c. = Astrag. glomeratus. hypogaeus, Stev. 1. $\mathrm{c}_{0}=$ Astrag. hypogaeus. rupifraga, Stev. 1. c. $152=$ Astrag. rupifragus. scabriseta, Stev. 1. c. $151=$ Astrag. scabrisetus.

AILLYA, De Vriese, in Nat. Verh. Haarl.x. (1854) $75=$ Goodenia, Sm.

umbellata, De Vriese, $1 . c_{c}=\mathrm{G}$. filiformis.

AIMORRA, Rafin. New Fl. Am. iv, 70 (1836). (Compos.)

acuminata, Rafin. 1, c.-Am. bor.

AINSLIAEA, DC. Prod. vii. 13 (1838). COM POSITAE, Benth. \& Hook. f. ii. 493.

Diaspananthus, Miq. in Ann. Mus. Lugd. Bat. ii. $186(1865)$.

acerifolia, Sch. Bip. in Zoll. Syst. Verz. Ind. Archip. 126.-Malaya.

affinis, Miq. Ann. Mus. Bot. Lngd. Bat. ii. 187= acerifolia.

angustifolia, Hook. f. \& Thoms. ex Clarke, in Fourn. Linn. Soc. xiv. (1875) 412.-Ind, or.

apiculata, Sch. Bip. in Zoll. Syst. Verz. Ind. Archip. 126. - Japon

aptera, DC. Prod. vii. 14.-Reg. Himal.

asperrima, Sch. Bip; in Pollichia, xx-xxi. (1863) 407. -Nepal,

Brandisiana, Kurz, in Fourn. As. Soc. Beng. xli. (1872) II. 318.-Burma.

cordifolia, Franch. \& Sav. Enum. Pl. Fap. ii. 416.Japon.

dissecta, Franch. \& Sav. l. c. i. 264.-Japon.

fragrans, Champ. ex Benth. in Hook. Kew Fourn. iv. 1852) 236.--Hongkong.

glumacea, Sch. Bip. in Pollichia, xx-xxi. (1863) 407 ;

Klatt, in Sitzb. Muench. Akad. (1878) $97=$ angustifolia.

latifolia, Sch. Bip. in Pollichia, xviii-xix. (1861) 190. -Nepal.

pteropoda, DC. Prod. vii. 14.--Reg. Himal.

sithetensis, C. B. Clarke, in Journ. Linn. Soc. xiv. (1875) $411=$ pteropoda.

uniflora, Sch. Bip. in Zoll. Syst. Verz. Ind. Archip. 126.-Japon.

Walkeri, Hook. f. Bot. Mag. t. 6225.-Hongkong.

AINSWORTHIA, Boiss. in Ann. Sc. Nat. Sér. III. i. (1844) $343=$ Tordylium, Linn. (Umbell.). Carmeli, Boiss. Diagn. Ser. I. x. 44.-Palestin. cordata, Boiss. in Ann. Sc. Nat. Sér. III. i. (1844) 343 $=\mathrm{T}$. cordatum.

elegans, Boiss. \& Bal. Diagn. Ser. II. v. 100.Taurus.

trachycarpa, Boiss. 1. c. Ser. I. x. 44.-Oriens.

AIOLOTHECA, DC. Prod. v. 508 (1836). СОМ. POSITAE, Benth. \& Hook. f. ii. 352.

parthenioides, $D C$. l. c.-Mexic.

AIOUEA, Anbl, Pl. Gui, i. 310, t. 120 (1775), LAURINEAE, Benth. \& Hook. f. iii. 153 ApIVEA, Steud. Nom. ed. I. 25 (1821). Colomandra, Neck. Elem. ii. 142 (1790).

Douglassia, Schreb: Gen. Pl. 809 (1791).

EHRHARDIA, Scop. Introd. 107 (1777).

brasiliensis, Meissn. in DC. Prod. xv, 1. 83.-Bras. 
AIOUEA :-

densiflora, Nees, in Linnaea, xxi. (1848) 513.-Am. trop.

elliptica, Meissn. in DC. Prod.xv. I. 83.-Am. trop. guianensis, Nees, Syst. Laurin. 363-(Cf. Meissn. in

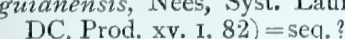

guianensis, Aubl. Pl. Gui. i. 310.-Guiana.

guyanensis, Griseb. ex Meissn. in DC. Prod, xv. I. 83 $=$ Aydendron riparium.

Malabonga, Blanco, Fl. Filip. ed. I. 233.-Ins. Philipp.

saligna, Meissn. in DC. Prod. X'v. I. 82.-Bras.

Schomburgkii, Meissn. l. c.-Am. trop.

tenella, Nees, in Linnaea, xxi. (1818) $512=$ guianensis.

tenuiflora, Nees, ex Meissn. in DC. Prod. xv. I. 510 (= Mespilodaphne indecora).

trinervis, Meissn. l. c. 83.-Am. trop.

AIPHANES, Willd. in Mém. Acad. Berl. (1804) $32=$ Martinezia, Ruiz \& Pav. (Palm.).

aculeata, Willd. 1. c. = M. Aiphanes.

caryotaefolia, H. Wendl, in Kerch. Palm. $230=\mathrm{M}$, caryotacfolia.

corallina, H. Wend1. 1. c. = M. corallina.

elegans, H. Wendl. 1. c. = M. elegans.

erinacea, $\mathrm{H}$. Wendl. 1. c.-N. Granat

Lindeniana, H. Wendl. 1, c. = M. Lindeniana.

Praga, H. B. \& K. Nov, Gen, et Sp. i. $303=$ Euterpe Praga.

truncata, H. Wendl. in Kerch. Palm. $230=\mathrm{M}$. truncala.

AIPYANTHUS, Stev, in Bull. Soc. Nat. Mosc. (1851) I. $599=$ Macrotomia, DC. (Borag.).

echioides, Stev. 1. c. $600=$ M, echioides.

AIRA, Linn. Fl. Lapp. 27 (1737); Gen. ed. I. 335. n. 838 (1737). GRAMINEAE, Benth. \& Hook. f. iii. 1156 .

Antinoria, Parl. Fl. Palerm. i. 92 (1845).

ASPRIS, ddans, Fam ii. $490^{\circ}$ (1763).

FIORINiA, Parl. Fl. Ital i. 232 (1848)

Fussia, Schur, Enum. Pl. Transs. 754 (1866).

LePTOPHOBA, Ehrh. Beitr. iv. 146 (1789).

Moline RIA, Parl. Fl. Ital. i. 236 (1848).

Periballia, Trin. Fund. Agrost. 133 (1848).

PROINEIA, Ehrh. Beitr. iv. 149 (1789).

acutigluma, Steud. Syn. Pl. Gram. 221.-Chili.

aegilopsoides, Walt. Fl. Carol. 78.-Carolina.

aetnensis, Guss. F1. Sic. Syn. i. 151=Corynephorus articulatus.

aggregata, Timer. ex Bor, Fl. Centr. Fr. ed. III. ii. $702=$ caryophyllea.

agrostidea, Guss, Fl. Sic. Prod, i. $61=$ insularis

agrostidea, Loisel. Notic. 16.-Europ. austr.

alba, Vahl, 'in Roem. \& Schult. Syst. ii. $688=$ Des champsia alba.

alba, Wulf. ex Kunth, Gram, $110=$ Sesleria elongata.

alpina, Liljebl. Utkast Sv. F1. ed, I. 49 ; ed. II. $41=$

Hierochloë alpina.

alpina, Linn. Sp. P1. $65=$ Deschampsia alpina.

alpina, Roth, Tent. F1. Germ. ii. I. $98=$ Deschampsia caespitosa.

alpina, Savi, Bot. Etrusc. i. $52=$ Deschampsia juncea. alpina, Vahl, in Fl. Dan. t. 961=atropurpurea.

alpina, Sobol. ex Rupr, in Beitr. Pf. Russ. Reich, iv. $37=$ Deschampsia flexuosa

altaica, Trin. in Bunge, Verz. Suppl. Fl. Alt. $8=$ Poa soongarica.

altissima, Lam. Fl. Fr. iii. $581=$ Deschampsia caespitosa.

ambigua, Michx. Fl. Bor. Am. i, 61=Deschampsia ambigua.

ambigua, De Not. in Ann. Sc. Nat. Sér. III. v. (1846) $\mathbf{3 6 5}=$ capillaris

Andraei, Auersw. ex Andrae, in Bot. Zeitschr. xiv.

(1856) $205=$ Deschampsia caespitosa.

anomala, Trin. in Linnaea, x. (1836) 301-Chili.

antarctica, Forst. f. Prod. $8=$ Trisetum antarcticum

antarctica, Hook. Ic. Pl. t. 150.-Ins. Antarct.

aquatica, Guss. Fl. Sic. Prod. i. $61=$ Catabrosa ochro-

leuca.

aquatica, Linn. Sp. Pl. 64 = Catabrosa aquatica

aquatica, Huds. Fl. Angl, ed. II. 34, pro parte=

Glycerin distans.

arctica, Spreng. Syst. Cur. Post. $3 Q=$ Deschampsia caespitosa.
AIRA :-

arenaria, F. W. Schmidt, in Neu. Abh. Boehm. Ges. i (1791) 11.-Europ.

argentea, Lowe, in Trans. Cambr. Phil. Soc. iv. (1831) 9.-Ins. Mader.

aristulata, Torr. Fl. U. St. 132-Am. bor.

articulata, Desf. Fl. Atlant. i. $70=$ Corynephorus articulatus.

arundinacea, Liljebl. Utkast Sv. F1. ed. I. $49=$ Graphephorum arundinaceum.

arundinacea, Linn. Sp. Pl. $64=$ Poa tatarica

atropurpurea, Wahlenb. Fl. Lapp. 37.-Europ.; Am bor.

atrovirens, Thuil. F1. Par。 ed. II. i. $37=$ Molinia caerulea.

aurea, Steud. in Flora, xii. (1829) $470=$ Airopsis aurea.

australis, Raoul, Choix, 12 = Deschampsia caespitosa. australis, Steud. Syn. Pl. Gram. 220=Deschampsia australis.

avenacea, Spreng. Syst. i. $278=$ Eriachne avenacea

avenacea, Willd, ex Steud. Nom. ed. II. i. $44=$ Trise tum palustre.

baetica, Trin. in Bull, Sc. Acad. Pétersb. i. (1836) 67 $=$ Deschampsia baetica.

benghalensis, J. F. Gmel. Syst. i. $174=$ Arundo bengalensis.

Berteroniana, Steud. Syn. Pl. Gram, 220.-Chili

Biebersteinii, Steud. 1. c, $219=$ Deschampsia caespitosa.

bottnica, Wahlenb. F1. Lapp. 36. t. 4=Deschampsia caespitosa.

brasiliensis, Raddi, Agrost. Bras. $36=$ Eragrostis airoides.

brasiliensis, Spreng. Syst. i. $278=$ Arundinella brasiliensis.

breviaristata, Gilib. Exercit. ii. 528=Deschampsia caespitosa.

breviculmis, Loisel. F1. Gall. i. $57=$ Corynephorus canescens.

brevifolia, Bỉeb. Fl. Taur. Cauc. iii. $63=$ Deschampsia caespitosa.

brevifolia, Pursh, Fl. Am. Sept. i. 76.-Missouri

brigantiaca, Chaix, in Vill. Hist. Pl. Dauph. ii. $378=$ Glyceria distans.

bulbosa, Krock. Fl. Sil. Suppl. i. $131=$ Koeleria cristata?

caerulea, Linn. Sp. P1. $63=$ Molinia caerulea.

caespitosa, Banks \& Soland. ex Hook. f. Fl. Antarct. ii 380 , pro parte $=$ Festuca fuegiana

caespitosa, Linn. Sp. Pl. $64=$ Deschampsia caespitosa.

caespitosa, Muhl. Desc. " Gram. $85=$ Deschampsia ambigua.

calycina, Steud. Syn. Pl. Gram. 220.-Peruv.

canescens, All. Fl. Pedem. ii. $244=$ Corynephorus articulatus.

canescens, Host, Gram. iv. t. $36=$ caryophyllea.

canescens, Linn. Sp. Pl. $65=$ Corynephorus canes cens.

capensis, Linn. f. Suppl. $108=$ Ehrharta calycina.

capensis, Steud, in Flora, xii. (1829) $468=$ Koeleria capensis.

capensis, Spreng. Syst, ii. $114=$ Ehrharta villosa.

capillacea, Hort. Madr. ex Wall. Cat. sub n. $3804=$ Leptochloa filiformis.

capillacea, Lam. Illustr. i. 177.-Am, bor.

capillaris, Guss. Fl. Sic. Prod. i. $64=$ Avena corym bosa.

capillaris, Host, Gram. iv. 20. t. 35.-Europ.; Oriens. capillaris, Lag. in Varied. Cienc. ii. IV. (1805) $39=$ Lagascae, Airopsis agrostidea.

capillaris, Salzm. ex Steud. Nom. ed. II. i. $44=$ caryo. phyllea.

capillaris, Savi, F1. Pis. i. $86=$ Deschampsia juncea caryophyllaea, Leers, F1. Herborn. ed. II. 24=Deschampsia flexuosa.

caryophyllea, Bertol. [ex Stend. ; an Fl. Ital. i. 455] = capillaris.

caryophyllea, Linn. Sp. Pl. 66.-Furop.; Oriens. catabrosoides, Steud. Syn. Pl. Gram.223.-Caucas.

cespitosa, Muhl. Desc. Gram. $85=$ Deschampsia ambigua.

Chamaemespilus, Host, Fl. Austr. ii. 8.-Europ.

chinensis, Rets. Obs. iii. 10.-Cbina.

cilinris, Kit. in Limneer, xxxii. (1863) 310-Austria.

ciliaris, Auct, ex Stcud. Nom, ed. I 28, 487=Koeleria

villosa.

ciliata, Spreng. Pugill. i. $7=$ Engrostis minutiflor

ciliata, Spreng. Syst. i. $278=$ Eriachne ciliata.
AIRA

clavata, Gilib. Exercit. ii. $526=$ Corynephorus canes cens.

clavata, Willd. ex Steud. Nom, ed. II. i. $44=$ Coryne phorus articulatus.

collina, Dum. Obs. Gram. Belg. $121=$ Deschampsia flexuosa.

compressa, Rafin. in Am. Monthly Mag. (1811) 356 nomen.-Am. bor.

controversa, Stend. Syn. Pl Gram, 224-Am, bor.

complanata, Steud. Nom. ed. II. i. $44=$ Chloris petraea.

corsica, Jord. Pugill. $353=$ sicula.

corsica, Tausch, in Flora, xx. (1837) $102=$ Deschampsi flexuosa.

corymbosa, Willd. ex Steud. Nom. ed. II. i. $44=$ caryophyllea.

corymbosa, Fauché \& Chaub. Fl. Pelop. 5. n. 120. t. 7

f. $1=$ intermedia.

cristata, Linn. Sp. Pl. $63=$ Koeleria cristata

Cupaniana, Guss. Fl. Sic. Syn. i. $145=$ caryophyllea.

cuprina, Fuss, F1. Transs. $722=$ Deschampsia flexuosa

curta, Jord. ex Bor. Fl. Centr. Fr. ed. III. i.. 701 in nota = caryophyllea.

dactyloides, Rochel, Pl. Rar. Ban. 32. f. $3=$ Koeleri glanca.

danthonioides, Trin. in Mém. Acad. Pétersb. Sér. VI, (1830) $57=$ Deschampsia calycina.

discolor, Thuil. Fl. Par. i. $39=$ setacea

distichophylla, Spreng. Syst, i. $276=$ Panicum subula

tum.

divaricata, Pourr. in Mém. Acad. Toul. iii. (1788) 307 $=$ caryophyllea

duriuscula, Poir. Encyc. Suppl. ii. 76.-Hab.

Edouardi, Reut. ex Jouve, in Bull. Soc. Bot. Fr. xii. (1865) $88=$ Avena corymbosa.

effusa, Spreng. Syst, i. $278=$ Eriachne pallescens.

elatior, 'Hoffmgg.' ex Steud. Nom. ed, II. i. $44=$

Melica Banhini ?

elatior, Steud. Syn. Pl. Gram. 423,-Reg. Magellan.

elegans, Willd. ex Gaud. Agrost. Helv. i. 130, $355=$

capillaris.

elegans, 'Vill.' ex Steud. Nom. ed. II. i. $44=$ Airopsis agrostidea.

elegantissima, Schur, in Verh. Siebenb. Ver. Naturw iv. (1853) $85=$ capillaris.

elodes, Brign. Fasc. Pl. Foroj. 10 ; cf. Flora (1840), 104 $=$ Poa nemoralis.

elongata, Hook. Fl. Bor. Am. ii. $243=$ Deschampsi elongata.

elongata, Salzm. ex Steud. Nom. ed. II. i. $44=$ Koeleria phleoides.

euflexuosa, Syme, Engl. Bot. ed. III. xi. $67=$ Deschamp-

sia flexuosa.

fascicularis, Steud. Syn. P1. Gram. $219=$ Corynephorus fasciculatus.

festucoides, Vill. Prosp. 16 ; Hist. P1. Dauph. ii. $86=$ Deschampsia alpina.

filiformis, Koen. ex Roxb. Fl. Ind. i. 328-Ind. or

flammosa, Buchoz, ex Honck. Syn. Pl. Germ. i. $521=$

Deschampsia flexuosa.

flexilis, Linn. ex Giseke, Prael. $147=$ Deschampsia

flexuosa.

flexuosa, Linn. Sp. Pl. $65=$ Deschampsia flexuosa

Gayana, Steud. Syn. Pl. Gram. 220,-Chili.

gigantea, Schrenk, ex Ledeb. Fl. Ross。 iv. $446=$ Mueh

lenbergia alpestris.

gigantea, Steud. Syn. Pl. Gram. 224.-Ind. occ.

glabra, Brot. Fl. Lusit. 91.-Lusit.

glabrata, Brot. 1. c. $92=$ lendiger

glauca, Hartm. ex Stend. Nom. ed. II. i. $t+=$ Des.

champsia caespitosa.

glauca, Rochel, Pl. Rar. Banat. $32=$ Koeleria dacty loides.

glareca, Spreng. Nachtr. Bot. Gart. Halle, i. $10=$ Dactylis glauca.

globosa, Thore, in Joum. Bot. Paris, i. (1808) $197=$ Airopsis globosa.

glomerata, G. Don, ex S. F. Gray, Nat. Arr. Brit. P). ii. $137=$ Deschampsia cacsuitoss.

Gmelini, [Honck.] Vere aller Gew. Teatschl. 213 praecox $?$

gracilis, Trin. ex Stcud. Nom. ed. II. i. $44=$ Koeleria cristata.

Granditora, Bertol. Fl. Ital i, 496 - Kueleris setacea grandifora, Steud. Syo. Pl. Gram, 220-Deschampiaia grandiflura.

grandis, Nym. Consp. 507 - Deschampjesia caespitosa. 
AIRA :-

Halleri, [Honck.] Verz. aller Gew. Teutschl. $212=$

Trisetum rigidum.

Hartmaniana, Nym. Consp. $807=$ Deschampsia caespitosa.

helodes, Steud. Nom. ed. II. i. $44=$ Poa nemoralis.

hirsuta, Hall. f. ex Schleich. Cat. Nov. $5=$ Koeleria hirsuta.

hispida, Spreng. Syst. i. $276=$ Eriachne capillaris.

holciformis, Steud. Syn. P1. Gram. 221=Deschampsia holciformis.

Holcus-lanatus, Vill. Hist. P1. Dauph. ii. $87=$ Holcus lanatus.

Holcus-mollis, Vill. 1. c. $88=$ Holcus mollis.

Hostii, Steud. Syn. Pl. Gram. 221.-Bohem

humilis, Bieb. Fl. Taur. Cauc. i. $57=$ Catabrosa humilis.

hybrida, Gand. Agrost. Helv. i. $124=$ Corynephorus articulatus.

incompleta, Bosc, ex Steud. Nom. ed. II. i. $44=$ Paspalum debile.

indica, Linn. Sp. P1. ed. II. $94=$ Panicum conglomera tum.

inflexa, Loisel. Fl. Gall. i. 56.t. $22=$ Avena corymbosa. insularis, Boiss. Fl. Orient. v. 528.-Europ. ; Oriens. intermedia, Guss. Fl. Sic. Prod. Suppl. i. 105.-Europ. interrupta, Rottl. ex Steud. Syn. Pl. Gram. $55=$ Panicum canaliculatum.

involucrata, Cav. Ic. i. 33. t. $44=$ Deschampsia involucrata.

ischaemoides, Koen. ex Trin. in Mém. Acad. Pétersb. Sér. VI. iii. (1834) $328=$ Panicum antipodum. juncea, Vill. Prosp. $16=$ Deschampsia juncea. juncifolia, Wulf. ex Kunth, Enum. i. $322=$ Sesleria tenuifolia.

Kingii, Hook, f. Fl. Antarct, ii, 376, t. $136=$ Des champsia caespitosa.

koelerioides, Peyr. in Linnaea, xxx. (1859-60) $5=$ Deschampsia koelerioides.

Koenigii, J. F. Gmel. Syst. i. 174=Eragrostis minutiflora.

labradorica, Steud. Syn. Pl, Gram, 220-Labrador.

laevigata, Sm. Eng. Bot. t. $2102=$ Deschampsia alpina.

laevis, Brot. Fl. Lusit. i. $90=$ Deschampsia laevis.

laevis, Spreng. Syst. 1. $278=$ Eriachne glauca.

Lagascae, Kunth, Gram. 1. 99.-Hispan.; Corsic.

latifolia, Honk, Fl. Bor. Am. ii. $243=$ Deschampsia latifolia.

latifolia, Steud. Syn. P1. Gram. 219=Deschampsia caespitosa.

latigluma, Steud. l. c. 221.-Abyss.

laxa, Rich, in Act. Soc. Hist. Nat. Par. i. (1792) $106=$ Orthoclada laxa.

Leersii, Kunth, Enum. PI. i. $289=$ caryophyllea

Legei, Bor. in Soc. Angers, xxiv. (1855); et Fl. Centr. Fr, ed. III. ii. $700=$ Deschampsia flexuosa.

lendigera, Lag. in Varied. Cienc. ii. IV. (1805) 39.Hispan.

Lensaei, Loisel. F1. Gall. ed. II. i. 58=caryophyllea.

Lensii, Reichb. F1. Germ. Excurs. $140^{5}=$ praec.

Lenzei, Gren. \& Godr. Fl. Fr. iii. 620=praec.

litoralis, Godr. ex Nym. Consp. $807=$ Deschampsia caespitosa.

macrantha, Ledeb. in Mém. Acad. Pétersb. v. (1812)

$515=$ Koeleria cristata.

macranthera, Steud. Syn. Pl. Gram. 219.-Hispan.

maderaspatana, Nees, ex Steud. l. c. 221.-Madras.

magellanica, Hook. f. Fl. Antarct. ii. 376. t. 134.-Reg. Magellan.

magellanica, Lam. ex Beatv. Agrost. $65=$ Hierochloe magellanica.

major, Syme, Engl. Bot. ed. III. xi. 63.-Deschampsia caespitosa, alpina.

media, Gouan, Illustr. 3 = Deschampsia juncea.

media, Trin. in Mém. Acad. Pétersb. Sér. V1. iv (1831) Suppl. $57=$ Deschampsia caespitosa.

melicoides, Michx. F1. Bor. Am. i. $62=$ Graphephorum melicoides.

micrantha, Steud. Syn. Pl. Gram. 423.-Madag.

miliacea, Vill. Hist. P1. Dauph. ii. $81=$ Poa miliacea.

minuta, Loefl. It. Hisp. 117.-Europ.; Oriens.

minuta, Loisel. Fl. Gall. i. $45=$ Airopsis agrostidea.

missurica, Spreng. Syst. ii. $578=$ brevifolia.

mollis, Muhl. Descr. Gram. $82=$ Eatonia purpurascens.

mollis, Schreb. Spicil. $51=$ Holcus mollis.

montana, Brot. ex Nym. Consp. $808=$ Deschampsia stricta.

\section{AIRA :-}

montana, Desv. Obs. Angers, $55=$ setacea. montana, Koel. Gram. 131 = Deschampsia flexuosa. montana, Linn. Sp. Pl. 65.-Europ.

mucronata, Spreng. Syst. i. $276=$ Eriachne brevifolia, mucronata.

multicautis, Kunth, Enum. Pl. i. $292=$ caryophyllea. multiculmis, Dum. Obs. Gram. Belg. $121=$ caryophyllea.

nana, Kunze, ex Steud. Nom. ed. II. i. $45=$ praecox.

nana, Spreng. ex Steud, 1. c. = caryophyllea.

nitida, Spreng. Mant. i. $32=$ Eatonia purpurascens.

nitida, Steud. Syn. Pl. Gram. 220.-Mexic.

nivea, Host, Fl. Austr. ii. 8.-Europ.

Notarisiana, Steud. Syn. Pl. Gram. $221=$ capillaris.

nutans, [Web. in] Wigg. Prim. Fl. Holsat. $7=$ Melica nutans.

obtusata, Michx, Fl. Bor. Am. i. 62=Eatonia obtusata. orzyetorum, Spreng. Pugill. ii. 18=Festuca arundinacea.

pallens, Muhl. Descr. Gram, $84=$ Trisetum palustre

pallens, Spreng. Fl. Hal. Mant. 36.-Hab.?

pallescens, Kit. in Roem. \& Schult. Syst. ii. 685.Hungar.

paludosa, Roth, Tent. Fl. Germ. ii. 1. 96=Deschampsia flexuosa.

paludosa, Wibel, Prim. Fl. Werth. $118=$ Deschampsia caespitosa.

palustris, Pollini, Cat. Ort. Veron. (1814) $8=$ Festuca arundinacea.

panicea, Willd, ex Steud. Nom, ed. II, i. $45=$ Leptochloa filiformis.

paradoxa, Steud.Syn. Pl.Gram. 223.-Guinea

parviflora, Thuil. Fl. Par. ed. II. i. 38=Deschampsia caespitosa.

parvula, Hook. f. Fl. Antarct. ii. 377.-Fuegia.

patulipes, Jord, ex Bor. Fl. Centr. Fr. ed. III. ii. $701=$ caryophyllea.

pensylvanica, Spreng. in Mém. Acad. Pétersb. (1810) 299. t. $7=$ Eatonia purpurascens.

petraea, Bellardi, ex Steud. Nom. ed. II. i. 45 ; ii. 361 $=$ Poa nemoralis.

phleoides, Steud. Nom. ed. I. $24=$ Koeleria phleoides.

pictigluma, Steud. Syn. Pl. Gram. 221.-Abyss.

pilosa, Kit. in Linnaea, xxxii. (1863) 310.-Austria.

plesiantha, Jord. ex Bor. FI. Centr. Fr. ed. III. ii. 701 $=$ caryophyllea.

poaeformis, Willd. ex Steud. Nom. ed. II. i. $45=$ Poa depauperata.

praecox, Linn. $S p . P l .65$.-Europ.; Am. bor.

provincialis, Gennar. ex" Nym. Consp. $814=$ Avena corymbosa.

provincialis, Jord. ex Jouve, in Bull. Soc. Bot. Fr. xii. (1865) 84. t. $1=$ capillaris,

pubescens, Vahl, Symb. Hii. $9=$ Koeleria villosa

pulchella, Nocca \& Balb. Fl. Tícin. i. 403 . t. add. $1=$ capillaris.

pulchella, Link, Hort. Berol. i. 130=Avena corymbosa.

pulchella, Willd. Enum. Hort. Berol. 101=lendigera. pulchra, Steud. Syn. Pl. Gram. 220.-Chili.

pumila, Agardh, ex Roem, \& Schult. Syst. ii. $578=$ minuta.

pumila, Pursh, Fl. Am. Sept. i. $76=$ Poa annua

pumila, Vill. ex Trin. in Mém. Acad. Pétersb. Sér. VI.

i. (1831) $572=$ Deschampsia juncea.

purpurea, Muhl. Descr. Gram. $85=$ Uralepsis aristulata.

purpurea, Walt: Fl. Carol. 78-Triplasis purpurea.

purpureo-argentea, Gilib. Exercit. ii. $526=$ caryophyllea.

pusilla, Schur, Enum. Pl. Transs. $754=$ praecox.

rara, Spreng. Syst. i. $278=$ Eriachne rara.

refracta, Lag. in Varied. Cienc. ii. IV. (1805) $39=$ Deschampsia refracta.

rigida, Dulac, Fl, Hautes-Pyr. $82=$ caryophyllea.

Ruprechtii, Griseb. ex Hook. f. in Trans. Linn. Soc. xxiii. (1861) $346=$ Avena Ruprechtii.

sabuletorum, Steud. Nom. ed. II. i. $45=$ sabulonum.

sabulonum, Labill. Sert. Austr. Caled. 16. t. 21.--Nov. Caled.

saburralis, Jan, Elench. 2, ex Guss. Fl. Sic. Syn. i. 148 $=$ caryophyllea.

saxatilis, Salzm, ex Trin. in Mém. Acad. Pétersb. Sér. VI. i. (1831) $59=$ capillaris

scabra, Kit. in Linnaea, xxxii. (1863) 309.-Austr.

scabra, Hort. ex Kunth, Enum. Pl. i. $370=$ Catabrosa viridula.
AIRA :-

scabra, Zuccagn. in Roem. Collect. $124=$ Catabrosa scrabra.

scabrosetacea, Knapp, Gram. Brit. t. $32=$ Deschampsia flexuosa.

semineutra, Waldst. \& Kit. in Schnlt. Oestr. Fl i. 199 = Poa semineutra.

serotina, Torr. sec. Trin. ex Steud. Nom. ed. II. i. 45. -Am. bor.

setacea, Huds. Fl. Angl. ed. I. 30 ; Retz. Obs. iii. 10.Europ.

setacea, Pourr. ex Nym. Consp. $808=$ Deschampsia juncea

setiformis, Host, sec. Trin. ex Steud. Nom. ed. II. i. 45.-Hab. ?

sicula, Spreng. Syst. i. $277=$ Holcus tenuis

sicula, Tod. Ind. Sem. Pan. (1872) 38 ; in Nuov. Giorn. Bot. v. (1873) 156.-Sicilia.

spectabilis, Steud. Syn. Pl. Gram. 224.-Afr. austr.

spicaeformis, Steud. l. c. 424.-Reg. Magell.

spicata, Linn. Sp. Pl. 63 = Trisetum subspicatum

spicata, Linn. 1. c. $64=$ Panicum indicum.

splendida, Willd. ex Steud. Nom. ed. II. i. $45=$ Deschampsia flexuosa.

squarrosa, Spreng. Syst. i. $278=$ Eriachne squarrosa.

stolonifera, Hausm. Fl. Tir. 890, sec. Neilr. Nachtr. $25=$ Deschampsia caespitosa

stricta, Nym. Consp. $808=$ Deschampsia stricta.

subaristata, Faye, ex Anderss. in Walp. Ann. vi. 992

$=$ Deschampsia juncea.

subspicata,Linn. Syst.ed. X. $873=$ Trisetum subspicatum. subspicata, Rainv. in Gort. F1. Belg. Foed. n. $74=$ praecox.

subtriflora, Lag. in Varied. Cienc, ii. IV. $39=$ Deschampsia juncea.

superbiens, Steud. Syn. Pl. Gram, 424-Reg. Magell. subulorum, D. Dietr. Syn. i. 339 err. = sabulonum

tenera, Kit. in Schult. Oestr. Fl. ed. II. i. 199.-Sla vonia; Banatus.

Tenorei, Fuckel, ex Willk \& Lange, Prod. i. $55=$ Agrostis capillaris.

Tenorii, Guss. Fl. Sic. Prod. i. $62=$ Avena corymbosa. tenuifolia, Steud. Syn. Pl. Gram. 223.-Chili

tenuissima, Spreng. Syst. i. $276=$ Sporobolus minuti florus.

Todari, Tenore, ex Tod. Ind. Sem. Hort. Panorm. (1859)

(Linnaea, xxx, (1859-60) 758)= caryophyllea

triaristata, Clarke, Trav. ii. 452.-Palaestina.

trichodes, Spreng. Syst. i. $276=$ Agrostis trichodes

triflora, Frivald. in Flora, xix. (1836) $433=$ Deschampsia caespitosa.

triflora, Ell. Sketch, i. 153=Graphephorum Elliotti.

triflora, Roem. \& Schult. Syst. ii. $680=$ Deschampsia juncea.

triflora, Willd. ex Steud. Nom. ed. II. i. $45=$ Corynephorus canescens.

triglumis, Steud. Syn. Pl. Gram. 223.-Texas.

truncata, Munl. Descr. Gram. $83=$ Eatonia obtusata.

truncata, Salzm. ex Trin. in Mém. Acad. Pétersb. Sér

VI. i. (1831) $58=$ caryophyllea.

uliginosa, Weihe, ex Boenn. Prod. F1. Monast. $25=$ setacea.

uniaristata, Cav. in Anales Cienc. Nat. vi. (1803) 148.-Hab. ?

valesiaca, Colla, Herb. Pedem. t. 94. f. $1=$ Koeleria setacea.

valesiana, Bertol, Fl. Ital. i. $438=$ praec

varia, Jacq. Hort. Vindob. $15=$ Sesleria caerulea.

variegata, Steud. Syn. Pl. Gram. 223.--Graecia.

versicolor, Roem. \& Schult. Syst. ii. 679.-'Port

Egmont.

vestita, Steud. Syn. Pl. Gram, 424.-Reg. Magell

viatica, Griff. Notul. iii. 54.-Reg. Himal.

villosa, Gilib. Exercit. ii. $527=$ montana.

villosa, Linn. f. Suppl, $109=$ Ehrharta gigantea,

violacea, Gilib. Exercit. ii. 525= Catabrosa aquatica.

violacea, Steud. Syn. Pl. Gram. 223.-Persia.

violacea, Willd. ex Steud. Nom, ed. II. i. $105=$ Panicum antipodum.

vivipara, Steud. Syn. Pl. Gram. 222,-Groenland,

viridula, Poir. Encyc. Suppl. ii. 75.-Hab. ?

Wibeliana, Sond. in Fl. Dan. t. 2461, 2522.-Europ,

Wilhelmsii, Steud. Syn. Pl. Gram. $219=$ Deschampsia caespitosa.

AIRIDIUM, Steud. Syn. Pl. Gram. 423 (1855)= Deschampsia, Beauv. (Gram.).

elegantulum, Steud. 1. c. = D. antarctica. 
AIROCHLOA, Link, Hort. Berol, i. 126 ; ii. 276 (1827) Koeleria, Pers. (Gram.)

albescens, Link, 1. c. i. $128=\mathrm{K}$. albescens.

capensis, Nees, in Mart. F1. Bras. ii. $321=\mathrm{K}$. capensis. caudata, Link, in Linnaea, xvii. (1843) $405=\mathrm{K}$. cras sipes.

cristata, Link, Hort. Berol. i. $127=$ K. cristata.

glauca, Link, ex Schur, Enum. PI. Transs. $751=\mathrm{K}$. glauca.

gracilis, Link, Hort. Berol. ii. $276=\mathrm{K}$. cristata

hirsuta, Link, l. c. i. $129=\mathrm{K}$. hirsuta.

hispida, Link, l. c. = K. hispida.

permollis, Nees, ex Steud. Syn. Pl. Gram. $293=\mathrm{K}$. permollis.

pubescens, Link, Hort. Berol. i. $128=$ K. cristata.

uniflora, Hochst. in Flora, xxxviii. (1855) 380.Afr. or.

valesiaca, Link, Hort. Berol. i. $127=\mathrm{K}$. setacea.

villosa, Link, 1. c. $128=\mathrm{K}$. villosa.

AIROPSIS, Desv. Journ. Bot. i. (1808) 200, pro parte. GRAMINEAE, Benth. \& Hook, f, iii. 1156. agrostidea, $D C$. Fl. Fr. Suppl. 262.-Europ. austr ampla, Nees, ex Steud. Nom. ed. II. i. 45.-Afr. austr. aurea, Nees, in Linnaea, vii. (1832) 317.-Afr. austr. brevifolia, Roem. \& Schult. Syst. ii, 578=Aira brevifolia.

Candolii, Desv. Journ. Bot. i. (1808) $200=$ agrostidea. capillaris, Schur, in Oestr. Bot. Zeitschr. ix. (1859) $328=$ Airæ capillaris.

caryophyllea, Schur, 1. c. = Aira caryophyllea.

Cupaniana, Lange, in Kjoeb. Vidensk. Meddel. (1860) $38=$ caryophyllea.

globosa, Desv. Fourn. Bot. i. (1808) 200.-Gall.; Hisp. glabra, Desv. Opuse. 64.-Ins. Borbon.

insularis, Nym. Syll. $411=$ Aira insularis.

involucrata, Desv. Journ. Bot. i. (1808) $201=$ Deschampsia involucrata. jubata, Griseb. in Goett. Abh. xxiv. (1879) 292,-Reg.
Argent.

lendigera, Lange, in Kjoeb. Vidensk. Meddel. (1860) $37=$ Aira lendigera.

millegrana, Griseb. in Goett. Abh. xix. (1874) $252=$ Eragrostis airoides.

minuta, Desv. Journ. Bot. i. (1808) $201=$ Catabrosa minuta.

multiculmis, Lange, in Kjoeb. Vidensk. Meddel. (1860) $38=$ Aira caryophyllea

obtusata, Desv. Journ. Bot. i. (1808) $200=$ Eatonia obtusata.

pallida, Nees, ex Steud. Nom. ed. II. i. $45=$ Eriachne pallida.

peruviana, [Nees \&] Meyen, Reise, i. 484=Dissanthelium supinum.

praecox, Schur, in Oestr. Bot. Zeitschr. ixa (1859) $328=$ Aira praecox. pulchella, Tenore, Fl. Nap. iii. 56, $102=$ Avena corym-
bosa.

Steudelii, Nees, in Linnaea, vii. (1838) $318=$ Eriachne capensis.

triseta, Nees, ex Steud. Nom. ed. II. i. $45=$ Eriachne triseta.

tuberculata, Nees, ex Steud. 1. c. =Eriachne tuberculata.

AITCHISONIA, Hemsl. ex Aitch. in Journ. Linn. Soc. xix. (1882) 166. t. 14. RUBIACEAE.

rosea, Hemsl. l. c.-Afghan.

AITHALES, Webb \& Berth. Phyt. Canar. i. 178 (1836) =Sedum, Linn. (Crassul.).

caespitosa, Webb \& Berth. 1. c. 179, $180=\mathrm{S}$. caespi. tosum.

rubens, Webb \& Berth. 1. c. $179=\mathrm{S}$. rubens.

AITITARA, Endl. Gen. 254. (1837)=ATITARA, Marcgr. =Evodia, Forst. (Kutac.).

AITONIA, Thunb. in Phys. Sallsk. Handl. i. (1776) 166 ; Nov. Gen, 52. SAPINDACEAE, Benth. llook. f, i, 411 .

Aytonia, Linn. f. Suppl. 49. 303 (1781).

capensis, Thunb. $l l . c c$. -Afr, austr.

AITOPSIS, Rafin. Fl. Tellur. iii. 91 (1836)=Salvia, Tourn. (Labiat.)

foliosa, Rafin. l. c. $=$ S. foliosa.
AIZODRABA, Fourr. in Ann. Soc. Linn. Lyon, N. S. xvi (1868) $335=$ Draba, Linn. (Crucif.).

airoides, Fourr. 1. $c_{0}=\mathrm{D}$. aizoides.

beugesiaca, Jord. \& Fourr. 1. c,-Gallia.

chrysantha, Jord. \& Fourr. 1. c.-Gallia.

ochroleuca, Jord. \& Fourr. 1. c, =D. algida.

saxigena, Fourr. 1. c. $=\mathrm{D}$, aizoides.

trichocarpa, Jord. \& Fourr. 1. c.-Gallia.

AIZOON, Linn. Gen. ed. I. 161 (1737). FICOIDEAE, Benth. \& Hook. f. i. 854.

Vestingra, Heist. Syst. (1748); Fabric. Hort

Helmst. 363 (1759)

angustifolium, D. Dietr. Syn. Pl. iii. $130=$ Acrosanthes angustifolia

argenteum, Eckl. \& Zeyh. Enum. $325=$ rigidum.

Camforosma, Reichb. ex Spreng. Syst. Cur. Post. 195. -Afr. austr.

canariense, Andr. Bot. Rep t. $201=$ Sesuvium pedunculatum.

canariense, Linn. Sp.Pl. 488.-Ins. Canar. ; Afr. bor.; Oriens.

contaminatum, Eckl. \& Zeyh. Enum, 326=Galenia secunda.

crystallinum, Eckl. \& Zeyh. 1.c. $327=$ Galenia crystallina.

elongatum, Eck1. \& Zeyh. 1. c. $326=$ Galenia secunda.

fistulasum, D. Dietr. Syn. P1. iii. $130=$ Acrosanthes fistulosa.

fruticosum, Eckl. \& Zeyh. Enum, $327=$ Galenia affinis.

fruticosum, Linn. f. Suppl. 261 = Galenia fruticosa.

galenioides, Fenzl, ex Harv. \& Sond. Fl. Cap. ii. 469. Afr. austr.

glinoides, Eckl. \& Zeyh. Enum, $325=$ Galenia secunda.

glinoides, Linn, f. Suppl, 261,-Afr, austr.

Herniaria, Reichb. ex Steud. Nom. ed. II. i. $46=$ Galenia herniariaefolia.

hirsutum, Eckl. \& Zeyh. Enum. $325=$ glinoides.

hispanicum, Linn. Sp. Pl. 488.-Hispan.

lanceolatum, Murr. Syst. Veg. ed. XIII. 392.-Afr austr.

microphyllum, Bartl. in Linnaea, vii. (1832) $541=$ Galenia herniariaetolia.

montevidense, Spreng. ex Rohr, in Mart. Fl. Bras. xiv.

II. $310=$ Sesuvinm Portulacastrum.

mossamedense, Welw. ex Oliver, Fl. Trop. Afr. ii. 584.-Afr. trop.

paniculatum, Linn. Sp. Pl. 488.-Afr. austr.

papulosum, Eckl. \& Zeyh. Enum. $326=$ Galenia papulosa.

perfoliatum, Linn. f. Suppl. $261=$ Tetragonia Zeyheri.

procumbens, Crantz, Inst. i. $135=$ canariense.

propinquum, Eckl. \& Zeyh. Enum, $326=$ Galenia secunda.

pubescens, Eckl. \& Zeyh. 1. c.= Galenia secunda.

quadrifidum, F. Muell. Fragm. ii. 148.-Austral

rigitum, Linn. f. Suppl. 261.-Afr. austr.

sarmentosum, Linn.f. l. c. 260.-Afr. austr.

secundum, Linn. f. 1. c. $261=$ Galenia secunda.

sericeum, Fenzl, ex Harv, \& Sond. Fl. Cap. ii. $470=$ rigidum.

sessiliflorum, Moench, Meth. $698=$ hispanicum.

spathulatum, Eckl. \& Zeyh. Entm. 325.-Afr. austr.

squamulosum, Eckl. \& Zeyh. 1. c。 $326=$ Galenia squamulosa.

stellatum, Lam. Encyc. iii. 418=sarmentosum.

teretifolium, D. Dietr. Syn. P1. iii. $130=$ Acrosanthes teretifolia.

tomentosum, Lam. Encyc. iii. 418 = paniculatum.

virgatum, Welsw. ex Oliver, Fl. Trop. Afr. ii. 584.Afrotrop.

Zeyheri, Sond. in Harv. \& Sond, Fl. Cap. i, 470.Afr. austr.

zygophylloides, F. Muell. Fragm. vii. 129.-Austral.

AIZOUM, Linn. Syst, ed. I. $(1755)=$ Aizoon, Linn. (Ficoid.).

AJAX, Salisb. in Trans. Hort. Soc, i. (1812) $343=$ Narcissus, Linn. (Amaryll.).

(NotA.-Cl. Baker Ajaces omnes ad Narcissum Pseudo-Narcissum ducit.)

abscissus, Haw. Rev, 116, $117=\mathrm{N}$, abscissus.

albicans, Haw. Monog. $2=\mathrm{N}$. Pseudo-Narcissus.

albus, Haw. Rev. $117=$ N. moschntus.
AJAX :-

bicalon, Salish. in Trans. Hort. Soc. $i_{\nu}$ (1812) $346=\mathrm{N}$ Pseudo-Narcissus.

breriflos, Haw. Monog. 2, n, $6=\mathrm{N}$. Pseudo-Narcissas, cambricus, Haw. 1. c. $3=$ N. Pseudo-Narcissus.

capax, M. Roem.Syn. Ensat. $201=$ N. Pseudo-Narcissus. cernu

cuneiflorus, Salisb. in Trans. Hort. Soc. i. (1812) 343 $=$ N. Pseudo-Narcissus.

cuneifolius, Haw. Rev. $43=\mathrm{N}$. Pseudo-Narcissus.

cyclamineus, Haw. Monog. 2. n, $4=\mathrm{N}$. Pseudo-Nar cissus.

fenestralis, S. F. Gray, Nat. Arr. Brit. P1. ii. $191=N$.

Psendo-Narcissus.

festalis, Salisb, in Trans. Hort. Soc. i. (1812) $347=\mathrm{N}$ Pseado-Narcissus, serratus.

glaucus, M. Roem. Syn. Ensat. $199=$ N. propinquus.

grandiflorus, Salisb. in Trans. Hort. Soc. i. (1812) 344 $=\mathrm{N}$. major.

hexangularis, Herb. Amar. 305.-Hab.?

hispanicus, M. Roem. Syn. Ensat. $200=$ N. PsendoNarcissus.

incomparabilis, Car. Prod. F1. Tosc. $616=\mathrm{N}$, in comparabilis.

lacinularis, Salisb. in Trans. Hort. Soc. i. (1812) 344 $=$ N. propinquas.

lobularis, Haw, in Phil. Mag. (1830) $131=$ N. Psendo Narcissus.

longiflorus, Salisb. in Trans. Hort. Soc. i. (1812) 349 $=\mathrm{N}$. tortuosus

lorifolius, Haw. Monog. 2. n. $7=$ N. Psendo-Nar cissus.

lusitanicus, M. Roena. Syn. Ensat. $202=$ N. triandrus. luteus, Herb. Amar. 304, 415. t. 38. f. $33=$ N. major. major, Haw. Rev, $116=\mathrm{N}$. major.

maximus, Haw. Monog. 3. n. $23=$ N. Pseudo-Nar. cissus.

minimus, Haw. 1. c. 1. n. $1=N$. Psendo-Narcissus.

minor, Herb. Amar. $299,415=\mathrm{N}$. Pseudo-Narcissus.

moschatus, Haw. Monog. $2=\mathrm{N}$. moschatus.

nanus, Haw. 1. c. 2. n. $5=$ N. Pseudo-Narcissus

nobilis, Haw. Syn. $327=$ N. Pseudo-Narcissus.

obvallaris, Haw. Rev. $120=\mathrm{N}$. Pseado-Narcissus.

odorus, Car. Prod. Fl. Tosc $616=\mathrm{N}$, odorus.

patulus, Salisb. in Trans. Hort. Soc. i. (1812) $348=1$

moschatus.

propinquus, Haw. Monog. iii. n. $22=$ N. PseudoNarcissus.

Pseudo-narcissus, Haw. 1. c. $2=$ N. Pseudo-Narcissus. pumilus, Haw. 1. c. 1. n. $3=\mathbf{N}$. Pseudo-Narcissus.

pygmaeus, M. Roem. Syn. Ensat. $201=$ N. Psetido-

Narcissus.

radians, M. Roem. 1. c. $193=$ N. Pseudo-Narcissus.

reflexa, M. Roem. 1. c. $202=\mathrm{N}$. triandrus.

Rudbeckit, M. Roem. 1. 201=N. Pseudo-Narcissus.

rugilobus, Haw, Monog, $3=\mathrm{N}$. Pseudo-Narcissus.

Sabiniamus, Herb. Amar. $306=\mathrm{N}$. Pseudo-Narcissus,

serratus, Haw. Rev, $114=\mathrm{N}$. serratus.

sexangularis, M. Roem. Syn. Ensat. $201=$ N. Pseudo-

Narcissus.

spurius, Haw. Syn. $327=$ N. Psendo-Narcissus.

Telamonius, Haw, 1, c $326=\mathrm{N}$. Pseudo-Narcissus.

tortuosus, Hav. Monog. $2=\mathrm{N}$. Pseudo-Narcissus.

tubaeflorus, Herb. Amar. $303=\mathrm{N}$. Pseudo-Narcissus.

AJOVEA, Juss. Gen. $80 \quad(1789)=$ Aiouea, Aubl. (Laurin.)

guianensis, Rafin. Sylva Tellur. 194=Aionea tenella.

AJUGA, Linn. Gen. ed. I. 167. n. 466 (17\%)

LABIATAE, Benth. \& Hook. 1. ii. 1222.

ABIGA, St. Lag. in Ann. Soc. Bot. Lyon, vii. Issi 85.

Bugula, Moench, Meth. $381(1 ; 94)$

Chamaepitys, Tourn. ex Rupp. Fl. Jen. ed. Hall, $220(1745)$

Moscharia, Forsk. Fl. Acgupt. Amb. 15 s $17 \% 5$

Phlebonatie, Tausch, in Flora, xi. 182s 320. acaulis, Brocchi, in Bibliot. Ital. xxix. 85.-Europ, adulterina $x$, Wallr. Beilr. Fl. Hercrn. 201.-Eurc: africana, Pers. Syn. ii. $109=$ Teucrium africanum, alpestris, Dum. Fl. Belg. $42=$ genevensis. alpiss, Fries, Mant iii. $34=$ reptans. alpina, Vill. Hist. Pl. Dauph. ii. 8ti pramidalis. alpina, Linn. Mant. $80=$ genevensis.

argyrea, Spapf, in Denkschr. Acad. Wim 1. 1ses)

108.-Lycir.

arenosa, Siev. ex Ledeb. Fl. Russ ii. $t \pm 1$ = oblonga: ... 


\section{AJUGA :}

astolonosa, Schur, Enum. Pl. Transs. 545.-Europ australis, R. Br. Prod. 503.-Austral.

Barrelieri, Tenore, F1. Nap. t. 240. f. $2=$ reptans. bombycina, Boiss. Fl. Orient iv, 803-As Min.

brachystemon, Maxim. in Bull. Acad. Pétersb. xxvii. (1883) 192.--Reg. Himal

bracteosa, Benth. in Wall. Pl. As. Rar. i. 59.-Afr. trop.; Ind. or.; As. or.

caespitosa, Schleich. ex Steud. Nom. ed. II. i. $46=$ pyramidalis.

capensis, Pers. Syn. ii, $109=$ Teucrium africanum.

Chamaecistus, Ging. ex Benth. Lab. Gen. et Sp. 698. -Persia.

Chamaepytis, Guss. F1. Sic. Prod, ii. $66=$ A. Chia.

Chamaepytis, Schreb. Pl. Vert. Unilab. 24.-Europ. Oriens.

Chia, Schreb. t. c. 25-Oriens.

ciliata, Bunge, Enum. Pl. Chin. Bor. 51.-Chin. bor.

comata, Stapf, in Denkschr. Acad. Wien, 1. (1885) 50 -Lycia.

controversa, Bor. in Mém. Soc. Acad. Maine-et-Loire,

vi. (1859) 136 ; xiv. (1863) 44-Gallia.

crenata, Hochst. ex Benth. in DC. Prod. xii. $597=$

bracteosa.

cryptostylon, Lagrèze-Fossat, ex Nym. Consp. $567=$ genevensis.

cuneatifolia, Stapf, in Denkschr. Acad. Wien, 1. (1885) 102.-Lycia.

decumbens, Tenore, Fl, Nap. Prod. 'p xxxiii'=acaulis.

decumbens, Thunb. Fl. Fap. 243.-Japon.

decumbens, D. Don, Prod. $108=$ maciosperma.

densifora, Wall. Cat. n. 2031; Benth. in Wall. Pl. As

Rar. j. $696=$ bracteosa.

densiflora, Tenore, F1. Nap. t. 239. f. 2 =reptans,

depressa, Maxim, in Bull. Acad. Pétersb, xxvil. (1883)

$192=$ parviflora

diemenica, Benth. Lab. Gen. et Sp. $695=$ australis.

disticha, Roxb. F1. Ind. iii. $2=$ Anisomeles malabarica

euphrasioides, Boiss. Diagn. Ser. I. vii. $63=$ A. Chamae

cistus.

flaccida, Baker, in Fourn. Linn. Soc. xx. (1884) 234.-

Madag.

foliosa, Tratt. Arch. Gewaechsk. i. $25=$ genevensis.

fruticosa, Roxb. Fl. Ind. iii. $1=$ Anisomeles mala

barica.

furcata, Link, Enum. Hort. Berol. ii. 99 = Crainotome

versicolor.

genevensis, Linn. Sp. Pl. 561.-Europ.; Oriens.

genevensis, With. Arr. Brit. Pl. ed. III. iii. $516=$ reptans.

geniculata, Maxim. in Bull. Acad. Pétersb. xxix. (1883)

$189=$ macrosperma

glabra, Benth. Lab. Gen. et Sp. $700=$ laevigata.

glabra, Presl, Fl. Sicul. Praef. $36=$ A. Chamaepitys,

glabrata, Benth. in Wall. Cat. n. $2041=$ Anisomeles ovata.

grosse-serrata, Franch. \& Sav. Enum. Pl. Fap. ii. 467 -Japon.

Hampeana x, A. Br. \& Vatke, in Oestr. Bot. Zeitschr. xxii. (1872) 357.-Europ.

humilis, Miq. Ann. Mus. Bot. Lugd. Bat. ii, 114.Japon.

hybrida $\times$, Kerner, in Oestr. Bot. Zeitschr. xxiv. (1874) 382.-Austria.

Hyosciami, Wall. ex Benth. in Wall. Pl. As. Rar. i. 59, $46=$ bracteosa

incisa, Maxim. in Bull. Acad. Pétersỏ. xxiii. (1877) 390.-Japon.

integrifolia, Buch.-Ham. in D. Don, Prod. Fl. Nep

108.-Nepal.

intermedia, Boiss. \& Orph. ex Boiss. Fl. Orient. iv. $802=$ A. Chia

interrupta, Dulac, F1. Hantes-Pyr. $407=$ genevensis. Iva, Schreb. Pl. Vert. Unilab. 15.--Reg. Mediterr. japonica, Miq. Ann. Mus. Bot. Lugd. Bat. ii. 114.Japon.

laevigata, Boiss. Fl. Orient. iv. 804-Oriens.

lanata, F. Mart. ex Steud. Nom. ed. II. i. $46=$ genevensis.

latifolia, Host, F1. Austr. ii. $119=$ genevensis.

latifolia, Schur, Enum. Pl. Transs. $545=$ astonolosa

Laxmanni, Benth. Lab. Gen, et Sp.697.-Oriens.

lobata, D. Don, Prod. Fl. Nep. 108.-Reg. Himal.

lucida, Bor. in Mém. Soc. Acad. Maine-et-Loire, xxi (1868) 9.-Corsica.

lupulina, Maxim. in Bull. Acad. Pétersb. xxiii. (1877) 390.-China. bor.

\section{AJUGA :-}

lycia, Stapf, in Denkschr. Acad. Wien, 1. (1885) 102. macrosperma, Wall. ex Benth. in Wall. Pl. As. Rar. i. 58.--Ind. or

mesogitana, Boiss. Diagn. Ser. I. vii. $62=$ A. Chia

mollissima, Wall. ex Steud. Nom. ed. II. i. $46=$ Anisomeles ovata.

montana, Reichb. F1. Germ. Excurs. $314=$ genevensis. moschata, Mill. ex Schreb. P1. Vert. Unilab. $26=$ A. Iva.

multiflora, Bunge, Enum. Pl. Chin. Bor. 51.-China bor.

nana, Gilib. Fl. Lituan. 323.-Europ.

Nanti, Bor. in Mém. Soc. Acad. Maine-et-Loire, xiv. 1863) 44.-Gallia.

oblongata, Bieb. Fl. Taur. Cauc. Suppl. 388.-Caucas, ophrydis, Burch. ex Benth. in DC. Prod. xii. 597.Afr. austr.

orientalis, Linn. Sp.Pl.561.-Oriens

ovata, Wall. Cat. n. 2036.-Burma

palaestina, Boiss. Diagn. Ser. I. xii. $92=$ A. Chia

parviflora, Benth. in Wall. Pl. As. Rar. i. 59.-Reg. Himal.

pserdoiva, Rob. Cast. ex DC. Fl. Fr. v. 395=A. Iva.

psendo-pyramidalis, Schur, in Verh. Siebenb. Ver. Naturw. iv. (1853) 60.-Europ.

pumila, Schur, Enum. Pl. Transs. 545.-Europ.

pygmaea, A. Gray, in Mem. Am. Acad. N. S. VI 1858-9) 402. -Japon.

pyramidalis, Bieb. F1. Taur. Cauc. ii. $32=$ genevensis.

pyramidalis, Huds. F1. Ang. ed. I. $219=$ reptans.

pyramidalis, Linn. Sp. Pl. 561.-Europ.

remota, Benth. in Wall. Pl. As. Rar. i. $59=$ bracteosa

repens, Gueldenst. ex Ledeb. Fl. Ross。 iii. $447=$ reptans.

repens, Roxb. Fl. Ind, iii. $3=$ macrosperma

reptans, Linn.Sp. Pl. 561.-Europ.

robusta, Baker, in Fourn. Linn. Soc. xx. (1884) 235.Madag.

rotundifolia, Willk. \& Cut. ex Willk. in Linnaea, xxx. (1859-60) 120.-Hispan.

rugosa Host, Fl. Austr, ii. $120=$ genevensis.

rupestris, Schleich. ex Steud. Nom. ed. II. i. $46=$ pyramidalis.

salicifolia, Schreb. Fl. Vert. Unilab. 26.-As. Min.

salicifolia, Stev. in Mém. Soc. Nat. Mosc. iii. (1812) $265=$ oblongata.

scoparia, Boiss. Diagn. Ser. I. vii. $63=$ A. Chamaecistus.

sikkimensis, Miq. Ann. Mus. Bot. Lugd. Bat. ii. 114 in $\mathrm{syn}_{.}=$macrosperma.

sinuata, R. Br. Prod. 503.-Austral.

stolonifera, Feanb. E Timb. in Bull. Sc. Phys. \& Nat. Toulouse, iii. (1875-76) 577.-Europ.

Tenorii, Presl, F1. Sicul. Praef. p. xxxvi = acaulis.

Thomsoni, Maxim. in Bull. Acad. Pétersb. xxix. (1883) $189=$ macrosperma

tridentata, Benth. Lab. Gen. et Sp. $701=$ australis

tridactylites, Ging ex Benth. 1. c. $699=\mathrm{A}$. Chia.

trifida, Dulac, Fl. Hautes-Pyr. $406=$ A. Chamaepitys.

trifidifotia, Stokes, Bot. Mat. Med. iii. 288=A Chamaepitys.

vesiculifera, Herd. in Bull. Soc. Nat. Mosc. xli. (1868) r. 394.-As. temp.

vestita, Boiss. Diagn. Ser. I. vii. 62.Graecia.

virgata, Benth. Lab. Gen. et Sp. $700=$ australis.

yesoensis, Maxim. ex Franch. \& Sav. Enum. Pl. Fap. ii. 467.-Japon.

AJUVEA, Steud. Nom. ed. I. $25(1821)=$ Aiouea, Aubl. (Laurin.).

AKANIA, Hook. fo in Benth. \& Hook. f. Gen, i. 409 (1862). SAPINDACEAE, Benth. \& Hook. f. i. 409. Hillii, Hook. f. l. c. -Austral,

AKEA, Stokes, Bot. Mat. Med. ii. 353 (1812)= Blighia, Koen. (Sapind.) solitaria, Stokes, 1. c. $354=$ B. sapida.

AKEBIA, Decne, in Arch. Mus. Par. i. (1837) 195.t. 13. BERBERIDEAE, Benth. \& Hook. f. i. 42. clematifolia, Sieb. Es Zucc. Fl. Fap. i. 146.-Japon. lobata, Decne, in Ann. Sc. Nat. Sér. II. xii. (1839) 107. -Japon.

quercifolia, Sieb. \& Zucc. Fl. Fap. i. 146.-Japon quinata, Decne. in Ann. Sc. Nat. Sér. II. xii. (1839) 107.-China.
AKEESIA, Tussac, Fl. Antill. i. $66(1808)=$ Blighia, Koen. (Sapind.)

africana, Tussac, I. $\mathrm{c}=\mathrm{B}$. sapida.

AKENTRA, Benj. in Linnaea, xx. (1847) $319=$ Utricu laria, Linn. (Lentib.).

inflata, Benj. 1. c.-Surinam.

AKLEMA, Rafin. F1. Tellur. iv. $114(1836)=$ Eu phorbia, Linn.

nudiflora, Rafin. 1. c. = E. nudiflora.

AKYLOPSIS, Lehm. Ind. Sem. Hort. Hamb. (1850) 3; of Otto Hamb. Gartz. viii. (1852) $549=$ Matricaria, Linn. (Compos.)

suaveolens, Lehm. 1. c. = M. discoidea

ALACOSPERMUM, Neck, Elem, i. $167(1790)=$ Cryptotaenia, DC. (UmbelI.).

ALAFIA, Thou. Gen, Nov. Madag. 11 (1809). APO CYNACEAE, Benth. \& Hook. f. ii. 717.

Blastotrophe, Didrichs, in Kjneb. Vidensk.

Meddel. (1854) 192.

madagascariensis, Rich. ex A. DC. in DC. Prod. viii $415=$ Thonarsil.

pauciflora, Radlk. in Bremen Abh. viii. (1883) 403.Afr. trop.

Thouarsii, Roem. Collect. i. 203.-Madag.

ALAGOPHYLLA, Rafin. Fl. Tellur. ii. $33(1836)=$ Gesnera, Linn.

dasyanthes, Rafin. 1. c.-Hab.?

ALAGOPTERA, Mart, Gen. Comm, 267 (1842)= ALLAGOPTERA, Nees=Diplothemium, Mart (Palm.).

ALALANTIA, Corr, in Ann. Mus. Hist. Nat. Par, vi 1804) 383, err. typ. = Atalantia, Corr. (Rutac.).

ALAMANIA, La Llave \& Lex. Nor. Veg. Descr. Fasc ii. (Orch. Opusc.) 31. ORCHIDEAE, Benth. \& Hook. f, iii. 526 .

punicea, La Llave Es Lex. l. c.-Mexic.

ALAMANNIA, Lindl. Orch. Scel. $14(1826)=$ praec

ALANDINA, Neck. Elem. ii. $45.6(\mathbf{1 7 9 0})=$ Moringa, Juss.

ALANGIUM, Lam. Encyc. i. 174 (1783). CORNA $C E A E$, Benth. \& Hook. f. i. 949

ANGOLAM, Adans. Fam, ii. 85 (1763)

KARA-ANGOLAM, Adans. Fam. ii. 84 (1763)

acuminatum, Wight, ex Steud. Nom. ed. II. i. $47=$ Lamarckii.

begoniaefolium, Baill. Hist. Pl. vi. 270=Marlea begoniaefolia.

cordifolium, Zoll. Es Mor. ex Zoll. Syst, Verz. Ind. Archip. 63.-Malaya.

decapetalum, Lam. Encyc. i. 174 = Lamarckii

ebenaceum, Griff. ex C. B. Clarke, in Hook. f. F1. Brit Ind. ii. $742=$ Marlea ebenacea .

frutescens, Zoll. E Mor. ex Zoll. Syst. Verz. Ind. Archip. 63.-Malaya.

glandulosum, Thw. Enum. P1. Zeyl. 133 = Lamarckii.

hexapetalum, Lam. Encyc. i. $174=$ Lamarckii.

Lamarckii, Thw. Enum. Pl. Zeyl. 133.-Geront. trop.

latifotium, Miq, ex C. B. Clarke, in Hook, f. Fl Brit Ind ii $741=$ Lamarckii

Mohillae, Tul. in Ann. Sc. Nat.Sér. IV. vi. (1856) 105. -Ins. Comor.

octopetalum, Blanco, Fl. Filip. ed. II. $310=\mathrm{La}$ marckii.

sundanum, Miq. Fl. Ind. Bat. i. I. 774=Lamarckii.

tomentosum, Lam. Encyc. i. $174=$ Lamarckii.

ALANIA, Endl. Gen. P1. 151 (1836). LILIACEAE, Benth. \& Hook. f. iii. 797.

Allania, Meissn. Gen. 401 (304) (1842)

Cunninghami, Steud. Nom. ed. II. 1. 47.-Austral

Endlicheri, Kunth, Enum. Pl. iv. $644=$ Cunning hami. 
ALARÇONIA, DC. Prod. v. $537(1836)=$ Wyethia Nutt. (Compos.).

anoustifolia, DC. 1. c. $=$ W. angustifolia.

helenioides, DC. 1. c. $=$ W. robusta.

ALATERNOIDES, Adans. Fam. ii. $304 \quad(1763)=$ Phylica, Linn. (Rhamnac.).

ALATERnUS, [Tourn.] Mill. Gard. Dict. ed, VI. $(1752)=$ Rhamnus, Linn,

alpinus, Moench, Meth. $344=$ R. alpinus.

angustifolia, Mill. Gard. Dict. ed. VIII. n. $3=\mathrm{R}$. Alaternus.

balearica, Duham. ex Steud. Nom. ed. I. $685=$ R. Alaternus.

cordatus, Rafin. Sylva Tellur. 27.-Hab. ?

glabra, Mill. Gard. Dict. ed. VIII. n. $2=$ R. Alaternus. glandulosus, Rafin. Sylva Tellur。 $27=\mathrm{R}$, glandulosus.

hispanicus, Hort. ex Stend. Nom. ed. I. $685=$ R. Alaternus.

hybridus, Rafin. Sylva Tellur. $27=$ R. hybridus.

integrifolizes, Rafin. 1. c. = R. integrifolius.

lanceolatus, Rafin. I. c. $=$ R. lanceolatus.

latifolia, Mill. Gard. Dict. ed. VIII. n, $4=$ R. Alaternus.

ovatus, Rafin. Sylva Tellur. 27.-Hab. ?

Phylica, Mill. Gard. Dict. ed. VIII. n. 1=R. Alaternus.

prinoides, Rafin. Sylva Tellur. $27=\mathrm{R}$. prinoides.

pumilus, Rafin. $1 . \mathrm{c} .=\mathrm{R}$. pumilus.

rotundifolia, Hort. ex Stend. Nom. ed. I. $685=$ R Alaternus.

sempervirens, Roehl. ex Steud. Nom. ed. I. $493=$ Lonicera sempervirens.

variegata, Hort. ex Stend. Nom. ed. I. $685=$ R. Alaternus.

ALATHRAEA, Steud. Nom. ed. II. ii. 13, in syn. (1841) $=$ seq.

ALATRAEA, Neck. Elem. i. $374(1790)=$ Phelypaea, Tourn. (Orobanch.)

ALBERSTA, Kunth, Fl. Berol. ed. II. ii. 144 (1838)= Amarantus, Linn.

arenaria, Schur, Enum. Pl. Transs. $566=$ Am. Blitum. ascendens, Fourr. in Ann. Soc. Linn. Lyon, N. S. xvii. 1869) $142=\mathrm{Am}$. ascendens

Blitum, Kunth, FI. Berol, ed. II. ii. $144=$ Am. Blitnm. caudata, Boiss. Fl. Orient. iv. $992=$ Am. viridis.

deflexa, Fourr. in Ann. Soc. Linn. Lyon, N. S. xvii. (1869) $142=$ Am. deflexus.

gracilis, Webb \& Berth. Phyt. Canar. iii. 287=Am. gracilis.

livida, Kunth, Fl. Berol. ed. II. 144=Am. Blitum. oleracea, Kunth, 1. c. = Am, Blitum.

polygama, Boiss. Fl. Orient. iv. $991=$ Am. polygamns. polygonoides, Kunth, Fl. Berol. ed. II. ii. $144=$ Am. polygonoides.

polystachya, Kunth, $\mathrm{l} . \mathrm{c} .=\mathrm{Am}$. polystachyus.

prostrata, Kunth, l. $\mathrm{c}_{\mathrm{o}}=\mathrm{Am}$. deflexus.

ALBERTA, E. Mey. in Linnaea, xii. (1838) 258. RUBIACEAE, Benth. \& Hook. f. ii. 109.

laurifolia, Baker, in Fourn. Linn. Soc. xviii. (1881) 271.-Madag.

magna, E. Mey, in Linnaea, xii. (1838) 258.-Afr. austr.

minor, Baill. Adansonia, xii. (1876-79) 247.Madag.

ALBERTIA, Regel \& Schmalh. in Act. Hort. Petrop v. (1877) 603. UMBELLIFERAE commutata, Regel \& Schmalh. l. c. 604.-Turkestan, margaritifera, Regel \& Sclimalh. l. c. 605.-Turkestan. paleacea, Regel \& Schmalh. .. c. 606.-Turkestan.

ALBERTINIA, Spreng. Neue Entcleck. ii. 133 (1821). COMPOSITAE, Benth. \& Hook. f. ii. 227

Symblomeria, Nutt. in Trans. Am, Phil. Soc. Ser. II. vii. (1841) 284

arborea, Gardn. in Hook. Lond. Joum. Bot. v. (1846) 236 $=$ Vanillosmopsis arboren

bardanoides, Mart. in DC. Prod, v. $81=$ Vernonia crotonoicles.

bicolor, DC. Prod, v. $81=$ Eremanthus bicolor.

\section{ALBERTINIA}

bicolor, Gardn. in Hook. Lond. Journ. Bot. v. (1846) $236=$ Eremanthus incanus.

brasiliensis, Spreng. Neue Entdeck, ii. 133.-Bras Candolleana, Gardn. in Hook. Lond. Joum. Bot. 1846) $235=$ Vanillosmopsis erythropappa. capitata, DC. Prod. v. $82=$ Vanillosmopsis capitata. Clausseni, Sch. Bip. ex Baker, in Mart. F1. Bras. vi. I $\mathbf{1 5}=$ Vanillosmopsis erythropappa

crotonoides, DC. Prod, v, $81=$ Vernonia crotonoides.

Elaeagnus, Mart. ex DC. 1. c $=$ Eremanthus Elaeagnus. erythropappa, DC. in Deless. Ic. Sel. iv. t. 5. Bras. erythropappa, Gardn. in Hook. Lond. Journ. Bot. y. (1846) $286=$ Vanillosmopsis polycephala.

glomerulata, DC. Prod, v. $82=$ Eremanthus glomerulatus.

gonoclados, Mart. ex Baker, in Mart. Fl. Bras. vi. II. $144=$ Piptolepis Martiana

groyazensis, Gardn. in Hook. Lond. Journ. Bot. vi (1847) $425=$ Eremanthus goyazensis.

incana, Less. in Linnaea, iv. (1829) $342=$ Eremanthus incanus.

incanescens, Mart, ex Baker, in Mart. Fl. Bras. vi. II $\mathbf{1 5}=$ Vanillosmopsis erythropappa.

mollis, Sch. Bip. ex Baker, 1. c. 164=Eremanthus mollis.

multiflora, Mart. in DC. Prod. v. $82=$ Vanillosmopsis polycephala.

obtusata, Mart. 1. c. $81=$ Eremanthus glomerulatus.

Oleaster, Mart. ex Baker, in Mart. Fl. Bras. vi. II. 145

=Vernonia Oleaster.

pallidiseta, DC. Prod.v. $81=$ Eremanthus glomerulatus, polycephala, DC. l. c. $82=$ Vanillosmopsis polycephala rufiseta, DC. 1. c. $81=$ Eremanthus glomerulatus.

saligna, Mart. in DC. 1. c. $82=$ Vanillosmopsis polycephala.

stellata, Gardn. in Hook. Lond. Fourn Bot. v. (1846) 235.-Bras

verbascifolia, Mart. in DC. Prod. v. $81=$ Vernonia crotonoides.

ALBERTINIA, DC. Prod. v. 82, pro parte (1836)= Vanillosmopsis, Sch. Bip. (Compos.).

ALBERTISIA, Bece. Malesia, i. (1877) 161. MENI SPERMACEAE

papuana, Becc. l. c. $162=$ N. Guin.

ALBIKIA, J. \& C. Pres1, Rel. Haenk. i. 184 et 34, 35 (1828) = Hypolytrum, Rich. (Cyperac.).

schoenoides, C. Presl, 1. c. $185=\mathrm{H}$, trinervium.

scirpoides, C. Presl, 1. c. $=$ H. latifolium.

ALBINA, Giseke, Prael. Linn. 199, 207 (1792)=Alpinia Linn. (Scitam.)

ALBINEA, Hombr. \& Jacquinot, ex Decne. Bot. Voy Astrol. et Zel. 37 (1853) = Pleurophyllum, Hook f. (Compos.

oresigenesa, Hombr. \& Jacquinot, ex Decne. 1. c. $=$ P. oresigenesum.

ALBIZIA, Auct. $=$ seq

ALBIZZIA, Durazz in Mag. Tosc jii. IV. (1772) 11 F. Muell. in Journ. Bot. x. (1872) 8. LEGUMI NOSAE, Benth. \& Hook. f. i. 596.

BesenNa, A. Rich. Tent. Fl. Abyss. i. 253 (1847). Serianthes, Benth. in Hook. Lond. Journ. Bot. iii (1844) 84 in nota.

SrRICANDRA, Rafin. Sylva Tellur. 119 (1838)

ZYGIA, Benth, in Hook. Lond. Journ. Bot. iii. (1844) 92.

acrodena, Miq. Fl. Ind. Bat. i. Suppl. 281.-Sumatra. affinis, Fourn. in Ann. Sc. Nat. Sér. IV. xiv. (1860) $371=$ amara

altissima, Hook. f. in Hook. Niger Fl. $332=$ Pithecolobium altissimum.

amara, Boiv. in Encyc. xix. Siccle, ii. 34.-Ind. or. amoenissima, F. Muell. Fragm, viii. 165.-Austral angolensis, Welw. in Oliver, Fl. Trop. Afr. ii. 360 . Afr. trop.

anthelmintica, Brongn. in Bull. Soc. Bot. Fr. vii. (1860) 902.-Abyss.

auriculata, Fourn, in Ann. Sc. Nat. Sér. IV. xii. (1S65) $400 .-N$. Caled.

basaltica, Benth. Fl. Austral. ii. 422,-Austral.

\section{ALBIZZIA}

Benthamiana, Blume, ex Miq. F1. Ind. Bat. i. 30 montana.

bigemina, F. Muell. Sel. Pl. Indust. Cult. 264 Pithecolobium bigeminum.

Boivini, Fourn. in Ann. Sc. Nat. Sér. IV. xiv. (1860) 378.--Madag.

brachycalyx, Oliver, Fl. Trop. Afr. ii. 361.-Afr. trop

Brownii, Walp. Rep. i. 928.-Afr. trop.

bubalina, Kurz, in fourn. As. Soc. Beng. xlv. (18\%6) II. 129.-Ins, Nicob.

canescens, Benth. Fl. Austral. ii. 423.-Austral.

Championi, Benth, in Hook. Kew Joum. iv. (1852) is $=$ Pithecolobium lucidum.

Charpentieri, Fourn. in Bull. Soc. Bot. Fr. xii. (1865) 400.-N. Caled.

clypearia, Kurz, in Fourn. As. Soc. Beng. xlv, (18\% II. 129.-Ins. Nicob.

conjugato-pinnata, Vatke, in Oestr. Bot. Zeitschr. xxy. 1880) 278.-Afr. trop.

coriacea, F. Muell. Sel. Pl. Indust. Cult. $264=$ Pitheco obium subcoriaceum.

coriaria, Welw. in Oliver, Fl. Trop. Afr. ii. 360.Afr. trop.

cyclosperma, Benth. in Hook. Lond. Journ. Bot. i. (1812) $527=$ fulgens

dulcis, F. Mrell. Sel. P1. Indust. Cult. $12=$ Pithecolobium dulce.

elata, Benth. in Hook. Lond. Journ. Bot. i. (1842) 527 $=$ procera.

elegans, Kurz, in Pegu Rep. App. B. 47.-Burma

elliptica, Fourn. in Ann. Sc. Nat. Sér. IV. xiv. (1860 374.-Abyss.

fasciculata, Kurz, in fourn. As. Soc. Beng. xlv. (1876) II. 129,-Ins. Nicob.

fastigiata, Oliver, Fl. Trop. Afr, ii. 361-A fr, trop.

ferruginea, Benth. in Hook. Lond. Fourn. Bot. iii. (1844) 88.-Abyss.

foribunda, Fenzl, Reliq. Kotschy (1868). 5. t. $4=$ anthelmintica.

Forbesii, Benth. in Hook. Lond. Fourn. Bot. iii. (1844) 92.-Afr. trop.

Fournieri, Vieill, in Bull. Soc. Linn. Normand, ix (1865) $341=$ Pithecolobium Eournieri.

fulgens, Benth. in Hook. Lond. Fourn. Bot. iii. (184) 85.-Austral.; N. Caled.

glaberrima, Benth. l.c. 88.-Guinea.

glabrescens, Oliver, Fl. Trop. Afr. ii. 357.-Afr. trop.

glomeriflora, Kurz, in Fourn. As. Soc. Beng. xlii. (1873) II. 74-Burma

granulosa, Benth. in Hook. Lond. Foncrn. Bot. iii. (1844) $85 \ldots \mathrm{N}$. Caled.

Harveyi, Fourn. in Bull. Soc. Bot. Fr. xii. (1865) 39: -Afr. trop.

Hendersonia, F. Muell. in Journ. Bot. x. (1872) $10=$ Pithecolobium Hendersonii.

heterophylla, Kurz, in Fourn. As. Soc. Beng. xlv. (1876) II. 300.-Burma.

hypoleuca, Oliver, Fl. Trop. Afr, ii. $356=$ Harveyi.

Isembergiana, Benth. in Hook. Lond. Joura. Bot. (1842) $527=\mathrm{A}$. Julibrissin.

Jaubertiana, Fourn. in Ann. Sc. Nat. Sér. IV. xiy. (1860) 381.-Madag.

Jiringa, Kurs, in Fourn. As. Soc. Beng. xlv. (1576) It. 300.-Burma.

Julibrissin, Durazs. in Mag. Tosc. iii. IV. (17\%2) 11.As.; Afr. trop.

Funghuhniana, F. Muell. in Journ. Bot. x. $(1872) 9=$ Pithecolobium Junghuhnianum.

latifolia, Boiv. in Encyc. xix. Siècle, ii. $33=$ A. Lebbek latisilioua, F. Mucll. Sel. Pl. Indust. Cult. $12=$ Lysiloma latisiliqua.

Lebbek, Benth. in Hook. Lond. Foum. Bot. iii. (184t) 87.-Geront. trop.

lebbekioides, Benth. l. c. 89=0doratissima.

lentiscifolia, Benth. in Trans. Linn. Soc. xex. (19is 559.-N. Calcd.

littoralis, Teijsm. \& Binn, in Tijdschr. Nev. Ind. xxix. (1866) 259 -Moluce.

lomatocarpa, DC. Prod. ii. $46 \%=$ odoratissima.

lophantha, Berth. in Hook. Lond. Gourn. Bot, iii. (184t) 86..-Austral.

lucida, Benth. 6. c.-Ind. or. : Malaya

macrothyrsa, Miq. Fi. Ind. Bof. i. Suppl. 281. - Iava.

malacophvlla, Walp. Ann. ii. $45 \%$ - ferruginea.

marginata, Buch.-Ham, ex Wall. Cat. D. 5:49 stipulata. 


\section{ALBIZZIA :}

micrantha, Boiv, in Encyc, xix. Siècle, ii. $34=$ odora tissima.

Milleti, Benth. in Hook. Lond. Fourn. Bot. iii. (1846) 89.-China.

mollis, Boiv. in Encyc. xix. Siècle, ii. $33=$ A. Julibrissin moluccana, Miq. Fl. Ind. Bat. i, 26.-Ins. Molucc. monilifera, F. Muell. in Fourn. Bot. x. (1872) 10.Austral.

montana, Benth. in Miq. Pl. Fungh. 267.-Java.

mossambicensis, Bolle, in Peters, Reise Mossamb. Bot i. 4.-Afr, trop.

myriophylla, Benth. in Hook. Lond. Fourn. Bot. 'iii. (1844) 90.-Ind, or

nefasia, Walp. Ann. ii. $457=$ Acacia abyssinica.

nellyrenza, R. Grah. in Wall. Cat. n. $5240=$ amara.

Nemu, Benth. in Hook. Lond. Journ. Bot. i. (1842) $527=$ A. Julibrissin.

Neumanniana, Heynh. Nom. ii. 17.-Austral.

obovata, Benth. in Trans. Linn. Soc. xxx. (1875) 558. -N. Caled.

odoratissima, Benth. in Hook. Lond. Fourn. Bot. iii. (1844) 88.- Ind. or.

paivana, Fourn. in Ann. Sc. Nat. Sér. IV. xv. (1861) 172.-N. Caled.

pallida, Fourn. l.c. xiv. (1860) 375.-Abyss.

pallida, Harv. in Harv. \& Sond, F1. Cap. ii. $284=$ Harveyi.

pedicellata, Baker, ex Benth. in Trans. Linn. Soc. xxx. (1875) 563.--Malacca.

Petersiana, Oliver, Fl. Trop. Afr. ii. 362.-Afr. trop. polyphylla, Fourn. in Ann. Sc. Nat. Sér. IV. xiv. (1860) 372.-Madag.

procera, Benth. in Hook. Lond. Fourn. Bot. iii. (1844) 89.-As. trop. ; Austral.

pruinosa, F. Muell, in Journ. Bot. x. (1872) $9=$ Pithecolobium pruinosum

purpurascens, Blume, ex Miq. FI. Ind. Bat. i. I. $28=$ stipulata.

purpurea, Boiv. ex Fourn. in Ann. Sc. Nat. Sér. IV. xiv. (1860) 378.-Ins. Comor.

Quartiniana, Walp. Ann. ii. 457.-Abyss.

ramiflora, F. Muell. Fragm.ix, 178.-Austral.

retusa, Benth. in Hook. Lond. Fourn. Bot. iii. (1844) 90.-Ins. Philipp.

rhombifolia, Benth. l.c. 87.--Senegal.

rivularis, Fourn. in Ann. Soc. Sc. Nat. Sér. IV. xv. (1861) $172=$ fulgens.

rosea, Carr. in Rev. Hortic. (1870-71) 490.-Am. bor.

rostrata, Blume, Miq. Fl. Ind. Bat. i. $24=$ Pithecolobium rostratum.

rotundata, Blume, l. c. 20.-N. Guinea.

rubiginosa, $M i q$. l. c. 27.-Java.

rufa, Benth. in Hook. Lond. Fourn. Bot. v. (1844) 101.-As. trop.; Java.

salajeriana, Miq. Fl. Ind. Bat. i. I. 21.-Ins. Salager.

Saman, F. Muell. Sel. Pl. Indust. Cult. $12=$ Pitheco-

lobium Saman.

saponaria, Blume, Miq. Fl. Ind. Bat. i. I. 19.-N. Guin. Schimperiana, Oliver, Fl. Trop. Afr. ii. 359.-Afr. trop. sericocephala, Benth, in Hook. Lond. Journ. Bot. iii.

(1844) $91=$ amara

Smithiana, Benth. l. c. i. (1842) $527=$ stipulata.

speciosa, Benth. 1. c. = A. Lebbek.

splendens, Miq. Fl. Ind. Bat. Suppl. 280.-Sumatra

stipulata, Boiv. in Encyc. xix. Siecle, ii. 33.-Ind. or.

streptocarpa, Fourn. in Bull. Soc. Bot. Fr. xii. (1865) 399. - N. Caled.

subfalcata, Benth. in Trans. Linn. Soc. xxx. (1875) 559.-N. Caled.

Sutherlandi, F. Muell. Fragm. vi. 22.-Austral.

tenerrima, De Vriese, in Miq. Pl. Jungh. $270=$ Acacia pennata.

tengerensis, Miq. Fl. Ind. Bat. i. 25.-Tava.

Teysmanni, Kurz, in Fourn. As. Soc. Beng. xlv. (1876)

II. 299, 300.-Burma.

Thozetiana, F. Muell. ex Benth. Fl. Austral. ii. 422.Austral.

tomentella, $\mathrm{Miq}$. Fl. Ind. Bat. i. I. 20.-Java.

Tozeri, F. Muell. in Journ. Bot. x. (1872) $10=$ Pithecolobium grandifforum.

umbrosa, Benth. in Hook. Lond. Journ. Bot. iii. (1844) $86=$ Calliandra umbrosa.

Vaillantii, F. Muell. Fragm. v. $9=$ Archidendron Vaillantii.

versicolor, Welw. ex Oliver, $\mathrm{Fl}$. Trop. Afr. ii.359,-Afr. trop.

\section{ALBIZZIA :-}

viridis, Fourn. in Ann. Sc. Nat. Sér. IV. xiv. (1860) 377.-Madag.

Welwitschii, Oliver, Fl. Trop. Afr, ii. 362.-Afr. trop.

Wightii, Wight \& Arn. Prod. $274=$ amara.

Wightiana, R. Grah. in Wall. Cat. n. $5259=$ amara.

ALBRADIA, D. Dietr. Syn. v. $280(\mathbf{1 8 5 2})=$ seq.

ALBRANDIA, Gaudich. in Freyc. Voy. Bot. $509(1826)=$ Streblus, Lour. (Urtic.)

Gaudichaudi, D. Dietr. Syn. Pl. v. $280=$ S. asper?

orientalis, D. Dietr. 1. c. $=\mathrm{S}$. asper

spinosa, D. Dietr. 1, $\mathrm{c}=$ Taxotrophis zeylanica

timorensis, D. Dietr. 1. c. $=$ Taxotrophis zeylanica.

ALBUCA, Linn. Sp. PI. ed. II. 438 (1762). LILIA$C E A E$, Benth. \& Hook. fo iii. 809 .

Branciona, Salisb. Gen. Pl. Fragm. 36 (1866)

FAlconera, Salisb. 1. c. (1866)

Nemaulax, Rafin. Fl. Tellur. iii. 52 (1836).

Pallastema, Salisb. Gen. Pl. Fragm. 36 (1866)

VIRDIKE, Adans. Fam. ii. (19) (1763).

abyssinica, Dryand, in Vet. Acad. Nya Handl.

Stockh. (1784) 297 ; Facq. Coll. i. 55.-Afr. austr.

alba, Lam. Encyc. i. $76=$ altissima.

altissima, Dryand. in Vet. Acad. Nya Handl. Stockh.

(1784) 292 ; $7 a c q$. Coll. ii. 264.-Afr. austr.

angolensis, Welw. Apont. 591 ; et in Saund. Ref. Bot.

t. 336.-Angola.

anthericoides, Sweet, Hort. Brit. ed. I. $417=$ Ornitho galum suaveolens.

aurea, Facq. Coll. iv. 202.-Afr. austr.

Bainesii, Baker, in Fourn. Linn. Soc. xiii. (1873) 290. -Afr. "trop.

caudata, Facq. Coll. iv. 203.-Afr. austr.

chlorantha, Welw. ex Baker, in Trans. Linn. Soc. Ser II. i. (1878) 251.-Angola.

coarctata, Dryand. in Vet. Acad. Nya Handl. Stockh.

(1784) 295.-Afr. austr.

Cooperi, Baker, in Fourn. Bot. xii. (1874) 366.-Afr. austr.

cornuta, [DC. in] Red. Liliac. i.t. $70=$ altissima.

elastica, Salisb. Prod. $239=$ abyssinica.

elata, Salisb. 1. c. $238=$ altissima.

Elwesi, Regel, in Act. Hort. Petrop. vi. (1879) $538=$ Wakefieldii.

exuviata, Ker-Gawl, in Bot. Mag. t. $871=$ Urginea exuviata.

fastigiata, Dryand. in Vet. Acad. Nya.Handl. Stockh 1784) 296-Afr. austr.

fibrosa, Baker, in Gard. Chron. (1874) II. 386.-Afr. austr.

filifolia, Ker-Gawl. Bot. Reg. vii. t. 557=Urginea filifolia.

flaccida, Baker, in Saund. Bot. Ref. t. $334=$ Cooperi.

flaccida, Facq. Coll. iv. 201.-Afr. austr.

fragrans, Facq. Hort. Schoenb i. 44. t. 84-Afr. austr. fugax, Ker-Gawl. Bot. Reg.iv, t.311=Urginea fragrans, galeata, Welw. ex Baker, in Trans. Linn. Soc. Ser. II. i. (1878) 251.-Angola.

Gardeni, Hook. Bot. Mag. t. $4842=$ Speirantha convallarioides.

glandulosa, Baker, in Gard. Chron. (1875) . . 814Afr. austr.; China.

juncifolia, Baker, l.c. (1876) I. 534.-Afr. austr.

juncifolia, Welw. ex Baker, in Trans. Linn. Soc. Ser. II. i. (1878) $251=$ monophylla.

longifolia, Fisch. ex Steud. Nom. ed. II. i, 47.-Afr. austr.

lutea, Lam. Encyc. i. $76=$ major, minor.

major, Linn. Sp. Pl. ed. II. 438.-Afr. austr.

maxima, Burm. f. Fl. Cap. Prod. 9-Afr. austr.

minor, Gleditsch, in Mem. Acad. Berl. $(1796) \cdot 91=$ Uropetalum serotinum.

minor, Linn. Sp. Pl. ed. H. 438.-Afr. austr.

monophylla, Baker, in Trans. Linn. Soc. Ser. TI. i. (1878) 251.-Angola.

myogaloides, Welw.ex Baker, l. c. 250.-Angola.

Nelsoni, N. E. Br. in Gard. Chron. (1880) II. 198.Afr. austr.

nematodes, Sweet, Hort. Brit. ed. II. 526.-Afr. austr. parviflora, Donn, Hort. Cant. ed. II. 41-Afr. austr. physodes, Ker-Gawl. in Bot. Mag. t. 1046=Urginea physodes.

polyphylla, Baker, in Gard. Chron. (1874) I. 471.-Afr. austr.

rigida, Salisb. Prod. 239.-Afr. austr.

setosa, facq. Coll. Suppl. 100. t. 14.-Afr. austr.
ALBUCA :-

Shawii, Baker, in Fourn. Bot. xii. (1874) 367.-Afr. austr.

sordida, Salisb. Prod. $238=$ major.

spiralis, Linn. f. Suppl. 196.-Afr. austr.

subspicata, Baker, in Trans. Linn. Soc. Ser. II. i.(1878) 251.-Angola.

tenuifolia, Baker, in Saund. Ref. Bot. t. 335.-Afr. austr.

viridiflora, Facq. Coll. Suppl. 98.-Afr, austr.

viscosa, Linn f. Suppl. 196.-Afr. austr.

vittata, Ker-Gawl. in Bot. Mag.t. $1329=$ Ornithogalum vittatum.

Wakefieldii, Baker, in Bot. Mag. t. 6429.-Afr. trop.

Yerburyi, Ridl. in Fourn. Bot. xxii. (1884) 370 .Aden.

ALBUCEA, Reichb. Fl. Germ. Excurs. $109(1830)=$ Ornithogalum, Linn. (Liliac.)

chlorantha, Reichb. Ic. FI. Germ. t. $1032=$ O. nutans nutans, Reichb. FI. Germ. Excurs. $110=$ O. nutans.

ALBUGA, Schreb. Gen. i. 221 (1789) err. typ. = Albuca, Linn. (Liliac.).

ALBUGOIDES, Medic. in Act. Acad. Theod. Palat. vi. Phys. (1790) $372=$ Albuca, Linn. (Liliac.). erectum, Medic. 1. c.-Afr, austr. ?

ALCAEA, Hill, Hort, Kew. 213 (1768) ; Burm. f. Fl. Ind. $149(1768)=$ Althaea, Linn. (Malrac.).

ALCAMASPINORA, Noronha, in Verh. Batav. Gen. v. (1790) ed. I. Art. IV. 6. - Quid?

ALCANNA, Gaertn. Fruct. ii. 133. t. 110 (1791)= Law sonia, Linn. (Lythrar.) spinosa, Gaertn, 1. c. = L. alba.

ALCANNA, Orph. in Bull. Congr. Bot. Pétersb. 1869 (1870) $138=$ Alkanna, Tausch (Borag.).

ALCEA [Tourn.] Linn. Syst. ed. I. (1735) = Althaea, Tourn. (Malvac.).

acaulis, Alef. in Oestr. Bot. Zeitschr. xii. (1862) $251=$ Alth. acaulis.

aegyptiaca, Boiss. Diagn. Ser. II. i. $103=$ Alth. lavataeriflora.

africana, Lour. Fl. Cochinch. 421=Alth. africana apterocarpa, Boiss. Fl. Orient. i. $830=$ Alth. apterocarpa. Aucheri, Alef, in Oestr. Bot. Zeitschr. xii. (1862) $252=$ Alth. Aucheri.

Calverti, Boiss. Fl. Orient, i. $832=$ Alth. Calverti. denudata, Boiss. 1. c. 833-Armenia.

digitata, Alef. in Oestr. Bot. Zeitschr. xii. (1862) $252=$ Alth. lavateraeflora.

ficifolia, Linn. Sp. P1. $687=$ Alth. ficifolia ficifolia, Nym. Consp. $127=$ Alth. rosea.

glabrata, Alef. in Oestr. Bot. Zeitschr. xii. (1862) 252 $=$ Alth. ficifolia.

Haussknechtii, Boiss. Fl, Orient. i, 830.-Syria.

Heldreichii, Boiss. 1. c. $832=$ Alth. Heldreichii.

Hohenackeri, Boiss. 1. c. $833=$ Alth. Hohenackeri.

indica, Burm. f. F1. Ind. 149.-Java.

kurdica, Alef. in Oestr. Bot. Zeitschr. xii. (1862) 252 , $253=$ Alth. kurdica.

lasiocalycina, Boiss. FL. Orient. i. 830.-Armenia.

lavateraeflora, Boiss. 1. c. $828=$ Alth. lavateraeflora.

lilacina, Boiss. 1. c. $831=$ Alth. apterocarpa.

microchiton, Alef, in Oestr. Bot. Zeitschr. xii. (1862)

254-As. Min.

pallida, Bess. Enum. PI. Volh. $28=$ Alth. pallida. palmata, Gilib. Fl. Lituan. i. $65=$ Malva Alcea. pinnatifida, Gilib. 1. c. $66=$ Malva moschata.

pontica, Janka, in Oestr. Bot. Zeitschr. xxiii. (1873) 201.-Turcia

procumbens, Medic. in Act. Acad. Theod. Palat. iii. Phys. (1775) 235. t. 17.-Hab. ?

remotifiora, Alef. in Oestr. Bot. Zeitschr, xii, (1862) $252=$ Alth. remotiflora.

rhyticarpa, Trautv. ex Boiss. Fl. Orient. i. $827=$ Alth. sulphurea.

rosea, Linn. Sp. Pl. $687=$ Alth. rosea

rosea, Falk, Beitr, ii $221=$ Alth ficifolia

rufescens, Boiss. Fl. Orient. i. $828=$ Alth. rufescens.

rugosa, Alef. in Oestr. Bot. Zeitschr. xii. (1862) $254=$ ficifolia.

schirazana, Alef. 1. c. $252=$ Alth. kurdica.

sétosa, Alef. 1. c. $255=$ Alth. setosa.

striata, Alef. 1. c. $252=$ Alth striata.

sulphurea, Alef.1. c. = A1th, sulphurea, 
ALCHEMILLA, Linn. Syst. ed. I. (1735). ROSA$C E A E$, Benth. \& Hook, f. i. 621. APHANES, Linn. Gen. ed. I. 33 (1737).

Percepier, Dill. ex Moench, Meth. 690 (1794). abyssinica, Fres. in Mus. Senkenb. ii. (1837) 161.Abyss.

achilleaefolia, Remy, in Ann. Sc. Nat. Sér. III. viii. (1847) 224, linea penultima = pinnata.

acutiloba, Stev, in Bull. Soc. Nat. Mosc. xxix. (1856)

II. $173=$ vulgaris

alata, Ruiz \& Pav. ex Steud. Nom. ed. II. i. $47=$ pinnata.

algidax, Bruegg. in Fahresb. Naturf. Ges, Graub. II. xxiii-xxiv. (1880) 64.-Europ.

alpestris, F. W. Schmidt, F1. Boëm. iii. $88=$ vulgaris.

alpina, Bieb. Fl. Taur. Cauc. i. $114=$ sericea.

alpina, Linn. Sp. Pl. 123.-Reg. bor. temp.

ambigens, Jord. ex Nym. Consp. $238=$ vulgaris

Aphanes, Leers, F1. Herborn. $54=$ arvensis.

apbanoides, Mutis, ex Linn. $f$. Suppl. 122.-N. Granat. argentea, Lam. F1. Fr. iii. $303=$ alpina.

arvensis, Scop. Fl. Carn. ed. II. i. 115.-Reg. bor. temp.

barbata, Presl, Epim. Bot. 199.-Peruv.

bifurcata, Hils. Eo Boj. ex Baill. in Bull. Soc. Linn. Par. i. (1882) 342.-Madag.

capensis, Thunb. Prod. Pl. Cap. 31.-Afr. austr.

ceylanica, Hook. f. Fl. Brit. Ind. ii. 361, sphalm. $=$ indica.

ciliata, Willd, ex Steud. Nom, ed. II. i. $4 \pi, 48=$ orbiculata.

conglomorata, F. W. Schmidt, F1. Boëm. iii. $89=$ vul-

garis.
conjuncta, Bab.in Mag. Nat. Hist. x. (1842) $25=$ alpina. cornucopioides, Roem. E'Schult. Syst. iii. 471.-Hispan. cryptantha, Steud. ex A. Rich. Tent. Fl. Abyss. i. 259. -Abyss.

cuneata, Gaud. Syn. F1. Helv, $117=$ pentaphyllea. cuneifolia, Nutt. ex Torr. \& Gray, Fl. N. Am. i. 432 $=$ arvensis.

dendroidea, Zoll. in Nat. en Geneesk. Arch. Neerl. Indie, i. (1844) 484.-Malaya.

diandra, Willd, ex Steud. Nom. ed. II. i, $48=$ mpestris. elongata, Eckl. E Zeyh. Enum. 264.-Afr. austr.

equisetiformis, Trev. in Bot. Zeit. vii. (1849) 215.Venezuela.

erodiifolia, Wedd. Chl. And. ii. 247.-N. Granat.

Eupatoria, Michx. Fl. Bor. Am. i. 287.-Am. bor.

fissa, Schum. ex Sturm, Deutschl. Fl. Heft 56 (1830) = pyrenaica.

frigida, Wedd. Chl. And. ii. 245.-Boliv.

galioides, Benth. Pl. Hartw. 134.-N. Granat.

galioides, Trev. in Bot. Zeit. vii. (1849) 215. Venezuela.

Geheebii, Siegfr. ex Bruegg. in Fahresb. Naturf. Ges. Graub. II. xxv. (1882) 70,-Europ.

glaberrima, F. W. Schmidt, F1. Boëm. iii. $89=$ vulgaris. glabra, Suffr. in Flora, xix. (1836) 321 = vulgaris.

glabrata, Tausch, ex Steud. Nom. ed. II. i. $48=$ vulgaris.

glaucescens, Wallr. in Linnaea, xiv. (1840) $549=$ vulgaris.

Gunae, Schweinf. in Verh. Zool.-Bot. Ges. Wien, xvii. (1868) 668.-Afr. trop.

helvetica $\times$, Bruegg. in Fahresb. Naturf. Ges. Graub. II. xxiii-xxiv. (1880) 64.-Europ.

heptaphylla, Schleich. ex Steud. Nom. ed. II. i. $48=$ pentaphyllea

hirsuta, H. B. E K.Nov. Gen.et Sp. vi. 226,-Am. anstr. hybrida, F. W. Schmidt, F1. Boèm. iii. $89=$ vulgaris. indica, Gardn. in Calc. Fourn. Nat. Hist. viii. (1847) 8.-Mont. Nilghir. ; Zeylan.

intermedia, [Clairv.] Man. Herb. 43=alpina.

latifolia, Salisb. Prod. $361=$ vulgaris

Lechleriana, Griseb. in Goett. Abh. xxiv. (1879) 124.Reg. Argent.

lobata, Pall. Reise, ii. 568 = vulgaris

lycopodioides, Trev. in Bot. Zeit. vii. (1849) 215.Venezuela.

madagascariensis, O. Hoffm. in Bremen Abh. vii. (1852) 336.-Afr. trop.

Mandoniana, Wedd. Chl. And. ii. 246.-Boliv

microcarpa, Boiss. \& Reut. Diagn. Hisp. 11.Hispan.

minor, Tausch, ex Host, Fl. Austr. i. $219=$ pyrenaica. minor, Huds, Fl. Angl. ed, I. 59 =vulgaris.

monandra, Stokes, Bot. Mat. Med. i. $236=$ arvensis.

monandria, Sw. Prod. Veg. Ind. Occ. 98.-Ind. occ.

montana, F. W. Schmidt, F1. Boëm. iii. 88 =vulgaris.

\section{ALCHEMILLA}

multicaulis, Tausch, ex Steud. Nom. ed. II. i. $48=$ vulgaris.

multifida, Scheele, in Flora, xxvi. (1843) 449 .Europ.

nivalis, $H . B . \&$ E $K$. Nov. Gen et Sp. vi. 224, t. 560 -

Equador.

occidentalis, Nutt. in Torr. \& Gray, F1. N. Am. i. 432 arvensis

orbiculata, Ruiz E Pav. Fl. Per. i. 68.-Peruv.

palmata, E. Mey. in Drege, Zwei Pfl. Docum. 163,

nomen.-Afr. austr.

palmata, Gilib. Exercit. ii. $429=$ vulgaris.

palmatifida, Tausch, ex Reichb. Pl. Crit. i. 6 pyrenaica.

paniculata, F. W. Schmidt, Fl. Boëm. iii. $89=$ vulgaris.

pectinata, H. B. \& K. Nov. Gen. et Sp. vi. $226=$ orbiculata.

pedata, Hochst. ex A. Rich. Tent. Fl. Abyss. i. 260.Abyss.

pentaphyllea, Linn. Sp. Pl. 123.-Europ.

pinnata, Ruiz \& Pav. Fl. Per, i. 69.-Peruy.

polylepis, Wedd. Chl. And. ii. 246.-Am. austr.

potentilloides, Hils. \& Boj. ex Baill. in Bull. Soc.

Linn. Par. i. (1882) $343=$ madagascariensis.

pratensis, F. W. Schmidt, Fl. Boëm. iii. 88 = vulgaris

pubescens, Bieb. Fl. Taur. Cauc. i. $114=$ vulgaris.

pubescens, Willd. Hort. Berol. t. $79=$ praec. ?

pusilla, Pomel, Nouv. Mat. Fl. Atl. 159.-Afr. bor.

pyrenaica, Dufour, in Ann. Gén. Sc. Phys. viii. (1821) 228.-Mont. Pyren.

repens, Presl, Epim. Bot. 199.-Peruv.

Rothii, Oliver, Fl. Trop. Afr. ii. 378.-Afr. trop.

rupestris, H. B. E $K$. Now Gen. et Sp. vi. 224. -Quito.

Rutenbergii, O. Hoffm. in Bremen Abh. vii. (1882) 336.-Afr. trop.

schizophylla, Baker, in fourn. Linn. Soc. xx. (1884) 137.-Madag.

sericata, Reichb. Pl. Crit. i. 6 , in obs, = vulgaris.

sericea, Willd. Enum. Hort. Berol. 171, in nota.Oriens.

sibbaldiaefolia, H. B. $K$. Nov. Gen. et Sp. vi. 226. t 561.-Mexic.

stemmatophylla, Wedd. Chl. And. ii. 248. t. 75.N. Granat.

subsericea, Reut. Compte-rend. Soc. Hallér. (1853-54) $20=$ alpina.

sylvestris, F. W. Schmidt, Fl. Boëm. iii, $88=$ vulgaris tenuicaulis, Hook. f. in fourn. Linn. Soc. vii. (1864) 191.-Afr, trop.

triloba, Gilib. Exercit. ii. $430=$ arvensis.

tripartita, Ruiz \& Pav. Fl. Per. i. 68.-Peruv.

truncata, Tausch, ex Steud. Nom. ed. II. i. $48=$ vulgaris.

velutina, S. Wats, in Proc. Am. Acad. xvii. (1881-82) 354.-Am. bor.

venusta, Cham. E' Schlecht.in Linnaea, v. (1830) 573. -Mexic.

villosa, Fungh, in Nat, en Geneesk. Arch. Neerl. Indie, ii. (1845) 46.- -Java.

vulcanica, Cham. \& Schlecht. in Linnaea, v. (1830) 573.-Mexic.

vulcanica, Zoll. E Mor, in Nat. en Geneesk. Arch. Neerl. Indie, ii. (1845) 587.-Malaya.

vulgaris, Linn. Sp. Pl. 123.--Reg. bor. temp.

vulgaris, Wight, Ic. t. $229=$ indica

ALCHORNEA, Sw. Prod. Veg. Ind. Occ. 98 (1788) EUPHORBIACEAE, Benth. \& Hook. f. iii. 314.

APARISTHMIUM, Endl. Gen. 1112 (1841).

BleEkeria, Miq. Fl. Ind. Bat. i. II. 407 (1859)

Cladodes, Lour. Fl. Cochinch. 574 (1790)

Coelebogrne, J. Sm. in Trans. Linn. Soc. xviii. (1841) 509. t. 36.

Diderotia, Baill. Adansonia, i. (1860-61) 274.

Hermesia, Humb. \& Bonpl, in Willd. Sp. Pl. iv. $809(1805)$

Lautembergia, Baill. Etud. Gén. Euph. 451 (1858).

ORFILEA, Baill. I. c. 452 (1858)

PAlissya, Baill, 1, c. 502 (1858)

Pseudotrewia, Miq. Fl. Ind. Bat, i. II. 414 (1859).

Schousnoea, Schum. Beskr. Guin. Pl. 449 (1827).

StIPEliakia, Benth, in Hook. Kew Journ. vi. (1854)?.

Wetria, Baill. Etud. Gén. Euph. 409 (155s).

\section{ALCHORNEA}

acutifolia, Muell. Arg. in Linnaea, xxxiv. (1865-66) 171.-Peruv.

Blumeana, Muell. Arg. lo c. 167.-Java

castaneaefolia, A. Fuss. Tent. Euph 42-Fl Orinoco.

columnularis, Muell. Arg. in Mart. Fl. Bras xi. It. 378. - Bras.

cordata, Benth. in Hook. Niger Fl. 507.-Afr. trop.

cordata, Muell. Arg. in DC. Prod. xv. II. 901.-Am. trop.

cordifolia, Muell. Arg. in Linnaea, xxxiv, (1865-66) 170.-Afr. trop.

coriacea, Muell. Arg. l. c. 168.-Madag.

cuneata, Miq. Ann. Mus. Bot. Lugd. Bat, iv, 122 . cuncifolia.

cuneifolia, Muell. Arg. in DC. Prod. xv. 11.900.Sumatra.

Davidi, Franch. Pl. Davidian. i. (1884) 264.Mongolia.

discolor, Poepp. E Endl. Nov. Gen. iii. 19.-Bras.

Duparquetiana, Baill. Adansonia, xi. (1873-76) 175 . Afr, trop.

erythrosperma, Klotzsch, ex Benth. in Hook. Ke Fourn. vi. (1854) 331.-Bras.

floribunda, Muell. Arg. in Fourn. Bot. i. (1863) 336.Afr. oce

Gardneri, Muell. Arg. in Flora, xlvii. (1864) 435.Bras.

glandulosa, Poepp. Eo Endl. Nov. Gen. et Sp, iii, 18 t. 221.-Bras.

glandulosa, Poit. ex Baill. Etud. Gén. Euph. $446=$ latifolia.

grandiflora, Muell. Arg. in Linnaea, xxxiv. (1865-66) 170.-Venezuela.

grandis, Benth. Bot. Sulph. Voy. 164-Am. trop.

Hilariana, Baill. Adansonia, v. (1864-65) 240.-Bras. hirtella, Benth. in Hook. Niger Fl. 507.-Afr. trop. ilicifolia, Muell. Arg. in Linnaea, xxxiv. (1865-66 170.-Austral.

intermedia, Klotzsch, ex Benth. in Hook. Kew Fourn.

vi. (1854) 331 - Bras.

Iricurana, Casar. Nov. Stirp. Bras. Dec. 24,-Bras.

javensis, Muell. Arg. in Linnaea, xxxiv. (1865-66) 170 = rugosa.

janeirensis, Casar. Noq. Stirp. Bras. Dec. $15=$ nemoralis.

latifolia, Klotzsch, in Hook. Lond. Journ, Bot. ii. (1813 $46=$ cordata

latifolia, Sw. Prod. Veg. Ind. Occ. 98.-Ind. occ.

macrophylla, Mart. Herb. FI. Bras. $271=$ cordata

madagascariensis, Muell. Arg. in DC. Prod. xv. II. 900. - Madag.

Martiana, Muell. Arg. in Mart. Fl. Bras. xi. II. 375. Bras.

megalophylla, Muell. Arg. in Flora, xlvi. (1861) 434 -N. Granat.

mollis, Muell. Arg. in Linnaea, xxxiv. (1865-66) 163 -Ind. or

multispicata, Muell. Arg. l. c. 168.-Madag.

nemoralis, Mart. Herb. Fl. Bras. 271-Bras.

parviflora, Muell. Arg. in Linnaea, xxxiv. (1565-66 168.--Ins. Philipp.

parvitolia, Klotssch, ex Benth. in Hook. Kew Fours.

vi. (1854) 331.-Bras.

parvifolia. Miq. in Linnaea, xxii. (184?) $797=$ nemoralis.

platyphylla, Muell. Arg. l. c. xxxiv. (1865-66) 171.Am. centr.

psilorhachis, Klotzsch, ex Benth. in Hook. Kew Jourm. vi. (1854) $831=$ nemoralis.

puberala, Klotasch, l.c.-Bras.

pycnogyne, Muell. Arg. in Mart. Fl. Bras. xi. II. $8 i s$

rotundifolia, Moric. ex Baill. Elud. Gén. Enph. 447 = nemoralis.

rufescens, Franch. Pl. Davidian. i. (1SE1) 265. Mongol.

rugosa, Muell. Arg, in Linnaca, xxxiv, $(1 \$ 65-66) 170$. Ind or. Malny

scandens, Muell. Arg. l. c. 170.-Cochinch.

Schomburgkii, Menth. in Hook. Kew Journ. vi. (1S5.t $\$ 30=$ Garineri.

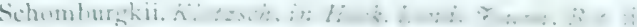
1848) 46. - Am austs.

sidnefolia, Baill. Efud. Gin. Euph. $47,-$ Bras.

similis, Macll. Arg. in Floriz, xlvit. 1s6t 194. Mexic. 


\section{ALCHORNEA :}

subrotunda, Baill. Etud. Gén. Euph. $447=$ glan-

dulosa. Austral.

tiliaefolia, Muell. Arg. in Linnaea, xxxiv. (1865-66) 168.-Ind. or.

trewioides, Muell. Arg. l. cs-China.

triplinervia, Muell. Arg. in DC. Prod. xv. Ir. $909=$ nemoralis.

villosa, Muell. Arg. in Linnaea, xxxiv. (1865-66) 168. - Malaya.

Zollingeri, Hassk. Cat. Hort. Bogor. Alt. 37 ; Retzia, $156=$ villosa .

ALCHORNEOPSIS, Muell. Arg. in Linnaea, xxxiv. (1865-66) 156. EUPHORBIACEAE, Benth. \& Hook. f. iii. 315 .

floribunda, Muell. Arg. l. c.-Peruv

ALCHYMILLA, Rupp. Fl. Jen. ed. Hall. $64(1745)=$ Alchemilla, Linn. (Rosac.).

ALCINA, Cav. Ic. i. 10. t. 15 (1791)= Melampodium, Linn. (Compos.)

minor, Cass. in Dict. Sc. Nat. lix. $243=$ M. sericeum. ovatifolia, Jacq. Eclog. Pl. 78=M. divaricatum. perfoliata, Cav. Ic. i. 11 . t. $15=$ M. perfoliatum.

ALCINIA, H. B. \& K. Nov. Gen. et Sp. iv. 274 (1820) = praec.

ALCIOPE, DC. Prod.v. 209 (1836). COMPOSITAE, Benth. \& Hook. f. ii. 439

Celmista, Cass, in Dict. Sc. Nat. vii. 356 (1817)

lanata, $D C$. Prod. v. 210,-Afr. austr.

tabularis, $D C$. l. c.-Afr. austr.

ALDAMA, La Llave, in La Llave \& Lex. Nov. Veg Desc. fasc. i. $14(1824)=$ Sclerocarpus, Jacq (Compos.).

dentata, La Llave, 1. c. $=$ S. dentatus

dentata, Less. in Linnaea, v. (1830) $154=$ S. Schiedeanus.

uniserialis, A. Gray, Pl. Lindh. $228=$ S. uniserialis.

ALDEA, Ruiz \& Pav. Prod. 19 (1794)= Phacelia, Juss. (Hydrophyll.)

circinnata, Willd. Enum. Suppl. $9=$ P. circinnata. magellanica, Willd. ex Stend. Nom. ed. II. i. $48=$ Hydrophyllum magellanicum.

peruviana, Ruiz \& Pav. Fl. Per. ii. 8. t. $114=$ P. peruviana.

pinnata, Ruiz \& Pav. 1。 c $=$ P. peruviana.

ALDELASTER, C. Koch, in Belg. Hortic. (1861) $324=$ ADELASTER, Veitch = Eranthemum? Linn (Acanth.).

ALDINA, Adans. Fam. ii. $328(\mathbf{1 7 6 3})=$ Brya, P. Br. (Legum.).

ALDINA, Endl. Gen. 1322 (1841). LEGUMINOSAE, Benth. \& Hook, f. i. 560

Allania, Benth, in Hook. Lond. Journ. Bot. ii. (1840) 91 .

discolor, Spruce, ex Benth. in Mart. Fl. Bras. xv. II. 12.-Bras.

heterophylla, Benth. l. c. 13.-Bras

insignis, Endl. in Walp. Rep. i. 843.-Guiana.

latifolia, Benth. in Mart. Fl.Bras. xv. II. 12.-Bras.

macrophylla, Spruce, ex Benth. l. c. 13.-Bras.

ALDINIA, Scop. Introd. $173(1777)=$ Justicia, Linn. (Acanth.).

ALDROVANDA, Monti, in Bonon. Sc. \& Art. Inst. Comm. ii. III. 404. t. 12 (1747); Linn. Diss. Chen. 39 (1751). DROSERACEAE, Benth. \& Hook. f. i. 663 verticillata, Roxb. F1. Ind. ii. $113=$ vesiculosa vesiculosa, Linn. Sp. Pl. 281.-Europ. ; Ind. or.

ALDUNATEA, Remy, in C. Gay, Fl. Chil. iii. 320.t. 38 (1849) = Chaetanthera, Ruiz \& Pav. (Compos.) chilensis, Remy, 1. c. 322. t. 38. f. 1 (=Oriastrum chilense).

\section{ALDUNATEA :-}

gnaphatioides, Remy, in C. Gay, Fl, Chil. iii. 323 (= Oriastrum gnaphalioides)

lycopodioides, Remy, 1. c. (=Oriastrum gnaphalioides).

ALECTORIDIA, A. Rich. Tent. Fl. Abyss. ii. 447. t. 99 (1851) = Arthraxon - Beauv. (Gramin.)

Quartiniana, A. Rich. 1. c. $448=$ Arth. ciliaris.

ALECTOROCTONUM, Schlecht, in Linnaea, xix. 252 $(1847)=$ Euphorbia, Linn

caracasanum, Klotzsch \& Garcke, in Abh. Akad. Berl. (1860) $40=$ E. caracasana.

cotinifolium, Schlecht. in Linnaea, xix. (1847) $252=\mathrm{E}$. cotinifolia.

cotinoides, Klotzsch \& Garcke, in Monatsb. Akad. Berl. (1859) $248=$ E. cotinoides.

dilatatum, Klotzsch \& Garcke, 1. c. = E. dilatata

nudiflorum, Klotzsch \& Garcke, 1. c. $40=\mathrm{E}$. nudiflora.

ovatum, Schlecht. in Linnaea, xix. (1847) $252=\mathrm{E}$. Schlechtendalii.

petiolare, Klotzsch \& Garcke, in Monatsb. Akad. Berl. (1859) $248=\mathrm{E}$. petiolaris.

Riedelianum, Klotzsch \& Garcke, in Abh. 1. c. (1860) $41=\mathrm{E}$. cotinoides.

sanguineum, Klotzsch \& Garcke, in Monatsb. 1. c. (1859) $248=\mathbf{E}$. haematodes.

scandens, Klotzsch \& Garcke, 1. $\mathrm{c}_{\mathrm{r}}=\mathrm{E}$, scandens,

Scotanum, Schlecht in Linnaea, xix. $(1847) 252=\mathrm{E}$. Scotanum.

viride, Klotzsch \& Garcke, in Monatsb. Akad. Berl. (1859) $248=\mathrm{E}$. viridis.

Willdenowii, Klotzsch \& Garcke, in Abh. I. c. (1860) $41=\mathrm{E}$. cotinifolia.

Wrightii, Klotzsch \& Garcke, in Monatsb. 1. c. (1859) $248=\mathrm{E}$. Wrightii.

Yavalquahuitl, Schlecht. in Linnaea, xix. (1847) $252=$ E. Scotanum.

ALECTOROLOPHUS, Hall. Enum. Stirp. Helv. ii. 623 (1742); Moench, Meth. $440(1794)=$ Rhinanthus, Iinn. (Scrophul.).

alpinus, D. Dietr. Syn. P1. iii. $553=$ R. major.

alpinus, Reichb. f。 Ic. Fl, Germ, xx, $66=\mathrm{R}$, Cristagalli.

angustifolius, D. Dietr. Syn. P1. iii. $553=$ R, angustifolius.

buccalis, Heynh. Nom. ii. $18=$ R. Crista-galli.

Crista-galli, Bieb. F1. Taur. Cauc. ii. $68=$ R. Cristagalli.

glaber, All. F1. Pedem. i. 58=R. Crista-galli

grandiflorus, Wallr. Sched. Crit. $316=$ R. Crista-galli.

hirsutus, All. F1. Pedem. i. $58=$ R. Crista-galli

major, Reichb. Ic. Pl. Crit. viii. 13. fig. 975 ; Ic. Fl.

Germ. xx. $65=\mathrm{R}$. major.

minor, Dum. Fl. Belg. $33=\mathrm{R}$. minor

minor, Reichb. F1. Germ. Excurs, 358=R. Cristagalli.

parviflorus, Wallr. Sched. Crit. $318=\mathrm{R}$. minor.

pulchella, Schum. ex Wimm. Fl. Schles. (1841) $277=$ R. Crista-galli.

pulcher, Schum. ex Wimm. 1. c. ed. III. (1857) $410=$ R. Crista-galli.

ramosus, Schur, Enum. Pl. Transs, 880, Index=R. minor.

stenophyllus, Schur, l: c. $=$ R. minor.

Trixago, Bieb. F1. Taur. Cauc. ii. $68=$ Bartsia Trixago.

villosus, Dum. Fl. Belg. $33=\mathrm{R}$. Crista-galli.

ALECTRA, Thunb. Nov. Gen. 81 (1784). SCROPHULARINEAE, Benth. \& Hook. f. ii. 966.

Glossostylis, Cham. \& Schlecht. in Linnaea, iii. (1828) 22.

HYMenospermum, Benth. in Wall. Cat. n. 3963 (1831).

SțARBIA, Thou. Gen. Nov. Madag. 7 (1806). abyssinica, A. Rich. Tent. Fl. Abyss. ii. 118.-Abyss. asperrima, Benth. in DC. Prod. x. 340.-Abyss. brasiliensis, Benth. l. c. 339.-Bras.

capensis, Thunb. Prod. Pl. Cap. 97.-Afr. austr. cordata, Benth. in DC. Prod. x. $339=$ indica. hirsuta, Klotzsch, in Peters, Reise Mossamb. Bot. 221. -Afr. trop.

indica, Benth. in DC. Prod. x. 339.-Ind. or.

lurida, Harv. Gen. S. Afr. Pl. 250.-Afr, austr.

\section{ALECTRA :-}

major, E. Mey. in Drège, Zwei Pfl. Docum. 163.-Afr. austr.

melampyroides, Benth. in DC. Prod. x. 339.-Afr. austr.

minor, E. Mey. in Drège, Zwei Pfi. Docum. 163.-Afr. austr.

orobanchoides, Benth. in DC. Prod. x. 340-Afr. austr.

parasitica, A. Rich. Tent. Fl. Abyss. ii. 117.Abyss.

pedicularioides, Baker, in fourn. Linn. Soc. $\mathrm{xx}_{\mathrm{v}}$ (1884) 214.-Madag.

Petitiana, A. Rich. Tent. Fl. Abyss. ii. 118.-Afr. trop. pumila, Benth. in DC. Prod. x. 340,-Afr. austr.

senegalensis, Benth.l. c. 339.-Afr. trop.

stricta, Benth. l. c. 338.-Bras.

Thomsoni, Hook. f. Fl. Brit. Ind. iv. 297.--Ind. or.

Vogelii, Benth. in DC. Prod. x. 339.-Afr. trop.

ALECTRYON, Gaertn. Fruct. i. 217. t. 46 (1788)

SAPINDACEAE, Benth. \& Hook. f. i. 410.

canescens, DC. Prod. i. 617.--Austral.

carinatum, Radlk. in Act. Congr. Bot. Amst. 1877 (1879) 119.-N. Caled.

connatum, Radlk, in Sitzb. Math.-Phys. Acad. Muench viii. (1878) 299, $307=$ Nephelium connatum.

coriaceum, Radlk. in Act. Congr. Bot. Amst. 1877 (1879) 118.-Austral.

excelsum, Gaert. Fruct. i. 216. t. 46.-N. Zel.

ferrugineum, Radlk. in Act. Congr. Bot. Amst. 1877 (1879) 84--Ins. Molucc

glabrum, Radlk. l.c.-Ins. Timor.

laeve, Radlk, l, c. 119.-Austral.

semicinereum, Radlk. l. c. 118.-Austral

serratum, Radlk. l. c.-Austral.

sphaerococcum, Radlk. l. c. 119.-Celebes.

subcinereum, Radlk. in Sitzb. Math.-Phys. Acad. Muench.ix. (1879) 524.-Austral.

subdentatum, Radlk. in Act. Congr. Bot. Amst. 1877 (1879) 117.-Austral

tomentosum, Radlk. $l$. c.-Austral

ALEGRIA, Moç. \& Sesse, ex DC. Prod. i. $516(1824)=$ Iuehea, Willd. (Tiliac.).

candida, Moç. \& Sesse, 1. c. $517=$ L. platypetala..

ALEOME, Neck. Elem. iii. $68(1790)=$ Cleome, Linn (Cappar.).

ALEPIDEA, La Roche, Eryng. Hist. 19. t. 1 (1808). UMBELLIFERAE, Benth. \& Hook. f. i. 878 amatymbica, Eckl. \& Zeyh. Enum. 339-Afr. austr. ciliaris, La Roche, Eryng. Hist. 19. t. 1.-Afr. austr. cordata, E. Mey. in Drège, Zwei Pf. Docum. $163=$ ciliaris.

ferrata, Stend. Nom. ed. II. i. 48 , sphalm. $=$ serrata. longifolia, E. Mey. ex Steud, 1. c, = amatymbica. peduncularis, Steud. ex A. Rich. Tent. Fl. Abyss. i 320.-Abyss.

serrata, Eckl. \& Zeyh. Enum. $339=$ ciliaris.

Woodii, Oliver, in Hook. Ic. Pl. t. 1452.-Afr. austr.

ALEPYRUM, B. Br. Prod. 252, 253 (1810)=Centrolepis, Labill.

monogynum, Hook. f. Fl. Tasm. ii. 77. t. $138=\mathrm{C}$ monogyna.

Muelleri, Hook. f. 1. c. $78=$ C. glabra.

muscoides, Hook. f. 1. c. $77=$ C. muscoides.

muticum, R. Br. Prod. $253=$ C. mutica.

pallidum, Hook, f. Fl. Nov. Zel. i. $268=$ Gaimardia pallida.

polygynum, R. Br. Prod. $253=$ C. polygyna.

Pumilio, R. Br. 1. c. = C. polygyna.

viride, T. Kirk, in Journ. Linn. Soc. xix. (1884) 286.N. Zel

ALETHRIS, Linn. Ord. Nat. (1764) =seq.

ALETRIS, Linn. Diss. Chen. 15 (1751); (Amoen. Acad. iii. 11). HAEMODORACEAE, Benth. \& Hook. f. iii. 677.

Stachyoporon, Klotzsch, in Bot. Ergeb. Waldem. Reise, 49. t. 94 (1862).

alba, Michx. Fl. Bor. Am. i. 189 = farinosa.

arborea, Willd. Enum. Hort. Berol. $381=$ Dracaena arborea.

anrea, Walt. Fl. Carol. 121.-Am. bor. 


\section{ALETRIS :}

bifolia, Burm. f. F1. Cap. Prod. $10=$ Lachenalia pendula. capensis, Linn. Syst, ed. X. $985=$ Veltheimia viridiflora.

chinensis, Lam. Encyc. i. $79=$ Dracaena terminalis. cochinchinensis, Lour. Fl. Cochinch. 204.-Cochinch dracaenoides, Roxb. ex Roem. \& Schult. Syst. vii. 347. -Ind. or.

farinosa, Ker-Gawl. in Bot. Mag. t. $1418=$ aurea.

farinosa, Linn. Sp. Pl. 319.-Am. bor.

farinosa, Thunb. F1. Jap. $136=$ japonica.

fragrans, Linn. Sp. Pl. ed. II. $456=$ Dracaena fragrans

glauca, Ait. Hort. Kew, i. $463=$ Veltheimia glauca.

guineensis, Jacq. Hort. Vind. i. 63. t. 84=Sanseviera guineensis.

hyacinthoides, Linn. Sp. P1. ed. II. $456=$ Sanseviera guineensis.

japonica, Houtt. Syst. xi. 486. t. 84. f. $2=$ Funkia subcordata.

japonica, Lamb. in Trans. Linn. Soc. x. (1811) 407.Japon.

japonica, Thunb. in Nov. Act. Ups. iii. (1780) $208=$ Funkia ovata.

linguaeformis, Burm. f. Fl. Cap. Prod. 10,-Afr. austr. littoralis, Koen. ex Steud. Nom. ed. II, i. $49=$ Urginia indica?

pumila, Ait. Hort. Kew. i. 464 (=Tritomanthe pumila).

pumila, Donn, Hort. Cant. ed. II. $42=$ Dracaena ovata.

punicea, Labill. P1. Nov. Holl. i. 85. t. $111=$ Bland fordia marginata.

sarmentosa, Andr. Bot. Rep. t. 54 (=Tritomanthe media).

Uvaria, Linn. Mant. $367=$ Kniphofia alooides.

zeylanica, Mill. Gard. Dict. ed. VIII. n. $4=$ Sanseviera lanuginosa.

ALEURITES, Forst. Char. Gen. iii. t. 56 (1776) EUPHORBIACEAE, Benth, \& Hook. f. iii. 292. Camirium, Gaertn. Fruct. ii. 194. t. 125 (1791) DRYANDRA, Thumb. Fl. Jap. 13. t. 27 (1784) Ela EOcocca, A. Juss. Euph. Tent. 38. t. 11 (1824). TelopeA, Soland. ex Baill. Etud. Gén. Euph. 345 (1858).

VERNICIA, Lour. F1, Cochinch. 586 (1790) Ambinux, Pers. Syn. ii. 579=triloba.

commutata, Geisel. Crot. Monogr. $82=$ triloba. cordata, Steud. Nom. ed. II. i. 49.-China; Japon. cordifolia, Steud. 1. c. = triloba.

japonica, Blume, in Miq. Ann. Mus. Bot. Lugd. Bat iv. $120=$ cordata.

laccifera, Willd. Sp. Pl. iv. $590=$ Croton aromaticus.

lanceolata, Blanco, F1. Filip. ed. I. $757=$ triloba.

lobata, Blanco, l. c. $756=$ triloba.

moluccana, Willd. Sp. Pl. iv. $590=$ triloba.

peltata, Geisel. Crot. Monogr. $81=$ Mallotus peltatus. pentaphylla, Wall. Cat. n. 7959.-Ind. or.

saponaria, Blanco, Fl. Filip. ed. II. 519.-Ins. Philipp. triloba, Forst. Char. Gen. 112.-As. trop.; Ins. Pacif trisperma, Blanco, Fl. Filip, ed. I. $755=$ triloba.

Vernicia, Hassk. in Flora, xxv. (1842); Beibl. ii. $40=$ corclata.

verniciflua, Baill. Hist. P1. v. $116=$ praec.

ALEURITIA, Spach, Hist. Vég. Phan. ix. $360(1840)=$ Primula, Linn.

cortusoides, Spach, 1. c. $361=\mathrm{P}$. cortusoides,

farinosa, Spach, $1, \mathrm{c},=\mathrm{P}$, farinosa

longiflora, Spach, 1. c. $362=\mathrm{P}$. longiflora.

ALEURODENDRON, Reinw, in Blume, Cat. Gew. Buitenz. 87 (1823), nomen; Syll. Ratisb. ii. (1828) 12 Melochia, Linn. (Sterculiat.)

album, Reinw. 11. cc.=M. Aleurodendron.

ALEVIA, Baill. Etud. Gén. Euph. 508 (1858)= Bernardia, P. Br. (Enphorb.)

leptostachya, Baill. 1. c. $509=$ B. interrupta.

ALEXA, Moq. in DC. Prod. xiii, Ir. 168 in nota (1849). LEGUMINOSAE, Benth. \& Hook. f i. 556 Alexandra, Schomb, in Hook, Lond. Journ. Bot. iv. (1845) 12

ATEXANDRA, Bunge, in Linnaea, xvii, (1843) 120. CHENOPODIACEAE, Benth. \& Hook, f, iii. 67. Pterocalyx, Schenk, in Bull. Phys. Math. Acad. Pétersb. i. (1848) 361.

Lehmanni, Bunge, in Linnaea (1843), 120,-Soongar.
ALEXANDRA, Schomb. in Hook. Lond. Journ. Bot. iv. (1845), 12; et Barbac. (1845) 18=Alexa, Moq. (Legum.).

Imperatricis, Schomb. 11. cc.-Guiana.

ALEXIA, Wight, Ic. t. $1293(1850)=$ Alyxia, R. Br. (Apocyn.).

ALEXIS, Salisb, in Trans. Hort. Soc. i. (1812) $284=$ Amomum, Linn. (Scitam.)

bifurca, Salisb. 1. c. = A, exscapum

grandiflora, Salisb. 1. c. =A. grandiflorum.

ALEXITOXICON, St, Lag, in Ann. Soc. Bot, Lyon, vii. 1880) $67=$ Vincetoxicum, Moench (Asclep.)

ALFONSIA, H. B. \& K. Nov. Gen. et Sp. i. 306 (1815) = Elaeis, Jacq. (Palm.)

oleifera, H. B. \& K. 1. c. $307=$ E. melanococca

ALFREDIA, Cass, in Bull. Soc. Philom. (1815) $175=$ Carduus, Linn. (Compos.)

acantholepis, Kar. \& Kir. in Bull. Soc. Nat. Mosc. xv. 1842) $394=$ C. acantholepis.

cernua, Cass, in Bull. Soc. Philom. (1815) $175=\mathrm{C}$ cernuus.

japonica, Miq. Ann. Mus. Bot. Lugd. Bat. ii. $185=$ Cnicus japonicus.

Karelini, Ledeb. F1. Ross. ii. $754=$ C. acantholepis.

nivea, Kar. \& Kir. in Bull. Soc. Nat, Mosc. xv. (1842) $395=\mathrm{C}$. niveus

squarrosa, 'Kostel. Select. Sem. Hort. Bot. Prag. (1838).'-Hab.?

stenolepis, Kar. \& Kir. in Bull. Soc. Nat. Mosc, (1841) $452=\mathrm{C}$. stenolepis

suaveolens, Rupr. Sert. Tiansch. $56=\mathrm{C}$. suaveolens. tianschanica, Rupr. 1. c.-As. centr.

ALGA, [Tourn.] Lam. Fl. Fr. iii. 539 (1778)=Zostera Linn. Naiad.)

marina, Lam. 1. c. $=$ Z. marina.

ALGAROBIA, Benth. Pl. Hartw. $13(1839)=$ Prosopis, Linn. (Legum.).

dulcis, Benth, 1. c. $=$ P. juliflora

glandulosa, Torr. \& Gray, F1. N. Am. i. $399=$ P juliflora.

juliflora, Heynh. Nom, ii. $18=$ P. juliflora.

ALGERNONIA, Baill. in Ann. Sc. Nat. Sér. IV. ix. 198 (1858). EUPHORBIACEAE, Benth. \& Hook. f. iii. 339 .

TETRAPlandRA, Baill. 1. c. 200 (1858).

brasiliensis, Baill. l. c. 199.-Bras.

obovata, Muell. Arg. in Mart. Fl. Bras. xi. II. 536.Bras.

ALGUELAGUEN, Feuill. ex Adans, Fam. ii. 505 (1763 = Sphacele, Benth. (Labiat.).

ALHAGI, Tourn. ex Adans. Fam. ii. 328 (1763) Desv. Journ. Bot. i. (1813) 120. t. 4. LEGUMI NOSAE, Benth. \& Hook. f. i. 512.

Manna, D. Don, Prod. Fl. Nep. 246 (1825) camelorum, Fisch. Hort. Gorenk, ed. II. (1812) 72.Oriens; As. centr.

graecorum, Boiss. Diagn. Ser. I. ix. 114.-Graecia karduch rum, Boiss. \& Haussk. ex Boiss. F1. Orient. ii. $55_{0}^{-0}=$ maurorum.

kirghisorum, Schrenk, Enum. Pl. Nov, 84=camelorum. mannifera, Desv. Journ. Bot. i. (1813) $120=$ maurorum. mannifera, Jaub. \& Spach, Illustr. t. $401=$ graecorum. maurorum, Medic. in Vorles. Churpf. Phys. Ges. ii

1787) 397 ; Desv. Fourn. i. (1813) 120. t. 4.-

Oriens; Ind. or.; Syria.

napaulensium, DC. Prod. ii. $352=$ maurorum.

persarum, Boiss. \& Buhse, in Nouv. Mém. Soc. Nat. Mosc. xii. (1860) $76=$ camelorum.

Pseudalhagi, Desv. Journ. Bot. i. (1813) $120=$ camelorum.

turcorum, Boiss. Diagn. Ser. I. ix, $118=$ camelorum.

ALHAGIA, Reichb. Nom. $153(1841)=$ praec.

ALIBERTIA, A. Rich. in Mém. Soc Hist. Nat. Par v. (1830) 234. t. 21. RUBIACEAE, Benth. \& Hook. f. ii. 81

CordierA, A. Rich, 1. c. 222 t. 20 (1880).

\section{ALIBERTIA}

GARAPATICA Karst Fl Colomb i. 57 4. 28 (1858, GARDENrola, Cham in Linnaea, ix. (1834) 247. Genipella, Rich. ex DC. Prod.iv. 443 (1830).

Melanopsidium, Poit. ex A. Rich. in Mém. So Hist. Nat. Par. v. (1830) 234.

SCePSEUThamNus, Cham. in Linnaea, ix. (1834) 248

THIELEODOXA, Cham. 1. c. 251 (1834).

edulis, A. Rich, in Mém. Soc. Hist. Nat. Par. y. (1830

234. t. 21.-Guiana.

hexagyna, Karst. FL. Colomb. i. 57.-N. Granat.

jacquinioides, Griseb. Cat. Pl. Cub. 123.-Cuba.

Melloana, Hook. f. in Trans. Linn. Soc. xxviii. (1873 520.-Bras.

utilis, A. Rich. in Mém. Soc. Nat. Hist. Par.v. (1830 $21=$ edulis.

ALIBREXIA, Miers, in Hook. Lond. Journ. Bot, iv (1845) $506=$ Dolia, Lindl. (Convolv.)

brevifolia, Phil. in Linnaea, xxxiii. (1864-65) 209.Chili.

Gayana, Gaudich. Bot. Voy. Bonite, AtI.t. 105.-Chili incana, Phil. F1. Atac. 45.-Chili.

revoluta, Miers, in Hook. Lond. Journ. Bot. iv. (1845 $508=$ D. revoluta.

rupicola, Miers, 1. c. $506=\mathrm{D}$. tomentosa

tomentosa, Miers, l. c. $508=\mathrm{D}$, tomentosa

villosa, Phil. Fl. Atac. 45.-Chili.

ALIBUM, Less. Syn. Comp. $152(1832)=$ Liabum Adans. (Compos.)

liaboides, Less. 1. c. $=$ L. lyratum.

ALICABON, Rafin. Sylva Tellur. 56 (1838)= Physalis Linn. (Solanac.)

barbadense, Rafin. 1. c. $57=$ P. barbadense.

somniferum, Rafin. 1. c. $56=\mathrm{P}$. somniferum.

ALICASTRUM, P. Br. Hist. Jamaic. $372(1756)=$ Brosimum, Sw. (Urticac.).

ALICOSTA, Dulac, Fl. Hautes-Pyr. 381 (1867) =

Bartsia, Linn. (Scrophul.)

alpina, Dulac, $1 . \mathrm{c}_{\mathrm{c}}=\mathrm{B}$, alpina.

spicata, Dulac, 1. $\mathrm{c}_{\mathrm{v}}=\mathrm{B}$. aspera.

ALIC'TERES, Neck, Elem, ii. $304(1790)=$ Helicteres Linn. (Sterculiac.).

ALIFANA, Rafin. Sylva Tellur. 101 (1838)= Brachyo tum, Triana (Melast.) etc

canescens, Rafin. 1. c. = Brachyotum canescens.

lutescens, Rafin. 1. c. = Micor ha lutescens.

montana, Rafin, 1, c, = Conostegia montana

striata, Rafin. 1. c. = Brachyotum strigosum.

ALIFANUS, Pluk, ex Adans, Fam, ii. $234(1763)=$ Rhexia, Linn. (Melast.)

ALINA, Adans. Fam. ii. 84 (1763).-Geu. dub.

ALIPENDULA, Neck. Elem. ii. $89(1790)=$ Spiraea Linn. (Rosac.).

ALIPSA, Hoffmgg. [Verz. Orchid. 20 (1840)] ex Linnaea, xvi. (1842) Litt. $228=$ Liparis, Rich. (Orchid.) foliosa, Hoffingg. 1. c. = L. reflexa?

ALISETA, Rafin. New Fl. Am. ii. $22(1 \$ 36)=$ Arnic日 Linn. (Compos.)

plantaginea, Rafin. 1. c. = A. alpina

ALISMA, [Dill.] Linn. Syst. ed. I. (1735). ALIS MACEAE. Benth. \& Huok. f. iii. 1004 . Bardellat, Parl. Nov. Gen. Pl. Monocot. 57 (1854 Caldesia, Parl, Fl. Ital. iii. 598 (1858

Helanthius, Engelm. ex Benth. Se Hook. f. Gen. iii. 1005 (1858)

Nectalisma, Fourr. in Aan. Soc Linn. Lyon, N. xvii. (1869) 156.

acanthocurpum, Fo M/well. Frofm, i. 28.-Anstml. alpestre, Coss, in Bull. Soc Bot. Fr. xi. (1sot) 938 Echinodorus alpestris

Ancile. Mart. ex steud. Nom, ed. II. i. 48 nomen Sagittaria guyanensis.

Andrienrii, Hook. \& Am. Bot. Beech. Voy. $\$ 11=$ - Echinotorus ellipticus. 


\section{ALISIMA}

angustifolium, Gilib. F1. Iituan. ii. $224=$ Echinodorus ranunculoides.

angustifolium, Hoppe, Taschenb. (1797) $13=$ A. Plantago.

apetalum, Buch.-Ham. ex Wall. Cat. n. $4996=$ oligococcum.

aphylla, Steud. Nom. ed. II. i. $49=$ praec.

arcuatum, Micheli, in Bull. Soc. Bot. Fr. i. (1853) 312 $=$ A. Plantago.

Berterii, Spreng. Syst. ii. $163=$ Echinodon rostratus.

Berteroanum, Balb. in Roem, \& Schult. Syst. vii. 1605 = Echinodorus rostratus.

Bourgaei, Nym. Syll. $379=$ Damasonium Bourgaei.

californicum, Micheli, in A. DC. Monog. Phan. iii. 34. -Calif.

calyophyllum, Wall. Cat. n. $4997=$ parnassifolium.

canaliculatum, A. Br. \& Bouché, Ind. Sem. Hort. Berol. $(1867) 4=$ A. Plantago.

cordifolium, Linn. Sp. Pl. $343=$ Echinodorus macrophyllus, rostratus.

cordifolium, Thunb. F1. Jap. $153=$ A. Plantago,

cristatum, Wall. Cat. n. $4994=$ Sagittaria guyanensis.

Damasonium, Desf. F1. Atlant. i. $324=$ Damasonium Bourgaei.

Damasonium, Linn. Sp. Pl. $343=$ Damasonium stellatum.

Damasonium, Willd. Prod. Fl. Berol. $132=$ parnassifolium,

difformifolium, Steud. in Lechl. Berb. Am. Austr. 53. -Chili.

diversifotium, Gilib. Fl. Lituan, ii. $223=$ Elisma natans.

dubium, Willd. Prod. F1. Berol. 132 =parnassifolium.

echinocarpum, Seub in Mart. F1. Bras, iii. I. 105. t. 13 f. $3=$ Sagittaria guyanensis

ellipticum, Mart. in Roem. \& Schult. Syst. vii, $1607=$ Echinodorus ellipticus.

enneandrum, Hochst. ex Micheli, in DC. Monog. Phan. iii. $82=$ Burnatia enneandra.

flavum, Linn. Sp. Pl. $343=$ Limnocharis flava.

flavum, Thunb. F1. Jap. $153=$ A. Plantago.

floribundum, Seub, in Mart. F1. Bras. iii, I. 109= Echinodorus grandifforus.

Geyeri, Torr. in Nicollet, Rep. Hydrog. Mississip. (1843) $162=$ A. Plantago.

glandulosum, Thw. Enum. Pl. Zeyl. $332=$ oligococcum.

gramineum, C. C. Gmel. Fl. Bad. iv. $256=\mathrm{A}$. Plantago.

graminifolium, Ehrh. ex Ledeb. Fl. Ross. iv. $40=$ A. Plantago.

grandiflorum, Cham, \& Schlecht. in Linnaea, ii. (1827) $152=$ Echinodorus grandiflorus.

Hamiltonianum, Wall. Cat. n. $4993=$ Sagittaria guyanensis.

heterophyllum, Schur, Enum. Pl. Transs. 880, Index = A. Plantago.

humile, Rich. ex Kunth, Enum. PI. iii. $154=$ Echinodorus humilis.

intermedium, Griff. ex Voigt, Hort. Suburb. Calc. 680 .Ind. or.

intermedium, Mart. in Roem. \& Schult. Syst. vii. 1609 $=$ Echinodorus Martii.

Kotschyi, Hochst. in Flora, xxvi. (1843) $492=$ Limnophyton obtusifolium.

lanceolatum, With. Bot. Arr. Brit. P1. ed. III. ii. $362=$ A. Plantago.

Lappula, Buch.-Ham. ex Kunth, Enum. Pl. iii. $162=$ Sagittaria Lappula.

latifolium, Gilib. Fl. Lituan, ii. 222=A. Plantago

Loeselii, Eichw. Skizze, $127=$ A. Plantago

macrophyllum, Kunth, Enum. PI. iii. $151=$ Echinodorus macrophyllus.

majus, S. F. Gray, Nat. Arr. Brit. Pl. ii. $216=$ A Plantago.

minus, Spreng. Syst. ii. $163=$ Damasonium australe. natans, Linn. Sp. P1. $343=$ Elisma natans.

natans, Pollich, Hist. Pl. Palat. iii. $319=$ A. Plantago. nathpurense, Steud. Nom. ed. II. i. $49=$ Echinodorus ellipticus.

nymphaeifolium, Griseb. Cat. $\mathrm{Pl}$. Cub. 218.-Cuba.

obtusifolium, Thw. Enum. P1. Zeyl. $332=$ Limnophyton obtusifolium.

odoratum, Rafin. F1. Ludov. $17=$ A. Plantago.

oligococcum, F. Muell. Fragm. i. 23.-Austral.

paleaefolium, Kunth, Enum. Pl. iii. 152=Echinodorus ellipticus.

\section{ALISMA :}

paniculatum, Stokes, Bot. Mat. Med. ii. $334=$ A. Plantago.

parnassifolium, Buch.-Ham, ex Wall. Cat. n. $4997=$ calophyllum.

parnassifolium, Bassi, ex Linn. Syst. ed. XII. ii. 230_-

Europ.; Ind. or.; Afr. trop.; Austral.

parviflorum, Pursh, F1. Am. Sept. 1. $252=$ A. Plantago. plantagineum, St, Lag. in Ann. Soc. Bot. Lyon, vii. (1880) $119=$ A. Plantago.

Plantago, Linn. Sp. Pl. 342 (A. Plantago-aquatica). -Reg. temp. bor.; Austral

polyspermum, Nym. Syll, 379= Damasonium polyspermum.

pubescens, Bnch.-Ham. ex Wall. Cat. n. $4995=$ Sagittaria guyanensis.

pubescens, Mart. in Roem. \& Schult. Syst. vii. 1607= Echinodorus ellipticus.

ranunculoides, All. F1. Pedem. i. 234=A. Plantago.

ranunculoides, Linn. Sp. Pl. $343=$ Echinodorus ranunculoides.

ranunculoides, Willd. Prod. FI. Berol. 133=Elisma natans.

reniforme, D. Don, Prod. Fl. Nep. $22=$ parnassifolium. repens, Lam. Encyc. ii. $515=$ Echinodorts ranunculoides. roseum, Rafin. in Med. Repos. New York, v. (1808) $354=$ A. Plantago

rostratum, Nutt. in Trans. Am. Phil. Soc. v. (1837)

$159=$ Echinodorus rostratus.

Sagittaria, Stokes, Bot. Mat. Med. ii, $335=$ Sagittaria sagittifolia.

sagittifolium, Willd. Sp. Pl. ii, $277=$ Limnophyton obtusifolium.

Sprengelii, Rich. ex Kunth, Enum. P1. iii. $154=$

Echinodorus rostratus.

stellatum, Buch.-Ham. ex Wall. Cat, n. $4993=$ Sagit. taria guyanensis.

stellatum, Lam. Fl. Fro iii. $77=$ Damasonium stellatum subalatum, Mart. in Roem. \& Schult. Syst. vii. $1609=$ Echinodorus subalatus.

subcordatum, Rafin. in Med, Repos. New York, v (1808) $362=$ A. Plantago.

subulatum, Linn. Sp. Pl. $343=$ Sagittaria natans. subulatum, Hill, Veg. Syst. x. $33=$ praec.?

taeniaefolium, Steud. in Lechl. Berb. Am. Austr. 53.Chili.

tenellum, Mart. in Roem. \& Schult. Syst. vii. $1600=$ Echinodorus tenellus.

trinerve, Link, ex Steud. Nom. ed. II. i. 49.-Lasitan.

triviale, Pursh, F1. Am. Sept. i. 252=A. Plantago. verticillatum, Dulac, $\mathrm{F} 1$. Hautes-Pyr. $45=\mathrm{A}$. Plantago virgatum, Hook. \& Am. Bot. Beech. Voy, $311=$ Echinodorus virgatus.

ALISMORCHIS, Thou. Orch. Afr. t. 35 (1822)= Calanthe, R. Br. (Orchid.)

Centrosis, Steud. Nom. ed. II. i. $49=$ C. sylvatica.

ALISSON, Vill. Prosp. $38(1779)=$ Alyssum, Linn (Crucif.).

ALISSUM, Neck. Delic. Gallo-BeIg. i. $276(1768)=$ praec

ALITUBUS, Dulac, Fl. Hautes-Pyr. 499 (1867) = Achillea, Linn. (Compos.)

Millefolium, Dulac, 1. c. $500=$ Ach. Millefolium.

pyrenaicus, Dulac, 1. c. = Ach. Ptarmica.

tomentosus, Dulac, 1. c. = Ach. tomentosa.

ALIX, Comm. ex DC. Prod. v. 318 (1836)-Psiadia, Jacq. (Compos.).

salsifolia, Comm. ex DC. 1. c. $319=$ P. retusa.

ALKANNA, Tausch, in Flora, vii. (1824) 234 BORAGINEAE, Benth. \& Hook, f. ii. 857 .

BAPHORHIZA, Link, Handb, ii. 578 (1829)

CAMptocarpus, C. Koch, in Linnaea, xvii. (1843) 304.

Campylocaryum, DC. Prod. x. 97 in syn. (1846). alba, Boiss. Voy. Espagne, $747=$ Nonea alba. amplexicaulis, A. DC. in DC. Prod. x. $101=$ Kotschy ana.

areolata, Boiss, Diagn. Ser. I. iv. 45.-As. Min.

Aucheriana, A. DC. in DC. Prod. x. $102=$ syriaca, rostellata.

azurea, Boiss. PI. Or. Dec. ii. $7=$ areolata.

baeotica, DC. Prod. $x, 98=$ graeca.

bicolor, Boiss. P1. Or. Dec. ii. $7=$ Kotschyana.

brachysolen, Boiss. l. c. = Kotschyana.

\section{ALKANNA:}

bracteosa, Boiss. Diagn. Ser. I. xi. 118.-Persia, calliensis, Heldr. ex Nym. Consp, $517=$ graeca. cappadocica, Boiss, \& Bal. Diagn. Ser. II. vi. $123=$ megacarpa.

controversa. A. DC in DC Prod x. 103-Hab.

cordifolia, C. Koch, in Linnaea, xxii. (1849) 640.Pontus.

filaginoides, DC. Prod. x. $98=$ Pinardi

frigida, Boiss. Diagn. Ser. I. vii. 32.-Persia.

galilaea, Boiss. l. c. Ser. I. xi. 118.-Palaestin.

graeca, Boiss. \&o Sprun. l. c. Ser. I. iv. 47.-Graecia.

hirsutissima, $A . D C$. in DC. Prod. x. 101.-Oriens.

incana, Boiss. Diagn. Ser. I. iv. 45.-As. Min.

Kotschyana, DC. Prod. x. 98.-Oriens.

Lehmanni, A. DC. in DC. 1. c. $588=$ tinctoria.

Jutea, A. DC. l. c. 102.-Europ.

macrophylla, Boiss. \& Heldr, Diagn. Ser. I. xi. 120.As. Min.; Syria.

macrosiphon, Boiss. E Heldr. l. c. 120.-Graecia.

Mathioli, Tausch, in Flora, vii. (1824) $234=$ tinctoria. megacarpa, $A . D C$. in $D C$. Prod. x. 101.-Oriens.

noneiformis, Griseb. Spicil. F1. Rumel, ii. $90=$ A. Pulmonaria.

orientalis, Boiss. Diagn. Ser. I. iv. 46.-Oriens.

Pinardi, Boiss. l. c. 48.-As. Min.

primuliflora, Griseb. Spicil. Fl. Rumel. ii. 89.-Thracia.

Pulmonaria, Griseb. l. c. 90.-Macedon.

rostellata, Boiss. Diagn. Ser. I. xi. 119.-Taurus.

Sartoriana, Boiss, \& Heldr. l. c. Ser. II, iii. 134.Graecia.

scardica, Griseb. Spicil. Fl. Rumel. ii. 91.-Macedon.

Sieberi, A. DC. in DC. Prod. x, 99.-Creta

strigosa, Boiss. E Hohenh. in Boiss. Diagn. Ser. I. iv. 46.--Syria.

syriaca, Boiss. \& Hohenh. Pl. Or. Nov. Dec, ii. 7.Syria.

tinctoria, DC. Prod, x. 99 = Sieberi.

tinctoria, Tausch, in Flora, vii. (1824) 234,-Oriens. tomentosa, Griseb. Spicil, F1, Rumel, ii. 88 in nota= Onosma mollis.

tubulosa, Boiss. Diagn. Ser. I. iv. 48-As. Min.

versicolor, Orph. in Bull. Congr. Bot. Pétersb. 1869 (1870) 138.-Graecia.

viscidula, Boiss. Diagn. Ser. I. xi, 118.-Cappadoc.

Wagneri, Bartl. ex Tchihat. Asie Min. Bot. ii. 107 , nomen.-As. Min.

ALKEKENGI, Toum. ex Hall. Enum. Stirp. Helv. ii. $508(1742)=$ Physalis, Linn. (Solanac.)

fissum, Moench, Meth. $472=\mathrm{P}$. viscosa

officinarum, Moench, Meth. Suppl. $177=$ P. Alkekengi. procumbens, Moench, Meth. $473=\mathrm{P}$. pubescens. pubescens, Moench, 1. c. $=\mathrm{P}$. peruviana.

villosa, Moench, Meth. Suppl. $178=$ P. pubescens

ALKIBIAS, Rafin. Fl. Tellur.iv. 119 (1836) (Compos.). hastata, Rafin. 1. c. (= Linosyris hastata). mucronata, Rafin. 1. c. = Iphinne juniperifolia. ovata, Rafin. 1. c. = Chrysocoma ovata.

ALLAEANTHUS, Thw, in Hook. Kew Journ. vi. (1854) 302. t. 9. URTICACEAE, Benth. \& Hook. f. iii. 361.

luzonicus, Benth. \& Hook, f. Gen. iii. 361.-Ins. Phil. zeylanicus, Thw. in Hook. Kew Fourn. vi. (1854) 302. -Zeylan.

ALI.AEOPHANIA, Thw. Enum. Pl. Zeyl. 147 (1859). RUBIACEAE, Benth. \& Hook. f. ii. 129. Arnottii, Hook. f. Fl. Brit. Ind. iii. 48-Zeylan. decipiens, Thw. Enum. Pl. Zeyl. 147.-Zeylan.

ALLAGANTHERA, Mart. Hort. Erlang. $69(1814)=$ Alternanthera, Forsk. (Amarant.).

Forskohlei, Mart. l. c. = Alt. sessilis.

ALLAGAS, Rafin. Fl. Tellur. iv. 53. (1836)= Halenia, Borckh. (Gentianac.).

ALIAGOPAPPUS, Cass. in Dict. Sc. Nat. lvi. 21. (1828) COMPOSITAE, Benth. \& Hook. f. ii. 333. chrysopsioides, Sch. Bip. in. Schweinf. Beitr. Fl. Aethiop. $153=$ Pulicaria petiolaris.

dichotomus, Cass. in Dict. Sc. Nat. 1vi. 22.-Ins. Canar. viscosissimus, C. Bolle, in Bonplandia, vii. (1859) 293.-Ins. Canar. 
ALLAGOPTERA, Nees, in Neuwied, Reise nach Bras. ii. 335 (1821) = Diplothemium, Mart. (Palm.) pumila, Nees, 1. $c_{v}=$ D. maritimum.

ALlAGOSPERMA, M. Roem. Syn. Pepon. 68 (1846) Cayaponia, Manso (Cucurb.).

ALlagostaChyum, Nees, ex Stend. Nom. ed. II. i. $50(1840)=$ Poa, Linn. (Gramin.).

lasiochloa, Nees, 1. c. $=$ Poa alternans.

ALIAMANDA, Linn. Mant. ii. 146. (1771). APOCYNACEAE, Benth, \& Hook, f. ii. 690. Orelia, Aubl. Pl. Gui. i. 270. t. 106 (1775). angustifolia, Pohl, Pl. Bras. i. 73. t. 59.-Bras. Aubletii, Pohl, l. c. $75=$ cathartica.

Blanchetii, A.DC in DC. Prod. viii. 319.-Bras. brasiliensis, Schott, ex Pohl, Pl. Bras. i. $73=$ Schottii. cathartica, Linn. Mant. ii. 214.-Am, trop. cathartica, Schrad. in Goett. Gelehrt. Anz. (1821) 707 $=$ Schottii.

Doniana, Muell. Arg. in Mart. Fl. Bras. vi. I. 11.Bras.

grandiflora, Lam. Encyc. iv. $601=$ cathartica.

Hendersoni, Bull, ex Dombr. Flor. Mag.v. (1866) t. 263.-Guiana.

latifolia, Presl, Bot. Bemerk. $103=$ cathartica.

Linnei, Pohl, Pl. Bras. i. $74=$ cathartica.

Martii, Muell. Arg. in Mart. Fl. Bras. vi. I. 12.-Bras. neriifolia, Hook. Bot. Mag. t. 4594.-Hab.?

nobilis, T. Moore, in Gard. Chron. (1868) 180, 918.Bras.

oenotheraefolia, Pohl, Pl. Bras. i. 71. t. 57.-Bras, parviflora, Presl, Bot. Bemerk. 103,-Ins. Martin. polyantha, Muell. Arg. in Mart. Fl. Bras, vi. I. 12.Bras.

puberula, A. DC. in DC. Prod. viii. 319.-Bras. Schottii, Hook. Bot. Mag. t. $4351=$ cathartica. Schotii, Pohl, Pl. Bras. i. 73. t. 58.-Bras. setulosa, Miq. in Linnaea, xviii. (1844) 743.-Surinam. thevetifolia, Muell. Arg. in Linnaea, xxx. (1859-60) 388.-Bras.

verrucosa, Gardn. ex Muell. Arg. in Mart. Fl. Bras. vi. I. $14=$ puberula

verticillata, Desf. Tabl. Bot. Par. ed. II. 93.-Hab.? violacea, Gardn. \& Field. Sert. t. $41=$ Blanchetii.

Wardleyana, Lebas, in Rev. Hortic. (1877) $20=$ Hendersoni.

ALLANBIACKIA, Oliver, in Benth. \& Hook, f. Gen. i. 980 (1867), GUTTIFERAE, Benth. \& Hook. f. i. 980 .

floribunda, Oliver, in Journ. Linn. Soc. x. (1869) 43.Afr. trop.

ALLANIA, Benth. in Hook. Lond. Journ. Bot. ii. (1840) $91=$ Aldina, EndI. (Legum.).

insignis, Benth. 1. c.-Guiana.

ALLANIA, Meissn. Gen. 401 (304), (1842)=Alania, Endl. (Liliac.).

ALIANTONIA, Miers, in Trans, Linn. Soc. $x x x$. (1874) 291. MYRTACEAE.

aulacocarpa, Miers, l. c. 296.-Bras.

Burchelliana, Miers, l. c. 294--Bras.

corbula, Miers, l. c. 297.-Bras.

cylindrica, Miers, l. c. 294.-Bras.

dictyocarpa, Miers, l. c. 297.-Bras.

fagifolia, Miers, l. c. 298.-Guiana.

lineata, Miers, l. c. 297.-Bras.

macrocarpa, Miers, l. c. 295.-Bras.

multiflora, Miers, l. c. 291,-Guiana.

scutellata, Miers, $l$. c. 296.-Bras.

subramosa, Miers, l. c. 292.-Guiana.

torulosa, Miers, l. c. 293,-Bras.

ALLARDIA, Decne. in Jacquem. Voy. Bot. 87. t. 95, 96 (1841 ?). COMPOSITAE, Benth. \& Hook. f. ii 424.

WALDHEIMIA, Kar̃. \& Kir. in Bull. Soc. Nat. Mose. (1842) 125

glabra, Decne. l. c. 88. t. 96.-Tibet.

Huegelii, Sch. Bip. in Pollichia, xx-xxi. (1863) $442=$ glabra.

incana, Klatt, in Siteb. Aknd. Muench. (1878) 88.Tibet.

\section{ALLARDIA :}

lanata, Kurz, ex C. B. Clarke, Comp. Ind, $144=$ tomentosa.

nivea, Hook. f. E Thoms. ex C. B. Clarke, l. c. 145. Tibet. occ.

Stoliczkai, C. B. Clarke, Comp. Ind. 145.-Tibet. occ. tomentosa, Decne. in Facquem. Voy. Bot. 87. t. 95.Tibet. occ.

tridactylites, Sch. Bip. in Pollichia, xx-xxi. (1863) 442 = glabra.

vestita, Hook. f. E Thoms. ex C. B. Clarke, Comp. Ind. 145.-Reg. Himal

ALLARDTIA, A. Dietr, in Otto \& Dietr. Allg, Gartenz xx. (1852) 242 = Tillandsia, Linn. (Bromel.). cyanea, A. Dietr. 1. c. $=$ T. cyanea.

Potockii, Antoine, in Oestr. Bot. Zeitschr. xxviii. (1878) $56=\mathrm{T}$. ntriculata.

ALLASIA, Lour. Fl. Cochinch. 84 (1790) Inc. sed.; cf. Benth. \& Hook, f. i. 820

Jobini, Manso, Enum. 36.-Bras.

Payos, Lour. Fl. Cochinch. 85.-Afr. or.

\section{ALLAZIA, Manso, Enum. 36. (1836)=praec.}

ALLELOTHECA, Steud. Syn. P1. Gram. 117 (1855)= Lophatherum, Brongn. (Gramin.)

Urvillei, Steud. 1. c. = L. gracile.

ALLEMANIA, End1. Gen, 304 in nota $(1837)=$ All mania, R. Br. (Amarant.).

ALLENDEA, La Llave, in La Llave \& Lex. Nov. Veg. Desc. fasc. i. $10(1824)$. COMPOSITAE, Benth. \& Hook. f. ii. 437 .

lanceolata, La Llave, l. c.-Mexic.

ALLETOTHECA, Benth. \& Hook, f. iii. 1191 (1883) sphalm. = ALLELOTHECA, Stend.=Lophatherum, Brongn. (Gramin.).

ALLIARIA, Marsh. ex Rupp. Fl. Jen. ed. Hall, 75 (1745); DC. Syst. Veg. ii. $488=$ Sisymbrium, Linn. (Crucif)

brachycarpa, Bieb. Fl. Taur. Cauc. Suppl. $445=$ Erysimum brachycarpon.

Fuchsii, Rupr. Fl. Canc. $85=$ S. Alliaria

Mathioli, Rupr. 1. c, =S. Alliaria

officinalis, Andrz. ex DC. Syst. Veg. ii. $489=$ S. Alliaria.

ALIIBERTIA, Marion, in Rev. Hort. Bouch. Rhone, Nov. (1882); ex Baker, in Gard. Chron. N. S. xix (1883) $176=$ Agave, Linn. (Amaryll.).

intermedia, Marion, ex Baker, 1. c. = A. Alibertii.

ALLINUM, Neck. Elem. i. $179(1790)=$ Selinum, Linn. (Umbell.)

ALLIONIA, Loefl. Iter, 181 (1758); Linn. Syst. ed. $\mathrm{X} .890$ (1759). NYCTAGINEAE, Benth. \& Hook. f. iii. 4 .

WEDELIA, Loefl. Iter, $180(1758)$.

aggregata, Spreng. Syst. i. $384=$ Oxybaphus aggregatus albida, Walt. Fl. Carol. $84=$ Oxybaphus albidus,

Cervantesii, Steud. Nom. ed. II. i. $50=$ Oxybaphus Cervantesii.

cucullata, Mey. ex. Fisch. Mey. \& Avé-Lall. Ind. Sem. Hort. Petrop. viii. $55=$ Oxybaphus cucullatus.

decumbens, Spreng. Syst. i. $384=$ Oxybaphus decnm bens.

hirsuta, Pursh, Fl, Am. Sept. ii. 728=Oxybaphus hirsutus.

incarnata, Linn. Syst. ed. X. 890.-Am. bor.; Ind. occ.; Am. austr.

linearis, Pursh, l. c. $=$ Oxybaphus angustifolius. malacoides, Benth. Bot. Voy. Sulph. $44=$ incarnata. mendocina, Phil. Sert. Mendoc. Alt. 41.-Chili. nyctaginea, Michx. F1. Bor. Am. i. $100=$ Oxybaphus nyctagineus.

ovata, Pursh, F1. Am. Sept. i. $97=$ Oxybaphus floribundus.

violacea, Linn. Syst. ed. X. $890=$ Oxybaphus violaceus.

ALLIUM, [Toum.] Linn. Syst. ed. I. (1795). LIL/A-

CEAE, Benth. \& Hook. f. iii. $80 \%$

Anguinum, Fourr. in Anu, Soc. Linn. Lyon, N, S. xvii. $(1869) 160$.

\section{ALLIUM}

Ascalonicum, Renault, F1. Dép. Orne, 33 (1800).

CEPA, Tourn. ex Linn. Gen. ed. I. 103. (1737)

Codonorrasum, Reichb. Consp. 66 (1828)

Geboscon, Rafin. Cat. 14 (1824).

Moenchia, Medic in Act. Acad. Palat. vi. Phys (1790) 343.

Molrum, Fourr. in Ann. Soc. Linn. Lyon, N. S. xvi $1869) 159$.

MoLy, Boerh, ex Moench, Meth. 286 (1794).

Nectaroscordum, Lindi. Bot. Reg. t. 1912 (1836).

OpHIOSCORODON, Wallr. Sched. Crit. 129 (1822)

Porrum, Tourn. ex Linn. Syst. ed. L. (1735).

RHIZIRIDEUM, Fonre 1 c 160

SAturnia, Marattí, Diss. Romul, et Sat, 18. $(1772)$.

Schoenoprasum, H. B. \& K. Nov. Gen. et Sp. i.2.27 (1815)

SCORODON, Fourr. l. c. 160

Trigones, Parlat, in Occhio, 161 (1839)

AglitheIS, ENDOTIS, GeTUONIS, GYNODON, KA

LABOTIS, KEPA, KROMON, LONCOSTEMO:

Maliga, Panstenum, Piexistena, Stelmesu

Stemodoxis, Rafin. Fl. Tellur. ii. 17-21 (1836)

Periloba, Praskoinon, Rafin. 1. c. iv. 87, 29 (1836)

BERENICE, BRISEIS, BUTOMISSA, CAMARILLA,

CANidia, Hexonychia, Hylogeron, JUi, us

Molyza, Phyllodolon, RaPhione, Schoeniss,

XylorhizA, Salisb. Gen. Pl. Fragm. 88-92 (1866 achaium, Boiss. E' Orph. ex Boiss. Fl. Orient. v, 259 -Graecia

acre, 7. E C. Presl, Delic. Prag. 147-Sicilia.

acuminatum, Hook. Fl. Bor. Am ii. 184.t. 196.-Am. bor acutangulum, Ambros. Fl. Tyr. Austr. i. $565=$ fallax acutangulum, Reichb. Ic. Crit. viii, t. $734=$ montanum. acutangulum, Schrad. Sem. Hort. Goett. $1808=$ angulosum.

acutiflorum, Bové, ex Regel, in Act. Hort. Petrop. iii.

II. (1875) $192=$ paniculatum.

acutiflorum, Loisel. in Desv. Journ. Bot. ii. (1809) 27: $=$ multiflorum

acutum, Spreng. Pugill. i. $28=$ A. Schoenoprasum.

adscendens, Kunth, Enum. P1. iv. $385=$ A. Ampeloprasum.

aestivum, Tineo, Pl, Rar. Sicil. $39=$ sphaerocephalum.

affine, Boiss. \& Heldr. Diagn. Ser. II. iv. $114=$ vineale. affine, Ledeb. Fl. Ross. iv. 166=margaritaceum. africanum, F. G. Dietr. Gartenlex. Nachtr. i. $160=$ odoratissimum.

afrum, Kunth, Enum. Pl. iv. $455=$ Ornithogalum afrum.

Aitchisoni, Boiss. Fl. Orient. v. 248.-Afghan

Akaka, Gmel. ex Roem. Eo Schult. Syst. vii. 1132.Sibir.

Akaka, Regel, in Act. Hort. Petrop. iii. (1875) $243=$ karataviense.

alataviense, Regel, in Bull. Soc. Nat. Mosc. xli. (1865)

1. 448.-Turkestan.

alatum, Schreb. ex Roth, in Roem. Arch. i. III. (179S $40=$ cernum.

Alberti, Regel, in Act. Hort. Petrop. v. (1877) 632.Turkestan.

albescens, Guss. Enum. PL Inarim. $338=$ A. Ampeloprasum.

albidum, Bieb. Fl. Taur. Cauc. iii. Suppl. $260=$ flave scens.

albidum, Fisch. Cat. Gorenk. (1812) 10.-Oriens; Sibir. albidum, J. \& C. Presl, Delic. Prag. $146=$ paniculatum. album, Hort. ex[Delar. in] Red. Lil. v. $300=$ ciliatuun. album, Santi, Viaggi, 352. t. $7=$ neapolitanum.

album, Spreng. Syst. ii. $38=$ pendulinum.

Alexcianum, Regel, in Act. Hort. Petrop. iii. (1875 244 - - Turkestan.

alibile, A. Rich. Tent. Fl. Abyss. ji. \$30-Abyss. alpicolum, Verl, in Bull. Soc. Stat, /stre, xiv, (18\%:? 897.-Gallia.

alpirum, Regel, in Act. Hort. Petrop. iii. II. (1s75 $181=$ narcissiflorum

alpinum, Hegetschw. Fl. Helv. $322=$ A. Schoenoprasum. altaicum. Pall. Reise, ii. $737=$ fistulosum.

altissimum, Regel, in Act. Hort. Petrop. viii. (1854) buti. -Bokhara

Amansii. Bor. Fl. Cent. Fr. edi. III. ii. tis1. in obs a paniculatum.

ambigurum, DC. FI. Fr. ili. $\$ 20=$ ochrolencum. ambiguum, Sibth. \& Sm. Fl. Graec. \&. \$2 $i=$ rosum amblyopetalum, Link, in Linnaca, ix. (1s3t' $139=$ neapulitanum. 


\section{ALLIUM :}

amblyophyllum, Kar. E Kir. in Bull. Soc. Nat. Mosc xv. (1842) 510.-Soongaria.

amethystinum, Tausch, in Syll. Ratisb. ii. $256=\mathrm{A}$. Ampeloprasum.

ammophilum, Heuff, in Flora, xxviii. (1845) 241 ; et

Verh. Zool.-Bot. Ges. Wien, viii. (1858) $210=$ angu losum.

amoenum, G. Don, in Mem. Wern. Soc. vi. (1827) 75 = roseum.

Ampeloprasum, Boiss. Voy. Espagne (ii. 615) = poly anthum, baeticum

Ampeloprasum, Linn. Sp. Pl. 295.-Europ.; Oriens,

Ampeloprasum, Thunb. Prod. Pl. Cap. $65=$ rotundum. amphibolum, Ledeb. Fl. Alt. ii. 5. t. 357.-Sibir. amplectens, Torr. in Pacif. Rail. Rep. iv. $148=$ attenui folitum.

anceps, Kellogg, in Proc. Calif. Ac. ii. (1863) 109. t. 32.-Calif.

Andersonii, G. Don, in Mem. Wern. Soc, vi. (1827) $59=$ senescens.

andicolum, Regel, in Act. Hort. Petrop. iii. (1875) 211 -Peruv.

angolense, Baker, in Trans. Linn. Soc. Ser. II. i. (1878) 262.-Afr. trop.

angulare, Pall. Reise, iii. 299.-Sibir. baic.

angulatum, Pall. 1. c. $408 .=$ praec.

angulosum, All, Fl. Pedem. ii. 158=albidum

angulosum, DC. Fl. Fr, iii. $222=$ fallax.

angulosum, Krock. F1. Sil. i. 524=acutangulum,

fallax, senescens.

angulosum, Linn. Sp. Pl. 300.-Sibir.

angulosum, Lour. F1. Cochinch, $203=$ uliginosum

angulosum, Pursh, Fl. Am. Sept. i. 223 =reticulatum.

angustum, G. Don, in Mem. Wern. Soc. vi. (1827) 33.

-Sibir.

anisopodium, Ledeb, Fl Ross, iv, 183=tenuissimum

apenninum, Huet, ex Nym. Consp. $740=$ paniculatum.

appendiculatum, Ram. ex Pers. Syn. i. $356=$ suaveolens.

approximatum, Gren. \& Godr. F1.Fr. iii. $200=$ sphaerocephalum.

arenarium, Linn. Sp. Pl. $297=$ A. Scorodoprasum.

arenarium, Sadler, Fl. Pesth. ex Reichb. Fl Germ.

Excurs. $40=$ sativum

arenarium, [Wahlenb. in ] Svensk. Bot. t. $691=$ vineale arenarium, Thubb. [F1. Jap. 132] = japonicum.

armenum, Boiss. \& Kotschy, ex Boiss. Fl. Orient.v. $254=$ flavum.

armerioides, Boiss. Diaon. Ser. I. vii 116.-Assyria.

arvense, Guss.-Ind. Sem. (1825) = sphaerocephalum.

ascalonicum, Linn. Amoen. Acad.iv. 454.Ubique cult.

ascalonium, Bory \& Chaub. Fl. Pelop. $21=$ gomphre noides.

ascendens, Tenore, Syll. 164=A. Ampeloprasum.

Aschersonianum, Barbey, Herbor, au Levant, 163. t. 4 -Oriens.

asperum, G. Don, in Mem. Wern. Soc. vi. (1827) $42=$ carinatum.

atropurpureum, Waldst. \& Kit. Ic. Pl. Rar. Hung. 16. t. $17=$ stenopetalum.

atrorubens, S. Wats. in Bat. King, Exp. 352 -Calif.

atrosanguineum, Kar. E Kir. in Bull. Soc. Nat. Mosc xv. (1842) 508.-As. med.

atroviolaceum, Boiss. Diagn. Ser. I. vii. $112=$ A. Ampeloprasum.

atroviolaceum, Hornem, ex Steud. Nom, ed. II. i. $50=$ sphaerocephalum

attenuatum, Kellogg, in Proc. Calif. Acad. ii. (1863)

110. f. 33.-Calif

attenuifolium, Kellogg, l. c. 110. f. 34.-Calif.

Aucheri, Boiss. Diagn. Ser. I. vii. 116.-Persia

aureum, Lam, Fl. Fr. iii. $260=$ A. Moly.

auriculatum, Kunth, Enum. Pl. iv, 418.-Ind, or.

australe, Guss. ex Kunth, 1. c. 404= paniculatum.

azureum, Bunge, in Mém. Sav. Etr. Acad. Pétersb. vii.

(1851) 510 ; Reliq. Lehm. 334.n. 1366=urceolatum

azureum, Ledeb. Fl. Alt. ii. $13=$ caeruletum.

Babingtonii, Borrer, in Engl. Bot. t. $2906=$ A. Scordoprasum.

bachtiaricum, Boiss. Fl. Orient. v. $285=$ bakhtiaricum.

Backhousianum, Regel, Gartenfl. (1885) 213.-Reg. Himal.

baeticum, Boiss. Diagn. Ser. I. vii. 113.-Hispan.

baicalense, Willd. Enum. Hort. Berol. $360=$ senescens.

Bakeri, Regel, in Act. Hort. Petrop. iii. (1875) 141.China ; Japon.

bakhtiaricum, Regel, l. c. 222.-Persia.

\section{ALIIUM:}

Balansae, Boiss. Fl. Orient. v. 268.-Pontus,

Bauerianum, Baker, in Gard. Chron. (1874) II. 131.Aegypt.; Turcia?

Baumannianum, C. Koch, in Linnaea, xxii. (1849) $241=$ rotundum

Beckerianum, Regel, Ind. Sem. Hort. Petrop. (1860) $30=$ tataricum

Bertoloni, De Not. Rep. F1. Lig. $414=$ A. Ampeloprasum.

bidentatum, Fisch. ex Regel, in Act. Hort. Petrop. iii. 1875) 157 = tenuissimum.

Bidwelliae, S. Wats. in Proc. Am. Acad. xiv. (1879) 231.-Am. bor.

bifolium, Willd. ex Schult.f. Syst. Veg. vii. $1117=$ decipiens.

Bigelovii, S. Wats, in Bot. King, Exped. v. 487. t. 38. f. 8 \& 9, -N. Mexic.

bisceptrum, S. Wats. l. c. 351 \& 487, t. 37. f. 1-3.Calif.

bisulcum, [Delar. in] Red. Lil. t. $286=$ A. Stellerianum.

blandum, Wall. Pl. As. Rar. iii. 38. t. 260,-Tibet. occ,

Bodeanum, Regel, in Act. Hort. Petrop. iii. (1875) 238. -Persia.

bogdoicolum, Regel, l. c. vi. (1879) 530.-Turkestan.

Boissieri, Haussk. ex Regel, l. c. iii. II. (1875) 205 frigidum.

Boissieri, Regel, 1, c. $75=$ Lehmannianum.

Bolanderi, S. Wats. in Proc. Am. Acad. xiv. (1879) 229-Calif.

bonariensis, Griseb. in Goett. Abh. xxiv. (1879) 319.Reg. Argent.

borbonicum, Regel, in Act. Hort. Petrop, iii. II. (1875) 218.-Ins. Borb.

Borbasii, Kerner, in Oestr. Bot. Zeitschr. xxix. (1879) 39.-Europ.

Borszczowi, Regel, in Act. Hort. Petrop.iii. II. (1875) 74.-Turkestan.

Boryanum, Kunth, Enum. Pl. iv. $411=$ paniculatum.

bosniacum, Kumm. \& Sendt. in Flora, xxxii. (1849) $762=$ sphaerocephalum

Bonddae, Debeaux, in Actes Linn. Soc. Bord. xxxii. (1878) 24 ; Fl. du Tché-fou, 137.-China.

brachyodon, Boiss. Diagn. Ser. I. vii. $117=$ strictum

brachystemum, [Delar. in] Red. Lil. vii. t. $374=$ subhirsutum.

brahuicum, Boiss. Fl. Orient. v, 278-Beluchist.

Brandegei, S. Wats. in Proc. Am. Acad xvii. (1881-82) 380.-Colorado.

brevicaule, Boiss. \& Bal. Diagn. Ser. II. iv. $119=$ paniculatum.

brevicuspis, Boiss. E Buhse, l. c. 114.-Persia.

brevipes, Ledeb. Fl. Ross. iv, $165=$ Aucheri.

breviscapum, Stapf, in Denkschr. Acad. Wien, 1. (1885) 14.--Persia.

brevistylum, S. Wats. in Bot. King, Exp. 350.Am. bor. occ

Breweri, S. Wats. in Proc. Am. Acad. xiv. (1879) 233. -Calif.

Broteri, Kunth, Enum. Pl. iv. $454=$ A. Schoenoprasum.

bucharicum, Regel, in Act. Hort. Petrop. viii. (1884) 660 .-Bokhara.

Buhseanum, Regel, l. c. iii.II. (1875) $81=$ A. Schoenoprasum.

Bungei, Boiss. Fl. Orient. v. 267.-Persia.

byzantinum, C. Koch, in Linnaea, xxii. (1849) $240=$ A. Ampeloprasum.

caerulescens, G. Don, in Mem. Wern. Soc. vi. (1832) $34=$ caeruleum

caerulescens, Boiss, Diagn. Ser. II. iv, 115.-Armenia caeruleum, Pall. Reise, ii. 737.-Sibir.

caeruleum, Stschégléew, in Bull. Soc. Nat. Mosc. (1854) I. $202=$ urceolatum.

caeruleum, Wall. Cat. n. $5070=$ Wallichii.

caesium, Schrenk, in Bull. Phys. Math. Acad. Pétersb.

ii. (1844) 113. - Turkestan.

caespitosum, Siev. in Pall. Neu. Nord. Beitr. iii. 304 -Soongaria.

calcareum, Reut. in Compte-rend. Soc. Hallér. (1855-56) 127.- Helvet.

calcareum, Wallr. Beitr. Fl. Hercyn. 196=angulosum. callidictyon, Regel, in Act. Hort. Petrop. iii. II. (1875) $74=$ Borszczowi.

callidyction, C. A. Mey. ex Kunth, Enum. Pl.iv. 413. -Oriens.

\section{ALIIUM :-}

allimischon, Link, in Linnaea, ix. (1834) $140=$ paniculatum

callistemon, Webb, ex Regel, in Act. Hort. Petrop. iii 1875) $189=$ flavum

calyptratum, Boiss. Diagn. Ser. I. xiii. 30.-Syria Cambiasii, De Not. Rep. H1. Lig. $412=$ rotundum campanulaeflorum, Gey. ex Hook. Kew Fourn. vii. (1855) 375.-Am. bor.

campanulatum, S. Wats. in Proc. Am. Acad. xiv (1879) 231.-Am. bor.

campestre, Schleich. ex Steud. Nom. ed. II. i. $51=$ vineale.

canadense, Hort. ex Schult. f. Syst, vii. $1007=$ Purshii.

canadense, Herbb. ex Schult. f. 1. c. $1095=$ mutabile. canadense, Linn. Sp. Pl. 1195.-Am. bor.

canadense, Michx. Fl. Bor. Am. i. 191=striatum.

candidissimum, Cav, Lecc. $994=$ neapolitanum

candidum, C. Presl, Fl. Sic. 42,-Sicilia

canescens, Hort. ex Schult. f. Syst. vii. $1067=$ glaucum. capillare, Cav. Icones, iii. 4. t. $206=$ moschatum.

capillare, Desf. Tabl. ed. I. $27=$ pusillum.

capitellatum, Boiss. Diagn. Ser. 1. vii. 118.-Persia; Affghan.

cappadocicum, Boiss. E' Balansa, ex Boiss. Fl. Orient. v. 241.-Cappadoc.

cardiostemon, Fisch. \& Mey. Ind. Sem. Hort. Petrop vi. 43 ,-Persia.

carduchorum, C. Koch, in Linnaea, xxii. (1849) $237=$ Aucheri.

caricifolium, Kar, \& Kir. in Bull. Soc. Nat. Mosc. (1841) $854=$ Pallasi

caricoides, Regel, in Act. Hort. Petrop. vi. (1879) 532 -Turkestan.

carinatum, Habl. Taur. $152=$ flavum

carinatum, Linn. Sp. Pl. ed. I. 297.-Europ.

carinatum, Schulz, Fl. Starg. $86=$ arenarium.

carinatum, Sm. Engl. Bot, t. $1658=$ oleraceum.

Carmeli, Boiss. Diagn. Ser. I. xiii. 28.-Palaestin

carneum, Tenore, F1, Nap. $159=$ roseum.

carneum, Hort. ex Schult. f. Syst. vii. $1028=$ sibiricum

carneum, Targ.-Tozz. Ist. Bot. ed. II. 1. t. $6=$ ambiguum.

carneum, Willd, Enum. Hort. Berol. 359=asca lonicum.

carolinianum, [Delar. in] Red. Lil. t. 101.-Carolina. caspium, Bieb. Fl. Taur. Cauc. i. 265 ; iii. 260 --Ross austr. ; Turkest. ; Sibir.

cassium, Boiss, Diagn. Ser. I. xiii. 28.-Taurus; Syria caucasicum, Bieb. Fl. Taur. Cauc. iii. $258=$ globosum caucason, Turra, ex Sacc. in Atti Ist. Venet. Ser. III ix. (1863-64) 487 = globosum.

Cepa, Banks, ex Schult. f. Syst. vii. $1008=$ proliferum.

Cepa, Falk, Beitr. ii. 157 = fistulosum.

Cepa, Linn. Sp. Pl. ed. I. 300.-Persia; Beluchist

Cepa, Willd. ex Ledeb. Fl. Ross. iv. 169=galanthum.

cepaeforme, G. Don, in Mem. Wern. Soc. vi. (1827) 31 $=$ A. Cepa.

cepaeum, St. Lag. in Ann. Soc. Bot. Lyon, vii. (1880) $113=\mathrm{A}$. Cepa

ceratophyllum, Bess. ex Schult. f. Syst. vii. $1029=$ fistulosum.

cernuum, Hort. ex Schult. f. 1. c. $1081=$ prostratum. cernuum, Roth, in Roem. Archiv, i. II. 40.-Am. bor Chamaemoly, Linn. Sp. Pl. 301.-Reg. Mediterr.

Chamaemoly, Viviani, Fl. Lib. Spec. $19=$ subvillosum. chamaespathum, Boiss. Diagn. Ser. I. vii. 113.Graecia.

chilense, Regel, in Act. Hort. Petrop. iii. II. (1875) 218.-Chili.

chinense, G. Don, in Mem. Wern. Soc. vi. $(1827) 83=$ Thunbergii.

chinense, Maxim. Prim. FI. Amur. 284=odorum.

chionantha, Boiss. Fl. Orient. v. $272=$ zebdanense.

chloroneuram, Boiss. l. c. 247.-Persia.

chloranthum, Boiss. Diagn. Ser. I, xiii, $33=$ flavum.

chloranthum, Lall. ex Regel, in Act. Hort. Petrop. iii.

II. $(1875), 246=$ decipiens

chloranthum, Schur, Enum. Pl. Transs. $672=$ globosum. Christii, Fanka, in Linnaea, xxx. (1859-60) 604.Europ. austr.

chrysantherum, Boiss. \& Reut. ex Boiss. Fl. Orient. v. 280.-Assyria.

chrysanthum, Regel, in Act. Hort. Petrop. iii. (1875) 91.

ciliare, [Delar. in] Red. Lil. vi. t. 311 =subhirsutum.
shina. 
ALLIUM :-

ciliatum, C. Koch, in Linnaea, xix. (1847) $11=$ sphaerocephalum.

ciliatum, Cyr. Pl. Rar. Neap. Fasc. ii. $16=$ subhirsutum. cilicicum, Boiss. Diagn. Ser. I. vii. 115.-As. Min. circinnatum, Sieber, Reise Kreta, ii. 316--Graecia cirrhosum, Raeusch. Nom. ed. III. $74=$ roseum.

cirrhosum, Vand. Fasc. Pl. 11 = flavum.

clathratum, Ledeb. Fl. Alt. ii. 18.-Sibir. alt.

Clusianum, Bory, Fl. Pelop. $21=$ circinnatum.

Clusianum, Retz. in Willd. Sp. P1. ii. $79=$ subvillosum.

colchicifolium, Boiss. Diagn. Ser. II. iv. 112.-Armenia.

collinum, Dougl. ex S. Wats. in Proc. Am. Acad. xiv.

1879) 228.-Am. bor. occ.

collinum, Gass. in Tenore, Syll. $169=$ paniculatum.

coloratum, Dulac, F1. Hantes-Pyr. $110=$ A. Schoenoprasum.

coloratum, Spreng. Syst. ii. $38=$ flavum.

commune, Noronha, in Verh. Batav. Gen. v. (1790) ed.

T. Art. iv. 6 ; ed. II. $68(1827)=$ A. Cepa

commutatum, Guss. Enum. Pl. Inarim, $17=$ rotundum. compactum, Thuil, Fl. Par. $167=$ vineale

complanatum, Boreau, Not. xxxv. p. $12=$ oleraceum.

condensatum, Turcz. in Bull. Soc. Nat. Mosc. xxvii

(1854) II. 121.-Sibir, baical.

confertum, Fisch. Cat. (1821).-Cf. G. Don, in

Mem. Wern. Soc. vi. (1827) $63=$ deflexum, strictum, senescens.

confertum, Jord. \& Fourr. Brev. Fl. Nov. fasc. ii. 127 = roseum.

congestum, G. Don, in Mem. Wern. Soc. vi. (1827) 66 $=$ Stellerianum.

consanguineum, Kunth, Enum. Pl. iv. 431.--Reg. Himal.

consimile, Jord. ex Gren. \& Godr. Fl. Fr. iii. $208=$ carinatum.

contortum, Stokes, Bot. Mat. Med.ii. $229=$ A. Scorodoprasum.

controversum, Costa, Suplem. Catal. $62=$ pyrenaicum. controversum, Schrad, Cat, Goett, ex Willd. Enum. Hort. Berol. $358=$ sativum.

convallarifolium, Pall. ex Ledeb. F1. Ross. iv, $184=$ A. Victorialis.

Coppoleri, Tineo, Cat. Pl. Hort. Panorm. 18= paniculatum.

corbariense, Timb. ex Nym. Consp. $737=$ subhir sutum.

cornutum, Clem. It. Dalm. t. 1. f. 1.-Dalmatia.

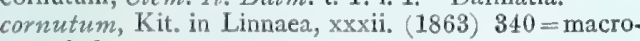
cephalum.

Cowani, Lindl. Bot. Reg. t. $758=$ neapolitanum.

Crameri, Aschers. \& Boiss. ex Boiss. Fl. Orient. v. 279 -Aegypt.

crinitum, Tausch, in Syll. Ratisb. ii. $255=$ sphaerocephalum

cristatum, Boiss. Fl. Orient. v. 237.-Thracia.

Cristophi, Trautv. in Act. Hort. Petrop. ix. (1884) 268. As. temp.

croceum, Torr, in Bot. Mex. Bound. 218.-Calif.

Cumaria, Buch.-Ham. ex Wall. Cat, n. $5072=\mathrm{A}$ Cepa.

Cupani, Guss, Pl. Rar. $143=$ moschatum

Cupani, Rafin. Caratteri, (1818) 86. n. 206.-Reg,

Mediterr.

cupuliferum, Regel, in Act. Hort. Petrop. iii. (1875) 234 . - Turkestan.

curtum, Boiss. E Gaillard, Diagn. Ser. II. iv. 116. Syria ; Acgypt.

Cusickii, S. Wats. in Proc. Am. Acad. xiv. (1879) 228. -Am. bor. occ.

cyaneum, Regel, in Act. Hort. Petrop.. iii. (1875) 174. -China.

Cydni, Schott \& Kotschy, ex Schott, in Oestr. Bot. Wochenbl. (1854) $217=$ cassium.

Cyrilli, Tenore, Fl. Nap. iii. 364.-Italia; Graeaic; Tauria.

danubiale, Reichb. ex Kunth, Enum. Pl. iv. $423=$ sencicens.

danubiale, Spreng. Fl. Hal. Mant. $38=$ angulosum.

darwasicum, Regel, in Act. Hort. Petrop. vii. (1884) 659.-Bokhara.

Decaisnei, Presl, Bot. Bemerk, $114=$ flavum

decipiens, Fisch. Hort. Gorenk. ed. II. (1812) 10,Reg. Caucrs: Turkest. = Sibir.

declinatum, Reichb. Ic. Fl. Hort. Germ. v. 46. t 477 - Stellerianum.

deflexum, Fisch. ex Kunth, Enumo. Pl. iv, $428=$ Stel. lerianum.

\section{ALLIUM}

deflexum, Willd. Sp. PI. ii. $65=$ lineare

delicatulum, Sievers, ex Willd. in Roem. E Schult. Syst. vii. 1133. - Sibir.

densiflorum, De Not. Rep. FI. Lig. $413=$ sphaeroce phalum.

denticulatum, Kit. in Linnaea, xxxii. (1863) $342=$ carinatum.

dentiferum, Webb \& Berth. Phyt. Canar, iii. 345. t. $234=$ paniculatum

denudatum, [Delar. in] Red. Lil. t. 357:=albidum.

Derderianum, Regel, in Act. Hort. Petrop. ii. (1875 242 = naemanthoides

descendens, Koch, Syn. Fl. Germ. ed. I. $719=$ vineale. descendens, Linn. Sp. Pl. ed. I. $299=$ sphaerocephalum descendens, Pall. Ind. Taur. ex Schult. f. Syst. vii. $1011=$ rotundum.

descendens, Sibth. \& Sm. Fl. Gr. iv. 15. t. $316=$ margaritaceum.

Déséglisei, Bor. Not. Nov. (1853) 17; (in Bull. Soc. Indust. d'Angers). - Cf. Ann. Soc, Linn. Maine-etLoire, i. (1857) 63 =sphaerocephalum.

deserti, Boiss. ex Regel, in Act. Hort. Petrop. iij (1875) $76=$ Boissieri.

desertorum, Forsk. Fl. Aegypt. Arab. 72.-Aegypt. diaphanum, Janka, in Linnaea, xxx. (1859-60) $605=$ tataricum.

dictyoprasum, Ledeb. F1. Ross. iv. 166 =dyctioprasum dilutum, Stapf, in Denkschr. Acad. Wien, 1. (1885) 13.-Persia.

Dioscoridis, Sibth. \& Sm. Prod. Fl. Gr. i. 222. Europ. austr. ; Oriens.

djimilense, Boiss. ex Regel, in Act. Hort. Petrop. ii II. (1875) 108. - Pontus

doloncarense, Regel, l. c. 113.-Sibir.

Donglasii, Hook. Fl. Bor. Am. ii. 184. t. 197.-Calif. Douglasii, Wood, in Proc. Philad. Acad. (1868) $170=$ unifolium, bisceptrum.

Dregeanum, Kunth, Enum. Pl, iv. $382=$ A. Scorodoprasum.

Drummondi, Regel, in Act. Hort. Petrop. iii. (1875) $112=$ mutabile

Duriaeanum, Regel, 1. c. $54=$ A. Ampeloprasum.

Durieuanum, Walp. Ann. Bot. i. $860=$ praec

Durtaeanum, J. Gay, in Ann. Sc. Nat. Sér. III. viii.

(1847) $218=$ A. Ampeloprasum.

dyctioprasum, C. A. Mey. ex Kunth, Enum.Pl.iv. 390 -Armenia.

effusum, Boiss. F1. Orient. v. $257=$ stamineum.

elatum, Regel, in Act. Hort. Petrop. viii. (1884) 665.Bokhara.

Elwesi, Regel, 1. c. v. (1877) $266=$ acuminatum ?

ellipticum, Wall. Cat. n. $5069=$ A. Victorialis.

eminens, Gren. ex Parl. Fl. Ital. ii. $567=$ sphaero cephalum.

Erdelii, Baker, in Bot. Mag. t. $6426=$ orientale,

Erdelii, Zucc. in Abh. Math. Phys. Acad. Muench. iii. (1843) 236. t. 5.-Palaestin.

erectum, G. Don, in Mem. Wern. Soc. vi. (1827) $18=$ rotundum.

ericetorum, Thore, Chlor. Land. $123=$ ochroleucum suaveolens.

eriophyllum, Boiss. Diagn. Ser. I. vii. 112.-Persia.

erubescens, C. Koch, in Linnaea, xxii. (1849) $242=$ rudbaricum.

erythraeum, Griseb. Spicil. Fl. Rumel. i1. 396.Macedon.

erythraeum, Weiss, ex Boiss. E1. Orient. v. $253=$ Weissii.

esculentum, Salisb. Prod. $235=$ A. Cepa.

euosmum, Link \& Otto, Ic. PI. Rar. Hort. Berol. i. 15. t. 8 = nudicaule

euschoenoprasum, Syme, Engl. Bot. ed. III. ix. $315=\mathrm{A}$ Schoenoprasum.

exaltatum, Kar. \& Kir. ex Ledeb. Fl. Ross. iv. $173=$ obliquum.

exile, Boiss. \& Orph. Diagn. Ser. II. iv. $118=$ sipylum. exsertum, Baker, in Journ. Bot. xii. (1874) $294=$ Bakeri.

exsertum, G. Don, in Mem. Wern. Soc. vi. (1827) 17 -Rossia.

falcifolium, Hook. E Arn. Bot. Beck. Voy, $400 .-$ Calif.

fallax, Schult. f. Syst. vii. 1072.-Europ.; As. Min.

Fedschenkoanum, Regel, in Act. Hort. Petrop. iii. II. (1875) 82.-Turkestan.

Fetisowi, Regel, l.c. v. (1877) 631.-Turkesıan.

filidens, Regel, l. co iii. II. (1875) 174.-Turkestan.

\section{ALLIUIM}

filiforme, Colla, Herb. Pedem. t. 90. \&. 3.-Italia

fimbriatum, S. Wats in Proc. Am. Acad. xiv. (1879) 232.-Calif

Fischeri, Bess. in Roem. \& Schult. Syst. vii. $1081=$ Stellerianum.

Fischeri, Regel, in Act. Hort. Petrop. iii. II. (1875 161.-Sibir.

fissile, S. F. Gray, Nat. Arr, ii, $183=$ A. Ascalonicum. fissile, Steud. Nom. ed. II. i. 51, nomen,-As. Min.

fistulosum, Linn.Sp.Pl. 301.-Sibir.

flavescens, Bess. Enum. Pl. Volh. 56=albidum.

flavescens, Poepp. ex Kunth, Enum. Pl. iv, 459 striatum.

flavidum, Ledeb. Fl. Alt. ii. 7.-Sibir.

flavum, Less. ex Ledeb. FI. Ross. jv. $172=$ delicatulum.

flavum, Linn. Sp. Pl. 299.-Europ.; Oriens.

flavum, Salisb. Prod. $235=$ A. Moly.

flexifolium, Jord. in Gren. \& Godr. Fl. Fr. iii. $208=$ carinatum.

flexum, Wallst. \& Kit. Pl. Rar. Hung, ii. $307=$ carinatum. flexuosum, Host, Fl. Austr. 1. $422=$ carinatum.

flexuosum, Urville, in Mém. Soc. Linn. Paris, i. (1820 $294=$ staticaeforme

foetidum, Willd. Enum. Suppl. 17 = flexum, carinatum

foliosum, Clar. ex [DC. in] Red. Lil. t. $214=\mathrm{A}$.

Schoenoprasum

Fontanesii, J. Gay, in Ann. Sc. Nat. Sér. III. viii. 1847) $209=$ flavum.

fragrans, Boj. Hort. Maurit. $348=$ Milla borbonica fragrans, Cyr. ex Tenore, Fl. Nap. iii. $364=$ Cyrilli. fragrans, Vent. Jard. Cels, $26=$ Nothoscordum fragrans. frigidum, Boiss. \& Heldr. Diagn. Ser. I xiii. 34. Graecia.

Frivaldzkyanum, Kunze, in Linnaea, xvi. (1812) 311 = margaritaceum.

fuscum, Schrad. ex Hornem. Hort. Hafn. ii. $962=$ pulchellum.

fuscum, Spreng. Syst. ii. $37=$ longispathum

fuscum, Waldst. \& Kit. Pl. Rar. Hung, iii. 267.

241 = paniculatum.

Fussii, Kerner, in Destr. Bot. Zeitschr. xxviii. (1878) 155.-Austria.

galanthum, Kar. E Kir. in Bull. Soc. Nat. Mosc. xy. (1842) 508.-Soongaria.

gaditanum, Perez-Lara, ex Willk. in Illustr. Fl. Hisp. 81.-Morocco.

Gardinia, Bertero, ex Stend. Nom. ed. II. i. $664=$ Brodiaea violacea.

Gasparrini, Guss, in Enum. P1. Inarim. 337. t. $16=\mathrm{A}$ Ampeloprasum

Gayi, Boiss. Fl. Orient, v, 271.-Cilicia

Geyeri, S. Wats. in Proc. Am. Acad. xiv. (1879) 227. -Calif.

Gherardi, De Not. Rep. Fl, Lig. $412=$ sphaerocephalum.

giganteum, Regel, Gartenf. (1883) 91.-Reg. Himal. glandulosum, Link \& Otto, Ic. Rar. i. 38. t. 17.Mexic.

glaucum, [Desf.] Hort. Par, ex [DC. in] Red. Lil. iv. t. $214=$ foliosum

glaucum, Hort. Par. ex Ledeb. Fl. Ross. iv. $167=\mathrm{A}$ Schoenoprasum

glaucum, Schrad. ex Poir. Encyc Suppl. i. 265= senescens.

globosum, Bieb. Fl. Taur. Cauc, i. 262 ; iii. 25-Europ. austr.; Reg. Cauc.; Sibir.

globosum, [DC. in] Red. Lil. iii. t. 179.-Hab。?

glumaceum, Boiss. \& Haussk. ex Boiss. Fl. Oricnt.v. 260 -Cataonis.

gomphrenoides, Boiss. E Heldr. Diagn. Ser. I. vii. 114.-Lycronia.

gorumsense, Boiss. Fl. Orient. v. 233.-Cilicia.

Gounani, G. Don, in Mem. Wera. Soc vi. (152i) $\$ 5$ neapolitanum.

Govanianum, Wall. Cat, n. 50\%1-Reg. Himal

gracile, Dryand. in] Ait. Hort. Kew. i. $t 2 y=$ Nocho scordum fragrans.

graecusn, J. Gay, ex Boiss. Fl. Orient. $\vee .271$ - Gavi. graecum, Urville, in Mim. Soc. Lina. Par. i. (182: $2: 13$ - trifoliatum.

gramine'sm, C. Koch, in Linnaea, xxii. (18f! ㄱ. 1 rotundum,

graminifulium, Buch, in Abh. Acad. Berl. xvii. (1810 $36^{\circ} .2$ - Ins. Canas.

graminifolium, Loisel. Fl. Gall. i. 259 = subhirsutum.

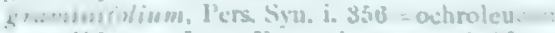

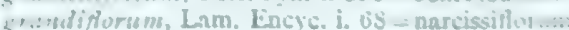




\section{ALLIUM :-}

Grazi, Rerel, in Act. Hort. Petrop. iii. (1875) 125.Japon.

Griffithianum, Boiss. Diagn. Ser. II. iv, $117=$ rubellum Grimmi, Regel, Dec. Pl. Nov. 10.-Cf. Act. Hort. Petrop. viii. (1883) 272.-Turkestan.

Guicciardii, Heldr. in Atti Congr. Bot. Firenze, 1874 (1876) $233=$ flavum.

guttatum, Stev, in Mém. Soc. Nat. Mosc. ii. (1809) 173. t. $11=$ margaritaceum

haemanthoides, Boiss. ex Regel, Act. Hort. Petrop. iii. II. (1875) 240.-Persia.

haematochiton, S. Wats, in Proc. Am. Acad. xiv. 1879) 227.-Calif.

Halleri, Bab. Man. Brit. Bot. ed. I. $305=$ A. Scorodoprasum.

Halleri, Crantz, Inst. i. $488=$ lineare.

Halleri, G. Don, in Mem. Wern. Soc. vi. (1827) $15=$ A. Ampeloprasum

Heldreichii, Boiss. Diagn. Ser. II. iv. 116.-Graecia. hierochuntinum, Boiss. Fl. Orient. v. 244.-Palaestin. himalayense, Regel, in Act. Hort. Petrop. iii. II. (1875) $118=$ Stocksianum

hirsutum, Lam. Fl. Fr. iii. 262 = subhirsutum.

hirsutum, Zucc. in Abh. Bayer. Akad. iii. (1843) 232. t. 2.-Palestin.

hirtifolium, Boiss. Fl. Orient. v. 281.-Persia.

hirtoraginatum, Kunth, Enum. Pl. iv, $412=$ Cupani

Hoeltzeri, Regel, in Act. Hort. Petrop. viii. (1884) 657 Regel, Gartenfi. (1884) 291.-Turkestan,

holmense, Mill, ex Kunth, Enum. Pl. iv, 384=A. Ampeloprasum.

Hookeri, Thw. Enum. Pl. Zeyl. $339=$ Wallichii.

humile, Kunth, Enum. Pl iv, 442,-Ind or

hyalinum, Curran, in Bull. Calif. Acad. n. 3. (1885) 155.-Calif.

hyemale, Rafin. Fl. Ludov. $19=$ fragrans.

hymenorrhizum, Ledeb. Fl. Alt. ii. 12.-Turkest.; Persia.

hymettium, Boiss. \& Heldr, Diagn. Ser. II, iv, 120.Graecia.

iliense, Regel, in Bull. Soc. Nat. Mosc. xli. (1868) I. 452 ,- -Soongaria.

illyricum, Jacq. Collect. iii. $273=$ roseum.

illyricum, Link \& Otto, ex Kunth, Enum. Pl. iv. 422= senescens.

inaequale, Janka, in Linnaea, xxx. (1859-60) $603=$ moschatum.

incarnatum, Hornem. Hort. Hafn. i. $323=$ roseum.

inderiense, Fisch. ex Roem. \& Schult. Syst. vii. 1133 $=$ tartaricum

inodorum, Ait. Hort. Kew. 1, 427 =Nothoscordum fragrans.

inodorum, Willd. Sp. Pl. ii. $76=$ angulosum.

insubricum, Boiss. \& Reut. Cat. Sem. Jard. Genèv. (1854).-Cf. Linnaea, xxix. (1857) $721=$ narcissi(1854).

intermedium, DC. Fl. Fr. vi. 318=tataricum, paniculatum.

intermedium, G. Don, in Mem. Wern. Soc. vi. (1827) $38=$ oleraceum

Jacquemonti, Regel, in Act. Hort. Petrop. iii. II. (1875) 162 - Ind, or

Facquemontii, Kunth, Enum. P1. iv. $399=$ rubellum. japonicum, Steud. Nom. ed. II. i. 50-Japon.

japonicum, Regel, in Act. Hort. Petrop. iii. II. (1875) 133.-Japon.

jeholense, Franch. in Nouv. Arch. Mus. Hist. Nat. Par. Sér. II. vii. (1884) 113; Pl. Davidian. i. (1884) 305. - China.

jenischianum, Regel, in Act. Hort. Petrop.iii..II. (1875) 237.-Persia.

jesdianum, Boiss. É Buhse, in Nouv. Mém. Soc. Nat. Mosc. xii. (1860) 217.-Persia.

juldusicolum, Regel, in Act. Hort. Petrop. vi. (1879) 523.-Turkestan

junceum, Jacquem. ex Baker, in Journ. Bot. xii. (1874) $295=$ Jacquemonti

junceum, Sibth. E S Sm. Prod. i. 226.-Cyprus.

juncifolium, D. Don, ex Steud. Nom. ed. II. i. 52.Chili.

karakense, Regel, in Act. Hort. Petrop. iii. II. (1875) 76.-Turkestan.

karataviense, Regel, l. c. 248.-Turkestan.

Kaufmanni, Regel, l. c. 84.-Turkestan

kermesinum, Reichb. Ic. Fl. Germ. x. $25=$ globosum

Kesselringi, Regel, in Act. Hort. Petrop. viii. (1883) 272.-Turkestan.

\section{ALLIUMI}

Klotzschi, Regel, in Act. Hort. Petrop. iii. II. (1875) 255 = lilacinum.

Kochii, Lange, ex Nym. Consp. $736=$ vineale.

kokanicum, Regel, in Act. Hort. Petrop. iii. II. (1875) 104.- Turkestan.

Korolkowi, Regel, l. c. ii. (1873) 407.-Turkestan.

Kotschyi, Boiss. Diagn. Ser. I. vii. 117.--Persia.

Kunthii, G. Don, in Mem. Wern. Soc. vi. (1827) 82.Mexic.

Kuschakerwiczi, Regel, in Act. Hort. Petrop. iii. Ir. (1875) 117.--Turkestan.

laceratum, Boiss. \& Noë, Diagn. Ser. II. iv. 112.Persia.

lachnophyllum, Payne, in Pal. Expl. Soc. Cat. Pl. 125 -Palaestin.

lacteum, Sibth. \& Sm. Prod. $226=$ neapolitanum.

lacunosum, S. Wats. in Proc. Am. Acad. xiv. (1879) 231.-Calif.

lacteum, Benth. Pl. Hartw. $339=$ Brodiaea lactea.

laetum, Pollini, Cat. Veron. (1812) 7 =neapolitanum.

laetum, Salisb. Prod. $235=$ A. Porrum.

Lallemanti, Regel \& Rach, in Ind. Sem. Hort. Petrop (1858) $24=$ decipiens.

latifolium, Gilib. Exercit. ii. $470=$ ursinum.

latifolium, Jaub. \& Spach, Illustr. Pl. Orient. ii. 3. t. $103=$ A. Akaka.

laxiflorum, Tausch, in Flora, xii. (1829) Erg. $46=$ vineale.

laxum, G. Don, in Mem. Wern. Soc. vi. (1827) $63=$ angulosum.

Ledebourianum, Schult. f. Syst. vii. 1029.-Rossia

Lehmannianum, Merckl. exBunge, in Mém. Sav. Etr. Pétersb. vii. (1851) 509; (Rel. Lehm. 333 --Tur kestan.

Lemmoni, S. Wats. in Proc. Am. Acad. xiv. (1879) 234.-Calif.

lepidum, Kunth, Enum. PI. iv. 408=paniculatum.

lepidum, Ledeb. Ic. F1. Ross. iv, $17=$ Pallasii.

leptophyllum, Schur, Enum. Pl. Transs. 674=senescens. leptophyllum, Wall. Cat. n. $5073=$ rubellum.

Lessingii, Kar. ex Ledeb. F1. Ross, iv. $170=\mathrm{sabu}$ losum.

leucantinum, C. Koch, in Linnaea, xxii. (1819) $240=$

A. Ampeloprasum.

leucocephalum, Turcz, ex Ledeb. Fl. Ross, iv, 179= flavidum

Libani, Boiss. Diagn. Ser. I. xiii. 26.-Syria.

ligusticum, De Not. Prosp. F1. Lig. $55=$ flavum

lilacinum, Klotzsch, in Bot. Ergeb. Waldem. Reise, 50 -Reg. Himal.

lilacinum, Royle, ex Regel, in Act. Hort. Petrop. iii. (1875) $89=$ rubens

liliflorum, Zeyh. Cat. Schwetz. (1818) $15=$ neapoli tanum.

lineare, Linn. Sp. $P l .295 .-$ Sibir.

lineare, Tenore, Fl. Nap. i. 154=sphaerocephalum.

lineare, Willd ex Kunth, Enum. Pl. iv, $419=$ strictum.

littoreum, Bertol. Amoen. It. 241 = vineale.

littoreum, G. Don, in Mem. Wern. Soc. vi. (1827) $8=$ monspessulanum.

longibulbum, Dulac, Fl. Hautes-Pyr. $110=$ A. Victorialis.

longicaule, Hornem. Hort. Hafn. Suppl. 130.Am. bor

longicaule, Hort. ex Schult. f. Syst. vii. $1067=$ glaucum. longicuspis, Regel, in Act. Hort. Petrop. iii. II. (1875 45.-Kokania.

longifolium, Spreng. Syst. ii. 38.-Am, mer.; Mexic longifolium, Lindl. Bot. Reg. t. 1034= glandulosum

longipetiolatum, St. Lag. in Ann. Soc. Bot. Lyon, vii. 1880) $119=$ ursinum.

longisepalum, Bertol. in Nov. Comm. Acad. Bonon. v (1842) $429=$ rubellum.

longispathum, [Delar. in] Red. Lil, t. 316=paniculatum.

longistylum, Baker, in Journ. Bot. xii. (1874) $294=$ sacculiferum.

loratum, Baker, l. c. 290.-Tibet. occ.

lusitanicum, Lam. Encyc. 1. 70.-Lusitan.

Insitanicum, Link, ex Regel, in Act. Hort. Petrop. iii. II. $(1875) 78=\mathrm{A}$. Schoenoprasum.

lusitanicum, [Delar. in] Red. Lil, t. 271=angulosum. luteum, Hort. ex Dietr. Lexic. Gart. ed. II. i. $265=$ obliquum.

Macleanii, Baker, in Bot. Mag. t, 6707.-Affghan.

Macnabianum, Hort. ex Regel, Gartenfl. (1873) 261. t. 77. f, 2-3.-Hab. ?

\section{ALLIUM :-}

macranthum, Baker, in Fourn. Bot. xii. (1874) 293.Reg. Himal.

macrocephalum, Kit. in Linnaea, xxxii. (1863) 340 Austria.

macrochaetum, Boiss. \& Haussk. ex Boiss. Fl. Orient. v. 239.-Assyria.

macrorhizon, Regel, in Act. Hort. Petrop. iii. II. (1875) 154.-Turkestan.

macrorrhiaum, Boiss. Diagn. Ser. I. xiii. $32=$ hymenorhizum.

macrospermum, Boiss. \& Kotschy, ex Boiss. Fl. Orient. v. $282=$ orientale

macrostemon, Bunge, in Mém. Sav. Étr. Acad. Pétersb. ii. (1835) 139, - China bor.

macrostylum, Regel, in Act. Hort. Petrop. vi. (1879) 296. - Tianschan.

macrum, S. Wats. in Proc. Am. Acad. xiv. (1879) 233. -Am, bor.

madiclum, S. Wats. l. c. 228.-Am. bor.

magicum, Linn. Sp. Pl. ed. II. 424 -nigrum.

majale, Cyr. Pl Rar Neap. Fasc i. 13, t. $4=$ roseum.

margaritaceum, Heldr. ex Regel, in Act. Hort. Petrop. iii. II. (1875) $201=$ staticiforme

margaritacezm, Moench, Meth. Suppl. $80=$ A. Scorodoprasum.

margaritaceum, Sibth. \& Sm. Fl. Graec. Prod. i. 224. -Europ. ; Oriens.

marginatum, Fanka, in Termesz. Füzetek, viii. (1884) 29.-Europ austr.

maritimum, RaGn. Caratt. 86. n. $205=$ pusillum.

maritimum, Torr. in Rep. U. St. $\mathcal{E}$ Mex. Bound. 217.-Calif.

Maximowiczi, Regel, in Act. Hort. Petrop. iii. II. (1875) 153.-As. or

medium, G. Don, in Mem. Wern. Soc. vi. (1827) $88=$ triquetrum.

megalobulbon, Regel, in Act. Hort. Petrop. vi. (1879) 526.-Turkestan.

melanantherum, Panć. Elem. 64,-Europ. merid.

microcephalum, Tausch, in Flora, ii. (1819) $462=$ strictum.

microcephalum, Willd. ex Kunth, Enum. Pl. iv. $425=$ angulosum.

minutiflorum, Regel, in Act. Hort. Petrop, iii. II. (1875) 242.-Persia.

mobilense, Rege1, 1. c. = mutabile.

modestum, Boiss. Diagn. Ser. I. xiii. $33=$ paniculatum. mogadorense, Willd. ex Kunth, Enum. Pl. iv. $384=\mathrm{A}$. Ampeloprasum.

Moly, Georgi, Beschreib. Russ. Reich. iii. IV. $896=$ decipiens.

Moly, Griseb. \& Schur, ex Regel, in Act. Hort. Petrop. iii. II. (1875) $199=$ globosum.

Moly, Linn. Sp. Pl. 301.-Europ

Moly, Ucria, Hort. Panorm. $153=$ subhirsutum.

monadelphum, Turcz. ex Kunth, Enum. Pl. iv. 393.Sibir. baical.

mongolicum, Regel, in Act. Hort. Petrop. iui. II. (1875) 160.-Mongolia.

monserratense, Pourr. ex Willk. \& Lange, Prod. Fl. Hisp. i. $207=$ carinatum.

monspessulanum, Gouan, Illustr. $24=$ nigrum.

monspessulanum, Willd. Enum. Suppl. $16=$ paniculatim.

montanum, Guss. P1. RaT. $142=$ tenuiflorum.

montanum, Reichb. Ic. Fl. Germ. x. t. 463. f. $1060=$ flavum.

montanum, Tenore, F1. Nap, iii. $367=$ Cnpani.

montanum, F. W. Schmidt, ex Schult. f. Syst. vii. 1072 $=$ losum.

montanum, Sibth. \& Sm. F1. Graec.t. $319=$ paniculatum. moschatum, Linn. Sp. Pl. ed. I. 299.-Europ.; Oriens moschatum, Moris, Stirp. Sard. Elench. i. $46=$ parciflorum.

moschatum, Sintenis, ex Regel, in Act. Hort. Petrop. iii. II. (1875) $199=$ globosum.

moschatum, Urville, in Mém. Soc. Linn. Par. i. (1822) $293=$ Cupani

multibulbosum, Jacq. Fl. Austr. i. $9=$ nigrum.

multiflorum, DC. Fl. Fr. vi. $316=$ polyanthum.

multiflorum, Desf. Fl. Atlant. i. 288.-Algeria.

multiflorum, Kunth, Enum. Pl. iv. $387=$ rotundum.

multiflorum, Regel, in Act. Hort. Petrop. iii. (1875) 61 pro parte $=$ rudbaricum

Murrayanum, Regel, in Gartenfl. (1873) 260.t. 770. f.

1 = acuminatum.

mutabile, Michx. Fl. Am. Bor. i. 195.-Georgia. 
ALLIUM

myrianthum, Boiss. Diagn. Ser. I. v. $59=$ A. Ampeloprasum.

Napus, Pall. ex. Kunth, Enum. Pl. iv. $395=$ A. Cepa narcissiflorum, Vill. Prosp. 18.-Europ.

narcissifolium, Lam. F1. Fr. iil. $263=$ pedemontanum narcissifolium, Scop. F1. Carn. ed. II. i. $238=$ senescens.

neapolitanum, Cyr. Pl. Rar. Neap. i. 13. t. 4.-Europ.; Oriens.

nebrodense, Guss. Prod. Fl. Sic. i. $404=$ flavum.

neglectum, Wender. in Schrift. Ges. Nat. Marb. ii

(1831) $211=$ A. Scorodoprasum.

nemorale, Salisb. Prod. $235=$ ursinum

Nereidum, Hance, in Ann. Sc. Nat. Sér. V. v. (1866) 244.-China.

neriniflorum, G. Don, ex Loud. Encyc. Pl. Suppl. it.

1342,-China.

nerinifolium, Baker, in Journ. Bot. xii. (1874) $290=$ Thunbergii.

nevadense, S. Wats. in Bot. King, Exp. 351, 487. t. 38. f. 1-3.-Calif.

Nevii, S. Wats. in Proc. Am. Acad. xiv. (1879) 231.Calif.

niorum, All. F1. Pedem. ii. 158, t. 25 f. $1=$ narcissiflorum.

nigrum, Bieb. F1. Taur. Cauc. i. $266=$ decipiens

nigrum, G. Don, in Mem. Wern. Soc. vi. (1827) $89=$ multibulbosum.

nigrum, Linn. Sp. Pl. ed. II. 430.-Europ. ; Oriens.

niorum, Sibth. \& Sm. Fl. Graec. t. $323=$ Bauerianum nipponicum, Franch. \& Sav. Enum. Pl. Fap. ii. 527. -Japon.

nitens, Sauzé \& Maill. Cat. P1. Deux-Sèvres, $51=$ vineale.

nitidulum, Fisch. ex Ledeb. F1. Ross, iv. 171= Pallasii.

Nitschmanni, Willd. ex Ledeb. 1. c. $175=$ flavum.

nivale, Jacquem. ex Regel, in Act. Hort. Petrop. iii. II. (1875) $178=$ Govanianum

niveum, Roth, Cat. Bot. fasc. ii. $35=$ subhirsutum.

Noëoanum, Reut. ex Regel, in Act. Hort. Petrop. iii

II. (1875) 235.-As. Min.

nudicaule, Lehm. Cat. Hort. Hamb. (1826).-Bras.

mutans, Herbb. quorr. ex Schult. f. Syst. vii. $1088=$ cernuum.

nutans, Linn. Sp. Pl. 299.-Sibir.

Nuttallii, S. Wats. in Proc. Am. Acad. xiv. (1879) 227. - Am. bor.

obliquum, Linn. Sp. Pl. 296.-Sibir.

obscurum, Bieb. ex Schult. f. Syst. vii. $1003=$ A Scorodoprasum.

obtusiflarum, [DC. in] Red. Lil. t. $118=$ pusillum.

obtusifolium, Klotasch, in Bot. Ergeb. Waldem. Reise,

51.-Reg. Himal.

accidentale, A. Gray, in Proc. Am. Acad. vii. (1868) $390=$ attenuifolium.

ochroleucum, Reichb. Ic. F1. Germ. x. t. 498. f. $1090=$ globosum.

ochroleucum, Waldst. \& Kit. Pl. Rar. Hung. ii. 204.

t. 186.-Europ.

adoratissimum, Desf. Fl. Atlant. i. 289. t. 83.-Afr bor.

odorum, Kar. \& Kir. in Bull. Soc. Nat. Mosc. (1841) $854=$ angulosum.

odorum, Lapeyr. Hist. Abr. Pl. Pyr. Suppl. $48=$ ochroleucum.

odorum, Linn. Mant. 62,-Sibir.

odorum, Lour, F1. Cochinch. $251=$ Thunbergii.

odorum, Tenore, Fl. Nap. Prod. $21=$ nigrum.

odorum, Thunb. F1. Jap. $132=$ Thunbergii.

oleracenm, Des Moul. Cat. Dord. 142, ex parte $=$ dentiferum.

oleracenm, Linn. Sp. Pl. 299,-Europ.

oliganthum, Kar, \& Kir, in Bull, Soc. Nat. Mose. (1841) $856=$ A. Schoenoprasum

Olivieri, Boiss. Fl. Orient. v. 284.-Mesopotamia.

olympicum, Boiss. Diagn. Ser. I. v. 58.-Thracia

Ophioscorodon, G. Don, in Mem. Wem. Soc. vi. (1827)

$5=$ sativum.

Opisii, Wolfner, in Lotos, iv. (1854) $176=$ triquetrum.

oreophiloides, Regel, in Act. Hort. Petrop. iis. II. (1875) 114.-Turkestan.

oreophilum, C.A. Mey. Vers. Pf. Cauc, 37.-Caucas. oreoprasum, Schrenk, in Bull. Sc. Acad. St. Pitersb.

x. (1842) 354.- Turkestan.

orientale, Boiss, Diagn. Ser. I. xiii. 25.-Oriens,

ornithogaloides, Walt. Fl. Carol. $121=$ striatum.

\section{ALLIUIM}

Ostrowskianum, Regel, in Act. Hort.Petrop. vii. (1880) 545.- Turkestan.

oviflorum, Regel, l. c. viii. (1884) 658.-Reg. Himal. oxypetalum, G. Don, in Mem. Wern. Soc. vi. (1827) $37=$ oleraceum.

Pallasii, Murr in Comm, Gott. vi. (1775) 32. t. 3. -Síbir.

pallens, Linn. Sp. Pl. ed. II. 427 = paniculatum.

pallens, Reichb. Ic, Fl. Germ. x. t. 484. f. $1062=$ flavum.

pallens, Sibth. \& Sm. Fl. Graec.t. 317.-Graecia.

Palmeri, S. Wats. Bot. in Rep. Geol. Expl. Fortieth Parallel, 487. t. 27. f. 10, 11.-N. Mexico.

palustre, Pourr. ex Lag. Elench. 13 = A. Schoenoprasum. palustre, Salisb. Prod. $235=$ sibiricum.

paniculatum, All. F1. Pedem. ii. $157=$ flavum.

paniculatum, Ker-Gawl, in Bot. Mag. t. 1432= caucasicum

paniculatum, Vill. Hist. Pl. Dauph. ii. $354=$ intermedium.

paniculatum, Linn. Syst. ed. X. 978.-_Europ.; Oriens. paniculatum, Sibth. \& Sm. F1. Graec. iv. t. $318=$ fuscum. paniculatum, Viv. Fl. Lib. Spec, $19=$ nigrum.

pannonicum, Gromow. ex Trautv. in Act. Hort. Petrop. ix. (1884) 273, nomen.-Europ.

papillare, Boiss. Diagn. Ser. I. xiii. 27.-Palaestin.

paradoxum, G. Don, in Mem. Wern. Soc. vi. (1827) 72.-Caucas. ; Persia.

parciflorum, Viv. App. Fl. Cors. Prod. 2.-Corsic

Parishii, S. Wats. in Proc. Am. Acad. xvii. (1881-82) 380.-Am. bor.

Parryi, S. Wats. l. c. xiv. (1879) 231.-Calif

parviflorum, Desf. Fl. Atlant. i. $290=$ paniculatum.

parviflorum, Desv. Fl. Anj. 96 = sphaerocephalum.

parviflorum, Linn. Sp. Pl. ed. II. 427.-Europ.

parviflorum, Thuill. Fl. Paris, ed. II. i. $166=$ oleraceum.

parvifolium, Crantz, Inst. i. $49=$ parviflorum.

parvum, Kellogg, in Proc. Calif. Acad. iii. (1863) 54. f. 13,-Calif.

Paterfamilias, Boiss. Diagn. Ser. II. iv. 114.-Reg. Caucas.

paucibulbosum, Haw. ex Steud. Nom. ed. II. i. 53.Hispan.

pauciflorum, Gren. \& Godr. Fl. Fr. iii. $210=$ parciflorum.

pauciflorum, Willd, ex. Ledeb. Fl. Ross. iv. $169=\mathrm{A}$. Cepa.

pedemontanum, Willd. Sp. PI. ii. $77=$ narcissiflorum. pendulinum, Tenore, Fl. Nap. i. 168.t. 31 = triquetrum. permixtum, Guss. F1. Sic. Prod. i, in add. $8=$ subhirsutum.

persicum, Fisch. ex Regel, in Act. Hort. Petrop. nii. II. $(1875) 43=$ A. Scorodoprasum

petiolatum, Lam, F1. Fr. iii. $261=$ ursinum.

petraeum, Kar. \& Kir. in Bull. Soc. Nat. Mosc。 xy. 1842) $511=$ globosum.

phalereum, Heldr. \& Sart. ex Heldr. in Atti Congr. Bot. Firenze, 1874 (1876) 233 =staticiforme.

phanerantherum, Boiss. \& Haussk. ex Boiss. Fl. Orient. v. 235.-Syria.

philistaeum, Boiss, Diagn. Ser. I. xiii. $26=$ Erdelii.

phrygium, Boiss, in Bal.ex Boiss. Fl. Orient. v. 256. Phrygia.

phthioticum, Boiss. \& Heldr. ex Boiss. l. c. 274.Oriens.

pilosum, Sibth. \& Sm. Fl. Graec, t. 321.-Archip. Graec.

pisidicum, Boiss. \& Heldr. ex Boiss. Diagn. Ser. I. xiii. $34=$ Cupani.

plantaginense, Willk. \& Lange, Prod. Fl. Hisp. i. $211=\mathrm{A}$. Victorialis.

plantagineum, Lam. Fl. Fr. iii. 262=A. Victorialis,

platycaule, S. Wats. in Proc. Am. Acrd. xiv. (1879) 234.-Calif.

platyspathum, Schrenk, Enum.7.-Turkestan.

platystemon, Kar. \& Kir. in Bull. Soc. Nat. MIosc. xv. 1842) $514=$ oreophilum.

pleianthum, S. Wats. in Proc. Am. Acad. xiv. (1879) 233.-Am. bor

Plummerae, S. Wats. ל. c. xviii, (1882-83) 195.Mexic.

Poeppigi, Kunth, Enum. Pl. iv. 456-Chili.

polyanthum, Schult. f. Syst. vii. $1016=$ rotundum.

polyphyllum, Kar. \& Kir. in Bull. Soc. Nat. Mosc. xv, (1842) 509.-Turkestan.

polyrhizum, Turcs. ex Regel, in Act. Hort. Petrop. iii. (1875) 162.-Sibir. baical.

\section{ALLIUM}

porphyroprasum, Heldr. \& Sart. ex Boiss. Fl. Orient จ. $233=$ rotundum

porraceum, S. F. Gray, Nat. Arr. ii. $181=$ A. Ampelo prasum.

Porrum, Georgi, Beschreib. Russ. Reich, iii. 1v. $891=$ obliquum.

Porrum, Linn. Sp. Pl. 295.-Europ.

Potanini, Regel, in Act. Hort. Petrop. vi. (1879) 295.Mongol.

praecissum, Reichb. Ic. Fl. Germ, v. 17. t. $429=$ paniculatum.

pratense, Schleich. ex Kunth, Enum. P1. iv. $382=$ carinatum.

Preslianum, Schult. f. Syst. vii. $1132=$ rotundum.

procerum, Trautv. in Act. Hort. Petrop. viii. (1884 663 ; ix. (1884) 274.-Bokhara.

proliferum, Schrad. ex Willd. Enum. Hort. Berol. 358 $=$ A. Cepa

prostratum, Maxim. Prim. Fl. Amur. 283=Maximo wiczi.

prostratum, Trev. Ind. Sem. Vratisl. $(1821)=$ Stellerianum.

pruinatum, Link, in Spreng. Syst. ii. $35=$ monspessalanum.

Przewalskianum, Regel, in Act. Hort. Petrop. iii. II (1875) 164.-China occ.

Pseudo-Cepa, Schrenk, in Bull. Sc. Acad. Pétersb. x. (1842) $355=$ galanthum.

Pseudo-ochroleucum, Schur, Enum. Pl. Transs. 673 = globosum.

pulchellum, G. Don, in Mem. Wern. Soc. vi. (1827) 46.-Europ.; Oriens.

pulchrum, Clark, Trav. iii. $337=$ nigrum

punctulatum, Schlecht. in Linnaea, xix. (1847) $401=$ A. Schoenoprasum.

purpureum, Salisb. Prod. $235=$ senescens.

purpureum, Schur, Enum. P1. Transs. $672=$ carinatum.

Purshii, G. Don, in Mem. Wern. Soc. vi. (1827) $10=$ vineale.

pusillum, Cyr. ex Tenore, Cat. Neap. (1813) 4.-Ital. pusillum, Presl, Delic. Prag. $147=$ Cupani.

pusillum, Willd. Enum. Hort. Berol. Suppl, 17= delicatulum.

pustulosum, Boiss. E Haussk. ex Boiss. Fl. Orient. $\nabla$ 243.-Cataonia.

pylium, De Not. in Linnaea, xviii. (1844) $157=\mathrm{A}$. Ampeloprasum.

pyrenaicum, Costa, Suplem. Catal. 92 ; Costa \& Vayr. in Anal. Soc. Esp. Hist. Nat. ix. (1880) 87.-Pyren.

Raddeanum, Regel, in Act. Hort. Petrop. iii. II. (1875) 155.-Sibiria.

ramosum, Georgi, Beschr. Russ. Reich. iii. IV. $892=$ odorum.

ramosum, Jacq. Misc. ii. $303=$ obliquum

ramosum, Linn. Sp. Pl. 296.-Sibirin.

ramosum, Pall. ex Ledeb. F1. Ross. iv. $184=$ tataricum.

reflexum, F. G. Dietr. Lexic. Gaert. ed. II. i. $285=$ A Schoenoprasum.

reflexum, Boiss. \& Reut. ex Boiss. Fl. Orient. $\nabla .281$ -Mesopot.

Regelii, Trautv. in Act. Hort. Petrop. ix. (1884) 275. -Transcauc.

Renari, Regel, l. c. vi. (1879) 521.-Turkestan.

reticulatum, Benth. P1. Hartw. $389=$ attenuifolium.

reticulatum, Fras, ex G. Don, in Mem. Wern. Soc. vi.

(1827) 36.-Am, bor.

reticulatum, J. \& C. Presl, F1. Cech. $73=$ strictam. reticulatum, St. Lag. in Ann. Soc. Bot. Lyon, vii. (1880) $119=\mathbf{A}$. Victorialis.

reticulatum, Wallr. Sched. Crit. $195=$ angulosum?

Reuterianum, Boiss. Diagn. Ser. I. v. 60.-As. Min.

riparium, Opiz, Natural. vi. (1S24) $50=$ sibiricum.

robustum, Kar. \& Kir. in Bull. Soc, Nat. Míose (1811) 853 = atropurpureum.

Rosenbachianum, Regel, in Act. Hort. Petrop, viii. (1884) 664.-Bokbara.

rosen, Krock. Fl. Siles. i. $516 . \mathrm{t}$. $43=$ sibiricum

roseum, Limn. Sp. Pl. ed. I. 290 - Keg. Mediter.

Rothii, Zucc, in Abr. Baver. Akad. iii. (1843) 232. t. 2

f. 2.-Pnlacstin.

rotundifolium, Lumnitz. ex Steud. Nom. ed. II. i. 59 $=$ rotundum.

roturdum, All. Fl. Pedem, ii. $155=$ scatifurum.

rotundum, Linn. Sp. Pl. ed. II \$23.-Lurop.; As Mtin

roturdum, Wimm. \& Gmb, Enum. 56 mincale

Roxburghi, Kunth, Enum. Pl. iv. $454=$ odoruta. 


\section{ALIIUM :}

rubellum, Bieb. Fl. Taur. Cauc. i. 264.-Europ.; Oriens; Sibir.

rubellum, Presl, F1. Sic. $42=$ rotundum

rubellum, Regel, in Act. Hort. Petrop. iii. II. (1875) $107=$ Tschulpias

rubellum, Willd.exLedeb. F1. Ross. iv. $179=$ globosum. rubens, Baker, in Fourn. Bot. xii. (1874) 293.--Reg. Himal.

rubens, Schrad, ex Willd. Enum. $360=$ Stellerianum.

rubicundum, Niven, ex G. Don, in Mem. Wern. Soc. vi. $(1827) 16=$ rotundum.

rubicundum, Willd. ex Kunth, Enum. Pl. iv. 439.Hab. ?

rubrovittatum, Boiss. \& Heldr. in Boiss. Diagn. Ser. I xiii. 29.-Creta.

rudbaricum, Boiss. E' Buhse, in Nouv. Mém. Soc. Nat. Mosc. xii. (1860) 215.-Persia

rupestre, Bieb. Fl. Taur. Cauc. iii. 259--iberia; Taur. rupestre, Fisch. ex Schrank, in Denkschr. Regensb. Bot. Ges. ii. (1822) $38=$ saxatile.

rupestre, Stev. in Mém. Soc. Nat. Mosc. iii. (1812) $260=$ paniculatum.

Ruprechti, Boiss. Fl. Orient. v. 264.-Caucas

ruthenicum, Steud. Nom. ed. II. i, $54=$ flavum.

sabulosum, Fisch.ex Goebel, Reise, ii. 311.-Reg. Casp sabulosum, Stew ex Kar \& Kir in Bull. Soc Nat. Mosc. (1842) 513.-Persia; Turkestan.

sacculiferum, Maxim. Prim. Fl. Amur. 281.-Reg. Amur.

sairamense, Regel, in Act. Hort. Petrop. vi. (1879) 520. - Turkestan.

Salesovianum, Fisch. ex Regel, 1. c. iii. II. (1875) 162 $=$ Fischeri

Sanbornil, Wood, in Proc. Ac. Nat. Sc. Philad. (1868) 171.-Calif.

sapidissimum, Hedw. in Roem. Collect. $76=$ fistulosum sarawschanicum, Regel, in Act. Hort. Petrop. iii. II. (1875) 244.-Turkestan.

sardoum, Moris, Stirp. Sard. Elench. fasc. ii. $10=$ sphaerocephalum.

sativum, Linn. Sp. Pl. 296.-Europ.

Savii, Parl. Fl. Ital. ii. $554=$ paniculatum

savranicum, Bess. Cat. Sem. Hort. Crem. Suppl. (1818) = globosum.

saxatile, Bieb. F1. Taur. Canc. i. $264=$ globosum.

saxatile, Hohen. ex Boiss. Fl. Orient, v. $263=$ lepidum saxatile, Pall. Reise, iii. 293 = fistulosum.

saxatile, Willd. ex Ledeb. F1. Ross. iv. $181=$ albidum. scaberrimum, Serres, in Bull. Soc. Bot. Fr. iv. (1857) $439=$ sphaerocephalum.

scabrellum, Boiss. \& Buhse, in Nouv. Mém. Soc. Nat. Mosc. xii. (1860) 215.-Persia.

scabriflorum, Boiss. Diagn. Ser. I. v. 60.-Cappadoc

scabriscapum, Boiss. l. c. xiii. 31.-Persia.

scabrum, Gilib Exercit ii $469=$ oleraceum

scaposum, Benth, in Pl. Hartwe. 26-Mexic. Texas.

scariosum, Jan, ex Schult. f. Syst. vii. $1011=$ rotundum. schergianum, Boiss. Fl. Orient. v. 251.-Syria.

Schmidtianum, Tausch, in Flora, xii. (1829) Erg. 45 -Bohemia.

schoenoprasioides, Fries, ex Nym. Consp. $741=\mathrm{A}$. Schoenoprasum.

schoenoprasoides, Regel, in Act. Hort. Petrop. v. (1877) 630.-Reg. Himal.

Schoenoprasum, Linn. Sp. Pl. 301.-Reg. temp. bor.

Schoenoprasum, Regel \& Tiling, F1. Ajan. $123=$ Ledebourianum.

Schrenki, Regel, in Act. Hort. Petrap. iii. II. (1875) 172.-Ind. or.

Schuberti, Zucc. in Abh. Bayer. Akad. iii. (1843 234. t. 3. f. 1.-Oriens.

Schulleri, Stev. ex Regel, in Act. Hort. Petrop. iii II. (1875) $69=$ Aucheri

scilloides, Dougl. ex S. Wats, in Proc. Am. Acad. xiv. (1879) $229=$ collinum

Scordoprassum, Aschers. Fl. Brandenb. $725=$ seq

Scorodoprasum, Linn. Sp. Pl. 297.-Europ.; Reg. Cauc.; Syria.

scorzoneraefolium, [DC. in] Red. Lil. ii. t. 92.-Europ. austr.

segetum, fan, ex Schult.f. Syst. vii. 1020.-Sicilia.

Sellovianum, Regel, in Act. Hort. Petrop. iii. II. (1875) 117.-Bras. ; Chili.

Semenovi, Regel, in Bull. Soc. Nat. Mosc. xli. (1868) I. 449.-Reg. Himal.

semiretschenskianum, Regel, in Act. Hort. Petrop. v. (1877) 630.-As. centr.

\section{ALIIUM :}

senescens, Ker-Gawl in Bot. Mag. t. $1150=$ glaucum senescens, Host, Fl. Austr. i. $420=$ fallax. senescens, Linn. Sp. Pl. 299.-Europ.; Sibir. senescens, Suter, Fl. Helv. i. $193=$ acutangulum senescens, Miq. Ann. Bot. Lugd. Bot. iii. $318=$ odorum.

senescens, Thunb, Fl. Jap. 132 = japonicum

serbicum, Vis, \& Pand, in Mem. Ist. Venet, xii. (1864) $479=$ moschatum

serotinum, Lapeyr. Fl. Pyr, t. $84=$ ochroleucum $x$ suaveolens.

serotinum, Schleich. ex G. Don, in Mem. Wern. Soc. vi. $(1827) 63=$ senescens.

servulatum, Boiss. F1. Orient. v. $241=$ atroviolaceum. serratum, S. Wats. Bot. King, Exped. 487. t. 37. f. 5.-Calif.

sessiliflorum, Fisch. ex Regel, in Act. Hort. Petrop. iii. II. $(1875) 140=$ senescens.

setaceum, Waldst. \& Kit. Pl. Rar. Hung. i. 70. t. $68=$ moschatum.

setifolium, Schrenk, Enum. 6-Soongaria.

Sewerzowi, Regel, in Bull. Soc. Nat. Mosc. xli. (1868) 453. - Turkestan.

sibiricum, Linn, Mant. $562=$ A. Schoenoprasum

Sibthorpianum, Schult. f. Syst. vii. $1057=$ paniculatum.

siculum, Ucria, in Roem. Arch. i. 68=Dioscoridis.

Sieberianum, Schult. f. Syst. vii. $1099=$ neapolitanum.

sikkimense, Baker, in Fourn. Bot. xii. (1874) 292. Reg. Himal

sinaiticum, Boiss. Diagn. Ser. 1. xiii. 31.-Arabia sindjarense, Boiss. Go Hausskn. ex Regel, in Act. Hort. Petrop. iii. II. (1875) 121.-Mesopotamia.

inicum, Noronha in Verh. Batav. Gen. v (1790) ed I. Art. IV. 6; ed, II. (1827) 68.-China

sipyleum, Boiss. Diagn. Ser. I. v. 58.-Lydia; Ins. Chios.

sordidum, Schur, Enum. Pl. Transs. $673=$ globosum. spathaceum, Steud. ex A. Rich. Tent. Fl. Abyss. ii. 330 $=$ subhirsutum.

speciosum, Cyr. Pl. Rar. Neap. Fasc. ii. 13=nigrum. spectabile, De Not. F1. Lig. $414=$ A. Ampeloprasum. sphaerocephalum, Crome, ex Schlecht. Fl. Berol. ii. 249 $=$ vineale.

sphaerocephalum, Linn. Sp, Pl, 297-Europ; Oriens spirale, Hort. Dorp. ex Kunth, Enum. P1. iv. $422=$ spurium.

spirale, Will. Enum. Suppl. $17=$ senescens, nutans

splendens, Miq. in Ann. Mus. Lugd. Bat. iii. $154=$ Bakeri.

splendens, Willd. ex Schult. f. Syst. vii. 1025.Sibiria.

spurium, G. Don, in Mem. Wern. Soc. vi. (1827) $59=$ senescens.

spurium, Hort. ex Schult. f. Syst. vii. $1067=$ glaucum,

stamineum, Boiss. Diagn. Ser. II. iv, 119.-_Oriens.

staticiforme, Sibth. \& Sm. Fl. Graec, iv, t. 320 Graecia.

stellatum, Fras. ex Ker.Gawl. in Bot. Mag. t. 1576.Am. bor.

Stellerianum, Bess. Cat. Hort. Crem. (1824) = albidum.

Stellerianum, Willd. Sp. Pl. ii. 82.-Sibiria.

Stellerianum, Ledeb. F1. Ross. iv. $179=$ flavidum

stenopetalum, Boiss. \& Kotschy, ex Regel, in Act. Hort. Petrop. iii. II. (1875) 231.-Cilicia.

stenopetalum, Guss. Sic. Syn. i. 394=margaritaceum. stenophyllum, Regel, ex Herd. in Bull. Soc. Nat. Mosc. xli. (1868) II $446=$ doloncarense.

stenophyllum, Schrenk, in Bull. Phys.-Math. Acad. Pétersb: iiị. (1844) 210.- Soongaria.

stenophyllum, Wall. Cat, n. $5073=$ Jacquemonti.

Stevenii, Willd. ex Ledeb. F1. Ross. iv. $176=$ globosum.

stipitatum, Regel, in Act. Hort. Petrop. vii. (1880) 546. -As. centr.

Stocksianum, Boiss. Diagn. Ser. II. iv. 117.-Beluchistan.

Stoliczki, Regel, in Act. Hort. Petrop. iii. Ir. (1875) 160. - Tibet. occ.

Stracheyi, Baker, in Fourn. Bot. xii. (1874) 293.-Reg. Himal.

stramineum, Boiss. \& Reut. Diagn. 25=A. Moly.

stramineum, Regel, Gartenfl. xxv. (1876) 355,-Manchuria.

stramineum, Schur, Enum. PI. Transs. 674=angulosum.

\section{ALIIUM :}

striatellum, Lindl. in Trans. Hort. Soc. vi. (1851) 97. -Chili.

striatum, Jacq. Coll. Suppl. $51=$ Nothoscordum striatum

strictum, Schrad. Hort. Goett. t. 1.-Europ.; Oriens. suaveolens, Gaud. Fl. Helv. ii. $491=$ strictum.

suaveolens, facq. Coll. ii. 305.-Europ.

suaveolens, Duby, Bot. Gall i. $470=$ ochroleucum.

subalbidum, Jord. \& Fourr. Brev. Pl. Nov, fasc. ii $128=$ roseum

subalpinum, Pall. Ind. Taur. ex Kunth, Enum. Pl. iv. $448=$ decipiens.

subbiflorum, Colla, in Mem. Acc. Torin. xxxix. (1836) 13. t. 52.-Chili.

subhirsutum, Delile, Fl. Aegypt. ex Boiss. Fl. Orient. v. $274=$ neapolitanum.

subhirsutum, Desf. Fl. Atlant. 286=subvillosum.

subhirsutum, Linn. Sp. Pl. 295.-Europ.; Oriens.

subhirsutum, Reichb. Fl. Germ. Excurs. $113=$ subvillosum.

subhirsutum, Sieber, ex Kunth, Enum. Pl. iv. $441=$ neapolitanum.

subquinqueflorum, Boiss. Fl. Orient. v. 264.-Armenia.

subtilissimum, Ledeb. Ic. Fl. Alt. ii. 22. t. 360.-Sibir. altaic.

subvillosum, Salzm. ex Schult. f. Syst. vii. 1104=sub hirsutum

sulcatum, [DC. in] Red. Lil. t. $482=$ neapolitanum

Sulvia, Buch.-Ham. in D. Don, Prod. F1. Nep. $53=$ fragrans.

Suworowi, Regel, in Act. Hort. Petrop. vii. (1880) 546. -As. centr.

Synnotia, G. Don, in Mem. Wern. Soc. vi. (1827) 19 $=$ rotundum

Synnotianum, Schult. f. Syst. vii. $1015=$ praec.

syntamanthum, C. Koch, in Linnaea, xxii. (1849) 238 = rubellum.

syriacum; Boiss. Fl. Orient. v. $232=$ A. Ampelo-

prasum.
Szovitsi, Regel, in Act. Hort. Petrop. iii. II. (1875) $171=$ strictum.

szurulense, Lerch. ex Kanitz, in Verh. Siebenb. Ver Naturw. xxxiv, (1884) 55.-Europ.

talassicum, Regel, in Act. Hort. Petrop. v. (1877) 628 -Turkestan.

tartaricum, [Dryand. in] Ait. Hort. Kew. ed. II. ii. $233=$ odorum.

tartaricum, Hort. ex Schult. f. Syst. vii. $1066=$ nutans.

tartaricum, Linn. f. Suppl. 196.-Rossia; Sibiria; Persia.

tauricolum, Boiss. Diagn. Ser. II. iv. $118=$ frigidum. tauricum, Hort. ex Schult. f. Syst. vii. $1051=$ flavum. tauricum, Pall. ex G. Don, in Mem. Wern. Soc. vi (1827) $50=$ globosum.

chefouense, Debeaux, in Actes Linn. Soc. Bord. xxxii. (1878) 25 ; Fl. Tché-Fou, 138.-China

Tchihatschewii, Boiss. in Tchihat. Asie Min. Bot. ii. 551.-Armenia.

Tenorii, Spreng. Pugill. i. 29 ; Syst. ii. $35=$ roseum.

tenue, C. Koch, in Linnaea, xxii. (1849) $238=$ rubellum.

tenue, Frivald. ex Griseb. Spicil. Fl. Rumel. ii. 396 =erythraeum.

tenue, G. Don, in Mem. Wern. Soc. vi. (1827) $34=$ Pallasii.

tenue, Regel, in Act. Hort. Petrop. iii. II. (1875) 206. - Turkestan.

tenuiflorum, Delastre, F1. Vienne, $420=$ sphaerocephalum.

tenuiflorum, Tenore, Fl. Nap. i. 165. t. $30=$ paniculatum.

tenuifolinm, Frivald. in Syll. Ratisb. ii. 33.-Europ.

tenuifolium, Salisb. Prod. $235=$ A. Schoenoprasum.

tenuifolium, Schur, in Verh. Siebenb. Ver. Naturw. iv. (1853) 76 = globosum.

tenuissimum, Habl. Taur. $162=$ moschatum.

tenuissimum, Linn. Sp. Pl. 301.-Sibiria.

teretifolium, Regel, in Act. Hort. Petrop. v. (1877) 629.-Turkestan.

thessalum, Boiss. Fl. Orient. v. $232=$ A. Ampeloprasum.

Thomsoni, Baker, in fourn. Bot. xii. (1874) 294.Reg. Himal.

Thunbergii, G. Don, in Mem. Wern. Soc. vi. (1827) 84.- Japon; China. 


\section{ALLIUIM}

tianschanicum, Rupr. in Mém. Acad. Pétersb. Sér. III. xiv. (1869) 33. (Sert. Tiansch. 33)=hymeno rhizum.

Tilingi, Regel, in Act. Hort. Petrop. iii. M. (1875) 124 -Calif.

Tinei, J. \& C. Presl, Delic. Prag. $145=$ subhirsutum.

Tolmiei, Baker, ex Coult. Rocky Mt. Bot. $349=$ tribracteatum.

tortwosum, Schur, in Verh. Siebenb. Ver. Naturw. iv. (1853) 76.--Europ.

tortuosum, Willd. ex Schult. f. Syst. vii. $1064=$ lineare.

Tourneuxii, Boiss. F1. Orient, v. $274=$ roseum.

trachyanthum, Griseb. Spicil. F1. Rumel. ii. 395 $=$ rotundum.

trachypus, Boiss. \& Sprun. Diagn. Ser. I. vii. $114=$ sphaerocephalum.

transsilvanicum, Lerch, ex Kanitz, in Verh. Siebenb. Ver. Naturw. xxxiv. (1884) 54.-Europ.

Trautvetterianum, Regel, in Act. Hort. Petrop. viii. (1884) 661.-Bokhara.

tribracteatum, Torr. in Pacif. Rail. Rep. iv. 148.Calif.

trichocnemis, F. Gay, in Ann. Sc. Nat. Sér. III. viii (1847) 210.-Algeria

tricoccum, [Soland. in] Ait. Hort. Kew. i. 428.-Am bor.

tricoccum, Blanco, Fl. Filip. ed. I. $239=$ uliginosum.

tricorne, Desv, ex Regel, in Act. Hort. Petrop. iii. II. (1875) $145=$ angulosum.

tricorne, Hort. ex Poir. Encyc. Suppl. i. $270=$ cernuum

triflorum, Rafin. in Med. Repos. New York, v. (1808) 362.-Pennsylv.

trifoliatum, Cyr. Pl. Rar. Neap. Fasc. ii. 11.-Europ.; Oriens.

tripedale, Trantv. in Act. Hort. Petrop. ii. (1873) 485 $=$ Dioscoridis.

triquetrum, Hort. ex Schrad, in Schult. f. Syst. vii. $1078=$ angulosum

triquetrum, Linn. Sp. Pl. 300.-Europ.; Afr. bor.

triquetrum, Lour. Fl. Cochinch, $202=$ Thunbergil.

triquetrum, Sebast. \& Maur. Prod. Fl. Rom. $126=$ pendulinum.

triste, Kunth \& Bouché, Ind. Sem. Hort. Berol. (1845). -Oriens.

trisulcum, Hort. Genev. ex Schult. f. Syst. vii. 1067 = glaucum.

Tschonoskianum, Regel, in Act. Hort. Petrop. iii. II. (1875) 160.- Japon.

Tschulpias, Regel, l. c. 107.-Turkestan

iuberosum, Rottl: ex Spreng. Syst. ii, 38.-Malabar.

tuberosum, Roxb. Hort. Beng. $24=$ odorum.

tulipaefolium, Ledeb. Fl. Alt. ii. 9 ; Ic. t. $37=$ decipiens.

turkestanicum, Regel, in Act. Hort. Petrop, iii. II. (1875) 197.-Turkestan.

turtschicum, Regel, l. c. vi. (1879) 529.-As. centr.

tythocephalum, Schult. f. Syst. vii. 1133. -Sibiria

uliginosum, G. Don, in Mem. Wern. Soc, vi. (1827) $60=$ odorum.

uliginosum, Kanitz, in Linnaea, xxxii. (1863) $399=$ angulosnm.

uliginosum, Ledeb. F1. Alt. ii. 16= Ledebonrianum.

umbellatum, Hall. ex Steud. Nom. ed. I. $29=$ odorum.

umbilicatum, Boiss. Diagn. Ser. II. iv. 113.-Beluchistan.

undulatum, Fisch. ex Stend. Nom. ed. I. 29=cas picum.

undulatum, Schonsb. ex Trev. All. Sp. 8. n. $9=$ nutans unifolium, Kellogg, in Proc. Calif. Acad. Nat. Sc ii. (1863) 112. f. 35.-Calif.

uratense, Franch. in Nouv. Arch. Mus. Hist. Nat. Par. Sér. II. vii. (1884) 112 (Pl. Davidian. i. 304).As. or.

urceolatum, Regel, Gartenfl. (1873) 236 ; et in Act. Hort. Petrop. ii. (1873) 405.-Turkestan.

ursinoides, G. Don, ex Sweet, Hort. Brit. ed. I. $422=$ ursinum.

ursinum, Linn. Sp. Pl. ed. I. 300.-Europ.; As. bor.

Urvillei, Heldr. \& Sart. ex Heldr. in Atti Congr. Bot Firenze, 1874 (1876) $238=$ staticiforme.

vaginatum, Pand. ex Boiss. Fl. Orient. v. $266=$ Cupani

valdense, Reut, in Comptes-rend. Soc. Hallér. (1854

56) $126=$ flavnm

valdensium, Nym. Consp. $740=$ Aavum.

\section{ALLIUM :}

validum, S. Wats. in Bot. King, Exp. 350.-Am. bor. variegatum, Boiss. Diagn. Ser. I. vii. 118.-Assyria. veratrifolium, Griseb. ex Tchihat. Asie Min. Bot. ii 555.-As. Min.

vernale, Tineo, in Guss. Fl. Sic. Prod. Suppl. i. $96=$ subvillosum.

veronense, Linn. Syst. ed. X. $978=$ paniculatum

veronense, Spreng. Pugill. ii. $60=$ sphaerocephalum.

verrucosum, G. Don, in Mem. Wern. Soc. vi. (1827) $20=$ rotundum.

versicolor, Nem. ex Chaub, in Actes Linn. Soc. Bord. xix. (1853) 50.-Europ.

verticillatum, Regel, in Act. Hort. Petrop. vi. (1875) 518. -Turkestan.

Victorialis, Linn. Sp. Pl. 295.-Europ.; Cancas. Sibir.

Vincetoxicum, Pall. ex Ledeb. F1. Ross. iv. $186=$ ursinum.

vineale, Sch. Bip. ex Regel, in Act. Hort. Petrop. iii. II. (1875) $46=$ sphaerocephalum.

vineale, Linn. Sp. Pl. 299.-Europ.

violaceum, Gilib. Exercit. ii. $470=$ arenarium

violaceum, Wall. ex Regel, in Act. Hort. Petrop. iii. II. $(1875) \quad 143=$ Wallichii

violaceum, Willd. Enum. Suppl. $17=$ carinatum.

virescens, Guss. in Tenore, Syll. $164=$ margaritaceum.

virescens, Lam. F1. Fr. iii. $259=$ oleraceum

virens, Lam. Encyc. i. $67=$ oleraceum.

viridi-album, Tineo, Cat. Pl. Hoit. Panorm. (1827) 275 = sphaerocephalum.

viridulum, Kar. \& Kir. in Bull. Soc. Nat. Mosc, (1841) 855 = delicatulum.

viridulum, Ledeh. Ic. Fl. Alt. iii. t. 378.--Sibir. altaic

viviparum, Kar. \&o Kir. in Bull. Soc. Nat. Mosc. (1841)

852.-Sibiria.

volhynicum, Bess. Cat. Hort. Crem. Suppl, iii. $2=$ strictum.

vulcanicum, Boiss. Diagn. Ser. I. xiii. $33=$ rubellum.

Waldsteinianum, Schult. f. Syst. vii. $1011=$ seq.

Waldsteini, G. Don, in Mem. Wern. Soc. vi. (1827) $17=$ rotundum.

Wallichianum, Hort. Leichtl. ex Regel, in Act. Hort.

Petrop. iik. II. (1875) $232=$ acuminatum

Wallichianum, Steud. Nom. ed. II. i. 53,-Reg. Himal.

Wallichii, Kunth, Enum. Pl. iv. $443=$ praec

Webbii, Clem, in Mem. Acc. Sc. Torino, Ser. II, xvi. (1857) 327. t. $8=$ flavum.

Weissii, Boiss. Fl. Orient. v. 253.-Ins. Cyclad,

Welwitschi, Regel, in Act. Hort. Petrop. iii. II. (1875) 66. - Lusit.

Weschniakowi, Regel, l. c. vi. (1879) 531.-Turkestan.

Wiedemannianum, Regel, l. c. iii. II. (1875) 199.Anatolia.

Wierzbickii, Heufel, ex Steud. Nom. ed. II. i. 55.Hungar.

Willdenovi, Kunth, Enum. Pl. iv. 452=delicatulnm.

Wildii, Heldr, in Atti Congr. Bot. Firenze, 1874 (1876) $232=$ A. Ampeloprasum.

Winklerianum, Regel, in Act. Hort. Petrop. viii. (1884) 661 -Bokhara.

xanthicum, Griseb. \& Schrenk, in Wiegm. Archiv, xviii 1852) I. $358=$ globosum

zebdanense, Boiss. \& Nö̈, Diagn. Ser. II. iv. 113.Syria ; Armenia.

ALLMANIA, R. Br. in Wall. Cat. n. 6890-92 (1832) AMARANTACEAE, Benth. \& Hook. f. iii. 27 albida, R. Br. l. c. n. 6891 -Ind. or.; Malaya. aspera, Wight, Ic. t. $1770=$ nodiflora.

dichotoma, Wight, 1. c. t. $1771=$ nodiflora esculenta, R. Br. in Wall. Cat n. $6892=$ nodiffora nodiflora, $R$. Br. c. n. 6890 - Ind, or ; Malays. procumbens, Wight, ex Hook. f. Fl. Brit. Ind. iv. $717=$ nodiflora.

ALLOBIA, Rafin. Fl. Tellur, iv, $116(1836)=\mathbf{E u}-$ phorbia, Linn

portlandica, Rafin. 1. c. $=$ E. portlandica.

ALLOBIUM, Miers, in Ann. Nat. Hist. Ser, II viii. (1881) $178,179=$ Phoradendron, Nutt. (Lorantb.)

ALLOBORGIA, Steud. Nom. ed. II. i. $55(1840)=$ seq.

ALLOBROGIA, Tratt. Fl. Austriac. ii. $71(1792)=$ Para disea, Mazz. (Liliac).
ALLOCARPUS, H. B. \& K Nor. Gen, et Sp, iv, 291 t. $405(1820)=$ Calea, Linn. (Compos.)

caracasanus, H. B. \& K. 1. c. 292.-Venezuela.

integrifolius, DC. Prod. $\vee .676=\mathrm{C}$. integrifolia.

Lindenii, Sch. Bip. ex Wedd. Chlor. And. i. 74,-N. Granat.

sabazioides, Less. Syn. Comp. $242=$ C sabazioides

scabrifolius, Hook. \&c Arn. Bot. Beech. Voy. $300=$ C scabrifolia.

ALLOCERATIUM, Hook. f. \& Thoms, in Journ. Linn Soc. v. (1861) 129, 135=Diptychocarpus, Trautv Crucif.

strictum, Hook. f. \& Thoms. 1. c. $135=$ D. strictus.

ALLOCHLAMYS, Moq. in DC. Prod, xiii. II. 463 (1849) Pleuropetalum, Hook. f. (Amarant.)

Darwinii, Moq. 1. c. $=$ P. Darwini

ALLOCHRUSA, Bunge, in Boiss, Fl. Orient, i. 559 (1867)

Acanthophyllum, C. A. Mey. (Caryophyll.

Bungei, Boiss. 1. c. $560=$ Ac. Bungei

persica, Boiss. 1, c.-Persia.

pulchella, Bunge, ex Boiss, 1. c. = persica.

versicolor, Boiss, 1. c. $559=$ Ac. versicolor

ALLODAPE, Endl. Gen. 749 (1839)=Lebetanthus, Endl. (Epacrid.).

americana, Endl. I. c. $=$ L. americanus.

ALLODAPHNE, Steud. Nom. ed. II. i. $55(1840)=$ praec

ALLOEOSPERMUM, Spreng. Anleit. ii. 901 (1818)= ALLOISPERMUM, Willd。=Calea,Linn. (Compos.)

ALLOHEMIA, Rafin. Sylva Tellur, 125 (1838)= Loranthus, Linn.

pedunculata, Rafin. $1, \mathrm{c},=\mathrm{L}$. pedunculatus.

purpurea, Rafin. 1. $c_{0}=\mathrm{L}$ 。 occidentalis.

ALLOIANTHEROS, Steud. Syn. P1. Gram. 217 (1855 $=$ seq.

ALLOIATHEROS, E11. Sketch, i. 146 (1817)= Gym nopogon, Beauv. (Gramin.

ambiguus, Ell. (cf. Sketch, i. 146) ex Kunth, Enum. i $284=\mathrm{G}$. racemosus.

aristatus, Rafin. in Ser. Bull. Bot. i. (1830) $221=\mathrm{G}$. racemosus.

lepturoides, Steud. Nom. ed. II. i. $55=\mathrm{G}$. racemosus

ALLOIOZONIUM, Kunze, in Linnaea, xvii. (1943) 572 Cryptostemma, R, Br. (Compos.)

arctotideum, Knnze, 1. $\mathrm{c}=\mathrm{C}$. calendnlaceum

ALLOISPERMUM, Willd. in Ges, Naturf. Fr. Berl. Mag i. (1807) $139=$ Calea, Linn. (Compos.).

divaricatum, Willd. l. c. (= Allocarpus caracasanus).

ALLOMIA, DC. Prod, vii. 310 (1838)= Alomia H. B. \& K. (Compos.).

ALLOMORPHIA, Blume, in Flora, xiv. (1831) 522 MELASTOMACEAE, Benth. \& Hook. f. i. 752. exigua, Blume, l. c. 523.-Ind. or.; Malaya.

Griffithii, Hook. f. ex Triana, in Trans. Linn. Soc xxviii. (1871) 74.-Malacca.

hispida, Kurs, in Gourn. As. Soc. Beng. xl. (1871) I1. 53.-Burma.

ovalifolia, Triana, in Trans. Linn. Soc. xrviii. (1571 74.-Ins, Fiji.

pauciflora, Benth. in Hook. Lond. Joum. Bot. i. (1642) $485=$ Oxyspora pauciflora

umbellulata, Hook. f. ex Triana, in Trans. Linn. Soo. xxviii. (18;1) 74 - Burma.

ALLOPHYLLUS, Gleditsch, Syst. $\$ 2(1761)=$ seq

ALIOPHYLUS, Linn. Fl. Zeyl. 58 17t; : 1:i Dass. $14(1747)$; Am. Acad, i. $395(1740$; s./\% DACEAE. Benth. \& Houk. f. i. 3!6,

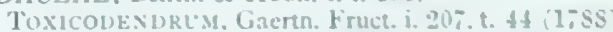
UsuBIs, Burm, f. Fl. Ind. S9. t. 32. f. i. (170s). africanus, Heauv. Fl. Owar. ii. 54 . L. $10 \%=z$ ylanicus. nuboinensis. Blume. Rumphina, iii. 129. - Anboina. aporeticus, Kura, in 'Purn. As. Sor. Beng. xluv. (15,5)

II. 185.-Burma.

Blancoi, Blume, Kumphia, iii. $129=$ A. Cubbe.

Cambessedei, Biume, 6. c.-Malaya. 


\section{AILOPHYLUS :-}

celebicus, Blume, Rumphia, iii. 128.-Ins. Celebes. Cobbe, Blume, l. c. 131.- As. or.

Cominia, Sw. Prod. Veg. Ind. Occ. $62=$ S. Cominia Commersoni, Blume, Rumphia, iii. 129.-Ins. Borbon. dimorphus, Radlk. in Act. Congr. Bot. Amst. 1877 (1879) 126.-Ins. Philipp.

filiger, Radlk. l. c.-Ins. Philipp.

fulvinervis, Blume, Rumphia, iii. 183.-Java.

integrifolius, Blume, $l . c .129$.-Malaya.

javensis, Blume, l. c. 126.-Java.

lanatus, Roxb. Hort. Beng. $88=$ A. Cobbe

leptococcus, Radlk. in Act. Congr. Bot. Amst. 1877 (1879) 126.-Ins. Key.

ligustrinus, Blume, Rumphia, iii. 126.-Sumatra.

litoralis, Blume, l.c. 124.-Java.

nigrescens, Blume, l. c. 129.-Madag.

ornitrophioides, Roxb. ex Wall. Cat. n. $8055=\mathrm{A}$. Cobbe.

Pervillei, Blume, Rumphia, iii. 123.-Madag

pinnatus, Roxb. Ic. t. $1407=$ Sapindus fruticosus

racemosus, Sw. Prod. Veg. Ind. Occ. $62=$ S. occidentalis.

rhusiphyllus, Balf. $f$. in Proc. Roy. Soc. Edinb. xi. (1882) 507 - Ins. Socotra

rigidus, Sw. Prod. Veg. Ind. Occ. $62=\mathrm{S}$. rigida rufescens, Blume, Rumphia, iii. 159.-Bormeo.

rugosus, Blume, l. c. 138.-Java.

salignus, Blume, l. c. 129.-Madag.

serratus, Kurz, in Fourn. As. Soc. Beng. xliv. (1875) II

185.-Burma.

sessilis, Blume, Rumphia, iii. 125.-Java.

sumatranus, Blume, l. c. 132. - Sumatra.

sundanus, Miq. F1. Ind. Bat. i. II. $575=\mathrm{A}$. Cobbe.

ternatus, Lour. Fl. Cochinch. $232=$ A. Cobbe

ternatus, Roxb. ex Steud. Nom. ed. II. i. $55=\mathrm{S}$. zey* lanicus.

timorensis, Blume, Rumphia, iii. 130.-Timor.

timorensis, Miq. F1. Ind. Bat. ii. I. $575=$ A. Cobbe.

zeylanicus, Linn.Sp. Pl. 348.- Himal.

ALLOPLECTUS, Mart. Nov. Gen. et Sp. iii. 53. 223 (1829). GESNERACEAE, Benth. \& Hook. f. ii 1008 .

Anisoplectus, Calanthus, Caloplectus, Caly coplectus, Corytoplectus, Erythranthus, Prionoplectus, Saccoplectus, Oerst. in Danske

Vid. Selsk. Skr. V. v. (1858) 117-121.

Crantzia, Scop. Introd. 173 (1777).

Heintzia, Karst. Ausw. Gew. Venez. 34. t. 11 (1848).

GLossaloma, Hanst. in Linnaea, xxvi. (1853-55) 209

Lophia, Desv, in Ham. Prod. Fl. Ind. Occ. 47 (1825)

LOPHAlIX, Rafin. Sylva Tellur. 70 (1838)

Macrochlamys, Decne. in Rev. Hortic. (1849) 243

Orobanchia, Vand. F1. Lusit. Spec. 41. f. 18, 19 (1788)

Polysthysania, Hanst. ex Oerst. in Danske Vid.

Selsk. Skr. V. v. (1858) 121.

Pterygoloma, Hanst. in Linnaea, xxvi. (1853-1855) 211.

Tyssacia, Reichb. ex Steud. Nom. ed. II. ii. 727 (1841).

VIREYA, Rafin. Specch. i. 194 (1814).

angustifolius, $D C$. Prod. vii. 546.-Bras.

bicolor, Klotzsch, ex Hanst. in Linnaea, xxxiv. (1865-66) 377-Bras.

bracteatus, Linden, Cat. n. $5(1850)$ 2.-Hab.

calcaratus, G. Don, Gen. Syst. iv. 655.-Reg. Andin.

capitatus, Hook. Bot. Mag. t. 4452.-Am. austr.

chrysanthus, Planch. E Linden, in Fl. des Serres,

Sér. I. viii. (1852-53) 211.-N. Granat.

circinnatus, Mart. Nov. Gen. et Sp. iii. 55. t. 223. f. 1 . -Bras.

coccineus, Mart. l. c. 57.-Guiana

concolor, Hook. Bot. Mag, t. $4371=$ dichrous,

coriaceus, Hanst. in Linnaea, xxxiv. (1865-66) 363.-

Costa Rica.

corymbosus, Klotzsch, ex Hanst. l. c. 371.-Peruy.

cristatus, Mart. Nov. Gen. et Sp. iii. 57.-Ind. occ.

darienensis, Seem. Bot. Voy. Herald, 187.-Darien.

dichrous, DC. Prod. vii. 546.-Bras.

dichrous, Hook. Bot. Mag. t. $4216=$ sparsiflorus

dimidiatus, Benth. Pl. Hartw. 235-N. Granat.

eriocalyx, Galeott. ex Hook. Bot. Mag. t. $4371=$ dichrous.

Forseithii, Hanst. in Linnaea, xxxiv. (1865-66) 375. -Am. centr.

\section{ALLOPLECTUS :-}

glaber, DC. Prod. vii. 546.-Mexic

hispidus, Mart. Nov. Gen. et Sp. iii. 57.-Am. austr. ichthyoderma, Hanst. in Linnaea, xxxiv. (1865-66) 372. - Costa Rica.

Kunthii, G. Don, Gen. Syst. iv, 655--N. Granat

lanatus, Seem. Bot. Voy. Herald, 186.-Panama.

macrophyllus, Hemsl. Biol. Centr. Am. Bot. ii. 484 - Costa Rica.

melittifolius, Mart. ex Loud. Encyc. Pl. 1402 = Tussacia pulchella.

meridensis, Klotzsch, ex Hanst, in Linnaea, xxxiy

1865-66) 373.-N. Granat.

multiflorus, Hanst. l. c. 361.-Costa Rica.

parviflorus, Hemsl. Biol. Centr. Am. Bot. ii. 484.Costa Rica.

Patrisii, DC. Prod. vii. 545.-Guiana

peltatus, Oliver, in Bot. Mag. $t .6333$. - Am, centr.

pendulus, Poepp. \& Endl. Nov. Gen. et Sp. iii. 6. t 205.-Peruv.

Pinelianus, Lem. in Fl. des Serres. Sér. I. ii.(Août 1846) t. v.-Bras.

repens, Hook. Bot. Mag. t. 4250,-Ind, occ.

sanguineus, Mart. Nov. Gen et Sp. iii. 57-Am austr. scabridus, Lem. Jard, Fleur, i. (1851) Misc. 51 = glaber

Schlimii, Planch. É Linden, in Fl. des Serres, Sér. I. viii. $(1852-53)$ 211. t. 827.-N. Granat.

Schottii, G. Don, Gen. Syst. iv. $655=$ dichrous

semicordatus, Poepp. E Endl. Nov. Gen. et Sp. iii. 5. -Peruy.

sparsiflorus, Mart. Nov. Gen. et Sp. iii. 55.-Bras.

speciosus, Hort ex Hook. Bot. Mag. t. $4452=$ capitatus.

speciosus, Poepp. E Endl. Nov. Gen. et Sp. iii. 6.Chili.

strigosus, Hanst. in Linnaea, xxxiv. (1865-66) 374.Mexic.

tenuis, Benth. Pl. Hartre. 235.-Peruv.

tetragonus, Hanst. in Linnaea, xxxiv. (1865-66) 368 -Costa Rica

tigrinus, Hanst. l. c. 366--N. Granat.

villosus, Hanst, in Mart. Fl. Bras. viii. 407.-Bras.

vittatus, André, in lllust. Hortic. xvii. (1870) t: 13.Peruv.

zamorensis, Linden $\mathcal{E}$ André, in Illust. Hortic. xix. (1872) 110.-N. Granat.

ALLOPLEIA, Rafin. Med. FI. ii. $109(1830)=$ Veronica, Tourn. (Scrophul.)

rotundifolia, Rafin. l. $\mathrm{c} .=\mathrm{V}$, rotundifolia.

ALLOPYTHION, Schott, Gen. Aroid. t. 24 (1858)= Thomsonia, Wall. (Aroid.)

Hookeri, Schott, 1. c. =T. Hookeri.

ALLOSAMPELA, Rafin. Med. F1. ii. $122(1830)=$ Vitis, Linn. (Ampel.)

heterophylla, Rafin. 1. c. $=$ V. heterophylla.

ALLOSCHEMONE, Schott, Prod. Syst. Aroid. 358 $(\mathbf{1 8 6 0})=$ Monstera, Adans. (Aroid.).

Poeppigiana, Schott, 1. c. $=$ M. occidentalis,

ALLOSPERMA, Rafin. F1. Tellur. iv. 122 (1836)= Commelina, Linn.

tuberosa, Rafin. 1. $\mathrm{c}_{\mathrm{a}}=\mathrm{C}$, tuberosa.

ALLOSTIS, Rafin. Sylva Tellur. 104 (1838)=Baeckea, Linn. (Myrtac.)

ALLOTEROPSIS, C. Presl, Rel. Haenk. i. 343. t. 47 (1830). Gen, dub. GRAMIN. Benth. \& Hook. f. ii. 1096 .

distachya, C. Presl, l. c.-Calif.

ALLOTRIA, Rafin. Fl. Tellur, iii. $70(1836)=$ Commelina, Linn

scabra, Rafin. 1. c. = C. scabra

ALIOTROPA, A. Gray, in Pacif. Rail. Rep. Bot. iv. 81 (1855); et in Proc. Am. Acad. vii. (1868) 368. MONOTROPEAE, Benth. \& Hook. f. ii. 607. virgata, Torr. \& Gray, in Proc. Am. Acad. l. c. -Calif

ALLOUYA, Plum. ex Aubl. Pl. Gui. ii. $931(1775)=$ Maranta, Linn. (Scitam.).

ALLOZYGIA, Naud. in Ann. Sc. Nat. Sér. III. xv. (1851) 309. t. 15= Oxyspora, DC. (Melast.). cernua, Naud. 1. c. $=$ O. cernua.
ALLUGHAS, Steud. Nom. ed. I. 29 (1821)=ALUGHAS, Lindl. = Alpinia, Linn. $($ Scitam. $)$.

ALMANA, Rafin. Fl. Tellur. iv. $68(1836)=$ Gloxinia Linn. (Gesner.)

hirsuta, Rafin. l. c. $=$ G. hirsuta.

ALMEIDA, Cham. in Linnaea, v. (1830) $56=$ seq.

ALMEIDEA, St. Hil. in Bull. Soc. Philom. (1823) 129. RUTACEAE, Benth. \& Hook. f. i. 284.

ARUBA, Nees \& Mart. in Nov. Act. Nat. Cur. xi. (1823) 152. t. 19, 27, 29.

acuminata, St. Hil. ex G. Don, Gen. Syst. i. 798.-Bras.

alba, St. Hil. ex G. Don, l. $c_{\text {- }}$-Bras.

caerulea, St. Hil. ex G. Don, l. c.-Bras.

lanceolata, St. Hil. Pl. Rem. 144.-Bras.

lilacina, St. Hil. in Bull. Soc. Philom. (1823) 129.Bras.

longifolia, St. Hil. l. c.-Bras.

longipes, Presl, Bot. Bemerk. 32.-Bras.

macropetala, Fisch. \& Mey. Sert. Petrop. t. 10.-Bras. myriantha, Cham. in Linnaea, v. (1830) 56.-Bras.

rubra, St. Hil. in Bull. Soc. Philom. (1823) 129.-Bras.

ALMELOVEENIA, Dennst. Sehluess. Hort. Malab. 32 $(1818)=$ Moullava, Adans. (Inc. Sed.)

spinosa, Dennst. 1. c.-Ind. or.

ALMIDEIA, Reichb. Nom. 197 (1841)=Almeidea St. Hil. (Rutac.).

ALMYRA, Salisb. in Trans. Hort. Soc. i. (1812) $336=$ Pancratium, Linn. (Amaryll.)

illyrica, Salisb. Gen. Pl. Fragm. $109=$ P. iliyricum. parviflora, Salisb. 1. c. = P. parviflorum.

stellaris, Salisb. in Trans. Hort. Soc. i. (1812) $336=$ P. illyricum.

ALNASTER, Spach, in Ann. Sc. Nat. Sér. II. xv. (1841) $200=$ Alnus, Tourn. (Cupul.).

fruticosus, Ledeb. F1. Ross. iii. $655=$ Alnus viridis. viridis, Spach, in Ann. Sc. Nat. Sér. II. xv. (1841) 201 $=$ Alnus viridis.

ALNOBETULA, Schur, in Verh. Siebenb. Ver. Naturw iv. (1853); (Enum. Pl. Trans.) $68=$ Alnus, Tourn. (Cupul.).

viridis, Schur, 1. c. = Alnus viridis.

ALNUS, [Tourn.] Linn. Syst. ed. II. (1735); Fl. Lapp. 260 (1737). CUPULIFERAE, Benth. \& Hook. f. iii 404.

Alnaster, Spach, in Ann. Sc. Nat. Sér. II. xv. (1841) 200.

Alnobetula, Schur, in Verh. Siebenb. Ver. Naturw. iv. (1858); (Enum. Pl. Trans. 68. n. 614). Clethropsis, Spach, in Ann. Sc. Nat. Sér, II. xv. (1841) 201.

Semidopsis, Zumag. Fl. Pedem. i. 249 (1849). acuminata, $H . B$. \& K. Nov. Gen. et Sp. ii. 20.-Am austr.

Alnobetula, C. Koch, Dendrol. ii. I. $625=$ viridis alpina, Borckh. Handb. Forstb. i. $477=$ viridis americana, Hort. ex C. Koch, Dendrol. ii. I. $636=$ serrulata.

arguta, Benth. Pl. Hartw. 348.-Mexic.

arguta, Spach, in Ann. Sc. Nat. Sér. Il. xv. (1841) 205 = acuminata.

aurea, Hort. ex C. Koch, Dendrol. ii. I. $630=$ glutinosa autumnalis, Hartig, ex Garcke, F1. Deutschl. ed. IV. $305=$ serrulata

badensis, Lange, ex Regel, in DC. Prod. xvi. Ir. $188=$ glutinosa.

barbata, Fries, ex Nym. Consp. 671 = pubescens. barbata, C. A. Mey. Verz. Pfl. Cauc. $43=$ glutinosa brembana, Rota, Prosp. Prov. Bergamasco, $79=$ viridis. canadensis, Lodd. $\mathrm{ex}$ Loud. Hort. Brit. $378=$ serrulata. castanaefolia, Mirb, in Mém. Mus. Par. xiv. (1827) 463. t. 21--Peruv.

cerifera, Hartig, ex Regel, in DC. Prod. xvi. I1. $187=$ glutinosa.

communis, Desf. Tabl. Hort. Par. ed. I. $213=$ glutinosa cordata, Desf. 1. c. ed. II. $244=$ cordifolia.

cordifolia, Tenore, Fl. Nap. Prod. 54. t. 99.-Europ. Oriens.

corylifolia, Kern. ex Dalla Torre, Atl. Alpenfl. 199.Europ. 


\section{ALNUS :-}

crispa, Hort. ex Steud. Nom. ed. II. i. $55=$ undulata. crispa, Pursh, Fl. Am. Sept. ii. 181.-Am. bor. cuneata, Geyer, ex Walp. Ann. i. $286=$ Cercocarpus parvifolius.

denticulata, C. A. Mey. Verz. Pf. Cauc. $43=$ glutinosa. dioica, Roxb. Fl. Ind. iii. $580=$ A porosa Roxburghii. dubia, Req. ex Regel, in DC. Prod, xvi. II. 187= glutinosa.

elliptica, Req. in Ann. Sc. Nat. Sér. I. v. (1825) $381=$ glutinosa.

emarginata, Krock, ex Steud. Nom. ed. I. $29=$ glutinosa. februaria, Kuntze, Taschen. Fl. Leipz. $238=$ glutinosa. ferruginea, $H . B$. \& $K$. Nov. Gen. et Sp. ii, 17.-N. Granat.

firma, Sieb. \& Zucc. in Abh. Acad. Muench. iv. III. (1845) 230.-Japon.

fruticosa, Rupr. Beitr. Pfl. Russ. Reich, ii. $53=$ viridis. glauca, Michx. f. Arb. Am, iii. 320. t. 4. f. 2 =incana glutinosa, Medic. Pfl. Anat. 393.-Europ.; As. bor.

Harinoki, Siebold, in Verh. Gen. Bat. xii. (1830) $25=$

japonica.
hirsuta, Turcz, in Bull. Soc. Nat. Mosc. (1838) 101; xxvii. (1854) I. $406=$ incana.

hybrida, Reichb. Ic. Fl. Germ. xii. t. 630. f. $1292=$ glutinosa, incana.

incana, Medic. Pfl. Anat. 393.-Reg. bor. temp.

incisa, Steud. Nom. ed. I. $29=$ glutinosa.

integrifolia, Roxb. ex Steud. Nom. ed. II. i. $56=$ Aporosa Roxburghii.

intermedia, Hort. ex C. Koch, Dendrol. ii. I. $631=$ oblongata.

intermedia, Schrad. ex Regel, in DC. Prod. xvi. II. 189 =incana.

japonica, Sieb. \& Zucc. in Abh. Akad. Muench. iv. III. (1845) $230=$ maritima.

japonica, Steud. Nom. ed. II. i. $55=$ Betula alba.

jorullensis, Benth. Pl. Hartw, $52=$ acuminata.

jorullensis, H. B. E K. Nov. Gen, et Sp. ii. 20.Mexic.

laciniata, Ehrh. Beitr. iii. $22=$ glutinosa.

lanuginosa, Gilib. Exercit. ii. 402 =incana.

latifolia, Desf. Cat. Hort. Par, ed. III, $352=$ serrulata.

Lindeni, Regel, in Nouv. Mém. Soc. Nat. Mosc, xiii. (1861) 144.-As. temp.

lobata, Nym. Consp. $671=$ incana.

longifolia, Bové, ex Spach, in Ann. Sc. Nat. Sér. II. iv. (1835) $348=$ orientalis.

macrocarpa, Lodd. ex Loud. Hort. Brit. $378=$ glutinosa. macrocarpa, Req. ex Nym. Consp. $672=$ cordifolia,

macrophylla, Desf. ex Steud. Nom. ed. I. 29; ed. II. i. $56=$ serrulata.

maritima, Nutt. Sylv. Am. Suppl. i. 34. t. 10 (1842), -Am. bor.

microphylla, Avvet, in Bull. Soc. Bot. Fr, xxvi. (1879) Bibl. 39,-Europ.

Mirbellii, Spach, in Ann. Sc. Nat. Sér. II. xv. (1841) 204.-Am. austr.

Mitchelliana, M. A. Curtis, ex A. Gray, in Am. Journ. Sc. xlii. (1842) $42=$ crispa.

montana X, Bruegg. in fahresb. Naturf. Ges. Graub.

II. xxiii-xxiv, (1880) 115, - Europ.

Morisiana, Bertol. F1. Ital, x. 163=glutinosa.

nana, [Clairv.] Man. Herb. 280.-Europ.

neapolitana, Savi, Tratt. Alb. Tosc. ed. II. ii. $21=$ cordifolia.

nepalensis, D. Don, Prod. Fl. Nep. 58.--Reg. Himal nigra, Gilib. Exercit. ii. $401=$ glutinosa.

nitens, C. Koch, in Linnaea, xxii. (1849) $334=$ glutinosa nitida, Endl. in Gen. Suppl. iv, II. 20,-Reg. Himal. obcordata, C. A. Mey. ex Steud. Nom. ed. II. i. 56, sphalm. = cordifolia.

oblongata, Kotschy, ex Regel, in DC. Prod. xvi. II $185=$ orientalis.

oblongata, Regel, Monog. 113. t. 7. f. $3-9=$ maritima, oblongata, Willd. Sp. Pl. iv. 335 - Europ. austr. oblongifolia, Torr. Bot. Mex. Bound. 204.-N. Mexic oregana, Nutt. Sylv. i. $9=$ rubra.

orientalis, Decne。 in Ann. Sc. Nat. Sér. II. iv. (1835) 348.-Oriens.

ovata, Lodd. But. Cab. t. $1141=$ crispa.

oxyacanthifolia, Lodd. Cat. (1836)=glutinosa.

plicata, Hort. ex C. Koch, Dendrol, ii. I, $638=$ incana.

prunifolia, Hort. ex C. Koch, 1. c. $630=$ glutinosa

pubescens, Tausch, in Flora, xvii. (1834) $520=$ glutinosa $x$ incana.

pumila, Steud. Nom. cd. I. 29.-Am. bor.

\section{ALNUS}

quercifolia, Willd. Berl. Baumz. $45=$ glutinosa.

repens, Wormsk. Fl. Dan. t. $2738=$ viridis.

rhombifolia, Nutt. Sylva, i. 33.-Calif.

rotundifolia, Bertol. F1. Ital. x. $160=$ cordifolia

rotundifolia, Stokes, Bot. Mat. Med. iv. $369=$ glutinosa

rubra, Bongard, in Mém. Acad. Pétersb. Sér. VI. il.

(1833) 162. - Am, bor. oce

rubra, Desf. ex Steud. Nom. ed. I. $29=$ serrulata.

rufescens, Liebm. ex Hemsl. Biol. Centr. Am. Bot. iii. $165=$ acuminata

rugosa, Hort. ex Regel, in DC. Prod, xvi. Ir. 188= serrulata.

rugosa, Spreng. Syst. iii, $848=$ acuminata.

serrulata, Willd. Sp. Pl. iv. 336.-Am. bor.

sibirica, Fisch. ex Turcz. in Bull. Soc. Nat. Mosc. (1838) 101; xxvii. (1854) I. $406=$ incana.

suavealens, Mor. ex Nym. Consp. $671=$ glutinosa.

suaveolens, Req.in Ann.Sc.Nat. v. (1825) 381,-Europ.

subcordata, C. A. Mey. Verz. Pfl. Canc, = cordifolia.

subrotunda, Desf. Tabl. Hort. Par. ed. II. 244.-Hab.

tiliaefolia, Hort. ex C. Koch, Dendrol. ii. I. $634=$ subcordata.

tenuifolia, Nutt. Sylva, i. 10.-Am. bor,

tirolensis, Nym. Consp. $671=$ incana,

tomentosa, Hartig, ex Regel, in DC. Prod. xvi. II. 185 $=$ orientalis.

tristis, Wormsk. ex Regel, 1. c. $182=$ viridis.

undulata, Willd. Sp. Pl. iv. 336.-Canada.

Vilmoriana, Hort. ex Lebas, in Rev. Hortic. (1866) 446. - Hab. ?

viridis, DC. Fl. Fr. iii. 304; Cham. in Linnaea, vi (1831) 538.-Europ.; As. bor.; Am. bor.

viridis, A. Gray, Man. Bot. N. Un. St. (1848) 424 = crispa.

vulgaris, Pers. Syn. ii. $550=$ glutinosa.

ALOCASIA, Neck. Elem。 iii, 289 (1790); Schott, in Schott \& Endl. Melet. 18 (1832). AROIDEAE, Benth. \& Hook. f. iii. 975 .

Ensolenanthe, Schott, in Bonplandia, ix. (1861) 368.

acuminata, Schott, in Bonplandia, vii. (1859) 28.Ind. or

alba, Schott, in Oestr. Bot. Wochenbl. ii. (1852) 59 ; (1854) 410.-Zeylan

argyroneura, C. Kech, Berl. Wochenschr. (1861) \& $=$ Caladium Schomburgkii.

Beccarii, Engl. in Bull. Soc: Tosc. Ortic. iv. (1879) 300. -Malaya.

commutata, Schott in Oestr. Bot. Wochenbl. (1854) $409=$ Alocasia odora

cucullata. Schott, in Schott \& Endl. Melet. 18.-Ind. or. cuprea, C. Koch, in Berl. Wochenschr. iv. (1861) 141 ; vii. (1864) 90,-Borneo.

decipiens, Schott, in Bonplandia, vii. (1859) 28,Ind. or.

denudata, Engl. in DC. Monog. Phan. ii. 507.Singapor.

erythraea, C. Koch, in Berl. Wochenschr. (1861) 8= Colocasia Schomburgkii.

fallax, Schott, in Bonplandia, vii. (1859) $28=$ navicularis.

fornicata, Schott, in Oestr. Bot. Wochenbl. (1854) 410. -Ind. or.

grandis, Clémenc. in Rev. Hortic. (1868) 380,-Hab.

heteroneura, C. Koch, in Berl. Wochenschr. (1861) 283 = Caladium Schomburgkii.

indica, Schott, in Oestr. Bot. Wochenbl. (1854) 410 pro parte.-Ind, or.; Malaya.

Fenningsit, Hort. Veiteh. Cf. Gard. Chron. (1868) 26 ; in Illustr. Hortic. $(1869)$ t. $585=$ Colocasia affinis

Fohnstonii, Hort. in Gard. Chron, xiii. (1880) 759 ; in Illustr. Hortic. xxvii. (1880) t. $395=$ Cyrtosperma Johnstonii.

Korthalsii, Schott, in Ann. Mus. Lugd. Bat. i. 124,Borneo.

Liervalii, Hort. ex Hérincq, L'Hortic. Franç. (1869) 243.-Ins. Philipp.

lobata, Rafin. Fl. Tellur. iii. 64.-Hab.?

longiloba, Mig. Fl, Ind, Bat, iii. 207-Malaya.

Lowii, Hook. Bot. Mag. t. 5376-—Borneo

macrorhiza, Schott, in Schott \& Endl. Melet. 18. -As. trop.; Austral.; Ins. Pacific.

Marchalli, Engl. in DC. Monog. Phan, ii. 494= Colocasia Marchalli,

montana, Schott, in Oestr. Bot. Wochenbl. (185t) $\$ 10$. -Ind. or. ; Malaya.

\section{ALOCASIA}

metallica, Hook. Bot. Mag, t. $5190=$ cuprea.

metallica, Schott, in Oestr. Bot. Wochenbl. (1854) 410 $=$ indica.

navicularis, C. Koch \& Bouché, Ind. Sem. Hort. Berol.

(1855) App. 2.-Reg. Himal.

odora, C. Koch, l. co (1854), App. 5.-Ind.

China.

pallida, C. Koch \& Bouché, 1. c: =alba

pedata, Rafin. Fl. Tellur. iii. $64=$ Sauromatum pe datum.

plumbea, Van Houtte, in Fl. des Serres, Sér. II. xì. 1875) 93. t. $2206=$ indica.

porphyroneura, Lem. in Illustr. Hortic. (1861) t. $297=$ Caladium picturatum.

Portei, Becc. \& Engl. in DC. Monog. Phan。 it. 645. N. Guin.

pubera, Schott, Syn. Aroid. 47.- Java.

Putzeysi, N. E. Br. in Illustr. Hortic。 xxix. (1882) t. 439, \& p. 22.-Sumatra.

rapiformis, Schott, Prod. Aroid. 157.-Burme

Regina, N. E. Br.-Cf. Gard. Chron. (1884) Y. 711,Borneo.

Roezlii, Hort. ex Gard. Chron. iii. (1875) $589=$ Cala dium marmoratum.

rugosa, Schott, in Oestr. Bot. Wochenbl. (1854) $410=$ cucullata.

scabriuscula, N. E. Br. in Gard. Chron. (1879) Ir. 296. - Borneo

Sedeni X, Hort. Veitch.-Cf. Gard. Chron. (1869) 587 , $615=$ cuprea $\times$ Lowii.

sinuata, N. E. Br. in Gard. Chron. (1885) Ir. 678.Malaya.

Thibautiana, Mast. l. c. (1878) I. 527.-Borneo.

undipes, C. Koch \& Bouché, in Ind. Sem. Hort. Berol. (1854), App. $5=$ Xanthosoma Jacquini.

wariegata, C. Koch \& Bonché, l, c. =indica.

Veitchii, Schott, in Ann. Mus. Bot. Lugd. Bat. i. $125=$ Lowii.

virginica, Rafin. Fl. Tellur. iii. $64=$ Peltandra virginica.

zebrina, C. Koch \& Veitch, in Berl. Wochenschr. y. (1863) 331.-Ins. Philipp,

ALOË, Tourn. ex Linn. Syst. ed. I. (1 735 )

CEAE, Benth. \& Hook. f. iii. 776 .

Agriodendron, Endl. Gen. 144 (1837)

BowreA, Haw. in Phil. Mag. (1824) 299.

Busipho, Salisb. Gen. Pl. Fragm. 76 (1866)

Catevala, Medic. Theodora, 67 (1786)

Kumara, Medic, 1. c. 69, t. $4\left(1780^{\circ}\right.$.

Pachidendron, Haw. Rev. P1. Succ. 35 (1521).

PTYAS, Salisb. Gen. Pl. Fragm. 76 (1866)

RHIPIDOI)ENDRon, Willd. in Ges. Naturf. Fr. Berl.

Mag. v. (1811) 164

abyssinica, Lam. Encyc. 1. 86,-Abyss,

acinacifolia, Jacq. Ecl. 49. to $31=$ Gasterıa acinacifolia.

acuminata, Haw. Syn. P1. Sncc. $84=$ A. humilis. acuminata, Lam. Encyc. i. $90=$ Gasteria verrucosa. africana, Mill. Gard. Dict. ed. VIII. n. 4.-Afr, austr. africana, Salm-Dyck, Cat, 31 = Salm. Dyckiana.

agavefolia, Tod. Hort. Bot. Panorm, i. 85. t. 23.-Afr trop.

albicans, Haw, in Trans. Linn. Soc. vii. (1804) $18=$

Haworthia albicans

albispina, Hav. l. c. 22.-Afr. austr.

albocincta, Haw. Suppl, PI. Succ. $43=$ striate.

altilinea, Schult. f. Syst. vii. $638=\mathrm{H}$ aworthia altilines. americana, Crantz, Inst. i. $466=$ Agare americana. andongensis, Baker, in Trans. Linn. Soc. Ser. II. i. (1878) 263.-Afr, trop

angolensis, Baker, l. c.-Afr. trop.

angulata, Willd. in Ges. Naturf. Fr. Berl. Mag. v.

(1811) $276=$ Gasteria distichn

angusta, Schult. f. Syst. vii. $710 \ldots$-Afro nustr.

angustifolia, Salm-Dyck, Obs. 37 = Gasteria disticha. anomala, Haw. in Trans. Linn. Soc. vii. (1sut) $25=$ Haworthia recurva

nrabicn, Lam. Encyc, is 91.-Amb.

arabica, Salm-1) yck, Cat. $27=$ microstigma.

arachuoider. Mill. Gard. Dict. ed. VIII. no $17=$

IIaworthia arachnoides

arachnoides, Thunb. Diss, Aloè, $7=$ Ilaworthin rachnosiles.

arboreda, Medic. Beobache. (1; \$\$) $905=$ arborescens arboresceus, Mill. Gard. Dict ed. VIII. D. 3.-Air austr. 


\section{ALOË :}

aristata, Haw. in Phit. Mag. (Oct. 1825) 280.-Afr. austr.

aristata, Schult. f. Syst. vii. 638.-Afr, austr.

aspera, Haw. in Trans. Linn. Soc. vii. (1804) 6= Apicra aspera.

asperiuscula, Schult. f. Syst. vii, $653=$ Haworthia as* periuscula.

asperula, Schult. f. 1. c. $635=$ Haworthia asperula.

Atherstonei, Baker, in Fourn. Linn. Soc. xviii. (1881) 170 - Afr, austr.

atrovirens, DC. P1. Grass. t. $51=$ Haworthia atrovirens.

attenuata, Haw. in Trans. Linn. Soc. vii. (1804) $11=$ Haworthia attenuata.

Bainesii, Dyer, in Gard. Chron. (1874) I. 567.Afr. austr.

barbadensis, Mill. Gard. Dict. ed. VIII. n, $2=$ vera.

Barberae, Dyer, in Gard. Chron. (1874) 1. $566=$ Bainesii.

Barteri, Baker, in Fourn. Linn. Soc. xviii. (1881) 168 -Afr, trop.

Bayfieldii, Salm-Dyck, Monog. ii. § 29. f. $14=$ Gasteria Bayfieldii.

bicarinata, Spreng. Syst. ii. 70 ; Schult. f. Syst. vii. 652 $=$ Apicra bicarinata

bicolor, Schult. f. 1. c. $682=$ Gasteria bicolor.

Polusii, Baker, in fourn. Linn. Soc. xviii. (1881) 179 -Afr. austr.

Bourea, Schult. f. Syst. vii. 704.-Afr. austr.

Boureana, Schult. f. 1. c. $662=$ Gasteria picta.

brachyphylla, Salm-Dyck, Hort. $332=$ Gasteria brevifolia.

Bradlyana, Jacq. Hort. Schoenbr, iv. 11, in nota ad t. $421=$ Haworthia atrovirens.

brevifolia, Mill. Gard. Dict. ed. VIII. in errat.-Afr. austr.

brevifolia, Haw. in Trans. Linn. Soc. vii. (1804) $23=$ distans.

brevioribus, Mill. Gard. Dict. ed. VIII. n. 8, sphalm.= brevifolia.

brevis, Schult. f. Syst. vii. 649.-Afr. austr

bullulata, Jacq. Fragm. 72. t. $109=$ A picra pentagona caesia, Salm-Dyck, Cat. 29.-Afr. austr.

Candelabrum, Tod. Hort. Panorm. (1876) 46.-Hab.?

candicans, Schult. f. Syst. vii. $681=$ Gasteria can dicans.

capitata, Baker, in Fourn. Linn. Soc. xx. (1883) 272.Madag.

carinata, Ker-Gawl. in Bot. Mag. t. $1331=$ Gasteria glabra.

carinata, DC. Pl, Grass. t. $63=$ Gasteria verrucosa

carinata, Mill. Gard. Dict. ed. VIII. n. $21=$ Gasteria carinata.

caroliniana, Hill, Veg. Syst. xiii. $64=$ Agave virginica. chinensis, Steud. Nom. ed. II. i. 56 ; Baker, in Bot. Mag. t. 6301 . - China.

chloracantha, Schult. f. Syst. vii. $641=$ Haworthia chloracantha.

chloroleuca, Baker, in Gard. Chron. (1877) II. 38.Afr. austr.

ciliaris, Haw. in Phil. Mag. (@et. 1825) 281.Afr. austr.

clariperla, Schult. f. Syst. vii. 646, $1712=$ Haworthia attenuata.

claviffora, Burch. Trav. i. 272,-Afr, austr.

coarctata, Schult. f. Syst. vii. $647=$ Haworthia coarc tata.

Commelyni, Willd. in Ges. Naturf. Fr. Berl. Mag. v. (1811) $282=$ mitriformis

commutata, Tod. Hort. Bot. Panorm. i. 75. t. 18 - Hab?

concinna, Schult. f. Syst. vii: $653=$ Haworthia viscosa. congesta, Salm-Dyck, Monog. i. $\S 2$. f. $1=$ Apicra congesta.

consobrina, Salm-Dyck, l. c. § 18. f. 2.-Afr, austr. conspurcata, Salm-Dyck, Obs. $59=$ Gasteria disticha. constricta, Baker, in fourn. Linn. Sac. xviii. (1881) 168.-Afr. trop.

Cooperi, Baker, in Gard. Chron. (1874) I. 628.-Afr. austr.

cordifolia, Schult. f. Syst. vii. $653=$ Haworthia cordifoli

crassifolia, Schult. f. 1. c. $664=$ Gasteria nigricans

crassipes, Baker, in Fourn. Linn. Soc. xviii. (1880) 162 -Afr. trop.

Croucheri, Hook. f. Bot. Mag. t. $5812=$ Gasteria Croucheri.
ALOH :-

cryptopoda, Baker, in Fourn. Bot. xxii. (1884) 52.Afr. trop.

curta, Spreng. Syst. ii. 69.-Afr. austr.

cuspidata, Schult. f. Syst. vii. $639=$ Haworthia cuspidata.

cylindracea, Lam. Encyc. i. 89=Apicra spiralis, et Haworthia rigida.

cymbaefolia, Schrad. Nenes Journ. ii. (1807) $17=$

Haworthia cymbiformis.

cymbiformis, Haw. in Trans. Iinn. Soc. vii. (1804) 8 = Haworthia cymbiformis.

decipiens, Schult. f. Syst, vii. $674=$ Gasteria decipiens. deltoidea, Hook. f. Bot. Mag. t. 6071=Apicra del toidea.

deltoideodonta, Baker, in Fourn. Linn. Soc. xx. (1883) 271.-Madag.

denticulata, Schult. f. Syst. vii. $639=$ Haworthia denticulata.

dependens, Steud. Nom. ed. I, $30=$ pendens.

depressa, Haw. in Trans. Linn. Soc. vii. (1804) 16.Afr. austr.

depressa, Salm-Dyck, ex Steud. Nom. ed. II. i. $57=$ distans.

dichotoma, Linn. f. Suppl. 206.-Afr. austr.

dictyodes, Schult. f. Syst. vii. $663=$ Gasteria retata.

distans, Haw. Syn. Pl. Succ. 78.-Afr. austr.

disticha, Linn. Sp. Pl. 321.-Afr. austr.

disticha, Mill. Gard. Dict. ed. VIII. n. $5=$ saponaria.

disticha, Thunb. Diss. Aloë, n. $9=$ Gasteria verrucosa.

dorsalis, Haw, in Trans. Linn. Soc, vii. (1804) 28 lineata.

drepanophylla, Baker, in Gard. Chron. iii. (1875) 814. -Afr. austr.

echinata, Wilid. Enum. Hort. Berol. $385=$ humilis.

Ecklonis, Salm-Dyck, Monog. ii. \$ 21. f. 2.-Afr. austr.

elegans, Tod. Ira. Sem. Panorm. (1880) 37.-Hab. ? elongata, Murr. in Comm. Gott. ix. (1789) $191=$ vera.

elongata, Salm-Dyck, Monog. § 29. f. $15=$ Gasteria trigona.

ensifolia, Schult. f. Syst. vii. $681=$ Gasteria acinacifolia. erecta, Schult. f. l. c. 649.-Afr. austr.

erecta, Salm-Dyck, Aloë, §6. f. $7=$ Haworthia margaritifera.

excavata, Willd. in Ges. Naturf. Fr. Berl. Mag. v. (1811) $276=$ Gasteria excavata

expansa, Haw. in Trans. Linn. Soc. vii. (1804) $8=$ Haworthia rigida.

falcata, Baker, in Fourn. Linn. Soc. xviii, (1880) 181. -Afr. austr.

fasciata, Salm-Dyck, in Schult. f. Syst. vii. $1713=$ Haworthia fasciata.

ferox, Mill. Gard. Dict. ed. VIII. n. 22-Afr, austr.

flabelliformis, Salisb. Prod. $246=$ plicatilis.

flava, Pers. Syn. i. $378=$ vera.

favispina, Haw. in Trans. Linn. Soc. vii. (1804) $22=$ mitriformis.

foetida, Crantz, Inst. i. $466=$ Agave americana

foliolosa, Haw. in Trans. Linn. Soc. vii. (1804) $7=$ Apicra foliolosa.

formosa, Schult. f. Syst. vii. 662.-Afr. austr.

fragrantissima, Jacq. Enum. Stirp. Vind. App. $399=$ Dracaena fragrans.

frutescens, Salm-Dyck, Cat. $30=$ arborescens

fruticosa, Lam. Encyc. i. $87=$ arborescens.

gasterioides, Baker, in Fourn. Linn. Soc. xviii. (1880) 166.-Afr. austr.

glabra, Salm-Dyck, Obs. $48=$ Gasteria glabra

glabrata, Salm-Dyck, Hort, $325=$ Haworthia glabrata.

glauca, Mill. Gard. Dict. ed. VIII. n. 16-Afr. austr.

gracilis, Haw. in Phil. Mag. (Oct. 1825) 280.-Afr. austr.

granata, Schult. f. Syst. vii. 650.-Afr. austr.

granata, Salm-Dyck, Aloë, § 6. f. $6=$ Haworthia margaritifera.

grandidentata, Salm-Dyck, Obs. (1822) 329.-Afr. anstr.

Greenii, Baker, in Fourn. Linn. Soc. xviii. (1880) 165. -Afr. austr.

guineensis, Jacq. Enum. Stirp. Vind. App. $308=$ Sanseviera guineensis.

guttata, Salm-Dyck, Hort. $332=$ Gasteria nigricans.

Hanburiana, Naud. in Rev. Hortic. (1875) $165=$ striata.

Haynaldi, Tod. Hort. Panorm. i. 75. t. 24.-Hab. ?

hebes, Schult. f. Syst. vii. $637=$ Haworthia cymbiformis.
ALOḦ :

herbacea, DC. Hort. Monsp. $76=$ Haworthia reticulata.

herbacea, Mill. Gard. Dict. ed. VIII, n. $18=$ Haworthia atrovirens.

heteracantha, Baker, in Fourn. Linn. Soc. xviii. (1880) 161 . - Hab.?

hexapetala, Salm-Dyck, Cat. 28.-Hab.?

horrida, Haw. in Trans. Linn. Soc. vii. (1804) $27=$ ferox.

humilis, Mill. Abr. Gard. Dict. ed. VI. n. 10 (1771),Afr, austr.

hyacinthoides, Linn. Sp. P1. $321=$ Sanseviera zeylanica, hybrida, Salm-Dyck, Cat. $7=$ Haworthia hybrida. imbricata, Haw. in Trans. Linn. Soc. vii. (1804) $7=$ Apicra spiralis.

incurva, Haw. Syn. Pl. Succ. $85=$ humilis.

indica, Royle, Illust. P1. Himal. $390=$ vera

indurata, Schult f Syst. vii. 654-Afr, austr.

inermis, Forsk. Fl. Aegypt. Arab̆. 74.-Arabia.

inermis, Hort. ex Baker, in Journ. Linn. Soc. xviii. 1880 $161=$ heteracantha.

insignis $\times, N . E . B r$. in Gard. Chron. xxiv. (1885) 40 . f. 8.-Hab.?

intermedia, Haw, in Trans. Linn. Soc. vii. (1804) $12=$ Gasteria verrucosa.

Kraussii, Baker, in Fourn. Linn. Soc. xviii. (1880) 159.-Afr. anstr.

laetepunctata, Schult. f. Syst. vii. $676=$ Gasteria laetepunctata.

laetevirens, Link, Enum. Hort. Berol. i. $335=$ Haworthia laetevirens.

laevigata, Schult. Syst. vii. $636=$ Haworthia albicans.

laevis, Salm-Dyck, Cat. 16.-Afr, austr.

latifolia, Haw. Syn. Pl.Succ. 82.-Afr. austr.

leptocaulon, Boj. Hort. Maurit. $345=$ oligophylla?

leptophylla, N. E. Br. ex Baker, in Journ. Linn. Soc xviii. (1881) $165=$ latifolia.

limpida, Schult.f. Syst. vii. 638.-Afr. austr.

lineata, Haw. in Trans. Linn. Soc. vii. (1804) 18.Afr. austr.

Lingua, Ker-Gawl. in Bot. Mag. t. 1322=Gasteria verrucose.

Lingwa, Willd, in Ges. Naturf. Fr. Berl. Mag. v. (1811) $277=$ sp. plurim.

Lingua, Thunb. Diss. Aloë, $8=$ Gasteria disticha. linguiformis, DC. P1. Grass. t. $68=$ Gasteria sulcata.

linguiformis, Linn. f. Suppl. $206=$ plicatilis.

linguiformis, Mill. Gard. Dict. ed. VIII. n. $13=$ Gasteria disticha.

linguiformis, Medic. Beobacht. (1783) 64.-Hab.?

linita, Schult.f. Syst. vii. 682,-Afr, austr.

littoralis, Baker, in Trans. Linn. Soc. Ser. II. Bot. i 1878) 293.-Afr. trop.

littoralis, Koen. ex Baker, in Journ. Linn. Soc, xviii (1880) $176=$ vera.

lomatophylloides, Balf. $f$. in Fourn. Limn. Soc. xvi. (1877) 22.--Ins. Mascar.

longiaristata, Schult. f. Syst. vi, $684=$ aristata.

longifolia, Haw. Syn. Pl. Succ $88=$ Gasteria disticha. longifolia, Lam. Encyc. i. 90=Tritomanthe Uvaria.

longistyla, Baker, in Fourn. Linn. Soc. xviii. (1880) 158.-Afr, austr.

Lynchii x, Baker, in Gard. Chron. (1881) I. 266.

macilenta, Nichols. Dict. Gard, i. $52=$ humilis.

Macowani, Baker, in fourn. Linn. Soc. xviii. (1881) 170.-Afr. austr.

macra, Haw. Suppl. PI. Succ. 45, $102=$ Lomatophyllum macrum.

macracantha, Baker, in fourn. Linn. Soc. xviii. (1880) 167.-Afr, austr.

macrocarpa, Tod. Hort. Bot. Panorm, 36. t. 9.Abyss.

macroclada, Baker, l. c. xx. (1883) 273.-Madag. maculata, Ker-Gawl. in Bot. Mag. t. $765=$ Gasteria pulchra,

maculata, Desf. Tabl. Hort. Par. ed. I. $25=$ obscura. maculata, Forsk. Fl. Aegypt. Arab. $73=$ abyssinica. maculata, Thunb. Diss. Aloë, $8=$ Gasteria maculata maculosa, Lam. Encyc. i. $87=$ obscura, saponaria. margaritifera, Burm, f. Fl. Cap. Prod. $10=$ Haworthia margaritifera.

marginalis, DC. Pl. Grass. t. $31=$ Lomatophyllum borbonicum.

marginata, Lam. Encyc. i. $89=$ Haworthia albicans.

marginata, Willd. Enum. Hort. Berol. $382=$ Lomatophyllum borbonicum.

marmorata, Hitchen, ex Stend. Nom. ed. II. i. $58=$ formosa. 
ALOH :

micracantha, Haw. Suppl. Pl. Succ. 105.-Afr. austr. microstigma, Salm-Dyck, Monog. ii. §26. f. 4.-Afr. anstr.

minor, Schult. f. Syst. vii. $648=$ Haworthia margaritifera.

mirabilis, Haw. in Trans. Linn. Soc. vii. (1804) $9=$ Haworthia mirabilis.

mitraeformis, DC. Pl. Grass. 99 ; Haw. Syn. Succ. 77 =distans, nobilis.

mitraeformis, Willd. Enum. Hort. Berol. $385=$ mitriformis.

mitriformis, Mill. Gard. Dict. ed. VIII. n. 1.-Afr. austr.

mollis, Schult. Syst, vii. $665=$ Gasteria mollis

mucronata, Schult. f. l. c.638.-Afr. austr.

multifaria, Schult. f. l. c. 635.-Afr. austr.

muricata, Haw. in Trans. Linn. Soc. vii. (1804) $25=$ ferox.

muricata, Schult. Obs. $70=$ glauca.

mutica, Schult. f. Syst. vii, 635.-Afr, austr

myriacantha, Schult. f. l. c. 704.-Afr. austr.

neglecta, Tenore, in Atti Accad. Sc. Nap. v. 1. (1837) p. 257.-Hab.?

nigra, Schult. f. Syst. vii. $657=$ Haworthia nigra.

nigricans, Haw. in Trans. Linn. Soc. vii. (1804) $13=$ Gasteria nigricans.

nitens, Baker, in fourn. Linn. Soc. xviii. (1880) 170. -Afr. austr.

nitens, Schult. f. Syst. vii. $680=$ Gasteria acinacifolia.

nitida, Salm-Dyck, Cat, $13=$ Gasteria nitida.

nobilis, Haw. Syn. Pl. Succ. 78.-Afr. austr.

obliqua, DC. PI. Grass. t. $91=$ Gasteria pulchra

obliqua, Haw. in Trans. Linn. Soc. vii. (1804) $14=$

Gasteria maculata.

obliqua, Jacq. Hort. Schoenb. iv, $9=$ Gasteria nigricans.

obscura, Mill. Gard. Dict. ed. VIII. n. 6.-Afr. austr.

obscura, Willd. in Ges. Naturf. Fr. Berl. Mag. v. (1811)

$275=$ Gasteria excavata

obscurevirens, Martinati, ex Vis. Orto Bot. Padov. 132.-Hab. ?

obtusa, Schult. f. Syst. vii. $679=$ Gasteria obtusa.

obtusifolia, Salm-Dyck, Obs. $62=$ Gasteria obtusifolia.

officinalis, Forsk. Fl. Aegypt. Arab. $73=$ vera.

oligophylla, Baker, in fourn. Linn. Soc. xx. (1883) 272.-Madag.

pallescens, Haw. Rev. PI. Succ. $41=$ serrulata.

pallida, Schult, f. Syst. vii. $641=$ Haworthia pallida.

palmiformis, Baker, in Trans. Linn. Soc. Ser. II. Bot. i. (1878) 263.-Angola.

paniculata, Jacq. Fragm. 48. t. $68=$ striata.

papillosa, Salm-Dyck, Cat. $7=$ Haworthia papillosa.

parva, Schult. f. Syst. vii. $653=$ Haworthia tessellata.

Peacockii, Baker, in Journ. Linn. Soc. xviii. (1880) 175 = abyssinica.

pellucens, Haw. Syn. Pl. Succ. $96=$ Haworthia translucens.

pendens, Forsk. Fl. Aegypt. Arab. 74.-Arabia.

pentagona, Haw, in Trans. Linn. Soc. vii. (1804) $7=$ Apicra pentagona.

pentagona, Facq. Fragm. 72. t. 111.-Afr. austr.

pentagona, Salm-Dyck, Monog. i. § 1. f. 4 =quinquangularis.

percrassa, Tod. Hort. Bot. Panorm. i. 81. t. $21=$ abyssinica.

perfoliata, Linn. Sp. Pl. 319, $320=$ sp. plurim.

perfoliata, Meyen, Reise, ii. $45=$ arborescens.

Perryi, Baker, in fourn. Linn. Soc. xviii. (1880) 161. -Ins. Socotra.

pertusa, Haw, in Trans, Linn. Soc. vii. (1804) $25=$ Crassula corymbulosa.

picta, Thunb. Diss. Aloè, $6=$ obscura.

planifolia, Baker, in Saund. Refug. Bot. t. $162=$ Gasteria planifolia.

planifolia, Schult. f. Syst, vii. $688=$ Haworthia cymbiformis.

platylepis, Baker, in Gard. Chron. (1877) 11. 38.-Afr. austr.

platyphylla, Baker, in Trans. Linn. Soc. Ser. II. i. (1878) 264 . - Angola.

plicatilis, Mill. Gard. Dict. ed. VIII, n. 7.-Afr.

austr.

pluridens, Haw. in Phil. Mag. (Oct. 1824) 299.-Afr.

ausir.

pluripunctata, Schult. f. Syst. vii. 681.-Afr. austr.

postgenita, Schult. f. l. c. 1714.-Afr, austr.
ALOH :-

pratensis, Baker, in fourn. Linn. Soc. xviii. (1880) 156 -Afr. austr.

prolifera, Haw. in Trans. Linn. Soc. vî. (1804) 16 =brevifolia.

pseudoafricana, Salm-Dyck, Cat. 31=africana.

pseudoangulata, Salm-Dyck, 1. c. $16=$ Gasteria subcarinata.

pseudoferox, Salm-Dyck, 1. c. $31=$ ferox

pseudonigricans, Salm-Dyck, 1. c. $17=$ Gasteria nigricans.

pseudorigida, Salm-Dyck, 1. c. 9 \& $41=$ Haworthia subrigida.

pseudotortuosa, Salm-Dyck, I. c. 8 \& $41=$ Haworthia viscosa.

pulchra, Jacq. Hort. Schoenbr. iv. 10. t. $419=$ Gasteria pulchra.

pumila, Linn. Sp. Pl. $322=$ sp. plurim.

Pumilio, Jacq. Hort. Schoenb. iv, 11= Haworthia reticulata.

punctata, Haw. in Trans. Linn. Soc. vii. (1804) $26=$ variegata.

punctata, Martinati, in Vis. Orto Bot. Padov. 132.Hab.?

purpurascens, Haw. in Trans. Linn. Soc. vii. (1804) 20.-Afr. austr.

purpurea, Lam. Encyc. i. $85=$ Lomatophyllum borbonicum.

pusilla, Schult. f. Syst. vii. 674.-Hab. ?

quinquangularis, Schult. f. l. c. 658.-Afr. anstr.

racemosa, Lam. Encyc. i. 91 = Gasteria verrucosa.

Radula, Jacq. Hort. Schoenb. iv. 11. t. $422=$ Haworthia Radula.

Radula, Ker-Gaw1. in Bot. Mag. t. 1345= Haworthia attenuata.

ramifera, Schult.f. Syst. vii. 636.-Afr. austr.

ramosa, Haw. in Trans. Linn. Soc. vii. (1804) $26=$ purpurascens.

recurva, Haw. 1. c. $10=$ Haw orthia recurva.

reflexa, Van Marum, ex Steud. Nom. ed. II. i. $59=$ distans.

Reinwardtii, Salm-Dyck, Obs. (1821) $37=$ Haworthia Reinwardtii.

repens, Schult. f. Syst. vii. $674=$ Gasteria repens.

reticulata, Haw. in Trans. Linn. Soc. vii. (1804) $9=$ Haworthia reticulata.

retusa, Linn. Sp. Pl. $322=$ Haworthia retusa.

retusifolia, Haw. ex Steud. Nom. ed. II. i. $59=$ Gasteria obtusifolia.

rhodacantha, DC. Pl. Grass. $44=$ glauca

rhodocincta, Hort. ex Baker, in Journ. Linn. Soc. xviii. 1880) $163=$ striata.

rigida, Ker-Gawl. in Bot. Mag. t. $1337=$ Haworthia tortuosa.

rigida, DC. Pl. Grass. t. $62=$ Haworthia rigida.

rigida, Salisb. Prod. $245=$ Kniphofia alooides.

rigida, Jacq. Fragm. t. $108=$ Haworthia subrigida.

rubescens, DC. Pl. Grass, t. $15=$ vera.

rufocincta, Haw. Suppl. Pl. Succ. $45=$ Lomatophyllum rufocinctum.

rugosa, Salm-Dyck, in Schult. f. Syst. vii. $1712=$ Haworthia rugosa.

Sabila, Karw. ex Steud. Nom. ed. II. i. 59.-Mexic.

Sahundra, Boj. Hort. Maurit. 345.-Madag.

Salm-Dyckiana, Schult. $f_{0}$ in Syst. vii. 710.-Afr. austr.

saponaria, Haw. in Trans. Linn. Soc. vii. (1804) 17.Afr. austr.

scaberrima, Salm-Dyck, Hort. 332 ; Schult. f. Syst. vii. $1713=$ Gasteria verrucosa.

scabra, Schult. f. Syst. vii. $644=$ Haworthia scabra.

Schimperi, Tod. Hort. Panorm. (1876) 46.-Abyss.

Schmidtiana, Regel, Gartenf. (1879) $97=$ Cooperi.

Schweinfurthii, Baker, in Fourn. Linn. Soc. xviii. (1880) 175.-Afr. trop

semiglabrata, Schult. f. Syst. vii. $650=$ Haworthia semiglabrata.

semimargaritifera, Salm-Dyck, Cat. $6=$ Haworthia margaritifera.

Serra, DC.Pl. Grass. t. 80.-Afr. austr.

Serra, Willd. in Ges. Naturf, Fr. Berl. Mag. v. (1811) $282=$ depressa.

serrulata, Haw. in Trans. Linn. Soc. vij. (1804) 18.Afr. austr.

setosa, Schult. f. Syst. vii. $641=$ Haworthia setata. sigmoidea, Baker, in Fourn. Linn. Soc, xviii. (1880) 177. - Afr. austr.

sinuata, Thunb. Diss. Aloë, 6 = succotrins,

sinuata, Willd. Sp. Pl. ii. 187 a purpurascens

\section{ALOE :}

soccotorina, Schult. f. Syst. vii, $701=$ seq.

soccotrina, DC. Pl. Grass. 61 . t. $85=$ succotrina sordida, Schult. f. Syst. vii. $644=$ Haworthia sordida. speciosa, Baker, in fourn. Linn. Soc. xviii. (1880) 178. -Afr. austr.

spicata, Linn. f. Suppl. 205; Haw. Syn. Succ. 76.Afr. austr.

spinulosa, Salm-Dyck, Obs. (1822) $4=$ mitriformis.

spiralis, Haw. in Trans. Linn. Soc. vii. (1804) $7=$ Apicra pentagona.

spiralis, Linn. Sp. Pl. $322=$ Apicra spiralis.

spirella, Salm-Dyck, Cat. $10=$ A picra pentagona

squarrosa, Baker, ex Balf. f. in Proc. Roy. Soc. Edinb.

xii. (1884) 97.-Ins. Socotr.

stenophylla, Schult. f. Syst. vii, $641=$ Haworthia angustifolia.

striata, Haw. in Trans. Linn. Soc. vir. (1804) 18.-

Afr. austr.

striatula, Haw. in Phil. Mag. (Oct. 1825) 281.-Afr austr.

strigata, Schult.f. Syst. vii. 676.-Afr. austr.

subalbicans, Salm-Dyck, Monog. i. \& 6. f. 1 = Haworthia margaritifera.

subattenuata, Salm-Dyck, in Schult. f. Syst. vii. $1712=$ Haworthia subattenuata.

subcarinata, Salm-Dyck, Obs. $51=$ Gasteria sul carinata.

suberecta, Haw, in Trans. Linn. Soc. vii. (1804) $16=$ humilis.

subfasciata, Salm-Dyck, in Schult. f. Syst. vii. 1712

Haworthia subfasciata.

subferox, Spreng. Syst. ii. 73.-Afr. anstr.

subnigricans, Spreng. 1. c. $71=$ Gasteria nigricans.

subrigida, Schult. 1. Syst. vii. $654=$ Haworthia sub-

rigida.

subtortuosa, Schult. f. 1. cs = Haworthia viscosa.

subtuberculatu, Haw. in Phil. Mag. (Oct. 1825) $250=$ humilis.

subulata, Salm-Dyck, in Schult. f. Syst. vii. $1712=$

Haworthia subulata.

subverrucosa, Salm-Dyck, Obs, $67=$ Gasteria subverIucosa.

succotrina, Lam. Encyc. i. 85.-Afr. austr.

sulcata, Salm-Dyck, Obs. $54=$ Gasteria sulcata.

supralaevis, Haw. in Trans. Linn. Soc. vii. (1804) 22 -Afr. austr.

tenuifolia, Lam. Encyc. i. 87.-Afr. austr.

tenuior, Haw. in Phil. Mag. (Oct, 1825) 281. - Arr. austr.

tessellata, Schult. f. Syst. vii. $635=$ Haworthia tes sellata.

Thraskii, Baker, in Fourn. Linn. Soc. xviii. (1880

180.-Afr. austr.

torquata, Schult. f. Syst. vii. $65 t=$ Haworthia viscosa.

tortuosa, Haw. in Trans. Linn. Soc. vil. (180!)

Haworthia tortuosa.

translucens, [Soland. in] Ait. Hort. Kew. ed. II. ii. 30u

$=$ Haworthia translucens.

triangularis, Lam. Encyc. i. $89=$ Haworthia riscosa.

trichotoma, Colla, Hort. Ripul. $13=$ saponaria.

tricolor, Baker, in Bot. Mag.t. 6324.-Afr. austr.

tricolor, Haw. in Trans. Linn. Soc. vii. (1804) $25=$

Haworthia venosa

trigona, Salm-Dyck, Monog. ii. § 29. f. 1S=Gasteria obtusa.

tripetala, Medic. Beobacht. (1783) $55=$ plicatilis.

tristicha, Medic. Theod. $74=$ Gasteria carinata.

tuberculata, Haw. in Trans. Linn. Soc. vii. (10ut) $10=$ humilis.

tuberculata, Lag. Gens, et Sp. Nov. 18.-Hab.

turgida, Schult. f. Svst. vii. $695=$ Haworthia turgida.

umbellata, DC. Pl. Grass. t. $98=$ saponaria.

undata, Schult. fo Syst. vii. $67 \%=$ Gasteria subearinata.

Uvaria, Linn. Sp. 11. 323 - Knipholia alooides.

vacillans, Forsk. Fl. Aeb!pt. Arnb. $7 t=$ vera.

variegata, Forsh. l. c. $7 \pm=$ anbica.

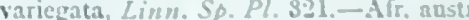

venosa, Lam. Encje. i. $89=$ Haworhia venosa.

venusta, Schult. f. Syst. vii. 631 . - Hab.

vera, Linn. Sp. Pl. S20,-Keg. medit.

yera. Mill. Gard. Dict. ed. VIII. n. $15=$ succolrinz.

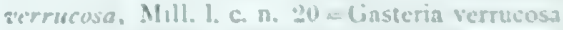

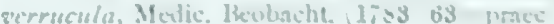

virens, Han in Trans. Linn. Sor vii. 1801: 17.-As

nustr.

virescens, Scliwlt. f. Sy'st. vii. 68\%.-113b. ! 


\section{ALOE:-}

virginica, Crantz, Inst. i. $466=$ Agave virginica riscos $\alpha$, Linn. Sp. Pl, $322=$ Haworthia viscosa. vittata, Schult. f. Syst. vii. 662.-Afr. austr. vivipara, Crantz, Inst. i. $466=$ Agave vivipara. vulgaris, Lam. Encyc. i. $86=$ vera.

zanthacantha, Willd. in Ges. Naturf. Fr. Berl. Mag. v. (1811) $282=$ mitriformis

yuccaefolia, A. Gray, in Proc. Am. Acad. vii. (1868) $390=$ Hesperaloë yuccaefolia

zebrina, Baker, in Trans. Linn. Soc. Ser. II. Bot. i. (1878) 264.-Afr, trop.

Zeyheri, Hort. ex Baker, in Journ. Linn. Soc. xviii. (1880) $178=$ Bainesii.

Zeyheri, Salm-Dyck, Aloë, § 29. f. 3bis=Gasteria Zeyheri.

zeylanica, Jacq. Hort. Vind. $310=$ Sanseviera zeylanica.

ALOËATHEROS, Fndl, Gen. 95 (1836)=ALLOIATHEROS, Ell. = Gymnopogon, Beauv.?(Gramin.).

ALOËXYLUM, Lour. F1. Cochinch. $267(1790)=$ Aquilaria, Lam. (Thymel.).

Agallochum, Lour. 1. c. = Aq. Agallochum.

verum, Lour. 1. c. = Aq. Agallochum.

ALOIDES, Boerh. ex Linn. Gen. ed. II. $253(1742)=$ Stratiotes, Linn. (Hydrochar.).

ALOIOZONIUM, Lindl. Veg. Kingd. 713 (1847)= ALLOIOZONIUM, Kunze=Cryptostemma, R. Br. (Compos.)

ALOITIS, Rafin. Fl. Tellur. iii. 21 (1836)= Gentiana Linn.

anceps, Rafin. 1. c. 22.-Hab.?

parviflora, Rafin. 1. c. $21=\mathrm{G}$. quinqueflora.

quinqueflora, Rafin. 1. c. $22=\mathrm{G}$. quinqueflora

ALOMIA, H. B. \& K. Nov. Gen. et Sp. iv. 151, 312. t. 354 (1820). COMPOSI TAE, Benth. \& Hook. f. ii. 240 Lycapsus, Phil. in Bot. Zeit. (1870) 499. t. 8. Orsinia, Bertol. ex DC. Prod.v. 104 (1836). ageratoides, $H . B$. \& K. Nov. Gen. et Sp. iv. 151. t. 354 . -Mexic.

alata, Hemsl. Biol. Centr. Am. Bot. ii. 79.-Mexic. angustata, Benth. ex Baker, in Mart. Fl. Bras. vi. II. 190.-Bras.

Armani, Baker, l. c. 191.-Bras.

cinerea, Benth. ex Baker, l. c.-Bras.

fastigiata, Benth, ex Baker, l. c. 192.-Bras.

foliosa, Benth. \& Hook. f. Gen. ii. 240.-Bras.

myriadenia, Baker, in Mart. Fl. Bras. vi. II. 192.-Bras,

Pohlii, Baker, l. c. 190.-Bras.

polyphylla, Baker, l.c. 191.-Bras.

spilanthoides, D. Don, ex Hook. \& Arn. in Hook. Comp.

Bot. Mag. i. (1835) $238=$ Gymnocoronis spilanthoides.

ALONA, Lindl. Bot. Reg. (1844) t. 46. CONVOLVU. LACEAE, Benth. \& Hook. f. ii. 879.

Rayeria, Gaudieh. Voy. Bonite, t. 108 (1839-46).

baccata, Lindl. Bot. Reg. (1844) sub t. 46.-Chili.

balsamiflua, Gaudich. Voy. Bonite, t. 107.-Hab. ?

carnosa, Lindl. Bot. Reg. (1844) sub t. 46.-Chili

coelestis, Lindl. l. c. - Chili.

deserticola, Phil. Fl. Atac. 44-Chili.

dubia, Phil.in Anales Univ. Chil.(1865) ii. 350,-Chili. ericifolia, Miers, in Hook. Lond. Fourn. Bot. iv. (1845) 500.-Chili.

floribunda, Phil. in Anales Univ. Chil. (1873) 525.Chili.

glandulosa, Lindl. Bot. Reg. (1844) sub t. 46.-Chili.

longifolia, Lindl. l. c.-Chili.

micrantha, Phil. Fl. Atac. 44.-Chili.

microphylla, Miers, in Hook. Lond. Fourn. Bot. iv. (1845) 501.-Chili.

mollis, Phil. Fl. Atac, 44-Chili.

obtusa, Lindl. Bot. Reg. (1844) sub t. 46.-Chili.

pusilla, Phil. Fl. Atac. 45.-Chili.

revoluta, Lindl. Bot. Reg. (1844) sub t. 46--Peruv.

rostrata, Lindl. 1. c. = Osteocarpus rostratus.

sphaerophylla, Phil. Fl. Atac. 44.-Chili.

tomentosa, Lindl. Bot. Reg. (1844) sub t. 46.-Chili.

vernicosa, Phil. Fl. Atac. 44.-Chili.

xerophila, Phil. l. c.-Chili.

ALONSOA, Ruiz \& Pav. Syst. Veg. 150 (1798). SCROPHULARINEAE, Benth. \& Hook. f. ii. 930 . HEMIMERIS, Pers. Syn. ii. 162 (1807) partim; H. B. \& K. Nov. Gen. et Sp. ii. 376 (1817).

\section{ALONSOA}

Hemitomus, L'Hérit. ex Desf. Tabl. ed. I. 66 (1804)

SCHISTANTHE, Kunze, in Linnaea, xvi. (1842) Litt. 109.

acutifolia, Ruiz \& Pav. Syst. Veg. 153.-Peruv caulialata, Ruiz \& Pav. l. c. 152.-Peruv. hirsuta, Steud. Nom. ed. II. 1. 60.-Bras.

incisifolia, Ruiz \& Pav. Syst. Veg. 154.-Peruv intermedia, Lodd. Bot. Cab, t. $1456=$ linearis linearifolia, Steud. Nom. ed. II. i. 60--Peruy. linearis, Ruiz \& Pav. Syst. Veg. 154.--Pertv. linifolia, Roezl, in Belg. Hortic. xxiv. (1874) 38.Peruv.

Mathewsii, Benth. in DC. Prod. x. 250.-Peruv. Mutisi, G. Don, Gen. Syst. iv. $513=$ caulialata. myrtifolia, Roezl, in Belg. Hortic. xxiv. (1874) 39.Peruty.

parviflora, G. Don, Gen. Syst. iv. 513.-Venezuela procumbens, Ruiz \& Pav. Fl. Per. 154.-Peruv. quadrifolia, G. Don, Gen. Syst. iv. 513.-Mexic. unilabiata, Ruiz \& Pav, ex Steud. Nom. ed. I. 57, $31=$

Diascia unilabiata.

urticaefolia, Steud. I. c, ed. II. i, 61 =incisifolia. Warscewiczii, Regel, in Gartenfl. iii. (1854) 211. t 91.--Peruv.

\section{ALONZOA, Brongn. Enum. Genr. 59 (1843)=praec.}

ALOPECIAS, Stev. in Bull. Soc. Nat. Mosc. iv. 266 (1832) = Astragalus, Tourn. (Legum.).

alopecuroides, Stev. 1. $\mathrm{c}_{\mathrm{v}}=$ Astr. alopecuroides

barbatus, Stev. 1. c. $266=$ Astr. barbatus.

chartaceus, Stev, 1. c. xxix. (1856) II. $143=$ Astr. chartaceus.

Clausii, Stev. I. c. $143=$ Astr. vulpinus.

dasyanthus, Stev. 1. c. iv. (1832) $266=$ Astr. dasyan thus.

dasycephalus, Stev. 1. c. $266=$ Astr. roseus.

emarginatus, Stev. 1. c. $266=$ Astr. emarginatus.

Kotschyanus, Stev. 1. c. xxix. (1856) II. 143=Astr Kotschyanus.

lanatus, Stev. I. c. iv. (1832) $266=$ Astr. lanatus.

Libanotis, Stev. 1. c. $266=$ Astr. lanatus,

macrocephalus, Stev. 1. c. $266=$ Astr. macrocephalus.

narbonensis, Stev, 1. c. $266=$ Astr. narbonensis.

orbiculatus, Stev. 1. c. xxix. (1856) II. $143=$ Astr orbiculatus.

ponticus, Stev. 1. c. iv. (1832) $266=$ Astr. ponticus.

roseus, Stev. 1. c. xxix. (1856) I1. $143=$ Astr. roseus.

Sieversianus, Stev. 1. c. $143=$ Astr. Sieversianus.

sphaerocephalus, Stev. 1. c. iv. (1832) $266=$ Astr. macrocephalus.

vulpinus, Stev. 1. c. $266=$ Astr. vulpinus

ALOPECURUS, Linn. Syst. ed. I. (1735) ; Gen. ed. I. 18 (1737). GRAMINEAE, Benth. \& Hook. f. iii. 1140.

Colobachne, Beanv. Agrost. 22. t. 6 (1812).

Tozzetia, Savi, in Mem. Soc. Ital. Sc. viii. (1798) 477.

aequalis, Sobol. F1. Petrop. $16=$ fulvus,

affinis, Desv. Opusc. 55-Hab.?

agrestis, Linn. Sp. Pl. ed. II. 89.-Europ.; Canc.

agrestis, Sieber, ex Kunth, Enum. Pl. i. $24=$ creticus,

alpestris, Wahlenb. ex Steud. Nom. ed. II. 1. $61=$ pratensis.

alpinus, Sm. Fl. Brit. iii. 1386,-Reg. bor. et arct.; Chili.

altissimus, Schur, in Oestr. Bot, Zeitschr. ix. (1859) $13=$ arundinaceus

angustifolius, Sibth. \& Sm. Fl. Graec. t. 64=vaginatus.

antarcticus, Gies, in Brewst. Edinb. Cycl, x, 494= alpinus.

antarcticus, Lechler, ex Steud. Syn. P1. Gram. $148=$

Lechleri.

antarcticus, Vahl, Symb. Bot. ii. 18=alpinus.

anthoxantoides, Boiss. Diagn. Ser. I. xiii. 42.-Oriens aquaticus, Dum. Obs. Gram. Belg. $133=$ nigrieans.

aristatus, Gouan, Hort. Monsp. $37=$ Polypogon monspeliensis.

aristulatus, Michx. Fl. Bor. Am. i. 43.-Europ.; Am. bor

arundinaceus, Poir. Encyc. viii. 766.-Europ.; Am. bor.; Oriens.

arvensis, Gromow. ex Trautv. in Act. Hort. Petrop. ix. (1884) $353=$ pratensis.

\section{ALOPECURUS :-}

Aucheri, Balansa, in Bull. Soc. Bot. Fr. xxi. (1874) 11 $=$ vaginatus

Aucheri, Boiss. Diagn. Sér. I. xiii, 41.-.Persia.

australis, Nees, in Hook. Lond. Journ. Bot. ii. (1843) $412=$ geniculatus

baikalensis, Turcz. ex Ledeb. Fl. Ross. iv. $462=$ brachystachyus.

borealis, Trin. Fund. Agrost. $58=$ alpinus.

brachyglossus, Peterm. Fl. Lips. (1844) $232=$ pratensis. brachystachyus, Bieb. Fl. Taur. Cauc. Suppl. 56.Sibir.

brachystachyus, C. Koch, in Linnaea, xxi. (1848) 383 $=$ vaginatus

brachystylus, Peterm. Fl. Lips. (1844) $230=$ pratensis. bulbosus, With. Bot. Arr. Brit. Pl. ed. II. i. $59=$ geniculatus.

bulbosus, Poir. Voy. Barb. ii. $94=$ macrostachyos.

caesius, Schur, Enum. Pl. Transs. 727 in syn.=geniculatus.

caespitosus, Trin.Sp. Gram. [xxi.t. 241. sec. Pritzel, Ic. Ind. ? - Am. bor.

candicans, Salzm. ex Steud. Nom, ed. II. i. $61=$ pratensis.

capensis, Eckl. ex Steud.Syn. Pl. Gram.294=Koeleria Alopecuros.

capensis, Thunb. Prod. Fl. Cap. 19.-Afr, austr.

capillaris, Raeusch. Nom. ed. III. 20.-Europ.

capitatus, Lam. Illustr. i. 168=Phleum Gerardi

carolinianus, Spreng. Nachr. i. Bot. Gart. Halle, 10 $=$ Agrostis Cornucopiae.

carolinianus, Walt. Fl. Carol. 74.-Am. bor.

cassius, Boiss. Diagn. Ser. I. xiii. 41 =vaginatus.

castellanus, Boiss. \& Reut. Diagn. Pl. Hispan. $26=$ brachystachyus.

caudatus, Thunb. in Nov. Act. Ups. iii. (1780) $208=$ Brylkinia caudata.

caudicans, Salzm. ex Ball, in Journ. Linn. Soc. xvi. (1878) $707=$ pratensis.

ciliatus, All.Fl. Pedem. ii. $235=$ Koeleria phleoides ciliatus, Vitm. Summa Pl. i. $178=$ Gerardi.

coerulescens, Steud. \& Hochst. ex Steud. Nom. ed. Ir. i. 60 , nomen.-As. Min.

colobachnoides, Trin. Fund. Agrost. $58=$ brachy stachyus.

creticus, Trin. in Spreng. N. Entdeck. ii. 45.-As. Min.; Crete.

creticus, Willk. ex Willk. \& Lange, Prod. F1. Hispan. i. $\mathbf{4 1}=$ agrestis

crypsoides, Griseb. Spicil. Fl. Rumel. ii. 466.-Macedonia.

dasyanthus, Trautv. in Act. Hort. Petrop. v. (1877) $486=$ vaginatus.

diandrus, Griff. Notul. iii. 11.--Ind, or

echinatus, Thunb. Prod. P1. Cap. 19=Lasiochloa adscendens.

effusus, Link, ex Kunth, Enum. Pl. i. $328=$ Agrostis effusa.

elongatus, Peterm. in Flora, xxvii. (1844) 230.Europ.

elongatus, Poir. Encyc. Suppl. v. $495=$ Polypogo elongatus.

exaltatus, Less. in Linnaea, ix. (1834) 207.-Sibir. ural.

fallacinus, Gren. Fl. Mass, Adven. (1859) 21.-Hab.?

fasciculatus, Poir. Encyc. viii. $780=$ Chaeturus fasciculatus.

foliosus, Clark, Trav. ii. $261=$ vaginatus.

fulvus, Forsk. ex Steud. Nom. ed. II. 1. $61=$ Heleochloa alopecurioides.

fulvus, Sm. Engl. Bot. xxi.t. $1467=$ geniculatus.

geniculatus, Linn. Sp. Pl. ed. I. 60.-Reg. bor. temp. geniculatus, Lindh. ex Scheele, in Linnaea, xxii. (1849) $340=$ Setaria polystachya

geniculatus, Sibth. ex Steud. Nom. ed. II. i. $61=$ Heleochloa alopecurioides.

Gerardi, Vill. Fl. Delph. 5; Hist. Pl. Dauph. ii. 66 t. 2.-Europ.; Oriens.

Gieseckeanus, Roem. \& Schult. Mant. ii. 154=alpinus. glacialis, C. Koch, in Linnaea, xxi. (1848) 382.Oriens.

glaucus, Less, l. c. ix. (1834) 206.--Sibir, ural.

glomeratus, Poir. Encyc. Suppl. v. $495=$ Muehlenbergia glomerata.

gracilis, Trautv. in Act. Hort. Petrop. v. (1877) $486=$ glacialis.

gracilis, Willd. ex Trin. Agrost. i, 16--Carolina.

granulatus, Beauv. Agrost. 4, nomen.-Hab. ? 


\section{ALOPECURUS}

hordeiformis, Linn. Sp. Pl. $60=$ Pennisetum compressum.

hordeiformis, Willd, ex Steud. Nom. ed. II. i. $61=$ Pennisetum orientale.

hybridus, Wimm. Fl. Schles. ed. III. (1857) 31.Europ

indicus, Murr. Syst. Veg. ed. XIII. $92=$ Pennisetum Linnaei.

intermedius, Hallier, in Bot. Zeit. xxi. (1863) App. i. 6.--Ins. Heligol

intermedius, Bock, ex Steud. Nom. ed. II. i. $61=$ arundinaceus.

interruptus, Poir. Encyc. Suppl. v. $495=$ Polypogon interruptus.

japonicus, Steud. Syn. Pl. Gram. 149.-Japon.

Konradii, Opiz, ex Mert. \& Koch, in Roehl. Deutschl. F1. i. 481 =geniculatus.

laguriformis, Schur, in Verh. Siebenb. Ver. Naturw. i. (1850) $182=$ brachystachyus.

laguroides, Balausa, in Bull. Soc. Bot. Fr. xxi. (1874) $11=$ vaginatus.

lanatus, Sibth. \& Sm. Prod. i. 43.-Oriens.

lasiochlamys, Boiss. Fl. Orient. v. $490=$ textilis.

lasiostachyus, Link, Hort. Berol. i. 71.--Hispan.

latifolius, Cav. Descr. 37.- - Ins. Tobago.

Lechleri, Steud. Syn. Pl. Gram. 148, Valdivia.

litoreus, All. Fl. Pedem. ii. $235=$ Koeleria villosa

longearistatus, Maxim. Prim. Fl. Amur. 327.-Manchuria.

longiradiatus, Regel, ex 'Trautv. in Act. Hort. Petrop. ix. (1884) $354=$ longearistatus

longistylus, Opis, in Lotos, ii. (1852) 228.-Bohem.

macrostachyos, Poir. Encyc. viii. 775.-Afr. bor.

magellanicus, Lam. Illustr. i. $168=$ antarcticus.

malacostachyus, A. Gray, in Perry, Exped. Jap. ii. 328 - japonicus.

maritimus, Poir. Encyc. viii. $780=$ Polypogon maritimus.

monspeliensis, Linn. Sp. P1. $61=$ Polypogon monspeliensis.

muticus, Kar, \& Kir. in Bull. Soc. Nat. Mosc. Xv. (1842) $527=$ arundinaceus.

myosuroides, Huds. Fl. Angl. $23=$ agrestis.

nepalensis, Trin. ex Steud. Syn. Pl. Gram. 148.Nepalia.

nigrescens, Jacq. Ecl. ii. t. $13=$ arundinaceus.

nigricans, Hornem. Hort. Hafn. i. $68=$ arundinaceus.

nigricans, Koch, Syn. Fl. Germ. ii. $896=$ pratensis.

nigricans, Wichura, in Jahrb. Schles. Ges. (1846) $61=$ hybridus,

obscurus, Schur, in Oestr. Bot. Zeitschr. ix. (1859) $13=$ pratensis.

otiporensis, Griff. Notul. iii. 94.-Affghan.

ovatus, Forst. F1. Austral. $8=$ alpinus?

ovatus, Knapp, Gram. Brit. $15=$ alpinus.

Pallasii, Trin. Sp. Gram, t. $2=$ vaginatus.

palliclus, Dum. Obs. Gram. Belg. 133.-Belg.

paludosus, Beauv. ex Mert. \& Koch, in Roehl.

Deutschl. Fl, i. $481=$ geniculatus .

paludosus, Crantz, Inst. i. $368=$ Polypogon monspeliensis.

panicers, Cav. Descr. $37=$ Polypogon maritimus.

paniceus, O. Muell. Fl. Dan. t. 861 = geniculatus.

paniceus, Linn. Sp. Pl. ed. II. 90 ; Lam. Fl. Fr. iii.

$560=$ Polypogon monspeliensis

paniculatus, Gueldenst. ex Ledeb. Fl. Ross. iv. 465.Reg. Caucas.

pedalis, Bosc, ex Beauv. Agrost. $4=$ gracilis.

pedatus, Steud. Nom. ed. II. i. $61=$ praec.

phalaroides, C. Koch, in Linnaea, xix.(1847) $5=$ Gerardi.

phleiformis, Beauv. Agrost. $4=$ villosus.

ponticus, C. Koch, in Linnaea, xxi. (1848) $382=$ glacialis.

pratensis. Bourg. ex Lange, in Bull. Soc. Bot. Fr. xi. (1864) $47=$ castellanus.

pratensis, Linn. Sp. Pl. 60.-Reg. bor. temp.

pratensis, Trin. Sp. Grom. t. $45=$ arundinacens,

pronus, Mitt. ex Hook. f. Steud. F1. ed. I. $428=$ geniculatus.

purpurascens, Link, in Linnaea, xvii. (1843) $400=$ agrestis.

ramosus, Poir. Encyc. viii, 776,-Carolina.

repens, Bieb. Fl. Taur. Cauc, iii, $54=$ arundinaceus,

ruthenicus, Weinm. F1. Dan. t. 2881 ; et Cat. Dorpat. (1810) $10=$ arundinaceus.

saceatus, Vasey, in Coult. Bot. Gas. vi. (1881) 290.Oregon.

\section{ALOPECURUS :-}

scaber, Opiz, Natural. n. ix. (1825) $166=$ pratensis. sericeus, Gaert. Fruct. i. 2. t. 1. f. $2=$ pratensis.

setarioides, Gren.in Mém. Soc. Emul. Doub̉s, Sér. III.

ii. (1858) 459,-Gallia.

sibiricus, Hort. Vind, ex Roem. \& Schult. Syst, ii. 271 = arundinaceus.

subaristatus, Pursh, F1. Am. Sept. i. $66=$ geniculatus. tenellus, Poir. Encyc. Suppl. y. $496=$ Polypogon tenellus.

textilis, Boiss. Diagn. Ser. I. xiii. 40.-Oriens.

tonsus, Dum. Obs. Gram. Belg. $132=$ agrestis.

transsilvanicus, Schur, Enum. F1. Transs. 727

brachystachyus.

trivialis, Seidl, ex Opiz, Natural. n. ix. (1825) $116=$ pratensis.

turicensis, Bruegg. in Fahresb. Naturf. Ges. Graub. II. xxv, (1882) 111.-Europ.

tuscheticus, Trantv. in Act. Hort. Petrop. ix. (1884) $354=$ gracilis

typhoides, Burm. f. Fl. Ind. $27=$ Penicillaria spicata

uralensis, Uspenski, Ekaterinenburg. 24.-Sibir. urai. utriculatus, [Soland. in] Russ. Aleppo, ed. II. ii. 243. -Europ.; Oriens.

vaginatus, Pall. in Nov. Act. Acad. Petrop.x. (1792) 304 , nomen.-Tauria; Oriens.

variegatus, Steud. Syn. Pl. Gram. 148.-Chili.

varius, Auct. ex Stend. Nom. ed. 1. $32,771=$ Sesleria caerulea.

ventricosus, Huds. Fl. Angl. ed. II. i. $28=$ Gastridium australe.

ventricosus, Pers. Syn. i. $80=$ arundinaceus.

villosus, Gilib. Exercit. ii. $517=$ pratensis.

villosus, Poir. Encyc, viii. 777.- Helvet.

Vlassovii, Trin. in Mém. Acad. Pétersb. Sér. VI. vi. II

(1845) $42=$ brachystachyus.

ALOPHIA, Herb, in Bot. Mag. sub t. $3779(1838)=$ Herbertia, Sweet (Irid.)

Drummondiana, Herb. 1. c. $=$ H. Drummondiana,

geniculata, Klatt, in Mart. F1. Bras. iii. I. 517.-Bras.

linearis, Klatt, in Linnaea, xxxi. (1861-62) $558=\mathrm{H}$. lineata.

linearis, Warm. in Kjoeb. Vidensk. Meddel. (1872) 128.-Bras.

pulchella, Benth. \& Hook. f. Gen, iii. $692=$ H. pulchella, lineata.

Sellowiana,Klatt, in Linnaea, xxxi.(1861-62)557.-Bras.

ALOPHIUM, Cass. in Dict. Sc. Nat. liv. 493 (1828)= Centaurea, Linn. (Compos.)

tenuifolium, Cass. 1. c. = C. Alophium.

ALOPHOCHLOA, Endl. Gen. 100 (1836) sphalm, = LOPHOCHLOA, Reichb. $=$ Koeleria, Pers. (Gram.).

ALOPHYLLUS, Linn. Sp. Pl. ed. II. $496(1762)=$ ALLOPHYLUS, Linn. $(1747)=$ Schmiedelia, Linn. (1764) (Sapind.).

ALOPICARPUS, Neck. Elem. i. $369(1790)=$ Paris, Rupp. (Liliac.).

ALORANTHUS, F. S. Voigt, in Rich. Anal. Frucht, 29 (1811) sphalm. $=$ Chloranthus, Sw.

ALOSEMIS, Rafin. Sylva Tellur. 96 (1838)= Melastoma, Linn.

grandiflora, Rafin. 1, c.-Hab.?

villosa, Rafin. 1. c.-Hab.?

seylanica, Rafin. 1. c.-Zeylan.

ALOYSIA, Ort. \& Palav. ex L'Hérit. Stirp. i. 21 (1784) = Lippia, Linn. (Verben.)

attenuata, Walp. Rep. iv. 42.-Bras.

chamaedryfolia. Cham, in Linnaea, vii. (1832) $234=\mathrm{I}$. chamaedryfolia

chamaedryoides, Steud. Nom, ed. II. i. $62=$ L. chamaedryfolia.

citriodora, Orteg. ex Pers. Syn. ii. $139=$ L. citriodora. floribunda, Mart. \& Gal, in Bull, Acad. Brux. xi. (18џ4) II. $320=\mathrm{L}$. lycioides.

lycioides, Cham. in Linnaen, vii. (1832) $237=\mathrm{L}$. lycioides, polygalacfolia, Cham. 1. c. $236=\mathrm{L}$. polygalaefolia. scorodonioides, Cham. 1. c, $234=\mathrm{L}$. scorodonioides. urticoides, Cham. 1. c. $238=\mathrm{L}$. urticoides.

virgata, Juss, in Ann. Mus. Par. vii. (1806) $73=\mathbf{L}$ articoides.
ALPHANDIA, Baill, Adansonia, xi. (1873) 85. EU. PHORBIACEAE, Benth. \& Hook. f. iii. 300. furfuracea, Baill. l. c. 86.-N. Caled.

resinosa, Baill. l. c. $86,-\mathrm{N}$. Caled.

ALPHITONIA, Reissek, ex Endl. Gen. 1098 (1840) RHAMNEAE, Benth. \& Hook. f. i. 381.

Emmenosperma, F. Muell. Fragm. iii. 63=Emmeno sperma alphitonoides.

erubescens, Baill. Adansonia, xi. (1874-76) 271.-N Caled.

excelsa, Reissek, ex Endl. Gen. 1098.-Anstra\}.

franguloides, A. Gray, Bot. U. St. Expl. Exped. i. 280 -Ins. Viti.

moluccana, Teijsm. \& Binn. Cat. Hort. Bogor. 221.Molucca.

xerocarpus, Baill. Adansonia, xi. (1873-76) $270-\mathbb{N}$ Caled.

zizyphoides, A. Gray, Bot. U. St. Expl. Exped. i. 278.Hab.?

ALPHONSEA, Hook. f. \& Thoms. F1. Ind. i. 152 (1855). ANONACEAE, Benth. \& Hook. f. i. 29. ceramensis, Scheff, in Ann. Fard. Buitenz. if. (1885 29.-Malaya.

elliptica, Hook. f. \& Thoms, in Fl. Brit. Ind. i. 90.Malacca.

javanica, Scheff. in Tijdschr. Nederl. Ind. xxxi. (1870) 340 ; in Flora, liii. (1870) 242.- - Java.

Iutea, Hook. f. E Thoms. Fl. Ind. i. 153.-Ind. or.

lutea, Teijsm. \& Binn. ex Scheff. in Flora, liii. (1870 242 = javanica.

madraspatana, Bedd. Fl. Sylv. i. t. 76.-Ind. or.

Maingayi, Hook. f. \& Thoms. in Fl. Brit. Ind. i. 90. Malacca.

sclerocarpa, Thw. Enum. Pl. Zeyl. 11.-Zeylan.

ventricosa, Hook. f. \& Thoms. Fl. Ind. i. 152.-Ind. or. Malaya.

zeylanica, Hook. f. E Thoms. l. c. 153.-Ind. or.

ALPINIA, Linn. Gen. ed. I. 332 (1737). SCITA MINEAE, Benth. \& Hook. f, iii. 648

Albina, Giseke, Prael. Linn. 199, 207 (1792)

ALUGHAS, Linn. Fl. Zeyl. 207 (1747)

Banglium, Buch.-Ham. ex Wall. Cat. sub n. $657 \mathrm{~s}$ (1832).

Bojeria, Rafin. F1. Tellur. iv. 50 (1836).

BuEkIA, Giseke, Prael. Linn. 199, 204 (1792).

Catimbium, Juss. Gen. 62 (1789)

Cenolophon, Blume, Enum. Pl. Jav. 60 (1830

Doxanthes, Rafin. Fl. Tellur. iv. 51 (1836).

Galanga, Noronha, in Verh. Batar. Gen. $\nabla .(1790$

ed. I. Art. iv. 2 ; ed. II. 65 (1827)

HELLENIA, Willd. Sp. Pl. i. 4 (1797)

Heritiera, Retz. Obs. vi. 17.t. 1 (1791)

Kolowratia, Presl, Rel. Haenk. i. 113.t. 20 (1827)

LANGUAS, Koen. in Retz. Obs. iii. 64 (1783)

Martensia, Giseke, Prael. Linn. 199, 207 (1792

Monocystrs, LindI. Introd. Nat. Syst. ed. II. 445 (1836).

ZERUMBET, Wendl. Sert, Hannov, fasc, iv, 3. t. 19 (1798)

acrostachya, Steud. Nom. ed. II. i. 62 (= Amomi sp.) -Java.

alba, D. Dietr. Syn. Pl. i. $12=$ Elettaria alba.

alba, Rosc, in Trans, Linn. Soc, viii. (180\%) 346.Ind or.

alata, A. Dietr. Sp. Pl. i. 45.-China. Allughas, Rosc. in Trans. Linn. Soc. viii. (1807) $\$ 16$.

Antillarum, Roem. \& Schult. Syst. Veg. i. 20.-Ind. occ. aquatica, Rosc. in Trans. Linn. Soc. viii. (1807) \$46.Ind, or.

arctiflora, F. Muell. Fragm, viii. 25.-Austral.

aromatica, Aubl. P1. Gui. i. $\$=$ Renealmia domir. gensis.

auriculata. Rosc. Scit. Pl. t. 74.-Ins. Molucc,

Blumei, D. Dietr. Syn. PI, i, 18 = javanica.

Boia, Seem. Fl. Vit 290 - Ins, Fiji.

bracteata, Rosc. in Trans, Linn. Soc. xi. (1815) $281=$ alata.

bractenta. Roxb, Fl. Ind. i, 61 Roxburghii.

brevilabris, Presl, Rel. Haenk. i. 110. t. 17.-Ins Luzon.

bremiscapa, Poepp. \& Endl. Nov. Gen. et Sp. ii. L 195

Renealmia brevicapa.

cacrulea. Benth. Fl. Austral. vi. 265. - Austml.

calcarata, Rose. in Trans. Linn. Soc. Mii. (180 $\$$ ) $\$ 1$.

-Ind. or. : China. 


\section{ALPINIA :-}

capitellata, fack, in Malay. Misc: ii. (1822) n. vII. 4. -Malaya.

Cardamomum, Roxb, in As. Res, xi. (1810) $356=$ Elet taria Cardamomum.

Cardamon-medium, Roxb. F1. Ind. i. 72=Amomum costatum

caribaea, Gaert. Fruct. i.36. t. $12=$ Renealmia racemosa. carnea, Griff. Notul. iii. 420.-Ind. or.

cernua, Sims, Bot. Mag. t. 1900.-Ind. or.

chinensis, Rosc. in Trans. Linn. Soc. viii. (1807) 346.China.

coccinea, D. Díetr. Syn. P1. i. $12=$ Amomum coccineum. comosa, Jacq. Coll. iv. $112=$ Costus comosus.

conchigera, Griff, Notul iii, 424 - - Ind or.

costata, Roxb. Corom. Pl, iii, 48, t. $252=$ Amomum costatum.

cristata, Griff. Notul, iii. 421.-Ind. or.

diffissa, Rosc. in Trans. Linn. Soc. xi. (1815) 281.China.

elatior, Fack, in Malay. Misc. ii. (1822) n. vII. 2.Malaya.

erecta, Lodd. ex Stend. Nom. ed. II. i. $62=$ calcarata.

exaltata, Roem. \& Schult. Syst. i. 21. add. $563=$ Renealmia exaltata

fasciculata, Stend. Nom. ed. II. i. $62=$ Amomum fasciculatum.

ferruginea, Steud. Nom ed. II i, $62=$ mollis

foetens, D. Dietr. Syn. Pl. i. $12=$ Amomum foetens.

Galanga, Willd. Sp. Pl. i. 12.-As. trop.

gigantea, Blume, Enum. Pl. Fav. 59.-Java.

gigantea, F. Vill, in Blanco, F1. Filip. ed. III. Nov. App.

225 = gracilis.

globosa, Horan. Prod. Scitam. 34.-China.

gracilis, Rolfe, in Fourn. Linn. Sóc. xxi. (1884) 316.Ins. Philipp.

Haenkei, Presl, Symb. 66. t. 43.-Chili

Hamiltoniana, Wall. Cat. n. 6579.--Ind. or.

hemisphaerica, D. Dietr. Syn. Pl. i. $13=$ Elettaria hemisphaerica.

hirsuta, Horan. Prod. Scitam. 34.-Cochinch.

humilis, Vell. F1. Flum. 1; i. t. 4 (=Renealmiae sp.) -Bras.

humilis, Teijsm. \& Binn. in Tijdschr. Nederl. Ind. xxiv. (1862) 327.-Java.

involucrata, Griff. Notul iii. 422.-Ind or.

jamaicensis, Gaert. Fract. i. 36. t. $12=$ Renealmin jamaicensis.

japonica, Miq. Ann. Mus. Bot. Lugd. Bat. iii, 140,Japon.

javanica, Blume, Enum. Pl. Fav. 59.-Java.

javanica, D. Dietr. Syn. Pl. i. $13=$ acrostachya.

latifolia, Willd, ex Koern. in Bull. Soc, Nat. Mosc. xxxv. (1862) I. $130=$ Calathea latifolia

linguiformis, Roxb. Fl. Ind. i. $73=$ Elettaria linguiformis.

macrantha, Poepp. \& Endl. Nov. Gen. et Sp. t. $134=$ Renealmia macrantha.

macrantha, Scheff. in Ann. Fard. Buitenz. i. (1876) 56.-Malaya

maculata, Rosc. in Trans, Linn. Soc, viii. (1807) 347.Ind. or.

magnifica, Rose. Scit. t. 75=Amomum magnificum. malaccensis, Presl, Rel. Haenk. i. $110=$ Haenkei.

malaccensis, Rosc. in Trans. Linn. Soc. viii. (1807) 345.-Ind. or. ; Java.

media, Spreng. Syst. i. 14=Amomum costatum

mesana, Horan. Prod. Scitam. $27=$ Zingiber macrostachyum.

minor, D. Dietr. Syn. PI. i. $12=$ Elettaria minor.

minuta, D. Dietr. 1. c. = Elettaria minuta.

missionis, Wall. Cat. n, 6589.--Ind, or.

mollis, Presl, Rel. Haenk. 110.-Ins. Luzon.

multicaulis, Roem. \& Schult. Syst. i, $21=$ Renealmia domingensis.

mutica, Roxb. in As. Res. xi, (1810) 354.-Ind. or.

Neesana, 7. Grah. Cat. Bomb. Pl. 207 - Tnd.

Nimmonii, J. Grah. 1. c. $206=$ Zingiber Nimmonia.

nutans, Rosc. in Sm. Exot. Bot. ii. 93.-Ind. or.

occidentalis, Sw. Prod. Veg. Ind. Occ. 11 = Renealmia

jamaicensis.

officinarum, Hance, in Fourn. Linn. Soc. xiii. (1873) 6.-China.

oxyphylla, Miq. in Fourn. Bot. Néerl. i. (1861) 93.-

Paco-Secora, Jacq. Fragm. 54.n. 17.t. $76=$ Renealmia Paco-Secora.

pallida, D. Dietr. Syn. Pl. i, $12=$ Elettaria pallida.

\section{ALPINIA :-}

paludosa, D. Dietr. Syn, P1. i. $12=$ Elettaria paludosa papuana, Scheff. in Ann. Fard. Buitenz. i. (1876) 56 -N. Guin.

parviflora, Rolfe, in Fourn. Linn. Soc. xxi. (1884 316.-Ins. Philipp.

penicillata, Rosc. in Trans. Linn. Soc. xi. (1814) 280.China,

phoenicea, Kamphoevener, ex Kurz, in fourn. As. Soc. Beng. xlv. (1876) II. 154, nomen.-Ins. Nicobar.

Pininga, D. Dietr. Syn. Pl. i. 12.-Java.

porrecta, Wall. Cat. n. 6576.--Ind, or.

Prestiana, Steud. Nom. ed. II. i. $62=$ Renealmia racemosa.

pumila, Hook.f. Bot.Mag.t. 6832.-China

punicea, Roxb. F1. Ind. i. $71=$ Elettaria punicea.

pyramidata, Blume, Enum. Pl. Fav. 58.-Java.

racemigera, F. Muell. Fragm. viii. 27.-Austral

racemosa, Linn. Sp. P1. ed. I. $2=$ Renealmía racemosa

racemosa, Sw. Obs. $5=$ A. Antillarum.

Rafflesiana, Wall. Cat. n. 6575.-Ind. or.

Renealmia, Sm. in. Rees, Cyclop. Suppl. xxxix. n. $14=$

Renealmia exaltata.

Rheedii, Wight, Ic, 6. t. 2026.-Malabar.

Roscoeana, Steud. Nom. ed. II. i. $63=$ alata

Roxburghii, Sweet, Hort. Brit. ed. I. 390.-Ind, or.

rubra, D. Dietr. Syn. Pl. i. 12.--Java.

Ruitriana, Steud. Nom. ed. II. i. $63=$ Renealmia Ruiziona.

serrulata, Willd. ex Steud. l. c.-Bras.

sessilis, Koen. in Retz. Obs, fasc. iii, 64=Kaempferia Galanga.

Simsii, Gasp. Observ. Boccodifalc. 5.-Hab.?

solaris, D. Dietr. Syn. P1. i. $12=$ Elettaria solaris

speciosa, D. Dietr. 1. c. $13=$ Elettaria speciosa

spicata, Jacq. Enum. Pl. Carib. $11=$ Costus spicatus.

spicata, Presl, Rel. Haenk. i. $109=$ Renealmia race mosa.

spicata, Roxb. in As. Res. xi. (1810) 356.-Ind. or.

spiralis, Jacq. Hort. Schoenb i. $1=$ Costus Pisonis.

stachyodes, Hance, in Fourn. Linn. Soc. xiii. (1873) 126.-China.

striata, Hort. Angl. ex Link, Enum. i. 5.-Ind, or.

strobilifera, Poepp. \& Endl. Nov. Gen. et Sp. t. $136=$

Renealmia strobilifera.

thyrsoidea, Steud. Nom. ed. II. i. $63=$ Renealmia thyrsoidea.

tomentosa, D. Dietr. Syn. Pl. i: 12.-Java

tubulata, [Rosc. in] Bot. Reg. t. 777.-Ind. occ.

uviformis, Horan. Prod. Scitam. 35.-Malaya.

viridiflora, Griff. Notul. iii. 423.-Ind. or.

vitiensis, Seem. Fl. Vit. 290.-Ins. Fiji.

Walang, D. Dietr. Syn. Pl. i. 13.-Java.

ALSCHINGERA, Vis. F1. Dalm. iii. 69 (1849)= Phy sospermum, Cusson (Umbell.)

acteaefolia, Vis. sec. Tomm. fide Nym. Consp. $315=$ P. verticillatum

verticillata, Vis, F1. Dalm. iii. $69=\mathrm{P}$. verticillatum.

ALSEIS, Schott, in Spreng. Syst. iv. Cur. Post. 40 (1827). RUBIACEAE, Benth. \& Hook. f. ii. 38 Blackiana, Hemsl, Diag. Pl. Nov. 30.-Panama.

floribunda, Schott, in Spreng. Syst. iv. Cur. Post. 404. -Bras.

ALSENOSMIA, Endl. Ench. 284 (1841) sphalm.= Alseuosmia, A. Cunn. (Caprifol.).

ATSEODAPHNE, Nees, in Wall. Pl. As. Rar, ii. 71 (1831). LAURINEAE, [Benth. \& Hook. f. iii. 157.] Euphoebe, Blume, ex Meissn. in DC. Prod. xv. I. 58,59 in syn. (1864).

Nothaphoebe, Blume, Mus. Bot. Lugd. Bat. i. 328 (1851).

amara, Kostel. Allg. med.-pharm. Fl. ii. $484=\mathrm{Nec}$ tandra cymbarum.

bancana, Miq. Fl. Ind. Bat. i. 915.-Banca.

breviflora, Benth. Fl. Hongk. 292.-China

chinensis, Champ.ex Meissn. in DC. Prod.xv. I. 28.-

Hongkong.

costalis, Nees, in Wall. Pl. As. Rar. ii. 72,-Ind. or.

Cujumary, Kostel. Allg. med.-pharm. Fl. ii. $484=$ Ocotea Cujumary

cymbarum, Kostel. 1. c. = Nectandra cymbarum.

excelsa, Blume, Mus. Bot. Lugd. Bat. 1. 332.-Java.

grandis, Kurz, For. F1. Burma, ii. $293=$ Dehaasia cuneata.
ALSEODAPHNE :-

grandis, Nees, in Wall. Pl. As. Rar, ii. $72=$ Phoebe opaca.

lucida, Nees, l. c.-Singapore.

opifera, Kostel. Allg. med.-pharm. F1. ii. $484=$ Ocotea opifera.

polyneura, Miq. Fl. Ind. Bat. i. 916.-Penang.

semicarpifolia, Nees, in Wall. Pl. As. Rar. ii. 72.Ind. or.

ALSFUOSMIA A. Cunn, in Ann. Nat Hist ii. (1839) 209. CAPRIFOLIACEAE, Benth. \& Hook, f. ii. 6
FAGOIDES, Banks \& Soland, ex A. Cunn, in Ann. Nat. Hist. ii. (1839) 210.

atriplicifolia, A. Cunn. 1. c. $210=$ Banksii.

Banksii, A. Cunn. l. c. 209-N, Zel.

bupleurifolia, A. Cunn. ex Heynh. Nom, ii. $27 .-\mathrm{N}$ Zel.

Hookeria, Colenso, Excurs. North Isl. 84.-N. Zel.

Ilex, A. Cunn. in Ann. Nat. Hist. ii. (1839) 210.-N Zel.

ligustrifolia, A. Cunn. 1. c. $209=$ linariifolia.

linariifolia, A. Cunn.l. c, - N. Zel

macrophylla, A. Cunn. l. c. 210.-N. Zel.

palaeiformis, A. Cunn. 1. c.=Banksii.

pusilla, Colenso, in Trans. N. Z. Inst. xvii. (1885 241.-N. Zel.

quercifolia, A. Cunn. in. Ann. Nat. Hist. ii. (1839) 210.-N. Zel

ALSINANTHE, Reichb. Ic. FI. Germ. y. (1841) 29. t. $209=$ Arenaria, Linn. (Caryophyll.).

biflora, Reichb. 1. c. 30. t. 209 . f. $4939=$ Ar. biflora

stricta, Reichb. 1. c. 29. t. 209. f. $4935=$ Ar. stricta

uliginosa, Reichb. 1. c. t. 209, f. $4935=\mathrm{A}$. stricta.

ALSINANTHEMOS, J. G. Gmel. FI. Sib. iv. 46 (1769) =Trientalis, Linn. (Primul.).

ALSINANTHUS, Reichb. Handb. 298 (1837)= Arenaria, Linn. (Caryophyll.).

trinervius, Fourr. in Ann. Soc. Linn. Lyon, N. S. xvi. (1868) $347=$ Ar. trinervia.

ALSINASTRUM, Schur, in Verh. Siebenb. Ver. Naturw. iv. (1853) 15 = Elatine, Linn.

callitrichoides, Rupr. Fl. Ingr. 197= E. triandxa. galiffolia, Schur, in Verh. Siebenb. Ver. Naturw. iv. (1853) $\mathbf{1 5}=\mathrm{E}$. Alsinastrum.

oyrospermum, Rupr. Fl. Ingr. $195=$ E. Hydropiper orthospermum, Rupr. 1. c. $196=\mathrm{E}$. Hydropiper? triandrum, Rupr. 1. c. $197=\mathrm{E}$. triandra.

ALSINE, Burm. Fl. Zeyl. 13. t. 8 (1737)= Mollugo Linn. (Ficoid.).

ALSINE, Tourn. ex Linn. Syst. ed. I. (1735) ; Gen. ed. I. $133(1737)=$ Arenaria, Linn., Stellaria, Linn, \&c. (Caryophyll.).

ALSINE, Scop. Fl. Carn, ed. II. 224 (1772); Wahlenb. Fl. Lapp. $127(1812)=$ Arenaria, Linn. (Caryo phyll.).

aizoides, Boiss. Diagn. Ser. I. i. 47.-Kurdistan. alpina, Willk. in Bot. Zeit. v. (1847) $238=$ Spergularia rubra.

Alsinastrum, Crantz, Inst. ii. $405=$ Elatine Alsinastrum.

anatolica, Boiss. Diagn. Ser. I. viii. $97=$ Ar. setacea.

apetala, Kit. ex Nym. Consp. 111 = Stellaria media arabica, Fisch. Mey. \& Avé-Lall. Ind. Sem. Petrop. xi. $49=$ Ar. tenuifolia.

arctica, Fenzl, Verbreit. Alsin. in tab. ad p. 18 ; et 36 = Ar. arctica.

Arduinei, Fenzl, 1. c. in tab. ad p. $57=$ Ar. graminifolia.

aretioides, Mert. \& Koch, in Roeh1. Deutsch. Fl. iii. $277=$ Ar. aretioides

aristata, [Soland. in] Russ. Aleppo, ed. II. ii. 249.Syria.

arvensis, Crantz, Inst. ii. $408=$ Spergula arvensis. arvatica, Guss. Fl. Sic. Syn. i. $503=$ Ar, mucronata.

attica, Boiss. \& Sprun. Diagn. Ser. I. v. $84=$ Ar. verna Aucheriana, Boiss. Fl. Orient. i. $678=$ Ar. Aucheriana austriaca, Wahlenb. Fl. Lapp. $129=$ Ar. austriaca. avicularum, Lam. F1. Fr. iii. $46=$ Stellaria media barbata, Stokes, Bot. Mat. Med. ii. $537=$ Stellaria media. 
ALSINE :-

Barrelieri, Bor. in Mém. Soc. Acad. Maine-et-Loire, vi. (1859) 57.-Gallia.

Bartolotti, Huet, ex Nym. Consp. $119=$ Arenaria procumbens.

banatica, Bluff \& Fingh. Comp. ed. II. ii. II. $99=\mathrm{Ar}$ banatica.

Bauhinorum, J. Gay, ex Lamotte, Prod. i. $144=$ Ar. linifolia.

bavarica, Crantz, Inst. ii. $407=$ Ar, bavarica

Biebersteinii, Rupr. F1. Cauc. 215.-Caucas.

biflora, Wahlenb. F1. Lapp. $128=$ Ar. scandinavica.

Billardieri, Boiss. Diagn. Ser. I. viii. $95=\mathrm{Ar}$ Meyeri.

bipartita, Gilib. F1. Lituan. ii. $150=$ Stellaria media.

brachycarpa, Boiss. Diagn. Ser. II. vi. $37=$ Ar. tenui folia.

brachypetala, Opiz, Natural. xi. (1826) $406=$ Stellaria

brevicaulis, Sternb. ex Nym. Consp. $119=$ Ar. lanceolata.

breviflora, Gilib. F1. Litnan. ii. $150=$ Ar. tenuifolia. brevifolia, Chapm. Fl. S. Un. St. $49=$ Ar. brevifolia. brevis, Boiss. Diagn. Ser. I. viii. 96.-Persia ; Arabia. Bufonia, Crantz, Inst. ii. $405=$ Bufonia perennis. caespitosa, Ehrh. ex Nym. Consp. $119=$ Ar. verna. campestris, Boiss. Voy. Espagne, ii. 723 (= Minuartia campestris.-Hispan.

campestris, Fenzl, Verbreit. Alsin. in tab. ad p. 57 Ar. montana.

canaliculata, Dulac, Fl. Hantes-Pyr, $246=$ Ar. Cherleria capillipes, Boiss, ex Steud. Nom. ed. II. i. $63=$ Ar capillipes.

cappadocica, Boiss. Diagn. Ser. II. i. $88=$ A. setacea.

catarctarum, Janka, in Közlem. Magyar Tudom

Akad. xii. (1876) 165.-Europ.

caucasica, Boiss. Diagn. Ser. II, i. $87=$ Ar. montana.

caucasica, Rupr. F1. Caucas. 203.-Caucas.

cerastivfolia, Fenzl, Verbreit. Alsin. in tab. ad p. 57 $=$ Ar. cerastiifolia.

Cherleriae, Fenzl, 1. c. $37=$ Stellaria petraea.

Cherleriana, St. Lag. in Ann. Soc. Bot. Lyon, vii. (1880) $144=$ Ar. Cherleria.

Cheveneauxii, Reut. ex Nym. Consp. $119=$ Ar. recurva ciliata, Crantz, Inst. ii. 408.-Italia.

condensata, Fenzl, Verbreit. Alsin. in tab. ad p. $57=$ Ar. condensata.

conferta, Jord. Pugill. $35=$ Ar. tenuifolia.

confusa, Heldr. \& Sart. ex Nym. Consp. 118=Ar. trichocalycina.

corymbulosa, Boiss. \& Bal. Diagn. Ser. II. vi. $37=\mathrm{Ar}$. setacea.

corymbulosa, Bor. in Mém. Soc. Acad. Maine-et-Loire vi. $(1859) 57=$ Ar. Barrelieri.

costata, Fen $z$ l, Verbreit. Alsin. $37=$ Ar. costata.

Cupaniana, Jord. \& Fourr. Brev. P1. Nov, fasc. ii. $19=$ Stellaria media.

decandra, Dalla Torre, Atl. Alpenfl. 78,-Europ.

decipiens, Fenzl, Pugill. Pl. Nov. Syr. 12.-Syria.

Delastrei, Bor. in Mém. Soc. Acad. Maine-et-Loire viii. $(1860) 12=$ Ar. Barrelieri.

diandra, Guss, F1. Sic. Syn. i. $501=$ Ar. diandra.

dianthifolia, Boiss. Diagn. Ser. I. viii. 99.-As. Min.

dichotoma, Fenzl, Verbreit. Alsin. in tab. ad p. $57=$ Minuartia dichotoma.

Dilleni, Vill. F1. Delphin. 30--Gallia.

Drummondii, Fenzl, ex Torr. \& Gray, Fl. N. Am. i. $675=$ Stellaria Nutlallii.

Elatina, Crantz, Inst. ii. $405=$ Elatine Hydropiper.

clegans, Fenzl, Verbreit. Alsin. tab. $18=$ Ar. elegans.

elongata, Jord. \& Fourr. Brev. Pl. Nov. fasc. ii. $19=$ Stellaria media.

emarginata, Fenzl, Verbreit. Alsin. in tab. ad p. $57=$ Ar. emarginata.

erecta, Crantz, Inst, ii. $405=$ Cerastium quaternellum.

erythrosepala, Boiss. Diagn. Ser. I. viii. 98.-As. Min

eurytanica, Boiss. 1. c. Ser. II. vi. 35.-Graecia.

extensa. Nym. Consp. $119=$ Ar. procumbens.

Facchinii, Hausm. H1. Tyr. 138. - Tyrol.

falcata, Griseb, Fl. Rumel. i. $200=$ Ar. setacea.

fasciculata, Wahlenb. Fl. Lapp. $129=\mathrm{Ar}$, fasciculata.

fastigiata, Bab. Man. ed, I. $5 \mathrm{I}=\mathrm{Ar}$, fastigiata,

formosa, Fenzl, in Flora, xxvi. (1843) 403.-Assyria.

Funkii, Jord. Pugill, $36=$ Ar. frsciculata.

fliformis, Fenzl, ex Heynh. Nom. ii. $27=$ Ar. picta.

Gerardi, Wahlenb. F1. Carpat. $132=$ Ar, verna.

Gieseckii, Fenzl, Verbreit. Alsin. tab. ad p. $18=\mathbf{A r}$ verna.
ALSINE:--

glabella, Jord. \& Fourr. Brev. PI. Nov. fasc. ii. $20=$ Stellaria media.

glabra, A. Gray, Man. ed. II. $57=$ Arenaria glabra

glandulosa, Dulac, Fl. Hautes-Pyr. 246=Ar. cerastiifolia.

glandulosa, Boiss. \& Huet, Diagn. Ser. II. v, $61=$ Ar. juniperina.

glandulosa, Mutel, ex Nym. Consp. $116=$ Ar. linifolia. globulosa, C. A. Mey. Verz. Pf. Cauc. $219=$ Ar globulosa.

glomerata, Fenzl, Verbreit. Alsin. in tab. ad p. $46=$ Ar. glomerata.

graminifolia, J. F. Gmel. Syst. $507=$ Ar. Rosani.

grandiflora, Crantz, Inst. ii. $408=\mathrm{Ar}$. grandiflora.

granuliflora, Fenzl, in Ledeb. F1. Ross. i. $346=$ Ar. setacea.

Griffithsii, Boiss. Diagn. Ser. II. i. $89=$ Ar. Griffithii. grineensis, Gren. \& Godr. F1. Fr. i. $252=$ Ar. Villarsii. groenlandica, Fenzl, Verbreit. Alsin. tab. ad p. $18=$ Ar. groenlandica.

Gussonii, Jord. \& Fourr. Brev. P1. Nov. fasc. ii. $20=$ Stellaria media.

Halophila, Turcz. in Bull. Soc. Nat. Mosc. xv. (1842) 587.-Altai.

Heldreichiana, Boiss. \& Heldr in Boiss. Fl. Orient. i $677=$ Ar. juniperina.

Helmii, Fenzl, Verbreit. Alsin. tab, ad p. $18=\mathrm{A}$ Helmii.

herniarioides, Rion, ex Nym. Consp. $119=\mathrm{Ar}$. aretioides.

heteromalla, Bieb. F1. Taur. Cauc. ․ $350=$ Ar. setacea heterosperma, Guss. Fl. Sic. Syn. i. 501--Sicil,

hirsuta, Fenzl, Verbreit. Alsin. in tab. $46=$ Ar. recurva. hirta, Hartm. Handb. Skand, F1. ed. IH. 104=Ar. verna.

hispanica, Fenzl, Verbreit. Alsin. in tab. ad p. $46=$ Queria hispanica.

hispida, Crantz, Inst. ii. $408=$ Ar. hispida.

hybrida, Jord. Pugill. $33=$ Ar, tenuifolia.

imbricata, C. A. Mey. Verz. Pf. Cauc. $217=$ Ar. imbricata.

inamoena, C. A. Mey. 1. c. $218=$ Ar. imbricata.

intermedia. Boiss. Fl. Orient, i. 685.-As. Min

intricata, Martr. Pl. Crit. Tarn, 15.-Gallia

irregularis, Vis. ex Boiss. F1. Orient. i. $684=\mathrm{Ar}$. globulosa.

Facquini, Koch, Syn. Fl. Germ. ed. II. $125=$ Ar. fasciculata.

Facquiniana, St. Lag, in Ann. Soc, Bot. Lyon, vii. 1880) $144=$ Ar. fasciculata.

juniperina, Wahlenb. Fl. Lapp. $129=$ Ar. juniperina, Furessi, Fenzl, Verbreit. Alsin. in tab. ad p. $57=$ Ar. Juressi.

kabylica, Pomel, Nouv. Mat. F1. Atl. 327.-Afr. bor. Kitaibelii, Nym. Consp. $116=$ Ar. laricifolia.

lanceolata, Mert. \& Koch, in Roehl. Deutsch, Fl. ed. III. ii. $275=$ Ar. lanceolata.

lancifolia, Vis. Ic. F1. Dalm. t. $34=$ Ar. globulosa.

Langii, G. Reuss, Květ. Slov. (1853) $76=\mathrm{Ar}$. laricifolia.

laricifolia, Crantz, Inst. ii. $407=$ Ar. laricifolia. laricifolia, Linn. ex Nym. Consp. $117=$ Ar. setacea

laricina, Crantz, Inst. ii. $408=$ Spergula laricina.

lateriflora, Crantz, l. c. $406=$ Ar. laterillora

latifolia, Dum. Fl. Belg. 109.-Belg.

laxa, Jord. Pugill. $34=$ Ar. tenuifolia.

leucocephala, Boiss. Diagn. Ser. I. i. 45.-As. Min.

libanotica, Boiss, 1. c. vili. 98.-Libanus,

lineata, C. A. Mey. in Ledeb. Fl. Ross. =Ar. juniperina.

liniflora, Vis. Fl. Dalmat. iii. I. $178=$ Ar. liniflora.

linifolia, Borb. in Rad. Jugos. Akad. Zagrab, xxxvi,

1876) 166.-Europ. austr.

Lydia, Boiss. Diagn. Ser. II. i. $86=$ Ar. tenuifolia,

macrocarpa, Fenzl, Verbreit. Alsin. tab. ad p. $18=\mathrm{Ar}$. macrocarpa.

marginata, C. A. Mey. Verz. PA. Cauc. $217=$ Spergularia media.

marginata, Fenzl, Verbreit. Alsin. tab. ad p. $18=$ Spergularia marginata.

marginata, Reichb. Fl. Germ. Excurs, 566. n. $866^{\circ}=$ Ar. media.

marginata, Schreb. Spicil. $81=$ Spergularia pentandra. marina, Webb \&c Berth. Phyt. Canar. i. $147=$ Spergularia Bourgeaei.

marisa, Mert. \& Koch, in Rochl. Deutsch. Fl, ii. 293 $=$ Spergularia media.
ALSINE:-

media, Linn. Sp. P1. ed. I. $272=$ Spergularia media media, Vell. Fl. Flum. 127 ; iii. t. $106=$ Drymaria cordata.

mediterranea, Gren. Fl, Massil. Adven. (1859) 8.

Gallia.

mesogitana, Boiss. Diagn. Ser. I. i. $45=$ Arenaria tenuifolia.

Meyeri, Boiss. 1. c. Ser. I. viii. $96=$ Arenaria globulosa mexicana, Bartl. ex Presl, Rel. Haenk, ii. 14=Ar. mexicana.

Michauxii, Fenzl, Verbreit. Alsin. tab. ad p. $18=\mathrm{Ar}$. stricta.

microsperma, Fenzl, ex Torr. \& Gray, Fl. N. Am. i. $674=$ Ar. Pitcheri

minuta, Rohrb. in Linnaea, xxxvii. (1871-72) 246.Chili.

Moehringia, Crantz, Inst. ii. $405=$ Ar. muscosa

moehringioides, Rohrb, in Linnaea, xxxvii. (1871-73'

247 (= Hymenella moehringioides).

molluginea, Lag. Gen, et Sp. Nov. (1815) $13=\mathrm{Ar}$. molluginea.

montana, Crantz, Inst. ii. $406=\mathrm{Ar}$. montana mucronata, Linn. Sp. Pl. ed. II. $389=$ Ar. mucronats. mucronata, Poir. Encyc. Suppl. iv. $310=$ Ar. fas. ciculata.

multicaulis, Crantz, Inst. ii. $406=\mathrm{Ar}$. multicaulis. multinervis, Boiss. F1. Orient. i. 683.-As. Min. Munbyi, Boiss. Diagn. Ser. II, i. $85=$ Ar. Munbyi. muscorum, Adams, ex Ledeb. Fl. Ross. i. $349=$ Ar.

mutabilis, Lap. ex Nym. Consp. $118=$ Ar. rostrata.

nemorum, Schreb. Spicil. $30=$ Stellaria nemorum. nodosa, Crantz, Inst. ii. $408=$ Sagina nodosa. occulta, Kar. \& Kir. in Bull. Soc. Nat. Mosc. xv. (1842) $590=$ Ar. polygonoides, artica.

octandra, Schur, Erum. Pl. Transs. 882, Index = Ar. aretioides.

Orphanides, Boiss. Diagn. Ser. II. I. $62=$ Ar. tenuifolia

pallida, Dum. Fl. Belg. 109 ; et in Bull. Soc. Bot. Belg, xii. (1873) 176.-Belg.

palustris, Kellogg, in Proc. Calif. Acad, iii. (1863) 61 = Ar. palustris.

paniculata, Fenzl, Verbreit. Alsin. $37=$ Ar. paniculata.

parnassica, Boiss. \& Sprun. Diagn. Ser. I. i. 46.Graecia.

patula, A. Gray, Man. Bot. U. St. ed. II. $58=$ Ar. patula.

pauciflora, Kit, ex Nym. Consp, $119=\mathrm{Ar}$. verna.

pentandra, Crantz, Inst. ii. $408=$ Spergularia pentandra.

peploides, Crantz, 1. c. $406=$ Ar. peploides.

Pestalozzae, Boiss. Diagn. Ser. I. viii. 99.-As. Min.

petraea, Jord. Obs, Pl. Crit. vii. (1849) $14=\mathrm{A}$. rostrata.

pharnaceoides, Fenzl, Verbreit. Alsin. in tab. ad p. 57 $=$ Ar. filiformis.

picta, Fenzl, 1. $c_{0}=$ Ar. filiformis.

pilifera, Turcz. in Bull. Soc. Nat. Mosc. xv. (1S12) $58 s$ =Spergula laricina.

pinifolia, Fenzl, Verbreit. Alsin. in tab, ad p. 46 Ar. pinifolia.

Pitcheri, Wood, Cl.-Book, $260=$ Ar. Pitcheri.

polycarpa, Crantz, Inst. ii. $405=$ Polycarpon tetr. phyllum.

Preslii, Reuss, Kvĕt. Slov. (1858) $75=$ Ar. graminifolia.

procumbens, Crantz, Inst. ii. $404=$ Sacina procumbens. procumbens, Fenzl, Verbreit. Alsin. in tab. ad p. $5 \hat{i}=$ Ar. geniculata.

propinqua, Lange, Fl. Dan, t. $2903=$ Ar. rema prostrata, Forsk. Fl. Aegy. At. Arab. $207=$ l'olycarpes prostrata.

pubescens, Presl, ex. Nym. Consp. 117 = Ar. tenuifolia. pulvinaris, Boiss. Diagn. Ser. I. i. 16.-Lydia

Pumilio, Fenzl, Verbreit. Alsin. tab. ad p. $18=$ Ar. arctica.

purpurascens, Bubani, in Nuov. Ann. Sc. Nat. Bolog. ix. (1s+3) 94. -Iralia ?

purpurea, Hevuh. Now. i. $\$ 8=$ Spergularia purpurea.

radicans, Guss, Fl. Sic. Sya. i. $502=$ Sperqularia rubra.

ramosissima, Fenzl, ex Schur, Enum. Pl. Transs 113 Ar. finsciculatn.

recurza, Winlenb. Fl. Helv. $s 7=$ Ar. recurva.

repens, Vell. Fl. Flum. 127 ; ii. ใ. 105 -Stellaria media. 
ALSINE :-

rimarum, Boiss. \& Bal. in Boiss. F1. Orient. i. 678.Cilicia.

Rosani, Guss. F1. Sic. Syn. i. $498=$ Arenaria Rosani rosea, Presl, ex Nym. Consp. $119=$ Ar. procumbens

Rossii, Fenzl, Verbreit. Alsin.tab. ad p. $18=$ Ar. stricta, rostrata, Fenzl, 1. c. $46=\mathrm{Ar}$. rostrata

rotundifolia, Stokes, Bot. Mat. Med. ii. $537=$ Drymaria cordata.

Roylei, Fenzl, ex Hook. f. Fl. Brit. Ind. i. $236=$ Ar. foliosa.

rubella, Schrenk, ex Ledeb. F1. Ross. i. $349=$ Ar, verna.

rubella, Wahlenb. Fl. Lapp. 128. t. $6=$ Ar. verna.

rubra, Webb \& Berth. Phyt. Canar. i. $148=$ Spergularia canariensis.

mbra, C. A. Mey. Verz, Pf. Cauc. $217=$ Spergularia salsuginea.

rubra, Crantz, Inst. ii. $407=$ Spergularia rubra.

rupestris, Fenzl, Verbreit. Alsin. in tab. ad p. $57=\mathrm{Ar}$. rupestris.

Sagina, Crantz, Inst. ii. $405=$ Bartonia tenella. saginoides, Crantz, 1, c. $408=$ Sagina Spergella. saxatilis, Crantz, 1. c. $407=\mathrm{Ar}$. saxatilis.

saxatilis, Wahlenb. F1. Helv. $87=$ Ar. verna.

Saxifraga, Boiss. Diagn. Ser. I. i. $47=$ Ar. Saxifraga

scabra, Stokes, Bot. Mat. Med. ii. 538=Stellaria Holostea.

Schimperi, Hochst. ex A. Rich. Tent. Fl, Abyss. i. 47. -Abyss.

sclerantha, Fisch. \& Mey. in Bull. Soc. Nat. Mosc. (1838) 400.-Caucas.

scleranthoides, Boiss. Diagn. Ser. II. i. $88=$ Ar. setacea.

sedoides, Froel. in Koch, Syn, Fl. Germ. ed. I. $114=$ Ar. sedoides.

segetalis, Linn. Sp. P1. $272=$ Spergularia segetalis

Seguieri, Turra, ex Sacc. in Atti Ist. Venet. Ser. III ix. (1863-64) 486. - Italia.

serpyllifolia, Crantz, Inst, ii. $406=$ Ar. serpyllifolia. setacea, Mert. \& Koch, in Roehl. Deutsch. Fl. iii. 286 $=$ Ar. setacea

sinaica, Boiss. Diagn. Ser. I. viii. $100=$ Ar. picta.

Smithii, Fenzl, Verbreit. Alsin. in tab. ad p. $57=\mathrm{Ar}$ globulosa.

spinuliflora, Fenzl, 1. c. = Habrosia spinuliflora.

squarrosa, Fenzl, ex A. Gray, Man. Bot. U. St. ed. II. $57=\mathrm{Ar}$. squarrosa.

striata, Crantz, Inst. ii. $407=$ Ar. striata.

striata, Gren. in Mém. Soc. Doubs, (1841) 33. t. 1. f. 1 $=$ Ar. laricifolia

stricta, Mert. \& Koch, in Roehl. Deutsch. Fl. iii. 278 $=$ Ar. stricta.

stricta, Wahlenb. Fl. Lapp. $127=$ Ar. lapponica

subtilis, Fenzl, ex Boiss. Fl. Orient. i. $687=$ Ar, tenuifolia.

subulifolia, Guss. Fl. Sic. Syn. i. $503=$ Ar. mucronata, succulenta, Delile, F1. Egypt. 211. t. $24=$ Polycarpon succulentum.

taurica, Stev, in Bull. Soc. Nat. Mosc. xxix. (1856) I.

$319=$ Ar. Villarsii.

Tchihatchewii, Boiss. in Ann. Sc. Nat. Sér. IV. ii. (1854) 247 .-As. Min.

tenella, Fuss, Fl. Transs. $112=$ Ar, austriaca.

tenuifolia, Crantz, Inst. ii, $407=$ Ar, tenuifolia.

tenuissima, Pomel, Nouv. Mat. F1. At1. 327.-Afr, bor

tetraquetra, Crantz, Inst. ii. $406=$ Ar. tetraquetra.

thymifolia, Fenzl, Verbreit. Alsin. in tab. ad p. $57=$ Ar. thymifolia.

trichocalycina, Heldr. \& Sart. Diagn. Ser. II. i. 87.Ital.; Graecia.

trifolia, Baring-Gould, ex Bab. in Journ. Linn. Soc. xi. (1871) $298=\mathrm{Ar}$, norvegica.

trinervia, Crantz, Inst. ii. $406=\mathrm{Ar}$, trinervia.

uliginosa, Vill. Prosp. Dauph. $48=$ Stellaria aquatica.

umbellata, Lam. Fl. Fr. iii. $45=$ Holosteum umbel-

latum.

umbellifera, Boiss. Diagn. Ser. II. v. 61.-Cilicia.

unilateralis, Moench, Meth. $228=$ Spergularia segetalis uralensis, Clerc, in Bull. Soc. Oural. iv. 105.-Ural.

velutina, Boiss. \&c Orphan. Diagn. Ser. II. vi. $636=$

Ar. glomerata.

verna, Wahlenb. Fl. Lapp. 129 ; Bartl. Beitr. ii. $63=$ Ar. verna.

verticillata, Noronha, in Verh. Batav. Gen. v. (1790) ed. I. Art. IV. 6.- Java.

Villarsii, Fenzl, in Ledeb. Fl. Ross. $350=$ Ar. juniperina.
ALSINE :-

Villarsii, Mert. \& Koch, in Roehl. Dentsch. F1. iii. 282 $=$ Arenaria Villarsii.

Villarsiana, St. Lag. in Ann. Soc. Bot. Lyon, vii 1880) $144=$ praec

villosa, Heynh. Nom. i. $39=$ Ar. villosa.

viscidula, Thouin, ex Nym. Consp. $117=$ Ar. tenuifolia.

viscosa, Schreb. Spicil. $30=$ Ar. tenuifolia.

vulgaris, Moench, Meth. 228 = Stellaria media.

ALSINELLA, Dill. ex Linn. Gen. ed. I. $118(1737)=$ Sagina, Linn. (Caryophyll.).

ALSINELLA, Hornem, Nom. 33 (1827)=Spergularia, J.\& C. Presl (Caryophyll.).

media, Hornem. 1. c. $=\mathrm{S}$. marina

ALSINELLA, [Sw.] Summa Veg. Scand. 17 (1814) pro parte; Benth. in Wall. Cat. n. $630(1832)=$ Stel-

laria, Linn. (Caryophyll.).

biflora, Sw, 1, $\mathrm{c}_{2}=\mathrm{S}$. biflora.

Wallichiana, Benth. 1. c. =S. media.

ALSINELLA, [Sw.] Summa Veg. Scand. 17 (1814) pro parte; S. F. Gray, Nat. Arr. Brit. Pl. ii. 655 (1821 = Arenaria, Linn. (Caryophyll.)

ciliata, S. F. Gray, 1. c. = Ar. ciliata

rubella, Sw. Summa Veg. Scand. $17=$ Ar. verna.

stricta, Sw, 1. c, = Ar. stricta.

trinervis, S. F. Gray, Nat. Arr. ii. $655=$ Ar. trinervia. viscosa, Hartm. Fl. Dan. t. $1754=$ Ar. tenuifolia. serpyllifolia, S. F. Gray, Nat. Arr. ii. $665=$ Ar. serpyllifolia.

ALSINELLA, Moench, Meth. $222(1794)=$ Cerastium Linn. (Caryophyll).

erecta, Moench, 1. c. $=$ C. quaternellum.

ALSINIDENDRON, H. Mann, in Proc. Bost. Soc. Nat. Hist. x. (1866') 311. CARYOPHYLLEAE, Benth. \& Hook, f, i. 978.

trinerve, H. Mann, l. c. 312.-Ins. Sandvic.

ALSOBIA, Hanst. in Linnaea, xxvi. (1853) $207=$ Episcia, Mart. (Gesnerac.)

antirrhina, Oerst. in Vidensk. Selsk. Skr. V. v. (1861) 114 - Am. centr.

punctata, Hanst. in Linnaea, xxvi. (1853) $207=\mathrm{E}$. punctata.

ALSOCYDIA, Mart. ex DC. Prod. ix. 149, \&c. (1845)= Bignonia, Linn. \&c.

acutiflora, Mart, ex Buek, Ind. DC. Prod. iii. $14=$ Lundia nitidula.

angustidens, Mart. ex DC. 1. c. ix. $179=$ Cuspidaria angustidens.

cordata, Mart. ex DC. 1. c. $163=$ Bign. cordifolia.

craterophora, Mart. ex Buek, Ind. DC. Prod. iii. $14=$ Bign. craterophora.

dichotoma, Mart. ex DC. 1. c. ix. $150=$ Bign. corymbifera.

erubescens. Mart. ex DC. 1. c. $157=$ Bign. erubescens.

firmula, Mart. ex DC. 1. c. $146=$ Bign. brachypoda.

glandulosa, Mart. ex DC. 1. c. 149, 164=Bign glandulosa, lanceolata.

glutinosa, Mart. ex DC. 1. c. $162=$ Bign. glutinosa

hebantha, Mart. ex Buck, Ind. DC. Prod. iì. $14=$ Lundia hebantha.

hirsuta, Mart. ex DC. 1. c. ix. $158=$ Bign. trichoclada. lasianthera, Mart. ex DC. 1. c. $180=$ Lundia cordata.

longidens, Mart. ex DC. 1. c. $190=$ Anemopaegma longidens.

nitidula, Mart. ex Buek, Ind. DC. Prod. iii. 14=Lundia nitidula.

noterophila, Mart. ex Buek, 1. c. = Bign. noterophila.

tetragonocaulos, Mart. ex DC. 1. c. ix. $169=$ Bign. tetragonocaulos.

triplinervia, Mart. ex Buek, Ind. DC. Prod. iii. $14=$ Bign. triplinervia.

variabilis, Mart. ex DC. 1. c. ix, $149=$ Bign, varians,

villosa, Mart. ex Buek, Ind. DC. Prod. iii. $14=$ Bign velutina.

virginalis, Mart. ex Brek, 1. c. = Lundia virginalis.

ALSODEIA, Thou. Hist. Vég. Afr. ii. 55. t. 17, 18 (1807). VIOLARIEAE, Benth. \& Hook. f. i. 118. Ceranthera, Beauv, Fl. Owar. et Ben. ii. 10 (1807).

\section{ALSODEIA}

Ceratanthera, Beauv. Fl. Owar. et Ben, ii. 10, in nota (1807).

Conohoria, Aubl. Pl. Gui. 239. t, 95 (1775)

CoNoria, Juss, Gen. 287 (1789)

Cuspa, Humb. Relat. i. $366(1814)$ ex H. B. \& K Nov. Gen. et Sp. vii. 242.

DiORYKTANDRA, Hassk. Retzia, 125 (1855).

Gonohoria, G. Don, Gen. Syst. i. 340 (1831).

Juergensia, Spreng. Syst. iii. 50 (1826).

MedusA, Lour. Fl. Cochinch. 406 (1790)

Medusula, Pers, Syn, ii. 215 (1807)

Passalia, Soland, ex R. Br. in Tuckey, Congo, 440 (1818)

Passoura, Aubl. Pl. Gui. [Suppl,] 21. t. 380 (1775). Pentaloba, Lour. Fl. Cochinch. 154 (1790).

Physiphora, Soland. ex R. Br. in Tuckey, Congo, 441 (1818).

Prosthesia, Blume, Bijdr. 866 (1826).

Riana, Aubl. Pl. Gui. 237. t. 94 (1775).

RinOREA, Aubl. 1. c. 235 . t. 93 (1775).

VARECA, Roxb. Fl. Ind. i. 647 (1832).

albicaulis, Turcz, in Bull. Soc. Nat. Mosc. xxxvi. (1863) I. 557-N, Granat.

andina, Tul. in Ann. Sc. Nat. Sér. III. vii. (1847) 366 -N. Granat

angustifolia, Thou. Hist. Vég. Afr. ii. 57. t. 18. f. 2.Madag.

arborea, Thou. l. c. 57. t. 17. f. 1.-Madag.

ardisiaeflora, Welw. in Oliver, Fl. Trop. Afr. i. 108.Afr. trop.

Aucuparia, Welw. l. c. 109.-Afr. trop.

auriculata, Tul. in Ann. Sc. Nat. Sér. V. ix. (1868) 319.-Madag.

bahiensis, Moric. Pl. Nouv. Am.68. t. 46.-Bras.

bengalensis, Wall. in Trans. Med. \& Phys. Soc. Calc. vii. (1846) 224.-Ind, or.

brachypetala, Turcz. in Bull. Soc. Nat. Mosc. xxxvi. (1863) I. 558.-Afr. trop.

brevipes, Benth. in Hook. Lond. Fourn. Bot. iv. (1842) 106.-Guiana.

Browni, Korth. in Neder. Kruid. Arch. i. (1848) $361=$ zeylanica.

caledonica, Turcz. in Bull. Soc. Nat. Mosc. xxxvi. (1863) I. 558.-N. Caled.

calophylla, Tul. in Ann. Sc. Nat. Sér. V. ix. (1868) 311.-Madag.

calycina, Tul. l. c. 313.-Madag.

castaneaefolia, Spreng. Syst. iv. Cur. Post. 99.-Bras. castanioides, Welw. in Oliver, Fl. Trop. Afr. i. 110. Afr. trop.

caudata, Oliver, l. c. 107.-Afr. trop.

cauliflora, Oliver, l. c. 111.-Afr. trop.

ceylanica, Auct. vide zeylanica.

chrysodasys, Miq. Fl. Ind. Bat. Suppl. i. 390.Sumatra.

corylifolia, Turcz. in Bull. Soc. Nat. Mosc. xxxvi. 1863) 1. 559.-Java.

Cuspa, Spreng. Syst. iv. Cur. Post. 99.-Cumana.

cymulosa, Miq. Fl. Ind. Bat. Suppl. i. 116.-Java.

cymulosa, Welw. in Oliver, Fl. Trop. Afr. 1. 108.Afr. trop.

dasycaula, Miq. F1. Ind. Bat. Suppl. i. $391=$ mollis. dasyprysis, Miq. l. c.-Sumatra.

decora, Trim. in fourn. Bot. xxiii. (1885) 203.Zeylan.

deflexa, Benth. Bot.Voy. Sulph. 67.--Peruv.

dentata, Beauv. Fl. Owar. et Ben. ii. 11. t. 65.-Afr trop.

disticha, Zoll. in Miq. Ann. Mus. Bot. Lugx. Bat. iv. 216.-Malaya.

echinocarpa, Korth. in Neder. Kruid. Arch. i. (1848) 360.-Sumatra.

elliptica, Oliver, Fl. Trop. Afr. i. 108.-Afr. trop.

falcata, Mart. ex Eichl. in Mart. Fl. Bras. xiii. I. 386. -Bras.

fasciculata, Turcz. in Bull. Soc, Nat. Mosc, xxxvi. (1863) I. 559.-Ins. Philipp.

flavescens, Spreng. Syst. i. 806.-Guiana.

floribunda, Moric. Pl. Nouv. Am. 70. t. $47=$ cas taneaefolia.

glabra, Burgersdyke, in Miq. Pl. Fungh. 122.Sumatra.

Gossypium, Tul. in Ann.Sc. Nat. Sér. III. vii. (1847) 367.-N. Granat.

grandis, Miq. Fl. Ind. Bat. Suppl. i. 391.-Sumatra.

Griffithii, Hook.f. \& Thoms. in Fl. Brit. Ind. i, 187 -Burma. 
ALSODEIA :-

guianensis, Eichl. in Mart. Fl. Bras, xiii. 1. 387.Bras.

guineensis, Spreng. Syst. i: 806.-Afr. trop.

haplobotrys, Hassk. in Versl. Kon. Akad. Wetensch. iv. (1855) 137. - Java.

Horneri, Korth. in Neder. Kruid. Arch. i. (1848) 360. -Borneo.

Horsfieldii, Miq. Fl. Ind. Bat. i. II. 117.-Java.

Horsfieldi, Turcz. in Bull. Soc. Nat. Mosc. xxxvi. (1863) I. 559.- Java.

ilicifolia, Welw. in Trans. Linn. Soc. xxvii. (1869) 12. -Afr. trop.

integrifolia, Steud. Nom. ed. II. i. 64.-Bras.

javanica, Miq. Fl. Ind. Bat. i. II. 117.-Sumatra.

lanceolata, Oudem. in Arch. Néerl. ii. (1867) 196; et in Miq.Ann. Mus. Bot. Lugd. Bat. iii. 68.-Ind. or.

latifolia, Thou. Hist. V'́g. Afr. ii. 57. t. 18. f. 3.Madag.

laxiflora, Benth. in Hook. Lond. Journ. Bot. iv. (1842) $107=$ guianensis.

leucoclada, Tul. in Ann. Sc. Nat. Sér. V. ix. (1868) 312.-Madag.

Lindeniana, Tul. 1. c. Sér. III. vii. (1847) $364=$ guianensis.

longiflora, Oudem. in Arch. Néerl. ii. (1867) 195; et in.Miq. Ann. Mus. Bot. Lugd. Bat. iii. (1867) 68.Guiana.

longipes, Tul. in Ann. Sc. Nat. Sér. V. ix. (1868) 309. -Madag.

longiracemosa, Kurz, in Fourn. As. Soc. Beng. xxxix (1870) II. 63.-Ind. or.

macrocarpa, Mart. ex Eichl. in Mart. Fl. Bras. xiii. I. 385.--Bras.

macrophylla, Decne. in Nouv. Ann. Mus. Par. iii. (1834) 468, t. 19.-Ins. Timor.

maculata, Tul. in Ann. Sc. Nat. Sér. V. ix. (1868) 816. -Madag.

Maingayi, Hook. $f$. E Thoms. ex Fl. Brit. Ind. i. 188. - Malacca.

marginata, Triana \& Planch. in Ann. Sc. Nat. Sér. IV. xvii. (1862) 127.-Nov. Granat.

Martinii, Turcs. in Bull. Soc. Nat. Mosc. xxxvi. (1863) I. 557.-Guin.

Maximiliana, Eichl. in Mart. Fl. Bras. xiii. I. 381.Bras.

megapotamica, Spreng. Syst. iv. Cur. Post. 99,-Bras. mollis, Hook. f. E Thoms. ex Fl. Brit. Ind. i. 188.Tenasserim.

monticola, Tul. in Ann. Sc. Nat. Sér. V. ix. (1868) 315. - Madag.

mutica, Tul: l. c. 318.-Madag.

nigricans, Boiv. ex Tul. 1. c. $305=$ pubescens

obtusa, Korth. in Neder. Kruid. Arch. 1. (1848) 359.Borneo.

owariensis, Spreng. Syst. i. 806.-Afr. trop.

pallida, Klot $\$ s c h$, in Schomb. Fauna et Fl. Guy. 1165. -Guiana.

paniculata, Mart. Nov. Gen. et Sp. i. 30.-Bras.

paradoxa, Blume, ex Oudem. in Arch. Neerl. ii. (1867) 204 ; et in Miq. Ann. Mus. Lugd. Bat. Bot. iii. 71. - Java.

pauciflora, Thou. Hist. Vég. Afr. ii. 57. t. 17.-

Madag.

Perrini, Spreng. Syst. i. 807.-Am. austr.

Pervillii, Oudem. in Arch. Néerl. ii. (1867) 206 ; et in Miq. Ann. Mus. Bot. Lugd. Bat. iii. 72.-Madag.

physiphora, Mart. Nov. Gen. et Sp. 1. 28.-Bras.

Piparea, Spreng, Syst, i. $807=$ Casearia dentata.

prunifolia, Spreng. l. c.-Guiana.

pubescens, Thow. Hist. Veg. Afr. ii. 57. t. 18. f. 3.Madag.

pubiflora, Benth. in Hook. Fourn. Bot.iv. (1842) 106. - Guiania.

pugionifera, Oudem. in Arch. Néerl. ii. (1867) 205 ; et in Miq. Ann. Mus. Bot. Lugd. Bat. iii. 71.Madag.

racemosa, Hook. f. \& Thoms. ex Fl. Brit. Ind. i. 187 = longiracemosa.

racemosa, Mart. \& Zucc. Nov. Gen. i. 29. t. 20.liras.

Regnellii, Walp. Ann. ii. $67=$ Ionidium atropurpureum.

Rinorea, Spreng. Syst. i. $807=$ pariculata.

Roxburghii, Hook. f. \& Thoms. ex F\%. Brit. Ind. i. 186. - Ind. or

rubra, Tul. in Ann. Sc. Nat. Sér. V. ix. (1868) 315.Madag.

\section{ALSODEIA :}

rugosa, Miq. Fl. Ind. Bat. Suppl. i. 390.-Sumatra sclerocarpa, Burgersdyke, in Miq. Pl. Fungh. 122. Sumatra.

semigyrata, Turcz. in Bull. Soc, Nat. Mosc, xxxvi. (1863) I. 559.-Java.

sessilis, Spreng. Syst. i. 806.-Cochinch.

socotrana, Balf. f. in Proc. Roy. Soc. Edinb. xii (1884) 402.-Ins. Socotra.

spinosa, Boivin, ex Tul. in Ann. Sc. Nat. Sér. V. ix (1868) 307.-Madag.

Sprucei, Eichl. in Mart. Fl. Bras. xiii. I. 385.-Bras. squamosa, Boivin, ex Tul. in Ann. Sc. Nat. Sér. V. ix. (1868) 307.-Madag.

Storckii, Seem. in Fourn. Bot. ii. (1864) 75.-Ins. Fiji.

subintegrifolia, Beauv. Fl. Owar. et Ben, ii. 11. t 66 -Afr. trop.

sylvatica, Seem. Bot. Voy. Herald, 79. t. 40.-

Panama

trigonocarpa, Zoll. \& Reichb. in Miq. Ann. Mus. Bot. Lugd. Bat. iv. 216.-Malaya.

ulmifolia, Spreng. Syst. i. 807.-N. Granat.

verticillata, Boivin, ex Tul. in Ann. Sc. Nat. Sér. V.

ix. (1868) 317.-Madag.

virgata, Thw, ex Hook. f. Fl. Brit. Ind i $189=$ Scyphyllandra virgata.

viridiflora, Tul. in Ann. Sc. Nat. Sér. V. ix. (1868) 310.-Madag.

Wallichiana, Hook. f. \& Thoms, in Fl. Brit. Ind. i. 187.--Penang.

Welwitschii, Oliver, Fl. Trop. Afr. i. 110.-Afr. trop. zeylanica, Thw. Enum. Pl. Zeyl.21.-Ind, or.

ALSODEIOPSIS, Oliver, in Benth. \& Hook. f, Gen i. 996 (1867). OLACINEAE, Benth. \& Hook. I. Manni, Oliver, in Fourn. Linn. Soc. x. (1869) 43. Afr. trop.

ALSOLINUM, Fourr. in Ann. Soc. Linn. Lyon, N. S. xvi (1868) $349=$ Linum, Tourn.

maritimum, Fourr. 1. $\mathrm{c}_{\mathrm{s}}=\mathrm{L}$. maritimum.

ALSOMITRA, M. Roem. Syn. Pepon. 117 partim (1846). CUCURBITACEAE, Benth. \& Hook. f. i 840.

angulata, M. Roem. 1. c. $117=$ Zanonia indica.

Beccariana, $\operatorname{Cog} n$. in DC. Monog. Phan. iii. 932.-Ins Kei.

brasiliensis, $\operatorname{Cogn}$. in Mart. Fl. Bras, vi. IV. 115.Bras.

capricornica, F. Muell. Fragm, vii. 61.-Austral

cissoides, M. Roem. Syn. Pepon. 118=Gynostemma pedata.

clavigera, M. Roem.l. c.; Benth. \& Hook. f. Gen. i. 840.- - Ind. or.

heterosperma, M. Roem. 1. $\mathrm{c}_{\mathrm{n}}=$ Gomphogyne heterosperma.

Hookeri, F. Muell. Fragm. vi. 188.-Austral.

laxa, M. Roem. Syn. Pepon. $118=$ Gynostemma laxa. macrocarpa, M. Roem. 1. c. $117=$ Zanonia macrocarpa. pedatifolia, Cogn. in Mart. Fl. Bras, vi. IV. 116.Bras.

sarcophylla, M. Roem. Syn. Pepon. 118.-Burma; Siam. Schefferiana, Cogn. in DC. Monog. Phan. iii. 932.Ins. Celebes.

Stephensiana, $\operatorname{Cogn}$. l. c. 934,-Ins. Barnardi

timorana, M. Roem. Syn. Pepon. 117.-Ins. Timor.

ALSTONIA, Mutis, ex Linn. f. Suppl, 39 (1781)=Sym plocos, Linn. (Styrac.)

ciliata, Benth. Pl. Hartw, $48=$ S. ciliata.

theaeiformis, Linn. f.' 1. c. $20^{\circ} 4=\mathrm{S}$. Alstonia.

ALSTONIA, Scop. Introd, 198 (1777)=Landolphia, R. Br. (A pocyn.)

ALsTonIA, R. Br. in Mem. Wern. Soc. i. (1S09) 75 APOCYNACEAE, Benth. \& Hook, f, ii. 705. Blaberopus, A. DC. Prod, viii. 410 (1814) PAlA, [Rheede] Juss, in Ann. Mus, Par. xv. (1825) 346.

acuminata, Miq. Ann. Mus. Bot. Lugd. Bat. iv, 140.Ins. Ceram.

angustifolin, Wall. Cat. n. 1650.-Malaya. angustiloba, Miq. Fl. Ind. Bat. ii. 438.-Malaya Batino, Blanco, Fl. Filip. ed. II. Suppl. $589=$ macro phylla.

calophylla, Miq. Fo. Ind. Bat. ii. $499 .-\mathrm{Java}$

\section{ALSTONIA:}

constricta, F. Muell. Fragm. i. 57.-Austral,

costata, R. Br. in Mem. Wern. Soc. i. (1809) 75.-Ins. Tahiti.

costata, Wall, Cat. n. $1649=$ macrophylla

costulata, Miq. Fl. Ind. Bat. Suppl, 556=Dyera costulata.

cuneata, Wall, Cat. n, $1645=$ spathulata.

Deplanchei, Heurck \& Muell. Arg. in Flora, liii. (1870 171.-N. Caled.

edulis, G. Benn. in fourn. Bot. v. (1867) 150.-N Caled.

eximia, Miq. Fl. Ind. Bat. Suppl. 555.-Ins. Banca.

grandifolia, Miq. l. c.-Sumatra.

Kurzii, Hook. f. Fl. Brit. Ind. iii. 643.-Ins. Andaman.

lanceolata, Heurck \&o Muell. Arg. in Heurck, Obs. Bot. 199.-N. Caled.

Legouixiae, Heurck \& Muell. Arg. in Flora, liii. (1870) 170.-N. Caled.

Lenormandii, Heurck \& Muell. Arg. l. c. 172,-N Caled.

linearis, Benth. Fl. Austral. iv. 314.-Austral.

longissima, F. Muell. Papuan Plants, 91.-N. Guin.

lucida, D. Don, Prod. Fl. Nep. 131 = Trachelospermum fragrans.

macrophylla, Wall. Cat. n, 1648 (Fl. Brit. Ind. iii. 643).-Malaya.

mollis, Benth. Fl. Austral. iv. 315.-Austral.

neriifolia, D. Don, Prod. Fl. Nep. 131.-Reg. Himal.

aleandraefolia, Lodd. ex Loud. Hort. Brit. 67 = scholaris

ophioxyloides, F. Muell. Fragm. i. 57.-Austral.

plumosa, Labill. Sert. Austr. Caled. 28, t. 32,-N. Caled. polyphylla, Miq. Fl. Ind.Bot. Suppl. 556.-Ins. Banca. quaternata, Heurck \& Muell. Arg. in Flora, liii. (1870 170.-N. Caled

Roeperi, Heurck \& Muell. Arg. in Heurck, Obs. Bot. 201.-N. Caled.

scholaris, R. Br. in Mem. Wern. Soc. i. (1809) 75.Geront. trop.

sericea, Blume, Bijdr. 1038.-Malaya.

spatulata, Blume, l. c. 1037.-Malaya

spectabilis, R. Br. in Mem. Wern. Soc. i. (1809) 75.Ins. Timor.

spectabilis, Kurz, For. F1. Burma, ii. $183=$ Kurzii

subsessilis, Miq. Ann. Mus. Bot. Lugd. Bat. iv. 140 .

Amboina.

venenata, R. Br. in Mem. Wern. Soc. i. (1809) 77. -Ind.

verticillosa, F. Muell. Fragm. vi. 116.-Anstral.

Vieillardii, Heurck \& Muell. Arg. in Flora, liii. (1870) 171.-N. Caled.

villosa, Blume, Bijdr. 1038.-Java; Austral.

villosa, Seem. Fl. Vit, $161=$ vitiensis.

vitiensis, Seem. l. c. 430 . - Ins. Fiji.

ALSTROEMERIA, Linn. Diss. Alstroem. 8(1762

AMARYLLIDEAE, Benth. \& Hook. fo iii. 736

LigTu, Adans. Fam. p. 20 (1768)

Lilavia, Rafin. Fl. Tellur. iv. 35 (1836).

Priopetalon, Rafin. Fl. Tellur. iv. 34 (1836)

acutifolia, Link \& Otto, Ic. Pl. Rar. Hort. Bot. Berol.

57. t. $29=$ Bomarea acutifolia.

affinis, Mart. \& Gal. in Bull. Acad. Brux. x. '15 13

reimpr. $6=$ Bomarea edulis.

albiflora, Presl, Rel. Haenk. i. 121. t. 22.-Chili.

amoena, Salisb. Prod. $248=\mathrm{A}$. Pelegrina.

anceps, Ruis \& Pav. Fl. Per. iii. 61.-Peruv.

andina, Phil, in Linnaes, xxix. $(1857-58) 69=$ spathulata.

angustifolia, Herb. Amar. $96=$ A. Ligtn.

araucana, Phil. in Anales Univ. Chil. (1879) 547 Chili.

argento-vittata, Lem. Illustr. Hortic. iv. (155i), M/is 88 ; vi. $(1858)$ t. 192 - Bras.

aurantiaca, D. Don, in Swe't, Brit. Flun. Gard. Ser. II. t. 205.-Chili,

aurea, R. Grah. in Edinb. Phil. Fourn. (1ะ33) 181.Chili.

aurea, Meyen, Reise, i. 311 = aurantiaca.

Banksiana, M. Koem, Sin. linsat. $25 !$ - pulchell.2.

Barklayana, Hort. ex Lord. Hort. Brit. Suppl. ii. 60s - Hab.?

Berteroiana, Penry, ex Loud. b. r. - Chili

bicolor, Hook. Exot. Fl. i. L. $95=$ A. Ligtu.

bractenta, Kuis हe Pas. F\%. Per. iii. 61. - Beruv.

brasiliemsis, Saremg. Syst. ii. \$1.-Bras.

Brertemeveriana. Willd. ex Kunth, Enum. Pl. ii. sos

Bomarea muleiflura. 


\section{ALSTROEMERIA :-}

Burchellii, Baker, in fourn. Bot. xy. (1877) 262.-Bras. Caldasiana, Hemsl. Biol. Centr. Am. Bot. iii. $336=$ seq Caldasii, H. B. \& K. Nov. Gen. et Sp. i. $283=$ Bomarea Caldasiana.

caryophyllacea, facq. Schoenbr. vi. 33. t. 465.-Bras. chilensis, F. Cree, ex Loud. Hort. Brit. Suppl. ii. 608, nomen.-Chili.

chilensis, Lem. in Fl. des Serres, Sér. I. i. (1845) 98.Chili.

chiloënsis, Phil. in Linnaea, xxix. (1857-58) 71,-Ins.

Chiloe.
chorillensis, Herb. in Bot. Reg. (1843) Misc. 64.-Chili. ciliata, Poepp. Fragm. Syn. 6.-Chili,

citrina, Phil. in Linnaea, xxxiii. (1864-65) $264=$ ver sicolor.

coccinea, Ruiz \&z Pav. Fl. Per. iii. 62=Bomarea coc cinea.

concolor, Steud. in Lechl. Berb. Am. Austr. $53=$ aurantiaca.

cordifolia, Ruis \& Pav. Fl. Per. iii. 64.-Peruv. crispata, Phil. in Linnaea, xxix. (1857-58) 70 -Chili crocea, Phil. l. c. xxxii. (1864-65) 263.-Chili.

crocea, Ruiz \& Pav. Fl. Per. iii. $61=$ Bomarea crocea. Cummingiana, Herb. Amar. 96, 396=versicolor.

Cunea, Vell. Fl. Flum. iii. t. 121; Seub. in Mart. Fl. Bras, iii. 172.-Bras.

Cunha, Vell. l. c. $131=$ praec

Curtisiana, E. Mey. ex Presl, Rel. Haenk. ii. $122=$ A Ligtu.

Curtisiana, Schult. f. Syst. vii. $735=$ caryophyllacea.

declinata, Poepp. \& Endl. Nov. Gen. ii. 44. t. $160=$ Bomarea dispar.

densiftora, Herb. in Bot. Mag. t. $5531=$ Bomarea tomentosa.

denticulata, Ruiz \& Pav. Fl. Per. iii. 62.-Peruv,

Despuenta, Pasq. Cat. Orto Bot. Nap. 7.-Hab.?

Diazi, Phil. in Linnaea, xxxiii. (1864) 261.-Chili.

Didierana, Faub. in Bull. Soc. Bot. Fr. viii. (1861) 118 -Peruv.

distichifolia, Ruiz \& Pav. Fl. Per. iii. 60.-Peruv

distichophylla, Spreng. Syst. ii. $80=$ Bomarea disticho phylla.

dulcis, Hook. Bot. Misc. ii. (1831) 237. t. $95=$ Bomarea glaucescens.

edulis, Andr. ex Poir. Encyc. Suppl. iv. $348=$ Bomarea edulis.

Errembanltii x, Hort. ex Lem. in Fl. des Serres, Sér. I. iii. (1847) 262.

exserens, Meyen, Reise, i. $34=$ A. Ligtu

Feuillaeana, E. Mey. ex Presl, Rel. Haenk. ii.=A. Ligtu.

flipendula, Seub. in Mart. F1. Bras. iii. I. $180=$ caryophyllacea.

fimbriata, Ruiz \& Pay. F1. Per, iii, $63=$ Bomare fimbriata.

flava, Phil. in Linnaea, xxxiii. (1864-65) 263.-Chili

floribunda, $H . B$. \& $K$. Nov. Gen. et Sp. i. 283.Ecuador.

Flos-Martini,[Ker-Gawl. in] Bot. Reg. t. $731=$ A. Ligtu

fluminensis, M. Roem. Syn. Ensat. 260.--Bras.

foliosa, Mart. in Schult. f. Syst. vii. 740.-Bras.

formosa, Pers. Syn. i. $381=$ seq.

formosissima, Ruiz \& Pav. Fl. Per. iii. 64=Bomarea formosissima.

Gardnexi, Baker, in Fourn. Bot. xv. (1877) 261.-Bras. Gayana, Phil in Linnaea, xxix. (1857-58) 71-Chili. glaucescens, H. B. \& K. Nov. Gen, et Sp. i. $282=$ Bomarea glaucescens.

gloriosa, Cham. \& Schlecht. in Linnaea, vi. (1831) 51 $=$ Bomarea edulis.

grandifolia, H. B. E K. Nov. Gen. et Sp. i. 285.-Bras. haemantha, Ruiz \& $\mathcal{F}^{\mathrm{Pav}}$. Fl. Per. iii. 60.-Chili.

Herbertiana, M. Roem. Syn. Ensat. $250=$ revoluta.

hirsuta, H. B. \& K. Nov. Gen. et Sp. i. $285=$ Bomarea hirsuta.

hirtella, H. B. \& K. 1. c. $284=$ Bomarea edulis.

hirtella, Phil. in Linnaea, xxix. (1857-58) 70.-Chili.

Hookeri, Lodd. Bot. Cab. t. $1272=$ A. Ligtu.

Hookeriana, C. Gay, Fl. Chil. v. 90.-Chili.

Hookeriana, Schult. f. Syst. vii. $733=$ A. Ligtu.

inaequalis, Phil.in Linnaea, xxix. (1857-58) 67.-Chili. inconspicua, Phil. Anales Univ. Chil. (1873) 546.Chili.

inodora, Herb. Amar. 90. t. 2. f. 1.-Bras.

insignis, Année, ex Hérincq, L'Hortic. Franc. iv. (1854) 2.-Peruy.

Isabellana, Herb. Amar. 88, 396. t. 6. f. 4-6.-Bras.

\section{ALSTROFIMERIA :}

Jacobi, Hort. ex Neumann, Ann. Fl.et Ponnone, (1834) t. 29.-Hab.?

Facquesiana, Lem. in F1. des Serres, Sér. I. ii. (Dec. 1846) t. $182=$ Bomarea Jacquesiana.

Kingii, Phil. in Anales Univ. Chil. (1873) $548=$ versicolor.

Kunziana, Klotzsch, ex Kunth, Enum. Pl. v. 769.Chili

latifolia, Ruiz \& Pav. Fl. Per. iii. 64.-Peruv.

Ligra, Crantz, Inst. i. $467=$ A. Ligtu.

Ligtu, Curt. Bot. Mag. t. 125=caryophyllacea.

Ligtu, Linn. Diss. Alstroem, 10.-Chili.

lineatiflora, Lindl. Bot. Reg. (1834) t. $58=$ chorillensis.

lineatiflora, Ruiz Es Pav. Fl. Per. iii. 60 t. 289.-Peruv.

linifolia, H. B. \& K. Nov. Gen. et Sp. i. $282=$ Bomarea linifolia.

longistaminea, Mart. in Schult. f. Syst. vii. 739.Bras.

longistyla, Schenk, in Mart. Fl. Bras, iii. I. 173.-Bras.

Macraeana, Herb. Amar. 90-Chili.

macrocarpa, Ruiz \&o Pav. Fl. Per, iii. 63.-Peruv.

magnifica, Herb. in Bot. Reg. (1843) Misc. 64.Chili.

Meyeniana, F. C. Schau. in Nov. Act. Nat. Cur. xix. Suppl. I. (1843) 440.-Chili.

miniata, Mart. \& Gal. in Bull. Acad. Brux. x. (1843) repr. $6=$ Bomarea edulis.

montana, Ker-Gəwl. in Journ. Sc. \& Arts, ii. (1817) $183=$ Ixiolirion montanum

monticola, Mart. in Schult. f. Syst. vii. 739.-Bras.

multiflora, Linn. f. Suppl. $207=$ Bomarea multiflora.

mutabilis, Kunze, ex Kunth, Enum. PI. v. $777=$ aurantiaca

Neilliana, Herb. Amar. $94=$ spathulata.

Neillii, Gill. ex Hook, in Bot. Mag. t. $3105=$ praec.

nemorosa, Gardn. in Bot. Mag. t. $3958=$ inodora.

nivalis, Meyen, Reise, i. $315=$ versicolor

nivalis, Phil. in Linnaea, xxix. (1857-58) 69.-Chili

nubigena, Phil. l. c. 67.-Chili.

Ochagavii, Anneé, ex Hérincq, L'Hortic. Frane. iv. 1854) 2-Chili.

oculata, Lodd. Bot. Cab. t. 1851=Bomarea Salsilla.

odorata, Knight \& Perry, ex Loud. Hort. Brit. Suppl. III. 486.- Hab. ?

Oreas, F. C. Schau. in Nov. Act. Nat. Cur. xix. Suppl. I. (1843) 440.-Am, austr.

ovata, Cav. Ic. i. 54. t. $76=$ Bomarea edulis

pallens, Phil. in Linnaea, xxxiii. (1864-65) 265.Chili.

pallida, R. Grah. in Edinb. N. Phil. Journ. (Jul.-Oct. 1829) $344=$ A. Ligtu

parvula, Phil. in Linnaea, xxxiii. (1864-65) 261.-Chili.

pauciflora, Hort. ex Lem. in Fl. des Serres, Sér. I. ii. (Dec. 1846) t. $182=$ Bomarea Jacquesiana

pauciflora, H. B. \& $K$. Nov. Gen. et Sp.i. $284 .-\mathrm{N}$. Granat.

paupercula, Phil. Fl. Atac. 51-Chili.

Pelegrina, Linn. Diss. Alstroem. 10; Amoen. Acad. vi. 247.-Peruv. ; Chili.

Pelegrina, Vell. Fl. Flum. 131; iii. t. $119=$ caryophyllacea.

peregrina, Ruiz \& Pav, F1. Per. iii. 51=A. Pelegrina.

peruviana, Van-Houtte, Fl. des Serres, xxi. (1875) 51. t. $2175=$ versicolor

plantaginea, Mart. in Schult. f. Syst. vii. 737.-Bras.

platyphylla, Baker, in Fourn. Bot. xv. (1877) 261.Bras.

Pohliana, Seub, in Mart. F1. Bras. iii. 1. $172=$ A. Cunea.

Preslana, Herb. Amar, 95. t. 1. f. $48=$ A. Ligtu.

Presliana, Kunth, Enum. P1. v. $773=$ praec.

psittacina, Lehm. Cat. Hort. Hamb. (1826) ex Schult.

. Syst. vii. $739=$ pulchella.

puberula, Phil. in Linnaea, xxix. (1857-58) $68=$ versicolor.

pulchella, Hort. ex Vilm. Fl. Pl. Terre, ed. II. $48=$ versicolor.

pulchella, Linn.f. Suppl. 206.-Am, austr.

pulchella, Sims, Bot. Mag. t. $2354=$ haemantha.

pulchella, Salisb. Prod. $248=$ A. Ligtu,

pulchra, Sims, Bot. Mag. t. $2421=$ A. Ligtu.

purpurea, Ruiz \& Pav. Fl. Per. iii. $63=$ Bomarea purpurea.
ALSTROFMERTA :-

purpurea, Willd. ex Steud. Nom. ed. II. i. $61,62=$ Bomarea Caldasiana

pygmaea, Herb. Amar. 100, 397. t. 8. f. 4-13.Peruv.

quillotensis, Herb. 1. c. 97. t. 2. f. 2=A. Pelegrina.

reclinata, Poepp. \& Endl. Gen. et Sp. ii. 44. t. 160.Chili.

recumbens, Herb. Amar. 97. t. 3. f. 2 =versicolor.

reflexa, M. Roem. Syn. Ensat. 252.-Chili.

revoluta, Ruiz $\mathcal{E}$ Pav. Fl. Per. iii. 59.-Chili.

Riedelliana, Andot, in Rev. Hortic. Sér. II. iv. (1845-46) 207--Bras.

rosea, Hook. Exot. Fl. t. $181=$ A. Ligtu

rosea, Phil. Sert. Mend. Alt. 43.-Chili.

rosea, Ruiz \& Pav. Fl. Per. iii. 61.-Peruv.

rosmarinifolia, Benth. Pl. Hartw. 258= Bomarea linifolia

rubra, Morel, in Rev. Hortic. Sér. IV. ii. (1853) 81. f 5.-Bras.

Salsilla, Linn. Diss. Alstroem. 10; Amoen. Acad. vi. $247=$ Bomarea Salsilla.

Salsilla, Vell. F1. Flum. 131; iii. t. $120=$ Bomarea edulis.

salsilloides, Mart. in Schult. f. Syst. vii. 748.Bras.

scaberula, Baker, in Fourn. Bot, xv. (1877) 261.Bras.

secundifolia, Ruiz \& Pav. Fl. Per. iii. $60=$ Bomarea secundifolia.

Sellowiana, Seub. in Mart. Fl. Bras. iii. I. 173.-Bras. sepium, Schott, ex Seub. 1. c. $168=$ Bomarea edulis. sericantha, J. C. Schau. in Nov. Act. Nat. Cur. xix. Suppl. 1. (1843) $441=$ spathulata.

setacea, Ruiz \& Pav. Fl. Per. iii. 62=Bomarea tomentosa.

Simsii, Spreng. Syst. ii. $80=$ haemantha.

Simsii, Sweet, Hort. Brit. ed. I. $408=$ A. Ligtu.

spathulata, Presl, Rel. Haenk. ii. 122. t. 22. f. 2.Peruv.

stenopetala, Phil. in Anales Univ. Chil. (1873) 547.Chili.

stenopetala, Seub. in Mart. Fl. Bras. iii. I. 174.Bras.

subrosulacea, Herb. Amar. 397. t. 5. f. 1. 2.-Chili.

tenuifolia, Herb. 1. c. 94. t. 1. f. $47=$ versicolor.

tigrina, Phil. in Linnaea, xxix. (1857-58) $68=$ versicolor.

tigrina, Seub. in Mart. Fl. Bras. iii. I. $174=$ brasiliensis.

tomentosa, Ruiz \& Pav. F1. Per. iii. 62=Bomarea tomentosa.

torta, H. B. \& K. Nov, Gen. et Sp. i. $283=$ Bomarea torta.

tricolor, Hook. Exot. Fl, t, $65=$ A. Ligtu

triflora, Griff. Notul. iii, $240=$ Ixiolirion montanum.

umbellata, Meyen, Reise, i. $356=$ spathulata.

uniflora, Matth. ex Kunth, Enum. Pl. v. $782=$ Bomarea glaucescens.

venustula, Phil. in Linnaea, xxxiii. (1864-65) 260.Chili.

versicolor, Ruiz \& Pav. Fl, Per, iii. 59,-Chili.

violacea, Knight \& Perry, ex Loud. Hort. Brit Suppl. iii. 486.-Hab.?

violacea, Phil. Fl. Atac. 51.-Chili.

viridiflora, Warm. in Kjoeb. Vidensk. Meddel. (1872)

113.-Bras.

xanthina, Phil. in Anales Univ. Chil. (1873) $546=$ versicolor.

zamioides, Baker, in Fourn. Bot. xv. (1877) 262.Bras.

ALTENSTEINIA, H. B. \& K. Nov, Gen. et Sp. i. 332. t. 72. 73 (1815). ORCHIDEAE, Benth. \& Hook. f. iii. 592.

AA, Reichb. f. Xen. Orchid. i. 18 (1858)

Myrosmodes, Reichb. f. 1. c. ג. 19. t. $8(1858)$

argyrolepis, Benth. \&o Hook.f. (in Herb.Kew.).-Ecuad. calceata, Reichb.f.l. c. iii. 19.-Peruy.

erosa, Reichb. f. Otia Bot. Hamb. 51.-Peruv.

fimbriata, H. B. \& K. Nov. Gen. et Sp. 1. 333, t. 72.Ecuad.

gymnandra, Reichb. f. Xenia Orch. iii. 18.-Boliv.

inaequalis, Reichb. l. c. 19.-Boliv.

Mandonii, Reichb. f. l. c.-Peruv.

marginata, Reichb.f. l. c. 20.-Peruv.

Matthewii, Reichb. f. l. c. 19.-Peruv.

nubigena, Reichb.f.l. c. 18 in nota.-Hab. ? 


\section{ATTENSTEINTA:}

paleacea, Kunth, Syn. i. 325.-Ecuad. paludosa, Reichb. f. Xenia Orch. iii. 19.-Boliv. pilifera, H. B. S. K. Nov. Gen. et Sp. i. 333. t. 73.Ecuad.

rostrata, Reichb. f. Xenia Orch. iii. 18.-Ecuad. Sceptrum, Reichb. f. l. c. i. 18.-Ecuad.

virescens, Lindl. in Ann. \& Mag, Nat. Hist. xy. (1845) 385.-N. Granat.

Weddelliana, Reichb. f. Xenia Orch. iii. 19.-Peruv.

ALTERNANTHERA, Forsk. Fl. Aegypt. Arab. 28 (1775). AMARANTACEAE, Benth. \& Hook. f. iii 39.

Allaganthera, Mart. Hort. Erlang. 69 (1814)

Illecerrum, Spreng. Anleit. ii. I. 317 (1817); Syst. i. $818(1825)$.

Lithophila, Sw. Prod. Veg. Ind. Occ. 14 (1788);

F1. Ind. Occ. i. 47. t. 1 (1797)

Litophil. Sw. Prod. 1, c.

Pityranthus, Mart. in Denks. Acad. Muench. v. (1817) 179.

acaulis, Anderss. Galap. Öarnes Veget. 164.-Ins. Galap.

Achyrantha, R. Br. Prod i. 417-Am, trop.

Achyranthes, Forsk. Fl. Aegyp.t. Arab. p. Ixix = sessilis.

albida, Griseb. in Goett. Abh. xix. (1874) (Pl. Lorent. 36).--Reg. Argent.

amabilis, Hort. ex Lem. Illnst. Hortic. xv. (1868) t.

$558=$ Telanthera ficoidea.

angustifolia, Moq. in DC. Prod. xiii. II. $324=$ poly. cephala.

angustifolia, R. Br. Prod. i. 417.-Austral.

argentata, Moq. in DC. Prod. xiii. II. 352.-Porto Rico.

aurata, Moq. l. c. 353.-Am. austi.

axillaris, D. Dietr. Syst. i. 866 in syn. $=$ spinosa.

Baueri, Mog in DC. Prod xiii. 1L. 354-Austral.

brachiata, Hort. ex Moq. 1. c. $304=$ Aerva brachiata

canescens, H. B. \& K. Nov. Gen, et Sp. ii. 204.Cumana.

canescens, Moq. in DC. Prod. xiii. II. $350=$ Iresine canesccns.

caracasana, H. B. \& K. Nov. Gen. et Sp. ii. 205.-

Venezuela.

caribaea, Moq. in DC. Prod. xiii. II. 354.-Ind. occ.

celosioides, Moq. l. c. 360.-Ins. Philipp.

ciliata, Poepp. ex Seub. in Mart. Fl. Bras. v. I. $183=$ A. Achyrantha.

decipiens, Benth. Fl. Austral, v. 251-Austral.

denticulata, R. Br. Prod. i. $417=$ nodifora

denticulata, Wall. Cat. n. $6922=$ sessilis.

dubia, Hort. Paris. ex Moq. in DC. Prod. xiii. II. 361 $=$ sessilis?

dubia, H. B. \& K. Nov. Gen. et Sp, ii. $209=$

Trommsdorffia canescens.

echinata, Hort. Bonn. ex Fisch. \& Mey. Ind. Sem Hort. Petrop. vi. $43=$ armata.

echinata, Sm. in Rees, Cyclop. Suppl. n. $10=$ A. Achyrantha.

erecta, Reichb. in DC. Prod. iii. $375=$ Polycarpaea linearifolia.

ficoidea, R. Br. Prod. 417 ; Roem. \& Schult. Syst. v $555=$ Telanthera ficoidea

ficoidea, Griseb. F1. Brit. W. Ind. $67=$ Telanthera maritima.

ficoides, Beauv. F1. Owar. ii. 66, f. 1 =denticulata.

ficoides, Reichb. ex Moq. in DC. Prod. xiii. Ir. $357=$ sessilis.

favescens, H. B. \& K. Nov. Gen, et Sp. ii. $207=$ Telanthera flavescens.

flavescens, Moq. in DC. Prod. xiii. Ir. 350.-N. Granat.

frutescens, R. Br. ex Spreng. Syst. i. 819 in syn.-Am. austr.

glabra, Moq. in DC. Prod. xiii. 1I. 361=denticulata?

gomphrenoides, $H . B . \&$ K K. Nov. Gen. et Sp. ii. 208. -Peruv.

berniarioides, Beurling, in Vet. Akad. Handl. Stockh. (1854) 149.--Panama.

iresinoides, H. B. \& K. Nov. Gen. et Sp. ii. $209=$ Gomphrena iresinoides

lanuginosa, Moq. in DC. Prod. xiii. Ir. $359=$ Cladothrix lannginosa.

lappulacea, Schlccht. ex Moq. 1. c. $329=$ Cyathula globulifera.

latifolia, Moq. 1. c. $851=$ Iresine latifolia.

leptophylla, Bentls. Fl. Austral. v. 251.-Austral.

leucantha, Moq. in DC. Prod. xiii. II. 357.-Jamaic.

\section{ALTERNANTHERA}

littoralis, Beauv. ex Moq. in DC. Prod. xiii. II. $365=$ maritima.

linearis, Bello, in Anal. Soc. Esp. Hist. Nat. xii. (1883) 107.-Porto Rico.

longipes, Benth. Fl. Austral.v. 252.-Austral.

lupulina, $H . B$. \& $K$. Nov. Gen et Sp. ii. 206.-Peruv. maritima, D. Dietr. Syn. Pl. i. 867.-Bras.

maritima, St. Hil. Voy. Brés. ii. $43=$ Telanthera maritima.

mexicana, Moq. in DC. Prod. xiii. II. 352.-Mexico?

muscoides, Benth. E Hook. f. Gen. iii. 39.-Ind. occ

nana, F. Bauer, ex Moq. in DC. Prod. xiii. II. $341=$ Iresine Brownii.

nana, R. Br. Prod. i. 417.-Austral.

nigriceps, Hook. Bot. Misc. ii. (1831) $237=$ Telanthera elongata.

nigripes, Steud. Nom. ed. II. i. 65. (sphalm.) = praec. nodifera, Griseb. in Goett. Abh. xxiv, (1879) 36.-Reg. Argent.

nodiflora, R. Br. Prod. i. 417.-Geront. trop.

paniculata, Bello, in Anal. Soc. Esp. Hist. Nat. xi (1883) 106.-Porto Rico.

paniculata, H. B. \& K. Nov. Gen. et Sp. ii. 208.Cumana.

paronychioides, Hort. ex Regel, Gartenfl. (1869) $102=$

Telanthera Bettzichiana.

paronychioides, St. Hil. Voy. Brés. ii. II. 43.-Am. austr parviflora, Moq. in DC. Prod. xiii. Ir. 360.-Mexic.? philoxeroides, Griseb. in Goett. Abh. xxiv. (1879) 36 . -Reg. Argent.

pilosa, Moq. in DC. Prod. xiii. II. 357.-Bras.

polycephala, Benth. Fl. Austral. v. 251.-Austral

polygonoides, R. Br. Prod. $417=$ Telanthera poly gonoides.

praelonga, St. Hil. Voy. Brés. ii. II. $409=$ Telanthera praelonga.

procumbens, Roem. \& Schult. Syst. v. 564.-Bras

prostrata, D. Don, Prod. F1. Nep. $76=$ sessilis.

puberula, D. Dietr, Syn. Pl, i. $866=$ Telanthera puberula.

pubescens, Hort. Prag. ex Moq. in DC. Prod. xiii. Ix.

pulchella, H. B. \& K. Nov. Gen. et Sp. ii, 205.Bras.

pulverulenta, Moq. in DC. Prod. xiii. II. 351.-Peruv. pungens, $H . B . \mathcal{E} K$. Nov. Gen. et $S p$. ii. 206.-Bras. purpurea, Hort. ex Pynaert, in Rev. Hortic. Belge, v. (1879) $25=$ Telanthera versicolor.

radicata, Hook. f. in Trans. Linn. Soc. xx. (1847) 262 -Ins. Galapag.

repens, Steud. Nom. ed. I. $34=$ sessilis.

repens, Stend. 1. c. ed. II. i. $65=$ A. Achyrantha

Richardi, Moq. in DC. Prod. xiii. II. $353=$ Iresine

interrupta.

rufa, D. Dietr. Syn. Pl. i. $866=$ Telanthera rufa

sericea, H. B. E K. Nov. Gen. et Sp. ii. 207.-Ecuad

sessilis, Lem. Illustr. Hortic. (1865) to $447=$ Telan

thera amoena.

sessilis, R. Br. Prod. i. 417.--Reg. trop.

sibirica, Steud. Nom ed. II. i. 65.-Sibir.

spathulata, Lem. Illustr. Hortic, xii. (1865) t, $445=$

Telanthera ficoidea.

spinosa, Roem. \& Schult. Syst. v. 555.-Am. trop

strigosa, Hassk. in Hoev. \& De Vriese, Tijdschr. (1838-39:259.-Malaya?

subscaposa, Hook. f. in Trans. Linn. Soc. xx. (1847) 189. - Ins. Galap.

suffruticosa, Torr. in Emory, Mex. Bound. Surv. 181 $-\mathrm{N}$. Mexico.

tenella, Colla, in Mem. Acc. Torin. xxxiii. (1829) 131 t. $9=$ Telanthera polygonoides

tenella, Moq. in DC. Prod. xiii. II, 355,-Hab. ?

tomentella, Seub in Mart. Fl. Bras. v. I. 186,-Bras.

triandra, Steud. Nom. ed. I. 33, 34= Telanthera ficoidea.

triandra, Lam. Encyc. i. $95=$ sessilis

truxillensis, H. B. \& K. Nov. Gen. et Sp. ii. 206.Peruv.

versicolor, Hort. ex Regel, Gartenf. (1869) $101=$ Telanthera versicolor

villiflora, Scheele, in Linnaea, xxii. (1843) 149.-Texas. villosa, D. Dietr. Syn. Pl. i. $867=$ Brandesia villosa. villosa, H. B. \& K. Nov. Gen. et Sp. ii. $208=$ Telan. thera villosa.

villosa, Sm. in Rees, Cycl. Suppl. n. 9.-Hab. ?

virgata, Spreng, ex Moq, in DC. Prod. xiii. 11. 36t

Telanthern polygonoide's.
ALTERNASEMINA, Silva Manso, Enum, 35 (1836) =

Cayaponia, Mart. (Cucurb).

Tayuia, Silva Manso, 1. c。=C. Taynya.

ALTHAEA, [Tourn.] Linn. Syst. ed. I $17 \%$ MALVACEAE, Benth, \& Hook. f. i. 200.

AlceA, [Tourn.] Linn. Gen, ed, I. $206(1737$

FERBERIA, Seop. Intrud. 281 (1777)

acaulis, Cav. Diss. ii. t. 27. f. 3 (p. 93).--Syria

aegyptiaca, Boiss. Diagn. Ser. II. i. $103=$ lavateraeflor.

africana, Lam. ex G. Don, Gen. Syst. i. 467.-Afr. or.

ambigua, Alef. in Oestr. Bot. Zeitschr. xii. (1862) 200

= Lavatera thuringiaca.

apterocarpa, Fenzl, in Del. Sem. Hort. Vind. 155

4.- - Oriens.

arborea, Alef, in Oestr. Bot. Zeitschr, xii. (1862) 260

Lavatera arborea

armeniaca, Tenore, Ind. Sem. Hort. Neap. (1837)

-Oriens.

atropurpurea, Alef. in Oestr. Bot. Zeitschr. xii. (186: $261=$ Malva atropurpurea.

Aucheri, Boiss. Diagn. Ser. I. vi. 28.-Persia; Affgha

borbonica, DC. Prod. i. 438 (=Pavonia?).-Ins. Ho bon.

borealis, Alef. in Oestr. Bot. Zeitschr, xii. (1862) $26 i 1=$ Malva borealis.

Burchellii, DC. Prod. i. $438=$ Pavonia Columella.

Calverti, Boiss. Diagn. Ser. II. v. 66.-Armenia.

cannabina, Linn. Sp. Pl. 686.-Europ.; Oriens.

caribaea, Sims, Bot. Mag. t. $1916=$ rosea

chinensis, Wall. Cat. n. $2689=$ rosea

coromandelina, Cav. Diss. ii. $93=$ rosea.

corymbosa, Sw. Prod. Veg. Ind. Occ. $101=$ Pavoni paniculata.

cretica, Weinm. in Syll. Ratisb. ii. (1828) $171=$ rosea

crispa, Alef. in Oestr. Bot. Zeitschr. xii. (1862) 261

Malva crispa.

digitata, Boiss. Diagn. Ser. I. viii. $106=$ lavaterac flora.

ficifolia, Cav. Diss. ii. 92. t. 28. f. 2.-Sibir

ficifolia, Sibth. \& Sm. Fl. Graec. t. $663=$ rosea.

flavo-virens, Boiss. Eै Buhse, in Nouv. Mim. Soc. Nat.

Mosc. xii. (1860) 44.-Sibir. baical.

flexuosa, Sims, Bot. Mag. t. $892=$ rosea.

Froloviana, Fisch.ex G. Don, Gen. Syst. i. 467.-Sibir.

Frutex, Hort. ex Mill. Gard. Dict. ed. VIII = Hibisclis syriacus.

garipensis, E. Mey. Zwei PA. Docum. $163=$ Ludwigi gariepina, E. Mey. ex Boiss. Fl. Orient. i. $82 t=$ prat. glabriflora, Ledeb. ex Sweet, Hort. Brit. ed. II. 60. Sibir.

Godroni, Alef. in Oestr. Bot. Zeitschr. xii. (1862) $26^{\circ}$ = Malva ambigua.

grandiflora, Scop. Del. Insub. ii. $38=$ Hibiscus roset

Heldreichii, Boiss. Diagn. Ser. II. i. 103_-Thessal.

hirsuta, Linn. Sp. Pl 687.-Europ: Oriens.

hirsuta, Sieber, ex Steud. Nom, ed. II. i. $66=\mathrm{Mal}$ w cretica.

hispida, Moench, Meth. 612 = hirsuta.

Hohenackeri, Boiss. \& Huet, Diagn. Ser. II. v. 6\%

Oriens.

indica, Steud. Nom. ed. II. i. 66.-Java.

Irolowiana, Steud. 1. c. sphalm. = Froloviana.

kirrindensis, Boiss. Diagn. Ser.II. v. 67 = lavateraeflora.

Kotschyi, Boiss. 1. c. Ser. II. i. $102=$ cannabina.

Kraussiane, Buching. ex Krauss, in Flora, scrvii.

(1844) $293=$ Pavonia Kraussiana.

kurdica, Schlecht. in Linnaea, xwii. (1543) 120. Oriens.

laevis, Moench, Meth. Suppl. $199=$ Ludwigii.

lavateraeflora, $D C$. Prod. i. 437 ,-Oriens

laxiflora, A.DC. ex Schlecht, in Bot. Zeit. vi. 1sty $3+1--\mathrm{Hab}$ ?

lencantha, Fisch, ex Loud. Hort. Brit, 2Si=ntuiflora.

lilacina, Boiss, \& Kotschy, ex Boiss, kil. Orient. is s\&i = apterocarpa.

longifiora, Boiss. \& Reut. Diagn. Pl. Hispan. $y=$ hirsula.

L.udwigii, Linn. Mant. .8. - Oriens: Mfr. bor. et auss:

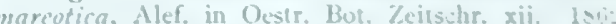

$2011=$ Malva marentica

mauritiana, Alef. 1. c. 260 . Malva mauritiana.

me'onantha, Link, in Linnacs. ix. 1s34: 5 sti $=$ rosea.

mexicann, Kunse, /. c. xx. 184:) 51. t04.-Mexic

microcarpa, Alef. in Mestr. 13ot. Zeitschr. xii. (1sir)

261 - Malsa parviflora.

multiftora, Reichb. ex Keyel, Ind, Sem. Ilort. I'ergor

156i) $30^{\circ}-$ armeniacis. 
AITHAEA :-

mutica, J. Gay, ex Ball, in Journ. Linn. Soc. xvi. (1878) $376=$ hirsuta

narbonensis, Jacq. Coll. ii. $275=$ cannabina.

narbonnensis, Pourr, ex Cav. Diss. ii. 94, t. 29, f. 2.Europ.

nicaeensis, Alef. in Oestr. Bot. Zeitschr, xii. (1862) $261=$ Malva nicaeensis.

nudiflora, Lindl. in Trans. Hort. Soc. vii. (1830) 251. -Sibir. altaic.

officinalis, Linn. Sp. Pl. ed, I. 686.-Europ.; Oriens.

pallida, Wald. EO Kit. Pl. Rar. Hung. t. 47.-Hungar. Turc.

parviflora, Alef. in Oestr. Bot. Zeitschr. xii. (1862) $261=$ Malva parvifiora.

plebeia, Schult, ex Steud. Nom. ed. II. i. $66=$ Lavatera plebeia.

pulchra, Klotzsch, in Bot. Ergeb. Waldem. Reise, 112. -Ind. or.

racemosa, Sw. Prod. Veg. Ind. Occ. $102=$ Pavonia racemosa.

remotiflora, Boiss. \& Heldr. Diagn. Ser. I. viii. 108. -As. Min.

rhyticarpa, Trautv. in Bull. Soc. Nat. Mosc. (1860) I.

$454=$ sulphurea.
rosea, Cav. Diss. ii. 91. t. 29. f. 3.-Oriens.

rosea, Hohen. ex Boiss. Diagn. Ser. I. v. $67=$ Hohenackeri.

rufescens, Boiss. Diagn. Ser. II. i. 102.-Syria.

setosa, Boiss. l. c. Ser. I. viii. 107.-Syria.

Sieberi, Hort. ex G. Don, in Loud. Hort. Brit. 486.Sicilia.

sinensis, Blanco, F1. Filip. ed. I. $552=$ rosea

sinensis, Cav. Diss. ii. t. 29. f, 3.-China

speciosa, Vis. Cat. Orto Bot. Padov. 132.-Hab.?

spicata, Spreng. Syst. iii. $108=$ Hibiscus spicatus.

s'riata, DC. Prod. i. 437.-Arab.

sublobata, Stokes, Bot. Mat. Med. iii. $530=$ officinalis.

sulphurea, Boiss. \& Hohen. Diagn. Ser. I. viii. 108.Persia; Affghan.; Soongar.

sylvestris, Briganti, ex Tenore, Syll. 540.-Italia.

tabrisiana, Boiss. \& Buhse, in Nouv. Mém. Soc. Nat. Mosc. xii. (1860) $44=$ ficifolia.

taurinensis, C. A. Mey. Verz. Pfl. Cauc. $207=a \mathrm{rme}$. niaca.

taurinensis, DC. Prod. i. $436=$ officinalis.

thuringiaca, Kuntze, Taschen-Fl. Leipz. 212 = Lavatera thuringiaca.

Tournefortiana, Tausch, in Flora, xii. (1829) 9.-Creta. ulmifolia, Pritzel, Ic. Ind. $50=$ Sida glomerata.

verticillata, Alef. in Oestr. Bot. Zeitschr. xii. (1862) $261=$ Malva verticillata

vulgaris, Alef. 1. c. $260=$ Malva vulgaris.

ALTHEA, Crantz, Stirp. Austr. $144(1769)=$ praec.

ALTHENIA, Petit, in Ánn. Sc. Observ. i. (1829) 451 NAIADACE AE, Benth. \& Hook. f. iii. 1016

Barraudonii, Duval-Jouve, in Bull. Soc. Bot. Fr. xix. (1872) p. Ixxxix; Compt.-rend. Ixxv. (1872) $95=$ filiformis.

filiformis, Petit, in Ann. Sc. Observ. i. (1829) 451.Gallia.

setacea, Delile, ex Petit, 1. c. = filiformis.

ALTHERIA, Thou. Gen. Nov. Madag. $19(1809)=$ Melochia, Linn. (Stercul.).

madagascariensis, DC. Prod. i. 493.-Madag.

ALTHINGIA, Steud. Nom. ed. II. i. $66(1840)=$ seq.

ALTINGIA, [G. Don, in] Loud. Hort. Brit. 403 (1830) = Araucaria, Juss. (Conif.)

Cunninghamii, [G. Don, ] l. c. = Ar. Cunninghamii.

excelsa, [G. Don, ] 1. c. = Ar. excelsa.

ALTINGIA, Noronha, in Verh. Bat. Gen, v. (1785) Art. ii. 9 ; ed. II. 41. HAMAMELIDEAE, Benth. \& Hook. f. i. 669 .

SEDGWICKIA, Griff, in As. Res. xix. (1836) 98. t. 15.

chinensis, Oliver, ex Hance, in Journ. Linn. Soc. xiii. (1873) 103.-China.

caerulea, Poir. Encyc. Suppl. v. $545=$ Liquidambar Altingia.

excelsa, Noronha, in Verh. Bat. Gen. v. ed. II. 4I (1827).-Malaya.

ALTORA, Adans. Fam. ii. $356(1763)=$ Cluytia, Linn. (Euphorb.).
ALUGHAS, Linn. Fl. Zeyl. 207 (1747)=Alpinla, Linn. (Scitam.).

ALVARADOA, Liebm. in Kjoeb. Vidensk. Meddel. (1853) 100. SAPINDACEAE, Benth. \& Hook. f. i. 411 .

amorphoides, Liebm. l. c. 101.-Mexic.

arborescens, Griseb. Cat. Pl. Cub. 50.-Cuba. jamaicensis, Benth. Pl. Hartw. 344.-Jamaica. mexicana, Liebm. ex Benth. l. c.-Mexic.

ALVARDIA, Fenzl, in Flora, xxvii. (1844) $312=$ Peucedanum, Linn. (Umbellif.).

arborescens, Fenzl, l, c. = P. fraxinifolium.

ALVAREZIA, Pav. ex Nees, in DC. Prod, xi. 465 (1847) -Blechum, R. Br. (Acanth.).

disticha, Pav. ex Nees, 1. c. $246=$ Lophostachys Alvarezia.

parviflora, Pav. ex Nees, 1. c. $466=$ B. Linnaei.

ALVESIA, Welw. Apont. 587.n. $47(1858)=$ Bauhinia, Linn. (Legum.)

bauhinioides, Welw. 1. c。 $=\mathrm{B}$. tomentosa

ALVFSTA, Welw. in Trans. Linn. Soc. xxvii. (1869) 55. t. 19. LABIATAE, Benth. \& Hook. f. ii. 1176. rosmarinifolia, Welw. l. c.-Afr. trop.

ALVISIA, Lindl. Fol. Orch. (1859)= Eria, Lindl. (Orchid.).

tenuis, Lindl, 1, c。= E. articulata.

ALYCIA, Willd. ex Steud. Nom. ed. II. i. $66(\mathbf{1 8 4 0})=$ Eriochloa, H. B. \& K. (Gramin.)

coarctata, Willd, ex Steud. 1. c. =E. polystachya

distachia, Willd. ex. Steud. 1. c. = E. polystachya.

ALYMERIA, D. Dietr. Syn. i. in Ind. p. xiii (1839) = AYLMERIA, Mart. = Polyearpaea, Lam. (Caryoph.).

ALYMNIA, Neck. Elem. i. $31(1790)=$ Polymnia, Linn. (Compos.).

ALYOGYNE, Alef. in Oestr. Bot. Zeitschr, xiii. (1863) 12 - Fugosia, Juss. (Malvac.).

- hakeifolia, Alef. 1. c. = F. hakeaefolia.

ALYPUM, Fisch. Hort. Gorenk, ed. II. (1812) $19=$ Globularia, Tourn. (Selagin.).

monspeliensium, Fourr, in Ann. Soc. Linn. Lyon, N. S. xvii. (1869) 142.-G. Alypum.

salicifolium, Fisch. Cat. Hort. Gorenk. ed. II. (1812) 19

=G. Alypum,
Solandri, Hort. ex Steud. Nom. ed. I. $373=\mathrm{G}$. Alypum.

ALYSICARPUS, Neck. Elem. iii. 15 (1790); Desv. Journ. Bot i. (1813) 120. t. 4. LEGUMINOSAE, Benth. \& Hook. f. i. 522 .

FABRICIA, Scop. Introd. 307 (1777)

Hallia, J. St. Hil. in Bull. Soc. Philom. (Dec. 1813) 192.

Hegetschweilera, Heer \& Regel, Cat. Sem. Hort. Turic. (1842); ex Bot. Zeit. i. (1843) 47.

Mysicarpus, Webb, in Hook. Niger Fl. 122 (1849) lapsu.

belgaumensis, Wight, Ic. t. 92,-Ind. or

bupleurifolius, Wall. Cat. n. $5761=$ rugosus.

bapleurifolius, DC. Prod. ii. 352,-Ind. or.

cylindricus, Desv. in Ann. Linn. Soc. Par. iv. (1826) $301=$ styracifolius.

diversifolius, Wall. Cat. n. $5772=$ vaginalis ferrugineus, Hochst. \& Steud. ex A. Rich Tent. Fl. Abyss. 1. 20\%-Abyss.

glaber, E. Mey. Comm. P1. Afr. Austr. $125=$ rugosus.

glumaceus, DC. Prod. ii. 353.-Arab.

glumaceus, Wall. Cat. n. $5764=$ rugosus.

gracilis, Edgew. in Journ. As. Soc. Beng. xxi. (1853) $170=$ bupleurifolins.

gramineus, Zoll. E Mor. in Nat. en Geneesk. Arch.

Neerl. Ind. iii. (1846) 59, nomen.-Malaya.

hamosus, Edgew. in Fourn. As. Soc. Beng. xxi. (1853) 171. - Ind. or.

Harnieri, Scheinf. Reliq. Kotschy, 24. t. $19=$ vaginalis.

heterophyllus, Benth. ex Baker, in Hook. f. FI. Brit. Ind. ii. $158=$ vaginalis.
ALYSICARPUS :-

Heyneanus, Wight \& Arn. Prod. i. $234=$ rugosus.

Hochstetteri, A. Rich. Tent. Fl. Abyss. i. $209=$ rugosus.

longifolius, Wight \& Arn, Prod. i. 233.-Ind. or.

ludens, Wall. Cat. n. $5762=$ bupleurifolius, rugosus.

lupulinus, Stocks, ex Baker, in Hook. f. Fl. Brit. Ind. ii. $159=$ rugosus.

monilifer, DC. Prod. ii. 353.-Ind. or.; Afr. trop.

nummularifolius, DC. $1 . c_{.}=$vaginalis.

nummularioides, Zipp. ex Span. in Linnaea, xv. (1841) $194=$ scaber

nummularius, Baill. in Bull. Soc. Linn. Par. i. (1884) $432=$ vaginalis

obovatus, Edgew. in Journ. As. Soc. Beng. xxi. (1853) $169=$ rugosus.

paradoxus, Boiv. ex Baill. in Bull. Soc. Linn. Par. i. (1884) 432--Madag.

parviflorus, Dalz. in Hook. Kew Journ. iii. (1851) 211 = Desmodium parviflorum.

pilifera, Wall. Cat. n. $5765=$ rugosus.

porrectus, Welw. ex Baker, in Oliver, Fl. Trop. Afr. ii. 171.-Afr. trop.

pubescens, Law, in Wight, Ic. i. t. 250.-Ind, or. pylifer, Steud. Nom. ed. II. i. $66=$ rugosus.

quadrangularis, Edgew. ex Baker, in Hook. f. Fl Brit. Ind. ii. $159=$ tetragonolobus.

Quartinianus, A. Rich. Tent. Fl. Abyss. i. 208= rugosus.

racemosus, Benth. in Linnaea, xxiv. (1851) $642=$ belgaumensis.

rotundifolius, Dalz. ex Hook. f. Fl. Brit. Ind. ii. 172 = Desmodium rotundifolium.

rotundifolius, Wight, ex Hook, f. 1. c. 157 =hamosus.

Rubibarna, Buch.-Ham, ex Wall. Cat. n. 5771= vaginalis, monilifera.

rugosus, $D C$. Prod. ii. 353.-Reg. trop.

rupicola, Edgew. in fourn. As. Soc. Beng. xxi. (1853) 170.-Ind, or.

scaber, Span. in Linnaea, xv. (1841) 194.-Malaya,

scariosus, R. Grah. in Wall. Cat. n. $5766=$ rugosus.

spicatus, Royle, ex Hook. f. Fl. Brit. Ind. 1i. $159=$ longifolius.

styracifolius, DC. Prod. ii. $353=$ rugosus.

tetragonolobus, Edgew. in Fourn. As. Soc. Beng. xxi. (1853) 169.--Ind. or.

timorensis, Span. in Linnaea, xv. (1841) 194.--Ins. Timor.

trifoliatus, Stocks, ex Hook. f. F1. Brit. Ind. ii. $158=$ vaginalis.

vaginalis, $D C$. Prod. ii. 353.-Ind, or.

vaginalis, Hochst. ex Baker, in Oliver, F1. Trop. Afr. ii. $170=$ monilifer

vaginalis, Wall. Cat. n. $5763=$ longifolius, rugosus.

varius, Wall. 1. c. n. $5768=$ vaginalis.

Wallichii, Wight \& Arn. Prod.i. $234=$ rugosus.

Zeyheri, Harv. in Harv. \& Sond. Fl. Cap. ii. 230.Afr. austr.

ALYSSOIDES, Tourn. ex Adans. Fam. ii. 419 (1763) $=$ Vesicaria, Lam. (Crucif.)

creticum, Medic. Phil. Bot. i. 189=Alyssum creticum. gemonense, Medic. 1. c. = Alyssum gemonense. leucoifolium, Medic. Pflanzeng. $63=\mathrm{V}$. graeca sinuatum, Medic. Phil. Bot. 1. 189=Alyssum sinuatum. tomentosum, Moench, Meth. 264=Alyssum creticum. utriculatum, Medic. Phil. Bot. $189=$ V. graeca.

ALYSSOPSIS, Boiss. Diagn. Ser. I. vi. 14 (1842). CRUCIFERAE, Benth. \& Hook. f. i. 74. deflexa,Boiss. in Ann. Sc. Nat. Sér. II. xvii. (1842) 58.- Persia.

Drumondii, Turez, in Bull. Soc. Nat. Mosc. xxvii. (1854) II. 291 = Sisymbrium brachypodum. Kotschyi, Boiss. Diagn. Ser. I. vi. 14.-Persia sagittata, Boiss. F1. Orient. i. $182=$ deflexum.

ALYSSOPSIS, Reichb. Nom. 181. n. 6961 (1841)= Vesicaria, Lam. (Crucif.).

ALYSSON, Crantz, Stirp. Austr. ed. II. 15 (1769)=seq.

ALYSSUM, Toum. ex Linn. Syst. ed. I. (1735). CRUCIFERAE, Benth. \& Hook. f. i. 73.

Aduseta, Adans. Fam. ii. $420(1763)$.

Anodontea, G. Don, Gen. Syst. i. 180 (1831).

Aurinia, Desv. Journ. Bot. iii. (1814) 152.

Berteroa, DC. Syst. ii. 290 (1821). 


\section{ALYSSUM :}

GLYCE, Lindl. Syn. Brit. F1, 26 (1828).

KonIG, Adans. Fam. ii. 420 (1763),

KonigA, R. Br. in Denh. Clapp. \& Oud. Voy. App. $214(1826)$

Lobularia, Desv. Journ. Bot. iii. (1814) 162

Meniocus, Desv. 1. c. 173 .

Moenchia, Roth, Tent. Fl. Germ. i. 273 (1788),

Octadenia, R. Br. ex Fisch. \& Mey. Ind. Sem. Hort. Petrop. iii. 41 (1836).

Odentarrhena, C. A. Mey, in Ledeb. Fl. Alt. iii. 58 (1831).

OnodonteA, G. Don, Gen. Syst. i. 148 (1831), sphalm.

Psilonema, C. A. Mey. in Ledeb. Fl. Alt. iii. 50 (1831).

Ptilotrichum, C. A. Mey. 1. c. 64 (1831).

SchivereCKIA, Andrz. ex DC. Syst. ii. 300 (1821)

Stevena, Andrz. ex DC. Syst. ii. 291 (1821).

affine, Tenore, Syll. $315=$ orientale.

aizoides, Boiss. in Ann. Sc. Nat. Sér. II. xvii. (1842)

153.-Armenia.

albescens, Schlecht. ex DC. Syst. ii. 309, et Prod. i. 162 $=$ montanum.

algeriense, Pomel, Nouv. Mat. Fl. Atl. 232,-Afr. bor.

alpestre, Bieb. F1. Taur. Cauc. ii. 102, Suppl. $432=$ Marschallianum.

alpestre, Linn. Mant. 92.-Europ.

alpestre, Wulf. ex Nym. Consp. $56=$ montanum.

alpestre, Salis, in Flora, xvii. (1877) II. Beibl. $77=$ Robertianum.

alpestre, Sibth. \& Sm. Fl. Graec. t. $623=$ argenteum.

alpinum, Scop. Fl. Carn. ed. Il. ii. $9=$ montanum.

alsinefolizım, Host, Fl. Austr. ii. $248=$ calycinum.

altaicum, C. A. Mey, in Ledeb. Fl. Alt. iii. $55=$

Fischerianum.

alyssoides, Linn. Syst. ed. X. 1130= calycinum

andinum, Rupr. Fl. Caucas. 103.-Reg. Caucas.

ar[c]ticum, Wormsk。 ex Vahl, in Fl. Dan. t. $1520=$ Vesicaria arctica.

arenarium, Loisel, Fl. Gallica, ed. I. 401=montanum arenarium, Presl, Fl. Sic. i. 58.-Sicilia.

argenteum, Vitm. Summ. iv. 30.-Europ.; Oriens.

argyrophyllum, Schott \& Kotschy, in Oestr. Bot.

Wochenbl. vii. (1857) 229.-As. Min.

armenum, Boiss. Fl. Orient. 1. 278.-Armenia.

arvaticum, Jord. Diag. i. $200=$ calycinum.

atlanticum, Desf. F1. Atlant. ii. 71. t. $149=$ mon-

tanum.

Aucheri, Boiss. in Ann. Sc. Nat. Sér. II. xvii. (1842) $156=$ foliosum

aurantiacum, Boiss. Fl. Orient. i. 276.-Lycia.

aureum, Boiss. l.c. 286. -Oriens.

Bertholonii, Desv. Journ. Bot. iii. (1814) 172 \& $185=$ argenteun.

Besseri, Stev. ex DC. Syst. ii. $300=$ podolicum.

heugesiacum, Jord. \& Fourr. Brev. Pl. Nov, fasc. ii. $10=$ montanum.

bidentatum, Nutt. ex Torr. \& Gray, Fl. N. Am. i. 108 $=$ Draba brachycarpa.

Bilimekii, Willk, in Willk. \& Lange, Prod. iii. 830.Hispan.

brachystachyum, Bieb. Fl. Taur. Cauc. iii. $434=$ umbellatum.

bracteatum, Boiss. Diagn. Ser. I. xiii. 77 sphalm. $=$ Acanthophyllum bresteatum.

bracteatum, Boiss. \& Bichse, in Nouv. Mém. Soc. Nat.

Mosc, xii. (1860) 18,-Persia; Armenia.

brevifolium, Jord. \& Fourr. Brev. Pl. Nov, fasc. ii. 11 $=$ montanum.

brigantiacum, Jord. \& Fourr. 1. c. 12=montanum.

Bungei, Boiss. Fl. Orient. i. 274.-Persia.

calicinum, Neck. Delic. Gallo-Belg. i. $277=$ calycinum. callichroum, Boiss. Diagn. Ser. II. y. $34=$ constellatum. calycinum, Haensel. ex Nym. Consp. $56=$ campestre. calycinum, Linn. Sp. Pl. ed. II. 908.-Europ.; Oriens. calycinum, Pall, ex DC. Syst. ii, $318=$ dasycarpum. calyocarpum, Rupr. Fl. Cauc. 103, in textu.-Tauria. campestre, Hoffim. FI. Deutschl. ed. II. ii. $48=$ caly cinum.

campestre, Linn. Syst. ed. X. 1190,-Europ.; Oriens. campestre, Marz. ex Poll. Fl. Ver. ii. $362=$ montanum. canariense, Del. ex Webb \& Berth. Phyt. Canar. i. 91 -lybicum.

cardidum, Schlecht. ex DC. Syst. ii. $308=$ Marschal lianum.

canescens, DC. Syst. ii. 322.-Sibir.; Reg. Himal.

\section{ALYSSUMI :}

assium, Boiss. Eo Heldr. Diagn. Ser. I. viii. 34.Syria.

castellanum, Bourg. ex. Nym. Consp. $57=$ serpyllifolium.

cedrorum, Schott \& Kotschy, in Oestr. Bot. Wochenbl. iv. (1854) $169=$ hirsutum

Cephalotes, Boiss. Diagn. Ser. II. i. 34.-Caria.

chalcidicum, Fanka, in Destr. Bot. Zeitschr. xxii. (1872) 175.-Turcia.

cheiranthifolium, Willd. Sp. Pl. iii. 468= Farsetia clypeata.

cheirifolium, Berger. ex Steud. Nom. ed. I. $34=$ saxatile.

chrysanthum, Boiss. Fl. Orient. i., $271=$ argenteum.

ciliatum, Lam. F1. Fr. ii. $479=$ Draba aizoides

cilicicum, Boiss. \& Bal. Diagn. Ser. II. v. 34.-Cilicia.

Clausonis, Pomel, Nouv. Mat. Fl. Atl. 236.-Afr. bor.

clypeatum, Linn. Sp. Pl. ed. I. 651 = Farsetia clypeata cochlearioides, Roth, Nov. Pl. Sp. $322=$ Cochlearia flava.

cochleatum, Coss. \& Dur. in Bull. Soc. Bot. Fr. iv. (18557) 11. - Afr. bor.

collinum, Brot. Phyt. Lusit. ii. 209. t. $180=$ campestre. collinum, Jord. \& Fourr. Brev. Pl. Nov, fasc. ii. $9=$ montanum.

compactum, De Not. ex Ces. Ic. Stirp. Ital. fasc. iii. 15. t. 5.-Sicilia.

condensatum, Boiss. \& Haussk. ex Boiss. Fl. Orient. i. 268,-As. Min. ; Syria.

confertum, Hort. Berol. ex Boiss. in Ann. Sc. Nat. Sér. II. xvii. (1842) $155=$ strictum.

constellatum, Boiss. l. c. Sér. IV. ii. (1854) 244.Cilicia.

contemptum, Schott \& Kotschy, in Oestr. Bot. Wochenbl. iv. (1854) 177 = Szowitsianum

cordatum, Spreng。 ex Steud. Nom. ed. II. 1. $67=$ obcordatum.

cornutum, Steph. ex Ledeb. Fl. Ross. i. $139=$ rostratum

corsicum, Duby, Bot. Gall. ed. II. i. 34.--Corsica

corsicum, Rob, ex Gren. \& Godr. Fl. Fr. i. 117 =

Robertianum.

corymbosum, Boiss. Fl. Orient. i. 265.-Turc.

corymbulosum, Boiss. 1. c. $282=$ umbellatum.

crenulatum, Boiss. \& Heldr. Diagn. Ser. I. viii. 33.Syria.

cretaceum, Adams, in Mím. Soc. Nat. Mosc. v. (1817) 109.-Sibir.

creticum, Linn. Sp. Pl. 661.-Creta.

cryptopetalum, Bunge, in Arb. Naturf. Ver. Riga, (1847) 142 ; Lehm. Rel. (1847) 142 = marginatum.

cuneifolium, Tenore, Fl. Nap. Prod. xxxvii. App.; Cat Neap. (1815) $58=$ montanum.

dagestanicum, Rupr. Fl. Caucas. 104.-Caucas.

dahuricum, Schlecht, ex DC. Syst. ii. $715=$ canescens. damascenum, Boiss. \& Gaill. Diagn. Ser. II. vi. 18. -Syria.

dasycarpum, Steph. in Willd.Sp.Pl. iii. 469.-Oriens; Turkest.; Affghan.

dauricum, Schlecht. in DC. Syst. ii. 322, \& Prod. i. $164=$ canescens.

davuricum, Willd. ex Ledeb. Fl. Ross。 i. $138=$ Fischerianum

decoloratum, Pomel, Nouv. Mat. Fl. Atl. 236.-Afr. bor.

decumbens, Herbich, Stirp. Rar. Bucov, $47=$ repens.

deltoideum, Linn. Sp. Pl. ed. II. 908=Aubrietia deltoidea.

densiflorum, Desf. Cor. Tourn. 65 . t. $48=$ strictum.

dentatum, Nutt. Gen, Am. ii. 63 =Draba ramosissima. dentatum, Willd. Enum. Hort. Berol. 671=Camelina sativa.

dicranoides, Boiss, \& Huet, Diagn, Ser. II. v。 $30=$ Draba rigida.

diffusum, Jord. \& Fourr. ex Nym. Consp. $57=$ argen teum.

diffusum, Tenore, App. Hort. Neap. (1815) $58=$ montanum.

Draba, Bieb, ex Willd. Enum. Hort. Berol, 672= linifolium.

Draba, Hort. ex Webb \& Berth. Phyt. Canar. i. $91=$ lybicum.

Draba. Willd. Enum. Hort. Berol, $672=$ hirsutum. dubium, Bory, in Ann. Gén. Soc. Phys, iii. (1520) $4=$

Lagascae.

edentulum, Waldst. \&e Kit. Pl. Rar. Hung, i. 95. t. 92 $=$ gemonense.

\section{ALYSSUM}

latum, Boiss. \&o Heldr. Diagn. Ser. I. viii. 33.-As Min.

emarginatum, Zahl。 ex Vis. Fl. Dalm. iii. 117.Dalmat.

erigens, Jord. \& Fourr. Brev. Pl. Nov. fasc. ii. $9=$ montanum.

eriocarpum, Pourr. ex Steud. Nom, ed. II. i. $67=$ Clypeola eriocarpa.

eriophorum, Willd. Enum. Hort. Berol. $671=$ Clypeola enophora.

eriophyllum, Boiss. \& Haussk. ex Boiss. Fl. Oriento i. 273.-As. Min.

erosulum, Genn. \& Pestal. ex Clem, in Mem. Acc. Sc.

Torin. Ser. II. xvi. (1857) $248=$ suffrutescens.

erraticum, Jord. Diag. i. $200=$ calycinum,

filifolium, Wahlenb. in Isis, xxi. 998.-As. Min.

Fischerianum, DC. Syst. ii. 311.-Sibir.

flexicaule, Jord. Obs. Pl. Crit. i. (1846) $10=\mathrm{mon}$ tanum.

floribundum, Boiss. Diagn. Ser. II. v. 33.-Cilicia.

foliosum, Bory \& Chaub. Nouv. Fl. Pélop. 42 n. 1030 -Graecia; As. Min.

fruticulosum, Steud. Nom, ed. I, $34=$ Vesicaria fruti. culosa.

fulvescens, Sibth. \& Sm. Prod. Fl. Graec, ii. 13.Graecia; As. Min.

gemonense, Linn. Mant. 92,-Europ.

gemonense, Roth, Tent. Fl. Germ. iii. 85 (err. glemo. nense) $=$ saxatile

globosum, Steud. Nom, ed. I. $34=$ Vesicaria globosa

glomeratum, Burch. ex DC. Syst. ii. 316. - Afr. austr.

Gmelini, Jord. \& Fourr. Brev. Pl. Nov, fasc, ii. $8=$ montanum.

gnaphalodes, DC. Syst. ii. $311=$ Vesicaria gnaphalodes

gracile, Rafin. in Am. Monthly Mag. (1811) 356, nomen.-Hab.?

granatense, Boiss. \& Reut. Pugill. Pl. Nov. (1852) $9=$ calycinum.

granatense, Nym. Consp. 57 = serpyllifolium.

halimifolium, DC. Fl. Fr. v. 594= pyrenaicum

halimifolium, Lap. Hist. Abr. P1. Pyr. 371=macrocarpum.

halimifolium, Linn. Sp. Pl. ed. I. $650=$ maritimum.

halimifolium, Pall. Reise, iii. $161=$ lenense.

halimifolium, Willd. Sp. Pl. iii. 460--Europ.

Heideri, Krock. Fl. Sil. Suppl. ii. 168.-Europ

Haussknechtii, Boiss. Fl. Orient. 1. 269.-As. Min

Heinzi, Ullep. in Oestr. Bot. Zeitschr. xxry. (1685) 307.-Europ.

helianthemifolium, Timb. \& Feanb. in Rev. Bot. Soc Fr. iii. (1884-85) 105.-Gallia.

heterophyllum, Ruiz \& Pav。 ex DC. Syst, ii. $512=$ Lepidium perfoliatum.

heterotrichum, Boiss. Diagn. Ser. I. vi. 15.-Persia

hirsutum, Bess. ex Nym, Consp. $56=$ rostratum.

hirsutum, Bieb. Fl. Taur. Cauc, ii. 106. -Oriens.

hirsutum, Hohen. Enum. Elisabethpol, 213=cam. pestre.

homalocarpum, Boiss. Fl. Orient. i. 285. - Arabin.

horebicum, Boiss. in Ann. Sc. Nat. Sér. II. xvii. (1842) $156=$ homalocarpum

Huetii, Boiss. Fl. Orient. i. 287.-As. Min.

hyperboream, Linn. Sp. Pl. 651--Am. bor.

idaeum, Boiss. \& Heldr.Diagn. Ser. I. viii. 35.-Creta.

illyricum, Willd. Enum. Suppl. $44=$ linifolium.

imbricatum, Schlecht. ex DC. Syst. ii. 308, \&e Prorl. i. $161=$ canescens.

incanum, Linn.Sp. Pl. 650.-Europ.; Sibir.

Fonthlaspi, [Clairv.] Mfan. Herb. $210^{\circ}=$ Clypeola Jonthlaspi.

Kotschyanum, Boiss. Fl, Orient. i. 2r0=masmenacum.

Lagascae, Ganka, in Termess. Fügetek, vii. (13:3 114.-Europ.

lanigerum, DC. Syst. ii. 30 S.-Persia.

lanuginosum, Pourr. ex DC. Syst. ii. $32 \pi=$ Clypeola eriophora.

Lapeyrousianum, ford. Obs. Pl. Crit. i. $1840,3=$ Mont. Pyтеп.

Intifolium, Vis. Fl. Dalmo, iii. 118,-Dalmat.

leiocarpum, Pomel, Nowv. Mat. F\%. A\&l. 235.-Afr. bor.

lenense, Adams, in Meim. Sor. Nał. Mose. v. 1181; 110.-Sibir.

lepidotum, Boiss. Diagn. Ser. I. i. 78.-As Min.

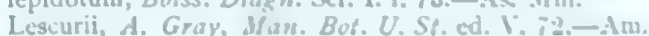
bur. 


\section{AIYSSUM :-}

leucadeum, Guss. Pl. Rar. 268.-Ital

libycum, Coss. in Bull. Soc. Bot. Fr. iv. (1857) 467.Afr. bor.

linearifolium, Lag. Gen. et Sp. Nov. 19=linifolium.

linifolium, Steph. ex Willd. Sp. Pl, iii, 467.-Europ.; Oriens.

litorale, Rupr. Fl. Cauc. 103. in textu.-Littora Maris Balt.

longicaule, Boiss. in Bibl. Genèr. (1838) 407.Hispan.

Iudovicianum, Nutt. Gen. Am. ii. $63=$ Vesicaria ludoviciana.

Innarioides, Spreng. ex DC. Syst. ii. $292=$ mutabile.

lunarioides, Willd. Sp. PI. iii. $461=$ Farsetia Iuna rioides.

lusitanicum, Brot. ex Nym. Consp. $56=$ campestre.

luteolum, Pomel, Nouv. Mat. Fl. Atl. 234.-Afr. bor macrocalyx, Coss, \& Dur. in Bull. Soc. Bot. Fr. iv. (1857) 12.-Afr. bor

macrocarpum, $D C$. Syst. ii. 321.-Gall. austr

macropodum, Boiss. \& Bal. Diagn. Ser. II. vi. 18.Cappadoc.

macrostylum, Boiss. EF Huet, ex Boiss. Fl. Orient. i. 279.-As. Min.

marginatum, Steud. Nom. ed. II. 1. 68 (ex Boiss. in Ann. Sc. Nat. xvii. (1842) 157).-Arab.; Persia; Affghan.

marginatum, Timb. \& Feanb. in Rev. Bot. Soc. Fr. iii. (1884-85) 106.-Gallia.

maritimum, Lam. Encyc. i. 98.-Europ.

Marschallianum, Andrz. ex DC. Syst. ii. 308.-Cancas. masmenaeum, Boiss. Diagn. Ser. II. v. 36.-Cappadoc. medium, Host, F1. Austr. ii. $244=$ gemonense.

meniocoides, Boiss, in Ann. Sc. Nat. Sér. II xvii.

(1842) 158.-Mesopot.

mesopotamicum, Fenzl, in T'chichat. Asie Min. Bot, i

$311=$ argenteum.

Meyerianum, Rupr. F1. Cauc, 100, in textu $=$ tortuosum.

micranthum, Fisch. \& Mey. in Linnaea, x. (1836) 83 = campestre.

microcarpon, Vis. Fl. Dalmat. iii. $115=$ corymbosum. microcarpum, Neilr. ex Nym. Consp. $55=$ gemonense. microcephalum, Boiss. Diagn. Ser. I. xiii. 77, sphalm. Acanthophyllum microcephalum.

micropetalum, Fisch. in DC. Syst, ii. $313=$ campestre. micropetalum, Kit. in Linnaea, xxxii. (1863) 497. Europ.

microphyllum, Steud. Nom. ed. II. i. 68.-Sibir. alt. minimum, Linn. Sp. Pl.651= maritimum. minimum, Pall. Reise, ii. $741=$ linifolium

minimum, Willd. Sp. $\mathrm{Pl}$. iii. 464.-Europ.; Oriens;

Reg. Himal.

minutiflorum, Boiss. Diagn. Ser. I. i. $73=$ alnestre minutulum, Schleich. ex DC. Syst. ii. $307=$ alpestre. minutum, Patr. ex DC. 1. c. $322=$ canescens. minutum, Schlecht. ex DC. L. c. 316.-Sibir. modestum, Boiss. Diagn. Ser. II. vi. $17=$ minutum. montanum, Brot. Fl. Lusit. ii. $558=$ campestre. montanum, Linn. Sp. Pl. 650.-Europ.; Oriens. montanum, Pall. Reise, i. $252=$ Fischerianum. montanum, Patr. ex DC. Syst. ii. $322=$ canescens. mouradicum, Boiss. \& Bal. Diagn. Ser. II. vi. 16.As. Min.

Muellerii, Boiss. \& Buhse, in Nouv. Mém. Soc. Nat. Mosc. xii. (1860) 16.-Armenia; Persia.

murale, Bieb. FI. Taur. Cauc. ii. $103=$ alpestre.

murale, Waldst. \& Kit. Pl. Rar. Hung, i. 5. t. $6=$ argenteum.

murcicum, Jord, ex Nym. Consp, $57=$ serpyllifolium. muricatum, Kit. in Linnaea, xxxii. (1863) 498.Europ.

mutabile, Vent. Fard. Cels, 85.-Ital.

myagroides, All. F1. Pedem. i. $241=$ Graellsia saxatilis

Myagrum, Wibel, Prim. Fl. Werth. 204=Camelina Sativa.

nanum, Pomel, Nouv. Mat. Fl. Atl. 236.-Afr. bor. nebrodense, Tineo, Pugill. P1. Sic. $12=$ serpyllifolium. novum, Kit. Ind. Pesth, t. $6=$ alpestre.

numidicum, Pomel, Nouv. Mat. Fl. Atl. 377.-Afr. bor.

obcordatum, DC. Syst. ii. 324-Hab. ?

obliquum, Sibth. \& Sm. Fl. Graec. t. $623=$ mutabile.

obovatum, Turcz. in Bull. Soc. Nat. Mosc. (1837) I. 57 = sibiricum.

obtusifolium, Stev. ex DC. Syst. ii. $305=$ alpestre.

\section{ALYSSUM :-}

ochroleucum, Boiss. Diagn. Ser. II. v. $36=$ montanum. Oederi, Durand, FI. Bourg. i. $161=$ Vesicaria utri culata.

orbiculare, Timb. \& Feanb. in Rev. Bot. Soc. Fr. iii. (1884-85) 106.-Europ.

orbiculatum, Urv. in Mém. Soc. Linn. Par. i. (1822) 335.-Graecia.

orientale, Ard. Animad. Alt. 32.-Graecia; As. Min. orophilum, Jord. \& Fourr. Brev. Pl. Nov, fasc. ii. $11=$ montanum.

ovirense, A. Kern. Sched. Fl. Exsicc. ii. 99.-Austria. oxycarpum, Boiss. E Bal. Diagn. Ser. II. v. 35.Cappadoc.

paniculatum, Desf. Choix, $67=$ Vesicaria paniculata. paniculatum, Willd. Enum. Hort. Berol. $671=$ Neslia paniculata.

parviflorum, Bieb. Fl. Taur. Cauc. iii, $434=$ campestre. parviflorum, Hochst. \& Steud. ex Steud. Nom. ed. II i. $68=$ marginatum

parviflorum, Schloss. ex Nym. Consp. $57=$ calycinum,

parvulum, Schrad. in Linnaea, x. (1836) Litt. 69.Hab. ?

patulum, Pomel, Nouv. Mat. Fl. Atl. 238,-Afr. bor.

pedemontanum, Rupr. Fl. Cauc. 102, in textu.Europ.

peltarioides, Boiss. in Ann. Sc. Nat. Sér. II. xvii (1842) 158.-.As. Min.

persicum, Boiss, l, c. 152.-Persia.

Perusianum, J. Gay, ex Gren. \& Godr. Fl. Fr. i. 118 =Lapeyrousianum.

petalodes, DC. Syst. ii. $312=$ Farsetia obovata

petraeum, Andrz. ex DC. 1. c. $302=$ saxatile.

petraeum, Ard. Animad. Alt. 30=gemonense.

petrophilum, Heldr. ex Nym. Consp. $56=$ montanum.

Peyrousianum, Willk. \& Lange, Prod. F1. Hisp. iii. $835=$ Lapeyrousianum

phymatocarpum, Schlosser \& Vukot. Syll. $156=$ calycinum.

pleiospermum, Fenzl, in Russeg. Reise, Illustr. $54=$ aureum.

podolicum, Bess. Cat. Hort. Crem. (1816) 8.-Europ.; As. Min.; Sibir

polyodon, Boiss. \& Buhse, in Nouv. Mém. Soc. Nat. Mosc. xii. (1860) $17=$ campestre.

porphyreticum, Jord. \& Fourr. Brev. Pl. Nov. fasc. i. $11=$ montanum.

praecox, Boiss. Fl. Orient. i. 275.-As. Min

psammeum, Jord. \& Fourr, Brev. Pl. Nov. fasc. ii. $9=$ montanum.

psilocarpum, Boiss. Voy. Bot. Espagne, App. ii. $718=$ calycinum.

purpureum, Lag. \& Rodr. in Anales Cienc. Nat. v. (1802) 275 = Lagascae.

pyrenaicum, Lapeyr. Hist. Abr. Pl. Pyr. 371. Suppl. 91.--Mont. Pyren.

ramosissimum, Webb, in Gionn. Bot. Ital. ii. (1846) 215.-Graecia.

repens, Baumg. Enum. Transs. ii. $237=$ montanum

rhodanense, Jord. \& Fourr. Brev. P1. Nov, fasc. ii. 10 $=$ montanum.

Robertianum, Bernard, ex Gren. \& Godr. Fil. Fr. i. 117.-Corsica.

Rachelii, Andrz. ex Reichb. Ic. Pl. Crit. xi. p. 8. n. $4273 \mathrm{~b}=$ montanum.

rostratum. Stev. in Mém. Acad. Pétersb. iii. (1809-10) 295. t. 15. f. 1.-Graecia; As. Min.

rostratum, Wierzb. ex Nym. Consp. $56=$ montanum.

ruderale, Jord. Diagn. i. $198=$ calycinum.

rupestre, Tenore, Fl. Nap.t. 60.-Europ.

rupestre, Willd. Enum. Hort. Berol. $672=$ Graellsia saxatilis.

sabulosum, Jord. Diag. i. $199=$ calycinum.

samariferum, Boiss. \& Haussk. ex Boiss. Fl. Orient. i. 272.-As. Min.

samolifolium, Desf. Choix, $66=$ Thlaspi samolifolium. sativum, Scop. Fl. Carn. ed. II. ii. $9=$ Camelina sativa.

savranicum, Andrz. ex Bess. Enum. P1. Volh. $82=$ alpestre.

saxatile, Bory \& Chaub. Nouv. F1. Pélop. $41=$ orientale.

saxatile, Crantz, Stirp. Austr. $16=$ gemonense.

saxatile, Linn. Sp. Pl. 650.-Europ.

saxatile, Sibth. \& Sm. Prod. F1. Graec. ii. $11=$ orientale.

scabrum, Weinm. Cat. Hort. Dorpat. (1810) $11=$ umbellatum.
ATYSSUM :-

Schlosseri, Heuff. ex Schlosser \& Vukot. Syll. $156=$ calycinum.

schirwanicum, Rupr. Fl. Cauc. $100=$ tortmosum.

Scovitzianum, Fisch. \& Mey. in Linnaea, xii. (1838) sphalm. $151=$ Szovitzianum

scutigerum, Dur. in Expl. Sc. Algér. t. 72. f. 4,-Afr. bor.

semidodecandra, Schrank, Baier. Fl. ii. 189.-Europ. serpyllifolium, Bieb. Fl. Taur. Cauc. ii. $103=$ tortuosum.

serpyllifolium, Desf. Fl. Atlant, ii. $70=$ alpestre.

sibiricum, Fisch. ex DC. Syst. ii. $311=$ Fischerianam.

sibiricum, Trevir. in Ges. Naturf. Fr. Berl. Mag. vii. (1811) $151=$ dasycarpum

sibiricum, Willd. Sp. Pl. iii. 465.-Sibir.

siculum, Jord. Diag. i. $202=$ calycinum.

simplex, Rudolphi, in Schrad. Journ. ii. (1799) $290=$ campestre.

sinuatum, Linn. Sp. Pl. 651.-Europ.; As. Min.

smyrnaeum, C. A. Mey. in Bull. Sc. Acad. Pétersb. vii. (1840) 132.-Smyrna.

spathulatum, Adams, in Mém. Soc. Nat. Mosc. v. (1817) $110=$ alpestre

spathulatum, Steph. in Willd. Sp. Pl. iii. 465.-Sibir. speciosum, Pomel, Nouv. Mat. Fl. Atl. 237.-Afr bor

sphacioticum, Boiss. \& Heldr. Diagn. Ser. I. viii. 35. -Creta.

spinosum, Linn. Sp. Pl. 650.-Europ.

Spruneri, Jord. \& Fourr. Brev. Pl. Nov, fasc. ii, $12=$ montanum.

strictum, C. A. Mey. Verz. PA. Cauc. $137=$ Szowitsianum.

strictum, Willd. Sp. Pl. iii. 464.-As. Min.

strigosum, [Soland. in] Russell, Aleppo, ed. II. ii, 257 = hirsutum.

strigulosum, Amo, Fl. Iber. vi. 571.-Hispan.

stylare, Boiss. \& Bal. ex Boiss. Fl. Orient. i. 287.As. Min.

styriacum, Jord. \& Fourr. Brev. Pl. Nov, fasc. ii. $7=$ montanum.

subalpestre, Schur, Enum. P1. Transs. $61=$ argenteum subalpinum, Pall. Ind. Taur. ex Bieb. Fl. Taur. Cauc ii. $103=$ tortuosum.

sublineare, Jord. Diagn, i. 201=calycinum

subtumidum, Boiss. \& Heldr. ex Nym. Consp. $56=$ foliosum.

suffrutescens, Boiss. Fl. Orient. i. 275.-Syria.

superbum, L'Hérit. ex DC. Syst. ii. $288=$ Farsetia suffruticosa.

Szovitsianum, Fisch. E Mey. Ind. Sem. Hort. Petrop.

iv. 31.-Oriens.

tenuifolium, Bieb. F1. Taur. Cauc. Suppl. $435=$ canescens.

tenuifolium, Steph. in Willd. Sp. Pl. iii. 4t0.-Ross.

tetraspermum, Bertol. in Nov. Comm. Acad. Bonon. vi. (1844) $226=$ meniocoides.

tetrastemon, Boiss. in Ann. Sc. Nat. Sér. II. xvii. (1842) 153.-As. Min.; Syria.

tortuosum, Rupr. Fl. Caucas. 98.-Caucas.

tortuosum, Waldst. \& Kit. P1. Rar. Hung. i. 94. t. 91 = alpestre.

transsylwanicum, Schur, Enum. P1. Transs. $63=$ montanum.

trichostachyum, Rupr. Fl. Caucas. 101.-Reg. Caucas.

triquetrum, Portenschl. ex DC. Syst, ii. $290=$ Farsetia triquetra.

trochocarpum, Fenzl, in Tchihat. Asie Min. Bot. i. 297 $=$ argenteum.

tuberculatum, Kit. in Linnaea, xxxii. (1863) $498=$ muricatum.

turkestanicum, Regel \& Schmalh. ex Regel, Pl. Nov. Fedsch.6.-Turkest.

umbellatum, Desv. Fourn. Bot. iii. (1814) 173 \& 184 -As. Min.; Syria.

utriculatum, Linn. Mant. i. $92=$ Vesicaria utriculata. utriculatum, Sibth. \& Sm. Fl. Graec, t. $607=$ Vesicari Barrelieri.

vagum, Jord. Diag. i. $198=$ calycinum.

vernale, Kit. ex Hornem. Hort. Hafn. 601=montanum.

Vesicaria, Linn. Sp. Pl. ed. I, $651=$ Vesicaria utriculata.

vesicarioides, Andrz. ex Steud. Nom, ed. II. i. $68=$ gemonense.

Wierzbickii, Heuff. in Flora, xviii. (1835) I. $242=$ rostratum. 


\section{ALYSSUM :-}

Willkommii, De Roem. ex Willk. in Linnaea, xxv. (1852) 8=granatense.

Wulfenianum, Willd. Enum. Hort. Berol. Suppl. $44=$ montanum.

xanthocarpum, Boiss. in Ann. Sc. Nat. Sér. xvii. (1842) $154=$ macrostylum.

xerophilum, Jord. \& Fourr. Brev. Pl. Nov. fasc. ii. 10 $=$ montanum

ALYXIA, Banks, ex R. Br. Prod. 469 (1810). APOCYNACEAE, Benth. \& Hook. f. ii. 697.

Gynopogon, Forst. Char. Gen. 35. t. 18 (1776), nomen prius.

actinophylla, A. Cunn, in Bot. Mag. subt. $3313=$ verticillosa.

affinis, Heurck \& Muell. Arg. in Heurck, Obs. Bot. 193.-N. Caled.

aromatica, Reinw. ex A. DC, in DC. Prod. viii. $346=$ stellata.

bracteolosa, Rich, ex A. Gray, in Proc. Am. Acad. v. (1862) 332 ,- Ins. Fiji.

breviflora, Heurck \& Muell. Arg. in Heurck, Obs. Bot. 195.-N. Caled.

buxifolia, R. Br. Prod. 470.-Austral.

calophylla, Wall. Cat. n. $1607=$ Winchia calophylla.

capitellata, Benth. in Enum. Pl. Hueg. $81=$ buxifolia.

ceylanica, Wight, Ic. Pl. t. 1293.-Zeylan.

coriacea, Wall. in Roxb. Fl. Ind. ed. Carey, ii. 541.

-Ind. or.
cuspidata, Wall. ex A. DC. in DC. Prod. viii. $351=$ Melodinus orientalis.

daphnoides, A. Cunn. in Hook. Bot. Mag. t. 3313.Ins. Norfolc.

disphaerocarpa, Heurck \& Muell. Arg. in Flora, li. (1870) $169 .-\mathrm{N}$. Caled.

erythrocarpa, Vatke, in Bremen Abh. ix. (1885) 124. -Ins. Mascar.

fascicularis, Benth. \& Hook. f. Gen. ii. 698, in nota ad Hunteriam.-Reg. Himal.

Forsteri, A. Cunn. ex Loud. Hort. Brit. Suppl. i. 580 $(1830)=$ A. Gynopogon.

glaucescens, Wall. in Roxb. F1. Ind. ed. Carey, ii. 542 ; G. Don, Gen. Syst. iv. $97=$ Winchia calophylla.

glaucophylla, Heurck \& Muell. Arg. in Flora, liii. (1870) $170 .-\mathrm{N}$. Caled.

gracilis, Benth. \& Hook. f. Gen. ii. 697, in nota ad Hunteriam.-Reg. Himal.

Gynopogon, Roem. E'Schult. Syst. iv, 440.-Ins. Norfolc.

Gynopogon, Wall. Cat. n. $1605=1$ ncida.

gynopogrona, St. Lag. in Ann. Soc. Bot. Lyon, vii. (1880) $119=$ seq.

Halmaheirae, Miq. Ann. Mus. Bot. Lugd. Bat. iv. 140. -Malaya.

ilicifolia, F. Muell. Fragm. iv. 149.-Austral.

laurina, Gaudich. in Freyc. Voy. Bot. 451. t. 62.-Ins. Moluce.

leucogyne, Heurck \& Muell. Arg. in Flora, liii. (1870) $170-\mathrm{N}$. Caled.

Lindii, F. Muell. Fragm. viii. 46.--Ins. D. Howe

lucida, Wall. in Roxb. Fl. Ind. ed. Carey, ii. 540.Malaya.

madagascariensis, A. DC. in DC. Prod. viii. 345.-

Madag.

obovata, Seem. Fl. Vit. 156, in nota.-Ins. Pinet.

obtusifolia, R. Br. Prod. 470.-Austral.

odorata, Wall. Cat. n. 1606.-Tenasserim.

olivaeformis, Gaudich. in Freyc. Voy. Bot. 451.-Ins. Sandyic.

pilosa, Mig. Fl. Ind. Bat. ii. 408.-Java.

podocarpa, Heurck so Muell. Arg. in Heurck, Obs. Bot. 197.-N. Caled.

pugioniformis, A. Cunn. in Hook. Bot. Mag. sub t. $3312=$ ruscifolia.

pumila, Hook. f. Fl. Brit. Ind. iii. 635.-Malacca.

quinata, Miq. Fl. Ind. Bat. ii. 407.-Sumatra.

Reinwardti, Blume, Cat. Gew. Buit. $43=$ stellata.

Richardsonii, Sweet, Hort. Brit. ed. I. $273=$ ruscifolia.

ruscifolia, $R . B r$. Prod. 470 - - Austral.

scandens, Rocm. \& Schult. Syst. iv. 440.-Ins. Societ.

sinensis, Champ. ex Benth. in Hook. Kew Gourn. iv.

(1852) 334.-Hongkong.

Spanogheana, Miq. Fl. Ind. Bat. ii. 409.-Ins. Timor.

spicata, R. Br. Prod. 470.-Austral.

squamulosa, C. Moore \& F. Mucll. in F. Muell. Fragm. viii. 47.-Ins. D. Howe.
ALYXIA :-

stellata, Roem. \&o Schult. Syst. iv. 439.-As. trop.; Malaya; Ins. Pacif.

sulcata, Hook. \& Am. Bot. Beech. Voy, $90=$ olivaeformis.

tetragona, R. Br. Prod. $470=$ spicata.

Thozetii, F. Muell. Fragm. x. 103.-Austral.

thyrsiflora, Benth. Fl. Austral. iv. 309.-Austral.

Tisserantii, Montr. in Mém. Acad. Lyon, x. (1860) 233. $\rightarrow$ N. Caled.

Torresiana, Gaudich. in Freyc. Voy. Bot. 451.-Ins. Marian.

zeylanica, Walp. Ann. iii. $33=$ ceylanica.

ALZALIA, F. G. Dietr. Lexik. Gaertn. i. 299 (1802)= Alzatea, Ruiz \& Pav. (Celastr.).

ALZINIANA, F. G. Dietr. ex Pfeiff. Nom. i. 129 (1873)= praec.

ALZATEA, Ruiz \& Pav. Prod. 40. t. 7 (1794) CELASTRINEAE, Benth. \& Hook. f, i. 362.

mexicana, F. G. Dietr. Lexik. Gaertn. i. 299 (1802) Nachtr. = verticillata.

verticillata, Ruiz \& Pav. Fl. Per. iii. 20.t. 241.-Peruv.

AMADEA, Adans. Fam. ii. $230(1763)=$ Androsaee, Tourn. (Primul.)

AMAGRIS, Rafin. in Préc. Somiol. 27 (1814) \&c Am. Monthly Mag. (1819) $190=$ Calamagrostis, Adans (Gramin.).

AMAIOUA, Aubl. P1. Gui. Suppl. 13. t. 375 (1775). RUBIACEAE, Benth. \& Hook. f. ii. 81.

Ehrenbergia, Spreng. Neue Entdeck. ii. 129 (1821) \& Syst. ii. 12 (1825).

Hexactina, Willd. ex Schult. f. Syst. vii. 91 (1830). affinis, Miq. in Linnaea, xviii. (1844) 613.-Surinam. africana, Spreng. Syst. ii. $126=$ Coffea zanguebarica. brasiliana, A. Rich. in Mém. Soc. Nat. Par. v. (1829) 251? (Mém. Rub. 170).-Bras.

corymbosa, H.B. \& K. Nov. Gen. et Sp. iii. 419. t. 294-Mexic.

edulis, Baill. Hist. Pl. vii. 387.-Guiana.

eriopila, Baill. l. c.-Guiana.

fagifolia, Desf. in Mém. Mus. Par. vi. (1820) 14. t. 5 . -Guiana.

grandifolia, Miq.in Linnaea,'xviii. (1844) 291.-Guiana guianensis, $A u b l$. Pl. Gui. Suppl. 13. t. 375.-Guiana. hirsuta, Poepp. E Endl. Nov. Gen. et Sp. iii. 25. t. 230. -Bras.

intermedia, Mart. in Schult. f. Syst, vii. 90.-Bras.

Laureaster, Mart. in Flora, xxiv. (1841); Beibl. ii. 84 -Bras.

longifolia, Poepp. \& Endl. Nov. Gen. et Sp. iii. 26.Bras.

peruviana, Desf. in Mém. Mus. Par. vi. (1820) 16. t. 4.-Peruv.

saccifera, Mart. in Schult. f. Syst. vii. 91.-Bras. surinamensis, Steud. in Flora, xxvi. (1843) 763.Surinam.

utilis, Baill. in Bull. Soc. Linn. Par. i. (1879) $220=$ Alibertia edulis.

AMALAGO, Rąin. Sylva Tellur. 84 (1838)= Piper, Linn.

antillana, Rafin. 1. c. $=$ P. officinarum.

Malamiri, Rafin. 1. c. = praec.

AMALIA, Hort. Hisp. ex Endl. Gen. 183 (1837)= Tillandsia, Linn. (Bromel.).

Aeris-incola, Hort. Hisp. ex Steud. Nom. ed. II. i. 69 $=\mathrm{T}$. dianthoidea.

AMALIA, Reichb. Nom. 52 (1841)=Laelia, Lindl. (Orchid.).

AMALIAS, Hoffmgg. Preis-Verz. Orch. ex Linnaea, xvi. (1842) Litt. $228=$ Laelia, Lindl. (Orchid.) anceps, Hoffmgg. 1. c, = Laelia anceps.

AMALOBOTRYA, Kunth, ex Meissn. in DC. Prod. xiv $185(1856-57)=$ Symmeria, Benth. (Polygon.). latifolia, Kunth, ex Meissn. I. c. - S. paniculata.

AMAMELIS, Lem, in Orbign. Dict. iv. $7 \$ 5(1819)=$ Hamamelis, Giron.
AMANNIA, Blume, Bijdr. 1130 (1826) = Ammannia, Houst. (Lythrar.).

AMANOA, Aubl. PI. Gui. i. 256, t. $101(1775)$ PHORBIACEAE, Benth, \& Hook, f iii. 268. acuminata, Thw. Enum. Pl, Zeyl.428=Cleistanthus acuminatus.

Boiviniana, Baill. Etud. Gén, Euph. 582,-Madag. bracteata, Rich. ex Baill. 1. c. $581=$ guianensis. bracteosa, Planch. in Hook. Ic. Pl. t. 797.-Afr. trop. brasiliensis, Baill. Etud. Gén. Euph. 581, n, $4=$ Gona togyne brasiliensis.

chartacea, Baill. 1. c. $582=$ Cleistanthas chartaceus. collina, Baill. 1. $\mathrm{c}_{\mathrm{*}}=$ Cleistanthus collinus.

Cunninghamii, Baill. Adansonia, vi. (1865-66) $335=$ Cleistanthus Cunninghamii.

Dallachiana, Baill. 1. c. = Cleistanthus Dallachyanus. divaricata, Poepp. Es Endl. Nov. Gen. et Sp. iii. 22. 226. - Am. austr.

faginea, Baill. Adansonia, vi. (1865-66) $336=$ Briedelia faginea.

ferruginea, Thw. Enum. Pl. Zeyl. $280=$ Cleistanthus ferrugineus.

grandiflora, Muell. Arg. in Flora, Iv. (1872) 2.Surinam.

guianensis, Aubl. Pl. Gui. i. 256. t. 101.-Guiana,

indica, Thw. Enum. P1. Zeyl. $428=$ Cleistanthus robustus.

indica, Wight, Ic. t. $1911=$ Cleistanthus patulus.

Leichardtii, Baill. Adansonia, vi. (1865-66) $336=$

Briedelia faginea.

oblongifolia, Muell. Arg. in Linnaea, xxxii. (1863 77.-Bras.

ovata, Baill. Adansonia, vi. (1865-60) $336=$ Briedelia exaltata.

pallida, Thw. Enum. Pl. Zeyl, $280=$ Cleistanthus pallidus.

patula, Thw. 1. c. $=$ Cleistanthus patulns.

purpurascens, Poepp. ex Baill. Etud. Gén. Euph. 598.-Bras.

racemosa, Poepp. E Endl. Nov. Gen. et Sp. iii. 23.Bras.

ramiflora, Poepp. \&c End1. 1. c. = Richeria grandis

robusta, Thw。 Enum. Pl. Zeyl. $428=$ Cleistanthus robustus.

strobilacea, Muell. Arg. in Flora, xlvii. (1864) 515.Afr. occ.

strobilantha, Planch. in Hook. Niger Fl. t. $47=$ bracteosa.

tomentosa, Baill. Adansonia, vi. (1865-66) $336=$ Briedelia tomentosa.

AMAPA, Steud. Nom. ed. I. 35 (1821)=Carapa, Aubl (Meliac.)

guianensis, Steud. 1. c. =C. guianensis.

AMARABOYA, Linden, ex Mast, in Gard. Chron (1871) 944. MELASTOMACEAE. amabilis, Linden, ex Mast. l. c.-N. Granat. princeps, Linden, ex Mast. l. c.-N. Granat. splendida, Linden, ex Mast. 1. c.-N. Granat.

AMARACANTHUS, Steud. Nom. ed. II. i. 69 (1840) spbalm. = seq.

AMARACARPUS, Blume, Bijdr. $954\left(1820^{\circ}\right) . \quad R L^{\circ}$ $B I A C E A E$, Benth. \& Hook. f. ii. 190 .

microphyllus, Miq. Ann. Mus. Bot. Lugd. Bato iv. 211.-Ins. Celebes.

pubescens, Blume, Bijdr. 954-Java.

AMARACUS, Gleditsch, Syst. $189(1 \% 61)=$ Origanum, Linn. (Labiat.)

cordifolius, Montbr. \& Anch. ex Bentb. in Ana. Sc. Nat. Sér. II. vi. (1S36) $\pm 8=0$. cordifulium. Dictamnus, Benth. Lab. Gen. et Sp. $\$ 33=0$. Dictamnus. sipyleus, Rafin. F1. Tellur. iii. $80=0$. sipyleus. tomentosis, Moench, Meth. Suppl, $187=0$. Dictamnos. Tournefortii, Benth. Lab. Gen, et Sp. $\$ \$ 3=0$. Toursefortii.

AMARALIA, Welw. ex Benth. \& Hnok. f. Gen. ii. so $(1879)=$ Sherbournia, G. Don (Kabiac). bignoniaefora, Welw. 1. c. ii. $91=\mathrm{S}$. foliuss. Donicasa, Welw. l. $c_{5}=\mathrm{S}$. foliosa.

AMARANTESIA, Hort. ex Regel, Gartenf. 1E6? $102=$ Tolanthera. K. Br. Amarnt. . brasiliensis, Hort. ex Regel, l. $c_{0}=$ T. Betuichiana. 
AMARANTHUS, Linn. Syst. ed. I. (1735); Gen. ed. I. 286 (1737). AMARANTACEAE, Benth. \& Hook. f. iii. 28.

Albersia, Kunth, Fl. Berol. ed. II. 144 (1838).

Amblogyna, Rafin. Fl. Tellur, iii. 42 (1836)。

Bajan, Adans. Fam. ii. 506 (1763).

BLITON, Adans. 1. c. $(1763)$

Blitum, Linn. Gen, ed. I. 20 (1737)

DimeiandRa, Rafin. Neogenyt. 2 (1825)

Dimeianthus, Rafin. Fl. Tellur. iii. 41 (1836)

Euxolus, Rafin. 1. c. 42 (1836).

Glomeraria, Cav. Descr. 319 (1827).

Mengea, Schau. in Nov. Act. Cur. xix. Suppl. I. (Pl. Meyen.) 405 (1843).

Pentrius, Rafin. Fl. Tellur. iii. 42 (1836)

Pyxidium, Moq. Tand. in DC. Prod, xiii. II. 262 (1849) (vox fructus desc. lapsu progenere habita).

RoEMERIA, Moench, Meth. 341 (1794).

Sarratia, Moq. ex DC. Prod. xiii. II. 233, 268 (1849).

Scleropus, Schrad. Ind. Sem. Hort. Goett. (1835). Acroglochin, Spreng. Syst. i. $927=$ Acroglochin chenopodioides.

adscendens, Auct. vide ascendens.

aeneus, Bess. Cat. Hort. Volhyn. (1816) 8-Hab.? aeruoides, Hochst. \& Steud. ex A. Rich. Tent. Fl.

Abyss, ii. $214=$ Aerva lanata.

albiflorus, Mog. in DC. Prod. xiii. II. 263:-Hab. ?

albus, Linn. Syst. ed. X. 1268.-Am. bor. (Europ. alien.).

albus, Robin, Voy. Louis. 374 ; ex Moq. in DC. Prod. xiii. II, $265=$ leucanthus.

albus, Rodsch. ex F. G. Dietr. Lex. Gaertn. Nachtr. II. i. $196=$ A. Blitum

albus, Thunb. Fl. Cap. ed. Schult. i. $215=$ Thunbergii.

Alopecurus, Hochst. ex A. Br. \& Bouché, Ind. Sem. Hort. Berol. App. (1872) $1=$ caudatus.

altissimus, Riddell, Syn. F1. West. St. (1835) $41=$ Acnida rusocarpa

amboinicus, Buch.-Ham. in Wall. Cat. n. 6987= gangeticus.

Anacardana, Hook. f. Fl. Brit. Ind. iv. $719=$ seq.

Anardana, Buch.-Ham. in Wall. Cat. n. $6903=$ paniculatus.

angustifolius, Bieb。ex Willd. Sp. Pl。iv。 $381=$ sylvestris.

angustifolius, Lam. Encyc. i. $115=$ A. Blitum.

Arardhanus, Sweet, Hort. Brit. ed. III. $569=$ panicn-

latus.

arctioideus, Perr. ex Moq. in DC. Prod. xiii. II. 332 = Pupalia lappacea

ascendens, Hornem. Hort. Hafn. Suppl. 107.-China. ascendens, Loisel. Not. $141=$ viridis.

atropurpureus, Roxb. Fl. Ind. iii. 608--Ind. or. atrosanguineus, Hort. Lugd. (1838) ex Moq. in DC.

Prod, xiii. II. $266=$ hypochondriacus ?

aureus, Bess. Cat. Hort. Volhyn. (1816) 8 =flavus ?

aureus, F. G. Dietr. Lexik. Gaertn. i. 310.-Nepal.

aureus, Hort. ex Moq. in DC. Prod, xiii. II. $259=$ hybridus.

bahiensis, Mart. Herb. Fl. Bras. n. 969,-Bahia.

Bellardi, Hort. ex Moq. in DC. Prod. xiii. II. $259=$ hybridus.

Berchtholdi, Hort. ex Moq. 1. c. 257 = paniculatus.

Berchtoldi, Seidl, ex Opiz, Boeheims Gew. 164; Natural. i. $(1823)[2]=$ A. Blitum.

Berchtholdi, Hort. ex Moq. in DC. Prod. xiii. II. $259=$ hybridus.

Bernhardi, Hort. ex Moq. 1. c. $258=$ flavus.

bicolor, Nocca, ex Willd. Sp.PI. iv. $384=$ melancholicus.

blitoides, S. Wats. in Proc. Am. Acad. xii。 (1877) 273. -Am. bor.

blitonius, St. Lag. in Ann. Soc. Bot. Lyon, vii. (1880) $119=$ A. Blitum.

Blitum, Auct, ex Moq. in DC. Prod. xiii. II. 267, $274=$ viridis.

Blitum, Linn. Sp.Pl. ed. I. 990.-Reg. temp. et trop. Blitum, Moq. in DC. Prod, xiii. II. $263=$ sylvestris.

Blitum, Reichb. Ic. ex Steud. Nom. ed. II. i. $69=$ polygonoides.

brasiliensis, Moq. in DC. Prod. xii. II. 266,--Bras.

bullatus, Bess. ex Spreng. Syst. i. $928=$ retroflexus. californicus, S. Wats. in Bot. Calif. ii. 42.-Calif.

campestris, Willd. Sp. Pl. iv. 382 .- Ind. or.

canariensis, Bess. Cat. Hort. Volhyn. (1816) 8,-Ins.

Canar.

\section{AMARANTHUS :-}

capitatus, Cat. Hort. Turic. (1827-28).-Hab.?

Caracam, Bess. Cat. Hort. Volhyn. (1816) $8=\mathrm{A}$. Cararu.

caracasanus, H. B. E⿱ $K$. Nov. Gen, et Sp. ii. 195.Venezuela.

Caracu, Zucc. ex Steud. Nom. ed. II. i, 69=A. Cararu.

Cararia, Bess. Cat. Hort. Volhyn. (1816) $8=$ praec. ?

Cararu, Hort. Paris. ex Moq. in DC. Prod. xiii. II. 274 = caudatus.

Cararu, Facq. ex Zuccag. in Roem. Collect. 158.-Hab.?

carneus, Hort. ex Moq. in DC. Prod. xiii. II. $257=$ paniculatus.

Cathecu, Hort. ex Mog. 1, c. $259=$ hybridus.

Caturus, Roxb. in Herb. Madr. sec. Wall. Cat. n 6900 -Ind or.

catdatus, Linn. Sp.Pl.990.-Oriens ; Afr. trop. ; Ind. or. cauliflorus, Link, Enum. Hort. Berol. ii. $389=$ Acroglochin chenopodioides.

celosioides, H. B. \& K. Nov. Gen. et Sp, ii, 194.-N, Granat.

cernuzs, Bess. in Cat. Hort. Turic. (1827-8) 'An Celosia?"

chlorostachys, Moq.-Tand. in DC. Prod, xiii. II. $259=$ paniculatus.

chlorostachys, Willd. Amarant. 34. t. 10, f. 19.Europ.; Oriens; Ind. or.

chlorostachys, Willk, ex Willk. \& Lange, Prod, Fl. Hisp. i. $275=$ retroflexus

circinnatus, Hort. Paris. ex Poir. Encyc. Snppl. 1. 311 $=$ lividus?

coesius, F. G. Dietr. ex Moq. in DC. Prod. xiii. II. 266. -Hab.?

commutatus, Kerner, in Oestr - Bot, Zeitschr xxy, (1875) 194.-Austr.

coracanus, Mart. Hort. Erlang. $197=$ caracasanus. crassipes, Schlecht. in Linnaea, vi. (1831) $757=$ poly gonoides.

cristatus, Noronha, in Verh. Batav, Gen. v. (1790) ed. I. Art. iv. $7=$ Celosia cristata.

crocatus, Bess. Cat. Hort. Volhyn. (1816) 9.-Hab. ?

cruentus, Linn. Syst. ed. X. $1269=$ paniculatus,

cruentus, Willd. ex Roxb. Fl. Ind. iif. $610=$ caudatus. curvifolius, Spreng. Syst. i. $928=$ retroflexus.

cuspidatus, Vis. Cat. Hort. Patav. (1841) = gangeticus. deflexus, Linn Mant, ii, 295-Europ.

Delilei, Richter \& Loret, in Bull. Soc. Bot. Fr. xiii. (1866) $316=$ patulus

diacanthus, Rafin. Fl. Ludov. 31.-Am. bor.

diandrus, Spreng. Neue Entdeck. iii. 20=Acroglochin chenopodioides.

diffusus, Dulac, F1. Hautes-Pyr, 174=A. Blitum

dioicus, Michx. ex Moq. in DC. Prod. xiii. II. $277=$ Acnida rusocarpa.

divaricatus, Andrz. ex Lindem. Prod. Fl. Cherson. 185.-Cherson.

dubius, Mart. Hort. Erlang. (1814) $197=$ tristis.

edulis, Michx. ex Moq. in DC. Prod. xiii. II. $277=$

Acnida cannabina.

emarginatus, Salzm. ex Moq.l.c. $274=$ viridis.

enervis, F. Muell. ex Benth. Fl. Austral. v. 216.Anstral.

esculentus, Bess. Cat. Hort. Volhyn. (1816) 9; ex Moq.

in DC. Prod. xiii. II. $266=$ paniculatus.

farinaceus, Roxb. ex Moq. 1. c. = paniculatus.

fasciatus, Roxb. Fl. Ind. iii. $609=$ viridis.

Fatine, Mart. Hort. Erlang. 197.-Hab.

fimbriatus, S. Wats. in Bot. Calif. ii. 42.-Calif.

flavescens, Hort. ex Moq. in DC. Prod. xiii. II. $259=$ hybridus.

flavus, Linn. Syst. ed. X. 1269.--Ind. or.

flexuosus, Hort. ex Moq. in DC. Prod. xiii. II. $260=$ tristis.

floridus, Benth. Bot. Voy. Sulph. 158. t. 51 = scariosus.

frumentaceus, Buch.-Ham, in Roxb. Fl. Ind. iii. $699=$ paniculatus.

frutescens, Hort. ex Moq. in DC. Prod. xiii. II. $348=$ Iresine amarantoides.

gangeticus, Linn. Syst. ed. X. 1268.-Reg. trop.

gangeticus, Wall. Cat. n. $6896=$ A. Blitum.

giganteus, Bess. Cat. Hort. Volhyn. (1816) 91; F. G.

Dietr. Lexik. Gaertn. i. 313.-Hab.

giganteus, L'Hérit. ex Moq. in DC. Prod, xiii. II. 277 = Acnida cannabina.

gracilis, Desf. Tabl. Hort. Par, ed. I. 43 = caudatus,

graecizans, Auct. Hisp. ex Cut. Fl. Comp. Madr. 579 =albus.

graecizans, Linn. Sp. P1.990= sylvestris

\section{AMARANTHUS :-}

Greggii, S. Wats. in Proc. Am. Acad. xii. (1877) 274 -Am. bor. occ.

ruadelupensis, Hort. ex Moq. in DC. Prod. xiii. II $257=$ paniculatus

hecticus, Willd. Amaranth. $25=$ hybridus,

hierichuntinus, Vis. in Att. Ist. Ven. Sc. Ser. III. iv. (1858-59) 139.--Syria.

Huttoni, Hort. Veitch. cf. Gard. Chron. (1872) $215=$ Celosia Huttoni.

hybridus, Linn. Sp. Pl. 990.-Am. bor.

hybridus, Vell. Fl. Flum, x. t. $28=$ flavus?

hypochondriacus, Linn. Sp. Pl. 991.-Am. bor (Europ. alien.)

inamoenus, Willd. Sp. Pl. iv. 386 (1805) Amar. $14=$ gangeticus.

incarnatus, Hort. ex Moq. in DC. Prod. xiii. II. $257=$ paniculatus

incomptus, Willd. Enum. Hort. Berol. 64=gangeticus. incurvatus, Gren. \& Godr. Prosp. Fl. Fr, $8=$ chlorostachys.

intermedius, Guss, ex Moq. in DC. Prod. xiii. II. 259 $=$ chlorostachys

interruptus, $R . B r$. Prod. 414.-Austral.

japonicus, Houtt. ex Steud. Nom. ed. I. $36=$ gangeticus

lacteus, Hort. Amstelod. (1814) $52=$ Aerva sanguino lenta.

laetus, Willd. Amaranth. 28 ; Sp. Pl. iv. $391(1805)=$ hybridus.

lanatus, Dum.-Cours. Bot. Cult. ed. I. i. $640=$ Aerva lanata.

lancefolius, Roxb. Hort. Beng. $67=$ gangeticus.

lanceolatus, Roxb. F1. Ind. iii. 607 = gangeticus.

lancifolius, Del. ex Moq, in DC. Prod, xiil. II. $276=$ interruptus.

laxiflorus, Comell. ex Poll. F1. Veron. iii. $114=$ patulus leptostachyus, Benth. Fl. Austral. v. 214.-Austral. leucanthus, Rafin. Fl. Ludov. 32.-Am. bor.

leucocarpus, S. Wats. in Proc. Am. Acad. x. (1875) 347.-Arizona.

lineatus, R. Br. Prod. $414=$ interruptus.

littoralis, Bernh. in Hort. Tur. (1813) ex Moq. in DC. Prod. xiii. II. $274=$ viridis.

littoralis, Hornm. Hort. Hafn. (1815) $893=$ albus.

lividus, Hort. Petrop. ex Hook. f. Fl. Brit. Ind. iv. 721 $=$ A. Blitum.

lividus, Linn. Sp. Pl. 990.-Am. bor.

lividus, Roxb. Fl. Ind. iii. $605=$ gangeticus.

macrocarpus, Benth. Fl. Austral. v. 216.-Austral.

macrocaulos, Poir. Encyc. Suppl. i. $314=$ Acnida cannabina.

macrostachyus, Merat, ex Moq. in DC. Prod. xiii. II $256=$ hypochondriacus.

major, Salzm. ex Moq. in DC. Prod. xiii. Ir. 274.-Hab.? mangostanus, Blanco, F1. Filip. ed. I. $711=$ melancholicus.

mangostanus, Linn. Cent. i. 32 ; Am. Acad. iv. 294.Ind. or.

Mantegazzianus, Passer. in Hort. Parm. (1864) 4.Am. austr.

maximus, Mill. Gard. Dict. ed. VIII. n. $5=$ caudatus. melancholicus, Linn. Sp. Pl. $989=$ gangeticus,

miamiensis, Riddell, Syn. Fl. West. St. (1835) 41.Am. bor.

minor, S. F. Gray, Nat. Arr. Brit. P1, ii. $289=$ A. Blitum minutus, Leschen. ex Moq. in DC. Prod. xili. II. $304=$ Aerva brachiata.

Mitchelli, Benth. Fl. Austral. v. 214.-Austral. monstrosus, Cat. Hort. Div. (1837); Hort. Tonelle, ex Moq. in DC. Prod. xiii. II. $256=$ hypochondriacus. montevidensis, Hort. ex Moq. 1. c. $257=$ paniculatus, morosus, Reichb. Fl. Germ. Excurs. 585.-Europ. mucronatus, Hort. Petrop. ex Hook. f. F1. Brit. Ind. iv $720=$ mangostanus

mucronatus, Poir. Encyc. Suppl. i, $311=$ A. Blitum. muricatus, Gill. ex Mog. in DC. Prod. xiii. II. 276 . Hab?

neglectus, Hort. ex Moq. 1. c. $259=$ hybridus.

nepalensis, Cat. Hort. Lugd. (1836); ex Moq. 1. c = hybridus.

obovatus, S. Wats. in Proc. Am. Acad. xii. (1877) 275 -Am, bor.

officinalis, Gromow, ex Trantv, in Act. Hort. Petrop. ix. (1884) $139=$ seq. ?

oleraceus, Linn. Sp. Pl. 1403.-Egypt. ; Ind. or. oleraceus, Rodsch. Essequib. $24=$ A. Blitum.

oleraceus, Roxb, Fl. Ind, iii. $605=$ gangeticus. olitorius, Bess. Cat. Hort. Volhyn. (1816) $9=$ oleraceus? 
AMARANTHUS :-

pachystachys, Reichb. ex Moq. in DC. Prod. xiii. II. $265=$ parisiensis

pallidiflorus, F. Muell. Fragm. i. 140.-Austral.

pallidus, Bieb. F1. T'aur. Cauc. ii. $399=$ A. Blitum.

Palmeri, S. Wats, in Proc. Am. Acad. xii. (1877) 274. -Calif.

paniculatus, Linn. Sp. Pl. ed. II. 1406.-Am. bor. (in Orient. alien.)

paniculatus, Wall, Cat. n. $6904=$ caudatus.

paraguayensis, Parodi, in Anal. Soc. Cient. Argent. v. (1878) 273; Contrib. 79.-Reg. Argent.

parisiensis, Schk. Handb. iii. 249.-Hab.?

patulus, Bertol. Comm. Neap. 171. t. 12.-Am. bor (in Europ. alien.).

pendulinus, Hort. ex Moq. in DC. Prod. xiii. I1, $255=$ caudatus.

pendulus, Hort, ex Moq. 1. $c_{s}=$ caudatus.

persicarioides, Hort. ex Poir. Encyc. Suppl. i. $311=$ Acroglochin chenopodioides.

polychroa, Raeusch. Nom. ed. III. $275=$ Pellionia brevifolia?

polyflagellus, Spreng. in Hort. Argent. (1834) ex Moq. in DC. Prod, xiii. II, 266.-Hab.?

polygamus, Linn. Cent. i.; Am. Acad.iv. 294.-Afr. trop.; Ind. or.

polygamus, Wall. Cat. n. 514=A. Blitum

polygamus, Thw. Enum. Pl. Zeyl. $247=$ mangostanus polygamus, Roxb. Fl. Ind. iii. $607=$ gangeticus.

polygonoides, Linn. Pl. Fam. Pugill. ii. 27.-Jamaic.; polygonoic
Zeyl.

polygonoides, Zolling. ex Moq. in DC. Prod. xiii. II, $274=$ A. Blitum.

polygonoides, Roxb. F1. Ind. iii. $721=$ polygamus. polystachyus, Buch.-Ham. in Wall. Cat. n. $6901=$ viridis.

polystachyus, Willd. Sp. Pl. iv, 385.-Ind. or.

Powellii, S. Wats, in Proc. Am. Acad. x. (1875) 347.

Powellii, S.

prostratus, Balb. Misc. Bot. 44. t. $10=$ deflexus. prostratus, Bast. F1. Maine-et-Loire, $344=$ A. Blitum pumilus, Rafin. in Med. Repos. New York, v. (1808) 360.-Am. bor.

purgans, Hort. ex Moq. in DC. Prod. xiii. II. $257=$ paniculatus.

pyramidalis, Noronha, in Verh. Batav. Gen. v. (1790), ed. I. Art. iv, $7=$ Celosia argentea.

quitensis, H. B. \& K. Nov. Gen. et Sp. ii. 194,--Peruv.

recurvatus, Desf. Cat. Jort. Par. ed. III. (1829) $39=$ retroflexus.

retroflexus, Linn. Sp. Pl. 991.-Am. bor. (in Europ. alien.).

rhombeus, R. Br. Prod. $414=$ interruptus.

rigidus, Schult. ex Steud. Nom. ed. II. i. $70=$ retroflexus,

rotundifolius, Herb. Par. ex Moq. in DC. Prod. xiii. II. 261 = gangeticus

rubescens, Hort. ex Moq. 1. c. $257=$ paniculatus.

rubricaulis, Page; Hort. Angl. ex Moq. in DC. Prod. xiii. 11. 267, nomen.-Ind. or.

ruderalis, Koch, ex Moq. 1. c. $274=$ A. Blitum.

salicifolius, Hort. Veitch, ex Gard. Chron. (1871) 1550. -Ins. Philipp

sanguineus, Linn. Sp. Pl. ed. II. $1407=$ paniculatus

sanguineus, Vell. Fl. Flum. x. t. 29.-Bras.

sanguinolentus, Schrad. ex Moq. in DC Prod. xiii. II. $267=$ paniculatus ?

scandens, Linn. f. Suppl. 419.-Am. austr.

scariosus, Benth. Bot. Voy. Sulph.158. t. 51.-Guatemala.

spathulatus, Desf. ex Moq. in DC. Prod. xiii. 1I. $276=$ lineatus.

speciosus, Sims, Bot. Mag. t. $2227=$ paniculatus.

spicatus, Lam. Fl. Fr. ii. $192=$ retroflexus.

spicatus, Wirzen, Diss. PI. Casan. $454=$ paniculatus.

spicatus, Reichb. Fl. Germ. Excurs. $585=$ patulus.

spinosus, Linn. Sp. Pl. 991.-Keg. trop.

spiratus, Zipp. ex Span. in Linnaea, xv. (1841) 345, nomen,-Malaya.

strictus, Tenore, Syll. $127=$ retroflexus.

strictus, Willd. Amaranth. $27=$ paniculatus.

sylvestris, Desf. Tabl. Hort. Par. ed. I. 44.-Europ.; Oriens.

temuiflorus, Fisch. Hort. Hal, ex Moq. in DC. Prod. xiii. $11.267=\operatorname{seq}$ ?

tenuifolius, Roxb. Fl. Ind, iii. $602=\mathrm{A}$. Blitum.

tenuifolius, Willd, Sp, Pl. iv, 381.-Ind, or

tenuifolius, Wall. Cat. n. $6893=$ polygamus

tenuis, Benth. Fl. Austral. v. 216.-Austral.

\section{AMARANTHUS :}

Thunbergii, Moq. in DC. Prod. xiii. J1. 262.-Afr. austr Timeroyi, Jord. ex Moq. 1. c. $259=$ patulus.

Torreyi, Benth. ex S. Wats. Bot. Calif. ii. 42.Am. bor.

tortuosus, Hornem. Hort. Hafn. Suppl. 107.-Ins. S Cruce.

tricolor, Iinn. Sp. Pl. 989= gangeticus.

tristis, Linn. 1. c, $=$ gangeticus.

tristis, Wall. Cat. n. $6905=$ mangostanus.

trivialis, Rota, in Giorn. Bot. Ital. ii. II. (1846) $287=$ patulus.

undulatus, Lindl. in Mitch. Trop. Austr. $102=$ Mitchelli?

undulatus, R. Br. Prod. $414=$ interruptus.

urceolatus, Benth. in Bot. Voy. Sulph. 158.-Guayaquil venulosus, S. Wats, in Proc. Am. Acad.xvii. (1881-82) 376.-Am. bor.

vernus, Opiz, ex Moq. in DC. Prod. xiii. II. 267, nomen -Europ.

verticillatus, Pav. ex Moq. in DC. Prod. xiii. II. $270=$ polygonoides.

violaceus, Hort. ex Moq. 1. co=paniculatus.

viridis, All. Fl. Pedem. hi. $19=\mathrm{A}$. Blitum.

viridis, Linn. Sp. Pl. ed. II. 1405.--Reg, trop.

viridis, Pall. ex Steud. Nom. ed. II. i. $36=$ pallidus.

viridis, Pollich, ex Mog. in DC. Prod. xiii. II. $268=$ prostratus.

Wrightii, S. Wats. in Proc. Am. Acad, xil. (1877) 275.-Am. bor.

zanensis, Hornm. ex Moq. in DC. Prod. xiii. II. 267.Hab, ?

AMARANTUS, Linn. Syst, ed. x. $1268(\mathbf{1 7 5 9})=\mathbf{A} \mathbf{m a}$ ranthus, Linn.

AMARELLA, Gilib. Fl. Lituan. i. $36(1781)=$ Gentiana

acuta, Rafin. Fl. Tellur. iii. $21=\mathrm{G}$. Amarella.

brevicaulis, Rafin. 1. c,-Hab.?

gracilis, Rafin. 1. c. = G. Amarella.

quadrifida, Gilib. Fl. Lituan. i. $36=\mathrm{G}$. campestris

quinquefida, Gilib. 1. c. = G. Amarella.

rugosa, Rafin. Fl. Tellur. iif. 21.-Hab.

vulgaris, Rafin. 1. c. $20=\mathrm{G}$. campestris.

AMARENUS, C. Presl, Symb. Bot. i. 46 (1830)= Tri folium, Linn. (Legum.)

agrarius, C. Presl, 1. C. $=$ T. agrarium.

aureus, Fourr. in Ann. Soc. Linn. Lyon, N. S, xvi (1868) $362=\mathrm{T}$, agrarium.

badius, C. Presl, 1. c. = T. badium.

campestris, Fourr. l. c. $=\mathrm{T}$. procumbens.

filiformis, C. Presl, l. c. =T. filiforme.

flavus, C. Presl, 1. c. = T. flavum.

micranthus, Fourr. 1. c. =T. filiforme.

patens, C. Presl, 1. c. = T. patens

procumbens, C. Presl, l. c. = T. procumbens.

Schreberi, Fourr. 1. c. $=$ T. procumbens.

Sebastiani, C. Presl, 1. c. =T. Sebastiani

spadiceus, C. Presl, l, c. = T. spadiceum.

speciosus, C. Presl, 1. c. = T. speciosum.

AMARIA, Mutis, ex Caldas, in Seman. Nuev, Gran. ii (1810) 25 = Bauhinia, Linn. (Legumin.) petiolata, Mutis, l. c. = B. petiolata. sessilifolia, Mutis, 1. c.-N. Granat.

AMARIDIUM, Hort. ex Lubbers, Cat. Pl. Rar. San Donato, $15(1880)=$ Camaridium, Lindl. (Orchid.)

AMARoRIA, A. Gray, Bot. U. St. Expl. Exped, i. $356^{\circ}$ t. 40 (1854). SIMARUBEAE, Benth. \& Hook. f. i.

314.
soulameoides, A. Gray, 1. c.-Ins. Fiji.

ANARYLLIS, Linn. Syst. ed. I. (1735), AWARYLLIDEAE, Benth. \& Hook. f. iii. 727.

Atamosco, Adans. Fam. ii. 57 (1763)

Belladonna, Sweet, Hort, Brit. ed. II. 506. (1830).

CALlicore, Link, Handb. i. 193 (1829).

CAllirö̈, Endl. Gen, 176 (183\%)

acuminata, Ker-Gawl. in Bot. Keg. t. $584=$ Hippeastrum rutilum.

advena, Ker-Gawl. 1. c. t. $1125=$ Hippeastrum advепแก.

aethnensis, 'Rafin.' vide etnensis.

africana, Lam. Encyc, i. $124=$ Lycoris aurea.

Agatha, Steud. Nom, ed. II. i. $72=$ H. reticulatum.

alba, Forsk. F1. Aegypt. Arab. $208=$ Crinum album.
AMARYIIIS :

Alberti, Lem. Illustr. Hortic. (1866) t. 498=Hippeastrum Reginae.

alta, Steud. Nom. ed. II. i. $72=$ Hippeastrum splendens,

Andersonii, Steud. 1. c. i. $71=$ Zephyranthes An dersoni.

andicola, Poepp. Fragm. Syn. 5 (=Habranthus andicolus

angusta, Schult. f. Syst. vii. $807=$ Hippeastrum bifidum. Aramasco, Linn. Sp. Pl. ed. II. 420 (sphalm.) = Zephy ranthes Atamasco.

arvensis, F. G. Dietr. Lexic. Gaertn. Nachtr, i. $204=$ peruviana.

Atamasca, Linn. Sp. Pl. $292=$ Zephyranthes Atamasc

Atamasco, Blanco, F1. Filip. ed. I. 254=Hippeastrum miniatum.

atanasia, Crantz, Inst. i. $486=$ Zephyranthes Ata masca.

aucta, Tratt. Thes. $45=$ Nerine undulata.

aulica, Ker-Gawl, in Journ. Sc. \& Arts, ii. (1817) 353 et in Bot. Reg. t. $444=$ Hippeastrum aulicum.

aurea, L'Herit. Sert. Angl. $14=$ Lycoris aurea.

aurea, Ruiz \& Pav. Fl. Per. iii. 56 (=Pyrolivion

aureum)

australasica, Ker-Gawl. in Bot. Reg. t, 426=Crinum flaccidum.

australis, Spreng. Syst. ii. $54=$ praec.

Bagnoldi, D. Dietr. Syn. Pl. ii. $1177=$ Hippeastrum Bagnoldi.

bahiensis, DC. Pl. Rar. Jard. Genève, 7mo Notice, $18=$ Hippeastrum bahiense.

Bangoldi, Steud. Nom. ed. II. i. 70, sphalm. Bagnoldi.

Banksiana, Lind1. Bot. Reg. (1842), t. 11. \& Append. $18=$ Brunsvigia Slateriana.

Belladonna, Linn. Sp. Pl. 293.-Afr. austr.

Belladonna, E. Mey, ex Steud. Nom. ed. II i. $70=$ Hippeastrum equestre.

Berterii, Spreng. Syst. ii, 49 (= Habranthus robustus)

bicolor, Ruiz \& Pav. Fl. Per. iii. 57=Hippeastrum bicolor.

bifida, Spreng. Syst. Cur. Post. $133=$ Hippeastrum bifidum

bifolia, Aubl. Pl. Gui. i. 304=Zephyranthes rosea

bivaginata, Donn, Hort. Cantab, ed. VIII. 95

Cyrtanthus pallidus.

blanda, Ker-Gawl, in Bot. Mag. t. $1450=\mathrm{A}$. Bella. donna.

brasiliensis, Andr. Bot. Rep. t. 358=Hippeastrum equestre, Reginae.

brasiliensis, Tratt. Tabul. t. $333=$ Hippeastrum rutilum.

Broussonetii, [DC. in] Red. Liliac. ii. $62=$ Crinum yuccaeflorum.

bulbisperma, Burm. f. Fl. Cap. Prod. $9=$ Crinum capense.

caerulea, Griseb. in Goett. Abh. xxiv. (1879) 320 .Reg. Argent.

calyptrata, Hoffmgg. in Linnaea, xvi. (1812) Litt. 27 -Hab. ?

calyptrata, Ker-Gawl. Rev. 11; et in Journ. Sc. \& Art; ii. (1817) $353=$ Hippeastrum calyptratum.

candida, Lindl. in Bot. Reg. t。 $724=$ Zephyranthes candida.

candida, Tratt. Tabul. t. $488=$ Crinum giganteum. capensis, Linn. Pl. Afr, 10? (Amoen. Acad, vi. Mi) =

Hypoxis stellatus.

capensis, Mill. Gard. Dict. ed. VIII. D. $12=$ Crinum longifolinm.

carinata, Spreng. Syst. Cur. Post. $152=Z$ ephyranthes carinata.

carnea, Schult. f. Syst. vii. $799=$ Zephyranthes rosea.

Carolinae, Sterler, Hort. Nymph. $(1: 2 b: 41=\mathrm{Hip}$. peastrum reticulatum.

caspia, Willd. Sp. Pl. ii. 62 Allium caspium.

chilensis, L'Herit. Sert. Angl. 11 = Hippeastrun. chilense.

chilensis, Ruiz \& Pav. FL. Per. iii. $50^{\circ}=$ Hippeastrum miniatum.

chloroleser, Ker-Gawl. in Tourn. Sc. \& Arts, ii. (1s)

347 . $8.8,1=7$ ephyranthes chlorolcucs.

ciliaris, Linn. Sp. Pl. ed. 11. $122=$ Buphane ciliaris. cinnamomea, L'Herit. Sert. Angl. $15=$ Hessen crispla citrina, Sibth. \& Sm. Fl. Gmec, iii. t. 311 a Steruberyia colchiciflora.

clas'ata, L'Hcrit. Sers. Angl, 11 = Cyrtanthus uniflorns

Clusiona, Keroliawl. in Juurn. Sc. Se Arts ii. 1sl:

$\$+0^{\circ}=$ Sicrabergia col biciflora. 


\section{AMARYLIIS :-}

coccinea, Molina, Saggio Chil. ed. II. $284=$ chilensis colchiciflora, Hort. Mosq. ex Schult. f. Syst. vii. $1135=$ Bulbocodium versicolor.

colchiciflora, Ker-Gawl. in Journ. Sc. \& Arts, ii. (1817) $345=$ Sternbergia colchiciflora.

concinna, Morris, Fl. Conspic. t. 44.-Hab.

coracina, Steud. Nom. ed. II. i. $70=$ seq.

coranica, Ker-Gawl. in Bot. Reg. ii. $139=$ Ammocharis falcata.

correiensis, Bury, Hexand. P1. $9=$ Hippeastrum organense.

corusca, Ker-Gawl. in Bot. Mag. fol, 1430= Nerine curvifolia.

crispa, Jacq. Hort. Schoenb. i. $37=$ Hessea crispa.

crocata, Ker-Gawl. in Bot. Reg. t. $38=$ Hippeastrum rutilum.

curvifolia, Jacq. Hort. Schoenb. i. $33=$ Nerine curvifolia.

Cybister, Herb. ex Fl. des Serres, v. t. $455,456=$ Hippeastrum Cybister.

cylindracea, L'Hérit. Sert. Angl. $15=$ Cyrtanthus angustifolius.

cyrtanthoides, Sims, Bot. Mag. t. $2399=$ Hippeastrum bicolor.

demissa, Steud. Nom. ed. II. i. 71.-Chili.

depauperata, Poepp. Fragm. Syn. 4=Zephyranthes depauperata.

disticha, Sims, Bot. Mag. sub t. $1943=$ Crinam yuccaeflorum.

disticha, Linn. f. Suppl. 195= Buphane disticha.

Drummondii, Steud. Nom. ed. II. 1. $71=$ Cooperia Drummondii.

Dryades, Vell. Fl. Flum. 130 ; iii. t. $117=$ Griffinia Dryades.

dubia, Houtt. Plantenk, xii. 181. t. 84, f, $1=$ Nerine samiensis.

dubia, Linn. Diss. PI. Surin. n. 39 ; et Am. Acad. viii $254=$ Hippeastrum equestre

elata. Jacq. Hort. Schoenb. i. $32=$ Vallota purpurea.

elegans, Spreng. Pngill. ii. $59=$ Hippeastrum solandraeflora.

Entreriana, Hoffmgg. in Linnaea, xliii. (1880-82) 137 $=$ Zephyranthes mesochloa.

equestris, Ait. Hort. Kew. i. $417=$ Hippeastrum equestre.

etnensis, Rafin. Caratteri, $84=$ Sternbergia colchiciflora.

exigua, Schousb. Vextr. Marokko, $160=$ Tapeinanthus humilis.

falcata, L'Hérit. Sert. Angl. $13=$ Ammocharis falcata.

falcata, Lee, ex Stend. Nom. ed. II. i. $73,475=$ Cyrtanthus angustifolius.

flaccida, Weinm. in Flora, iii. (1820) $608=$ Crinum flaccidum.

flammea, Ruiz \& Pav, F1. Per. iii. 56 (=Pyrolirion flammeum).-Peruv.; Chili.

flava, Pav, ex Roem. \& Schult. Syst, vii. $805=$ Zephyranthes flava.

favovirens, Schott, ex Stend. Nom. ed. II. i. 71.-Cf. fulvovirens.

flexuosa, Jacq. Hort. Schoenb. i. $35=$ Nerine flexuosa.

Forbesii, Lindl. in Trans. Hort. Soc. vi (1826) $87=$

Crinum Forbesianum

formosa, Salisb. Prod. $234=$ seq .

formosissima, Linn. Sp. Pl. 293 = Sprekelia formosisima.

Fothergillia, Andr. Bot. Rep.iii. $163=$ Nerine curvifolia

Fothergillii, Poir. Encyc. Suppl. i. $320=$ praec.

fulgida, Ker-Gawl. in Bot. Reg. t. $226=$ Hippeastrum rutilum.

fulvovirens, Schott, in Sehreib. Nachr. Oesterr. Naturf. $129=$ Hippeastrum calyptratum.

Gardneri, Seub. in Mart. Fl. Bras. iii. 149=Hippeastrum organense.

gigantea, Ait. Hort. Kew. ed. II. ii. $226=$ Crinum giganteum.

gigantea, Van Marum, in Verh. Maats. Haarl. iii (1806) $345=$ Brunsvigia Josephinae.

glaucescens, Mart. in Schult. f. Syst. vii. $813=$ Hippeastrum rutilum.

gracilifolia, Schult. f. 1. c. 806 (=Habranthus gracilifolius)

gracilis, Spreng. Syst. Cur. Post. 133= praec

grandiflora, D. Dietr. Syn. Pl. 11. $1181=$ Brunsvigia grandiflora.

grandifiora, Steud. Nom. ed. II. i. $73=$ Sprekelia formosissima.

\section{AMARYLLIS :-}

guttata, Linn. Sp. Pl, $294=$ Buphane ciliaris.

haemanthoidea, Tratt. Gartenpfl. $38=$ Haemanthus amarylloides.

humilis, Jacq. Hort. Schoenb. i. $36=$ Nerine humilis

humilis, Link, Enum. i. $313=$ Cyrtanthus uniforus.

hyacinthina, Ker-Gawl. in Bot. Reg. t. 163=Griffinia hyacinthina.

ignea, Lindl. Bot. Reg. t. $809=$ Hippeastrum bicolor.

ignescens, Regel, Gartenfl. xxiii. (1874) $150=$ Hippeastrum ignescens.

illustris, Vell. F1. Flum. 131; iii. t. 118= Hippeastrum psittacinum.

insignis, Ker-Gawl. Bot. Reg. t. 579=Crinum latifolium.

intermedia, Lindl. Bot. Reg. t. 1148 (= Habranthus intermedius)

intermedia, Spreng. Syst. iv. Cur. Post. 133=Griffinia intermedia.

Facquinii, Tratt. Gartenpfl. $43=$ Nerine sarniensis.

Fagus, Thomps. Bot. Displ. t. $6=$ Crinum giganteum.

Fosephinae, [Del.] Red. Lil. vii. $370=$ Brunsvigia Josephina.e.

Fosephiniana, Herb. Amar. $278=$ praec.

Karwinskii, Zucc. in Otto \& Dietr. Allg. Gartz. ii (1834) $245=$ Sprekelia formosissima.

kermesiana, Lindl. in Bot. Reg. t. 1638= Hippeastrum bifidum.

lateritia, A. Dietr. in Otto \&o Dietr. Allg. Gartz. xviii. (1850) 65.-Guinea.

laticoma, Ker-Gawl. in Bot. Reg. vi. 497 = Nerine Iucida

latifolia, Lam. Encyc. i. $124=$ Crinum giganteum.

latifolia, L'Hérit. Sert. $14=$ Crinum ornatum.

leonensis, Van Houtte, Hort. Vanhoutt. fasc. i. (1845) 5.-Afr. trop.

Leopoldii, Hort. Veitch. in Gard. Chron. (1870) $733=$ Hippeastrum Leopoldi.

Lindleyana, Schult. f. Syst. vii. $802=$ Zephyranthes carinata, Lindleyana.

linearifolia, Molina, Chile, ed. II. $284=$ Hippeastrum chilense.

linearis, Willd. Sp. P1. ii. $53=$ Crinum lineare

lineata, Colla, Hort. Rip. $3=$ Hippeastrum vittatum. lineata, Lam. Encyc. i. 123=Crinum zeylanicum. littoralis, Salisb. Prod. $230=$ Crinum latifolium.

liturata, Reichb. Ic. t. 82.-Hab.?

longa, Hort. ex Schult. f. Syst. vii. $854=$ Crinum yuccaeflorum

longiflora, Steud. Nom. ed. II. i. 70, 71=Hippeastrum solandrifolium.

longifolia, Linn. Sp. PI. $293=$ Crinum longifolium.

longipetala, Lem. Illustr. Hortic. xiii. (1866) Misc. 78. -Hab?

lorifolia, Stend. Nom. ed. II. i. 71 (=Habranthus lorifolius).--Am. austr.

Lowii, Morr. in Ann. Soc. Agr. Gand, ii. (1846) 141. t. 62.-Hab. ?

lucida, D. Dietr. Syn. Pl. ii. $1181=$ Nerine Iucida.

lutea, Bieb. Fl. Taur. Canc. iii. $255=$ Sternbergia Fischeriana

lutea, Linn. Sp. P1, $292=$ Sternbergia lutea.

lutea, Pav. ex Roem. \& Schult. Syst. vii. 797.Cf. lutescens.

lutescens, Herb. ex Kunth, Enum. P1. v. $497=$ Hippeastrum chilense.

maculata, L'Hérit. Sert. Angl. 10 (= Habranthus maculatus).

maranensis, Ker-Gawl. in Bot. Reg. t. $719=$ Hippeastrum stylosum.

marginata, Jacq. Hort. Schoenb. i. $34=$ Nerine marginata.

mesochloa, Steud. Nom. ed. II. i. $71=$ Zephyranthes mesochloa.

mexicana, Hort, ex Savi, Fl. Ital. iii. 29. t. $94=$ Vallota purpurea.

miniata, Ker-Gawl. in Journ. Sc. \& Arts, ii. (1817) $355=$ Hippeastrum rutilum.

miniata, Ruiz \& Pav. Fl. Per. iii. 57=Hippeastrum miniatum.

minima, Griseb. in Goett. Abh. xxiv. (1879) $321=$ Zephyranthes minima.

minima, Ker-Gawl in Journ. Sc. \& Arts, ii. (1817) 350 ; Rev. $8=$ Zephyranthes verecunda. minor, D. Dietr. Syn. Pl. ii. $1180=$ Brunsvigia minor. minuta, H. B. \& K. Nov. Gen. et Sp. i. $278=$ Zephyranthes verecunda.

moluccana, Ker-Gawl, in Journ. Sc. \& Arts, iii. (1817) $109=$ Crinum latifolium.

\section{AMARYIIIS :-}

montana, Labill. Ic. PI. Syr. Dec. ii. 5=Ixiolirion montanum.

multiflora, D. Dietr. Syn. P1. ii. $1180=$ Brunsvigia gigantea.

multiflora, Tratt. Gartenpfl. $37=$ Haemanthus multiflorus.

nervosa, H. B. \& K. Nov. Gen. et Sp. i. $278=$ Zephyranthes tubispatha.

nervosa, Poir. Encyc. Suppl. i. 321=Brunsvigia striata nivea, Schult. f. Syst. vii. $799=$ Zephyranthes candida.

nobilis, Salisb. Prod. 235 = Brunsvigia gigantea

ochrolenca, Ker-Gawl. ex Schult. f. Syst. vii. $797=$ Zephyranthes chloroleuca.

orientalis, Linn. Sp. Pl. $293=$ Brunsvigia gigantea

ornata, Ait. Hort. Kew. i. $418=$ Crinum yuccaeflorum.

ornata, Ker-Gawl. in Bot. Mag. t. $1171=$ Crinum zeylanicum.

Osbeckii, Sabine, ex Desf. Cat. ed. III. 388=Crinum Osbeckii.

ovigera, Schult. f. Syst. vii. $840=$ Peliosanthes javanica ? pallida, [Del.] Red. Liliac. viii. $479=$ A. Belladonna.

pallida, Willd. ex Schult. f. Syst. vii. $801=$ Zephyranthes verecunda.

pardina, Hook. f. Bot. Mag. t. $5645=$ Hippeastrum pardinum.

parvula, Seub. in Mart. Fl. Bras, iii, 145=Zephy. ranthes minima.

pendula, Salisb. Prod. $231=$ Cyrtanthus obliquus.

peruviana, Ker-Gawl. in Bot. Mag. sub t. 1089 (=Pyrolirion aureum).

phycelloides, Steud. Nom. ed. II. i. $72=$ Hippeastrum phycelloides.

platypetala, Lindl. ex Bury, Hexand. P1. 15=Lycoris aurea.

praeclara, Sweet, Hort. Brit. ed. II. 506= Hippeastrum reticulatum.

Princeps, Vell. Fl. Flum. 130 ; iii. t. $115=$ Hippeastrum reticulatum.

Principis, Salm-Dyck, in Nov. Act. Nat. Cur. x. (1821) $154=$ Hippeastrum reticulatum.

procera, Duchart, in Bull. Soc. Bot. Fr. x. (1863) $75=$ Hippeastrum procerum.

procera, Salisb. Prod. $230=$ Crinum erubescens

propinqua, Salisb. l. c-Panama.

psittacina, Ker-Gawl. in Bot. Reg.t. $199=$ = Hippeastrum

psittacinum.
pudica, Ker-Gawl. in Journ. Sc. \& Arts, ii. (1817) 348 $=$ A. Belladonna

pulchella, Salisb. Prod. $229=$ Zephyranthes Atamasco. pulchella, Spreng. ex Kunth, Enum. Pl. ii. $633=$ Hessea crispa.

pulchra, Salisb. Prod. $233=$ Nerine sarniensis

pulverulenta, Lodd. Bot. Cab. t. $484=$ Hippeastrum rutilum.

pumila, Spin. Jard. Sébast. 28; ex Spreng. Neue Entdeck. i. $252=$ Zephyranthes pumila.

Pumilio, Ait. Hort. Kew. i. 415=Cyrtanthus uniflorus. punicea, Lam. Encyc. 1. $122=$ Hippeastrum equestre. purpurea, Ait. Hort. Kew. i. $417=$ Vallota purpurea. radiata, L'Hérit. Sert. Angl, $15=$ Lycoris radiata.

Radula, Jacq. Hort. Schoenb. i. $35=$ Brunsvigia Radula.

Rayneri, Hook. Bot. Mag. t. $5883=$ Hippeastrum procerum.

regalis, Salisb. Prod. $232=$ A. Belladonna,

Reginae, Linn. Syst. Nat. ed. X. ii. $977=$ Hippeastrum Reginae.

reticulata, L'Hérit. Sert. Ang1. 12 = Hippeastrum reticulatum.

revoluta, L'Hérit. 1. c. $13=$ Crinum lineare.

riparia, Burch. ex Kunth, Enum. Pl. ii. $580=$ Crinum longifolium.

robusta, A. Dietr. in Otto \& Dietr. Allg. Gartz. xviii. 1850) $41=$ Hippeastrum aulicum.

robusta, Sweet, ex Steud. Nom. ed. II. 1. 74 (=Habran thus robustus).

Roezli, Regel, Gartenfl. (1874) 290. f. $809=$ Hippeastrum equestre.

rosea, Lam. Encyc, i. 122=A. Belladonna.

rosea, Spreng. Syst. iv. Cur. Post. $133=$ Zephyranthes Tosea.

rotundifolia, Lam. Encyc. i. $124=$ Eurycles sylvestris. Rougieri, Hort. ex Carr. in Rev. Hortic. (1882) $312=$ Hippeastrum aulicum.

utila, Ker-Gawl. Rev. 16; in Bot. Reg. i. t. $23=$ Hippeastrum rutilum. 


\section{AMARYILIS :}

rutilans, Lodd. ex Stend. Nom. ed. II. i. $74=$ Hippeastrum rutilum.

sarniensis, Linn. Sp. P1. $293=$ Nerine sarniensis. scillifolia, Hort. Angl. ex Schult. f. Syst. vii. $854=$ Crinum distichum.

semibarbata, Steud. Nom. ed. II. i. 72, sphalm. (loco Antherici) = Bulbine bulbosa.

Slateriana, Lindl. Bot. Reg. (1844) App. $76=$ Brunsvigia Slateriana.

solandraeflora, Lindl. Coll. Bot. t. $11=$ Hippeastrum solandraeflorum.

spathacea, Schult. f. Syst. vii. 808 (= Habranthus spathaceus).-Bonaria.

speciosa, L'Hérit. Sert. Angl. 12 = Vallota purpurea.

spectabilis, Andr. Bot. Rep. t. $390=$ Crinum yuccae florum.

spectabilis, Lodd. Bot. Cab. t. 159=Hippeastrum Reginae

spiralis, L'Hérit. Sert. Angl. $10=$ Hessea spiralis.

staminea, Seub. in Mart. F1. Bras. iii. $150=$ Hippeastrum stylosum.

stellaris, Jacq. Hort. Schoenb. i. $37=$ Hessea stellaris, stilosa, Bury, Hexand. Pl. t. 33= Hippeastrum stylosum striata, Jacq. Hort. Schoenb. i. 36=Brunsvigia striata striata, Lam. Encyc. i. $125=$ Hippeastrum rutilum. striatula, Schult. f. Syst. vii. $801=$ Zephyranthes verecunda.

stylosa, Sweet, Hort. Brit. ed. I. $403=$ Hippeastrum stylosum.

subbarbata, Schult. f. Syst. vii. $819=$ Hippeastrum rutilum.

superba, Bury, Hexand. P1. t. $31=$ Hippeastrum vittatum.

Sweetiana, Stend. Nom. ed. II. i. $72=$ Hippeastrum adoenum.

Sweetii, Herb. ex Sweet, Hort. Brit. ed. II. $506=$ Hippeastrum reticulatum.

sylvatica, Mart. in Schult. f. Syst. vii. 807 (=Habranthus sylvaticus).

Symoni, Funck, in fourn. Hort. Prat. Sér. II. iii. (1859) 242.t. 20.-Hab.?

tatarica, Georgi, Beschreib. Russ. Reich. iii, Iv. 890 = Ixiolirion Ledebouri.

tatarica, Pall. Reise, iii. $727=$ Ixiolirion tataricum.

tenella, Thunb. ex Steud. Nom. ed. II. i. $72=$ Carpolyza spiralis.

toxicaria, D. Dietr. Syn. Pl. ii. $1181=$ Brunsvigia toxicaria.

tubiflora, L'Hérit. Sert. Angl. 10 (= Pyrolirion aureum). -Peruv.

tubispatha, L'Hérit. 1. c. $9=$ Zephyranthes tubispatha Umbella, L'Hérit. 1. c. 15 = Cyrtanthus obliquus. undulata, Linn. Syst. ed. XII. $237=$ Nerine undulata unguiculata, Mart. ex Schult. f. Syst. vii. $189=$ Hippeastrum calyptratum.

vaginata, D. Dietr. Syn. P1. ii. $1181=$ Strumaria vaginata,
truncata.

valparadisiaca, Steud. Nom. ed. II. i. 183 (=Habranthus pallidus).-Chili.

variabilis, Jacq. Hort. Schoenb. iv. $14=$ Crinum variabile.

venusta, Ker-Gawl, in Bot. Mag. t. 1090=Nerine sarnicnsis.

verecunda, Salisb. Prod. $229=$ Zephyranthes Atamasco. verecunda, Schult. f. Syst. vii. $800=$ Zephyranthes verecunda.

vernalis, Mill. Gard. Dict. ed. VIII. n. $10=$ Hypoxis stellatus.

Verreauxii, Hort.-Cf. Fourn. et Flore des fardins, ii. (1832) t. 119.-Hab. ?

versicolor, Spreng. Syst. Cur. Post. $133(=$ Habranthus versicolor

vittata, L'Hérit. Sert. Angl. 13= Hippeastrum vittatum. vivipara, Lam. Encyc. i. $123=$ Crinum defixum yuccaeoides, Thomps. Bot. Displ. t. $12=$ Crinum yuccaeflorum.

seylanica, Linn. Sp. Pl. $293=$ Crinum zeylanicum.

AMARYLLIS, Sweet, Hort. Brit. ed. II. $506(\mathbf{1 8 3 0})=$ Hippeastrum, Herb

AMASONIA, Linn. f. Suppl. 48, 294 (1781). VER$B E N A C E A E$, Benth. \& Hook. 1. ii. 1147.

DiPHYSTEMA, Neck. Elem. i. 382 (1790)

Diplostemma, 'Neck' ex DC. Prod, vii. 306 , in nota (1588) lapsu.

TAligalea, Aubl. Pl. Gui. ii. 625, t. 252 (1775)

\section{AMASONIA :}

angustifolia, Mart. E Schau. in DC. Prod. xi.678.Bras.

arborea, H. B. \& K. Nov. Gen. et Sp. ii. 253.Venezuela.

erecta, Linn.f. Suppl. 294.-Guiana.

hirta, Benth. in Ann. Nat. Hist. ii (1839) 451Guiana.

integerrima, Spreng. Syst. ii. 765,-N. Granat.

lasiocaulon, Mart. \&o Schau. in DC. Prod. xi. 678.Am. austr.

punicea, Vahl, Eclog. ii. 51.-Ins. Trinit.

Taligalea, Auct. ex Steud. Nom. ed. II. i. $74=$ erecta.

velutina, Schau, in DC. Prod. xi. 677.-Bras.

AMATHEA, Rafin. Fl. Tellur, iv. 65 (1836)=Aphelandra, R. Br. (Acanth.)

pulchra, Rafin. 1. c.=Aph. pulcherrima.

AMATULA, Medic. Bot. Beobacht. 38 (1782); Malv. 106 (1787) = Lycopersicum, Mill. (Solan.).

flava, Medic. Malv. $106=\mathrm{L}$. esculentum.

rubra, Medic. l. $c_{\diamond}=\mathrm{L}$. esculentum.

AMAURIA, Benth. Bot. Voy. Sulph. 31 (1844). COMPOSITAE, Benth. \& Hook. f. ii. 404.

dissecta, A. Gray, Pl. Fendl. 104.-N. Mexic.

rotundifolia, Benth. Bot. Voy. Sulph. 31.-Calif.

AMAXITIS, Adans. Fam. ii. $34(1763)=$ Dactylis, Linn. (Gramin.).

AMBAIBA, Adans. 1. c. $377(1763)=$ Cecropia Loef. (Urtic.).

AMBASSA, Steetz, in Peters, Reise Mossamb. Bot. 364 $(1863)=$ Vernonia, Schreb. (Compos.)

Hochstetteri, Steetz, 1, c. $=$ V. Hochstetteri.

AMBELANIA, Aubl. Pl. Gui. i. 265. t. 104 (1775). $A P O C Y N A C E A E$, Benth. \& Hook, f, ii. 694.

BenteCA, Adans. Fam, ii. 166 (1763)

Kasailo, Dennst. Schluess. Hort. Malab. 30 (1818).

Willughbeia, Scop. in Schreb. Gen. 162 (1789).

acida, $A u b l$. Pl. Gui. i. 265. t. 104.-Guiana.

cuneata, Muell. Arg. in Mart.Fl. Bras. vi. I. 17.-Bras.

laxa, Muell. Arg. l.c.-Am. austr.

macrophylla, Muell. Arg. l. c. 18.-Bras.

quadrangularis, Muell. Arg. l. c.-Bras.

Sagoti, Muell. Arg. in Linnaea, xxx. (1859-60) 389 -Guiana.

tenuiflora, Muell. Arg. in Mart. Fl. Bras. vi. I. 16.

-Bras.

AMBERBOA,Less. Syn. Comp. 8 (1832)=Volutarella, Cass. etc. (Compos.),

abyssinica, A. Rich. Tent. F1. Abyss. i, $453=$ Centaurea Hochstetteri.

Bollei, Sch. Bip. ex C. Bolle, in Bonplandia, vii. (1859) 297.-Ins. Canar.

carthamoides, DC. Prod. vi. 561 (=Phaeopappus carthamoides)

crupinoides, DC. 1. c. $559=\mathrm{V}$. bicolor.

decurrens, DC. 1. c. $560=$ Centaurea decurrens.

discolor, Lojac, in Natural. Sicil. iv, (1885) 133.-Sicil. erucifolia, DC. Prod. vi. $559=\mathrm{V}$. erucifolia.

glauca, Less. Syn. Comp. $8=$ Centaurea moschata ? Goniocaulon, DC. Prod.vi. 558 = Goniocaulon glabrum Hochstetteri, Buching. ex Oliver, F1. Trop. Afr, iii, 438 = Centaurea Hochstetteri.

incanescens, DC. Prod. vi. $561=$ Centaurea integrifolia indica, DC. 1. c. $558=$ Goniocaulon glabrum lancifolia, DC. 1. c. $661=$ Centaurea lancifolia. leucantha, Coss. Ind. P1. Maroc. 21.-Algeria. Lippii, DC. Prod. vi. $559=$ V. Lippii.

micractis, Boiss. \& Reut.Diagn. Ser. II iii.62-Algeria. moschata, Less. Syn. Comp. $8=$ Centaurea moschata muricata, DC. Prod. vi. $559=$ V. muricata. odorata, DC. 1. c. = Centauren moschata.

Perralderiana, Coss, in Bull. Soc. Bot. Fr, xxii. (1S75) 62, nomen. - Afr. bor.

phaeopappa, DC. Prod. vi. $560=$ Centaurea leuzeoides, sinaica, DC, 1, c. $559=\mathrm{V}$, bicolor.

spectabilis, DC. 1. c. 561 (= Placopapous spectabilis). Wallichiana, DC. 1. c. $558=$ Centaurea Wallichiana. xanthocephala, DC. 1. c. 561 ( $=$ Psephellus xanthocephalus).
AMBERBOI, Adans. Fam.ii. $117(1763)=$ AMBERBOA.

AMBINAX, Comm. ex Juss. Gen.389(1789) = Aleurites Forst. (Euphorb.).

AMBLACHAENIUM, Turcz, ex DC. Prod, vii. 94 (1838 = Hypochoeris, Linn. (Compos.) aurantiacum, Turcz. ex DC. 1. c = $=$ H. grandifora.

AMBLA TUM, [Toum.] G. Don, Gen. Syst. iv. 635 (1837) =ANBLATUM, Toum.=Lathraea, Linn. (Orobanch.).

AMBLEIA, Spach, Hist. Vég. Phan. ix. 166 (1840), nomen =Stachys, Linn. (Labiat.)

AMBLIRION, Rafin, in Am. Monthly Mag. (1818) $26 \%$ = Fritillaria, Linn. (Liliac.

album, Sweet, Hort. Brit. ed. II $538=\mathrm{F}$ alba camtschacense, Sweet, 1. c. = F. kamtschatcensis grecum, Rafin. F1. Tellur. ii. $35=\mathrm{F}$. graecum? lanceolatum, Sweet, l. c. = F. kamtschatcensis pudicum, Rafin. in Am. Monthly Mag. (1818) $265=\mathrm{F}$ pudica.

AMBLOGYNA, Rafin. Fl. Tellur. ini. $42(1836)=$ Ama ranthus, Linn.

fimbriata, A. Gray, in Proc. Am. Acad. v. (1861) 167 $168=$ Amar. fimbriatus.

polygonoides, Dalz. \& Gibs. Bomb. Fl. $219=$ Amar polygamus.

polygonoides, Rafin. Fl. Tellur, iii. $42=$ Amar. poly gonoides.

scariosa, Moq. in DC. Prod. xiii. II. 269; A. Gray, in Proc. Am. Acad. v. (1861) $169=$ Amar. scariosus. squarrulosa, A. Gray, 1. c.-Ins. Galap.

Torreyi, A. Gray, 1. c. $167,169=$ Amar. Torreyi. urceolata, Moq. in DC. Prod xiii. II. 269: A. Gray,

1. c. $168=$ Amar. urceolatus.

AMBLOSTIMA, Rafin. Fl. Tellur. ii. 26 (1836)= Schoenolirion, Torr. (Liliac.)

albiflora, Rafin. 1. $\mathrm{c}=$ Sc. Elliottii

crocea, Rafin. 1. $c_{1}=$ Sc. croceum.

latifolia, Rafin ex S. Wats, in Proc. Am. Acad xiv.

(1879) $242=$ Sc. Elliottii.

AMBLOSTOMA, Scheidw. in Otto \& Dietr. Gartenz vi. (1838) 383 . ORCHIDEAE, Benth. \& Hook. f. iii. 522 .

cernuum, Scheidw. l. c.-Bras,

densum, Reichb. f. Xenia Orch. iii. 22.-Peruv,

micranthum, Reichb. f. in Saund. Refug. sub t. 101 -Boliv.

tridactylum, Reichb. f. in Walp. Ann. vi. 485= cernumm.

AMBLYACHYRUM, Hochst. ex Steud. Syn. P1. Gram. $413(1855)=$ A pocopis, Nees (Gramin.)

mangalorense, Hochst. ex Steud. I. c.; et in Flora, xxxix. (1856) $26=$ Apoc. Wightii.

AMBLVANTHERA, Blume, Mus. Bot. Lugd. Bat. i. 50 (1849) = Osbeckia, Linn. (Melast.

parvifolia, Blume, 1. $\mathrm{c}_{\mathrm{a}}=\mathrm{O}$. parvifolia.

truncata, Blume, $1 . c_{.}=0$. truncata.

AMBLYANTHERA, Muell. Arg, in Mart. Fl. Bras, vi. I. 141 t. $44,45(1860)=$ Mandevilla, Lindl. (Apocyn.).

acutiloba, Muell. Arg. in Linnaen, xxx. (1859-60) 420 $=$ Echites acutiloba

andina, Muell. Arg. 1. c. 425= Echites andina

Andrieuxii, Muell. Arg. L. c. $422=$ Mandevilla An. drieuxii.

angustifolia, Muell. Arg. 1. c. $430=$ Echitcs angustifolia.

antennacea, Muell. Arg. 1. c. $448=$ Echites antennocen

Benthemi, Muell. Arg, 1, c. 451 = Echites Fenthami. bogotensis, Mruell. Arg. 1. c. $152=$ Lichites bogotensis. brachyloba, Mucll. Arg. 1. c. $423=$ Lehies brachyloba. Bridgesii, Muell. Arg. 1. c. 420,-Boliv:

campestris, Muell. Arg. in Mart. Fl. Bras. vi. I. $149=$

Echites campestris.

ciliata, Mfucll. Arg. 1. c. $\mathbf{1 4 5}=$ Echites ciliata.

Claussenii, Miers, Apocjz. S. Am. 2it, 6. 25.- Am, anstr.

convolwulacen, Mfuell. Arg. in Linnaca, xxx. (1\$5:-6i $\$ 30=\mathrm{M}$. convolvulaces. 
AMBLYANTHERA :-

crassifolia, Muell. Arg. in Mart. Fl. Bras. vi. I. 143= Echites crassifolia.

cuiabensis, Muell. Arg. 1. c. $145=$ Echites cuyabensis. cuyabensis, Muell. Arg. in Linnaea, xxx. (1859-60) 450

= praec.
Fendleri, Mnell. Arg. 1. c. 417.-Venezuela.

foliola, Muell. Arg. 1. c. $427=$ Mandevilla foliosa.

fuminensis, Muell. Arg. in Mart. Fl. Bras. vi. I. $148=$ Echites fluminensis.

funiformis, Muell. Arg. 1. c. $144=$ Echites funiformis.

guyanensis, Muell. Arg. in Linnaea, xxx. (1859-60)

$448=$ Echites guianensis.

hirsuta, Miers, Apocyn. S. Am. 185=M. hispida?

hispida, Muell. Arg. in Mart. Fl. Bras.vi. 1. $147=\mathrm{M}$ hispida.

Karwinskii, Muell. Arg, in Linnaea, xxx. (1859-60)

$426=$ M. Karwinskii.

lasiocarpa, Muell. Arg. in Kjoeb. Vidensk. Meddel. (1869) $113=\mathrm{M}$, hispida.

leptophylla, Muell. Arg. in Mart. F1. Bras. vi. I. $142=$ Echites leptophylla.

macrophylla, Muell. Arg. in Linnaea, xxx. (1859-60) $449=$ Echites macrophylla.

madida, Muell. Arg. in Mart. Fl. Bras. vi. I. $150=$ Echites madida.

membranacea, Mnell. Arg. in Linnaea, xxx. (1859-60) 423 , in nota $=$ Echites membranacea.

mexicana, Muell. Arg. 1. c. $424=$ Echites mexicana.

microcalyx, Muell. Arg. 1. c. $428=$ Echites microcalyx Moritziana, Muell. Arg. 1. c. 421.-N. Granat.

ovata, Miers, Apocyn. S. Am. 188.-Boliv.

oaxacana, Muell. Arg. in Linnaea, xxx. (1859-60) 447 = M. oaxacana.

palustris, Muell. Arg. in Mart. Fl. Bras, vi. I. $145=$ M palustris.

pandurata, Muell. Arg. in Linnaea, xxx. (1859-60)

$448=$ Echites pandurata

Pavonii, Muell. Arg. 1. c. $450=$ Echites Pavonii.

Prieurei, Muell. Arg. 1. c. $448=$ Echites Prieurei.

Schlimi, Muell. Arg. 1. c. $419 .-\mathrm{N}$. Granat.

Spruceana, Muell. Arg. in Mart. Fl. Bras. vi. I. 143.Bras.

suaveolens, Muell. Arg. in Linnaea, xxx. (1859-60) 447 $=\mathrm{M}$. suaveolens.

subsessilis, Muell. Arg. 1. $\mathrm{c} .=$ Echites subsessilis. torosa, Muell. Arg. 1. c. $446=$ Echites torulosa. tubiflora, Muell. Arg. 1. c. $454=$ Echites tubiflora. versicolor, Muell. Arg. in Mart. F1. Bras. vi. I. $146=$ Echites versicolor.

AMBLYANTHUS, A. DC. in Ann. Sc. Nat. Sér. II XVI. (1841) 83.t. 6. MYRSINEAE, Benth. \& Hook. f. ii. 648 .

glandulosus, A. DC.l. Cn-Reg. Himal.

AMBLYCARPUM, Lem, in Orb. Dict. i. 335 (1841)= Amblyocarpum, Fisch. \& Mey. (Compos.).

AMBLYCHLOA, Link, in Linnaea, xvii. (1843) $399=$ Sclerochloa, Beauv. (Gramin.)

dura, Link, 1. c. =S. dura.

AMBLYGLOTTIS, Blume, Bijdr. 369. t. $64(1825)=$ Calanthe, R. Br. (Orchid.)

abbreviata, Blume, 1. c. $371=$ C. abbreviata angustifolia, Blume, 1. c. $369=\mathrm{C}$. angustifolia. emarginata, Blume, 1. c. $370=\mathrm{C}$. emarginata.

flava, Blume, 1. c. t. $64=$ C. veratrifolia.

pilosa, De Vriese, ex Lindl. Fol. Orch. Calanthe, $11=$ C. pilosa.

pulchra, Blume, Bijdr. $371=$ C. curculigoides.

speciosa, Blume, 1. c. $371=$ C. speciosa.

veratrifolia, Blume, 1. c. $370=$ C. veratrifolia.

AMBLYGONUM, Reichb. Handb. $236(1837)=$ Poly gonum, Linn.

AMBLYLEPIS, Decne. in Orb. Dict. i. 337 (1841)= Amblyolepis.

AMBLYOCALYX, Benth. in Benth. \& Hook. f. Gen ii. 698 (1876). APOCYNACEAE, Benth. \& Hook. f. ii. 698 .

Beccarii, Benth. in Hook. Ic. Pl. t. 1179.-Borneo.

AMBLYOCARPUM, Fisch. \& Mey. Ind. Sem. Hort. Petrop. iii. 30 (1837). COMPOSITAE, Benth. \& Hook. f. ii. 336

inuloides, Fisch. \& Mey. l. c.-Reg. Caspica.
AMBLYOGLOSSUM, Turcz. in Bull. Soc. Nat. Mosc. xxv. (1852) II. 310=Tylophora, R. Br. (Asclep.). brevipes, Turcz. 1. c. $311=\mathrm{T}$. brevipes.

longipes, Turcz. 1. c.-Malaya.

AMBLYOLEPIS, DC. Prod.v. 667 (1836)= Helenium, Linn. (Compos.).

setigera, DC. 1. C.-Mexic.

AMBLYOPAPPUS, Hook. \& Am, in Hook. Journ. Bot. iii. (1841) 321. COMPOSITAE, Benth. \& Hook. f. ii. 406 .

Aromia, Nutt. in Trans. Am. Phil. Soc. Ser. II. vii. (1841) 395

InfanteA, Remy, in C. Gay, F1. Chil. iv. 257.t. 48 (1849).

mendocinus, Phil. Sert. Mend. Alt. 26.-Chili. neo-mexicanus, A. Gray, in Pacif. Rail. Rep. iv. 106. Mexic.

pusillus, Hook. Es Arn. in Hook. Fourn. Bot. iii. (1841) 321.-Chili.

AMBLYOPELIS, Steud. Nom. ed. II. i. 75 (1840), sphalm. = AMBLYOLEPIS, DC.

AMBLYOPOGON, Fisch. \& Mey. ex DC. Prod. vi. 561 $(1837)=$ Centaurea, Tourn. (Compos.).

Balansae, Boiss. F1. Orient. iii. 604, in syn. $=$ C. Balansae.

concinnus, Boiss. \& Huet, Diagn. Ser. II. iii. $65=\mathrm{C}$. pulcherrima.

incanescens, Fisch. \& Mey. ex DC. Prod. vi. 561=C. integrifolia.

speciosus, Boiss. Fl. Orient. iii. 604, in $\mathrm{syn} .=\mathrm{C}$. pulcherrima.

AMBLYORHINUM, Turcz. in Bull. Soc. Nat. Mosc. xxv. (1852) II. $168=$ Phyllactis, Pers. (Valerian.).

angustifolium, Turez. 1. c. 169.-Venezuela.

grandiflorum, Turcz. 1. c. 168.-Venezuela.

phylicoides, Turcz. 1. c. 171.-Venezuela.

spicatum, Turcz. 1. c. $170=\mathrm{P}$. cordifolia

triplinerve, Turcz. 1. c.-Venezuela.

AMBLYSPERMA, Benth. in Enum Pl. Hueg. 67 (1837) = Trichocline, Cass. (Compos.).

scapigerum, Benth. 1. c. $=$ T. scapigera.

AMBLYSTIGMA, Benth. in Benth. \& Hook. f. Gen. ii. 748 (1876). ASCLEPIADEAE, Benth. \& Hook. f. ii. 748 .

cionophorum, Fourn. in Ann. Sc. Nat. Sér. VI. xiv. (1882) 366.--Reg. Argent.

hypoleucum, Benth. in Hook. Ic. Pl. xii. 76. t. 1188.Bolivia.

pedunculare, Benth. l. c. 77. sub t. 1188.-Bolivia.

AḾBLYTES, Dulac, F1. Hautes-Pyr. 80 (1867) = Molinia, Scop. (Gramin.).

caerulea, Dulac, 1. c. $=$ M. caerulea

AMBORA, Juss. Gen. 401 (1789) = Tambourissa Sonn. (Monim.)

alternifolia, Tul. in Ann. Sc. Nat. Sér. IV. iii. (1855) $31=\mathrm{T}$. alternifolia

amplifolia, Tul. in Arch. Mus. Par. viii. (1855-56) $299=\mathrm{T}$. amplifolia

cymosa, Tul, in Ann. Sc. Nat. Sér. IV. iii. (1855) 31 (an Rubiacea?).-Hab.?

elliptica, Tul. 1. c. = T. elliptica.

Ficus, Tul. 1. c. $30=$ T. Ficus.

fruticosa, Boiv. ex Tul. 1. c.=T. purpurea

grandifolia, R. Br. ex Baker, Fl. Maurit. $287=\mathrm{T}$. amplifolia.

leptophylla, Tul. in Ann. Sc. Nat. Sér. IV. iii. (1855) $29=\mathrm{T}$. leptophylla

neglecta, Tul. in Arch. Mus. Par. viii. (1855-56) $432=$ T. neglecta.

obovata, Tul. in Ann. Sc. Nat. Sér. IV. t. iii. (1855) 31 $=\mathrm{T}$. obovata

peltatus, R. Br. ex Baker, F1. Maurit. $288=$ T. peltata purpurea, Tul. in Ann. Sc. Nat. Sér. IV. iii. (1855) 30 = T. purpurea.

quadrifida, Poir. Encyc. vii. $565=$ T. quadrifida.

racemosa, R. Br. ex Baker, Fl. Maurit. $288=\mathrm{T}$. quadrifida.

religiosa, Tul. in Ann. Sc. Nat. Sér. IV. iii. (1855) 30 $=\mathrm{T}$. religiosa.
AMBORA :-

sempervirens, F. G. Dietr. Lexik. Gaertn. i. $342=\mathrm{T}$ quadrifida.

Sieberi, Tul. in Arch. Mus. Par. viii. (1855-56) $304=$ T. Sieberi.

Tambourissa, Lam. ex Stend. Nom. ed. I. 37, 535=T quadrifida.

Tambourissa, Tul. in Arch. Mus. Par. viii. (1855-56) $303=\mathrm{T}$. Boivinii.

tetragona, Boiv. ex Tul. in Ann. Sc. Nat. Sér. IV. iii. (1855) $30=\mathrm{T}$. tetragona.

tomentosa, Bory, Voy.i.317.t. 13= Monimia rotundifolia tomentosa, Sieber, ex Tul in Ann. Sc. Nat. Sér. IV. Bii. (1855) $31=T$. Sieberi

vestita, Tul. l. $\mathrm{c}_{\mathrm{s}}=\mathrm{T}$. vestita.

AMBORELLA, Baill. Hist. PI. i. 328 in nota (1869); et Adansonia, x. 354 (1873). MONIMIACEAE, Benth. \& Hook. f. iii. 142.

trichopoda, Baill. l. c.-N. Caled.

AMBRARIA, Cruse, Rub. Cap. 16. t. 1, f. 3, 4 (1825)= Nenax, Gaertn. (Rubiac.)

acerosa, Sond. in Harv. \& Sond. F1. Cap. $34=\mathrm{N}$. acerosa.

olabra, Cruse, Rub. Cap. 16. t. $1=$ N. acerosa.

hirta, Cruse, 1. c-Afr. austr.

microphylla, Sond. in Harv. \& Sond. F1. Cap. 34.Afr. austr.

AMBRARIA, Heist. Syst. 11 (1748)=Anthospermum, Linn. (Rubiac.)

Heisteri, Willd. Sp. Pl. iv. 732 in syn. =Anth. aethio picum.

AMBRINA, Spach, Hist. Vég. Phan. v. 295 (1836)= Chenopodium, Linn.

ambrosioides, Spach, 1. c. $297=$ C. ambrosioides. anthelmintica, Spach, 1. c. $298=$ C. ambrosioides Botrys, Moq. Chen. Enum. $37=$ C. Botrys.

carinata, Moq. 1. c. $41=$ C. carinatum.

chilensis, Spach, Hist. Vég. Phan. v. $297=$ C. chilense. denudata, Phil. in Linnea, xxix. (1857-58) $37=$ Roubieva multifida.

dissecta, Moq. Chen. Enum. $38=$ C. bipinnatifidum.

foetida, Moq. 1. c. $38=$ C. Botrys.

graveolens, Moq. 1. c. $41=\mathrm{C}$. graveolens.

incisa, Moq. 1. c. $36=\mathrm{C}$. incisum.

obovata, Moq. 1. c. $40=$ C. obovatum.

pinnatisecta, Spach, Hist. Vég. Phan. v. $296=$ Roubieva multifida.

Pumilio, Moq. Chen. Enum. $42=$ C. Pumilio.

retusa, Moq. 1. c. $40=$ C. retusa.

spathulata, Moq. 1. c. $39=\mathrm{C}$. spathulatum.

tenuis, Moq. 1. c. $42=$ Roubieva multifida.

tomentosa, Moq. 1. c. $37=$ C. tomentosum.

AMBROMA, Linn. f. Suppl.54, 341 (1781)= Abroma Jacq. (Stercul.)

Augusta, Linn. f. 1. c. $341=$ Abr, fastuosum.

AMBRosIA, Bassi, in Comm. Bonon. v. (1763) $82=$ Ambrosinia, Linn. (Aroid.).

AMBROSIA, Linn. Gen. ed. I. 287. n. 718 (1737) COMPOSITAE, Benth. \& Hook. f. ii. 354. abrotanifolia, Wall. Cat. n. 3234.--Bras

absynthyfolia, Michx. Fl. Bor. Am. ii. 183=artemisinefolia.

acanthicarpa, Hook. Fl. Bor. Am. i. $309=$ Franseria Hookeriana.

aptera, DC. Prod. v. 527.-Am. bor

arborescens, Lam. Encyc, i. $127=$ Franseria artemisioides arborescens, Mill. Gard. Dict. ed. VIII. n. 5.-Peruv.

artemisioides, Meyen of Walp, in Nov. Act. Nat. Cur. xix. Suppl.i. (1843) 268.-- Peruv.

artemisiaefolia, Bess. Prim. Fl. Galic. ii. $390=$ maritima.

artemisifolia, Linn. Sp. Pl. 988.-Am. bor.

bidentata, Michx. Fl. Bor. Am. ii. 182-Am. bor.; Ind. occ.

cheiranthifolia, A. Gray, in Torr. Bot. Mex. Bound, 87.-Mexic.

chilensis, Hook. \& Arn. in Hook. Fourn. Bot. iii. (1840) 311.-Chili.

confertifiora, DC. Prod. v. 526=Franseria tenuifolia. coronopifolia, Torr. \& Gray, Fl. N. Am. ii. $271=$ psilostachya.

crithmifolia, DC. Prod. v. $525=$ hispida. 
AMBROSIA :-

cumanensis, H. B. \& K. Nov. Gen. et Sp. iv. 276.Venezuela.

elata, Salisb. Prod. $175=$ artemisifolia.

elatior, Bess. Prim. F1. Galic. ii. $389=$ maritima.

elatior, Linn. Sp. Pl. 987 = artemisifolia.

fruticosa, DC. Prod. v. $525=$ Franseria tenuifolia

fruticosa, Medic. in Act. Acad. Theod. Palat. iii. Phys. 1775) $247=$ arborescens.

glandulosa, Scheele, in Linnaea, xxii. (1849) $157=$ psilostachya.

heterophylla, Muhl. ex Willd. Sp. Pl. iv. $377=$ artemisifolia.

hispida, Pursh, Fl. Am. Sept. Suppl. 743.-Florida.

hispida, Torr, in Ann. Lyc. N. York, ii. (1828) $216=$ psilostachya.

humilis, Vell. Fl. Flum.x. t. 25.-Bras.

incisa, F. G. Dietr. Lexik. Gaertn, i. 344=artemisifolia. integrifolia, Muhl. ex Willd. Sp. Pl. iii. $275=$ trifida.

Lindheimeriana, Schcele, in Linnaen, xxii. (1849) 156 = psilostachya.

longistylis, A. Gray, Pl. Fendler. 79=Franseria tenuifolia.

longistylis, Nutt, in Trans. Am. Phil. Soc. N. S. vii. 1841) 344 - Am. bor

maritima, Ferrero, ex DC. Prod.v. 525=crithmifolia

maritima, Linn. Sp. Pl. 988.-Europ.; Oriens; Afr. bor.

maritima, Vell. Fl. Flum. x. t. $26=$ polystachya.

microcephala, DC. Prod v. 527.-Guiana.

orobanchifera, Meven, Reise, i. 444.-Peruy.

paniculata, Michx. Fl. Bor. Am. ii. 183=artemisifolia.

peruviana, DC. Prod. v. $526=$ psilostachya.

peruviana, Willd. Sp. Pl. iv. 377.--Peruv.

Pitcheri, Torr. ex Hook. Comp. Bot. Mag. i. (1835) 99 = Iva ciliata.

polystachya, $D C$. Prod. v, 526,-Bras.

psilostachya, $D C$. $l . c .-\mathrm{Am}$. bor.

pumila, A. Gray, in Proc. Am. Acad. xvii. (1881-82) 217.-Am. bor.

pusilla, Rafin. ex DC. Prod. v. $527=$ artemisifolia.

scabra, Hook. \& Arn, in Hook. Fourn. Bot. iii. (1840)

311.-Bras.

senegalensis, DC. Prod. v. $525=$ maritima

simplicifolia, Raeusch. Nom, ed. III. $274=$ artemisifolia.

tacorensis, Meyen, Reise, i. 456.-Peruv.

tenuifolia, Gren. \& Godr. Fl. Fr. ii. $395=$ Franseria tenuifolia.

tenuifolia, Spreng. Syst. iii. $851=$ polystachya?

tomentosa, Nutt. Gen. Am. ii. $186=$ Franseria discolor

trifida, Linn. Sp. Pl. 987.-Am. bor.

umbellata, Moench, Meth. Suppl. $272=$ maritima.

villosissima, Forsk. Fl. Aegypt. Arab. 160.-Arabia.

AMBROSINIA, Linn. Gen. ed. VI. 517 (1764)= $A R O I D E A E$, Benth. \& Hook. f. iii. 964.

Ambrosia, Bassi, in Comm. Bonon. v. (1763) 82

Bassii, Linn. Gen, ed. VI. 517.-Europ.

ciliaris, Spreng. Syst. iii. $771=$ seq

ciliata, Roxb. P1. Corom. iii. $90=$ Cryptocoryne ciliata.

maculata, Ucria, in Roem. Arch. i. $70=$ A. Bassi.

nervosa, Lam. Encyc. i. $128=$ A. Bassii.

reticulata, Tin. Cat. Hort. Panorm, 24, $170^{\circ}$, sec. Guss.

Fl. Sic. Syn. ii. II. $595=$ A. Bassii.

retrospiralis, Roxb. Hort. Beng. $65=$ Cryptocoryne retrospiralis.

Roxburghiana, Voigt, Hort. Suburb. Calc. $685=$ Cryptocoryne unilocularis.

spiralis, Roxb. Hort. Beng. $65=$ Cyptocoryne spiralis.

unilocularis, Roxb. Fl. Ind. iii. $493=$ Cryptocoryne unilocularis.

velutina, Blume, ex Heynh. Nom. ii. $32=$ A. Bassii.

AMBULI, Adans. Fam, ii. $208(1763)=$ seq.

AMBULIA, Lam. Encyc. i. 128 (1783)=Limnophila, R. Br. (Scrophul.)

alata, Rafin. Fl. Tellur. iv, $58=$ Gratioln tetragona. aromatica, Lam. Encyc, i. $128=\mathrm{L}$. gratissima. rigida, Rafin. Fl. Tellur. iv. $58=$ Gratiola tetragona.

AMiUUYA, Rafin. Fl. Tellur, iv. $98(\mathbf{1 8 3 6})=$ Aristo lochia, Tourm.

labiosa, Ratin. l. c, = Ar. cymbifera.
AMEBIA, Regel, PI, Nov, Fedsch, 58 (1882) err. typ.= Arnebia, Forsk. (Boragin.).

AMECARPUS, Benth. in Lindl. Veg. Kingd. 554 (1847) = Indigofera, Linn. (Legumir.).

AMECHANIA, DC. Prod. vii. 578 (1839)= Agarista D. Don (Ericac.

hispidula, DC. 1. c. $579(=$ Leucothoë hispidula $)$

subcanescens, DC. 1. c. (=Leucothoë subcanescens)

AMELANCHIER, Medic. Phil. Bot. i. 135 (1789) ROSACEAE, Benth. \& Hook, f. i. 628.

Aronia, Pers. Syn. ii. 39 (1807)

Peraphyllum, Nutt. in Torr. \& Gray, Fl. N. Am i. $474(1840)$.

Xeromalon, Rafin. New FI Am iii, II (1836).

alnifolia, Nutt. in Fourn. Acad. Phil. vii. (1834) 22.Am. bor

asiatica, Endl, in Walp. Rep. ii. $55=$ canadensis

Bartramiana, M. Roem. Syn. Rosifl. $145=$ canadensis.

Botryapium, DC. Prod. ii. $632=$ canadensis

canadensis, Medic. Gesch. 79; Torr. \& Gray, Fl. N Am.i. 473.-Am. bor.; As, or.

chinensis, Hort. ex C. Koch, Dendrol. i. $186=$ Sorbus arbutifolia.

cretica, DC. Prod ii. $632=$ volgaris

denticulata, C. Koch, Dendrol, i. $183=$ Cotoneaster denticulata.

florida, Lindl. Bot. Reg. t. $1589=$ alnifolia

grandiflora, Dougl. ex M. Roem. Syn. Rosifl. $145=$ canadensis.

integrifolia, Boiss. \& Hohen. Diagn. Ser. I. iii. $8=$ vulgaris.

intermedia, Spach, Hist. Vég. Phan. ii. $85=$ canadensis?

japonica, Hort. ex C. Koch, Dendrol. i. $179=$ canadensis.

melanocarpa, Decne, in Nouv. Arch. Mus, Par. Sér. I x. (1874) 136.- - Hab.?

oblongifnlia, M. Roem, Syn. Rosif. $147=$ canadensis.

oligocarpa, M. Roem. 1. C. $145=$ canadensis.

orbicularis, Borck. ex Steud. Nom. ed. II. i. $76=$ vulgaris.

ovalis, Medic. Gesch. $78=$ canadensis

parviflora, Boiss. Diagn. Ser. I. iii. 9-As. Min

parviflora, Hort. ex Loud. Arb. Brit. ii. $877=$ alnifolia

pisidica, Boiss. \& Heldr. Diagn. Ser. I. x. 2 =parvi flora.

pumila, Nutt. ex Torr. \& Gray, Fl. N. Am. i. $474=$ alnifolia.

racemosa, Lindl. in Bot. Reg. (1847) sub. t. $38=$ Exochorda grandiflora.

rotundifolia, M. Roem. Syn. Rosif. $146=$ canadensis.

sanguinea, DC. Prod. ii. $633=$ canadensis

spicata, C. Koch, Dendrol, i. 182 = canadensis?

suborbicularis, Borkh. Forstbot. ii. $1262=$ vulgaris.

tomentosa, Stend. Nom, ed. II. ii. 136 in $\mathrm{syn}_{\circ}=$ vulgaris?

vulgaris, Moench, Meth.682.-Europ.; Oriens

Wangenheimiana, M. Roem. Syn. Rosif. $116=$ canadensis.

AMELETIA, DC. in Mém. Soc. Phys. Genèv. iii. II. (1826) 82 = Ammannia, Houst. (Lythrar.)

acutidens, Miq. Fl. Ind. Bat, i. I, $617=$ Amman peploides.

diandra, F. Mucll. Fragm. iii. 108=Amman. diandra

elatinoides, Blume, Mus, Bot. Lugd, Bat. ii. $136=$ Amman, elatinoides.

elongata, Blume, 1. c. $135=$ Amman. peploides.

floribunda, Wight, Illustr. Ind. Bot. $206=$ Amman. floribunda

indica, DC. in Mém. Soc. Hist. Nat. Genèv. iii. II. (1825) 2 \& 82. t. 3. f. A. = Amman. peploides. polystachya, Wall. Cat. n, $2094=$ Amman. peploides, rotundifolia. Wight, Ic. t. $258=$ Amman, rotundifolia. subspicata, Benth. in Hook. Kew Journ. iv. (1S42) $81=$ Amman. rotundifolia.

tenella, Blume, Mus. Bot. Lugd. Bat. ii. 136= Amman. tenella.

tenuis, Wight, Ic. Pl. Ind. Or. t. $257 \mathrm{~B}=$ Amman. tunuis.

uliginosa, Miq. Ann. Mus. Bot. Lugd. Bat. ii. $261=$ Amman. peploides.

AMELIA, Alefeld, in Linanea, xxviii. (1856) 25 = Pyrola Tourn. Ericac.)
AMELIA :-

media, Alef, in Linnaea, xxviii. (1856) $30=$ Pyrola media.

minor, Alef. 1. c. $25=$ P. minor.

AMELINA, C. B. Clarke, Commel et Cyrt, Beng. 38 . $26(1874) \approx$ Aneilema, R. Br. (Commelin).

Wallichii, C. B. Clarke, 1. c. 39. t. 26=Aneilema aequinoctiale.

AMELLUS, P. Br. Hist. Jamaic. $317(1756)=$ Melan thera, Rohr. (Compos.).

AMELIUS, Linn. Syst. ed. x. 1225 (1759) COM

POSITAE, Benth. \& Hook. f. ii. 265

Haenelia, Walp. Rep. ii. 974 (1843)

KRAUSSIA, Sch. Bip. in Flora, xxvii. (1844,672

alternifolius, Roth, Catalecta, ii. $111=$ strigosus.

anisatus, Cass, in Dict. Sc. Nat. xxxvii, 489.A austr.

annuus, Willd. Sp.Pl. iii, 2215.-Afr. austr.

carolinianus, Walt. Fl. Carol, $213=$ Eclipta alba.

coilopoclius, DC. Prod. v. 214.-Afr, austr.

diffusus, Forst. in Comm. Gott. ix. (1787, $39=$

Chiliotrichum amelloideum.

divaricatus, Gater. Fl. Montaub. $147=$ Aster NoviBelgii.

floribundus, Willd. ex DC. Prod. v. $96=$ Liabum igniarium.

flosculosus, DC. I'rod. $\nabla .214=$ hispidus.

hispidus, $D C$, $. c-$ Afr austr.

Lychnitis, Linn. Syst. ed. X. 1255-Afr. austr.

Lychnitis, E. Mey. ex Steud. Nom. ed. II. i. $76=$ tenuifolius.

microglossus, DC. Prod. v. 215.-Afr. austr.

mutabilis, Gater. FI. Montaub. $147=$ Aster mutabilis.

nanus, $D C$. Prod. v, 215. - Afr austr.

officinalis, Gater. Fl. Montaub, $147=$ Aster Amellus.

pallidus, Salisb. Prod. 205=A. Lychnitis.

pedunculatus, Orteg. ex Milld. Enum. Hort. Berol. $916=$ Tridax procumbens.

rosmarinifolius, Poepp. ex DC. Prod. v. $216=$

Chiliotrichum rosmarinifolium.

scabridus, $D C$. l. c. 214.-Afr, austr.

speciosus, Gater. Fl. Montaub. $146=$ Aster chinensis.

spinulosus, Pursh, Fl. Am. Sept. ii. 564.-Am. bor.

s'rigosus, Less. in Linnaea, vi. (1831) $110=$ annuus.

tenuifolius, Burm. f. Fl. Cap. Prod. 28.-Afr. austr.

tridactylus, $D C$. Prod. v. 215.-Afr. austr.

umbellatus, Linn. Pl. Jam. Pugill. 24 Syst. ed. X.

1225) = Liabum Brownei.

villosus, Parsh, Fl. Am. Sept. ii. $56 t=$ Chrysopsis villosa.

AMERIMNON, P. Br. Hist. Jamaic. $288(1756)$; DC.

Prod, ii. 421 (1825) = Dalbergia, Lins. (Legumin.

affine, Spreng. Syst. iii. 192.-Am. austr.

Brownei, Sw. Fl. Ind. Occ. $123 t=$ Dalbergia Amerimnum.

Brownii, Jacq. Enum. Pl. Carib. 27.-Ind. occ

Ebenus, Sw. Prod. Veg. Ind, Occ. $104=$ Brya Ebenus.

fasciculatum, Buch.-Ham. ex Baker, in Hook. f. Hi.

Brit. Ind. ii. $109=$ Millettia fruticosa.

guianense, Klotzsch, in Schomb. Faun. et Fl. Guy.

1204.-Guiana.

horridum, Dennst. Schluess. Hort. Malab. 34 iquid?

Ind. or.

latifolium, Willd. Sp. Pl, iii. $909=$ Lonchocarpus lacifolius.

mimosella, Blanco, Fl. Filip. ed. I. $5 b^{\circ} 3=$ Dalbergin lanceolaria.

obovatum, Buch.-Ham. ex Baker, in Hook, f. Fl. Brit. Ind. ii. $246=$ Derris thyrsiflora.

pallidum, Buch.-Ham. ex Baker, 1. c. 108 - Millettia suriculata,

parviflorsm, Spreng. Nicue Enteleck, ii. 159.-Bras.

pinnatum, Jacq. Sel. Stirp. Am. $200=$ Dalbergia Ame rimnum.

polystachyon, Spreng. Syst. Cur. Post. $200 \mathrm{~s}=$ Eysen. hardtia amorphuides.

pubescens, Willd. Sp. Pl. iii. $909=$ Perocarpus scandens scandins, Willd. I. $c=$ I'terocarpus scandens

secundum, Buch.-Ham. ex liaker, in Houk. I. Fl. Brit. Ind. ii. $24 i=$ Dersis secunda.

Sieberi, Keichb. ex DC. Prod. ii. $120=$ Eicastaphy yllum lirowni.

strigulasem, 11. B. \& K. Nor, Gea. et Sp, vi. \$8!? Vencezuela. 
AMERINA,DC. in Meissn. Gen.278(1840)= Aegiphila, Jacq. (Verben.)

ternifolia, DC. Prod. ix. 513.-N. Granat,

tomentosa, DC. I. c. = Aeg. tomentosa?

triphylla, DC. 1. c.-Afr. austr.

AMERINA, Noronha, in Verh. Batav. Gen. v. (1790) Art. iv. 1; ed. II. (1827) $64=$ Aglaia, Lour. (Meliac.)

AMERINA, Rafin. Alsog. Amer. 15 (1838)=Salix, Tourn. Balduiniana, Rafin. 1. c. 16.-Am. bor. caroliniana, Rafin. l. c. $15=\mathrm{S}$. nigra. glandulosa, Rafin. 1. $\mathrm{c}_{\mathrm{。}}=\mathrm{S}$. pentandra Houstoniana, Rafin. 1. c. = S. nigra. missurica, Rafin. 1. c. 16-Am, bor. nigra, Rafin. 1.c. $15=\mathrm{S}$. nigra. tinctoria, Rafin. 1. c. 15.-Am. bor. tomentosa, Rafin. 1. c. = S. Lapponum.

AMETHYSTEA, Linn. Amoen. Acad i. 385 (1749). $L A B I A T A E$, Benth. \& Hook. f. ii. 1220.

Amethrsina, Mess. ex Hall. in Act. Upsal. 1742 (1748) 51. t. 4.

caerulea, Linn. Sp. Pl. 21.-Sibiria.

corymbosa, Pers. Syn. i. $24=$ caerulea.

trifida, Hill, Veg. Syst. xvii. $44=$ caerulea.

AMETHystinA, Mess. ex Hall. in Act. Upsal. 1742 (1748) 51.t. $4=$ praec.

AMETRON, Rafin. Sylva Tellur. $160(1838)=$ Rubus, Tourn. (Rosac.).

pedatum, Rafin, 1. c. $161=$ R. pedatus.

pyrifolium, Rafin. l. $\mathrm{c}_{\mathrm{s}}=\mathrm{R}$. pyrifolins.

AMHERSTIA, Wall. Pl. As. Rar. i. 1. t. 1, 2 (1830). LEGUMINOSAE, Benth. \& Hook. f. i. 578 . nobilis, Wall. l. c.-Burma.

AMIANTANTHUS, Kunth, Enum. Pl. iv. 179 (1843)= AMIANTHIUM, A. Gray=Zygadenus, Michx. (Liliac.).

AMIANTHEMUM, Steud. Nom. ed. II. i. $76\left(1840^{\circ}\right)=$ seq.

AMIANTHIUM, A. Gray, in Ann. Lyc. N. York, iv. (1848) $121=$ Zygadenus, Michx. (Liliac.). angustifolium, A. Gray, 1. c. $124=\mathrm{Z}$. angustifolius. aspericaule, A. Gray, 1.c. $126=$ Melanthium aspericaule leimanthoides, A. Gray, 1. c. $125=\mathrm{Z}$. leimanthoides. macrotox, Rafin. Fl. Tellur. iv. $27=Z$. muscaetoxicum. muscaetoxicum, A. Gray, in Ann. Lyc. N. York, iv. (1848) $122=\mathrm{Z}$. muscaetoxicum

Nuttallii, A. Gray, 1. c. $123=$ Z. Nuttallii, paniculatus.

AMIANTHUM, Rafin. Fl. Tellur, iv, $27(\mathbf{1 8 3 6})=$ praec.

AMICIA, H. B. \& K. Nov. Gen. et Sp. vi. 511 . t. 600. (1823). LEGUMINOSAE, Benth. \& Hook. f. i. 514.

Zygomeris, Moç. \& Sesse, ex DC. Prod. ii. 315 (1825). glandulosa, $H . B . \& \mathcal{E} K . l . c .-\mathrm{N}$. Granat.

medicaginea, Griseb. in Goett. Abh, xxiv, (1879) 105 -Reg. Argent.

Zygomeris, DC. Prod. ii. 315.-Mexico.

AMIC'TONIS, Rafin. Sylva Tellur. 161 (1838)= Callicarpa, Linn. (Verbenac.)

japonica, Rafin. 1. c. = C. longifolia.

AMIDA, Nutt. in Trans. Am. Phil. Soc. Ser. II. vii. (1841) $390=$ Madia, Molina (Compos.) gracilis, Nutt. 1. c. = M. glomerata. hirsuta, Nutt. 1. c. = M. glomerata.

AMIDENA, Adans. Fam. ii. 470 (1763)=Arisaema Mart. (Aroid.).

japonica, Rafin. Fl. Tellur. iv. $\mathbf{1 5}=$ Arisaema japonicum.

AMIRIS, La Llave, in La Naturaleza, vii. Apénd. 71 (1885) = Amyris, Linn. (Rutac.).

AMIROLA, Pers. Syn. ii. $565(1807)=$ Llagunoa, Ruiz \& Pav. (Sapindac.).

glandulosa, Hook. \& Arn. Bot. Beech. Voy. $12=\mathrm{LI}$. glandulosa.

mollis, DC. Prod. i. $616=\mathrm{Ll}$. mollis.

nitida, Pers. Syn. ii. $565=\mathrm{Ll}$. nitida.

parvifolia, Steud. Nom. ed, II. i. $76=$ Ll. nitida.

prunifolia, DC. Prod. i. $616=$ Ll. prunifolia.
AMISCHOTOLYPE, Hassk. in Flora, xlvi. (1863) 391 Forrestia, A. Rich. (Commelin.).

glabrata, Hassk. 1. c. $392=$ F. glabrata

marginata, Hassk. 1. c. $=\mathrm{F}$. marginata.

mollissima, Hassk. l. $\mathrm{c}_{\mathrm{a}}=\mathrm{F}$. mollis

AMMANELLA, Miq. Fl. Ind. Bat. i. I. $618(1855)=\mathbf{A m}$ mannia, Linn. (Lythrar.).

linearis, Miq. 1. c. $619=$ Ammannia octandra.

AMIMANNIA, Houst,] Linn. Gen. ed. I. 337 (1737). LYTHRARIEAE, Benth. \& Hook. f. i. 776

Ameletia, DC. in Mém. Soc. Phys. Genèv. iii. II. (1826) 82 .

Cornelia, Ard. Specim. ii. 9.t. 1 (1764).

CryptothecA, Blume, Bijdr. 1128 (1826).

Nexilis, Rafin. New FI. Am. iv. 9 (1836).

OrTEGiotdes, Soland. ex DC. Prod, iii. 76 (1828)

NimmorA, Wight, in Madras Journ. Sc. vii. (1837) 311. t. 20 .

Rotala, Linn. Mant. ii. 143 (1771).

Sellowia, Roth, ex Roem. \& Schult. Syst. v. 407 (1819).

SUFFRENIA, Bellardi, in Act. Taur. vii. (1796) 445. t. 1

TrithecA, Miq. Fl. Ind. Bat. i. 614 (1855).

Winterlia, Spreng. Syst. i. 519 (1825).

acutidens, Miq. Fl. Ind. Bat. i. I. $617=$ peploides.

aegyptiaca, Kotschy, ex Koehne, in Engl. Bot. Jahrb.

i. (1881) $253,254=$ urceolata, apiculata

aegyptiaca, Willd. Hort. Berol. t. $6=$ salicifolia

alata, Steud. Nom. ed. II. i. 76.-Reg. Caucas.

anagalloides, Sond, in Linnaea, xxiit. (1850) $40=$ Nesaea anagalloides.

apiculata, Koehne, in Engl. Bot. Fahrb. i. (1881) 254. -Afr. trop.

arenaria, H. B. \& K. Nov. Gen. et Sp. vi, $190=$ senegalensis.

aspera, Guill. \& Perr. Tent. Fl. Seneg. i. $304=$ Nesaea aspera.

attenuata, Hochst. ex A. Rich. Tent. Fl. Abyss. i. 278 $=$ baccifera.

auriculata, Willd. Hort. Berol. i. 7, t. 7 =senegalensis.

australasica, F. MuelJ. in Trans. Phil. Soc. Vict. i. (1855) $41=$ multiflora

baccifera, Roth, Sp. Nov. $100=$ leptopetala.

baccifera, Linn SP, Pl 120-Geront calid.

baccifera, Pollini, Fl. Veron. i. $178=$ salicifolia.

Boraei, Guép. Suppl. Fl. Maine-et-Loire, $39=$ Lythrum nummularifolium.

borysthenica, DC. Prod. iii. $78=$ Lythrum nummularifolium.

borysthenica, Kar. \& Kir. in Bull. Soc. Nat. Mosc. xiy. (1841) $421=$ Peplis alternifolia.

caspia, Hohen. Enum. Talysch. $133=$ baccifera.

caspica, Bieb. Fl. Taur. Cauc. ii. 457; Suppl. $111=$ salicifolia.

catholica, Cham. \& Schlecht. in Linnaea, ii. (1827) $378=$ latifolia

catholica, Hook. \& Arn. ex Seem. Bot. Voy. Herald, $284=$ latifolia

coccinea, Pers. Syn. i. $147=$ octandra.

coccinea, Rottb. Pl. Hort. Univ. (Havn.) Programm.

Descr. (17'73) 7 =latifolia.

cordata, Wight \& Arn. Prod. 304,-Ind. or.

crassicaulis, Guill. \& Perr. Tent. F1. Seneg. i. $303=$

Nesaea polyantha.

crinipes, F. Muell, in Trans. Phil. Inst. Vict. iii. (1859) $49=$ Nesaea crinipes.

cryptantha, Baker, in Fourn. Linn. Soc. xxi. (1884) 345.-Madag.

debilis, Ait. Hort. Kew. ed. I. i. $163=$ baccifera,

densiflora, Miq. ex C. B. Clarke, in Hook. f. Fl. Brit. Ind. ii. $569=$ salicifolia.

densiflora, Roth, Sp. Nov. $99=$ pentandra.

dentifera, A. Gray, Pl. Wright. ii. 55.-Am. bor.

dentelloides, Kurz, in Fourn. As. Soc. Beng, xxxix (1870) II. 76.-Bengal.

diandra, F. Muell. Fragm. iii. 108.-Austral.

diffusa, Willd. Enum. Hort. Berol. i. $167=$ senega lensis.

dodecandra, DC. in Mém. Soc. Phys. Genèv. iii. II (1825) 89.t. $2=$ Nesaea Candollei.

elatinoides, $D C$. l. c. 92. t. 3. f, B.-Afr. trop-

elatinoides, Schimp. ex Hiern, in Oliver, Fl. Trop.

Afr. ii. 468 (=Rotala stagnina).

elongata, Blume, Mus. Bot. Lugd. Bat. ii. $135=$ peploides.

\section{AMMANNIA :}

fliformis, Baill. Hist. Pl. vi. 438 (=Rotala filiformis).

fliformis, DC. in Mém. Soc. Phys. Genèv. îi. II. (1825) t. $79=$ senegalensis

fimbriata, Wight, ex C. B. Clarke, in Hook. f. Fl. Brit. Ind. ii. $569=$ pentandra.

floribunda, C. B. Clarke, l. c, 567.-Ind. or.

floribunda, Guill. \& Perr. Tent. Fl. Seneg. i. $302=$ senegalensis, multiflora.

glauca, Wall. Cat, n, 2100= salicifolia

gracilis, Guill. \& Perr. Tent. Fl. Seneg. i. $301=$ senegalensis

hastata, DC. Prod. iii. $78=$ latifolia.

hexandra, Wall. Cat. n. 2103=pentandra.

Heyneana, Wall. 1. c. $2104=$ pentandra.

Hildebrandtii, Koehne, in Engl. Bot. Fahrb. 1. (1881) 257.- Afr. trop.

humilis, Michx. Fl. Bor. Am. i. 99.-Am. bor.

hyrcanica, Fisch. ex Stend. Nom. ed. II. i. $77=$ auriculata.

illecebroides, Arn. ex Koehne, in Engl. Bot. Jahrb. i. 1881) 161 (= Rotala decussata)

indica, Lam. Illustr. 1. 311. n. $1555=$ baccifera

japonica, Miq. in Ann. Mus. Bot. Lugd. Bat. ii. 261.Japon.

lanceolata, Heyne, in Wall. Cat. n. 2106.-Ind. or.

latifolia, Linn. Sp. Pl. 119.-Am. bor.; Ind. occ.

latifolia, Wall. Cat. n. $2096=$ peploides.

latifolia, Walp. Rep. ii. $102=$ sanguinolenta

leptopetala, Blume, Mus. Bot. Lugd. Bat. ii. 134.Java.

lingulata, Griseb. Cat. Pl. Cub. 106=latifolia.

littorea, Miq. Ann. Mus. Bot. Lugd. Bat. ii. 261.Japon.

loandensis, Welw. ex Hiern, in Oliver, F1. Trop. Afr. ii. $480=$ Nesaea loandensis.

longipes, Wright, in Sauv. Fl. Cub. 53.-Ind. occ. lythrifolia, Salisb. Prod. $65=$ latifolia,

madagascariensis, Boiv. ex Tul. in Ann. Sc. Nat. Sér.

IV. vi. (1856) $129=$ multiflora.

microcarpa, DC. in Mém. Soc. Phys. Genèv. iui. II. 1825) $93=$ multiflora ?

monoflora, Blanco, Fl. Filip. ed. I. $64=$ latifolia

multiflora, Roxb. Hort. Beng. 11; Fl. Ind. ed. Carey, i. 447.-Ind. or.

nana, Roxb. 11. ce. 11, 448=peploides

nana, Roxb. in Wall. Cat. n, $2105=$ pentandra.

Nuttallii, A. Gray, Man. Bot. N. U. St. ed. IV. add. p. xcii = Didiplis linearis.

occidentalis, DC. Prod. iii. $78=$ humilis.

octandra, Linn.f. Suppl. 127.-Ind. or.; Malaya.

octandra, Cham. \& Schlecht. in Linnaea, if. (1827) $376=$ latifolia.

pallida, Lehm. Sem. Hort. Hamb. (1823) 3; (Linnaea, iii. (1829) 9) = latifolia

parviflora, DC. Prod. iii. $77=$ multiflora.

passerinoides, Welw. ex Hiern, in Oliver, Fl. Trop.

Afr. ii. $480=$ Nesaea passerinoides

pentandra, Roxb. Fl. Ind. i. 448.--Geront. trop.

peploides, Spreng. Syst. i. 444.-Oriens; As. trop.

pinnatifida, Linn. f. Suppl. 127.--Java.

polystachya, Wall. Cat, n. $2094=$ peploides.

Portula, Baill. in Bull. Soc. Linn. Par. i. (1874) $87=$ Peplis Portula.

Prieuriana, Guill. \& Perr. Tent. Fl. Seneg. 1. $303=$ senegalensis.

prostrata, Buch.-Ham. ex Blume, Mus. Bot. Lugd. Bat. ii. 132 = baccifera

purpurea, Lam. Encyc. i. $131=$ humilis.

pusilla, Sond, in Linnaea, xxiii. (1848) $40=$ senegalensis.

pygmaea, Kurz, in Fourn. Bot. v. (1867) 376.-Ind. or. racemosa, Poir. Encyc. Suppl. i. $329=$ arenaria. racemosa, Roth, Catalect. fasc. iii. $25=$ octandra. ramosa, Hill, Veg. Syst. xi. $14=$ humilis.

ramosior, Blanco, Fl. Filip. ed. II. $64=$ peploides. ramosior, Linn. Sp. Pl, $120=$ humilis.

ramosior, Linn. Mant. ii. $332=$ latifolia.

repens, Rottl. ex Mart. in Acad. Muench. Phil. vi. (1820) 150, ex DC. Prod. iii. $80=$ peploides.

retusa, Koehne, in Engl. Bot. Jahrb. i. (1881) 254.Afr. trop.

Ritchiei, C. B, Clarke, in Hook. f. Fl, Brit. Ind.ii. 566. -Ind. or.

robusta, Heer, Ind. Sem. Hort. Turic. $(1842)=$ latifolia.

rosea, Poir. Encyc. Suppl, i. 329 (= Rotala mexicana). 


\section{AMMANNIA :}

Rotala, F. Muell. Fragm, iii. 108.-Geront. trop. rotundifolia, Buch.-Ham. in D. Don, Prod. Fl. Nep 220.-Ind. or.; China.

rubra, Buch.-Ham. 1. c. = pentandra.

sagittata, DC. Prod. iii. $80=$ latifolia.

salicifolia, Hiern, in Oliver, Fl. Trop. Afr, ii. $478=$ baccifera.

salicifolia, Monti, in Comm. Bonon. i. (1767) 112.As. \& Afr. trop.

salsuginosa, Guill. \& Perr. Tent. Fl. Seneg. i. 302.Afr. trop.

sanguinolenta, Cham. \& Schlecht. in Linnaea, v. (1830) $568=$ auriculata.

sanguinalenta, Heyne, ex Steud. Nom. ed. II. i. $77=$ salicifolia.

sanguinolenta, Sw. Prod, Veg. Ind. Occ. $33=$ Jatifolia. sanguinolenta, Hook. \& Arn. ex Seem. Bot. Voy. Herald, 284 = latifolia.

sarcophylla, Welw. ex Hiern, in Oliver, Fl. Trop. Afr. ii. $479=$ Nesaea sarcophylla.

senegalensis, Lam. Illustr. i. 312.n. 155. t. 77. f. 2.Geront. trop.

simpliciuscula, Kurz, in Fourn. As. Soc. Beng. xl. (1871) II. 54.-Ind. or.

stylosa, Fisch. et Mey. Ind. Sem. Hort. Petrop. vii. 41 $=$ latifolia.

subrotunda, Wall. ex Kurz, in Fourn. As. Soc. Beng. xl. (1871) II. 55.-Ind. or.

subspicata, Benth. in Hook. Lond. Journ. Bot. i. (1843) $484=$ rotundifolia.

subspicata, Hohen. ex Hook. f. F1. Brit. Ind. ii. $568=$ pentandra.

tenella, Guill. \& Perr. Tent. Fl. Seneg, i. 297.-Afr. trop.

tenuis, C. B. Clarke, in Hook. f. Fl. Brit. Ind. ii. 567. -Ind. or.

texana, Scheele, in Linnaea, xxi. (1848) $588=$ latifolia

triflora, R. Br. ex Benth. Fl. Austral. iii. $297=$ Nesaea lanceolata.

triflora, Wall. Cat. n. $6323=$ Nesaea triflora.

undulata, C. A. Mey. Ind. Sem. Hort. Petrop. ix. $56=$ senegalensis.

urceolata, Hiern, in Oliver, Fl. Trop. Afr. ii. 478.Afr. trop.

verticillaris, Baill. Hist. Pl. vi. 439 (=Rotala verticillaris).

verticillata, Boiss. Fl. Orient. ii. $743=$ baccifera.

verticillata, Lam. Encyc, i. 131 = salicifolia.

verticillata, Wight \& Arn. Prod. i. $304=$ lanceolata.

vesicatoria, Roxb. Hort. Beng. 11; Fl. Ind. ed. Carey, i. 447 = baccifera.

viridis, Willd. ex Hornem. Hort. Hafn. i. $146=$ baccifera.

Wallichii, Kurz, in Journ. As. Soc. Beng. xlvi. (1877) II. $84=$ Hydrolythrum Wallichii.

Wormskioldii, Fisch. et Mey. Ind. Sem. Hort. Petrop. vii. 42.-Bras.

Wrightii, A. Gray, Pl. Wright. ii. 55.-Am. bor.

AMMANTHUS, Boiss. \& Heldr. Diagn. Ser. I. xi. 18 1849) $=$ Chrysanthemum, Tourn. (Compos.)

geratifolius, Boiss. \& Heldr, ex Boiss. Fl. Orient. iii. ageratifolius, Boiss. 80
$358=\mathrm{C}$. maritimum.

filicaulis, Boiss. \& Heldr. ex Boiss. Diagn. Ser. I. xi. 19.-Ins. Creta.

maritimus, Boiss. \& Heldr. 1. c. $=$ C. maritimum.

AMMI, [Tourn.] Linn. Syst. ed. I. (1735); Gen. ed. I. 72 (1737). UMBELLIFERAE, Benth. \& Hook. f. i. $88 \%$.

DAsyspermum, Neck. Elem, i. $276(1790)$

GOHORIA, Neck. 1. c. 172 (1790).

VisnaGA, Riv, ex Gaertn, Fruct. i, 92.t. 21 (1788). acaule, Spreng. in Roem. \& Schult. Syst. vi. $530=$ Chamaesciadium acaule.

anethifolium, Lam. Encyc. i. 132.-Oriens; Sibir.

anethifolium, Ledeb. Fl. Ross. ii, $246=$ Artedia squamata.

Boeberi, Hellan. ex Hoffm. Gen. Umbell. p. xviii; Hornem. Suppl. $32=$ majus.

Broussonetii, DC. Prod. iv. $113=$ majus ?

capillaceum, Michx. Fl. Bor. Am, i. 164=Discopleura capillacca.

cicutaefolium, Willd. ex Roem. \&c Schult. Syst. vi. 531 $=$ majus.

cicutarium, Willd, ex Rocm. \& Schult, 1. c.-Am. calicl.

\section{AMIMI :-}

copticum, Linn. Mant. 56=Carum copticum.

costatum, Ell. Sketch FI. Carol. i. $350=$ Discopleura capillacea.

crinitum, Guss, Pl. Rar. 128, t, 25,-Calabr. Sicil.

daucifolium, Buch.-Ham. in Wall. Cat. n. $7209=$ Seseli dancifolium.

daucifolium, Scop. F1. Carn. ed. II. 1. 207=Libanotis athamantoides.

daucoides, Salzm. ex DC. Prod. iv. $113=$ Ammiopsis daucoides.

dilatatum, St. Lag, in Ann. Soc. Bot. Lyon, vii. (1880) $119=\mathrm{A}$. Visnaga.

divaricatum, Michx. Fl. Bor. Am. i. $168=$ Apium divaricatum

elatum, Salisb. Prod. $162=$ majus

ferulaceum, Link, Enum. Hort. Berol, i. $266=$ Ligusticum ferulaceum.

ferulaefolium, Lag. ex Loud. Hort. Brit. $103=$ praec.?

glaucifolium, Blanco, Fl. Filip. ed. I. $213=$ Carum copticum.

glaucifolium, Linn. Sp. Pl, $243=$ majus.

Hunti, H. C. Wats, in Hook. Lond. Fourn. Bot. vi. 1847) 384.--Ins. Azor.

indicum, Buch.-Ham. in Wall. Cat. n. 7208.-Ind. or. intermedium, DC. Prod. iv. $113=$ majus.

majus, Linn. Sp. Pl. ed. I. 243.-Europ.; Oriens Afr. bor.

majus, Walt. Fl. Carol. $113=$ Discoplenra capillacea, meoides, Pers. Syn. i. $308=$ anethifolium.

minus, Griseb. Hort. Gotting. (1876) 8.--Europ.

pauciradiatum, Hochst. ex A. Rich. Tent. Fl. Abyss, i. $322=$ majus.

petroselinoides, Presl, ex DC. Prod. iv. 102=Carum peregrinum,

procerum, Lowe, Man. Fl. Mad. 351.--Madera.

pumilum, DC. Prod. iv. 113,-Lusitan.

pyrenaicum, Lapeyr. Hist. Abr. Pl. Pyr. 145.-Pyren.

rubricaule, Hornem. Hort. Hafn. i. $272=$ Discopleura capillacea.

saxatile, Turcz. ex Bess. in Flora, xvii. (1834) I. Beibl. 13, nomen.-Rossia.

trachycarpum, Fisch. ex Boiss. Fl. Orient. ii. $855=$ Aphanopleura trachysperma.

Visnaga, Lam. Fl. Fr. iü. 462.-Reg. Mediterr.

AMMIANTHUS, Spruce, ex Benth. \& Hook. f. Gen. ii. $98(1873)=$ Retiniphyllum, Humb, \& Bonpl (Rubiac.).

AMMIOPSIS, Boiss. Diagn. Ser. II. ii. 96 (1856). UMBELLIFERAE, Benth. \& Hook. f, i. 927 daucoides, Boiss. l. c. 97.-Mauritan.

AMmIOS, Moench, Meth. $99(1794)=$ Carum, Tourn, (Umbellif.)

muricata, Moench, 1. c. = C. copticum.

AMMOBIUM, R. Br. in Bot. Mag. t. 2459 (1824). COMPOSITAE, Benth. \& Hook. f. ii. 316.

alatum, $R . B r . l . c .-$ Austral.

craspedioides, Benth. Fl. Austral. iii. 584.-Austral. plantagineum, G. Don, in Loud. Hort. Brit. 333.Austral.

spathulatum, Gaudich. Voy. Freyc. Bot. 467.t. $91=$ alatum.

AMMOBROMA, Torr. in Ann. Lyc. N. York, viii. (1867) 51.t. 1. LENNOACEAE, Benth. \& Hook. f. (1867) 622 .

Sonorae, Torr. l. c. 52.-N. Mexic.

AMMOCHARIS, Herb. App. 17 (1821), AMARYL LIDEAE, Benth. \& Hook. f. iii. 727

Palinetes, Salisb. Gen. Pl. Fragm. 116 (1866),

coranica, Herb. App. $17=$ falcata.

falcata, Herb. l. c. - Afr, austr.

Iongifolia, M. Roem. Amar. 62 = Crinum longifolinm.

Slateriana, Kunth, Enum. Pl, v, 613=Brunsvigi Slateriana.

AMMOCHLOA, Boiss, Dingn, Ser. I. xiii. 51 (1953) GRAMINEAE, Benth. \& Ilook. f, iit. 1181

Cepralochuon, Coss, \& Dur. in Ann. Sc. Nat. Ser. IV. i. (1854) 220

palaestina, Boiss. Dingn. Ser. I. xiii, $52=$ subacaulis.
AMMOCHTOA :-

pungens, Boiss. Diagn. Ser. I. xiii. 52.-Afr. bor. subacaulis, Balansa, ex Coss. in Bull. Soc. Bot. Fr. i. (1854) 317 ; iv. (1857) 399. -Syria; Afr. bor.

AMMODAUCUS, Coss. \& Dar, in Bull Soc Bot. Fr. vi 1859) $393=$ Daucus, Linn. (Umbellif.)

leucotrichus, Coss. l. c. et xxii. (1875) 60,-Algeria.

AMMODENDRON, Fisch. ex DC. Prod. ii. 529 (1825). LEGUMINOSAE, Benth. \& Hook. f. 554.

caspium, Eichw. Casp.-Cauc. $7=$ Eichwaldii

Conollyi, Bunge, ex Boiss. Fl. Orient. ii. 627.Turkest

Eichwaldii, Ledeb. \& Mey. in Eichw. Casp.-Cauc. 37 t. 33.-Reg. Casp.

Karelini, Bunge, Pl. Rel. Lehm. $69=$ Conollyi.

Karelinii, Fisch. \& Mey. in Ledeb. Fl. Ross, i. 717. Reg. Casp.

Lehmanni, Bunge, ex Boiss. Fl. Orient. ii. 626.'Turkest.

persicum, Bunge, ex Boiss. l. c. 627.-Persia.

Sieversii, DC. Prod. ii. 523.-Soongaria.

Zablotskii, Fisch. E Mey, ex Kar. in Bull. Soc. Not. Mose. (1839) 150, nomen,-Rossia.

AMmodeniA, Patrin. ex J. G. Gmel. Fl. Sibir. iv. 160 (1769) = Arenaria, Linn. (Caryophyli.)

peploides, Rupr, in Beitr. PA. Russ, Reich. iڤ. $25=$ Ar. peploides.

AMMODIA, Nutt. in Trans. Am, Phil. Soc. Ser. II, vii. (1841) $321=$ Chrysopsis, Nutt. (Compos.). oregana, Nutt. 1. c.=C. oregana.

AMMODYTES, Stev, in Bull. Soc. Nat. Mosc. iv. (1832) $263=$ Astragalus, Tourn. (Legum.). melilotoides, Stev. 1. c. = Astr. melilotoides.

AMMOGETON, Schrad. Ind. Sem. Hort. Goett. (1833 $1=$ Troximon, Nutt. (Compos.). scorzoneraefolius, Schrad.1. c. = T. glaucum。

AMMOIDES, Adans, Fam. ii. $96 \quad(1 ; 63)=$ Carum Tourn. (Úmbellif.).

AMMOLIRION, Kar, \& Kir. in Bull, Soc. Nat, Mosc xv. (1842) $515=$ Eremurus, Bieb. (Liliac.) stenophyllum, Boiss. \& Buhse, in Nouv. Mém. Soc. Nat. Mosc. xii. (1860) $218=\mathbf{E}$. Bungei.

Steveni, Kar. \& Kir. 1. c. =E. inderiensis.

AMMONALIA, Desv. ex Endl. Gen.966, in syn. (1840) = Arenaria, Linn. (Caryophyll.)

AMMOPHILA, Host, Gram. Austr. iv. 24. $t .4$ (1809). GRAMINEAE, Benth. \& Hook. f, iii. 1153. Psamma, Beauv. Agrost. 143. t. 6. f. 1. (1812) arenaria, Link, Hort. Berol. i. $105=$ arundinaces. arundinacea, Host, Gram. Austr. iv. 24, t. 41.-Europ. Am. bor.

baltica, Link, Hort. Berol. i. 105 ; Dum. Fl. Bely. 152 -Europ.

brevipilis, Benth. ex Vasey, Cat. Gram. U. St. 52.Am. bor.

Curtissi, Vasey, in Torrey Bot. Club, xi. (158t) 7.Florida.

longifolia, Vasey, Agric. Grasses U. St.71.-Am. bor.

AMMORRHIZA, Ehrh. Phytophyl. (1789); lheitr. iv $146=$ Carex, Linn.

AMMOSELINUM, 'T'orr. \& Gmy, in Pacif Rail, Ren, ii. 165 (1855). U.MBELLIFERAE, Benth. \& Hool. f. i. 1009

Popei, Torr. \& Gray, /. c.-Texas.

AMMOSERIS, Endl. Gen. 500 (1S38)= Launaea, Cass. asplenifulia, D. Dietr. Syn. Pl. iv. $1919=1$. aspleni. asplensifuli
colin. bellidifulia, D. Dietr. 1. c. $19: 0=$ L. bellidifolia. Dregeruna, D. Dietr. 1. c.-Afr. auste. nudicuulis. D. Dictr. I. c $1319=\mathrm{L}$, nudicaulis patens, D. Dietr. I. c.-Ind. or.
sarmenfosus, D. Dicer. I. c. = L. pinuatilida. surinamensis, D. Dietr. L. c-Guian. 
AMMOSPERMA, Hook. f. in Benth. \& Hook. f. Gen. i. 82 (1862), CRUCIFERAE, Benth. \& Hook f. i. 82

cinerea, Hook. f.l. c.; Baill. Hist. Pl. iii. 278.Afr. bor.

AMMOTHAMNUS, Bunge, Enum. PI. Lehm. 67. t. 12 (1847). LEGUMINOSAE, Benth. \& Hook. f.i. 555 .

gibbosus, Boiss. Fl. Orient. ii. 628.-Assyria

Lehmanni, Bunge, l. c. 243.-Turkest.

AMMYRSINE, Pursh, Fl. Am. Sept. i. 301 (1814)= Leiophyllum, Hedw. f. (Ericac.).

buxifolia, Pursh, $\mathrm{l}, \mathrm{c}=\mathrm{L}$, buxifolium.

Lyoni, Sweet, Hort. Brit. ed. II. $344=$ L. buxifolium. prostrata, Sweet, ex Steud. Nom. ed. II. i. $78=\mathrm{I}$ buxifolium.

thymifolia, Forbes, Hort, Woburn. $93=$ L. buxifolium.

AMNI, Brongn. Enum. Genr, 110 (1843) err. typ.= Ammi, Tourn.

AMOGETON, Neck. Elem. iii. $267(\mathbf{1 7 9 0})=$ Aponogeton, Thunb. (Naiad.)

AMOLEIACHYRIS, Sch. Bip. in Walp. Rep. ii. 951 (1843), sphalm. = AMPHIACHYRIS, Nutt. = Gutierrezia, Lag. (Compos.)

AMOMIS, Berg, in Linnaea, xxvii. (1854) $416=$ Pimenta, Lindl. (Myrtac.)

acris, Berg, 1. c. $417=\mathrm{P}$. acris

oblongata, Berg, 1. c. 421 ('= P. acrís ?).-Ind. or. cult.; Guiana

Pimento, Berg, 1. c. 418 (=P. acris ?).-Ind. occ. Guiana

pimentoides, Berg, 1. c. $420=\mathrm{P}$. acris

AMOMOPHYLLUM, Engl. in Gard. Chron. (1877) I. $139=$ Spathiphyllum, Schott (Aroid.) floribundum, Engl. 1. c. $140=\mathrm{S}$. floribundum.

Patini, Engl. 1. c. $139=$ S. Patini.

A MOMUM, Linn. Mus. Cliff. 26 (1736); Gen. ed. I. 330 (1737). SCITAMINEAE, Benth. \& Hook. fo iii. 644.

ACHASMA, Griff. Notul. iii. 426 (1851).

Alexis, Salisb. in Trans. Hort. Soc. 1. (1812) 284.

CENolophon, Horan. Prod. Monog. Scitam. 36 (1862).

Diracodes, Blume, Enum. P1. Jav, i. 55 (1830).

DONACODES, Blume, 1. c. 54 (1830).

Etlingera, Giseke, Prael. Linn. 199, 209 (1792)

Geanthus, Reinw. in Syll. Ratisb, ii. (1828) 5.

Geocallis, Horan. Prod. Monog. Scit. 33 (1862).

Greenwaya, Giseke, Prael. Linn. 199, 206 (1792).

HoRnsTeDTIA, Retz. Obs. vi. 18 (1791).

Marogna, Salisb. in Trans, Hort. Soc i (1812) 283.

Meistera, Giseke, Prael. Linn, 199, 205 (1792)

Nicolaia, Horan. Prod. Monog. Ścitam.32. t. 1 (1862).

Paludana, Giseke, Prael, Linn. 199, 207 (1792).

Phaeomeria, Lindl. Introd. Nat. Syst, ed, II. 446 (1836).

Stenochasma, Griff. Notul. iii. 431 (1851)

Torymenes, Salisb. in Trans. Hort. Soc. i. (1812) 283.

Wurfainia, Giseke, Prael. Linn. 199, 206 (1792). ZEDOARIA, Rafin. Fl. Tellur. iv. 53 (1836).

gculeatum, Roxb. in As. Res. xi. (1810) 344.-Malaya acuminatum, Thw. Enum. Pl. Zeyl. 317.-Zeylan.

Afzelii, Rosc. in Trans. Linn. Soc. viii. (1807) $354=$ A. Granum-paradisi.

Alpinia, Rottb. in Coll. Soc. Med. Havn. ii. (1775) 245

t. 2 = Renealmia racemosa

angustifolium, Hanb. in Journ. Linn. Soc. xiii. (1873) $155=$ Danielli.

angrustifolium, Salisb. Prod. $4=$ Zingiber officinale. angustifolium, Sonner. Voy. Indes, iii. 276.-Madag aquaticum, Raeusch. Nom. ed. III, 1.-Zeylan. arboreum, Lour. F1. Cochinch. $7=$ Costus Loureiri. aromaticum, Roxb. Hort. Beng. 1; Fl. Ind. i. 44.Ind. or.

arundinaceum, Oliver \& Hanb. in Fourn. Linn. Soc. vii. (1864) 109.-Afr. trop.

Benthamianum, Trim. in Fourn. Bot. xxiii. (1885) 265 -Zeylan.

\section{AMOMUM}

bifidum, Stokes, Bot. Comment. i. $163=$ Alpinia Allughas.

biflorum, fack, in Malay. Misc. i. (1820) n. 1. p. 2.-. Penang.

cannaecarpum, Benth. \& Hook.f.Gen. iii. 644.--Ind. or. capitatum, Roxb. ex Link, Fahrb. ii. (1811) 64.Ind. or.

Cardamomum, Koen. in Retz. Obs. fasc. iii. $59=$ seq.

Cardamon, Linn. Sp. Pl. 1.-Ind. or. : Malava.

Cardamomum, Willd. Enum. Hort. Berol. Suppl. $1=$ Alpinia striata.

cereum, Hook. f. in Kew Fourn. Bot. iv. (1854) 296. -Afr. trop.

Cevuga, Seem. Fl. Vit. 291.-Ins. Fiji

ciliatum, Blume, Enum. Pl. Fav. 49.-Java.

citratum, Pereira, Mat. Med, ii. $1137=$ cereum.

Clusii, Hook. f. Bot. Mag. t. $5250=$ Danielli.

Clusii, Sm. in Rees, Cyclop. xxxix. n. 4.-Afr. trop.

coccineum, Benth. \& Hook f. Gen. iji. 644.-Java.

compactum, Roem. \& Schult. Syst. i. $28=$ A. Car-

damon.

corynostachyum, Wall. Pl. As. Rar. i. 48 t. 58.Ind. or.

costatum, Benth. \& Hook. f. Gen. iii. 285.-Ind. or.

Curcuma, Jacq. Hort. Vindob. iii. 5. t. $4=$ Curcuma longa.

Dallachyi, F. Muell. Fragm. viii. 25.-Austral.

Danielli, Hook. f. in Kew Fourn. iv. (1854) 129. t. 5 - Afr. trop.

dealbatum, Roxb. Hort. Beng. 1; Fl. Ind. i. 43.Ind. or.

echinatum, Willd. Sp. P1. i. 8.-Ind. or.

elatum, Salisb. Prod. $5=$ A. Granum-paradisi.

Ensal, Raensch. Nom. ed. III. 1=Elettaria Cardamomum.

exscapum, Sims, in Kon. \& Sims, Ann. Bot. i. (1805) $549=$ A. Granum-paradisi

fasciculatum, Benth. \& Hook.f. Gen. iii.645.-Ind. or.

Fenzlii, Kurz, in Fourn. As. Soc. Beng. xlv. (1876) II.

154.-Ins. Nicobar.

floribundum, Benth. E Hook.f. Gen. iii. 644.-Zeylan

foetens, Benth. \& Hook.f.l. c.-Java.

fulviceps, Thw. Enum. Pl. Zeyl. 317.-Zeylan

Galanga, Lour. Fl. Cochinch. $5=$ Alpinia Galanga.

giganteum, Oliver \& Hanb. in Fourn. Linn. Soc. vii.

(1864) 109.-Afr, trop.

glaberrimum, Benth. \& Hook. f. Gen. iii. 644.Malaya.

globosum, Lour. Fl. Cochinch. $4=$ Alpinia globosa.

gracile, Blume, Enum. Pl. Fav. 49.-Java.

gramineum, Wall Cat.n. 6558--Ind, or.

graminifolium, Thw. Enum. Pl. Zeyl, 430.-Zeylan.

grandiflorum, Sm. Exot. Bot. ii. 103. t. $11=\mathrm{A}$.

Granum-paradisi.

Granum-paradisi, Linn. Sp. Pl. 2.-Afr. trop.

heteranthum, Blume, Enum. Pl. Fav. 49.-Java.

hirsutum, Lam. Illustr. i. 134. t. $3=$ Costus speciosus.

hirsutum, Lour, F1. Cochinch. $5=$ Alpinia hirsuta.

hypoleucum, Thw. Enum. Pl. Zeyl. 318.-Zeylan.

involucratum, Benth. \& Hook. f. Gen. iii. 644.Zeylan.

Koenigii, Roem. E Schult. Syst, i. 30,-Ind. or. latifolium, Afzel. Remed. Guin. i. 5.--Afr. trop. latifolium, Salisb. Prod. $4=$ Curcuma Zedoaria.

Leonurus, Koen. ex Retz. Obs. fasc. iii. 69.-Malacca.

limbatum, Oliver \& Hanb. in Fourn, Linn. Soc. vil. (1864) 110.-Afr. trop.

linguiforme, Benth. छ Hook. f. Gen. iii. 644.-Ind. or littorale, Koen. ex Retz. Obs. fasc, iii. 52.-Burma.

longiscapum, Hook. f. in Fourn. Bot. vi. (1854) 296 .Afr, trop.

macrospermum, Sm. in Rees, Cyclop. xxxix. n. $3=$ Clusii.

madagascariense, Lam. Illustr. t. 2. f, $1=$ angustifolium. magnificum, Benth. \& Hook. f. Gen. iii. 644.-Ins. Maurit.

Mannii, Oliver \& Hanb. in Fourn. Linn. Soc. vii. (1864) 110.-Afr. trop.

marginatum, Roxb. ex Spreng. Schrad. \& Link, Fahrb.

ii. (1811) 64 .--Ind or

masticatorium, Thre. Enum. Pl. Zeyl. 317.-Zeylan.

maximum, Roxb. in As. Res, xi. (1810) 344.-Malaya. medium, Lour. Fl. Cochinch. $4=$ Hellenia alba.

Melegueta, Rosc. Monog. Scitam. t. 98.-Afr. trop.

Mioga, Thunb. F1. Jap. 14=Zingiber Mioga.

montanum, Koen, ex Retz. Obs. fasc. iii. $51=$ Zingiber Cassumunar.

\section{AMOMUM :}

muricatum, Bedd. in Madr. Fourn. Sc. Ser. III. i.

1864) 59.- - Ind, or

nemorale, Benth. \& Hook, f. Gen iii, 644,-Zeylan. nemorosum, Boj. Hort. Maurit. $327=$ Danielli.

nigrum, Raeusch. Nom. ed. III. $1=$ Alpinia Allughas. nutans, Roem. \& Schult. Syst. i. Mant. $40=$ Alpinia nutans.

palustre, Afzel. Stirp. Med. Nov, 9.-Afr, trop.

parviflonm, Presl, Rel. Haenk. ii, 112, t. $19=$ Alpinia parviflora.

petiolatum, Lam. Encyc. i. $136=$ Costus spicatus. pierardioides, Bedd. in Madr. Fourn. Sc. Ser. III. (1864) 58.-Ind. or.

pilosum, Oliver \& Hanb. in Fourn. Linn. Soc. vii. (1864) 110.-Afr. occ.

pterocarpum, Thw. Enuni. Pl. Zeyl. 317.-Zeylan.

pulchellum, Thw. 1. c. $318=$ Cyphostigma puIchellum. pyramidale, Lam. Encyc. i. 135=Renealmia racemosa. racemosum, Lam. Illustr. t. 2. f. $2=$ A. Cardamon. racemosum, Ruiz \& Pay. Fl. Per. i. $2=$ Renealmia Ruiziana.

Renealmia, Lam. Mllustr. i. $5=$ Renealmia exaltata.

repens, Sonner. Voy. Indes, iii. $272=$ Alpinia Cardamomum

roseum, Benth. \&o Hook. f. Gen. iii. 644.-Malaya.

roseum, Roxb. Pl. Corom. 2. t. $126=$ Zingiber roseum.

Rumphii, Sm. in Rees, Cyclop. xxxix. n. $15=$ Elettaria musacea.

rufescens, Benth. \& Hook. f. Gen. iii. 645.-Zeylan.

Sceptrum, Oliver \& Hanb. in Fourn. Linn. Soc. vii. (1864) 109.-Afr. trop.

Scottii, F. Muell. Fragm. viii. $24=$ Elettaria Scottiana. scyphiferum, Koen. ex Retz. Obs. fasc. iii. 68.Malacca.

sericeum, Roxb. Hort. Beng. 1; F1. Ind. i. $44=$ dealbatum.

spirale, Hort. ex Steud. Nom, ed. II. i. $78=$ Costus Pisonis.

spurium, J. F. Gmel. Syst. 1. $6=$ Zingiber Zerumbet. spurium, Roem. \& Schult. Syst. i. 30.-Ind. or.

striatum, Stokes, Bot. Comment, i. $159=$ Renealmia sylvestris.

strobilaceum, Sm. in Rees, Cyclop. xxxix. n. 8.-Afr. trop.

subsericeum, Oliver \& Hanb. in Fourn. Linn. Soc. vii. (1864) 110.-Afr. trop.

subulatum, Roxb. Pl. Corom. t. 227 ; Fl. Ind. i. 43.Reg. Himal.

sylvestre, Poir. Encyc. Suppl.v. 548=Zingiber Zerumbet.

sylvestre, Sw. Prod. Veg. Ind. Occ. $11=$ Renealmia sylvestris.

Taraca, Horan. Prod. $30=$ Alpinia Allughas.

Taracca, Roxb. ex Rosc. Monog. Scitam. in Obs. de Amomo $=$ praec.

thyrsoideum, Ruiz \& Pav. Fl. Per.i. 2.t. $2=$ Renealmia thyrsoidea.

uliginosum, Koen. ex Retz. Obs. fasc. iii. 56.-Ind. or.

uncinatum, Stokes, Bot. Comment, i. $161=$ A. Carda-

mon.
villosum, Lour. Fl. Cochinch. 1. 4.-Ind. or.; China. vitellinum, Lindl. in fourn. Hort. Soc. ii. (1847) 245 -Ind. or. ?

xanthioides, Wall. Cat. n, 6557.-Burma

xanthorhiza, Roxb. ex Steud. Nom. ed. II. i. $78=$ Zingiber Cassumunar.

Zedoaria, Berg. Mat. Med. $41=$ Curcuma Zedoaria

Zerumbet, Koen. ex Retz. Obs. fasc. iii, $55=$ Curcuma Zedoaria

Zerumbet, Linn. Sp. Pl. 1 =Zingiber Zerumbet. Zingiber, Blanco, Fl. Filip. $2=$ Zingiber Blancoi. Zingiber, Linn. Sp. P1. 1 = Zingiber officinale. Zinziba, Hill, Veg. Syst. xvi. $50=$ praec.

AMONIA, Nestl. Mon. Potent. 17 (1816)=Agrimonia,

Linn. (Rosac.)

agrimonoides, Steud. Nom. ed. I. 39, $19=$ Agæ.. Eupatoria.

AMOORA, Roxb. Pl. Corom. iii. 54. t. 258 (1819) MELIACEAE, Benth. \& Hook. f. i. 334.

Andersonia, Roxb. Hort. Beng. 87 (1814); Fi Ind. ii. $212(1832)$

APHANAMIXIS, Blume, Bijdr. 165 (1825).

Monosoma, Griff. Notul. iv. 502 (1854)

Nimmota, Wight, in Calc. Journ. Nat. Hist. vii. (1847) 13 
AMOORA:-

OraOMA, Turcz. in Bull. Soc. Nat. Mosc. (1858) I. 411.

Sphaerosacme, Wall. in Roxb. Fl. Ind. ed. Carey, ii. $429(1824)$

amboinensis, Miq. in Ann. Mus. Bot. Lugd. Bat. iv. 36.-Amboina.

Aphanamixis, Schult.f. Syst. vii. 1621.-Malaya.

auriculata, Miq. Ann. Mus. Bot. Lugd. Bat. iv. $37=$ cucullata.

Balanseana, C. DC. in DC. Monog. Phan. i. 590.-N. Caled.

borneensis, Miq. in Ann. Mus. Bot. Lugd. Bat. iv. 36. -Borneo.

canarana, Hiern, in Hook. f. Fl. Brit. Ind. i. 560. Ind. or.

Championii, Benth. \& Hook. f. Gen. i. 335; Hiern, in

Hook. f. 1. c. $562=$ Psendocarapa Championii.

chittagonga, Hiern, in Hook. f. l. c. 559.-Ind, or.

cucullata, Roxb. Pl. Corom. iii. 54. t. 258.-Ind. or.

Cumingiana, C. DC. in DC. Monog. Phan. i. 580.-Ins. Philipp.

decandra, Hiern, in Hook. f. Fl. Brit. Ind. i. 562.Ind. or.

dysuxyloides, Kurg, in fourn. As. Soc. Beng. xliv. (1875) 11. 200.-Burma.

filiciformis Wight, Illustr. Ind. Bot. i. 147.-Ind. or.

Ganggo, Kurz, in Journ. As. Soc. Beng. xlv. (1876) II

123 = Aglnia Ganggo.

grandifolia, Walp. Kep. i. 429 ; C. DC. in DC. Monog.

Phan. i. $581=$ A. Aphanamixis.

Korthalsii, Miq. in Ann. Mus. Bot. Lugd. Bat. iv. 36.

-Borneo.
lactescens, Kurz, in Fourn. As. Soc. Beng. xliv. (1875) II. 200.-Burma.

lanceolata, Hiern, in Hook. f. Fl. Brit. Ind. i. 560.Malacca.

Lawii, Benth. \& Hook. f. Gen. i. 335.-Ind, or.

laxa, Wight \& Arn. Prod. $119=$ cucullata.

macrophylla, Nimmo, in J. Grah. Cat. Bomb. P1. t. 31 $=$ A. Rohituka.

Maingayi, Hiern, in Hook. f. Fl. Brit. Ind. i. 562.Malacca.

moulmeiniana, C. DC. in DC. Monog. Phan. i. 584.Burma.

nitidula, Benth. Fl. Austral. i. 383.-Austral.

Perrottetiana, Steud. Nom. ed. II. i. 89.-Ins. Philipp. polystachya, Wight \& Arn. Prod. i. $119=$ A. Rohituka Rohituka, Wight \& Arn. l. c-Ind. or

Roxburghiana, Korth. ex Blume, Mus. Bot. Lngd. Bat. i. $211=$ Santiria laevigata.

rubescens, Hiern, in Hook. f. Fl. Brit. Ind. i. 561.Singapore.

rubiginosa, Hiern, l. c.-Malacca.

spectabilis, Miq. in Ann. Mus. Bot. Lugd.Bat. iv. 37. Burma.

sumatrana, Miq. l.c. 35--Sumatra.

Teysmanniana, Miq. Fl. Ind. Bat. Suppl. i. $503=$ Aglaia Teysmanniana.

timorensis, Wight \& Arn. ex Steud. Nom. ed. II. i. 78. -Ins. Timor.

tomentosa, Korth. ex Blume, Mus. Bot. Lugd. Bat. i 211 = Santiria tomentosa.

Vieillardi, C. DC. in DC. Monog. Phan. i. 591.-N Caled.

AMOORTA, Walp. Rep. i. 640 (1842), sphalm. = AMORIA, C. Presl, =Trifolium, Tourn. (Legum.)

AMORDICA, Neck. Elcm.i. $241(1790)=$ Momordica, Tourn. (Cucurb.).

AMOREA, Moq. in Delile, Cat. Hort. Monsp. (1844)= Cycloloma, Moq. (Chenopod.)

platyphylla, Delile, 1. $\mathrm{c}_{0}=\mathrm{C}$. platyphyllum.

AMOREUXJ.A, Moç. \& Sesse, ex DC. Prod. ii. 638 (1825). BIXINEAE, Benth. \& Hook, f. i. 124.

EURYANTHE, Cham, \& Schlecht. in Linnaea, v. (1830) $2 \cdot 2 \cdot$

malvacfolia, A. Gray, Pl. Wright. 1. 29.-Am. bor.

palmatifida, Moç. \& Sesse, ex DC. Prod. ii. $638=$ Schiecleana

Schiedeana, Planch. in Hook. Lond. Gourn. Bot. vi. (1846) 140. t. 1.-Am, bor.

Wrightii, A. Gray, Pl. Wright. ii. 20.-Am. bor.
AMOREUXIA, Moq in Mém. Soc. Hist. Nat. Monsp. (1826) = Cycloloma, Moq. (Chenopod.) platyphylla, Mog. 1. c. =C. platyphylium.

AMORGINE, Rafin. New FI. Am.iv. 44 (1836)=Achy ranthes, Linn. (Amaranth.).

albescens, Rafin. 1. c.-Am. bor

AMORIA, C. Presl, Symb. Bot. $15(1830)=$ Trifolium, Tourn. (Legum.)

angulata, C. Presi, 1. c. $47=\mathrm{T}$. angulatum.

Biasollettiana, C. Presl, l. c. $=$ T. repens.

caespitosa, C. Presl, 1. c. $=$ T. Thalii.

calycina, C. Presl, l, c. 43. t. $30=$ T. calycinum.

caroliniana, C. Presl, 1. c. $47=\mathrm{T}$. carolinianum

elegans, C. Presl, 1. c. = T. elegans.

hybrida, C. Presl, 1. c. $=$ T. hybridum.

isthmocarpa, C. Presl, 1. c. $50=$ T. Jaminianum. macropoda, C. Presl, 1. c. 51. t. $31=$ T. macropodum.

Micheliana, C. Presl, I, c. $47=$ T. Michelianum.

migrescens, Fourr. in Ann. Soc. Linn. Lyon, N. S, xyi.

1868) $362=\mathrm{T}$. Micheilanum.

obcordata, C. Presl, Symb. Bot. i. $47=$ T. polymorphum. pallescens, C. Presl, 1. $\mathrm{c}=\mathrm{T}$. pallescens.

parviflora, C. Presl, l. c. $=$ T. parviflorum.

polymorpha, C. Presl, 1. c. $=$ T. polymorphum.

repens, C. Presl, 1. c. $=$ T. repens.

reflexa, $\mathrm{C}$. Presl, $1 . \mathrm{c}_{\mathrm{n}}=\mathrm{T}$. reflexum.

Thalii, Fourr. in Ann. Soc. Linn. Lyon, N. S. xvi. (1868) $362=\mathrm{T}$. Thalii

Vivianii, C. Presl, ex Stend. Nom. ed. II. 1. $78=$ T. caeruleum.

AMORPHA, Linn. Gen, ed. I. 229 (1737). LEGUMINOSAE, Benth. \& Hook. f. i. 492

californica, Nutt. ex Torr. E Gray, Fl. N. Am. i. 306. -Calif.

canescens, Nutt. in Fras. Cat. (1813).-Am. bor.

caroliniana, Croom, in Am. Journ. Sc. xxv. (1834) 74 $=$ fruticosa.

coevulea, Lodd. Cat. $(1830)=$ fruticosa

croceo-lanata, Wats. Dendrol. t. $139=$ fruticosa?

cynostachya, M. A. Curt. ex Torr. \& Gray, Fl. N. Am. i. 305 (cit. falsa) $=$ fruticosa

elata, Bouché, ex Schlecht. in Linnaea, xxiv. (1851) 687.-Hab. ?

elata, Hayne, Dendrol. Fl. $134=$ fruticosa.

emarginata, Sweet, Hort. Brit. ed. I. 121. n. $466=$ fruticosa.

fragrans, Sweet, Brit. F1. Gard. iii. t. $241=$ fruticosa

fruticosa, Linn. Sp. Pl. 713,-Am. bor.

fruticosa, Torr. Bot. Mex. Bound. $53=$ californica.

fruticosa, Thunb. F1. Jap. $278=$ Cladrastis amurensis

Gaertneri, Hort. ex C. Koch, Dendrol. i. $70=$ fruticosa.

Gardneri, Hort. ex C. Koch, 1. c. Index, $701=$ praec.

glabra, Desf. Tabl. Hort. Par. ed. I. 192=fruticosa

glandulosa, Blanco, Fl. Filip. ed. I. 555.-Ins. Philipp.

herbacea, Walt. Fl. Carol. 179.-Am. bor.

herbacea, Schlecht. Ind. Sem. Hort. Hal. (1848) 8.-Cf. Linnaea, xxiv, (1851) $185=$ fruticosa

humilis, Tausch, in Flora, xxi.(1838) II. $750=$ fruticosa? laevigata, Nutt.ex Torr. \& Gray, Fl. N. Am. i. 306.Am. bor.

Lewisit, Lodd. ex Loud. Hort. Brit. Suppl. ii. $609=$ fruticosa.

Ludwigii, Hort. ex C. Koch, Dendrol. i. $70=$ fruticosa lutea, Rafin. Fl. Ludow, 105.-Am. bor.

microphylla, Pursh, Fl. Am. Sept. ii. 466.-Am, bor. nana, Nutt. in Fras. Cat. $(1813)=$ fruticosa?

nonperforata, Schk. Bot. Handb. ii. $383=$ fruticosa

ornata, Wender. Ind. Sem. Hort. Marb. (1835) = fruticosa.

paniculata, Torr. \& Gray, Fl. N. Am. i. 306.-Am. bor. pedalis, Blanco Fl Filip ed. I 553.-Ins. Philipp. pendula, Carr, in Rev. Hortic. (1868) $340=$ fruticosa perforata, Schk. Bot. Handb. ii. $333=$ fruticosa.

pribescens, Schlecht. in Linntea, xxiv. (1851) 691 fruticosa.

pubescens, Willd. Berl. Baumz, $17=$ herbacea.

pumila, Michx, Fl, Bor, Am, ii. 64=herbacea.

pumila, Schlecht. Ind. Sem. Hort. Hal. (1548) 8.-Cf.

Linnaea, xxiv. (1851) $185=$ fruticosa

punctata, Rafin. Nov. Fl. Am. iii. 14.-Am. bor.

Rabiae, Lex, in La Llave \& Lex. Nov. Veg. Desc. fas i. $22 .-$ Mexic.

Rormeriana, Schcele, in Linnaea, xxi. (1848) 461 paniculata.

\section{AMORPHA:}

sis, Schult. in Kunze, Del. Sem. Hort. Lips. 1848) = fruticosa

texana, Buckl. in Proc. Acad. Sc. Philad. ' 1861 ' (1862 $452=$ laevigata

tomentosa, Rafin. Fl. Ludow. 105.-Am. bor.

AMORPHOCALYX, Klotzsch, in Rich. Schomb. Faun. \& Fl. Guian. 1104, nomen, (1848) (Legumin. Roraimae, Klotzsch, l. c.-Guiana.

AMORPHOPHALIUS, Blume, in Batav. Diar (1825); ex Decne. Herb. Tim. Descr. 38 (183\%) AROIDEAE, Benth. \& Hook. f. iii. 970.

Brachyspatha, Schott, Syn. Aroid. 35 (1856) Candarum, Reichb. ex Schott, Melet. i. 17 (1832). Conophallus, Schott, Syn. Aroid. 34 (1856). Corynophaluus, Schott, in Oestr. bot. Wochenbl. (1857) 389.

Hansal1A, Schott, in Oestr. Bot. Zeitschr. (1858) 8\%

Hyorosme, Sichott, in Oestr. Bot. Wochenbl, (1857) 389

KUNDA, Rafin. F1. Tellur. ii. 82 (1836)

Proternophal.Lus,|Hook.f. Bot. Mag.t. 6195 (1875)

Pythion, Mart, in Flora, xiv. (1831) 45y.

Tapernophallus, Baill. Dict. Hot. i. Ic sine desc. (1877)

Beccarii, Engl. in Engl. Bot. Fahrb̆. i. (1881) 182.Sumatra.

Blumei, Schott, in Ann. Mus. Lugd. Bat. i. $124=$ giganteus.

bulbifer, Blume, Rumphia, i. 148.-Ind, or.

campanulatus, Blume, ex Decne. Herb. Timor. 38.-As. trop.

Chatty, André, Illustr. Hortic. xix. (1872) 361.-Ind. or commutatus, Engl. in DC. Monog. Phan. ii. 319.Ind. or.

consimilis, Blume, Rumphia, i. 149.-Afr, trop.

decurrens, Kunth, Enum. Pl. iii. 581.-Ins. Philipp.

difformis, Blume, Rumphia, i. $149=$ Anchomane difformis.

dubius, Blume, l.c. 142.-Ind. or. : Malaya.

Fontanesii, Kunth, Enum. Pl. iii. 35.-Afr. trop.

Gigras, Teijsm. \& Binn, in Nat. Tijdschr. Neder. Ind. xxiv, (1862) 329, - Sumatra.

giganteus, Blume, Rumphia, i. 144. t. 34-Ind. or. Malaya

gracilis, Engl. in Engl. Bot. Fahrb. i. (1881) 183.Sumatra.

hirsutus, Teijsm. os Binn. in Nat. Tijdschr. Neder. Ind. xxiv. (1862) 332. - Java.

imperialis, Hort. cf. Gard. Chron. (1SS3) I. 510.Ins. Philipp.

Konjac, C. Koch, in Berl. Allg. Gartcnz. (1858) 166 Rivieri.

Lacourii, Linden. \& Andre, in Illustr. Hortic. xxv. (1878) t. 316.-Cochinch.

leonensis, Lem - in Fr. des Serres, Sér. I. ii. '1Stio 161.-Afr. trop.

longistylus, Kurs, Rep. Andam.50, nomen.-Ins. An daman.

lvratus, Kunth, Enum. Pl, iii. 34-Ind. or.

margaritifer, Kunth, 1. c. = Plesmonium margaritiferum mossambicensis, Klotzsch, ex Garcke, in Peters, Reis Mossamb. Bot. 509.-Afr. trop.

Mulleri, Blume, Rumphia, i. 143.-Jari.

nivosus, Lcm. Illustr. Hortic. xii. (1865: t. $124=$ Dra contium asperum.

palmaeformis, Dur. ex Riv. in Act. Iinn. Soc. Burd. xxviii. (1869) 15; Ririère, L'Amorph. 4, $5=$ Rivieri. papillosus, Hort. ex Rafarin, in Res. Hortic. 18i1 476.-Hab.

Peyri, cf. Gard. Chron. (1880) II, 120,-Ins. Serchelles planus, Teijsm \& Binn. in . Tat. Tijdschr. lieder. Ind. xiv. (1:6.2) 3\$1. - Sumatra

punctulatus, Blume, Rumphia i. Its-Java

Rivieri, Dur. ex Riviére, in Act. Limn. Sux. Burd. xxviit. (1869) 15.-Cochinch. ; Japon.

sativus, Blume, Rumphia, i. 115.-Ins. Moluce

spectabilis, Engl. in DC. Honog. Phan. ii. \$16.-Java struticus, Kunth, Enum. Pi. iii. $\$ t=$ Simanehorias siluaticus.

Tisanum. Bere, in Bul!. Sor: Tose. Orfic. 1sitt 11

tuberculiger, Engl, in DC. Honog. Ptons. ii. 31:- $-\mathrm{Reg}_{\mathrm{c}}$ llimal.

tariabilis, Blomse, Romalsis, i. 1f6. \&. 95,-Java; Ins l'hilipp. 


\section{AMORPHOPHALLUS :-}

virosus, N. E. Br. in Gard. Chron. (1885) I. 759.-Siam. Wallisii, Regel, Gartenfl. (1861) $322=$ Dracontium asperum.

zebrinus, Hort.-Cf. Gard. Chron. (1865) 485.-Hab.? zeylanicus, Blume, Rumphia, i. 148.-Java ; Zeylan.

AMORPHOSPERMUM, F. Muell. Fragm. vii. 112 (1870) =Lucuma, Juss. (Sapotac.).

antilogum, F. Muell. 1. c.-Austral.

AMOSA, Neck。Elem. ii. $459(1790)=$ Inga, Plum. (Legum.),

AMOUREUXIA, C. Muell. in Walp. Ann. iv. 340 (1857), sphalm. = Amoreuxia, Moç. \& Sesse (Bixin.).

AMPALIS, Boj. Hort. Maurit. 291 (1837)。 URTICACEAE, Benth. \& Hook. f. iii. 365.

madagascariensis, Boj.l. c.-Madag.

AMPELANUS, Rafin. in Am. Monthly Mag. (1819) 192 =Enslenia, Nutt. (Asclep.).

AMPELOCERA, Klotzsch, in Linnaea, xx. (1847) 541. URTICACEAE, Benth. \& Hook, f, iii. 353. cubensis, Griseb. Cat. Pl. Cub. 57. -Ind, occ. Ruizii, Klotzsch, in Linnaea, xx. 542.-Peruv.

AMPELOCISSUS, Planch. in Journ. Vigne Am. (1884) $374=$ Vitis, Linn. (Ampelid.)

abyssinica, Planch. in Journ. Vigne Am. (1885) $24=$ V. abyssinica.

acetosa, Planch. 1. c. 96.-Austral.

aculeata, Planch. 1. c. $95=\mathrm{V}$. aculeata.

angolensis, Planch. 1. c. $48=\mathrm{V}$, angolensis.

arcuata, Planch. 1. $\mathrm{c}_{.}=\mathrm{V}$. arcuata.

asarifolia, Planch. 1. c. $29=\mathrm{V}$. asarifolia.

Bakeri, Planch. 1. c. $30=$ V. Schimperiana.

bombycina, Planch. 1. c. $31=\mathrm{V}$. bombycina.

cavicaulis, Planch. 1. c. $32=\mathrm{V}$. cavicaulis.

Chantinii, Planch. 1. c. $27=\mathrm{V}$. Chantinii.

cinnamochroa, Planch. 1. c. 31,-Am, trop.

concinna, Planch. 1. c. $48=\mathrm{V}$. concinna.

dissecta, Planch. 1. $\mathrm{c}_{0}=\mathrm{V}$. dissecta.

divaricata, Planch. 1. c. (1884) $375=$ V. divaricata.

elephantina, Planch. 1. c. 379.--Irs. Borbon.

Harmandi, Planch. 1. c. 378.-Cochinch.

heracleifolia, Planch. 1. c. (1885) $48=$ V. heracleifolia, indica, Planch. 1. c. (1884) $375=\mathrm{V}$. indica.

ipomeaefolia, Planch. 1.c. (1885) 26 =V. ipomeaefolia. Iatifolia, Planch. 1. c. (1884) $374=\mathrm{V}$, latifolia. Lecardii, Planch. 1. c. (1885) $29=\mathrm{V}$. Lecardii. leonensis, Planch. 1. c. $30=\mathrm{V}$. leonensis. Leprieurii, Planch. 1. c. $44=$ V. multistriata. mossambicensis, Planch. 1. c. $49=\mathrm{V}$. mossambicensis. obtusata, Planch. 1. c. $48=$ V. obtusata.

platanifolia, Planch. 1. c. $47=\mathrm{V}$. platanifolia. rugosa, Planch. 1. c. (1884) $374=\mathrm{V}$. lanata, indica. salmonea, Planch. 1. c. $(1885) 31=\mathrm{V}$. salmonea. sarcocephala, Planch. 1. c. $45=\mathrm{V}$. sarcocephala. Schimperiana, Planch. I. c. $26=$ V. Schimperiana sikkimensis, Planch. 1. c. (1884) $375=\mathrm{V}$. sikkimensis. tomentosa, Planch. 1. c. $375=$ V. tomentosa.

AMPELODAPHNE, Meissn. in DC. Prod. xv. I. 81 (1864). LAURINEAE, Benth. \& Hook. f. iii. 153. arunciflora, Meissn. l. c.-Bras.

dasyantha, Meissn. l. c.-Bras.

macrophylla, Meissn. l.c.-Bras.

AMPELODESMA A Beauv. Agrost. 78, t. 15. f. 11 (1812). GRAMINEAE, Benth. \& Hook. fo iii. 1178.

australe, Brongn. in Duperr. Voy. Bot. $31=$ Arundo pilosa.

bicolor, Kunth, Gram. i. 79.-Afr. trop.

effusum, Steud. Syn. Pl. Gram. 195.-Afr. bor.

festucoides, Steud. $1 . \mathrm{c} .=$ tenax.

tenax, Link, Hort. Berol i. 136.-Reg. Mediterr.

AMPELODESMOS, Link, Hort. Berol. i. $136(1827)=$ praec.

AMPELODESMUS, Woods, in Trans. Linn. Soc. xviii. (1838) $34=$ praec.
AMPELOPLIS, Rafin. Sylva Tellur. $33(1838)=$ Rhamnus, Linn.

chinensis, Rafin, l. $\mathrm{c} .=\mathrm{R}$. theezans.

AMPELOPSIS, [Rich. in] Michx. Fl. Bor. Am. i. 159 (1803) ex parte $=$ Vitis, Linn. (Ampelid.). aconitifolia, Bunge, Enum. Pl. Chin. Bor. $12=\mathrm{V}$. serjaniaefolia.

africana, Steud. Nom. ed. II. i. $219=$ V. africana. bipinnata, Míchx, Fl. Bor. Am. i. $160=\mathrm{V}$. arborea. Botria, DC. Prod, i. $633=$ V. africana

brevipedunculata, Maxim. ex Trautv. in Act. Hort Petrop. viii. (1883) 176.-As. or.

citrulloides, Lebas, in Rev. Hortic. (1875) 179.Hab.?

cordata, Michx. F1. Bor, Am, i. $159=\mathrm{V}$. indivisa. cordifolia, Rafin. Med. Fl. ii. $122=$ praec.

dissecta, Carr. in Rev. Hortic. (1868) $10=$ V. serjaniaefolia.

hederacea, DC. Prod. i. $633=$ V. hederacea.

heptaphylla, Buckl. in Proc. Acad. Sc. Philad. '1861' 1862) $450=V$. hederacea

heptaphylla, Roem. \& Schult. Syst. vo $321=$ V. heptaphylla.

heterophylla, Blume, Bijdr. $194=$ V. Landuk.

heterophylla, Sieb. \& Zucc. in Abh. Akad. Muench. iv II. $(1846) 196=\mathrm{V}$. heterophylla.

himalayana, Royle, Illustr. Himal. Bot. $149=\mathrm{V}$. himalayana.

hirsuta, Donn, Hort. Cantab. $166=$ hederacea

humulifolia, Bunge, Enum. Pl. Chin. Bor. 12=V. heterophylla.

indica, Blume, Bijdr. $193=\mathrm{V}$. indica.

japonica, Hort.-Cf. Gard. Chron. (1868) 1118. =V inconstans.

latifolia, Tausch, in Flora, xxi. (1838) II. 738; Kostel. Allg. Med.-Pharm. FI. iv. $1198=$ V. latifolia.

lucida, Carr. in Rev. Hortic. (1868) $39=\mathrm{V}$. serjaniaefolia.

minima, Hort.-Cf. Gard. Chron. (1873) $1469=\mathrm{V}$. inconstans.

napiformis, Carr. in Rev. Hortic. (1870-71) 16.China.

neilgherrensis, Wight, Spicil. Neilgh. i. 32. t. 36 ; et Ic. t. $965=\mathrm{V}$. himalayana.

palmiloba, Carr. in Rev. Hortic. (1867) 451.-China. pinnata, Roem. \& Schult. Syst. V. $322=\mathrm{V}$. pinnata. pubescens, Schlecht. in Linnaea, x. (1836) $251=\mathrm{V}$. pubescens.

quinquefolia, Michx. F1. Bor. Am. i. 159. t. $162=\mathrm{V}$. hederacea.

Regeliana, Carr. Rev. Hortic. (1866) 440.-Japon? sempervirens, Hort.-Cf. Gard. Chron. (1882) II, 491 \& $790=$ V. striata

serianaefolia, Bunge, Enum. Pl. Chin. Bor. $12=\mathrm{V}$. serjaniaefolia.

ternata, DC. Prod, i. $633=$ V. tomentosa.

tricuspidata, Sieb. \& Zucc. in Abh. Akad. Muench. iv (1846) $196=\mathrm{V}$. inconstans.

triloba, Carr, in Rev. Hortic. (1868) $39=\mathrm{V}$. serjaniaefolia.

tripartita, Carr, 1. c. $=$ V. serjaniaefolia.

tuberosa, Carr. 1. c. $(1870-71) 16=\mathrm{V}$. serjaniaefolia.

Veitchii, Hort.-Cf. Gard. Chron. (1868) $814=\mathrm{V}$. inconstans.

AMPELOSICYOS, (AMPELOSYCIOS), Thou. Hist Vég. Isles Afr. austr. 68. t. $22(1807)=$ Telfairia Hook. (Cucurb.)

scandens, Thou. 1. $\mathrm{c} .=\mathrm{T}$. pedata.

AMPELYGONUM, Lindl, in Bot. Reg. (1838) Misc. 62 Polygonum, Linn.

chinense, Lindl. l. c. $=$ P. chinense

tinctorium, Steud. Nom. ed. II. i. $79=$ P. tinctorium.

AMPEREA, A. Juss. Euph. Tent. 35. t. 10 (1824) EUPHORBIACEAE, Benth. \& Hook. f. iii. 265. conferta, Benth. Fl. Austral. vi. 83.-Austral.

cuneiformis, F. Muell. ex Baill. Etud. Gén. Euph. 455 =spartioides.

ericoides, A. Fuss. Tent. Euph. 112. t. 10.-Austral. micrantha, Benth. Fl. Austral. vi. 83.-Austral. protensa, Nees, in Lehm. Pl. Preiss. ii, 229.-Austral. rosmarinifolia, Klotzsch, in Lehm. 1. c. i. $176=$ ericoides.

spartioides, Brongn. in Duperr. Voy. Bot. 226. t. 49.Austral.

\section{AMPERE $\dot{A}$ :}

subnuda, Nees, in Lehm. Pl. Preiss. ii. 229.-Austral. volubilis, F. Muell. ex Benth. Fl. Austral. vi. 82.Austral.

AMPHANIA, Banks, ex DC. in Mém. Soc. Phys. Genèv. i. (1821) $408=$ Ternstroemia, Linn.

integrifolia, Soland. ex DC. 1. c. $410=$ T. elliptica.

AMPHEREPHIS, H. B. \& K. Nov, Gen, et Sp. iv. 31. t. $314,315(1820)=$ Centratherum, Cass. (Compos.) aristata, H. B. \& K. 1. c. $25=$ C. punctatum.

indica, Wall. [Cat. n. 2956]; Less。 in Linnaea, vi. (1831) $686=\mathrm{C}$. reticulatum

intermedia, Link, Abbild. 5. t. $29=$ C. intermedium. mollis, Wall. Cat, n, $2957=\mathrm{C}$. molle.

mutica, H, B. \& K. Nov. Gen. et Sp. iv. 26, $315=$ C. muticum.

pilosa, Cass. ex Steud. Nom. ed. II. i. 324, in syn. =C. muticum.

psilocarpa, Nees \& Mart. in Nov. Act. Nat. Cur. xii. (1824) 4=Oiospermum involucratum.

pulchella, Cass. ex Steud. Nom. ed. II. i. $79=$ C pulchellum.

senegalensis, Less. in Linnaea, vi. (1831) $687=$ Herderia truncata

Wightiana, Wall. Cat. n. $2958=$ Carpesium cernuum.

AMPHIACHYRIS, Nutt. in Trans. Am. Phil. Soc. Ser. II. vii. (1841) 313. COMPOSITAE, Benth. \& Hook. f. ii. 250 .

Amphrpappus, Torr. \& Gray, in Proc. Bost. Soc. i. (1844) 210

dracunculoides, $N$ utt. l. c.-Am. bor.

Fremontii, A. Gray, in Proc. Am. Acad. viii. (1873) 633:-Calif.

AMPHIANTHUS, Torr. in Ann. Lyc. N. York, iv. (1837) 82. SCROPHULARINEAE, Benth. \& Hook. f. ii. 958 .

pusillus, Torr. l. c.-Am. bor.

AMPHIBECIS, Schrank, in Syll. Ratisb. i. (1821) $86=$ Centratherum, Cass. (Compos.).

violacea, Schrank, 1. c. $=$ C. intermedium.

AMPHIBLEMMA, Naud, in Ann. Se. Nat, Sér. III xiv. (1850) t. 7 ; xy, (1851) 50. MELASTOMACEAE, Benth. \& Hook. f. i. 754

cymosum, Naud. l. c. xv. (1851) 51,-Afr. trop molle, Hook. f. in Oliver, Fl. Trop. Afr. ii. 456; in Trans. Linn. Soc. xxviii. (1871) 79.-Afr. trop. setosum, Hook. f. ll. cc.-Afr. trop.

AMPHIBOLIS, C. Agardh, Sp. Alg. ii. I. 474 (1822) NAIADACEAE, Benth. \& Hook. f. iii. 1015. Graumuellera, Reichb. Consp. 43 (1828). antarctica, Aschers. in Linnaea, xxxv. (1867-68) $164=$ Cymodocea antarctica.

bicornis, C. Agardh, Sp.Alg. ii. r. 474.-Austral zosteraefolia, C. Agardh, 1. c. $475=$ Cymodocea antarctica.

AMPHIBROMUS, Nees, in Hook. Lond. Joum. Bot. ii. (1843) 420. GRAMINEAE, Benth. \& Hook. f. iii. 1161.

fluitans, $T$. Kirk, in Trans. N. Zeal. Inst. xvi. (1884) 374. t. 28.-N. Zel.

Neesii, Steud. Syn. Pl. Gram. 328.-Austral.

AMPHICALEA, Gardn. in Hook. Lond. Journ. Bot. vii. (1848) $411=$ Calea, Linn. (Compos.)

fruticosa, Gardn. 1. c. $412=$ C. rotundifolia.

gentianoides, Gardn. 1. c.= Geissopappus gentianoides.

AMPHICALYX, Blume, F1. Jav. Praef. p. vii $(1828)=$ Diplycosia Blume (Ericac.).

AMPHICARPAFA, E11. in Journ. Acad. Philad. i. (1818) 372 (Amphicarpa). LEGUMINOSAE, Benth. \& Hook. f. i. 529 .

CRYPTOLOBUS, Spreng. Syst. iii. 218 (1826).

FALCATA, J. F. Gmel. Syst. 1131 (1791).

Lobomon, Rafin. New FI. Am。 i. 81 (1836).

SAviA, Rafin. in Med. Repos. N. York, v. (1808) 352 .

Tetrodea, Rafin. New Fl. Am. i. 81 (1836)

ciliata, Rafin. l. c. 82.-Am. bor. 


\section{AMPHICARPAEA :-}

comosa, G. Don, in Loud. Hort. Brit, $314=$ monoica. cuspidata, Rafin. New Fl. Am. i. 83,-Am. bor. deltifolia, Rafin. 1. c. = monoica.

Edgeworthi, Benth. in Miq. Pl. Fungh. 231.-Reg. Himal.

Ellioti, Rafin. New Fl. Am. i. $83=$ monoicn

ferruginea, Benth. in Miq. Pl. Jungh. $231=$ Shuteria ferruginea.

heterophylla, Rafin. New Fl. Am. i. $82=$ monoica. monoica, Ell. in fourn. Acad. Philad. i. (1818) 372 ; E ex Nutt. Gen. Am. ii. 115.-Am. bor.

Pitcheri, Torr. \& Gray, Fl. N. Am. i. 292.-Am, bor. sarmentosa, Ell. ex Nutt. Gen. Am. ii. $114=$ monoica trisperma, Baker, in Hook. f. Fl. Brit. Ind. ii. 181, in obs. = Edgeworthii

villosa, Rafin. New Fl. Am, i. $82=$ monoica

AMPHICARPON, Rafin. in Am. Monthly Mag. (Jan. 1818) $175=$ seq.

AMPHICARPUM, Kunth, Gram, i. 28 (1829) GRAMINEAE, Benth. \& Hook. f. iii. 1099 floridanum, Chapman, Fl. S. U. St. 572,-Florida. Purshi, Kunth, Gram. i. 28.-Am. bor.

AMPHICOME, Royle, Illustr. Himal. P1. 296. t. 72. f. 1 (1835), BIGNONIACEAE, Benth. \& Hook. f. ii. 1049 . arguta, Royle, l.c.-Reg. Himal.

Emodi, Royle, ex Lindl. Bot. Reg. (1838) t. 19.-Reg. Himal.

AMPHIDERRIS, Spach, Hist. Vég. Phan. x. 402 (1841) Orites, R. Br. (Proteac.)

AMPHIDETES, Fourn. in Mart. F1. Bras. vi. IV. 213 (1885). ASCLEPIADEAE.

laciniatus, Fourn. l. c. 214.-Bras.

quinquedentatus, Fourn.l.c. 213.-Bras.

AMPHIDONAX, Nees, in Lindl. Introd. Nat. Syst. ed. II. 449 (1836) = Arundo, Linn. (Gramin.)

bengalensis, Nees, 1. c. = Arundo bengalensis

AMPHIDONAX, Nees, ex Steud. Syn. Pl. Gram. $197=$ Zenkeria, Trin. (Gramin.)

bifaria, Nees, ex Steud. 1. c.-Japon.

Heyni, Nees, ex Steud. 1. c. =Z. elegans,

obtusiflora, Thw. Enum. P1. Zeyl. 370=Z. obtusiflora. tenella, Wight \& Arn. ex Steud. Syn. Pl. Gram. 197. -Ind. or.

AMPHIDOXA, DC. Prod. vi. 246 (1837). COMPOSITAE, Benth. \& Hook. f. ii. 300.

filaginea, Ficalho of Hiern, in Trans. Linn. Soc. Ser. II. ji. (1881) 21.-Afr. trop.

gnaphalodes, $D C$. l. c.-Afr. austr.

AMPHIGENES, Janka, in Linnaea, xxx. (1859-60) 619 = Festuca, Linn. (Gramin.).

carpathica, Janka, 1. c. = F. carpathica.

nutans, Janka, l. c. $=$ F. nutans.

AMPHIGLOSSA, DC. Prod. vi. 258 (1837). COMPOSITAE, Benth. \& Hook. f. ii. 324.

alopecuroides, Sch. Bip. in Pollichia, xviii-xix. (1861) 182.-Afr. austr.

callunoides, $D C$. Prod. vi. 259.-Afr. austr.

corrudaefolia, $D C$. $l$.., 258 , - Afr. austr.

nitidula, $D C$. $l$. c. 259-Afr. austr.

perotrichoides, DC. 1. c. $258=$ Pterothrix perotrichoides.

tomentosa, Harv. in Harv. \& Sond. Fl. Cap. iii. 276. -Afr. austr.

triflora, DC. Prod. vi. $258=$ Pterothrix spinescens.

AMPHIGLOTTIS, Salisb. in Trans. Hort. Soc. $i_{\text {. }}(1812)$ 294 = Epidendrum, Linn. (Orchid.). lurida, Salisb. 1. c. $=$ E. anceps.

secunda, Salisb. 1. $\mathrm{c}_{\mathrm{.}}=\mathrm{E}$. secundum

AMPHILOBIUM, Lond, Hort. Brit. 242 (1880), sphalm. - Amphilophium, H. B. \& K. (Bignon.)

AMPHILOCHIA, Mart. Nov, Gen. et Sp. i. 127, t. 77 (1824) = Qualea, Aubl. (Vochysiac.).

\section{AMPHILOCHIA :-}

acuminulata, Gardn. in Hook. Lond. Journ. Bot. ii

(1843) $343=Q$. cryptantha

cordata, Mart. Nov, Gen, et Sp i. $129=0$ cordata.

dichotoma, Mart. 1. c. 128. $.77=0$ dichotoma.

Lundii, Warm. in Kjoeb. Vidensk. Meddel. (1867) 27 $=\mathrm{Q}$. Lundii

marginata, Miq. in Linnaea, xxii. (1849) $796=0$. marginata.

AMPHILOPHIUM, Kunth, in Joum. Phys, lxxxvii. 1818) 451. BIGNONIACEAE, Benth. \& Hook. f. (1818) 45
ii. 1039 .

glanduliferum, Mart. ex DC. Prod. ix. 193=Vauthieri.

macrophyllum, H. B. \& K. Nov. Gen. et Sp. iii. 149. - N. Granat.

molle, Cham. E Schlecht. in Linnaea, v. (1830) 120. -Mexic.

Mutisii, H. B. \& K. Nov. Gen. et Sp. iii. 149. t. 219. -N. Granat.

paniculatum, $H . B . \&$ K . l. C.-Honduras.

pubescens, Spreng. Syst. ii. $836=$ Bignonia fallax

Vauthieri, DC. Rev. Bignon. (1838); Prod. ix.193.Bras.

AMPHINOMIA; DC.Prod. ii. 522 (1825)=Lotononis,

Eckl. \& Zeyh. (Legumin.)

decumbens, DC. 1. c. $=$ L. polycephalus

AMPHIOLANTHUS, Griseb. Cat. Pl. Cub. 186 (1866) = Micranthemum, Michx. (Scrophul.)

arenaroides, Griseb. 1. c. 187.-Cuba.

bryoides, Griseb. 1. c. 186.-Cuba.

AMPHION, Salisb. Gen. Pl. Fragm. 66 (1866) = Semele Kunth (Liliac. ).

AMPHIONE, Rafin. Fl. Tellur. iv. $79(1836)=$ Ipomaea,

Linn. (Convolv.)

asarifolia, Rafin. 1. c. = I. asarifolia.

chenopodia, Rafin. 1. c.-Hab.

cymosa, Rafin. 1, c. = I, cymosa.

lobata, Rafin. 1. c.-Hab.

splendens, Rafin. Sylva Tellur. $130=$ Argyreia splendens.

venosa, Rafin. F1. Tellur. iv, $79=\mathrm{I}$, venosa.

AMPHIPAPPUS, Torr. \& Gray, in Proc. Bost. Soc. i. (1844) 210 ; Bost. Journ. Nat. Hist. v. (1847) $107=$ Amphiachyris, Nutt. (Compos.)

Fremontii, Torr. \& Gray, 1. c. $108=$ Amphiachyris Fremontii.

AMPHIPLEIS, Rafin. Fl. Tellur. iii. $75 \quad(1836)=$ Nicotiana, Linn. (Solanac.)

fetida, Rafin. 1. c.-Hab.?

quadrivalvis, Rafin. 1. c. $=$ N, quadrivalvis.

AMPHIPOGON, R. Br. Prod $175(1810)$ GRAMI NEAE, Benth. \& Hook, f iii, 1145.

Aegopogon, Beauv. Agrost. 122. t. 22. f. 4 (1812), partim.

Gamelythrum, Nees, in Hook. Lond. Journ. Bot. ii. (1843) 415 .

Pentacraspedon, Steud. Syn. Pl, Gram. 151 (1855) avenaceus, R. Br. Prod. $175(1810)=$ strictus.

Brownei, F. Muell. Fragm. viii. 201 = strictus.

caricinus, F. Muell. in Linnaea, xxv. (1852) $445=$ strictus.

cygnorum, Nees, in Lehm. Pl. Preiss. ii. 100.-Austral. debilis, $R$. Br. Prod. i. 175-Austral.

gracilis, Nees, in Lehm. Pl. Preiss, ii. $101=$ strictus.

laguroides, F. Muell. Fragm. viii. $201=$ cygnorum.

laguroides, $R, B r$. Prod. i. 175.-Austral.

strictus, R. Br. l. $c_{0}$ - Austral.

turbinatus, $R . B r . l . c$ - A ustral.

AMPHIREPHIS, Nees \& Mart in Nor Act Aad. Nat Cur, xii. (1824) 4=AMPHEREPIIS, H. B \& K = Centratherum, Cass. (Compos.).

AMPHIRHAPIS, DC. Prod. v. $343(1836)=$ Inula Linn.; Microglossa, DC. \& Sclidago, Linn, (Compos.)

albescens, DC. Prod, $\vee, 349=\mathrm{M}$. alhescens.

chinensis, Sch. Bip. in Flora, xxxv. (1852) 58 Solidago Virga-aurea.
AMPHIRHAPIS :-

cuspidata, DC. Prod. v. $343=$ Inula cuspidata.

heterotricha, DC, $1 . c_{0}=\mathrm{I}$, eupatorioides.

indica, 'Less.' ex Hook. f. F1. Brit. Ind. iii. 227, in syn. $=$ Centratherum reticulatum.

japonica, Míq. Ann. Mus. Bot. Lugd. Bat. ii. 172.Japon.

eiocarpa, Benth. in Hook. Lond. Joum. Bot. i. (1842 488 = Solidago Virga-aurea

mollis, 'Wall.' ex Hook. f. Fl. Brit. Ind. iii. 227, in syn. $=$ Centratherum molle.

peduncularis, DC. Prod, v, $344=$ Aster asperulus,

pubescens, DC. 1. c. $343=$ Solidago Virga-aurea.

rubricaulis, DC. 1. c, =I. rubricaulis,

Wightiana, Hook. f. Fl. Brit. Ind, iii. 301 = Carpesium abrotanoides.

zeylanica, DC. Prod, vii. $279=\mathrm{M}$, zeylanica

Zollingeriana, Sch. Bip. in Zoll. Syst. Verz. Ind Archip. 126, nomen.-Malaya.

AMPHIRRHOX, Spreng. Syst. Cur. Post. 51 (1827)

VIOLARIEAE. Benth. \& Hook. fo i. 118

I3RADIULEYA, Vell. Fl. Flum, ii.t. 140 (1827)

SPATHULAPIA St Hil P1 Rem. 317 t 28 (1824).

latifolia, Mart. ex Eichl. in Mart. Fl. Bras. xiii. 376.-Bras.

longifolia, Spreng. Syst. Cur. Post. 51.-Bras. surinamensis, Eichl, in Mart. Fl. Bras, xiii. i. 377.Bras.

AMPHISCOPIA, Nees, in Wall. Pl. As. Rar. iii. 11: $(1832)=$ Justicia, Linn. (Acanth.)

aequilabris, Nees, in DC. Prod, xi. 358.-Bras.

Beyrichii, Nees, in Mart. Fl. Bras. ix. $130=$ J. nummularia.

ciliata, Moricand, ex Nees, 1. c.-Bras.

ciliata, Nees, in DC. Prod. xi. 359.-Reg. Argent.

comosa, Nees, 1. c: $360=\mathrm{J}$. comosa

cuneifolia, Nees, in Mart. F1. Bras, ix. $130=\mathrm{J}$. cuneifolia.

inficiens, Nees, in DC. Prod, xi. $357=\mathrm{J}$. inficiens. lancifolia, Nees, 1. c.-Peruy.

Martiana, Nees, in Mart. Fl. Bras, ix. 130,-Bras. Middletoni, Nees, in DC. Prod. xi. 356.-Afr. trop.

montana, Nees, 1. c. 359.-Bras.

Moricandiana, Nees, 1. c. 357.-Bras.

Pohliana, Nees, 1. c..30 $9 .-$ Bras.

polystachya, Nees, 1. c. $356=\mathrm{J}$. polystachya

retusa, Nees, 1. c. $357=\mathrm{J}$. retusa.

rosea, Nees, 1. c. $358=$ Eranthemum roseum

serpens, Nees, 1. c. $357=$ Hypoëstes serpeus ?

strobilacea, Nees, 1. c. 358.-Bras.

venosa, Nees, 1. c. $358=$ J. cristata

AMPHISCOPIUM, St. Lag. in Ann. Soc. Bot. Lyon, vii. $119(1880)=$ praec

AMPHISTELMA, Griseh. F1. Brit. W. Ind. 417 (1864 = Vincetoxicum, Moench (Asclep.).

angulatum, Fourn. in Mart. Fl. Bras. vi. IV, 226.Bras.

aphyllum, Fourn. 1. c:-Bras.

ephedroides, Griseb. Cat. Pl. Cub. 174.-Cuba

exsertum, Griseb. in Goett. Abh. xxiv. (1879) 229,Reg. Argent.

ferrugineum, Fourn, in Mart. Fl. Bras, vi. IV. (15s5 224 .- liras.

fliforme, Griseb. Fl. Brit. WV. Ind. 418.-Ind. oce.

graminifolium, Griseb. Cat. Pl. Cub. 174.-Cuba.

leptocladon, Griseb. Fl. Brit. WV. Ind, $\$ 18=V$. lepto. cladum.

linearifolium, Griseb. Cat. PI. Cub. 175,-Cuba.

melanthum, Foum, in Mart. Fl. Bras. vi. $11,220=V$. melanthum.

parviflorum, Fourn. 1. c. 224 -Bras

Ricdelii. Foum. I. c. 225.-Bras.

salinarum, Wright, ex Griscb. Cat. PI. Cub. 175.Cuba.

Selloanum, Fonm, in Mart. Fl. Bas, vi. 15. 224.Bras.

streptolobium, Fourn. 1. c. 225.-Bras.

tomertosum. Fourn. 1. c. 220.-Bris.

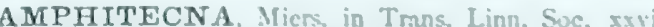
(1865) 163. B/G.VO.V\%.ACE.AE macrophylla, Mirs, ar Buill, in Rer. Horlic, 1. 465.-Am. centr.

nigripes, Baill. 1. c.-Am. trop. 
AMPHITHAIFA, Eckl. \& Zeyh. Enum. 167 (1836). LEGUMINOSAE, Benth. \& Hook. f. i. 472.

Cryphiantha, Eckl. \& Zeyh. Enum. 171 (1836). EPISTEMUM, Walp. in Linnaea, xiii. (1839) 473.

Ingenhoussia, E. Mey. Comm. Pl. Afr, Austr. 20 (1835).

ciliaris, Eckl. \& Zeyh. Enum. 169=Coelidium ciliare.

cuneifolia, Eckl. \& Zeyh. l.c. 167.-Afr. austr.

densa, Eckl. \& Zeyh. l.c.-Afr. austr.

densiflora, Eckl. \& Zeyh. 1. c. $168=$ ericaefolia.

ericaefolia, Eckl. \& Zeyh. l. c. 169.-Afr. austr.

hilaris, Eckl. \& Zeyh. 1. c. =ericaefolia.

hrtmilis, Eckl. \& Zeyh. 1.c. $168=$ intermedia.

incurvifolia, Eckl. \& Zeyh. 1. c. = ericaefolia

intermedia, $E_{c} k l$. \& Zeyh l.c.-Afr. austr.

Kraussiana, Meissn. in Hook. Lond. Journ. Bot. ii (1843) $65=$ virgata.

micrantha, Walp. in Linnaea, xiii. (1839) 470.Afr. austr.

multiflora, Eckl. \& Zeyh. Enum. $168=$ ericaefolia. perplexa, Eckl, \& Zeyh. l. c. $170=$ Coelidium roseum. phylicoides, Eckl. \& Zeyh. l.c.-Afr. austr. spinosa, Steud. Nom. ed. II. i. $80=$ Coelidinm spinosum.

tortilis, Steud, $1_{\text {. }} \mathrm{c}_{2}=$ Coelidium Vogelii.

verticillata, Steud, 1. c. = Priestleva elliptica.

violacea, Benth. in Hook. Lond. Fourn. Bot. ii. (1843) 451.-Afr. austr.

virgata, Eckl. E̋ Zeyh. Enum. 169.-Afr. austr.

Vogelii, Walp. in Linnaea, xiii. (1839) $472=$ ericaefolia. Williamsonii, Harv. in Harv. \& Sond. Fl. Cap. ii. 23 -Afr. austr.

AMPHIZOMA, Miers, in Trans. Linn. Soc, xxviii. (1872) $422=$ Salacia, Linn. (Hippocrat.)

laxiflora, Miers, 1. c. $=$ S. laxiflora.

Martiana, Miers, 1. c. $423=\mathrm{S}$. Martiana

tenuicula, Miers, l. c.-Bras.

AMPHOCHAETA, Anderss. in Vet. Akad. Hand. Stockh. (1853) $136=$ Pennisetum, Pers. (Gramin.) exaltata, Anderss. 1. $c_{.}=$P. exaltatum.

AMPHODUS, Lindl. Bot. Reg. t. $1101(1827)=$ Kennedya, Vent. (Legum.).

ovatus, Lindl. $\mathrm{l}$. $\mathrm{c} .=\mathrm{K}$. rubicunda.

AMPHORCHIS, Thou. Orch. Iles Afr. Tabl. Synopt (1822) $=$ Cynorehis, Thou. (Orchid.)

calcarata, Thou, l. c. t. $4=$ C. squamosa

colorata, Steud. Nom. ed. II. i. 80, sphalm. = praec.

inermis, Thou. Orch. Isles Afr. t. 5=Arnottia inermis.

laxiflora, Blume, Mus, Bot. Lugd. Bat. ii. 190.Malaya.

lilacina, Ridl. in Journ. Linn. Soc. xxi. (1885) 518.Madag.

nilarmis, Steud. Nom. ed. II. i. 80, sphalm.=inermis occidentalis, Lindl. in Journ. Linn. Soc. vi. (1862) 139.-Afr. trop.

AMPHORICARPUS, Visiani, Fl. Dalm. ii. 27. 10. f. 2 (1844). COMPOSITAE, Benth, \& Hook. f. ii. 465 .

Neumayeri, Visiani, Fl. Dalm. ii. 28. t. 10. f. 2,Dalmat.

AMPHORICARPUS, Spruce, ex Miers, in Trans. Linn Soc, xxx (1874) $288=$ Couratari, Aubl. (Myrtac.). uaupensis, Spruce, ex Miers, l. c. $=$ C. uaupensis.

AMPHYMENIUM, H. B. \& K. Nov. Gen. et Sp. vi. 380 $(1823)=$ Pterocarpus, Linn. (Legum.).

cordatum, Klotzsch, in Schomb. Faun, et Fl, Guyan. 1205 , nomen.-Guiana.

floridum, Benth. in Hook. Kew Journ. ii. (1850) 234 $=\mathrm{P}$. Rohrii

latifolium, Klotzsch, in Sehomb. Faun. et Fl. Guyan. 1205, nomen,-Guiana.

laxiflorum, Benth. in Hook. Lond. Journ. Bot. ii.(1840) 65.-Bras.

laxum, Klotzsch, in Schomb. Faun. et Fl. Guyan. 1205, nomen.-Guiana.

longifolizm, Benth. in Mart. Fl. Bras. xv. 1. $269=\mathrm{P}$. ancylocalyx.
AMPHYMENIUM :-

mediterraneum, Benth. in Ann. Wien. Mus, ii. (1838) $95=$ Martia parvifolia

nitidum, Klotzsch, in Schomb. Faun. et Fl. Guyan. 1205 , nomen.-Guiana.

orbiculatum, Benth. in Ann. Wien. Mus. ii. (1838) 95 $=\mathrm{P}$. orbiculatus

pubescens, H. B. \& K. Nov. Gen. et Sp. vi. $380=$ P. Amphymenium.

veticulatum, Klotzsch, in Schomb. Faun. et Fl. Guyan. 1205, nomen.-Guiana.

Rohrii, H. B. \& K. Nov. Gen. et Sp. vi. $380=$ P. Rohrii.

tenuifolium, Klotzsch, in Schomb. Faun. et Fl. Guyan, 1205, nomen,-Guiana.

villosum, Benth. in Ann. Wien. Mus. ii. (1838) $95=$ P. villosus.

violaceum, Walp. Rep. i. $793=$ P. violaceus.

AMPOMELE, Rafin. Sylva Tellur. $160(1838)=$ Rubus, Tourn. (Rosac.).

triphylla, Rafin. 1. c. $=$ R. trifidus.

ATMSINCKIA, Lehm. Del. Sem. Hort. Hamb. (1831)

7. BORAGINEAE, Benth. \& Hook. f. ii. 851 .

Benthamya, Lindl. Nat. Syst. ed. I. 241 (1830).

angustifolia, Lehm. l. c.-Chili.

basistaminea, Cesati, in Atti Acc. Sc. Nap. v. (1873) VII. 14.--Reg. Andin.

Douglasiana, A. DC. in DC. Prod. x. $118=$ spectabilis.

echinata, A. Gray, in Proc. Am. Acad. x. (1874) 54.Calif

humifusa, Walp. in Nov. Act. Nat. Cur. xix. Suppl. i. 1843) 371.-Keg. Argent.

intermedia, Fisch. \& Mey. Ind. Sem. Hort. Petrop. ii 1836) 26 .-Calif

lycopsioides, Lehm. Del. Sem. Hort. Hamb (1831) 7.Calif.

mexicana, Mart. \& Galeot. in Bull. Acad. Brux. xi. 1844) reimpr. 23.-Mexic.

parviftora, Bernh. Del. Sem. Hort. Erf. (1833) = angustifolia.

spectabilis, Fisch. \& Mey. Ind. Sem. Hort. Petrop. ii. 1836) 26.-Calif.

tessellata, A. Gray, in Proc. Am. Acad. x. (1874) 54.Calif.

vernicosa, Hook. \& Am. Bot. Beech. Voy. 370.-Calif.

AMSONIA, Walt. FI. Carol. 98 (1788). APOCYNACEAE, Benth. \& Hook. f. ii. 702.

angustifolia, Michx. Fl. Bor. Am. i. 121.-Am. bor.

brevifolia, A. Gray, in Proc. Am. Acad. xii. (1877) 64. -Utah; Arizona.

ciliata, Walt. F1. Carol. $98=$ angustifolia

elliptica, Roem. \& Schult. Syst. iv. 432.-Tapon.

latifolia, Michx. Fl. Bor. Am. i. $121=$ A. Tabernaemontana.

longiflora, Torr. Bot. Mex. Bound. 159.-N. Mexic.

orientalis, Decne. in Jacquem. Voy. Bot. 105 = Rhazya orientalis.

Palmeri, A. Gray, in Proc. Am. Acad. xii. (1877) 64.Arizona.

salicifolia, Pursh, FI. Am. Sept. i. $184=$ A. Tabernaemontana

Taberuaemontana, Walt. Fl. Carol.98.-Am. bor.

tomentosa, Torr. É Frém, in Frém. Rep. 1843-44 1845) 316.-Am. bor.

tristis, Sm. in Rees, Cycl. xxxv. ad calc. art. Tabernaemontanae, n. $2=\mathrm{A}$. Tabernaemontana.

AMSORA, Bartl. Ord. 536 (1830), sphalm. = Amoora, Roxb. (Meliac.)

AMURA, Schult. f. Syst. vií. p. 11, 75 (1829)=Amoora, Roxb. (Meliac.)

AMYDRIUM, Schott, in Miq. Ann. Mus. Lngd. Bat i. 127 (1863), AROIDEAE, Benth. \& Hook. f. iii. 993 humile, Schott, l. c.-Borneo.

AMYGDALOPHORA, Neck. Elem. ii. $70(1790)=$ Prunus, Tourn. (Rosac.).

AMYGDALOPSIS, Carr, in Rev, Hortic. (1862) $91=$ Prunus, Tourn. (Rosac.)

eburnea, M. Roem. Syn. Rosif. $16=$ P. eburnea

furcata, M. Roem. I. c. = P. eburnea,

horrida, M. Roem. 1. c. 15 (=Amygdalus horrida).Persia.
AMYGDALOPSIS :Lindleyi, Carr. in Rev. Hortic. (1862) 91; (1868) 197
$=$ P triloba.

Lycioides, M. Roem. Syn. Rosif. 15 (=Amygdalus (ycioides).-As. Min.; Syria

Scorpius, M. Roem. 1. c. = P. eburnea.

virgata, Carr, in Rev. Hortic. (1872) $200=$ P. virgata.

AMYGDALUS, [Tourn.] Linn. Syst. ed. I. (1735)= Prunus, Tourn. (Rosac.)

agrestis, Boiss. Diagn. Ser. I. x. 1.-Syria

amara, Hayne, Arzn. iv, in nota ad t. 39. $\mathrm{f}_{\mathrm{f}} \mathrm{i},=\mathrm{P}$ Amygdalus.

amygdalina, Oken, ex M. Roem. Syn. Rosiff. $8=$ P.

Amygdalus.

arabica, Olivier, Voy, t. 47.-Arabia.

argentea, Lam. Encyc. i. $103=$ orientalis.

Armeniaca, Dum. F1. Belg. $91=$ P. Armeniaca.

Armeniacaria, Oken, ex M. Roem. Syn. Rosifl. $10=$ P Amygdalus.

Balansae, Boiss. Diagn. Ser. II. vi. 71.-Phrygia.

Besseriana, Schott, ex Schlecht. in Abh. Naturf. Ges. Halle, ii. (1854) $1=$ P. nana

Boissierii, Carr. in Rev. Hortic. (1875) 352.-As Min

Bovei, Spach, in Ann. Sc. Nat. Sér. II. xix. (1843) 124. -Syria.

brahuica, Boiss. Fl. Orient, ii, 645.-Beluchist.

camelliaeflora, Morr. in Belg. Hortic. viii. (1858) 97. t. $26=$ P. Persica

campaniflora, Carr. in Rev. Hortic. (1872) 129.Hab.?

campestris, Bess, Enum. P1, Volh. $46=$ P. nana.

caryophyllacea, Hort. ex C. Koch, Dendrol. i. $85=$ P. Persica.

cerasina, Oken, ex M. Roem. Syn. Rosifl, 9=P Amygdalus.

chinensis, Hort. ex C. Koch, Dendrol, i. $85=$ P. Persica

chinensis, Leroy, ex C. Koch, 1, c. $79=$ P. nana.

cochinchinensis, Lour. F1. Cochinch. 316.-Cochinch collinus, Wall. Cat. n. $723=$ P. Persica.

communis, Bunge, Eutm. Pl. Chin. Bor. 21=P. Persica.

communis, Linn. Sp. Pl. ed. I. 473=P. Amygdalus.

cordifolia, Roxb. Fl. Ind, ii. 500.-China.

dasylebis, Miq. in Journ. Bot. Néerl. i. (1861) $122=$ P Persica.

dianthiflora, Hort. ex C. Koch, Dendrol. i. $85=$ P Persica.

discolor, M. Roem. Syn. Rosiff, $12=$ orientalis

dulcis, Mill. Gard. Dict, ed. VIII, 11, 2=P. Amygdalus.

eburnea, Spach, in Ann. Sc. Nat. 'Sér. II. xix. (1843) 123.-Persia.

elaeagrifolia, Spach, 1. c. 120.-Persia.

elata, Salisb. Prod, $356=\mathrm{P}$. Amygdalus,

Fischeriana, Spach, in Ann. Sc. Nat. Sér II. xix. (1843) 125. - Hab? ?

fragilis, Hell. Fl. Wirceb. i. $500=$ P. Amygdalus, frutescens, Steud. Nom. ed. II. i. $81=$ (A. fruticosa) fruticosa, Wender. in Bot. Zeit. (1865) 338. t. 12. Hab.?

furcatus, Spach, in Ann. Sc. Nat. Sér. II. xix. (1843) $124=$ P. eburnea.

Gaertneriana, Schlecht. in Abh. Ges. Halle, ii. (1854) $19=$ P. nana

georgica, Desf. Hist. Arbr. ii. $221=$ P. nana.

glandulosa, Hort. ex C. Koch, Dendrol. i. $118=$ P microphvlla.

glandulosa, Hook. Ic. P1. t. $288=$ P. glandulosa.

glandulosa, Leroy, ex C. Koch, Dendrol. i. $116=$ P. japonica.

grandiflora, Hort. ex C. Koch, 1. c. $81=$ P. Amygdalus.

grandiflora, Hort. Gall. ex C. Koch, 1. c. i. $80=$ P. Persica.

grata, Salisb. Prod. $356=$ P. Persica.

heterophylla, Hort. ex C. Koch, Dendrol. i. $81=$ P, Amygdalus.

Heuckeana, Schlecht. in Abh. Ges. Halle, (1854) I. 22. -Sibir.

horrida, Spach, in Ann. Sc. Nat. Sér. II. xix. (1843) 121.-Persia

humilis, Edgew. in Trans. Linn. Soc. xx. (1846) $44=$ P. Jacquemontii.

hybrida, Dierb. ex M. Roem. Syn. Rosifl. 11=P. Amygdalus. 
AMYGDALUS :-

incana, Pall. Fl. Ross, i. 13. t. 7 =Prunus prostrata.

ispahanensis, Thouin, in Ann. Mus. Par. Sér. I. viii. (1826) $425=$ P. Persica.

Kotschyi, Hohen. ex Spach, in Ann. Sc. Nat. Sér. II. xix. (1843) $117=$ eleagnifolia.

laevis, D. Dietr. Syn. Pl. iii. $42=$ P. Persica.

Ledebouriana, Schlecht. in Abh. Ges. Halle, (1854) 1 $=\mathrm{P}$. nana.

leiocarpa, Boiss. Diagn. Ser. I. vi. 52.-Persia.

lycioides, Spach, in Ann. Sc. Nat. Sér. II. xix. (1843) 120.-As. Min.; Syria.

microphylla, H. B. \& K. Nov. Gen. et Sp. vi. 245. t. $564=$ P. microphylla.

minor, Duh. Arbr. Fruit. i. t. 7.-- Hab.?

nana, Linn. Sp. Pl. 473.-Europ.; Reg. Canc.; Sibir.

Nuci-persica, Reichb. Fl. Germ. Excurs. $647=\mathbf{P}$. Persica.

orientalis, Mill. Gard. Dict. ed. VIII. n. 4.-As. Min.; Syria.

Pallasiana, Schlecht. in Abh. Ges. Halle, (1854) $1=$ P. nana.

Pallasii, Turcz. ex Steud. Nom. ed. II. i. $81=$ P. pedunculata.

pedunculata, Bunge, Enum. Pl. Chin. Bor. $22=$ P. triloba.

pedunculata, Pall, in Nov. Act. Petrop. vii. (1789) 355. t. 8,9-Sibir.

Persica, Linn. Sp. P1. $472=$ P. Persica.

persico-amygdala, Reichb. F1. Germ. Excurs. $647=\mathrm{P}$. Amygdalus.

persicoides, C. Koch, Deudrol. i. $84=$ P. Persica.

pilosa, Turcz, in Bull. Soc. Nat. Mosc. v. (1832) 189 . China.

prostrata, Sweet, Hort. Brit. ed. II. $173=$ P. prostrata. pumila, Linn. Mant. i. $74=$ P. japonica.

Reuteri, Boiss. \& Buhse, in Nouv. Mém. Soc. Nat. Mosc, xii. (1860) $79=$ horrida.

rosaeflora, Hort. ex C. Koch, Dendrol, i. $85=$ P. Persica. salicifolia, Boiss. \& Bal. Diagn. Ser. II. vi. $671=$ Webbii.

sativa, Mill. Gard. Dict. ed. VIII. n. $3=$ P. Amygdalus. scoparia, Spach, in Ann. Sc. Nat. Sér. II. xix. (1843) 109.-Persia.

scorpius, Spach, 1. c. $122=\mathrm{P}$, eburnea.

serratifolia, Hort. ex C. Koch, Dendrol. i. $79=$ P. nana.

sibirica, Lodd. ex Loud. Hort. Brit. 199.-Sibir.

sinensis, Hort. ex Steud. Nom. ed. II. i. $81=$ cochinchinensis.

spartioides, Spach, in Ann. Sc. Nat. Sér. II. xix. (1843) 108.-Syria; Persia.

spathulata, Boiss. Diagn. Ser. I. vi. $53=$ P. eburnea.

spinosissima, Bunge, Rel. Lehm. 106.-Turkest.

Stocksiana, Boiss. Diagn. Ser. II. ii. 45.-Beluchist

tomentosa, Hort. ex C. Koch, Dendrol. i. $81=\mathrm{P}$. Amygdalus.

tomentosula, Steud. Nom. Bot. ed. II. i. $81=\mathrm{P}$.

Amygdalus.
Webbii, Spach, in Ann. Sc. Nat. Sér. II, xix. (1843) 117.-Phrygia.

AMYRIS, P. Br. Hist. Jam. 208 (1756). BURSERA$C E A E$, Benth. \& Hook, f, i. 327.

ELEMI, Adans. Fam ii. $342(1763)$

Elemifera, Linn. Hort. Cliff. $486^{\circ}$ (1737).

RITINOPHORA, Neck, Elem. ii. 229 (1790)

acuminata, Poir. Encyc. Suppl. ii. 136=Icica acuminata.

acuminata, Roxb. Hort. Beng. 28 ; Fl. Ind. ii. 246 = Commiphora caudata.

Agallocha, Koxb. Hort. Beng. 28 (1814)=Commiphora Agallocha.

altissima, Willd. Sp. P1. ii. $836=$ Protium altissimum. ambrosiaca, Linn. f. Suppl. $216=$ Protium Icicariba

ambrosiaca, Moc. \& Sesse, in DC. Prod. ii. $77,78=$ Icica serrata.

ambrosiaca, Spreng. Syst. ii. 218, pro parte = Protium guianense.

ambrosiaca, Willd. Sp. ii. $335=$ Protinm heptaphyllum. ambrosiaca, Vell. Fl. Flum, iv. t. $3=$ Protium heptaphyllum?

anisata, Roxb. ex Steud. Nom. ed. II. i. $81=$ Clausena heptaphylla.

anisata, Willd. Sp. Pl. ii. $337=$ Clausena anisatum

ariensis, Spreng. Syst. iv. Cur. Post. $149=$ Elaphrium ariense.

armata, Spreng. Syst. ii. $219=$ Zanthoxylon Thunbergii, axilliflora, Griseb. Cat. Pl. Cub, 68,-Cuba.

\section{AMYRIS :-}

balsamifera, Linn. Syst. ed, X. 1000,-Jamaica.

bicolor, Willd. ex Engl. in DC. Monog. Phan. iv. $54=$ Bursera bicolor.

bipinnata, Moç. \& Sesse, ex DC. Prod. ii. $82=$ Bursera bipinnata.

brachybotrys, Turcz. in Bull. Soc. Nat. Mosc. xxxvi 1863) I. 614-Bras.

brasiliensis, Spreng. Syst. ii. 217 = Protium brasiliense brasiliensis, Willd. ex Engl. in DC. Monog. Phan. iv $64=$ Protium heptaphyllum.

capensis, Spreng. Syst. ii. 218 (=Fagarastrum capense

Carana, Humb, Relat, ii. $421=$ Protium Carana caranifera, Willd. ex Engl, in DC. Monog. Phan, iv. $49=$ Bursera graveolens.

Commiphora, Roxb. Fl. Ind, ii. (1824) $244=$ Commi phora Agallocha.

Cataf, 'Forsk.' = A. Kataf.

copallifera, Oliva, in La Naturaleza, (1870) 40.-

Mexico.

copallifera, Spreng. Syst. ii. $219=$ Elaphrium copalliferum.

cymosa, Reichb. ex Steud. Nom. ed. II. i. $81=$ sylvatica decandra, Brotero, ex Pritz. in Bot. Zeit. i. 1843

561.-Bras.

decandra, Willd. Sp. Pl. ii. $336=$ Icica decandra

dentata, Blume, Bijdr. $1160=$ Clausena javanica

dentata, Willd. Sp. Pl. ii. $337=$ Clausena Willdenowii. diatrypa, Spreng. Neue Entdeck. iii. 48; Syst. ii. 217 -Ins. S. Doming.

dioica, Hort. ex Steud. Nom. ed. II. i. $81=$ Schinus dependens.

Elaphrium, Spreng. Syst. ii. $219=$ Bursera glabra.

elegans, Willd. ex Engl. in DC. Monog. Phan. iv. 57 - Bursera excelsa.

elemifera, Koen. ex Blume, Mus. Bot. Lugd. Bat. i.

$218=$ Canarium zeylanicum

elemifera, Linn. Syst. ed, X, $1000=$ Plumieri

enneandra, Willd. Sp. Pl, ii. $335=$ Protium decandrum.

fagaroides, Spreng. Syst. iv. Cur. Post. $148=$ Bursera fagaroides.

floridana, Ware, ex Nutt. in Am. Fourn. Sc. v. (1822) 294.-Florida.

Funckiana, Turcz. in Bull. Soc. Nat. Mosc. (1858) I. 475.-Venezuela.

fruticosa, Roxb. Hort. Beng. 28.-Ind. or.

gileadensis, Roxb. Hort. Beng. 28 ; Fl. Ind. ii. $246=$ C. Berryi.

giliadensis, Linn. Diss. Opob. ; Amoen. Acad. vii., $68=$ Commiphora Opobalsamum.

graveolens, Buch.-Ham. ex Steud. Nom. ed. II i. $81=$ Clausena excavata.

graveolens, Spreng. Syst. iv. Cur. Post. $148=$ Bursera graveolens.

guianensis, Aubl. Pl. Gui. i. 336.-Guiana.

guianensis, Willd. Sp. Pl. ii. $325=$ Protium guianense

heptaphylla, Roxb. Hort. Beng. 28; Fl. Ind. ii. $248=$ Clausena heptaphylla.

heterophylla, Willd. Sp. P1. ii. $335=$ Protium Aracouchini.

hexandra, Ham. Prod. Fl. Ind. Occ. 31=Dacryodes hexandra.

Hypelate, Robinson, ex Lunan, Hort. Jamaic. i. $149=$ Hypelate trifoliata.

inaequalis, Spreng. Syst. ii. $218=$ Clausena inaequalis.

jorullensis, Spreng. Syst. Cur. Post. $148=$ Bursera jorullensis.

Kafal, Forsk. Fl. Aegypt. Arab. $80=$ an seq.?

Kataf, Forsk. 1. c.=Commiphora Kataf.

lanuginosa, Spreng. Syst. iv. Cur. Post. $149=$ Bursera lanuginosa.

Linaloë, La Llave, in La Naturaleza, vii. (1885) Apénd. $73=\mathrm{seq}$

Iinanoë, La Llave, ex Schlecht, in Linnaea, xvii. (1843) $252=$ Bursera Aloëxylon.

lineata, C. Wright, ex Griseb. in Mem. Am. Acad. N. S. viii. (1861) 177. - Ind. occ

Lunani, Spreng. Syst. ii. $217=$ maritima

Lypelata, Steud. Nom. ed. II. i. 81, sphaim $=$ Hypelate trifoliata.

maritima, facq. Enum.Pl. Carib. 19.-Am. trop.

maritima, Llanos, in Mem Acad. Madr. Ser. III. ii. IIr. (1856) 503.-Ins. Philipp. ?

maritima, Moc. \& Sesse, ex DC. Prod. ii. $82=\mathrm{A}$.

Tecomaca.

multijuga, Turcs. in Bull. Soc. Nat. Mosc, xxxi. 1858 I. 476. -Bras.
AMYRIS

nana, Roxb. Hort Beng, $28=$ Clausena Willdenowit Novae-Hollandiae, Hort. ex Steud. Nom. ed. II. i. 81 = Botryceras laurinum

oleosa, Lam. Encyc. i. $362=$ Canariam microcarpum. Opobalsamum, Linn. Diss. Opob.; Amoen. Acad. vij.

68; Forsk. Fl. Aegypt. $79=$ Commiphora Opobalsamum.

papyrifera, Caill. ex Del. Voy. Meroé, $99=$ Boswellia papyrifera.

penicillata, Spreng. Syst. ii. $219=$ Bursera penicillata

pentaphylla, Roxb. Hort. Beng. 28; Fl. Ind. ii. $247=$

Clausena pentaphylla.

pernambucensis, Arruda, in Koster, Trav, Braz. 500 Bras.

Philippaea, Robinson, ex Lnnan, Hort. Jam. i. $150=$ Hypelate trifoliata.

pinnata, H. B. \& K. Nov. Gen. et Sp. vii. 37.-Am trop.

Plumieri, DC Prod ii. 81.-Ind, occ.

polygama, Cav. Ic. iii. $20=$ Schinus dependens.

Protium, Linn. Mant. i. $65=$ Protium javanicum

pubescens, Willd. ex Schlecht. in Linnaea, xvii. (1842 $527=$ Elaphrium pubescens.

punctata, Roxb. Hort. Beng. 28; Fl. Ind. ii. $251=$ Clausena exeavata.

Robinsonii, DC. Prod. ii. 82,-Jamaica.

rugosa, Willd. ex Engl. in DC. Monog. Phan. iv. $58=$ Bursera jorullensis.

serratifolia, Rottl. ex A. W. Benn. in Hook. f. Fl. Brit. Ind. i. $529=$ Balsamodendron Roxburghii.

simplicifolia, Roxb. Fl. Ind. ii. $244=$ Atalantia Roxburghiana.

suffruticosa, Roxb. I. c. $250=$ Clausena suffruticosa

sumatrana, Roxb. Hort. Beng. 28 ; Fl. Ind. ii. $250=$ Clausena excavata.

sylvatica, Facq. Am. Select. 10\%.-Ind. or.

Tecomaca, Moç. E Sesse, Fl. Mex. ined. t. 195, ex DC Prod ii. 82,-Mexico.

erebinthifolia, Tenore, Ind. Sem. Hort. Neap. (1837, 1-Bras.

thyrsiflora, Turcz. in Bull. Soc. Nat. Mosc. xxxi. (1858 I. 475.-Mexico.

tomentosa, Spreng. Syst. ii. $219=$ Bursera tomentosa toxifera, Linn Syst. ed. X, 1000-Ind. oce.

ventricos $\alpha$. Llave, ex Schlecht, in Linnaea, xvii. (1843, $246=$ Bursera fagaroides.

zeylanica, Retz, Obs. fasc, iv. $25=$ Canarium zey lanicum.

AMYRSIA, Rafin. Sylva Tellur. 106 (1838)=Eugenia Linn. (Myrtac, )

compressa, Rafin. 1. c. = E. compressa.

discolor, Rafin. 1. c. = E, discolor.

foliosa, Rafin. 1. $\mathrm{c}_{\mathrm{o}}=\mathrm{E}$. foliosa.

microphyla, Rafin. 1. c. (=Myrtus microplyylla)

ANABAENA, A. Juss. Euph. Tent. 46. t. 15 (1821)= Plukenetia, Linn. (Euphorb.).

tamnoides, A. Juss. 1. c. t. $15=\mathrm{P}$, tamnoides

ANABASIS, Linn. Pl. Camts. (1750) (Amoen. Acad, if 347). CHENOPODIACEAE, Benth. \& Hook, f iii. 7? BORITH, Adans. Fam, ii, 262 (1763)

Brachylepis, C. A. Mey. Fl. Alt. i. 370 (1829)

Fredolia, Coss. \& Dur. ex Moq. \& Coss, in Ball.

Soc. Bot. Fr. ix. (1562) 301.

Microlepis, Eichw. Casp. Cauc 2 (1881).

affinis, Bunge, Rel. Lehm, $480=$ Arthrophytum subalifolium.

affinis, C. A. Mey, in Schrenk, Enum. Pl. Nov. Song (1841) $10=$ brevifolia.

alopecuroides, Moq. in DC. Prod. xiii. II. $210=$ Halo. geton alopecuroides.

Ammodendron, C. A. Mey, in Ledeb. Fl. Alt. i. $\$ 75=$

Haloxylon Ammodlendron.

annua, Bunge, Anab. Rev. $40_{0}^{\circ},-$ Persia.

aphylla, Linn. Sp. Pl. 228.-Oriens; Sibir.

arbuscula, Thunb. ex Sterud. Aom. cd. II. i. S1.-Iab. aretioides, Moq. So Coss. in Bull. Soc. Bot. Fr. ix $150^{\circ}$

301. t. 2.-Afr. bor.

arficulata, Choulette, ex Pomel, Nouv. Mat. Fl. Ach. $934=$ prostrata.

articulata, Mog. in DC. Prod. xiii. 11. 212.-Afr. bor. Syria.

brachinta, Fisch. \& Mcy. ex Kar. \& Kir. in Bu

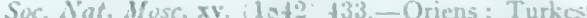
Brachiata, har. \& hir. l. c. = truncata. 


\section{ANABASIS}

brachylepis, D. Dietr. Syn. Pl. ii. 995.-Reg. Casp.

brevifolia, C. A. Mey. in Ledeb. Fl. Alt. i. 377.-Sibir alt.

caespitosa, Steph. ex Moq. in DC. Prod. xiii. II. $216=$ Nanophyton caspicum

cinerea, Mog. 1. c. $214=$ Seidlitzia forida

clavata, S. G. Gmel. It. ii. 41 = Salsola clavifolia

conjugata, Hoffm. Hort. Mosq. (1808) No. $184=$ Petrosimonia brachiata.

crassa, Moq. Chenop. Enum. 166=articulata.

cretacea, C. A. Mey. Enum. ex Bunge, Anab. Rev. $39=$ brachiata.

cretacea, Pall. Reise, i. 493--Sibir

cretica, Vitm. Summ. Pl. ii. $104=$ cretacea

Echinus, Bieb. Beschr. Laend. Casp. $152=$ Noaea spinosissima

Ehrenbergii, Schweinf. ex Boiss. Fl. Orient. iv. 970 in nota.-Nubia; Arab.

florida, Bieb. Fl. Taur, Cauc, i, $190=$ Seidlitzia florida.

foliata, Pall. ex Bunge, Anab. Rev. $47=$ Salsola foliosa.

foliosa, Pall. Reise, i. $380=$ Salsola clavifolia.

foliosa, Linn. Sp. Pl. 223 = Salsola foliosa .

glomerata, Bieb. in Mém. Soc. Nat. Mosc. i. (1808) $110=$ Halogeton glomeratus

Haussknechti, Bunge, ex Boiss. Fl. Orient. iv. 969.-Persia.

heterophylla, Walp. Ann. i. 571 (sphalm. = seq.).

heteroptera, Jaub. \& Spach, Illustr. ii. 45. t. $134=$ Girgensohnia oppositiflora.

intermedia, Mog. in DC. Prod. xiii. II. $214=$ phyllophora?

juncea, Bieb. ex Moq. 1. c. $203=$ Ofaiston monandrum.

Kareliniana, Fenzl, in Ledeb. Fl. Ross, iii. $825=$ truncata.

lutea, Moq. in DC. Prod. xi1i. II. 215=setifera.

macroptera, Moq. l. c. 213.-Affghanist.

monandra, Schrad. Neues Journ. iii. (1809) $89=$ Ofaiston pauciflorum.

multiflora, Moq. in DC. Prod. xiii. II. $212=$ Haloxylon multiflorum.

oppositiflora, Bieb. in Mém. Soc. Nat. Mosc. i, (1808) $148=$ Girgensohnia oppositiflora

oppositifolia, Bieb. Beschr. Laend. Casp. App. $154=$ Petrosimonia crassifolia.

oppositifolia, Schrad. Neues Journ. iii. (1809) $89=$ Halogeton oppositifl rus.

phyllophora, Kar. \& Kir. in Bull.' Soc. Nat. Mosc. (1841) 731.--Syria ; Soongaria.

prostrata, Pomel, Nouv. Mat. Fl. Alt. 334.-Afr. bor.

ramosa, Sievers, in Pall. N. Nurd. Beitr. vii. 304.Sibiria.

setifera, Moq. Chenop. Enum. 164.-Aegypt, ; Oriens.

Sieversii, Willd. in Roem. \& Schult. Syst. vi. $223=$ Nanophyton caspicum.

spinosissima, Linn. f. Suppl, $173=$ Noaea spinosissima

subulifolia, C. A. Mey, in Bull. Acad. Pétersb. Sér. IV. i. (1843) $360=$ phyllophora.

tamariscifolia, Linn. Syst. ed. X. $949=$ Salsola tamariscifolia.

tamariscifolia, Webb, Iter Hisp. $17=$ Salsola Webbii.

tatarica, Pall. Illustr. 13. t. $8=$ aphylla

Tournefortii, Jaub. \& Spach, Illustr. Pl. Or. ii. 43.t. 132 = Noaea Tournefortii.

triandra, Bieb. Beschr. Laend. Casp. App. 154= Petrosimonia Volvox.

truncata, Bunge, Anab. Rev. 38.-Reg. Casp

ANABATA, Willd. ex Roem. \& Schult. Syst. iv, 60 , 707 (1819). Gen. dub. LOGAN. Bentb. \& Hook. f。 ii. 788 .

Sulzeria, Roem. \& Schult. l. c.

odorata, Humb. ex Roem. \& Schult. l. c.-Am. austr.

ANACAMPSEROS, Linn. Syst. ed. I. (1735); Gen. ed. I. 152 (1737). PORTULACEAE, Benth. \& Hook. f. i. 157.

Ruelingra, Ehrh. Beitr, iii, 132 (1788)

TAlinum, Adans, Fam. ii. 245 (1763)

'Telephiastrum, Medic. Phil. Bot. i. 100 (1789). angustifolia, Sweet, Hort. Brit. ed. I. 170.-Afr. austr.

arachnoides, Sims, Bot. Mag.t. 1368.-Afr. austr.

filamentosa, Sims, l. c. 1367.-Afr. austr.

intermedia, Haw. ex G. Don, Gen. Syst. iii. $75=$ A Telephiastrum.

\section{AN ACAMPSEROS}

lanceolata, Sreeet, Hort. Brit. ed. I. 170-Afr. austr. lanigera, Burch. Trav. ii. 333.-Afr. austr.

papyracea, E. Mey. ex Sond. in Harv. \& Sond. Fl. Cap. ii. 383.-Afr. austr.

polyphylla, Sweet, Hort. Brit. ed. I. 170.-Afr. austr quinaria, E. Mey. ex Sond. in Harv. \& Sond. Fl. Cap. ii. 383 . - Afr. austr

rotundifolia, Sweet, Hort. Brit. ed. I. 170.-Afr. austr. rubens, Sweet, 1. c, $170=$ arachnoides.

rufescens, Sweet, 1. c. $170=$ arachnoides.

Telephiastrum, DC. Cat. Hort. Monsp. 77.-Afr, austr. trigona, DC. Prod. iii. 356.-Afr. austr.

ustulata, E. Mey. ex Sond. in Harv. \& Sond. Fl. Cap. ii. 383.-Afr. austr

varians, Sweet, Hort. Brit. ed. I. $170=$ A. Telephiastrum.

ANACAMPSEROS, [Tourn.] Adans. Fam. ii. 248 (1763); Haw. Syn. Pl. Succ. $111(1812)=$ Sedum, Linn. (Crassul.).

Aizoon, Haw. Syn. P1. Succ. $112=$ S. Aizoon.

albicans, Haw. 1. c. $111=$ S. albicans.

albida, Haw. ex DC. Prod. iii. $402=\mathrm{S}$. Telephium ?

alpestris, Jord. \& Fourr. Brev. Nov. Pl. fasc. i. $22=\mathrm{S}$. maximum.

angustifolia, Timb. in Bull. Soc. Hist. Nat. Toulouse, iv. (1870) 168.-Gallia.

aprica, Jord. \& Fourr. Brev. Pl. Nov. fasc. i. $19=\mathrm{S}$. maximum.

arguta, Haw. Rev. Pl. Succ. $25=\mathrm{S}$. argutum.

assurgens, Jord. \& Fourr. Brev. P1. Nov. fasc. i. $24=\mathrm{S}$. maximum.

aurigerana, Jord. \& Fourr, 1. c. $30=$ S. Telephium.

beugesiaca, Jord. \& Four. 1. c. $24=\mathrm{S}$. Telephium.

Borderi, Jord. \& Fourr. 1. c. $30=\mathrm{S}$. Telephium.

buxicola, Jord. \& Fourr. 1. c. $27=\mathrm{S}$. Telephium. caerulescens, Timb. in Bull. Soc. Sc. Phys, et Nat. Toulouse, ii. (1874) $70=\mathrm{S}$. caeruleum?

Cepaea, Willd. Sp. Pl. ii. $762=\mathrm{S}$. Cepaea

cebennensis, Jord. \&c Fourr. Brev. Pl. Nov. fasc. i. $18=$

S. maximum.

chlorotica, Jord. \& Fourr. 1. c. $20=$ S, maximum.

ciliaris, Haw. Syn. $\mathrm{Pl}$. Succ. $113=\mathrm{S}$. involucratum.

collina, Jord. \& Fourr. Brev. Pl. Nov. fasc. i. $23=\mathrm{S}$.

maximum

conferta, Jord. \& Fourr. Ic. Pl. Eur. i. $36=\mathrm{S}$. Telephium.

convexa, Jord. \& Fourr. Brev. P1. Nov, fasc. i. $29=\mathrm{S}$. Telephium.

corsica, Jord. \& Fourr. 1. c. $17=$ S. maximum.

delphinensis, Jord. \& Fourr. 1. c. $21=\mathrm{S}$. maximum

dentata, Haw. Rev. P1. Succ. $26=\mathrm{S}$. dentatum.

divaricata, Haw. Syn. Pl. Succ. $113=$ S. divaricatum.

dumeticola, Jord. \& Fourr. Brev. Pl. Nov, fasc. i. $28=$

$\mathrm{S}$. Telephium.

erubescens, Jord. \& Fourr. I. c. 18=S. maximum.

formosa, Timb. in Bull. Soc. Hist. Nat. Toulouse, iv. (1870) 168.-Gallia

hybrida, Haw. Syn. Pl. Succ. $113=$ S. hybridum

Fulliana, Jord. \& Fourr. Ic. Pl, Eur. i. $36=\mathrm{S}$.

Telephium.

lapidicola, Jord. \& Fourr. Brev. Pl. Nov. fasc. i. $29=\mathrm{S}$ Telephium.

linguaefolia, Hort. ex Lem. Illustr. Hortic, x. (1863)

Misc. $81=$ Cotyledon linguaefolia.

livida, Haw. Rev. PI. Succ. $25=\mathrm{S}$. lividum.

lugdunensis, Jord. \& Fourr. Brev. Pl. Nov, fasc, i. 28 $=\mathrm{S}$. Telephium.

maxima, Haw. Syn. Pl. Succ. ed. Germ. $121=$ S maximum

Millieri, Jord. \& Fourr. Brev. Pl. Nov. fasc. i, $23=\mathrm{S}$. maximum.

minor, Jord. \& Fourr. 1. c. $19=$ S. maximum.

monticulorum, Jord. \& Fourr. I. c. $26=\mathrm{S}$. Telephium

Navieri, Jord. \& Fourr. 1. c. $27=$ S. Telephium.

pachyphylla, Jord. \& Fourr. 1. c. $17=$ S. maximum.

paucidens, Haw. Rev. Pl. Succ. 24.-Hab.?

pectinata, Haw. l. c. $24=\mathrm{S}$. pectinatum.

populifolia, Haw. Syn. Pl. Succ. $113=$ S. populifolium

Pourretii, Jeanb. ex Timb. in Bull. Soc. Sc. Phys. et Nat

Toulouse, iii. (1875-76) 556.-Gallia.

praecelsa, Jord. \& Fourr. Brev. Pl. Nov. fasc. i. $25=\mathrm{S}$

Telephium.

praeruptorum, Jord \& Fourr. I. c. $20=\mathrm{S}$. maximum.

purpurea, Haw. ex DC. Prod. iii. $402=$ S. Telephium.

pycnantha, Jord. \& Fourr. Brev. Pl. Nov. fasc. i. $25=$ S. Telephium.
ANACAMPSEROS:-

pyramidalis, Timb. in Bull. Soc. Hist. Nat. Toulouse, iv. $(1870)$ 169.-Gallia.

recurva, Jord. \& Fourr. Brev. Pl. Nov, fasc. i. $20=\mathrm{S}$. maximum

repens, Jord. \& Fourr. 1. c. $31=\mathrm{S}$. Telephium.

rhodanensis, Jord. \& Fourr. 1. c. $24=$ S. Telephium.

rubella, Jord. \& Fourr. 1. c. $30=\mathrm{S}$. Telephium.

rupifraga, Jord. \& Fourr. 1. c. $29=\mathrm{S}$. Telephium.

Saxifraga, Jord. \& Fourr. 1. c. $26=\mathrm{S}$. Telephium.

sempervirens, Haw. Syn. Pl. Succ. 112=S. Anacampseros.

serotina, Jord. \& Fourr. Brev. Pl. Nov. fasc. i. $22=\mathrm{S}$. maximum.

silvatica, Timb, in Bull. Soc. Hist. Nat. Toulouse, iv (1870) 167.-Gallia.

spathulata, Hort. ex Steud. Nom. ed. II. i. $82=$ S. spathulatum.

spectabilis, Jord. \& Fourr. Ic. PI. Eur. i. $37=\mathrm{S}$, spectabile.

spuria, Haw. Rev, Pl. Succ. $25=$ S. stoloniferum

stellata, Haw. Syn. P1. Succ, $114=$ S. stellatum.

subalbida, Jord. \& Fourr. Brev. PI. Nov, fasc. i. $27=\mathrm{S}$ Telephium

subrotunda, Jord. \& Fourr. 1. c. $19=\mathrm{S}$. maximum.

subpyrenaica, Timb. in Bull. Soc. Hist. Nat. Toulouse, iv (1870) 169 -Gallia.

telephioides, Haw. Syn. Pl. Succ. $114=$ S. telephioides. ternata, Haw. 1. c. =S. ternatum

ternata, Jord. \& Fourr. Brev. P1. Nov. fasc. i. $21=\mathrm{S}$. maximum.

Thevensei, Timb. in Mém. Acad. Toulouse, Sér. VII. vi. 1874) 646.-Gallia.

triphylla, Haw. Syn. Pl. Suce, $111=$ S. Telephium

Verloti, Jord. \& Fourr. Brev. Pl. Nov. fasc. 1. $22=\mathrm{S}$ maximum.

viridula, Jord. \& Fourr. 1. c. $26=\mathrm{S}$. Telephium.

vogesiaca, Jord. \& Fourr. 1. c. $31=$ S. Telephium.

vulgaris, Haw. Syn. Pl. Succ. $112=$ S. Telephium.

ANACAMPTA, Miers, Apocyn. S. Amer. 64 (1878)= Tabernaemontana, Linn. (Apocyn.).

acutissima, Miers, 1. c. $66=\mathrm{T}$. acutissima

angulata, Miers, 1. c, $65=\mathrm{T}$. angulata.

congesta, Miers, 1. c. $=$ T. rubrostriolata.

hirtula, Miers, 1. c. $67=\mathrm{T}$. hirtula.

longifolia, Miers, 1. c. $66=$ T. longifolia.

submollis, Miers, 1. c. $67=\mathrm{T}$. submollis.

ANACAMPTIS, Rich. in Mém. Mus. Par. iv. (1818) 47 $55=$ Orchis, Linn

Brancifortii, Lindl. Gen. et Sp. Orch. $275=$ O. Brancifortii.

condensata, C. Koch, in Linnaea, xxii. (1849) 285, in syn, $=O$. pyramidalis.

Durandi, Bréb. Fl. Norm. ed. II. $258=$ O. pyramidalis.

pyramidalis, Rich. in Mém. Mus. Par. iv. (1818) $55=$ O. pyramidalis.

quadripunctata, Lindl. Gen. et Sp. Orch. $275=\mathrm{O}$. Brancifortii.

trichocera, C. Koch, in Linnaea, xxii. (1849) $286=\mathrm{O}$. quadripunctata.

ANACARDIA, St. Lag. in Ann. Soc. Bot. Lyon, vii. (1880) $119=$ Anacardium, Linn.

rhinocarpa, St. Lag. 1. c. = Anacardium Rhinocarpus.

ANACARDIUM, Linn. Syst. ed. I. (1735); Gen. ed. I. $129(1737)$; Rottb. in Act. Hafn. ii. (1775) 252. ANACARDIACEAE, Benth. \& Hook. f. i. 420.

ACAjOU, Tourn. ex Adans. Fam. ii. 344 (1763).

ACAJUBA, Gaertn. Fruct. i. 192. t. 40 (1788).

Cassuvium, Lam. Encyc. i. 22 (1783).

Monodynamus, Pohl, Pl, Bras. ii. 67.t. 144 (1831)

Rhrnocarpus, Bert. \& Balb. ex H. B. \& K. Nov. Gen. et Sp. vii. 5. t. 601 (1825).

brasiliense, Barb. Rodr. in Rev. Engenh. (28 Jul. 1883) repr. p. 5.-Bras.

curatellaefolium, St. Hil. in Ann. Sc. Nat. Sér. I. xxiii. (1831) 272.-Bras.

dubium, Roxb. Hort. Beng. [88] ; Fl. Ind. ii. $313=$ Gluta Benghas.

encardium, Noronha, in Verh. Batav. Gen. v. (1790) ed. I. Art. iv. 5-Malaya

giganteum, Hancock, ex Engl. in Mart. Fl. Bras. xii. II. 410 (errore Hance).-Bras. 


\section{ANACARDIUM:-}

giganteum, Loud. ex Steud. Nom. ed. II. i. 82, nomen. -Guiana.

humile, Engl, in Mart. Fl. Bras. xii. II. $411=$ nanum. humile, Mart. Reise, i. 314= pumilum.

humile, St. Hil. in Ann. Sc. Nat. Sér. I. xxiii. (1831) 272.-Bras

latifolium, Lam. Encyc. i. 139=Semecarpus Ana cardium.

longifolium, Lam. 1. c. =Semecarpus Anacardium mediterraneum, Vell. Fl. Flum. 163 ; iv. t. 46.-Bras nanum, St. Hil. in Ann. Sc. Nat. Sér. I. xxiii. (1831) 272.-Bras

occidentale, Linn. Sp. Pl. ed. I. 383.-Ind. occ.

officinale, Pritz. Ind. Ic. $59=$ Semecarpus Anacardium officinarum, Gaertn. Fruct. i. 192=Semecarpus Anacardium.

orientale, Auct. ex Steud. Nom. ed. II. i. $82=$ Semecarpus Anacardium.

pumilum, Walp. Rep. i. 555=nanum.

Rhinocarpus, DC. Prod. ii. 62,-Am. austr.

solitarium, Stokes, Bot. Mat. Med. ii. $159=$ Semecarpus Anacardium.

Spruceanum, Benth.ex Engl. in Mart. Fl. Bras, xii. II, 410.-Bras.

subcordatum, Presl, Bot. Bemerk. $40=$ curatellaefolium.

subterraneum, Liais, Climats, etc., Brésil, 604 = humile,

ANACHARIS, Rich. in Mém. Inst. ii. (1811) $62=$ Elodea, Michx. (Hydroch.).

Alsinastrum, Bab. ex Plauch. in Ann. Sc. Nat. Sér. III. xi. $(1849) 74=\mathrm{E}$. canadensis.

callitrichoides, Rich. in Mém. Inst. ii. (1811) 7. t. 2.Bras.

canadensis, Planch. in Ann. Sc. Nat. Sér. III. xi. (1849) $75=\mathrm{E}$. canadensis

chilensis, Planch. 1. c.-Chili

Hilariana, Casp. olim ex Casp. in Monatsb. Ber Akad. $(1857) 13=$ E. Naias

Matthewsii, Planch. in Ann. Sc. Nat. Sér. III. xi. (1849) 73.-Peruv.

Nuttallii, Planch. 1. c. $74=\mathrm{E}$, canadensis

pomeranica, Peterm. Deutschl. Fl. (1849) 529. t. 82 fig. $650=\mathrm{E}$. canadensis

Tripteris, Steud. Nom. ed. II. i. 82 (sphalm.=Anacis, Schrank $=$ Coreopsis Tripteris.

ANACHEILIUM, Hoffmgg. ex Linnaea, xvi. (1842) Litt. $229=$ Epidendrum, Linn. (Orchid.). cochleatum, Hoffmgg. 1. c. = E. cochleatum.

ANACHYRIS, Nees, in Hook. Kew Journ. ii. (1850) $103=$ Paspalum, Linn. (Gramin.)

paspaloides, Nees, 1. c. = P. malacophyllum.

ANACHYRIUM, Steud. Syn. Pl. Gram. $33(1855)=$ praec.

ANACIS, Schrank, in Denkschr. Acad. Muench. v. (1817) 5 = Coreopsis, Linn. (Compos.).

Tripteris, Schrank, 1. c. =C. Tripteris.

ANACOLOSA, Blume, Mus. Bot. Lugd. Bat. i. 250, t. 46 (1850). OLACINEAE, Benth. \& Hook. f, i. 348. crassipes, Kur, in fourn. As. Soc. Beng. xliv. (1875) II. 153.--Pegu.

densiflora, Bedd. in Madr. Fourn. Ser. III. i. (1864) 88. - Travancor.

frutescens, Blume, Mus. Bot. Lugd. Bat. 1. 251.-Java,

Griffithii, Mast. in Hook. $f$. Fl. Brit. Ind. i, 580 .Burma.

heptandra, Maingay, ex Mast. l. c. 581-Malacca.

ilicoides, Mast. l. c. 580,-Reg. Himal.

Maingayi, Mast. l. c.--Singapore.

Pervilleana, Baill. Adansoniu, iii. (1862-63) 119.Ins. Mascar.

puberula, Kurs, in fourn. As. Soc. Beng. xli. (1872) 11. 297.-Ins. Andaman.

ANACOLUS, Griseb, in DC. Prod, ix. $70(1845)=$ Hockinia, Gardn. (Gentian.)

Gardneri, Griseb. 1. c. = H. montana.

ANACTORION, Rafin, Fl. Tellur, iv, $34(1836)=$ Synnotia, Sweet (Irid.)

bicolor, Rafin. I. c. $=\mathrm{S}$, bicolor.

galeatum, Kafin, 1. c. $=$ S. galeata.
ANACTINIA, Remy, in C. Gay, F1. Chil. iv. 8 (1849) = Nardophyllum, Hook. (Compos.)

Hookeri, Remy, l. c. $=$ N. humile.

ANACTIS, Cass, in Dict. Sc. Nat. xlvii. 510 (1827)= Atractylis, Linn. (Compos.).

caespitosa, Cass. 1. c. 1. $56=$ At. caespitosa

glabra, Rafin. F1. Tellur, ii, $44=$ Aster vimineus

pilosa, Rafin. 1. c. = Carthamus lanatus

serratuloides, Cass. in Dict. Sc. Nat. 1. $56=$ At. serratuloides.

ANACYCLODON, Jungh. in Nat. en Geneesk. Arch Néerl. Indie, ii. (1845) $49=$ Leucopogon, R. Br. (Epacrid.)

pungens, Jungh. 1. c. = L. javanicus.

ANACYCLUS, Linn. Gen, ed, I. 256 (1737), COM POSITAE, Benth. \& Hook. f. ii. 419

ARThrolepis, Boiss. Diagn. Ser. I. xi. 14 (1849)

C'yrtolepis, Less. in Linnaea, vi. (1831) 166.

Hiorthia, Neck. Elem. i. $97(1790)$

Leucocyclus, Boiss. Diagn. Ser. I. xi, 13 (1849).

lexandrinus, Willd. Sp. $P l$, iii. 2173.-Afr, bor.

anomalus, J. Gay, ex Boiss. F1. Orient. iii. $283=$

Anthemis palestina.

anthemoides, Lag. ex Spreng. Syst. iii. $497=$ Anthemis abrotanifolia.

aristulatus, Link, ex Nym. Consp. $363=$ clavatus.

aureus, Brot. F1. Lusit. i. $363=$ radiatus

aureus, Lam. ex DC. F1. Fr iv, $202=$ Matricaria aurea aureus, Linn. Mant. ii. $287=$ Anthemis aurea

australis, Sieber, ex Spreng. Syst. iii. $497=$ Cotula australis

Barrelieri, Guss. Pl. Rar. $357=$ Achillea Barrelierii.

bicolor, Pers. Syn. ii. $465=$ radiatus.

Candolii, Nym. Syll. $8=$ clavalus.

ciliatus, Traut. in Bull. Soc. Nat. Mosc. xli. (1868) I $461=$ Anthemis ciliata.

clavatus, Pers. Syn. ii. 465.-Reg. Mediterr.

creticus, Linn. Sp. P1. $892=$ Anthemis cretica.

cyrtolepidioides, Pomel, Nouv. Mat. Fl. Atl. 54.-Afr. bor.

depressus, Ball, in Fourn. Bot. xi. (1873) 365.Marocco

dissimilis, Pomel, Nouv. Mat. Fl. Atl. 53,-Afr. bor divaricatus, Cav. ex Steud. Nom, ed. i. 41 = clavatus. formosus, fenzl, ex Boiss. Diag. Ser. I. xi. 14.Cilicia.

hirsutus, Lam. Fl. Fr. ii. $47=$ valentinus

inconstans, Pomel, Nouv. Mat. Fl. Atl.52.-Afr. bor inflatus, Lehm.ex Stend. Nom. ed. II. i. 82.-Sibir. lanuginosus, Moench, Meth. $581=$ valentinus.

linearilobus, Boiss. \& Reut. Pugill. Pl. Hispan. 57.Hispan.

maroccanus, Ball, in Fourn. Bot. xi. (1873) 365.Marocco

mauritanicus, Pomel, Nouv. Mat. Fl. Atl.55.-Afr. bor membranaceus, Benth. \& Hook. f. Gen. iii. 419.Syria.

mucronulatus, Guss. Pl. Rar. 356=Achillea Barre lierii.

mucronulatus, Hort. ex Stend. Nom. ed. II. i. $82=$ clavatus.

nigellaefolius, Boiss. Diagn. Ser. I. xi. 13.-Syria; Assyr.

officinarum, Hayne, Arzneigerv. ix. t. 46.-Europ. austr.

orientalis, Linn. Sp. Pl. $892=$ Anthemis montana

pallescens, Guss. Fl. Sic. Syn. ii. $494=$ radiatus.

pectinatus, Bory \&c Chaub. Fl. Pélop. 59. t. $30=$ Anthemis taygetea.

pedunculatus, Pers. Syn ii. 465.-Barbar.

prostratus, Pomel, Nouv. Mat. Fl. Atl. 52.-Afr. bor.

Pseudopyrethrum, Aschers. in Bonplandia, vi. (1858) 123.-Hab.?

pubescens, Brot. ex Link, Handb. i. 763; Reichb. Fl Exc. ii. $225=$ clavatus.

pulcher, Bess, ex DC. Prod. vi. 16=officinarum. purpurascens, DC. FI. Fr. v. 481 = radiatus.

Pyrethraria, Spreng. Syst. iii. $497=$ Cotula Pyrethraria,

Pyrethrum, DC. Fl. Fir. Si6ppl. 480.-Afr. bor. Oriens.

radiatus, Loisel. Fl. Gall. ed. I. 583; Pers. Syn. ii. 465.-Keg, Mediterr.

tomentosus, DC. Fl. Fr. Suppl. $481=$ clavatus

truncatus, J. Gay, in Boiss. Fl. Orient. iii. $299=$ Anthemis palestina.

valentinus, Limu. Sp. Pl. 892. - Reg. Mecliters.
ANACYLANTHUS, Steud. Nom. ed. II. i. 82 (1840) sphalm. = Ancylanthos, Desf. (Rubiac.).

ANADELPHIA, Hack. in Engl. Bot. Jahrb. vi. (188\%) $240=$ Andropogon, Linn. (Gramin.).

virgata, Hack. 1. c. $241=$ Andr. leptocomus.

ANADENDRUM, Schott, in Bonplandia, v. (1857) 45. AROIDEAE, Benth. \& Hook. f. iii. 991. affine, Schott, in Ann. Mus. Lugd. Bat. i. 282.Sumatra.

cordatum, Schott, l. c. 283,-Sumatra.

Lobbi, Schott, in Bonplandia, v, (1857) $45=$ mon tanum.

marginalum, Schott, in Oestr. Bot. Wochenbl. (1857) 116.-Ind. or.

medium, Schott, in Bonplandia, v。 (1857) $45=\mathrm{Epi}$ premnum medium.

montanum, Schott, l. c.-Java

punctulatum, Schott, Prod. Aroid. $393=$ Monstera punctulata.

semivestitum, Schott, in Ann. Mus. Lugd. Bat. 1. 283 $=$ affine.

ANADENDRON, Wight, Illustr. Ind. Bot. ii, 164 (1850 err. typ. = Anodendron, A. DC. (Apocyn.)

ANADEMIA, Agardh, Aphor. 236 (1826), sphalm seq.

ANADENIA, R. Br. in Trans. Linn. Soc. x. (1809) 166 = Grevillea, R. Br. (Proteac.)

anethifolia, A. Cunn, ex Benth. Fl. Austral. v. $483=$ G. anethifolia.

Aquifolium, Lindl. Swan River App. $31=\mathrm{G}$. monticola.

Caleyi, R. Br. Prot. Nov. $16=\mathrm{G}$. ramosissima

filifolia, Endi. in Ann. Wien. Mus. ii. (1838) $209=\mathrm{G}$ didymobotrya.

flexuosa, LindI. Swan River App. 31=G. Alexuosa.

gracilis, Lindl. 1. c. $\equiv$ G. Synapheae.

hakeoides, Lindl. 1. c. $30=$ Hakea nndulata.

ilicifolia, R. Br. in Trans. Linn. Soc. x. (1809) $167=$ $\mathrm{G}$, ilicifolia.

integrifolia, Endl. in Ann. Wien. Mus. ii. (1838) 203 $=\mathrm{G}$. integrifolia.

Manglesiz, R. Grah. in Hook. Ic. PI. t. $337=$ Manglesia cuneata.

pulchella, R. Br. in Trans. Linn. Soc. ж. (1809) 167 $=\mathrm{G}$. pulchella

Roëi, Endl. Gen. Suppl. iv. Ir. $83=$ G. didymobotrya. tenuiflora, Lindl. Swan River App. $31=\mathrm{G}$. tenuiflora. trifida, R. Br. in Trans. Linn. Soc. $x .(1809) 167=\mathrm{G}$. trifida.

triternata, A. Cunn. ex Heynh. Nom. ii. $34=$ G. triternata.

ANAECTOCALYX, Triama, ex Benth. \& Hook. $f$ Gen. i. 765 (1867). MELASTOMACEAE, Benth. \& Hook. f. i. 765 .

bracteosa, Triana, l. c. \& in Trans. Limn. Soc. xxriii. (1871) 97. -Venezuela.

ANAECTOCHILUS, Lindl. Orch. $498(18 \pm 0)=$ Anoec tochilus, Blume (Orchid.)

ANAFRENIUM, Arn, in Hook, Lond. Journ. Bot iii. (1841) $148=$ ANAPHRENIUM, E. Mey, = Rhus, Linn. (Anacard.).

ANAGALLIDASTRUM, Mich, ex Adans, Fam. ii. 230 1763) = Centunculus, Linn. (Primul.

ANAGALLIDIUM, Griseb. Gen. et Sp. Gent. $\$ 11$ (1830 =Swertia, Linn. (Gentian.

dichotoma. Griseb. 1. c. $\$ 12=\$$. dichotoma.

tetrapetalum, Griseb. I. $\mathrm{c} .=\mathrm{S}$. tetrapetala.

ANAGALLIS, [Tourn.] Linn. Sist. ed. I. (1795) Gen. ed. I. $43(1737)$. PRIML'LACE.AE, Benth. \& Hook. f. ii. 68

EUPAREA. Banks \& Soland, in Gacru. Fruce. i. 230,50 (1-58)

IRASEK1A, S. F. Gray, Nat. Arr. ii. 299 1S:11.

JiRastikia, F. W. Schmide, Neue u. Selt. Pf. 49 (17:9)

TikAstiki, G. Don, in Sweet, Hort. Brit, ed. IlI. 503 (183!) 


\section{ANAGALLIS :-}

alba, Buch.Ham. ex Steud. Nom, ed. II. i. 83.(Quid?) Ind. or.

alternifolia, Cav. Ic. vi. 3. t. 506.-Chili.

angustifolia, Salisb. Prod, $121=$ linifolia

aquatica, Emdl, ex Ledeb. F1. Ross, iii. $31=$ Samolus Valerandi.

arabica, Duby, in DC. Prod. viii. 69.-Arab.

arvensis, Linn. Sp. Pl. 148.-Europ.; As. temp.

caerulea, Lam. Fl. Fr. ed. I. ii. $285=$ arvensis.

capensis, Linn. Sp. Pl. 149.-Afr. austr.

carnea, Schrank, Baier, Fl. i. $461=$ arvensis.

Centunculus, Afzel. Veget. Suecan. (1785) $1=$ Cen-

tunculus minimus

collina, Schousb. Marok. $64=$ linifolia.

crassifolia, Thore, Chlor. Land.62.-Hispan.; Marocco.

filiformis, Cham. E Schlecht. in Linnaea, i. (1826)

225.-Bras.

foemina, Mill. Gard. Dict. ed. VIII. n. 2 =arvensis.

fruticosa, Vent. Choix, $14=$ linifolia.

Gmelini, Steud. Nom. ed. II. i. 83.-Camtsch.

grandiflora, Andr. Repos. t. $367=$ linifolia

Huttoni, Hary. in Proc. Dub. Univ. Zool. E Bot.

Assoc. i. (1859) 141.-Afr, austr.

indica, Sweet, F1. Gard, t. 132=arvensis.

Facquemontii, Duby, in DC. Prod. viii. $69=$ arvensis.

latifolia, Linn. Sp. Pl. $148=$ arvensis.

linifolia, Linn. l. c. ed. II. 212,-Europ.

Marryattae x, Sweet, ex G. Don, in Sweet, Hort. Brit. ed. III. 563.

mas, Vill. Hist. Pl. Dauph. ii. $461=$ arvensis.

Monelli, Bieb. Fl, Taur. Cauc. i. $143=$ arvensis.

Monelli, Linn. Sp. PI. $148=$ linifolia.

multangularis, Buch.-Ham. ex Hook, f. Fl. Brit, Ind.

iii. $503=$ I ysimachia pyramidalis.

nummularifolia, Baker, in fourn. Linn.Soc. xx. (1884)

196.--Madag.

orientatis, Hort. ex Fisch. Mey. \& Avé-Lall. Ind. Sem.

Hort. Petrop. xi. $49=$ arvensis.

ovalis, Ruiz \& Pav. F1. Per. ii. $8=$ Centunculus pentandrus.

palustris, [Clairv.] Man. Herb. $59=$ tenella.

parviflora, Hoffmgg. \& Link, Fl. Port. i. 325. t. 64.-

Lusitan.

parviflora, Loisel. in Mém. Soc. Linn. Par. vi. (1827) $491=$ arvensis.

pedunculata, Salzm. ex Duby, in DC. Prod. viii. $72=$

Centunculus pentandrus.

peploides, Baker, in Fourn. Linn. Soc. xx. (1884)

196.-Madag.

Philipsii, Hort. ex Duby, in DC. Prod. viii. 70linifolia.

phoenicea, Scop. Fl. Carn. ed. II. i. $139=$ arvensis.

pilosa, Buch.-Ham. ex D. Don, Prod. F1. Nep. $83=$ Lysimachia japonica.

platyphylla, Baudo, in Exped. Alg. t. 67.-Algeria.

pulchella, Salisb. Prod, $120=$ arvensis.

pumila, Sw. Prod. Veg. Ind. Occ. $40=$ Centanculus pentandrus.

punctifolia, Stokes, Bot. Mat. Med. i. $305=$ arvensis.

pusilla, Salisb. Prod. 121 = Centunculus minimus.

repens, DC. Fi. Fr. v. $381=$ arvensis.

repens, Pomel, Nouv. Mat. Fl. Atl. 126.-Algeria.

rubricaulis, Boj. ex Duby, in DC. Prod. viii. $72(=$

Micropyxis rubricaulis).

serpens, Hochst. ex A. DC. Prod. viii. 668.-Abyss.

serpyllifolia, Dum. F1. Belg. $29=$ tenella.

sessilis, Salzm. ex Duby, in DC. Prod. viii. $72=$ Centunculus pentandrus.

spicata, Noronha, in Verh, Batav. Gen. v. $(1790)$ ed. I, Art. iv. 6.-Malaya.

tenella, Linn. Mant. 335.-Europ.

tenuicaulis, Baker, in fourn. Bot. xx. (1882) 172 .Madag.

verticillata, All. F1. Pedem. i. $87=$ arvensis

Webbiana, Penny, ex Loud. Gard. Mag. v. (1829) 471 $=$ Marryattae.

Wellsiana x, Penny, ex Loud. Hort. Brit. Suppl. i. 580.

Willmoreana, Don, ex Hook. Bot. Mag. t. $3380=$ linifolia.

ANAGALLOIDES, Krock. Fl. Siles. ii. I. $398(1790)=$

Vandellia, Linn. (Scrophul.)

procumbens, Krock. 1. c. =V. erecta.

ANAGANTHOS, Hook. f. in F1. N. Zeal. i. 226 (1854) = Australina, Gaudich. (Urticac.).
ANAGLYPHA, DC. Prod. v. 311 (1836), COMPOSITAE, Benth. \& Hook. f. ii. 326.

OXYLAENA, Benth. in Hook, Ic. Pl, t. 1109 (1876)

acicularis, Benth. l. c. xii. 9, t, 1109.-Afr. austr.

aspera, $D C$. Prod. v. 311.-Afr. austr.

ANAGYRIS, Linn. Syst. ed. I. (1735); Gen. ed. I. 219 (1737). LEGUMINOSAE, Benth. \& Hook. f. i. 219

barbata, R. Grah, in Wall. Cat. n. $5341=$ Thermopsis barbata.

cretica, Mill. Gard. Dict. ed. VIII. n. 2.-Ins, Archip.

foetida, Linn.Sp. Pl. 374.-Reg. Mediterr.; Oriens.

foetida, Lour. F1. Cochinch. 260 ; ed. Willd, i. $318=$ sinensis.

glauca, Hort. ex Loud. Hort. Brit. $162=$ foetida.

indica, Hort. ex Steud. Nom. ed. II. i. $83=$ sinensis.

indica, Lindl. in Trans. Hort. Soc, vii. (1830) 245

$=$ Piptanthus nepalensis.

inodora, Lour. Fl. Cochinch. 260.-Cochinch.

latifolia, Brouss. ex Willd. Enum. Hort. Berol. 439.Teneriffa.

neapolitana, Tenore, Syll, $198=$ foetida

nepalensis, R. Grah, in Wall. Cat. n. 5340= Piptanthus nepalensis.

sinensis, Steud. ex DC. Prod. ii. 98 ("forte ad Ormosiam referend.').-China,

ANAITIS, DC. Prod.v. 628 (1836)=Sanvitalia, Linn, (Compos.)

acapulcensis, DC. 1. c. $629=$ S. acapulcensis.

ANALECTIS, Juss. in Jaume St. Hil. Expos. ii. 362 (1805) = Symphorema, Roxb. (Verben.).

ANALITON, Rafin. F1. Tellur. iii. $46(1836)=$ Rumex, Tourn. (Polygon.).

bipinnatus, Rafin. 1. c. $=\mathrm{R}$. lacerus.

ANALYRIUM, E. Mey. Zwei Pf. Docum. 163 (1843) nomen; Presi, in Abh. Boehm. Ges. V. iii. (1845) $505=$ Peucedanum, Koch (Umbell.).

millefolium, E. Mey. 1. c. = P. millefolium.

ANAMENIA, Vent. Malm. 22. t. $22(1803)=$ Knowltonia, Salisb. (Ranunc.)

capensis, Hoffmgg. Verz. Pf. Nachtr. i. $204=\mathrm{K}$. rigida.

coriacea, Vent. Malm. $22=\mathrm{K}$. rigida.

daucifolia, Vent. ex Cav. in Anal. Cienc. Nat. vi. (1803) $344=\mathrm{K}$. daucifolia.

gracilis, Vent. Malm. i. 22, obs. $=\mathrm{K}$. gracilis.

hirsuta, Vent. ex Cav. in Anal. Cienc. Nat. vi. (1803) $344=\mathrm{K}$. hirsuta.

laserpitiifolia, Vent. ex Cav. 1. c. $=\mathrm{K}$. vesicatoria.

vesicatoria, Dum.-Cours. Bot. Cult. iv. $438=\mathrm{K}$. vesicatoria.

ANAMIR TA, Colebr. in Trans. Linn. Soc. xiii. (1822) 52. MENISPERMACEAE, Benth. \& Hook. f. i. 35 .

Baueriana, Endl. Atakt. Bot. t. 39, 40=A. Cocculus.

Cocculus, Wight \& Arn. Prod. i. 446=paniculata.

flavescens, Miq. Fl. Ind. Bat. i. If. 79=A. Cocculus.

florescens, C. Muell. in Walp. Ann. vii. 63 , sphalm. = flavescens.

jucunda, Miers, Contr. Bot. iii. 55.-Java.

lemniscata, Miers, $l$. $c$. 54.-Java.

Lourieri, Pierre, Fl. For. Coch. Chin. t. 110.-Cambodia.

luctuosa, Miers, Contr. Bot. iii. 55.-Java

paniculata, Colebr. in Trans. Linn. Soc. xiii. (1822) 66. - Ind. or.

populifera, Miers, Contr. Bot. iii. 54.-Timor.

racemosa, Colebr. ex Steud. Nom. ed. II. i. $83=$ Cocculus suberosus.

toxifera, Miers, Contr. Bot. iii. $53=$ paniculata.

ANAMOMIS, Griseb. F1. Brit. W. Ind. $240(1864)=$ Myrtus, Linn.

esculenta, Griseb. 1. c. in obs. = Eugenia esculenta.

ferruginea, Griseb. Cat. Pl. Cub. 91=Engenia ferruginea? fragrans, Griseb. F1. Brit. W. Ind. $240=$ Myrcia
fragrans?
ANAMOMIS :-

Guayabillo, Griseb. Cat. Pl. Cub. $90=$ Eugenia Guayabillo.

punctata, Griseb. FI. Brit. W. Ind. $240=$ Myrcia Balbisiana.

ANAMORPHA, Karst. \& 'Triana, in Linnaea, xxviii. (1856) $443=$ Melochia, Linn. (Stercul.).

waltherioides, Karst. \& Triana 1. c.= M. lupulina.

ANANAS, Gaertn. Fruct. i.30.t. 11 (1788)=Bromelia, Linn.

Pinguin, Gaertn. 1. c. $=$ B. Pinguin.

ANANAS, Tourn. ex Linn. Syst. ed. I. (1735); Mill Gard. Dict. ed. VI. (1752) ; Adans. Fam. ii. 67 (1763) $B R O M E L I A C E A E$, Benth. \& Hook. f. iii. 662

Acanthostachys, Link, Klotzsch \& Otto, Ic. Pl. Rar. i. 21. t. 9. (1841)

Ananassa, Lindl, Bot. Reg. sub t. 1068 \& t. 1081 (1827).

arvensis, Steud. Nom. ed. II. i. 83.-Bras.

bracteatus, Schult. $f$. Syst. vii. 1286.-Bras.

debilis, Schult. f. 1. c. $1287=$ sativus.

glaber, Mill. Gard. Dict. ed. VIII. n. 3 (et corr.) $=$ sativas.

lucidus, Mill. 1. c. n. $4=$ sativus.

macrodontes, E. Morr. Belg. Hortic. xxviii. (1878) 140. t. 4 et 5.-Bras.

Mordilona, Hort. Linden, ex E. Morr. in Belg. Hortic. xxix. (1879) $302=$ sativus

muricatus, Schult. f. Syst. vii, $1287=$ bracteatus.

oratus, Mill. Gard. Dict, ed. VIII, n, 1 =sativus.

Porteanus, Hort. Veitch, ex C. Koch, Wochenschr. xiv. (1871) $130=$ sativus.

pyramidalis, Mill. Gard. Dict. ed. VIII. n. 2 = sativus. Sagenaria, Schult. f. Syst. vii. $1286=$ bracteatus.

sativus, Schult. f. l. c. 1283.-Am. trop.

semiserratus, Schult, f, 1. c, $1286=$ sativus

serotinus, Mill. Gard. Dict. ed. VIII. n. $5=$ sativus.

viridis, Mill. 1. c. n. $6=$ sativus.

ANANASSA, Lindl. Bot. Reg. sub t. 1068 et t. 1081 (1827) = Ananas, Tourn. (Bromel.).

bracamorensis, Linden, Cat. n. 98. (1878) $3=$ Ananas sativus.

bracteata, Lindl. Bot. Reg. sub t. 1068 et t. $1081=$ Ananas bracteatus.

debilis, Lindl. 1. c. sub t. $1068=$ Ananas sativus

lucida, Lindl. 1. $\mathrm{c}_{\mathrm{n}}=$ Ananas sativus.

Mordilona, Linden, Cat. n. 22. (1869) $2=$ Ananas sativus.

muricata, D. Dietr. Syn. Pl.ii. 1088= Ananas bracteatus. Porteana, Carr. in Rev. Hortic. (1878) $140=$ Ananas sativus.

Sagenaria, D. Dietr. Syn. Pl. ii. $1088=$ Ananas bracteatus:

sativa, Lindl. Bot. Reg. sub t. $1068=$ Ananas sativus. semiserrata, D. Dietr. Syn. Pl. ii. $1088=$ Ananas sativus.

ANANDRIA, Siegesb. ex Linn. Amoen. Acad. i: 243. t. $11(1745)$ = Gerbera, Gronov. (Compos.).

Bellidiastrum, DC. Prod. vii. $40=\mathrm{G}$. Anandria.

dimorpha, Turcz. in Bull. Soc. Nat. Mosc. xxi. (1848) II. $88=\mathrm{G}$. Anandria.

discoidea, Less. in Linnaea, v. (1830) 347. t. $3=\mathrm{G}$. Anandria.

radiata, Less. 1. c. 346 . t. $4=\mathrm{G}$. Anandria.

ANANTHERIX, Nutt. Gen. Am, i. 169 (1818)=Asclepiodora, A. Gray (Asclep.)

angustifolia, Rafin. Atl. Journ. 146.-Am. bor.

Bungei, G. Don, Gen. Syst. iv. 146= Pycnostelma chinense.

connivens, A. Gray, in Proc. Am. Acad. xii. (1877) 66 $=$ Asc. viridis.

decumbens, Nutt. in Trans. Am. Phil. Soc. v. (1837) $203=$ Asc. decumbens.

grandiflora, Rafin. in New F1. Am, iv. 59.-Am. bor. Nuttaliana, G. Don, Gen. Syst. iv, $146=$ Asc. decumbens.

ovata, Rafin. Atl. Joum. 146.-Am. bor.

paniculata, Nutt. in Trans. Am. Phil. Soc. v. (1837) $203=$ Asc. viridis

pumilis, Nutt. 1. c.-Am. bor.

Torreyana, G. Don, Gen. Syst. iv. $146=$ Asc. viridis verrucosa, Rafin. New Fl, Am. iv. $60=$ Asc. viridis. viridis, Nutt. Gen. Am. i. $169=$ Asc. viridis . 
ANANTHOCYCLUS, Vaill. ex Linn. Syst. ed. I. (1735) = Cotula, Tourn. (Compos.).

ANANTHOPUS, Rafin. F1. Ludov. $20(1817)=$ Com melina, Linn.

clandestinus, Rafin. 1. c. $21=$ C. ignorata.

cordatus, Rafin. 1. c. $22=\mathrm{C}$. Rafinesquei.

undulatus, Rafin. F1. Tellur, iii. $70=$ C. undulata.

ANAPHALIS, DC. Prod. vi. 271 (1837). COMPOSITAE, Benth. \& Hook. f. ii. 303.

MARgaripes, DC. ex Steud. Nom. ed. II. ii. 101 (1841).

adnata, DC. Prod. vi. 274.-Reg. Himal.

alata, Maxim. in Bull. Acad. Pétersb. xxvii. (1881) 478.-As. or

araneosa, DC. Prod. vi. 275.-Reg. Himal.

aristata, $D C$. in Wight, Contrib. 21.-Ind. or.

Beddomei, Hook. f. Fl. Brit. Ind. iii. 282.--Ind, or.

brevifolia, DC. Prod. vi, 273.-Zeylan.

Busua, DC, 1. c. $275=$ araneosa.

chionantha, DC. 1. c. $273=$ Royleana

cinnomomea, C. B. Clarke, Comp. Ind. 104.-Ind. or.; China; Japon

contorta, Hook. f. Fl. Brit. Ind. iii. 284.-Reg. Himal.

cuneifolia, Hook. f. l. c. 280.-Reg. Himal.

cutchica, C. B. Clarke, Comp. Ind. 111.-Kutch.

elliptica, DC. Prod. vi. $274=$ oblonga.

Falconeri, C. B. Clarke, Comp. Ind. $107=$ contorta

fruticosa, Hook. f. Fl. Brit. Ind. iii. 282.-Zeylan.

Griffithii, Hook. f. l. c. 280.-Reg. Himal.

Hancockii, Maxim. in Bull. Acad. Petersb. xxvii. (1881) 479.-China.

Hookeri, C. B. Clarke, in Hook. f. Fl. Brit. Ind. iii. 282.-Reg. Himal.

japonica, Maxim. in Bull. Acad. Pétersb. xxvii. (1881) 480.-Japon.

javanica, Sch. Bip. in Zoll. Syst. Verz. Ind. Archip. 124.-Java,

lactea, Maxim. in Bull. Acad. Pétersb. xxvii. (1881) 479.-As. or.

leptophylla, $D C$. Prod. vi. 273.-Ind. or.

linearis, DC. 1. c. $274=$ marcescens?

longifolia, DC. 1. c.-Java.

marcescens, $C, B$. Clarke, in Hook. $f$. Fl. Brit. Ind. iii. 286.-Ind or

margaritacea, Benth. \& Hook.f. Gen. ii. 303.-Am. bor.

monocephala, DC. Prod. vi. $272=$ nubigena.

mucronata, DC. 1. c. =nubigena.

neelgerryana, $D C$. l. c.--Ind. or.

Notoniana, DC. l. c. 273.-Ind. or.

nubigena, $D C$, l. c. 272.-Reg. Himal.

oblonga, DC. l. c. 274 .-Ind. or.

oligandra, $D C$. l. c. 275.-Madag.

polylepis, DC. 1. c. $272=$ Royleana

pterocaulon, Maxim. in Bull. Acad. Pétersb. xxvii. (1881) 478 .-As. or.

racemifera, Franch. in Ann. Sc. Nat. Sér. VI. xvi (1883) 310.-As. or.

Royleana, DC. Prod. vi. 272.--Reg. Himal.

Royleana, C. B. Clarke, Comp. Ind. $104=$ Griffithii.

semidecurrens, C. B. Clarke, 1. c. $109=$ araneosa.

sinica, Hance, in Fourn. Bot. xii. (1874) 261.-China.

Stoliczkai, C. B. Clarke, Comp. Ind. 108.-Tibet. occ.

subumbellata, C. B. Clarke, l.c. 104.-Reg. Himal.

tenella, DC. Prod. vi. $273=$ contorta.

Thwaitesii, C. B. Clarke, Comp. Ind. 110,-Zeylan.

Timmua, D. Don, Prod. F1. Nep. $174=$ cinnamomea

triplinervis, Sims, ex C. B. Clarke, Comp. Ind.105.Reg. Himal.

triplinervis, Benth. ex Hance, in Journ. Bot. xvi. (1878) $12=$ Hancockii

virgata, Thoms. in C. B. Clarke, Comp. Ind. 107.Reg. Himal.

viscida, $D C$. Prod. vi, 274.-Java.

Wightiana, Thw. Enum. Pl. Zeyl. $166=$ zeylanica.

Wightiana, DC. Prod. vi, 273.-Ind. or.

xylorhiza, Sch. Bip, ex Hook. f. Fl. Brit. Ind. iii. 281.-Reg. Himal.

yedoensis, Maxim. in Bull. Acad. Petersb. xxvii. (1881) 480.-Japon.

zeylanica, C. B. Clarke, in Hook. f. Fl. Brit. Ind. iii. 286.-Zeylan.

Zollingeri, Turcz, in Bull. Soc. Nat. Mosc, xxiv. (1851) II. $54=$ Antennaria saxatilis.

Zollingeriana, Sch. Bip. ex Zoll. Syst. Verz. Ind. Archip. $124=$ pracc,
ANAPHRAGMA, Stev. in Bull. Soc. Nat. Mosc. iv. 265 (1832) = Astragalus, Tourn. (Legum.).

ANAPHRENIUM, E. Mey. ex Endl. Gen. Suppl. i. 1425 (1841). ANACARDIACEAE, [Benth. \& Hook f. i. 419 ].

Heeria, Meissn. Gen. Comm. 55 (1837)

Ozoroa, Delile, in Ann. Sc. Nat. Sér. II. xx. (1843) 91. t. 1 .

Roemeria, Thunb. Nov. Gen. Pl. ix. 130 (1798), pro parte.

abyssinicum, Hochst. in Flora, xxvii. (1844) 32.-Afr. trop.

argenteum, E. Mey. Zwei Pf. Docum. 163.-Afr austr.

concolor, E. Mey. l.c.-Afr. austr.

dispar, E. Mey. l. c.-Afr. anstr.

longifolium, Bernh. in Flora, xxvii. (1844) I. $349=$

Protorhus longifolia.

mucronatum, Bernh.l. c.-Afr, austr.

mucronifolium, Sond. in Harv. \& Sond. Fl. Cap. $522=$ praec

paniculosum, Engl. in DC. Monog. Phan. iv. 358.Afr. austr.

pulcherrimum, Schweinf. Fl. Aethiop. Beitr. i. 32.Afr. trop.

ANAPHYLLUM, Schott, Gen. Aroid. t. 83 (1858) $A R O I D E A E$, Benth. \& Hook. f. iii. 996.

Wightii, Schott, l. c.--Ind. or.

ANAPODOPHYLLUM, Toum. ex Moench, Meth. 277 $(1794)=$ Podophyllum, Linn. (Berberid.).

peltatum, Moench, 1. c: $=$ P. peltatum.

ANARMODIUM, Schott, in Bonplandia, ix. 368 (1861) Dracunculus, Schott (Aroid.)

canariense, Schott, 1. $c_{1}=\mathrm{D}$. canariensis.

ANARMOSA, Miers, ex Hook. Bot. Misc. iii. (1833) 338 $=$ Tetilla, DC. (Saxifrag.)

gracilis, Miers, ex Hook. 1. c. $=$ T. hydrocotylifolia.

ANARRHINUM, Desf. Fl, Atlant. ii. 51 (1800) SCROPHULARINEAE, Benth. \& Hook. f. ii. 933

Cardiotheca, Ehrenb. ex Steud. Nom. ed. II. i $282(1840)$.

Simbuleta, Forsk. Fl. Aegypt. Arab. 115 (1775)

abyssinicum, Faub. \& Spach, Illustr. Pl. Or. v. 52. t. 447.-Abyss.

arabicum, Faub. \& Spach, l.c. v. 50. t. 446.-Arabia. bellidifolium, Desf. Fl. Atlant. ii. 51 ; Chav. Monog. 175. t. 10.-Reg. Mediterr.

bellidifolium, Fenzl, ex Jaub. \& Spach, Illustr. Pl. Or. v. $54=$ orientale

brevifolium, Coss. \& Kral. in Bull. Soc, Bot. Fr. iv. (1857) 407.-Afr. bor.

canadense, Poir. Encyc. Suppl. 1. 334, in obs. = Linaria canadensis.

corsicum, Jord. \& Fourr. Brev. P1. Nov, fasc. i. $41=$ bellidifolium.

crassifolium, Willd. Sp. P1. iii. $261=$ Linaria origanifolia.

Duriminium, Pers. Syn. ii, 159,-Lusitania,

ecalcaratum, Fenzl, ex Jaub. \& Spach, Illustr. Pl. Or. v. $54=$ orientale.

fruticosum, Desf. Fl. Atlant. ii. 52.-Afr. bor.

fruticosum, Schimp. ex Benth. in DC. Prod. x. $289=$ orientale.

hirsutum, Hofimgg. \& Link, Fl. Port. 227. t. $33=\mathrm{A}$ Duriminium.

incarnatum, Poir. Encyc. Suppl. iv. 18, in obs.= Linaria bipartita.

Linnaeanum, Jord. \& Fourr. Brev. Pl. Nov. fasc. i. 41 = bellidifolium.

laxiflorum, Boiss. Elench. 71.-Hispan.

lusitanicum, Jord. \& Fourr. Brev. Pl. Nov, fasc. i. $41=$ bellidifolium.

murale, Pourr. ex Willk. \& Lange, Prod. Fl. Hisp. ii. $557=\mathrm{A}$. Duriminium.

orientale, Benth in DC. Prod. x. 289-Oriens.

pedatum, Desf. Fl. Atlant. ii. 51. t. 141.-Afr. bor.

pedicellatum, $T$. Anders. in Fourn. Linn. Soc. v. Suppl. i. (1860) 26.-Aden.

pubescens, Fresen. in Mus. Senkenb. i. 89.-Arab. petr. pubescens, Hort. ex Loud. Hort. Brit. $250=\mathrm{A}$. Duriminium.

tenellum, Willd. Sp. Pl. jii. 262.-I Hispan.

violacewm, Dulac, Fl. Hautes.Pyr. 873 = bellidifolium.
ANARTHRIA, R. Br. Prod. 248 (1810). RESTIA.

CEAE, Benth. \& Hook. f. iii. 1030 .

canaliculata, Nees, in Lehm. Pl. Preiss. ii. 62 gracilis.

gracilis, R. Br. Prod. 249.-Austral.

gracilis, Nees, ex Benth. Fl. Austral. vi. $216=$ Lepy

rodia Anarthria.

grandiflora, Nees, in Ann. \& Mag. Nat. Hist. Ser. I.

vi. $(1841) 50=$ gracilis.

humilis, Nees, 1. c. = gracilis.

ischaemoides, Nees, in Lehm. Pl. Preiss, ii. 62 = gracili. laevis, $R . B r$. Prod. 249.-Austral.

pauciflora, R. Br. 1. c. $249=$ prolifera.

polyphylla, Nees, in Lehm. Pl. Preiss, ii. 63.Austral

prolifera, R. Br. Prod. 249,-Austral.

scabra, R. Br. l. c.-Austral.

ANARTHROPHYLLUM, Benth, in Benth,

Hook. f. Gen, i. 478 (1865). LEGUMINOSAE;

Benth. \& Hook. f. i. 478 .

andicolum, Phil. f. Cat. Pl. Chil. 52.-Chili.

Bergii, Hieron. in Bol. Acad. Nac. Cordova, iii. (187's

340.-Reg. argent.

Cumingi, Phil. f. Cat. Pl. Chil. 52.-Chili

desideratum, Benth. in Benth. \& Hook. f. Gen. i. 478 -Patagon.

elegans, Phil. f. Cat. Pl. Chit. 52.-Chili

juniperinum, Phil.f.l. c.-Chili.

rigidum, Hieron. in Bol. Acad. Nac. Cordova, ii. (1879) 340.-Reg. Argent.

umbellatum, Phil.f. Cat. Pl. Chil. 52.-Chili.

ANARTHROSYNE, E, Mey. Comm. Pl. Afr. Aust $124(1835)=$ Pseudarthria, Wight \& Arn. (Legum.) abyssinica, Hochst. ex A. Rich. Tent. Fl. Abyss, i. 204 $=$ Desmodium spirale.

cordata, Klotzsch, in Peters, Reise Mossamb. Bot. 3y.

t. $7=$ Desmodium latifolium.

densiflora, Klotzsch, 1. c. $41=$ P. Hookeri.

gracilis, Klotzsch, 1. c. $40=\mathrm{P}$. confertiflora

robusta, E. Mey. Comm. Pl. Afr. Austr. 124=I. Hookeri.

ANARTIA, Miers, Apocyn. S. Amer.79. (1878) = Tabernaemontana, Linn. (Apocyn.)

bogotensis, Miers, 1. c. 82 -N. Granat.

flavescens, Miers, 1. c. = Malouetia flavescens,

flavicans, Miers, 1. c. $=$ T. flavicans.

glabrata, Miers, 1. c. $81=T$. oblongifolia.

Meyeri, Miers, 1. c. $80=$ T. Meyeri.

recurva, Miers, $1, \mathrm{c} .=\mathrm{T}$, recurva.

Wulfschlaegelii, Miers, 1. c. $81=$ T. Wullschlaegelii.

ANASCHOVADI, Adans. Fam. ii. $122(1763)=$ Ele phantopus, Vaill. (Compos.)

ANASSER, Juss. Gen. $150(1789)=$ Geniostoma, Forst. (Logan.)

Borboniae, J. F. Gmel. Syst. i. $303=$ G. borbonicum. borbonica, Lam. Illustr. ii. $40=\mathrm{G}$. borbonicum. moluccana, Lam. 1. c. = Strychnos Pseudo-quina Rumphii, Span. in Linneea, xv. $(\mathbf{1 8} \pm 1) 325=$ Pitto. sporum timorense.

ANASSERA, Pers. Syn. i. 265 (1805)= praec.

ANASTATICA, Linn. Gen. ed. I. 191 1737

CRUCIFERAE, Benth. \& Hook, f. i. 71 .

Hiericontis, Adans. Fam. ii, 421 (1763).

IERIKontis, Adans. 1. c. 565 (1763)

hierachuntica, Crantz, Stirp. Austr. ed. II. fasc. i. Euclidium syriacom.

hierochuntica, Linn. Sp. Pl. ed. II. 895.-Oriens. littoralis, Salish, Prod. $266^{\circ}=$ hierochuntica.

syriaca, Linn. Sp. Pl. ed. II. $895=$ Euclidiam syriacum.

ANASTRABE, E. Mey. ex Benth. in Hook. Comp Bot. Mag. ii. (1836) 54. SCROPHCLARI.VEAE. Benth. \& Hook. 1. ii. $93 \%$

integerrima, E. Mey, ex Benth. b. c.-Afr. austr.

serrulata, E. Mép. es Bewph. L. c.-Afr. austr.

ANASTRAPHIA, D. Don, in Trans, Linn. Soc rvi. 1830 2!5. C(MMPOSITAE. Benth. S Hook. f. ii. 491 . ilicifolia, D. Don, l. c.-Am. trop.

intertexta, Wright, ex Griseb. Cas. Pl. Cas. 15s.Cuba.

mantuensis, H'right, ex Griseb. l. c. Cuba.

microcephala, Griseb. l. c.-Cuba. 
ANASTREPHIA, Decne, in Orb. Dict. i. $432(1841)=$ Anastraphia, D. Don (Compos.).

ANASTROPHEA, Wedd in DC. Prod. xvii. 78 (1873) =Sphaerothylax, Bisch. (Podostem.)

abyssinica, Wedd. 1. c. 79.-Abyss.

ANASTROPHUS, Schlecht, in Bot, Zeit. viii. (1850) 681 = Paspalum, Linn. (Gram.).

barbatus, compressus, dissitiflorus, nematanthus, pectinatus, pellitus, platycaulis, platyculmis, pulchellus, setifolius, Schlecht, 1. c. 682, 683, omne Paspali homonymae.

ANASYLLIS, E. Mey. Zwei Pfl. Docum. 16 (1843)= Loxostylis, Spreng. (Anacard.).

angustifolia, E. Mey. 1. cs $=$ L. alata.

latifolia, E. Mey. 1. c. = L. alata.

ANATHALLIS, Barb. Rodrig. Orch. Nov. i. $23(1877)=$ Pleurothallis, R. Br. (Orchid.).

densiflora, Rodrig. 1. c. ii. 73.-Bras.

fasciculata, Rodrig. 1. c. i. 23.-Bras.

hebesepala, Rodrig. 1. c. ii. 75.-Bras.

heterophylla, Rodrig. 1. c. ii. 74.-Bras.

micrantha, Rodrig. 1. c. ii. 76.-Bras.

nectarifera, Rodrig. 1. c. ii. 74.-Bras.

osmosperma, Rodrig. 1. c. ii. 73.-Bras.

parahybunensis, Rodrig. 1. c. ii. 76.-Bras.

pulvinata, Rodrig. 1. c. ii. 77.-Bras.

racemosa, Rodrig 1 c 24 -Bras.

secunda, Rodrig. 1. c. ii. 72.-Bras.

ANATHERIX, Steud. Nom. ed. I. 41 (1821) err. typ. = ANANTHERIX, Nutt. = Asclepiodora, A. Gray (Asclep.).

ANATHERUM, Beauv. Agrost. 128, t. 22, f, 10, 11 (1812) = Andropogon, Linn. (Gram.).

abortivum, Beauv. Agrost. 169=Panicum abortivum.

Berterianum, Spreng. ex Roem. \& Schult. Syst. ii

Mant. ii. $443=$ Imperata exaltata.

bicorne, Beauv. Agrost. $128=$ Androp. bicornis.

brasiliense, Spreng. ex Steud. Nom. ed. II. i. $84=$

Androp. leucostachyus.

caudatum, Schult. Mant. ii. 445 = Imperata exaltata.

domingense, Roem. \& Schult. Syst. ii. $809=$ Androp leucostachyus.

glabrum, Schult. Mant. ii. $446=$ Androp. intermedius.

holcoides, Nees, Agrost. Bras. 324=Saccharum holcoides.

inerme, Griseb. Cat. Pl. Cab. $236=$ Androp. spathi florus.

macrurum, Griseb. P1. Wright. Cub. ii. $534=$ Androp macrourus.

megapotamicum, Spreng. Syst. Cur. Post. $33=$ Elionurus rostratus.

montanum, Roem. \& Schult. Syst. Mant. ii. $445=$ Androp. montanus.

muricatum, Beauv. Agrost. $150=$ Androp. squarrosus muticum, Beauv, 1. c.= Chloris petraea?

nitidum, Spreng. Syst. i. $290=$ Chrysopogon fuscus. parviflorum, Spreng. 1. c. = Chrysopogon violascens.

pedunculosum, Desv. Opusc. 70.-Ind. occ

portoricense, Spreng. 1. c. = Imperata exaltata.

refractum, Beauv. Agrost. $150=$ Androp. refractus.

scoparium, Desv. Opuse. 70,-Afric.

setifolium, Spreng. Syst. i. $290=$ Androp. setifolium

spathiflorum, Griseb. Cat. Pl. Cub. $236=$ Androp. spathiflorus.

squarrosum, Beauv. Agrost. 128, $150=$ Panicum abor tivum.

tripsacoides, Spreng. Syst. i. $290=$ Elionurus tripsa coides.

virgatum, Desv. Opusc. $71=$ Androp. spathiflorus

virginicum, Spreng. Pugill. ii. $16=$ Androp. virginicus

ANATROPA, Ehrenb, in Linnaea, iv. (1829) $402=$ Tetradiclis, Stev. (Rutac.)

tenella, Ehrenb. 1. c. $404=$ T. salsa

ANAUA, Miq. FI. Ind. Bat. Suppl. $410(1860)=$ Hemicyclia, Wight \& Am. (Euphorb.).

sumatrana, Miq. $\mathrm{l} . \mathrm{c}_{\mathrm{n}}=\mathrm{H}$. sumatrana.

ANAUXANOPETALUM, Teijsm. \& Binn, in Journ. Bot. Néerl. i. (1861) $368=$ Swintonia, Griff. (Anacard.)

Schwenkii, Teijsm, \& Binn. 1. c. $\approx$ S. Schwenkii.
ANAVINGA, Adans. Fam. ii. 448 (1763) ; Lam. Illustr. t. 355 = Casearia, Jacq. (Samyd.)

comocladifolia, Rafin. Sylva Tellur. $149=\mathrm{C}$. comocladifolia.

fuliginosa, Blanco, F1. Filip. ed. I. $372=$ C. fuliginosa. ilicifolia, Rafin. Sylva Tellur. $149=$ C. ilicifolia. lanceolata, Lam. Encyc. i. $148=\mathrm{C}$. tomentosa? ovata, Lam. 1. c. = C. ovata

parvifolia, Lam. Tab1. ii. $484=$ C. parvifolia.

Samyda, Gaertn. f. Fruct. iii. 240. t. $224=$ C. Samyda.

ANAXAGORAEA, Mart. Fl. Bras, xiii. I. $39(1841)=$ seq.

ANAXAGOREA, St. Hil. in Bull. Soc. Philom. (1825) 91, ANONACEAE, Benth. \& Hook. f. i. 25. Rhopalocarpus, Teijsm. \& Binn. ex Miq. Ann. Mus. Bot. Lugd. Bat. ii. 22 (1865).

acuminata, St. Hil. l. c.-Bras.

brevipes, Benth. in Hook. Kew Fourn. v. (1853) 8.Bras.

crassipetala, Hemsl. Diagn. Pl. Nov. 2.-Nicaragua fruticosa, Scheff. in Flora, lii. (1869) 302.-Malaya? javanica, Blume, Fl. Fav. Anon. 66.-Java.

luzonensis, A. Gray, Bot. U. St. Expl. Exped. i. 27.Ind. or. ; Ins. Philipp.

Meyeriana, Zoll. in Linnaea, xxix. (1857-58) 323.Java.

phaeocarpa, Mart. Fl. Bras. xiii. 1. 40.-Bras. prinoides, St. Hil. É A. DC. in Mém. Soc. Phys, Genèv. v. (1832) 211.-Bras.

sumatrana, Miq. Fl. Ind. Bat. Suppl. i. 382,-Sumatra zeylanica, Hook. f. \& Thoms. FI. Ind. i. 144=luzonensis.

ANAXFTON, Gaertn. Fruct. ii. 406 (1791) ; Càss. in Dict. Sc. Nat. xxvi. (1823) 52; xxxiv, 37 (1825). COMPOSITAE, Benth. \& Hook. f. ii. 314.

ARgYranthus, Neck. Elem. i. 75 (1790). arborescens, Less. Syn. Comp. $354=$ arboreum. arboreum, Gaertn. Fruct. ii. 407.-Afr. austr. asperum, DC. Prod. vi, 268.-Afr. austr.

crispum, Gaertn. Fruct. ii. $407=$ Helichrysum crispum. floridum, Lam. Tabl. iii. $269=$ arboreum

foetidum, Gaertn. Fruct. ii. 406. t. $\mathbf{1 6 6}=$ Helichrysum foetidum.

hirsutum, Less. Syn. Comp. 356.-Afr. austr.

nudifolium, Gaertn. Fruct. ii. $407=$ Helichrysum nudifolium.

nycthemerum, Less. Syn. Comp. 355.-Afr, austr

recurvum, $D C$. Prod. vi. 368 . - Afr, austr.

septentrionalis, Vatke, in Oestr. Bot. Zeitschr. xxvii. (1877) $194=$ Gnaphalium stenophyllum.

virgatum, $D C$. Prod. vi. 268.-Afr, austr.

ANAXETON, Schrank, in Denkschr. Acad. Muench. viii. (1824) 146 et $162=$ Helipterum, DC. (Compos.). eximium, Schrank, l. c, =Helipterum eximium.

racemosum, Schrank, 1. c. = Helichrysum mucronatum.

ANBLATUM, Tourn. ex Adans. Fam. ii. $207(\mathbf{1 7 6 3})=$ Lathraea, Linn. (Orobanch.).

tartaricum, Fisch. Hort. Gorenk. ed. II. 19= Phelipaea salsa.

Tournefortii, G. Don, Gen. Syst. iv. $635=$ Lathraea Squamaria.

ANCANA, F. Muell. Fragm. v. 27. t. $35(1865)=$ Unona, Linn. f. (Anonac.)

stenopetala, F. Muell. 1. c. =U. Ancana.

ANCANTHIA, Steud. Nom. ed. II. i. 85 (1840) err. typ. $=$ seq.

ANCATHIA, DC. in Guill. Arch. Bot. ii. (1833) $331=$ Cnicus, Tourn. (Compos.)

igniaria, DC. in Deless. Ic. Sel. iv. t. $73=$ C. igniarius.

ANCHIETEA, A. St. Hil. in Ann. Sc. Nat. Sér. I ii. (1824) 252; in Mém. Mus. Par. xi. (1824) 464 ; P1. Us. t. 19 (1824); PI. Rem. Bras. 290 (1824). VIOLARIEAE, Benth. \& Hook. f. i. 117.

exaltata, Eichl. in Mart. Fl. Bras. xiii. I. 355.Bras.

pyrifolia, G. Don, Gen. Syst. i. $340=$ salutaris.

pyrifolia, A. St. Hil. Pl. Rem. Bras. 290.-Bras.

Roquefeilliana, Spreng. Syst. iv. Cur. Post. $98=$ salutaris.

\section{ANCHIETEA :-}

salutaris, A. St. Hil. in Ann. Sc. Nat. Sér. I ii (1824) 252.--Bras

Selloviana, Cham. \& Schlecht. in Linnaea, ii. (1827) 148.-Bras.

ANCHIONIUM, Reichb, Consp. 181. err. typ. Anchonium, DC

ANCHOMANES, Schott, in Oestr. Bot. Wochenbl. iii. (1853) 314. AROIDEAE, Benth. \& Hook. fo iii. 973.

difformis, Engl. in DC. Monog. Phan. ii. $304=$ Hookeri

dubius, Schott, Prod. Aroid. 135.-Afr, occ.

Hookeri, Schott, in Oestr. Bot. Wochenbl. iii. (1853 314.-Afr. trop.

ANCHONIUM, DC, in Mém. Mus. Par. vii. (1821) 242. CRUCIFERAE, Benth. \& Hook. fi i. 101

Billardierii, $D C$. l. C.--Syria

elichrysifolium, Boiss. F1. Orient. i. $240=$ Tourne fortii.

Tournefortii, Boiss. in Ann. Sc. Nat. Sér. II. xvii. (1842) 386.-Oriens.

ANCHUSA, Linn. Syst. ed. I. (1735). BORAGINEAE, Benth. \& Hook. f. ii. 855

BrunNera, Stev。 in Bull. Soc. Nat. Mosc. (1851) I 582.

Buglossoides, Tausch, ex Reichb. Fl. Germ. Excurs. 344 (1831)

Buglossum, Gaertn. Fruct. i, 322. t. 67 (1788).

Caryolopha, Fisch. \& Trautv. Ind. Sem. Hort. Petrop. iii. 31 (1837)

PentaglotTis, Tausch, in Flora, xii. (1829) 643.

Stomotechium, Lehm. Asperif. 395 (1818).

Adami, [Pieri] in Ionios Anthol. v. $182=$ semper virens.

aegyptiaca, DC. Prod, x. $48=$ flava

aegyptiaca, Maly, ex Nym. Consp. iii. $511=$ Lycopsis variegata.

affinis, R. Br. in Salt, Voy. Abyss. App. 62.--Abyss.

africana, Burm.f. Prod. Fl. Cap. 4.-Afr. austr.

Agardhii, Lehm. Asperif. 241.--Sibir.

aggregata, Lehm.l. c. 219.t. 47.-Sicil,; Oriens.

alpestris, Stev. in Trans. Linn. Soc. xi. (1815) 409. t. 32 $=$ Nonea alpestris.

altissima, Desf. Cat. Hort. Par. ed. III. 397.--Hab.?

amoena, J. F. Gmel. Syst. ii. $318=$ italica.

amplexicaulis, Sibth. \& Sm. Prod. Fl. Graec. i, $116=$ hybrida.

angustifolia, Balb. Misc. Alt, $9=$ undulata.

angustifolia, DC. Fl. Fr. ed. III. iii. $632=$ officinalis.

angustifolia, Georgi, It. i. 200 (= Stenosolenium saxatile).

angustifolia, Linn. Sp. Pl. 133.-Europ. austr.

angustifolia, Willd. Enum. Hort. Berol. i. $178=$ ochrolenca.

angustissima, Bourg. ex Nym. Consp. $510=$ undulata. angustissima, C. Koch, in Linnaea, xxii. (1849) $633=$ ochroleuca.

annua, Pall. Ind. Taur, ex A. DC. in DC. Prod. x. 48 $=$ stylosa.

arvalis, Reichb. Fl. Germ. Excurs, $343=$ officinalis.

arvensis, Bieb. F1. Taur. Cauc. i. $123=$ Lycopsis arvensis.

arvensis, Tausch, in Flora, vii. (1824) $233=$ officinalis aspera, Boiss. in Ann. Sc. Nat. Sér. IV. ii. (1854) 243 $=$ ochroleuca.

asperrima, Delile, Fl. Aeg. Illustr. $55 \approx$ Arnebia hispidissima.

atlantica, Ball, in Fourn. Bot. xi. (1873) 373.Maroeco.

Aucheri, A. DC. in DC. Prod. x. 49.-As, Min. azurea, Mill. Gard. Dict. ed. VIII. n. $9=$ italica, azurea, Schur, Enum, Pl. Transs. $466=$ ochroleuca Barrelieri, Vitm. Summa Pl. i. 388.-Europ.; As Min.

Baumgarteni, Nym. Consp. iii. $510=$ officinalis. biceps, Vest, in Flora, iv. (1821) 148.-Ital.

bracteolata, Viv. F1. Lib. Spec. 10. t. $4=$ Alkanna tinctoria.

bulbosa, [Pieri] in Ionios Anthol. v. 182.-Corcyra. calcarea, Boiss. Voy. Espagne, ii. 431. t. I23.Hispan.

canescens, Muhl. Cat. 19=Lithospermum canescens.

canescens, Stev. ex Ledeb. Fl. Ross, iii. $118=0$ chro leuca. 


\section{ANCHUSA :}

Capellii, Moris, Stirp. Sard. Elench. ii, $6=$ hybrida. capensis, Thunb. Prod. Pl. Cap. 34.-Afr. austr. Cesatiana, Fenzl, in Frieder. Reise in N. Griech. $282=$ Pulmonaria mollis.

cespitosa, Lam, Encyc, i. 504,-Creta

ciliata, Cham. in Linnaea, iv. (1829) 440.-Bras.

ciliata, Schlecht. ex Ledeb. Fl. Ross, iii. $118=$ ochroleuca.

clavata, Viv. ex DC. Prod. x. $52=$ undulata.

coronensis, Schur, Enum. Pl. Transs, $466=$ Barrelieri. cretica, Mill. Gard. Dict. ed. VIII. n. $7=$ Lycopsi variegata.

crispa, Moris, Stirp. Sard. Elench. iii. 9.-Sardinia. crispa, Viviani, Fl. Cors. App. $1=$ hybrida.

crispata, Presl, Fl. Sic. i. p. xxxiii =hybrida.

cruciata, Cham. in Linnaea, iv. (1829) $438=$ Antiphytum cruciatum.

dasyantha, Cham.l.c. 437.-Bras

deflexa, Lebm. Ind. Sem. Hort: Hamb. (1823) $17=$ hispida.

divaricata, Murr. in Nov. Comm. Gotting. (1776) $25=$ Nonea lutea.

Dregei, A. DC. in DC. Prod. x. 44.-Afr. austr. dubia, Nocca, Hort. Ticin. t. $3=$ Nonea lutea. echinata, Lam. Encyc. i. $505=$ strigosa.

echioides, Bieb. F1. Taur. Cauc. i. $123=$ Macrotomia echioides.

exasperata, Clark, Trav. ed. III. i. $625=$ ochroleuca. flava, Forsk. Fl. Aegypt. Arab. $40=$ aegyptiaca. foliosa, Lehm. ex DC. Prod. x. 53= Myosotis foliosa. Gmelini, Ledeb. ex Spreng. Syst. i. $562=$ ochroleuca. granatensis, Boiss. Voy. Espagne, ii. 430.-Hispan.

granatensis, Lange, Pugill. $191=$ hybrida.

hirta, Michx. ex DC. Prod. x. 53=Lithospermum hirtum.

hispida, Forsk. Fl. Alogyt. Arab. 40.-Oriens; Turkest. ; Ind. bor

hispida, Pall. ex Ledeb. F1. Ross. iii. $120=$ stylosa.

hispidissima, Sieber, ex DC. Prod. x. 94=Arnebia hispidissima.

hyalotricha, Boiss. Pl. Or. Nov, Dec. ii. $9=$ Aucheri.

hybrida, Boiss. ex DC. Prod. x, $42=$ granatensis.

hybrida, Tenore, Fl. Nap. i. 65. t. 11.-Ital.; Oriens.

incana, Ledeb. Fl. Ross. iii. $117=$ ochroleuca.

incarnata, Schrad. ex Steud. Nom. ed. I. $42=$ officinalis.

intermedia, Schur, Enum, PI. Transs, $466=$ ochroleuca italica, Rets. Obs. i. 12.-Reg. Mediterr.

Kunthii, Walp, in Nov. Act. Nat. Cur. xix. Suppl. i. (1843) $372=$ Antiphytum Walpersi.

lanata, Linn. Syst. ed, X, $914=$ Cynoglossum cheirifolium.

lanceolata, Willd. ex Steud. Nom, ed. II. i. $85=$ Krynitzkia linifolia.

lateriflora, Dum. Fl. Belg. Prod. 41.-Belgia.

latifolia, Lebm. Sem. Hort. Hamb. (1821) $2=$ Nonea rosea.

laxiflora, DC. Fl. Fr. iii. $681=$ Borago laxifora

leiosperma, Bory, Fl. Pélop. t. 7.f. $3=$ Nonea obtusifolia.

leptophylla, Koch, Syn. Fl. Germ. ed. II. ii. $573=$ officinalis

leptophylla, Roem. \& Schult. Syst. iv, $90=$ ochroleuca, leucantha, Willd, ex DC. Prod. x. $122=$ Antiphytum linifolium.

leucojifolia, Lebm. Asperif. $249=$ Echinospermum barbatum.

licopsipula, Tardent, Ess. Hist. Nat. Bessar. $57=$ Nonea pulla.

limbata, Boiss. Diagn. Ser. I. xi. 99-As. Min.

linearifolia, Hochst. in Lorent, Wanderungen, $884=$ ochroleuca.

linearifolia, Urville, in Mém. Soc. Linn. Par. i. (1822) $276=$ ochroleuca.

linifolia, Lehm. Asperif. $215=$ Krynitzkia linifolia.

littorea, Moris, in Atti Ottava Riun. Ital. Sciensi, 566. - Sardin.

longifolia, Lam. Encyc. i. 504.-Italia.

Lorenti, A. DC. in DC. Prod. $x, 52=$ ochroleuca.

lucida, Vittm. Summa Pl. i. $387=$ italica.

Luscbani, Wettstein, ex Stapf, in Denkschr. Acad. Wien, 1. (1885) 86.-Lycia.

lutea, Bieb. Fl. Taur. Cauc. i. $126=$ Nonea lntea.

lutea, Cav. Ic. i. $50=$ Myosotis versicolor

Lycopsidis, Bess. ex Link, Lnum. Hort. Berol. i. $166=$ officinalis.

\section{ANCHUSA}

Lycopsidis, Ret\%. f. Pugill. $8=$ Nonea lutea

macrocarpa, Boiss. E Hohen. Diagn. Ser. I. iv, 42.Kurdist

macrophylla, Desf. Fl. Atlant i. 157-Marocco

maculata, Hornem. ex Steud. Nom ed. II i. $85=$ officinalis.

micrantha, Roem. \& Schult. Syst. iv. $98=$ aggregata.

microcalyx, Vis. in Flora, xii. (1829) 8.-Dalmat.

Milleri, Willd. Enum. Hort. Berol. i. 179.-Aegypt.; Arab.

moltkioides, Benth. in Royle, Illustr. PI. Himal, t. 73. f. 1 = Mertensia moltkioides

myosotidiflora, Lehm. Asperif. 234.--Sibir. ; Caucas.

neglecta, $A . D C$. in DC. Prod. x. 49.-Oriens.

nigricans, Brot. Fl. Lnsit. i. $298=$ Nonea nigricans.

nonneoides, Fisch. \& Mey. in Ann. Sc. Nat. Sér. IV. 1854) $35=$ undulata.

obliqua, Vis. Ind. Sem. Hort. Patav. (1836).-As. Min.

ochroleuca, Baumg. Fl. Transs. i. $120=$ officinalis ochroleuca, Bieb. Fl. Taur. Cauc. i. 125.-Transsyly. Oriens.

officinalis, Bieb. 1. c. 124=ochroleuca

officinalis, Gouan, Hort. Monsp. 81; Lam. Encyc. $502=$ italica.

officinalis, Linn. Sp. Pl. 133.-Europ.

officinalis, Thunb. Prod. 34; Fl. Cap. ed. Schult. 162 Eriparia.

oppositifolia, H. B. \& K. Nov, Gen. et Sp. iii. $91=$

Krynitzkia linifolia.

orientalis, Linn. Sp. P1. $133=$ Alkanna orientalis.

orientalis, Reichb. f. Ic. F1. Germ. xviii. 63 t. $1310=$

Lycopsis orientalis.

orientalis, Pall. Reise, iii. $694=$ Nonea lutea

ovata, Lehm. Asperif. $222=$ Lycopsis orientalis.

paniculata, Ait. Hort. Kew. i. $177=$ italica.

parnassica, Boiss. \& Orph. Diagn. Ser. II. iii. $134=$ officinalis.

parviflora, Sibth. \& Sm. Fl. Graec. ii. 57. t. $167=$ aggregata.

parviflora, Willd. Sp. P1. i. 759. (Sp. delenda ; cf. Boiss F1. Or. iii. 162). As. Min.

pauciflora, Roem. \& Schult. Syst. iv. $774=$ Eritrichium rupestre.

perlata, Lam. Encyc. i. 504 ; Illustr. n. $1820=$ Lycopsis variegata.

petiolata, Hook. Bot. Mag. t. $3858=$ Cynoglossum petiolatum.

picta, Bieb. Fl. Taur. Cauc, i, $127=$ Nonea picta

Pinardi, Boiss. Pl. Or. Nov. Dec. ii. $8=$ hybrida

procera, Bess. ex Link, Enum. Hort. Berol. i. $166=$ ochroleuca.

pubescens, Kit. in Rochel, Pl. Bann. 11,-Bannat.

pulla, Bieb. Fi. Taur. Canc. i. $125=$ Nonea pulla.

pustulata, Schur, Enum. Pl. Transs. 465.-Trunssylv.

pygmaea, H. B. \& K. Nov. Gen, et Sp. iii. $92=$

Krynitzkia linifolia.

racemosa, DC. Prod. x. $50=$ Mertensia racemosa

rhizochroa, Viv, Dec, n, $20=$ Alkanna tinctoria.

riparia, DC. Prod. x. 43.-Afr. austr.

rosea, Bieb. FI. Taur. Cauc. i. $125=$ Nonea rosea

rupestris, Roem. \& Schult. Syst. iv. $101=$ Eritrichium rupestre.

ryssosperma, Steud. ex A. Rich. Tent. Fl. Abyss. ii. 88 = Milleri.

sabulosa, Stev. ex Ledeb. F1. Ross. iii. $118=$ ochroleuca.

saxatilis, Pall. Reise, iii. 718 (=Stenoselenium saxa tile).

Sellowiana, Cham, in Linnaea, viii. (1833) 115.Bras.

sempervirens, Linn. Sp.Pl. 184.-Europ

sericea, Roem. \& Schult. Syst. iv. $77 \pm=$ Eritrichium sericeum.

sikkimensis, C. B. Clarke, in Hook. f. Fl. Brit. Ind. iv. 168.- Reg. Himal.

spathulata, R. Br. ex Roem. \& Schult. Syst. iv. $100=$ Myosotis spathulata.

spicata, Lam. 1llustr. n, $1810=$ angustifolia.

spinocarpos, Forsk. Fl. Acgypt. Arab. $40=$ Echino. spermum spinocarpum.

Spruneri, Boiss. Diagn. Ser. I. xi. $98=$ stylosa.

stoechadifolia, Cham, in Linnaca, iv, (1629) $439=$

Antiphytam stoechadifolium.

stricta, Herbich, in Flora, xxxviii. (1\$55) 641,-Europ.

strigosa, Labill. Syr. Dec. iii. 7. 1. 4.-Syria; Persia.

\section{ANCHUSA :}

trigosa, [Soland. in] Russ. Aleppo, ed. II. ii. 246.-

stylosa, Bieb. Fl. Taur. Cauc. i. 123.-Graecia; As.

Min.; Tauria

subrepanda, Kit. in Linnaea, xxxii. (1863 437.Europ.

tenella, Hornem. Hort. Hafn。i. $176=$ Bothriospermum tenellum.

tenuiflora, Fisch, ex Ledeb, Fl, Ross, iii. $142=$ Eritrichium saxatile.

tetraquetra, Cham. in Linnaea, viii. (1833) $113=$ Antiphytum tetraquetrum.

thessala, Boiss. E Sprun. Diagn. Ser. I. xi. 99.Thessal.

tinctoria, Linn. Sp. Pl. ed. II. i. 192=Alkanna tinctoria.

tinctoria, Pall. Ind. Taur. ex Lehm. Asperif. $266=$ Nonea pulla.

tinctoria, Sieber, ex Steud Nom. ed. II. i. $86=$ Lycopsis orientalis.

tinctoria, Woodv, Med. Bot, t. $92=$ officinalis.

tomentosa, Boiss. Diagn. Ser. II. ii, $133=$ ochrolenca.

tuberculata, Forsk. Fl. Aegypt. Arab. $40=$ Alkanna tinctoria.

tuberosa, H. B. \& K. Nov. Gen. et Sp. zii. 92.-Amer. austr.

undulata, Linn. Sp. Pl. 133--Reg. Mediterr.

undulata, Pall. Reise, iii. $682=$ ochroleuca.

undulata, Sibth. \& Sm. F1. Graec. ii. t. $165=$ hybrida.

undulata, Vahl, ex DC. Prod. X. 42 = granatensis.

variegata, Lehm. Asperif. $223=\mathrm{Lycopsis} \mathrm{variegata.}$

ventricosa, Sibth. \& Sm. F1. Graec, ii. 58, t. $169=$

Nonea alba.

ventricosa, Viv. F1. Lib. Spec. 10, t. 6. f, $1=$ Nonea Vivianii.

verrucosa, Lam. Encyc. i. 504 ; Illustr. 403. ᄁ. 1819= aegyptiaca.

verrucosa, Lejeun. ex Reichb. F1. Germ. Excurs. $312=$ Lycopsis variegata.

versicolor, Schur, Enum. Pl. Transs. $466=$ ochroleuca.

versicolor, Stev. in Mém. Soc. Nat. Mosc. iii. (1812) $254=$ Nonea rosea.

villosa, Roem. \& Schult. Syst. iv. $775=$ Eritrichium villosum.

villosa, Spreng. Syst. i. 560,-Hab.

virginiana, Linn. Sp. Pl. 133 (= Lithospermum hirtum?).-Am. bor.

virginica, Lind. Syst. ed. XII. $145=$ praec.

vulgaris, Dum. Fl. Belg. $41=$ sempervirens.

seylanica, Jacq. f. Eclog. i. 47. t. $29=$ Bothriospermum tenellum.

seylanica, Vahl, ex Hornem. Hort. Hafn. i. $176^{\circ}=$ Cynoglossum denticulatum.

ANCHUSOPSIS, Bisch. Del. Sem. Hort. Heidelb. (1852) 8= Lindelofia, Lehm. (Borag.)

longifora, Bisch. 1. $\mathrm{c}_{\mathrm{r}}=\mathrm{L}$. spectabilis.

ANCISTROCARPHUS, A. Gray, in Proc, Am. Acar. vii. (1868) $355=$ Micropus, Linn. (Compos.) filagineus, A. Gray, 1. c. 356.-Calif.

ANCISTROCARPUS, H. B. \& K. Nov, Gen. et. Sp. i. 186. t. 122. $(1817)=$ Microtea, Sw. (Phytolacc) hexander, J. Gay, ex Moq. in DC. Prod. xiii. 17. 17, 18 $=$ M. maypurensis.

maypurensis, H. B. \& K. Nov, Gen. et Sp. ii. $186=$ M. maypurensis.

maypurensis, Spreng. Neue Entdeck. i. 257= M. Sprengelii.

Schrankis, Ledeb. Ind. Sem. Hort. Dorp. $(152 ?)=M$ maypurensis.

ANCISTROCARPUS, Oliver, in Joum. Linn. So\% ix. (1867) 173. TILIACEAE, Benth. A Ilook. fo . $48 b^{\circ}$

brevispinosus, Oliver, l. c. 174.-Afr. trop.

densispinosus, Olizer, 1. c.-Afr. trop.

ANCISTROCARYA, Maxim. in Bull. Acad. Petersh xvii. $(15 ; 2)$ 443. BOR.tG/.1.E.tE, Bench. S llonk: f. ii. $\$ 61$.

japonien, Marim. l. c. ttt,-Japon.

ANCISTROCLADUS, Wall. Cat, ฉ. 1052 18:32 DIPTEROC AR'PEAE. Benrh. \& Hook. f. i. $1: 1$. BIGAMEA Koenig, ex Endl. Cien. 11s's 1sto. 


\section{ANCISTROCLADUS:-}

Wormra, Vahl, in Skrift. Nat. Selsk. Kjobenh. vi. (1810) 104.

attenuatus, Dyer, in Hook. f. Fl. Brit. Ind. i. 300.Burma.

Burma.
extensus, Wall. Cat. n. 1052,-Burma.

extensus, Wall. Cat. n. 1052.-Burma.
Griffithii, Planch. in Ann. Sc. Nat. Sér. III. xuii. (1849) 318.-Burma.

guineensis, Oliver, Fl. Trop. Afr. i. 175.-Afr. trop.

Heyneanus, Wall, Cat. n. 7262,-Ind, or.

pinangianus, Wall.l.c.n. 1054.-Malaya.

sagittatus, Wall. 1, c. n. $1055=$ Tetramerista glabra,

stelligerus, Wall. 1. c. n. $1053=$ Wallichii.

Vahlii, Arn. in Nov. Act. Nat. Cur. xviii. (1836) 325. - Zeylan.

Wallichii, Planch. in Ann. Sc. Nat. Sér, III. xiii.

(1849) 319.-Ind. or.

ANCISTRODESMUS, Naud, in Ann. Sc. Nat. Sér. III. xiii. (1850) $302=$ Microlepis, Miq. (Melast.).

oleaefolius, Naud. 1. c. $303=$ M. oleaefolia.

ANCISTROLOBUS, Spach, in Ann. Sc. Nat. Sér. II. v، (1836) 352, t. $6=$ Cratoxylon, Blume (Hyper.).

brevipes, Turcz. in Bull. Soc. Nat. Mosc. xxxi. (1858) I. $383=$ C. polyanthum.

floribundus, Turcz. 1. c. $382=$ C. floribundum.

formosus, Zoll. \& Mor. Syst. Verz. Zoll. $25=\mathrm{C}$. formosum.

glaucescens, Turcz. in Bull. Soc. Nat. Mosc. xxxi. (1858) I. $383=\mathrm{C}$, arborescens.

ligustrinus, Spach, in Ann. Sc. Nat. Sér. II. v. (1836) $352=\mathrm{C}$. polyanthum

micradenius, Turcz. in Bull. Soc. Nat. Mosc. xxxi. (1858) I. $382=$ C. Blancoi.

ANCISTROPHORA, A. Gray, in Mem. Am. Acad. Ser. II. vi. (1859) $457=$ Verbesina, Linn. (Compos.). Wrightii, A. Gray, 1. c. $=$ V. Wrightii.

ANCISTROPHYLLUM, G. Mann \& H. Wendl. in Kerch. Palm. 230 (1878). PALMAE, Benth. \& Hook. f, iii. 937 .

LAccosperma, G. Mann \& H.Wendl. 1. c. 249 (1878)

secundiflorum, G. Mann \& H. Wendl. l. c.-Afr. trop.

ANCISTROSTIGMA, Fenzl, in Ann. Wien. Mus. ii. (1838) 293 ; Nov. Stirp. Dec. $85(1838)=$ Trian thema, Linn. (Ficoid.)

cypseleoides, Fenzl, 1. c. $=$ T. cypseleoides.

ANCISTRUM, Forst. Char. Gen. 3. t. $2(\mathbf{1 7 7 6})=$ Acaena, Linn. (Rosac.)

Acaena, Lag. Gen. et Sp. Nov. $7=$ Acaena sericea. acorna, DC. Prod. ii. 592, sphalm. = praec.

adscendens, Poir. Encyc. Suppl. 1. $347=$ Acaena adscendens.

anserinaefolium, Forst. Char. Gen. 4=Acaena San guisorbae.

argenteum, Poir. Encyc. Stppl. i. $346^{\circ}=$ Acaena argentea.

barbatum, Lam. Illustr. i. 77.t. 22. f. 3=Margyricarpus setosus.

cylindristachyum, Poir. Encyc. Suppl, i. $347=$ Acaena cylindristachya.

decumbens, Gaertn. Fruct. i. 163. t. $32=$ Acaena Sanguisorbae.

decumbers, Thunb. Prod. Pl. Cap. $6=$ Acaena latebrosa.

diandrum, Forst. f. Prod. $10=$ Acaena Sanguisorbae.

elongatum, Poir. Encyc. Suppl. i. $345=$ Acaena elongata.

humile, Pers. Syn. i. $30=$ Acaena adscendens

laevigatum, Lag. Gen. et Sp. Nov. $7=$ Acaena laevigata. lappaceum, Poir. Encyc. Suppl. i. $344=$ Acaena lappacea.

latebrosum, Ait. Hort. Kew. i. 16=Acaena latebrosa.

lucidum, Ait. 1. e. $15=$ Acaena lucida.

magellanicum, Lam. Illustr. i. 76. t. 22. f. $2=$ Acaena adscendens, laevigata.

ovalifolium, Sweet, Hort. Brit. ed. I. 148=Acaena ovalifolia.

pinnatifidum, Poir. Encyc. Suppl. i. $345=$ Acaena pinnatifida.

pumilum, Poir. 1. c. $347=$ Acaena pumila.

repens, Vent. Jard. Cels, 6. t. $6=$ Acaena ovalifolia.

Sanguisorbae, Linn. f. Suppl. $89=$ Acaena Sanguisorbae.

\section{ANCISTRUM:-}

sarmentosum, Thou. Fl. Tristan d'Acugna, 44=Acaena Sanguisorbae.

trifium, Poir. Encyc. Suppl. i. 346=Acaena trifida.

ANCLYANTHUS, A. Juss. in Orb. Dict. xi. 254 (1849) = Ancylanthos, Desf.

ANCRUMIA, Harv. ex Baker, in Hook. Ic. PI. 1227 (1877). LILIACEAE, Benth. \& Hook. fo iii. 806.

cuspidata, Harv. ex Baker, l. c.-Chili.

ANCYLANTHOS, Desf. in Mém. Mus. Par。 iv (1818) 5. t. 2. RUBIACEAE, Benth. \& Hook. f. ii. 112.

Bainesii, Hiern, in Oliver, Fl. Trop. Afr. iii. 160.Afr. trop.

cinerascens, Welw. ex Hiern, l. c. 159.-Afr. trop.

cistifolius, Welw. ex Hiern, l. c.-Afr. trop.

fulgidus, Welw. ex Hiern, l. c- -Afr, trop.

Monteiroi, Oliver, in Hook. Ic. Pl. t. 1208.-Afr.

trop.
rubiginosa, Desf. l. c-Angola.

ANCYLOCALYX, Tul, in Ann. Sc. Nat. Sér. II. xx. (1843) 136. t. $2=$ Pterocarpus, Linn. (Legumin.). acuminata, Tul. 1. c. $137=$ P. Ancylocalyx.

ANCYLOCLADUS, Wall. P1. As, Rar. iii. 45 (1832)= Willughbeia, Roxb. (Apocyn.).

ANCYLOGYNE, Nees, in Mart. F1. Bras. ix. 63. t. 7 (1847) = Sanchezia, Ruiz \& Pav. (Acanth.). capitata, Nees, in DC. Prod. xi. 222.-Peruy. longiflora, Hook. f. Bot. Mag. t. 5588.-Ecuador. macrocnemis, Nees, in Mart. FI. Bras, ix. 64.-Am. trop.

munita, Nees, 1, c.-Am. trop.

peruviana, Nees, in DC. Prod, xi. 222.-.Peruv.

ANCYROSSEMON, Poepp. \& Endl. Nov. Gen. et Sp. iii. t. $272(1845)=$ seq.

ANCYRostemma, Poepp. \& Endl. Nov. Gen. et Sp. iii. $65(1845)=$ Sclerothrix, Presl (Loasac.). micranthum, Poepp. \& EndI. 1. c. = S. fasciculata.

ANDA, A. Juss. [in Dict. Sc. Nat. ii. 113 (1816)] ; Euph. Tent. 39. t. $12(\mathbf{1 8 2 4})=$ Joannesia, Vell. (Euphorb.).

brasiliensis, Raddi, in Mem. Mod. xviii. ; Fis. (1820) $404=\mathrm{J}$. Princeps.

Gomesii, A. Juss. Euph. Tent. 39, t. $12=$ J. Princeps.

Fomesii, Mart. in Regensb. Arch. Gew. iv. (1830) 85= praec.

Pisonis, Mart. ex Steud. Nom. ed. II. i. $86=\mathrm{J}$. Princeps.

ANDACA, Rafin. Fl. Tellur. iii. $82(1836)=$ Lotus, Tourn. (Legumin.)

arabica, Rafin. I. c. $=$ L. arabicus.

ANDERSONIA, R. Br. Prod. $553(1810)$. EPACRIDEAE, Benth. \& Hook. f. ii. 617.

ANTHEROCEPHALA, DC. Prod, vii. 755 (1839)

Homalostoma, Stschegl. in Bull. Soc. Nat. Mosc. (1859) I. 22.

Sphincterostoma, Stschegl. 1. c. 21. aristata, Lindl. Swan Riv. App. 25.-Austral. brachyanthera, F. Muell. Fragm. vi, 61.-Austral. brachyota, F. Muell. l. c. iv. $125=$ parvifolia brevifolia, Sond. in Lehm. Pl. Preiss. i. 332.Austral.

coerulea, R. Br. Prod. 554.-Austral.

colossea, F. Muell. Fragm. vi.63.-Austral.

depressa, R. Br. l. c. 553.-Anstral.

depressa, A. Cunn. ex DC. Prod, vii. $767=$ squarrosa.

Fraseri, Sond. in Lehm. Pl. Preiss. i. $331=$ sprenge lioides.

gracilis, DC. Prod. vii. 767.-Austral.

grandiflora, Stschegl. in Bull. Soc. Nat. Mosc. xxxii, (1859) I, 21.-Austral.

heterophylla, Sond. in Lehm. Pl. Preiss. i. 333.Austral.

homatostoma, Benth. Fl. Austral. iv. 253.-Austral. involucrata, Sond. in Lehm. Pl. Preiss. i. 331.Austral.
ANDERSONIA :-

lanuginosa, A. Cunn. ex DC. Prod. vii. $767=$ depressa. latiflora, F. Muell. Fragm. vi. 61.-Austral.

Lehmanniana, Sond. in Lehm. Pl. Preiss. i. $330=$ sprengelioides.

macranthera, F. Muell. Fragm. iv, $124=$ heterophylla.

macronema, F. Muell. 1. c. viii. $51=$ Sprengelia macronema.

micrantha, R. Br. Prod. 553.-Austral.

parvifolia, R.Br. L. C-Austral.

patens, Sond. in Lehm. Pl. Preiss. i. $331=$ sprengelioides.

patricia, F. Muell. Fragm. vi. 79.-Austral.

panciflora, Sond. in Lehm. Pl. Preiss. i. 332.Austral.

prostrata, Sond. 1. c. $333=$ depressa.

pubescens, Sond. 1. c. $331=$ sprengelioides.

setifolia, Benth. Fl. Austral. iv. 252-Austral.

spirophylla, F. Muell. Fragm. vi. $62=$ grandiflora.

sprengelioides, R. Br. Prod. 553.-Austral.

squarrosa, R. Br. Prod, $553=$ depressa.

subsessilis, Panch. ex Brongn. \& Gris, in Bull. Soc. Bot. Fr. xi. (1864) 67,-N. Caled.

subulata, Benth. Fl. Austral. iv. 256.-Austral.

variegata, Sond. in Lehm. Pl. Preiss. i. 334.-Austral.

ANDERSONIA, Buch.-Ham, ex Wall. Cat. sub n. 4014 (1832) = Anogeissus, Wall. (Combret.).

acuminata, Roxb. ex Wight \& Arn. Prod. $316=$ Anog acuminata.

altissima, Roxb. ex Wight \& Arn. 1. c.=Anog. latifolia.

lanceolata, Bucb.-Ham. ex Wall. 1. c.=Anog. acuminata.

ANDERSONIA, Roxb. Hort. Beng. [87] (1814); F1 Ind. ii. $212(1832)=$ Amoora, Roxb. (Meliac) cucullata, Roxb. 11. cc. = Am. cucullata.

Rohituka, Roxb. Il. cc. $87,213=$ Am. Rohituka.

ANDERSONIA, Willd. ex Roem. \& Schult. Syst. v $21(1819)=$ Gaertnera, Lam. (Logan.)

vaginata, Willd. ex Roem. \& Schult. $\mathrm{l}_{\mathrm{r}} \mathrm{c} .=\mathrm{G}$. vaginata.

ANDICUS, Vell. Fl. Flum, $80(1825)=$ Joannesia

Vell. (Euphorb.

pentaphyllus, Vell. 1, c. $=$ J. Princeps.

ANDIRA, Lam. Encyc. i. 171 (1783). LEGUMINOSAE, Benth. \& Hook. f. i. 550 .

LUMBRICIDIA, Vell. F1. Flum. 305 (1825)

Poltolobium, Presl, Bot. Bemerk. 63 (1844).

Vouacapoua, Aubl. PI. Gui. Suppl. 9. 1. 373 (1775)

acuminata, Benth, in Ann. Wien. Mus. ii. (1838) 109 $=$ inermis

Amazonum, Mart. ex Benth. l. c. 107.-Bras.

anthelminthica, Benth. l. c. 108.-Bras.

Araroba, Aguiar, Mem. sobre a Araroba, 31.-Cf Pharm. Fourn. Ser. III. x. (1879-80) 44.-Bras.

Aubletii, Benth. in Ann. Wien. Mus. ii. (1838) 108.Guiana.

bracteosa, Benth. 1. c. $107=$ Amazonum.

cinerascens, Mart. Herb. Fl. Bras. n. $1156=$ Tipuana macrocarpa.

cubensis, Benth. in Fourn. Linn. Soc. iv. (1860) Suppl. 121.-Cuba.

cuiabensis, Benth. in Mart. Fl. Bras. xv. I. 295.-Bras.

excelsa, $H . B$. \& K. Nov. Gen. et Sp. vi. 385.-Mexic, fraxinifolia, Benth. in Ann. Wien. Mus. ii. (1838) 108. -Bras.

frondosa, Mart. in Walp. Rep. i. 803.-Bras.

gabonica, Baill. in Adansonia, vi. (1866) 219 (adnot.) -Afr. trop.

grandiflora, Guill. \& Perr. Tent. F1. Seneg. i. 254= inermis.

Harfieldi, Leschen. in Ann. Mus. Par, xvi. (1810) t. $24=$ seq.

Horsfieldii, Leschen. 1. c. 481 (err. Harsfieldii)= Euchresta Horsfieldii.

humilis, Mart. ex Benth. in Ann. Wien. Mus. ii. (1838) 109.-Bras.

inermis, H. B. \& $K$. Nov. Gen. et Sp. vi. 385.-Ind. occ.; Bras.

laurifolia, Benth. in Ann. Wien. Mus. ii. (1838) 109. -Bras. 


\section{ANDIRA :-}

microcarpa, Griseb. in Mem. Am. Acad. N. S. viii. (1861) 179 -Cuba.

nitida, Mart. ex Benth. in Ann. Wien. Mus. ii. (1838) 109.-Bras.

oblonga, Benth. in Journ. Linn. Soc. iv, Suppl. (1860) $121=$ retusa.

ormosioides, Benth. in Ann. Wien. Mus. ii. (1838) 108 $=$ anthelminthica.

paniculata, Benth. i. c. 109.-Bras

parvifolia, Mart. ex Benth. l. c. 108.-Bras.

panciflora, Benth. l. c. 109 -Bras.

Pisonis, Auct. ex Steud. Nom, ed. II. i. $87=$ A. Aubletii.

Pisonis, Mart. ex Benth. in Ann. Wien. Mus. ii. (1838) 108.-Bras.

racemosa, Lam. Encyc. i. $17=$ excelsa.

retusa, $H . B . \&$ K . Nov. Gen. et $S p$. vi. 385.-Guiana riparia, $H . B . \&$ \& $K . l . c .-N$. Granat.

rosea, Mart. ex Benth. in Ann. Wien. Mus. ii. (1838) 108.-Bras.

sapindoides, Benth. in fourn. Linn. Soc. iv. Suppl. (1860) 123.-Ind. occ.

spinulosa, Mart. ex Benth. in Ann. Wien. Mus. ii. (1838) 108-Bras.

stipulacea, Benth. l. c. 107.-Bras.

vermifuga, Mart. ex Benth. l.c. 108.-Bras.

ANDISCUS, Vell. Fl. Flum. ii, t. $86(1827)=$ Andicus, Vell.

ANDOUINIA, Reichb. Consp. 160 (1828) err. typ.= Audouinia, Brongn. (Bruniac.).

ANDRACHNE, Linn. Syst. ed. I. (1735). EU. PHORBIACEAE, Benth. \& Hook, f, iii. 270.

ARACHNe, Neck. Elem. ii. 348 (1790).

Eraclissa, Forsk. Fl. Aegypt. Arab. 208 (1775).

Lepidanthus, Nutt. in Trans. Am. Phil. Soc. v (1841) 175

LEPTOPUS, Decne. in Jacquem. Voy. Bot. 155. t. 156 (1844).

Miscralanthus, Nutt. in Trans. Am. Phil. Soc. y. (1837) 175

Phyllanthidia, Didrichs. in Vidensk. Meddel Kjoeb. (1857) 150 .

Telephioides, Tourn. ex Moench, Meth. Suppl. 310 (1802).

apetala, Roxb. ex Wall. Cat. n, $7956=$ Bischofia javanica.

arborea, Mill. Gard. Dict. ed. VIII. n. 3.-Campech.

aspera, Spreng. Syst. iii. 884.-Oriens; Afr. trop. Ind. or.

australis, Zoll. \& Mor. in Natur. en Geneesk. Arch Neerl. Indie, ii. (1845) 17.-Java

Cadishaco, Roxb. ex Wall. Cat, n. $7877=$ Cleistanthus collinus.

capensis, Baill. in Adansonia, iii. (1862-63) 163.Afr. austr.

chinensis, Bunge, Enum Pl. Chin. Bor. 59-China,

colchica, Fisch. \& Mey. ex Boiss. Fl. Orient. iv. 1137 Caucas.

cordifolia, Muell. Arg. in DC. Prod. xv. II. 234.--Reg Himal.

Decaisneana, Baill. Etud. Gén. Euphorb. $577=$ cordifolia.

Decrisnci, Benth. Fl. Austral. vi. 88.-Austral.

Doonkyboisca, Heyne, ex Wall. Cat. n. $7879=$ Bridelia retusa.

Dregeana, Baill. Adansonia, iii. (1862-63) 164.-Afr. austr.

elliptica, Roth, Nov. Sp. 364,-Ind, or.

frutescens, Ebret, in Phil. Trans. Ivii. (1768) 114. t. 6 = Arbutus Andrachne.

fruticosa, Decne. ex Muell. Arg. in DC. Prod. Xv. II. $285=$ Decaisnei.

fruticosa, Linn. Sp. Pl. 1014.-China ; N. Hisp. fruticosa, Heyne, ex Hook, f. F1. Brit. Ind. iv. $287=$ Phyllanthus suberosus.

fruticulosa, Boiss. Diagn. Ser. I. vii. 86.-Persia.

maroccana, Ball, in Fourn. Bot. xiii. (1875) 205.Marocco.

microphylla, Baill. Etud. Gin. Euph. 577.-Peruv, orbicularis, Mucll. Arg. in DC. Prod. xv. 11. 510, in syn. $=$ sey.

orbiculata, Roth, Nov, Sp, $364=$ Cleistanthus collinus. ovalis, Muell. Arg. in Linnaea, xxxii. (1868) 78.-Afr austr.

\section{ANDRACHNE :}

vata, Lam. ex Poir. Encyc. Suppl. i. 243, in syn.=

Agyneia ovata.

phyllanthoides, Muell. Arg. in DC. Prod. xv. Ir. 435, in syn, $=$ Roemeriana

Roemeriana, Muell. Arg. l. c. 234.-Amer, bor. rotundifolia, Eichw, ex C. A. Mey. Casp. 18. t. $20=$ telephioides.

telephioides, Linn. Sp. Pl. 1014.-Reg. Mediterr.; Oriens; Ind, or

tenera, Miq. Fl. Ind. Bat. i. II. 365.-Malaya trifoliata, Roxb. Hort. Beng. 70 ; F1. Ind. iii. $728=$ Bischofia javanica.

ANDRADEA, Allemão, Diss. Andrad NYCTAGINEAE, Benth. \& Hook. f. iii. 11 floribunda, Allemão, l. c. -Bras

ANDRASTIS, Rafin. ex Benth, in Ann. Wien. Mus, ii (1838) $86=$ Virgilia, Lam. (Legum.)

ANDREOSKIA, Boiss. Fl. Orient, i. 303 (1867)= Andrzeiowskia, Reichb. (Crucif.)

ANDREOSKIA, DC. Prod. i. $190(1824)=$ Dontostemon, Andrz. (Crucif.)

crassifolia, Bunge, ex Turcz, in Bull. Soc. Nat. Mosc. xv. (1842) 271.-Mongolia.

dentata, Bunge, Enum. Pl Chin Bor $6=$-D. dentatus. eglandulosa, DC. Prod. i. $190=$ D. eglandulosus. integrifolia, DC. 1. c. = D, integrifolius.

parviftora, Turcz. Cat. Pl. Baic. n. 155. sec. Bull. Soc. Nat. Mosc. xv. (1842) $269=$ Malcolmia Ledebourii. pectinata, DC. Prod, i. $190=$ D. pectinatus.

ANDREUSIA, Dun. in DC. Prod. vii. 560 (1839)= Hornemannia, Vahl (Vaccin.) guadalupensis, Dun. 1. c. = H. martinicensis.

ANDREUSTA, Vent. Jard. Malm. 108. t. 108 (1807)= Myoporum, Banks.

debilis, Vent. 1. c. sub t. $108=$ M. debile.

glabra, Vent. 1. c. t. $108=$ M. ellipticum

salicifolia, Hort. ex Steud. Nom. ed. II. i. $87=$ Freylinia cestroides.

scabra, Zeyh. ex Steud. 1. c. = M. parviflorum

ANDREWSIA, Spreng. Anleit. ii. I. 474 (1817); Syst. i. $428(1825)=$ Bartonia, Muhl. (Gentian.). autumnatis, Spreng. Syst. i. $162=\mathrm{B}$. tenella. paniculata, Bart. ex Steud. Nom. ed. II. i. $87=$ B. tenella.

verna, Spreng. Syst. i. $162=$ B. verna.

ANDRIALA, Decne. in Orb. Dict. i. 485 (1841) err. typ. $=$ Andryala, Linn. (Compos.)

ANDRIAPETALUM, Pohl, Pl. Bras. Ic. i. 113 (1827)= Panopsis, Salisb. (Proteac.)

cayennense, Klotzsch, ex Meissn. in Mart. Fl. Bras. v. I. 78.-Bras.

ferrugineum, Meissn, in DC. Prod. xiv. 345.-Peruv. multiflorum, Schott, ex Endl. Suppl. iv. II. 82.-Bras. polystachya, Schott, ex Meissn, in DC. Prod. xiv. 345. -N. Granat.

reticulatum, Pohl, Pl. Bras. i. 115. t. 92,-Bras.

rubescens, Benth. ex Meissn. in DC. Prod, xiv. $347=$ Sprucei.

ruber

sessilifolium, Benth. ex Meissn. in DC. Prod. xiv. 346 = cayennense

sessilifolium, Klotzsch, in Linnaca, xv。(1841) $53=\mathrm{P}$ hamelinefolia.

Sprucei, Meissn, in DC. Prod. xiv, 347.-Bras.

suaveolens, Klotzsch, in Linnaea, xx. (1847) $472,-\mathrm{N}$ Granat.

Yolombo, Posado, in Bull. Soc. Bot. Fr. xviii. (1871) 374.-N. Granat.

ANDRIEUXIA, DC. Prod. v. $559(1836)=$ Heliopsis, Pers. (Compos.)

mexicana, DC i c, et in Deless. Ic. Sel, iv. t. $91=\mathrm{H}$. buphthalmoides.

quitensis, Benth. P1. Hartw. 206.-Ecuador.

ANDROCENTRUM, Lem. in Fl, des Serres, Sér. I. iii. (1847) 242, verso, ACANTHACEAE, Benth. \& Hook, f ii. 10st. multillorum, Lem. 6. c.-Mexico.
ANDROCERA, Nutt, Gen. Am, i. $129(1818)=$ Solanum, Linn.

lobata, Nutt. 1. c。 $=$ S. rostratum.

ANDROCHILUS, Liebm. in Bot. Notiser, (1844) $101=$ Liparis, Rich. (Orchid.)

campestris, Liebm.1. c. 197.-Mexico.

ANDROCOMA, Nees, in Hook. Journ. Bot. ii. (1840) $396=$ Scirpus, Linn. (Cyperac.)

speciosa, Nees, I, c. $397=$ S. giganteus .

ANDROCYMBIUM, Willd, in Ges. Naturf. Fr. Berl, Mag. ii. (1808) 21. 1. 2. LILIACEAE, Benth. \& Hook, f. iii. 822

Cymbanthes, Salisb. in Trans. Hort. Soc. i. (1812) 329.

ERYTHrostictus, Schlecht. in Linnaea, i. (1826) 90. Plexinium, Rafin. Fl. Tellur. ii. 32 (1836)

Burchellii, Baker, in fourn. Bot. xii. (1874) 246.-Afr. austr.

Burkei, Baker, l. c.-Afr. austr

circinatum, Baker, in Fourn. Linn. Soc. xvii. (1880) 443.-Afr. austr.

cucullatum, Eckl. Verz. 7.-Afr. austr.

cuspidatum, Baker, in Fourn. Boto xii. (1874) 245.Afr, austr.

Dregei, Presl, Bot. Bemerk. 116.-Afr. austr

eucomoides, Sweet, Brit. Flow. Gard. t. $165=$ leucan thum.

eucomoides, Willd. in Ges. Naturf. Fr. Berl. Mag. ii. 1808) 21.-Afr. austr.

leucanthum, Willd. l. c.-Afr. austr.

littorale, Eckl. Verz. 7.-Afr. austr.

longipes, Baker, in Fourn. Bot. xii. (1874) 246.-Af. austr.

melanthioides, Willd. in Ges. Naturf. Fr. Berl. Mag. ii. (1808) 21.-Afr. austr.

palaestinum, Baker, in Fourn. Linn. Soc. xvii. (1880) 445.-Palaestin.

punctatum, Baker, in Journ. Bot. xii. (1874) $246=$ leucanthum.

punctatum, Baker, in Fourn. Linn. Soc. xvii. (1880 445. - Afr. bor.

striatum, Hochst. ex A. Rich. Tent. Fl. Abyss. ii. 336. -Abyss.

subulatam, Baker, in Fourn. Bot. xii. (1874) 245. Afr. austr.

volutare, Burch. Trav. i. 213.-Afr. austr.

volutum, Butch. ex Baker, in Journ. Bot. xii. (1874) $245=$ volutare

ANDROGLOSSA, Benth, in Hook. Kew Journ. ix (1852) $42=$ Sabia, Colebr.

reticulatum, Benth. $1 . \mathrm{c}_{0}=\mathrm{S}$. limoniacea.

ANDROGRAPHIS, Wall. P1. As. Rar. iij. 77 (1832) $A C A N T H A C E A E$, Benth. \& Hook. fo ii. 1099

ERIANTHERA, Nees, in Wall. Pl. As. Rar. iii. 77 (1832).

affinis, Nees, l. co iii. 116-Ind or

alata, Nees, in DC. Prod. xi. 516.-Ind, or.

Beddomei, C. B. Clarke, in Hook. f. Fl. Brit, Ind. iv. 506 - - Ind. or.

ceylanica, Nees, in Hook. Comp. Bot. Mag. ii. '1\$36 $313=$ macrobotrys.

ceylanica, Wight, Ic. t. $1560=$ viscosula.

echioides, Nees, in Wall. Pl. As. Rar iii. 117-Ind.or. elongata, T. Anders, in Foumn. Linn. Soc. ix. (180)

$50^{\circ}$, - Ind. or.

glandulosa, Nees, in Wall. Pl. As. Rar. iii. 115.-Ind.

gracilis, Nees, in DC. Prod. xi. $516=$ Wightiana. humifusa, Wall, ex Nees, 1. c. $51 . t=$ sernyllifolia. lineata Nees, in Wall. Pl ds. Rar. iii. 116.-Ind. or. lobelioides, Wight, Ic. t. 155i.-Ind. or. macrobotrys, Nees, in DC. Prod. xi. 510.-Ind. or. Neesiana, Benth. ex C. B. Clarke, in Hook. f. F1. Brit Ind. iv, $504=$ stellulati

Neesiana, Ir iy/t, Ic. t. 1561.-Ind, or.

orbiculata, Wiall. ex Nees, in DC. Prod. xi. $514=$ serpyllifolia.

ovinta, Benth. \& Hook. f. Gen. ii. 1100.-Ind. or.

paniculata, Nees, in Hiall. Pl. As. Rar. iii. 116. -Incl.

Rothii, C. B. Clarke, in Hook. f. F\%. Brit. Inat. iv. $500^{\circ}$ -Ind or.

serpyllitolia, Highs, Jc. t. 51\%,-Iad. or. 


\section{ANDROGRAPHIS :}

stellulata, C. B. Clarke, in Hook. f. Fl. Brit. Ind. iv. 504.-Ind. or.

stenophylla, C. B. Clarke, l. c. 503.-Ind. or. subspathulata, C. B. Clarke, l. c. 502.-Ind. or. tenuiflora, T. Anders, in Fourn. Linn. Soc. ix. (1867) 502.-Ind. or

viscidula, Steud. Nom. ed. II. i. $87=$ viscosula.

viscosula, Nees, in Wall. Pl. As. Rar, iii. 116.-Ind.

Wightiana, Arn. ex Nees, in DC. Prod. xi. 517.-Ind.

Wightiana, T. Anders. in Thw. Enum. P1. Zeyl. 232 $=$ macrobotrys.

ANDROGYNE, Griff. Notul. iii. 279 (1851)= Panisea, Lindl. (Orchid.).

ANDROLEPIS, Brongn. ex Houil. in Rev. Hortic. xlii. (1870) 12 = Aechmea, Ruiz \& Pav. (Bromel.).

Skinneri, Brongn. l. c.-Guatemala.

ANDROMACHIA, Humb. \& Bonpl. Pl. Aequin. ii. 104. t. $112(1809)=$ Liabum, Adans. (Compos.) acaulis, H. B. \& K. Nov, Gen, et Sp, iv, $98=\mathrm{L}$. acaule. alternifolia, Kunze, ex Steud. Nom. ed. II. i. $87=$ Aplopappus chrysanthemifolius.

Deppeana, Less, in Linnaer, vi. (1831) $401=$ L. Deppeanum.

excelsa, Poepp. \& Endl. Nov. Gen. et Sp, iii. 44.Peruv.

grandifiora, H. B. \& K. Nov. Gen. et Sp. iv, $99=$ L. grandiflorum

hieracioides, H. B. \& K. 1. c. $98=$ L. hieracioides.

igniaria, Humb. \& Bonpl. Pl. Eq. ii. 104. t. $112=\mathrm{L}$ igniarium.

Fussieui, Cass. in Bull. Soc. Philom. (1817) $184=\mathbf{L}$ Jussieni.

melastomoides, H. B. \& K. Nov. Gen. et Sp. iv. 101. t $137=\mathrm{L}$. melastomoides.

nubigenum, H, B, \& K. 1, c, $102=\mathrm{L}$. nubigenum.

Poiteaui, Cass. in Bull. Soc. Philom. (1817) $184=\mathrm{L}$ Brownei.

sessilifolia, H. B. \& K. Nov. Gen. et Sp. iv. $102=$ L. sessiliflorum.

solidaginea, H. B. \& K. 1. c. $100=$ L. solidagineum verbascifolia, $\mathrm{H}, \mathrm{B} . \& \mathrm{~K} .1, \mathrm{c},=\mathrm{L}$, verbascifolium

volubitis, H. B. \& K. 1. c. $102=\mathrm{L}$, volubile.

ANDROMEDA, Linn. Syst. ed. I. (1735); Gen. ed. I 123 (1737), pro parte. ERICACEAE, Benth. \& Hook f. ii. 587 .

Xolisma, Rafin. in Am. Monthly Mag. (1819) 193 acuminata, Ait. Hort. Kew, ii. $70=$ Leucothoë acuminata.

acuminata, Sm. Exot. Bot. ii, $59=$ Leucothoë Cates baei

adenothrix, Miq. Ann. Mus. Bot. Lugd. Bat. i. $31=$ Gaultheria adenothrix.

alata, Herb. Dombey, ex Dun. in DC. Prod. vii. 562 (=Proclesia alata .-Peruv.

ambigua, Schrad. in Goett. Gel. Anz. i. (1821) 710.Hab. ?

americana, Hort. ex DC. Prod, vii. $607=$ A. Polifolia, anastomosans, Mutis, ex Linn. f. Suppl. $830=$ Gaultheria anastomosans.

angustifolia, Pursh, F1. Am. Sept. i, $291=$ Cassandra calyculata.

arborea, Linn. Sp. PI. ed. I. $394=$ Oxydendrum arboreum.

axillaris, Lam. Encyc. i. $157=$ Leucothoë axillaris.

axillaris, Michx. Fl. Bor. Am. i. 253=Leucothoe Catesbaei.

baccata, Wangenh. Beitr. Am. 30. t. 39. f. $69=$ Gaylussacia resinosa

bracomorensis, H. B. \& K. Nov. Gen. et Sp. iii, 288. t. $263=$ Agarista bracomorensis

bracteata, Cav. Ic, vi. 42 = Gaultheria bracteata, tomentosa.

bracteosa, DC. Prod. vii. $607=$ Arctostaphylos tomentosa

bryantha, Linn. Mant. $238=$ Bryanthus Gmelini. buxifolia, Lam. Encyc. i. 159=Agauria buxifolia. caerulea, Linn. Sp. Pl. $393=$ Phyllodoce taxifolia. calyculata, Linn. 1. c. $394=$ Cassandra calyculata. campanulata, Miq.Ann. Mus. Bot. Lugd. Bat. i. 31.Japon

canadensis, Cels, ex Lam. Encyc. i. 158=A. Polifolia.

\section{ANDROMEDA}

candida, Vell. Fl. Flum. 175 ; iv. t. $98=$ Gaultheria candida.

capricida, Buch.-Ham. ex D. Don, Prod. F1. Nep. 148

= Pieris ovalifolia.

cassinefolia, Vent. Jard. Cels, $60=$ Zenobia speciosa.

Catesbaei, Walt. Fl. Carol. $13 \bar{\gamma}=$ Leucothoë Catesbaei

cerea, Linn. f. Suppl. 238 = Vaccinium cereum.

cernua, Miq. in Ann. Mus. Bot. Lugd. Bat. i. 31.Japon.

chinensis, Lodd. Bot. Cab. t. $1642=$ Vaccinium bracteatum.

chlorantha, Cham. in Linnaea, viii. (1833) $508=$ Leucothoë chloranthus.

ciliata, Nees, in Princ. Neuwied, Reise, i. 104=Leucothoë ciliata.

cilizcalyx, Miq. in Ann. Mus. Bot. Lugd. Bat, i. $30=$ Menziezia ciliicalyx.

ciliosa, Boj. ex DC. Prod. vii. $603=($ Lencothoë Bojeri $)$. -Madag.

coccinea, Nees, in Princ. Neuwied, Reise, i. $104=$ Leucothoë coccinea.

coccinea, Schrad, in Goett. Gel. Anz. i. (1821) $709=$ Gaylassacia Pseudo-vaccinium.

columellaris, Fisch. ex Herd, in Act. Hort. Petrop. (1871-72) $330=$ Cassiope Redowskyi.

coriacea, Ait. Hort. Kew. ed. I. ii. $70=$ Pieris nitida.

coriifolia, Thunb. \& Billb. Pl. Bras. Dec. 1. n. $5=$ Leucothoë coriifolia.

crassifolia, Pohl, Pl. Bras, ii. $34=$ Leucothoë crassifolia. crispa, Hort. Paris. ex Poir. Encyc. Suppl. i. $356=$ Cassandra calyculata.

cubensis, Griseb. Cat. Pl. Cub. 51.-Cuba.

cupressiformis, Wall. ex D. Don, in Mem. Wern. Soc. iii. (1821) $411=$ Cassiope fastigata.

cupressina, Hook. Fl. Bor. Am. ii. $38=$ Cassiope Mertensiana.

Daboëcia, Linn. Syst. ed. XII. $300=$ Daboëcia polifolia. Daboecia, Pall. F1. Ross. ii. $57=$ Phyllodoce taxifolia. dealbata, Lindl. Bot. Reg. t. $1010=$ Zenobia speciosa droseroides, Linn. Mant. $239=$ Erica glutinosa.

elegans, Meerb. Pl. Sel. Ic. Pict. t. $27=$ Leucothoë racemosa.

elliptica, Sieb. \& Zucc. in Abh. Akad. Muench. iv. III. (1846) $126=$ Pieris ovalifolia

empetrifolia, Lam. Encyc. i. $155=$ Pernettya empetr folia.

ericoides, Pall, F1, Ross, i, II, 56= Cassiope ericoides, eriophylla, Vell in Vandel. FI Lusit. et Bras. Sp. ed. Roem. $107=$ Gaultheria ferruginea

eucalyptoides, Cham. \& Schlecht. in Linnaea, i. (1826) $518=$ Leucothoè encalyptioicles.

fasciculata, Sw. Prod. Veg. Ind. Occ. $73=$ Lyonia fasciculata.

fastigiata, Wall, in As. Res. xiii. (1820) 394=Cassiope fastigiata.

ferruginea, Walt. Fl. Carol. 138=Lyonia ferruginea.

flexuosa, Moon, Cat. ex Walp. Ann. i. 480=Gaultheria

fragrantissima.

floribunda, Pursh, Fl. Am. Sept. i. $293=$ Pieris floribunda.

Fontanesiana, Steud. Nom. ed. II. i. 88=Leucothoë axillaris.

formosa, Wall, in As. Res. xiii. (1820) 395 ; Wall. Cat. n. $761=$ Pieris formosa

formosissima, Bart. Trav. N. \& S. Car. Georg. ii. (1791) $=$ Leucothoë acuminata.

frondosa, Pursh, F1. Am. Sept. i. $295=$ Lyonia paniculata.

glandulosa, Wright, in Sauv. Fl. Cub. 84.-Cuba

glauca, Hort. ex C. Koch, Dendrol. ii. I. $118=$ Zenobia speciosa.

glaucifolia, Wender. Ind. Sem. Hort. Marb. (1827) in App, n, $2=$ A. Polifolia

glaucophylla, Link, Enum. Hort. Berol. i. $394=$ A. Polifolia.

globulifera, Hort, ex DC. Prod. vii. $599=$ Lyonia paniculata.

glomerata, Cav. Ic. vi. $42=$ Gaultheria anastomosans. grandiflora, Hort. ex Steud. Nom. ed. II. i. $88=\mathrm{A}$. Polifolia.

grandiflora, Herb. Mus. Par, ex Dun. in DC. Prod. vii. $553=$ Ceratostemma grandiflorum

grandiflora, Meerb. Pl. Sel. Ic. Pict. t. $25=$ Pieris Mariana.

Hahniana, Meerb. l. c. t. 24.-Hab.?

Halmiana, Steud. Nom. ed. I. 44 ; ed. II. i. 88 , sphalm. =Hahniana.
ANDROMEDA :-

hirsuta, Vell. Fl. Flum. 175; iv. t. $99=$ Gaultheria ferruginea.

hirta, Willd. Enum. Hort. Berol. Suppl. $23=$ Leucothoë hirta.

hispidula, Mart. ex Meissn, in Mart. Fl. Bras. vii. 155 =Leucothoë Martii

humilis, Banks \& Soland. ex Hook. f. F1. Antarct. ii. $326=$ Pernettya pumila

hypnoides, Linn. Sp. Pl. ed. I. $393=$ Cassiope hypnoides.

ilicifolia, Pers. Syn. 1. $481=$ Leucothoë ilicifolia

jamaicensis, Sw. Prod. Veg. Ind. Occ. $73=$ Lyonia jamaicensis.

japonica, Naves, in Blanco, F1. Filip. ed. III. $120=$ Micromelum tephrocarpum.

japonica, Thunb. F1. Jap. $181=$ Pieris japonica.

kalmiaefolia, Hoffmgg. Verz. Pfl. Nachtr. i, 204.Am. bor.

katagherensis, Hook, Ic. PI. t. $246=$ Gaultheria fragrantissima.

lacustris, Wright, in Sauv. Fl. Cub. 85.-Cuba.

lanceolata, Desf. Cat. Hort. Par. ed. III. 136=Leucothoë Catesbaei.

lanceolata, Wall. in As. Res. xiii. (1820) $390=$ Pieris ovalifolia.

lanceolata, Vell. F1. Flum. 175; iv. t. $97=$ Leucothoë multiflora.

latifolia, Wright, in Sauv. Fl. Cub. 85.-Cuba.

laurina, Michx. Fl. Bor. Am. i. $253=$ Leucothoè acuminata.

laxiflora, Mart. ex Meissn. in Mart. F1. Bras, vii. $157=$ Leucothoë laxiflora.

ledifolia, H. B. \&. K. Proleg. p. xvi=Arctostaphylos polifolia.

ligustrina, Muhl. Cat. 44 ; Ell. Sketch, i. $490=$ Lyonia paniculata.

littoralis, Steud. Nom. ed. II. i. $88=$ Leucothoë littoralis.

longifolia, Pursh, Fl. Bor. Sept. i. $293=$ Leucothoẻ Catesbaei.

Iucida, Jacq. Coll. i. $95=$ Leucothoë acuminata.

lucida, Lam. Encyc. i. 157 = Pieris nitida.

lycopodioides, Pall. FI. Ross. i. II. $55=$ Cassiope lycopodioides.

marginata, Duham. Arb. ed. nov. i. 188. t. $40=$ Pieris nitida.

mariana, Jacq. Ic. Rar. iii. t. $465=$ Pieris nitida.

mariana, Linn. Sp. Pl. $393=$ Pieris mariana.

Mertensiana, Bong. Veget. Ins. Sitcha, 152. t. $5=$ Cassiope Mertensiana.

mexicana, Hemsl. in Biol. Centr. Am. Bot. ii. 282.Mexico.

montana, Buckl. in Am. Journ. Sc. xlv. (1843) $172=$ Pieris floribund

montana, Salisb. Prod. $290=$ Daboëcia polifolia

multiflora, Pohl, Pl. Bras. ii. 33. t. $122=$ Lencothoe multiflora.

musciformis, Poir. Encyc. Suppl. i. $353=$ Bryanthus Gmelini.

myrsinites, Lam. Encyc. i. 155.-Reg. Magell.

myrtifolia, Salisb. Prod. $290=$ Pieris nitida.

myrtifolia, Willd. ex DC. Prod. vii. $603=$ Agarista bracamorensis.

nana, Maxim. in Bull. Acad. Pétersb. xviii. (1873) 47 -Japon.

nereifolia, Cham. \& Schlecht, in Linnaea, i. (1826) 522 Leucothoë nereifolia.

nitida, Bartr. ex Marsh. Arbust. (1785) $8=$ Pieris nitida.

nitida, Vell. Fl. Flum. 174; iv. t. 94=Leucothoẻ revoluta.

nummularia, Cham. \& Schlecht. in Linnaea, i. (1826) $520=$ Lencothoë nummularia.

obtusa, Wright, in Sauv. Fl. Cub. 84.-Cuba.

octandra, Sw. Prod. Veg. Ind. Occ. $73=$ Lyonia octandra.

oleaefolia, Hoffmgg. Verz. Pf. Nachtr. i, 204.-Hab. oleifolia, Cham. in Linnaea, viii. (1833) $504=$ Leucothoë oleifolia.

oleifolia, Hort. ex Steud. Nom. ed. II. i. $89=$ A. Polifolia.

ovalifolia, Wall. in As. Res. xiii. (1820) 391 ; Cat. $n$. $763=$ Pieris ovalifolia.

ovata, Soland, ex DC. Prod. vii, 598=Zenobia speciosa.

paniculata, Linn. Sp. Pl. $394=$ Leucothoë racemosa. paniculata, Willd. Sp. Pl. ii. $612=$ Lyonia paniculata 


\section{ANDROMFDA :-}

parabolica, Duham. Arb. ed. II. i. 191=Lyonia parabolica.

perulata, Miq, in Ann. Mus. Bot. Lugd. Bat. i. $31=$ Enkianthus japonicus.

phillyreaefolia, Hook. Ic. PI. t. $122=$ Pieris philly reatfolia.

pilulifera, Hort. ex DC. Prod. vii. II. $599=$ Lyonia paniculata.

Pistrix, Cham. in Linnaea, viii. (1833) $508=$ Leucotho subrotunda.

Polifolia, Linn. Sp. Pl. 393. - Reg. bor. et arct.

polyantha, Steud. Nom. Bot. ed. II. i. $89=$ Lyonia paniculata.

populifolia, Lam. Encyc. i. $159=$ Leucothoë acuminata prostrata, Cav. Ic. vi. 43 = Pernettya microphylla.

pubescens, Poir. Encyc. Suppl. i. $355=$ Lyonia rubiginosa.

pulchella, Cham. ex Meissn. in Mart. Fl. Bras. vii. 161 =Leucothoë pulchra.

pulchella, Cham. in Linnaea, viii. (1833) $509=$

Leucothoë pulchella.

pulchella, Salisb. Prod. $289=$ Pieris mariana.

pulchra, Vell. Fl. Flum. 174; iv. t. $96=$ Gaultheria venusta.

pulchra, Cham. \& Schlecht. in Linnaea, i. (1826) $521=$ Leucothoë pulchra.

pulverulenta, Bartr. Trav. N. \& S. Car. Georg. ii. 476 = Zenobia speciosa.

punctata, Domb. ex Dun. in DC. Prod. vii. $564=$ Thibaudia punctatifolia.

pyrifolia, Thou. Obs. 14; Pers. Syn. i. 481=Agauria salicifolia.

racemosa, Linn. Sp. Pl, $394=$ Leucothoë racemosa.

racemosa, Walt. Fl. Carol. 138=Lyonia paniculata.

recurva, Buckl. in Am. Journ. Sc. xlv. (1843) $172=$ Leucothoë recurva.

Redowskii, Cham. \& Schlecht. in Linnaea, i. (1826) $517=$ Cassiope Redowskii.

reticulata, Walt. Fl. Carol. $137=$ Leucothoë acnminata.

revoluta, Bouton, ex DC. Prod. vii. II. $603=$ Lencothoe Bojeri.

revoluta, Hort. ex Steud. Nom. ed. II. i. $89=$ A.

Polifolia.

revoluta, Spreng. Neue Entdeck, ii. $131=$ Lencothoë revoluta.

rhomboidalis, Veill. in Duham. Arb. ed. II. i. $192=$ Gaultheria ferruginea,

rigida, Humb. Itin. i. $397=$ Gaultheria rigida

rigida, Pursh, Fl. Am. Sept. i. $292=$ Lyonia ferruginea.

rosmarinifolia, Gilib. Fl, Lithuan. i. $3=$ A. Polifolia.

rubiginosa, Pers. Syn. i. $481=$ Lyonia rubiginosa rupestris, Forst. f. Prod. n. $195=$ Gaultheria rupestris, salicifolia, Lam. Encyc. i. 159=Agauria salicilolia. secunda, Moench, Meth, $457=$ A. Polifolia.

Sellowii, Stend, Nom. ed. II. i. $89=$ Leucothoë Sellowii,

serrata, Sm, ex DC. Prod. vii. II. $609=$ Leucothoe acuminata.

serrata, Vell. F1. Flum. 174; iv, t. $95=$ Gaultheria elliptica.

serratifolia, Hort. ex DC. Prod. vii. $602=$ Zenobia speciosa.

serrulata, Cham. in Linnaea, viii. (1833) $506=$ Leucothoë serrulata.

sinensis, Steud. Nom. ed. II. i. $89=$ Vaccinium bracteatum.

speciosa, Michx, Fl, Bor. Am. i, 256=Zenobia speciosa.

speciosa, Willd. ex Steud. Nom. ed. II. i. $89=$ Leucothoë racemosa.

spicate, Wats. Dendrol, i. t. $\$ 6=$ Leucothoë racemosa.

spinulose, Pursh, Fl. Am. Sept, i. $293=$ Lencothoe Catesbaci.

squamulosa, D. Don, Prod. Fl. Nep. $149=$ Pieris ovalifolia.

Stelleriana, Pall. Fl. Ross. i. Ir. $58=$ Cassiope Stchleriana.

subrotunda, Pohl, Pl. Bras. ii. 32. t. $121=$ Lencothoi subrotuncla.

subsessilis, Miq. Ann. Mus. Bot. Lugd. Bat. i. $32 .-$ Japon.

symplocifolia, Wall. Cat, n. $1522=$ Vaccinium Le. schenaultii.

\section{ANDROMEDA :-}

taxifolia, Pall. Fl. Ross. ii. 64. t. 72. f. 2 =Phyllodoce taxifolia.

tetragona, Linn. Sp. PI. $393=$ Cassiope tetragona

tomentosa, Dum.-Cours. Bot. Cult. ed. II. iii. $495=$ Lyonia racemosa.

trinervis, Domb. ex Dun. in DC. Prod. vii. 563 (= Proclesia bracteata).-Peruv.

vaccinifolia, Hort. ex C. Koch, Dendrol. ii. I. $116=$ Pieris floribunda.

venulosa, DC.Prod. vii. $607=$ Arctostaphylos Hookeri. villosa, Wall. Cat. n. $762=$ Pieris villosa.

Walteri, Willd. Enum. Hort. Berol. $453=$ Leucothoẻ Catesbaei.

Watsoniana, Steud. Nom. ed. II. i. $89=$ Lyonia parabolica.

ANDROMYCIA, A. Rich. F1. Cub. Fanerog. ii. 282. t. 89 (1853). AROIDEAE, Benth. \& Hook. f. iii. 987.

cubensis, $A$. Rich $l, c-C$ -

ANDROPHORANTHUS, Karst, in C. Koch \& Fint. Wochenschr. (1859) $5=$ Caperonia, St. Hil. (Euphorb.)

glandulosus, Karst. 1. c. $6=$ C. palustris.

ANDROPHILAX, Steud. Nom. ed. II. i. $89(1840)=$ seq.

ANDROPHYLAX, Wendl. Beobacht. 38 (1798)= Cocculus, Linn. (Menisp.)

scandens, Wendl. $\mathrm{l}$. c. $=\mathrm{C}$. carolinus.

ANDROPHTHOË, Scheff in Flora, liit. (1870) 249, err. typ. = DENDKOPHTHOE, Mart. = Loran. thus, Linn.

ANDROPHYSA, Moq. ex seipso in DC, Prod. xiil. II. $201(1849)=$ Halocharis, Moq. (Chenop.).

ANDROPOGON, Linn. Sp. Pl, ed. I, 1045 (1753) GRAMINEAE, Benth. \& Hook. f. iii. 1133.

AgEnium, Nees, in Lindl. Introd. Nat. Syst. ed. II. 447 (1836).

Alloianthena, Steud. Syn. Pl. Gram. 217 (1855)

Altoiatheros, Rafin, in Ser. Bull. Bot. 221 (1830).

ANADELPHIA, Hack, in Engl. Bot. Jahrb. vi. (1885) 240

Anatherum, Beauv, Agrost. 128. t. 22 (1812).

ARTHRostachys, Desv. Opusc. 74.t. 6 (1831)

Cymbachne, Retz. Obs. vi. 36 , obs. ad calc. (1791).

Cymbopogon, Spreng. Pugill, ii 14 (1815)

Dichanthium, Willem. in Ust, Ann, Bot, xviii. 11 (1796).

Diectomis, H. B. \& K. Nov. Gen. et Sp. i. 193, t. 64 1815

Dimerostemon, Rafin. Neogenyt. 4 (1825).

Diplasanthum, Desv. Opusc, 66 (1831)

Dischanthium, Kunth, Enum. Pl. i. 498 (1833)

EriopodiuM, Hochst. in Flora, xxix. (1846) 115 in obs.

EUKLASTAXON, Steud, in Flora, xxxiii. (1850) 1. 229 ; Syn. PI. Gram. 412 (1854).

EuPOGon, Desy, Opusc. 67, in obs, (1831)

ExoTHEcA, Anderss, in Nov. Act. Upsal. ii. (1856) 253. t. 3 .

Graya, Arn. ex Steud. Nom. ed. II. i. 705 (1840).

Gymandropogon, Munro] Duthie, in Atkins.

Gaz. N. W. Ind. 638 (1878?), nomen

Gymnanthelia, Anderss, in Schweinf. Beitr. Fl. Acth. $299(\mathbf{1 8 6 7})$

HeterochloA, Desv. Opusc. 66, t. 5. f. 3 (1831)

HomoEatherum, Nees, in Hook. \& Am. Bot. Beceh. Voy. $239(1836)$

Hyparkhenia, Anderss, in Nov. Act. Upsal. it, 1856) 231, nomen.

Hypogxniua, Nees, Agrost, Bras. 364 (1829)

LeNormandia, Steud, in Flora, xxxiii. (1850) 229 nomen; Syn. Pl. Gram. 35!) (185t).

LEPEOCERCis, Trin. Fund. Agrost. 203 (1820).

MANDElorna, Steud, Sym. Pl. Gram, 559 (1854).

OROPOGON, Neck litem, iii. 211 (1790).

Pithecurus, Willd. ex Kunth, Erimm. Pl. i. 490 (183:3).

Schizachy Rium, Nees, Agrost. Bras. 391 (1829)

SCHIZOpugon, Reichb. Consp. 52 (1528.

Spirotheros, kafin. in Ser. Bull. Bot. i. (1\$30) 221.
ANDROPOGON:-

Vetiveria, Thou, ex Virey, in Journ. Phar. Sér. I xiii. (1827) 499

abyssinicus, R. Br.ex Fres. in Mus.Senkenb. ii. (1837) 146.-Abyss

acicularis, Willd. Sp. Pl. iv. 906=Chrysopogon aciculatus.

aciculatus, Retz. Obs. v. 22=Chrysopogon aciculatus.

aculeatus, Steud. Nom.ed. II. i. $90=$ Chrysopogon aciculatus.

adustus, Trin. in Mém. Acad. Pétersb. Sér. VI, II 18:33) $259=$ Elionurus latiflorus.

aesthenos, Steud. Syn. I1. Gram. 376=Ischaemum ciliare.

aethiopicus, Rupr. ex Steud, Syn. P1. Gram, $372=$ Gayanus,

afer, Bruce, Trav. v. App. 47 (Polliniae sp. ?).-Afr. bor affinis, J. Presl, in Kel. Haenk. i. $343=$ Sorghum halepense.

affinis, R. Br. Prod. i. 201.-Austral

affinis, Spreng. Nov. Prov. $5=$ annulatus.

Agenium, Steud. Syn. Pl. Gram. $395=$ Neesi

agrostoides, Speg. in Anal. Soc. Cient. Argent. xvi (1883) 136.- Reg. Argent.

agrostoides, Speg. Pl. Nov. Am. Austr. Dec. ii. 27 ; ex Anal. Soc. Cient. Argent. xvi. (1883) $15=$ Chryso pogon avenaceus.

albescens, Fourn. Mex, P1, Enum. Gram. 56; ex

Hemsl. Biol. Centr. Am. iii. $530=$ Chrysopogon nutans.

albidus, Wall. Cat. n, 8821.-Ind. or.

Alectoridia, Stend. Syn. Pl. Gram. 383=Arthraxon ciliaris.

Allionii, DC. FI. Fr. iii. $97=$ Heteropogon contortus.

alopecuroides, Linn. Sp. P1. 1045 = Erianthus saccha roides.

alternans, J. Presl, in Rel. Haenk. i. $342=$ Chrysopogon violascens.

altissimus, Colla, in Mem. Acc. Torin. xxxix. (1836) 29. t. $60=$ saccharoides

altissimus, Hochst. ex A. Br. in Flora, xxiv. (1841) 277 -Abyss.

amaurus, Buese, in Miq. Pl. Jungh. $360=$ Pollinia praemorsa.

ambiguus, Gennari, ex Barbey, Consp. Fl. Sard. 190 Heteropogon hirtus.

ambiguus, Michx. Fl. Bor. Am. i. 58=Gymnopogon racemosus.

ambiguus, Steud. Syn. P1. Gram. $385=$ exaltatus.

amethystinus, Steud. l. c. 371.-Afr. trop.

amplectens, Nees, Fl. Afr. Austr. 104.-Afr. austr.

amplexifolius, Trin. in Mém. Acad. Pétersb. Sér. VI.

ii. (1833) $274=$ Aithraxon ciliaris.

ampliforus, Steud. Syn. Pl. Gram. $388=$ A. Nardus.

amplus, J. Presl, in Rel. Haenk. i. $339=$ glaucescens.

angustatus, Steud. Syn. i. $370=$ apricus.

angustifolius, H. B. \& K. Nov. Gen. et Sp. i. 184=

Trachypogon angustifolius.

angustifolize, Parl. Fl. Palerm. i. $269=$ pertusus.

angustifolius, Sibth. \& Sm. Prod. Fl. Graec. i. $47=\mathrm{A}$. Ischaemum.

anias, Llanos, Fragm.29.-Ins. Philipp.

annulatus, F. Muell. Fragm, viii. $128=$ sericeas.

annulatus, Forsk. Fl. Aegyept. Arab. 173,-Afr. bor.

Ind, or.; Austral.

annulatus, F. Schmidt, F1. Ins. Capverd. $157=\mathrm{A}$. Ischaemum.

annulatus, Schult. Mant. ii. $453=$ foreolatus.

annuus, Hack in Flora, lxviii. (18s5) 18\%.-Afr.

trop.

anomalus, Stend.Syn. Pl. Gram. 397.-Arabia.

anthephoroides, Sieud. 1. c. $375=$ Ischnemum anthephoroides.

anthisterioides, Hochst. ex A. Rich. Tent. Fl. Abyss. ii. 463.-Abyss.

anthisterioides, Rupr, in Bull. Acad. Brux. ix. (15t2) $245=$ Ruprechtii.

appendiculatus, Nies, Fl. Afr. Austr. 105.-Afr. anstr.

apricus, Trin. in Bull. Sc. Acad. Pibersb. i. (1880) 70. -Keg. trop.

arctatus, Chosm. in Coult. Bof. Gas. iii. (18;s) 20.Flurida.

arcuotus, Stcud. Syn. PI. Gram. Sit 1.............. insciculatum.

arenarius, Hacts. in fobra, Ixviii. (1Ess) 194. Uruguay: 


\section{ANDROPOGON}

argenteus, DC. Cat. Hort. Monsp. 77 = saccharoides. argenteus, Ell. Sketch, $148=$ argyreus.

argutus, Steud. Syn. P1. Gram. 391=Chrysopogon argutus.

argyreus, Schult. Mant. ii. 450.-Am. bor.

Ariani, Edgew. in Journ. Linn. Soc. vi. (1862) $208=$ A. Iwarancusa.

aristatum, Poir. Encyc. Suppl. i. $585=$ caricosus.

aristidoides, Steud. Syn. Pl. Gram. $397=$ Chrysopogon ciliolatus.

aristulatus, Hochst. ex Steud. Syn. Pl. Gram. $397=$ Chrysopogon Wightianus.

aristulatus, Steud. Syn. Pl. Gram. 372 (Ischaemi sp, ?).-Ins. Borbon.

armillaris, Willd. ex Steud. Nom. ed. II. i. 90.Ind. or.

Arnottianus, Steud. Syn. Pl. Gram. $375=$ Ischaemum rugosum.

Amottii, Nees, ex Steud. l. c. 380.-Ind. or

aromaticus, Roxb. ex Schult. Mant, $442=$ muricatus. aromaticus, Sieber, ex Schult. 1. c. $481,388=$ A. Schoenanthus.

arrhenobasis, Hochst. ex A. Rich. Tent. Fl. Abyss. ii. $460=$ Heteropogon arrhenobasis.

arundinaceus, Berg. Desc. P1. Cap. $356=$ Bergii.

arundinaceus, Scop. F1. Carn. ed. II. ii. $274=$ Sorghum halepense.

arundinaceus, Voigt, Hort. Suburb. Calc. $706=$ Anthistiria gigantea.

asper, Kunth, Rev. Gram. i. 166= Danthonia papillosa.

asperifolius, Hack. in Flora, lxviii. (1885) $140=$ Zollingeri.

assimilis, Steud. Syn. Pl. Gram. 397=Chrysopogon pictus.

asthenos, Steud. 1. c. $376=$ Ischaemum ciliare

asthenostachys, Steud. 1. c. $381=$ Pollinia articulata.

astictus, Buese, in Miq. Pl. Fungh. 360.-Sumatra.

attenuatus, Bertol. in Mem. Acc. Sc. Bolog. x. (1859)

34; Misc. Bot. xx. 10. t. 2,-Guatemala

Aucheri, Boiss. Diagn. Ser. I. v. $77=$ Chrysopogon serrulatus.

aureo-fulvus, Steud. Syn. Pl. Gram. $373=$ Pollinia Cumingii.

aureo-villosus, Steud. Syn. PI. Gram. $380=$ Pollinia aurea.

aureus, Bory, Voy. i. 367. t. $21=$ Pollinia aurea.

australis, Spreng. Syst. i. 287.-Austral, ; Timor.

avenaceus, Berg. Desc. Pl. Cap. $356=$ Bergii.

avenaceus, H. B. \& K. Nov. Gen. et Sp. i. $189=$ Sorghum halepense.

avenaceus, Michx. Fl. Bor. Am. i. $58=$ Chrysopogon avenaceus.

barbatus, Linn. Pl. Fam. Pugill. 30; Mant. ii. 302 $=$ Chloris barbata.

barbigerus, Steud. Syn. Pl. Gram. 376=Ischaemum aristatum.

barbinodis, Lag. Gen. et Sp. Nov. $3=$ saccharoides.

Barteri, Hack. in Flora, lxviii. (1885) 124.-Afr. trop.

Bellardi, Bubani, in Nuov. Giorn. Bot. Ital. v. (1873) $317=$ Heteropogon contortus

bellariensis, Hack. in Flora, lxviii. (1885) 123.Ind. or.

Belvisii, Desv. Opusc. $67=$ argyreus.

Benthamianus, Steud. Syn. P1. Gram. $382=$ condensatus.

Bergii, Roem. \& Schult. Syst. ii. 813.-Afr, austr.

Berteronianus, Steud. \& Hochst. ex Steud. Syn. Pl. Gram. $380=$ saccharoides.

Besseri, Kunth, Rev. Gram. i. $166=$ Sorghum vul. gare.

besukiensis, Steud. Syn. P1. Gram. 367=Heteropogon contortus.

biaristatus, Steud. 1. c. $379=$ Pollinia ciliata.

bicolor, Nees, Fl. Afr. Austr. 113=dichrous.

bicolor, Roxb. Hort. Beng. 21; Fl. Ind. i. $272=$ Sorghum vulgare.

bicornis, Benth. Pl. Hartw. $263=$ condensatus.

bicornis, Linn. Sp. Pl. 1046.-Am. austr.

bicornis, Forsk. Fl. Aegypt, Arab. 173=A. Schoenanthus.

bifidus, Steud. Syn. Pl. Gram. $373=$ Ischaemum ciliare.

bifoveolatus, Steud. 1. c. $380=$ pertusus.

bilinguis, Trin. in Mém. Acad. Pétersb. Sér. VI. ii. (1833) $262=$ Elionurus bilinguis.

\section{ANDROPOGON :}

binatus, Retz. Obs, v, $21=$ Spodiopogon pertusus.

binatus, Roxb. Hort. Beng. 6; F1. Ind. i. $255=$ tenellus.

bipennatus, Hack. in Flora, lxviii. (1885) 142,-Afr. trop.; Madag.

bisquamulatus, Hochst. in Flora, xxvii. (1844) $245=$ Gayanus.

Bladhii, Retz. Obs. ii. $27=$ annulatus.

Blumii, Stend. Syn. Pl. Gram. $373=$ Spodiopogon Blumii.

Boivini, Steud. l. c. 431.-Ins. Nossibé.

bombycinus, R. Br. Prod. i. 202.-Austral.

Bourgaei, Hack. in Flora, 1xviii. (1885) 134.Mexico.

bourowensis, Steud. Syn, Pl. Gram, $382=$ Ischaemum digitatum.

brachyatherus, Hochst. in Flora, xxvii. (1844) 241.Abyss.

brachystachyus, Chapm. Fl. S. Un. St. Suppl.668.Florida.

bracteatus, Willd. Sp. Pl. iv. 914.-Am. trop.

breviaristatus, Steud. Syn. Pl. Gram. 396=Chrysopogon Wightianus.

brevifolius, Sw. Prod. Veg. Ind. Occ. 26.-Geront. trop.

brevis, Trin. in Mém. Acad. Pétersb. Sér. VI. ii. (1833) $268=$ lateralis

Brongniarti, Steud. Nom. ed. II. i. 90.--Ins. Molucc

Brommii, Kunth, Rev. Gram. i. $163=$ Ischaemum laxum.

Byronis, Steud. Syn. Pl. Gram. 398=Spodiopogon Byronis.

Cabanisii, Hack. in Flora, Ixviii. (1885) 133.Am. bor.

caerulescens, Kunth, Enum. PI. i. 504=Chrysopogon violascens.

caespitosus, A. Rich. Tent. F1. Abyss, ii. $451=$ Elionurus argenteus.

caespitosus, Phil. in Linnaea, xxxiii. (1864-65) $275=$ hirtiflorus.

caffrorum, Kunth, Rev. Gram. i. $165=$ Sorghum vulgare.

campestris, Kunth, Enum. Pl. i. $489=$ tener

campestris, Trin. in Mém. Acad. Pétersb. Sér. VI. ii 1833) $277 .-$ Bras

camporum, Trin, ex Stend, Syn. i. $378=$ campestris,

canaliculatus, Schum. Beskriv. Guin. Pl. 52,Guinea.

candidus, Trin. in Mém. Acad. Pétersb. Sér. VI. ii. (1833) $260=$ Elionurus candidus.

canescens, Kunth, Enum. Pl. i. 487=Trachypogon polymorphus.

canus, Steud. Nom. ed. II. i. 90-Mexico.

capensis, Houtt. Plant.-Syst. xii. t. 93. f. $3=$ Chloris petraea.

capillaris, Heyne, ex Steud. Syn. Pl. Gram. $116=$

Arundinella mutica.

capillaris, Kunth, Rev.Gram. i, 166.-Afr, austr.

capilliflorus, Steud. Syn. Pl. Gram. 397=Chrysopogon violascens.

caricosus, Linn. Sp. Pl. ed. II. 1480,-As. trop.; Ins. Mascar.

carinatus, Nees, Agrost. Bras. ii. 330.-Bras.

castratus, Griff. Notul. iii. $89=$ Arthraxon rude?

caucasicus, Trin. in Mém. Acad. Pétersb. Sér. VI ii

(1833) $286=$ intermedius.

caudatus, Bieb. Tabl. Prov, Côte Occ. Mer Casp. 58 $=$ Erianthus Ravennae.

ceresiaeformis, Nees, Fl. Afr. Austr. 109.-Afr. austr. ceriferus, Hack. in Mart. Fl. Bras. ii. III. $281=$ A. Nardus.

cernuus, Kunth, Enum. P1. i. 501=Sorghum halepense.

cernuus, Roxb, Fl. Ind. i. $270=$ Sorghum vulgare.

chloridiformis, Gaudich. in Freyc. Voy. Bot. $412=$ Dimeria pilosissima.

chlorostachys, Trin. in Mém. Acad. Pétersb. Sér. VI.ii. (1833) $260=$ Elionurus rostratus.

chordatus, Steud. Syn. PI. Gram. 398=Spodiopogon Blumii.

chrysatherus, F. Muell. in Linnaea, xxv. (1852) $443=$ sericeus.

chrysopus, Coss. in Bull. Soc. Bot. Fr. xxii. (1875) 68 $=$ Aucheri.

chrysostachyus, Steud. Syn. Pl. Gram. 377.-Abyss. ciliaris, Trin. in Mém. Acad. Pétersb. Sér. VI. ii. (1833) $260=$ Elionurus latiflorus,

\section{ANDROPOGON :}

ciliatus, Ell. Sketch, i. $144=$ Chrysopogon avenaceus.

ciliatus, Thunb. Fl. Jap. $40=$ Anthistiria barbata . ciliolatus, Steud. Syn. P1. Gram. 396= Chrysopogon serrulatus.

cinctus, Steud. 1. c. $398=$ Chrysopogon violascens circinnatus, Hochst. \& Steud. ex Steud. 1. c. $387=$ laniger.

cirratus, Hack. in Flora, lxviii. (1885) 119.-Am. bor.

citratus, Hort. ex DC. Cat. Hort. Monsp. $78=\mathrm{A}$. Schoenanthus.

citreus, R. Br. Prod. i. $203=$ Elionurus citreus.

citriodorus, Hort. ex Desf. Tabl. ed. II. $15=\mathbf{A}$. Schoenanthus,

citrosus, Hort. ex Stend. Nom. ed. II. i. $90=$ A. Nardus

clandestinus, Hale, ex Vasey, Gram. Un. St. 19= Elliottii.

clandestinus, Nees, ex Steud. Syn. P1. Gram. 388=A. Schoerianthus.

coeruleus, Steud. 1. c. $395=$ Chrysopogon serrulatus. coesius, Nees, ex Hook. \& Arn. Bot. Beech. Voy. $244=$ A. Schoenanthus.

cognatus, Steud. Syn. PI. Gram. $374=$ schirensis.

coleotrichus, Steud.l.c. 386.-Abyss.

commutatus, Aitch. in Journ. Linn. Soc. xix. (1882) $191=$ laniger

commutatus, Steud. Syn. Pl. Gram. 387.-Abyss.

comoroënsis, Steud. 1. c, 431 (=Ischaemi sp.)

comosus, Hochst. ex A. Rich. Tent. F1. Abyss. 1i. $461=$ coleotrichus.

comosus, Link, Hort. Berol. i. $239=$ annulatus, compactus, Brot. Fl. Lusit. i. $88=$ Sorghum halepense. condensatus, $H . B . \& K$. Nov. Gen. et Sp. i. 188.Amer. austr.

condensatus, Rupr. in Bull. 'Acad. Brux. ix. (1842) 244 = Chrysopogon Francavillanus.

condylotrichus, Hochst. ex Steud. Syn. Pl. Gram. 377. -Abyss.

confertiflorus, Steud. 1. c. $385=$ A. Nardus.

confinis, Hochst. ex A. Rich. Tent. Fl. Abyss. ii. 461.Abyss.

conjugatus, Roxb. Hort. Beng. 6 ; F1. Ind. i. 260 (Polliniae sp.).-Bengal.

connatus, Hochst. ex A. Rich. Tent. F1. Abyss. ii. 464 $=\mathrm{A}$. Schoenanthus.

consanguineus, Kunth, Enum. Pl. i. 494.--Bras.; Uruguay.

consanguineus, Trin. in Linnaea, x. (1836) $291=$ condensatus.

consimilis, Steud. Syn. P1. Gram. 394=serratus.

contortus, Linn. Sp. PI. ii. $1045=$ Heteropogon contortus.

controversus, Steud. Syn. Pl. Gram. 391=Sorghum halepense.

cordatifolius, Steud. I. c. $376=$ Ischaemum conjugatum, cordofanus, Hochst. in Flora, xxvii. (1844) $245=$ Gayanus.

Cornucopiae, Hack. l. c. Ixviii. (1885) 126.-Afr. trop, corollatus, Steud. Syn. Pl. Gram. $369=$ Ischaemum corollatum.

cotulifer, Thunb. F1. Jap. $41=$ Pollinia cotulifera. courtallumensis, Steud. Syn. P1. Gram. $377=$ Apocopis Wightii.

corassipes, Steud. 1. c. $375=$ Ischaemum Sieboldii.

crinitus, Thunb. Fl. Jap. $40=$ Pogonatherum saccharoideum.

Crupina, Kunth, Rev. Gram. i. $166=$ Sorghum halepense.

cryptatherus, Steud. Syn. P1. Gram. $376=$ Ischaemum australe.

cubensis, Hack. in Flora, lxviii. (1885) 121.-Cuba.

curtipendulus, Steud. Nom. ed. II. i. $90=$ Eutriana curtipendula.

Curtisianus, Steud. Syn. P1. Gram. 390=virginicus.

cuspidatus, Hochst. ex A. Rich. Tent. Fl. Abyss. ii. $456=$ Arthraxon cuspidatus.

cymbarius, Linn. Mant. ii. 303.-Afr. trop. ; Ind. or. dactyloides, Steud. Syn. P1. Gram. 381 = Trachypogon polymorphus.

debilis, Kunth, Enum. PI. i, $488=$ brevifolius.

decolorans, H. B. \& K. Nov. Gen. et Sp. i. $190=$ Sorghum halepense.

decussatus, Steud. Syn. PI. Gram. $377=$ koleostachys, demissus, Steud. l. c. 388.-Ind. or.

densiflorus, Steud. 1. c. $386=$ A. Schoenanthus. 


\section{ANDROPOGON :-}

densus, Desv, in Ham. Prod. Fl. Ind. Occ. $8=$ condensatus.

depauperatus, Kunth, Rev. Gram. i. 166,-Bengal. depressus, Steud. Syn. Pl. Gram. $373=$ Spodiopogon depressus.

Dianae, Stend. 1. c. $371=$ leucostachyus

diatherus, Steud, 1. c. $378=$ Ischaemum latifolium.

dichroanthus, Steud. 1. c. $393=$ serratus.

dichroos, Steud. l. c. 389,-Afr. austr.

digitatus, Hochst. ex Steud. 1. c. $382=$ Trachypogon dactyloides.

digitatus, Vahl, ex Trin. Fund. 186.-Hab.?

diplandrus, Hack。 in Flora, lxviii. (1885) 123,-Afr. trop.

dissitiflorus, Michx. Fl. Bor. Am. i. $57=$ virginicus,

dissitiflorus, Trin. in Mém. Acad. Pétersb. Sér. VI. ii. (1833) $267=$ consanguineus.

dissolutus, Steud. Syn. Pl. Gram, 381=Trachypogon polymorphus.

distachyos, Linn.Sp. Pl. 1046.-Reg. Meditern

distans, Nees, ex Steud. Syn. Pl. Gram. $387=$ A.

Nardus.

divaricatus, Humb. \& Bonpl. ex Willd. Enum. Hort. Berol. i. $99=$ Aristida Humboldtiana.

divaricatus, Linn.Sp. Pl. 1045.-Virginia.

diversiflorus, Steud. in Zoll. Syst. Verz. $58=$ Pollinia praemorsa.

domingensis, Fourn. Mex. Pl. Enum. Gram. 61; ex Hemsl. Biol. Centr. Am. iii. 530=leucostachyus.

domingensis, Spreng. ex Steud. Nom. ed. II. 1. $91=$

Trachypogon polymorphus.

domingensis, Steud. 1. c. $45=$ leucostachyus,

Donianus, Benth. in Hook. Niger Fl. $570=$ Elionurus platypus.

Dregeanus, Nees, Gram. Afr. Austr. $112=$ Schimperi.

Drummondii, Steud. Syn. Pl. Gram. $393=$ Sorghum vulgare.

dubitatus, Steud.1. c. $394=$ Sorghum halepense

dubius, C. Koch, in Linnaea, xxi. (1848) $443=$ Sorghum halepense.

ducius, Kunth, Rev. Gram. i. $166=$ Elionurus rostratus. dulcis, Burm.f. Fl. Ind. $219=$ Sorghum vulgare.

durus, Steud. Nom, ed. II. i. 91= Erianthus strictus.

echinatus, Edgerw. in Fourn. As, Soc. Beng. xxi. (1853) 182.-Ind. or.

echinatus, Heyne, in Steud. Nom. ed. II. i. $91=$ Arthraxon lanceolatus.

echinulatus, Steud. Syn. Pl. Gram. $397=$ Chrysopogon Gryllus.

elatus, Steud. 1. c. $376=$ Ischaemum aristatum.

elegans, J. Gay, ex Steud. 1. c. $364=$ Elionurus elegans.

elegantissimus, Steud. 1. c. = Elionurus Royleanus.

Elliottii, Chapm. Fl. S. Un. St. 581.-Am. bor.

elongatus, Spreng. Syst. i. $287=$ Chrysopogon elongatus.

elythrophyllus, Steud. Syn. Pl. Gram. 378.--Mexico

emersus, Fourn. Mex. Pl. Enum. Gram. 58; ex Hemsl, Biol. Centr. Am. iii. $527=$ saccharoides.

erianthoides, F. Muell. Fragm. x. 75.-Austral.

Erianthus, Link, Hort. Berol. i. $243=$ Erianthus saccharoides.

eriophorus, Scheele, in Flora, xxvii. (1844) $51=$ virginicus.

eriophorus, Willd. Sp. Pl. iv. $910=$ laniger.

eriostachyus, J. Presl, in Rel. Haenk. i. $339=$ ternatus.

erythrocoleos, Stend. Syn. Pl. Gram. 391.-Nepal.

Esenbeckii, Steud, 1, c. $375=$ Ischaemum aristatum.

eucnemis, Trin. in Mém. Acad. Pétersb. Sér. VI. ii.

(1833) 275.-Guinea.

eucomus, Nees, Fl. Afr. Austr. 104.-Afr. trop. et austr.

exaltatus, $R . B r$. Prod, i. 202.-Austral.

exaratus, Hack, in Flora, lxviii. (1885) 135.-.Paraguay.

excavatus, Hochst. 1. c. xxix. (1846) $116=\mathrm{A}$. Schoenanthus.

exilis, Hockst. l.c. xxvii. (1844) 142,-Afr. trop.

exsertus, Steud. Syn. Pl. Gram. $366=$ brevifolius. falcatres, Steud. 1.c. $\$ 69=$ Ischaemum pectinatum.

familiaris, Stend. l.c. 385.-Afr. trop.

fascicularis, Roxb. Hort. Beng. 82; Fl. Ind. i. 269.Ind. or

fascicularis, Thw. Enum. Pl. Zeyl. $497=$ intermedius. fasciculatus, Linn. Sp. Pl. $1047=$ Chloris radiata. fasciculatus, Steud. Syn. Pl. Gram. 382 = Ischaemum fasciculatum.

fastigiatus, Sw. Prod. Veg. Ind. Occ. 26. -Reg. trop.

\section{ANDROPOGON :-}

feensis, Fourn, Mex. Pl. Enum. Gram. 62; ex Hemsl. Biol. Centr. Am. iii. 527 = hirtiflorus

ferrugineus, Hochst. ex Steud. Syn. PI. Gram. $377=$ chrysostachyus.

festucoides, J. Presl, in Rel. Haenk. i. $340=$ squarrosus. filifolius, Steud. Syn. Pl. Gram. 374.-Afr. austr.

filiformis, Pers, Syn。 i. $103=$ caricosus.

filiformis, Roxb. Hort. Beng. 6; Fl. Ind. i. $260=$ Dimeria ornithopoda.

filipendulus, Hochst. in Flora, xxix. (1846) 115.-Afr trop.; Zeylan.; Austral.

finitimus, Hochst, ex A. Rich. Tent. Fl. Abyss. ii. 465. -Abyss.; Ins. Mascar.

firmandus, Steud. Syn. Pl. Gram. 370= Pollinia praemorsa.

firmus, Kunth, Enum. PI. i. $486=$ Heteropogon firmus.

flabelliformis, Roxb. ex Spreng. Pugill. ii, 9.-Ind. or. flaccidus, A. Rich. Tent. Fl. Abyss, ii, $452=$ brevifolius, flavescens, F. Presl, in Rel. Haenk. i. 339.-Peruv.

flexile, Poir. Encyc. Suppl. i. $583=$ scoparius.

flexuosus, Nees, ex Steud. Syn. P1. Gram. 388=A. Nardus.

floridus, Trin. in Mém. Acad. Pétersb. Sér. VI. ii. (1833) $265=$ brevifolius

foliatus, Steud. Syn. Pl. Gram. $389=$ A. Schoenanthus foveolatus, Delile, Fl. Egypte, 160. t. 8. f. 2.-Afr, et As. trop.

fragilis, R. Br. Prod. i. $202=$ brevifolius.

fragillimus, Hochst. ex Steud. Syn. Pl. Gram. 381= exilis.

Francavilleanus, Fourn. Pl. Mex. Enum. ii. 56 ; ex Hemsl. Biol. Centr. Am, iii. $530=$ Chrysopogon avenaceus.

fulvibarbis, Trin. in Mém. Acad. Pétersb. Sér. VI. ii. (1833) 287.-Afr. trop.

fulvicomus, Hochst. ex A. Rich. Tent. Fl. Abyss, ii $463=$ rufus

fulvispica, Stend. Syn. Pl. Gram. $379=$ Pollinia Cumingii.

fulvus, Spreng. Pugill. ii. 8.-Bengal.

furcatus, Muhl, in Willd. Sp. PI. iv. $919=$ provincialis

fuscus, J. Presl, in Rel. Haenk. i. $342=$ serratus

Galeottii, Fourn. Mex. Pl. Enum, Gram. 56 ; ex Hemsl.

Biol. Centr. Am. iii. $527=$ Chrysopogon nutans.

galloinsulanus, Steud. Syn. Plo Gram. 371.-Ins. Mascar.

garipensis, Steud. 1. c. $379=$ annulatus.

Gayanus, Kunth, Rev. Gram. i. 163.-Senegal.

geniculatus, Stend. Syn. Pl. Gram. 376=1schaemum aristatum.

Gerardi, Vitm. Summa P1. vi. $16=$ provincialis

gibbus, Steud. Syn.Pl.Gram. 376 = Ischaemum aristatım.

Gidarba, Buch.-Ham. in Wall. Cat. n. 8797.-Ind. or

giganteus, Fenzl, ex Steud. Syn. Pl. Gram. $386=$ A Iwarancusa.

giganteus, Hochst. in Flora, xxvi.. (1844) $242=\mathrm{A}$ Schoenanthus.

giganteus, Tenore, Fl. Nap. v. $285=$ Heteropogon hirtus.

glaber, Roxb. Hort. Beng. 7 ; Fl. Ind. i. $271=$ intermedius.

glabratus, Steud. Nom. Bot. ed. II. i. $91=$ Pollinia glabrata.

glabratus, Steud. Syn. P1. Gram. 395=Chrysopogon Gryllus.

glabrescens, Hochst. ex Steud. 1. c. $374=$ polyatherus,

glabriusculns, Hochst. ex A. Rich. Tent. Fl. Abyss, ii. 468.-Abyss.

glaucescens, Fourn. P1. Mex. ii. 60; ex Hemsl. Biol. Centr. Am. iii. 527, partim = Bourgaei

glaucescens, H. B. \& K. Nov. Gen. et Sp, i. 186.-Am. austr.

glaucescens, Schlecht. in Linnaea, vi. (1831) $39=$ virginicus.

glaucopsis, Ell. ex Steud. Nom. ed. II. i. 91 = macrourus, glaucopsis, Steud. Syn. Pl. Girm. $897=$ montanus. glancus, MuhI. Descr. Uber. $278=$ macrourus. glaucus, Retz, Obs, vo $20=$ A pluda mutica.

glaucus, Torr. in Ann. Lyc. N. York, i. (1824) $157=$ saccharoides.

Glaziovii, Hack. in Mart. Fl. Bras. ii, III, 2S6.-Rio de Janeiro

Gocringi, Stcud. in Flora, xxix. (1846) $22=\mathrm{A}$ Narilus.

gracilipes, Hack. in Flora, lxviii. (1S85) 120.- Гaraguay.

\section{ANDROPOGON}

gracitis, Presl in Rel. Haenk i. $336=$ tener

gracilis, Spreng. Syst. i. 284,-Ind. occ.

grandiflorus, Hack. in Flora, Ixviii. (1885) 127.-Afr. trop.

grandis, Nees, ex Steud. Syn. Pl. Gram. 3yy=A Nardus.

Grayia, Steud. Nom. ed. II. i. $91=$ pseudograya

Griffithsiae, Steud. Syn. P1. Gram. $375=$ Ischaemum rugosum

Grisebachii, Steud. 1. c. $365=$ Elionurus Royleanus, Gryllus, Linn. Cent. Pl. ii. 83 = Chrysopogon Gryllus. guianensis, Steud. Syn. Pl. Gram. 382=Ischaemum guianense.

guineensis, Schum. Beskr. Guin. Pl. $51=$ Gayanus,

Haenkei, J. Presl, in Rel. Hacnk. i. $340=$ intermedius. halepensis, Brot. Fl. Lusit. i. $89=$ Sorghum halepense Hallii, Hack. in Sitzb. Acad. Wien, lxxxix. (1884) 127 -Am. bor.

hamatulus, Hook. \& Arn. Bot. Beech. Voy. 244=A Nardus.

hamulatus, Nees, ex Steud. Syn. PI. Gram, 388=A. Nardus.

hermaphroditum, Pourr, in Mém. Acad. Toul. iii. (1788 308 = Stipa aristella.

heteranthus, Steud. Syn. Pl. Gram. 370.-Hab.?

heteranthus, Trin. exSteud. Nom. ed. II. i. $91=$ bicomis. heteroclitus, Nees, Fl. Afr, Austr, 115.-Ind or. hexastachyus, Steud. Syn. Pl. Gram. $380=$ Pollinia argentea.

Hildebrandtii, Hack. in Flora, 1xviii. (1885) 141.Marlag.

himalayensis, Steud. Syn. Pl. Gram. 377=Apocopis Royleanus.

hirsutus, H. B. \& K. Nov, Gen. et Sp. i. $186=$ saccharoides.

hirtiforus, Kunth, Rev, Gram, ii. 569. t. 198.-Am. trop. hirtifolius, f. Presl, in Rel. Haenk. i. 338.-Mexicu. hirtinoides, Regel, in Act. Hort. Petrop. vii. (1880) $657=$ Ischaemam hirtinodes

hirtus, Linn. Sp. Pl. 1046 = Heteropogon hirtus,

hispidissimus, Steud. Syn. P1. Gram. $367=$ Heteropogon contortus.

hispidus, Willd. Sp. P1. iv. 908=Arundinella brasiliensis.

Hochstetteri, Steud. Syn. Pl. Gram. 384= fastigiatus.

Hohenackeri, Hochst. ex Stead. 1. c. $368=$ Heteropogon contortus.

holcoides, Kunth, Rev. Gram. ii. 49. t. $160=$ Saccharam holcoides.

Humboldtianus, Stend. Syn. PI. Gram. 392=Chrysopogon avenaceus.

humilis, Hochst. ex A. Rich. Tent. Fl. Abyss. ii. 453.Abyss.

humilis, Wright, ex Steud. Syn. Gram. i. $3 \& 8=$ demissus. hypogynus, Hack. in Mart. Flo Bras. ii. III. 2!0.Bras.

imberbis; Hack. in Flora, 1xviii. (1885) 119.-Paracuay. imberbis, Steud. Syn. Pl. Gram. $375=$ Ischaemum aristatum.

importunus, Steud. l. c. 382.-China.

incertus, Steud. 1. c. $375=$ Ischaemum ciliare.

incomepletus, J. Presl, in Rel. Haenk. i. $342=$ Chryso pogon gutans.

increscens, Steud. Syn. Pl. Gram. $396=$ Chrysopogon serrulatus.

incurvatus, Koen. ex Trin. in Spreng. Neue Entdeck. ii. $91=$ caricosus.

incurvatus, Retz. Obs. v. 21.-Ind. cr.

inermis, Steud. Syn. Pl. Giram. $390=$ spathifforus.

infirmus, Steud. 1. c. $369=1$ schaemum fracile.

insculptus, Anderss, in Schweinf, Beitr. Y1. Aethiop. 316 = Ischaemum laxum.

insculptus, Hochst. ex A. Rich. Tent. Fl. Abyss it $458=$ pertusus.

insularis, Linn. Pl. Jam. I’ugill. 30 ; Syst. ed. X. $1304=$ Panicum leucophacum

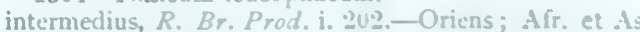
trop; ; Austral.

intonsus, Nees, Fl. Afr. Austr. $114=$ lepidus. intortum, Crantz, Inst. i. 898 = Spurobolus indicus. intrans, fo, Mtucll. Cersts, 19:2. - Ausent. inundatus, $F$. Mluell, in Linnaea, xx\%. (185:) \#t intermedius

intolucratus, Koen. ex Secud. Nom. ed. II, i. $91=$ Apluda arictata.

ineoludus, Steuti. Syn. Pl. Grom, $3 ; 3=$ Spodiopogon angusulolitus. 


\section{ANDROPOGON}

Ischaemum, Linn. Sp. Pl. 1047.-Eur.; As. et Afr. trop. et temp.

Ischaemum, Thunb. F1. Cap. 1. $108=$ appendiculatus. ischyranthus, Steud. Syn. P1. Gram. $367=$ triticeus. Iwarancusa, Boiss. Fl. Orient. v. $466=\mathrm{A}$. Schoenanthus. Iwarancusa, Nees, F1. Afr. Austr. $117=$ A. Nardus.

Iwarancusa, Roxb. in Phil. Trans. 1xxx. (1790) 284.Ind. or.; Afr. trop.

Famesii, Torr. in Marc. Rep. (1852) $302=$ saccharoides. javanicus, Miq. Fl. Ind. Bat. iii. 448.-Java.

javanicus, Steud. Syn. P1. Gram. 396=Chrysopogon aciculatus.

jubatus, Balansa, in Bull. Soc. Bot. Fr. xix. (1872) 322 = sericeus.

junceus, Rich. ex Steud. Nom. ed. II. i. 91.-Ins. S. Domingo.

juncifolius, Desv. in Ham. Prod. Fl. Ind. Occ. 9.-Ins.

S. Cruz.

Koenigii, Raeusch. Nom. ed. III. $293=$ caricosus.

koleostachys, Steud. Syn. Pl. Gram. 376.-Ins. Mascar.

koretrostachys, Trin. in Mém. Acad, Pétersb. Sér. VI. ii. $(1833) 273=$ Pollinia articulata.

lachnatherus, Benth. F1. Austral. vii. $534=$ filipendulus. laguriformis, Griseb. in Goett. Abh. xxiv. (1879) 309 = saccharoides.

laguroides, DC. Cat. Hort. Monsp. $78=$ saccharoides.

lanatus, R. Br. Prod. i. $202=$ exaltatus

lanceolatus, Baker, F1. Maur. and Seych. $414=$ Arthraxon cuspidatus.

lanceolatus, Roxb. Hort. Beng. 6; F1. Ind. i. $262=$ Arthraxon lanceolatus.

lancifolius, Trin. in Mém. Acad. Pétersb. Sér. VI. ii. (1)33) $271=$ Arthraxon microphyllus.

laniger, Desf. Fl. Atlant. ii. 379.-Oriens; Ind. or.; Afr. bor.

laniger, Munro, in Journ. Linn. Soc. xix. (1882) $409=$ Spodiopogon laniger.

lanuginosus, H. B. \& K. Nov. Gen. et Sp. i. 187= leucostachyus.

lasiocoleus, Steud. Syn. P1. Gram. 383=Arthraxon ciliaris.

Iateralis, Nees, Agrost. Bras. ii. 329.-Am. trop.

latiflorus, Steud. Syn. Pl. Gram. $364=$ Elionurus latiflorus.

latifolius, Kunth, Rev. Gram. i, 166= Centotheca lappacea.

latifolius, Spreng. Syst. i. $286=$ Ischaemum latifolium. laxiflorus, Steud. Syn. Pl. Gram. $380=$ Trachypogon polymorphus.

laxus, Roxb. Hort. Beng. 7 ; FI. Ind. ed. Carey, i. 271 =Sorghum halepense.

laxus, Willd. Sp. Pl. iv, $907=$ serratus.

Lechleri, Stend. ex Hack. in Mart. F1. Bras. ii. III. 297 $=$ condensatus.

lepidus, Nees, Fl. Afr. Austr. 113,-Abyss.

leptanthus, Steud. Syn. Pl. Gram. $391=$ intermedius,

leptocladus, Hack. in Flora, Ixviii. (1885) 122, Paraguay.

leptocomus, Trin. in Mém. Acad. Pétersb. Sér. VI. ii. 1833) 264.-Sierra Leone.

leptophyllus, Trin. 1. $\mathrm{c}$ = =tener.

leptos, Steud. Syn. Pl. Gram. $397=$ tener.

leptostachyzs, Benth. in Hook. Niger Fl. $571=$ semiberbis.

Leschenaultianus, Decne. Herb. Timor. Descr. $29=$ Pollinia Cumingii.

leucopogon, Nees, in Linnaea, xix. (1847) $694=$ saccharoides.

leucostachyus, H. B. E K. Nov.Gen. et Sp. i. 187.Am. trop.

Lhotskyi, Steud. Syn. P1. Gram. i. $384=$ condensatus.

lianatherus, Steud. 1. c. $367=$ Heteropogon insignis.

Liebmanni, Hack. in Flora, 1xviii. (1885) 132.-Mexico.

ligularis, Kunth, Enum. Pl. i. 497=Trachypogon polymorphus.

Lindeni, Steud. Syn. Pl. Gram. $389=$ apricus

lineatus, Steud. 1. c. $369=$ Ischaemum laxum.

lithophilus, Trin. in Mém. Acad. Pétersb. Sér. VI. ii. (1833) 277.-Bras.

lividus, Thw. Enum. Pl. Zeyl. 367.-Ind. or

lodicularis, Steud. Syn. P1. Gram. $375=$ Ischaemum aristatum.

lolioides, Fourn. Mex. Pl. Enum. Gram. 62 ; ex Hemsl. Biol. Centr. Am. iii. $528=$ scoparius,

longiberbis, Hack. in Flora, lxviii. (1885) 131.Florida.

\section{ANDROPOGON :-}

longipes, Hack, $l$. c. 138.-Ind or

Louisianae, Steud. Syn. Pl. Gram. 383=virginicus,

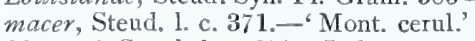

Macraei, Steud. 1. c. $377=$ Ischaemum ciliare.

macroglossus, Steud. 1. c. $368=$ Trachypogon polymor phus.

macrolepis, Hack. in Flora, 1xviii. (1885) 125.-Afr trop.

macrostachyus, Anderss, in Schweinf. Beitr. Fl. Aethiop. $310=$ Ischaemum laxum.

macrothrix, Fourn. Mex. HI.Enum.Gram. 60 ; ex Hemsl.

Biol. Centr. Am. iii. 528=Liebmanni.

macrothrix, Trin. in Mém. Acad. Pétersb. Sér. VI. ii. 1833) $270=$ ternatus.

macrourus, Michx. Fl. Bor. Am. i. 56.-Am. bor. Mexico.

madagascariensis, Hack. in Flora, lxviii. (1885) $136=$ trichozygus.

malacophyllus, Hochst. ex Steud. Syn. Pl. Gram. $372=$ Ischaemum ciliare.

malacostachyus, Fourn. P1. Mex. P1. Enum. Gram. 62 ex Hemsl. Biol. Centr. Am. iii. $528=$ hirtiflorus.

malacostachyus, F. Presl, in Rel. Haenk. 1. 337.-Am. centr.

Mannii, Hook. f. in Fourn. Linn. Soc. vii. (1864) 232. - Fernando Po.

marginatus, Steud. in Flora, xii. (1829) $472=\mathrm{A}$ Nardus

Mariannae, Steud. Syn. Pl. Gram. $382=$ Ischaemum digitatum.

maritimus, Chapm. F1.S. Un. St. Suppl.668 = scoparius

Martini, Roxb. Hort. Beng. 7; Fl. Ind. i. $280=\mathrm{A}$ Schoenanthus

Martini, Thw. Enum. Pl. Zeyl. $367=$ A. Nardus

medius, Steud. Syn. Pl. Gram. $382=$ Ischaemum inter medium.

megapotamicus, Spreng. Syst. iv. Cur. Post. $33=$ Trachypogon polymorphus.

melanocarpus, Ell. Sketeh, i. 146= Heteropogon acuminatus.

messanensis, Biv. ex Parl. Fl. Ital. i. $148=$ Heteropogon contortus.

Meyenianus, Steud. Syn. Pl. Gram. $375=$ Ischaemum aristatum.

micans, Steud. 1. c. $382=$ Arthraxon cuspidatus.

micranthus Kunth, Rev. Gram. i. $165=$ Chrysopogon violascens.

microphyllus Trin. in Mém Acad. Pétersb. Sér. VI. ii. (1833) $275=$ Arthraxon microphyllus.

microstachyus, Desv. in Ham. Prod. Fl. Ind. Occ. 8. -Ind. occ.

miliaceus, Roxb.Hort.Beng. 7 ; Fl. Ind.i. 276.-Ind.or. miliformis, Schult. Mant. ii. $448=$ praec

Minarum, Kunth, Enum. Pl. i. 507=Chrysopogon stipoides.

minor, Steud. Syn. Pl. Gram. $377=$ Ischaemum Urvil leanum.

minutiflons, Steud. 1. c. $379=$ Pollinia argentea.

mollicomus, Kunth, Rev. Gram.i. 365. t. $96=$ caricosus mollis, Kunth, 1. c. ii. 561. t. $195=$ Trachypogon poly morphus.

monandrus, Roxb. Hort. Beng. 82 ; Fl. Ind. i. $264=$ Pogonatherum saccharoideum.

monatherus, A. Rich. Tent. Fl. Abyss. ii. 462.-Abyss. monostachys, Spreng. Pugill. ii. $9=$ foveolatus monastachyus, Steud. Syn. P1. Gram. $369=$ Ischaemum aristatum.

montanus, Koen. ex Trin. in Spreng. Neue Entdeck. ii $93=$ Chrysopogon montanus.

montanus, Nees, in Nov. Act. Nat. Cur. xix. Suppl. I. (1843) $188=$ micranthus.

montanus, Roxb. Hort. Beng. 82; Fl. Ind. i. $271=$

Chrysopogon pictus.

monticolus, Schult. Mant. iii. $665=$ Chrysopogon montanus.

Montufari, H. B. \& K. Nov. Gen. et Sp. i. $184=$ Trachypogon polymorphus.

Muehlenbergianus, Schult. Mant. ii. $455=$ argyreus.

multicaulis, Steud. Syn. Pl. Gram. 383=Arthraxon microphyllus.

multinervis, Hochst. ex Steud. 1. c. $\mathbf{3 7 4}=$ polyatherus. muricatus, Retz. Obs. iii. $43=$ squarrosus.

murinus, Steud. Syn. Pl. Gram. $377=$ Ischaemum murinum.

muticus, Linn. Sp. Pl. ed. II. $1482=$ Chloris petraea? muticus, Sleud. Syn. Pl. Gram. $374=$ Ischaemum muticum.

\section{ANDROPOGON :-}

Myosurus, Hack. in Mart. F1. Bras. ii. III. $300=$ hirtiflorus.

Myosurus, F. Presl, in Rel. Haenk. i. 337.-Mexico. nardoides, Nees, Fl. Afr. Austr. $116=$ A. Schoenan thus.

Nardus, Linn.Sp. Pl. 1046.-Reg. trop.

Nardus, Trin. in Spreng. Neue Entdeck, ii. $90=$ A. Schoenanthus.

Neesi, Kunth, Enum. Pl. i. 491.-Bras.

Neesii, Trin. in Mém. Acad. Pétersb. Sér. VI. ii. (1833) $263=$ tener.

nemophyllus, Steud. Syn. Pl. Gram. $377=$ Ischaemum fliforme.

nervatus, Hochst. in Flora, xxvii. (1814) $243=\mathrm{A}$, Schoenanthus.

nervosus, Rottl. in Ges. Naturf. Fr. Nete Schr. iv. (1と03) $218=$ Ischaemuin laxum.

Newtonii, Hack. in Bol. Soc. Broter. iii. (1885) 137.Angola.

niger, Kunth, Rev. Gram. i. $164=$ Sorghum vulgare,

nigritanus, Benth. in Hook. Niger F1. $573=$ squar. rosus.

nitens, Schreb. ex Steud. Nom. ed. II. i. $92=$ serratus. nitidus, Kunth, Rev. Gram. i. $166=$ serratus.

nodulibarbis, Hochst. ex Steud. Syn. Pl. Gram. $396=$ Chrysopogon Amottianus.

nodulosus, Hack. in Flora, 1xviii. (1885) 116.-Afr.

trop.
notopogon, Steud. Syn. Pl. Gram. $373=$ Spodiopogon angustifolius

nudus, Steud. 1. c. $383=$ Arthraxon ciliaris.

Nuttallii, Chapm. F1. S. Un. St. $580=$ Elionurus tripsacoides.

nutans, Linn. Mant. ii. $303=$ Anthistiria ciliata.

nutans, Linn. Sp. PI. $1045=$ Chrysopogon nutans

nutans, Muhl. Descr. Uber. 2 ¿ $4=$ avenaceus.

obliquiberbis, Hack. in Flora, 1xviii. (1885) 117.N. Caledon.

obtusifolius, Poir. Encyc. Suppl. i. $583=$ brevifolius.

obtusus, Nees, in Hook. \& Ain. Bot. Beech. Voy. 243 = annulaius.

obvallatus, Stend. Syn. Pl. Gram, 373=Spodiopogon angustifolius.

odoratus, Auct. ex Steud. Nom. ed. II. i. $92=$ squarrosus.

oliganthus, Hochst. ex Steud. Syn. Pl. Gram. 368.Ind. or.

oligostachyus, Chapm. F1. S. Un. St. $581=$ hirtiflorus.

Olivieri, Boiss. Diagn. Ser. I. v. $76=$ laniger.

orthos, Schult. Mant. ii. $455=$ foveolatus.

pachnodes, Trin. in Mém. Acad. Pétersb. Sér. VI. ii. (1.833) $284=$ A. Schoenanthus.

paleaceus, Steud. Syn. Pl. Gram. $376=$ Apocopis Royleanus.

pallidus, Kunth, Rev. Gram. i. 165=Chrysopogon Gryllus.

paniceus, Steud. Syn. P1. Gram. i. 375=Ischaemum intermedium.

paniculatus, Kunth, Enum. Pl. i. $494=$ condensatus.

paniculatus, Lam. Fl. Fr. iii. $633=$ Chrysopogon Gryllus.

panormitanus, Parl Fl. Ital. i. $140=$ pertusus.

papillipes, Hochst. ex A. Rich. Tent. Fl. Abyss. ii. 460. -Abyss.

papillosus, Hochst. ex A. Rich. l. c. 457.-Afr. trop.

parviflorus, Roxb. Hort. Beng. 82 ; Fl. Ind. i. $277=$ brevifolius.

parvispica, Steud. Syn. Pl. Gram. $397=$ Chrysopogon violascens.

patentivillosus, Steud. 1. c. $373=$ Ischaemum ciliare.

patulus, Moench, Meth. $180=\mathrm{A}$. Ischaemum.

pauciflorus, Salzm. ex Steud. Syn. Pl. Gram. $371=$ virginicus.

pectinatus, Steud. l. c. $369=$ Ischaemum pectinatum.

pedicellatus, Steud. 1. c. $394=$ serratus.

peduncularis, Kunth, Rev. Gram. i. 166.-Ind. or.

peduncularis, Baker, F1. Maur, 444=A. Alopecurus.

pendulus, Nees, ex Steud. Syn. Pl. Gram. 388=A. Nardus.

peninsulae, Steud. 1. c. $396=$ Chrysopogon Arnottianus.

pennatus, Willd. ex Steud. Nom. ed. II. i. $92=$ lanuginosus.

perforatus, Trin. ex Fourn. Mex. Pl. Enum. Gram. 59, ex Hemsl. Biol. Centr. Am. iii. 529 = saccharoides. 


\section{ANDROPOGON :-}

perfossus, Nees \& Meyen, ex Steud. Nom. ed. II. i. 92 =intermedius.

pertusus, Willd. $S p$. Pl. iv. 922-Sicil. ; As. et Afr. trop.; Austral.

petiolaris, Steud. Syn. P1. Gram. $398=$ Pollinia Lehmanni.

Petitianus, Balansa, in Bull. Soc. Bot. Fr. xix. (1872) $322=$ obliquiberbis

Petitianus, A. Rich. Tent. F1. Abyss. ii. $451=$ exilis. pilifer, Steud. Syn. P1. Gram. $373=$ pilosus.

pilosus, Klein, ex Willd. Sp. Pl. iv, 920.-Ind. or.

pilosus, Sieber, ex Kunth, linum. Pl. i. $514=$ Ischaemum latifolium.

piptatherus, Hack. in Mart. Fl. Bras. ii. III. 293.Bras.

plagiopus, Hochst. ex Stend. Syn. P1. Gram. $374=$ polyatherus.

platypus, Trin. in Mém. Acad. Pétersb. Sér. VI. ii. (1833) $261=$ Elionurus platypus

plumosus, Humb. \& Bonpl. ex Willd. Sp. Pl. iv. $918=$ Trachypogon polymorphus.

podotrichus, Hochst. ex Stend. Syn. Pl. Gram. $384=$ Heteropogon hirtus.

poecilotrichns, Hack. in Bol. Soc. Broter. iii. (1885) 138.-Afr. trop.

pogonanthus, Boiss. \& Bal, in Bull. Soc. Bot. Fr. v. (1858) $168=$ Spodiopogon pogonanthus.

Pohlianus, Hack. in Mart. Fl. Bras. ii. III. 304.Bras.

polyatherus, Hochst. ex A. Rich. Tent. Fl. Abyss. ii. 455.-Abyss.

polydactylon, Linn. Amoen. Acad. v. 412 ; Sp. Pl. ed. II. $1483=$ Chloris polydactyla.

polymorphus, Steud. Syn. Pl. Gram. 375=Ischaemum muticum.

polyneuros, Steud. 1. c. $385=$ A. Schoenanthus,

polyptychos, Steud. l. c. 380.-Zeylan,

polystachyus, Roxb. Hort. Beng. 82; Fl. Ind. i. $265=$ Heteropogon contortus.

polystichus, Hochst. ex Stend. Syn. Pl. Gram. $369=$ Heteropogon acuminatus.

Preslii, Kunth, Enum. Pl. i. $489=$ tener

Princeps, A. Rich. Tent. Fl. Abyss. ii. $470=$ Thelepogon elegans.

prionodes, Steud. Syn. Pl. Gram. 383 = Arthraxon lanceolatus.

procerus, F. Muell. Fragm. viii. $124=$ filipendulus.

procerus, $R$. Br. Prod. i. 202.-Austral.

productus, Regel, in Bulk. Acad. Pétersb. x. (1866) 378 Pollinia tenuis.

propinquus, Kunth, Enum. Pl. i. $502=$ Sorghum halepense.

prostratus, Linn. Mant. ii, $304=$ Anthistiria prostrata.

provincialis, Retz. Obs. iii. $43=$ Chloris radiata

provincialis, Lam. Encyc. i. 376.--Europ.; Am. bor.

proximus, Hochst. ex A. Rich. Tent. Fl. Abyss. ii. $464=$ A. Iwarancusa.

pruinosus, Nees, ex Steud, Syn. Pl. Gram. 388=A. Schoenanthus.

psendograya, Steud. l. co 365.-Zeylan.; China; Madag.

pseudohirtus, Steud. in Flora, xii. (1829) $471=$ A. Nardis.

pseudoischaemum, Nees, ex Steud. Syn. Pl. Gram. 380. -Ind. or.

pubescens, [Dryand. in] Ait. Hort. Kew, ed. I. iii. 423 $=$ Chloris ciliata.

pubescens, Visiani, in Flora, xii. (1829) I. Erg. 3= Heteropogon hirtus.

pubescens, Willd. ex Kunth, Enum. P1. i. $498=$ mollicomis.

pubiflorus, Fourn. Mex. FI. Enum. Gram. 57; ex Hemsl. Biol. Centr. Am. iii. 529 = hirtifolius.

pulchellus, D. Don, in Hook. Niger Fl. 571,-Afr. trop.

pumilus, Roxb. Hort. Beng. 7; Fl. Ind. i. 277.Ind. or.

punctatus, Roxb. 11. cc. $82,268=$ intermedius.

purpuruscens, Muhl。ex Willd. Sp. PI. iv. $913=$ scoparius.

purpureo-sericeus, Hochst. ex A. Rich. Tent. Fl. Abyss. ii. 469 - Abyss.

pusillus, Hook. f. in Gourn, Linn. Soc. vii. (1864) 233. -Afr. trop.

quadrivalvis, Linn. Syst. ed. XIII. $758=$ Anthistiri ciliata.

\section{ANDROPOGON :}

Qnartinianus, A. Rich. Tent. Fl. Abyss. ii. 469,Abyss.

quinqueplumis, Hochst. ex A. Rich. 1. c. $450=$ Chrysopogon serrulatus.

radicans, Lehm. Ind. Hort. Hamb. (1828); ex Kunth, Enum. Pl. i. $499=\mathrm{A}$. Ischaemum.

racemosus, Poir. ex Stend. Nom. ed. I. 412, in syn $=$ ramosus.

ramosus, Blanco, Fl. Filip. ed. I. $37=$ Ischaemum ciliare

ramosus, Forsk. Fl. Aegypt. Arab. 173.-Aegypt.; Arab.

Ravennae, Linn. Sp. Pl. ed. II. $1481=$ Erianthus Ravennae.

reconditus, Steud. Syn. Pl. Gram. $386=$ Gayanus.

rectirhachis, Fourn. Mex. Pl. Enum.Gram. 61; ex Hemsl. Biol. Centr. Am. iii. 529.-Mexico.

rectus, Steud. Syn. PI. Gram. $389=$ A. Nardus

refraclus, $R$. Br. Prod. i. 202.-Ins. Molucc. et Pacific.

Austral.

elictus, Steud. Syn. Pl, Gram. $377=$ Ischaemum muticum.

repens, Steud. 1. c. $374=$ Ischaemum muticum.

Retzii, Stend. 1. c. $375=$ Ischaemum ciliare.

rhizophorus, Stend. 1. c. $381=$ Spodiopogon albidus.

Riedelii, Trin. in Mém. Acad. Pétersb. Sér. VI. ii. (1833) 263 -Am austr.

Robertianus, Stend. Syn. Pl. Gram. $369=$ Ischaemum laxum.

rostratus, Trin. in Mém. Acad. Pétersb. Sér. VI. ii (1) 33) $261=$ Elionurus rostratus.

rottboellioides, Steud. Syn. Pl. Gram. $382=$ Rottboellia ophiuroides.

Roxburghianus, Schult. Mant. ii. $451=$ Dimeria ornithopoda.

Roxburghii, Nees, ex Stend. Syn. Pl. Gram. $395=$ A Nardus.

Royleanus, Steud. 1. c. $397=$ Chrysopogon Gryllus. rubens, Kunth, Rev. Gram. i. $164=$ Sorghum vulgare. rudis, Stend. Syn. Pl. Gram. $383=$ Arthraxon rudis. rufidulus, Steud. 1. c. $392=$ Chrysopogon avenaceus. rufispica, Steud. l, c. 379.- Java.

rufus, Kunth, Enum. Pl. i. 492-Afr. trop.; Bras,

nufus, Rich. ex Kunth, 1. c. $473=$ Saccharum cayennense.

rugosus, Stend. Syn. Pl. Gram. 376=Ischaemum rugosum.

Ruprechtii, Hack. in Flora, 1xviii. (1885) 126-Afr. trop.; Mexico.

saccharatus, Kunth, Enum. Pl. i. $502=$ Sorghum vulgare.

saccharatus, Roxb. Hort. Beng. 7 ; Fl. Ind. i. $274=$ Sorghum vulgare.

saccharoides, Sw. Prod. Veg. Ind. Occ. 26.-Am. temp. et trop.

sanguinarius, Schreb. Beschr. Graes. ii. 48.-Afr, hor. scaberrimus, Kunth, Enum. Pl. i. 504=Chrysopogon nutans.

scabriflorus, Rupr. ex Hack. in Mart. Fl. Bras. ii. Ins, 2:19.-Bras. ; Paraguay.

scandens, Roxb. Hort. Beng. 7; F1. Ind. i. $262=$ annulatus.

Schaffneri, Griseb. ex Fourn. Mex. Pl. Enum. Gram. 57: ex Hemsl. Biol. Centr. Am. iii. $529=$ hirti. folius.

schangulensis, Rupr. ex Steud. Syn. Pl. Gram. $369=$ Ischaemum laxum.

Schimperi, Hochst. ex A. Rich. Tent. Fl. Abyss. ii. 466. -Abyss.

schirensis, Hochst $l$ c 456 -Abyss.

Schlumbergerii, Fotrn. Mex. Pl. Enum. Gram. 59, ex Hemsl. Biol. Centr. Am. iii, 529.-Mexico.

Schoenanthus, Benth. Fl. Austral, vii. $584=$ A. Nardus,

Schoenanthus, Linn. Sp. Pl. 1046.-As, et Afro trop. et subtrop.

Schoenanthus, Thunb. Fl. Cap. i. 108; Wall. Pl. As. Rar. t. $2 \diamond 0=A$. Narclus.

Schottii, Rupr. ex Hack, in Mart. Fl. Bras, ii. III. 299. -Am. trop.

Schweinfurthii, Hack. in Flora, lxviii。 (1S85) 118.Afr. trup.

scoparius, Michx. Fl. Bor. Am, i. 57-Am. bor. Mexico.

scoparius, J. Presl, in Rel. Hacnk. i. $838=$ condensatus.

scrobiculatus, Kunth, Ènum. Pl. i. $507=$ Hetcropogon acuminatus.

\section{ANDROPOGON}

secundus, Kunth, Enum. Pl. i. 487=Trachypogon polymorphus.

secundus, Willd. ex Nees, Agrost. Bras, $364=$ Heteropogon contortus.

segaenensis, Steud. Syn. Pl. Gram. $367=$ Heteropogon acuminatus.

segetum, Steud. 1. c. $376=$ Ischaemum rugosum.

Sehima, Steud. 1. c. $369=$ Ischaemum laxum.

semiberbis, Kunth, Enum. Pl. i。 489.-Afro et Am. trop.

semisagittatus, Steud. Syn. Pl. Gram. 376=Ischaemum semisagittatum.

sennarensis, Hochst, in Flora, xxvii. (1844) $243=$ A. Iwarancusa.

sericeus, R. Br. Prod. i. 201.-Malaya; Austral

serratus, Miq. Ann. Mus. Bot. Lugd. Bat, ii. $290=$ Chrysopogon violascens.

serratus, Retz. Obs. v. 21 = caricosus.

serratus, Thunb. Fl. Fap. 41.-As. et Afro trop. Austral.

serrulatus, Link, Enum. Hort. Berol, i. 241=Ar thraxon lanceolatus.

setifolius, Kunth, Rev. Gram. i, 166.-Afr. austr.

setosus, Griseb. Cat. Pl. Cub. $235=$ Chrysopogon avenaceus.

sibiricus, Steud. Syn. Pl. Gram. 398= Spodiopogon sibiricus.

simillimus, Steud. 1. c. $373=$ Ischaemum ciliare.

simplex, Schum. Beskr. Guin. Pl. 49.-Afr, trop.

sinaicus, Del. Ind. Sem. Hort. Monsp. (1836); et in Ann. Sc. Nat. Sér. II. vii. (1837) 280 = Heteropogon hirtus.

Smithianus, Hook. fo. in fourn. Linn. Soc, vii. (1864 232.-Afr. trop.

Sorghum, Brot. Fl. Lusit. i. $88=$ Sorghum vulgare.

spathaceus, Trin. Fund. Agrost. $186=$ macrourus.

spathiforus, Kunth, Enum. Pl. i. 496.-Bras.

speciosus, Hort. Goett. ex Steud. Nom. ed. II. i. $93=$ saccharoides.

speciosus, Steud. Syn. Pl. Gram. $375=$ Rottboellia speciosa.

spicatus, Steud. Nom. ed. II. i. $98=$ Trachypogon polymorphus.

Sprengelii, Kunth, Rev. Gram。 i, $166=$ Chrysopogon montanus.

squamulatus, Hochst. in Flora, xxvii. (1844) $244=$ Gayanus.

squarrosus, Koen. ex Kunth, Enum. Pl. i. $126=$ Panicum abortivum et paludosum.

squarrosus, Linn. f. Suppl. 433.-Reg. trop.

stenophyllus, Roem. \& Schult. Syst. ii. $819=$ Trachy pogon angustifolius.

stipaeformis, Steud. Syn. Pl. Gram. $37 \pi=$ Dimeria ornithopoda.

stipoides, Cham. E Schlecht. in Linnaea, vi. (1831) 39 $=$ Chrysopogon Francavillanus.

stipoides, H. B. \& K. Nov. Gen. et Sp. i. $189=$ Chryso pogon avenáceus.

stipoides, Kunth, Enum. P1. i. 487=Trachypogon polymorphus.

stipoides, Steud. Syn. Pl. Gram. 368=Trachypogon polymorphus.

stipoides, Trin. in Mém. Acad. Pétersb. Sér. VI. ii. (1833) $288=$ Chrysopogon avenaccus.

striatus, Klein, ex Willd. Sp. Pl. iv. $903=$ Ischaemum laxum.

strictus, Host, Gram. ii. 2. t. $2=$ Erianthus IIostii

strictus, Roxb. Hort. Beng. 82; Fl. Ind. i. $265=$

foveolatus.

subglabrescens, Steud. Syn. PI. Gram. $893=$ Sorghum vulgare.

submembranaceus, Steud. l. c. 431.-Ins. Mascar.

submuticus. Steud. 1. c. $382=$ Arthraxon clliaris. subrepens, Steud. 1. c. $397=$ montanus.

subtilis, Stend. l. c. $396=$ Chrysopogon subtilis.

subulatus, I. Presl, in Rel. Hacnk. i. $\$ t l=$ Chrvsopogon aciculatus.

subunifoveolatus, Steud. Syn. Pl. Gram. $850=$ per tusus.

superciliatus, Hack. in Engl. Bot. Gahrb. vi. (15:5 23:, - Austral.: Timor.

Tabina. Steud. in Lechl. Berb. Am, Austr. $56^{\circ}=$ hirtiAorus.

tacasensis, Stcud. Syn. Pl. Gram. $369=1$ schaemum laxum.

tahikensis, Ilook, \& Arn. Bot. Becch. Voy, it2 tefractus. 


\section{ANDROPOGON :-}

Tamba, Hochst. ex Steud. Syn. P1. Gram. $385=$ lepidus.

tectorum, Schum. \& Thonn. Beskr. Guin. Pl. 49.Guinea.

tenellus, J. Presl, in Rel. Haenk. i. $385=$ brevifolins. tenellus, Roxb. Hort. Beng. 6; Fl. Ind. i. 259.Bengal.

tener, Kunth, Rev. Gram. ii, 565. t. 197.-Am. bor. et austr.

tenuiculus, Steud. Syn. Pl. Gram. $371=$ sericeus. tenuifolius, Steud. 1. c. $365=$ Ehonurus argenteus. tenuipedicellatus, Stend. 1. c. $393=$ australis? tenuirachis, Fourn. Mex. P1. Enum. Gram. 58; ex Hemsl. Biol. Centr. Am. iii. $529=$ saccharoides, tenuis, R. Br. Prod. i. $201=$ Heteropogon contortus. ternarius, Bertol. Bot. Misc. xi. $14=$ provincialis. ternarius, Desv. Opusc, $68=$ squarrosus,

ternarius, Michx. F1. Bor. Am. i. 57 =provincialis? ternatus, Nees, Agrost. Bras. ii. 326.-Am. austr. tetrastachyus, Ell. Sketch, i. 150=virginicus.

Thunbergii, Kunth, Rev. Gram. i. 166=Danthonia livida.

thymiodorus, Steud. Syn. P1. Gram. $365=$ Elionurus thymiodorus.

timorensis, Steud. 1. c. $376=$ Spodiopogon Blumii tomentellus, Steud. 1. c. $371=$ Gayanus?

Tong-Dong, Steud. 1. c. $375=$ Ischaemum rugosum. Torreyanus, Steud. Nom. ed. II. I. 93 = saccharoides. tortus, Willd. ex Steud. Nom. ed. II. i. $92=$ Trachy pogon polymorphus.

trachypus, Trin. in Mém. Acad. Pétersb. Sér. VI. ii (1833) $280=$ bracteatus.

trichozygus, Baker, in Fourn. Limn. Soc. xx, (1884) 300.-Madag.

tridentatus, Hochst. in Flora, xxvii. (1844) $246=$ Gayanus.

tridentatus, Roxb. Hort. Beng. 82 ; Fl. Ind. i. $261=$ Apocopis tridentata.

Trinii, Steud. Syn. P1. Gram, 395=Chrysopogon serrulatus.

tripsacoides, Trin ex Stend. Nom. ed. II. i. 92 ; et Syn. Pl. Gram. $364=$ Elionurus tripsacoides.

trispicatus, Schult. Mant. ii. $452=$ Pollinia argentea. tristachyos, Roxb. Hort. Beng. 6; F1. Ind. i. $261=$ Pollinia argentea

tristachyus, H. B. \& K. Nov. Gen. et Sp. i. $187=$ glaucescens.

triticeus, R. Br. Prod. i. $201=$ Heteropogon insignis

triticiformis, Stend. Syn. Pl. Gram. $376=$ Ischaemum triticeum.

tropicus, Kunth, Enum. Pl. i. $503=$ australis.

tropicus, Spreng. Syst. i. $287=$ serratus.

truchmenorum, Walp. Ann. iii. $801=$ Sorghum vulgare.

truncatus, Steud. 1. c. $368=$ Trachypogon polymorphus.

tumbackianus, Roxb. ex Kunth, Enum. Pl. i. 507, in syn.-Afr. austr.

timbuckianus, Steud. Nom. ed. II i. $93=$ praec

z mbrosus, Hochst. ex A. Rich. Tent. F1. Abyss. ii. 467 = lepidus.

undatus, Jacq. Coll. iii. $237=$ Oplismenus Jacquini.

undulatus, Pers. Syn. i. $105=$ annulatus.

urceolatus, Hack. in Flora, 1xviii. (1885) 115.-Afr. centr.

Urvilleanus, Steud. Syn. Pl. Gram. $376=$ Ischaemum Urvilleanum.

usorum, Steud. 1. c. $392=$ Sorghum vulgare.

Vachellii, Nees, ex Hook. \& Am. Bot. Beech. Voy.

$243=$ intermedius.

vaginatus, E1l. Sketch, 148 = virginicus.

vaginatus, J. Presl, in Rel. Haenk. i. $336=$ semiberbis.

velatus, Kunth, Enum. P1. i. 488=semiberbis.

venustus, Thw. Enum. Pl. Zevl. 367.-Zeylan.

versicolor, Nees, ex Steud. Syn. Pl. Gram. 388=A.

Schoenanthus.

verticillatus, Boj. Hort. Maurit. i. $57=$ squarrosus.

verticillatus, Roxb. Hort. Beng. 82 ; F1. Ind. i. $267=$ Chrysopogon verticillatus.

verticillatus, Schum. Beskr. Guin. Pl. $50=$ fulvibarbis. verticilliflorus, Steud. Syn. Pl. Gram. $393=$ Sorghum halepense?

vestitus, Steud.l.c. 378.-Bras.

villiferus, Steud. 1. c. $376=$ Ischaemum australe.

villosulus, Steud. 1. c. $397=$ Chrysopogon violascens.

villosus, Gilib. Exercit. ii. $522=$ A. Ischaemum.

\section{ANDROPOGON:-}

villosus, Lam. Fl. Fr. iii. $634=$ A. Ischaemum et provincialis.

villosus, Thunb. Prod. Pl. Cap. $20=$ Pollinia villosa. vimineus, Trin. in Mém. Acad. Pétersb. Sér. VI. ii (1833) $268=$ Pollinia imberbis

violaceus, Heyne, ex Steud. Syn. Pl. Gram. $414=$ Arthraxon ciliaris.

violascens, Nees, ex Steud. 1. c. $396=$ Chrysopogon violascens.

virens, Spreng. Syst. i. $287=$ Arundinella brasiliensis,

virgatus, Desv, in Ham. Prod. Ind. Occ. $9=$ spathiflorus.

virginicum, Linn. Sp. Pl. 1046.-Am. bor.

virginicus, Trin. in Mém. Acad. Pétersb. Sér. VI. ii. 1833) $269=$ leucostachyus

Wightianus, Steud. Syn. Pl. Gram. 395= Chrysopogon Wightianus.

Wrightii, Hack. in Flora, lxviii. (1885) 139.-Am. bor. xanthoblepharis, Trin. in Mém. Acad. Pétersb. Sér. VI. ii. (1833) 281.-Afr. trop.

Wrightii, Munro, ex Wright, in Sauv. Fl. Cub. 201. - Cuba.

Zeae, Roem. E Schult. Syst. ii. 818.-N. Granat

zeylanicus, Arn. ex Benth. Fl. Hongk. $423=$ A pseudograya.

zeylanica, Steud. Syn. P1. Gram. $397=$ Chrysopogon Arnottianus.

Zollingeri, Steud. l. c. 369.-Java.

ANDROSACE, [Tourn.] Linn. Syst. ed. I. (1735): Gen ed. I. 40 (1737). PRIMULACEAE, Benth. \& Hook. f. ii. 632 .

f. Hi. 632 .

Aretia, Linn. Sp. PI. ed. I. 141 (1753)

acaulis, Hort. ex Duby, in DC. Prod. viii. $52=$ septentrionalis.

acaulis, Otto, ex Duby, l.c. 55.-Sibiria.

acutifolia, Turcz. ex Steud. Nom. ed. II. i. $93=$ A. Chamaejasme.

affinis, Biroli, in Brugnat. Giorn. Fis. II. iii. (1820) 143. t. $6=$ obtusifolia

Aizoon, Duby, in DC. Prod. viii. 50.--Reg. Himal.; China.

alba, Duby, l. c. 55.-Am. bor.

albana, Stev. in Trans. Linn. Soc. xi. (1815) 410. t. 34.-As. Min. ; Caucas.

alismoides, Hornem. Hort. Hafn. i. $185=$ lactiflora.

alpina, Lam. Fi. Fr. iii. 642.-Europ.

altaica, C. Koch, in Linnaea, xxiii. (1850) 612.-Reg. altaic.

apennina, Huet, ex Nym. Consp. $60 \%=$ alpina.

aquatica, [Clairv.] Man. Herb. $58=$ Hottonia palustris. arachnoidea, Schott, Nyman \& Kotschy, Anal. Bot. $17=$ villosa

aretica, Cham. in Linnaea, i. (1826) 220.-Am. arct

Aretia, D. Dietr. Syn. i. $632=$ bryoides.

Aretia, Lap. Hist. Abr. Pl. Pyr. 91 =imbricata.

Aretia, Vill. Hist. Pl. Dauph. ii, 469,-Europ.

aretioides, Heer, ex Duby, in DC. Prod. viii. $51=$ obtusifolia

aretioides $x$, Kerner, in Oestr.Bot.Zeitschr. xxv. (1875) 159.-Europ

argentea, Lap. Hist. Abr. P1. Pyr. $92=$ imbricata.

arizonica, A. Gray, in Proc. Am. Acad. xvil. (1881-82)

221.-Am. bor.

armeniaca, Duby, in DC. Prod. viii. 52.-As. Min.

articulata, Schur, Enum. Pl. Transs. 551.-Europ

baikalensis, Fisch. ex Ledeb. Fl. Ross. ii. 19=lacti flora.

baikalensis, Schlecht. ex Roem. \& Schult. Syst. iv. 786 = ochotensis.

bidentata, C. Koch, in Linnaea, xxiii. (1850) $610=$ multiscapa.

Bocconi, Hort. ex Hornem. Hort. Hafn. i. $184=$ elongata.

brevifotia, Vill. Hist. Pl. Dauph. ii. $480=$ septentrionalis.

brigantiaca, Jord. \& Fourr. Brev. Pl. Nov, fasc. ii. $105=$ carnea.

Brueggeri $x$, faegg. ex Bruegg. in Fahresb. Naturf. Ges. Graub. Neue Fol. xxi1. (1879) p. xxix.-Helvet. bryoides, DC. Fl. Fr. iii. 440.-Helvet.

caespitosa, Lehm. ex Spreng. in Isis, (1817) 1288. n 162 t. 9.-Persia

cana, Willd. ex Steud. Nom. ed. II. i. 93.-Am austr.

capitata, Willd. ex Roem. \& Schult. Syst. iv. $786=$ A. Chamaejasme.

\section{ANDROSACE :-}

arinata, Torr. in Ann. Lyc. Nat. Hist. New York, i. (1824) $30=\mathrm{A}$. Chamaejasme.

carnea, Linn. Sp. Pl. 142.-Europ.

carnosula, Duby, in DC. Prod viii. $54=$ saxifragaefolia Chaixi, Gren. \& Godr. Fl. Fr, ii. 458.-Europ. Dahuria?

Chamaejasme, Bieb. Fl. Taur. Cauc. iii. $132=$ villosa.

Chamaejasme, Willd. Sp.Pl. i. 799.-Europ.; As. Min.

As, bor.

Chamaejasme, Wulf. in Jacq. Coll. i. 194=obtusifolia. Charpentieri, Heer, in Moritzi, Graub. Verz. 113.Helvet.

ciliata, DC. Fl. Fr. iii, 441.-Europ.

commutata, Schlecht. in Bot. Zeit. xiv. (1856) 521.As. temp.

cordifolia, Wall, in As. Res. xiii. (1820) 371.-Reg. Himal.

coronopifolia, Andr. Bot. Repos. t. $647=$ lactiflora.

Croftii, Watt, in Fourn. Linn. Soc. xx. (1884) 17.Reg. Himal.

cylindrica, DC. Fl. Fr. iii. 439.-Mont. Pyren.

dasyphylla, Bunge, in Ledeb. Fl. Alt. i. $218=$ villosa.

Diapensia, Vill. Hist. Pl. Dauph. ii. $472=$ bryoides.

diapensioides, Lap. Hist. Abr. P1. Pyr. 93=pyrenaica.

elegans, Duby, in DC. Prod. viii. $55=$ rotundifolia.

elongata, Linn. Sp. Pl. ed. II. App. 1668.-Europ.; Caucas.

elongata, Richards. App. Frank1. 1st Voy. $733=$ septentrionalis.

elongata, Pall. ex Ledeb. F1. Ross, iii. 21 = filiformis.

Escheri x, Bruegg. in Fahresb. Naturf. Ges. Graub. Neue Fol. xxiii-xxiv. (1880) 100.-Helvet.

farinosa, Spreng. Pugill. ii. $37=$ Primula farinosa

fasciculata, Willd. ex Roem. \& Schult. Syst. iv. $786=$ septentrionalis.

filiformis, Retz. Obs. ii. 10.-Persia ; As. bor. ; Am. bor foliosa, Duby, ex Deene. in Jacquem. Voy. Bot. 142. t. $146=$ sarmentosa

fotiosa, Klatt, in Linnaea, xxxii. (1863) $293=$ strigilosa. Friesii. Trautv. in Act. Hort. Petrop. ix. (1884) 7.N. Zemlaya.

frutescens, Lap. Hist. Abr. P1. Pyr. 92=cylindrica. geraniifolia, Watt, in fourn. Linn. Soc. xx. (1882) 17. -Reg. Himal.

glacialis, Hoppe, in Koch, Syn. ed. II. ii. $670=$ alpina. globifera, Duby, in DC. Prod. viii. 48.-Reg. Himal

globifera, Klatt, in Linnaea, xxxii. (1863) $292=$ microphylla.

globifera, Schur, Enum. Pl. Transs. $551=$ villosa.

Gmelini, Gaert. Fruct. i. 232.-Sibir.

Halleri, [Honck.] Verz. Gew. Tentschl. $561=$ carnea.

Halleri, Linn. Sp. Pl. 142.-Europ.

Hausmanni, Leyb. in Flora, xxxy. (1852) 101--Austria hedreantha, Griseb. Spicil. Fl. Rumel. ii. 3.-Thracia. Heerii, Hegetschw. ex Hausm. F1. Tirol. iii, 1474= Hausmanni

Heerii, Koch, Syn. F1. Germ. ed. II. $670=$ bryoides.

helvetica, All. Fl. Pedem, i. $91=$ bryoides.

hirtella, L. Dufour, in Act. Soc. Linn. Bord. viii. (1836) $100=$ pubescens

Hookeriana, Klatt, in Linnaea, xxxii. (1863) 293.Reg. Himal.

hybrida x, Kerner, in Oestr. Bot. Zeitschr. xxv. (1875) 159.-Europ.

imbricata, Lam. Fl. Fr. ii. 253.-Europ.

incana, Lam. Illustr, i. $432=$ villosa.

incisa, Wall. in Roxb. Fl. Ind. ed. Carey, ii. $16=$ rotundifolia.

intermedia, Ledeb. Fl. Ross. iii. $20=$ armeniaca.

Facquemontii, Duby, in DC. Prod. viii. $50=$ villosa.

Lachenalii, C. C. Gmel. Fl. Bad. i. $2=$ carnea.

lactea, Linn. Sp. Pl. 142.-Europ.

lactea, Vill. Hist. Pl. Dauph. ii. $476=$ obtusifolia,

lactea, Pall. Reise, ii. $618=$ septentrionalis.

lactiflora, [Fisch.] Hort. Gorenk. ed. I. (1808) 30.Sibir.

lactiflora, Kar. \& Kir. in Bull. Soc. Nat. Mosc. (1841) 728. n. $717=$ septentrionalis.

Laggeri, Huet, in Ann. Sc. Nat. Sér. III. xix. (1853) 254.--Europ.

lanuginosa, Wall. in Roxb. Fl. Ind.ed. Carey, ii. 15.Reg. Himal.

Lehmanni, Wall. Cat. n. 617.-Reg. Himal

Lehmanniana, Spreng. in Isis, (1817) $1289=\mathrm{A}$ Chamaejasme.

linearis, R. Grah. in Edinb. N. Phil. Journ. (Apr.-June, 
ANDROSACE:

longifolia, C. Koch, in Linnaea, xxiii. (1850) $610=$ albana.

longifolia, Turcz. in Bull. Soc. Nat. Mosc. v. (1832) 202.-Mongolia.

longiscapa, C. Koch, in Linnaea, xxiii. (1850) $611=\mathrm{A}$. Chamaejasme.

longiseta, Schur, in Verh. Siebenb. Ver. Naturw. iv. (1853) $61=$ obtusifolia.

lutea, Lam. F1. Fr. ii. $253=$ Douglasia Vitaliana. macrantha, Boiss. \&o Huet, Diagn. Ser. II. iii. 119.Armen.

macrocarpa, Ledeb. ex Duby, in DC. Prod. viii. 55, nomen.-Sibir.

Mathildae, Levier, in Nuov. Giorn. Bot. ix. (1877) 43 =alpina.

maxima, Linn. Sp. Pl. 141.-Europ.; Oriens; As. et Afr. bor.

microphylla, Hook. f. Fl. Brit. Ind. iii. 498,-Reg. Himal. ; Chin.

mucronifolia, Watt, in Fourn. Linn. Soc. xx. (1884) 17.--Reg. Himal

multiflora, Lam. FI. Fr. ii. $252=$ septentrionalis multiflora, Steud. Nom. ed. II. i. $94=$ imbricata.

multiscapa, Duby, in DC. Prod. viii. 51.-As. Min.; Syria.

muscoidea, Duby, l. c. 48.-Reg. Himal.

nana, Hornem. Hort. Hafn. i. $184=$ elongata.

neglecta, Cleve, in Bull. Soc. Nat. Mosc. xlv. (1872) I.

430 - Mont. Ural.

obovata, Wall. ex Duby, in DC. Prod. viii. $35=$ Primula floribunda.

obtusifolia, All. Fl. Pedem. i. 90. t. 46. f. 1.-Europ.

obtusifolia, Willd, ex Ledeb. F1. Ross, iii, $18=$

A. Chamaejasme.

occidentalis, Pursh, Fl. Am. Sest, i. 137.-Am, bor.

ochotensis, Willd. ex Roem. E Schult. Syst. iv. 786.Sibir.

odoratissima, Schreb. Dec. Pl. Min. Cogn. 7. t. $4=$ villosa.

olympica, Boiss. Diagn. Ser. I. iv. $37=$ villosa

orbicularis, Roem. \& Schult. Syst, iv, 816, Ind.= Gmelini.

Pacheri, Leyb. in Flora, xxxvi. (1853) 585=alpina.

parviflora, Jacq. ex Duby, in DC. Prod. viii. $54=$ rotundifolia.

patens, Wright, ex A. Gray, in Mem. Am. Acad. N.S.

vi. $(1858-9) 401=$ saxifragaefolia.

pauciflora, Vill. Hist. Pl. Dauph. ii. $477=$ obtusifolia

pedemontana, Reichb Ic. F1. Germ. xvii. $48=$ obtusifolia.

pedunculata, [Clairv.] Man. Herb. 57.-Europ.

penicillata, Schott, Nyman \& Kotschy, Anal. Bot. 18 = villosa.

pennina, Gaud. Fl. Helv, ii. $108=$ alpina.

pleiocarpa, Walp. Ann, iii. $7=$ seq.

pleioscapa, C. Koch, in Linnaea, xxiii. (1850) $611=$ armeniaca.

primulina, Spreng. Syst. iv. Cur. Post. $56=$ Primula pusilla.

primuloides, D. Don, Prod. $81=$ Primula pusilla.

primuloides, Duby, in DC. Prod. viii. $51=$ sarmentosa.

primuloides, Moench, Meth. Suppl. 152=Primula cortusioides.

puberula, Jord. \& Fourr. Brev. Pl. Nov. fasc. ii. $105=$ carnea.

pubescens, DC. Fl. Fr. iii. $438=$ alpina.

pyrenaica, Lam. Illustr. i. 432.-Pyren.

radiata, Lehm. in Roem. \& Schult. Syst. iv. $164=$ filiformis.

Reverchoni, Jord. \& Fourr. Brev. Pl. Nov. fasc. ii. 105 = carnea.

rosea, Jord. \& Fourr. 1. c. $104=$ carnea.

rotundifolia, Hardw. in As. Res. iv. (1795) 350.-Reg, Himal. ; China.

rotundifolia, Lehm. ex Roem. \& Schult. Syst. iv. 165 Gimelini.

rotundifolia, Sm. Exot. Bot. ii. $107=$ saxifragaefolia. rugosa, [Clairv.] Man. Herb. $57=$ Douglasia Vitaliana. sarmentosa, Wall. in Roxb. Fl. Ind. ed. Carey, ii. 14. - Reg. Himal.

saxifragacfolia, Bunge, Enum. Pl. Chin. Bor, 53.(hina.

Selago, Hook. f. \& Thoms, ex Watt, in Gourn. Linn. Soc. xx. (1882) 18.-Reg. Himal.

sempervivoides, Facquem. ex Duby, in DC. Prod. viii. 50.-Reg. Himal.; Mongol.

\section{ANDROSACE :-}

septentrionalis, Linn. Sp. Pl. 142.-Europ.; Caucas.;

As. et Am. bor.

spathulata, Cav. Ic, v. $56=$ Samolus spathulatus.

spatulata, Steud. Nom. ed. II. i. $93=$ praec.

stricta, Hartm. ex Duby, in DC. Prod. viii. $44=$

Primula stricta.

strigilosa, Franch. in Bull. Soc. Bot. Fr. xxxii. (1885) 10.-China.

tomentosa, Schlecht. ex Duby, in DC. Prod. viii. $47=$ imbricata:

triflora, Adans. in Mém. Soc. Nat. Mosc. y. (1817) 89 -Sibir.

valerianoides, Lehm, ex Spreng. in Isis, (1817) $162=$ albana.

villosa, Hook. f. \& Thoms. in Hook, f. Fl. Brit. Ind, iii. $498=$ microphylla.

villosa, Jacq. Fl. Austr, t. $352=\mathrm{A}$. Chamaejasme

villosa, Linn. Sp. Pl. 142.-Europ.; Oriens; As. temp. villosa, S. G. Gmel. It. ii. $196=$ maxima

Vitaliana, Lap. Hist. Abr. Pl. Pyr. 94=Donglasia Vitaliana.

Wiedemanni, Boiss. Fl. Orient. iv. 16.-Anatol.

Wulfeniana, Sieber, ex Koch, Syn. Fl. Germ. ed. II. ii. $670=$ hedreantha.

ANDROSAEMUM, [Tourn.] ex Adans. Fam. ii. 444 $(1763)=$ Hypericum, Linn

calycinum, Presl, ex Steud. Nom. ed. II. i. $94=\mathrm{H}$ calycinum.

Cambessedesii, Coss. ex Nym. Consp. 131.-Ins. Balear. foetidum, Spach, ex Willk. \& Lange, Prod. iii. $589=$ H. hircinum.

grandifolium, Reichb. Ic. Fl. Germ. xvi. 70,-Europ. hircinum, Spach, Hist. Vég. Phan. v, $419=\mathrm{H}$. hircinum. officinale, All. Fl. Pedem, ii. $147=\mathrm{H}$. Androsaemum. parviflorum, Spach, in Ann. Sc. Nat. Sér. II. v. (1836) $361=$ H. elatum

pyramidale, Spach, Hist. Vég. Phan. v. $417=\mathrm{H}$ elatum.

vulgare, Gaert. Fruct. i. 282, t. $59=\mathrm{H}$. Androsaemum. Webbianum, Spach, Hist. Vég. Phan. v, $418=\mathrm{H}$ grandifforum.

xylosteifolium, Spach, 1. c. $420=\mathrm{H}$. inodorum.

ANDROSCEPIA, Brongn. in Duperr. Voy. Coq. Bot. 77 (1829) = Anthistiria, Linn. (Gram)

Anathera, Anderss. in Nov. Act. Upsal. Ser. III. ii. (1856) $249=$ Anth. Anathera.

Barteri, Anderss. ex Oliver, in Trans. Linn. Soc. xxix. (1875) $176=$ Anth. Barteri

gigantea, Brongn. in Duperr. Voy. Coq. Bot. $78=$ Anth. gigantea.

tremula, Anderss, in Nov. Act. Upsal. Ser. III. ii. (1856) $247=$ Anth. tremula.

ANDROSEMUM, Neck. Elem. ii. 395 (1790)= praec.

ANDROSTEMMA, Lind1. Swan Riv. App. 46 (1839) = Conostylis, R. Br. (Haemodor.).

juncerm, Lindl, l, $\mathrm{c} .=\mathrm{C}$. Androstemma.

ANDROSTEPHIUM, Torr, in Bot. Mex, Bound. 218 (1858). LILIACEAE, Benth. \& Hook. f. iii. 801 breviflorum, S. Wats. in Amer. Natural. vii. (1873) 303.-Utah.

violaceum, Torr. in Bot. Mex. Bound. 219.-Texas.

ANDROSTOMA, Hook. f. Fl. Antarct. i. 44. t. 30 $(1845)=$ Cyathodes, Labill. (Orchid.).

empetrifolia, Hook, f. l, c. = C. empetrifolia.

ANDROSTyLIUM, Miq. in Nat. Verh. Wet. Haarl. vii. (Stirp. Surin.) 93 (1851)=Clusia, Linn. (Guttif.).

Fockeanum, Miq. 1. c. = C. Fockeana.

ANDROSYNE, Salisb. Gen. Pl. Fragm. 61 (1866). An Dioscorea, Linn. 'Genus duhium, prope Paridem. - Cf. Benth. \& Hook. f. Gen. iii. 762.

gracilis, Salisb. 1. c.-Ins. Nicob.

ANDROTRICHUM, Brongn in Dupers. Voy. Coq Bot. $17 \%+32$ (1829). CYPERACEAE, Benth. \& Hook. f. iii. 1046

Comostemus, Nees, in Linnaea, ix. (1884) 283 polycephalum, Brongr. b. $c_{\text {. }}$-Bras.
ANDROTROPIS, R. Br. ex Wall. Cat, n. 8398 (1847) Acranthera, Arn. (Rubiac.)

tomentosa, R. Br, ex Wall. 1. $c_{\circ}=$ Acranth, tomentos?

ANDRYALA, Linn. Gen。ed. I, 238 (17:37), COM

POSITAE, Benth. \& Hook. f. ii. 517.

ErIophorus, Vaill, ex DC. Fl. Fr. iv. 36 (1808)

FoRnEUM, Adans. Fam. ii. 112 (1763).

Rothia, Schreb. Gen. PI. 531 (1791)

Voigtia, Roth, in Roem. \& Ust. Mag. iv. (x.) 17 $(1790)$

aestivalis, Pomel, Nouv. Mat. Fl. Atl. 259 (err. typ. oestivalis),-Afr. bor

Agardhii, Haensel. ex DC. Prod. vii. 244.-Hispan

allochroa, Hoffmgg. E Link, Fi. Port. ii, 154.-

Hispan.

arenaria, Boiss. \& Reut. Pugill. PI. Hispan, $71=$

integrifolia.

aurea, Scop. Ann. ii. Hist. Nat. (1769) $58=$ Crepi: aurea.

Bourgeauii, Sch. Bip. ex Webb. \& Berth. Phyt. Canar. ii. $417=$ pinnatifida

candidissima, Desf. Cat. Hort. Par. ed. III. 399= varia.

cheiranthifolia, L'Hérit. Stirp. Nov. 35. t. 18=varia.

cheiranthifolia, Link, ex Steud. Nom. ed. II. i, $94=$ pinnatifida.

chondrilloides, Scop. Fl. Carn. ed. II. ii. 115.-Eurol. coronopifolia, Hoffmgg. \& Link, Fl. Port. ii. 155 pinnatifida.

corymbosa, Brot. Fl. Lusit. i. $337=$ nigricans.

corymbosa, Lam. Hllustr. iii. t. $657=$ sinuata

cossyrensis, Guss. F1. Sic. Syn. ii. 407 = dentata.

crithmifolia, Ait. Hort. Kew. iii. 129.-Ins. Canar.

dentata, Sibth. \& Sm. Fl. Graec, t. 811.-Reg. Mediter

denudata, Soland, ex Lowe, Man. Fl. Mad. i. 563

cheirantbifolia,

diffusa, Jan, ex DC. Prod. vii. $246=$ integrifolia

dissecta, Hofmgg. E' Link, Fl. Port. ii. 153.-Hispan.

Ficalheana, Daveau, in Bolet. Soc. Brot. i. (1883) 4"?

51.-Lusit.

floccosa, Pomel, Nouv. Mat. Fl, Atl. 3.-Afr. bor.

glandulosa, Lam. Encyc. i. $154=$ varia

gomeraea, Sch. Bip. ex Webb \&c Berth. Phyt. Canar. ii. $417=$ pinnatifida

incana, DC. Fl. Fr. Suppl. $445=$ ragusina

integrifolia, Linn. Sp. Pl. 808.-Keg. Mediter

integrifolia, Ucria, Hort. Panhorm. 336, ex Guss. Fl

Sic. Syn , ii $404=$ Hieracium crinitum.

laciniata, Lam. Encyc. 1. $153=$ ragusina.

lanata, Habl. Taur. 155 = Leontodon biscutellaefolins.

lanata, Linn. Cent. i. n. 57 , in Amoen. Acad. iv. $288=$

Hieracium andryaloides,

Lanata, Vill. Hist. Pl. Dauph, iii. $65=$ integrifolia

lanata, Sibth. \& Sm. Prod, ii. $141=$ Hieracium pan= nosum.

laxiflora, DC. Prod. vii. 246.-Hispan.; Marocc.

lyrata, Pourr. in Mém. Acad. Toul. iii. (1788) $308=$ ragusina.

macrocephala, Boiss. ex DC. Prod. vii. $244=$ ragusina.

malacitana, Haensel. ex Willk. in Willk. \& Lange

Prod. ii. $272=$ laxiflora.

mogadorensis, Coss. ex Hook. f. Bot. Mag. t. 6010.Marocc.

mollis, [Asso] Mant. Stirp. Arag. 175=integrifolia.

nemausensis, Vill. Prosp, $37=$ Pterotheca sancta

nigricans, Poir. Voy. Barb. ii. 228.-Numidia.

nudicaulis, Lam. Encyc. i. $154=$ Pterotheca sancta.

oestivalis, err. typ. vide aestivalis.

parviflora, Lam. Fl. Fr. ii. 117 =integrifolia

pinnatifida, Ait. Hort. Kerv. ed. I, iii. 129,-lns. Canar.

pontana, Vill. Prosp, $37=$ Crepis montana.

ragusina, Linn. Sp. Pl. ed. II. 1136.-Keg. Mediterm.

ramosissima, Boiss. Elench. $63=$ ragusina,

Reboudiana, Pomel, Nonv. Mat. F\%. A\%. 259.-Afr. bor.

robusta, Lowe, in Trans, Camb. Phil. Soc. vi. (1S3s

repr. 18 -Ins. Mnder.

Rothia, Pers. Syn. ii. 378,-Hispan.

runcinata, Pers. 1. c. = integrifolia.

sinuata, Linn. Sp. Pl. sos=intestifolia

sinuata, Reichb. Ic. Fl. Germ. xiץ. 1486 = integrifolia,

sinuata, Willk. \& Lange, Prod. ii. 271= mgusina.

tenuifolia, $D C$. Prod, vii. 245 . - Sicilia.

temuifolia, Tenore, Fl. Neap. syll. App. Ү. $\$ 9=$

clentata.

tomentosa, Salisb. Prod. $182=$ ragusina. 


\section{ANDRYALA :-}

tomentosa, Scop. Delic. Insub, 11. 12=varia undulata, J. \& C. Presl, Delic. Prag. $113=$ integrifolia.

uniflora, Schrank, Baier. F1. ii. $343=$ integrifolia. varia, Lowe, ex DC. Prod. vii. 245.-Ins. Mader. Webbiana, Sch. Bip. ex Webb \& Berth. Phyt. Canar. iii. $417=$ pinnatifida

ANDRZEIOWSKIA, Reichb, Pl, Crit. j, 15. t. 13 (1837) CRUCIFERAE, Benth. \& Hook f i 70 Macroceratium, Reichb. Consp. 184 (1828). Cardamine, Reichb. l. c.-Pontus; Syria.

ANECHITES. Griseb. F1. Brit. W. Ind. 410 (1864) APOCYNACEAE, Benth. \& Hook, f. ii. 707. adglutinata, Miers, Apocyn. S. Am. 236.-Ind. occ. Asperuginis, Griseb. Fl. Brit. W. Ind. 410,-Cuba circinalis, Miers, Apocyn. S. Am. 236.-Ind. occ. lappulacea, Miers, l. c. 237.-Ins. S. Doming. revoluta, Miers, l. c. 238.-Bras.

thomasiana, Miers, $l . c .237$.-Ins. S. Thomae.

ANECIO, Neck. Elem. i. $28(1790)=$ Senecio, Linn. (Compos.)

ANECOCHILUS, Blume, Bijdr. 411. t. $15(1825)=$ Anoectochilus, Blume (1828) (Orchid.).

ANECTOCHILUS, Blume, Orch. Archip. Ind. 44 (1858) $=$ Anoectochilus, Blume (Orchid.).

ANEILEMA, R. Br. Prod. 270 (1810). COMMELINACEAE, Benth. \& Hook. f. iii. 849

Amelina, C. B, Clarke, Commel. et Cyrt. Beng. 38 t. $26(1874)$.

ANilema, Kunth, Enum. Pl. iv. 64 (1843).

APHylax, Salisb. in Trans. Hort. Soc. i. (1812) 271.

Bauschia, Seub, in Vidensk. Meddel. Kjoeb. 123 (1872).

Dichoespermum, Wight, Ic. vi. 31, t. 2078 (1853)

Dictyospermum, Wight, 1. c. 29. t. 2069 (1853).

Dilasia, Rafin. F1. Tellur. iv. 122 (1836).

LAmprontrhyros, Hassk. in Peters, Mossamb. Reise, Bot. 529 (1863)

Murdannia, Royle, Illustr. Bot. Himal. 403. t. 95 (1839)

Prletocarpus, Hassk. in Flora, xlix. (1866) 212.

Prionostachys, Hassk. 1. c.

RHOPALEPHORA, Hassk, ex Mohl \& Schlecht, in

Bot. Zeit. (1864) 58

Strep'Tylis, Rafin. Fl. Tellur. iv. 122 (1836).

TAlipulis, Rafin. 1. c. ii. 17 (1836)

acuminatum, Benth. Fl. Austral, vii. $85=1$ laxum.

acuminatum, R. Br. Prod. 270.-Austral.

adhaerens, Kunth, Enum. Pl. iv. $72=$ aequinoctiale.

aequinoctiale, Kunth, l. c.-Afr. trop.

affine, R. Br. Prod. 271= oramineum.

africanum, Beauv. Fl. Owar. ii. 57. t. $93=$ Floscopa africana

anthericoides, R. Br. Prod. $271=$ gramineum

asperum, Buch.-Ham. ex Wall. Cat. sub n. $5204=$

Floscopa scandens.

beninense, $K u n t h$, Enum. Pl. iv. 73.-Afr. trop.

biflorum, R. Br. Prod. 270.-Austral

bracteolatum, Mart. in Flora, xxiv. (1841) II. Beibl. ii. $59=$ ovato-oblongum.

brasiliense, C. B. Clarke, in DC. Monog. Phan. iii. 225. -Bras.

calandrinoides, F, Muell. Fragm ix, 191-Austral

canaliculatum, Dalz. in Hook. Kew Joum. iii. (1851)

$137=$ spiratum

compressum, Dalz. 1. c, $138=$ nudiflorum.

conspicuum, Kunth, Enum, Pl. iv. 69.-Ind, or.

cordatum. Buch.-Ham. ex Wall. Cat. sub n. $5223=$

Commelina herbacea

crispatum, R. Br. Prod. $270=$ Pollia crispata

crocea, Griff. Notul. iii. $235=$ ochraceum.

cymosum, Kunth, Enum. Pl. iv. 69 = Floscopa scandens debile, Wall. Cat. n. $5215=$ nudiflorum

densiflonum, Kunth, Enum. Pl. iv, 69 =Floscopa scandens.

diandrum, Buch.-Ham, in Wall. Cat, n, 5211=nudiflorum.

didymum, Buch.-Ham. 1. c. n. $5202=$ Commelina didyma.

didymum, Seem. Bot. Voy. Herald, $422=$ Pollia sorzogonensis.

\section{ANEITEMA :-}

dimorphum, Dal.z. in Hook. Kew fourn. iii. (1851) 138 - Ind or.

dimorphum, Thw. Enum. P1. Zeyl. $322=$ zeylanicum

divergens, C. B. Clarke, Commel. et Cyrt. Beng. 28. t. 16.-Ind. or

diversifolium, Hassk. in Miq. Pl. Jungh. $142=$ nudiflorum.

Dregeanum, Kunth, Enum. Pl. iv. 73.-Afr. austr.

Ehrenbergii, C. B. Clarke, in DC. Monog. Phan. iil. 229.-Afr. trop.

elatum, Dalz. in Hook. Kerv Fourn. iii. (1851) 137 -Ind. or.

elatum, Kunth, Enum. Pl. iv. $70=$ herbaceum

ensifolium, Wight, Ic. Pl. Ind. Or. t. $2072=\mathrm{gi}$ ganteum

esculentum, Wall. Cat, n, 5208,-Ind, or

esculentum, Wall, 1. c. litt. C. (nec A. B. $)=$ sinicum.

fliforme, Buch.-Ham. Wall. 1. c. n. $5209=$ vaginatum.

filipes, Mart. in Flora, xxiv. (1841) II. Beibl. ii. $59=$ geniculatum

floribundum, Hook. \& Am. Bot. Beech. Voy, $311=$ Leptorhoeo filiformis.

foliosum, Hassk. in Miq. Pl. Jungh. $144=$ nudiflorum.

Forskalei, Kunth, Enum. Pl. iv. 71.-Arab

Gardneri, Seub. in Mart. Fl. Bras. iii. 259.-Bras

giganteum, R. Br. Prod. 271.-Austral.

glaucum, Thw. ex C. B. Clarke, in DC. Monog. Phan.

iii. 200.-Zeylan.

gracile, C. B. Clarke, l. c. 228.-Afr. occ.

gramineum, R. Br. Prod. 270.-Austral.

Hamiltonianum, Wall. Cat. n. 5222.-Assam.

herbaceum, Wall.l.c. n, 5223. - Ind, or.; Malaya.

herbaceum, Wall. 1. c. n. $8223=$ protensum

hirtum, A. Rich. Tent. Fl, Abyss. ii. 343.-Abyss.

hispidum, D. Don, Prod. $45=\mathrm{Floscopa} \mathrm{scandens.}$

Hookeri, C. B. Clarke, Commel. et Cyrt. Beng. 28. t 17.- - Ind, or

japonicum, Kunth, Enum. Pl. iv. 70.-Japon.

Funghunianum, Miq. Fl. Ind. Bat. iii. $528=$ nudiflorum

Keisak, Hassk. Commel. Ind. 32.-Japon.

Koenigii, Wall. Cat. n. 5214.-Ind. or

anceolatum, Baker, ex C. B. Clarke, in DC. Monog

Phan. iii. $227=$ Schweinfurthii.

lanceolatun, Benth. in Hook. Niger Fl.546.-Afr. trop.

lancifolium, Griff. Notul, iii. $236=$ nudiflorum.

lanuginosum, Wall. Cat, n. 5221.-Ind. or

latifolium, Wight, Ic. Pl. Ind. Or. t. $2072=$ herbaceum

laxum, R. Br. Prod. $270=$ Commelina laxa.

laxiflorum, Benth. ex C. B. Clarke, in DC. Monog,

Phan. iil. $226=$ ovato-oblongum.

laxum, $R$. Br Prod. 270-Austral.

lineolatum, Kunth, Enum. Pl. iv. $69=$ herbaceum.

longifolium, Hook. Exot. F1. t. 204 = giganteum.

longifolium, Wall. Cat. D. $5213=$ divergens.

loriforme, Hassk. in Miq. Pl. Jungh. 143=nudiflorum.

Loureirii, Hance, in Seem. Fourn. Bot. vi. (1868) 250 .

- China.

macrophyllum, R. Br. Prod. $270=$ Pollia macrophylla. medicum, R.Br.l.c. 271.-China.

melanosticum, Hance, in Seem. Journ. Bot. vii. (1869)

$167=$ esculentum.

micranthum, Kunth, Enum. Pl. iv. 70.-Ind. or

minutum, Kunth, 1. c. $661=$ nudiflorum

monadelphum, R. Br. ex Kunth, l. c. 70.-Java

montanum, Thw. Enum. Pl, Zeyl. $322=$ zeylanicum.

montanum, Wight, in Wall. Cat. n. 5203.-Ind, or

nanum, Kunth, Enum, Pl. iv, $65=$ spiratum.

mzdicaule, Kunth, 1. c, $67=$ nudiflormm.

nudiflorum, F. Muell. Fragm. viii. $62=$ giganteum.

mudiforum, Miq. ex C. B. Clarke, in DC. Monog.

Phan, iii. 206, 215 = dimorphum, Koenigii

nudiflorum, R.Br. Prod. 271 . -Ind, or.

nudiflorum, Wall. Cat. n. $5224=$ vaginatum.

Nummularia, Miq. Fl. Ind. Bat. $535=$ spiratum

ochraceum, Dalz. in Hook. Kew fourn. ii. (1851) 135. - Ind, or.

oliganthum, Franch. \& Sav. Enum. Pl. Jap. ii. $522=$ Keisak.

ovalifolium, Hook. f. ex C. B. Clarke, in DC. Monog.

Phan, iii. 219.-Ind, or.

ovatum, Wall. Cat.n. 5206.-Malaya.

ovato-oblongum, Beauv. Fl. Owar. ii. 71. t. 104."-Afr. trop.

paniculatum, Wall. Cat. n. 5216.-Ind, or

paniculatum, Wight, Ic. Pl. Ind. Or. t. $2075=$ dimorphum.

\section{ANEILEMA:-}

pauciflorum, Dalz. in Hook. Kew Journ. iii. (1851) $136=$ vaginatum

pauciflorum, Wight, Ic. Pl. Ind. Or. t. 2077.Ind. or.

pedunculosum, C. B. Clarke, in DC. Monog. Phan. iii 228.-Afr. austr.

Petersii, C. B. Clarke, l. c. 225.-Afr. trop.

pilosum, Wall. Cat, n. $5219=$ Commelina pilosa

poaeoides, Seub. in Mart. Fl. Bras. iii. 259.--Bras.

protensum, Wall. Cat. n. 5218.-Ind. or.

protensum, Thw. Enum. Pl. Zeyl. $322=$ zeylanicum radicans, D. Don, Prod. F1. Nep. $45=$ nudiflorum reniforme, Buch.-Ham. in Wall. Cat. n. $5205=$ Pollia subumbellata.

rivulare, A. Rich. Tent. Fl. Abyss. il. $342=$ Floscopa rivularis.

scaberrimum, Kunth, Enum. Pl, iv. $69=$ protensum.

scapiflorum, Kostel. Allg. Med.-Pharm. Fl. i. 127.

Ind. or.

scapiflorum, Hook. f. \& Thoms, ex C. B. Clarke, in DC. Monog. Phan. iii, $203=$ divergens.

Schomburgkianum, Kunth, Enum. Pl. iv. 661.Bras.

Schweinfurthii, C. B. Clarke, in DC. Monog. Phan. iii 227.-Afr. trop

sclerocarpum, F. Muell. Fragm, viii. 61.-Austral.

secundum, Wight, Ic. Pl. Ind Or, t, 2074=sinicum.

secundiflorum, Kunth, Enum. PI. iv. $69=$ Pollia sorzogonensis

semiteres, Dalz. in Hook. Kew Journ. iii. (1851) $138=$ paniculatum.

sepalosum, C. B. Clarke, in DC. Monog. Phan. iii. 202 -Afr. trop.

serotinum, Don, ex C. B. Clarke, 1. c. $200=$ scapiflorum.

siliculosum, F. Mnell. Fragm. viii. 61 =acuminatum.

siliculosum, R. Br. Prod. 2\%0.-Austral.

simplex, Kunth, Enum. Pl. iv, $71=$ sinicum.

sinicum, Herb. Berol. ex C. B. Clarke, in DC. Monog. Phan. iii. $211=$ nudiflorum.

sinicum, [Lindl. in ] Bot. Reg.t. 659.-China

spectabile, Kurz, in Journ. As. Soc. Beng. xi. (1871) II $77=$ Loureirii.

spicatum, Wall. Cat. n. $521.7=$ Loureirii.

spiratum, R. Br. Prod. 271-Ind or

Tacazreanum, Hochst. ex A. Rich. Tent. Fl. Abyss. ii. $343=$ aequinoctiale

Tacazzeanum, Baker, in Trans. Linn. Soc. xxix. (1872 $163=$ lanceolatum.

terminale, Wight, Ic. PI. Ind. Or. t, $2076=$ nudiflorum.

Thomsoni, C. B. Clarke, in Fourn. Linn. Soc. Xv. (1877) 121.-Reg. Himal.

trichocoleum, Schau. in Nov. Act. Acad. Leop. Carol. xix. (1843) Suppl, i. 448 (Pl. Meyen.) = nudifforum.

triquetrum, Wall. Cat. n. 5220.-Ind. or.

tuberosum, Buch.-Ham. in Wall. Cat. n. $5207=$ scapiflorum.

umbrosum, Kunth, Enum. Pl. iv. $71=$ ovato-oblongum vaginatum, R. Br. Prod. 271.-Ind. or.

versicolor, Dals. in Hook. Kew Fourn. iii. (1851) 136. -Ind. or.

violaceum, F. Muell. ex C. B. Clarke, in DC. Monog Phan. ii. $205=$ gramineum.

vitiense, Seem. Fl. Vit. 314. t. 96.-Ins. Fiji.

Welwitschii, C. B. Clarke, in DC. Monog. Phan. iii. 229.-Angola.

zeylanicum, C. B. Clarke, l.c. 204.-Zeylan.

ANELASMA, Miers, in Ann. \& Mag. Nat. Hist. Ser. II vii. (1851) $42=$ Abuta, Aubl. (Menisp.).

concolor, Miers, in Ann. \& Mag. Nat. Hist. Ser. III xiv. (1864) $260=\mathrm{Ab}$, concolor.

Gardnerianum, Miers, 1. c. Ser. II. vii. (1851) $43=$ Ab. concolor.

guianense, Miers, 1. c. = Ab. concolor.

intaminatum, Miers, 1. c. Ser. III. xiv. (1864) 260.Bras.

jamaicense, Miers, ex Benth. in Journ. Linn. Soc. v. Suppl. ii. (1861) $50=$ Pachygone domingensis. laurifolium, Sagot, ex Benth. 1. $\mathrm{c}=\mathrm{Ab}$. concolor. laurifolium, Miers, in Ann. \& Mag. Nat. Hist. Ser III. xiv. (1864) 260.-Ins. S. Thomae.

Martianum, Miers, $1 . \mathrm{c} .=\mathrm{Ab}$. concolor.

minutiflorum, Sagot, ex Benth, in Journ. Linn. Soc. Suppl. ii. (1861) $50=$ Pachygone domingensis. 
ANFLASMA :-

pallidum, Miers, in Ann. \& Mag. Nat. Hist. Ser. III. xiv. (1864) $260=\mathrm{Ab}$, concolor.

Sellowianum, Miers, 1. c.-Bras.

Spruceanum, Miers, ex lenth. in Hook. Kew Jour iii. (1851) $116=\mathrm{Ab}$. concolor.

strumosum, Miers, in Ann. \& Mag. Nat. Hist. Ser. III. xiv. (1864) 260,-Bras.

urophyllum, Miers, l. c.-Bras.

ANEMAGROSTIS, Trin. Fund. Agrost. $128(1820)=$ Apera, Adans. (Gram.).

interrupta, Trin. 1. c. $129=$ Ap. interrupta.

Neesiana, Wight \& Arn. ex Stend. Syn. Pl. Gram. 115 = Panicum semialatum.

Spica-venti, Trin. Fund. Agrost: $129=$ Ap. Spicaventi.

tenella, Wight, ex Steud. Syn. Pl. Gram. 115 = Arundinella tenella.

ANEMANTHUS, Fourr. in Ann. Soc. Linn, Lyon, N. S xvi. (J868) $323=$ Anemone, Tourn. (Kantnc.) nemorosus, Fourr. 1. c. = Anemone nemorosa. ranunculoides, Fourr. 1. c. = Anemone ranunculoides,

ANEMARRHENA, Bunge, in Mém. Acad. Pétersb ii. (1831) 140 (Enum. Pl. Chin. Bor, 66). LILIA $C E A E$, Benth. \& Hook. f. iii. 782

asphodeloides, Bunge, $l l$.cc. - China.

ANEMIA, Nutt. in Ann. Nat. Hist. Ser. I. i. (1838) 136 =Houttuynia, Thunb. (Piperac.)

californica, Nutt. l. $c_{1}=\mathrm{H}$, californica.

ANEMIOPSIS, Endl. Gen. Suppl. I. 1374 (1841)= ANEMOPSIS, Hook. \& Arn.

ANEMITIS, Rafin. Fl. Tellur. iii, $87(1836)=$ Phlomis, Tourn. (Labiat.)

rigida, Rafin. 1. c. $=$ P. Herba-venti

ANEMONANTHEA, S. F. Gray, Nat. Arr. Brit. Pl. ii. 724 (1821) = Anemone, Linn. (Ranunc.) apennina, S. F. Gray, 1. c. $724=$ Anemone apennina nemorosa, S. F. Gray, l. c. $725=$ Anemone nemorosa. ranunculoides, S. F. Gray, I. c. $=$ Anemone ranunenloides.

ANEMONE, Linn. Syst. ed. I. (1735). RANUNCULACEAE, Benth. \& Hook. f. i. 4.

Anemanthus, Fourr. in Ann. Soc. Linn. Lyon, N. S. xvi. (1868) 323.

Anemonanthea, S. F. Gray', Nat. Arr. Brit. Pl. ii 724 (1821).

Anemonelia, Spach, Hist. Vég. Phan. vii. 240 (1839).

Barneoudia, C. Gay, Fl. Chil. i. 29. t. 1 (1845).

Flammara, Hill, Veg. Syst. xvi. 37 (1770).

HARTIANA, Rafin. Néogenyt. $2(1825)$

HePatica, Dill. ex Linn. Syst. ed. I (1735).

Homalocarpus, Schur, Enum. Pl. Transsyl. 3 $(1866)$.

Isopyrum, Adans. Fam. ii: 460 (1763)

OrIBA, Adans. 1. c. $459(1763)$

Preonanthus, Ehrh. Beitr, iv, 149 (1789)

Pulsatilla, [Toum.] Linn. Syst, ed. I (1735)

Syndesmon, Hoffmgg. in Flora, xv. (1832) Intell. 34

acanthifolia, Rich. Ind. Sem. Hort. Patav. (1841).Hab.?

aconitifolia, Michx. FI. Bor. Am. i. $320=$ dichotoma. aconitifolia, Turcz, in Bull. Soc. Nat. Mosc. (1840) $61=$ narcissifora.

acutiloba, Laws. Ranunc. Canad. 30-Am. bor.

acutipetala, Schleich. Cat. Pl. Helv, ed. III. $6=$ A

Pulsatilla.

aequinoctialis, Poepp. Fragm. Syn. 27.-Peruv.

affinis, G. Don, Gen, Syst. i. $21=$ pratensis.

alba, Gilib. Fl. Lituau. ii. $275=$ nemorosa.

alba, Juss. in Ann. Mus. Par. iii. (1804) 248, t. 20. f. $1=$ sylvestris.

alba, Goaty \& Pons, in Bull, Soc. Bot. Fr. xxx. (1883)

p. 1xxix = coronaria.

albana, Stev, in Mem. Soc. Nat. Mosc. iii. (1812) 264 -Oriens: As. bor.

alborosea, Gilib. Fl. Lituan. ii, $276=$ vernalis.

alchemillnefolia, E. Mey. ex Pritø. in Linnaea, xv.

1811) 758.-Afr, aust.

\section{ANEMONE :-}

alpina, Linn. Sp. Pl. 539,_Europ.; Caucas, ; Am. bor alpina, Scop. F1. Carn, ed. II. i. $384=$ baldensis. altaica, Fisch. ex Ledeb. Fl. Alt. ii. 362 - Sibir, a'taic ambigua, Turcz. ex Pritz. in Linnaea, xv. (1841) $601=$ albana.

angulosa, Lam. Encyc. i. 169,-Europ, or

anomala, Rafin. Fl. Ludov. 82 (quid ?).-Am, bor.

antucensis, Poepp. Fragm. Syn. 27-Chili.

apennina, Auct. Orient. ex Boiss, F1. Orient. i. $13=$ blanda.

apennina, Linn. Sp. Pl. 541.--Europ.

apiifolia, Scop. Fl. Carn. ed. II, i. $385=$ alpina,

arborea, Hort, ex Stend. Nom. ed. II. i. $95=$ capensis.

arctica, Fisch. in Linnaea, vi. (1831) $574=$ Richardsoni.

argentea, Raim. ex Wedd. Chlor. Andina, ii. $305=$ Ranunculus Raimondii.

armena, Boiss. Fl. Orient. i. 10_-As. Min.

baicalensis, Turcz. in Bull. Soc. Nat. Mosc. xv. (1842) 40, - As. temp.

baldensis, G Don, Gen Syst i. 18=multifida,

baldensis, Lam. Encyc. i. 614=alpina.

baldensis, Linn. Mant. i. 78.-Europ.

barbulata, Turcz. in Bull. Soc. Nat. Mosc. (1837) n VII. 149, - China.

Bauhini, Tausch, in Flora, xxv. (1842) 1. 69.-Europ.

Berlandieri, Pritz, in Linnaea, xy, (1841) $628=$ decapetala.

bicolor, Poepp. ex Pritz. 1. c. $624=$ decapetala.

biflora, DC. Syst. i. 201.-Oriens; Reg. Himal.

bilobata, Phil. f. Cat. P1. Vasc. Chil. $5=$ decapetala.

blanda, Schott \& Kotschy, in Oestr. Bot. Wochenbl. iv. (1854) 129,-Oriens.

Bogenhardiana, Pritz. in Linnaed, xy, (1841) 591.Europ.

borealis, Richards. in Frankl. Ist Journ. ed. II. App. $22=$ parviflora

Bungeana, Pritz. in Linnaed, xy. (1841) 603.Sibiria.

Burseriana, Scop. F1. Carn. ed. II. i. $385=$ alpina.

caelestina, Franch. in Bull. Soc. Bot. Fr. xxxii. (1885) 4.-China.

caerulea, DC. Syst. i. 203.-Sibir,

caerulea, Lam. Fl. Fr. iii. $318=$ appenina.

caffra, Harv, Gen. S. Afr. Pl. 9,-Afr, austr.

Campanella, Fisch. ex Ledeb. Fl. Ross. i. $22=$ albana. campaniflora, Stokes, Bot. Mat. Med. iii. $247=$ pratensis.

canadensis, Linn. Syst. ed. XII. iii. App. $231=$ dichotoma.

capensis, Lam. Encyc. i. 164.-Afr. austr.

caroliniana, Torr. \& Gray, Fl. N. Am. i. 12, partim = heterophylla.

caroliniana, Walt. Fl. Carol, $156=$ decapetala

caucasica, Willd. ex Rupr. FI. Caucas. $14=$ blanda

cernua, Thunb. Fl. Fap. 238.-Japon.

chilensis, Spreng. ex Eichl. in Mart. Fl. Bras. xiii. I $152=$ decapetala.

chinensis, Bunge, Enum. Pl. Chin. 2.-China.

coccinea, Jord. Diag. i. $57=$ coronaria.

collina, Salisb. Prod, $371=$ A. Pulsatilla

Commersoniana, DC. in Deless. Ic. i. $4=$ multifida.

coronaria, Linn. Sp. Pl. 539.-Reg. Mediterr.; Oriens. coronarioides, Hanry, Prod. Hist. Nat. Var, $142=$ coronaria.

crassifolia, Hook. Ic. Pl. t. 257.-Tasmania.

cuneata, Schlecht. in Linnaea, vi. (1831) $574=$ parviflora.

cuneifolia, Jnss. in Ann. Mus. Par. iii. (1804) 248.t $21=$ parviflora

curta, Wall. Cat. n. $4690=$ Clematis montana

cyanea, Risso, Fl. Nice, 7 = coronaria.

cylindrica, A. Gray, in Ann. Lyc. N. York, iii. (182836) 221.-Am. bor.

cynosurus, Griff. Notul. iv, $735=$ Rannnculus falcatus, dacica, Freyn, ex Borb, in Just, Bot. Jahresb. (18it 1076, err. typ. = Arabis dacica.

dahurica, Fisch. ex DC. Prod. i. 17.-As. temp. debilis, Fisch, ex Turco. in Bull. Soc. Nat. Mosc. xxvii. (1854) Ir. 274 [bis].--Sibir.

decapetala, J. F. Gmel. Syst, $871=$ Geum rivale decapetala, Arduini, Animad. alt. 27.-Am. bor, et austr.

decaphilla, Krock, Fl. Sit. ii. I. $235=$ Geum rivale deltoidea, Dougl. in Hook. Fl. Bor. Amer. i. 6. t. 3. A.-Am. bor. occ

demissa, Hook.f. \& Thoms. Fl.Ind, i. 23.-Reg. Himal,

\section{ANEMONE:-}

dichotoma, Linn. Sp. Pl. 540.-As, bor. Am, bor. discolor, Royle, Illustr. Bot Himal. $52=$ obtrisiloba dodecaphilla, Krock, Fl. Sil. ii. I. $235=$ Geum rivale. Drummondii, S. Wats. Bot. Calif. ii. 424.-Calif. dubia, Bell. App. F1. Perlem, $202=$ narcissiflora. dubia, Wall. Cat, n. $4697=$ rivularis.

elegans, Decne, in Rev. Hortic. (1852) 41. cum ic. = japonica.

elongata, D. Don, Prod. Fl. Nep. 194.-Reg. Himal.

eranthoides, Regel, in Act. Hort. Pétrop. viti. (1884) 691.-As. temp.

exigua, Maxim. in Bull. Acad. Pétersb. xxiii. (18\% 306.-China.

Falconeri, Thoms, in Hook. Ic. Pl. t. 899-Res Himal.

Fanninii, Harv. Gen. S. Afr. Pl. ed. II. 2, nomen.Natal.

fasciculata, Linn. Sp. Pl. $542=$ narcissiflora

fasciculata, Vahl, Symb. Bot. iii. $74=$ umbellata.

Fischeriana, DC. Prod. i. 20-Sibiria.

flaccida, Fr. Schmidt, Reisen Amurl. 103.-Japon. China.

flava, Gilib. Fl. Lituan. ii. $274=$ ranunculoides.

flavescens, Zucc. in Flora, ix. (1826) 1. $371=$ patens.

flemmensis, Scop. Ann. ii. Hist. Nat. (1796) 54 alpina.

formosa, Clark, Trav, ii. 145,-As, Min

fragifera, Wulf. in Jacq. Misc. ii. $55=$ baldensis

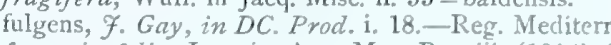

fumariaefolia, Juss. in Ann. Mus. Par. iii. (1804) 21 = triternata.

geraniifolia, Wall. Cat, n. $4693=$ rivularis.

gigantea, Raim. ex Wedd. Chlor. And. ii $304=$ Ranunculus giganiea.

glacialis, [Clairv.] Man. Herb. $180=$ Halleri,

Glazioviana, Urb. in Linnaea, xliii. (1880-82) 25.Bras.

globosa, Nutt. ex Pritz, in Linnaea, xv. (1841) $673=$

multifida.

Gmeliniana, Presl, ex Pritz, l. c. 697.-Sibiria

Gortschakowii, Kar. \& Kir. in Bull. Soc. Nat. Mosc

xv. (1842) $131=$ biflora.

Govaniana, Lindl. Bot. Reg. (1814) Misc. $45=$ polyanthes.

Govaniana, Wall. Cat. n. $4688=$ obtusiloba

gracilis, Fr. Schmidt, Reisen Amurl. 102.-Japon.

grandiflora, Hoppe, ex Reichb. F1. Germ. Excurs. 732 - alpina.

grassensis, Goaty \& Pons, in Bull. Soc. Bot. Fr. xxx. (1883) p. lxxviii = coronaria.

Grayi, Behr. ex Kellogg, in Bull. Calif. Acad. n. I. (1884) 5.-Calif.

Griffithii, Hook. f. \& Thoms. Fl. Ind. i. 24--Reg Himal.

groenlandica, O. F. Muell. in Fl. Dan. t. 566:

Coptis trifolia.

Hackelii, Steud. Nom. ed. I. $48=$ Halleri.

Halleri, All. Fl Pedem ii. 170.-Europ.

helleboriflora, Richter, ex Pritz. in Linnaea, xv. (1841) $598=$ pratensis.

helleborifolia, DC. Syst. i. 211.-Am, austr,

Hepatica, Linn. Sp. Pl. 538.-Europ.; Oriens; Am.

hepaticifolia, Hook. Ic. Pl.t. 1.-Chili

heterophylIa, Nutt. ex Torr. \& Gray, Fl. N. Am. i. 12 -Am. bor.

hirsuta, Gilib. Fl. Lituan. ii. $276=$ sylvestris.

hirsuta, Moench, Meth. Suppl. $105=$ virginiana.

hispida, Wall. Cat. n. $4694=$ rivularis.

hortensis, Linn. Sp. Pl. $540=$ stellata.

hortensis, Thore, Chl. Land. $238=$ fulgens

Hudsoniana, Richards. in Frank1. Ist Journ. ed. II. App. $22=$ multifida.

hybrida, Hort. ex Vilm. Fl. P1. Terre, ed. I. $74=$ japonica.

hybrida, Miq. ex Pritz, in Linnaea, xv. (18\$1) 573

Halleri.

incisa, Ledeb. Ind. Hort. Dorp. Suppl. (1824) I caerulea.

indeterminata, Banks, ex Walp. Rep. i. 23, sphalm. parviflora.

integrifolia, Humb. \& Bonpl. ex DC. Syst. i. 21\%.dm. merid.

intermedia, G. Don, Gen. Syst. i. 21 = patens.

intermedia, Huppe, ex Sieud. Nom. ed. I. $48,49=$ montana.

intermedia, Schult. Obs. $101=$ A. Pulsatilla. 


\section{ANEMONE}

intermedia, Winkl. ex Pritz. in Linnaea, xv. (1841) $652=$ A. nemorosa.

irregularis, Lam. Encyc, i, $167=$ dichotoma

isopyroides, Fuss. in Ann. Mus. Par. iii. (1804) 249 - Sibir.

Jamesoni, Hook. Ic. Pl. t. 670.-Ecuador.

Jankae, F. Schultz, in Flora, xxxix. (1856) 205.Transsyl.

japonica, Sieb. E Zucc. Fl. Fap. i. 15.-Japon.

lancifolia, Pursh, Fl. Am. Sept, ii. $386=$ nemorosa.

Zanigera, C. Gav, F1. Chil. i. $22=$ multifida

latifolia, Bell, ex Re, in Mem. Acc. Sc. Torin. xxxiii. (1829) $233=$ fulgens

Laxmanni, Steud. Nom. ed. II. i. $96=$ dichotoma

lepida, Jord. Diag. i. $59=$ hortensis.

lineariloba, Fisch. ex Pritz. in Linnaea, xv. (1841)

697.-Kamtschatka.

linearis, Schleich. ex Pritz. 1. c. $661=$ caerulea.

lobata, Pers. Syn. ii. $96=$ palmata.

longipetala, Schleich. ex Steud. Nom. ed. I. 48, $49=$ patens.

longiscapa, Wall. Cat. n. $4691=$ polyanthes.

Indoviciana, Nutt. Gen. Am. ii, $20=$ patens.

Iutea, Lam. Fl. Fr. iii. $318=$ ranunculoides.

macrorrhiza, Domb. ex Eichl. in Mart. Fl. Bras. xiij. I. $151=$ decapetala.

malvifolia, Linn. Sp. P1. $1197=$ palmata.

mexicana, H. B. E K. Kov. Gen. et Sp. v. 33Mexic.

micrantha, Hort. ex Steud. Nom. ed. II. i. $96=$ alpina micrantha, Klotzsch, in Bot. Ergeb. Waldem. Reise $133=$ obtusiloba.

millefoliata, Bertol. Amoen. 574=alpina.

minima, DC. Syst, i. $206=$ nemorosa.

minuta, Laxm. ex Sievers, in Pall. Neu. Nord. Beitr. vii. 153.-Sibir.

mollis, Wall. Cat. n. $4689=$ obtusiloba.

montana, Hoppe, ex Sturm, Fl. Deutschl. Heft xc n. 2.-Europ.; Caucas.

Mouansii, Hanry, ex Arduino, F1. Alp. Marit. $12=$ coronaria.

multifida, Poir. Encyc. Suppl. i. 364.-Am. bor. et austr.

myrrhidifolia, Vill. Prosp. $50=$ alpina

narcissiflora, Linn. Sp. Pl. 542.-Europ.; Oriens

As. bor. ; Am. bor.

narcissiflora, Hook. \& Arn. Bot. Beech. Voy. $121=$ multifida.

nemorosa, Linn.Sp.Pl.541.-Europ.; As. bor.; Am.bor. nemorosa, Schang. in Pall. Neu. Nord. Beitr. vi. $34=$ altaica.

nemorosa-alba, Crantz, Stirp. Austr. ed. I. fasc. ii. 101

ed. II. $121=$ nemorosa.

memorosa-lutea, Crantz, $1 . \mathrm{c}=$ ranunculoides.

nikoënsis, Maxim. in Bull. Acad.Pétersb. xviii. (1875) 275.-Japon.

nobilis, Jord. Diag. i. $57=$ coronaria

Nuttalliana, DC. Syst. i. $193=$ patens.

Nuttallii, Nutt. in Journ. Acad. Soc. Nat. Phil. v. (1825) $158=$ patens.

obsoleta, Hort. ex Steud. Nom. ed. II. i. $98=$ pratensis. obtusiloba, D. Don, Prod. 194.-Reg. Himal.

obtusiloba, Lindl. Bot. Reg. xxx. (1844) t. $65=$ scaposa occidentalis, S. Wats. in Proc. Am. Acad.xi. (1876) 121 -Calif.

ochotensis, Fisch. Hort. Gorenk. ed. II. (1812) 47 $=$ sylvestris.

ochroleuca $\times$, Bruegg. in Fahresb̆. Naturf. Ges. Graub II. xxiii-xxiv. (1880) 77.-Helvet.

octopetala, Patrin, ex Pritz. in Linnaea, xv. (1841)

697, nomen.-Hab.

Oenanthe, Ucria, in Roem. Arch. i. $69=$ coronaria.

palmata, Linn. Sp. Pl. 538.- Reg. Mediterr.

parviflora, Michx. Fl. Bor. Am. i. 319.-Am. bor.

patens, Hoppe, in Sturm, Deutschl. Fl. Heft xlvi. $1=$

Halleri.

patens, Linn. Sp. Pl. 538.-Europ.; Am. bor.

Pavoniana, Boiss. Diagn. Ser. II. i. 6 ; et ex Leresche $\mathcal{E}$

Levier, in fourn. Bot. xvii. (1879) 196.-Iberia.

pavonina, Lam. Encyc. i. $166=$ hortensis.

pedata, Rafin. in Med. Repos. New York, v. (1808) 361 $=$ nemorosa.

pennsylvanica, Linn. Mant. $247=$ dichotoma.

pentaphylla, Hook. ex Pritz. in Linnaea, xv. (1841) 657 =nemorosa.

pinnatifida, Dulac, F1. Hautes-Pyr. $214=$ Halleri

pisciensis, Sism. Agr. Tosc. $223(1801)=$ A. Pulsatilla

\section{ANEMONE :-}

Pittonii x, Glowacki, in Verh. Zool.-Bot. Ges. Wien, xix. (1869) 901.-Europ

polyanthes, D. Don, Prod. Fl. Nep. 194.-Reg. Himal.

praecox, Salisb. Prod. $371=$ A. Hepatica.

praestabilis, Jord. Diagn. i. $58=$ coronaria

pratensis, C. Koch, in Linnaea, xv. (1841) $248=$ montana

pratensis, Linn. Sp. Pl. 539.-Europ.

pratensis, Pall. ex Pritz. in Linnaea, xv. (1841) $637=$ ylvestris.

pratensis, Sibth, F1.Ox. 169; With. Arr. Brit. Pl. ed.III

$498=$ A. Pulsatilla

propinqua, G. Don, Gen. Syst. i. $21=$ pratensis.

pubescens, Domb. ex Steud. Nom. ed. I. 458, in syn. $=$ Ranunculus Krapfia.

Pulsatilla, Bieb. Fl. Taur. Cauc. ii. $18=$ montana.

Pulsatilla, Linn. Sp. Pl. 539.-Europ.

Pulsatilla, Sturm, Fl. Deutschl. i. Heft lxxxix. $12=$ pratensis.

punica, Sism. Agr. Tosc. $223=$ A. Pulsatilla.

pusilla, DC. Syst. i. $197=$ coronaria.

pusilla, Gaertn. ex Stend. Nom. ed. I. $49=$ Geun anemonoides.

pysmaea, Hort. ex Vilm. Fl. P1. Terre, ed. III. $90=$ apennina.

pyrenaica, Pall. ex Pritz. in Linnaea, xv. (1841) $640=$ apennina.

quinquefolia, Linn. Sp. Pl. $541=$ nemorosa

Raddeana, Regel, in Bull. Soc. Nat. Mosc. xxxiv. (1861) II. 16.-Reg. Amur.

ranunculifiora, St. Lag. in Ann. Soc. Bot. Lyon, vii. 1880) $119=$ ranunculoides

ranunculiformis, St. Lag. 1. c. 67 =ranunculoides.

ranunculoides, Linn. Sp. Pl. 541.--Europ.; Caucas.; Sibir.

ranunculoides, Richards, in Frankl. 1st Journ, App. 12 $=$ Richardsoni.

ranunculoidi-nemorosa, Knnze, in F1. Dan. t. $2723=$ nemorosa.

reflexa, Ledeb. ex Spreng. Syst. ii. $662=$ caerulea reflexa, Steph, in Willd. Sp. Pl, ii. 1282,-Sibir.

Regina, Risso, Fl. Nice, $6=$ coronaria?

Richardsoni, Hook. Fl. Bor. Am. i. 6. t. 4.-Am. arct.

rigida, C. Gay, Fl. Chil. i. 25.-Chili

Rissoana, Jord. Diag. i. $58=$ coronaria.

rivularis, Buch.-Ham ex DC. Syst. i. 211.-Ind. or

rivularis, Wall. Cat, n, $4692=$ elongata.

rosea, Hanry, ex Nym. Consp. $3=$ coronaria.

Rossii, S. Moore, in Fourn. Linn. Soc. xvii. (1880) 376 t. 16,-China.

rubra, Lam. Encyc. i. $163=$ A. Pulsatilla

rupestris, Jacquem. Bot. Voy. 5 = rupicola

mpestris, Wall. Cat. n. 4696.-Reg. Himal.

rupicola, Camb. in facquem. Bot. Voy. iv. 5.-.Reg. Himal.

Salesovii, Fisch. ex Pritz. in Linnaea, xv. (1841) $655=$ altaica.

sanguinea, Pursh, ex Pritz, 1. c. $672=$ multifida

scaposa, Edgew. in Trans. Linn. Soc. xx. (1851) $27=$ polyanthes.

Sellowii, Pritz. in Linnaea, xv. (1841) 667.-Bras

sibirica, Linn. Sp. Pl. 541.-Sibir.

silvestris, vide sylvestris.

slavica, Reuss, Bericht. Oestr. Litt. i. 82.-Europ.

sordida, Schur, Enum. PI Transs. $3=$ sylvestris.

speciosa, Adams, ex Pritz. in Linnaea, xv. (1841) 685 $=$ narcissiflora

speciosa, Rupr. Fl. Caucas. 12.-Caucas.

sphenophylla, Poepp. Fragm. Syn. 27.-Chili.

stellata, Lam. Encyc. i. $166=$ hortensis

stolonifera, Maxim. in Bull. Acad. Pétersb xxii. (1877) 225.-Japon.

sulphurea, All. F1. Pedem. ii. $170=$ vernalis.

sulphurea, Linn. Mant. $78=$ alpina.

sumatrana, De Vriese, in Miq. Pl. Fungh. 76.Sumatra.

sylvestris, Linn. Sp. Pl. 540.-Europ.; Caucas.

sylvestris, Vill. Hist. Pl, Dauph. iii. $726=\mathrm{A}$. Pulsatilla tenella, Banks, ex Pritz. in Linnaea, xv. (1841) $632=$ parvifiora.

tenella, Pursh, F1. Am. Sept. ii. $386=$ decapetala

tenuifolia, DC. Syst. i, 196.-Afr, austr.

tenuifolia, Schleich. Cat. Pl. Helv. ed. IV. $7=$ Bogen hardiana.

tetrasepala, Royle, Illustr. Bot. Himal. 53.-Reg. Himal.

thalictroides, Linn. Sp. Pl. 542,-Am. bor.
ANFMONF.-

Thomsoni, Oliver, in fourn. Linn. Soc. xxi. (1885) 397.-Afr. trop.

transylvanica, Heuff. in Verh. Zool.-Bot. Ver. Wien, (1858) 42.-Europ.

trifolia, DC. Prod i, $20=$ reflexa.

trifolia, Linn. Sp. Pl. 540,-Europ.; Am. bor

trifoliata, Georgi, Beschr. Russ. Reich. iii. IV. $1058=$ reflexa.

triloba, Stokes, Bot. Mat. Med. iii. $243=$ A. Hepatica trilobata, Juss. in Ann. Mus. Par. iii. (1804) 247.t. 1= decapetala.

trilobata, Pers. Syn. ii. $97=$ parviflora

triternata, Vahl, Symb. Bot. iii. 74. t. 65.-Am. austr. trullifolia, Hook. f. \& Thoms. Fl. Ind. i. 22.-Reg Himal.

Tschernaewi, Regel, in Act. Hort. Petrop. viii. (1884) 690.-As. temp.

udensis, Trautw. \& Mey, in Middend. Reise (Fi. Ochot. 6).-Manchur.

umbellata, Lam. Fl. Fr. iii. 322 ; Willd. Sp. Pl. ii $1284=$ narcissiflora.

umbrosa, C. A. Mey. in Ledeb. Fl. Alt. ii. 361.Sibir.

uniflora, Pursh, ex Steud. 'Nom. ed. II. i. $96=$ Thalictrum anemonoides.

uralensis, Fisch. ex DC. Prod. i. $19=$ caerulea, bal deasis.

Vahlii, Hornem. Fl. Dan. t. $2176=$ Richardsoni.

variata, Jord, ex Nym. Consp, $3=$ hortensis.

Ventreana, Hanry, ex Arduino, Fl. Alp. Marit. $12=$ coronaria.

vernalis, $\operatorname{Linn}$. Sp. Pl. 538.-Europ.

versicolor, Jord. Pugill. (1852) 1 = coronaria versicolor, Salisb. Prod. $371=$ hortensis.

villosa, Royle, Illustr. Bot. Himal. $52=$ polyanthes.

virginiana, Linn. Sp. Pl. 540 - Am, bor

vitifolia, Buch.-Ham.ex DC. Syst. i. 210.-Reg. Himal Wahlenbergii, Szontagh, ex Nym. Consp. 2.-Europ. Wallichiana, Koyle, Illustr. Bot. Himal. $52=$ albana,

Walteri, Pursh, Fl. Am. Sept. ii. 387.-Am. bor.

Wightiana, Hook. Ic. Pl. ii. t. 176,--Ind. or.

Wightiana, Wall. Cat. n. $4697=$ rivularis

Wolfgangiana, Bess. ex Koch, in Roehl. Deutschl. Fl iv. 106.-Europ.

ANEMONELLA, Spach, Hist. Vég. Phan. vii. 239 (1839 Anemone, Linn. (Ranunc.)

thalictroides, Spach, 1. c. $240=$ Anemone thalictroides,

ANEMONOPSIS, Pritz. Ind. Ic. 71 , sphalm. $=$ ANEMOPSIS, Hook.

ANEMONOPSIS, Sieb. \& Zncc, in Abh. Akad. Muench. iv. II. (1846) 181. RANUNCULACEAE Benth. \& Hook. f. i. 8 .

Xaveria, Endl. Gen. Suppl. iv. 30 (1847).

macrophylla, Sieb. E Zucc.l.c. 182.-Tapon.

ANEMONOSPERMUM, Commers. ex Steud. Nom. ed II. i. 450 , in syn. $(1840)=$ Cryptostemma, R. Br. (Compos.).

ANEMOPAEGMA, Mart, ex DC. Prod. ix. 187 (1845). BIGNONIACEAE, Benth. \& Hook. f. ii. 1037

acutifolium, $D C$. Prod, ix, 188--Bras.

album, Mart. ex DC.l.c.-Bras.

citrinum, Mart. ex DC. l. c. 189.-Bras.

clematideum, Griseb. in Goett. Abh. xix. (1874) 222 -Reg. Argent.

floridum, Mart. ex DC. Prod. ix. 188.-.Bras.

glaucum, Mart ex DC. l.c-Bras. Peruy ?

laeve, $D C$. l. c. 189 - Bras.

lanceaefolium, DC. l. C. 188,-Bras.

longidentatum, St. Lag. in Ann. Soc. Bot. Lyon, vii. (1880) $119=$ seq

longidens, DC. Prod. ix, 190.-Bras

mirandum, Mart. ex DC. l. c. 187.-Bras.

orbiculatum, $D C$. $l$. $c .190$-.-Panama.

Poeppigii, $D C$. l. $c$ - $-\mathrm{Am}$. austr.

prostratum, DC. l. c. 189.-Bras.

quinquedentatum, Mart. ex DC. l. c. 190.-Bras.

racemosum, Mart. ex DC. l. c. 189.-Bras.

scabriusculum, Mart. ex DC.l. c. 188,-Bras

sessilifolium, Mart. ex DC.1. c. 187=mirandum.

triplinervium, Mart. ex DC. l. c. 188.-Bras.

Vargasianum, $D C . l . c .190 .-B r a s$.

velutinum, Mart. ex DC. l.c. 189.-Bras. 
ANEMOPSIS, [Hook.] in Ann. Nat. Hist. i. (1838) 136, in nota; Hook. \& Arn. Bot. Beech. Voy. 390, t. 92 = Houttuynia, Thunb. (Piperac.)

Berlanderi, C. DC. in Linnaea, xxxvii. (1871-73) 333 $=\mathrm{H}$. californica.

californica, Hook. \& Arn. Bot. Beech. Voy. 390. t. 92 $=\mathrm{H}$. californica.

Ludovici-Salvatoris, Willk, in Regel, Gartenfl. xxvi. (1877) 228.-Calif

ANEPSA, Rafin. Fl. Tellur. ii. 31 (1836) = Veratrum, Tourn. (Liliac.).

carinata, graminifolia, latifolia, spicata, Rafin. 1. c.(Spp. ignotae).

ANEPSIAS, Schott, Gen. Aroid, t. $73(1858)=$ Rhodospatha, Poepp. (Aroid.)

Moritzianus, Schott, 1. c.-Venezuela.

ANERINCLIISTUS, Korth. in Verh. Nat. Gesch. ed. Temminck, 250, t. 68 (1842). MELASTOMACEAE, Benth. \& Hook. fo i. 753 .

Griffithii, Hook. f. ex Triana, in Trans. Linn. Soc. xxviii. (1871) 75.-Ind, or.

Helferi, Hook. f. ex Triana, l.c.-Ind, or.

hirsutus, Korth. in Verh. Nat. Gesch. 250. t. 68.Sumatra.

ANERMA, Schrad. ex Nees, in Mart. Fl. Bras. ii. x. 170 $(1842)=$ Scleria, Berg. (Cyperac.)

hispidula, Schrad. ex Nees, l. c.=S. hispidula.

ANESLEA, Reichb. Consp. 46 (1828) = ANNESLEA, Andr. = Euryale, Salisb. (Nymph.).

ANESORHLZA, Endl. Gen. 773 (1839), sphalm.= Annesorhiza, Cham. \& Schlecht. (Umbell.)

ANETANTHUS, Hiern, ex Benth. \& Hook. f. Gen. ii. 1025 (1876). GESNERACEAE, Benth. \& Hook. f. ii. 1025

f. 1i. 1025.
alatus, Benth. \& Hook. f. Gen. ii. 1025.-Bras.

gracilis, Hiern, in Kjoeb. Vidensk. Meddel. (1877-78) 93.--Bras.

parviflora, Benth. \& Hook.f. Gen. ii. 1025.-Mexic. villosa, Benth. \& Hook. l. c.-Bras.

ANETHUM, Tourn. ex Linn. Gen. ed. I. $82(1737)=$ Peucedanum, Linn. (Umbell.).

arvense, Bess. Ind. Sem. Hort. Crem. $(1820)=$ Carum Ridolfia.

arvense, Salisb. Prod. $168=$ Peucedanum graveolens. capense, Thunb. in Hoffm. Phytogr. Blaett. i. (1803) $26=$ Carum capense.

chryseum, Boiss. \& Heldr. Diagn. Ser. I. x. 32.Hispan. cymbocarpum, DC. Prod. iv. $186=$ Cymbocarpum
anethoides.

dulce, DC. Cat. Hort. Monsp. $78=$ Foeniculum vulgare.

erythraeum, DC. Prod. iv. $186=$ Cymbocarpum erythraeum.

Foeniculum, Linn. Sp. Pl. $263=$ Foeniculum vulgare .

Foeniculum, Thunb. Prod. Pl. Cap. $51=$ Carum capense.

graveolens, Linn. Sp. Pl. 263 = Pencedanum graveolens. graveolens, Ucria, Hort. Pan. $138=$ Carum Ridolfia minus, Gouan, Illustr. $20=$ Foeniculum vulgare. Panmori, Roxb. Fl. Ind. ii. $94=$ F oeniculum vulgare Panmorium, Roxb. ex Flem. in As. Res. xi. (1810) 156 $=$ praec.

Pastinaca, Wibel, Prim. F1. Werth. $146=$ Peucedanum Pastinaca.

pinnatum, Ruiz \& Pav. ex Urban, in Mart. Fl. Bras. xi. I. $342=$ Apium Ammi.

piperitum, Ucria, in Roem. Arch. i. $68=$ Foeniculum piperitum.

pusillum, Hort. ex Steud. Nom, ed, II. i, 97 = Carum Ridolfia.

rupestre, Salisb. Prod. $168=$ Foeniculum vulgare.

segetum, Linn. Mant. $219=$ Carum Ridolfia.

Sowva, Roxb, ex Flem, in As. Res. xi. (1810) $156=$ Peucedanum graveolens.

trifoliatum, Roxb. Hort. Beng. 86 ; Fl. Ind. ii. $96=$ Pimpinella Heyneana.

ANETIA, Endl. Gen. $923 \quad(1839)=$ Byrsanthus, Guill.' (Samyd.)

Byrsanthzes, Stend. Nom. ed. II. i. $97=$ B. Brownii.
ANEULOPHUS, Benth. in Benth. \& Hook. f. Gen. i 244 (1862). LINEAE

Caucanthus, Forsk. F1. Aegypt. Arab. 91 (1775) africanus, Benth. $l$. $c$.-Afr. trop.

ANEURISCUS, Pres1, Symb. Bot. i. 71. t. $48(1832)=$ Symphonia, Limn. (Guttif.)

Aubletii, Presl, 1. c. $72=$ S. globulifera.

exserens, Presl, 1. c. t. $48=\mathrm{S}$. globulifera.

ANGADENIA, Miers, Apocyn, S. Amer. 173 (1878) APOCYNACEAE.

almadensis, Miers, $l$. c. 179.-Bras.

amazonica, Miers, 1.c. 175 (=Anisolobus amazonicus)

Berterii, Miers, l. c. 180.-Ins. S. Doming.

cognata, Miers, 1. c. 176 (=Anisolobus cognatus).

coriacea, Miers, l. c. 17\%.-Guiana.

cubensis, Miers, l.c. 182.-Cuba.

Cururu, Miers, 1. c. 175 (=Anisolobus Cururu).

elegans, Miers, l. c. 178.--Reg. Amazon.

elliptica, Miers, l. c. 180.-Bras.

geminata, Miers, 1. c. $178=$ Odontadenia geminata

grandifolia, Miers, l. c. 175,--Reg. Amazon.

havanensis, Miers, l. c. 181-Cuba.

hypoglauca, Miers, 1. c. $173=$ Odontadenia hypoglauca.

latifolia, Miers, l.c. 176.-Bras.

Lindeniana, Miers, l. c. 180.-Cuba.

majuscula, Miers, l.c. 174--Reg. Amazon.

nitida, Miers; 1. c. $177=$ Odontadenia nitida.

pandurata, Miers, 1. c. $182=$ Echites pandurata

Poeppigit, Miers, 1. c. $179=$ Odontadenia Poeppigii.

Prieuri, Miers, l. c. 182.-Guiana.

pruinosa, Miers, l. c. 177.-Bras.

reticulata, Miers, l.c. 179 -Bras

Sagraei, Miers, 1. c. $181=$ Echites Sagraei.

Sprucei, Miers, l. c. 176 (=Anisolobus Sprucei)

sylvestris, Miers, 1. c. $174=$ Odontadenia sylvestris.

Valenzuelana, Miers, 1.c. $181=$ Echites Valenzuelana.

ANGEJA, Vandelli, Fasc. P1. $13(1771)=$ Quid ?

Vandellii, Steud. Nom. ed. II. i. 97.-Bras.

ANGELANDRA, Endl. Gen. Suppl. iii. 69 (1843)= Engelmannia, Torr. \& Gray (Compos.)

pinnatifida, Endl. ex Walp. Rep. ii. $976=$ E. pinnatifida.

ANGELANDRA, Endl. Gen. Suppl, iv. III. 91 (1850)= Croton, Linn. (Euphorb.).

elliptica, Baill: Etud. Gén. Euph. 379=C. ellipticum.

ANGELESTA, Korth. in Ned. Kruidk. Arch. iii. (1855 $384=$ Trichocarya, Miq. (Rosac.)

splendens, Korth. 1. c. = T. splendens.

ANGELICA;, [Riv.] Linn. Syst, ed, I (1735). UMBELLIFERAE, Benth. \& Hook. f. i. 916

Angelophyllum, Rupr. Rev. Umb. Kamtsch. 8 (1859).

CAllisaCE, Fisch. in Hoffm. Gen, Umb. ed. II, 170 $(1816)$.

Eustylis, Hook. f. Fl. N. Zel; t. 19 (1853)

Gingrorum, Forst. Char. Gen. 41. t. 21 (1776

Gomphopetalum, Turcz. in Bull. Soc. Nat. Mosc

(1841) 537.

Ostericum, Hoffm. Gen. Umb. 162:(1814)

alpina, Krock. ex Steud. Nom. ed. I. $49=$ sylvestris,

angustifolia, Hoffm. Gen. Umb. $162=$ Peucedanum angustifolium

anomala, Avé-Lall, in Ind. Sem. Hort. Petrop. ix. $57=$ sylvestris.

aquilegifolia, Lam. Fl. Fr iii, $452=$ Siler trilobum.

Archangelica, Linn. Sp. PI. 250=Archangelica officinalis.

arguta, Nutt. ex Torr. E Gray, Fl. N.Am. i. 620.Am. bor.

atropurpurea, Linn. Sp. Pl. ed. I. 251=Archangelica atropurpurea.

bracteata, Roxb, in Beats. Tracts, App. $297=$ Sium helenianum.

Breweri, A. Gray, in Proo. Am. Acad. vii. (1868) 348 -Calif.

Candollei, Wall. Cat. n. 582=Selinum Candollii.

Carvifolia, Vill. Prosp. 25; Spreng. Umbellif. Prod. 16 - Selinum Carvifolia.

chaerophyllea, Lotterm. ex Eysenh. Diss. Accur. Pl. Pruss. 12.-Livon.

citriodora, Hance, in fourn. Bot. ix. (18;1) 131.China.

\section{A.NGELICA}

controversa, Zumag. Fl. Pedem. ii. 11.-Italia

Curtisii, Buckl. in Am. Fourn. Sc. xlv. (1843) 173

Am. bor.

dahurica, Maxim. in Bull. Acad. Pétersb.xxiv. (1878)

35.-As. or

Dawsoni, S. Wats. in Proc. Am. Acad. xx. (1885) 369 -Am. bor.

decipiens, Hook. f. Handb. New Zeal. Fl. 98,-N Zel.

Dieffenbachii, Benth. \& Hook. f. Gen, i. 916-N. Zel.

diversicolor, Dulac, F1. Hautes-Pyr. 345=Razulii.

dura, C. Koch, in Linnaea, xvi. (1842) 357 (=Tomma

sinia purpurascenss

ebulifolia, Lap. Hist. Abr. P1. Pyr, $156=$ sylyestris

Fischeri, Spreng. in Roem. \& Schult. Syst, vi. $605-$ Silaus longifolius.

flavescens, Hoffm. Gen. Umb. $162=$ sylvestris

Florenti, Franch. \& Sav. ex Maxim. in Bull. Acad. Pétersb. xix. (1874) 274. -Japon.

geniculata, Hook. f. Handb. New Zeal. Fl. 98.N. Zel.

genuflexa, Nutt. ex Torr. E Gray, Fl. N. Am. i. 620. - Am. bor.

Gingidium, Hook. fo Handb. New Zeal. Fl. 97. N. Zel.

glauca, Edgew. in Trans. Linn. Soc. xx. (1846) 53.-

Reg. Himal.

Gmelini, Wormsk. ex DC. Prod. iv. $170=$ Archangelica Gmelini.

gracilis, Franch. in Mím. Soc. Sc. Nat. Cherb. xxiv. (1884) 222.-China

graveolens, Steud. Nom. ed. II ii. 555 in $\mathrm{syn} .=$ Pencedanum graveolens.

grosseserrata, Maxim. in Bull. Acad. Pétersb, xix. (1874) 275 . - China bor.

hakonensis, Maxim.l. c. 277.-Japon.

heterocarpa, Lloyd, in Bull. Soc. Bot. Fr. vi. (1859) 709.-Hispan.

hirsuta, Muhl. Cat. 30=Archangelica hirsuta

inaequalis, Maxim. in Bull. Acad. Pétersb. xix. (187 184.-Japon.

integrifolia, Walt. $\mathrm{Fl}$. Carol. 115.-Carolina.

intermedia, Schult. ex. Steud. Nom. ed. I. $49=$ Arch angelica officinalis.

japonica, A. Gray, in Mem. Am. Acad. N. S. vi. (1858-9) 390.-Japon.

Kiusiana, Maxim. in Bull. Acad. Pétersb. xviii. (1873) 284.- -Japon.

laevigata, Fisch. Cat. Hort. Gorenk. (1812) $45=$ Peucedanum latifolium.

laevis, 7. Gay, in Ann. Sc. Nat. Sér. II. vi. (1836 221 (err. typ. 121).- - Hispan.

lancifolia, Spreng. Syst. i. 916.-Hab. ?

leporina, S. Wats, in Proc. Am. Acad. xii. (1877) 252. -Am. bor.

Levisticum, All.Fl. Pedem.ii. $10=$ Levisticum officinal

lineariloba, A. Gray, in Proc. Am. Acad, vii 1868 347.-Calif.

litoralis,-Fries, Fl. Halland. .51=Archangelica offici nalis.

lobata, Walt. Fl. Carol. 115.-Am. bor.

lucida, Linn. Sp. Pl. 251.-Canada.

Lyallii, S. Wats. in Proc. Am. Acad. xvii. (1881-k2 374.-Am, bor.

macrophylla, Schur, Enum. P1. Transs. $262=$ sylvestris. maculata, Turcs. in Bull. Soc. Nat. Mose. (18t0) $72 .-$ Ins. Kuril.

major, Gilib. Fl, Lituan.. ii. $24=$ Archangelica officinalis.

major, Lag. Gen. et Sp. Noo. 13.-Hispan,

Maximowiczii, Benth. ex Maxim. in Bull. Acad. Pétersb. xix. (1874) 274. -Sibir.

mexicana, Vatke, App. Sem. Hort. Berol. (1876) App. 2. n. 12.-Mexico.

minor, Gilib. Fl, Lituan, ii. $23=$ sylvestris,

Miqueliana, Maxim. in Bull. Acad. Pétersb. xix. 1874) 276 .- Japon.

mongolica, Franch.in Nouv. Arch. Mus. Par. Sér. II vi. (1883) 21; Pl. Davidian. i. (18\$4) 141.Mongol.

montana, Brot. Fl. Lusit. i. $426=$ sylvestris

nemorosa, Tenore, Fl. Nap. t. 231 ; Syll. $561=$ sylvestris.

norvegica, Nym. Syll. Suppl. 26.-Norveg.

officinalis, Bernh. Syst. Verz. Erf. $170=$ Peacedanum Ostruthium. 


\section{ANGELICA:-}

officinalis, Moench, Meth. $81=$ Archangelica officinalis.

pachycarpa, Lange, Descr. Ic. Ill. 7. t. 9.-Hispan. pachyptera, Avé-Lall. Ind. Sem. Hort. Petrop. ix. 58 $=$ sylvestris.

paludapifolia, Lam. Fl. Fr. iii. 451 = Levisticum officinale.

palustris, Hoffm. Gen. Umb. 162.-.-Europ.

paniculata, Lam. Encyc. i. $172=$ Trochiscanthes nodiflorus.

pinnata, S. Wats. in King, Rep. v. 126.-Am, bor.

polyclada, Franch. in Bull. Soc. Bot. Fr. xxvi. (1879) 86. -Japon,

polymorpha, Maxim. in Bull. Acad. Pétersb. xix. (1874) 185.- Japon.

pratensis, Bieb. in Fisch. Hort. Gorenk. (1812), ex Bess, Enum. Pl. Volh. $94=$ palustris.

pratensis, J. \& C. Presl, Fl. Cech. $61=$ sylvestris.

pubescens, Maxim. in Bull. Acad. Pétersb. xxiv. (1878) 34.- Japon.

procera, Salisb. Prod. $164=$ Archangelica officinalis. pyrenaea, Spreng. Umb. $62=$ Selinum pyrenaeum.

Kazulii, Gouan, Illustr. 13. t. 6.-Pyren.

Razulii, All. Fl. Pedem. ii. $10=$ sylvestris.

refracta, F. Schmidt, Reisen Amurl. 138.-Ins. Sachalin.

Reuteri, Boiss. Diagn. Ser. II. ii. 87.-Hispan.

rosaefolia, Hook. IC. Pl. t. 581.-N. Zel.

ruthenica, Schott, ex Ledeb. Fl. Ross, ii. $296=$ sylvestris.

sachalinensis, Maxim. Prim. Fl. Amur, 127.-As, or.

sativa, Mill, Gard. Dict. ed. 'VIII. n. $\mathbf{1}=$ Archangelica officinalis.

saxatilis, Turcz. in Bull. Soc. Nat. Mosc, xvii. (1844) 729.-Sibir.

scabra, Petit, in Ann. Sc. Obs, i. 99. t. $3=$ Xatardia scabra.

scotica, Lam. Encyc. i. $173=$ Ligusticum scoticum.

Sieboldi, Miq. Ann. Mus. Bot. Lugd. Bat. iii. 61 (fide Maxim. = A. pubescens, Kiusiana et dahurica). Japon.

songorica, Regel \& Schmalh, in Act. Hort. Petrop. v. 1877) 590.-Kokania.

Strattoniana, Aitch. \& Hemsl. in fourn. Linn. Soc. xix. (1882) 164.-Affghan.

sylvestris, Linn. Sp. Pl. 251.-Europ.; Oriens; As. bor.

ternata, Regel \& Schmalh. ex Regel, Pl. Nov. Fedsch. 32.-As. temp.

tomentosa, S. Wats. in Proc. Am. Acad. xi. (1876) 141.-Calif.; Am. bor.

Tournefortiana, Cusson, ex Steud. Nom. ed. I. $50=$ Razulii.

Traversii, Hook. f. Handb. N. Zeal. F1. $729=$ Aciphylla Traversii.

triloba, Desf. ex Stend. Nom. ed. I. $464,50=$ Siler trilobum.

triquinata, Michx. Fl. Bor. Am..i. $167=$ Archangelica atropurpurea.

triquinata, Turcz. ex Trauty. \& Mey. in Middend. Reise (F1. Ochot. 44)=Physolophium saxatile.

ursina, Regel, in Act. Hort. Petrop. v. (1877) 590.Kamtsch.

verticillaris, Linn. Mant. $217=$ Peucedanum verticillare.

verticillata, Geyer, ex Hook. Lond. Fourn. Bot. vi. 1847) 233.-Am. bor.

villosa, Lag. Gen. et $\mathrm{S}_{\mathrm{p}}$. Nov, $12=$ sylvestris.

Wheeleri, S. Wats. in Am. Natural. vii. (1873) 301.Amer, bor.

ANGELINA, Pohl, ex Tul in Arch. Mus. Nat. Par. viii. (1885) 363 = Siparuna, Aubl. (Monim.).

divergentifolia, Pohl, ex Tul. 1. c. = S. guianensis

ANGELOCARPA, Rupr. in Mém. Acad. Sc. Pétersb. Sér. VII xiv. (1869) n. IV. (Sert. Tiansch.) p. 48. UMBELLIFERAE.

brevicaulis, Rupr. l. c.-As. centr.

ANGELONIA, Humb. \& Bonpl. PI. Aequin. ii. 92. t. 108 (1809). SCROP HULARINEAE, Benth. \& Hook. f. ii. 930.

Phylacanthus, Benth. Scroph. Ind. 1 (1835).

Prysidium, Schrad, in Goett. Gel. Anz. i. (1821) 714.

SCHElveria, Nees \& Mart. in Flora, iv. (1821) 299.

\section{ANGELONIA :-}

Tirylacantha, Nees \& Mart. in Nov. Act. Nat. Cur. xi. (1822) 45. angustifolia, Benth. in DC. Prod. x. 254,-Mexic.

arguta, Benth. l. c. 252.-Bras.

biflora, Benth. l. c. 254-Bras.

bisaccata, Benth. l. c. 252,-Bras

Blanchetii, Benth. l. c. 253.-Bras.

campestris, Nees \& Mart. in Flora, iv. (1821) I. 299. -Bras.

ciliata, Gardn. ex Hook. Bot. Mag. sub t. $3848=$ cornigera.

ciliolata, Benth. in DC. Prod. x. 252=Hookeriana

Coffreana, Moric. ex Benth. in DC. Prod. X. $252=$ procumbens.

cornigera, Hook. Bot. Mag. t. 3848.-Bras.

crassifolia, Benth. in DC. Prod. x. 252.-Bras.

eriostachys, Benth. l. c. 254.-Bras.

Gardneri, Hook. Bot. Mag* t. 3754.-Bras

goyayensis, Benth. in DC. Prod. x. 253.-Bras,

grandifora, C. Morr, in Ann. Soc. Hort. Gand, iii (1847) 93. t. 119.-Bras.

hirta, Cham. in Linnaea, viii. (1833) 27.-Bras.

Hookeriana, Gardn. ex Benth. in DC. Prod. x. 251.Bras.

integerrima, Spreng. Syst. iv. Cux. Post. 235.-Bras.

Leandri, F. Kickx, in Bull. Acad. Belg. vi. I. (1839) 309.-Bras.

linearifolia, Moric. ex J. A. Schmidt, in Mart. Fl Bras, viii. $2+2=$ Blanchetii.

lobelioides, Mart. ex J. A. Schmidt, 1. c. $246=$ cornigera.

micrantha, Benth. in DC. Prod. x. 252.-Bras

minor, Fisch. So Mey. Ind. Sem. Hort. Petrop. v, 33.Bras.

pilosella, F. Kickx, in Bull. Acad. Belg. vi. I. (1839) 309.-Cuba.

pratensis, Gardn. ex Benth in DC. Prod. x. 253.Bras.

procumbens, Nees \& Mart. in Nov. Act. Nat. Cur. xi (1822) 45 - - Bras.

pubescens, Benth. in Hook. Comp. Bot. Mag. ii. (1836) 15.-Bras.

salicariaefolia, Humb. \& Bonpl. Pl. Aequin. ii. 92 t 108.-Am, austr.

serrata, Benth. in DC. Prod. x. 253.-Bras.

spectabilis, Moric. ex J. A. Schmidt, in Mart. F1. Bras. viii. $243=$ eriostachys.

tomentosa, Moric. ex Benth. in DC. Prod. x. 254.Bras

veronicoides, Mart. ex J. A. Schmidt, in Mart. Fl. Bras. viii. $240=$ procumbens

viscosa, Mart. ex J. A. Schmidt, 1. c. $244=$ tomentosa.

ANGELOPHYLIUM, Rupr. in Beitr. Pf. Russ, Reich. xi. (Rey. Umb. Kamtsch.) $8=$ Angelica, Linn. (Umbell.)

dahuricum, Rupr. 1. c. $9=$ Angelica sylvestris.

ursinum, Rupr. 1. c. $8=$ Angelica ursina.

ANGELOPOGON, Poepp. ex Poepp. \& Endl. Gen. et Sp. i. I $(1835)=$ Myzodendron, Banks \& Soland Santal.).

ANGERVILLA, Neck. Elem. i. $351(179.0)=$ Stemodia Linn. (Scrophul.)

ANGIANTHUS, Wend1. Coll, ii. 31. t. 48 (1809), COMPOSITAE, Benth. \& Hook. f. ii. 319.

Cephalosorus, A. Gray, in Hook. Kew Journ. iii. (1851) 152.

Chrysocoryne, Endl. in Bot. Zeit. i. (1843) 457.

Crossolepsis, Benth. in Enum. Pl. Hueg. 61 (1837).

Cylindrosorus, Benth. 1. c. 62 (1837).

Dithyrostegia, A. Gray, in Hook. Kew Journ. iii (1851) 100.

EPITRICHe, Turcz. in Bull. Soc. Nat. Mosc. xxiv. (1851) II. 74.

Eriocladium, Lindl. Swan Riv. App, 24 (1839).

Gamozygis, Turcz. in Bull. Soc. Nat. Mose. xxiv (1851) II, 75 .

HYalochlamis, A. Gray, in Hook. Kew Journ. iii. (1851) 101.

Ogcerostylus, Cass, in Dict. Sc. Nat. xlix. 221 (1827)

Oxerostylus, Steud. Nom. ed. II. ii. 242 (1841), sphalm.
ANGIANTHUS :-

Phyllocalymma, Benth. in Enum. Pl. Hueg. 61 (1837)

Prptostemma, Turcz. in Bull. Soc. Nat. Mosc. xxiv. (1851) I. 191.

Pleuropappus, F. Muell, in Trans, Vict. Inst. (1855) 37

Pogonolepis, Steetz, in Lehm. Pl. Preiss. i. 440 (1845)

Siloxerus, Labill. Pl. Nov. Holl. ii. 57. t: 209 (1806), nomen pritus.

SKIRRHOPHORUS, DC. ex Lindl. Introd. Nat. Syst. ed. II. $260(\mathbf{1} 836)$

STYloncerus, Spreng. Syst. iii. 356, 451 (1826).

amplexicaulis, Benth. Fi. Austral. iii. 568. - Austral.

brachypappus, F. Muell. in Trans. Phil. Soc. Vict. i. 1855) 44.-Austral.

codonopappus, F. Muell. Fragm. ix. 2.-Austral.

Cunninghamii, Benth. Fl. Austral. iii. 565.-Austral

demissus, Benth. l. c. 567.-Austral.

Drummondii, Benth. l.c.566.-Austral.

eriocephalus, Benth. I. c. 567.-Austral.

flavescens, Steetz, in Lehm. Pl. Preiss, i. $438=$ tomentosus.

globifer, Benth. Fl. Austral, iii. 567-Austral.

humifusus, Benth. l. c. 563.-Austral.

microcephalus, Benth. l. c.566.-Austral.

micropoides, Benth. l. c. 565.-Austral.

Milnei, Benth. l. c. 564.-Austral.

myosuroides, Benth. l. c. 563.-Austral.

phyllocephalus, Benth. l. c. 565-Austral.

platycephalus, Benth. l. c.566.-Austral.

pleuropappus, Benth. l. c. 563.-Austral.

plumiger, Benth. L. c. 568.-Austral.

Preissianus, Benth. l. c. 566.-Austral.

pusillus, Benth. l. c. 564.-Austral.

pygmaeus, Benth.l.c.567.-Austral

strictus, Benth. l, c. 568.-Austral.

tenellus, Benth. l. c. 564.-Austral.

tomentosus, Wendl. Coll. ii. 31. t. 48 (1809).Austral.

ANGIOPET ALUM, Reinw. in Syll. Ratisb. ii. (1828 7. MYRSINEAE.

punctatum, Reinw. l. c.-Java.

ANGKALANTHUS, Balf. f. in Proc. Roy. Soc Edinb. xii. (1884) 88. ACANTHACEAE.

oligophylla, Balf. f. l. c. 89.-Socotra.

ANGOLAFA, Wedd, in DC Prod xvii. 300 (1873) PODOSTEMACEAE, Benth. \& Hook, f. iii. 111 fluitans, Wedd. l. c.-Afr. trop.

ANGOLAM, Adans. Fam. ii. 85 (1763)=Alangium, Linn. (Cornac.).

ANGOLAMIA, Scop. Introd. $107(1777)=$ praec.

ANGOPHORA, Cav. Ic. iv. 21. t. 338 (179t) MYRTACEAE, Benth. \& Hook. f. i. 707

cordifolia, Cav. l. c-Austral.

floribunda, Sweet, Hort. Brit. ed. II. 209=Eugeni Smithii, Ventenatii.

intermedia, $D C$. Prod. iii. 222.-Austral.

lanceolata, Cav. Ic. iv. 22. t. 337.-Austral.

subvelutina, F Muell. Fragm. i. 31.-Austral.

Woodsiana, F. M. Bailey, in Proc. Linn. Soc. N. S. W vi. (1881) 143.-Austral.

ANGORCHIS, Nees, in R. Br. Verm. Schrift. ii. 423 , in adnot. $(1826)=$ Angraecum, Bory (Orchid.)

ANGOSTURA, Roem. \& Schult. Syst. iv. $188(1819)=$ Galipea, Aubl. (Rutac.).

Cupare, Roem. \& Schult. l. c. = G. trifoliata

ANGOSTYLES, Benth. in Hook. Kew Journ. vi (1854) 328. EUPHORBIACEAE, Benth. \& Hook f. iii. 327 .

longifolia, Benth. l. c.-Bras.

ANGRAECUM, Bory, Voy. i. 359. t. 19 (1804) ORCHIDEAE, Benth. \& Hook. f, iii. 583.

AËRANGIS, Reichb. f. in Flora, xlviii. (1865) 190. AËOBION, Kaempf. ex Spreng. Syst. iii. 679 (1826)

ANgorchis, Nees, in R. Br. Verm. Schrift. ii. 423 in adnot. (1826). 


\section{ANGRAECUMT :-}

Listrostachys, Reichb. f. in Bot. Zeit. x. (1852) 930.

Microcaelia, Hochst. ex A. Rich. 'Tent. F1. Abyss. ji. $285(1851)$

Plectrelmintiuus, Rafin. Fl. Tellur. iv. 42 (1836) alcicome, Reichb. f. Otia Bot. Hamb. 117.-Afr. trop. aphyllum, Thou. Orch. Afr.t. 73.-Ins. Masc. apiculatum, Hook. Bot. Mag. t. 4159.-Afr. trop arachnoj, Reichb. f. in Bonplandia, ii. (1854) 93 .

Afr. trop.
arcuatum, Lindl. in Hook. Comp. Bot. Mag. ii. (1836) 204.-Afr. austr.

arcuatum, Lindl. ex Hook. f. in Bot. Mag. t. $5589=$ Chaillnanum.

armeniacum, Lindl. in Bot. Reg. (1839) Misc. 67.Afr. trop.

articulatum, Reichb. f. in Gard. Chron. (1872) 73. Madag.

ashantense, Lindl. in Bot. Reg. (1843) Misc. 56.-Afr. trop.

bicaudatum, Lindl. in Hook. Comp. Bot. Mag. ii. (1836) 205.-Afr. austr.

bilobum, Lindl. Bot. Reg. (1840) Misc. 69.-Afr. occ.

Boutoni, Reichb. f. Otia Bot. Hamb. 117.-Ins. Comor bracteostm, Balf. f. \& S. Moore, in Fourn. Bot. xiv. (1876) 293 - Ins. Borbon.

brevifolium, Lindl. Bot. Reg. (1840) sub t. 68.-Bras,

Brongniartianum, Reichb. f.ex Linden, Pescatoria, i. t. 16.--Ins. Mascar.

Burchellii, Reichb. f. in Flora, 1. (1867) 117.-Afr. austr.

Calceolus, Thou. Orch. Afr. t. 78.-Ins. Mascar. campyloplectron, Reichb. f. in Bonplandia, iii. (1855) 226 - Hab?

capense, Lindl. Gen. et Sp. Orch. 248=Mystacidium filicorne.

capitatum, Lindl. in Fourn. Linn. Soc. vi. (1862) 137. -Afr. trop.

carinatum, Kostel. Allg. Med.-pharm. F1. i. $250=$ Eulophia virens.

carpophorum, Thou. Orch. Afr. t. 76.-Afr. trop.

caudatum, Lindl. Bot. Reg. t. 1844.-Afr. trop.

caulescens, Thou. Orch. Afr. t. $75=$ Mystacidium caulescens.

Chailluanum, Hook. f. Bot. Mag. t. 5589-Afr. trop.

Chiloschistae, Reichb. f. in Linnaea, xx. (1847) 678. -Natal.

Christyanum, Reichb. f. in Gard. Chron. (1880) I, $80 \mathrm{~b}^{\circ}-\mathrm{Hab}$ ?

citratum, Thou. Orch. Afr. t. 61.-Madag.

clandestinum, Lindl. in Hook. Comp. Bot. Mag. ii (1835) 206. - Afr. trop.

clavigerum, Ridl. in fourn. Linn. Soc. xxi. (1885) 485.-Madag.

conchiferum, Lindl. in Hook. Comp. Bot. Mag. ii (1836) 205.-Afr. austr.

cornutum, Reichb. fo in Flora, lxviii. (1885) 538 . Ins. Comor.

Cowanii, Ridl, in Fourn. Linn. Soc. xxi. (1885) 484. -Madag.

crassum, Thou. Orch. Afr, tt, 70 et 71 .- Madag. cryptodion, Reichb. f. in Gard. Chron. (1883) I. 307. - Madag.

cucullatum, Thou. Orch. Afr.t. 48.-Ins. Mascar,

culicifernm, Reichb. f. in Flora, lxviii. (1885) 538.Ins. Comor.

descendens, Reichb. $f$. in Gard. Chron. (1882) I. 558 - - Hab. ?

distichum, Lindl. Bot. Reg. t. 1781.-Afr. trop. eburneum, Lindl. 1. c. (1832) xviii. 1522=superbum eburneum, Bory, Voy. i. 359. t. 19.-Ins. Borbon. elatum, 'T hou. Orch. Afr. t. $79=$ Cryptopus elatus. Ellisii, Rcichb. f. in Flora, lv. (1872) 2;8.-Madag. cxpansum, Thou. Orch. Afr. t. 57.-Ins. Mascar. falcatum, Lindl. Coll. Bot. 15,-China.

fasciola, Lindl. Bot. Reg. xxvi. (1840) sub t. 68.Demerura.

fastuosum, Reichb. f. in Gard. Chron. (1881) I1. 748, 844.- Madag.

filicornu, Thou. Orch. Afr, t. 52,-Ins. Mascar.; Madag.

filiforme, Lindl. Gen. et Sp: Orch. 248.-Ind. oce

florulentum, Reichb. f. in Gard. Chron. (18s5) 1. 787 ; in Flora, Ixviii. (1885) 380.-Ins. Comor.

fragrans, Thou. Orch. Afr.t. 54.-Ins. Mascar.

funale, Lindi. in Gard. Chron. (1846) $135=$ Dendrophylax funalis.

\section{ANGRAECUM :-}

Miscatum, Reichb. f. in Gard. Chron. (1882) II. 488.Madag.

Galeandrae, Reichb, f in Flora, xlviii. (1865) 189. Afr. occ.

Gilpinae, Reichb. f. \& S. Moore, in Fourn. Linn. Soc. xvi. (1877) 206.-Madag.

gladiifolium, Thou. Orch. Afr. t. 53.-Ins. Mascar. Madag.

globulosum, Hochst. ex A. Rich, Tent. Fl. Abyss. it $285=$ Guyonianum.

glomeratum, Ridl. in Gard. Chron. (1885) II. 678. Afr. trop.

gracile, Thou. Orch. Afr. t. 77.-Ins. Mascar.

Grantii, Bateman, ex Baker, in Trans. Linn. Soc xxix. $(1875) 153=$ Kotschyi.

Guyonianum, Reichb. f. in Linnaea, xxii. (1819) 865. Abyss.

Hildebrandtii, Reichb. f, in Gard. Chron. (1878) 725.-Afr. trop.

Humblotii, Reichb. f. in Flora, lxviii. (1885) 381.-

Ins. Comor

hyaloides, Reichb.f. in Gard. Chron. (1880) I. 264.Madag.

chneumoneum, Lindl. in fourn. Linn. Soc. vi. (1862) 136. - Afr. occ.

imbricatum, Lindl. l. c. 137.-Afr. occ.

implicatum, Thou. Orch. Afr. t. 58.-Madag.

inapertum, Thou. 1. c. t. $50=$ Mystacidium inapertum infundibulare, Lindl. in Fourn. Linn. Soc. vi. (1862) 136. -Afr. occ.

jamaicense, Reichb. f. \& Wullschl. in Walp. Ann. vi. 901.-Jamaic.

japonicum, Linden, Illustr. Hortic. xxviii. (1881) 64 Japon.

Kotschyi, Reichb. f. in Gard. Chron. (1880) II. 456.Afr. trop.

Lansbergii, Reichb. f. in Nederl. Kriudk. Arch. iv. 1859 316. - Caracas.

Leonis, Hort.-Cf. Gard. Chron. (1885) II. 80-81= Aëranthus Leonis.

lepidotum, Reichb. f. l. c. (1880) I. 806, in obs.-Hab.

Lindenii, Lindl. l. c. (1846) 135.-Cuba

luridum, Lindl. ex Steud. Nom. ed. II. i. 98.-Afr trop.

maculatum, Lindl. Coll. $15=$ Eulophia maculata. maxillarioides, Ridl. in Fourn. Linn. Soc. xxi. (1885) 479.-Madag.

megalorrhizum, Reichb. f. Otia Bot. Hamb. 117.-Afr trop.

micranthum, Lindl. Bot. Reg. xxi. t. 1772.-Afr. trop. modestum, Hook. f. Bot. Mag. t. 6693.-Madag. monodon, Lindl. \& Paxt. Flow. Gard ii. (1851-5.) 102.-Afr. occ.

monophyllum, A. Rich. in Mém. Soc. Hist. Nat. Par iv. (1828) $58=$ Eulophia monophylla.

multiflorum, Thou. Orch. Afr. t. $74=$ Mystacidiun caulescens.

Mystacidii, Reichb. f. in Linnaea, xx. (1847) 677.Natal.

odoratissimum, Reichb.f.in Bonplandia,iv. (1856) 326 - Hab. ?

organense, Reichb. f. in Walp. Ann. vi. 901.-Bras. ornithorhynchum, Lindl. Bot. Reg. xxvi. (1840) sub t. 68.--Bras.

palmatum, Thou. Orch. Afr. t. $69=$ palmiforme.

palmiforme, Thow. l. c. 68,-Ins. Mascar.

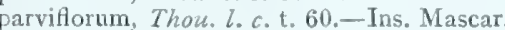

parvulum, Ayres, ex Baker, Fl. Maurit. 357.-Ins.

Mascar.

pectinatum, Thou. Orch. Afr. t. 51.-Ins. Mascar, Madag.

pellucidum, Lindl. in Fourn. Linn. Soc. vi. (1862) 134. - Afr. occ

pertusum, Lindl. in Hook. Comp. Bot. Mag. ii. (1836) 205.-Afr. occ.

Pescatorianum, Lindl, in Fourn. Hort. Soc, iv. (1849) 263 - Ins. Borbon.

physophorum. Reichb. f. Otia Bot. Hamb. (18s1) 77 et 449.-Ins. Mascar. Poeppigii, Reichb. $f$. in Linnaea, xxii. (1849) 858.-

polystachyum, Lindl. Bot. Reg. xxvi. (1840) sub t. 68 -Peruv.

polystachyum, A. Rich. in Mim. Hist. Nat. Par. iv. 1828) $66=$ Aeonia polystachya.

pugioniforme, Klotssch, Ind. Sem. Hort. Berol. App. (1851) 12. Venezuela.

\section{ANGRAECUM}

pusillum, Lindl. in Hook. Comp. Bot. Mag. ii. (1836) 205. Afr anstr.

pygmaeum, Linden, Illustr. Hortic. xxviii. (1881) 64 -Japon.

ramosum, Thou. Orch. Afr.t. 59.-Ins. Mascar

rectum, Thou. l. c. 55.-Ins. Mascar.

recurvum, Thou. $l$. c. t. 56.-Ins, Mascar.

rhipsalisocium, Reichb. $f$. in Flora, xlviii. (1865) 189. -Afr. occ.

Rohrii, Reichb. f. Otia Bot. Hamb. 117.-Abyss.

rostellare, Reichb. f. in Flora, 1xviii. (1885) 380 ; et in Gard. Chron. (1885) I. 726.-Ins. Comor.

rostratum, Ridl. in Fourn. Linn. Soc。 xxi. (1885) 4 ह. - Madag.

Rutenbergianum, Kraentz. in Bremen Abh. vii. (18s? 257.-Afr. trop.

sacciferum, Lindl. in Fiook. Comp. Bot. Mag. ii. (18:3 205.-Afr. austr.

Schiedei, Reichb. f. in Linnaea, xxii. (1849) $857=$ Campylocentron Schicdei.

Schimperianum, Reichb. $f$. in Walp. Ann. iii. 573.Abyss.

Scottianum, Reichb. f. in Gard. Chron. (1878) Ir. 556.-Ins. Comor.

Sedeni, Hort, ex Nichols. Dict. Gard, i. $79=$ arcuatur.

Sellowii, Reichb. f. in Linnaea, xxii. (1849) 857 - - Bras. sesquipedale, Thou. Orch. Afr. tt. 66 et 67 .-Madag. spathulatum, Ridl. in fourn. Linn. Soc. xxi. (18c: 478. - Madag

striatum, Thou. Orch.Afr. t. 72.-Ins. Mascar. subulatum, Lindl. in. Hook. Comp. Bot. Mag. ii. (1\{3t 206.-Afr. occ.

superbum, Thou. Orch. Afr, tt. 62 et 64.-Madag. tenue, Lindl. Bot. Reg. xxvi. (1840) sub t. 68.- bira teretifolium, Ridl. in fourn. Linn. Soc. xxi. (188, 484.-Madag.

tridens, Lindl. l. c. vi. (1862) 135.-Afr. trop.

tridentatum, Harv. Thes. Cap. ii. 6.-Afr. austr.

triquetrum, Thou. Orch. Afr. t. 49.-Ins. Mascar.

vagans, Lindl. in Fourn. Linn. Soc. vi. (1862) 13\%.Afr. oce.

virens, Lindl. Bot. Reg. (1847) t. $19=$ eburncum.

vesicatum, Lindl. l. c. (1843) Misc. 6.-Afr. trop.

Weigelti, Reichb. f. in Linnaea, xxii. (1819) 857 Guiana.

xylopus, Reichb. f. in Flora, 1xvii. (1885) 538.-Ins. Comor

yuccaefolium, Boj. Hort. Maurit. 318.-Ins. Maurit.

yeylanicum, Lindl. in Fourn. Linn. Soc. iii. (185.) 40. -Ind, or.

ANGUILIARIA, R, Br. Prod. 273 (1810), IILI

$C E A E$, Benth. \& Hook. fo iii. 824

australis, F. Muell. Fragm, vil. $74=$ dioica.

biglandulosa, R. Br. Prodr. $273=$ dioica

capensis,. Spreng. Syst. ii, $146=$ Androcymbium lea canthum.

caricina, Schult. f. Syst. vii. 1539.-Ind. or.

cochinchinensis, Spreng. Syst. ii. 147.-Cochinch.

densiflora, Benth. Fl. Austral. vii. 29.-Austral.

dioica, R. Br. Prod. 273.-Austral.

Heyneana, Wall. Cat. n. $5086=$ Iphicrenia indica.

indica, R. Br. Prod. $273=$ Iphigenia indica.

monantha. Endl. in Lehm. Pl. Preiss, ii. $4 \overline{5}=$ dioica.

pygmaea, Eridl. 1. c. = Wurmbea pygmaea.

racemosa, Schult. f. Syst. vii. $1539=$ Iphigenia indica.

tenella, Endl. in Lehm. PI. Preiss. ii. $45=11$ urmbea

tenella.

uniftora, R. Br. Prod. $273=$ dioica.

ANGUILLARIA, Gaert. Fruct, i. $872(1 ; 8)=$ Ardisia. Sw. (Myrsin.).

bahamensis, Gaertn. 1. c. $373=$ Ar. excelsa, Barthesia, Lam. Hlustr. ii. $109=$ Ar. Barthesia. chrysophylla, Lam. l. $\mathrm{c}_{\mathrm{s}}=$ Ar, serrulata. coriacea, Poir. Encyc. vii. $6 \$ 5=$ Ar. corincen cremulat $a$. Poir. 1. c. $688=$ Parathesis cremulata. excelsa, Lam. Illustr. ii. $110=$ Ar. excelsa. Icacorea, Lam. 1. c. $10 y=\mathrm{Ar}$. acuminata. lateriflora, Lam. l. c. = Ar. lateriflora. latifolia, Steud. Nom. ed. II. i. $98=$ Ar. Inurifolia. laurifolia, Lam. Illustr. ii. 109)=Ar. laurifulia. parasitica, Lam. 1. c. = Cirmmadenia parasitica. puramidalis, Cav. Ic. vi. 1 = Ar. pyramidalis. serrata. Cav. 1. c. $2=$ Ar. Cavaniliesis. serrulata, Poir. Encyc vii. tis $6^{\circ}=$ Ar. serrulata. solanacta, Puir. l. c. bs - Ar. humilis 


\section{ANGUILLARIA}

tinifolia, Lam. Illustr. ii. $109=$ Ardisia tinifolia. zeylanica, Gaertn. Fruct. i. 373 . t. 77 . f. $1=\mathrm{Ar}$. Moonii.

ANGUINA, Mich. ex Linn. Syst. ed. I. $(1735)=$ Trichosanthes, Linn. (Cucurb.)

ANGUINUM, Fourr, in Ann. Soc. Linn. Lyon, N. S xvii. $160(\mathbf{1 8 6 9})=$ Allium, Tourn. (Liliac.)

Victorialis, Fourr. 1. c. =Allium Victorialis.

ANGULOA, Ruiz \& Pav. Prod. Fl. Per. 118. t. 26 (1794) ORCHIDEAE, Benth. \& Hook. f. iii. 548. Clowesii, Lindl. Bot. Reg. (1844) Misc. 26.-Venezuela.

dubia, Reichb.f. in Gard. Chron. (1882) I. 764.-N. Granat.

eburnea, Hort. ex Nichols. Dict. Gard. i. 79.-N. Granat.

grandiflora, H. B. \& K. Nov, Gen. et Sp. i. $345=$ Stanhopea Bucephalus.

Hernandezii, Kunth, Syn. i. $332=$ Stanhopea tigrina,

Hohenlohii, Morr. in Belg. Hortic. iii. (1853) 201. t. 31.-N. Granat.

lurida, Link, in Preuss. Gart. Ver, i. 289. t. $6=$ Catasetum luridum

media x, Reichb. f. in Gard. Chron. (1881) II. 38.

purpurea, Linden, in Illustr. Hortic. xxviii. (1881) t. 427. - Venezuela.

Ruckeri, Lindl. Bot. Reg. (1846) t. 41.-N. Granat.

squalida, Poepp. \& Endl. Nov. Gen. et Sp. i. 74.Peruv.

superba, H. B. \& K. Nov. Gen. et Sp. i. 343. t. $93=$ Acineta Humboldtii.

uniflora, Ruiz \& Pav. Syst. 228.-Peruv.

virginalis, Hort.—Cf. Gard. Chron. (1851) $392=$ uniflora.

ANGURIA, [Tourn.].Linn. Syst. ed. I. (1735). CU CURBITACEAE, Benth. \& Hook. f, i. 833.

aculeolata, Schlecht. in Linnaea, xxiv. (1851) $748=$ Wilbrand:a verticillata.

affinis, Schlecht. 1. c. $760=$ pedata.

Arrabidae, Schlecht. 1. c. $736=$ Gurania multiflora.

bignoniacea, Poepp. \& Endl. Nov. Gen. et Sp. ii. $53=$ triphylla, Gurania cissoides.

Boissieriana, $\operatorname{Cog} n$. in DC. Monog. Phan. iii. 673.Permv.

capitata, Poepp. \& End1. Nov. Gen. et Sp. ii. $52=$ Gurania capitata.

cissoides, Benth. in Hook. Kew Journ. ii. (1850) $242=$ Gurania cissoides.

Citrullus, Mill. Gard. 'Dict. ed. VIII. add. $=$ Citrullus vulgaris.

dentata, Schlecht. in Linnaea, xxiv. (1851) $713=$ pedata.

dubia, Hook. \& Arn. Bot. Beech. Voy. 292 = Cayaponia attenuata.

eriantha, Poepp. \& EndI. 'Nov. Gen. et Sp. ii. 52. t. $169=$ Gurania eriantha

eriantha, Seem. Bot. Voy. Herald, $127=$ Gurania Seemanniana.

Gaudichaudiana, Schlecht. in Linnaea, xxiv. (1851) $753=$ Wilbrandia verticillata.

glomerata, Eggers, F1. St. Croix \& Virgin. Isl. $55=$ Corallocarpus glomeratus.

grandiflora, Cogn. in Mém. Cour. Acad. Belg. 8vo. xxvii, (1877).-Bras.

guianensis, Klotzsch, in Schomb. Reis. Brit. -Guian, iii $988=$ Gurania guianensis.

heterophylla, Willd. ex Schlecht. in Linnaea, xxiv, 1851) $772=$ Gurania cissoides.

integrifolia, Nees \& Mart. in Nov. Act. Nat. Cur. xii. 1824) 9.-Bras.

indica, Noronha, in Verh. Batav. Gen. vo (1790) ed. I. Art. iv. 6.-Malaya.

Facquiniana, Schlecht, in Linnaea, xxiv. (1851) $708=$ trilobata.

Kegeliana, Schlecht. 1. c. $776=$ Gurania Kegeliana.

Kunthiana, Schlecht . l. c. 762.-Bras.

laciniosa, Schlecht. 1. c. $755=$ Apodanthera laciniosa

leptantha, Schlecht. 1. c. $779=$ Helmontia leptantha.

lobata, Linn. Amoen. Acad. viii. 263.-Guian.

longipedunculata, Cogn. in Mém. Cour. Acad. Belg. 8 vo. xxvii. (1877), - - Mexic.

Makoyana, Lem. in Fl. des Serres, Sér. I. iii. (1847) $222=$ Gurania Makoyana.

\section{ANGURIA :-}

Meyeniana, Schlecht in Linnaea, xxiv. (1851) $750=$ Wilbrandia verticillata.

multiflora, Miq. in Linnaea, xviii. (1846) $366=$ Gurani multiflora.

obtusiloba, Schlecht, in Linnaea, xxiv. (1851) $744=$ (Vitis sp.)

Ottoniana, Schlecht. l. c. 758-Cuba,

pallida, Cogn. in Mém. Cour. Acad. Belg. 8vo, xxvii. (1877) 10, 22.-Ecuador

pedata, Facq. Enum. Pl. Carib. 3.-Ins. S. Doming pedata, Willd, ex Cogn. in DC. Monog. Phan. iii. 828 = Cyclanthera leptostachya.

pedatisecta, Nees \& Mart. in Nov. Act. Nat. Cur. xii. 1824) $10=$ Cyclanthera pedata.

pedisecta, Nees \& Mart. l. $c_{0}=$ Apodanthera pedisecta.

Plumieriana, Schlecht. in Linnaea, xxiv. (1851) 709 --Ins. Martinic.

Poeppigiana, Schlecht. 1. c. $769=$ Dieudonnaea rhizantha.

polyanthos, Klotzsch, in Schomb. Reis. Brit. Guian.

iii. $988=$ Gurania Klotzschiana, G. subumbellata.

polyphyllos, Schlecht. in Linnaea, xxiv. (1851) $712=$ pedata.

rhizantha, Poepp. \&c Endl. Nov. Gen. et Sp. ii. 52. t. $171=$ Dieudonnaea rhizantha.

rosea, H. B. \& K. Nov. Gen, et Sp. ii. $122=$ trilobata

Schomburgkiana, Schlecht. in Linnaea, xxiv. (1851)

765.-Guiana.

Sellowiana, Schlecht, 1. c. $746=$ Grurania Sellowiana

Sellowiana, Wawra, Bot. Maximil. Reise, i. 57. t. $52=$

Gurania Wawraei.

sinuata, Benth. in Hook. Kew Journ. ii. (1850) $242=$ Gurania sinuata.

speciosa, Poepp. \&\& EndI. Nov. Gen. et Sp. ii. 51.t. $169=$ Gurania speciosa.

spinulosa, Poepp. \& End1. 1. c. 52. t. $170=$ Gurania spinulosa.

subumbellata, Miq. in Nat. Verh. Wet. Haarl. vii (1851) (Stirp. Surin. Select.) $103=$ Gurania subum bellata.

ternata, M. Roem.Syn. Pepon. i. 26.-Bras.

trifoliata, Aubl. Pl. Guian. ii. $842=$ Gurania cissoides trifoliata, Linn. Sp. $P l$. ed. II. 1376.-Ins. S Doming

trifoliata, Vell. F1. Flum. x. t. 2 = ternata

trilobata, Facq. Enum. Pl. Carib. 31.-N. Granat.

trilobata, Vell. Fl. Flum. x. t. $\mathbf{I}=$ Gurania multiflora.

triphylla, Klotzsch, in Schomb. Reis. Brit. Guian. iii. 988 = Schomburgkiana.

triphylla, Miq. in Linnaea, xix. (1847) 136.-Guian.

umbrosa, H. B. E K. Nov. Gen. et Sp. ii. 121.Mexic.

Wageneriana, Schlecht. in Linnaea, xxiv. (1851) 785 = Gurania Wageneriana.

Warmingiana, Cogn. in Mém. Cour. Acad. Belg. 8 vo. xxvii. (1877) 21.-Bras.

Warmingii, Cogn. l. c.-Bras.

Warscewicziana, Hort. Belg. ex Cogn. 1. c. $18=$ seq.

Warscewiczii, Hook. f. in Bot. Mag. t. 5304. Mexic.

ANGUStineA, A. Gray, Bot. U. St. Expl. Exped. i. 593, in syn. (1854) =AUGUSTINEA, St. Hil. \& Naud. = Miconia, Ruiz \& Pav. (Melast.).

ANHALONIUM, Lem. Cact. Nov. Gen. et Sp. 1. (1839 = Mammillaria, Haw. (Cact.).

areolosum, Lem. Illustr. Hortic. vi. (1859) Misc. 35. Mexic.

elongatum, Salm-Dyck, Cact. Hort. Dyck. (1845) 15 $=\mathrm{M}$. elongata

Engelmanni, Lem. Cact. $42=$ M. fissurata.

fissipedum, Monv. Cat. ex Forst. Cact. Handb. ed. II. i. $232=$ sulcatum.

fissuratum, Engelm. Cact. Mex. Bound. $75=$ M. fissurata.

Kotchubeyi, Lem. ex Salm-Dyck, Cact. Hort. Dyck ed. II. 5=Mammillaria sulcata.

Kotschoubeyanum, Lem. Cact, 41 ; Illustr. Hortic. xvi. (1869) Misc. 72.-Mexic.

prismatioum, Lem. Cact. Nov. Gen. et Sp. $1=$ M. prismatica.

pulvilligerum, Lem. Illustr. Hortic. xvi. (1869) 72 ; Hort. Monv, i. 275 = Mammillaria elongata.
ANHALONIUM :-

retusum, Salm-Dyck, Cact. Hort. Dyck. (1845) $15=$ Mammillaria prismatica.

sulcatum, Salm-Dyck, 1. c. ed. II. 5, 78.-Mexic

Williamsii, Lem. ex Forst. Handb. Cact. ed. II. i. 233 = Echinocactus Williamsii.

ANIA, Lindl. in Wall. Cat. n. 3740-41; et Gen. et Sp. Orch. $129(1831)=$ Tainia, Blume (Orchid.).

angustifolia, Lindl. in Wall. Cat. n. 3740.--Ind. or. ; China.

bicornis, Lindl. in Bot. Reg. (1842) Misc. $37=\mathrm{T}$. bicornis.

latifolia, Lindl. in Wall. Cat. n. 3741 = T. latifolia.

latifolia, Wight, Ic. P1. iii. $914=$ T. bicornis?

maculata, Thw. Enum. P1. Zeyl, 301=(Chrysoglossi sp.).-Zeylan.

ANIBA, Aubl. Pl. Gui. i. 327 (1775)= Ocotea, Aubl. (Laurin.).

grianensis, Aubl. 1. c. $=$ O. commutata.

ANICTOCLEA, Nimmo, in J. Grah. Cat. Pl. Bomb, 252 (1839) = Tetrameles, R. Br. (Datisc.).

Grahamiana, Nimmo, 1. c. =T. nudiflora

ANIDRUM, Neck. Elem, i, $188(1790)=$ Bifora, Hoffm. (Umbell.).

ANIGOSIA, Salisb. in Trans. Hort. Soc. i. (1812) $327=$ Anigozanthos, Labill. (Haemodor.)

flavida, Salisb. 1. e. = Anigozanthos flavida

ANIGOZANTHOS, Labill. Voy. i. 409. t. 22 (1798). HAEMODORACEAE, Benth. \& Hook, f iii. 676.

Anigosia, Salisb. in Trans. Hort. Soc. i. (1812) 327.

SchWAEgrichenia, Spreng. Syst. ii. 26 (1825). bicolor, Endl. in Lehm. Pl. Preiss, ii 26.-Austral. coccinea, Paxt. Bot. Mag. v. $271=$ flavida.

Aavescens, Steud. Nom. ed. II. i. $98=$ flavida.

flavida, [DC. in] Red. Lil.t. 176--Austral.

fulliginosa, Hook. Bot. Mag. t. 4291=Macropodia fumosa.

grandiflora, Salisb. Parad. Lond. t. $97=$ flavida. humilis, Lindl. Swan Riv. App. 46. t. 6 B.-Austral. Manglesii, D. Don, in Sweet, Brit. Fl. Gard. Ser. II. t. 265.-Austral.

Manglesii, Maund, Botanist, $t .67=$ flavida.

minima, Lehm. Pl. Preiss. ii. $274=$ Preissii.

Preissii, Endl. in Lehm. l. c. 26.--Austral,

pulcherrima, Hook. Bot. Mag. t. 4180.-Austral.

rufa, Labill. Voy. i. 409. t. 22.-Austral.

tyrianthina, Hook. Bot. Mag. t. 4507 = rufa.

viridis, Endl. in Lehm. Pl. Preiss. ii. 25.-Austral.

ANILEMA, Kunth, Enum. P1. iv. 64 (1843)= Aneilema, R. Br. (Commel.).

ANIOTUM, Soland. ex End1. Gen. 332 (1837)=Inocarpus, Forst. (Legum.).

ANISA CANTHA,R. Br. Prod. 410 (1810). CHENO PODIACEAE, Benth. \& Hook. f. iii. 62

bicornis, F. Muell. Fragm. vii. $14=$ Sclerolaen bicomis.

bicuspis, F. Muell. in Trans. Vict. Inst. (1855) 133.Austral.

Birchii, F. Muell. Fragm. viii. 163.-Austral.

brevicuspis, $F$. Muell. l. c. iv. 150.-Austral.

diacantha, Nees, in Lehm. Pl. Preiss. i. $635=$ Sclero laena diacantha.

divaricata, R. Br. Prod. 410.-Austral.

Drummondii, Benth. Fl. Austral. v. 199.-Austral.

echinopsila, F. Muell. Fragm. vii. 14.-Austral.

erinacea, Moq. in DC. Prod. xili. II. 122.-Austral.

glabra, F. Muell. ex Benth. Fl. Austral. v. 200.Austral,

gracilicuspis, F. Muell. Fragm. ii. 170.-Austral. incana, A. Cunn, ex Moq. in DC. Prod. xiii. Ir. 122 muricata.

kentropsidea, F. Muell. in Trans. Vict. Inst. (1855) 133 = Sclerolaena diacantha.

lanicuspis, F. Muell. Fragm. ii. $170=$ Sclerolaena lanicuspis.

muricata, Moq. Chenop. Enum. 84.-Austral.

quinquecuspis, Muell. in Trans. Vict. Inst. (1885) 134 $=$ muricata.

tricuspis, F. Muell. l. c. 133.--Austral. 
ANISACANTHUS, Nees, in Linnaea, xvi. (1842) 307. ACANTHACEAE, Benth. \& Hook, f. ii. 1117. Birnbaumia, Kostel. Ind. Pl. Hort. Prag. (1844) 21.

Greggii, A. Gray, Synop. Fl. N. Am. ii. 328,-Mexic. juncea, Hemsl. Biol. Centr. Am, Bot. 522. Mexic.

pumilus, Nees, in DC. Prod. xi. 445.-Mexic

Thurberi, A. Gray, Synop. Fl. N. Am. ii. 328.-Am. bor.

virgularis, Nees, in DC. Prod. xi. 445--Mexic

Wrightii, A. Gray, Synop. Fl. N. Am ii. 328.-Am. bor.

ANISACTIS, Dulac, F1. Hautes-Pyx. $347 \quad(1867)=$ Carum, Linn. (Umbell.).

segetalis, Dulac, 1. c. = C. Petroselinum.

ANISADENIA, Wall. Cat.n. 1510 (1830). LINEAE, Benth, \& Hook. f. i. 243

khasyana, Griff. Notul. iv. $584=$ saxatilis.

pubescens, Griff. l. c. 535.-Reg. Himal.

saxatilis, Wall. Cat. n. 1510.-Reg. Himal.

ANISANDRA, Bartl. in Lehm. Pl. Preiss. i. 361 (1845) $=$ Microcorys, $\mathrm{R}$. Br. (Labiat.).

glabra, Bartl. 1. c. = M. glabra.

ANISANDRA, Planch. ex Oliver, Fl. Trop. Afr. i. 348 in syn. (1868)= Ptychopetalum, Benth. (Olacin.). nigrescens, Planch. 1 . $\mathrm{c}_{\mathrm{o}}=\mathrm{P}$. anceps.

ANISANTHA, C. Koch, in Linnaea, xxi. (1848) 394 =Bromus, Linn. (Gramin.).

pontica, C. Koch, 1. c. = B. tectorum.

ANISANTHERA, Griff. Notul. iv. $100(1854)=$ Adenosma, R. Br. (Scrophul.).

ANISANTHERA, Rafin. F1. Tellur, iii. 80 (1836)= Caccinia, Savi (Borag.),

ciliata, Rafin. 1. c. = C. Rauwolfii.

ANISANTHERA, Rafin. F1. Tellur. ii. 60 (1836)= Crotalaria, Toum. (Legum.).

hastata, Rafin. 1, c. $61=$ C. verrucosa.

versicolor, Rafin. 1. c. $60=$ C. verrucosa

ANISANTHUS, Sweet, Hort. Brit. ed. I. 396 (1827)= Antholyza, Linn. (Irid.)

abyssinicus, Klatt, in Abh. Naturf. Ges. Halle, xii.

(1882) $\mathbf{3 4 4}=$ Antholyza abyssinica.

caryophyllaceus, Klatt, 1. c. =- Watsonia humilis

Cunonia, Sweet, Hort. Brit. ed. I. $397=$ Anth. Cunonia.

huillensis, Klatt, in Abb. Naturf. Ges. Halle, xii.

(1882) 344 -Afr, trop.

quadrangularis, Sweet, Hort. Brit. ed. I. $397=$ Anth. quadrangularis.

saccatus, Klatt, in Linnaea, xxxy. (1867-68) $300=$ Anth. saccata

splendens, Sweet, Brit. Flow. Gard. Ser. II. i. t. $84=$ Anth, caffra.

ANISANTHUS, Willd. ex Roem. \& Schult. Syst. v. p. xiv $(1819)=$ Symphoricarpos, Juss. (Caprifol.). microphyllus, Willd. ex Roem. \& Schult. 1, c. $223=$ S. microphyllus.

ANISEIA, Choisy (Conv. Or. 99) in Mém. Soc. Genèv. vi. (1838) 481 ; viii. (1838) $65=$ Ipomoea, Linn. (Convolv.).

Afrelii, G. Don, Gen. Syst, iv, $295=$ Hewittia bicolor.

arifolia, Meissn, in Mart. F1. Bras. vii. 319.-Bras.

aurea, Kellogg, in Proc. Calif. Acad. v. (1873) 83.Calif.

barlerioides, Choisy, Conv. Or. $102=\mathrm{I}$, barlerioides.

biflora, Choisy, l, c, $101=\mathrm{I}$, biflora

bracteata, Hassk. Pl, Rar. Jav, 516=Hewittia bi color.

calycina, Choisy, Conv. Or. $100=\mathrm{I}$. calycina

calystegioides, Choisy, in DC. Prod. ix. $431=\mathrm{I}$. crassipes.

carnea, Griseb. F1. Brit. W. Ind. 471, sphalmo= cermeas

cernua, Moric. N. Pl. Am. t. 38.-Bras.

costata, Walp. in Nov. Act. Nat. Cur. xix. Suppl. (1843) 367 . - Chili.

diversifolia, Walp. 1. c.-Chili
ANISEIA :-

emarginata, Hassk. Cat. Hort. Bog. Alt. $139=$ Ipomoea martinicensis.

ensifolia, Choisy, Conv. Rar. $144=\mathrm{I}$. martinicensis

fulvicaulis, Hochst. ex Choisy, in DC. Prod. ix. 431. Abyss.

gracillima, Choisy, 1. c. 430.-Bras.

hastata, Meissn. in Mart. Fl. Bras. vii. $319=\mathrm{I}$. phyllo neura.

heterantha, Choisy, in DC. Prod. ix. 430.-Bras.

heterophylla, Meissn. in Mart. Fl. Bras. vii. $321=\mathbf{I}$ heterophylla.

martinicensis, Choisy, Conv. Rar. $144=$ I. martinicensis

Medium, Choisy, Conv. Or. $100=1$. denticulata.

nitens, Choisy, Conv. Rar. 145.-Bras.

salicifolia, Choisy, 1. c. 144=I. martinicensis.

tomentosa, Meissn. in Mart. Fl. Bras. vii. $321=\mathrm{I}$. martinicensis.

uniflora, Choisy, Conv. Or. 101=I. martinicensis.

Velloziana, Choisy, in DC. Prod. ix. 430.-Bras.

ANISEION, St. Lag. in Ann. Soc. Bot. Lyon, vii. 119 $(1880)=$ praec.

ANISEPTA, Rafin. Cat. $13(1824)=$ Croton, Linn. (Euphorb.).

graveolens, Rafin. 1. c.-Am. bor.

ANISOCALYX, Hance, in Walp. Ann. iii. 195 (1853)= Herpestis, Gaertn. (Scrophul.)

limnanthiflorus, Hance, l. c. $=\mathrm{H}$. Monniera.

ANISOCARPUS, Nutt, in. Trans. Am. Phil. Soc. Ser. II. vii. (1841) $388=$ Madia, Molina (Compos,

Bolanderi, A. Gray, in Proc. Am. Acad, vii. (1868) $360=$ M. Bolanderi.

madioides, Nutt, in Trans. Am. Phil, Soc. Ser. II. vii (1841) $388=$ M. Nuttallii.

ANISOCENTRA, Turcz. in Bull. Soc. Nat. Mosc, xxxyi (1863) $593=$ Tropaeolum, Linn. (Geran.) cardiopetala, Turcz. 1. c. $=$ T. speciosum.

ANISOCENTRUM, Turcz, in Bull, Soc Nat. Mosc (1862) I, 322= Acisanthera, P. Br. (Melast.) Gardneri, Turcz. 1. c. $323=$ Ac. punctatissima.

ANISOCHAETA, DC. Prod. v. 109 (1836)。 COMPOSITAE, Benth. \& Hook. f. ii. 493.

mikanioides, $D C, l, c, 110$-Afr, austr.

ANISOCHILUS, Wall. P1. As. Rar. ii. 18 (1831) LABIATAE, Benth. \& Hook. f. ii. 1177. adenanthus, Dalz. \& Gibs. Bomb. Fl. 206.-Ind, or. albidus, Wight, Ic. iv, t. $1435=$ dysophylloides carnosus, Wall. Pl. As. Rar. ii. 18.-Ind, or crassus, Benth. in DC. Prod. xii. $81=$ carnosus, decussatus, Dalz. \& Gibs. Bomb. F1. $206=$ eriocephalus.

dysophylloides, Benth. in Wall. Pl. As. Rar. ii. 19.Ind. or

eriocephalus, Benth. in DC. Prod. xii. 81.-Ind. or euneurus, Miq. Fl. Ind. Bat. ii. 957.-Java.

glaber, Schrad. Ind. Sem. Hort. Gott. (1833) $1=$ carnosus.

pallidus, Wall. $\mathrm{Pl}$. As. Rar, ii. 18.-Ind. or,

paniculatus, Benth. in DC. Prod. xii. 82. Ind. or

plantagineus, Hook. f. Fl. Brit. Ind. iv. 628.Ind. or.

polystachys, Benth. in Wall. Pl. As. Rar. ii. 19.Ind. or.

purpureus, Wight, Ic. iv. t. $1435=$ dysophylloides.

robustus, Hook f. Fl. Brit. Ind iv 629.-Ind or.

rupestris, Wight, ex Hook. f. Fl. Brit. Ind. iv. $627=$ carnosus.

scaber, Benth. in DC. Prod. xii. 81.-Ind, or

sericeus, Benth. l. c. 82.-Ind. or.

sinensis, Hance, in Fourn. Bot. xxiii. (1885) 327. China.

suffruticosus, Wight, Ic. iv, t. 1487.-Ind. or.

suffruticosus, Thw. Enum. Pl. Zeyl. 238=panicu latus?

verticillatus, Hook. f. Fl. Brit. Ind. iv. 629.Ind. or.

Wightii, Hook. f. l. c. 628,-Ind. or.
ANISOCOMA, Torr. \& Gray, in Bost. Journ. Nat Hist. v. (1844) 111. t. 13. COMPOSITAE, Benth \& Hook. f. ii. 518.

Pterostephanus, Kellogg, in Proc, Calif. Acad, iii. 1863) 20 . f. 4

acaulis, Torr. \& Gray, l. co-Calif.

ANISODENS, Dulac, F1. Hautes-Pyr。 465 (1867)= Scabiosa, Toum. (Dipsac.)

arvensis, Dulac, $1 . \mathrm{c}_{0}=\mathrm{S}$. arvensis.

longifolius, Dulac, $1 . \mathrm{c}_{\mathrm{.}}=\mathrm{S}$. sylvatica

sylvaticus, Dulac, I. $c_{0}=$ S. sylvatica.

ANISODERIS, Cass. in Dict. Sc. Nat. xlviii. 429 (1827 Crepis, Linn. (Compos.)

foetida, Fisch. \& Mey. Ind. Sem. Petrop. iv. $32=\mathrm{C}$. foetida.

rhoeadifolia, Fisch. \& Mey. 1. c. = C. foetida.

rubra, Cass. in Dict. Sc. Nat. xlviii. $429=$ C. rubra.

ANISODONTEA, Presl, Bot. Bemerk. 18 (1844) (in Abh. Boehm. Ges. Fol. V. iii.) = Sphaeralcea, St Hil. (Malvac

Dregeana, Presl, I. c. $=$ S. Dregeana.

ANISODUS, Link \& Otto, Ic. Sel. Pl. 77. t. 35 (1824) Scopola, Jacq. (Solanac.)

humilis, Hook. f. ex C. B. Clarke, in Fl. Brit. Ind. iv $242=$ Mandragora caulescens.

luridus, Lisk \& Otto, Ic. Sel. Pl. $77=$ S. lurida.

stramonifolius, G. Don, in Load. Hort. Brit. $61=\mathrm{S}$. lurida.

ANISOLEPIS, Steet 2 , in Lehm. Pl. Preiss. i. 446 (1845 $=$ Helipterum, DC. (Compos.).

Pyrethrum, Steetz, 1. c. $447=$ H. Pyrethrum

ANISOLOBUS, A. DC. Prod. viii. $395(1844)=$ Odonta denia, Benth. (Apocyn.)

amazonicus, Muell. Arg. in Mart, Fl. Bras. vi. I. 114. -Bras.

anomalus, Heurck \& Muell. Arg. Obs. Bot. 160.Peruy.

cognatus, Muell. Arg. in Mart. F1. Bras. vi. I. 113.-Bras Cururu, Muell. Arg. 1. c. 112.-Bras.

distinctus, Miers, Apocyn. S. Am, 169-Am, austr.

Fockei, Miq. in Nat. Verb. Wet. Haarl. vii, (1851 (Stirp. Surin. Sel.) 159.-Guian.

gracilipes, Muell. Arg. in Mart. FI. Bras. vi. I. 115.Bras.

hebecarpus, Muell. Arg. I. c. 111.-Bras

Hostmanni, Miq. in Nat. Verh. Wet. Haarl. vii. (1851

(Stirp. Surin. Sel.) 159.-Surinam.

Kappleri, Miq. in Linnaea, xviii. (1844) $737=$ Cururu.

oblongus, Miers, Apocyn. S. Am. 169.-Am. austr.

Perrottetii, A. DC. in DC. Prod. viii. 395.-Bras.

Pohlianus, Miers, Apocyn. S.Am. 171.-Am. anstr.

psidiifolius, Miers, 1. c. 172.-Am. austr.

pulcherrimus, Miers, 1. c. 171.-Am. austr.

puncticulosa, Miq. in Nat. Verh. Wet. Haarl. vii.

(1851) (Stirp. Surin. Sel.) 158.-Guian.

rubidulus, Miers, Apocyn. S. Am. 173.-Am. austr.

Salzmanni, A. DC in DC. Prod. viij. 395.-Bras.

Sprucei, Muell. Arg. in Mart. Fl. Bras, vi. 1. 114.-Bras.

Stadelmeyeri, Muell. Arg. 1. c. 113.-Bras.

Zuccarinianus, Miers, Apocyn. S. Am. 171.-Am. austr.

ANISOLOTUS, Bernh. Sem. Hort. Erf. (1837); Linnaea, xii. (1838) Litt. $75=$ Hosackia, Dougl. (Legum.) anthylloides, Bernh. 11. $\mathrm{cc}=\mathrm{H}$. subpinnata.

Poeppigiana, Bernh. 11. cc.-Chili.

Wrangeliana, Bernh. 11. cc. $=\mathrm{H}$. subpinnata.

ANISOMALLON, Baill. Adansonia, xi. (187 $19 \%$ $O L A C I N E A E$.

clusiaefolium, Baill. l. c.-N. Caled.

ANISOMELES, R. Br. Prod. 508 (1810), LABIATAE, Benth. \& Hook, f. ii. 1207 albiflora, Miq. Fl. Ind. Bat. ii. 976.-Malaya. australis, Spreng. Syst. iv. Cur. Post. 226.-Austral candicans, Benth. in I"all. Pl. As. Rar. i. 59.-Ind. or. cuneata, Facg. Ecl. Pl. 127 -Ind or.

distiche, Heyne, ex Roth, Nov. Pl. Sn. $254=$ orats.

furcata, Loud. Hort. Brit. $282=$ Craniotome versicolor. glabrata, Benth. in Wall. Cat. 1. $2041=0$ rata. Heyneana, Berth. in Wiall. Pl. As. Rar. i. 59.-Ind. or. 


\section{ANISOMELES :-}

nodora, R. Br. Prod. 503.-Austral.

internedia, Wight, in Benth. Lab. Gen. et Sp. $703=$ malabarica.

malabarica, R. Br.ex Sims, Bot. Mag. t. 2071.-Ind. or. ; Ins. Masc.

mollissima, Wall. Cat. n. $2039=$ ovata

moschata, R. Br. Prod. 503.-Austral.

nepalensis, Spreng. Syst. ii. $706=$ Craniotome versi. color.

ovata, R. Br. in Ait. Hort. Kew. ed. II. iii. 364.-Ind. or.; Malaya.

salviaefolia, R. Br. Prod. 503.-Austral.

ANISOMERIA, D. Don, in Edinb. N. Phil. Journ. xiii. 1832) 238. PHYTOLACCACEAE, Benth. \& Hook, f. iii, 85 .

coriacea, D. Don, l. c.-Chili

drastica, Moq. in DC. Prod. xiii. II. 25.-Chili.

fruticosa, Phil. in Linnaea, xxix. (1857-8) 38.-Chili. littoralis, Moq. in DC. Prod. xiii. II. 25.-Chili.

ANISOMERIS, Presl, Symb. Bot. ii. 5. t. 54 (1833) Chomelia, Jacq. (Rubiac.)

diversifolia, Wawra, in Oestr. Bot. Zeitschr, xii. (186? 211.-Bras

spinosa, Presl, Symb. Bot. ii. 5. t. $54=$ C. Anisomeris

ANISOMETROS, Hassk. in Flora, xx. (1847) $602=$ Pimpinella, Linn. (Umbell.)

alpina, Hassk. 1. c. = P. javana

ANISONEMA, A. Juss. Euph. Tent. 19. t. 4 (1824)= Phyllanthus, Linn. (Euphorb.)

dubium, Blume, Bijdr. $589=\mathrm{P}$. reticulatus.

eglandulosum, Decne. Herb. Tim. Descr. $154=P$ reticulatus.

glaucinum, Miq. Fl. Ind. Bat. Suppl. 449.-Sumatr.

hypoleucum, Miq. 1. c.-Sumatr.

intermedium, Decne, in Nouv. Ann. Mus. Par. iii. (1831) $482=$ P. reticulatus

jamaicense, Griseb. F1. Brit. W. Ind, $716=\mathrm{P}$. jamaicensis.

multiflorum, Wight, Ic. t. $1899=$ P. reticulatus

reticulatum, A. Juss. Euph. Tent. t. 4. fo $11=$ P. reticulatus.

Zollingeri, Miq. F1. Ind. Bat. i. II. $375=\mathrm{P}$. reticulatus.

ANTSOPAPPUS, Hook. \& Arn. Bot. Beech. Voy. 196 (1836). COMPOSITAE, Benth. \& Hook. f. ii. 339 .

africanus, Oliver \& Hiern, in Oliver, Fl. Trop. Afr. iii. 369.-Afr. trop

chinensis, Hook. \& $\mathcal{F}^{3}$ Arn. Bot. Beech. Voy. 196.China,

ANISOPETALA, Walp. Rep. iv. 228 (1848)= Pelargonium, L'Hérit. (Geran.).

crispa, Walp. 1. c. $=$ P. crispum.

purpurascentia, Walp. 1. c. $=\mathbf{P}$. purpurascens.

Radulae, Walp. 1. c. =P. Radula, etc.

tomentosa, Walp. 1. $\mathrm{c}_{\mathrm{r}}=\mathrm{P}$. tomentosa

ANISOPETALUM, Hook. Exot. Fl, t, 149 (1825)= Bulbophyllum, Thou. (Orchid.).

Careyanum, Hook. 1. $\mathrm{c}_{\mathrm{s}}=\mathrm{B}$. Careyanum.

ANISOPHYLLEA, R. Br. ex Sabine, in Trans. Hort. Soc. v. (1824) 446. RHIZOPHOREAE, Benth. \& Hook. f. i. 683.

Anisophyllum, G. Don, ex'Hook. Niger Fl. 342, 575 (1849).

TetracarpaEA, Benth. in Journ. Linn. Soc. iii. (1859) 72 , sphalm.

Tetracrypta, Gardn. \& Champ. in Hook. Kew Journ. i. (1849) 314.

Beccariana, Baill. Adansonia, xi. (1875) 311.Borneo.

disticha, Baill. 1. $\mathrm{c}_{\mathrm{.}}=$ trapezoidalis.

Gaudichaudiana, Baill. l. c.-Am. trop.

grandis, Benth. in Fourn. Linn. Soc. i. (1857) 79 , in nota.-Penang.

grandifolia, G. Henslow, in Hook, f, Fl. Brit. Ind ii. $442=$ grandis.

Griffithii, Oliver, in Linn. Trans. Soc. xxiii. (1862) 460.-Malacca.

laurina, R. Br. ex Sabine, in Trans. Hort. Soc. v. (1824) 446.-Afr.trop.

\section{ANISOPHYLLEA :-}

homboidea, Baill. Adansonia, xi. 1875) 310.Borneo.

trapezoidalis, Baill. l. c. iii. (1862) 4-Singapur,

zeylanica, Benth. in Hook. Niger Fl. 343, 575. Zeylan.

ANISOPHYLLUM, Boiv. ex Baill. Adansonia, i. (1860-

61) $153=$ Croton, Linn. (Euphorb.).

acutifolium, Boiv. ex Baill. 1. $\mathrm{c}_{\mathrm{v}}=\mathrm{C}$. muricatus.

scutelligerum, Boiv. ex Baill. 1. c. $154=\mathrm{C}$. Payeri antus.

ANISOPHYLLUM, G. Don, ex Benth. in Hook. Niger F1. $342,575(1849)=$ Anisophyllea, $\mathrm{R} . \mathrm{Br}$ (Rhizoph.)

ANISOPHYLLUM, Haw. Syn, P1. Succ, 159 (1812)= Euphorbia, Linn.

aegypticum, Schweinf. Beitr. Fl. Aethiop. $34=\mathrm{E}$ aegyptiaca.

affine, Klotzsch \& Garcke, in Abh. Akad. Berl. 1859 (1860) $29=\mathrm{E}$. Balbisii.

amoenum, Klotzsch \& Garcke, 1. c. $33=$ E. adenoptera.

arabicum, Schweinf. Beitr. Aethiop. $34=\mathrm{E}$ arabica.

arenarium, Klotzsch \& Garcke, in Abh. Akad. Berl. $1859(1860) 24=$ E. zygophylloides.

Atoto, Klotzsch \& Garcke, 1. c. $37=\mathrm{E}$. Atoto.

bahiense, Klotzsch \& Garcke, 1. c. $33=\mathrm{E}$. bahiensis.

Berterianum, Klotzsch \& Garcke, 1. c. $32=\mathrm{E}$. Ber teriana.

Besseri, Klotzsch \& Garcke, 1. c. $30=$ E. Besseri.

Burmannianum, Klotzsch \& Garcke, 1. c. $25=\mathrm{E}$ thymifolia.

caecorum, Klotzsch \& Garcke, 1. c. $38=\mathbf{E}$. cae corum.

californicum, Klotzsch \& Garcke, 1. c. $36=$ E. Dep peana.

centunculoides, Klotzsch \& Garcke, 1. c. $38=\mathrm{E}$ centunculoides.

Chamaesyce, Haw. Syn. Pl. Succ. $160=$ E. Cha maesyce.

Chamissonis, Klotzsch \& Garcke, in Abh. Akad. Berl $1859(1860) 22=\mathrm{E}$. Chamissonis

cheirolepis, Klotzsch \& Garcke, 1. c. $21=$ E, cheirolepis.

congenerum, Klotzsch \& Garcke, 1. c. $22=$ E. con genera.

convolvuloides, Klotzsch \& Garcke, 1. c. $34=\mathrm{E}$ convolvuloides.

cordatum, Klotzsch \& Garcke, 1. c. $38=\mathrm{E}$. cordata

crassipes, Klotzsch \& Garcke, 1. c. = E. macropus.

densiflorum, Klotzsch \& Garcke, 1. c. $28=\mathrm{E}$. adenoptera.

dentatum, Haw. Syn. Pl. Succ. $162=$ E. dentata.

dioicum, Klotzsch \& Garcke, in Abh. Akad. Berl.

$1859(1860) 31=\mathrm{E}$. dioica

emarginatum, Klotzsch \& Garcke, 1. c. $24=$ E. emar ginata.

Fendleri, Klotzsch \& Garcke, 1. c. 26=E. Fendleri.

flexuosum, Klotzsch \& Garcke, 1. c. $35=\mathrm{E}$. flexuosa

Forskaliz, Klotzsch \& Garcke, 1, c. $25=$ E. Forskalii.

Geyeri, Klotzsch \& Garcke, 1. c. $23=$ E. Geyeri.

glabratum, Klotzsch \& Garcke, 1. c. $35=\mathrm{E}$. glabrata.

glaucophyllum, Klotzsch \& Garcke, 1. c. = E. glauco phylla.

golianum, Klotzsch \& Garcke, 1. c. $29=$ E. goliana.

granulatum, Schweinf. Beitr. Fl. Aethiop. $34=\mathrm{E}$. granulata.

Humboldtii, Haw. Syn. P1. Succ. $160=$ E. graminea.

humifusum, Klotzsch \&c Garcke, in Abh. Akad. Berl $1859(1860) 21=\mathrm{E}$. humifusa.

humistratum, Klotzsch \& Garcke, 1. c. $26=$ E. humistrata.

hypericifolium, Haw. Syn. Pl. Succ. $161=$ E. hypericifolia.

hyssopifolium, Haw. 1. c. = E. hyssopifolia.

hyssopifolium, Boiss. in DC. Prod. xv. II. $23=\mathrm{E}$. hypericifolia.

inaequale, Klotzsch \& Garcke, in Abh. Akad. Berl. $1859(1860) 27=\mathbf{E}$. adenoptera.

inaequilaterum, Klotzsch \& Garcke, 1. c. $22=\mathrm{E}$. inae quilatera.

indicum, Schweinf. Beitr. Fl. Aethiop. $34=$ E. hypericifolia.

Ipecacuanha, Haw. Syn. Pl. Succ. 164=E. Ipecacuanha.
ANISOPHYLLUM :-

laevigatum, Klotzsch \& Garcke, in Abh. Akad. Berl. $1859(1860) 35=\mathrm{E}$, laevigata.

lasiocarpum, Klotzsch \& Garcke, 1. c. =E. 1asiocarpa.

leiospermum, Klotzsch \& Garcke, 1. c. $23=$ E. obliqua. leucanthum, Klotzsch \& Garcke, 1. c. $27=\mathrm{E}$. leucantha.

Lindenianum, Klotzsch \& Garcke, 1. c. $37=\mathrm{E}$. Linde niana.

lineare, Klotzsch \& Garcke, 1. c. $38=\mathrm{E}$. linearis.

macropus, Klotzsch $8 x$ Garcke, 1. c. $33=\mathrm{E}$. macropus. maculatum, Hàw. Syn. P1. Succ. $162=$ E. maculata. melanadenium, Klotzsch \& Garcke, in Abh.Akad. Berl. 1859.(1860) $23=$ E. melanadenia.

Meyenianum, Klotzsch \& Garcke, 1. c. $25=\mathrm{E}$. Meyeniana.

mossambicense, Klotzsch \& Garcke, 1. c. $30=\mathbf{E}$. mozambicensis.

multiforme, Klotzsch \& Garcke, 1. c. $37=\mathrm{E}$. multiformis.

Mundii, Klotzsch \& Garcke, 1. c. 25=E. parvifolia.

Nagleri, Klotzsch \& Garcke, 1. c. $31=$ E. Nagleri.

nanum, Klotzsch \& Garcke, 1. c. $32=\mathrm{E}$. chamaerrhodos.

nodosum, Klotzsch \& Garcke, 1. c. $22=\mathbf{E}$. clusiaefolia.

novo-mexicanum, Klotzsch \& Garcke, 1. c. 31.-N. Mexic.

ocymoideum, Haw. Syn. P1. Succ. $161=$ E. ocymoidea. orbiculatum, Klotzsch \& Garcke, in Abh. Akad. Berl. $1859(1860) 24=\mathrm{E}$. orbiculata.

ovalifolium, Klotzsch \& Garcke, 1. c. $26=\mathrm{E}$. ovalifolia.

Peplis, Haw. Syn. P1. Succ. $159=$ E. Peplis.

piluliferum, Haw. 1. c. $162=\mathrm{E}$. pilulifera.

polycnemoides, Klotzsch \& Garcke, in Abh. Akad. Berl. $1859(1860) 34=\mathrm{E}$. polycnemoides.

polygonifolium, Haw. Syn. P1. Succ. $160=$ polygonifolia.

prostratum, Haw. 1. c. $163=\mathrm{E}$. prostrata.

ramosissimum, Klotzsch \& Garcke, in Abh. Akad. Berl. 1859 (1860) $30=$ E. Garckeana.

rhytispermum, Klotzsch \& Garcke, 1. c. $34=\mathrm{E}$. rhytisperma.

roseum, Haw. Syn. Pl. Succ. $163=\mathrm{E}$. rosea

Ruizianum, Klotzsch \& Garcke, 1. c. $37=\mathbb{E}$. Ruiziana. scordifolium, Klotzsch \& Garcke, l. c. $35=$ E. scordifolia.

Selloi, Klotzsch \& Garcke, 1. c. $32=$ E. Selloi senile, Klotzsch \& Garcke, ]. c. $28=$ E. stictospora. serpens, Klotzsch \& Garcke, 1. c. $23=$ E. serpens. setigerum, Klotzsch \& Garcke, I. c. $29=$ E. setigera tenuiflorum, Klotzsch \& Garcke, 1. c. $26=\mathrm{E}$. velligera. tettense, Klotzsch \& Garcke, 1. c. $34=\mathrm{E}$. tettensis. thymifolium, Haw. Syn. Pl. Succ. $160=$ E. thymifolia.

Vahlii, Klotzsch \& Garcke, I. c. $36=$ E. Vahlii.

velleriflorum, Klotzsch \& Garcke, 1. c. $28=\mathrm{E}$, velleriflora.

virgatum, Klotzsch \& Garcke, 1. c. $36=$ E. Hookeri.

ANISOPHYLLUM, Jacq. Select. Am.283 (1763) (Quid?). pinnatum, Jacq. 1. c.--Ins. Baru.

ANISOPLECTUS, Oerst. in Vidensk. Selsk. Skr. V: v. (1861) 120 (Gesn. Centr. Am. 46)=Alloplectus, Mart. (Gesnerac.)

pendulus, Oerst. 11. cc. = Allop. pendulus.

ANISOPLEURA, Fenzl, in Flora, xxvi. (1843) $459=$ Prangos, Lindl. (Umbell.).

crenata, Fenzl, l. c.-Mesopotam

ANISOPOGON, R. Br. Prod, 176 (1810), GRAMINEAE, Benth. \& Hook. f. iii. 1162.

avenaceus, $R . B r . l, c$-Austral.

capensis, Nees, Gram. Afr. Austr. 265.-Afr. austr

ANISOPTERA, Korth. Verh. Nat. Gesch. Bot. ed. Temminck, 65. t. 6 (1839). DIPTEROCARPEAE Benth \& Hook f i 192

Antherotriche, Turcz, in Bull. Soc. Nat. Mosc. (1846) II. 505.

bantamensis, Hassk. Retzia, i. $140=$ Vatica bantamensis.

costata, Korth.Verh. Nat. Gesch. Bot. 65. t. 6.-Borneo. glabra, Kurz, in Fourn. As. Soc. Beng. xlii. (1873) II. 


\section{ANISOPTERA :}

Guiso, A. DC in DC. Prod. xvi. ii. 616.-Ins. Philipp. lanceolata, Walp. Ann. i. $113=$ thurifera.

Mangachapoi, A. DC. in DC. Prod. xvi. II. $616=$ Vatica Mangachapoi.

marginata, Korth. Verh. Nat. Gesch. Bot. 66. t. 6.Borneo.

melanoxylon, Hook. f. in Trans. Linn. Soc, xxiii. (1860) $\mathbf{1 6 0}=$ Vatica melanoxylon.

oblonga, Dyer, in Hook. f. Fl. Brit. Ind. i. 301.Burma.

odorata, Kurz, in Flora, 1v. (1872) $190=$ Vatica grandiflora.

palembanica, Miq. Fl. Ind. Bat. Suppl. i. 485.Sumatr.

plagata, Blume, Mus. Bot. Lugd. Bat, ii. 42.-Ins. Philipp.

polyandra, Blume, l. c. t. 6.-N. Guin.

thurifera, Blume, l. c.-Ins. Philipp.

ANISORA, Rafin. Sylva Tellur. $74(1838)=$ Helicteres, Linn. (Stercul.).

angulata et Murri, Rafin. 1. c.-Hab. ?

ANISORAMPHUS, DC. Prod. vii. 251 (1838)= Crepis, Limn. (Compos.)

hypochaerideus, DC. 1. c.-Afr. anstr.

hypochaeroides, Hook. f. in Journ. Linn. Soc. vii. (1864) $204=$ C. Hookeriana

ANISOSCIADIUM, DC. Coll. Mém. v. 63. t. 15 (1829); Prod. iv. $234(1830)=$ Echinophora, Linn. (Umbell.).

orientale, DC. Prod. 1. c.-Persia.

ANISOSPERMA, Manso, Enum. Subst. Bras. 38 (1836). CUCURBITACEAE, Benth. \& Hook. fo i. 820.

Passiflora, Manso, l. c.-Bras.

ANISOSTACHYA, Nees, in DC. Prod. xi. 368, 730 (1847) = Justicia, Linn. (Acanth.).

Bojeri, Nees, in DC. Prod. xi. 368, 730.-Madag.

Commersoni, T. Anders. in Journ. Linn. Soc. vii. (1864)

$46=\mathrm{J}$. haplostachya.

velutina, Nees, in DC. Prod. xi. 730.-Madag.

ANISOSTEMON, Turcz. in Bull. Soc. Nat Mosc. xx. (1847) I. 152=Connarus, Linn.

trifoliatus, Turez. 1. c. =C. polyanthus.

ANISOSTICHUS, Bur. Monog. Bign. 43. t. $6(1864)=$ Bignonia, Tourn.

capreolata, Bur. 1. c. = B. capreolata.

ANISOSTICTUS, Benth. \& Hook. f. Gen. ii. 1033 (1883), lapsu $=$ ANISOSTICHUS, Bur. = Bignonia, Tourn.

ANISOTES, Nees, in DC. Prod. xi. 424 (1847). ACANTHACEAE, Benth. \& Hook. f. ii. 1111.

Calasias, Rafin. Fl. Tellur. iv. 64 (1836), nomen prius.

diversifolius, Balf. f. in Proc. Roy. Soc. Edinb. xii. (1884) 88.-Ins, Socotr.

trisulcus, Nees, in DC. Prod. xi. 424.-Arab.

ANISOTES, Lindl, Introd. Nat. Syst. ed. II. 100, 441 (1836) = Lythrum, Linn.

anomalus, Lind1. 1. c. $441=\mathrm{L}$. anomalum.

Hilarianus, Meissn. Gen. Comm. $84=\mathrm{L}$, anomalum.

ANISOSTICTE, Bartl. Ord. $294(1830)=$ Capparis, Linn. (C. frondosa, Jacq.).

ANISOTOMA, Fenzl, in Linnaea, xvii. (1843) 330. ASCLEPIADEAE, Benth. \& Hook. f. ii. 781. Anisotomaria, Presl, Bot. Bemerk. 103 (1844) Decaceras, Harv. Thes. Cap. ii. 9. t. 114 (1863). Lophostephus, Hary, 1. c. 118 (1863)

Arnottii, Benth. \& Hook. f. Gen. ii. 781.-Afr. austr. cordifolia, Fensl, in Linnaea, xvii. (1843) 331.-Afr. austr.

ANISOTOMARIA, Presl, Bot. Bemerk. 103 (1844)= Anisotoma, Fenzl (Asclep.)

mollis, Presl, 1. c. = Anisotoma cordifolia.
ANISOTOME, Hook. f. Fl. Antarct. 16. t. 8, 9 (1844

Aciphylla, Forst. (Umbell.)

antipoda, Hook. f. Fl. Antarct 17.-Ins, Antarct.

aromatica, Hook. f. Fl. N. Zeal. i. 89.-N. Zel.

geniculata, Hook. f. 1. c. $90=$ Angelica geniculata

Gingidium, Hook. f. 1. c. $89=$ Angelica Gingidium.

intermedia, Hook. f. l. c. = Ligusticum intermedium

latifolia, Hook. f. Bot. Antarct. $16=$ Ligusticum latifolium.

Lyallii, Hook. f. Fl, N. Zeal, i. $88=$ Ac. Lyallii.

rosaefolia, Hook. f. 1. c. $90=$ Angelica rosaefolia.

ANISTYLIS, Rafin. Neogenyt. $4(1825)=$ Liparis Rich. (Orchid.)

Convallaria, Rafin. 1. $c_{0}=\mathrm{L}$. liliifolia,

lutea, Rafin. I. $c_{*}=$ L。 Loeselii.

ANISUM, Riv, ex Linn. Gen. ed. I. 83 (1737) = Pimpinella, Linn. (Umbell.)

caffrum, Eckl. \&c Zeyh. Enum. $341=$ P. caffra

officinale, DC. Prod. iv. $122=$ P. Anisum.

officinarum, Moench, Meth. $100=$ P. Anisum.

stadense, Eckl. \& Zeyh. Enum. $341=$ P. stadensis.

vulgare, Gaertn. Fruct. i. $28=\mathrm{P}$. Anisum.

ANKYLOBUS, Stev. in Bull. Soc. Nat. Mosc. xxix. (1856 II. $148=$ Astragalus, Tourn. (Legum.)

caspicus, Stev. 1. $\mathrm{c}_{\mathrm{r}}=$ A. caspius.

contortuplicatus, Stev. 1. c. $=$ A. contortuplicatus.

cruciatus, Stev. 1. c. = A. cruciatus.

hamosus, Stev, 1. c. = A. hamosus.

reticulatus, Stev. 1. $\mathrm{c}_{0}=\mathrm{A}$. reticulatus.

ANKYROPETALUM, Fenzl, in Bot. Zeit. i. (1843) 393 Gypsophila, Linn. (Caryophyll.)

arsusianum, Kotschy, in Boiss. FI. Orient. i. 533.Syria.

coelesyriacum, Boiss. Diagn. Ser. I. viii. 59.-Oriens. gypsophiloides, Fenzl, in Bot. Zeit. i. (1843) 393.Mesopot.

Renteri, Boiss. \& Haussk in Boiss. Fl. Orient. i. 533.Oriens.

ANNESLEA, W. Hook. in Salisb. Parad. Lond. t. 64 $(1807)=$ ANNESLIA, Salisb.

ANNESLEA, Roxb. ex Andr. Bot. Rep. t. 618 (1810)

Fl. Ind. ii. $573(1832)=$ Euryale, Salisb. (Nymph.) amazonica, Presl, Bot. Bemerk. $103=$ Victoria regia.

brasiliana, Pres1, 1. c. = Victoria regia.

spinosa, Andr. Bot. Rep. x. t. $618=\mathrm{E}$. ferox

ANNESLEA, Wall. Pl. As, Rar. i. 5. t. 5 (1829) TERNSTROEMIACEAE, Benth. \& Hook. f. i. 182. Callosmia, Presl, Bot. Bemerk. 103 (1844). crassipes, Hook. ex Choisy, in Mém. Soc. Phys. Genèv. xiv. (1855) 121.-Malaya.

fragrans, Wall. Pl. As. Rav. i. 5. t. 5.-Burma.

monticola, Kurz, in fourn. As. Soc. Beng. xlii. (1873) II. 59.-Burma.

ANNESLEIA, = ANNESLEA, W. Hook, = Callian dra, Benth. (Legum.).

+ANNESLIA, Salisb. Parad. Lond. t. 64 (1807)=Cal liandra, Benth. (1840) (Legum.)

falcifolia, Salisb. 1. c. in textu $=$ C. Honstoni. grandiflora, Salisb. 1. c.. t. $64=$ C. Houstoni. Houstoni, Sweet, Hort. Brit. ed. II. $163=$ C. Hous. toni.

ANNESORHIZA, Cham. \& Schlecht. in Linnaea, (1826) 398. UMBELLIFERAE, Benth. \& Hook. f. i. 913 .

Acroglyphe, E. Mey. Zwei Pf. Docum. 100 (1843). Glia, Sond. in Harv. \& Sond. Fl. Cap. ii. 547 (1862).

Stenosemis, E. Mey. Zwei Pfl. Docum. 141, 148 (1843).

capensis Cham. \& Schlecht. l. c. 399-Afr. äustr.

elata, Eckl. \& Zeyh. Enzm. 345.-Afr. austr.

filicaulis, Eckl. \& Zeyh. l. c.-Afr. austr.

hirsuta, Eckl. \&o Zeyh.l. c.-Afr. austr.

macrocarpa, Eckl. \& Zeyh.l. c.-Afr, austr,

montana, Eckl. \& Zeyh.l. c. 944.-Afr. austr.

spuria, Eckl. \& Zeyh. l. c. 345.-Afr, austr.

villosa, Sond. in Harv. \& Sond. Fl. Cap. ii. 546.-Arr. austr.
ANNONA, Linn. Hort. Cliff. 222 (1737); Forsk. Fl. Aegypt, Arab. $102=$ Anona, Linn.

ANNULARIA, Hochst. in Flora, xxiv. (1841) $670=$ Voacanga, Thou. A pocyn.

natalensis, Hochst. 1. c. $671=\mathrm{V}$. Dregei

ANOCHEILE, Hoffmgg. ex Reichb. Nom. 235 (1841, Epidendrum, Linn. (Orchid.)

ANODA, Cav. Diss. i. 38. t. 10, f. 8 (1785). MALVACEAE, Benth. \& Hook. f. i. 202.

Cavanillea, Medic. Malv. 19 (1787)

acerifolia, Cav. in Anal. Cienc. Nat. vi. (1803) 336 DC. Prod. i. $459=$ hastata.

angustifolia, Spreng. Nachtr. i. Bot. Gart. Halle, 11.$\mathrm{Hab}$ ?

arenariaeflora, Hort. ex Steud. Nom. ed. II. i. 100= crenatiflora.

brachyantha, Reichb. Hort. Bot. t. $34=$ triangularis.

crenatiflora, Orteg. Hort: Matr. Dec. $96=$ parviflora

cristata, Schlecht. in Linnaea, xi. (1837) $210=$ lavaterioides.

Dilleniana, Cav. Diss. i. 40. t. 11. f. $1=$ cristata.

fernandeziana, Steud. in Flora, xxxix. (1856) 437.Ins. Juan Ferm.

hastata, Cav. Diss. i. 39. t. 10. f. 3.-Mexic.; Ind.

hirsuta, Phil. in Linnaea, xxviii. (1856) 675.-Chili.

incarnata, $H . B$. है $K$. Nov. Gen. et Sp. v. 266.Mexic.

incarnata, Spreng. ex Steud. Nom. ed. II. i. 100= triangularis.

lanceolata, Hook. \& Arn. Bot. Beech. Voy. 411.Mexic.

lavateroides, Medic. Malv. 19.-Mexic

Ochsenii, Phil. in Linnaea, xxviii. (1856) $613=$ Abatilon Ochsenii.

Ortegae, Spreng. Nachtr. i. Bot. Gart. Halle, $11=$ crenatiflora.

ovata, Meyen, Reise, ii. $139=$ Sida fallax.

parviflora, Cav. Ic v, 19. 431.-Mexic.

pentaschista, A. Gray, Pl. Wright. ii. 22.-Nov.

Mexic.

populifolia, Phil. in Linnaea, xxviii. (1856) 313.Chili.

pubescens, Schlecht. in Linnaea, xi. (1837) 218.Mexic.

punicea, Lag. Gen. et Sp. Nov. t. 21.-Mexic.

reticulata, $S$. Wats, in Proc. Am. Acad xvii. (1881-8? 368.-Am. bor

strictiflora, Steud. in Flora, xxxix (1856) 437.Chili.

triangularis, $D C$. Prod. i. 459.-Mexic.

triloba, Cav. Diss. i. 39. t. 10. f. 3 =lavaterioides.

Wrightii, A. Gray, Pl. Wright. ii. 22.-No Mexic.

ANODENDRON, A. DC. Prod. viii. 443 (184. APOCYNACEAE, Benth. \& Hook. f. ii. 719,

Candolleanum, Wight, Ic. iv, t. 1309.-Malaya coriaceum, Miq. Fl. Ind. Bat. ii. 455.-Java inflatum, Hassk. in Flora, xxviii. (1845) 269,-Jara laeve, Maxim. ex Franch. \& Sav. Enum. Pl. Fap. 315.-Japon.

moluccanum, Miq. Ann. Mus. Bot. Lugd. Bat. iv 140.-Malaya.

paniculatum, A. DC, in DC. Prod. viii. 444.-Ind. or. Malaya.

pauciflorum, Hock. f. Fl. Brit. Ind. iii. 669.Penang.

rhinosporum, Thav. Enum. Pl. Zevyl. 194.-Zeylan.

rubescens, Teijsm. \& Bino. Cat. Hort. Bogor. $127=$ Candollcanum.

tenuiflorum, Miq. Ann. Mus. Bot. Lagd. Bat. iv. 110 . -Sumatr.

ANODIA, Hassk. in Flora, xxv. (1\&42) 11. Beibl. \$8, in nota $=$ Anoda, Cav. (Malvac).

ANODISCUS, Benth, in Benth. \& Houk. \& Gea. i 998 (18;6). GESIERACE.AE. Benth. \& Hook, I. ii. 998 .

peruvianus, Benth. in Hook. Ic. Pl. t. 1199.-Perav.

ANODONTEA, Sweet, Hort. Brit ed. I. 187 152Alyssum, Tourn. (Crucif.)

arenaria, G. Don, Gea. Syst. i. 1 So = Al. montmum 


\section{ANODONTEA :-}

Aucheri, D. Dietr. Syn. Pl. iii. $643=$ Alyssum foliosum. canescens, Sweet, Hort. Brit. ed II. $25=$ Alyssum canescens.

dasycarpa, Sweet, 1. c. = Alyssum dasycarpum edentula, Sweet, 1. c. ed I. $467=$ Alyssum gemonense hatimifolia, Sweet, 1. c = Alyssum halimifolium. macrocarpa, Sweet, 1. c. = Alyssum macrocarpum. marginata, D. Dietr. Syn. P1. iii. $643=$ Alyssum marginatum.

meniocoides, D. Dietr. 1. c. $=$ Alyssum meniocoides. peltarioides, D. Dietr. 1. c. = Alyssum peltarioides.

pyrenaica, G. Don, Gen, Syst. i. $180=$ Alyssum pyrenaicum

mupestris, Sweet, Hort Brit. ed. I. 467 = Alyssum rupestris. spinosa, Sweet, 1. c. = Alyssum spinostum.

tenuifolia, G. Don, Gen. Syst. i. 180=Alyssum tenuifolium.

xanthocarpa, D. Dietr. Syn. Pl. iii. $643=$ Alyssum macrostylum.

ANODOPGTALUM, A. Cunn. ex Endl. Gen. 818 (1839). SAXIFRAGEAE, Benth. \& Hook. f. i. 65\%. biglandulosum, A. Cunn. ex Hook.f. Fl. Tasm. i. 148 -Austral.

glandulosum, Baill. Hist. P1. iii. $378=$ biglandulosum.

ANOFCTOCHIIUS, Blume, Bijdr. 411. t. 15 (1825) (Anecochilus). ORCHIDEAE, Benth. \& Hook. f iii. 598.

albo-lineatus, Par. \& Reichb. $\mathrm{f}$. in Trans. Linn. Soc xxx. (1874) $141=$ brevilabris,

albo-marginatus, Lour. Encyc. Pl. Suppl. ii. 1539.Cochinch.

argenteus, Hort. ex Loud. Hort. Brit. Suppl. iii. 608 $=$ Physurus argenteus

argyroneurus, C. Koch \& Lauche, in Berl. Allg. Gartenz. Xxv. (1857) 4.-Java.

aureus, Hort. ex C. Koch \& Lauche, 1. c. = setaceus

brevilabris, Lindl. Gen. et Sp. Orch. 499.-Ind, or.

Bulleni, Low, ex Morr. in Belg. Hortic. xii. (1862) 10 -Borneo.

crispus, Lindl. in Fourn. Linn. Soc. i. (1857) 180.Ind. or.

Croesus x, Reichb. f. in Hamb. Gartenz. xvi. (1860) 424.-Hab. ?

Dawsonianus, Low, ex Reichb. f, in Gard. Chron. (1868) $1038=$ Haemaria discolor.

Dominii x.-Cf. Burbridge, in Gard. Chron. (1871) 44 elatus, Lindl. in Fourn. Linn. Soc. i. (1857) 178.Ind. or.

elongatus, Miq. Fl. Ind. Bat. iii. 734.-Java.

flavescens, Blume, Bijdr. $412=$ Odontochilus flavescens.

flavus, Benth. \& Hook f. Gen. iii. 598=Odontochilus

flavus.
Frederici-Augusti, Reichb. $f$. in Hamb. Gartenz. xvi. (1860) 177, 424.-Hab.?

glaber, Miq. Fl. Ind. Bat. iii. 733.--Malaya.

gracilis, Blume, Bijdr. 413.-Malaya.

grandiflorus, Lindl. in Journ. Linn. Soc. i. (1857) 179 $=$ Odontochilus grandiflorus.

Hasseltii, Miq. Fl. Ind. Bat. iii. 734.-Java.

intermedius, Hort. ex Loud. Encyc. Pl. Suppl. ii. 1492. -Ind. or.

intermedius, Reichb. f. in Hamb. Gartenz. xvi. (1860)

177.-Hab.?

Faubertii, Gaudich. in Voy. Bonite, t. $100=$ Odontochilus Jaubertii.

lanceolatus, Lindl. Gen. et Sp. Orch. $499=$ Odontochilus lanceolatus.

latomaculatus, Hort. ex Blume, Coll. des Orch. 1. $50=$ Roxburghii.

Lobbianus, Planch, in F1. des Serres, Sér. I. v. (1849) $519=$ Roxburghii.

longiflorus, Reichb. f. in Seem. F1. Vit. $294=$ Odontochilus longiflorus.

Lowii, Hort. ex Loud. Encyc. P1. Suppl. ii. $1492=$ Dossinia marmorata.

luteus, Lindl. in Journ. Linn. Soc. i. (1857) $179=$ Odontochilus lanceolatus.

neglectus, Blume, Orch. Arch. 47 in nota.-Zeylan. ?

occultus, Miq. Fl. Ned. Ind. iii. 734.-Java.

Ordianus, Hort.-Cf. Gard. Chron. (1869) $1236=$

Haemaria discolor.

Ortgiesi, Hort. ex Van-Geert, Cat. n. $70(1873),-\mathrm{N}$. Granat.

Nevilleana, Low, ex C. Morr. in Belg. Hortic. xii. (1862) 10.-Hab. ?

\section{ANOECTOCHILUS :-}

pictus, Hort ex Loud. Hort. Brit. Suppl. iii. $608=$ Physurus pictus.

pubescens, Blume, Bijdr. 412.-Java.

regalis, Blume, Orch. Arch. Ind. 46.-Zeylan.

regalis, Low, ex C. Morr. in Belg. Hortic. xil. (1862) $4=$ setaceus.

Reinwardtii, Blume, Orch. Arch. Ind. 48.-Malaya.

Roxburghii, Lindl. in Wall. Cat. n. 7387--Ind. or.

Ruckeri, Low, ex C. Morr. in Belg. Hortic. xii. (1862) 10.-Borneo.

Rumphii, Low, ex C. Morr. l. c. 5.-Malaya

sandwicensis, Lindl. Gen.et Sp. Orch. 500.-Ind. Sandy.

setaceus, Blume, Bijdr. 412.- Java.

setaceus, Lindl. Bot. Reg. t. $2010=$ regalis.

setaceo-pictus, C. Koch \& Lauche, in Berl. Allg. Gartenz. Xxv. (1857) 4,-Hab.?

spicatus, Miq. Fl. Ind. Bat. iii. 734.-Borneo.

striatus, Hort. ex Loud. Encyc. P1, Suppl. ii. $1492=$ Zeuxine regia.

uniflorus, Miq. Fl. Ind. Bat. iii. 733.-Sumatra.

Veitchianus, Hort. ex Blume, Coll, des Orch. i. $119=$ Macodes petola.

xanthophyllus, Planch. Fl. des Serres, Sér. I. V. (1849) $519=$ Frederici-Augusti.

ANOGEISSUS, Wall. Cat. n. 4014 (1832) COM. BRETACEAE, Benth. \& Hook. f. i. 687.

ANDERSONIA, Buch.-Ham. ex Wall Cat. 1. c. (1832). acuminata, Wall. Cat. n. 4014.-Ind. or.

hirta, Wall. Cat. n. $4016=$ acuminata.

latifolia, Wall. Cat. n. 4015.-Ind. or.

leiocarpa, Guill. E Perr. Tent. Fl. Seneg. i. 280. t. 65. -Afr. trop

myrtifolia, Wall. Cat. n. $4017=$ pendula

pendula, Edgew. in Fourn. As. Soc. Beng. xxi. (1853)

171 - Ind or.

phillyreaefolia, Heurck \& Muell. Arg. Obs. Bot. 209. - Burma.

ANOGRA, Spach, in Nouv. Ann. Mus. Par.iv. (1835) 339 = Oenothera, Linn. (Onagr.).

Douglasiana, Spach, 1. c. $340=0$. albicaulis.

Nuttalliana, Spach, 1. c. $=$ O. albicaulis.

pinnatifida, Spach, 1. c. $341=0$. albicaulis.

ANOGYNA, Nees, in Hook. Journ. Bot. 11. (1840) 395 = Lagenocarpus, Nees (Cyperac.).

tremula, Nees, 1. c. = L. tremula.

ANOIGANTHUS, Baker, in Journ. Bot. xvi. (1878) 76. AMARYLLIDEAE, Benth. \& Hook. f. iii. 722 . breviflorus, Baker, l. c.-Natal.

luteus, Baker, 1. c. $77=$ breviflorus.

ANOMA, Lour. Fl. Cochinch. $278($ (1790)=Moringa, Juss.

cochinchinensis, Lour. 1. c. 280 (Caesalpinaeae sp. ?) Moringa, Lour. 1. c. $279=$ M. pterygosperma.

Morunga, Lour. 1. c. = M. pterygosperma.

ANOMALANTHUS, Klotzsch, in Linnaea, xii. (1838) $238=$ Simocheilus, Klotzsch (Ericac.).

discolor, Klotzsch, 1. c. 239.-Afr. austr.

scoparius, Klotzsch, 1. c.-Afr, austr.

ANOMALOPTERIS, G. Don, Gen. Syst. i. $647(1831)=$ Acridocarpus, Guill. \& Perr. (Malpig.). longifolia, G. Don, 1. c. = Ac. Smeathmanni. obovata, $\mathrm{G}_{*}$ Don, $\mathrm{I}_{\mathrm{c}} \mathrm{c}_{\mathrm{n}}=\mathrm{Ac}$. plagiopterus. spicata, G. Don, 1. c. =Ac. Smeathmanni.

ANOMALOSTEMON, Klotzsch, in Peters, Reise Mossamb. Bot. 162. t. $28(1861)=$ Cleome, Linn. (Capparid.).

bororensis, Klotzsch, 1. c.-Afr. trop.

ANOMALOTIS, Steud. Syn. Pl. Gram. 198 (1855)= Trisetaria, Forsk. (Gramin.). quinqueseta, Steud. 1. c. = T. quinqueseta.

ANOMANTHODIA, Hook. $f$, in Benth. \& Hook. Gen. ii. 87 (1873). RUBIACEAE, Benth. \& Hook. f. ii. 87 . auriculata, Hook. f. l.c.-Malaya.

ANOMANTIA, Rafin. ex DC. Prod. v. 617 (1836)= Verbesina, Linn. (Compos.). (V. virginica, Linn.)
ANOMATHECA, Ker-Gawl, in Kon. \& Sims, Ann. Bot. i. (1805) $227=$ Lapeirousia, Pourr. (Irid.).

angolensis, Baker, in Journ. Bot. xiv. (1876) 337.Afr, austr.

calamifolia, Klatt, in Abh. Naturf. Ges. Halle, xii. (1882) 355.-Afr. austr.

cruenta, Lindl. Bot. Reg. t. 1369.-Afr. austr.

grandiflora, Baker, in Journ. Bot. xiv. (1876) 337.Afr, austr.

juncea, Ker-Gawl. in Kon. \& Sims, Ann. Bot. i.(1805) $227=\mathrm{L}$. juncea.

xanthospila, Ker-Gawl. ex Spreng. Syst. i. 154.Afr. austr.

ANOMAZA, Laws. ex Salisb. in Trans. Hort. Soc. i (1812) $323=$ Lapeirousia, Pourr. (Irid.).

excisa, Laws. Cat. 2 ; ex Salisb. 1. c. =L. juncea.

ANOMIANTHUS, Zoll, in Linnaea, xxix. (1857-58) 324. ANONACEAE, Benth. \& Hook. f. i. 27.

heterocarpus, Zoll. l. c.-Ins. Bantam.

ANOMOCARPUS, Miers, in Ann. \& Mag. Nat. Hist Ser. III. vi. (1860) 351 ; Contrib. ii. $28=$ Calicera, Cav.

axillaris, Miers, 11. cc. 352 ; 28.-Chili.

eryngioides, Miers, 1l. cc. 353 ; $29=$ C. eryngioides.

leucanthemus, Miers, 11. cc. 355; 31.-Chili.

pulvinatus, Miers, in Ann. \& Mag. Nat. Hist, Ser. III. vi. $(1860) 354=$ C. pulvinata.

subsessiliflorus, Miers, 1. c. 352 ; Contrib. ii. $29=\mathrm{C}$. sessilifiora.

tenuifolius, Miers, 11. cc. $356 ; 33=\mathbf{A}$. tenuifolia.

tenuis, Miers, 11. cc. 356 ; 32.-Chili.

ANOMOCHLOA, Brongn. in Ann. Sc. Nat. Sér. III xvi. (1851) 368, t. 23. GRAMINEAE, Bentb. \& Hook. f. iii. 1111.

macrantoidea, Pritz. Ind. Ic. $74=$ marantoidea.

marantoidea, Brongn. in Ann. Sc. Nat. Sér. III. xvi (1851) 369.-Bras.

ANOMORHEGMJA, Meissn. Gen. i. 303 (1840)= Stauranthera, Benth. (Gesner.).

Miquelii, Meissn. 1. c. ii. $212=\mathrm{S}$. ecalcarata.

ANOMOSANTHES, Blume, Rumphia, iii. 151, in obs. $(1847)=$ Hemigyrosa, Blume (Sapind.).

deficiens, Blume, 1. c. $=\mathrm{H}$. deficiens.

ANOMOSPERMUM, Dalz. in Hook. Kew Journ. iii. (1851) $228=$ Actephila, Blume (Euphorb.).

excelsum, Dalz. 1. c. = Actephila excelsa.

ANOMOSPERMUM, Miers, in Ann. \& Mag. Nat Hist. Ser. II. vii. (1851) 39. MENISPERMACEAE, Benth. \& Hook. f. i. 35.

Elissarkhena, Miers, 1. c. Ser. III. xiii. (1864) 124 axilliflorum, Griseb. Cat. Pl. Cub. 4,-Cuba.

grandifolium, Eichl. in Flora, xlvii. (1864) 388.Bras.

Hostmanni, Miers, in Ann. \& Mag. Nat. Hist. Ser. III. xiv. (1864) $103=$ Schomburgkii.

japurense, Eichl. in Flora, xIvii. (1864) 388.Bras.

lucidum, Miers, in Ann. E Mag. Nat. Hist. Ser. III. xiv. (1864) 103.-Guian

nitidum, Miers, 1. c. $=$ Schomburgkii.

oblongatum, Miers, l. c.-Bras.

ovatum, Miers, l. $c$.-Bras.

reticulatum, Eichl. in Flora, xlvii. (1864) 388.Bras.

Schomburgkii, Miers, in Ann. \& Mag. Nat. Hist. Ser. II. vii. (1851) 102; Ser. II. xiv. (1864) 103.Guian.

ANOMOSTEPHIUM, DC. Prod. v. $560(1836)=$ As pilia, Thou. (Compos.).

angustifolium, Gardn. in Hook. Lond. Journ. Bot. vii. (1848) $290=$ Aspilia foliacea.

buphthalmoides, DC. in Deless. Ic. Sel. iv. t. 32.Guadalup.

ellipticum, DC. Prod. v. $560=$ Aspilia elliptica.

foliosum, Gardn. in Hook. Lond. Journ. Bot. vii. (1848) $290=$ Aspilia foliosa.

oblongifolium, DC. Prod. v. $560=$ Aspilia foliacea. ovatifolium, DC. 1. c. = Aspilia ovalifolia 
ANONA, Linn. Syst. ed. I. (1735) ; Gen. ed. I. 158 (1737). ANONACEAE, Benth. \& Hook. f. i. 27. ANNONA, Linn. Hort. Cliff. 222 (1737).

acutiflora, Mart. Fl. Bras. xiii. I. 10.-Bras.

aethiopica, Steud. Nom. ed. II. ii. $737=$ Xylopia aethio

pica.

africana, Linn. Sp. Pl. 537.--Hab.?

amara, Raeusch. Nom ed. III, 161.-Guiana

Ambotay; Aubl. Pl. Gui, i. 616. t. 249.-Am. trop.

amplexicaulis, Lam. Encyc. ii. 127.-Madag.; Ins. Mascar.

antioquensis, Linden, Cat. n. 87 (1871).-N. Granat arenaria, Schum. \& Thonn. Beskr. Guin. Pl. $257=$ senegalensis.

aromatica, Boj. Hort. Maurit. $6=$ Xylopia Richardi.

asiatica, Heyne, ex Wall. Cat. sub n. $6475=$ Unona pannosa.

asiatica, Linn. Sp. Pl. 537.-Zeylan.

asiatica, Vahl, Symb. Bot. iii. $73=$ Forskahlii

atabapensis, H. B. \& K. Nov. Gen. et Sp. v. 58,Guian.

australis, St. Hil. Fl. Bras. Mer. i. 33.-Bras.

axilliflora, $D C$. Prod. i. 86.-Guian.

Barteri, Benth. in Trans. Linn. Soc. xxiii. (1862) 477.

-Afr. trop.

bibracteata, Hook. Ic. Pl. iv, t. $328=$ Guatteria bibrac teata.

Bonplandiana, H. B. \& K. Nov. Gen. et Sp. v. $58=$ muricata.

bullata, A. Rich. Ess. Fl. Cub. 31.-Cuba

cacans, Warm. in Kjoeb. Viäensk. Meddel. (1873)

155.-Bras.

cascarilloides, Griseb. Cat. Pl. Cub. 2,Cuba.

cauliflora, Mart. Fl. Bras. xiii. I. 16-Bras.

Cherimolia, Mill. Gard. Dict. ed. VIII. n. 5.-Am. trop.

cherimolioides, Triana \& Planch. in Ann. Sc. Nat.

Sér. IV. xvii. (1862) 27.-N. Granat.

cheriquensis, Linden, Cat. n, 87 (1871).-N. Granat.

chrysocarpa, Lepr. in Guill. \& Perr. Tent. Fl. Seneg. i. $6=$ palustris.

chrysopetala, Steud. in Flora, xxvi. (1843) 754.-Guian chrysophylla, Boj. in Ann. Sc. Nat. xx. (1830) 53.-

Ins. Mascar.

cinerea, Dunal, Monog. Anon. 71. t. 8.-Ind. occ.

colorata, Vell. Fl. Flum. 239; v. t. 129.-Bras.

conica, Ruiz \& Pav.Fl.Per.v.t. 490 ; ex G. Don, Gen. Syst. i. 88.-Peruv.

conophylla, Triana E Planch. in Ann. Sc. Nat. Sér.

IV. xvii. (1862) 27.-N. Granat.

coriacea, Mart. Fl. Bras. xiii. I. 6.-Bras.

cornifolia, St. Hil. Fl. Bras. Mer. i. 33.-Bras.

crassifolia, Mart. Fl. Bras. xiii. I. 6.-Bras.

crotonifolia, Mart. l. c. 46.-Bras.

densicoma, Mart. l. c. 9.-Bras.

depressa, Baill. in Adansonia, vỉi. (1868) 267.Mexic.

dioica, St. Hil. Fl. Bras. Mer. i. 34.-Bras.

distincta, Raeusch. Nom. ed. III. $160=$ Forskahlii.

distincta, Willem. in Ust. Ann. Bot. xviii. $42=$ Gnatteri

Willemetiana.

dodecapetala, Lam. Encyc ii. 127 = Talauma Plumieri. dolabripetala, Raddi, in Mem. Mod. xviii. Fis. (1820) $394=$ Rollinia longifolia.

echinata, Dunal, Monog. Anon. p. 68. t. 4-Guian.

exalbida, Vell. F1. Flum. 240 ; v. t. $131=$ Rollini exalbida.

excelsa, H. B. \& K. Nov. Gen. et Sp. v. 59.-Mexic

exsucca, Dunal, Monog. Anon. $77=$ Kollinia exsucca.

fagifolia, St. Hil. \& Sul. in Ann. Sc. Nat. Sér. II xvii. (1812) 132.-Bras.

foetida, Mart. Fl. Bras, xiii. I. 16.-Bras.

Forskahlii, DC. Syst. i. 472.-Aegypt.

furfuracea, St. Hil. Fl. Bras. Mer. i. 34,-Bras.

glabra, Forsk. Fl. Aegypt. Arab. $102=$ Forskahlii.

glabra, Linn. Sp. Pl. 537.-Hab.?

glauca, Schum. \& Thonn. in Dan. Vid. Selsk. Afh. iv. (1824) 31.-Guinea.

globiflora, Schlecht. in Linnaea, x. (1836) 235.Mexic.

grandiflora, Lam. Encyc. ii. 126.-Ins. Mascar.; Madag. grandiflora, Bart. Trav. 20 \& 171. t. 2 = Asimina grandiftora.

grandifolia, St. Hil. \& Tul. in Ann. Sc. Nat. Sér. II xvii. (1842) 131.-Bras.

haematantha, Miq. in Linnaea, xxii. (1849) 465.Guian.

hexapetala, Linn. f. Suppl. $270=$ Artabotrys odoratissima.

\section{ANONA}

Hostmanni, Steud. in Flora, xxvi. (1843) II, 754.Guian.

Humboldtiana, H. B. \& K. Nov. Gen. et Sp. v. $56=$ seq.

Humboldtii, Dunal, Monog. Anon. 64. t. 3.-Cumana. humilis, Benth. in Hook. Kew fourn. iii. (1851) 113 -Bras.

hypoglanca, Mart. Fl. Bras, xiii. 1. 13.-Bras.

involucrata, Baill. Adansonia, viii. (1868) 265.-Mexic.

ionophylla, Triana, \& Planch. in Ann. Sc. Nat. Sér.

IV. xvii. (1862) 27.-N. Granat.

laevigata, Mart. Fl. Bras, xiii. I. 17.-Bras.

laevis, $H . B . \& K$. Nov. Gen. et Sp. v. 60 .-Guian. ; Venezuela.

lanceolata, Willd. ex Steud. Nom. ed. II. i. $100=$ Guatteria maypurensis.

lasiocalyx, Mart. Fl. Bras. xiii. I. 16.-Bras.

laurifolia, Dunal, Monog. Anon. 65.-Ind. oce.

lepidota, Miq. in Linnaea, xix. (1847) 129.-Guian.

Liebmanniana, Baill. Adansonia, viii. (1868) 266. Mexic.

longifolia, Aubl. P1. Gui. i. 615. t. $248=$ Dugnetia longifolia.

madagascariensis, Pers. Syn. ii. $95=$ grandiflora.

Manirote, H. B. \& K. Nov. Gen. et Sp. v. 59.-

Guian.

Mannii, Oliver, in Hook. Ic. Pl. t. 1010-Afr. trop

Marcgravii, Mart. Fl. Bras. xiii. I. 5.-Bras,

mexicana, Lodd. ex G. Don, in Loud. Hort. Brit. 227. -Mexic.

micrantha, Bert. ex Spreng. Syst. ii. 640.-Ins. S.

Doming.

microcarpa, Jacq. Fragm. 40. t. $44=$ Diospyros Cargillia.

microcarpa, Ruiz \& Pav. Fl. Peruv. v. t. 487

ex G. Don, Gen. Syst. 1. 90-Peruy.

montana, Macfad. Fl. Famaic. i. 7.-Jamaic.

monticola, Mart. Fl. Bras, xiii. I. 7.-Bras

mucosa, Jacq. Obs. i. $16=$ Rollinia mucosa.

muricata, Linn. Sp. Pl. 536.-Am. trop.

muscosa, Aubl. Pl. Gui. i. $618=$ Rollinia mucosa.

Myristica, Gaertn. Fruct. ii. 194.t. 125=Monodora Myristica.

nitida, Mart. Fl. Bras. xiii. I. 9.-Bras.

nitida, Willd. ex Steud. Nom. ed. II. i. 101= Guatteria maypurensis.

obovata, Willd. Sp. P1. ii. 1269=Asimina grandiflora. obtusiflora, Tuss. Fl, Antill. t. $28=$ Rollinia mucosa.

obtusifolia, DC. Prod, i. $84=$ Rollinia mucosa

paludosa, Aubl. Pl. Gui. i. 611. t. 246.-Guian.

palustris, Linn. Sp. Pl. ed. II. 757.-Am. et Afr. trop

Pavonii, G. Don, Gen. Syst. i. 89.-Peruv.

peduncularis, Steud. in Flora, xxvi. (1843) ii. 754.-

Guian.

pendula, Salisb. Prod. $380=$ Asimina triloba

Perrottetii, A. DC. in Mém. Soc. Phys. Genèv. v. (1832) 197.- - Senegal

peruviana, Humb. \& Bonpl. ex Dunal, Monog. Anon. $67=$ uliginosa

phaeoclados, Mart. Fl. Bras. xiii. I. 46.-Bras.

Pisonis, Mart. l. c. 5.-Bras.

polycarpa, DC. Syst. i. 499.-Afr. trop.

Porpetac, Boiv. ex Baill. in Bull. Soc. Linn. Par.

(1882) $341=$ senegalensis.

pubescens, Salisb. Prod. $380=$ A. Chermolia.

punctata, Aubl. Pl. Gui. i. 614. t. 247.-Guian.

punicifolia, Triana \& Planch. in Ann. Sc. Nat. Sér.

IV. xvii. (1862) 26.-N. Granat.

purpurea, Moc. E Sesse, ex Dunal, Monog. Anon 64.-Mexic.

pygmaea, Bartr. Trav. 18. t. $1=$ Asimina pygmaea.

pyriformis, Boj. Hort. Maurit. 5 ; Baker, Fl. Maurit.

3.-Ins. Mascar.

quinduensis, H.B. \& K. Nov. Gen. et Sp. v. $60 .-\mathrm{N}$. Granat.

reticulata, Linn. Sp. Pl. 587.-Am. trop.

reticulata, Sieber, ex A. DC in Mém. Soc. Phys.

Genèv. v. (1832) $200=$ Rollinia mucosa.

reticulata, Vell. F1. Flum. 239 ; v. t. $130=$ Pisonis,

rhizantha, Eichl. in Eichl. Gahrb. Berl. ii. (1883) 322 - Bras.

rhombipetala, Ruis \& Pav. Fl. Per.v. t. 489; ex G.

Don, Gen. Syst. i. 87.-Peruv.

riparia, H. B. \& K. Nov. Gen. et Sp. v. 59.-Peruv.

rufa, Presl, Rel. Hacnk, ii. 75-Am. trop.

rufescens, 'Aubl.' ex Steud. Nom. ed. I. 51 (lapsu pro 'Abuta rufescens').-Guian.
ANONA.

Salzmanni, A.DC. in Mém. Soc. Phys. Genèv. ซ. (1832) 1.7. - Jiras.

senegalensis, Pers. Syn. 1i. 95.-Afr. trop.; Guian,

sericea, Dunal, Monog. Anon, 69.-Guian.

sessiliflora, Benth. in Hook. Kew Fourn. พ. (1853) 8.Bras.

silvestris, Vell. Fl. Flum. 239; v. t. 128=Rollinia sylvatica.

sinensis, Raeusch. Nom. ed. III. 160.-China

sphaerocarpa, Splitg. in Hoeven o De Vriese, Tijdschr.

ix. (1842) 96.-Guian.

spinescens, Mart. Fl. Bras. xiii. 1. 11.-Bras.

squamosa, Delile, Ill. Aegvpt. $17=$ Forskablii.

squamosa, Linn. Sp. Pl. 537.-Ind. occ.

squamosa, Vell. ill. Flum. 239; v. t. $127=$ obtusi flora.

surriffa, Roxb. Hoxt. Beng. 43, nomen.-Ind or

sylvatica, St. Hil. Fl. Bras. Mer, i. $32=$ Rollinia syl vatica.

sylvestris, Auct.-Cf. silvestris.

tenuiflora, Mart. Fl. Bras. xiii. I. 10.-Bras

tenuifolia, A. DC. in Mém. Soc. Phys. Genev. v. (1832)

198.-Guian.

triloba, Linn. Sp. P1. $537=$ Asimina triloba.

tripetala, Ait. Hort. Kew. ii. $252=$ A. Cherimolia.

tuberosa, Noronha, in Verh. Batav. Gen. v. (1750 ed. I. Art. iv. 7.-Malaya.

uliginosa, H. B. \&0 K. Nov. Gen. et Sp. จ. 56.-Peruv.

uncinata, Lam. Encyc. ii. 127=Artabotrys odora. tissima.

uniflora, Dunal, Monog. Anon. $76=$ Duguetia Can dollei.

velutina, St. Hil. \& Tul. in Ann. Sc. Nat. Sér. II.

xvii. (1842) 132.-Bras.

vepertonum, Mart. Fl. Bras. xiii. I. 16.-Bras.

xestropetala, Spreng. Syst. ii. $641=$ Rollinia longifolia

xylopifolia, St. Hil. \& Tul. in Ann. Sc. Nat. Sér. II. xvii. (1842) 132.-Bras.

ANONIS, Tourn. ex Scop. Fl. Carn. ed. II. ï. 54 (1772, Ononis, Linn. (Legum.)

americana, Aubl. Pl. Gui. ii. $763=$ Stylosanthe procumbens, viscosa.

arvensis, Lam. F1. Fr. ii. $611=0$. arvensis

fruticosa, Lam. 1. c. $612=0$. fruticosa

minutissima, Lam. 1. c. $608=0$. minutissima.

Natrix, Scop. Fl. Carm. ed. II. ii. $55=0$. Natrix.

pinguis, Lam. Fl. Fr. ii. $609=0$. Natrix.

pusilla, Lam.1. c. $610=0$. reclinata?

reclinata, Lam. 1. c. $611=0$. reclinata.

rotundifolia, Lam. 1. c. $612=0$. rotundifolia

scariosa, Moench, Meth. $157=0$. mitissima.

spinosa, Scop. F1. Carn. ed. II. ii. $54=0$. spinosa

variegata, Lam. Fl. Fr. ii. $608=0$. variegata.

viscosa, Lam. 1. c. $609=0$. viscosa.

ANONYCHIUM, Schweinf, Reliq. Kotschy. 7.

$(1868)=$ Prosopis, Linn. (Legum.).

lanceolatum, Schweinf. 1. $\mathrm{c}$. $=\mathrm{P}$. oblonga.

ANONYMOS, Walt. Fl. Carol. (1788) (passim pro omnibus dubiis)

aquatica, Wait. 1. c. 37 =Limnanthemum trachyspermum.

aquatica, Walt. 1. c. $230=$ Planera aquatica. aquatica, Walt. 1. c. $109=$ Saururus cernuus. aquatica, Walt. 1. c. $137=$ Nesaea verticillata.

asteroides, Michx. ex DC. Prod. v. $\$ 01=$ Boltonia asteroides.

bracteata, Walt. F1. Carol. $181=$ Zomia tetraphylla. capitata, Walt. 1. c. $69=$ Burmannia capitata. carolinensis, 11 islt. 1 c. $60=$ Elytraria virgata. carolinensis, Walt. 1. c. $91=$ Lithospermum birtum. carolinensis, Walt. 1. c. $16 \$=$ Verbena Aubletia. carolinensis, Walt. 1. c. $108=$ Kuellia carolinensis. carolinensis, Walt. 1. c. 1Ss=Amphicarpaen mo

noicen.

cassioides, Walt. 1. c $171=$ Sevnoeria tenuifolia.

ciliata, Walt. J. c. $197=$ Liatris graminifolia

corymbosus, Wialt. 1. c. 18\%.-Am. bor.

dioscoroides, Croom, in Am. Joum. Sc. xxix. (1585

$165=$ Croomia pauciflora.

erecta, Walt. F1. Carol. 170 = Houstunia caerulea.

Aarus, Walt. 1. $c=$ Gerardia flava

frondosus, Walt. 1. c. 198_-Am. bor. 


\section{ANONYMOS:-}

frutescens, Walt. Fl. Carol, $186=$ Wistaria speciosa. graminifolia, Walt. 1. c. $197=$ Liatris graminifolia? ligustrinus, Walt. 1. c. 139.-Am. bor. odoratissima, Walt. 1. c. $198=$ Trilisia odoratissima. paniculata, Walt. 1. c. = Trilisia paniculata. pedicularis, Walt. 1. c. $170=$ Gerardia? petiolata, Walt. 1. c. $108=$ Mitreola petiolata pilosa, Walt. 1. c. $197=$ Liatris pycnostachya. pinnatifida, S. Wats. Bibl. Ind. 247, lapsu = seq. pinnatus, Walt. F1. Carol. $103=$ Petalostemon corymbosus.

procumbens, Walt. 1. c. $86=$ Anotis rotundifolia. pudica, Walt. l. c. $123=$ Uvularia perfoliata. purpurea, Walt. 1. c. $170=$ Gerardia purpurea. quaternata, Walt. 1. c. $246=$ Gerardiae sp. quinata, Walt. I. c. = Gerardiae sp.

ramosa, Walt. 1. c. $198=$ Liatris scariosa.

repens, Walt. 1. c. $110=$ Dichondra repens.

repens, Walt. 1. c. $160=$ Mitchella repens.

rotundifolia, Walt. 1. c. $181=$ Crotalaria ovalis. sagittalis, Walt. $I_{\text {. }} c_{\mathrm{r}}=$ Crotalaria sagittalis. sempervirens, Walt. 1. c. $98=$ Gelsemium sempervirens.

sessilifolia, Walt, 1. c. $108=$ Mitreola petiolata. setaced, Walt. 1. c, $170=$ Gerardia setacea? tinctoria, Walt. 1. c. $68=$ Lachnanthes tinctoria. umbrosa, Walt. 1. c. $63=$ Micranthemum orbiculatum. uniflora, Walt. 1. c. $198=$ Carphephorus bellidifolius?

ANOOSPERMA, Kunze, in Bot. Zeit. i. (1843) 661, err. typ.= Oncosperma, Blume (Palm.).

ANOPLANTHUS, End1. Gen. $727(1839)=$ Phelypaea, Tourn, et Aphyllon, Mitch, (Orobanch.). Biebersteinii, Reut, in DC. Prod. xi. $42=$ P. coccinea. coccineus, Walp, Rep, iii。, $481=\mathrm{P}$. coccinea. comosus, Walp. 1. c. $480=$ Aphyllon comosum. fasciculatus, Walp. 1, c. = Aphyllon fasciculatum. Tournefortii, Reut. in DC. Prod. xi, $42=\mathrm{P}$. coccinea. uniflorus, Endl. Ic. Gen. t. $72=$ Aphyllon uniflorum.

ANOPLOCARYUM, Ledeb, Fl. Ross. iii. $154(1847)=$ Eritrichium, Schrad, (Borag.).

compressum, Ledeb. 1. c.-Rossia.

ANOPLON, Reichb. Consp. 212 b ${ }^{\text {}}(1828)=$ Phelypaea, Tourn, et Aphyllon, Mitch. (Orobanch.)

Biebersteiniz, C. A. Mey. Verz. Pf. Canc. 104=Phelypaea coccinea.

biftorum, G. Don, Gen. Syst. iv. $634=$ Aphyllon uniflorum.

fasciculatum, G. Don, 1. c. $633=$ Aphyllon fasci-

culatum.

Tournefortii, G. Don, 1. c. = Phelypaea coccinea.

ANOPLOPHYTUM, Beer, in Flora, xxxvii. (1854) 346 = Tillandsia, Linn. (Bromel.).

aëranthos, Beer, Bromel. $40=$ T. dianthoidea.

amoenum, E. Morr. ex C. Morr. in Belg. Hortic. xxxiii. (1883) 265. t. $17=$ T. pulchra.

Benthamianum, Beer, Bromel. $263=$ T. Benthamiana. bicolor, Beer, 1. c. $41=$ T. stricta.

calothyrsum, Beer, 1. c. $263=$ T. calothyrsus.

dianthoideum, Beer, 1. c. $41=$ T. dianthoidea.

didistichum, E. Morr. ex C. Morr. in Belg. Hortic. xxxi. (1881) $164=T$. Lorentziana.

Duratii, Beer, Bromel. $42=\mathrm{T}$. Duratii.

flexuosum, Beer, 1. c. $43=$ T. flexuosa.

geminiflorum, E. Morr. ex C. Morr. in Belg. Hortic. xxix. (1879) 226, \& xxx. 191. t. $111=T$. geminiflora. guianense, Beer, Bromel. 44.-Guian.

incanum, E. Morr. ex C. Morr. in Belg. Hortic. xxxi. (1881) 209. t. $11=$ T. Gardneri

lineare, Beer, Bromel. $42=\mathrm{T}$. linearis.

longebracteatum, Beer, 1. c. $264=$ T. purpurea

pulchellum, Beer, l. c. $41=$ T. pulchra.

Rollissoni, E. Morr. ex C. Morr. in Belg. Hortic. xxix, (1879) $275 .-$ Bras

roseum, Beer, Bromel. $40=\mathrm{T}$. dianthoidea.

rubidum, Beer, $1_{0} c_{.}=\mathrm{T}$. geminiflora.

setaceum, Beer, 1. c. $265=$ T. compressum ?

stramineum, C. Koch, in Ind. Sem. Hort. Berol. (1856) $7=\mathrm{T}$. straminea.

Sprengelianum, Beer, Bromel, 266 $=$ T. Sprengelianum.

\section{ANOPLOPHYTUM :-}

strictum, Beer, Bromel. $39=$ Tillandsia stricta. strobilanthum, Beer, 1. c. $42=$ T. strobilantha. vestitum, Beer, 1. c. $266=$ T. Benthamiana. violaceum, Beer, $1 . c .=T$. violacea.

vittatum, Beer, 1. c. $43=$ T. vittata.

ANOPTERUS, Labill. Pl. Nov. Holl. i. 85. t. 112 (1804). SAXIFRAGEAE, Benth. \& Hook. f. i. 648.

glandulosus, Labill. l. c. 86- - Tasman.

Macleayanus, $F$. Muell. in fourn. Pharm, Soc. Vict. (1858) 43.-Austral。

ANOSMIA, Bernh. in Linnaea, vii. (1832) $608=$ Smyrnium, Linn. (Umbell.).

idaea, Bernh. I. c. $609=$ S. apiifolium.

ANOSPORUM, Nees, in Linnaea, ix. (1835) $287=$ Cyperus, Linn.

Cephalotes, Kurz, in Journ. As. Soc. Beng. xxxix. (1870) II. $84=$ C. Cephalotes.

Colymbetes, Boeck. in Bot. Zeit. xxvii. (1869) $26=$ C. Colymbetes.

cubense, Boeck. 1. c. $=$ Scirpus cubensis.

monocephalum, Nees, in Linnaea, ix. (1835) $287=\mathrm{C}$. Cephalotes.

nudicaule, Boeck. in Bot. Zeit. xxvii. (1869) $26=$ C nudicaulis.

pallidum, Boeck. in Linnaea, xxxyi, (1869-70) $412=$ C. platystylis.

ANOTIS, DC. Prod, iv, 431 (1830). RUBIACEAE, Benth, \& Hook. f. ii. 59.

affinis, Benth. \& Hook. fo Gen。 ii. $59=$ Leschenaultiana.

boerhaavioides, Maxim. in Bull. Acad. Pétersb. xxix. (1883) 165.--China.

calycina, Hook. f. Fl. Brit. Ind. iii. 73.-Ind. or. capitata, Korth. in Ned. Kruid. Arch. ii. (1851) $151=$ Hedyotis stipulata?

camosa, Benth. \& Hook, f, Gen, ii. 59.-Ind. or.

Cervantesii, DC. Prod. iv, $432=$ Hedyotis Cervantesii.

ciliolosa, G. Don, Gen. Syst. iii. $585=$ Houstonia purpurea.

coerulea, G. Don, 1. c. $=$ Houstonia caerulea.

conferta, DC. Prod, iv. $431=$ Mallostoma conferta. decipiens, Hook. f. Fl. Brit. Ind. iii. 72.-Ind. or. dentelloides, Stend. Nom. ed. II. i. $101=$ Oldenlandia dentelloides

ericoides, DC. Prod. iv. $433=$ Hedyotis ericoides.

filiformis, DC, 1. c. $431=$ Mallostoma filiformis.

Finlaysoniana, Benth. \& Hook. f. Gen. ii. 60.Sumatr.

foetida, Benth. Ev Hook. f. Gen. ii. 59.-Ind. or.

gentianoides, Walp. Rep. iv. $230=$ Houstonia caerulea.

gracilis, Hook. f. Fl. Brit. Ind. iii. 71,--Reg. Himal hypnoides, DC. Prod. iv. 432=Hedyotis hypnoides. ingrata, Benth. $\mathcal{E}$ Hook. f. Gen. ii. 59 ; et Hook. f. Fl Brit. Ind. iii. 71,-Reg. Himal. juniperifolia, DC. Prod. iv. $432=$ Mallostoma juniperi-
folia.

lanceaefolia, Benth. \& Hook. f. Gen. ii. 59=lancifolia.

lanceolata, DC. Prod. iv. $433=$ Honstonia purpurea lancifolia, Hook. f. Fl. Brit. Ind. iii. 73.--Ind. or. laricifolia, DC, Prod. iv, $432=$ Mallostoma laricifolia.

Lechleriana, Schlecht. in Linnaea, xxviii. (1856) 488 $=$ OIdenlandia Lechleriana.

Leschenaultiana, Benth. \& Hook.f. Gen. ii. 59; et Hook. f. Fl. Brit. Ind. iii. 72.-Ind. or.

longiflora, Benth. Pl. Hartw. $23=$ Houstonia triflora.

longifolia, G. Don, Gen. Syst. iii. $535=$ Houstonia purputea.

microphylla, DC. Prod. iv. $432=$ Hedyotis microphylla.

mitrasacmoides, Benth. \& Hook. f. Gen. ii. 60.Austral.

monosperma, Benth. \& Hook. f. l. c. 59 ; et Hook. f. Fl. Brit. Ind. iii. 75.-Ind. or.

Montholoni, Hook. f. Fl. Brit. Ind. iii. 73.-Ind, or.

nummularia, Benth. \& Hook. f. Gen. ii. 60 ; et Hook. f. Fl. Brit. Ind. iii. 75 .-Zeylan.

nummulariformis, Benth. \& Hook. f. I. c. = praec.

oxyphylla, Hook. f. l. c. 72.-Ind, or.
ANOTIS :-

pilifera, Schlecht. in Linnaea, xxviii. (1856) 487.Peruv.

pterospora, Benth. \& Hook. fo Gen, ii. 60,-Austral. purpurea, G. Don, Gen. Syst, iii. $535=$ Houstonia purpurea

quadrilocularis, Benth. \& Hook. f. Gen. ii. 59 ; et Hook. f. Fl. Brit. Ind. iii. 74.-Ind, or.

Rheedii, Benth. E Hook. f. l.c. ; et Hook. f. l. c. 73.Ind. or.

Richardiana, Benth. E Hook.f.l.c.; et Hook.f.l.c. 75.-Ind. or.

Ritchiei, Hook.f. Fl. Brit. Ind. iii. 74.-Ind. or.

rotundifolia, $D C$. Prod. iv. 433.-Am. bor.

Salzmanni, DC. 1. c. = Oldenlandia Salzmanni.

serpens, $D C$. l. C.-Am. austr.

serpyllifolia, G. Don, Gen. Syst. iii. $535=$ Houstonia serpyllifolia.

setosa, DC. Prod. iv. $432=$ Mallostoma setosa.

tenella, G. Don, Gen. Syst. iii. $535=$ Houstonia tenella.

Thwaitesiana, Maxim. in Bull. Acad. Pétersb. xxix. 1883) 165 . - China.

thymifolia, DC. Prod. iv. $432=$ Mallostoma thymifolia. urophylla, Benth. \& Hook. f. Gen. ii. 59; et Hook. f. Fl. Brit. Ind. iii. 72.-Ind. or.

Wightiana, Benth. \& Hook.f.l. c. 60 ; et Hook.f.l.c. 75.-Ind. or.

ANPIECTRUM, A. Gray, Bot. U. St. Expl. Exped. i. 597 (1854). MELASTOMACEAE, Benth. \& Hook. f. i. 758 .

APLECTRUM, Blume, in Flora, xiv. (1831) 502.

annulatum, Triana, in Trans. Linn. Soc. xxviii. (1871 84.--Penang.

assamicum, C. B. Clarke, in Hook.f. Fl. Brit. Ind. ii 546.--Reg. Himal.

barbatum, Triana, in Trans. Linn. Soc. xxviii. (1871) 84.-Burma.

biligulatum, Triana, l. c. 85.-Sumatr.

confine, Blume, Mus. Bot. Lugd. Bat. i. 38.Sumatr.

cyanocarpum, Triana, in Trans. Linn. Soc. xxviii. (1871) $84=$ glancum

divaricatum, Triana, $l_{0} c$.-Ind. or.

glaucum, Triana, l.c.-Malaya.

Korthalsii, Triana, l. c. 85.-Borneo.

latifolium, Triana, $l_{\text {. co. }}$-Borneo.

ligulatum, Triana,. . c.-Java.

myrtiforme, Naud. in Ann. Sc. Nat. Sér. III. xv. (1851) $305=$ Medinilla myrtiformis.

myrtifolium, Miq. Fl. Ind. Bat. i. I. $555=$ Medinilla myrtiformis.

nodosum, Blume, Mus. Bot. Lugd. Bat. i. 37.Sumatr.

nodosum, Blume, $l . c .37$.-Sumatr.

ovalifolium, A. Gray, Bot. U. St. Expl. Exped. i. 597 =Allomorphia ovalifolia.

pallens, Blume, Mus. Bot. Lugd. Bat. i. 38.-Malaya. parviflorum, Benth. Fl. Hongk. 116=Blastus cochinchinensis

reformatum, Triana, in Trans. Linn. Soc. xxviii. (1871) 85.-Borneo,

rostratum, Blume, in Flora, xiv. (1831) 502.-Malaya. stipulare, Blume, l.c. 503.-Java.

viminale, Blume, l. c. 502, - Malaya.

ANQUETILIA, Decne. in Jacquem. Voy. Bot. 161. t $161(1848)=$ Skimmia, Thunb. (Rutac.).

Laureola, Decne. 1. c. =S. Laureola.

ANREDERA, Juss. Gen. 84 (1789). CHENOPODIACEAE, Benth. \& Hook. f. iii. 78, 1219.

Beriesa, Steud. Nom. ed. II. i. 199 (1840).

Clairisia, Benth. \& Hook. fo Gen. iii. 78 (1880).

Clarisia, Abat, in Act. Soc. Med. Sev. x. 418; ex Spreng. Gen. i. $202(1830)$.

SIEBERA, Presl, in Oken, Isis, xxi. (1828) 275.

Cumingii, Hassk. in Flora, xlviii. (1865) $401=$ spicata.

scandens, Moq. in DC. Prod. xiii. II. $230=$ spicata. spicata, Pers. Syn. i. 297.-Am. trop.; Ins. Philipp. vesicaria, Gaertn. f. Fruct. iii. 176. t. $213=$ spicata. vesiculosa, Poir. Encyc. Suppl, i. $391=$ spicata.

ANSELLIA, Lindl. Bot. Reg. xxx. (1844) sub t. 12. ORCHIDEAE, Benth. \& Hook. f. iii. 537. africana, Lindl. l. c.-Afr. trop.

gigantea, Reichb. f. in Linnaea, xx. (1847) 673.-Natal. 
ANSERINA, Dum. Fl. Belg. $21 \quad(1827)=$ Chenopodium, Linn.

Bonus-Henricus, Dum. 1. c. = C. Bonus-Henricus.

ANSONIA, Bert. ex Hemsl. Bot. Voy. Challenger, i. III $53(1884)=$ Lactoris, Phil. (Piperac.). nodulosa, Bert. ex Hemsl. 1. c. $=$ L, fernandezia.

ANSONIA, Rafin. New F1. Am. iv. (1836) 58 = Amsonia, Walt. (Apocyn.).

elliptica, Rafin. 1, c.-Am. bor.

latifolia, Rafin. 1. c. = Amsonia Tabernaemontana salicifolia, Rafin. 1. c, = Amsonia Tabernaemontana tenuifolia, Rafin. 1. c.-Am. bor.

ANSTRUTHERIA, Gardn, in Calc. Journ. Nat. Hist. vi. (1846) 344. t. $4=$ Weihea, Spreng. (Rhizoph.) africana, Benth. in Journ. Linn. Soc. iii. (1859) $78=$ W. africana.

ceylanica, Gardn, in Calc. Journ. Nat. Hist. vi. (1846) $345=\mathrm{W}$. ceylanica

madagascariensis, Benth, in Journ. Linn. Soc. iii. (1859) $78=$ W. madagascariensis.

zeylanica, Henslow, in Hook. f. Fl. Brit. Ind, ii. $441=$ W. ceylanica.

ANTACANTHUS, Rich. ex DC. Prod. iv. $484(1830)=$ Scolosanthus, Vahl (Rubiac.).

ANTAGONIA, Griseb, in Goett. Abh. xix. (1874) $144=$ Cayaponia, Manso (Cucurb.).

citrullifolia, Griseb. 1. c, $145=\mathrm{C}$. citrullifolia

Sandia, Griseb. in Lorentz, Veg. del Nordest. Prov. Entre-Rios, $69=$ C. Sandia.

ANTAUREA, Neck. Elem. i. $70(1790)=$ Centaurea, Linn. (Compos.)

ANTFLAEA, Gaertn. Fruct. i. 277. t. 68 (1788). Genus inc sed

canescens, Cels, ex Heynh. Nom. ii. 38.-Hab.? javanica, Gaertn. Fruct. i. 277.-Java.

ANTENNARTA, Gaertn. Fruct. ii. 410. t. 167 (1791) COMPOSITAE, Benth, \& Hook. f. ii. 301

Disynanthus, Rafin. in Am. Monthly Mag. (1818) 268.

alpina, Gaertn. l. c.-Reg. bor.

andina, A. Gray, in Proc. Am. Acad. v. (1861) 138.-

Am. austr.

aretioides, $A$. Gray, l. c.-Peruy.

argentea, Benth. Pl. Hartw. 319.-Calif

carpathica, R. Br. in Trans. Linn. Soc. xii. (1818) 123 Reg. temp. bor.

chilensis, Remy, in C. Gay, Fl. Chil. iv. 235.-Chili

cinnamomea, DC. Prod. vi. $270=$ Anaphalis cinnamomea.

contorta, D. Don, in Bot. Reg. t. $605=$ Anaphalis contorta.

dimorpha, Torr. \& Gray, Fl. N. Am. ii. 431.-Am bor.

dioica, Gaertn. Fruct. ii. 410. t. 167. f. 3.-Europ.

As. bor.

Alagellaris, A. Gray, in Proc. Am. Acad. xvii. (188182) 212. - Am, bor

Geyeri, A. Gray, Pl. Fendl. 107.-Am. bor.

hyperborea, D. Don, ia Engl. Bot. Suppl. t. $2640=$ dioica.

japonica, Miq. Ann. Mus. Bot. Lugd. Bat. ii. 1\%8= Anaphalis margaritacea.

japonica, Sch. Bip. in Zoll. Syst. Verz. Ind. Archip. 126; Turcz. in Bull. Soc. Nat. Mosc. xxiv. (1851) I. 200 = praec. ?

javanica, DC. Prod. vi. 271.-Tava

labradorica, Nutt, in Trans. Am. Phil. Soc. N. S, vii (1841) $406=$ alpina.

leontopodina, DC. Prod. vi. $269=$ Leontopodium sibiricum.

Leontopodium, Gaertn. Fruct. ii. $410=$ Leontopodium alpinum.

leucophylla, Holl. \& Reichb. in Flora, xiii. (1830) 382 $=$ Helichrysum obconicum.

linearifolia, Wedd. Chlor. And. i. 150,-Bolivia.

luzuloides, Torr. \& Gray, Fl. N. Am. ii. 430.-Am bor. occ.

magellanica, Sch. Bip. in Flora, xxxviii. (1855) 117.Reg. Magell.

margaritacea, R. Br. in Trans. Linn. Soc. xii. (1817) 128 = Anaphalis margaritacea.

\section{ANTENNARIA}

Meredithae, F. Muell. in Papers Roy. Soc. Tasm

(1870) $15=$ Leontopodium Meredithae

microcephala, A. Gray, in Proc. Am. Acad. x. (1874)

74.-Calif.

monocephala, DC. Prod. vi, $269=$ alpina

monoica, Wedd. Chlor. And. i. 150.-N. Granat

montana, S. F. Gray, Nat. Arr. ii. $458=$ dioica.

muscoides, Hook. f. E Thoms. ex C. B. Clarke, Comp Ind. 100.-Reg. Himal.

nana, Hook. f. E Thoms. ex C. B. Clarke, l.c.-Reg.

Himal

nivalis, Tenore, ex Nym. Consp. $383=$ Leontopodium alpinum.

mubigena, F. Muell. in Trans. Phil. Soc. Vict. i. (1855) $45=$ Raoulia catipes.

parvifolia, Nutt, in Trans. Am. Phil. Soc. N. S, vii (1841) $406=$ dioica.

Planchoni, F. Muell. Census, $80=$ Raoulia Planchoni. plantaginea, R. Br. in Trans. Linn. Soc. xii. (1.817) 123.-Am. bor.

plantaginifolia, Hook. Fl. Bor. Am. i. $330=$ planta ginea.

racemosa, Hook. l. c.-Am. bor.

mbicunda, C. Koch, in Linnaea, xvii. (1843) $49=$ Helichrysum arenarium

saxatilis, DC. Prod. vi. 271.-Java.

semidecurrens, DC. 1. c. = Anaphalis araneosa

sordida, Sch. Bip. in Zoll. Syst. Verz. Ind. Archip. 124.-Java.

Steetziana, Turcz. in Bull. Soc. Nat. Mosc. (1857) I. Add. p. xxxix - Dahuria.

stenophylla, A. Gray, in Proc. Am. Acad. xvii. (188182) 213.-Am. bor.

triplinervis, Sims, Bot. Mag. t. $2468=$ Anaphalis triplinervis.

uniceps, F. Muell. in Trans. Phil. Soc. Vict. i. (1855) 105.-Austral.

villosissima, D. Don, Prod. F1, Nep. $175=$ Anaphalis araneosa.

viscida, Sch. Bip. in Zall. Syst. Verz. Ind. Archip. 124 - Malaya.

ANTENORON, Rafin. FI. Ludov. $28(1817)=$ Poly gonum, Linn.

racemosum, Rafin. 1. c. $=\mathrm{P}$. virginianum

ANTEPHORA, Stend. Syn. Pl. Gram. $111(1855)=$ Anthephora, Schreb.(Gram.).

ANTERISCIUM, Meyen, Reise, i. 315 (1834) sphalm.= Asteriscium, Cham. \& Schlecht. (Umbellif.).

ANTHACANTHA, Lem. Illustr. Hortic. (1858) Misc. $64=$ Euphorbia, Linn

Desmetiana, Lem. 1. c. = E. hexagona.

ANTHACANTHUS, Nees, in DC. Prod. xi. 460 1847) ACANTHACEAE, Benth, \& Hook, f ii 1097.

Crateola, Rafin. F1. Tellur, iv. 64 (1836).

Oplonia, Rafin. 1. c.

acicularis, Nees, l. c.- Jamaica.

armatus, Nees, l. c.-Jamaica.

bispinosus, Griseb. in Mem. Am. Acad. N. S. viii. (1863) 525.-Ind. occ.

cuneatus, Nees, in DC. Prod. xi. 461.-Jamaica.

cuneifolius, Nees, 1. c. $432=$ cuneatus.

emarginatus, Nees, l. C. 461 .-Ins. S. Thom.

jamaicensis, Griseb. Fl. Brit. W. Ind, 457--Jamaica,

lycioides, Nees, in DC. Prod. xi. 461.-Ind. occ.

microphyllus, Nees, l. c.-Ind. occ.

purpurascens, Griseb. Cat. Pl. Cub. 198.-Cuba.

repandus, Nees, in DC. Prod. xi. 462.-Ins. Tanna.

sinuatus, Nees, l. c.-Ins. Tanna.

spinosus, Nees, l. c. 460.-Am. austr.

Sprengelii, Nees, l. c. 461.-Ins. S. Doming.

tetrastichus, Griseb. Cat. Pl. Cub. 197.-Cuba.

vincoides, Nees, in DC. Prod.xi. 461.-Madag.

ANTHACANTHUS, Rich. ex DC. Prod. iv. 484 (1830) =Scolosanthus, Vabl (Rubiac.).

ANTHaCtinIA, Bory, in Ann. Gén. Sc. Phys, ii. (1819) $139=$ Passiflora, Linn.

Horsfieldii, M. Roem. Syn. Pepon. $191=$ P. Horsfieldii.

longipes, Bory, in Ann. Gén. Sc. Phys. ii. (1819) $139=$ $\mathrm{P}$. longipes.
ANTHACTINIA :-

moluccana, M. Roem. Syn. Pepon. $190=$ Passiflora moluccana.

nepalensis, M. Roem. 1. c。 $=$ P. nepalensis

penangiana, M. Roem. 1. c. $192=$ Modecca nicobarica singaporiana, M. Roem. 1. c. = Modecca singiporiana.

sumatrana, M. Roem. 1. c. $191=$ = . sumatrana.

timorensis, M. Roem. 1. c. $=$ P. moluccana.

Walkerii, M. Roem. 1. $c_{0}=\mathrm{P}$, suberosa.

ANTHADENIA, Lem. Hort. Vanhoutt. fasc. (1845); Fl. des Serres, ii. (Avr. 1846) 10, t. 6 Sesamum, Linn. (Pedalin.).

sesamoides, Lem. Il. cc.-Afr. trop.

ANTHAFNANTTA, Beany, Agrost 48, $10 \mathrm{f}$ (1812), GRAMINEAE, Benth. \& Hook. f. iii. I098. Anthenantia, R. Br. in Flind. Voy. ii. App. II 582 (1814).

Aulaxanthus, Ell. Sketch Bot. Carol. i. 102 (1817)

Aulaxia, Nutt. Gen. Am. i. 47 (1818).

Leptocoryphium, Nees, Agrost. Bras. 83 (1824)

lanata, Benth. in fourn. Linn. Soc. xix. (1882) 39.Mexic.

rufa, Schult. Mant. ii. 258.-Am. bor.

villosa, Beauv. Agrost. 48. t. 10. f. 7.-Am, bor.

ANTHAERIUM, Schott, in Oestr. Bot, Zeitschr. (1858) $179 \mathrm{err} . t_{y p}=$ Anthurium, Schott (Aroid.

ANTHALOGEA, Rafin. New Fl. Am. iv. 88 (1836) = Polygala, Linn.

polygama, Rafin. 1. c. = P. rubella.

ANTHANEMA Rafin F1. Tellor iv. 90 (1836)= Cuscuta, Lina. (Convolv)

capitata, Rafin. 1. c. = C. capitata.

paradoxa, Rafin. 1. $\mathrm{c}_{\mathrm{s}}=$ C. glomerata.

verticillata, Rafin. 1. c. =C. glomerata.

ANTHANOTIS, Rafin, Fl, Ludov, 52, 149 (1817)= Asclepiodora, A. Gray (Asclep.)

pedicellata, Rafin. 1. c. $52=$ Podostigma pubescens. procumbens, Rafin. 1. c. 149,-Am. bor.

viridis, Rafin. 1. c. $52=$ Asc. viridis.

ANTHEIDOSORUS, A. Gray, in Hook. Kew Journ. iil (1851) $173=$ Myriocephalus, Benth. (Compos.). gracilis, A. Gray, 1. c. = M. gracilis.

ANTHEILEMA, Rafin. Fl. Tellur. iv. 66 (1836) = Phaylopsis, Willd. (Acanth.)

imbricata, Rafin. 1. c. = P. Iongifolia.

paniculata, Rafin. 1. c. = Rnellia paniculata

ANTHEISCHIMA, Korth. Verh. Nat. Gesch. Bot. ed Temminck, 137 t. $27(1840)=$ Gordonia, Ellis (Ternstroem.)

excelsa, Korth, 1, $c_{-}=\mathrm{G}$. excelsa.

ANTHELIA, Schott, in Ann. Mus. Bot. Lugd. Bat. 127 (1863-64). AROIDEAE, Benth. \& Hook. f. iii 963

nobilis, Schott, l. c-Celebes.

ANTHELIS, Rafin. Chl. Aetn. $9(1813)=$ Helianthe mum, Tourn. (Cistin.)

albidus, Rafin. 1, c.-Italia.

arenaria, Rafin. New Fl. Am. iii. 31.-Am. bor.

glaucus, Rafin. Chl. Aetn. $9=\mathrm{H}$. glaucum.

glutinosus, Rafin. 1. c. $=$ H. glutinosum.

laevipes, Rafin. 1. $c_{0}=H$. laevipes.

podanisia, Rafin. New F1. Am. iii. 30.-Am. bor.

ANTHELMINTHICA, P. Br. Hist. Jamaic $156\left(1750^{\circ}\right.$ $=$ Spigelia, Linn. (Logan.)

ANTHEMA, Medic. Malv. 42 (1787) = Lavatera Tourn. (Malvac.)

arborea, Medic. 1. c. $=\mathrm{L}$. arboren,

cretica, Medic. 1. c. = L cretica

scabra, Moench, Meth. $612=\mathrm{L}$. cretico.

Tenoreana. Presl, Fl. Sicul, i. $181=$ L. cretica.

ANTHEMIOPSIS, Boj. ex DC. Prod. ₹. $5 \pm 7,54 \$$ (1S:

Wedelia, Jacq. (Compos.)

elongata, Boj. 1. c. $548=11$. clongata.

macrophylla, Boj. 1. c. 547.-Afr. trop. 
ANTHEMIS, Mich. ex Linn. Syst. ed. I. (1735) COMPOSITAE, Benth. \& Hook, f. ii. 420.

Chamaemelum, Tourn.ex Adans. Fam.ii.128 (1763). Chamomilta, Godr. Fl. Lorr. î. 19 (1843)

CotA, J. Gray, in Guss. Fl. Sic. Syn. ii. 866 (1844). Lepidophorum, Neck. Elem. i. $14(1790)$. LeUCANTHEMuM, Adans. Fam. ii. 127 (1763) Lyonnetia, Cass. in Dict. Sc. Nat. 1. 106 (1827) Marcelia, Cass. 1. c. xxxiv. 107 (1825) Maruta, S. F. Gray, Nat. Arr, ii. 456 (1821) Matricaria, Tonm. ex Adans. Fam. ii. 127 (1763). ORMENIS, Cass. in Dict. Sc. Nat. xxix. 180 (1823). Perideraea, Webb, Iter Hisp. 37 (1838).

Rhetinolepis, Coss. in Bull. Soc. Bot. Fr。 iii. 707 $(1856)$.

abrotanifolia, Guss. Fl. Sic. Syn. ii. 490,-Italia Lusitan.

abrotanifolia, Willk. in Bot. Zeit. v. (1817) $858=$ montana.

absinthifolia, Boiss. \& Sprun. Diagn. Ser. I. iv. 8.Caria.

abyssinica, J. Gay, ex A. Rich. Tent. F1. Abyss. i. 418 $=\mathrm{A}$. Cotula.

abyssinica, Sch. Bip.ex Schweinf. Beitr. Fl. Aethiop. 142 , nomen.-Abyss.

aciphylla, Boiss. Diagn. Ser. I. iv. 7.-As. Min.

adonidifolia, Boiss. Fl. Orient. iii. 317.-Armenia.

aetnensis, Schouw, in Spreng. Syst. iii. 595.-Mont. Aetna.

afra, Burm. f. FI. Cap. Prod. $27=$ Osmites dentata afra, Linn. Syst. ed. X. 1223.-Afr. austr.

ageratifolia, Sibth. \& Sm. Fl. Graec. ix. 68. t. $887=$ Achillea ageratifolia.

agrestis, Presl, Fl. Sic. p. xxix, nomen,--Sicilia. agrestis, Wallr. Sched. Crit. $484=$ arvensis.

aizoides, Boiss. \& Orph. ex Hook. f. Bot. Mag. t. 6117 $=$ Achillea ageratifolia.

Aizoon, Griseb. Spicil. Fl. Rumel. ii. $210=$ Achillea ageratifolia.

albida, Boiss, Diagn. Ser. I. iv. 10,-As, Min.

alsina, Gouan, F1. Monsp. $370=$ montana.

alpina, Linn. Cent. ii. 31. n. 195.-Europ.

alpina, Moric. ex Nym. Consp. $360=$ carpatica.

altaica, Fisch. Hort. Gorenk. ed. II. (1812) 41.Sibir. alt.

altissima, Boiss. Diagn. Ser. I. xí, $12=$ coelopoda. altissima, Bell. in Mém. Acad. Torin. v. (1790-91) $245=$ peregrina

altissima, Guss. ex Nym. Consp. $359=$ brachycentros. altissima, Linn. Sp. Pl. 893.-Europ.; Oriens.

americana, Linn. I. c. $895=$ Chrysanthellum procum bens.

americana, Mutis, in Linn. f. Suppl。378=Spilanthes Mutisii.

ammophila, Boiss. \& Heldr. Diagn. Ser. I. xi. 9,Pamphyl.

Anacyclus, J. Gay, ex Boiss. Fl. Orient. lii. 299= cretica.

anatolica, Boiss, Diagn. Ser. I. xi. 10.-As. Min. anemonifolia, Boj. ex Steud. Nom. ed. II. i. 102= Epallage anemonifolia.

anglica, Spreng. Syst. iiî. $594=$ arvensis,

apennina, Tausch, in Syll. Ratisb. ii. 250.-Europ, apiifolia, R. Br. in Bot. Reg. t. $527=$ parthenoides. arabica, Linn. Sp. P1. $896=$ Cladanthus arabicus. arabica, Viv. FI. Lib. Spec. $56=$ Cyrtolepis alexandrina. arenicola, Boiss. Fl. Orient. iii. 306.-Cilicia. argaea, Boiss. \& Bal. Diagn. Ser. II. vi. $97=$ ptarmicaeformis.

artemisiaefolia, Willd. Sp.PI. iii. $2184=$ Chrysanthemum sinense.

artemisifolia, Willd. in Ges. Naturf. Fr. Neue Schr. iii. (1801) $431=$ praec.?

arvensis, Linn. Sp. Pl. ed. I. 894.-Europ. ; Oriens

arvensis, Pall. ex Bieb. Fl. Taur. Cauc。 ii. $330=$ altissima.

asperula, Bertol. Fl. Ital. ix. 368-Corsica.

atlantica, Pomel, Nowv. Mat. Fl. Atl. 289,-Afr. bor. atrata, Schur, ex Heimerl. in Denkschr. Acad. Wien, xlviii. (1884) 137.-Europ. anstr.

Aucheri, Boiss. Diagn. Ser. I. xiii. 77, sphalm. = Achillea Aucheri.

aurea, Brot. Fl. Lusit. i. 394.-Europ. austr. aurea, DC. Prod, vi. $7=$ nobilis.

aurea, Webb, ex Nym. Consp. $375=$ Matricaria aurea auriculata, Boiss. Diagn. Ser. I. iv. 5.-As. Min. australis, Sibth. \& Sm. F1. Graec. ix. $67=$ cypria australis, Willd. Sp. Pl. iii. 2177 = incrassata.

\section{ANTHEMIS :-}

austriaca, facq. Fl. Austr. v. 22.-Europ.; Oriens. Barrelieri, Tenore, Fl. Nap. ii. $245=$ Achillea Barrelieri, Baumgarteniana, Schur, Enum. Pl. Transs. $334=$ montana.

Bellidiastrum, Linn. Syst. ed. X. 1223=Osmites Bellidiastrum.

biaristata, DC. F1. Fr. iv. 204=Anacyclus clavatus. Biebersteiniana, C. Koch, in Linnaea, xxiv. (1851) 320. -Oriens.

Blancheana, Boiss. Fl. Orient. iii. 292.-Syria.

Bolleix, Asch. ex Nym. Consp. ii. $363=$ A. Cotula

Bourgei, Boiss. \& Reut. Pugill. Pl. Hispan. 56. Hispan.

Boveana, 7. Gay, in Expl. Sc. Algér. t. 60. f. 2.Algeria.

Bowei, Willk. \& Lange Prod. ii. $91=$ praec.

Brachmanni, Boiss. \& Heldr, in Boiss. Diagn. Ser. I. vi. 84.-Graecia

brachycentros, F. Gay, in Koch, Syn. Fl. Germ. ed. II 414.-Graecia; As. Min.

brachyglossa, C. Koch, in Linnaea, xxiv. (1851) $318=$ tinctoria.

buphthalmoides, Jacq. Hort. Schoenb. ii. $13=$ Heliopsis buphthalmoides.

byzantina, C. Koch, in Linnaea, xxiv. (1851) $321=$ montana.

caespitosa, Herbich, in Flora, xl. (1857) $509=$ tenuifolia.

cairica, Vis. F1. Quaed. Aegypt. 36. t. 6.-Aegypt.; Arab.

callichroa, Boiss. Diagn. Ser. I. xiii. 77 , sphalm. $=$ Achillea callichroa

camptocarpa, Boiss. F1. Orient. iii. $319=$ tripolitana. candicans, Boiss. l. c. 293.-Lycia

candidissima, Willd. ex Spreng. Syst. iii. 593.-Oriens Lycia.

canescens, Brot. Fl. Lusit. i. 395.-Lusit

canescens, Tenore, ex Nym. Consp. $359=$ brachycentros.

carnea, Boiss. Diagn. Ser. I. iv, 4-As, Min.

carpathica, Willd. Sp. Pl. iii. 2179.-Europ.; As. Min.

Cassia, Boiss. Diagn. Ser. I. xi. 10.-Graecia.

caucasica, Adam, in Weber \& Mohr, Beitr. i. $71=$ Chrysanthemum caucasicum.

caucasica, Henckel, in Donnersm. Pl. Select. H

Halens. $9=$ tinctoria

caucasica, Hornem. Hort. Hafn. 832= Triumfetti

caucasica, C. A. Mey. Verz. Pf. Cauc, $75=$ iberica

Chamomilla, Tenore, Syll. $440=$ brachycentros.

Chamomilla, Willd. Enum. Hort. Berol.910.--'Europ. austr.'

Chamomilla-romana, Crantz, Inst, i, 300=nobilis.

chamomilloides, Steven, ex Bieb. F1. Taur. Cauc, it

$331=$ candidissima

chia, Linn. Sp. Pl. 894.-Graecia; As. Min.

chilensis, Walp. in Nov. Act. Nat. Cur. xix. Suppl. i.

1843) 247.-Chili.

chronia, Nym. Syll. Suppl. $2=$ montana

chrysantha, 7. Gay, in Expl. Sc. Algér. t. 60. f. 2.-Afr. bor.

chrysantha, Schur, Enum. P1. Transs. i. $331=$ tinctoria chrysocephala, Boíss. \& Reut. Diagn. Ser. II. iii. $25=$ montana

chrysoleuca, F. Gay, ex Fisch. \& Mey. Ind. Sem. Hort. Petrop.xi. 50.-Algeria.

ciliata, Boiss. Fl. Orient. iii. 312.-Reg. Caucas.

cinerea, Panc. Elem. 39.-Europ. austr.

Clausonis, Pomel, Nouv. Mat. Fl. Atl.50.-Afr. bor

clavata, Desf. Fl. Atlant. ii. $287=$ Anacyclus clavatus.

clavata, GuSs. Fl. Sic. Syn. ii. 865.-Sicilia.

coarctata, Sibth. \& Sm. Fl. Graec. ix. $68=$ tinctoria.

coelopoda, Boiss, Diagn. Ser. I. xi, 12.-As, Min. Syria.

collina, Jord. Cat. Jard. Dijon, (1848) $18=$ montana concinna, Guss. Fl. Sic. Syn, ii. $870=$ intermedia. confusa, Pomel, Nouv. Mat. Fl. Atl. 49.-Afr. bor coronopifolia, Willd. Sp. Pl. iii. 2176.-Hispan. Cornucopiae, Boiss. Diagn. Ser. I. xi. 8--Palaest. corymbosa, Haenke, in Jacq. Coll. ii. $73=$ Achillea atrata.

corymbulosa, Boiss. E Haussk. in Boiss. Fl. Orient. iii. 316.-Mesopot.

Cossoniana, Reichb. f. Ic. F1. Germ. xvi. 63. t. $1000=$ austriaca.

cossyrensis, Guss. FI. Sic. Syn. ii. $870=$ secundiramea. Cota, Koch, Syn. Fl. Germ. $414=$ brachycentros.

Cota, Linn. Sp. Pl. 893.-Europ. austr.

Cota, Savi, ex DC. Prod, vi. 11 = austriaca.

\section{ANTHEMIS :}

Cota, Sibth. \& Sm. Fl. Graec, t. $880=$ mixta

Cotula, Blanco, Fl. Filip. ed. I. $638=$ Eclipta erecta

Cotula, Linn. Sp, Pl. 894-Europ.; Afr. bor.; Oriens.

Cotula-foetida, Crantz, Inst. i. $300=$ A. Cotula.

cotuloides, Rafin. ex DC. Prod. vi. 13=A. Cotula

crassifolia, Humb. ex Steud. Nom. ed. II. i. $102=$ Iva cheiranthifolia.

crassipes, Boiss. Diagn. Ser. I. xi. $9=$ hyalina.

cretica, Linn. Sp. Pl. 895.-Reg. Mediterr.

cronia, Boiss. \& Heldr. Diagn. Ser. II. iii. $22=$ montana.

Cupaniana, Tod. ex Nym. Consp. $\mathbf{3 6 0}=$ montana

cypria, Boiss. Fl. Orient. iii. 300.-Ins. Cyprus.

cyrenaica, Coss. in Bull. Soc. Bot. Fr. xix. (1872) 82.As. Min.

dalmatica, Scheele, in Linnaea, xviii. (1844) 464.Europ. austr.

damascena, Boiss. EF Gaill. in Boiss. Fl. Orient. ii 315.-Syria.

dentata, Boj. ex DC. Prod. vi. $4=$ Epallage dentata.

dentata, DC. Prod. vi. 291, in syn.=Osmites anthemoides.

dentata, Moench, Meth. $606=$ austriaca.

deserti, Boiss. Fl. Orient. iii. 305.-Arab.

diffusa, Salzm, ex DC. Prod, vi. $5=$ arvensis

discoidea, Spreng. Nachtr. 1. Bot. Gart. Halle, 11.$\mathrm{Hab}$.

discoidea, Willd. Sp. Pl. iii. $2187=$ tinctoria

divergens, Boiss. Fl. Orient. iii. 300.-Cappadoc.

drepanensis, Huet, ex Nym. Consp, $361=$ maritima.

dubia, Stev, in Bull. Soc. Nat. Mosc. xxix. (1856) II. $380=$ arvensis.

Duriaei, Delile, Ind, Sem. Hort. Monsp. (1843) ex

Fisch. \& Mey. Ind. Sem. Hort. Petrop. xi. $50=$ chrys

oleuca.

erucaefolia, F. E C. Presl, Delic. Prag. 102,-Sicilia.

euxina, Boiss. Fl. Orient. iil. 282.-Reg. Caucas.

fallax, Willd. Enum. Hort. Berol. Suppl. $60=$ fuscata.

fimbriata, Boiss. Fl. Orient. iii. 306.-Cilicia

foetida, Lam. F1. Fr. ii. 164=A. Cotula.

fruticosa, C. Sm. ex DC. Prod, vi. 14=Gonospermum revolutum.

fruticosa, Linn. Cent. Pl. ii.31. n. 196; Amoen. Acad. iv. 330 - - Afr. trop.

fruticulosa, Bieb. Fl. Taur. Cauc, ii. 329.-Reg. Caucas.

fumariaefolia, Boiss. Fl. Orient. iii. 304.-Cappadoc.

fumarioides, Hochst. in Lorent, Wanderungen, 330.Armen.

fungosa, Boiss. $\mathcal{E}$ Haussk. in Boiss. Fl. Orient. iii. 318.-Persia.

fuscata, Brot. Fl, Lusit. i. 394-Reg. Mediterr. occ

Garcini, Burm. f. Fl. Ind, 183=Anvillea Garcini.

Gayana, Boiss. Fl. Orient. iii. 313.-Persia ; Beluchist Gemmellari, Tineo, Pl. Rar. Sicil. 47.-Mont. Etna. Gerardiana, Jord. Obs. Pl. Crit. vii. (1849) $31=$ montana.

glabra, Jacquem. ex Decne. in Jacquem. Voy. Bot. iv. $88=$ Allardia glabra

globosa, Orteg. Hort, Matr. $46=$ Zaluzania globosa .

granatensis, Boiss. Elench. $60=$ arvensis.

grandiflora, Host, Fl. Austr. ii. 506=carpatica.

grandiflora, Jacquem. Voy. Bot. iv. $87=$ Allardia tomentosa

grandiflora, Des Moul. in Act. Linn. Soc. Bord. xx. (1855) 556.-Gallia.

grandiflora, Ramatuelle, in Journ. Hist. Nat. Par. ii. (1792) $234=$ Chrysanthemum sinense

granulata, Pomel, Nouv. Mat. Fl. Atl.290.-Afr. bor. graveolens, Schur, in Verh. Siebenb. Ver, Naturw, ii (1852) (Sert. Fl. Trans.) $40=$ carpatica.

graveolens, Boiss. Fl. Orient. iii. 295.-Lycia

Guicciardii, Heldr. \& Sart. ex Boiss. Fl. Orient. iii $308=$ peregrina

halimifolia, Munby, in Bull. Soc. Bot. Fr. ii. (1855) 284.-Algeria.

halophila, Boiss. \& Bal. in Boiss. Fl. Orient. iii. 285 -Cilicia.

Haussknechtii, Boiss. \& Reut. l. c. 310.-Syria; Mesopot.

Haynaldi, Janka, in Oestr. Bot. Wochenbl. vi. (1856) $1=$ arvensis.

hebronica, Boiss. \& Kotschy, Diagn. Ser. II. v. 108.Palaest.

hemisphaerica, Herbich, Stirp. Rar. Bucov. $59=$ macrantha.

hemistephana, Boiss, Fl. Orient. iii. 314.-Persia. 


\section{ANTHEMIS}

heracleotica, Boiss, \& Heldr. ex Nym. Consp. $362=$ peregrina.

heterophylla, Ball, in Fourn. Linn. Soc. xvi. (1878 507.-Marocco.

heterophylla, Wallr. Beitr. Fl. Hercyn. 281.-Europ.

hirpina, Tenore, ex Guss. Fl. Sic. Syn. ii. $868=$ montana.

hispanica, Zuccagni, in Roem. Collect. $155=$ mixta.

hondensis, Willd. ex Steud. Nom. ed. II. i. $102=$ Wedelia acapulcensis

hungarica, Hornem. Hort. Hafn. Suppl. 101=austriaca.

hyalina, DC. Prod. vi. 4.-Syria; Mesopot

hydruntina, Groves, in fourn. Linn. Soc. xxi. (1885) 533. - Ital.

iberica, Bieb. Fl. Taur. Cauc, ii. 328.-Reg. Caucas incisa, Viviani, Fl. Ital. 9.-Italia

inconspicua, Fisch, ex Herd. in Bull. Soc. Nat. Mosc xxxviii. (1865) I, $409=$ Matricaria discoidea.

incrassata, Link, Enum. Hort. Berol. ii. $345=$ Anacy clus clavatus.

incrassata, Loisel. Not. $129=$ arvensis

indurata, Delile, Fl. Egypte, 274. t. 47. f. 3.-Aegypt

inodora, Gilib. Fl. Lituan. i. 223 = arvensis.

intermedia, Guss. Fl. Sic. Syn. ii. 491.-Sicil.

italica, Linn. Syst. ed. X, 1223-Ital.

kahirica, Boiss. F1. Orient. iii. $316=$ cairica.

Kitaibelii, DC. Prod. vi. 7 = carpatica.

Kitaibelii, Spreng. Syst. iii. $592=$ montana.

Kotschyana,-Boiss. Diagn. Ser. II. iii. 23.-Cilicia.

lanuginosa, Moench, Meth. $606=$ Anacyclus radiatus.

laxa, Spreng. Fl. Hal. Mant. 52.-Hab.?

leucantha, Linn. Pl. Rar. Afr. $23=$ Osmites anthe moides.

leucanthemifolia, Boiss. \& Blanch. Diagn. Ser. II. iii. 20.-Syria.

leucanthemoides, Boiss. l. c. Ser. I. iv. 9.-Smyrna.

leucocephala, Schur, Enum. Pl. Transs. $334=$ montana.

libanotica, DC. Prod. vi. $9=\mathrm{A}$. chia.

Lindleyi, Nym. Syll. $7=$ montana.

lithuanica, Bess. ex DC. Prod. vi. 13=A. Cotula.

littoralis, Roj.-Clem. Ens. Vit. And. $307=$ maritima.

lutescens, Cerv. in La Llave et Lex. Nov. Veg. Desc.

fasc, i. $30=$ Zaluzania angusta.

lyonnetioides, Boiss. Fl. Orient. iii. 286.-Syria.

macedonica, Boiss. \& Orph. Diagn. Ser. II. vi. 97.Macedon.

macrantha, Heuff. in Flora, xvi. (1833) 362.-Austria.

maritima, Urville, Enum. P1 Orient, $114=$ secun-

diramea.

maritima, Linn. Sp. Pl. 893.-Reg. Mediterr.

maritima, Pall. ex Bieb. Fl. Taur. Cauc. ii. 330 ruthenica.

maritima, Sibth. \& Sm. Fl. Graec. ix. $64=$ tinctoria.

Marschálliana, Willd. Sp. Pl. iil. $2187=$ Bieberstei niana.

Melampodia, Spreng. Syst. iii. $592=$ seq .

melampodina, Delile, Fl. Egypte, 268. t. 45.-Aegypt.; Arab.

melanacme, Boiss. \& Haussk. in Boiss. Fl. Orient. iii. 315.-Mesopot.

melanoloma, Trautv, in Bull. Soc. Nat. Mosc. xli. (1868) $x, 461=$ rigescens.

membranacea, Labill. Ic. Pl. Syr. dec. iii. $14=$ Achillea membranacea.

Micheliana, Bertol. Cat. Sem. Hort. Bonon. (1838); et Fl Ital. ix, 364=maritima.

Micheliana, Guss. Fl. Sic. Syn. ii. II. 868 , obs. $=$ montana.

micrantha, Boiss. \& Haussk. in Boiss. Fl. Orient. iii. 300.-Assyria.

microsperma, Boiss. \& Kotschy, Diagn. Ser. II. v. 108.-Aegypt. ; Arab.

millefolia, Linn. Sp. Pl. $896=$ Chrysanthemurn millefoliatum.

millefoliata, Pall. Reise Statthalt. Russ. Reich. i. 87, $129=$ praec.

roinuta, Lehm. ex Steud. Nom. ed. II. i. 103.-Hab. misella, 'H. S.' ex Nym. Consp. 361 = parnesia.

mixta, Linn. Sp. Pl, 894.-Reg. Mediterr.

monantha, Willd. Sp. Pl. iii. 2187 = tinctoria

monilicostata, Pomel, Nouv. Mat. Fl. Atl. 41.-Afr. bor.

montana, Koch, Syn. Fl. Germ. ed. II. $415=$ carpatica.

montana, Ledeb, Fl. Ross, ii. $523=$ sterilis

montana, Linn. Sp. Pl. ed. II. 1261.-Europ.; Oriens.

\section{ANTHEMIS}

montana, Sibth. \& Sm. Prod. F1. Graec ii. 190 carpatica.

mucronulata, C. Koch, in Linnaea, xxiv. (1851) $319=$ Chrysanthemum caucasicum.

mucronulata, Bertol. Amoen. $46=$ Achillea Barrelierii.

mucronulata, Hort. ex Steud. Nom. ed. II. i. $103=$ Anacyclus clavatus.

mucronulata, Reichb. Fl. Germ. Excurs, $227=$ carpatica.

multicaulis, Boiss. \& Heldr. in Boiss. Fl. Orient. iii. $301=$ arvensis.

multicaulis, Fanka, in Oestr. Bot. Wochenbl. vi. (1856) 363. - Europ. austr.

muricatn, Guss. Fl. Sic. Syn. ii. 490.-Sicil.

mysorensis, Herb. Madr. ex DC. Prod. v. 551= Guizotia oleifera

Neilreichii, Ortm. in Flora, xxxy. (1852) $676=$ ruthenica.

nicaeënsis, Willd, Sp. Pl, iii. $2182=$ arvensis.

nigrescens, Vest, in Flora, iii. (1820) 8 =austriaca

nigricans, Hort ex G. Don, in Sweet, Hort. Brit. ed. III. $365=$ rigescens.

nobilis, Linn. Sp. Pl. 894.-Europ.

occidentalis, Willd. Sp. P1. iii. $2185=$ Spilanthes Mutisii.

odontostephana, Boiss. Diagn. Ser. I. vi. 85.-Persia

Ind. or.

odorata, Ait. Hort. Kew. iii. 238 =Ursinia odorata

odorata, Lam. Fl. Fr. ii. $163=$ nobilis.

oppositifolia, Lam. Encyc. i. $576=$ Spilanthes Mutisii.

ormenioides, Boiss. Diagn. Ser. I. iv, $5=$ Wiede manniana.

ovatifolia, Orteg. Hort. Matr. $73=$ Heliopsis buphthalmoides.

oxylepis, Boiss. Fl. Orient. iii. 282.-Cilicia.

oxyloba, Schur, Enum. P1. Transs. 884, sphalm. $=$

Achillea oxyloba.

paecilolepis, Boiss, F1. Orient, iii. $288=$ Kotschyana

palestina, Reut. ex Boiss. l. c. 283.-As. Min. Syria.

pallescens, Heldr. ex Nym. Consp. ii. $359=$ tinctoria

pamphylica, Boiss. \& Heldr. Diagn. Ser. I. xi. 8.

As. Min.

parnassica, Nym. Syll. Suppl. 1 = tinctoria

Parnassii, Boiss. \& Heldr. ex Nym. Consp. $359=$ tinctoria.

parnesia, Boiss. \& Heldr. in Boiss. Fl. Orient. iii. 305. -Graecia.

parthenioides, Benth, ex Hornem. Hort. Hafn, ii. 833

-Hab.?

pauciloba, Boiss. Diagn. Ser. 1. vi. 83.-Syria Mesopot.

pectinata, Boiss. \& Reut. l. c. Ser. I. iv, 6.-As. Min.

peduncularis, Benth. \& Hook. f. Gen. ii. 422.Afr. bor.

pedunculata, Bory \& Chaub.F1. Pélop. 5.9= Anacyclus clavatus.

pedunculata, Desf, Fl. AtI. ii. 288=Anacyclus pedunculatus.

pentelica, Boiss, ex Nym. Consp. $360=$ montana. peregrina, Bieb. Fl. Taur. Cauc ii, $331=$ candidissima. peregrina, Linn. Syst. Nat. ed. X. 1223, - Ital. peregrina, Linn. Syst.

persepolitana, Boiss. Diagn. Ser. I. xi. 7.-Persia.

persica, Boiss. l. c. Ser. I. vi. 85--Persia

Pestalozzae, Boiss. l.c. Ser. I. xi. 12.-Lycia.

petraea, Tenore, Fl. Nap. ii. $246=$ carpatica.

philistea, Boiss. Fl. Orient. iii. 302.-Palestin.

piscinalis, Durieu, ex Munby, Fl. Algér. 95, nomen.Algeria.

platyglossa, C. Koch, in Linnaea, xxiv. (1851) $319=$ rigescens.

plebeia, Boiss. \& Noë, in Boiss. Fl. Orient. iii. 313. Kurdist.

poecilolepis, Boiss. Diagn. Ser. II. iii. $24=$ Kotschyana.

pontica, Urville, Enum. PI. Orient. $114=$ ruthenica pontica, Sibth. \& Sm. Fl. Graec. ix. $66=$ tricolor. pontica, Willd. Sp. Pl, iii. $2184=$ montana.

praccox, Link, ex Willd. l, c. $2182=$ fuscata

prolifera, Pers. Syn. ii. $467=$ Cladanthus arabicus

pseudo-atrata, Schur, Enum. Pl. Transs. $327=$ tenui folia.

psendocota, Visiani, Fl. Dalm. ii. $78=$ brachycentros. pseudocotula, Boiss. Diagn. Ser. I. vi. 86.-Oriens. psorosperma, Tenore, Viag. Abruz, $128=\mathrm{A}$. Cotula.

\section{ANTHEMTS}

tarmicaefolia, Adam, in Weber \& Mohr, Beitr. i. $71=$ Achillea grandiflora.

ptarmicaeformis, C. Koch, in Linnaea, xxiv. (1851) 319 -As. Min.

pterygantha, C. Koch, 1. c. xvii. (1843) $44=$ candidissima.

pubescens, Willd. Sp. Pl. iii. $2177=$ Anacyclus cla vatus.

punctata, Guss, ex Nym. Consp. $360=$ montana.

punctata, Vahl, Symb. Bot. ii. 91. t. 46.-Atlas Sicilia.

purpurascens, Nym. Consp. $363=$ Anacyclus radiatus.

pygmaea, Bertol. in Nov, Comm. Acad. Bonon. vi. (1843) 237 (Misc. Bot. ii. 23)=Matricaria praecox.

pygmaea, Sch. Bip. ex Schweinf. Beitr. Fl. Aethiop. 142, nomen.-Afr. trop.

pyrenaica, Miégev. in Bull. Soc. Bot. Fr. xii. (1865 397-Mont Pyren.

pyrenaica, Sch. Bip. in Oestr. Bot. Wochenbl. iv. (1854 $164=$ austriaca.

pyrethriformis, Schur, Enum. Pl. Transs, $335=$ carpatica.

Pyrethrum, Gouan, Fl, Monsp. $370=$ montana

Pyrethrum, Linn, Sp. Pl. $395=$ Anacyclus Pyre thrum

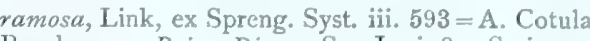

Rascheyana, Boiss. Diagn. Ser. I. xi. 8.-Syria.

reflectens, Reichb. f. Ic. Fl. Germ. xvi. 61. t. $1006=$ arvensis.

reflexa, Moench, Meth. $605=$ altissima.

repanda, Linn. Sp. Pl. 895-Lusitan.

repens, Walt. Fl. Carol. $211=$ Spilanthes repens.

Requienii, Sch. Bip. ex Nym. Consp. $361=$ ruthenica

retusa, Delile, Fl. Aeg. Illustr. $74=$ cairica.

retusa, Link, ex Spreng. Syst. iii. $593=$ ruthenica.

retusa, Tenore, ex Nym. Consp. $359=$ brachycentros.

Reuteriana, Boiss, Diagn. Ser. I. iv. $8=$ smyrnaea.

revoluta, Chr. Sm. ex Buch, in Berl. Acad. Abh. 1816

17 (1819) $370=$ Gonospermum revolutum.

rhodensis, Boiss. Diagn. Ser. I. xi. 11.-Ins. Rhodus

rigescens, Willd. Hort. Berol. i. t. 62.-Reg. Caucas.

rosea, Jacquem. Voy. Bot. iv. $88=$ Allardia glabra.

rosea, Sibth. \& Sm. Fl. Graec. t. 887.-Cyprus.

rotata, Boiss. Fl. Orient. iii. 318. - Aegypt. ; Arab.

Rudolphiana, Adam, in Weber \& Mohr, Beitr. i. 79 - Biebersteiniana.

rupestris, Boj. ex Steud. Nom. ed. II. i. $103=$ Epallage rupestris.

ruthenica, Bieb. Fl. Taur. Cauc. ii. 330. n. 1772.Europ. austr. or.; Reg. Caucas.

ruthenica, Sch. Bip. ex Schur, Entrm. P1. Transs, 33 = austriaca.

salvifolia, Boj. ex DC. Prod. マ. $3=$ Epallage salvifolia.

santolinoides, Munby, in Bull. Soc. Bot. Fr. ii. (1855 284.-Algeria.

saxatilis, Baumg. ex Schur, Enum. Pl. Transs. $394=$ Baumgarteniana.

saxatilis, Bieb. Fl. Taur. Canc. iii. $581=$ sterilis

saxatilis, DC. ex Willd. Enum. Hort. Berol. $910=$ montana.

scaposa, J. Gay, in Boiss. Fl. Orient. iii. 313 Gayana.

scariosa, Boiss. Diag. Ser. I. xi. $7=$ persepolitana.

scariosa, DC. Prod. vi. 4.-Syria ; Mesopot.

scariosa, [Soland. in] Russ. Aleppo, ed. II. ii 263.Syria.

schizostephana, Boiss. \& Haussk. in Boiss. Fl. Orient. iii. 314 . - Kurdist.

Schurii, Heimerl, in Denkschr. Acad. Wien, xlviti (1884) $187=$ Achillea oxyloba.

secundiramea, Bivona, Sicul. Pl. Cent. ii. 10.-Sicil. Aegypt.

segetalis, Tenore, Fl. Neap. Syll. App. $\nabla .54=$ brachy centros.

sessilis, Salisb. Prod. $204=$ Cladanthus arabicus,

Sibthorpii, Griseb. Spicil. F\%. Rumel. ii. 210.Graccia

sicula, Guss, Fl. Sic. Syz, ii. $86^{\circ}{ }^{\circ}=$ arrensis

simuata, Cerv, in La Llave et Lex. Nor. Veg. Dest. fasc. i. $30=$ Zaluzania triloba.

Sismondaeana. Clems. in Mem. Accad. Se. Turino. Ser. II. xvi. (1857) 297 (Sert. Orient. 61) - Byzanc smyrunea, Boiss. Diagn. Ser. I. iv. 7.-Smyma.

spltacelata, Willk. in Bot. Zcit. v, 15tit $85 \mathrm{~s}$ Anacyclus clavatus. 


\section{ANTHEMIS}

sphacelata, F. Eo C. Presl, Delic. Prag. 103.-Sicilia.

Spruneri, Boiss. \& Heldr. Diagn. Ser. II. iii. $24=$ montana.

sterilis, Stev. in Bull. Soc. Nat. Mosc. xxix. (1856) II. 379.-Tauria.

stiparum, Pomel, Nouv. Mat. Fl. Atl. 48.-Afr. bor,

stipulacea, Moench, Meth. Suppl. 258=Chrysan-

themum sinense.

styriaca, Vest, in Syll. Ratisb. i. $12=$ carpatica.

suaveolens, Schwaegr. ex Steud. Nom. ed. II. i. 103.-

Hab.?

subulicola, Pomel, Nouv. Mat. Fl. Atl. 49.-Afr. bor.

suffruticosa, Hornem. Hort. Hafn. Suppl. 101.Hab. ?

sulphurea $\times$, Wall. ex Nym. Consp. $363=$ A. Cotula.

Tatrae, Kit. ex Schult. Fl. Austr, ii. 534.-Europ.

taygetea, Boiss, \& Heldr. Diagn. Ser. I. vi. 83.Graecia.

tenella, Host, Fl. Austr.ii. 507.-Europ.

tenuifolia, Schur, in Verh. Siebenb. Ver. Naturw. ii. (1851) 171 - Transsylvan.

tenuiloba, Boiss. Diagn. Ser. II. iii. $25=$ montana.

tenuisecta, Ball, in fourn. Bot. xi. (1873) 365.Marocco.

tenuisecta, Boiss. Fl. Orient. iii. 301.-Armenia.

tenuisecta, Pomel, Nouv. Mat. Fl. Atl. 50.-Algeria

tenuispherica, Herbich, Stirp. Rar. Bucov. 59.Austria.

tigrensis, 7. Gay, ex A. Rich. Tent. Fl. Abyss. i. 418 -Abyss.

tinctoria, Linn. Sp. Pl. 896.-Europ.; Oriens.

tomentosa, Gouan, ex Boiss. F1. Orient. iii. $321=$ Anacyclus clavatus.

tomentosa, Linn. Sp. Pl. 893.-As. Min

tomentosa, O. F. Muell. in F1. Dan. xi1. t. $685=$ arvensis.

tomentosa, Linn. ex Boiss. Fl. Orient. iii. $291=$ montana.

tomentosa, Willd. Sp. Pl. iii. $2176=$ peregrina

tricolor, Boiss. Fl. Orient. iii. 288.-Cyprus.

triloba, Orteg. Hort. Matr. 72 = Zaluzania triloba,

trinervia, Raeusch. Nom ed. III. 249-Am. merid.

tripolitana, Boiss. \& Blanch. Diagn. Ser. II. iii, 22.Syria.

Triumfetti, All. F1. Pedem. i. $187=$ austriaca

Trotzkiana, Claus, in Beitr. Pflanz. Russ. Reich. viin. 299.-Turkestan.

tubaeformis, Guss. Fl. Sic. Syn. ii. $870=$ Anacyclus clavatus.

tuberculata, Boiss. Elench. 59. n. 107.-Hispan.; Afr. bor.

tubicina, Boiss. \& Haussk. in Boiss. Fl. Orient. iii. 319.-Mesopot.

ubensis, Pomel, Nouv. Mat. Fl. Atl. 289.-Afr. bor.

umbilicata, Boiss. \& Huet, Diagn. Ser. II. iii. 24.Armenia.

Urvillaeana, Sch. Bip. ex Nym. Consp. ii. $362=$ tomentosa.

Urvillaei, Nym. Syll, 7 = cretica.

valentina, Linn. Sp. P1. $895=$ Anacyclus radiatus.

viridis, Blanco, Fl. Filip. ed. II. $436=$ Eclipta erecta.

Visianii, Weiss, ex Boiss. Fl. Orient. iii. $311=$ chia.

vulgaris, Fl. Dan, ex Steud. Nom. ed. I, 53=Matri caria inodora.

vulgaris, Linn. ex Steud. Nom. 1. c,=Matricaria Chamomilla.

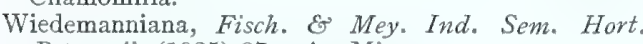
Petrop. ii. (1835) 27.-As. Min.

ANTHEPHORA, Schreb. Beschr. Graes. ii. 105. t. 44 1779). GRAMINEAE, Benth. \& Hook. f. iii. 1122 .

Antephora, Steud. Syn. Pl. Gram. 111 (1855).

Hypudaeurus, Reichb. Nom. 37 (1841).

abyssinica, A. Rich. Tent. F1. Abyss. ii. $389=$ Hochstetteri.

axilliflora, Steud. Syn. PI. Gram. $111=$ Buchloë dactyloides.

Belangeri, Steud. 1. c. = Hilaria cenchroides.

cuspidata, Anderss. Enum. Pl. Ins. Galap. 141.-Ins. Galap.

elegans, Rupr. ex Steud. Syn. Pl. Gram. 111=Hochstetteri.

elegans, Schreb. Beschr. Graes. ii. 105. t. 44.Mexico.

\section{ANTHFPHORA:-}

Hochstetteri, Nees, in Flora, xxvii. (1844) 249.Abyss.

Kotschyi, Hochst. ex Steud. Syn. PI. Gram, 111= Hochstetteri.

persica, Boiss. Diagn. Ser. I. xiii. 44.--Persia.

pubescens, Nees, Fl. Afr. Austr. i. $74=$ Cenchrus pubescens.

punctulata, Steud. Syn. Pl. Gram. i. 111.-Mexico.

villosa, Spreng. Neue Entdeck. iii. $14=$ elegans.

ANTHERICLIS, Rafin. in Am. Monthly Mag. (1819) 195 ; Journ. Phys. Ixxxix. (1819) $261=$ Tipularia, Nutt. (Orchid,)

ANTEERICUM, Linn. Syst. ed. I (1735). LILIA$C E A E$, Benth. \& Hook. f, iii. 788.

Dilanthes, Salisb. Gen. Pl. Fragm. 70 (1866).

Hesperanthes, S. Wats, in Proc. Am. Acad, xiv. (1879) 241 .

Liliago, Salisb. Gen. P1. Fragm. 70 (1866)

Pessularia, Salisb. 1. c. $(1866)$

Phalanganthus, Schrank, ex Haw. Syn. Pl. Succ. 67 (1819).

Phalangium, Juss. Gen. 52 (1789).

TRACHYANDRA, Kunth, Enum. Pl iv. 573 (1843)

BLEPHANTHERA, ENDOGONA, LICINIA, OBSI-

Tila, Trachinema, Rafin. Fl. Tellur. ii. 27, 59 ; iii. 57 .

adenanthera, Forst, f. Prod $24=$ Dianella ensifolia.

affine, Baker, in Fourn. Bot. x. (1872) 138.-Afr. austr.

Aitoni, Baker, in Journ. Linn. Soc. xv. (1876) (= Bulbinella, Gen. P1.) 294.-Afr. austr.

albucoides, Ait. Hort. Kew. i. $449=$ Ornithogalum suaveolens.

aloifolium, Salisb. Prod, $250=$ Bulbine alooides.

alooides, Linn. Sp. Pl. $311=$ Bulbine alooides

altissimum, Mill. Gard. Dict. ed. VIII. n. $8=$ Bulbine longiscapa.

amoenum, Salisb. Prod. $250=$ A. Liliago.

anceps, Baker, in Fourn. Linn. Soc. xv. (1876) 305.Afr. austr.

anceps, Soland, ex Baker, 1. c. $363=$ Tricoryne

anceps.
andongense, Baker, in Trans. Linn. Soc. Ser. II. i. (1878) 257.-Afr. trop.

angulicaule, Baker, in Fourn. Linn. Soc. xv. (1876) 305.-Afr. austr.

angustifolium, Hochst. in A. Rich. Tent. Fl. Abyss. ii. 332.- Abyss.

annum, Linn. Sp. P1. $311=$ Bulbine annua.

annuum, Pourr, ex Willk. \& Lange, Prod. F1. Hisp. i.

$203=$ Asphodelus tenuifolius.

aphyllum, Forsk. Fl. Aegypt. Arab. 209.-Arabia.

arenarium, Baker, in Trans. Linn. Soc. Ser. II. i

(1878) 259.-Afr. trop.

asperatum, Baker, in Fourn. Bot. x. (1872) 138.Afr. austr.

asphodeloides, Ait, Hort. Kew. i. $450=$ Bulbine longiscapa.

asphodeloides, Linn. Sp. P1. $311=$ Balbine asphodeloides.

asphodelum, Forsk. Fl. Aegypt. Arab. 209.-Ins. Rhodus.

auratum, Fisch.ex Trautv. in Act. Hort. Petrop. ix. (1884) 281.--Soongaria.

autumnale, Scop. Fl. Carn. ed. II. i. $247=$ Scilla autumnalis.

baeticum, Steud. Nom. ed. II. i. 103=A. Liliago

benguellense, Baker, in Trans. Linn. Soc. Ser. II. i.

1878) 257.-Angola.

bicolor, Desf, Fl. Atl, i. $304=$ Morgagnia bicolor.

bifolium, Scop. FI. Carn. ed. II. i. $247=$ Scilla bifolia.

bipedunculatum, Jacq. Coll. Suppl. $88=$ triflorum.

blepharophoron, Schult. f. Syst. vii. $461=$ ciliatum.

boeticum, Boiss. Voy. Espagne, ii. 619. t. $172=$ A. Liliago.

brasiliense, Baker, in Fourn. Linn. Soc. xv. (1876) 306.-Bras

Brehmeanum, Baker, in Fourn. Bot. x. (1872) 139.Afr. austr.

brevicaule, Baker, in Fourn. Linn. Soc. xy. (1876) 298. -Afr. austr.

brevifolium, Thunb. Prod. Pl. Cap. 62.-Afr. austr.

bulbosum, R. Br. Prod. $275=$ Bulbine bulbosa.

\section{ANTHERICUM :-}

Burkei, Baker, in Journ. Bot. x. (1872) $140=$ Bulbinella Burkei.

caeruleum, Ruiz \& Pav. Fl. Per. iii. 67. t. $299=$ Pasithea caerulea.

calyculatum, Georgi, It. i. 206= Tofieldia cernua.

calyculatum, Linn. Sp. Pl. $311=$ Tofieldia calyculata.

calyculatum, Pall. Reise, iii. $33=$ Tofieldia palustris.

calyptrocarpum, Baker, in Trans. Linn. Soc. Ser. II. i 1878) 258 . - Afr. trop.

Cameroni, Baker, in Fourn. Linn. Soc. xv. (1876) 96, 314.-Afr. trop.

canaliculatum, Ait. Hort. Kew. i. 448.-Afr. austr.

capillare, Spreng. Syst. ii. 83 ; Schult. f. Syst. vii. 457 $=$ Bulbinella capillaris.

carnosum, Baker, in Journ. Linn. Soc. xv. (1876) 296 = Bulbinellae sp. Gen, Pl. . - Hab.?

Cauda-felis, Linn. f. Suppl. $202=$ Bulbinella caudata.

caudatum, Thunb. Prod. Pl, Cap. $63=$ Bulbinella caudata.

caulescens, Baker, in Fourn. Linn. Soc. xv. (1876) 303.-Afr. trop.

cernuum, Hornem. Hort. Hafn. i, 332-Hab. ?

Chamaemoly, Hochst. in A. Rich. Tent. F1. Abyss. ii 332 = Chlorophytum tetraphyllum.

ciliatum, Linn. f. Suppl. 202.-Afr. austr.

ciliatum, Schult. f. Syst. vii. $466=$ Humboldtii

ciliatum, Spreng. l. c. ii. 84.-Venezuela.

ciliolatum, Baker, in Journ. Bot. x. (1872) $137=$

Bulbinella ciliolata.

cirrhatum, Forst. f. Prod. n.' $148=$ Arthropodium cirrhatum

coarctatum, Ruiz \& Pav. F1. Per. iii. $67=$ Excremis ramosa.

colubrinum, Welw. ex Baker, in Trans. Linn. Soc. Ser. II. i. (1878) $256=$ Dasystachys colubrina

comosum, Thunb. Prod. Pl. Cap. $63=$ Chlorophytum Sternbergianum.

contortum, Linn.f. Suppl. 202.-Afr. austr.

Cooperi, Baker, in Fourn. Linn. Soc. xv. (1876) 304 -Natal.

corymbosum, Baker, in Fourn. Bot. xv. (1877) 71.Afr. trop.

costatum, Andr. Bot. Rep. t. 298.-Afr. austr.

crispum, Thunb. Prod. Pl. Cap. $63=$ Chlorophytum crispum.

croceum, Schult. f. Syst, vii. 476.-Georgia.

dendroides, Stev. in Mém. Soc. Nat. Mosc. iii. (1812) $249=$ Asphodeline prolifera.

dissitiflorum, Baker, in Trans. Linn. Soc. Ser. II. i (1878) 257.-Angola.

divaricatum, Jacq. Hort. Schoenb. iv. $7=$ revolutum.

Dorsetii, Hort, ex Baker, in Journ. Linn. Soc. xv. (1876) $301=$ ramosum

Dregeanum, Baker, in Fourn. Bot. x. (1872) 139.Afr, austr.

Drimiopsis, Baker, in Fourn. Linn. Soc. xv. (1876) 301.-Afr. trop.

eccremorrhizum, Ruiz \& Pav. Fl. Per. iii. 67.Yeruv.

echeandioides, Baker, in Bot. Mag. cxi. (1885) t. 6809 . -Mexic.?

elatum, Ait. Hort. Kew. i. $448=$ Chlorophytum elatum.

elongatum, Willd. Sp. P1. $136=$ Jacquinianum.

ensatum, Banks \& Soland. ex Hook. f. FI. N. Zeal. i $255=$ Dianella intermedia.

ensiforme, Vell. Fl. Flum. 143; iii. t. 162.-Bras.

ericetorum, Berger. Fl, Pyr. ii. 168=Simethis bicolor.

esculentum, Spreng. Syst. ii. $84=$ Camassia esculenta. exuviatum, Jacq. Coll. Suppl. $89=$ Urginea exuviata. falcatum, Linn. $f$. Suppl. 202.-Afr. austr.

falcatum, Welw. ex Baker, in Trans. Linn. Soc. Ser. II i. $(1878) 256=$ Dasystachys falcata.

fasciculatum, Baker, in Fourn. Linn. Soc. xv. (1876) 316.-Afr, austr.

fastigiatum, Steud. Nom. ed. I. 53=Chlorophytum elatum.

favosum, Thunb. Prod. Pl. Cap. $63=$ Bulbine favosa filifolium, Jacq. Coll. Suppl. $93=$ Urginea filifolia. filifolium, Thunb. Prod. P1. Cap. $62=$ Urginea nematodes.

filiforme, Ait. Hort. Kew. i. 451 = Bulbinella triquetra. 


\section{ANTHERICUM :-}

filiforme, Thunb. Prod. Pl. Cap. $62=$ Jacquinianum.

fimbriatum, Steud. Nom, ed, I, 35=Dichopogon Sieberianus?

fimbriatum, Thunb. Prod. Pl. Cap. $63=$ longifolium.

flagelliforme, Baker, in Journ. Bot. x. (1872) $140=$ Schizobasis flagelliformis.

flavescens, Schult. f. Syst. vii. 1692.-Mexic.

fexifolium, Jacq. Coll. Suppl. $93=$ Jacquinianum.

flexifolium, Linn. f. Suppl. 201,-Afr. austr.

flexuosum, R. Br. ex Benth. F1. Austral. vii. $50=$ Corynotheca dichotoma.

floribundum, Ait. Hort. Kew. i. $447=$ Bulbinella latifolia.

fragrans, Jacq. Hort. Schoenb. i. $45:=$ Urginea fragrans.

frutescens, Linn. Sp. Pl, $310=$ Bulbine frutescens.

fruticosum, Salisb. Prod. $250=$ praec

fugax, Moris, Elench, i. $46=$ Urginea fugax.

Gerrardi, Baker, in fourn. Bot.x. (1872) 137.-Afr. austr.

glaucum, Ruis \& Pav. Fl. Per. iii. 68.-Peruv.

Gmelinianum, Schult. f. Syst. vii. $481=$ Melanthium sibiricum.

gracile, Baker, in Journ. Bot. x. (1872) $137=$ Bulbinella gracilis.

gracile, Salisb. Prod. $249=$ ranosum.

gracillimum, Regel, in Act. Hort. Petrop. vi. (1879) 289.-Hab.?

graecum, Linn. Sp. Pl. ed. II. $444=$ Lloydia graeca

gramineum, Vell. Fl. Flum. 143 ; iii. to 161,-Bras.

gramineum, Baker, in fourn. Linn. Soc. xv. (1876

302.-Madag.

graminifolium, Willd. Sp. P1. ii. $139=$ undulatum.

grandiflorum, Salisb. Prod. $250=$ Paradisea Lili astrum.

graminiforme, Dulac, Fl. Hautes-Pyr. $115=$ Paradisea

Liliastrum.

Grantii, Baker, in Trans. Linn. Soc. xxix. (1875) 160

t. $103 \mathrm{~B}$. - Af. trop.

graptophyllum, Baker, in Gard. Chron. (1882) I. 460 -Ins. Socotra.

Heynei, Rottl, ex Baker, in Journ. Linn. Soc. xv.

(1876) $323=$ Chlorophytum Heyneanum.

hirsutum, Thunb. Prod. Pl. Cap. 63.-Afr. austr.

hispidum, Linn. Sp. Pl. ed. II. 446.-Afr. austr.

Hookeri, Colenso, ex Hook. f, Handb. New Zeal. Fl 286 (= Bulbinellae sp. Gen. PI.).-N. Zel.

Humboldtii, Hemsl. Biol. Centr. Am. Bot. iii. 374. -Mexic.

humile, Hochst. ex A. Rich. Tent. Fl. Abyss. ii. 331. Abyss.

hyacinthoides, Willd. ex Kunth, Enum. Pl. iv. $336=$ Scilla indica.

inconspicuum, Baker, in Fourn. Bot. xv. (1877) 71.-

Afr. trop.

incurvum, Thunb. Prod. Pl. Cap. $62=$ Bulbine rostrata.

intermedium, Willk. in Willk. \& Lange, Prod. Fl. Hisp. i. $202=$ A. Liliago.

intricatum, Baker, in Journ. Bot. x. (1872) $140=$ Schizobasis intricata.

involucratum, Baker, in fourn. Linn. Soc. xv. (1876) 311.-Afr. austr.

Jacquinianum, Schult. f. Syst. vii. 462.-Afr. austr.

japonicum, Thunb. Fl. Fap. 138.-China; Japon.

lagopus, Thunb. Prod. PI. Cap. $63=$ Bulbine longi-

$$
\text { scapa. }
$$

latifolium, Linn. f. Suppl. 202=Bulbinella latifolia.

latifolium, Schult. f. Syst. vii. $477=$ simplex.

latifolium, Banks \& Soland. ex Kunth, Enum. P1. iv $622=$ Arthropodium cirrhatum.

leptophyllum, Baker, in fourn. Linn. Soc. xv. (1876) 317.-Mexic.

Liliago, Linn. Sp. Pl, 310.-Europ.; Afr. bor

Liliastrum, Linn. 1. c. ed. II. $445=$ Paradisea Lili astrum.

limosum, Baker, in Trans. Linn. Soc. Ser. II. i. (1878) 257.-Afr. trop.

longepcdunculatum, Steud. ex Schult. f. Syst. vii. 457, 1692.-Afr. austr.

longifolium, A. Rich. Tent. Fl. Abyss. ii. $393=$ Chlorophytum longifolium.

longifolium, Facq. Coll. Suppl. 92.-Afr. anstr.

longipes, N. E. Br. in Gard. Chron. (1882) Ir. 297. - Bras.

longiscapum, Jacq. Coll. Suppl. $84=$ Bulbine longiscapa.

\section{ANTHERICUN .}

ongistylum, Baker, in fourn. Linn. Soc. xv. (1876) 305.-Afr. austr.

Macowani, Baker, l. c. 309.-Afr. austr.

macrophyllum, A. Rich. Tent. Fl. Abyss. ii. $334=$ Chlorophytum macrophyllum.

Makoyannm, Regel, Gartenf. (1880) 36.-Hab.

marginatum, Thunb. Prod. Pl. Cap. $63=$ Urginea marginata.

Mattiazzi, Vand. Fasc. P1. $12=$ Simethis bicolor.

mesembryanthemoides, Baker, in Jour. Bot. x. (1872) $136=$ Bulbine mesembryanthemoides.

milleflorum, [DC. in ] Red. Lil. t. $58=$ Arthropodium paniculatum.

minus, Steud. Nom. ed. I. $53=$ Arthropodium minus.

molle, Baker, in Trans. Linn. Soc. Ser. II. i. (1878), 259.-Angola.

monophyllum, Baker, in Fourn. Bot. xvi. (1878) 324 -Afr. trop.

muricatum, Linn. f. Suppl. 202.-Afr. austr.

nanum, Baker, in Fourn. Linn. Soc. xv. (1876) 305.Mexic.

nematodes, Schult. f. Syst. vii. $472=$ Urginea nematodes.

nepalense, Spreng. Syst. iv. Cur. Post. $135=$ Chlorophytum nepalense.

nidulans, Baker, in Fourn. Linn. Soc. xy. (1876) 314. -Afr. trop.

Nimmonii, J. Grah. Cat. P1. Bomb. $220=$ Chlorophytum glaucum.

niveum, Spreng. Syst. ii. 84 ; Schult. f. in Roem. \& Schult. Syst. vii. $480=$ Chlorophytum tuberosum. non-ramosum, Gilib. Exercit ii. $465=\mathrm{A}$. Liliago

nubicum, Baker, in Fourn. Linn. Soc. xv. (1876) 301 , -Afr. trop.

Nuttallianum, Schult. f. Syst. vii. 477.-Am. bor.

nutans, Jacq. Coll. Suppl. $86=$ Bulbine nutans.

nutans, Thunb. Prod. Pl. Cap, 63.-Afr. austr.

Oatesii, Baker, in Fourn. Bot. xvi. (1878) 324.-Afr. trop.

orchideum, Welw. ex Baker, in Trans. Linn. Soc. Ser. II. i. (1878) 258.-Afr. trop.

rnithogaloides, Baker, in Journ. Linn. Soc. xv. (1876) $294=$ Bulbinella ornithogaloides.

ornithogaloides, Hochst. ex A. Rich. Tent. Fl. Abyss ii. $332=$ Chlorophytum tuberosum.

ossifragum, Georgi, Beschreib. Russ. Reich. iii. IV. 907 = Tofieldia cernua.

ossifragum, Linn. Sp. Pl. $311=$ Narthecium ossifragum.

pachyphyllum, Baker, in Fourn. Linn. Soc. xv. (1876) 304.-Afr, austr.

palustre, Salisb. Prod. $250=$ Narthecium ossifragum. paniculatum, Andr. Bot. Rep. t. $395=$ Arthropodium paniculatum.

paradoxum, Schult.f. Syst. vii. 459.-Afr, austr.

Parkeri, Baker, in fourn. Bot. xx. (1882) 269. Madag.

parviflorum, Benth. F1. Hongk. $373=$ Chlorophytum laxum.

parvum, N.E. Br. in Gard. Chron. (1880) II. 588.Bras.

pauciflorum, Thunb. Prod. P1. Cap. $63=$ triflorum

pendulum, Hornem. Hort. Hafn. i. $333=$ Arthropodium paniculatum.

peronatum, Baker, in Journ. Bot. x. (1872) $137=$ Bulbinella peronata.

peruvianum, Willd, ex Kunth, Enum. Pl. iv. $596=$ Humboldtii.

physodes, Jacq. Coll. Suppl. 94 ; Ic. t. $418=$ Urginea physodes.

pilosum, Jacq. 1. c. 87 ; Ic. t. $416=$ Ornithogalum hispidum.

planifolium, Linn. Mant. ii. $224=$ Simethis bicolor.

pleiostachyum, Welw, ex Baker, in Trans, Linn. Soc.

Ser. II. i. (1878) $255=$ Dasystachys pleiostachya.

plumosum, Ruiz \& Pav. Fl. Per. iii. 68=Bottione thysanotoides.

pomeridianum, Ker-Gawl. in Bot. Reg. t. $564=$ Chlorogalum pomeridianum.

praemorsum, Jacq. Coll. Suppl. $85=$ Bulbine prnemorsa.

Pseudo-asphodelus, Jacq. Enum. Vind. 59, 233= Tofieldia calyculata.

pterocaulon, Welw. ex Baker, in Trans. Linn. Soc. Ser. II. i. (1878) 258.-Angola.

pubescens, Baker, in Gourn. Linn. Soc. xy. (1876) 309. -Afr. anstr.

\section{ANTHFRICUM :-}

pubirhachis, Baker, l. c. 302.-Afr. trop.

pudicum, Baker, l. c. 308.-Afr. austr.

pugioniforme, Jacq. Coll. Suppl. $83=$ Bulbine pugioni

pulchellum, Baker, in Fourn. Bot. x. (1872) 140.Afr. austr.

pusillum, Jacq. Coll. Suppl. $95=$ Urginea pusilla.

pyrenicarpum, Welw. ex Baker, in Irans. Linn. So Ser. II. i. (1878) 259-Afr. trop

Quamash, Steud. Nom. ed. I. $54=$ Camassia esculenta. ramosissimum, Schult. f. Syst. vii. 469.-Mexic.

ramosum, Steud. Nom. ed. I. $54=$ Melasphaerula graminifolia

ramosum, Linn. Sp. Pl. 310.-Europ.

reflexum, Cav. Ic. iii. $21=$ Echeandia terniflora.

revolutum, Linn. Sp. Pl. 310.-Afr. austr.

rigidum, Baker, in Fourn. Bot. x. (1872) 141.-Afr austr.

Rossii, Hook. f. Handb. Nerm Zeal. Fl. 285 (=Balbinellae sp. Gen. P1.).-N. Zel.

rostratum, Jacq. Coll. Suppl. $82=$ Bulbine rostrata.

Saltii, Baker, in fourn. Linn. Soc. xv. (1876) 309.Abyss.

sardoum, Muell. ex Kunth, Enum. Pl. iv. $335=$ Urginea fugax.

scabrelly

Mexic.

aker, in Fourn. Linn. Soc. xv. (1876

cabram, Linn. f. Suppl. 202.-Afr. anstr.

Schultesii, Baker, in Fourn. Bot. x. (1872) 140.-Af. austr.

scilliflorum, Eckl. ex Steud. Nom. ed. II, i. 248, in syn.

et ex Baker, in fourn. Linn. Soc. xv. (1876) 298.Afr. austr.

scilloides, Schult. f. Syst. vii. 477.-Reg. Argent.

semibarbatum, Hook. Bot. Mag. t. $3129=$ Bulbine bulbosa.

semibarbatum, R. Br. Prod. $275=$ Bulbine semibarbata.

serotinum, Linn. Sp. Pl. ed. II. $444=$ Lloydia alpina.

sessiliflorum, Steud. Nom. ed. IT. i. $104=$ scilli florum.

setosum, Willd. ex Schult. f. Syst. vii. I. $473=$ Balbi nella robusta.

sibiricum, Hort. Erf. ex Sterd. Nom. ed. II, i. 104.Sibir.

simplex, Willd. ex Kunth, Enum. Pl. iv. 596.-Reg. Colomb.

Skinneri, Baker, in fourn. Linn. Soc. xv. (1876) 318. -Am. trop.

sphacelatum, Baker, l. c. 303.-1fr. trop.

spirale, Linn. Mant. it. $224=$ Eriospermum spirale.

spiratum, Thunb. Prod. Pl. Cap. 62=Urginea filifolia, squameum, Linn. f. Suppl. $202=$ hispidum.

stenocarpum, Baker, in fourn. Linn. Soc. xv. (1876) 317.-Mexic

Sternbergianum, Schult. f. Syst. vii. $1693=$ Chloro phytum Sternbergianum.

strictum, Steud. ex Steud. Nom. ed. I. 54=Dichopogon strictus.

subpetiolatum, Baker, in fourn. Linn. Soc. xr. (1876 302.-Afr. trop.

subtrigynum, Jacq. Coll. iii. $273=$ Amianthium mus caetoxicum.

succulentum, Salisb. Prod. $250=$ Bulbine asphode loides.

sulphureum, Waldst. \& Kit. Pl. Rar. Hung. i. 98 Ornithogalum pyrenaicum.

superpositum, Baker, in Foum. Bot. xri. (1858. 324 - Afr. trop.

tenellum, Welw. ex Baker, in Trans. Lirn. Soc. Ser. II. i. (1878) 256.-Afr. trop.

thrysoideum, Baker, in fourn. Bot. x. (18i2) 199. Afr. austr.

Torreyi, Baker, in Fourn. Linn. Soc. xr. 187i) $91 \%$.

-Mexic.
triflorum, Ait. Hort. Kear. i. 448.-Afr. austr.

trinervium, Viviani, Fl. Lib. Spec 21. L. 8. f. 2 = Lloydia alpina.

tripedale, Baker, in fourn. Bot. xx. (1852) 269. Madag.

triguetrum, Linn. f. Suppl. 202 = Bulbinella triquetra

tuberosum, Roxb. Pl. Corom. ii. 20. L $198=$ Chloro. phytum tuberosum.

undulatum, Gacg. Coll. Suppl. 87.-Afr. austr.

undulatum, Thunh, Prod, Fl. Cap. $68=$ hispidum. nniflorum, Roxb. Hort. Beng. 8\%; Fl. Ind. ii. 1to. Ind. or.

U 2 


\section{ANTHERICUM :-}

ustulatum, Welw. ex Baker, in Trans. Linn. Soc. Ser II. i. (1878) 258.-Afr. trop.

variegatum, Hort. ex Fl. Mag. N. S. t. $152=$ Chlorophytum elatum.

vermiculare, Soland. ex Baker, in Jonrn. Linn. Soc. xv. (1876) $308=$ longepedunculatum.

vespertinum, Jacq. Hort. Schoenb: i. $44=$ falcatum. vestitum, Baker, in fourn. Linn. Soc. xv. (1876) 307 - Mexic.

villosum, Labill. Ic. PI. Syr. Dec. v. 14. t. 9 = Gagea bohemica.

viscosum, Baker, in Fourn. Bot. x. (1872) 141.-Afr austr

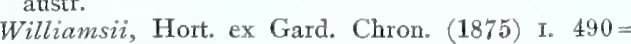
Chlorophytum elatum.

yedoënse, Maxim. ex Franch. E Sav. Enum. Pl. Fap. ii. 529.- Japon.

zanguebaricum, Baker, in Fourn. Linn. Soc. xv. (1876) 302.-Afr. trop

Zeyheri, Baker, in Fourn. Bot. x. (1872) 140.-Afr austr

ANTHEROCEPHALA, DC. Prod. vii. $755(1839)=$ An dersonia, R. Br. (Epacrid.)

Drummondii, DC. 1. c.=And. aristata.

ANTHEROCERAS, Bert. in Am. Journ. Sc. xix. (1831) 301 = Leucocoryne, Lindl. (Liliac.), odorata, Bert. (Merc. Chil. 561) in Am. Journ. Sc xix. (1831) 301.-Chili.

ornithogaloides, Bert. 11. cc._Chili.

ANTHEROSPERMA, Poir, ex Steud. Nom. ed. II. i. 105 (1840), err. typ. = Atherosperma, Labill. (Monim.)

ANTHEROTOMA, Hook. $f$ in Benth. \& Hook. f. Gen. i. 745 (1867). MELASTOMACEAE, Benth. \& Hook, f. i. 745 .

Afzelii, Hook. f. in Oliver, Fl. Trop. Afr. ii. 444. Afr trop.

Naudini, Hook. f. in Benth. \& Hook. f. l. c.-Madag.

ANTHEROTRICHE, Turcz. in Bull. Soc. Nat. Mosc, (1846) II. 505 = Anisoptera, Korth. (Dipterocarp.). lanceolata, Turcz. 1. c. $506=$ Anisopt. thurifera.

ANTHERURA, Lour. Fl. Cochinch. 144 (1790) $R U B I A C E A E$, Benth. \& Hook, f. ii. 29

rubra, Lour. l. c.-Cochinch.; Molucc.

ANTHERYLIUM, Rohr \& Vahl, in Skr. Naturh. Selsk. Hafn. ii. (1792) I. 211.t.8. LYTHRARIEAE, Benth. \& Hook, f. i. 782.

floribundum, Spreng. Syst. ii. $474=$ Adenaria flori bunda.

grisleoides, Spreng. 1. c. = Adenaria floribunda.

nudiflorum, Hemsl. Diagn. Pl. Nov. 13.-Mexic.

purpuratum, Spreng. 1. co= Adenaria floribunda.

Rohrii, Vahl, in Skr. Naturh. Selsk. Hafn. ii. (1792)

I. 211.-Ind. occ.

ANTHERYTA, Rafin. Sylva Tellur. $95(1838)=$ Tetrazygia, Rich. (Melast.)

gramulosa, Rafin. 1. c. $96=$ T. granulosa.

ANTHESTERIA, Spreng. Anleit. ii. I. $79(1817)=$ Anthistiria, Linn. f. (Gramin.).

ANTHILLIS, Neck. Delic. Gallo-Belg. ii. 303 (1768)= Anthyllis, Linn. (Legum.)

ANTHIPSIMUS, Rafin. in Journ. Phys. Ixxxix. (1819) $105=$ Panicum, Linn.? (Gramin.) gonopodos, Rafin. 1. c.-Am. bor.

ANTHIRRINUM, Moench, Meth. $521(1794)=$ Antir. rhinum, Tourn. (Scroph.).

ANTHISTIRIA, Linn. f. Nov. Gram. Gen. 35 (1779) (Amoen. Acad. x. 38). GRAMINEAE, Benth. \& Hook. f. iii. 1136.

Androscepia, Brongn, in Duperr. Voy. Coq. Bot. 77 (1829).

Aristaria, Jungh. in Hoev. \& De Vriese, Tijdschr. vii. (1840) 296.

\section{ANTHISTIRIA :-}

ExothecA, Anderss. in Nov. Act. Upsal. Ser. IIt. i. $(1856) 253$.

Germainia, Balansa \& Poitrasson, in Bull. Soc Hist. Nat. Toul, vii. (1873) 344

HETERELYTRON, Jungh, in Hoev, \& De Vriese, Tijdschr. vii. $(1840) 294$

IseIlema, Anderss. in Nov, Act. Soc. Upsal. Ser. III. i. $(1856) 250$

Perobachne, Presl, Rel. Haenk. i. 348. t. 48 (1830)

THEMEDA, Forsk. Fl. Aegypt. Arab. 178 (1775).

abyssinica, Hochst, ex A. Rich. Tent. Fl. Abyss. ii. 449 -Abyss.

anathera, Nees, in Steud. Syn. Pl. Gram. 402.-Ind. or.

andropogonoides, Steud. 1.c. = Andropogon bracteatus. argentea, Nees, Gram. Afr. Austr. $127=$ imberbis.

arguens, Willd. Sp. Pl. iv. 901.-Ins. Molucc.

arguens, Nees, F1. Afr. Austr. $124=$ imberbis.

arguta, Nees, ex Steud. Syn. Pl. Gram. 401.-Ind. or. Burma.

arundinacea, Hassk. in Hoev. \& De Vriese, Tijdschr.

$x$. (1843) $115=$ argmens.

arundinacea, Roxb. Hort. Beng. 6 ; Fl. Ind. i. $251=$ gigantea.

australis, R. Br. Prod. i. $200=$ imberbis.

avenacea, F. Muell. Fragm. v. $206=$ gigantea.

barbata, Desf. in Journ. Phys. xl. 294. t. 2 = ciliata.

Barteri, Munro, ex Oliver, in Trans. Linn. Soc, xxix.

1875) 176.-Afr. trop.

basisericea, F. Muell. Fragm. v. $207=$ gigantea.

Bladhii, Wight, in Wall. Cat. n. 8770.-Ind, or

brachyantha, Boiss. Diagn. Ser. I. xiii. $71=$ imberbis

caespitosa, Anderss. in Nov. Act. Upsal. Ser. III. ii

1856) $241=$ imherbis.

caudata, Nees, ex Hook. \& Arn. Bot. Beech. Voy. 245 = gigantea.

ciliata, Cav. ex Spreng. Syst. i. $291=$ australis,

ciliata, Linn. f. Diss. Nov. Gram. Gen. 35. -Ind. or. ; Afr.; Jamaic.

ciliata, Retz. Obs. fasc. iii, $11=$ imberbis

cimicina, Edgew. in Journ. As. Soc. Beng. xxi. (1853) $182=$ prostrata

cuspidata, Anderss. in Nov. Act. Upsal. Ser. III. ii. (1856) $242=$ imberbis.

cymbaria, Roxb. Hort. Beng. 6; Fl. Ind. i. 251.Ind. or.

depauperata, Anderss. in Nov. Act. Upsal. Ser. III. ii. (1856) $243=$ imberbis.

Desfontainii, Kunth, Rev. Gram. i. 161=imberbis

dissoluta, Nees, ex Steud. Syn. PI. Gram. 400 (est Andropoginis sp. ign.).-Afr. trop.

fasciculata, Thw. Enum. Pl. Zeyl. 366=Andropogon filipendulus.

flosculosa, F. Muell. Fragm. x. $75=$ gigantea?

foliosa, H. B. \& K. Nov. Gen. et Sp. i. $191=$ Cymbopogon Humboldtii.

Forskalii, Kunth, Rev. Gram. i. $162=$ imberbis.

frondosa, R. Br. Prod.i. $200=$ arguens.

gigantea, Cav, Ic, v. 35.-Ins. Philipp.

glabrifolia, Desv. Opusc. 71 (='ciliata, Sw.").--Ind occ.

glandulosa, Wight, ex Steud. Syn. P1. Gram. $400=$ prostrata.

glauca, Desf. F1. Atl. ii. 380 . t. $254=$ imberbis.

heteroclita, Roxb. Hort. Beng, 6; Fl. Ind, i. $249=$ Andropogon heteroclitus.

hispida, Thunb. F1. Cap. i. $403=$ imberbis

Hookeri, Griseb. in Goett. Nachr. (1868) 91 = gigantea

Humboldtii, Nees, Agrost. Bras. $369=$ Cymbopogor Humboldtii.

imberbis, Retz. Obs, iii. 11-Afr, austr.

japonica, Willd. Sp. Pl iv $901=$ imberbis.

Funghuhniana, Nees, ex Anderss. in Nov. Act. Upsal. Ser. III. ii. (1856) $233=$ arguens

latifolia, Anderss. in Peters, Reise Mossamb. Bot. 562 $=$ Andropogon lepidus.

laxa, Anderss. in Nov. Act. Upsal. Ser. III. ii. (1856) 243 =imberbis.

Linneana, Steud. Syn. P1. Gram. $401=$ prostrata

membranacea, Lindl. in Mitch. Trop. Austr. 88.Austral.

multiplex, Hochst. ex A. Rich. Tent. FI. Abyss. ii. 449 $=$ Andropogon multiplex.

mutica, Hassk. in Hoev. \& De Vriese, Tijdschr. $\mathrm{x}$ (1843) $117=$ gigantea

paleacea, Ball, in Fourn. Linn. Soc. xvi. (1878) 734.Marocco.

\section{ANTHISTIRIA :}

pilifera, Steud. Syn. Pl. Gram. $400=$ arguens.

pilosa, Presl, Rel. Haenk. i. 348= Cymbopogon

Humboldtii.

polystachya, Roxb. Hort. Beng. 6; F1. Ind. i. $248=$ imberbis.

prostrata, Willd. Sp. Pl. iv. 901.-Ind. or

pseudo-cymbaria, Steud. Syn. Pl. Gram. $399=$ Cymbo pogon elegans

puberula, Anderss, in Nov. Act. Upsal. Ser. III. ii (1856) $240=$ imberbis.

punctata, Hochst. ex A. Rich. Tent. Fl. Abyss, ii. 448 $=$ imberbis.

quinqueplex, Steud. Syn. P1. Gram. $400 \Rightarrow$ Cymbopogon elegans.

ramosa, Thunb. ex Anderss, in Nov. Act. Upsal. Ser III. ii. (1856) $247=$ Apluda gigantea.

reflexa, H. B. \& K. Nov. Gen, et Sp. i, $191=$ Cymbopogon Humboldtii.

scandens, Roxb. Hort. Beng. 6; F1. Ind. i. $248=$ ciliata.

setosa, Thunb. ex Anderss, in Nov. Act. Upsal. Ser. III ii. (1856) $233=$ arguens.

subglabra, Buese, in Miq. Pl. Jungh. $363=$ imberbis.

subsericans, Nees, ex Steud. Syn. P1. Gram. 401= gigantea.

syriaca, Boiss. Diagn. Ser. I. xiii. $72=$ imberbis.

tortilis, Presl, Rel. Haenk. i. $347=$ Andropogon Nardus.

tremula, Nees, ex Steud. Syn. Pl. Gram. 401.Ind. or.

villosa, Lam. Illustr. t. 841. f. $3=$ gigantea.

vulcanica, Steud. Syn. Pl. Gram. 400.-Ins. Santorin. vulpina, Anderss, in Nov. Act. Upsal. Ser. III. ii (1856) 245 = gigantea.

Wightii, Nees, ex Steud. Syn. Pl. Gram. $400=$ prostrata.

ANTHOBOLUS, R. Br. Prod. 357 (1810). SANTALACEAE, Benth. \& Hook. f. iii. 230. exocarpoides, F. Muell. Fragm. ix. 3.-Austral filifolius, $R$. Br. Prod. 357-Austral. foveolatus, F. Muell. Fragm. 1. 212.-Austral leptomeroides, F. Muell. l.c. 21.-Austral. triqueter, A. Cunn. ex A. DC. in DC. Prod. xiv. $687=$ filifolius.

triqueter, R. Br. Prod. 357.-Austral.

ANTHOCEPHALUS, A. Rich. in Mém. Soc. Hist Nat. Par. v. (1834) 237 , excl. syn. ; Korth. Verh. Nat. Gesch. 154. t. 48 (1840?), RUBIACEAE, Benth. \& Hook. f. ii. 29

Cephalidium, A. Rich, 1. c. 290

Cadamba, Miq. Fl. Ind. Bat. ii. $135=$ morindaefolius.

chinensis, Hassk. in Flora, xxviii. (1845) $231=$ Cephalanthus orientalis.

chinensis, Walp. Rep. ii. 491 = Nauclea purpurea.

indicus, A. Rich. in Mém. Soc. Hist. Nat. Par, v. (1834) $238=$ Nauclea purpurea

morindaefolius, Korth. Verh. Nat. Gesch. 154. t. 48; Obs. Naucl. Ind. 20.-Sumatr. ; Ind. or.

ANTHOCERAS, Baker, in Journ, Linn. Soc. xi. 374 $(1871)=$ ANTHEROCERAS, Bert. = Leucocoryne, Lindl. (Liliac.).

ANTHOCERASTES, A. Gray, in Hook. Kew Journ. iv. (1852) $225=$ Toxanthus, Turcz. (Compos.).

Drummondii, A. Gray, 1. c. $=$ T. perpusillus.

Muelleri, Sond. in Linnaea, xxv. (1852) $480=\mathrm{T}$. Muelleri.

ANTHOCERCIS, Labill. Nov. Holl. Pl. ii. 19. t. 158 (1806). SOLANACEAE, Benth. \& Hook. fo ii. 912 .

Cyphanthera, Miers, in Ann. Nat. Hist. Ser. II. xi. (1853) 376 .

Eadesia, F. Muell. in Trans. Phil. Inst. Vict. ii (1858) 71

albicans, A. Cunn, in Field, New South Wales, App. 335. t. 2.-Austral

amblyantha, F. Muell. Fragm. i. $179=$ myosotidea. angustifolia, $F$ Muell. in Trans. Phil. Soc. Vict. (1855) 21.-Austral.

anisantha, Endl. in Ann. Wien. Mus. ii. (1838) 201.Austral. 


\section{ANTHOCERCIS :-}

arborea, F. Muell. Fragm. i. 212.-Austral. Eadesii, F. Muell. l. c. ii. 139.-Austral. fasciculata, F. Muell. l. c. i. 122,-Austral genistoides, Miers, Illustr. S. Am. Pl. ii. App. 27. t. 83 D.-Austral.

glabella, Miers, 1. c. $=$ viscosa.

gracilis, Benth. in DC. Prod. x. 192,-Austral

Hopwoodii, F. Muell. Fragm. ii. 138.-Austral. ilicifolia, Hook. Bot. Mag. sub t. $2961=$ viscosa. intricata, F. Muell. Fragm。 i, 211- - Austral.

Leichhardtii, F. Muell. l. c. vi. 142.-Austral.

Littorea, Endl. Iconogr. t. $68=$ viscosa.

littorea, Labill. Pl. N. Holl. ii. 19. t. 158.-Austral. microphylla, F. Muell. Fragm. i. 179.-Austral. myosotidea, F. Muell. in Trans. Phil. Soc. Vict. i. (1855) 20.-Austral.

Odgersii, F. Muell. Fragm.x. 19.-Austral, racemosa, F. Muell. L. c. i. 211.-Austral. scabrella, Benth. in DC. Prod. x. 192.-Austral. spinescens, F. Muell. Fragm. i. 122= genistoides. tasmanica, Hook. f. Fl. Tasm. i. 289. t. 92,-Austral. viscosa, R. Br. Prod. 448.-Austral.

ANTHOCEROS dissectus, Mont. ex Wedd. in DC. Prod. xvii. $62(=$ Neolacis dissecta $)=$ Apinagia, Tul (Podost.).

ANTHOCHLAMYS, Fenzl, ex Endl. Gen. 300 (1837.). CHENOPODIACEAE, Benth. \& Hook. f. iii. 58 .

Peltispermum, Moq. Chenop. Enum. 102 (1840). polygaloides, [Fenzl?] Moq. l. C. 102,-Reg. Cancas.

ANTHOCHORTUS, Endl. Gen. 121 (1837); Kunth, Enum. P1. iii. $485(1841)=$ ANTOCHORTUS, Nees =Willdenowia, Thunb. (Restiac.).

ANTHOCHYTRUM, Reichb. f. Ic. Fl. Germ, xix. 39. t. $1432(1859)=$ Crepis, Vaill. (Compos.) alpinum, Reichb. f. 1. c. 39. t. $81=$ C. alpina.

ANTHOCLEISTA, Afzel. ex R. Br. in Tuckey, Congo, App. 449 (1818). LOGANIACEAE, Benth \& Hook. f. ii. 795 .

madagascariensis, Baker, in fourn. Bot. xx. (1882) 173.-Madag.

macrophylla, G. Don, in Loud. Hort. Brit. 471.-Afr. trop.

nobilis, G. Don, Gen. Syst. iv. 68.-Afr. trop.

scandens, Hook. f. in Fourn. Linn. Soc. vi. (18\$2) 16.Afr. trop.

Vogelii, Planch, in Hook. Ic. Pl. t. 793.-Afr. trop.

ANTHOCOMA, Zoll. \& Mor, in Nat, en Geneesk. Arch. Neerl. Indie, ii. (1845) $569=$ Phlomis, Linn. (Labiat.)

flavescens, Zoll. \& Mor. 1. c. 570.-Malaya.

ANTHOCOMETES, Nees, in DC. Prod, xi. 311 (1847) = Monothecium, Hochst. (Acanth.).

aristatus, Nees, 1. c. $312=\mathrm{M}$, aristatum

ANTHODENDRON, Reichb. in Moessl. Handb. i. p. xl. $244,308(1827)=$ Rhododendron, Linn. (Ericac.). flavum, Reichb. 1. c. $309=$ R. flavum.

nudiflorum, Reichb, 1. $c_{2}=\mathrm{R}$. nudiflorum.

ponticum, Reichb. Fi. Germ. Excurs. $416=$ R. ponticum.

viscosum, Reichb. in Moessl. Handb. ed. II. i. $424=$ R. viscosum.

ANTHODISCUS, Endl. Gen. 1091 in syn. (1841)= ANTHODON, Ruiz \& Pav。=Salacia, Linn. (Hippocrat.).

ANTHodiscus, G. F. W. Mey. Prim. Fl. Esseq 193 (1818). TERNSTROEMIACEAE, Benth. \& Hook, f. i. 181

guianensis, G. F. W. Mey, l.c.-Guiana.

peruanus, Baill. Adansonia, x. (1872) 241--Peruv.

trifoliatus, G. F. W. Mey. Prim。. Fl. Esseg. (1818) 194. -Guiana.

ANTHODON, Ruiz \& Pav. Fl. Per. i. 45. t. 74 (1798) Salacia, Linn. (Hippocrat.).

apiculatum, Miers, ex Peyr. in Mart. Fl. Bras, xi. $x$. $137=$ Hippocratea megacarpa

crassifolium, Mart. in Schult. Mant. i. $848=$ S. cras sifolia.

\section{ANTHODON :-}

decussatum, Rniz \&r Pay, Fl, Per, i. 45, t. 74, f. $2=$

Hippocratea decussata.

ellipticum, Mart. in Schult. Mant, i. 348=Salacia elliptica.

glomeratum, Mart. 1, $\mathrm{c}_{\mathrm{s}}=\mathrm{S}$. glomerata.

grandiflorum, Benth. in Hook. Kew Journ. iv. (1852) $10=\mathrm{S}$. grandiffora.

grandifolitum, Mart. in Schult. Mant. i. $348=$ S. grandifolia.

laevigatum, Steud. Nom. ed. II. i. $105=$ S. laevigata. laxiflorum, Benth. in Hook. Kew Journ. iv。 (1852) 10 $=\mathrm{S}$. laxiflora.

micranthum, Mart. in Schult. Mant。 i. $348=\mathrm{S}$. micrantha.

oblongifolium, Mart. 1. c. = S. elliptica.

paniculatum, Mart. 1. $\mathrm{c},=\mathrm{S}$. paniculata

Selloanum, Schult. Mant. iii. Add. II. 411.-Bras.

trinerve, Schult. 1. c.-Bras.

undulatum, Mart. in Schult. Mant. i. $348=$ S. arborea. verucosum Griseb, in Mem. Am. Acad. N. S, viii. (1861) 172.-Cuba

ANTHODUS, Mart. ex Roem. \& Schult. Syst. Mant. i. $253(1822)=$ ANTHODON, Ruiz \& Pav。 = Salacia, Linn. (Hippocrat.)

ANTHOGONIUM, Wall. ex Lindl. Introd. Nat. Syst. ed. II. 341 (1836), nomen. ORCHIDEAE, Benth. \& Hook. f. iii. 515.

gracile, Wall. Cat. n. 7398.-Reg. Himal.

Griffithii, Reichb. f. in Bonplandia, ii. (1854) $90=$ gracile.

ANTHOLOMA, Labill. Voy. Rech. Pérouse, ii. 235. t. 41 (1800). TILIACEAE, Benth. \& Hook. f. i. 239.

Billardieri, Vieill, in Bull. Soc. Linn. Normand. ix. (1865) $335-\mathrm{N}$. Caled.

montana, Labill. Voy. Rech. Pérouse, 236. t. 41, -N. Caled

ANTHOLYZA, Linn. Syst. ed. I. (1735); Gen. ed. I. 10 (1737). IRIDEAE, Benth. \& Hook. f. iii. 710

Anisanthus, Sweet, Hort. Brit. ed. II. $500(1830)$ Brit. Fl. Gard. Ser. II. t. 84 (1838).

Cunonia, Mill. Gard. Dict. ed. VIII. (1768

GLADIOLUS, Gaertn. Fruct. i. 31. t. 11. f. 4. (1788)

Homoglossum, Salisb. in Trans. Hort. Soc. i. (1812) 325.

PeTAMenes, Salisb. 1, c. 324.

abbreviata, Pers. Syn. i. $42=$ quadrangularis.

abyssinica, A. Brongn. in A. Rich. Tent. Fl. Abyss. ii. 306.-Abyss.

aethiopica, Linn. Syst, ed. X. 863.-Afr. anstr.

aletroides, Burm. f. Fl. Cap. Prod. 1=Watsonia aletroides.

bicolor, Gasp. ex Tenore, Cat. Orto Nap. (1845) 78; fide $\mathrm{E}$, Morr. in Belg. Hortic. ii. (1852) 145 aethiopica.

brevifolia, Hort. ex Stend. Nom. ed. II. i. $105=$ Gladiolus brevifolins.

brevifolia, Eckl. ex Ball, in Journ. Linn. Soc. xvi. 1878) $179=$ caffra.

caffra, Banks, ex Ker-Gawl. in Konig \&o Sims, Ann. Bot. i. (1805) 232.-Afr. austr.

caryophyllacea, Burm. f. Fl. Cap. Prod, $1=$ Watsonis humilis.

caryophyllea, Vahl, Enum. P1. ii. 123=Watsonia

cepacea, Linn. Mant. ii. 176.-Afr. austr.

coccinea, Spreng. Neue Entdeck. i. $253=$ A. Cunonia.

Cunonia, Linn. Sp. Pl. 37.-Afr. austr

fimbriata, Klatt, in Linnaea, xxxv。(1867-68) $299=$ Babiana fimbriata.

floribunda, Salisbo in Trans. Hort. Soc. i. (1812) 324 - aethiopica.

fucata, Baker, in Fourn. Linn. Soc. xvi. (1878) 180.Afr, austr.

fulgens, Andr. Bot. Rep. t. $192=$ Watsonia Meriana

hirsuta, Klatt, in Linnaea, xxxy。(1867-68) $379=$ Gladiolus sericco-villosus

hirsuta, Lam. Encyc, ii. 211=Gladiolus mollis

hirta, Pers. Syn. i. 42 = Babiana Thunbergii

huillensis, Welyv, ex Baker, in Trans. Lirnn. Soc. Se. II. i. (1878) 270 - -Afr. trop.

hypogaea, Klatt, in Abh. Naturf. Ges. Halle, xii. 1s82) 345 . - Afro austr.
ANTHOLYZA :-

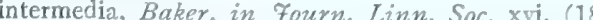

180, nomen.-Afr, anstr.

lucidior, Linn. f. Suppl. 96.-Afr. austr.

lucidior, Vahl, Enum. Pl. ii. $122=$ Watsonia planta. ginea.

Ludrwigii, Eckl. Verz. 34 = aethiopica

marginata, Page, ex Steud. Nom, ed. II. i. 106

Watsonia marginata.

Maura, Linn. Mant. ii. $175=$ Witsenia Maura

Meriana, Blanco, Fl. Filip. ed. I. 24=Sisyrinchium palmifolium.

Meriana, Linn. Sp. Pl. ed. II. $54=$ Watsonia Meriana Merianella, Curt. Bot. Mag. t. $441=$ Watsonia aletroide Merianella, Murr. Syst. ed. XIII. 77-Afr austr.

Meriania, Linn. Syst. ed. X. $863=$ Watsonia Meriana montana, [Ker-Gawl. in] Konig \& Sims, Ann. Bot. (1805) $233=$ Gladiolus montanus.

nemorosa, Klatt, in Abh. Naturf. Ges. Halle, xii. 1882) 346.-Afr. austr.

nervosa, Thunb. Prod. Pl. Cap. 7.-Afr. austr.

orchidiflora, Klatt, in Linnaea, xxxii. (1863) $733=$ Gladiolus arenarius.

paniculata, Klatt, in Linnaea, xxxv. (1867-68) 379.Afr. austr.

plicata, Linn. fo Suppl. $96=$ Babiana Thunbergii praealta, [Del. in] Red. Liliac, vii. t. $387=$ aethiopica quadrangularis, Burm. f. Fl. Cap. Prod. 1. - Afr. anstr. quinquenervia,Schrank, Comm. Irid.Cap. 56.-Afr. austr. ramosa, Klatt, in Linnaca, xxxii. (1863) $734=$ Gladiolus montanus.

revoluta, Burm. f. Fl. Cap. Prod. 1.-Afr. austr.

ringens, Andr. Bot. Rep, t. $32=$ aethiopica.

ringens, Linn. Sp. P1. $37=$ Babiana ringens

rupestris, Eckl. ex Baker, in Journ. Linn. Soc. xvi (1877) $179=$ caffra.

saccata, Baker, in Fourn. Linn. Soc. xvi. (1877) 180. -Afr. austr.

spicata, Andr. Bot. Rep. t. $56=$ Watsonia brevifolia.

spicata, Brehm, ex Klatt, in Abh. Naturf. Ges. Halle. xii. (1882) 345.-Afr. austr.

spicata, Mill. Gard. Dict. ed. VIII. n. 2 =Gladiolus Milleri.

splendens, Steud. Nom. ed. II. i. 106.-Afr. austr.

striata, Klatt, in Abh. Naturf. Ges. Halle, xii. (1852, 346.-Afr. austr.

tubulosa, Andr. Bot. Rep. t. $174=$ Watsonia aletroides. vittigera, Salisb. in Trans. Hort. Soc. i. (1812) $324=$ aethiopica.

ANTHOMELES, M. Roem. Syn, (Rosiforae) 1028 \& $1 \downarrow 0$ (1847)= Crataegus, Linn. (Rosac.)

aestivalis, M. Roem. 1. c. $141=$ Cr. aestivalis. Douglasii, M. Roem. 1. c. $140=$ Cr. Donglasii. flava, M. Roem. 1. c. $142=$ Cr. flava,

flexispina, M. Roem. l. c. = $\mathrm{C}_{\mathrm{r}}$ parvifolia. glandulosa, M. Roem. 1. c. $141=$ Cr. flava opaca, M. Roem. l. $c_{s}=\mathrm{Cr}$. aestivalis rotundifolia, M. Roem. I. c. $140=\mathrm{Cr}$. coccinea sanguinea, M. Roem. 1. c. = Cr. sanguinea. stipulosa, M. Roem. 1. c. $142=$ Cr. slipnlosa. subserrata, M. Roem. l. c. =Cr. subserrata. turbinata, M. Roem. l. c. $=$ Cr. flava

ANTHONOTA, Beauv, Fl. Owar, et Ben。 i. 70. to 4t $(1805)=$ Macrolobium, Schreb. (Legun). crassifolia, Baill. Adansonia, vi. (1S64-65) 179-A Arr. trop.

elliptica, Desv, in Ann. Sc. Nat. Sér. I. ix. 1826 , 490. - Am. merid.

macrophylla, Beauv. Fl. Owar, et Ben. i. 70. t. 42 M. Palisoti.

ANTHOPHY LLUM, Steud. Syn. Pl. Cyp. 160 1855)= Scirpus, Linn. (Cyper.

Urvillei, Steud, 1. c. =S. frondosus

ANTHOPOGON, Neck. Elem. ii. 12,1790 ? = Gentiana. Linn.

barbuta. Rafin. Fl. Tellur. iii. 25 G. barbata.

ciliata, Rafin. 1. c. $=\mathrm{G}$, ciliata.

crinita, Rafin. I. c. $=$ G. crinita.

detonsa, Ratio, 1, $c_{1}=\mathrm{G}$, serraia

ivirgata, Rafin. 1. c-Am, bor.

ATIlopogon, Nutt. Gien. Am. i. sl , 1sisj Gym. nopogon, Benuv, Giram

albescens, Ratin. Now fil. Aur. iv. 91.-An, bor. 
ANTHOPOGON :-

brevifolium, Rafin. New Fl. Am. iv. 91=Gymnopogon brevifolius.

incarnatum, Rafin. 1. c. 90-Am. bor.

lepturoides, Nutt. Gen. Am. i. $82=\mathrm{G}$. racemosus.

ANTHOPTERUS, Hook. Ic. P1. t. $243(1840)$ VACCINIACEAE, Benth. \& Hook. f. ii. 568.

calycinus, Spruce, ex Benth. \& Hook. f. Gen, ii. $570=$ Ceratostema calycinum.

longiflorus, Bentb. ex Benth. \& Hook. f. 1. c. = Ceratostema longiflorum, Benth. \& Hook. $f$.

mucronatus, Benth. Pl. Hartw. 221.-Reg. Colomb.

racemosus, Hook. Ic. Pl. iii., t. 243.-Peruy.

Wardii, Ball, in Hook. Ic. Pl. t. 1465.-Reg. Colomb.

ANTHORA, Hall. in Rupp. Fl, Jen. 290 (1745); DC. Prod. i. $56=$ Aconitum, Tourn. (Ranunc.) saxatilis, Fourr, in Ann, Soc, Linn. Lyon, N. S. xvi (1868) $326=$ Ac. Anthora.

versicolor, Stev。 ex Ser. in DC. Prod. i. $57=\mathrm{Ac}$. Anthora.

ANTHOSACHNE, Steud. Syn. P1. Gram. $237(1855)=$ Agropyron, J. Gaertn. (Gramin.)

australasica, Steud. 1. c. = Agrop. scabrum.

ANTOSCHMIDTIA, Steud. Syn. Pl. Gram. 199 (1855 = Schmiatia, Steud. (Gramin.).

ANTHOSCIADIUM, Fenz1, in Endl. Gen. Supp1. iv. III. $9(1850)=$ Selinum, Linn. (Umbell.).

ANTHOSPERMUM, Linn. Gen. ed. I. 302 (1737) RUBIACEAE, Benth. \& Hook. fo ii. 140. Chrysospermum, Reichb. Consp. 166 (1828)? aethiopicum, Linn. Sp. Pl. 1058.-Afr. austr. ambrosiacum, Moench, Meth. Suppl. 269=aethiopicum.

aromaticum, Salisb. Prod. $59=$ aethiopicum asperuloides, Hook. f. in Fourn. Linn. Soc. vi. (1862) 11. - Fernando Po,

Bergianum, Cruse, Rub. Cap. 8.-Afr. austr.

Burkei, Sond. in Hart. \& Sond. Fl. Cap. iii. 29.-Afr. austr.

calycophyllum, Sond. l.c. 31.-Afr. austr

ciliare, Linn. Sp. Pl. ed. II. 1521--Afr. austr.

ciliare, Thunb. ex Sond. in Harv. \& Sond. Fl. Cap. iii. $30=$ hirtum

confertum, Cruse, in Walp. Rep. ii. 462-Afr. austr.

Crocyllis, Sond. in Harv. \& Sond. Fl. Cap. iii. 32,Afr. anstr.

Dregei, Sond. l. c. 29.-Afr. austr.

Ecklonis, Sond. l. c. 32.-Afr. austr.

emirnense, Baker, in Fourn. Bot. xx. (1882) 139.Madag.

ferrugineum, Eckl. \& Zeyh. Enum. 366.-Afr. austr.

foetidum, Eckl. \& Zeyh. ex Harv. \& Sond, F1. Cap. iii. $30=$ lanceolatum.

galioides, Reichb. ex Spreng. Syst. iv. Cur. Post. $338=$ ciliare.

Galopina, Thunb. Prod. P1. Cap. $32=$ Galopina circaeoides.

hedyotideum, Sond. in Harv. \& Sond. Fl. Cap. iii. 30. -Afr. austr.

herbaceum, Linn. f. Suppl. $440=$ lanceolatum.

hirsutum, DC. Prod, vi. $580=$ hirtum.

hirtum, Cruse, Rub. Cap. 11.-Afr, austr.

hispidulum, E. Mey. ex Harv. \& Sond. Fl. Cap. iii. 29. -Afr. austr.

lanceolatum, Sieber, ex Harv. \& Sond. 1. c. $30=$ hirtum.

lanceolatum, Thunb. Prod. Fl. Cap, 32-Afr. austr.

latifolium, E. Mey, ex Harv, \& Sond. I. c. $30=$ lanceolatum.

Lichtensteinii, Cruse, Rub. Cap. 9, 15.-Afr. austr.

muriculatum, Hochst. ex A. Rich. Tent. Fl. Abyss. 345.--Abyss.

nodosum, E. Mey, ex Harv. \& Sond. Fl. Cap. iii. $30=$ lanceolatum.

pachyrrhizum, Hiern, in Oliver, Fl. Trop. Afr. iii. 229. -Afr. trop.

paniculatum, Cruse, Rub. Cap. 9, 15.-Afr. austr.

plicatum, Hilsenb. \& Boj. ex Baker, in Joum. Linn.

Soc. xx. (1884) $143=$ Myosurandra moschata.

polyacanthum, Baker, l. c. 171.-Madag.

\section{ANTHOSPERMUM :-}

prostratum, Sond. in Harv. \& Sond. Fl. Cap. iii. 28. -Afr. austr.

pumilum, Sond. l. c. 31.--Afr. austr.

rigidum, Eckl. \& Zeyh. Enum. 367.-Afr. austr.

rubiaceum, Reichb. ex Spreng. Syst. iv. Cur. Post. 338 $=$ hirtum.

scabrum, Thunb. Prod. Pl. Cap. $32=$ Carpacoce scabra.

spathulatum, Spreng. Neue Entdeck. iii. $45=$ ciliare.

spermacoceum, Reichb. ex Spreng. Syst. iv. Cur. Post. $338=$ Carpacoce Spermacoce.

thymoides, Baker, in Fourn. Linn. Soc. xx. (1884) 171.-Madag.

tricostatum, Sond. in Harv. \& Sond. Fl. Cap. iii. 28.Afr. austr.

ANTHOSTEMA, A. Juss. Euph. Tent. 56. t. 18 (1824)。EUPHORBIACEAE, Benth. \& Hook. fo iii. 261.

madagascariense, Baill. Étud. Gén. Euph.60, 544.Madag.

senegalensis, fuss. Euph. Tent. 117.-Afr. trop.

ANTHOTIUM, R. Br. Prod. 582 (1810)。GOODE NOVIEAE, Benth. \& Hook. f. ii. 537.

glabrum, Poir. in Dict. Sc. Nat. ii. Suppl. $80=$ humile.

humile, R. Br. Prod. 582.-Anstral.

rubriflorum, F. Muell. ex Benth. Fl. Austral. iv. 45.Austral.

ANTHOTROCHE, Endl. Nov. Stirp. Dec, 6 (1839). SOLANACEAE, Benth. \& Hook, f. ii. 912.

Blackii, F. Muell. Fragm. viii. 232.-Austral.

pannosa, Endl. Nov. Stirp. Dec. 7.-Austral.

Walcattii, F. Muell. Fragm. i. 123.-Austral.

ANTHOXANTHUM, Linn. Gen. ed. I. 18 (1737) GRAMINEAE, Benth. \& Hook. f. iii. 1138.

Xanthanthos, St. Lag. in Ann. Soc. Bot. Lyon, viii. 189 (1881).

Xanthonanthos, St. Lag. 1. c. vii. (1880) 119; viii. 189 (1881)

aculeatum, Linn. f. Suppl. $89=$ Crypsis aculeata. alpinum, Schur, Enum. Pl. Transs. $725=$ odoratum, amarum, Brot. Phyt. Lusit. 11. t. 4. f. 1.-Lusitan. angustifolium, Plan.-Gir. Ensaya Fl. Gallega, $398=$ Puelii.

aristatum, Boiss. Voy. Espagne, 638.-Hispan. aristatum Bor. Fl Centr. Fr. ed. II. $576=$ Puelii. asperum, Mann, ex Opiz, Natural. vii. (1824) $51=$ odoratum.

avenaceum, Pourr. ex Lange, in Kjoeb. Vidensk. Meddel. (1860) 26 =amarum.

avenaceum, Retz. Obs. 3, 8.-Ind. or.

Carrenionum, Parl. Pl, Nov, $37=$ aristatum.

crinitum, Linn. f. Suppl. $90=$ Dichelachne crinita.

giganteum, Walt. F1. Carol. $65=$ Erianthus saccharoides.

glaucum, Vahl, ex Roem. \& Schult. Syst. i. $288=$ amarum.

gracile, Bivon. Stirp. Rar. Sicil. i. [13] t. 1. f. 2.Reg. Mediterr.

indicum, Linn. Sp. Pl, 28 = Perotis latifolia.

lasianthum, Salzm. ex Ball, in fourn. Linn. Soc xvi. (1878) 709,-Marocco.

Lloydii, Jord. ex Bor. Fl. Centr. Fr. ed. III. ii. $697=$ aristatum.

myrthense, Tod. ex Nym. Consp. $790=$ Puellii.

odoratum, Linn.Sp. Pl. 28.-Europ.; As. bor.; Afr. bor.

ovatum, Lag. Elench. 2. n. 15.-Hispan.; Marocco.

paniculatum, Linn. Sp. Pl. $28=$ Festuca spadicea.

Puelii, Lecoq \& Lamotte, Cat. Pl. Auver. 385.Europ.

pulchellum, D. Dietr. Syn. PI. i. 625, err. typ. $69=$ pulcherrimum.

pulcherrimum, Lour. Fl. Cochinch. 36.-Cochinch.

Sommierianum, Ricei, in Nuovo Giom. Bot. xiii. 1881) $135=$ aristatum.

spiculaeforme, Auct. ex Steud. Nom. ed. II. i. $106=$ Perotis latifolia.

villosum, Dum. Obs. Gram. Belg. $129=$ odoratum.

ANTHRISCUS, Bernh. Syst. Verz. Erf. 113 (1800). UMBELLIFERAE, Benth, \& Hook. f. i. 899 .
ANTHRISCUS :-

abortiva, Jord. Obs. Pl. Crit. vii. $28=$ alpestris.

africana, Hook. f. in Fourn. Linn. Soc. vii. (1864) 195.-Afr. occ.

alpestris, Wimm. \& Grab. Fl. Silesiae, i. 289.Europ.

alpina, Jord. Obs, P1. Crit, vii. $29=$ sylvestris.

anatolica, Boiss. in Ann. Sc. Nat. Sér. III. ii. (1844)

$59=$ nemorosa

capensis, Spreng. in Roem. \& Schult. Syst. vi. $526=$ Cartm hispidum.

Caucatis, Bieb. Fl. Taur. Cauc. i. $230=$ vulgaris.

Cerefolium, Hoffm. Gen. Umb. 41, 47. t. 1.-Europ.

Oriens; As. bor.

chaerophyllus, St. Lag. in Ann. Soc. Bot. Lyon, vii. (1880) $119=$ A. Cerefolium.

Cicutaria, Duby, in DC. Bot. Gall. i. $239=$ alpestris.

dubia, Kabath, Fl. Gleiw. $80=$ alpestris.

elatior, Bess. Enum. Pl. Volh. $55=$ sylvestris,

fumarioides, Spreng. Umb. Prod. 27.-Europ.

gracilis, Hampe, in Flora, xxv. (1842) I. $64=$ tenerrima.

heterosantha, Schur, Enum. Pl. Transs. 273=alpestris. humilis, Bess. Enum. Pl. Volh. $13=$ alpestris.

intermedia, Schur, in Verh. Siebenb. Ver. Naturw. iv. (1858) $31=$ sylvestris.

Kotschyi, Fenzl, ex Boiss. Diagn. Ser. II. v. 102.Oriens.

laevigata, Griseb. Spicil. Fl. Rumel. i. 367=sylvestris.

lamprocarpa, Boiss. in Ann. Sc. Nat. Sér. III. ii (1844) 59.-Syria ; Cilic.

longirostris, Bertol. Fl. Ital iii. $197=$ A. Cerefolium. macrocarpa, Boiss. \& Heldr. Diagn. Ser. II. ii. $100=$ nemorosa.

mollis, Boiss. \& Reut. L. c. 99.-Afr. bor.

neglecta, Boiss. \& Rent. ex Lange, Ind. Sem. Haun (1854) 22 ; Losc. \& Pard. Ser. Inconf. Arag. $46=$ vulgaris.

nemorosa, Baker \& S. Moore, in Journ. Linn. Soc xvii. (1879) $382=$ sylvestris.

nemorosa, Spreng. Umb. Prod. 27.-Europ.; Oriens. nitens, Bernh. in Linnaea, xii. (1838) Litt. $76=$ Ruthenia.

nitida, Garcke, Fl. Deutschl. ed. VII. 180,-Europ.

nodosa, Pers. Syn i. $320=$ Chaerophyllum nodosum.

odoratissima, Gueldenst. Reisen durch Russl. i. 190.Rossia.

pilosa, Schur, Enum. P1. Transs. $272=$ sylvestris.

Prescottii, Veesenm. in Beitr. Pfl. Russ. Reich. ix. 84 - Rossia.

procera, Bess. Enum. Pl. Volh. $13=$ sylvestris.

rivularis, Dolliner, ex Vukot. in Rad. Jugos. Akad.

Zagrab, xxxix. (1877) $209=$ nemorosa.

rupicola, Godet, Fl. Jura, i. $300=$ alpestris.

Ruprechti, Boiss. Fl. Orient. ii. 914.-Reg. Caucas.

sativa, Bess. Enum. Pl. Volh. 13=A. Cerefolium.

scandens, Steud. Nom. ed. II. i. 107, sphalm. = seg

Scandix, Bieb. FI. Taur. Cauc. i. $231=$ Chaerophyllum nodosum.

sicula, DC. Prod. iv. 223.-Sicil.

sicula, Vis. ex Nym. Consp. $301=$ fumarioides.

sylvestris, Hoffm. Gen. Umb. 40, 46. t. 1. f. 19.-Europ. Reg. Caucas. ; As. bor.

tauxica, Fisch. ex Loud. Hort. Brit. 101.-Tauria. tenerrima, Boiss. \& Sprun. in Ann. Sc. Nat. Sér. III ii. (1869) 60.-Graecia; As. Min.

torquata, Duby, in DC. Bot. Gall. i. $239=$ alpestris. trachysperma, Reichb. ex Nym. Consp. $301=\mathrm{A}$ Cerefolium.

trichosperma, Pers. Syn. i. $320=$ Cancalis tricho sperma.

trichosperma, Spreng. in Roem. \& Schult. Syst. vi. 525 $=$ A. Cerefolium.

tuberculata, Spreng. in Roem. \& Schult. Syst. vi. 527. $-\mathrm{Hab}$ ?

villosa, Boiss. Fl. Orient. ii. $911=$ nemorosa.

vulgaris, Bernh. Syst. Verz. Erf. 168.--Europ.; Oriens.

ANTHROCEPHALUS, [Schlecht. in] Linnaea, xiv. (1840) Litt. 179, sphalm. = Anthocephalus, A. Rich (Rubiac.).

ANTHROPODIUM, Sims, in Bot. Mag. Ind. (1816) 5, err. typ $=$ Arthropodium, R. Br. (Liliac.)

ANTHROSTYLIS, D. Dietr. Syn. Pl. i. 129, 207 (1839), err. typ. $=$ Arthrostylis, R. Br. (Cyper.). 
ANTHURIUM, Schott, in Wien. Zeitschr. f. Kunst, iii. 828 (1829). AROIDEAE, Benth. \& Hook. f. iii. 998. Pleurospa, Rafin. F1. Tellur. iv. 8 (1836). STRepanthera, Rafin, 1. c. 13 (1836).

acaule, Poepp. \& Endl. Nov. Gen. et Sp. iii. 83. t. 294.--Peruv.

acaule, Schott, Melet. i. 22 .-Ind. occ.

acuminatum, Schott, in Oestr. Bot. Wochenbl. v. (1855) $66=$ gracile.

aduncum, Schott, Prod. Aroid. 478.-Bras.

aemulum, Schott, in Bonplandia, vii. (1859) 165.Mexic.

aeranthe, Hort. ex Baker, in Saund. Ref. t. 278.-Am. trop.

affine, Schott, in Oestr. Bot. Wochenbl. v. (1855) 82. -Bras.

agnatum, Schott, in Oestr. Bot. Zeitschr. (1858) 181. - Nicaragua.

albo-costatum, Miq. Hort. Amstelod. (1853).-Hab. ? alienatum, Schott, Prod. Aroid. 507.-Peruv.

alienigenum, Schott, ex Engl. in DC. Monog. Phan, ii. $130=$ Olfersian um

amoenum, Kunth, Ind. Sem. Hort. Berol. (1848) 11.Peruv.

amplum, Kunth, Enum. Pl. ii. $77=$ Hookeri

andegavense $\times$, Hort. cf. Gard. Chron. (1883) r. 510. Andersonii, Schott, in Oestr. Bot. Wochenbl. (1857) 325. - Ind. occ

andicola, Liebm. in Kjoeb. Vidensk. Meddel. (1849) 22 - Mexic.

Andraeanum, Linden, Illustr. Hortic. (1877) 43. t. 271. -Reg. Colomb.

angustatum, Kunth, Enum. Pl. iii. 79.-Venezuela.

Appunianum, Schott, Prod. Aroid. 512.-Venezuela.

araliaefolium, Regel, in Ind. Sem. Hort. Petrop. (1869) 10 ; Gartenf. (1870) 98. t. 648.- 'N. Caled.

assimile, Schott, in Oestr. Bot. Wochenbl. (1855) $82=$ Harrisii.

attenuatum, Miq. Cat. Hort. Amstel. (1853)=acaule, Aubletii, Kunth, Enum. P1. iii. $81=$ pentaphyllum. augustinum, C. Koch \& Lauche, Ind. Sem. Hort. Berol. (1855) $7=$ trinervium.

bahiense, N. E. Br. ex Engl. in DC. Monog. Phan. ii. $638=$ bellum

Bakeri, Hook.f. Bot. Mag.t. 6261.-Am. centr.

Belangeri, Engl. in Engl. Bot. Jahrb. 1. (1881) $480=$

bellum, Schott, in Oestr. Bot. Zeitschr. (1859) 100.Bras.

Beyrichianum, Kunth, Enum. Pl. iii, $69=$ Harrisii

Binoti, Linden, in Regel, Gartenfl. (1872) t. $723=$ bellum.

bogotense, Schott, in Oestr. Bot. Wochenbl. (1857) 302.-Reg. Colomb

bombacifolium, Schott, in Oestr. Bot. Zeitschr. viii. (1858) 182,-Costa Rica.

Boucheanum, C. Koch, Ind. Sem. Hort. Berol. (1855) App. 7.-Venezuela.

brachygonatum, Schott, Prod. Aroid. 468.-Mexic

brachyspathum, C. Koch \& Bouché, in Koch, Allg. Gartenz. (1857) $233=$ trinerve.

Bredemeyeri, Schott, in Oestr. Bot. Wochenbl. vii.(1857) 269.-Bras.

breviscapum, Kunth, Enum. Pl. iii. 78; Poepp. \& Endl. Nov. Gen. et Sp. iii. 84.--Peruv.

Brownii, Mast. in Gard. Chron. (1876) II. 744.-Reg. Colomb.

candidum, Bull, Cat. (1875) 3.t. 11 =brevirostre.

cardiophyllum, C. Koch \& August, Ind. Sem. Hort.

Berol. (1854) App. 9=nymphaeifolium.

carinatum, Engl. in Engl. Bot. Fahrb. vi. (1885) 275 - Reg. Colomb.

cartilagineum, Kunth, Enum. Pl. iii. 79.-Venezuela. caucanum, Engl. in Engl. Bot. Fahrb. vi. (1885) 274 -Reg. Colomb.

caudatum, Kanth, Enum. Pl. iii. $80=$ undatum.

Chamissonis, Schott, in Oestr. Bot. Wochenbl. (1857) $269=$ Gaudichaudianum

chetseiensis $\times$, N. E. Br. in Gard. Chron. (1885) II. 650. clavigerum, Poepp. \& Endl. Nov. Gen. et Sp. iii. 84 . -Peruv.

cochleatum, Moritz, ex Schott, Prod. Aroid. $499=$ nymphaeifolium.

colocasiaefolium, Devans. in Rev. Hortic. (1879) 452 -Am. trop.?

commutatum, Schott, in Bonplandia, x. (1862) 148 -Hab.?

comtum, Schott. l. c. 87.-Bras.

\section{ANTHURIUM :}

concinnatum, Schott, Prod. Aroid. $522=$ bogotense. concinnum, Schott, in Oestr. Bot. Wochenbl, yii. (1857) $301=$ Guildingii.

consanguineum, Kunth, Enum. Pl. iii. $71=$ Harrisii consimile, Schott, in Oestr. Bot. Wochenbl. vii. (1857) 294.-Peruy.

consobrinum, Schott, l. c. v. (1855) 66.-Nicaragua. contemtum, Schot, ex Lngl. in DC. Monog. Phan. ii $129=$ Harrisii

corallinum, Poepp. E Endl. Nov. Gen. et Sp. iii.84.Peruv.

cordato-sagittatum, Schott, in Oestr. Bot. Zeitschr. ix. (1859) $100=$ rubrinervium

cordatum, C. Koch \& H. Sello, Ind. Sem. Hort. Berol. 1853) App. 5.--Venezucla.

ordatum, G, Don, in Sweet, Hort. Brit. ed, III. $633=$ Pothos cordata.

cordatum, Schott, Prod. Aroid. $491=$ Lhotzkyanum.

cordifolium, Hort. ex Gard. Chron. (1865) $934=$ grande.

cordifolium, Kunth, Enum. Pl. iii. 76.-Costa Rica.

coriaceum, G. Don, in Sweet, Hort. Brit. ed. III. 633. -Bras.

costatum, C. Koch \& Bouche, Ind. Sem. Hort. Berol. (1853) App. 6.-Venezuela.

crassifolium, N.E.Br. in Gard. Chron. (1883) 1. 10 -Reg. Colomb.

crassinervium, Hort. ex Engl. in DC. Monog. Phan. ii. $138=$ acaule

crassinervium, Schott, Melet.i. 22.-Panama.

crenatum, Kunth, Enum. P1. xii. $75=$ acaule.

cristallinum, Linden \& André, in Linden, Cat. (1873) n. 90.t. 128.-Peruv,

cucullatum, Koch \& Sello, Ind. Sem. Hort. Berol. 1853) App. $6=$ andicola

cupreum, Engl. in Engl. Bot. Fahrb. vi. (1885) 278.Reg. Colomb,

cuspidatum, Mast. in Gard. Chron. (1875) I. 428.Reg. Colomb.

cuspidifolium, Schott, in Oestr. Bot. Zeitschr. (1858) 180.-Costa Rica.

cymatophyllum, C. Koch \& Sello, in C. Koch, Wochenschr. xi. (1868) 276.-Bras.

Dechardi, André, in Illustr. Hortic. xxiv. (1877) t. 269 = Spathiphyllum cannaeforme.

decurrens, Poepp. \& Endl. Nov. Gen.et Sp. iii.83, t. 293.--Peruv.

denudatum, Engl, in Engl, Bot. Jahrb. vi. (1885) 280 - Reg. Colomb.

Devansayanum x, Hort.-Cf. Gard.Chron. (1883) I. 510 .

digitatum, G. Don, in Sweet, Hort. Brit. ed. III. 633. -Pernv.

dolosum, Schott, in Oestr. Bot. Zeitschr. viii. (1858) $179=$ scandens.

Dombeyanum, Brongn. ex Engl. in DC. Monog. Phan ii. 146.-Peruv.

dominicense, Schott, in Oestr. Bot. Zeitschr. (1858) 350.-Ind. occ.

egregium, Schott, Prod. Aroid. $475=$ ellipticum elatum, C. Koch \& Bouché, Ind. Sem. Hort. Berol. (1853) App. $5=$ pentaphyllum.

elegans, Engl. in Engl. Bot. Fahrb. i. (1881) 482.Ins. Martinica.

ellipticum, C. Koch \& Bouché, Ind. Sem. Hort. Berol. (1853) App. 6.-Venezuela.

emarginatum, Baker, in Saund. Refug. t. 274.Am. trop.

eminens, Schott, in Oestr. Bot. Wochenbl. v. (1855) 273.-Peruy.

erythropodum, Miq. Hort. Amstelod. (1853) 8= Harrisii.

fallax, Schott, in Oestr. Bot. Wochenbl. vii. (1857) $309=$ Guildingii.

Fendleri, Schott, Prod. Aroid. 468.-Venezuela.

Ferrierense x.-Cf. Gard. Chron. (1883) II.758.

fissum, C. Koch, in Ender, Ind. Aroid. 102.-Reg. Colomb.

flavescens, Poepp. \& Endl. Nov. Gen. et Sp. iii. 88.Peruv.

flavidum, N. E. Br. in Gard. Chron. (1S85) 11.651.Reg. Colomb.

flexile, Schott, in Oestr. Bot. Zeitschr. (1858) 180.Costa Rica.

flexuosum, Kunth, Enum. Pl. iii. 82.-Venezuela.

floribundum, Linden \& André, in Illustr. Hortic. 1874) 22. t. $159=$ Spathiphyllum floribundum.

\section{ANTHURIUM}

Fontanesii, Schott, in Bonplandia, x. (1862) 347. Venezuela.

formosum, Schott, in Oestr. Bot. Zeitschr. (1858) 181. - Costa Rica.

Fraseri, Engl. in DC. Monog. Phan. ii. 112.Ecuador.

fraternum, Schott, in Oestr. Bot. Wochenbl. vii. (1857 $293=$ Lindenianum.

Friedrichsthalii, Schott, 1. c. v. $(1855 ; 65=$ Rudgeanum.

fucatum, Schott, 1. c. viii. (1858) $387=$ nymphati folium.

funiferum, Klotzsch \& Karst. ex Engl, in DC. Mono Phan. ii. $111=$ Bredemeyeri

Galeottianum, C. Koch, in Ind. Sem. Hort. Berol. (1855) App. 5.-Bras.

Galeottii, C. Koch, थ. c: (1854).-Mexic.

Gaudichaudianum, Kunth, Enum, Pl, iif, 74-Bras.

Geitnerianum, A. Regel, in Ind. Sem. Hort. Petrop. (1866) 88.-Am. trop.

Ghiesbrechtii, Linden, ex Schott, Prod. Aroid. $538=$ podophyllum.

gladiifolium, Schott, in Fourn. Bot. i. (1863) 5.Bras.

glaucescens, Kunth, Enum. PI. iii. $73=$ coriacenm.

glaucum, Schott, Melet. i. $22=$ coriaceum.

Glaziovii, Hook. f. Bot. Mag. t. 68:33. - Bras.

gracile, Lindl. Bot. Reg. t. 1635.-Guiana.

grande, Hort. Bull, ex Gard. Chron. (1865) 934.-

Am. austr.

grandifolium, Kunth, Enum. Pl. iii. 77.-Reg.

Colomb.

grossum, Schott, in Oestr. Bot. Zeitschr. (1859) $101=$ pentaphyllum.

Guildingii, Schott, in Oestr. Bot. Wochenbl. (1857) 301.-Ind. occ.

Gustavi, Regel, Gartenf. (1878) 324, nomen; (1882) 67.-Reg. Colomb.

gymnopus, Griseb. Cat. Pl. Cubb. 219.-Caba occ.

Hahnii, Engl. in Engl. Bot. Fahrb. i. (1881) 481.-Ins. Martinica.

Harrisii, G. Don, in Sweet, Hort. Brit. ed. III. 633.Bras.

helleborifolium, Hort. ex Engl. in DC. Monog. Phan. ii. 205 = variabile

helleborifolium, Schott, in Bonplandia, x. (1862) 148. - Hab?

Hoffmanni, Schott, in Oestr. Bot. Zeitschr. (1858) 181. - Costa Rica.

Hoffmannsegii, Schott, in Oestr. Bot. Wochenbl. vii. (1857) 325 .-Bras

Holtonianum, Schott, l. c. 317.-Reg. Colomb.

Hookeri, Kunth, Enum. Pl. iii. 74.-Ind. occ.

Hookeri, Schott, Prod. Aroid. 472=tetragonum.

Huegelii, Schott, in Oestr. Bot. Wochenbl. v. (1855) 83 $=$ Hookeri.

Humboldtianum, Kunth, Enum. P1. iii, $78=$ rabri. nervium.

Humboldtianum, Schott, Prod. Aroid, 52t=polyrrhizon.

humile, Schott, 1. c. $442=$ amoenum.

hybridum, Hort. ex Engl. in DC. Monog. Phan. ii. 191.- - Hab. ?

hygrophilum, Engl. in Bot. Fahrb. vi. (18ฐ5) 276.Reg. Colomb.

ianthinopodum, Schott, ex Engl. in Mart. Fl. Bras, iii. II. $89=$ Harrisi.

illepidum, Schott, in Oestr. Bot. Zeitschr. 1859 10 $10=$ longifolium.

imperiale, Miq. ex Schott, Prod. Aroid. $\$ 65$ - - Hab. inamoenum, Schott, 1. c. $50 t=$ nymphaeifolium. inconditum, Schott, in Oestr. Bot. Zeitschr. 1858) 181 $=$ gracile.

inconspicuum, N.E. Br. in Gard. Chran, '18\$5' 1. - 87 . -Bras.

indecoram, Schott, in Oestr. Bot. Zeitsctsr. 1858350. -Peruv

indecorum, Schott, ex Engl. in DC. Monog. Phan. ii. $205=$ variabile.

insigne, Hast. in Gard. Chrons. 18:\$) 1. $430 .-\mathrm{k} e \mathrm{~s}$ Colomb.

intermedium. Kunth. Enum. Pl. iii. $70=$ Harrisii. Isertianum, Schott, Prod. Aroid. 4 : $3=$ = Gilhinerii. Filekii, Schott, in Bonplandia, $\left.x, 1+6^{2}\right) 5=$ Harrisii. Kalbreyeri, Hort. ex Gard. Chron. 1851) 11. 11i.-) Ciranot.

Karwinskyi, Schoot, in Oestr. Bo!. Zeitsithr. ix. : 101 ; Prod. Aroid. 553.-Aw. cent. 


\section{ANTHURIUM :-}

Kastelskii, Schott, in Oestr. Bot. Zeitschr. (1859) 100. Chili.

Kellermanni, Schubert, ex Kellerm. in Wien. Illustr. Gart. Zeit. ix. (1884) 6.-Hab.?

Kunthianum, Liebm, in Ann. Sc. Nat. Sér. IV. ii. (1854) 372.-Mexic.

Kunthii, Poepp. E Endl. Nov. Gen.et Sp. iii. 84.-Peruv. lactiforum, Engl. in Engl. Bot. Fahrb. vi. (1885) 277. Reg. Colomb.

lanceolatum, Kunth, Enum. Pl. iii. 71.-Am. austr.

lanceolatum, G. Don, in Sweet, Hort. Brit. ed. III. 634 = Willdenowii.

lancifolium, Schott, in Oestr. Bot. Zeitschr. (1858) 180 Costa Rica.

Langsdorffii, Schott, Prod. Aroid. 458.-Bras

lapathifotium, Schott, in Oestr. Bot. Wochenbl. vii. 1857) $309=$ ochranthum

Laucheanum, C. Koch, in Allgem. Gartenz. (1857) 191.-Bras.

Lechlerianum, Schott, Prod. Aroid. 534.-Peruv,

leptostachyum, Schott, in Oestr. Bot. Wochenbl. v. 1855) $66=$ Olfersianum.

leucocarpum, Schott, 1. c. (1857) $53=$ scandens.

leuconeurum, Lem. in Illustr. Hortic. ix. (1862) t. 314. Am. trop.

Lhotzkyanum, Schott, Prod. Aroid. 491.-Bras.

Libonianum, Lindl. \& Regel, in Gartenfl. (1867) 291. t. 558= Gaudichaudianum.

Liebmanni, Schott, in Bonplandia, vii. (1859) 165.Mexic.

Lindenianum, Hort. ex Engl. in DC. Monog. Phan. ii $\mathbf{1 7 6}=$ nymphaeifolium.

Lindenianum, C. Koch \& August, in C. Koch, Allg. Gartenz. (1857) 234.-Reg. Colomb.

Lindigii, Hérincq, L'Hortic. Franç. (1866) 17 ; N. E Br. in Gard Chron. (1879) II. 554=Lindenianum.

tinguifolium, Hort. ex Engl. in DC. Monog. Phan. ii. $124=$ Geitnerianum

longifolium, Hort. ex Engl. 1. c. $129=$ Harrisii

longifolium, G. Don, in Sweet, Hort. Brit, ed. III. 633 Kunth, Enum. Pl. iii. 69.-Bras.

lonoispathum, Schott, Prod. Aroid. 520-Costa Rica lucidum, Kunth, Enum.Pl. iii. 73.-Bras.

Luschnathianum, Kunth, 1. c.=Olfersianum.

macilentum, Schott, in Bonplandia, vii. (1859) $165=$ gracile.

Macleani, Schott, in Oestr. Bot. Zeitschr. (1858) 350. - Peruy.

macrolobium x, Hort. Bull, in Gard. Chron. (1883) I $404,-\mathrm{Hab}$ ?

macrophyllum, G. Don, in Sweet, Hort. Brit. ed. III. 633 = Pothos macrophylla.

macrophyllum, Schott, in Oestr. Bot. Wochenbl.v. (1855) $83=$ Selloum

macrospadix, Lem. Illustr. Hortic. ix. (1862) Misc. 20. -Guiana.

magnificum, Linden, in Belg. Hortic. xv. (1865) 98.Reg. Colomb.

magnificum, Hort. ex Gard. Chron. (1865) $934=$ grande

Malyi, Maximil (Archd. Austr.) ex Schott, in Bonplandia, x. (1862) 322.--Bras.

mandiocanum, Schott, Prod. Aroid. $454=$ Harrisii.

margaritaceum, Baker, in Saund. Refug. t. $280=$ Hoffmanni.

Martianum, C. Koch \& Kolb, in C. Koch, Wochenschr. xi. (1868) 276.-Guiana.

Martini, Schott, in Oestr. Bot. Wochenbl. vii. (1857) 325.-Guiana.

martinicense, Engl. in Engl. Bot. Fahrb̆. i. (1881) 480 , -Ins. Martinica.

Maximiliani, Schott, in Bonplandia, x. (1862) 5.-Bras. membranuliferum, Schott \& Ohlend. ex Engl. in DC. Monog. Phan. ii. $196=$ podophyllum.

metallicum, Linden, ex Schott, Prod. Aroid. 506.Hab.?

mexicanum, Engl. in DC. Monog. Phan. ii. 105.-Mexic. mexicanum, Liebm. in Kjoeb. Vidensk. Meddel. (1849) $21=$ Schlechtendalii.

microphyllum, G. Don, in Sweet, Hort. Brit. ed. III. 633.-Bras

microspadix, Schott, in Oestr. Bot. Zeitschr. (1858) 180 $=$ porrectum

microstachyum, Kunth, Enum. Pl. iii. 72.-Reg. Colomb.

Miquelianum, C. Koch \& August, Ind. Sem. Hort Berol. (1855) 5.-Bras.

montanum, Hemsi. Diag. Pl. Nov. 36. -Guatemala.

\section{ANTHURIUM:}

myosuroides, Endl. ex Kunth, Enum. Pl. iii. 72.-Reg. Colomb.

neglectum, Miq. in Cat. Hort. Amstel. (1853)=Hookeri nitidum, Benth. Pl. Hartw. 255.--Reg. Colomb.

nymphaefolium, C. Koch Eै Bouché, Ind. Sem. Hort. Berol. (1853) App. 6.-Venezuela.

obliquatum, Schott, in Oestr. Bot. Zeitschr. (1858) 387.--Venezuela.

oblongatum, Schott, ex Engl. in Mart. Fl. Bras. iii II. $290=$ Olfersianum.

obtusifolium, G. Don, in Sweet, Hort. Brit. ed. III. 633; Kunth, Enum.Pl.79.-Barbadoes.

obtusilobum, Schott, in Oestr. Bot. Zeitschr. (1858) 181.-Costa Rica.

ochranthum, C. Koch, Ind. Sem. Hort. Berol. (1853) App. 6.-Am. trop.

Oerstedtianum, Schott, in Oestr. Bot. Zeitschr. (1858) 180.-Costa Rica.

Olfersianum, Kunth, Enum. Pl. iii. 72.-Bras

ornatum, Schott, in Oestr. Bot. Wochenbl. (1857) 294 = nymphaeifolium.

Ottonianum, Kunth, Enum. Pl. iii. 82.-Bras.

oxybelium, Schott, in Oestr. Bot. Wochenbl. vii. (1857) $310=$ nitidum

oxycarpum, Poepp. \& Endl. Nov. Gen. et Sp. iii. 83,Peruv.

pachiraefolium, Schott, in Oestr. Bot. Wochenbl. v. (1855) 273--Bras.

pallens, Schott, in Oestr. Bot. Zeitschr. (1858) 180.Costa Rica.

palmatifidum, Van Houtte, ex Schott, Prod. Aroid. 557.-Hab.?

palmatum, G. Don, in Sweet, Hort. Brit. ed. III. 633 Kunth, Enum. Pl. iii, 80.-Ins. Dominic.

panduraeforme, Schott, Prod. Aroid. 536.-Costa Rica.

panduratum, Mart. ex Schott, in Oestr. Bot. Wochenbl. (1855) 273 --Bras.

panduratum, Schott, 1. c. = panduraeforme.

parvispathum, Hemsl. Biol. Cent. Am. Bot. iii. 432 -Guatemala.

Patini, R. Hogg, in Gard. Chron. (1875) I. $524=$ Spathiphyllum Patini

pedatifidum, Regel \& Linden, Petrop. (1865) 44 ; et in Gartenf. $(1866) 66$. t. $501=$ pedato-radiatum.

pedato-radiatum, Schott, in Bonplandia, vii. (1859 337.-Mexic.

pedatum, Endl. ex Kunth, Enum. Pl. iii. 79.-N. Granat.

peltatum, Poepp. \& Endl. Nov. Gen. et Sp. iii. 83. t. $294=$ Homalonema peltata.

pentaphyllum, G. Don, in Sweet, Hort. Brit. ed. III. 633; Kunth, Enum. Pl. iii. 81.-Bras.

podophyllum, Kunth, l. c. 80-Mexic

Poiteanum, Kunth, 1. c. $68=$ gracile

Poiteauanum, Schott, Prod. Aroid. $453=$ gracile polyrrhizon, C. Koch \& August, Ind. Sem. Hort. Berol. (1855) App. 7.-Venezuela.

polytomum, Schott, in Bonplandia, vii. (1859) $337=$ podophyllum.

popayense, Engl. in Engl. Bot. Fahrb. vi. (1885) 274 -Reg. Colomb.

porrectum, Schott, in Oestr. Bot. Zeitschr. (1858) 180 -Costa Rica.

protensum, Schott, l. $c .181$.-Am. centr.

pseudopodophyllum, Schott, in Bonplandia, vii. (1859) $338=$ podophyllum

pulchellum, Engl. in Engl. Bot. Fahrb. vi. (1885) 273 -Reg. Colomb.

Purdieanum, Schott, in Oestr. Bot. Wochenbl. (1857)

53.--Reg. Colomb.

quindiuense, Schott, l. c. $293=$ fraternum.

quinquenervium, Kunth, Enum. Pl. iri. 76.--Reg. Colomb.

quinquevulnerum, Schott, ex Engl in Mart. F1. Bras iii. II. $100=$ undatum.

radicans, C. Koch \& A. Haage, Ind. Sem. Hort. Berol. 1854) App. 10.-Bras.

recusatum, Schott, Prod. Aroid. 467.Cuba

reflexum, Hort. Par. ex Regel, Gartenfl. (1866) 259.Am. trop.

reflexum, G. Don, in Sweet, Hort. Brit, ed. III. $633=$ coriaceum.

regale, Linden, in Belg. Hortic. xvi. (1866) 200.-Am. trop.

Regnellianum, Engl. in Mart. Fl. Bras. iii. II. 96.Bras.

\section{ANTHURIUM}

repandum, Schott, in Oestr. Bot. Wochenbl. (1857) 317 -Reg. Colomb.

reptans, G. Don, in Sweet, Hort. Brit. ed. III. 633.Bras.

reticulatum, Benth, Pl. Hartwy, 255.-Peruy.

rigidulum, Schott, in Oestr. Bot. Zeitschr. (1858) 180 - Costa Rica.

Roezlii, Regel, in Gartenfl. (1872) 331.-Reg. Colomb. Rothschildianum $\times$, Hort.-Cf. Gard. Chron. (1883) I. 510.

rubescens, G. Don, in Srveet, Hort. Brit. ed. III. 634 Bras.

rubidum, Schott, ex Engl. in DC. Monog. Phan. ii $129=$ Harrisii.

rubricaule, Kunth, Enum. Pl. iii. $39=$ Harrisii.

rubrinervium, G. Don, in Sweet, Hort. Brit. ed. III. 633. -Venezuela.

Rudgeanum, Schott, in Oestr. Bot. Wochenbl. v. (1855) 65.-Bras.

rugosum, Schott, in Oestr. Bot. Zeitschr. (1858) 389. -Venezuela.

sagittaria, Linden, ex Schott, Prod. Aroid. $537=$ pan duraeforme.

sagittatum, G. Don, in Sweet, Hort. Brit. ed. III. 633 = rubrinervium

Salviniae, Hemsl. Diag. Pl. Nov. 36.-Guatemala.

sanguineum, Engl. in Engl. Bot. fahrb. vi. (1885) 279. -Reg. Colomb.

Saundersii, Hook. f. Bot. Mag. t. 6218.--Bras.

scandens, Engl. in Mart. Fl. Bras, iii. II. 78,-Bras.

Scherzerianum, Schott, in Oestr. Bot. Wochenbl. (1857) 53.-Guatemala.

Schlechtendalii, Kunth, Enum. Pl. iii. 75.-Mexic

scolopendrinum, Kunth, 1. c. $68=$ gracile

scolopendroides, Hort. ex Engl in DC. Monog. Phan. ii. $129=$ Harrisii

Selloum, C. Koch, Ind. Sem. Hort. Berol. (1854).Ins. S. Juan.

Sellowianum, Kunth, Enum. Pl. iii. 70.-Bras

signatum, C. Koch \& L. Mathieu, Ind. Sem. Hort Berol. (1855) 8.-Reg. Colomb.

sinuatum, Benth. ex Schott, in Destr. Bot. Wochenbl. (1857) 318. - Bras

smilaciforme, C. Koch, Ind. Sem. Hort. Berol. (1855) $8=$ undatum

solitarium, Schott, Prod. Aroid. $478=$ affine

Sonderianum, Schott, in Bonplandia, vi. (1858) $372=$ pentaplsyllum.

sororium, Schott, Prod. Aroid. 522,-Peruy.

spathiphyllum, N. E. Br. in Gard. Chron. (1877) I. 652. - Hab.?

spectabile, Hérincq, L'Hortic. Franç. (1866) 17.-N. Granat.

spectabile, Schott, in Oestr. Bot. Zeitschr. (1858) 181 - Costa Rica.

splendidum, Hort. Bull, ex Illustr. Hortic. xxx. (1883)

t. 510. (Cf. Gard. Chron. (1883) I. 381).--Reg. Colomb.

stipitatum, Benth. Pl. Hartw. 255.-Reg. Colomb.

striatum, C. Koch \& L. Mathieu, Ind. Sem. Hort. Berol. (1855) 7.-Peruv.

strictum, N. E. Br. in DC. Monog. Phan. ii. 638 . -Paraguay.

subcordatum, Schott, in Oestr. Bot. Zeitschr. (1858) 181.-Guatemala.

subhastatum, Schott, l. c. 350.-Reg. Colomb.

subsagittatum, Kunth, Enum. Pl. iii. 79.-Venezuela.

subsignatum, Schott, in Bonplandia, ix. (1862) 368.Costa Rica.

subtriangulare, Engt. in Engl. Bot. Fahrb. vi. (1885) 279.-Reg. Colomb.

subtrilobum, Schott, in Oestr. Bot. Wochenbl. (1857) 198.-Venezuela.

surinamensis, Miq. in Nat. Verh. Wet. Haarl. vii. (1851) 211.-Surinam.

Swartzianum, Schott, in Oestr. Bot. Wochenbl. (1857) 238.- - Ind. occ.

tapinostachyum, Schott, in Oestr. Bot. Zeitschr. (1858) 180. - Costa Rica

tetragonum, Hook. ex Schott, Prod. Aroid. 475.-Hab. ? tolimense, Engl. in Engl. Bot. Fahrb. vi. (1885) 277. -Reg. Colomb.

trifidum, Oliver, in Hook.f. Bot. Mag.t.6339 =signatum. trilobum, Hort. Lindl. in Illustr. Hortic. xxiv. (1877) t. $283=$ signatum

trinerve, Miq. in Linnaea, xvii. (1843) 67.-Bras.

trinervium, Kunth, Enum. Pl. iii. 76.-Bras. 
ANTHURIUM:-

triphyllum, Brongn. ex Schott, Prod. Aroid. 548.Bolivia.

truncatulum, Engl. in Engl. Bot. Fahrb. vi. (1885) 275.-Reg. Colomb.

umbrosum, Liebm. in Kjoeb. Vidensk. Meddel. (1849) 21.-Mexic.

undatum, Schott, Melet. i. 22.-Bras.

undulatum, C. Koch \& Bouché, Ind. Sem. Hort. Berol. (1854) App. $107=$ Harrisii

undulifolium, C. Koch, ex Ender, Ind. Aroid. $17=$ undatum.

Urvilleanum, Schott, Prod. Aroid. $459=$ Harrisii.

variabile, Kunth, Enum. Pl. iii. 81.-Bras.

varians, Miq. Hort. Amstel. (1853)=acaule.

Veitcheum, Hort. in Rev. Hortic. (1877) $37=$ seq.

Veitchi, Mast. in Gard. Chron. (1876) 775.-Reg. Colomb.

Vellozianum, Schott, Prod. Aroid. 482=Olfersianum.

venosum, Griseb. Cat. Pl. Cub. 219.-Cuba.

violaceum, Schott, Melet. i. $22=$ scandens.

violascens, Schott, in Oestr. Bot. Wochenbl. (1854) $89=$ costatum.

viride, C. Koch \& Bouché, Ind. Sem. Hort. Berol. (1855) $6=$ Sellowianum.

virgosum, Schott, in Oestr. Bot. Zeitschr. ix. (1859) 100.-Bras.

Wagenerianum, C. Koch \& Bouché, Ind. Sem. Hort. Berol. (1853) App. 7.-Venezuela.

Wallisii, Mast. in Gard. Chron. (1875) 429,-Reg. Colomb.

Waluiewi, Regel, in Act. Hort. Petrop. vi. (1879) 290 -Venezuela.

Warocqueanum, Moore, Florist \& Pomol. (1878) 101 -Reg. Colomb.

Warscewiczii, C. Koch, Ind. Sem. Hort. Berol. (1855 App. 4 ; et in Ender, Ind. Aroid. $17=$ sinuatum.

Wendlandii, Schott, in Oestr. Bot. Zeitschr. (1858) 182 - Costa Rica.

Willdenowii, Kunth, Enum. Pl, iii. $71=$ lanceolatum.

Williamsi, Hort. ex Engl, in DC. Monog. Phan. ii. $117=$ Scherzerianum

ANTHYLLIS, Riv。 ex Linn. Syst. ed. I (1735), LEGUMINOSAE, Benth. \& Hook. f. i. 488.

Acanthyllis, Pomel, Nouv. Mat. Fl, Atl. 179 (1874).

BARBA-Jovis, Tourn. ex Adans. Fam. ii. 321 (1763)

Cornicina, Boiss. Voy. Bot. Espagne, 162 (1843).

DORYCNOPSIS, Boiss. 1. c. $163(1843$

FAKELOBA, Rafin. Sylva Tellur. 69 (1838).

Physanthyllis, Boiss. Voy. Bot. Espagne, t. 162 (1843).

Pogonitis, Reichb. Handb. 226 (1837)

Tripodion, Medic. in Vorles. Churpf. Phys. Ges. ii (1787) 348.

Vulneraria, Toum. ex Hall. Enum. Stirp. Helv. ii. 569 (1742).

ZENOPOGON, Link, Handb. ii. 481 (1831)

affinis, Britting. ex Koch, in Rochl. Deutschl, F1, ed. III. v. $124=$ A. Vulneraria.

alpestris, Kit. ex Schult. Oestr. Fl. ed. II. ii. $317=$ A. Vulneraria.

alpina, G. Don, in Lond. Hort. Brit, $283=$ A. Vulneraria.

argentea, Desv. in Ann. Sc. Nat. Sér. I. ix. (1826) 408 $=$ Cytisopsis dorycnifolia.

argentea, Salisb. Prod. $832=\mathrm{A}$. Barba-Jovis,

arundana, Boiss. \& Reut. Pugill. Pl. Nov. (1852) $35=$

A. Vulneraria.

Aspalathi, Ser. in DC. Prod. ii. $169=$ A. Hermanniae

asphaltoides, Linn. Cent. Pl. ii. ; Amoen. Acad. iv. 326 $=$ Aspalathus anthylloides.

aurea, Welden. ex Host, Fl. Austr. ii. 319,-Graecia ; Dalmat.

balearica, Coss. ex Mares \& Vigin. Cat. Pl. Balear. 75. - Ins. Balcar.

Barba-Jovis, Linn. Sp. Pl.720.-Reg. Mediterr. bicephalos, Gilib. Fl. Lituan. ii. $96=\mathbf{A}$. Vulneraria. bicolor, Bertol. Fl. Ital. vii. $401=$ A. Vulneraria.

bidentata, Munby, Fl. Alger. 76.-Algeria.

biflora, [Soland. in] Russ. Aleppo. cd. II. ii. 259.Syria.

calcicola, Schur, Enum. Pl. Transs. $150=$ A. Vulneraria.

capensis, Lam. Encyc. i. $205=$ Lebeckia cytisoides.

carpatica, Pantol. in Magyar Növént. Lapok, vi. (1882)

162.-Europ.

\section{ANTHYLLIS:-}

chilensis, Bert, ex Steud. Nom. ed. II. i. 107=Adesmia Loudonia.

chilensis, Ser. in DC. Prod. ii. $171=$ Hosackia subpinnata.

cicerifolia, Pourr. ex Colm. in Anal. Soc. Hist. Nat. i. (1872) 88.-Hispan.

collina, Salisb. Prod. 332=A. Vulneraria

cornicina, Linn. Sp. Pl. 719.-Hispan.

cornicina, Pall, ex Georgi, Beschr. Russ. Reich. Nachtr. 294 = Medicago cretacea.

cornicina, Poir, Voy. Barb. ii. $211=$ hamosa.

cretica, Lam. Encyc. i. $204=$ Ebenus eretica.

cuneata, Buch.-Ham, ex D. Don, Prod. FI. Nep. $246=$

Lespedeza eriocarpa.

cytisoides, Linn. Sp. Pl. 720,-Europ.

Dillenii, Schult. ex Stetd. Nom. ed. I. $56=$ A. Vul-

neraria.

Erinacea, Linn. Sp. Pl. $720=$ Erinacea pungens.

flava, Gouan, Herbor. 173, nomen = A. Vulneraria.

Genistae, Dufour, ex DC. Prod. ii, 169.-Hispan.

genistoides, Dufour, in Bull. Soc. Bot. Fr. vii. (1860)

$324=$ A. Genistae

Gerardi, Linn. Mant. 100.-Reg. Mediterr. occ.

glaucescens, Kit. in Linnaea, xxxii. (1863) $612=$ alpestris.

gracilis, Salisb. Prod, $332=$ A. cytisoides

hamosa, Desf. Fl. Atlant. ii. 151.-Hispan. Afr, bor.

Hermanniae, Linn. Sp. Pl. 720.-Reg. Mediterr. Oriens.

heterophylla, Linn.l.c. ed. II. 1013.-Hispan,

hispida, Boiss. \& Rent. Pugill. Pl. Nov. (1852) $36=$

A. Vulneraria.

Hystrix, Sweet, Hort. Brit, ed. I. 114, nomen = Erinacea pungens?

incise, Willd. Sp. Pl. iii. $1017=$ Cicer ervoides.

indica, Lour. Fl. Cochinch. 429.-Cochinch.

involucrata, Linn. Mant. $265=$ Lotononis involucrata.

italica, Hort. ex Loud. Hort. Brit. Suppl. ii. $610=A$.

Vulneraiia.

Jacquini, A. Kern. in Zeitschr. Ferdinand. Tirol. III. xv. (1870) 287.-Europ

leguminosa, S. F. Gray, Nat. Arr. Brit. Pl. ii. $597=$

A. Vuheraria.

Lemanniana, Lowe, in Hook. Kerw fourn. viii. (1856) 291.-Ins. Madera.

linifolia, Linn. Mant. $265=$ Aspalathus linearifolia.

lotoides, Linn. SP. PL. 720.-Hispan.

macrocarpa, Walp. Rep. i. $634=$ A. Vulneraria

macrocephala, Wender. in Linnaea, v. (1830) Litt. $54=$

A. Vulneraria.

maritima, Schweig in Fl. Dan. t. $2728=\mathrm{A}$. Vulneraria. monocephalos, Gilib. Fl. Lituan. ii. $97=$ A. Vulneraria montana, Linn. Sp. Pl. 719.-Europ.

numidica, Coss. E Dur. in Bull. Soc. Bot. Fr. iv.

(1857) 396, nomen.-Algeria.

onobrychioides, Cay. Ic ii. 40, t. 150-Hispan.

onoides, Burm. f. Fl. Cap. Prod. $2 \mathbf{I}=$ Ononis anthylloides.

pallida, Opiz, ex Nym. Consp. 164=A. Vulneraria

pentaphylla, Steud. Nom. ed. II. i. 107.-Sibir.

podocephala, Boiss. Elench. 34.-Hispan.

polycephala, Desf. Fl. Atlant. ii. 150. t. 195.-Atlas.

polycephala, Reichb. F1. Germ. Excurs. $516=$ aurea.

polyphylla, Kit. ex DC. Prod. ii. $170=$ A. Vulneraria

pseudo-cytisus, Walp. Rep. ii. $846=$ Cytisopsis dory cnifolia.

pubescens, Stokes, Bot. Mat. Med. iii. 517=A. Vul-

neraria.

quinqueflora, Linn. f. Suppl. $325=$ Aspalathus araneosa, parviflora.

Ramburei, Boiss. Elench. 35. - Hispan.

rosea, Willk, ex Rodr. in Anal. Soc. Esp. Hist. Nat. viii. $(1879) 58=$ balearica.

rubicunda, Wender. ex Steud. Nom. ed. II. i. $107=$ A. Vulneraria.

rubra, Gouan, Herbor. 173, nomen=A. Vulneraria

rupestris, Coss. Notes Crit. 155,-Hisp.in.

rustica, Mill. Gard. Dict. ed. VIII. D. $8=$ A. Vulneraria.

rusticana, Wender. in Linnaen, v. (1830) Litt. $54=\mathrm{A}$.

Vulneraria.

sanguinea, Schur, Enum. Pl. Transs, 150, in syn. $=A$. Vulneraria.

sericea, Lag. Gen. et Sp. Nov. 22.-Hispan.

sericea, Willd. Sp. 11. iii. $1014=$ Ebenus Sibthorpii.

splendens, Willd. 1. c. $1018=A$. Barba-Joris.

Spruneri, Helur. ex Nym. Consp. $16 t=\mathrm{A}$. Vulneraria

\section{ANTHYLLS:-}

ubsimplex, Pomel, Nown Mat Fl Atl, 320-Al geria.

tejedensis, Boiss. Elench.35.-Hispan.; Marocc

tetraphylla, Linn. Sp. Pl. 719.--Keg. Mediterr.

Tournefortii, Schult. ex Stend. Nom. ed. I. $56=$ A Vulneraria.

tragacanthoides, Desf. Fl. Atlant. ii. $150=$ Astragalus armatus.

tragacanthoides, Labill. Ic. Pl. Syr. Dec. ii. $16=$ Astra galus coluteoides.

tricolor, Vukot. in Rad. Fugos. Akad. Zagrab, xxxiv 1876).-Europ.

variegata, Boiss, Diagn. Ser. II. v. $81=\mathrm{A}$. Vulneraria.

visciflora, Linn. f. Suppl. 335.-Afr. austr.

Vulneraria, Linn. Sp. Pl. 719.-Europ.; Oriens: Abyss.

vulnerarioides, Bonj. ex Reichb. Fl. Germ. Excur 515.-Ital.

Webbiana, Webb, ex Walp. Rep. i.63=tejedensis.

Webbiana, Hook. Bot. Mag. t. 3284=A. Vulneraria.

Weldeniana, Reichb. Fl. Germ. Excurs. $515=\mathrm{A}$. Vul neraria.

ANTIARIS, Lesch. in Ann. Mus. Par. xvi。 (1810) 478 t. 22. URTICACEAE, Benth. \& Hook. f. iii. 371. Antschar, Horsf, in Verh, Bat. Gen, vii. (1814) 8 . Ipo, Pers. Syn. ii. $566^{\circ}$ (1807)

Lepuranida, J. Grah. Cat. PI. Bomb. 193 (1839).

Bennettii, Seem. in Bonplandia, x. (I>62) 3.- Ins. Fiji.

dubia, Span. ex Hook. Comp. Bot. Mag. i. (1835) 31 $=$ toxicaria.

innoxia, Blume, Rumphia, 172. t. $54=$ toxicaria.

macrophylla, R. Br. in Flind. Voy. ii. 602 . t. 5. Austral.

palembanica, Miq. Fl. Ind. Bat. Suppl. i. 124.Sumatra.

rufa, Miq. l. c. 423.-Sumatra.

saccidora, Dalz. in Hook. Kew Journ. iii. (1851) $23 *$ $=$ toxicaria.

toxicaria, Lesch. in Ann. Mus. Par. xvi. (1810) 478. Ind. or.; Malaya.

zeylanica, Seem. in Bonplandia, x. $(1862 ; 4$, in nota; et Fl. Vit. $253=$ toxicaria.

ANTICHARIS, Endl. Nov. Stirp. Dec. 22 ; Gen. 65: 1839); Iconogr. t. 93. SCROPHULARINEAE. Benth. \& Hook. f. ii. 928

Doratanthera, Benth, in Endl. Gen. 685 (1839) Meisarrhena, R. Br. in Salt, Abysin. App. 63 (1818)

arabica, Endl. Nov. Stirp. Dec. 23.-Arabia.

arabica, Hochst. ex Benth, in DC. Prod. $x .347$

linearis.

glandulosa, Aschers. in Monatsb. Acad. Berl. (1866 880.-Aegypt.; Arab.; Ind. or.

linearis, Hochst. ex Aschers. l. c. 882.-Afr. trop. Arab. : Ind. or.

ANTICHLOA, Stend, Nom, ed. II, i. $108(1840)=A C$ TINOCHLOA, Willd.=Bouteloua, Lag. (Gram.

ANTICHORUS, Linn. Mant. i. $9(\mathbf{1 7 6})=$ Corchorus Linn. (Tiliac.).

depressus, Linn. 1. c. $64=$ C. Antichorus.

ANTICLEA, Knnth, Enum. Pl. iv. $191,(1843)=$ Z 5 ga denus, Michx. (Liliac.).

Fremonti, Torr, in Pacif. Rail. Rep. iv, $14 t=\mathrm{Z}$. Fremonti.

glauca, Kunth, Enum. Pl. ir. 192 = Z. glaucus.

mexicana, Kunth, 1. c. $193=\mathrm{Z}$. mexicanus.

Nuttallit, Tors. in Pacif. Rail. Rep. i». $14 t=\%$ Nuttallii.

sibirica, Kunth, Enum. Pl. iv. $191=Z$. sibiricus.

volcanica, Baker, in Journ. Linn. Soc. xvii. 185 $482=Z$. volcanicus.

ANTICORYYE, Turcz. in Bull. Math.-Phys. Acs?

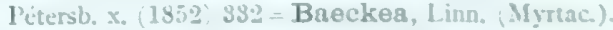
diosmoide's. Turcz. 1. c. $=$ B. ovalifulia.

ANTIDAPHNE, Poepp. \& Findl. Nov. Cien. et Sp, ro. t. $194,1 \leqslant y$
llouk. f. vii. 216 viscoidea, Pocsp. E Endl. 1. c.-Pcrav. 
ANTTDFSMA, Burm, ex Linn. Diss, de Anandr. 6

1745); Amoen. Acad. i. 249 (1749). EUPHOR

BIACEAE, Benth. \& Hook. fo iii. 284

Bestram, Adans. Fam. ii. 354 (1763)

Minutalia, Fenzl, in Flora, xxvii. (1844) 312.

Rhytis, Lour. F1. Cochinch. 660 (1790).

Stillago, Linn. Mant. i. 16 (1767).

acidum, Retz. Obs. v. $30=\mathrm{A}$. Ghesaembilla.

acuminatum, Wight, Ic. t. 1991.-Ind. or.

Alexiteria, Gaertn. Fruct. i. 188. t. $39=$ A. Menasu?

Alexiteria, Linn. Sp. Pl. 1027.-Ind, or.

Alexiteria, Willd. Sp. PI. iv. $762=$ nigricans.

alexiterium, Presl, Epim. Bot. $234=$ leptocladum

alnifolium, Hook. Ic. Pl. t. 481.-Afr, austr.

amboinense, Miq. Ann. Mus. Bot. Lugd. Bat. i. $218=$ stipulare.

attenuatum, Wall. Cat. n. $7286=$ velutinosum

auritum, Tul. in Ann. Sc. Nat. Sér. III. xv. (1851)

203.-Java.

barbatum, Presl, Epim. Bot. $233=$ rostratum.

bicolor, Hassk. Cat. Hort. Bog. Alt. $81=$ Excaecaria biculor:

bifrons, Tul. in Ann. Sc. Nat. Sér. III. xv. (1851) 229 = venosum.

Blumei, Tul. 1. c. $211=$ tetrandrum

Boivinianum, Baill. Adansonia, ii. (1861-62) $45=$ venosum.

Boutoni, Baker, Fl. Maurit. 306.-Ins. Mascar.

Bunius, Spreng. Syst. i. 826.-Ind, or.; Malaya.

Bunius, Wall. Cat. n. $7282 \mathrm{~A}=$ nicricans.

celebicum, Miq. in Ann. Mus. Bot. Luod. Bat. i. 218.

Ins. Celebes.

ciliatum, Presl, Epim. Bot. $234=$ A. Bunius

comptum, Tul. in Ann. Sc. Nat. Sér. xv. (1851) 190. -Ind. or.

cordifolium, Presl, Epim. Bot. $235=$ A. Bunius.

coriaceum, Tul. in Ann. Sc. Nat. Sér. III. xy. (1851) $204=$ fallax.

Cumingii, Muell. Arg. in DC. Prod. xv. II. 249.Ins. Philipp.

cuspidatum, Muell. Arg. in Linnaea, xxxiv. (1865-66) 67.- Ind. or.

Dallachyanum, Baill. Adansonia, vi. (1865-66) 337.-

Austral.

diandrum, Heyne, ex Roth, Nov. Pl. Spec. 369.Ind. or.

diandrum, Spreng. Syst. i. 826; Tul. in Ann. Sc. Nat.

Sér. III. xy. (1851) 196.-Ind. or.

Diepenhorstii, Miq. Fl. Ind. Bat. Suppl. 467.Sumatra.

digitaliforme, Tul. in Ann. Sc. Nat. Sér. III. xv. (1851) 191.-Ins. Philipp.

diversifolium, Miq. Fl. Ind. Bat. Suppl. 468.Sumatra.

erostre, F. Muell. ex Benth. Fl. Austral. vi. 87.Austral.

erythrocarpum, Muell. Arg. in DC. Prod. xv. Ir. 258. - Java.

erythroxyloides, Tul. in Ann. Sc. Nat. Sér. III. xy. (1851) 208.-Madag.

excavatum, Miq. in Ann. Mus. Bot. Lugd. Bat. i. 218. -Ins. Celebes.

fallax, Muell. Arg. in Linnaea, xxxiv. (1865-66) 68.Malaya.

filiforme, Blume, Bijdr. 1124=Bennettia filiformis.

flexuosum, Tul. in Ann. Sc. Nat. Sér. III. xv. (1851) 225 = nigricans.

floribundum, Tul. 1. c. $189=$ A. Bunius.

frutescens, Fack, in Malay. Misc. ii. (1890) n. VII. 91.- Sumatra.

fruticosum, Muell. Arg. in DC. Prod. xv. II. 259.Cochinch.

fruticulosum, Kurz, in Fourn. As. Soc. Beng. xlii. (1873) Ir. 237.-Pegu.

Ghesaembilla, Gaertn. Fruct. i. 189. t. 39.-Ind. or. ; Malaya; Austral.; Afr. trop.

glabrum, Tul. in Ann. Sc. Nat. Sér. III. xv. (1851) $188=$ A. Bunius

Grossularia, Raeusch. Nom.ed.III. $287=$ Embelia Ribes. guineensis, G. Don, ex Hook. Niger F1. 515, nomen = Uapaca guineensis.

heterophyllum, Blume, Bijdr. 1123.-Java.

heterophyllum, Presl, Epim. Bot. $234=$ leptocladum.

japonicum, Sieb. E Zucc. in Abh. Baier. Akad. iv, III. (1846) 212.-China; Japon.

laciniatum, Muell. Arg. in Flora, xlvii. (1864) 529,Afr. occ.

lancaefolium, Boj. Hort. Maurit. 289.-Ins. Mascar.

\section{ANTIDESMA :}

Zanceolarium, Wall. Cat n. $7284=$ diandrum.

lanceolarium, Moritzi, Syst. Verz. Pfl. Zoll. $73=$ lanceolatum.

lanceolatum, Dalz. \& Gibs. Bomb. Fl. $237=\mathrm{A}$ Menasu.

lanceolatum, Tul. in Ann. Sc. Nat. Sér. III. xv. 1851) 195. - Ind. or

leptobotryum, Muell. Arg. in Flora, xlvii. (1864) 529 -Afr. trop

leptocladum, Tul, in Ann. Sc. Nat. Sér. III. xv. (185I) $199=$ Moritzii.

lencopodum, Miq. Fl. Ind. Bat. Suppl. 465. -Sumatra. littorale, Blume, Bijdr. 1123.- - Java.

Lobbianum, Muell. Arg. in DC. Prod. xv. II. 254. Java.

longifolium, Boj. Hort. Maurit. 289.-Ins. Mascar.

longifolium, Decne. ex Baill. Adansonia, v. (1865) 349, nomen $=$ Richeria grandis

Iunatum, Miq. F1. Ind. Bat. Suppl. $467=$ Aporosa lunata.

macrophyllum, Wall. ex Voigt, Hort. Suburb. Calc. 295, nomen.-Ind. or.

madagascariense, Lam.Encyc. i. 206.-Madag.

Mannianum, Muell. Arg. in Flora, xlvii. (1864) $519=$

Thecacoris Manniana.

martabanicum, Presl, Epim. Bot. 232.-Burma.

membranaceum, Muell. Arg. in Linnoea, xxxiv (1865-66) 68.-Afr. occ.

Menasu, Miq. ex Tul. in Ann. Sc. Nat. Sér. III. xv 1851) 215.--Ind. or

Menasu, Kurz, For, Fl. il. $360=$ martabanicum.

minus, Blume, Bijdr. 1123.-Tava.

minus, Wall. Cat. n. $7288=$ coriaceum.

molle, Wall. Cat. n. 7287 ; Muell. Arg. in Linnaea, xxxiv. $(1865-66) 67=$ velutinosum.

montanum, Blume, Bijdr. 1124.--Java.

montanum, Thw. Enum. Pl. Zeyl. 289=pyrifolium.

Moritzii, Muell. Arg. in Linnaea, xxxiv. (1865-66) 67. -Ind. or. : Malaya.

natalensis, Harv. Thes. Cap. ii. $45=$ venosum.

nervosum, Wall. Cat. n. $7289=$ Gironniera nervosa

neurocarpum, Miq. Fl. Ind. Bat. Suppl. 466.Sumatra.

nigricans, Tul. in Ann.Sc. Nat. Sér. III. xv. (1851) 225. -Ind. or.

nitidum, Tul. 1. c. $193=$ leptocladum.

oblongatum, Muell. Arg. in DC. Prod. xv. II. 254.Ind. or.

oblongifolium, Blume, Bijdr, 1125.-Tava.

ovalifolium, Zipp.ex Span. in Linnaea, xv. (1841) 350.-Ins. Timor.

pacificum, Muell. Arg. in DC. Prod. xv. II. 254.Ins. Pacif.

palembanicum, Miq. Fl. Ind. Bat. Suppl. i. 465.Sumatra.

saniculatum, Roxb, ex Willd. Sp. Pl. iv. $764=\mathrm{A}$ Ghesaembilla.

parvifolium, F. Muell. Fragm. iv. 86.-Austral.

persimile, Kurs, in Fourn. Bot. xiii. (1875) 330.--Ins. Nicobar.

petiolare, Tul. in Ann. Sc. Nat. Sér. III. xv. (1851) 207.-Madag.

platyphyllum, H. Mann, in Proc. Am. Acad. vii. (1867) 202.-Hawaii

pleuricum, Tul. in Ann. Sc. Nat. Sér. III. xv. (1851) 213.--Ins. Philipp.

puberum, Zipp.ex Span. in Linnaea, xv. (1841) 350 -Ins. Timor.

pubescens, Moritzi, Verz. Pfl. Zolling. 73=Moritzii

pubescens, Roxb. Pl. Corom. î. 35.t. $167=\mathrm{A}$. Ghae sembilla.

puncticulatum, Miq. Fl. Ind. Bat. Suppl. 468.Sumatra.

pyrifolium, Muell. Arg. in Linnaea, xxxiv. (1865-66) 68,-Zeylan.

refractum, Muell. Arg. in DC. Prod. xv. II. $257=$ acuminatum.

retusum, Zipp. ex Span. in Linnaea, xv. (1841) 350 , nomen.-Ins. Timor.

rhamnoides, Brongn. ex Tul. in Ann. Sc. Nat. Sér. III xv. (1851) 21\%.-Hab.?

Ribes, Raeusch. Nom. ed. III. $287=$ Embelia Ribes. rostratum, Tul. in Ann. Sc. Nat. Sér. III. xv. (1851)

218. - Ins. Philipp.

rotatum, Muell. Arg. in DC. Prod. Xv. II. $256=$ cuspidatum.

rotundifolium, Boj. Hort. Maurit. 289.-Ins. Mascar.

\section{ANTIDESMA :-}

Roxburghii, Wall Cat n 2283 . Tul. in Ann. Sc. Nat. Sér. III. xv. (1851) 234.-Ind. or.

rufescens, Tul. in Ann. Sc. Nat. Sér. III. xv. (1851) $231=$ venosum.

rugosum, Wall. ex Voigt, Hort. Suburb. Calc. 295, nomen.-Ind. or.

Rumphii, Tul. in Ann. Sc. Nat. Sér. III. xv. (1851) 238.-Amboina

salaccense, Zoll. \& Moritzi, Syst. Verz, Zoll. $74=$ tetrandrum.

salicifolium, Miq. Fl. Ind. Bat.Suppl.1.467.-Malaya. salicifolium, Presl, Epim. Bot. $233=$ rostratum.

scandens, Lour Fl. Cochinch ii. 617.--China

Schultzii, Benth. Fl. Austral. vi. 86.-Austral.

simile, Muell. Arg. in DC. Prod. xv. II, 259=acuminatum.

sinuatum, Benth. Fl. Austral. vi. 87.-Austral.

sphaerocarpum, Muell. Arg. in DC. Prod. xv. Ir. 255. -Ins. Pacif.

spicatum, Blanco, F1. Filip.ed. I.794 = A. Ghesaembilla. stenopetalum, Muell. Arg. in Flora, xlvii. (1864) 520 $=$ Thecacoris stenopetala.

Stilago, Poir. Encyc. Suppl. i. 403.-Hab. ?

stipulare, Blume, Bijdr. 1125.-Ins, Molucc.

sylvestre, Lam. Encyc. i. $207=$ A. Ghesaembilila et A. Bunius.

sylvestre, Wall. Cat. . $7281=$ diandrum

tetrandum, Blume, Bijdr. 1124. - Java.

Thwaitesianum, Muell. Arg. in DC. Prod. xv. II. 263 $=$ A. Bunius.

tomentosum, Blume, Bijdr. 1126.-Java.

tomentosum, Blume, ex Miq. Fl. Ind. Bat. i. II. $427=$ velutinosum

tomentosum, Voigt, Hort. Suburb. Calc. 294 ; Wight, Ic. t. $767-768=$ Roxburghii.

triplinervium, Spreng. Neue Entdeck. ii. $116=\mathrm{Al}$ chornea triplinervia.

Tulasneanum, Baill. Etud. Gén. Euph. 602,-Ins. Mascar.?

velutinosum, Blume, Bijdr. 1125.-Burma; Malaya

velutinosum, Miq. Fl. Ind. Bat. i. II. $428=$ molle.

velutinum, Tul. in Ann. Sc. Nat. Sér. III. xv. (1851) 223.-Burma.

venosum, E. Mey. ex Tul. l.c. 232.-Afr. austr.

vestitum, Presl, Epim. Bot. $232=$ A. Ghesaembilla.

Vogelianum, Muell. Arg. in Flora, xlvii. (1864)529.Afr. trop.

Wallichianum, Presl, Epim. Bot. $235=$ diandrum.

zeylanicum, Lam. Encyc. 1. 207; Buch.-Ham. in Wall. Cat. n. 8572,-Zeylan.

zeylanicum, Pres1, Epim. Bot. $234=$ pleuricum.

ANTIGONA, Vell. F1. Flum. 186; iv. t. $145(1827)=$ Casearia, Jacq. (Samyd.)

serrata, Vell. 11. cc. 187 . t. $145=$ C. lasiophylla.

ANTIGONON, Endl. Gen. 310 (1837). POLYGONACEAE, Benth. \& Hook. f. iii. 103. cinerascens, Mart. \& Gal. in Bull. Acad. Brux. x. (1843) 14.-Mexic.

cordatum, Mart. $\mathcal{E}$ Gal. T. c.-Mexic

guatemalense, Meissn. in DC. Prod. xiv. 184.-Guatemala.

insigne, Mast. in Gard. Chron. (1877) I. $780=$ guatemalense.

leptopus, Hook. \& Arn. Bot. Beech. Voy. 308. t. 69.Am. austr.

platypus, Hook. \& Arn. l. c. 309.-Mexic.

ANTINORIA, Parl. F1. Palerm. i. $92(\mathbf{1 8 4 5})=$ Aira Linn. (Gram.).

agrostidea, Parl. 1. c. 95= Aira agrostidea.

insularis, Parl. 1. c. 94= Aira insularis.

ANTIPHYLA, Rafin. New F1. Am.iv. $16(1836)=$ Melochia, Dill. (Stercul.).

serrata, Rafin. 1. c. = M. serrata

ANTIPHYLLA, Haw. Enum. Saxif. 43 (1821) = Saxifraga, Linn

arctica, Haw, l, c. $45=\mathrm{S}$. muscoides.

biflora, Haw. 1. c. $44=\mathrm{S}$. biflora.

caerulea, Haw. 1. c. $43=\mathrm{S}$. oppositifolia.

oppositifolia, Fourr. in Ann. Soc. Linn. Lyon, N. S. xvi.

(1868) $386=\mathrm{S}$. oppositifolia.

retusa, Haw. Enum. Saxif. $44=$ S. retusa

spathulata, Haw. 1. $\mathrm{c}_{\mathrm{n}}=\mathrm{S}$. spathulata. 
ANTIPHYTUM, DC. ex Meissn. Gen. 280 (1840). BORAGINEAE, Benth. \& Hook. f. ii. 859. cruciatum, DC. Prod. x. 121.-Bras.

floribundum, A. Gray, in Proc. Am. Acad. x. (1874) $55=$ Krynitzkia floribunda.

fruticosum, Mog. ex DC. Prod. x. $121=$ mexicanum. heliotropioides, A. DC. 1. c. $122=$ IKrynitzkia heliotropioides.

linifolium, DC. 1. c. = Krynitzkia linifolia. mexicanum, $D C$. l. c.-Mexic

Parryi, S. Wats. in Proc. Am. Acad. xviii. (1882-83) $122=$ Krynitzkia Parryi.

staechadifolium, DC. Prod. x. 121.-Bras.

tetraquetrum, DC. l. c. 122.-Bras.

Walpersii, $A . D C$. l. c.-Peruv.

ANTIRRHOEA, Comm.ex Juss. Gen. 204 (1789 (Antirhea). RUBIACEAE [Benth. \& Hook. f. ii. 100]. GuetTardella, Champ. in Hook. Kew Journ. iv 197 (1852).

Pittoniotis, Griseb, in Bonplandia, vi. (1858) 8

Stenostomum, Gaertn. f. Fruct. iii. 69 (1805).

SturMia, Gaertn. 1. c. t. 192 (1805).

aristata, Benth. \& Hook. f. Gen. ii. 100.-Ind. occ.

bifucata, Benth. \& Hook. l. c.-Ind. occ.

borbonica, J. F. Gmel. Syst. i. $244=$ Quivisia Sieberi.

dichotoma, Hernsl. Biol. Centr. Am. Bot. ii. 42.-Mexic

dioca, Bory, ex DC. Prod. iv. $459=$ verticillata.

frangulacea, $D C$. Prod. iv. 459.-Ins. Mascar.

lucida, Benth. \& Hook. f. Gen. ii. 100.-Ind. occ.

Lostaeana, Comm. ex DC. Prod. iv. $459=$ borbonica.

philippinensis, Rolfe, in fourn. Linn. Soc. xxi. (1884 312. - Ins. Philipp,

protracta, Hemsl. Biol. Centr. Am. Bot.ii. 42.-Mexic

rotundata, Benth. E Hook f. Gen ii 100-Cuba.

strigosa, Korth. in Neder. Kruid. Arch. ii. II. (1851) 217. - Sumatr.

tenuifolia, F. Muell. ex Benth. Fl. Austral. iii. 418.Austral.

trichantha, Hemsl. Biol. Centr. Am. Bot. ii. 42.-

Panama.

verticillata, DC. Prod. iv. $459=$ borbonica

viscosa, Benth. E Hook. f. Gen. ii. 100,-Ind, occ.

ANTIRRHINUIM, Tourn. ex Linn. Syst, ed. I (1735) SCROPHULARINEAE, Benth. \& Hook. f. ii. 934.

Agorrhinum, Fourr. in Ann. Soc. Linn. Lyon, N. S. xvii. (1869) 126.

Asarina, Tourn. ex Mill. Gard. Dict. ed. VIII (1768).

Gambelia, Nutt. in Journ. Acad. Phil. Ser. II. i. (1847) 149 .

Orontium, Pers. Syn. ii. 158 (1807)

SaIrocarpus, Nutt. ex A. DC. in DC. Prod. $x$. $592(1846)$.

acutangulum, Tenore, Fl. Nap. ii. 47. t. 59=Linaria Cymbalaria.

Adamii, Willd. ex Ledeb. F1. Ross, iii. $207=$ Linaria

macroura.

negyptiacum, Forsk. Fl. Aegypt. Arab. 112.-Arab.

aegyptiacum, Linn. Sp. Pl. ed. I. $613=$ Linaria aegyptiaca.

aequitrilobum, Viv. F1. Lib. Spec. 68; F1. Cors. Sp. Nov. $10=$ Linaria aequitriloba.

aerugineum, Gouan, Illustr. $38=$ Linaria tristis.

albescens, Medic. Beobacht. (1783) $136=$ Linaria aegyptiaca.

albifrons, Sibth. \& Sm. Prod. i. $432=$ Linaria albifrons. album, Lam. Fi. Fr. ii. $345=$ Linaria chalepensis. alpinum, Linn. Sp. P1. $615=$ Linaria alpina.

alsinaefolium, Viv. F1. Lib. Spec. 67 ; Fl. Cors. Sp.

Nov. $10=$ Linaria alsinaefolia

ambignum, Lange, in Kjoeb. Vidensk. Meddel. (1863) 37 (Pugill. 208), - Hispan.

amethysterm, Vent, in Lam. Encyc. iv. $353=$ Linaria amethystea.

amethystinum, Stend. Nom. ed. II. i. $108=$ Linaria ainethystea.

angustifolizm, Poir. Encyc. Suppl. iv. $27=$ siculum. angustifolizm, Urv. in Mém. Soc. Linn. Par. i. (1822) $\mathbf{3 2 9}=$ tortuosum ?

angustissimum, Loisct. Not. Suppl. $167=$ Linaria italica.

aparinoides, Willd. Sp. Pl. iii. $2 \$ 7=$ Linaria stricta.

aphyllum, Thunb. Prod. P1. Cap. $105=$ Utricularia crpensis

aquaticum, Lour. Fl. Cochinch. ii. 984 (Utriculariae sp. ?).-Cochinch.

\section{ANTIRRHINUM}

arenarium, Poir. Encyc. Suppl. iv. $26=$ Linaria arenaria.

arvense, Linn. Sp. Pl, 614 = Linaria arvensis

asarifolium, Salisb. Prod. $98=$ seq.

Asarina, Linn. Sp. Pl. 612.-Italia

asarinum, Lam. Fl. Fr. ii. $348=\mathrm{A}$. Orontium,

assurgens, Bianca, ex Caruel, in Parl. Fl. Ital. vi. 656 = siculum.

auriculatum, Linn. Fl. Fr. ii. $339=$ Linaria Elatine

barbatum, Thunb. Prod. Pl. Cap. 105. - Afr. austr.

Barrelieri, Bor. Graines Rec. Fard. Bot. Angers (1854). - Hispan.

Bauhinii, Gaud. Fl. Helv, iii. 154=Linaria italica.

bellidifolium, Linn. Sp. Pl. $617=$ Anarrhinum bellidifolium.

bicorne, Linn. Pl. Rar. Afr. 11 (Amoen. Acad. vi. 88) $=$ Nemesia bicornis.

bipartitum, Vent. Jard. Cels, t. $82=$ Linaria bipartita

bipunctatum, Cav. Ic. i. t. 33. f. 1 =Linaria am thystea.

bipunctatum, Linn. Sp. Pl. ed. I. $614=$ Linaria glauca.

bipunctatum, Thuill. F1. Paris, ed. II, $311=$ Linaria supina.

breviflorum, Gilib. Fl. Lituan. i. $137=$ A. Orontium.

Breweri, A. Gray, in Proc. Am. Acad. vii. (1868) 374 -Calif.

Broussonetii, Poir. Encyc. Suppl. iv. $23=$ Linaria multipunctata.

caesium, Lag. ex Pers. Syn. ii. $157=$ Linaria tristis?

calycinum, [Soland.in] Russ. Aleppo, ed. II. ii. 256. Syria.

calycinum, Vent, in Lam. Encyc. iv. 365=A. Orontium.

canadense, Linn. Sp. Pl. 618= Linaria canadensis.

capense, Burm. f. Fl. Cap. Prod. 16.-Afr. austr.

capense, Thunb. Prod. Pl. Cap. $105=$ Nemesia linearis.

capitatum, C. \&. J. Presl, Delic. Prag. $74=$ sempervirens.

capitellatum, Vent. in Lam. Encyc. iv. $353=$ Linaria glauca.

caprarium, Caruel, in Parl. Fl. Ital. vi. $362=$ Linaria capraria.

caucasicum, Willd, ex Ledeb. FI. Ross. iii. $205=$ Linaria spuria.

chalepense, Linn. Sp. Pl. $617=$ Linaria chalepensis.

Charidemi, Lange, in Kjoeb. Vidensk. Meddel. (1881) 99.-Lusit.

chytrospernum, A. Gray, in Proc. Am. Acad. xii. (1877) 81. - Arizona.

cimbalaria, Neck. Delic. Gallo-Belg. i. $267=$ Linaria Cymbalaria.

cirphosum, Linn. Mant. ii. $249=$ Linaria cirrhosa

comintanum, Blanco, Fl. Filip. ed. I. 502=Hygrophila salicifolia.

commune, Lam. Fl. Fr. ii. $340=$ Linaria vulgaris

compositum, Lojac. in Natural. Sicil. ii. (1883) 297.Sicilia.

confertiflorum, Benth. in DC. Prod. x, 592=Mohavea viscida.

confertum, Jan, ex Benth. 1. c. 278= Linaria striata

Cooperi, A. Gray, in Proc. Am. Acad. vii. (1868) 376. -Calif.

cordatum, Buch, ex Chav, Monog, $181=$ Linaria lanigera.

cornutum, Benth. Pl. Hartw. 328.-Calif.

cornutum, Durand, in Pacif. Rail. Rep.v. 11. t. $10=$ leptaleum.

corsicum, Vitm. Summa, iii. 495.-Corsica

Coulterianum, Benth in DC Prod. x. 592-Calif

craniolare, Stokes, Bot. Mat. Med iii. $383=$ A. Orontium.

crassifolium, Cav. Ic. ii. $11=$ Linaria origanifolia

cyathiferum, Benth. Bot. Voy. Sulph. 40.t. 19.-Calif.

Cymbalaria, Gueldenst. ex Ledeb. F1. Ross. iii. $205=$ Linaria Elatine.

Cymbalaria, Linn. Sp. Pl. ed. I. $612=$ Linaria Cymbalaria.

Cymbalaria, Sicber, ex Benth. in DC. Prod. x. 267 Linaria acutangula.

dalmaticum, Gucldenst. ex Ledeb. Fl. Ross, iii. 209 Linaria genistifolia.

dalmaticum, Linn. Sp. Pl. ed. I. $616=$ Linaria dalmatica.

delawariana, Roxb. Hort. Beng. 45, nomen.-Am. bor.?

dentatum, Poir. Encyc. Suppl. iv, $22=$ Nemesia monomotapensis.

\section{ANTIRRHINUM :-}

dentatum, Vahl, Symb. Bot. ii. $66=$ Linaria scariosa diffusum, Bernh. ex Steud. Nom. ed. II. i. $108=$ atifolium.

diffusum, Brot. Phyt. t. $141=$ Linaria multicaulis.

diminutum, Pomel, Nouv. Mat. Fl. Atl. 100,Algeria.

aubium, Vill. Hist. Pl. Dauph. ii, $437=$ Linaria supina Duriminium, Brot. Fl. Lusit. i. $197=$ Anarrhinum Duriminium

ecaudatum, Lucé, Topog. Nachr. Oesel, 218.-Ross.

Elatine, Linn. Sp. P1. $612=$ Linaria Elatine.

elatiniflorum, Wahlenb. in Isis, xxi. $989=$ Linaria Llatine.

elatinioides, Tenore, Syll. 48. f. $2=$ Linaria Elatine

elatinoides, Willd. Sp. Pl. iii. $235=$ Linaria clatinoid

elegans, Pers. Syn ii. 156 = Linaria amethystea

elegans, Tenore, Viag. Abruz. $175=\mathrm{A}$. Orontium

fliforme, Poir. Encyc. Suppl. iv. 27=Linaria rub folia.

filipes, A. Gray, in Bot. Ives, Report, 19.-Colorado. flavum, Poir. Voy. Barb. ii. $191=$ Linaria flava.

flexuosum, Pomel, Nouv. Mat. Fl. Atl. 100,-Algeri. flexuosum, Willd. Sp. Pl. iii. 250 = Linaria flexuosa. fragrans, Pall. Reise Statth. Russ. Reich. i. 111, 129. Keg. Casp.

fruticans, 'lhunb. Prod. Pl. Cap. $105=$ Nemesia fruticans.

fruticosum, Willd. Sp. Pl, iii. $237=$ Linaria fruticosa fugax, Boiss. Diagn. Ser. II. iii. $160=$ Linaria persica. gallioides, Vent. in Lam. Encyc. iv. $351=$ Linaria striata.

genistaefolium, 'Vill.' ex Benth. in DC. Prod. x. 27 = Linaria italica.

genistifolium, Lapeyr. Hist. Abr. Pl. Pyr. 354

Linaria vulgaris.

genistifolium, Linn. Sp. Pl, $616=$ Linaria genistifolia genistifolium, Vill. Hist. PI. Dauph. ii. $440=$ Linaria italica.

gibbosum, Wall. Pl. As. Rar, ii. $44=$ A. Orontium.

glandulosum, Lejeune, Fl. Spa, $320=$ Linaria vul-

garis.

glandulosum, Lindl. Bot. Reg. t. 1893.-Calif.

glaucophyllum, Brot. Phyt. Lusit. $138=$ Linaria glancophylla.

glaucum, Lapeyr. Hist. Abr. P1. Pyr. 352 = Linaria supina.

glaucum, Linn. Cent. 1. D. 43 ; in Amoen. Ac iv. 27 $=$ Linaria glauca.

glaucum, Stocks, in Wight, Ic. iv. t. $1159=$ Schweinfurthia sphaerocarpa.

glaucum, Thore, Chl. Land, $265=$ Linaria thrmifolia glutinosum, Boiss. \& Reut. Pugill. Pl. Nov. (1১52) 8? - Hispan.

gracile, Pers. Syn. ii. 156 = Linaria Pelisseriana,

gracile, Reut. Ind. Sem. Hort. Genev. (1852) 4 ; Lange, in Willk. \&c Lange, Prod. Fl. Hisp. if. $582=$ A. Orontium.

graecum, Bory \& Chaub. Fl. Pélop. 175. t. 21 Linaria graeca.

grandiflorum, Stokes, Bot. Mat. Med. iii. $384=$ majus. gratissimum, Roxb. ex Hook. f. Fl. Brit. Ind. iv. '20', =Limnophila Roxburghii.

Haelava, Forsk. Fl. Aegypt. Arab. $111=$ Linaria Haelava.

hederaceum, Lam. Fl. Fr. ii. $338=$ Linaria Csmba laria.

hederaefolium, Salisb. Prod. $96=$ Linaria Cymbalaria hepaticifolium, Poir. Encyc. Suppl. iv. $19=$ Linaria hepaticaefolia.

heterophyllum, Schousb. Vextr. Marokko, 194; Willd. Sp. Pl. iii. $234=$ Linaria heterophylla.

hexandrum, Forsk. Fl. Aegypt. Arab. 43 = Vandellia crustacea.

hirtum, Linn. Sp. Pl. ed. I. $616=$ Linaria hirta.

hispanicum, Chav. Monog. \$3.-Hispap.

Huctii, Reut. in Ann. Sc. Nat. Sir. IV, ii. 155t: S:0 = sempervirus.

humile, Salisb. Prod. $98=$ A. Orontium.

hybridum, Benth. Cat. Pl. Pyren. 60.-Mont. Pyren. incarnatum, Vent. in Lam. Encyc. iv. Sof = Linaria bipartita.

indicum, Royle, ex Ball, in Joum. Linn. Soc, xvi: (15is 545 - A Orourium.

intermedium, Debenux, in Bull. Soc. Bot. Fr. xx. $18 ; 9$ 13 = lacifulium

intermedium, Hort ex Stcud. Nom. ed. II. i. 108 striatum. 


\section{ANTIRRHINUIM :-}

intricatum, Ball, in Fourn. Bot. xiii. (1875) 173.-

Marocco.

italicum, Mill. Gard. Dict, ed. VIII, n. $5=$ majus.

jamaicense, Fisch. ex Steud. Nom. ed. II. i. $108=$ siculum.

junceum, A. Gray, in Proc. Am. Acad. vii. (1868) 377 -Calif.

junceum, Linn. Cent. i.; Amoen. Acad. iv. 277 Vent, in Lam. Encyc. iv. $352=$ Linaria spartea junceum, Pall. Reise, ii. $332=$ Linaria Loeselii.

Kelloggii, Greene, in Torrey Bot. Club, x. (1883) 126. Calif.

Kingii, S. Wats. in Bot. King, Exp. 215. t. 21.Utah.

laevigatum, Herb. Banks, ex Benth. in DC. Prod. $\mathrm{x}$. $258=$ Diascia parviflora

lagopodioides, Linn. f. Suppl. $279=$ Linaria saxatilis.

lanigerum, Willd. Sp. Pl. iii. $233=$ Linaria lanigera.

latifotium, Bourg. ex Willk. \& Lange, Prod. ii. $584=$ hispanicum.

latifolium, Mill. Gard. Dict. ed. VIII. n. 4; DC. Fl. Fr, v. 411--Europ.

latifolium, Willd. Sp. Pl. iii. $238=$ Linaria latifolia laxiflorum, Willd. 1. c. $242=$ Linaria laxiflora. leptaleum, A. Gray, in Proc. Am. Acad. vii. (1868) 373.-Calif.

Linaria, Linn. Sp. Pl. $616=$ Linaria vulgaris.

linarioides, Linn. 1. c. ed. II. $853=$ Linaria vulgaris

linifolium, Linn. 1. c. $858=$ Linaria linifolia

linifolium, Pall. Ind. Taur. 161= Linaria macroura.

Linkianum, Boiss. \& Reut. Diagn. Ser. II. iii. $160=$ latifolium.

linogriseum, Brot. Phyt. $135=$ Linaria bipartita.

littorale, Bernh. in DC. F1. Fr. v. 410 ; Poir. Encyc Suppl. iv. $20=$ Linaria littoralis.

longicorne, Thunb. Prod. Pl. Cap. $105=$ Diascia Thunbergiana.

lusitanicum, Vent. in Lam. Encyc. iv. $361=$ Linaria tristis.

lusitanicum, Link, ex Steud. Nom. ed. II. i. $109=$ Linaria pedunculata.

macrocarpum, Soland. in Ait. Hort. Kew. ii. $335=$

Nemesia chamaedrifolia.

macrourum, Bieb. F1. Taur. Cauc, ii. $75=$ Linaria

macroura.

maculatum, Moc. \& Sesse, ex DC. Prod, vii. $534=$

Achimenes foliosa.

majus, Linn. Sp.Pl. 617.-Reg. Mediterr.

marginatum, Desf. in Act. Soc. Hist. Nat. Par. i. (1794 36. t. $7=$ Linaria tristis.

maritimum, Poir. Encyc. Suppl. iv, $23=$ Linaria supina massiliense, Poir. ex Steud. Nom ed. II i. 5\%, $482=$

Linaria maritima.

maurandioides, A. Gray, in Proc. Am. Acad. vi. (1868) 376.-Texas.

medium, Hort. ex Steud. Nom. ed. II. i. $109=$ striatum meionanthzm, Brot. Phyt. t. $126=$ sempervirens

meonanthum, Hoffmgg. \& Link, Fl. Port. i. 261. t. 51 $=$ sempervirens.

micranthum, Cav. Ic. i. $51=$ Linaria parviflora.

microcarpum, Pomel, Nouv. Mat. Fl. Atl. 99.

Algeria.

minus, Linn. Sp. Pl. $617=$ Linaria viscida

molle, Blanco, Fl. Filip. ed. I. $503=$ Hygrophila undulata.

molle, Boiss. Voy. Espagne, $449=$ hispanicum.

molle, Linn. Sp. Pl. 1198.--Mont. Pyren.

molle, St. Amans, Bouq. Pyren. n. $154=$ sempervirens.

monspessulanum, Georgi, Beschr. Russ. Reich. iii. IV.

$1106=$ Linaria Loeselii

monspessulanum, Linn. Sp. PI. 616= Linaria striata.

montevidense, Mart. ex Colla, in Mem. Acc. Torino xxxy. (1831) $178=$ majus.

multibracteatum, Brot. ex Steud. Nom. ed. II. i. 109 = variabile

multicaule, Linn. Sp. Pl. $615=$ Linaria multicaulis.

multicaule, Tenore, Fl. Nap. Prod. $36=$ Linaria stricta.

multipunctatum, Brot. Fl. Lusit. i. 195=Linaria amethystea.

murale, Salisb. Prod. $98=$ majus.

muralis, Pers. Syn. ii. $155=$ Linaria Cymbalaria

neglectum, Spreng. Neue Entdeck. iii. 160=Linaria triphylla.

nicaeense, Risso, Fl. Nice, 347 = latifolium

Nevinianum, A. Gray, in Coult. Bot. Gazette, ix. (1884) $54 .-$ Calif

\section{ANTIRRHINUM}

Nuttallanum, Benth. in DC. Prod. x. 592.-Calif.

ochroleucum, Salisb. Prod. $98=$ Linaria vulgaris

ocimifolium, Pourr, ex Spreng. Syst. ii. $793=$ Linaria ocimifolia.

odoratissimum, Gueldenst. ex Ledeb. Fl. Ross. iii. 208 = Linaria Loeselii.

odorum, Bieb. Fl. Taur. Cauc. ii. $75=$ Linaria Loeselii. oppositiflorum, Poir. Encyc. Suppl. iv. $23=$ Linaria villosa.

orbiculare, Medic. Beobacht. (1788) 242-Hab.?

orchidiflorum, [Desf.] ex Pers. Syn. ii. 155=Linaria bipartita.

Orcuttianum, A. Gray, in Coult. Bot. Gazette, ix. (1884) 53.-Calif.

origanifolium, Gouan, Hort. Monsp. 301=Linaria rubrifolia.

origanifolium, Linn. Sp. P1. $615=$ Linaria origanifolia.

Orontium, Linn. Sp.Pl.617.-Europ. ; As. Min.; Afr. bor.

ottomanum, Fanka, in Termész. Füzetek, iv. (1880) 297.-Turcia

Osyris, Cyrill. Pl. Neap. Nov. Fasc. ii. $21=$ Linaria chalepensis.

pallidiflorum, Lam. F1. Fr. ii. 341 = Linaria genistifolia, pallidum, Tenore, Fl. Nap. i. $323=$ Linaria pilosa,

papilionaceum, Linn. Mant. $86=$ Schweinfurthia sphaerocarpa.

parviflorum, Jacq. Coll. iv. 204=Linaria arvensis.

parviflorum, Willd. SP. PI. iii. $245=$ Linaria parviflora. patens, Thunb. Prod. PI. Cap. $105=$ Nemesia patens.

panciflorum, Steud. Nom. ed. II. i. 109=Linaria multicaulis.

pauciflorum, Poepp. ex Chav. Monog. $149=$ Linaria canadensis.

pedunculatum, Linn. Sp. Pl. ed. II. $857=$ Linaria pedunculata.

Pelisserianum, Linn. I. c. ed. I. $615=$ Linaria Pelisseriana.

Pelisserianum, Mout.-Font. ex Chav. Monog. $155=$ Linaria gracilis.

pilosum, Bory, Fl. Pélop. $39=$ Linaria microcalyx.

pilosum, Jacq. Obs. Bot. ii. $28=$ Linaria pilosa. pinifolium, Poir. Voy. Barb. ii. 193 = Linaria reticulata, pinnatum, Linn. f. Suppl. $280=$ Nemesia pinnata. polygalaefolium, Brot. Phyt. t. $138=$ Linaria supina.

polygalaefolium, Poir. Encyc. Suppl. iv. $21=$ Linaria italica.

polygalaefolium, Willd. ex Steud. Nom. ed. II. i. $109=$ Linaria tristis.

polygonifolium, Poir. Encyc. Suppl. iv. $26=$ Linaria amethystea.

porcinum, Lour. Fl. Cochinch. ii. 384.-Cochinch.

praecox, Brot. Phyt. t. $131=$ Linaria spartea.

prostratum, Cyrill. ex Chav. Monog. $120=$ Linaria reflexa.

pterospermum, A. Rich. Tent. F1. Abyss. ii. $115=$ Schweinfurthia pterosperma.

pubescens, Pers. Syn. ii. $157=$ Linaria arenaria.

pubescens, Tenore, Fl. Nap. Prod. $36=$ Linaria pallida.

pumilum, Poir. ex Steud. Nom. ed. II. i. $109=$ Linaria flava.

purpureum, Dulac, F1. Hautes-Pyr, $374=\mathrm{A}$. Orontium. purpureum, Linn. Sp. Pl. ed. I. $613=$ Linaria purpurea pygmaeum, Gouan, Illustr. 37.-Europ. austr.

pyramidale, Vent. in Lam. Encyc. iv. $360=$ Linaria pyramidata.

pyramidatum, Benth. in DC. Prod. x. $272=$ praec.

pyrenaicum, Ram. ex DC. F1. Fr. iii. $581=$ Linaria supina.

quaririfolium, G. Shaw, Cimel. Phys. 84. t. 44.-Hab. ?

quinquelobatum, St. Lag. in Ann. Soc. Bot. Lyon, vii. 1880) $119=$ A. Asarina.

quinquelobum, Stokes, Bot. Mat. Med. iii. 385=Linaria Cymbalaria.

ramosissimum, Coss. E Dur. in Bull. Soc. Bot. Fr. ii. (1855) 254.-Algeria

reflexum, Linn. Syst. ed. X. $1112=$ Linaria reflexa, repens, Linn. Sp. Pl. $614=$ Linaria striata.

reticulatum, Sm. Ic. Fict. $[2]=$ Linaria reticulata.

Rhodium, Boiss, ex Benth. in DC. Prod. x. 291 =majus

rhytidospermum, Fisch. \& Mey. Ind. Sem. Hort. Petrop. ii. $27=$ Linaria persica.

romanum, Seb. \& Maur. ex Nym. Consp. $536=$ tortuosum.

rosmariuifolium, Noronha, in Verh. Batav. Gen. v. (1790) ed. I. Art. IV. 6.-Malaya.

\section{ANTIRRHINUM :}

rotundifolium, Gilib. Fl. Lituan. i. 138=Linaria spuria.

rubrifolium, Poir. Encyc. Suppl. v. $737=$ Linaria rubrifolia.

mpestre, Boiss. \& Reut. Pugill. P1. Nov. (1852) $82=$ glutinosum.

mpestre, Bourg. ex Willk. \& Lange, Prod. ii. $585=$ hispanicum.

ruscinonense, Debeaux, in Bull. Soc. Bot. Fr. xx 1873) $14=$ Barrelieri

rytidocarpum, G. Don, Gen. Syst. iv. $516=$ Linaria persica.

rytidospermum, Fisch. \& Mey. Ind. Sem. Hort. Petrop. ii. $27=$ Linaria persica

sagittatum, Poir. Encyc. Suppl, iv, $19=$ Linaria sagittata.

saphyrinum, Brot. Fl. Lusit. i. $197=$ Linaria amethystea saphyrinum, Sieber, ex Steud. Nom. ed. II. 1. $109=$ Linaria Pelisseriana.

saxatile, Bonani, Nann. Prod. $69=$ Linaria arenaria.

saxatile, Linn. Cent. Pl. i, $16=$ Linaria saxatilis,

scabrum, Thunb. Prod. Pl. Cap. $105=$ Nemesia chamaedrifolia.

scariosum, Vent. in Lam. Encyc. iv. $349=$ Linaria scariosa.

sempervirens, Lapeyr. Fl. Pyr. i. 7. t. 4; Hist. Abr. Pl. Pyr. 354--Mont. Pyren.

serpyllifolium, Pourr. ex Chav. Monog. $93=$ Linaria villosa

siculum, Mill. Gard. Dict. ed. VIII. n. 6; Ucria, in Roem. Arch. i. 69.-Sicilia.

simplex, Link, in Schrad. Neues fourn. ii. (1799) 300. Gallia.

simplex, Willd. Sp. Pl iii, $243=$ Linaria arvensis sparteum, Linn. Sp. Pl. ed. I. $1197=$ Linaria spartea

sparteum, Viviani, Fl. Lib. Spec. $33=$ Linaria viscosa spartum, Linn. Cent. i. 17, postea sparteum.

speciosum, Donn, Hort. Cant. ed. IV. $139=$ Linaria bipartita.

speciosum, A. Gray, in Proc. Am. Acad. vii. (1868) 376.-Calif.

spinescens, Viviani, F1. Lib. Spec. 32. t. 27. f. $2=$ Linaria aegyptiaca.

spurium, Brot. ex Steud. Nom. ed. II. i. $109=$ Linaria reticulata.

spurium, Linn. Sp. Pl. $613=$ Linaria spuria.

striatum, Lam. Fl. Fr. ii. $343=$ Linaria striata.

striatum, Schrank, ex Steud. Nom. ed. I. 57.Europ.

strictum, A. Gray, in Proc. Am. Acad. vii. (1868) 375 . - Calif.

strictum, Sibth. \& Sm. Fl, Graec, vi, 75. t. $594=$ Linaria Sibthorpiana.

strumosum, Banks, ex Benth. in DC. Plod. x. $260=$ Nemesia strumosa.

subalpinum, Brot. Fl. Lusit.i. 196=Linaria alpina.

subcordatum, A. Gray, in Proc. Am. Acad. xx. (1885) 306.-Calif.

subsessile, A. Gray, in Coult. Bot. Gazette, ix. (1884) 53.-Calif.

subulatum, Cyrill. ex Chav. Monog. $136=$ Linaria Loeselii.

supinum, Brot. Fl. Lusit. 1. 191=-Linaria reticulata.

supinum, Linn. Sp. Pl. $615=$ Linaria supina

supinum, Pall. Reise, ii. 522= Linaria Loeselii.

supinum, Sibth. 8c. Sm. Fl. Graec. vi. 75. t. $595=$ Linaria genistifolia.

tenellum. Cav, Ic. ii. 61. t. 180. f. $1=$ Linaria tenella. tenue, Viviani, Fl. Lib. Spec. 33. t. 16. f. 5-6 ; Spreng Syst ii. $495=$ Linaria viscosa.

Thuillierii, Poir. Encyc. Suppl. iv. $26=$ Linaria supina. thymifolium, Vahl, Symb. Bot. ii. $67=$ Linaria thymi folia.

tortuosum, Bosc, ex Lam. Encyc, iv. 365.-Reg. Mediterr. occ.

Tourneforti, Poir, Encyc, Suppl. iv, $24=$ Linaria Tournefortii.

tricolor, Hort. ex Chav. Monog. $118=$ Linaria triphylla. tricolor, Pourr. ex Chav. 1. c. $172=$ Linaria amethystea triornithophorum, Linn. Sp. Pl. $613=$ Linaria triornithophora.

triphyllum, Cav, Ic. ii. 61. t. $179=$ Linaria Cava nillesii.

triphyllum, Linn. Sp. PI. $613=$ Linaria triphylla

triste, Linn. 1. $\mathrm{c}=$ Linaria tristis.

uniflorum, Moc. \&. Sesse, ex DC. Prod. vii. 532-3= Gesneria uniflora. 


\section{ANTIRRHINUM}

unilabiatum, Linn. f. Suppl. $279=$ Diascia unilabiata. vagans, A. Gray, in Proc. Am. Acad. vii. (1868) 375 -Calif.

variable, Link, ex Steud. Nom. ed. I. 57.-Lusit. versicolor, Linn. Sp. P1. $866=$ Linaria versicolor. vexillo-calyculatum, Kellogg, in Proc. Calif. Acad. i. ed. II. (1873) 7,26.-Calif

villosum, Lap. Fl. Pyren. $353=$ Linaria origanifolia villosum, Linn. Sp. P1. ed. II. $852=$ Linaria villosa violaceum, Salisb. Prod. $97=$ Linaria Pelisseriana Virga, A. Gray, in Proc. Am. Acad. vii. (1868) 373 Calif.

virgatulum, Brot. Fl. Lusit, i. $193=$ Linaria spartea. virgatum, Poir. Voy, Barb, ii. $192=$ = Linaria virgata. viscosum, Curt. Bot. Mag. t. $368=$ Linaria hirta viscosum, Linn. Cent. ii. $21=$ Linaria viscosa.

ANTISOLA, Rafin. Sylva Tellur. 97 (1838)= Miconia, Ruiz \& Pav. (Melast.).

racemosa, Rafin. 1. $\mathrm{c}_{\mathrm{n}}=\mathrm{M}$. racemosa.

ANTISTHIRIA, Pers. Syst. 127 (1797), err. typ. = Anthistiria, Linn. (Gramin.).

ANTISTROPHE, A. DC. in Ann. Sc. Nat. Sér. II xvi. (1841) 84. MYRSINEAE, Benth. \& Hook, f, ii 647 .

oxyantha, A.DC.l.c.-Reg. Himal.

serratifolia, Hook. f. in Benth. \& Hook. f. Gen. ii. 647 -Ind. or.

ANTITAXIS, Miers, in Ann, \& Mag. Nat. Hist. Ser II. vii. (1851) 37 ; Ser. III. xx, (1867) 13. MENI SPERMACEAE, Benth. \& Hook. f. Gen. i. 33 959 , iii. 256

calocarpa, Kurz, in Fourn. Bot. xiii. (1875) 324.Ins. Nicob.

cauliflora, Miers, in Ann. \& Mag. Nat. Hist. Ser. III. $\mathrm{xx}$. (1867) 14.- - Java.

fasciculata, Miers, l..c.-Malaya.

longifolia, Miers, $l$. c.-Ins. Timor

lucida, Miers, l. c.-Java.

ANTITHRIXIA, DC. Prod. vi. 277 (1837). COMPOSITAE, Benth. \& Hook. f. ii. 329.

abyssinica, Benth. \& Hook. f. Gen. ii. 329.-Afr. trop.

angustifolia, Oliver \& Hiern, in Oliver, Fl. Afr. Trop. iii. 356.-Afr, trop.

flavicoma, $D C$. Prod. vi. 278.-Afr. austr.

ANTITRAGUS, Gaertn. Fruct. ii. 7. t. 80 (1791)= Crypsis, Ait. (Gram.)

aculeatus, Gaertn. 1, c。 $=$ C. aculeata.

AN'TIZOMA, Miers, in Ann. \& Mag. Nat. Hist. Ser. II. vii (1851) 41 ; Ser. III. xvii. (1866) $266=$ Cissampelos, Linn. (Menisp.).

angustifolia, Miers, ex Harv. \& Sond. F1. Cap. i. $11=$ C. angustifolia.

Burchelliana, Miers, 1. c, =C calcarifera.

calcarifera, Miers, 1, c. $12=\mathrm{C}$. cilcarifera.

Harveyana, Miers, 1. c. $=\mathrm{C}$. angustifolia.

lycioides, Miers, in Ann. \& Mag. Nat. Hist. Ser. III. xvii. (1866) 266.-Afr. austr.

Miersiana, Harv, in Harv. \& Sond. Fl. Cap. i. 13.Afr. austr.

ANTOCHORTUS, Nces, in Lindl. Introd. Nat. Syst. ed. II. $451(1896)=$ Willdenowia, Thunb. (Restiac.). Ecklonii, Nees, 1. c. $=$ W. striata?

ANTODON, Neck. Elem. i. $58(\mathbf{1 7 9 0})=$ Leontodon Linn. (Compos.)

ANTOMMARCHIA, Colla, Hort. Ripul. App. ii. 345 (1826) $=$ Correa, Sm. (Rutac.).

rubra, Colla, 1. c. 25 . t. $72=$ C. speciosa.

speciosa, Schlecht. in Linnaea, iv. (1829) Litt. $56=$ C. speciosa

ANTONIA, R. Br, in Wall. Pl. As, Rar, iii. 65 (1892)= Rhynchoglossum, Blume (Gesner.)

obliqua, R. Br. 1. c. = R. obliquum.

ANTONIA, Pohl, Pl. Bras. Ic. ii. 18. t. 109 (1831) LOGANIACEAE, Bentb. \& Hook, f. ii. 796.

\section{ANTONIA :-}

Griffithii, Wight, Illustr. Ind. Bot. ii. t. $156 \mathrm{~b}=\mathrm{Nor}$ risia malacensis.

ovata, Pohl, Pl. Bras. ii. 13. t. 109.-Bras.

pilosa, Hook. Ic. Pl. t. $64=$ ovata

pubescens, Bong. in Mém. Acad. Pétersb. Sér. VI. iii

(1835) 2.t. $1=$ ovata.

ANTONIANA, Tuss. Fl. Antill. 2。 t. 16 (1818) ex Griseb. Fl, Brit. W. Ind $338=$ Faramea, Aubl. (Rubiac.)

laurifolia, Tuss. 1. c. = F. odoratissima.

ANTOPETITIA, A. Rich. in Ann. Sc. Nat. Sér. II. xiv (1840) 261 = Ornithopus, Linn. (Legum.).

abyssinica, A. Rich. 1. c. $262=0$, coriandrinus.

cancellata, Hochst. ex A. Rich. Tent. Fl. Abyss. i. 210 = Helminthocarpon abyssinicum.

ANTOPHYLAX, Poir. in Dict. Sc. Nat. ii. Suppl. 95 (1816), err. typ. = ANDROPHYLAX, Wendl. = Cocculus, DC. (Menisp.).

ANTOSCHMIDTIA, Steud. Syn. Gram. 199 in syn Schmidtiae $(1855)=$ Schmidtia, Steud. (Gram.). quinqueseta, Boiss. F1. Orient. v。 $559=\mathrm{S}$. quinqueseta.

ANTRIBA, Rafin. Sylva Tellur. $126(1838)=$ Loran thus, Linn.

budleoides, Rafin. 1. c. = L. Scurrula.

ANTROLEPIS, Welw. Apont. 578 (1858)= Ascolepis Nees (Cyper.)

anthemiflora, Welw. 1. $\mathrm{c}_{s}=\mathrm{A}$. anthemiflora.

elata, Welw. 1. c. = A. elata.

leucantha, Welw. 1. c. =A. protea

santolina, Welw, $1, \mathrm{c}=\mathrm{A}$, protea.

sulphurea, Welw. 1. c, =A. protea.

ANTROSPERMUM, Sch. Bip. in Flora, xxvii. (1844) $773=$ Venidium, Less. (Compos.)

floribundum, Passer. Ind. Sem. Parm. (1859).-Hab. Kraussii, Sch. Bip. in Flora, xxvii. (1844) $773=$ V. Kraussii.

ANTSCHAR, Horsf. in Verh. Bat. Gen. vii. (1814) $8=$ Antiaris, Lesch. (Urtic.).

ANTURA, Forsk. Fl. Aegypt. Arab. $63 \quad(1775)=$ Carissa, Linn. (Apocyn.)

hadiensis, J. F. Gmel. Syst. $405=$ C. edulis.

ANUBIAS, Schott, in Oestr. Bot. Wochenbl. (1857 398. AROIDEAE, Benth. \& Hook. f. iii. 975. Afzelii, Schott, l. c. 399.-Afr. occ.

Barteri, Schott, Prod. Aroid. 159.-Afr. occ heterophylla, Engl. in DC. Monog. Phan. ii.435.Afr. trop.

ANURUS, Presl, in Weitenw. Beitr, ii. (1837) $24=$ Lathyrus, Linn. (Legum.)

linifolius, Presl, 1. c. = L. Nissolia.

Nissolia, Fourr. in Ann. Soc. Linn. Lyon, N. S, xvi (1868) $366=$ L. Nissolia.

ANVILLEA, DC. Prod. v. 487 (1836). POSITAE, Benth. \& Hook f ii. 338. Sycodium, Pomel, Nouv, Fl. Atl. 39 (1874) Garcini, DC. Prod. v. 487.-Aegypt.; Persia. radiata, Coss. \& Dur. in Bull. Soc. Bot. Fr. iv. (1857) 471, nomen.-Algeria.

ANYCHIA, Michx. F1. Bor. Am. i. 112 (1808) ILLECEBRACEAE, Benth. \& Hook. f. iii. 16. Buinalis, Rafin. New Fl. Am. iv. 40 (1836).

Argyrocoma, Michx. Fl. Bor. Am. i. 114=Paronychia Argyrocoma.

Baldruini, Torr. \& Gray, Fl. N. Am, i. $172=$ Parony chia Baldwinii.

canadensis, Ell. Sketch, i. 307.-Am. bor

capillacea, DC Prod iii. 869-Am, bor.

conferta, Rafin. Atl. Fourn. (1S82) 16.-Am. bor.

dichotoma, Michx. Fi. Bor. Am. i. 113.-Am. bor divaricata, Rafin. New Fl. Am, iv. 42-Am. bor. fastigiata, Rafin. Atl. Fourn. (1832) 16.-Am. bor Herniariae, Pers. Syn. i. $261=11$ lecebrum herniarioides. herniarioides, Ell Sketch, i. $\$ 08=$ Werniaria americans. herniarioides, Michx. Fl. Bor. Am. i. $119=$ Paronychi

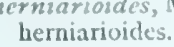

\section{ANYCHIA.}

lateralis, Rafin. Atl. Fourn.(1832) 16.-Am. bor. nudiflora, Rafin. New Fl. Am. jv, 43-Am. bor.

polygonoides, Rafin. Atl. Fourn. (1832) 16.-Am. bor.

AOPLA, Lind1. Bot. Reg. sub t. $1701(1835)=$ Habe naria, Linn

reniformis, Lind1. 1. $\mathrm{c} .=\mathrm{H}$. reniformis

AOTUS, Sm. in Kon. \& Sims, Ann. Bot. i. (1805) 504 LEGUMINOSAE, Benth. \& Hook. f. i. 470.

carinata, Meissn.in Lehm. Pl. Preiss, 1i. 215.-Austral. cordifolia, Benth. in Enum. Pl. Hues, 96.-Austral.

cordifolia, Lindl. \& Paxt. Fl. Gard. i. $76=1$ ulenaen ternata.

dillwynioides, Meissn. in Lehm. Pl. Preiss. i. $60=$ Dillwynia floribunda.

Drummondii, T. Moore, in Gard. Comp. (1852) 97.Austral.

ericoides, G. Don, Gen. Syst. ii. $120=$ villosa

ferruginea, Labill. Pl. Nov. Holl. i. t. $132=$ villosa

genistoides, Turcz. in Bull. Soc. Nat. Mosc. xxy. (1853) I. 268.-Austral.

gracilis, Loud. Hort. Brit. Suppl. ii. $610=$ gracillima. gracillima, Meissn. in Lehm. Pl. Preiss. i. 5y.Austral.

intermedia, Meissn. 1. c. $60=$ gracillima.

lanigera, A. Cunn. ex Benth. in Ann. Wien. Mus. 1838) 78.-Austral.

mollis, Benth. in Mitch. Fourn. Trop. Austral. 236.Austral.

passerinoides, Meissn. in Lehm. Pl. Preiss, i. 61.-

Austral.

phylicoides, F. Muell. ex Benth. Fl. Austral. ii. 92.Austral.

Preissii, Meissn. in Lehm. Pl Preiss, ii. 214.-Austral. procumbens, Meissn. 1. c. i. $60=$ Preissii

Tietkensii, F. Muell. Fragm. ‥33.-Austral.

villosa, Sm. in Kon. E Sims, Ann. Bot. i. (1805 504. -Austral.

virgata, DC. Prod. ii. 108.-Austral.

Wuerthii, Regel, in Bot. Zeit. ix. (1851) $596=$ Dillwynia floribunda.

APABUTA, Griseb. Ges. Abhandl. 280 (1880), nomen. $M E N I S P E R M A C E A E$.

APACTIS, Thunb. Nov. Gen. $66(1783)=$ Roydsia, Roxb. (Capparid.).

japonica, Thunb. l. c.-Japon.

APALANTHE, Planch, in Ann. \& Mag. Nat. Hist. Ser. II. i. (1848) $87=$ Elodea, Michx. (Hydroch.).

granatensis, Planch. 1. c. =E. granatensis. guyanensis, Planch. 1. c. = E. guyanensis. Schroeinitzii, Planch. 1. $\mathrm{c}_{\mathrm{s}}=\mathrm{E}$. canadensis.

APALANTUS, 'Adans. Fam ii. p. (19)' fide Pfeiff. Nom. i. $225(1870)=$ Hapalanthus, Jacq.

APALATOA, Aubl. Pl. Gui. i. 382. t. 147 (1775 Crudia, Schreb. (Legumin.)

aromatica, Lam. Encyc. iv. $559=$ C. aromatica bantamensis, Baill. Hist. Pl. ii. 104,-Java guianensis, Lam. Encyc. i. 208 = C. Apalatoa. spicata, Aubl. Pl. Gui. i. $383=$ C. Apalatoa.

APALOCHLAMY'S, Cass, in Dict. Sc Nat. ….. (1828)= Cassinia, R. Br. (Compos.) Billardierii, DC. Prod. vi. $15 \bar{i}=$ C. spectabilis. Endlicheri, DC. 1. c. = C. spectabilis. Kerrii, DC. 1. c, $=$ C. spectabilis.

APALOPTERA. Nutt. $c x$ A. Gray, in Am. Journ. S Ser. II. xv. (1853) $\$ 19$ - Abronia Juss. Nuctag. annua, Nutt, ex Hook, Kew Joum. v. 135y 201 Ab. cycloptera.

APALUS, DC, Prod. $v$. 50" 1590 Blennosperma Less. (Compos.) anthemifolius, DC. I. C 13. chilcnse.

APAMA, Lam. Eircyc i 91 lis\$-Bragantia Lour. (Arisioloch.

lasurifolia, Ratin. Silva Tellur. 19= R. Wallichii.

siliguosa, Lam. Lncyc. i. $91=1$ B. Wallichii. 
APARGIA, Scop. F1. Carn. ed. II. ii. $113(1772)=$ Leontodon, Linn. (Compos.)

alpina, Willd. Sp. Pl. iii. $1547=\mathrm{I}$, pyrenaicus angustifolia, Schleich. ex DC. Prod. vii. $102=\mathrm{L}$ tenuiflorus.
tentifolias

annua, Visiani, Pl. Aeg. 38. t. $6=$ L. hispidulus, arenaria, Moretti, ex DC. Prod. vii. $103=$ L. Berinii. aspera, Sprun, ex Nym. Consp. 468=L. graecus. aspera, Waldst. \& Kit. Pl. Rar. Hung, ii. $114=\mathrm{L}$. asperus.

aurantiaca, Tenore; Syll. $392=\mathrm{L}$. pyrenaicus.

aurea, F. W. Schmidt, Samml. Phys, Aufs, i. (1795) 282 (Hoppe, ex DC. Prod. vii. 167)= Crepis aurea autumnalis, Hoffm. Dentschl. Fl. ed. II. ii. $113=\mathrm{L}$ autumnalis.

Berinii, Jan, ex DC. Prod, vii. $103=$ L. Berinii

borealis, Bongard, Veget. Ins. Sitcha, $146=\mathrm{L}$. borealis. Brumati, Schicd. ex Steud. Nom. ed. II. i. $110=\mathrm{L}$. hastilis.

bulbosa, Balb. in Mem. Acad. Tor. (1808) $224=\mathrm{L}$. tuberosus.

canescens, Sieber, ex DC. Prod, vii, $103=$ L. Berinii. caucasica, Bieb. Fl. Taur. Cauc. ii. $247=\mathrm{L}$. hastilis. caucasica, Reichb. in Moessl. Handb. ed. II. ii. $1373=$ L. asperus.

chillensis, H. B. \& K. Nov. Gen, et Sp. iv. $3=\mathrm{L}$ chillensis.

cichoracea, Tenore, Prod. 46; F1. Nap, ii. $166=\mathrm{I}$ cichoraceus.

ciliata, Presl, FI. Sicul, p. xxxi = L. Preslii.

communis, Spenn. Fl. Friburg. ii. $558=\mathrm{L}$. hispidus

coronopifolia, Willd. Sp. Pl. iii. $1553=$ Picris radicata crispa, Willd. 1. c. $1551=\mathrm{L}$, crispus.

crocea, Less, in Linnaea, ix. (1834) 152, t. 182,-Sibir ural.

crocea, Pollin. Fl. Veron. ii. 565. t. 2. f. $8=$ L. pyrenaicus. danubialis, Scop. F1. Carn. ed. II. in. $114=\mathbf{L}$. hastilis dubia, Willd. Sp. Pl. iii. $1549=\mathrm{L}$. hastilis.

ericetorum, Richt. [Taschenb. ed. II. $(1830)]=\mathrm{L}$. hastilis.

fasciculata, Bivona, Stirp. Rar. Sicil. ii. [11] t. $2=$ L. cichoraceus.

Gouani, Schleich. Cat. P1. Helv. ed. IV. $7=$ L. hirtus. guestphalica, Boenning. ex Reichb. in DC. Prod. vil $102=\mathrm{L}$, hastilis

Haenkei, Sternb. ex Steud. Nom, ed. II. i. $110=\mathrm{L}$. pyrenaicus.

hastilis, Host, Syn. $423=$ L. hastilis.

hastilis, Viviani, F1. Lib. Spec. 50, t. 26. f. $1=\mathrm{L}$ Salzmannia.

heterophylla, Moench, Meth. $543=\mathrm{L}$. hastilis.

hieracioides, Willd. Sp. Pl. ii. 1554=Picris hiera cioides.

hirta, Geners. ex Steud. Nom. ed. II. 1. 110; ii. $23=$ L. pyrenaicus.

hirta, Steud. 1. c. i. $110=$ L. hispidus

hirta, Scop. F1. Carn. ed. II. ii. $114=$ L. hirtus.

hispanica, Bieb. FI. Taur. Cauc. ii. $248=$ L. asperus,

hispanica, Willd. Sp. PI. iii. $1552=$ L. hispanicus.

hispida, Bory, in Ann. Sc. Gén. Phys. iii. (1820) $5=\mathrm{L}$ Boryi.

hispida, Hoffm. Deutschl. F1. ed. II. ii. $113=\mathrm{I}$, hispidus.

hispida, Willd. Sp. P1. iii. $1553=$ L. hastilis.

hyoseridiflora, Saut. ex Schur, Enum. Pl. Transs, $359=$ L. caucasicus

hyoseridifolia, Less. Syn. Comp. $132=$ Crepis hyoseridi folia.

hyoseroides, Sieber, in Spreng. Syst. iv. $664=\mathrm{L}$. creticus. hyoseroides, Vest, in Flora, iii. $(1820) 7=\mathrm{L}$, hirtus? incana, Mart. FI. Mosq. $135=\mathrm{L}$. hastilis

incana, Scop. Fl. Carn. ed. II. ii. $114=\mathrm{L}$. incanus. incrassata, Moench, Meth. Suppl. $220=$ L. hispidus intermedia, Schult. ex Steud. Nom. ed. II. i. $110=\mathrm{L}$ hastilis.

laevis, Moench, Meth. $541=\mathrm{L}$. hirtus.

livida, Moench, l, c, $543=$ L hastilis.

lucida, Tenore, Cat. Hort. Neap. App. $(1819) 71=\mathrm{L}$. lucidus.

Iyrata, Tenore, Fl. Nap. Prod. $46=$ L. tuberosus.

macrorrhiza, Guenth. ex Spreng. Syst. iii. $665=\mathrm{L}$ macrorrhizus.

media, Host, Fl. Austr, ii. $404=\mathrm{L}$, pyrenaicus.

obtusa, Kit. in Linnaea, xxxii. (1863) 405.-Europ. austr.

pratensis, Link, Handb. i. $791=\mathrm{L}$. autumnalis.

pyrenaica, Sternb. \& Hoppe, ex Steud. Nom. ed. I. 58 $=$ L. alpinus.

\section{APARGIA :}

igens, Mart. ex Reichb. in Moessl. Handb. ed. II. ii $1377=$ Picris hieracioides

Rosani, Tenore, Fl. Nap. App.'v. 26=Leontodon Villarsii.

salina, Gaert. Meyer \& Scherb. Fl. Wett. iii. $146=\mathrm{L}$. crispus.

salsa, Schur, Enum. Pl. Transs. 884, Index $=$ Taraxacum palustre.

saxatilis, Tenore, Cat. Hort. Neap. (1819) $59=\mathrm{L}$ crispus.

scabra, Nocca, ex Steud. Nom. ed. II. i. $110=$ Picris asplenioides.

serotina, Jan, ex Steud. 1. c. =Hypochoeris radicata. setosa, Moench, Meth. Suppl. $219=$ Crepis setosa

sicula, Guss. Fl. Sic. Syn. ii. $399=$ L. hastilis.

sinuata, Kit. in Linnaea, xxxiḱ. (1863) 404.-Europ. austr.

strigosa, Bieb. Fl. Taur. Cauc. ii. $249=$ L. asperrimus sudetica, Link, ex Spreng. Syst. iii. $664=\mathrm{L}$. hispidus.

Taraxaci, Hornem. in Fl. Dan. t. $1523=\mathrm{L}$. autumnalis.

Taraxaci, Willd. Sp. Pl. iii. $1550=$ L. Taraxaci.

taraxaciflora, Viv. F1. Lib. Spec. 50. t. 22. f. $1=$ Picris taraxaciflora

tenuiflora, Gaud. Fl. Helv. vi. 362=I. alpinus. tergestina, Hoppe, ex DC. Prod. vii. 103=L. crispus. tuberosa, Willd. Sp. Pl. jii. $1549=\mathrm{L}$. tuberosus. umbellata, Schrank, in Denkschr. Regensb. Bot. Ges. ii. (1818) $66=$ Picris hieracioides.

variegata, Willd. Sp. P1. ii. $1552=$ Hypochoeris variegata.

verna, Salzm. in Delile, Sem. Hort. Monsp. $(1836)=\mathrm{L}$. Salzmanni.

Villarsii, Willd. Sp. PI. iii. $1553=$ L. Villarsii.

APARGIDIUM, Torr. \& Gray, Fl. N. Am. ii. 474 (1841) = Leontodon, Linn. (Compos.)

boreale, Torr. \&c Gray, 1. c. = L. borealis.

APARINANTHUS, Fourr. in Ann. Soc. Limn. Lyon, N S. xvi. (1868) $397=$ Galium, Toum. (Rubiac.) muralis, Fourr. 1. c. = G. murale.

verticillatus, Fourr. 1. $\mathrm{c}=\mathrm{G}$, verticillatum.

APARINE, Toum. ex Mill. Gard. Dict. ed. VI. $(1752)=$ Galium, Toum. (Rubiac.)

borealis, Hill, Herb. Brit. ii. $151=\mathrm{G}$. boreale, hispida, Moench, Meth. $640=\mathrm{G}$. Aparine. latifolia, Moench, 1. c.=G. Cruciata. minima, All. ex DC. Prod. iv, $610=\mathrm{G}$. murale pariscensis, Hill, Herb. Brit. ii. $150=\mathrm{G}$. parisiense. spuria, Fourr. in Ann. Soc. Linn. Lyon, N. S. xvi. (1868) $397=\mathrm{G}$. spurium

tenera, Fourr. 1. c. = G. spurium.

tricornis, Fourr. l. $\mathrm{c}_{\mathrm{n}}=\mathrm{G}$. tricome.

verrucosa, Moench, Meth $640=\mathrm{G}$, saccharatum. viscidiflora, Rafin. Ann. Nat. (1820) 14-Am, bor.

Vaillantii, Fourr. in Ann. Soc. Linn. Lyon, N. S. xvi, (1868) $397=\mathrm{G}$. spurium.

vulgaris, Hill, Herb. Brit. ii. $149=\mathrm{G}$. Aparine.

APARINELLA, Fourr. in Ann. Soc. Linn. Lyon, N. S. xvi. (1868) $397=$ Galium, Tourn. (Rubiac.)

decipiens, Fonrr. 1. $c_{\circ}=\mathrm{G}$. parisiense.

divaricata, Fourr. $\mathrm{I}_{\text {. }} \mathrm{c}_{\mathrm{*}}=\mathrm{G}$. divaricatum.

litigiosa, Fourr. 1. c. = G. parisiense.

parisiensis, Fourr. 1. $\mathrm{c}_{*}=\mathrm{G}$. parisiense

ruricola, Fourr. 1. $\mathrm{c}_{\mathrm{s}}=\mathrm{G}$. parisiense.

setacea, Fourr, $\mathrm{l}, \mathrm{c}=\mathrm{G}$, setaceum.

tenuicaulis, Fourr. 1. c. = G. divaricatum.

APARISTHMIUM, Endl. Gen. $1112(1840)=$ Alchornea, Sw. (Euphorb.)

cordatum, Baill. Adansonia, v. (1863-64) $307=\mathrm{Al}$ cordata.

javense, Hassk. Hort. Bogor. $235=\mathrm{Al}$. rugosa.

Spruceanum, Baill. Adansonia, v. (1863-64) $307=\mathrm{Al}$. cordata.

sumatranum, Reichb, f. \& Zoll. in Verh. Nat. Ver. Nederl. Ind. i. (1856) $28=\mathrm{Al}$. villosa

APATANTHUS, Viv. F1. Lib. Spec. 54. t. 7. f. 3 (1824) = Hieracium, Linn. (Compos.)

crinitus, Viv. l. $_{\text {. }}=\mathrm{H}$. crinitum.

APATELIA, DC. Mém. Ternstr. 34.t. $8(1822)=$ Saurauja, Willd. (Ternstroem.).
APATELIA :-

biserrata, DC. Prod. i. $526=\mathrm{S}$. biserrata. glabrata, DC. Prod, i. $526=$ Saurauja serrata. lanceolata, DC. 1. $\mathrm{c},=\mathrm{S}$. lanceolata. scabra, G. Don, Gen. Syst. i. $569=$ S. excelsa tomentosa, G. Don, 1. c. $568=\mathrm{S}$. tomentosa.

APATEMONF, Schott, Gen. Aroid. t. 57 (1858) AROIDEAE, Benth. \& Hook. f. iii. 984 Motleyana, Schott, l. c.-Borneo.

APATITIA, Desv. in Ham. Prod. Pl. Ind. Occ. 42 (1825) = Bellucia, Neck. (Meliac.)

blakeoides, Desv. 1. c. = B. Aubletii

APATURIA, Lindl. Gen. et Sp. Orch. $130(1831)=$ Pachystoma, Blume (Orchid.)

chinensis, Lindl. 1. c. $131=\mathrm{P}$. chinense

Lindleyana, Wight, Ic. Pl. Ind. V. $1662=$ P. senile montana, Lindl. in Wall. Cat. $\mathrm{n} .3738=\mathrm{P}$. senile. senitis, Lindl. 1. c. n. $3739=\mathrm{P}$. senile.

Smithiana, Lindl. l. c. n. $3737=\mathrm{P}$, senile.

APEGIA, Neck. Elem. i. $251(1790)=$ Ceropegia, Linn. (Asclep.).

APEIBA, Aubl. Pl. Gui. i. 537. t. 213 ad 216 (1775) TILIACEAE, Benth. \& Hook, f. i. 237.

Aubleria, Schreb. Gen, 353 (1789)

OXYTANDRUM, Neck. Elem. ii. 255 (1790).

aspera, Aubl. l. c. i. 545. t. 216.-Guiana.

australis, A. Rich. FI. Nov. Zel. t. $34=$ Entelea arborescens.

Cimbalaria, Arruda, in Koster, Trav. Braz. 488.-Bras,

discolor, G. Don, Gen. Syst. i. 555.-Bras.

echinata, Gaertn. Fruct. ii. 189. t. 121.-Hab.?

emarginata, Lam. Encyc. 1. $210=$ Sloanea emarginata.

glabra, Aubl.Pl. Gui. i. 541.t. 214.-Guiana.

hirsuta, Lam. Encyc. i. 208-A. Tibourbou.

hispida, Gaertn. Fruct. ii. t. $121=$ A. Petoumo.

hypoleuca, Stend. in Flora, xxvi. (1843) II. 755.Guiana.

laevis, G. Don, Gen. Syst. i. 555.-Guiana.

lacvis, Sw. Prod. Veg. Ind. Occ. $83=$ glabra.

levis, Aubl. Pl. Gui. t, 214= glabra.

membranacea, Spruce, ex Benth. in fourn. Iinn. Soc. v. (1861) Suppl. ii. 61.-Venezuel.

Petoumo, Aubl. Pl. Gui. i. 543. t. 215.-Guiana.

Tibourbou, Aubl. l. c. 538. t. 213.-Guiana; Venezuel.

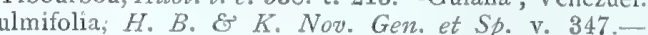
Venezuel.

APEMON, Rafin, Fl, Tellur. ii. $11(1836)=$ Datura Linn. (Solan.)

crassicaule, Rafin. 1. c. = D. ceratocaula.

APENTOSTERA, Rafin. New Fl. Am. ii. 72 (1836)= Penstemon, Mitch, et Chelone, Linn. (Scrophul.) secundiflora, Rafin. 1. c. = P. Menziesii.

triflora, Rafin. 1. c. $73=$ Chelone nemorosa.

APELLA, Scop. Introd. 107 (1777)=APPELLA, Adans = Laurus, Linn.

APENULA, Neck. Elem. i. $234(\mathbf{1 7 9 0})=$ Specularia Heist. (Campan.)

APERA, Adans. Fam. ii. 495 (1763). GRAMINEAE Benth. \& Hook. f. iii. 1152.

Anemagrostis, Trin. Fund, Agrost. 128 (1820).

arundinacea, Hook. f. F1. N. Zeal. 295. t. 67 (=Stipae sp.).-N. Zel.

aspera, Beauv. Agrost. $151=$ Sporobolus asper.

crinita, Beauv, 1. c. $31=$ Dichelachne crinita.

effusa, S. F. Gray, Nat. Arr. Brit. Pl. ii. $148=$ A. Spica venti.

interrupta, Beauv. Agrost. 31.-Rossia austr.; Oriens.

palustris, S. F. Gray, Nat. Arr. Brit. Pl. ii. $148=$ Agrostis alba.

procumbens, Auct. ex Steud. Nom. ed. II. i. $111=$ Agrostis alba, vulgaris.

purpurea, Beauv. Agrost. 31 ; et Reichb. Ic. Fl. Germ. i. $32=$ A. Spica-venti.

Spica-venti, Beauv.l. c.-Europ.; Oriens.

tenuiflora, Beauv. 1. c. $151=$ Muchlenbergia Willdenowii.

APERIPHRACTA, Nees, ex Meissn. in DC. Prod. xy. I. $111(1864)=$ Ocotea, Aubl. (Laurin.). 
APERIPHRACTA :-

cuneata, Nees, ex Meissn. in DC. Prod. xv. I. 119 (=Oreodaphne cuneata).-Peruv.

Martiana, Nees, 1. c. $117=$ Ocotea rufo-tomentosa

Minarum, Nees, 1. c. $140=0$. umbrosa.

velutina, Nees, 1. c. $132=0$, velutina.

APERULA, Blume, Mus. Bot. Lugd. Bat. i. 365 (1851) = Lindera, Thunb. (Laurin.).

assamica, Meissn. in DC. Prod. xvi, $240=$ L. assamica citriodora, Blume, Mus. Bot. Lugd. Bat. i. 366.-Japon confusa, Meissn. in DC. Prod. xv. 1. 243.-Java. cuspidata, Blume, Mus. Bot. Lugd. Bat. i. 367.-Ins, Celebes.

densiflora, Meissn. in DC. Prod. xv, I. 242.-Java. insignis, Blume, in Mus. Bot. Lugd. Bat. i. 367.Sumatr.

lanceolata, Blume, 1. c.-Java.

lucida, Blume, 1. c. 366 .-Java.

macrophylla, Blume, 1. c. 367.-Java.

Neesiana, Blume, 1. c. $366=\mathrm{L}$. Neesiana

oxyphylla, Blume, 1, c。=L。 oxyphylla.

piporicarpa, Meissn. in DC. Prod. xv, X. 242-Sumatr. polyantha, Blume, Mus. Bot. Lugd. Bat. i. 366.-Java. puberula, Blume, 1. c. 367.--Java.

reticulata, Blume, $1 . c_{.}=\mathrm{L}$. reticulata.

salicifolia, Blume, 1. c--Java.

APERULA, Gled, in Mém. Acad. Berl. (1751) 12\%, sphalm. = Asperula, Linn. (Rubiac.).

APFTAHIA, Baill. in Bull. Soc. Linn. Par. i. (1882) 311. LOBELIACEAE. raiateensis, Baill. l. c.-Ins. Pacif.

APETALON, Wight, Ic. y, 22. t. 1758 (1852)=Didymoplexis, Griff. (Orchid.) minutum, Wight, I. c. $=\mathrm{D}$. pallens.

APHACA, [Tourn.] Linn, Gen. ed. I. $217(1737)=$ Isathyrus, Linn. (Legum.).

disperma, Alef. in Oestr. Bot. Zeitschr. xi. (1861) 282.Aegypt.

marmorata, Alef. 1. c. $=$ L. polyanthus.

pseudophaca, Alef. in Bonplandia, ix. (1861) $139=\mathrm{L}$. psendoaphaca.

vulgaris, C. Presl, in Weitenw. Beitr. ii. (1837) $24=$ L. Aphaca.

APHAENANDRA, Miq. Fl. Ind. Bat. ii. 341 (1856). RUBIACEAE.

sumatrana, Miq. l. c.-Sumatr.

APHA FREMA, Miers, in Proc. Hort. Soc. iii. (1863) 294. SAMYDACEAE, Benth. \& Hook. f. i. 799. spicata, Miers, l. c.-Bras.

APHANACTIS, Wedd. Chlor. And. i. 142. t. 37 A (1855). COMPOSITAE, Benth. \& Hook. f. ii. 360. Jamesoniana, Wedd. l. c.-Ecuador.

APIIANAMIXIS, Blume, Bijdr. 165 (1825)=Amoora, Roxb. (Meliac.).

Blumei, Span. Ic. 14; et in Linnaea, xv. (1841) $182=$ Am. timorensis.

grandiflora, Blume, Bijdr. 165=Am. grandifolia Perrottetiana, A. Juss. Mém. Mél. 108=Am. Perrottetiana.

mbiginosa, Griff. ex C. DC. in DC. Monog. Phan. i. $585=$ Am. zubiginosa.

timorensis, A. Juss. Mém. Mél. $107=$ Am. timorensis.

APHANANTHE, Link, Enum. Hort. Berol. i. 383 (] 821) = Microtea, Sw. (Phytolacc.).

celosioides, Link, 1. c. = M. naypurensis.

APHANANTHE, Planch, in Ann. Sc. Nat. Sér. III. x. (1848) 265. URTICACEAE, Benth. \& Hook. f. iii. 355 .

Homoroceltis, Blume, Mus, Bot. Lugd. Bat, ii. 64. t. $34(1852)[1856]$

aspera, Planch. in DC. Prod. xvii. 208.-Japon. cuspidata, Planch. 1. c. $209=$ Gironniera reticulata. philippinensis, Planch. in Anm.Sc. Nat. Sér. III. x. (1848) 387.-Austral.

rectinervis, Planch. in DC. Prod. xvii. 208.-Austral
APHANANTHEMUM, Steud. Nom. ed. II, i, 111

$(1840)=$ Helianthemum, Tourn. (Cistin.).

salicifolium, Fourr, in Ann. Soc. Linn. Lyon, N. S. xvi.

(1868) $340=\mathrm{H}$. salicifolium.

APHANES, Linn. Gen. ed. I. $33(1737)=$ Alchemilla, Linn. (Rosac.

alata, Steud. Nom. ed. I. $58=$ AI. pinnata.

arvensis, Linn. Sp. Pl, ed. I. $123=\mathrm{Al}$. arvensis.

cornucopioides, Lag. Gen. et Sp. Nov. 99. n. $7=\mathrm{Al}$. cornucopioides.

monogyna, [Pieri] in Ionios Anthol. iii. (1834) $694=$ $\mathrm{Al}$, arvensis.

orbiculata, Pers. Syn. i. 150. = Al. orbiculata

pinnata, Pers. 1. c. = Al. pinnata.

triloba, Gilib. Exercit. il. $430=\mathrm{Al}$. arvensis.

tripartita, Pers. Syn, i. $150=$ Al. tripartita.

wulgaris, Schur, Enum. Pl. Transs. $884=$ Al. arvensis.

APHANIA, Blume, Bijdr. $236(1825)=$ Sapindus

Linn.

bifoliata, Radlk. in Sitzb. Math.-Phys. Acad. Muench.

viii. (1878) $238=\mathrm{S}$. bifoliatus.

cuspidata, Radlk. 1. c. $=\mathrm{S}$. cuspidatus.

Danura, Radlk. 1. c. =S. Danura.

longipes, Radlk. Sapind. Holland-Ind. Nachtr. 68.Malaya.

microcarpa, Radlk. in Sitzb. Math.-Phys. Acad.

Muench. viii. (1878) $238=\mathrm{S}$. microcarpus.

montana, Blume, Bijdr. $236=\mathrm{S}$. montanus.

paucijuga, Radlk. Sapind. Holland-Ind. Nachtr. 68 - Malaya.

rubra, Radlk. in Sitzb. Math.-Phys. Acad. Muench. viii

(1878) $238=\mathrm{S}$. attenuatus.

senegalensis, Radlk. l. $\mathrm{c}_{0}=\mathrm{S}$. abyssinicus.

sphaerococca, Radlk. in Act. Congr. Bot. Amst. 1877 (1879) 91.-N. Guinea.

APHANISMA, Nutt. ex Moq. in DC. Prod. xiii. $\mathrm{n}$ 54 (1849). CHENOPODIACEAE, Benth. \& Hook. f. iii. 50 .

Cryptanthus, Nutt. ex Moq. 1. c.

blitoides, Nutt. ex Mog.l. c.-Calif.

APHANOCALYX, Oliver, in Hook. Ic. P1. xi. 53. t. 1066 (1870), LEGUMINOSAE.

cynometroides, Oliver, $l_{\text {. }} c_{\mathrm{n}}$-Afr. occ.

APHANOCHILUS, Benth. in Bot. Reg. sub t. 1282

$(1829)=$ Fisholtzia, Willd. (Labiat.)

blandus, Benth. 1. $\mathrm{c}_{\mathrm{s}}=\mathrm{E}$. blanda

eriostachyus, Benth. 1. c. =E. eriostachya.

favus, Benth. 1. $\mathrm{c}_{\mathrm{s}}=\mathrm{E}$. flava.

foetens, Benth. 1. c. $=\mathrm{E}$. incisa.

incisus, Benth. 1. c. $=\mathrm{E}$. incisa,

paniculatus, Benth. 1, c, = E. incisa

pilosus, Benth. 1. c. =E. pilosa.

polystachyus, Benth. 1, c.=E. polystachya

APHANODON, Nand. in Ann. Sc. Nat. Sér. III. xviii.

(1852) $110=$ Henriettella, Naud. (Melast.).

APHANOMYRTUS, Miq. Fl. Ind. Bat. i. I. 480 (1855). LAURIN. gen. dub. (= Baeckia?). rostrata, Miq.l.c. 481.-Malaya.

APHANOMYXIS, DC. Prod. vii. II. 766 , in nota (1839) =APHANOMIXIS, Blume = Amoora, Roxb. (Meliac.).

APHANOPAPPUS, Endl. Gen. Suppl. ii. $43\left(184^{2}\right)=$ Lipochaeta, DC. (Compos.)

Nuttallii, Walp. Kep. ii. $620=$ L. micrantha.

APHANOPETALUM, Endl. Gen. S18 (1839) SAXIFRAGEAE, Benth. \& Hook. f. i. 650 .

Platyptelea, J. Drum, in Hook. Kew Journ, vii. (1855) 55 .

occidentale, F. Muell. Fragm. i. 228.-Austral.

resinosum, Endl. Nov. Stirp. Dec. 35.-Austral.

APHANOPIEURA, Boiss. Fl. Orient. ii. 855 (18 72 ) UMBELLIFERAE.

trachysperma, Boiss. l.c.-Armenia.

ApHANosteman, St 11il. Fl. Bras. Mer. i. 12 (18:5) Ranunculus, Lin.

apiifolia, St. 1 iil. 1. c. $19=$ k. spiifolius.
APHANOSTEPHUS, DC. Prod, v. 310 (1836): COMPOSITAE, Benth. \& Hook. f. ii. 262.

KEERLIA, DC. Prod. v. 309 (1836), ex parte.

LEUCOPSIDIUM, DC. Prod. vi. 43 (1837)

arizonicus, A. Gray, in Proc. Am. Acad. xvi. (1881 $81=$ humilis

arkansanus, A. Gray, Pl. Wright. i. 93.-Texas.

humilis, A. Gray, l. c.-Texas.

pilosus, Buckl. in Proc. Acad. Sc. Philarl. '1881' (1862)

$457=$ ramosissimus.

ramosissimus, $D C$. Prod. v. $310 .-$ Tezas,

ramosus, A. Gray, in Proc. Am. Acad.

-Mexic.

Riddelii, Torr. \& Gray, F1. N. Am. ii. 189=ramosis. simus.

APHANTOCHAETA, A. Gray, in Pacif. Rail. Rep. iv. 99 (1856). COMPOSITAE, Benth. \& Hook. I. ii. 251.

exilis, A. Gray, l. c. 100.-Calif.

APHARICA, Schlecht in Linnaca, vi. (1831) Litt. $78=$ APHANIA, Blume= Sopindus, Linn.

APHELANDRA, R. Br. Prod, 475 (1810). THACEAE, Benth, \& Hook. f. ii. 1102.

Amathea, Rafin, Fl. Tellur. iv. 65 (1836).

HemisañRA, Scheidw. in Bull. Acad. Brux. (1842) 22 .

Hemitome, Nees, in DC. Prod. xi. 295 (1847)

Hydromestus, Scheidw. in Otto \& Dietr. Garten?.

$x_{0}(1842) 285$

Lagochillum, Nees, in Mart. Fl. Bras, ix, 85. t. 10 (1847)

Poecilocnemis, Mart. ex Nees, in DC. Prod. xi. 295 (1847)

STROBILORHACHIS, Link, Klotzsch \& Otto, Ic. Pl. Rar. 117. t. 48 (183!)

Synandra, Schrad. in Goctt. Gel, Anz. i. (1821 715.

acanthifolia, Hook. Ic. Pl. t. 113.-Peruw.

Acanthus, Nees, in DC. Prod. xi. 302.-Leuadur.

acutifolia, Nees, l. c. 299.-Ind. occ.

atrovirens, N.E. Br. in Illustr. Hortic xxxi. (18E

t. 527.-Bras.

aurantiaca, Lindl. Bot. Reg. 31. t. 12.-Mexic.

bullata, H. Wendl. in Hamb, Gartenz. xix. (1863; 30 - Am. centr.

carduifolia, Hook. Ic. Pl. t. $718=$ formosa,

chartacea, T. Anders, in Fourn. Bot. ii. (1864) 259.Peruv.

Chamissoniana, Nees, in Mart. Fl. Bras. ix. 90.Bras,

Clava, Wawra, in Oestr. Bot. Zeitsclir. xii. (1862) 174. -Bras.

cristata, R. Br. Prod. 475, in obs-Ind. occ.

cristata, H. B. \& K. Nov. Gen. et Sp. ii. $236=$ pectinata.

cristata, Lindl. Bot. Reg. t. $147 i=$ tetragona.

Dehnhardtii, Tenore, Ind. Sem. Hort. Neap. (1s:g 14.-Hab.

Deppeana, Cham. \& Schlecht. in Linnaea, r. (1530. 96.-Alevic.

Fiascinator, Linden \& Audrí, Illustr. Hortic xxi : $1 S_{i t}$

t. 164.-Am. trop.

Rava, Nees, in DC: Prod. xi. 297.-Keg. Colomb.

formosa, Nees, l. c. 301.-Peruv.

fulgens, Decne, in Rev. Hortic. Sér. III. i. $184_{1}, 21$.

Ilexic.

fulgens, Hort.

$3.2=$ tenuiflor

glabrata, Willd. $d x$

merid. Ser. I iv (1SAS Hort. ex Lem. in Fl. des Serres,

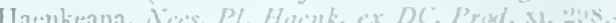

line centr.

Hatwegrians.

Martwegian.
Columb.

Columb. lieg

Lirsuta, Mart. ex Nees in 1): l'ruxl. xi. $11^{-}$- lkclu perune hirsuta.

hydromestus, Hensl. Biol. Censtr. Am. But, ii. 3ld Mexic.

ignea, Nees, ex Steud. Nom. ex?. 11. i. 111. Sectandrium igneum. 


\section{APHELANDRA :-}

illustrata.C.C. Gard. Chron. v. (1876) 603.-Bras.

lateritia, Loud. Encyc. Pl. 1539,-Guatemala.

Leopoldii, Van Houtte, in Fl. des Serres, ix. Sér. I. (1853) 85 - squarrosa.

Liboniana, Linden, ex Hook. f. Bot. Mag. 5463. Am. trop.

longiracemosa, Hort. ex Lindl, in Paxt. FI. Gard. ii. $78=$ Thyrsacanthus callistachys.

longiscapa, Hort. ex Lem. in Fl. des Serres, Sér. I. iii. 1847) $240=$ Thyrsacanthus Lemairianus.

lutea, Nees, in DC. Prod. xi. 300.-Bras.

lyrata, Nees, l. c. 302-Am. anstr.

macrostachya, Nees, in Mart. Fl. Bras. ix. 88.-Bras.

Margaritae, E. Morr. in Belg. Hortic, xxxiii. (1883) 315. t. 19.-Bras.

marginata, Nees \& Morr. in Nov. Act. Nat. Cur. xi. (1823) i. 52.-Bras.

mediaurata, Cogn. \& March. Pl. Ornem. i. (1873) t. 30.--Bras.

melgariensis, Nees, in DC. Prod. xi. 297.--Reg, Colomb.

micans, Moritz.ex Vatke, Ind. Sem. Hort. Berol. (1876) App. 1.-Venezuela.

monticola, Mart. ex Nees, in DC. Prod. xi. $364=$ Jacobinia monticola.

mucronata, Nees, in DC. Prod. xi. 301.-Peruy

nemoralis, Mart. ex Nees, in Mart. Fl. Bras, ix. 90.Bras.

nervosa, T. Anders. in Fourn. Bot. ii. (1864) 289.Peruy

nitens, Hook.f. Bot. Mag. t. 5741.-Reg. Colomb,

nitida, Nees \& Mart. in Nov. Act. Nat. Cur. xi. (1823) $57=$ Geissomeria nitida.

nobilis, Hort.-Cf. Gard. Chron. (1867) 461.-Hab.

nuda, Nees, in Mart. Fl. Bras. ix. 89.-Bras.

oostachya, Wawra, in Oestr. Bot.Zeitschr. xii. (1862) 172.--Bras.

ornata, T. Anders. in Fourn. Bot. ii. (1864) 289.Bras.

pectinata, Willd. ex Nees, in DC. Prod.xi. 297.-Am. austr.

Porteana, Morel, in Fl. des Serres, Sér. I. x. (1854-55) 41. t. 981.-Bras

prismatica, Hiern, in Kjoeb. Vidensk. Meddel. (187778) 78.-Am. centr.

pulcherrima, H. B. \& $K$. Nov. Gen. et Sp. Pl. ii. 236. -Reg. Colomb.

pulcherrima, Willd, ex Nees, in DC. Prod. xi. $295=$ tetragona.

pumila, Nichols, Dict. Gard. i. 91.-Bras.

punctata, Hort.-Cf. Gard. Chron. (1881) II. 86;

Illustr. Hortic. xxix. (1882) t. 457.-Am. merid.

quercifolia, Nees, in DC. Prod. xi. 302.-Reg. Colomb. repanda, Nees, l. . . 728 .- Peruv.

Roezlii, Carr. in Rev. Hortic. (1872) $100=$ aurantiaca.

runcinata, Klotzsch, ex Nees, in DC. Prod. xi. 302.

Reg. Colomb.

Schiedeana, Cham. \& Schlecht. in Linnaea, v. (1830) 95.-Mexic.

sciophila, Mart. ex Nees, in Mart. Fl. Bras. ix. 91.Bras.

Sinclairiana, Nees, in Benth. Bot. Voy. Sulph. 146. t. 47.-Am. centr.

Sinitzini, Linden, Cat. n. 95 (1876); Rev. Hortic. (1876) 237.-Peruy.

squarrosa, Nees, in Mart. Fl. Bras. ix. 89.-Bras.

stephanophysa, Nees, l. c. 90.-Am. austr.

sulphurea, Hook. f. Bot. Mag. t. 5951.-Ecuador.

tarapotensis, Linden, ex Rafarin, in Rev. Hortic. (1877 $38=$ Sinitzini

tenuiflora, Regel \& Rach, Gartenfl. (1858) 342--Hab.? tetragona, Nees, in DC. Prod. xi. 295. - Reg. Colomb. tridentata, Hemsl. Biol. Centr. Am. Bot. ii. 513.Costa Rica.

variegata, Morel, Fl. des Serres, Sér. I. x. (1854-55) 33. t. 981.-Hab.?

verticillata, Nees, in DC. Prod. xi. 281.--Mexic.

APHELANDROS, St. Lag. in Ann. Soc. Bot. Lyon, vii. $119(1880)=$ Aphelandra, R. Br. (Acanth.).

APHELEXIS, D. Don, in Mem. Wern. Soc. v. (1826) $546=$ Helichrysum, Tourn. (Compos.). adhaerens, Boj. ex DC. Prod. vi. 217.-Madag.

Candollei, Boj. ex DC. 1. c.-Madar.

ericoides, Sweet, Hort. Brit. ed. I. $223=$ Helichrysum ericoides.
APHELEXIS :-

fasciculata, D. Don, in Mem. Wern. Soc. v. (1826) $546=\mathrm{H}$. sesamoides.

filiformis, D. Don, 1. c. $547=$ H. sesamoides.

heterophylla, G. Don, in Sweet, Hort. Brit. ed. III. $378=$ Helipterum heterophyllum.

humilis, D. Don, in Mem. Wern. Soc. v. (1826) $547=$ H. humile.

hypnoides, DC. Prod. vi, 218.-Madag.

incana, G. Don, in Sweet, Hort. Brit. ed. III. $3 \varsigma 9=$

Helipterum incanum.

lycopodiodes, Boj. in DC. Prod。 vi. 217.-Madag

macrantha, Paxt. F1. Mag. xv. $269=$ H. humile.

selaginifolia, DC. Prod. vi. 217.-Madag.

sesamoides, D. Don, in Mem. Wern. Soc. v. (1826) 546

$=\mathrm{H}$. sesamoides.

APHELIA, R. Br. Prod. 251 (1810). CENTROLEPIDEAE, Benth. \& Hook. f. iii. 1026.

Brizula, Hieron. in Abh. Naturf. Ges. Halle, xii. (1873) 206, 208 (Centrolep. 92, 94)

Brizula, F. Muell. Fragm. v. 203.-Austral.

cyperoides, R. Br. Prod. i. 252.-Austral.

Drummondii, Benth. Fl. Austral, vii. 201.-Austral

gracilis, Sond. in Linnaea, xxviii. (1855) 227.-

Anstral.

Gunniz, Hook. f. Fl. Tasm. ii. 75. t. $138=$ gracilis

monogyna, Hieron. in Abh. Naturf. Ges. Halle, xii (1873) 208 (Centrolep. 94) = Centrolepis monogyna nutans, Hook. f. ex Benth. Fl. Austral. vii. 200.Austral.

Pumilio, F. Muell. in Linnaea, xxviii. (1855) 226.Austral.

APHILLANTHES, Neck. Elem. iii. $199(1790)=$ Aphyllanthes, Tourn. (Liliac.).

APHLOIA, Benn. Pl. Jav. Rar. 192 (1838) in adnot BIXINEAE, Benth. \& Hook. f. i. 126. NeUmannia, A. Rich. Fl. Cub. 96 , in adnot. (1845). integrifolia, Benn. Pl. Jav. Rar. 192 in adnot.= mauritiana.

madagascariensis, Clos, in Ann. Sc. Nat. Sér. IV. viii (1857) 273.-Madag

mauritiana, Baker, Fl. Maurit. 12.-Ins. Mascar.

theaeformis, Benn. P1. Jav. Rar. 192, in adnot.=mauritiana.

APHOMA, Rafin. F1. Tellur. ii. 31 (1836)=Iphigenia Kunth (Liliac.)

angustiftora, Rafin. 1. c. $32=$ I. indica

cuneata, Rafin. 1. c. $=\mathrm{I}$. indica.

APHOMONIX, Rafin. Fl. Tellur. ii. 65 (1836)= Saxi fraga, Tourn.

hederacea, Rafin. 1. c. = S. sarmentosa.

APHONINA, Neck. Elem. iii. $287(1790)=$ Paxiana Aubl. (Gramin.).

APHORA, Neck. Elem. iii. $50(1790)=$ Virgilia, Lam. (Legum.).

APHORA, Nutt. in Trans. Am. Phil. Soc. Ser. II. y. (1837) $174=$ Argithamnia, P. Br. (Euphorb.). Blodgettii, Torr. ex Chapm. Fl. S. U. St. 408.-Florida. catamariensis, Griseb. in Goett. Abh. xxiv. (1879) 58 $=$ Arg. catamariensis.

Drummondii, Engelm. \& Gray, P1. Lindh. i. 25.Texas.

humilis, Engelm. \& Gray, I. c. $54=$ Arg. humilis.

humilis, Torr. Bot. Mex. Bound. $196=$ Arg. neomexicana.

laevis, A. Gray, ex Torr. 1. c.=Arg. laevis.

lanceolata, Engelm. \& Gray, P1. Lindh. i. 25= Arg. lanceolata.

mercurialina, Nutt. in Trans. Am. Phil. Soc. N. S. v. (1837) $174=$ Arg. mercurialina.

pilosissima, Torr. in Bot. Mex. Bound. 197=Arg. mercurialina.

serrata, Torr. 1. c. = Arg. serrata.

APHRAGMIA, Nees, in Lindl. Nat. Syst. ed. II. 444 (1836) = Ruellia, Linn. (Acanth.)

Haenkei, Nees, 1. c. $=$ R. albicaulis.

rotundifolia, Nees, ex Benth. Bot. Voy. Sulph. $146=$ $\mathrm{R}$. Hloribunda.
APHRAGMUS, Andrz. ex DC. Prod. i. $209(1824)=$ Braya, Sternb. \& Hoppe, (Crucif.)

Eschscholtziana, Andrz. ex DC. 1. c.-Ins. Aleutian.

APHYLAX, Salisb, in Trans. Hort. Soc. i. (1812) $271=$ Aneilema, R. Br. (Commelin.).

spiralis, Salisb. 1, c. = An, spiratum.

APHYLLANTHES, Tourn, ex Linn, Gen, ed, I. 357 (1737). LILIACEAE, Benth. \& Hook, f, iii. 795 juncea, Salisb. Parad. Lond. t. $9=$ monspeliensis. monspeliensis, Linn. Sp. Pl. 294,--Reg. Mediterr.

APHYLlEIA, Champ. in Calc. Journ. Nat. Hist, vii. (1847) $468=$ Seiaphila, Blume (Triurid.)

erubescens, Champ. 1. c. $=\mathrm{S}$. erubescens.

APHYLLOCAULON, Lag. Amen. Nat, i. 38 (1811)= Gerbera, Gronov. (Compos.).

APHYLLOCLADUS, Wedd. Chlor. And. i. 11. t. 3 $(1855)=$ Hyalis, D. Don (Compos.).

decussatus, Hieron. Ic. Pl. Argent. 28. t. 5. f. 1.-Reg. Argent.

spartioides, Wedd. 1. c--Bolivia.

APHYLLON, Mitch. in Act. Phys. Med. Acad. Nat. Cur. viii. (1748) 221. OROBANCHACEAE, Benth. \& Hook. f. ii. 983.

ANOPLON, Reichb. Consp. 212 (1828).

Gymnocaulis, Nutt. ex Benth. \& Hook. f. Gen. ii. $983(1876)$

LoXanthes, Rafin. Neogenyt. 3 (1825).

Myzor RhizA, Phil. in Linnaea, xxix. (1857-58) 36.

Thalesia, Rafin. in Am. Monthly Mag. (1818) 267.

californicum, A. Gray, in Bot. Calif. i. 584-Am. bor. occ.

comosum, A. Gray, L. c.-Am. bor. occ.

Cooperi, A. Gray, in Proc. Am. Acad. xx. (1885) 307. -Am. bor. oce.

Dugesii, S. Wats. in Proc. Am. Acad. xviii. (1882-83) 132.-Mexic.

fasciculatum, Torr. Eo Gray, in A. Gray, Man. Bot. U. St. ed. I. 281.-Am. bor.

ludovicianum, A. Gray, in Bot. Calif. i. 585.-Am. bor. multiflorum, A. Gray, l. c. - -N. Mexic.

pinetorum, A. Gray, l. c.-Am. bor. occ.

tuberosum, A. Gray, l. c.-Calif.

uniflorum, A. Gray, Mann. Bot. U. St. ed. I. 290.Am. bor.

APHYLIIORCHIS, Blume, 'Bijdr. t. 77 (1825)' (nobis latet). ORCHIDEAE, Benth. \& Hook. f. iii. 606.

Hasseltii, Blume, Mus. Bot. Lugd. Bat. i. 31.-Java. montana, Reichb. f. in Linnaea, xli. (1877) 57.-Ind. or.

pallida, Blume, Bijdr. t. 77; Mus. Bot. Lugd. Bat. i. 30.-Malaya.

Spiculaea, Reichb. f. in Linnaea, xli. (1877) 58.Borneo.

APHYTEIA, Linn. Diss, Aphyt. 7 (1776); (Amoen. Acad. viii. 310. t. 7$)(1785)=$ Hydnora, Thunb. (Cytin.).

Acharii, Stend. Nom. ed. II. i. 111, sphalm. (Cf. Thunb. Fl. Cap, ed. Schult. 499)=H. africana.

Hydnora, Linn. f. Diss, $10=\mathrm{H}$. africana.

multiceps, Burch. Trav。 i. 213, in nota = Cytinus dioicus. triceps, Steud. Nom. ed. II. i. $111=\mathrm{H}$. triceps.

APIASTRUM, Nutt. ex Torr. \& Gray, Fl. N. Am. i. 643 (1840), UMBELLIFERAE, Benth. \& Hook f. i. 888 .

angustifolium, Nutt. l.c. 644.-Calif.

latifolium, Nutt. 1. c. = angustifolium

APICRA, Willd. in Ges. Naturf. Fr. Berl. Mag. V (1811) 167. LILIACEAE, Benth. \& Hook. f. iii. 776.

APRICA, D. Dietr. Syn. ii, 1097 (1840)

Cateriala, Medic. Theod, 67 (1786)

albicans, Willd. 1. c. $271=$ Haworthia albicans. anomala, Willd. 1. c. $273=$ Haworthia recurva arachnoides, Willd. 1. c. $168=$ Haworthia arachnoides.

aspera, Willd.l.c.274.-Afr. austr. 
APICRA :

asperula, Haw. ex Steud. Nom. ed. II. i. $111=\mathrm{Ha}-$ worthia asperula.

atrovirens, Willd, in Ges. Naturf. Fr. Berl. Mag. v.

(1811) $168=$ Haworthia atrovirens.

attemuata, Willd. 1. c. $270^{\prime}=$ Haworthia attenuata.

bicarinata, Haws. Suppl. 63.-Afr. austr.

bullulata, Willd. in Ges. Naturf. Fr. Berl. Mag. v (1811) $273=$ pentagona.

congesta, Baker, in Yourn. Linn. Soc, xviii. (1880) 218 -Afr. austr.

cymbaefolia, Willd. in Ges. Naturf. Fr. Berl. Mag. v. (1811) $271=$ Haworthia cymbiformis.

deltoidea, Baker, in Fourn. Linn. Soc. xviii. (1880) 217. -Afr. austr.

expansa, Willd. in Ges. Naturf. Fr. Berl. Mag. v.

(1811) 272 - Haworthia rigida.

fasciata, Willd. $1, c_{2}=$ Haworthia fasciata.

foliolosa, Willd. l. c. 274.-Afr. austr.

granata, Willd. 1. c. $269=$ Haworthia margaritifera

imbricata, Willd. 1. c. $273=$ spiralis.

margaritifera, Willd. 1. c. $269=$ Haworthia mar-

garitifera.

maxima, Stend. Nom. ed. I. 59 ; ed. II. i. $112=\mathrm{Ha}$

worthia margaritifera.

minor, Steud. ll. cc. $=$ Haworthia margaritifera.

mirabilis, Willd. in Ges. Naturf. Fr. Berl. Mag. v. (1811) $269=$ Haworthia mirabilis.

nigra, Haw. in Phil. Mag. (1824) $302=$ Haworthia nigra.

patula, Willd. in Ges. Naturf. Fr. Berl. Mag. v. (1811) $272=$ Haworthia rigida

pentagona, Willd. l. c. 273,-Afr. austr.

pseudo-rigida, Haw. Suppl, $62=$ Haworthia subrigida. Pumilio, Willd. in Ges. Naturf, Fr. Berl. Mag, y.

(1811) 271 = Haworthia reticulata.

quinquangularis, Sweet, Hort. Brit. ed. II. $521=$ Aloè quinquangularis.

Radula, Willd. in Ges. Naturf. Fr. Berl. Mag. v. (1811) $270=$ Haw orthia Radula.

recurva, Willd. 1. $c_{1}=$ Haworthia recurva.

reticulata, Willd. 1. c. $272=$ Haworthia reticulata.

retusa, Willd, 1. c. $271=$ Haworthia retusa.

rigida, Willd. 1. c. $272=$ Haworthia subrigida.

spiralis, Baker, in Fourn. Linn. Soc. xviii. (1880) 217. -Afr, austr.

spiralis, Willd. in Ges. Naturf. Fr. Berl. Mag. v.

(1811) $273=$ pentagona.

spirella, Willd. ex Haw. Suppl. Pl. Succ. $64=$ pentagona.

tortuosa, Willd. in Ges. Naturf. Fr. Berl. Mag. v. (1811) $274=$ Haworthia viscosa.

transhucens, Willd. 1. c. $168=$ Haworthia translucens.

tricolor, Willd. 1. c. $271=$ Haworthia venosa

viscosa, Willd. 1. c. $274=$ Haworthia viscosa

APILIA, Rafin. Alsog. Am. 39 (1838)= Fraxinus, Tourn. (Oleac.).

laciniata, Rafin. 1. c. = F. excelsior, var.?

macrophyla, Rafin. l. c. =F, macrophylla.

pendula, Rafin. 1. c. $=$ F, excelsior.

APINAGIA, Tul. in Ann. Sc. Nat. Sér. III. xi. (1849) 97. PODOSTOMACEAE, Benth. \& Hook. f. iii. 111

Blandowia, Willd. in Ges. Naturf. Fr. Berl. Mag.

iii. (1809) 100. t. 4. f. 2 , nomen princeps.

Monostylis, Tul. Podost. Monog. 201 (1852)

NEolACIS, Wedd. in DC. Prod. xvii. 59 (1873).

divaricata, Tuit. \& Wedd. ex Tul. l. c.-Bras.

fucoides, Tul. l. c. 98,-Bras.

Gardneriana, Tul. l. c.-Bras,

membranacea, Tul. l. c. 99.-Bras.

Preissii, Tul. in Arch. Mus. Par. vi. (1852) 108. Italia.

psyllophora, Tul. \& Wedd.ex.Tul. in Ann. Sc. Nat. Sér. III. xi. (1849) 97.-Bras.

pusilla, Tul. l. c. 99.-Guiana.

pygmaea, Tul. l. c.-Bras.

Riedelii, Tul. l. c. 98.-Bras

ruppioides, Tul.l. c. - Reg. Colomb.

striata, Griseb. ex Wedd. in DC. Prod. xvii. 64.Pernv.

Willdenowii, Tul. in Arch. Mus. Par. vi. (1852) 106. -Perav.; Chili.

APINELLA, Neck. Elem. i. $191(1790)=$ Trinia, Hoffm. (Umbellif.).
APINUS, Neck, Elem. iii. $369(1790)=$ Pinus, Tourn. (Conif.).

APIOCARPUS, Montrous, in Mém. Acad, Lyon, x. (1860) $190=$ Akania, Hook.? (Sapindac.

Moguini, Montrous. 1. c. 191.-N. Caled.

APIOPETALUM, Baill. Adansonia, xii. (1878) 133. $A R A L I A C E A E$.

glabratum, Baill. l.c. 134.-N. Caled.

velutinum, Baill. l. c. -N. Caled.

APIOS, Moench, Meth. 165 (1794)。 LEGUMINOSAE, Benth. \& Hook. fo i. 532

Bradlea, Adans. Fam. ii. 324 (1763)

Cyrtotropis, Wall. Pl. As. Rar. i. 49. t. 62 (1830). americana, Medic, in Vorles. Churpf. Phys. Ges. ii. (1787) 355.-Am. bor.

carnea, Benth. ex Baker, in Hook. f. Fl. Brit. Ind. ii 188.-Reg. Himal.

chinensis, Spreng. Syst. iii. $310=$ Wisteria chinensis.

Fortunei, Maxim. in Bull. Acad. Pétersb. xviii. (1873) 396. - China; Japon

frutescens, Pursh, FI. Am. Septo ii. $474=$ Wisteria frutescens.

tuberosa, Moench, Meth. 165.-Am. bor.

APIOSPERMUM, Klotzsch, in Abh. Akad. Berl. (1853) 351, 352 = Pistia, Linn. (Aroid.). obcordatum, Klotzsch, 1. c. = P. Stratiotes.

APIROPHORUM, Neck. Elem. ii. $72(1790)=$ Pyrus, Tourn. (Rosac.).

APISTA, Blume, Bijdr. $296(1825)=$ Podochilus, Blume (Orchid.

tenuis, Blume, 1. c. $=$ P. tenuis.

APIUM, [Tourn.] Linn. Syst. ed. I. (1735), UMBELLIFERAE, Benth. \& Hook. f. i. 888 .

Celeri, Adans. Fam. ii. 498 (1763)

Ciclospermum, Lag. Amen. Acad. Madr. ii. $10 x$ (1811).

Critamus, Hoffm. Gen. Umb. 182 (1814)

CYClOSPERMUM, DC. Prod. iv. 105, in sym $(1830)$

HeLodium, Dum. Fl. Belg. 77 (1827).

Heloscia, Dum. Anal. Fam. 34 (1829)

Helosciadium, Koch, in Nov. Act. Nat. Cur. xii. I. (1825) 125.

Leptocaulis, Nutt. ex DC. Prod. iv. 107 (1830).

MaUchartia, Neck. Elem. i, 172 (1790)

SELINoN, Adans. Fam. ii. p. '(23)' 603 (1763).

SiUmis, Rafin. New Fl. Am. iv. 31 (1836)

Spermolepis, Rafin. Neogenyt. 2 (1825).

Ammi, Crantz, Stirp. Austr. ed. I. fasc. iii. 109; ed.

II. $217=$ Ammi majus.

Ammi, Urban, in Mart. Fl. Bras. xi. I. 341.-Bras.

Amomum, Stokes, Bot. Mat. Med. ii. $156=$ Sison Amomum.

Anisum, Crantz, Cl. Umb. Emend. 101=Pimpinella Anisum.

australe, Thon. Fl. Trist. d'Acugn, $43=$ prostratum. bipinnatum, Walt. Fl. Carol. $115=$ Selinum canadense biternatum, Stokes, Bot. Mat. Med. ii. $150=$ Aegopodium Podagraria.

Carsonii, Benth. \& Hook. f. Gen. i. 888.-Am. bor.

Carvi, Crantz, Stirp. Austr. ed. I. fasc. iii. 110; ed. II. $218=$ Carum Carvi.

Celleri, Gaertn. Fruct. i. t. $22=$ graveolens.

chilense, Hook. \& Arn. in Hook. Bot. Misc, iii. (1833) 353.-Chili.

Commersoni, DC. Prod. iv, 101.-Hab.

crassipes, Reichb. f. Ic. Fl. Germ, xxi. 9.-Hispan.

crispum, Mill. Gard. Dict. ed. VIII. n. 2 = Carum Petroselinum.

decumbens, Eckl. \& Zeyh. Enum. $340=$ graveolens

divaricatum, Benth. \& Hook. fo ex S. Wats. Bibl. Ind N. Am. Bot. 412-Am. bor

dulce, Mill. Gard. Dict. ed. VIII. n. $5=$ graveolens.

echinatum, Benth. \& Hook. f. ex S. Wats. Bibl. Ind N. Am. Bot. 412,-Am. bor.

filiforme, Hook. Ic. t. $819=$ prostratum.

flexuosum, Phil.in Linnaea, xxxiii. (186t-65) 91.-Chili fractophyllum, Hornem. Hort. Hafn. Suppl.128. - Hab. glaucescens, H. B. \& K. Nov. Gen. èt Sp. v. 17,-Reg. Colomb.

glaucum, Crantz, Cl. Umb. Emend. $100=$ Trinia vul

garis.
gracile, Benth. \& Hook.f. Gen. i. 888.-Chili.

\section{APIUM}

graveolens, Cham. in Linnaea, i. (1826) $388=$ pro-

graveolens, Linn. Sp. Pl. 264.-Europ.; Oriens; Ind bor. occ.; Calif.

humile, Benth. E Hook. f. Gen. i. 888.-Afr. austr. inundatum, Reichb. f. Ic. Fl. Germ. xxi. 9,-Europ involucratum, Roxb, ex Flem, in As. Res, xi. (1810 $157=$ Carum Roxburghianum.

junceum, Stokes, Bot. Mat. Med. ii. 155=Carum segetum.

laetum, Salisb. Prod, $169=$ Carum Petroselinum.

latifolium, Mill. Gard, Dict. ed. VIII. n. $3=$ Carum Petroselinum.

latifolium, Poir. Encyc. iv. $369=$ Carum peregrinum.

leptophyllum, F. Muelt. ex Benth. Fl. Austral. iii. 372 -Austral.

lineare, Benth. \& Hook.f. Gen. i. 888.-Am, bor.

lobatum, Gilib. Fl. Lituan. ii. 41 = graveoiens,

Iusitanicum, Mill.Gard. Dict. ed. VIII. n.7 = graveolens. maritimum, Salisb. Prod. $169=$ graveolenis

montanum, H. B. \& K. Nov. Gen. et Sp. v. 17. - Reg. Colomb.

nodiflorum, Reichb.f. Ic. Fl. Germ. xxi. 10,-Europ. patens, S. Wats. Bibl. Ind. N. Am. Bot. 413.-Am. bor. peregrinum, Crantz, Cl. Umb. Emend, 101 = Carum peregrinum.

petraeum, Crantz, l. c. $104=$ Ammi majus.

Petroselinum, Cham. in Linnaea, i. (1826) $389=$ pro stratum.

Petroselinum, Linn. Sp. Pl. ed. I. $264=$ Carum Petrose linum.

Popei, A. Gray, in Proc. Am. Acad. vii. (1868:343.Am. bor.

prostratum, Labill. Relat. i. 141; Vent. Fard. Malm 81.-Austral, ; Reg. Antarct.

pumilum, Crantz, Stirp. Austr. ed. I. fasc. iii 103 ; ed.

II. $213=$ Trinia vulgaris

anunculifoliam, H. B. \& K . Non. Gen et Sp, v, 18, t 421.-Reg. Colomb.

rapaceum, Mill. Gard. Dict. ed. VIII. n. $6=$ graveolens repens, Reichb. f. Ic. Fl. Germ. xxi. 10.-Europ.

romanum, Zuccagni, in Roem. Collect. $135=$ Carum Petroselinum.

segetum, Dum. Fl. Belg. 71 = Carum segetum

Sium, Crantz, Stirp. Austr. ed. I. fasc. iii, 106; ed. II $215=$ Sium erectum.

ternatum, Pall. ex Steud. Nom. ed. II. i. $112=$ Archan gelica Gmelini.

ternatum, Schlecht. ex Roem. \& Schult. Syst. vi. 431 $=$ Ligusticum scoticum.

ternatum, Siebold, in Verh. Batav. Gen. xii. (1830) 46 $=$ Ligusticum acutilobum.

trifoliatum, Wight \& Am. Prod. i. 368, sphalm. Pimpinella Heyneana.

tuberosum, Steud. Nom. ed. I. $59=$ Caram Petroselinam Visnaga, Crantz.Cl. Umb, Emend. 10t= Ammi Visnaga vulgare, Lam. Fl. Fr. iii. 444 = Carum Petroselinum.

APLACTIS, Rafin. Fl. Tellar, ii. 42 (1836)= Solidago Tourn. (Compos.)

paniculata, Rafin. 1. c. =S. pauciflosculosa.

APLARINA, Rafin. New Fl. Am. iv. 99 (1836)=Eu phorbia, Tourn.

microphyla, Rafin. 1. c. $100=\mathrm{E}$, thymifolia.

prostrata, Rafin. I. c. $99=$ E. prostrata.

APLECTRA, Rafin. Cat. 13 (1824)=Aplectrum, Nutt (Orchid.).

elatior, Rafin. 1. c. = Aplectrum hyemale.

APLECTROCAPNOS, Boiss, \& Reut. Diam. Ser. I. v $79(1844)$-Sarcocapnos, DC. (Papar.). boetica, Boiss. \& Reut. 1. c. $=$ S. baetica. integrifolia, Boiss. Diaga. Ser. II. i. $18=\mathrm{S}$, baetica.

APLECTRUM, Tort. Comp. Fl. St. 322:15:6). ORCHIDEAE, Benth. \& Hook. f. iii. 497 .

APLECTRA, Kafin. (at. 18 182 s)

hyemale, Torr. l. c.-Am. bor.

APLECTRUM, Blame, in Flora, xiv. (1531) $502=\mathbf{A n}$ plectrum, A. Gray (Melast.

confine, Blume, Mus. Bot. Lugd, Bat. i. $\$ 9$ = Anpl. coafine myrtiforme, Naud, in Ann. Se. Nat. Ser. III. xv, 155I s05. Medinilla myrtifurmis

nodosum, Blume, Mus. Bot. Lugd. Bat. i. Si-Aapl nudusum. 


\section{APLECTRUM :}

ovalifolium, Naud. ex A. Gray, Bot. U. St. Expl. Exp. i. $597=$ Allomorpha ovalifolia.

pallens, Blume, Mus. Bot. Lugd. Bat. i. $38=$ Anplectrum pallens.

rostratum, Blume, in Flora, xiv. (1831) 502=Anpl. rostratum.

stipulare, Blume, 1. c. $503=$ Anpl. stipulare.

viminale, Blume, 1. c. $502=$ Anpl. viminale.

APLEURA, Phil. in Linnaea, xxxiii. (1864-65) 89. UMBELLIFERAE, Benth. \& Hook. f. i. 875.

nucamentacea, Phil. l. c. 90.-Chili.

APLEXIA, Rafin. Neogenyt. 4 (1825)= Leersia, Sw. (Gram.)

virgata, Rafin. in Ser. Bull. Bot. $220=$ L. virginica, virginica, Rafin. Neogenyt. $4=\mathrm{L}$. virginica.

APLILIA, Rafin. New F1. Am.iii. 93 (1836)=Fraxinus, Tourn. (Oleac.)

laciniata, Rafin. 1. c. =F. excelsior. macrophyla, Rafin. 1. c. =F. excelsior,

APLINA, Rafin. F1. Tellur.iv. $119(1836)=$ Staehelina, Linn. (Compos.).

fuscata, Rafin. 1. c. = S. unifloscula.

APLOCA, Neck. Elem. i. $255(1790)=$ Periploca, Tourn. (Asclep.).

APLOCARYA, Lindl. Bot. Reg. (1844) sub t. $46=$ Dolia, Lindl. (Convolv.) divaricata, Lindl. 1. c.-Chili.

APLOCHIAMIS, Steud. Nom. ed. II. i. 309, in syn. (1840) sphalm. = APALOCHLAMYS, Cass. $=$ Cas sinia, $\mathrm{R}$. Br. (Compos.).

APLOLEIA, Rafin. Fl. Tellur, ii. 17 (1836)= Tradescantia, Linn. (Commelin.) diffusa, Rafin. I. c.--Hab.?

APLOLOPHIUM, Cham. in Linnaea, vii. (1832) 556. BIGNONIACEAE, Benth, \& Hook. f. ii. 1038. Haplolophium, Endl. Gen. 712 (1839)

Blanchetii, DC. Prod. ix. 192.--Bras.

bracteatum, Cham. in Linnaea, vii. (1832) 556.-Bras. Lundii, DC. Prod. ix. 192.-Bras.

APLOPAPPUS, Cass, in Dict. Sc. Nat. 1vi. 168 (1828). COMPOSITAE, Benth. \& Hook. f. ii. 253.

Acamphopappus, A. Gray, in Proc. Am. Acad. viii. (1873) 634

Chronlema, Bernh. Del. Sem. Hort. Erf. (1840).

Croilema, Heynh. Nom. ii. 171 (1846).

Croptilon, Rafin. F1. Tellur. ii. 47 (1836).

Eriocarpum, Nutt, in Trans. Am. Phil. Soc. Ser. II. vii. (1841) 320 .

Haplopappus, Endl. Gen. 385 (1838).

Homopappus, Nutt, in Trans. Am. Phil. Soc. Ser. II. vii. (1841) 330.

HoOREBEKIA, Corneliss. in Mussch. Hort. Grand, 120 (1817), nomen princeps.

Isopappus, Torr. \& Gray, Fl. N. Am. ii, 239 (1841)

Prionopsis, Nutt. in Trans. Am. Phil. Soc. Ser. II vii. (1841) 329.

Pyrrocoma, Hook. F1. Bor. Am. i. 306. t. 107 (1833).

Sideranthus, Fras. ex Sweet, Hort. Brit. ed. I. $227(1826)$

Stenotus, Nutt. in Trans. Am. Phil. Soc. Ser. II. vii. (1841) 334.

acaulis, A. Gray, in Proc. Am. Acad. vii. (1868) 353. - Calif.

acerosus, Bert. ex Phil. in Linnaea, xxviii. (1856) 724. -Chili.

acuminatus, DC. Prod, v, $348=$ Iencopsis sericeus.

alpigenus, Torr. \& Gray, Fl. N. Am. ii. $241=$ Aster pulchellus.

alternifolius, Stend. Nom. ed. II. i. 87, sphalm.= chrysanthemifolius.

anthylloides, Meyen \& Walp. in Nov. Act. Nat. Cur. xix. Suppl. i. (1843) ¿61.-Chili.

apargioides, A. Gray, in Proc. Am. Acad. vii. (1868) 354.-Calif.

araucanus, Phil. in Anal. Univ. Chil. (1873) 491.Chili.

arbutoides, Remy, in C. Gay, Fl. Chil. iv. 53.-Chili. arenarius, Benth. Bot. Voy. Sulph. 24 (Asteris sp.?).Calif.

argenteus, Steud. Nom. ed. II. i. 112.-Chili.

\section{APIOPAPPUS :-}

rmerioides, A. Gray, Color. Exp. Surv. Bot. (1860) 16.-N. Mexic.

aureus, A. Gray, Pl. Fendl. 76.--Texas.

baccharoides, Benth. Bot. Voy. Sulph. $24=$ Solidago occidentalis.

Baylahten, Remy, in C. Gay, Fl. Chit. iv. 42.-Cbili. bellidioides, Hook. f. in Hook. Lond. Journ. Bot. vi (1847) $112=$ Erigeron pappochroma.

Berberidis, A. Gray, Syn. Fl. N.Am. i. II. 126.-Calif Berterii, DC. Prod. v. 348.-Chili.

blephariphyllus, A. Gray, P1. Wright. i. $97=$ Aster gymnocephalus.

Bloomeri, A. Gray, in Proc. Am. Acad. vi. (1865) 541.-Am. bor.

Brandegei, A.Gray, Syn. Fl.N.Am. i. II. 132,-二Am. bor bustillosianus, Remy, in C. Gay, Fl. Chit.iv. 49.-Chili caespitosa, Nutt. in Trans. Am. Phil. Soc. N. S. vii (1841) 330.-Chili.

calendulaceus, Griseb. in Goett. Abh. xxiv. (1879) 179. - Reg. Argent.

canescens, DC. Prod. v. $349=$ Chrysopsis villosa.

carthamoides, A. Gray, in Proc. Acad. Sc. Philad. (1863) 65. -Am. bor:

cervinus, Rothrock, in Wheeler, Geogr. Surv. 40. t. 6.Am. bor.

cervinus, S. Wats. in Am. Natural. vii. (1873) $301=$ nanus.

Chamissonis, DC. Prod. v. 347.-Chili

chrysanthemifolius, $D C$. $l$. c. 348.-Chili

ciliatus, $D C . l$. c. 346.-Am. bor.

coronopifolins, DC. l.c. 347.-Chili.

Coulteri, Harv. \& Gray, ex A. Gray, P1. Fendl. $75=$ spinulosus.

croceus, A. Gray, in Proc. Acad. Sc. Philad. ' 1863 (1864) 65.-Am. bor.

cuneatus, A. Gray, in Proc. Am. Acad. viii. (1873) 635. Calif.

cuneifolius, Nutt. in Trans. Am. Phit. Soc. N. S. vii. (1841) 330.-Chili.

decurrens, Remy, in C. Gay, Fl. Chil. iv. 58.-Chili.

densifolius, Remy, l.c. 53.-Chili.

diffusus, DC. Prod. v. $349=$ Leucopsis diffusa.

Diplopappus, Remy, in C.Gay, Fl.Chil.iv.53.-Chili. discoideus, DC. Prod. v. $350=$ Bigelovia veneta.

divaricatus, A. Gray, in Pacif. Rail. Rep. iv. 99.Am. bor.

Doellianus, Phit. in Anal. Univ. Chil. (1873) 489.Chili.

ericoides, $D C$. Prod. v. 347.-Calif.

filifolius, DC. Prod. vii. $280=$ Erigeron filifolius

florifer, Hook. \&c Arn. Bot. Beech. Voy. $351=$ Townsendia florifera.

foliosus, $D C$. Prod. v. 346.-Chili.

Fremonti, A. Gray, in Proc. Acad. Sc. Philad. (1863) 65.-Am. bor.

glabratus, Phil. in Linnaea, xxviii. (1856) 727.-Chili.

glutinosus, Cass. ex DC. Prod. v. $347=$ coronopifolius, pulchellus.

glutinosus, DC. Prod. v. 347.-Chili

gracilis, A. Gray, Pl. Fendl. 76.-Texas.

gramineus, Benth. Pl. Hartw. 65 (err. typ. 61) = Chrysopsis graminifolia.

Greenei, A. Gray, in Proc. Am. Acad. xvi. (J.881) 80 -Am. bor

grindelioides, DC. Prod. v. 348.-Chili.

Gunnii, Hook. f. in Hook. Lond. Journ. Bot. vi. (1847)

111. = Erigeron pappochroma

gymnocephalus, DC. Prod. v. $346=$ Aster gymnocephalus.

Haenkei, DC. 1. c. $349=$ Corethrogyne filaginifolia.

Hallii, A. Gray, in Proc. Am. Acad. viii. (is72) 389 -Oregon.

hirtellus, Phil. in Linnaea, xxviii. (1856) 726.-Chili.

hirtus, A. Gray, Syn. Fl. N.Am. i. II. 127.-Am. bor. hispidulus, DC. Prod. v. 348.-Chili.

Hookerianus, A. Gray, Syn. Fl. N. Am. i. II. 131.Texas.

Hookerianus, DC. Prod. vii. 279.-Chili.

Hookerianus, A. Gray, Pl. Lindh, i. $40=$ divaricatus.

Hoorebelia, DC. Prod.v. 346.-Chili.

Hawellii, A. Gray, Syn. Fl. N. Am. i. II. 446.-Oregon. hypoleucus, Turcz. in Bull. Soc. Nat. Mosc. xxiv. (1851) I. $177=$ Eigelovia hypoleuca.

ilicifolius, Remy, in C. Gay, Fl. Chil. iv. 55.-Chili. illinitus, Phil. in Linnaea, xxviii. (1856) 727.-Chili. integrifolius, T. C. Porter, ex A. Gray, in Proc. Am. Acad. xvi. (1881) 79.-Am. bor.
APLOPAPPUS :-

inuloides, Torr, \& Gray, Fl. N. Am. ii. $241=$ uniflorus, junceus, Greene, in Bull. Acad. Calif. i. (1884) $190=$ spinulosus.

lanatus, Hook.f. in Trans. Linn. Soc. xx. (1847) 215 -Ins. Galapag.

lanceolatus, Torr. \& Gray, Fl. N. Am, ii, 241.-Calif. lanuginosus, A. Gray, Bot. U. St. Expl. Exped. ii. 347. -Am. bor.

laricifolius, A. Gray, Pl. Wright. ii. 80.-N. Mexic.

Lastarrianus, Remy, in C. Gay, Fl. Chil.iv. 45.-Chili. linearifolius, Buckl. in Proc. Acad. Sc. Philad. ' 1861 (1862) $457=$ Maccharis texana ㅇ.

linearifolius, $D C$. Prod. v. 347-C-Calif.

Lyallii, A. Gray, in Proc. Acad. Sc. Philad. ' 1863 (1864) 64.-A Am. bor.

Macraeanus, A. Gray, in Proc. Am. Acad. v. (1861) 122.-Chili.

macrocephalus, DC. Prod. v. 348.-Chili.

Macronenia, A. Gray, in Proc. Am. Acad. vi. (1864) 542.-Am. bor.

marginalis, Phil. in Linnaea, xxxiii. (1864-65) 139.Chili.

marginatus, Griseb. Cat. Pl.Cub. 149.-Cuba.

medicinalis, Phil. in Linnaea, xxviii. (1856) 729.Chili.

Menziesii, Torr. \& Gray, F1. N. Am. ii. $241=$ Bigelovia Menziesii.

Meyenii, Walp. in Nov. Act. Cur.xix. Suppl. i. (1843) 261-Chili.

mollis, A. Gray, in Proc. Am. Acad. xvi. (1881) $80=$ Greenei.

monactis, A. Gray, in Proc. Am. Acad. xix. (1883) 1. -Calif.

mucronatus, Hook. E Amn. Bot. Beech. Voy. 147.-Chili. multicaulis, A. Gray, in Am. Natural. viii. (1874) 213. -Am. bor.

namus, Eaton, in Bot. King, Exped. 159-Am, bor nevadensis, Kellogo, in Proc. Calif. Acad. iii. (1863) 9. Calif.

Nuttallii, Torr. E Gray, Fl. N. Am. ii. 242.-Am. bor. ochagavianus, Phil. in Linnaea, xxviii. (1856) 725 .Chili.

Orcuttii, A. Gray, in Proc. Am. Acad.xx. (1885) 297.Am. bor.

Palmeri, A. Gray, l. c. xi. (1876) 74.-Calif.

paniculatus, A. Gray, 1. c. vii. (1868) $354=$ racemusus.

paniculatus, Phil. in Anal. Univ. Chil. (1873) 490.Chili.

pappochroma, Hook. fo in Hook. Lond. Journ. Bot. vi. (1847) $111=$ Erigeron pappochroma.

Parryi, A. Gray, in Am. Foum. Sc. Ser. II. xxxiii. 1862) 239.-Am. bor.

parvilolius, A. Gray, in Proc. Am. Acad. v. (1861) 122.-Chili.

patagonicus, Phil. in Linnaea, xxviii. (1856) 726.Chili.

paucidentatus, Phil. in Anal. Univ. Chil. (1873) 492.-Chili.

pectinatus, Phil. in Linnaea, xxxiii. (1864-65) 140.Chili.

pedunculosus, Remy, in C. Gay, Fl. Chil. iv. 51.Chili.

phyllocephalus, DC. Prod. v。 $347=$ rubiginosus.

pinifolius, A. Gray, in Proc. Am. Acad. viii. (1873) 636.-Calif.

pinnatifidus, Nutt. in Trans. Am. Phil. Soc. N. S. vii. (1841) 330.-Am. bor.

Poeppigianus, A. Gray, in Proc. Am. Acad. v. (1862) 121.-Chili

polyphyllus, Phil. in Linnaea, xxx. (1859-60) 192.Chili.

prunelloides, DC. Prod. v. 346.-Chili.

pulchellus, $D C$. I. c. 347.-Chili

pygmaeus, A. Gray, in Am. Fourn. Sc. Ser. II. xxxiii (1862) 239.-Am. bor.

racemosus, Torr. in Sitgreave, Rep. 162.-Am. bor.

racicans, Remy, in C. Gay, Fl. Chil. iv. 45.-Chili.

ramulosus, DC l'rod. $v, 350=$ Baccharis ramulosa.

reflexus, Phil. in Linnaea, xxviii. (1856) 728.-Chili.

Remyanus, Wedd.Chlor. And. i. 210.-Chili.

Rengifoanus, Remy, in C. Gay, Fl. Chil. iv. 43.Chili.

resinosus, A. Gray, Bot. U. St. Expl. Exped. ii. $346=$ nanus.

reticulatus, Phil. in Linnaea, xxviii. (1856) 725.Chili. 


\section{APLOPAPPUS:}

rigidus, Phil. Fl. Atac. 30 -Chili.

rubiginosus, Torr. \& Gray, Fl. N. Am. ii. 240.Am. bor.

scaposus, DC. Prod. v. $350=$ Leucopsis scaposa scaposus, Remy, in C. Gay, Fl. Chil, iv, 50.-Chili. scrobiculatus, DC. Prod. v. 348.-Chili.

sericeus, $D C$. . . C. 349.-Chili.

sericeus, Phil. in Linnaea, xxviii. (1856) $724=$ Poeppigianus.

sphaerocephala, Harv. \& Gray, ex A. Gray, Pl. Fendl. 76.-Calif.

spinulosus, Phil. in Anal. Univ. Chil. (1873) 490. Chili.

spinulosus, DC. Prod.v. 347.-Am. bor.

squarrosus, Hook. E Arn. Bot. Beech. Voy. 146.-

Calif.

stellatus, Hook. f. in Lond. Journ. Bot. vi. (1847) 112 $=$ Erigeron pappochroma.

stelliger, Remy, in C. Gay, Fl. Chil. iv. 52.-Chili.

stenophyllus, A. Gray, Bot. U. St. Expl. Exped. ii. 347. - Calif.

stoloniferus, $D C$. Prod v 349 - Mexic

suffruticosus, Eaton, in Bot. King, Exped. $159=$ Watsoni.

suffruticosus, A. Gray, in. Proc. Am. Acad. vi. (1865) 542.-Calif.

tasmanicus, Hook. f. in Lond. Journ. Bot. vi. (1847)

$110=$ Erigeron pappochroma

tenuicaulis, Eaton, in Bot. King, Exped. $160=$ lanceolatus.

tortifolius, Torr. \& Gray, in Bost. Journ. Nat. Hist. v. (1845) $109=$ Aster tortifolius

uncibatus, Phil. in Linnaea, xxviii. (1856) 728.-Chili iniflorus, Torr. \& Gray, Fl.N.Am. ii. 241.-Am. bor velutinus, Remy, in C. Gay, Fl. Chil. iv. 57.-Chili.

villosus, Phil. in Linnaed, xxviii. (1856) 725.Chili. virgatus, Phil. in Anal. Univ. Chil. (1873) 491.-Chili. Watsoni, A. Gray, in Proc. Am. Acad. xvi. (1881) 79 -Am. bor

Whitneyi, A. Gray, l. c. vii. (1868) 353.-Calif

APLOPHYLLUM, Cass, in Dict. Sc. Nat. xxxiii. 472 (1824) = Mutisia, Linn. (Compos.)

decurrens, Cass. 1. c. = M. decurrens.

ilicifolium, Cass. 1. $\mathrm{c}_{\mathrm{r}}=\mathrm{M}$. ilicifolia

linearifolium, Cass. 1. $\mathrm{c}_{\mathrm{s}}=\mathrm{M}$. linearifolia

APLOPHYLLUM, A. Juss, in Mém. Mus. Par. xii. (1825 $464=$ Ruta, Linn.

acutifolium, G. Don, Gen. Syst, i. $780=$ R. acutifolia. arabicum, Boiss. Diagn. Ser. I. viii. $127=$ R. tuber culata.

arbusculum, Franch, in Revoil, Comali, 23.-Afr. trop.

armenum, Spach, in Ann. Sc. Nat. Sér. III. xi. (1849) $179=\mathrm{R}$. suaveolens

Besseri, Spach, 1. c. $=$ R. Besseri.

Biebersteinii, Spach, 1. c. $178=$ R. Buxbaumii.

Blanchei, Boiss. F1. Orient. 1. 937.-Oriens.

Boisscianum, Viv, \& Panc. in Mem. Ist. Venet. xy. (1870) $14=$ R. patavina.

Bourgaei, Boiss. Fl. Orient. i. 928.-Armenia.

Broussonetianum, Coss, in Bull. Soc. Bot. Fr. xx (1873) 244; xxii. (1875) 56, nomen.-Afr. bor.

Buhsei, Boiss. Fl. Orient, i. 926.-Persia.

Bungei, Trautv, in Act. Hort. Petrop. viii. (1883) 183 - Turkestan.

Buxbaumii, G. Don, Gen. Syst. i. $780=$ R. Buxbaumii. Buxbaumii, Schur, Enum. Pl. Transs. $140=$ R. sua veolens.

canaliculatum, Boiss, Diagn. Ser. I. viii. 128.-Persia, Candolleamum, Spach, ex Jaub. \& Spach, Tllustr. PI. Or. t. $270=$ R. glabra

cappadocicum, Spach, ex Jaub. \& Spach, 1. c. t. 263.Cappadoc.

Chesneyanum, Boiss. Fl. Orient. i. 941.-Mesopot.

ciliatum, Griscb. Spicil. Fl. Rumel. i. $130=$ R. suaveolens.

cilicicum, Buiss, Fl. Orient, i, 927.-Cilicia.

congestum, Jaub. \& Spach, Illustr. Pl. Or. iii. $77=\mathrm{R}$. suaveolens.

consanguineum, Bunge, ex Boiss. F1. Orient. i. 941.Persia.

cordatum, G. Don, Gen. Syst. i. $780=$ R. cordata,

coronatum, Griseb. Spicil. Fl. Rumel. i. $129=\mathrm{R}$. patavina.

corymbulosum, Boiss. Diagn. Ser. II. i. $116=$ R. Bux. baumii.

\section{APILPHYLLUM :}

crenulatum, Boiss. Diagn, Ser. II. i. 117.-Beluchist

dahuricum, Juss. in Mém. Mus. Par, xí. (1825) 464

Ruta dahurica.

davuricum, Ledeb. F1. Ross i. $492=$ praec

dichotomum, G. Don, Gen. Syst. i. $780=$ R. dichotoma. dichotomum, Griseb. Spicil. Fl. Rumel, i. $131=\mathrm{R}$. Buxbaumii.

elatum, Fisch. \& Mey. ex Kar. in Bu1l. Soc. Nat. Mosc. (1839) 149 - - Turcomania.

erythraeum, Boiss. Diagn. Ser. II. i. 114.-Afghan.

filifolium, Spach, ex Jaub. \& Spach, Illustr. Pl. Or. t. 265.-Persia.

flexuosum, Boiss. Diagn. Ser. II. i. 118.-Afghan.

fruticulosum, G. Don, Gen. Syst. i. $780=$ R. fruticulosa.

furfuraceum, Bunge, in Boiss. F1. Orient. i. 934.Persia.

glaberrimum, Bunge, 1. c. 930.-Persia

glabrum, G. Don, Gen. Syst. i. $780=$ R. glabra

Griffithianum, Boiss. Diagn. Ser. II. i. 115.-Afghan.

halepense, Spach, in Jaub. \& Spach, Illustr. Pl. Or. t. $266=\mathrm{R}$. Buxbaumii.

hirsutum, Regel \& Schmalh. ex Regel, P1. Nov, Fedsch, 17.-As. temp. or

hispanicum, Spach, in Ann. Sc. Nat. Sér. III. xi. (1849) $176=\mathrm{R}$. linifolia

hispidulum, Bunge, in Boiss. Fl. Orient. i. 933.Persia.

Kotschyi, Spach, in Ann. Sc. Nat. Sér. III. xi. (1849) 186.--Persia

Korvalenskyi, Stschég. in Bull. Soc. Nat. Mosc. xxiv. 1851) II. 467.-Reg. Caticas

lasianthum, Bunge, in Schrift. Naturf. Ver. Riga, i. 1847) 206 ; et Pl. Lehm. 239.-Turkest.

latifolium, Kar. \& Kir. in Bull. Soc. Nat. Mosc. (1841) 398.-As. cent.

lineare, G. Don, Gen. Syst. i. $780=$ R. linearis.

linifolium, G. Don, 1. c. = R. linifolia.

linifolium, Reichb, ex Nym. Consp. $142=\mathrm{R}$. patavina. linifolium, Schur, Enum. Pl. Transs. $140=\mathrm{R}$, suaveolens.

longifolium, Boiss. Diagn. Ser. I. viii. 127.-Palaestin. mesopotamicum, Boiss. 1. c. Ser. II. i. $116=$ R. Buxbaumii.

myrtifolium, Boiss. 1. c. Ser. I. i. 63.-As. Min

obtusifolium, Ledeb. Fl. Ross. i. $490=$ R. obtusifolia

patarinum, G. Don, Gen. Syst. i. $780=$ R. patavina,

pedicellatum, Bunge, ex Boiss. F1. Orient. i. 925.Persia.

perforatum, Kar. \& Kir. in Bull. Soc. Nat. Mosc.

1841) $397=$ R. acutifolia.

pilosum, Franch. in Ann. Sc. Nat. Sér. VI. xy. (1883) 248, t. 13.-Turkest.

pilosum, Sczegl. ex Turcz. in Bull. Soc. Nat. Mosc. xxxii. (1859) I. 273.-Persia.

propinquum, Spach, in Ann. Sc. Nat. Sér. III. xi. (1849) 189.-Mesopot.

ptilostylum, Spach, ex Jaub. \& Spach, Illustr. Pl. Or. t. 267.-Persia.

pubescens, Boiss. Voy. Bot. Espagme, i. $371=\mathrm{R}$. linifolia.

pubescens, G. Don, Gen. Syst. i. $780=$ R. pubescens.

pumilum, Boiss. Diagn. Ser. I. i. 62.-As. Min.

Reuteri, Boiss. 1. c. I. v. 87.-Calia.

robustum, Bunge, in Schrift. Naturf, Ver. Riga, (1847) 208, et P1. Lehm. 249. - Persia,

rosmarinifolium, G. Don, Gen. Syst. i. $781=R$. rosmarinifolia.

Sieversii, Fisch. in Schrenk, Enum. Pl. Nov. $89=\mathrm{R}$ acutifoliz.

spathulatum, Reichb. ex Nym. Consp. $143=$ R. Buxbaumii.

Stocksianum, Boiss. Diagn. Ser. II. i. 117,-Beluchist suaveolens, G. Don, Gea. Syst. i. $780=$ R. suaveolens suaveolens, Sweet, Hort. Brit. ed. III. $126=$ R. Buxbaumii.

subcordatum, Bunge, in Boiss. Fl. Orient. i. 932.Persia.

sulphureum, Boiss. Diagn. Ser. I. v. 87.-As. Min.

sylvaticum, Boiss. 1. c. viii. 126,-Syria.

tauricum, Spach, in Ann. Sc. Nat. Sér. III. xi. (1S49) $178=R$. taurica.

Tchihatchewi, Boiss. Diagn. Ser. II. vi. $41=$ sulphureum.

telephioides, Boiss. Fl. Orient. i. 929.-Cappadoc.

tenue, Boiss. 1. c. 932.-Armenia.

thesioides, G. Don, Gen. Syst. i. $780=\mathrm{R}$. thesioides.
APLOPHYLLUM :-

trichostylum, Bunge, in Boiss. F1. Orient. i. 941. Persia.

tuberculatum, Juss, in Mém. Mus. Par. xii. (1825) 528. t. $17=\mathrm{R}$. tuberculata.

versicolor, Fisch. \& Mey. in Bull. Phys. Math. Akad. Pétersb. iii. (1845) $307=$ lasianthum.

villosulum, Boiss. \& Ilaussk. in Boiss, Fl, Orient. i. 936 -Syria.

villosum, G. Don, Gen. Syst. i. $780=$ R villosa.

virgatum, Spach, ex Jaub. \& Spach, Illustr. Pl. Or. t. 267 -Persia.

vulcanicum, Hoiss. \& Heldr. Diagn. Ser. I. viii. 126. Lycaonia.

APLOSTELLIS, Thou. Orch. Iles Afr. t. 24 (1822) Pogonia, Juss. (Orchid.

anbigua, A. Rich. in Mém. Soc. Hist. Nat. Par. iv (1828) $36=\mathrm{P}$. Thouarsii.

simplex, Thow. Orch. Isles Afr. t. $24=\mathrm{P}$. Thouarsii.

truncata, Lind1. Gen, et Sp. Orch. 411.-Ins, Mascar.

APLOSTEMON, Rafin, in Journ. Phys. Ixxxix. (181y $105=$ Scirpus, Linn, etc. (Cyper.)

atropurpureum, Rafin. 1. c. = Eleocharis atropurpurea. bracteatum, Iafin. 1. $\mathrm{c}_{\mathrm{s}}=\mathrm{S}$. bractealus. compressum, Rafin. l. c. $=\mathrm{S}$. Caricis.

polytrichoides, Rafin. 1. c. = Fimbri-tylis polytrichoides. triquetrum, Rafin. 1. c, = Fimbristylis argentea.

APLOSTYLIS, Rafin. Fl. Tellur. iv. 91 (1836)= Cus cuta, Linn, (Convolv.)

lupuliformis, Rafin. 1. c. = C. lupuliformis.

APLOTAXIS, DC in Guill. Archiv. Bot. ii. (1833) 330 =Saussurea, DC. (Compos.).

albescens, DC. Prod. vi. $5 \pm 0=$ S. albescens.

andryaloides, DC. 1. c. $512=\mathrm{S}$. sorocephala.

auriculata, DC. 1. c. $541=\mathrm{S}$. hypoleuca.

australasica, F. Muell. Fragm, i. $36=$ S. affinis,

Bungei, DC. Prod, vi. $539=\mathrm{S}$. affinis.

Bungei, Less. ex Ledeb. F1. Ross. ii. $753=$ Leazea salina.

caespitosa, DC. Prod. vi. $539=$ S. taraxacifoliz.

candicans, DC. 1. c. $540=\mathrm{S}$. candicans.

Candolleana, DC. 1. c. $541=\mathrm{S}$. Candolleana.

carthamoides, $\mathrm{Ham}$. in DC. 1. c. $540=\mathrm{S}$, afinis,

cirsoides, DC. 1. c. $=$ Cnicus arvensis.

deltoideo, DC. 1. c. $541=\mathrm{S}$, delioidea

denticulata, DC. 1. c. $539=\mathrm{S}$. denticulata.

discolar, DC. 1. c. $541=$ S. piptathera.

fastuosa, Decne. in Jacquem. Voy. Bot. 97. t. 105=S denticulata.

foliosa, Edgew. in Trans, Linn. Soc. xx. (1846) $77=$ S. foliosa.

Frolovii, DC. Prod. vi. $538=$ S. Frolovii.

gnaphalodes, Royle, Illustr. Bot. Himal. 251. t. 59 f. $1=\mathrm{S}$. sorocephala.

gossypina, DC. Prod. vĩ. $541=$ S, gossvpiphom involucrata, Kar. \& Kir. in Bull. Soc. Mat. Mosc.

(1842) 389-As, temp.

Facea, Klotzsch, in Bot. Ergeb. Waldem. Reise, 79. $79=\mathrm{S}$. Jacea.

Lappa, Decne. in Jacquem. Voy. Bot. 96. t. $104=\mathrm{S}$ Lappa.

centodontoides, DC. Coll. Mém. ix. 29. t. 10 'Prod. vi.

$539)=$ S. Kunthiana

multicaulis, DC in Deless. Ic, Sel. iv, t. $68=\mathrm{S}$. affinis.

nepalensis, DC.1.c. t. $67=\mathrm{S}$. Eriostemon.

nivea, DC. Prod. vi. $541=$ S. delioided.

obvallata, DC. in Deless. Ic. Sel, iv. t. $t^{3} 9=\mathrm{S}$. obvallata.

pungens, DC. Prod, vi. $539=$ Cnicus arvunsis.

Roylei, DC. Prod, vi, $535=$ S. Ruylci

scaposa, Edgew, in Trans. Linn. Soc. xx. $\left(1 \$ 40^{\circ} ; \mathbf{b}^{\circ}=\mathrm{S}\right.$. candicans.

Simpsoniana, Ficld. \& Gardn. Sert. Pl. L $26=$ S andryaluides

soroctphala, Schrenk, Enum. PI. Nov. (1S 1 ) $\{S=S$. sorucephala.

taraxacifolia, DC. Proxl, vi. 532 = S. Aaraxacifolia.

uniflora, DC. 1. C. $539=\mathrm{S}$. unillora.

Al'LOTHICA, Mtart. ex Cham, in Linuaca, $y$, 1530.y

Froelichia. Moench. Amarant?

interropta, Mart. ex C'bau. 1. c. - 16. intcrrupta. 
APIUDA, Linn, Sp. Pl. ed. I. 82 (1753). GRA. MINEAE, Benth. \& Hook. f. iii. 1137. Calamina, Beauv. Agrost. 128. t. 23. f. 1 (1812). Diectomis, Beauv. 1. c. 132. t. 23. f. 5 (1812). aristata, Linn. Cent. ii. 7; Sp. Pl. ed. II. $1487=$ mutica.

ciliata, Anderss. in Oefver. Vet. Acad. Stockh. (1855) 177.- - Ind. or.

communis, Nees \& Arn. in Nov. Act. Nat. Cur. xix. Suppl. i. (1843) $194=$ mutica.

Cumingii, Buese, ex De Vriese, Pl. Ind. Bat. Reinw. $105=$ mutica.

digitata, Linn. f. Suppl. $434=$ Polytoca bracteata

distachya, Beauv. Agrost. 133, $151=$ Andropogon distachyus.

geniculata, Roxb. Hort. Beng. 8; F1. Ind. i. $327=$ mutica.

gigantea, Spreng. Syst. i. $290=$ matica.

glauca, Schreb. Graes, ii, $99=$ mutica

Gryllus, Beauv. Agrost. $133=$ mutica.

Gryllus, Presl, Cyp. \& Gram. Sic. $55=$ Chrysopogon Gryllus

humilis, Kunth, Enum. Pl. i. $517=$ mutica.

imberbis, Steud. Nom. ed. II. i. 251, sphalm. = Anthistiria imberbis.

inermis, Regel, in Act. Hort. Petrop. vii. (1880) $658=$ mutica.

Kobila, Buch.-Ham. ex Nees, in Nov. Act. Nat. Cur. xix. Suppl. i. (1843) $194=$ mutica.

microstachya, Nees, l. c. $193=$ mutica.

mucronata, Steud. Syn. PI. Gram. 404=mutica

mutica, Linn. Sp. Pl. 82.-As. trop.; Polynes. Austral.

pedicellata, Buese, ex De Vriese, P1. Ind. Bat. Reinw. $105=$ mutica

rostrata, Arn. \& Nees, in Nov. Act. Nat. Cur, xix. Suppl. i. (1843) $194=$ mutica

scabra, Anderss. in Oefver. Vet. Acad. Stockh. (1855) $179=$ mutica

scirpoides, Walt. F1. Carol. 250 (pl. dubia)-Carolina villosa, Schreb. Graes. ii. $92=$ mutica.

Zeugites, Linn. Syst. ed. X. 1306; P1. Jam. Pugill. 30 Zeugites americana.

Zeygites, Aubl. Pl. Gui. ii. $933=$ Ichnanthus pallens.

APOBALLIS, Schott, in Oestr. Bot. Zeitschr. (1858) 318 =Schismatoglottis, Zoll. (Aroid.)

neglecta, Schott, 1. c. $317=\mathrm{S}$. rupestris

APOCHORIS, Duby, in DC. Prod. viii. 67 (1844). PRIMULACEAE, Benth. \& Hook. f. ii. 635. pentapetala, Duby, l. c.-China.

APOCOPIS, Nees, in Proc. Linn. Soc. i. (1841) 93. GRAMINEAE, Benth. \& Hook. f. iii. 1128.

Amblyachyrum, Hochst. ex Steud. Syn. Pl. Gram. $413(1885)$

Beckettii, Thw. ex Trimen, Cat. P1. Ceylon, $107=$ Wightii.

Royleana, Nees, in Proc. Linn. Soc. i. (1841) 94.Ind. or.

tridentata, Benth. in fourn. Linn. Soc, xix. (1882) 67. -Ind. or.

Wightii, Nees, ex Steud. Syn. Pl. Gram. 377.-Ind. or.; China.

Wrightii, Munro, in Proc. Am. Acad. iv. (1864-65) $363=$ Wightii.

APOCOPSIS,Meissn. Gen. $429(328)(1843)=$ Apocopis, Nees (Gram.)

APOCYNUM, [Tourn.] Linn. Syst. ed. I. (1735) Gen. ed. I. 65 (1737). APOCYNACEAE, Benth. \& Hook f ii. 716 .

QUirivelia, Poir. Eneyc. vi. 42 (1804).

Acouci, Aubl. Pl. Gui. i. $274=$ Forsteronia Acouci.

africanum, Lour. Fl. Cochinch.i. 168 (Qnid?).-Zanzib. agglomeratum, Poir. Encyc. Suppl. i. 407.-Ins. S. Doming.

alterniflorum, Lour. Fl. Cochinch. i. 168=Strophanthus alterniflorus.

androsaemifolium, Linn. Sp. Pl. 213.-Am. bor.

bursiflorum, Noronha, in Verh. Batav. Gen. v. (1790) ed. I. Art. IV. 5.-Malaya.

canariense, Lam. Encyc. i. 212.-Ins. Canar.

cannabinum, Linn. Sp. Pl. 213.-Am. bor.

citrifolium, Descourt. F1. Med. Antill. iii. 180. t. $191=$ Echites citrina.

compressum, Moench, Meth. $464=$ venetum.

\section{APOCYNUM :}

cordatum, Mill. Gard. Dict. ed. VIII. n. $10=$ Rhabda denia cordata.

cordatum, Thunb. Prod. Pl. Cap. $47=$ Astephanus cordatus.

cordifolium, Tenore, ex Steud. Nom. ed. II. i. $113=$ praec.?

cotinifolium, Lam. Encyc. 1. 215.-Java.

crassifolium, Salisb. Prod. $149=$ Ichnocarpus frutescens. cumanense, Willd. ex Roem. \& Schult. Syst. vi. $796=$ Metaplexis fimbriatum.

erectum, Vell. Fl. Flum. 123 ; iii. t. 87 = Barjonia racemosa.

fliforme, Thunb. Prod. PI. Cap. $47=$ Eustegia filiformis

floristratum, Noronha, in Verh. Batavं. Gen. v. (1790) ed, I. Art. IV. 5=Strophanthus dichotomus.

foetidum, Burm. f. FI. Ind. $71=$ Paederia foetida

frutescens, Afzel. Remed. Guin. Coll. iv. $28=$ Ichnocarpus Afzelii.

frutescens, Linn. Sp. Pl. $213=$ Ichnocarpus frutescens.

hastatum, Thunb. Prod. PI. Cap. $47=$ Eustegia hastata.

Hendersonii, Hook. f. in Hume \& Henders. Lahore to Yarkand, 327. - Turkest.

hypericifolium, Ait. Hort. Kew. ed. I. i. $304=$ cannabinum.

indicum, Lam. Encyc. 1. $214=$ reticulatum.

Fuventas, Lour. Fl. Cochinch. $167=$ Tylophora ovata.

lanceolatum, Thunb. Prod. P1. Cap. 47=Astephanus lanceolatus.

lineare, Linn. f. Suppl. $169=$ Astephanus linearis

maculatum, Descourt. F1. Med. Antill. iii. 177. t. 190 $=$ Echites maculata.

minutum, Linn. f. Suppl. i. $169=$ Eustegia hastata.

mucronatum, Blanco, F1. Filip. ed. I. $852=$ Toxocarpus gracilis.

muscipulum, Moench, Meth. 464=androsaemifolium

nervosum, Mill. Gard. Dict. ed. VIII. n. 9.--Vera Crux.

obliquum, Mill. 1. c. n. $8=$ Echites umbellata odoratissimum, Lour. ex Pritz. Ic. Indd. 83.-Malaya. orixense, Rottler, ex Hook, f, Fl, Brit. Ind. iv, $6=$ Cryptolepis elegans.

paniculatum, Lam. Encyc. i, $214=$ Forsteronia Acouci. pictum, Schrenk, in Bull. Phys. Math. Acad. Pétersb. ii. (1844) 115.-Soongaria.

piscatorium, Dougl. ex A. DC. in DC. Prod. viii. 439 = cannabinum.

platyanthum, Salzm. ex A. DC. 1. c. $594=$ Philibertia cynanchoides.

pubescens, R. Br. in Mem. Wern. Soc. i. (1809) $68=$ cannabinum.

purpureum, Tausch, in Flora, xix. (1836) II. 385.Am. bor.

rectinerve, Salzm, ex Decne, in DC. Prod. viii, $603=$ Blepharodon pallidum.

reticulatum, Herb. Madras, ex Wall. Cat. n. 8247 $=$ Decalepis Hamiltonii.

reticulatum, Linn. Sp. $P$ l. 214.-.Ind, or

reticulatum, Lour. F1. Cochinch.208=Parsonsia Helicandra.

salicifolium, Medic. in Act. Acad. Theod. Palat, vi. Phys. (1790) $406=$ Gomphocarpus fruticosus.

salicifolium, Willd. ex Roem. \& Schult. Syst. iv. 796

-Ins. S. Doming.

scandens, Mill. Gard. Dict. ed. VIII. n. $5=$ Echites asperuginis.

sibiricum, Jacq. Hort. Vindob. iii. $37=$ cannabinum.

sibiricum, Pall. ex Roem. \& Schult. Syst. iv. $405=$ venetum.

soleare, Noronha, in Verh. Batav. Gen. v. (1790) ed. I, Art. 1V. 5.-Malava.

speciosissimum, Mill. Gard. Dict. èd. VIII. n. (= Haemadictyon suberectum).

stellatum, Noronha, in Verh. Batav. Gen. v. (1790) ed. I. Art. IV. 5.-Malaya.

stylospermum, Noronha, l. c.-Malaya.

syriacum, S. G. Gmel. Reise, ii. 198, $257=$ Calotropis procera.

tiliaefolium, Lam. Encyc. i. $214=$ Dregea volubilis. triflorum, Linn. f. Suppl. $169=$ Astephanus triflorus, umbellatum, Aubl. P1. Gui. i. 275=Thenardia umbellata.

umbellatum, Salzm. ex Decne. in DC. Prod, viii. 585 -Oxypetalum densiflorum.

venetum, A. DC. Prod. viil. $440 \doteq$ cannabinum

venetum, Linn. Sp. Pl. 213.-Reg. Mediterr.; Oriens As. bor.; Ind, or.

\section{APOCYNUM}

villosum, Mill. Gard. Dict. ed. VIII. n. 11.-Vera Crux.

viminale, Bassi, in Comm. Bonon. (1753) ex Roem. \& Schult. Syst. vi. $113=$ Sarcostemma viminale vincaefolium, Burm. f. Fl. Ind.71,-Ind, or, volubile, Vell. Fl. Flum. 123; ii. t. $88=$ Araujia calycina.

APODANTHERA, Arn. in Hook. Journ; Bot. iii. 274 (1841). CUCURBITACEAE, Benth. \& Hook. f. i. 834 .

argentea, Cogn. in Mém. Cour. Acad. Belg. 8vo xxviii. (1878) 42.-Bras.

aspera, $\operatorname{Cog} n$. l. c. $43 .-$ Mexic.

biflora, $\operatorname{Cog} n . l . c .-$ Ecuador.

Buraeavi, Cogn.l.c. 44.-Mexic.

Galeottii, Cogn l. c. 45.-Mexic

gracilis, Benth. Bot. Voy. Sulph. $99=$ Melothria fluminensis.

laciniosa, Cogn. in Mém. Cour. Acad. Belg. 8vo. xxviii. (1878) 12.-Bras.

Mandonii, $\operatorname{Cog} n . l$. c. 41-Bolivia.

Mathewsi, Arn. in Hook. Fourn. Bot. iii. (1841) 274 -Peruv.

mucronata, Cogn. in Mém. Cour. Acad. Belg. 8vo. xxviii. (1878) 40.-Peruv.

pedisecta, $\operatorname{Cogn}$. l. c. 17.-Bras

scabra, $\operatorname{Cog} n$. in Bull. Acad. Belg. Sér. II. xlix. (1880) 192.-Ecuador.

smilacifolia, Cogn. in Mém. Cour. Acad. Belg. 8vo. xxviii. (1878) 42.-Bras.

undulata, A. Gray, Pl. Wright. ii. 60.-N. Mexic

AFODANTHES, Poit. in Ann. Sc. Nat. Sér. I. iii. (1824) 422. t. 26. CYTINACEAE, Benth. \& Hook. f. iii. 118.

Frostia, Bertero, ex Guill. in Ann. Sc. Nat. Sér. II. ii. (1834) 19, in nota.

Pilostyles, Guill. in Ann. Sc. Nat. Sér. II. ii. (1834) 21 . t. 1.

SARna, Karst. in Nov. Act. Nat. Cur. xxvi. (1858) $920 . t, 65$.

Berterii, Gardn. in Hook. Ic. Pl. t. 655-Chili.

Blanchetii, Gardn. l. c. t. 655 b.-Bras.

Calliandrae, Gardn. l. c.t. 644.-Bras.

Caseariae, Poit. in Ann. Sc. Nat. Sér. I. iii. (1824 422. t. 26.-Am. austr.

Flacourtiae, Karst. in Linnaea, xxviii. (1856) 413.Venezuela.

APODOCEPHALA, Baker, in Journ. Linn.Soc. xxi. (1885) 417. COMPOSITAE.

pauciflora, Baker, l. c.-Madag.

APODOLIRION, Baker, in Journ. Bot. xvi. (1878) 74. AMARYLLIDEAE, Benth. \& Hook. f. iii. 722.

Bolusii, Baker, l. c. 75.-Afr. austr.

Buchanani, Baker, l. c.-Natal.

lanceolatum, Benth. \& Hook. f. Gen. iii. 722.-Afr.

Mackenii, Baker, in fourn. Bot. xvi. (1878) 75.Natal

APODOSTACHYS, Turcz, in Bull. Soc. Nat. Mosc. xxi. (1848) I. $557=$ Ercilla, A. Juss, (Phytolac.).

densiflora, Turez. 1. c. $=$ E. volubilis.

APODYNomene, E. Mey. Comm. P1. Afr. Austr. 111 $(1835)=$ Tephrosia, Pers. (Legum.).

aemula, E. Mey. 1 . c. $113=$ T. aemula.

diffusa, E. Mey. 1. c. $=$ T. diffusa.

grandiflora, E. Mey. 1. c. $111=$ T. grandiflora

macropoda, E. Mey. 1. c. $112=$ T. macropoda.

Meyeri, Presl, Bot. Bemerk. $57=$ T. grandiflora.

APODYTES, E. Mey. ex Bernh. in Linnaea, xii. (1838) 136 ; et ex Arn. in Hook. Journ. Bot. iii. (1841) 155 OLACINEAE, Benth. \& Hook, f. i. 351

Nothapodytes, Blume, Mus. Bot. Lugd. Bat. i. 248 (1850).

Rhaphiostylis, Planch. ex Benth, in Hook. Niger F1. 259 (1849).

acutifolia, Hochst. ex A. Rich. Tent. F1. Abyss. i. 92 $=$ dimidiata.

andamanica, Kurz, Andam. Rep. 33.--Ins. Andam.

Beddomei, Mast. in Hook. f. Fl. Brit. Ind. i. 588.Ind, or.

beninensis, Hook. f. in Hook. Ic. Pl. t. 778,-Afr. trop 
APODYTES :-

Benthamiana, Wight, Ic. t. 1153.-Ind. or. brachystylis, F. Muell. Fragm. ix. 149. - Austral

dimidiata, E. Mey. ex Bernh. in Linnaea, xii. (1838) 136. - Afr. austr.

Gardneriana, Miers, in Ann. \& Mag. Nat. Hist. Ser. 1I. ix. (1852) $389=$ Benthamiana

grandifolia, Benth. \& Hook. f. Gen, i. 352_-Madag.

mauritiana, Benth. \& Hook. f. l. c.-Ins. Mascar.

APOGANDRUM, Neck. Elem. i. $216(1790)=$ Erica, Linn.

APOGETON, Schrad, ex Steud. Nom. ed. II. i. 114 $(\mathbf{1 8 4 0})=$ Aponogeton, Linn. f. (Naiad.).

APOGON, Ell. Sketch, ii. 267 (1824). COMPOSITAE, Benth. \& Hook. f. ii. 509.

LAXANON, Rafin. New Fl. Am. ii. 16 (1836).

gracilis, DC. Prod. vii. 79.-Am. bor.

humilis, Ell. Sketch, ii. 267.-Am. bor

humilis, Nutt. in Trans. Am. Phil. Soc. N. S. vii. (1841) $424=$ gracilis.

lyratum, Nutt. in Journ. Acad. Philad. vii. (1834) 71 $=$ humilis.

Wrightii, A. Gray, Syn. Fl. N. Am. i. II. 411.Texas.

APOGONIA, Fourn. Gram. Mex. 63 ex Benth. \& Hook. f. Gen. iii. $1130(\mathbf{1 8 8 3})=$ Rottboellia, Linn. (Gramin.).

glabrata, Fourn. ex Hemsl. Biol. Centr. Am. Bot. iii. $521=$ Andropogon imberbis.

ramosa, Fourn. ex Hemsl. l. c. = R. aurita.

AlOLANESIA, Reichb. Nom. 154 (1841) = Apoplanesia, Presl (Legum.)

APOLEPSIS, Hassk. Cat. Hort. Bogor. Alt. 150 (1844) = Lepidagathis, Willd. (Acanth.).

dispar, Hassk. 1. c. $=$ L. repanda.

repanda, Nees, in DC. Prod.xi. $261=\mathrm{L}$. repanda.

APOLLINARIS, Linn. Syst. ed. I. (1735)= Nicotiana, Linn.? (Solan.)

APOLLONIAS, Nees, Laurin. Expos. 10 (1833). LAURINEAE, Benth. \& Hook. f. iii. 152.

Arnottii, Nees, Syst. Laurin.670.-Ind. or

barbusana, A. Br. in Verh. Befoerd. Gartenb. Preuss. xxi. (1852) $10=$ canariensis.

canariensis, Nees, Syst. Laurin. 696.-Ind. or.

seylanica, Thw. Enm. Pl. Zeyl. $253=$ Bcilschmiedia oppositifolia.

APOMAEA, Neck. Elem。ii. $24(1790)=$ Ipomoea Linn. (Convolv.).

APOMOEA, Stend. Nom. ed. II. i. $114(1840)=$ praec.

APONOA, Rafin. Sylva Tellur. 84 (1838)=Columnea, Linn. (Gesner.)

repens, $\mathrm{Rafin} .1$. $\mathrm{c}_{0}=\mathrm{C}$. scandens?

APONOGETON, Linn. f. Suppl. 32 (1781). NAIA. $D A C E A E$, Benth. \& Hook. f. iii. 1013.

AMOGETON, Neck. Elem. iii. 267 (1790)

Apogeron, Schrad. ex Stend. Nom. ed. II. i. 11 $(1840)$

Hydrogeton, Pers. Syn. i. 400 (1805)

Limnogeton, Edgew. in Lindl. Veg. Kingd. 210 (1847).

OUVIRANDRA, Thou. in Roem. Collect. 196 (1809); Gen. Nov. Madag. 2 (1810).

Spathium, Edgew, in Journ. As. Soc. Beng. (1842) 145.

abyssinicum, Hochst. ex A. Rich. Tent. Fl. Abyss. ii. 851.-Abyss.

angustifolium, Ait. Hort. Kew. i. 495.-Afr. austr.

Bernerianum, Hook. $f$. in Benth. \& Hook. f. Gen. iii.

1014.-Madag.

crinifolium, Lehm, ex Steud. Nom, ed. II. i. 114.Afr. austr.

crispum, Thunb. Nov. Gen. 73.-Zeylan

desertorum, Zeyh. ex Stcud. Nom. ed. II. i. 114.Afr. austr.

distachys, Ldgew. in Hook. Lond. Journ. Bot. iii (1844) $402=$ distacbyum.

\section{APONOGETON :-}

distachyum, Thunb. Nov. Gen. 74.-Afr. austr.

echinatum, Roxb. Hort. Beng. [87]; et Fl. Ind ed. Carey, ii. 210.-Ind. or.

elongatum, F. Muell. ex Benth. Fl. Austral. vii. 188. - Austral

fenestrale, Hook. f. in Benth. E Hook. f. Gen. iii.

1014.-Madag

Holubii, Oliver, in Hook. Ic. Pl. to 1470.-Afr. trop. junceum, Lehm. ex Steud. Nom. ed. II. i. 114.-Afr. austr.

leptostachyum, E. Mey. ex Baker, in Trans. Linn. Soc xxix. (1875) 158.-Afr. austr.

lineare, Vahl, Symb. Bot. iii. $51=$ monostachyon. microphyllum, Roxb. Hort. Beng. 26 ; Fl. Ind. ed. Carey, ii. 211.-Ind. or

monostachys, Edgew. in Hook. Lond. Journ. Bot. iii. 1844) $402=$ seq.

monostachyon, Linn.f. Suppl. 214.--Ind. or, ; China,

natalense, Oliver, in Hook. Ic. Pl. t. 1471.-Afr austr.

Rehmanni Oliver, l. c, 1471 B.-Afr. trop

spathaceum, E. Mey. in Drege, Zwei Pf. Docum. 165 nomen.-Afr. austr.

quadrangulare, Baker, in Fourn. Linn. Soc, xvili. (1881) 279.-Madag.

ulvaceum, Baker, l. c.-Madag.

undulatum, Roxb. Hort. Beng. 26 ; Fl. Ind. ed. Carey, ii. $211=$ crispum.

vallisnerioides, Baker, in Trans. Linn. Soc. xxix 1875) 158.-Afr. trop.

zosteraefolium, Schrad. ex Steud. Nom. ed. II. i. 114 (an lapsu $=$ Potamogeton zosteraefolius? Schum.) -Am. bor.

APOPHRAGMA, Griseb. Gen. et Sp. Gent. 163 (1839) Curtia, Cham. \& Schlecht. (Gentian.)

tenuifolium, Griseb. 1. c.-Guiana.

APOPHYLLUM, F. Muell, in Hook. Kew Journ, ix (1857) 306. CAPPARIDEAE, Benth.\& Hook. f. i. 109

anomalum, F. Muell. l. c. 307.--Austral,

APOPLANESIA, Presl, Symb. Bot, i. 63. t. 41 (1831). LEGUMINOSAE, Benth. \& Hook. f. i. 492 paniculata, Presl, l. c.-Mexic.

APOPLEUMON, Rafin. Fl. Tellur. iv. $72(1836)=$ Ipomoea, Linn. (Convolv.)

bignonioides, Rafin. 1. c. = I. bignonioides.

APORANTHUS, Bromf. Fl. Vect. $117(1856)=$ Trigo nella, Linn. (Legum.)

Trifoliastrum, Bromf. 1. c. $=$ T, ornithopodioides.

APORETIA, Walp. Ann. ii. $217(1851-52)=$ seq.

APORETICA, Forst. Char. Gen. 131. t. $66(1776)=$ Schmidelia, Linn. (Sapind) gemella, Blanco, Fl. Filip. ed. II. $203=$ S. Cobbe gemella, DC. Prod. i. $610=\mathrm{S}$. cochinchinensis. penicillata, Blanco, Fl. Filip. ed. I. $291=$ S. Cobbe pinnata, Forst. f. Prod, n, $392=$ S. Cobbe. pinnata, Hook. \& Arn. Bot. Beech. Voy. $61=$ Guioa lentiscifolia

ternata, Forst. Char. $132=\mathrm{S}$. Cobbe.

APOKOCACTUS, Lem. Illustr. Hortic. vii. (1860) Misc $67=$ Cereus, Linn, (Cact).

Baumanni, Lem. 1. c. =C. Baumanni.

colubrinus, Lem. 1. c. =C. colubrinus.

flagelliformis, Lem. 1, c. $=$ C. flagelliformis.

flagriformis, Lem. Cact. $58=$ C. Aagriformis.

APOROSA, Blume, Bijdr, 514 (1824), EUPHOR BIACEAE, Benth. \& Hook. f. iii. 282.

LEIOCARPUS, Blume, Bijdr. 581 (1825)

LEPIDOSTACHYS, Wall. Cat. n. 6816 (1832)

SCEPA, Lindl. Introd. Nat. Syst. ed. I1. 441 (1836)

Tetractinostigma, Hassk. Hort. Bogor, Descr. $55(1855)$

acuminata, Thw. Enum. Pl. Zeyl. 288.-Ind. or.

affinis, Baill. Etud. Gén. Euph. $645=$ Lindleyana.

arborea, Muell. Arg, in DC. Prod. xv. 11. 170 .- Java, arborescens, Muell. Arg. L. C.-Java.

aurita, Baill. Elsd. Gén. Euph.645.-Ins. Philipp. aurita, Miq. Fl. Ind, Bat, i. $11.191=$ microcalyx.

\section{APOROSA.}

australiana, Fi Muell. Census, 20-Austral.

Cumingiana, Baill. Etud. Gén. Euph. 645 = micro calyx.

dioica, Muell. Arg. in DC. Prod, xv. 11. $472=$ Roxburghii.

ficifolia, Baill.Adansonia, xi.(1873-76) 177.-Malaya; Cochinch.

frutescens, Blume, Bijdr. 514.-Java.

frutescens, Benth. Fl. Hongk, $317=$ microcalyx.

fruticosa, Muell. Arg. in DC. Prod. xv. II. 475.-Java. fusiformis, Thw. Enum. Pl. Zeyl.286.-Zeylan.

glabrifolia, Kurz, in fourn. Bot. xiii. (1875) 330.Ins. Nicobar.

lanceolata, Kurz, For. Fl. Burma, ii. $363=$ Plancho niana.

lanceolata, Thw. Enum. Pl. Zeyl. 288.-Zeylan.

latifolia, Thw. l.c.-Zeylan.

leptostachya, Benth. Fl. Hongk. $317=$ microcalyx

Lindleyana, Baill. Etud. Gén. Euph. 645 (Lynd.

leyana).-Ind, or.

lunatum, Kurz, in Fourn. As. Soc, Beng, x]ii. (1873) II. 239.-Malaya.

macrophylia, Muell. Arg. in DC. Prod. xv. II. 470.Burma.

microcalyx, Hassk. in Bull. Soc. Bot. France, vi. (185?)

714.-China; Austral.; Malaya.

microstachya, Muell. Arg. in DC. Prod. xy. II. 474.Burma.

Miqueliana, Muell. Arg.l. c.-Sumatra.

oblonga, Muell. Arg. in Linnaea, xxxii. (1863) 78.Burma.

Planchoniana, Baill. Elned. Gén. Euph. 645.-Burma. quadrilocularis, Muell. Arg. in DC. Prod. xv, II. 47 to. - Sumatra.

Roxburghii, Baill. Etud. Gén. Euph. 645.-Ind. or. sphaerocarpa, Mucll. Arg. in Flora, xlvii. (186.) $51:$ $=$ Lindleyana.

tetrapleura, Hance, in Fourn. Boto xiv. (1876) 260. Cambodin.

Thwaitesi, Baill. Etud. Gén. Euph. 645 =fusiformis.

Tulasneana, Baill. 1. c. = microstachya.

villosa, Baill. l. c.-Burma; Cochinch.

villosula, Kurz, in fourn. As. Soc. Beng. xlii. (1873 II. 239.-Burma.

APORRHIZA, Radlk, in Sitzb, Math. Phys, Acad. Muench. viii. (1878) 338. SAPINDACEAE. paniculata, Radlk. l. c. 339.-Afr. trop.

APORUM, Blume, Bijdr. 334.t. $39(1825)=$ Dendro bium, Sw. (Orchid.).

acinaciforme, Griff. in Calc. Journ. Nat. Hist. v. (18tú $370=$ D. acinaciforme

anceps, Lindl. in Wall. Cat. n. $2020=$ D. Nathanielis. anceps, Lind!. Gen. et Sp. Orch. $71=\mathrm{D}$. anceps. concinnum, Lindl. ex Reichb. f. in Trans. Linn. Soc. xxx. (1874) $149=$ D. atropurpureum. cuspidatum, Wall. ex Lindl. in Bot. Reg. (18t1) Misc. $2=$ D. Nathanielis.

incrassatum, Blume, Bijdr. $394=\mathrm{D}$. incrassatum. incrassatum, Brongn. ex Lindl, in Journ. Linn. Soc. iil. (1859) $60=$ Epidendrum aporoides ?

indivisum, Blume, Bijdr. $334 . t .39=\mathrm{D}$ indivisum. indivisum, Lindl. Gen. et Sp. Orch. $70=$ D. Leonis

Fenkinsii, Griff. in Calc. Journ. Nat. Hist. v. $18 ₫ 5$ $367=\mathrm{D}$. parcifforum

Leonis, Lindl. in Bot. Keg. (1840) Misc. $59=$ D. Leonis. lobatum, Blume, Bijdr. $334=$ D, lobatum.

micranthum, Griff. in Calc. Journ. Nat. Hist iv, 1844 $375, t, 16$, f $7=$ D. Serra.

Roxburghii, Griff. 1. c. v. $(18+5) 370=$ D. Koxburghii. Serra. Lindl. in Wall. Cat. n. $2021=\mathrm{D}$. S.rm. sinuatum, Lindl. in Bot. Keg. (1541), Misc. $1=\mathrm{I}$. sinuatum.

subteres, Griff. in Calc. Journ. Nat. Hist. v. $(1 \leqslant 45$ $370=$ D. acerosum.

APOSERIS, Neck. Elem. i. 5i $(1790)=$ HFoseris Linn. (Compos.)

foctida, Cass. in Dict. Sc. Nat. xlviii. $127=11$. Pucida. foctida, Less. Syn. Comp. 129 - H. foetida. lucida, Less. 1. c. - H. lucida.

APOSTASIA, Blume, Bijdr. 428. $1,5,1525)$. OR CHIDEAE, lenth. H Hook. fo iii. 6\$s

MEsilnctilis, Wall. Pl. As. Kar. i. it, in " 1530 


\section{APOSTASTA :-}

NEUMAYERA, Reichb. fo in Flora, 1v. (1872) 278

Niemeyera, F. Muell. Fragm. vi. 96 (1867)

Brunonis, Griff. Notul. iii. $243=$ nuda

Lobbii, Reichb. f. in Flora, lv. (1872) 278.-Borneo. nuda, R. Br. in Wall. Pl. As. Rar. i. 76. t. 85.-Ind, or.; Malaya.

odorata, Blume, Bijdr. 423.-Java.

stylidioides, Reichb. f. in Flora, lv. (1872) 278. Austral.

Wallichii, R. Br, in Wall. Pl. As. Rar, i. 75. t. 84.Ind. or, Malaya.

APOTERIUM, Blume, Bijdr. 218 (1825)=Calophyllum, Linn. (Guttif)

Sulatri, BIume, 1. c. =C. spectabile.

APOXYANTHERA, Hochst, in Flora, xxvi. (1843) 78 = Raphionacme, Harv. (Asclep.).

pubescens, Hochst. l. c. $=$ R. pubescens.

APOZIA, Willd. ex Steud. Nom. ed. II. i. $114(1840)=$ Micromeria, Benth. (Labiat.).

chamaedryoides, Willd. ex Steud. 1. c, = M. Brownei herniarioides, Willd. ex Steud. 1. c. $=$ Herpestis herniarioides.

serpyllacea, Willd. ex Steud. 1. c。=M. Brownei.

APPELLA, Adans. Fam. ii. 84 (1763)=Laurus, Linn.

APPENDICULA, Blume, Bijdr。297. t。 40 (1825) ORCHIDEAE, Benth. \& Hook. f, iii. 588

Conchochilus, Hassk, in Hoev, \& De Vriese, Tijdschr. ix. (1812) 146 .

Metachilum, Lind1. Gen. et Sp. Orch. 74 (1830)

Scoliochilus, Reichb. f. Xenia Orch. ii. 118, in obs. (1872).

alba, Blume, Bijdr. 299.--Java.

anceps, Blume, l.c.-Java.

angustifolia, Blume, l. c. 301.-Java.

bifaria, Lindl. ex Benth. in Hook. Kew Fourn. vii. (1855) 35.--Ind. or.; China.

bracteosa, Reichb. f. in Seem. Fl. Vit. 299.-Ins. Fiji.

buxifolia, Blume, Bijdr. 300.-Java.

callosa, Blume, l. c. 303.-Burma; Malaya.

carnosa, Blume, l. c. 300.-Java,

Chalmersiana, F. Muell. in Wing, South. Sc. Record, N. S. (I. May 1885),-N. Guin.

congenera, Blume, Bijdr. 303.-Java.

cornuta, Blume, l.c. 302.-Java.

cristata, Blume, l. c. 298.-Java.

elegans, Reichb. f. in Bonplandia, v. (1857) 41.Java.

graminifolia, Teijsm. \& Binn. in Tijdschr. Neder. Ind. xxiv. (1862) 322.-Java.

Hasseltii, Blume, Bijdr. 304-Burma.

Hasseltii, Wight, Ic. t. $1748=$ Agrostophyllum khasyanum.

Kuhlii, Reichb. f. Xenia Orch. ii. 116.-Java

Lewisii, Griff. in Calc. Fourn. Nat. Hist.iv. (1844) 378. -Malaya.

longifolia, Blume, Bijdr. 304.-Java.

membranacea, Teijsm. \& Binn. in Kruid. Arch nii. (1855) 399.-Tava.

micrantha, Lindl. in Ann. Nat. Hist. xv. (1845) 386. Ins. Phïlipp.

monoceras, Reichb. f. in Bonplandia, v. (1857) 41.Java.

muricata, Teijsm. E Binn. in Tijdschr. Neder. Ind. xxiv. (1862) 322,-Java.

pauciflora, Blume, Bijdr. 300.-Java.

pendula, Blume, l. c. 298.-Java

penicillata, Blume, Rumphia, iv. 46.-N. Guin.

peruligera, Reichb. f. in Bonplandia, v. (1857) 41. Java.

purpurascens, Blume, Bijdr. 302.-Java.

ramosa, Blume, l. c. 299.-Java.

reduplicata, Par. \& Reichb. f. Otia Bot. Hamb. $45=$ bifaria.

reflexa, Blume, Bijdr. 301.--Tava.

rhodiola, Reichb. f. Xenia Orchid. ii. 118.-Java

sororia, Miq. Fl. Ind. Bat. iii. 703.--Java.

stipulata, Griff. Notul. iii. $358=$ callosa.

teres, Griff. 1. c. $359=$ Ceratostylis teres.

tomentella, Zoll. in Nat. en Geneesk. Arch. Neerl.

Indie, i. (1844) 403.-Java.

torta, Blume, Bijdr. 303.-Malaya.

\section{APPEINDICULA :-}

ricornis, Reichb. f. in Bonplandia, v. (1857) 41.-Mab. undulata, Blume, Bijdr. 301, - Java.

Vielllardi, Reichb. f. in Linnaea, xli. (1877) 76.-N. Caled.

viridiflora, Teijsm. E Binn. in Tijdschr. Neder. Ind. xxiv. (1862) 321.-Java.

xytriophora, Reichb. f. in Seem. Fl. Vit. 299.-Malaya.

APPEIVDICUIARTA, DC. Prod. iii. 114 (1828) MELASTOMACEAE, Benth. \& Hook. f. i. 741. thymifolia, DC. l. c.-Guiana.

APPUNIA, Hook. f. in Benth. \& Hook. f. Gen. ii 120 (1873). RUBIACEAE, Benth. \& Hook. f. ii 120.

BkLlynkia, Muell. Arg. in Flora, xlviii. (1875) 465. angulata, Baill. Hist. Pl. vii. 415.-Bras. tenuiflora, Benth. E Hook.f. Gen. ii. 120.-Guiana.

APRADUS, Adans. Fam. ii. $102(1763)=$ Arctopus, Linn. (Umbell.)

APRELLA, Stend. Nom. ed. II. i. 152 (1840), err. typ.= ASPRLLLA, Schreb. = Leersia, Sw. (Gram.).

APREVALIA, Baill. in Bull. Soc. Linn. Par, i. (1884 428. LEGUMINOSAE floribunda, Baill. l. c.-Madag.

APTANDRA, Miers, in Ann. \& Mag. Nat. Hist. Ser. II vii. (1851) 201. OLACINEAE, Benth. \& Hook. f. i. 345

Benthamiana, Miers, 1. c. Ser. III. iv. (1859) $360=$ liriosmoides.

liriosmoides, Spruce, ex Miers, l. c.-Bras

Spruceana, Miers, l. c. Ser. II. viii. (1851) 202.-Bras. tubicina, Benth. ex Miers, l. c. Ser. III. iv. (1859) 360 -Bras.

APTERIA, Nutt. in Journ. Acad. Sc. Philad, vii (1834) 64. t. 9. BURMANNIACEAE, Benth. \& Hook f iii. 458 .

Nemitis, Rafin. F1. Tellur iv, 33 (1836)

Stemoptera, Miers, in Proc Linn Soc i $(1840) 6 \%$

hymenanthera, Miq. in Verh. Nat. Wet. Haarl. vii (1851) 216.t. $64=$ setacea

lilacina, Miers, in Trans. Linn. Soc. xviii. (1841) 546 t. $37=$ setacea.

orobanchioides, Hook. Ic. PI. t. $254=$ Dictyostega orobanchioides.

setacea, Nutt. in Fourn. Acad. Sc. Philad. vii. (1834) 64. t. 9.-Am. bor.

APTERANTHES, Mik, in Noy, Act. Nat. Cur, xvii (1835) 593. t. $4 \mathrm{l}=$ Boucerosia, Wight \& Am. (Asclep.)

cylindrica, Decne. in Ann. Sc. Nat. Sér. V. xiii (1870-1) 406.-Abyssin.

Gussoneana, Mik, in Nov. Act. Nat. Cur. xvii. (1835) 594. t. $41=\mathrm{B}$. Gussoniana.

tessellata, Decne. in Ann. Sc. Nat, Sér. V. xiii. (1870-1) $406=$ Echidnopsis cereiformis.

APTEROCARYON, Opiz; in Lotos, v. (1855), $258=$ Betula, Linn. (Cupulif.)

Michauxii, Opiz, 1. c, $259=$ B. Michauxii.

APT'ERON, Kurz, in Journ. As. Soc. Beng. xli.. (1872) II. 300. RHAMNEAE.

lanceolatum, Kurz, l.c. 301.-Tenasserim

APTEUXIS, Griff. Notul.iv. 672 (1854)=Pternandra, Jack (Melast.).

trinervis, Griff, 1, $\mathrm{c}=\mathrm{P}$, caerulescens.

APTOSIMUM, Burch. Trav. i. 219 (1824). SCRO PHULARINEAE, Benth. \& Hook. f. ii. 927.

CHILostigma, Hochst. in Flora, xxiv. (1841) 372

OHLendorfia, Lehm. Ind. Sem. Hort. Hamb. (1835).

abietinum, Burch. Trav, i. 308-Afr, austr.

depressum, Burch. .. c. i. 260.-Afr. austr.

eriocephalum, E. Mey. ex Benth. in Bot. Reg. sub t 1882.-Afr. austr.

indivisum, Burch. Trav. i. 219.-Afr. austr.

procumbens, Burch. ex Steud. Nom. ed. II. i. $114=$ depressum.

\section{APTOSIMUM :}

pumilum, Benth. in DC. Prod. X. 345,-Afr. austr. tragacanthoides, E. Mey. ex Benth. in Bot. Reg. sub t. 1882.-Afr, austr.

viscosum, Benth. l. c.-Afr. austr.

APTOTHECA, Miers, Apocyn. S. Am. 150 (1878). $A P O C X N A C E A E$

corylifolia, Miers. l. c.-Cuba.

APULEIA, Gaertn. Fruct, ii。439, t. $171(1791)=$ Berkheya, Ehrh. (Compos.).

asteroides, Gaertn. 1. c. $440=\mathrm{B}$. fruticosa

atractyloides, Less. Syn. Comp. 64 (= Stobaea atractyloides)

fruticosa, Bart1. Sem. Goett. (1835).-Cf. Linnaea, xii. (1838) Litt. $80=$ B. fruticosa

fruticosa, Gaertn. Fruct. ii. $440=$ B. grandiflora heterophylla, Less. Syn. Comp. 65 (=Stobaea heterophylla).

rigida, Gaertn. Fruct. ii. 439. t. 171 (=Stobaea Gaertneri).

Zeyheri, Less. Syn. Comp. $64=$ B. Zeyheri.

APULEIA, Mart. Herb. Fl. Bras, 123 (1837). LE GUMINOSAE, Benth. \& Hook. f. i. 574.

ZENIERIA, Arn. in Mag. Zool. \& Bot.ii. (1838) 548 molaris, Spruce, ex Benth. in Mart. Fl. Bras, Xv. II. 17\%.-Bias.

praecox, Mart. Herb. Fl. Bras. 123.-Bras.

AQUARTIA, Jacq. Enum. Pl. Carib. i. $12(1760)=$ Solanum, Linn.

aculeato, Jaca, 1. $\mathrm{c}=\mathrm{S}$. Aquartia.

microphylla, Lam. Illustr. n. 1604.t. 82. f. $2=$ S. micro phyllum.

microphylla, Willd. Sp. P1. i. 622.-Ins. S. Doming. solanacea, Willd. ex Steud. Nom. ed. II. i. 114. N. Granat.

toinentosa, Lam. Illustr. n. 1603, t. 82 f. $\mathbf{1}=\mathrm{S}$. Aquartia.

AQUIFoliUM, Tourn. ex Hall. Enum. Stirp. Helv. ii. $467(1742)=$ Ilex, Linn.

croceum, Rafin. Sylva Tellur, 44=I. Aqnifolium?

ferox, Mill. ex Rafin. 1. c. =I. Aquifolium.

heterophyllum, Rafin. 1. c. =I. Aquifolium.

Ilex, Scop. Fl. Carn. ed. II. i. $116=1$. Aquifolium

japonicum, Rafin. Sylva Tellur. $44=$ Berberis japonica. lanceolatum, Rafin. 1. c.-Hab.?

planifolium, Rafin. 1.c.-Hab,?

spinosum, Lam. F1. Fr. iii. $652=$ I. Aquifolium.

undulatum, Rafin. Sylva Tellur. $44=1$. Aquifolium.

vulgare, St. Lag. in Ann. Soc. Bot. Lyon, vii. (1880 $128=$ I. Aquifolium

AQUILARIA, Lam. Encyc. ii. 610 (1783). THYMELAEACEAE, Benth. \& Hook f iii 200

AgAllochum, Lam. Encyc. i. 47 (1783).

OPHiospenMum, Reichb. Consp. 82 (1828)

OPHISPERMUM, Lour. F1. Cochinch. 280 (1790)

Agallocha, Roxb. Hort. Beng. 33 ; Fl. Ind. ii. 422.Ind. or.; Burma.

bancana, Miq. H'1. Ind. Bat. Suppl. $355=$ Gonostylus Miquelíans.

chinensis, Spreng. Syst. ii. $356=$ A. Ophispermum. grandiflora, Benth. Fl. Hongk. 297.-China. macrophylla, Miq. Fl. Ind. Bat. Suppl. $356=$ Gonostylus Miquelianus.

malaccensis, Benth. in Hook. Kew Journ. v. (1853) $195=$ grandiflora

malaccensis, Lam. Encyc. i. 49.-Malaya.

microcarpa, Baill. Adansonia, xi. (1873-76) 304.Borneo.

Ophispermum, Poir. in Dict. Sc. Nat. xviii. 161.China.

ovata, Cav. Diss. vii. $377=$ malaccensis

pentandra, Blanco, Fl. Filip. ed. I. 373.-Ins. Philipp. secundaria, $D C$. Prod. ii. 59.-Ins. Molncc.

AQUILFGIA, [Tourn.] Linn. Syst. ed, I. (1735) RANUNCULACEAE, Benth. \& Hook. f. i. 8. advena, Regel, in Ind. Sem. Hort. Petrop. (1856) 32. - Hab.?

aggericola, Jord. Diagn. i. $87=$ vulgaris

alpina, Deless. Ic. $t .48=$ jucunda.

alpina, Georri, It i. $220=$ glandulos

alpina, Lam. Encyc. i. $150=$ pyrenaica. 


\section{AQUILEGIA :-}

lpina, Linn. Sp. Pl. 533.-Europ.; Sibir

Amaliae, Heldr. in Boiss. Diagn. Ser. II. i. 11.Thessal.

anemonoides, Willd. in Ges. Nat. Fr. Berl. Mag. v. (1811) 401 t. 9. f. $6=$ Isopyrum grandiflorum.

aragonensis, Willk. in Willk. \& Lange, Prod. Fl. Hisp. iii. 966.-Hispan.

arbascensis, Timb. in Bull. Soc. Sc. Phys, et Nat, Toulouse, ii. (1874) 449; (Massiv d'Arbas, 85).Europ.

arctica, Lond. Hort. Biit. $610=$ formosa.

atrata, Koch, in Flora, xiii. (1830) I. $118=$ vulgaris. atropurpurea, Miq. in Ann. Mus. Lugd, Bat. iii. $8=$ Buergeriana.

atropurpurea, Willd. Enum. Hort. Berol. $577=$ viridiflora.

aurea, Janka, in Oestr. Bot. Zeitschr. xxii. (1872) 174 = chrysantha.

Bauhini, Schott, in Verh. Bot. Zool. Ver. Wien, iii. (1853) $128=$ Einseleana.

Bernardi, Gren. \& Godr. Fl. Fr. i. $45=$ vulgaris

Bertolonii, Schott, in Verh. Bot. Zool. Ver. Wien, iii. (1853) 127.-Europ.

bicolor, Ehrh. Beitr. viii. $146=$ sibirica

blanda $\times$, Lem. Illustr. Hortic. (1857) t. $146=\mathrm{vul}$ -

garis.
brachyceras, Turcz. ex Fisch. \& Mey. in Maund, Bot. Gard. n. $755=$ leptoceras.

Braunii, Borbas, in Magyar Tudom. Akad. xii. n. VI. (1882) 10, nomen.-Lurop.

brevistyla, Hook. Fl. Bor. Am. i. 24.-Am. bor.

Buergeriana, Sieb. \& Zucc. in Abh. Akad. Muench. iv. I1. (1846) 183.-Tapon.

caerulea, fames, in Long, Exped. Rocky Mount. ii. 345.-Am. bor. occ.

californica, A. Gray, in Proc. Am. Acad. vii. (1868) 328.-Am, bor. occ.

californica, Hartw. in Gard. Chron. (1854) $836=$ formosa.

campylocentra, Borbas, in Magyar Tudom. Akad. xii. n. VI. (1882) 10.-Europ.

canadensis, Hook. Fl. Bor. Am. i. $24=$ formosa.

canadensis, Linn. Sp. Pl. 533.-Am. bor.

canadensis, Pall. Reise, i1 i. $230=$ viridiflora.

caucasica, Ledeb. ex Rupr. Fl. Canc. $32=0$ lympica.

chrysantha, A. Gray, in Proc. Am. Acad. viii. (1873) 621 -N. Mexic.

coevulea, Auct. = caerulea.

collina, Jord. Diag. i. $84=$ vulgaris

concolor, Fisch. ex Stcud. Nom. ed. II. i. $115=$ vulgaris.

confusa, Rota, Prosp. Fl. Bergamo, $99=$ Einseleana. corniculata, Vill. Cat. Hort. Strasb. $250=$ vulgaris. cornuta, Gilib. F1. Lituan. ii. $286=$ vulgas is. corsica, Soleir. ex Nym. Consp. $18=$ vul garis. cyclophylla, Jeaut). \& Timb. in Bull. Soc. Sc. Phys

et Nat. Toulouse, iii. (1875-76) 555; (Massif Lamrenti, 139) = pyrenaica

dahurica, Patr. in Deless. Ic. Sel. t. 49=viridiflora. dichroa, Freyn, in Flora, xliii. (1880) 26.-Europ dioica, Borbas, in Magyar Tudom. Akad. xii. n. VI.

(1852) 10, nomen.-Europ.

discolor, Stend. Nom. cd. II. i. $115=$ glandulose

discolor, Levier \& Leresche, in Fourn. Bot. xvii. (1879) 197.-Hispan.

dumeticola, Jord. Ding. i. $86=$ vulgaris.

Ebneri, Zimm. ex Nym. Consp. $18=$ vulgaris.

ecalcarata, Hort. ex Steud. Nom. ed. II. i. $115=$ vulgais.

Einseleana, Fr. Schultz, Arch. Fl. Fr. et Allem. 135. - Europ

elata, Ledeb. Ind. Hort. Dorp. Suppl. (1824) $41=$ vulgaris.

elegans, Pope, ex Steucl. Nom. ed. II. i, $115=$ vulgaris. elegans, Salisb. Prod. $374=$ canadensis.

eximia, Borbas, in Magyar Tudom. Akad. xii. n. VI. (1882) 10, nomen.-kurop.

eximia, Van Houtte, ex Planch, in Fl. des Serres, Sér. II. ii. $(1857) 13 . t .1188=$ fol mosa.

flabellatn, Sieb. \& Zucc. in Abh. Akad. Muench. iv, It. (1816) 183.- Japon.

flave, Lam. Encyc, i. $149=$ viridiflora.

Havescens, S. Wats. in Bot. King, Exp. 10.-Calif.

flavifora, Tenney, in Am. Natural. i. (1868) $388=$

canadensis.

formosa, Fisch. in DC. Prod. i. 50,-.Kamtsch.

formosa, Hook. f. Bot. Mag. t. $6552=$ Hookeri.

\section{AQUILEGIA :-}

fragrans, Benth.in Maund, Botanist, iv, t, 181,-Reg. Himal.

Gaertneri, Borbas, in Magyar Tudom. Akad. xii.n. vi (1882) 10, nomen. - Europ.

Garnieriana, Sweet, Brit. F1. Gard. Ser. II. v. t. 103= sibirica.

Gebleri, Bess. ex Turcz. in Flora, xvii. (1834) I. Beibl. 5.-Europ.

glandulosa, Fisch. Hort. Gorenk. ed. II. (1812) 48 ; et ex Link, Enum. Hort. Berol. ii. 84.-Sibir. altaic. glandulosa, Miq. in Ann. Mus. Lugd. Bat. iii. $8=$ flabellata.

glanca, Lindl. Bot. Reg. xxvi. (1840) t. 46.-Reg. Himal.

glaucescens, Baker, in Gard. Chron, (1878) II. 203 vulgaris.

glaucophylla, Stend. in Flora, xxxix. (1856) $407=$ vulgaris.

grandiflora, Patr. ex DC. Syst. i. $337=$ alpina.

grandiflora, Schangin, in Pall. N. Nord. Beitr, vi, $49=$ glandulosa.

grata, Maly, ex Borbas, in Magyar Tudom. Akad. xii. n. VI. (1882) 8, nomen.-Europ.

Haenkeana, Koch, Syn. F1. Germ. $23=$ vulgaris

Haynaldi, Borbas, in Magyar Tudom. Akad. xil.n. VI. 1882) 9.-Europ.

hirsuta, Timb.-Cf. Bull. Soc. Bot. Fr. xxix. (1882),

Bibl. 47.-Gallia merid

hispanicn, Borbas, in Magyar Tudom. Akad. xii.n. vi. (1882) 10.-Hispan.

Hookeri, Borbas, in Termész. Fï̈zetek, viii. (1884) 311 -Am, bor.

Huteri, Borbas, in Magyar Tudom. Akad. xii. n, vi (1882) 9. - Europ

hybrida, Sims, in Bot. Mag. t. $1221=$ vulgaris

inversa, Mill. Gard. Dict. ed. VIII. n. 3 =vulgaris.

Jonesii, Parry, in Am. Natural. viii. (1874) 211.Am. bor.

jucunda, Fisch. \& Lallem. Ind. Sem. Hort. Petrop. vi 1840) $43=$ glandulosa.

jucunda, Fisch. \& Mey. ex Ledeb. F1. Ross. i. $736=$ vulgaris.

kanaoriensis, Jacquem. ex Camb. in Jacquem. Voy. Bot. 7. t. $5=$ Moorcroftiana.

Karelini, Baker, in Gard. Chron. (1878) II $76=$ vulgaris.

Kareliniana, C. A. Mey. ex Trautv. in Act. Hort Petrop. viii. (1883) 53.-Hab.?

Kilaibelii, Schott, in Verh. Bot. Zool. Ver. Wien, ii. (1853) 129.-Armenia.

lactillora, Kar. Kor. in Bull. Soc. Nat. Mosc. (1841) 374. - Sibir.

leptoceras, Fisch. Es Mey. Ind. Sem. Hort. Petrop. iv. 33.- -Sibir.

leptoceras, Nutt. in Journ. Ac. Philad. vii. (1834) $9=$ caerulea.

longisepala, Zimm. ex Borbas, in Magyar Tudom. Akad. xii. n. VI. (1882) 9, nomen.-Europ.

longrissima, A. Gray, ex S. Wats. in. Proc. Am. Acad. xvii. (1881-82) 317.-Am. bor.

lutea. Lam. Encyc, i. 149,-Hab.

lutescens, Borbas, in Magyar Tudom. Akad. xii. n. vr. (1882) 10, nomen.-Europ.

macrantha, Hook. \& A. Bot. Beech. Voy. 317. $72=$ caerulea

macrocntra, Borbas, in Magyar Tudom. Akad. xii.n. VI. (1882) 10, nomen,--Europ.

Magnolii. Loret, in Loret \& Barraud. F1. Montp. ii $796=$ Kitaibelii.

mexicana, Hook. Bot. Mag. t. $3919=$ Skinneri.

minuta, Steph. ex Ledeb. F1. Ross. i. 58=Isopyrum grandiflorum.

mollis, feanb. ex Timb. in Bull. Soc. Sc. Phys. et Nat. Toulouse, iii $(1875-76) 555$ - - Gallia.

montana, Sterab. in Regensb. Denkschr. ii. (1818) 60 $=$ alpina.

Moorcroftiana, Wall. Cat, n. 4713.-Reg. Himal.

Moorensteniana, Steud. Nom. ed. II. i. 115, sphalm. = praec.

nemoralis, Ford. Diag. i. 83.-Gallia.

nevadensis, Boiss. \&ै Reut. Cat. Hort. Genev. (1854) 4: et in Apn. Sc. Nat. Sér. IV, ii, (1854) 380. Hispan.

nigricans, Baumg, Enum. Stirp. Transs. ii. $104=$ vulgais

nivalis, Falc. ex Baker, in Gard. Chron. (1878) It. 76 $=$ glauca.

\section{AQUILEGIA}

nivea, Baumg. ex Baker, in Gard. Chron. (1878) Ir $76=$ vulgaris

olympica, Boiss. in Ann. Sc. Nat. Str. II. xvi. (1841) 360 .--Oriens.

orthantha, Borbas, in Magyar Tudom. Akad. xil. n. v . (1882) 10, nomen.-Europ.

Ottonis, Orph. ex Boiss. Diagn. Ser. II. i. 11.Graecia.

oxysepala, Trautv. \& Mey. in Middend. Reise (Fl. Ochot. 10).-As, or.

paraplesia, Schur, Enum. PI. Transs. $28=$ vulgaris parviflora, Ledeb. in Mém. Acad. Pétersb. v. (1814) 544 -Silir.

platysepala, Reichb. Ic. FI. Germ.t. $4730=$ vulgaris. plena, Hort. ex Steud. Nom. ed. II. i. $115=$ vulgaris. praecox, Jord. Diag. i. $85=$ vulgaris.

pubillora, Wall. Cat. n. 4714.--Ind. or.

pycnotricha, Borbas, in Magyar Tudom. Akad. xii. n. vI. (18S2:10.-Europ.

pyrenaica, DC, Fil. Fr, iv, 912,-Pyren: Appenin.

pyrenaica, Koch, Syn. Fl. Germ. ed. II. $24=$ Einseleana pyrenaica, Reichb. Ic. Fl. Germ. t. $4732=$ Bertolonii. Reuteri, Boiss. Diagn. Ser. II. i. $10=$ Bertolonii. Reuteriana, Reichb. f. ex Nym. Consp. 18=alpina. ruscinonensis, Timb. E Feanb. in Bull. Soc. Sc. Nat. Toulouse, iii. (1875-76)554.-Gallia.

Schinneri, Poit, in Rev. Hortic. Sér. II. iv. (1845-4 $185=$ Skinneri.

Schottii, Borbas, in Magyar Tudom. Akad. xii. n. (1\&82) 10.-Europ.

sibirica, Don, ex Steud. Nom. ed. II. i. $115=r u l-$ garis.

sibirica, Lam Encyce i. 150-Sibir.

sibirica, Schur, ex Nym. Consp. $18=$ glandulosa.

silvestris, Neck. Delic. Gallo-Belg. i. $231=$ rulgaris.

sinensis, Heynh. Nom. ii. 41.-China.

Skinneri, Hook. Bot. Mag. t. 3919.-Mexic.

speciosa, DC. Syst. i. $330=$ sibirica.

speciosa, Timb, in Bull. Soc. Hist. Yat. Toulouse, iv.

(1870) $155=$ arbascensis.

spectabilis, Lem. in Illustr. Hortic. xi. (1864) t. $103=$

\section{sibirica.}

stellata,

stenopetala, Borbas, in Uagyar Tudom. Aknd. xii. n.

vi. (1882) 8, nomen.-Europ.

Sternbergii, Reichb. Fl. Germ. Excurs. $7 \pm 9=$ alpina.

subalpina, Bor. Fl. Centr. Fr. ed. III. ii. $24=$ vulgaris.

subscaposa, Borbas, in Maøyar Tudom. Akad. xii. n.

vI. $(18 \searrow 2) 18=$ vulgaris.

sulphurea, Zimm. ex Borbas, l. c. 9.-Europ.

sylvestris, vide silvestris.

sylvestris, Schur, in Verh. Siebenb. Ver. Naturw. iv. (1853) $4=$ vulgaris.

Szaboi, Borbas, in Magyar Tudom. Akad, xii, n.

(1882) 10, nomen.-Europ.

thalictrifolia, Schott \& Kotschy, in Verh. Bot. Zool

Ver. Wien, iii. $(1553) 130=$ Einselcana.

thalictroides, Schlecht. in Linnaea, vi. (1S31) $581=$ parviflora.

transsilvanica, Schur, in Verh. Siebenb. Ver. Naturns. iii. $(1 \& 52) 94$; iv. $(1 \leq 53) t=$ vulgaris.

truncata, Fisch. \& Mey. Ind. Sem. Hort. Petrop.

(1843) Suppl. $8=$ formosa.

variegata, Moench. Meth. $311=$ canadersis.

versiculor, Salisb. Prod. $37 \neq=$ vulgari

viridiflora, Pall. in Act. Petrop. (17;9) 200. t. 11.Sibir.

viscosa, Gounn, FI. Monsp, $267=$ Kitaibelii.

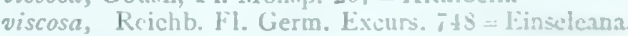

viscosa, Sufr. ex Reichb. 1. c. $7 \pm 9=$ pyrenaict.

volubilis, Manck, ex Trautio in Act. Hort. Pestrop. viii.

(18S3) $54 .-$.lanchuria.

vulgaris, Limn. Sp. Pl. 533.-Europ.; Oricns.

vulgaris, Richards. App. Frankl. Journ. ed. II, $21=$ brevistyla.

vulgaris, Thunb. F1. Jap. $232=$ Alabellata.

Wittmanniana, Stev. ex Fisch. \& Mey. \& Arciall.

Ind. Sem. Hort. Petrop. xi. Suppl. $15^{\circ}=$ olympica.

AQUILICIA, Linn. Mant. ji. 211 (17il Lees, Iinn. (Ampel.)

Ottilis, Gacrtn. Fruct. i. $275=$ L. sambueina.

sambacisa, Linn. Mant. $211-\mathrm{L}$. sambucina.

ARAIBI)AEA.-Cr. Kev, Ilortic. (1stis) 15t-Arra bidrea, $\mathrm{DC}$. (Bignon.). 
ARABIDIUM, Spach, Hist, Vég. Phan. vi. $436(\mathbf{1 8 3 8})=$ Arabis, Linn. (Crucif.)

alpestre, Spach, 1. c. $438=$ Arabis alpina.

alpinum, Fourr. in Ann. Soc. Linn. Lyon, N. S. xvi (1868) $332=$ Arabis alpina.

saxaticolum, Fourr. $1_{0} \mathrm{c}_{\mathrm{o}}=$ Arabis saxatilis

ARABIDOPSIS, Schur, Enum. Pl. Transs. 55 (1866)= Sisymbrium, Linn. (Crucif.).

pinnatifida, Rupr. Fl. Caucas, $86=$ Braya pinnatifida. Thaliana, Schur, Enum. Pl. Transs. $55=\mathrm{S}$. Thalianum.

ARABIS, Adans, Fam. ii. $422(1763)=$ Iberis, Dill. (Crucifo).

ARABIS, Linn. Gen. ed. I. 198 (1737). CRUCI FERAE, Benth. \& Hook. f. i. 69.

Abasicarpon, Andrz, ex Reichb. in Moessl. Handb. ii. 1150 (1828).

Ar abidium, Spach, Hist. Vég. Phan. vi. 436 (1838).

ARABISA, Reichb. Handb. 260 (1841).

Caulopsis, Fourr. in Ann. Soc. Linn. Lyon, N. S. xvi. (1868) 332 .

LOMASPORA, DC. ex Steud. Nom, ed, II, ii. 65 (1841)

Pilosella, Kostel. Hort. Prag. 104 (1844).

Psilarabis, Fourr, in Ann. Soc. Linn. Lyon, N. S. xvi. (1868) 332 .

SteVenia, Adams \& Fisch. in Mém. Soc. Nat. Mosc. v. 84 (1820)。

TURRITIS, Tourn. ex Linn. Syst. ed. I. (1737)

accedens, Jord. Diag. i. $115=$ hirsuta.

aizoides, Bonato, Cat. Pl. Hort. Patav. (sec. Steud. Nom. ed. II. i. 115),-Hab.

alaschanica, Maxim. in Bull. Acad. Pétersb. xxvi. (1880) 421.-Mongolia.

albida, Stev. in Fisch. Cat. Hort. Gorenk. 51.-Reg. Mediterr.; Oriens.

Alliaria, Bernh. Syst. Verz. Erf. $195=$ Sisymbrium Alliaria.

Allionii, DC. Fl. Fr. iv. 676. -Pedemont.

alpestris, Schleich. ex Reichb. Ic. Fl. Germ. ii. 13. n. 4338 b.- Helvetia.

alpina, Georgi, Beschr. Russ. Reich. iii. IV. $1137=$ albida.

alpina, Krock. ex Steud. Nom. ed. II. i. 115 = sagittata.

alpina, Linn. Sp. Pl. 664,--Europ.; Am. bor.

alpina, Lucé, F1. Osil. $228=$ Gerardi.

amara, Banks, ex DC. Syst. ii. $246=$ Cardamine rhomboidea.

ambigua, DC. Syst. ii. $231=$ petraea

amplexicaulis, Edgerw. in Trans. Linn. Soc. xx. (1851) 31.-Reg. Himal.

andicola, H. B. \& K. Nov. Gen. et Sp. v. $81=$ Sisymbrium hispidulum.

androsacea, Fenzl, Pugill. Pl. Nov. Syr. 13.-As. Min.

angustifolia, Lam. Encyc. i. $220=$ Hutchinsia alpina.

apennina, Tausch, in Syll. Ratisb. ii. (1828) 244.Italia.

arcuata, Dulac, F1. Hautes-Pyr. $200=$ Sisymbrium Thalianum.

arcuata, A. Gray, in Proc. Am. Acad. vi. 187.-Calif. arcuata, Shuttlw. ex Godet, FI. Jura, i. (1852) $38=$ alpestris.

arenaria, Schrank, Fl. Monac. iii. 256.-Europ.

arenosa, Cham. \& Schlecht. in Linnaea, i. (1826) $17=$

kamtschatica.

arenosa, Scop. Fl. Carn. ed. II. ii. 32.-Europ.

arvensis, Bernh. Syst. Verz. Erf. $195=$ Conringia austriaca.

arvensis, Edgew. in Trans. Linn. Soc. Xx. (1851) 32. -Ind. bor. occ.

aspera, All. Ped. Auct. 18. t. 2. f. $2=$ auriculata.

attenuata, Royle, ex Hook. f. in Jonrn. Linn. Soc.' vi 1862) $143=$ tibetica.

aubrietioides, Boiss. Fl. Orient. i. 175.-Cilicia.

Aacheri, Boiss. in Ann. Sc. Nat. Sér. II. xvii. (1842) 52.-As. Min.; Syria.

auriculata, Lam. Encyco i. 219,-Europ.; Oriens.

Balansae, Boiss. \& Reut. Diagn. Sér. II. v. 17.Algeria.

Barbarea, Bernh. Syst. Verz. Erf. 195 = Barbarea vulgaris.

bellidifolia, Crantz, Stirp. Austr. ed. I. fasc. i., 42 ; ed. II. $44=$ pumila.

bellidifolia, Facq. Obs. Bot. i. 22.-Europ.

bellidifolia, Scop. F1. Cam. ed. II. ii. 31 = Cardamine alpina.

\section{ARABIg:}

bellidioides, Lam. Encyc. i. $220=$ Cardamine alpina.

bijuga, Watt, in Fourn. Linn. Soc. xviii. (1881) 378 Reg. Himal.

Billardieri, DC. Syst. ii. $218=$ albida

blepharophylla, Hook. E Arn. Bot. Beech. Voy. 321.Calif.

Boissieri, Griseb. Spicil. Fl. Rumel. i. $248=$ drabae formis.

borealis, Andrz. ex Fisch. \& Mey. Ind. Sem. Hort Petrop. v. $33=$ hirsuta

Boryi, Boiss. Voy. Bot. Espagne, ii. 26. t. $5=$ Braya pinnatifida.

brachycarpa, Rupr. Fl. Cauc. 73, in textu.-Reg. Caucas.

brachypoda, Boiss. Elench. 8 = parvula.

bracteata, Wedd. in Ann. Sc. Nat. Sér. V. i. (1864) 291.-Bolivia.

brassicaeformis, Wallr. Sched. Crit. 359.-Europ.

Breutelii, Lange, Consp. Fl. Groenl. 1. 50.-Groenl.

brevifolia, DC. Syst. ii. $218=$ albida.

Breweri, S. Wats. in Proc. Am. Acad. xi. (1876) 123 - Calif.

bryoides, Boiss. in Ann. Sc. Nat. Sér. II. xrii. (1842) 55.-Graecia.

bulbosa, Muhl. Cat. 63 ; Spreng. Fl. Hal. Mant. $46=$ Cardamine rhomboidea.

bursifolia, Lam. Fl. Fr. ii. $511=$ Sisymbrium bursifolium.

cadmea, Boiss. Diagn. Ser. I. viii. 21.-Caria

caerulea, Haenke, in Facq. Collect. ii. 56.--Europ.

caespitosa, Schleich. Cat. Pl. Helv. ed. IV. 8.- Helvet.

camtschatica, Willd, ex DC. Syst, ii. $242=$ Stelleri.

canadensis, Linn. Sp. Pl. 665.-Am. bor.

canadensis, Mill. Gard. Dict. ed. VIII. n. $6=$ Diplotaxi muralis.

canescens, Brocchi, in Bibliot. Ital. xxix. $90=$ alpina.

canescens, Nutt. in Torr. E Gray, Fl. N. Am. i. 83.Am. bor.

cantabrica, Leresche \& Levier, in Fourn. Bot. xvii. (1879) 197.-Hispan.

capensis, Linn. Syst. ed. X. 1135; Burm. f. Prod. Fl Cap. $18=$ Heliophila pusilla.

Cardamines, Turcz, in Bull. Soc Nat. Mosc. xxvii. (1854) II 292 - Austral.

carduchorum, Boiss. Fl. Orient. i. 173.-Armenia

carpetana, Willk. in Willk. \& Lange, Prod. Fl. Hisp. iii. 822,-Hispan.

caucasica, Willd. Enum. Hort. Berol. Suppl. $45=$ albida.

cebennensis, DC. Syst. ii. 234.-Gallia

cenisia, Reut. Cat. Jard. Bot. Genèv. (1853) $4=$ alpestris.

chinensis, Rottl. ex Wight, Illustr. i. sub t. $12=$ Lepidium sativum.

ciliaris, Willd, Enum. Hort. Berol. $684=$ pumila.

ciliata, $R$. Br, in Ait. Hort. Kew. ed. II. iv, 107.Europ.

ciliata, Auct. ex Nym. Consp. i. $33=$ alpestris.

iliata, Tausch, Ind. P1. Sudet. (sec. Steud. Nom. ed

II. i. 117) = hirsuta

cilicica, Boiss. \& Bal. Diagn. Ser. II. v, $17=$ ionocalyx.

Clusiana, Schrank, Fl. Monac. ii. $125=$ alpina.

coerulea, vide caerulea.

colchaguensis, Turcz. in Bull. Soc. Nat. Mosc. xxvii 1854) II. 293-Chili

collina, Tenore, Prod. Fl. Nap. 39.-Italia.

collisparsa, Jord. Diagn. i. $116=$ hirsuta

colorata, Tausch, in Flora, xix. (1836) rI. 405.-Europ

Commersonii, DC. Syst. ii. 228--Reg. Argent.

conferta, Willd. ex Reichb. Fl. Germ. Excurs. $680=$ hirsuta.

conringioides, Ball, in Fourn. Bot. xi. (1873) 297.-

Marocc

constricta, Griseb. Spicil. Fl. Rumel. i. $249=$ hirsuta.

contracta, Celak. Prod. Fl. Boehm. 155.-Bohem.

contracta, Spenn. Fl. Friburg. 1ii. $925=$ hirsuta.

cordata, Boiss. in Ann. Sc. Nat. Sér. II. xviii. (1842) $51=$ laxa.

Costae, Willk. in Willk. E Lange, Prod. Fl. Hisp. iii. 820.-Hispan

Crantziana, Ehrh. Beitr. v. $177=$ petraea.

crassifolia, Ledeb. in Eaier. Bot. Ges. Denkschr. ii. (1841) 107.--Rossia.

cremocarpa, Boiss. \& Bal. Diagn. Ser. II. v. $16=$ laxa crepidiopoda, Griseb. ex. Pant, in Oestr. Bot. Zeitschr. xxiii. (1873) $268=$ pseudoturritis.

\section{ARABIS}

cretica, Boiss. \& Heldr. Diagn. Ser. I. viii. $20=$ muralis.

crispata, Willd. Enum. Hort. Berol. $684=$ alpina.

croatica, Schott, ex Nyman \& Kotschy, Analect. Bot. $44=$ neglecta.

cuneifolia, Hochst. ex A. Rich. Tent. Fl. Abyss. i. $17=$ alpina.

curtisiliqua, DC. Syst. ii. 223 = hirsuta

Cusickii, S. Wats. in Proc. Am. Acad. xvii. (1881-82 363.-Am. bor.

dacica, Heuff, ex Griseb. \& Schenk, in Wiegm. Archiv, xviii. (1852) I. $307=$ Halleri.

dasycarpa, Andrz. ex DC. Syst. 11. $244=$ auriculata.

declinata, Schrad. Ind. Sem. Hort. Goett. (1831); (ex Linnaea, viii. (1833) Litt. 22) = Holboellii.

decumbens, Ball, in Fourn. Bot. xi. (1873) 297.Marocco.

deflexa, Boiss, Fl. Orient. i. 175 -Lycia

dentata, [Clairv]. Man. Herb. 223 = Braya pinnatifida dentata, Torr \& Gray, Fl N. Am, i. 80-Am. bor

docica, Fuss, in Verh. Siebenb. Ver. Naturw. xiii. (1862) 150 , sphalm. = dacica

Douglassii, Torr. in Torr. \& Gray, Fl. N. Am. i. 83, in syn. (cum cit. falsa) = Cardamine rotundifolia

drabaeformis, Boiss, in Ann. Sc. Nat. Sér. II. xvii. (1842) 55.-Bithyn

drabaeformis, Griseb. Spicil. F1. Rumel. i. $248=$ bryoides.

Dregeana, Harv. \& Sond. Fl. Cap. i. 22.-Afr. austr.

Drummondii, A. Gray, in Proc. Am. Acad. vi. 187.Am. bor.

elongata, Salisb. Prod. 272=A. Turrita

eriocarpa, Schur, Enum. Pl. Transs. $46=$ A. Turrita

eriopoda, Turcz. in Bull. Soc. Nat. Mosc. (1840) 63. -Sibir. or.

erubescens, Ball, in Fourn. Bot. xi, (1873) 297.Marocco.

erysimoides, Kar. \& Kir. in Bull. Soc. Nat. Mosc. xv. (1842) 145.-Soongaria.

Eschscholtziana, Andrz. ex Ledeb. F1. Ross. i. $118=$ hirsuta.

falcata, Michx. Fl. Am. Bor. i. 31 = canadensis

falcata, A. Rich. Tent. Fl. Abyss, i. 17-Abyss.

falklandica, Benth. \& Hook. f. Gen. 1.69=macloviana

farinacea, Rupr. Fl. Caucas. 71.-Caucas.

fastigiata, Hook. f. F1. N. Zel. ii. $324=$ Cardamine fastigiata.

flagellosa, Miq. in Ann. Mus. Bot. Lugd. Bat. ii. 72.Japon.

flavifora, Bunge, in Mém. Acad. Pétersb. Sér. VI. vii. (1859) 582.-Armenia.

flexuosa, Hort. Berol. ex Reichb. Fl. Germ. Excurs. $679=$ serpyllifolia

floribunda, Schur, Enum. Pl. Transs. $44=$ petraea.

foliosa, Royle, ex Hook. f. E Thoms, in Fourn. $\operatorname{Lin} n$. Soc. v. (1862) 160.-Reg. Himal.

fruticulosa, C. A. Mey. in Ledeb. Fl. Alt, iii. 19.Sibir. alt.

furcata, S. Wats. in Proc. Am. Acad. xvii. (1881-82) 362.-Am. bor

Gerardi, Bess. in Koch, Syn. Fl. Germ.ed. I. 38.Europ.; Reg. Canc.

gigantea, Hook. Ic. Pl. t. $259=$ Cardamine stylosa.

glabra, Bernh. Syst. Verz. Erf. $195=$ perfoliata.

glandulosa, Kar. \& Kir, in Bull. Soc. Nat. Mosc. xv.

1842) 146.-Tibet. : Soongar

glareosa, Schur, in Verh. Siebenb. Ver. Naturw. i. (1850) 106 ; iv. (1853) $59=$ arenosa.

glastifolia, Reichb. Ic. Fl. Germ. xii. 13.-Europ.

Gmelini, Willd. ex Ledeb. F1. Ross。 i. $131=$ Parrya macrocarpa.

gracilescens, Jord. Diag. i. $119=$ hirsuta

gracilis, Willd, ex Ledeb. F1. Ross. i. $185=$ Sisymbrium mollissimum.

gracilis, Royle, ex Hook. f. \& Thoms. in Journ. Linn. Soc. v. (1861) $158=$ Sisymbrium Wallichii.

grandiflora, Linn. Amoen. Acad. ii. $279=$ Parrya macrocarpa.

grandiflora, Royle, ex Hook. f. \& Thoms. in Journ. Linn. Soc. v. (1861) $142=$ alpina.

Halleri, Linn. Sp. Pl. ed. II. 929.-Europ.

Halleri, Lucé, F1. Osil. $228=$ arenosa.

hastulata, Bert. ex DC. Prod. i. $150=$ Cardamine resedifolia.

Heliophila, DC. Syst. ii. $237=$ Farsetia Jacquemonti.

hesperidoides, A. Gray, Man. Bot. U. St. ed. V. $68=$ Thelypodium pinnatifidum. 


\section{ARABIS :}

heteromalla, Schrad. Ind. Sem. Hort. Goett. ex Linnaea, viii. (1833) Litt. $22=$ Holboellii.

heterophylla, Forst. ex DC. Syst. ii. $265=$ Cardamine hirsuta.

heterophylla, Nutt, ex Torr. \& Gray, F1. N. Am. i. 81 $=$ laevigata.

heterophylla, Schur, in Verh. Siebenb. Ver. Naturw. iv. (1853) 59.-Austria.

himalaica, Edgew. in Trans. Linn. Soc. xx. (1851) 31. - Reg. Himal.

hirsuta, DC. Fl. Fr. iv, $675=$ ciliata.

hirsuta, Scop. Fl. Carn. ed. II. ii.30.-Europ.; Oriens ; Am. bor.

hirsuta, Royle, ex Hook. f. \& Thoms. in Journ. Linn. Soc. v. (1861) $142=$ alpina.

hirta, Lam. Encyc. i. $220=$ stricta.

hirtella, Jord. Diag. i. $120=$ hirsuta.

hispida, Soland. in Ait. Hort. Kew. ed. I. ii. $400=$

stricta.
hispida, Murr. Syst. Veg. ed. XIII. 501 (cf. Linn. f. Suppl. 298) = petraea.

hispida, Moench, Meth. $258=$ pendula.

Holboellii, Hornem. Fl. Dan. t. 1879.-Am. bor.

Holboelliana, Hort. Hafn. ex Trevir. in Flora, xvi, 1833) $124=$ praec

Hookeri, Lange, Consp. Fl. Groenl. i. 50.-Groenl

Hornungiana, Schur, Enum. Pl. Transs. 43.Transsylv.

Huetii, Trautv. in Act. Hort. Petrop. ii. (1878) 496.Reg. Cancas.

humilis, Schleich. ex DC. Syst. ii. $224=$ muralis.

hybrida, Reut. Suppl. Cat. Pl. Genèv. $8=$ alpestris.

idanensis, Jord. Diag. i. $117=$ hirsuta.

incana, Moench, Meth. $257=$ alpina.

incana, Roth, Catalect. Bot. i. 79.-Europ.

incana, Willd. Enum, ex Stend. Nom. ed. II. i. $116=$ muralis.

incana, Willd. Herb. ex Steud. 1. c. = collina

incanescens, Munro, Pl. Agra, 6, ex Hook, f. \& Thoms, in Journ. Linn. Soc. v. (1861) $148=$ Farsetia Hamiltonii.

incarnata, Lamb. ex DC. Syst. ii. 210.-Sibir.

integrifolia, Lapeyr. Hist. Abr. Pl. Pyr. 385. Suppl. 93. -Europ.

intermedia, Bruegg. in Fahresb. Naturf. Ges. Graub. II. $x \times v$. (1882) 92.--Europ.

intermedia, Hoppe, ex Steud. Nom. ed. II. i. $116=$ bellidifolia.

ionocalyx, Boiss. Eo Heldr. Diagn. Ser. I. viii. 20.As. Min.

japonica, Regel, Gartenft. (1863) 308. t. 414.Japon.

japonica, A. Gray, in Mem. Am. Acad. N. S. vi. (1858) $381=$ Arabis Stelleri.

jugicola', Jord, Diag. i. 121 = bellidifolia.

kamtschatica, Auct. vide camtschatica, Willd.

kamtschatica, Fisch. ex DC. Syst. ii. 231,-Kamtschatca.

kamtschatica, Pall. ex Ledeb. Fl. Ross. i. $185=$ Sisymbrium mollissimum.

kanawarensis, Royle, ex Hook. f. \& Thoms. in Journ. Linn. Soc. v. (1861) $142=$ amplexicaulis.

Kochii, Jord. Diag. i. $112=$ Gerardi.

kokanika, Regel, Pl. Nov. Fedsch, 6.-Turkestan.

Korolkowi, Regel \& Schmalh. in Act. Hort. Petrop. v. (1877) 232.-Turkestan.

lactea, Stev. ex Rupr. Fl. Cauc. $289=$ mollis.

laevigata, $D C$. Syst, ii, 237.-Am. bor.

laevigata, Hook. F1. Bor. Am. i. 43=Drummondii?

lanata, Walp. in Nov. Act. Nat. Cur. xix. Suppl. i. (1843) 248.-Peruv.

lasioloba, Link, Enum. Hort. Berol. ii. 163.-Mexico. lateripendens, St. Lag. in Ann. Soc. Bot. Lyon, vii. 1880) $120=$ A. Turrita.

latifolia, Dur. in Expl. Sc. Algér. t. 72. -Algeria.

latifolia, Willd. ex Ledeb. H1. Ross. i. 181=Parrya Linnaeana.

laxa, Sibth. \& Sm. Prod. Fl. Graec. ii. 28.-As. Min.

leptocarpa, Wall. Cat. n. $4784=$ Sisymbrium Wallichii.

leptocarpaea, Fisch. ex Reichb. Fl. Germ. Excurs. $680=$ alpina

Lerchenfeldiana, Schur, Enum. Pl. Transs. $42=$ alpina.

levigata, Poir. Encyc. Suppl, i. $411=$ laevigata.

lilacina, Schrad. Ind. Scm. Hort. Goctt. vii. (1832) $42=$ IIolboellii.

longesiliçua, C. \& F. Presh, Delic. Prag. 16.--Sicilia.

\section{ARABIS}

longifolia, DC. Syst. ii, $219=$ albida

longirostris, S. Wats. in Bot. King, Exp. 17.Calif.

longisiliqua, Wallr. Sched. Crit. $359=$ A. Turrita.

lucens, Dulac, F1. Hautes-Pyr, $202=$ bellidifolia.

lucida, Linn.f. Suppl. 298.-Europ.

ludoviciana, C. A. Mey. ex Fisch. Mey. Ẽ Avé-Lall. Ind. Sem. Hort. Petrop. ix. 60.-Am. bor.

lusitanica, Boiss. Diagn. Ser. II. i. 20.-Lusitan.

Lyallii, S. Wats. in Proc. Am. Acad. xi. (1876) 122. -Am. bor. occ.

lyraefolia, DC. Syst. ii, $244=$ canadensis.

lyrata, Linn.Sp.Pl. 665 . - Am. bor.

macloviana, Hook. IC. Pl. t. 498.--Ins. Falkland.

macrocarpa, Torr. Mex. Bound. Rep. $32=$ perfoliata,

madonia, C. E $\mathcal{F}$. Presl, Delic. Prag. 15.-Sicilia.

major, S. F. Gray, Nat, Arr. Brit. Pl。 ii, $676=$ A

Turrita.

Marschalliana, Hort. ex Steud. Nom. ed. II. i. $116=$ hirsuta.

mexicana, S. Wats. in Proc. Am. Acad. xvií. (1881-82 319.-Mexico

microphylla, Nutt, ex Torr. \& Gray, Fl. N. Am. i. $82=$ Drummondi1

minor, Hort. Berol. ex DC. Syst, ii. $226=$ incana.

mollis, Rafin, in Am. Monthly Mag. ii. (1817) $43=$ canadensis

mollis, Ster. in Mém. Soc. Nat. Mosc. iii. (1812) 270 -Reg. Caucas.

montana, Bernh. ex. DC. Syst. ii. $225=$ stricta.

montana, Lam. Encyc, i. $219=$ hirsuta.

Montbretiana, Boiss. in Ann. Sc. Nat. Sér. II. xvii. (1842) 53.-Oriens.

monticola, Jord. Diag, i。 $107=$ alpina,

moschata, Hort. ex Reichb. Fl. Germ. Excurs. $680=$ incana.

multicaulis, Bell. ex DC. Syst. ii. $233=$ Halleri.

multiflora, DC. Syst. ii. 243-Mont. Pyren.

multijuga, Borb. in Linnaea, xli. (1877) 604.Europ.

muralis, Bertol. Rar. Ital. Pl. Decad. ii. 37.Graecia.

muralis, Salisb. Prod. $272=$ Sisymbrium Thalianum. muricola, Jord. Diag. i. $125=$ muxalis.

Nasturtium, [Clairv.] Man. Herb. $223=$ Nasturtium officinale.

neglecta, Schult. Oestr. Fl. ii. 248.-Mont. Carpath.

nemoralis, Steud. Nom. ed. II. i. 117 = hirsuta,

nemorensis, C. A. Mey. Verz。 Pfl. Cauc. $179=$ Gerardi.

nemorensis, Reichb. Fl. Germ. Excurs. 681 =hirsuta nepetaefolia, Boiss. Fl. Orient. i. 177.-Persia. nivalis, Guss. Pl. Rar. $389=$ serpyllifolia.

nizalis, Spreng. Syst. ii. $893=$ Macropodium nivale.

Nordmanniana, Rupr. Fl. Cauc. $72=$ mollis.

nova, Vill. Prosp. $39=$ saxatilis

nuda, Bélang. ex Boiss. in Ann. Sc. Nat. Sér. II. xvii 1842) $54=$ Sisymbrium nudum.

nudicaulis, DC. Syst, ii. $240=$ Parrya macrocarpa. nudiuscula, E. Mey. ex Harv. E' Sond. Fl. Cap. i. 22. -Afr. austr.

nutans, Moench, Meth. $258=$ pumila.

nutans, Sims, Bot. Mag, t. $2219=$ Allionii

oblongata, Wender. Hort. Marb. (1824) ex Steud. Nom. ed. II. i. $117 .-$ Hab. ?

obtusifolia, Schur, in Verh. Siebenb. Ver. Naturw. iv

(1853) $58,6=$ alpina.

ochroleuca, Boiss. E Heldr. Diagn. Ser. II. i. 21.Graecia.

ochroleuca, Lam. Encyc. i. $218=$ A. Turrita.

olympica, Sibth. ex DC. Syst, ii. $219=$ albida.

ovata, Poir. Encyc. Suppl. v. $557=$ hirsuta.

ovirensis, Wulf. in Jacq. Coll. i. $196=$ Halleri.

owaihiensis, Cham. \& Schlecht in Linnaea, i. (1826)

17.-Ins. Sandvic.

oxyota, DC. Syst, ii. $236=$ pendula

pachyrhiza, Kar. E' Kir. in Bull. Soc. Nat. Moscoxv. (1842) 144.- Soongaria.

pangiensis, Watt, in Gourn。Linn. Soc. xviii, (1881) 378. - Reg, Himal.

parviflora, Rafin. in Am. Monthly Mag. ii. (1817) 43 $=$ Sisymbrium Thalianum.

parvula, Dufour, in DC. Syst. ii. 228.-Europ. austr. patens, Royle, ex Hook, fo \& Thoms. in Journ. Linn. Soc. v. (1861) $142=$ amplexicaulis.

patens, Sulliv. in An. Gourn. Sc, i. (1819) 42, 49.Am. bor.

\section{ARABIS}

Patriniana, DC. Syst. ii. $236=$ pendula .

patula, Host, Fl. Austr. ii. 271.-Austria

patula, Torr. Bot. Mex. Bound. $32=$ Holboellii

patula, Weinm. Cat. Hort. Dorp. (1810 18 =auriculat.

pauciflora, Garcke, Fl. Deutschl. ed. IV. 22 = brassicacformis.

pedemontana, Boiss. Diagn. Ser. I. i. $69=$ cebennensis. pelligera, Fenzl, in Kotschy, Reise Cilic. Taur, 391 ionocalyx

pendula, Lachen. ex Reichb. Fl. Germ. Excurs, 681 A. Turrita.

pendula, Linn. Sp. Pl. ed. I. 665.-Sibir. Am. bor pendula, Stell. ex DC. Syst. ii. $242=$ Stelleri.

perfoliata, Lam. Encyco i. 219.-Europ.; Sibir.; Reg. Himal.

permixta, Jord. Diag. i. $110=$ C'serardi,

petiolaris, A. Gray, in Proc. Am. Acad. vi. (18b4-63, 187.-Texas.

petiolata, Bieb. Fl. Taur. Cauc. ii. $126=$ Sisymbrium Alliaria.

petraea, Lam. Encyc. i. 221.-Reg. bor. temp.

petricola, Jord. Diag. i. 121 = hirsuta.

petrogena, Kern, in Oestr. Bot. Zeitschr. xiii. 1863 $141=$ arenosa

Piasezkii, Maxim. in Bull. Acad. Pétersb. xxyi. (1880 420.-China.

pinnatifida, Lam. Encyc. i. 221 = Braya pinnatifida.

planisiliqua, Pers, ex Reichb. Ic. Fl. Germ. xii. 13 Gerardi.

platysperma, A. Gray, in Proc. Am. Acad. vi. (186t-85 519.-Calir.

praecox, Waldst. \& Kit. ex Willd. Enum. Hort. Berol. $684=$ procuriens,

procera, Jord. Diag. i. $114=$ Gcrardi.

procurrens, Waldst. E Kit. Pl. Rar. Hung. ii. 154 t.

144.-Hungar.; Banat.; Thracia.

propera, Jord. Diag. i. $118=$ hirsuta.

propinqua, Jord. 1. co = hirsuta.

psendoturritis, Boiss. \& Heldr. Diagn. Ser. II. i. 20.Graecia.

pterosperma, Edgew. in Trans. Linn. Soc. xx. (1851) 33 =alpina.

puberula, Nutt. ex Torr. \& Gray, Fl. N. Am. i. 82

canescens.

pubescens, Poir. Encyc. Suppl. i. 413.-Algeria.

pubicalyx, Miq. in Ann. Mus. Bot. Lugd. Bat. ii. 72 -Japon.

pubigera, Jord. Diag. i. $115=$ Gerardi.

pumila, facq. Fl. Austr. iii, 44.-Europ.

purpurascens, Presl, Fl. Sicul, i. $50=$ longisiliqua.

purpurea, Sibth. E Sm. Fl. Graec. vii. to 643.-Ins. Cyprus.

ramosa, Lam. F1. Fr. ii, $510=$ Sisymbrium Thalianun recta, Vill. Hist. Pl. Dauph. iii. $319=$ auriculata.

Reichenbachii, Syme, Eng. Bot, ed. III. i. 168

hirsuta.

repanda, S. Wats. in Proc. Am. Acad. xi. (1876) 12? -Calif.

reptans, Lam. Encyc. i. $222=$ Draba caroliniana?

resedifora, H. B. \& $\mathrm{K}$. Nov. Gen. et Sp. v. 81

Nasturtium arabiforme.

resedifolia, Lam. Fl. Fr. ii. $511=$ Cardamine resedi folia.

retrofracta, R. Grah. in Edinb. Phil. Journ. (152: $=$ Holboellii.

Retgiana, Beurl. ex Nym. Consp. i. 33 = hirsuta. rhaetica, Bruegg. in Fahresb. Naturf. Ges. Graub. II

xxv, 1852) 85 ,-Europ

rhomboidea, Pers. Syn, ii. 204=Cardamine shom-

boidea.

rigida, Dulac, Fl. Hautes-Pyr. $200=$ brassicneformis. rigida, Wallr. Beitr. Fl. Hercyn. 22!y = auriculata. rigidula, Jord. Diag. i. $108=$ Gerardi.

Rocmeriana, Andrz. ex DC, Svst, ii. $22.28=$ parvula.

rosea, DC. Syst. ii, $215=$ murnlis.

rosella, Jord, Diag. i. $120=$ mural

rotundifolia, Rafin. in Am. Monthly Mag. ii. (181:

$43=$ Draba carolinianat

rubricaulis, Jord. Ding. i. $118=$ Gerardi.

rugosa, Mounch, Meth. 250=A. Turrita.

runcinata, Lam, Encyc, i. $2202=$ petrate.

runcinata, S. Wiats. in Proc. A m. Acad. xvii. (1s81-s:

31:, - Am. bor.

rupesiris, Nutt. ex Torr. \& Gray, Fl. X. Amo. i. \&1 hissut.s.

sabauda, frucges in Gaheresb. Nasurf. Ges. Graah. II $\mathrm{xxv}$. (lis:2) si. - Europ. 


\section{ARABIS}

sagittata, DC. Fl. Fr. vi. $592=$ hirsuta

saxatilis, All. Fl. Pedem. i. 268.-Europ.

saxeticola, Jord. Diag. i. $106=$ alpina.

saxicola, Edgew. in Trans. Linn. Soc. xx. (1846) 33.-

Reg. Himal.

saxigena, Tord. Diag. i. $127=$ muralis.

scabra, All. F1. Pedem. i. $268=$ serpyllifolia pumila

scabra, Gilib. F1. Lituan. ii. $61=$ Sisymbrium Thalia num.

scapigera, Boiss. in Ann. Sc. Nat. Sér. II. xvii. (1842) $54=$ Sisymbrium nudum.

Schievereckiana, Andrg. in DC. Prod. i. 145.-Tyrol.

Scopoliana, Boiss. ex Nym. Consp. i. 35.-Europ.

segetalis, Schur, Enum. PI. Transs. $45=$ arenosa.

serpyllifolia, Hoppe, ex DC. Syst. ii. $241=$ vochinensis.

serpyllifolia, Vill. Prosp. 39.-Europ.

serrata, Franch. छ Sav. Enum. Pl. Fap. i. 33.Japon.

sibirica, Hort. ex Steud. Nom ed. II i. 117.-Sibir.

sicula, Huet, ex Reut. Cat. Grain. (1857).-Sicilia.

sicula, Stev. ex Nym. Suppl. 32 = albida.

Sieberi, Tausch, in Flora, xix. (1836) II. 405.Austr.

siliculosa, Lam. Encyc, i, 221 = Parrya macrocarpa. simplicifolia, Schur, Enum. Pl. Transs. $43=$ petraea. sinaica, Boiss. Diagn. Ser. I. viii. 21 =auriculata. sinaica, Steud. Nom. ed. II. i. 117, nom.-Arab. sinuata, Turcz. in Bull. Soc. Nat. Mosc. (1840) 64.Sibir

sisymbroides, Hook. ex Hook. f. in Trans. Linn. Soc. xxiii. (1861) $314=$ petraea

Sophia, Bernh. Syst. Verz. Erf. $196=$ Sisymbrium Sophia.

Soyeri, Reut. E Huet, ex Huet, in Ann. Sc. Nat. Sér. III. xix. (1853) 251.-Mont. Pyren.

sparsiflora, Nutt. ex Torr. \& Gray, Fl. N. Am. i. $81=$

Holboellii.

spathulata, DC. Syst, ii. 227.-Am. austr.

spathulata, Nutt. ex Torr. E Gray, Fl. N. Am. i. 81 -Am. bor.

Stelleri, DC. Syst. ii. 242.-As. bor. or.

stellulata, Desv. \& Berthol. in Desv. Journ. Bot. ii. (1813) $76=$ pumila

stenocarpa, Boiss. \& Reut. Diagn. PI. Nov. Hisp. $4=$ saxatilis.

stenopetala, Willd. Enum. Hort. Berol. Suppl. 46.Hab.?

Steveniana, Rupr. Fl. Cauc. 289.-Reg. Cauc. stolonifera, Clairv, ex DC. Syst. ii. $233=$ Halleri stolonifera, Hornem. Hort. Hafn, ii, 618-Hab. stricta, Costa, Ampliac. $22=$ Costae.

stricta, Huds. Fl. Angl. 292.-Europ.; Am. bor stricta, Sieber, ex Tausch, in Flora, xix. (1836) II. 406 $=$ alpestris.

subcoriacea, Gren. ex Nym. Consp. $34=$ bellidifolia.

subnivalis, Bruegg. in Fahresb. Naturf. Ges. Graub.

II. xxv. (1882) 88.-Europ.

subnitens, Jord. Diag. i. $124=$ alpestris.

subpinnatifida, S. Wats. in Proc. Am. Acad. xx. (1885) 353.-Am. bor. occ.

sudetica, Tausch, in Flora, xix. (1836) II. $407=$ hirsuta.

suecica, Fries, Summa Veg. 30, 147=Sisymbrium suecicum.

suffrutescens, S. Wats, in Proc. Am. Acad. xvii (1881-82) 362.-Am. bor, occ.

sulphurea, Boiss. Fl. Orient. i, 173.-Persia.

supina, Lam. Fl. Fr. ii. $512=$ Sisymbrium supinum.

sylvestris, Scop. F1. Cam. ed. II. ii. $32=$ Brassica Cheiranthos.

taraxacifolia, T. Anders. in Hook. f. Fl. Brit.Ind. i. 136 $=$ arvensis.

tatarica, Pall. Reise, ii. $676=$ Parrya macrocarpa

tenella, Guss. E Tenore, Fl. Neap. Syll. App. v. 20.Lucania.

tenella, Host, Fl. Austr. ii. $273=$ Halleri.

Tenorii, Huet, ex Nym. Consp. $34=$ albida

Thaliana, Crantz, Stirp. A ustr. ed. II. $39=$ petraea.

Thaliana, Linn. Sp. Pl. $665=$ Sisymbrium Thalianum.

Thomsoni, Hook. f. \& Thoms. in Journ. Linn. Soc. v. (1861) $145=$ tibetica

thyrsoidea, Sibth. \& Sm. F1. Graec. t. $642=$ albida.

tibetica, Hook. f. E Thoms. in Fourn. Linn. Soc. (1861) 143.-Reg. Himal.

toxophylla, Bieb. Fl. Taur. Cauc. iii. $448=$ Sisymbrium toxophyllum.

transsilvanica, Schur, Enum. Pl. Transs. $43=$ petraea.

\section{ARABIS :-}

trichopoda, Turcz. in Bull. Soc. Nat. Mosc. (1840) 63. -Rossia.

tuberosa, Muhl. ex Pers. Syn. ii. 204=Cardamine rhomboidea.

Turczaninowii, Ledeb. Fl. Ross. i. 123.-Sibir.

Turrita, Linn. Sp. Pl. 665.-Europ.; Oriens.

Turritis, [Clairv.] Man. Herb. 223=A. Turrita.

umbrosa, Crantz, Stirp. Austr. ed. I. fasc. i. 43 ; ed. II $41=$ A. Turrita.

umbrosa, Turcz. ex Steud. Nom. ed. I. ii. $118=$ petraea undulata, Link, Enum. Hort. Berol, ii, 161=alpina uralensis, Willd. ex Ledeb. F1. Ross. i. $120=$ petraea. verna, R. Br. in Ait. Hort. Kew. ed. II. iv. 105.-Reg. Mediterr

vesula, Jord. Diag. i. $123=$ alpestris.

violacea, Moench, Meth. $259=$ verna.

virescens, Jord. Diag. i. $109=$ Gerardi

virginica, Poir. Encyc. Suppl. i. $413=$ Cardamine hirsuta.

viscosa, DC. Syst. ii. $216=$ albida.

vochinensis, Spreng. Pugill. i. 46. n. 81.-Austria.

wolgensis, Willd. ex Ledeb. FI. Ross. i. $185=$ Sisym brium toxophyllum.

yokoscensis, Franch. Er Sav. Enum. Pl. Fap. 1. 34., Japon.

Zeyheriana, Turcs. in Bull. Soc. Nat. Mosc. xxvii (1854) II. 292.-Afr. austr.

ARABISA, Reichb. Handb. $260($ 1837) = Arabis, Linn. (Cracifo).

ARACHIDNA, Plum. ex Moench, Meth. 121 (1794)= Arachis, Linn. (Legum.)

hypogaea, Moench, 1. c. 122= Arachis hypogaea quadrifolia, Noronha, in Verb. Batav. Gen. v. (1790) ed. I. Art. IV. 7.-Malaya.

ARACHIS, Linn. Syst. ed. I. (1735). LEGUMINOSAE, Benth, \& Hook, f. i. 518.

Arachidna, Moench, Meth. 121 (1794)

Mundubi, Adans. Fam. ii. 323 (1763).

africana, Burm. f. F1. Cap. Prod. $22=$ Voandzeia sub terranea.

africana, Lour. F1. Cochinch. ii. $430=$ hypogaea.

americana, Tenore, in Mem. Ist. Incorr. i. (1811) $48=$ hypogaea.

aprica, Walt. F1. Carol. $183=$ Stylosanthes elatior

asiatica, Lour. Fl. Cochinch. ii. $430=$ hypogaea.

fruticosa, Retz. Obs. Fasc. v. $26=$ Stylosanthes mucronata.

glabrata, Benth. in Trans. Linn. Soc. xviii. (1841) 159.-Bras.

hypogaea, Linn. Sp. Pl. 741.-Reg. trop. (cult.). marginata, Gardn. in Hook. Ic. Pl. t. 500.-Bras prostrata, Benth. in Trans. Linn. Soc. xviii. (1841) 159.-Bras.

pusilla, Benth. l.c.-Bras.

tuberosa, Benth. l. c-Bras

villosa, Benth. l. c.-Am. austr.

ARACHNANTHE, Plume, Rumphia, iv, 55. t. 196 1828) ORCHIDEAE, Benth. \& Hook. f. iii. 572 ARACHNIs, Blume, Bijdr. 365 (1825).

ARModorum, Breda, Orch. Kuhl. \& Hass. (1827).

Arrhynchium, Lindl. in Paxt. Fl. Gard. i. 142 (1851).

Esmeralda, Reichb, f. Xenia Orch, ii, 38 (1874)

bilinguis, Benth. in fourn. Linn. Soc. xviii. (1881) 332.-Ind. or.

Cathcartii, Benth. E Hook. f. Gen. iii. 573.-Reg. Himal.

Lowei, Benth. E' Hook. f. l. c.-Borneo

moschifera, Blume, Rumphia, iv, 55.-Malaya.

Sulingi, Benth. in Fourn. Linn. Soc. xviii. (1881) 332. -Malaya.

ARACHNE, Neck. Elem. ii. $348(1790)=$ Andrachne, Linn. (Euphorb.).

ARACHNIMORPHA, Desv, in Ham. Prod. Fl. Ind, Occ. 28 (1825) = Rondeletia, Linn. (Rubiac.) incana, Ham. 1. c. = R. incana.

ARACHNIS, Blume, Bijdr. 365 (1825)= Arachnanthe, Blume (Orchid.)

moschifera, Blume, 1. c. = Arachnanthe moschifera.
ARACHNITES, F. W. Schmidt, Fl. Boëm. i. 74 (1793 =Ophrys, Linn. (Orchid.)

alpina, F. W. Schmidt, 1. c. = Herminium alpinum. anthropophora, F. W. Schmidt, 1. c. $77=$ Aceras anthropophora.

apifera, Hoffm. Deutschl. Fl. ed. II. ii. $180=0$. apifera. atrata, Tod. Hort. Panor. ii. t. $28=0$. aranifera. Benoitii, Tod. 1. c.-Hab. ?

Bertolonii, Tod. Orch. Sicul. $79=$ O. Bertolonii

Biancae, Tod. 1. c. $83=0$. Biancae.

bombyliftora, Tod. 1. c. $91=\mathrm{O}$. bombyliflora.

fuciflora, F. W. Schmidt, Fl. Boëm. j. 76=O. Arach nites.

fusca, Tod. 1. c. $98=$ O. fusca

Insengae, Tod. Nouv. Gen. $12=0$. Inzengae

lunulata, Tod. Orch. Sicul. $77=0$. Innulata.

lutea, Tod. 1. c. $95=0$. fusca

Monorchis, Hoffm. Deutschl. FI. ed. II. ii. $179=$ Herminium Monorchis.

musciflora, F. W. Schmidt, FI. Boëm. i. $75=$ O. muscifera.

oxyrhynchus, Tod. Orch. Sicul. $81=0$. Arachnites.

pallida, Tod. 1. c. $100=\mathrm{O}$. pallida

Speculum, Tod. 1. c. $93=0$. Speculum

tenthredinifera, Tod.1. c. $85=0$. tenthredinifera

ARACHNITIS, Phil, in Bot, Zeit. 217 (1864) BURMANNIACEAE, Benth. \& Hook, f. iii. 460. uniflora, Phil. l. c.-Chili.

ARACHNOPOGON, Berg, ex Haberl, Cat. Pesth.; ex Steud. Nom. ed. II. i. $118(\mathbf{1 8 4 0})$, nomen.

heterospermum, Berg, 1. c.-Hab.?

ARACHNospermum, Berg (sec. Steud. Nom. ed. II. i. 118) = Hypochaeris, Linn. (Compos.).

ARACHNOSPERMUM, F. W. Schmidt, Samml. Phys. Aufs i. $274(1795)=$ Scorzonera, Linn. (Compos.). laciniatum, F. W. Schmidt, l. c, $=$ S, laciniata resedifolium, F. W. Schmidt, 1. c. = praec.?

ARACHNOTHRIX, Walp. Ann. ii. 776 (1852)=seq.

ARACHNOTHRYX, Planch. in FI. des Serres, Sér. I. v. (1849) sub t. $442=$ Rondeletia, Linn. (Rubiac.). buddleioides, Planch. 1. c. $=\mathrm{R}$. buddleoides. discolor, Planch. 1. c. $=\mathrm{R}$. discolor. elongata, Planch. $\mathrm{l}, \mathrm{c}=\mathrm{R}$, elongata

hispidula, Griseb. Fl. Brit. W. Ind. 325.-Ind. occ. laniflora, Planch. in Fl. des Serres, Sér. I. v. (1849) sub t. $442=\mathrm{R}$. laniflora.

leucophylla, Planch. 1. $\mathrm{c}_{0}=\mathrm{R}$. lencophylla. reflexa, Planch. $1 . \mathrm{c} .=\mathrm{R}$. reflexa.

rosea, Linden, Hort. Linden. (1859) 3.-N. Granat.

ARACHUS, Medic, in Vorles. Churpf. Phys. Ges. ii. (1787) $360=$ Vicia, Tourn. (Legum.).

vicioides, Medic. 1. c. $=$ V. bithynica.

ARACIUM, Neck. Elem. i. $49(1790)=$ Crepis, Linn. (Compos.).

alpinum, Monn. Ess. Hierac. $73=$ C. alpina. aureum, D. Dietr. Syn. Pl. iv. $1329=$ C. aurea chondrilloides, D. Dietr. 1. c. $1330=$ C. Jacquini cydoniaefolium, D. Dietr. 1. c. = Hieracium cydoniae folium

Froelichianum, D. Dietr. 1. c. = C. incarnata

Gmelini, D. Dietr. 1. c. =C. Gmelini.

incarnatum, D. Dietr. 1. c. $1329=$ C. incarnata.

laevigatum, Miq. Fl. Ind. Bat. ii. $111=\mathrm{C}$. laevigata lyratum, Herd. in Bull. Soc. Nat. Mosc. xliii. (1870) I. $214=$ C. lyrata

mauritianum, D. Dietr. Syn. Pl. iv. $1330=$ C. mauritianum.

multicaule, D. Dietr. 1. c. $=$ C. multicaulis.

paludosum, Monn. Ess. Hierac. $73=$ C. paludosa.

Pancicii, Sch. Bip. in Pollichia, xxii-iv. (1866) 320.Europ.

praemorsum, D. Dietr. Syn. Pl. iv. $1329=$ C. praemorsa.

prenanthoides, D. Dietr. 1. c. $1330=$ Hieracium prenanthoides.

pubescens, C. Koch, in Linnaea, xxiii. (1850) 681.As. Min.?

pygmaeum, Miq. F1. Ind. Bat. ii. $111=$ C. nudicanlis. succisaefolium, D. Dietr. Syn. Pl. iv. $1330=$ C. succisaefolia. 
ARAFOCOCCUS, Brongm. in Ann. Sc. Nat. Sér. II. xv. (1841) 370, BROMELIACEAE, Benth. \& Hook. f. iii. 664 .

micranthus, Brongn.l. c.-Guiana

ARAGUS, Steud. Nom. ed. II. i. $118(1840)=$ ARAGALLUS, Neck.=Astragalus, Tourn. (Legumin.).

A RALIA, Tourn. ex Linn. Syst. ed. I. (1735); Gen. ed. I. 88 (1737). ARALIACEAE, Benth. \& Hook. f. i.936. Aureliana, Lafit. ex Catesb. Nat. Hist. Carol. App. 16 (1754).

BLAKWELLIA, Scop. Introd. 326 (1777).

Dimorphanthus, Miq. Comm. Phyt. 95 (1840),

Gynapteina, Spach, Hist. Vég. Phan. viii. 113 (1839).

MoTherwellia, F. Muell. Fragm. vii. 107 (1870). Nalagu, Adans. Fam. ii. 445 (1763)

abyssinica, Hochst. ex A. Rich. Tent. Fl. Abyss. i. 336

= Heptapleurum abyssinicum.

acerifolia, Willd. ex Roem. \& Schult. Syst. vi. $699=$ Oreopanax acerifolium.

aculeata, Ham. ex Seem. in Journ. Bot. vi. (1868) 136 = Brassaiopsis aculeata.

acutifolia, Willd. ex Roem. \& Schnlt. Syst. vi. $697=$

Brassaiopsis aculeata.

angularis, Willd. 1. c. $698=$ Oreopanax angulare.

arborea, Linn. Pl. Jam. Pugill, ii. 11 ; Syst. ed. X. 967

=Dendropanax arboreum

arborea, Vell. Fl. Flum. 129 ; iii. t. $110=$ Gilibertia brasiliensis.

argentata, H. B. \& K. Nov. Gen. et Sp. v. $4=$ Oreopanax argentatum.

argentea, Linden, Cat. n. 18. p. 7.-Hab. ?

armata, Seem, in Fourn. Bot. vi. (1868) 134.-Ind. or. aromatica, Blume, Bijdr. 271 ( $=$ Agalma aromaticum). - Java.

avicenniaefolia, H. B. \& K. Nov. Gen. et Sp. v. 2. t. $2=$ Oreopanax avicenniaefolium.

Bastardiana, Decne. Bot. Vénus, $24=$ Panax Bastardianum.

bipinnata, Reinw. ex De Vriese, Pl. Ind. Bat. Reinw. $83=$ montana

bipinnata, Blanco, Fl. Filip. ed. I. 222= javanica

bipinnatifida, C. B. Clarke, in Hook. f. Fl. Brit. Ind.

ii. 722,-Reg. Himal

brevifolia, March. in Bull. Acad. Belg. Sér. II. xlvii. (1879) 74.-Mexic.

cachemirica, Decne. in Facquem. Voy. Bot. 72. t. 81.Reg. Himal.

californica, S. Wats. in Proc. Am. Acad.xi. (1876) 144. -Calif.

calyculata, Zoll. \& Moritzi, Syst. Verz. Zoll. $41=$ Macropanax oreophilum.

canescens, Sieb. \& Zucc. F1. Jap. Fam. Nat. i. $94=$ spinosa.

capitata, Jacq. Enum. Pl. Carib. 18=Oreopanax capitatum.

capitulata, Fungh. E De Vriese, in Ann. Sc.Nat. Sér. III. vi. (1846) 116. - Sumatra,

catalpaefolia, Willd. ex Roem. \& Schult. Syst. vi, 697 $=$ Oreopanax capitatum.

cheirophylla, Spreng. Syst. i. $953=$ Oreopanax cheirophyllum.

chinensis, Blume, Bijdr. $870=$ dasyphylla

chinensis, Linn. Sp. Pl. $273=$ spinosa.

cissifolia, Griff. ex Seem. in fourn. Bot. vi. (1868) 134. -Reg. Himal.

cochleata, Lam. Encyc. i. 224 = Panax cochleatum

cordata, Thunb. Fl. Fap. 127.-Japon.

crassifolia, Soland, ex A. Cunn. in Ann. Nat. Hist. ii. 1839) $214=$ Psendopanax crassifolium.

crassinervia, H. B. \& K. Nov. Gen. et Sp. v. $5=$ Oreopanax crassinervium.

cumanensis, H. B. \& K. 1. c. $3=$ Oreopanax cumanense. dasyphylla, Miq. Fl. Ind. Bat. i. I. 751.-Java.

Decaisneana, Hance, in Journ. Bot. iv. (1866) $172=$ spinosa.

decomposita, Reinw. ex De Vriese, Pl. Ind.Bat. Reinw. 84.- Java.

digitata, Roxb. Hort. Beng. 22; F1. Ind. ii. $107=$ Heptapleurum venulosum.

digitata, Willd. ex Roem. \& Schult. Syst, vi. $701=$ Oreopanax xalapense.

discolor, H. B. \& K. Nov. Gen. et Sp. v. 4=Oreopanax discolor.

disperma, Blume, Bijdr. 872 = Macropanax oreophilum.

\section{ARALIA :-}

dubia, Spreng. Syst. iv. Cur. Post. $125=$ Trevesia pal mata.

Echinops, Cham. \& Schlecht. in Linnaea, v. (1880) $409=$ Oreopanax Echinops

edulis, Sieb. \& Zucc. Fl. Jap. 1. 57. t. $25=$ cordata

elata, Seem. in Journ. Bot, vi. (1868) $134=$ spinosa

elegantissima, Veitch, in Gard. Chron. (1873) 782.Hab.?

erinacea, Hook. in Brewst. Edinb. Journ. Sc. vi. (1827) $64=$ Fatsia horrida.

Faribuki, Sieb. ex Miq. in Ann. Mus. Bot. Lugd. Bat. i. 16.-Japon.

farinosa, Delile, ex Ferr. \& Galin. Voy. Abyss. iii. 135 $=$ Panax pinnatum.

ferox, Miq. Fl. Ind. Bat. i. I. 750.-Malaya

ferruginea, Willd. ex Roem. \& Schult. Syst. vi. $701=$ Sciadophyllum ferrugineum.

filicifolia, Chr. Moore, ex Fourn. in Illustr. Hortic xxiii. (1876) 72. t. 240.-Ins. Pacif.

Finlaysoniana, Seem. in Fourn. Bot. vi. (1868) 184.Ind. or.

floribunda, H. B. $8 c$ K. Nov. Gen. et Sp. v. 6. t. $416=$ Oreopanax floribundum.

foliolosa, Seem. in Fourn. Bot. vi. (1868) 134.-Reg. Himal.

fragrans, G. Don. ex Loud. Hort. Brit. $112=$ Hetero. panax fragrans.

Gemma, Linden.-Cf. Gard.Chron. (1880) II. 1\&0.N. Caled.

georgica, Miq. Ann. Mus. Bot. Lugd. Bat. i. 8.-Am. bor.

Ghiesbrechtii, Versch. ex Morr. in Belg. Hortic. xiii. 1863) $3=$ Oreopanax xalapense

Ginseng, Baill. Hist. Pl. vii. 197.-China

glomerulata, Blume, Bijdr. $873=$ Brassaiopsis speciosa gracillima, Linden, in Rev. Hortic. (1877) $38=$ Veitchii.

grandis, Miq. Comm. Phyt. $95=$ elata.

Guilfoylei, $\operatorname{Cog} n$. E March. Pl. Ornem, ii, (1874), t 58.-Ins. Pacif.

heptaphylla, Willd. ex Spreng. Syst. i. $952=$ Sciada phyllum ferrugineum.

heterophylla, A. Cunn. ex Hook. 1c. Pl. t. 583-584= Pseudopanax crassifolium.

heterophylla, Mutis, ex H. B. \& K. Nov. Gen. et Sp. v $1=$ Oreopanax Mutisianum.

heterophylla, Willd. ex Roem. \& Schult. Syst. vi. $698=$ Oreopanax acerifolium.

hispida, Vent. Fard. Cels, t. 41; Michx. Fl. Bor. Am i. 185 - Am. bor.

Humboldtiana, Roem, \& Schult. Syst, vi. $699=$ Oreopanax floribundum.

humilis, Cav. Ic. iv. 7. t. 313.-N. Mexic.

hypoleuca, Pres], Epim. Bot. $250=$ spinosa

incisa, Willd. ex Roem. \& Schuit. Syst. vi. $699=$ Oreo panax floribundum.

japonica, Hort. ex Seem. in Journ. Bot, vi. (1868) 135 $=$ Leroana

japonica, Thunb. Fl. Jap. $128=$ Fatsia japonica.

jatrophaefolia, H. B. \& K. Nov. Gen. et Sp. v. $6=$ Oreopanax jatrophaefolium.

javanica, Miq. Fl. Ind. Bat. i. I. 749.-Java.

Kleinii, Steud. Nom. ed. II. 1. 118=Miquelia Kleinii.

laetevirens, C. Gay, Fl. Chil. iii. $151(=$ Cheiroden dron laetevirens).-Chili.

lappaefolia, Raeusch. Nom. ed. III. 88 ; et Rets. Obs. vi. 27.-Ind. or.

Laribuki, Keiske, ex Miq. in Ann. Mus. Bot. Lugd. Bat. i. 16.-Japon.

latifolia, Wight \& Arn. Prod. $376=$ Polyscias pinnata

Leroana, C. Koch, Wochenschr. vii. (1864) 369.-Am. bor.

Lessoni, Hook. f. Fl. Nov. Zel. $96=$ Pseudopanax Lessoni.

longifolia, D. Dietr. Syn. Pl. ii. 1085.-Java

longifolia, Reinw. ex App. Hort. Spaam. Berg. $2=$ Brassaia littorea.

lucescens, Blume, Bijdr. 872 (= Heptapleuri sp.).-Java. lucida, Hassk. Cat. Hort. Bogor. Alt. 164.-Malaya.

lutescens, Auct, ex Steud, Nom, ed. II. err, typ. $=$ lucescens.

Lyallii, T. Kirk, in Trans. N. Z. Inst. xvii. (1885) 222, $295=$ (Pseudopanacis sp. ?). $-\mathrm{N}$. Zel.

macrophylla, A. Cunn. in Sweet, Hort. Brit. Suppl. i. $501=$ Meryta latifolia.

macrophylla, Lindl. in Bot. Reg. (1844) Misc. $79=$ cachemirica.

\section{ARALIA}

malabarica, Bedd. Fl. Sylv. ii. 121. - Ind. or mandschurica, Seem. in Journ. Bot. vi. (1868) 134 spinosa.

mandshurica, Rupr. in Bull. Acad. Pétersb. xv. (185́6) 134.-As. or.

Maralia, Roem. \& Schult. Syst. vi. $704=$ Panax Maralia.

Maximowiczii, Van Houtte, F1. des Serres, Sér. II. xx. (1874) 39. t. $2067=$ Acanthopanax ricinifolium. micans, Willd. ex Roem. \&c Schult Syst. vi. $701=$ Panax splendens.

Mitsde, Siebold, in Linnaea, xxyi. (1853-55) 754

Dendropanax japonicum.

monogynia, Vell. F1, Flum. 129; iii, t, $111=$ Gili

bertia monogyna.

montana, Blume, Bijdr. 870.-Java.

Moorei, F. Muell. Fragm, ii. $108=$ Heptapleurum venulosum.

Motherwelli, F. Muell, l. c. vii. 107-Anstral.

Muehlenbergiana, Roem. \& Schult. Syst. vi. $704=$ hispida.

multiflora, Pohl, ex DC. Prod. iv. 262=Oreopana capitatum

Mutisiana, H. B. \& K. Nov, Gen. et Sp. v. $1=$ Oreo. panax Mutisianum.

obilis, Hort. Williams-Cf. Gard. Chron. (1878) II. $56 ;(1880)$ I. 759 . - Hab.?

nodosa, Blume, Bijdr. $873=$ Polyscias nodosa.

nudicaulis, Blume, 1. c. $870=$ cordata.

nudicaulis, Linn. Sp. Pl. 274.-Ano. bor.

nutans, Franch. E' Sav. Enum. Pl. Fap. ii. 376.Japon.

obtusiloba, H. B. \& $\mathrm{K}$. Nov. Gen. et Sp. $.5=$ Oreopanax obtusilobum.

occidentalis, Schlecht. ex Ledeb. F1. Ross. ii 375 Fatsia horrida.

octonata, Stokes, Bot. Mat. Med. ii. 181= Hepta pleurum octophyllum.

octophylla, Blancu, Fl. Filip. ed. II. $158=$ Heptapleuram rigidum.

octophylla, Lour. F1. Cochinch. i. $187=$ Heptapleurum octophyllum.

palmata. Lam. Encyc. i. $224=$ Trevesia Zippeliana.

palmata, Lour. Fl. Cochinch. 187 = Brassaiopsis Hainla palmata, Reinw. ex De Vriese, Pl. Ind. Bat. Reinw. 8 $=$ Trevesia sundaica.

palmata, Willd. ex Roem. \& Schult. Syst. vi. $699=$ Oreopanax cheirophyllum.

paniculata, Phil. in Linnaea, xxvili. (1856) 694

Panax valdiviense.

papyrifera, Hook. Kew Journ, iv. (1852) $50=$ Fatsi: papyrifera.

parvifolia, Panch. E Sebert, Not. Bois. Nouv. Caled 204.-N. Caled.

pendula,Blanco, Fl. Filip. ed. I. $223=$ Polyscias nodosi pennata, Poir. Encyc. Suppl. i. 418, sphalm.

Trevesia palmata.

pentaphylla, Thunb. Fl. Jap. 128 = Acanthopanax spinosum.

pergamacea, Blume, Bijdr. $873=$ Heptapleurum pergamaceum.

pinnata, Hochst. ex A. Rich. Tent. Fl. Abyss. i. 335.Abyss.

pinnatifida, Jungh. \& De Vriese, in Ann. Sc. Nat. Sir. III. vi. (1846) $115=$ Aralidium pinnatifidum.

Planchoniana, Hance, in Journ. Bot. iv. (1866) 172 Acanthopanax spinosum.

platanifolia, H. B. \& K. Nov. Gen. et Sp. v. 6 Oreopanax platanifolium.

polaris, Hombr. \& Jacquinot, ex Decne. Bot. Voy. Astrol. et Zel. $55=$ Stil bocarpa polaris.

Polyscias, Spreng. ex Seem. in Journ. Bot, vi. (186y $138=$ Polyscias umbellata.

Pseudo-ginseng, Benth. $a x$ C. B. Clarke, in Hook. Fl. Brit. Ind. ii, 721.-Reg. Himal.

pubescens, DC Cat. Hort. Monsp. (1\$18) $80=$ humilis!

quinduensis, H. B. \& K. Nov. Gen. et Sp. v. \&

Sciodaphyllum quinduense.

quinquefolia, Decne. E Planch. in Res. Hortic. Ser. I

iii. (185\$) 105. - Am. bor.

racemosn, Linu, Sp. Pl. 273.-An, bor.

ramiflora, Hobl, ex March. in Mart. Fl. Bras. xi. 1. 250 -Giliterria cuneata.

Kegelinna, March. in Bui.. Acad. Betg. Sér. II. xlvi (1573) 73.-Mexico.

Reinswardtiana, Seem, in Joum. Bot. vi. (1s6is) 18 Trevesia sumdaico. 


\section{ARALIA :-}

reticulata, Willd. ex Roem. \& Schult. Syst. vi. $699=$ Oreopanax reticulata.

rigida, Blume, Bijdr. $874=$ Heptapleurum rigidum. rugosa, Blume, 1. c. 872 (= Heptapleuri sp.).-Java salicifolia, Vent. ex Seem. in Fourn. Bot. vi. (1868) 138. - Hab.?

scabra, Presl, ex DC. Prod. iv. 258=pubescens.

scandens, Poir. Encyc. Suppl, i, $419=$ Brassaiopsis Hainla.

Scheffera, Spreng. PI. Pugill, i. $28=$ Schefflera digitata Sciodaphyllum, Sw. Prod. Veg. Ind. Occ. $55=$ Sciodaphyllum Brownei.

septemnervia, H. B. \& K. Nov. Gen. et Sp. v. 3= Oreopanax capitatum.

Sieboldii, Hort. ex C. Koch, Dendrol, i. 678 = Fatsia japonica.

simillima, Blume, Bijdr. 871 (=Heptapleurisp.).-Java。 soratensis, March. in Bull. Acad. Belg. Sér. II, xlvii (1879) 75,--Bolivia.

spectabilis, Hort. Bull.-Cf. Gard. Chron. (1876) I. 603 =filicifolia.

spinosa, Linn. Sp. Pl. 273.-Am. bor.

tarchonanthifolia, Willd. ex Roem. \& Schult. Syst. vi. $698=$ Oreopanax avicenniaefolium.

tenuifolia, Pancher, ex Baill. Adansonia, x. (1871-72) 372. - N. Caled.

Thibautii, Versch.ex Morr.in Belg. Hortic. xiii. (1863) -Mexic.

Thomsonii, Seem. in Fourn. Bot. vi. (1868) 134.Reg. Himal.

trifolia, Banks \& Soland. ex Walp. Ann. v. $84=$ Pseudopanax crassifolinm.

trifolia, Decne. E Planch. in Rev. Hortic. Sér. IV. iii. (1854) 105.-Am. bor.

trifoliata, Meyen, Reise, ii. $332=$ Acanthopanax aculeatum.

trigyna, Gaudich. Voy. t. 98 (=Panacis sp.).-Hab. triphylla, Poir. Encyc. Suppl. i. $418=$ trifolia.

tripinnata, Blanco, Fl. Filip. ed I. 223=Panax fruti cosum.

turbacensis, H. B. \& K. Nov, Gen。 et Sp. v. 3= Oreopanax turbacense.

umbellata, Pav. ex Seem. in Journ. Bot. vi. (1868) 138 $=$ Gilibertia umbellata.

umbellata, Pohl, ex March. in Mart. Fl. Bras. xi. I. $250=$ Gilibertia cuneata

umbellifera, Lam. Encyc. 1. 225=Osmoxylon amboinense.

umbraculifera, Roxb. Hort. Beng. 22; Fl. Ind. iii. $108=$ Polyscias nodosa

urticaefolia, Blume, ex Miq. in Ann. Mus. Bot. Lugd. Bat. i. 9.-Hab.

valdiviensis, C. Gay, Fl. Chil, iii. 152 = Panax valdiviense.

Veitchii, Hort. ex T. Moore, in Flor. E Pom. (1874) 5. -Hab.?

vitiensis, A. Gray, Bot. U. St. Expl. Exped. i. $715=$ Schefflera vitiensis.

Wallichiana, D. Dietr. Syn. Pl. ii. 1035.-Ind. or

xalapensis, H. B. \& K. Nov. Gen. et Sp. v. 8. $=$ Oreo panax xalapense.

ARALIDIUM, Miq. F1. Ind. Bat. i. I. 762 . t. 13 (1855). ARALIACEAE, Benth. \& Hook. f, i. 936. dentatum, Miq. Fl. Ind. Bat. Suppl. 340.-Sumatra. pinnatifidum, Miq. l. c. i. I. 763. t. 13.-Malacca.

ARALIOPSIS, Kurz, in Andam. Rep. 39 (1870) = Brassaiopsis, Decne. \& Planch. (Araliac.). andamanica, Kurz, 1. c. = B. palmata.

ARAPABACA, Adans. Fam. ii. 225 (1763)=Spigelia, Linn. (Logan.).

ARARIBA, Mart. in Sitzb. Acad. Muench. (1860) 323 = Sickingia, Willd. (Rnbiac.). alba, Mart. 1. c. 324.-Bras. rubra, Mart. 1. c.-Bras.

ARARocaRPUS, Scheff. in Ann. Jard, Buitenz, ii. (1885) 10. ANONACEAE. velutinus, Scheff. 1. c.- Java.

ARASCHCOOLIA, Sch. Bip. Pl. Kotsch. Nub. Exs. n. 101 (1873); ex Benth. \& Hook. f. Gen. ii. 337= Geigeria, Griessel. (Compos.).

acaulis, Sch. Bip. ex Oliver, F1. Trop. Afr. iii. $368=$ G. acaulis.
ARAUCARIA, Juss. Gen. Pl. 413 (1789), CONI-

FERAE, Benth. \& Hook. fo iii, 437.

Altingia, Loud. Hort. Brit. $403(1830)$

Columbea, Salisb. in Trans. Linn. Soc. viii. (1807) 317.

DoMbeya, Lam. Encyc. ii. 301. t. 828 (1786).

EuTACTA, Link, in Linnaea, xv. (1841) 543.

Eutassa, Salisb. in Trans. Linn. Soc. viii. (1807) 316

Quadrifaria, Manetti, ex Gord. Pinet. Suppl. 14 (1862)

albospica, Hort. ex Carr. Conif. ed. II. $611=$ excelsa.

araucana, C. Koch, Dendrol. ii. II. $206=$ imbricata.

Balansae, Brongn. E Gris, in Ann. Sc. Nat. Sér. V xiii. (1870-71) 351.-N. Caled.

Bibbiani, Hort. Ital. ex Gord. Pinet. 24 = brasiliana.

Bidwillii, Hook. Lond. Fourn. Bot. ii. (1843) 503. t. 18, 19.-Austral.

brasiliana, A. Rich. in Dict. Class. Hist. Nat. i. 512.Bras.

brasiliensis, Loud. Hort. Brit. $403=$ praec.

chilensis, Mirb. in Mém. Mus. Par. xiii. (1825) $49=$ imbricata.

columnaris, Hook. in Bot. Mag. t. $4635=$ Cookii.

Cookii, R. Br. ex D. Don, in Trans. Linn. Soc. xviii. (1841) 164.-N. Caled

Cunninghamii, Sweet, Hort. Brit. ed. II. 475.-Austral. Dombeyi, A. Rich. Conif. 86. t. $20=$ imbricata.

elegans, Hort. ex Carr. Conif. ed. I. $415=$ brasiliana.

excelsa, R. Br. in Ait. Hort. Kerw, ed. II. v, 412Austral.; Ins. Norf.

glauca, Antoine, Conif. 105. t. $44=$ Cunninghami

Goldieana, Hort. ex T. Moore, Flor. E Pom. (1877) 39. - N. Caled.

gracilis, Hort. ex Carr. Conif. ed. I. $415=$ brasiliana.

imbricata, Pav, in Mem. Acad. Med. Madr i. (1797) 199. -Chili.

intermedia, R. Br. ex Vieill. in Ann. Sc. Nat. Sér. IV. xvi. (1861) $54 .-\mathrm{N}$. Caled.

lanceolata, Hort, ex Carr. Conif. ed. I. $171=$ Cunninghamia sinensis

Lindleyana, Van Houtte, ex Gord.Pinet. $24=$ brasiliana montana, Brongn. Eo Gris, in Ann. Sc. Nat. Sér. V. xiii. (1870-71) 358.-N. Caled.

Muelleri, Brongn. \& Gris, l. c. 362.-N. Caled.

Ridolfana, Savi fo in Atti Firenz. (1841) 458 et 783 ; et Giorn. Bot. Ital. ii. (1846) fasc, i. $52=$ brasiliana.

Rulei, F. Muell.ex Lindl. in Gard. Chron.(1861) 868. $-\mathrm{N}$. Caled.

Saviana, Parl. in Bull. Soc. Bot. Fr. viii. (1861) 89.Bolivia.

subulata, Vieill. in Ann. Sc. Nat, Sér. IV. xvi. (1861) 55.-N. Caled

ARAUCASIA, Benth. \& Hook. f. Gen. iii. 919 (1883), sphalm. $=$ ARAUSIACA, Blume = Orania, Zipp. (Palm.).

ARAUJIA, Brot in Trans. Linn Soc, xii. (1818) 62 ASCLEPIADEAE, Benth. \& Hook. f. ii. 751

Lagenia, Fourn. in Mart. Fl. Bras. vi. IV, 293 $(1885)$.

Pentaphragma, Zucc. ex Reichb. Consp. 131 (1828)

Physianthus, Mart. Nov. Gen. et Sp. i. 53. t. 32 (1824)

SCHU BERTIA, Mart. 1. c. 55. t. 33 (1824).

albens, G. Don, Gen. Syst. iv. $149=$ sericifera. angustifolia, Steud. Nom. ed. II. i. 119.-Bras calycina, Decne. in DC. Prod. viii. $534=$ sericifera.

fusca, Griseb. ex Lorentz, in Goett. Abh. xxiv. (1879) $232=$ megapotamica

hortorum, Fourn. in Mart. Fl. Bras. vi. rv. 293.Bras.

megapotamica, G. Don, Gen. Syst. iv, 149.-Bras.

sericifera, Brot. in Trans. Linn. Soc, xii. (1818) 62.Peruv.

subhastata, Fourn. in Mart. Fl. Bras, vi. IV. 293.Bras.

undulata, Visiani, Hort. Patav. (1832) $134=$ hortorum.

ARAUSIACA, Blume, Rumphia, in praef. p. 8. (1836) tt. 119, $122=$ Orania, Zipp. (Palm.).

excelsa, Blume, $\mathrm{I}_{\mathrm{s}} \mathrm{c}_{ }=\mathrm{O}$. regalis.

ARBUTUS, [Tourn.] Linn. Syst. ed. I (1735). ERI$C A C E A E$, Benth. \& Hook. f. ii. 581.

Unedo, Hoffmgg. \& Link, Fl. Port. i. 415 (1809) acadiensis, Linn. Sp.Pl. 395 (planta obscura).-Am. bor.

\section{ARBUTUS}

acerba, Gilib. Fl. Lituan。 i. $5=$ Arctostaphyios Uva-ursi.

alpina, Linn. Sp. Pl. $395=$ Arctostaphylos alpina

Andrachne, Linn. Syst. ed. X. 1024. п. 488.-Reg. Mediterr. or

andrachnoides $\times$, Link, Enum. Hort. Berol. i. 395.Hab.?

arguta, Zucc. ex Steud. Nom. ed. II. i. 120, $119=$ Arctostaphylos arguta.

buxifolia, Stokes, Bot. Mat. Med. ii. 509=Arctosta phylos Uva-ursi.

Callicarpa, Buch, Canar. $146=$ canariensis

canadensis, Poir. ex Steud. Nom. ed. I. 62.-CCanada. canariensis, Duham. Arb. ed. II. i. 80.-Ins. Canar. cassinifolia, Hort. ex Steud. Nom. ed. II. i. 119.Ins. Madera.

coriacea, Blume, Cat. Gew. Buitenz. $67=$ Vaccinium Korthalsii.

crispa, Hoffmgg. Verz. Pf. Nachtr. i. (1824) $204=$ A Unedo.

Croomii, Hort,-Cf, Gard. Chron. (1884) II. $492=$ A Unedo.

densiflora, Benth. P1. Hartw. 15=glandulosa.

densillora, H. B. E" K. Nov. Gen. et Sp. iii. 280.t. 260 -Mexic

discolor, Hook. Ic. Pl. t. $29=$ Arctostaphylos arguta

empetrifolia, Pers. Syn. i. $483=$ Pernettya empetri tolia.

ferruginea, Linn.f. Suppl. 238.-Reg. Colomb.

filiformis, Lam. Encyc. i. $228=$ Chiogenes serpylli folia.

horibunda, Mart. \& Gal. in Bull. Acad. Brux. ix. 1842) 534 - Mexic.

furiens, Hook. Bot. Beech. Voy, 33-Chili.

glaberrima, Noronha, in Verh. Batav. Gen. v. (1790) ed. I. Art. IV. 6.-Malaya.

glandulosa, Mart. E Gal. in Bull. Acad. Brux. ix. (1842) 533.-Mexic

herpetica, Coleb. ex Roxb. Hort. Beng. [90]; Fl. Ind. ii. $412=$ Pieris ovalifolia.

hybrida, Ker-Gawl. in Bot. Reg. t. $619=$ andrachnoides. integrifolia, Lam. Encyc. 1. $227=$ A. Andrachne.

integrifolia, Sieber, ex Klotzsch, in Linnaea, xxiv. 1851) $71=$ Sieberi

integrifolia, Sims, Bot. Mag. t. $2319=$ A. Unedo.

intermedia, Heldr. ex Nym. Consp. $490=\mathrm{A}$. Unedo.

lanceolata, Lam. Encyc. i. $227=$ Prunus caroliniana.

laurifolia, Buch.-Ham. ex D. Don, Prod. FI. Nep 151 - Gaultheria fragrantissima.

laurifolia, Linn. f. Suppl. 238 (Cf. A. Gray, Syn. Fl

N. Am. ii. I. 396) = A. Unedo.

laurifolia, Lindl, Bot. Reg. (1839) t. $67=x a l a p e n s i s$

laurina, Mart. Eo Gal. in Bull. Acad. Brux. ix. (1842) 535.--Mexic.

leucocarpa, Poepp. \& Kunze, ex DC. Prod. vii. $586=$ Pernettya leucocarpa.

longifolia, Andr. Bot. Rep. x. $664=$ canariensis.

lucida, Hort. ex Steud. Nom. ed. II. i. $119=$ A Andrachne.

macrophylla, Mart. E Gal. in Bull. Acad. Brux. ix. (1842) 534.-Mexic

Madrono, Humb. Nouv. Espagne, ii.454, ex H.B. \& K. Nov. Gen. et Sp. iii. $282=$ Arctostaphylos pungens.

Menziesii, Pursh, Fl. Bor. Am. i. 282.-Äm. bor. Mexic.

microphylla, Forst. f. in Comm. Gotting. ix. (1789) 32 = Pernettya microphylla.

microphylla, Hort.-Cf. Gard. Chron. (1884) II. $49=$ A. Unedo.

Milleri, Sweet, Hort. Brit. ed. II. 331.-Oriens.

mollis, H. B. E' K. Nov. Gen. et Sp. iii. 281. t. 260.Mexic.

mucronata, Linn. f. Suppl. $239=$ Pernettya mucronata myrtifolia, Willd. ex Steud. Nom. ed. II. i. 120, $119=$ Arctostaphylos pungens.

myrtilloides, Humb, ex Steud. Nom, ed. II. i $119=$

Vaccinium stamineum.

myrtilloides, Poepp. ex DC. Prod. vii. $593=$ Pernettya myrtilloides.

muda, Steud. Nom. ed. II. i. $119=$ Arctostaphylos pungens.

obtusifolia, Rafin. Fl. Ludov. 55.-Am. bor.

officinalis, Boiss. Fl. Orient. iii. $967=$ Arctostaphylo Uva-ursi.

ovata, Mart. E Gal. in Bull. Acad. Brux. ix. (1842 533.-Mexic.

paniculata, Mart. E Gal. l. c. 535.-Mexic. 
ARBUTUS :

petiolaris, H. B. E K. Nov. Gen. et Sp. iii. 281.Mexic.

phyllireaefolia, Pers. Syn. i. $483=$ Pernettya phyllireaefolia.

pilosa, R. Grah. in Bot. Mag. t. $3177=$ Pernettya pilosa.

procera, Dougl. ex Lindl. Bot. Reg. t. $1753=$ Menziesii.

procera, Soland. ex DC. Prod. vii. $581=$ canariensis.

procumbens, Kluk, ex Bess. Fl. Galic. ii. 355.Galicia.

procumbens, Salisb. Prod. $289=$ Arctostaphylos Uvaursi.

prostrata, Cav. Ic. vi. 43. t. $562=$ Pernettya parvifolia.

prunifolia, Klotssch, in Linnaea, xxiv. (1851) 73.Mexic.

pumila, Forst. f. in Comm. Gotting. ix. (1789) $32=$ Pernettya empetrifolia.

punctata, Hook. E Arn. Bot. Beech. Voy. 33.Calif.

pungens, Hook. \& Arn. 1. c. $144=$ Arctostaphylos Hookeri.

rigida, Banks, ex Hook. f. Fl. Antarct. ii. $326=$ Pernettya mucronata.

rigida, Bert. ex Colla, in Mem. Acc. Sc. Torin. xxxviii. (1835) $120=$ Pernettya rigida.

rigida, Willd. ex Steud. Nom. ed. II. i. 120, $119=$ Arctostaphylos pungens.

rubescens, Bertol. F1. Guatimal. 20. t. $7=$ Arctostaphylos rubescens.

salicifolia, Cels, ex Hoffmgg. Verz. Pfl. Nachtr. i. (1824) 204.--Oriens.

serpyllifolia, Lam. Encyc. i. 225 = Gaultheria antipoda.

serratifolia, Lodd. Bot. Cab. t. $580=$ A. Andrachne serratifolia, Salisb. Prod. $288=$ A. Unedo.

sibirica, Forbes, Hort. Woburn. 95, nomen.-Sibir.

Sieberi, Klotzsch, in Linnaea, xxiv, (1851) $71=\mathrm{A}$. Andrachne.

spinulosa, Mart. E Gal. in Bull. Acad. Brux. ix. (1842) 532.-Mexic.

texana, Buckl. in Proc. Acad. Sc. Philad. '1861' 1862) $460=$ Menziesii.

thymifolia, Ait. Hort. Kew. ii. $72=$ Chiogenes serpyllifolia.

tomentosa, Pursh, Fl. Am. Sept. i. 282=Arctostaphylos pungens.

turbinata, Pers. ex Reichb. Fl. Germ. Excurs. i. $416=$ A. Unedo.

Unedo, Linn. Sp. Pl. 395.-Reg. Mediterr.; Hibern.

Uva-ursi, Linn. 1. c. = Arctostaphylos Uva-ursi.

varians, Benth. Pl. Hartw. 77.-Mexic.

vernalis, Poepp. \& Endl. Nov. Gen. i. 26. t. $42=$ Gaultheria vernalis.

villosa, Willd. ex Klotzsch, in Linnaea, xxiv. (1851) $72=$ glandulosa

xalapensis, Andr. ex Hook. Ic. Pl, t. $27=$ Arctostaphylos oaxacana.

xalapensis, H. B. E K. Nov. Gen. et Sp. iii. 279,Mexic.

xanthocarpa, Wangen. Beitr. 30.-Am. bor.

ARCANGELISIA, Becc. Malesia, i. (1877) 145. MENISPERMACEAE

inclyta, Becc. l. c. 147.- Java; Celebes.

lemniscata, Becc. l. c.-N. Guin.

ARCAULA, Rafin. Alsog. Am, 30 (1838)= Quereus, Tourn. (Cupul.)

spicata, Rafin. 1. c. = Q. spicata.

ARCEUTHOBIUM, Bieb. Fl. Taur. Cauc. Suppl, 629 (1819). LORANTHACEAE, Benth. \& Hook, f iii. 213 .

Razoumowskis, Hoffm. cx Bieb. 1. c. (1819).

abietinum, Engelm, in Proc. Am. Acad. viii. (1873) $401=$ occidentale.

americanum, Nutt. ex A. Gray, in Bost. Journ. Nat. Hist. vi. (1850) $214=$ A. Oxycedri.

campylopodum, A. Gray, l. C-Am bor

capense, J. S. Presl, Rostl, ii. $28=$ Viscum capense.

cryptopodum, A. Gray, in Bost. Journ. Nat. Hist. vi. (1850) 214 = vaginatum.

divaricatum, Engelm. in Wheeler, Rep. vi. 253.-Am. bor.

Douglasii, Engelm. l. c.-Am, bor.

\section{ARCEUTHOBIUM:-}

gracile, Engelm. in A. Gray, Pl. Fendl. 59.-Am. bor.

minutum, Engelm, in Bull. Torrey Bot. Club, ii. (1871) 43, 47.-Am. bor.

occidentale, Engelm. ex S. Wats. in Bot. Calif. ii. 107 -Calif.

opuntioides, J. Presl, Rostl. ii. $28=$ Dendrophthora opuntioides.

Oxycedri, Bieb. Fl. Taur. Cauc. Suppl. 629.-Europ.; Am. bor.

robustum, Engelm. in A. Gray, Pl. Fendl. 59.-Am. bor.

vaginatum, F. Presl, Rostl. ii. 28. $\ldots$ Am. bor

ARCEUTHOBIUM, Griseb. F1. Brit. W. Ind. 314 (1864) $=$ Dendrophthora, Eichl. (Loranth.)

Bonaniae, Griseb. Cat. Pl. Cub. $121=\mathrm{D}$. Bonaniae.

cupressoides, Griseb. F1. Brit. W. Ind. $315=\mathrm{D}$. cupressoides.

domingense, Griseb. Cat. Pl. Cub. 121=D. domin gensis.

Epiviscum, Griseb. in Mem. Am. Acad. N. S. viii. (1861) $192=$ D. Epiviscum

glaucum, Griseb. Fl. Brit. W. Ind. $315=$ D. glaucum gracile, Griseb. ]. c. = D. gracilis

Mancinellae, Wright, ex Griseb. Cat. Pl. Cub. 121= D. Mancinellae.

ARCEUTHOS, Ant. \& Kotschy, in Oestr. Bot. Wochenbl. (1854) $249=$ Juniperus, Linn. (Conif.) drupacea, Ant. \& Kotschy, 1. c. =J. drupacea.

ARCHAIGELICA, Hoffm. Gen. Umb. ed. I. 161 1814); ed. II. 166 (1816). UMBELLIFERAE, Benth. \& Hook, f, i. 917

Coelopleurum, Ledeb. Fl. Ross. ii. 361 (1844)

Czerniajevia, Turcz, in Bull. Soc. Nat. Mose. (1838) 93.

atropurpurea, Hoffm. Gen. Umb. 162.-Am. bor. brevicaulis, Reichb. f. in Fourn. Bot.xiv. (1876) 46.As. temp.

commutata, C. A. Mey.ex Rupr. in Beitr. Pf. Russ. Reich. xi. 13.-Kamtschatka.

decurrens, Ledeb. F1. Alt. i. $316=$ officinalis

dentata, Chapm. in Torr. E Gray, Fl. N. Am. i. 622. -Florida.

discocarpa, Fries, in Bot. Notiser, (1857) 50.Europ.

Gmelini, DC. Prod. iv. 170.-Am. bor.; As. bor. occ. hirsuta, Torr. E Gray, Fl. N. Am. i. 622.-Am. bor. inaequalis, Maxim. ex Franch. E Sav. Enum. Pl. Fap. i. 188.- -Japon.

Keiskei, Miq. Ann. Mus, Bot. Lugd. Bat, iii. 62,Japon.

littoralis, Agardh, ex DC. Prod. iv. 170.-Europ. arct.

major, Lag. Gen, et Sp. Nov, $13=$ littoralis ?

norwegica, Rupr. in Beitr. Pfl. Russ. Reich. ii. $37=$ officinalis.

officinalis, Hoffm. Gen. Umb. 162.-Europ.; Sibir. Reg. Himal

officinalis, Hook. Fl. Bor. Am. i. $267=$ Gmelini.

peregrina, Nutt. ex Torr. \& Gray, Fl. N. Am. i. $622=$ Gmelini.

Roylei, Lindl. in Royle, Illustr. Bot. Himal. $232=$ officinalis.

sativa, Bess. Enum. $13=$ officinalis

slavica, Reuss, Květ. Slov. (1853) $184=$ officinalis spuria, Wahlenb. Fl, Casp. 84 , in obs, =littoralis.

ARCHEMORA, DC. Prod. iv. $188(1830)=$ Peuce danum, Linn. (Umbell.)

ambigua, DC 1 . c. = P. ternatum

denticulata, DC. . . $\mathrm{C},=\mathrm{P}$. ternatum

Fendleri, A Gray, Pl. Fendl, 56.-Texas,

rigida, DC. Mém. Ombell. 52 ; Prod. iv, $188=\mathrm{P}$ ternatum.

ternata, Nutt. ex Torr. \& Gray, FI. N. Am. i. $681=$ P ternatum.

tricuspidata, DC. Prod. iv, $188=$ P. ternatum.

ARCHERIA, Hook. f. FI. Tasm. i. 262. t, S0, 81 EPACRIDEAE, Benth, \& Hook, f. ii. 616 . eriocarpa, Hook, f. l. c. 263. t. 80 B.-Tasmania. hirtella, Hook.f.l. c. t. 81.-Tasmania. minor, Hook. f. 1. c. $264=$ serpyllifolia.
ARCHERIA

racemosa, Hook, ff Handb. New Zeal. Fl 180,-N. Zel.

serpyllifolia, Hook. f. Fl. Tasm. i. 263. t. 80 B.T asmania.

Traversii, Hook. f. Handb. New Zeal. Fl. 180.N. Zel.

ARCHIDENDRON, F. Muell. Fragm, v. 59 (1865) LEGUMINOSAE, Benth. \& Hook. i. i. 1004.

Lucyi, F. Muell. l. c. vi. 201.-Austral.

Vaillantii, F. Muell. l.c. v. 60-Austral.

ARCHIMEDEA, Leandr. Sacram. ex A. St. Hil, in Ann. Sc. Nat. Sér. II. vii. (1837) $32=$ Lophophytum Schott \& Endl. Balanoph.)

pyramidalis, Leandr. Sacram. 1. c. = L. mirabile.

ARCHITAEA, Mart. Nov, Gen, et Sp. i. 116. t. 73 (1824) = Archytaea, Mart. (Ternstr.

ARCHONTOPHOENIX, H. Wendl. \& Drude, in Linnaea, xxxix. (1875) 182. PALMAE, Benth \& Linnaea, xxxix.
Hook. f, iii. 889 .

Alexandrae, H. Wendl. E Drude, l. c. 212.-Austral.

Cunninghamii, H. Wendl. \&̊ Drude, l. c. 214 . Austral.

Veitchii, H. Wendl. E Drude, l. c.-Hab.?

ARCHYTAEA, Mart. Nov. Gen, et Sp, i, 117 (1824). TERNSTROEMIACEAE, Benth. \& Hook f. i. 188 .

Plolarum, Korth. Verh. Nat. Gesch. Bot. 135. t. 25

multiflora, Benth. in Hook. Lond. Fourn. Bot. ii (1843) 363.--Guiana.

sessilis, Scheff. in Tijdschr. Nederl. Ind. xxxii. (1871) 406.- Malaya.

triflora, Mart. Norv. Gen. et Sp. i. 117-Bras.

Vahlii, Choisy, in Mém. Soc. Phys. Genìv. xiv. (105j 163.-Malaya.

ARCTAGROSTIS, Griseb, in Ledeb. Fl, Ross, iv 434 (1853), GRAMINEAE, Benth. \& Hook. fo iii. 1150

latifolia, Griseb. l. c.-Reg. Arct.

ARCTIO (et ARCTION), Lam. Encyc. i. 235 (1783, Berardia, Vill. (Compos.).

lanuginosa, Lam. 1. c. = B. subacaulis.

ARCTIODRACON, A. Gray, in Mem. Am. Acad. Ser. II. vi. (1858-9) $408=$ Lysichitum, Schot (Aroid.).

camtschaticum, A. Gray, 1.c. $409=\mathrm{I}$ camtschatensc. japonicum, A. Gray, 1. c. = L. camtschatense.

ARCTIUM, Lam. F1. Fr. ii. $70 \quad(1778)=$ Berardia Vill. (Compos.)

lanuginosum, Lam. 1. c. = B. subacaulis.

ARCTIUM, Linn. Syst. ed. I (1735). COMPOSIT 4 E Benth. \& Hook. f. ii. 460 .

LAPPA, Juss. Geд. 173 (1789)

adhaerens, Gilib. F1. Lituan, i. 182= A. Lappa.

Bardana, Willd. Sp. Pl. iii. $1632=$ A. Lappa.

Carduelis, Linn. Mant. i. $108=$ Carduus arctioides.

conglomeratum, Schur, ex Nym. Syll. Suppl. $t=$ minus.

euminus, Syme, Engl. Bot. ed. III. จ. $20^{\circ}$ minus.

grandiflonum, Desf. Cat. Hort. Par. ed. III. 15t= majus.

intermedium, Bab. in Ann. \& Mag. Nat. Hist. Ser. Il. xvii. (1856) $374=$ majus.

intermedium, Lange, Fl. Dan. t. 26its numorosum.

Lappa, Kalm, Fl. Fennic. n. 149 ; Sm. Engl. Bot. $1.28=$ minus.

Lappa, Willd.Sp. Pl. iii. 1681 - majus.

Lappa, Linn. Sp. Pl. $810^{\circ}$ (=majus, minus, Sec. -Europ.

majus, Beruh. Syst. Verg. Erf. 151.-Europ.

minus, Berrh. I. c.-Europ.

montansm, Schweig. ex Sieud. Nom. ed. 11. i. 120. mints.

nemorosum, Lejenne, in Rrishb. Ic. ... Germm. xr. s. - Liurop.

Persomata, Lina. Sp. P1. $810=$ Carduus I'ersonata, 


\section{ARCTIUM}

Personata, Pall. Reise, iii. 439 (planta ignota).Davuria.

pubens, Bab. in Ann. \& Mag. Nat. Hist. Ser, II. xyii. (1856) $376=$ nemorosum

mederale, Salisb. Prod. $184=$ A. Lappa

tomentosum, Mill. Gard. Dict. ed. VIII. n. 3; Bernh Syst. Verz. Erf, $154=$ majus.

ARCTOCALYX, Fenzl, in Otto \& Dietr. Allg. Gartenz. xvi. $305(1848)=$ Solenophora, Benth. (Gesner.).

Endlicherianus, C. Heller, ex Fenzl, 1. c. $307=$ S. Endlicheriana.

insignis, Fenzl, 1. c. $306=\mathrm{S}$. insignis.

ARCTOCARPUS, Blanco, FI. Filip. ed. I. 666 (1837)= Artocarpus, Forst. (Urtic.).

ARCTOGERON, DC. Prod。v, $260 \quad(1836)=$ Aster, Linn. (Compos.).

gramineum, DC. 1. c. 261.-Sibir.

ARCTOMECON, Torr. \& Frém, in Frém. Rep. 312. t. 2 (1845). PAPAVERACEAE, Benth. \& Hook. f. i. 52 .

californicum, Torr. Ẽ Frém. l. c.-Calif.

ARCTOPHILA, Rupr. in Beitr. Pfl. Russ, Reich. ii. 62 $(1845)=$ Poa, Linn. (Gram.)

fulva, Nym. Consp. $830=$ P. fulva.

Laestadii, Rupr. in Beitr. Pfl. Russ. Reich. ii. $62=\mathrm{P}$. Laestadii.

pendulina, Nym. Consp. $830=$ P. Laestadii.

ARCTOPUS, Linn. Coroll. Gen. 21 (1737); Hort. Cliff. 495 (1737). UMBELLIFERAE, Benth. \& Hook. f. i. 879 .

ApratuUs, Adans. Fam. ii. 102, 509 (1763).

Dregei, Sond. in Harv. E Sond. Fl. Cap. ii. 565.Afr, austr.

echinatus, Linn. Sp. Pl. 1058.-Afr. austr.

monacanthus, Carmich. ex Hary. E Sond. Fl. Cap. ii. 565.-Afr. austr.

ARCTOSTAPHYLOS, Adans. Fam. ii. 165 (1763). ERICACEAE, Benth. \& Hook. f. ii. 581

Comarostaphylis, Zucc. in Abh. Akad. Muench. ii. (1837) 331 .

DAPHNIDOSTAPHYLIS, Klotzsch, in Linnaea, xxiv. (1851) 78.

Mairania, Neck. Elem, i. $219(1790)$

Uva-uRSI, Tourn. ex Moench, Meth. 470 (1794).

Xerobotrys, Nutt. in Trans. Am. Phil. Ser. II. viii (1843) 267.

XYlococcus, Nutt. in Trans. Am. Phil. Soc. Ser. II. viii. (1843) 258.

acuta, Nutt. in Trans. Am. Phil. Soc. Ser. II. viii. (1843) $258=$ Hookeri $?$

alpina, Payot.-Cf. Bull. Soc. Bot. Fr. xxix. (1882) Bibl. 43, lapsu=angustifolia.

alpina, Spreng. Syst. ii. 287.-Am. bor. et arct.

Andersonii, A. Gray, in Proc. Am. Acad. ix. (1876)

83.-Calif.

angustifolia, Hemsl. Biol. Centr. Am. Bot. ii. 278. -Mexic.

angustifolia, Payot, Fl. du Mont Blanc, Phan. $174=$ A. Uva-ursi.

arbutoides, Hemsl. Biol. Centr. Am. Bot. ii. 278.Guatemala.

arguta, Zucc. in Linnaea, xii. (1838) Litt. 86; DC Prod. vii. 585.-Mexic.

attenuata, Hemsl. Biol. Centr. Am. Bot. ii. 278.Mexic.

bicolor, A. Gray, in Proc. Am. Acad. vii. (1868) 366 -Calif.

Clevelandi, A. Gray, I. c. xii. (1877) $61=$ bicolor

cordifolia, Lindl. Bot. Reg. sub t. 1791=tomentosa.

discolor, DC. Prod. vii. $585=$ arguta.

diversifolia, Parry, ex A. Gray, Syn. Fl. N. Am. ii. I.

397.-Calif.

glauca, Lindl. Bot. Reg. sub t. 1791.-Calif.

glauca, S. Wats. in Bot. King, Exped. $210=$ pungens.

glaucescens, $H . B$. E K. Nov. Gen. et $S p$, ini. 278.Mexic.

Hartwegiana, Hemsl. Biol. Centr. Am. Bot. ii. 278. -Mexic.

Hookeri, G. Don, Gen. Syst. iii. 836.-Calif.

latifolia, Walp. Rep. ii. $726=$ seq.

\section{ARCTOSTAPHYLOS :-}

ledifolia, Mart. E Gal. in Bull. Acad. Brux. ix. (1842) 536.-Mexic.

longiiolia, Benth. Pl. Hartw. 44.-Mexic.

mucronata, Hemsl. Biol. Centr. Am. Bot. ii, 279.Mexic.

mucronifera, DC. Prod. vii. 585.-Mexic

nevadensis, A. Gray, Syn: $F l . N . A m$. ii. I. 27.-Calif nitida, Benth. Pl. Hartw. $66^{\circ}=$ arguta.

nummularia, A. Gray, in Proc. Am. Acad. vii. (1868) 366.-Calif.

oaxacana, Benth. PI. Hartw. $45=$ Hartwegiana.

oaxacana, DC. Prod. vii. 585.-Mexic.

officinalis, Wimm. \& Grab. Fl. Siles. i. $391=\mathrm{A}$ Uva-ursi.

oppositifolia, Parry, in Proc. Davenport Acad. Nat. Sc. iv. (1884) 37.-Calif.

polifolia, H. B. E K. Nov. Gen. et Sp. iii. 277. t. 258. -Mexic

polifolia, Torr. Bot. Mex. Bound. $108=$ oppositifolia. procera, Lindl. ex Pritz. Ind. Ic. 90, sphalm. = tomentosa.

procumbens, Patze, Mey. \& Elk. F1. Preuss. $188=$ A. Uva-ursi

pumila, Nutt. in Trans. Am. Phil. Soc. Ser. II. viii. (1843) 266 .-Calif.

pungens, A. Gray, in Bot. Calif. i. 453, partim= Hookeri.

pungens, H. B. E K. Nov. Gen. et Sp. iii. 278, t. 259. -Calif.; Mexic.

rubescens, Hemsl. Biol. Centr. Am. Bot. ii. 279.Guatemala.

salicifolia, Parry, in Proc. Davenport Acad. iv. (1884) $37=$ oppositifolia

spinulosa, Mart. \& Gal. in Bull. Acad. Brtx. ix. (1842) $537=$ argnta.

tomentosa, Lindl. Bot. Reg. t. 1791.-Calif.

Uva-ursi, Spreng. Syst. ii. 287.- - Reg, bor, et arct.

Veatchii, Kellogg, in Proc. Calif. Acad. ii. (1863) $19=$ bicolor:

ARCTOTHECA, Wendl. Beobacht. 41 ; et Hort. Herrenh. 8. t. 6 (1798). COMPOSITAE, Benth. \& Hook. f. ii. 458

grandiflora, Drège, ex Turcz. in Bull. Soc. Nat. Mosc xxiv. (1851) $93=$ Arctotis Dregei

grandiflora, Schrad. in Ind. Sem. Hort. Goett. (1832) $1=$ repens.

hirta, Schrad. ex Steud. Nom. ed. II. i. 120.-Afr. austr. repens, Wendl. Beobacht. 41 ; et Hort. Herrenh. 8. t. 6.-Afr, austr.

ARCTOTIS, Linn. Gen. ed. I. 261 (1737). COMPOSITAE, Benth. \& Hook. f. ii. 458

Anemonospermos, Adans. Fam. ii. 127 (1763).

Lycotis, Hoffmgg. Verz. Pf. Nachtr. ii. 99 (1826).

Odontoptera, Cass, in Dict. Sc. Nat. xxxy. 396 (1825).

Steganotus, Cass. 1. c. (1825)

abrotanifolia, Steud. Nom. ed. II. i. $120=$ Ursinia abrotanifolia

acaulis, E. Mey. ex DC. Prod. vi. $486=$ canescens. acaulis, Jacq. Hort Schoenb. ii. 16. t. $158=$ adpressa acaulis, Linn. Sp. Pl. ed. II. 1306.-Afr. austr. adpressa, $D C$. Prod. vi. 485 .-Afr. austr.

adpressa, Eckl. ex Harv. \& Sond. Fl. Cap. iii. $465=$ Haplocarpha lyrata.

aenea, Facq. f. Eclog. 1. t. 52.-Afr. austr.

amoena, Facq. Fragm. 75.-Afr. austr.

amplexicaulis, Less. Syn. Comp. 25.-Afr. austr.

angustifolia, Jacq. Hort. Schoenb. ii. 21 = aspera.

angustifolia, Linn. Sp. Pl. 923.-Afr. austr.

anthemoides, Linn. Syst. ed. X. $1234=$ Ursinia anthemoides.

anthemoides, Thunb. ex Harv. \& Sond. Fl. Cap. iii. $152=$ Ursinia chrysanthemoides

arborescens, Facq. Hort. Schoenb. ii. 23.-Afr. austr.

arborescens, Willd, ex Harv. \& Sond. F1. Cap. iii. 453 = aspera.

argentea, Ait. Hort. Kew. iii. $273=$ linearis.

argentea, Thunb. Diss. Arct. 4 et 7.-Afr. austr.

aspera, Linn. Sp. Pl. 922.-Afr. anstr.

asplenifolia, Burm. f. F1. Cap. Prod. $28=$ Gazania pinnata.

aurea, Burm. f. Fl. Cap. Prod. 28.-Afr, austr.

aureola, Ker-Gawl. in Bot. Reg. i. t. $32=$ aspera.

auriculata, Jacq. Hort. Pl. Schoenb. 2. t. 169=aspera,

bellidifolia, Berg. Desc. Pl. Cap. 318.-Afr. anstr.

\section{ARCTOTIS :-}

bicolor, Willd. Enum. Hort. Berol. $936=$ aspera

breviscapa, Thunb. Diss. Arct. $12=$ leptorhiza.

Calendula, Linn. Sp. Pl. 922=Cryptostemma calendulaceum.

calendulacea, Linn. Syst. ed. XII. 578=Cryptostemma calendulaceum.

calendulacea, Thunb, ex Harv. \& Sond. F1. Cap. iii. $463=$ Venidium hirsutum.

campanulata, DC. Prod. vi. 485.-Afr. austr.

candida, Thunb. Diss. Arct. 14.-Afr. austr.

canescens, $D C$. Prod. vi. 485.-Afr, austr.

carduifolia, Burm. f. Fl. Cap. Prod. 28.-Afr. austr.

caroliniana, Walt. Fl. Carol. 216.-Carolina,

caulescens, Thunb. Diss. Arct. $11=$ aspera.

cernua, Thunb. 1. c. $17=$ Ursinia anthemoides.

Cineraria, facq. Hort. Schoenb. ii. 24.-Afr. austr

coronopifolia, Salisb. Prod. $210=$ Ursinia crithmifolia

corruscans, DC. Prod. vi. $496=$ Cryptostemma calen-

dulaceum.

crithmifolia, Harv. in Harv. \& Sond. Fl. Cap. iii. 144 =Ursinia crithmifolia

crithmoides, Berg. Desc. P1. Cap. $326=$ Ursinia crithmifolia

crithmoides, Jacq. Hort. Schoenb. ii. $15=$ Ursinia pilifera.

cuneata, DC. Prod. vi. $489=$ stoechadifolia.

cuprea, Hort. ex Stend. Nom. ed. II. i. $120=$ aenea.

cuprea, Jacq. Hort. Schoenb. ii. $25=$ aspera.

decumbens, Jacq. 1. c. iii. $68 . t$. 381 =angustifolia

decumbens, Thunb. Diss. Arct. $9=$ stoechadifolia.

decurrens, Jacq. Hort. Schoenb. ii. 20. t. $165=$ angustifolia.

dentata, Linn. P1. Afr. Rar. 25 ; Amoen. Acad. vi. 107 $=$ Ursinia dentata.

dentata, Thumb. Diss. Arct.17 (= Sphenogyne discolor). -Afr. austr.

denudata, Thunb. 1. c. $14=$ laevis.

diffusa, Thunb. 7, c. 9.-Afr. austr.

Dregei, Turcz, in Bull. Soc. Nat. Mosc. xxiv, (1851) Ir. 93.-Afr. austr

echinata, DC. Prod. vi. $486=$ Landtia hirsuta.

elatior, Facq. Hort. Schoenb. ii. 23.-Afr. austr

elatior, Willd. ex DC. Prod. v. $488=$ amplexicaulis.

elegans, Thunb. Diss. Arct. $14=$ Chrysanthemum indicum.

elongata, Thunb. l. c. 9.-Afr, austr.

fastuosa, Facq. Hort. Schoenb. ii. 20. t. 166.-Afr austr.

flaccida, Facq. l. c. 19.-Afr. austr.

flammea, Facq. f. Fragm. 41.-Afr, austr.

foeniculacea, Jacq. Hort. Schoenb. ii. $15=$ Ursinia foeniculacea.

formosa, Thunb. Diss. Arct. $11=$ aspera.

gigantea, A. Rich. Tent. Fl. Abyss. i. 449.-Abyss.

glabrata, Jacq. Hort. Schoenb. ii. $25=$ laevis.

glandulosa, Thunb. Diss. Arct. 8.-Afr. austr.

glaucophylla, Jacq. Hort. Schoenb. ii. $22=$ candida.

glutinosa, Sims, Bot. Mag. t. $1343=$ Dimorphotheca cuneata.

grandiflora, Ait. Hort. Kew. iii. $272=$ acaulis. grandiflora, Jacq. Hort. Schoenb. iti. t. $378=$ laevis.

grandis, Thunb. Diss. Arct. $8=$ stoechadifolia.

hispidella, Juss, ex DC. Prod. vii. 258=Hispidella hispanica.

humilis, Salisb. Prod. $210=$ acaulis.

hypochondriaca, Willd. Sp. P1. iii. $2343=$ Cryptostemma calendulaceum.

incisa, Thunb. Diss. Arct. $10=$ aspera.

interrupta, Thunb. 1. c. $12=$ Arctotheca repens.

facobaea, Sch. Bip. in Flora, xxvii. (1844) $772=$ aspera.

Kraussii, Sch. Bip. 1. c. $771=$ angustifolia.

laciniata, Lam. Encyc. i. 237.-Afr. austr.

laevis, Thunb. Diss. Arct. 10.-Afr. austr.

lanata, Thunb. 1. c. $11=$ Haplocarpha Thunbergii

lancea, Thunb. ex DC. Prod. vi. 503=Didelta tomentosum.

lanceolata, Harv. in Harv. E Sond. Fl. Cap. iii. 455 - Afr. austr.

Leichlliniana, Lynch, in Gard. Chron. (1885) II. 38 -Afr. anstr.

leiocarpa, Harv. in Harv. E Sond. Fl. Cap. iii. 451.Afr. austr.

leptorhiza, $D C$. Prod. vi. 486--Afr. austr.

leucantha, Hoffmog. Verz. Pf. 40.-Hab.

leucanthemoides, Facq. Hort. Schoenb, ii. 19. t. 164.Afr, austr. 


\section{ARCTOTIS :}

linearis, Thunb. Diss. Arct. 7.-Afr. austr. lyrata, Willd. Sp. Pl. iii. $2356=$ aspera. maculata, Jacq. Hort. Schoenb. iii. $67=$ aspera Massoniana, Spreng. Syst. iv. Cur. Post. $304=$ laevis. melanocycla, Willd. Enum. Hort. Berol. $937=$ aspera. micrantha, Thunb. ex DC. Prod.vi. $493=$ Venidium decurrens.

muricata, Thunb. Diss. Aret. $10=$ bellidifolia nodosa, Thunb. 1. c. $15=$ Chrysanthemum nodosum nudicaulis, Thunb.1.c. 16 (=Sphenogyne nudicaulis). -Afr, austr.

odorata, Steud. Nom. ed. II. i. $121=$ Ursinia odorata. oocephala, $D C$. Prod. vi. 486.-Afr. anstr.

paleacea, Linn. Pl. Afr. Rar. 25; Amoen. Acad. vi. $107=$ Ursinia crithmifolia.

paleacea, Thunb. Diss. Arct. $16=$ Ursinia paleacea. paniculata, Jacq. Hort. Schoenb. iii. $68=$ bellidifolia. pannucea, $f a c q . l$. c. iv. 21.-Afr, austr

paradoxa, Ait. Hort. Kew. iii. $373=$ Ursinia anthemoides.

paradoxa, Linn. Cent, ii. 32 ; Amoen. Acad. iv. $330=$ Ursinia paradoxa.

paradoxa, Thunb. Diss. Arct. $17=$ Ursinia chrysanthemoides.

pectinata, Thunb. 1. c. $14=$ Ursinia dentata

petiolata, Thunb.l.c. 10.-Afr. austr.

pilifera, Thunb. 1. c. $18=$ Ursinia pilifera

piligera, Berg. Desc. PI. Cap. $325=$ Ursinia dentata.

pinnata, Thunb. Diss. Arct. $16=$ Ursinia filiformis

pinnatifida, Thunb. l. c. 7-Afr, austr.

plantaginea, Linn. Sp. PI. ed. II. $1306=$ Venidium semipapposum.

plantaginifolia, Salisb. Prod. $210=$ Venidium semipapposum.

populifolia, Berg. Desc. Pl. Cap. $323=$ Cryptostemma niveum.

prostrata, Salisb. Prod. $210=$ Arctotheca repens.

punctata, Thunb. Diss. Arct. 15 (=Sphenogyne punctata).-Afr. austr.

purpurea, Willd. Enum.ex Steud. Nom.ed. II. i. 121.Afr. austr.

pusilla, DC. Prod, vi, 489.-Afr. austr.

pygmaea, A. Rich. Tent. Fl. Abyss.'i. 448.-Abyss.

radicans, Linn. Mant. ii. $479,480=$ angustifolia.

repens, Jacq. Hort. Schoenb. iil. $31=$ Arctotheca repens.

reptans, facq. l. c. 69. t. 382.-Afr. austr.

revoluta, facq. l. c. ii. 24.-Afr. austr.

rigida, Burm, f. F1. Cap. Prod. 28=Gazania Pavonia.

rosea, Jacq. Hort. Schoenb. ii. $18=$ stoechadifolia

runcinata, Hoffmgg. Verz. Pfl. 40.-Hab.?

scabra, Thunb. Diss. Arct. $9=$ Venidium semipapposum.

scapigera, Thunb. 1. c. $12=$ acaulis.

scariosa, Ait. Hort. Kew. iii. $274=$ Ursinia scariosa.

sericea, Thunb. Diss. Arct. 18 (=Sphenogyne sericea).

-Afr. austr.

serrata, Thunb. 1. c. $8=$ Ursinia serrata.

spathulata, Thunb. ex Spreng. Syst. iii. $628=$ Venidium perfoliatum.

speciosa, Jacq. Hort. Schoenb. ii. 18=acaulis.

speciosa, Salisb. Prod. $209=$ Cryptostemma calendulaceum.

spinulosa, Jacq. Hort. Schoenb. ii. 21 = fastuosa.

squarrosa, Jacq. 1. c. $25=$ laevis,

staticefolia, Poir. Encyc. Suppl. i. $438=$ Gazania subulata.

stoechadifolia, Berg. Desc. Pl. Cap. 324.-Afr. austr.

sulphurea, Gaertn. Fruct. ii. $439=$ Cryptostemma hypochondriacum.

sulphurea, Salisb. Prod. $210=$ aspera.

superba, Linn. Cent. ii. 32 ; Sp. Pl. ed, II, $1305=$ Cryptostemma calendulaccum.

tenuifolia, Linn. Mant. 288= Ursinia tenuifolia.

tenuifolia, Poir. Encyc. Suppl. i. $439=$ Dimorphotheca graminifolia.

tenuifolia, Salisb. Prod. $210=$ Ursinia scariosa.

tomentosa, Thunb. ex DC. Prod. vi. $492=$ Venidium semipapposum.

tricolor, Jacq. Hort, Schoenb, ii. 16=acaulis.

tricolor, Willd. ex DC. Prod. vi. $486=$ elongata.

trifida, Thunb. Diss. Arct. 15 (=Sphenogyne trifida). -Afr. austr.

trifurcata, Burm. f. Fl. Cap. Prod. 28=Ursinia crithmifolia.

tristis, Linn. Sp. P1. $922=$ Cryptostemma calendulacenm.

undulata, Gaertn. Fruct. ii, $438=$ laciniats

undulata, Jacq. Hort. Schoenb. ii. $16=$ acaulis.

\section{ARCTOTIS :}

undulata, Thunb. Diss. Arct. $13=$ aspera.

venidioides, $D C$. Prod. vi. 489.-Afr. austr.

verbascifolia, Harv. in Harv. E Sond. Fl. Cap. iii. 452

-Afr. austr.

virgata, Facq. Hort. Schoenb. iii. 32.-Afr. austr.

vitellina, Hoffmgg. Verz. Pft. 40,- - Hab.?

ARCYNOSPERNUMI, Turcz, in Bull. Soc. Nat Mosc. (1858) I. 191. MALVACEAE (gen. dub.), Benth. \& Hook. f. Gen. i. 199.

nodiflorum, Turcz. l. c.-Mexic.

ARCYPHYLLUM, E11, in Journ. Acad. Philad, i. (1818) $371=$ Rhynchosia, Lour. (Legum.)

caribaeum, Ell. I. c. $372=\mathrm{R}$, caribaea.

capitatum, Benth, in Linnaea, xxii. (1849) $525=\mathrm{R}$. Clausseni.

difforme, Ell. in Journ. Acad. Phil. i. (1818) $372=\mathrm{R}$. tomentosa.

erectum, Ell. 1. c. $=\mathrm{R}$, tomentosa.

leucophyllum, Benth. in Linnaea, xxii. (1849) $525=\mathrm{R}$. leucophylla.

reticulatum, Ell. in Journ. Acad. Philad. i. (1818) 372 $=\mathrm{R}$. reticulata

rhombifolium, Ell. 1. c. = R. minima.

simplicifolium, Ell. 1. c. $371=$ R. tomentosa

ARCYTHOPHYLLUM, Willd. ex Schlecht. in Linnaea, xxviii. (1856) $491=$ seq.

ARCYTOPHYLLUM, [Willd.] Roem. \& Schult, Mant. iii. $5(1827)=$ Mallostoma, Karst. (Rubiac.) blaerioides, [Willd, ex] Roem. \& Schult. I. c. $=$ M caracasana.

nitidum, Schlecht, in Linnaea, xxviii. (1856) $492=\mathrm{M}$, nitida.

setosum, Schlecht. 1. c. = M. setosa.

ARDERNIA, Salisb. Gen. Pl. Fragm, $35(1866)=$ Ornithogalum, Linn. (Liliac.).

fuscata, Salisb. 1. c. =0. fuscatum

ARDINGHELIA, Comm. ex A. Juss. Tent. Euph. 21 (1824) = Phyllanthus, Linn. (Euphorb.).

ARDISIA, Gaertn. Fruct. ii. 78. t. 94 (1791)=Cyathodes, Labill. (Epacrid.).

acerosa, Gaertn. 1. c. $=$ C. acerosa.

lanceolata, Gaertn. f. 1. c. iii. 148. t. 210.-Austral.

montana, Gaertn. f. 1. c. 149.-Austral.

procumbens, Gaertn. f. 1. c. $149=$ Melichrus rotatus.

ruficarpa, Gaertn. f. 1. c. 148. t. 210.-Austral.

ARDISIA, Sw. Prod. Veg. Ind. Occ. 3. 48 (1788); Fi Ind. Occ. i. 467. t. 10 (1797). MYRSINEAE, Benth \& Hook. f. ii. 645

Anguillaria, Gaertn. Fruct. i. 372 (1788).

Badula, Juss. Gen. 420 (1789).

BladHIA, Thunb. Nov, Gen. i。 6 (1781), nomen prius.

BARTHESIA, Comm, ex A. DC. in Trans. Linn. Soc. xvii. (1837) 112

Climacandra, Miq. Pl. Jungh. i. 199 (1852).

Galizlol.A, Rafin. Sylva Tellur. 167 (1838)

ICACOREA, Aubl. Pl. Gui. ii. Suppl. i. t. 368 (1775)

KatouthekA, Adans, Fam. ii. 159 (1763)

Mitnea, Rafin. Sylva Tellur. 167 (1838).

Monoporus, A. DC. in Ann. Sc. Nat. Sér. II. xvi. (1841) 91.

Pickeringia, Nutt. in Journ. Acad. Sc. Philad. vii. (1834) 95.

Purkinjia, Presl, Symb. Bot. ii. 17. t. 64 (1833).

Pyrgus, Lour. FI Cochinch, i. $120(1790)$

Stylogyne, A. DC. in Ann. Sc. Nat. Sér. II. zevi. (1841) 91

Wedelia, Steud. Nom. ed. II. i. 133 (1840)

VEDELA, Adans. Fam, ii. 502 (1763).

acuminata, Spreng. Syst. i. $661=$ lateriflora.

cuminata, Willd. Sp. Pl. i. 1062.-Ind, occ.

adenanthera, Miq. in Mart. F1. Bras. x. $285=$ Parathesis adenanthera.

affnis, Blume, ex A. DC. in DC. Prod. viii. $96=$ Myrsine aftinis.

alternata, A. DC in Ann. Sc. Nat. Sér. II ii. (1S41)

296, sphalm = oxyphylls.

ambigua, Mari. Herb. Fl. Bras. 303.-Bras.

\section{ARDISIA}

amboinensis, Scheff. Comm. Myrsin. 75.-Amboin

Amherstiana, A. DC. in Trans. Linn. Soc. xvii. (1834) $120=$ reflexa.

amplexicaulis, Bedd. Ic. Pl. Ind. Or. i. 37.-Ind. or.

anceps, Blume, Bijdr. $685=$ Blumii.

anceps, Wall. in Roxb. Fl. Ind, ed. Carey, ii. $280=$ colorata.

andamanica, Kurz, For. Fl. Burma, ii. 108.Malaya.

angustifolia, A. $D C$. in $D C$. Prod. vili. 134.-Ins. Philipp.

arborescens, Wall Cat. n. 2289 - humilis.

arguta, H.B. E K. Nov. Gen, et Sp. iii. 247.-Am. austr.

attenuata, Wall. Cat. n. $2286=$ oxyphylla

avenis, Blume, Bijdr. $691=$ Myrsine capitellata.

bahamensis, A. DC. in Trans. Linn. Soc. xvii. (1834)

$128=$ excelsa.

Barthesia, Steud. Nom. ed. I. 64.-Zeylan.

Basaal, Roem. \& Schult. Syst. iv. $517=$ Embelia robusta.

bhotanica, C. B. Clarke, in Hook. f. Fl. Brit. Ind. iii. 528.-Keg. Himal.

bipinnata, Baker, in fourn. Linn. Soc. xx. (1884) 201. - Madag.

Blumii, A. DC, in Trans. Linn. Soc. xvii. (1834) 117 = colorata

Boissieri, A. DC. in DC. Prod. viii. $129=$ lanceolata

borneensis, Scheff. Comm. Myrsin. 79.-Bomeo.

bracteata, Baker, in Oliver, Fl. Trop. Afr. iii. 495.Afr. trop.

bracteosa, A. DC. in Trans. Linn. Soc. xvii. (1834) 127 -Mexic.

Brandisiana, Kurz, in Fourn. As. Soc. Beng.xl. (1871) Ir. 67.-Burma.

brasiliensis, Spreng. Syst. i. 662.-Bras.

breviflora, A.DC. in DC. Prod. viii. 122.-Peruv.

brevipedata, F. Muell. Fragm. vi. 163.-Austral.

bumelioides, Griseb. in Mem. Am. Acad. N. S. vii. (1863) 516.-Caba.

calothyrsa, Scheff. in Tijdschr. Nederl. Ind. xxxi. (1870)

371 ; et in Flora, liii. (1870) 254. - Sumatra.

calycosa, Hemsl. Biol. Centr. Am. Bot. ii. 292.Nicaragua.

canaliculata, Lodd. Bot. Cab. t. 1083-Reg. Colomb.

capitata, A. Gray, in Proc. Am. Acad. y. (1861-62) 331.-Ins. Fiji.

capollina, Mof. E Sesse, ex A. DC. in Trans. Linn Soc. xvii. (1834) 116.-Mexic.

caribaea, A. DC. ex Miq. in Mart. Fl. Bras. x. 289, in adnot.-Ins. Dominica.

cauliflora, Mart. \& Miq. in Mart. Fl. Bras. x. 291.Bras.

Cavanillesii, Roem. E Schult. Syst. iv. 515.-Ins. Philipp.

celebica, Scheff. Comm. Myrsin. 83.-Ins. Celebes.

cestrifolia, $H, B . \Xi^{\circ} K . N o v$. Gen, et Sp, vii. 213.-Reg.

Colomb.

chinensis, Benth. Fl. Hongk. 207.-China.

chrysophylloides, Miq. Fl. Ind. Bat. Suppl. $574=$ tuberculata.

clusioides, Griseb. Fl. Brit. W. Ind. 396.-Ind. occ

coccinea, Fungh, in Hoev. \& De Vriese, Tijdschr. vii.

(1840) 304 ('104' err. typ.).-Java.

colorata, Link, Enum. Hort. Berol. i. $194=$ paniculata.

colorata, Roxb. Hort. Beng. 16; Fl. Ind. i. 581.Ind. or.

complanata, Wall. in Roxb. Fl. Ind. ed. Carey, ii. 250 = colorata.

compressa, H. B. E K. Noo. Gen, et Sp. iii. 245.-Reg.

Colomb.

confinis, Mig. Fl. Ind. Bat. Suppl. 576.-Sumatra.

coriacea, Ledru, ex Choisy, in Mem. Soc. Phys. Genèv.

xiv. (1855) $105=$ Ternstroemia brevipes.

coriacea, Sw, Prod. Veg. Ind. Occ. 18.-Ind. oxc

courtallensis, Wight, Ic. t. 1215.-Ind. or.

crassa, C. B. Clarke, in Hook. f. Fl. Brit. Ind. iii. 51

-Malays.

crenata, Sims, in Bot. Mag. to 1950.-China,

crenata, Roxb. Hort. Berg. 85; Fl. Ind. i. 5\$3.-

Malaya ; China.

cremulato, Lodd. Bot. Cab. t. $2=$ = crenata.

crenulata, Vent. Choix, t. 5 = Parathesis crenulata

crispa, A. DC. in Trans. Linn. Soc. siii. (1:81) 124=

crenata.

cubana. A. DC. l. c. - Cuba.

Cumingians, A. $D C$ in $D C$. Prod viii. 136.-Ins

Philipp.

cuspidata, Benth. Bot. Voy. Suiph. 129.-Ins. Cocos. 


\section{ARDISIA :}

cybianthoides, Miq. Fl. Ind. Bat. ii. 1028,-Malaya.

cymosa, Baker, in Oliver, Fl. Trop. Afr. iii. 495.-Afr trop.

cymosa, Blume, Bijdr. 689.-Tava.

decipiens, A. DC. in DC. Prod. viil. 125.-Peruv.

decus-montis, Miq. Pl. Fungh. 193.-Tava.

demissa, Miq. Fl. Ind. Bat. ii. 1018.-Malaya.

densa, Miq. 1. c. Suppl. $575=$ crenata.

denticulata, Blume, Bijdr.691,-Java.

depressa, C. B. Clarke, in Hook. Fl. Brit. Ind. iii. 522 -Reg. Himal.

disticha, A. DC. in DC. Prod. viii. 129=Pimelandra disticha.

divaricata, Willd.ex Roem. E Schult. Syst. iv. 804.Hab.

divergens, Roxb. Hort. Beng. 85; Fl. Ind. i. 583.-

Malaya.

divergens, Thw. Enum. Pl. Zeyl. 174 pro parte=

Doca, Buch.-Ham. ex A. DC. in DC. Prod. viii. $126=$ paniculata

Doma, Wall. ex A. DC. in Trans. Linn. Soc. xvii. (1834 $118=$ humilis.

domingensis, Willd. ex Roem. E־ Schult. Syst. iv. 803 - Ins. S. Domingo

dubia, Scheff. Comm. Myrsin.67.-Malaya.

durifolia, H. B. \& K. Nov. Gen. et Sp. iii. 214.-N Granat.

elegans, Andr. Bot. Repos. t. $623=$ lentiginosa.

elliptica, Bedd. For. Man. $138=$ humilis.

elliptica, Thunb. Nov. Gen, viii. 119.-Zeylan.

erythroxyloides, Thou. ex Roem. \& Schult. Syst. iv. 804.--Madag

escallonioides, Schlecht. \& Cham. in Linnaea, vi (1831) 393.-Mexic

esculenta, Pa\% ex A. DC. in Trans, Linn. Soc, xvii. (1834) 128.-Am. austr.

eugeniaefolia, Kurz, For. Fl. Burma, ii. $111=$ Pime landra Griffithii

eugeniaefolia, Wall. Cat. n. 2276=Pimelandra eugeniaefolia.

excelsa, Ait. Hort. Kerv. i. 261.-Ins. Baham.; Mader

eximia, Miq. Pl. Fungh. 196.-Java.

ferruginea, $H . B$. E $K$. Nov. Gen. et $S p$. iii. 244.-N Granat.

fertilis, Miq. Fl. Ind. Bat. Suppl. 576.-Sumatra.

floribunda, Roem. E Schult. Syst. iv. 804.-Madag.

floribunda, Wall. in Roxb. Fl. Ind. cd. Carey, ii. 272 $=$ neriifolia.

floribunda, Willd.ex Steud. Nom. ed. II. i. 122, nomen. - Madag.

foetida, Willd. ex Roem E Schult. Syst. iv. 803.Am. austr.

formosana, Rolfe, in Journ. Bot. xx. (1882) $358=$ Sieboldii.

Forstenii, Scheff. Comm. Myrsin. 61-Malaya.

frangulaefolia, Zipp. et Scheff. l. c. 82,-Malaya.

fuliginosa, Blume, Bijdr. 692.--Java.

fusca, Oerst. in Kjoeb. Vidensk. Meddel. (1861) 127. t. 2.-Costa Rica.

fusco-pilosa, Baker, in Fourn. Limn. Soc. xx. (1884) 200.-Madag.

Gardneri, C. B. Clarke, in Hook. f. Fl. Brit. Ind. ii. 521.-Zeylan.

glabra, A. DC. in Trans. Linn. Soc. xvii. (1834) $123=$ japonica.

glabrata, Blume, Bijdr. $692=$ villosa

glandulosa, Blume, 1. c. $690=$ crenata

glandulosa, Roxb. Hort. Beng. 16; Fl, Ind. i. $584=$ Amblyanthus glandulosus.

glandulosa-marginata, Oerst. in Kjoeb. Vidensk. Meddel. (1861) 128.-Costa Rica.

gracilis, Miq. in Mart. Fl. Bras. x. 287.--Bras.

grandiflora, Wall. Cat. n. $2272=$ colorata.

grandifolia, A. DC. in Trans. Linn. Soc. xvii. (1834 122.-Burma

grandis, Seem. in Bonplandia, ix. (1861) 259 ; Fl. Vit. 150.-Ins. Fiji.

Griffithii, C. B. Clarke, in Hook. f. Fl. Brit. Ind. iii. 523. -Reg. Himal.

guadalupensis, Duchass. ex Griseb. in Goett. Abh. vii. (1857) 237.-Ins. Dominic.

Hamiltonii, A. DC. in Trans. Linn. Soc. xvii. (1834) 126.-Ind. occ.

Hasseltii, Blume, ex Scheff. Comm. Myrsin. 86. = lanceolata.

\section{ARDISIA :-}

Helferiana, Kurz, in fourn. As. Soc. Beng. xlii. (1873) II. 86.-Burma.

hortorum, Maxim. in Gartenfl. (1865) 363. t. 491.Japon.

Hostmanni, Miq. in Mart. Fl. Bras. x. 288.-Guian.

humilis, Blume, Bijdr. 687 = javanica.

humilis, Vahl, Symb. Bot. iii. 40,-Ind. or.; Malaya.

Hymenandra, Wall. in Roxb. Fl. Ind. ed. Carey, ii. $282=$ Hymenandra Wallichii.

Icara, Buch.Ham. in Wall. Cat. n. 2264.-Ind. or.; Burma.

insularis, Baker, Fl. Maurit. 190.--Maurit.

involucrata, Kurz, in Fourn. As. Soc. Beng. xl. (1871) II. 68.-Reg. Himal.

irasuensis, Oerst. in Kjoeb. Vidensk. Meddel. (1861) 124. - Costa Rica.

jacquinioides, Griseb. in Mem. Am. Acad. N. S. viri. 1863) 517.--Ind. occ.

jambosioides, Miq. Pl. Jungh. $196=$ crassa

japonica, Blume, Bijdr. 690.-China; Japon.

javanica, A. DC. in DC. Prod. viii. 130.-Tava.

Junghuhniana, Miq. Pl. Fungh. 192.-Sumatra

Keenani, C. B. Clarke, in Hook. f. Fl. Brit. Ind. iii. 526.-Reg. Himal.

khasiana, C. B. Clarke, l.c. 527.--Reg. Himal.

Korthalsiana, Scheff. Comm. Myrsin. 57 =Pimelandra Wallichii

Kurzii, C. B. Clarke, in Hook. f. Fl. Brit. Ind. iii. 525. -Burma.

laevigata, Blume, Bijdr. 690.-Java.

laevis, Oerst. in Kjoeb. Vidensk. Meddel. (1861) 125. - Costa Rica.

lamponga, Miq. Fl. Ind. Bat.Suppl.577.-Sumatra

lanceolata, Roxb. Hort. Beng. 85 ; Fl. Ind. i. 583.Malaya.

lateriflora, Sw. Prod. Veg. Ind. Occ. 48.-Ind. occ.

latifolia, Roem. \& Schult. Syst. iv. $514=$ laurifolia.

latifolia, Sieber, ex A. DC. in Trans. Linn. Soc. xvii. 1834) $113=$ rnadalupensis

latipes, Mart. Herb. Fl. Bras. n. 570.-Bras.

laurifolia, A. DC. in Trans. Linn. Soc. xvii. (1834) 116.-Ind. occ.

lentiginosa, Ker-Gawl. in Bot. Reg. t. $533=$ crenata.

lepidota, H. B. E K. Now. Gen. et Sp. iii, 247.-N Granat.

leptantha, Miq. in Mart. Fl. Bras. x. 286.-Bras.

Leschenaultii, A. DC. in DC. Prod.viii. 133=lanceolata

Lhotskya, A. DC. in Trans. Linn. Soc. xvii. (1834) 127.-Bras.

Liebmannii, Oerst. in Kjoeb. Vidensk. Meddel. (1861) 129. t. 2,-Mexico.

Lindleyana, D. Dietr. Syst. I. $617=$ crenata.

linearifolia, Miq. Fl. Ind. Bat. Suppl. 577.-Sumatra.

lineata, Roem. E Schult. Syst. iv. 804.-Am. austr.

littoralis, Andr. Bot. Rep. t. $630=$ humilis.

Lobbiana, C. B. Clarke, in Hook. f. Fl. Brit. Ind. iii. 529.-Ind. or.

longifolia, Mart. ex Miq. in Mart. Fl. Bras. x. 290.Bras.

longipes, Baker, in Fourn. Linn. Soc. xxi. (1885) 421. -Madag

Iurida, Blume, Bijdr. 687.-Java.

luzonensis, Presl, Rel. Haenk. ii. 65.-Ins. Philipp. macrocalyx, Scheff. Comm. Myrsin. 91.-Borneo. macrocarpa, Wall. in Roxb. Fl. Ind. ed. Carey, ii. 277 - Reg. Himal.

macrophylla, Reinw. ex Blume, Bijdr. 691.-Java.

macrophylla, Wall. Cat. n. $2290=$ grandifolia.

macroscypha, Baker, in Fourn. Linn. Soc, xxi. (1885) 420.-Madag.

maculata, Poit.ex A. DC. in Trans. Linn. Soc. xvii (1834) 116.-Ins. S. Doming.

mamillata, Hance, in Fourn. Bot. xxii. (1884) 290.China.

marginata, Blume, Bijdr. 688.-Java.

Martiana, Miq. in Mart. Fl. Bras. x. 285.-Bras.

melanosticta, Schlecht. in Linnaea, viii. (1833) $526=$ Parathesis melanosticta.

membranacea, Wall. Cat. n. 2288 ; ex A. DC. Prod. viii. 134.--Reg. Himal.

metallica, N. E. Br. in Illustr. Hortic. xxviii. (1881) t. 421.-Sumatra.

micrantha, H. B. E K. Nov. Gen. et Sp. iii. 246.Venezuela.

microphylla, Roem. E Schult. Syst. iv. 804.-Madag.

Miqueliana, Scheff. in Tijdschr. Nederl. Ind. xxxi.

(1870) 367 ; et in Flora, liii, (1870) 253.-Malaya.
ARDISIA :-

missionis, Wall, Cat, n, 6524; et ex A, DC Prod. viii. $130 .-Z$ Zeylan.

mollis, Blume, Bijdr, $689=$ villosa

Moonii, C. B. Clarke, in Hook. f. Fl. Brit. Ind. iii 523.-Zeylan.

mucronata, Blume, Bijdr. $685=$ lanceolata

multiflora, Griseb. in Mem. Am. Acad. N. S. viii. 1863) 516.-Ind. oce

multiflora, Willd. ex Roem. \& Schult. Syst. iv. $804=$ revoluta.

myriantha, Baker, in Fourn. Linn. Soc. xxi. (1885) 419. - Madag.

myristicaefolia, Blume, ex Scheff. Comm. Myrsin. 63 Malaya.

nana, Buch.-Ham. ex A. DC. in Trans. Linn. Soc. x̊vii (1834) $118=$ humilis.

nerifolia, A. DC. Prod. viii. 127, pro parte=anda manica.

neriifolia, Kurz, in Journ. As. Soc. Beng. xlvi. (1877 II. $225=$ depressa

neriifolia, Wall. Cat. n. 2278.-Reg. Himal

nicaraguensis, Oerst. in Kjoeb. Vidensk. Meddel. (1861) 123.-Nicaragua.

nigrescens, Oerst. l. c. 130.t. 2.-Mexic.

nigricans, Miq. in Mart. Fl. Bras. x. 289.-Bras.

nitidula, Baker, in Fourn. Linn. Soc. xx. (1884) 200

-Madag.

nigro-punctata, Oerst. in Kjoeb. Vidensk. Meddel. (1861) 127. t. 2.-Costa Rica.

nutans, A. DC. in Trans. Linn. Soc. xvii. (1834) 121. -Java.

oblonga, A. DC. 1. c. =oxyphylla.

Obovata, Blume, Bijdr. $688=$ humilis.

obovata, Ham. Prod. Fl. Ind. Occ. $26=$ Hamiltonii.

odontophylla, Lindl. Bot. Keg. t. $1892=$ chinensis

odontophylla, Wall. Cat. n. 2279.-Reg. Himal.

oleracea, Buch.-Ham, ex A. DC. in Trans. Linn, Soc xvii. (1834) $118=$ humilis.

oligantha, Baker, in fourn. Linn. Soc. xxi. (1885 419. - Madag.

Oliveri, Mast. in Gard. Chron. (1877) II. 680.-Costa Rica.

Opegrapha, Oerst. in Kjoeb. Vidensk. Meddel. (1861) 126. - Costa Rica.

orinocensis, H. B. E K. Nov. Gen. et Sp. iii. 244.Fluy Orinoco.

ovata, Thunb. Nov. Gen. viii. $119=$ colorata

oxyantha, Wall. Cat. n. $2275=$ Antistrophe oxyantha. oxyphylla, Wall.l.c. n. 2291 ; A. DC. Prod. vii.. 130 -Burma; Malaya.

palembanica, Miq. Fl. Ind Bat Suppl. 575.-Sumatra. paniculata, A. DC. in LC. Prod. viii. $139=$ A. Samara paniculata, Roxb. Hort. Beng. 16; Fl. Ind. i. 580. Ind. or.

parasitica, Sw. Prod. Veg. Ind. Occ. $48=$ Grammadenia parasitica.

parvifolia, Humb. ex Willd. sec. Roem. Es Schult. Syst, iv. 804.-Peruv.

pauciftora, Benth. Fl. Hongk. $206=$ pentagona. pauciflora, Heyne, ex Roxb. Fl. Ind. ed. Carey, ii. 279 -Ind. or.

pavonina, Buch.-Ham. ex A. DC. Prod. viii. $136=$ odontophylla.

pedunculata, Boj. ex Baker, in Journ. Linn. Soc. xx (1884) $203=$ Oncostemum pedicellatum.

pedunculosa, Wall. in Roxb. Fl. Ind.ed. Carey, ii. 279 -Reg. Himal.

pellucida, Oerst. in Kjoeb. Vidensk. Meddel. (1861)

130. t. 2,-Mexic

pentagona, A. DC. in Trans. Linn. Soc. xvii, (1834) 124.- Java.

pergamacea, Blume, ex A. DC. in DC. Prod. viii. $85=$ Embelia pergamacea.

Perrottetiana, A. DC. in Ann. Sc. Nat. Sér. II. xvi (1841) 95.-Ins. Philipp.

peruviana, Miq. in Mart. Fl. Bras. x. 290.-Peruv. petocalyx, Scheff. Comm. Myrsin. 91.-Sumatra. philippinensis, A. DC. in DC. Prod. viii. 128.-Ins. Philipp.

Pickeringia, Torr. Eo Gray, ex DC. Prod. viii. 124.Florida.

plagioneura, Scheff. Comm. Myrsin. 85.--Malaya. polycarpa, Wall. Cat. n. $2285=$ colorata.

polycephala, Wall. l. c. n. 2293; A. DC. Prod. vii

131.-Burma.

polycephala, Wight, Illustr. t. $145=$ humilis

polygama, $A . D C$. in $D C$. Prod. viii. 138.-Molucca 
ARDISIA

polyneura, Miq. P1. Jungh. $198=$ colorata.

polysticta, Miq. Fl. Ind. Bat. Suppl. $576=$ crenata.

porosa C. B. Clarke, in Hook. f. Fl. Brit. Ind. iii, 522.

-Malaya.

primulaefolia, Gardn. Eo Champ. in Hook. Kew fourn.

i. (1849) 324.-China.

procumbens, Gaertn. f. Fruct. iii, t. $210=$ Melichrus rotatus.

propinqua, H. B. E K. Nov. Gen. et Sp. vii, 213.Venezuela.

pseudo-Icacorea, Miq. in Mart. Fl. Bras. x. 283.-Bras, psendojambosa, F. Muell. Fragm. iv. 81.-Austral.

pterocaulis, Miq. Pl. Fungh. 194.-Sumatra.

pteropoda, Miq. Fl. Ind. Bat. ii. 1025.-Malaya.

pubicalyx, Miq.l.c. Suppl. 575.-Sumatra.

pumila, Blume, Bijdr. $688=$ Labisia pothoina

punctata, Blume, 1. c. $687=$ nutans.

punctata, Jack, in Roxb. F1. Ind. ed. Carey, ii. $275=$ divergens.

punctata, Lindl. Bot. Reg. t. $827=$ crenata

punctulasa, D. Dietr. Syn. P1. i. 615 =divergens.

purpurea, Reinw. in Blume, Bijdr. $684=$ lanceolata.

pusilla, A. DC. in Trans. Linn. Soc. xvii. (1834) 126. - Tapon.

pyramidalis, Pers.Syn. i. 238; A. DC. in Trans. Linn.

Soc. xvii. (1834) 123. - Ind. occ.

pyramidalis, Roth, Nov. Pl. Sp. $123=$ colorata.

pyrgina, St. Lag. in Ann. Soc. Bot. Lyon, vii. (1880)

$119=$ A. Pyrgus.

Pyrgus, Roem. \& Schult. Syst. iv. 518.-Chin

pyrifolia, Willd.ex Roem. E'Schult.l. c. 804.

quinquangularis, $A . D C$. in Ann. Sc. Nat. Sér. II. xvi.

(1841) 95.-Assam.

muinquegona, Blume, Bijdr. $689 \doteq$ pentagona.

racemosa, Spreng. Syst. i. 661.-Bras.

ramiflora, Oerst. in Kjoeb. Vidensk. Meddel. (1861) 132. - Costa Rica.

reclinata, Scheff. Comm. Myrsin. 69.

reflexa, Wall. Cat. n. $2282 ; A . D C$.

Burma.

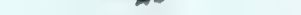

revoluta, $H$. B. \& $K$. Nov. Gen. et $S p$. iii. $246 .-$ Mexico.

rhomboidea, Wight, Ic. Pl. t. 1213.-Ind, or.

rhynchocarpa, Scheff. Comm. Myrsin. 68.-Malaya.

rhynchophylla, C. B. Clarke, in Hook. f. Fl. Brit.Ind.

iii. 529.-Reg. Himal.

rigida, Kurz, in fourn. As. Soc. Beng. xlii. (1873) $\mathrm{I}$. 87.-Burma.

rostrata, Hassk. in Flora, 1i. (1868) 26 =humilis.

Rothii, A. DC. in Trans. Linn. Soc. xvii. (1834) $117=$ colorata.

Roxburghiana, D. Dietr. Syn. Pl, i, $617=$ Amblyanthus glandulosus.

rubiginosa, Miq. Pl. Fungh. 192.-Sumatra.

salicifolia, A. DC in DC. Prod. viii. $129=$ humilis.

Samara, A. DC. ex Buek, Index, iii. praef. 8.-Ind, or

sanguinolenta, Blume, Bijdr. $685=$ colorata.

sanguinolenta, Wall. Cat. $\mathrm{n} .2287=$ Wallichii.

scandens, Blume, Bijdr. 686.- -Java.

Schomburgkiana, Miq.in Mart. Fl. Bras.x. 289.-Bras

scrobiculata, Seem. Fi. Vit. 150.-Ins. Fiji.

semicrenata, Mart. Herb. Fl. Bras. $571=$ acuminata.

semidentata, Miq. Pl. Fungh. 191.-Java.

serrata, Pers. Syn. i. $233=$ Cavanillesii.

serratifolia, Bedd. in Madr. Journ. Ser. III. i. (1864)

51 - Antistrophe serratifolia.

serrulata, Kurz, in Journ. As. Soc. Beng. xlii. (1873) II. $87=$ A. Icara.

scrrulata, Sw. Prod. Veg. Ind. Occ. 48.-Ind. occ.

sessilis. Scheff. Comm. Myrsin. 59.-Malaya.

Sicheri, Baker, Fl. Maurit. 190,-Maurit.

sieboldi, Miq. in Ann. Mus. Bot. Lugd. Bat. iii. 190 - Japon.

sinensis, Hort. ex Stend. Nom. ed. II. i. $122=$

A. Pyrgus.

solanacea, Roxb. Hort. Beng. 16 ; Fl. Ind. i. $580=$ humilis.

Spanoghei, Scheff. Comm. Myrsin. 62.-Malaya.

speciosa, Blume, Bijdr. $684=$ lancculata.

sphenobasis, Scheff. Comm. Myrsin. 65.-Malaya.

spicata, Wall. Cat, n, $2273=$ Labisia pothoina.

squamulosa, Prest, Rel. Haenk. ii. 65.--Ins. Luzon.

Storckii, Seem. Fl. Vit. 150,-Ins. Fiji.

Storckii, Seem. Fl. Vit. 150.-Ias. Fiji.
stylosa, Miq. Pl. Fungh. 196.-Java.

subcuneata, Miq. Fl. Ind. Bat. ii. 1028.-Malaya.

sumatrana, Miq. Pl. Fungh. 195.-Sumatra.

sumbavana, Miq. Fl. Ind. Bat. ii. 1027.-Malaya.

\section{ARDISIA}

surinamensis, Miq. in Mart. Fl. Bras, x. 288.-Guiana. tavoyana, A. DC. in Trans. Linn. Soc. xvii. (1834) 125 $=$ villosa.

synneura, Scheff. Comm. Myrsin.80.-Malaya.

tenuiflora, Kollmann, ex A. DC. Prod, viii. 127 pauciflora.

tenuifolia, Blume, Bijdr.686.-Java

tenuiramis, Miq. Pl. Fungh. 198.-Java.

ternatensis, Scheff. Comm. Myrsin. 58.Ins. Ternate.

tetrandra, H. B. \& K. Nov, Gen et Sp. iii. $243=$ Cybianthus Humboldtii.

Teysmanniana, Scheff. in Tijdschr. Nederl. Ind. xxxi. (1870) 368; et in Flora, liii. (1870) 253.Malaya.

thyrsiftora, D. Don, Prod. Fl. Nep, $148=$ neriifolia

tinifolia, Sw. Prod. Veg. Ind. Occ. 48.-Tamaica.

tomentosa, Prest, Rel. Haenk. ii. 66.-Ins. Luzon.

Tsjeriam-Cottam, Roem. \& Schult. Syst. iv. 518

Embelia robusta

tuberculata, Wall. Cat. n.2274.-.Malaya.

turbacensis, H.B. Eo K.Nov. Gen. et Sp. iii. 245.-N Granat.

umbellata, Baker, in Fourn. Linn. Soc. xxi. (1885) 420.--Madag.

umbellata, Roxb. Hort. Beng. 16; F1. Ind. i. $582=$ humilis.

umbrosa, Zoll. Eg Mor. in Nat. en Geneesk. Arch. Neerl. Indie, ii. (1845) 575.-Java.

undulata, C. B. Clarke, in Hook. f. Fl. Brit. Ind. iii. 524. - Reg. Himal

verrucosa, Presl, Rel. Haenk. ii. 65.-Ins. Philipp.

vestita, Wall. in Roxb. Fl. Ind. ed. Carey, ii. 274 villosa.

villosa, Roxb. Hort. Beng. 85; Fl. Ind. i. 582.Malaya.

virens, Kurz, For. Fl. ii. 575.--Reg. Himal, ; China. viridiflora, Blume, ex A. DC. in DC. Prod. viii. 88. Malaya.

vitiensis, Seem. Fl. Vit. 150.-Ins. Fiji.

volubilis, Wall. ex Steud. Nom. ed. II. i, $122=$ colorata.

Wallichii, A. DC. in Trans. Linn. Soc. xvii. (1834) 123. -Burma.

Wallichii, Thw. Enum. P1. Zeyl. 174= Moonii.

Wightiana, Wall. Cat. n. $2330=$ humilis.

xylosteoides, Griseb. Fl. Brit. W. Ind. 395,-Jamaica

zeylanica, C. B. Clarke, in Hook. Fl. Brit. Ind. iii. 520. Zeylan.

Zollingeri, A. DC. in DC. Prod. viii. $670=$ colorata.

ARDISIANDRA, Hook. f. in Journ. Linn. Soc. vii. (1864) 205. t. 1. PRIMULACEAE, Benth. \& Hook, f, ii. 633 .

sibthorpioides, Hook. f. l. c.-Afr. trop. occ

ARDUINA, Adans. Fam. ii. $499 \quad(1763)=$ Kundmannia, Scop. (Umbell.

ARDUINA, Mill. Ic. ii. t. 300 (1759); Linn. Mant. i. $7(1767)=$ Carissa, Linn. (Apocyn. acuminata, E. Mey. Comm. Pl. Afr. Austr. $191=$ C. acuminata.

bispinosa, Linn. Mant. i. $52=$ C. bispinosa.

bispinosa, Lodd. Bot. Cab. t. $387=$ C. ferox.

edulis, Spreng. Syst, i. $669=$ C. edulis.

erythrocarpa, Eck1. in S. Afr. Journ. i. $(1830) 372=$ C, erythrocarpa.

ferox, E. Mey. Comm. P1. Afr. Austr. $191=$ C. ferox

grandiflora, E. Mey, 1. c. $190=$ C. grandiflora

haematocarpa, Eckl, in S. Afr. Joum. i. (1830) $372=$

C. haematocarpa

macrocarpa, Eck1. 1. c. =C. macrocarpa

ARECA, Linn. Sp. Pl. ed. I. 1189 (1753). PALMAE

Benth. \& Hook. f. iii. 883

A RECCA, Linn. F1. Zeyl. 186 (1747)

alba, Bory, Voy. i. $306=$ Dictyosperma album.

Alicae, W. Hill, ex F. Muclh. in Gartenfl. (1879) 199 -Austral.

angulosa, Giseke, Linn. Praclect. 80.-Ind, or.

arundinacen, Becc. Malesia, i. (1877) 23.-13orneo.

augusta, Kurz, in Journ. Bot. xiii. (1575) $331=$

Ptychoraphis angusta.

aurea, Hort. in $\mathrm{kl}$. des Serres, Ser. II. vii. (1867-68) 43 = Dictyosperma aureum

Bacaba, Arruda, in Koster, Trav. Bras. $490 .-$ Pornambuc.

\section{ARECA}

Banksii, A. Cunn. ex Kunth, Enum. P1. iii. 185 Rhopalostylis Paueri.

Baueri, Hook.f, ex Lom. Illustr. Hortice xy, 1868 $575=$ Rhopalostylis Baveri.

borbonica, Hort. ex Kunth, Enum. Pl. iii. $186^{\circ}=$ Dictyosperma album.

borneensis, Becc. Malesia, i. (1877) 22,-Borneo.

Calapparia, Blume, kumphia, ii. t. 100. f. $2=$ Actino

rhytis Calapparia.

Catechu, Linn. Sp. Pl. 1189.-Ind. or.; Malaya.

Cathecu, Burm. f. FI. Ind. $241=$ A. Catechu.

cincta, Walp. Ann. v. $808=$ Acanthophoenix crinita.

cocoides, Griff. in Calc. Journ. Nat.

communis, Zipp. ex Blume, Rum

Rumphia, ii, $\pi 3,11 \%$

t. $128=$ Drymophloeus cormmunis.

concinna, Thw. Enum. Pl. Zeyl. 328.-Zeylan.

cornuta, Giseke, Linn. Praelect. 81. - Ind. or

coronata, Blume, in Mart. Hist. Nat. Palm, 179

Pinanga coronata.

costata, Kurz, in Journ. As. Soc. Beng, xliii. (1874, If. $200(=$ Inangae sp.).-Ins. Nicobar.

crinita, Bory, Voy. i. $307=$ Acanthophoenix crinita.

cuncifolia, Stokes, Jot. Mat. Med. i. 318=humilis

curvata, Griff. Ic. Pl. As. L. $248=$ Pinanga disticha.

curvata, Griff. Notul. iii. $164=$ Pinanga paraduxa.

Dicksonii, Roxb. Hort Beng. [105]; Fl. Ind. jii. 616

Pinanga Dicksoni.

disticha, Roxb. 11. cc, $620=$ Pinanga disticha,

laeocarpa, Reinw. ex Kunth, Enum. P1. iii. $195-$

Drymophloeus olivaeformis.

erythrocarpa, H. Wendl. ex Kerch. Palm. 231

erythropoda.

erythropoda, Miq. in Journ. Bot. Néerl. i. (1861, $6=$

Cyrtostachys Renda.

Faufel, Gaertn. Fruct. i. 19. t. 7. fig. $2=$ A. Catechu

furcata, Becc. Malesia, i. (1877) 23.-Borneo.

furfuracea, Hort. ex II. Wendl. in Kerch. Palm. 23

Dictycsperma furfuraceum.

gigantea, Hort. 1. c. $254=$ Pinanga ternatensis.

glandiformis, Lam. Encyc. i. 211.-Ins. Molucc.

globulifera, Lam. Encyc. $895=$ Pinanga Kuhlii.

gracilis, Koxb. Hort. Beng. 68; Fl. Ind. iii. $619=$

Pinanga gracilis.

gracilis, Thou. ex Kunth, Enam. Pl. iii. $1 £ 8=$ Dypsis

pinnatifrons.

gracilis, Giseke, Linn. Praelect. $80=$ Drymophloeu appendiculata.

haematocarpon, Griff. Notul. iii. 165=Pinanga ma laiana.

hexasticha, Kurz, in Journ. As. Soc. Beng. xliii. (187t II. $201=$ Pinanga hexasticha

himalayana, Giff. ex H. Wendl, in Kerch. Palm. $231=$

A. Catechu.

horrida, Griff. in Calc. Joum. Nat. Hist. v 1845 $465=$ Oncosperma horrida

hortensis, Lour. F1. Cochinch. 568, in obs, = A. Calcchu. humilis, Blanco, ex H. Wendl, in Kerch. Palm. $231=$ triandra?

humilis, Roxb. ex H. Wendl. 1. c. = Pinanga disticha.

humilis, Willd. Sp. Pl. iv. $595=$ Drymophloeu. saxatilis.

jobiensis, Becc. Malesia, i. (1877) 21.-N. Guin.

lactea, Hort. Bogor. ex Miq. Fl. Ind. Bat. iii. I0

Dictyosperma album.

lansiformis, Giseke, Linn. Praplect. 81.-Ind. or.

latisecta, Sicheff. in Tijdschr. Nederl. Ind. Nxii. (15:-1) $168=$ Pinanga latisecta .

laxa. Buch,-Ham. in Mem. Wern. Soc, v, $1 \leqslant 243$ lie. -Ins. Andam.

litoralis, Blume, Rumphia, ii. 123, in obs. = Drymo. phloeus communis.

lutescens, Bory, Voy. ii. $296=$ Chrysalidocarpus lutesecns.

macrocalyx, Zipp. ex Blume, Rumplia, if. 75. ᄂ. $101,160,163 \mathrm{D}$.- N. (iuineat

madagascarica, Stadtmamb, ex Boj. Hort. Maz rit. 305 - Madar

madagnscariensis, Mart. Hist. . Vat XWte-17. If

malaiana, Grifl. in Calc. Journ. Nat. Mlist. v. (1845 $45 i$ - rinanga malaiana.

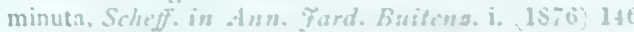
-liurncis.

menostachya, Mart. Mist. Xat. Palm. 1is. 1. 1 5. f. t Bacularia monostachesa.

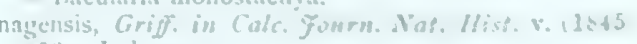
458. - Ind. ur. 


\section{ARECA :-}

Nenga, Blume, in Mart. Hist. Nat. Palm. $179=$ Nenga Wendlandiana.

Nibung, Griff. ex H. Wendl. in Kerch. Palm. $231=$ Oncosperma filamentosa.

Nibung, Mart. Hist. Nat. Palm. 173. t. 150. f. $4=$ Oncosperma horrida.

nigra, Giseke, ex H. Wendl. in Kerch. Palm, $231=\mathrm{A}$. Catechu.

nobilis, Hort.-Cf. Gard. Chron. (1868) $349=$ Nephrosperma Van-Houtteana.

Normanbyi, F. Muell. Fragm. viii. 235.-Austral,

oleracea, Jacq. Am. Select. $278=$ Oreodoxa oleracea

olivaeformis, Giseke, in Ord. Nat. Pl. $79=$ Drymophloeus olivaeformis.

orizaeformis, Gaertn. Fruct, i. $20=$ Pinanga Kuhlii.

oviformis, Giseke, Linn. Praelect. 81.-Ind. or.

oxycarpa, Miq. in Verh. Kon. Akad. Wetensch. xi. 1868) n. v. 1.- Malaya.

paniculata, Scheff. ex H. Wendl, in Kerch. Palm. 231 $=$ Mischophloeus paniculata.

paradoxa, Griff. in Calc. Journ. Nat. Hist. v. (1845) $463=$ Pinanga paradoxa.

parva, Noronha, in Verh. Batav. Gen. v. (1790) ed. I. Art. IV. 6.-Malaya.

polystachys, Miq. ex H. Wendl. in Kerch. Palm. 232. - Malaya.

propria, Hort. Bogor. ex Mio. F1. Ind. Bat. iii, $10=$ Dictyosperma album.

procera, Zipp. ex Blume, Rumphia, ii. $95=$ Kentia procera.

pumila, Blume, in Mart. Hist. Nat. Palm. 177. t. 153. fig. $1-3=$ Nenga Wendlandiana

punicea, Zipp. ex Blume, Rumphia, ii. 72. t. $122=$ Drymophloeus puniceus.

purpurea, Hort. in Illustr. Hortic. xxiv. (1877) t. 298. -Maurit.

rubra, Bory, Voy. i. $306=$ Acanthophoenix rubra.

rubra, Hort. ex H. Wendl. in Kerch. Palm. 232=Dic tyosperma rubrum.

sanguinea, Zipp. ex Blume, Rumphia, ii. $72=$ Drymo phloeus puniceus.

sapida, Soland. ex Forst. f. P1. Esc. $66=$ Rhopalostylis sapida.

saxatilis, Burm. f. Fl. Ind. $42=$ Drymophloeus saxatilis.

spicata, Lam. Encyc. i. 241 = Calyptrocalyx spicatus.

spinosa, Hasselt \& Kunth, Enum. Pl. iii. $185=$ Oncosperma filamentosum

sylvestris, Lour. Fl. Cochinch. ii. $568=$ glandiformis.

tenella, Becc. Malesia, i, (1877) 22.-Bomeo.

tigillaria, Jack, in Malay. Misc. ii. (1820) n. VII. p. $88=$ Oncosperma filamentosum

triandra, Roxb. Hort. Beng. 68; Fl. Ind. iii. 617.Ind, or.

umbrosa, Link, Enum. Hort. Berol. ii. 403, nomen.-Hab?

vaginata, Giseke, Linn. Praelect. $78=$ Drymophloeus appendiculatus.

Verschaffelti, Hort. ex Lem, in Illustr. Hortic xiii. (1866) t. $462-3=$ Hyophorbe Verschaffelti.

vestiaria, Giseke, Linn. Praelect. 78.--Hab. ?

Wallichiana, Mart. Hist. Nat. Palm. 178=Iguanura Wallichiana.

Wendlandiana, Scheff. ex H. Wendl. in Kerch. Palm. $332=$ Nenga Wendlandiana.

ARELINA, Neck. Elem. i. $83(1790)=$ Berkheya Ehrh. (Compos.)

AREMONIA, Neck. Elem.ii. $100(1790)=$ Agrimonia, Linn. (Rosac.).

agrimonoides, DC. Prod. ii. 588=Agrimonia Eupatoria.

ARENARTA, Adans. Fam. ii. $256(1763)=$ Spergula, Linn. (Caryophyll.).

ARENARIA, Rupp. ex Linn. Syst. ed. I. (1735). CARYOPHYLLEAE, Benth. \& Hook. f. i. 149.

Adenarium, Rafin. in Am. Monthly Mag. (1818) 266.

Alsinanthus, Reichb. Handb. 298 (1837).

AIsINe, Scop. F1. Carn. ed. I. 224 (1772)

Alsinella, [Sw.] Summa Veg. Scand. 17 (1814), pro parte; S. F. Gray, Nat. Arr. Brit. PI. ii. 655 (1821).

\section{ARENARIA :-}

Ammodenta, Patrin, ex S. Gmel. Fl. Sibir. iv, 160 (1769).

Bigelonia, (Bigelowia) Rafin. in Journ. Phys: lxxxix. (1819) 289

Brachystemma, D. Don, Prod. Fl. Nep. 216 (1828)

Cherleria, Hall. It. Helv, ii. n. 79. t. 1 (1740).

Chetropis, Rafin. Fl. Tellur. iii. 80 (1836)

Dolophragma, Fenzl, in Ann. Wien. Mus. i. (1836)

63. t. 7 .

Eremogone, Fenzl, Verbr. Alsin. 13. t. ad p. 18 (1833)

Euthalia, Rupr. Fl. Caucas. 220 (1869)

Facchinia, Reichb. Ic. Fl. Germ. v. 29 (1841).

Gouffera, Robill. \& Cast. in DC, Fl. Fr. v. 609 (1815).

Greniera, J. Gay, in Ann. Sc. Nat. Sér. III. iv. 27 (1845)

GyPSOPHYTum, Adans. Fam. ii. 256 (1763)

Halianthus, Fries, Fl. Halland. 75 (1817).

HonkenYa, Ehrh. Beitr. ii. 180 (1788)

LEPTOPHYLLUM, Ehrh. 1. c. iv. 147 (1789).

LEPYRodiclis, Fenzl, in Endl. Gen. 966 (1840).

Merckia, Fisch. ex Cham. \& Schlecht. in Linnaea, i. $(1826) 59$

MerkiA, Reichb. Handb. 298 (1837)

Minuartia, Linn. Sp. Pl. 89 (1753)

MoEHRINGIA, Linn. Syst. ed. II. $22(1740)$

Neumayera, Reichb. Ic. Fl. Germ. 30 (1841)

Odon tostemma, Benth. in Wall. Cat. n. 645 (1828) G. Don, Gen. Syst. i. 449 (1831).

Pettera, Reichb. Ic. F1. Germ, v. 33. t. 220 (1841); Nom. 205 (1841)

Puinthine, Reichb. Handb. 298 (1837)

Rhodalsine, J. Gay, in Ann. Sc. Nat. Sér. III. iv. $25(1845)$.

Sabulina, Reichb. F1. Germ. Excurs. 785 (1832).

Siebera, Hoppe, in Flora, ii. (1819) 24.

Somerauera, Hoppe, 1. c. 26 (1819)

Strophium, Dulac, Fl. Hautes-Pyr。 247 (1867)

TryPhane, Reichb. Nom. 205 (1841)

WIERZBICKIA, Reichb. 1. c. (1841).

Wilhelmsia, Reichb. Consp. 206 (1828)

Xeralsine, Fourr. in Ann. Soc. Linn. Lyon, N. S xvi. (1868) 347

abietina, J. \& C. Pres1, Delic. Prag. i. $63=$ grandiflora acerosa, Boiss, E Heldr. Diagn. Ser. I viii. 103.As. Min.

achalensis, Griseb. in Goett. Abh. xxiv. (1879) 26.Reg. Argent

acicularis, Fisch. ex DC. Prod. i. $403=$ juniperina.

aculeata, S. Wats, in Bot. King, Exp. 40.-Am. bor

adenotrichia, Bong. ex Ledeb. F1. Ross, i. $291=$ Gypsophila petraea.

affinis, Willd. ex Schlecht. in Ges. Naturf. Fr. Berl. Mag. vii. (1813) 198.-Hab.?

africana, Hook. f. in Fourn. Linn. Soc. vii. (1864) 184.

$$
\text { -Afr. trop. }
$$

agglomerata, Poir. Encyc. Suppl. v. 6=glomerata

aggregata, Boiss. Elench. 23, in obs. = erinacea.

aggregata, Loisel. Fl. Gall. i. $317=$ tetraquetra. airaefolia, Fisch. ex DC. Prod, i. $402=$ capillaris.

algarbiensis, Welw.ex Willk. Ic. Pl. Hispan. i. 93.Lusitan.

Alpamarcae, A. Gray, Bot. U. St. Expl. Exped.i. 116 -Peruv.

alpicola, Tenore, Fl. Nap. iv. $224=$ graminifolia

alpina, Porter, Fl. Colorad. $14=$ obtusa

alsinoides, Raddi, Brev. Observ.13= Stellaria uliginosa. alsinoides, Willd, ex Schlecht. in Ges. Naturf. Fr.

Berl. Mag. vii. (1813) $201=$ lanuginosa.

altaica, Fisch. ex DC. Prod. i. $404=$ arctica.

amabilis, Bory, in Ann. Gén. Sc. Phys. iii. (1820) $5=$ tetraquetra.

andicola, Gill. in Hook. Bot. Misc. iii. (1833) 148. Chili.

andina, Rohrb. in Linnaea, xxxvii. (1871-72) 255.Bolivia.

androsacea, Fisch. ex DC. Prod. i. $402=$ rigida.

apetala, Vill. Prosp. $48=$ biflora

aphanantha, Wedd. in Ann. Sc. Nat. Sér. V. i. (1864) 293.-Peruv.

arabica, Hort. Berol. ex Fisch. Mey. \& Avé-Lall. Ind. Sem. Hort. Petrop. xi. $49=$ tenuifolia.

arctica, Stev. ex DC. Prod. i. 404.-Reg. bor. et arct.

Arduini, Vis. Stirp. Dalm. 8. t. 3. f. $2=$ gramini

folia.

\section{ARENARIA :}

retioides, Portenschl. ex F. Gay, in Ann. Sc. Nat. Sér. I. iii. (1824) 34, nota.-Europ.

aristata, Rafin. Caratteri, n. 187= setacea

armeniaca, Boiss. Diagn. Ser. I. i. 48.-Armenia

Armeriastrum, Boiss. Elench. 22.-Hispan.

armerina, Bory, in Ann. Gén. Sc. Phys. iii. (1820) 5 - Hispan.

arvatica, Presl, F1. Sicul. $163=$ mucromata.

arvensis, Wallr. Sched. Crit. $200=$ Spergula arvensis.

Aucheriana, Boiss. Diagn. Ser. I. i. 50.-Persia.

austriaca, All. Fl. Pedem, ii. 112. t. 64. f. $2=$ Villarsii

austriaca, Facq. Fl. Austr. iii. 39. t, 270.-Europ.

baetica, Salzm. ex Ball, in Journ. Linn. Soc. xvi. (1877) $365=$ emarginata

baicalensis, Stend. Nom. ed. II. i. $127=$ uliginosa.

Balansae, Boiss. Fl. Orient. i.700.-As. Min. ; Persia.

baldensis, Reichb. ex Nym. Consp. $113=$ bavarica

balearica, Linn. Syst. Nat. ed. XII. App. 230.-Ins. Balear.; Corsic.

banatica, Heuff. in Flora, xxi. (1838) 359--Hungaria. Barrelieri, Vill. Hist. P1. Dauph. iv. $634=$ tenuifolia. Bartolloti, Tineo, Pl. Rar Sic Pugill. i. 10-Sicilia bavarica, Linn. Cent. ii. 17 ; Amoen. Acad. iv. 315. Europ.

bavarica, Pall. Reise, ii. 522.-Rossia

Benthamii, Edgew. E Hook. f. in Hook. f. Fl. Brit. Ind. i. 242.- Reg. Himal.

Benthamii, Fenzl, ex Torr. \& Gray, Fl. N. Am. i. 675. -N. Mexic

Berteroana, Phil. in Linnaea, xxviii. (1856) $673=$ Spergularia villosa?

Biebersteinii, Schlecht, in Ges. Naturf. Fr. Berl. Mag. vii. (1813) $202=$ graminifolia.

biflora, Griseb. Spicil. F1. Rumel. i. $203=$ rotundifolia. biflora, Linn. Mant. 74.-Europ.

bisulca, Fenzl, ex Rohrb. in Linnaea, xxxvii. (1871-73) 248.-Peruv.

blepharophylla, Boiss. Fl. Orient. i. 693.-Armenia.

Bocconi, Soleir. ex Steud. Nom. ed. II. i. 123, 125 = Spergularia media.

bonariensis, Gill. in Hook. Bot. Misc. iii. (1833) 148. -Reg. Argent.

Bourgaeana, Coss. ex Willk. in Linnaea, xl. (1876 117 = incrassata.

Bourgaei, Hemsl. Diagn. Pl. Nov. 21.-Mexic. brevicaulis, Sternb, in Spreng. Pugill. i. $31=1$ anceolata. breviflora, Gilib. F1. Lituan. ii. 155=serpyllifolia. brevifolia, Nutt. ex Torr. E Gray, Fl. N. Am. i. 180 - Am. bor.

Brotherana, Trautv. in Act. Hort. Petrop. viii. (1883) 151.--Rossia.

bryoides, Fisch. ex DC. Prod. i. $404=$ arctica.

bryoides, Willd. ex Schlecht. in Ges. Naturf. Fr. Berl. Mag. vii. (1813) 201.-Mexic.

buxifolia, Poir. Encyc. vi. $362=$ lateriflora.

caerulescens, Rudolph, ex Ledeb. F1. Ross. i. $291=$ Gypsophila petraea.

caespitosa, Ehrh. Beitr. v. $177=$ verna.

caespitosa, Phil in Linnaea, xxviii. (1856) 673--Chili. caespitosa, Salisb. Prod. $299=$ balearica.

caespitosa, J. Vahl, ex Nym. Consp. $121=$ Sagina nivalis.

californica, Brewer, in Bot. Calif. i. 69.-Calif calycantha, Ledeb. in Mém. Acad. Sc. Pétersb. y. (1812) $534=$ Stellaria borealis.

calycina, Haensel. ex Willk. \& Lange, Prod. iii. $603=$ Sagina subulata.

calycina, Hort. ex Ledeb. F1. Ross. i. $343=$ tenuifolia calycina, Poir. Voy. Barb. ii. 167.-Afr. bor.

calyculata, Poir. Encyc. Suppl. v. 7.-Hungaria? campestris, All. Fl. Pedem. ii. $114=$ Spergularia rubra canadensis, Pers. Syn. i. $504=$ Spergularia rubra. canescens, Vahl, ex Hornem. Hort. Hafn. i. 964.Hab.?

cantabrica, Amo, F1. Iber. vi, $140=$ serpyllifolia. capensis, Steud. Nom. ed. II. i. 124.-Afr, austr capillacea, All. F1. Pedem ii. $365=$ grandiflora.

capillacea, Willd. ex Ledeb. F1. Ross. i. $367=$ capillaris.

capillaris, Poir. Encyc. vi. 380.-Sibir. ; Am. bor.

capillipes, Boiss. Voy. Bot. Espagne, 98. t. 27.-

Hispan,; Afr. bor.

capitata, Lam. Fl. Fr. iii. 39.-Hisp. ; Lusit. caricifolia, Boiss. in Tchihat. Asie Min. Bot. i. 235.Armenia.

caroliniana, Walt. F1. Carol. $141=$ squarrosa

cassia, Boiss, Diagn. Ser. I. viii. 101.-Syria. 


\section{ARENARIA :}

caucasica, Adams, ex Ledeb. F1. Ross. i. $354=$ pinifolia Cephalotes, Bieb. Fl. Taur. Cauc. i. 346.-Tauria. cerastiiflora, Spreng. Syst. v. 62 Ind, = cerastiifolia. cerastiifolia, Ramond, ex DC. Fl. Fr. v. 783.-Pyren.

cerastioides, Pers. Syn. i. $502=$ purpurascens. cerastioides, Poir. Voy. Barb. ii. $166=$ spathulata Cervianae, Cham. Es Schlecht. in Linnaea, i. (1826) 52.-Chili.

Cherleria, Hook. f. Stud. Fl. ed. I. 60--Europ.

Cherleriae, Fisch, ex DC, Prod, i. $409=$ Stellaria petraea.

cherlerifolia, G. Don, in Loud. Hort. Brit. $478=$ hirta. cherlerioides, Vill. Prosp. $48=$ lanceolata.

chilensis, DC. in Mém. Soc. Phys. Genèv. vi. (1833) 222.-Chili.

ciliatis, Losc. Trat. Pl. Aragon, i. 69, 79.-Hispan.

ciliata, Linn. Sp. Pl. 425.-Europ.; Am. bor.

ciliata, Sibth. \& Sm. Fl. Graec. t. $438=$ cretica.

ciliolata, Edgew. E Hook. f. in Hook. f. Fl. Brit. Ind. i. 240 - - Reg. Himal.

cinerea, DC. Fl. Fr. v, 611-Gallia.

clandestina, Portenschl. Pl, Dalm. 13.-Dalmatia. coerulescens, Auct. vide caerulescens.

collina, Turcz. ex Ledeb. F1. Ross, i. $349=$ verna. colorata, Turcz. ex Steud. Nom. ed. II. i. 124 capillaris.

condensata, C. \& J. Presl, Delic. Prag. i. $62=$ recurva. conferta, Boiss. Diagn. Ser. I. i. 51.-Graecia.

conferta, Wedd. in Ann.Sc. Nat. Sér. V.i. (1864) 293. -Bolivia.

congesta, Nutt. ex Torr. Eray, Fl. N.Am. i. 178.Calif.

conica, Boiss. Voy. Bot. Espagne, ii. 98. t. 31.-Hispan. conimbricensis, Brot. Fl. Lusit. ii, 200-Lusitan. Hispan.

conimbricensis, J. Gay, ex Gren. \& Godr. Fl. Fr. i. $260=$ controversa

connata, Rafin. Atl. Fourn. 151.-Am. bor.

controversa, Boiss. Pugill. Pl. Nov. Hisp. 100.-

Hispan, 'Gallia.

corsica, Stend. Nom. ed. II i, $124=$ balearica.

costata, Bunge, ex Ledeb. Fl. Alt. ii. 170.-Sibir.

cretica, Spreng. Syst. ii. 396.-Graecia; Cyprus; Creta.

cucubaloides, Sm. Pl. Ic. Ined. i. 17, t. 17.-Armenia.

dahurica, Fisch. ex DC. Prod. i. $402=$ juncea.

davurica, Spreng. Syst. ii. $398=$ Stellaria petraea.

debilis, Hook. f. FI. Brit. Ind. i. 242.-Reg. Himal.

debilis, Turcz. ex Ledeb. Fl. Ross. i. $348=$ verna.

decussata, Salisb. Prod. $299=$ tetraquetra.

decussata, Willd. ex Schlecht. in Ges. Naturf. Fr. Berl. Mag. vii. (1813) 212.-Mexic.

deflexa, Decne. in Ann. Sc. Nat. Sér. II. iii. (1835) 277 = graveolens.

densa, Kit. ex Schlecht. in Ges. Naturf. Fr. Berl. Mag. vii. $(1813) 200=$ gracilis.

densissima, Wall. Cat. n. 640.-Reg. Himal.

denticulata, Phil. Fl. Atac. 10,-Chili.

depauperata, C. Gay, Fl. Chil. i. 270,-Chili.

diandra, Guss. F1. Sic. Prod. i. $515=$ Spergularia diandra.

dianthoides, Hort. ex Ledeb. F1. Ross. i. 365=gypsophiloides.

dianthoides, $S m$. Pl. Ic. Ined. i. 16. t. 16.-Armen.; Persia.

dichotoma, Krock. Fl. Sil. ii. I. 55.-Silesia.

dichotoma, Moench, Meth. $224=$ tenuifolia.

dicranoides, H. B. E K. Nov. Gen. et Sp. vi. 34.-Mexic.

diffusa, Ell. Sketch, i. $519=$ lanuginosa.

digyna, Willd. ex Schlecht. in Ges. Naturf. Fr. Berl.

Mag, vii. (1813) $201=$ scopulorum.

divaricata, Adams, ex Ser. in DC. Prod. i. $405=$ verna.

Douglasii, Fenzl, ex Torr. E Gray, Fl. N. Am. i. 674. -Calif.

drypidea, Boiss. Diagn. Ser. I. i. 49-As. Min.

dubia, Suter, Fl. Helv. i. 266,-Helvet.

echinata, Poir. Encyc. vi. 377.-Europ. austr.

elegans, Cham. \& Schlecht. in Linnaea, i. (1826) $57=$ stricta.

elongata, Balbis, ex Schlecht. in Ges. Naturf. Fr. Berl. Mag. vii., (1813) $200=$ austriaca, grandifora

emarginata, Brot. Fl. Lusit. ii. 202.-Lusitan.; Marocco.

erinacea, Boiss. Voy. Bot. Espagne, ii. 103.-Hispan. erythrosepala, Boiss. Diagn. Ser. I. viii. $98=$ setacea.

\section{ARENARIA}

extensa, Dufour, in Ann. Sc. Gén. Phys. vii. (1820) 291.-Hispan

fasciculata, Forsk. Fl. Aegypt. Arab. 211.-Arabia.

fasciculata, Gouan, Illustr. 30.-Europ

fasciculata, Hohen. Enum. Pl. Elisabethpol. $232=$ scle rantha.

fasciculata, Pall. Ind. Taur.; Bieb. Casp. App. $209=$ glomerata.

fasciculata, Sibth. \&c Sm. Fl. Graec. v. $30=$ globulosa. fastigiata, Phil. in Linnaea, xxviii. 1856) 673.-Chili. fastigiata, Sm. Eng. Bot. xx.t. $1744=$ rostrata.

fastigiata, Schur, Enum. Pl. Transs. 112.-Transsylv.

Fendleri, A. Gray, Pl. Fendl. 13.-Am. bor.

festucoides, Benth. in Royle, Illustr. Bot. Himal. 81 t. 21. f. 3.-Reg. Himal.

filicaulis, Fenzl, in Griseb. Spicil. Fl. Rumel. i. $203=$ graveolens.

filifolia, Bieb. Fl. Taur. Cauc. i. $344=$ graminifolia.

filifolia, Forsk. Fl. Aegypt. Arab. $211=$ setacea

filiformis, Labill. Ic. Pl. Syr. dec. iv. $8=$ picta.

fimbriata, Bieb. ex Ledeb. Fl. Ross, i. $352=$ laricina.

fimbriata, Salzm. ex Kindberg, Monog. Lepigon. 22

Spergularia fimbriata

Aaccida, [Clairv.] Man. Herb. $149=$ Villarsii.

flaccida, Froel. ex Reichb. F1. Germ. Excurs, $790=$ lanceolata.

flaccida, Roxb. Hort. Beng. 34; F1. Ind. ii. $447=$ Spergula pentandra.

flaccida, Schleich. Cat. PI. Helv. ed. III. 46=verna.

flexuosa, Rafin. Atl. Fourn. 151.-Am. bor.

floribunda, C. Gay, Fl. Chil. i. 269.-Chili.

foliosa, Royle, ex Edgew. E Hook. f. in Fl. Brit. Ind. i 236.-Reg. Himal.

formosa, Fisch. ex DC. Prod, i. $402=$ capillaris.

Franklinii, Dougl, ex Hook. Fl. Bor. Am. 1. 101.-Am. bor.

frigida, Rupr. Fl. Caucas. 202.-Caucas.

frutescens, Kit. ex Schult. Oestr. Fl. ed. II. i. $667=$ setacea.

galioides, Ser, in DC. Prod. i. 410,-Hab.

geniculata, Poir. Voy, Barb, ii. 166.-Reg, Mediterr.

Gerardi, Willd. Sp. Pl, ii. $729=$ verna.

Giesekii, Hornem. Fl. Dan. t. $1518=$ verna.

glabra, Balb. Misc. 21 = Villarsii.

glabra, Ell. Sketch, i. $520=$ Stellaria uniflora.

glabra, Michx. Fl. Bor. Am. i. 274.-Am, bor.

glabra, Torr. Fl. U. St. $455=$ groenlandica

glabrata, Cham. \& Schlecht, in Linnaea, i. (1826) $56=$ verna.

glanduligera, Edgew. in Hook. f. Fl. Brit. Ind. i. 240 Reg. Himal.

glandulosa, facq. Hort. Schoenb. iii. 56.-Afr. austr.

globifora, Wall. Cat. n.639.-Reg. Himal

globosa, Spreng. Syst, ii. $400=$ globulosa.

globulosa, Labill. Ic. Pl. Syr, dec. iv. 6.-Oriens.

glomerata, Bieb. Fl. Taur. Cauc. i. 350.-Tauria.

glutinosa, Bieb. 1. c. $344=$ Holosteum umbellatum.

glutinosa, Boiss. in Ann. Sc. Nat. Sér. IV. iî. (1854)

247. t. $2=$ Ledebouriana.

glutinosa. Willd ex Ledeb. Fl. Ross, i. $353=$ imbricata

Gmelini, Bong. ex Ledeb. 1. c. $351=$ Villarsii.

Gmetini, Fisch. ex DC. Prod. i. $402=$ Gypsophila Gmelini.

gorgonea, 7. A. Schmidt, Beitr. Fl. Cap. Verd. Ins. 278.--Ins. Cap. Verd.

gothica, Fries, Mant. ii. 33.-Europ.

Gouffeia, Puel, in Duch. Rev. Bot. i. (Avr. 1846) 450 $=$ controversa

Gouffeia, Chaub. Fl. Pélop. n. 701. t. 24. f. 2,Gall. occ.

gracilis, Kit. ex Schult. Pl, Rar. Hung. iii. 305.Croat.; Dalmat.

graeca, Boiss. ex Nym. Consp. 114= graveolens

graminea, Auct. ex Steud. Nom. ed. II. i. $124=$ grandiflora.

graminea, C. A. Mey. Vers. Pfl. Cauc. 220,-Reg. Caucas.

graminifolia, Arduin. Animad. Alt. 25.-Italia; Dalmat.

graminifolia, Schrad. Hort. Goett. i. 5.-Hungar.; Reg Cauc. ; Sibiria.

grandiflora, Coss. ex Willk, in Linnaea, xl. (1876) 117 $=$ incrassata

graudiflora, Linn. Syst. ed. X. 1034.-Europ.

grandiflora, Pall. Reise, iii. $\$ 4=$ arctica.

grandis, H. B. \& K. Nov. Gen. et Sp. vi. $30=$ Spergu. laria grandis.

\section{ARENARIA}

graveolens, Schreb. in Nov. Act. Nat. Cur. iii. (1767) 478.-Graecia; As. Min.; Syria ; Arab. Griffithii, Boiss. Fl. Orient. 1.697.-Tibet. occ.; Afghan grineensis, Thomas, Suppl. Cat. $(1842)=$ Villarsii.

groenlandica, Spreng. Syst. ii, 402,-Am, arct.

Guicciardii, Heldr. in Boiss. Diagn. Ser. II. ช. 60. Graecia.

Guilielmi-Waldemarii, Klotzsch, in Bot. Erget.

Waldem. Reise, $142=$ festucoides.

gypsophiloides, Linn. Mant. i. 71.-As. Min.; Persia. gypsophiloides, Stev. ex Ledeb. Fl. Ross. i. $365=$ cucu

gypsophiloides, Willd. ex Ledeb. 1. c. $366=$ juncea.

Haenkeana, Bartl. ex Presl, Rel. Haenk. ii. $15=$ lateri flora.

Halleri, Raensch. Nom. ed. III. $130=$ tenuifolia

Halleri, Vitm. Summa, iii. $109=$ biflora.

halophila, Bunge, ex Ledeb. Fl. Alt. ii. $163=$ Spergulari media.

Helmii, Fisch. ex DC. Prod.i. 404.-Sibir. ural. herniarifolia, Desf. Fl. Atlant. i. $358=$ geniculata.

heteromalla, Pers. Syn. i. $504=$ setacea.

heterosperma, Guss, Fl. Sic. Syn, i. 501=Spergulari media.

hirsuta, Bieb. F1. Taur, Cauc. i. $349=$ recurva

hirta, Sieber, ex Presl, in Oken, Isis, xxi. (1828) $272=$ cretica.

hirta, Worsmsk. in Fl. Dan. t. $1646=$ verna.

hispanica, Spreng. Syst. ii. $396=$ = spatbulata.

hispida, Linn. Sp. Pl. 425. -Euror.

hispida, Salzm. ex Presl, Fl. Sicul. 164=Salzmanni.

Holostea, Bieb. Fl. Taur. Cauc. i. 345.-Reg. Cauca:

Holostea, Beaupr. ex Ser. in DC. Prod. i, $402=$ rigida

holosteoides, Edgew. in Hook. f. Fl. Brit. Ind. i. 241 Reg. Himal.

Hookevi, Nutt. ex Torr. \& Gray, Fl. N. Am, i. $178=$

Franklinii.

Howellii, S. Wats. in Proc. Am. Acad. xx. (1885, 354.-Oregon.

humifusa, Wahlenb. F]. Lapp. $129=$ ciliata

Huteri, Kern. in Oestr. Bot. Zeitschr. xxii. (187:368.-Europ.

hybrida, Vill. Prosp. $48=$ tenuifolia

imbricata, Banks, ex Stend. Nom. ed. II. i. $124,125=$ glabra.

imbricata, Bieb. Fl. Taur. Cauc. i. 344.-Reg. Caucas imbricata, Lag. Rodr. in Anal. Cienc. Nat. v. (1802 $278=$ tetraquetra.

imbricata, Rafin. in Med. Repos. N. York, v. (1808 $361=$ squarrosa

inamoena, Steud. Nom. ed. II. i. $125=$ imbricata.

incrassata, Lange, Pl. Nov. Hisp. fasc. i. 3. t. 4. f. 2.Hispan.

intricata, Dufour, ex Ser. in DC. Prod. i. $\$ 10=$ montana.

intricata, F. Gay, ex Willk. \&o Lange, Prod. Fl. Hisp iii. 617 , in syn.-Hispan.

isaurica, Boiss. Fl. Orient. i. 695.-As. Min.

Jamesoniana, Rohrb. in Linnaea, xxxvii. (1S71-i? 267.-Ecuador.

juncea, Bieb. Fl. Taur. Cauc, iii. 809,-Tauria

juniperina, Linn. Mant. 72.-Oriens; Turkest. juniperina, Pursh, Fl. Am. Sept. $319=$ verna. juniporina, Vill. Hist. Pl. Dauph. iii. $62 t=$ grandiflora. Juressi, Willd. ex Schlecht. in Ges. Naturf. Fr. Berl. Mag, vii. (1818) 212.-Hispan.

Jussiei, St. Hil. Fl. Bras. Med. ii. 174.-Bras.

kansuensis, Maxim. in Bull. Acad. Petersb.xxvi. 1ss 428.-China.

kashmirica, Edgerv. in Hook. f. Fl. Brit. Ind. i. 286.Reg. Himal.

Koriniana, Fiscly ex Ledéb. Fl. Ross, i. \$033.-Rossia. Kotschyana, Fenzl, in Kussegg. Reise, ii. 930 - tmoles. lanceolata, All. Fl. Pede'm. ii. 11 \&-Europ.

lanuginosa, Rohrb. in Mart. Fl. Bras. xiv. I1. 2: i. Am. bor. et austr.

lapponica, Spreng. Syst. ii. 402.-Lappon. laricifolis, Bieb. Fl. Taur. Cauc i. $\$ 4 t$ a pinifolia. laricifolia, Lapeyr. [Abr. i. 255 ] ex Sieud. Nom. ed. It i. $124=$ grandiflura.

laricifolia, Limn. SP. Pl. 424.-Europ.

laricifolia, Pall. lnd. "laur. [51] ex Seeud. Norn. ed. I vio : ed. II. i. $1 \geq 7=$ setace:

Paricifolia, Pursh, Fl. Aas. Sept. i. \$1:1 untica. laricina. Cham. \& Schlechto in Limnaea. i. $1=26$ ) $5 i$ Sipergula laricina.

Interitlora, Limn. Sp. Pl. 123.-Sibir. ; Am. bor 


\section{ARENARIA}

lateriflora, Dar1. F1. Cestr. $277=$ Stellaria borealis. laxa, Fisch. ex Ser. in DC. Prod. i. $404=$ grandiflora. Laxmanni, Fisch. ex Ser. 1. c. $402=$ capillaris.

Ledebouriana, Fenzl, in Russegg. Reise, ii. 931. Armenia

leptoclados, Guss. Fl. Sic. Syn. 1i. 284=serpyllifolia.

leptoclados, Boiss. Fl. Orient. i. 701.-Europ.; Afr. bor.; Oriens.

leptophylla, Cham. Es Schlecht. in Linnaea, v. 1830) 233.-Mexic

Lessertiana, Fenzl, in Russegg. Reise, ii. 932.-Persia. lesurina, Loret, Herb. Loz. et Prost. 13.-Gall. mer.

libanotica, Kotschy, in Boiss. F1. Orient. i. $699=$ setacea.

Liebmanniana, Rohrb. in Linnaea, xxxvii. (1871-72) 274.-Bras.

ligericina, Lec, \& Lamotte, Cat. P1. Cent. Fr. 104=lesurina.

lignosa, Phil. Fl. Atac, 10.-Chili.

linearifolia. Poir. Encyc. vi. $366=$ montana

lineata, C. A. Mey, ex Ledeb. Fl. Ross. i. 351.-Rossia.

liniflora, Jacq. F1. Austr. $\mathrm{v} .22=$ verna.

liniflora, Linn. Sp. Pl. ed. II. $607=$ laricifolia

liniflora, Willd. ex Spreng. Syst. ii, $399=$ grandiflora

littoralis, Phil. in Linnaea, xxviii. (1856) 673.--Chili.

littoralis, Salisb. Prod. $299=$ peploides.

Lloydii, Jord. Pugill. $37=$ serpyllifolia.

longifolia, DC. Prod. i. $402=$ graminifolia.

longifolia, Bieb. F1. Taur. Cauc. i. $345=$ saxatilis.

Loscosii, Texid. in Losc. Trat. Pl. Aragon, ii. 28. Hispan.

lychnidea, Bieb. Fl. Taur. Cauc. i. 347.-Reg. Cancas.

lychnidea, Willd. ex Ledeb. Fl. Ross, i. $367=$ capillaris.

lycopodioides, Willd. ex Schlecht. in Ges: Naturf. Fr. Berl. Mag, vif. (1813) 212.-Mexic

macradenia, S. Wats. in Proc. Am. Acad. xvii. (188182) 367. -Am. bor.

macrocalyx, Tausch, in Syll. Ratisb. ii. (1828) 243.Syria

macrocarpa, Hornem. Hort. Hafn. i. $964=$ canesceus. macrocarpa, Kit. ex Ser. in DC. Prod. i. $404=$ laric folia.

macrocarpa, Pursh, Fl. Am. Sept. i. 316.-Am. bor

macrophylla, Hook. Fl. Bor. Am. i. 102.-As. or. ; Am bor, occ.

macrorrhiza, Guir, ex Willk. \& Lange, Prod. Fl Hisp. iii, $166=$ Spergularia media

macroryhiza, Requien, ex Loisel. Nouv. Not. $22=$ Spergularia macrorrhiza.

macrosepala, Boiss. Diagn. Ser. I. i. 52.-As. Min. macrotheca, Hormem. ex Cham. \& Schlecht. in Linnaea, i. $(1826) 53=$ Spergularia macrotheca.

Mandoniana, Wedd. in Ann. Sc. Nat. Sér. V. i. (1864) 294.-Reg. And,

marginata, DC. Fl. Fr. $\nabla .793=$ Spergularia marginata.

marginata, Schlecht. in Ges. Naturf. Fr. Berl. Mag. viï. (1813) 212,-Sibir. or

marina, All. Fl, Pedem. ii. $114=$ Spergularia media marina, Pall. Reise, iii. $603=$ Spergularia marina marina, Roth, Tent. Fl. Germ. i. $189=$ Spergulari salina.

maritima, Steud. Nom. ed. II. i. $125=$ Spergularia media.

Marschlinsii, Koch, in Flora, xxiv. (1841) r. $509=$ serpyllifolia.

media, DC. Prod. i. $401=$ Spergularia marina

media, Linn. Sp. Pl. ed. II. $606=$ Spergularia media

media, Poll. ex Steud. Nom, ed. II. ii. 617, in syn. Spergula pentandra.

mediterranea, Ledeb. ex Link, Enum. Hort. Berol. i. $431=$ mucronata

melandryoides, Edgew. in Hook. $f$. Fl. Brit. Ind. i. 241.-Reg. Himal.

mexicana, Steud. Nom. ed. II. i. 125.-Mexic

Meyeri, Edgew. E Hook.f. in Fl. Brit. Ind. i. 236.-

Oriens; Ind. bor. occ.

Meyeri, Fenzl, ex Ledeb. Fl. Ross. i. 368.-As. temp.

Michauxi, Hook. f. in Trans. Linn. Soc. xxii. (1861) $287,322=$ stricta.

microphylla, Phil. in Linnaea, xxviii. (1856) 673.Peruy.

minuta, C. Gay, Fl. Chil. i. 273.-Chili.

mixta, Lapeyr. Hist. Abr. Pl. Pyr. 255=grandiflora

modesta, Dufour, in Ann. Sc. Gén. Phys. vii. (1820 291.-Hispan.

\section{ARRNARTA :}

molluginea, Ser. in DC. Prod. i. 400.-Mexic.

molluginifolia, Pourr, ex Schlecht. in Ges. Naturf. Fr Berl. Mag, vii. (1813) 201.-Hispan.

montana, Linn. Cent. i. 12; Amoen. Acad. iv. 272.Gall.; Hisp.

montana, Sieber, ex Steud. Nom. ed. II. i. $125=$ macro calyx

monticola, Buckl. in Proc. Acad. Sc. Philad. '1861.' (1862) $449=$ Benthamii

monticola, Edgew. in Hook. f. Fl. Brit. Ind. i. 238.Reg. Himal.

Moritzii, Bruegg. in Zeitschr. Ferdinand. Tirol. III ix. (1860) 117.-Europ.

mucronata, DC. Fl. Fr. iv. 791 = rostrata. mucronata, Linn.Sp.Pl. 424.-Ital.; Gall. mucronata, Sibth. \& Sm. Fl. Graec. t. $294=$ tenuifolia multicaulis, Linn. Amoen. Acad i. $162=$ ciliata

multicaulis, Phil in Linnaea, xxviii. (1856) 673.Chili.

Munbyi, Munby, Cat. Pl. Algér. 6.-Algeria. muralis, Sieber, ex Spreng. Syst. 1i. $397=$ graveolens. musciformis, Triana E Planch. in Ann. Sc. Nat. Sér.

IV xvi, (1862) 150-N, Granat.

musciformis, Wall. Cat. n. 6401.-Tibet.

muscipula, Fenzl, Verbr. Alsin. anal. tab, iii.-Afr bor.

muscoides, H. B. E K. Nov. Gen. et Sp. vi. 34.-Am. austr.

muscorum, Adams, sec. Fisch. ex DC. Prod. i. $407=$ aliginosa.

nuscorum, Fisch. ex DC. l. c. 409.-Kamtschatka. muscosa, Med. in Act. Acad. Theod. Palat. iii. Phys 1775) 202. t. 12.-Europ.

mutabilis, Lapeyr. Hist. Abr. Pl. Pyr. $256=$ fasciculata.

nana, Boiss. E Heldr. Diagn. Ser. I. viii. 103,-Creta nana, Willd. ex Schlecht. in Ges. Naturf, Fr. Berl Mag. vii. (1813) $201=$ muscoides.

nardifolia, Ledeb. ex Hook. F1. Bor. Am. i. 98 (1830) = capillaris.

neeloherrensis, Wight \& Arn. Prod. i. 43.-Keg.

Himal.; Mont. Nilgiri

nentorosa, H. B. \& K. Nov. Gen. et Sp. vi. $35=$ lanuginosa

nemorosa, Steud. Nom. ed. II. 1. 126, $127=$ trinervia. nepalensis, Spreng. Syst. Cur. Post. 181.-Nepal. nerrosa, Lam. Fl, Fr, iii. $36=$ trinervia, nevadensis, Boiss. Diagn. Ser. II. i. $90=$ conferta. nilgherensis, Fenzl, var. $\alpha, \gamma$, ex Boiss. Fl. Orient. 700, in syn. $=$ Balansae.

nitida, Rohrb. in Linnaea, xxxvii. (1871-73) 249.Peruy.

nodosa, Bory \& Chaub. Fl. Pélop. 28, t. $\mathbf{1 5}=$ juniperina.

nodosa, Wall. Sched. Crit. 200, in obs. = Sagina noclosa.

horvegica, Gunn. Fl. Norv, ii. 1100. t. 9. f. 7-9 ; ex Hornem. in Fl. Dan. t. 1269,-Scandin.

mudiuscula, Bertol. Bot. Misc, ii, 222. t. $8=$ picta

obtusa, All. Fl. Pedem. ii. $114=$ polygonoides.

obtusa, Torr. in Ann. Lyc. New York, ii. (1828) 170. Am. bor

obtusiflora, Kunze, in Flora, xxix. (1846) 632.Hispan.

occulta, Fisch. ex DC. Prod. i. 408=polygonoides, arctica.

oligosperma, C. Gay, Fl. Chil. i. 272.-Chili

orbicularis, Vis. Fl. Dalm. iii. 180.-Europ.

orbiculata, Royle, ex Hook. f. Fl. Brit. Ind. i. 240.Reg. Himal.

Orbignyana, Wedd. in Ann. Sc. Nat. Sér. V. i. (1864) 293.-Bolivia.

oreophila, Hook. f. Fl. Brit. Ind. i. 238.-Tibet.

otitoides, Adams, ex Fisch. in DC. Prod. i. 402.Sıbir.

oxypetala, Sibth. E Sm. Fl. Graec. Prod. i. 303.Graecia; Creta.

palusiris, C. Gay, Fl. Chil. i. 271.-Chili.

palustris, S. Wats. Bot. Calif. i. 70.-Calif

pamphylica, Boiss. E Heldr. Diagn. Ser. I. viii. 102. As. Min.

paniculata, Bunge, in Ledeb. Fl. Alt. ii. 168.-Sibir. alt.

papillosa, Steud. Nom. ed. II. i. $126=$ graveolens.

paradoxa, Bartl. ex Presl, Rel. Haenk. ii. 15=lanuginosa.

parviflora, Benth. Pl. Hartw. 163.-N. Granat
ARENARIA :-

patagonica, Phil. in Linnaea, xxviii. (1856) 671.Patagonia.

patula, Martr. Fl. Tam, $107=$ serpyllifolia.

patula, Michx. Fl. Bor. Am. i. 273.-Am. bor.

pauciflora, Kit. in Linnaea, xxxii. 1863) 510 Hungar.

pedunculosa, Wedd. in Ann. Sc. Nat. Sér. V. i. (1864 294.-Bolivia

pendula, Waldst. E Kit. Pl. Rar. i. 90. t. 87.Banat.; Thracia.

pensylvanica, Muhl. Ind. F1. Lanc. $169=$ lateriflora?

pentagyna, Mo६. E Sesse, ex DC. Prod. i. 395.-Mexic pentandra, Dufour, in Ann. Sc. Gén. Phys. vii. (1820 $292=$ tenuifolia.

pentandra, Maxim. in Bull. Acad. Pétersb. xxvi. (1880) 429.- Soongaria.

pentandra, Turcz. in Flora, xvii. (1834) I. Beibl. 8. Sibir. baical.

pentandra, Waldr. Sched. Crit. $206=$ Spergula pentandra.

peploides, Lapeyr. Hist. Abr. P1. Pyr. 251=Polycarpon peploides.

peploides, Linn. Sp. Pl. 423.-Reg. bor. temp. et aret.

persica, Boiss. Diagn. Ser. I. i. $49=$ Lessertiana.

peruviana, Poepp. ex Rohrb. in Mart. Fl. Bras, xiv. II. $275=$ lanuginosa

Peyritschii, Rohrb. in Linnaea, xxxvii. (1871-73) 264 - Mexic.

pharnaceoides, Ser. in DC. Prod.i. $408=$ picta.

physodes, Fisch ex DC. L. C. 413.-Am. bor.

picta, Sibth. E Sm. Fl. Graec. Prod.i. 304.-As. Min.; Syria.

pilifera, Fisch. ex Ledeb. Fl. Ross. i. $352=$ Spergula Iaricina

pinfolia, Bieb. Fl. Taur. Cauc. i. 348.-Reg. Caucas.

Pissisi, Phil. in Linnaea, xxxiii. (1864-65) 20.Chili.

Pitcheri, Nutt. ex Torr. E Gray, Fl. N. Am. i. 180.Am. bor.

plantaginea, Mert. \& Koch, in Roeh1. F1. Deutschl. iii. 273, in syn. = trinervia.

Poeppigiana, Rohrb. in Linnaea, xxxvii. (1871-72 265.-Peruv.

polycnemifolia, Boiss. Diagn. Ser. I. i. 48.-Armenia; Persia.

polygonoides, Wulf. in Facq. Coll. i. 241, t. 15.-Europ, ; As. bor

polytrichoides, Edgew. in Hook. f. Fl. Brit. Ind. i 237.-Reg. Himal.

Pomeli, Munby, in Bull. Soc. Bot. Fr. xi. (1864) 45.Algeria.

Ponae, Reichb. Ic. Pl, Germ, ii, $26=$ bavarica

portulacea, Lam. FI. Fr. ïi. $38=$ peploides.

Preslii, Nym. Consp. $113=$ graminifolia.

procera, Spreng. ex Hornem. Hort. Hafn. $424=$ graminifolia.

procumbens, Bove, ex Decne. in Ann. Sc. Nat. Sér. 11. iii. (1835) $277=$ graveolens.

procumbens, Rupr. Fl. Cauc. 202.-Caucas.

procumbens, Vahl, Symb. Bot. i. 50. t. $33=$ geni culata.

propinqua, Richards. in Frankl. 1st Journ. ed. II. App. $17=$ verna.

prostrata, Ser. in DC. Prod. i. $400=$ Polycarpaea prostrata.

Przewalskii, Maxim. in Bull. Acad. Pétersb. xxvi. (1880) 428.-China.

pseudarmeriastrum, Rouy, in Bull. Soc. Bot. Fr. xxix. (1882) 46.-Gallia.

pubescens, Pres1, ex Steud. Nom. ed. II. i. $126=$ pubigera.

pubescens, Redowski, ex Ledeb. Fl. Ross. i. 349.Rossia.

pubescens, Steud. Nom.ed. I. $66=$ Spergularia media. pubescens, Urville, in Mém. Soc. Linn. Par. i. (1822) $306=$ graveolens.

pubigera, Steud. Nom. ed. II. i. 126.-Sicilia.

puilchella, Hoffm. Hort. Mosq. 4=Gypsophila elegans. pulchra, Willd. ex Schlecht. in Ges. Naturf. Fr. Bert. Mag. vii. (1813) 212.-Armenia.

pulvinata, Edgew, in Hook. f. Fl. Brit. Ind. i. 238.Reg. Himal.

Pumilio, R. Br. in Parry, 2nd Voy. App. $391=$ arctica. pungens, Clem. in Lag. Gen. et Sp. Nov. 15.-Hispan. Marocco. 


\section{ARENARIA :-}

pungens, Steph. ex Ser. in DC. Prod. i. $403=$ subulata. pungens, Nutt. ex Torr. E Gray, Fi. N. Am. i. 179.Am. bor. occ

purpurascens, Ramond, ex DC.F7. Fr. iv. 785.-Pyren purpurea, Pers. Syn. i. 504=Spergularia purpurea.

purpurea, Willd. ex Schlecht. in Ges. Naturf. Fr. Berl. Mag. vii. (1813) $211=$ rubicunda.

Purshiana, Ser. in DC. Prod. i. $414=$ Stellaria humifusa pusilla, S. Wats. in Proc. Am. Acad. xvii. (1881-82) 367. - Am. bor.

pycnophylla, Rohrb. in Linnaea, xxxvii. (1871-72) 250 .-Bolivia.

pyrenaica, Hort. ex Steud. Nom. ed. II. i. $126=$ montana.

quadrivalvis, R. Br. in Parry, 1stVoy. App. $271=$ verna. querioides, Pourr. ex Willk. in Bot. Zeit, v. (1847) 239 $=$ capitata.

lacemosa, Willk.l.ce-Hispan

Raddiana, Ser. in DC. Prod. i. $412=$ Stellaria uliginosa. radians, Benth. Pl. Hartw. 163--N. Granat.

radicans, Hort. ex Stend. Nom. ed II. i. $126=$ pendula. radicans, Spreng. Syst. ii. $400=$ SF ergularia-rubra. Rafinesquiana, Ser, in DC. Prod. i. $409=$ squarrosa. Ramondi, Poir. Encyc. Suppl. v, $3=$ cerastiitolia. ramosissima, Bieb. ex Steud. Nom. ed. I. $67=$ setacea. ramosissima, Willd. Enum. Hort. Berol. Suppl. 24.Hungar.

recurva, All. Fl. Pedem, ii. 113. t. "89. f. 3.-Europ. Oriens.

Redowskii, Cham. E Schlecht. in Linnaea, i. (1826) 5 r.-As. or.

repens, Sex in DC. Prod. i, 410,-Hab.?

reptans, Hemsl. Diag. Pl. Nov. 22.-Mexic.

retusa, Boiss. Voy. Bot. Espagne, 99. t. 27.-Hispan.

rhodia, Boiss. Diagn. Ser. I. i. $52=$ oxypetala.

rigida, Bieb. Fl. Taur. Cauc. i. 346.- Lauria.

rivularis, Phil. Fil. Atac. 10.-Chili.

Rohrbachiana, Garcke, in Linnaea, xxxvii. (1871-72) 311.-Mexic.

Rosani, Tenore, Prod. Fl. Nap. 26.-Ital.; Dalmat. rosea, Presl, F1. Sicul. $165=$ geniculata

rosea, Salzm. ex Ball, in Journ. Linn. Soc. xvi. (1878) $365=$ emarginata.

Rossii, R. Br. in App. Parry, Voy. $13=$ stricta.

Roylei, Fenzl, ex Klotzsch, in Bot. Ergeb. Waldem. Keise, 142 = festucoides.

rostrata, Waldst. \& Kit. ex Willd. Enum. Hort. Berol. $481=$ laricifolia.

Iostrata, Pers. Syn. i. 504.-Europ. alp.

rotundifolia, Bieb. Fl. Taur. Cauc. i. 343.-Graecia

Rerr. Cauc. : As. Min.

mubella, Sm. Engl. Bot. Suppl. t. $2538=$ verna.

rubicunda, Spreng. Syst. ii. 399.--Sibir.

rubra, Linn. Sp. Pl. $423=$ Spergularia rubra.

rupestris, Labill. Pl. Syr, dec, iv, 8. t. 4. f. 1.-Liban.

rupicola, Hook. f. FI. Brit. Ind. i. 243 err. typ. $=\mathrm{sec}$

rupifraga, Fenzl, ex Ledeb. FI. Ross. i. $780=$ Thylacospermum rupifragum.

ruscifolia, Poir. Encyc. vi. 365-Canada.

ruscifolia, Requien, in Guer. Vaucl. ed. II. $254=$ cinerea. sabulinea, Griseb, in Russegg. Reise, ii. 333.-Mesopot. gianensis, Willd ex Schlecht in Ges. Naturf. Fr. Berl. Mag. vii. (1813) 200.-Sibir. alt

salina, Ser. in DC. Prod. i. 401 = Spergularia marina.

salsuginea, Bunge, ex Ledeb. F1. Alt. i1. $163=$ Spergularia diandra.

Salzmanni, Presl. Fl. Sicul. 163.-Sicil.

sancta, fanka, in Terméss. Füisetek, vi. (1882) 165.Europ. austr.

saponarioides, Boiss. E Bal. Diogn. Ser. II. vi. 35.Phrygia.

saxatilis, Bont. ex Willk, in Willk. \& Lange, Prod. Fl. Hisp. iii. $621=$ obtusiflora.

saxatilis, Auct. ex Steud. Nom, ed. II. i. 127=setacea. saxatilis, C. C. Gmel. H1. Bad. ii. $267=$ verna.

saxalilis, Linn. Sp. Pl, 423.-Europ.; Sibir.

saxatilis, Vill. Fl. Delphill. $43=$ rostrata.

Saxifraga, Frivald. in Flora, xix. (1ऽ36) I1. 434.-

Rumelia.

saxosa, A. Gray, Pl. Wright. ii. 18.-N. Mexic.

scabra, Poir. Encyc. vi. 377. - Europ.

scandinavica, Spreng. Syst. ii. $399=$ Stellaria biflora.

scario a, Boiss. in Tchihat. Asie Min. Bot. 1.234.-Armenia.

scopulorum, H. B. E K. Nov. Gen. et Sp. vi. 31.-Peruv, sedoicles, Froel. ex Koch, Syn. Fl. Germ. ed. I. 114.Tyrol.

\section{ARENARIA}

segetalis, Lam. Fl. Fr. iii. $43=$ Spergularia segetalis, sericea, Ser. in DC. Prod, 1. $414=$ purpurea. serpens, Fisch. ex Ser. 1. c. $404=$ arctica. serpens, H. B. \& $K$. Now. Gen. et Sp. vi. 32.Ecuador.

serpyllifolia, Bourg. ex Willk. \& Lange, Prod. Fl. Hisp. iii. $619=$ nevadensis.

serpyllifolia, Linn.Sp. Pl. 423.-Europ.; As. temp. Ind. or.

serpyllifolia, Guss. FI. Sic. Syn. i. $495=$ leptoclados. serpylloides, C. Gay, Fl. Chil. i. 271.-Chili.

setacea, Fisch. ex Ser. in DC. Prod. i. $402=$ lychnidea

setacea, Adams, ex Ser. 1. c. $403=$ capillaris.

setacea, Thuill. Fl. Par. ed. II. 220.-Reg. Mediterr. Oriens; Sibir.

setosa, Willd. ex Ledeb. F1. Ross. i. 368=capillaris.

sibivica, Pers. Syn. i. $504=$ capillaris

sipylea, Boiss. Diagn. Ser. I. i. $51=$ graveolens:

sitchensis, D. Dietr. Syn, Pl, ii, $1565=$ peploides.

Smithii, Steud. Nom. ed. II. 1. $127=$ globulosa.

soratensis, Rohrb. in Linnaea, xxxvii. (1871-72) 266 - Bolivia.

sordida, Chaub. Fl. Pélop. n. 699. t. 24. f. 1.-Graecia

spathulata, Desf. Fl. Atlant. 1. 358.-Hispan.; Afr bor.

Spergula, Dufour, in Ann. Gén. Sc. Phys. vii. (1820) 293 = Spergularia media

sperguloides, Rafin. Att. Fourn. 153.-Am, bor sperguloides, Trevir. ex Steud. Nom. ed. II. I. 127.Chili.

sphaerocarpa, Martr. Fl. Tarn, $107=$ patula

sphaerocarpa, 'lenore, Syll. Fl. Neap. iv. $222=$ serpyllifolia.

spinuliflora, Ser. in DC. Prod.i. $406=\mathrm{Habrosia}$ spinuli flora.

squarrosa, Michx. Fl. Bor. Am. i. 273.-Am. bor.

stellarioides, Pers. Syn. i. $503=$ austriaca

stellarioides, Willd. ex Schlecht. in Ges. Naturf. Fr.

Berl. Mag. vii. (1813) 209.-Caucas

stenocarpa, Phil. Fl. Atac. 10.-Chili.

stenopetala, Turcz. Cat. Baikal. n. 257, in Bull. Soc

Nat. Mosc. (1838) $89=$ arctica.

stenophylla, Ledeb. Ind. Hort. Dorp.; Fl. Alt. ii. 165 = graminifolia

Steveniana, Boiss. Fl. Orient. i. 692.-Armenia.

stolonifera, Vill. ex DC. Prod. i. $404=$ grandiflora.

Stracheyi, Edgew. in Hook. f. Fl. Brit. Ind. i. 240.Tibet.

striata, Linn. Cent. ii. $17=$ capillacea, cephaelotes,

laricifolia, recurva, saxatilis, verna.

striata, Vill. Hist. Pl. Dauph. iv. 630. t. 47.-Gallia.

stricta, Michx. Fl. Eor. Am. i. 274--Am, bor.

stygia, Boiss. \& Heldr. Diagn. Ser. II. i. $91=$ cretica.

subulata, Ser. in DC. Prod. i. 403.-Sibir.

subulifolia, Pres1, Fl. Sicul, 162=mucronata.

succulenta, Ser. in DC. Prod. i. $400=$ Polycarpon succulentum.

sulcata, Schlecht. in Ges. Naturf. Fr. Berl. Mag. vii (1813) $212=$ hirta

Szowitsii, Boiss. Fl. Orient. i. 695.-Reg. Caucas.

tenella, Kit. in Schult. Oestr. Fl. ed. II. i. 662.-

Hungar.

tenella, Nutt. ex Torr. E Gray, Fl. N. Am. i. 179 - Am. bor.

tenella, Turcz. ex Stend. Nom. ed. II. i. $127=$ stricta.

tenera, Edgew. in Hook. f. Fl. Brit. Ind. i. 242.-Reg.

Himal.

tenuiflora, Schrad. ex Steud. Nom, ed. II. i, 12t--

Hab. ?

tenuitolia, Linn. Sp. Pl. 424.-Europ.

tenuis, F. Gay, in Walp. Ann. vii. 300,-Hispan.

teres, Kit. ex Steud. Nom. ed. I. $67=$ setacea.

teretifolia, Phil. Fl. Atac. 10,-Chili.

tetragyna, Willd. ex Schlecht. Ges. Naturf. Fr. Berl.

Mag. vii. (1813) 201.-Am, austr.

tetraquetra, Linn. Sp.Pl. 423.-Gallia.

tetrasticha, Boiss. Diagn. Ser. I. i. 50.-Persia.

thesiifolia, Froel. ex Reichb. Ic. Fl. Germ. v. t. 219.-

Alp. Algoviae.

thymifolia, Pursh, F1. Am. Sept. i. $817=$ Stellaria

humifusa.

thymifolia, Sibth. \& Sm. Fl. Graec. Prod. i. 304.-

Creta.

tmolea, Boiss. Diagn. Ser. I. i. 50.-As. Min.

tomentosa, Willk. in Linnaea, xxv. (1852) 15.-Hispan.

tremula, Boiss. Diagn. Ser. I. viii. 101-Syria.

triandra, Schrank, Hort. Monac. t. 31 = mucronata.

\section{ARENARIA}

richocalycina, Tenore Es Guss ex Boiss Fl Orient. 681.-Graccia.

trichotoma, Boiss. Diagn. Ser. II, v. $60=$ Ledebouriana

tríchotoma, Royle, ex Hook. f. Fl. Brit. Ind. i. 235.Reg. Himal.

triflora, Linn. Mant. $240=$ grandiflora.

triflora, Vill. Prosp. $48=$ Villarsii.

trinervia, Linn. Sp. Pl. 423.-Europ.

tschuktschorum, Regel, in Bull. Soc. Nat. Mosc. xxxy. 1862) 1.254.-Sibir.

ucranica, 'Spreng. in Ersch.' sec. Steud. Nom. ed. II. $124,127=$ yraminifolia

uliginosa, Schleich. ex Schlecht in Ges. Naturf. Fr. Berl. Mag. vii. (1813) $207=$ stricta.

umbellata, [Clairv.] Man. Herb. 149=Holosteum umbellatum

umbellata, Sibth. \& Sim. Fl. Graec. v. $28=$ Holostcum tenerrimum.

umbellata, [Soland, in] Russell, Aleppo, ed. II. ii. 252. -As. Min.

umbrosa, Bunge, in Ledeb. Fl. Alt. ii. 173.-Sibir. alt.

unifora, Luce, Topog. Nachr. Oesel, 141.-Ins. Ossil.

uniflora, Poir. Encyc. vi. $375=$ recurva.

unilateralis, Steud. Nom. ed. II. i. $12 \pi$ = segetalis.

uralensis, Pall. ex Spreng. Syst. ii. 396. - Sibir. ural.

varia, Dulac, Fl. Hautes-l'yr. $249=$ serpyllufolia.

valentina, Boiss. Diagn. Ser. II. i. 90.-Europ.

verna, Georgi, Beschr. Kuss. Reich. iii. IV. $979=$ setacea.

verna, Hort. ex Vilm. F1. Pl. Terre, ed. I. $756^{\circ}=$ Sagina subulata.

verna, Linn. Mant. 72.-Europ.; Am, bor.

verticillata, Willd. Sp. $\mathrm{Pi}$. ii. $725=$ Acanthophyllum verticillatum

Villarsii, Balb. ex Schlecht. in Ges. Naturf. Fir. Berl. Mag. vii. (1813) 199. - Europ. med.

villosa, Ledeb. in Mém. Acad. Pétersb. v. (1812) 534. -Sibir. or.

villosa, Wulf. in Jacq. Coll. iv. $319=$ Wulfenii.

violacea, Ledeb. in Mém. Acad. Pétersb. v. (1812) j33. - Silir.

viscida, Loisel. Not. $68=$ serpyllifolia.

viscidula, Thuill. Fl. Par. i. $219=$ tenuifolia.

viscosa, Fisch. ex Ser. in DC. Prod, i, 403 = subulata.

viscosa, Pers. Syn. i. $504=$ tenuifolia

viscosa, Pourr. ex Webb \& Berth. Phyt Canar. i. 14' $=$ procumbens.

vulcanorum, Maxim. in Franch. E Sav. Enum. Pl.

fap. i. 52.-Japon.

vulgaris, Bernt. Syst. Verz. Erf. $259=-$ Stellaria media.

Wallichiana, Ser. in DC. Prod. i. $411=$ serpylli. folia.

Wulferii, Steud. Nom. ed. II. i. 128.-Alp. Carniol.

ARENBERGIA, Mart. \& Gal. in Bull. Acad. Brox. xi. I. (1844) $373=$ Eustoma, Salisb. (Gentian.).

glauca, Mart. \& Gal. 1. c. $374=\mathrm{E}$. exaltatum.

ARENGA, Labill. in Mém. Inst. Par. iv. (1801) 209 PALMAE, Benth. \& Hook. f, iii. 917.

Gomutus, Correa, in Ann. Mus. I'ar. ix. (150" 28

t. 24. f. 1

SAguerus, Adans. Fam. ii. 24 (1763).

Griffithi, Seem. ex H. Wendl. in Kerch. Palm. $232=$ saccharifera.

jaranica, Hort. ex H. Wendl. l.c.-Java.

obtusifolia, Mart. Hist. Nat. Palm. 191. Ł. 147, 14sInd. or. : Malaya.

saccharifera, Labill in Mćm. Inst. Par. iv. 1801) ?(04. -Malaya.

Westerhoutii, Griff. in Calc. Joum. Nat. Hist.

(1845) $474=$ obtusifolia.

Wightii, Griff. 1. c. $\$ 75$.-Ind. or

ARETHUSA, Gronov, Fl, Virg, 1st $(17+\$), O R=$ CHIDEAE, Benth. \& Hook, fo iii. 114

CRYBE, Lindl. Introd. Aat. Syst. cd. II. $146^{\circ} 1530^{\circ}$

EpIPACTIS, Adans, Fam, ii. 70 (1703

Orchidros, Mfitchell, in Act. Nat. Cur. viii. lits 218 , App.

alaris, Raeusch. Nom, ed. III. 26:-2 ['tervigodium catholicum.

alata, Poir. Encye. Suppl. i. $\$ 43=$ Pterestylis praceox. bengalensis, Herb. (alc. ex Hemsl, in Joura. Linn. Sa $x x .(1+81) 311=1$ ) idynuplexis pallens.

biplumata, Linn. f. supfl. 405 - lijpinnala bonaricnsis. bulbosa, Linn. Sp. Pl. 950.-Am. bor. 


\section{ARETHUSA}

A

$111=$ Disperis capensis

catenata, Sm. Exot. Bot. ii. $89=$ Caladenia carnea.

ciliaris, Linn. f. Suppl. $405=$ Bartholina pectinata.

cordata, Poir. Encyc. Suppl, i. $444=$ Disperis cordata.

crispa, Thunb. Prod. Pl. Cap. $3=$ Corycium crispum.

cucullata, Poir. Encyc. Suppl. i. $444=$ Disperis cucullata.

divaricata, Linn. Sp. Pl. 951 = Pogonia divaricata

ecristata, Griff. Notul. iii. $378=$ Didymoplexis pallens foliosa, Walt. Fl. Carol. 222.-Am. bor.

gentianoides, Sw. Fl. Ind. Occ. iii. $1436=$ Pogonia gentianoides.

glutinosa, Blanco, Fl. Filip. ed. I. $641=$ Geodorum semicristatum

japonica, A. Gray, in Mem. Am. Acad. N. S. vi (1858-9) 409.-Japon.

Iutea, Gaudich. in Ann. Sc. Nat. Sér. I. v. (1825) 101 = Chloraea Gaudichandii.

medeoloides, Pursh, F1. Am. Sept. ii. 591=Pogonia verticillata.

ophioglossoides, Linn. Sp. P1. 951=Pogonia ophio glossoides.

parviflora, Michx. Fl. Am. Bor. ii. 160=Pogonia pendula.

pendula, Willd. Sp. P1. iv. $82=$ Pogonia pendula.

petraea, Pers. Syn. ii. 512.-Afr. trop.

picta, Anders. in Trans. Soc. Arts, xxv. (1807) $199=$ Spiranthes picta.

plicata, Andr. Bot. Rep. v. $321=$ Pogonia plicata.

racemosa, Walt. F1. Carol. $222=$ Ponthieva glandulosa rosea, Benth. in Fourn. Linn. Soc. xviii. (1881) 348. Mexic.

secunda, Thunb. Prod. Pl. Cap. $3=$ Disperis secunda

simplex, Thou, Orch. Afr:t. $24=$ Pogonia Thoursii

spicata, Walt. F1. Carol. 222=Aplectrum hyemale

tigridiaefolia, La Llave E" Lex. Nov. Veg. Desc. fasc. ii. (Orch. Opusc.) 14.-Mexic.

trianthophoros, Sw. in Vet. Akad. Nya Handl. Stockh. (1800) $230=$ Pogonia pendula

verticillata, Muehl. ex Willd. Sp. Pl. iv. $81=$ Pogonia verticillata.

villosa, Linn. f. Suppl. $405=$ Disperis villosa.

ARETIA, Hall, Enum. Stirp. Helv, ii. 485 (1742) Linn. Sp. Pl. ed. I. 141 (1753) = Androsace, Linn (Primul.).

alba, Rafin. Fl. Ludov. $31=$ Andr. alha.

alpina, Linn. Sp. Pl, 141=Andr. alpina

alpina, Wulf. in Jacq. F1. Austr. $36=$ Andr. hedreantha.

argentea, Gaertn. f. Fruct. iii. $107=$ Andr. imbricata.

baldensis, Turra, F1. Ita1. Prod. 63.-Italia.

brevis, Hegetschw. Fl. Schw. $190=$ Andr. alpina

brutia, Nym. Consp. $607=$ Andr. hedreantha.

bryoides, Loisel. Fi. Gall. ed. I. $111=$ Andr. bryoides.

cana, Willd. ex Steud. Nom. ed. II. i. 129, $527=$ Draba aretioides.

Charpentieri, Heer, in Hegetschw. F1. Schw. $987=$ Andr. imbricata.

ciliata, Loisel. F1. Gall. ed. I. $112=$ Andr. alpina.

cylindrica, Loisel. 1. c. $111=$ Andr. cylindrica.

glacialis, Schleich. Cat. Pl. Helv. ed. IV. $8=$ Andr alpina.

Halleri, Linn. Sp. P1. ed. II. 204, in syn.=Andr.

Hausmanni, Nym. Consp. $607=$ Andr. Hausmanni.

hedraeantha, Nym. 1. c. = Andr. hedreantha.

Heeri, Hegetschw. Fl. Schw. $188=$ Andr. Haus manni

helvetica, Georgi, Beschreib. Rusș. Reich. iii. IV. 760 $=$ Andr. villosa.

helvetica, Murr. Syst. ed. XIII. $162=$ Andr. bryoides.

hirtella, Nym. Consp, $607=$ Andr. alpina.

longiflora, Fisch. ex A. DC. in DC. Prod. viii. $668=$ Dionysia odora.

multiflora, Vand. Fasc. P1. 8.-Lusit,?

pennina, Murith, Bot. Val. $53=$ Andr, alpina.

pubescens, Loisel. F1. Gall. ed. I. $111=$ Andr. alpina.

pyrenaica, Loisel. 1. c. = Andr. pyrenaica.

rubra, Schleich. ex Steud. Nom. ed. II. i. $128=$ Andr hedreantha.

tomentosa, Schleich. Cat. Pl. Helv. ed. III. 8 = Andr.

imbricata, bryoides.

Vandeli, Turra, F1. Ital. Prod.63.-Italia
ARETIA :-

Vitaliana, Murr. Syst. ed. XIII. $162=$ Douglasia Vitaliana.

Wulfeniana, Sieber, ex Nym. Consp. $607=$ Andr hedreantha.

ARETIA, Link, Handb. ii. 411 (1829)= Primula, Linn auriculata, Link, 1. c. = P. Auricula,

carniolica, Link, 1. c. $412=\mathrm{P}$, carniolica

ciliata, Link, $1 . c_{。}=P$. ciliata

crenata, Link, 1. c. $411=\mathrm{P}$. marginata?

Floerkeana, Link, 1. c. $413=\mathrm{P}$. Hloerkeana

glaucescens, Link, 1. c. $412=\mathrm{P}$. calycina.

glutinosa, Link, l. c. $413=\mathrm{P}$. glutinosa.

integrifolia, Link, 1. c. $412=\mathrm{P}$. integrifolia

minima, Link, 1, c. $413=$ P. minima.

Palinuri, Link, 1. c. $411=$ P. Palinuri.

spectabilis, Link, 1. c. $412=$ P. spectabilis.

truncata, Link, 1. c. $413=$ P. minima.

villosa, Link, 1. c. $411=\mathrm{P}$, villosa

ARETIASTRUM, Spach, Hist. Vég. Phan. x. 304 (1841) =Valeriana, Linn

ARGAN, Dryand. in Trans. Linn. Soc. ii. (1794) $225=$ seq.

ARGANIA, Roem. \& Schult. Syst. iv. 46 (1819), SAPOTACEAE, Benth. \& Hook. f. ii. 655 .

VERLANGIA, Neck. Elem. ii. 125 (1790); Rafin. Sylva Tellur. 33 (1838)

Sideroxylon, Roem. ES Schult. l. c. 502.-Marocco.

ARGELASIA, Fourr. in Ann. Soc. Linn. Lyon, N. S. xvi. (1868) $357=$ Genista, Tourn. (Legum.)

corsica; Fourr. $1 . c_{0}=\mathrm{G}$. corsica.

Scorpius, Fourr. 1. c. = G. Scorpius.

ARGELIA, Decne in Ann. Sc. Nat, Sér. II. ix. (1838) 331. t. 11, G=Solenostemma, Hayne (Asclep.). Delilii, Decne. 1. c. $=$ S. Argel.

ARGEMONE, Tourn. ex Linn. Syst. ed. I. (1735). PAPAVERACEAE, Benth. \& Hook. f. i. 52. Echrrus, Lour. Fl. Cochinch. 344 (1790) alba, Lestib. Bot. Belg. ed. II. iii. II. 133 (=seq. ?) alba, Rafin. Fl. Ludov, $83=$ mexicana. albiflora, Hornem. Hort. Hafn. $469=$ mexicana. armeniaca, Linn. Sp. Pl. $509=$ Papaver armeniacum. Barclayana, Penny, ex Loud. Gard. Mag. vi. (1830) 11 - Mexic.

cambrica, Desf. in Dict. Sc. Nat. ii. $481=$ Meconopsis cambrica.

fruticosa, Thurber, ex A. Gray, in Mem. Am. Acad. N. S. v. (1855)(Pl. Nov. Thurb.) 306.-Mexic. Georgiana, Croom, in Am. Journ. Sc. Ser, I. xxv. 1834) $75=$ mexicana

grandiflora, Sweet, Brit. Flow. Gard. ini. t. $226^{\circ}=$ mexicana.

hispida, A. Gray, Pl. Fendl. 5.-Am. bor.

Hunnemanni, Otto, in Otto \& Dietr. Allg. Gartenz. (1833) $298=$ Hunnemannia fumariaefolia? intermedia, Sweet, Hort. Brit. ed. II. $585=$ Barclayana. mexicana, Linn. Sp. Pl. 508.-Am. bor.; Mexic. mucronata, Dum.-Cours, ex Steud. Nom, ed. II. i. 12 $=$ mexicana

munita, Dur. \& Hilg. in Journ. Acad. Nat. Sc. Philad. Ser. II. iii. $(1855) 37=$ hispida.

ochroleuca, Sweet, Brit. Fl. Gard. iii. t. 242.-Mexic. platyceras, Link Eo Otto, Ic. ii. 43.--Mexic

pyrenaica, Linn. Sp. PI, $509=$ Papaver pyrenaicum.

rosea, Hook. Bot. Misc. ii. (1831) 207.-Chili sexvalvis, Stokes, Bot. Mat. Med. iii. $195=$ mexicana. spinosa, Moench, Meth. $227=$ mexicana.

sulphurea, Sweet, ex Loud. Hort. Brit. $216 \Rightarrow$ ochroleuca.

versicolor, Salisb. Prod. $376=$ mexicana

ARGENOPE, Salisb. Gen. P1. Frag. $102(1866)=$ Narcissus, Linn. (Amaryll.).

serotina, Salisb. 1. c. $=\mathrm{N}$. serotinus.

ARGENTINA, Lam. Fl. Fr. iii. $118(17$ ( 8$)=$ Poten tilla, Tourn. (Rosac.)

rubra, Lam. 1. c. $120=$ P. palustris.

rupestris, Lam. 1. c. $=$ P. rupestris

supina, Lam. 1. c. $119=$ P. supina

vulgaris, Lam. 1. c. $=\mathrm{P}$. Anserina.
ARGITHAMNIA, Sw. Prod. Veg. Ind. Occ. 39

(1788), emend, in ej. Fl. i. 335 (1797), EUPHOR

BIACEAE, Benth. \& Hook, f, iii. 303.

Aphora, Nutt. in Trans. Am. Phil. Soc. Ser. II. v. 174 (1837)

Argothamnia, Spreng. Syst. iii. 847 (1826).

Argyrothaminia, Muell. Arg. in Linnaea, xxxiv, (1865) 65.

Argythamnia, P. Br. Hist. Jamaic. 338 (1756)

Chiropetalum, A. Juss. in Ann. Sc. Nat. Sér. I. XXV. (1832) 21

Chlorocaulon, Klotzsch, in Endl. Gen. Suppl. iv. III, 89 (1847).

Desfontaena, Vell. F1. Flum. 95 (1825).

Ditaxis, A. Juss. Euph. Tent. 27. t. 7 (1824)

Philyra, Klotzsch, in Wiegm. Archiv, vii. (1841) 199.

Serophyton, Benth. Bot. Voy. Sulph. 52 (1844).

Stenonia, Didrichs, in Kjoeb. Vidensk. Meddel. (1857) 146.

adenophora, A. Gray, in Proc. Am. Acad. viii. (1870 294.-Mexic.

anisotricha, Muell. Arg. in Mart. Fl. Bras, xi. Ir. 314.-Bras

aphoroides, Muell. Arg. in Linnaea, xxxiv. (1865-b6)

146. - Texas.

Berteroana, Muell. Arg. l. c. 151.-Chili.

boliviensis, Muell. Aro, l. c. 149,-Chili.

brasiliensis, Muell. Arg. l. c. 144.-Bras.

breviramea, Muell. Arg. l. c. 146.-Bolivia

calycina, Muell. Arg. in Flora, lv. (1872) 10.-Ind.

candicans, Sw. Prod. Veg. Ind. Occ. 39.-Ind occ.

canescens, Phil.f. Cat. Pl. Vasc. Chil. 262.-Chili.

cantonensis, Hance, in Fourn. Bot. xvi. (1878) 14.China.

catamarcensis, Hieron. in Bull. Acad. Nac. Cordova, iv. (1881) 449.--Reg. Argent.

desertorum, Muell. Arg. in Mart. Fl. Bras. xi. II 310.-Bras.

dioica, Muell. Arg. in Linnaea, xxxiv. (1865-66) 145. -Bras.

fasciculata, Muell. Arg. l.c. 146.-Ind. occ.

Fendleri, Muell. Arg. l. c. 145.-Venezuela.

foliosa, Muell. Arg. l. c. 150.-Bras.

Gardneri, Muell. Arg. in Mart. Fl. Bras. xi. I1. 310 -Bras.

guatemalensis, Muell. Arg. in Linnaea, xxxiv. (186566) 145 .-Mexic.

gymnadenia, Muell. Arg. in Mart. Fl. Bras. xi. II. 316.-Bras.

herbacea, Spreng. Syst. iii. 848.-Am. bor.

heterantha, Muell. Arg, in DC. Prod. xv. II. 735.Mexic.

humilis, Muell. Aro. in Linnaea, xxxiv. (1865-66) 147.-Mexic

illimaniensis, Muell. Arg. l. c. 146.-Mexic.

laevis, Muell. Arg. l. c. 147.-Mexic.

lanceolata, Muell. Arg. l. c. 148.-Calif.

lancifolia, Muell. Arg. l. c. 145--Ind. occ

lineata, Baill. Adansonia, iv. (1863-64) 288. Bras.

melochiaeflora, Muell. Arg. in DC. Prod. xv. II. 736 -Bras.

mercurialina, Muell. Arg. in Linnaea, xxxiv. (1865 -66) 148.-Texas.

mollis, Baill. Adansonia, iv. (1863-64) 289.-Bras.

montevidensis, Muell. Aro, in Linnaea, xxxiv. (1865

66) 147.-Reg. Argent.

neo-mexicana, Muell. Arg. l. c.-N. Mexic

pauciflora, Mirb. ex Steud. Nom. ed. II. i. 128.-Am austr.

Pavoniana, Muell. Arg. in Linnaea, xxxiv. (1865-66) 149.--Peruv.

pilosissima, Muell. Arg. l. c. 148.-Texas.

quinquecuspidata, Muell. Arg. l. c. 150.-Peruv.

Ruiziana, Muell. Arg. l. c. 151.-Peruv.

Schiedeana, Muell. Arg. l. c. 150.-Mexic.

sericea, Griseb. Fl. Brit. W. Ind. 44.-Ind. occ.

sericophylla, A. Gray, in Bot. Calif. ii. 70.-Calif serrata, Muell. Arg. in Linnaea, xxxiv. (1865-66) 147 - Calif.

Simoniana, Muell. Arg. l. c. 145.-Bras.

sponiella, Muell. Arg. l. c. 148.-Peruv.

tricocca, Muell. Arg. l. c. 150.-Bras.

tricuspidata, Muell. Arg. l. c.-Chili

tuberculata, Muell. Arg. l. c. 144.-China 
ARGOLASIA, Juss. Gen. $60(1789)=$ Lanaria, Ait. (Haemodor.). aurea, Pursh, F1. Am. Sept, i. 224, in syn.=Lophiola aurca

capensis, J. F. Gmel. Syst. ii. $560=$ L. plumosa lanata, Lam. ex Poir. Encyc. Suppl. i. $448=\mathrm{L}$. plumosa.

plumosa, Juss. Gen. ed. Usteri, $67=$ L. plumosa.

ARGOPHILUM, Blanco, Fl. Filip. 186 (1837)=Aglaia, Lour. (Meliac.).

pinnatum, Blanco, l.c. $186=$ Aglaia angustifolia

ARGOPHYLLUM, Blanco, Fl. Filip. p. $1 \times 18(1837)=$ praec.

ARGOPHYLLUIM, Forst Char. Gen. 29. t. 15 (1776). SAXIFRAGEAE, Benth, \& Hook, f. i. 646. ellipticum, Labill. Sert. Aust. Caled. 39. t. 41.N. Caled.

Lejourdani, F. Muell. Fragm. iv. 33.-Austral.

nitidum, Forst. Char. Gen. 30.-N. Caled.

sericeum, Poir. Encyc. Suppl. i. $449=$ nitidum.

ARGORIPS, Rafin. Alsog. Am. 13 (1838)=Salix, Tourn.

alba, Rafin. 1. c. $=$ S. alba

cerulea, Rafin. 1. c. $=\mathrm{S}$. alba.

ARGOSTEMMA, Wall. in Roxb. Fl. Ind. ed. Carey, ii. 324 (1824). RUBIACEAE, Benth. \& Hook. f. ii.

Pomangium, Reinw. in Syll, Ratisb, ii. (1828) 10. acutum, Wall, ex Hook, f. Fl. Brit. Ind, iii. 43 verticillatum

angustifolium, Miq. Fl. Ind. Bat. ii. 163.-Malaya. begoniaceum, Miq. l. c. 348.-Malaya.

borragineum, Blume, in DC. Prod. iv. 417.-Java.

calycinum, R. Br. ex Benn. PI. Jav. Rar. i, $97=$ Neurocalyx Wightii.

coenosciadicum, Suring. in Arch. Néerl. v. $(1870 ; 116$. - Java.

connatum, Dalz. in Hook. Kew Journ. iii. (1851) $345=$ courtallense.

courtallense, Arn. in Ann. Nat. Hist. ii. (1839) 22,Ind. or.

Elatostemma, Hook. f. Fl. Brit. Ind. iii. 45.Malaya

fulvum, Zoll. E Moritzi, Syst. Verz. Zoll. 61.-Java. glaberrimum, Dalz. in Hook. Kew Journ. iii. (1851) $345=$ verticillatum.

humile, Benn. Pl. Fav. Rar. i. 94.-Reg. Himal.

inaequale, Benn. $l$. c. 96 .-Sumatra.

inaequilaterum, Benn. l. c. 95.-Java.

Junghuhnii, Miq. Fl. Ind. Bat. ii. 164.--Malaya.

khasianum, C. B. Clarke, in Hook. f. Fl. Brit. Ind. iii. 43.-Reg. Himal.

Korthalsii, Miq. Fl. Ind. Bat. ii. 165.-Malaya.

Kurzii, C. B. Clarke, in Hook. f. Fl. Brit. Ind. iii. 45 -Burma.

laeve, Benn. Pl. Fav. Rar. i. 96.-Java.

laevigatum, Benn.l.c.-Java.

Lobbii, Hook. f. Fl. Brit. Ind. iii. 44.-Burma.

longifolium, Benn. Pl. Fav. Rar. 1. 97.-Sumatra.

macrosepalum, Mig. Fl. Ind. Bat. ii. 349.-Malaya

microcnide, Miq. l. c. Suppl. 539.-Sumatra.

montanum, Blume, in DC. Prod. iv. 418.-Java.

Neesianum, Walp. in Nov. Act. Nat. Cur. xix. Suppl.

i. (1843) [Pl. Moyen.] 349.--Ins. Philipp.

neurocalyx, Miq. Ann. Mus. Bot. Lugd. Bat. iv. 229.Malaya.

oligantha, Kurs, in Fourn. As. Soc. Beng. xlvi. (1877) II. 131. - Ins. Andam.

ophirense, Maing. ex Hook. f. Fl. Brit. Ind. iii. 45.Malaya.

Parishii, Hook. f. l. c. 44,-Burma.

parvifolium, Benn. Pl. Fav. Rar. i. 96.-Malaya.

pauciflorum, Blume, in DC. Prod. iv. 418.-Java.

pedunculosum, Miq. Fl. Ind. Bat. ii. 349.-Malaya.

pictum, Korth. in Neder. Kruid. Arch. ii. II. (1851)

122. - Sumatra.

pictum, Wall, in Roxb. Fl. Ind. ed. Carey, ii. 327.Penang.

pulchrum, Korth. in Neder. Kruid. Arch. ii. 11. (1851) 122.- Sumatra.

pumilum, Benn. Pl. Fav. Rar. 1. 95.,-Ind. or. ; Afr. trop. rostratum, Wall. in Roxb. Fl. Ind. ed. Carey, ii. 326 .

-Reg. Himal.

sarmentosum, Wall.l.c. \$24_-Reg. Himal.

\section{ARGOSTEMMA :}

soneriloides, Kurz, in fourn. As. Soc. Beng. xli. (1872) II. 310.-Ins. Andaman.

spinulosum, C. B. Clarke, in Hook. f. Fl. Brit. Ind. iii. 46.- Singapore.

subinaequale, Benn. Pl. Fav. Rar. i. 96.-Java.

tavoyanum, Wall. ex Benn.l.c. 94-Burma.

Teysmannianum, Miq. Fl. Ind. Bat. ii. 349.-Java. timorense, Benn. Pl. Fav. Rar, i. 95.-Timor. uniflorum, Blume, in DC. Prod. iv. 418.-Java. unifolium, Benn. Pl. Fav. Rar. i. 94.-Penang. unifolium, Kurz, in Journ. As. Soc. xlvi. (1877) II $131=$ Kurzii.

verticillatum, Wall'. Cat. n. 8394 partim $=$ khasianum verticillatum, Wall. in Roxb. Fl. Ind. ed. Carey, ii. 325.-Ind. or.

Wallichii, Walp. in Nov. Act. Nat. Cur, xix. Suppl. i. 350 (1843) [PI. Meyen.],-Ins. Philipp

ARGOTHAMNIA, Spreng. Syst. iii. 847 (1826)= Argithamnia, Sw. (Euphorb.)

ARGUZIA, Amm. ex Steud. Nom. ed. I. 68 (1821) Stev. in Bull. Soc. Nat. Mosc. (1851) I. $558=$ Tourne fortia, Linn. (Borag.)

cimmerica, Stev. 1. c. $560=$ T. sibirica.

Messerschmidia, Stev, 1. $\mathrm{c}_{\mathrm{o}}=\mathrm{T}$, sibirica

montana, Steud. Nom. ed. I. $68=$ T. Arguzia

repens, Rafin. Sylva Tellur. 167.--Sibir.

rosmarinifolia, Stev. in Bull. Soc. Nat. Mosc. (1851)

1. $559=$ T. sibirica

ARGYLIA, D. Don, in Edinb. Phil. Journ. ix. (1823) 260. BIGNONIACEAE, Benth. \& Hook. f. it 1043.

adscendens, $D C$. Prod. ix. 235.-Chili.

australis, Phil. in Anal. Univ. Chil. (1873) 512.Chili.

Bustillosii, Phil. in Linnaea, xxix. (1857-58) 13,Chili.

canescens, D. Don, in Edinb. Phil. Fourn. (Apr.-Fune 1829) 88.-Chili.

chrysantha, Phil. in Linnaea, xxxiii. (1864-65) 180.Chili.

eremophila, Phil. l. c.-Chili.

Feuillei, DC. Prod. ix. 235.-Chili

geranioides, $D C$. l. c.-Chili.

glabriuscula, Phil. in Linnaea, xxxiii.(1864-65) 179 -Chili.

glutinosa, Phil. Fl. Atac. 36.-Chili.

huidobriana, Clos, in C. Gay, Fl. Chil. iv, 411.Chili,

incana, Phil. Fl. Atac. 36.-Chili.

lutea, Phil. in Anal. Univ. Chil. (1873) 511,-Chili.

potentillaefolia, DC. Prod. ix. 235.-Chili.

puberula, $D C$. l. C.-Chili.

radiata, D. Don, in Edinb. Phil. Fourn, ix. (1823) 260 . -Peruv.

radiata, Endl. Ic. n. $4112=$ canescens.

tomentosa, Phil. Fl. Atac. 36.-Chili.

trifoliata, DC. Prod. ix. $237=$ uspallatensis.

uspallatensis, $D C$. l. c. 236.-Chili.

villosa, Phil. in Anal. Univ. Chil. (1873) 512.Chili.

viridis, Phil. in Linnaea, xxxiii. (1864-65) 181.-Chili.

ARGYRA, Noronha, ex Baill. Adansonia, i. (1860-61) $162=$ Croton, Linn. (Euphorb.).

fasciculata, Noronha, ex Baill. 1. c. =C. Noronhae

ARGYRANTHEMUM, Webb, ex Sch. Bip. in Webb \& Berth. Phyt. Canar. ii. $258(1836-50)=$ Chrysan themum, Linn. (Compos.)

anethifolium, Webb, 1. c. $265-267=\mathrm{C}$, anethifolium coronopifolizm, Webb 1. c. $272=\mathrm{C}$ coronopifolium. crithmifolium, C. Bolle, Ind. Sem. Hort. Berol. App. (1861) $5=\mathrm{C}$. anethifolium.

dissectum, Lowe, Man. FI. Mad. i. $464=$ C. dis sectum.

foeniculaceum, Webb, ex Sch. Bip, in Webb \& Berth.

Phyt. Canar, ii. $262=\mathrm{C}$, anethifolium.

frutescens, Sch. Bip. 1. c. $264=$ C. frutescens,

gracile, Sch. Bip. 1. c. $2 b^{\prime} 1=$ C. gracile.

haematomma, Lowe, Man. Fl, Mad. i. $463=\mathrm{C}$. haematomma.

jacobaeifolium, Webb, in Webb \& Berth. Phyt. Canar. ii. 251.-Ins. Canar.

ochrolencum, Webb, 1. c. $259=\mathrm{C}$, ochroleucum.

\section{ARGYRANTHEMUM:-}

pinnatifidum, Webb, in Webb \& Berth. Phyt. Canar ii. $269=\mathrm{C}$. pinnatifidum.

Webbii, Sch. Hip. in Webb \& Berth. 1. c. =C. Webbii.

ARGXRANTHUS, Neck. Elem, i。 $75(1790)=$ Helip terum, DC. (Compos.)

ARGYREIA, Lour. F1. Cochinch. 131 (1790) VOLVULACEAE, Benth. \& Hook. f. ii. 86?

ADAMBö́, Rafin. Fl. Tellur, iv, 73 (1836)

Argyreon, St. Lag. in Ann, Soc. Bot. Lyon, vii (1880) 120.

SAMUDRA, Rafin. Fl. Tellur iv, 72 (1836)

abyssinica, Choisy, in DC. Prod. ix. 332.-Abyss.

acuta, Benth. Fl. Hongk. 237 , in syn. = Champion

acnta, Lour. Fl. Cochinch. 135.-China; Ind. or.

aggregata, Arn. ex Choisy, Conv. Or. $45=$ Lettsomia aggregata.

alata, Montrous. in Mém. Acad. Lyon, x. (1860) 236. -N. Caled.

alulata, Miq. F1. Ind. Bat. ii. $587=$ Ipomoea Tur pethum.

ampla, Choisy, Conv. Or. $38=$ Roxburghii.

arborea, Lour. Fl. Cochinch. 135-China.

argentata, Miq. Fl. Ind. Bat. ii. 588.-Malnya.

argentea, Arn. ex Choisy, Conv. Or.36.-Ind. or.

barbigera, Choisy, 1. c. $42=$ Lettsomia barbigera.

Bona-nox, Sweet, Hort. Brit. ed. I. $289=$ Rivea hypocrateriformis.

bracteata, Choisy, Conv. Or. 39,-Ind. or.

capitata, Arn. ex Choisy, 1. c $41=$ Lettsomia strigosa.

capitata, Brand. For. Fl. $343=$ Lettsomia Thom soni.

capitata, Kurz, For. Fl. Burm. ii. $216=$ Lettsomia peguensis.

Championi, Benth. Fl. Hongk. $236=$ Lettsomia Cham pioni.

Choisyana, Regel EN Koern. in Ind. Sem. Hort. Petrop (1858) 40.-Hab.

Choisyana, Wight, ex Hook. fo in Fl. Brit. Ind. iv. 190.-Ind. or.

courtallensis, Wight, ex Choisy, in DC. Prod. ix. $329=$ malabarica.

cuneata, Ker-Gawl. in Bot. Reg. t. 661.-Ind. or.

cymosa, Sweet, Hort. Brit. ed. I. 289.-Ind. or. Malaya.

Daltoni, C. B. Clarke, in Hook. f. Fl. Brit. Ind. iv. 190.--Ind. or.

elliptica, Arn. ex Choisy, Conv. Or. 35=Lettsomia elliptica.

festiva, Wall. Pl. As. Rar. 68. t. 76.-China.

floribunda, Wall. ex Voigt, Hort. Suburb. Calc. 352, nomen.-Ind. or.

ulgens, Choisy, Conv. Or. 33.-Ind. or.

glabra, Choisy, ex Zoll. Syst. Verg. Ind. Archip, 128 , 130.-Malaya

Guichenotii, Choisy, Conv. Or. 41.-Malaya

hancorniaefolia, Gardn. ex Thw. Enum. Pl. Zeyl. 21 =Lettsomia hancomiaefolia.

hirsuta, Wight \& Arn. in Nov. Act. Nat. Cur. xriit.

(1836) I. $356^{\mathrm{c}}$ - - Ind, or.

Hookeri, C. B. Clarke, in Hook, f, Fl. Brit. Ind.iv.

185.-Reg. Himal.

involucrata, C. B. Clarke, l. c. 187.-Ind. or.

lanceolata, Choisy, Conv. Or.39.-Burma; Malaya. laurifolia, Voigt, Hort. Suburb. Calc. 351 =Lettomi. elliptica.

Lawii, C. B. Clarke, in Hook. f. Fl. Brit. Ind. ir. 190 Ind or.

Leschenaultii,

malabarica,

- Kegr. Argent.

mollis, Choisy,, Conv. Or. 3s. -Ind. or. ; Malaya. multiflora, Voigt, Hurt. Suburb. Calc. $35 \%=$ Rox burghii.

nelly'gherya, Choisy, Cons. Or. 32.-Ind. or.

nervosa, Boi. Hort, Wururit, 201.-Ins. Mascar.

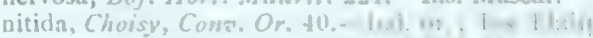
oblongra, Benth. But. lous. Soul .. ¿... Mt. obtectn, C. B. Clarke, in Book. f. Fl. Brib. Ind. iv. 1s: Burma; Malaya.

ubtusifulin, Lour. Fl. Cochinch. $185=$ obtects ormuti, Siscet. Hort. birit. ed. I. $20 y=$ kives ornata. 


\section{ARGYREIA :}

osyrensis, Choisy, in DC. Prod, ix, $334=$ Lettsomia aggregata.

pallida, Choisy, Conv. Or. 34.-Burma.

pilosa, Wight E Amn. in Nov. Act. Nat. Cur. xviii. (1836) I. $356^{\circ}$. - Ind. or.

pomacea, Choisy, Conv. Or.32.--Ind. or.

populifolia, Choisy, l. c.-Zeylan.

populifolia, Choisy, in DC. Prod. ix. $329=$ Hookeri.

Reinwardtiana, Miq. Fl. Ind. Bat. ii. 589.-Malaya.

Roxburghii, Arn. ex Choisy, Conv. Or. 37.-Ind. or

rubicunda, Choisy, 1. c. $44=$ Lettsomia rubicunda.

sericea, Dalz. Ë Gib. Bomb. Fl. 169.-Ind. or.

sericea, St. Lag. in Ann. Soc. Bot. Lyon, vii. (1880

$120=$ argentea

setosa, Arn. ex Choisy, Conv. Or. $43=$ Lettsomia setosa. speciosa, Boj. Hort. Maurit. 224.-Maurit.

speciosa, Sweet, Hort. Brit. ed. I. 289.-Ind. or.; Malaya.

splendens, Sreeet, l. c.-Ind, or.

tiliaefolia. Wight, Ic. iv. I. 12. t. 1358 (sphalm. tillaefolia). Ind. or.

tomentosa, Choisy, Conv. Or. 44.-Burma

uniflora, Sweet, Hort. Brit. ed. I. $289=$ Rivea hypo crateriformis.

venusta, Choisy, Conv. Or. $37=$ argentea

Wallichii, Choisy, $l$. $c .39$.- Ind. or

zeylanica, Kurz, For. F1. Brit. Burma, ii. 215, excl.

syn.= Lettsomia Kurzii.

zeylanica, Voigt, Hort. Suburb. Calc. $351=$ pomacea.

ARGYRELLA, Nand, in Ann. Sc. Nat. Sér. III. xiii. (1850) 300. t. 6=Dissotis, Benth. (Melast.). canescens, Harv. Gen. S. Afr. Pl. ed. II. 113=D. incana incana, Naud. in Ann. Sc. Nat. Sér. III. xiii. (1850 300. t. $6 . \mathrm{f} .7=\mathrm{D}$. incana.

phaeotricha, Nand. 1. $\mathrm{c}_{0}=$ D. phaeotricha.

ARGYREON, St. Lag. in Ann. Soc. Bot. Lyon, vii. 120 $(1880)=$ Argyreia, Lour. (Convolv.).

ARGYREXIAS, Rafin. F1. Tellur. iv. $86(1836)=$ Echium, Tourn. (Borag.).

candicans, Rafin, 1. c. $=\mathbf{E}$. candicans.

ARGYROCHAETA, Cav. Ic. iv. 54, t. $378(\mathbf{1 7 9 1})=$ Parthenium, Linn. (Compos.)

bipinnatifida, Cav. 1. c. $=$ P. Hysterophorum.

ARGYROCOMA, Rafin. New F1. Am. iv. 41 (1836)= Anychia, Rich. (Illecebr.).

imbricata, Rafin. 1. c. $43=$ Anychia dichotoma

ARGYROCOME, Gaertn. Fruct. ii. 410 (1791); Schrank, in Denkschr. Acad. Wiss. Muench. viii. (1824) $146 \mathrm{et}$ $163=$ Helipterum, DC. (Compos.)

apiculata, Cass, in Dict. Sc. Nat, xxxix, $40=$ Heli. chrysum apiculatum.

bracteata, Cass. 1. c. $=$ Helichrysum rutilans?

ericoides, Poir. Tabl. Encyc. ili. $270=$ Helichrysum ericoides.

ferruginea, Schrank, in Denkschr. Acad. Wiss. Muench. viii. (1824) $163=\mathrm{Helip}$. speciosissimum

imbricata, Buek, Ind. DC. Prod. ii. $15=$ Metalasia uniflora.

retorta, Cass. in Dict. Sc. Nat. xxxiv. $39=$ Helichrysum stoloniferum.

retorta, Gaertn. Fruct. ii. t. $167=$ Helichrysum retortum seminula, Schrank, in Denkschr. Acad. Wiss. Muench. viii. (1824) $164=$ Helip. speciosissimum.

semipapposum, Cass. in Dict. Sc. Nat. xxxix. $40=$ Helichrysum semipapposum.

Staehelina, Schrank, in Denkschr. Acad. Wiss. Muench. viii. (1824) $165=$ Helichrysum squamosum.

vermiculata, Poir. Tabl. Encyc, iii. $270=$ Metalasia uniflora.

vulnerata, Schrank, in Denkschr. Acad. Wiss. Muench. viii. $(1824) 164=\mathrm{H}$. canescens.

ARGYRODENDRON, Klotzsch, in Peters, Reise Mossamb. Bot. 100 (1861)=Croton, Linn. (Euphorb.). bicolor, Kloizsch, 1. c. $102=$ C. pulchellus.

ovatum, Boiv. ex Baill. Adansonia, i. (1861) $152=\mathrm{C}$. Bernieri.

Petersii, Klotzsch, in Peters, Reise Mossamb. Bot. i. 101 (=Combreti sp.),-Afr, trop.
ARGYRODENDRON, F. Muell. Fragm. i. $2(1858)=$ Tarrietia, Blume (Stercul.)

trifoliolatum, F. Muell. 1. c.=T. Argyrodendron.

ARGYROGLOTTIS, Turcz. in Bull. Soc. Nat. Mosc. xxiv (1851) Ir. $83=$ Helichrysum, Vaill. (Compos.).

turbinata, Turcz. 1. c. $81=$ H. Argyroglottis.

ARGYROLOBIUM, Eckl. '\& Zeyh. Enum. 184 (1835). LEGUMINOSAE, Benth. \& Hook. f. i. 480 Chamaecytisus, Vis. Fl. Dalm. 272. t. 55 (1850). Chasmone, E. Mey. Comm. Pl. Afr. Austr. 71 1836).

Diolotus, Tausch, in Filora, xxv. (1842) 284.

Gamochilum, Walp. in Linnaea, xiii. (1839) 509

Tephrothamnus, Sweet, Hort. Brit. ed. II. 126 (1830), nomen prius.

Trichasma, Walp. in Linnaea, xiii. (1839) 510. abyssinicum, Faub. E Spach, Illustr. i. 115.-Abyss. aequinoctiale, Welw. ex Baker, in Oliver, Fl. Trop. Afr. ii. 46.-Afr. trop.

Andrewsianum, Steud. Nom. ed. II. i. 129.-Afr. austr. angustifolium, Eckl. E Zeyh. Enum. 188.-Afr. austr. arabicum, Faub. E Spach, Illustr. i. 115; Boiss. Diagn.

Ser. I. ii. 13.-Arab.

argenteum, Eckl. E Zeyh. Enum. 184-Afr. austr.

argenteum, Willk. in Willk. \& Lange, Prod. Fl. Hisp. iii. $464=$ Linnaeanum.

ascendens, Walp. in Linnaea, xiii. (1839) 507.-Afr. austr.

baptisioides, Walp. l. c. 506.-Afr, austr.

barbatum, Walp. Rep. ii. 845.-Afr. austr.

biflorum, Eckl. E Zeyh. Enum. 186.-Afr. austr.

Bottae, Faub. E Spach, Illustr. 1. 115.-Arab.

calycinum, Ball, in Journ. Linn. Soc. xvi. (1878) 396 , in obs. = Linnaeanum.

calycinum, Faub. E Spach, Illustr. i. 115.-Dalmat.;

Reg. Cancas.; Persia.

candicans, Eckl. E Zeyh. Enum. 186.-Afr, austr.

collinum, Eckl. E Zeyh. l. c.-Afr. austr.

comanthum, Vog. ex Steud. Nom. ed. II. i. $129=$ baptisioides.

connatum, Harv. in Harv. E\% Sond. Fl. Cap. 72.-Afr. austr.

crassifolium, Eckl. E Zeyh. Enum. 184.-Afr. austr,

crinitum, Walp.in Linnaea, xiii. (1839) 506.-Afr.austr. crotalarioides, Faub. E Spach, Illustr. i. 114, 116.Syria.

dasycarpum, Hochst. ex Baker, in Oliver, Fl. Trop. Afr. ii. $46=$ A. Schimperianum.

divaricatum, Jaub. \& Spach, Illustr. i. 116= flaccidum. dorycncides, Baker, in Oliver, Fl. Trop. Afr. ii. 45.Afr. trop.

emirnense, Baker, in fourn. Linn. Soc. xx. (1883) 125. -Madag.

fallax, Ball, in Journ. Bot. xi. (1873) $302=$ Linnaeanum. filiforme, Eckl. E Zeyh. Enum. 186.-Afr. austr. flaccidum, Faub. E Spach, Illustr. 1. 115.-Ind. or goodioides, Walp. Rep. ii. 845.-Afr, austr.

gracile, Fenzl, in Flora, xxvi. (1843) I. $394=$ crotalaroides.

grandiflorum, Boiss. E Reut. Pugill. Pl. Nov. (1852) 29. - Afr. bor.

incanum, Eck1. \& Zeyh. Enum. 185=crassifoliam.

involucratum, Harv, in Harv. E Sond. Fl. Cap. 75.Afr. austr.

Kotschyi, Boiss. Diagn. Ser. I. vi, 32.--Persia.

Krebsianum, Prest, Bot. Bemerk. 139.-Afr, austr.

lanceolatum, Eckl. Eo Zeyh. Enum. 186. -Afr. anstr.

Linnaeanum, Walp. in Linnaea, xiii. (1839) 508.-Reg Mediterr.

longifolium, Walp. Rep. ii. 844.-Afr. austr.

lotoides, Bunge, ex Trautv. in Act. Hort. Petrop. ii. (1873) 519.-Armenia.

lotoides, Harv. in Harv. E Sond. Fl. Cap. 595.-Afr. austr.

microphyllum, Ball, in Fourn. Bot. xi. (1873) 303.Marocco.

modestum, Hochst. in Flora, xxvii. (1844) I. $100=$ abyssinicum.

molle, Eckl. Ë Zeyh. Enum. 187.-Afr. austr.

obcordatum, Steud. Nom. ed. II, i. 130.-Afr. austr.

obovatum, Eckl. E Zeyh. Enum. 185.-Afr, austr.

obsoletum, Harv. in Hary. E' Sond. Fl. Cap. ii. 70 .

Afr. anstr.

ornithopodioides, Jaub. \& Spach, Illustr. i. $116=$

patens, Eckl. E Zeyh. Enum. 185.-Afr. austr.

\section{ARGYROLOBIUM}

pauciforum, Eckl. Ev Zeyh. Enum. 186.-Afr. austr. pedunculare, Benth. in Hook. Lond. Fourn. Bot. iii (1844) 348.-Madag.

petiolare, Steud. Nom. ed. II. i. 130.-Afr. austr. Petitianum, A. Rich. Tent. Fl. Abyss, i. 163.-Abyss. pilosum, Harv. in Harv. E Sond. Fl. Cap. 71.-Afr austr.

polyphyllum, Eckl. E Zeyh. Enum.184.-Afr. austr. prostratum, Boiss. Diagn. Ser. I. ii. 13.-Assyria. puimilum, Eckl. E Zeyh. Enum. 185.-Afr. austr. ramosissimum, Baker, in Oliver, Fl. Trop. Afr.ii. 46. -Afr. trop.

remotum, Hochst. ex A. Rich. Tent. Fl. Abyss. i. 162 - Abyss.

roseum, Faub. E Spach, Illustr. i. 116.-Persia; Beluchist.

rupestre, Walp. in Linnaea, xiii. (1839) 508.-.Afr. austr.

Saharae, Pomel, Nouv. Mat. Fl. Atl. 177.-Algeria.

Sandersoni, Harv. in Harv. E Sond. Fl. Cap. ii. 594.Afr. austr.

Schimperianum, Hochst. in Flora, xxvii. (1844) I. 100 - Afr. trop.

sericeum, Eckl. E\% Zeyh. Enum. 184.-Afr. austr.

sessilifolium, Fanka, in Oestr. Bot. Zeitschr, xxii. (1872) 175.-Turcia.

speciosum, Eckl. E Zeyh.Enum. 187.-Afr. austr

splendens, Walp. Rep. ii. 845.-Afr. austr.

stenophyllum, Boiss. Fl. Orient. ii. 32.-Afghan

stipulaceum, Ball, in Fourn. Bot. xi. (1873) 302.-

Marocco.

stipulaceum, Eckl. Eo Zeyh. Enum.187.-Afr. austr.

strictum, Steud. Nom. ed. II. i. 130.-Afr, austr.

Sutherlandi, Harv. in Harv. E' Sond. Fl. Cap. 594.Afr. austr.

syriacum, Boiss. Diagn. Ser. I. ii. $13=$ crotalarioides tenue, Walp. Rep. i. 632.-Afr. austr.

trigonelloides, Faub. E Spach, Illustr. i. 116, 118.Persia.

tuberosum, Eckl. E' Zeyh. Enum. 188.-Afr. anstr."

nmbeliatum, Vog. ex Steud. Nom. ed. II. i. 130.-Afr. austr.

unifforum, Harv. in Harv. E\% Sond. Fl. Cap. ii. 72.Afr. austr.

uniflorum, Faub. \& Spach, Illustr. i. 115.-Oriens.

velutinum, Eckl. E Zeyh. Enum.186.-Afr。austr

venustum, Eckl. Eo Zeyh. l.c. 185.-Afr. austr.

virgatum, Baker, in Oliver, Fl. Trop. Afr. ii. 46.--Afr. trop.

ARGYROPHANES, Schlecht. in Linnaea, xx. (1847 596 - Helichrysum, Vaill. (Compos.).

Behrii, Schlecht. 1. c. = H. Baxteri.

ARGYROPHYLLUM, Pohl, ex Baker, in Mart. F1. Bras vi. II. $150(1873)=$ Soaresia, Sch. Bip. (Compos.). ovali-ellipticum, Pohl, ex Baker, l. $\mathrm{c}_{0}=\mathrm{S}$, velutina.

ARGYROPHYTON, Hook. Comp. Bot. Mag. ii. (1836) $163=$ Argyroxiphium, DC. (Compos.). Douglasii, Hook. 1. c. = Argyroxiph. sandwicense.

ARGYROPSIS, M. Roem. Syn. Ensat. $125(1847)=$ Zephyranthes, Herb. (Amaryll.) candida, M. Roem. 1. c. = Z, candida.

ARGYRORCHIS, Blume, Orch. Archip. Ind. 120.t 31, 36 (1858). ORCHIDEAE, Benth. \& Hook. it. iii. 506 .

javanica, Blume, l. c.-Java.

ARGYROTHAMNIA, Muell. Arg. in Linnaea, xxxiv (1865) $144=$ Argithamnia, Sw. (Euphorb.).

ARGYROXIPHIUIM, DC. Prod. v. 668 ; et Mém. Comp. t. 8 (1836). COMPOSITAE, Benth. \& Hook f. ii. 393 .

Argyrophyton, Hook. Comp. Bot. Mag. ii. (1836, 163.

macrocephalum, A. Gray, in Proc. Am. Acad.ii. (1852) 160.-Ins. Sandvic.

sandwicense, DC. Prod. v. 668.-Ins. Sandvic.

ARGYTAMNIA, Duchesne, in Dict. Sc. Nat. iv. 98 $(1804)=$ Argithamnia, Sw. (Euphorb.).

ARGYTHAMNIA, P. Br. Hist. Jamaic. $338(\mathbf{1 7 5 6}$, sphalm. = Argithamnia, Sw. (Euphorb.). 
ARHYNCHIUM, Lindl \& Paxt Flow Gard, i. (185051) $142=$ Arachnanthe, Blume (Orchid.).

ARIA, Jacq. f. Cat. Hort. Vindob. (1826) ex Host, Fl Austr. ii. 7 (1831) = Pyrus, Linn. (Rosac.) alnifolia, Decne. in Nouv. Arch. Mus. Par. Sér. I. x. (1874) $166=\mathrm{P}$. alnifolia

alpina, M. J. Roem. Syn. iii. Rosif. $124=$ P. alpina. ambigua, Decne, in Nouv. Arch. Mus. Par. Sér. I. (1874) 165.-Hab. ?

arouta, M. J. Roem. Syn iii Rosif. $129=$ P intermedia betulaefolia, M. J. Roem. 1. c. $124=$ P. betulaefolia.

Chamaemespilus, Host, F1. Austr. ii. $8=$ P. Chamaemespilus.

crenata, Decne. in Nouv. Arch. Mus. Par, Sér. I. x. 1874) $162=\mathrm{P}$. crenata

cuspidata, M. J. Roem. Syn. iii. Rosifl. $125=$ P. cuspi data.

Decaisneana, Lavall. Arbor. Segrez. 61.-Hab. ?

decipiens, M. J. Roem. Syn. iii. Rosif. $129=$ P. rotundifolia.

edulis, Guimp. ex Lavall. Arbor. Segrez. $63=$ Decais-

neana.
edulis, M. J. Roem. Syn. iii. Rosifl. $124=$ P. edulis

flabellifolia, M. J. Roem. 1. c. 127 = Crataegus corym. bosa.

graeca, M. J. Roem. 1. c. $=$ P. Aria

Hostii, Carr. Rev. Hortic. (1877) $210=$ P. Hostii.

Hostii, Jacq. f. Cat. Hort. Vindob. (1826) ex Host, Fl. Austr, ii. $8=$ P. intermedia.

intermedia, Schur, Enum. Pl. Transs. $207=\mathrm{P}$. intermedia.

japonica, Decne. in Nouv. Arch. Mus. Par. Sér. I. x. 1874) $164=\mathrm{P}$. japonica.

kamaonensis, M. J. Roem. Syn, iii. Rosifl, $130=$ P. lanata.

kumaonensis, Decne. in Nouv. Arch. Mus. Par. Sér. I. x. (1874) $162=$ praec

lanata, Decne. 1. c. $163=$ P. lanata

latifolia, M. J. Roem. Syn. iii. Rosifl. $128=$ P. rotundifolia.

Mougeoti, Fourr. in Ann. Soc. Linn. Lyon, N. S, xvi. (1868) $378=$ P. Aria

nivea, Host, Fl. Austr. ii. $8=$ P. Aria

obtusata, M. J. Roem. Syn. iii. Rosifl. $125=$ P. obtusata.

rotundifolia, M. T. Roem. 1. c. $129=$ P. rotundifolia. scandica, M. J. Roem. 1. c. $127=$ P. intermedia semilobata, M. J. Roem. 1. c. $129=$ P. rotundifolia Szovitsii, Decne. in Nonv. Arch. Mus. Par. Sér. I. x. 1874) 165.-Hab, ?

tiliaefolia, Decne. 1. c, $166=\mathrm{P}$. alnifolia

vestita, M. J. Roem. Syn, iii. Rosifl. $125=$ P. vestita.

ARIETINUM, Beck, Bot. N. and Midl. U. St. 352 (1833) = Cypripedium, Linn. (Orchid.)

americanum, Beck, 1. c. $=$ C. Arietinum.

ARILLARIA, Kurz, in Journ. As. Soc, Beng. xlii. (1873) II. $70=$ Oxmosia, Jack (Legum.)

robusta, IKurz, 1. c. $71=0$, robusta.

AKILLASTRUM, Panch, ex Brongn. \& Gris, in Bull. Soc. Bot. Fr. xiv. (1867) $253=$ Spermolepis, Brongn. \& Gris (Myrtac.)

gummiferum, Panch. $\mathrm{l} . \mathrm{c}_{0}=\mathrm{S}$. gummiferum.

ARINEMIA, Rafin. Sylva Tellur. $49(1838)=$ Ilex Tourn.

lanceolata, Rafin. 1. c. =I. lanceolata.

ARIOCARPUS, Scheidw. in Bull. Acad. Brux. v. (1838) $491=$ Mammillaria, Haw. (Cactac.)

retusus, Scheidw. 1. c. 492 . t. $1=$ M. prismatica.

ARIODENDRON, Meissn. Gen. Comm. 301 ('1836-48'), sphalm. = AGRIODENDRON, Endl. = Aloë, Linn. (Liliac.).

ARIONA, Pers. Syn. i. $212(1805)=$ Arjona, Comm. (Sautal.).

ARIOPSIS, J. Grah. Cat. Bomb. Pl. 252 (1839), $A R O I D E A E$, Benth. \& Hook. f. iii. 973.

peltata, f. Grah. l. c.-Reg. Himal.

protanthera, N. E. Br. in Rep, Roy. Gard, Kew, (1877) $51=$ pcltala.
ARISACONTIS, Schott, in Bonplandia, v. (1857) 129. AROIDEAE? Benth. \& Hook. f. iii. 963. Chamissonis, Schott, l. co-Ins. Radack.

ARISAFMA, Mart, in Flora, xiv. (1831) II. 459 $A R O I D E A E$, Benth. \& Hook. f. iii. 965.

AMIDENA, Rafin. Fl. Tellur. iv. 15 (1836)

abbreviatum, Schott, in Oestr. Bot. Zeitschr. (1857) 382.-Reg. Himal.

affine, Schott, in Bonplandia, vii. (1859) $27=\mathrm{con}$ cinnum.

album, N. E. Br. in. Fourn. Linn. Soc. xviii. (1882) 247.-Siam.

alienatum, Schott, in Bonplandia, vii. (1859) $26=$ concinnum.

amplissimum, Blume, Rumphia, i. 110.-Janon.

amurense, Maxim. Prim. Fl. Amur. 264.-Keg. Amur angustatum, Franch. E' Sav. Enum. Pl. Fap. ii. 507.Japon.

atrormbens, Blume, Rumphia, i. 97.-Am. bor

Boscii, Blume, 1. c. $104=$ A. Dracontium.

Bottae, Schott, Prod. Aroid. 42.-Arabia.

brasitianum, Blume, Rumphia, i. $97=$ atrorubens,

caudatum, Engl.in DC. Monog. Phan, ii. 559.-Ind. or.

cochinchinense, Blume, Rumphia, i. $107=$ Pinella Wawrae.

commutatum, Schott, in Bonplandia, vii. (1859) $26=$ tortuosum.

concinnum, Schott, l. c. 27.-Reg. Himal,

consanguineum, Schott, 1. c. = erubescens.

cornutum, Schott, l. c.-Reg. Himal.

costatum, Mart. in Flora, xiv. (1831) II. 459.-Reg. Himal.

Cumingii, Schott, Syn. Aroid. 28.-Ins. Philipp. curvatum, Hook. Bot. Mag. t. $5931=$ tortuosum. curvatum, Kunth, Enum. Pl. iii. 20.-Reg. Himal. cuspidatum, Engl, in DC. Monog, Phan, ii. 536 . Penang.

decipiens, Schott, in Oestr. Bot. Zeitschr. (1857) 373. Java.

dolosum, Schott, in Bonplandia, vii. (1859) $26=$ inter medium.

Dracontium, Schott, Meletem, i. 17.-Am. bor.

echinatum, Schott, l. c.-Reg. Himal.

eminens, Schott, in Oestr. Bot. Zeitschr. (1857) $35 \%=$ speciosum.

enneaphyllum, Hochst. in A. Rich. Tent. Fl. Abyss. ii. 352.-Abyss.

erubescens, Schott, Meletem.i. 17.-Reg. Himal.

exile, Schott, in Bonplandia, vii. (1859) 26.- Reg Himal.

fallax, Schott, in Miq. Ann. Mus. Lugd. Bat. i. $123=$ filiforme.

filicaudatum, $N, E, B r$. in Fourn. Linn. Soc. xviii. (1882) 253.-Zeylan

filiforme, Blume, Rumphia, i. 102. t. 28.-Java.

fliforme, Thw. Enum. P1. Zeyl. $334=$ neglectum

fimbriatum, Mast. in Gard. Chron. (1884) II. 680. Ins. Philipp.

flavum, Schott, Prod. Aroid. 40.-Arabia.

Franchetianum, Enol. Bot. Fahrb. i. (1881) 487.Tibet.

fraternum, Schott, in Bonplandia, vii. (1859) $26=$ Leschenaultii.

galeatum, N.E. Br. in Gard. Chron. (1879) II. 102 -Reg. Himal.

gracile, Kunth, Enum. Pl, iii. $21=$ Typhonium gracile Griffithii, Schott, Syn. Aroid. 26.-Keg. Himal. hastatum, Blume, Rumphia, i. $96=$ atrorubens. helleborifolium, Schott, Syn. Aroid. $29=$ tortuosum. heptaphyllum, Blume, Rumphia, i. 109.-Ind. or. heterophyllum, Blume, l. c. $110=$ Thunbergii.

Hookerianum, Schott, in Oestr. Bot. Wochenbl. (1857) $334=$ Griffithit.

Hookeri, Schott, Gen. Aroid. 6. f. 11-19=Griffithii. Huegelii, Schott, Syn. Aroid. $27=$ Leschenaultii inclusum, N. E. Br. in Fourn. Linn. Soc. xviii. (1881) 249.-Java.

intermedium, Blume, Rumphia, i. 102.-Reg. Himal.

Jacquemontii, Blume, l. c. 95. - Reg. Himal.

japonicum, Blume, l. c. 106.-Japon.

laminatum, Benth. 11 . Hongk. $342=$ penicillatum.

laminatum, Blume, Rumphia, i. 95. t. 27.-China

latisectum, Blume, 1. c. $110=$ japonicum.

Leschenaultii, Blume, L c. 93.-Ind or.

lobatum, Engl. Bot. Gahtr. i. (1681) 487.-Tibet

Loureiri, Blume, Rumphia, i. 108=Pincllin tuberilera.

macrospatbum, Benth. Pl. Hartw. 52.-Mexic

\section{ARISAEMA}

macrourum, Kunth, Enum. Pl. iii. $644=$ Pinellia tuberifera

Makoyanum, Kunth, in Ind. Sem. Hort. Berol. (1845) $9=$ filiforme

mirabile, Schott, in Oestr. Bot. Zeitschr. (1857) 366 speciosum.

Murrayi, Hook. Bot. Mag. t. 4388 = Jacquemontii neglectum, Schott, in Bonplandia, vii. (1859) 26.Zeylan.

nepenthoides, Mart. in Schott, Meletem. i. 17.-Reg. I Iimal.

ochraceum, Schott, in Bonplandia, vii. (1859) 27.Reg. Himal.

ornatum, Miq. Fl. Ind. Bat. iii, 220.-Sumatra. papillosum, Steud. ex Schott, Prod, Aroid. $46=$ Lesche naultii.

penicillatum, N. E. Br. in Fourn. Linn. Sac, xviii (1881) 248. t. 5.- Hongkong.

pentaphyllum, Schott, Meletem. i. 17.-Ind. or.; China Plukenetii, Hlume, Rumphia, i. $110=$ A. Dracontium praecox, De Vriese, ex C. Koch, Allg. Gartenz. (1857 $8.5=$ ringens.

propinquum, Schott, in Oestr. Bot. Zeitschr. (1857 $333=$ intermedium.

pulchrum, N. E. Br. in fourn. Linn. Soc. xviii. (1881 252. t. 6.--Ind. or

pumilum, Blume, Rumphia, 1. $107=$ trilobatum.

Pythonium, Blume, 1. c. $168=$ Zomicarpa Pythonium

quinatum, Schott, Syn. Aroid. 28.-Am. bor.

ringens, Schott, Meletem, i. 17.-Japon.

Roxburghii, Kunth, Enum. P1. iii. 18=cuspidatum.

Schimperianum, Schott, in Bonplandia, vii. (1859) 27 -Abyss.

serotinum, Miq. ex Franch. \& Sav. Enum, Pl. Jap. ì.

4 = Sierotium.

serratum, Schott. Meletem. i. 17 = japonicum.

Sieboldii, De Vriese, ex C. Koch, Allg. Gartenz. (1857 85 = ringens.

Sierotium, Siebold, ex Regel, in Ind. Sem. Hort. Petrop. (1865) 44.-Japon.

sikokianum, Franch. E Sav. Enum. Pl. Fap. ii. 507 - Japon.

speciosum, Mart. in Schott, Meletem, i. 17.-Rer.

Himal.

Steudelii, Schott, in Bonplandia, vii. (1859) 26.Ind. or.

stictopodum, Miq. Fl. Ind. Bat. iii. $219=$ filiforme

Stracheyanum, Schott, in Oestr. Bot. Zeitschr. 1857) 333 - intermedium.

Tatarinowii, Schott, in Bonplandia, vii. (1859) 27. China.

Thunbergii, Blume, Rumphia, i. 105.-Japon.

tortuosum, Schott, Meletem, i. 17-Keg. Himal.

tortuosum, Steud, ex Engl, in DC. Monog. Phan. ii

$544=$ Steudelii.

tripartitum, Engl. l. c. 538.-Japon.

triphyllum, Schott, Meletem. i. 17.-Am. bor.

utile, Hook.f. ex Engl. in DC. Monog. Phan. ii. 53

- Reg. Himal.

verrucosum, Schott, in Oestr. Bot. Wochenbl. 155. 341.-Reg. Himal.

vituperatum, Schott, in Bonplandia, vii. (1859) $28=$ erubescens.

Wightii, Hook. f. Bot. Mag. t. 550\%=neglectum.

Wightii, Schott, in Bonplandia, vii. (185y) $20^{\circ}=$ Jacque montil.

sebrinum, Hort. ex Nichols. Dict. Gard. i. 112. = triphyllum.

ARISARON, Adans, Fam. ii. 470 (1763)=A Arisarum Tourn. (Aroid.)

ARISARUM, Hall. in Rupp. F1. Jea. ed. II. 251 1745 Calla, Rich. (Aroid.

ARISARUM, [Tourn.] Targ. Toz, in Anal. Mu. Fis. Fir. ii. 11. 1810) 67. AROIDEAE, Benth. A llook. f. iii. 165 .

Arisaron, Adans. Fam, ii. tio 1-63. Bammisa, Lrg, Gen. eq Sp, Nov, $17,1516^{\circ}$

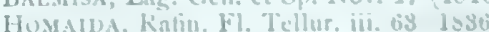

aspergillum, Dun, in Mcm. Acad. Montp. (Secl Sc. $18+7) 8$ simurrhinum.

australe, Kich. in Guill. Arch. i. (158\$ $20=v$ valgar asoricum. Scholt, in Oestr. Bot. Wochenbl. 1 $1250^{\circ}$ vulgare.

Balansare, Schote, 1. c. = vulgare

Clusii, Schot!, l'rod. Aroid. $23=$ vulgare. 


\section{ARISARUM :-}

crassifolium, Schott, in Bonplandia, ix. (1861) $369=$ vulgare.

Forbesii, Schott, in Oestr. Bot. Wochenbl. (1857) 190 $=$ vulgare.

hastatum, Pomel, Nouv. Mat. Fl. Atl. 390.-Algeria.

italicum, Rafin. FI. Tellar. iii. $63=$ Arum italicum.

Facquini, Schott, Prod. Aroid. $22=$ vulgare.

Libani, Schott, 1. c. 21 = vulgare.

maculatum, Rafin. Fl. Tellur. iii, 63=Arum maculatum oligocarpum, Pomel, Nouv. Mat. Fl. Atl. 390.Algeria.

ovatum, Rafin. F1. Tellur. iii. $63=$ Lagenandra toxicaria pictum, Rafin. 1. c. = Arum pictum.

proboscicum, Savi, Osserv. Div. Piante, 6.-Italia.

serpentrium, Rafin. F1. Tellur. iii. $63=$ Arisarum vulgare.

Sibthorpii, Schott, Prod. Aroid, $21=$ vulgare.

simorrhinum, Dur. in Duch. Rev. Bot. i. (1845-46) 360.-Algeria.

subalpinum, Kotschy, ex Engl. in DC. Monog. Phan. ii. $563=$ vulgare,

subexertum, Webb \& Berth. Phyt. Canar. iii. $293=$ vulgare.

tingitanum, Schott, Prod. Aroid. $22=$ vulgare.

Veslingii, Schott, 1. c. $20=$ vulgare.

vulgare, Targ. Toz. in Anal. Mus. Fis. Fir. ii. II. (1810) 67.-Reg. Mediterr.

ARISTAEA, A. Rich, in Orb. Dict. ii. $136(1842)=$ Aristea, Soland. (Irid.).

ARISTARIA, Jungh. in Hoev. \& De Vriese, Tijdschr vii. (1840) $296=$ Anthistiria, Linn. (Gramin.) barbata, Jungh. 1. c. $297=$ Anth. arguens.

ARISTEA, [Soland, in] Ait. Hort. Kew. i. 67 (1789) iii. 506. IRIDEAE, Benth. \& Hook. f. iii. 701. Cleanthe, Salisb. in Trans. Hort. Soc. i. (1812) CleAN 312 .

Genlisia, Reichb. Consp. 60 (1828)

Nivenia, Vent. Dec. Gen. Nov. 5 (1808).

WrEDOWra, Eckl. Verz. 16 (1827)

africana, Hoffmgg. Verz. Pf. 40.-Afr. trop.

alata, Baker, in fourn. Linn. Soc. xxi. (1885) 405.Afr, trop.

anceps, Eckl. ex Klatt, in Linnaea, xxxiv. (1865-66) 550.-Afr. austr.

angolensis, Baker, in Trans. Linn. Soc. Ser. II. i. (1878) 270 .-Afr. trop.

angustifolia, Baker, in Fourn. Linn. Soc. xx. (1884) 269.-Madag.

bracteata, Pers. Syn. 1. $41=$ capitata.

capitata, Ker-Gawl. in Bot. Mag. t. 605.-Afr. austr. cladocarpa, Baker, in Fourn. Linn. Soc. xx. (1884) 268.-Madag.

coerulea, Vahl, Enum. ii. $124=$ capitata

compressa, Buching. ex Baker, in Fourn. Linn. Soc xvi. (1878) 111.-Natal.

cyanea, [Soland. in] Ait. Hort. Kew. 1. 67.-Afr. austr. dichotoma, Eckl. ex Klatt, in Linnaea, xxxiv. (186566) $551=$ Eckloni.

dichotoma, Ker-Gawl. Gen. Irid. 13.-Afr. austr.

diffusa, Eckl. Verz. 16, nomen.-Afr. austr.

Eckloni, Baker, in Fourn. Linn. Soc. xvi. (1878) 112. -Afr. austr.

eriophora, Pers. Syn. i. $41=$ cyanea.

fruticosa, Pers. 1. C.-Afr. austr.

glauca, Klatt, in Abh. Naturf. Ges. Halle, xii. (1882) 381.-Afr. austr.

intermedia, Eckl. Verz. $16=$ dichotoma

juncifolia, Eckl. l.c. ; Baker, in Fourn. Bot. xiv. (1876) 267.-Afr, austr.

Kitchingii, Baker, in Fourn. Linn. Soc. xx. (1884) 269.-Madag.

lacera, Stokes, Bot. Comment. i. $224=$ cyanea.

lugens, Hort. ex Steud. Nom. ed. II. i. $130=$ melaleuca. madagascariensis, Baker, in fourn. Bot. xiv. (1876) 267.-Madag.

major, Andr. Bot. Rep.t. $160=$ capitata

melaleuca, Ker-Gawl. in Kon. E'Sims, Ann. Bot. i. 1805) 236. - Afr, austr.

pusilla, Ker-Gazol. l. c.-Afr. austr.

racemosa, Baker, in Fourn. Bot. xiv. (1876) 267.Afr. austr.

repens, A. Dietr. Sp. $P l$. ii. 516.-Afr. austr.

schizolaena, Harv.ex Baker, in Fourn. Bot. xiv. (1876) 267. -Afr. austr.

\section{ARISTEA}

spathacea, Spreng. Syst. i. 158 = Bobartia spathacea.

spicata, Pers. Syn. i. $41=$ capitata.

spiralis, Ker-Gawl.in Kon. \& Sims, Ann. Bot. i. (1805) 236.-Afr. austr.

torulosa, Klatt, in Abh. Natuvf. Ges. Halle, xii. (1882) 382.-Afr, austr.

umbellata, Spreng. Syst. i. 158.-Afr. austr.

Wredowia, Steud. Nom. ed. II. i. 130.-Afr, austr.

ARISTEGA, Miers, Contrib. Bot. iii. 375 (1871), MENISPERMACEAE.

laevifolia, Miers, $l . c .376$. t. 51.-Ind, or.

ARISTELLA, Bertol. Fl. Ital. i. 690 (1833)=Stipa, Linn. (Gram.).

bromoides, Bertol. 1. $\mathrm{c}_{0}=\mathrm{S}$. Aristella.

longiflora, Regel, in Act. Hort. Petrop. vii. (1880) 645.-As. temp.

ARISTIDA, Linn. Sp. P1. ed. I. 82 (1753). GRAMINEAE, Benth. \& Hook. f. iii. 1140.

Arthratherum, Beauv. Agtost. 32. t. 8. f. 8 (1812).

Chaetaria, Beanv. 1. c. 30. t. 8. f. 5, 6 (1812).

Curtopogon, Benuv, 1. c. 32, t. 8.f. 7 (1812)

Krelboul, Adans. Fam. ii. 31 (1763).

Moulinsia, Rafin. in Ser. Bull. Bot. i. (1830) 221

Ortachne, Nees, in Seem. Bot. Voy. Herald, 225 $(1852-57)$.

Schistachne, Figar. \& De Not. in Mem. Accad. Torin. Ser. II. xii. (1852) 252

Stipagrostis, Nees, in Linnaea, vii. 290 (1832)

Streptachne, H. B. \& K. Nov. Gen. et Sp. i. 124 t. $40(1815)$

Trixostis, Rafin. in Ser. Bull. Bot. i. (1830) 221. abyssinica, Trin. \& Rupr. in Mém. Acad. Pétersb. Sér.

VI. vii. (1849) $134=$ coerulescens.

acutifora, Trin. E Rupr. l. c. 167.-Aegypt. ; Arabia. adoënsis, Hochst. in A. Rich. Tent. Fl. Abyss. ii. 370 -Abyss.

Adscensionis, Linn. Sp. Pl. 82.--Reg. temp. et calid.

Adscensionis, Walt. Fl. Carol. 74 = oligantha

Adscensionis, Sw. Obs. $40=$ cognata.

aequiramea, Schlecht. in Linnaea, xxii. (1849) 343.Texas.

aethiopica, Trin. \& Rupr. in Mém. Acad. Pétersb. Sér.

VI. vii. (1849) $134=$ Adscensionis.

affinis, Kunth, Rev. Gram. i. $61=$ purpurascens.

americana, Linn. f. Pl. Jam. Pugill. 7 ; Syst. ed. X. $879=$ Bouteloua bromoides, juncifolia.

amplissima, Trin. Ẽ Rupr. in Mém. Acad. Pétersb. Sér.

VI. vii. 1849) 155.-Afr. trop.

Antillarum, Poir. Encyc. Suppl. i. 451--Ind. occ.

Antoniana, Steud. in Lechl. Berb. Am. Austr. 56 -Peruv.

arabica, Trin. \& Rupr. in Mém. Acad. Pétersb. Sér. VI. vii. (1849) $135=$ Adscensionis

arenaria, Gaudich. in Freyc. Voy. Bot. 407.-Austral. arundinacea, Limn, Mant. 146.-Ind. or.

avenaria, Trin. in Bull. Sc. Acad. Pétersb. i. (1836) 68 $=$ setifolia.

barbata, Fourn. Mex. Pl. Enum. Gram. 78, ex Hemsl. Biol. Centr. Am. Bot. iii. 532.-Mexic.

barbicollis, Trin. E Rupr. in Mém. Acad. Pétersb.

Sér. VI. vii. (1849) 152-Abyss.

basiramea, Vasey, in Coult. Bot. Gaz. ix. (1884) 76.Am. bor.

Behriana, F. Muell. in Trans. Vict. Inst. i. (1855) 44. - Austral.

Beyrichiana, Trin. Ev Rupr. in Mém: Acad. Pétersb. Sér. VI. vii. (1849) 104.-Am. centr.

bipartita, Steud. Syn. Pl. Gram. 140.-Afr. austr.

brachypoda, Tausch, in Flora, xix. (1836) 506.Aegypt.; Arabia.

brachyptera, Coss. E Bal. in Bull. Soc. Bot. Fr. v. 1858) 169.-Afr. bor.

brevifolia, Steud. Nom, ed. II. i. 130-Afr. austr.

breviseta, Buckl. in Proc. Ac. Sc. Philad. '1862' (1863) $92=$ purpurea

bromoides, $H$. B. E K. Nov. Gen. et $S p$. i. 122.-Am. bor. occ.; Ecuador.

bromoides, Salzm. ex Trin. \& Rupr. in Mém. Acad. Pétersb. Sér. VI. vii. (1849) $118=$ longifolia.

caffra, Bory, Voy. ii. 376.-Afr. trop.

californica, Thurb. ex Boland. in Trans. Calif. Agr. Soc. (1864) 134.-Calif.

\section{ARISTIDA :-}

caloptila, Boiss. Fl. Orient. v. $497=$ paradisea

calycina, R. Br. Prod. i. 173.-Austral.

canariensis, Willd. Enum. Hort. Berol. $99=$ Adscen sionis.

capensis, Savi, in Mem. Moden. (1837) $198=$ plumosa. capensis, Thunb, Prod. Pl. Cap. 19-Afr. austr

capillacea, Cav. Ic. v. 43. t. 468. f. 1 =Cumingiana.

capillacea, Lam. Illustr. i. 156.-Ind, or.; Am. austr.

capillaris, Kunth, Enum. PI. i, 188, in syn.= Cumingiana.

caudatum, Anderss. Enum. Pl. Ins. Galap. 144.-Ins. Galap.

chaetophylla, Steud. Syn. Pl. Gram. 420.-Madag

chapadersis, Trin. in Bull. Sc. Acad. Pétersb. i. (1836 68.-Bras.

chinensis, Munro, in Proc. Am. Acad. iv. (1864-65) 363.-China.

Chloris, Salzm. ex Doell, in Mart. Fl. Bras. ii. III. 83 = Gymnopogon foliosus.

chrysopila, Steud. Nom. ed. II. i. 131.-Arabia.

ciliata, Desf. in Schrad. N. Fourn. iii. (1809) 255.-

Afr. bor. austr. ; Arabia.

ciliata, Steud. \& Hochst. ex Steud. Nom. ed. II. i. 131 $=$ hirtigluma.

coarctata, H. B. \& K. Nov. Gen. et Sp. i. $122=$ seti folia.

coarctata, Lichtst. ex Kunth, Enum. Pl. i. 195=congesta.

coerulescens, Desf. F1. Atlant. i. $109=$ Adscensionis.

coerulescens, Sieber, ex Trin. in Mém. Acad. Pétersb. Sér. VI. i. (1831) $88=$ Sieberiana.

coerulescens, Hochst. ex Steud. Syn. P1. Gram. $13 y=$ adoënsis

cognata, Trin. \& Rupr. in Mém. Acad. Pétersb. Sèr VI. vii. (1849) $127=$ purpurascens, stricta.

compacta, Anderss. Enum. Pl. Ins. Galap. 145.-Ins. Galap.

complanata, Trin. in Mém. Acad. Pétersb. Sér. VI. i. 1831) $85 .-$ Bras

concinna, Sond. ex 7. A. Schmidt, Beitr. Fl. Cap. Verd. Ins. 140 - Afr. austr.

condensata, Chapm. in Coult. Bot. Gaz. iii. (1878) 19 - Am. bor.

congesta, Roem. EN Schult. Syst. 1i. 401.-Afr. austr. contorta, F. Muell, in Trans. Vict. Inst. i. (1855) $44=$ arenaria.

crinita, Steud. Nom. ed. II. i. 131=Stipa crinita

crinita, F. Presl, in Rel. Haenk. i. 223.-Peruy.

Cumingiana, Trin. E Rupr. in Mém. Acad. Pétersb.

Sér. VI. vii. (1849) 141.-Ins. Philipp.

curtiseta, A. Gray, in Proc. Acad. Sc. Philad. '1862' (1863) $334=$ purpurea

curvata, Nees, ex A. Rich. Tent. Fl. Abyss. ii. 392.Abyss.; Afr, austr.

curvifolia, Fourn. Mex. Pl. Enum. Gram. 78, ex Hemsl. Biol. Centr. Am. Bot. iii. 533.-Mexic.

cyanantha, Steud. Syn. Pl. Gram. 141.-Afghan.

decorata, Steud. l. c. 4.1.-Palaestin.

delicatula, Hochst. ex A. Rich. Tent. Fl. Abyss. ii. 393. -Abyss.

densispica, Steud. Syn. Pl. Gram. 139.-Afr. trop

depressa, Retz. Obs. iv. $22=$ Adscensionis.

depressa, Trin. Gram. Unifl. $175=$ setacea.

desmantha, Trin. E* Rupr. in Mém. Acad. Pétersb.

Sér. VI. vii. (1849) 109.-Texas

dichotoma, Michx. Fl. Bor. Am. i. 41.-Am. bor.

diffusa, Trin. in Bull. Sc. Acad. Pétersb. i. (1836) $68=$ vestita.

dispersa, Trin. E Rupr. in Mém. Acad. Pétersb. Sér. VI, vii. (1849) 129.-Mexic.

divaricata, Humb. Es Bonpl. ex Willd. Enum. Hort. Berol. 99.-Mexic.

divaricata, Jacq. Eclog. 7. t. $6=$ coerulescens

divaricata, Lag. Elench. $3=$ spadicea.

divnlsa, Anderss. Enum. Pl. Ins. Galap. 143.-Ins. Galap.

domingensis, Kunth, Rev. Gram. i. 62=Andropogon hirtiflorus

Dregeana, Trin. E Rupr. in Mém. Acad. Pétersb. Sér VI. vii. (1849) 169,-Afr. austr.

Ehrenbergii, Trin. EN Rupr. Stipac. 136.-Arabia.

elatior, Cav. Ic. vi. 65 . t. $589=$ Adscensionis.

elegans, Rudge, F1. Guian. 22. t. $30=$ capillace

Elliotiana, Steud. Syn. Pl. Gram. 133.-Carolina.

elliptica, Kunth, Enum. Pl. i. 193.-Bras. 
ARISTIDA :-

fasciculata, Torr. in Ann. Lyc. N. York, i. (1824) 154. -Canada.

Fendleriana, Steud. Syn. Pl. Gram, 420,-N. Mexic.

festucoides, Poir. Encyc. Suppl. 1. 453.-Afr, trop.

flipendula, Buckl. in Proc. Ac. Sc. Philad. '1862' (1863) $93=$ purpurea.

flaccida, Trin. Ë Rupr. in Mém. Acad. Pétersb. Sér, VI. vii. (1849) 117.-Bras.

flexnosa, Fourn. Mex. Pl. Enum. Gram. 77, ex Hemsl. Biol. Centr. Am. Bot. iii. 533.-Mexic.

floccosa, Coss. \& Dur. in Expl. Sc. Algér. i. $82=$ plumosa.

floridana, Vasey, Gram. U. St. 21.-Am. bor.

foenicularis, Edgew. in Fourn. As. Soc. Beng. xxi. (1852) 160,183 .- -Ind. or

Forskaehlei, Tausch, in Flora, xix. (1836) $506=$ plu mosa.

Freycinetii, Steud. Nom. ed. II. i. 131=Stipa crinita. funicularis, Trin. ex Steud. l. c.-Nubia.

funiculata, Trin. E Rupr. in Mém. Acad. Pétersb. Sér. VI. vii. (1849) 159.-Afr. bor.; Arab. ; Beluchist.

furcata, Poit. ex Roem. \& Schult. Syst. ii. $711=$ Boutelona bromoides.

Gardneriana, Stend. Syn. Pl. Gram. $137=$ setifolia.

geminata, Willd. ex Steud. Nom. ed. II. i. $131=$ Gymnopogon foliosa.

geminiflora, Fourn. Mex. Pl. Enum. Gram. 77, ex Hemsl. Biol. Centr. Am. Bot. 1ii. 533.-Mexic.

geminiflora, Steud. Syn. P1. Gram, $144=$ geminifolia.

geminifolia, Trin. E Rupr. in Mém. Acad. Pétersb.

Sér. VI. vii. (18t9) 169.-Afr. austr.

geniculata, Rafin. Am. Monthly Mag. (1817), ex

Trin. in Mèm. Acad. Pétersb. Sér. VI. vii. (1849) 179.-Am. bor.

Geyeriana, Steud. Syn. Pl. Gram. $133=$ purpurascens.

gibbosa, Kunth, Enum. Pl. i. 189.-Bras.

gigantea, Linn. f. Suppl. $113=$ Adscensionis

glaberrima, Steud. Syn. Pl. Gram. 135.-Chili.

glauca, Steud. 1. c. =longiramea.

gossypina, Bosc, ex Beauv. Agrost. 30, nomen ; Roem. Es Schult. Syst. ii. 391. - Carolina.

gracilis, Ell. Sketch, i. 141.-Am. bor.

gracillima, Oliver, in Trans. Linn. Soc. xxix. (1875)

173. - Afr. trop.

Grisebachiana, Fourn. Mex. Pl. Enum. Gram. 78, ex Hemsl. Biol. Centr. Am. Bot. iii. 533.-Mexic.

guineensis, Trin. E Rupr. in Mém. Acad. Pétersb. Sér. VI. vii. (1849) 137.-Guinea.

gyrans, Chapm. in Coult. Bot. Gaz. iii. (1878) 18.-Am.

bor.
Heymanni, Regel, in Act. Hort. Petrop. vii. (1880) 649. - As. centr.

hirtigluma, Steud. Nom. ed. II. i. 131 ; Trin. E Rupr. in Mém. Acad. Pétersb. Sér. VI. vii. (1849) 17]. Aegypt.; Syria; Arabia.

hordeacea, Hochst. ex Steud. Syn. Pl. Gram. 142=Steudeliana.

hordeacea, Kunth, Rev. Gram. ii, t. 173.-Afr, trop.

Humboldtiana, Trin. O Rupr. in Mém. Acad. Pétersb. Sér. VI. vii. (1849) 118.-Mexic.

humilis, H. B. $\xi^{K}$. Nov. Gen. et $S p$. i. 121.-Venezuela.

hygrometrica, R. Br. Prod. 174.-Austral.

Hystrix, Linn. $f$. Suppl. 113.-Afr. austr.

implexa, Trin. in Bull. Sc. Acad. Pétersb. i. (1836)68. liras.

interrupta, Cav. Ic. v. 45. t. 471, f. 2.-Mexic.

Jacquiniana, Tausch, in Flora, xix. (1836) 508.-Am austr.

jorullensis, Kunth, Rev. Gram. i. 62.-Mexico.

junciformis, Trin. E Rupr. in Mem. Acad. Pétersb. Sér. VI. vii (1849) 143.-Afr. austr.

Karwinskiana, Trin. E Rupr. l. c. 121.-Mexic.

Kotschyi, Hochst. ex Steud. Syn. Pl. Gram. $142=$ funiculata.

Kunthiana, Trin. E Rupr. in Mém. Acad. Pétersb. Sér. VI. v. (1849) 151.-Afr. trop.

laevis, Kunth, Enum. Pl. i. 192.-Bras.

Lamarckii, Steud. Nom. ed. I. $69=$ amplissima.

lanata, Forsk. Fl. Aegypt. Arab. $25=$ plumosa

lanata, Poir. Encyc. Suppl. i. 453-Am bor.

lanosa, Muhl. Descr. Uber. 174.-Am. bor.

lanuginosa, Bosc, ex Trin. in Mém. Acad. Pétersb. Sér. VI. iv. 1 . (1838) $46=$ stricta

laxa, Cav. Ic, v. 44, t. 470.-Ins. Philipp. ; Am. austr.

\section{ARISTIDA :-}

laxa, Trin. in Mém. Acad. Pétersb. Sér. VI. i. (1831) $85=$ flaccida

laxa, Willd, ex Trin. \& Rupr. 1. c. vii. (1849) $130=$ dispersa.

leiocalycina, Trin. \& Rupr. l. c. 161.-Guinea.

leptopoda, Benth. Fl. Austral. vii. 562.-Austral. Liebmannii, Fourn. Mex. Pl. Enum. Gram. 78, ex

Hemsl. Biol. Centr. Am. Bot. iii. 534.-Mexic

longeradiata, Steud. Syn. Pl. Gram, 140,-Afr. trop.

longespica, Poir. Encyc. Suppl. 1. 452.-Am. bor

longifolia, Trin. in Mém. Acad. Pétersb. Sér. VI. i. (1831) 84.-Bras.

longiramea, 7 . Presl, in Rel. Haenk. i. 224.-Mexic

longiseta, Steud. Syn. Pl. Gram. 420.-N. Mexic.

lutescens, Steud. l. c. 145.-Afr. austr.

Iuzoniensis, Cav. Ic. v. 45. t. 470.-Ins. Philipp.

macranthera, Hochst. ex Boiss. Fl. Orient. v. $493=$ funiculata.

macrathera, A. Rich. Tent. Fl. Abyss. ii. $393=$ praec macrochaeta, Steud. Syn. Pl. Gram. 134.-Am. bor. macrochloa, Hochst. in Flora, xxxviii. (1855) 200.Afr. or.

maritima, Steud. Syn. Pl. Gram. 137.-Guadel. mauritiana, Hochst. ex A. Rich. Tent. Fl. Abyss. ii. 392.-Abyss.

mauritiana, Kunth, Rev. Gram. i. 265. t. $44=$ Adscensionis.

meccana, Hochst, ex Trin. E Rupr. in Mem. Acad. Pétersb. Sér. VI. vii. (1849) 152.-Arabia.

megapotamica, Spreng. Syst. Cur. Post. 31.-Bras mendocina, Phil. Sert. Mend. Alt. 47.-Chili. micropoda, Trin. E Rupr. in Mém. Acad. Pétersb. Sér. VI. vii. (1849) 107.-Am. bor

minuta, Poit. ex Roem. \& Schult. Syst. ii. 711 (=Eutriana Ledebourii).-Ins. S. Doming. modatica, Steud. Syn. Pl. Gram.139.-Abyss. muehlenbergioides, Fourn. Mex. Pl. Enum. Gram. 79, ex Hemsl. Biol. Centr. Am. Bot. ii. 534. Mexic.

murina, Cav. Ic. v. 44. t. 469.--Reg. Argent.

mutabilis, Trin. E Rupr. in Mém. Acad. Petersb. Sér. VI. vii. (1849) 150.-Afr. trop.

namaquensis, Trin. E Rupr. l.c. 174.--Afr. austr

nana, Steud. Nom. ed. II. i. 131. - Chili.

Neesiana, Trin. E̋ Rupr. in Mém. Acad. Pbtersb. Sér.

VI. vii. (1849) 113. - Bras.

nigrescens, F. Presl, in Rel. Haenk. i. 223.-Mexic

nutans, Ehrenb. \& Hempr. ex Trin. E Rupr. in Mém Acad. Pétersb. Sér. VI. vii. (1849) 135.-Arabia.

nutans, Hort. Berol. ex Steud. Nom. ed. II. i. $131=$

Adscensionis.

obtusa, Delile, Fl. Egypte, 175. t. 13.f. 2.-Afr. bor. et austr.; Arab.

oligantha, Michx. Fl. Br. Am. i. 41.-Am. bor

orizabensis, Fourn. Mex. Pl. Enum. Gram. 78, ex Hemsl. Biol. Centr. Am. Bot. iii. 534.-Chili.

pallens, Nutt. Gen. Am. i. $57=$ oligantha.

pallens, Cav. Ic. v. 43. t. 468.-Chili.

Palmeri, Vasey, in Torrey Bot. Club, x. (1883) 42.Am. bor.

pallida, Steud. Syn. Pl. Gram. 143.-Nubia,

palustris, Vasey, Cat. Gram. U. St. 35.-Am, bor.

paniculata, Forsk. Fl. Aegypt. Arab. 25.-Arabia.

papposa, Trin. E Rupr. in Mém. Acad. Pétersb. Sér

VI. vii. (1849) 173.-Abyss.

paradisea, Edgerv. in Fourn. As. Soc. Beng. xvi. (1847) 11. 1219.-Persia; Afghan.; Aegypt.; Arab.

paradoxa, J. A. Schmidt, Beitr. F1. Cap. Verd. Ins

$140=$ funiculata

parviflora, Steud. Syn. Pl. Gram. $140=$ vagans.

pauciflora, Buckl. in Proc, Ac. Sc. Philad. ' 1862 '

(1863) $92=$ oligantha.

pennata, Trin. in Mém. Acad. Pétersb. vi. (1815) 488 - Persia; Turkestan.

perennis, Pang. ex Trin. Es Rupr. l. c. Sér. VI. vii

(1849) 104.-Carolina.

piligens, Burch. ex Spreng. Syst. i. $269=$ capensis,

piligera, Burch. ex Roem. \& Schult. Syst. ii. Mant. 579 $=$ capensis.

pilosa, Labill. Sert. N. Caled. 12. t. 17.-N. Caled.

plumosa, Desf. Fl. Atlant. i. $109=$ ciliata.

plumosa, Linn. Sp. Pl. ed. II. 1666.-Keg. Mediterr.

Persia: Arab.

pogonoptila, Boiss. Fl. Oricnt. v. 496-Belachistan.

prodigiosa, Welw. in Trans. Linn. Soc. xxvii. (1869)

80.-Afr, trop.

proximn, Steud. Syn. Pl. Gram. 145.-Afr. austr.

\section{ARISTIDA}

pseudo-hystrix, Stend. Syn, Pl. Gram. 142-Afr austr pumila, Decne. in Ann. Sc. Nat. Sér. II. iv. (1835) 8 $=$ Adscensionis

pungens, Desf. Fl. Atlant. i. 109. t. 35.-Afr. bor. Turkestan.; Sibiria.

pungens, Sieber, ex Trin. Gram. Unifl. Diss. i. $181=$ vulnerans.

pungens, Steud. Syn. PI. Gram. $145=$ scoparia.

purpurascens, Poir. Encyc. Suppl. 1. 452.-Am. bor. Jamaic.

purpurea, Nutt. in Trans. Am. Phil. Soc. v. (1837) 145.-Am. bor.

pusilla, Trin. E Rupr. in Mém. Acad. Pétersb. Sér.

VI. vii. (1849) 140,-Afr. austr.

quinqueseta, Steud. Syn. Pl. Gram.420.-Maurit.

racemosa, Muhl. Desc. Uber. 172 = purpurascens.

racemosa, Spreng. Mant. i. 35.-Ins. S. Helen.

Raddiana, Savi, in Mem. Moden. (1837) 198.-Aegypt.

ramosa, $R$. Br. Prod. i. 173.-Austral.

ramosissima, Engelm. ex A. Gray, Man. Bot. U. St. ed.

V. 618,-Am. bor.

recurvata, H. B. E K. Now. Gen et Sp, i. 123.-Am austr.

refracta, Griseb. Cat. Pl. Cub. 228.-Cuba

repens, Trin. in Mém. Acad. Pétersb. Sér. VI. 1. 1831 87.-Ins. Galap.

Riedeliana, Trin. E Rupr. l. c. Sér. VI. vii. (1849) 113 -Panama.

rigescens, Roem. E Schult. Syst. ii, 400.-Ind. or.

rigida, Cav. Ic. v. 44. t. 469.-Ins. Philipp.

rigida, Roth, Nov. Pl. Sp. $42=$ rigescens.

riparia, Trin. in Bull. Acad. Pétersb. i. (1836) 68 -Bras.

Texas.

Royleana, Trin. E Rupr. in Mém. Acad. Pétersb. Sér.

VI. vii. (1849) 160.-Ind. or.

rufescens, Steud. Syn. Pl. Gram. 421.-Ins. Mascar.

sabulosa, Kunth, Enum. Pl. i. $197=$ setifolia.

Sanctae-Luciae, Trin. Diss. ii. 25.-Bras.

scabra, Kunth, Rev. Gram, i. 62.-Mexico.

Schaffneri, Fourn. Mex. Pl. Enum. Gram. 78,

Hemsl. Biol. Centr. Am. Bot. jii. 534.-Mexic.

Schiediana, Trin. E Rupr. in Mém. Acad. Peitersb.

Sér. VI. vii. (1849) 120.Mexic.

Schimperi, Hochst. \&c Steud. ex Steud. Syn. Pl. Gram. $143=$ ciliat.

Schweinfurthii, Boiss. Fl. Orient. v. 493.-Aegypt. Arab.

scoparia, Trin. Eo Rupr. in Mim. Acad. Pétersb. Sér. VI. viî. (1849) 176.--Aegypt.

secunda, Ledeb. ex Steud. Nom. ed. II. i. 192 (=E triana Ledebourii).--Ins. S. Doming.

sericea, Ehrenb. ex Boiss. F1. Orient. v. $497=$ paradisea. setacea, Hort. ex Steud. Nom. ed. II. i. 132= Adscensionis.

setacea, Retz. Obs. iv. 22.-Ind. or.

setacea, Trin. in Mém. Acad. Pétersb. Sér. VI. i. (1831

$84=$ Adscensionis.

setifolia, $H . B . \&, K . N o v$. Gen, et $S p$. i. 122.-Mexic Bras.

Sieberiana, Trin. in Spreng. Neue Entdeck. ii. 61.Afr. bor.; Creta; Syria.

similis, Steud. Syn. Pl. Gram. 420.-Madag.

simpliciflora, Chapm. in Coult. Bot. Gas. iii. (1578' 18

-Am. bor.

simplicissima, Steud. Syn. Pl. Gram. 139.-Ins. Borbon.

sorzogonensis, F. Presl, in Rel. Haenk. i. 224.-Ins.

Luzon.

spadicea, H. B. E K. Nov. Gen. et Sp. i. 123.-Am. austr.

spadicea, Trin. in Mém. Acad. Pétersb. Sér. VI. iii. II.

(1838) $43=$ tincta.

spiciformis, Ell. Sketch, i. 141.-Am. bor.

spicigera, Trin. E Rupr. ins Mim. Acad. Pitersb. Ser.

VI. vii. (1849) 136. - Arab.

squarrosa, Trin. in Spreng. Nese Enideck. ii. 62.Am. bor.

Steudeliana, Trin. \& Rupr. in Mim. Acad. Péprsé Sér. VI. vii. (1S4?) 155.-Abuss.

stipacea, Ehrenb. \& Hempr.ex Boiss. Fl. Orient. v.49: funiculata.

stipacformis, Hochst. ex Stcud. Syn. P1. Gram. 1t3 pallida.

stipiformis, Lam. Illustr. i. 157.-Afr. trop.

stipoides, R. Br. Provl. i. 1\% f.-Austral.

stricts. Sfichix. Fl. Bor. Am. i. 11.-Am, hor. c austr. 


\section{ARISTIDA :}

stricta, Muhl. Desc Gram, 174=spiciformis stricta, Auct. ex Steud. Nom, ed. II. i. $132=$ virgata. stricta, Steud. Syn. PI. Gram. $133=$ purpurascens. subacaulis, Steud. Nom. ed. II. i. 132.-Afr. austr. subaequans, Doell, in Mart. Fl. Bras. Ii. III. 19.-Bras subbifora, Steud. Syn. Pl. Gram. 138,-Ins. Guadeloupe.

subrecurvata, Beauv. Agrost. 152, nomen.-Hab.?

subspicata, Trin. E Rupr. in Mém. Acad. Pétersb. Sér.

VI. vii. (1849) 125.-Ins. Galap.

Swartziana, Steud. Syn. Pl. Gram. $137=$ purpurascens.

Teneriffae, Steud. l. c. 420.-Ins. Teneriffa.

tenuiflora, Steud. l. c. 138.-Afr. trop.

tenuis, Hochst. in Flora, xxxvii. (1855) 200.-Abyss.

tenuis, Kunth, Rev.Gram, i. 62.Cumana; Mexic.

ternipes, Cav. Ic. v. 46.-Panama.

Thonningii, Trin. Es Rupr. in Mém. Acad. Pétersb.

Sér. VI. vii. (1849) 137.-Afr. trop.

tincta, Trin. E Rupr. l. c. 111.-Guiana

torta, Kunth, Enum. Pl. i. 190.-Bras.

trichodes, Nees, in Hook. Kew Fourn. ii. (1850) 101

-Ins. Philipp.

tripilis, Thunb. F1. Ceyl. Diss. 2, ex Trin. \& Rupr. in Mém. Acad. Pétersb. Sér. VI. vii. (1849) $147=$ Hystrix.

tuberculosa, Nutt. Gen. Am. i. 57.-Am. bor.

unilateralis, Willd ex Steud, Nom. ed. II. i, $132=$

Bouteloua aristioides.

uniplumis, Lichtst. in Roem. Ev Schult. Syst. ii. 401.Afr. austr

Urvillei, Steud. Syn. Pl. Gram. 141,-Ins. Falkland.

vagans, $C a v . I c$. v. 45 . t. 471.-Austral.

vestita, Thunb. Prod. Pl. Cap. 19-Afr austr.

virgata, Trin. in Spreng. Neue Entdeck. ii. 60.Am. bor.

Virleti, Fourn. Mex. Pl. Enum. Gram. 76, ex Hemsl. Biol. Centr. Am. Bot. iii. 535.-Mexic

unlgaris, Trin. \& Rupr. in Mém. Acad. Pétersb. Sér

VI. vii. (1849) $131=$ Adscensionis.

vulnerans, Trin. \& Rupr. 1. c. $175=$ pungens,

valpioides, Hance, in Ann. Sc. Nat. Sér. V. v. (1866) 251.-China.

Zeyheri, Steud. Nom. ed. II. i. 132.-Afr. austr.

Zittelii, Aschers, in Verh. Bot. Ver. Brand, xxi. (1880) 70.-Aegypt.

ARISTIDIUM, Lindl. Veg. Kingd. $116(1847)=$ Boute loua, Lag. (Gramin.).

ARISTOMENIA, Vell. Fl. Flum. 345 (1825) viii. t. 84 = Stifftia, Mikan (Compos.)

fruticosa, Vell. 1. c. 346 ; viii. t. $84=$ S. chrysantha.

ARISTOLOCHIA, Tourn, ex Linn. Syst. ed. I. (1735). ARISTOLOCHIACEAE, Benth. \& Hook. f. iii. 123; 1220.

AmbUYA, Rafin. Fl. Tellur. iv. 98 (1836)

Dictyanthes, Rafin, in Loud. Gard. Mag. viii. 1832) 247

Drglosselis, Rafin. F1. Tellur. iv. 98 (1836)

Einomeia, Rafin. Med. F1. i. 62 (1828).

ENDODECA, Rafin. 1. c. (1828)

Glossüla, Reichb. Handb, 173 (1837)

GuACo, Liebm. in Forhandl. Skandin. Naturf. 1844 (1847) 203.

HeXAPlECTRIs, Rafin. Fl. Tellur. iv. 97 (1836),

Hocquartia, Dum. Comm. Bot. 30 (1822).

Howardia, Klotzsch, in Monatsb. Acad. Berl. (1859) 607

Isiphia, Rafin. Med, Fl. ii. 232 (1830).

IsotremA, Rafin. in Am. Monthly Mag. (1819) 195.

Pistolochia, Rafin. Fl. Tellur. iv. 98 (1836).

Plagistra, Rafin. l. c. (1836).

Psophiza, Rafin. 1. c. 99. (1836)

Pteriphis, Rafin.1, c. $\left(1836^{\circ}\right)$.

Siphisia, Rafin. Med. F1. i. 62 (1828).

Tropexa, Rafin. F1. Tellur, iv. 98 (1836).

abbreviata, Mart. ex Mast. in Mart. Fl. Bras. iv. II. $109=$ cymbifera.

abyssinica, Klotzsch, in Monatsb. Akad. Berl. (1859) $598=$ bracteata

acuminata, Lam. Encyc. i. 254.-Ind. or

acuminata, Roxb. Hort. Beng. 64 ; F1. Ind. iii. $489=$ Roxburghiana.

acutifolia, Duch. in Ann. Sc. Nat. Sér. IV. ii. (1854) 54.-F1. Amazon.

\section{ARISTOLOCHIA :-}

aethiopica, Welw. Apont. 548.-Afr. trop.

albida, Duch. in Ann. Sc. Nat. Sér. IV, ii. (1854) 75 . -Afr. occ.

altissima, Desf. Fl. Atlant. ii. 324. t. 249.--Reg. Mediterr. or.

anatolica, Boiss. Fl. Orient. iv. $1080=$ maurorum.

anguicida, Faca. Enum. Pl. Carib. 30.-Am. austr.

anguicida, Pav. ex Duch. in DC. Prod. xv. I. $443=$ velutina.

anguicida, Sieber, ex Duch. 1. c. $479=$ acuminata.

angulata, Boj. ex Duch. l. c. 497.-Madag.

angulisans, Michx. Fl. Bor. Am. ii. 258=tomentosa.

angulosa, Wall. ex Duch, in DC. Prod, xv, I. $480=$

Roxburghiana.

angustifolia, Boj. Hort. Maurit. 277.--Ins. Maurit.

angustifolia, Cham. in Linnaea, vii. (1832) 211.Bras.

antihysterica, Mart. ex Duch. in DC. Prod. xv. I. 477. -Bras.

appendiculata, Vell. Fl. Flum. ix. t. 98=macroura.

arborescens, Linn. Sp. Pl. 960.-Am.

arcuata, Mast. in Mart. Fl. Bras, iv. 11. 101.-Am.

arenicola, Hance, in Fourn. Bot. xiv. (1876) 261.Cambodia.

argentina, Griseb. in Goett. Abh. xix. (1874) 156.Keg. Argent.

arkasana, Lodd. Cat. ed. XIV. (1826) 37.-Am. bor.

atlantica, Pomel, Nouv. Mat. Fl. Atl. 136.-Algeria.

attica, Orphan. ex Duch. in DC. Prod. Xv. I. $487=$ longa.

Aucherii, Jaub. \& Spach, Illustr. 1. 174. t. $99=$ maurorum.

aurantiaca, Duch. in DC. Prod. xy. I. 475.

Venezuela.

auricularia, Boiss. Diagn. Ser. I. v. 49.-As. Min.

aurita, Duch. in DC. Prod. xv. I. 482.-Madag.

baetica, Linn. Sp.Pl. 961.-Europ.

barbata, Facq. Coll, iii. 221-Veneznela.

Baueri, Duch. in DC. Prod. xv. I. $484=$ Thozetii

Bernieri, Duch. l. c. 482.-Madag.

biflora, Willd. ex Duch. 1. c, $457=$ maxima

bilabiata, Linn. Sp. Pl. ed. II. 1361.-Ins. S. Doming.

Billardieri, Faub. E Spach, Illustr. i. 175. t. 100.Syria; Cilicia.

bilobata, Linn. Sp. Pl. 960.-Ins. S. Doming.

birostris, Duch. in Ann. Sc. Nat. Sér. IV. ii. (1854) 60.- - Bras.

Bodamae, Dingl. in Flora, xlvi. (1883) 301.Thracia.

Bonplandi, Tenore, Cat. Sem. Hort. Neap. (1842) 12 = fimbriata.

Bottae, Jaub. \& Spach, Illustr. i. 173. t. $98=$ maurorum.

brachyura, Duch. in DC. Prod. xv. I. 446.-Ins. S. Doming.

bracteata, Retz. Obs. v, 29.-Ind, or.

bracteolata, Lam. Encyc. i, $258=$ bracteata.

bracteosa, Duch. in Ann. Sc. Nat. Sér. IV. ii. (1854 37.-Mexic.

Braniciana, Andrz. ex Trautv. in Act. Hort. Petrop. ix. (1884) 155, nomen.-Hab,?

brasiliensis, Mart. Ev Zucc. Nov. Gen. et Sp. i. 77.Bras.

brevipes, Benth. Pl. Hartw. 15.-Mexic.

Bridgesii, Duch. in DC. Prod. xv. I. 463,-Chili

Bruguieri, Jaub. \& Spach, Illustr. ii. 40. t. $129=$ Olivieri.

Burchellii, Mast. in Mart. Fl. Bras, iv. II. 90.Am. trop.

californica, Torr. in Pacif. Rail. Rep. iv. 128.-Calif. campanaeformis, DC. ex Duch. in DC. Prod. xv. $432=$ Holostylis reniformis.

caracasana, Spreng. Syst. iii. $753=$ trilobata

caudata, Herb. Berol. ex Duch. in DC. Prod. xv. I. 446 =brachyura.

caudata, Booth, ex Lindl. in Bot. Reg. t. $1453=$ macroura.

caudata, Facq. Enum. Pl. Carib. 30.-Ins, S. Doming. caudata, Parodi, in Anal. Soc. Cient. Argent. v. (1878) 155 (Contrib. 48),-Reg. Argent.

Chamissonis, Duch. in DC. Prod. xv. I. 462.-Bras.

chilensis, Miers, Trav. Chil. ii. 531.-Chili.

chiquitensis, Duch. in Ann. Sc. Nat. Sér. IV. ii. (1854 49.--Bolivia.

ciliata, Hook, Bot. Mag, t. $3756=$ fimbriata

ciliosa, Benth. in Maund, Bot. t. $90=$ fimbriata.
ARISTOLOCHIA :-

Claussenii, Duch. in Ann. Sc. Nat. Sér, IV. ii. (1854) 57.-Bras.

clavidenia, Griseb. Cat. Pl. Cub. 115,-Cuba

Clematitis, Linn.Sp.Pl. 962.-Europ.; Reg. Caucas. As. Min.

clypeata, Linden E André, Illustr. Hortic. xvii. (1870) t. 40-N. Granat.

conduplicata, Poit. ex Duch. in DC. Prod. xv. I. $460=$ oblongata.

conferta, Mill. Gard. Dict. ed. VIII. n. 11.-Mexic

constricta, Griseb. in Goett. Abh. vii. (1857) 225. - Reg Argent.

contorta, Bunge, Enum. Pl. Chin. Bor. 58.-China bor.

cordiflora, Mutis, ex H. B. E K. Nov. Gen. et Sp. ii 149 - N. Granat.

cordigera, Willd.ex Klotzsch, in Monatsb. Akad. Berl. 1859) 621.-Bras

coriacea, Rafin. Atl. Fourn. 146.-Hab.?

cornuta, Mast: in Mart. Fl. Bras. iv, II. 97-Am. trop.

costaricensis, Duch. in DC. Prod. xv. I. 450.-Costa Rica.

crenata, Ehrenb. ex Duch. 1. c. $478=$ bracteata.

cretica, Lam. Encyc. i. 225.-Creta.

cubensis, Linden, Cat. n. 11. Suppl. (1856) 12.Cuba.

cucullata, Pohl, ex Duch. in DC. Prod. xv. I. $432=$ Holostylis renifor mis.

cyclochilia, Duch. in Ann. Sc. Nat. Sér. IV. ii. (1854 $45=$ passifloraefolia.

cymbifera, Mart. छ Zucc. Nov. Gen. et Sp. i. 76. t. 49.-Bras.

cynanchifolia, Mart. E Zucc. l.c. 77. t. 51-Bras

debilis, Sieb. E Zucc. in Abh. Akad. Muench. iv. III (1846) 197.--Japon

deltantha, F. Muell. Fragm. vi. 179.-Austral

del toidea, H. B. K . Nov. Gen. et Sp.ii. 146. t. 112 -Bras.

dictyantha, Duch. in Ann. Sc. Nat. Sér. IV. ii. (1854) 40. - Venezuela.

Duchartrei, André, Le Mouv. Hortic. (1867) 61; Mast. in Gard. Chron. (1868) $516=$ Ruiziana.

durior, Hill, Veg. Syst. xxi. 57.-Am. bor

ecaudata, DC ex Duch, in DC. Prod, xy, $\mathrm{r}, 446=$ dietyantha.

egensis, Poepp. ex Duch. l. c. $465=$ acutifolia

Ehrenbergiana, Cham. in Linnaea, vii. (1832) 210.Ins. S. Doming.

elegans, Mast. in Gard. Chron. (1885) II. 301.Bras.

elliptica, Duch. in Ann. Sc. Nat. Sér. IV. ii. (1854) 51 $=$ tigrina.

emarginata, Duch, in DC. Prod. xv. I. 467.-Bras.

emarginata, Willd. ex Duch. 1. c. $466=$ rummularifolia.

erecta, Linn. Sp. Pl. ed, II, 1362,--Vera Crux.

eriantha, Mart. Eo Zucc. Nov. Gen.et Sp. i. 78. t. 53.Bras

Eschscholtzii, Ledeb. ex Duch. in DC. Prod. xv. I. 481 $=$ A. Tagala.

eurystoma, Duch. in Ann. Sc. Nat. Sér. IV. ii. (1854 41.-Bras.

fasciculata, Lam. F1. Fr. iii. $387=$ A. Pistolochia

filipendula, Duch. in Ann. Sc. Nat. Sér. IV. ii. (1854) 70.-Bras.

fimbriata, Cham. in Linnaea, vii. (1832) 210.t.6.-Bras.

flexuosa, Duch. in Ann. Sc. Nat. Sér. IV. ii. (1854) 36. Mexic.

floribunda, Lem. Illustr. Hortic. (1868) t. 568.-Bras. fluminensis, Buek, in DC. Prod. Index, iv. $28=$ odora foetens, Lindl. Bot. Reg. t. 1824.-Ind. occ.

foetida, H. B. E K. Nov. Gen. et Sp. ii. 147. t. 114.Mexic.

Fontanesii, Boiss. \& Reut. Pugill. P1. Hispan. $108=$ longa.

Fordiana, Hemsl. in fourn. Bot. xxiii. (1885) 286 .China.

fragrantissima, Ruiz, in Mem. Bejuc. Estrell. (1805) 46.-Peruv

frutescens, Marsh. Arb. Am. $24=$ macrophylla.

galeata, Mart. E Zucc. Nov. Gen. et Sp. i. 76. t. 50.Bras.

galeata, Moritzi, Syst. Verz. $70=$ cymbifera

Galeotti, Duch. in Ann. Sc. Nat. Sér. IV, ii. (1854 44.-Mexic. 
ARISTOLOCHIA :-

Gardneri, Duch. in Ann. Sc. Nat. Sér. IV. ii. (1854) 69.-Bras.

Gaudichaudii, Duch. l. c. 72.-Ins. Rawak.

geminiflora, H. B. \& K. Nov. Gen, et Sp. ii. 148. t. $117=$ maxima.

gibbosa, Duch. in Ann.Sc. Nat. Sér. IV. ii. (1854) 53. -Mexic.

Giberti, Hook. Bot. Mag. t. 5345.-Reg. Argent.

gigantea, Hook. I. c. $\$ 221=$ grandiflora

gigantea, Mart. E Zucc. Nov. Gen. et Sp. i. 75. t. 48. -Bras,

Gigas, Lindl. in Bot. Reg. (1842) Misc. 51. t. $60=$ grandiflora.

glandulosa, Kickx, in Bull. Acad. Brux, déc. vii. (1839) n. 11.-Cuba

glauca, Desf. F1. Atlant, ii. t. $250=$ baetica.

glauca, Salisb. Prod. 215 = subglauca.

glaucescens, H. B. E K. Nov. Gen. et $S p$. ii. 147.t. 115.-N. Granat.

Glaziovii, Mast. in Mart. Fl. Bras. iv. II. 90.-Am. trop.

Goldieana, Hook. f. in Trans. Linn. Soc. xxv. (1865) 185. t. 14.-Afr. trop.

Goudotii, Duch. in Ann. Sc. Nat. Sér. IV. ii. (1854) 66.-N. Granat.

gracilis, Duch. in DC. Prod. xv. I. 460.-Am, austr.

grandiflora, Arruda, in Koster, Trav. Braz. 499.-

Pernamb.

grandiflora, Gomez, Obs. Bot. Med. ii. (1803) 14. t. 3 ; et in Mem. Ac. Lisboa, iii. (1812) Mem. dos Corresp. $64=$ cymbifera.

grandiflora, Sre. Prod. Veg. Ind. Occ. 126,-Jamaica.

grandifolia, Salisb. Prod. $215=$ macrophylla.

Griffithi, Hook. f. E Thoms. ex Duch. in DC. Prod. xv. I. 437.- Reg. Himal

hastata, H. B. \& K. Nov. Gen. et Sp. ii. $148=$ pentandra.

hastata, Fack, in Malay. Misc. ii. (1822) n. viI. 6.Malaya.

hastata, Klotzsch, in Monatsb. Acad. Berl. (1859) 597 = Zollingeri.

hastate, Nutt. Gen. Am. ii. $200=$ A. Serpentaria.

hians, Willd. in Mém. Soc. Nat. Mosc. ii. (1809) 100 - Venezucla.

Hilariana, Duch. in DC. Prod. xv, I. 451.-Bras.

hirsuta, Linn. Syst. ed. XII, 601 = hirta.

hirsuta, Muhl. Desc. Uber. $18=$ tomentosa.

hirta, Buek, in DC. Prod. Index, iv. $28=$ torta.

hirta, Georgi, Beschreib. Russ. Reich. iii. v. $1275=$ pontica.

hirta, Linn. Sp. Pl. 961-As. Min.

hispida, Pohl, ex Duch. in DC. Prod. xv. I. 498.Bras.

iberica, Fisch. E Mey, ex Duch. in DC. Prod. xv. I. 493.-Reg. Caucas.

imbricata, Mast. in fourn. Linn. Soc. xiv. (1875) 494. -Ins. Philipp.

incisa, Duch. in DC. Prod. xv. I. 490.-Anatolia.

indica, Linn. Sp. Pl. 960.-Ind. or.

infesta, Salisb. Prod. $215=\mathrm{A}$. Clematitis.

inflata, H. B. \& $K$. Nov. Gen. et Sp. ii. 145. t. 111.N. Granat.

insignis, Versch, ex Gard. Chron. (1868) 349.-Bras.

Ipemi, Parodi, in Anal. Soc. Cient. Argent. v. (1878)

153 (Contrib. 46).-Paraguay.

Fackii, Steud. Nom. ec. II. i. 141 = hastata.

japonica, Miq. Ann. Mus. Bot. Lugd. Bat. ii. 136.Japon.

Kaempferi, Willd. Sp. Pl. iv. 152.-Japon.

Karwinskii, Duch, in DC Prod xv, I. 442-Mexic.

Kotschyi, Hochst. in A. Rich. Tent. Fl. Abyss. ii. 237 $=$ bracteata.

labiata, Willd. in Mém. Soc. Nat Mosc. ii. (1809) 101. t. $6=$ brasiliensis

labiosa, Ker-Gawl. in Bot. Reg. (1822) t. $689=$ cymbifera.

lanceolata, Wight, Ic. v. t. $1858=$ indica

Leprieurii, Duch.in DC. Prod. xv. 1. 451.-Guiana.

leuconeura, Linden, in Belg. Hortic. viii. (1858) 165. -Am. austr.

Lindeniana, Duch, in DC. Prod xv, I. 453,-Cuba.

linearifolia, Wright, ex Griseb. Cat. Pl. Cub. 115.Cuba.

lineata, Duch. in Rev. Hortic. Sér. IV. iii. (1854) 284. t. 15 - Japon.

littoralis, Parodi, in Anal. Soc. Cient. Argent.v. (1578) 155 (Contrib. 47).-Reg. Argent.

\section{ARISTOLOCHIA}

longa, Georgi, Beschr. Russ, Reich. iii. V. $1274=\mathrm{A}$ Clematitis.

longa, Linn.Sp. Pl. 961.-Reg. Mediterr.

longa, Thunb. F1. Japon. $144=$ debilis.

longa, Woodv. Med. Bot. ii. t. $107=$ baetica.

longiflora, Engelm. E A. Gray, in Bost. Fourn. Nat Hist. v. (1845) 259.-Texas.

longifolia, Champ. ex Benth. in Hook. Kew fourn. vi (1854) 116.-Hongkong.

longifolia, Roxb. Hort. Beng. [102]; Fl. Ind. iii. 490 $=$ moluccana.

lutea, Desf. Choix, 13. t. $8=$ pallida

lutescens, Duch. in DC. Prod. xv. I. 461.-Bras.

macradenia, Hook. Bot. Mag. t. $4467=$ glandulosa.

macrocarpa, Duch. in DC. Prod. xy, I. 497.-Afr, occ. macroglossa, Jaub, \& Spach, Illustr. ii. 38. t. $127=$ Tournefortii.

macrophylla, Duch. in Ann. Sc. Nat. Sér. IV. ii. (1854) 68.- Guiana.

macrophylla, Lam. Encyc. i. $252=$ A. Sipho.

macrota, Duch.in Ann.Sc. Nat. Sér. IV. ii. (1854) 43 -Grilana.

macroura, Gomez, in Mem. Ac. Lisboa, iii. (1812) Mem. dos Corresp. 77.- Bras.

Mannii, Hook. f. in Trans. Linn.Soc. xxy. (1865) $186^{\circ}$ -Afr. trop.

marsupiiflora, Schrad. in Goett. Gel. Anz. i. (1821) 719 - Hab. ?

Mathewsii, Duch. in DC. Prod.xv. I. 497.-Peruv.

mauritiana, Pers. Syn. ii. $527=$ bracteata.

maurorum, Klotzsch, in Monatsb. Acad. Berl. (1859) $598=$ bracteata.

maurorum, Linn. Sp. Pl. ed. II. 1363.-As, Min. Persia.

maxima, Cham. in Linnaea, vii. (1832) $208=$ Chamis sonis.

maxima, Facq. Enum. Pl. Carib. 30.-Ind. occ.

maysorensis, Fisch. ex Duch. in DC. Prod. xv. I. $479=$ indica.

melastoma, Manso, ex Duch. l.c. 461.-Bras

mexicana, Kostel. Allg. Med.-Pharm. Fl. ii. 467.Mexic.

mexicana, A. Dietr. Syn. v. $196=$ maxima

micrantha, Duch. in Ann. Sc. Nat. Sér. IV. ii. (1854) 35. t. 5.-Mexic

microphylla, Willd. Enum. Hort. Berol. Suppl. 68.Hab.?

microstoma, Boiss. E Sprun. Diagn. Ser. I. v. 50.Graecia.

microura, Pohl, ex Duch. in DC. Prod. xv. I. $496=$ setos?.

mollissima, Hance, in Fourn. Bot. xvii. (1879) 300.China.

moluccana, Duch. in DC. Prod. xv. I. 438.-Ins Molucc.

moschata, Wedd. ex Duch. 1. c. $475=$ odoratissima. multiflora, Duch. in Ann. Sc. Nat. Sér. IV. ii. (1854 73.-Ins. Comoro.

multinervis, Pomel, Nouv. Mat. Fl. Atl. 137.Algeria.

nervosa, Duch. in DC. Prod. xv. I. 480.-Ind. or nummularifolia, H. B. E K.Nov. Gen. et Sp. ii. 145. Venezuela.

oblonga, Vell. Fl. Flum. ix. t. $99=$ rumicifolia.

oblongata, Facq. Hort. Schoenb. ii. 29.-Hab. ?

obtusata, Sw. Prod. Veg. Ind. Occ. 126.-Ind. occ.

odora, Steud. Nom. ed. II. i. 133.-Bras.

odoratissima, Benth. Pl. Hartw. 82 = gibbosa.

odoratissima, Linn. Sp. Pl. ed. II. 1362.-Jamaica.

odoratissima, Vell. F1. Flum. ix.t. $97=$ odora

officinalis, T. Nees, P1. Offic. t. $144=$ A. Serpentaria.

Olivieri, Colleg. ex Boiss. Diagn. Ser. I. v. $50 .-$ Mesopot.

orbicularis, Duch. in Ann. Sc. Nat. Sér. IV. ii. (1854. 59.-Bras.

orbiculata, Vell. Fl. Flum, ix, t. $96=$ cymbifem. ornithocephala. Hook. Bot. Mag. t. $4120=$ brasiliensis. Ottonis, Klotzsch, ex Duch. in DC. Prod. xv. I. $476^{\circ}$ pandurata.

ovalifolia, Duch. in Ann. Sc. Nat. Sér. IV. ii. (185t)

50.-Mexic.

precilantha, Boiss. Diagrn. Ser. I. xii. 104-Syria.

pallida, Salzm, ex Ball, in Journ. Linn. Soc, xvi. (1578) $656=$ longa

pallida, Willd. Sp. Pl. iv, 162.-Europ. ; As. Min.

pandurata, facq. Hort. Schoesb. iv. 49, t. 497

Venezuela.

\section{ARISTOLOCHIA}

pandurata, Wall. ex Duch. in DC. Prod. xv. 1. 479= indica.

panduriformis, Willd. Sp. Pl. iv. 152 = pandurata.

pannosa, Mast. in Fourn. Linn. Soc. xxiv. (1875) 493. - Peruv.

papillaris, Mast. in Mart. Fl. Bras. iv. II. 100.-Am. trop.

paraguariensis, Parodi, in Anal, Soc. Cient. Argent. (1878) 156 (Contrib. 48),-Paraguav.

paramaribensis, Duch. in DC. Prod. x\%. 1. 496.-Bras. pardina, Duch. in Ann. Sc. Nat. Sér. IV. ii. (1854) 47. - Mexic.

parviflora, Griseb. in Goett. Abh. xxiv. (1879) 148.Reg. Argent.

parvifolia, Sibth. E Sm. Fl. Graec Prod, ii, 222 Syria; Cyprus; Graecia?

parvifolia, Sprun, ex Duch. in DC. Prod. Xv. I. 485 microstoma.

passifloraefolia, A. Rich. Fl. Cub. Fanerog. ii. 195.Cuba.

paucinervis, Pomel, Nouv. Mat. Fl. Atl. 136.-Alyeria.

Pavoniana, Duch. in Ann. Sc. Nat. Sér. IV ii. (185t) 54.-Mexic

Pearcei, Mast. in Fourn. Linn. Soc. xiv. (1875) 493.Peruv.

Pearcei, Phil. in Ann. Univ, Chil. i. (1861) 68; Linnaea, xxxiii. (1865) 231.-Chili.

pcltata, Linn. Sp. Pl. 960.-Ins. S. Doming.

peltata, Sw. Obs. $341=$ reniformis.

pentandra, facq. Enum. Pl. Carib. 30.-Cuba.

Petersiana, Klotzsch, in Monatsb. Akad. Berl. 185!) 599.-Afr. trop.

picta, Karst. Ausw. Schoen. Pf. Venez. ii. $34=$ pan durata.

pilosa, H. B. E K. Nov. Gen. et Sp. ii. 146. t. 113.Ecuador.

piperifolia, Griff. Itin. Bot. 19.-Reg. Himal.

Pistolochia, Aucher, ex Duch. in DC. Prod. xv. 1. 491 - incisa.

Pistolochia, Linn. Sp. Pl. ed. II. 162.-Reg. Mediterr. occ.

platanifolia, Duch. in DC. Prod. xv. I. 437.-Mexic

platyloba, Garcke, in Linnaea, xxii. (1849) 69.Guiana.

podocarpa, A. Bertol. in Nov. Comm. Acad. Sc. Bon. iv. (1840) 437. - Guatem.

Pohliana, Duch. in DC. Prod. xv. I. 496.-Bras.

polyrrhizos; Spreng. Syst. iv. Cur. Post. 310.Am. bor. pontica, Lam. Encyc. i. 255.-As. Min.

praevenosa, F. Muell. Fragm. ii. 166.-Austral.

promissa, Mast. in Gard. Chron. (1879) I. 494-Afr. trop.

prostrata, Duch, in Ann. Sc. Nat. Sér. IV, ii. (1Sప̃ 63.-Bolivia.

pubera, F. Baver, ex Duch. in DC. Prod. xv, 1. $484=$ Thozetii.

puhera, R. Br. Prod. 349.-Austral.

puberula, F. Muell. ex Duch, in DC. Prod. xv. I. $48 t$ pubera.

pubescens, Hort. ex C. Koch, Dendrol. ii. 1. 395 tomentosa.

pubescens, Page, ex Steud. Nom. ed. II. i. 133.-Am. bor.

pubescens, Willd, ex Duch, in DC. Prod, xy, I. $450,-$ Bras.

punctata, Balbis, ex Duch. 1. c $\$ 16=$ brachyuri punctata, Lam. Encyc. i. 253.-Ins. S. Doming. pusilla, Pohl, ex Duch. in DC. Prod. xv. 1. to.

Clausseni.

anadriflora, Gueldenst. Reisen Russl. i. 1.21.K....

Caucas.

Raja, Mart. E Zucc. Non. Gen. el Sp. i. z \&.-Bras.

recurvilabra, Hance, in Fourn. But. xi. Isis 75. China.

refracta, Burch. ex Mast. in Mart. Fl. Bras. ir. 11. I\$

Chamissonis:

reniformis, Vell, Fl, Flum, ix, $100=\mathrm{A}$ Kaja.

reniformis, Willd. Sp. Pl. iv, 158.-Ins. S. Noming. repens, Mill. Gard. Dicl. ed. VIll. n. 12.-Mexic. reticulata. Holton, ex I) uch, in DC. Prod, xv, $1, t^{2}$ maxima.

reticulata. Nute, in Trans, ftm. I'hill, Sex. (1s3i) $162-\mathrm{Am}$. bou

reficulata, Seem. 13ot. Vov, Merald, 193 3 = Mathewsi

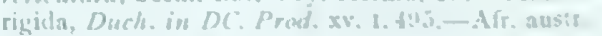
ringens, Link \& Oito, Ic. Pl. Scl. i. \$3. t. IS bravilieusis. 


\section{ARISTOLOCHIA}

ringens, Vahl, Symb. Bot. iii. 99.-Ind. or

rotunda, Bové, ex Duch. in DC. Prod.xv. I. $487=$

longa.

rotunda, Georgi, Beschr, Russ. Reich. iii.v. $1274=\mathrm{A}$

Clematitis.

rotunda, Linn. Sp. Pl. 962,--Reg. Mediterr.

rotunda, Moç. \& Sesse, ex Duch. in DC. Prod. xv. I $442=$ bracteosa.

Roxburghiana, Klotzsch, in Monatsb. Akad. Berl. (1859) 596.-Ind or ; Malaya.

rubromarginata, Fisch. ex Duch, in DC. Prod. xv, $451=$ Leprieurii.

rufomarginata, Leprieur, ex Duch. 1. c. = Leprieurii. rugosa, Lam. Encyc. i. $252=$ obtusata.

Ruiziana, Duch. in DC. Prod. xv. I. 476.-Peruv. rumicifolia, Mart. Es Zucc. Nov. Gen. et Sp. i. 79. Bras.

rumicifolia, R. Schomb. ex Duch. in DC. Prod. xv. I. $44 \pi=$ dictyantha

Rumphii, Kostel. Allg. Med.-Pharm. Fl. ii. 465.-Ins. Banda.

saccata, Hook. f. \& Thoms. ex Klotzsch, in Monatsb. Akad. Berl. (1859) $603=\mathrm{seq}$

saccata, Wall. Pl. As. Rar. ii. 2. t. 103.-Reg. Himal. sagittata, Muhl. ex Duch.in DC. Prod. xv. I, $434=\mathrm{A}$. Serpentaria.

scabrida, Boiss. ex Duch, in DC. Prod. xv, I. $494=$ hirta.

scabridula, Boiss. Diagn. Ser. I. xii. $105=$ paecilantha scandens, Mill. Gard. Dict. ed. VIII. n. 10.-Hispan. Sellowiana, Duch. in DC. Prod. XV. I. $458=$ triangu laris.

sempervirens, Forsk. Fl. Aegypt. Arab. 156.--Arabia. sempervirens, Linn. Sp. Pl. 961.-Creta.

sempervirens, Orph, ex Nym. Consp. $645=$ altissima. sepicola, Mast. in Mart. Fl. Bras. iv. II. 100.-Am. trop.

sericea, Benth. Pl. Hartw. 81.-Mexic.

sericea, Blanco, Fl. Filip. 283.-Ins. Philipp.

Serpentaria, Linn.Sp. Pl. 961.-Am. bor.

sessiflora, DC. ex Duch. in DC. Prod, xv. I, $480=$ nervosa.

sessilifolia, Duch. l. c. 464.-Bras.

setigera, Klotzsch, in Monatsb. Acad. Berl. (1859) 617 $=$ chilensis.

setosa, Duch. in DC. Prod. xv. I. 496.-Bias.

sicula, Tineo, in Guss. Fl. Sic. Syn. ii. 878.-Sicilia.

sinarum, Lindl. in Gard. Chron. (18,59) 708.-China.

Sipho, L'Hérit. Stirp. Nov. 13.-Am. bor.

smilacina, Duch. in DC. Prod. xv. I. 459.-Bras.

somaliensis, Oliver, in Hook. Ic. Pl. t. 1273.-Afr. trop.

Soyauxiana, Oliver, $l$. c. t. 1410.-Afr. trop.

spathulata, Duch. in DC. Prod. xv. I. 448.- Cuba

Sprucei, Mast. in Mart. Fl. Bras. iv, II. 88.-Am. Am. trop

strictiflora, Duch. in DC. Prod. xv. r. $484=$ pubera. subclausa, S. Wats. in Proc. Am. Acad. xx. (1885) 372. -Mexic.

subcordata, Willd. ex Duch. in DC. Prod. xv, I. $468=$ deltoidea.

subglauca, Lam. Encyc. i. 257 ; Brot. F1. Lusit. ii. 593 = baetica.

subsagittata, Blanco, F1. Filip. ed. I. $283=$ A. Tagala surinamensis, Miq. in Linnaea, xviii. (1844) $246=$ macrota.

surinamensis, Willd. $S_{p}$. Pl. iv. 151.-Guiana.

Tagala, Cham. in Linnaea, vii. (1832) 207.-Ins Luzon.

taliscana, Hook. Ar Arn. Bot. Beech. Voy. 309.Mexic.

tamnifolia, Duch in DC. Prod. xy, I. 448.-Bras.

tapetotricha, Lem. Illustr. Hortic. iii. (1856) Misc. 22 $=$ N. macroura.

tenera, Pohl, ex Duch. in DC. Prod. xv. I. 466.Granat.

theriaca, Mart. ex Duch. l. c. 455.-Bras.

Thozeti, F. Muell. Fragm. ii. 167.-Austral.

Thwaitesii, Hook. Bot. Mag. t. 4918.-China

tigrina, A. Rich. Fl. Cub. Fanerog. ii. 194.-Cuba

timorensis, Decne. Herb. Tim. Descr. 41,--Ins. Timor.

tomentosa, Sims, Bot. Mag. t. 1369.-Am. bor.

torta, Willd. ex Duch, in DC. Prod, xy, I, $458=$ inflata

Tournefortii, faub. E Spach, Illustr. ii. 38. t 128 . As. Min.; Ins. Chios.

triactina, Hook. f. in Trans. Linn. Soc. xxv. (1865) 186.-Afr. trop.

\section{ARISTOLOCHIA}

Trianaei, Duch. in DC. Prod. xv. I. 462.-N. Granat

triangularis, Cham. in Linnaea, vii. (1832) 209. t. 6.Bras.

tricaudata, Lem. Illustr. Hortic, xii. (1865) Misc. 49 ; xiii. (1866) t. 523,-Mexic.

trichostoma, Griseb. in Mem. Am. Acad. N. S. viii (1861) 190.-Cuba.

trifida, Lam. Encyc. i. $251=$ trilobata

triloba, Salisb. Prod, $214=$ trilobata.

trilobata, Lam. Encyc. i. 251 = surinamensis.

trilobata, Lindl. Bot. Reg. t. $1399=$ macroura

trilobata, Linn. Sp. Pl. 960.--Ind. occ.

tripteris, Rafin. Fl. Ludov. 24.-Am. bor

trulliformis, Mast. in Mart. Fl. Bras. iv. II. 101.Am. trop.

truncata, Field. E Gardn. Sert. Pl. t. 44.-Peruv.

turbacensis, $H . B . \varepsilon K$. Nov. Gen. et Sp. ii. 149.Am. bor.

Uhdeana, Duch. in DC. Prod. xv. I. 465.-Mexic

undata, Moench, Meth. $719=$ sempervirens.

nngulifolia, Mast. in Fourn. Linn. Soc. xiv. (1875)

494. - Borneo.

utriculata, Seem. Bot. Voy. Herald, $193=$ Mathewsii

valentina, Duch. in Ann. Sc. Nat. Sér. IV. ii. (1854) 39.--Mexic.

variifolia, Duch. l. c. 65.-Mexic

velutina, Duch l. c. 39 -Mexic.

veraguensis, Duch. in DC. Prod. xv. I. 458.-Am. centr.

Wageneriana, Schlecht. in Linnaea, xxvi. (1853) 631. -N. Granat.

Warmingii, Mast. in Mart. Fl. Bras. iv. II. 109.Am. trop.

Weddellii, Duch. in Ann. Sc. Nat. Sér. IV. ii. (1854) 62.-Bras.

Westlandi, Hemsl. in Fourn. Bot. xxiii. (1885) 286.China.

Wrightii, Seem. Bot. Voy. Herald, 331. t. $72=$ brevipes. Zollingeri, Miq. Fl. Ind. Bat. i. 1066.-Java.

ARISTOTELA, Adans. Fam. ii. $125(1763)=$ Othonna, Linn. (Compos.)

ARISTOTELA, J. F. Gmel. Syst. $751(1791)=$ Aristotelia, L'Hérit. (Tiliac.).

ARISTOTELEA, Lour. F1. Cochinch. $522(1790)=$ Spiranthes, Rich. (Orchid.). spiralis, Lour. 1. $\mathrm{c}_{\mathrm{n}}=\mathrm{S}$. australis.

ARISTOTELEA, Spreng. Syst. ii. $450(1825)=$ Aristo telia, L'Hérit. (Tiliac.)

ARISTOTELIA, L'Hérit. Stirp. Nov. 31. t. 16 1784). TILIACEAE, Benth. \& Hook. f. i. 239, Beaumaria, Deless, ex Steud. Nom.ed. II. i. 192 (1840)

Friesia, DC, Prod, i. 520 (1824)

australasica, F. Muell. Fragm. ii. 79.-Austral.

Braithwaitei, F. Muell. in Wing, South. Sc. Record, (1881) $149 .-\mathrm{N}$. Hebrid

Colensoi, Hook, f. Handb. Nerw Zeal. Fl. 33.-N. Zel. erecta, 7. Buch in Trans. N. Z. Inst. iii. (1871) 209 -N. Zel.

fruticosa, Hook. f. Fl. N. Zeal. i. 34.-N. Zel.

glabra, Miers, in Ann. \& Mag. Nat. Hist. Ser. IV. ii (1868) 44 ; et Contrib. Bot. ii. 180.-Am. merid. glandulosa, Ruiz \& Pav. Syst. Veg. $125=$ A. Macqui. Incida, Salisb. Prod. $345=$ A. Macqui.

Macqui, L'Hérit. Stirp. Nov. 31. t. 16.-Chili megalosperma, F. Muell. Fragm. ix. 84.-Austral. peduncularis, Hook. f. Fl. Tasm. i. 52.-Tasmania racemosa, Hook. f. Fl. N. Zeal. i. 33.-N. Zel.

ARIVELA, Rafin. Sylva Tellur. $110(1838)=$ Cleome Linn. (Capparid.).

viscosa, Rafin. 1. c. = C. viscosa.

ARIVONA, Steud. Nom. ed. II. i. $130(1840)=$ Arjona Comm. (Santal.).

ARJONA, Comm. ex Cav, Ic. iv. 57. t. 383 (1797) SANTALACEAE, Benth. \& Hook, f. iii. 220

ARIVONA, Steud. Nom. ed. II. i. 130 (1840) ArJoona, Endl. Gen. 325 (1838)

andina, Phil. in Anal. Univ. Chil. ii. (1862) 405 ; et in Linnaea, xxxiii. (1864-65) 232.-Chili.

\section{ARJONA :-}

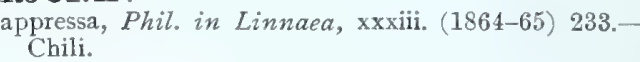

linearis, Miers, in Fourn. Linn. Soc, xvii. (1880) 133. Reg. Argent

Iongifolia, Phil. in Anal. Univ. Chil. ii. (1862) 405.Chili.

minima, Hieron. in Bol. Acad. Nac. Cordova, iv. (1881) 30.-Chili

patagonica, Homb. E' facquinot, ex Decne. Bot. Voy. Astrol. et Zél. 22.-Patagon.

pungens, Phil. in Anal. Univ. Chil. (1873) 537.Chili.

pusilla, Hook.f. Fl. Antarct. ii. 342.-Patagon

rigida, Miers, in Fourn. Linn. Soc. xvii. (1880) 132.Reg. Argent.

ruscifolia, Poepp. in Nov. Act. Nat. Cur. xix. Suppl. i. (1843) (Pl. Meyen.) 112.-Chili.

tuberosa, Cav. Ic. iv. 57. t. 383.-An. merid

tuberosa, Phil. in Linnaea, xxxiii. (1864-65) $231=$ rigida.

ARKEZOSTIS, Rafin. New Fl, Am. iv. $100(1836)=$ Cayaponia, Manso (Cucurb.)

quinqueloba, Rafin. 1. c. =C. Boykinii.

ARKOPODA, Rafin. Fl. Tellur. iii. $73(\mathbf{1 8 3 6})=$ Reseda Tourn.

Luteola, Rafin. 1. c. = R. Luteola

ARMANIA, Bert. ex DC. Prod. v. $576(1836)=$ Encelia, Adans. (Compos.)

fruticulosa, Bert. 1. c.-Am. austr.

ARMENIACA, Toum. ex Mill. Gard. Dict. ed. VI (1752) = Prunus, Tourn, $($ Rosac $)$

amarella, Schur, Enum. P1. Transs. $178=$ P. amarella atropurpurea, Loisel. in Duham. ed. Nov. v. 172. t. $552=\mathrm{P}$, dasycarpa

berricoccia, Delarb. F1. Auv, ed. II. $326=\mathrm{P}$. Ar meniaca.

brigantiaca, Pers. Syn. ii. $36=$ P. brigantiaca.

dasycarpa, Pers. 1. c. = P. dasycarpa.

Davidiana, Carr. in Rev. Hortic. (1879) 237.-China, duracina, Dierb. ex Steud. Nom. ed. II. i. $133=$ P. amarella.

epirotica, Gaertn. Mey, \& Scherb. FI. Wett. ii. 167 $=$ P. Armeniaca.

fusca, Turp. \& Poit. in Nouv. Duham. Arb. Fruit. i. 123. t. $60=\mathrm{P}$. dasycarpa

longifolia, Desc. Fl. Antill. ii. $108=$ P. occidentalis. lucida, May, in Rev, Hortic, (1875) 179= P. Iucida.

Mume, De Vriese, Tuinb. Fl. i. (1855) 1. t. $1=\mathrm{P}$. Mume.

nigra, Pers. Syn. ii. $36=$ P. dasycarpa.

pedunculata, Hort. ex Loud. Hort. Brit. Suppl. ii. $610=\mathrm{P}$. pedunculata

persicifolia, Loisel. in Duham. ed. Nov. v. 172. t. 552 $=\mathrm{P}$. dasycarpa.

sibivica, Pers. Syn. ii, $36=\mathrm{P}$ sibirica

verrucosa, May, in Rev. Hortic. (1875) 299.-As. Min. trichocarpa, M. Roem. Syn. Rosif. $34=$ P. tomentosa. vulgaris, Lam. Encyc. i. $2=$ P. Armeniaca.

ARMENIASTRUM, Lem. Jard. Fleur. iv. (1854) Misc $76=$ Fspadaea, A. Rich. (Verben.)

apiculatum, Lem. 1. c. $78=$ E. apiculata.

ARMERIA, Linn. Syst. ed. I. (1735); Willd. Enum. Hort. Berol. 333 (1809). PLUMBAGINEAE, Benth. \& Hook. f. ii. 626.

Polyanthemum, Medic. in Staatsw. Vorles. Churpf. Phys. Oek. Ges. i. (1791) 228.

alliacea, Ebel \& Hoffmgg. in Hoffmgg. \& Link, Fl. Port. i. 441 = plantaginea,

alliacea, Griseb. Spicil. Fl. Rumel. ii. $296=$ cariensis. alliacea, Mutel, Fl. Fr. iii, 86. f, $405=$ plantaginea,

alliacea, Roem. E Schult. Syst. vi. 773.-Reg. Mediterr, occ.

alliacea, Schousb. Vext. Marok. $146=$ baetica

alliacea, Webb, ex Ball, in Journ. Linn. Soc. xvi (1878) $560=$ mauritanica.

allioides, Boiss. Voy. Bot. Espagne, ii. 524.-Hispan. allioides, Willk. ex Willk. \& Lange, Prod. F1. Hisp. ii. $366=$ longearistata

alpina, Ebel, Armeriae Gen. Diss. (1840) $28=$ Halleri alpina, Frivald. ex Griseb. Spicil. F1. Rumel. ii. 296 = cariensis. 


\section{ARMERTA :-}

alpina, Guss. F1. Sic. Prod. $378=$ nebrodensis.

alpina, Tenore, Syll. 160, ex Boiss. in DC. Prod. xii. $685=$ majellensis

alpina, Turcz. in Bull. Soc. Nat. Mosc. (1838) 99 ;

Xxv. (1852) II. $399=$ sibirica

alpina, Willd. Enum. Hort. Berol. 333.-Europ.

andicola, C. Gay, ex Boiss. in DC. Prod. xii. $682=$ andina.

andina, Poepp. ex Boiss. l. c. - Chili.

androsacea, Boiss. 1. c. $679=$ vulgaris

aretica, Wallr. Beitr. i. 193.-Unalashka.

arcuata, Welw. ex Boiss. \& Reut. Pugill. Pl. Nov. 101 $=$ boetica.

arenaria, Schult. in Roem. \& Schult. Syst. vi. $771=$ maritima.

argyrocephala, Wallr. Beitr. i. 206.-Europ.

atlantica, Pomel, Nouv. Mat. Fl. Atl. 134.-Algeria.

australis, Boiss. Voy, Bot. Espagne, ii. 526.-Hispan.

berlengensis, Daveau, in Bol. Soc. Broter. ii. (1884) 24.-Lusitan.

boetica, Boiss. Voy. Bot. Espagne, ii. 749.-Hispan.

Boissieriana, Coss. Notes Crit. 44.--Hispan.

Bourgaei, Boiss, ex Nym. Consp. $615=$ Duriaei.

brachyphylla, Boiss. in DC. Prod. xii. 682.-Chili.

brevifolia, Kunze, ex Boiss. 1. c. $=$ chilensis.

bupleuroides, Gren. \& Godr. Fl. Fr. ii. $736=$ plantaginea.

caespitosa, Boiss. in DC. Prod. xii. 679.-Hispan.

Lusitan.

campestris, Wallr. Beitr. i. $203=$ maritima.

canescens, Boiss. in DC. Prod. xii. 686.-Dalmatia.

cantabrica, Boiss. E Reut. ex Willk. E Lange, Prod. Fl. Hisp. ii. 366.-Hispan.

cariensis, Boiss. in DC. Prod. xii. 677.-As. Min.

Cephalotes, Hook. Bot. Mag. t. $4128=$ mauritanica

Cephalotes, Hoffmgg. \& Link, Fl. Port. i. $440=$ latifolia.

Cephalotes, Schousb. Vext. Marok. 146=plantaginea.

Cephalotus, Boiss. in DC. Prod. xii. $675=$ pinifolia.

chilensis, Boiss. l. c. 681.-Chili.

Choulettiana, Pomel, Nouv. Mat. Fl. Atl. 135.Algeria.

cinerea, Welw. ex Boiss. E Reut. Pugill. Pl. Nov. 101.-Lusitan.

curvifolia, Colla, in Mem. Acc. Torin. xxxix. (1835) 5.-Hab.?

curvifolia, Bert, in Merc. Chil. 563; et Bull. Férussac, xx. (1830) $108=$ chilensis

denticulata, Bertol. Amoen. Ital. 77.-Italia.

denticulata, Portensch. Pl. Dalm. t. $6=$ canescens.

dianthoides, Hornem. \& Spreng. ex Boiss. in DC.

Prod. xii. $683=$ plantaginea.

Duriaei, Boiss. l. c. 684.- Hispan.

duriuscula, Bab. in Ann. Nat. Hist. Ser. II. iii. (1849) $436=$ pubescens

ebractenta, Pomel, Nouv. Mat. Fl. Atl. 132.-Algeria. elongata, Hofm. Deutschl. Fl. i. 150.-Europ.

elongata, Koch, in Mert. \& Koch, Roehl. Dentschl. FI. ed. III. ii. $487=$ maritima.

eriophila, Willk. in Bol. Soc. Broter. ii. (1884) 145.-$$
\text { Lusitan. }
$$

expansa, Wallr. Beitr. i. $197=$ pubescens.

fasciculata, Willd.Enum.Hort.Berol.i. 334.-Hispan. ; Sardin.

fibrosa, Pomel, Nouv. Mat. Fl. Atl. 133.-Algeria.

filicaulis, Boiss. Voy. Bot. Espagne, ii. 527. t. 154.Hispan.

formosa, Hort. ex Vilm. Fl. Pl. Terre, ed. I. $848=$ Statice Pseudo-armeria,

formosa, Heynh. Nom. ii, 45 = mauritanica.

fruticosa, Lodd. Bot. Cab. t. 1587.-Europ. austr.

gaditana, Boiss. in DC. Prod. xii. 675.-Hispan.;

Irarocco.

glauca, Wallr. Arm, 215 - boetica

glaucescens, Desf. Cat. Hort. Par. ed. III. 79.-Hab. ? globosa, Link, ex, Boiss. in DC. Prod. xii. $684=$ latitolia.

gracilis, Tenore, Syll. $158=$ nebrodensis.

grandifora, Hort. Schwetz. ex Boiss. in DC. Prod. xii. 684 - Intifolia.

Gussonei, Boiss. in DC. Prod. xii. 687.-Sicil.

Halleri, Wallr. Beitr, i. $194=$ alpina.

heterophylla, Wall. i. c. 188 =nebrodensis.

hirta, Pourr. ex Willk. \& Lange, Prod. Fl. Hisp. ii. $369=$ pubigera.

hirta, Willd. Enum. Hort. Berol. 393 - boctica.

humilis, Link, Handb. ii. $263=$ caespitosa.

\section{ARMERIA}

intermedia, Link, ex Boiss, in DC. Prod, xii. $681=$ pubescens.

juncea, Girard, in Ann. Sc. Nat. Sér. III. ii. (1844) 324.-Gall. merid.

juncea, Wallr. Beitr. i. $212=$ allioides.

juniperifolia, Ebel, Armeriae Gen. Diss. (1840) $30=$ filicaulis.

juniperifolia, J. Gay, ex Boiss. in DC. Prod. xii. 684 =Duriaei.

juniperifolia, Koch, in Flora, vi. (1823) $711=1$ euco cephala.

juniperifolia, Willd. ex Hoffmgg. \& Link, F1. Port. i. $442=$ caespitosa

Kochii, Boiss. in DC. Prod. xii. $686=$ leucocephala. labradorica, Wallr. Beitr. i. 185.-Groenl. ; Labrador. lachnolepis, Pomel, Nouv. Mat. Fl. Atl. 134.Algeria.

Langei, Boiss. ex Lange, in Kjoeb. Vidensk. Meddel. (1861) 59.-Hispan.

latifolia, Moris, Fl. Sard. Elench. fasc. iii. $10=$ Morisii.

latifolia, Willd. Enum. Hort. Berol. 334.-Lusitan. leucantha, Salzm. ex Boiss. Voy. Bot. Espagne, ii $525=$ allioides

leucocephala, Koch, in Flora, vi. (1823) 712.-Corsica. littoralis, Boiss. in DC. Prod. xii. $670^{\circ}=$ Welwitschii.

littoralis, Hoffmgg. E Link, Fl. Port. t. i. 441. Lusitan.

littoralis, Willd. Enum. Hort. Berol. $333=$ boetica longearistata, Boiss. Ev Reut. Pugill. Pl. Nov. 103.Hispan.

longearistata, Bourg. in Bull. Soc. Bot. Fr. ii. (1855) $643=$ plantaginea

longifolia, Desf. Cat. Hort. Par. ed. III. 79, nomen.Hab. ?

lusitanica, Link, ex Boiss. in DC. Prod. xii. 675 pinifolia.

macloviana, Cham, in Linnaea, vi. (1831) 567. Ins. Falkland.

macrophylla, Boiss. E Reut. Pugill. Pl. Nov. 100.Hispan.

macropoda, Boiss. in DC. Prod. xii. 688.-Italia.

maculata, Poepp. ex Boiss. 1. c. $082=$ andina.

maderensis, Lowe, in Trans. Camb. Phil. Soc. vi. (1833) 12.-Madera.

majellensis, Boiss. in DC. Prod. xii. 685.-Italia maritima, Girard, ex Boiss. 1. c. $680=$ ruscinonensis. maritima, Willd. Enum. Hort. Berol. 333.-Europ.

mauritanica, Wallr. Beitr. i. 217.-Afr. bor.

meridionalis, Poepp. ex Boiss. in DC. Prod. xii. $682=$ chilensis.

montan $\alpha$, G. Don, ex Loud. Hort. Brit. $114=$ maritima montana, Soleir. ex Wallr. Beitr. i. 196=leucocephala montana, Wallr, 1. c. $210=$ plantaginea.

Morisii, Boiss. in DC. Prod xii. 687.-Sicil.

Muelleri, Huet, in Ann. Sc. Nat Sér. III xix. (1853) $255=$ alpina

multiceps, Wallr. Beitr. i. $196=$ leucocephala. nebrodensis, Guss. Fl. Sic.Syn. i. 366.-Italia neglecta, Girard, in Ann. Sc. Nat. Sér. III. ii. (1844) 324.-Lusitan.

Orphanidis, Boiss. Diagn. Ser. II. iv. $71=$ majellensis. pinifolia, Bourg. ex Nym. Consp. $614=$ macrophylla. pinifolia, Hoffmgg. E Link, Fl. Port. i. 437.-Lusitan planifolia, Nym. Consp. 616 . n. $35=$ pubescens. plantaginea, Boiss. Voy. Bot. Espagne, $526=$ boetica. plantaginea, Willd. Enum. Hort. Berol.334.-Europ. plantaginea, Webb, It. Hisp. $18=$ latifolia.

praecox, Jord. in Bull. Soc. Dauph. fasc. iii. $79=$ plantaginea.

pseudoarmeria, Brot. Fl. Lusit. i. $488=$ plantaginea. psend-Armeria, Murr. Syst. Veg. ed. XIV. $300=$ latifolia.

pubescens, Heyne, ex Stcud. Nom. ed. II. i. $133=$ maritima.

pubescens, Link, 'in Repert. Nat. Cur. Berol. i. 180,'Europ.

pubigera, Boiss, in DC. Prod. xil. $678=$ maritima.

pubinervis, Boiss. l. c. 688,-Gallia.

pungens, Hoffmgg. E Link, Fl. Port. i. 499.-Lusitan. purpurea, Koch, in Flora, vi. (1823) $710=$ elongata,

rhenana, Gremli, Exc. F1. Schw. ed. IV. $850=$ maritima.

rigida, Wallr. Beitr. i. $199=$ plantaginea

rumelica, Boiss, in DC. Prod, xii. $677=$ cariensis

ruscinonensis, Girard, in Ann. Sc. Nat. Sér. III. ii.

(1844) 323.- Hispan

\section{ARMERIA :}

abulosa, Jord. ex Bor. F1. Centr. Fr. ed. III. ii. $537=$ plantaginea.

sanguinolenta, Wally. Beitr. i. 207.-Am. bor.

sardoa, Spreng. Syst. Cur. Post. 127.-Sardin, ; Corsic scabra, Kunze, ex Boiss, in DC. Prod. xii, $683=$ andina. scabra, Pall. in Willd ex Roem. Es Schult. Syst. yi. 776.-As. bor.

scabriuscula, Kunze, ex Boiss. in DC. Prod. xii. $683=$ andina.

scorzoneraefolia, Tenore, Syll. $160=$ macropoda

scorzoneraefolia, Willd. Enum. Hort. Berol. $334=$ plantaginea.

corzoneraefolia, Link, in Schrad. Journ. iii. (1800) $60=$ latifolia

scorzonerifolia, Balb. \& Nocca, F1. Ticin. t. $B=$ planta ginea.

scorzonerifolia, Friv. ex Nym. Consp. $615=$ rumelica.

setacea, Delile, ex Nym. I. c. $616=$ juncea.

seticeps, Reichb. Ic. F1. Germ. v. $54=$ plantaginea.

sibirica, Turcz. ex Boiss. in DC. Prod. xii. 678. Sibiria.

sicula, Heldr. ex Boiss. 1. c. $685=$ nebrodensis

simplex, Pomel, Nouv. Mat. Fl. Att. 132.-Algeria

Soleiroliz, Duby, Bot. Gall. Suppl. $1032=$ leucoce phala.

spinulosa, Boiss, in DC. Prod. xii. 675.-Parbaria.

splendens, Boiss. Voy. Bot. Espagne, ii. 749.-Hispan.

stenophylla, Girard, in Ann. Sc. Nat. Sér. III. 1844) $323=$ plantaginea.

tenuis, Balb, ex Boiss, in DC. Prod. xii. $685=$ sardoa.

tenuis, Wallr. Beitr i 184 - filicaulis.

thessala, Boiss. Diagn. Ser. II. iv. $70=$ cariensis

Thomasii, Nym. Consp. 615 -leacocephala.

tingitana, Boiss. \& Reut. Pugill. P1. Nov. $102=$ gaditana.

trigonoides, Hort. Berol, ex Ebel, Armeriae Gen. Diss. (1840) $34=$ plantaginea.

undulata, Boiss. in DC. Prod. xii. $685=$ argyro cephala.

velutina, Welw. ex Buiss, E Reut. Pugill. Pl. Nor. 100.-Lusitan.

vestita, Willk. in Willk. \& Lange, Prod. Fl, Hisp. it. $366=$ longearistata

villosa, Girard, in Ann. Sc. Nat. Sér. III. ii. (184t) 323.-Hispan.

vulgaris, Moris, Elench. ex Nym. Consp. $615=$ sardoa.

vulgaris, Vis, Fl, Dalmat. ii. $6=$ canescens.

vulgaris, Willd, Enum. Hort. Berol. $333=$ elongata.

Welwitschii, Boiss. in DC. Prod. xii. 676.-Hispan.

Willkommii, Henriques, in Bol. Soc. Broter. iii. il 158 199, 224.-Hispan.

ARMERIASTRUM, Lind1. Veg. Kingd. 641 (1847) = Acantholimon, Boiss. (Plumbag.)

ARMODORUM, Breda, Orch. Kuhl. \& Hass. (1827) Arachnanthe, Blume (Orchid.)

distichum, Breda, 1. c. [t. 6]=Arachnanthe Sulingi,

ARMORACIA, Gaertn. Mey. ò Scherb. Fl. Wett. i. 426 (1800); Bernh. Syst. Verz. Erf. ' 258 ' (1800)= Cochlearia, Linn. (Crucif.)

amphibia, Peterm. Fl. Lips. Excurs. $477=$ Vasturtium amphibium.

aquatica, Kostel. Allg. Med.-Pharm. Fl. v. Iiile Nasturtium amphibium.

austriaca, Wimm. Fl. Schles. 1841) $30=$ Nasturtium austriacum.

lapathifolia, Gilib. Fl. Lituan. ii. $58=$ C. Armoracia. macrocarpa, Baumg. Enum. Sitip. Transsylv. ii. $2 t U=$ C. macrocarpa.

rustica, Schur, in Verh. Siebenb. Ver. Naturw. (185s) $8=$ seq

rusticana, Gaertn. Mey. \& Siherb. HL. Wert. ii. $426^{\circ}=$ C. Armoracis

sativa, Bernh. Syst. Verz. Erf. 191 C. Armoracia. valdiviana, Phil. in Linnaca, xxviii. (1850) 6il. Chili.

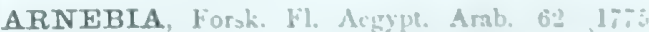
$B() R^{2}+G / A E A E$. Benth. \& Houk. fo ii, $\$ 6$ ?

DIOCLEA, Sprong. Syst, i. 502,1325

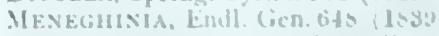

StenosolextuM. Turcz, in liull. Soe Nat, Mose $1040 \div 253$. 


\section{ARINEBIA :}

Strobila, G. Don, Gen. Syst. iv. 327 (1837)

Toxostigma, A. Rich. Tent. F1. Abyss, ii. 86. t. 77 (1851).

Bungei, Boiss, Fl. Orient. iv. 215.-Persia

calycina, Stev, in Bull. Soc. Nat. Mosc. (1851) $598=$ cornuta.

Cephalotes, A. DC. in DC. Prod. X. $96=$ Macrotomia Cephalotes.

cornuta, Fisch. \& Mey. Ind. Sem. Hort. Petrop. i. 1835) 22.-Oriens; Turkest.

decumbens, Coss, Ev Kralik, in Bull. Soc. Bot. Fr, iv. 1857) 398, 402.-Oriens.

densiflora, Ledeb. F1. Ross. iii. $140=$ Macrotomia Cephalotes.

echioides, A. DC. in DC. Prod. x. 96= Macrotomia echioides.

endochroma, Aitch, in Journ. Linn. Soc. xviii. (1882) $81=$ Macrotomia perennis.

fimbriata, Maxim. in Bull. Acad. Pétersb. xxvii. (1881) 507.-As. centr

fimbriopetala, Stocks, in Hook. Kew Fourn. iii. (1851) 180.-Persia; Beluchist.

flavescens, Boiss. Diagn. Ser. I, xi. 117=linearifolia.

Griffithii, Boiss. l. c. Ser. II. iii. 135.-Ind. bor. occ. Affghan.

guttata, Bunge, Ind. Sem. Hort. Dorpat. (1840) 7.Sibir.

hispidissima, DC. Prod. x. 94.-Afr. trop.; Arab.; Ind. bor. occ.

linearifolia, $D C$. . . c. 95.-Aegypt.; Syria; Persia

longiflora, C. Koch, in Linnaea, xxii. (1849) $640=$ Macrotomia echioides.

minima, Wettstein, ex Stapf, in Denkschr. Acad. Wien, 1. (1885) 30.--Persia.

obovata, Bunge, in Mém.Sav. Etr. Pétersb. vii. (1851) 407 (Lehm. Rel. Bot. 231).-Turkest.; Ind. or.

Olgae, Regel, Pl. Nov. Fedsch. 58.-As. centr.

perennis, A. DC. in DC. Prod. x. $95=$ Macrotomia perennis.

Sewerzowi, Regel, Pl. Nov. Fedsch. 58.-As. centr.

tetrastigma, Fiorsk. Fl. Aegypt. Arab. 62.-Arab.

Thomsoni, C. B. Clarke, in Hook. f. Fl. Brit. Ind. iv 176.- Tibet. occ

tibetana, Kurz, in Fourn. As. Soc. Beng. xliii. (1874) II. 189.- Tibet. occ.

tinctoria, Forsk. Fl. Aegypt. Arab. 63.-Aegypt.; Arab.

tinorens, A. DC in DC. Prod. x, 96= Macrotomia

perennis.
Vivianii, Coss. \& Dur. ex Coss. in Ann. Sc. Nat. Sér. IV.i. (1854) $240=$ cornuta.

ARNEDINA, Reichb. Nom. 'n. 1984' (1841)= Arundina, Blume (Orchid.).

ARNICA, Rupp. ex Linn. Syst. ed. I. (1735), COMPOSITAE, Benth. \& Hook. f. ii. 440.

alpina, Olin $\mathcal{F}^{\prime}$ Ladau, Diss. 11.-Europ.; Am. bor.

alpina, Salisb. Prod. $201=$ Doronicum scorpioides.

alpina, Willd, ex Steud. Nom. ed. I. $70=$ montana.

altaica, Turcz. in Bull. S c. Nat. Mosc. xx. (1847) II. 12.-Mont. Altai.

amplexicaulis, Nutt. in Trans, Am. Phil. Soc. N. S. vii. (1841) 408.-Am. bor. occ

amplexicaulis, Wall. ex DC. Prod. vi. $314=$ Senecio amplexicaulis.

angustifolia, A. Gray, in Am. Journ. Sc. Ser. II. xxxiii. (1862) $238=$ Parryi.

angustifolia, Turcz. ex Ledeb. F1. Ross. ii. 622= montana.

angustifolia, Vahl, F1. Dan. t. 1524=alpina.

auriculata, Willd, ex Ledeb. F1. Ross. ii. $632=$ Senecio caucasicus.

austriaca, Hoppe, ex Schur, Enum. P1. Transs. $340=$ Doronicum austriacum

Bellidiastrum, All. F1. Pedem. i. $205=$ Aster Bellidiastrum.

brevicanlis, Rafin. New Fl. Am. ii. 23.-Am. bor.

caffra, Linn. Syst. ed. X. 1219.-Afr. austr.

Chamissonis, Less. in Linnaea, vi. (1831) 238.-Am. bor.; Unalaschk

ciliata, Thunb. Fl. Jap. $318=$ Hypochoeris grandiflorus.

Claytoni, Pursh, Fl. Am. Sept. ii. 527=nudicaulis.

Chusii, All. Fl. Pedem. i. 205. t. 17. f. $1=$ Doronicum Clusii.

\section{ARNICA :-}

cordata, E. Mey. ex DC. Prod. vii. $16=$ Gerbera tomentosa.

cordata, Thunb. Prod. P1. Cap. 154=Gerbera cordata cordata, Wulf. in Roem. Arch. iii. III. 408=Doronicum cancasicum.

cordifolia, Hook. Fl. Bor. Am. i. 331.-Am. bor.

coronopifolia, Linn. Sp. P1. $885=$ Gerbera coronopifolia.

corsica, Loisel. F1. Gall. 576. t. $20=$ Doronicum corsicum.

crenata, Thunb. Prod. Pl. Cap. $154=$ Mairia crenata. crocea, Linn. Sp. PI. $885=$ Gerbera Burmanni.

discoides, Benth. Pl. Hartw. 319.-Calif.

Doronicum, Jacq. F1. Austr. i. $57=$ Senecio Doronicum.

Doronicum, Pursh, Fl. Am. Sept. ii. 528=Senecio Pseudo-arnica.

floccosa, Bert. ex DC. Prod. vi. $357=$ Senecio arachnoideus.

foliosa, Nutt. in Trans. Am. Phil. Soc. N.S. vii. (1841 407.-Am. bor.

fulgens, Pursh, Fl. Am. Sept. ii. $527=$ alpina.

Gerbera, Burm. f. F1. Cap. Prod. $27=$ Gerbera ferrurinea.

Gerbera, Linn. Sp. Pl. $885=$ Gerbera asplenifolia

glacialis, Wulf. in Jacq. Coll. i. 230 ; et Ic. Rar. iii 15. $t .586=$ Doronicum glaciale.

grandis, Thunb. Prod. P1. Cap. 154=Alciope lanata. helvetica, G. Don, ex Loud. Hort. Brit. $351=$ montana hirsuta, Forsk. Fl. Aegypt. Arab. $151=$ Gerbera hirsuta.

incana, Pers. Syn. ii. $452=$ Trichocline incana.

intermedia, Turcz. in Bull. Soc. Nat. Mosc. xxiv. (1851) I. 203.--Sibir.

inuloides, Vahl, Symb. Bot. ii. $91=$ Heterolepis decipiens.

japonica, Thunb. Fl. Jap. $319=$ Senecio japonicus. lanata, Thunb. Prod. Pl. Cap. $154=$ Alciope lanata. lanceolata, Nutt. in Trans. Am. Phil. Soc, N. S. vii. (1841) $407=$ Chamissonis

lanigera, Tenore, Prod. Fl. Neap. (1811) $49=$ Senecio arachnoidens.

latifolia, Bongard, V'́g. Isl. Sitch. 29.-Am. bor, occ. linifolia, Wall. Cat. n. $3285=$ Senecio linifolius. longifolia, Eaton, in Bot. King, Exped. 186.-Am. bor. occ.

macrophylla, Nutt. in Trans. Am. Phil. Soc. N. S. vii 1841) $408=$ cordifolia

maritima Linn. Sp. Pl. $884=$ Senecio Pseudo-arnica

Menziesii, Hook. Fl. Bor. Am. i. 331 = latifolia.

microphylla, Walp. Rep. ii. 652 , err. typ.=macro phylla.

Mollii, Schrank, Prim. Fl. Salisb. 213.-Europ.

mollis, Hook. Fl. Bor. Am. i. $331=$ Chamissonis.

montana, Hook. ]. c. 330 (pro parte) $=$ foliosa

montana, Linn.Sp. Pl. 884.-Europ.; As. bor

nevadensis, A. Gray, in Proc. Am. Acad. xix. (1883) 55 -Calif.

nivea, Wall. Cat. n. $3143=$ Gerbera nivea

nudicaulis, Ell. Sketch ii 333.-Am. bor.

obtusifolia, Less. in Linnaea, vi. (1831) 236.-Una laschk.

obtusifolia, Wall. ex DC. Prod. vi. $314=$ Senecio arnicoides.

operina, Rich. \& Less. Fl. Nov, Zel. 231=seq

oporina, Forst. f. Prod. $56=$ Olearia operina

palmata, Thunb. F1. Jap. $319=$ Senecio syneilesis

Parryi, A. Gray, in Am. Nat. viii. (1874) 213.Am. bor. occ.

parviflora, A. Gray, in Proc. Am: Acad. vii. (1868) 363 - Calif.

peruviana, Pers. Syn. ii. $452=$ Werneria rigida.

petiolata, Schur, Enum. Pl. Transs. 342.-Lurop.

Pilosella, Burm. ex DC. Prod. vii. 17. (= an Arctotidea -Cf. $D C$. in loc.). - Afr. austr.

piloselloides, Linn. P1. Afr. Rar. 22. n. $73(1760)=$ Gerbera piloselloides.

plantaginea, Pursh, Fl. Am. Sept. ii. 527.-Am. arct.

plantaginisfolia, Gilib. F1. Lituan. i. $210=$ montana. pyrolaefolia, Pers. Syn. ii. $454=$ Gerbera Burmanni. rotundifolia, Willd. Sp. Pl. iii. $2110=$ Bellium rotundifolinm.

sachalinensis, A. Gray, in Proc. Am. Acad.xix. (1883 55.-Ins. Sachal.

scorpioides, Adams, ex Ledeb. F1. Ross. ii. $632=$ Senecio caucasicus.
ARNICA :-

scorpioides, Facq. Austr. iv. 26.t. 349.-Europ scorpioides, Linn. Sp. Pl. $884=$ Doronictm grandi-
florum.

senecionoides, Fenzl, ex Boiss. Fl. Orient. iii. $396=$ Senecio cilicius.

serrata, Thunb. F1. Cap. ed. Schult. $669=$ Gerbera ferruginea.

sinuata, Thunb. Prod. Pl. Cap. 154= Gerbera ferruginea. spinulosa, Pers. Syn. ii. $452=$ Alciope tabularis.

styriaca, Vill. Prosp. $32=$ Doronicum Clusii.

tabularis, Thunb. Prod. Pl. Cap. 154=Alciope tabilaris.

tussilaginea, Burm. f. F1. Ind. $182=$ Senecio Kaem-

pferi.
unalaschkensis, Less. in Limnaea, vi. (1831) 238.-Ins. Aleut.; Unalaschk.

viscosa, A. Gray, in Proc. Am. Acad. xiii. (1878) 374. -Calif.

Wulfeniana, Pollini, in Giom. Fis. Pav. ix. (1826) 185 Doronicum Columnae.

ARNOCRINIUM, Endl. \& Lehm, ex Lehm. Pl Preiss. ii. 41 (1846). LILIACEAE, Benth. \& Hook. f. iii. 795

Drummondii, Endl. ex Lehm. l. c.-Austral.

glabrum, Baker, in Fourn. Linn. Soc. xvii. (1880) 416 - Austral.

Preissii, Lehm. Pl. Preiss. ii. 42.-Austral.

ARNoGlossuM, S. F. Gray, Nat. Arr. Brit. Pl. ii. 292 (1821) = Plantago, Tourn

alpinum, S. F. Gray, 1. c. $294=$ P. alpina

gramineum, S. F. Gray, 1, c. $293=$ P. maritima

incanum, S. F. Gray, 1. c. $292=$ P. media

lanceolatum, S. F. Gray, 1. c. $293=$ P. lanceolata maritimum, S. F. Gray, 1. c. = P. maritima. subulatum, S. F. Gray, I. c. $294=$ P. Coronopus.

ARNOGLOSSUM, Rafin. FI. Ludov. 64 (1817). COMPOSITAE.

plantagineum, Rafin. 1. c. 65 (quid?).-Am. bor.

ARNOLDIA, Blume, Bijdr. $868(1826)=$ Weinmannia, Linn. (Saxifr.)

fraxinifolia, Blume, in Flora, xli. (1858) $254=\mathrm{W}$ fraxinifolia, $M i q$.

heterophylla, Blume, Bijdr. $868=\mathrm{W}$. Blumei, $A$. Gray

pinnata, Blume, 1. c. =W. Blumei, Planch.

ARNOLDIA, Cass. in Dict. Sc. Nat. xxx. $330(1824)=$ Dimorphotheca, Moench (Compos.).

aurea, Cass. 1. c. $331=\mathrm{D}$. chrysanthemifolia.

chrysanthemifolia, Steud. Nom. ed. II. i. $256=\mathrm{D}$ chrysanthemifolia.

Tragus, Steud. Nom. ed. II. i. $256=$ D. Tragus.

Ventenatiana, Presl, Repert. 192, in nota $=$ D. chrysanthemifolia.

viscosa, Steud. Nom. ed. II. i. $256=$ D. cuneata.

ARNOPOGON, Willd. Sp. P1. iii. $1496(1803)=$ Uro spermum, Scop. (Compos.).

asper, Willd. 1. c. $1497=\mathrm{U}$. picroides

capensis, Willd. I. $c_{.}=\mathrm{U}$. picroides.

Dalechampii, Willd. 1. c. $1496=$ U. Dalechampii.

picroides, Willd. 1. $\mathrm{c} .=\mathrm{U}$. picroides.

ARNOSERIS, Gaertn. Fruct. ii. 355. t. 157 (1791) COMPOSITAE, Benth. \& Hook. f. ii. 507

foetida, Dum. F1. Belg. $63=$ Crepis foetida.

gracilis, Sch. Bip. in Pollichia, xxii-xxiv. (1866) $301=$ Apogon gracilis.

humitis, Sch. Bip. 1. c. = Apogon humilis.

minima, Dum. F1. Belg. $63=$ pusilla.

pusilla, Gaertn. Fruct. ii. 355. t. 157.-Earop.

ARNOTTIA, A. Rich, in Mém. Soc. Hist. Nat. Par. iv. (1828) 29. ORCHIDEAE, Benth. \& Hook. f. iii. 622.

inermis, S. Moore, in Baker, Fl. Maurit. 339.-Ins. Mascar.

mauritiana, A. Rich. in Mem. Soc. Hist. Nat. Par. iv. (1828) 30.-Ins. Mascar.

AROMADENDRON, Blume, Bijdr. 10 (1825)=Ta lauma, Juss. (Magnol.).

elegans, Blume, 1. c. $10=$ T. elegans.

glaucum, Korth. ex Miq. Fl. Ind. Bat. i. 2. 16= T. glauca. 
AROMADENDRON, Andr, ex Steud, Nom. ed. II. i. 134 (1840) et AROMADENDRUM, Andr. ex Stend. 1. c. 599, in syn. $(1840)=$ Eucalyptus, L'Hérit. (Myrtac.).

AROMIA, Nutt. in Trans. Am. Phil. Soc. Ser. II. vii. (1841) $395=$ Amblyopappus, Hook. (Compos.). tenuifolia, Nutt. 1. c. $396=$ Amblyop. pusillus.

ARON, Adans. Fam. ii, 470 (1763).

dracunculum, St. Lag, in Ann. Soc. Bot. Lyon, vii. (1880) $119=$ Dracunculus vulgaris.

colocasium, St. Lag. 1. c. = Colocasia antiquorum.

ARONGANA, Choisy, in DC. Prod. i. 541 (1824)= Haronga, Thou. (Hyperic.).

ARONIA, Mitchell, in Act. Acad. Nat. Cur. viii. (1748) 206, App $=$ Orontium, Linn. (Aroid.).

A.RONIA, Medic. Phil. Bot. i. $140(1789)=$ Osteomeles, Lindl. (Rosac.).

ARONIA, Pers. Syn. ii. $39(1807)=$ Amelanchier, Lindl. (Rosac.).

affinis, Neum. ex Tausch, in Flora, xxi. (1838) r. Beibl. i. $77=$ Amel. canadensis.

alnifolia, Nutt. Gen. Am. i. $306=$ Amel. alnifolia.

Amelanchier, Dum, Fl. Belg. $92=$ Amel. vulgaris.

arborea, Barton, Comp. Fl. Phil. i. $228=$ Amel. canadensis.

arbutifolia, Medic. Phil. Bot. i. $140=$ Pyrus arbuti. folia.

aria-chamaemespilus, Reichb. Fl. Germ. Excurs. $630=$ Pyrus Chamaemespilus

asiatica, Sieb, \& Zucc. Fl. Jap. i. 87. t. $42=$ Amel. canadensis.

Botryapium, Pers. Syn. ii. $39=$ Amel. canadensis.

Chamaemespilus, Pers, 1. c. = Pyrus Chamaemespilus.

cordata, Rafin. Med. Fl. ii. $196=$ Amel. canadensis.

cretica, Pers. 1. c. $40=$ Amel, vulgaris.

densiftora, Spach, Hist. Vég. Phan. ii. $88=$ Pyrus arbutifolia.

depressa, Spach, 1. c. $90=$ Pyrus arbutifolia.

floribunda, Spach, 1. c. $89=$ Pyrus arbutifolia

floribunda, Sweet, Hort. Brit. ed. I. $485=$ Pyrus spectabilis.

glabrescens, Spach, Hist. Vég. Phan. ii. $89=$ Pyrus arbutifolia.

grandifolia, Sweet, Hort. Brit. ed. II. $177=$ Pyrus arbutifolia.

Hostii, Carr. in Rev. Hortic. (1873) $470=$ Pyrus intermedia.

japonica, Hort. ex C. Koch, Dendrol. i. 179= Pyrus japonica.

latifolia, Riddell, Suppl. Cat. Pl. Ohio, 24=Amel. canadensis?

melanocarpa, Nutt. ex Ell. Sketch, i. $556=$ Fyrus arbutifolia.

nivea, Neum. ex Tausch, in Flora, xxi. (1838) $714=$ Amel. canadensis.

ovalis, Pers. Syn. ii. $39=$ Amel. canadensis.

petraea, Wallr. Beitr. Fl. Hercyn. 206.-Europ.

praecox, Neum. ex Tausch, in Flora, xxi. (1838) $715=$ Amel. canadensis.

pubens, Spach, Hist. Vég. Phan. ii. $90=$ Pyrus arbutifolia.

pumila, M. Roem. Syn. iii. Rosiff. 161= Pyrus arbutifolia.

pyrifolia, Lam. Encyc. i. $83=$ Pyıus arbutifolia.

racemosa, Schur, Enum. Pl. Transs. 207 = Amel racemosa,
cretica.

rotundifolia, Pers. Syn. ii, $39=$ Amel. vulgaris.

sanguinea, Nutt. Gen. Am. i. $306=$ Amel. canadensis. sorbifolia, Spach, Hist. Veg. Phan. ii. $87=$ Pyras spuria.

spuria, M. Roem. Syn. iii. Rosifl, $158=$ Pyrus spuria.

subcordata, Rafin. ex DC. Prod, ii, $632=$ Amel, canadensis.

tomentosa, Wallr. Beitr. Fl. Hercyn. 206=Amel. vulgaris?

Watsoniana, M. Roem. Syn. iii. Rosif. 159=Pyrus pinnatifida.

ARONICUM, Neck. Elem. i. $27(1790)=$ Doronicum, Linn. (Compos.)

altaicum, DC. Prod, vi. $320=$ D. altaicum.

\section{ARONICUM :-}

Bauhini, Reichb. f. Ic. Fl. Germ. xvi. $32=$ D hirsutum.

carpathicum, Schur, in Verh. Siebenb. Ver. Naturw. x. (1859) $137=\mathrm{D}$. grandiftorum.

Clusii, Koch, Syn, ed. I. $382=$ D. hirsutum.

cordatum, Schur, in Verh. Siebenb. Ver. Naturw. iv. 1853) $41=\mathrm{D}$. cordatum.

corsicum, DC. Prod. vi. $319=$ D. corsicum.

Doronicum, Reichb. F1. Germ. Excurs. $233=$ D. Clusii. glaciale, Reichb. 1. c. $234=$ D. glaciale.

latifolium, Reichb. 1. $\mathrm{c}=$ = D. grandiflorum.

scorpioides, DC. Prod. vi. 319 ; Koch, Syn. ed. I. $382=$ D. grandiflorum.

scorpioideum, St. Lag. in Ann. Soc. Bot. Lyon, vii (1880) $119=\mathrm{D}$, grandiflorum.

wiscosum, Freyn \& Gantier, in Bull. Soc. Bot. Fr. xxviii (1881) 50.-Europ.

AROSMA, Rafin. Fl. Tellur. iii. $66(1836)=$ Caladium Vent. (Aroid.)

acutifolia, Rafin. I. $\mathrm{c}_{\mathrm{s}}=\mathrm{C}$. bicolor?

obtusifolia, Rafin, 1. c, = C. bicolor?

AROTON, Neck. Elem. ii. $336(1790)=$ Croton, Linn (Euphorb.).

AROUNA, Aubl. Pl. Gui. i. 16. t. 5 (1775)=Dialium, Linn. (Legumin.).

divaricatum, Willd. Sp, $\mathrm{Pl}$, i, $156=\mathrm{D}$, divaricatum. guianensis, Aubl. PI. Gui. i, $16=$ D. divaricatum.

ARPITIUM, Neck. Elem. i. $168(1790)=$ Ligusticum Linn. (Umbell.)

simplex, Sweet, Hort. Brit. ed. II. $591=\mathrm{L}$. simplex.

ARPOPHYLLUM, Llave \& Lex. Nov, Veg. Descr fasc. ii. (Orch. Opusc.) 19 (1825). ORCHIDEAE Benth. \& Hook. f. iii. 492.

alpinum, Lindl. in Benth. Pl. Hartw. 93 (1842).Mexic.

cardinale, Linden $\mathrm{E}^{\circ}$ Reichb. f. in Bonplandia, ii. (1854) 282.-Mexic

giganteum, Hartw. ex Lindl. in Ann. Nat. Hist. iv (1840) 384--Mexico.

medium, Reichb. f. Beitr. Orch. Centr. Am. 89.Guatemala.

spicatum, Llave Er Lex. Nov. Veg. Descr. fasc. ii. (Orch. Opusc). 20,-Mexico.

squarrosum, Hort. Donat. ex Lubbers, Cat. P1. Rar. San Donato $(1850) 15=$ spicatum.

ARRABIDAFA, DC. in Bibl. Univ, Genèv, xvii (1838) 126 (Rev, Bign, 10), BIGNONIACEAE, Benth. \& Hook. f. ii. 1032 .

Chasmia, Sichott, in Spreng. Syst. Cur. Post. 409 (1827).

VASCONCELliA, Mart. in Flora, xxiv. (1841) II

Beibl. 12 (Herb. Fl. Bras. 252)

acutifolia, $D C$. Prod. ix. 185.-Bras.

Agnus-castus, DC. l. c. 183.-Bras.

argentea, Wawra, in Oestr. Bot. Zeitschr. (1879) 216 -Bras.

Blanchetii, DC. Prod. ix. $186=$ Bignonia Blanchetii.

candicans, $D C$. l. c. 185 -Guiana.

Chica, Verl. in Rev. Hortic. (1860) $154=$ Bignonia Chica.

Clausseni, DC. l. c. 186.-Bras.

conjugata, Mart. in Flora, xxiv. (1841) I1. Beibl. 46.Bras.

corchoroides, DC. Prod. ix. 183.-Bras.

cordifolia, Klotzsch, in Schomb. Fauna है Fl. Guy.

1158.-Guiana.

desertorum, DC. Prod. ix. 185.-Bras.

fasciculata, $D C$. l. c.-Bras.

forida, DC.l.c. 184.-Bras

obovata, DC. . . C. 185--Bras.

Orbignyana, $D C$. l. c. 184-Bolivia.

paniculata, Seem. in Trans. Linn. Soc. xxiii, (1862) 14 -Ins. Martinic.

platyphylla, $D C$. Prod. ix. 180.-Bras.

Pleei, DC. l. c. 184.-Venezuela.

pruinosa, Klotosch, in Schomb. Fanna E Fl. Guy. 1158

$$
\text { -Guiana. }
$$

rosea, $D C$. Prod. ix. 185.-Bras.

rubrinervis, Miers, in Proc. Roy. Hort. Soc. iii. (1863) 192.-Bras.

Salzmanni, DC: Rev. Bign. 10. (1838).-Bras.

\section{ARRABIDAEA}

Sego, DC. in Bibl. Univ. Genèv. xvii. (1838) 126 ; et Prod. ix. $183=\mathbf{A}$. Agnus-castus.

Sieberi, DC. l. c. 186.-Bras.

subincana, DC. 1. c. $184=$ Lignonia subincana.

tuberculata, $D C$. l. . c.-Bras.

virescens, $D C$. l. $C$. - Bras.

ARRABIDAEA, Stend. Nom. ed. II. i. $135(1840)=$ Cormonema, Reissek (Rhamn.)

spinosa, Steud. 1. c. =C. spinosum.

ARRACACHA, DC. in Bibl. Univ. Genèv. xl. (1829) 74 et Prod. iv. $243(1830)=$ seq.

ARRACACIA, Bancr. in Jamaic, Journ, iv. (1826 18. UMBELLIFERAE, Benth. \& Hook. f. i. 884. Arracacira, DC: in Bibl. Univ. Genèv. xl. (Is29) 74 ; et Prod. iv. 243 (1830)

Bancrofta, Eillb, in Linneska Samfund. Handl, i. 1832 (1833) 39

DEWEYA, Torr. \& Gray, Fl. N. Am, i. 641 (1840)

PENTACRYPTA, Lehm, in Linnaea, y (1830, 380, t. 5 .

Velaea, DC. Prod. iv. 230 (1830).

acuminata, Benth. Pl. Hartw. 187.-Mexico.

atropurpurea, Benth. Eo Hook. f. ex Hemsl. Biol. Centr. Am. Bot. i. 564.-Mexico.

decumbens, Benth. Eo Hook. f. l. c.-Mexico.

esculenta, DC. Prod. iv. $244=$ xanthorrhiza.

glaucescens, Benth. Pl. Hartw. 187.-Mexico. moschata, DC. Prod. iv. 244.-Am. merid.

tolucensis, Hemsl. Biol. Centr. Am. Bot. i. 564.

Mexico.

xanthorrhiza, Bancr. in Famaic. Fourn. iv. (1826) 18. -Jamaica.

ARRHENACHNE, Cass, in Dict. Sc. Nat. lii. 253 $(1828)$ = Baccharis, Linn. (Compos.)

juncea, Cass. 1. c. = B. juncea.

ARRHEN ATHERUMI, Beauv, Agrost. 55. t. 11. . . 5 (1812). GRAMINEAE, Benth. \& Hook. f. jii. 1161 .

americanum, Beauv. 1. c. $56=$ Avena pensylvanica. asperum, Opiz, in Lotos, iii. 1853) $65=$ avenaceum avenaceum, Beauv. Agrost. 55. t. 11. f. 5-Europ. avenaceum, Boiss. Voy. Bot. Espagne, ii. $657=$ erianthum.

biaristatum, Peterm. Fl. Lips. Excurs. $106=$ avenaceum bulbosum, Kunze, ex Anderss. in Malp. Ann. vi. 1003 = erianthum.

bulbosum, Presl, Cyp. et Gram. Sic. 29 = avena ceum.

cechicum, Opiz, in Lotos, iii. (1853) $66=$ avenaceum. elatius, Beauv. Agrost. $56=$ avenaceum.

erianthum, Boiss. E Reut. Diag. Pl. Hispan. 121. -Lusit.; Alg.

exserens, Opiz, in Lotos, iii. (1853! 65 = avenaceurn,

kentuckense, Torr. ex Stered. Nom ed. II i. 135.

Am. bor.

Kotschyi, Boiss. Diagn. Ser. I. vii. 122.-Oriens.

longifolium, Dulac, $\mathrm{Fl}$. Hautes-Pyr. 78 = pallens. palaestinum, Boiss. Diagn. Ser. I. xiii. $51=$ avenacenm. pallens, Link, Hort. Berol. i. 124.-Lusit; Hisp. pennsylvanicum, Torr. Fl. N. Am. i. $130=$ Avena pensylvanica.

precatorium, beauv. Agrost. $56=$ avenaceum.

rivulare, Opis, in Lotos, ii.. (1853) 65.-Europ.

rupestre, Dum. Obs. Gram. Belg. 146.-Europ.

Thorei, Desm. Cat. Dord. $(\mathbf{1 8 4 0})=$ pallens.

ravadilianum, Opiz, in Lotos, iii. (155\$) 66 avenaceum.

ARRHOSTOXYLON, Mart. ex Nees, in Mart. F1. Bras. ix. 57. t. 6 et $209(184 \vec{i})=$ seq.

ARkHostoxyl.UM, Mart ex Vies, in DC. Prod. xi. $209(154)=$ Ruellia, Linn. Acanth.

achimenifurum, Oerst. in Kjocb. Vidensk. Medilel. $(1854) 131=\mathrm{R}$. achimenillurum.

acutangulam, Mart. ex Nees, in Mart. Fl. Bras. ix. 35 $=\mathbf{K}$. acutangula.

afine, Nces, in Mart. Fl. Bras, ix. 59.-Bras.

album, Nees, I. c. $60=$ Kiucilia alba.

amplexicaule, Necs, I. c. 59.- - lbras.

ciliatiflorum, Nees, in DC. Prod. xi. $210=$ R. ciliati llura. 
ARRHOSTOXYLUM :-

coccineum, Nees, in Mart. Fl. Bras. ix. $63=$ R. coccinea.

costatum, Nees, 1. c. $61=$ R. costata

curvifiorum, Nees, 1. c. $62=\mathrm{R}$. curviflora.

formosum, Nees, in DC. Prod. xi. $215=\mathrm{R}$. formosa.

fulgidum, Nees, in Mart. Fl. Bras. ix. $59=\mathrm{R}$. fulgida.

glabrum, Nees, 1. c. 58.-Bras.

Haenkeanum, Nees, in DC. Prod. xi. 211.-Peruv.

Hartwegianum, Nees, 1. c. 209.-N. Granat.

inflatum, Nees, 1. c. $215=\mathrm{R}$. inflata.

jussieuoides, Nees, 1. c. $212=\mathrm{R}$. jussieuoides.

laxum, Nees, in Mart. Fl. Bras, ix. 57.-Bras.

longiflorum, Nees, 1. c. $62=$ seq.

longifolium, Nees, in DC. Prod. xi. $214=\mathrm{R}$. longifolia.

microphyllum, Nees, in Mart. Fl. Bras. ix. 61=Calophanes microphylla?

nitidum, Nees, 1. c. 59,-Bras.

pedunculosum, Nees, in DC. Prod. xi. $211=$ R. pedunculosa.

repens, Mart. Fl. Bras. ix. 60.-Bras.

roseum, Nees, 1. c. 61.-Bras.

rubrum, Nees, in DC. Prod. xi. $209=$ R. rubra.

silvaccola, Nees, in Mart. Fl. Bras。 ix. $60=\mathrm{R}$. formosa.

splendidulum, Nees, 1. c.-Bras.

stemonacanthoides, Oerst. in Kjoeb. Vidensk. Meddel. 1854) $130=\mathrm{R}$, stemonacanthoides

subsessile, Nees, in Mart. Fl. Bras, ix. 58.-Bras.

terminale, Nees, in DC. Prod. xi. 214.-Peruv.

violaceum, Nees, 1. c. $216=\mathrm{R}$. violacea.

Willdenovianum, Nees, 1. c. 209.-Ind. occ.

ARRHYNCHIUM, Lindl. in Paxt. Flow. Gard. i. 142 $(1850-51)=$ Arachnanthe, Blume (Orchid.).

labrosum, Lindl. \& Paxt. 1. c。=Arachn, bilinguis.

ARROSTIA, Rafin. Caratteri, $75(1810)=$ Gypsophila, Linn. (Caryophyll.).

altissima, Rafin. F1. Tellur. ii. $54=\mathrm{G}$. altissima.

dichotoma, Rafin. Caratteri, $75=\mathrm{G}$. Arrostii.

paniculata, Rafin. Fl. Tellur. ii. $53=$ G. paniculata.

ARROWSMITHIA, DC. Prod. vii. 254 (1838) COMPOSITAE, Benth. \& Hook. f. ii. 329.

styphelioides, $D C$. l. c. -Afr. austr.

ARROZIA, Schrad. ex Kunth, Enum, Pl. i. 11 (1833)= Luziola, Juss. (Gramin.)

micrantha, Schrad. 1. c. (=Caryochloa brasiliensis). -Bras.

ARRudeA, A. St. Hil. \& Camb. Fl. Bras. Mer. i. 318. t. $66(1827)=$ Clusia, Linn. (Guttif.).

bicolor, Benth, in Hook. Kew Journ. iii. (1851) $166=$ C. bicolor.

clusioides, A. St. Hil. et Camb. FI. Bras. Mer. i. 319.Bras.

purpurea, Splitg. in Hoev. \& De Vriese, Tijdschr。 ix. (1842) 103.-Guiana.

ARSACE, Fourr. in Ann. Soc. Linn. Lyon, N. S. xvii. (1869) $113=$ Erica, Linn

arborea, Fourr. 1. c. $=\mathrm{E}$. arborea.

ARSIS, Lour. Fl. Cochinch. $335(1790)=$ Grewia, Linn. (Tiliac.).

rugosa, Lour. 1. c. = G. Microcos.

ARTABOTRYS, R. Br. in Bot. Reg. t. 423 (1820). ANONACEAE, Benth. \& Hook. f. i. 24

Ropalopetalum, Griff. Notul. iv. 16 (1845)

Blumei, Benth. Fl. Hongk. $10=$ honkongensis.

Blumei, Hook.f. E Thoms. Fl. Ind. i. 128. -Java.

brachypetalus, Benth. in Trans. Linn. Soc. xxiii. (1862) 467 . -Afr.

burmanicus, DC. in Mém. Soc. Phys. Genèv. v. (1832) 212.-Burma

caudatus, Wall. Cat. n. 6417.-Reg. Himal.

crassifolius, Hook. f. Eo Thoms, in Hook. f. Fl. Brit. Ind. i. 54,-Burma; Malaya.

Cumingianus, Vidal, Phan. Cuming. Philipp. 169.Ins. Philipp.

densiflorus, Wall. ex Voigt, Hort. Suburb. Calc. 16, nomen-Ind, or.

hamatus, Benth. in Hook. Kew Journ. iii. (1851) 257 $=$ honkongensis.

\section{ARTABOTRYS}

hamatus, Blume, Fl. Jav。 Anon. 60, t. $29=$ odoratissimns.

Hildebrandtii, O. Hoffm. Sert. Pl. Madag. 3.Madag.

honkongensis, Hance, in Fourn. Bot. viii. (1870) 71 . -Hongkong.

inodorus, Zipp. in Ann. Mus. Bot. Lugd. Bat. ii. 41. -N. Guinea.

intermedius, Hassk. Cat. Pl. Hort. Bogor. 175.-Java.

Kurzil, Hook. f. E Thoms. in Hook. f. Fl. Brit. Ind. i.

54.-Burma.

macrophyllus, Hook. f. in Hook. Niger Fl. 207.-Afr. trop.

madagascariensis, Miq. Ann. Mus. Bot. Lugd. Bat. ii. 42.- Madag

Maingayi, Hook. f. E Thoms, in Hook. f. Fl. Brit.

Ind. 1. 55.-Malacca.

malayanus, Griff. Notul, iv, $713=$ Xylopia ferruginea.

odoratissimus, Blume, Fl. Jav. Anon. $59=$ honkongensis.

odoratissimus, R. Br. in Bot. Reg. t. 423.-Ind. or.;

Malaya.

parviflorus, Miq. Ann. Mus. Bot. Lugd. Bat. ii. 41.Sumatr.

pleurocarpus, Maing. ex Hook.f. E Thoms. in Hook. f. Fl. Brit. Ind. i. 54.-Malacca.

polygynus, Miq. Ann. Mus. Bot. Lugd. Bat. ii. 41.Borneo.

siamensis, Miq.l.c. 42.-Siam.

speciosus, Kurz, ex Hook. f. E Thoms, in Hook. f. Fl.

Brit. Ind. i. 55.-Ins. Andam.

suaveolens, Blume, Fl. Fav. Anon. 62.-Ind. or. Malaya.

sumatranus, Miq. Fl. Ind. Bat. Suppl. i. 375.Sumatr.

Thomsoni, Oliver, Fl. Trop. Afr. i. 29.-Afr, trop. unguiculatus, Wall. Cat. n. $6415 \mathrm{~F}$.-Ind. or. uncatus, Baill. Hist. P1. i. $232=$ odoratissimus zeylanicus, Hook. $f$. E Thoms. Fl. Ind. i. 128.Ind. or.

ARTANEMA, D. Don, in Sweet, Brit. Flow. Gard. Ser. II. t. 234 (1829). SCROPHULARINEAE, Benth. \& Hook, f. ii. 953.

ACHIMenes, Vahl, Symb. Bot. ii. 71 (1791)

Diceros, Pers. Syn. ii. 164 (1807)

angustifolium, Benth. Scroph. Ind. 39.-Singapore.

fimbriatum, D. Don, in Sweet, Brit. Flow. Gard. Ser. II. t. 234.-Austral.

sesamoides, Benth. Scroph. Ind. 39.-Ind. or.

ARTANTHE, Miq. Comm. Phyt. 40, t. 7, $8(1840)=$ Piper, Linn.

abutilifolia, Miq. Syst. Pip. $385=$ P. abutilifolium. abutiloides, Miq. 1. c. $384=\mathrm{P}$. abutíloides. acutifolia, Miq. 1. c. $428=\mathrm{P}$ acutifolium. adenandra, Miq. 1. c. $515=\mathrm{P}$. adenandrum. adenophora, Miq. 1. c. $514=\mathrm{P}$. adenophorum. adenophylla, Miq. in Linnaea, xx. (1847) $170=\mathrm{P}$ colubrinum.

adunca, Miq. Comm. Phyt. 49.t. $4=\mathrm{P}$. aduncum. aequalis, Miq. Syst. Pip. $511=$ P. aequale aequirophylla, Mi ${ }^{\prime}$. 1. c. $391=\mathrm{P}$. cardiophyllum. affinis, Miq. in Linnaea, xviii. (1844) $228=\mathrm{P}$. affine alaris, Miq. Syst. Pip. $406=\mathrm{P}$, alare albida, Miq. l. c. $415=\mathrm{P}$. albidum.

alnoides, Miq. 1. c. $462=\mathrm{P}$. alnoides.

alpina, Miq. in Hook. Lond. Journ. Bot. iv. (1845) $451=\mathrm{P}$. alpinum.

alveolata, Miq. Syst. Pip. $406=$ P. alveolatum

amazonica, Miq. in Linnaea, xx. (1847) $146=\mathrm{P}$. amazonicum.

ampla, Miq. Syst. Pip. $501=$ P. Rohrii.

amplectens, Miq. in Linnaea, xx. (1847) $154=\mathrm{P}$. amplectens.

andicola, Miq. Syst. Pip. $415=$ P. andicolum

angusta, Miq. 1. c. $398=\mathrm{P}$. angustum.

angustifolia, Miq. 1. c. $528=\mathrm{P}$. consanguineum.

anonaefolia, Miq. 1. c. $504=\mathrm{P}$. anonaefolium.

apiculata, Klotzsch, in Hook. Journ. Bot. iv. (1842)

$321=\mathrm{P}$. anonaefolium.

appendiculata, Bentb. P1. Hartw. $254=$ P. appendiculatum.

arcuata, Miq. Syst. Pip. $533=$ P. Opizianum

areolata, Miq. in Hook. Lond. Journ. Bot, iv. (1845)

$454=\mathrm{P}$. areolatum.

aspera, Miq. 1. c. $456=$ P. hirsutum.
ARTANTHE :-

asperifolia, Miq. Syst. Pip. $441=$ Piper hirsutum. asperiuscula, Miq. 1. c. $464=\mathrm{P}$. hirsutum. auriculata, Miq. in Linnaea, xx. (1847) $167=\mathbf{P}$. auriculatum.

aurita, Miq. Syst. Pip. $400=$ P. auritum.

avellana, Miq. 1. c. $478=\mathrm{P}$. avellanum.

baccans, Miq. in Linnaea, xx. (1847) $166=\mathrm{P}$. baccans. bahiensis, Presl, Epim. Bot. $227=$ P. bahiense

barbata, Miq. Syst. Pip. $414=$ P. barbatum.

Barclayana, Miq. in Hook. Lond. Journ. Bot. iv.

(1845) $460=$ P. hirsutum.

Bartlingiana, Miq. Syst. Pip. $510=$ P. Bartlingianum

Beecheyana, Miq. 1. c. $403=$ P. ellipticum.

begoniaefolia, Miq. I. c. = P. begoniaefolium.

Benthamiana, Miq. in Hook. Lond. Journ. Bot. iv.

(1845) $447=$ P. Benthamianum.

berbicensis, Miq. Syst. Pip. $500=$ P. Hostmannianuna.

Blanchetii, Miq. 1. c. $473=\mathrm{P}$. Blanchetii.

Botrytis, Miq. 1. c. $533=$ P. Botrytis.

brachypoda, Benth. Bot. Voy. Sulph. 167. t. $54=\mathbf{P}$ brachypodon.

brachystachya, Miq. ex C. DC. in DC. Prod, xvi. I

$296=$ P. brachystachyum.

brasiliensis, Miq. in Linnaea, xx. (1847) 140.-Bras.

Bredemeyeri, Miq. Syst. Pip. $429=$ P. Bredemeyeri

brevispicata, Miq. 1. c. $508=\mathrm{P}$. brevispicatum.

Brongniartii, Miq. 1. c. $486=$ P. Brongniartii.

Brunoniana, Miq. 1. c. $509=$ P. lanceolatum.

caladiffolia, Miy. 1. c. $387=$ P. caladiifolium.

caldasiana, Miq. in Verh. Kon. Akad. Wetensch. II.

(1871) 237 ; et in Arch. Néerl. vi. (1871) 175.-Bras.

calocoma, Miq. in Seem. Bot. Voy. Herald, $199=\mathbf{P}$. calocoma.

Cambessedei, Miq. in Linnaea, xx. (1847) $161=\mathbf{P}$. Cambessedesii.

caracasana, Miq. Syst. Pip. $398=$ P. caracasanum. cardiophylla, Presl, Epim. Bot. $225=$ P. cardiophyllum caripensis, Miq. Syst. Pip. $522=$ P. caripense. casapiensis, Miq. in Hook. Lond. Journ. Bot. iv (1845) $463=\mathrm{P}$. casapiense.

cassinoides, Miq. Syst. Pip. $490=$ P. cassinoides catalpaefolia, Miq. in Versl. en Medel. Kon. Nederl.

Inst. ' 1842 ' (1843) $197=$ P. marginatum.

caudata, Miq. 1. c. $196=$ P. marginatum

cearensis, Miq. Syst. Pip. $456=\mathrm{P}$. angustifolium

celtidifolia, Miq. 1. c. $452=\mathrm{P}$. celtidifolium,

cernua, Presl, Epim. Bot. $225=$ P. cernuum.

Chamissonis, Miq. Syst. Pip. $457=\mathrm{P}$. Chamissonis.

chavicoides, Miq. in Linnaea, xx. (1847) $135=$ P. chavi coides.

chelseana, Miq. Syst. Pip. $533=$ P. tomentosum.

chimonanthifolia, Miq. 1. c. $460=$ P. chimonanthi folium.

Churumayu, Miq. 1. c. $481=$ P. Churumayu.

cinnamomifolia, Miq l. c. 419.-Peruv

Clausseniana, Miq. in Linnaea, $\mathrm{xx},(1847) 153=\mathrm{P}$

Claussenianum.

coccoloboides, Miq. Syst. Pip. $397=$ P. coccoloboides

colubrina, Miq. J. c. $512=\mathrm{P}$. colubrinum.

concinna, Miq. in Linnaea, xx. (1847) $151=\mathrm{P}$. concinnum.

consanguinea, Miq. Syst. Pip. $528=$ P. consanguineum. controversa, Miq. 1. c. $448=$ P. hispidum.

cornifolia, Miq. 1. c. $479=\mathrm{P}$. cornifolium.

coruscans, Miq. 1. c. $411=\mathrm{P}$. coruscans.

corylifolia, Klotzsch, in Hook. Journ. Bot. iv. (1842)

$321=\mathrm{P}$, dilatatum

corylifolia, Miq. Syst. Pip. $474=$ P. dilatatum.

crassispicata, Miq. 1. c. $521=\mathrm{P}$. crassispicatum.

crocata, Miq. 1. c. $429=\mathrm{P}$. crocatủm.

cumanensis, Miq. 1. c. $484=\mathrm{P}$. cumanense.

curvata, Miq. l. c. $522=\mathrm{P}$. curvatum.

cuspidata, Miq. in Hook. Lond. Journ. Bot. iv. (1845)

$468=\mathrm{P}$. pseudo-peruvianum

dasyoura, Miq. 1. c. $452=\mathrm{P}$. dasyourum.

dasypoda, Miq. 1. c. $458=\mathrm{P}$. dasypodum.

decipiens, Miq. Syst. Pip. $462=\mathbf{P}$. decipiens,

decurrens, Miq. 1. c. $402=\mathrm{P}$. tuberculatum.

decurrens, Fourn. in 1llustr. Hortic, xxiii. (1876) $t$ $239=\mathrm{P}$ decurrens

demerarana, Miq. in Hook. Lond. Journ. Bot iv

(1845) $464=\mathrm{P}$. demeraranum.

denudans,Miq. in Linnaea, xx. (1847) $172=\mathrm{P}$. denudans dimidiata, Presl, Epim. Bot. $225=$ P. dimidiatum. diospyrifolia, Miq. Syst. Pip. $477=$ P. diospyrifolinm divergens, Presl, Epim. Bot. $228=\mathrm{P}$. divergens. dubia, Miq. Syst. Pip. $535=\mathrm{P}$. chilense. 
ARTANTHE :-

Durvilleana, Miq. Syst. Pip. $507=$ P. anonaefolium. elongata, Miq. 1. c. $434=\mathrm{P}$. angustifolium. enckeoides, Miq. 1. c. $412=\mathrm{P}$. crassinervium.

Endlicheriana, Miq. in Hook. Lond. Journ. Bot. iv. (1845) $447=P$. formosum.

eriopoda, Miq. 1. c. $459=\mathrm{P}$. eriopodon.

eucalyptifolia, Miq. Syst. Pip. $505=$ P. eucalyptifolium.

excavata, Miq. 1. c. $534=$ P. excavatum.

eximia, Miq. 1. c. $393=$ P. obliquum.

exserens, Miq. in Linnaea, xx. (1847) $148=\mathrm{P}$. crassi nervium.

flagellaris, Miq. Syst. Pip. $393=$ P. nobile.

flexicaulis, Miq. 1. c. $533=$ P. tlexicaule,

flexuosa, Miq. l. c. $454=$ P. flexuosum.

formosa, Miq. 1. c. $386=$ P. formosum.

fuliginea, Miq. 1. c. $455=\mathrm{P}$. fuligineum.

fuscescens, Miq. in Linnaea, xx. (1847) $144=\mathrm{P}$. estrellense.

Gabrieliana, Miq. Syst. Pip. $476=$ P. Gabrielanum.

Galeottii, Miq. 1. c. $451=\mathrm{P}$. aduncum.

Gaudichaudiana, Miq. 1. c. $469=$ P. Gaudichaudianum.

geniculata, Griseb. Cat. Pl. Cub. $65=\mathrm{P}$. rigidum.

geniculata, Miq. in Versl. en Medel. Kon. Nederl.

Inst. ' 1842 ' (1843) $194=\mathrm{P}$. geniculatum.

glabella, Miq. Syst. Pip. $518=$ P. glabellum.

glabrata, Miq. 1. c. $481=\mathrm{P}$. cumanense.

glabrescens, Miq. in Hook, Lond. Journ. Bot. iv. (1845) $461=\mathrm{P}$. glabrescens.

gracilis, Miq. Syst. Pip. $448=$ P. gracile.

grandifolia, Miq. 1. c. $408=$ P. grandifolium.

granulosa, Miq. 1. c. $435=\mathrm{P}$. angustifolium.

guianensis, Klotzsch, in Hook. Journ. Bot. iv. (1842) $322=$ P. guianense.

Guilleminiana, Miq. Syst. Pip. $409=$ P. crassinervium.

Haenkeana, Miq. in Linnaea, xx. (1847) $145=\mathrm{P}$.

\section{Paulianum}

halesiaefolia, Miq. Syst. Pip. $419=$ P. halesiaefolium

Hartwegiana, Benth. Pl. Hartw. $254=$ P. Hartwe gianum.

heterophylla, Miq. Syst. Pip. $502=$ P. heterophyllum. hexagyna, Miq. 1. c, $412=\mathrm{P}$. Betle.

Hilariana, Miq. 1. c. $421=$ P. Hilarianum,

hirsuta, Miq. 1. c. $446=\mathrm{P}$, hirsutum.

hirtula, Presl, Epim. Bot. $226=$ P. hirtulum.

hispida, Miq. Comm. Phyt. 50. t. viii. f. $\mathrm{A}=\mathrm{P}$. asperifolia.

Hookeriana, Miq. in Hook. Lond. Journ. Bot. iv. (1845) $446=\mathrm{P}$. Hookerianum.

Hostmanniana, Miq. 1. c. $465=$ P. Hostmannianum. hymenophylla, Miq. Syst. Pip. $532=$ P. Kegelii.

imperialis, Miq. in Seem. Bot. Voy. Herald, 198. t. $38=\mathrm{P}$. imperiale

insignis, Miq. Syst. Pip. $394=$ P. insigne.

facquemontiana, Miq. 1. c. $463=\mathrm{P}$. citrifolium

jalapensis, Miq. 1. c. $444=$ P. jalapense.

jamaicensis, Griseb. Fl. Brit. W. Ind. $170=\mathrm{P}$. geniculatum.

japurensis, Miq. in Linnaea, xx. (1847) $168=\mathbf{P}$. japurense.

javitensis, Miq. Syst. Pip. $401=$ P. javitense.

Fussiacana, Mio, 1. c, $420=\mathrm{P}$. Jussizeanum.

Karvinskiana, Miq. 1. c. $476=$ P. Karwinskianum.

Kegeliana, Miq. in Linnaea, xxii. (1849) $77=\mathbf{P}$, Kegelianum.

Kunthiana, Miq. Syst. Pip. $453=$ P. hirsutum.

lacunosa, Miq. 1. c. $427=\mathrm{P}$. lacunosum.

lanceaefolia, Miq. 1. c. $433=$ P. lanceaefolium.

lanceata, Miq. ]. c. $526=\mathrm{P}$. lancifolium.

lapathifolium, Miq. 1. c. $401=$ P. lapathifolium.

laurifolia, Miq. 1. c. $520=$ P. laurifolium.

Lehmanniana, Miq. in Hook. Lond. Joum. Bot. iv.

(1845) $466=\mathrm{P}$. salicariaefolium.

lentaginoides, Miq. Syst. Pip. $520=$ P. rivinoides

Leprieurii, Miq. l. c. 525.-Guiana.

leptura, Miq. 1. c. $528=$ P. lepturum.

Lessertiana, Miq. 1. c. $405=P$. lapathifolium.

leucophylla, Miq. 1. c. $460=\mathrm{P}$. verbascifolium.

Lhotskyana, Miq. l. c. $417=$ P. Lhotzkyanum.

Lindeniana, Miq. in Hook. Lond. Journ. Bot. iv. (1845) $453=\mathrm{P}$. Artanthe.

lineata, Miq. Syst. Pip. $459=$ P. lineatum.

linguifolia, Miq. 1. c. $583=\mathrm{P}$. linguaefolium

Lucaeana, Miq. 1. c. $523=$ P. Lucacanum.

Luschnathiana, Miq. 1. c. $494 \equiv$ P. geniculatum.
ARTANTHE:-

macrophylla, Griseb. Fl. Brit. W. Ind. $171=$ P. geniculatum.

macrophylla, Miq. Syst. Pip. $423=$ P. macrophyllum

macrorhyncha, Miq. in Linnaea, xx. (1847) $173=$

P. macrorhynchon.

macrostachya, Presl, Epim. Bot. $227=$ P. macro-

stachyum.

magnifica, Linden, ex Fourn. in Illustr. Hortic. xxiii.

(1876) t. $239=\mathrm{P}$, decurrens.

magnifica, Miq. Syst. Pip. $391=$ P. obliquum.

malacophylla, Presl, Epim. Bot. $227=$ P. malacophyllum.

marginata, Miq. Syst. Pip. $381=$ P. marginatum.

Martiana, Miq.1. c. $422=$ P. Martianum.

Martinicae, Miq. 1. c. 413.-Ins. Martinica.

Maximiliana, Miq. in Linnaea, xx. (1847) $169=$

P. juliflorum.

melanosticta, Miq. Syst. Pip. $404=$ P. melanostictum mexicana, Miq. 1. c. $458=\mathrm{P}$. mexicanum

Meyeniana, Klotzsch, ex Miq. I. c. $524=$ P. lepturum.

Meyeri, Miq. I. c. $454=\mathrm{P}$, divaricatum.

microstachya, Miq. 1. c. $527=\mathrm{P}$. microstachyon.

Miersiana, Miq. in Hook. Lond. Journ. Bot. iv. (1845) $449=$ P. Miersinum.

Mikaniana, Miq. Syst. Pip. $383=$ P. Parthenium.

mitis, Miq. 1. c. $407=\mathrm{P}$. mite.

modesta, Miq. l. c. $517=$ P. modestum.

mollicoma, Miq. 1. c, $438=\mathrm{P}$. mollicomum.

mollis, Miq. in Linnaea, xx. (1847) $165=\mathrm{P}$. mollipilosum.

Moritziana, Miq. 1. c. xviii. (1844) $714=$ P. Moritzianum.

nitida, Miq. Comm. Phyt. 47. t. vii $=$ P. nitidum

nitidula, Miq. Syst. Pip. $534=$ P. nitidulum.

nubigena, Miq. 1. c. $432=\mathrm{P}$. crocatum.

obesa, Miq. 1. c. $470=$ P. scabrum.

oblonga, Miq. 1. c, $480=\mathrm{P}$. oblongum.

oblongata, Miq. 1. c. $535=\mathrm{P}$. oblongatum.

oblongifolia, Klotzsch, in Hook. Journ. Bot. iv. (1842)

$322=\mathrm{P}$. oblongifolium

obovata, Miq. Syst. Pip. $508=$ P. colubrinum.

obtusa, Miq. 1. c. $416=\mathrm{P}$. fuminense

obumbrata, Miq. in Linnaea, xx. (1847) $142=$ P. obum bratum.

Olfersiana, Klotzsch, in Hook. Journ. Bot. iv. (1842) $321=\mathrm{P}$. hirsutum

Opizii, Miq. Syst. Pip. $440=$ P. asperifolium.

opulifolia, Miq. in Linnaea, xx. (1847) $160=$ P. Cam bessedesii.

paraënsis, Miq. 1. c. $156=$ P. paraënse.

Parkeriana, Miq. in Hook. Lond. Journ. Bot. iv. (1845) $46=$ P. Parkeriantum.

patens, Miq. Syst. Pip. $534=$ P. nervosum.

patula, Miq. 1. c. $554=$ P. patens

Pavoni, Miq. in Hook. Lond. Journ. Bot. iv. (1845) $450=$ P. Pavoni

peduncularis, Miq. Syst. Pip. $531=\mathrm{P}$. pedunculare. persicariaefolia, Miq. 1. c. $499=\mathrm{P}$. persicariaefolium peruviana, Miq. 1. c. $482=$ P. pseudo-peruvianum. phthinotricha, Miq. 1. c. $527=\mathrm{P}$. phthinotrichon. phytolaccaefolia, Miq. I. c. $534=\mathrm{P}$. phytolaccaefolium. pilosiuscula, Miq. 1. c. $476=\mathrm{P}$. pilosinsculum. plantaginea, Miq. 1. c. $389=\mathrm{P}$. plantagineum. Poeppigii, Miq. 1. c. $437=$ P. psendo-mollicomam. polyneura, Miq. 1. c. $504=\mathrm{P}$. indecorum

populifolia, Miq. 1. c. $418=\mathrm{P}$. populifolium pothifolia, Mic. 1. c. $399=\mathrm{P}$. pothifolium. pothomorpha, Miq. 1. c. $403=$ P. Pothomorphe prunifolia, Miq. 1. c, $423=$ P. prunifolium.

pseudo-churumayu, Miq. i. c. $407=$ P. pseudochurumayu.

psilostachya, Miq. 1. c. $448=$ P. psilostachyum.

punctata, Miq. 1. c. $522=\mathrm{P}$. punctatum.

pyrifolia, Miq. in Linnaea, xx. (184i) $159=$ P. Mastersianum.

Radula, Mig. 1. c. $426=$ P. Bredemeyeri.

ramiflora, Miq. ex C. DC. in DC. Prod. xvi. 1. $288=$

P. Hostmannianum.

Regnellii, Miq. in Linnaea, xxii. (1849) $574=\mathbf{P}$ Regnellii.

renitens, Miq. in Mart. F1. Bras. iv. I. 221.-Am, trop. reticulosa, Miq. Syst. Pip. $554=\mathrm{P}$, reticulosum.

rhododendrifolia, Miq. 1. c. $506=$ P. anonnefolium.

phynchostachya, Mị. 1. c. $526=\mathrm{P}$. rhynchostachyum

richardiaefolia, Mig. 1. c. $395=\mathrm{P}$. richardiaefolium.

riparia, Miq. 1. c, $409=\mathrm{P}$. grandifolium.

rivinoides, Miq. 1. c, $519=\mathrm{P}$. rivinoides.
ARTANTHE :-

Rudgeana, Miq. in Linnaea, xxii. (1849) $77=\mathrm{P}$. Rad geanum.

rudis, Miq. Syst. Pip. $467=$ P. rude

rugosa, Miq. 1. c. $488=$ P. Rohrii.

Ruiziana, Miq. in Hook. Lond. Journ. Bot. iv. (1845) $444=\mathrm{P}$. pangoënse.

rumicifolia, Miq. in Linnaea, xx. (1847) $14 \mathrm{I}=\mathrm{P}$ rumicifolium.

salicariaefolia, Miq. Syst. Pip. $468=$ P. salicariae Eolium.

salicifolia, Miq. I. c. $533=\mathrm{P}$. salicifolium.

saliunca, Miq. 1. c. $528=\mathrm{P}$. salicinum.

salviaefolia, Miq. l. c. $430=$ P. salviaefolium.

sancta, Miq, in Linnaea, xviii, (1844) $714-P$. sanctum.

saururoides, Miq. Syst. Pip. $414=\mathrm{P}$. saururoides.

scabra, Miq. 1. c. $447=\mathrm{P}$. hirsutum.

scabrata, Presl, Epim. Bot. 226.-Mexico

scabrifolia, Miq. Syst. Pip. 461=P. scabrifolium.

scabriuscula, Miq. 1. c. $447=$ P. scabriusculum.

Schachii, Miq. in Hook. Lond. Journ. Bot. iv. (1845)

$448=\mathrm{P}$. Schachii.

Schlechtendalii, Miq. Syst. Pip. $386=$ P. reticulatum.

Schomburgkii, Klotzsch, in Hook. Journ. Bot. iv. (1842) 322.-Guiana.

Schottii, Miq. in Linnaea, xx. (1847) $157=$ P. Schottii. scopulorum, Miq. Syst. Pip. $396=$ P. scopuloram. scutata, Mig, in Hook. Lond. Journ. Bot. iv. (1845) $445=$ P. subscutatum.

secunda, Miq. Syst. Pip. $516=$ P. secundum.

Seemanniana, Miq. in Seem. Bot. Voy. Herald, 199.

$39=\mathbf{P}$. auritum

Selloviana, Mig. Syst. Pip. $416=$ = P. Sellovianum.

septuplinervia, Miq, in Seem. Bot. Voy. Herald, 199

t. $40=$ P. septuplinervium.

sororia, Miq. in Hook. Lond. Journ. Bot. iv. (1845 $443=\mathrm{P}$. sororium

spectabilis, Miq. in Linnaea, xx. (1847) $138=\mathrm{P}$. cernuum.

staminea, Miq. in Hook. Lond. Journ. Bot. iv. (1845) $461=\mathrm{P}$. geniculatum.

stellipila, Miq. in Linnaca, xx. (1847) $163=$ P. stelli pilum.

stupposa, Miq. Syst. Pip. $430=\mathrm{P}$. crocatum.

subaequalis, Presl, Epim. Bot. $226=\mathrm{P}$. subaequale.

subauriculata, Miq. in Linnaea, xx, (1847) $150=\mathrm{P}$.

subauriculatum.

superba, Miq. 1. c. $137=$ P. obliquum.

Swartziana, Miq. Syst. Pip. $490=$ P. Swartzianum. tectoniaefolium, Miq. 1. c. $396=$ P. tectoniaefolium. tejucensis, Miq. 1. c. $496=\mathrm{P}$. tejucense.

tenuicuspis, Miq. in Hook. Lond. Journ. Bot. iv. (1845 $457=\mathrm{P}$. tenuicuspe.

tiliaefolia, Miq. Syst. Pip. $388=$ P. tiliaefolium.

trichoneura, Miq. 1. c. 483.-Guiana.

trichostachya, Miq. 1. c. $488=$ P. citrifolium

tricuspis, Miq. ex Seem. Bot. Voy. Herald, 200.

42.-Panama.

trinervis, Mig 1. c. $200, \mathrm{t}, 41=\mathrm{P}$, trinerve.

tuberculata, Miq. Syst. Pip. $497=$ P. tuberculatum

tumida, Miq. 1. c. $465=$ P. tumidum.

ulmifolia, Miq. 1. c. $472=\mathrm{P}$. dilatatum.

umbrosa, Miq. 1. c. $470=\mathrm{P}$, nmbrosum.

variegata, Miq. 1. c. $485=\mathrm{P}$. variegatum.

Vellosiana, Mio 1. c. $436=\mathrm{P}$, aduncum.

velutina, Mig. l. c. $471=\mathrm{P}$, velntinum.

verbascifolia, Miq. 1. c. $431=\mathrm{P}$. verbascifolium.

verrucosa, Griseb. Fl. Brit. W. Ind. $171=$ P. genica. latum.

Warakabacoura, Miq. in Hook. Lond. Journ. Bot. iv.

(1845) $469=$ P. Warakaboura

Wydleriana, Mig. Syst. Pip, 187 - P. cuspidatum.

xestophylla, Miq. 1. c. $491=$ P. geniculatum.

xylopioides, Miq. 1. c. $492=$ P. geniculatum.

xylosteoides, Miq. 1. c, $422=\mathrm{P}$. xylosteoides.

ARTEDIA, Linn. Gen, ed, I. il (1;

(:MBELL)

FERAE Benth. \& Hook, f. i. 927.

muricata, Linn. Sp. Pl. $212=$ Daucus muricates.

squamata, Lirn. l. c.-Oriens.

squamata, Pall. in Nov. Act. Petrop. x 1797 ) $\$ 0 s$

Sanicula crithmifulia.

ARTEMISIA, Linn. Syst ed. I (1\%35). COMPO

SJT.AE. Benth. \& Hook. f. ii. 135 .

Amrotanua, [Toum.] Neck. Elem. i. $98(1 ; 90)$,

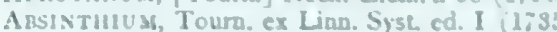

C c 2 


\section{ARTEMISIA :-}

Oligosporus, Cass, in Bull. Soc. Philom. (1817) 33. Picrothamnus, Nutt, in Trans. Am. Phil. Soc. Ser II. vii. (1841) 417 .

abrotanifolium, Salisb. Prod. 191=A. Abrotanum. abrotanifolium, Siev. in Pall. N. Nord. Beitr. vii. 309. -Rossia.

abrotanoides, Jacq. ex DC. Prod. vi. $\mathbf{1 0 6}=$ vestita.

abrotanoides, Nutt. in Trans. Am. Phil. Soc. Ser. II

vii. (1841) $399=$ californica.

Abrotanum, Habl. Taur. $128=$ maritima.

Abrotanum, Linn. Sp. Pl. 845.-Europ.; As. temp.

Abrotanum, Savi, Mat. Med. t. $38=$ camphorata.

Abrotanum, S. G. Gmel. It. i. $21=$ procera.

absinthia, St. Lag. in Ann. Soc. Bot. Lyon, vii. (1880)

$119=\mathrm{A}$. Absinthium

Absinthit, Heyne, ex Hook. f. F1. Brit. Ind. iii. $329=$ pallens.

absinthioides, Poir. Encyc. Suppl. i. $461=$ Siversiana.

Absinthium, Linn. Sp. Pl. 848.-Europ.

abyssinica, Sch.Bip, in A. Rich.Tent. Fl. Abyss, i. 420. Afr, trop.

acetica, Jacquem, ex Bess. in Bull. Soc. Nat. Mosc. ix (1836) $86=$ maritima.

achilleaefolia, Tenore, F1. Nap. 190=camphorata

achilleoides, Turcz. in Bull. Soc. Nat. Mosc. v. (1832)

$195=$ Tanacetum achilleoides.

Adamsii, Bess, in Nouv. Mém. Soc. Nat. Mosc. iii.

(1834) 27.-As. bor. or.

aemula, Steph. ex Besș. 1. c. $22=$ rntaefolia.

aethiopica, Linn. Sp. PI. $845=$ A. Herba-alba.

affinis, Hassk. in Flora, xxv. (1842) II. Beibl. $22=$

vulgaris.

affinis, Steud. Nom, ed. II i. 136-Sibir.

afra, Facq. Hort. Schoenb. iv. 34. t. 467.-Afr. austr.

alba, Habl. Taur. $144=$ anstriaca.

alba, Pall. Reise, i. $502=$ maritima

alba, Turra, F1. Ital. Prod. $67=$ camphorata

albida, Ledeb. Fl. Alt. iv. $85=$ maritima.

albida, Willd, ex Ledeb. H1. Ross. ii. $566=$ inodora.

Allionii, Nym. Consp. $377=$ nana.

alpina, Pall. ex Willd. Sp. Pl. iii. $1824=$ lanata.

alpina, DC. ex Steud. Nom. ed. II. i. $136=$ campestris.

alpina, Sch. Bip. ex Willk. in Flora, xxxiv. (1851) 746

=lanata.

altaica, Desf. Cat. Hort. Paris. (1829) $160=$ pontica. altissima, Ehrh. ex DC. Prod. vi. $108=$ procera.

ambigaa, Linn. Sp. PI. ed. II. $1190=$ Tríchogyne larici folia.

ambigua, Thunb. Prod. Pl. Cap. $147=$ Seriphium vermiculatum.

Ammaniana, Bess, in Bull. Soc. Nat. Mosc, viii. (1835) $60 .-$ Sibir.

amorpha, Rafin. Fl. Ludov. 69.-Louisiana.

amygdalina, Decne. in Facquem. Voy. Bot. 92. t. 100 Reg. Himal.

andicola, Don, ex Hook. \& Arn. in Hook. Journ. Bot.

iii. (1841) $325=$ mendozana

androsacea, Seem. Bot. Voy. Herald, 34. t. $6=$ senjavinensis.

anethifolia, Fisch. ex DC. Prod. vi. $108=$ procera.

anethifolia, Weber, ex Stechm. Artem. 29.-Sibir.

anglica, Hort. ex DC. Prod. vi. $103=$ maritima.

angustifolia, S. F. Gray, Nat. Arr. Brit. PI. ii. $450=$

A. Abrotanum.

annua, Linn. Sp. Pl. 847.-Oriens; As. bor.

annua, Pall. Reise, ii. $523=$ sacrorum.

anomala, S. Moore, in Fourn. Bot. xiii. (1875) 227.-

China.

anthriscifolia, Presl, ex Steud. Nom. ed. II, i. 136.-

$\mathrm{Hab}$ ?

apetala, Hort. Pest. ex Steud. 1. c. = vulgaris.

apiacea, Hance, in Walp. Ann. ii. 895.-China.

aprica, Gebl. ex DC. Prod. vi. $125=$ frigida.

aquatica, Lour. Fl. Cochinch. ii. 490.-China.

aragonensis, Lam. Encyc. ii. $269=\mathrm{A}$. Herba-alba

arborescens, Linn. Sp. Pl. ed. II. 1188.-Reg. Meditern.

arbuscula, Nutt. in Trans. Am. Phil. Soc. Ser. II. vii

(1841) 398.-Am. bor, occ.

arctica, Bess, ex Hook. Fl. Bor. Am. i. $323=$ Richardsoniana.

arctica, Less. in Linnaea, vi. (1831) $213=$ norvegica. arenaria, DC. Prod. vi. 94.-Reg. Caucas.

argentea, Buch, Beschr. Canar. 148, $164=$ canariensis argentea, L'Hérit. Sert. Angl. 22.-Sicil.; Madera. argentea, Seb. \& Maur, ex Willk. \& Lange, Prod. Fl.

Hisp. ii. $68=$ arborescens.

argyrophylla, Ledeb. Fl. Alt. iv. 106.-Silir.

\section{ARTEMISIA :-}

armeniaca, Lam. Encyc. i. 263--Armenia.

armeniaca, Willd. ex Ledeb. Fl. Ross. ii. $592=$ Tourne fortiana.

Assoana, Willk. in Willk. \& Lange, Prod. Fl. Hisp. ii. $69=$ lanata

arragonensis, Auct, vide aragonensis.

Athanasia, Bess. in Bull. Soc. Nat. Mosc. vii. (1834)

$24=$ Tanacetum fruticulosum

atlantica, Coss. \& Dur. in Bull. Soc. Bot.Fr. ix. (1862) 298.-Algeria.

atrata, Lam. Encyc. i. $253=$ spicata

atropurpurea, Fisch. ex Herd. in Bull. Soc. Nat. Mosc. 1867) $\mathrm{I} .231$ =arctica.

Aucheri, Boiss. Fl. Orient. iii. 367.-Persia.

australis, Ehrh. ex DC. Prod. vi. $120=$ biennis.

australis, Less, in Linnaea, vi. (1831) 522.-Ins. Sandvic.

austriaca, Facq. Fl. Austr. i. 61.-Europ. or.; Oriens; As. bor.

baicalensis, Willd. ex DC. Prod. vi. $107=$ sacrorum.

Balsanita, Willd. Enum. Hort. Berol. Suppl. $57=$ pontica.

bargusinensis, Spreng. Syst, iii. $493=$ borealis.

Barrelieri, Bess. in Bull. Soc. Nat. Mosc. ix. (1836) 87 - Hispan.

basilica, Webb, ex Willk. \& Lange, Prod. Fl. Hisp. ii, $70=$ granatensis,

Baumgarteni, Bess. in Nouv. Mém. Soc. Nat. Mosc. iii (1834) 73.-Europ. anstr. or.

Besseriana, Ledeb. Fl. Ross. ii. $590=$ lagocephala,

Biasolettiana, Visiani, Ind. Sem. Hort. Patav. $(1836)=$ camphorata.

biennis, Willd. Phyt. 11. n. 39--Am. bor.; Sibir. ; Reg. Himal.

biflora, Spreng. Nachr. i. Bot. Gart. Halle, 12.-Hab.?

Bigelovii, A. Gray, in Pacif. Rail. Rep. iv. 110.-Am. bor.

Billardieriana, Hess. in Bull. Soc. Nat. Mosc. ix. (1836) $81=$ A. Herba-alba.

blepharolepis, Bunge, in Mém. Sav. Etr. Pétersb, vii (1851) 340 (Lehm. Reliq. Bot. 164).-As. centr.

Bocconi, All. Fl. Pedem. i. $169=$ nana, spicata.

Bolanderi, A. Gray, in Proc. Am. Acad. xix. (1883) 49.-Calif.

borealis, Pall. Reise, iii. 755-Am, bor, et arct. ; Sibir. Boschniakiana, DC. Prod. vi. 104 = maritima.

brachyloba, Franch. Pl. Davidian. i. 171.-Mongol. brevifolia, Wall. Cat. n. $3306=$ maritima.

caerulescens, Linn.Sp.Pl. 848.- - Reg. Mediterr.

caespitosa, Bess, in Hook, Fl. Bor. Am. i. $324=$

Richardsoniana.

caespitosa, Ledeb. Fl. Alt. iv. 80.-Sibir, alt.

californica, Less. in Linnaea, vi. (1831) 523.-Calif.

Campbellii, Hook. f. E Thoms. ex Clarke, Comp. Ind. 164.-Reg. Himal.

campestris, Auct. Hisp. ex Willk. \& Lange, Prod. Fl. Hisp. ii. $72=$ glutinosa.

campestris, Ledeb. Fl. Alt. iv. 86 = commutata.

campestris, Linn. Sp. Pl. 846.-Europ.; As. bor.; Oriens; Ind, or

campestris, Pursh, Fl. Am. Sept. ii. $522=$ canadensis? campestris, Scop. ex Steud. Nom. ed. II. i. $136=$ camphorata.

campestris, Turcz, ex DC. Prod. vi. 96=Ledebouriana camphorata, Vill. Presp. 31.--Europ. austr.

camtschatica, Schlecht. ex Ledeb. F1. Ross. ii, $568=$ borealis.

cana, Pursh, Fl. Am. Sept. 621.-Am. bor.

canadensis, Michx. Fl. Bor. Am. ii, 129.-Am. bor.;

As. bor. or.

canariensis, Less. in Linnaea, vi. (1831) 217.-Ins. Canar.

canescens, Willd. Sp. Pl. iii. $1843=$ armeniaca.

cannabina, Jacquem. ex Bess. in DC. Prod. vi. $97=$ desertorum.

capillaris, Miq. in Ann. Mus. Bot. Lugd. Bat. ii. $175=$ scoparia.

capillaris, Thunb. Fl. Fap. 309.-Japon

capillifolia, Fisch. ex DC. Prod. vi. $122=$ subviscosa capillifolia, Lam. Encyc. i. $266=$ Eupatorium foeniculaceum.

carnifolia, Buch.-Ham, ex Roxb. Fl. Ind. iii. $422=$ seq caruifolia, Roxb. Hort. Beng. 61.-Ind. or.; China. carvifolia, Bess. in Nouv. Mém. Soc. Nat. Mosc. ii (1834) 81 = caruifolia.

caucasica, Willd. Sp. Pl. iii. 1823.-Reg. Caucas. caudata, Michx. Fl. Bor. Am, ii, 129,-Am. bor.

\section{ARTEMISIA :-}

centiflora, Maxim. in Bull. Acad. Pétersb. xxvi. (1880) 493.--Mongolia.

cephalantha, Fisch. ex Herd. in Bull. Soc. Nat. Mosc. xl. (1867) $1,227=$ glomerata.

cernua, Dufour, ex Willk. \& Lange, Prod. F1. Hisp. ii. $71=$ hispanica.

cernua, Nutt. Gen. Am. ii. $143=$ dracunculoides

cernuiflora, Dufour, ex Willk. \& Lange, Prod. Fi. Hisp. ii. $71=$ hispanica.

chamaemelifolia, Vill. Prosp. 32.-Gall. ; Reg. Caucas. Persia.

Chamissoniana, Bess. ex Hook. Fl. Bor. Am. i. $324=$ norvegica.

chamomillifolia, Parrot, in Engelh. \& Parrot, Reise Krym. Kank. ii. 131 = chamaemelifolia ?

Chiajeana, Kunze, ex Rich. Bot. Méd. ii. 612 ; ex Steud. Nom. ed. II. i. 137.--Oriens?

chinensis, Bess. in Linnaea, xv. (1841) 92 =lagocephala. chinensis, Burm. ex DC. Prod. vi. $125=$ mollis.

chinensis, Linn. Sp. Pl. 849,-China: Sibir.

chinensis, Pursh, F1. Am. Sept. ii. $521=$ Stelleriana,

chrysantha, Fisch. ex DC. Prod. vi. $125=$ frigida.

chrysantha, Steph. ex Ledeb. Fl. Ross. ii. $597=$ ru. pestris.

Chrysanthemum, Russ. ex DC. Prod. vi. $140=$ Sphaeromorphaea Russeliana.

Cina, Berg, Darstell. iv. t. 29c -Oriens.

cinerea, Hort. Par. ex DC. Prod. vi. $122=$ camphorata Clausonis, Pomel, Nouv. Mat. Fl. Atl. 55.-Algeria.

coarctata, J. H. Fors. in Linn. Inst. Skrift. (reimpr. 12 $=$ vulgaris.

coarctata, Turcz, ex Ledeb. Fl. Ross, ii. $567=\mathrm{cam}$ pestris.

coerulescens, Pall. Reise, ii. $285=$ sericea

coerulescens, Presc. ex Ledeb. Fl. Ross. ii. $564=$ Ammaniana.

collina, Schur, in Verh. Siebenb. Ver. Naturw. iv. (1853) $39=$ campestris.

columbiensis, Nutt. in Trans. Am. Phil. Soc. N. S. vii. (1841) $398=$ cana

Columnae, Tenore, Ind. Sem. Hort, Neap. (1829) $14=$ camphorata.

commutata, Bess. in Bull. Soc. Nat. Mosc. viii. (1835 $70=$ campestris.

compacta, Fisch. ex DC. Prod. vi. $102=$ maritima.

Contra, Linn. Mant. $282=$ Sieberi

Contra, Willd. ex Spreng. Syst. iii. $494=$ maritima

controversa, Jan, ex DC. Prod. vi. $126=$ Siversiana.

Copa, Phil. Fl. Atac. 33.-Chili.

corymbosa, Fisch. ex Bess. in Nouv. Mém. Soc. Nat.

Mosc. iii. (1834) $74=$ glomerata.

corymbosa, Lam. Encyc. i. $265=$ camphorata.

crithmifolia, Linn. Sp. Pl. 846.-Lusit.; Gall.

crithmifotia, Sievers, in Pall. N. Nord. Beitr. vii. $333=$ glabella.

cuneifolia, DC. Prod. vi. $126=$ parviflora.

cuneifolia, Scheele, in Linnaea, xxii. (1849) $162=$ mexicana?

curilensis, Bess. in Nouv. Mém. Soc. Nat. Mosc. iii 1834) $6 \tau=$ Meyeriana

curilensis, Spreng. Syst. iii. $489=$ leontopodioides.

Cyna, Pall. Reise, iii. $630=$ maritima.

Czekanowskiana, Trautv. in Act. Hort. Petrop.v. (1877) 72.-Sibir.

davurica, Vitm. Summa, v. 12.-Dahuria.

Decaisnei, F. W. Klatt, in Abh. Naturf. Ges. Halle xv. (1882) 329.-Ind, or.

Deliliana, Bess. Enum. P1. Volh. Suppl. $89=$ mono sperma.

delphinensis, Bess. in Bull. Soc. Nat. Mosc. ix. (1836) $19=$ Mutellina

densiflora, Viv. App. Alt. Cors. ii. 4, t. 2 =gallica

dentata, Willd. Sp. Pl. iii. $1826=$ rupestris.

depressa, Turcz ex DC. Prod. vi. 107=Adamsii.

desertorum, Bess. ex Hook. Fl. Bor. Am. i. $325=$ canadensis.

desertorum, Spreng. Syst. iii. 490.-As. centr, ; Sibir. Reg. Himal

discolor, Dougl. ex DC. Prod. vi. 109.-Am. bor. occ.

discolor, Torr. \& Gray, in Pacif, Rail. Rep. ii. $126=$ franserioides.

Douglasiana, Bess. in Nonv. Mém. Soc. Nat. Mosc. iii (1834) $60=$ ludoviciana.

dracunculoides, Pursh, Fl. Am. Sept. 742,-Am. bot.

Dracunculus, Linn. Sp. Pl. 849.-Europ. or, O Oriens;

Reg. Himal. 
ARTEMISIA :

Dracunculus, Pursh, Fl. Am. Sept. ii. $521=$ dracun culoides.

dubia, Wall. Cat, n. $3307=$ vulgaris

Echegarayi, Hieron. in Bol. Acad. Nac. Córdova, iv (1881) 42.--Reg. Argent.

elegans, Fisch. ex Ledeb. F1. Ross. ii. $579=$ prncera.

elegans, Jan, ex Bess. in Bull. Soc. Nat. Mosc. ix. (1836) $104=$ glacialis

elegans, Roxb. Hort. Beng. 61; Fl. Ind. iii. $421=$ scoparia.

elegans, Salisb. Prod. 191=arborescens

eranthema, Bunge, in Mèm. Sav. Etr. Pétersb. vii (1851) 339 (Lehm. Reliq. Bot. 163).-Turkest.

eriantha, Tenore, Ind. Sem. Hort. Neap. (1830) $14=$ Baumgarteni.

eriocarpa, Bunge, in Mém. Sav. Etr. Pétersb. vii (1851) 336 (Lehm. Reliq. Bot. 160). - Persia 'Turkestan.

eriophora, Schlecht. ex Ledeb. Fl. Rass. ii. $586=$ vulgaris.

eriopoda, Bunge, Enum. Chin. Bor. 37.-Chin. bor.

Lschscholtziana, Bess. in Nouv. Mém. Soc. Nat. Mosc iii. (1834) 24.-Ins. Sandvic.

exilis, Fisch, ex DC. Prod. vi. $119=$ annua.

Falconeri, C. B. Clarke, in Hook. f. Fl. Brit. Ind. iii. 328. - Tibet. occ.

fasciculata, Bieb. Fl. Taur. Cauc. ii. 293.-Reg. Caucas. Persia.

fasciculata, Hook. f. \& Thoms. ex Hook. f. Fl. Brit Ind. iii. $318=$ Tanacetum artemisioides.

filaginoidea, Stechm. Artem, $24=$ vallesiaca

filifolia, Torr. in Ann. Lyc. N. York, ii. (1828) 211. Am. bor.

Fischeriana, Bess. in Nouv. Mém. Soc. Nat. Mosc. iii (1834) $21=$ californica.

foeniculacea, Stev. ex DC. Prod. vi. $108=$ procera,

foetida, Jacquem. ex Bess. in Bull. Soc. Nat. Mosc. ix. (1836) $96=$ desertorum.

foliosa, Nutt. in Trans. Am. Phil. Soc. Ser. II, vii. (1841) 397 = californica.

Fontanesiana, Bess. in Bull. Soc. Nat. Mosc. viii. (1835) 52,-Hab.?

fragrans, Eichw. Casp. Cauc. $6=$ Sieberi.

fragrans, Willd. Sp. Pl. iii. $1835=$ maritima.

franserioides, Greene, in Bull. Torrey Club, x. (1883) 42 - Am. bor, occ.

frigida, Eichw. Casp. Cauc. $31=$ austriaca.

frigida, Willd. Sp. Pl. xii. 1838.-Sibir.; Am. arct.

frutescens, Pall. Reise Statth. Russ. Reich. i. 94, 177

-Rossia.

fruticans, Comm. ex DC. Prod. vi. 261=Stoebe paniculata.

fruticosa, Willd. ex DC. 1. c. $94=$ arenaria.

furcata, Bieb. Fl. Taur. Cauc. iii. $567=$ trifurcata?

gallica, Schur, Enum. P1. Transs. $324=$ maritima

gallica, Willd. Sp. Pl. iii. 1824.-Gall.; Hisp.

garganica, Tenore, ex DC. Prod, vi. $122=$ camphorata.

Gayana, Bess. in Bull. Soc. Nat. Mosc. viii. (1835) 35 -Hispan

gelida, Ledeb. in Mém. Acad. Pétersb. v. (1805) 565 = borealis.

Genipi, Stechm. Artem. 17 = spicata.

gilvescens, Miq. Ann. Mus. Bot. Lugd. Bat, ii, 175.Japon.

glabella, Kar. E Kir. in Bull. Soc. Nat. Mosc. (1841) 441.- - Soongaria.

glabra, Jacquem. ex Bess. in DC. Prod. vi. $97=$

desertorum.

glabrata, DC. in Wight, Contrib. $20=$ parviflora.

glabrescens, Stokes, Bot. Mat. Med. iv, 188=campestris.

glacialis, Bourg. ex Willk. \& Lange, Prod. Fl. Hisp. ii. $70=$ granatensis.

glacialis, Vitm. Singg, $44=$ lanata

glacialis, Herb. Mosc, ex Bess, in Nouv, Mém. Soc. Nat. Mosc. iii. (1834) $67=$ Triniana.

glacialis, Linn. Sp. Pl. ed. II. 1187.-Lurop. austr. med. glacialis, Wult. in Jacq. Coll. ii. $118=$ Mutellina.

glacialis, Schang. in Pall. N. Nord. Beitr. vi. $98=$ commutata.

glauca, Bieb. ex Ledeb. F1. Ross. ii. 564=Amma niana.

glauca, Pall. ex Willd.Sp. Pl. iii. 1831.-Reg. Himal. Sibir.

globularia, Cham. ex Bess, in Nouv. Mém. Soc. Nat. Mosc. iii. (1834) $64=$ norvegica.

\section{ARTEMISIA :-}

globularia, Ledeb. ex Maxim. in Bull. Acad. Pétersb. xvii. (1872) $435=$ glomerata.

glomerata, Hook. \& Arn. Bot. Beech. Voy, $125=$ senjavinensis.

glomerata, Ledeb. in Mém. Acad. Pétersb. v. (1805) 564.-Am. occ. et As. or, arct.

glomerata, Sieber, ex Spreng. Syst. iii. $489=$ Sieberi.

glomerulata, Sieber, ex Spreng. Syst. iii. $489=$ Sieberi.

glutinosa, Boiss. ex Walp. Rep. vi. $214=$ variabilis.

glutinosa, Ұ. Gay, in DC. Prod. vi. 95.-Gallia; Ital.

Gmelini, Fisch. ex Bess. in Nouv. Mém. Soc. Nat. Mosc.

iii. (1834) $28=$ sacrorum.

Gmelini, Stechm. Artem. 30.-Sibir.

Gmelini, Willd. ex Bess, in Nouv. Mém. Soc. Nat. Mosc. iii. (1834) $67=$ Lagopus.

gnaphalioides, Bess, in DC. Prod. vi. $105=$ mendozana.

gnaphalodes, Nutt. Gen. Am, ii. 143 =ludoviciana gorgonum, Webb, in Hook. Niger Fl. 142.-Ins. Cap. Verd.

gracilis, L'Hérit. ex DC. Prod. vi. $100=$ scoparia.

granatensis, Boiss. ex DC. l. c. 298.-Hispan.

grandiflora, $D C . l . c .122$ - - Sibir

grandiflora, Fisch. ex Herd. in Bull. Soc. Nat. Mosc.

xl. (1867) I, $217=$ pontica.

grandiflora, Hoffm. Deutschl, Fl, ed. II. ii. 136rupestris.

grata, Heyne, ex Stend. Nom. ed. II. i. $137=$ Rox burghiana?

grata, Wall. Cat. n. 3294; Comp. n. $404=$ Roxburghiana.

Griffithiana, Boiss, Diagn. Ser. II. iii, $81=$ macrocephala.

groenlandica, Wormsk. in F1. Dan. t. $1585=$ borealis.

Halimodendron, Ledeb, in Hook. f. Fl. Brit, Ind, ii $321=$ salsoloides.

Halodendron, Turcs. in DC. Prod. vi. 94,-Dahur. Mongol.

Haussknechtii, Boiss. Fl. Orient. iii. 374.-Persia.

helvetica, Schleich. Cat. Pl. Helv。 ed. III. $8=$ nana.

hemisphaerica, Roxb. Hort. Beng. 61 ; Fl. Ind. iii. 422 = Cotula hemisphaerica.

Herba-alba, Asso, Syn. Arag. 117.-Hispan. ; Marocc. Oriens.

herbacea, Clarke, ex DC. Prod. vi. $108=$ procer

herbacea, Ehrh. in Willd. Sp. Pl. iii. 1828.-Sibir.

herbacea, Hort. Wratisl, ex Bess. in Nouv. Mém. Soc. Nat. Mosc. iii. (1834) $30=$ procera.

hermaphrodita, Kit, ex Ledeb. Fl. Ross. ii. $566=$ campestris.

heterophylla, Bess. in Nouv. Mém. Soc. Nat. Mosc. iii. 1834) $74=$ Richardsoniana?

heterophylla, Nutt. in Trans. Am. Phil. Soc. N. S, vii. 1841) $400=$ vulgaris

Heyneana, Wall. Cat, n. $3295=$ vulgaris.

hirsuta, Rottl. in Spreng. Syst. iii. $490=$ Cyathocline lyrata.

hispanica, Jacq. Coll. i. $98=$ biennis

hispanica, Lam. Encyc. i. 263.-Hispan

hispanica, Stechm. ex Bess. in Bull. Nat. Soc. Mosc. ix 1836) $114=$ vulgaris

hololeuca, Bieb. ex Bess. in Nouv. Mém. Soc. Nat. Mose. iii. (1834) 46.-Ukrania.

hololeuca, Boiss. \& Haussk. in Boiss. Fl. Orient. iii. $374=$ Haussknechtii.

holosericea, Ledeb. Fl. Alt. iv. $65=$ sericen

Hookeriana, Bess. in Nouv. Mém. Nat. Soc. Mosc. iii. (1834) $39=$ ludoviciana.

humilis, Bieb. Casp. App. $83=$ maritima

humilis, Mill. Gard. Dict. ed. VIII. n. $7=$ A. Abrotanum.

humilis, Wulf, in Jacq. Coll. iv. $295=$ camphorata. hypoleuca, Edgew. in Trans. Linn. Soc. xx. (1846) 71 $=$ Roxburghiana.

hyrcana, Spreng. Syst. iii. $434=$ annua.

iberica, Boiss. ex Boiss. E Buhse, in Nouv. Mím. Soc, Nat. Mosc. xii. (1860) 120.-Reg. Cauc. igniaria, Maxim. Prim. Fl. Amur, $161=$ vulgaris. incanescens, Jord. in Ann. Soc. Agric. Lyon ; ex Gren, \& Godr Fi. Fr. ii. $127=$ camphorata

incompta, Nutt in Trans. Am. Phil. Soc. Ser. II vii. (1841) $400=$ discolor

inconspicua, Spreng. Nachr. i. Bot. Gart. Halle, 12: biennis.

inculta, Delile, Fl. Egypte, 20 $t=$ A. Herba-alba.

\section{ARTEMISIA}

inculta, Sieber, ex DC. Prod vi. 95=monosperma. indica, Willd. Sp. Pl, iii. $1846=$ vulgaris.

infirma, S. G. Gmel. ex Ledeb. F1. Ross. ii. $566^{\circ}$ campestris.

inodora, Bieb. Fl. Taur. Cauc. 1i, 295=campestris.

inodora, Hook. \& Am. Bot. Beech. Voy. 150= dracunculoide:

inodora, Mill. Gard. Dict, ed. VIII. n, $16=$ A. Absinthium.

inodora, Willd. Enum. Hort. Berol. $861=$ A. Dracunculus.

insipida, Schur, Enum. Pl. Transs. 322.-Transsylv. insipida, Vill.Prosp. 32.-Gallia.

integrifolia, Falk, Beitr. ii. 239--Reg. Casp.

integrifolia, Linn. Sp. Pl. $848=$ vulgaris.

integrifolia, Pursh, F1. Am. Sept. $520=$ ludoviciana.

integrifolia, Richards. App. Frankl. Journ. ed. II. 30 Purshiana.

intermedia, Host, Fl. Austr, ii. $160=$ camphorata

intricâta, Franch. Pl. Davidian, i. 170-Mongol.

involucrata, Turcz. ex Ledeb. Fl. Ross, ii $598=$ frigida.

italica, Bieb. ex Ledeb. 1. c. $566=$ campestris.

italica, Stechm. Artem. 28.-Italia.

Facquemontiana, Bess. in Bull. Soc. Nat. Mrsc.

1835. $59=$ desertorum.

facquini, Raeusch. Nom. ed. III. $237=$ biennis

japonica, Thunb. Fl. Fap. 310._Japon.

japonica, F. Schmidt, F1. Sachal. $149=$ Keiskeana

jenisea, Willd. ex Ledeb. Fl. Ross. ii. $598=$ seq.

jeniscensis, Willd. ex Spreng. Syst. iii. $489=$ frigida.

judaica, Linn. Fl. Palaest. in Amoen. Acad. iv. 463; et

Mant. 281.-Aegypt.; Arab.

judaica, Lour, Fl. Cochinch. $489=$ Loureir

juncea, Kar. E Kir. in Bull. Soc. Nat. Mosc. 1842) 383.- Soongaria.

Jussieana, Ұ. Gay, ex Bess. l. c. viii. (1835) 28. Hispan.

kamtschatica, Willd ex Bess. 1. c. $6 \overline{1}=$ leontopo dioides.

Keiskeana, Miq. in Ann. Mus. Bot. Lugd. Bat. ii. 176.- Japon.

Koelreuteriana, Bess. in Bull. Soc. Nat. Mosc. viii. (1835) 16.-Hab.

kohatica, Klatt, in Sitzb. Akad. Muench. (1878) 91.Ind. or.

Kotzebuensis, Bess, in Nouv. Mém. Soc. Nat. Mosc. iii. 1834) $80=$ Chrysanthemum bipinnatum.

Krascheninnikoviana, Bess. 1. c. $41=$ macrobotrys, latifolia.

Kruhsiana, Bess, 1. c. $22=$ lagocephala

kulbadica, Boiss. E Buhse, in Nouv. Mem. Soc. Nat. Mosc. xii. (1860) 120.-Reg. Casp.

kurilensis, Walp. Rep. vi. $217=\mathrm{A}$. Lagopus.

laciniata, Willd. $S p$. Pl. iii. 1843.-Reg. IIimal. Sibir.

lactiflora, Wall. ex DC. Prod, vi. 115=vulgaris.

lagocephala, Fisch. ex Bess, in Nowv. Mem. Soc. Nat. Mosc. iii. (1834) 22.- Sibir

lagopina, St. Lag. in Ann. Soc. Bot. Lyon, vii. (18s0 $119=\mathrm{sec}$

Lagopus, Fisch. ex Bess. in Nouv. Mém. Soc. Nat. Mosc. iii. (1834) 69,--Sibir.

lanata, Koch, Syn. Fl. Germ, ed. II $402=$ nitida

lanata, Lam. Encyc. i. $267=$ variabilis.

lanata, Willd. Sp.Pl. iii. 1S23.-Hisp.; Ital.; Taur.

lanuginosa, Poir. Encyc. Suppl. i. $46^{\circ}=$ lanata.

laricifolia, S. G. Gmel. It. ii. $3=$ maritima

lasiocline, Boiss. Dingn. Ser. I. vi. $92=$ splendens.

latifolia, Ledeb, in Mém. Acad. Pétersb. v. (1805. 569 $=$ laciniata.

lavandulacfolia, DC. Prod. vi. $110=$ vulgaris

lavandulifolia, Salisb. Prod. 191 = caerulesces

Ledebouriana, Bess, in Bull. Sor. Nat. Mose. viii. 1835) 37.-Sibir.

ledricensis, Rochel, ex Spreng. Pugill, ii. $\because ;=$ campestris.

Lehmanniana, Bunge, in Mim. Sas. Elr. Pricrsb. vii. (1851) 340 (Lihm. Reliq. Bof. 16t).-Arghan. Turkest.

leontopodioides, Fisch. ex Bess, in Nouv. Mem. Soc. Nat. Mosc. iii. 1894) 33 = glomerata.

leptophylla, D. Don. Prod. F\%. Nicp. 183 sp. dubia).Nepal.

leptostachyo. DC: l'rod. vi. 113 = vulgaris.

Lercheana, Kar. \& Kir. in Bull. Soc. Nal. Mose Ist1 t1- - 


\section{ARTEMISIA :}

Lexcheand, Presc ex Bess Bull. Soc. Nat. Mosc. viii. $(1835) 33=$ arenaria.

Lercheana, Weber, ex Stechm. Artem. 24=fragrans.

Lerchii, Boeber, ex Georgi, Beschr. Russ. Reich. iii. IV. $1235=$ maritima

Lessingiana, Bess. in Linnaea, xv. (1841) 90.Sibir.

leucanthemifolia, Desf. ex DC. Prod. vi, 98=desertorum

leucodes, Schrenk, in Bull. Phys.-Math. Acad. Pétersb. iii. (1845) 106.-Soongor.

leucophylla, Turcz. ex C. B. Clarke, Comp. Ind. 162= vulgaris.

Lervisii, Torr. \& Gray, Fl. N. Am, ii. 417 (nom delend.).

Libanotis, Bieb. ex Bess. in Nouv. Mém. Soc. Nat. Mosc. iii. (1834) $42=$ macrobotrys.

Lindheimeriana, Scheele, in Linnaea, xxii. (1849) 163 $=$ mexicalia.

Lindleyana, Bess. in Nouv. Mém. Soc. Nat. Mosc. iii. (18:34) $35 .-\mathrm{Am}$. bor. occ.

linearis, Gueldenst. ex Ledeb. F1. Ross. ii. $56 \mathrm{C}=$ salsoloides.

Lippii, Jan, ex Bess, in Bull. Soc. Nat. Mosc. ix. (1836) $79=$ A. Herba-alba.

lithophila, Turcz, ex DC. Prod. vi. $122=$ lagocephala. littoralis, Retz. Obs. v. $28=$ Epaltes australis.

Lobelii, All. Fl. Pedem. i. $166=$ camphorata.

lobulifolia, Boiss. Fl. Orient. iii. 364.-Affghan.

longepedunculata, Rudolphi, ex Bess. in Nouv. Mém. Soc. Nat. Mosc. iii. (1834) 77 = norvegica.

longifolia, Nutt. Gen. Am. ii. 142.-Am. bor. occ.

Loureiri, Kostel. Allg. Med. Pharm. Fl. ii. 669.China.

ludoviciana, Bess, in Nouv. Mém. Soc. Nat. Mosc. iii. (1834) $38=$ discolor.

ludoviciana, Nutt. Gen. Am. ii. 143.-Am. bor, occ.

macra, Boiss. \& Haussk. in Boiss. Fl. Orient. iii. 364. -Cataonia.

macrantha, Ledeb, in Mém. Acad. Pétersb. v. (1805) $573=$ sacrorum

macrobotrys, Ledeb. F1. Alt. iv. $73=$ laciniata,

macrocephala, Facquem. ex Bess. in Bull. Soc. Nat. Mosc. ix. (1836) 28.-Affohan.; Tibet, As, centr. macrophylla, Fisch. ex Bess. in Nouv. Mém. Soc. Nat. Mosc. iii. (1834) 41 = laciniata.

macrorhiza, Turcz. in Bull. Soc. Nat. Mosc. (1840) 73.-Sibir.

maderaspatana, Linn. Sp. Pl. $849=$ Grangea maderaspatana.

magellanica, Sch. Bip. in Flora, xxxviii. (1855) 116.Reg. Magell.

maracandica, Bunge, in Mém. Sav. Etr. Pétersb. vii. (1851) 345 (Lehm. Rel. Bot. 169)= fragrans.

maritima, Linn. Sp. Pl. 846.-Europ.; Reg. Caucas. Sibir.

maritima, Pourr. ex Willk. \& Lange, Prod. Fl. Hisp. ii. $74=$ gallica

maroccana, Coss. in Bull. Soc. Bot. Fr. xxii. (1875) 61.-Marocco.

Marschalliana, Spreng. Syst. iii. $496=$ campestris.

matricarioides, Less. in Linnaea, vi. (1831) $210=$ Matricaria discoidea.

megacephala, Rupr. Sert. Tiansch. 52.-As. centr. melanolepis, Boiss. Diagn. Ser. I. xi. 27.--Persia. mendozana, DC. Prod. vi. 105.-Am. austr. Mertensiana, Wallr. Sched. Crit. 466. t. 4 =laciniata. Messerschmidiana, Bess. in Nouv. Mém. Soc. Nat. Mosc. iii. (1834) $27=$ sacrorum.

Messerschmidii, Weber, ex Stechm. Artem. $19=$ mari tima.

mexicana, Willd. ex Spreng. Syst. iii. 490.-Mexico.

Meyeriana, Bess. in Linnaea, xv. (1841) $96=\mathrm{A}$ Lagopus.

Michauxiana, Bess, in Nouv. Mém. Soc Nat. Mosc. iii. (1834) 71 =discolor.

Michauxii, Bess. ex Hook. Fl. Bor. Am. i. $324=$ praec.

millefoliata, Bieb. ex DC. Prod. vi. $107=$ sacrorum.

minima, Linn. Sp. Pl. $849=$ Centipeda orbicularis.

minor, Facquem. ex Bess, in Bull. Soc. Nat. Mosc. ix. (1836) 22.-Tibet.

mollis, F. Gay, in DC. Prod. vi. 125.-Hab. ?

mollissima, D. Don, Prod. Fl. Nep. 182 (sp. ignot.).Nepal.

molluccana, Roxb. Hort. Beng. [101]; Fl. Ind. iii. 417. - Ins. Moluce.

\section{ARTFMISIA :-}

mongolica Fisch, ex Bess, in Nouv, Mém. Soc. Nat. Mosc. iii. (1834) $53=$ vulgaris

monogyna, Waldst. \& Kit. Pl. Rar. i. 177. t. $75=$ fragrans.

monosperma, Delile, Fl. Egypte, 263.-Syria ; Aegypt. Arab.

monostachya, Bunge, ex Maxim. Fl. Amur. 482.Mongolia.

monspeliensis, Nym. Consp. $377=$ glutinosa

montana, Schlecht. ex Ledeb. Fl. Ross. ii. $591=$ Richardsoniana.

montevidensis, Spreng. Syst. iii. 487.-Reg. Argent.

monticola, C. Koch, in Linnaea, xxiv. (1851) $347=$ caucasica.

Moorcroftiana, Wall. Cat. Comp. n. 406.-Himal. bor.

Moxa, DC. Prod. vi. 121.-China.

multicaulis, Ledeb. F1, Alt. iv. $60=$ anethifolia.

mutabilis, Salisb. Prod. $191=$ A. Santonicum.

Mutellina, S. G. Gmel. It. i. $159=$ splendens.

Mutellina, Vill. Prosp. 31.-Europ. med.

myriantha, Wall. Cat. n. $3297=$ vulgaris

nana, Gaud. Fl. Helv. v. 231.-Helvet

naronitana, Visiani, ex DC. Prod. vi. $108=$ procera.

neapolitana, Tenore, Prod. Fl. Nap. App. v. $28=$ variabilis.

neglecta, Spreng, in Willd. Enum. Hort. Berol. ii $860=$ desertorum.

nepalensis, Nees, in Flora, xiv. (1831) 290.--Ind. or.

nilotica, Linn. Cent. i. 27 ; Sp. Pl. ed. II. $1188=$ Cotula anthemoides.

nitens, Stev. ex Ledeb. F1. Ross. ii. $595=$ sericea.

nitida, Bertol. Mant. 53.-Italia.

nitrosa, Weber, ex Stechm. Artem. 24.-Sibir.

nivea, Redowsk. ex Willd. Enum. Hort. Berol. $863=$ austriaca.

norica, Leyb. in Flora, xxxvii. (1854) $369=$ nana.

norvegica, Fries, Novit. Suec. ed. I. (1817) 56.Norveg.

nubigena, Wall. Cat. n. $3233=$ Tanacetum nubigenum

nutans, Fras. ex Pursh, Fl. Am. Sept. $742=$ dracunculoides.

nutans, Willd. Sp. Pl, iii. $1831=$ maritima,

Nuttalliana, Bess, ex Hook. Fl Bor, Am. i. $326=$ dracunculoides.

obtusiloba, Ledeb. Fl. Alt. iv. 68.-Sibir. alt

occitanica, Salzm, ex DC. Prod, vi. $96=$ campestris.

odoratissima, Desf. Fl. Atlant. ii. 263.-Algeria

officinalis, Gater. Fl. Montaub. $144=$ vulgaris.

officinalis, Gueldenst. ex Ledeb. Fl. Ross. ii. 600.Rossia.

ohotensis, Steph. ex Ledeb. 1. c. $597=$ rupestris

oligantha, Miégev. in Bull. Soc. Bot. Fr. xviii. (1871) $368=$ Mutellina

Oliveriana, Bunge, in Mém. Sav. Etr. Pétersb. vii (1851) 342 (Rel. Lehm. 150)= fragrans.

oliveriana, J. Gay, ex Bess. in DC. Prod. vi. $101=\mathrm{A}$ Herba-alba

Ontina, Dufour, in Ann. Gén. Sc. Phys. vii. (1820) $294=$ A. Herba-alba

orientalis, Herb. Madr. ex DC. Prod. vi. $120=$ pallens.

orientalis, Willd. Sp. Pl. iii. $1836=$ austriaca .

pachystachya, DC. Prod. vi. $114=$ pycnocephala

pacifica, Nutt. in Trans. Am. Phil. Soc. Ser. II. vii. (1841) $401=$ canadensis.

Pallasiana, Fisch. ex Bess. in Nouv. Mém. Soc. Nat. Mosc. iii. (1834) 61.-Rossia.

Pallasii, Spreng. Syst. iii. $494=$ maritima.

Pallasii, Willd. ex Spreng. 1. c. $493=$ borealis

pallens, Wall. ex DC. Prod. vi. 120.-Ind, or.

pallida, Salisb. Prod. $191=$ pontica.

palmata, Lam. Encyc. i. $268=$ caerulescens.

palmata, Lap. Hist. Abr. Pl. Pyr. 504=gallica.

palmata, Steph. ex Bess. in Nouv. Mém. Soc. Nat Mosc. iii. (1834) 22 =rutaefolia.

Palmeri, A. Gray, in Proc. Am. Acad. xi. (1876) 79.Calif.

palustris, Linn. Sp. Pl. 846.-Dahur,; Mongol.

paniculaeformis, DC. Prod. vi. $107=$ vulgaris.

paniculata, Lam. Encyc. i. 265.-Ital.; Gall.

paniculata, Rottl. ex Wight, Contrib. $12=$ Cyathocline lyrata.

paniculata, Roxb. Hort. Beng. 61; F1. Ind. iii. $418=$ vulgaris.

\section{ARTEMISIA .}

paniculata, Sch. Bip. ex Willk. in Flora, xxxiv. (1851) $747=$ variabilis

Parishii, A. Gray, in Proc. Am. Acad. xvii. (1881-82) 220.-Calif.

Parryi, A. Gray, l. c. vii. (1868) 361.-N. Mexico.

parviflora, Buch.-Ham. ex Roxb. Hort. Beng. 61; Fl. Ind. ii.. 420.-Ind. or. ; Burma.

parviflora, Wight, Cat. n. $1460=$ vulgaris.

pauciflora, Bieb. Fl. Taur. Cauc. ii. $290=$ arenaria.

pauciflora, Georgi, Beschr. Russ. Reich. Nachtr. $306=$ maritima.

pauciflora, Spreng. Syst. iii. $491=$ desertorum.

pectinata, Pall. Reise, iii. 255.-Dahur.; Mongol.

pedatifida, Nutt. in Trans. Am. Phil. Soc. Ser. II vii. 1841) 399.-Am. bor.

pedemontana, Balb. ex Loisel. Not. $126=$ lanata

peduncularis, Bieb. Fl. Taur. Cauc. iii. $566=$ splen dens.

pedunculata, Steud. Nom. ed. II. $72=$ splendens.

pedunculosa, Miq. in Ann. Mus. Bot. Lugd. Bat. ii 176.-Japon.

pendula, Salisb. Prod. $191=$ A. Absinthium.

pendula, Schur, in Verh. Siebenb. Ver. Naturw. iv (1853) $39=$ fragrans.

persica, Boiss.Diagn. Ser. I. vi. 91.-Persia ; Affghan. ; As. centr.

petraea, Turcz. ex Ledeb. Fl. Ross. ii. $598=$ frigida. petrosa, Jan, ex DC. Prod. vi. $118=$ Baumgarteni.

peucedanifolia, Juss. ex DC. Prod. vi. $99=$ cana densis.

pinnatifida, Jacquem. ex DC. Prod. vi. $120=$ Tournefortiana.

piperita, Pall. ex Ledeb. Fl. Alt. iv. $88=$ scoparia.

plattensis, Nutt. in Trans. Am. Phil. Soc. Ser. II vii. (1841) $397=$ filifolia.

plumosa, Fisch. ex Bess. in DC. Prod. vi. $119=$ annua. pontica, Burm. f. Prod. $26=$ afra.

pontica, Linn.Sp.Pl. 847.-Europ.; Reg. Caucas.; Soongaria.

potentillaefolia, Fisch. ex Spreng. Syst. iii. $494=$ armeniaca.

potentilloides, A. Gray, in Proc. Am. Acad. vi. (1864) $551=$ Tanacetum potentilloides.

Prescottiana, Bess. in Nouv. Mém. Soc. Nat. Mosc. iii. (1834) 72.-Am. bor. occ.

procera, Lap. Hist. Abr. Pl. Pyr. $503=$ variabilis.

procera, Willd. Sp. Pl. iii. 1818.--Europ. austr. or. As. Min.; Sibir.

procumbens, Schrad. ex DC. Cat. Hort. Monsp. $80=$ frigida.

pseudo-pontica, Schur, Enum. Pl. Transs. 323.Europ.

pubescens, Ledeb. in Mém. Acad. Pétersb. v. (1805) 568.- Sibir. or.

pulchella, Gmel. ex DC. Prod. vi. $102=$ maritima.

pumila, Hort. ex Link, Enum. Hort. Berol. ii. $316=$ frigida.

pumila, Nutt. in Trans. Am. Phil. Soc. Ser. II. vii (1841) $640=$ Lindleyana.

punctata, Bess. in Nouv. Mém. Soc. Nat. Mosc. iii. (1834) 43 = latifolia, macrobotrys

purpurascens, Jacquem. ex Bess. in Bull. Soc. Nat.

Mosc. ix. (1836) $60=$ Roxburghiana.

Purshiana, Bess. in Nouv. Mém, Soc. Nat. Mosc. iii (1834) 59 .-Am. bor.

pusilla, Luce, Topog. Nachr. Oesel, 272.-Europ. bor.

pycnocephala, DC. Prod. vi. 99.-Sibir.

pycnorrhiza, Ledeb. Fl. Alt. iv. 79.-Sibir, alt.

pycnostachya, Torx. \& Gray, F1. N. Am. $422=$ pycnocephala.

pyromacha, Viviani, Fl. Lib. Spec. 54. t. 13. f. $5=$ hispanica.

quadripedalis, Gilib. Fl. Lituan. i. $174=$ vulgaris

quinqueloba, Trautv. in Bull. Soc. Nat. Mosc. xxxix (1ð66) I. 348.-As. temp.

racemifera, Steph. ex Bess. in Nouv. Mém. Soc. Nat. Mosc. iii. (1と34) $28=$ sacrorum.

racemosa, Kit. in Linnaea, xxxii. (1863) 386.Europ.

racemosa, Miégev. in Bull. Soc. Bot. Fr. xii. (1865 341 ; xviii. (1871) $367=$ spicata

radicans, C. Sm. ex DC. Prod. vi. $102=$ reptans

ramosa, C. Sm. ex Link, in Buch, Beschr. Canar. Ins. 148.-Ins. Canar.

ramosa, Lag. ex Willk. \& Lange, Prod. Fl. Hisp. ii. 71 = hispanica. 


\section{ARTEMISTA :}

Redorskyi, Ledeb. in Mém. Acad. Pétersb. v. (1805) $574=$ A. Dracunculus.

repens, Pall. ex Willd. Sp. Pl. iii. $1840=$ austriaca.

reptans, C. Sm. ex Link, in Buch, Beschr. Canar.

Ins. 148.-Ins. Canar.

vevoluta, Edgew. in Trans, Linn. Soc. xx. (1846) $72=$ Roxburghiana.

rhodantha, Rupr. Sert. Tiansch. 52.-As. centr.

Richardsoniana, A. Gray, in Am. Journ. Sc. Ser. II. xxxiii. (1862) $239=$ norvegica,

Richardsoniana, Hook. Fl. Bor. Am. 323.-Am. arct. rigida, A. Gray, in Proc. Am. Acad. xix. (1883) 49.Am. bor. occ.

riparia, Buch.-Ham. ex DC. Prod. vi. $119=$ carvifolia. Rothrockii, A. Gray, in Bot. Calif. i. 618.-Calif.

Roxburghiana, Bess. in Bull. Soc. Nat. Mosc. ix. (1836 57.-Reg. Himal.

Royleana, DC. Prod. vi. 115 (sp. dubia).-Ind. bor. occ.

ribella, Moench, Meth. $572=$ caerulescens.

rubriftora, Turcz. ex Bess. in Nouv. Mém. Soc. Nat. Mosc. iii. (1836) $54=$ vulgaris.

ruderalis, Salisb. Prod. $191=$ vulgaris.

rupestris, All. F1. Pedem. i. $169=$ Mutellina.

rupestris, Asso, Syn. Arag. $117=$ lanata.

rupestris, Lag. \& Rodr, in Anal. Cienc. v. (1802) $284=$ granatensis.

rupestris, Lam. Encyc. i. $262=$ splendens.

rupestris, Linn. Sp. Pl. 847 ; It. Goth. 285.-Oeland. ;

Saxon. : Sibir.

rupestris, O. F. Muell, in Fl. Dan. t. $801=$ norvegica.

rupestris, Scop. Fl. Carn. ed. II. ii. $146=$ camphorata.

rupestris, Vill. Hist. Pl. Dauph, iii. $246=$ spicata.

rutacea, Stev。 ex DC. Prod. vi. $106=$ rutaefolia.

rutaefolia, Steph. ex Spreng. Syst. iii, 488.-Sibir. or.

sabulosa, Stev. ex DC. Prod. vi. $108=$ procera.

sabulosa, Willd ex Ledeb. FI. Ross, ii. 561 = arenaria

sachaliensis, Tiles. ex Bess, in Bull. Soc. Nat. Mosc. viii. (1835) $48=$ capillaris.

sacrorum, Ledeb. in Mém. Acad. Pétersb. v. (1805)

571.-Rossia ; Tibet. ; Sibir.

Saharae, Pomel, Nouv, Mat. Fl. Atl. 56.-Algeria.

saligna, Tenore, Prod. Fl. Nap. Suppl. i. $63=$ variabilis.

salina, Bess. Enum. P1. Volh. $76=$ maritima.

salina, Willd.Sp. Pl. ii. 1834.-Europ.

salsa, F. Martini, Gesch. Nat. vii. $283=$ nitrosa.

salsoloides, Willd. Sp. Pl. iii. 1832.-Reg. Caucas.;

Tibet.; Sibir.

samamisica, Bess. in Nouv. Mém. Soc. Nat. Mosc. iii. (1834) $50=$ vulgaris

santolinaefnlia, Turcz, ex Bess. 1. c. $87=$ sacrorum

Santonica, Lam. Encyc. i. $268=$ caerulescens.

Santonica, Pursh, Fl. Am. Sept. 521 (sp. obscura).-

Am, bor

Santonica, Woodw. Med. Bot. t. $123=$ suaveolens.

Santonicum, Linn. Sp. Pl. 845.-As. bor.

Santonicum, Sievers, ex Bess. in Bull. Soc. Nat. Mosc. ix. (1336) $112=$ campestris.

saxatilis, Reichb. Fl. Germ. Excurs, $202=$ incanescens. saxatilis, Waldst. \& Kit. in Willd. Sp. Pl. iii. $1830=$ camphorata.

saxorum, F. Schmidt, Reisen Amurl. 50, err. typ. $=$ sacrorum

scariosa, Rich. ex Bess, in DC. Prod. vi. 126=Sieversiana.

Schimperi, Sch. Bip. ex Schweinf. Beitr. Fl. Aethiop. 142 , nomen.-Afr. trop.

Schlagintweitiana, Klatt, in Sitzb. Acad. Muench (1878) 90.-Turkestan.

Schmidtiana, Maxim. in Bull. Acad. Pétersb, xvii. (1872) 439.-Japon.

Schrenkiana, Ledeb. Fl. Ross. ii. 575.-Sibir.

scopaeformis, Ledeb. l. c. -Sivir.

scoparia, Waldst. E' Kit. Pl. Rar. Hung. i. 66. t. 65.Europ. ; Oriens ; Ind. or.

scopulorum, A. Gray, in Proc. Ac. Sc. Philad. ' 1863' (1864) 66.-Am. bor. occ.

selengensis, Turcz, ex Bess, in Nouv. Mém. Soc. Nat.

Mosc. iii. (1834) $50=$ vulgaris.

semavinensis, Bess. 1. c. $65=$ senjavinensis.

Semsek, Forsk. Fl. Aegypt. Arab. 218,-Arabia.

Senecionis, Facquem. ex Bess. in Bull. Soc. Nat. Mosc. ix. $(1836) 75$. - Ind, or.

senjavinensis, Bess l. c. 64.-Am. occ. et As, or. arct.

sericen, Weber, in Stechm. Artem. 16. n, 5.-Sibir.

\section{ARTEMISIA}

sericophylla, Rupr. in Beitr. Pf. Russ. Reich. ii. $41=$ borealis.

Seriphium, Pourr, ex Willk. \& Lange, Prod. Fl. Hisp. ii. $71=$ hispanica.

Seriphium, Wallr. Sched. Crit. $458=$ maritima

serotina, Bunge, in Mém. Sav. Etr. Pétersb. vii. (1851)

340 (Lehm. Reliq. Bot. 165).-Turkestan.

serrata, Nutt. Gen. Am. ii. 142.-Am. bor.

sibirica, Maxim. in Bull. Acad. Pétersb. xvii. (1872) $429=$ Tanacetum sibiricum.

Sieberi. Bess. in Bull. Soc. Nat. Mosc. ix. (1836) $80=$

A. Herba-alba.

sipontina, Tenore, F1. Nap. v. $215=$ caerulescens.

Siversiana, Ehrh. ex Willd. Sp. Pl. iii. 1845,-Rossia ; As. bor.; Reg. Himal

sogdiana, Bunge, in Mém. Sav. Etr. Pétersb. vii (1851) 343 (Lehm. Reliq. Bot. 167).-Turkestan. soongarica, Schrenk, Enum. Pl. Nov. 49 (1871).Soongaria ; Turkest.

spicata, Wulf. ex Facq. Fl. Austr. v. 46.-Europ.

spicigera, C. Koch, in Linnaea, xxiv. (1851) $345=$ fragrans.

spinescens, Eaton, in Bot. King, Exp. 180. t. 19.-Am. bor, occ.

spithamaea, Pursh, F1. Am. Sept. $522=$ borealis

splendens, Willd. Sp. Pl. iii. 1822,-As. Min.; Reg Caucas.

Stechmanniana, Bess. in Nouv. Mém. Soc. Nat. Mosc. iii. (1834) $35=$ chamaemelifolia.

Stelleri, Stev. ex Ledeb. Fl. Ross. ii. $568=$ borealis.

Stelleriana, Bess, in Nouv, Mém. Soc Nat. Mosc. iii

(1834) 79.-Am. bor.; Graecia; Kamtschatka.

sternutatoria, Roxb. Hort. Beng. 61 ; Fl. Ind. iii. 423 =Centipeda orbicularis.

Steveniana, Bess. in Nouv. Mém. Soc. Nat. Mosc. iii. 1834) $64=$ glomerata.

Stewartii, C. B. Clarke, Comp. Ind. $163=$ anntua.

Stracheyi, Hook. f. E Thoms. ex C. B. Clarke, Comp Ind. 164.-Tibet. occ.

stricta, Edgew. in Trans. Linn. Soc. xx. (1846) 73. Reg. Himal.

stricta, Fisch. ex Herd. in Bull. Soc. Nat. Mosc. xl. (1867) I. $204=$ desertorum.

stricta, Heyne, ex DC. Prod. vi. $374=$ Cyathocline lyrata.

suaveolens, Fisch. in DC. 1. c. $119=$ annua.

suaveolens, Lam. Encyc. i. 269--Europ.

suavis, Ford. Ind. Sem. Hort. Divion. (1848) 18.Gallia.

subcanescens, Willd. Enum. Hort. Berol. $861=$ camphorata.

subspinescens, Boiss. Diagn. Ser. I. vi. $91=$ persica. subulata, Willd. ex Steud. Nom. ed. II. i. $140=$ arenaria.

subulosa, Willd ex DC. Prod. vi. $94=$ arenaria.

subviscosa, Bess, in Bull. Soc. Nat. Mosc. ix. (1836) 24 -Sibir.

succulenta, Ledeb. Fl. Alt. iv. 81.-Sibir

supina, Stev. ex DC. Prod. vi. $112=$ hololenca

sylvatica, Maxim. Prim. Fl. Amur, 161,-Mandchur.

sylvatica, Schlecht. ex Ledeb. Fl. Ross. ii. $581=$ laciniata.

tanacetifolia, All. Fl. Pedem. i. 166=spicata

tanacetifolia, Georgi, It. i. $229=$ sacrorum.

tanacetitolia, Linn. Sp. Pl. 848.- Sibir.

tanacetoides, Less. in Linnaea, vi. (1831) $210=$ Matri caria multiflora.

tatarica, Weber, ex Stechm. Artem. 19.-Tataria.

taurica, Bieb. Fl. Taur. Cauc. ii. 291.-Taur.

taurica, Less. in Linnaea, x. (1835-36) $170=$ Lessin giana.

taurica, Willd. Sp. Pl. iii. $1897=$ fragrans

tenella, Weber, ex Stechm. Artem. 26.-Hab.

tenuiflora, Jacquem. ex Bess, in Bull. Soc. Nat. Mosc.

ix. (1836) $62=$ Tanacetum tenuifolium

tenuifolia, Adams, in DC. Prod. vi. $107=$ Adamsii.

tenuifolia, Ehrh. ex Ledeb. Fl. Ross, ii. $567=\mathrm{com}$ mutata.

tenuifolia, Moench, Meth. $571=$ pontica.

tenuifolia, Willd. Sp. Pl. iii. $1819=$ Eupatorinm forniculaceum.

tenuissima, Spreng. ex Bess, in Nouv. Mém. Soc. Nat. Mosc. iii. (1834) $30=$ procera.

Thunbergiana, Maxim. in Bull. Acad. Pétersb. xvii (1872) $432=$ apiacea.

thuscula, Cav. in Anal. Cienc. Nat. iv. (1801) 86.lns, Teneriffa.

\section{ARTEMISIA :}

tibetica, Hook, f. FI. Brit. Ind. iii. $329=$ minor.

tifliensis, Adams, ex Bess. in Nouv. Mém. Soc. Nat.

Mosc. iii. (1834) 62 = fasciculata.

Tilesii, Ledeb. in Mém. Acad. Pétersb. v. (1805) $568=$ vulgaris.

tomentella, Trautv, in Bull. Soc Nat. Mosc zxxix (1866) I. 351. - As. centr.

Toumefortiana, Reichb. Ic. Exot. i. 6. t. 5.-Oriens; Reg. Himal.

transsilvanica, Schur, Enum. Pl. Transs, $321=$ Baumgarteni.

Trautvetteriana, Bess, in Mém. Sav. Etr. Pétersb. iv. (1845) 464. t. 5.-Oriens; Afghan.

trichophylla, Wall. Cat. n. $3305=$ scoparia

tridentata, Nutt. in Trans. Am. Phil. Soc. Ser. II vii. (1841) 398.-Am. bor. occ.

trifida, Nutt. l. c.-Am. bor. occ.

trifida, Turcz. in Bull. Soc. Nat. Mosc. v. (1832) $196=$ Tanacetum trifidum.

trifurcata, Desf. Cat. Hort. Par. ed. III. (1829) 161 et $399=$ Fontanesiana

trifurcata, Steph. ex Spreng. Syst. iii. 488.-Soongaria.

Triniana, Bess. in Nouv. Mem. Soc. Nat. Mosc. iii. (1834) 67.-Sibir.

Tschernieviana, Bess, in Bull. Soc. Nat. Mosc viii. 1835) $33=$ arenaria.

Turczaninoviana, Bess. in Nouv. Mém. Soc. Nat. Mosc iii. (1834) 23.-Afghan.

turkestanica, Franch. in Ann. Sc. Nat. Sér. VI. xví. 1883) 311.-Turkestan

ucranica, Bess. ex Nym. Consp. $378=$ Haussknechtii.

umbelliformis, Linn. Encyc, i. 262= Mutellina.

umbrosa, Turcz. ex DC. Prod. vi. $113=$ selengensis.

uralensis, Spreng. ex Bess. in Flora, xvii. (1834) Beibl. 16, nomen.-Sibir.

Vahliana, Kostel. Allg. Med.-Pharm. Fl, ii. 698.Persia.

valentina, Lam. Encyc. i. $269=$ A. Herba-alba.

vallesiaca, All. Fl. Pedem. i. $169=$ seq.

vallesiana, Lam. Encyc. i. 269.-Helv, austr.; Ital.

variabilis, Tenore, Fl. Neap. Prod. App. v. 28.-Neap.

Hisp.

Verlotorum, Lamotte, in Mém. Assoc. Franç. Cong.

Clerm.-Ferr. (1876) 511 = yulgaris.

vermiculata, Linn. Mant. 291 = Stoebe artemisioides.

vermiculata, Schang. ex DC. Prod. vi. $99=$ borealis.

vestita, Wall. Cat.n. 3301.-Reg. Himal.; China.

Villarsii, Gren. \& Godr. Fl, Fr, ii, $130=$ Baumgarteni.

violacea, Desf. Tabl. ed. II. $112=$ vulgaris.

violacea, Ledeb. in Mém. Acad. Pétersb. v. (1805) 567 $=$ borealis.

virens, Moench, Meth. Suppl. $238=$ valgaris.

virgata, Gueldenst. ex Ledeb. Fl. Ross. ii. 600.Ucrania.

virgata, Richards. in Frankl. Journ, App. $306=$ frigida viridifolia, Ledeb. Ind. Sem. Hort. Dorpat. (1828) $2=$ rupestris.

viridis, Willd. ex DC. Prod. vi. 124 =rupestris

viscosa, DC. 1. c. $95=$ glutinosa

vulgaris, Burm. f. Fl. Ind, $177=$ indica.

vulgaris, Linn. Sp. Pl. 848-Reg. temp. bor.

Wadei, Edgew, in Trans, Linn. Soc. xx. (1846) $72=$ annua.

Wallichiana, Bess, in Nouv. Mém. Soc. Nat. Mosc. ii (1834) $69=$ Roxburghiana.

Willdenowii, Dietr. ex Bess. in Bull. Soc. Nat. Mosc. ix. (1836) $115=$ camplorata.

Wrightii, A. Gray, in Proc. Am. Acad xix (1sss) 48 . -Mexico

Wulfenii, Schleich. Cat. Pl. IIelv. ed. IV. $8=$ Mutellina.

Zollingeriana, Sch. Bip. in Zoll. Syst. Vers. Ind. Arckip. 126.-Malaya.

ARTENEMA, G. Don, in Sweet, Hort. Brit, ed. III $516(1839)$ = Artanema, D. Don (Scrophul.).

ARTHOSTEMA, Neck. Elem.ii. $280(1 ; 90)=$ Gnetum. Linn.

ARTIIRATIIERM, Beauv. Agrost. 32. t. 8. f. 8 191? A ristida, Lina. Granin

arenarium, Nees, in Lehm. Pl. Preiss, ii. 9S. Aristida arenaria.

brachyatherum, Coss. \& Dur. Expl. Algrer Glum. 291 = Aristida acutillora. 


\section{ARTHRATHERUM :}

brevifolium, Nees, Fl. Afr. Austr. i. $183=$ Aristida brevifolia.

caloptilum, Jaub. \& Spach, Illustr. iv. 54=Aristida paradisea.

capense, Nees, F1. Afr. Austr. $177=$ Aristida capensis.

ciliatum, Nees, in Linnaea, vii. (1832) $287=$ Aristida ciliata.

comosum, J. Gay, ex Kunth, Enum. P1. i. 194=Aristida stipiformis.

elatum, Boiss. \& Buhse, Diag. Ser. Ir. iv. 128 $=$ Aristida pogonoptila.

hirtiglume, Jaub. \& Spach, Illustr. iv. $52=$ Aristida hirtigluma.

hygrometricum, Beauv. Agrost. $33=$ Aristida hygrometrica.

Hystrix, Nees, in Linnaea, vii. (1832) $287=$ Aristida vesrita.

Kotschyi, Hochst, ex Trin. in Mém. Acad. Pétersb. Sér. VI, vii. (1849) $159=$ Aristida funiculata.

lutescens, Nees, F1. Afr. Austr. i. 179=Aristida lutescens.

megapotamicum, Nees, ex Trin. in Mém. Acad. Pétersb. Sér. VI. vii. (1849) $124=$ Aristida implexa. namaquense, Nees, Fl. Afr. Austr. i, 185=-Aristida namaquensis.

obtusum, Nees, 1. c. $179=$ Aristida obtusa

pauciflorum, Boiss. \& Buhse, Diag. Ser. II. iv. 127.Persia.

plumosum, Nees, Fl. Afr. Austr. i. 182=Aristida plumosa.

pogonoptilum, Jaub. \& Spach, Illustr. iv. 56=Aristida pogonoptila.

pungens, Beauv. Agrost. $33=$ Aristida pungens rigidum, Schult. Mant. ii. $212=$ Aristida rigescens.

Schimperi, Nees, F1. Afr. Austr. $178=$ Aristida ciliata. stipoides, Beauv. Agrost. $33=$ Aristida stipoides. subacaule, Nees, F1. Afr. Austr. $180=$ Aristida subacaulis.

uniplume, Nees, 1. c. $181=$ Aristida uniplumis.

vestitum, Nees, 1. c. $174=$ Aristida vestita.

Zeyheri, Nees, 1. c. $177=$ Aristida Zeyheri.

ARTHRAXON, Beauv. Agrost. 111. t. 11.f. 6 (1812) GRAMINEAE, Benth. \& Hook. f. iii. 1128.

Alectoridia, A. Rich. Tent. Fl. Abyss. ii. 447 t. $99(1851)$.

Batratherum, Nees, in Edinb. N. Phil. Journ. xviii. (1835) 180 .

LASIOLYTRUM, Steud. in Flora, xxix. (1846) 18.

LucaEA, Kunth, Rev. Gram. ii. 48 \% t. $159(1830)$

Pleuroplitis, Trin. Fund. Agrost. 174 (1820).

Psilopogon, Hochst. ex Reichb. Nom. 26 (1841).

ciliaris, Beauv. l. c.-Oriens; As. et Afr. trop.; Austral.

coloratus, Hochst. in Flora, xxxix. (1856) $188=$ ciliaris.

cuspidatus, Hochst. l. c.-Ind. or.

echinatus, Hochst. l. $\mathrm{c}$. = lanceolatus.

gracilis, Hochst. 1. $\mathrm{c} .=$ ciliaris.

japonicum, Miq. Ann. Mus. Bot. Lugd. Bat. ii. $288=$ ciliaris.

Junghuhnii, Hochst. in Flora, xxxix. (1856) 189.Java.

lanceolatus, Hochst. l. c. 188.-Ind. or.; Abyss.; Tapon.

lancifolius, Hochst. 1. c. = microphyllus.

Langsdorfianus, Hochst. 1. c. = ciliaris.

lasiocoleos, Hochst. 1. c. $189=$ ciliaris.

major, Hochst. 1. c. $188=$ ciliaris.

micans, Hochst. l. c.-Ind, or.

microphyllus, Hochst. l. c.--Ind, or.

minor, Hochst. 1. c. = microphyllus

nudus, Hochst. 1. c. $=$ ciliaris.

plumbeus, Hochst. 1. c. $189=$ ciliaris.

rudis, Hochst. l. c. $188=$ cuspidatus.

Schimperi, Hochst. 1. c. $189=$ ciliaris

Schmidtii, Hochst. 1. $c_{0}=$ ciliaris.

serrulatus, Hochst. 1, c. $188=$ lanceolatus.

submuticus, Hochst. 1, c. = ciliaris.

violaceus, Hochst. 1. $\mathrm{c}_{\mathrm{r}}=$ ciliaris.

ARTHROCARPUM, Balf. f. in Proc. Roy. Soc. Edinb. xi. (1々82) 510, LEGUMINOSAE.

gracile, Balf. f. 1. c. 511.-Ins. Socotra.

ARTHROCHILUS, F. Muell. Fragm. i. $42(1858)=$ Drakaea, Lindl. (Orchid.)

irritabilis, F. Muell. I. c. $43=\mathrm{D}$. irritabilis.
ARTHROCHORTUS, Lowe, in Hook. Kew Journ. viii. (1856) $301=$ Lolium, Linn. (Gram.)

loliaceus, Lowe, 1. c.-Ins. Dezsertas (Madera).

ARTHROCLIANTHUS, Baill. Adansonia, ix. 1870) 296. LEGUMINOSAE.

sanguineus, Baill. l. c. 297.-N. Caled.

ARTHROCNEMUM, Moq. Chenop. Enum, 111 (1840), partim. CHENOPODIACEAE, Benth. \& Hook. f. iii. 65 .

ambiguum, Moq. Chenop. Enum. 112.-Austral.

arbuscula, Moq. 1. c. $113=$ Salicornia arbuscula.

australasicum, F. Muell. ex Ung. Sternb. in Atti Congr. Bot. Firenze, 1874 (1876) $303=$ Salicornia quinqueflora.

Belangerianum, Moq. Chenop. Enum. $112=$ Halocnemum caspicum.

bidens, Nees, in Lehm. Pl. Preiss. i. 633=Salicornia bidens.

caspicum, Moq. in DC. Prod. xiii. II.150= Halocnemum caspicum.

ciliolatum, Bunge, in Linnaea, xxviii. (1856) 573 nomen.-As. Min.?

coralloides, Losc. E Pard. Ser. Imperf. Pl. Arag. 90 ed. II. 351.-Hispan.

fruticosum, Moq. Chenop. Enum. 111=Salicornia fruticosa.

fruticosum, Torr. in Stansbury, Rep. $394=$ Spirostachys occidentalis.

glaucum, Delile, Fl. Egypt. 69; Ung. Sternb. in Att Congr. Bot. Firenze, 1874 (1876) 283.-Graecia; Afr. trop. : Ind. or.

halocnemoides, Nees, in Lehm. Pl. Preiss, i. $632=$ Salicornia arbuscula.

indicum, Moq. Chenop. Enum. 113.-Ind. or. ; Afr. trop.

indicum, Thw. Enum. P1.Zey1. $246=$ Salicornia brachiata macrostachyum, Bunge, ex Ung. Sternb. Vers. Syst. Salicom. 67.-Reg. Mediterr.

macrostachyum, Mor. \& Delporte, in Ind. Sem. Hort. Bot. Taur. (1854) 35 = glaucum.

macrostachyum, Torr. Bot. Mex. Bound. Surv. $184=$ Spirostachys occidentalis.

triandrum, F. Muell. Fragm. i. $139=$ Salicornia robusta.

ARTHROLEPIS, Boiss. Diagn. Ser. I. xi. $14(1849)=$ Achillea, Vaill. (Compos.).

imbricata, Boiss. 1. c. $15=$ Ach. membranacea. membranacea, Boiss. 1. c。=Ach. membranacea,

ARTHROLOBIUM, Reichb. Consp. 151 (1828)= ARTROLOBIUM, Desv. = Ornichopus, Linn (Legum.)

ebracteatum, Auct. $=0$. ebracteatus.

ARTHROLOBUS, Andrz. ex DC. Syst. ii. 430 (1821)= Rapistrum, Crantz (Crucif.).

perennis, Andrz. ex DC. 1. c. $431=$ R. perenne

rugosus, Andrz. ex DC. 1. c. $432=\mathrm{R}$. rugosum.

ARTHROLOBUS, Stev. ex DC. Syst. ii. $579(1821)=$ Sterigma, DC. (Crucif.)

torulosus, Stev. ex DC. 1. c. $580=\mathrm{S}$. torulosum.

ARTHROMISCHUS, Thw. Enum. Pl.Zeyl. 47 (1858)= Paramignya, Wight (Rutac.).

armatus, Thw. l. c. = P. armata.

ARTHROPHYLLUM, Blume, Bijdr. 878 (1826) ARALIACEAE, Benth. \& Hook. f. i. 944.

MORMORAPHIS, Jack, ex Wall, Cat. n, 4931 (1831). atternifolium, Maing. ex C. B. Clarke, in Hook. f. F] Brit. Ind. ii. $734=$ pinnatum

Blumeanum, Zoll. \& Moritzi, Syst. Verz. Pf. Zoll. 41 = diversifolium.

ceylanicum, Miq. in Ann. Mus. Bot. Lugd. Bat. i. 27. -Zeylan. ?

dilatatum, Miq. Fl. Ind. Bat. i. I. 768.-Java.

diversifolium, Blume, Bijdr. 879.-Malaya.

ellipticum, Blume, 1. c.= diversifolium.

javanicum, Blume, I. c.=diversifolium.

ovalifolium, Jungh. \& De Vriese, in Ann. Sc. Nat. Sér.

III. vi. (1846) $117=$ diversifolium.

pinnatum, Maing. ex C. B. Clarke, in Hook. $f$. Fl. Brit. Ind. ii. 734.-Malaya.

reticulatum, Blume, ex Miq. in Ann. Mus. Bot. Lugd. Bat. i. 27.-Malaya.

serratifolium, Miq.Fl.Ind.Bat.Suppl.341.-Ins. Banca.
ARTHROPHYLLUM, Boj. Hort. Maurit. 221 (1837)= Phyllarthron, DC. (Bignon.). comorense, Boj. 1. $c_{\text {. }}=\mathrm{P}_{\mathrm{i}}$ comorense.

madagascariense, Boj. 1. c.-Madag.

ARTHROPHYTUM, Schrenk, in Bull. Phys.-Math Acad. Pétersb. iii. (1845) 211. CHENOPODIA$C E A E$, Benth. \& Hook. f. iii. 70.

Lehmannianum, Bunge, Revis. Anab. $46=$ subulifolium.

subulifolium, Schrenk, l.c.-Turkestan.; Soongaria.

ARTHROPODIUIM, R. Br. Prod. 276 (1810). LILIACEAE, Benth. \& Hook. f. iii. 790.

appendiculatum, Avé-Lall.ex Fisch. Mey. \& Avé-Lall. Ind. Sem. Hort. Petrop. xi. 52,-Austral,

caespitosum, Spreng. Syst. ii. 87 = Stypandra eaespitosa.

candidum, Raoul, Choix Pl. Nouv. Zél. 14.-N. Zel. capillipes, Endl. in Lehm. Pl. Preiss. ii. 34.-Austral. cirrhatum, R. Br. in Bot. Mag. t. 2350-N. Zel. dianellaceum, F. Muell. Fragm. x. 65.-Austral. elongatum, DC. Cat. Hort. Monsp. 81, in obs. = paniculatum.

fimbriatum, R. Br. Prod. $276=$ Dichopogon Sieberianus. glaucum, Spreng. Syst. ii. $87=$ Stypandra glanca. hispidum, Spreng. 1. c. = Anthericum hispidum imbricatum, Spreng. 1. c. = Stypandra glauca.

laxum, Hook. f. Fl. Tasm. ii. $51=$ Dichopogon strictus. laxum, Sieber, ex Schult. f. Syst. vii. 441.-Austral, Lindleyi, Kunth, Enum. Pl. iv. $621=$ paniculatum. minus, Lindl. Bot. Reg. t. $866=$ paniculatum.

minus, R. Br. Prod. 276.-Austral.

muricatum, Spreng. Syst. ii. $87=$ Anthericum muricatum.

neo-caledonicum, Baker, in fourn. Linn. Soc. xv. (1877) $352,-\mathbf{N}$. Caled.

paniculatum, R. Br. Prod. 276.-Austral.

pendulum, DC. Cat. Hort. Monsp. $80=$ paniculatum

Preissii, Endl. in Lehm. Pl. Preiss, ii, 35.-Austral.

scabrum, Spreng. Syst, ii. $87=$ Agrostocrinum stipandroides.

strictum, R. Br. Prod, 276= Dichopogon strictus

umbellatum, Spreng. Syst. ii. $87=$ Stypandra umbellata.

ARTHROPOGON, Nees, Agrost. Bras. 319 (1829). GRAMINEAE, Bentl. \& Hook. f. iii. 1119.

stipitatus, Hackel, in Sitzb. Acad. Wien, lxxxix.(1884) 125.-Cuba.

villosus, Nees, Agrost. Bras. 319.-Bras.

ARTHRosolen, C. A. Mey. in Bull. Phys-Math. Acad. Pétersb. i. (1843) 359. THYMELAEACEAE, Benth. \& Hook. f. iii. 193.

anthylloides, C. A. Mey. 1. c. $=$ Lasiosiphon anthylloides.

calocephalus, C. A. Mey. l. c.-Afr. austr.

chrysanthus, Solms, ex Schweinf. Beitr. Fl. Aethiop. 165.-Afr. trop.

glaucescens, Oliver, in Fourn. Linn. Soc. xv. (1871) 96.-Afr. trop.

gymnostachys, C. A. Mey. in Bull. Phys.-Math. Acad. Pétersb. i. (1843) 359--Afr. austr.

inconspicuus, Meissn. in DC. Prod. xiv. 560.-Afr. austr.

laxus, C. A. Mey. in Bull. Phys.-Math. Acad. Péterso. i. (1843) 359.-Afr. austr.

ornatus, Meissn. in DC. Prod. xiv. 559.-Afr. austr pimelioides, Meissn. l. c. 560.-Natal.

polycephalus, C. A. Mey. in Bull. Phys.-Math. Acad. Pétersb. i. (1843) 359.-Afr. austr.

sericocephalus, Meissn. in DC. Prod. xiv. 561.-Afr. austr.

somalensis, Franch. in Revoil, Comali, 62. t. vi.Somali.

spicatus, C. A. Mey. in Bull. Phys.-Math. Acad. Pétersb. i. (1843) 359 -Afr, austr.

subspicatus, Endl. Gen. Suppl. iv. II. $63=\mathrm{Wikstroemia}$ subspicata.

AR'THROSPRION, Hassk. Retzia, i. $212(1855)=$ Acacia, Willd. (Legum.).

stipulatum, Hassk. 1. c. = Acacia concinna.

ARTHROSTACHYA, Link, Hort. Berol. i. 151 (1827) = Gaudinia, Beauv. (Gram.).

coarctata, Link, $1 . \mathrm{c}_{\mathrm{v}}=\mathrm{G}$. geminiflora 
ARTHROSTACHYS, Desv. Opusc. $74(\mathbf{1 8 3 1})=$ Andropogon, Linn. (Gramin.).

gracilis, Desv. 1. c.-Ind. or

ARTHROSTEMA, Ruiz \& Pav. F1. Per. iv. t. 326 (1802). MELASTOMACEAE, Benth. \& Hook. f. i. 740.

Heteronoma, DC. Prod. iii. 122 (1828).

MELANIUM, Rich. ex DC. 1. c. 135 (1828).

alatum, Triana, in Trans, Linn. Soc. xxviii. (1871) 35. -Venezuela.

alpestre, Naud. in Ann. Sc. Nat. Sér. III. xiii. (1850 $357=$ Pterolepis alpestris

angusturense, DC. Prod. iii, $135=$ Pterolepis glomerata Aubletii, DC. 1. c. $137=$ Comolia Aubletii.

Bonplandii, DC. 1. c. $138=$ Monochaetum Bonplandii brachyandrum, Cham. in Linnaea, ix. (1834) $454=$ Pterolepis glomerata, Tibouchina versicolor.

calcaratum, DC. Prod. iii. 138=Monochaetum cal caratum.

campanulare, DC. 1. c. $\mathbf{1 3 6}=$ Brachyotum campanulare campanulare, DC. 136 . Brachyotum campanulare (1871) 35.-Am. trop.

capitatum, Naud. in Ann.Sc. Nat. Sér. III. xiii. (1850 361 . - Ind. occ,

cataphractum, Naud. 1. c. $360=$ Pterolepis cataphracta caulialatum, Ruiz \& Pav. Fl. Per. iv. t. $327=$ Aciotis caulialata.

cerastiifolium, DC. ex Naud. in Ann. Sc. Nat. Sér. III. xiv. (1850) $122=$ Tibouchina cerastifolia

ciliatum, Ruiz Es Pav. Fl. Per. iv. t. 326.-Peruv

clidemioides, Miq. in Linnaea, xxii. (1849) 541

Pterolepis clidemioides.

cubense, A. Rich. Ess. Fl. Cub. $550=$ Chaetolepis cubensis.

Deppeanum, Schlecht. \& Cham. in Linnaea, v. (1830) $566=$ Monochaetum Deppeanum.

dicranantherum, DC. Prod. iii. $138=$ Monochaetum dicranantherum.

exiguum, Naud. in Ann. Sc. Nat. Sér. III. xiií. (1850) $359=$ Pterolepis exigua.

filiforme, Naud, 1. c. $358=$ Pterolepis filiformis.

floribundum, Schlecht. in Linnaea, xiii. (1839) $431=$ Monochaetum rivulare.

fragile, Lindl. in Fourn. Hort. Soc, iii. (1848) 74.Mexic.

glomeratum, Cham. in Linnaea, (1834) ix. $454=$ Pterolepis glomerata.

Goudotianum, Naud. in Ann. Sc. Nat. Sér. III. xii (1850) $359=$ Pterolepis Goudotiana

herbaceum, DC. Prod. iii. $137=$ Tibouchina herbacea heterostemon, Naud, in Ann. Sc. Nat. Sér. III. xii (1850) $360=$ Pterolepis filiformis.

hirsutissimum, DC. Prod. iii. $137=$ Tibouchina herbacea.

hirsutissimum, Nand. in Ann. Sc. Nat. Sér. III. xiii. (1850) $357=$ Pterolepis pauciflora.

ladanoides, DC. Prod, iii. $136=$ Pterolepis pusilla

lanceolatum, Griseb. in Mem. Am. Acad. N. S. viii (1861) 186.-Cuba.

latifolium, D. Don, in Mem. Wern. Soc. iv. (1823) 299.-Guiana.

lineatum, D. Don, l. c. = Monochaetum lineatum.

lutescens, $D C$. Prod. iii. $136=$ Brachyotum lutescens,

macranthera, Miq. in Linnaea, xxii. (1849) $540=$ Tibouchina sebastianopolitana.

Martinsianum, DC. Prod. iii. $137=$ Tibouchina sebas tianopolitana.

multiflorum, DC. 1. c. $138=$ Monochaetum multiflorum.

multiflorum, D. Don, in Mem. Wern. Soc. iv. (1823) $299=$ Monochaetum dicranantherum.

myrtoideum, DC. Prod. iii. $138=$ Monochaetum myrtoideum.

nitidum, R. Grah, in Edinb. N. Phil. Jonrn, xii. (1382 $186=$ Tibouchina nitida

nummularioides, DC. Prosl, iii. 137 = Comolia nummularioides.

paniculatum, D. Don, in Mem. Wern. Soc. iv. (1823) $299=$ Oxyspora paniculata.

pauciflorum, Naud. in Ann. Sc. Nat. Sér. III. xiii. (1850) $357=$ Pterolepis pauciflora.

piloselloides, DC. Prod. iii. $136=$ Castratella piloselloides.

polygonoides, DC. 1. c. $197=$ Pterolepis polygonoides, pumilum, Naud. in Ann. Sc. Nat. Sér. III. xiii. (1850 $\mathbf{8 5 7}=$ Pterolepis pasilla

pusillum, Naud. 1. c. $361=$ Pterolepis pusilla.

\section{ARTHROSTEMA}

quinquenerve, DC. Prod. iii. $136=$ Brachyotum quin quenerve.

rosmarinifolium, DC. 1. c.= Brachyotum rosmarinifolium.

Salzmannii, Naud. in Ann. Sc. Nat. Sér. III. xiii 1850) $356=$ Pterolepis Salzmannii

Schiedeanum, Steud. Nom. ed. II. i. 141 (=Pleroma longiflorum?).-Mexic.

uruguayense, Cham. in Linnaea, ix, (1834) $453=$ Tibouchina nitida.

versicolor, DC. Prod. iii. $137=$ Tibouchina versicolor

villosum, DC. 1. c. = Comolia villosa.

villosum, Mart. Herb. F1. Bras. n. $499=$ Comolia ovalifolia.

volubile, Triana, in Trans. Linn. Soc. xxyiii. (1871) 35.-N Granat.

Weddellianum, Naud. in Ann. Sc. Nat. Sér. III. xiii. (1850) $356=$ Pterolepis Weddelliana.

ARTHROSTEMMA, DC. Prod. iii. 134 (1828) pro parte Brachyotum, Triana (Melast.

ARTHROSTEMMA, Naud. in Ann. Sc. Nat. Sér. III xiii. (1850) $355=$ Pterolepis, Miq. (Melast.)

ARTHROSTYGMA, Steud. Nom. ed. II. i. 141 (1840) Petrophila, R. Br. (Proteac.)

ARTHROSTYLIDIUM, Rupr. in Mém. Acad. Pétersb. Sér. VI, v. (1839) 117. GRAMINEAE, Benth. \& Hook. f. Gen. iii. 1208.

Aulonemia, Goudot, in Ano. Sc. Nat. Sér. III. v (1846) 75. t. 5 .

Burchellii, Munro, in Trans. Linn. Soc. xxvi. (1868) 43.-Bras.

capillifolium, Griseb. in Mem. Am. Acad. N. S. viii 1863) 531.- - Ind. occ.

cubense, Rupr. in Mém. Acad. Pétersb. Sér. VI. v. (1839) 118.t. 4. f. 13.-Cuba.

excelsum, Griseb. Fl. Brit. W. Ind. 529.-Ind. occ.

fimbriatum, Griseb. in Mem. Am. Acad. N. S. viii. (1863) 531.-Ind. occ.

Haenkei, Rupr. in Mém. Acad. Pétersb. Sér. VI. y. (1839) 117. t. 3. f. 12.-Peruv.

leptophyllum, Doell, in Mart. Fl. Bras. ii. III. 175.Bras.

longiflorum, Munro, in Trans. Linn. Soc. xxvi. (1868) 41.-Venezuela.

maculatum, Rupr. in Mém. Acau. Pétersb. Sér. VI. v. (1839) 118. t. 5.-Peray,

pubescens, Rupr. l. c. 119. t. 4. f. 14.-Ind. occ.

racemiflorum, Steud. Syn. Pl. Gram. 336.-Mexic

Schomburgkii, Munro, in Trans. Linn. Soc. xxvi. 1868) 41.-Guiana.

Trinil, Rupr. in Mém. Acad. Pétersb. Sér. VI. 1839) 119. t. 4. f. 15.-Bras.

ARTHROSTYLIS, R. Br. Prod. 229 (1810). CYPE RACEAE, Benth. \& Hook. f. iii. 1058.

aphylla, Boeck. in Linnaea, xxxvii, (1871-73) $524=$ Actinoschoenus Thouarsii.

aphylla, $R$. Br. Prod. 229.-Austral.

chinensis, Benth. Fl. Hongk. $397=$ Actinoschoenus chinensis.

filiformis, Thw. Enum. Pl. Zeyl. $352=$ Actinoschoenus filiformis.

Thouarsit, Kunth, Enum. P1. ii. $284=$ Actinoschoenus Thouarsii.

ARTHROSTYLIS, Boeck. in Linnaea, xxxvii. (1871-73) $523=$ Actinoschoenus, Benth. (Cyperac.)

aphylla, Boeck. 1. c. $524=$ Act. Thouarsii.

filiformis, Boeck. 1. c. = Act. filiformis

ARTHROTAXIS, Endl. Gen. Suppl. i. 1372 (1841) err. typ. = Athrotaxis, D. Don (Conif.).

ARTHROTHAMNUS, Klotzsch \& Garcke, in Monatsb. Akad. Berl. (1859) $251=$ Euphorbia, Lin.

Bergii, Klotzsch \& Garcke, in Abh. Akad. Berl. (1860) 63.-Afr. austr.

brachiatus, Klotzsch \& Ginrcke, in Monatsb. Akad. lierl. (1859) 251; et Abh. Akad. Berl. (1860) $62=$ E. brachiata.

Burmanni, Klotzsch \& Garcke, 11. $\mathrm{cc}_{0}=$ E. Bur manni.

cymosus, Klotzsch \& Garcke, 11. cc. $251,68=$ E. nudi tlora.

\section{ARTHROTHAMNUS:-}

densiflorus, Klotzsch \& Garcke, in Monatsb. Akad. Berl. (1859) 251; et Abh. Akad. Berl. (1860) 62. Afr. austr.

Ecklonii, Klotzsch \&c Garcke, 11. cc. 251, 63.-Afr. austr. scopiformis, Klotzsch \& Garcke, 11. cc. =E. scopiformis.

Tirucalli, Klotzsch \& Garche, 1l. cc, 251, 62=F Tirucalli.

ARTHROTRICHUM, F. Muell, in Trans. Bot. Soc Edinb. vii. (1863) 500; et Ldinb. N. Phil. Journ. N. S. xvii. (Jan.-Apr. 1863) $234=$ Trichinium, R. Br. (Amarant.)

calostachyum, F. Muell. 11. cc, $=$ T. calostachyum.

ARTHROZAMIA, Reichb. Consp. 40 (1828)=Ence phalartos, Lehm. (Cycad.)

ARTOCARPUS, Forst. Char. Gen, 101, t, 51 (1776)

URTICACEAE, Benth, \& Hook, f. iii, $376^{\circ}$

DURio, Adans, Fam, ii. 399 (1763)

Polyphema, Lour. Fl. Cochinch. 546 (1790)

RADERMACHIA, Thunb. in Handl. Vet. Akad. Stock h. (1776) 252 .

Rima, Sonner. Voy. Nouv, Guir. 99. t. 57 ad 60 (1776).

Sitodium, Gaertn. Fruct. i. 344. t. 71, 72 (1791)

angustifolia, Roxb. Hort. Beng, 66, nomen.-Ins. Malay.

anisophylla, Miq. Fl. Ind. Bat. Suppl. 422.-Sumatra. benghalensis, Roxb, ex Wall. Cat. sub a. $4655=\mathrm{A}$. Lakoocha.

bifaria, Wall. ex Miq. Ann. Bot. Mus. Lugd. Bat. ii $213=$ Sloetia Sideroxylon.

biformis, Miq. Fl. Ind. Bat. Suppl. 419.-Sumatra.

Blumei, Tréc. in Ann. Sc. Nat. Sér. III. viii. (1847 111.-Java.

brasiliensis, Gomez, in Mem. Ac. Lisboa, iii. (1812; Mem. dos Corresp. 84.-Bras.

calophylla, Kurz, For. Fl. ii. 431.-Tenasserim.

Camansi, Blanco, Fl. Filip. ed. I. 670.-Ins. Philipp.

canarana, Miq: in Verh. Nederl. Inst. III. v. (1852 Anal. Bot. Ind.) 20.-Ind or.

Cannoni, Hort. Bull, ex Van Houtte, in Fl. des Serres,

xxi. (1875) 131. -Ins. Soc.

cerifera, Miq. Ann. Mus. Bot. Lugd. Bat. iii. 212.Java.

Chama, Buch.-Ham. ex Wall. Cat. sub n. $4657=\mathrm{A}$ Chaplasha

Champeden, Spreng. Syst. iii. $804=$ A. Polyphema

Chaplasha, Roxb. Hort. Beng. 66 ; et Fl. Ind. iii. 525 . -Ind. or.

communis, Forst. Char. Gen. $100=$ incisa?

Cumingiana, Tréc. in Ann. Sc. Nat. Sér. III. viii. (1847) 119.-Ins. Philipp

cuspidata, Griff. Notul. iv. $400=$ rigida.

Dadak, Mig. Fl. Ind. Bat. Suppl, +20-Sumatra

dasyphylla, Miq. Ann. Mus. Bot. Lugd. Bat. iii. 21 . -Ins. Celebes.

dimorphophylla, Miq. Fl. Ind. Bat. Suppl. $117 .-$ Ins. Banca.

echinata, Roxb. Hort. Beng. 66 ; et Fl. Iad. iii. 527 rigida.

elastica, Reinw, in Blume, Bijdr, 481.-Borneo.

elongata, Miq. F1. Ind. Bat. Suppl. $\$ 19=$ Sloetia Sideroxylon.

erythrocarpa, Korth. ex Miq. Ann. Mus. Bot. Lugd. Bat. iii. $213=$ A. Dadak.

erythrocarpa, Teijsm, ex Mio, I c. $212=i$...4is (la

exculpta, Hort.-Cf, Gard. Chron. (Is-s) I1, *

Hab. ?

Finlaysoniana, Wall. Cat. D. 4662.-Malaya,

glauca, Blume, Bijdr. $483 .-$ Java.

glaucescens, Tréc ing Aunt. So. Nat. Ser. III viii. (1847) 120.-Java.

Gomeziana, Wall. ex Tric. L. c. 118.-Ind. or.

heterophylla, Lam. Encyc. vii. $204=$ integrilolia.

hissuta, Lam. Ency'c. vii. 211.-Ind. or.

hirsutissims, Kürs, in Tijdschr. Niderl. Ind. xxiti. (1864) 152.-Ins. Panca.

hypargyren, Hance, ex finth. Fl. Hangt. 9:5 -

Hongkung.

incisifolia, Stokes, Bot. Mat. Med. iv. \$1 = incisa

incisa, Linn. $f$. Suppl. 111. - Malaye; Ins. Pacif

integrifolia, Linn. f. /. c. \$12.-Ind. or. ; Malaya,

Faca, Lam. Encyc. iii. 20 ! $=$ integrifolia.

Kemando, Miq. Fl. Ind. Baf. Suppl. t1s.- sumatu 


\section{ARTOCARPUS :}

Kertau, Zoll. Syst. Verz. Ind. Archip. 89, 95.Malaya.

laciniata, Hort.-Cf. Gard. Chron. (1875) II. 159 ; et Rev. Hortic. (1877) 38.-Ins. Pacif

Lacucha, Roxb. Hort. Beng. 66, nomen=A. Lakoocha. laevis, Hassk. in Hoev. E De.Vriese, Tijdschr. x. (1843) 124.-Java.

Lakoocha, Roxb. Fl. Ind iii. 524-Ind. or. ; Malaya. lamellosa, Blanco, Fl. Filip. ed. I. $667=$ nitida. lanceaefolia, Roxb. Hort. Beng. [103]; Fl. Ind. iii. 527.-Malaya.

lanceolata, Tréc. in Ann. Sc. Nat. Sér. III. viii. (1847) 121-Manila.

Limpato, Miq. Fl. Ind. Bat. Suppl. 421.-Sumatra. madagascariensis, Boj. Hort. Maurit. 290.-Madag. mariannensis, Tréc. in Ann. Sc. Nat. Sér. III. viii. (1847) 114. - Ins. Mariann.

maxima, Blanco, F1. Filip. ed. I. $669=$ integrifolia. mollis, Miq. Fl. Ind. Bat. Suppl. 420.-Sumatra. mollis, Wall. Cat. n. 4661=A. Lakoocha.

Nanca, Noronha, in Verh. Bataw. Gen. v. (1790) ed. I Art. IV. 7.-Malaya.

nitida, Tréc. in Ann. Sc. Nat. Sér. III. viii. (1847) 119. -Ins. Philipp.

nobilis, Thw. Enum. Pl. Zeyl. 282.-Zeylan.

odoratissima, Blanco, Fl. Filip, ed. I, 671.-Ins. Philipp ovata, Blanco, 1. c. $666=$ Cumingiana

ovata, Noronha, in Verh. Batav. Gen. v. (1790) ed. I. Art. IV. 7.-Malaya.

palembanica, Miq. Fl. Ind. Bat. Suppl. 424.-Tava

parviflora, Voigt, in Syll. Ratisb. ii, (1828) 53.Hab. ?

peduncularis, Kurz, in Fourn. Bot. xiii. (1875) 331.Ins. Nicobar.

petiolaris, Miq. Fl. Ind. Bat. Suppl. 422.-Sumatra.

philippensis, Lam. Encyc. iii. 210.-Ins. Philipp.

pilosa, Noronha, in Verh. Batav. Gen. v. $(1790)$ ed. I. Art. IV. 7.-Malaya.

pilosa, Reinw. ex Miq. Ann. Mus. Bot. Lugd. Bat. iii $211=$ A. Polyphema.

Polyphema, Pers. Syn. ii. 531.-Malaya.

pomiformis, Teijsm. \& Binn. in Tijdschr. Nederl. Ind. xxy. $(1863) 400=$ Gomeziana.

Ponga, Dennst. Schluessel, $30=$ Broussonetia integrifolia.

pubescens, Blume, Bijdr. 481.-Java.

pubescens, Moon, Cat. P1. Ceyl. $61=$ nobilis.

pubescens, Willd. Sp. Pl. iv. $189=$ integrifolia.

reticulata, Heyne, ex Wall. Cat. sub n. $4655=\mathrm{A}$

Lakoocha.

reticulata, Miq. Ann. Mus. Bot. Lugd. Bat. ii. 213.Ins. Celebes.

Riedelii, Miq. l. c.-Ins. Celebes.

rigida, Blume, Bijdr. 482.-Burma; Malaya.

rigida, Wall. Cat, n, $4658 \mathrm{~A}=$ Gomeziana.

Rima, Blanco, Fl. Filip, ed, I, $671=$ incisa

rufa, Miq. Fl. Ind. Bat. Suppl. 423.-Malaya.

rufescens, Kurz, For. Fl, ii, 431, - Ind, or.

rufescens, Miq. Ft. Ind. Bat. Suppl. 420.-Malaya

serrata, Roxb. Hort. Beng. 66, nomen.-Ind. or.

Tampang, Miq. Fl. Ind. Bat. Suppl. $421=$ rufescens, Miq.

tephrophylla, Miq.l.c. 422,-Sumatra.

Teysmanni, Miq. l. c. 418.-Sumatra.

tylophylla, Miq. Fl. Ind. Bat. i. II. 289.-Malaya

varians, Miq. Fl. Ind. Bat. Suppl. 417.-Sumatra.

venenosa, Zoll. E Mor. in Nat. en Geneesk. Arch.

Neerl. Indie, ii. (1845) 213.-Java.

Vriesiana, Miq. Ann. Mus. Bot. Lugd. Bat. iii. 212.Ins. Celebes.

Zollingeriana, Miq. in Zoll. Syst. Verz. Ind. Archip. 90,95 - Malaya.

ARTROLOBIUM, Desv. Journ. Bot. i. (1813) 121. t. 4 = Coronilla, Linn., Ornithopus, Linn., etc. (Legumin.)

creticum, Desv, 1. c. $=$ Coronilla cretica

durum, Desv. 1. c. =Ornithopus durus.

ebracteatum, Desvi, 1. c:=Onithopus ebracteatus.

micranthum, Benth. in Mart. F1. Bras, xv. I. 51.-Am. trop.

repandum, DC. Prod. ii. $311=$ Ornithopus repandus. scorpioides, Desv. Journ. Bot. i. (1813) $121=$ Coronilla scorpioides.

Spasskii, Kalen. in Bull. Soc. Nat. Mosc. xviii. (1845) I. 233.-Tauria.

tauricum, Kalen. 1. c.-Tauria.
ARUANA, Burm. f. Ind. Alt. (sign. G, verso) (1769) $=$ Myristica, Linn

silvestris, Burm. f. 1. c. = M. moschata.

ARUBA, Aubl. Pl. Gui. i. 293. t. $115(1775)=$ Simaba Aubl. (Simarub.)

guianensis, Aubl. 1. c.-Guiana.

ARUBA, Nees \& Mart. in Nov. Act. Nat. Cur. xi. (1823) 172. t. 19, 27, $29=$ Almeidea, St. Hil. (Rutac.).

acuminuta, Nees \& Mart. 1. c. $\mathbf{1 7 5}=$ Almeidea acuminata.

alba, Nees \& Mart. 1. c. $174=$ Almeidea alba.

coerulea, Nees \& Mart. 1. c. = Almeidea caerulea.

myriacantha, Nees \& Mart. ex Steud. Nom. ed. II. i $142=$ Almeidea myriantha.

ARUM, [Tourn.] Linn. Syst. ed. I. (1735), partim. AROIDEAE, Benth. \& Hook. f. Gen. iii. 967.

Gymnomesium, Schott, in Oestr. Bot. Wochenbl. (1855) 17.

abysinicum, A. Rich. Tent. FI. Abyss. ii. $352=$ Sauromatum abysinicum.

aculeatum, Steud. Nom. ed. I. $73=$ Caladium aculeatum.

alatum, Noronha, in Verh. Batav. Gen. v. $(1790)$ ed. I Art. IV. 4.-Malaya.

albinervium, Kotschy, ex Engl. in DC. Monog. Phan. ii. $590=$ hygrophilum

albispathum, Hort. ex Engl. 1. c. $591=$ italicum.

albispathum, Stev. ex Ledeb. Fl. Ross. iv, $9=$ orientale.

alpinum, Schott \& Kotschy, in Bot. Zeit. ix. (1851) $285=$ maculatum

alternans, Engl. in DC. Monog. Phan. ii. $372=$ Philodendron crassinervium.

alternum, Vell. F1. Flum. ix, t. $116=$ Philodendron crassinervium.

amphibium, Vell. 1. c. $112=$ Philodendron amphibium.

aquaticum, Noronha, in Verh. Batav. Gen. v. (1790) ed. I. Art. IV.5.-Malaya.

angulatum, Griff. Notul. iii. 143.-Ind. or.

aphyllum, Hook. in W. Gray, Western Afr. 386. t. A $=$ Amorphophalli sp.

arborescens, Linn. Sp. Pl. $967=$ Montrichardia arborescens.

Arisarum, Linn. 1. c. $966=$ Arisarum vulgare.

Arisarum, Lour. F1. Cochinch. $655=$ Typhonium cochinchinense

atrombens, Ait. Hort. Kew. iii. $315=$ Arisaema atrorubens.

atrorubens, Spreng. Syst. iii. $769=$ Pinellia tuberifera auritum, Linn. Syst. ed. X. 1251; Pl. Jam. Pugill. 26 =Syngonium auritum.

auritum, Vell. Fl. Flum. ix. t. 113 = Syngonium Vellozianum.

balearicum, Buchoz, Dec. PI. viii. $11=$ pictum.

Besserianum, Schott, in Oestr. Bot. Zeitschr.-(1858) $349=$ maculatum.

betifolium, Mill. Gard. Dict. ed. VIII. n, 12.-Am. bor.

bicolor, Ait. Hort. Kew, iii, $316=$ Caladium bicolor bubalinum, Noronha, in Verh. Batav.Gen. v. (1790) ed. I. Art. IV. 4.-Malaya.

bulbiferum, Roxb. Hort. Beng. 65; Sims, Bot. Mag. t. $2072=$ Amorphophallus bulbifera.

bulbiferum, Salisb. Prod. $260=$ Pinellia tuberifera.

bulbosum, Pers. ex Kunth, Enum, Pl. iii. 54=Pinellia tuberifera?

byzantinum, Schott, in Oestr. Bot. Wochenbl. (1857) 212 = italicum

caeruleo-punctatum, Zipp. ex Kunth, Enum. P1. iii. 33 $=$ Amorphophallus variabilis.

calyptrale, Salisb. Prod. $261=$ Arisarum vulgare

campanulatum, Roxb. Hort. Beng, 65; F1. Ind. iii $509=$ Amorphophallus campanulatus

canariense, Webb \& Berth. Phyt. Canar. iii. $293=$ italicum.

cannaefolium, Linn. f. Pl. Surin. n. $123=$ Spathiphyllum cannaeforme?

carratracense, Haensel. in Bot. Zeit. iv. (1846) $313=$ Biarum Bovei.

catavericum, Noronha, in Verh. Batav. Gen. v. (1790) ed. I. Art. IV. 4.-Malaya.

ciliatum, Hort. ex Loud. Encyc. Suppl. ii. 1508= Cryptocoryne ciliata.

\section{ARUM :-}

ilicicum, Kotschy, ex Engl. in DC. Monog. Phan. ii. $589=$ rupicolum.

clavatum, Desf. Cat. Hort. Par, ed. III. $385=$ Sauromatum pedatum.

Colocasia, Linn. Sp. P1. $965=$ Colocasia antiquorum

colocasioides, Desf. Cat. Hort. Par. ed. III. 7 et $385=$ Colocasia antiquorum.

concinnatum, Schott, Ic. Aroid. t. $39=$ italicum.

conophalloides, Kotschy, ex Schott, Prod. Aroid. $97=$ orientale

consobrinum, Schott, l. c. 87.-Reg. Cauc.

cordatum, Vell. Fl. Flum, ix. t. $111=$ Philodendron cordatum.

cordifolium, Bory, Voy. i. 376 ; ii. $67=$ Alocasia indica corsicum, Loisel. FI. Gall. ii. $617=$ pictum.

costatum, Wall. Tent. Fl. Nep. t. $19=$ Arisaema costatum

crassipes, Boiss. Diagn. Ser. I. xiii. $9=$ Helicophyllum crassipes,

crenatum, Wight, in Hook. Bot. Misc. ii. (1831) 100 $=$ Theriophonum crenatum.

creticum, Boiss. E Heldr. Diagn. Ser. I. xiii. 9.Creta.

crinitum, Ait. Hort. Kew. iii. $314=$ Helicodiceros muscivorus.

crudele, Salisb. Prod. $261=$ Dieffenbachia Seguine.

cucullatum, Lour. F1. Cochinch. ii. $536=$ Alocasia cucullata

curvatum, Roxb. Hort. Beng. 65 ; F1. Ind. ini. $506=$ Arisaema curvatum.

cuspidatum, Blume, Cat. Gew. Buitenz, 101= Typho nium cuspidatum.

cuspidatum, Roxb. Hort. Beng. 65 ; Fl. Ind. iii. $506=$ Arisaema cuspidatum.

cylindraceum, Gasp. in Guss. F1. Sic. Syn. ii. II. $597=$ italicum.

cyprium, Schott, in Bonplandia, x. (1861) 368=Dioscoridis.

decurrens, Blanco, Fl. Filip. ed. I, $656=$ Amorphophallus decurrens.

detruncatum, C. A. Mey. ex Schott, Prod. Aroid. 8.Pers. bor.

Dioscoridis, Sibth. E Sm. Fl. Graec. Prod. ii. 245.Graecia; As. Min.

discolor, Voigt, in Syll. Ratisb. ii. 50.-Hab.

divaricatum, Dulac, F1. Hautes-Pyr. $46=$ italicum.

divaricatum, Linn. Sp. P1. 966=Typhonium divari catum.

diversifolium, Blume, Cat. Gew. Buitenz. $102=\mathrm{Ty}$ phonium divaricatum.

Dracontium, Linn. Sp. Pl. 964=Arisaema Dracontium.

Dracontium, Lour. F1. Cochinch. $533=$ Pinellia Wawrae.

Dracontium, Thunb. F1. Jap. $233=$ Arisaema Thunbergii.

Dracontium, Vell. F1. Flum, ix, t. $103=$ Stăurostigma Luschnathianum.

Dracunculus, Linn. Sp. Pl. 964 = Dracunculus vulgaris.

Dracunculus, Thunb. Fl. Jap. $233=$ Arisaema japonicum.

echinatum, Wall. P1. As. Rar. ii. 30. t. 136= Arisaema echinatum.

Ehrenbergii, Schott, in Oestr. Bot. Zeitschr. viil. (1858) 386.-Syria.

elongatum, Stev. in Bull. Soc. Nat. Mosc. xxx. (1857) II. $67=$ orientale

erubescens, Wall. Pl. As. Rar. ii. 30.t. $135=$ Arisaema erubescens.

esculentum, Linn. Sp. P1. $965=$ Colocasia antiquorum. exsertum, Salisb. Prod. $260=$ A. Dracontium.

filiforme, Reinw. in Blume, Cat. Gew. Buitenz. 103 = Arisaema filiforme.

flagelliterum, Griff. Notul. iii. 144.-Ind. or.

flagelliforme, Roxb. Hort. Beng. 65 ; Lodd. Bot. Cab. t. $396=$ Typhonium cuspidatum

flavum, Forsk. Fl. Aegypt. Arab. $157=$ Arisaema flavum.

foetidum, Salisb. Prod. $261=$ italicum

fornicatum, Roth, Pl. Ind. Or. $362=$ Pinellia tuberifera fornicatum, Roxb. Hort. Beng. 65 ; Fl. Ind. iii. $501=$

Alocasia fornicata.

fornicatum, Wight, Ic. iii. t. $789=$ Alocasia decipiens fugax, Salisb. Prod. $260=$ venosum.

gracile, Roxb. Hort. Beng. 65 ; F1. Ind. iii. $505=$ Typhonium gracile.

gracile, Unverr. ex Schott, Prod. Aroid. $91=$ maculatum gramineum, Lam. Encyc. iii. $30=$ Biarum gramineum. 
ARUM:-

gramineum, [Soland, in] Russ. Aleppo, ed. II. ii, 264 $=$ Biarum Russellianum.

grandifolium, Jacq. Hort. Schoenbr. t. $189=$ Philodendrum grandifolium.

gratum, Schott, Syn. Aroid. $11=$ orientale.

Griffithii, Schott, l. c. 15.-Afghanist.

guellekense, Kotschy, ex Engl. in DC. Monog. Phan. ii. $589=$ rupicolum

guttatum, Salisb. Prod. $260=$ Dracunculus vulgaris

guttatum, Wall. Pl. As. Rar, ii. 10. t. $115=$ Sauromatum guttatum.

hederaceum, Jacq. Enum. Pl. Carib. $31=$ Philodendron Hoffmannii.

hederaceum, Willd. Sp. Pl. iv, $486=$ Philodendron hederaceum.

Heldreichi, Orph. ex Boiss. F1. Orient. v. $40=$ maculatum.

helleborifolium, Jacq. Coll. iii. $217=$ Xanthosoma helleborifolium.

heterophyllum, Aucher, ex Blume, Rumphia, i. $121=$ Helicophyllum Rauwolffii.

hygrophilum, Boiss. Diagn. Ser. I. xiii. 8.-Syria.

immaculatum, Reichb. Ic. Fl. Germ. vii. 6; Schott, Prod. Aroid. $94=$ italicum.

incomptum, Schott, 1, c. $89=$ orientale.

incurvatum, Lam. Fl. Fr. iii. $538=$ Arisarum vulgare

indicum, Lour. F1. Cochinch. ii. 536= Colocasia indica

integrifolium, Link, Enum. Hort. Berol. ii. $394=$ Aglaonema integrifolium.

intermedium, Schur, ex Schott, Prod. Aroid. 91= maculatum.

intortum, [Soland, in] Russ. Aleppo, ed. II. ii. $264=$ Helicophyllum Rauwolffii.

italicum, Mill. Gard. Dict. ed. VIII. n. 2.-Europ.

Jacquemontii, Blume, Rumphia, i. 118.-As, trop.

Korolkowi, Regel, in Act. Hort. Petrop. ii. (1873) 407. - Turkestan.

Kotschyi, Boiss. \& Hohen. Diagn. Ser. I. xiii. 8.Pers. bor.

laceratum, Noronha, in Verb. Batav. Gen. v. (1790) ed. I. Art. IV. $4=$ seq. ?

lacerum, Jacq. Hoxt. Schoenb. iv. $35=$ Philodendron lacerum.

lanceolatum, Vell. F1, Flum. ix. t. 114=Philodendron crassinervium.

Liepoldii, Schott, Prod. Aroid. $77=$ Dioscoridis

lingulatum, Linn. Pl. Fam. Pugill. 26; Syst. ed. X. 1251.-Jamaica.

liniferum, Arruda, in Koster, Trav. Braz. $483=$ Montrichardia linifera.

lividum, Salisb. Prod, $260=$ Colocasia antiquorum.

longicyrrhum, Schott, Syn. Aroid. 14=hygrophilnm.

longispathum, Reichb. Ic. Fl. Germ, vii. $5=$ orientale.

lyratum, Roxb. Hort. Beng. [103]; Fl. Ind. iii. 508 = Amorphophallus lyratus.

macrorĭhizum, Linn. Sp. Pl. $965=$ Alocasia macrorrhiza.

macrourum, Bunge, Enum. Pl. Chin. Bor, 67.-China bor.

maculatum, All. Fl. Pedem. ii. 228=italicum.

maculatum, Gueldenst. ex Ledeb. Fl. Ross. iv. $9=$ orientale.

maculatum, Linn. Sp. Pl. 966.-Europ.

Malyi, Schott, Prod. Aroid. $93=$ maculatum.

margaritiferum, Roxb. Hort. Beng. 65 ; Fl. Ind. iii. $512=$ Plesmonium margaritiferum.

maximum, Noronha, in Verh. Batav. Gen. v. (1790) ed. I. Art. IV. 5.-Malaya.

marmoratum, Schott, Prod. Aroid. $85=$ italicum.

melanopus, Boiss. Fl. Orient. v. 40.-Oriens.

minutum, Willd. Sp. Pl. iv. $484=$ Theriophonum crenatum

montanum, Roxb. Hort. Beng. 65 ; F1. Ind. iii. $497=$ Colocasia montana.

mucronatum, Lam. Encyc. iii. 12 = Alocasia macrorrhiza.

mucronatum, Spreng. Syst. iii. $769=$ Xanthosoma mucronatum.

Mulleri, Zipp, ex Blume, Rumphia, i, $143=$ Amorphophallus Mulleri.

Murrayi, J Grah. Cat. Bomb, Pl. 229=Arisaema Jacquemontii.

muscivorum, Linn. f. Suppl. $410=$ Helicodiceros muscivorus.

nepcnthoides, Wall. Tent. F1. Nep, 26, t. 18= Arisaema nepenthoides.

Nickellii, Schott, Prod. Aroid. $85=$ italicnm.

\section{ARUM:-}

igrum, Schott, in Oestr. Bot. Wochenbl. (1857) 212 .-

Europ

nigrum, Vell. F1, Flum, ix, t $107=$ Xanthosom violaceum.

Nordmanni, Schott, Syn. Aroid. $12=$ orientale

novum, Linn. f. Pl. Surin. n. 122,-Guiana.

numidicum, Schott, Syn. Aroid 10 - italicum.

nymphaeifolium, Roxb. Hort. Beng. 65; Fl. Ind. ii $495=$ Colocasia antiquorum

oblongum, Vell. Fl. Flum. ix. t, $115=$ Philodendron oblongum.

obtusilobum, Link, Enum. Hort. Berol. ii. 393.Hab.?

odoratum, Heynh. Nom. ii. $46=$ seq

odorum, Roxb. Hort. Beng. 65 ; 11. Ind. iii. $499=$

Alocasia odora.

orientale, Bieb. Fl. Taur. Cauc. ii. 207.-Taur, Caucas.

orientale, Vis, ex Nym. Consp. $754=$ nigrum

orixense, R. Br. Prod. $336=$ Typhonium Brownil

arixense, Roxb. ex Andr. Bot. Repos. t. $356=$ Typho nium trilobatum.

ovatum, Linn. Sp. P1. $967=$ Lagenandra toxicaria.

palaestinum, Boiss. Diagn. Ser. I. xiii. 6.-Oriens.

pedatum, Fisch. ex Spreng. Syst. iii. $769=$ Sauromatum guttatum.

pedatum, Willd. Enum. Hort. Berol. Suppl. $54=$ Sauromatum pedatum.

pellucidum, Fulchir, ex Kunth, Enum. PI. iii. $42=$ Caladium bicolor.

peltatum, Lam. Encyc. iii. 13 = Caladium esculentum. pentaphyllum, Linn. Sp. Pl. 964=Arisaema penta phyllum.

pentaphyllum, Vell. F1. Flum, ix. t. 104=Xanthosoma pentaphyllum.

peregrinum, Linn. Sp. P1. $966=$ Alocasia macrorrhiza

Petteri, Schott, Syn. Aroid, $12=$ orientale.

philistaeum, Kotschy, ex Schott, Prod. Aroid. 79.Palaestina.

phrygium, Boiss. ex Tchihat. Asie Min. Bot. ii. 648.As. Min.

pictum, Linn.f. Suppl. 410.-Ins. balear.; Corsic

pictum, Pett. Bot. Wegw. (1832); ex Schott, Syn.

Aroid. $13=$ orientale

pinnatifidum, Jacq. Hort. Schoenb, ii. $31=$ Philodendron pinnatifidum.

pinnatifidum, Vell. F1. Flum. ix. t. $110=$ Philodendron bipinnatifidum.

polymorphum, Buckl. in Am. Fourn. Sc. xlv. (1843) 173.-Am, bor

polyphyllum, Link, Enum. Hort. Berol. ii. 393.Am. austr.

ponticum, Schott, in Bonplandia, x. (1862) $148=$ italicum.

proboscideum, Linn. Sp. Pl. $966=$ Arisarum proboscideum.

stychiurum, Zipp. ex Kunth, Enum. Pl. iii. $26=$ Typhonium cuspidatum.

pulchrum, Salisb. Prod. $260=$ Caladium bicolor.

pumilum, Kotschy, ex Engl. in DC. Monog. Phan. ii $586=$ philistaeum

pumilum, Lam. Encyc. iii. $8=$ Typhonium trilobatum. punctatum, Desf. Cat. Hort. Par. ed. III. $385=$ Alocasia indica.

punctulatum, Zipp. ex Kanth, Enum. Pl. iii. $34=$ Amorphophallus bulbifer.

purpureum, Thunb. Fl. Fav. 20.-Tapon,

pyrenaeum, Dufour, in Lap. Hist. Abr. PI. Pyr. Suppl.

143 = maculatum

Pythonium, Mart. Auswahl, $18=$ Zomicarpa Py thonium.

quinatum, Nutt. Gen. Am. ii. $222=$ Arisaema quinatum.

ramosum, Link, Enum. Hort. Berol. ii. 394.-Hab. rapiforme, Roxb. Hort. Beng. 65 ; Fl. Ind. iii. 497 Alocasia rapiformis.

Raurvolffi, Blume, Rumphia, i. $122=$ Helicophyllum Rauwolffii.

regnium, Rodsch, 'in Rald. Diar. xrviii. 32'; ex G. F. W. Mey. Esseq. $273=$ Dicfenbachia Seguine. ringens, Thunb. in Trans. Linn. Soc. ii. (1794) 337.Japon.

Rumphii, Gaudich. in Freyc. Voy. Bot. 127. t. $34=$ Amorphophallus campanulatus.

rupicola, Boiss. Diagn. Ser. I. xiii. 7.-Syria. sagittaefolium, Hort. ex Steud. Nom. ed. II. i. 14S Caladium hastifolium.

\section{ARUM:-}

sagittaefolium, Linn. Sp. Pl. 966=Xanthosoma sagit taefolium.

sagittatum, Noronha, in Verh. Batav, Gen. y. (1790) ed. I. Art. IV. 4.-Malaya.

sagittifolium, Link, Enum. Hort. Berol. ii. $393=$ Xanthosoma hastifolium.

sagittifolium, Rodsch. Observ. $30=$ Urospatha sagittifolia.

Sarensoo, Burger, ex Kunth, Enum. Pl. iii, 19 Arisaema japonicum.

Seguine, Jacq. Enum. Pl, Carib. $31=$ Dieftenbachia Seguine.

Seguinum, Linn. Sp. Pl. ed. II. $1371=$ Dieffenbachia Seguine.

serratum, Thunb. in Trans, Linn. Soc. ii. (1794) $338=$ Arisaema japonicum.

sessiliforum, Roxb. Hort. Beng. 65 ; Fl. Ind. iii. 507. -Ind. or.

simlense, Hort. ex Engl, in DC. Monog. Phan. ii. 571 Sauromatum venosum.

speciosum, Wall. Tent. Fl, Nep. 29. t. $20=$ Arisaema speciosum.

spectabile, Schott, in Oestr. Bot. Wochenbl. (1857) 175 Dioscoridis.

spectabile, Zipp. ex Kunth, Enum. PI. iii. 34=Amor phophallus bulbifer

spiculatum, Blume, Rumphia, i, $12 I=$ Helicophyllum crassipes.

spirale, Retz. Obs. i. $30=$ Cryptocoryne spiralis.

spirale, Salisb. Prod. $259=$ Helicodiceros crinitus.

stercorarium, Zipp. ex Kunth, Enum, Pl. iii. $33=$ Amorphophallus variabilis.

strepsiceros, Sieber, ex Sterd. Nom, ed. II, i. 143.Palaestina.

subulatum, Desf. Cat. Hort. Par. ed. III. 7 et $385=$ Pinellia tuberifera.

sylvaticum, Roxb. Hort. Beng. [103] ; Fl. Ind. iii. 51.1 $=$ Synantherias silvaticus.

syriacum, Blume, Rumphia, i, $119=$ Dioscoridis

syriacum, Spreng. Syst. iii. $768=$ Biaram Russel lianum.

tenuifolium, Linn. Sp. Pl. $967=$ Biarum tenuifolium.

ternatum, Thunb. F1. Jap. $233=$ Pinellia toberifera

tortuosum, Wall. Pl. As, Rar, î. $10=$ Arisaema tortuosum.

trapezuntinum, Schott, ex Engl. in DC. Mouog. Phan. ii. $592=$ italicum.

trifidum, Desf. Cat. Hort. Par. ed. III. 7 et $385=$ Hydrosme Fontanesii.

trifoliatum, Noronha, in Verh. Batav. Gen, v. (1790) ed. I. Art. IV. 4.-Malaya.

trilobatum, Linn. Sp. P1. $965=$ Typhonium divari catum.

trilobatum, Thunb. F1. Jap. $234=$ Pinellia tripartita.

tripartitum, Jacq. Hort. Schoenb. ii. 33, t. $190=$ Philodendron tripartitum.

triphyllum, Houtt. Plantenk. ii. II. 184=Pinellia tuberifera.

triphyllum, Linn. Sp. Pl. $965=$ Arisaema atroru bens.

triphyllum, Thunb. Fl. Jap. $233=$ Arisaema ringens. variolatume, Schott, Prod. Aroid. 81 =Xanthosoma violaceum

venosum, Ait. Hort. Kew. iii. $315=$ Sauromatun guttatum.

venosum, Balb. ex Engl. in DC. Monog. Phan. ii. Is: =Xanthosoma helleborifolium.

ventricosum, Hoffmgg. Verg, PA. Nachtr, ii. 25. Bras.

vermitoxicum, Vell. Fl. Flum. ix. to $10 \mathrm{~S}=$ Caladiam bicolor.

vernale, Salisb. Prod, $261=$ maculatum

virginicum, Linn. Sp. PL, $966=$ Peltandm virginica virginicum, Linn. Sp. Pl. 966 = Peltandra virginica. Kemusatia vivipara.

virescens, Stapf, in Denkschr. Acad. Wirn, 1. 15851 - Persia

vittatum. Salish. Prorl. $260=$ Arisaema atrorubens. vulgare, Lam. Fl. Fr. iii. 597= maculatum. xanthorrhison, lact. Hort. Schoenbr, if $8:$ - Xianthosoma sagittitulium.

\%elehori, Schott, l'rod. Aroid. of - maculatum.

ARLNA, Schreb. Gen. i. $261789^{\prime}-A K 0[X A, A u b 1$ Dialium, Linn. Legumin. 
ARUNCUS, Linn. Syst ed, I. (1735); Gen. èd, I. 310 $(1737)=$ Spiraea, Tourn. (Rosac.)

americanus, Rafin. Sylva Tellur. 152 = S. Aruncus. astilboides, Maxim. in Act. Hort. Petrop. vi. (1879) $171=$ S. Aruncus.

sylvester, Kostel. Ind. Hort. Prag. $15=\mathrm{S}$. Aruncus. vulgaris, Rafin. Sylva Tellur, $152=\mathrm{S}$. Aruncus.

ARUNDINA, Blume, Bijdr. 401 (1825). ORCHI $D E A E$, Benth. \& Hook. f. iii. 521.

Dilochia, Lindl. Gen, et Sp. Orch. 38 (1830).

affinis, Griff. Notul, iii. $330=$ chinensis.

bambusifolia, Lindl. in Wall. Cat. n. 3751.-Ind, or.; Malaya.

chinensis, Blume, Bijdr. 402.-Reg. Himal. ; China.

densa, Lindl, in Bot. Reg. (1842) Misc. 25.-Singapore.

Meyenii, Reichb. f. in Linnaea, xxv. (1852) 227.China.

minor, Lindl. Gen. et Sp. Orch. 125.-Zeylan.

pentandra, Reichb. f. Xenia Orch. ii. 11.-Java.

Philippi, Reichb. f. in Linnaea, xxv. (1852) $227=$ chinensis.

pulchella, Teijsm. E Binn. in Nederl. Kruid.Arch. iii (1855) 400 - China.

pulchra, Miq. in Fourn. Bot. Néerl. i. (1861) 90.China.

speciosa, Blume, Bijdr. 401. t. $73=$ densiflora

tahitensis, Nadeaud, Enum. Pl. Tahiti, 37.-Ins Pacif.

Wallichii, Reichb. f. Xenia Orch. ii. 13. t. 105.Malaya.

ARUNDINARIA, Michx. Fl. Bor. Am. i. 73' (1803) GRAMINEAE, Benth. \& Hook. f. iii. 1207

Ludolfra, Willd. in Ges. Naturf. Fr. Berl. Mag. ii. (1808) 320 .

Macronax, Rafin. in Med. Repos. New York, y. (1808) 352.

Miegia, Pers. Syn. i. 101 (1805)

Thamnocalames, Munro, in Trans. Linn. Soc. xxvi. (1868) 33 .

TriglossuM, Fisch. Cat. Jard. Gorenk. (1812). acuminata, Munro, in Trans. Linn. Soc. xxvi. (1868) 25.-Mexic.

amplissima, Nees, in Linnaea, ix. (1834) 479.-Bras. aristulata, Doell, in Mart. Fl. Bras. ii. III. 165. Bras.

attenuata, Doell, l. c. 170.--Bras.

bambusina, Trin. Fund. Agrost. $97=$ macrosperma.

callosa, Munro, in Trans. Linn. Soc. xxvi. (1868) 30. -Reg. Himal.

debilis, Thw. Enum. Pl. Zeyl. 375,-Zeylan.

decalvata, Doell, in Mart. Fl. Bras. ii. III. 170.Bras.

densifolia, Munro, in Trans. Linn. Soc. xxvi. (1868) 32.-Zeylan.

distans, Trin. in Mém. Acad. Pétersb. Sér. VI. iii. II (1835) 621.-Bras.

elegans, Kurz, in Fourn. As. Soc. Beng. xlii. (1873) II. 249. - Burma.

falcata, Nees, in Linnaea, ix. (1834) 478.-Reg. Himal.

flexuosa, Hance, in Fourn. Bot. xiv. (1876) 339.China.

floribunda, Thry. Enum. Pl. Zeyl. 375.-Zeylan.

Fortunei, Fenzi, in Gard. Chron. (1876) II. 773 = Simoni

Fortunei, Riviere, in Bull. Soc. Acclim. Sér. III v. (1878) 897.- Japon.

gigantea, Nutt. Gen. Am. i. 39.-Am. bor.

glaucescens, Beauv. Agrost. 144, 152.-Ind or. China?

Griffithiana, Munvo, in Trans. Linn. Soc, xxvi. (1868) 20. - Reg. Himal.

Hindsii, Munro, lo c. 31.-Hongkong.

hirsuta, Munro, l. c. 30.-Reg. Himal

hispida, Stend. Syn. P1. Gram. $335=$ Wightiana.

Hookeriana, Munro, in Trans. Linn. Soc. xxvi. (1868) 29.--Reg. Himal.

intermedia, Munro, l. c. 28.-Keg. Himal.

interrupta, Trin. in Mém. Acad. Pétersb. Sér. VI. iii. II. (1835) $620=$ falcata.

japonica, Sieb. E Zucc. ex Steud. Syn. Pl. Gram. 334. -Japon.

khasiana, Munro, in Trans. Linn. Soc. xxvi. (1868) 28. - Reg. Himal.

kurilensis, Rupr. in Bull. Phys.-Math. Acad. Pétersb. viii. (1850) 121.-Ins. Kurile.

\section{ARUNDINARIA :}

longifolia, Fourn. Mex. Pl. Enum. Gram. 131, ex Hemsl. Biol. Centr. Am. Bot. iii. 586.-Mexic.

longiramea, Munro, in Trans. Linn. Soc. xxvi. (1868) $19=$ sinica.

macrosperma, Michx. Fl. Bor. Am. i. 74.-Am. bor macrostachya, Nees, in Linnaea, ix. (1834) 481. Bras.

Maximowiczii, Hort. ex A. \& C. Rivière, in Bull. Soc. Acclim. Sér. III. v. (1878) $783=$ Simoni

Metake, Siebold, ex Miq. Ann. Mus. Bot. Lugd. Bat. ii. $284=$ japonica.

microphylla, Munro, in Trans. Linn. Soc. xxvi. (1868) 32.-Reg, Himal.

moliniformis, Hochst. ex Munro, 1. c. $19=$ Wightiana. multiflora, Doell, in Mart. Fl. Bras. ii. III. 166.Bras.

parviflora, Trin. in Mém. Acad. Pétersb. Sér. VI. iii. II. (1835) $619=$ Arthrostylidium Trinii.

pinifolia, Nees, in Mart. Fl. Bras. ii. 525=Chusquea pinifolia.

procera, Wall. ex Murro, in Trans. Linn. Soc. xxvi. (1868) $34=$ spathiflora

racemosa, Munro, l. c. 17.-Reg. Himal,

radiata, Rupr. in Mém. Acad. Pétersb. Sér. VI. v. (1839) 115.'t. 15. f. 9-Bras.

Schomburgkii, Benn, in Trans, Linn. Soc, xviii. (1841) $562=$ Arthrostylidium Schomburgkii.

Simoni, A. \& C. Rivière, in Bull. Soc. Acclim. Sér, III. v. (1878) 774 .-China.

sinica, Hance, in Ann. Sc. Nat. Sér. IV. xviii. (1862) 235.-China.

spathiflora, Trin. in Mém. Acad. Pétersb. Sér. VI. iii. II. (1835) 617.-Reg. Himal

stolonifera, Kurz, Cat. Hort. Bot. Calcut. $79=$ Phyllo. stachys nigra.

suberecta, Munro, in Trans. Linn. Soc. xxvi. (1868) 32.-Reg. Himal

tecta, Muhl. Desc. Uber. 191-Am. bor.

tessellata, Munro, in Trans. Linn. Soc. xxvi. (1868) 31.-Afr, austr.

Trianae, Munro, l. c. 25.-N. Granat.

Trinii, Hack, in Mart. F1, Bras. ii. III. 174= Arthrostylidium Trinii.

utilis, Cleghorn, in Journ. Agr. Soc. Ind. xiii. (1865) $388=$ falcata

verticillata, Nees, in Mart. Fl. Bras. ii. III. 523.-Bras.

Walkeriana, Munro, in Trans. Linn. Soc. xxvi. (1868) 21.-Zeylan.

Wightiana, Nees, in Linnaea, ix. (1834) 482, Ind, or

Wightiana, Thw. Enum. Pl. Zeyl. $444=$ Walkeriana.

Wightii, Benth. F1. Hongk. $434=$ sinica.

ARUNDINFII A, Raddi, Agrost. Bras, 37. t. I 1823) GRAMINEAE Benth. \& Hook, f iii. 1118 Acratherum, Link, Hort. Berol. i. 230 (1834). Brandtia, Kunth, Rev. Gram. ii. 511. t. 170 (1830)

CALAMOChlö, Reichb. Consp. 52 (1828)

Goldbachia, Trin. in Spreng. Neue Entdeck. ii. 81 1821)

Riedelia, Trin. ex Kunth, Enum. Pl. i, 515 (1833).

Thysanachne, Presl, Thysan. Nov. Pl. Gen. (1829); et Rel. Haenk. i. 252 (1830).

Acratherum, Nees, ex Steud. Nom. ed. II. i. 143.Ind or

agrostoides, Trin. Ic. xxiii, t. $265=$ holcoides anomala, Steud. Syn. Pl. Gram. 116.-Japon auletica, Rupr. in Bull. Acad. Brux. ix. (1842) II. 242 - Deppeana.

avenacea, Munro, ex Thw. Enum. Pl. Zeyl. 362.Zeylan.

brasiliensis, Raddi, Agrost. Bras, 37.-Bras.

ciliata, Nees, ex Miq. in Verh. Nedert. Inst. III. iv. (1851) 30.-Ind. or.

crinita, Trin. in Linnaea, x. (1836) 299.-Peruv

cubensis, Griseb. in Mem. Am. Acad. N. S. viii. (1863) 533.-Ind, occ

Deppeana, Nees, in Bonplandia, iii. (1855) 84.Mexic.

Ecklonii, Nees, F1. Afr. Austr. $80=$ nepalensis.

elegantula, Hook. f. in Fourn. Linn. Soc. viu. (1864) 233.-Afr. occ.

flammida, Trin, Gram. Sp. xxiii, t. 267.-Bras.

fuscata, Nees, ex Buese, in Miq. Pl. Fungh. 359.Ind. or.

glabra, Hook. \& Arn. Bot. Beech. Voy. 237.-China.

\section{ARUNDINEITIA :-}

Goeringii, Steud. Syn. Pl. Gram. 116.-Japon. hirsuta, Hochst. ex Steud. 1. c. $115=$ setifera. hirsuta, Nees, ex Steud. l. c.-Reg. Himal.

holcoides, Trin. in Bull. Sc. Acad. Pétersb. i. (1836) 71 $=$ Brandtia holcoides.

indica, Trin. ex Steud. Nom. ed. II. i. 143.-Ind. or.

khasiana, Nees, ex Steud. Syn. Pl. Gram. 115.-Reg

Himal.

latifolia, Fourn. Mex. Pl. Enum. Gram. 54 ; ex HemsI Biol. Centr. Am. Bot. iii. $515=$ Deppeana.

martinicensis, Trin. Gram.Panic. ii. 62,-Ins. Martinic. mesophylla, Nees, ex Steud. Syn. Pl. Gram. 115.Ind. or.

Metzii, Hochst. ex Miq. in Verh. Nederl. Inst. III, iv. 1851) 31 . - Ind. or

Mikani, Nees, Agrost. Bras. $465=$ brasiliensis. mutica, Nees, ex Steud. Syn. Pl. Gram. 116.-Ind, or. nepalensis, Trin. Sp. Gram. t. 268.--Ind. or.

nervosa, Nees, ex Hook. \& Arn. Bot. Beech. Voy. 237 =Panicum semialatum.

pallida, Nees, Agrost. Bras. 465.-Mexic.

peruviana, Steud. Syn. Pl. Gram. 115.-Peruv

phragmitoides, Griseb. Cat. Pl. Cub. 234.-Cuba

pilosa, Hochst. ex Miq. in Verh. Nederl. Inst. III. iv

(1851) $30=$ ciliata

pumila, Steud. Syn. Pl. Gram. 114.-Abyss.

purpurea, Hochst. ex Steud. l. c. 115.-Ind. or

rigida, Nees, Fl. Afr. Austr. 80.-Afr. austr.

Schultzii, Benth. Fl. Austral. vii. 545.-Austral.

scoparia, Fourn. Mex. Pl. Enum. Gram. 55; ex Hemsl.

Biol. Centr. Am, Bot. iii. $515=$ Deppeana.

setifera, Steud. Syn. Pl. Gram. 115.-Ind. or.

setosa, Trin. Gram. Panic. 65.-Nepal.

stipoides, Hack. in Sitzb. Acad. Wien, Ixxxix. (1884 123.-Madag.

stricta, Nees, in Hook. Kew Fourn. ii. (1850) 102.Hongkong

tenella, Nees \& Wight, ex Steud. Nom. ed. II. i. 143 -Ind. or.

tricuspidula, Buese, in Miq. Pl. Fungh. 360.-Java.

villosa, Arn. ex Steud. Syn. Pl. Gram. 115.-Zeylan.

Wallichii, Nees, ex Stend. l. c. 114.-Ind. or.

Zollingeri, Steud. l. c. 115.-Java.

ARUNDO, Beauv. Agrost. 60. t. 13. f. $2(1812)=$ Phragmites, Trin. (Gram.)

ARUNDO, Tourn, ex Linn. Gen. ed. I. 19 (1737) GRAMINEAE, Benth. \& Hook. f. iii. 1179.

Amphidonax, Nees, in Lindl. Introd. Nat. Syst. ed. II. $449(1836)$

Donacium, Fries, Bot. Notiser, (1843) 131.

Don $\Lambda x$, Beauy, Agrost. 77 (1812), pro parte.

ScolochloA, Mert. \& Koch, in Roehl. Deutschl. Fl. i. 528 (1823).

acutifiora, Pollini, Fl. Veron. i. $88=$ Deyeuxia varia

acutiflora, Schrad. Fl. Germ. i. $217=$ Deyeuxia acutiflora.

aegyptia, Delile, Fl. Aeg. Illustr, 4=A. Donax.

aegyptiaca, Hort. ex Vilm. Fl. Pl. Terre, ed. III. $984=$ praec.

aggerum, Kit. in Linnaea, xxxii. (1863) 307.-Europ agrestis, Lour. Fl. Cochinch. $57=$ Bambusa agrestis.

Agrostis, Lap. ex Willk. \& Lange, Prod. Fl. Hisp. i $88=$ Molinia caerulea

Agrostis, Scop. F1. Carn. ed. II. i. $88=$ Deyenxia acutiflora.

Agrostis, [Weber, in] Wigg. Prim. F1. Holsat. $10=$ Deyeuxia acutiflora?

agrostoides, Pursh, FI. Am. Sept. i. $86=$ Deyeuxia cana densis.

airaeformis, Raddi, Obs. Madera, 10.-Madera.

airoides, Poir. Encyc. vi. 270.-Am. bor.

Alopecuros, Gaudich. ex Urv. in Mém. Soc. Linn. Par iv. (1826) $602=$ Festuca Alopecuros.

alpestris, Hall. ex Roem. \& Schult. Syst. ii. $503=$ Deyeuxia Halleriana.

alpina, [Honck.] Verz. Gew. Teutschl, 321; Schult. Oestr. Fl. ed. II. i. $189=$ Calamagrostis tenella

alpina, Vill. ex Kunth, Enum. P1. i. $238=$ Deyeuxia Halleriana.

altissima, Benth. Cat. Pl. Pyr. 62= Phragmites communis.

Ampelodesmos, Cyrill. Pl. Rar. Neap. Fasc, ii. $30=$ Ampelodesma tenax.

annulata, Roem. \& Schult. Syst. ii. $503=$ Calama grostis littorea. 


\section{ARUNDO}

antarctica, Urv. in Mém. Soc. Linn. Par. iv. (1826) $602=$ Festuca antarctica

arborea, Mill. Gard. Dict. ed. VIII. n. 5=Bambusa arundinacea.

arenaria, Gorter, Fl. Ingr. $18=$ Deyeuxia neglecta. arenaria, Linn. Sp. Pl. $82=$ Ammophila arundinacea argentea, [Clairv.] Man. Herb. 16.--Helvet.

australis, Cav. ex Roem. \& Schult. Syst. ii. $511=$

Phragmites australis.

australis, A. Rich. ex Steud. Nom. ed. II. i. 143, 250 $=$ conspicua.

baltica, Fluegg. ex Schrad. F1. Germ, 223. t. 5. f. $4=$ Ammophila baltica.

Bambos, Burm. ex Steud. Nom. ed. II. i. $143=$ Bam busa agrestis.

Bambos, Linn. Sp. Pl. $81=$ Bambusa arundinacea.

Bambu, Lour. Fl. Cochinch. $56=$ praec.

bengalensis, Boj. Hort. Maurit. $368=$ Phragmites communis.

bengalensis, Retz. Obs, v. 20,--Bengal.

bicolor, Desf. Fl. Atlant. i. 107; Poir. Voy, Barb. ii 104.-Afr. bor.

Biebersteiniana, Roem. \& Schult. Syst. ii. Mant. 285 $=$ Calamagrostis littorea.

bifaria, Retz. Obs. iv. 22,-Ind. or.

biflora, Lam. Illustr. i. $196=$ Ampelodesmos tenax.

Boivini, Steud. Syn. Pl. Gram. 423.-Madag.

brevipilis, Torr. Fl. U. St. $95=$ Ammophila brevipilis,

Calamagrostis, Bieb. F1. Taur. Cauc. i. 78 ; ii. $456=$

Calamagrostis epigeios.

Calamagrostis, Hall. f. in Roem. Arch. i. II. $10=$

Deyeuxia Halleriana.

Calamagrostis, Leyss. Fl. Halens. $28=$ Deyeuxia sylvatica.

Calamagrostis, Linn. Sp. P1. $82=$ Calamagrostis lan ceolata.

Calamaria, Salisb. Prod. $24=$ Calamagrostis lanceolata.

calycina, Willd, ex Steud. Nom, ed. II. i. $144=$ nitida.

canadensis, Michx. Fl. Am. Bor. i. $73=$ Deyeuxia canadensis.

canadensis, Steud. Nom. ed. II, i. $144=$ Deyeuxia Nuttalliana.

canescens, [Weber, in] Wigg. Prim. Fl. Holsat. $10=$ Calamagrostis epigeios, lanceolata.

canila, Molina, ex Steud. Syn. Pl. Gram. $336=$ Chus quea Cumingii.

capillata, Nem. ex Chaub. in Actes Linn. Soc. Bord xix (1853) 44,-Hab, ?

ciliata, [Clairv.] Man. Herb, 16.-Helvet.

cinnoides, Muhi. Desc. Uber. $187=$ Deyeuxia Nuttal liana.

Clarionis, Loisel. Fl. Gall. $719=$ Deyeuxia Halleriana

coarctata, Poir. Encyc. Suppl. iv. $704=$ Deyeuxia coarctata.

coarctata, Torr. F1. U. St. $94=$ Deyeuxia Nuttalliana.

collina, Tenore, Fl, Nap. t. $108=$ Pliniana

colorata, Ait. Hort. Kew. i. $116=$ Phalaris arundinacea.

confinis, Willd. Enum. Hort. Berol. 127=Calama grostis confinis.

conspicua, Forst. f. Prod. 9.-N. Zel.

contracta, Gilib. Exercit. ii. $542=$ Calamagrostis lanceolata.

cuspidata, Schult. Mant. iii. $604=$ Calamagrostis cuspi data.

cylindrica, J. Gay, ex Steud. Nom. ed. II. i. $144=$ Deyeuxia acutiflora.

dioeca, Spreng. Syst. i. $361=$ Gynerium argenteum.

dioica, Lour. Fl. Cochinch, 70,-Cochinch

Donax, Georgi, Beschreib. Russ. Reich. iii. IV. $705=$ Arundinaria kurilensis.

Donax, Linn. Sp. Pl. 81.-Reg. Mediterr.; Oriens.

effusa, C. C. Gmel. Fl. Bad. $262=$ Calamagrostis

littorea.

effusa, Poir. Encyc. Suppl. iv, $706=$ Deyeuxia effusa.

Egmontiana, Roem. \& Schult. Syst. ii. $511=$ Phrag mites Egmontianus.

epigeios, Forsk. ex Steud. Nom, ed. II. i. $144=$

Imperata arundinacea.

epigeios, Huds. Fl. Ang, ed. I. 43; ed, II. $54=$

Calamagrostis lanceolata.

epigeios, Linn. Sp. Pl. 81 = Calamagrostis epigeios.

eriantha, Poir. Encyc. Suppl. iv. $705=$ Deyeuxis eriantha.

excelsa, Salisb. Prod. $24=$ Bambusa arundinacea.

farcta, Aubl. Pl. Gui. i. 52 = Calamagrostis farcta.

\section{ARUNDO}

fastuosa, Willd. ex Steud. Nom, ed. II, i. $144=$ Gynerium saccharoides.

Fax, Lour. F1, Cochinch. $58=$ Melocanna humilis.

festucacea, Willd. Enum. Hort. Berol. 126=Graphe phorum arundinaceum.

festucoides, Desf. Fl. Atlant. i. $108=$ Ampelodesmos tenax.

filiformis, Hassk. in Hoev. E De Vriese, Tijdschr. x. (1843) 117. - Java.

fissa, Willd. ex Steud. Nom. ed. II. i, $144=$ Deyeuxia canadensis.

flexuosa, Brongn. in Duperr. Voy, Bot. 29. t. $4=$ Phragmites flexuosus.

flexuosa, [Clairv.] Man. Herb. 16= Aira flexuosa. fulvida, F. Buch. in Trans. N. Z. Inst. vi. (1874) 249 - N. Zel.

Gayana, E. Desv. in C. Gay, Fl. Chit. vi. 326.Valdivia.

gigantea, Walt. Fl. Carol. $81=$ Arundinaria macro sperma.

glauca, Bieb. Fl. Taur. Cauc, i. $79=$ Calamagrostis littorea.

glauca, Hornem. Hort. Hafn. $74=$ Deyeuxia Nuttalliana.

graeca, Link, in Linnaea, ix. (1834) $136=$ Phragmites communis.

groenlandica, Schrank, in Regensb. Denkschr. i. II. (1818) $8=$ Calamagrostis groenlandica.

Halleri, Willd. Prod. F1. Berl, 60=Stipa Calamagrostis.

Halleriana, Gaud. Agrost. Helv. i. $97=$ Deyeuxia Halleriana.

Henslowiana, Hook. E" Arn. Bot. Beech. Voy. 248.China.

Hostii, Roem. \& Schult. Syst. ii. $508=$ Deyeuxia varia. humilis, Roem. \& Schult. 1. c. $510=$ Calamagrostis lanceolata, tenella.

hyperborea, Trin. ex Steud. Syn. PI. Gram. 236 (=Dupontia psilothantha)

indica, Noronha, in Verh. Batav. Gen. v. $(1790) \mathrm{ed}$. I. Art. IV. 7.-Malaya.

intermedia, C. C. Gmel. Fl. Bad. i. $266=$ Calama grostis epigeios.

isiaca, Delile, Fl. Aeg Illustr. $82=$ Phragmites com munis.

junciformis, Poir. Encyc. Suppl. iv. 705=Deyeuxia junciformis.

Kakao, Steud. Syn. Pl. Gram. 194=conspicua?

Karka, Retz. Obs. iv. 21 ; Roxb. Hort. Beng. 8 ; Fl, Ind. i. 348.-Ind or

Kila, Spreng. ex Steud. Nom. ed. II. i. 144=Gynerium argenteum.

laevis, Steud. Nom. ed. II. i. $144=$ Poa laevis

Langsdorfii, Link, Enum. Hort. Berol. i. $74=$ Deyeuxia purpurea.

lapponica, Wahlenb. F1. Lapp. 27.t. 1=Deyeuxia lapponica.

latifolia, Salisb. Prod. $24=$ A. Donax

laxa, Roem. \& Schult. Syst. ii. $502=$ Calamagrostis littorea.

Leersii, Oett. Syst. Verz. Oberlaus. $17=$ Calamagrostis lanceolata.

Leersii, J. Koch, Handb, $49=$ Stipa Calamagrostis.

levis, Poir. Encyc. Suppl, iv. $707=$ Poa laevis.

ligulata, Poir.l. c. $706=$ Deyeuxia ligulata.

lithuanica, Schult. Mant. ii. $602=$ Calamagrostis lanceolata.

litorea, Schrad. Fl. Germ. 212 = Calamagrostis littorea, littoralis, Stend. Nom. ed. II. i. $144=$ Ammophila arundinacea.

madagascariensis, Kunth, Rev. Gram, i. 273. t. 48.Madag.

maritima, Agardh, in Flora, vii. (1824) 561.-Scandin, mauritanica, Poir. Voy. Barb. ii. 104; Desf. F Atlant i. $106=$ Pliniana.

maxima, Forsk. Fl. Aegypt. Arab. 24=Phrngmites communis.

maxima. Lour. F1. Cochinch. $58=$ Bambusa maxima micrantha, Lam. Illustr. i. $196=$ Pliniana.

minutiflora, Brongn. in Duperr. Voy. Bot. 29.-Ins.

Molucc.

mitis, Lour. Fl. Cochinch, $57=$ Bambusa mitis,

montana, [Clairy.] Man. Herb. $15=$ Deyeuxia montana.

montana, Roem. \& Schult. Syst. ii. $508=$ Deyeuxia sylvatica.

multiplex, Lonr. Fl. Cochiuch. $58=$ Gigantochloa verucillata.

\section{ARUNDO :-}

Naga, Koen. ex Steud. Nom, ed, II, i. $144=$ Phragmites australis.

Naya, Koen. ex Steud. 1. c, ii. 321=praec

neglecta, Ehrh. Beitr. vi. 84, $137=$ Deyeuxia neglecta. nemorosa, Schult. Oestr. F1. ed. II. i, $187=$ Deyeuxia varia.

nitida, H. B. E K. Nov. Gen. et Sp. i. 149. t. 688.Ecuador.

occidentalis, Sieber, ex Schult, Mant ii 289 - Ins. Martin.

orientalis, Mill. Gard, Dict, ed. VIII, n, $6=$ Saccharum fuscum.

pallens, Muhl. ex Steud. Nom. ed. II. i. 144.-Am.

palustris, Salisb. Prod. $24=$ Phragmites communis

penicillata, Labill. Nov. Holl. Pl. i. 26=Danthonia racemosa.

Phragmites, Linn. Sp. P1. $81=$ Phragmiles communis。 picta, Kunze, ex Steud. Nom, ed. II. i. $144=$ Poa picta.

pilosa, Urv. in Mém. Soc. Linn. Par. iv. (1826 603.-Ins. Falkland.

piscatoria, Lour. Fl. Cochinch. 55.-Cochinch.

planifolia, Poir. Encyc. Suppl. iv. $707=$ Deyeuxia planifolia.

plebica, Poir. 1. $\mathrm{c}_{\mathrm{s}}=$ Deyeaxia plebeia

Pliniana, Turra, Farset. 11 ; Fl. Ital. Prod.63.-Regt Mediterr.

Plinii, Turra, Farset. $11=$ Pliniana

plumosa, Schult. Mant. $604=$ Stipa papposa.

poaeformis, Labill. Nov. Holl. Pl. i. 27. t. $35=$ Poa Billardieri.

poaeoides, Poir. Encyc Suppl. iv. $705=$ Poa subuniflora Pseudophragmites, Hall. fo in Roem. Arch. i. II. $11=$ Calamagrostis littorea.

Pseudophragmites, Iejeune, F1. Spa, 64=Phragmites communis.

Pseudophragmites, Schrad. Fl. Germ, 213=Deyeaxia Halleriana.

Pseudophragmites, Wahlenb. Fl. Lapp. $28=$ Calama grostis lapponica.

pungens, Auct. ex Steud. Nom. ed. II. i. $144=$ Phrag mites communis.

purpurascens, Schult. Mant. iii. $603=$ Deyeuxia purpurascens.

purpurea, Trin. in Spreng. Neue Entdeck. ii. $52=$ Deyeuxia purpurea.

pygmaea, Moretti, ex Pollini, in Brugnat. Giorn. Fis. ix. (1816) 22. -Italia.

pygmaea, Spreng. Pugill. i. $9=$ Trisetum hispanicum.

Ouila, Molina, Sagg. Chil. $279=$ Chusquea Femandeziana.

Quila, Poir. Encyc. vi. $274=$ Chusquea Quila

quitensis, Poir. 1. c. Suppl. iv. $70 t=$ Muehlenbergia calamagrostidea.

Ragamowskii, Hort.-Cf. Gard, Chron, (1876) II. \$47 - Bambusa tessellata.

ramosa, Schult. Oestr. Fl. ed. II. i. 185 = Calamagrostis lanceolata.

recta, Poir. Encyc. Suppl. iv, $706=$ Deyeuxia recta.

Reynaudiana, Kunth, Rev. Gram. i. 275. t. 49.Pegu.

rigida, Poir. Encyc. Suppl. iv, $705=$ Deyeuxia rigicla.

riparia, Salisb. Prod. $24=$ Phalaris arundinacea

riparia, Willd. ex Steud. Nom. ed. II. i. $1 \pm t=$ Calama grostis lanceolata.

rivularis, Auct. ex Steud. Nom. ed. II. i. $144=$ Phrag. mites communis.

Roxburghii, Kunth, Rev. Gram. i. $79=$ A. K-rka

Rugi, Molina, Sagg. Chil. 279.-Chili.

Sabuli, Kit. in Linnaea, xxxis. (1stis: S00.-Europ.

saccharoides, Poir. Encyc. Sujpl. iv, $703=$ Gynerium saccharoides.

sagittata, Pers, Syn, i. $102=$ Gynerium saccharoides.

sative, Lam. Fl. Fr. iii. $610=$ A. Donax.

Schlcicheriane, Bess. Fl. Galic i. $69=$ calamagrostis lanceolata.

Schwabii, Schult. Mant, iii. bi1 = Gastridium australe. scriptoria, Linn. Amoen. Ac. iv. $150=$ A. Donax. sedenensis, Luisel. Fil. Gall. ; $19=$ Deycuxia varia. Selloans, Schult. Mant. iii. 605 = (iynerium argent -...

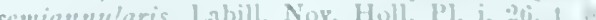

Danthonia semiannularis

semifarcta, Hort. Ticin. ex Steud. Nom. ed. II. i. 11t Hiniana.

speciosa, Schrad. Fl. Germ. i. 219. 1. 5. 1. 8-Sip̧ra Colamagrostis 


\section{ARUNDO}

splendida, Schkr. ex Steud. Nom. ed. II. i. $144=$ Deyeuxia acutiflora.

stricta, Gilib. Exercit. ii. 542= Calamagrostis epigeios stricta, Hofft. Cat. Kursk. $7=$ Deyeuxia neglecta. stricta, Spreng. Neue Entdeck. i. $247=$ Deyeuxia Nuttalliana.

stricta, Timm, in Siemss. Meklenb. Mag. if. 235, ex Schrad. Fl. Germ. $215=$ Deyeuxia stricta

strigosa, Wahlenb. Fl. Lapp. 29. t. 2 = Deyeuxia strigosa.

subulata, J. Gay, ex Reichb. F1. Germ. Excurs. $27=$ Deyeuxia acutiflora.

sylvatica, Schrad. F1. Germ. i. 218. t. 4. fo $7=$

Deyeuxia sylvatica

Tabacaria, Lour. F1. Cochinch. $58=$ Bambusa Tabacaria.

tecta, Blanco, F1. Filip. ed, I. $48=$ A. Karka

tecta, Walt. F1. Carol. $81=$ Arundinaria tecta

tenax, Vahl, Symb. Bot. ii. $25=$ Ampelodesmos tenax.

tenella, Schrad. Fl. Germ. $220=$ Calamagrostis tenella.

tenella, Spreng. Pugill. ii. $6=$ Muehlenbergia tenuifolia.

tenuifolia, Poir. Encyc. Suppl. iv. $704=$ Muehlenbergia tenuifolia.

tolucensis, Poir. 1. c, 705=Deyeuxia tolucensis.

triodioides, Trin. Sp. Gram. t. $351=$ Schedonorus littoralis.

valdiviana, Molina, Saggio Chit. 279.-Chili

Vallatoria, S. F. Gray, Nat. Arr. Brit. Pl. ii. $128=$ Phragmites communis.

varia, Schrad. Fl. Germ, $216=$ Deyeuxia acutiflora.

versicolor, Mill. Gard. Dict. ed. VIII, n. $3=\mathrm{A}$, Donax.

villosa, Auct. ex Schult. Mant, iii. $287=$ Calamagrostis sylvatica.

villosissima, Forsk. ex Steud. Nom. ed. II. i, 145.-Reg. Byzant.

vilnensis, Schult. Mant. iii. $602=$ Calamagrostis lanceolata.

viridescens, Stend. Syn. P1, Gram. $192=$ seq.

viridiflavescens, Poir. Encyc, vi. $271=$ Deyeuxia viridiflavescens.

vulgaris, Lam. F1, Fr. iii. $615=$ Phragmites communis. vulnerans, Gilib. Exercit. ii. $541=1$ 'hragmites communis.

Webbiana, Steud. Syn. Pl. Gram. 194.-Afr. austr.

Wilhelmsii, Ledeb. in Mém. Acad. Pćtersb. vi. (1814) $593=$ Trisetum rigidum

Zollingeri, Buese, in Miq. Pl. Fungh. 243.-Java.

ARUNGANA, Pers. Syn. ii. $91(1807)=$ Haronga Thou. [1809] (Hyperic.)

crenata, Pers. I. $_{\mathrm{o}}=\mathrm{H}$. crenata.

mollusca, Pers. I. c. $=$ H. mollusca.

paniculata, Pers. I. c. = H. madagascariensis.

ARUNIA, Pers. Syst. 251 (1797), sphalm.=Brunia, Linn.

ARVERSIA, Cambess, in St. Hil. F1. Bras. Mer, ii. 184 t. $112(1829)=$ Polycarpon, Linn. (Caryophyll.). depressa, Klotzsch, in Peters, Reise Mossamb. Bot, i. depressa, Klotzsch, in
$140=\mathrm{P}$. depressum.

frankenoides, Cambess. in St. Hil. F1. Bras. Mer. ii. $184=\mathrm{P}$. depressum.

Loeffingii, Walp. Rep. i. $263=$ P. depressum

ARVIELA, Salisb. Gen. Pl. Fragm. 135 (1866)= Zephyranthes, Herb. (Amaryll.).

tubispatha, Salisb. 1. $\mathrm{c}_{*}=\mathrm{Z}$. tubispatha.

ARYTERA, Blume, Rumphia, iii. 170 (1847)= Ratonia, DC. (Sapind.)

angustifolia, Radlk. in Sitzb. Math.-Phys. Acad. Muench, ix. (1879) 552.-Hab.?

arcuata, Radik. 1. c. 554--N. Caled.

brachyphylla, Radlk. 1. c. $552 .-\mathrm{N}$. Guin.

Brackenridgei, Radlk. 1. c. 555.--Ins. Fiji.

chartacea, Radlk. 1. c. 553.-Ha.b. ?

distylis, Radlk. 1. c.-Austral.

divaricata, F. Muell, in Trans. Phil. Inst. Victoria, iii 1859) $25=$ Nephelium divaricatum

foveolata, F. Muell. 1. c. = Nephelium foreolatum.

gigantosperma, Radlk. in Sitzb. Math.-Phys. Acad, Muench. ix. (1879) 674.-Sumatra.

Karang, Miq. F1. Ind. Bat. Suppl. i. 510.-Sumatra.

\section{ARYTERA :-}

Leichhardtii, Radlk, in Sitzb. Math.-Phys. Acad Muench. ix. (1879) 553-Austral.

lepidota, Radlk. 1. c. $555,-\mathrm{N}$. Caled

littoralis, Blume, Rumphia, iii. 170.--Sumatra.

macrocarpa, Miq. F1. Ind. Bat. Suppl. i. $510=$ Triomm malaccensis.

microphylla, Radlk. in Sitzb. Math.-Phys. Acad

Muench. ix. (1879) 553.-Austral.

montana, Blume, Rumphia, iii. 171,-Malaya,

morocarpa, Miq. F1. Ind. Bat. Suppl. i. 510.-Su-

oligolepis, Radlk. in Sitzb. Math.-Phys. Acad. Muench 1x. (1879) 555.-Ins. Navig.

O'Shanesiana, Radlk. 1. c. 554.-Austral.

pachyphylla, Radlk. 1. c.-N. Caled.

rufescens, Radlk. I. c. 552.-Ins. Philipp.

semiglauca, F. Muell. in Trans. Phil. Inst. Victoria iii. (1859) $25=$ Cupania semiglauca.

Silaka, Miq. Fl. Ind. Bat. Suppl. i. 510.--Sumatra.

ASACARA, Rafin. Neogenyt. $2(1825)=$ Gleditschia, Linn. (Legum.)

aquatica, Rafin. 1. c. = G. monosperma

ASAFMIA, Harv, in Harv. \& Sond. Fl. Cap. iii. 187 (1864), in syn. COMPOSITAE, Benth. \& Hook. f ii. 433 .

axillaris, Hary. $l$. c.-Afr. austr.

ASAGRAFA, Baill, Adansonia, ix. (1870) 232 LEGUMINOSAE.

spinosa, Baill. l. c. 233.-Am. bor. occ.

ASAGRAEA, Lindl. Bot. Reg. t. 33 (1839)=Schoeno caulon, A. Gray (Liliac.).

caracasana, Ernst, in Journ. Bot. (1871) $91=\mathrm{S}$ officinale.

caricifolia, Kunth, Enum. Pl, iv. $666=\mathrm{S}$. officinale. officinalis, Lindl. in Bot. Reg. (1839) t. $33=\mathrm{S}$. officinale. tenuifolia, Kunth, Enum. Pl, iv. 700=S. officinale.

ASAPHES, DC. Prod. ii. 90 (1825)=Toddalia, Juss. (Rutac.).

undulata, DC. 1. c. $=$ T. lanceolata.

ASAPHES, Spreng. Syst. iv. Cur. Post. $222(1827)=$ Morina, Tourn. (Dipsac.)

nepalensis, Spreng. 1. c. $232=\mathrm{M}$. persica.

ASARCA, Poepp. ex Lindl. in Quart. Joum. R. Instit. i 1827) 52 =Chloraea, Lindl. (Orchid.)

acutiflora, Poepp. \& Eadl. Nov. Gen, et Sp. ii. 14.t 120, A.-Chili.

acutifolia, Steud. Nom. ed. II. i. 145, sphalm. = praec alaris, Lindl. Gen. et Sp. Orch. $408=\mathrm{C}$. alaris.

arauacana, Phil. in Linnaea, xxix. (1857-58) 56.Chili.

aurantiaca, Lindl, in Hook. Journ. Bot. i. (1834) $4=$ C. aurantiaca.

Berteri, Reichb. f. in Linnaea, xix. (1847) 377. Chili.

bidentata, Poepp. \& Endl. Nov. Gen. et Sp. ii. 15. t. 121-Chili.

brachychila, Phil. in Anal. Univ. Chil. (1865) II. 332 -Chili.

chrysostachya, Phil. in Linnaea, xxix. (1857-58) 55.Chili.

Commersonii, Hook. f. F1. Antarct. ii. $351=$ C. Com mersonii.

glandulifera, Poepp. \& Endl. Nov. Gen. et Sp. ii. 14. t. $120 . \mathrm{B}=\mathrm{C}$. volucris.

Kingii, Hook. f. F1. Antarct. ii. 351.-Reg. Magell.

leucantha, Poepp. \& Endl. Nov. Gen. et Sp. ii. 13. t.

119.-Chili.

maculata, Steud. Nom. ed. II i. $145=$ seq

maculosa, Poepp. Fragm. Syn. Pl. Chil. $20=$ C galeata.

odoratissima, Poepp. \& Endl. Nov, Gen, et Sp. ii. 13.

t. 118.-Chili.

parviflora, Poepp. Fragm. Syn. Pl. Chil. 20,-Chili.

platyantha, Reichb. f in Linnaea, xxii. (1849) 862 .Chili.

sinuata, Lindl. Gen. et Sp. Orch. $408=$ C. longibracteata.

speciosa. Lindl, in Quart. Journ. R. Instit. i. (1827) 52 $=$ C. Pavonii.
ASARCA :-

spectabilis, Phil. in Linnaea, xxix. (1857-58) $55=$

Chloraea spectabilis.

sulphurea, Phil. 1, c. 57.Chili.

verrucosa, A. Rich. ex C. Gay, Fl. Chil. v. 465. t. 66 C. verrucosa.

ASARINA, Toum. ex Mill. Gard. Dict. ed. VIII. (1768 = Antirrhinum, Tourn. (Scrophul.).

cordifolia, Moench, Meth. Suppl. 172=Ant. Asarina.

erecta, Mill. Gard. Dict. ed. VIII. n. $2=$ 'Penstemon,' Mitch. ?-Am. bor.

Lobelii, Quer, F1. Esp. iii. 115. t. $30=$ Ant. Asarina.

procumbens, Mill. Gard. Dict, ed. VIII. n. $1=$ Ant. Asarina.

ASARUM, [Tourn.] Linn. Syst, ed, I (1735), ARISTOLOCHIACEAE, Benth. \& Hook. f. iii. 122 Heterotropa, Morr. \& Decne. in Ann. Sc. Nat. Sér. II. ii. (1834) 314. t. 10 .

Hexastylis, Rafin. Neogenyt. 3 (1825).

albivenium, Regel, Gartenf.x. xiii. (1864) 295. t. 440 Japon.

arifolium, Michx. Fl. Bor. Am. i, 279.-Am. bor

Blumei, Duch. in DC. Prod. xv. I. 427.-Japon.

canadense, Linn. Sp. Pl. 442.-Am. bor,

caulescens, Maxim. in Bull. Acad. Pétersb. xvii. 1872) 162.-Japon.

carolinianum, Walt. Fl. Carol. $143=$ canadense. caudatum, Lindl. Bot. Reg. sub t. 1399.-Calif. caudigerum, Hance, in Fourn. Bot. xix. (1881) 142.China.

elegans, Duch. in DC. Prod. xv. I. 426.- Japon europaeum, Linn. $S p . P l$. 442.-Europ.; As. Min.; Sibir.

furcatum, Rafin. New Fl. Am. ii. 20.-Am. bor. grandifolium, Lodd. Cab. ex Loud. Hort. Brit. 187.Am. bor.

grandiflorum, Klotzsch, in Monatsb. Acad. Berl. (1859) 586. - Am. bor.

grandiflorum, Steud. Nom. ed. II. 1. $145=$ grandifolium.

Hartwegii, S. Wats. in Proc. Am. Acad. x. (1875) 346.-Calif

heterotropoides, F. Schmidt, Reisen Amurl. $171=$ Sieboldii.

himalaycum, Hook. f. E Thoms. ex Klotrsch, in Monatsb. Akad. Berl. (1859) 585.-Reg. Himal.

Hookeri, Field. \& Gardn. Sert. t. $32=$ caudatum.

Hypocistis, Linn. Sp. Pl. $442=$ Cytinus Hypocistis.

ibericum, Stev. ex Ledeb. Fl. Ross. iii. $553=$ europaeum. latifolium, Salisb. Prod. $344=$ canadense.

Lemmoni, S. Wats, in Proc. Am. Acad xiv. (1879) 294. - Calif

leucodictyon, Miq. Ann. Mus. Bot. Lugd. Bat. ii. 135 $=$ albivenium.

lucidum, Salisb. Prod. $344=$ europaeum.

maculosum, Stokes, Bot. Mat. Med. iii. 7 =virrinicum. medium, Rafin. New Fl. Am. ii. $20=$ arifolium? officinale, Moench, Meth. $292=$ europaeum.

parviflorum, Regel, Ind. Sem. Hort. Petrop. (1866 $89=$ elegans.

parvifolium, Rafin. New Fl. Am. ii. $20=$ virginicum. renifolium, Stokes, Bot. Mat. Med. iii. $5=$ europaeum reniforme, Gilib. Exercit. ii. $424=$ europaeum.

rotundifolium, Rafin. New Fl. Am. i1. 21 = virginicum. Sieboldii, Miq. Ann. Mus. Bot. Lugd. Bat. ii. 134.Japon.

Thunbergii, A. Br. Ind. Sem. Hort. Berol. (1861) App.

13.-Japon

variegatum, A.Br. E Bouché, l. c. 12.-Japen.

villosum, Muhl. ex Duch, in DC. Prod. Xv. I. $424=$ caradense.

virginianum, Crantz, Inst. i. $134=\mathrm{seq}$

virginicum, Linn. Sp. $\mathrm{Pl}$. 442,-Am, bor.

virginicum, Thunb. F1. Jap. $190=$ albivenium.

virginicum, Walt. Fl. Carol. 143 = arifolium.

viridiflorum, Regel, Ind. Sem. Hort. Petrop. (1869) 83 =variegatum.

ASCALEA, Hill, Veg. Syst. iv. $14(1762)=$ Carduus

Linn. (Compos.)

lanceata, Hill, Hort. Kew. $60=$ Cnicus lanceolatus.

nutans, Hill, 1. c. = Card. nutans.

ASCALONICUM, Renault, Fl. Dép. Orne, $33(1800)=$

Allium, Tourn. (Liliac.)

sativum, Renault, 1. c. = All. Ascalonicum. 
ASCALONICUM :-

Schoenoprasum, Renault, F1. Dép. Orne, $33(\mathbf{1 8 0 0})=$ Allium Schoenoprasum

Scorodoprasum, Renault, 1. c. = All. Scorodoprasum.

ASCANICA, Crantz, Inst. ii. 313 (1766)= Patagonula, Linn. (Borag.).

patagonica, Crantz, 1. $c_{0}=$ P. americana.

ASCARICIDA, Cass. in Dict. Sc. Nat. iii. Suppl. 38 $(1816)$ = Vernonia, Schreb. (Compos.).

adoënsis, Steetz, in Peters, Reise Mossamb. Bot. 358= V. adoënsis.

anthelminthica, Sweet, Hort. Brit. ed. I. $219=\mathrm{V}$, anthelminthica.

Buchingeri, Steetz, in Peters, Reise Mossamb. Bot. $359=\mathrm{V}$. Buchingeri.

indica, Cass. in Dict. Sc. Nat. iii. Suppl. $38=$ V. anthelminthica.

Kotschyana, Steetz, in Peters, Reise Mossamb. Bot. $359=\mathrm{V}$. Kotschyana.

mossambiquensis, Steetz, 1. c. $358=$ V. mossambiquensis.

Richardi, Steetz, l. c. $=$ V. adoënsis.

triplinervia, G. Don, in Loud. Hort. Brit. $333=$ Baccharis triplinervis.

ASCARIDIA, Reichb. Nom. 99 (1841)=praec.

ASCARINA, Forst. Char. Gen. 117. t. 59 (1776). CHLORANTHACEAE, Benth. \& Hook. f. iii. 134.

lanceolata, Hook. f. in fourn. Linn. Soc. i. (1856) 127. - Ins. Pacif.

lucida, Hook. f. Fl. N. Zel. i. 228.-N. Zel.

lurida, Solms, in DC. Prod. xvi. I. $478=$ rubricaulis.

polystachya, Forst. Char. Gen. 59, 117. t. 59.-Ins. Societ.

rubra, Poir. Encyc. ix. $475=$ Myrica sapida

rubricaulis, Solms, in DC. Prod. xvi. I. $478 .-\mathrm{N}$. Caled.

serrata, Blume, Enum. Pl. Jav. i. $79=$ Chloranthus brachystachyus.

ASCHAMIA, Salisb. Gen. Pl. Fragm, 134 (1866)= Hippeastrum, Herb. (Amaryll.).

equestris, Salisb. 1. c. $=$ H. equestre.

psittacina, Salisb. 1. c. = H. psittacinum.

Reginae, Salisb. 1. c. =H. Reginae.

ASCHENBORNIA, Schau, in Linnaea, xix. (1847) 716. COMPOSITAE, Benth. \& Hook. f, ii. 241. heteropoda, Schau. l. c-Mexic.

ASCHENFELDTiA, F, Muell. ex Meissn. in DC. Prod. xiv. 515 $(1856)=$ Pimelea, Banks \& Soland. pimeleoides, F. Muell. ex Meissn. 1. c. = P. microcephala.

ASCIADIUM, Griseb, Cat. Pl. Cub. 118 (1866). UMBELLIFERAE

coronopifolium, Griseb. l. c.-Cuba.

ASCIUM, Schreb. Gen. $358(\mathbf{1 7 8 9})=$ Norantea, Aubl. (Ternstr.).

adamantium, Steud. Nom. ed. II. i. $145=$ N. ada. mantium.

anomalum, Spreng. Syst. iv. Cur. Post. $207=$ N. anomala.

Aubletii, Spreng. Syst. ii. $599=$ N. guianensis.

Berterii, Spreng, 1. c. $=$ N. Berterii,

goyazense, Steud. Nom. ed. II. i. $145=$ N. goyazensis. japurense, Steud. 1. $c_{0}=\mathrm{N}$. japurensis.

Norantea, Raeusch. Nom. ed. III, $156=$ N. guianensis.

parainse, Steud. Nom. ed. II. i. $145=$ N. paraënsis.

Selloi, Spreng. Syst, ii. $599=$ N. cuneifolia, brasiliensis.

violaceum, Vahl, Ecl. Am. ii. 41. t. $20=$ N. guianensis.

ASCLEIA, Rafin. Sylva Tellur. 53 (1838) (= Lycium ? Linn.) (Solan.)

mexicana, Rafin. 1. c. (=L. capsulare),-Mexic.

ASCLEPIAS, Linn, Gen, ed. I. 64 (1737). ASCLEPIADEAE, Benth. \& Hook. f. ii. 754.

Acerotis, Rafin. New Fl. Am. i 49 (1896).

\section{ASCLEPIAS}

Crassa, Rupp. F1. Jen. ed. Hall. 26 (1745).

Dassovia, Neck. Elem. i. 257 (1790).

Oligoron, Rafin. New Fl. Am. iv. 60 (1836)

OTANEMA, Rafin. I. c. 61 (1836)

OTARIA, Kunth, in H. B. \& K. Nov. Gen. et Sp. iii. 192 (1818).

acanthocarpus, Gmel. ex Decne. in DC. Prod. viii. 571 $=$ Gonolobus hirsutus.

aceratoides, $M$. Curt. in Am. Fourn. Sc. Ser. II. vii. (1849) 407.-Am. bor.

acida, Roxb. Hort. Beng. 20; Fl. Ind. ii. $31=$ Sarco stemma brevistigna.

acornuta, Kellogg, in Proc. Calif. Acad. i. (1865) 54. -Calif.

acuminata, Pursh, F1. Am. Sept. i. $182=$ rubra.

acuminata, Roxb. Hort. Beng. 21 ; Fl. Ind. ii. $55=$ Gymnema acuminatum.

acuminata, Willd. ex Roem. \& Schult. Syst. vi. 82,

$145=$ Klaprothiana.

aequicornu, Fourn, in Mart. Fl. Bras. vi. IV, 201.Bras.

ageratoides, M. Curt. in Am. Fourn. Sc. Ser. II. vii (1849) 407.-Am. centr.

alba, Cav. Ic. iv. $5=$ Sarcostemma Dombeyanum ?

alba, Mill. Gard. Dict. ed. VIII. n. 1; Lam. Fl. Fr. ii. $301=$ Vincetoxicum officinale.

albiflora, Rafin. New Fl. Am. iv, 62.-Am. bor

albo-aurantiaca, Hort. ex Jacq. Fragm. $86=$ nivea

alexicaca, Jacq. Coll. ii. $101=$ Hoya pendula.

alexitoxica, St. Lag. in Ann. Soc. Bot. Lyon, vii. (1880)

$120=$ Vincetoxicum officinale

alpina, Vell. Fl. Flum. 116 ; iii. t. $57=$ Oxypetalum megapotamicum

alticola, Fourn. in Ann. Sc. Nat. Sér. VI, xiv. (1882) 371.-Mexic.

altissima, Facq. Enum. Pl. Carib. 17.-Ind. occ.

amoena, Brongn, in Ann. Sc. Nat. Sér. I. xxiv. (1831)

275 . t. 13 = incarnata.

amoena, Linn. Sp. Pl. $214=$ purpurascens

amplexicaulis, Michx. Fl. Bor. Am. i. 115.-Am. bor angulosa, Regel, Cat. Pl. Hort. Aksakov. 13.-Hab. ? angustifolia, Ell. Sketch, i. $385=$ Michauxii.

angustifolia, Hort. Berol. ex Roem. \& Schult. Syst. ví. $70=$ praec

angustifolia, Schweig. Enum.Pl. Hort. Bot. Regiomont. (1812) 13.-Mexic.

angustissima, Anderss. Om Galap. Oarnes Veget. 196 -Ins. Galapag.

annularia, Roxb. Hort. Beng. 20; Fl. Ind. ii. $37=$ Holostemma Rheedianum.

aphylla, Boj. ex Decne. in DC. Prod. viii. $546=$ Decanema Bojerianum.

aphylla, Forsk. F1. Aegypt. Arab. $50=$ Sarcostemma Forskohlianum.

aphylla, Roxb. ex Wight, Contrib. $60=$ Sarcostemma brevistigma.

aphylla, Thunb. Prod. P1. Cap. 47 =Sarcostemma aphyllum.

Apocinum, Gater. Desc. Pl. Montaub. $58=$ syriaca.

arborea, Salisb. Prod. $150=\mathrm{seq}$.

arborescens, Linn. Mant. $216=$ Gomphocarpus arborescens.

arenaria, Torr. in Bot. Mex. Bound. 162,-Am. bor. occ.

argentata, Noronha, in Verh.Batar. Gen.v. (1790) ed. I. Art. IV. 6.-Malaya.

armata, Spreng. Syst. i. 849.-N. Granat.

arvensis, Vell. F1. Flum. 117 ; iii. t. $63=$ Oxypetalum campestre.

asthmatica, Linn. f. Suppl. $171=$ Tylophora asthmatica. aurantiaca, Salisb. Prod. $150=$ curassavica.

auriculata, $H$. B. E $K$. Nov. Gen. et Sp. iii. 191. t. 228 -Mexic.

axillaris, Vell. Fl. Flum. 115 ; iii. t. 51 -Bras,

barjoniaefolia, Fourn. in Ann. Sc. Nat. Sér. VI. xiv. (1882) 372 -Bolivia.

bicolor, Moench, Meth. $717=$ curassavica.

bidentata, Hemsl. Biol. Centr. Am. Bot. ii. 322,Mexic.

Blanchetii, Fourn. in Mart. Fl. Bras. vi. IV. 201.Bras.

brachystephana, Engelm. ex Torr. in Bot. Mex. Bound. 169. - Am. bor. oco.

boliviensis, Fourn. in Ann.Sc. Nat. Ser. VI, xiv. (1883) 381.-Bolivia.

bracteolata, Fourn. in Mart. Fl. Bras. vi. IV. 200.Bras.

\section{ASCLEPIAS :}

brevicornu, Scheele, in Linnaea, xxi. (1848) $756=$ Asclepiodora decumbens.

Bridgesii, Fourn. in Ann. Sc. Nat. Sér. VI. xiv. (1882 383.-Bolivia.

campestris, Decne. in DC. Prod. viii. 568.-Bras. campestris, Vell. Fl. Flum. iii. t. $63=$ Oxypetalum campestre.

cancellata, Burm. f. Fl. Cap. Prod. 7.-Afr. austr.

candida, Vell. Fl. Flum. 118 ; iii. t. 65.-Bras.

canescens, Willd. in Ges. Naturf. Fr. Neu. Schr, iii (1801) 418=Cynanchum glaucum.

canina, Noronha, in Verh. Batav. Gen. vo (1790) ed. I.

Art. IV. 6.-Malaya.

carnosa, Blanco, Fl. Filip.ed. I. $208=$ Hoya multiflora

carnosa, Linn. f. Suppl. $170=$ Hoya carnosa.

ciliata, Murr. ex Decne. in DC. Prod, viit. $572=$

Xysmalobium undulatum.

cinerea, Walt. Fl. Carol. 105.-Am. bor.

cirrosa, Ehrenb. ex Schweinf. Beitr. Fl. Aethiop. 132

Afr. trop.

citrifolia, Hook. \& Arn. in Hook. Journ. Bot. i. (1834) $295=$ campestris.

citrifolia, Jacq. Coll. ii. $290=$ variegata

clausa, Jacq. Enum. P1. Carib. $17=$ Sarcostemma glaucum.

clusiaefolia, Horsf. ex Roem. E Schult. Syst. vi.82.Java.

communis, Vell. Fl. Flum. 115; iii. t. $53=$ Oxypetalum Banksii.

compressa, Moench, Meth. $717=$ purpurascens

connivens, Baldw. in Ell. Sketch, i. $320=$ Asclepiodora viridis.

consanguinea, Kunze, in Limnaea, xx, (1847) 26.Hab. ?

contorta, Forsk. Fl. Aegypt. Arab. p. cviii. D. $188=$ Sarcostemma Forskohlianum.

convolvulacea, Heyne, ex Decne. in DC. Prod. viii. 572 =Holostemma Rheedianum.

convolvulacea, Willd. Sp. P1. i. $1269=$ Daemia angolensis.

cordata, Burm. f. Fl. Ind. 72 = Pergularia minor

cordata, Forsk. Fl. Aegypt. Arab. 49=Daemia cordata.

cordata, Walt. Fl. Carol. $105=$ rubra?

cordata, Vell. Fl. Flum. 116; iii. t. 56-Roulinia fuminensis.

Cornuti, Decne. in DC. Prod. viii. 564=syriaca

Coulteri, A. Gray, in Proc. Am. Acad. xii. (1877) 71. -Mexic.

crassifolia, Hort, Par, ex Decne, in DC. Prod, viii. $572=$ Gomphocarpus arborescens.

crassifolia, Linn. ex Decne. I, $c_{0}=$ Gomphocarpus fruticosus.

crispa, Berg. Desc. Pl. Cap. $75=$ Gomphocarpus crispas. cryptoceras, S. Wats. in Bot. King, Exp. 283. t. 28.Ám. bor, occ.

cubensis, Wender, in Bot. Zeit. i. (1843) 830.-Cuba.

curassavica, Griseb, in Goett. Abh. xix. (1874) $159=$ campestris.

curassavica, Linn. Sp. Pl. 215 ; Willd. Sp. Pl. i. 1266. -Am. austr.

curassavica, Lour. Fl. Cochinch. 170=Toxocarpus Wightianus.

Curtissii, A. Gray, in Proc. Am. Acad. xix (1853) 85. -Am, bor

Curupi, Fourn. in Ann. Sc. Nat. Sir. VI. xiv. (188? 384.-Paraguay.

cutea, Rafin. in Am. Monthly Mag. (181i) 35\%-Am. bor.

cynanchoides, Humb. E Bonpl. ex Rocm. E Schult. Syst. vi. 86.-Venczuela.

Daemia, Blanco, Fl. Filip. ed. I. $2(18=$ Gymema tingens.

Daemia, Forsk. Fl. Aegypt. Arab. 51 - Dacmia extensa.

dasypus, Rafin. Atl. Yourn. 15․-Am. bor.

davurica, Willd. Sp. Pl, i. $1272=\mathrm{Cynanchum}$-eum.

debilis. Michx. F\%. Am. Bor. i, 116,-Am. bor.

decumbens, Linn. Sp. Pl. $216=$ unberosa,

densa, facq. Ensm. Pl. Carib. 17,-Ind. ucc.

dichotoma, Rotk. in Wall. Cat. n. 8200 - Tylophora dichoroma,

Donglasii, Ilook. Fl, Bor. Am, ii. 59, t, $9 \bar{i}=$ speciost.

echinata. Herb. Madr. ex Hevk. 6. Fl. Bris. Mnl. it. $\$ 3$ Marstenia tenacissima.

chinata, Roxb. Hurt Beng. 20 ; Fl. Int. ii. It

1) actuia extensa. 


\section{ASCLFPIAS :}

echinata, Decne in DC. Prod, viii, 544=Daemia angolensis.

ecornuta, Kellogg, ex A. Gray, Syn. Fl. N. Am. ii. I. 100 Gomphocarpus cordifolius.

elata, Benth. Pl, Hartw. $290=$ glaucescens.

elegans, Vell. Fl. Flum. I16; iii. t. 55.-Bras.

eriocarpa, Benth. Pl. Hartw. 323.-Calif

eriocarpa, Torr, in Pacif. Rail. Rep. iv. $128=$ vestita.

erosa, Torr. in Bot. Mex. Bound. 162.-Calif.

euphorbiaefolia, Engelm. in Proc. Am. Acad. xvi. (1881) 104.-Mexic.

exaltata, Linn. Amoen. Acad. iii. $404=$ syriaca

exaltata, Link, ex Spreng. Syst. i. $848=$ Asclepiotora viridis.

exaltata, Muhl. ex Bigel. F1. Bost. $102=$ phytolaccoides.

fascicularis, Decne. in DC. Prod. viii. $509=$ mexicana.

fasciculata, Hemsl. Biol. Centr. Am. Bot. ii. 324, sphalm. $=$ praec。

Feayi, Chapm. ex A. Gray, in Proc. Am. Acad. xii. (1876) 72 -Am. bor. trop.

ferruginea, Humb. Er Bonpl. ex Roem. Es Schult. Syst. vi. 83,-Venezuela.

filiformis, Jacq. Enum. Pl. Carib. 17=Sarcostemma Jacquini.

filiformis, Linn. f. Suppl. 169 (=Lagarinthus tenuis). -Ind. occ.; Afr. austr.

floridana, Lam. Encyc. i. $284=$ Gomphocarpus longifolia.

foetida, Cav. Ic. ii. 45. t. $158=$ Roulinia Jacquini.

Forskohlei, Roem. E Schult. Syst. vi. 85.-Arab.

fragrans, Decne in DC. Prod viii. 571-Guatemala.

fragrans, Rafin. in Med. Repos. N. York, v. (1808) 354 - Am. bor

Frémontii, Torr. in Pacif. Rail. Rep. vi. 87.-Calif.

fruticosa, Linn. Sp. P1. $216=$ Gomphocarpus fruticosus.

fusca, Lour. FI. Cochinch. $170=$ Vincetoxicum medium.

fuscata, Willd. Enum. Hort. Berol. Suppl. 13=

Graecti, Fourn. in Bull. Soc. Bot. Fr. xiv. (1867) 250. -Mexic.

galioides, H. B. \& K. Nov. Gen. et Sp. iii. $148=$ verticillata.

geminata, Roxb. Hort. Beng. 20 ; Fl. Ind. ii. $45=$ Gymnema sylvestre

gigantea, Linn. Sp. Pl. $214=$ Calotropis procera

gigantea, Willd. Sp. Pl. i. 1264=Calutropis gigantea.

glabra, Forsk. Fl. Aegypt. Arab. 51=- Doemia glabra.

glabra, Mill. Gard. Dict. ed. VIII. n. $12=$ Gompho carpus fruticosus.

glaucescens, H. B. E* K. Nov. Gen. et Sp. iii. 290. 227.-N, Mexic.

globosa, Stokes, Bot. Mat. Med. ii. 4 =syriaca.

gonocarpos, J. F. Gmel. Syst. $446=$ Gonolobus carolinensis.

graminea, Lam. Encyc. i. 283.-Ind. or

grandiflora, Linn. f. Suppl. $170=$ Gomphocarpus gran diflorus.

grandiflora, Fourn. in Ann. Sc.Nat. Sér. VI. xiv. (1882) 379.-Mexic.

grandifolia, Bertol, in Mem, Acc, Sc, Bolog. iii. 1851) 189 (Misc. Bot, xii. 47) = syriaca.

Greeniana, Nutt. ex Loud. Hort. Brit. Suppl. iii. 493. - Am. bor.

Hallii, A. Gray, in Proc. Am. Acad, xii. (1877) 69.Colorado.

hastata, Bunge, in Mém. Sav. Etr. Acad. Pétersb. ii. (1835) $117=$ Cynanchum Bungei.

herbacea, Roxb. Hort. Beng. 21; F1. Ind. ii. $50=$ Calotropis Acia

hispida, Vell. Fl. Flum. 115; iii. t. 52=Ditassa Guilleminiana.

humistrata, Walt. F1. Carol. $105=$ amplexicaulis.

hybrida, Michx. F1. Am. Bor. i. $115=$ variegata.

illinoënsis, Michx. ex Steud. Nom. ed. II, i. $146=$ syriaca.

incarnata, Linn. Sp. Pl. 215.-Am. bor

incarnata, Walt. F1. Carol. 106=Gomphocarpus longifolius.

involucrata, Engelm. ex Torr. in Bot. Mex. Bound. 163.-N. Mexic.

Facquiniana, Spreng. Syst. iv. Cur. Post. $341=$ Sarcostemma Jacquini

Jamesii, Torr. Bot. Mex. Bound. 162.-Am. bor.

javanica, Burm. ex Decne. in DC. Prod, viii. $628=$ Leptadenia reticulata.

\section{ASCLEPIAS :-}

Klaprothiana, Roem. E Schult. Syst. vi. 82.-Am. bor.

lactifera, Linn. Sp. P1. 216= Gymnema lactiferum

lanceolata, Ives, in Am. Journ. Sc. i. (1819) $252=$ Gomphocarpus viridiflorus.

lanceolata, Walt. H. Carol. $105=$ paupereula.

lancifolia, Steud. Nom. ed. I. $77=$ rubra.

laniflora, Forsk. Fl. Aegypt. Arab, 51=Kanahia laniflora.

Langsdorffi, Fourn. in Mart. Fl. Bras. vi. IV. 203.Bras.

lanuginosa, H. B. E K. Nov. Gen. et Sp. iii. 193.Mexic.

lanuginosa, Nutt. Gen. Am. i. 168 (=Acerates lanuginosa).-Am. bor.

latifolia, Rafin. Atl. Fourn. 146.-Am. bor

laurifolia, Michx. Fl. Bor. Am. i. $117=$ rubra

laurifolia, Roxb. Hort. Beng. 20; Fl. Ind. ii. $49=$ Genianthus laurifolius.

laxiflora, Decne. in DC. Prod. viii, 571.-Mexic

Lemmoni, A. Gray, in Proc. Am. Acad, xix. (1883) 85.-Arizona.

leucophylla, Engelm. in Am. Natural. ix. (1875) $348=$ erosa.

Linaria, Cav. Ic. i. 42. t. 57.-Mexic

Lindheimeri, Engelm. \& A. Gray, P1. Lindh. $250-$ longicornu.

Lindleyi, Gill. ex Steud. Nom. ed. II. i. 145, 146 variegata.

linearifolia, Pav. ex Decne. in DC. Prod. viii. 539= Sarcostemma Dombeyanum.

linearis, Scheele, in Linnaea, xxi. (1848) $758=$ verticillata.

linifolia, H. B. \& K. Nov. Gen. et Sp. iii. $190=$ angustifolia, virgata?

linifolia, Lag. ex Spreng. Syst. i. 847.-Mexic.

longicornis, Kellogg, in Proc. Calif. Acad. i. ('1855') 65. - Calif.

longicornu, Benth. in Pl. Hartw. 24.-Calif.

longiflora, Jacq. Enum. P1. Carib. $17(=$ Schubertia longiflora).-Ind. occ.

longifolia, Michx. Fl. Bor. Am. i. 116.-Am. bor.

longipetala, Scheele, in Linnaea, xxi. (1848) $757=$ Asclepiodora viridis.

longistigma, Roxb. Hort. Beng. 85 ; F1. Ind. ii. $46=$ Toxocarpus Roxburghii.

lutea, Rafin. in Med. Repos. N. York, v. (1808) 361.-Am. bor.

intea, Mill. Gard. Dict. ed. VIII. n. $3=$ Vincetoxicum luteum.

macrantha, Hochst, ex Decne, in DC. Prod, viii. 558 Abyss.

macrophylla, Humb. E Bonpl.in Roem. E Schult. Syst. vi. 86,-Cumana.

macrophylla, Nutt. in Journ. Acad. Philad. Ser. II. i. 1847) $180=$ mexicana

macrotis, Tory, Bot. Mex. Bound 164, t. 45-N Mexic.

margaritacea, Hoffmgg. ex Roem. E Schult. Syst. vi. 86 . -Bras.

marginata, Decne. in DC. Prod, viii. $566=$ candida. maritima, Jacq. Enum. Pl. Carib. $17=$ Ibatia maritima, maritima, Pall. Reise, iii. 557.-Rossia austr.

maritima, Rafin. ex Decne, in DC. Prod. viii. $567=$ incarnata.

Meadii, Torr. ex A. Gray, Man. Bot. U. St. ed. II Add. 704.-Am. bor.

media, Hort ex Steud. Nom ed. II i $146=$ Vincetoxicum medium.

megalotis, Rafin. New Fl. Am. iv. 61.-Am. bor. melantha, Decne. in DC. Prod. viii. 570.-Mexic mellodora, St. Hil. Pl. Rem. Bras. $227=$ nervosa mexicana, Cav. Ic. i. 42. t. $58=$ Calif. : Mexic.

Michauxii, Decne, in DC, Prod, viii. 569-Am. bor micrantha, Roxb. Hort. Beng. 21; Fl. Ind. ii. 50Ind. or.

microphylla, Heyne, ex Roth, Nov. Sp. Pl. $177=$ seq. ? microphylla, Roxb. Hort. Beng. 85 ; Fl. Ind. ii. $35=$ Pentatropis microphylla.

monantha, Vell. Fl. Flum. 115 ; iii. t. $54=$ Oxypetalum monanthum.

montana, Roxb. Hort. Beng. 85; Fl. Ind. ii. $45=$ Gymnema tingens.

montevidensis, Spreng. ex Fourn. in Mart. Fl. Bras,

vi. IV. 202,-Reg. Argent.

mucronata, Thunb. Prod. Pl, Cap. 47 (=Metaplexis mucronata) - Afr, austr.
ASCLEPIAS :

multicaulis, Vell. Fl. Flum. 117 ; iii. t. $60=$ Oxypetalum campestre.

multinervis, Fourn. in Ann. Sc. Nat. Sér. VI. xiv (1882) 383.-Paraguay.

muricata, Schum. \& Thonn. Beskr. Guin. P1. $153=$ Doemia angolensis.

neglecta, Hemsl. Biol. Centr. Am. Bot. ii. 325.Mexic.

nervosa, Decne, in DC. Prod. viii. 568.-Bras.

nigra, Linn. Sp. P1. $216=$ Vincetoxicum nigrum

nitida, Vell. Fl. Flum. 116; ii. t. $59=$ Oxypetalum umbellatum.

nivalis, J. F. Gmel. Syst. $444=$ seq.

nivea, Forsk. F1. Aegypt. Arab. $51=$ Forskohlei

nivea, Linn. Sp. Pl. 215.-Ind. occ.

nivea, Sims, Bot. Mag. t. $1181=$ phytolaccoides

nuda, Thonn. Es Schum. Beskr. Guin. Pl. 155.-Afr. trop.

nummularia, Torr. Bot. Mex. Bound. 163. t. 45.Am. bor.

nutans, Muhl. ex Steud. Nom. ed. II. i. 146 (=Acerates viridiflorus).-Am, bor.

Nuttalliana, A. Gray, Man. Bot. U. St. ed. II. 352, 704 = ovalifolia.

Nuttalliana, Torr, in Ann. Lyc. N. York, ii. (1828) 218 (=Acerates lanuginosa).-Am. bor.

nyctaginifolia, A. Gray, in Proc. Am. Acad. xii. (1877) 69.-Calif.

obovata, Ell. Sketch, 321.-Am. bor.

obtusifolia, Hort. Prag. ex Kunze, in Linnaea, xx. (1847) $27=$ consanguinea

obtusifolia, Michx. Fl. Bor. Am. i. 115-Am bor

odoratissima, Roxb. Hort. Beng. 20; F1. Ind. ii. $47=$ Pergularia minor.

oenotheroides, Cham. \& Schlecht. in Linnaea, v. (1830 123 = longicornu.

otarioides, Fourn. in Ann.Sc. Nat. Sér. VI. xiv. (1882) 373.-Mexic

ovalifolia, Decne in DC. Prod. viii. 567-Am, bor.

ovata, Auct. ex Steud. Nom. ed. II. i. $146=$ Vince ioxicum officinale.

ovata, Mart. E Gal. in Bull. Acad. Brux.xi. (1842) 363.-Mexic,

pallida, Fourn. in Ann. Sc. Nat. Sér. VI. xiv. (1882) 383.-Paraguay.

pallida, Roxb. Hort. Beng. 20 ; F1. Ind. ii. $48=\mathrm{Per}$ gularia pallida.

paniculatum, Bunge, Enum. Pl. Chin. Bor. 43.China

parasitica, Roxb. Hort. Beng. 20; Fl. Ind. ii. $42=$ Hoya parasitica.

parviflora, Ait. Hort. Kew. 1. $307=$ perennis.

parviflora, Leconte, ex Decne. in DC. Prod. viii. $570=$ verticillata.

parviflora, Roem. \& Schult. Syst. vi. 82 , sphalm.= parvifolia.

parvifolia, Decne. in DC. Prod. viii. $568=$ perennis

parvifolia, Roem. E Schult. Syst. iv. 801, ind.-Am. austr.

patula, Auct. ex Decne. in DC. Prod. viii. $536=$ Calotropis procera.

paupercula, Michx. Fl. Bor. Am, i. 118.-Am. bor

pedicellata, Walt. FI. Carol. 106=Podostigma pubescens.

pellucida, Fourn. in Ann. Sc. Nat. Sér. VI. xiv. (1882) 381.-Mexic.

pendula, Roxb. Hort. Beng. 85 ; Fl. Ind. ii. $36=$ Hoya pendula.

peregrina, Blanco, F1. Filip. ed. I. $207=$ Sarcolobus carinatus.

perennis, Walt. Fl. Carol. 107.-Am. bor.

periplocaefolia, Nutt. Gen. Am. i. $167=$ rubra.

phytolaccoides, Lyon, ex Pursh, Fl. Am. Sept. i. 180. - Am, bor.

pilosa, Vell. F1. Flum. 117 ; iii. t. $62=$ Oxypetalum foliosum.

pinifolia, Greene, in Torrey Bot. Club, viii. (1881) $5=$ A. Linaria.

planiflora, Jacq. Enum. Pl. Carib. 17=Gonolobus planiflorus.

plicata, Heyne, ex Roth, Nov. Pl. Sp. 176.-Ind. or.

polystachya, Walt. F1. Carol. $107=$ rubra

pratensis, Benth. Pl. Hartw. 45.-Mexic.

Princeps, Bartl. Ind. Sem. Hort. Gott. (1839); ex

Kunze, in Linnaea, xx. (1847) 27.-Am. bor.

procera, Ait. Hort. Kew. i. $305=$ Calotropis procera.

procumbens, Rafin. Fl. Ludov. 51.-Am. bor. 


\section{ASCIEFIAS :-}

psendosarsa, Roxb. Hort. Beng. 20; Fl. Ind. ii. $39=$ Hemidesmus indicus.

puberula, A. Gray, in Proc. Am. Acad. xvi. (1881) 104.-Mexic.

pubescens, Linn. Mant. $215=$ Gomphocarpus arbo rescens.

pubescens, Moench, Meth. $716=$ syriaca.

pubigera, Dum. F1. Belg. $52=$ syriaca.

pulchella, Roxb. Hort. Beng. 21; F1. Ind. ii. $54=$ Raphistemma pulchellum.

pulchella, Salisb. Prod. $150=$ perennis

pulchra, Ehrh. ex Willd. Enum. Hort. Berol. 278:-

incarnata.

pulchra, Vell. F1. Flum. 116 ; iii. t. $58=$ Oxypetalum pulchrum.

purpurascens, Georgi, Beschr. Russ. Reich, iii. IV $813=$ Vincetoxicum purpurascens.

purpurascens, Linn. Sp. Pl. 214.-Am. bor.

purpurascens, Walt. Fi. Carol. $105=$ obtasifolia.

purpurea, Pall. Reise, iii. 260 (=Cynoctonum roseum) -Rossia.

quadrifolia, facq. Obs. Bot. ii. 8.-Am. bor.

quinquedentata, A. Gray, in Proc. Am. Acad. xii.

(1877) $71 .-N$. Mexic.

quinqueflora, Vell. Fl. Flum. 118; iii. t. 68.-Bras.

racemosa, Jacq. Enum. Pl. Carib. $17=$ Roulinia Jacquini.

racemosa, Roxb. Hort. Beng. 20 ; F1. Ind. ii. $32=$ Cosmostigma racemosum.

radians, Forsk. Fl. Aegypt. Arab. $49=$ Steinheilia

radians. 373.-Bolivia.

repanda, Forsk. ex Steud. Nom. ed. I. 76 ; ed. II. i. 146 $=$ Gomphocarpus crispus.

revoluta, Rafin. Fl. Ludor. 51.-Am. bor.

rosea, H. B. E K. Nov. Gen. et Sp. iii. 189.-Mexic. rosea, Roxb. Hort. Beng. 20 ; Fl. Ind. ii. $40=$ Oxystelma esculentum.

Jotundifolia, Mill. Gard. Dict. ed. VIII. n. 15.-Afr. austr.

rotundifolia, Rafin. Att. Fourn. 152.-Hab. ?

rabra, Linn. Sp. Pl. 217.-Am. bor.

mubra, Sievers, in Pall. N. Nord. Beitr. vii. $329=$ $=$ Apocynum Venetum.

rubricaulis, $H . B$. छ $K$. Nov. Gen. et $S p$. iii. 148.Mexic.

salicifolia, Lodd. Bot. Cab. t. 272.-Mexic.

scandens, Beauv. Fl. Owar. i. 93. t. $56=$ Daemia angolensis.

scandens, Mill. Gard. Dict. ed. VIII. n. 19 = Sarcostemma Swartzianum.

Schafineri, A. Gray, in Proc. Am. Acad. xvi. (1881) 103.-Mexic.

Selloana, Fourn, in Mart. Fl. Bras, vi. IV. 202,-Bras. Serpentaria, Rafin. Fl. Ludov. 52.-Am. bor

setosa, Benth. Pl. Hartw. 24.-Mexic.

setosa, Forsk. Fl. Aegypt. Arab. $51=$ Gomphocarpus setosus.

sibirica, Linn. Sp. Pl. 217.-Sibir.

sibirica, Murr. in Comm. Gotting. (1779) 23 = Vince. toxicum sibiricum.

similis, Hemsl. Biol. Centr. Am. Bot. ii. 326.-Mexic. singularis, Vell. Fl. Flum. 117 ; iii. t. 61.-Bras. sinuosa. Burm. f. Fl. Cap. Prod. 7.-Afr. austr. speciosa, Torr. in Ann. Lyc. N. York, ii. (1828) 218. -Am. bor. occ.

spinosa, Vell. Fl. Flum. 118; iii. t. 67.-Bras.

spiralifiora, Stokes, Bot. Mat. Med. ii. $6=$ seq.

spiralis, Forsk. F1. Aegypt. Arab. $49=$ Pentatropis spiralis.

stellata, Burm. ex Decne. in DC. Prod. viii. $573=$ Hoya multiflora.

stenophylla, A. Gray, in Proc. Am. Acad. xii. (1876)

72.-Am. bor.

stipitacea, Forsk. Fl. Aegypt. Arab. 51=Sarcostemma stipitaceum.

suaveolens, Leconte, ex Decne, in DC. Prod. viii. $569=$ Michauxii.

suberosa, Roxb. Hort. Beng. 85 ; Fl. Ind. ii. $38=$ Leptadenia reticulata.

subulata, Decre. in DC. Prod. viii. 571.-Calif.

subulata, Forsk. Fl. Aegypt. Arab. p. cviii. n. 198. t. 7 Caralluma subulata.

Sullivantii, Engelm. ex A. Gray, Man. Bot. ed. I. 366. -Am. bor.

Sullivantii, Torr. Bot. Mex. Bound. 168 = glaucescens.

\section{ASCLEPIAS :-}

Sussuela, Roxb. Hort Beng. 20; Fl. Ind ii. $31=$ Hoya imperialis.

syriaca, Blanco, Fl. Filip. ed. I. 204=curassavica.

syriaca, Linn. Sp. Pl. ed. II. 214.-Am. bor.

tenacissima, Roxb. Pl. Corom, iii. 35. t. $240=$ Marsdenia tenacissima.

tenuis, Herb. Heyne, ex Hook. f. Fl. Brit. Ind, iv, 41 =Tylophora capparidifolia.

tenuissima, Roxb. Hort. Beng. 20 ; F1. Ind. ii. $41=$ Tylophora tenuissima.

tetrapetala, Dennst. Schluess. Hort. Malab. $35=$ Pentatropis microphylla.

tinctoria, Roxb. Hort. Beng. 20; Fl. Ind ii. $43=$ Marsdenia tinctoria.

tingens, Buch.-Ham. ex Roxb. Hort. Beng. 21; F Ind. ii. $53=$ Gymnema tingens.

tomentosa, Herb. Madr, ex Hook. f. Fl. Brit. Ind, ir. $35=$ Marsdenia tenacissima

tomentosa, Ell. Sketch, i. 320,-Am, bor.

tomentosa, Thonn. ex Decne. in DC. Prod. viii. 628 Leptadenia lancifolia.

toxicaria, Salisb. Prod. $150=$ Vincetoxicum officinale. truncata, Willd. Enum. Hort. Berol. Suppl. 13. Hab.

truncata, Roxb. ex Decne. in DC. Prod. viii. $529=$ Cynanchum alatum.

tuberosa, Linn. Sp. Pl. 217.-Am. bor.

tuberosa, Hort. ex Kunze, in Linnaea, xx. (1847) 27. Hab.?

tuberosa, Roxb. Fl. Ind. ii. $38=$ Leptadenia retica lata.

tunicata, Roxb. Hort. Beng. 20 ; 1. c. $35=$ Cynanchum pauciflorum.

tunicata, Hort. Calc. ex Hook. f. F1. Brit. Ind. iv, 45 = Tylophora asthmatica.

nmbellata, Vell. Fl. Flum.118; iii. t. 66-Bras. uncialis, Greene, in Coulter, Bot. Gaz. v. (1880) 64 -Am. bor. occ.

undulata, Jacq. Enum. Pl. Carib. $17=$ Xysmalobium undulatum.

undulata, Linn. Sp. PI, $214=$ Pachycarpus crispus.

Vanilla, Rafin. in Am. Monthly Mag. iv. (1818) $39=$ quadrifolia.

variegata, Linn. Sp. Pl. 215.-Am. bor.

verecunda, Salisb. Prod. $150=$ incarnata.

verticillata, $\operatorname{Linn} . S p . P l .217 .-\mathrm{Am}$. bor.

vestita, Hook. \& Arn. in Bot. Beech. Voy. 363.Calif.

vicinalis, Mart. Fl, Bras. vi. IV. $235=$ Sarcostemma barbatum.

villosa, Balb. in Mem. Acc. Torin. vii. (1802-3) 386= Lachnostoma Balbisii.

villosa, Mill. Gard. Dict. ed. VIII. n. 14=Gomphocarpus fruticosus.

villosa, Rafin. in Med. Repos. N. York, ץ. (1808) 353, nomen.-Am. bor.

viminalis, Steud. Nom, ed. II. i. $146=$ Sarcostemma viminale.

viminalis, Sw. Prod. Veg. Ind. Occ. 53 = Philibertia viminalis.

Vincetoxicum, Linn. Sp. Pl. 216 = Vincetoxicum officinale.

virgata, Balb. in Cat. Hort. Taur. (1813) $14=$ angustifolia.

viridiflora, Rafin. in Med. Repos. N. York, v. (1808) 360 ; Pursh, Fl. Am. Sept. i. 181= Gomphocarpus viridiflorus.

viridiflora, Roxb. ex Decne. in DC. Prod. viii. $573=$ Hoya viridiflora.

viridis, Walt. Fl. Carol. $107=$ Asclepiodora viridis

viridula, Chapm. Fl. S. U. St. 363.-Am. bor. trop.

Virletii, Fourn. in Ann. Sc. Nat. Sér. VI. xiv. (1882) 378.-Mexic.

volubilis, Herb. Madr. ex Hook. f. Fl. Brit. Ind. iv. 69 =Leptadenia reticulata.

volubilis, Linn. f. Suppl, $170=$ Dregea volubilis

volubilis, Domb. ex Decne. in DC. Prod. viii. $539=$ Sarcostemma Dombeyanum.

Domitoria, Koen, ex Hook. f. Fl. Brit. Ind, iv, 45

Tylophora asthmatica.

Weddellii, Fourn. in Ann. Sc. Nat. Sér. VI. xiv. (1882) 381.-Bolivia.

Wrightii, Greene, in Proc. Am. Acnd. xvi. (18\$1) 102 =nyctaginifolia.

seylanica, Burm. ex Decne. in DC. Prod. viii. 628

Leptadenia reticulata.
ASCLEPIODORA, A. Gray, in Proc. Am. Acad, xii (1876) 66. ASCLEPIADEAE.

ANANTHERIX, Nutt. Gen. Am。 i. 169 (1818)

Anthanotis, Rafin. F1. Ludov. 52, 149 (1817), nomen prius.

asperula, Fourn.

369.-Mexic.

circinalis, Fourn. 1. c. = Asclepias brachystephana.

decumbens, A. Gray, in Proc. Am. Acad. xii. (1876) 67.-Am. bor.

gomphocarpoides, Tourn. in Ann. Sc. Nat. Sér. VI. xiv. (1882) 369.-Mexic.

viridis, A. Gray, in Proc. Am. Acad. xii. (1876) 66.Am. bor.

A.SCOCHILUS, Blome, Fl. Jav. Praef. p. vi. (1828) Geodorum, Jack (Orchid.).

ASCOLEPIS, Niees, ex Steud. Syn. Pl. Cyp. 105 1855). CYPERACEAE, Benth. \& Hook. f iii. 1054. Antrolepis, Welw. Apont. Phyto-Geograph. in Annaes do Consel. Ultramarin. (1858) 578.

Platylepis, Kunth, Enum. Pl. ii. 269 (1835

Pteracine, Schrad. ex Nees, in Mart. Fl. Bras, it. I. 62 , in nota $(18 \pm 2)$

PTerogyNe, Schrad. ex Nees, in Mart. 1. c. (1842) anthemiflora, Welw. in Trans. Linn. Soc. xxvii. (1869 77.-Angola.

capensis, Ridl. in Trans. Linn. Soc. Ser. II. Bot. Ii. (1884) 164.-Afr. austr. et trop.

elata, Welw. in Trans. Linn. Soc. xxvii. (1869) 79. Angola.

eriocaulides, Nees, ex Steud. Syn. Pl. Cyp. 105.Abyss.

kyllingioides, Steud. 1. c. = Lipocarpha microcephala. protea, Welw. in Trans. Linn. Soc. xxvii. (1869) 75Afr. trop.

pusilla, Ridl.

in Trans. Linn. Soc. Ser. II Bot, it. 1851) 164.-Afr. occ.

speciosa, Welw. in Trans. Linn. Soc. xxvii. (1809) 78 - Angola.

tenuior, Steud. Syn. Pl. Cyp. $105=$ Scirpus squarrosus.

ASCRA, Schott, in Spreng, Syst. iv. Cur, Post. $40 \%$ $(1827)=$ Banara, Aubl. (Samyd.)

brasiliensis, Schott, $1 . \mathrm{c}=\mathrm{B}$. brasiliensis.

ASCYRUM, Linn. Gen.ed. I. 231 (173\%). HYPERI

CINEAE, Benth. \& Hook. f. i. 164

HYPERICOIDES, Adans. Fam, ii. 443 (1763).

IsopHYLlUM, Spach, in Ann. Sc. Nat. Ser. II. 1836) 367

amplexicaule, Michx. Fl. Bor. Am. ii. 77.-Am. bor.

calicinum, Poir. Tabl. Encyc. iii. $199=$ Hypericum calycinum.

coriaceum, Moench, Meth. $130=$ Hypericum calrcinum. cruciatum, St. Lag. in Ann. Soc. Bot. Lyon, vii. (1880 $69=\mathrm{A}$. Crux-Andreae.

Crux-Andreae, Linn. Sp. Pl. 787 = Hypericum motilum.

Crux-Andreae, Linn. Sp. Pl. ed. II. 110\%.-Am. bor. Ind. occ.

cubense, Griseb, Cat, Pl, Cub. 40-Cuba.

filicaule, Dyer, in Hook. f. Fl. Brit. Ind. i. 252.-Reg. Himal.

glandulosum, Moench, Meth. Suppl. $42=$ Hypericum balearicum.

grandiflorum, Rafin. Fl. Ludov, $8 \bar{T}=$ stans.

helianthemifolium, Spach, Hist Vég. Phan, $160=$

A. Crux-Andreae.

humifusum, Labill. Nor. Holl, PL ii. 39. t. 175= Hypericam japonicum.

hypericifolium, Sw. ex Rafin. Sylva Tellur. $110=\mathrm{A}$. Hypericoides.

Hypericoides, Linn. Sp. Pl. isS \& ed. II. 1108 pro max. parte. - Ind. occ.

Hypericoides, Marsh. Arbust. $14=$ stans.

grandiforum, Rafin. Fl. Ludov, 8i = stans.

noolutum, Labill. Nov. Holl. PL ii. \$2. L 1it

Hypericum gramincum.

linifolium, Spach, Hist. Veg. Phan. $v .459=\mathrm{A}$. CraxAndreae.

Michauxii, Spach, 1. c $f$ tio = A. Crux-Andreac.

microsepalam, Torr. \& Gray, FL. N. Am. i 15:

Hypericum micruseinalum.

monogynum, Mocnch, Mcch. Suppl. t? Hypricum monngynum.

munbanum, Rafin. Sylva Tellur. 110 A. IIypricoides. 


\section{ASCYRUM}

multicaule, Michx. ex Willd. Sp. Pl. iii. $1472=\mathrm{A}$ Crux-Andreae.

nummularifolium, Banks, ex Steud. Nom. ed. I. $77=$ pumilum.

cblongifolium, Spach, Hist. Vég. Phan. v. $461=\mathrm{A}$ Crux-Andreae.

pauciflorum, Nutt. Gen. Am. ii. $15=$ pumilum.

Plumierii, Bertol. in Mem. Acc. Sc. Bolog. iv. (1853) 77 (Misc. Bot. xiii. 19)=A. Crux-Andreae. pumilum, Michx. Fl. Bor. Am. ii. 77.-Am. bor. sibiricum, Poir. Tabl. Encyc. iii. $200=$ Hypericum Ascyrum.

simplex, Zeyh. ex Turcz. in Bull. Soc. Nat. Mosc. xxxi (1858) т. $389=$ stans.

spathulatum, Spach, Hist. Vég. Phan. v. $462=\mathrm{A}$ Crux-Andreae.

stans, Michx, Fl. Bor. Am. ii. 77.-Am. bor.

tetragronum, Moench, Meth, $130=$ Hypericum Ascyron villosum, Linn. Sp. PI. $788=$ Hypericum setosum.

ASCYUM, Vahl, ex DC. Prod.i. 566 (1824)=ASCIUM, Schreb. $=$ Norantea, Aubl. (Ternstr.)

ASEMEIA, Rafin. New Fl. Am. iv. $88(1836)=$ Polygala, Linn.

alba, Rafin, 1. c. = P. alba

carnea, Rafin. 1. c.-Am, bor.

leptopsis, Rafin. I. c--Am. bor

rosea, Rafin. 1. c. = P. Senega.

ASEMNANTHA, Hook. f. in Benth. \& Hook. f, Gen, ii 106 (1873). RUBIACEAE, Benth, \& Hook, f. ii. 106

pubescens, Hook. f. l. c. 107.-Mexic.

ASEPHANANTHES, Bory, ex DC. Prod. iii. 323 (1828) $=$ Passiflora, Linn

ASICARIA, Neck. Elem. ii. $211(1790)=$ Polygonum, Tourn.

ASIMIA, H. B. \& K. Nov, Gen. et Sp. v. 61 (1821)= Asimina, Adans. (Anonac.).

ASIMINA, Adans, Fam, ii. 365 (1763). ANONACEAE, Benth. \& Hook. f. i. 24

OrCHIDOCARPum, Michx, FI. Bor. Am, i. 329 (1803).

aurantiaca, Zipp. ex Miq. Ann. Mus. Bot. Lugd. Bat. ii. $25=$ Orophea aurantiaca.

Blainii, Griseb. Cat. Pl. Cub. 3.-Cuba.

campechiana, $H$. B. \& $K$. Nov. Gen. et Sp. v. 61.Mexic.

campaniflora, Spach, Hist. Vég. Phan. vii. $528=$ triloba.

conoidea, Spach, 1. c. $530=$ triloba?

cuneata, Shuttlw. ex Chapm. F1. S. U. St. $15=$ grandiflora.

glabra. Hort. ex C. Koch, Dendrol. i. $384=$ triloba.

grandiflora, Dun. Monog. Anon. 84. t. 11.-Am. bor.

grandiflora, Hort. ex Spach, Hist. Vég. Phan. v. $530=$ conoidea.

lanceolata, Hook. f. in Journ. Linn. Soc. i. (1857) 129, err. $t y p_{.}=$Ascarina lanceolata.

neglecta, Griseb. Cat. Pl. Cub. 3.-Cuba.

parviflora, Dun. Monog. Anon. 82. t. 9.-Am. bor, pygmaea, Dun. l. c. 84. t. 10.-Am. bor. reticulata,Shuttlw.exChasm. Fl.S.U.St.15.-Florida rhombifolia, Griseb. Cat. Pl. Cub. 3,-Ind, occ.

secundiflora, Shuttlw. ex Chapm. Fl. S. U. St. 15 = pygmaea.

triloba, Dun. Monog. Anon. 83.--Am. bor.

ASIPHONIA, Griff. in Trans, Linn. Soc. xix, (1845) 333. t. $37=$ Bragantia, Lour. (Aristoloch.).

piperiformis, Griff. 1. c. = B. corymbosa.

ASKIDIOSPERMA, Stend. in Flora, xxxiii. (1850) 229, nomen; et Syn. Pl. Cyp. ii. 257 (1855). RESTIACEAE, Benth. \& Hook. f. iii. 1032

capitatum, Steud. $l l . c c .-$ Afr. austr.

ASKOFAKE, Rafin. FI, Tellur. iv. 108 (1836)= Utricularia, Linn. (Lentib.)

recurva, Rafin. $1, \mathrm{c}_{\mathrm{a}}=\mathrm{U}$. recurva.
ASKOLAME, Rafin. F1. Tellur. ii. $11(1836)=$ Milla,

Cav. (Liliac.)

biflora, Rafin. 1. c. $12=$ M. biflora

ASPALATHUS, Linn. Sp. P1. 711 (1753). LEGU.

MINOSAE, Benth. \& Hook. f. i. 478.

Acropodium, Desv, in Ann. Sc. Nat. ix. (1826) 408.

CYPHOCALYX, HeTEROLATHU, LAPASANTHUS,

Pachy Raphea, Paraspalathus, Plagiostigma,

Psilolepus, Streptosema, et Trincuria, Presl,

in Abh. Boehm. Ges. Wiss. Folge V. iii. 556-562

(Bot. Bemerk. 126-132 (1844)

Diallosperma, Rafin. Sylva Tellur. 69, (1838).

ERIOCYlax, Neck. Elem. iii, 25 (1790)

Nefrakis, Rafin. Sylva Tellur. 69 (1838).

Sarcocalyx, Walp. in Linnaea, xiii. (1839) 479.

SARCOPHYLlUS, Thunb. in Schrad. Journ. i. (1799) 323.

Scaligera, Adans. Fam. ii. 373 (1763).

Semetor, Rafin. Sylva Tellur. 69 (1838)

abietina, E. Mey. Comm. Pl. Afr. Austr. 48 = aciphylla.

abietina, Thunb. Prod. Pl. Cap. 128.-Afr. austr.

acanthes, Eckl. E Zeyh. Enum 215. -Afr. austr

acanthophylla, Eckl. \& Zeyh. L. c. $221=$ Chamissonis.

acicularis, E. Mey. Comm. Pl. Afr. Austr. 46.-Afr. austr.

aciphylla, Harv. in Harv. E' Sond. Fl. Cap. ii. 129.Afr. austr.

aculeata, Thunb. Prod. Pl. Cap. 128.-Afr. austr.

aculeata, Willd. ex Walp. in Linnaea, xiii. (1839) 486

$=$ tridentata.

acuminata, Lam. Encyc. i. 287.-Afr. austr

acuminata, Thunb. Prod. Pl. Cap. 125 = ambigua.

adelphea, Eckl. E Zeyh. Enum. 212.-Afr。 austr.

adscendens, Steud. Nom. ed. II. i. 147=elongata.

aemula, E. Mey. Comm. Pl. Afr. Austr.42.-Afr. austr.

affinis, Eckl. \& Zeyh. Enum. 212 = microdon.

affinis, E. Mey. Comm. Pl. Afr. Austr. $60=$ pinguis.

affinis, Thunb. Prod. Pl. Cap. 127.-Afr. austr.

Agardhiana, DC. Prod. ii. 143.-Afr. austr.

albanensis, Eck1. \& Zeyh. Enum. $211=$ frankenioides.

albens, E. Mey. ex Benth. in Hook. Lond. Journ. Bot. vii. (1848) $648=$ exilis

albens, Linn. Mant. ii. 261; Thunb. Prod. Pl. Cap. 126.-Afr, austr.

albens, Willd. ex Walp. in Linnaea, xiii. (1839) $499=$ armata.

albiflora, Eckl. \& Zeyh. Enum. 207=thymifolia.

alopecuroides, E. Mey. Comm. Pl. Afr. Austr. $52=$ setacea.

Alopecurus, Burch. ex Benth. in Hook. Lond. Fourn. Bot. vii. (1848) 628, (err. typ. 618).-Afr. austr. alpina, Eckl. \& Zeyh. Enum. $218=$ rubro-fusca.

alternifolia, Harv, in Harv. \& Sond. Fl. Cap, ii. 141 -Afr. austr.

alternifolia, Spreng. Syst. iii. 187.-Afr。 austr.

ambigua, DC. Prod. ii. 143.-Afr. austr.

angustissima, E. Mey. Comm. Pl. Afr. Austr. 44.Afr. austr.

anthylloides, Berg. Desc. PI. Cap. $211=$ lotoides.

anthylloides, Linn. Sp. Pl. ed. II. 1002.-Afr. austr.

appendiculata, E Mey. in Linnaea, vii. (1832) $157=$ ciliaris

arachnoidea, Otto, ex Steud. Nom. ed. II. i. 147, $149=$ setacea.

arachnoidea, Walp. in Linnaea, xiii. (1839) 497.Afr. austr.

araneosa, Linn. Sp. Pl. 712.-Afr. austr.

arborea, Lour. Fl. Cochinch, 431.-Cochinch.

argentea, Eckl. \& Zeyh. Enum. $203=$ aemula

argentea, Linn. Sp. Pl. 713.-Afr. austr.

argentea, T. F. Gmel. Syst. $1093=$ sericea.

argyraea, DC. Prod. ii, 139.-Afr. austr.

arida, E. Mey. in Linnaea, vii. (1832) 156.-Afr. austr.

armata, Thunb. Prod. Pl. Cap. 126.-Afr. austr.

ascendens, E. Mey. Comm. P1. Afr. Austr. $41=$ elongata.

asparagoides, Linn.f. Suppl. 321.-Afr. austr.

astroides, Willd. ex Walp. in Limnaea, xiii. (1839) $503=$ racemosa.

astroites, Linn. Sp. Pl. 711.-Afr. austr.

astroites, Thunb. Prod. Pl. Cap. $128=$ racemosa.

aulonogena, Eckl. \& Zeyh. Enum. 216= ciliaris.

batodes, Eckl, \& Zeyh. 1. c. $215=$ aciphylla,

Benthamii, Harv. in Harv. E Sond. Fl. Cap. ii. 111 -Afr. austr.
ASPALATHUS:-

bicolor, Eckl. \& Zeyh. Enum. $205=$ retroflexa

biflora, E. Mey. Comm. Pl. Afr. Austr. $64=$ pedunculat

bracteata, Thunb. Prod. Pl. Cap. 128.-Afr. austr.

Burchelliana, Benth. in Hook. Lond. Fourn. Bot. vii.

1848) 623.-Afr. austr.

calcarata, Harv. in Harv. E Sond. Fl. Cap. ii. 116. -Afr. austr.

callosa, Linn. Sp. Pl. 713.-Afr. austr.

callosa, Sims, Bot. Mag. t. $2329=$ araneosa

canaliculata, E. Mey. Comm. PI. Afr. Austr. $44=$ stenophylla.

candicans, Ait. Hort. Kew. ed. II. iv. 264.-Afr. austr. canescens, Linn. Mant. ii. 262,-Afr. austr.

capillaris, Benth. in Hook. Lond. Fourn. Bot. vii. (1848) 653.-Afr. austr.

capitata, Linn.Pl. Afr. Rar. 14 ; Amoen. Acad. vi. 92 -Afr. austr.

capitella, Burch. ex Benth. in Hook. Lond. Journ. Bot.

vii. (1848) $597=$ inops.

carmaënsis, Eckl. \& Zeyh. Enum. 1404=thymifolia.

carnosa, Berg. Descr. Pl. Cap. 206.-Afr. austr.

carnosa, Eckl. \& Zeyh. Enum. 220= pachyloba.

carnosa, Linn. Mant. 261 = sarcantha.

Cephalotes, Benth. in Hook. Lond. Joum. Bot. vii.

1848) $615=$ Forbesii.

Cephalotes, Thunb. Prod. Pl. Cap. 126.-Afr. austr.

cerrhantha, Eckl. \& Zeyh. Enum. $208=$ spicata.

Chamissonis, Vog. in Linnaea, x. (1835-36) 597.Afr. austr.

Chenopoda, Linn.Sp. Pl.711.--Afr. austr.

chortophila, Eckl. \& Zeyh. Enum. 211 = frankenioides.

ciliaris, Sims, Bot. Mag. t. $2233=$ A. Chenopoda.

ciliaris, Linn. Mant. 262.-Afr. austr.

cinerascens, E. Mey. Comm. Pl. Afr. Austr. 54.-Afr. austr.

cinerea, Thunb. Prod. Pl. Cap. $125=$ cytisoides.

coerulescens, E. Mey, Comm. Pl. Afr. Austr. 54= Lebeckia microphylla.

cognata, Presl, Bot. Bemerk. $126=$ corymbosa

collina, Eckl. E Zeyh. Enum.220.-Afr. austr.

comosa, Eckl. \& Zeyh. 1. c. $209=$ A. Alopecurus.

comosa, E. Mey, Comm. Pl. Afr. Austr. $56=$ Benthamii.

comosa, Thunb. Prod. Pl. Cap. 126.-Afr. austr

comosa, Willd. ex Walp. in Linnaea, xiii. (1839) $490=$ capitata.

conferta, Benth. in Hook. Lond. Journ. Bot. vii. (1848) $596=$ exigua.

corrudaefolia, Berg. Descr. Pl. Cap. $207=$ genistoides, pungens.

corrudaefolia, DC. Prod. ii. $139=$ rigescens.

corymbosa, E. Mey. in Linnaea, vii. (1832) 159.-Afr. austr.

costulata, Benth. in Hook. Lond. Fourn. Bot. vii. (1848) 641.-Afr. austr.

crassifolia, Andr. Bot. Rep. t. 351.-Afr. austr.

cretica, Linn. Sp. Pl. $712=$ Anthyllis Hermanniae

cuneata, D. Don, Prod. Fl. Nep. $246=$ Lespedeza sericea.

cuneata, E. Mey. Comm. Pl. Afr. Austr. 37.-Afr. austr.

cymbaeformis, DC. Prod. ii. $140=$ uniflora.

cytisoides, Lam. Encyc. i. 292.-Afr. austr.

dasyantha, Eckl. E Zeyh. Enum. 201.-Afr. austr.

deciduifolia, Eckl. \& Zeyh. 1. c. $210=$ nigra.

densifolia, Benth. in Hook. Lond. Fourn. Bots vi (1848) 632 -Afr austr.

diffusa, Eckl. E Zeyh. Enum. 208.-Afr. austr.

divaricata, Thunb. Prod. Pl. Cap. 128.-Afr. austr.

divergens, E. Mey. Comm. Pl. Afr. Austr. $45=$ praec.

divergens, Willd. ex Walp. in Linnaea, xiii. (1839) $493=$ microphylla

Dorycnium, Lam. Encyc. i. $290=$ Dorycnium suffruticosum.

Dregeana, Walp. in Linnaea, xiii. (1839) $486=$ incurva.

dubia, E. Mey, in Linnaea, vii. (1832) $157=$ ciliaris. dubia, Willd. ex Walp. in Linnaea, xiii. (1839) $504=$ Amphithalea ericaefolia

Ebenus, Linn. Syst. ed. X. 1158=Brya Ebenus.

echinata, E. Mey. Comm. Pl. Afr. Austr. $51=$ rigescens.

echinata, St. Lag. in Ann. Soc. Bot. Lyon, vii. (1880) $119=$ A. Hystrix

Ecklonis, Vog. ex Walp. in Linnaea, xiii. (1839) $489=$ ciliaris. 


\section{ASPALATHUS}

elongata, Eckl. E\% Zeyh. Enum. 202.-Afr. austr. elongata, E. Mey. Comm. Pl. Afr. Austr. $63=$ incurva, ericaefolia, Berg. Desc. Pl. Cap. $205=$ uniflora ericifolia, Linn. $S p, P l$. 711 .-Afr. austr.

ericaefolia, Willd. ex Walp. in Linnaea, xiii. (1839) $495=$ thymifolia.

evicoides, E. Mey. in Linnaea, vii. (1832) $160=$ ericifolia.

erinacea, Lam. Encyc. i. 291.-Afr. austr.

eriophylla, Walp. in Linnaea, xiii. (1839) 499.-Afr. austr.

erythrodes, Eckl. Eo Zeyh. Enum. 200.-Afr. austr exigua, Benth. in Hook. Lond. Journ. Bot. vii. (1848) $597=$ marginata

exigua, Eckl. Er Zeyh. Enum, 198.-Afr. austr.

exilis, Harv. in Harv. $\xi^{\circ}$ Sond. Fl. Cap. ii. 136.Alr. austr.

falcata, Benth. in Hook. Lond. Fourn. Bot. vii. (1848) 655.-Afr, austr.

ferox, Harv. in Harv. \& Sond. Fl. Cap. ii. 138.Afr. austr.

ferruginea, Banks, ex Benth. in Hook. Lond. Fourn. Bot. vii. (1848) 607.-Afr. austr.

filicaulis, Eckl. E Zeyh. Enum. 204.Afr. austr.

filifolia, E. Mey. in Linnaea, vii. (1832) $158=$ abietina.

favescens, Presl, Bot. Bemerk. $126=$ spinosa

flexuosa, Thunb. Prod. PL. Cap. $127=$ mollis

Aexuosa, Willd. ex Walp. in Linnaea, xiii. (1839) 495 $=$ ericifolia

floribunda, Benth. in Hook. Lond. Fourn. Bot. vii. 1848) 636.-Afr. austr.

Forbesii, Harv. in Harv. \& Sond. Fl. Cap. ii. 114.Afr. austr.

fornicata, Benth. in Hook. Lond. Fourn. Bot. vii. 1848) 646.-Afr, austr.

frankenioides, DC. Prod. ii. 139.-Afr. austr.

frankenioides, Eckl. \& Zeyh. Enum. 207=thymifolia.

frutescens, Vog. ex Walp. in Linnaea, xiii. (1839) 487 = pinea.

fusca, Thunb. Prod. Pl. Cap. 125 ; F1. Cap. ed. Schult. $574=$ callosa

galeata, E. Mey. Comm. Pl. Afr. Austr. 49.-Afr. austr.

galioides, Berg. Desc. Pl. Cap. $210=$ retroflexa.

galioides, Linn. Mant. ii. 260; Thunb. Diss. Aspal.

19.-Afr, austr.

galioides, Sieber, ex Walp. in Linnaea, xiii. (1839) 502 = divaricata.

galioides, Willd. ex Walp. 1. c. 493,502=pedunculata, garipensis, E. Mey. Comm. Pl. Afr. Austr. 44.-Afr. anstr.

genistoides, Eckl. \& Zeyh. Enum. $21.5=$ laricifolia. genistoides, Linn. Mant. 261.-Afr. austr.

genistoides, Thunb. Prod. Pl. Cap. $128=$ pungens.

Gillii, Benth. in Hook. Lond. Journ. Bot. vii. (1848) $627=$ setacea

glauca, Eckl. \& Zcyh. Enum. $221=$ obtusata.

globosa, Andr. Bot. Rep. t. 510.-Afr. austr.

globosa, Hort. ex Steud. Nom. ed. II. i. $148=$ nigra.

globosa, Eckl. \& Zeyh. Enum. $209=$ spicata.

globulosa, E. Mey. in Linnaea, vii. (1832) $159=$ nigra.

glomerata, Benth. in Hook. Lond. Fourn. Bot. vii.

(1848) 623.-Afr. austr.

glomerata, Linn. f. Suppl. 321 = capitata.

grandiflora, Benth. in Hook. Lond. Fourn. Bot. vii. (1848) 632.-Afr. austr.

heterophylla, E. Mey. Comm. Pl. Afr. Austr. 40.-Afr. austr.

heterophylla, Linn. f. Suppl. 321 ; Thunb. Prod. Pl. Cap. $126=$ lotoides

hiaturem, Eckl. \& Zeyh. Enum, $212=$ frankenioides.

hilaris, Lckl. \& Zeyh. 1, c. $214=$ laricifolia.

hirta, E. Mey. in Linnaea, vii. (1832) 156.-Afr. austr.

hispida, Sieber, ex Presl, Bot. Bemerk. $131=$ unifora. hispida, Thunb. Prod, Pl. Cap. $127=$ thymifolia.

holosericen, E. Mey. Comm. Pl. Afr. Austr. 37 Bucheuroedera holosericea.

horrida, Eckl. \& Zeyh. Enum. $221=$ spinosa.

Hystrix, Eckl. \& Zeyh. 1. c. $219=$ Willelenowinna.

Hystrix, Linn. f. Suppl. 322.-Afr. auste.

incomta, E. Mey. ex Benth, in Hook. Lond. Journ. Bot. vii. $(18 \pm 8) 643=$ lactea.

incomta, Thunb. Prod. Pl. Cap. 127.-Afr. austr.

incurva, Eckl. \& Zeyh. Enum. 208= comosa.

incurva, Thunb. Prod. Pl. Cap. 127.-Afr. austr.

\section{ASPALATHUS :}

incurvifolia, Vog. ex Walp. in Linnaea, xiii. (1839)

497.-Afr, austr.

indica, Linn. Sp. Pl. $712=$ Indigofera aspalathoides.

iniquua, Eckl. \& Zeyh. Enum. $212=$ adelphea

inops, Eckl. E Zeyh. l. c. 197.-Afr. austr.

intermedia, Eckl. \& Zeyh. 1. c. 211 = frankenioides

involucrata, E. Mey. Comm, PI. Afr. Austr. $38=$ undulata.

involucrata, Pappe, ex Harv. \& Sond. Fl. Cap. ii. 11 =nigra

Jacobaea, E. Mey. Comm. Pl. Afr. Austr. 41.-Afr. austr.

Foubertiana, Eckl. \& Zeyh. Enum, $214=$ canescens. juniperina, Thunb. Prod. Pl. Cap. $128=$ galioides. kannaënsis, Eckl. \& Zeyh. Enum. 207=ericifolia.

Kraussiana, Meissn. in Hook. Lond. Joum. Bot. ii. (1848) $69=$ anthylloides.

lactea, Thunb. Prod. Pl. Cap. 127.-Afr austr

lanata, E. Mey. Comm. Pl. Afr. Austr, 64.-Afr. austr

lanceolata, E. Mey. l. c. 37.-Afr. austr.

laricifolia, Berg. Desc. Pl. Cap. 204.-Afr. austr

laricifolia, Lam. Encyc. i. $287=$ leptophylla.

laricina, DC, Prod. ii. 141 = laricifolia.

laricina, Steud. Nom. ed. II. i. $149=$ tridentata.

laxata, Linn. Mant. 263.-Afr. austr.

lepida, E. Mey. Comm. Pl. Afr. Austr. 58.-Afr. austr.

leptocoma, Eckl. \& Zeyh. Enum. 205= divaricata.

leptophylla, Eckl. E Zeyh. l. c. 219.-Afr. austr.

leptothria, Eckl. \& Zeyh. 1. c. $213=$ frankenioides.

leucocephala, E. Mey. Comm. Pl. Afr. Austr. $41=$ virgata.

leucophaea, Harv. in Harv. E Sond. Fl. Cap. ii. 112. -Afr. austr.

linearifolia, De. Prod. ii. 142.-Afr. austr

linifolia, E. Mey, in Linnaea, vii. (1832) $162=$ lineari folia.

linifolia, Steud. in Flora, xiii. (1830) $543=$ heterophylla.

longifolia, Benth. in Hook. Lond. Fourn. Bot. vii. (1848) 624-Afr. austr.

longipes, Harv. in Harv. E Sond. Fl. Cap. ii. 141.Afr. austr.

lotoides, E. Mey. Comm. Pl. Afr. Austr. $42=$ Meyeri. lotoides, Thunb. Prod. Pl. Cap.126.-Afr. austr.

lotoides, Willd. ex Walp. in Linnaea, xiil. (1839) 486, $503=$ tridentata

macrantha, Harv. in Harv. \& Sond. Fl. Cap. ii. 117.Afr. austr.

macrocarpa, Eckl. E Zeyh. Enum. 203.-Afr. austr macrosepala, Steud. Nom. ed. II. i, 149.-Afr, austr. marginalis, Eckl. E Zeyh. Enum. 213.-Afr. austr. marginata, Harv. in Harv. E' Sond. Fl. Cap. ii. 103. Afr. austr.

melanoides, Eckl. \& Zeyh. Enum. $210=$ nigra.

Meyeri, Harv. in Harv. E Sond. Fl. Cap. ii. 106.-Afr austr.

Meyeriana, Eckl. \& Zeyh. Enum. $218=$ cilliaris.

micrantha, E. Mey. in Linnaea, vii. (1832) $161=$ thymifolia.

microcarpa, Burch.ex DC. Prod. ii. 139.-Afr. austr.

microdon, Benth. in Hook. Lond. Fourn. Bot. vii.

1848) 642.-Afr. austr.

microphylla, DC. Prod. ii. 143 = divaricata.

microphylla, Steud, in Flora, xiii. (1830) II. 545.-Afr. ansir.

minutifolia, Vog. ex Walp. in Linnaea, xiii. (1889) $500=$ pinguis

mollis, Lam. Encyc. i. 290,-Afr. austr

mucronata, Linn. f. Suppl. $320=$ Viborgia armata. multiflora, Thunb. Prod. Pl. Cap. 128=thymifolia

multiflora, Sieber, ex Walp. in Linnaea, xiii. (1839) $495=$ ericifolia.

Mundiana, Eckl. \& Zeyh. Enum. $220=$ verrucosa. muraltioides, Eckl. \& Zeyh. 1. c. $209=$ mollis. myrtillifolia, Benth. in Hook. Lond. Fourn. Bot. vii. (1848) 597-Afr. austr.

neanthes, Eckl. \& Zeyh. Enum. $218=$ canescens,

nervosa, E. Mey. Comm. Pl. Afr. Austr. 62.-Afr. austr.

nigra, Linn. Mant. 262.-Afr. austr.

nigrescens, E. Mey, in Linnaen, vii. (1Ł82) $159=$ nigra.

nivea, Thunb. Prod. Pl. Cap. 126.-Afr. austr.

nivea, Willd. ex Walp. in Limaca, xiii. (1539) $486=$ purpurea.

nodosa, Vog. ex Walp. l. c. 496.-Afr, austr.

\section{ASPALATHUS:}

nudiflora, Harv. in Harv. \& Sond. Fl. Cap. ii. 140.Afr. austr.

obtusata, Thunb. Prod. Pl. Cap. 125.-Afr, austr. opaca, Eckl. \& Zeyh. Enum. 217.-Afr. austr. orbiculata, Benth. in Hook. Lond. Fourn. Bot. 1848) 595.-Afr, austr.

oresigena, Eckl. \& Zeyh. Enum. 217 = ciliaris. orientalis, Linn. Mant.263.-Oriens.

pachyloba, Benth. in Hook. Lond. Fourn. Bot. vit. (1848) 638.-Afr. austr.

pallens, Eck1. \& Zeyh. Enum. $210=$ nigra.

pallescens, Eckl. \& Zeyh. l. c. 218.-Afr, austr

papillosa, Eckl. \& Zeyb. 1. c. $217=$ ciliaris.

Pappeana, Harv. in Harv. E Sond. Fl. Cap. ii, 117.

Afr. austr.

parviflora, Berg. Desc. Pl. Cap. 208; Thunb. Prod. Pl. Cap. 122.-Afr. austr.

pedicellata, Harv. in Harv. E Sond. Fl. Cap. ii. 135 -Afr. austr.

pedunculata, E. Mey. ex Walp. Ann. ii. $338=$ bracteata, capillaris.

pedunculata, L'Hérit. Sert. Angl. t. 26.-Afr, austr.

persica, Burm. f. F1. Ind. $155=$ Lotus Garcini.

pilosa, Eckl. \& Zeyh. Enum. 202 =tridentata.

pilosa, Linn. Mant. 263.-Afr. austr.

pilosa, Sieber, ex Walp. in Linnaea, xiii. (1839) 488

pinea, Thunb. Prod. Pl. Cap. 128.-Afr. austr.

pinguis, Eckl. \& Zcyh. Enum. $220=$ arida.

pinguis, E. Mey. Comm. Pl. Afr. Austr. $60=$ affinis.

pinguis, Thunb. Prod. Pl. Cap. 127.-Afr. austr.

pinnata, Linn. Pl. Rar. Afr. 14 ; Amoen. Acad. vi.92.

-Afr. austr.

Plukenetiana, Eckl. \&c Zeyh. Enum. $200=$ rugosa.

poliotes, Eckl. \& Zeyh. 1. c. $213=$ frankenioides.

polyantha, Walp. in Linnaea, xiii. (1839) 485.-Afr

austr.

polycephala, E. Mey.Comm. Pl. Afr. Austr. 39.-Afr

Priori, Harv. in Harv. E Sond. Fl. Cap. it. 127.

Afr. austr.

procumbens, Eckl. E Zeyh. Enum. 202.-Afr. austr.

procumbens, E. Mey. in Linnaea, vii. (1532) 162

lotoides.

propinqua, E. Mey. Comm. Pl. Afr. Azstr. 53.-Afr.

austr.

prostrata, Eckl. E Zeyh. Enum. 206.-Afr. austr.

psoraleoides, Benth. in Hook. Lond. Fourn. Bot. vit.

(1848) 598.-Afr. austr.

pulchella, E. Mey. Comm. Pl. Afr. Austr. $38=$ Buchew

roedera tenuifolia.

pungens, Thunb. Prod. Pl. Cap. 129.-Afr. austr.

purpurascens, E. Mey. Comm. Pl. Afr. Austr. $44=$

purpurea.

purpurea, Eckl. E Zeyh. Enum. 201.-Afr. austr.

quinquefolia, Linn. Pl. Rar. Afr. 14; Amoen. Acad

vi. 92 =lotoides.

quinquefolia, Thunb. Fl. Cap. $575=$ virgata,

racemosa, E. Mey, in Linnaea, vii. (1832) 157.-Afr.

austr.

ramulosa, E. Mey. 1. c. $163=$ acmula.

recurva, Benth, in Hook. Lond. Fourn. Bot. vii. (1sts

612.-Afr, austr.

remota, Eckl. E Zeyh. Enum. 218.-Afr. austr.

retroflexa, Eckl. \& Zeyh. 1. c. $204=$ abictina

retroflexa, Linn. Sp. Pl. 712.-Afr. austr.

rigescens, E. Mey. Comm. Pl. Afr. Austr. 52,-Arr. austr.

rostrata, Benth. in Hook. Lond. Fourn. Bot. vii. (1sts

631.-Afr. austr.

rubens, Thumb. Prod. Pl. Cap, 126.-Afr. austr.

rubescens, Eckl. \& Zeyh. Enum. 218 = adelphta.

rubrofusca, Eckl. E Zeyh. l.c. 216.-Air. austr.

rugosa, Thunb. Prod. Pl. Cap. 125.-Air. austr.

sanguinea, Eckl. \& Zeyb. knum. $212=$ vermiculata.

sanguinea, Thunb. Prod. Pl. Cap. 120,-Dfro austr.

sarcautha, Vog. ex IIalp. in Limnara, xiii. (1835) ist

-Afr. austr.

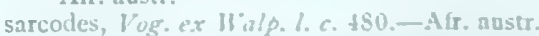

scaphoides, Eckl. \& Zey. Luum. 2U6 - unitlors

Schulliana, Presl, Bot. Bemerh. 124. - Afr. austr.

secunda, E. Mey. Comm. Pl. Afr. Austr. i. $47=$

pungens.

securifolia, Eckl. E Zovh. Ensm. 198. - Mr, austr.

sericantha, E. Acy. Comm. Il. Afr. Auser, fy =lario

folin

serices, Berg. Dess. Pl. Cap. 212.-Afr. austr. 


\section{ASPALATHUS :-}

sericea, Eckl. \& Zeyh. Enum. $202=$ Jacobaea. sericea, Lam. Encyc. i. $288=$ nivea.

sericea, Linn.f. Suppl. 321.-Afr. austr.

sericea, Thunb. Prod. Pl. Cap. $125=$ Argyrolobium obsoletum.

setacea, Eckl. E Zeyh. Enum. 216.-Afr. austr.

Simsiana, Eckl. \& Zeyh. l. c. $200=$ araneosa. spathulata Eckl \& Zeyh l c. $198=$ securifolia speciosa, Steud. in Flora, xiii. (1830) 544.-Af austr.

spicata, Thunb. Prod. Pl. Cap. 127.-Afr. austr spinescens, DC. Prod. ii. $138=$ arida.

spinescens, Eckl. \& Zeyh. Enum. $221=$ divaricata spinescens, Thunb. Prod. Pl Cap. 129-Afr. anstr. spiniftora, L'Hérit. ex Steud. Nom, ed. II. i. 107, 149 $=$ Anthyllis Hermanniae.

spinosa, Linn. Sp. Pl. ed. II. 1000.-Afr. austr.

squamosa, Thunb. Fl. Cap. ed. Schult. $581=$ pedun culata.

squarrosa, Thumb. Prod. Pl. Cap. $128=$ pednnculata.

stachyera, Eckl. \& Zeyh. Enum. 202=lotoides.

staurantha, Eckl. \& Zeyh. l. c.=argentea.

stellaris, Eckl. Er Zeyh. l. c. 197.-Afr. austr.

stenophylla, Eckl. \& Zeyh.l.c.-Afr. austr.

Steudeliana, B [rongn.] in Bull. Féruss. xxvi. (1831) $278=$ microphylla.

stricta, Steud. in Flora, xiii. (1830) II. $543=$ elongata.

suaveolens, Eckl. Eo Zeyh. Enum. 199.-Afr. austr.

subinermis, Benth. in Hook. Lond. Fourn. Bot. vii.

1848) 643.-Afr. austr.

subtingens, Eckl. \& Zeyh. Enum, 212=adelphea.

subulata, Thunb. Prod. Pl. Cap. 128.-Afr austr.

succulenta, E. Mey. in Linnaea, vii. (1832) $159=$

verrucosa.

suffruticosa, DC. Prod. ii. 144.-Afr. austr

sulcata, Vog. ex Walp. in Linnaea, xiii. (1839) $490=$ erythrodes.

tenuifolia, DC. Prod. ii. 143.-Afr. austr.

teres, Eckl. E' Zeyh. Enum. 215.-Afr, austr

thymifolia, Lam. Encyc. i. $288=$ canescens.

thymifolia, Linn. Sp. Pl.711.-Afr. austr.

thymifolia, Thunb. Prod, P1. Cap. 127=comosa.

tomentosa, E. Mey. Comm. Pl. Afr. Austr. $55=$ frankenioides.

trichodes, E. Mey. 1. c. $38=$ Buchenroedera trichodes.

tridentata, Berg. ex Walp. in Linnaea, xiii. (1839) 482 $=$ pilosa.

tridentata, Eckl. \& Zeyh. Enum. $201=$ ferruginea.

tridentata, Linn. Sp.Pl. 712.-Afr. austr.

trigona, Thunb. Prod.Pl.Cap. 128.-Afr, austr

triquetra, Thunb. l. c. 127.-Afr. austr.

truncata, ${ }^{2 E}$ ckl. E' Zeyh. Enum. 197.-Afr. austr.

tuberculata, Walp. in Linnaea, xiii. (1839) 497.-Afr. austr.

tylodes, Eck1. \& Zeyh. Enum. $200=$ callosa

ulicina, Eckl. \& Zeyh. l. c. 205.-Afr. austr.

undulata, Eckl. E Zeyh. l. c. 199.-Afr, austr.

uniflora, Eckl. \& Zeyh. 1. c. $219=$ macrantha.

uniflora, Linn. Sp. Pl. 712.-Afr, austr

uniflora, Thunb. Diss. Aspal. $20 \equiv$ Willdenowiana.

warians, Eckl. \& Zeyh. Enum. $209=$ ericifolia.

variegata, Eckl. छ Zeyh. l. c. 201.-Afr. austr.

venosa, E. Mey. Comm.Pl. Afr. Austr. 39.-Afr. austr.

vermiculata, Lam. Encyc, i. 288.-Afr. austr.

verrucosa, Eckl. \& Zeyh. Enum. $220=$ tuberculata.

verrucosa, $\operatorname{Linn}$. Sp. Pl. 712.-Afr. austr.

verrucosa, Willd. ex Walp. in Linnaea, xiii. (1839) 486 =Willdenowiana.

versicolor, E. Mey. Comm. PI. Afr. Austr. $48=$ collina.

villosa, Thunb. Prod. Pl. Cap. 125.-Afr, austr

viminea, E. Mey. Comm. Pl. Afr. Austr. $38=$ Buchen-

roedera viminea.

virgata, Thunb. Prod. Pl. Cap. 126.-Afr. austr.

volvularis, Noronha, in Verh. Batav. Gen. v. (1790) ed. I. Art. IV. 7.-Malaya.

vulnerans, Benth. in Hook. Lond. Journ. Bot. vii. (1848) $621=$ hirta.

vulnerans, Thunb. Prod. Pl. Cap. 128.-Afr. austr.

Willdenowiana, Benth. in Hook. Lond. Fourn. Bot, vii. (1848) 630 - Afr, austr.

Wurmbeana, E.Mey.Comm. Pl. Afr. Austr. 58.-Afr. austr.

ASPALATUS, St. Hil. in Dict. Sc. Nat. iii. 211 (1804) = Aspalathus, Linn. (Legum.).
ASPALTHIUM, Medic. Phil. Bot. i. $211(1789)=$ AS

PHALTHIUM, Medic.$=$ Psoralea, Linn. (Legum.)

ASPARAGOPSIS, Kunth, in Abh. Akad. Berl. (1842)

$35=$ Asparagus, Tourn. (Liliac.).

abyssinica, Kunth, Enum. Pl. v. $101=$ Asparagus racemosus.

acerosa, Kunth, 1. c. 102=Asparagus acerosus. adscendens, Kunth, 1. c. = Asparagus adscendens. aethiopica, Kunth, 1. c. $95=$ Asparagus aethiopicus. alba, Kunth, 1. c. $84=$ Asparagus albus.

arborescens, Kunth, 1. c. $79=$ Asparagus arborescens, ascendens, Baker, in Journ. Linn. Soc. xiv. (1875) 62

= Asparagus adscendens.

Brownei, Kunth, Enum. Pl. v. 103 = Asparagus racemosus.

consanguinea, Kunth, 1. c. $76=$ Asparagus consangui neus

Curilla, Kunth, 1. c. $102=$ Asparagus Curillus. Decaisnei, Kunth, 1. c. $103=$ Asparagus racemosus. decumbens, Kunth, 1. c. $77=$ Asparagus crispus. densiflora, Kunth, 1. c. $96=$ Asparagus sarmentosus, denudata, Kunth, 1. c. $82=$ Asparagus denudatus. Dregii, Kunth, 1. c. $84=$ Asparagus Thunbergianus flagellaris, Kunth, 1. c. $103=$ Asparagus flagellaris floribunda, Kunth, 1. c. $98=$ Asparagus racemosus. grandiflora, Kunth, 1. c. $80=$ Asparagus umbellatus.

Hohenackerii, Kunth, 1. c. $100=$ Asparagus race mosus.

humilis, Hassk. in Versl, en Med. Akad. Wetensch. v. 1857) 93.-Japon.

javanica, Kunth, Enum. Pl. v. $100=$ Asparagus racemosus.

juniperina, Kunth, 1. c. $85=$ Asparagus africanus. Krebsiana, Kunth, 1. c. $93=$ Asparagus racemosus. Lamarckii, Kunth, I. c. $87=$ Asparagus africanus. lancea, Kunth, 1. c. 104=Asparagus sarmentosus, Lowei, Baker, in Journ. Linn. Soc. xiv. (1875) 611

Asparagus umbellatus.

microrhaphis, Kunth, Enum. Pl.v. $83=$ Asparagus microrhaphis.

minutiflora, Kunth, 1. c. $89=$ Asparagus minutiflorus. Niveniana, Kunth, 1. c. $88=$ Asparagus africanus. passerinoides, Kunth, l. c. $90=$ Asparagus capensis.

retrofracta, Kunth, 1. c. $88=$ Asparagus retrofractus.

retrofracta, Schweinf, ex Baker, in Journ. Linn. Soc.

xiv. (1875) $623=$ Asparagus racemosus

rubricaulis, Kunth, Enum. $\mathrm{Pl} . \mathrm{v} \cdot 87^{\circ}=$ Asparagus rubricaulis.

sarmentosa, Dalz. \& Gibs. Bomb. F1. $246=$ Asparagus racemosus.

sarmentosa, Kunth, Enum. Pl. v. $97=$ Asparagus sarmentosus.

scandens, Kunth, 1. c. $78=$ Asparagus scandens.

Schlechtendalii, Kunth, 1. c. $90=$ Asparagus Thunbergianus.

scoparia, Kunth, 1. c. $80=$ Asparagus asiaticus. setacea, Kunth, 1. c. $82=$ Asparagus declinatus.

sinica, Miq. in Journ. Bot. Néerl. i. (1861) $90(=$ Asparagus lucidus?).-Hongkong.

spinescens, Kunth, Enum. P1. v. $93=$ Asparagus stipulaceus.

stipulacea, Kunth, 1. c. 91 = Asparagus stipulaceus, suaveolens, Baker, in Journ. Linn. Soc. xiv. (1875) 617 $=$ Asparagus suaveolens.

subquadrangularis, Kunth, Enum. Pl. v, $94=$ Asparagus racemosus.

Thunbergii, Kunth, 1. c. $85=$ Asparagus Thubergianus

triacantha, Kunth, 1. c. $91=$ Asparagus stipulaceus, umbellata, Kunth, 1. c. $79=$ Asparagus umbellatus. umbellulata, Kunth, 1. c. $81=$ Asparagus umbellulatus. Willdenowii, Konth, 1. c. $86=$ Asparagus asiaticus

Zeyheri, Kunth, l. c. $92=$ Asparagus stipulaceus

ASPARAGUS, Tourn. ex Linn. Syst. ed. I. (1735) Gen. ed. I. $93(1737)$. LILIACEAE, Benth. \& Hook. f. iii. 765 .

Asparagopsis, Kunth, in Abh. Akad. Berl. (1842) 35 .

ELIDE, Medic Phil Bot ii 71 (1791).

Hecatris, Salisb. Gen. Pl. Fragm, 66 (1866)

Myrsiphyllum, Willd. in Ges. Naturf. Fr. Berl Mag. ii. (1808) 25.

abyssinicus, Hochst. ex A. Rich. Tent. Fl. Abyss. ii 319.-Abyssin.

abyssinicus, Schweinf. ex Baker, in Journ. Linn. Soc. xiv. (1875) $616=$ Schweinfurthii.

\section{ASPARAGUS :}

cerosus, Roxb. Hort. Beng. 24; Fl. Ind. ii. 150Ind. or. ; Burma.

acerosus, Thunb. ex Schult. f. Syst. vii. 337.-Afr. austr.

acutifolius, Linn. Sp. Pl. 314.-Reg. Mediterr

adscendens, Roxb. Hort. Beng. 24 ; Fl. Ind. ii. 153.-

Reg. Himal. ; Afghan.

aethiopicus, Linn. Mant. 1.-Afr. austr.

aetnensis, Tornab. in Atti Acc. Gioenia, Ser. II. xii. 1856) $345=$ acutifolius

africanus, Lam. Encyc. i. 295.-Afr. austr.

Agul, Forsk. Fl. Aegypt. Arab. p. Ixv. ex Schult.f. Syst. vii. 337.-Arabia.

albus, Linn. Sp. Pl. 313.-Reg. Mediterr, occ

albus, Thunb. Prod. Pl. Cap, $66=$ Thunbergianus.

altilis, Aschers, Fl, Brandenb. $730=$ officinalis.

altissimus, Munby, in Bull. Soc. Bot. Fr, ii. (1855) 287.-Algeria.

amarus, DC. Cat Hort. Monsp. $81=$ scaber

ambiguus, De Not. Rep. Fl. Lig. $401=$ acutifolius.

angolensis, Baker, in Trans. Linn. Soc. Ser. II.

(1878) 254,-Afr. trop.

aphyllus, Linn. Sp.Pl. 314.-Reg Mediterr.

arborescens, Willd. ex Schult. f. Syst. vii, 337.-Ins, Teneriffa.

ascendens, Auot. vide adscendens.

asiaticus, Linn. Sp. Pl. 313.-Ind. or.; Afr, trop. et austr.

asiaticus, Wight, Ic. t, $2055=$ subalatus.

benguellensis, Baker, in Trans. Linn. Soc. Ser. II."i (1878) 253.-Angola.

brachyphyllus, Turcz. in Bull. Soc. Nat. Mosc. (1840)

78.-Reg. Danub.; Soongaria; Afghan.

Breslerianus, Schult. f. Syst. vii. $323=$ maritimus.

brevifolius, Boiss. ex Baker, in Fourn. Linn. Soc. xiv. (1875) 602.-Lycia.

brevifolius, Tornab. in Atti Acc. Gioenia, Ser. II. xii (1856) $359=$ acutifolius.

Broussonetii, Facq. Eclog. 3. t. 40.-Afr. bor.

Burchellii, Baker, in fourn. Linn. Soc. xiv. (1875) 618.-Afr. austr.

Burkei, Baker, l. c. 607.-Afr. austr.

Buxbaumius, Gueldenst. ex Ledeb. F1. Ross, iv. $199=$ verticillatus.

capensis, Linn. Sp. Pl. 314.-Afr, austr.

capitatus, Baker, in fourn. Linn. Soc. xiv. (1875) 607. -Ind. bor. occ.; Beluchist.

caspius, Hohen. Enum. Pl. Talusch. $24=$ officinalis.

caspius, Hort. Vind. ex Schult. f. Syst. vii. 322,-

Reg. Casp.

Chesneyi, Baker, in Journ. Linn. Soc. xiv. (1875) 603 = filifolius.

collinus, Jan, ex Parl. Fl. Ital. iii. $14=$ tenuifolius. collinus, Schur, in Oestr. Bot. Zeitschr. X. (1860) 355 $=$ officinalis.

commutatus, Tenore, Fl. Nap. iii. $374=$ acutifolius

consanguineus, Baker, in fourn. Linn. Soc. xiv. (1875)

615. - Afr, austr.

Cooperi, Baker, in Gard. Chron. (1874) 1. 818.-Afr austr.

Corruda, Scop. Fl. Carn. ed. II. 1, $248=$ acutifolius.

crispus, Boj. Hort. Maurit. $350=$ umbellulatus.

crispus, Lam. Encyc. i. 295. - Afr, austr

Curillus, Buch.-Ham. ex Roxb. 24 ; Fl. Ind. ii. 152.Reg. Himal.

Curillus, Wall. Cat. n. $5155 \mathrm{E}=$ filicinus.

cuscutoides, Burch. ex Baker, in fourn. Linn. Soc. xiv. (1875) 606.-Afr, austr.

davuricus, Fisch ex Link, Enum. Hort. Berol. i. 348. - Davuria,

declinatus, Eckl. \& Zeyh. ex Baker, in Journ. Linn. Soc. xiv. (1875) $615=$ consanguineus,

declinatus, Linn. Sp. Pl. 313.-Afr. austr.

declinatus, Sieber, ex Baker, in Journ. Linn. Soc. xiv. (1875) $621=$ retrofractus.

declinatus, Schonsb. Vextr. Marok. $173=$ foeniculaceus. decumbens, Jacq. Hort. Schoenb. i. $51=$ crispus.

deflexus, Baker, in Trans. Linn. Soc. Ser. II. i. (1878) 254.-Angola.

densus, Soland. ex Baker, in fourn. Linn. Soc. xiv. (1875) 616.-Afr. austr.

denudatus, Baker, l. c. 606.-Afr. austr.

dependens, Schlecht. ex Kunth, Enum. P1. v. 85= juniperinus.

dependens, Thunb. Prod. Pl. Cap. $66=$ africanus.

dichotomus, Brouss. ex Webb \& Berth. Phyt. Canar. jii. $327=$ umbellatus, 


\section{ASPARAGUS :}

divaricatus, Rottl. ex Baker, in Journ. Linn. Soc. xiv. (1875) $618=$ asiaticus.

divaricatus, Royle, Illustr. Bot. Himal. i. 393.Ind. or.

Draco, Linn. Sp. Pl. ed. II. $451=$ Dracaena Draco.

Dregeanus, Hort.-Cf. Gard. Chron. (1877) II. 598.Afr. austr.

drepanophyllus, Welw. ex. Baker, in Trans. Linn. Soc Ser. II. 1. (1878) 254-Afr, trop.

dubius, Decne. in Nouv. Ann. Mus, Par, iii. (1834) 363 = racemosus.

dumosus, Baker, in Fourn. Linn. Soc. xiv. (1875) 608 -Sindh.

Eckloni, Baker, l. c. 615.-Afr. austr.

equisetifolius, Ledru, ex Webb \& Berth. Phyt. Canar. iii. $328=$ arborescens.

equisetoides, Welw. ex Baker, in Trans. Linn. Soc.

Ser. II, i. (1878) 253.-Angola.

erectus, Thunb. Prod. Pl. Cap. 65.-Afi, austr.

esculentus, Salisb. Prod. $252=$ officinalis.

euphraticus, Kunth, Enum. Pl.v. 73 = filifolius.

exaltatus, C. Sm. \& Buch, ex Webb \& Berth. Phyt.

Canar. iii. $326=$ scoparius.

exuvialis, Burch. Trav. i, 432.-Afr. anstr.

falcatus, Benth. in Hook. Lond. Journ. Bot. i. (1842) $493=$ lucidus

falcatus, Linn. Sp. Pl. 313.-Afr. trop. \& austr. Zeylan.

falcatus, Thunb. F1. Jap. $189=$ lncidus

fasciculatus, R. Br. Prod. $281=$ racemosus, acerosus.

fasciculatus, Thunb. Fl. Cap. ii. 329.-Afr. austr.

filicinus, Buch.-Ham. ex D. Don, Prod. Fi. Nep.49.Reg. Himal.; Burma.

filifolius, Bertol. Nov. Comm. Acad. Bonon. v. (1842) 430 (Misc, Bot. i. 20).-Mesopot.

flagellaris, Baker, in Fourn. Linn. Soc. xiv. (1875) 614.-Senegambia.

flexuosus, Thunb. Prod. Pl. Cap. $66=$ crispus,

floribundus, Rottl. ex Baker, in Journ. Linn. Soc. xiv, (1875) $611=$ Rottleri.

floribundus, Royle, Illustr. Bot. Himal. i. 393.-Ind or.

foeniculaceus, Lowe, in Fourn. Linn. Soc. v. (1864) 44 -Marocco.

fragilis, Burch. ex Baker, in Journ. Linn. Soc. xiv (1875) $606=$ denudatus

Gaudichandianus. Kunth, Enum. Pl. v. 71-Cochinch.

gibbus, Bunge, Enum. Pl. Chin. Bor. $65=$ davuricus.

glycycarpus, Kunth, Enum. Pl. v. $61=$ davuricus.

gonocladus, Baker, in Fourn. Linn. Soc. xiv. (1875) 627.-Ind. or:

gracilis, Royle, Illustr. Bot. Himal. i. 393.-Reg. Himal.

gracilis, Salisb. Prod. $252=$ asiaticus.

graminifolius, Linn. Sp. PI. ed. II. $450=$ Dracaena graminifolia.

grandiflorus, Willd. ex Webb \& Berth. Phyt. Canar. iii. $327=$ umbellatus.

Griftithii, Baker, in fourn. Linn. Soc. xiv. (1875) 604.

-Afghan.

hedecarpus, Andr. ex Baker, 1. c. 599 = caspius, officinalis.

horridus, Linn. f. Suppl. $203=$ stipularis.

horridus, Murr. Syst. ed. XIII. 274.-Hab, ?

hortensis, Mill. ex Baker, in Journ. Linn. Soc. xiv. (1875) $598=$ officinalis.

inarimensis, Tornab, in Atti Acc. Gioenia, Ser, II. xii. (1856) $368=$ acutifolius.

inderiensis, Blume, ex Ledeb. F1. Alt. ii. $44=$ maritimus.

insularis, Hance, in Ann. Sc. Nat. Sér. V. v. (1866) $215=$ lucidus.

irregularis, Baker, in Fourn. Linn. Soc. xiv. (1875) 620.-Afr, austr.

Jacquemonti, Baker, l. c. 615.-Ind. or.

Krausii, Baker, l. c. 628,-Afr. austr.

laetus, Salisb. Prod. $253=$ aethiopicus

laevissimus, Steud. ex Baker, in fourn. Linn. Soc, xiv. (1875) 623.--Ind. or.

lanceus, Thunb. Prod. Pl. Cap. 66.-Afr. austr.

laricinus, Burch. Trav. i. 537,-Afr, austr.

lignosus, Burm.f. Fl. Cap. Prod. 10.-Afr. austr.

littoralis, Stev, in Bull. Soc. Nat. Mosc. xxx. (1857) II. $92=$ scaber

longiflorus, Franch. Pl. Davidian, i. 300 -As, or

longifolius, Fisch. ex Steud. Nom. ed. II. i. 150.Sibiria.

\section{ASPARAGUS :}

Lowei, Kunth, Enum. Pl. v. 73.-Madera

Lownei, Baker, in Fourn. Linn. Soc. xiv. (1875) 601. Palaestin

lucidus, Lindl. Bot. Reg. (1844) Misc. 29.-Japon

Macowani, Baker, in fourn. Linn. Soc, xiv. (1875) 609.-Afr, austr.

madagascariensis, Baker, l.c.xvi. (1878) 206.-Madag. marinus, Reichb. Ic. Fl. Germ. t. $520=$ scaber. maritimus, Mill. Gard. Dict. ed. VIII n, 2 =scaber. maritimus, Pall. Reise, ii. 329.-Rossia; Reg. Cauc. Persia; Sibiria.

mauritianus, Lam. ex Desf. Tabl. ed. I. $20=$ declinatus.

medeoloides, Thunb. Prod. Pl. Cap. 66.-Afr. austr

micranthus, Lindl. Swan Riv. App. 58=Corynotheca dichotoma.

micranthus, Sieb. \& Zucc, ex Baker, in Journ. Linn. Soc. xiv. (1875) $604=$ schoberioide

microphyllus, Burch, ex Baker, 1. c. $619=$ africanus.

microraphis, Baker, l. c. 612.-Afr. austr.

minutiflorus, Baker, l.c. 616-Afr, austr.

mitis, A. Rich. Tent. Fl. Abyss. ii. 319,-Abyss.

monophyllus, Baker, in Fourn. Linn. Soc xiv. (1875) 604.-Beluchist.

mozambicus, Kunth, Enum. Pl. v. 72.-Afr. trop

multiflorus, Baker, in fourn. Linn. Soc. xiv. (1875) 610.-Afr. austr.

neglectus, Kar. \& Kir. in Bull. Soc. Nat. Mosc. (1841) $750=$ trichophyllus.

Nelsoni, Baker, in Fourn. Linn. Soc. xiv. (1875) 617. -Afr. austr.

nepalensis, Baker, l. c. 622.-Reg. Himal.

Nivenianus, Schult. f. Syst. vii. 331.-Afr. austr.

nodosus, Soland. ex Baker, in Fourn. Linn. Soc. xiv. 1875) 608.-Afr. austr

officinalis, Linn. Sp. Pl. 313.--Europ.; Reg. Caucas. Sibir.

aligoclonos, Maxim, Prim. Fl.Amur. 286.-Reg.Amur. oligophyllus, Baker, in Fourn. Linn. Soc. xiv. (1875) 604.-As. temp.

orientalis, Bess. Cat. Hort. Crem. (1814) - Hab.

oxyacanthus, Baker, in fourn. Linn. Soc, xiv. (1875) 625.-Afr. austr.

oxycarpus, Stev. in Bull. Soc. Nat. Mosc. $x \times x$. (1857) II. $92=$ officinalis

palaestinus, Baker, in fourn. Linn. Soc. xiv. (1875) 602:-Palaestin.

pallidus, Salisb. Prod. $252=$ albus.

paragus, Gueldenst. ex Ledeb. F1. Ross. iv. $197=$ officinalis.

parviflorus, Turcz. in Bull. Soc. Nat. Mosc. xxvii. (1854) II. 130.-Sibir. baical.

Pastorianus, Webb \& Berth. Phyt. Canar. iii. 329. t. $229=$ albus

Pauli-Guilelmi, Solms, in Schweinf. Beitr. Fl. Aethiop. 203.-Afr. trop.

pectinatus, [DC, in] Red. Lil. t. $407=$ scandens

penduliflorus, Zipp. ex Span. in Linnaea, xv. (184I)

$476=$ dubius.

persicus, Baker, in Fourn. Limn. Soc. xiv. (1875) 603 -Persia.

Petersianus, Kunth, Enum. Pl. v. 72.-Afr. trop.?

Petitianus, A. Rich. Tent. Fl. Abyss. ii. 320.-Abyss.

phyllacanthus, Lam. Encyc. i. $296=$ aphyllus.

pilosus, Baker, in Fourn. Linn. Soc. xiv. (1875) 610 - Afr. trop.

planiuscula, Burm. f. Fl. Cap. Prod. 10.-Afr. austr.

plocamoides, Webb, in Steud. Nom. ed. II. i. $150=$ scoparius.

plumosus, Baker, in Fourn. Linn. Soc. xiv. (1875) 613. -Afr. austr.

polyphyllus, Stev. ex Ledeb. Fl. Ross. iv. $1: 1=$ officinalis.

prostratus, Dum. F1. Belg. $188=$ officinalis

psilurus, Welw. ex Baker, in Trans. Linn. Soc. Ser. II i. (1878) 253.-Angola.

puberulus, Baker, in Fourn. Linn. Soc. xiv. (1875) 618.-Afr. austr.

pubescens, Baker, in Trans. Linn. Soc. Ser. II. i. (1878) 254.-Angola

purpurascens, Bicb. ex Baker, in Joum. Linn. Soc. xiv. (1875) 602 =trichophyllus.

racemosus, Willd. Sp. Pl. ii. 152.-Ind. or.; Afr. trop. Austral.

ramosissima, Baker, in Gard. Chron. (1874) 11. 6.Afr. austr.

retrofractus, Forsk. Fl. Aegypt. Arab. 73.-Arabia.

\section{ASPARAGUS}

retrofractus, Linn. Sp. Pl. 313.-Afr. austr

retrofractus, C. Sm. ex Webb \& Berth. Phyt. Canar. iii. $328=$ arborescens.

retrofractus, Schousb. Vextr. Marok. 174 (sp. dubia). -Marocco.

rivalis, Burch. ex Schult.f. Syst. vii. 337.-Afr. austr. Rottleri, Baker, in Fourn. Linn. Soc. xiv. (1875) 611 -Ind. or.

ruber, Burm. f. Fl. Cap. Prod. 10.-Afr. austr.

rubricaulis, Baker, in fourn. Linn. Soc. xiv. (1875) 616.-Ind. or.

mubicundus, Berg. Desc. P1. Cap. 88 = africanus, capensis, stipulaceus.

sarmentosus, Heyne, in Wall. Cat. n. 5154=volubilis. sarmentosus, Linn. Sp. Pl. 314.-Ind. or

sativus, Mill. Gird. Dict. ed, VIII. Add, =officinalis. scaber, Brign. Fasc. Pl. Forojul. 22.-Reg. Mediterr. Caucas.

scaber, Lowe, in Trans. Camb. Phil. Soc. iv. (1831) 11 $=$ umbellatus.

scaberulus, A. Rich. Tent. Fl. Abyss. ii. 320-Abyss,

scandens, Gueldenst. ex Ledeb. Fl. Ross. iv. 199 verticillatus.

scandens, Thunb. Prod. Pl. Cap, 66.-Afr, anstr.

schoberioides, Kunth, Enum. Pl. v. 70.-Japon.

Schweinfurthii, Baker, in Fourn. Linn. Soc. xiv. (1875 616.-Afr. trop.

coparius, Lowe, in Trans. Camb. Phil. Soc. iv. (1831, 11.-Marocco; Ins. Madera.

Sieboldii, Maxim. Prim. Fl. Amur. 287.-Tapon.

simulans, Baker, in Fourn. Linn. Soc. xiv. (1875) 609 - Madag.

sinensis, Noisset, ex Baker, 1. c. $607=$ crispus.

Smithianus, Webb, ex Steud. Nom. ed. II. i. 150, nomen. - Ins. Teneriff.

spinescens, Steud. in Schult. f. Syst. vii. 334.-Air. austr.

squarrosus, F. A. Schmidt, Beitr. Fl. Cap. Verd. Ins 165.-Ins. Cap. Verd.

stachyoides, Spreng. ex Baker, in Fourn. Linn. Soc. xiv. (1875) 624.-Afr. austr.

stellatus, Baker, l. c. 612.-Afr. austr.

stipulaceus, Lam. Encyc. i. 296.-Afr, austr.

stipularis, Forsk. Fl. Aegypt. Arab. 72.-Reg. Mediter. Ins. Canar.

striatus, Thunb. Prod. Pl. Cap. 65.-Afr. austr. suaveolens, Burch. Tray, i. 226.-Afr. austr. subalatus, Stend ex Baker, in Fourn. Linm. Soc xiv. (1875) 614 (err. subulatus). - Ind, or.

subulatus, Thunb. Prod. Pl. Cap. 66.-Afr. austr.

sylvaticus, Burch. ex Baker, in Saund. Ref. Bot. t $214=$ virgatus.

sylvaticus, Waldst. \& Kit. Pl. Rar. Hung. iii. $223=$ tenuifolius.

Tauscheri, Fisch, ex Ledeb. Fl, Alt, ii, $44=$ maritimus. tenuifolius, Gilib. Exercit. ii. $459=$ officinalis. tenuifolins, Lam. Encyc. i. 294.-Europ. austr.

terminalis, Linn. Sp. Pl. ed. II. $450=$ Cordyline terminalis.

tetragonus, Bresler, Diss, n, $15=$ racemosus.

Thunbergianus, Schult. f. Syst. vii. 333.-Afr, austr.

triacanthus, Burm. f. Fl. Cap. Prod. 10.-Afr. austr.

tricarinatus, C. Koch, in Linnaea, xxii. (1849) 266 verticillatus.

tricarinatus, [Delile, in] Red. Lil.t. 451.-Hab.?

trichophyllus, Bunge, Enums. Pl. Clins, Bor. 65.Afghan.; As, med, Chin, bor.

umbellatus, Link, in Buch, Beschr. Canar. Ins. 140.Ins. Canar.

umbellatus, Royle, Illustr. Bot. Himal, i. 393.-Ind. or. umbellulatus. Bresler. Diss. D. 24. -Ins. Maurit. umbricola, Kit. ex Kanits, Retiq. Kitaib. 121; in Verh. Zool. Bot. Ges. W"icn, xiii. (1069: 545.Europ.

undulatus, Thunb. Prod. Pl. Cap. 66.-Afr. austr. vaginellatus, Boj. ex Boker, in Y̌ourn. Linn. Soc. xiv (1875) 612.-Madas.

verticillaris, Lam. Lincyc. i. $307=$ verticillatus

certicillatus, Linn. Sp. Pl ed. 11. $\$ 50$ - Ross, austs. Oriens.

virgatus, Baker, in Sasund. Ref. Bot. t. 214.-Air austr.

volubilis, Georgi, Beschreib. Russ. Reich. Nacher. 2tis Everticillatus.

yolubitis, Buch.,Han, ex Wall. Cat. ম. $3154=2$ scenciens.

volubilis, Thanb. Prat, P: Caß, 60.-Afr. austr. 


\section{ASPARAGUS}

vulgaris, Gueldenst. ex Ledeb. F1. Ross. iv. $197=$ officinalis.

Wrightii, A. Gray, in Mem. Am. Acad. N. S. vi. (1858-59) 413.- Japon.

zanzibaricus, Baker, in Fourn. Linn. Soc. xiv. (1875) 614.-Afr. trop.

ASPASIA, Lindl. Gen. et Sp. Orch. 139 (1833). ORCHIDEAE, Benth. \& Hook. f. iii. 560.

Trophianthus, Scheidw. in Otto \& Dietr. Allg. Gartenz, xii. (1844) 218

Biberiana, Reichb. f. in Walp. Ann. vi. $849=$ seq.

Bibriana, Reichb. $f$. in Bonplandia, i. (1854) 90. Hab. ?

epidendroides, Lindl. in Hook. Fourn. Bot. i. (1834) 6.-Panama.

fragrans, Klotzsch, Ind. Sem. Hort. Berol. (1853) 12 $=$ epidendroides.

lunata, Lindl. Bot. Reg. xxii. (1836) sub t. 1907.-Bras. lyrata, [Reichb.f. in] Bot. Zeit. x. (1852) 721.-Bras. papilionacea, Reichb. f. in Gard. Chron. (1876) Ir. 100. - Costa Rica.

principissa, Reichb. f. in Bot. Zeit. x. (1852) 637.Veraguas.

psittacina, Reichb. f. in Gard. Chron. x. (1878) II. 684. -Ecuad.

variegata, Lindl. Bot. Reg. xxii. t. 1907.-Am. austr.

ASPASIA, E. Mey. ex Pfeiff. Nom, i. 295 (1873)= Stachys, Linn. (Labiat.)

ASPASIA, Salisb. Gen. Pl. Fragm. 34 (1866)= Ornitho galum, Linn. (Liliac.)

aurea, Salisb. 1. c. $=0$. thyrsoides.

flavescens, Salisb. 1. c. $=0$. thyrsoides.

lactea, Salisb. 1. c. = O. lacteum

revoluta, Salisb. 1. $\mathrm{c}_{\mathrm{s}}=\mathrm{O}$, revolutum.

thyrsoides, Salisb. 1. c. $=$ O. thyrsoides.

ASPEGRENIA, Poepp. \& Endl. Nov. Gen. et Sp. ii. 12. t. $116(1837)=$ Octomeria, R. Br. (Orchid.) scirpoidea, Poepp. \& Endl. 1. $\mathrm{c}_{1}=$ O. scirpoidea

ASPELINA, Cass. in Dict. Sc. Nat. xli. 166 (1826)= Senecio, Linn. (Compos.). nivea, Cass. 1. c. =S. Aspelina.

ASPERA, Columna, ex Moench, Mcth. 641 (1794)= Galium, Tourn. (Rubiac.).

muralis, Lowe, Man. Fl. Mad. i. $393=\mathrm{G}$. murale. nutans, Moench, Meth. $641=\mathrm{G}$. murale.

ASPERELIA, Humb. in Roem. \& Ust. Mag, iii. viI $5(1790)$. GRAMINEAE, Benth. \& Hook. f, iii. 1207 5 (1790). GRAMINEAE, Benth. \& Hook. f. ii. 1207
(Asprella). Gymnostichum, Schreb. Beschr. Graes. ii. 127. $t$. $47(1810)$.

Hys'rRIX, Moench, Meth. 294 (1794).

Hystrix, Humb. l. c.-Oriens.

ASPERUGO, [Tourn.] Linn. Syst, ed. I. (1735). BORAGINEAE, Benth. \& Hook. f. ii. 853.

aegyptiaca, Linn. Sp. Pl, ed. II. $198=$ Anchusa flava. alba, [Pieri] in Ionios Anthol. v. $192=$ procumbens. divaricata, Murr. in Nov. Comm. Gotting. (1776) 25. t. $2=$ Nonea lutea.

procumbens, Linn. Sp. Pl. 138.-Europ.; Arab.; Oriens; As. bor.

vulgaris, Dum.-Cours. Bot. Cult. ii. $167=$ procumbens. verrucosa, Boiss. Fl. Orient. iv. 159 , in syn. = Anchusa flava

ASPERULA, Linn. Syst. ed. I (1735). RUBIACEAE, Benth. \& Hook, f ii 150.

Leptunis, Stev. in Bull. Soc. Nat. Mose. xxix.(1856) II. 396 , in textu.

Blepharostemma, Chlorostemma, Cynanchica, et Galiopsis, Fourr. in Ann. Soc. Linn. Lyon, N. S. xvi. (1868) 398.

acerosa, C. Koch, in Linnaea, xix. (1847) $31=$ lilaciflora.

affinis, Boiss. \& Huet, Diagn. Ser. II. ii. $110=$ cynanchica.

algerica, Pers. Syn. i. 124=hirsuta

Allionii, Baumg. Enum, i. $80=$ hexaphylla.

alpigena, Schur, Enum. P1. Transs. $277=$ cynanchica

alpina, Bieb. Fl. Taur. Cauc. Suppl, $103=$ cynanchica.

Aparine, Bess. Fl. Galic. i. 114,-Europ. austr. occ. ; Oriens; Sibiria.

\section{ASPERULA}

areadiensis, Sims, Bot. Mag. t. 2146.-Graecia. arenicola, Reut. Cat. PI. Genève, ed. II. $101=$ cynanchica.

aristata, Griseb. Spicil. F1. Rumel. ii. $165=$ longiflora aristata, Linn. f. Suppl. 120.-Europ.; Oriens. arundana, Ball, ex Nym. Consp. ii. $334=$ pendula arvensis, Linn. Sp.Pl. 103.--Europ.; Oriens. aspera, Boiss. Fl. Orient. iii. 28.-Reg. Cauc.; Persia asperrima, Boiss. Elench. 56.-Hispan.

Athoa, Boiss. Diagn. Ser. I. x. $62=$ suberosa.

azurea, Jaub. \& Spach, Illustr. i. 151.t. $82=$ orientalis Boissieri, Steud. ex Boiss. Voy. Bot. Espagne, $737=$ effusa Boissieriana, Steud. Nom. ed. II. i. $151=$ praec. brachyantha, Boiss. Diagn. Ser. II. vi. 66.-Persia. breviflora, Boiss. l. c. Ser. I. x. 63.-Syria.

brevifolia, Vent. Fard. Cels, t. 63.-As. Min.

brunnea, Boiss. F1. Orient. iii. $32=$ brevifolia

bryoides, Stapf, in Denkschr. Acad. Wien, 1. (1885) 106.-Lycia.

calabrica, Linn. f. Suppl. $120=$ Putoria calabrica.

canescens, Vis. Fl. Dalmat. iii, 11. t. $-25=$ aristata

capitata, Kit. ex Reichb. f. Ic, Fl. Germ. xvil. t. 1182

$=$ hexaphylla.

cespitosa, Boiss. F1. Orient. iii. $39=$ lilaciflora.

chlorantha, Boiss. E Heldr. Diagn. Ser. II. vi. 90.Graecia.

ciliaris, DC. Prod. iv. $582=$ stylosa,

ciliata, Moench, Meth. $484=$ Pntoria calabrica

ciliata, Rochel, Banat. t. ix. f. 22; Regel, Ind. Sem.

Hort. Petrop. (1864) 21.-Bannat.

collina, Salisb. Prod. 58 = cynanchica.

commutata, Presl, F1. Sic. Prod. $62=$ longiflora

conferta, Hook. f. in Lond. Fourn. Bot. vi. (1847) 463

[bis].-Austral.

consanguinea, Klotzsch, in Bot. Ergeb. Waldem

Reise, $87=$ Galium triflorum.

crassifolia, Linn. Mant. $37=$ tomentosa.

cretacea, Willd. ex Roem. \& Schųlt. Syst. iii. $529=$ cynanchica.

cruciata, Vell. Fl. Flum. 44 ; i. t. 114.-Bras.

cyanea, Vell.l.c. 44 ; i. t. 113.-Bras.

cynanchica, Linn. Sp. Pl. 104-Europ.; As. Min.

Danilevskiana, Basiner, in Bull. Phys.-Math. Acad Pétersb. ii. (1844) 202.-Turkestan.

debilis, Ledeb. Ind. Hort. Dorp. Suppl. (1824) $2=$ humifusa.

deficiens, Viviani, in Ann. Stor. Nat, iv, 231.-Corsica denudata, Vahl, ex Willk. \& Lange, Prod. Fl. Hisp. ii. $301=$ hirsuta .

digyna, Dufour, in Ann. Sc. Gén. Phyt. vil. (1820) $295=$ aristata.

divaricata, Bischoff, Del. Sem. Hort. Heidelb. (1848) 4 - Hab?

divergens, Boiss. Diagn. Ser. II. vi. $90=$ graveolens.

dubia, Willd. ex Roem. \& Schult. Syst. iii. Mant. 189 $=$ arvensis.

effusa, Boiss. Voy, Bot. Espagne, 280.-Hispan.

elongata, Schrenk, Enum. Pl. Nov. 58.-Soongaria.

eriocarpa, Boiss. Elench. $57=$ asperrima.

fallax, Ehrh. ex Steud. Nom. ed. II. i. 151=laerigata.

fasciculata, Boiss. Diagn. Ser. I. x. $60=$ stricta.

flaccida, Tenore, F1. Nap. t. $110=$ longiflora

foetida, Pers. Syn. i. $524=$ Putoria calabrica

fragillima, Boiss. E Haussk. in Boiss. Fl. Orient. iii 36.-Persia.

fragrantissima, Armst. in Trans, N. Z. Inst, xiv. 1882) 359.-N. Zel

gatioidea, St. Lag. in Ann, Soc, Bot. Lyon, vii. (1880 13 ; et viii. (1881) $161=$ galioides.

galioides, Bieb. Fl. Taur. Cauc. i. 101.-Europ.; Reg. Cauc.

galioides, Bourg. ex Willk. \& Lange, Prod. F1. Hisp ii. $312=$ Galium murcicum .

galioides, Jacquem. Journ. ex Hook. f. F1. Brit. Ind, iii $205=$ Galium triflorum.

geminifolia, F. Muell. Fragm. v. 147.-Austral

glaberrima, Bunge, ex Nym. Consp. $333=$ involucrata

glabra, C. Koch, in Linnaea, xix. (1847) $31=$ involucrata.

glauca, Bess. Enum. P1. Volh. $7=$ galioides

glomerata, Griseb. Spicil. Fl. Rumel. ii. 166.-Oriens.

gracilis, C. A. Mey. Verz. Pfl. Cauc. 154.-Reg.

Caucas.

graveolens, Bieb. ex Bess. in Roem. E' Schult. Syst. iii. Mant. 376.-Tauria; As. Min.

Gunnii, Hook. $f$. in Hook. Lond. Fourn. Bot. vi. (1847) 463 [bis].-Austral.

\section{ASPERULA :}

Gussonii, Boiss. Diagn. Ser. I. x. 63.-Sicil

Haussknechtii, Boiss. Pl. Or. Nov. Dec. i. 1.-Assyria. hexaphylla, All. Fl. Pedem. i. 12. t. 77. f. 3.-Ital.; Hungar.

hexaphylla, Georgi, Beschr, Russ, Reich. iii. IV. $728=$ cretacea.

hirsuta, Desf. Fl. Atlant. i. 127.-Lusit. ; Afr. bor. hirta, Ramond, in Bull. Soc. Philom. (1800) 131. t. 9 -Mont. Pyren.

Hoffmeisteri, Klotzsch, in Bot. Ergeb. Waldem. Reise, 87 = Galium triflorum

humifusa, Bess. Cat. Hort. Crem. (1811) Suppl. ii.. 4; Bieb. Fl. Taur. Cauc. Suppl. 105.-Podol.; Oriens. incana, Bory \& Chaub. Nouv. F1. Pélop. $10=$ tay getea.

incana, Sibth. E Sm. Prod. Fl. Graec, i. 88. Creta. involucrata, Wahlenb, in Isis, xxi. (1828) 971.As. Min.

Fordani, Perr. \& Song. ex Nym. Consp. $334=$ Iongiflora.

Kotschyana, Boiss. Fl. Orient. iii. 27.-Kurdistan.

laevigata, DC. Prod. iv. 582, partim = involucrata.

laevigata, Linn. Mant. 38.-Europ. austr.

laxiflora, Boiss. in Bal. ex Boiss. Fl. Orient. iii. 37.Pontus.

libanotica, Boiss. Diagn. Ser. I. x. 59.-Syria

lilaciflora, Boiss. l. c. iii. 33.-As. Min.

littoralis, Sibth. \& Sm. Prod. Fl. Graec. i. 88.Pontus.

longiflora, Noë, ex Nym. Consp. $333=$ cynanchica.

longiffora, Waldst. E' Kit. Pl. Rav. Hung. ii. 162.t. 150.-Europ.

longifolia, Sibth. \& Sm. Fl. Graec. Prod. i. 87= Galium longifolium.

lutea, Sibth. \& Sm, l.c. 88.-Graecia.

Lycia, Stapf, in Denkschr. Acad. Wien, 1. (1885) 105.-Lycia.

macroclada, Huet, in Ann. Sc. Nat. Sér. III. xix. 1853) $253=$ cynanchica.

macrorrhiza, Hoffmgg. \& Link, F1. Port. ii. 41. t. 84. $=$ aristata.

maritima, Tenore, ex Nym. Consp. $334=$ tomentosa.

matrisylva, Gilib. Exercit. Bot. Univ. Viln. $5=$ odorata microphylla, Boiss. Diagn. Ser. I. iii. 34.-Persia.

minima, Hook. f. in Lond. Fourn. Bot. vi. (1847) 464 [bis].-Tasmania.

minor, S. F. Gray, Nat. Arr. Brit. Pl. ii. $481=$ cynanchica.

mollis, Boiss. Diagn. Ser. I. iii. $31=$ arcadiensis.

molluginoides, Reichb. Fl. Germ. Excurs. 206.-Reg Caucas.

montana, Waldst. \& Kit, ex Willd. Enum. Hort. Berol. $151=$ cynanchica.

mucronata, Otto, ex Steud. Nom. ed. II. i. 151.Hab.?

multiflora, Lapeyr. Hist. Abr. Pl. Pyr. $62=$ cynanchica.

Mungieri, Boiss. \& Heldr. Diagn. Ser. I. x, $61=$ lutea.

muscosa, Boiss. Eo Heldr. l. c. Ser. II ii, 109 Thessalia.

mutica, Boiss. F1. Orient. iii. $43=$ suavis.

neglecta, Moris, Elench. Sard. ii. $4=$ pumila.

neglecta, Guss. Pl. Rar. 70. t. 13. f. 2.-Italia.

Neilreichui, Beck, in Verh. Zool.-Bot. Ges. Wien, xxxii. (1883) 182.-Europ.

nemoralis, Salisb. Prod. $58=$ taurina.

nitens, Guss. Pl. Rar. 70. t. 13. f. 2 = neglecta.

nitida, Sibth. E Sm. Fl. Graec. Prod. 1. 89-As. Miu. odora, Salisb. Prod. $57=$ odorata.

odorata, Linn. Sp.Pl. 103.-Europ.; Oriens

oligantha, F. Muell. ex Miq. in Nederl. Kruidk, Arch. iv. $(1859) 111,112=$ Rubia syrticola.

oppositifolia, Regel Eั Schmalh. ex Regel, Pl. Nov Fedsch. 42.-As. centr.

orientalis, Boiss. E Hohen. Diagn. Ser. 1. iii. 30, As. Min. ; Reg. Caucas.

ovalifolia, Boiss. \& Huet, Diagn. Ser. II. ii. 113= gracilis.

palustris, Tenore, F1. Nap. 111 =tinctoria.

paniculata, Boiss. Elench. $56=$ effusa.

paniculata, Bunge, in Ledeb. Fl. Alt. i. 140.-Sibir alt.

papillosa, Kern. ex Nym. Consp. 325=Galium aristatum.

papillosa, Lange, in Kjoeb. Vidensk. Meddel. 111 (Pugill. ii. 161).-Hispan.

pendula, Boiss. Elench. 55.--Hispan. 


\section{ASPERULA:}

perpusilla, Hook. Fl. Nov. Zel. 114.-N. Zel.

Pestalozzae, Boiss. Diagn. Ser. II. ii. $113=$ graveolen Platygalium, Maxim. in Bull. Acad. Pétersb. xix. (1874) 284.-Manchur.

pontica, Boiss, Fl. Orient. iii. 39,-Pontus.

prostrata, C. Koch, in Linnaea, xxiv. (1851) 461.Armenia,

pulvinaris, Nym. Consp. ii. $334=$ lutea. pumila, Moris, in Mem. Acc. Torin. xxxviii. (1835) 26.
-Sardinia.

pusilla, Hook. f. in Hook. Lond. Journ. Bot. vi.

(1847) 464 [bis] = Gunnii.

pycnantha, Boiss. Diagn. Ser. I, x. $64=$ humifusa.

pyrenaica, Linn. Sp. PI. 104= cynanchica.

repens, Brot. F1. Lusit. i. 152 = hirsuta.

rigida, Sibth. E Sm. Fl. Graec. Prod. 1. 89.-Creta.

rivalis, Sibth. \& Sm. 1. c. $87=$ A. Aparine.

rotundifolia, Linn. Mant. ii, $230=$ laevigata.

rubeola, Gratel. in Bull. Soc. Nat. Hist. Bord, i. (1826)

$311=$ cynanchica.

rubeola, Lam. Fl. Fr. iii. $375=$ cynanchica, tinctoria

rubioides, Schur, Enum, Pl. Transs. 276.-Europ.

rumelica, Boiss. Diagn. Ser. II. ii. $113=$ graveolens,

rupestris, Reichb. Fl. Germ. Excurs, $205=$ scutellaris

rupicola, Jord. Pugill. $76=$ cynanchica.

saxatilis, Lam. Illustr. n. $139=$ nitida, pyrenaica.

scabra, Link, Enum. Hort. Berol. i. $134=$ tomentosa?

scabra, Moris, Elench. Sard. ii. $4=$ pumila.

scabra, J. \& C. Presl, Delic. Prag. $124=$ aristata.

scoparia, Hook. f. in Hook. Lond. Fourn. Bot. vi.

(1847) 463 [bis].-Austral.

scutellaris, Vis. Sem. Rar. Hort. Patav. (1836) Albania.

seticornis, Boiss, Diagn. Ser. I. vi. 65.-Persia.

setosa, Faub. \& Spach, Illustr. i. 152. t. 82. B.-Syria

Persia.

setulosa, Boiss. Dingn. Ser. I. x. 61 =littoralis.

shcrardioides, Faub. \& Spach, Illustr. i. 153,-Persia

sinaica, Delile, ex Decne. in Ann. Sc. Nat. Sér. II. ii (1834) 268 = Galium sinaicum.

squarrosa, C. Koch, in Linnaen, xxiv. (1851) $461=$ glomerata.

Staliana, Vis. Fl. Dalmat, iii. 11--Dalmatia

stricta, Boiss. Diagn. Ser。 I. iii. 38.-Graecia; As. Min.

strictissima, Schur, Enum. Pl. Transs, $277=$ galioides stylosa, Boiss. Diagn. Ser. I. iii. 31.--Persia.

suaveolens, Schrad. ex DC. Prod. iv, $583=1$ longiflora.

suavis, Fisch. Mey. \& Avé-Lall: Ind. Sem. Hort.

Petrop. ix 62.Anatolis.

subalpina, Schur, Enum. P1. Transs. $277=$ cynanchica.

suberosa, Guss. Fl. Sic. Syn. i. $180=$ Gussonii.

subcrosa, Sibth. EN Sm. Fl. Graec. Prod. i. 89.-Graecia.

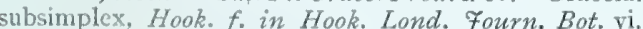

(1847) 463 「bis].-Tasmania.

subvelutina, DC. Prod. iv. 585 = Galium leiophyllum.

suffruticosa, Boiss. \& Heldr. Diagn. Ser. II. ii. 111.Graecia

supina, Bieb. Fl. Taur. Canc. i. $101=$ cynanchica.

taurina, Linn. Sp. Pl. 103.-Europ.; Oriens.

tayyetea, Boiss. \& Heldr. Diagn. Ser. I. x. 60-Grnecis.

Tenori, Wallr. ex Roem. \& Schult. Syst. iii. Mant. 189, in adn. $=$ tomentosa

tenuiflora, Jord. Pugill. $77=$ cynanchica.

tenuifolia, Boiss. Diagn. Ser. I. iii. 32.-As. Min.

tenuissima, C. Koch, in Linnaea, xxiv. (1851) 462.-

$$
\text { Oriens. }
$$

thessala, Boiss. \& Heldr. Diagn. Ser. II. ii. 111=longiflora.

tinctoria, Linn. Sp. Pl. 104.-Europ.

tomentosa, Tenore, Prod. Fl. Neap. p. xii.-Ins. Caprae.

Tournefortii, Sieber, Reise Kreta, i. 239; ii. 316.Creta.

triandra, Gilib. Fl. Litnan. i. $14=$ tinctoria.

trichodes, F. Gay, in DC. Prod. iv. 582.-Persia.

trinervia, Lam. Fl. Fr. iii. $376=$ taurina.

tubifora, Gueldst. ex Stend. Nom, ed. I. 80 ; ed。 II. i.

$151=$ molluginoides.

fyraica, Ress, knum. Pl.Volh. 41 = galioides,

umbellata, Willd. ex DC, l'rod. iv. 586 = hexaphylla.

ASpHalathus, Burm, f. Fl. Ind. 155; et Fl. Cap Prod. $21(1768)=$ Aspalathus, Linn. (Legum.).

Asrinaltirum, Medic. in Vorles. Churpf. Phys. Ges. ii. $\left(1787^{7}\right) 380=$ Psoralea, Linn. (Legum.).
ASPHALTHIUM

bituminosum, Medic. Phil. Bot. i. $211=$ Psoralea bituminosa

ellipticum, Medic in Vorles. Churpf. Phys. Ges. ii. 1787) $381=$ seq ?

frutescens, Medic. 1. c. $380=\mathrm{P}$, bituminosa

herbaceum, Medic. 1. c. $381=$ praec. ?

nigrum, Medic. 1. c. = praec.?

palaestinum, Medic. 1, c. $=\mathrm{P}$. palaestina.

ASPHALTIUM, Fourr. in Ann. Soc. I.yon, 'N. S. xvi (1868) $365=$ ASPHALTHIUM, Medic。= Psoralea Linn. (Iegum.).

ASPHODELINE, Reichb. Fl. Germ. Excurs, 116 (1830). LILIACEAE, Benth. \& Hook. f. iii. 783 Dorydium, Salisb. Gen. Pl. Fragm. 72 (1866) Heroron, Rafin. Fl. Tellur. iv. 12 (1836)

ambigua, F. Gay, ex Baker, in Fourn. Linn. Soc. xv. (1877) 276.-Oriens.

Balansae, F. Gay, ex Baker, l. c. 277.-Cilicia.

brevicaulis, f. Gay, ex Baker, l. c. 276.-As, Min.

Mesopot.

capillaris, Kunth, Enum. Pl. iv. 562.-Hab.?

cretica, Boiss. ex Baker, in Journ. Linn. Soc. xv. (1877) $276=$ brevicaulis

cretica, Vis. Fl. Dalm. i. $152=$ liburnica.

damascena, Baker, in fourn. Linn. Soc. xv. (1877) 276 -Syria.

globifera, F. Gay, ex Baker, l. c. 274.-Syria

isthmocarpa, $\mathscr{F}$. Gay, ex Baker, l. c. 278.-As. Min.

liburnica, Reichb. F1. Germ. Excurs. 116.-Europ. austr, or

lutea, Reichb. l. c.-Reg. Mediterr. et Cancas.; As. Min.

Morisiana, Clem, in Mem. Acc. Torin. Ser. II. xvi. (1857) $326=$ taurica.

parviflora, Baker, in Fourn. Linn. Soc. xv. (1877) 276. -Byzantium

prismatocarpa, F. Gay, ex Boiss. Fl. Orient. v. 320 Cappadoc.

prolifera, Kunth, Enum. Pl. iv. 563.-Armenia; Reg. Cauc.

rigidiflora, Baker, in fourn. Linn. Soc. xv, (1877) 277 . -As. Min.

Szovitsii, C. Koch, in Linnaea, xxii, (1849) $261=$ tenuior.

taurica, Kunth, Enum.Pl. iv. 561.-Oriens.

tenuior, Ledeb. Fl. Ross. iv. 193.-Oriens; Reg. Caucas. Persia.

ASPHODELOIDES, Moench, Meth. $634(1794)=$ As phodelus, Linn. (Liliac.)

ramosa, Moench, 1. c. = Asphodelus ramosus

ASPHODELOPSIS, Steud, ex Baker, in Journ. Linn. Soc. xv. (1876) $321=$ Chlorophytum, Ker-Gawl. arangadirensis, Stend, ex Baker, l. $332=\mathrm{C}$ attent atum.

ASPHODELUS, [Tourn.] Linn. Syst. ed. I (1735) LILIACEAE, Benth. \& Hook. f, iii. 782. Asphodeloides, Moench, Meth. 634 (1794) Clausonia, Pomel, Mat, Fl. Atl 1 (1874) Gethosyne, Salisb. Gen. Pl. Fragm. 72 (1866). OPHIOPRASON, Salisb. 1. c. (1866)

Verinea, Pomel, Mat. Fi. Atl. 1 (187t)

abyssinicus, Hort. ex Schult. f. Syst. vii. $500=$ Albuca abyssinica.

acanlis, Desf. Fl. Atlant. i. 302. t. \$9.-Barbaria.

aestivus, Brigant. Stirp. Rar. i. $5=$ Asphodeline

liburnica.

aestivus, Brot. Fl. Lusit, i. 525=microcarpus,

aestivus, Reichb. Pl. Crit. t. $451=$ tenuifolius. affinis, Parl. Fl. Ital. ii. $596=$ microcarpus. africantes, Lam. Encyc. i. $300=$ Albuca abyssinica. africanus, Jord. in Bull. Soc. Bot. Fr. vii. (1860) 730 $=$ ramosus.

albus, Boiss. Voy. Bot. Espngne, $618=$ cernsiferus.

albus, Mill. Gard. Dict. ed. VIII. n. $8=$ ramosus.

albus, T. Necs, Gen. iv. t. $20=$ fistulosus.

albus, Willd. Sp. Pl. ii. 193.-Furop, anste.

altaicus, Pall. in Act. Acad. Petrop. (1779) 11. 258.

$10=$ Eremurus altaicus.

ambigens, Ford. in Bull. Soc. Bot. Fr. vii. (1860) 735 . -Gallia.

\section{ASPHODELUS}

apiocarpus, Hofimgg. ex Kunth, Enum. Pl. iv. $557=$ aestivus.

approximatus, Gren. \& Godr Fl. Fr iii. $223=$ fistulosus. Arrondeaui, Lloyd, FI. Onest Fr ed. III $317=$ albus.

asiaticus, Haw. Syn. Pl. Succ. 332.-Asia.

Audibertii, Requien, ex Schult. f. Syst. vii. $1695=$ ramosus.

australis, Jord. \& Fourr. Brev. P1. Nov, fasc. ii. $124=$ ramosus.

bracteatus, Willd. ex Schult, f. Syst. vii. $484=$ Aspho-

deline taurica.

brevicaulis, Bertol. in Nov. Comm. Acad. Bonon. (1842) 430 (Misc. Bot. i. 20)=Asphodeline brevicaulis canariensis, C. Sm. \& Buch, in Abh. Acad. Berl. (1816-17) 362, $368=$ intermedius.

capensis, Burm. f. Fl. Cap. Prod. 10 (=Cyanella?)-

Afr, austr.

capensis, Linn. Syst. ed. X. $982=$ Chlorophytum elatum.

capillaris, [DC. in] Red. Lil. t. $380=$ Asphodeline liburnica.

cerasiferus, 7. Gay, in Bull. Soc. Bot. Fr, iv. (1857) 610 ; et in Ann. Sc. Nat. Sér. IV. vii. (1857) 127.Reg. Mediterr. occ.

Chamaemoly, Hochst. ex Baker, in Journ. Linn. Soc. xy. (1877) $328=$ Chlorophytum tetraphyllum.

Chambeironi, Jord. in Bull. Soc. Bot. Fr. vii. (1860)

$7: 36=$ ramosus

clavatus, Roxb. Hort. Beng. 24; Fl. Ind. ii. $148=$ tenuifolius.

clavosus, Don, ex Steud. Nom. ed. II. i. 152, sphalm.= clavatus.

collinus, Jord. \& Fourr. Brev. Pl. Nov, fasc. ii. $123=$ ramosus.

comosus, Houtt. Plantenk, xii, 336, t, $83=$ Encomis punctata.

comosus, Jord, in Bull. Soc. Bot. Fr. vii. (1860) $737=$ ramosus.

corsicus, Jord.-Cf. Bull. Soc. Bot. Fr. vij. (1860) 73! ramosus.

creticus, Lam. Encyc. i. $200=$ Asphodeline libumica.

crinipes, Jord. in Iull. Soc. Bot. Fr. vii. (1860) $729=$ albus.

damascenus, Boiss, Diagn. Ser. I. xiii. $22=$ Asphodeline damascena.

delphinensis, Gren. \& Godr. in Mém. Soc. Emul. Doubs, Sér. JI. vi. $(1855) 13=$ albus.

Déséglisei, Jord. \& Fourr. Brev. P1. Nov, fasc. ii. $121=$ ramosus.

fistulosus, Linn. Sp. Pl. 309.-Reg. Mediterr. ; Oriens. fuscatus, Jord. \& Fourr. Brev. Pl. Nov, fasc. ii. 123= ramosus.

glaucus, Aucher, ex Boiss. Fl. Orient. v. $323=$ Eremurus cappadocicus.

glaucescens, Jord.-Cf. Bull, Soc. Bot. Fr. vii. (1\$60 $739=$ ramosus.

gramineus, Mill. ex Steud. Nom. ed. I. 80, 273: ed. II

i. $152=$ Melasphaerula graminea.

grandiflorus, Jord. \& Fourr. Brev. Pl. Nov. fasc. ii. $123=$ ramosus

inderiensis, Stev. in Ball. Soc. Nat. Mosc. iv. (1832) $257=$ Eremurus inderiensis

infestus, Parl. Fl. Ital. ii. 600 = microcarpus,

intermedius, Hornem. Hort. Haf́n. Suppl. 131 = fistulosus.

latifolius, Breyn. ex Schult. f. Syst. vii. $485=11$ achendorfia paniculata.

liburnicus, Scop. Fl. Carn. ed. II. i. $215=$ Asphodeline liburnica.

littoralis, Jord. in Bull. Soc. Bot. Fr. vie. 1960 ': albus.

Zuterus, Linn. Sp, Pl, 309=Asphodleline lutea.

macrocarpus, Parl. Fl. Ital. ii. $604=$ albus.

major, Pourr, ex Willk. \& Lange, I'rod. Fl. Hisp. $204=$ albus.

micranthus Coss, \& Kralik, ex Coss, in liull. Sur. Hol Fr. iv. (1心in 407 - viscidulus.

microcarpus, Reicbb. Fl. Germ. Excurs. 11; ; Ic. Fl. (ierm. ix. So, n. $1110^{\circ}$ - tenuifolius.

microcarpus, lisvani, F\%. Cors. 5.-Keg. Mevliterr. Ins. Canar.

Murisiunus, Parl. IF. Itol. ii. E016.-Italia. neglectus, Schult. f. Syst. vii. $485=$ allous.

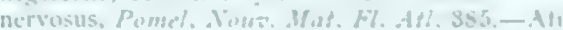
ocrideneralis, Jurd. in liull. Soc. Bot. Fr. vii. 1 scie - albus 


\section{ASPHODELUS :}

olbiensis, Jord. \& Fourr. Brev. Pl. Nov, fasc. ii. $122=$ ramosus.

Ozanoni, Jord. in Bull. Soc. Bot. Fr. vii. (1860) $733=$ ramosus.

parviflorus, Wight, Ic. t. $2062=$ fistulosus.

pendulinus, Coss, \& Dur. in Bull. Soc. Bot. Fr. iv, 1857) 399, 497.-Algeria; Arab.

persicus, Fisch. \& Mey. ex Boiss. Fl. Orient. v. 317 =Asphodeline tenuior

persicus, Jaub. \& Spach, Illnstr. ii. 2.t. $102=$ Eremurus persicus.

pratensis, Pourr. ex Willk. \& Lange, Prod. F1. Hisp. i. $203=$ microcarpus.

procerus, Jord. \& Fourr. Brev. Pl. Nov. fase. ii. 124= ramosus.

proliferus, Bieb. F1. Taur. Cauc. i. $280=$ Asphodeline prolifera.

proterophyllus, Jord. in Bull. Soc. Bot. Fr. vii. (1860) $737=$ ramosus.

pyrenaicus, Jord. 1. c. $732=$ albus.

racemosus, Link, Entum. Hort. Berol. 1. $328=$ ramosus. ramosus, Colm. ex Willk. \& Lange, Prod. Fl. Hisp. i. $203=$ microcarpus.

ramosus, Grouan, ex Willk. \& Lange, 1. c. $204=$ cerasiferus.

ramosus, Lapeyr. Hist. Abr. Pl. Pyr. $188=$ neglectus.

ramosus, Linn. Sp. Pl. ed. I. 310.-Europ. austr.

ramosus, Linn. 1. c. ed. II. $444=$ microcarpus, cerasiferus.

ramosus, Murr. in Nov. Comm. Gotting. (1776) 37. t. $71=$ albus.

ramosus, Sturm, Deutschl. Fl. Heft vi. t. $6=$ fistulosus. refractus, Boiss. Diagn. Ser. I. xiii. (1854) $23=$ pendulinus.

regius, Hort. ex Heynh. Nom. ii. $48=$ Eremurus spectabilis.

repens, Pomel, Nouv. Mat. Fl. Atl. 256.-Afr. bor.

rigidifolius, Boiss. \& Heldr. Diagn. Ser. I. xiii. 22 Asphodeline rigidifolia.

Rouxii, Jord. in Bull. Soc. Bot. Fr. vii. (1860) $738=$ ramosus.

serotinus, Sibth. ex Jacq. Eclog. 113=Asphodeline liburnica.

sibivicus, Hort. ex Schult. f. Syst. vii. $483=$ Asphodeline lutea.

sibiricus, Sievers, in Pall. N. Nord. Beitr. vii. $257=$ Eremurus altaicus.

simplex, Pers. Syn. i, $367=$ albus.

sphaerocarpus, Gren. \& Godr. Fl. Fi", iii. $223=$ albus,

spicatus, Desf. ex Baker, in Journ. Linn. Soc. Xv. (1877) $271=$ ramosus.

stoechadensis, Jord. \& Fourr. Brev. P1. Nov. fasc, ii. $122=$ ramosus.

strictus, Burm. f. Fl. Cap. Prod. 10.-Afr, austr.

subalpinus, Gren. \& Godr. Fl. Fr. iii. $224=$ albus.

Szovitsii, C. Koch, in Linnaea, xxil. (1849) $261=$ Asphodeline tenuior.

tardiflorus, Jord, in Bull. Soc. Bot. Fr. vii. (1860) 736 = ramosus.

tauricus, Lodd. Bot. Cab. t. $1102=$ Asphodeline tenuior.

tauricus, Pall. in Nov. Act. Petrop. x. 309; Bieb. F1. Taur. Cauc. i. $279=$ Asphodeline taurica.

tenuiflora, C. Koch, in Linnaea, xxii. (1849) $261=$ Asphodeline tenuior.

tenuifolius, Cav. in Anal. Cienc. Nat. iii. (1801) 46.Ind. or.

tenuior, Fisch. Cat. Hort. Gorenk. (1812) 9=Asphodeline tenuior.

validus, Jord.-Cf. Bull. Soc. Bot. Fr, vii. (1860) 740 = ramosus

Villamosii, Verl. ex Jord. Billotia, 107, 109; et in Bull.
Villo Soc. Stat. Isère, Sér. II. iv. (1860) $151=$ ramosus.

virgatus, Jord.-Cf. Bull. Soc. Bot. Fr. vii. (1860) 738 - ramosus.

viscidulus, Boiss. Diagn. Ser. I. vii. 118.-Afr. bor.; Arab.

ASPICARIA, D. Dietr. Syn. i, 2, $27(1839)=$ seq.

ASPICARPA, Rich, in Mém. Mus, Par. ii. (1815) 398. t. 1; Lag. Gen, et Sp. Nov. 1 (1816). MALPIGHIACEAE, Benth. \& Hook. f. i. 261.

Acosmus, Desv. in Desf. Cat. Hort. Par. (1829) 283.

Hartwegiana, A. Fuss. in Arch. Mus. Par. iii. (1843) 598.-Mexic.

\section{ASPICARPA :-}

hirtella, Rich. in Mém. Mus. Par. ii. (1815) 399. t. 13 -Mexic.

hyssopifolia, A. Gray, in Bost. Journ. Nat. Hist. vi. 1850) 167.-Texas.

longipes, A. Gray, Pl. Wright. i. 37.-N. Mexic

sericea, Griseb. in Goett. Abh. xxiv. (1879) 68.-Reg Argent.

urens, Lag. Gen. et Sp. Nov. i. 1. n. $5=$ hirtella.

ASPIDALIS, Gaertn. Fruct. 1i.t. $171(1791)=$ Berkheya Ehrh. (Compos.)

araneosa, Gaertn. 1. c. = B. cernua.

ASPIDANDRA, Hassk. in Versl. en Med. Akad. Wetensch. iv. (1855) 141. EUPHORBIACEAE 'Gen, dub.'

fragrans, Hassk. l. c.-Java.

ASPIDANTHERA, Benth. in Hook. Journ. Bot. iii (1841) $217=$ Ferdinandusa, Pohl (Rubiac.). rudgeoides, Benth. 1. c.-Bras.

ASPIDEIUM, Zollik. ex DC. Prod. vii. 150 (1838)= Chondrilla, Tourn. (Compos.).

ASPIDISTRA, Ker-Gawl. in Bot. Reg. t. 628 (1823) LILIACEAE, Benth. \& Hook. f. iii. 772 .

Macrogyne, Link \& Otto, Ic. P1. Sel. t. 31 (1823).

Plectogyne, Link, in Otto \& Dietr. Allg. Gartenz. (1834) 266.

Porpax, Salisb. Gen. P1. Fragm. 9 (1866).

elatior, Blume, in Hoev. E De Vriese, Tijdschr. i. (1834) 76. t. 4.-Japon.

lurida, Ker-Gazol. in Bot. Reg. t. 628.-China, lurida, Sieber, ex Presl, in Flora, xii. (1829) $568=$ Wachendorfia hirsuta.

punctata, Lindl. in Bot. Reg. t. $977=$ lurida.

variegata, Regel, in Flora, xxxiii. (1850) $354=$ elatior

ASPIDOCARPUS, Neck. Elem. ii. $123(1790)=$ Rham nus, Tourn.

ASPIDOCARYA, Hook. f. \& Thoms. Fl. Ind. i. 180 (1855). MENISPERMACEAE, Benth. \& Hook, f. i. 33 .

hirsuta, Becc. Malesia, i. (1877) 136.-Malaya.

uvifera, Hook. f. E Thoms. Fl. Ind. i. 180,-Reg. Himal.

ASPIDOGLOSSUM, E. Mey. Comm. Pl. Afr. Austr. 200 (1837) =Schizoglossum, E. Mey. (Asclep.).

biflorum, E. Mey. 1, c. 201.-Afr. austr.

fasciculare, E. Mey, 1. c. 200-Afr, austr.

heterophyllum, E. Mey. 1. c.-Afr. austr.

ASPIDOPTERYS, A. Juss. in Ann. Sc. Nat. Sér. II xiii. (1840) 266. MALPIGHIACEAE, Benth. \& Hook. f. i. 259

canarensis, Dalz. in Hook. Kew Fourn. iii. (1851) 37. -Ind. or.

concava, A. Fuss. in Ann. Sc. Nat. Sér. II. xiii. (1840) 266.-Burma.

cordata, A. Fuss. l. c. 267.-Ind, or.

elliptica, A. Fuss. l. c. 266.-Ind. or

glabriuscula, A. Juss. l. c. $267=$ Roxburghiana.

glomerata, Wight, Ic. t. $1986=$ canarensis.

Helferiana, Kurz, in fourn. As. Soc. Beng. xliii. (1874) II. 137.-Burma.

hirsuta, A. Fuss. in Ann. Sc. Nat. Sér. II. xiii. (1840) 267.-Burma.

lanuginosa, A. Juss. $1, \mathrm{c}_{\mathrm{r}}=$ nutans

nutans, A. Juss, 1. c. = Wallichii

nutans, Hook. f. Fl. Brit. Ind.i. 421.--Reg. Himal. oxyphylla, A. Juss. in Ann. Sc. Nat. Sér. II. xiii. (1840) $267=$ Roxburghiana

rotundifolia, A. Juss. 1. c. = nutans.

Roxburghiana, A. Fuss. l. c.-Ind, or,

tomentosa, A. Fuss. l. c.-Java.

Wallichii, Hook. f. Fl. Brit. Ind. i. 421.-Reg. Himal.

ASPIDOSPERMA, Mart. \& Zucc. Nov. Gen. et Sp. i. 57. t. 34 ad 36 (1824). APOCYNACEAE, Benth \& Hook. f. ii. 702.

MACAGLIA, Rich: ex Vahl, in Skrivt. Nat. Selsk. Kiobenh. vi. (1810) 107.

Peltospermum, DC. in Bibl. Univ. Genèv. xvii. (1838) 133.

\section{ASPIDOSPER MA :}

anomalum, Muell. Arg. in Mart. Fl. Bras. vi. I. 61.Bras.

argenteum, Muell. Arg. in Kjoeb. Vidensk. Meddel. (1869) 104.-Bras

australe, Muell. Arg. in Mart. Fl. Bras. vi. I. 58.Bras.

bicolor, Mart. Nov.Gen. et Sp. i. 60_-Bras,

camporum, Muell. Arg. in Mart. Fl. Bras. vi. 1. 49.Bras.

condylocarpon, Muell. Arg. l. c. 55.-Bras.

cylindrocarpum, Muell. Arg. l. c. 54.-Bras.

dasycarpon, A.DC. in DC. Prod. viii. 396.-Bras.

decipiens, Muell. Arg. in Linnaea, xxx. (1859-60) 398 -Venezuela.

desmanthum, Benth. ex Muell. Arg. in Mart. Fl. Bras. vi. I. 52.-Bras.

discolor, A. DC. in DC. Prod. viii. 398-Bras.

dispermum, Muell. Arg. in Mart. Fl. Bras. vi. I. 60.Bras.

eburneum, Allem. ex Saldanha, in Ann. Sc. Nat. Sér. V. xix. (1874) 213.-Bras.

excelsum, Benth. in Hook. Fourn. Bot. iii. (1841) 245.-Guiana.

Francisii, A. DC. in DC. Prod. viii. 398.-Guiana

Gardneri, Muell. Arg. in Mart. Fl. Bras. vi. 1. 47.Bras.

Gomezianum, A. DC. in DC. Prod. viii. 397.-Bras.

Hilarianum, Muell. Arg. in Mart. Fl. Bras. vi. I. 50Bras.

lagoënse, Muell. Arg. in Kjoeb. Vidensk. Meddel. (1869) 102.-Bras.

latisiliqua, $A . D C$. in $D C$. Prod. viii. 676.-Guiana.

leucomelanum, Muell. Arg. in Kjoeb. Vidensk. Meddel. (1869) 105.-Bras.

Lhotzkianum, Muell. Arg. in Mart. Fl. Bras. vi. I. 60. -Bras.

macrocarpon, Mart. Now. Gen. et Sp. i. 59.-Bras. macrophyllum, Muell. Arg. in Linnaea, xxx. (1859-60 397.-Guiana.

Martii, Silva Manso, in Mart. Herb. Fl. Bras. 163.Bras.

megalocarpon, Muell. Arg. in Linnaea, xxx. (1859-60) 400.-Mexic.

melanocalyx, Muell. Arg. in Mart. Fl. Bras. vi. I. 52. - Bras.

molle, Mart. Herb. F1. Bras. $162=$ pyrifolium. multiflorum, $A . D C$. in $D C$. Prod. viii. 397.-Guiana nitidum, Benth. ex Muell. Arg. in Mart. Fl. Bras. vi. I. 59.-Bras.

nobile, Muell. Arg. l. c. 44.-Bras.

oblongum, A. DC. in DC. Proà. viii. 399.-Guiana.

obscurum, Muell. Arg. in Mart. Fl. Bras, vi. I. 48.Bras.

olivaceum, Muell. Arg. l.c. 57.-Bras.

pachypterum, Muell. Arg. l. c. 51.-Bras.

pallidiflorum, Muell. Arg. in Kjoeb. Vidensk. Meddel (1869) 101.-Bras.

parvifolium, A. DC. in DC. Prod. viii. 398.-Bras. platyphyllum, Muell. Arg. in Mart. Fl. Bras, vi. I. 46.-Bras.

polyneuron, Muell. Arg. l. c. 57.-Bras.

Pohlianum, Muell. Arg. l. c. 44.-Bras.

populifolium, A. DC. in DC. Prod. viii. 397.-Bras.

pyricollum, Muell. Arg. in Mart. Fl. Bras. vi. I. 58.Bras.

pyrifolium, Mart. Nov.Gen. et Sp. i. 60.-Bras,

Quebracho-blanco, Schlecht. in Bot. Zeit. xix. (1861) 137.-Am. austr.

Quebracho-colorado, Schlecht. l. c. 139.-Am. austr.

ramiflorum, Muell. Arg. in Mart. Fl. Bras. vi. I. 55.Bras.

refractum, Mart. Nov. Gen. et Sp. i. 60.-Bras.

Riedelii, Muell. Arg. in Mart. Fl. Bras. vi. I. 56.Bras.

Sellowii, Muell. Arg. l. c.-Bras.

sessiliflorum, Muell. Arg. in Linnaea, xxx. (1859-60) 399.-Ins. Trinit.

Spruceanum, Benth. ex Muell. Arg. in Mart. Fl. Bras. vi. I. 52.-Bras.

subincanum, Mart. Herb. Fl. Bras. n. 262; ex A. DC in DC. Prod. vili. 397.-Bras.

tomentosum, Mart. Nov. Gen. et Sp. i. 58. Ł. 34.Bras.

Vargasii, A. DC. in DC. Prod. viii. 399.-Venezuela. velutinum, Fisch. ex Muell. Arg. in Mart. F1. Bras. vi I. $45=$ tomentosum.

verbascifolium, Muell. Arg. l. c. 46.-Bras. 


\section{ASPIDOSPERMA :-}

venosum, Muell. Arg. in Kjoeb. Vidensk. Meddel. (1869) 103.-Bras.

verruculosum, Muell. Arg. in Mart. Fl. Bras. vi. I. 51. -Bras.

Warmingii, Muell. Arg, in Kjoeb. Vidensk. Meddel. (1869) 101.-Bras.

ASPIDOSTIGMA, Hochst. in Flora, xxvii. (1844) $18=$ Toddalia, Juss. (Rutac.).

acuminatum, Hochst. 1. $\mathrm{c} .=$ T. nobilis.

A.SPILIA, Thou. Gen. Nov. Madag. 12 (1806). COM POSITAE, Benth. \& Hook. f. ii. 371

Anomostephium, DC. Prod. v. 560 (1836)

Coronocarpus, Schum. \& Thonn. Beskr. Guin. Pl 393 (1827).

DipterothecA, Sch. Bip. in Flora, xxv. (1842) 434.

Harpephora, Endl. Gen. Suppl. i. 1382 (1841)

Wirtgenia, Sch. Bip. in Flora, xxv. (1842) 435.

abyssinica, Oliver \& Hiern, in Oliver, Fl. Trop. Afr. iii. 379.-Afr. trop,

abyssinica, Vatke, in Linnaea, xxxix. (1875) 495. Abyss.

angustifolia, Oliver \& Hiern, in Oliver, Fl. Trop. Afr. iii. 380.-Afr. trop.

anomala, Baker, in Mart. Fl. Bras. vi. III. 204_-Bras.

aristata, Griseb. in Goett. Abh. xxiv. (1879) 191.-Reg Argent.

asperrima, Baker, in Mart. Fl. Bras. vi. iii. 200.-Bras. attenuata, Baker, l. c. 199.-Bras.

aurantiaca, Griseb. in Goett. Abh. xix. (1874) 183.Reg. Argent.

Baroni, Baker, in Fourn. Linn. Soc. xx. (1884) 188.Madag.

Bojeri, DC. Prod. v. 561.-Madag.

buphthalmiflora, Griseb, in Goett. Abh, xix. (1874) 136. -Reg. Argent.

Burchellii, Baker, in Mart. Fl. Bras, vi. IrI. 194.Bras.

calendulacea, Griseb. in Goett. Abh. xxiv. (1879) 191 $=$ buphthalmiflora

Clausseniana, Baker, in Mart. Fl. Bras. vi. III. 202.Bras.

ecliptaefolia, Baker, l. c. 197.-Bras

elegans, Benth. E Hook. f. Gen. ii. 372.-Bras.

elliptica, Baker, in Mart. Fl. Bras. vi. III. 192.-Bras.

floribunda, Baker, l. c. 198.-Bras.

foliacea, Baker, l. c. 193.-Bras.

foliosa, Benth. E Hook. f. Gen. ii. 372.-Bras.

fruticosa, Baker, in Mart. Fl. Bras. vi. III. 204.-Bras

Gayana, Benth. E Hook.f. Gen. ii. 372.-Afr. trop.

glabra, Benth. \& Hook. f. l. c.-Bras.

gracilis, Baker, in Mart. Fl. Bras. vi. IIr. 198.-Bras.

helianthoides, Benth. \& Hook. f, Gen ii. 372.-Afr. trop.

hirsuta, Benth. E Hook. f. l. c.-Bras.

hispidula, Baker, in Mart. Fl. Bras. vi. III. 201.Bras.

Kotschyana, Benth. E Hook. f. Gen. ii. 372,-Afr.

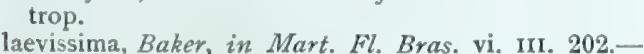
Bras.

latifolia, Oliver \& Hiern, in Oliver, Fl. Trop. Afr. iii. 379.-Afr. trop.

linearifolia, Baker, in Mart. Fl. Bras. vi. III. 192.Bras.

linearifolia, Oliver $\&$ Hiern, in Oliver, Fl. Trop. Afr. iii. 380.-Afr. trop.

Martii, Baker, in Mart. Fl. Bras. vi. III. 195.-Bras.

mexicana, Benth. E Hook. f. Gen. ii. 372.-Mexic.

multiflora, Oliver E Hiern, in Oliver, Fl. Trop. Afr.

iii. 378. - Afr. trop.

oblonga, Baker, in Mart. Fl. Bras. vi. III. 198.-Bras. ovalifolia, Baker, l. c. 199.-Bras.

pascaloides, Griseb. in Goett. Abh. xxiv. (1879) 191.Reg. Argent.

phyllostachya, Baker, in Mart. Fl. Bras. vi. III. 201. -Bras.

podophylla, Baker, l. c. 200-Bras.

Pohlii, Baker, l.c. 201.-Bras.

Prieureana, Benth. E Hook. f. Gen. ii. 372.-Afr. trop. procumbens, Baker, in Mart. Fl. Bras. vi. III. 194. Bras.

pusilla, Baker, L.c. 193.-Bras.

reflexa, Baker, l. c. 196. - Bras.

reticulata, Baker, l. c. 202.-Bras.

Kiedelii, Baker, l. c. 196.-Bras.

\section{ASPILIA}

udis, Oliver E Hiern, in Oliver, Fl. Trop. Afr. iii. 380 . - Afr. trop

Schimperi, Oliver \& Hiern, l. c. 379.-Afr. trop.

serrulata, Baker, in Mart. Fl Bras vi III 204

Bras.

setosa, Griseb. in Goett. Abh. xxiv. (1879) 192.-Reg. Argent.

silphioides, Benth. E Hook. f. Gen. ii. 372,-Bras.

Smithiana, Oliver E Hiern, in Oliver, Fl. Trop. Afr. iii. 380.-Afr. trop.

squarrosa, Baker, in Mart. Fl. Bras. vi. III. 203.Bras.

strigosa, Benth. E Hook. f. Gen. ii. 372,-Mexic.

subalpestris, Baker, in Mart. Fl. Bras. vi. IIr. 202. Bras.

subpetiolata, Baker, l. c. 203.--Bras.

Thouarsii, DC. Prod. v. 561.-Madag.

tomentosa, Baker, in Mart. Fl. Bras, vi. III 199 Bras.

Warmingii, Baker, l. c. 192.-Bras.

wedeliaeformis, Vatke, in Oestr. Bot. Zeitschr. xxyii.

(1877) 197.-Afr. trop.

ASPILOBIUM, Soland. ex A. Cunn. in Ann. Nat. Hist (Sept. 1838) $45=$ Geniostoma, Forst., (Logan.)

ASPII.OTUM, S[oland.] exSteud.Nom.ed. II. i. 669, 152 $(1840)=$ Geniostoma, Forst. (Logan.)

laevigatum, S[oland.] ex Steud. 1. $\mathrm{c}_{\mathrm{v}}=\mathrm{G}$. ligustrifolinm.

ASPITIUM, Neck. ex Steud. Nom. ed. II. ii. 10 (1841 $=$ Laserpitium, Linn. (Umbell.)

ASPLA, Reichb. Nom. 50 (1841) err. typ. =AOPLA, Lindl. = Habenaria, Linn. (Orchid.)

ASPRELLA, Host, Gram. Austr, iv. 17. t. $29(1809)=$ Psilurus, Trin. (Gram.).

nardiformis, Host, 1. c. $=$ P. nardoides.

ASPRELLA, Willd. Ennm. Hort. Berol. $132(1809)=$ Asperella, Humb. (Gram.)

ASPRELLA, Schreb. Gen. $45(1789)=$ Leersia, Sw。 (Gram.).

australis, Roem. \& Schult. Syst. ii. $267=$ L. hexandra brasiliensis, Roem. \& Schult. Mant. $153=$ L. brasiliensi digitata, Lam. Illustr. i. $167=\mathrm{L}$. digitata.

echidnea, Rafin. in Am. Monthly Mag. (1813) 190.Am. bor.

flexuosa, Dulac, Fl. Hautes-Pyr. $71=\mathrm{L}$. oryzoides hexandra, Roem. \& Schult. Mant. $551=\mathrm{L}$. hexandra Hystrix, Link, Enum. Hort. Berol, 100=Asperell Hystrix.

imbricata, Roem. \& Schult. Syst. iî. 268=L. virginica lenticularis, Roem. \& Schult. 1. c. $267=$ L. lenticularis. major, Fres. ex Steud. Nom. ed. II. i. $150=$ Asperell Hystrix.

mexicana, Roem. \& Schult. Mant. 551=L. hexandra. monandra, Roem. \& Schult. l. c. = L. monandra oryzoides, Lam. Illustr, i. 167 ; Beauv, Agrost. 2. t. 4 f. $2=\mathrm{L}$. oryzoides.

ovata, Roem. \& Schult. Syst. ii. $267=$ L. lenticularis purpurea, Boj. Hort. Maurit. $376=\mathrm{L}$. hexandra. sibivica, Trauty. in Act. Hort. Petrop. v. (1877) 192.Sibir.

virginica, Roem. \& Schult. Syst. ii. $266=$ L. virginica

ASPRIS, Adans. Fam. ii. $496(1763)=$ Aira, Linn (Gramin.) (=Aira praecox).

ASSA, Houtt. Plantenk. Ү. $275(1776)=$ Tetracera Linn. (Dillen.)

exotica, F. G. Gmel. Syst. $839=$ T. Assa.

indica, [Christm. \& Panz. in] Houtt. Pflanz. Syst. iv. 40 $=$ T. Assa.

ASSARACUS, Haw Monog, Narciss. 4 ; in Sweet, Brit. Flow. Gard. iv. $(1838)=$ Narcissus, Linn (Amaryll.)

capax, Haw. 1. $c_{0}=\mathrm{N}$. triandrus

reflexus, Haw. 1 , $c_{0}=\mathrm{N}$. triandrus.

ASSONIA, Cav. Diss. iii. 120.t. $42(1786)=$ Dombeya Cav. (Stercul.)

Erythroxylon, Sims, Bot. Mag. subt. $1000=$ Trochetia Erythroxylon.

populnea, Cav. Diss, iii, 120, t. 42, f. $3=$ D. populnea. viburnoides, DC. Prod, i. 498,-Ins. Borbon.
ASTARTEA, DC. in Dict. Class, xi. 400 (1826); Prod ii. 210 (1828). MYRTACEAE, Benth. \& Hook. f i. 702 .

ambigua, F. Muell. Fragm. ii. 32.-Austral.

aspera, Schau, in Linnaea, xvii. (1843) $242=$ fascicularis. clavulata, Turcs, in Bull. Phys.-Math. Acad. Pétersb. x. (1852) 333,-Austral.

corniculata, Schau. in Lehm. P1. Preiss. i. $113=$ fascica laris.

Endlicheriana, Schau. in Linnaea, xvii. (1843) 242. fascicularis.

fascicularis, $D C$ - Prod iii 210-Austral

glomerulosa, Schau. in Linnaea, xvii. (1843) 242 fascicularis

intratropica, F. Muell. Fragm. i. 83.-Austral.

laricifolia, Schau, in Linnaea, xvii. (1843) $242=$ fas cicularis.

leptophylla, Schau. I. $\mathrm{c}$ = fascicularis

muricata, Turcz. in Bull. Phys.-Math. Acad. Pétersb. x. (1852) 334.-Austral.

scoparia, Schau. in Linnaea, xvii. (1843) $242=$ fascicularis.

ASTELIA Banks \& Soland, ex R. Br. Prod. 291 (1810 LILIACEAE, Benth. \& Hook. f. iii. 781

Funck1A, Willd. in Ges. Naturf. Fr. Berl. Mag. ii. (1808) 19.

Hamelinia, A. Rich. Voy. Astrolob.; Fl. Nouy. Zél. 158. t. 24 (1832).

albicans, Colenso, in Trans. N.Z. Inst. xvii. (1885) 252. -N. Zel.

alpina, R. Br. Prod. 291.-Austral.

Banksii, A. Cunn. in Hook. Comp. Bot. Mag. ii. (1836) $374 .-\mathrm{N}$. Zel.

Cunninghamii, Hook. f. Fl. N. Zel. i. 259.-N. Zel.

fragrans, Colenso, in Trans. N. Z. Inst. xv. (1883, 333.-N. Zel.

grandis, Hook. f. ex T. Kirk, in Trans. N. Z. Inst. i. (1868) 93.-N, Zel.

Hookeriana, T. Kirk, 1. c. iv. (1872) $244=$ Cunninghamii.

linearis, Hook. f. Fl. Antarct. 76.-Ins. Antarct.

Menziesiana, Smo in Rees, Cycl. xxxix. Appo; Schult. f. Syst. vii. 1506.-Ins. Sandvic.

microsperma, Colenso, in Trans. N. Z. Inst. xvii. (1885) 251.-N. Zcl.

montana, Seem. Fl. Vit. 313.-Ins. Fiji.

nervosa, Banks E Soland. ex Hook. f. Fl. N. Zel. i. 260.-N. Zel.

polyneuron, Colenso, in Trans. N.Z. Inst. xiv. (1882 233.-N. Zel.

psychrocharis, F. Muell. in Hook. Kew Journ. viii. 1856) $332=$ alpina.

pumila, R. Br. Prod. 291.-Terr. Magell.

Ricardi, Kunth, Enum. PI. iii. $365=$ Banksii.

sericea, Banks \& Soland. ex Hook. f. FL. N. Zel. i. 261 $=$ Banksii.

Solandri, A. Cunn. in Hook. Comp. Bot. Mag. ii. (1836) $374 .-\mathrm{N}$. Zel.

spicata, Colenso, in Trans. N. Z. Inst. ziv. (1882 335. - N. Zel

stylosa, F. Muell. in Hook. f. Fl. Tasm. ii. $61=$ Milligania stylosa.

trinervia, T. Kirk, in Trans. N. Z. Inst. i. (1868) 99. $-\mathrm{N}$. Zel.

veratroides, Gaudich. in Freyc. Voy. Bot. 420.t. 31. Ins. Sandvic.

Waialealia, Wawra, in Flora, lviii. (18i5) 213.Ins. Sandvic.

ASTELMA, R. Br. in Bot. Reg. sub t. $592\left(1820^{\circ}=\right.$ Helichrysum, Vaill. et Helipterum, DC (Compos.)

canescens, D. Don, in Mem. Wern. Soc. v. (1821) 545 = Helipterum canescens.

crassifolium, D. Don, 1. c. 548 = Helipterum ferrugineum.

eximium, R. Br. in Bot. Reg. sub t. $592=$ Helipterum eximium.

frograns, Sweet, Hort. Brit. ed. I. $222=$ = Helichrysum fragrans.

fruticans, Ker.Gawl. Bot. Reg.t. 726 = Helichrysum truticans.

imbricatum, D. Don, in Mem. Wern. Soc. r. 1521 $544=$ Helichrysum imbricatum.

lineare, D. Don, 1. $c=$ Helichrusum ericuefulium.

millefionum, D. Don, 1. c. $5 t^{2}=$ Helipterum phlo. moides.

E 
ASTELMA :-

modestum, Sieber, ex Hook. Bot. Mag. t. $2710=$ Helipterum gnaphaloides.

proteoides, D. Don, in Mem. Wern. Soc. v. (1824) 543. -Afr. austr.

retortum, D. Don, ex Steud. Nom. ed. II. i. $152=$ Helichrysum retortum.

speciosissimum, D. Don, in Mem. Soc. Wern. v. (1824)

$544=$ Helipterum speciosissimum.

spirale, G. Don, in Sweet, Hort. Brit. ed. III. $378=$ Helipterum variegatum

Staehelina, D. Don, in Mem. Wern. Soc. v, (1824) $543=$ Helipterum speciosissimum.

variegatum, D. Don, 1. c. $544=$ Helipterum variegatum.

virgatum, G. Don, in Sweet, Hort. Brit. ed. III. $378=$ Helipterum virgatum.

ASTFMMA, Less. Syn. Comp. 216 (1832). COMPOSITAE, Benth. \& Hook. f. ii. 356.

dubium, Less. l. c.-Ecuador.

ASTEMON, Regel, Ind. Sem. Hort. Petrop. (1860) 38 = Bystropogon, L'Hérit. (Labiat.).

graveolens, Regel, 1. c. (an Hyptis suaveolens?).Bolivia.

ASTEPHANANTHES, Bory, in Ann. Gén. Sc. Phys. ii. (1819) $138=$ Passiflora, Linn.

bilobata, Bory, l. c. = P. bilobata.

ASTEPHANUS, R. Br. in Mem. Wern. Soc. i. (1809) 54. ASCLEPIADEAE, Benth. \& Hook. f. ii. 747. Haemax, E. Mey. Comm. Pl. Afr. Austr. 223 (1837) Tylodontia, Griseb. Cat. Pl. Cub. 175 (1866). arenarius, Decne. in DC. Prod. viii. 507.-Madag.

badius, E. Mey. Comm. Pl. Afr. Austr. 224.-Afr. austr.

Berterii, Spreng. Syst. i. 855.-N. Granat.

cernuus, Decne. in Ann. Sc. Nat. Sér. II. ix. (1838) 342.-Ins. Pemba.

cordatus, R. Br. in Mem. Wern. Soc. i. (1809) 54.Afr. austr

cordifolius, Phil. in Anal. Univ. Chil. ii. (1862) 399 ; et Linnaea, xxxiii. (1864-65) 175.-Chili.

cubensis, $H . B$. \& $K$. Nov. Gen. et Sp. iii. 206. t. 237. -Cuba.

Dregei, D. Dietr. Syn. Pl. ii. 909.-Afr, austr.

dumosus, D. Dietr. 1. c. = Rhyssolobium dumosum.

frutescens, E. Mey. Comm. Pl. Afr. Austr. 223.Afr. austr.

fruticosus, Steud. Nom. ed. II. i. $153=$ frutescens.

Gardneri, Fourn. in Mart. Fl. Bras. vi. IV. 199 Bras.

geminiflorus, Decne. in Ann. Sc. Nat. Sér. II. ix. (1838) 342.-Chili.

lanceolatus, R. Br. in Mem. Wern. Soc, i. (1809) 54 -Afr. austr.

linearis, R.Br. l. c.-Afr. austr.

marginatus, Decne. in DC. Prod viii. 508-Afr, austr.

Massoni, Roem. E' Schult. Syst. vi. 124.-Afr. austr.

mitophorus, Griseb. in Goett. Abh. xix. (1874) 205.Reg. Argent.

mucronatus, Schlecht. in Linnaea, viii. (1833) 518.Mexic.

nigrescens, Fourn, in Ann. Sc. Nat. Sér. VI. xiv. (1881) 367.-Mexic.

ovalifolius, A. Rich. Fl. Cub. Fanerog. ii. 95.-Cuba. ovatus, Decne. in Ann. Sc. Nat. Sér. II. ix. (1838) 342.-Madag.

pauciflorus, E. Mey. Comm. Pl. Afr. Austr, 224.Afr. austr.

peruvianus, Fourn, in Ann. Sc. Nat. Sér. VI. xiv. (1882) 367.-Peruv.

recurvatus, Klotzsch, in Peters, Reise Mossamb. Bot 274.-Afr. trop.

Schimperi, Vatke, in Oestr. Bot. Zeitschr. xxvi. (1876) 145.-Afr. trop.

streptocarpus, Fourn. in Ann. Sc. Nat. Sér. VI. xiv. (1882) 367.-Paraguay.

triflorus, R. Br. in Mem. Wern. Soc。 i. (1809) 54 .Afr, austr.

urceolatus, Griseb. Cat. Pl. Cub. 173.-Cuba.

utahensis, Engelm. in Am. Natural. ix. (1875) 349.Am. bor. occ.

Zeyheri, Turcz. in Bull. Soc. Nat. Mosc. xxv. (1852) II. 314.-Afr, austr.
ASTER, Tourn. ex Linn. Syst. ed. I (1735). COMPOSITAE, Benth. \& Hook. f. ii. 271.

Actipsis, Aglotoma, Anactis, Diplactis, FimBRISTIMA, Galactella (Galatella), KalIMARES, LeIACHENIS, Mesoligus, Tripolion,

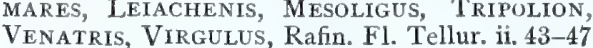
(1836).

ArCtogeron, DC. Prod. v. 260 (1836).

Belliviastrum, Cass. in Dict. Sc. Nat. xxxvii. 458 (1835)

Brotia, DC. Prod. v. 264 (1836).

Calimeris, Nees, Gen, et Sp. Aster, 225 (1833)

Crinita, Moench, Meth. 578 (1794)

Crinitaria, Cass. in Dict. Sc. Nat. xxxvii. 475 (1825).

Dieteria, Nutt. in Trans. Am. Phil. Soc. Ser. II. vii. (1841) 300

Diplopappus, Cass. in Bull. Soc. Philom. (1817) 137 et in Dict. Sc. Nat. xiii. 308 (1819).

Doellingeria, Nees, Gen. et Sp. Aster. 177 (1833).

Eucephalus, Nutt. in Trans. Am. Phil. Soc. Ser. II. vii. (1841) 298 .

Euryeia, S. F. Gray, Nat. Arr. Brit. Pl. ii. 464 (1821).

Exathamnus, D. Don, ex Hook, \& Arn. in Hook. Comp. Bot. Mag. ii. (1836) 46.

GalateA, Cass. in Bull. Soc. Philom. (1818) 165 ; et in Dict. Sc. Nat. xviii. 56 (1820)

Heleastrum, DC. Prod. v. 263 (1836).

Hersilea, Klotzsch, Bot. Ergeb. Waldem, Reise Bot. $83(1862)$.

Heterochaeta, DC. Prod. v. 282 (1836)

Homostyliu M, Nees, in Linnaea, xviii. (1844) 513.

Kalimeris, Cass. in Dict. Sc. Nat. xxxvii. 464 (1825).

LiNosy RIS, Cass. 1. c. 460, 476 (1825)

Machaeranthera, Nees, Gen. et Sp. Aster. 224 (1833)

Margarita, Gand. Fl. Helv. v. 335 (1829).

Noticastrum, DC. Prod. v, 279 (1836)

Pinardia, Neck, Elem. i.. 5 (1790).

Psychrogeton, Buiss. Fl. Orient. iii. 156 (1875)

Rhinactina, Less. in Linnaea, vi. (1831) 119

Symphyotrichum, Nees, Gen. et Sp. Aster. 135 (1833).

Tripolium, Nees, 1. c. 152 (1833).

TurCZaninowia, DC. Prod.v. 257 (1836).

Virgaria, Rafin. ex DC. Prod. v. 243 (1836).

Xylorhiza, Nutt, in Trans. Am. Phil. Soc. Ser. II. vii. (1841) 297

abbreviatus, Nees, Syn. Aster. $\mathbf{1 6}=$ patulus.

abyssinicus, Hochst. ex A. Rich. Tent. Fl. Abyss. i. $383=$ Felicia Richardi.

acaulis, Wedd. Chlor. And. i. 189.-Peruv.

Acmellus, Pall. Reise, iii. $320=$ A. Amellus.

acris, S. G. Gmel. It. 1. 172. t. 38. f. 2 =dracunculoides. acris, Lapeyr. Hist. Abr. Pl. Pyr. 518= salignus.

acris, Leyss. Fl. Halens, $215=\mathrm{A}$. Amellus.

acris, Linn. Sp. $P l$. ed. II. 1228.-Europ. austr.; Cancas

acris, Willd. Sp. Pl. iii. $2023=$ trinervis

aculeatus, Labill. Nov. Holl. Pl. ii. 52. t. $200=$ Olearia ramulosa.

acuminatus, Michx. Fl. Bor. Am. ii. 109.-Am. bor. acuminatus, Nees, Gen. et Sp. Aster. $60=$ patulus. adenolasius, F. Muell. Fragm. v. $67=$ Olearia adeno lasia.

adenophorus, F. Muell. 1. c. $78=$ Olearia adenophora. adfinis, Less. Syn. Comp. $174=$ Felicia adfinis. adnatus, Nutt. in Fourn. Acad. Philad. vii. (1834) 82. -Ám. bor.

adscendens, Lindl. in DC. Prod. v, 231.-Am. bor

adulterinus, Willd. Enum. Hort. Berol. ii. $884=$ Novi Belgii.

aestivus, [Dryand. in] Ait. Hort. Kew, ed. I. iii. $203=$ longifolius.

aestivus, A. Gray, Man. Bot. U. St. ed. V. 233 partim $=$ junceus.

aestivus, Rothrock, in Wheeler, Rep. 364=occidentalis.

aethiopicus, Burm. F. Fl. Cap. Prod. 27.-Afr. austr. ageratoides, Turcz. in Bull. Soc. Nat. Mosc. (1837) n.

VII. $154=$ trinervius.

Aitonii, Forbes, Hort. Woburn. 188.-Hab. ?

alatus, Aikin, in Eaton \& J. W right, Man. Bot. $146=$ patens.

albescens, Wall. Cat. n. $2974=$ Microglossa albescens.

\section{ASTER}

albus, Eaton \& J. Wright, Man. Bot. $147=$ ptarmicoides. albus, Willd. ex Spreng. Syst. iii. $528=$ A. Amellus. alpicola, F. Muell. Fragm. v. $70=$ Olearia alpicola.

alpigenus, A. Gray, in Proc. Am. Acad. viii. (1872) $389=$ pulchellus

alpinus, Gueldenst. ex Ledeb. Fl. Ross. ii. $476=$ A Amellus.

alpinus, Linn. Sp. Pl. 872.-Europ.; Oriens; As. bor. altaicus, Willd. Enum. Hort. Berol. 881.-Persia; Reg. Himal.; As. bor

altissimns, Mill. Gard. Dict. ed. VIII.n.20.-Am. bor. altissimus, Moench, Meth. $601=$ Novae-Angliae alwartensis, Lodd. Cat. (1807) ex Sims, Bot. Mag. t. $2321=$ Erigeron pulchellus.

alyssoides, Turcz. in Bull. Soc. Nat. Mosc. v. (18ז2) 198.-Mongol.

amabilis, Wender. ex Nees, Gen. et Sp. Aster. 282.Hab. ?

ambiguus, Bernh. ex Nees, 1. c. $138=$ macrophyllus.

amelloides, Hoffm. in Goett. Gel. Anz. xx. (1800) $1325=$ A. Amellus.

Amellus, Aitch. in Journ. Linn. Soc. xix. (1882) $168=$ pseudamellus.

Amellus, Linn.Sp. Pl. 873.-Europ.; As. Min.; Reg. Caucas.

amethystinus, Nutt. in Trans, Am. Phil. Soc. Ser. II vii. (184.1) 294.-Am. bor.

Ammani, Lindl. ex DC. Prod, v, $229=$ sibiricus.

amoenus, Harv. in Harv. E Sond. Fl. Cap. iii. 84.Afr. austr.

amoenus, Lam. Encyc。 i. 306, 307=puniceus. amplexicaulis, Lam. 1. c. $304=$ Novae-Angliae. amplexicaulis, Muhl. in Willd. Sp. Pl.iii. $2046=$ laevis amplexicaulis, Michx. Fl. Bor. Am. ii. $114=$ patens. amplus, Lindl. in DC. Prod. v. 236.-Am. arct. amygdalinus, Lam. Encyc. i. $305=$ umbellatus. Andersoni, A. Gray, in Proc. Am. Acad. vii. (1868) 352.-Calif.

Andersonii, E. Forst. ex Forbes, Hort. Woburn. 188 . Am. bor.

andinus, Nutt. in Trans. Am. Phil. Soc. Ser. II. vii 1841) 290 - Am. bor.

angustifolius, Jacq. Hort. Schoenb. iii. $63=$ Felicia angustifolia.

angustifolius, Lindl. in Royle, Illustr. Bot. Himal. 251. t. $58=$ altaicus.

angustissimus, Tausch, in Flora, xi. (1828) $487=$

Heteropappus hispidus.

angustus, Nees, Syn. Aster. $26=$ paniculatus.

angustus, Schur, Lnum. P1. Transs. $306=$ Kayserianus

angustus, Torr. E' Gray, Fl. N. Am. ii. 162,-As. bor.; Am. bor.

annectens, Harv. in Harv. E Sond. Fl. Cap. iii. 78.Afr. austr.

annuus, Linn. Sp. P1. $875=$ Erigeron annuus

anomalus, Engelm. in Torr. E Gray, Fl. N. Am. ii 503.-Am. bor.

Ansif, Mart, in Denkschr. Muench. Akad. vi. (1820) 195.-Arabia.

antirrhinifolius, Salisb. Prod. $197=$ Cymbalariae.

aragonensis, Asso, Syn. 121. t. 8. f. 2 ; Lam. Encyc. i 302.- Hispan.

aragonensis, Bout. ex Willk. \& Lange, Prod. Fl. Hisp. ii. $36=$ Willkommii.

ardense, Forbes, Hort. Woburn. 188.-Hab. ?

arenarioides, Eaton, ex A. Gray, in Proc. Am. Acad viii. (1873) 647.-Am. bor. occ.

argenteus, Michx. F1. Bor. Am. ii. 111=sericeus.

argophyllus, Labill. Nov. Holl. Pl. ii. 52. t. $201=$ Olearia argophylla.

argunensis, DC. Prod. v. $227=$ flaccidus

argutus, R. Br. ex Benth. F1. Austral. iii. $488=$ Olearia arguta.

argutus, Nees, Gen. et Sp. Aster. $69=$ Novi-Belgii.

Arnottii, Nees, ex Torr. \& Gray, Fl. N. Am. ii. 115= patens.

arragonensis, Auct. $=$ aragonensis,

artemisiaeflorus, Poir. Encyc. Suppl i. $500=$ Tradescanti.

artemisioides, F. Muell. Fragm. v. $65=$ Olearia tubuliflora.

ascendens, Hook. F1. Bor. Am, ii. 8=adscendens asper, Buch.-Ham. ex DC. Prod. v. $277=$ asperrimus asper, Nees, Gen. et Sp. Aster. 84.-Am. bor. asperrimus, Less. in Linnaea, v. (1830) 143.-Mexic. asperrimus, Nutt. in Trans. Am. Phil. Soc. Ser. II. vii. 1841) $293=$ grandiflorus 
ASTER :-

asperrimus, Wall. Cat. n. $2970=$ trinervis.

asperugineus, Eaton, in Bot. King, Exp. 142 = Erigeron asperugineus.

asperulus, Torr. \& Gray, Fl. N. Am. ii. $120=u n d u$ latus.

asperulus, Wall. Cat. n. 2968, ex Nees, Gen. et Sp Aster. 281.--Reg. Himal.

asterotrichus, F. Muell. Fragm. v. $79=$ Olearia asterotricha.

attenuatus, Lindl, ex Hook. Comp. Bot. Mag. i. (1835) $97=$ virgatus.

atticus, Pall. Reise Stath. Russ. Reich. i. $345=$ A Amellus ?

aurantius, Linn. Sp. Pl. $877=$ Dyssodia appendiculata

aureus, D. Don, Prod. F1. Nep. $178=$ Solidago aurea

auriculatus, Schloss. ex Nym. Consp. 387 = salignus.

auritus, Lindl. in DC. Prod. v. $232=$ patens.

australis, Hort. ex DC. 1. c. $270=$ Olearia ramu

losa.

autumnalis, Wender. ex Nees, sec. Torr. \& Gray, Fl

N. Am. ii. $119=$ undulatus.

axillaris, F. Muell. Fragm. v. $64=$ Olearia axillaris.

azureus, Lindl. ex Hook. Comp. Bot. Mag. i. (1835) 98. -Am. bor.

baccharoides, Steetr, in Seem. Bot. Voy. Herald, 385

-China.

Baldwinii, Torr. \& Gray, Fl. N. Am. ii. $127=$ undulatus.

Balli, F. Muell. Fragm. viii. 143.-Austral.

barbatus, Harv. in Harv. E Sond. Fl. Cap. iii. 81.Afr. anstr.

Behrii, Schlecht. in Linnaea, xxi. (1848) $446=$ Vitta dinia australis.

Bellidiastrum, Nees, ex Walp. in Nov. Act. Nat. Cur. xix. Suppl.i. (1843) 258.-Chili.

Bellidiastrum, Scop. Fl. Carn. ed. II. ii. 168.-Europ. bellidiflorus, Nees, Syn. Aster. $21=$ lencanthemus. bellidiflorus, Steud. Nom. ed. II. i. $153=$ spectabilis bellidiflorus, Willd. Enum. Hort. Berol. 886 = panicu latus.

bellidioides, Buch.-Ham. ex D. Don, Prod. FI. Nep $\mathbf{1 7 7}=$ Erigeron bellidioides.

bellidioides, Baker, in Mart. Fl. Bras. vi. III. 24.-Bras.

benghalensis, Heyne, ex DC. Prod. v. 292 = Erigeron asteroides.

Benthami, F. Muell. Census, 78.-Austral.

Benthamii, Steetz, in Seem. Bot. Voy. Herald, $385=$ trinervius.

berberifolius, A. Cunn, ex DC. Prod. v. 268 = Olearia myrsinoides.

Bergerianus, Havv. in Harv. E Sond. Fl. Cap. iii. 78. -Afr. austr.

bessarabicus, Bernh. ex Reichb. Fl. Germ. Excurs. 246 $=$ A. Amellus.

bicolor, Dietr. ex DC. Prod, v. $239=1$ longifolius.

bicolor. Nees, Syn. Aster. 25 ; Gen, et Sp. Aster. $283=$

Solidago bicolor.

biennis, Ledeb. in Ind. Sem. Hort. Dorpat. Suppl. i. (1811) = hispidus.

biennis, Nutt. Gen. Am. ii. $155=$ canescens.

biennis, Torr. in Ann. Lyc. N. York, i. (1824) $211=$ commutatus, oblongifolius.

bifidus, Nees, Syn. Aster. $18=$ dracunculoides

biflorus, Michx. Fl. Bor. Am. ii. 114=Radula.

biflorus, Presc. ex DC. Prod.v. 231=sibiricus.

bifrons, All. Fl. Pedem. i. $197=$ Inula bifrons.

bifrons, Lindl. in DC. Prod, v. $243=$ diffusus.

Bigelovii, A. Gray, in Pacif. Rail. Rep, iv, 97. t. 10Am, bor. oce.

blandus, Pursh, Fl. Am. Sept. ii. $555=$ puniceus

blepharophyllus, $A$. Gray, Pl. Wright. ii. 77.-Mexic

Bloomeri, A. Gray, in Proc. Am. Acad. vi. (1864-65)

$599=$ campestris

bonariensis, Spreng. Syst. iii. $528=$ Erigeron glaucum.

borealis, Provanch. Fil. Canad, i. $308=$ junceus.

Borreri, Forbes, Hort. Woburn. 188.-Hab. ?

bostoniensis, Hort. ex Baker, in Gard. Chron. (1884) II. $744=$ amethystinus.

botryantbus, C. Koch, in Linnaea, xxiii. (1850) 701(= foliaceus ?), -Oriens.

Bowiei, Harv, in Harv. \& Sond. Fl. Cap. iii. 73.-Afr. austr.

brachycomoides, F. Muell. Fragm. v. 86 =Vittadinia brachycomoides.

\section{ASTER :}

bracteatus, Turcz. ex Herd. in Bull. Soc. Nat. Mosc. xxxviii. (1865) I. $387=$ tataricus.

bracteolatus, Nutt. in Trans. Am. Phil. Soc. Ser. II. vii. (1841) $293=$ Hallii.

breviflorus, Phil. in Linnaea, xxxiii.(1864-65) 131.Chili.

brevipes, Benth. Fl. Hongk. 175.-China

britannicus, All. Fl. Pedem. i. $197=$ Inula britannica.

brumalis, Nees, Gen. et Sp. Aster. $70=$ Novi-Belgii

Bubonium, Scop. Fl, Carn. ed. II. ii. $173=$ Inula spiraeifolia.

bupleurifolius, Hort. Monsp. ex Nees, Gen. et Sp Aster. $286=$ laevis.

bupleuroides, Forbes, Hort. Woburn. 188.-Hab.?

Burchellii, Hook. f. Ic. P1. sub t. $1056=$ Commidendron Burchellii.

Burkei, Harv. in Harv. E Sond. Fl. Cap. iii. 76.Afr. austr.

cabulicus, Lindl. Bot. Reg. (1843) Misc. 62 Microglossa albescens.

caespitosus, Hort. ex Lindl. Bot. Reg. xix. t. $1571=$ Novi-Belgii.

caespitosus, E. Forst. ex Forbes, Hort. Woburn. 188. Hab.?

caffrorum, Less. Syn. Comp. $179=$ Felicia caffroram.

calcareus, F. Muell. Census, 78.-Austral

calendulaefolius, Loisel. Herb. Amat. iv, 274, - Hab.

californicus, Less. in Linnaea, vi. (1831) $33=$ Erigero glaucus.

campestris, Nutt. in Trans. Am. Phil. Soc. Ser. II. vii (1841) 293.-Am. bor. occ.

camporum, Gardn. in Hook. Lond. Fourn. Bot. vii. (1848) 79.--Bras.

Canbyi, Vasey, ex A. Gray, Syn. Fl. N. Am. i. $193=$ foliaceus.

Candollii, Harv. in Harv. Eo Sond. Fl. Cap. iii. 80.Afr. austr.

canescens, Pursh, Fl. Am. Sept. ii. 547.-Am. bor, occ. canus, Waldst. E' Kit. Pl. Rar. Hung. i. 28.-Europ. capensis, Less. Syn. Comp. $168=$ rotundifolius.

Capusi, Franch in Ann. Sc. Nat. Sér. VI xvi. (1883) 304.-Turkest.

caricifolius, H. B. \& K. Nov. Gen. et Sp. iv, 92. $333=$ pauciflorus.

carneus, Fries, ex Baker, in Gard. Chron. (1884) Ir $680=$ paniculatus.

carneus, Nees, Syn. Aster. 26. -Am. bor.

carneus, Torr. \& Gray, partim, ex Baker, in Gard. Chron. (1884) II. $680=$ salicifolius.

camosus, A. Gray, ex Hemsl. in Biol. Centr. Am. Bot

ii. 120 -Am, bor. occ.

carnosus, Gilib. Fl. Lituan. i. $214=$ A. Tripolium.

carolinianus, Walt. Fl, Carol. 208.-Am, bor

caryophyllus, Stend. Nom. ed. II. i. 154, sphalm.= argophyllus.

cassiarabicus, Maund. Bot. Gard. vi. n. 672.-Rossia.

Cassiniae, F. Muell. Fragm. v. $68=$ Olearia Cassiniae

catalaunicus, Willk. Es Costa, in Linnaea, xxx. (1859

60) 105.-Hispan

caubulicus, Hook. Bot. Mag. Ixxiii. (1847) App. $34=$ Microglossa albescens.

caucasicus, Willd. Sp. Pl. iii. 2020,-Reg. Caucas

Celmisia, F. Muell. Fragm. v. 84=Celmisia longifolia chamaedrifolius, Lam. ex DC. Prod. vii. $13=$ Printzia Bergii.

Chamissonis, A. Gray, in Torr. Bot. U. St. Expl. Exped. 341.-Calif.

Chapmani, Torr. E Gray, Fl. N. Am. ii. 161.-Am. bor.

Charieis, Less. Syn. Comp, 171=strigosus.

chilensis, Nees, Gen, et Sp. Aster. $123=$ Chamissonis. chinensis, Linn. Sp. Pl. $877=$ Callistephus hortensis.

chrysanthemifolius, Hort. ex Steud. Nom. ed. II. $154=$ filifolius

chrysanthemoides, Willd. ex Spreng. Syst. iii. $538=$ tanacetifolius.

chrysocomifolius, Hort. ex Steud. Nom. ed. II. i. $154=$ Nolletia chrysocomoides.

chrysocomoides, Desf. Arb. i. $282=$ Nolletia chrysoco moides.

chrysocomoides, Turcz. ex DC. Prod. vii. $272=$ alpinus. chrysophyllus, A. Cunn. ex DC. 1. c. v. $266=$ Olearia chrysophylla.

ciliaris, Thunb. ex DC 1. c. 218 = Mairia taxifolia.

ciliatus, Nutt. in Trans. Am. Phil. Soc. Ser. II. vii. (1841) $295=$ phyllolepis

ciliatus, Walt. Fl. Carol. 209 (sp. dub.).-Am. bor.

\section{ASTER :}

ciliatus, Muhl, in Willd. Sp. P1. iii. $2027=$ multiflorus.

ciliolatus, Lind1. in DC. Prod. v. $235=$ Lindleyanus. coerulescens, DC. 1. c. $235=$ salicifolius

Collinsii, Nutt. in Journ. Acad. Philad. vii. (1834) 82 $=$ Sericocarpus tortifolius.

collinus, Salisb. Prod. $198=$ A. Amellus.

coloradoënsis, A. Gray, in Proc. Am. Acad. xi. (1876)

76.-Colorado.

commutatus, A. Gray, Syn. Fl. N. Am. 1. II. 185. Am. bor oce.

concinnus, Colla, Hort. Ripul. App. iii. 22. t. $12=$ Novae-Angliae.

concinnus, Salisb. Prod. $197=$ fruticosus.

concinnus, Willd. Enum. Hort. Berol. 884-Am. bor.

concolor, Linn. Sp. Pl. 874 - Am bor.

confertus, Desf. Cat. Hort. Par. ed. III. $401=$ puniceu.

confertus, Nees, Syn. Aster. $21=$ versicolor

conocephalus, F. Muell. Fragm, v. $67=$ Olearia cono cephala.

consanguineus, Ledeb. FI. Ross. ii. $473=$ peregrinus,

conspicuus, Fisch. ex Turcz. in Bull Soc. Nat Mosc. xix. (1846) $144=$ tataricus.

conspicuus, Lindl. in DC. Prod. v. 230-Am. bor. occ.

Conyzae, Griessel. Kleine Bot. Schrift. $122=$ Inula vulgaris.

conyzoides, Desf. Cat. Hort. Par. ed. III. $175=$ Felicia angustifolia.

conyzoides, Willd. Sp. Pl. iii. 2043 = Sericocarpus conyzoides.

cordifolius, Lam. Encyc. i. $307=$ paniculatus

cordifolius, Linn. Sp. Pl. 875.-Am. bor.

cordifolius, Michx. Fl. Bor. Am. ii. $112=$ corymbosus

cordifolius, Muhl. ex Willd. Sp. Pl, iii. 2035 = sagittifolius.

coriaceus, Forst. f. Prod. 56. n, $297=$ Celmisia coriacea.

coriaceus, Hort. ex DC. Prod. v, $276=$ fruticosus.

coridifolius, Michx. ex Willd. Sp. Pl. iii. $2028=$ dumosus.

cornifolius, Muhl. ex Willd. 1. c. $2039=$ infirmus.

Cornuti, Mill. ex Nees, in DC. Prod. $\mathbf{7} .234=$ abbreviatus.

Cornuti, Wendl. ex Nees, Gen. et Sp. Aster. $58=$ patulus.

corymbosus, [Dryand. in] Ait. Hort. Kew, ed. I, iii. $20 \%$. -Am. bor.

corymbosus, Moench, Meth. Suppl. $250=$ Inula germanica.

crassifolius, F. W. Klatt, in Abh. Naturf. Ges. Halle, xv. (1882) 326.-N. Granat.

crenatus, Less. Syn. Comp. $166=$ Mairia crenata

crinitus, Linn. Pl. Rar. Afr, 21 = Atbrixia heterophylla.

crinitus, Thunb. Prod. Pl. Cap. 160=Athrixia capensis.

crispus, Forsk. Fl. Aegypt. Arab. $150=$ Pulicaria crispa.

crocatus, Bertol. Fl. Guatimal. 34.-Guatemals.

crocifolius, $H . B$. \& K. Nov. Gen. et Spo iv. 89,-N. Granat.

cuneatus, A. Cunn. ex Stead. Nom. ed. II. i. $154=$ Olearia stellulata.

Cunninghami, F. Muell. Census, 78.-Austral.

Curtisii, Tom, \& Gray, Fl. N. Am ii. 110.Am, bor.

Cusickii, A. Gray, in Proc. Am. Acad. vi. (1881) 99 - Am. bor. occ

cyaneus, Hoffim. Phyt. Blaett. i. (1808) $71=$ laevis

cyanodiscus, F. Muell. Fragm, v. $82=$ Olearia ramosissima.

cydoniaefolius, A. Cunn. ex DC. Prod. v. 267 Olearia cydoniaefolia.

cylleneus, Orphan. ex Nym. Consp. $387=$ alpinas.

Cymbalarine, Ait. Hort. Kers. ii. 197; Thunb. Prod. Pl. Cap. 100.-Afr. austr.

dahuricus, Benth, ex Baker, ins Gard. Chron. (1535

t. 208.-Sibir.

debilis, Boj. ex DC. Prod. vi. $276=$ Athrixin debilis.

decorus, Desf. ex UC. 1. c. v. $2 \$ 0^{\circ}=$ laevis.

decumbens, Baker, in Mart. Fl. Bras, vi. III. 24.Bras.

decrurrens, A. Cunn. ex DC. Prod. จ. 200 Olearit decurrens.

decurrens, Moench, Meth. Sappl. 251 Inula hifrons. defferus, Muench, 1. c. $250=2 c r i s$

deflexus, Tansch, in Flora, xxii. (1839) 77.-Hab. I

demisus, Forbes, Hort. Wiourn. 18s.-Hab. 


\section{ASTER :-}

. Fap. iii. 79 -Afr. austr.

dentatus, Andr. Bot. Rep, t. $61=$ Olearia dentata dentatus, Thunb. Prod. P1. Cap. $159=$ Felicia fragilis denudatus, Nutt. in Trans. in Am. Phil. Soc. Ser. II. vii. 1841) $292=$ adscendens.

depressus, Kit. in Linnaea, xxxii. (1863) $373=\mathrm{A}$ Tripolium.

desertorum, Tchertk. in Bull. Soc. Nat. Mosc. vi (1833) 15.-Rossia.

dichotomus, Ell. Sketch, ii. $366=$ reticulatus

diffusus, DC. Prod, v, 242, partim = vimineus.

diffusus, [Dryand. in] Ait. Hort. Ker\%. ed. I. iii. 205. -Am. bor.

dimorphophyllus, Franch. E Sav. Enum. Pl. Fap. i 224. - Japon

diplostephioides, Benth. E Hook.f. Gen. ii. 272.-Reg Himal.

discoideus, Boiss. \& Reut. Pugill. 54=Willkommii. discoideus, Ell. Sketch, ii. $358=$ Solidago discoidea. discoideus, Sond. ex Harv. E' Sond. Fl. Cap. iii. 76.-

Afr. anstr.

distortus, Turcz. ex Avé-Lall. in Ind. Sem. Hort. Petrop. viii. 53. n, 546=altaicus.

divaricatus, Lam, Encyc. i. $305=$ acuminatus.

divaricatus, Linn. Sp. Pl. $873=$ corymbosus.

divaricatus, Nutt. in Torr \& Gray, Fl. N. Am ii 163. - Am, bor. et austr

divaricatus, Rafin. ex DC. Prod. v. $241=$ divergens.

divaricatus, Spreng. Syst. iii. $529=$ umbellatus.

divaricatus, Torr. \& Gray, FI. N. Am. ii. $163=$ exilis.

divergens, [Dryand, in] Ait. Hort. Kew. ed. I. iii. 205 $=$ diffusus.

diversifolius, Michx. F1. Bor. Am. ii. 113=undulatus. diversifolius, Spreng. Syst. iii. $533=$ heterophyllus,

Donii, E. Forst. ex Forbes, Hort. Woburn. 188.-

$\mathrm{Hab}$ ?

Douglasii, Eaton, Bot. King, Exp. $141=$ foliaceus.

Douglasii, Lindl. in DC. Prod. v. 239.-Am. bor, occ

dracunculoides, Bess. Enum. P1. Volh. $33=$ acris.

dracunculoides, Lam. Encyc. i. 303.-Europ. austr.

As. bor.

dracunculoides, Willd. Sp. P1. iii. $2050=$ paniculatus.

Dregei, Harv, in Harv. E Sond. Fl. Cap. iii. 74.-Afr austr.

Drummondii, Lindl, ex Hook. Comp. Bot. Mag. i. (1835) 97 .-Am. bor.

dumosus, DC. Prod, v. $241=$ multiflorus.

dumosus, Hoffm. Phytogr. Blaett. i. (1803) $68=$ ericoides.

dumosus, Linn. Sp. Pl. 873.-Am. bor.

dumosus, Nees, Syn. Aster. $31=$ ericoides.

Durandii, Nutt. ex Durand, in Pacif. Rail. Rep. v. $8=$ Menziesii.

dysentericus, Scop. F1. Carn. ed. II. ii. $171=$ Pulicaria dysenterica

echinatus, Less. Syn. Comp. $177=$ Felicia echinata

Ecklonis, Less. l. c. 170.-Afr, austr.

Ehrenbergii, Sch. Bip. in Seem. Bot. Voy. Herald, 302.--Mexic.

elaeagnifolius, A. Cunn. ex DC. Prod. v. $267=$ Olearia furfuracea.

elaeophilus, A. Cunn. 1. c. $269=$ Olearia hetero phila.

elatus, Bert. ex Steud. Nom. ed. II. i. $154=$ corym bosus.

elegans, Hort. Par. ex A. Gray, Syn. Fl. N. Am. i. II. $184=$ concinnus

elegans, Hook. f. E Thoms. ex C. B. Clarke, Comp. Ind. 44.-Sikkim.

elegans, Nees, Syn. Aster. $20=$ A. Amellus.

elegans, Torr. Ev Gray, Fl. N. Am. ii. 159.-Am. bor. occ.

elegans, Willd. Sp. Pl. iii, $2042=$ spectabilis

Elliottii, Torr \& Gray, Fl N Am ii 140 - Am bor.

ellipticus, A. Cunn. ex DC. Prod. v. $271=$ Oleari elliptica.

elodes, Torr. \& Gray. Fl. N. Am. ii. $136=$ Novi Belgii.

elongatus, Thunb. Prod. Pl. Cap, 160.-Afr, austr. elongifolius, A. Cunn. in Ann. Nat. Hist. ii. (1839) 127 , sphalm. = elaeagnifolius.

eminens, Lindl. in Bot. Reg. t. $1614=$ Novi-Belgii.

eminens, Nees, Gen. et Sp. Aster. $87=$ junceus, paniculatus.

\section{ASTER :-}

eminens, Willd. Enum. Hort. Berol, $886=$ salicifolius. Engelmannii, A. Gray, in Am. Fourn. Sc. Ser. II xxxiii. (1862) 238.-Am. bor. occ.

ensifolius, Scop. F1. Cain. ed. II. ii. $174=$ Inula ensifolia.

erectus, Forbes, Hort. Woburn. 188.-Hab. ?

eremophilus, Bunge, Verz. Suppl. Fl. Alt. 103.-Sibir. altaic.

ericaefolius, Forsk. Fl. Aegypt. Arab. $150=$ Athrixia ericaefolia.

ericaefolius, Rothr. in Coulter, Bot. Gaz. ii. (1877) 70 -Mexic. ; Texas.

evicoides, Lam. Encyc. i. 304=multiflorus

ericoides, Linn. Sp. Pl. 875.-Am. bor.

erigeroides, Harv. in Harv. E Sond. Fl. Cap. iii. 74 - Afr. austr.

evigeroides, Hook. \& Arn. in Hook. Comp. Bot. Mag ii. (1836) $48=$ Erigeron fraticosus.

erubescens, Sieber, ex Benth. Fl. Austral. iii. $471=$ Olearia myrsinoides.

eryngiifolius, Torr. E Gray, Fl. N.Am. ii. 502.Am. bor.

espenbergensis, Nees, Gen. et Sp. Aster. $36=$ sibiricus. exasperatus, Link, Enum. Hort. Berol, ii. $328=$

Olearia ramulosa.

exiguifolius, F. Muell. Fragm, v. $67=$ Olearia exiguifolia.

exilifolius, F. Muell. 1. c. $69=$ Olearia exilifolia

exilis, Ell. Sketch, ii. 344.-Am. bor.

exscapus, Richards. App. Frankl. Journ. ed. II. $32=$ Townsendia sericea.

expansus, Nees, Syn. Aster. $23=$ laevis.

Exsul, Lindl. Swan Riv. P1. App. 24=Olearia rudis

falcatus, Eaton, in Bot. King, Exped. 140, ex parte= adscendens.

falcatus, Lindl. in DC. Prod. v. 241.-Am. arct

fascicularis, E. Mey. ex DC.1. c. $220=$ Felicia muricata. fastigiatus, Fisch. in Mém. Soc. Nat. Mosc. ii. (1812) 74 - -Sibir

fastigiatus, Ledeb. Ic. Pl. Fl. Ross, t. 161= Hauptii.

Fendleri, A. Gray, Pl. Fendl. 66.-Am. bor.

Ferresii, F. Muell. Fragm. v. $75=$ Olearia Ferresii.

ferrugineus, Edgew. in Trans. Linn. Soc. xx. (1846) $64=$ Microglossa albescens.

ferrugineus, Wendl. in Flora, ii. (1819) $676=$ Olearia dentata.

ficoidea, Harv. in Harv. Es Sond. Fl. Cap. iii. 76.Afr. austr.

filaginifolius, Hook. \& Arn. Bot. Beech. Voy. $146=$ Corethrogyne filaginifolia

filifolius, Vent. Fard. Malm, 82,-Afr, austr.

filifolius, Willd. ex Nees, Gen. et Sp. Aster. $210=$ Felicia muricata.

fliformis, Eckl. ex DC. Prod. v. 218=Mairia taxifolia.

filiformis, Steud. Nom. ed. II. i. 154=Felicia muricata.

firmus, Nees, Syn. Aster. 25.-Am. bor.

Fischeri, E. Forst. ex Forbes, Hort. Woburn. 188.Hab.?

Fischerianus, DC. Prod. v. 247.-Sibir.

flaccidus, Bunge, in Mém. Sav. Etr. Pétersb. ii. (1835) 599.-Sibir

flexuosus, Fisch. in Mém. Soc. Nat. Mosc. iii. (1812) $73=$ Fischerianus

flexuosus, Nutt. Gen. Am. ii. $154=$ tenuifolius.

floribundus, Nutt. l. c. 158.-Am. bor

floribundus, Willd. Sp. Pl. iii. $2048=$ Novi-Belgii

florulentus, F. Muell. Fragm, v, $82=$ Olearia floribunda.

fluminensis, Veli. Fl. Flum. viii. t. 123.-Bras.

foliaceus, Lindl. in DC. Prod. v. 228.-Am. bor. occ.

foliolosus, [Dryand. in] Ait. Hort. Kew. ed. I. iii. 202 = vimineus.

foliolosus, Ell. Sketch, ii, $345=$ dumosus

foliosus, Pers. Syn. ii. $443=$ dumosus.

formosissimus, Hort. ex Heynh. Nom. ii. 51. nomen; Vilm. Fl. Pl. Terre, ed. 1.98.-Hab.

Forsteri, Borr. ex Forbes, Hort. Woburn. 188.Hab. ?

fragilis, Lindl. in Bot. Reg. t. $1587=$ dumosus.

fragilis, Jacq. ex Stend. Nom. ed. I. 82 =linariifolius

fragilis, Nees, Gen. et Sp. Aster. $101=$ vimineus.

fragilis, Schloss. E Vukot. Syll. Fl. Croat. 57.Croatia.

fragilis, Willd. Sp. P1. iii. $2051=$ Tradescanti.
ASTER :-

Fremonti, A. Gray, Syn. Fl, N. Am. i. II. 191.-Am. bor, occ.

frondosus, Torr. E Gray, Fl. N. Am. ii. 165.-Am. bor. occ.

frutetorum, Wimm. ex Nym. Consp. ii. $387=$ salignus fruticosus, Linn. Sp.Pl. 872.-Afr, austr.

fruticulosus, Sims, Bot. Mag. t. $2286=$ pluriflorus.

fruticulosus, Burm. f. Prod. $27=$ Felicia angustifolia.

fruticulosus, Krebs, ex DC. Prod, v. $276=$ filifolius.

fruticulosus, Willd. Sp. Pl. ili. 2018, pro parte = obtusatus.

fruticulosus, Murr. Syst. Veg. ed. XIII. $633=$ frnticosus.

fugax, Brot. Fl. Lusit. $385=$ aragonensis

furfuraceus, A. Rich. \& Lesson, Fl. Nov. Zel. $216=$

Olearia furfuracea.

Gardneri, Baker, in Mart. Fl. Bras. vi. IlI. 25.-Bras.

Garibaldii, Bruegg. in Verh. Schweiz. Naturf. Ges. Samaden, 1863 (1864) $229=$ alpinus.

Gayanus, DC. Prod. v. 227.-Chili.

Gebleri, Bess. ex DC. 1. c. $259=$ altaicus.

Garlachii, Hance, in fourn. Bot. xviii. (1880) 262.China.

giganteus, Hort. ex Vilm. F1. P1. Terre, ed I $928=$ Vernonia noveboracensis.

Gilliesii, Hook. Eూ Arn. in Hook. Comp. Bot. Mag. ii. 1836) 49.-Chili.

glabellus, Nees, Syn. Aster, $31=$ ericoides

glaber, E. Mey. ex Nees, Gen. et Sp. Aster. $68=$ vimineus.

glaber, Mill. Gard. Dict. ed. VIII. n. 17.-Am. bor.

glabriusculus, Torx. \& Gray, Fl. N. Am. ii. $159=$ xylorrhiza.

glacialis, Nutt. in Trans. Am. Phil. Soc. Ser. II. vii. (1841) 291.-Am. bor

glandulosus, Labill. Nov. Holl. Pl. ii. 50. t. $197=$ Olearia glandulosa.

glaucescens, Wender. ex Nees, Gen. et Sp. Aster. 133 $=$ laevis

glaucus, Nees, Syn. Aster. $23=$ laevis

glaucus, Torr. Es Gray, Fl. N. Am. ii. 159.-Am. bor. occ.

glomeratus, Bernh. ex DC. Prod. v. $265=$ macrophyllus.

Glehni, F. Schmidt, Reisen Amurl. 146.-As, or

glutescens, F. Muell. Fragm. v. $77=$ Olearia glutinosa glutinosus, Cav, Ic. ii. $53=$ Grindelia glutinosa.

glutinosus, Roxb. in Beats. App. $303=$ Commidendron rugosum

Gmelini, Ledeb. in Denkschr. Baier. Bot. Ges. iii. (1841) $77=$ Senecio Gmelini.

Gmelini, Tausch, in Flora, xi. (1828) 486=Heteropappus hispidus.

Gmelini, Tausch, 1. c. xxii. (1839) I. $78=$ altaicus.

gracilentus, Banks, ex DC. Prod. v. $327=$ Chrysopsis villosa.

gracilentus, Torr. \& Gray, FI. N. Am, ii. 166=virgatus.

gracilis, Nutt. Gen. Am. ii. 158.-Am. bor

graminifolius, Pursh, F1. Am. Sept. ii. $545=$ Erigeron hyssopifolius.

grandiflorus, Hoffm. Phyt. Blaett. i. (1803) 65.Hab. ?

grandiflorus, Linn. Sp. Pl. 877.-Am. bor.

grandiflorus, Nutt. Gen. Am. ii. $156=$ paludosus

graveolens, Nutt. in Journ. Ac. Nat. Sc. Phil. ii. (1821) $116=$ oblongifolius

gravis, F. Muell. Fragm, v. $82=$ Olearia gravis.

Greenii, Nees, ex Torr. \& Gray, Fl. N. Am. ii. 158:= nemoralis.

Greenii, Torr. \& Gray, 1. c. $134=$ salicifolius.

gummiferus, Hook. f. Ic. Pl. t. 1056=Commidendron spurium.

gymnocephalus, A. Gray, in Proc. Am. Acad. xv. (1880) 32.-Texas: Mexic.

Haenkei, Nees, Gen. et Sp. Aster. 63.-Chili

Hallii, A. Gray, in Proc. Am. Acad. viii. (1872) $388=$ Am. bor, occ.

Hauptii, Ledeb. Fl. Alt. iv. 100.-Sibir.

Hauptii, Turcz. ex DC. Prod. v. $256=$ dahuricus.

Haydeni, Porter, in Hayden, Geol. Rep. 1871 (1872) $485=$ pulchellus.

hebecladus, DC. Prod. v. $242=$ multiflorus

Helenium, Scop. Fl. Carn. ed. II. ii. $171=$ Inula Helenium.

heleophilus, F. Maell. Fragm. v. $66=$ Olearia heleophila. 
ASTER :-

Hersilei, Klatt, Comp. Herb. Schlag. Hochas. 368.As. temp.

Herveyi, A. Gray, Man. Bot. U. St. ed. V. 230.-Am. bor.

hesperius, A. Gray, Syn. Fl. N. Am. i. II. 192.-Am. bor. occ.

heterochaeta, C. B. Clarke, Comp. Ind. $44=$ Heterochaeta asteroides.

heteromallus, Wender. in Schrift. Marb. ii. (1831) vI. $\mathbf{5 4}=$ undulatus

heterophyllus, Nees, Syn. Aster. $15=$ paniculatus.

heterophyllus, Thunb. Prod. P1. Cap. $160=$ Athrixia heterophylla.

heterophyllus, Willd. Sp. P1. iii. $55=$ cordifolius.

heterophyllus, Schloss. E Vukot. Syll. Fl. Croat. 55.Croatia.

Heynei, F. Muell. Fragm. v. $86=$ Olearia xerophila

hiemalis, Nees, Gen. et Sp. Aster. $77=$ longifolius.

himalaicus, C. B. Clarke, Comp. Ind. 43.-Reg. Himal.

hirsuticaulis, Lindl, in DC. Prod. v. $242=$ diffusus.

hirsutus, Host, Fl. Austr, ii. $485=$ alpinus.

hirsutus, Harv. in Harv. E' Sond. Fl. Cap. iii. 80.-Afr austr.

hirtellus, Lindl. in DC. Prod. v. $233=$ sagittifolius.

hirtus, Harv. in Harv. \& Sond. Fl. Cap. iii. 82.-Afr. austr.

hirtus, C. Koch, in Linnaea, xxiii. (1850) 701.Armenia.

hirtus, Scop. F1, Carn. ed. II. ii. $173=$ Inula hirta.

hirtus, Thunb. Prod. Pl. Cap. $159=$ Felicia angustifolia.

hispidus, Baker, in Saund. Ref. Bot. t. 342.-Afr. austr.

hispidus, Lam. Encyc. i. $307=$ puniceus.

hispidus, Thunb. Fl. Jap. $315=$ Heteropappus hispidus.

holosericeus, Forst. f. Prod. 56. n. $296=$ Celmisia holosericea.

homolepis, F. Muell. Fragm. v. $65=$ Olearia homolepis.

Hookerii, Forbes, Hort. Woburn. 189.-Hab.?

horizontalis, Desf. Cat. Hort. Par. ed. III. $402=$ diffusus.

Huegelii, F. Muell. Fragm. v. $79=$ Olearia ciliata.

humilis, Banks \& Soland. ex Hook. f. Fl. N. Zel. i. $125=$ Vittadinia anstralis.

humilis, Willd. Sp. Pl. iii. $2038=$ infirmus.

hungaricus, Poir. Encyc, Suppl. i, $496=$ salignus

Hunnemanni, E. Forst. ex Forbes, Hort. Woburn. 189 -Hab. ?

hybernus, E. Forst. ex Forbes, l. c.-Hab. ?

hydrabadensis, Wall. Cat. n. $2973=$ Pulicaria Wightiana.

hygrophilus, A. Cann. ex DC. Prod. v. $269=$ Olearia hygrophila.

hyssopifolius, Berg. Desc. P1. Cap. $287=$ Felicia angustifolia.

hyssopifolius, Cav. Ic. t. $232=$ sedifolius.

hyssopifolius, Linn. Mant. $114=$ acris.

ibericus, Stev. ex Bieb. Fl. Taur. Cauc, ii. $311=$ A. Amellus.

ignoratus, Kunth E Bouche, Ind. Sem. Hort. Berol. (1845) 11.-Ind. or.

ilicifolius, A. Cunn. ex DC. Prod. v. $268=$ Olearia myrsinoides.

illitus, F. Muell. Fragm. v. $76=$ Olearia elliptica.

imbricatus, Linn. Pl. Rar. Afr. 21.-Afr. austr.

imbricatus, Walp. Rep. ii. $574=$ arenarioides.

inaequalis, Hill, Hort. Kew. 16.-Am. bor.

incanus, A. Gray, in Bot. Calif, i. 322.-Calif, ; Mexic.

incisus, Fisch. in Mèm. Soc. Nat. Mosc, iii. (1812) 76. -Sibir.

inconspicuus, Less. in Linnaea, v. (1830) 143.Mexic.

indicus, Heyne, in Wall. Cat. n. $2971=$ Pulicaria Wightiana.

indicus, Linn. Sp. Pl. $876=$ Boltonia indica

infirmus, Michx. Fl. Bor. Am, ii. 109.-Am, bor.

inflexus, Desf. Tabl. ed. II 122,-Hab.?

integrifolius, Franch. in Mém. Soc. Sc. Nat. Cherb. xxiv. (1884). 224.-China.

integrifolius, Nutt. in Trans. Am. Phil. Soc. Ser. II. vii. (1841) 291.-Am. bor, occ.

intermedius, Turcz. ex DC. Prod, vii. $272=$ Aaccidus. intybaceus, Kunth \& Bouclié, Ind. Sem. Hort. Berol. (1845) 11 =tataricus.

inulaefolius, Boiss. E Bal. ex Boiss. Fl. Orient. iu. 159. -Reg. Caucas.

\section{ASTER}

inuloides, D. Don, Prod. Fl. Nep. $178=$ Erigeron multiradiatus.

inuloides, Fisch. ex DC. Prod, v. 231 = sibiricus.

iodochrous, F. Muell. Fragm, v, $81=$ Olearia iodochroa ircutianus, DC. Prod. v. $229=$ tataricus

italicus, Hill, Veg. Syst. ii. 88.-Italia.

jamaicensis, Less. in Linnaea, v. (1830) 144.-Mexic.

Ind. occ.

japonicus, Less. ex Nees, Gen. et Sp.Aster: 33, 34Japon.

junceus, Ait. Hort. Kew. iii. 204.-Am, bor

junceus, Nees, Syn. Aster. $26=$ tenuifolius.

Kayserianus, Schur, Enum. Pl. Transs. 306.Europ.

Kingii, Eaton, Bot. King, Exp. 141.t, 16.-Am. bor, occ

Kraussii, Harv, in Harv. E Sond.Fl. Cap. iii.84.-Afr. austr.

Kumleini, Fries, ex A. Gray, Syn. F1. N. Am. i. II. 179 $=$ oblongifolius.

lacerus, Lindl. ex DC. Prod, v. $231=$ sibiricus.

lactuarum, Aitch. E Hemsl. in Fourn. Linn. Soc xix (1882) 168.-Afghan.

laetus, Fisch. ex Ledeb. Fl. Ross. ii. $479=$ punctatus.

laevigatus, Hook. Bot. Mag. t. $2995=$ laevis.

laevigatus, Lam. Encyc. i. $307=$ Novi-Belgii

laevigatus, Pursh, F1. Am. Sept, ii. $553=$ longifolius.

laevigatus, Willd. Sp. P1. iii. $2046=$ versicolor

laevis, Lindl, in Bot. Reg. t. $1500=$ versicolor.

laevis, Linn. Sp. Pl. 876.-Am. bor.

laevis, Vahl, ex DC. Prod. v. $23.8=$ longifolius

Laka, C. B. Clarke, Comp. Ind. 49,-Reg. Himal.

Lamarckianus, Nees, Gen. et Sp. Aster. $100=$ panicn. latus.

lanceolatus, Willd. Sp. Pl. iii. $2050=$ paniculatus.

lanceolatus, Nutt. Gen. Am. ii. $158=$ salicifolius.

lanuginosus, Wendl. Beytr. ii. 9.-Afr. austr.

lasiocarpus, Harv, in Harv. E Sond. Fl. Cap. iii. 76.Afr. austr.

lateralis, Hort. Bonn. ex Nees, Gen. et Sp. Aster. $74=$ longifolius.

latifolius, Desf. Cat. Hort. Par, ed. III, $176=$ macro phyllus.

latifolius, Banks, ex Steud. Nom. ed. II. i. $155=$ acuminatus.

latifolius, Mill. Gard. Dict. ed. VIII. n. 26=trinervis? lantureanus, Franch, in Mém. Soc. Sc. Nat. Cherb. xxiv, (1884) 224,-China.

lavandulaceus, Willd. ex DC. Prod.v. 274.-Mexic.

laxifolius, Lindl. in Hook. F1. Bor. Am. ii. $10=$ junceus.

laxifolius, Nees, Gen. et Sp. Aster. $69=$ longifolius.

laxus, Torr. \& Gray, FI. N. Am. ii. 134=Novi-Belgii.

laxus, Willd. Enum. Hort. Berol. ii. $857=$ paniculatus.

ledifolius, A. Cunn. ex DC. Prod, v. $269=$ Olearia ledifolia

ledifolius, Pursh, F1. Am. Sept. ii. $544=$ nemoralis.

ledophyllus, A. Gray, in Proc. Am. Acad. xvi. (1880) $98=$ Engelmanni.

leiocarpus, Harv. in Harv. E Sond. Fl. Cap. iii. 84.Afr. austr.

Lehmanni, F. Muell. Fragm.v. $66=$ Olearia heleophila leiophyllus, Franch. E Sav. Enum. Pl. Fap. i. 223.Japon.

leiophyllus, Schloss. \& Vukot. Syll, FI. Croat, $56=$ salignus.

Lemmoni, A. Gray, Syn. Fl. N. Am. i. I. 199.Arizona.

lepidophyllus, Pers. Syn, ii. $442=$ Olearia lepidophylla. leptophyllus, Desf. Tabl. ed. II. 268; DC. Prod. v. 256. - Am, bor.

leptophyllus, Fisch. Hort. Gorenk. ed. II. (1812) 39 nomen.-Sibir.

leptophyllus, Hort. Par. ex DC. Prod. v. $242=$ ericoides.

Lerchenfeldianus, Schur, Enum. Pl. Transs. 306.Hungar.

leucanthemus, Desf. Cat. Hort. Par. ed. III. $401=$ Tradescanti.

leucanthemus, Rafin. in Med. Repos. N. York, v. (1808) 359.-Am, bor.

liatroides, Mubl. ex DC. Prod. v. $280=$ surculosus.

lilacinus, Hoffmgg. Vers. Pf. 41.-Hab. ?

Lima Lindl in DC Prod. v. 230.-Mexic.

linarifolius, Linn. Sp. Pl. 874.-Am. bor.

Lindeni, Sch. Bip. in Srem. Bot. Voy. Horald, 902.Mexic.
ASTER :-

Lindleyanus, Torr. Gray, Fl. N.Am. i1. 122,-Am. bor.

linifolius, Burm. f. Prod. $27=$ Senecio rosmarinifolius. linifolius, Harv. in Harv. E Sond. Fl. Cap. iii. 81.Afr. austr.

linifolius, Linn. Sp. P1. $874=$ acris.

linifolius, Torr. \& Gray, FI. N. An. ii. $162=$ sube. latus.

linoides, Hort. Gaybac. ex DC. Prod, v. $221=$ Felicia caffrorum.

Linosyris, Bernh. Syst. Verz. Erf. 151.-Europ.

liratus, Sims, Bot. Mag. t. $1509=$ Olearia stellulata lithospermifolius, Desf. Tabl. ed.II. 268; DC. Prod. $259=$ altaicus?

litoralis, Phil. in Anal. Univ. Chil. (1873) 486. Chili.

lividus, E. Forst. ex Forbes, Hort. Woburn. 189. Hab. ?

longicaulis, Desf. ex DC. Prod. v. $253=$ A. Tripolium. ongifolius, Desf. Cat. Hort. Par, ed. III. 400.Hab.

longifolius, A. Gray, Man. Bot. U. St. ed. V. $233=$ Novi-Belgii.

longifolius, Lam. Encyc. i. 306.-Am. bor.

longifolius, Nees, Syn. Aster. $26=$ laxifolius

longipes, Gardn. in Hook. Lond. Joum. Bot. vii. (1848) $78=$ Leucopsis scaposa.

lucidus, Hort. Kew. ex Loud. Hort. Brit. $347=$ laevis.

lucidus, Wender. in Flora, xii. (1829) I. Erg. $25=$ puniceus.

Iucidus, Moench, Meth. Suppl. 252.-Hab.

lusitanicus, Brot. Phyt. 63. 2. $29=$ aragonensis.

lutescens, Torr. \& Gray, Fl. N. Am. ii. 160=ptarmi coides.

luxurians, Spreng. Syst. iii. 538; Nees, Gen. et Sp. Aster. $83=$ Novi-Belgii.

lyratus, Nees, Gen. et Sp. Aster, 188, in syn.=Olearia stellulata.

Maackii, Regel, in Mém. Acad. Pétersb. Sér. VII iv. (1861) D. IV. 81.-Japon.

Macleaii, E. Forst ex Forbes, Hort. Woburen 189.Hab.

macrophyllus, Linn.Sp. Pl. ed. II. ii. 1232.-Am. bor. macrorrhizus, A. Cann. ex DC. Prod. v. $260=$ Vitta dinia macrorrhiza.

macrorrhizus, Thunb. Prod. Pl. Cap, 159-Afr austr. magellanicus, Lam. Illustr, iii. 259 t $681=$ Perezia lactucoides.

magellanicus, Spreng. Syst. iii. $526=$ Chiliotrichium amelloideum.

magniflorus, F. Muell. Fragm. v. $80=$ Olearia magni flora.

marginatus, H. B. E $K$. Nov. Gen. et Sp. iv. 91.-N. Granat.

maritimus, Salisb. Prod. $198=$ A. Tripolinm.

Martii, Baker, in Mart. Fl. Bras. vi. III. 23.-Bras. marylandicus, Michx. F1. Bor. Am. ii. $108=$ Sericocarpus conyzoides.

maximus, Less. Syn. Comp. $182=$ Erigeron maximus.

megalophyllus, F. Muell. Fragm. V. $70=$ Olearia megalophylla.

megapotainicus, Spreng. Syst. iii. 526,-Bms,

Menziesii, Lindl. in DC. Prod. v. 243.-Am, bor. occ. mesopotamicus, Steud. Nom. ed. I. $82=$ megapo tamicus.

mesopotamicus, Spreng. Nachr. i. Bot, Gart. Halle, 13. - Hab.?

mespilifolius, Less. Syn. Comp. $180=$ Nidorella mespilifolia.

microcephalus, Franch. E Sav. Enum. Pl. Fap. 223.-Japon.

microphyllus, Labill. Nov. Holl. Pl. ii, 5l = Olearia lepidophylla.

microphyllus, Torr. ex Lindl. in DC. Prod. $v .2 t t=$ adnatus.

microphyllus, Vent. Jard. Malm. sub t. $83=$ Olearia ramulosa.

microspermus, Harv. in Harv. E Sond. Fl. Cap. iii. $\mathbf{i}^{\circ}$.

- Air. austr.

Milleri, Forbes. Hort. Woburn, 159.-Hate!

mirabilis, Torr. \& Gray, F\%. N. Am. ii. lri5.-Am. bor.

miser, [Dryand. in] Ait. Hort. Kew. ed. I. iii. "21:

Tradesianti.

miser, Lam. Encye. i. $\$ 0 S=$ virgatus

miser, Linn. Sp. Pl. 877 (delend.-C6. A. Lray, Sym. Fl. i. 11. 17, 


\section{ASTER :}

miser, Nutt. Gen. Am. ii. $158=$ diffusus.

Mitchellii, F. Muell. Fragm. v. 78.-Austral

modestus, Lindl. in DC. Prod. v. 231.-Am. bor. occ.

molliusculus, Wall. Cat. n. 2972.-Reg. Himal

monanthus, Vell. Fl. Flum. viii. t. 121.--Bras.

mongolicus, Franch. Pl. Davidian. i. 161.-As. or

monocephalus, Boiss. in Bal. ex Boiss. Fl. Orient. iii.

$160=$ caucasicus.

montanus, All. Fl. Pedem. i. $195=$ Inula montana.

montanus, Nutt. Gen. Am. ii. $155=$ sericeus.

montanus, R. Br. in Richards. App. Frankl. Journ. ed.

I. $749=$ sibiricus.

montevidensis, Griseb. in Goett. Abh. xix. (1874) 170

= Leucopsis diffusa.

monticolus, Lindl. ex DC. Prod. v. $287=$ Erigeron monticolus.

Mooneyi, F. Muell. Fragm. viii. 144.-Austral

moranensis, H. B. E K. Nov. Gen. et $S p$. iv. 93.Mexic.

Muehlenbergii, Tausch, in Flora, xxii. (1839) 77, in adnot, = amplexicaulis.

Muelleri, F. Muell. Census, 78.-Austral.

multiceps, Lindl. in DC. Prod.v. $237=$ oblongifolius

multiflorus, [Dryand. in] Ait. Hort. Kew. ed. I. ii

116. - Am. bor,; Mexic.

multiflorus, Bertol. Misc. Bot. v. t. $5=$ dumosus.

multiflorus, Nutt. Gen. Am. ii. $155=$ vimineus.

multiradiatus, Wall. Cat. n. $2969=$ Erigeron multiradiatus.

muricatus, F. Muell. Fragm. v. $66=$ Olearia muricata.

muricatus, Thunb. Prod. Pl. Cap. $159=$ Felicia muricata.

mutabilis, [Dryand. in] Ait. Hort. Kew. ed. I. iii. 205 $=$ Novi-Belyii.

mutabilis, Vell. Fl. Flum. viii. t. 122.-Bras.

mutabilis, Linn. Sp. Pl. 876 (sp. obscura).- $-\Lambda \mathrm{m}$. bor

mutabilis, Willd. Sp. Pl. iii. $2045=$ versicolor.

mutatus, Torr. \& Gray, F1. N. Am. ii. 142=modestus.

myriantus, Carr. in Rev. Hortic. (1866) 439,-Hab.?

myrsinoides, Labill. Nov. Holl. Pl, ii. 53. t. $202=$

Olearia myrsinoides.

myrtifolius, Willd. Enum. Hort. Berol. Suppl. $59=$ miser.

namaquanus, Harv. in Harv. E Sond. Fl. Cap. iii. 79 - Afr. austr.

nanus, E. Mey. ex DC. Prod. v. $218=$ Mairia microcephala.

natalensis, Harv. in Harv. E Sond. Fl. Cap. iii. 81.Afr. austr.

Neesii, Sch. Bip. in Flora, xxxix. (1856) $354=$ Chamissonis.

nemoralis, [Dryand. in] Ait. Hort. Kew. ed. I. iii. 198. -Am. bor.

Nernstii, F. Muell. Fragm. v. $81=$ Olearia Nernstii nervosus, Mill. Gard. Dict. ed. VIII. n. 23.-Am. bor nitidulus, DC. in Wight, Contrib. 9.-Ind. or.

nivalis, Adam, in Weber \& Mohr, Beitr, i. $67=$ alpinus.

Noëanus, Sch. Bip. ex Nym. Consp. $387=$ A. Amellus.

notosericeus, Griseb. in Goett. Abh. xxiv. (1879) 178.Reg. Argent.

Nova-Angliae, Linn.Sp. Pl. 875.-Am. bor.

Novae-Scotiae, Forbes, Hort. Woburn. 189; Steud.

Nom. ed. II. i. 156.-N. Scotia.

Novi-Belgii, Linn.Sp.Pl. 877.-Am. bor.

nudicaulis, Lam. Encyc. i. 308=Lagenophora Commersonit.

nudiflorus, Nutt. Gen. Am. ii. 157=A. Radula.

Nuttallii, Torr. \& Gray, Fl. N. Am. ii. 126=adscendens.

obcordatus, F. Muell. Fragm.v. $69=$ Olearia obcordata

obliquus, DC. Prod. v. $237=$ carneus.

obliquus, Nees, Syn. Aster. $27=$ salicifolins.

oblongifolius, Nutt. Gen. Am. ii. 156.-Am. bor

obovatus, Ell. Sketch, ii. $368=$ reticulatus.

obovatus, C. A. Mey. in Ledeb. Fl. Ait. iv. 95.-Sibir. altaic.

obtusatus, Thunb. Prod. Pl. Cap. 159.-Afr. austr.

occidentalis, Tor\%. Es Gray, $\mathrm{Fl}$. N. Am. ii. 164.-Am. bor, occ.

ochraceus, H. B. \& K. Nov. Gen. et Sp iv. $94=$ Tetramolopium ochraceum.

Oculus-Christi, Cav, ex Steud. Nom. ed. II. i. $156=$ Inula Oculus-Christi.

odontophyllus, Wall. Cat. n. $3285=$ Senecio linifolius.

odorus, All. Fl. Pedem. i. 197.-Italia.

officinalis, All. 1. c. $194=$ Inula Helenium

\section{ASTER :-}

oliganthemus, F. Muell. Census, 78.-Austral.

onustus, Nees, Gen. et Sp. Aster. $122=$ Novi-Belgii.

oolentangiensis, Riddell, Syn. Fl. W. States, 55= azureus.

oppositifolius, Linn. Amoen. Acad. v. $369=$ Cymbalariae.

orarius, F. Muell. Fragm. v. $78=$ Olearia glutinosa.

oreganus, Torr. छ Gray. Fl. N. Am. ii. 163.-Am.

bor occ.

rientalis, S. G. Gmel. It. i. 155. t. 36. f. $1=$ Inula

britannica.

ornatus, Hort. Angl. ex Steud. Nom. ed. II. i. $156=$ Herveyi.

Ottonis, E. Forst. ex Forbes, Hort. Woburn, 189.-

Hab.?

pallens, Willd. Enum. Hort. Berol. Suppl. 58= patulus.

pallidulus, B. C. Vog. in Trew, P1. Rar. t. $28=$ cor difolius.

Palmeri, A. Gray, in Proc. Am. Acad. xvii. (1881-82) 209.-Texas.

paludosus, [Dryand. in] Ait. Hort. Kew. ed. I. iii. 201. -Am bor.

palustris, Lam. F1. Fr. ii. $143=$ A. Tripolium.

panduratus, Nees, ex Walp. in Nov. Act. Nat. Cur xix. Suppl. i. (1843) 258.-China.

paniculatus, [Dryand. in] Ait. Hort. Kew. ed. I. iii. $207=$ Lindleyanus

paniculatus, Lam. Encyc. i. 306.-Am. bor

paniculatus, Mill. Gard. Dict. ed. VIII. n. 24.-Hab.

paniculatus, Muhl. in Ell. Sketch, ii. $365=$ sagitti folius.

paniculatus, Nutt. Gen. Am. ii. $156=$ undulatus.

paniculatus, Willd. Sp. Pl iii. $2035=$ cordifolins

pannonicus, Jacq. Hort. Vindob. i. $3=$ A. Tripolium.

pannosus, F. Muell. Fragm. v. $83=$ Olearia pannosa.

Pappei, Harv. in Harv. E Sond. Fl. Cap. iii. 79.-

Afr. austr.

papposus, Willd. ex Spreng. Syst. iii. 525=Printzia Bergii.

Parryi, A. Gray, in Am. Natural. viii. (1874) 212.Am. bor. occ.

parviflorus, A. Gray, in Bot. Calif. i. 322.-Mexic.

parviflorus, Darlingt. Fl. Cestr. 446 =diffusus.

parviflorus, Nees, Syn. Aster, $29=$ Tradescanti.

patens, [Dryand. in] Ait. Hort. Kew. ed. I. iii. 201.-

Am. bor.

patentissimus, Lindl. in DC. Prod. v. $232=$ patens

Pattersoni, A. Gray, in Proc. Am. Acad. xiii. (1878) 272.-Colorado.

patulus, Lam. Encyc, i. 308.-Am. bor.

paucidentatus, F. Muell. Fragm. v, $66=$ Olearia paucidentata.

pauciflor us, Lindl. ex DC. Prod, v, 231=sibiricus.

pauciflorus, Martens, in Bull. Acad. Brux. viii. (1841) $67=$ ericoides.

pauciflorus, Nutt. Gen. Am. ii. 154.-Am. bor.; Mexic peduncularis, Wall. Cat. n. $2967=$ asperulus.

pellitus, $H . B$. \& $K$. Nov. Gen. et Sp. iv. 91.-

N. Granat.

pendulus, [Dryand. in] Ait. Hort. Kew. ed. I. iii. 205 $=$ diffusus.

pensilvanicus, Poir. Encyc. Suppl. i. $498=$ laevis.

peregrinus, Less. in Linnaea, vi. (1831) $123=$ folia ceus.

peregrinus, Pursh, Fl. Am. Sept. ii. 556.-As. or.; Am. bor. arct.

perezioides, Less. Syn. Comp. $167=$ Mairia perezioides.

persoonioides, A. Cunn. in DC. Prod. v. $267=$ Olearia persoonioides.

pesthiensis, $D C$. Prod. v. 237.-Hungar.

petiolatus, Harv. Thes. Cap. ii. 35.t. 154.-Afr, austr

philadelphicus, Bart. Fl. Phil. Prod. 81.-Am. bor.

phlogifolius, Muhl. in Willd. Sp. Pl. iii. 2034= patens.

phlogopappus, Labill. Nov. Holl. P1. ii. 49. t. $495=$ Olearia stellulata

phlogotrichus, Spreng. Syst. iii. $525=$ Olearia stellulata.

phylicoides, H. B. \& K. Nov. Gen. et Sp. iv. $98=$ Tetramolopium phylicoides.

phyllolepis, Torr. E Gray, Pl. N. Am. ii. 113.-Am bor

pichinchensis, Willd, ex Nees, Gen. et Sp. Aster. 203 ='Tetramolopium tenerrimum.

pilosus, Willd. Sp. Pl. iii. $2025=$ ericoides.

\section{ASTER :}

pimeleoides, A. Cunn. in DC. Prod, v. 268=Olearia pimeleoides.

pinifolius, F. Muell. Fragm, v. $71=$ Olearia pinifolia. pinifolius, Nees, Syn. Aster. $29=$ polyphyllus.

pinnatus, Cav. Ic. iii. 6. t. $212=$ Dyssodia pubescens. plantagineus, Poepp. ex DC. Prod. v. $418=$ Senecio plantagineus.

plantaginifolius, Nutt. ex Nees, Gen, et Sp. Aster, 299 = Sericocarpus conyzoides.

pluriflorus, G. Don, in Loud. Hort. Brit. 346.-Afr. austr.

Pohlii, Baker, in Mart. Fl. Bras. vi. III. 23.-Bras.

polifolius, Linn. $S p$. Pl. ed. II. $1224=$ Printzia Bergii

politus, Nees, Syn. Aster. $23=$ laevis.

polyphyllus, Moench, Meth. Suppl. $253=$ macrophyllus. polyphyllus, Pursh, ex DC. Prod. v, $245=$ tenuifolius,

polyphyllus, Willd. Enum. Hort. Berol. 888.Am. bor.

Porteri, A. Gray, in Proc. Am. Acad. xvi. (1880) 99 -Am. bor. occ.

potosinus, A. Gray, l. c. xv. (1880) 32.-Mexic.

pradensis, Phil in Linnaea, xxviii. (1856) 729.Chili.

praealtus, Torr. \& Gray, F1. N. Am. ii. $134=$ Novi Belgii.

praealtus, Poir. Encyc. Suppl. i. $493=$ salicifolius

praecox, Lindl, in Hook. Fl. Bor. Am. ii. $9=$ Lindleyanus.

praecox, Mill. Gard. Dict. ed. VIII. n. $19=$ pyrenaeus.

praecox, Willd. Enum. Hort. Berol. Suppl. $58=$ patulus.

pratensis, Rafin. Fl. Ludov. 67.-Am. bor.

Preissii, F. Muell. Fragm. v. $66=$ Olearia heleophila. prenanthoides, Muhl in Willd. Sp. Pl. iii. 2046.Am. bor.

Prescottii, Lindl. in DC. Prod. v. $231=$ sibiricus.

procumbens, Mill. Gard. Dict. ed. VIII. n. 32.Mexic.

propinquus, A. Cunn. ex DC. Prod. v. $270=$ Olearia ramulosa.

pseudamellus, Wender. in Schrift. Marb. ii. (18 1) 226 = amelloides.

pseudamellus, Hook. f. Fl. Brit. Ind. iii. 249.Ind. or.

pseudoamellus, DC. Fl. Fr. Suppl. v. $469=$ A Amellus.

pseudodiffusus, E. Forst. ex Forbes, Hort. Woburn. 189.-Hab. ?

pseudodumosus, E. Forst, ex Forbes, l. c.-Hab. ?

ptarmicoides, Torr. E Gray, Fl. N. Am. ii. 160.Am, bor.

pubescens, Hornem. Hort. Hafn. Suppl. $98=$ heterophyllus.

pubescens, Lam. Encyc. i. $307=$ tataricus

pubescens, Moench, Meth, $600=$ Inula squarrosa

pubescens, Nees, Syn. Aster. $16=$ sagittifolius.

prichellus, Eaton, in Bot. King, Exp. 143. t. 16.Am. bor. occ.

pulchellus, Hohen, in Bull. Soc. Nat. Mosc. vi. (1833) $255=$ alpinus

pulchellus, Willd. Sp. P1. iii. $2019=$ Erigeron pulchellus.

pulchellus, Turcz. ex Herd. in Bull. Soc. Nat. Mosc. xxxviii, $(1865)$ I, $376=$ flaccidus.

pulcherrimus, Lodd. Bot. Cab, i, t. $6=$ linariifolius.

Pulicaria, All. Fl. Pedem. i. $197=$ Pulicaria vulgaris.

pulicarius, Scop. Fl. Carn. ed. II. ii. $172=$ Pulicaria vulgaris.

pulverulentus, Hoffmgg. Verz. Pfl. Nachtr. i. (1824) $165=$ Olearia stellulata.

pumilus, Banks \& Soland. ex Hook, f. FI. N. Zeal. i. $125=$ - Vittadinia australis.

pumilus, Fisch. Cat. Hort. Gorenk. (1808) 62; ed II. 1812) $39=$ altaicus

punctatus, Lapeyr. Hist. Abr. Pl. Pyr. 513= Jasione tuberosa.

punctatus. Waldst. \& Kit. Pl. Rar. Hung. ii. t. $109=$ acris.

puniceus, Ell. Sketch, ii. $255=$ Elliottii

puniceus, Linn. Sp. Pl. 875.-Am. bor.

purpurascens, Sch. Bip. in Seem. Bot. Voy. Herald, 156.-Mexic

purpuratus, Nees, Gen. et Sp. Aster. $118=$ virgatus. purpureo-caerulescens, Hill, Hort. Kew. 17.-Am. bor. purpureus, Gueldenst. ex Ledeb. F1. Ross. ii. $477=$ A. Amellus?

purpureus, Facq. ex Steud. Nom. ed. I. 83.-Hab.? 


\section{ASTER :-}

pusillus, Hornem. Hort. Hafn. ii. 812.-Hab. ? pygmaeus, Lindl. in DC. Prod. v. 228.-Am. arct, pyrenaeus, DC.Fl. Fr. iv. 146.-Mont. Pyren. pyrenaicus, Pourr. in Mém. Acad. Toul. iii. (1788) 308 = Erigeron uniflorus.

pyrrhopappus, Boiss. Fl. Orient. iii. 158.-Afghan. quercifolius, Less. ex Walp. Rep. vi. $123=$ Erigeron quercifolius.

quercifolius, Sieber, ex DC. Prod. v. $272=$ Olearia stellulata.

quitensis, Willd. ex Spreng. Syst. iii. 533.-Ecuador.

racemosus, Ell. Sketch, ii. 348 -Am. bor.

Radula, [Dryand. in] Ait. Hort. Kew. ed. I. iii. 210.Am. bor.

Radula, Less. in Linnaea, vi. (1831) $125=$ Chamissonis.

radulinus, A. Gray, in Proc. Am. Acad. viii. (1872)

388.-Am. bor. occ

ramosissimus, Mill. Gard. Dict. ed. VIII. n. $21=$ ericoides.

ramosus, G. Don, in Loud. Hort. Brit. 346.-Am. bor.

ramulosus, Labill. Nov. Holl. Pl. ii. $51=$ Olearia ramulosa.

ramulosus, Lindl. in DC. Prod. v. $243=$ falcatus.

ramulosus, Nutt. in Trans. Am. Phil. Soc. Ser. II. vii.

(1841) 293 = adscendens.

ranunculoides, Moench, Meth. Suppl. 254,-Hab.?

recurvatus, Guenth. ex Nees, Gen. et Sp. Aster. $97=$

bellidiflorus.

recurvatus, Nees, 1 . c. $93=$ tenuifolius

recurvatus, Pursh, F1. Am. Sept. ii. $556=$ Tradescanti.

recurvatus, Spreng. in Schrad. Journ. Bot. (1800) 195 $=$ squarrulosus.

recurvatus, Willd. Sp. Pl. iii. $2047=$ diffusus,

reflexus, Linn. Sp. Pl. $877=$ Felicia reflexa.

regalis, Salisb. Prod. $198=$ Callistephus hortensis,

Regnellii, Baker, in Mart. Fl. Bras. vi. III. 21.Bras.

repens, H. B. \& K. Nov. Gen. et Sp. iv. 90. t. 332.N. Granat.

reticulatus, Pursh, Fl. Am. Sept. ii. 548.-Am. bor.

retroflexus, A. Cunn. ex Hook. f. Fl. N. Zeal. i. $148=$ Senecio glastifolius.

retroflexus, Lindl. in DC. Prod. v. 242,-Am. bor. Reversi, Hort. ex Decne. in Rev. Hortic. Sér. IV. i $(1852) 181=$ ericoides.

revolutus, $F$. Muell. Census, 78.-Austral.

rhomboideus, Lindl. ex DC. Prod. v. $230=$ tataricus.

Richardsonii, Spreng. Syst. iii. $528=$ sibiricus.

rigidulus, Desf. Tabl. ed. II. $122=$ salicifolins.

rigidulus, Nees, Syn. Aster. $29=$ leucanthemus,

patulus.

rigidus, Linn. Sp. Pl. 874 (ex parte)=linariifolius.

rigidus, Moench, Meth. Suppl. 251=Inula salicina.

riparius, H.B. \& K. Nov. Gen.et Sp. iv. 92.-Arizona ; Mexic.

riparius, Nees, Gen. et Sp. Aster. $280=$ pesthiensis.

rivularis, Cass. ex Loud. Hort. Brit. 347.-Am. bor

rivularis, Less, in Linnaea, v. (1830) $148=$ Erigeron repens.

robustus, Hort. Bonn. ex Nees, Gen. et Sp. Aster. 282 $=$ strictus.

robustus, Hort. ex Nees, 1. c. $300=$ salicifolius.

roseus, Bieb. ex Stev. in Mém. Soc. Nat. Mosc. iii. (1812) 245.-Reg. Caucas.

roseus, Desf. Cat. Hort. Par, ed. III. $401=$ NovaeAngliae.

rosmarinifolius, A. Cunn. ex DC. Prod. v, 268= Olearia rosmarinifolia.

rosmarinifolius, Spreng. Syst. iii. $526=$ obtusatus.

rotundifolius, Thunb. Prod. Pl. Cap. 160.-Afr. austr.

Roxburghii, Hook. f. in Hook. Ic. Pl, xi. $45=$ Commidendron robustum.

ruber, Forbes, Hort. Woburn. 189.-Hab. ?

rubicundus, Forbes, l. c.-Hab. ?

rubricaulis, Lam. Encyc, i. $305=$ laevis

rufbarbis, Harv. in Harv. \& Sond. Fl. Cap. iii. 76.Afr. austr.

rugulosus, Maxim. in Bull. Acad. Petersb. xv. (1871) 226, 220.-Japon.

rupestris, H. B. \&c K. Nov. Gen. et Sp. iv. $94=$ Tetramolopium rupestre.

rutacodorus, A. Cunn. ex DC. Prod. v. $269=$ Oleatia glandulosa.

sagittifolius, Ell. Sketch, ii. 262 = undulatus.

\section{ASTER :-}

agittifolius, Wedem. ex Willd. Sp. Pl. iii. 2035.Am. bor.

salicifolius, Ait. Hort. Kew. iii. 203; Lam. Encyc. i. 306.-Am. bor.

salicifolius, Nees, Syn. Aster. $26=$ longifolius

salicifolius, Richards. App. Frankl. Journ. ed. I. $748=$ junceus.

salicifolius, Scholl. Fl. Barb. Suppl. 328=panicnlatus.

salicinus, Nees, Gen. et Sp. Aster. 171, in syn.= salignus.

salicinus, Scop. Fl. Carn. ed. II. ii. $172=$ Inula salicina.

salignus, Willd. Sp. Pl, iii. $2040=$ paniculatus.

salinus, Schrad. Hort. Gotting. $9=\mathrm{A}$. Tripolium.

salsuginosus, Hook. Fl. Bor. Am. ii. 6, partim= peregrinus.

salsuginosus, Less. in Linnaea, vi. (1831) $124=$ sibiricus.

salsuginosus, Richards, ex R. Br. in App. Frankl. Journ. ed. T. $749=$ Erigeron salsuginosus.

sanguineus, Willd. ex Spreng. Syst. iii. 533=paniculatus.

satureiaefolius, Banks, in Reliq. Houston. t. $19=$ Pectis satureioides.

Sayianus, Nutt. in Trans. Am. Phil. Soc. Ser. II. vii. (1841) $294=$ modestus

scaber, Ell. Sketch, ii. $363=$ undulatus.

scaber, Moench, Meth. Suppl. 253.-Hab.

scaber, Thunb. Fl. Fap. 316.-Japon.

scaberrimus, Less. in Linnaea, v. (1830) 143.Mexic.

scaberulus, Miq. in Fourn. Bot. Néerl. i. (1861) 100.China.

scabridus, E. Mey. ex DC. Prod. v. 225.-Afr. austr.

scabridus, Hook. f. \& Thoms, ex C. B. Clarke, Comp. Ind. $47=$ trinervius.

scabris, Mill. Gard. Dict. ed. VIII. n. 16=alpinus.

scabrosus, Bertol. Misc. Bot. vi. $29=$ Sericocarpus tortifolius.

scandens, Jacq. f. ex Spreng. Syst. iii. $524=$ carolinianus.

scapigerus, Ledeb. Fl. Ross. ii. 472.-Sibiria.

scaposus, Klatt, in Sitzb. Akad. Muench. (1878) $84=$ molliusculus.

scepusiensis, Kit. in Linnaea, xxxii. (1863) $373=\mathbf{A}$. Amellus.

Schreberi, Nees, Syn. Aster. $16=$ macrophyllus.

scoparius, DC. Prod. จ. $242=$ multiflorus

scoparius, Nees, Syn. Aster. $28=$ diffusus, Tradescanti

scopulorum, A. Gray, in Proc. Am. Acad. xvi. (1880) 98.-Am. bor. occ.

scorpioides, Scop. Fl. Carn. ed.II. ii. $169=$ Doronicum scorpioides.

scorzonerifolius, Regel, Gartenfi. (1873) 1; et in Act. Hort. Petrop. ii. (1873) 308.-Mexic.

secundiflorus, Desf. Tabl. ed. II. $268=$ vimineus.

secundirameus, Zeyh. ex Sch. Hip. Tanacet. $20=$ Matricaria nigellaefolia.

sedifolius, Linn. Sp. Pl. $874=$ acris.

seliger, Nees, in Neuwied, Reise Nord. Am. ii. $439=$ diffusus.

sericeus, Vent. Fard. Cels, t. 33.-Am. bor.

serotinus, Willd. Sp. Pl. iii. $2049=$ Novi-Belgit.

serratifolius, Schloss. \& Vukot. Syll. Fl. Croat. 57

paniculatus.

serratus, Lag. ex DC. Prod. v. $315=$ Grindelia inoloides.

serratus, Thunb. Prod. Pl. Cap. 160.-Afr. anstr.

serrulatus, Harv. in Harv. E Sond. F\%. Cap. iii. 73.Afr. austr.

sessilifolius, Fisch. ex Steud. Nom. ed. II. i. 157.Am. bor.

setosus, Baker, in Mart. Fl. Bras. vi. III. 22.-Bras.

shastensis, A. Gray, in Bot. Calif. i. 322 .-Calif.

Shortii, Lindl. ex Hook. Fl. Bor. Am. ii. 9 ; Riddell, Syn. Pl. W. States, 55.-Am. bor.

sibiricus, Lam. Encyc. i. $305=$ pyrenacus.

sibiricus, Linn. Sp.Pl. 872.-Sibir.; Am. bor. occ.

sibiricus, Turcz. ex Tors. \& Gray, Fl. N. Am. ii. 107 $=$ montanus.

Siemsenii, F. Muell. Fragm. v. $71=$ Olearia viscidula, sikkimmensis, Hook.f. E Thoms. in Bot. Mag.t. 4557 . -Ind. or.

silenifolius, Turcs, in DC. Prod. v. 227.-Sibiria.

simplex, Eaton, in Bot. King, Exped. $140=$ oreganus.
ASTER :-

simplex, Willd. Enum. Hort. Berol. $887=$ paniculatus.

simulans, Harv. in Harv. E Sond. Fl. Cap. iii. 73.Afr. austr.

sinuatus, A. Cann. ex DC. Prod. v. $272=$ Olearia quercifolia.

Solandri, E. Forst. ex Forbes, Hort. Woburn. 189.Hab.?

solidagineus, Michx. ex Willd. Sp. P1. iii. $2024=$ Sericocarpus solidagineus.

solidaginoides, Pers. Syn. ii. $443=$ Sericocarpas solidagineus.

Sonderi, F. Muell. Fragm. v. $83=$ Olearia grandiflora.

Sonorae, A. Gray, Pl. Wright. ii. $76=$ riparius.

sparsiflorus, Michx. Fl. Bor. Am. ii. $112=$ dumosus.

sparsiflorus, Pursh, Fl. Am. Sept. ii. $547=$ tenuifolius.

spartioides, C. B. Clarke, Comp. Ind, $46=$ altaicus

spathularis, Brouss. ex DC. Prod. v. $315=$ Grindelia inuloides.

spathulatus, Hort. ex Steud. Nom. ed. II. i. $157=$

Inula salicina.

spathulatus, Lag. ex Nees, Gen. et Sp. Aster. $283=$

Grindelia inuloides.

spathulatus, Lindl. in DC. Prod.v. 231.-Am. arct.

spathulifolius, Maxim. in Bull. Acad. Pétersb. xvi. (1871) 216.-Japon.

speciosus, Hornem. Hort. Hafn. ii. $816=$ spectabilis.

spectabilis, [Dryand.in] Ait. Hort.Kew.ed. I. iii. 209. - Am bor.

spectabilis, Hook. \& Am. Bot. Beech. Voy. 146=

Chammissonis.

spectabilis, Willd. Sp. Pl. iii, $2048=$ Novi-Belgii.

spinosus, Benth. Pl. Hartw. 20-Am. bor. ; Mexic.

spinulosus, Chapm. Fl. S. U. St. 199,-Florida.

spurius, Willd. Sp. Pl. iii. $2032=$ Novae-Angliae

squarrosulus, Nees, Gen. et Sp. Aster. $86=$ longifolius.

squarrosus, All. Fl. Pedem. i. 196=Inula spiraeifolia. squarrosus, Banks, ex Steud. Nom. ed. II. i. $157=$ linariifolius.

squarrosus, Walt. Fl. Carol. 209-Carolina.

Steetzii, F. Muell. Fragm. v. $66=$ Olearia strigosa

stellulatus, Labill. Nov. Holl. Pl. ii. 50.t. $196=$ Olearia stellulata.

stenomeres, A. Gray, in Proc.Am. Acad. xvii. (1881-82) 209. - Am, bor. occ.

stenophyllus, Lindl, in DC. Prod. $\nabla .242=$ salicifolius.

Stracheyi, Hook. f. Fl. Brit. Ind. iii. 250,-Reg. Himal.

striatus, Champ.ex Benth. in Hook. Kew Fourn. iv, (1852) 233.-China.

strictus, Poir. Encyc. Suppl. i. $498=$ paniculatus.

strictus, Pursh, Fl. Am. Sept. ii. $556=\mathrm{A}$. Radula,

strictus, Wender, in Schrift. Marb. ii. (1839) v1. $54=$ dracunculoides.

strigosus, Lichtenst.ex Hary. E Sond. Fl. Cap. iii. 83. -Afr. austr.

strigosus, Thunb. Prod. PI. Cap. $159=$ Amellas annuas

Stuartii, F, Muell. Fragm, vo $76=$ Olearia Stuartii.

subasper, Lindl. ex Hook. Comp. Bot. Mag. i. (1835 $97=$ salicifolius.

subcymosus, Bernh. ex Nees, Gen. et Sp. Aster. 198= macrophyllus.

subspicatus, Nees, 1. c. $7 t=$ Douglasii.

subulatus, Hort. ex Stend. Nom. ed. II. i. $157=$ ericoides.

subulatus, Michx. Fl. Bor. Am. ii. 111.-Am. bor. succulentus, Gilib. Exercit. i. $174=\mathbf{A}$. Tripolium. surculosus, Michx. Fl. Bor. Am. ii. 113.-Am. bor. tanacetifolius, H. B. E K. Noo. Gen. ef Sp. iv. 95.Calif.: Mexic.

tardiflorns, Linn. Sp. Pl ed. II. 1291.-Am. bor. tardiflorus, Willd. Sp. Pl. iii. $2049=$ Novi-Belgii. tataricus, Lisn. f. Suppl. 379.-Tataria.

tataricus, Turez. in liull. Soc Nat. Muse (1S35) 91 sibiricus.

taxifolius, Linn. Pl. Afr. 22; Amoen. Acad. vi. 102 Maria taxifolia.

terellus, Linn. It. ce. = Felicia fragilis

tenellus, Thund. F\%. Cap. 686. - Mfr. austr.

tener, Haro in Hart. G Sond. Fl. Cop. iii. 80.-Arr, austs.

cenerrimus, Less in Linnaen, iv. $(10290120=$ Tetramolopium tencrimum. 


\section{ASTER :}

tenue, Kellogg, in Proc. Calif. Acad. vii. (1877) 114 -Calif.

tenuiculus, Bart. Fl. Phil. Prod. 81.-Am. bor.

tenuifolius, Ell. Sketch, ii. $347=$ vimineus.

tenuifolius, Linn. Sp. Pl. 873-Am. bor

tenuifolius, Nees, Syn. Aster. 119, partim = polyphyllus.

tenuifolius, Willd. Sp. P1. iii. $2026=$ ericoides.

tenuis, Less. ex Ledeb. Fl. Ross. ii. 483.-Rossia

teretifolius, F. Muell. Fragm. v. $77=$ Olearia teretifolia.

Thomsoni, C. B. Clarke, Comp. Ind. 48.-Reg. Himal.

thyrsiflorus, Hoffm. Phyt. Blaett. i. (1803) $83=$ Novi-Belgii

tibeticus, Hook. f. Fl. Brit. Ind. iii. 251.-Tibet. occ.

Tilesii, Wichstr. in Nya Handl. Stockh. (1822) $13=$ peregrinus.

tinctorius, Wallr, Beitr. Fl. Hercyn. 271 ; et in Linnaea, xiv. (1840) 641. =A. Amellus.

tomentellus, Hook. \& Am. Bot. Beech. Voy. 146= Corethrogyne filaginifolia.

tomentosus, Schrad. in WendI. Sert. Hann. 8. t. $24=$ Olearia dentata.

tortifolius, A. Gray, in Proc. Am. Acad. vii. (1868) 353.-Am. bor. occ

tortifolius, Michx. Fl. Bor. Am. ii. $109=$ Sericocarpus tortifolius.

Townshendii, Hook. f. Bot. Mag. t. $6430=$ Bigelovii.

Tradescanti, Hoffm. Phyt. Blaett. i. (1803) 68. t. A. f. 2 $=$ patulus.

Tradescanti, Linn. Sp. Pl. 876.-Am. bor.

Tradescanti, Michx. F1. Bor. Am. ii. 118=diffusus.

Tradescanti, Nees, Syn. Aster. 28 = paniculatus.

trianthus, Vell. Fl. Flum. viii. t. 120.-Bras.

tricephalus, C. B. Clarke, Comp. Ind. 43.-Reg. Himal.

tricolor, Spreng. in Flora, xiii. (1830) I. Beil. 15 nomen.-Afr. austr.

trifurcatus, Banks \& Soland. ex Hook. f. F1. Antarct. ii. $317=$ Senecio trifurcatus

trilineatus, Sch. Bip. ex Klatt, in Leopoldina, xx. (1884) 91--Mexic.

trinervifolius, Less. in Linnaea, ix. (1834) $183=$ paniculatus.

trinervis, Desf. Tabl. ed. II. 122.-Gallia.

trinervis, Ruiz \& Pay. ex DC. Prod. vii. 22 (=Dia zenxis trinervis).--Peruv.

trinervius, Gilib. Fl. Lithwan, iii, 214=A. Amellus,

trinervius, Raxb. Hort. Beng. 61; Fl. Ind. iii. 433.Reg. Himal.

Tripolium, Linn. Sp. Pl. 872.-Europ.; Afi. bor. Oriens; As, bor.

Tripolium, Walt. FI. Carol. $209=$ tenuifolius

tubuliftorus, F. Muell, Fragm,v, $65=$ Olearia tubuliflora.

turbinatus, S. Moore, in Fourn. Bot. xvi. (1878) 132. -China.

turbinellus, Lindl. ex Hook. Comp. Bot. Mag. 1. (1835) 98.-Am bor.

Turczaninowii, F. Muell. Fragm. $\nabla .67=$ Olearia imbricata.

turkestanicus, Franch. in Ann. Sc. Nat. Sér. VI. xvi (1883) 303.-Turkestan.

umbellatus, Mill. Gard, Dict. ed. VIII. n. 22.-Am bor.

unalaschkensis, Less, in Linnaea, vi. (1831) $122=$ peregrinus.

unalaschkensis, Less. ex Bong. Veg. Isl. Sitcha, 148 $=$ salsuginosus

unctuosus, Steud. Nom. ed. II. i. $157=$ Novi-Belgii.

undulatus, Ell. Sketch, ii. $361=$ patens.

undulatus, Linn. Sp. Pl. 875. -Am bor

undulatus, Moench, Meth. $600=$ Inula britannica.

uniflorus, Michx. Fl. Bor. Am. ii. $110=$ nemoralis

uniflorus, Moench, Meth. $602=$ Novi-Belgii.

urophyllus, Lindl. in DC. Prod. v. $233=$ sagittifolius.

vagans, E. Forst. ex Forbes, Hort. Woburn. 190 Hab. ?

Vaillantii, All. Fl. Pedem, i. $196=$ Inula Vaillantii.

Vahlii, Hook. E Arn. in Hook. Comp. Bot. Mag. ii. (1836) 49,-Chili.

vernicosus, F. Muell. Fragm, v. $67=$ Olearia passeri noides.

vernus, Linn. Sp. Pl. $876=$ Erigeron nudicaulis.

versicolor, Hort. ex Steud. Nom. ed. II i. $157=$ mutabilis.

\section{STER :-}

versicolor, Willd. Sp. Pl. iii. 2045.-Am, bor.

villosus, Sch. Bip. in F. Schultz, Arch. Fl. 130.Europ.

villosus, Michx. Fl, Bor. Anr, ii. $113=$ ericoides.

villosus, Thunb. Prod. Pl. Cap. $159=$ Felicia angustifolia.

vimineus, Lam. Encyc. i. 306.-Am. bor.

vimineus, Nees, Gen. et Sp. Aster. $68=$ tardiflorus.

vimineus, Willd. Sp. Pl. iii. $2046=$ virgatus.

virgatus, Ell. Sketch, ii. 353.-Am. bor:

virgatus, Moench, Meth. Suppl. $250=$ tennifolius.

virgatus, Nees, Syn. Aster, $27=$ salicifolius.

virgineus, Nees, 1. c. 22 =longifolius.

viscosus, Labill. Nov. Holl. Pl. ii. $53=$ Olearia vis. cosa.

Walpersianus, Nees, in Nov. Act. Nat. Cur. xix Suppl. i. (1843) 259-China.

Warmingii, Baker, in Mart. Fl. Bras. vi. III. 23.-Bras.

Watsoni, A Gray, Syn. Fl. N. Am i. II. 201.-Am.

bor. occ

Willdenovii, E. Forst. ex Forbes, Hort. Woburn. 190. - Hab. ?

Willkommii, Sch. Bip. ex Willk. in Flora, xxxiv. (1851) 742.-Hispan.

Wolfii, Favrat, in Bull. Soc. Murith. vii-viii. (1879) 4 $=$ alpinus.

Wrightii, A. Gray, Pl. Wright. ii. 75.-Mexic. ; Texas. xerophilus, F. Muell. Fragm, v. $76=$ Olearia xerophila. xylorrhiza, Torr. E Gray, Fl. N. Am. ii. 158.-Am. bor. occ.

Zeyheri, Less. Syn. Comp. $177=$ Felicia Zeyheri.

ASTERACANTHA, Nees, in Wall. Pl. As. Rar. iii. 75 (1832) = Hygrophila, R. Br. (Acanth.)

auriculata, Nees, in DC. Prod, xi. $248=\mathrm{H}$, spinosa longifolia, Nees, in Wall. Pl. As. Rar, iii. $90=\mathrm{H}$ spinosa.

macracantha, Hochst. ex A. Rich. Tent. F1. Abyss. ii. $146=$ H. spinosa

ASTERANDRA, Klotzsch, in Wiegm. Archiv, vii. (1841 $200=$ Phyllanthus, Linn. (Euphorb.).

cornifolia, Klotzsch, 1. $\mathrm{c}_{\mathrm{s}}=\mathrm{P}$. grandifolius.

Sellowiana, Klotzsch, 1. c. = P. grandifolius

ASTERANTHA, Reichb. Handb. $190(1837)=$ ASTE RACANTHA, Nees, = Hygrophila, R. Br. (Acanth.).

ASTERANTHEMUM, Kunth, Enum. Pl. v, 151 (1850) Smilacina, Desf. (Liliac.)

dahuricum, Kunth, 1. c. $153=\mathrm{S}$. daharica

trifoliatum, Kunth, 1. c. = S. trifolia.

vulgare, Kunth, 1. c. $152=\mathrm{S}$. stellata

ASTERANTHERA, Hanst in Linnaea, xxvi. (1853) 211. GESNERACEAE, Benth. \& Hook. f. ii. 1011. chiloënsis, Hanst. l. c.-Chiloe.

ovata, Hanst. l. c. xxxiv. (1865 66) 417.-Chili.

ASTERANTHOS, Desf, in Mém. Mus. Par. vi.(1820) 9. t. 3. MYRTACEAE, Benth. \& Hook. f i. 724. Asteranthus, Spreng. Syst. ii. 568 (1825) brasiliensis, Desf. l. c. - Bras.

ASTERANTHUS, Endl. Gen. $293(1837)=$ ASTRANTHUS, Lour = Homalium, Jacq. (Samyd.).

ASTERIAS, Borckh. in Roem. Arch. i. I. (1796) $25=$ Gentiana, Linn.

hybrida, G. Don, Gen. Syst. iv. $184=\mathrm{G}$. lutea.

lutea, Borckh. in Roem. Arch. i. I. (1796) $25=\mathrm{G}$. lutea

ASTFRIASTIGMA, Bedd. Forest. Man. Bot, 236 (1873), BIXINEAE

macrocarpa, Bedd. l.c.-Ind. or.

ASTERIDEA, Lindl. Swan Riv. App. $24(1839)=$ Athrixia, Ker-Gawl. (Compos.).

gracilis, A. Gray, in Hook. Kew Journ. iv. (1852 $274=$ Athr. gracilis

multiceps, A. Gray, 1. c. = Athr. multiceps.

puberulenta, Lindl. Swan Riv. App, $24=$ Athr. australis.

stricta, A. Gray, in Hook. Kew Journ. iv. (1852) 275 $=$ Athr. stricta.
ASTERIDIUM, Engelm, ex Walp. Rep. ii. 958 (1843)= Chaetopappa, DC. (Compos.)

ASTERINGA, E. Mey. ex DC. Prod. vi. 138 (1837) = Pentzia, Thunb. (Compos.).

ASTERIOIDES, Ponted. ex Linn. Class. Pl. 530 (1747) =Buphthalmus, Linn. (Compos.).

ASTF RIPHOLIS, Ponted. ex Linn. Class. Pl. 530 $(1747)=$ Aster, Linn. (Compos.).

ASTERISCIUM, Cham. \& Schlecht. in Linnaea, (1826) 254.t. 5. UMBELLIFERAE, Benth. \& Hook. f. i. 877 .

Bustillosia, Clos, in C. Gay, Fl. Chil. iii. 106.t. $32(1847)$.

Cassinocarpus, Presl, ex DC. Prod. iv, 82 (1830).

Dipterygia, Presl, 1. c. $80(1830)$

Eremocharis, Phil. Fl. Atacam. 25. t. 2 B (1860).

Gymnophyton, Clos, in C. Gay, Fl. Chil. iii. 102 t. $32(1847)$.

Tritaenicum, Turcz. in Bull. Soc. Nat. Mosc. xx. (1847) 1. 169.

aemocarpon, Clos, in C. Gay, Fl. Chil, iii. 101.Chili.

anethoides, Turcz. in Bull. Soc. Nat. Mosc. xx. (1847) I. 170.-Chili.

chilense, Cham. E' Schlecht. in Linnaea, i. (1826) 254. t. 5.-Chili.

flexuosum, Hemsl. Diag. Pl. Nov. 16.-Mexic.

isatidicarpum, Hook. E $\xi^{\circ}$ Arn. in Hook. Bot. Misc. iii. (1833) 349.-Chili.

oemocarpum, Walp. Ann. i. $978=$ aemocarpon

Poeppigii, DC. Prod. iv. $82=$ chilense.

polycephalum, Gill. E Hook, in Hook. Bot. Misc. i. 1830) 332.-Chili.

pozoides, Clos, in C. Gay, Fl. Chil. iii. 100.-Chili

ramosissimum, Phil. in Linnaea, xxxiii. (1864-65) 90 - Chili.

robustum, Baill. Hist. $\mathrm{Pl}$, vii. 145,-Chili

verrucosum, Meyen, Reise, i. $315=$ chilense.

ASTERISCUS, Moench, Meth. $592(1794)=$ Odontospermum, Neck. (Compos.)

aquaticus, Less. Syn. Comp. $210=0$. aquaticum

aureus, Lange, Pugill. ii. 118.-Hispan.

brachiatus, Jord. \& Four. Brev. Pl. Nov, fasc. ii, $60=$ O. maritimum.

Daltoni, Walp. Ann. ii. $844=$ O. Daltoni

flosculosus, Decne. in Ann. Sc. Nat. Sér. II. iv. (1835) $202=$ Anvillea Garcini.

graveolens, Less. Syn. Comp. $210=\mathrm{O}$. graveolens.

imbricatus, DC . Prod, v. $487=0$. imbricatum.

lanuginosus, Aucher, ex DC. 1. c. vii. $287=0$. lanuginosum.

littoralis, Jord. \& Fourr. Brev. Pl. Nov, fasc, ii. $60=0$, maritimum

maritimus, Less. Syn. Comp. $210=0$. maritimum

mauritanicus, Jord. \& Fours. Brev. Pl. Nov, fasc. ii. $61=\mathrm{O}$. maritimum

nanus, Nym. Consp. $391=$ O. aquaticum

odorus, DC. Prod. v. $486=$ O. odorum.

pygmaeus, Coss. \& Dur. in Bull. Soc. Bot. Fr. iv. (1857)

471. - Afr. bor.; Palaest. ; Beluchist.

Schimperi, Boiss. Fl. Orient. iii. 180.-Arab.

sericeus, DC. Prod. v. $486=\mathrm{O}$. sericeum.

sessilis, Moench, Meth. $592=0$. aquaticum

Smithii, Walp. Ann. ii. $844=$ O. Smithii.

Vogelii, Walp. 1. c. $845=0$. Vogelii.

ASTERISCUS, Tourn. ex Sch. Bip. in Webb, Phytogr. Canar. ii. $229(1835-60)=$ Pallenis, Cass. (Compos.) spinosus, Sch. Bip. 1. c. $230=$ P. spinosa.

ASTERISCUS, Reichb. Consp. $144(1828)=$ Asteris cium, Cham. (Umbell.).

ASTEROCARPUS, Eckl. \& Zeyh. Enum. $122(1835)=$ Pterocelastrus, Meissn. (Celastrin.)

arboreus, Eckl. \& Zeyh. 1. c. $123=$ P. variabilis

Burmanni, Eckl. \& Zeyh. l. c. $122=$ P. tricuspidatus litoralis, Eckl. \& Zeyh. 1. c. = P. litoralis nervosus, Eckl. \& Zeyb. 1. c. $123=$ P. variabilis rostratus, Eckl. \& Zeyh. 1. c. $=$ P. rostratus. stenopterus, Eckl. \& Zeyh. 1. c. $=$ P. stenopterus tetrapterus, Eckl, \& Zeyh, 1, c. $=$ P. variabilis. tricuspidatus, Eckl. \& Zeyh. 1. c. $124=$ P. rostratus. typicus, Eckl. \& Zeyh. 1. c. $122=$ P. tricuspidatus. 
ASTEROCARPUS, Reichb. Handb. 261 (1837); Gren. \&. Godr Fl Fr i, 190=Astrocarpus, Neck. (Resed.).

ASTEROCEPHALUS, [Vaill.] Adans. Fam. ii. 152 $(1763)=$ Scabiosa, Linn. (Dipsac.).

acutiflorus, Reichb. F1. Germ. Excurs, $194=$ S. maritima.

africanus, Spreng. Syst. i. $380=$ S. cretica. agrestis, Spreng. 1. c. $383=$ S. gramontia.

altissimus, Spreng. l. c. $=$ S. africana.

ambiguus, Reichb. Fl. Germ. Excurs. $194=$ S. maritima.

amoenus, Spreng. Syst. i. $381=$ S. amoena

arenarius, Vis, $\mathrm{Pl}$. Aeg. 6. t. $1=\mathrm{S}$, arenaria

argenteus, Spreng. Syst. i. $382=$ S. ucranica.

atropurpureus, Reichb. Ic. Fl, Germ, xii. t. $1363=$ S. maritima.

atropurpureus, Spreng. 1. c. $381=\mathrm{S}$. atropurpurea,

bannaticus, Spreng. Syst. i. $\mathbf{3 8 3}=\mathrm{S}$. banatica.

Biebersteinii, Sweet, Hort. Brit. ed. I. $205=$ S. micrantha.

bipinnatus, Jord. \& Fourr. Brev. Pl. Nov. fasc. ii. $58=$ S. ochroleuca.

brachiatus, Reichb. Fl. Germ. Excurs. $194=$ S. brachiata.

brevicomus, Jord. \& Fourr. Brev. PI, Nov, fasc, ii, $57=$ S. rotata.

canescens, Lag. Gen. et Sp. Nov. 8 , in obs.; Spreng. Syst. i. $380=\mathrm{S}$. suaveolens.

caucasicus, Spreng. 1. c. $381=$ S. caucasica.

cochinchinensis, Spreng. 1. c. $380=\mathrm{S}$. cochinchinensis,

Columbaria, Wallr. Sched. Crit. $48=\mathrm{S}$. Columbaria.

Columnae, Reichb. Fl。Germ。 Excurs, $195=\mathrm{S}$. holosericea.

crenatus, Spreng. Syst. i. $382=$ S. crenata.

creticus, Spreng. 1. c. $380=$ S. cretica.

daucoides, Spreng. 1. c. $383=$ S. daucoides.

dentatus, Jord. \& Fourr. Brev. Pl. Nov. fasc. ii. $57=$ S. stellata.

dichotomus, Lag, Gen, et Sp. Nov, $8=\mathrm{S}$. dichotoma.

diffusus, Spreng. Syst. iv. Cur. Post. $38=\mathrm{S}$, diffusa.

divaricatus, Lag. ex Steud. Nom. ed. I. 84 ; ed. II. i. $158=$ S. sicula.

eburneus, Spreng. Syst. i. $382=$ S. ucranica.

elegans, Lag. Gen. et Sp. Nov. $8=$ S. caucasica.

flavescens, Schur, in Verh. Siebenb. Ver. Naturw. x.

(1859) $61=\mathrm{S}$. ochroleuca.

graminifolius, Spreng. Syst. i. $380=$ S. graminifolia.

gramuntius, Spreng. 1. c. i., $383=$ S. gramontia.

grandiflorus, Sweet, Hort. Brit. ed. I. $205=\mathrm{S}$.

maritima.

Hladnikianus, Schur, in Verh. Siebenb. Ver. Naturw. x. 1859) $171=\mathrm{S}$. lucida.

holosericeus, Spreng. Syst. i. $381=$ S. holosericea.

holosericeus, Webb, Iter, $40=$ S. sphaciotica.

induratus, Spreng. Syst. i. $380=$ S. africana.

integrifolius, Lag. ex Steud. Nom, ed. II. i. $158=$ S. integrifolia

intermedius, Lag. Gen. et Sp. Nov. $8=\mathrm{S}$. lusitanica.

isetensis, Spreng. Syst. i. $383=\mathrm{S}$. isetensis.

legionensis, Spreng. 1. c. $379=$ S. legionensis.

limonifolizes, Spreng. 1. c. $380=$ S. limonifolia.

lobatus, Jord. \& Fourr. Brev. Pl. Nov, fasc. ii. $57=$ S. rotata.

lucidus, Spreng. Syst. i. $380=$ S. nitens.

lyratus, Spreng. 1. c. $381=$ S. sicula.

maritimus, Spreng. 1. c. $382=$ S. maritima.

Massoni, Sweet, Hort. Brit. ed. I. $205=$ S. nitens

micranthus, Spreng. Syst. i. $381=$ S. micrantha.

mollissimus, Spreng. 1. c. $383=$ S. Columbaria.

monspeliensis, Zumag. Fl. Pedem. i. 182; Jord. \&

Fourr. Ic. Pl. Europ. 1. $47=$ S. monspeliensis.

montanus, Schur, Enum. Pl. Transs. $299=\mathrm{S}$. ochroleuca.

ochroleucus, Wallr. Sched. Crit. 50 ; Spreng. Syst. i. $383=\mathrm{S}$. isetensis.

palaestinus, Spreng. 1. c. $380=$ S. palaestina

paucisetus, Loud. Hort. Brit. Suppl, ii. 581=S. gramontia.

pectinatus, Lag. Gen. \& Sp. Nov. $8=$ S. pectinata

pilosus, Lag. 1. $\mathrm{c}_{\mathrm{s}}=\mathrm{S}$. ucranica.

polytomus, Jord. \& Fourr. Brev. P1. Nov, fasc. ii. $58=$ S. rotata.

prolifer, Spreng. Syst. i. $\mathbf{3 8 0}=\mathrm{S}$. prolifera,

pseuda-banaticus, Schur, Enum. Pl. Transs. $300=$ S lucida.

pumilus, Spreng. Syst. ì, $382=\mathrm{S}$. Columbaria.
ASTEROCEPHALUS :-

pyrenaicus, Sweet, Hort. Brit. ed. I. $205=\mathrm{S}$. Columbaria.

rotatus, Spreng. Syst. i. $381=$ S. rotata

rutaefolius, Sweet, Hort. Brit. ed. I. $205=$ S. rutaefolia saxatilis, Spreng. Syst. i. $379=$ S. saxatilis.

Scopolii, Reichb. Fl. Germ. Excurs. 195 = S. Scopolii. sericeus, Jord. \& Fourr, Brev。 Pl. Noy, fasc. ii. $59=\mathrm{S}$. graminifolia.

setifer, Spreng. Syst. i. $381=\mathrm{S}$. setifera.

siculus, Spreng. $1, \mathrm{c},=\mathrm{S}$. sicula

silenifolius, Spreng. 1, c. $380=$ S. brachiata

simplex, Spreng. 1. c. $383=$ S. monspeliensis.

sphacioticus, Spreng. 1. c. $382=$ S. sphaciotica.

stellatus, Reichb. F1. Germ. Excurs. 194; et Ic. Fl.

Germ. xii. f. $1370=$ S. stellata.

stellatus, Spreng. Syst. i. $381=$ S. monspeliensis.

strictus, Spreng. 1. c. $380=$ S. lucida.

suaveolens, Lag. Gen. \&c Sp. Nov, 8, in obs. ; Wallr.

Sched. Crit. $51=\mathrm{S}$. suaveolens,

Succisa, Wallr. Sched. Crit. $52=$ S. Succisa.

tomentosus, Spreng. Syst. i. $381=$ S. Succisa,

triniaefolius, Vis, in Mem. Ist. Venet. xxi. (1880-82)

$482=\mathrm{S}$, triniaefolia.

ucranicus, Spreng. Syst. i. $382=$ S. ucranica.

urceolatus, Spreng. 1. c. $=$ S. rutaefolia.

vestinus, Facch. ex Reichb. Ic. Fl. Germ. xii. 20. n.

$1373=$ S. vestina

virescens, Jord. \& Fourr. Brev. P1. Nov. fasc. ii. $59=\mathrm{S}$. graminifolia.

Webbianus, Spreng. Syst. i. $381=$ S. ochroleuca.

Wulfenii, Reichb. Fl, Germ. Excurs. 194, in syn. n.

$1156=\mathrm{S}$. ucranica.

ASTEROCHAETE, Nees, in Linnaea, ix. (1834) 300 CYPERACEAE, Benth. \& Hook. f. Gen. iii. 1062. angustifolia, Nees, l. c.-Afr. austr.

arundinacea, Kunth, Enum. Pl. ii. 312,-N. Caled. capitellata, Nees, in Linnaea, ix, (1834) 300 ; x. (1836)

194.-Afr. austr.

elongata, Kunth, Enum. Pl. ii. 312.-Ins. Maurit.

glomerata, Nees, in Linnaea, ix. (1834) 300 ; x. (1836) 194-Afr, austr.

Ludwigii, Hochst. in Flora, xxviii. (1845) 759, in nota. -Afr. austr.

nitens, Kunth, Enum. Pl. ii. 313.-Ins. Maurit.

tenuis, Kunth, lo c. 312.-Afr, austr.

ASTEROCHITON, Turcz. in Bull. Soc. Nat. Mosc. xxv. (1852) Ir. 138= Thomasia, J. Gay (Stercul.). pygmaeus, Turcz. 1, c. $139=$ T. pygmaea

ASTEROCHLAENA, Garcke, in Bot. Zeit. viii. (1850) $666=$ Pavonia, Cav. (Malvac) cuspidata, Garcke, 1. c. 668.--Peruv.

ASTEROCYTISUS, Schur, ex Fuss, F1. Transs. 154 $(1866)=$ Genista Linn。 (Legumin.).

radiatus, Schur, ex Fuss, I. c. =G. radiata.

ASTEROGEUM, S. F. Gray, Nat. Arr. Brit. Pl. ii. 294 (1821) = Plantago, Tourn

laciniatum, S. F. Gray, l. c. $=$ P. Coronopus.

ASTEROGYNE, H. Wendl, ex Benth. \& Hook f Gen, iii. 914 (1883), PALMAE, Benth. \& Hook, f iii. 914.

ASTEROLASIA, F. Muell, in Trans, Phil. Soc Vict i. (1855) 9; et Hook. Kew Journ. viii. (1856) 34. RUTACEAE, Benth. \& Hook. fo i. 294, 990. PLeURANDropsis, Baill. Adansonia, x. (1872) 305

Urocarpus, J. Drumm。 in Hook. Kew Journ. vii. (1855) 54

buxifolia, Benth. Fl. Austral. i. 351.-Austral. chorilaenoides, F. Muell, in Trans. Vict. Inst. i. (1855)

$116=$ Microcybe pauciflora.

correifolia, Benth. Fl. Austral. i. 350-Austral.

grandiflora, Benth.l. c. 352.-Austral.

mollis, Benth. l. c. 351.-Austral.

Muelleri, Benth. l. c. 350.-Austral

pallida, Benth. l.c. 352-Austral.

phebalioides, Benth. lo co-Austral.

phebalioides, F. Muell. in Trans. Phil. Soc. Vict. (1855) $10=$ pleurandroides

pleurandroides, F. Muell, ex Benth. Fl. Austral. i. 351. -Austral.

squamuligera, Benth. l. c. 352.-Austral.

\section{ASTEROLASTA :}

trymalioides, F. Muell. in Trans. Phil. Soc. Vict. i. (1855) 10.-Austral

ASTEROLINION, Brongn. Enum. Gen. $69(1843)=$ seq

ASTEROLINON, Hoffmgg. \& Link, F1. Port. 332 (1820). PRIMULACEAE, Benth. \& Hook f ii. 636 .

Pelletiera, A. St. Hil, in Mém. Mus. Par. ix. (1822) 365

adoënse, Kunze, in Linnaea, xx. (1847) 37.-Abyss.

Linum-stellatum, Duby, in DC. Prod. viii. $68=$ stellatum.

lysimachioideum, St. Lag. in Ann. Soc. Bot. Lyon, vii. (1880) $64=\mathrm{A}$. stellatum.

serpyllifolium, Ball, in Fourn. Linn. Soc. xxi. (1884) 226. - Patagon.

stellatum, Hofjmgg. E Link, Fl. Port. i. 333.Lusitan.

trinum, Baudo, in Ann. Sc. Nat. Sér. II. xx (1843) 350 -Chili.

ASTEROMAEA, DC. Prod, v. $302(1836)=\mathrm{seq}$.

ASTEROMOEA, Blume, Bijdr. 901 (1826)=Boltonia L'Hérit. (Compos.)

indica, Blume, 1. c. = B, indica.

pekinensis, Hance, in Ann. Sc. Nat. Sér. IV. xv. (1861) $225=$ B. pekincnsis.

ASTEROMYRTUS, Schau, in Linnaea, xvii. (1843) 242 - Melaleuca, Linn. (Myrtac.)

Gaertneri, Schau. 1. c. $243=\mathrm{M}$. angustifolia.

ASTEROPEA, Tul, in Ann. Sc. Nat. Sér. IV. viji. (1857) $79=$ seq.

ASTEROPEIA, Thou. Hist. Vég. Afr. 51. t. 15. (1807) SAMYDACEAE, Benth. \& Hook. f. i. 801.

amblyocarpa, Tul. in Ann. Sc. Nat. Sér. IV. viii. (1857) 81.-Madag.

densiflora, Baker, in Fourn. Bot, xx (1882) 49.

Madag.

multiflora, Thou. Hist. Veg. Afr. 51. t. 15.-Madag.

ASTEROPHYLLUM, Schimp. \& Spenn. in Spenn. F1. Friburg. ii. $1077(1829)=$ Asperula, Linn (Rubiac.), 8cc.

Aparine, Schimp. \& Spenn. 1. $\mathrm{c}_{\circ}=$ Galium Aparine. Asperula, Schimp. \& Spenn. 1. c. = Asperula odorata. galioides, Schimp. \& Spenn. 1. c. in obs. = Asperula galioides.

Galium, Scbimp. \& Spenn. 1. c. = Galium verum.

Scherardianum, Schimp. \& Spenn. 1. c. =Sherardia arvensis.

sylvaticum, Schimp. \& Spenn. 1. co in obs. = Asperula odorata.

tinctorium, Schimp. \& Spenn. 1. c. = Asperala tioctoria

ASTEROPSIS, Less. Syn. Comp. 188 (1832)= Podo coma, Cass. (Compos.)

macrocephala, Less. 1. c-Bras.

ASTEROPTERUS, Adans. Fam. ii. 124 (1763); Gaertn. Fruct. ii. 460 , t. $173(1791)=$ Leysera, Lino. (Compos.)

Callicornia, Gaertn. Fruct. ii. $460=$ L. Callicomia.

ceruleus, Rafin. Fl. Tellur. ii. $48=$ an praec. ?

ASTEROPUS, Schult. Mant, iii. $15(182 \%)=$ ASTROPUS Spreng. $=$ W altheria, Linn. (Stercul.)

ASTEROSCHOENUS, Nees, in Mart. FL. Bras ii. I. 124 (1842) = Rynchospora, Vahl (Cyperac)

consanguineus, Nees, l. c. $125=\mathbb{K}$ consanguinea.

rigidus, Nees, l. c. $126=\mathrm{R}$. rigida .

speciosus, Nees, L. c. $125=$ R. speciosa.

ASTEROSPERMA, Less. Sym. Comp. 389 , 18\$2i= Felicia, Cass. (Compos.)

chrysocomoides, Less, 1. c.-Afr. ausir.

ASTEROSTEMM A. Decne. in Ann. Ac. Nat. Scr. Il ix. (1538) 2i1. t. 10. ASCLEP/.ADE.tE, Bench. \& Hook. 1. ii. 775 .

repandum, Decne. l. c. Java. 
ASTEROSTIGMA, Fisch. \& Mey, in Bull. Phys.-Math. Acad, Pétersb iii. (1845) 148; Schott, in Oestr. Bot. Wochenbl. (1852) 67 = Staurostigma, Scheidw. (Aroid.).

colubrinum, Schott, in Bonplandia, x. (1862) $86=$ $\mathrm{S}$. concinnum.

concinnum, Schott, in Oestr. Bot. Wochenbl. (1852) $67=\mathrm{S}$. concinnum.

Langsdorffii, C. Koch, in Ind. Sem. Hort. Berol. (1854) $8=\mathrm{S}$. concinnum

lineolatum, Schott, in Bonplandia, x. (1862) $86=$ $\mathrm{S}$. concinnum.

Luschnathianum, Schott, Syn. Aroid. $126=\mathrm{S}$. Luschnathianum.

Pavonii, Schott, Prod. Aroid. $339=$ S. Pavoni.

Tweedianum, Schott, in Oestr. Bot. Zeitschr. (1859) $39=\mathrm{S}$. Tweedianum.

Vellozianum, Schott, Syn. Aroid. $126=$ S. Luschnathianum.

vermitoxicum, Griseb. in Goett. Abh, xix. (1874) 247 $=\mathrm{S}$. vermitoxicum

zebrina, Linden, in Belg. Hortic. xv. (1865) 98.-Bras,

Asterostoma, Blume, Mus. Bot. Lugd. Bat. i. 50 $(1849)=$ Osbeckia, Linn. (Melast.)

aspera, Blume, $\mathrm{l} . \mathrm{c} .=\mathrm{O}$. aspera.

decandra, Blume, $1_{0} \mathrm{c}_{\mathrm{o}}=\mathrm{O}$. decandra

decumbens, Blume, 1. $\mathrm{c}_{\mathrm{s}}=\mathrm{O}$, decumbens.

Kleinii, Blume, 1. c. $=$ O. aspera.

multiflora, Blume, $\mathrm{I}_{\mathrm{c}} \mathrm{c}_{\mathrm{r}}=\mathrm{O}$. multiflora.

octandra, Blume, $1, \mathrm{c} .=0$. octandra.

repens, Blume, $1 . \mathrm{c}_{\mathrm{s}}=$ Melastoma repens.

rotundifolia, blume, $\mathrm{l}_{\mathrm{c}} \mathrm{c}=\mathrm{O}$. rotundifolia

virgata, Blume, $1 . c_{.}=0$. virgata.

Walkeri, Blume, 1. c. $=0$. Walkeri.

Wightiana, Blume, 1. $c_{\circ}=0$. octandra.

ASTEROTHRIX, Cass, in Dict. Sc. Nat, xlviii. 434 (1827) =Leontodon, Linn. (Compos.).

asperrima, Cass, $1 . \mathrm{c}=\mathrm{L}$. asperrimus.

crispa, Fourr. in Ann. Soc. Linn. Lyon, N. S. xvii. (] $\& 69) 100=\mathrm{L}$. crispus.

hispanica, DC. Prod. vii. $127=$ L. hispanicus.

ASTEROTRICHION, Klotzsch, in Link, Klotzsch \& Otto, Ic. Pi. 19. t. 8 (1841)= Plagianthus, Forst. (Malvac.).

sidoides, Klotzsch, 1. c. = P. sidoides.

ASTHENOCHLOA, Buese, in Miq. Pl. Jungh. 367 (1854). GRAMINEAE, Benth. \& Hook. f. Gen. iii. 1096 .

tenera, Buese, l. c. 368.-Java.

ASTHOTHECA, Miers, ex Planch. \& Triana, in Ann. Sc. Nat. Sér. IV. xiv. (1860) $254=$ Clusia, Linn. (Guttif.).

ASTIANTHUS, D. Don, in Edinb. Phil. Journ. ix. (1843) 262 = Tecoma, Juss. (Bignon.).

longifolius, $\mathrm{D}$. Don, $1 . \mathrm{c}_{\mathrm{。}}=\mathrm{T}$, viminalis

ASTILBE, Buch.-Ham. in D. Don, Prod. Fl. Nep. 210 (1825).SAXIFRAGEAE, Benth. \& Hook. f. i. 634. Hoteia, Morr. \& Decne. in Ann. Sc. Nat. Sér. II. ii. (1834) 316.t. 11

Aruncus, Trev. in Bot. Zeit. xiii. (1855) $819=$ Spiraea Aruncus.

barbata, Hort.-Cf. Gard. Chron. (1871) $547=$ japonica.

chinensis, Franch. E Sav. Enum. Pl. Fap. i. 144.China; Japon.

decandra, D. Don, Prod. Fl. Nep. 211.-Am. bor

japonica, A. Gray, in Hook. Lond. Fourn. Bot. ii. (1843) 124.--Japon.

odontophylla, Miq. Ann. Mus. Bot. Lugd. Bat. iii. $96=$ chinensis.

podophylla, Baill. Hist. Pl. iii. $332=$ Rodgersia podophylla.

rivularis, Buch.-Ham. in D. Don, Prod.Fl. Nep. 210.Reg. Himal.

rubra, Hook. f. EJ Thoms. ex Hook. Bot. Mag. t. 4959. -Reg. Himal,

speciosa, Jungh. Java, i. (1853) $250=$ rivularis.

Stoliczkai, Kurz, ex Seem. in Fourn. Bot.v. (1867) 240 (Spiraeae sp. ?).-Himal bor occ.

Thunbergii, Miq. Ann. Mus. Bot. Lugd. Bat. iii. 96.Japon.
ASTIRIA, Lindl. in Bot. Reg. (1844) Misc. 27. t. 49. STERCULIACEAE, Benth. \& Hook, f. i. 221.

rosea, Lindl. l. c.-Maurit.

ASTOMA, DC. Coll. Mém. v. 71. t. 17 (1829); et Prod. iv. 249 (1830), UMBELLIFERAE, Benth. \& Hook. f. i. 885 .

AstomaeA, Reichb. Handb, 218 (1837).

seselifolium, $D C$. $l l . c c$. -Syria.

ASTORGanthuS, Endl. Cat. Hort. Vindob. ii. 196 $(1843)=$ Melicope, Forst. (Rutac.).

Huegelii, Endl. 1. c. = M. simplex.

ASTRADELPHUS, Rémy, in Ann. Sc. Nat. Sér. III. xii (1849) $185=$ Erigeron, Linn. (Compos.).

calbucanus, Phil. in Anal. Univ. Chil. (1873) 485.Chili.

chilensis, Rémy, in Ann. Sc. Nat. Sér. III. xii. (1849) $185=\mathrm{E}$. chilensis.

ASTRAEA, Klotzsch, in Wiegm. Archiv, vii. (1841) 194 Croton, Linn. (Euphorb.)

divaricatum, Klotzsch, 1. $\mathrm{c}_{\mathrm{c}}=\mathrm{C}$. Klotzschii.

diversifolia, Klotzsch, 1. c. =C. Klotzschii.

glandulifera, Klotzsch, ex Wawra, Bot. Ergeb. Maxim.

Bras. 31. t. $42=$ C. Klotzschii.

fatropha, Klotzsch, in Wiegm. Archiv, vii. (1841) 194 = C. carnosus.

Klotzschii, Didr. in Kjoeb. Vidensk. Meddel. (1857) $137=$ C. Klotzschii.

lobatum, Klotzsch, in Wiegm. Archiv, vii. (1841) 194 $=$ C. lobatus.

Manihot, Klotzsch, 1。 $\mathrm{c}_{\mathrm{o}}=\mathrm{C}$. lobatus.

palmata, Klotzsch, 1. c. = C. lubatus.

Paulina, Didr. in Kjoeb. Vidensk. Meddel. (1857) 138 $=\mathrm{C}$. Paulinus.

prunifolia, Klotzsch, in Wiegm. Archiv, vii. (1841) 194 $=\mathrm{C}$. Klotzschii.

Seemanni, Klotzsch, in Seem. Bot. Voy. Herald, $103=$ C. lobatus.

tomentosum, Klotzsch, in Wiegm. Archiv, vii. (1841) $194=$ C. comosus.

ASTRAEA, Schau, in Linnaea, xvii. (1843) $238=$ Thryptomene, Endl. (Myrtac.).

saxicola, Schau. 1. c. $239=\mathrm{T}$. saxicola.

ASTRAGALOIDES, Adans, Fam. ii. 323 (1763) = Astragalus, Tourn. (Legum.)

Alopecurus, Moench, Meth. 168=Astragalus alopecuroides.

alpina, Medic. in Vorles. Churpf. Phys. Ges. ii. (1787) $373=$ Astragalus alpinus.

australis, Medic. 1. c. = Astragalus australis.

bicolor, Moench, Meth. Suppl. $57=$ Astragalus uliginosus.

Cicera, Moench, Meth, $168=$ Astragalus Cicer

frigida, Medic. in Vorles. Churpf. Phys. Ges. ii. (1787) $373=$ Astragalus frigidus.

Glaux, Moench, Meth, $168=$ Astragalus Glaux.

syphilitica, Moench, l. c。=Astragalus exscapus.

ASTRAGALUS, Tour. ex Linn. Gen. ed. I. 215 (1737). LEGUMINOSAE, Benth. \& Hook. f. i. 506.

Ailuroschia, Stev, in Bull. Soc. Nat. Mose. xxix.

(1856) II. 151

Alopecias, Stev. 1. c. 143 (1856).

AMMODYTES, Stev. 1. c. iv. (1832) 263.

ANKYlobus, Stev. 1. c. xxix. (1856) II. 148.

ARAGalus, Neck. Elem. iii. 12 (1790)

Aragus, Steud. Nom. ed. II. i. 118 (1840).

Aulosema, Walp. Rep. i. 694 (1842)

Caryolobium, Stev, in Bull. Soc. Nat. Mosc. iv. (1832) 266.

CHONDROCARPUS, Stev. 1. c. 268 (1832).

Craccina, Stev. 1. c' xxix. (1856) II. 144

Cymbicaryus, Stev, 1. c. iv. (1832) 266.

Cystrum, Stev, 1. c. xxix. (1856) II. 147.

Didymopelta, Regel \& Schmalh, in Act. Hort Petrop. v. (1877) 669

Dipelta, Regel \& Schmalh. 1. c. 578 (1877).

Diplotheca, Hochst. in Flora, xxix. (1846) 595.

Erophaca, Boiss. Voy. Bot. Espagne, $176(1839-45)$

Eullus, Stev. in Bull. Soc. Nat. Mosc. xxix. (1856)

II. 149 .

EUPREPIA, Stev. 1. c. iv. (1832) 268.

\section{ASTRAGALUS :-}

Feidanthus, Stev, in Bull. Soc. Nat. Mosc. zxix (1856) II. 148.

Glandula, Medic. in Vorles. Churpf. Phys. Ges. ii. (1787) 374

Glottis, Medic. 1. c. 377 (1787).

Glycyphylla, Stev. in Bull. Soc. Nat. Mosc. iv. (1832) 266.

Hamaria, Fourr. in Ann. Soc. Linn. Lyon, N.S. xvi (1868) 364 .

Hamosa, Medic, in Vorles. Churpf. Phys. Ges. ii. (1787) 376.

Hedyphylla, Stev. in Bull. Soc. Nat. Mose. xxix. (1856) II. 142.

Homalobus, Nutt. ex Torr. \& Gray, Fl. N. Am. i. $350(1840)$

HypoglotTrs, Fourr. in Ann. Soc. Linn. Lyon, N. S. xvi. (1868) 364.

Kentrophyta, Nutt. ex Tort. \& Gray, Fl. N. Am. i. $353(1840)$.

KirChNerA, Opiz, in Lotos, viii. (1858) 65.

Macrosema, Stev. in Bull. Soc. Nat. Mosc. xxix. (1856) Ir. 145.

MEDYPHYLLA, Opiz, in Lotos, viii. (1858) 65.

Myobroma, Stev, in Bull. Soc. Nat. Mosc. xxix. (1856) II. 150.

ONIX, Medic. in Vorles. Churpf. Phys. Ges. it. (1787) 378.

Pedina, Stev. in Bull. Soc. Nat. Mosc. xxix. (1856) II, 144.

Phaca, Roy. ex Linn. Coroll. 13 (1737).

Phrlammos, Stev. in Bull. Soc. Nat. Mosc. xxix (1856) II. 146.

Physondra, Rafin. Atl. Journ. 145 (1832)

Picraena, Stev, in Bull. Soc. Nat. Mosc. iv. (1832) 263.

Ponochrea, Fourr. in Ann. Soc. Linn. Lyon, N. S. xvi. (1868) 364

Podolotus, Royle, Illustr. Bot. Himal. 198 (1835)

Proselias, Stev, in Bull. Soc. Nat. Mosc. iv. (1832) 268

Psychridium, Stev. 1. c. 263 (1832).

RYsodium, Stev. 1. c. (1832).

SEWERzowia, Regel \& Schmalh, in Act. Hort

Petrop. v. (1877) 580

Solenotus, Stev, in Bull. Soc. Nat. Mosc. xxix (1856) II. 143.

Spiesia, Neck. Elem. iii. 13 (1790)

Stella, Medic. in Vorles. Churpf. Phys. Ges. ii. (1787) 377 .

THIU M, Stend, Nom, ed. I. 833 (1821).

TIUm, Medic. in Vorles. Churpf. Phys. Ges. ii. (1787) 373

Triquetra, Medic. 1. c. 376 (1787).

Xerophysa, Stev. in Bull. Soc. Nat. Mose. xxix. (1£56) II. 150.

abakanensis, Less, ex Bunge, Astrag. ii. $22=$ multicaulis.

abbreviatus, Kar. E Kir. in Bull. Soc. Nat. Mosc. xv (1842) II. 343.-As. temp.

aboriginorum, Richards. in Frankl. 1st fourn. App. 746.-Am. bor. arct.

abyssinicus, Steud. ex A. Rich.Tent. Fl. Abyss. i.193.Abyss.

acanthostachys, Fisch. in Bull. Soc. Nat. Mosc. xxvi. (1853) II. $326=$ Roussaeanus.

acaulis, Baker, in Hook. f. Fl. Brit. Ind. ii. 132.-

Reg. Himal.

acicularis, Bunge, Astrag. i. 90 ; ii. 161.-Cappadoc. acinaciferns, Boiss. Diagn. Ser. I. ix. 72.-Arab.

acmonotrichus, Fenzl, Pugill. Pl. Nov. Syr. 5.Cilicia.

acmophyllus, Bunge, Astrag. i. 93 ; ii. 166.-Cappadoc. acmotrichus, Bunge, 1. c. i. 109; ii. $189=$ acmonotrichus. acutiflorus, Benth. ex Baker, in Hook, f. Fl. Brit. Ind ii. $120=$ Falconeri.

acutifolius, Bunge, Astrag. i. 130 ; ii. 227.-Persia. acutifolius, DC. ex Steud. Nom. ed. I. $88=$ A. Stella. acutifolius, Schleich. Cat. Pl. Helv. ed. IV. 9.Europ.

acutirostris, S. Wats, in Proc. Am. Acad. xx. (1885) 360-Calif.

acntus, Bunge, Astrag. i. 71 ; ii. 118.-Persia.

adesmiaefolius, Benth. ex Bunge, l. c. i. 4 ; ii. 2Tibet. occ.

adpressus, Ehrenb. ex Walp. Ann. iv. 502=gummifer. adscendens, Boiss. E Haussk. ex Boiss. Fl. Orient. ii 317.- Persia. 
ASTRAGALUS :-

adsurgens, Pall. Astrag, 40, n. 44. t. 31--Sibir.; Am. bor.

adsurgens, Torr. in Stansbury, Rep. $385=$ iodanthus. adsurgens, Willd. ex Steud. Nom. ed. II. i. $159=$ virgatus.

adunciformis, Boiss, Diagn, Ser. I ii, 42-As, Min. aduncus, Bunge, Astrag. i. 102; ii. $179=$ usturtensis.

aduncus, Bieb. F1. Taur. Cauc. ii. 195=Bungeanus.

aduncus, Hohen. Talysch. $107=$ Cephalotes.

aduncus, Willd. Sp. Pl. iii. 1269.-Keg. Caucas.

adustus, Bunge, Astrag. i. 80 ; ii. 134.-Kurdistan.

Aegiceras, Willd. Enum. Hort. Berol. Suppl. $52=$ Ins. Chio.

aegobromus, Boiss. E Hohen. Diagn. Ser. I. ix. 74.Persia.

aegyptiacus, Mill. Gard. Dict. ed. VIII. n. $11=$ anuularis.

aegyptiacus, Spreng. Syst. iii. $298=$ kahiricus.

aeluropus, Bunge, Astrag, i. 89; i. 157.-Reg.

Caucas.; Persia.

aesicarius, Pall. Reise, iii. 751.-Sibir

affghanus, Boiss. Fl. Orient. ii. 1095 (emend.).Beluchist.

affinis, Steud. Nom. ed. II. i. 159-Chili.

africanus, Bunge, Astrag. i. 61 ; ii. 104-Algeria,

Agraniotii, Orph. ex Boiss. Diagn. Ser. II. ii. 29.Laconia.

agrestis, Dougl. ex Hook. Fl. Bor. Am. i. $148=$ hypoglottis.

aintabicus, Boiss. Diagn. Ser. I. ix. 86.-Syria; Meso-

potam.
Aitchisoni, Baker, in Hook. f. Fl. Brit. Ind. ii. 121.Ind, bor. occ.

Ajfreidii, Aitch. Eo Baker, in Fourn. Linn. Soc. xix. 1882) 157.-Afghanist.

ajubensis, Bunge, Astrag, i. 61 ; ii. 102,-Persia.

akkensis, Coss, in Bull. Soc. Bot. Fr. xxii. (1875) 57 , nomen.--Afr. bor.

aksuensis, Bunge, Astrag: i. 25 ; ii. 30--Sibir. altaic.

alaschanus, Bunge, ex Maxim. in Bull. Acad. Pétersb. xxiv. (1878) 31.-Mongolia.

alatavicus, Kar. E' Kir. in Bull. Soc. Nat. Mosc. xv. (1842) 344.-Alatau.

albens, Greene, in Bull. Calif. Acad. i. ("1885') 156. -Calif.

Alberjilla, Steud. Nom. ed. II. i. 159.-Chili.

Alberti, Bunge, in Act. Hort. Petrop. vii. (1880) 375. -Turkestan.

albicans, Bong. Verz. Pfl. Saisang-Nor, 21. t. 2.Soongaria.

albicaulis, $D C$. Astrag. 132. n. 59, t. 21.-Reg. Caucas.

albicaulis: Ledeb. F1. Ross, i. $628=$ medius.

albidus, Waldst. \& Kit. Pl. Rar. Hung. i. 39. t. $40=$ vesicarius.

aleppicus, Boiss. Diagn. Ser. I. ii. 58.-Syria ; Mesopotam.

alexandrinus, Boiss. l. c. ix. 75.-Aegypt.; Arab. Sy ria.

algarbiensis, Coss. ex Bunge, Astrag. i. 9 ; ii. 6Hispan.

alienus, A. Gray, Bot. U.St.Expl. Exped.i. 418.-Peruv. alindanus, Boiss. Diagn. Ser. I. ii. 85.-Caria.

allochorus, A. Gray, in Proc. Am. Acad. xiii. (1878) 366. - Am. bor.

Alopecias, C. Koch, ex Bunge, Astrag. ii. $97=$ maximus.

Alopecias, Pall. Astrag. 12. t. 9.-Persia; Turkestan.

alopecuroides, Ledeb. Fl. Ross. i. 693, n. $88=$ maximus (ex parte).

alopecuroides, Linn. Sp. Pl. 755.-Sibiria; Hely; Kamtechatka.

alopecuroides, Pall. Astrag. 9. t. $7=$ vulpinus

alopecuroideus, Lam. F1. Fr. ii. $636=$ narbonnensis.

alopecuros, Pall. ex DC. Astrag. 11. t. 8.-As. med.

Alpamarcne, A. Gray, Bot. U. St. Expl. Exped. i. 417. -Peruv.

alpinus, Lerdeb. FI. Ross, i. $601=$ arcticus.

alpinus, Linn, Sp. Pl, i. 760- - Reg, hor, et arct.

alpinus, Vill. Hist. Pl. Dauph. i. $903=$ A. Onobrychis.

altaicus, Bunge, Astrag. i. 37 ; ii. 46.-Mont. Altai,

altaicus, Pall. $\Lambda$ strag. $56=$ Oxytropis brevirostra.

alyssoides, Kotschy, ex Walp. Ann. ii. $374=$ clbru-

sensis.

alyssoides, Lam. Encyc. i. 317.-Armenia.

\section{ASTRAGALUS}

amalecitanus, Boiss, Diagn. Ser. I. ix. 46.-Palaestin amanus, Boiss. Fl. Orient, ii. 290.-Syria. amarus, Pall. Astrag. 8. t. 6.-Reg. Casp. amatus, Clos, in C. Gay, Fl. Chil. ii. 115.-Chili. ambiguus, Bunge, Astrag. i. 86 ; ii. 150.-Syria. ambiguus, Pall. Astrag. $54=$ Oxytropis amligua amblolepis, Fisch, in Bull Soc. Nat. Mosco xxyi. (1853) II. 372.-Kurdistan.

Amherstianus, Benth. in Royle, Illustr. Bot. Himal. 199.-Reg. Himal.

ammocryptus, Boiss. Diagn. Ser. I. ix. 59.=tribuloides. Ammodendron, Bunge, Astrag. i. 130 ; ii. 228.-As med.

Ammodytes, Pall. Voy. Ed. Gall. App.n. 372.t. 83.Sibir. or.

ammophilus, Bieb. ex Bess. in Flora, Xv。 (1832) II. Beibl. $33=$ virgatus.

ammophilus, Kar. E Kir. in Bull. Soc. Nat. Mosc. xv. (1842) 335.-Persia ; Soongaria

ammotrophus, Bunge, Astrag. i. 112; ii. 192.-Turkestan.

amoenus, Fenzl, Pugill. Pl. Nov. Syr. 4.-Cilicia. amphilogus, Bunge, Astrag. i. 90 ; ii. 161.-Anatolia amphioxys, A. Gray, in Proc. Am. Acad. xiii. (1878) 366.-Am, bor.

ampullarius, S. Wats, in Am. Natural. vii. (1873) 300 -Calif.

ampullatus, Pall. Reise, i. $750=$ Oxytropis ampullata.

ampullifer, Griseb. Spicil. F1. Rumel. i. 58=physocalyx.

amygdaliger, Less, in Linnaea, ix. (1834) $176=$ testiculatus.

amygdalinus, Bunge, Astrag. Fedsch, 228.-As. temp. anacamptus, Bunge, Astrag. i. 110 ; ii. 190.-Persia anacardius, Bunge, l. c. i. 61 ; ii. 105.-Persia. anatolicus, Boiss. Diogn. Ser. I ii. 77-Anatolia. ancistrocarpus, Boiss. E Haussk. ex Boiss. Fl. Orient. ii. 463.-Mesopotam

ancistron, Pomel, Nouv. Mat. Fl. Atl. 186.-Algeria. ancocarpus, Pomel, l. c. 187.-Algeria.

ancyleus, Boiss. Fl. Orient. ii. 240.-Cappadoc.

andalanicus, Boiss. E Haussk. ex Boiss. l. co 345.Persia.

Andersonii, A. Gray, in Proc. Am. Acad. vi. (1864-65) 524.-Calif

Andrachne, Bunge, Astrag. i. 89 ; ii. 158.-Syria ; Mesopotam.

andrachnaefolius, Fenzl, Pugill. Pl. Nov.Syr.4.-As,

Min.; Syria

anemophilus, Greene, in Bull. Calif. Acad. i. (1885) 186.-Calif.

anfractuosus, Bunge, Astrag. i. 125; ii. $218=$ subulatus.

angarensis, Turca. ex Bunge, l. c. i. 126 ; ii. 222.Sibir, baical.

angorensis, Bunge, 1. c. ii. $176=$ leucocyaneus

angulosus, DC. Astrag. 234. t. 45.-Syria. angustatus, Boiss. Diagn. Ser. I. ix. $47=$ ruscifolius. angustatus, Bunge, Astrag. i. 125 ; ii. 220.-Persia angustiflorus, C. Koch, in Linnaea, xv. (1840) 720 . Armenia; Persia.

angustifolius, Lam. Encyc. i. 321.-Graecia; As. Min

angustissimus, Bunge, Astrag. i. 135 ; ii. $232=0 x y$ petalus.

anisacanthus, Boiss. Diagn. Ser. I. ix. 103.-Afghan. anisacanthus, Bunge, Astrag, ii. 128 =jubatus, anisomerus, Bunge, Astrag. Fedsch. 228.-As. temp. ankylotus, Fisch. E Mey. Ind. Sem. Hort. Petrop. ii 27.-Reg. Casp. ankylotus, Stschegl. in Bull. Soc. Nat. Mosc. (1854) I.

annularis, Forsk. Fl. Aegypt. Arab. 139.-Aegypt.; Syria.

annuus, DC. Astrag. 127. n. 25.-Hab.?

anomalus, Bunge, Astrag. i. 35 ; ii. 62 -Tibet. occ. anserinaefolius, Boiss. Diagn. Ser. I. ii. 76.-Persia.

antabicus, Boiss. l. co ix. 86. -Anatolia.

anthylloides, Lam. Encyc. 1. 820,-As. Min.

anthylloides, Pall. Astrag, 15 = inflatus.

Antilibani, Bunge, Astrag. i. 55 ; ii. 90.-Syria.

Antiselli, A. Gray, in Bot. Calif. i. 152.-Calif.

antoninus, S. Wats. in Proc. Am. Acad. xvii. (1881-

82) 343.-Am. bor. occ.

Apollinens, Boiss. Diagn. Ser. II. ii. 27.-Graecia.

apricus, Bunge, Astrag. i. 40 ; ii. 58.-Pervia.

\section{ASTRAGALUS}

arabicus Ehrenb, ex Baker, in Hook, f. Fl, Brit. Ind, ii $121=$ prolixus

arabicus, Ehrenb. ex Bunge, Astrag. i. 9; ii. $6=$ fatinensis.

arabicus, Kotschy, in Sitzb. Acad. Wien, Math.-Nat. lii. Abth. I. (1866) 264.-Arabia.

arborescens, Bunge, Astrag, ii. $225=$ paucijugus.

Arbuscula, Pall. Astrag. 19. n. 24. t. 17.-Sibir.

Arbuscula, Willd, ex Ledeb. Fl. Ross. i. 633 fruticosus.

arcticus, Bunge, Astrag. i. 23 ; ii. 27.-Europ. arct.

arcticus, Spreng. Syst. iv. Cur. Post. $288=$ Uxytropis uralensis.

arcticus, Willd. Enum. Hort. Berol. Suppl. 51.Hab. ?

arcuatus, Kar. E Kir. in Bull. Soc. Nat. Mosc. (1841 407.-As. Min.

arcuatus, Steph. ex Ledeb. Fl. Ross. i. $649=$ scaberrimus.

arenarius, Lapeyr. Hist. Abr. Pl. Pyr. $429=$ baionnensis.

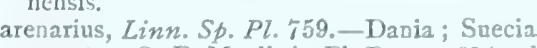

arenarius, O. F. Muell. in F1. Dan. t. $614=$ danicus. arenarius, Pall. Astrag, t, $34=$ hypoglottis.

arenicola, Pomel, Nouv. Mat. Fl. Atl. 184.-Algeria. arenosus, S. G. Gimel. ex Pall. Astrag. 25 = hyrcanus. arequipensis, Vog. in Nov. Act. Nat. Cur. xix. Suppl. I. (1843) 17.-Peruv.

argaeus, Boiss. E Bal. Diagn. Ser. II. vi. 53.Cappadoc.

arganaticus, Bunge, in Bull. Soc. Nat. Mosc. xxxix. (1866) II. 23.-As. temp.

argentatus, Pall. Astrag. 60. t. $48=$ Oxytropis argentata.

argenteus, Bertol. ex Vis. in Flora, xii. (1829) I. Erg. $18=$ Muelleri.

argophyllus, Nutt. ex Torr. \& Gray, Fl. N. Am. i. 331 = glareosus.

arguricus, Bunge, Astrag. i. 103 ; ii. 181.-Mont Ararat.

argutensis, Bunge, l. c. i. 98 ; ii. 170.-Armenin.

argyrophyllus, Boiss. E Gaill. ex Boiss. Fl. Orient. ii. 358.- Syria.

argyrostachyus, Boiss. Diagn. Ser. I. vi. 41.-Persia. argyrothamnus, Boiss. l. c. ix. 89.-Syria

aridus, A. Gray, in Proc. Am. Acad. vi. (1864) 223.Am. bor. occ.

aristatus, L'Hérit. Stirp. Nov. 170.-Europ. austr. aristatus, Sieber, ex Steud. Nom. ed. II. i. $159=$ angustifolia.

aristatus, Sibth. \& Sm. FI. Graec, viii, 25. t. $734=$ Parnassi.

arizonicus, A. Gray, in Proc. Am. Acad. vii. (1868) 398.-Arizona.

arkalycensis, Bunge, Astrag. i. 139 ; ii. 238.-As. temp.

armatus, Willd Sp. Pl iii. 1330-Numidia.

armeniacus, Boiss. Diagn. Ser. I. ii. 86.-Armenia

armeriastrum, Decne. ex Boiss. F1. Oricnt. ii. $387=$ cephalanthus.

arnacantha, Bieb. Fl. Taur. Cauc. ii. 205.-Reg. Caucas.

arnoceras, Bunge, Astrag. i. 18 ; ii. 14=brachycems

arpilobus, Kar. \& Kir. in Bull. Soc. Nat. Nosc. xv. (1842) 336.-As. temp.

arrectus, A. Gray, in Proc. Am. Acad. viii. $(1870) 289$ -Am. bor.

Arthu-Schottii, A. Gray, 1. c. vi. (1864) $209=$ Coulteri artipes, A. Gray, l. co xiii. (1878) 970. - Am. bor. asaphes, Bunge, Astrag. Fedsch. 251.-As. temp. asciocalyx, Bunge, Astrag. i. 187; ii. 284-As. Min. ascophorus, Fisch. ex Bunge, 1. c ii. $60=$ brachystachys.

askius, Bunge, l. c. i. 120 ; ii. 208.-Persia.

aspadanus, $B$ unge, l.c. i. 68 ; ii. $100^{\circ}$-Persia

asper, Facq.Ic. Rar. i. 13. t. 152.-Europ, austr. ; Reg. Caucas.

asperulus, Dufour, in Ann. Sc. Gen. vii. (18:0) 295 A. epiglotcis.

Asterias, Stev, in Bull. Soc. Nat. Mosc iv. (1532) $36^{\circ}$ cruciatus.

astraboides, Pamel, Now\%. Mat. Fl. Afl. 186.-Alseria. atlanticus, Ball, in Fow ${ }^{2}$. Bof. xi. (18;3) 906. - Afr. bor. occ.

atratus, S. Wols. in Bot. Aing, Exp. B9.-Am. bor.

atropatanus, Bunge, Astrog. i. 82; ii. 188.-Persia. 


\section{ASTRAGALUS}

atropatanus, Fisch. ex Bunge, Astrag, ii. $90=$ pulchellus. atropurpureus, Boiss. E Heldr. Diagn. Ser. I. ix. 54.As. Min.

atticus, Nym. Consp. $190=$ Wulfenii.

Aucheri, Boiss. Diagn. Ser. I. ii. 46.-Armenia.

Aucherianus, Fisch. in Bull. Soc, Nat. Mosc. xxvi. (1853) II. 398. = ptilodes

auganus, Bunge, Astrag. i. 36 ; ii. 45.-Afghanist. aulacolobus, Boiss. Diagn. Ser. I. ix. 64.-Syria Mesopotam.

aureus, Willd. in Mém. Acad. Berl. (1794-95) 29. t. 1. -Oriens.

Austinae, A. Gray, Bot. Calif. i. 156.-Calif

australis, Lam. Fl. Fr. ii. 637 ; Bunge, Astrag. i. 22 ; ii. 24.-Mont. Pyren.; Hispan.

austriacus, Delarb. Fl. Auv. ed. II. $466=$ hamosus.

austriacus, Linn. Sp. Pl. 1070.-Europ. ; Reg. Caucas. ; Sibiria.

austriacus, Pall. ex Steud. Nom ed. II. i. $159=$ versicolor.

austriacus, Thore, ex DC. Prod. ii. $283=$ baionnensis

bachtiaricus, Bunge, Astrag. i. 38 ; ii. 53.-Persia.

bactrianus, Fisch. in Bull. Soc. Nat. Mosc. xxvi. (1853) 354.-Turkestan.

baeticus, Linn. Sp. Pl. ed. II 1068-Hispan.; Sicil.

baghensis, Bunge, Astrag. i. 80 ; ii. 135.-Persia.

baibutensis, Bunge, l. c. 1. 91 ; ii. 162.-Armenia.

baicalensis, Bunge, l.c. i. 139 ; ii. 238.-As. centr.

baicalensis, Pall. Astrag. 64. t. $52=$ Oxytropis coerulea.

baicalia, Pall. Astrag. 93. t. 77. f. $1=$ Oxytropis baicalia.

baionnensis, Loisel. Fl. Gall. ed. I. 474-Gallia occ.

bakaliensis, Bunge, in Mém. Sav. Etr. Pétersb. vii. (1851) 268 (Pl. Lehm. 92. t. 14).-Persia.

bakuensis, Bunge, Astrag. i. 37 ; ii. 45.-Reg. Casp. ; Ind. bor. occ.

Balansae, Boiss. Diagn. Ser. II. vi. 59-Cappadoc.

banaticus, Rochel, ex Nym. Consp. $189=$ chlorocarpus.

Barba-Aronis, Ehrenb. ex Bunge, Astrag. ii. $65=$ Sieberi.

Barba-Jovis, DC. Astrag. 188.-As, Min

Barba-Fovis, Fenzl, ex Bunge, Astrag. ii. 149 Fenzlii.

Barba-Mosis, Ehrenb. ex Fisch. in Bull. Soc. Nat. Mosc. xxvi. (1853) II. 486.-Mont. Sinai.

barbatus, Lam. Encyc. i. 314.-Armenia.

barbatus, Sibth. \& Sm. Fl. Graec. Prod. ii. $88=$ Sibthorpianus.

Barrelieri, Dufour, in Ann. Sc. Gén. vii. (1820) $297=$ incanus.

basianicus, Boiss. E Haussk. ex Boiss. Fl. Orient. ii. 361.-Mesopotam

bayonnensis, Auct. vide baionnensis.

Beckerianus, Trautv. in Act. Hort. Petrop. iv. (1876) 363.-Reg. Caucas.

Beckwithii, Torr. E" Gray, in Pacif, Rail. Rep. iii. (1854) 120.-Am. bor. occ

Behen, Bertol. in Nov. Comm. Bonon. vi. (1844) 233 (Misc. Bot. ii. 19) = Russelii.

Belangerianus, Fisch. in Bull. Soc. Nat. Mosc. xxyi (1853) $484=$ leioclados.

Benthamianus, Gill. in Hook. Bot. Misc. iii. (1833) 187.-Chili.

Bergii, Hieron. in Bol. Acad. Nac. Cordova, iii. (1879) 343.--Reg. Argent.

Berteri, Colla, in Mem. Acc. Torin. xxxvii. (1834) 57. Chili.

berytheus, Boiss. E Blanche, Diagn. Ser. II. ii. 33.Syria.

berytius, Bunge, Astrag. i. 50 ; ii. 78.-Cataonia.

bethlehemiticus, Boiss. Diagn. Ser. I. ix. 85.Palaestin.

bhotanensis, Baker, in Hook, f. Fl. Brit. Ind. ii. 126. - Reg. Himal.

bicarinatus, Steud. Nom. ed. II. i. 159=Gueldenstaed tia pauciflora

bicolor, Desf. Cat. Hort. Par. ed. III. $473=$ pictus.

bicolor, Lam. Encyc. i. 317.-Armenia.

bicolor, Steud. Nom. ed. II. i. $159=$ uliginosus.

bicristatus, A. Gray, in Proc. Am. Acad. xix. (1883) 75.-Calif.

bicuspis, Boiss, Fl. Orient. 1094 (emend.).-As. Mìn.

bicuspis, Fisch. in Bull. Soc. Nat. Mosc. xxvi. (1853) II. 406. -Tibet, occ.

bidentatus, H.B. E K. Nov. Gen. et Sp. vi. 493.Am. calid.

\section{ASTRAGATUS:}

bidentatus, Ehrenb. ex Bunge, Astrag. ii. $17=$ his-

piebersteinii, Bunge, l.c. i. 114 ; ii. 194.-Reg. Cancas. Bienerti, Bunge, l.c. i. 80 ; ii. 133.-Persia.

bifidus, Turcz. ex Ledeb. Fl. Ross, i. $605=$ multicaulis

biflorus, Linn Mant $273=$ Crotalaria biflora

biflorus, Pall. Reise, uii. $206=$ Gueldenstaedtia pauciflora

biflorus, Viv. Fl. Lyb. Spec. 44. t. 20.-Afr. bor.

Bigelovii, A. Gray, Pl. Wright. ii. 42.-Am. bor. Mexic.

bingoellianus, Kotschy \& Boiss. ex Boiss. Fl. Orient. ii. $357=$ muschianus

biovulatus, Bunge, Astrag. i. 11; ii. 11.-Persia

biserratus, St. Lag. in Ann. Soc. Bot. Lyon, vii. (1880) $120=$ A. Biserrula

Biserrula, Bunge, Astrag. i. 11 ; ii. 9.-Persia.

bisulcatus, A. Gray, in Pacif. Rail. Rep. xii. 42. t. 1. -Am. bor. occ.

bludhistanus, Bunge, Astrag. i. 76 ; ii. 129.Beluchist.

Bodeanus, Fisch. in Bull. Soc. Nat. Mosc. xxvi. (1853) II. 435.-Persia.

boeticus, Linn.Sp.Pl. 758.-Reg. Mediterr.

bohemicus, Mayer, in Abh. Boehm. Ges. iii. (1787) 314. $1=$ virgatus

Boissieri, Fisch. in Bull. Soc. Nat. Mosc. xxvi. (1853 II. 324.-Hispan.

Boissieri, Bunge, Astrag. ii. 132, pro parte =creticus.

Bolanderi, A. Gray, in Proc. Am. Acad. vii. (1868) 337.-Calif.

bombycinus, Boiss. Diagn. Ser. I. ii. 50.-Aegypt. Arab. ; Persia.

Bonanni, J. \& C. Presl, Delic. Prag. (1822) $42=$ leucophaeus.

Bonannianus, Bunge, Astrag. ii. $242=$ depressus.

bounacanthus, Boiss. Fl. Orient. ii. 370.-Lycia.

bounophilus, Boiss. E Hohen. Diagn. Ser. I. ix. 99.Persia.

Bourgaeanus, Coss. Notes Crit. 160.-Hispan,

Bourgovii, A. Gray, in Proc. Am. Acad. vi. (1864) 227.-Am, bor. occ.

brachybius, Stev. in Bull. Soc. Nat. Mosc. iv. (1832) $267=$ hamosus.

brachybotrys, Bunge, Del. Sem. Dorp. (1839) 8; et in Linnaea, xiv. (1840) Litt. 116.--Sibir. alt.

brachycalyx, Fisch.ex Boiss.Diagn. Ser. I. ix. 90 ; et in Bull. Soc. Nat. Mosc. xxvi. (1853) II. 350.Kurdist.

brachycarpus, Bieb. Fl. Taur. Cauc. ii. 201.-Reg. Caucas.

brachycentrus, Fisch. in Bull. Soc. Nat. Mosc, xxvi (1853) II. 337.-Persia.

brachyceras, C. Koch, ex Bunge, Astrag. ii. $7=$ tribuloides.

brachyceras, Ledeb. Cat. Hort. Dorp. (1822) 3.-Syria Persia ; Tauria.

brachycladus, Boiss. Fl. Orient. ii. 393.-Persia.

brachylobus, DC. Prod. ii. 285.-Reg. Casp.

brachyodontus, Boiss. Diagn. Ser. I ii. 46-Persia.

brachyphyllus, Fisch. in Bull. Soc. Nat. Mosc. xxyi (1853) II. $394=$ condensatus.

brachypodus, Boiss. Diagn. Ser. I. ii. $69=$ lagurus.

brachypterus, Fisch. in Bull. Soc. Nat. Mosc. xxvi (1853) II. 397.-Oriens.

brachỳpus, Schrenk, Enum. Pl. Nov. 79,-Soongaria. brachystachys, $D C$. Prod. ii. 303.-Syria; Mesopotam. brachytropis, C. A. Mey. Verz. Pfl. Cauc. 140.-Reg. Caucas.

Brackenbridgei, A.Gray, Bot. U. St. Expl. Exped. i. 416.-Peruv.

bracteolatus, DC. Astrag. 208 = angustifolius.

bracteosus, Boiss. E Noë, Diagn. Ser. II. ii. 31.Anatolia.

bracteosus, C. A. Mey. ex Bunge, Astrag. ii. $185=$ hyalolepis.

bracteosus, Klotzsch, in Bot. Ergeb. Waldem. Reise, $160=$ melanostachys

Brandegei, Porter \& Coult. Fl. Col. 24.-Am. bor. occ brahuicus, Bunge, Astrag. i. 119, 205.--Beluchist.

brazoënsis, Buckl. in Proc. Acad. Sc. Philad. ' 1861 (1862) 452.-Texas.

brevicarinatus, DC. Astrag. 241. t. $49=$ Gueldenstaedtia pauciflora.

breviflorus, DC. 1. c. 194 . t. $31=$ eriocephalus

breviflorus, Fisch. in Bull. Soc. Nat. Mosc, xxvi. (1853) II. $358=$ polyanthus,

\section{ASTRAGALUS}

breviflorus, Fenzl, ex Bunge, Astrag. ii. $149=$ Fenzlii. brevifolius, Ledeb. Fl. Alt. iii. 334.-Sibir. alt.

brevipes, Bunge, Astrag. i. 99 ; ii. 172.-Persia

brevirostris, Poir. Encyc. Suppl. i. 528=Oxytropis brevirostra.

Breweri, A. Gray, in Proc. Acad. Calif. iii. (1863) 103 - Calif.

Bruguieri, Boiss. Diagn. Ser. I. ix. 102.-Persia.

Buceras, Willd. Enum. Hort. Berol. Suppl. 51.-Ins. Maurit.

buchtormensis, Pall. Astrag. 176. t. 62.--Sibiria.

buchtormensis, Willd. ex Ledeb." Fl. Ross. i. $585=$ Oxytropis Pallasii.

Buhseanus, Bunge, Astrag. i. 120 ; ii. 207.-Persia.

Bulla, Fisch. in Bull. Soc. Nat. Mosc. xxvi. (1853) II. $438=$ cephalanthus.

bullarius, Pall. Reise, iii. $213=$ Oxytropis mixotricha.

Bungeanus, Boiss. Fl. Orient. ii. 436.-Reg. Caucas.

Burkeanus, Benth. ex Harv. Thes. Cap. i. 52. t. Ixxxii. -Afr. austr.

Bustillosii, Clos, in C. Gay, Fl. Chil. ii. 117.-Chili.

byzantinus, Fisch. in Bull. Soc. Nat. Mosc. xxvi (1853) $379=$ prusianus.

cabulicus, Boiss. Diagn. Ser. I. ix. $48=$ Oxytropis cabulica.

cachinalensis, Phil. Fl. Atac, 15.-Chili.

cadmicus, Boiss. Diagn. Ser. I. ii. 44.-As. Min. caelestis, Boiss. Fl. Orient. ii. 470.--Reg. Caucas caeruleus, Pall. Reise, iii. $293=$ Oxytropis caerulea.

caeruleus, Hort. Par. ex Bunge, Astrag. i. 103; ii 184.-Zeylan.

caespitosus, A. Gray, in Proc. Am. Acad. vi. (1864) 230. - Am. bor, oce

caespitosus, Pall. Astrag. 70. t. $57=$ Oxytropis caespitosa.

calabricus, Fisch. in Bull. Soc. Nat.Mosc.xxvi. (1853) 402. - Calabria.

californicus, Greene, in Bull. Calif. Acad. n. 3 (1885) 157.-Calif.

callichrous, Boiss. Diagn. Ser. I. ix. 62.-Palaestin. calliphysa, Bunge, Astrag. i. 76 ; ii. 128.-Persia. callistachys, Buhse, in Bull. Soc. Nat. Mosc. xxvi. (1853) II. 463.-Persia.

calophyilus, Boiss. \& Heldr. Diagn. Ser. II, ii. 26.Anatolia.

calvescens, Bunge, Astrag. i. 42 ; ii. 65.-Persia.

calycinus, Bieb.Fl. Taur. Cauc. ii. 199.--Reg. Caucas. calycosus, Torr. ex S. Wats, in Bot. King, Exp. 66.Calif.

camelorum, C. E W. Barbey, Herb. Levant, 131. t. 3. -Aegypt.

campestris, A. Gray, in Proc. Am. Acad. vi. (1864) 229.-Am. bor. occ.

campestris, Linn. Sp. Pl. $761=$ Oxytropis campestris. camporum, Benth. ex Bunge, Astrag, ii. 3, -Afghanist. camptoceras, Bunge, l. c. i. 12 ; i1. 12.-Cappadocia. campylanthus, Boiss. Diagn. Ser. I. vi. 42.-Persia. campylorhynchus, Fisch. \& Mey. Ind. Sem. Hort. Petrop. i. 23.-As. Min.; Persia; Soongaria. campylosema, Boiss. Diagn. Ser. I. ii. 82.-Cilicia. campylotrichus, Bunge, Astrag. Fedsch. 207.-As. temp.

canadensis, Linn.Sp. Pl.757.-Am. bor.

canaliculatus, Willd. Enum. Hort. Berol. Suppl. $52=$ scorpioides.

cancellatus, Bunge, Astrag. ii. 178.-Persia.

candicans, Greene, in Bull. Calif. Acad. n. 3 (1885) 156.-Calif.

candicans, Pall. Astrag. 61. t. $49=$ Oxytropis candicans. candidissimus, Ledeb. Fl. Alt, iii. 309.-Sibir. alt.; Calif.

Candolleanus, Boiss. Diagn. Ser. I. ii. 80.-Persia.

Candolleanus, Royle, lllustr. Bot. Himal. 199= Royleanus.

canescens, Bunge, Astrag, ii. 174.-Armenia.

canescens, DC. Astrag. 114. t. $16=$ onobrychoides. canescens, Soland. ex Lowe, in Trans. Camb. Phil. Soc. iv. (1831) $34=$ Solandri.

canescens, Kit. in Linnaea, xxxii. (1863) 625.-Hungar. caniculatus, Willd. Enum. Hort. Berol. Suppl. 52= scorpioides.

cano-ater, Bunge, Astrag. i. 50 ; ii. 80 -Cappadoc.

canus, Bunge, l. c. ii. 180-Persia.

canus, Willd. ex Ledeb. Fl. Ross, i. $606=$ multicaulis.

capillipes, Fisch. ex Bunge, Astrag. i. 20 ; ii. 21.China. 


\section{ASTRAGALUS :}

capitatus, Lam. Fl. Fr. ii. $640=$ A. Glaux.

capitatus, Linn. Sp. Pl. $755=$ =marginatus.

Capito, Boiss. E Hohen. Diagn. Ser. I. ix. 40.-Persia.

cappadocicus, Boiss. Diagn. Ser. I. ii. 74.-As. Min.

caprinus, Guss. Fl. Sic. Syn, ii. $315=$ Hnetii.

caprinus, Linn. Sp.Pl. ed. II, 1071.-Barbaria ; Oriens. caprinus, Pall. Reise, ii, $329=$ dasyanthus.

Caraganae, Fisch. E' Mey. in Bull. Soc. Nat. Mosc. (1838) 344,--Reg. Caucas.; Persia.

carduchorum, Boiss. E Haussk, ex Boiss. Fl. Orient. ii. 310.-Persia.

cariensis, Boiss. Diagn. Ser. I, ix. 56.-As. Min.

carinalis, Benth. ex Bunge, Astrag. i. 23 ; ii. $28=$ himalayanus.

carnosus, Nutt. Gen. Am. ii. $100=$ caryocarpus.

carnosus, Pursh, Fl. Am. Sept. ii. $740=$ Sophora sericea.

carolinianus, Linn. Sp. Pl. $757=$ canadensis.

caryocarpus, Ker-Gawl. in Bot. Reg. t. 176.-Am. bor. caryocarpus, Torr. in Ann. Lyc. N. York, ii. (1828) $179=$ plattensis.

caryolobus, Bunge, Astrag. i. 37.--Persia

casapaltensis, Ball, in Fourn. Linn. Soc. xxii. (1885)

36.-And. Peruv,

Casei, A. Gray, in Bot. Calif, i. 154,-Calif,

caschmirensis, Bunge, Astrag, i. 30 ; ii. 34--Kashmir

caspicus, Bieb. Fl. Taur. Cauc. ii. 204.-Reg. Casp. As. temp.

caspius, Hohen. ex Ledeb. Fl. Ross. i. $641=$ praec.

castanaeformis, S. Wats. in Proc. Am. Acad.xx. (1885)

361.-Arizona.

castellanus, Bunge, Astrag, i. 9 ; ii. 5,-Hispan.

catacamptus, Bunge, l. c. ii. 191.-Persia.

catalinensis, Nutt. in Journ. Acad. Sc. Phil. N. S. i.

(1847) $152=$ didymocarpus.

cataonicus, Boiss. Fl. Orient. ii. $247=$ affghanus.

cataonicus, Bunge, Astrag. i. 107; ii. 188.-Cataonia.

coucasicus, Bieb. Fl. Taur. Cauc, ii. $205=$ Marschal-

lianus.

caucasicus, Pall. Astrag. 2. t. 2.-Reg. Cancas.

caudatus, Pall. 1. c. 62 . t. $50=$ Oxytropis songorica

caudiculosus, Boiss. Diagn. Ser. II. ii. 25. - Armenia.

cauquenensis, Phil in Anal. Uniw, Chil. (1872) 691.

Chili.

Cedreti, Boiss. Diagn. Ser. I. ix. 39.-Mont. Libanus.

cephalanthus, DC. Astrag. 169. t. 38.-Persia.

cephalanthus, Hohen, ex Bunge, Astrag. ii, $117=$

Hohenackeri.

cephalanthus, Kotschy, ex Bunge, 1. c. ii. $120=$ schirasicus.

cephalonicus, Fisch. in Bull. Soc. Nat. Mosc. xxvi. 1853) II. $424=$ aristatus.

cephalonicus, Presl, Bot. Bemerk. 57.-Cephalonia

Cephalotes, Pall. Astrag. 29. t. 24.-Reg. Caucas.

Cephalotes, [Soland. in] Russell, Aleppo, ed II. ii. 260

A. Andrachne.

cerasinus, Baker, in Fourn. Linn. Soc. xviii. (1878) 47 . -Afghan.

cerasocrenus, Bunge, Astraga i. 93; ii. 167.-Persia.

ceratoides, Bieb. Fl. Taur. Cauc, iii. 492.-Sibir. alt.

ceratoides, Bunge, Enum. Alt. $71=$ stenoceras.

Cervini, Thomas, ex Steud. Nom. ed. II. i. $160=$ lapponica.

chaborasicus, Boiss. E Haussk. ex Boiss. Fl. Orient. ii. 487.-Mesopotam.

chaetodon, Bunge, in Mém. Sav. Etr. Acad. Pétersb. vii. (1851) 272 (Pl. Lehm, 96), -Turkestan.

chaetodon, Torr. ex A. Gray, in Proc. Am. Acad, vi (1866) $194=$ Spaldingii.

chaetolobus, Bunge, in Mém. Sav. Etr. Acad. Pétersb. ii. (1835) 592 .-Sibir, alt.

chaetopodus, Bunge, Astrag. ii. 208,-Persia.

chalaranthus, Boiss. E Haussk. ex Boiss. Fl. Orient. ii. 390.- Persia.

Chamaeleuce, A. Gray, in Ives, Rep. Bot. 10.-Am. bor. occ.

Chardini, Boiss. Diagn. Ser. I. ii. 74.-Persia.

chartaceus, Ledeb. Fl. Ross. i. 634,-Persia

chartostegius, Boiss. G Haussk. ex Boiss. Fl. Orient. ii. 810 - Oriens; Persia.

Chaubardi, Bunge, Astrag. i. 118 ; ii. $202=$ Wulfeni.

chinensis, Linn. f. Decad. i. t. 3.-China.

chionobius, Bunge, Astrag. ii. 74.-Persia.

chionophilus, Boiss. E Heldr. Diagn. Ser. I. ix. 52. As. Min.

chionophyllus, Kotschy, ex Bunge, Astrag. ii. $76=$ depressus.

\section{ASTRAGALUS :}

chius, Boiss. \& Orph. ex Boiss. Fl. Orient. ii. $370=$ trojanus.

chiwensis, Bunge, Astrag. Fedsch. 247.-Khiva.

chloranthus, Pall. Astrag. 30. t. $25=$ asper

chlorocarpus, Griseb. Spicil. Fl. Rumel. i. $50=$ A. Onobrychis.

chlorocyaneus, Boiss. E. Reut. Diagn. Ser. I. ix. 56.Hispan.; Afr. bor. occ.

chlorodontus, Bunge, in Bull. Soc. Nat. Mose. xxxix. 1866) II. 29.-As. temp.

chlorophaeus, Bunge, Astrag. i. 50 ; ii. $79=$ oxytropifolius.

chlorosphaerus, Boiss. E Noë, Diagn, Ser, II. ii. 28.Oriens.

chlorostachys, Hook. f. \& Thoms. ex Bunge, Astrag. ii. 28 = carinalis.

chlorostachys, Lindl. in Trans. Hoxt. Soc. vii. (1830) 249.-Reg. Himal.

chlorostegius, Boiss. E Haussk. ex Boiss. Fl. Orient. ii. 413.-Mesopotam.

choicus, Bunge, Astrag. i. 119 ; ii. $204=$ latifolius.

chorassanicus, Bunge, l. c. i. 83; ii. 145.-Persia

chordorrhizus, Fisch. ex Bunge, $l$. co i. 52 ; ii. 86. Reg. Caucas.

chorinensis, Bunge, l. c. i. 22 ; ii. 24-Sibir

Christianus, Aucher, ex Bunge, 1. c. $36=$ diptherolobus.

Christianus, Heldr. ex Bunge, 1. c. ii. $38=$ pisidicus

Christianus, Linn.Sp.Pl. 755.-As. Min.; Syria.

Christianus, Russell, ex Bunge, Astrag. ii. $36=$ aleppicus.

Christianus, Pinard, ex Bunge, 1. c. ii. $38=$ columnaris. Christianus, Siev, in Pall. N. Nord. Beitr. vii. 293= Sieversianus.

Christianus, Sibth. \& Sm. F1. Graec. Prod. ii. $85=$ graecus.

Christianus, Vabl, Symb. Bot. i. 57 =tomentosus.

chromolepis, Boiss. \& Hohen. Diagn. Ser. I. ix. $84=$ aureus.

chrysanthus, Boiss. EF Hohen.l. c. 73.-Persia

chrysochlorus, Boiss. \& Kotschy, in Boiss. 1. c. Ser. II v. $86=$ pannosus.

chrysomallus, Bunge, Astrag. Fedsch.310.-As. temp. chrysophyllus, Boiss. Diagn. Ser. I ix. 38-Syria.

chrysopteros, Bunge, ex Maxim. in Bull. Acad. Pétersb. xxiv. (1878) 32.-China.

chrysostachys, Boiss. Diagn. Ser. I. ii. 69.-Persia. chrysotrichus, Boiss. l. c. 75.-Persia

chtonocephalus, Boiss. E Bal. Diagn. Ser. II. vi. 57. -Cappadoc.

Cicer, Linn.Sp.Pl. 757.--Europ. austr. ; Reg. Caucas. Sibiria

cicerellus, Boiss. E Bal. Diagn. Ser. II. vi. 53.Cappadoc.

cicerifolius, Royle, ex Bunge, Astrag. i. .44; ii. 70.Reg. Himal.; Tibet. occ.

cicerifolius, Royle, ex Fisch. in Bull. Soc. Nat. Mosc. xxvi. (1853) II, $404=$ scariosus

cicerinus, St. Lag. in Ann. Soc. Bot. Lyon, vii. (1880) $120=$ A. Cicer

cilicius, Boiss, Diagn. Ser. I. ii. 59.-Cilicia.

ciliolatus, Benth. ex Bunge, Astrag. i. 27 ; ii. 33.Reg. Himal.

cinerascens, DC. ex Steud. Nom. ed. II. i. $160=$ rupi fragus, testiculatus.

cinereus, Bess. Enum. Pl. Volh. $29=$ pallescens.

cinereus, DC. Astrag. $178=$ reduncus.

cinereus, Turcz. Fl. Baic.-Dah. i. $322=$ multicaulis.

cinereus, Willd. Sp. Pl. iii. 1315. - Armenia.

citrinus, Bunge, Astrag. i. 34 ; i. 42.-Persia.

clandestinus, Roth, ex Spreng. Syst. iii. $300=$ cymbiformis.

Clausii, C. A. Mey. in Goebel, Roise, ii. 265. t. $5=$ vulpinus.

clavatus, $D C$. Astrag, 230, t, 44.-Armenia.

clavatus, Ledeb. F1. Ross. i. $648=$ brachycarpus,

Clevelandi, Greene, in Torrey Bot. Club. ix. (1882) 121. - Am. bor.

Closianus, Phil. in Anal. Univ. Chil. (1872) 691.Chili.

Clusii, Boiss. Diagn. Ser. I. ix. 101.-Hispan.

Clusii, Pollini, ex Sterd. Nom. ed. I. 85 ; ed. II. i. 160.-Italia.

conrctatus, Trauto. in Act. Hort. Petrop. iv. (1876) 365.-Armenia.

cobrensis, A. Gray, Pl. Wright. ii. 48, in adnot.-An. bor. occ.

\section{ASTRAGALUS :}

cognatus, C. A. Mey. in Schrenk, Enum. Pl. Nov. 81 $-\mathrm{As}$. centr.

collinus, Boiss. Fl. Orient, ii. 438.-As. Min

collinus, Dougl. ex Hook. Fl. Bor. Am. 141, in syn.Am. bor. occ.

columnaris, Boiss. Diagn. Ser. I. ix. 70-As. Min.

coluteocarpus, Boiss. l. c. 65. - Tiket. occ. ; Afghanist.

coluteoides, Willd. in Mém. Acad. Berl. (1794-95) 27. -Syria.

commixtus, Bunge, in Arb. Nat. Ver. Riga, i. (1847)

246.-As. Min.; Persia; Turkest.

comosus, Bunge, Astrag. i. 56 ; ii. 93.-Persia.

compactus, Fisch. ex Bunge, in Iull. Soc Nat. Mosc. (1853) II. $368=$ zachlensis, strictifolius.

compactus, Lam. Encyc. i. 322.-Armenia.

compactus, C. A. Mey. Verz. P丹. Cauc. $143=$ Meyeri

complanatus, R. Br. ex Bunge, Astrag. ii. 1.-Chin.

complicatus, Gill, in Hook. Bot. Misc. iii. (1833) 187. -Chili.

compressus, Ledeb. Fl. Alt. iii. 304.-Sibir. alt

concinnus, Benth. ex Bunge, Astrag. ii. 50.Beluchist.

concretus, Benth, in Royle, Illustr. Bot. Himal. 199 $=$ vicioides.

condensatus, Ledeb. Fl. Ross. i. 639--Reg. Cancas.

conduplicatus, Bertol. in Nov. Comm. Bonon. vi. (1844) 231 (Misc. Bot. ii. 17).-Syria; Mesopotam.

confertiforus, A. Gray, in Proc. Am. Acad. xii. (1878) 368.-Am. bor.

confertus, Benth. ex Bunge, Astrag. ii. $27=$ hippocrepidis.

confusus, Bunge, l. c. ii. 216.-Persia.

Congdoni, S. Wats. in Proc. Am. Acad. xx. (1885 360.-Calif.

congestus, Baker, ex Aitch. in Fourn. Linn. Soc. xix. (1882) 158.-Ind, or.

conjunctus, S. Wats in Proc. Am. Acad. xrii. (188182) 371 -Am bor

consanguineus, Bong, E C. A. Mey. Verz, Pf. Saisang-Nor, 22. t. 3.-China.

contortuplicatus, Linn. Sp. Pl. 758.-Europ. austr occ. ; Sibiria ; Ind. or.

contortuplicatus, Sibth. \& Sm. Fl. Graec. viii. 21. t. $729=$ cruciatus.

Cooperi, A. Gray, Man. Bot. U. St. ed. II. 98.An. bor.

cordatus, Bunge, Astrag. i. 69 ; ii. 114.-Persia.

coriaceus, Hemsl. Biol. Centr. Am. Bot. i. 269.Mexic.

corniculatus, Bieb. Fl. Taur. Cauc iii. 492-Bessarab.; Podol.

corniculatus, Turcz. Cat. Fl. Baic. $356=$ angarensis comutus, Bunge, Astrag.i. 76 ; ii. 130.-Afghanist. cornutus, Pall. Reise, i. $499=$ vimineus.

Coronilla, Bunge, Astrag, ji, 10,-Persia.

corrugatus, Bertol. Amoen. Ital. 38.-Aegypt. Arab.

Pers. ; Afghanist.

corydalinus, Bunge, in Act. Hort. Petrop. iii. (1875) 101.-Turkestan.

Cossonii, Bunge, Astrag. i. 118; ii. $192=$ chlorocraneus. costatus, Bunge, l. . . i. 35; ii. 61.-Afghanist.

Coulteri, Benth. Pl. Hartw. 307.-Calif.

Cracca, DC. Astrag. 101. t. 9.-Perav.

crassicarpus, Fras, Cat. ex DC, Prod. ii. $287=$ caryocarpus.

crassicaulis, R. Grah, in Wall. Cat. n, $5932=$ Caragana crassicaulis.

crassinervius, Boiss, Diggn, Ser. II. v, S8-Kurdistan. crassipes, Fras. ex Stead. Nom. ed, II. i. $160=$ caryocarpus.

crassispinus, Bunge, Astrag. i. 132; ii. 280.Afghanist.

crassus, Bunge, l. c. i. 42 ; ii. $69 .-$ Persia.

crenatus, Schult. Obs. $186=$ corrugatus.

crenophilus, Boiss. Diagn. Ser. I. ix. 90,-Kurdistan.

cretaceus, Boiss. 1. c. Ser. II. F. S4.-Syria.

cretaceus, Pall. in Nov. Act. Petrop. $\mathrm{x}$. $(17,6) 56=$ tauricus.

cretensis, Pall, Astrag. 5 = caspicus.

creticus, Boiss, Yoy, Bot. Espnume, 181 = Boissieri.

creficus, DC. ex Boiss. Diagn, Ser. I. ix, \$2 = cruenth

florus.

creticus, creficus, Willd. in Mcm. Acad. Berl. (1;94-95) 13 cchinoides. 


\section{ASTRAGATUS :}

creticus, Sibth. Fl. Graec. viii. 26. t. $736=$ prusianus. criacanthus, Stev. ex Fisch. in Bull. Soc. Nat. Mosc xxvi. (1853) II. 331 = arnacantha

crinitus, Boiss. Diagn. Ser. I. ii. 55.-Armenia.

cristatus, Gouan, Illustr. $50=$ pentaglottis.

Cristophi, Trautv. in Act. Hort. Petrop. viii. (1884) 378.-Rossia

Crotalariae, A. Gray, in Proc. Am. Acad, vi. (1864) $216=$ oocarpus.

cruciatus, Link, Enum. Hort. Berol. ii. 256.-As. Min.

cruciatus, Auct. ex Bunge, Astrag. ii. $8=$ pseudostella cruciatus, Auct. quib. ex Boiss. Fl. Orient. ii. 226 , in nota = polyactinus.

cruentiflorus, Boiss. Diagn. Ser. I. ix. 82,-Syria.

cruentus, Balb. Cat. Taur. App. i. $8=$ corrugatus,

Cruikschankii, Griseb. in Goett. Abh. xxiv. (1879)

103.-Reg. Argent

cryptanthus, Wedd. Chlor. And. ii. 259,-Am. austr

cryptocarpos, DC. Astrag. 187.-Armenia

cucullaris, Boiss. Diagn. Ser, I, vi. 39.--Mesopotam.

cumanus, Bieb. ex Ledeb. FI. Ross. i. $607=$ lasio

glottis.

cumanus, Willd ex Steud. Nom. ed. II i, 160, $159=$

aduncus.

cuneifolius, Bunge, Astrag. i. 44; ii.68.-Afghan

curtipes, A. Gray, in Proc. Calif. Acad. iii. (1863) 103.-Am. bor. occ.

curviflorus, Boiss, Diagn. Ser. I. ii. 67.-Persia.

curvirostris, Boiss. l. c. Ser. I vi. 38-Oriens.

Cuscutae, Bunge, Astrag. i. 120; ii. 207.--Reg. Caucas.

Cusickii, A. Gray, in Proc. Am. Acad. xiii. (1878)

370.-Am. bor.

cuspidatus, Bunge, Astrag. i. 117 ; ii. 198 = schizop terus.

cyaneus, A. Gray, Pl. Fendl. 34.-Am. bor. occ

cygneus, Fisch, ex Bunge, Astrag. ii. $190=$ subbijugus,

cylindraceus, $D C$. Astrag. 223.-Armenia.

cylindraceus, C. A. Mey. Verz. Pfl. Cauc. $143=$ macrourus.

cylleneus, Boiss. Es Heldr. in Bull. Soc. Nat. Mosc. xxvi, (1853) II. 355,-Graecia.

cymbaecarpus, Brot. Fl. Lusit. ii. 167.-Lusit

cymbiformis, Willd. ex Brot. Phyt. $59=$ cymbaecarpus. cymbostegis, Bunge, Astrag. 1. 85 ; ii. 14.-Cataonia.

cyprius, Boiss. Fl. Orient, ii. 469-Ins. Cyprus.

cyrenaicus, Coss, in Bull. Soc. Bot. Fr. xix. (1872) 80 . - Cyren.

cyrtobasis, Bunge, ex Boiss. Fl. Orient. ii. 497. -Turkestan.

cyrtoides, A. Gray, in Proc. Am. Acad. vi. (1864) 201 = Gibbsii.

cysticalyx, Ledeb. Fl. Ross. i. 643-Rossia.

cytisoides, Bunge, Astrag. i. 128; ii. 224.-Turkestan

dacicus, Heuff. in Verh. Zool. Bot. Ges. Wien, (1858) 93.-Europ.

dactylocarpus, Boiss. Diagn. Ser. I. ii. 60.-Meso potam.

daenensis, Boiss l. c. Ser. I. vi. 35-Persia.

daguricus, Pall. Astrag. 88. t. $72=$ Oxytropis prostrata dahuricus, $D C$. Prod. ii. 285.-Dahuria; China.

dahuricus, Patrin, ex DC. 1. c. $277=$ Oxytropis dissitiflora.

dalguricus, Willd. Sp. Pl. iii. 1301= Oxytropis pro strata.

dalmaticus, Bunge, ex Nym. Consp. $190=$ Soyeri.

Daltonianus, Bunge, Astrag. i. 44 ; ii. $69=$ polyacanthus.

damascenus, Boiss. E Gaill. Diagn. Ser. II. vi. 56.Syria.

damascenus, DC. Prod. ii. $298=$ coluteoides.

danicus, Retz. Obs iii. 41-Europ.

Darumbinm, C. Gay, Fl.Chil. ii. 112.-Chili

dasyanthus, Pall. Astrag. 79. t. 65 ; Reise, iii. 749.Hungar.; Sibir.; Reg. Cauc.

dasycephalus, Bess. ex Stev. in Bull. Soc. Nat. Mosc. 1832) $264=$ roseus.

dasyglottis, Fisch. ex DC. Prod. ii. $282=$ A. Hypoglottis.

dasyglottis, Pall. ex Steud. Nom. ed. II. i. $160=$ pentaglottis.

dasyphyllos, Pall. Astrag. 91. t. $75=$ Oxytropis lanata.

dauricus, C. Koch, in Linnaea, xv. (1841) $719=$ Stevenianus.

dauricus, Auct. $=$ dahuricus

\section{ASTRAGATUS}

davuricus, Ledeb. Ic. F1. Ross, t. 318 =dahuricus.

davuricus, Patrin, ex Ledeb. F1. Ross. 1. $597=\mathrm{Oxy}$ tropis dissitifiora.

dealbatus, Ehrenb. ex Bunge, Astrag. ii. $164=$ Roussaeanus.

dealbatus, Pall. Astrag. t. 23. f. $1=$ albicaulis.

debilis, A. Gray, in Proc. Acad. Sc. Philad. 1863 (1864) 60.-Am. bor.

decemjugus, Bunge, Astrag. i. 43 ; ii. $67=$ psilacanthus. decipiens, Bunge, 1.c. i. 107 ; ii. $188=$ Sibthorpianus. declinatus, Saliib. Prod. $337=$ monspessulanus. declinatus, Willd. Sp. Pl iii. 1294-Armenia.

decumbens, Boiss. Hi. Oiient. ii. $429=$ leucocyaneus.

decumbens, A. Gray, in Proc. Am. Acad. vi. (1864) 229.-Am. bor. occ.

decurrens, Boiss. Diagn. Ser, I. vi. 40.-Mesopotam.

deflexus, Pall. in Act. Acad. Petrop. ii. (1779) 268.t. $15=$ Oxytropis deflexa

deinacanthus, Boiss, Diagn Ser. I ix. 76--Syria

deluensis, Bunge, Astrag. 1. 55 ; ii. $91=$ grisens.

demavendicus, Boiss. Ë Buhse, in Nouv. Mém. Soc. Nat. Mosc. xii. (1860) 70.--Persia.

demissus, Boiss. \& Heldr. Diagn. Ser. I. ix, $50=$ amoenus.

dendridium, Fisch. in Bull. Soc. Nat. Mosc. xxvi 1853) II. $427=$ lycioides.

dendroides, Kar. E" Kir. l. c. xv. (1842) 339.Dahuria.

densiflorus, Kar. E Kir. l. c. 329.-Reg. Himal, ; Sibir. densifolius, Lam. Encyc. i. 317.-Armenia.

densifolius, Torr. in Pacif. Rail. Rep. vii. $10=$ Menziesii.

denudatus, Kotschy, ex Fisch. in Bull. Soc. Nat. Mosc. xxvi. (1853) II. $335=$ myriaca itius.

denudatus, Stev. 1. c. $328=$ microcephalus.

depauperatus, Ledeb. Fl. Alt. ii. 314.-Sibir, alt

dependens, Bunge, ex Maxim, in Bull. Acad. Pétersb. xxvi. (1880) 471.-China oce

depressus, Bertol. in Nov. Comm. Bonon. vi. (1844) 232 (Misc. ii, 232) = cruciatus.

depressus, Linn. Cent. Pl. ii. 29 ; Amoen. Acad. iv. 327.-Europ. austr. ; Oriens.

depressus, Pall. Reise, i. $239=$ diffusus

depressus, Sibth. \& Sm. F1. Graec. viii. 24. t. $733=$ leucophaeus.

derbendicus, Bunge, Astrag. i. 40 ; ii. 55.-Persia.

desertorum, Lehm.ex Spreng. Syst. iii. 300.-Deserta Asiae.

dianthus, Bunge, Astrag. Fedsch. 283.-As. centr.

diaphanus, Tougl. ex Hook. Fl. Bor. Am. i. $151=$ lentiginosus.

dichopterus, Pall. Astrag. t. $39=$ austriacus.

dictyocarpus, Boiss. Diagn. Ser. I. ii. 84.-Syria.

dictyolobus, C. A. Mey. ex Bunge, Astrag. i. 60 ; ii 98.-Persia.

dictyophysus, Reut. ex Bunge, l. c. i. 74; ii. 124.Pontus.

dicystis, Bunge, Astrag. Fedsch. 225.-As. centr

didymocarpus, Hook. E Arn. Bot. Beech. Voy. 334.Calif

didymophysus, Bunge, Astrag. i. 113; ii. 193.-Persia diffusus, Willd. Sp. P1. iii. $1321=$ dolichophyllus.

dilectus, Phil. in Anal. Univ. Chil. (1872) 690.Chili.

dilutus, Bunge, Del. Sem. Dorpat. (1840) 7.-Cf. Linnaea, xv. (1841) Litt. 85.-Oriens.

diopogon, Bunge, Astrag. i. 70 ; ii. 117.-Beluchist

dioriticus, Schott, ex Boiss. F1. Orient. ii. $503=$ Oxytropis dioritica.

dipelta, Bunge, in Act. Hort. Petrop. vii. (1880) 368. -Turkestan.

diphacus, S. Wats. in Proc. Am. Acad. xvii. (1881-82) 342.-Am. bor. occ

diphtherites, Fenzl, in Flora, xxvi. (1843) 396.Mesopotam.

diphtherolobus, Bunge, Astrag. i. 31; ii. 36. -Syria.

diphyllus, Lam. Encyc. i. $330=$ Oxytropis microphylla.

diphysus, A. Gray, Pl. Fendl. 34.-Am. bor. occ.

dipodurus, Bunge, Astrag. i. 88 ; ii. 156 .- Syria

dipsaceus, Bunge, l.c. i. 59; ii. 97.-Anatolia

discolor, Bunge, ex Maxim. in Bull. Acad. Pétersb. xxiv. (1878) 33. -Mongolia.

dispermus, A. Gray, in Proc. Am. Acad. xiii. (1878) 365 -Ám. bor.

dissitiflorus, Bunge, in Mém. Acad. Pétersb. Sér. VI. vii. (1859) 585.-As, temp.
ASTRAGALUS :-

distans, Benth. ex Baker, in Hook. f. Fl. Brit. Ind. ii $128=$ macropterus

distans, Fisch. in Bull. Soc. Nat. Mosc. xxvi. (1853) II. 472.-Persia.

distans, A. Gray, Bot. U. St. Expl. Exped. i. 412.Patagonia.

distortus, Torr. E Gray, Fl. N. Am. i. 333.-Am. bor.

divaticatus, Bunge, Astrag. i. 93 ; ii. 166.-Persia

diversifolius, A. Gray, in Proc. Am. Acad. vi. (1864) $230=$ junceus.

Dodtii, Phil. in Linnaea, xxxiii. (1864-65) 48-Am. austr.

dolichophyllus, Pall. Astrag. 84. n. 90. t. 68.--Reg. Caucas.

dolius, Boiss. E Haussk. ex Boiss. Fl. Orient. ii. 340 -Kurdistan.

Dombeyi, Fisch. in Bull. Soc. Nat. Mosc. xxvi. (1853) 483.-Peruv.

Donianus, DC. Prod. ii. 283.-Nepal.

dorcoceras, Bunge, Astrag. i. 13; ii. 14.-Cilicia Mesopot.

dorychnoides, Scop. Delic. Insub. ii. 104=lusitanicus.

dorycnioides, Dougl. ex G. Don, Gen. Syst. ii. $258=$ succumbens.

Douglasî, A. Gray,-in Proc. Am. Acad. vi. (1864) 215. - Am. bor. occ.

drepanocarpus, Hochst. ex Bunge, Astrag. i. 14; ii $16=$ gyzensis.

drepanolobus, A. Gray, in Proc. Am. Acad.xix. (1883) 75. - Am. bor. occ.

drepanophorus, Griseb. in Goett. Abh. xxiv. (1879) 102.-Reg. Argent.

Drummondii, Dougl. in Hook. Fl. Bor. Am. i. 153.Am. bor.

drupaceus, Orphan. ex Boiss. Diagn. Ser. II. ii. 32.Graecia.

drusorum, Boiss. Diagn. Ser. I. ix. 78.--Syria.

dubius, DC. Astrag. 167. n. $115=$ buchtormensis.

dyctiocarpus, Boiss. Diagn. Ser. I. ii. 84, sphalm. $=$ dictyocarpus.

ebenoides, Boiss. l. c. Ser. I. ii. 70.-Persia

ecbatanus, Bunge, Astrag. i. 71; ii. 118.-Persia.

Echegarayi, Hieron. in Bol. Acad. Nac. Cordova, iv. (1881) 22,--lieg. Argent.

Echidna, Bunge, Astrag. i. 82 ; ii. 143.--Persia. echinatus, Murr. Hort. Bot. Stirp. 222 = pentaglottis.

echinoides, L'Hérit. Stirp. Nov. $170=$ ungustifolius.

Echinops, Aucher, ex Boiss. Diagn, Ser. I. ii. 57.Syria.

Echinus, Boiss, ex Willk. \& Lange, Prod. Fl. Hisp iii. $280=$ Boissieri

Echinus, DC. Astrag, 197. t. 34.-Syria.

Echinus, C. A. Mey. Verz. Pfl. Cauc. $143=$ caspius.

echioides, Willd. Sp. Pl. iii. $1326=$ angustifolius

edulis, Dur. ex Coss. in Ann. Sc. Nat. Sér. IV. i (1854) 222.-Afr. bor.

effusus, Bunge, Astrag. i. 102 ; ii. 179.-Persia.

Ehrenbergii, Bunge, l.c. i. 61; ii. 102 -Syria

elatus, Boiss. E Bal. Diagn. Ser. II. vi. 57.-Cappadoc

elbrusensis, Boiss. $l$. c. Ser. I. ix. 45.-Persia.

elegans, Bunge, Astrag. i. 55; ii. 89.-Persia.

Elliotii, D. Dietr. Syn. Pl. iv. $1080=$ obcordatus.

ellipsoideus, Bong. \& Mey. Suppl. Alt. 84, partim=

kurtschumensis.

ellipsoideus, Ledeb. Fl. Alt. iii. 319,-Sibir. alt.

elmaluensis, Bunge, Astrag, i. 121; ii. 211.-Lycia

elongatus, Willd. Sp. Pl. iii. 1314.-As. Min.

elymaiticus, Boiss. E Haussk. ex Boiss. Fl. Orient. ii 346.-Persia

emarginatus, $D C$. Astrag. 150.-Oriens.

emarginatus, Labill. Ic. Pl. Syr. Dec. i. 19.-Syria

Emodi, Steud. Nom, ed. II. i. 161.-Reg. Himal.

enoplus, Trautv. in Act. Hort. Petrop. iv. (1876) 364 -Reg. Caucas.

entomophyllus, Boiss. E Haussk, ex Boiss. Fl. Orient

ii. 25.9.-Persia

ephippium, Pomel, Nouv. Mat. Fl. Atl. 183.-Algeria. epiglossus, St. Lag. in Ann. Soc. Bot. Lyon, vii. (1880 $120=$ epiglottis.

epiglottis, Linn.Sp. Pl. 759.-Reg. Mediterr.

epiglottoides, Willk. in Bot. Zeit. iii. (1845) $428=\mathrm{A}$ Epiglottis.

episcopus, S. Wats. in Proc. Am. Acad. x. (1875) 346. -Am. bor. occ.

eremophilus, Boiss. Diagn. Ser. I. ii. 54--Aegypt. Arab. ; Beluchist. 


\section{ASTRAGALUS :}

eremospartoides, Regel, in Act. Hort. Petrop. iii. (1875) 103.-Turkestan.

eremothamnus, Kar. E Kir. in Bull. Soc. Nat. Mosc, xv. (1842) 334.-Soongaria.

eriacmus, Boiss. Fl. Orient. ii. 345.-Cappadoc.

erianthus, Fisch. ex Boiss. Fl. Orient. ii. $328=$ crenophilus.

erianthus, Willd. Sp. Pl. iii. $1332=$ gummifer.

erinaceus, Fisch. EN Mey. in Bull. Soc. Nat. Mosc.

xxvi. (1853) II. 325.-Persia.

erinzceus, Presl, Bot. Bemerk. $57=$ angustifolius.

eriocalyx, Bunge, Astrag. i. 86 ; ii. 150 .-Cilicia.

eriocarpus, DC. Astrag. 237 . t. $47=$ mollis.

eriocarpus, S. Wats. in Bot. King, Exp. 71 \& 440.Am. bor. occ.

eriocaulos, DC. Astrag. $188=$ microcephalus.

eriocephalus, Balansa, ex Bunge, Astrag. ii. $161=$ acicularis.

eriocephalus, Waldst. \& Kit. PI. Rar. Hung. i. 45. t. $46=$ dasyanthus.

eriozephalus, Willd. $S p$. Pl. iii. 1333.-Armenia.

erioceras, Fisch. EO Mey. in Ledeb. Fl. Ross. i. 626. As. med.

eriolobus, Bunge, in Mém. Sav. Etr. Acad. Pétersb. ii. (1835) 591 -depauperatus.

erionotus, Benth. ex Bunge, Astrag. i. 33 ; ii. $40 .-$ Afghan.

eriophyllns, Boiss. Diagn. Ser. I. ix. 39.-As. Min

eriopodus, Boiss. l. c. Ser. I. ii, 48.--Persia.

criosphaerus, Boiss. Es Haussk. ex Boiss. Fl. Orient. ii. 347.-Persia.

eriostylus, Boiss. E Haussk. ex Boiss, l.c. 316.-Persia. erpocaulos, Boiss. Diagn. Ser. I. ix. $58=$ tribuloides ervoides, Hook. G Arn. Bot. Beech. Voy. 417.-Mexic. ervoides, Turcz. in Bull. Soc. Nat. Mosc. (1838) $90=$ miniatus.

erythrolepidius, St. Lag. in Ann. Soc. Bot. Lyon, vii. 1880) $120=$ erythrolepis.

erythrolepis, Boiss. Diagn. Ser. I. ii. 65-Persia.

erythrotaenius, Boiss. l. c. vi. 39.-Mesopotam.

eschkerensis, Boiss. E Haussk. ex Boiss. Fl. Orient. ii. 328.-Persia.

eubrychioides, Boiss. Diagn. Ser. I. ix. 41.-Cappadoc. eucephalus, Boiss. l. c. ii. 56.-Syria.

euoplus, Trautv. in Act. Hort. Petrop. iv. (1876) 364. -As, temp.

exaltatus, Bunge, Astrag. i. $25=$ secundus.

eximius, Bunge, Astrag. Fedsch. 244.-As. centr.

expansus, Boiss. Diagn. Ser. I. ix. $43=$ Kotschyanus.

exsiapus, Linn. Mant. 275.-Europ.

exscapus, Auct. Transs, - Cf. Nym. Consp. 193=pubiflorus.

fabaceus, DC. Prod. ii. $302=$ utriger.

fabaceus, Bieb. Fl. Taur. Cauc, iii. 496.-Reg. Caucas.

fabaceus, Tan, ex Nym. Consp. $193=$ Huetii

falcatus, Desf. F1. Atlant. ii. $188=$ falciformis.

falcatus, Lam. Encyc. i. 310.-Reg. Caucas.; Sibir.

falciformis, Desf. Emend. Atl. ex DC. Astrag. 176.Alueria.

falcinellus, Boiss. Diagn. Ser. I. ix. 63.-Aegypt.

Falconeri, Bunge, Astrag, i. 4; ii. 2.-Tibet. occ.

fallax, Fisch. in Bull. Soc. Nat. Mosc. xxvi. (1853) II. $340=$ mesoleios.

fallax, S. Wats. in Proc. Am. Acad. xx. (1885) 362.Mexic.

farctus, Bunge, in Mem. Sav. Etr. Pétersb. vii. (1851) 276 (Pl. Lehm, 100),-Turkestan.

fasciculatus, Bertol. in Nov. Comm. Bonon. vi. (1844) 23.-Hab.?

fasciculifolius, Boiss. Diagn. Ser. I. ii. 73.-Persia.

fasticliosus, Greene, in Bull. Calif. Acad. n. 4 (1885) 186. - Calif.

fatmensis, Hochst. ex Bunge, Astrag. ii. 16.-Arabia ; Beluchist.

Fendleri, A. Gray, Pl. Wright. i. 44.-N. Mexic.

Fenzlii, Boiss. Diagn. Ser. II. v. 89.-Cilicia.

ferrugineus, C. Gay, Fl. Chil. ii 114.-Chili.

filagineus, Boiss, Diagn. Ser. I. ix. $89=$ gossypinus.

filamentosus, Bunge, Astrag. i. 99 ; ii. 51 -Kurdist.

filicaulis, Fisch. O Mey. Enum. Pl. Turc. et Pers. 256. -Reg. Casp.; Turkest.; Afghan.

filifolius, A. Gray, in Pacif. Rail. Rep. iv. $80=$ pictus. filifolius, Clos, in C. Gay, Fl. Chil. ii. 111.-Chili.

filiformis, Poir. Encyc. Suppl. i. 628 = tauricus.

filipes, Torr.ex A. Gray, in Proc. Am. Acad.vi. (1866)

$2: 26 .-A m$ bor occ

fuitimus, Bunge, Astrag. i. 61; ii. 102.-Persia.

\section{ASTRAGALUS}

Fischeri, Buhse, in Bull. Soc. Nat. Mosc. xxvi. (1853) II. $429=$ mucronifolius.

Fischerianus, Bunge, Astrag. i. 90 ; ii. $160=$ pilodes. flaccidus, Bieb. Fl Taur. ii. 196. n. 1484,-Reg Caucas.

flaccidus, Ledeb. F1. Ross. i. $607=$ onobrychioides. flavescens, Boiss. Diagn. Ser. I. ii. 64.-As. Min. flavus, Nutt. ex Torr. \& Gray, Fl. N. Am. i. 335. Am. bor.

flexuosus, Dougl. ex Hook. Fl. Bor. Am. i. 141, in syn. -Am. bor.

flexus, Fisch. in Bull. Phys.-Math. Acad. Pétersb. iii. (1844) 307, in nota.-Persia; Beluchist. ; Soongaria. floccosus, Boiss. Diagn. Ser. I. ii. 61.-Persia.

floribundus, Pall. Astrag. 47. t. $37=$ Oxytropis floribunda.

floridus, Benth.ex Bunge, Astrag. i. 24 ; ii. 28.-Reg. Himal.

floridus, Scop. Delic. Insub, ii. $108=$ Christianus.

florulentus, Boiss. E Haussk. Fl. Orient. ii. 3.17.Persia.

fodinarum, Boiss. E Noë, ex Bunge, Astrag. i. 121 ; ii. 209.-Arrnenia.

foetidus, Vill. Prosp, $42=$ Oxytropis foetida

foliolosus, Bunge, Astrag. 1. 74 ; ii. 125.-Anatolia.

folli iularis, Pall. Astrag. 19. t. 14.-As. centr.

Fontanesii, Coss. Fo Dur. ex Bunge, Astrag. i. 75 ; ii. 126. - Algeria.

Forskahlei, Boiss. Diagn. Ser. I. ix. 101.-Aegypt.; Arab.; Syria.

fragiferus, Bunge, Astrag. i. 72 ; ii. 119.-Persia.

fragiformis, Willd. Sp. Pl. iii. 1261 = inflatus.

fragrans, Willd.l. c. 1294.-Oriens.

Fraxinella, Bunge; Astrag. i. 39 ; ii. 52.-Persia.

fraxinifolius, $D C$. Astrag. 142. n. 71.-Armenia.

Frémontii, Torr in Pacif Rail. Rep。iv. $80=$ malacus, lentiginosus.

Fresenii, Decne, in Ann.Sc. Nat. Sér. II. iii. (1835) 266.-Arab.

Frickii, Bunge, Astrag.i. 117 ; ii. 201.-Reg. Caucas. frigidus, A. Gray, in Proc. Am. Acad. vi. (1864) 219 -Am, bor.

Friwaldskianus, Boiss. Diagn. Ser. I. ii. $73=$ physocalyx. frutescens, Hort. ex Kunth, Ind. Hort. Berul. (1845) 12 = Brongniartia robinioides.

fruticosus, Asso, Oryctogn. Arag. t. 2. f. $3=$ Clusii.

fruticosus, Forsk. Fl. Aegypt. Arab, $139=$ tomentosus.

fruticosus, Steud. Nom. ed. II. i. 161=Hedysarum fruticosum.

fruticosus, Pall. Astrag. 21. n. 24. t. 19.-Sibir. or. fruticosus, Ledeb. Fl. Alt. iii. $303=$ viminens.

gaeobotrys, Boiss. \& Bal. in Boiss. Diagn. Ser. II. vi, 52. - Cappadoc.

Gaillardoti, Boiss. Fl. Orient. ii. 375.-Syria.

galactites, Ledeb. Fl. Ross. i. 656, ex parte=brevi folius.

galactites, Pall. Astrag. 85. t. 65.-Sibir.; Dahur. galegiformis, Hohen. Enum. P1. Elisabethpol. 250 A. Glycyphyllos

galegiformis, Linn.Sp.Pl. 756.-Reg. Caucas. galegiformis, Pall. Reise, ii. $192=$ uliginosus. galegoides, Nutt. Gen. Am. ii. $100=$ racemosus. Garbancillo, Cav. Ic. i. 59, in textu.-Peruv. Garbanzillo, Pers. Syn. ii. $386=$ praec.

Garvanzillo, Cav. Ic. i. t. $85=$ Garbancillo.

Gebleri, Fisch. ex Bong. Vers. Pf. Saisang-Nor,

24, t. 4.-Soongaria.

geminanus, Boiss. E Haussk. ex Boiss. Fl. Orient. ii 330.-Persia.

geminiflorus, Humb. E Bonpl. Pl. Aequin. i. 126. Ecuador.

genargenteus, Moris, Stirp. Sard. Elench. $11=$ sirinicus.

geniculatus, Desf. Fl. Atlant. ii. 186. t. 205.-Algeria genistoides, Boiss. Diagn. Ser. I. ix. 97.-Afghanist. geobotrys, Boiss, l. c. Ser. II. vi. 52.-Phrygia. geocyamus, Boiss. Fl. Orient. ii. 474-Cappadoc. georgicus, Boiss. Diagn. Ser. I. ii. 42 =Cephalotes. Gerardi, Fanka, in Terméss. Fïsetek, viii. (1884) 310 - Europ.

Gerardianus, R. Grah. in Wall. Cat. D. $5998=$ Caragana Gerardiana.

gerensis, Boiss. Diagn. Ser. I. ix. 71.-Persia,

gerensis, Boiss. \& Bubse, ex Bunge, Astrag. ii. $64=$ spinescens.

Germanii, Phil. in Linnaea, xxviii. (1856) 621.-Am. austr.

\section{ASTRAGATUS :-}

Geyeri, A. Gray, in Proc. Am. Acad. vi. (1864) 214. Am. hor. occ

ghilanicus, Fisch. in Bull. Soc. Nat. Mosc. xxvi. (1853) II. 329.-Persia.

gibberosus, Bertol. in Nov, Cnmm. Bonon. vi. (1844) 231 (Misc. Bot. ii. 17)= Chesneya rhytidosperma.

gibbosus, DC. Prod. ii. $300=$ Ammothamnus gibbosus. Gibbsii, Kellogg, in Proc. Calif. Acad. ii. (1863) 161 f. 50.-Calif.

giganteus, S. Wats. in Proc. Am. Acad. xvii. (1881-82) 370.-Am. bor.

gilensis, Greene, in Torrey Bot. Chub, viii. (1881) 97.

-N. Mexic.

Gilliesii, Phil. in Anal. Univ. Chil. (1862) II. 393.Am. austr.

gilvus, Boiss. Diagn. Ser. I. ix. 71.-Caria.

glaber, DC. Astrag. $118=$ fragrans.

glaber, Michx. Fl. Bor. Am, ji. 66.-Am, bor.

glaber, Lam. Encyc. i. $525=$ Oxytı apis glabra.

glabrifolius, Bunge, Astrag. i. 93 ; ii. 167. Afghanist.

glabriusculus, A. Gray, in Proc. Am. Acad. vi. (1864) 204.-Am, bor. occ.

gladiatus, Boiss, Diagn. Ser. I. ii. 45.-As. Min. Syria.

glanduliferus, Debeaux, in Act. Linn. Soc. Bord. xxxiii. (1879) 39.-China.

glareosus, Dougl. ex Hook. Fl. Bor. Am. i. 151.-Am. bor. occ.

glaucacanthos, Fisch. in Bull. Soc. Nat. Mosc, xxvi. (1853) II. 481.-Persia.

glauciformis, Pomel, Nouv. Mat. Fl. Atl. 183.Algeria.

glaucoides, S. G. Gmel. It, i. 127. t, 21 = Coronilla varia glancophylius, Bunge, Astrag - i. 118 ; ii. 200. Anatolia.

glaucus, Bieb. F1. Taur. Cauc. ii. $203=$ vesicarius.

Glaux, Linn.Sp. Pl.759.-Hispan.; Afr. bor. occ.

Glaux, Pall. Reise, ii. $464=\mathrm{A}$. Hypoglottis.

gliciphillos, Neck. Delic, Gallo-Belg。 ii. (1768) 312

A. Glyciphyllos.

globiceps, Bunge, in Act. Hort. Pctrop. vii. (1880)

372 - As. centr.

globiflorus, Boiss. Diagn. Ser. I. ix. 81.-Persia.

globigerus, C. Koch, in Linnaea, xix. (1847) $64=$ hirsutus.

globosus, Vahl, Symb. Bot. 1. 60.-Armenia.

glomeratus, Ledeb. Fl. Alt. iii, 327.-Sibir. alt.

glumaceus, Boiss. Diggn Ser. I ii. 69,-Persia.

glycyphylloides, DC. Prod. ii. 292.-Reg. Caucas.

Glycyphyllos, Linn. Sp. Pl. 758.-Europ. ; Reg.

Caucas.; Sibiria.

Gmelini, Scop. Delic. Insub. ii. 109.-Earop.

Gmelini, Steud. Nom. ed. II. i. 161 = Laxmanni.

gomboeformis, Pomel, Nouv. Mat. Fl. Atl. 187.-

Algeria.

Gombo, Coss. E' Dur. ex Bunge, Astrag. i. 42 ; ii. 69. -Algeria.

Gompholobinm, Benth. ex Bunge, l. c. i. 39 ; ii. 50 Beluchist.

goniatus, Nutt. ex Torr. \& Gray, F1. N. Am. i. $330=$ hypoglottis.

gossypinus, Fisch, in Bull.Soc. Nat. Mosc. xxri. (1853) 11. 373.-Kurdist. ; Persia.

Govanianus, R. Grah. in Wall. Cat. ‥ $5925=$ chlorostachy's.

gracilentus, A. Gray, in Proc. Am. Acad. vi. (1864) 223. - Am. bor. occ

gracilipes, Benth.ex Bunge, Astrag. i. 15 ; ii. 17 . Tibet.

gracilis, Nutt. Gen. Anv. ii. 100,-Am, bor,

gracilis, Stev. ex Ledeb. Fl. Ross i. buy Stevenianus. gracilis, Torr, in Ann. Lyc. N. York, ii. (1s:28) 179

microlobus.

graecus, Boiss. Dirgn. Ser. I. ii. 57.-Graecia.

Grahami, Steud. Nom. ed. II. i. 161 =viciniles.

Grahamianus, Fisch. in Bull. Soc. Nat. Mose (1853) II. $106=$ Jacquemontiu.

Grahamianus, Koyle, Illustr. Bot Ilimal. 199. t. 96. f. 2 = polvacanthus

grammocalyx, Boiss. E Hohen. Diagn. Ser. I. ix. 52 - Persia.

granatensis, Iam. ex Steud. Nom. ed. I. $80^{\circ}$; ed. II.

$161=$ A. Poteriun

granabensis, lange, in Kjoeb. Vidensk. Metelel. 1865)

177 (P'ugill. $37^{\circ}$ ) : A. Claux.

grandiflorus, Bumge, Asirag. Pedsch. 229.-As crutr. 


\section{ASTRAGALUS}

grandiflorus, Linn. Sp. Pl. $761=$ Hedysarum grandiflorum.

grandiflorus, Pall. Astrag. 57.t. $46=$ Oxytropis grandiflora.

grandiflorus, $S$. Wats, in Proc. Am. Acad. xvii. (188182) $370 .-\mathrm{Am}$. bor.

Grantii, Bunge, Astrag. i. 83 ; ii. 50.-Afghanist graveolens, Buch.-Ham. in Wall. Cat. n. 5929.-Reg. Himal.

Grayii, Parry, ex S. Wats in Am. Natural, viii. (1874) 212.-Am. bor. oce.

Greenei, A. Gray, in Proc. Am. Acad. xvi. (1881) 105 $-\mathrm{N}$. Mexic.

Greggii, S. Wats. l. c. xvii. (1881-82) 343.-Am. bor.

Griffithii, Benth. ex Bunge, Astrag. ii. 192.Afghanist

griseus, Boiss. Diagn. Ser, I. vi. 36.-Persia

gryphus, Coss. \& Dur. ex Bunge, Astrag. i. 12; ii. 13 -Algeria.

guatemalensis, Hemsl. Biol. Centr. Am. Bot. i. 264. Guatemala.

gudrunensis, Boiss. E' Haussk. ex Boiss. Fl. Orient. ii. 462.-Assyria

Guldenstaedtiae, Bunge, Astrag. i. 119; ii. 203.Persia.

gummifer, Labill. in Fourn. Phys. (1790) 46.-Syria.

guttatus, [Soland. in] Russell, Aleppo. ed. II. ii. 260 -Aleppo.

gymnolobus, Fisch. in Bull. Soc. Nat. Mosc. xxvi (1853) II. 426.-Armenia.

gymnopodus, Boiss. Diagn. Ser. I. ix. 66.-Afghanist. gypsophilus, Rouy, in Bull. Soc. Bot. Fr. xxxi. (1884) 278 , nomen.-Gallia

gyzensis,Delile, Fl.Egypt.Suppl.64.-Afr. bor *; Arab.; Persia; Soongaria

Haarbachii, Sprun. in Boiss. Diagn. Ser. I, ii, 50.Graecia.

haematocarpus, Bunge, Astrag. i. 118 ; ii. 201.-Reg Caucas.

halepensis, Fisch. ex Boiss. Fl. Orient. ii. $274=$ aleppicus.

halicacabus, Lam. Encyc. i. 220.-Armenia.

halicacabus, Ledeb. Fl. Ross. i. $643=$ mesites

Halleri, All. Fl. Pedem. i. $343=$ Oxytropis foetida.

Hallii, A. Gray, in Proc. Am. Acad, vi, (1864) 224.Am. bor. occ.

Halodendron, Bunge, in Bull. Soc. Nat. Mosc. xxxix. (1866) IJ. 21.—As. temp.

hamatus, Lam. ex Willk. \& Lange, Prod. F1. Hisp. iii. $271=$ A. Stella.

hamosus, Balansa, ex Bunge, Astrag. ii. $17=$ commixtus. hamosus, Kotschy, ex Bunge, Astrag. ii. 14=arnoceras. hamosus, Linn. Sp. Pl. 758.-Reg. Mediterr.; Transcauc.; Ind. bor. occ

hamosus, Pall. Reise, iii. $653=$ reduncus, trimestris.

Hancockii, Bunge, ex Maxim. in Bull. Acad. Pétersb. xxvi. (1880) 471.-China bor.

harpilobus, Boiss. F1. Orient. ii. 234, in syn.= gyzensis.

Hartwegi, Benth. Pl. Hartw. 10. n. 53.-Am. bor. occ.

hasbeyanus, Boiss. Diagn. Ser. I. ix. 77.-Syria.

Hanarensis, Boiss. 1. c. Ser. I. ix. $63=$ gyzensis

Hausknechtii, Bunge, Astrag. i, 49; ii. 77-Cataonia

Haydenianus, A. Gray, in Brandegee, Fl. S. W. Col. 235.-Am. bor. occ.

hedysaroides, Linn. Sp. P1. $756=$ Hedysarum obscurum. hedysaroides, Sievers, in Pall. N. Nord. Beitr. vii. 265 $=\mathrm{A}$. Onobrychis.

hedysaroides, Willd. Sp, Pl, iii. $1264=$ macrostachys.

heldaviensis, Lerch. ex Schur, in Verh. Siebenb. Ver Naturw. iv. (1853) $19=$ A. Cicer.

Heldreichii, Boiss. Diagn. Ser. I. ix. 43.-As. Min

hellenicus, Boiss. Fl. Orient. ii. 292.-Graecia.

Helleri, Fenzl, in Bonplandia, viii. (1860) 56.Mexic.

Helmii, Fisch. ex DC. Prod. ii. 301.-Mont. Ural.

helminthocarpus, Vill. Prosp. $42=$ depressus.

hemiphaca, Kar. E Kir. in Bull. Soc. Nat. Mosc. xv. (1842) 328.- Sibir

Hemsleyi, Aitch. \& Baker, ex Aitch. in fourn. Linn. Soc. xix. (1882) 158.-Afghanist.

Hendersoni, Baker, in Hook. f. Fl. Brit. Ind. ii. 120.Tibet. occ.

heratensis, Bunge, Astrag. i. 83 ; ii. 145.-Afghanist.

hermoneus, Boiss. Diagn. Ser. I. ix. 94.-Syria.

heterodoxus, Bunge, Astrag. i. 53; ii. 88.-Persia.

\section{ASTRAGALUS :-}

Heydei, Baker, in Hook. f. Fl. Brit. Ind. ii. 118.Tibet. occ.

hians, Jacq. Coll. i. $87=$ Oxytropis deflexa.

hilaris, Bunge, Astrag. i. 89 ; ii. 158.-Syria

himalayanus, Klotzsch, in Bot. Ergeb. Waldem. Reise, 160.-Reg. Himal

himalayensis, Hort. Par, ex Bunge, Astrag. ii. $32=$ chlorostachys.

himalayensis, Jacquem. ex Heynh. Nom. ii. $52=$ seq. himalensis, Jacquem. ex Baker, in Hook. Fl. Brit. Ind. ii. $128=$ chlorostachys.

Hinkei, Sadl. ex Bunge, Astrag. ii. $217=$ argenteus.

hippocrepidis, Benth. ex Bunge, 1. c. i. 5; ii. 3.Afghanist.

hippoglossus, St. Lag. in Ann. Soc. Bot. Lyon, vii. 1880) $120=$ hypoglottis

hirsutissimus, DC. Astrag. 119. t. 19.--Syria

hirsutus, Vahl, Symb. Bot. 1. 59.-As. Min.

hirtellus, Ledeb. Fl. Ross. i. $606=$ viciaefolius

hirticalyx, Boiss. E Kotschy, ex Boiss. Fl. Orient. ii. 380 . Kurdistan.

hirtulus, Ledeb, Fl. Ross, i. $606=$ viciaefolius.

hirtus, Bunge, Astrag. i. 54 ; ii. 87.-Persia.

hispanicus, Coss. ex Bunge, l. c. i. 135 ; ii. 231.Hispan.

hispidulus, DC. Astrag. 132, t. 13.-Arabia.

hispidulus, Michx. ex Stend. Nom. ed. I. $86=$ gummifer.

hispidus, Labill. Ic. P1. Syr. Dec. i. 18 = barbatus.

Hoantchy, Franch. Pl. Davidian. i. 86.-As. or.

Hohenackeri, Boiss. Diagn. Ser. I. ii. 70.-Reg. Caucas.

holargyreus, Bunge, in Mem. Sav. Etr. Pétersb. vii. 1851) 273 (Pl. Lehm. 97) = Schrenkianus

hololeucus, Boiss. E'Buhse, in Nouv. Mém. Soc. Nat. Mosc. xii. (1860) 59.-Persia.

holopsilus, Bunge, Astrag. i. 56 ; ii. 93.-Persia

holopterus, Turcz. ex Bunge, l. c. i. 98 ; ii. 170. Sibiria.

holosemius, Bunge, $l$.c. i. 55; ii. 89 -Persia

Hookerianus, D. Dietr. Syn. Pl. iv. $1086=$ ervoides

Hookerianus, A. Gray, Proc. Am. Acad. vi. (1864) 215.-Am. bor. occ.

horizontalis, Kar. \& Kir. in Bull. Soc, Nat. Mosc. 1841) $406=$ Arbuscula

Hornii, A. Gray, in Proc. Am. Acad. vii. (1868) 398. -Am. bor. occ.

horridus, Boiss. Diagn. Ser. I. ii. 66.-Persia

horridus, Willd. ex Bunge, Astrag. ii. $135=$ arnacantha.

Hosackiae, Greene, in Bull. Calif. Acad. i. n. 3 (1885) 157.-Calif.

hosackioides, Benth. ex Baker, in Hook. f. Fl. Brit. Ind. ii. 123.-Reg. Himal.

hostilis, Boiss. Fl. Orient. ii. 306.-Beluchist.

Howelli, A. Gray, in Proc. Am. Acad. xv. (1880) 46. -Am. bor.

Huetii, Bunge, Astrag. i. 37 ; ii. 49.-Sicilia.

Humboldtii, A. Gray, in Proc. Am. Acad. vi. (1864) 195.-Am. bor.

humifusus, Jacquem. ex Baker, in Hook. f. Fl. Brit Ind. ii. $119=$ subumbellatus

humifusus, Willd. Sp. Pl. iii. $1286=$ viciaefolius.

humilis, Bieb. Fl. Taur. Cauc. ii. 203.-Reg. Caucas.

humilis, Geyer, ex Hook. Lond. Journ. Bot. vi. (1847) $211=$ Shortianus

humilis, Willd. ex Boiss. Diagn. Ser. I. ix. $83=$ Lamarckii.

humillimus, A. Gray, in Brandegee, Fl. S. W. Col. 235. Am. bor. occ.

humistratus, A. Gray, Pl. Wright. ii. 43.-Am. bor.

hyalolepis, Bunge, Astrag. i. 105; ii, 185.-Reg. Caucas.

hybernus, Ehrenb. ex Bunge, 1. c. ii. 81 = hirsutissimus.

hybridus, S. G. Gmel. It. i. t. $18=$ flaccida.

hybridus, Willd. ex Ledeb. F1. Ross. i. $628=$ vesicarius.

hymenocalyx, Boiss. Diagn. Ser. I. ii. 55,-Persia.

hymenocarpus, Fisch. ex Bunge, Astrag. ii. $95=$ chartaceus.

hymenochlaenus, Fisch. ex Bunge, 1. c. i. 38 ; ii. $51=$ angustiflorus.

hymenocystis, Fisch. E Mey. in Bull. Soc. Nat. Mosc. xxvi. (1853) IL 449.-Persia.

hymenostegis, Fisch. \& Mey. l.c. 448.-Persia.
ASTRAGALUS :-

hypogaeus, Ledeb. Fl. Ross. Alt. t. 95 ; Fl. Alt. iii. 329. -Sibir. alt.

hypoglottis, Brot. Phytogr. t. $60=$ pentaglottis

hypoglottis, Linn. Mant. 274.--Reg. bor. temp.

hypoglottis, Desf. Fl. Atlant. ii. $183=$ A. Glaux

hypoglottis, DC. Astrag. $118=$ danicus

hypoglottoides, Baker, in Hook. f. Fl. Brit. Ind. ii. 124. - Tibet. occ.

hypoleucus, Schau. in Linnaea, xx. (1847) 747.Mexic.

hypoxylus, S. Wats. in Proc. Am. Acad. xviii. (1882-83) 192.-Am. bor, occ.

hypsogeton, Bunge, Astrag. i. 82 ; ii. 140.-Persia.

hyrcanus, Kar. in Bull. Soc. Nat. Mosc. (1839) $152=$ A. Ammodendron.

hyrcanus, Pall. Astrag. 25. t. 22.-Reg. Casp.

Hystrix, Fisch, in Bull. Soc. Nat. Mosc. xxvi. (1853) If. 403.-Persia.

ibicinus, Boiss. E Haussk. ex Boiss. Fl. Orient. ii. 293. -Persia.

ictericus, Dingl. in Flora, lxiv. (1881) 381,-Thracia. idaeus, Bunge, Astrag. i. 107; ii, 187.--Ins. Creta.

iliensis, Bunge, in Bull. Soc. Nat. Mosc. xxxix. (1866) II. 20.-As. temp.

illyricus, [Bernh.] Sel. Sem. Hort. Erf. (1836).-Cf Linnaea, xii. (1838) Litt. $74=$ Wulfenii.

immersus, Baker, ex Aitch. in Fourn. Linn. Soc. xviii. (1881) 45.-Afghanist.

impressus, Ehrenb. ex Bunge, Astrag. ii. 19=pere grinus.

inarius, Pall. Astrag. 94. t. 77. f. $2=$ Oxytropis inaria incanus, Chaub. ex Bunge, Astrag. ii. $202=$ Chaubarti.

incanus, Gilib. F1. Lithuan. ii. $\mathbf{1 1 2}=$ arenarius.

incanus, Linn. Syst. ed. X. 1175.-Gall. austr.

incanus, Pall. Astrag. iii. t. $84=$ brachycarpus.

incanus, Sibth. \& Sm. Fl. Graec. t. $732=$ Spruneri.

incanus, Siev. ex Ledeb. F1. Ross. i. $592=$ Oxytropis argentata.

incanus, Wulf. in Jacq. Coll. i. $320=$ Wulfeni

incertus, Ledeb. Fl. Ross. i. 647.-Reg. Caucas.; Armenia.

inconspicuus, Baker, in Hook. f. Fl. Brit. Ind. ii. 126. - Reg. Himal.

incurvus, Desf. Fl. Atlant. ii. 182. t. 103.-Hispan. Afr. bor. occ.

incurvus, Reichb. Fl. Germ. Excurs. 512=Wulfeni

inderiensis, Claus, in Beitr. Pf. Russ. Reich. viii. 64 -Rossia.

indigoferoides, Horan. ex Bunge, Astrag. ii. $21=$ capillipes.

ineptus, A. Gray, in Proc. Am. Acad. vi. (1864-65) $525=$ lentiginosus.

infestus, Boiss. Diagn. Ser. I. ix. 95.-Afghanist.

infirmus, Steud. Nom. ed. II. i. 161.-Chili.

inflatus, $D C$. Astrag. 90. n. 13.-Desert. Kirgh.

inflatus, Gill. ex Steud. Nom. ed. II. i. 161.-Chili.

inflexus, Dougl, ex G. Don, Gen. Syst. ii.256.-Am. bor. occ.

insularis, Kellogg, in Bull. Calif. Acad. n. i. (1884) 6 . -Calif

intarrensis, Franch. in Ann. Sc. Nat. Sér. VI. xy. (1883) 258.-Turkest

intermedius, Boiss. Diagn. Ser. I. ii. $53=$ commixtus. intermedius, Host, Fl. Austr. ii. 361.-Europ.

intermedius, Kar. E Kir. in Bull. Soc. Nat. Mosc. xv. (1842) 340.-Dahuria.

interruptus, Benth. ex Bunge, Astrag. ii. $10=$ ammophilus.

iodanthus, S. Wats. in Bot. King, Exp. 70.-Am. bor: occ.

iodotropis, Boiss. E Hohen. Diagn. Ser. I. ix. 100.Persia.

iranicus, Bunge, Astrag. i. 56 ; ii. $92=$ mollis.

ischredensis, Bunge, $l$. c. i. 37 ; ii. 47-Persia

isetensis, Hort. ex Willd. Enum. Hort. Berol. $783=$

falcatus, falciformis.

isopetalus, Boiss. Diagn. Ser. I. ix. $67=$ kahiricus.

ispahanicus, Boiss. $l$. $c$. Ser. I. ii. 52.-Persia.

ispirensis, Boiss. E Huet, l. c. Ser. II. ii. 25.-Armenia

Facquemontii, Bunge, Astrag. i. 44 ; ii. $68=$ polyacanthus.

janthinus, Boiss. E' Haussk. ex Boiss. Fl. Orient.ii. 328 -Persia.

Jaubertianus, Boiss. Fl. Orient. ii. 24.-Phrygia.

Faubertianus, Bunge, Astrag. i. 90 ; ii. $160=$ macrop tilus. 
ASTRAGALUS :-

jejunus, S. Wats. in Bot. King, Exp. 73, 442.-Am

bor. occ.

jeniseensis, Less, ex Bunge, Astrag. ii, $183=$ semibilocularis.

jesdianus, Boiss. E Buhse, in Nowv. Mém. Soc. Nat. Mosc. xii. (1860) 61.-Persia.

Jessenii, Bunge, Astrag. i. 61 ; ii. 101.-Persia.

jodostachys, Boiss. E' Buhse, in Nouv. Mém. Soc

Nat. Mosc. xii. (1860) 60.-Persia.

Johannis, Boiss. Diagn. Ser. I. vi. 41.-Persia

jubatus, Boiss. $l$. c. ix. 104.-Persia; Afghan.

junceus, A. Gray, in Proc. Am. Acad. vi. (1864) 230 -Am. bor. occ.

junceus, Ledeb. in Spreng. Syst. iii. $297=$ Stevenianus. juvenalis, Delile, Ind. Sem. Hort. Monsp. (1836) 22. Aegypt.

kadschorensis, Bunge, Astrag. i. 103 ; ii. 182.--Reg. Caucas.

kahiricus, DC. Prod. ii. 292.-Aegypt.; Arab. ; Persia Afghan.

kapherrianus, Fisch. in Bull. Soc. Nat. Mosc. xxvi. (1853) II. 446 = persicus.

karabaghensis, Bunge, Astrag. i. 93 ; ii. 165.Persia.

karakugensis, Bunge, in Arb. Naturf. Ver. Riga, i (1847) 232.-As. Min.

karamasicus, Boiss. \& Bal. Diagn. Ser. II. vi. $50=$ orthodontus.

Karelini, Fisch, in Bull. Soc. Nat. Mosc. (1839) $152=$ commixtus.

karputanus, Boiss. Diagn. Ser. II. ii. 26.-Armenia.

karsianus, Bunge, Astrag. ii. 115.-Armenia,

kashmirensis, Bunge, 1. c. ii. 246, Index = caschmirensis.

kellalensis, Boiss. EN Haussk. ex Boiss. Fl. Orient. ii. 388.-Persia.

kentrodes, Buhse, in Bull. Soc. Nat. Mosc. xxvi. (1853) II. 412.-Persia.

kentrophyta, A. Gray, in Proc. Acad. Philad. (1863) 60.-Am. bor. occ

keratensis, Bunge, Astrag. i. 73 ; ii. 122.-Persia.

Kessleri, Trautv, in Bull. Soc. Nat. Mosc. xxxiii (1860) I. 496.-Soongaria.

Keyserlingii, Bunge, Astrag. i. 82 ; ii. 139.-Persia.

khasianus, Benth. ex Bunge, l. c. i. 27 ; ii. 32.-Reg Himal.

kirghisicus, Stschegl. in Bull. Soc. Nat. Mosc. xxvii (1854) $1.161=$ tribuloides.

kirrindicus, Boiss.Diagn. Ser. II. ii. 32.-Persia.

koburensis, Bunge, Astrag. i. 116; ii. 196.-Mongolia

kohistanus, Franch. in Ann. Sc. Nat. Sér. VI xy. (1883) 254.-Turkest.

kohrudicus, Bunge, Astrag. i. 67 ; ii. 109.-Persia.

kokandensis, Bunge, Astrag. Fedsch. 216.-As. temp.

kongrensis, Benth. ex Baker, in Hook. f. Fl. Brit. Ind ii. 120 . - Him. bor. occ.

Korolkowii, Bunge, Astrag. Fedsch.230.-As. temp.

koschukensis, Boiss. Fl. Orient. ii. 492.-Afghan.

Kotschyanus, Boiss. Diagn. Ser. I. ii. 44.-Syria; Mesopotam.

Kotschyanus, Fisch. ex Bunge, Astrag. ii. 19 = tuberculosus.

Krauseanus, Regel, in Act. Hort. Petrop. iii. (1875) 104.-Turkestan.

kuhistanus, Bunge, Astrag. i. 82 ; ii. 141.-Persia

kuldshensis, Bunge, in Act. Hort. Petrop. vii. (1880) 374.- Turkestan.

kuramensis, Baker, in Fourn. Linn. Soc. xviii. (1881) 46.-Afyhan.

kurdicus, Boiss. Diagn. Ser. I. ix. 84.-Kurdistan ; Syria.

kurrumensis, Bunge, in Act. Hort. Petrop. vii. (1880) 370.-Afghan.

kurtschumensis, Bunge, Astrag. i. 139; ii. 236.Soongaria.

labradoricus, DC. Prod. ii. $287=a$ alpinus.

lacteus, Heldr. E Sart. in Boiss. Diagn. Ser, II. ii. 31. - Graecia.

lactiflorus, Ledeb. Fl. Alt. iii. $393=$ testiculatus,

laetus, Bunge, Astrag. i. 34 ; ii. 41.-Afghan.

lagocephalus, Fisch. E Mey.ex Schrenk, in Bull. Phys. Math. Acad. Pétersh. ii. (1844) 197.-As. temp.

lagonyx, Fisch. in Bull. Soc. Nat. Mosc. xxvi. (1853) 11. 364.-Persia

lagopodioides, Vahl, Symb. Bot. i. 64 =lagopoides

logopoides, Bunge, Astrag. i. 67 ; ii. $111=$ uranio limneas.

\section{ASTRAGALUS :-}

lagopoides, Lam. Encyco i. 322.-Armenia.

Lagowskii,Trautv in Bull. Phys-Math. Acad. Pétersb. xvi. (1858) 324.-Armenia

laguroides, Pall. Reise, iii. 750.-Sibir

Lagurus, Eichw. Casp. Cauc. $631=$ persicus.

Lagurus, Pall. Astrag. 18. t. $16=$ laguroides

Lagurus, Willd. in Mem. Acad. Berl. (1794-95) 28.Reg. Caucas.; Persia.

Lamarckii, Boiss. Diagn. Ser. I. ix. 82,-As, Min.

Lambertii, Spreng. Syst. iii. 308=Oxytropis Lambertii.

lanatus, Labill. 1c. Pl. Rar. Syr. i. 21. t. 11.-Syria.

lanatus, Pall. Astrag. 108. t. $81=$ Oxytropis Pallasii.

lancearius, A. Gray, in Proc. Am. Acad. xiii. (1878) 370.-Am. bor.

lanceolatus, Bunge, Astrag, i. 35 ; ii. 60.-Afghan

lanceolatus, Buch.-Ham. ex D. Don, Prod. Hl. Nep. $246=$ stipulatus

lanigerus, Desf. Fl. Atlant. ii. 181. t. 202,-Afr. bor

lanigerus, Viv. Fl. Lib. Spec, $44=$ alexandrinas,

lanuginosus, Clos, in C. Gay, Fl. Chil. ii. 121.-Chili.

lanuginosus, Desc. F1. Pitt. Antill. Ind, viii. 53 Sophora tomentosa.

lanuginosus, Kar. E Kir. in Bull. Soc. Nat. Mos (1841) 409.-As, temp.

laricus, Boiss. Eo Hohen. Diagn. Ser. I. ix. 61.Persia.

lasianthus, C. A. Mey. in Bong. \& Mey. Suppl. Fl. Alt. n. $92=$ lasiopetalus.

lasiocaulos, Bunge, Astrag. i. 83 ; ii. 144=pachyacanthus.

lasiocladus, Benth. ex Baker, in Hook. f. Fl. Brit. Ind. ii. $135=$ bicuspis

lasioglottis, Bieb. Fl. Taur. Cauc. iii. 486.-Reg. Caucas.

lasiopetalus, Bunge, in Del. Sem. Dorp. (1839).-Cf. Linnaea xiv. (1840) Litt. 117.- Soongaria

lasiophyllus, Ledeb. Fl. Ross. i. 627.-Oriens.

lasiosemius, Boiss. Diagn. Ser. I. ix. 96.-Afghan,

lasiostylus, Fisch. in Bull. Soc. Nat. Moso. (1853) II. 367.-Turkestan.

latebracteatus, Boiss. in Tchihat. Asie Min. Bot. i. 54. $=$ macrochlamys.

lateritius, Boiss. E' Haussk, ex Boiss. Fl. Orient. ii. 339.-Kurdistan.

latifolius, DC. Astrag. 235 = Candolleanus

latifolius, Lam. Encyc i 319-Armen.; Persia

laxiflorus, Boiss. F1. Orient. ii. $413=$ bracteosus

laxiflorus, Fisch. in Bull. Soc. Nat. Mosc. xxvi. (1853) II. $390=$ psilodontius

Laxmanni, Jacq. Hort. Vind. iii. 22. t. $37=$ adsurgens.

Laxmanni, Nutt. Gen. Am. ii. $99=$ striatus.

laxus, Boiss. \& Haussk. ex Boiss. Fl. Orient. ii. $269=$ remotifolius.

Layneae, Greene, in Bull. Calif. Acad.i. n. 3. (1885) 156.-Calif.

Lehmannianus, Bunge, in Arb. Nat. Ver. Riga, i (1847) 252.-Turkestan.

leiocalyx, Benth. ex Bunge, Astrag. i. 36 ; ii. $49=$ laetus.

leiocarpus, Shuttlew. in Mag. Zool. \& Bot. ii. (1838) $520=$ exscapus.

leioclados, Boiss, Diagn. Ser. I. ii. 62.-Persia.

leiolobus, Bunge, Astrag. i. 14 ; ii. 15-Persia.

leiophysa, Bunge, in Act. Hort. Petrop. iii. (1875) 104. - Turkestan.

Lemmoni, A. Gray, in Proc. Am. Acad. viii. (1873 626. - Am. bor. occ

lentiformis, A. Gray, in Bot. Calif. i. 156.-Calif

lentiginosus, Dougl. ex Hook. Fl. Bor. Am. i. 151.Am. bor. occ.

leontinus, Wahlenb. F1. Lapp. 191. t. 12. f. $4=$ oroboides.

leontinus, Wulf. in Facq. Misc. ii. 59.-Austr. Hely.

leontonyx, Bunge, Astrag. i. 89 ; ii. $157=$ oleae folius.

lepidanthus, Boiss. Diagn. Ser. I. ix. 85. - Syria

leporinus, Boiss, l. c. Ser. II. ii. 30.-Armenia

lepsensis, Bunge, Astrag. i. 25 ; ii. 29.-Soongaria

leptacanthus, Benth. ex Bunge, 1. c. i. 44 ; ii. $69=$ leptocentrus.

leptacanthus, Boiss. E Buhse, in Bull. Soc. Nat. Mosc. (1853) 11. 432.--Persia.

leptaleus, A. Gray, in Proc. Am. Acad. vi. (1864) 220 -Am. bor. occ

\section{ASTRAGALUS:-}

eptocarpus, Torr. E Gray, Fl. N. Am. i. 334.Texas.

leptocaulis, Ledeb. Fl. Alt. iii. 296.-Sibir. altaic.

eptocentrus, Bunge, Astrag. i. 44; ii. 69.-Keg. Himal.

leptodendron, Fisch. in Bull. Soc. Nat. Mosc. xxvi (1853) II. $345=$ caspius.

leptodermus, Bunge, Astrag. Fedsch. 210.-As, centr. leptophyllus, Desf. Fl. Atlant. ii. 188. to 207 Algeria.

leptophyllus, Nutt. in Journ. Acad. P'nilad. vii. (1834) $18=$ stenophyllus.

leptophyllus, Pall. Reise, iii. $749=$ Oxytropis leptophylla.

leptopus, Benth. ex A. Gray, Pl. Wright. ii. 43.Mexic.

leptostachys, Pall. Astrag. 50.t. $40=$ sulcatus.

leptostachys, Siev. in Willd. Sp. Pl. iii. $1265=$ puberulus.

leptothalamus, Boiss. ex Bunge, Astrag. i. 135 ; i1. 232 $=$ seq.

leptothamnus, Boiss. Fl. Orient. ii. 480.-Cilicia

leptus, Boiss. l. c. 305.-Afghan.

lessertioides, Benth. ex Bunge, Astrag. i. 24 ; ii. 28. Reg. Himal.

leucacanthus, Boiss. Diagn. Ser. I. ix. 93.-Aegypt.

leucanthus, Pall. Astrag. 59. t. $47=$ Oxytropis leucantha.

leucocephalus, R. Grah. in Wall. Cat. n. 5923.-Reg. Himal.

leucocladus, Bunge, in Bull. Soc. Nat. Mosc. xxxix. (1866) 27.-As. temp.

leucocyaneus, Griseb. Spicil. Fl. Rumel. i. 50.-As. Min.

leucolachnus, Boiss. Fl. Orient. ii. 357-Syria

leucomallus, Phil. in Linnaea, xxx. (1859-60, 186. Am. austr.

lencomelas, Bunge, Astrag. i. 32 ; ii. 38.-Afghan.

leucophaeus, Sm. in Trans. Linn. Soc. i. (17y1) 252. -Sicilia.

leucophyllus, Hook. Lond. Journ. Bot. vi. (1847) $211=$ arrestus.

leucophyllus, Torr. E Gray, Fl. N.Am. i. 336.-Am. bor. occ.

leucophyllus, Willd. Sp. Pl. iii. 1331=angustifolius.

leucopsis, Torr. Bot. Mex. Bound. 56. t. 16.-Calif.

leucoptilus, Boiss. \& Haussk, ex Boiss. Fl. Orient. ii. 320.-Kurdistan.

leucospermus, Bunge, in Arb. Nat. Ver. Riga, i. (1847, $250=$ A. Alopecias

libanoticus, Boiss. Diagn. Ser. II. v. $87=$ A. Echinus.

Libanotis, Willd. Sp. P1. vii. 1308 = lanatus.

lignosus, $D C$. Astrag. 175. t. 39.-Sibiria.

lilacinus, Boiss. Diagn. Ser. I. ix. 42.-Persia.

Lindheimeri, Engelm. ex A. Gray, Pl. Wright. i. 52. -Am. bor. occ.

linearifolius, Pers. Sya. ii. $\$ 36=$ A. Onobrychis.

linearius, Willd. Sp. Pl. iii. $1902=$ Oxytropis inaria

lineatus, Lam. Encyc. i. 314.-Armenia.

Listoniae, Boiss. Diagn. Ser. I. ix. 37.-Anatolia.

lithophilus, Kar. E Kir. in Bull. Soc. Nat. Mose. xv. 1842) 344.--Soongar.

litoreus, Phil. in Linnaea, xxxii. (1864-65) 47.Chili.

litostachyus, Boiss, Eaussk, ex Boiss. Fl. Orient. ii. 350 -Oriens; Kurdistan.

lividus, Monb. ex Bunge, Astrag. ii. $19=$ taberculosus lobophorus, Boiss. Diagn. Ser. II. ii. S1.-Persia.

lonchocarpus, Torr. in Pacif. Rail. Rep. iv. 80,-Am. bor. occ.

longebracteatnes, Steud. Nom. ed. II. i. 162=sanguinolentus.

longicaulis, Baker, in Hook. f. Fl. Brit. Ind. ii. 129.Kashmir.

longicaulis, Pomel, Nowv. Mat. Fl. Atl. 185.Algeria.

longricuspidatus, St. Lag. in Ann. Soc, Bot Lyon, vii (1S80) $120=$ longicuspis

longiscuspis, Bunge, Astrag. i. 121; ii. 211.-Reg Caucas.

longiforus, Delile, Fl. Exypte, 256. t. $99=$ kahiricus. longifterus, Gilib. Fl. Lithuan. ii. $111=\mathrm{A}$. Onobrychis.

longiflons, Pall. Astrag. 73. t. 60.-Reg. Casp.

longiflons, Pall. Astrag. 78. t. $60 .-\mathrm{Keg}$. Cass

longripes, Boiss \& Helur. ex Buiss. Fl. Orient ii. 1 s. Apollineus.

11 


\section{ASTRAGALUS :}

longipes, Stend. Nom. ed. II. i. $162=$ rupifragus.

longipes, Kar. \& Kir. in Bull. Soc. Nat. Mosc. (1841) $405=$ macropterus

longirostrus, Poir. Encyc. Suppl. i. 528=Oxytropis longirostra.

longistylus, Bunge, Astrag. i. 81 ; ii. 137.-Persia.

lotiflorus, Hook. Fl. Bor. Am. i. 152.-Am. bor. occ.

lotoides, Lam. Encyc. i. $316=$ sinicus.

lunatus, Gilib. F1. Lithuan, ii. $110=$ glycyphyllos.

lunatus, Pall. Astrag. 44.-Persia.

lupulinus, Pall. Reise, iii. 750.-Sibiria.

lusitanicus, Lam. Encyc. i. 312.-Reg. Mediterr. As. Min.

luteo-caeruleus, Baker, in Fourn. Linn. Soc. xviii (1878) 47.-Afghanist.

luxurians, Bunge, Astrag. i. 23 ; ii. 25.-Sibir.

Lyalli, A. Gray, in Proc. Am. Acad. vi. (1864) 195.-

Am. bor. occ.

lycioides, Boiss. Diagn. Ser. I. ii. 66.-Persia.

lycius, Boiss. l. c. ix. 45.--Lycia.

lydius, Boiss. 1. c. ii. $43=$ leucocyaneus.

lydius, Fisch. in Bull. Soc. Nat. Mosc. xxvi. (1853) II. $393=$ amphilogus.

macranthus, Willd. ex Ledeb. Fl. Ross. i. $650=$ brachycarpus.

macrobotrys, Bunge, Astrag. i. 129 ; ii. 226 .-Persia.

macrocarpus, DC. Astrag. 143. t. 28.-Syria.

macrocarpus, Pall. in Nov. Act. Petrop. x. (1776) 56 $=$ subulatus.

macrocephalus, Willd. Sp. Pl. iii. 1260.-As. Min.; Syria.

macroceras, C. A. Mey. ex Bong. Verz. Pf. Saisang Nor, $24=$ macrolobus.

macrochlamys, Boiss, ex Bunge, Astrag. i. 49 ; ii. 77. -As. Min.

macrocladus, Bunge, Astrag. Fedsch. 293.-As. centr. macrodon, A. Gray, in Proc. Am. Acad. vi. (1864) 216. -Am. bor. occ

macrolacis, Boiss. \& Bubse, in Nouv. Mém. Soc. Nat. Mosc. xii. (1860) $63=$ stenolepis.

macrolobus, Bieb. Fl. Taur. Cauc. iii. 493.-Sibir. altaic.

macrolobus, Bunge, Enum. Alt. $70=$ macroceras.

macrolobus, Ledeb. Fl. Alt. iii. $307=$ eriolobus, chaetolobus.

macronyx, Bunge, Astrag. Fedsch. 236.-As. centr.

macropelmatus, Bunge, Astrag. i. 36 ; ii. 43.--Persia macropetalus, Schrenk, in Bull. Phys.-Math. Acad.

Pétersb. iii. (1844) 307.-As. temp.

macropodius, Fisch. in Bull. Soc. Nat. Mosc. xxvi. (1853) ฯ. $352=$ aureus.

macropterus, $D C$. Prod. ii. 283.-Tibet. occ. ; Sibir. macroptilus, Boiss. ex Bunge, Astrag. i. 90 ; ii. 160.Phrygia.

macropus, Boiss. Diagn. Ser. II. vi. $51=$ macroscepus. macropus, Bunge, in Arb. Nat. Ver. Riga, i. (1847) 238.-As. med.

macrorrhizus, Cav. Ic. ii, 28. t. 133.--Hispania.

macrorshizus, D. Don, Prod. Fl. Nep. $245=$ Donianus. macroscepus, Boiss. in Bunge, Astrag. i. 49 ; ii. 77.Cappadocia.

macrosemius, Boiss. E Hohen. Diagn. Ser. I. ix. 93.Persia.

macrostachys, $D C$. Astrag. 141. t. 15.-Armenia.

macrotropis, Bunge, Astrag. i. 127; ii. 223.-Soon garia.

macrourus, Fisch. Eo Mey, in Bull. Soc. Nat. Mosc. (1838) 346.-Reg. Caucas. ; Persia.

maculatus, Bunge, Astrag. i. 119 ; ii. 206.-Persia

maculatus, Lam. Encyc. i. $316=$ annularis.

Maddenianus, Benth. ex Baker, in Hook. f. Fl. Brit. Ind. ii. 127.-Reg. Himal.

majellensis, Huet, ex Nym. Consp. $193=$ australis

malacensis, Salzm. ex Bunge, Astrag. ii. $12=$ sesameus.

malacophyllus, Benth. ex Bunge, l. c. i. 36 ; ii. $61 .-$ Reg. Himal.

malacophyllus, Hort. ex G. Don, in Loud. Hort. Brit. $\mathbf{3 0 7}=$ galegiformis.

malacotrichus, Fisch. \& Kotschy, ex Bunge, Astrag. ii. $164=$ Roussaeanus.

malacus, A. Gray, in Proc. Am. Acad. vii. (1868) 336. -Am. bor. occ.

mareoticus, Delile, Fl. Egypt. 257. t. 39. f. 3.Aegypt.

maritimus, Moris, Fl. Sard. i. 523.-Sardinia

maroniensis, Dingl. in Flora, lxiv. (1881) 382:Thracia.

\section{ASTRAGALUS :-}

maroniticus, Boiss. \& Balansa, Diagn. Ser. II. v. $\mathbf{5} 8=$ drusorum.

marosportensis, Lerch. ex Schur, in Verh. Siebenb. Ver. Naturw. iv. (1853) $19=$ dasyanthus.

Marschallianus, Fisch. in Bull. Soc. Nat. Mosc. xxvi. (1853) Ir. 328.- Oriens ; Reg. Caucas.

marusiensis, Lerch. ex Schur, in Verh. Siebenb. Ver. Naturw. iv. (1853) $19=$ arenarius.

masanderanus, Bunge, Astrag. i. 114 ; ii. 193.Persia.

massiliensis, Lam. Encyc. i. 320.-Gallia.

Matthewsii, S. Wats. in Proc. Am. Acad. xviii. (188283) 192.-Am. bor.

mauritanicus, Coss, in Bull. Soc, Bot. Fr. iii. (1856) 673.-Algeria.

mauritanicus, Stev. in Bull. Soc. Nat. Mosc. iv. (1832) 267.-Algeria.

Maximowiczii, Trautv. in Act. Hort. Petrop. ix. (1884) 379.-Rossia.

maximus, Lam. ex Steud. Nom. ed. II. i. $162=\mathrm{A}$. Onobrychis.

maximus, Willd. Sp. Pl. iii. 1258.-Reg. Caucas.; Armenia.

Maxwellii, Royle, Illustr. Bot. Himal. $199=$ tibetanus ? medicagineus, Boiss. Diagn. Ser. I. ix. $42=$ Kotschyanus.

medius, Schrenk, in Bull. Phys.-Math. Acad. Pétersb. ii. (1843) 196.--Soongaria.

medullaris, Boiss. Diagn. Ser. 1. ix. $66=$ graveolens.

megacarpus, A. Gray, in Proc. Am. Acad. vi. (1864)

215.-Am. bor. occ.

megalanthus, DC. Astrag. 131. t. 20-Sibir

megalocystis, Bunge, l. c. ii. 122.-Persia.

megalomerus, Bunge, in Act. Hort. Petrop. vii. (1880) 379.-As. centr.

megalotropis, C.A.Mey. ex Bunge, Astrag. i. 60 ; ii. 99.-Reg. Caucas.

melaleucus, Bunge, Astrag. ii. 100.-Persia.

melanocalyx, Boiss. in Nouv. Mém. Soc. Nat. Mosc xii. (1860) 59.-Persia.

melanocarpus, Bunge, Astrag. 1. 51 ; ii. 81.-Oriens. melanocarpus, Hook. Fl. Bor. Am. i. 150.-Am. bor. melanocarpus, Richards. App. Frankl. Journ. ed. II. $87=$ missouriensis

melanocephalus, Boiss. Diagn. Ser. I. ix. 50.As. Min.

melanodon, Boiss. l.c. Ser. I. vi. 36-Persia.

melanophrurius, Boiss. Fl. Orient. ii. 276.-Cappadoc. melanostachys, Benth. ex Bunge, Astrag. i. 21 ; ii. 22.

-Reg. Himal.

melanotrichus, Buiss. ex Bunge, 1. c. ii. $188=$ cataonicus.

melanotrichus, Ledeb. Fl. Alt. iii. 323. - Sibir. altaic.

melilotoides, Pall.Voy. t. 33 ; Desc. iii. 748.-Sibir. ; China.

melinus, Boiss. Fl. Orient. ii. 446.-Cappadocia.

melitenensis, Boiss. Diagn. Ser. I. ii. 43.-Cappadocia

membranaceus, Bunge, Astrag. i. 25; ii. $30 .-$ As temp.

membranaceus, Moench, Meth. $167=$ trimestris.

Menziesii, A. Gray, in Proc. Am. Acad. vi. (1864) 217 $\rightarrow$ Calif.

Mercklinii, Boiss. E Buhse, in Nouv. Mém. Soc. Nat. Mosc. xii. (1860) 70.-Persia

meridionalis, Bunge, Astrag. i. 61 ; ii. 104.-Persia.

meschedensis, Bunoe, l. c. i. 82 ; ii. 140.-Persia.

mesites, Buhse, in Nouv. Mém. Soc. Nat. Mosc. xii. (1860) 66.-Armenia.

mesogitanus, Boiss. Diagn. Ser. I. ii. 41.-As. Min. mesoleios, Boiss. \& Buhse, in Nouv. Mém. Soc. Nat Mosc. xii. (1860) $63=$ radkanensis.

mesoleios, Boiss. E Hohen. Diagn. Ser. I. ix. 91.Persia.

mesopotamicus, Boiss. l. c. ii. 68.--Mesopotam.

mesopterus, Griseb. Spicil. Fl. Rumel. i. 49.Macedon.

mexicanus, A. Gray, P1. Lindh. $176=$ plattensis.

mexicanus, A. DC. Pl. Nor. Hort. Genèr. v. 17.-Am. bor.

Meyeri, Boiss. Diagn. Ser. I. ix. 88.-Armenia

Michauxianus, Boiss. l. c. ii. 62.-Kurdistan.

micracme, Boiss. E Nö̈, $l$. c. Ser. II. v. 87.-Armenia

micrancistrus, Boiss. Eم Haussk. ex Boiss. Fl. Orient

ii. 475,-Oriens; Assyria.

micranthellus, Wedd. Chlor. And. i. 262.-Peruv.

micranthus, Desv. Fourn. Bot. iii. (1814) 78.-Hab. ?

\section{ASTRAGALUS :-}

micranthus, Nutt. in Journ. Acad. Philad. ii. (1821) $122=$ Nuttallianus

micranthus, Pall. ex Ledeb. F1. Ross. i. $637=$ striatellus.

microcarpus, DC. Astrag. 104.-Sibir.

microcephalus, Willd. Sp. Pl. iii. 1332.-As. Min.

microcystis, Bunge, Astrag. Fedsch. 306.-As. centr.

microcystis, A. Gray, in Proc. Am. Acad. vi. (1864) 220.-Am. bor. occ

microdontus, Baker, in Fourn. Linn. Soc. xviii. (1881) 46.-Afghan.

microlobus, A. Gray, in Proc. Am. Acad. vi. (1864) 203.-Am. bor.

microphyllus, Bess. ex Steud. Nom. ed. II. i. $162=$ A Onobrychis.

microphyllus, Georgi, Beschr. Russ. Reich. Nachtr. $296=$ adsurgens.

microphyllus, Linn. Sp. Pl. 757.-Sibir.

microphyllus, Jacquem. ex Baker, in Hook. f. Fl. Brit.

Ind. ii. $134=$ cicerifolius.

microphyllus, Pall. Astrag. 92. t. $76=$ Oxytropis microphylla. microphyllus, Schuebl. \& Martens, Fl. Wuertemb. 474
=A. Cicer.

microphysa, Boiss. Diagn. Ser. I, ii. 71.-Persia.

micropterus, Fisch. in Bull. Soc. Nat. Mosc. xxvi. (1853) II. 396.-Anatolia.

microrchis, Barbey, in Bull. Soc. Vaud. Sc. Nat. xxi. (1883) 95.-Helvetia.

microthamnus, Boiss. E Haussk. ex Boiss. Fl. Orient. ii. 393.-Assyria.

miniatus, Bunge, Astrag. i. 98; ii. 169,-Mongolia minimus, DC. Astrag. $64=$ alpinus.

minimus, Vog. in Nov. Act. Nat. Cur. xix. Suppl. i. (1843) 18.-Peruv.

minor, Clos, in C. Gay, Fl. Chil. ii. 107.-Chili.

minutissimus, Wedd. Chlor. And. ii. 257.-Peruv.

minutus, Boiss. Diagn. Ser. I. ix. $58=$ tribuloides.

minutus, Buhse, ex Bunge, in Mém. Acad. Pétersb. Sér. VII. xv. (1869) n. I. 1I= biovulatus.

mirpoureanus, Camb. in Jacquem. Voy. Bot. 39. t. $46=$ Gueldenstaedtia mirpourensis.

miser, Dougl. in Hook. Fl. Bor. Am. i. 152.-Am. bor, occ.

missouriensis, Nutt. Gen. Am. ii. 99.-Am. bor.

Mitchellianus, Boiss. Diagn. Ser. I. ix. 80.-Phrygia.

mixtus, Bieb. Cent, Pl. Kar. i, t. $26=$ vesicarius

modestus, Boiss. E Hohen. Diagn. Ser. I. ix. 75.Persia.

modestus, Wedd. Chlor. And. i. 263.-Am. austr.

Moellendorffi, Bunge, ex Maxim. in Bull. Acad. Pétersb. xxvi. (1880) 472.-China bor.

mogollonicus, Greene, in Torrey Bot. Club, viii. (1881) 97.-Calif.

mohavensis, S. Wats, in Proc. Am. Acad. xx. (1885) 361.-Am. bor. occ

mokiacensis, A. Gray, in Proc. Am. Acad. xiii. (1878) 367.-Am. bor. occ

moldavicus, Steud. Nom. ed. I. $87=$ A. Onobrychis.

mollis, Bieb. Fl. Taur. Cauc. iii. 495,-Reg. Caucas.

Persia.

mollissimus, Presl, Bot. Bemerk. 57=bethlemiticus.

mollissimus, Torr. in Ann. Lyc. N. York, ii. (1828) 178.-Am. bor. occ.

monadelphus, Bunge, ex Maxim. in Bull. Acad. Pétersb. xxiv. (1878) 32.-China.

monanthemus, Boiss. Diagn. Ser. 1. ii. 78.-Persia.

mongholicus, Bunge, Astrag. i. 25 ; ii. 30.-Mongolia.

monophyllus, Bunge, ex Maxim. in Bull. Acad. Pétersb. xxvi. (1880) 473.-Mongolia.

monspessulanus, Griseb. Spicil. Fl. Rumel. i. $60=$ Wulfeni.

monspessulanus, Linn. Sp. Pl. 761.--Europ. austr.; Reg. Cauc.

montanus, Bieb. Fl. Taur. Cauc. ii. $197=$ Oxytropis cyanea.

montanus, Lapeyr. Hist. Abr. Pl. Pyr. $429=$ Oxytropis pyrenaica.

montanus, Linn. Sp. Pl. 760= Oxytropis montana.

montanus, Pall. Reise, iii. $199=$ Oxytropis uralensis.

montanus, Brot. ex Steud. Nom. ed. I. $87=$ ma crorrhizus.

montanus, Jacq. Fl. Austr. $131=$ alpinus.

monticola, Phil. in Linnaea, xxxiii. (1864-65) 47.Chili. 
ASTRAGALUS

Moorcroftianus, R. Grah. in Wall. Cat. n. $5933=$ Sophora Moorcroftiana.

Mortoni, Nutt. in Fourn. Acad. Phil. vii. (1834) 19. -Am. bor, occ.

mossulensis, Bunge, Astrag. i. 101; ii. 177.--Persia; Mesopotam.

mucidus, Bunge, ex Boiss. Fl. Orient. ii. 279.Turkestan.

muciferus, Bunge, Astrag. Fedsch. 223.-As centr. mucronatus, $D C$. Astrag. 140. t. 25.-Armenia. mucronifolius, Boiss. Diagn. Ser. I. ii. 68.-Persia.

Muelleri, Steud. \& Hochst. in Flora, x. (1827) $72=$

A. Onobrychis.

mugodsharicus, Bunge, Astrag. i. 124 ; ii. $216=$ mugosaricus.

mugosaricus, Bunge, in Arb. Naturf. Ver. Riga, i. (1847) 236. - Transural.

multicaulis, Ledeb. Fl. Alt. iii. 295.-Sibir. altaic. et baical.

multicaulis, Nutt. ex Torr. \& Gray, Fl. N. Am. i. 335 $=$ pubentissimus.

multicaulis, Turcz. in Bull. Soc. Nat. Mosc. (1838) $90=$ bifidus.

multiceps, Wall. Cat. n. 5287 ; Bunge, Astrag. ii. 69. -Reg. Himal.

multiflorus, A. Gray, in Proc. Am. Acad. vi. (1864) 226.-Am. bor. occ.

multijugus, $D C$. Prod. ii. 301.-Mesopotam.

Munroi, Benth. ex Bunge, Astrag. i. 30 ; ii. $85 .-$ Reg.

Himal, ; Kashgar.

muradicus, Bunge, l.c. i. 90 ; ii. 161.-Phrygia.

muricatus, Pall. Astrag. 89. t. $73=$ Oxytropis muricata

murinus, Boiss. Diagn. Ser. I. ii. 72.-Persia.

muschianus, Kotschy \& Boiss. ex Boiss. Fl. Orient. ii. 357.-Armenia.

mutabilis, Boiss. Fl. Orient. ii. $448=$ paecilanthus, mutabilis, Jacquem. ex Baker, in Hook. f. Fl. Brit.

Ind. ii. $125=$ strictus

myriacanthus, Boiss. Diagn. Ser. I. ix. 91.-Persia.

myriophyllus, Bunge, Astrag. Fedsch. 232.-As. centr.

myriophyllus, Pall. Astrag. 87. t. $71=$ Oxytropis myriophylla.

nanodes, Bunge, in Act. Hort. Petrop. vii. (1880) 377. -Turkest.

nanus, $D C$. Astrag. 114. t. 17.-Cilicia; Syria.

narbonensis, Gouan, Illustr. 49.-Gallia ; Hispan.

narbonensis, Pall. Astrag. 13. t. $10=$ ponticus.

narbonensis, C. A. Mey. Verz. Pf. Cauc. $143=$ megalotropis.

nebrodensis, Presl, ex Steud. Nom. ed. II. i. $162=$ Boissieri.

neglectus, Fisch. ex Steud. l. c.-Sibir.

nematodes, Bunge, ex Boiss. Fl. Orient. ii. 425.-

Turkestan.

nervistipulus, Boiss. E Haussk. ex Boiss. Fl. Orient. ii. 384 .- Kurdistan.

neurocarpus, Boiss. Diagn. Ser. I. ii. 59.-Syria.

neurophyllus, Franch. in Ann. Sc. Nat. Sér. VI. xv. (1883) 260.-Turkest.

nevadensis, Boiss. Diagn. Ser. I. ii. 63.-Hispan.

Newberryi, A. Gray, in Proc. Am. Acad. xii. (1877) 55.-Utah.

nicharensis, Bunge, Astrag. i. 39 ; ii. 50.-Beluchist.

nigrescens, A. Gray, in Am. Journ. Sc. Ser. II. xxxiii. (1862) $410=$ multiflorus

nigrescens, Nutt. in Joum. Acad. Philad. Ser. II. i. (1847) $153=$ diclymocarpus.

nigrescens, Pall. Astrag. 65 . t. $53=$ Oxytropis nigrescens. nigrostriatus, C. Koch, in Linnaea, xv. (1841) $719=$ ornithopodioides.

nitens, Boiss. \& Buhse, in Nouv. Mém. Soc. Nat. Mosc. xii. 1860$) 61=$ viridis.

nitens, Boiss, Er Heldr. Diagn. Ser, I ix. 51.-As. Min.

nitens, Host, Fl. Austr. ii. 362 -Europ.

nitidus, Dougl. ex Hook. FI. Bor. Am. i. $149=$ adsurgens.

nivalis, Kar. E Kir. in Bull. Soc. Nat. Mosc. xv. (1842) 341.-Tibet, occ. ; Soongaria.

niveus, Coq. Monbr. ex Bunge, Astrag. ii. $189=$ pelliger.

Noxëanus, Boiss. Diagn. Ser. II. ii. 24-Armenia.

nodiflorus, Stev. in Bull. Soc. Nat. Mosc. xxix. (1856) II. 147.-Rossia.

Nortonii, Nutt. in Fourn. Acad. Phil. vii. (1834) 19. -Am. bor.

norvegicus, Grawer, Dec. 19.-Norvegia.

\section{ASTRAGALUS}

nothoxys, A. Gray, in Proc. Am. Acad.vi. (1864) 232 -Am. bor. occ.

nubigenus, D. Don, Prod. Fl. Nep. $245=$ Caragana crassicaulis.

nuciferus, Bunge, Astrag. Fedsch. 223.-Cappadoc. : Mesopotam.

nucleiferus, Boiss. Diagn. Ser. I. ii. 83.-Oriens,

nudatus, Bunge, Astrag. i. 85 ; ii. $147=$ kurdicus.

nudus, Clos, in C. Gay, Fl. Chil. ii. 115 (1846).Chili.

nudus, S. Wats. in Bot. King, Exp. 74, 443.-Am.

bor. occ.

nummularioides, Desf. Fl. Atlant. Emend. ex DC. Astrag. 233.-Numidia.

nummularius, $D C$. Astrag. 221. t. 2. f. 2.-Ins. Creta,

nummularius, Desf. Fl. Atlant. ii. $182=$ nummu larioides.

nummularius, Lam. Encyc. i. $317=$ pinetorum.

nummularius, C. A. Mey, ex Bunge, Astrag. ii. 57

talyschensis.

nurensis, Boiss. E Buhse, in Nouv. Mém. Soc. Nat. Mosc. xii. (1860) 58.--Persia.

Nuttallianus, DC. Prod. ii. 289.-Am. bor. occ.

obcordatus, Boiss. Diagn. Ser. I. vi. 38 = anacardius.

obcordatus, Ell. Sketch, ii. 227.-Am. bor

oblongifolius, Clos, in C. Gay, Fl. Chil.ii. 109.-Chili.

obscurus, S. Wats. in Bot. King, Exp. 69, 437.-Am. bor. occ.

obtusifolius, DC. Prod. ii. 295.-Assyria.

obvallatus, Ehrenb. ex Bunge, Astrag. ii. $149=$ cruentiflorus.

obvelatus, Ehrenb. ex Bunge, 1. c. ii. $163=$ drusorum

ochreatus, Bunge, l. c. 1. 127; ii. 224.-Persia.

Ochrias, Bunge, ex Maxim. in Bull. Acad. Pétersb. xxiv. (1878) 33.-Mongolia.

ochrobius, Bunge, Astrag. i. 82; ii. 141.-Persia.

ochroleucus, Coss. in Bull. Soc. Bot. Fr, xxii. (1875)

57.-Marocco

ochroleucus, Gilib. F1. Lituan. ii. $111=$ pilosus

ocrochlorus, Boiss. E Hohen. Diagn. Ser. I. ix. 83.Persia.

odessanus, Bess. Enum. Pl. Volh. $30=$ fruticosus.

odoratus, D. Dietr. Syn. Pl. iv. 1080 in syn. =obcordatus.

odoratus, Lam. Encyc. 1. 311.-Reg. Caucas.; Persia; Soongaria

oleifolius, DC. Astrag. 192.-As, Min

oleifolius, Fisch. in Bull. Soc. Nat. Mosc. xxvi. (1853) $362=$ aeluropus

Olgae, Bunge, Astrag. Fedsch. 223.-As. centr.

Olgini, Bunge, Astrag. i. 130 ; ii. $177=$ mossulensis.

oliganthus, Horan. ex Bunge, 1. c. ii. $1=$ complanatus. oliganthus, Kar. \& Kir. in Bull. Soc. Nat. Mosc. xv

(1842) $337=$ reticulatus.

oligophyllus, Boiss, Diagn. Ser. I. ii. 47.-Persia.

oligophyllus, Schrenk, in Bull. Phys.-Math. Acad.

Pétersb. ii. (1844) 197 = unijugus.

Olivieri, Klotzsch, ex Bunge, Astrag. i. 69 ; ii. $115=$ mesopotamicus.

olopterus, DC. Prod. ii. $284=$ austriacus.

olopterus, Turcz. ex Steud. Nom. ed. II. i. 162, $164=$ versicolor.

olympicus, Bunge, Astrag. ii. $162=$ baibutensis

olympicus, Lam. ex Walp. Ann. iv. $514=$ angustifolius. olympicus, Pall. Astrag. 4. t. $4=$ angustifolius.

oncotrichus, Bunge, Astrag. ii. 11.-Persia.

onobrychioides, Bieb. Fl. Taur. Cauc, iii. $486=$

A. Cephalotes.

onobrychioides, Bunge, Astrag. ii. $183=$ Bungeanus

Onobrychis, Linn. Sp. Pl.760.-Europ. austr.; Oriens Sibir.

Onobrychis, Poll. Hist. Pl. Palat. ii. $\mathbf{3 2 7}=$ hypoglottis oocarpus, A. Gray, in Proc. Am. Acad. vi. (1864) 213. -Am. bor. occ.

oocephalus, Boiss. Diagn. Ser. I. ii. 56.-Syria.

oophorus, S. Wats. in Bot. King, Exp.73, 441.-Am bor. occ.

ophiocarpus, Benth. ex Boiss. Fl. Orient. ii. 224.Persia; Tibet. occ.

oplites, Benth, ex Baker, in Hook. f. Fl. Brit. Ind. ii $134=$ cicerifolius.

orbicularis, Walp. Rep. i. $702=\mathrm{seq}$.

orbiculatus, Ledeb. Fl. Ross. Alt. t. 290 ; Fl. Alt. iii. 311. - Afghan.; Turkest. ; Sibir. altnic.

Orbignyanus, Wedd.Chlor. And. ii. 260.-Bolivia.

Orcuttianus, S. Wats. in Proc. Am. Acad. xx. (1885) Sol.-Calis.

\section{ASTRAGATUS:-}

oreades, C. A. Mey. Verz. Pf. Cauc. 141.-Reg Caucas.

oreganus, Nutt. ex Torr. E Gray, Fl. N. Am. i. 335 -Am. bor. occ.

orientalis, Pers. ex DC. Prod. ii. $295=$ macrocephalus. ornithopodioides, Lam. Encyc. i. 312.-As. Min.; Persia. oroboides, Hornem. in Fl. Dan.t. 1396.-Am bor

orthanthus, A. Gray, in Proc. Am. Acad. vi. (1864) 195.-Mexic.

orthocarpus, Boiss. Diagn. Ser. I. ix, 68.-Afghan. orthocarpus, Dougl. ex A. Gray, in Proc. Am. Acad.

vi. (1864) $196=$ canadensis.

orthodontus, Bunge, Astrag. i, 101; ii. $176=$ karamasicus.

ortholobus, Bunge, l. c. i. 127 ; ii. 223.-Mont. Ural. otiporensis, Boiss. Fl. Orient. ii. 271.-Afghan,

ourmitanensis, Franch. in Ann. Sc. Nat. Ser. VI. xv.

(1883) 256.-Turkest.

ovalis, Boiss. Eo Bal. Diagn. Ser. II vi. 52,-Cappadoc.

ovallensis, Clos, in C. Gay, Fl. Chil. ii. 116.-Chili.

ovatus, DC. Astrag. 212. n. 107.-Armenia.

ovigerus, Boiss. Diagn. Ser. 1. ii. 67.-Persia.

ovinus, Boiss.l.c. 76.-Armenia.

Owerini, Bunge, Astrag. i. 105 ; ii. 186.-Reg. Caucas. oxyglottis, Sters in Bieb. Fl. Taur. Cauc. ii. 192.Reg. Caucas.; Persia; Turcoman.

oxyodon, Baker, in Hook. f. Fl. Brit. Ind. ii. 125.Tibet. oce.

oxypetalus, Bunge, Astrag. Fedsch. 273.-As. centr.

oxyphyllus, Boiss. E Haussk. ex Boiss. Fl. Orient. it.

375.-Syria.

oxyphyllus, Pall. Astrag. 90, t. 74=Oxytropis oxy phylla.

oxyphysus, A. Gray, in Proc. Calif. Acad. iii. (1863 103. -Am. bor. occ

oxyrhynchus, Hemsl. Biol. Centr. Am. Bot. i. 265.Mexic.

oxysemius, Bunge, Astrag i. 118; ii. 202,-Anatolia. oxytropifolius, Boiss. Diagn. Ser. I. ix. 37.-As. Min. oxytropoides, Bunge, in Mém. Acad. Pétersb. Sér. VI vii. (1859) 585 ; Sér. VII. xv. (1869) $185=$ incertus. pachyacanthus, Bunge, Astrag. i. 82 ; ii. 143.Persia.

pachycarpus, Torr. \& Gray, Fl. N. Am. i. $332=$ caryocarpus.

pachypus, Greene, in Bull. Calif. Acad. i. D. 3. (1885 157. -Calif.

pachystachys, Bunge, Astrag. i. 80 ; ii. 184.-Persia. paecilanthus, Boiss. E' Heldr. Diagr. Ser. 1I. vi. 54.Phrygia.

Pallasii, Fisch. Hort. Gorenk. (1813) 71 ; et ex DC Prod. ii. 305 (1825).-Deserta Casp

Pallasii, Spreng. Fl. Hal. Mant. (1807) 48.-Rossia.

pallescens, Bieb. Fl. Taur. Cauc. iii. 489.-Bessarab.

Podol.

pallidus, Boiss. F1. Orient. ii. $372=$ drasorum.

Palliseri, A. Gray, in Proc. Am. Acad. vi. (1864) 227. - Am. bor.

Palmeri, A. Gray, l. c. vii. (1868) 398.-Am. bor, ooc

pamphylicus, Boiss. Fl. Orient. ii. 239.-Cilicia.

Pancicit, Heuff. in Flora, xxxvi. (1غ53) 621.-Europ.

panduratus, Bunge, Astrag, i. 59 ; ii. 95-Anatolia.

pannonicus, Schult. Oestr. Fl. ed. II. ii. $835=$ dasyanthus.

pannosus, Fensl, in Tchihat. Asie Min. Bot.i. 2-

Cilicia.

paphlagonicus, Bunge, Astrag. i. 121; ii. $210=$ atropurpurens.

paradoxus, Bunge, l.c. i. 64 ; ii. 108.-Persia.

paralipomenus, Bunge, l. c. i. 81 ; ii. 136.-Persia.

paralurges, Bunge, l. c. i. 67 ; ii. 111.-Persis

paraplesius, Bunge, l. c. i. 46 ; ii. 78.-Persia.

Parishii, A. Gray, in Proc. Am. Acad. xix. (18s8) 75 -Am. bor.

Pamassi, Boiss. Diagn. Ser. Io ix 80,-Graecia ; Oricns.

Parmassi, Heldr. ex Nym. Consp. 19\%= aristatus, cephalonicus.

parrowianus, Boiss. E Haussk. ex Boiss. Fl. Orient. it 3:0.-Penin.

Parryi, C Anders. Cat. Pl. Nev. 120 = malacus.

Parryi, A. Gray, in Am. Gourn. Sc Ser. II. xxxii. (1562) $410 .-$ Am. bor. occ.

parviceps, Bunge, Aistrag, i. 91 : ii. 162-As. Min paraiflarus, Desf. ex Spreng. Syst. iii. Suw, in sym.

racemesus.

parvifiorus, Lam. Encyc i. $310=0 x y$ tropis deflexa 


\section{ASTRAGALUS :}

parvifolius, Nutt. ex A. Gray, in Proc. Am. Acad. vi. (1864) $202=$ gracilis.

parvus, Hemsl. Biol. Centr. Am. Bot. i. 266.-Mexic, Pastellianus, Pollini, in Brugnat. Giorn. Fis. ix. (1816) $95=$ vesicarius.

Pattersoni, A. Gray, in Brandegee, Fl. S. W. Col. 285. -Am. bor. occ

pauciflorus, A. Gray, in Proc. Acad. Philad. (1863) 60 = leptaleus.

pauciflorus, Hook. in Lond. Journ. Bot. vi. (1849) 210 =alpinus.

pauciflorus, Hook. Fl. Bor. Am. i. 149.-Am. bor. occ.

pauciflorus, Pall. Astrag. 81. t. $66=$ Gueldenstaedtia pauciflora.

paucijugus, Schrenk, in Bull. Phys-Math. Acad. Pétersb. ii. (1844) 196. - Turkestan.

pauper, Bunge, Astrag. Fedsch. 224.-As. centr.

pectinatus, Dougl. ex Hook. Fl. Bor. Am. i. 142.-Am.

bor.

pectinatus, Boiss. Diagn. Ser. I. ii. 54.-Syria

peduncularis, Royle, Illustr. Bot. Himal. 199.-Tibet.

occ.

Pehuenches, Niederl. in Roca, Exped. Rio Negro, ii. 206.-Patagonia.

pelliger, Fenzl, Pugill. Pl. Nov. Syr. 5.-Cilicia.

pellitus, Bunge, Astrag. i. 33 ; ii. 39.-Persia.

penduliflorus, Lam. Fl. Fr. ii. $636=$ alpinus.

pendulus, DC. Astrag. $232=$ elongatus.

pendulus, Bunge, Astrag, ii. $211=$ caelestis

pennatus, Bunge, l. c. ii. 148.-Cataonia

pentaglottis, Linn. Mant. 274.-Reg. Mediterr.

pentapetaloides, Bunge, in Mém. Sav. Etr. Pétersb. vii.

(1851) $274=$ flexus

peregrinus, Fisch. \& Mey. ex Bunge, Astrag. ii. $34=$ A. Caraganae.

peregrinus, Vahl, Symb. Bot. i. 57.-Aegypt.; Palaestin. peristereus, Boiss. Eo Haussk. ex Boiss. Fl. Orient. ii. 351.-Persia.

permiensis, C. A. Mey. ex Rupr. F1. Bor. Ural. ii. 82. t. $11=$ Helmii.

perpusillus, Bertol. in Nov. Comm. Bonon. vi. (1844) $230=$ tribuloides.

persepolitanus, Boiss. Diagn. Ser. I. ix. $60=$ ammophilus.

persicus, Fisch. E Mey. Ind. Sem. Hort. Petrop. i. 3.Reg. Casp.; Persia.

peruvianus, Vog. in Nov. Act, Nat. Cur. xix. Suppl. i, (1843) 18.-Peruv.

Pestalozzae, Boiss. Diagn. Ser. I. ix. $41=$ cadmicus. petraeus, Kar. Eo Kir. in Bull. Soc. Nat. Mosc. xv. (1842) 333.--Mont. Alatav.

petropylensis, Bunge, Astrag. i. 139; ii. 237.-Sibir.

phacaeformis, Bunge, in Mém. Sav. Etr. Pétersb.

ii. 590 ; Verz. Suppl. Fl. Alt. 90.-Sibir. altaic.

phlomoides, Boiss. Diagn. Ser. I. ii. 56.-Persia.

physaloides, DC. Prod. ii. 300.-Anatolia vel Syria.

physocalyx, Fisch. in Bull. Sc. Acad. Pétersb.ii. (1837) 74. - Thracia.

physocalyx, Kar. \& Kir. in Bull. Soc. Nat. Mosc. (1841) $409=$ cysticalyx

physocarpus, Ledeb. Fl. Alt. iii. $335=$ physodes

physodes, Linn. Sp. Pl. 760 - - Reg. Casp.

Pickeringii, A. Gray, Bot. U.St. Expl. Exped. 1. 415.Peruy.

pictus, Boiss. \& Gaill. Diagn. Ser. II. vi. $55=$ conduplicatus.

pictus, A. Gray, in Proc. Am. Acad. vi. (1864-65) 214. - Am bor occ.

pictus, Steud. Nom. ed. II. i. 163.-Chili.

piestolobus, Bunge, Astrag. i. 38 ; ii. 52.--Persia

pilosus, Linn. Sp. P1. $756=$ Oxytropis pilosa.

Pinardi, Boiss. Diagn. Ser. I. ix. 56.-As. Min

pinetorum, Boiss. l. c. ii. 77.-As. Min.; Syria

piptocephalus, Boiss. \& Haussk. ex Boiss. Fl. Orient ii. 376.-Persia.

pisidicus, Boiss. E Heldr. Diagn.Ser. I. ix. 70.-Pisidia.

Pistacia, Rost. ex DC. Prod. ii. $305=$ elongatus.

placens, Clos, in C. Gay, Fl. Chil. ii. 109.-Chili.

plattensis, Nutt. ex Torr. E Gray, Fl. N. Am. i. 332. -Am. bor.

platyphyllus, Fisch. ex Bunge, Astrag. ii. $205=$ choicus.

platyphyllus, Kar. E Kir. in Bull. Soc. Nat. Mosc. xv. (1842) 345 .-Soongar.

platyraphis, Fisch. ex Bunge, Astrag. i. 37 ; ii. 48.-

Syria; Kurdist.; Mesopot.

platysematus, Bunge, Astrag. i. 120 ; ii. 205.-Persia.

\section{ASTRAGALUS :-}

platytropis, A. Gray, in Proc. Am. Acad. vi. (1864-65) 526.-Am. bor. occ.

plebejus, Boiss. Diagn. Ser. I. vi. 37.-Persia.

plumosus, DC. ex Bunge, Astrag. ii. 148= Lamarckii

plumosus, Sieber, ex Bunge, 1. c. ii. 59 =bethlemiticus.

plumosus, Willd.Sp. Pl. iii. 1333.-Galatia.

podocarpus, C. A. Mey. Vers. Pfl. Cauc. 142,-Reg. Caucas.; Persia.

podocarpus, R. Grah. in Wall. Cat. n. $5930=$ A. Emodi.

podocarpus, Buch.-Ham. in Wall. l. c.-Ind. or.

podolobus, Boiss. E' Hohen. Diagn. Ser. I. ix. 49.Persia.

podosphaerus, Boiss. E Haussk. ex Boiss. Fl. Orient. ii. 255.-Kurdistan.

poecilanthus, Bunge, Astrag. ii. $188=$ paecilanthus.

polaris, Benth. in Trans. Linn. Soc. xxiii. (1861) 323. -Am. arct. occ.

polemius, Boiss. Fl. Orient. ii. 306.--Beluchist.

polemoniacus, Bunge, Astrag, i. 135; ii. 233.-Anatolia.

poliotes, Bunge, Astrag. i. 116; ii. 197.-Sibir. altaic

polyacanthus, Royle, Illustr. Bot. Himal. 199.-Reg Himal.

polyacanthus, Wall. Cat. n. 5934=Caragana poly. acantha.

polyactinus, Boiss. Fl. Orient. ii. 226, in nota.Hispan.; Afr. bor.

polyanthus, Bunge, Astrag. i. 93 ; ii. 165.-Persia

polybotrys, Boiss. Diagn. Ser. I. ix. 64.-Afghan.

polycephalus, Tenore, ex Bunge, Astrag. ii. $95=$ ponticus.

polyceras, Kar. E Kir. in Bull. Soc. Nat. Mosc. xv. (1842) 332.-Soongar.

Polygala, Pall. Astrag. n, 116. t. 83 = sanguinolentus.

polyphyllus, Bunge, Astrag. i. 35 ; ii. $59 .-$ Reg. Caucas.

polyphyllus, Willd. Sp. P1. ini. $1300=$ Oxytropis microphylla.

ponticus, Pall. Astrag. 14. t. 11.-Reg. Caucas.; As, Min.

porphyracmus, Boiss. Fl. Orient. ii. 367.-Cappadoc. porphyrobaphis, Fisch. in Bull. Soc. Nat. Mosc. (1853) II. 462.-Persia

porphyrolepis, Fisch. 1. c. $378=$ radkanensis.

porrectus, S. Wats. in Bot. King, Exp. 75, 411.-Am. bor. occ.

Poterium, DC. Astrag. $160=$ Clusii.

Poterium, Pall. Astrag. 1. t. I=amacantha.

Poterium, Vahl, Symb. Bot. i. 63.-Hispan.

praecox, Baumg. Enum. Stirp. Transs. ii. $362=$ Wulfeni.

praetermissus, Ball, in Fourn. Bot. xi. (1873) 306.Marocco.

Preussii, A. Gray, in Proc. Am. Acad. vi. (1864-65) 222. - Am. bor. occ.

procerus, Boiss. E' Haussk. ex Boiss. Fl. Orient. ii 464.-Persia

procerus, A. Gray, in Proc. Am. Acad. xiii. (1878) 369 -Am. bor.

procumbens, Hook. E Arn. Bot. Beech. Voy. 18.-Chili. procumbens, Mill, Gard. Dict. ed. VIII. n. $18=$ pentaglottis.

procumbens, S. Wats. in Proc. Am. Acad. xx. (1885 361.-N. Mexic.

prolixus, Sieber, ex Bunge, Astrag. i. 9 ; ii. 6.-Afr bor.; Ind. bor. occ.

prostratus, Fisch. ex Turcz. in Bull. Soc. Nat. Mosc. (1838) $90=$ adsurgens.

prostratus, Hook. E' Arn. Bot. Beech. Voy. 18.-Chili. prostratus, Scop. Delic. Insub. ii. $106=$ Oxytropis prostrata.

prusianus, Boiss. Diagn. Ser. I. ix, $88=$ Boissieri.

Przewalskii, Bunge, ex Maxim. in Bull. Acad. Pétersb. xxiv. (1878) 32.-China.

pseudaustralis, Fisch. E Mey. Ind. Sem. Hort. Petrop. xi. Suppl. 16.-Sibir. altaic.

pseudocaspius, Fisch. in Bull. Soc. Nat. Mosc. (1853) II. 347.-Anatolia.

pseudocicer, Opiz, in Flora, iv, (1821) $758=\mathrm{A}$ Cicer.

pseadonobrychis, Andrz. ex Trautv. in Act. Hort. Petrop. viili. (1883) 238, nomen.-Hab. ?

pseudopentaglottis, Boiss. \& Noë, ex Boiss. Fl. Orient. ii. 226 = triradiatus.

pseudostella, Delile, Fl. Egypt. Suppl. 64.-Graecia Aegypt.; Arab.

\section{ASTRAGAIUS}

pseudotragacantha, Pall. Astrag. 3. t. $3=$ aureus.

pseudotragacantha, Urv, in Mém. Linn. Soc. Par. i 1822) $348=$ thracicus

psilacanthus, Boiss. Diagn. Ser. I. ix. 97.-Afghan. psilacanthus, Fisch. in Bull. Soc. Nat. Mosc. xxvi.

(1853) $407=$ tenuispinus.

psilacmos, Bunge, Astrag. i. 86 ; ii. 151.-Syria.

psilocentros, Fisch. in Bull. Soc. Nat. Mosc. (1853) II $405=$ polyacanthus

psilodontius, Boiss. Diagn. Ser. I. ix. 86.--Syria. psiloglottis, Stev. in DC. Prod. ii. $288=$ oxyglottis. psilopterus, Bunge, Astrag. i. 45 ; ii. $71=$ genistoides. psilopus, Schrenk, in Bull. Sc. Acad. Pétersb. x. (1842 $254=$ spartioides.

psilostylus, Bunge, Astrag. i. 87 ; ii. 152.-Persia. psoraleoides, Boiss. ex Bunge, 1. c. ii. $235=$ asciocalyx psoralioides, Willd.Sp.Pl. ii. 1309.-Cappadoc,

psoraloides, Lam. Encyc. i. 317 ; DC. Astrag. 145. t. $18=$ canescens.

pterocarpus, S. Wats. in Bot. King, Exp. 71.-Am. bor. occ.

pterocephalus, Bunge, Astrag. Fedsch. 252.-As. centr. pterostylis, DC. Prod. ii. 294.--Austral.

ptilocephalus, Baker, ex Aitch. in Fourn. Linn. Soc. xviii. (1881) 47.-Afghan.

ptilodes, Boiss. Diagn. Ser. I. ix. 81.-As. Min.

ptychophyllus, Boiss. l. c. vi. 42.-Persia.

pubentissimus, Torr. E Gray, Fl. N.Am. i.693.-Am bor. occ.

puberulus, Kar. \& Kir. in Bull. Soc. Nat. Mosc. (1841) 405. n. $240=$ macropterus.

puberulus, Ledeb. Fl. Alt. iii. 299.-Sibir. altaic.

pubescens, Schrank, Prim. Sal. $2=$ frigidus.

pubiflorus, DC. Astrag. 173.-Sibir

pubigerus, Pall, ex Trautv. in Act. Hort. Petrop. viii (1883) $238=$ pubiflorus.

pugioniferus, Fisch.ex Bunge, Astrag. i. 125 ; ii. 219. - Macedonia.

pugniformis, L'Hérit. Stirp. Nov. $170=$ longifolius. pugniformis, Willd. Sp. Pl. iii. 1334=oleaefolius pulchellus, Boiss. Diagn. Ser. I. ii. 86.-Persia.

pulchellus, Salisb. Prod, $337=$ danicus.

Pulsiferi, A. Gray, in Proc. Am. Acad. x. (1874) 69. -Am. bor. occ.

pulvinatus, Bunge, Astrag. i. 82 ; ii. 142.-Persia. Pumilio, Pall. Astrag. 67. t. $55=$ Oxytropis Pumilio. punctatus, Bunge, Astrag. i. 120 ; ii. 209.-Persia. pungens, Willd. Sp. Pl. iii. $1325=$ angustifolius. purpurascens, Bunge, Astrag. i. 35 ; ii. 42.-Afghan. purpurascens, Jacg. f. ex Steud. Nom. ed. II. i. 163 A. Onobrychis.

purpureus, Lam. Encyc. i. $314=$ hypoglottis.

Purshii, Dougl.ex G. Don, Gen. Syst. ii. 271.-Am. bor. occ.

pusillus, Vog. in Nov.Act. Nat. Cur. xix. Suppl. i. (1843) 19.-Peruv.

pycnocephalus, Fisch. in Bull. Soc. Nat. Mosc. (1853) II. 371 .-Kurdistan.

pycnocladus, Boiss. E Haussk. ex Boiss. Fl. Orient. ii. 336.-Persia.

pycnolobus, Bunge, in Mém. Sav. Etr. Pétersb. ii. (1835) 594.- Sibir. altaic.

pycnophyllus, Kotschy, ex Bunge, Astrag. ii. $138=$ mesoleios.

pycnophyllus, Stev. in Mém. Soc. Nat. Mosc.iv. (1814) $57=$ microcephalus.

py cnorrhizus, Wall. Cat. n. 5927.-Reg. Himal.

pycnostachyus, A. Gray, in Proc. Am. Acad. vi. (186465) 527 - Am. bor. occ.

pygmaeus, DC. ex Bunge, Astrag. ii. $86=$ nanus.

pygmaeus, Pall. Astrag. 66.t. $54=$ Oxytropis nigrescens.

pyramidulus, Salzm. ex Bunge, Astrag. ii. $5=$ epi-

glottis.

pyrrhotrichus, Boiss. Diagn.Ser. I. ix. 73.-Afghan.

quadrisulcatus, Bunge, in Arb. Naturf. Ver. Riga, i. (1847) 248.-Persia; Afghan.; Turcoman.

quinquefoliolatus, Bunge, Astrag. i. 119; ii. 204.Persia.

Quisqualis, Bunge, Astrag. Fedsch. 222.-As. centr. racemosus, Pursh, Fl. Am. Sept. ii. Suppl. 740.-Am. bor.

racemulosus, Boiss. E Haussk. ex Boiss. Fl. Orient. ii. 391.-Persia.

Raddeanus, Regel, Ind. Sem. Hort. Petrop. (1865) 40 $=$ flaccidus.

radians, Pomel, Nouv. Mat. Fl. Atl. 185.-Algeria

radiatus, Steud. Nom. ed. II. i. $163=$ Sieberi. 
ASTRAGALUS :-

radiatus, Ehrenb. ex Bunge, Astrag. i. 11; ii. 8-Aegypt. ; Arab.

radiatus, Stev. in Bull. Soc. Nat. Mosc. iv. (1832) 267 $=$ A. Stella.

radicans, Hornem. Hort. Hafn. ii. 708,-Hab.? radicatus, Decne. in Ann. Sc. Nat. Sér. II. iii. (1835) $268=$ Síeberi

radiciflorus, Steud. Nom. ed. II. i. $163=$ testiculatus.

radkanensis, Bunge, Astrag. i. 81 ; ii. 138.-Persia.

ramósissimus, Scop. Delic. Insub. ii. 105.-Sibir.

raphiodontus, Boiss. Diagn. Ser. I. ix. 96.-Afghan.

rariflorus, Ledeb. Fl. Alt. iii. 313, -Soongaria.

Rattani, A. Gray, in Proc. Am. Acad. xix. (1883) 75. -Calif.

Rauwolfi, Vahl, Symb. Bot. i. $63=$ Russelii.

Reboudii, Coss. ex Bunge, Astrag. i. 37; ii. 49.-Afr. bor.

recognitus, Fisch. in Bull. Soc. Nat. Mosc. xxvi. (1853) II. 452.-Persia.

recurvus, Greene, in Bull. Calif. Acad. i. n. 3. (1885) 155.-Calif.

reduncus, Pall. Astrag. 109. t. 82.-Reg. Caucas,

reflexistipulus, Miq. Ann. Mus. Bot. Lugd. Bat. iii. 44.--Japon

reflexus, Torr. Eo Gray, Fl. N. Am. i. 334-Am, bor. occ. refractus, Boiss, \& Buhse, in Boiss. Diagn. Ser. II. ix. $57=$ Buhseanus.

refractus, C.A.Mey. Verz. Pf. Cauc. 144.-Reg. Caucas. Regelii, Trautv in Act. Hort. Petrop. ii. (1873) 472. -Armenia.

Reinii, Ball, in Fourn. Linn. Soc. xvi. (1878) 432.Marocco.

remotiflorus, Boiss. Diagn. Ser. I. ii. 72.-Persia.

remotifolius, Boiss. E Haussk. ex Boiss. Fl. Orient. ii. 1095 (emend.).-Persia.

remotijugus, Boiss. E Hohen. Diagn. Ser. I. ix. 74.-

Persia.

reptans, Willd. Hort. Berol. ii. 88, t. 88-Mexic.

resupinatus, Bieb. Fl. Taur. Cauc. iii. $493=$ fragrans.

retamocarpus, Boiss. E Hohen. ex Boiss. Diagn. Ser. I. ix. 68.-Persia.

reticulatus, Bieb. Fl. Taur. Cauc. iii. 491.-Reg. Caucas.; Afghan.

retroflexus, Pall. Astrag. 33. t. $27=$ Oxytropis deflexa. retusus, DC. Astrag. 205. t. $36=$ coluteoides.

retusus, Willd. in Mém. Acad. Berl. (1794-95) 24. t. 2 = angustifolius.

Reuterianus, Boiss. Diagn. Ser. I. ii. 71.-Persia.

reventus, A. Gray, in Proc. Am. Acad. xv. (1880) 46. -Am, bor.

rhacodes, Bunge, Astrag. Fedsch.308.-As. temp.

rhizanthus, Boiss. Diagn. Ser. I. ii. $83=$ cariensis.

rhizanthus, Royle, Illustr. Bot. Himal. 199.-Reg. Himal.

rhizocephalus, Baker, ex Aitch. in Fourn. Linn. Soc. xviii. (1878) 46. - Ind. or.

rhodochrous, Boiss. E Haussk, ex Boiss, Fl. Orient. ii. 325. - Kurdistan.

rhodosemius, Boiss. E Haussk. l. c. 363.--Persia

Richii, A. Gray, Bot. U. St. Expl. Exped. i. 414. Peruv.

rigidulus, Benth.ex Bunge, Astrag, ii. 25 -Reg. Himai. rigidus, Boiss. \& Bal. Diagn. Ser. II. vi. $55=$ melanocephalus.

Robbinsii, A. Gray, Man. Bot. U. St. ed. II. 98.Am. bor.

Robbinsii, Matthew, Pl. Acad, 15=alpinus

robustus, Bunge, Astrag, i. 122 ; ii. 212.-Persia.

Rochelianus, Heuff, ex Griseb. \& Schenk, in Wiegm. Archiv, xviii. (1852) 1. $293=$ A. Onobrychis.

roseus, Ledeb. Fl. Alt. 1ii. 380.-Sibir. altaic.

Rostani, Boiss. Diagn. Ser. I. ii. $45=$ densifolius, chrysophyllus.

rostratus, C. A. Mey. Vers. Pf. Cauc, 144.-Reg. Caucas.

rotundifolius, Presl, ex Steud. Nom. ed. II. i. $168=$ glycyphyllus.

rotundifolius, Royle, Illustr. Bot. Himal. 199= graveolens.

rotundifolius, Willd. Sp. Pl. iii. 1817 = nummularioides.

Roussaeanus, Boiss. Diagn. Ser. I. ii. 61.-Syria ; Mesopotam.

Royleanus, Bunge, Astrag. i. 80 ; ii. $84=$ Candolleanus.

Royleanus, D. Dietr. Syn. Pl. iv, 1090 =strobiliferus, Royle.

subriflorus, Burge, Astrag. i. 67 ; ii. 109.-Persia.

\section{ASTRAGALUR:-}

rubrostriatus, Bunge, Astrag. i. 68 ; ii. 113.-Persia. rudbaricus, Bunge, 1. c. i. 123 ; ii. $215=$ confusus, rugosus, Fisch.ex Bunge, l. c. ii. 53.-Kurdistan. rumelicus, Bunge, 1. c. 81 ; ii. $137=$ veluchensis. runcinatus, Boiss. Fl. Orient. ii. 368.-Cappadoc. rupicola, Ehrenb. ex Bunge, Astrag. ii. $19=$ peregrinns. rupifragus, Pall. Astrag, 86, t. 70.-Keg. Caucas. Ural.

Ruprechti, Bunge, Astrag. i. 101; ii. 174.-Reg. Caucas.

Rusbyi, Greene, in Bull. Calif. Acad.i.n. 1 (1884) 8.Calif.

ruscifolius, Boiss. Diagn. Ser. I. ii. 47.-Persia.

Russelii, [Soland. in] Russ. Aleppo, ed. II. ii. 260. to 13.-Syria; Mesopotam.

rytidocarpus, Ledeb. Fl. Alt. iii. 315. -Sibir. altaic rytilobus, Bunge, Astrag. Fedsch.209.-As. temp. sabuletorum, Kar. \& Kir. in Bull. Soc. Nat. Mosc.

1841) $408=$ arkalycensis.

sabuletorum, Ledeb. Fl. Alt. vii, 321-Sibir, altaic.

sabulorum, A. Gray, in Proc. Am. Acad. xiii. (1878) 368.-Am. bor

saccatus, Boiss. Diagn. Ser。 I. ix. 53.-Persia

saccharensis, Ehrenb. ex Bunge, Astrag. ii. $16=$

gyzensis.

saccocalyx, Schrenk, Enum. Pl. Nov. 83.-Soongaria. sachalinensis, Bunge, Astrag. i. 23 ; ii. 26 .-Ins. Sachalin.

saganlugensis, Trautv. in Bull. Phys.-Math. Acad. Pétersb. xvi. (1858) 323.-Armenia,

Saharae, Pomel, Nouv. Mat. Fl. Atl. 184.-Algeria.

Sahendi, Buhse, in Bull. Soc. Nat. Mosc xxvi. (1853) II. 415 .- Persia.

sakkarensis, Ehrenb. ex Boiss. Fl. Orient. ii. $234=$ gyzensis.

salatavicus, Bunge, Astrag. i. 117 ; ii. 201.-Reg Caucas.

salsugineus, Kar. E Kir. in Bull. Soc, Nat. Mosc. xv. (1842) 341.-Soongaria.

salsula, Scop. Delic. Insub. ii. 104.-Sibir.

salvatoris, Willk, in Willk. \& Lange, Prod. Fl. Hisp. iii. $281=$ massiliensis

samamensis, Boiss. E Buhse, in Nouv. Mém. Soc. Nat. Mosc. xii. (1860) 68.-Persia.

sanctus, Boiss. Diagn. Ser. I. ix. 47.-Syria.

sanguinolentus, Bieb. Casp. 190.-Reg. Caucas.

saratagius, Bunge, Astrag. Fedsch.269.-As. temp.

scaberrimus, Bunge, in Mém. Sav. Etr. Pétersb. ii.

1835) 91.-China bor.

scabrifolius, Boiss. Diagn. Ser. I. ii. 81.-Armenia

scabrisetus, Bong. Verz. Pf. Saisang-Nor, n. 89.t 5.-Soongaria.

scaposus, A. Gray, in Proc. Am. Acad. xiii. (1878 $366 . \mathrm{Am}$. bor.

scariosus, Benth. ex Bunge, Astrag. i. 44 ; ii. $71=$ polyacanthus.

chahrudensis, Bunge, l. c. i. 61 ; ii. 103.--Persia.

Schanginianus, Pall. Astrag. 77. to 73.-Sibiria.

Schelichowii, Turcs. in Bull. Soc. Nat. Mosc. (1840) 68.-Ochotsk.

Schimperi, Boiss. Diagn. Ser. I, ii. 53.-Arabia.

schirasicus, Fisch, in Bull. Soc. Nat. Mosc.

(1853) II. 457.--Persia.

schistocalyx, Bunge, Astrag. i. 46; ii. 75.-Persia

schistosus, Boiss. E' Hohen. Diagn. Ser. I. ix. 49 Persia.

schizopterus, Boiss. lo c. ii. 82.-Cilicia; Syria

Schmalhauseni, Bunge, in Act. Hort. Petrop. vis

(1880) 369.-Turkestan.

Schottianus, Boiss. Diagn. Ser. II. v. 89.-Cilicia Cappadoc.

Schrenkianus, Fisch. E Mey. in Bull. Phys.-Math. Acad. Pétersb. ii. (1844) 197.-Turkestan. schurabicus, Bunge, Astrog, i. 76 ; ii. 129.-Persia. sciadophorus, Franch. Pl. Davidian. i. 84.-As. or.

sciurens, Boiss. E Hohen. Diagn. Ser. I. ix. 98.Persia.

sclerocarpus, A. Gray, in Proc. Am. Acad. vi. (186465) 225. -Am. bor. occ.

sclerocladus, Bunge, Astrag, i. 46 ; ii. 75.-Persia, scleropodius, Ledeb. Fl. Alt. iii. $92 t^{\circ}$; Fl. Ross. Alt. t. 295. - Sibir. altaic.

scleroxylon, Bunge, in Arb. Naturf. Ver. Riga, i. (1847) 241.-Turkestan.

scopaeformis, Ledeb. Fl. Ross. i. $615=$ tauricus.

scoparins, Schrenk, Ensum. Pl. Noz\% 82,-As, temp.

scopulorum, Porier 6 Coult. F\%. Col. 21-Colorado.

\section{ASTRAGALUS:-}

corpioides, Pourr. ex Willd. Sp. Pl. iii. 1280.Hispan,

scorpius, Boiss. Diagn. Ser. I. ix. 103.-Persia.

scorpius, Buhse, ex Bunge, Astrag. ii. $127=$ glauca canthus.

Scorpiurus, Bunge, 1. c. i. 5 ; ii. $3=$ hippocrepidis

Scottianus, Stocks, ex Bunge, 1. c. ii. $31=$ medullaris.

scrobiculatus, Boiss. Fl. Orient. ii. $490=$ gymnolobus.

secundus, DC. Astrag. 128. n. 55.-Sibir. austr.

secundus, Michx. Fl. Bor. Am. ii. $67=$ alpinus,

segetalis, Boiss. Fl. Orient. ii. $277=$ nctrocarpus.

Segethi, Phil. in Linnaea, xxxiii. (1864-fi5) 47.-Chili.

seidabadensis, Bunge, Astrag. i. 68 ; ii. 113 .-Persia.

Seidlitzii, Bunge, l. co i. 40 ; ii. 56-Uersia.

Semenovii, Bunge, in Bull. Soc. Nat. Mosc. xxxix. (1866) II. 22.-As. temp.

semibilocularis, DC. Astrag. 170.-Sibiria.

semibilocularis, Fisch. ex Bunge, Astrag. i. 103; it.

183.-Sibir. altaic.

semipellitus, Bunge, lo c.i. 83 ; ii. 144.-Persia.

sempervirens, Lam. Encyc. i. $320=$ aristatus.

senganensis, Bunge, Astrag. i. 82 ; it. 142.-Persia.

serbicus, Panc. ex Boiss. Fl. Orient. i1. $268=$ glycy. phylloides.

sericeus, DC. Astrag. $148=$ globosus,

sericeus, Lam. Fl. Fr. ii. $645=$ versicarius, A. Oxytropis, sordida.

sericeus, Willd. Enum. Hort. Berol. Suppl. $51=$ hamosus.

sericoleucus, A. Gray, in Am. Fourn. Sc. Ser. II

xxxiii. (1862) 410-Am. bor. occ.

sericophyllus, Griseb.Spicil.Fl.Rumel. i. 53.-Graecia.

sericostachyus, Stocks, in Hook. Kew Fourn. iv. (1852)

146.-Beluchist.

serotinus, A. Gray, in Pacif. Rail. Rep. xii. 18, 51.-

Am. bor. occ.

sesameus, Linn.Sp. Pl. 759.-Reg. Mcditerr.

sesameus, Pall. Astrag. $98=0 x y g l o t t i s$.

sesamoides, Boiss. Diagn. Ser. I. ix. 59.-Afghan.

sesbanoides, Benth. in Royle, Illustr. Bot. Himal. 199 = trichocarpus.

sesquiflorus, S. Wats. Proc. Am. Acad. x. (1875) 346

-Utah.

setiferus, DC. Prod.ii. 296 = Cornulaca tragacanthoides

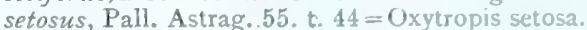

setulosus, Boiss. EF Bal. Diagn. II. vi. 50.-Cappadoc.

Sewersowii, Boiss. Fl. Orient. ii. $289=$ sec

Sewertzowii, Bunge, Astrag. i. 38 ; ii. 54.-Turkest.

seytunensis, Bunge, l. c. i, 87; ii. 15t.-Syria.

Shortianus, Nutt.ex Torr. E- Gray, Fl. N. Am. i. 331

-Am. bor. occ.

Shortianus, S. Wats. Pl. Wheeler, $7=$ cyaneus.

sibiricus, Scop. Delic. Insub. ii. 104.-Sibiria.

Sibthorpianus, Boiss. Diagn. Ser. I, ii 84.-Bithynia.

siculus, 'Bivon. Giorn. Palerm. n. 4.-Sicilia.

siculus, Gasp. ex Nym. Consp. 192 = calabricus.

siculus, Schimp. ex Nym. 1. c. = cephalonicus,

Sieberi, DC. Prod. ii. 295.-Aegyt. ; Arab.

Sieversianus, Pall. Astrag. 15. t. 12.-I'ersia; Soon

garia. Oxytropis argentata.

Sieversii, Coq. Monb. ex Bunge, Astrag. ii. $36=$ diphtherolobus.

sigmoideus, Bunge, l. c. i. 123 ; ii. 214.-Anatolia.

silkimensis, Benth. ex Bunge, l. c. i. 29 ; ii. $28 .-\mathrm{Keg}$.

Himal.

siliquosus, Boiss. Diagn. Ser. I. ii. 51.-Persia.

siliquosus, Boiss. 1. c. vi. $40=$ lobophorus,

silvicolus, Pritz. Ic. Ind. $128=$ Oxytropis sylvatica.

simplicifolius, A. Gray, is Proc. Ams. Acnd. vi. 180̈4 65) 281.-Am, bor. occ.

sinaicus, Boiss, Diton, Ser. I. ix, $57=$ pscudostella

singarensis, Boiss. E Haussk. ex Buiss. Fl. Orient. ii.

263.-Mesopotam

sinicus, Limn. Want. i. 109.-China

sinicus, Thunb. Fl. Jap. $290=$ lotoides.

sirinicus, Tenore, "Prud. Fl. Serop. Asp. v. $25\left(1826^{\circ}\right)$

Fl. Neap. v. 132. t. 171.-Italis.

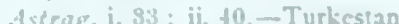

sitiens, Bunge, l. c. i. 120 ; ii. 220 - Persia.

sivasicus, $B u n g c$, l. c. i. 98 ; ij. 1000 - Armenia

skythropos, Bunge, ex Marime in Bull. Acad. Pefersb.

xxiv. (18;s) 81 - C hina.

solicus, Bunge, Astrag. i. 81 ; ii. 196.-Pervis.

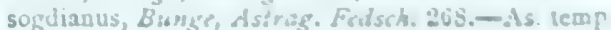




\section{ASTRAGALUS :}

Solandri, Lowe, in Hook, Kere fourn, viii. (1856) 294 - Marocco; Madera.

somcheticus, C. Koch, in Linnaea, xv. (1841) $720=$ sanguinolentus.

songaricus, Pall. Astrag. 63. t. $51=$ Oxytropis songarica.

Sonorae, A. Gray, Pl. Wright. ii. $44=$ arizonicus.

sordidus, Willd. Sp. Pl. iii. $1313=$ Oxytropis cam pestris.

Soyeri, Buching. ex Bunge, Astrag。 i. 118 ; ii. 199.Dalmat.

Spachianus, Boiss. Er Buhse, in Nouv. Mém. Soc. Nat. Mosc xii. (1860) 67.-Persia.

Spaldingii, A. Gray, in Proc. Am. Acad. vi. (1864 65) 524.-Am, bor. occ.

sparsiflorus, A. Gray, in Proc. Acad. Philad. (1863) 60.- Am. bor, occ.

sparsus, Decne. in Ann. Sc. Nat. Sér. II. iii. (1835) 267.-Arab.

spartioides, Kar. Eo Kir, in Bull. Soc, Nat. Mosc. xy. (1842) 330.-Soongar.

speciosus, Boiss. E' Hohen. Diagn. Ser. I. ix. 67.Persia.

speirocarpus, A. Gray, in Proc. Am. Acad. vi. (186465) 225.-Am. bor, occ.

sphaeranthus, Boiss, Diagnn. Ser. I. vi. 37.-Persia

sphaerocalyx, Ledeb. Fl. Ross. i. 647.-Mont. Ararat.

sphaerocarpus, Clos, in C. Gay, Fl. Chil. ii. 117.Chili.

sphaerocarpus, Desf. ex Steud. Nom. ed. II. i. 163.Chili.

sphaerocephalus, Trautv. in Act. Hort. Petrop. viii (1883) 241.-Reg. Caucas.

sphaerocystis, Bunge, in Mém. Sav. Etr. Pétersb. vii. (1851) 273 (Lehm. Rel. Bot. (1847) 97).-As. centr. sphaerophysa, Kar. EJ Kir. in Bull. Soc. Nat. Mosc xv. (1842) 338.-Soongar.

spicatus, Burm. ex Guill. \& Perr. Tent. Fl. Seneg. 182 $=$ Indigofera hirsuta.

spicatus, Pall. Reise, ii. 742,-Soongar

spicatus, Nutt. in Torr. \& Gray, H1. N. Am. i. $336=$ Mortoni.

spinellus, Boiss. E Haussk. ex Boiss. Fl. Orient. ii. 315-Persia.

spinescens, Bunge, Astrag. i. 42; ii. 64.-Persia.

spinosissimus, St. Lag. in Ann. Soc. Bot. Lyon, vi (1880) $120=$ A. Tragacantha.

spinosissimus, Wall. Cat. n. 5935.-Ind. or.

Spruneri, Boiss. Diagn. Ser. I. ii. 79. - Graecia.

squalidus, Boiss. l. C. Ser. II ii. 29,-As. Min.

squamulosus, Poir. Encyc. Suppl。i. $528=$ Oxytropis squamulosa.

squarrosus, Bunge, Astrag. i. 129 ; ii. 226--Persia.

Ssahendi, Boiss. Fl. Orient. ii. $311=$ Sahendi.

Stella, Bieb. Fl. Taur. Cauc, ii, $191=$ cruciatus,

Stella, Gouan, Illustr, 50-Gall austr.; Afr. bor.

stellatus, Lam. F1. Fro ii. $641=\mathrm{A}$. Stella.

stenanthus, Bunge, Astrag. Fedsch. 274.-As. temp.

stenoceras, C. A. Mey. in Bong. Verz. Pfl. SaisangNor, 24.--Soongar

stenocystis, Bunge, Astrag. Fiedsch. 301.-As. temp.

stenolepis, Fisch, in Bull. Soc. Nat.Mosc. xxvi. (1853)

II. 387.--Persia.

stenolobus, Bunge, in Mém. Sav. Etr. Pétersb. ii. (1835) $593=$ ceratoides.

stenophyllus, Torr. E Gray, Fl. N. Am. i. 329.-Am. bor.

stenorhachis, Fisch. in Bull. Soc. Nat. Mosc. xxvi (1853) II. $388=$ andrachnaefolius.

stenosemius, Boiss. Diagn. Ser. II. ii. 27.-Armenia.

stenostegius, Boiss, E Haussk. ex Boiss. Fl. Orient. ii. 314.- Kurdistan.

Stevenianus, DC. Prod. ii. 285.-Reg. Caucas. ; Persia

Stewartii, Baker, in Hook, f. Fl. Brit. Ind. ii. 129.Ind. bor. occ.

stipitatus, Benth. ex Boiss. Fl. Orient. ii. 305.Afghanist.

stipitatus, Sims, Bot. Mag. t. $2380=$ stipulatus.

stipularis, Sims, ex D. Don, 1. c. 1. Index = seq.

stipulatus, $D$. Don, ex Sims, $l$. c. to 2380.-Reg. Himal.

stipulatus, Jacquem. ex Baker, in Hook. f. Fl. Brit. Ind. ii. 131 = graveolens.

Stocksii, Benth. ex Bunge, Astrag. i. 6 ; ii. 4.Afghan.

stolzenburgensis, Lerch. ex Schur, Enum. Pl. Transs. $164=$ eriocephalus.

\section{ASTRAGALUS :-}

stramineus, Boiss. Diagn. Ser. II. y. 85.-Syria. streptopus, Greene, in Bull. Calif. Acad. in. 155.-Calif.

striatellus, Bieb. Fl. Taur. Cauc. ii. 189.--Reg. Caucas.

striatus, Nutt. in Torr. \& Gray, F1. N. Am. i. $330=$ adsurgens.

strictifolius, Boiss. Diagn. Ser. I. ix. 78.-Kurdistan.; Persia.

strictispinus, Boiss. Fl. Orient. ii. 366.-Lycia.

strictissimus, Sievers, ex Pall. Astrag. $16=$ follicularis.

strictus, R. Grah. in Wall. Cat. n. 5924.-Reg. Himal.

strictus, Siev. ex Fisch. in DC. Prod. ii $301=$ follicularis.

strigillosus, Bunge, Astrag. i. 102; ii. 178.-Anatolia.

strigulosus, H. B. E K. Nov. Gen. et Sp. vi. 494.Mexic.

strobiliferus, Lindl. in Bot. Reg. (1849) Misc. 39.Armenia.

strobiliferus, Royle, Illustr. Bot. Himal. 199.-Reg. Himal.

stromatodes, Bunge, Astrag. i. 85 ; ii. 148.--Syria.

subacaulis, Bunge, 1. c. i. 101 ; ii. $176=$ karputanuts.

subalpinus, Boiss. छ Buhse, in Nouv. Mém. Soc. Nat. Mosc, xii. (1860) 69.-Persia

subbarbellatus, Bunge, Astrag. Fedsch. 227.Turkestan.

subbiflorus, Lag. ex DC. Prod. ii. $289=$ scorpioides subbijugus, Ledeb. Fl. Ross. i. 627.-Turkestan.

subcaulescens, Ledeb. Fl. Ross, i. $644=$ Ruprechti hyalolepis.

subcaulescens, Royle, Illustr. Bot. Himal. 199.Ind. or.

subcinereus, A. Gray, in Proc. Am. Acad. xiii. (1878) 366.-Am. bor.

subcompressus, A. Gray, in Brandegee, Fl. S. W. Col 234.-Am. bor. occ.

suberosus, [Soland. in] Russell, Aleppo, ed. II. ii. $260=$ tuberculosa.

submitis, Boiss. E Hohen. Diagn. Ser. I. ix. 100.Persia.

subsecundus, Boiss. \& Hohen. l. c. 54,-Persia

subulatus, Desf. F1. Atlant. ii. $186=$ annularis,

subulatus, Koch, in Flora, ex Steud. Nom. ed. II. i 159 , in syn. $=$ argenteus.

subulatus, Pall. ex Bieb. Fl. Taur. Cauc. ii. 193.-Reg.

Caucas.; Tibet. : Afghan. Sibir.

subuliferus, Boiss. E Kotschy, ex Bunge, Astrag. i. 31 ; ii. 37.-Cilicia.

subuliformis, DC. Astrag. $107=$ subulatus.

subumbellatus, Klotzsch, in Bot, Ergeb. Waldem.

Reise, $\mathbf{1 5 9}=$ hippocrepidis.

succulentus, Richards. in Frankl. 1st Journ. App. $746=$ caryocarpus.

succumbens, Dougl.ex G. Don, Gen. Syst.ii. 263.-Am bor. occ.

succumbens, Torr. \& Gray, in Pacif. Rail. Rep. ii. $163=$ Parryi

suffalcatus, Bunge, Astrag. i. 125; ii. 219.-Afghan.

suffruticosus, $D C$. Astrag. 82.-Sibir.

suffruticosus, Pall. Reise, i. $440=$ fruticosus.

suidunensis, Bunge, in Act. Hort. Petrop. vii. (1880) 378.-Turkestan.

sulcatus, Lam. Fl. Fr. ii. $639=$ austriacus.

sulcatus, Linn. Sp. Pl. 756.-Sibir

sulfureus, Bunge, Astrag. i. 29 ; ii. 33.-Afghan.

sultanensis, Bunge, 1. c. i. 17 ; ii. $19=$ bombycinus.

superbus, Bunge, l. $c_{0}$ i. 62 ; ii. 105.-Persia

supinus, C. A. Mey. ex Bunge, l. c. i. 51 ; ii. 82 .Persia.

surugensis, Boiss. E Haussk. ex Boiss. Fl. Orient. ii. 402.-Mesopotam

susianus, Boiss. Diagn. Ser. I. ii. 64.--Persia.

susianus, Kotschy, ex Bunge, Astrag. ii. $119=$ acutus.

sylvaticus, Willd. Sp. Pl. iii. $1300=$ Oxytropis sylvatica.

sylvicolus, Pall. Astrag. 95 = Oxytropis sylvatica.

syriacus, Linn. Sp. Pl. 759.-Syria

syriacus, Pall. ex Ledeb. F1. Alt. iii. 295=Laxmanni.

syriacus, Linn. Herb. ex Bunge, in Boiss. Fl. Orient. ii. $479=$ vimineus.

syrtschensis, Bunge, Astrag. i. 46 ; ii. 74.-Persia.

Szovitsii, Fisch. \& Mey. in Bull. Soc. Nat. Mosc, xxyi,

(1853) II. 473.-Armenia.

\section{ASTRAGALUS :-}

tabrizianus, Buhse, in Bull. Soc. Nat. Mosc, xxvi 1853) II. 445.-Persia.

taeniolepis, Boiss. \& Hohen. Diagn. Ser. I. ix. $99=$ persicus.

talagonicus, Boiss. E Hohen. l.c. 87.-Persia.

talasseris, Boiss. E Bal. l. c. Ser. II. vi. 58.Cappadoc.

talyschensis, Bunge, Astrag. i. 40 ; ii. 57.-Reg Caucas.

tanaiticus, C. Koch, in Linnaea, xxiv. (1851) 94.Oriens.

tarijensis, Wedd. Chlor. And. ii. 262.-Bolivia.

taschkendicus, Bunge, Astrag. Fedsch. 280.-As. temp. tataricus, Franch. Pl. Davidian. i. 87-Mongolia. tauricolus, Boiss. Diagn. Ser. II. v. 86.-As. Min.

tauricus, Claus, in Goebel, Reise, ii. $269=$ scopae formis

tauricus, Pall. Astrag. 48. t. 38.-Reg. Caucas. ; Ural. ; Soongar.

Tavernieri, Boiss. E Diagn. Ser. I. ii. 78.-Persia

tegetarius, S. Wats. in Bot. King, Exp. 76, 444.Am. bor. occ

teheranicus, Boiss. \& Hohen. in Boiss. Diagn. Ser. I. ix. 44.-Persia.

tenax, Bunge, Astrag. i. 67 ; ii. 110.-Persia.

tenellus, Bungre, l. o i. 120 ; ii. 206_-Persin.

tenellus, Pursh, Fl. Am. Sept. ii. $473=$ multiflorus

tenellus, Willd. ex Steud. Nom. ed. II. i. $164=$ strigulosus.

tener, A. Gray, in Proc. Am. Acad. vi. (1864) 206.Calif.

tennesseensis, A. Gray, ex Chapm. Fl. S. U. St. $98=$ plattensis.

tenuicaulis, Benth. ex Bunge, Astrag. i. 23 ; ii. 28 .Reg. Himal.

tenuifolius, Desf. Fl. Atlant. ii. 186.-Algeria.

tenuifolius, Georgi, It. i. $226=$ versicolor.

tenuifolius, Linn. Sp. Pl. ed. II. $1065=$ A. Onobrychis. tenuirugis, Boiss. Diagn. Ser. I. ix. 61.-Arab.

tenuis, Turcz. in Bull. Soc. Nat. Mosc. (1838) 90 (Cat. Baikal. n. 354).—Sibir. baical.

tenuispinus, Bunge, Astrag. i. 44 ; ii. $70=$ cicerifolius. tephrodes, A. Gray, Pl. Wright. ii. 45.-N. Mexic. tephrolobus, Bunge, Astrag. i. 127 ; ii. 222.-Sibir altaic

tephrosioides, Boiss. Diagn, Ser. I. ix. 69.-Afghan. teres, Lam. Encyc. 1. $524=$ Oxytropis floribunda. terminalis, S. Wats. in Proc. Am. Acad. xvii. (1881-82) 370.-Am. bor. occ.

testiculatus, Pall. Astrag. 82. t. 67.-Reg. Caucas.; Soongar.; Sibir.

tetragonocarpus, Boiss. Diagn. Ser. I. ii. 52.-Persia tetrapterus, A. Gray, in Proc. Am. Acad. xiii. (1878 369.-Am. bor, occ.

tetrastichus, Bunge, Astrag. Fedsch 279-As. temp. thessalus, Boiss. Diagn. Ser. I. ii. $80=$ Spruneri

Thompsonae, S. Wats. in Proc. Am. Acad. x. (1875) 345 . - Am. bor. occ.

Thomsonianus, Benth. ex Bunge, Astrag. ii. $234=$ nivalis.

thracicus, Griseb. Spicil. Pl. Rumel. 1. 55.-Thracia.

Thurberi, A. Gray, in Mem. Acad. Am, N. S. v. (1855) 312.-Arizona

tianschanicus, Bunge, in Rupr. Sert. Tiansch. 43.As. temp.

ibetanus, Benth. ex Bunge, Astrag. i. 52; ii. 85.Afghanist.

tigreensis, Hochst. ex A. Rich. Tent. Fl. Abyss. i. 193 = venosus

Tigridis, Boiss. Diagn. Ser. I. ix. 55.-Mesopotam. timuranus, Franch. in Ann.Sc. Nat. Sér. VI, xv. (1883) 256.-Turkest.

tmoleus, Boiss. Diagn. Ser. I. ix. 79.-Lydia.

toeniolepis, Boiss. \& Hohen. ex Boiss. 1. c. $99=$ persicus.

tokatensis, Fisch. in Bull. Soc. Nat. Mosc. xxvi. (1853) II. 370.-Anatolia.

tomentosus, Lam. Encyc. i. 312.-Aegypt.

torrentum, Bunge, Astrag. i. 40 ; ii. 55.-Persia.

tortuosus, DC. Prod. ii. 299.-Mesopotam.

Tournefortii, Boiss. Diagn. Ser. I. ix. 92.-Cappadoc trachyacanthos, Fisch. in Bull. Soc. Nat. Mosc. xxvi (1853) Ir. 381.--Persia.

trachytrichus, Bunge, Astrag. i. 101; ii. 173.Armenia.

Tragacantha, Ucria, Hort. Panor. $316=$ siculus

Tragacantha, Habl. Taur. 112 - arnacantha. 


\section{ASTRAGALUS :-}

Tragacantha, Linn. Sp.Pl. 762.-Reg. Medit. or. Tragacantha, Pall. Astrag. t. 4. f. 1. Pl. $2=$ massiliensis. Tragacantha, Vill. Hist. PI. Dauph. iii. $470=$ aristatus. tragacanthoides, Hohen. Enum. P1. Talysch. $3=$ talyschensis.

tragacanthoides, Lam. ex Steud. Nom. ed. II. i. $164=$ declinatus.

tragacanthoides, Linn. Sp. Pl. $762=$ longilorus. tragacanthoides, Willd. Sp. Pl. iii. $1323=$ lanigerus tragacanthoides, Pall. Reise, i. 148=diffusus.

tragacanthus, Lam. Fl. Fr. ii. $642=$ A. Tragacantha. tragoides, Linn. Syst. ed. X. $1175=$ longiflorus. transoxanus, Fisch. in Bull. Soc, Nat. Mosc. xxvi. (1853) II. 338.-Turkestan.

transsilvanicus, Fanka, in Termész. Füzetek, viii. (1884) 307.-Europ.

Trautvetteri, Bunge, Astrag. i. 39 ; ii. 54.-Soongaria. triangularis, DC. Prod. ii. 291.-Hab. ?

tribulifolius, Benth. ex Bunge, Astrag. i. 4 ; ii. 2.Tibet. occ.

tribuliformis, Hochst. ex Boiss. F1. Orient. iii. $225=$ tribuloides.

tribuloides, Delile, Fl. Aegypt. Illustr. 70.-Afr. bor.; Oriens.

tribuloides, Kotschy, ex Bunge, Astrag. ii. $10=$ ammophilus.

tricarinatus, A. Gray, in Proc. Am. Acad. xii. (1877) 56.-Am. bor.

trichocalyx, Nutt. ex Torr. \& Gray, Fl. N. Am. i. 332 = mexicanus.

trichocalyx, Trautv. in Act. Hort. Petrop. iv. (1876) 362.-Reg. Caucas.

trichocarpus, R. Grah. in Wall. Cat. n. 5926.-Reg. Himal.

trichocarpus, Young, Fl. Texas, $228=$ Nuttallianus.

tricholobus, DC. Prod. ii. 299.-Persia.

trichopodus, A. Gray, in Proc. Am. Acad. vi. (186465) 218.-Am. bor. occ.

trichopterus, Boiss. Fl. Orient. ii. 292.-Syria.

trichostigma, Bunge, Astrag. i. 40; ii. 57.-Anatolia.

tricolor, Bunge, l. c. i. 139; ii. 237.-Soongar.

tridactylicus, A. Gray, in Proc. Am. Acad. vi. (186465) $527 .-\mathrm{Am}$. bor. occ.

triflorus, A. Gray, Pl. Wright. ii. 45.-Am. bor. occ. trifoliatus, Phil. in Linnaea, xxviii. (1856) 681.Chili.

trifoliolatus, Boiss. Diagn. Ser. I. ii. 48.--Syria.

trigonelloides, Boiss, l. c. 49.-Armenia.

trigonocarpus, Bunge, Astrag. i. 22; ii. 23.-As. centr.

trigonus, DC. Astrag. 186.-Aegypt.; Arab.

trigonus, Sieber, ex DC. Prod. ii. $295=$ Sieberi.

trimestris, Bieb. F1. Taur. Cauc. ii. $190=$ brachyceras.

trimestris, Linn. Sp. Pl. 761.-Aegypt.

trimestris, Pall. ex Ledeb. F1. Ross. 1. $368=$ hamosus

trimorphus, Viv. F1. Lyb. Spec. 44. t. $10=$ annularis.

triphyllus, Pall. Astrag. 68, t. 56. f. a=Oxytropis triphylla.

triphyllus, Pursh, Fl. Am. Sept. ii. 740.-Am. bor.

triquetrus, A. Gray, in Proc. Am. Acad. xiii. (1878 367.-Am. bor.

triradiatus, Bunge, Astrag. i. 10 ; ii, 7.-Cilicia; Meso-

potam.
tristis, Nutt. in Torr. \& Gray, Fl. N. Am. i. $336=$ Mortoni.

troglodytus, S. Wats. in Proc. Am. Acad. xx. (1885) 362.-Arizona.

trojanus, Stev. in Bull. Soc. Nat. Mosc. xxvi. (1853) 1I. 401.-Graecia; As. Min.; Oriens.

tschujensis, Bunge, Astrag. i. 22 ; ii. 24.-Sibir. altaic.

tuberculosus, DC. Astrag. 33. t. 22.-Syria; Mesopotam.

tumidus, Bieb. F1. Taur. Canc, ii. $198=$ fabaceus.

tumidus, DC. Astrag. $165=$ Russelii.

tumidus, Willd. in Mém. Acad. Berl. (1794-95) $26=$ Clusii.

tunetanus, Willd. Sp. Pl. iii, 1277,-Algeria,

turbinatus, Bunge, in Arb. Naturf. Ver. Riga, i. (1847) 251.-Persia; Turkestan.

turcomanicus, Bunge, Astrag. i. 130 ; ii. 227.Turcom.

Turczaninowii, Kar. G Kir. in Bull. Soc. Nat. Mosc. xv. (1842) 342.-Turkestan.

turkestanus, Bunge, ex Boiss. Fl. Orient. ii. 278.Turkestan.

tyrophresteus, Boiss. E Sprun. Diagn. Ser. I. ii. 63. -Graecia.

\section{ASTRAGALUS :}

tyrolensis, Sieber, ex Stend. Nom. ed. II. i. $164=$ Oxytropis campestris.

ulachanensis, Franch. Pl. Davidian. i. 87.-Mongolia. uliginosus, Bieb. Fl. Taur. Cauc. ii. $188=$ glycyphylloides.

uliginosus, Linn. Sp. Pl. 757.-Sibiria.

umbellatus, Bunge, Astrag. i. $24 ;$ ii. $29-$ N. Zemlaia.

umbellatus, Pers. Syn. ii. $335=$ lotoides

uncatus, Linn. Sp. Pl. ed. II. 1072.-Aleppo.

uncatus, Linn. Herb. ex Boiss. F1. Orient. $i .234=$ trimestris.

uncinatus, Berrtol. Fl. Ital. viii. 54.-Ios. Corsica.

uncinatus, Moench, Meth. $166=$ baeticus.

uncinatus, Pomel, Nouv. Mat. Fl. Atl. 322.-Algeria.

uniflorus, DC. Astrag. 243. t. 50.-Peruv.

unifoliatus, Bunge, in Arb. Naturf. Ver. Riga,

(1847) 231.-Turkestan.

unifultus, L'Hérit. Stirp. Nov. 168.-Peruv, ; Chili.

unijugus, Bunge, Astrag。 i. 130 ; ii. 228.-Soongaria

unilateralis, Kar. of Kir. in Bull. Soc. Nat. Mosc.

(1841) 404.-Sibir. altaic.

uralensis, Linn. Fl. Suec. $257=$ Oxytropis campestris.

uralensis, Vahl, in Fl. Dan. t. $1041=$ Oxytropis sordida.

uraniolimneus, Boiss. Fl. Orient. ii. 380.-Armenia.

urmiensis, Bunge, Astrag. i. 37 ; ii. 44--Persia.

ursinus, A. Gray, in Proc. Am. Acad. xii1. (1878) 367. -Am. bor.

ustiurtensis, Bunge, Astrag. i. 102; ii. 179.-Reg. Casp.

utahensis, Torr. E Gray, in Pacif. Rail. Rep.ii. (1854)

120.-Am. bor. occ.

utriger, Friv. ex. Bunge, Astrag. ii. $108=$ physocalyx.

utriger, Boiss. \& Buhse, ex Boiss. Fl. Orient. ii. $261=$

macropelmatus.

utriger, Pall. Astrag. 75. t. 61.-Tauria.

utriger, C. A. Mey. Verz. Pfl. Cauc. $143=$ baknensis.

utriger, Willd. ex Ledeb. Fl. Ross. 1. $654=$ pubitlorus.

vaccarum, A. Gray, $P l$. Wright. ii. 43.-Am, bor, occ.

vaginans, $D C$. Astrag. 210 . t. 37 .-Cilicia.

vaginatus, Pall. Astrag. 46. t. 36.-Sibiria

vaginatus, Richards, in Frank!. 1st Journ. App. $746=$ Hallii.

valesiacus, Thomas, ex Koch, Syn. Fl. Germ. ed. I. $182=$ Oxytropis lapponica.

Vanillae, Boiss. Diagn. Ser. I. ii. 60.-Persia.

variabilis, Bunge, ex Maxim. in Bull. Acad. Pétersb. xxiv. (1878) 33.-Mongolia.

variegatus, Franch in Ann. Sc. Nat. Sér. VI. xv, (1883) 259.-Turkest.

varius, S. G. Gmel. It. i. 116. t. 17 =virgatus.

Vaseyi, S. Wats. in Proc. Am. Acad. xvii. (1881-82)

370.-Am. bor. occ.

vegetus, Bunge, Astrag. i. 102 ; ii. 181.-Persia.

vegliensis, Sadl. Fl. Pest. i. 199 in nota $=$ Mnelleri.

veluchensis, Boiss. Fl. Orient. ii. 319.-Graecia.

velutinus, Sieber, ex Stend. Nom. ed. II. i. $164=$ Oxytropis Halleri.

venosus, Aucher, ex Bunge, Astrag. ii. $217=$ Aucheri. venosus, Hochst. ex A. Rich. Tent. Fl. Abyss, i. 193. -Abyss.

venosus, Ehrenb. ex Bunge, Astrag. ii. 229 = angustifolius.

ventorum, A. Gray, ex S. Wats. in Am. Natural. viii.

1874) 212.-Am. bor. occ.

venulosus, Boiss, Diagn. Ser. I. ii. 75-Cappadoc.

vernus, Georgi, Bemerk. Reise Russ. Reich.i. 226.-

Rossia.

verrucosus, Moris, Stirp. Sard. Elench. 12.-Sardinia.

versicolor, C. Koch, in Linnaea, xix. (1847) $65=$ Sibthorpianus.

versicolor, Pall. Astrag. 45. t. 35.-Sibiria or.

verticillaris, Bunge, Astrag, i. 53; ii. 88.-Afghanist. verticillaris, Linn. Mant. ii. $275=$ Oxytropis myriophylla.

verticillaris, Georgi, Beschr. Russ. Reich. iii. Iv,

$1185=$ Oxytropis verticillaris.

verticillaris, Scop. Delic. Insub. ii. 107.-Sibiria.

verus, DC. ex Bunge, Astrag. ii. $164=$ Roussaeanus.

verus, Olivier, Voy, iii. t. 44.-Persia

vesicarius, Lam. F1. Fr. ii. $637=$ A. Cicer.

vesicarius, Linn. Sp. Pl. 760.-Europ. austr. ; Tauria.

vesicarius, Pall. Reise, iii. App. $751=$ Oxytropis cen

spitosa.

vesicarius, Sicv. in Pall. N. Nord. Beitr. vii. $274=$

inflatus.

vesiculosus, Clos, in C. Gay, Fl. Chil. ii. 120.-C'hili.

\section{ASTRAGALUS :-}

esiculosus, Jacquem. ex Baker, in Hook. f. Fl. Brit. Ind. iii. $138=$ mollis

vestitus, Boiss. E Heldr. Diagn. Ser. I. ix. 98.Graecia.

vestitus, S. Wats. Bibliog. Ind 202.-Calif

vexillaris, Boiss. Diagn. Ser. I. ii. 49.-Mesopotam.

viciaefolius, DC. Astrag. 119.-Reg. Caucas.; As. Min

vicioides, $R$. Grah. in Wall. Cat. in. 5931.-Reg. Himal.

vicioides, Ledeb. Fl. Alt. iii. $301=$ macropterus.

villosissimus, Bunge, Astrag. i. 129 ; ii. 225 . -Tur. kestan.

villosus, Gueldenst, ex Ledeb. Fl. Ross. i. 6jit= pubiflorus.

villosus, Michx. Fl. Bor. Am. ii. 67.-Am, bor.

vimineus, Pall. Astrag. 24. t. $21=$ fruticosus.

virescens, Ait. Hort. Kew, iii. $73=$ falcatus,

virgatus, Pall. Astrag. 20. t. 18.-Hung.; Taur

virgatus, Reichb. Fl. Germ. Excurs. $510,868=$ Muelleri

viridis, Bunge, Astrag. i. 135 ; ii. 231.-Armenia.

viscosus, Chaix, ex Vill. Prosp. $42=$ Oxytropis cam pestris.

Volckmanni, Phil. in Anal. Univ. Chil, (1861) I. 46. -Chili.

Vulnerariae, DC. Prod. ii. 300.-As. Min.

vulnerarioides, All. Fl. Pedem. i. $3 \pm 3=$ Anthyllis Vul. neraria.

vulpinus, Ledeb. F1. Alt. iii. 318=lagocephalus.

vulpinus, Willd. Sp. Pl. iii. 1259.-Turkestan.

Wagneri, Bartl. ex Bunge, Astrag. ii. 125.-Persia.

Wardii, A. Gray, in Proc. Am. Acad. xii. (1877) 55. Utah.

urtoënsis, Boiss. Er Kotschy, ex Bunge, Astrag. i. 87 ; ii. 153.-Armenia

Webberi, A. Gray, in Bot. Calif. i. 15t.-Calif.

Webbianus, R. Grah. in Wall. Cat. R. 5yzo,-Reg. Himal.

Weidmannianus, Fisch. in Bull. Soc. Nat. Mosc. xxvi. (1853) Il. 395.-Anatolia.

Whitneyi, R. Gray, in Proc. Am. Acad. vi. (1864-65) 526. - Calif.

Wilhelmsii, Fisch. ex Ledeb. Fl. Ross. i. $603=$ resupinatus.

wingatanus, S. Wats. in Proc. Am. Acad. xviii. (188283) 192.-Am. bor. occ.

wolgensis, Bunge, Astrag. L. 36 ; ii. 47.-Rossia.

Wrightii, A. Gray, in Bost. Fourn. Nat. Hist. vi. (1850) 176.-Texas.

Wulfeni, Koch, Syn.Fl.Germ.ed. II. 207.-Dalmatia; Graecia.

xanthomelas, Bunge, Astrag. Fedsch. 314.-As. temp, xanthotrichos, Ledeb. Fl. Alt. iii. 324.-Sibir, altaic. xerophilus, Ledeb. Fl. Ross. i. 607.-Mont. Ararat.

Xiphidium, Bunge, Astrag。 i. 25; ii. 218.-Reg. Caucas.

xiphocarpus, Benth. ex Bunge, l. c. i. 27 ; ii. 32.Reg. Himal.

xylorrhizus, Bunge, Astrag. Fedsch.267.-As, temp.

yuralicus, Boiss. Fl. Orient. ii. 366.-Cappadocia.

zacharensis, Bunge, Astrag. i. 23; ii. 27.-Syria.

zachlensis, Bunge, l. c. i. 88 ; ii. 154-Syria.

zagrosicus, Boiss. E Haussk. ex Boiss Fl. Orient. ii. ¿286.-Persia.

zanskarensis, Benth. ex Bunge, Astrag. i. 43 ; ii. $67 .-$ Reg. Himal.

zerdanus, Boiss. Diagn. Ser. I. ii. 51.-Persia.

geylanicus, Ledeb. ex Bunge, Astrag, ii. $184=$ caerulcus.

Zohrabi, Bunge, 1. c. i. 65 ; ii. $112=$ lagupoides.

ASTRANTHIUM, Nutt. in Trans, Am. Phil. Suc. Ser. II. vii. (1841) $312=$ Bellis, Linn. Compos.

integrifolia, Nutt. 1. c. = B. integrifulia

ASTRANTHUS, Lour. Fl. Cochinch. 221 (1;y0)= Homalium, Jacg. (Samyd.)

cochinchinensis, Lour. 1. c. 222 = 11. ragifolium. foetida, Wall. ex Mast in Hook. f. FL Brit. Ind. ii. 595 $=\mathrm{H}$. foetidum.

ASTRANTIA, [Toum.] Linn. Syst. ed, I (1735) L.MBELLIFERAE, Benth. \& Himik. f. i. sit: Actinolema, Fenzl, I'ugill. I']. Syr, 68.2. 1:2 (1st? alpina, Stur, ex Nym. Consp. $318=$ gracilis. alpina, [Clairv.] IInn. Berb. is = minor.

basarica, schult, in Flura, xli. (1sis) $161=$ gracilis 


\section{ASTRANTIA}

Biebersteinii, Fisch. E Mey. Ind. Sem. Hort. Petrop. ii. 28.-Reg. Caucas.

candida, Mill. Gard. Dict. ed. VIII. n. $2=$ major,

carinthiaca, Hoppe, ex Koch, Syn. Fl. Germ. ed. I. 281 $=$ major.

carniolica, Wulf. in Facq. Fl. Austr, v. 31.-Carinth. carniolica, Koch, Syn. Fl. Germ. ed. I. $280=$ gracilis. caucasica, Willd. ex Spreng. Umb. $17=$ major.

ciliaris, Linn: f. Suppl. 177.-Afr. austr.

croatica, Tomm. ex Vukot. in Rad. Fugos. Akad. Zagrab, xliv. (1878) 216.-Croatia.

Diapensia, Scop. FI. Carn. ed. II. i. $186=$ Sanicula europaea.

digitata, Moench, Meth. $94=$ minor.

dondiaefolia, Schur, Enum. Pl. Transs. $245=$ gracilis. elatior, Frivald. in Flora, xix. (1836) $434=$ major.

Epipactis, Scop. F1. Carn. ed. II. i. $185=$ Hacquetia Epipactis.

europaea, Linn. ex Rehm. Notiz. Veg. Gest. Schwarz. Meer. $63=$ major

gracilis, Bartl. in Linnaea, xv. (1841) Litt. 93.Carniolia.

gracilis, Schur, in Oestr. Bot. Zeitschr. (1858) $22=$ carniolica.

grandiflora, Poepp. ex DC. Prod. iv. 668 (=Pozoa coriacea),-Reg. Andin.

helleborifolia, Salisb. Prod. 159.-Reg. Caucas.

heterophylla, Willd. in Ges. Naturf. Fr. Berl. Neue

Schr. iii. (1801) $419=$ helleborifolia.

intermedia, Bieb. Fl. Taur. Cauc. Suppl. 194=major.

major, Bieb. 1. c. n. $509=$ Biebersteinii.

major, Linn. Sp. Pl. 235.-Reg. Caucas. maxima, Pall. in Nov. Act. Petrop. vii. (1793) 357. t.

microphylla, Schur, Enum. Pl. Transs. $245=$ gracilis.

minor, Linn. Sp. Pl. 235.-Europ.

minor, Scop. F1. Carn. ed. II. i. 187 = carniolica.

minor, Vitm. Summa Veg. ii. $124=$ pauciflora.

montana, [Clairv.] Man. Herb. $78=$ major.

neglecta, C. Koch E Bouché, in App. Sem. Hort. Berol.

(1853) 22.-.-Europ.

nigra, Scop. Fl. Carn. ed. II. i. $188=$ major.

pallida, Presl, ex Koch, Syn. Fl. Germ. ed. I. 280 ; ed.

II. $309=$ major.

pauciflora, Bertol. in Desv. Fourn. Bot. ii. (1813) 76.Italia.

rananculifolia, Reichb. f. Ic. Fl. Germ. xxi. 3.-Europ. saniculaefolia, Salisb. Prod. $159=$ major.

speciosa, Hort. ex Heynh. Nom. ii. $53=$ helleborifolia transsilvanica, Schur, Enum. Pl. Transs. $245=$ carniolica.

tridentata, Parrot, Reise Krym Kauk. ii. 130, nomen. -Reg. Caucas.

trifida, Hoffm. Umb. ed. II. 1. praef. 8 in nota=major.

ASTRAPAEA, Lind1. Coll. Bot. t. $14(1822)=$ Dom. beya, Cav. (Stercul.).

penduliflora, DC. in Mém. Soc. Phys. Genèv. iv. (1828) $90=\mathrm{D}$. Wallichii.

tiliaefolia, Sweet, Hort. Brit. ed. I. $58=$ D. acutangula.

viscosa, Sweet, 1. c. = D. cannabina

Wallichii, Lindl. Coll. Bot. t. $14=$ D. Wallichii.

ASTREBI.A, F. Muell. [Fragm, x, 76 (1876), nomen] ex Benth. Fl. Austral. vii. 602 (1878). GRAMINEAE, Benth. \& Hook. f. iii. 1170 .

elymoides, F. Muell. ex F. M. Bailey, Grass. Queensl.i. - Austral. pectinata, F. Muell. ex Benth. Fl. Austral. vii. 602.-
Austral.

triticoides, F. Muell. l. c.-Austral.

ASTREPHIA, Dufr. Hist. Valer. 50 (1811), pro parte. VALERIANEAE, Benth. \& Hook. f. ii. 153. OLIGACOCE, Willd. ex DC. Prod. iv. $632(1830)$. carnosa, Dufr. 1. c. $51=$ Valeriana carnosa. chaerophylloides, DC. Prod. iv. 629.-Peruv. chinensis, Dufr. Hist. Valer. 51.-China. coarctata, Dufr. 1. c. = Valeriana coarctata. crispa, Dufr. l. $c .-$ Chili.

hyalinorrhiza, Dufr. 1. c. $52=$ Valeriana hyalinorrhiza. interrupta, Dufr. 1. c. $41=$ Valeriana interrupta. laciniata, Dufr. 1. c. $56=$ chaerophylloides

laxa, Hook. Es Arn. in Hook. Bot. Misc, iii. (1833) 364. -Chili.

lobata, Hook. Eo Arn. b. c.-Chili.

\section{ASTREPHIA:}

mexicana, Hook. \& Arn. Bot. Beech. Voy. Suppl. 431 $=$ Phyllactis mexicana.

mexicana, Seem. Bot. Voy. Herald, $297=$ Valeriana mexicana.

oblongifolia, Dufr. Hist. Valer. $60=$ Valeriana oblongifolia.

polystachya, Dufr. 1. c. $51=$ Valerianopsis polystachya.

pratensis, Benth. Pl. Hartw. $39=$ Phyllactis pratensis. serrata, Dufr. Hist. Valer. $50=$ Valeriana serrata.

ASTROCARPUS, Neck. Elem. ii. 243 RESEDACEAE, Benth. \& Hook. f, i. 111. Sesamella, Reichb. Consp. 186 (1828). abyssinicus, Hochst. ex Oliver, Fl. Trop. Afr. i. $103=$ Caylusea abyssinica.

Clusii, F. Gay, in F. Schultz, Arch. Fl. Fr. et Allem. 33.- Hispan.

cochlearifolius, Nym. in Ofver. Vet. Akad. Stockh. xviii. (1861) 191.-Lusitan.

interruptus, Bor. in Mém. Soc. Acad. Maine-et-Loire, viii. (1860) $7=$ sesamoides.

minor, Lange, in Kjoeb. Vidensk. Meddel. (1865) 85 (Pugill. 280. t. 4. f. 1).-Europ.

purpurascens, Rafin. F1. Tellur. iii. $73=$ Clusii.

sesamoides, Colm. ex Willk. \& Lange, Prod. Fl. Hisp. iii. $899=$ Clusii.

sesamoides, DC. ex Duby, Bot. Gall. i. 67.-Europ.

spathulaefolius, Revell, ex Bor. in Mém. Soc. Acad. Maine-et-Loire, i. (1857) 87.-Gallia.

suffruticosus, Lange, in Kjoeb. Vidensk. Meddel. (1865) 83 (Pugill. 278. t. 4).--Hispan.

astrocaryUM, G. F. W. Mey. Prim. Fl. Esseq 265 (1818). PALMAE, Benth. \& Hook. f. iii. 942. Toxophoenix, Schott, Nachr. K. K. Oester. Naturf in Brasil. Anh. ii. (1822).

acanthopodium, Barb.-Rodr. Enum. Palm. Nov. 20.Bras.

acaule, Mart. Hist. Nat. Palm. ii. 78. t. 24. 63. f. 5 . -Bras.

aculeatum, Barb.-Rodr Enum. Palm. Nov, $20=$ Rodriguesii.

aculeatum, G. F. W. Mey. Prim. Fl. Esseq. 266.Guiana.

aculeatum, Hort ex H. Wendl. in Kerch. Palm. 230 = Acrocomia sclerocarpa.

aculeatum, Wallace, Palm Trees Amaz. 111. t. $43=$ minus?

argenteum, Hort. Bull.-Cf. Gard. Chron. (1875) I. 491.- Hab. ?

aureum, Griseb. E H. Wendl. in Griseb. Fl. Brit. W. Ind.521.-Ind. occ

Awarra, De Vriese, in Jaarb. Maatseb. (1848) $12=$ aculeatum.

A yri, Mart. Hist. Nat. Palm. ii. 71. t. 59n.-Bras.

Borsigianum, C. Koch, ex Regel, Gartenfi. (1861) 29 $=$ Stevensonia grandifolia.

campestre, Mart. Hist. Nat. Palm. ii. 79. t. 63. f. 4. -Bras.

candescens, Barb.-Rodr. Enum. Palm. Nov. 22.Bras.

Chichon, Linden, Illustr. Hortic. xxviii. (1881) $15=$ mexicanum.

Chonta, Mart. in Palmet. Orb. 84. t. 4. f. 1. 2.Peruv.

farinosum, Barb-Rodr. Enum, Palm, Nov, 21,Bras.

flexuosum, Hort. ex H. Wendl. in Kerch. Palm. 232. -Hab. ?

guianense, Splitg. ex Mart. Hist. Nat. Palm. nii. 323. -Guiana.

gynacanthum, Mart. l. c. ii. 71. t. 60,61.-Bras.

gynacanthum, Wallace, Palm Trees Amaz. 103. t. $39=\mathrm{A}$. Munbaca?

Huaimi, Mart. in Palmet. Orb. 86. t. 13. fig. 3.Bolivia.

humile, Wallace, Palm Trees Amaz. 115. t. 45.Bras.

Jauari, Mart. Hist. Nat. Palm. ii. 76. t. 52 et 65. f. 1. -Bras.

Fucuma, Linden, Illustr. Hortic. xxviii. (1881) 15, sphalm. $=$ A. Tucuma.

Malybo, Karst. in Linnaea, xxviii. (1856) 245.-N. Granat.

mexicanum, Liebm.ex Mart. Hist. Nat. Palm. iii. 323. -Mexic.

\section{ASTROCARYUM :}

minus, Trail, in fourn. Bot. xv. (1877) 78.-Bras Munbaca, Mart. Hist. Nat. Palm. ii. 74:-Bras.

Murumura, Mart. l. c. 70. t. 58,59--Bras.

Murumuru, Wallace, Palm Trees Amaz. 101. t. 38. -Bras.

panamense, Linden, Illustr. Hortic, xxxviii. (1881) 15 -N. Granat.

Paramaca, Mart. in Palmet. Orb. 88.-Guiana.

plicatum, Drude, in Mart. Fl. Bras. iii. II. 375.Guiana; Bras.

Princeps, Barb.-Rodr. Enum. Palm. Nov. 22.-Bras,

pygmaeum, Drude, in Mart. Fl. Bras. iii. II. 385.Bras.

pumilum, Hort. ex H. Wendl. in Kerch. Palm. 232.Hab.?

Rodriguesii, Trail, in Fourn. Bot. xv. (1877) 79.Bras.

rostratum, Hook. Bot. Mag. t. 4773-Bras.

sclerocarpum, Hort. ex H. Wendl. in Kerch. Palm. $232=$ Acrocomia sclerocarpa.

sclerophyllum, Drude, in Mart. Fl. Bras. iii. II. 377 -Bras.

segregatum, Drude, l. c. 382.-Bras

tenuifolium, Linden, Illustr. Hortic. xxviii. (1881) 15. -Bras.

Tucuma, Mart. Hist. Nat. Palm. ii. 77. t. 65. f. 2 -Bras.

tucumoides, Drude, in Mart. Fl. Bras. iii. Ir. 381.-Bras. vulgare, Mart. Hist. Nat. Palm. ii. 74. t. 62, 63.Bras.

Warszewiczii, Karst. in C. Koch E Fint. Wochenschr. (1858) 297.-Am. austr

Weddellii, Drude, in Mart. Fl. Bras. iii. II. 383.Bras.

ASTROCEPHALUS, Rafin. F1. Tellur. iv. 94 (1836) ASTEROCEPHALUS, Vaill.= Scabiosa, Tourn. (Dipsac.).

ciliata, integrifolia, rigida, sylvatica, tatarica, ura lensis, Rafin. 1. c. = Scabiosae totidem homonymae.

ASTROCOCCUS, Benth. in Hook. Kew Journ. vi (1854) 327. EUPHORBIACEAE, Benth. \& Hook. f. iii. 326 .

coriaceus, Baill in Adansonia, v. 308.-Bras.

cornutus, Benth. in Hook. Kew fourn. vi. (1854) 327. -.-Bras.

ASTROCOMA, Neck. Elem. i. $112(\mathbf{1 7 9 0})=$ Staavia Dahl (Bruniac.).

ASTRODENDRUM, Dennst. Schluess. Hort. Malab. 30 $(1818)=$ Sterculia, Linn

malabaricum, Dennst. 1. c. $=$ S. guttata.

ASTROGLOSSUS, Reichb. f. ex Benth. \& Hook. f. Gen. iii. 588 (1883)= Trichoceros, H. B. \& K. (Orchid.)

ASTROGYNE, Benth. P1. Hartw, 14 (1839)=Croton, Linn. Euphorb.

crotonoides, Benth. 1. c. = C. gracilis.

ASTROGYNE, Wall. ex Laws. in Hook. f. F1. Brit Ind. i. (1875) $629=$ Siphonodon, Griff. (Celastr.). coriacea, Wall. ex Laws. 1. $\mathrm{c} .=\mathrm{S}$. celastrineus.

ASTROLOBIUM, DC. Prod, ii. $311(1825)=$ Ornithopus, Linn. et Coronilla, Linn. (Legumin.). creticum, DC. 1 . c. $310=$ C. cretica. durum, DC. 1. c. $311=0$. durus. ebracteatum, DC. I. C. $=$ O. ebracteatum. repandum, DC. $1, \mathrm{c}_{,}=\mathrm{C}$. repanda. scorpioides, DC. 1. c. $=$ C. scorpioides.

ASTROLOMA, R. Br. Prod. 538 (1810). EPACRI $D E A E$, Benth. \& Hook. f. ii. 611. Mesotricha, Stschegl. in Bull. Soc. Nat. Mosc. (1859) I. 6.

Pentataphrus, Schlecht, in Linnaea, xx. (1847) 618 .

Stenanthera, R. Br. Prod. 538 (1810).

Stomarrhena, DC. Prod. vii. 738 (1838).

Ventenatia, Cav. Ic. iv. $79(1797)$.

VivTenatia, Cav 1 c. 28 (1797).

Baxteri, A.Cunn. ex DC. Prod. vii. 739.-Austral.

Candolleanum, Sond. in Lehm. Pl. Preiss. i. 302,Austral.

compactum, R. Br. Prod. 538.--Austral. 
ASTROLOMA :-

conostephioides, F. Muell. ex Benth. Fl. Austral. iv. 158.-Austral.

cuneifolium, Sond. in Lehm. Pl. Preiss, i. $299=$ compactum.

denticulatum, R. Br. Prod. $538=$ humifusum.

dilatatum, Sond. in Lehm. P1. Preiss. i, $298=$ longiflorum.

discolor, Sond. 1. c. = longiflorum

divaricatum, Sond. l. c. 299.-Austral.

Drummondii, Sond. l. c.-Austral.

foliosum, Sond. $l_{\text {. }}$ c. 297.-Austral.

glaucescens, Sond. 1. c. $298=$ macrocalyx.

hirsutum, Stschegl. in Bull. Soc. Nat. Mosc. (1859) I. 7 Drummondii

humifusum, R. Br. Prod. 538.-Austral.

juniperinum, F. Muell. Fragm. vi. $36=$ microphyllum lasionemum, F. Muell. 1. c. $40=$ stomarrhena.

latifolium, Sond. in Lehm. PI. Preiss. i. $302=$ tectum.

longiflorum, Sond. l. c. 297.-Austral

macrocalyx, Sond. l. c. 301 -Austral.

marginatum, Sond. 1. c. $299=$ divaricatum.

microcalyx, Sond. l. c, 298.-Austral.

microdonta, F, Muell. ex Benth. Fl. Austral. iv. 155. -Austral.

microphyllum, Stschegl. in Bull. Soc. Nat. Mosc. (1859) I. 7.-Austral.

pallidum, $R, B r$. Prod. 538,-Austral.

pallidum, Sond. in Linnaea, xxvi. (1853-55) $246=$

humifusum.

pinifolium, Benth. Fl. Austral. iv. 159.-Austral. C

prostratum, R. Br. Prod. 538.-Austral.

pungens, Stschegl. in Bull. Soc. Nat. Mosc. (1859) I. 8 = divaricatum.

splendens, Planch. in Fl. des Serres, Sér. I. x. (1854-55)

129. t. $1018=$ divaricatum.

stomarrhena, (Sond. in Lehm. Pl. Preiss. i. 301.-

Austral.

tectum, $R . B \nmid$. Prod. 538.-Austral.

xerophyllum, Sond. in Lehm. Pl. Preiss. i. 301.Austral.

ASTRONIA, Noronha, in Verh. Batav. Gen. v. (1790) ed. I. Art. IV. 1; Blume, Bijdr. 1080 (1826). $M E$ LASTOMACEAE, Benth. \& Hook. f. i. 771.

Astronidium, A. Gray, Bot. U. St. Expl. Exped. i. $582, t, 72(1854)$

Lomanodia, Rafin. Sylva Tellur. 97 (1838).

Naudinia, Decne. ex Triana, in Seem. Fl. Vit. 86 (1866).

concolor, Zipp. ex Steud. Nom. ed. II. i. 165=macrophylla.

confertiflora, A. Gray, Bot. U. St. Expl. Exped, i. 579 -Ins. Fiji.

Cumingiana, Vidal, Phan. Cuming. Philipp. 174.Ins. Philipp.

Forsteri, Naud. in Ann. Sc. Nat. Sér. III. xviii. (1852) 258. - Ins. Tahiti.

fratema, A. Gray, Bot. U. St. Expl. Exped. i. 576. t. 72. - Ins. Tahiti.

fraterna, Seem. Fi. Vit. $85,86=$ Forsteri.

glabra, Triana, in Trans. Linn. Soc. xxviii. (1871) 152 Forsteri.

intermedia, Blume, Mus. Bot. Lugd. Bat. i. $9=$ spectabilis.

macrophylla, Blume, Bijdr. 1080.-Malaya.

ovalifolia, Naud. ex Decne. Bot.Voy. Vénus, 27.-Ins. Tahiti.

papetaria, Blume, Bijdr. 267.-Ins. Molucc.

parviflora, Triana, in Trans. Linn. Soc. xxviii. (1871) 152.-Ins. Fiji.

Pickeringi, A. Gray, Bot. U. St. Expl. Exped. i. 577. t. 72 - -Ins. Fiji

pileolata, Triana, in Trans. Linn. Soc. xxviii. (1871) 152.-Ins. Tahiti.

robusta, Seem. Fl. Vit. 86.-Ins. Fiji

Rolfei, Vidal, Phan. Cuming. Philipp. 174.-Ins. Philipp.

samoënsis, S. Moore, in fourn. Bot. xviii. (1880) 3.Ins. Samoa.

smilacifolia, Triana, in Trans. Linn. Soc. xxviii. (1871) 152.-Malaya.

spectabilis, Blume, Bijdr. 1080 - Јауя.

spectabilis, Zipp. ex Steud. Nom. ed. II. i. $165=$ papetaria.

Storckii, Triana, in Trans. Linn. Soc. xxviii. (1871) 152.-Ins. Fiji.

\section{A.STRONIA :}

subcordata, A. Gray, Bot. U. St. Expl. Exped. i. 580. -Ins. Samoa.

tomentosa, Seem. Fl. Vit. 86.-Ins. Fiji.

ASTRONIDIUM, A. Gray, Bot. U. St. Expl. Exped. i. 581. t. $72(1854)=$ Astronia, Blume (Melast.)

parviflorum, A. Gray, 1. c. 582 . t. $72=$ Astronia parviflora.

Storckii, Seem. F1. Vit. $87=$ Astronia Storckii.

ASTRONIUM, Jacq. Enum. P1. Carib, 10. ANA$C A R D I A C E A E$, Benth. \& Hook. f. i. 423.

Balansae, Engl. in Bot. Fahrb. i. (1881) 45.--Paraguay.

Candollei, Engl. l. c.-Paraguay.

concinnum, Schott, in Spreng. Syst. Cur. Post. 404.Bras.

fraxinifolium, Schott, in Spreng. l. c.-Bras.

gracile, Engl. Bot. Fahrb. 1. (1881) 75.-Bras. graveolens, Facq. Enum. Pl. Carib. 33.-N. Granat. insigne, March. Rev. Anac. $177=$ Parishia insignis. juglandifolium, Griseb. in Goett. Abh. xxiv. (1879) $94=$ A. Urundeuva.

Libonianum, 7. Linden, Cat. n. 17. (1862) 7.-Bras. macrocalyx, Engl. Bot. Fahrb. i. (1881) 75,-Bras. obliquum, Griseb. Fl. Brit. W. Ind. 176.-Ind, oce. Planchonianum, Engl. in Mart. Fl. Bras. xii. II. 399 -Am. trop.

Urundeuva, Engl. Bot. Fahrb. i. (1881) 45.-Bras.

ASTROPANAX, Seem. in Journ. Bot. iii. 176 (1865) Heptapieurum, Gaertn. (Araliac.)

abyssinicum, Seem. 1. c. $177=\mathrm{H}$. abyssinicum.

Baikiei, Seem. l. c. $=$ H. Baikiei.

Barteri, Seem. 1. $\mathrm{c}=\mathrm{H}$. Barteri.

elatum, Seem, $1 . \mathrm{c},=\mathrm{H}$, elatum.

Manni, Seem. 1. c. $=$ H. Mannii

ASTROPETALUM, Griff. Notul. iv. 411. t. 565 (1854) =Swintonia, Griff. (Anacard.

ASTROPHEA, Reichb. Consp. 132 (1828)= Passiflora, Linn.

emarginata, M. Roem. Syn. Pepon. $152=$ P. emar ginata.

glaberrima, Klotzsch, in Schomb. Fauna \& Fl. Guy.

1168, nomen.-Guiana.

glauca, M. Roem. Syn. Pepon. 151= P. arborea

ovata, M. Roem. 1, c. = P. ovata.

ASTROPHIA, Nutt. in Torr. \& Gray, Fl. N. Am. i. 278 (1838)= Lathyrus, Linn. (Legum.)

littoralis, Nutt. 1. c. = L. littoralis.

ASTROPHYLLUM, Torr. \& Gray, in Bot. Pope Exped. (Pacif, Rail. Rep. ii.) 161 (1855), RU. TACEAE, Benth. \& Hook. f. i. 296.

dumosum, Torr. \& Gray, l. c.-Am. bor. occ.

ASTROPHYTUM, Lem. Cact. Gen. Nov, Gen. et Sp. 3 (1839) = Echinocactus, Link \& Otto (Cact.)

Asterias, Lem. Cact. $50=\mathrm{E}$. Asterias.

myriostigma, Lem. Cact. Gen. Nov. et Sp. $4=\mathrm{E}$. myriostigma.

prismaticum, Lem. Cact. $50=$ E. myriostigma.

ASTROPUS, Spreng. Nene Entdeck. iii. 64 (1822)= Waltheria, Linn. (Stercul.)

tomentosus, Spreng. 1. c. =W. Astropus.

ASTROSCHOENUS, Lindl. Veg. Kingd. 119 (1847)= Asteroschoenus, Nees (Cyperac.).

ASTROSTEMmA, Benth. in Hook. Ic. Pl. xiv. 7. t. 1311 (1880). ASCLEPIADEAE. spartioides, Benth. l. c.-Bomeo.

ASTROTRICHA, DC. Coll. Mém. v. 29 t. 5 (1829); Prod. iv. $74(1830)$. ARALIACEAE, Benth. \& Hook. f. i. 937.

asperifolia, F. Muell. ex Klatt, in Linnaca, xxix,

(1858) $709=$ ledifolia

floccosa, $D C$. Coll Mim, v. 30. t. 5-Austral.

Hamptoni, F. Muell. Fragm. vi. 125.-Austral.

hoveoides, A. Cunn. ex Benth. Enum. Pl. Hucget. 55. -Austral.

latifolia, Benth. l. c. 54.-Austral.

\section{ATROTRICHA}

ledifolia, $D C$ Coll Mim v 30, t. 6.-Austral.

linearis, A. Cunn. ex Benth. Enum. Pl. Huegel. 55.Austral.

longifolia, Benth.l.c.-Austral.

pterocarpa, Benth. Fl. Austral. iii. 379.-Anstral.

ASTYDAMIA, DC Coll, Mém, v. 53 (1829 Prod. iv. 190 (1830), UMBELLIFERAE, Benth. \& Hook. f. i. 909

canariensis, DC. Prod. iv. 190.-Ins. Teneriff.

latifolia, Baill. Hist. Pl. vii. $208=$ canariensis

ASTYLIS, Wight, Ic. t. $1992(1853)=$ Hemieyclia Wight \& Arn. (Euphorb.) venusta, Wight, $1 . c_{.}=\mathrm{H}$. venusta.

ASTYLUS, Dulac, F1. Hautes-Pyr. 188 (1867) Hutchinsia, R. Br. (Crucif.) alpinus, Dulac, $1 . \mathrm{c} .=\mathrm{H}$. alpina.

petraea, Dulac, $\mathrm{l}_{\mathrm{c}} \mathrm{c}_{\mathrm{o}}=\mathrm{H}$. petraea

ASTYRIA, Lindl. Veg. Kingd. $364(1847)=$ Astiria Lindl. (Stercul.).

ASYNEUMA, Griseb. \& Schenk, in Wiegm. Archiv xviii. (1852) I. $335=$ Phyteuma, Linn. (Campan. canescens, Griseb. \& Schenk, 1. c. $=$ P. canescens.

ASYST ASIA, Blume, Bijdr. 796 (1826). ACAN THACEAE, Benth \& Hook. f. ii. 1094.

Dicentranthera, T. Anders, in Journ. Linn. Soc vii. (1863) 52

HENFREYA, Lindl. Bot. Reg. (1847) t. 31.

InTRUSARIA, Rafin. Fl. Tellur, iv. 66 (1836

MACKAYA, Jarv. Thes. Cap. i. 8. t. 13 (1859)

Ramusia, E. Mey, in Drege, Zwei Pf. Docum. 215 (1843).

acuminata, Klotasch, in Peters, Reise Mossamb. Bot 201.-Afr. trop.

africana, Hort. Bogor, ex T. Anders. in Fourn. Agri.Hort. Soc. Ind. N. S. j. (1868) 287.-Afr. trop. atroviridis, T. Anders. in fourn. Linn. Soc. ix. (1867 526.-Reg. Himal.

Blumei, Nees, in DC. Prod. xi. $167=$ intrusa

Bojeriana, Nees, 1. c. $166=$ coromandeliana.

calycina, Benth. in Hook. Niger Fl. 478=Strobilanthes Helictus.

capensis, Nees, in Linnaea, xv. (1841) $356=$ coroman deliana.

Charmian, S. Moore, in Fourn. Bot. xviii. (1880) 38.Afr. trop.

chelonoides, Nees, in Wall. Pl. As. Rar. iii. 89.Ind. or.

chinensis, S. Moore, in Fourn. Bot. xiii. (1875) 228.China.

comorensis, Boj. ex Nees, in DC. Prod. xi. $166=$ coromandeliana.

coromandeliana, Nees, in Wall. Pl. As. Rar. iii. 89.Ind. or.; Malaya ; Afr. trop. et austr.

coromandetiana Wight, Ic. t. $1506=$ crispata.

crispata, Benth. in Linnaea, xxiv. (1851) 647.Ind. or.

denticulata, Nees, in Wall. PI. As. Rar. iii. 89 Strobilanthes denticulatus.

floribunda, Klotssch, in Peters, Reise Mossamb. Bob. 200.-Afr. trop.

formosa, Hort. Calc, ex T. Anders, in Journ. AgriHort. Soc. Ind. N. S. i. (1868) $270=$ Rnellia formosa. gangetica, T. Anders, in Thw. Enum. Pl. Zeyl. 235 coromandeliana.

intrusa, Blume, Bijdr. 796.-Malayn

intrusa, Nees, in DC. Prod. xi. $166^{\circ}=$ coromandeliana.

Kunthiana, Nees, in Wall. Pl. As. Rar. iii. 89. Penang.

lanceolata, $T$. Anders, in Gourn. Limn. Soc. ix. (186? 524 - - Burma.

Lawiana, Dals. in Hook. Kew Gourn. iv. (1852) S44.Ind. or.

macrocarpa, Nees, in Wall. Pl. As. Rar, iii. 89.-Reg. Himal.

multiflora, Klotesch, in Peters, Reise Mossamb. Bot 208.-Afr. trop.

mysurensis, T. Anders. in Journ. Linn. Soc ix. (1\$6: $524=$ Lawiana.

Necsiana, Nies, in 11 all. Pl. As. Rar. iii. 89.Ind. or. ; Burma.

nemorum. Nees, 1. c. $90=$ intrusa.

Panichanga, Nees, 1. c. - Strobilanthes Panichanga. 


\section{ASYSTASIA}

Parishii, T. Anders. in Journ. Linn. Soc. ix. (1867) $526=$ Eranthemum Parishii.

pauciflora, Nees, in Wall. Pl. As, Rar. iii. $90=$ Codonacanthus pauciflorus.

plumbaginea, Nees, 1. c. $89=$ coromandeliana

podostachys, Klotzsch, in Peters, Reise Mossamb. Bot. 199.-Afr. trop.

pubescens, Klotzsch, l. c. 202.-Afr, trop.

quarterna, Nees, in DC. Prod. xi. 166.-Afr. trop.

querimbensis, Klotzsch, in Peters, Reise Mossamb, Bot. 204.--Afr. trop.

rostrata, Solms, in Schweinf. F1. Aethiop. $242=$ Schimperi.

scabrida, Klotzsch, in Peters, Reise Mossamb. Bot. 202.-Afr. trop.

scandens, Hook. Bot. Mag. t. 4449.-Afr. trop.

Schimperi, T. Anders. in Fourn. Linn. Soc. vii. (1864) 40, 53 .-Abyss.

subhastata, Klotzsch, in Peters, Reise Mossamb. Bot. 200 - - Afr. trop.

thyrsacanthus, T. Anders. in Journ. Linn. Soc. ix. (1867) $525=$ Eranthemum indicum.

travancorica, Bedd. Ic. Pl. Ind. Or. i. 39.-Ind. or

violacea, Dalz, ex C. B. Clarke, in Hook. f. Fl. Brit. Ind. iv. 494.-Ind. or.

violacea, Dalz. in Hook. Kew Journ. ii. (1850) $139=$ coromandeliana.

Vogeliana, Benth. in Hook. Niger Fl. 479.-Afr. trop.

Welwitschii, S. Moore, in Fourn. Bot. xviii. (1880) 308. t. 213.-Afr. trop

ATACCA, Lem. Jard. Fleur. ii. (1852) t. $186,187=$ seq.

ATACCIA, Presl, Rel. Haenk. $149(1828)=$ Tacea Forst.

aspera, Kunth, Enum. Pl. v. $464=$ T. integrifolia. cristata, Kunth, 1. c. $466=\mathrm{T}$. cristata. integrifolia, Presl, Rel. Haenk. $149=$ T. integrifolia, laevis, Kunth, Enum. PI. v. $466=$ T. laevis. lancaefolia, Kunth, 1. c. $465=$ T. lancaefolia.

ATADINUS, Rafin. Sylva Tellur. 30 (1838)= Rham nus, Linn.

alpinus, Rafin. I. $c_{0}=\mathrm{R}$. alpinus.

ATAENIA, Endl. Gen. Suppl. v. 5 (1850)=ATENIA, Hook. \& Arn. = Carum, Linn. (Umbell.).

ATALANTA, Nutt. Gen. Am. ii. $73(1818)=$ Cleome, Linn. (Cappar.)

serrulata, Nutt. 1. c. = C. serrulata

ATALANTHUS, D. Don, in Edinb. N. Phil. Journ. (Mar. 1829) 311 = Sonchus, Linn. (Compos.). angustifolius, Pomel, Nouv. Mat. Fl. Atl. $8(=$ Zollikoferia angustifolia).-Afr. bor.

arboreus, Sweet, Hort. Brit. ed. II. $273=\mathrm{S}$. arboreus.

Candolleanus, Pomel, Nouv. Mat. Fl. Atl. 8 (=Zolli koferia Candolleana).-Afr. bor

divaricatus, Pomel, 1. c. $7=\mathrm{S}$. divaricatus.

longilobus, Pomel, 1. c. (=Zollikeferia longiloba).Afr. bor.

nudicaulis, Pomel, 1. c.= Launaea nudicaulis.

pinnatus, D. Don, in Edinb. N. Phil. Journ. Mar. 1829) $311=$ S. leptocephalus.

quercifolius, Pomel, 1. c. $8=\mathrm{S}$. quercifolius.

resedifolius, Pomel, 1. c. (=Zollikoferia resedifolia) - Afr. bor.

spinosus, D. Don, in Edinb. N. Phil. Journ. (Mar. 1829) $311=$ Launaea spinosa.

ATALANTIA, Correa, in Ann. Mus. Par. vi. 383 (1805). RUTACEAE, Benth. \& Hook. f. i. 305 Chilocalyx, Turcz. in Bull. Soc. Nat. Mosc. (1863) I. 588.

Helie, M. Roem. Syn. Hesper. 42 (1846)

-Lampetia, M. Roem. 1. c. (1846)

Malnaregam, Adans. Fam. ii. 344 (1763).

Merope, M. Roem. Syn. Hesper. 44 (1846).

Risso A, Am. in Nov. Act. Nat. Cur. xviii. (1836) 324.

Sclerostylis, Blume, Bijdr. 133 (1825).

Severinta, Tenore, Ind. Sem. Hort. Neap. (1840).

bilocularis, Wall. Cat. n. $6356=$ Limonia bilocularis.

buxifolia, Oliver, in Benth. Fl. Hongk. 51.-China.

\section{ATALANTIA :-}

buxifolia, Oliver, in Journ. Linn. Soc. v. Suppl. ii (1861) $26=$ Limonia bilocularis.

capitellata, Lindl. in Wall. Cat. n. $6355=$ racemosa.

carissoides, Wall. 1. c. n. $6354=$ monophylla.

caudata, Hook. f. Fl. Brit. Ind. i. 513.-Reg. Himal.

ceylanica, Oliver, in fourn. Linn. Soc. v. Suppl.ii.

(1861) 25.--Ind, or.

citrifolia, Kurz, in fourn. As, Soc. Beng. xxxix.

(1870) II, 69.-Burma

floribunda, Wight, Ic. iv. t. $1611=$ monophylla.

glanca, Benth. E' Hook. f. Gen. i. 305.-Austral

Hindsi, Oliver, in fourn. Linn. Soc. v. Suppl. ii. (1861) 26.-China.

longispina, Kurz, in Fourn. As. Soc. Beng. xli. (1872) II. 295.-Burma

Loureiriana, M. Roem. Syn. Hesper. 37.-Cochinch. macrophylla, Kurz, in fourn. As. Soc. Beng. xliv. (1875) II. 136. - Ins. Nicobar.

missionis, Oliver, in Fourn. Linn. Soc. v. Suppl. ii. (1861) 25.-Ind. or.

montophylla, Benth. in Hook. Lond. Journ. Bot. i. (1842) $483=$ Hindsii

monophylla, $D C$. Prod. i. 535 .-.Ind. or.

monophylla, Hook. \& Axn. Bot. Beech. Voy. $172=$ buxifolia.

nitida, Oliver, in Fourn. Linn. Soc. v. Suppl. i1. (1861) 25.-Malaya.

parvifolia, M. Roem. Syn. Hesper. $37=$ racemosa.

platystigma, Wight, Illustr. Ind. Bot. i. $108=$ monophylla.

puberula, Miq. Ann. Mus. Bot. Lugd. Bat. i. 211.Siam.

racemosa, Wight \& Arn. Prod. 91; et in Hook. Fourn. Bot. i. (1834) 64.-Ind. or.

recurva, Benth. Fl. Austral. i. 370.-Austral.

Roxburghiana, Hook. f. Fl. Brit. Ind. i. 513.-Malaya Roxburghii, Oliver, in Journ. Linn. Soc. v. Suppl. il 25 = caudata.

trimera, Oliver, l. c.-Malaya

umbellata, M. Roem. Syn. Hesper. $37=$ monophylla.

ATALAYA, Blume, Rumphia, iii. 186 (1847). SAPIN$D A C E A E$, Benth. \& Hook. f. i. 401.

annularis, Blume, Rumphia, iii. 186.-Malaya.

australis, Radlk. in Sitzb. Math.-Phys. Acad, Muench. viii. (1878) $327=$ Sapindus australis.

bijuga, Span. Ic. n. 19; in Linnaea, xv. (1841) $180=$ Cupania salicifolia.

cochinchinensis, Blume, Rumphia, iii. 186.-Cochinch coriacea, Radlk. in Sitgb. Math.-Phys. Acad. Muench viii. (1878) 326--Ins. Dom. Howe.

hemiglauca, F. Muell. ex Benth. Fl. Austral. i. 463.Austral.

multiflora, Benth. l. c.-Austral

salicifolia, Blume, Rumphia, iii. 186.-Timor.; Anstral. variifolia, F. Muell. ex Benth. Fl. Austral. i. 463.Austral.

ATAMASCO, Rafin. Neogenyt. 3 (1825)=Amaryllis, Linn.

ATAMISQUEA, Miers, Trav. Chili, ii. 529 (1826). CAPPARIDEAE, Benth. \& Hook. f. i. 109. emarginata, Miers, l. c.-Chili.

ATAMOSCO, Adans. Fam. ii. 57=Amaryllis, Linn.

ATAMOSKO, Adans. Fam. ii. 523=praec.

ATASITES, Neck. Elem. i. $7(1790)=$ Gerbera, Gronov. (Compos.).

ATAXIA, R. Br. Chlor. Melv, in App. Parry, Voy, 292 $(1824)=$ Hierochloë, S. G. Gmel. (Gramin.).

Ecklonis, Nees, ex Trin. in Mém. Acad. Pétersb.v (1840) $77=$ H. Ecklonii.

Hookeri, Griseb. in Goett. Nachr. (1868) 77.-Ind. or. Horsfieldii, Kunth, Gram, i. 22; R. Br, in Benn. Pl. Jav. Rar. 8. t. 3.-Java.

mexicana, Rupr. in Bull. Acad. Brux, ix. (1842) $233=$ H. mexicana.

tenuis, Trin. in Mém. Acad. Pétersb. v. (1840) 78. - Afr, austr.

Tongo, Nees, ex Trin. 1. c. $=$ H. Tongo.

ATE, Lindl. Gen. et Sp. Orch. $326(1835)=$ Habenaria, Willd. (Orchid.).

acuminata. Thw. Enum. Pl. Zeyl. $309=$ H. acuminata. virens, Lindl. Gen, et Sp. Orch. $327=$ H. barbata.
ATECOSA, Rafin. Fl. Tellur. iii. $46(\mathbf{1 8 3 6})=$ Rumex Linn. (Polygon.)

ATELANDRA, Bello, in Anal. Soc. Esp. Hist. Nat. x. (1881) 289. t. 10. MYRSINEAE.

laurina, Bello, l. c.-Porto Rico.

obtusifolia, Bello, l. c.-Porto Rico.

ATELANDRA, Lindl. Swan Riv. App. 40. t. 5 (1839) $=$ Hemigenia, R. Br. (Labiat.).

incana, Lindl. 1. c. $=\mathrm{H}$. incana.

polystachya, Lindl. 1. c. $40=\mathrm{H}$. incana.

ATELEA, A. Rich. P1. Vasc. Cub. $454(1845)=$ Ateleia Moç. \& Sessé (Legumin.).

ATELANTHERA, Hook. f. \& Thoms, in Journ. Linn. Soc. v. (1861) 129. CRUCIFERAE, Benth. \& Hook. f. i. 68.

perpusilla, Hook.f. E Thoms. l. c. 138.-Tibet, occ.

ATELEIA, Moç. \& Sessé, ex DC. Mém. Lég. 395. t. 57 (1825). LEGUMINOSAE, Benth. \& Hook. f. i. 558. apetala, Griseb. Cat. Pl. Cub. 80.-Cuba.

cubensis, Griseb. in Mem. Am. Acad. N. S. viii. (1861) 180.-Cuba.

Glazioveana, Baill. in Bull. Soc. Linn. Par. i. (1881) 306.-Bras.

gummitera, D. Dietr. Syn. Pl. iv. 1219.-Ins. S. Doming.

microcarpa, $D$. Dietr. $l$. c.-Am. austr.

peltaria, $D$. Dietr. $l . c$.-Afr. austr.

pterocarpa, Moc. Eo Sessé, ex DC. Lég. Mém. 394.Mexic.

ATELESTE, Sond. in Linnaea, xxiii. (1850) 9, 10 = Aberia, Hochst. (Bixin.

tristis, Sond. 1. c. $9=$ Aberia tristis

Zeyheri, Sond. 1. c. $10=$ Aberia Zeyheri.

ATELIANTHUS, Nutt. ex Benth. in DC. Prod. $x .455$, in nota $(1846)=$ Synthyris, Benth. (Scrophul.).

veronicoides, Nutt. ex Benth. 1. c. $=$ S. plantaginea.

ATENIA, Hook. \& Arn. Bot. Beech. Voy. 349 (1840)= Carum, Linn. (Uimbell.).

Gairdneri, Hook. \& Am. 1. c. = C. Gairdneri.

ATERAMNUS, P. Br. Hist. Jamaic. 339 (1756); "nom delend.' Benth. \& Hook. f. Gen. iii. 256.

ATHALMUS, Neck. Elem. i. $20 \quad(1790)=$ Pallenis, Cass. (Compos.).

ATHAMANTA, Linn. Syst. ed. I (1735), UMBEL IIFERAE, Benth, \& Hook. f i. 900.

Killinga, Adans. Fam. ii. 498 (1763)

Libanotis, Hall, Enum. Stirp. Helv. ii. 450 (1742). Petro-Carvi, Tausch, in Flora, xvii. (1834) 355.

Tribula, Hill, Veg. Syst. vi. 10 (1764)

TURBITH, Tausch, in Flora, xvii. (1834) 343. achilleifolia, Wall. Cat. n. $568=$ Pimpinella achilleifolia.

Ajowan, Wall. Cat. n. 572 = Carum copticum.

alato, Bieb. F1. Taur. Cauc. i. 214=Ligusticum alatum.

alpina, Stokes, Bot. Mat. Med. ii. $79=$ cretensis. ambigua, Retz. Obs. iii. 28.-Hab.?

anethifolia, Wall. Cat. n. $569=$ Carum anethifolium. annua, Linn. Sp. Pl. $245=$ cretensis.

arctica, Nym. Syll. 155.--Europ.

aurea, Vis. ex Reichb. Ic. Fl. Germ. xxi. t. 1935.Europ.

canescens, DC. Prod. iv. 155 (certe non Ath. sp. ex Boiss. Fl. Orient ii. 971) - Oriens.

capensis, Burm. f. Fl. Cap. Prod. $7=$ Ligusticum capense.

capillacea, Lam. Encyc. i. $325=$ cretensis,

caruifolia, [Web. in] Wigg. Prim. F1. Hols. $27=$ Selinum Carvifolia.

carvifolia, Steph. ex Roem. E Schult. Syst. vi. 496.Rossia.

carvifolia, Willd. ex Ledeb. F1. Ross. ii. $272=$ Seseli Hippomarathrum.

carvifolia, Willd. ex Ledeb. I. c. 314=Peucedanum baikalense.

caucasica, Hort. Par. ex Fisch. \& Mey. Ind. Sem. Hort. Petrop. iii. $39=$ Seseli athamantoides. 
ATHANANTA :

Cervaria, Linn, Syst, ed. X. $956=$ Peucedannm Cervaria.

cervariaefolia, DC. Prod. iv. 155.-Ins. Teneriff

cervariaefolia, Schrad. ex Spreng. Pugill, ii. $56=$ Seseli buchtormensis.

cervariaefolia, Viv. ex Steud. Nom, ed. II. i. $166=$ Lecokia cretica.

chiliosciadia, Boiss. E Heldr. Diagn. Ser. II. ii. 86.Graecia.

chinensis, I.inn. Sp. Pl. $245=$ Selinum Monnieri.

coarctata, Ag. ex Nym. Consp. $296=$ Seseli granatense

collina, Salisb. Prod. $163=$ Seseli Libanotis.

compacta, Ledeb. Fl. Alt. i. $327=$ Schultzia compacta.

condensata, Linn. Sp. Pl. $1195=$ Seseli condensatum.

condensata, Pall. ex Steud. Nom. ed. II. i. 166= Pallasiana.

cretensis, Linn. Sp. Pl. 245.-Europ, austr

cretensis, Schrank, Baier. Fl. i. 545= Matthioli

cretensis, Ucria, Hort. Panorm. $127=$ sicula.

crinita, Ledeb. F1. Alt. i. $326=$ Schultzia crinita.

crithmifolia, Juss. ex DC. Prod. iv, 145 = Seseli gummiferum.

crithmoides, Lapeyr. Hist. Abr. Pl. Pyr. $148=$ Seseli Monnieri.

daucifolia, Host, Fl. Anstr. 1. $362=$ Seseli Monnieri. daucoides, J. F. Gmel. Syst. $477=$ Seseli Libanotis.

decussata, Gilib. 11. Lituan. it. $18=$ Peucedanum Cervaria.

densa, Boiss. E Orph. Diagn. Ser. II. v. 98.Graecia.

denudata, Fisch. ex Hornem. Hort. Hafn. Suppl. 32 (=Cenolophium Fischeri).-Rossia.

depressa, D. Don, Prod. Fl. Nep. $184=$ Cortia Lindleyi.

diffusa, Wall. Cat. n. $570=$ Seseli indicum.

divaricata, Gilib. F1. Lituan. ii. $\mathbf{1 7}=$ Peucedanum Oreoselinum.

divaricifolia, Stokes, Bot. Mat. Med. ii. $78=$ praec

flavescens, Vis. Orto Bot. Padov. (1842) $135=$ Portenschlagia ramosissima.

flexuosa, Juss. ex DC. Prod. iv. $179=$ Peucedanum palustre.

Galatta, Gmel. ex DC. Prod. iv. $230=$ Pleurospermum Golaka.

Golaka, Hacq. PI. Carn. t. $5=$ Pleurospermum Golaka. gigantea, D. Don, Prod. Fl. Nep. 184 (Sp.dubia). Nepal.

Haynaldi, Borb. \& Uechtr. in Termész. Füzetek, i. 1877) 30.t, 6, $7=$ Matthioli.

hungarica, Borb. ex Nym. Consp. 294= Matthioli.

incana, Steph. ex Willd. Sp. Pl. i. $1402=$ Seseli graveolens.

lasiantha, Willd. ex Roem. \& Schult. Syst. vi. $494=$ Pimpinella villosa.

lateriflora, Eckl. E Zeyh. Enum. 348.-Afr. austr.

latifolia, Viv. F1. Ital. $22=$ Peucedanum Cervaria

leucospermum, Poir. Encyc. Suppl. i. $532=$ Seseli leucospermum.

Libanotis, Linn. Sp. P1. $244=$ Seseli Libanotis

lucida, Retr. Obs, ii. 29.-Hab?

macedonica, Spreng. in Roem. E Schult. Syst. vi. 491 - Graecia; Afr. bor.

Mathioli, DC. Fl. Fr. iv, $318=$ cretensis

Mathioli, Wuelf. in Facq. Coll. i. 211.-Eur. austr. or maxima, Choisy, in DC. Prod. iv. $155=$ cervariaefolia media, Nym. Syll. 154.-Europ.

Meum, Linn. Sp. Pl. $245=$ Meum athamanticum

Moum, Pall. Reise, ii. $28=$ Schultzia crinita.

monstrosa, Steph. ex Roem. \& Schult. Syst. Veg. vi. $495=$ Schultzia compacta.

multiflora, Sibth. \& Sm. Fl. Graec. iii. 69. t. $276=$ Carum multiforum.

mutellinoides, Lam. Encyc. i. $325=$ cretensis,

Oreoselinum, Huds, Fl. Angl, $115=$ Seseli Libanotis.

Oreoselinum, Linn. Sp. Pl. $244=$ Peucedanum Oreose linum.

Pallasiana, Vest, ex Steud. Nom. ed. II, i. 166.Sibiria.

panacifolia, Spreng. Sp. Umb. $140=$ Magydaris panacina, tomentosa.

pisana, Savi, in Ust. Ann. Bot. xxi. 7 =Peucedanum palustre.

pubescens, Retz. Obs. iii. $28=$ Seseli Libanotis

pyrenaica, Jacq. Hort. Vindob. ii. $99=$ Seseli Monnicri.

ramosissima, Link \& Hoffmgg. F1. Port. 405. t. 106=

Seseli tortuosum.

\section{ATHAMANTA}

rmosissima, Portschl. in Roem. \& Schult. Syst. yi $496=$ Portenschlagia ramosissima

Reichenbachii, Nym. Syll. 154.-Europ.

rigida, Hornem. Hort. Hafn, $960=$ Seseli buchtor mensis.

rigida, Roth, Enum. Pl. Phan. Germ. i. 907.Europ.

Riviniana, Host, ex Stend. Nom. ed. II. i. $166=$ Seseli Libanotis.

Roxburghiana, Wall. Cat. n. $571=$ Carum Rox burghianum

rupestris, Reichb. F1. Germ. Excurs. $470=$ Matthioli.

rupestris, Vill. Hist. Pl. Dauph. ii. $648=$ cretensis.

scabra, Burm. f. Prod. Fl. Cap.7.-Afr. austr.

sibirica, Linn. Sp. Pl. $244=$ Seseli sibiricum.

sicula, Linn. l. c.-Ital.; Afr. bor.

sicula, Ucria, Hort. Panor. $137=$ Kundmannia sicula

stricta, Ledeb. ex Steud. Nom. ed. II. i. 166.-

Sibiria.

sylvestris, [Web. in] Wigg. Prim. Fl. Hols. $26=$

Angelica sylvestris.

tenuifolia, Pall. ex Roem. \& Schult. .Syst. vi. $495=$ Seseli tenuifolium.

tenuifolia, Willd, ex Spreng, in Roem. \& Schult. 1. c. $=$ Peucedanum. salinum.

teres, D. Don, Prod. Fl. Nep. 185 (Sp. dub.).Nepal.

tortuosa, Spreng. Syst. i. 900 (=Deverra tortuosa).A egypt.

Turbith, Brot. Phytog. Lusit. 200, t, $169=$ Seseli tortuosum.

verticillata, Portschl. Enum. Pl. Dalm. 14. t. $4=$ Portenschlagia ramosissima.

verticillata, Sibth. \& Sm. Fl. Graec. iii. 68. t. $275=$ Carum graecum.

ATHAMUS, Neck. Elem. i. 85 (1790)=Carlina, Linn. (Compos.)

ATHANASIA, Linn. Sp. P1, ed. II, 1180 (1762) COMPOSITAE, Benth. \& Hook. f. ii. 416.

Bembycodium, Kunze, in Linnaea, xvi. (1842) 316.

Holophyllum, Less. Syn. Comp. 262 (1833).

Hymenolepis, Cass. in Bull. Soc. Philom. (1817) 138; et in Dict. Sc. Nat, xxii. 315 (1821).

Metagnanthus, Endl. Gen. 438 (1838).

Morysia, Cass, in Dict. Sc. Nat, xxxiii. 59 (1824).

Pristocarpha, E. Mey. ex DC. Prod. vi. 86 (1837).

Saintmorysia, Endl. Gen. 438 (1838)

acerosa, D. Dietr. Syn. Pl. iv. 1401.-Afr. austr. annua, Linn. Sp. Pl. ed. II. $1182=$ Lonas inodora aspera, Thunb. Prod. Pl. Cap. 145.-Afr. austr.

canescens, Thunb. l. c. 144.-Afr. austr.

capitata, Berg. Desc. Pl. Cap. $237=$ scabra.

capitata, Linn. Pl. Rar. Afr. n. 50; Amoen. Acad. vi. 97.-Afr. austr.

cinerea, Linn. f. Suppl. $361=$ tomentosa

coronopifolia, Harv. in Harv. E Sond. Fl. Cap. iii. 191.-Natal.

crenata, Linn. Sp. Pl. 1180 -Afr, austr

crithmifolia, Linn. l. c. 1181.-Afr. austr

cuneifolia, Lam. Encyc. i. 327.-Afr, austr.

cuneiformis, DC. Prod. vi. 89.-Afr. austr.

cupressiformis, Comm. ex DC. Prod. $\vee .314=$ Lepidophyllum cupressiforme.

dentata, Linn. Sp. Pl. ed. II. 1181.-Afr. austr.

dentata, Linn. f. Suppl. 361 = serrata.

dimorpha, DC. Prod. vi. 87.-Afr. austr.

Dregeana, Harv. in Harv. Eo Sond. Fl. Cap. iii. 191.Afr. austr.

ebracteata, E. Mey. ex DC. Prod. vi. 87.-Afr. austr. eriopoda, $D C$. $l$. c. 89.-Afr. austr.

fasciculata, D. Dietr. Syn. Pl. iv, 1401.-Afr. austr. filiformis, Linn. $f$. Suppl. 361.-Afr. austr.

fabellifera, Salisb. Prod. $189=$ Pentzia fabelli formis.

flexuosa, E. Mey, ex DC. Prod, vi, $91=$ microcephala.

fexuosa, Thunb. Prod. Pl. Cap. 144-Afr, austr.

genistaefolia, Linn. Mant. $464=$ Kelhania genistacfolia.

glabra, Thunb. Prod. PI. Cap. $144=$ capitata, microphylla.

glabrescens, DC. Prod. vi. 88.-Afr. ณustr.

\section{ATHANASIA:-}

glutinosa, E. Mey, ex DC. Prod. yi. $288=$ Relhania genistaefolia.

graminifolia, Walt. Fl. Carol, $200=$ Marshallia angustifolia.

hastata, Walt. 1. c. $201=$ Melanthera hastata.

hirsuta, Thunb. Prod. Pl. Cap. 144.-Afr. austr.

imbricata, Harv, in Harv. Eo" Sond. Fl. Cap, iii. 196Afr. austr.

incisa, Harv. l. c. 190,-Afr. austr.

indica, Roxb. Hort. Beng. 61; FI. Ind. iii. 417

Goniocaulon glabrum.

indivisa, Harv. in Harv. oै Sond. Fl. Cap. iii. 190.Afr. austr.

juncea, D. Dictr. Syn. $\mathrm{Pl}$.iv, 1401.-Afr. austr.

laevigata, Linn. Pl. Afr. В. 50; Amoen. Acad. $51=$ aspera.

lanuginosa, Cav. Ic. i. $2=$ canescens.

leucoclada, Harv. in Harv. E Sond. Fl. Cap. iii. 191. -Afr. austr.

linifolia, Harw 6 . 198 -Afr anstr.

linifolia, Burm. f. F1. Cap. P'rod. $23=$ longifolin

longifolia, Lam. Encyc. i. 326.-Afr. austr.

maritima, Linn. Sp. PI. ed. II. $1182=$ Dirsti maritima.

microcephala, D. Dietr. Syn. Pl. iv. $1401=$ linifolia. microphylla, DC Prod vi. 87-Afr, austr.

Mundtii, Harv. in Harv. EN Sond. Fi. Cap. iii. 196 Afr. austr.

obovata, Walt. Fl. Carol. 201 = Marshallia lanceolata pachycephala, $D C$. Prod. vi. 88.-Afr. austr. palmatifida, $D C$. l. c. 89 -Afr. austr. alba.

parvifiora, Ait. Hort. Kewv. iii. 167.-Afr. austr.

parviflora, Thunb. Prod. Pl. Cap. 145.-Afr. austr. pauciflora, D. Dietr. Syn. Pl. iv. 1401.-Afr. austr. pectinata, Linn.f. Suppl. 361.-Afr. austr.

pinnata, E. Mey, ex DC. Prod. vi. $85=$ incisa.

pinnata, Linn.f. Suppl. 361.-Afr, austr.

pubescens, Linn.Sp.Pl. ed. II. 1182.-Afr. austr.

pubescens, Thunb. Prod. Pl. Cap. 14t=ragulosa. pumila, Linn. f. Suppl. $362=$ Relhania pedunculata. punctata, Berg. Desc. Pl. Cap. 238 = capitata.

punctata, Harv. in Harv. E Sond. Fl. Cap. iii. 190. Afr, austr.

punctata, Thunb. Prod. Pl. Cap. $144=$ capitata.

quinquedentata, Thunb. Prod. Pl. Cap. 145.-Afr. austr.

recurvifolia, Salisb. Prod, $189=$ dentata.

rotundifolia, $D C$. Prod. vi. 87.-Aír. austr.

rugulosa, $E$. Mey. ex $D C$. . c c-Afr. austr.

salicifolia, Dietr. ex Sterd. Nom. ed. I. 91.-A r. austr.

scabra, Thunb. Prod. Pl. Cap. 144-Afr. austr.

scariosa, DC. Prod. vi. 88.-Afr. austr.

schizolepis, Harv. in Harv. E Sond. F\%. Cap. iii. 19

-Afr. austr.

serrata, Vitm. Summa Veg. iv. 487.-Afr. austr.

sertulifera, $D C$. Prod. vi. 87.-Afr. austr.

sessiliflora, Linn. f. Suppl. $362=$ Relhania sessiliflora spathulata, D. Dietr. Syn. Pl. iv. 1401.-Afr. ausu. squarrosa Linn. Pl. Rar. Afr. D. 52; Amoen. Acad. " $98=$ Relhania squarrosa.

tanacetifolia, Roth, Catalecta, ii. 104-Afr. austr.

tomentosa, Thunb. Prod. Pl. Cap. 114.-Afr. austr.

tricuspis, Poir. Encyc. Suppl. i. $533=$ trifureala.

tridentata. Salisb. Prod. 18:1 = trifurcata.

trifurcata, Linn. Sp. Pl, ed. 11. 1181.-Afr. austr.

trinervio, Walt. Fl, Carol, 201 = Marshallia latifols

unifora, Linn. f. Suppl. 36? = Relhania cuneata.

velutina, $D$. Dietr. Syn. Pl. iv. 1401.-Afr. austr.

virgata, Facq. Hort. Schoenb. ii. 11. to 148.-A sustr.

ATHECIA, Gacrta. Fruct. i. $1 \notin 1(1 ; s)^{\prime}=$ Forstera Linn. f. ? (Stylid.).

glabra, Gacrta. l. c. $=F$. sedifolia ?

ATILNAEA, Adans. Farn. ii. 121 (1763)-8pargano phorus, Vaill. (Compos.).

ATIII:ALA. Schreb Gen, 259 (1780) Casearia Jacq. (Samyd.).

ATIENAEA. Sendt. in Mart. Fl. Rras. x. 193 15 fi

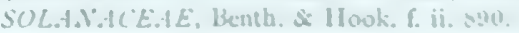




\section{ATHENAEA :-}

LARNAX, Miers, in Ann. \& Mag. Nat. Hist. Ser. II. iv. (1849) 37 .

Witheringia, Miers, 1. c. iii. (1849) 145. anonacea, Sendt. in Mart. Fl. Bras. x. 137. t. 18.-Bras. hirsuta, Sendt. l. c. 137.-Bras.

Martiana, Sendt. l. c. 136.-Bras.

micrantha, Sendt. l. c. 135.-Bras.

picta, Sendt. l. c. 134.-Bras.

pogogena, Sendt. l. c. 135.-Bras.

Pohliana, Sendt. l. c. 136.-Bras.

Schottiana, Sendt.l. c. 135.-Bras.

xalapensis, Hemsl. Biol. Centr. Am. Bot。 ii. 4iz2.Mexic.

A THenanthia, Kunth, in Mém. Mus. Par. ii. (1815) 71 = Anthaenantia, Beauv. (Gramin.).

ATHEOLAENA, Reichb. Consp. 106 (1828) = AETHEOLAENA, Cass. = Senecio, Linn. (Compos.).

ATHERANDRA, Decne. in DC. Prod. viii。 497 (1844). ASCLEPIADEAE, Benth. \& Hook. fo ii. 743 . acuminata, Decne. l.c.-Java.

acutifolia, Decne. l. c.-Malaya.

cuspidata, Blume, Mus. Bot. Lugd. Bat. i. $147=$ acutifolia.

pubescens, Blume, $1 . \mathrm{c}_{ }=$acutifolia.

Wallichii, Benth. \& Hook. f. Gen, ii. $744=$ Atherolepsis Wallichii.

ATHERANTHERA, Mast. in Oliver, Fl. Trop. Afr. ii. 519 (1871); Trans, Linn. Soc, xxvii. (1871) 640. PASSIFLOREAE

paniculata, Mast. in Oliver, Fl. Trop. Afruiti. 519.Afr. trop.

Welwitschii, Mast. in Trans, Linn. Soc. xxvii. (1871) $640=$ paniculata.

ATHERNOTUS, Dulac, Fl. Hautes-Pyr. $74(1867)=$ Calamagrostis, Adans. (Gramin.).

epigeios, Dulac, $1 . \mathrm{c} .=$ C. epigeios.

lanceolatus, Dulac, 1 . c. $75=\mathrm{C}$. lanceolatus.

pyramidalis, Dulac, l. $\mathrm{c}=$ Deyeuxia sylvatica.

ATHEROCEPHALA, DC. Prod. vii. 755 (1839)= Andersonia, R. Br. (Epacrid.).

Drummondii, DC. 1. c. = Andersonia aristata.

ATHEROLEPSIS, Hook. f. in Hook. Ic. Pl, xv, 26. t. 1433 (1883). ASCLEPIADEAE.

Wallichii, Hook. f. l. c. - Burma.

ATHEROPHORA, Willd. ex Steud. Nom. ed. II. i. 167 $(\mathbf{1 8 4 0})=$ Aegopogon, Humb, \& Bonpl. (Gramin.). secund $a$, Willd. 1. c. = Aegopogon geminiflorus.

ATHEROPOGON, Muhl. ex Willd. Sp. Pl. iv. 937 $(1805)=$ Bouteloua, Lag. (Gramin.).

acuminatus, Fourn. Mex. Pl. En. Gram. 139; ex Hemsl. Biol, Centr. Am. Bot. iii. 564.-Mexic. affinis, Fourn. ex Benth. \& Hook. f. Gen, iii, $1169=$ B. disticha?

americanus, Fourn. Mex. Pl. En. Gram. 140; ex Hemsl. Biol. Centr. Am. Bot. iii. $561=$ B. bromoides Antillarum, Spreng. Syst. i. $294=$ Aristida Antillarum apludoides, Willd. Sp. Pl. iv. $937=$ B. racemosa aristidoides, Koem. \& Schult. Syst. ii. $415=\mathrm{B}$, aristidoides.

bromoides, Roem. \& Schult. 1, c. = B. bromoides. chondrosioides, Roem. \& Schult. I. c. $416=$ B. ovata curtipendulus, Fourn. Mex. Pl. En. Gram. 138; ex Hemsl. Biol. Centr. Am. Bot. iii. $563=$ B. racemosa.

distichus, Spreng. Syst. i. $294=$ B. disticha

domingensis, Spreng. 1. c. 293 (=Eutriana juncea) -Ins. S. Doming.

filiformis, Fourn. Mex. Pl. En. Gram. 140; ex Hemsl.

Biol. Centr. Am. Bot. iii. 564.--Mexic

gracilis, Spreng. Syst. i. $293=$ B. oligostachya

hirtus, Spreng. 1. c. $=\mathrm{B}$. hirsuta.

humilis, Spreng. 1. $\mathrm{c}_{0}=\mathrm{B}$. prostrata.

juncifolius, Spreng. 1. c. $294=$ B. juncifolia.

medius, Fourn. Mex. Pl. En. Gram. 139; ex Hemsl.

Biol. Centr. Am. Bot, iii. 564.--Mexic.

oligostachyus, Nutt. Gen. Am. i, 78=B. oligostachya.

\section{ATHEROPOGON :-}

Pentarhaphis, Spreng. Syst. i. 294 (=Eutriana Pentarrhaphis).-Mexic.

polymorphus, Fourn. Mex. Pl. En. Gram. 141; ex Hemsl, Biol. Centr. Am. Bot. iii. 564.-Mexic. procumbens, Jacq. Eclog. Gram, $12=$ B. tennis. radicosus, Fourn. Mex, Pl. En. Gram. 140; ex Hemsl. Biol. Centr. Am. Bot. iii. $561=$ B. bromoides. repens, Roem. \& Schult. Syst. ii. $416=$ B. bromoides. scorpioides, Spreng. Syst. i. $293=$ B. scorpioides. stolonifer, Fourn. Mex. Pl. En. Gram. 140; ex Hemsl. Biol. Centr. Am. Bot. iii. 565.-Mexic.

Triaena, Spreng. Syst. i. $293=$ B. Triathera.

villosus, Steud. Nom. ed. II. i. 167 (=Eutriana villosa),-Bras.

ATHEROSPERMA, Labill. Nov. Holl, Pl. ii. 74. t. 224 (1806). MONIMIACEAE, Benth. \& Hook. I iii. 144 .

integrifolium, A. Cunn. ex A. DC. in DC. Prod. xvi II. $676=$ mos st atum.

micranthum, Tul. in Ann. Sc. Nat. Sér. IV. iii. (1855) $46=$ Daphnandra micrantha.

moschatum, Labill. Nov. Holl. Pl. ii. 74. t. 224. -Austral.

Novae-Zelandiae, Hook. f. Handb. New Zeal. Fl. 240. $-\mathrm{N}$. Zel.

repandulum, F. Muell. Fragm. x. 105.-Austral.

Sassafras, A. Cunn. ex A. DC, in DC. Prod, xvi. II. $676=$ Doryphora Sassafras.

sempervirens, Baill. Adansonia, ix. (1868) 116 ; Hist. Pl. i. 322.-Chili.

ATHEROSTEMON, Blume, Mus. Bot. Lugd. Bat. i. 126 (1849). ASCLEPIADEAE.

javensis, Blume, l. c.-Burma; Java.

ATHERSTONEA, Pappe, Sylva Cap. ed. II. 29 (1862) $=$ Strychnos, Linn. $($ Logan.$)$.

decussata, Pappe, 1. c. = S. Atherstonei.

ATHERURUS, Blume, Rumphia, i, 136 (1835)= Pinella, Tenore (Aroid.)

ternatus, Blume, $\mathrm{l}_{0} \mathrm{c}_{\mathrm{c}}=\mathrm{P}$. tuberifera.

tripartitus, Blume, 1. c, $137=\mathrm{P}$, tripartita.

ATHESIANDRA, Miers, ex Benth. \& Hook. f. Gen. i. $346(1862)=$ Ptychopetalum, Benth. (Olacin.) anceps, Miers, ex Oliver, Fl. Trop. Afr. i. $348=\mathrm{P}$. anceps.

ATHLIANTHUS, Endl. Gen. Suppl, ii. $63(1842)=$ Justicia, Linn. (Acanth.).

spiciflorus, Heynh. Nom. ii, 54,-Afr, trop.

ATHRIXIA, Ker-Gawl, in Bot. Reg. t. 681 (1823) COMPOSITAE, Benth. \& Hook. f. ii. 328.

AsteridiA, Lindl. Swan Riv. App. 24 (1839).

Chrysodiscus, Steetz, in Lehm. Pl. Preiss, i. 460 (1845)

KLENZEA, Sch. Bip. ex Steud. Nom. ed. II. i. 847 (1840) ; et in Walp. Rep. ii. 973 (1843), partim.

Trichostegia, Turcz. in Bull. Soc. Nat. Mosc. xxiv.

(1851) II. 81.

angustissima, $D C$. Prod. vi. 277.-Afr. austr.

australis, Steetz, in Lehm. Pl. Preiss. i. 482.-Austral. capensis, Ker-Gawt. in Bot. Reg. to 681.--Afr. austr. Chatopodo, F. Muell. Fragm. x. 56.-Austral.

debilis, DC. Prod. vi. 276,-Madag.

elata, Sond. in Linnaea, xxiii. (1850) 67.-Afr. austr. ericaefolia, DC. Prod. vi. 277.-Arabia.

fontana, Mac Owan, in fourn. Linn. Soc. xviii, (1881) 391, -Afr. austr.

Gerrardi, Harv. in Harv. E Sond. Fl. Cap, iii. 292.Afr, austr.

glandulosa, Kunth, Ind. Sem. Hort. Bexol. (1848) 15. -Afr. austr.

gracilis, Benth. Fl, Austral, iii. 599,-Austral.

heterophylla, Less. Syn. Comp. 365.-Afr, austr.

multiceps, Benth. Fl. Austral. iii. 599.-Austral.

phylicoides, $D C$. Prod. vi. 277.-Afr. austr.

rosmarinifolia, Oliver \& Hiern, in Oliver, Fl, Trop.

Afr, iit. 355,-Afr. trop.

sessilifolia, $D C$. Prod, vi. 277.-Afr. austr.

stricta, Benth. Fl. Austral. iii. 600.-Austral

tenella, Benth. l. c.-Austral.

tomentosa, Less. Syn. Comp. $364=$ Pterothrix tomentosa.
ATHRODACTYLIS, Forst. Char. Gen, 149 (1776) = Pandanus, Linn.

spinosa, Forst. 1. c. $150=$ P, odoratissimus.

ATHRoIsmA, DC, in Guill. Arch. Bot. ii. (1833 516. COMPOSITAE, Benth. \& Hook. f. ii. 296.

laciniatum, $D C$. l. c. 517.-Ind. or.

viscida, Zoll. \& Mor. in Nat. en Geneesk. Arch. Nerl. Indie, ii, (1845) 232 = laciniatum.

ATHROISMA, Griff. Notul. iv. $477(1854)=$ Trigo nostemon, Blume (Euphorb.).

dentatum, Griff. 1. c. $478=\mathrm{T}$. longifolius.

serratum, Griff. 1. c. $477=\mathrm{T}$. heteranthus.

ATHRONIA, Neck. Elem. i. 32 (1790)=Spilanthes Jacq. (Compos.).

ATHROOSTACHYS, Benth. ex Benth. \& Hook. f. Gen. iii. 1208 (1883). GRAMINEAE, Benth. \& Hook. f, iii, 1208.

capitata, Benth. l.c. 1209.-Bras.

ATHROTAXIS, D. Don, in Trans. Linn. Soc. xviii. (1839) 171.t, 13, 14. CONIFERAE, Benth. \& Hook. f. iii. 430 .

Arthrotaxis, Endl. Gen. Suppl. i. 1372 (1841). alpina, Van Houtte, ex Gord. Pinet. $31=$ selaginoides. araucarioides, Brongn. ex Parl. in DC. Prod xvi. $496=$ Dacrydium araucarioides.

cupressoides, D. Don, in Trans. Linn. Soc. xviii. (1839) 173. t. 13. - Tasmania.

Doniana, Henk. \& Hochst. Nadelh. $221=$ laxifolia.

Gunneana, Hook. ex Carr, Conif. ed. II. 207.-Tasmania,

imbricata, Hort. ex Carr. 1. c. $204=$ selaginoides.

imbricata, Maule, ex Gord. Pinet. Suppl. $16=$ cupres sioides.

Foucadan, Hort. ex Carr. Conif. ed. II. $55=$ Juniperns gracilis.

laxifolia Hook, Ic, Pl t. 573,-Tasmania.

selaginoides, - D. Don, in Trans, Linn, Soc. xviii. (1839) 172. t. 14.-Tasmania.

tetragona, Hook. Ic. Pl. t. $560=$ Microcachrys tetragona.

ATHRUPHYLLUM, Lour. Fl, Cochinch, $120(1790)=$ Myrsine, Linn.

lineare, Lour. 1. c. = M. Athruphyllum.

ATHYMALUS, Neck. Elem. ii. $353 \quad(1790)=$ Eu phorbia, Linn.

ATHYROCARPUS, Schlecht. in Linnaea, xxvi (1853-55) 454. COMMELINACEAE, Benth. \& Hook, f. iii. 847

Phaeosphaerion, Hassk, in Flora, (1866) 212

leiocarpus, Benth. \& Hook. f. ex Hemsl. Biol. Centr Am. Bot. iii, 386,-Mexic

pallidus, Hassk. ex C. B. Clarke, in DC. Monog. Phan. iii. $151=$ Commelina pallida

pallidus, Schlecht, in Linnaea, xxvi. (1853-55) 454.Am. trop.

persicariaefolius, Hemsl. Biol. Centr. Am. Bot. iii. 386.-Panama

ATHVRUS, Neck. Elem. iii. $39(1790)=$ Iathyrus, Linn. (Legumin.)

ATHYSANUS, Greene, in Bull. Calif. Acad. i. (1885 72. CRUCIFERAE

ppisillus, Greene, $l$. c.-Calif

ATIMETA, Schott, Gen. Aroid. t. $71(1858)=$ Rodospatha, Poepp. (Aroid.)

filamentosa, Reissek, ex Peyr. Aroid. Maxim. 28. t. 19 20 .-Bras.

Martii, Schott, Prod. Aroid. $349=\mathrm{R}$, oblongata

Videniana, Schott, Gen. Aroid. t. $71=$ R. oblongata.

ATIRSITA, Rafin. New Fl. Am. iv. 36 (1836)= Eryngium, Tourn. (Umbell.)

pumila, Rafin. 1. c. $37=$ E. gracile.

ATITARA, Marcgr. ex Juss, in Dict. Sc. Nat. iii. 277 (1816) = Evodia, Forst. (Rutac.).

ATKINSONIA, F. Muell. Fragm. v. 34 (1865)= Loranthus, Linn.

ligustrina, F. Muell. 1. c. v, $34 ;$ vi. $252=$ L. epigaeus. 
A TLANTIA, Kurz, For. Fl. Brit. Burma, i. 194 (1877)= Atalantia, Correa (Rutac.).

ATOCION, Adans. Fam. ii. $254(1763)=$ Silene, Linn. (Caryophyll.).

Armeria, Fourr. in Ann. Soc, Linn, Lyon, N. S. xvi. (1868) $344=\mathrm{S}$. Armeria.

ATOLARIA, Neck. Elem. iii. $31(1790)=$ Crotalaria, Linn. (Legum.).

ATOMOSTyLIS, Steud. in Flora, xxxiii. (1850) 229 ; Syn. Pl. Cyp. $315(1855)=$ Cyperus, Linn. cyperiformis, Steud. Syn. Pl. Cyp. $315=$ C. nudicaulis flavescens, Steud, in Flora, xxxiii. $(18,0) 2290=$ C. nudicaulis.

ATOSSA, Alef. in Bonplandia, ix. (1861) $100=$ Vicia, Lian. (Legum.).

Clusii, Alef, 1. c. $101=\mathrm{V}$. oroboides.

sepium, Alef. 1. c, =V. sepium.

ATRACTYLIA, Reichb. Nom. 'n. 3416' (1841)= seq.

ATRACTYLIS, Linn. Gen. ed. I. 246 (1737). COMPOSITAE, Benth. \& Hook. f. ii. 465.

ACARNA, All. F1. Pedem. i. 153 (1785).

ANACTIS, Cass, in Dict. Sc. Nat xlvii. 510 (1827)

Atrractylodes, DC. Prod. vii. 48 (1838).

Chamaeleon, Cass. in Dict. Sc. Nat. xlvii. 509 (1827).

Cirsellium, Gaertn. Fruct. ii. 454. t. 163 (1791).

Crocodylus, 'Adans,' ex Steud. Nom. ed. II. i.

$16 t$, in syn. (1840)

Spadjactis, Cass. in Dict. Sc. Nat. xlvii. 510 (1827).

acaulis, Pers. Syn. ii. 382 , in syn. = gummifera.

amplexicaulis, Poir. Encyc. vi. 30 (= Stabaeae sp.).Afr. austr.

angustifolia, Houtt. Plantenk. x. $518=$ Berkheya lanceolata.

armena, Poir. Encyc. Suppl. iv, 637 (=Onobroma armenum).-Armen.; Persia.

caespitosa, Desf. Fl. Atlant. ii. 254. t. 225.-Afr: bor. occ.

caespitosa, Viv, Fl, Lib. Spec. $52=$ cancellata.

cancellata, Linn. Sp. Pl.830,-Reg. Mediterr. ; Oriens. canescens, Salzm. ex Ball, in Fourn: Linn. Soc, xvi. (1878) $519=$ cancellata

hinensis, DC. Prod. vi. $549=$ ovata

ciliaris, Linn. Syst. ed, X. 1202.-- Aethiopia."

citrina, Coss. \& Kralik, in Bull. Soc. Bot. Fr, iv. (1857) $471=$ flava.

comosa, Sieber, ex Cass, in Dict. Sc. Nat. 1. 58.Syria.

cuneata, Boiss. Fl. Orient. iii. 454.-Afghanist

diffusa, Coss. in Bull. Soc. Bot. Fr. iv. (1857) 396 nomen.-Algeria.

echinata, Pomel, Nouv. Mat. Fl, Atl. 274.-Algeria.

fava, Coss, \& Dur.-Cf. Bull. Soc. Bot. Fr. iv. (1857) $471=$ citrina

Aava, Desf. Fl. Atlant: ii. 254. t.262.-Afr. bor.; A.rab. Bcluchist.

fruticosa, Linn. Sp. Pl. $829=$ Berkheya fruticosa

Fusus-agrestis, Gaertn. Fruct, ii. 381, t, $161=$ Carthamus lanatus.

gummifera, Linn. Sp. Pl.829,-Reg. Mediterr.

gummifera, Salzm. ex Ball, in Journ. Linn. Soc. xvi (1878) $519=$ Carlina racemosa

humilis, Linn. Sp. Pl. 829.-Europ. austr. occ.; Marocco.

lanata, Scop, F1. Carn. ed, II. ii. $134=$ Carthamus lanatus.

lancea, Thunb. Fl. Jap. $806=$ ovata

leucocephala, Moench, Meth. 553:= Carthamus lanatus.

leucophaea, Gaertn. Fruct. ii. $321=$ Carthamus leuco caulis.

macrocephala, Desf. Fl. Atlant. ii. 253.-Afr. bor. occ. macrophylla, Desf. l. c. 255.-Algeria.

mexicana, Linn. f. Suppl. $350=$ Lycoseris mexicana microcephala, Coss. \& Dur. in Ans. Sc. Nat. Sér. IV i. (1854) $240=$ serratuloides.

oppositifolia, Linn. Mant. ii. $477=$ Berkheya grandiflora.

ovata, Thunb. Fl. Fap. 306.-Japon

persica, Boiss. Diagn. Ser. I. vi. $110=$ Thevenotia persica.

phacolepis, Pomel, Nouv. Mat. Fl. Atl.279.-Algeria

pilosa, Moench, Meth, $553=$ Carthamus lanatus,

\section{ATRACTYLIS :}

polycephala, Coss, in Bull. Soc. Bot. Fr. iv. (1857) 481, nomen.-Algeria.

Preauxiana, Sch. Bip. in Webb E Berth. Phyt. Canar. ii. 350.-Ins. Canar.

prolifera, Boiss. Diagn. Ser. I. x. 96.-Palaestina purpurata, Linn. ex Sm. Ic. fasc. iii. $65=$ seq purpurea, Linn. f. Suppl. $349=$ Onoseris purpurea. radiciflora, DC. Prod. vi. 551.-Gall. austr rigida, Poir. Encyc. Suppl.iv. $637=$ Cartharaus rigidus scabra, Boiss. Diagn. Ser. I. vi. 109.-Persia serrata, Pomel, Nouv. Mat. Fl. Atl. 20.-Afr. bor serratuloides, Sieber, ex Cass. in Dict. Sc. Nat. 1. 58.Algeria ; Palaest.

speciosa, DC. in Deless. Ic. Sel. iv, t. $71=$ comosa. triplinervia, Vahl, ex Stend, Nom, ed II. i. 168; ii. 83 $=$ Lycoseris triplinervia

ATRACTYLODES, DC. Prod.vii. $48(1838)=$ Atrac tylis, Linn. (Compos.)

lancea, DC, 1, c. = Atractylis ovata

Iyrata, Sieb, \& Zucc. in Abh. Akad. Muench. iv. III. (1846) $193=$ A tractylis ovata.

ovata, DC. Prod. vii. $48=$ Atractylis ovata

ATRAGENA, Iinn. Syst. ed. I. (1735) = seq.

ATRAGENE, Linn. Diss. Dass. 21 (1747); Amoen Acad. i. 132 = Clematis, Einn. (Ranunc.)

alpina, Linn. Sp. Pl. 542 ; Rev. Hortic. (1855) 323. t 17. f. $1=$ C. alpina

alpina, Pall. Fl. Ross. ii, $69=\mathrm{C}$. verticillaris.

americana, Sims, Bot. Mag. t. $887=\mathrm{C}$. verticillaris.

austriaca, Scop. F1. Carn, ed. II. i. $387=$ C. alpina.

austriaca, Wender. in Linnaea, xi. (1837) 648, in obs. C. Wenderothii.

balearica, Pers. Syn. ii. $98=$ C. cirrhosa

capensis, Burm. f. Fl. Cap. Prod. 16, pro parte $=$

Anemone tenuifolia

capensis, Linn. Sp. Pl. $543=$ Anemone capensis.

ceylanica, Steud. Nom. ed. II. i. 168, vide zey

lanica.

cirrhosa, Pers. Syn. ii. 98= C. cirrhosa

Clematides, Crantz, Stirp. Austr. ed. I. fasc. ii. 111

ed. II. $127=$ C. alpina.

columbiana, Nutt. in Journ. Acad. Phil vii. (1834) $7=\mathrm{C}$, verticillaris

cordata, Wender. ex Steud. Nom. ed. II. i. $168=$ C. Wenderothii.

florida, Pers. Syn. ii. $98=$ C. florida.

indica, Desf. Tabl. ed. I. $123=$ C. florida.

indica, Heyne, ex Stend. Nom, ed. II, i, $168,379=\mathrm{C}$. Gouriana.

japonica, Thunb. Fl. Jap. $238=$ C. polypetala

japonica, Wight, ex Steud. Nom. ed. II. i. $168=\mathrm{C}$ Gouriana.

lobata, Llanos, Fragm, $73=$ Naravelia zeylanica macropetala, Ledeb. Fl, Alt. ii. $376=\mathrm{C}$, macropetala occidentalis, Hornem. Hort. Hafn. ii. $520=$ C. occidentalis.

ochotensis, Pall. F1. Ross. i. II. $69=$ C. ochotensis. patens, Decne, in Belg. Hortic. (1853) $16=\mathrm{C}$. patens. platysepala, Trautv. \& C. A. Mey, in Middend. Reise, (Fl. Ochot, 5). -As. bor. occ.

polygama, Jacq. Am. Select. $171=$ C. dominica.

polypetala, Thunb. F1. Jap. $239=$ Anemone japonica sibirica, Linn. Sp. ed. I. $343=$ alpina.

speciosa, Weinm. in Bull. Soc. Nat. Mosc. (1850) 538.-Rossia.

tenuifolia, Linn. f. Suppl. $270=$ Anemone tenuifolia tenuis, Thunb, Fl. Jap. 239=Anemone tenuifolia. triternata, DC. Syst. i. $150=$ C. tritemata.

Wenderothii, Schlecht. in Linnaea, xi. (1837) $650=\mathrm{C}$ Wenderothii.

seylanica, Blanco, F1, Filip. ed. I. $461=$ Naravelia laurifolia.

seylanica, Linn. Sp. Pl. 542= Naravelia zeylanica.

ATRAPHAXIS, Lim. Syst. ed. I (1795). POLY GONACEAE, Benth. \& Hook. f. iii, 96 .

Pedalium, Adans. Fam. ii. 277 (1768)

Persicaria, Neck. Elem, ii. 210 (1790)

Tragopyrum, Bieb, Fl. Taur. Cauc, ii. 28 (1819).

afghanica, Meissn. in DC. Prod.xiv. 76.-Afghanist. angustifolia, Gaub. E Spach, lllustr. Pl. Or. ii. 16,

21. t. 115,-Armenin.

aphylla, Pall. Rcise, i, 386,-Rossia.

\section{ATRAPHAXIS:-}

Aucheri, Faub. E Spach, Illustr, Pl. Or. ii. 15, 20. t. 114.-Persia.

Billardieri, faub. \& Spach, l. co 14, 17. t. 111-Graecia; As. Min.; Syria.

buxifolia, Faub. E Spach, l. c. 14.-Reg. Cancas.

Calverti, Boiss. Diagn. Ser. II. iv. $76=$ spinosa.

candida, Boiss. Es Haussk. ex Boiss. Fl. Orient. iv.

1021.-Persia.

canescens, Bunge, Ind. Sem. Hort. Dorpat. (1839) 3

-As. bor

compacta, Ledeb. Fl. Alt. ii. 55.-Turkestan

crassifolia, Agardh, in Schult. fo. Syst. vii. $138=$ spinosa.

cuneifolia, Poir. Encyc. Suppl. i. 535.-Am. bor

davurica, Jaub. \& Spach, Illustr. Pl. Or. if $15=$

Laxmanni.

decipiens, Jaub. \& Spach, 1. c.= Laxmanni.

densiflora, C. Koch, in Linnaea, xxii. (1849) $212=$ spinosa.

dioica, Bosc, ex Meissn. in DC. Prod. xiv. 80 Polygonella parvifolia.

Fischeri, Jaub. \& Spach, Illustr. Pl. Or. ii. $12=$ spinosa.

frutescens, C. Koch, Dendrol. ii. I. $360=$ Laxmanni.

graeca, Meissn. in DC. Prod. xiv. $77=$ Billardieri.

grandiflora, Faub. Es Spach, Illustr. Pl. Or. ii. 15. 19. t. 113.-Armenia ; Cappadoc.

inermis, Mill Gard. Dict, ed. VIII, n, $2=$ undulata.

Karelini, Jaub. \& Spach, Illustr. PI. Or. ii. $12=$

spinosa.

lactevirens, Faub. E Spach, l. c. 14.-Soongaria.

lanceolata, Bunge, in Mém. Sav. Etr. Pétersb. vil

(1851) 483. (Lehm. Rel. 307).-As. temp.

lanceolata, Meissn, in DC. Prod, xiv, $78=$ Laxmanni.

Laxmanni, Agardh, in Schult. f. Syst. vii. 1382 . Sibir.

micrantha; Faub. Es Spach, Illustr. Pl. Or. ii. 15.-

Sibiria.

pungens, faub. E Spach, l. c. 14.-Soongaria.

pyrifolia, Bunge, in Mém. Sav Elr. Pétersb, vij.

(1851) 483 (Lehm. Rel. 307).-Turkestan.

replicata, Lam. Encyc. i. $329=$ spinosa.

sinaica, Fresen. in Mus. Senkenberg. i. 74 ; Jaub. \&

Spach, Illustr. Pl. Or. ii. $12=$ spinosa

spinosa, Eichw. Casp. Cauc. $7=$ compacta.

spinosa, Laxm. ex Agardh, in Schult. f. Syst. vii. 1382 =crassifolia, Laxmanni.

spinosa, Linn. Sp. Pl. 475.-Oriens.

suaedaefolia, faub. \& Spach, Illustr. Pl. Or. ii. 15.Persia.

Tonmeforti, Faub. Es Spach, l. c. 14, 18. t. 112.Armenia.

undulata, Linn. Sp. Pl. $333=$ Polygonum atraphaxoides.

undulata, Willd. Sp. Pl. ii. 249.-Afr. austr.

variabilis, Jaub. \& Spach, Hlustr. Pl. Or. ii. 11, 13, 16. t. $110=$ Billardieri

ATRATEGIA, Bedd ex Hook f. Fl. Brit. Ind is it (1872)= Gonothalamus, Blume (Anonac)

Thomsoni, Bedd. ex Hook. f. 1. c. $75=\mathrm{G}$. cardiopetalus

ATREMA, DC, Coll, Mém, v, 71 t, $18(18-29)$; ef Prod. iv, $250(1830)=$ Bifora, Hoffm. (Umbellif. americanum, DC. Coll. Mém. vo il. t, $18=\mathrm{B}$. ameri cana.

testiculatum, Miq. F1. Ind. Bat. i. I, $T t 1=$ B. testi culata.

ATRICHOSERIS, A. Gmy, Syn Fl. $\mathrm{N}$ Am, i. H. 410 (1884). COIIPOSITAE.

platyphylla, A. Gray, l. c.-Am, bor. occ

ATRIPLEX, [Toum.] Linn. Syst. ed. I $(1 ; 35)$; Gen. $317(1737)$. CHENOPODIACEAE, Benth. \& Hook f iii. 53 .

Exporepts, Torr. ex A. Gray, in Pacif. Rail. Rep. xii. 47. t. 8 (150io

Harimus, Wallr. Sehed. Crit. 117 (18.2)

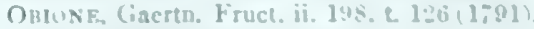

l'HÝl.otilec, Nult. ex Mog. in DC'. I'rud. xiii. Ih.

$$
98 \text { (1) } 190
$$

PMerocarya, Nutt, ex Mix. I. c. $106^{\circ} 1849^{\circ}$

PTERochitus, Tort. in Frem. Kep. Sis 1845

ScHzoturea, Lindl. Vog. Kingl, 513 (184)

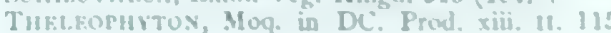
$(8+2)$ 


\section{ATRIPLEX :-}

abbreviata, Opiz, in Flora, vii. (1824) I. Beil. $81=$ laciniata.

acanthocarpa, S. Wats. in Proc. Am. Acad. ix. (1874) 117.-Texas.

acuminata, Bieb. Fl. Taur. Cauc. iii. $641=$ hor tensis.

acuminata, Waldst, \& Kit. Pl. Rar. Hung. ii. 107. t. $103=$ nitens.

agrestis, Schur, Enum. Pl. Transs. $575=$ patula

alaskensis, S. Wats. in Proc. Am. Acad. ix. (1874) 108. -Am. bor. occ.

alba, Crantz, Inst. i. $206=$ Chenopodium album

alba, Salisb. Prod. $152=$ Exomis atriplicioides.

alba, Scop. Delic. Insub ii. 16 , t. $8=$ rosea.

albicans, [Soland. in] Ait. Hort. Kew. ed. I. iii. $430=$

Exomis atriplicioides.

albicans, Bess. Prim. F1. Galic. i. $194=$ rosea

albicans, Willd. Sp. P1. iv. $962=$ laciniata.

Aldamae, Griseb. Cat. Pl. Cub. 282.-Cuba.

alexandrina, Boiss. Fl. Orient iv 914-Aegypt.

amarantoides, Gmel. ex Moq. in DC. Prod. xiii, II. 116 = Axyris amaranthoides.

amblyostegia, Turcz. in Bull. Soc. Nat. Mosc. xxv. (1852) II. 416.-As, centr.

ambrosioides, Crantz, Inst. i. $207=$ Chenopodium ambrosioides.

angulata, Benth. Fl. Austral. v. 174.-Austral.

angustifolia, Sm. F1. Brit. 1092 = patula.

anthelmintica, Crantz, Inst. i. $207=$ Chenopodium ambrosoides.

arabicum, Ehrenb. ex Boiss. F1. Orient. iv. $917=$ farinosa.

arenaria, Nutt. Gen. Am. i. 198.-Am. bor.

arenaria, Tineo, Cat. Hort. Panorm. 270; Woods, in Bab. Man. ed. III. $271=$ laciniata.

argentea, Nutt. Gen. Am. i. 198; ex S. Wats. Rev. Chenop. 117.-Am, bor. occ.

argentea, Pall. ex Steud. Nom. ed. II. i. $168=$ nitens.

argentea, Schrad. ex Moq. in DC. Prod. xiii. II. $92=$ rosea.

aristata, Crantz, Inst. i. $208=$ Chenopodium aristatum.

Assoi, Dufour, in Bull. Soc. Bot. Fr. vii. (1860) 432. - Hispan.

astracanica, Balb. Hort. Turic. $(1813)=$ laciniata

astracanica, Lag. Gen. et Sp. Nov. (1816) 3.-As. temp.

astrachanica, Ledeb. F1. Ross. iii. $719=$ laciniata.

atacamensis, Phil. Fl. Atac. 48.-Chili

Aucherii, Moq. Chenop. Enum. $51=$ nitens.

australasica, Moq. 1. c. $59=$ patula

axillaris, Tenore, Fl. Nap. Prod. i. $54=$ rosea.

Babingtonii, Woods, in Bab. Man. ed. III. $270=$ patula.

Barclayana, D. Dietr. Syn. Pl. v. 537.-Am. bor. occ.

Belangeri, D. Dietr. l. c. 535.-Persia; Afghanist.

benghalensis, Lam. Encyc. i. $276=$ hortensis.

Berlandieri, Moq. Chenop. Enum. $65=$ canescens

Besseriana, Roem. \& Schult. Syst, vi. $284=$ rosea.

Billardieri, Hook. f. Fl. N. Zel. i. 215.-Austral.; N. Zel.

Bocconi, Guss, FI. Sic. Syn, ii. $588=$ laciniata

Bonus-Henricus, Crantz, Inst. i. $206=$ Chenopodium Bonus-Henricus.

Botrys, Crantz, l. c. $207=$ Chenopodium Botrys

bracteosa, Trautv. in Act. Hort. Petrop. i. n. 1 (1870) $17=$ dimorphostegia

bracteosa, S. Wats, in Proc. Am. Acad.ix. (1874) 115. -Calif.

Breweri, S. Wats. l. c. 119..-Calif

Bunburyana, F. Muell. in Wing, Sowth Sc. Record, ii. (188\%) 274.-Austral.

californica, Moq in DC, Prod, xiii. II 98.-Calif.

calotheca, Fries, Novit. Fl. Suec. Mant. iii. 164.Suecia.

campanulata, Benth. Fl. Austral. v, 177.-Austral

campestris, Koch \& Ziz, Cat. Pl. Palat. $24=$ tatarica.

cana, C. A. Mey. in Ledeb. Fl. Alt. iv. 306; Moq. Chenop. Enum.61.-Sibiria.

candicans, Link, ex Steud. Nom. ed. II. i. 168. Lusitan.

canescens, fames, Cat. 178.-Am. bor. occ.

canescens, Nutt. Gen. Am. i. $197=$ Nuttallii.

capensis, Mog. Chenop. Enum. 63.-Afr. austr.

\section{ATRIPLEX :-}

Chanicowii, Bunge, ex Boiss. Fl. Orient. iv. 9]3.Persia.

chilensis, Colla, in Mem. Acc. Torin. xxxix. (1836) 7 . t. 49.-Chili.

chrystallina, Hook. f. in Hook. Lond. Journ. Bot. vi. (1847) $279=$ Billardieri.

cinerea, Poir. Encyc. Suppl. i. 471.-Austral.; N. Zel.

confertifolia, S. Wats, in Proc. Am. Acad. ix. (1874) 119. -Am. bor. occ.

coriacea, Forsk. Fl. Aegypt. Arab. 175.-Aegypt.

coriacea, Raddi, ex Moq. in DC. Prod. xiii. II. $108=$ glauca.

coronata, S. Wats, in Proc. Am. Acad.ix. (1874) 114. -Calif,

Coulteri, D. Dietr. Syn. Pl. v. 537.-Calif

crassifolia, C. A. Mey. in Ledeb. Fl. Alt. iv. 309.Turkestan. ; Ind. or. ; Sibir.

crispa, D. Dietr. Syn. Pl. v. 536.-Persia.

cristata, Heyne, ex Moq. in DC. Prod. xiii. II. 99 ; Koen. ex Moq. 1. c. $109=$ repens.

cristata, Humb. E Bonpl. ex Willd. Sp. Pl. iv. 959.N. Granat.

crystallina, Moq. 1. c. $105,116=$ Billardieri

crystallina, Ehrenb. ex Boiss. Fl. Orient. iv. 915.Aegypt.

decumbens, Roem. $8 x$ Schult. Syst. vi. $289=$ prostrata decumbens, S. Wats. in Proc. Am. Acad. xii. (1877) 275.-Calif.

deltoidea, Bab. Man. ed. I. $253=$ hastata

denticulata, Moq. in DC. Prod. xiii. II. $97=$ semibaccata.

deserticola, Phil. Fl. Atac, 47.-Chili.

diffusa, Tenore, Prod. Fl. Nap. i. $57=$ laciniata

dimorphostegia, Kar. E Kir. in Bull. Soc. Nat. Mosc. xv. (1842) 438. - Soongar.

dioica, Rafin. in Am. Monthly Mag. (1818) $176=$ Purshiana.

Drummondii, Moq in DC, Prod, xiii. II. 102, Austral.

elachophylla, F. Muell. Fragm. vii. 8.-Austral elaeagnoides, Moq. Chenop. Enum. $65=$ cinerea elegans, D. Dietr. Syn. Pl, v. 537.-Mexic.

elongata, Guss, F1. Sic, Syn, ii $592=$ hastata.

Endolepis, S. Wats. in Proc. Am. Acad.ix. (1874) 110 -Am. bor.

erecta, Huds. Fl. Angl. ed. I. $376=$ patula

exilifolia, F. Muell. Fragm. vii. 9.-Austral

expansa, S. Wats, in Proc. Am. Acad. ix. (1874) 116.

-Am. bor. occ.

farinosa, Dum. Fl. Belg, $20=$ laciniata.

farinosa, Moq. Chenop. Enum. $55=$ Verreauxii.

farinosa, Forsk. Fl. Aegypt. Arab. 123.-Aegypt.; Arab fasciculata, S. Wats. in Proc. Am. Acad. xvii. (188182) 377 .- Am. bor.

fissivalvis, F. Muell. Fragm. ix. 123.-Austral.

Flabellum, Bunge, ex Boiss. Fl. Orient. iv, 912,-

Persia: Turkestan.

flavescens, Dum. F1. Belg. 20 (Quid ?).-Belgium

flexuosa, Moq. Chenop. Enum. 57.-Afr. austr.

foliolosa, Link, in Schrad. Journ. (1800) I. $54=$ rosea.

foliolosa, Phil. in Bot. Zeit. xxviii. (1870) 500 ; Anal. Univ. Chil. (1875) 192.--Chili.

foliosa, Guss. ex Nym. Consp. $628=$ rosea

fruticosa, Nutt. ex Moq. in DC. Prod. xiii. Ir. $112=$ canescens.

Gardneri, D. Dietr. Syn. Pl. v. $537=$ Gordoni

gigantea, Poir. ex Moq. in DC. Prod. xiii. II. $94=$ hastata.

glauca, Brot. Fl. Lusit. i. $472=$ candicans

glauca, Crantz, Inst. i. $207=$ Chenopodium glaucum.

glauca, Pall. ex Roem. \& Schult. Syst. v. $277=$ verrucifera.

glauca, Pall. Reise, i. $494=$ cana.

glauca, Salzm. ex Ball, in Journ. Linn. Soc. xvi. (1878) 645 - - laciniata.

glauca, Linn. Cent. i. 33.-Europ.

glomulifera, Nees, in Lehm. Pl. Preiss. i. 634.Austral.

Gmelini, C. A. Mey. in Bong. Veg. Sitch. 42.-As. bor. or.

Gordoni, Hook. Kew Fourn. v. (1853) 261.-Am. bor.

gracilis, Nutt. ex Moq. in DC. Prod. xiii. II. $95=$ hastata.

graeca, Sibth. \& Sm. Fl. Graec. x. t. $963=$ tatarica.

graeca, Willd. Sp. Pl. iv. $958=$ hastata.
ATRIPLEX :-

Graeci, Tineo, Cat Hort Panorm. $277=$ rosea

Greggii, S. Wats. in Proc. Am. Acad. ix. (1874) 118 - Mexic.

Griffithii, Moq. in DC. Prod. xiii. II. 102.-Persia Afghanist.

halimoides, Lindl. in Mitch. Three Exp. i. 285. Austral.

halimoides, Rafin. in Am. Monthly Mag. (181.8) 176 $=$ hastata.

halimoides, Tineo, Cat. Hort. Panorm. 277.-Hab. ?

Halimus, R. Br. Prod. $406=$ cinerea.

Halimus, Linn. Sp. Pl. 1052.-Afr. bor. et austr.

Halimus, Nees, in Lehm. Pl. Preiss. i. $633=$ cinerea isatidea.

Halimus, Pall. Reise, ii. $477=$ cana

Halimus, Ritter, ex Moq. in DC. Prod. xiii. II. 110 (= Obione crispa).-Ins. S. Doming.

hastaefolia, Salisb. Prod. $153=$ hastata.

hastata, Geners. ex Steud. Nom. ed. II. i. $169=$ laciniata.

hastata, Koch, Syn. F1. Germ. ed. II. $702=$ calo theca.

hastata, Linn. Sp. Pl. 1053.-Europ.; As. bor.

hastilifolia, Reichb. ex Steud. Nom. ed. II. i. $169=$ patula.

Hermannii, Villem. Phytogr, iii. $1222=$ nitens.

heterantha, Wight, Ic. v. t. $1787=$ hortensis.

heterophylla, Nutt. ex Moq. in DC. Prod. xiii. Ir. 112 = canescens

heterosperma, Bunge, in Mém. Sav. Etr. Pétersb. vii. (1851) 448 (Lehm. Rel. 272).-As. centr.

hispanica, S. G. Gmel. It. iv. 40.-Ross. austr.

holocarpa, F. Muell. Rep. Babb. Exp. 19.-Austral.

hortensis, Linn.Sp. Pl. 1053.-Cosmopol. (cult.).

humilis, F. Muell. Fragm. iv. 48.-Austral.

hybrida, Crantz, Inst. i. $207=$ Chenopodium hybridum hymenelytra, S. Wats, in Proc. Am. Acad. ix. (1874

119. -Am. bor. occ

hymenotheca, Mog. in DC. Prod. xiii., II. 101Austral.

hypolenca, Nees, in Lehm. Pl. Preiss. i. $633=$ cinerea.

imbricata, D. Dietr. Syn. Pl. v. 536.--Bolivia

incand, F. G. Dietr. Vollst. Gaertn. Lexik. Nachtr. i. 418.-..Hispan

incisa, Bieb. F1. Taur. Cauc, iii. $641=$ tatarica

incisa, Hohen. ex Ledeb. F1. Ross. iii. $720=$ laciniata incrassata, F. Muell. Rep. Babb. Exp. 20.-Austral inflata, F. Muell. in Trans. Phil. Inst. Vict. ii. (1858 $75=$ halimoides.

integrifolia, Krock. ex Steud. Nom. ed. II. i. $169=$ triangularis.

isatidea, Moq. Chenop. Enum, 63.-Austral

julacea, S. Wats. in Proc. Am. Acad. xx. (1885) 370. Calif.

Kataf, Ehrenb. ex Boiss. Fl. Orient. iv. $916=\mathrm{A}$ Halimus.

Koenigii, Wall. Cat. n. $6951=$ repens

Kunthiana, D. Dietr. Syn, Pl. v. 536.-Am, austr.

lacera, Desf. Cat. Hort. Par. ed. III. $389=$ calotheca

laciniata, Aitch. Cat. P1. Panjab $125=$ crassifolia

laciniata, Bieb. Fl. Taur. Cauc. iii, $641=$ rosea.

laciniata, Linn. Sp. Pl. 1053.-Europ.; Am. bor.

laciniata, Pursh, Fl. Am. Sept. i, $199=$ Purshiana.

laciniata, Schkuhr, Handb. t. $349=$ hastata

laevis, C. A. Mey. in Ledeb. Fl. Alt. iv. 60.-Sibir.

Lampa, Gill. ex Moq. in DC. Prod. xiii. II. 110.Chili.

lasiantha, Boiss. Diagn. Ser. I. xii. $95=$ tatarica.

latifolia, Wahlenb. FI. Suec, ii, $660=$ hastata.

Lehmanniana, Bunge, in Mém. Sav. Etr. Pétersb. vii. (1851) $451=$ turcomanica.

lenticularis, C.A. Mey. ex Turcz. in Bull. Soc. Nat Mosc. (1838) 99, nomen.-As. temp.

lenticularis, Tausch, in Flora, xxiii. (1840) I. $16=$ Tauschii.

lentiformis, S. Wats. in Proc. Am. Acad. ix. (1874) 118.-Am. bor. occ.

leptocarpa, F. Muell. in Trans. Phil. Inst. Vict. ii. (1858) 74.-Austral.

leptoclada, Boiss. Diagn. Ser. II. iv. $74=$ turcomanica.

leucoclada, Boiss. Diagn. Ser. I. xii. 95.-Aegypt. Arab.

leucophylla, D. Dietr. Syn. Pl. v. 536.-Calif.

limbata, Benth. Fl. Austral. v. 178.-Austral.

limosa, Schur, Enum. Pl. Transs. 576.-Europ.

Lindleyi, Mog. in DC. Prod. xiii. II. $100=$ halimoides 
ATRIPLEX :-

linifolia, Humb. E Bonpl. ex Willd. Sp. Pl. iv, 958.Mexic.

littoralis, Linn. Sp. Pl. 1054,-Reg. bor. temp.

longipes, Drejer \& Fries, Summa Veg. Scand. 201= hastata.

lucida, Desf. ex Mert. \& Koch, in Roehl. F1. Deutschl. ii. $311=$ nitens.

lucida, Moench, Meth. Suppl. 121=sibirica.

Iunulata, Del. ex Moq. in DC. Prod. xiii. II. $99=$ mollis.

macrodira, Guss. Fl. Sic. Syn. ii. $592=$ patula. macrotheca, Hort. ex Moq. in DC. Prod. xiii. II. $94=$ calotheca.

marina, Linn. Mant. ii. $300=$ littoralis

maritima, Crantz, Inst. i. $208=$ Suaeda maritima maritima, $\mathrm{Pall}$. Reise, ii. $289=$ littoralis.

mauritanica, Boiss. E' Reut. Pugill. Pl. Nov. 106.Hispan.

micrantha, Kar. \& Kir. in Bull. Soc. Nat. Mosc. (1841)

$738=$ nitens

micrantha, C. A. Mey, in Ledeb. Fl. Alt. iv. $308=$ hastata.

micrantha, Moq. Chenop. Enum.62.-Sibir.

microcarpa, D. Dietr. Syn. Pl. v. 536.-Calif.

microcarpa, Benth. Fl. Austral. v. 176.-Austral.

microcarpa, Waldst. \& Kit. Pl. Rar. Hung. iii. 278.

t. $250=$ hastata.

microphylla, D. Dietr. Syn. Pl. v. 536=parvifolia H. B. \& K.

microphylla, Willd. Sp. Pl. iv. $958=$ Chenopodium microphyllum.

microphylla, Phil. Fl. Atac, 48,-Chili.

microphylla, Schur, Enum. P1. Transs. 578=laciniata.

microsperma, Bab. Man. ed. I. 253 = hastata.

microsperma, Waldst. \& Kit. P1. Rar. Hung. iii. 278 t. $250=$ hastata.

microtheca, Fries, Corp. Fl. Suec. $133=$ hastata. microtheca, Moq. in DC. Prod. xiii. II. $91=$ hortensis. mollis, Desf. Fl. Atlant. ii. 391.-Algeria.

mollis, Uspenski, Jekaterinenburg. $106=$ verrucifera.

Moneta, Bunge, ex Boiss. Fl. Orient. iv. 912.-Persia Afghanist.

monilifera, S. Wats. in Proc. Am. Acad. ix. (1874) 111 - Am. bor.

monoica, Moench, Meth. $353=$ rosea

montevidensis, Spreng. Syst. iii. 918.--Reg. Argent.

Moquiniana, Webb, ex Mog. in DC. Prod. xiii. Ir. 97 -Austral.

mucronata, Rafin. in Am. Monthly Mag. (1818) $176=$ arcnaria.

mucronata, Phil. Fl, Atac, 47.-Chili.

Muelleri, Benth. Fl. Austral. v. 175.-Austral.

multifida, Crantz, Inst. i. $207=$ Roubieva multifida

multifida, Desf. Tabl. ed. II. $51=$ calotheca.

muralis, Crantz, Inst. i. $206=$ Chenopodium murale

muricata, Humb. E Bonpl. ex Willd. Sp. Pl. iv. 959.-

Am. austr.

nemorensis, Schur, Enum. Pl. Transs. $575=$ patula.

nitens, Schkuhr, Handb. iri. (1803) 541.-Europ. Oriens.

nudicaule, Boguslaw, in Erman, Archiv, vi. 65.Rossia.

nummularia, Lindl. in Mitch. Fourn. Trop. Austr. (1848) 64.- - Austral.

Nuttalii, S. Wats. in Proc. Am. Acad. ix. (1874) 116. - Am. bor. occ.

oahuensis, Meyen, Reise, ii. 127.-Ins. Sandvic.

oblongifolia, Host, Fl. Austr, j. 320 = hastata.

oblongifolia, Waldst. \& Kit. Pl. Kar. Hung. iil. 278. t. 211 = patula

obovata, Moq. Chonop. Enum.61.-Mexic.

obtusa, Willd. Sp. Pl. iv. 964.-Sibiria.

obtusata, Lange, in Kjocb. Vidensk. Meddel. (1861)

42.-Hispan.

occidentalis, D. Dietr. Syn. Pl, v. $587=$ canescens

ocymifolia, Viv. Eg. $23=$ coriacea.

odorata, Pers. Syn. $\mathrm{i} .293=$ Exomis albicans.

Olivieri, Moq. Chenop. Enum. $52=$ tatarica.

oppositifolia, DC. Rapp. i. 12 = hastata.

oppositifolia, Vill. Prosp. 21.-Gallia.

oppositifolia, S. Wats. in Proc. Am. Acad. ix. (1874)

118.-Mexic.

orbicularis, S. Wats. l. c. xvii. (1881-82) 377.-Am, bor.

palnestina, Boiss. Dingn. Ser. I. xii, 96.-Syria;

Assyria.

\section{ATRIPLEX:-}

Palmeri, S. Wats. in Proc. Am. Acad. xi. (1876) 146. -Calif.

paludosa, R. Br. Prod. 406.-Austral

paludosa, Nees, in Lehm. Pl. Preiss. i. $633=$ Drum mondii.

pamparum, Griseb. in Goett. Abh. xix. (1874) 69.Reg. Argent.

Parishii, S. Wats. in Proc. Am. Acad. xvii. (1881-82 377.-Am. bor

Parryi, S. Wats. l. c. 378.-Am, bor.

parviflora, Steud. Nom. ed. II. i. $169=\mathrm{seq}$

parvifolia, H. B. E K. Nov. Gen. et Sp. ii. 192.Mexic.

parvifolia, Love, in Trans. Camb. Phil. Soc. iv. (1831) 16.-Marocco: Ins. Canar.

patagonica, D. Dietr. Syn. Pl. v. 536,--Patagonia.

patula, Linn. Sp. Pl. 1053 - Reg. temp. bor, et austr.

patula, Sm. Fl. Brit. 1091; Engl. Fl. iv, $257=$ hastata

pedunculata, Linn. Cent. Pl. 1.33.-Europ.; As. bor.

Oriens.

persica, Boiss. Diagn. Ser. I. xii. 96.-Persia,

peruviana, Moq. in DC. Prod. xiii. II. 102.-Peruv.

Pharaonis, Hort. Avenion, ex Moq. 1. c. $91=$ micro theca.

philippica, Weinm. in Syll. Ratisb. ii. (1828) 29.

Ins. Philipp.

phyllostegia, S. Wats. in Proc. Am. Acad. ix. (1874)

108.-Am. bor. occ.

Piqueres, Lag. Pl. Barrill. $67=$ laciniata

platysepala, Guss. H1. Sic. Syn. ii. $590=$ hastata

plebeja, Carmich. in Trans. Linn. Soc. xii. (1819) 508. -Ins. Trist. d'Acunha.

polycarpa S. Wats. in Proc. Am. Acad. ix. (1874) 117.-Calif.

polygama, Sessé, in Lag. Gen. et Sp. Nov. 12.-M Mexic polymorpha, Coss. Germ. et Wedd. Cat. Pl. Par. 108 hastata, patula.

polysperma, Crantz, Inst. i. $207=$ Chenopodium poly spermum.

polysperma, Tenore, Prod. Fl. Nap. i. $57=$ rosea

portulacoides, Linn. Sp. Pl. 1053.-Europ.; Syria Afr. bor.

portulacoides, Pall. Ind. Taur, $59=$ verrucifera.

Powellii, S. Wats. in Proc. Am. Acad. ix. (1874) 114.

$$
\text { -Arizona. }
$$

procumbens, Jundz. F1. Lituan. $78=$ patula.

procumbens, Less. in Linnaea, ix. (1834) 203.-Sibir alt.

prostrata, Bouch. Fl. Abbev. 76; Bab. Man. ed. I $252=$ hastata

prostrata, R. Br. Prod. i. 406.-Austral.

prostrata, Moq. in DC. Prod. xiii. II. $99=$ cinerea

prostrata, Phil. in Anal. Univ. Chil. (1873) 535.Chili.

pruinosa, Sieber, ex Moq. in DC. Prod. xiii. II. $93=$

laciniata.

pruinosa, Sieber, ex Boiss. Fl. Orient. iv. $910=$ tatarica.

Pseudo-nitens, Schur, Enum. Pl. Transs. 574.Hungaria.

Pumilio, R. Br. Prod. 406.-Austral.

pungens, Trautv. in Bull. Soc. Nat. Mosc: xli: (186r) II. 53.-Sibiria.

Purshiana, Moq. Chenop. Enum. 55.-Am. bor.

pusilla, S. Wats. in Proc. Am. Acad. ix. (1874) 110.Am. bor. acc.

ramosissima, Nutt. ex Moq. in DC. Prod. xiì. MI. 111 $=$ microcarpa.

recta, Schur, Enum. Pl. Transs. 575 et Ind.=patula.

recurva, Ury in Mém. Soc. Linn. Par. i. (18\%2) $284=$ tatarica.

reniformis, R. Br. Prod. $406=$ paludosa.

reniformis, F. Muell. Fragm. vii. $9=$ stipitata

repens, Aitch. Cat. Pl. Panjab, $125=$ Stocksii.

repens, Roth, Nov. Pl. Sp. 377.-Ind. or.

retusa, C. Gay, Fl. Chil, v. 240.-Chili.

rhagodioides, F. Muell. in Trans. Phil. Inst. Vict. ii (1858) 74.-Austral.

rosea, Bab. Man. Brit. ed. I. $253=$ crassifolia.

rosea, Linn. Sp. Pl. ed. II. 1498.-Europ.; As. Min.

Afr, bor.

rosea, F, Muell, Fragm, vii. $9=$ Muelleri.

rotundifolia, Dombey, ex Mog. Chenop. Enum.70. Peruv.

rotundifolia, Boiss. Fl. Orient. iv, $915=$ crystallina.

ruberrima, Hort. ex Mog. in DC. P'rod. xiii. 11.91 =

hortensis.

\section{ATRIPLEX :-}

rubra, Crantz, Inst. i. $206=$ hortensis.

ruderalis, Wallr. Sched. Crit. 115 = hastata.

saccaria, S. Wats. in Proc. Am. Acad. ix. (1874) 112. -Utah.

Sackii, Rostc. \& Schum. Fl. Sedin. 401. t. 1 = hastata.

sagittata, Borckh, in Reinsch. Mag. $477=$ nitens.

salicifolia, Lag. ex Moq. Chenop. Enum. $74=$ polygama.

salicina, Pall. Reise, i. $495=$ littoralis.

salina, Sievers, in Pall. N. Nord. Beitr. vii. $327=$ littoralis.

salina, Desf. in Journ. Bot. i. (1813) $48=$ patula

scoparia, Crantz, Inst. i. $208=$ Kochia scoparia.

semibaccata, R. Br. Prod. 406-Austral.

semibaccata, Moq. in DC. Prod, xiii. $11.97=$ spon.

giosa.

emibracteata, Steud. Nom. ed. II. i. 169, sphalm.= semibaccata.

serotina, Crantz, Inst. i. $206=$ Chenopodium serotinum. serpyllifolia, Bunge, in Act. Hort. Petrop. v. (1877) 642,-Sibiria ; Turkest.

serrata, Huds. Fl. Angl. ed. I, $377=$ littoralis.

sibirica, Linn. Sp. Pl. ed. II. 1493.-Sibiria.

sicula, Ucria, in Roem. Arch. i. 70.-Sicilia.

sinuata, Hoffm. Deutschl, Fl. ed. II. ii. $277=$ laciniata.

Smithii, Syme, Eng. Bot. ed. III. viii. 32 = hastata.

spectabilis, Ehrh, ex Mog. in DC. Prod. xiii. 1I. $91=$

hortensis.

spicata, Stokes, Bot. Mat. Med. ii. $24=$ Anredera scandens?

spicata, S. Wats. in Proc. Am. Acad. ix. (1871) 108. -Calif.

spinacifolia, Stokes, Bot. Mat. Med, ii, 23 = hastata.

spinosa, D. Dietr. Syn. Pl. v, 536.-Am. centr.

spongiosa, F. Muell. in Trans. Phil. Inst. Vict. ii. (1858) 74.-Austral.

stipitata, Benth. Fl. Austral. v, 168.-Austral.

stipitate, Westerl. in Linnaea, xl. $(1876) 165=\mathrm{cal} 0$

theca.

Stocksii, Boiss. Diagn. Ser. II. iv. 73.-Scinde.

stylosa, Viv. Pl. Eg. 23. f. 21.-Lybia.

subopposita, Schur, in Verh. Siebenb. Ver. Natura.

iv. (1853) 63.-Europ.

Suckleyana, S. Wats. in Proc. Am. Acad. ix. (1574)

111.-Am. bor.

sulcata, Michx, ex Roem. \& Schult. Syst. vi. 290 = littoralis.

tartarica, Crantz, Inst. i. $205=$ tatarica,

tatarica, Auct. fid. Boiss. Fl. Orient. iv. $909=$ patula.

tatarica, Linn. Sp. Pl. 1053.-As. centr.

tatarica, Schkuhr, Handb. t. $349=$ oblongifolia

Tauschii, D. Dietr. Syn. Pl. ₹. 538.-Hab. ?

tetrandra, Torr. ex Mog. in DC. Prod. xiii. II. $93=$ Purshiana.

texana, S. Wats. in Proc. Am. Acrd. ix. (1874; 113.Texas.

thumbergiaefolia, Boiss. Fl. Orient. iv. 911.-Babylonia.

Thunbergiana, Roem. \& Schult. Syst. vi. 281 =laciniata.

Tornabeni, Tinee, in Guss. Fl. Sic. Syn. ii. 559 laciniata.

Torreyana, Rafin. Atl. Fourn. 146.-Am. bor

Torreyi, S. Wats. in Proc. Am. Acad. ix. (18, 1) $11 \mathrm{~s}$ -Am. bor. occ.

transsilvanica, Schur, Enum. Pl. Transs. hastata.

triangularis, Willd. Sp. Pl. iv. 963 = bastata.

truncata, A. Gray, in Proc. Am. Acad. viii. 1573 319. -Am. bor. oce.

turcomanica, Fiscl, E Mcy, or fiorel. irs Bull. Soc. Not. Mosc. (1830) 11, 169.-Persia.

turcomanica, Turcz. ex Ledeb. Fl. Ross, iii. $\rightarrow 20=$ laciniata.

undulata, D. Dietr. Syn. Pl. v. 590,-I'atagon.

urbica, Crantz, Inst. i. $200^{\circ}=$ Chenonudium urbicum.

velutinella, E. Mtuell. Re*. Babb. Exp. 20.-Austral.

vereta, Mon. Chenop. Enum. $5.4=$ microtheen.

veneta, Moq. Chenop. Enum.

verreauxi, Bloq, in DC. Prod. xiii. 11. 95. - Mr. sustr.

verrucifera, Bieb. Fl. Taur. Casac. ii. $111 .-\mathrm{ke}$.

Caucas. ; Persia.

verticilluta, Lag. (ien. el Sn, Nov. 12 a rosea.

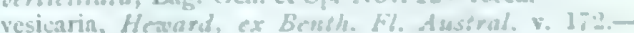
Austral.

sirgota, Koth, Nov. Sp. Pl. si i = hortensis.

virgrafa, Scop. Delic. Insub. ii. 11; Hoffm. Devticbl.

il. ed. 1I. ii, 27i = parula. 


\section{ATRIPIFX}

viridis, Crantz, Inst. i. $207=$ Chenopodium album. viridis, Hort. ex Moq. in DC. Prod. xiii. II. $90=$ nitens.

Vulvaria, Crantz, Inst. i. $207=$ Chenopodium Vulvaria.

Wolfi, S. Wats, in Proc. Am. Acad. ix. (1874) 112.Am. bor.

Wrightii, S. Wats. l. c. 113.-N. Mexic.

zosteraefolia, S. Wats. l. c. 109.-Am. bor.

ATROPA, Linn. Gen. ed. I. 49 (1737), SOLANA$C E A E$, Benth. \& Hook. f. ii. 900.

Belladona, Adans. Fam. ii. $219(1763)$

acaulis, Stokes, Bot. Mat. Med. i. $396=$ Mandragora officinarum.

acuminata, Royle, Hllustr. Bot. Himal. $279=\mathrm{A}$ Belladonna.

ambigua, Salisb. Prod. 132 = Sicopola carniolica.

arborea, Willd. ex Dun. in DC. Prod. xiii. I. $497=$

Acnistus arborescens.

arborescens, Linn. Cent. ii. 10 (Amoen. Acad. iv. 307) $=$ Acnistus arborescens.

arborescens, Roem. \& Schult. Syst. iv. $685=$ Acnistus Plumieri.

arenaria, Willd. ex Roem. \& Schult. Syst. iv. $686=$ Nectouxia formosa.

aristata, Poir. Encyc. Suppl. i. $609=$ Withania aristata.

aspera, Ruiz \& Pav. Fl. Peruv. ii. $45=$ Hebecladus asperus.

baetica, Willk. in Linnaea, xxv. (1852) 50.-Hispan.

Belladonna, Linn. Sp. Pl. 181.-Europ.; Oriens; Ind, or.

bicolor, Ruiz \& Pav. F1. Peruv, ii. $45=$ Hebecladus bicolor.

biflora, Ruiz \& Pav. 1. c.= Hebecladus biflorus.

contorta, Pers. Syn i. $219=$ Saracha contorta

daturaefolia, Thore, Chlor. Land. $74=$ Nicandra physaloides

dentata, Pers. Syn: i. $219=$ Saracha dentata

dependens, Mathews, ex Hook. Ic. P1. t. $107=$ Salpichroa dependens.

evecta, Hornem. Hort. Hafn. $957=$ Hebecladus biflorus.

erecta, Zuccagni, in Roem. Collect. $129=$ Saracha Zuccagniana.

flexuosa, Willd. ex Roem. \& Schult. iv. 686; Dun, in DC. Prod. xiii. $465=$ Hebecladus viridiflorus.

frutescens, Linn. Sp. Pl. 182=Withania frutescens.

glandulosa, Hook. Bot. Misc. ii. (1831) $230=$ Salpichroa glandulosum.

gymnosperma, Schmid. Ic. 67. t. $18=$ Nolana prostrata.

herbacea, Mill. Gard. Dict. ed. VIII. n. 3--Campechia.

hirsuta, Meyen, Reise, i. $466=$ Salpichroa hirsutum.

hirsuta, Meyen, Reise, 1. $466=$ Salpich
hirtella, Spreng. Syst. i. $699 .-$ Bras.

humifusa, Gotian, Hort. Monsp. $106=$ Nolana prostrata.

humilis, Salisb. Prod. $132=$ Mandragora officinarum.

lethalis, Salisb. 1. $\mathrm{c}_{a}=\mathrm{A}$. Belladonna.

lutescens, Jacquem. ex. C. B. Clarke, in Hook. f. Fl Brit. Ind. iv. $241=\mathrm{A}$. Belladonna.

Mandragora, Linn. Syst. ed. X. 933 = Mandragora officinarum.

Mandragora, Sibth. \& Sm. Fl. Graec. iii. 26. t. $232=$ Mandragora autumnalis.

origanifolia, Desf. Cat. Hort. Par. ed. III. $396=$ Physalis curasavica, origanifolia.

physalodes, Linn. Sp. P1. 181=Nicandra physaloides. physaloides, Georgi, Beschr. Russ. Reich. Nachtr. 261 = Scopola physaloides.

physaloides, Linn. Syst. ed. XII. $171=$ physalodes.

plicata, Roth, Catalecta, ii. $24=$ Saracha procumbens.

procumbens, Cav. Ic. i. $53=$ Saracha procumbens.

punctata, Pers. Syn. i. 219. = Saracha punctata.

ramosissima, Mathews, ex Dunal, in DC. Prod. xiii. I.

$473=$ Salpichroa ramosissimum.

reflexa, Walp. Rep. iii. 103, in syn. =seq.

revoluta, F. G. Dietr. Vollst. Gaertn. Lexik. Nachtr. i $422=$ Hebecladus umbellatus.

rhomboidea, Gill. \& Hook. in Hook. Bot. Misc. i (1830) $135=$ Salpichroa rhomboideum.

Rothii, Poir. Encyc. Suppl. i. $610=$ Hebecladus umbellatus.

sideroxyloides, Willd. ex Roem. \& Schult. Syst. iv. $486=$ Acnistus arborescens.

\section{ATROPA :}

solanacea, All. ex Steud. Nom. ed. II. 1. $170=$ Acnistus arborescens.

solanacea, Linn. Mant. ii. $205=$ Solanum aggregatum. spinosa, Meyen, Reise, i. $466=$ Dunalia lycioldes umbellata, Ruiz \& Pav. Fl. Peruv. ii. $44=$ Hebecladus nmbellatus.

villosa, Zuccagni, in Roem. Collect. $130=$ Hebecladus umbellatus.

viridiflora, H. B. \& K. Nov. Gen. et Sp. iii. $11=$ Hebecladus viridiflorus.

ATROPIS, Rupr. Fl. Samoj. [Beitr. F1. Russ. Reich. ii.] $64(1845)=$ Glyceria, R. Br. (Gramin.).

angustata, Griseb. in Ledeb. Fl Ross. iv, $390=\mathrm{G}$. distans.

californica, Munro, ex A. Gray, in Proc. Acad. Sc. Philad. '1862' (1863) 336.-Am. bor. occ. capillaris, Schur, Enum. Pl. Transs. $779=\mathrm{G}$. distans. carinata, Griseb. in Goett. Abh. xxiv. (1879) 29I.Reg. Argent.

convoluta, Griseb, in Ledeb. F1. Ross. iv. $389=\mathrm{G}$. distans.

distans, Rupr. F1. Samoj. 64; Griseb. in Ledeb. Fl. Ross. iv. $388=\mathrm{G}$. distans.

festucaeformis, Schur, Enum. Pl. Transs. $780=\mathrm{G}$. maritima.

intermedia, Schur, 1. c. $779=\mathrm{G}$. maritima.

magellanica, E. Desv. in C. Gay, F1. Chil. vi. $394=$ G. magellanica.

maritima, Griseb. in Ledeb. Fl. Ross. iv. $389=\mathrm{G}$. maritima.

paucifiora, Thurb. in S. Wats. Bot. Calif. ii. $310=$ Poa pauciflora.

procumbens, Thurb. 1. c. 309.-Am. bor.

Pseudo-maritima, Schur, Enum. PI. Transs. $780=$ G. maritima.

pumila, T. Kirk, in Gard. Chrop. (1882) I. 261 ; Trans. N. Z. Inst. xiv, (1882) $379-\mathrm{N}$. Zel

scabrella, Thurb. in S. Wats. Bot. Calif. ii. $310=$ Poa scabrella.

tenuiflora, Griseb. in Ledeb. F1. Ross. iv. $389=\mathrm{G}$. distans.

tenuifolia, Thurb. in S. Wats. Bot. Calif. ii. $310=\mathrm{G}$. tenuifolia

transsilvanica, Schur, Enum. Pl. Transs. 889, Index= G. maritima.

ATRUTEGIA, Bedd. in Madr. Fourn. Ser. III. i. (1864) 37. f. 1. ANONACEAE, Benth. \& Hook. f. Gen. i. 957 .

wynadensis, Bedd. l. c.-Ind. or.

ATTALEA, H. B. \& K. Nov. Gen, et Sp. i. 309 (1815). PALMAE, Benth. \& Hook. f. iii. 947.

acaulis, Hort. ex H. Wendl. Cycl. Pand. Cycad. 4.Hab. ?

agrestis, Barb.-Rodr. Enum. Palm. Nov. $42=$ microcarpa.

amygdalina, H. B. E K. Nov. Gen. et Sp. i. 310. t. 95. -Am. austr.

blepharopus, Mart. in Palmet. Orb. 116. t. 5. f. 2.Bolivia.

butyrosa, Lodd. ex H. Wendl. in Kerch. Palm. $232=$ humilis.

Cephalotus, Poepp. ex Mart. in Palmet. Orb. $119=$

Scheelea Cephalotes.

Cohune, Mart.l.c. 121; et Hist. Nat. Palm. iii. 300. t. 167.- Honduras,

compta, Mart. Hist. Nat. Palm. i1. 137. t. 41, 75, 97. -Bras.

coronata, Lodd. ex H. Wendl. Cycl. Pand. Cycad.5.$\mathrm{Hab}$ ?

excelsa, Mart. Hist. Nat. Palm, ii. 138. t. 96. f. 3. -Bras.

exigua, Drude, in Mart. Fl. Bras. iii. II. 439.Bras.

funifera, Mart. Hist. Nat. Palm. ii. 136. t. 95, 96. f. 4. -Bras.

gomphococca, Mart. l. c. 301.-Am. austr.

grandis, Hort. ex H. Wendl. in Kerch. Palm. 233.Hab.?

Humboldtiana, Spruce, Palm. Amaz. 163.-Am. trop. humilis, Mart. in Spreng. Syst. ii. 624.-Bras.

limbata, Seem. ex H. Wendl. in Kerch. Palm. 233.Hab. ?

macrocarpa, Linden, Illustr. Hortic. xxviii. (1881) 15.
ATTALEA :-

Magdalenae, Linden, Illustr. Hortic. xxviii. (1881) 15 -N. Granat.

Manaca, Linden, $l$. c.-N. Granat.

maracaibensis, Mart. in Palmet. Orb. 124.-Peruv.

Maripa, Mart. 1. c. 123= Maximiliana Maripa.

microcarpa, Mart. l. c. 125.-Bras.

monosperma, Barb.-Rodr. Enum. Palm. Nov. $42=$ spectabilis.

nucifera, Karst. in Linnaea, xxviii. (1856) $255=$ amygdalina.

phalerata, Mart. in Spreng. Syst. ii. 624.-Bras.

Pixuna, Barb.-Rodr. Enum. Palm. Nov. $43=$ spectabilis.

Princeps, Mart. in Palmet. Orb. 113. t. 4. f. $2=$ Scheelea Princeps.

purpurea, Linden, Illustr. Hortic. xxviii. (1881) 16.N. Granat.

puruënsis, Linden, $l, c .-\mathrm{Fl}$. Amazon.

racemosa, Spruce, Palm. Amaz. $166=$ Orbignia racemosa.

Rossii, Lodd. ex Loud. Hort. Brit. 387.-Bras.

rostrata, Oerst. in Kjoeb. Vidensk. Meddel. (1858) 50 . - Costa Rica.

speciosa, Mart. Hist. Nat. Palm. ii. 138.-Bras.

spectabilis, Mart. l. c. 136. t. 96. f. 1, 2.-Bras.

spinosa, Meyen, Reise, i. 469.--Peruv.

Tiasse, Linden, Illustr. Hortic. xxviii. (1881) 16 , nomen.-F1. Amazon.

transitiva, Barb.-Rodr. Prot. App. 49.-Bras.

venatorum, Mart. Hist. Nat. Palm. iii. $325=$ Maximiliana venatorum.

ATTRACTIILS, Hall. ex Scop. Introd. (1777) $124=$ Atractylis, Linn. (Compos.).

ATULANDRA, Rafin. Sylva Tellur. 31 (1838) = Rhamnus, Linn.

arragonensis, Rafin. 1. c. $=\mathrm{R}$. lycioides.

valentina, Rafin. 1. c. $=$ R. pumila.

ATUNA, Rafin. Sylva Tellur. $153(1838)=$ Heritiera Dryand. (Stercul.)

racemosa, Rafin, 1. c. $=\mathrm{H}$. littoralis.

ATYLOSIA, Wight \& Arn. Prod. 257 (1834) LEGUMINOSAE, Benth. \& Hook. f. i. 542.

Cantharospermum, Wight \& Arn. Prod. 255 (1834).

albicans, Benth. in Miq. Pl. Fungh. 243.-Ind. or.

barbata, Baker, in Hook. f. Fl. Brit. Ind. ii. 216.Ind. or.; Malaya.

calycina, Kurz, in fourn. As. Soc. Beng. xliii. (1874) II. 186.-Ind. or.

candicans, Kurz, l. c. = Rhynchosia arvensis.

Candollei, Wioht E Arn. Prod. i. 257.-Ind. or.

cinerea, F. Muell. ex Benth. Fl. Austral. ii. 264.Austral.

circinnalis, Benth. in Miq. Pl. Jungh. $244=$ Dunbaria circinalis.

elongata, Benth. l. c. 243.--Ind. or.

geminiflora, Dalo. in Fourn. Limn. Soc. xiii. (1873) 185. - Ind. or.

glandulosa, Dalz. 1. c $=$ mollis

goënsis, Dalz. 1. c. $186=$ barbata

grandiflora, Benth. ex Baker, in. Hook. f. Fl. Brit. Ind ii. 214.-Reg. Himal.

grandifolia, F. Muell. ex Benth. Fl. Austral. ii. 264.Austral.

kulnensis, Dale. in Fourn. Linn. Soc. xiii. (1873) 186 -Ind. or.

Lawii, Dalz. l. c.-Ind. or.

Lawii, Wight, Ic. i. t. $93=$ lineata.

lineata, Wight \& Arn. Prod. i. 258.-Ind. or

major, Wight \& Arn. 1. c. $257=$ Candollei.

marmorata, Banks, ex Benth. Fl. Austral. ii. 263. Austral.

mollis, Benth. in Miq. Pl. Fungh. 243.--Ind, or.; Malaya.

nivea, Benth. l. c.-Burma

platycarpa, Benth. $l_{\text {. }} c_{0}-$-Reg. Himal.

pluriflora, F. Muell. ex Benth. Fl. Austral. ii. 264.Austral.

punctata, Dalz. in Journ. Linn. Soc. xiii. (1873) $186=$ Dunbaria conspersa.

reticulata, Benth. Fl. Austral. ii. 263.-Austral. rostrata, Baker, in Hook. f. Fl. Brit. Ind. ii. 216.Ind. or.

rugosa, Wight E Arn. Frod. i. 257.-Ind. or. 
ATYLOSIA :-

scarabaeoides, Benth. in Miq. Pl. Fungh. 242.-Austral.

sericea, Benth. ex Baker, in Hook. f. Fl. Brit. Ind. ii. 213. - Ind. or.

subrhombea, Miq. Ann. Mus. Bot. Lugd. Bat. iii. $51=$ Dunbaria subrhombea.

villosa, Benth. ex Baker, in Hook. f. Fl. Brit. Ind. ii. 214,-Reg. Himal.

ATYLUS, Salisb. Parad. Lond. sub t. $67(1807)=$ Petro phila, R. Br. (Proteac.)

anemonifolia, Salisb. 1. c, = Isopogon anemonifolius.

fucifolia, Salisb. 1. c. = P. pulchella.

AUBENTONIA, Domb. ex Steud. Nom. ed. I. 93 (1821) $=$ Waltheria, Linn. (Stercul.).

tomentosa, Domb. ex Steud. 1. c. =W. ovata.

AUBERTIA, Bory, Voy. i. 356. t. 18 (1804)=Zan thoxylum, Linn.? (Rutac.).

Bajarnardia, Buch.-Ham. in Wall. Cat. sub n. 7118 $=\mathrm{Z}$. Bajarnardia.

borbonica, Bory, Voy, i. 356. t. 18 (an Enodiae sp. ?-Cf Benth. \& Hook. f. Gen. i. 296)=Z. Aubertia.

piperita, Buch.-Ham。 ex Wall. Cat. sub n. $7117=\mathrm{Z}$ Hamiltonianum.

Timbor, Buch.-Ham. ex Wall. 1. c. n. $7116=\mathrm{Z}$, acan thopodium.

tomentosa, Bory, ex Steud. Nom. ed. II. i. $171=$ Z Aubertia.

AUBERTIA, Chapel, ex Baill. Adansonia, i. (1861) 162, $\mathbf{1 6 6}=$ Croton, Linn. (Euphorb)

argentea, Chapel. ex Baill. 1, c, $162=\mathrm{C}$. Noronhae. glandulosa, Chapel. ex Baill. l. c. $166=\mathrm{C}$. Chapelieri.

AUBION, Rafin. Sylva Tellur. $110(1838)=$ Cleome, Linn. (Capparid.).

Chelidoni, Rafin. 1. c. = C. Chelidonii.

AUBLETIA, Gaertn. Fruct. i. 379. t. 78. f. $2(1788)=$ Sonneratia, Linn. f. (Lythrar.).

caseolaris, Gaertn. 1. c. $=$ S. acida

AUBLETIA,Lour. Fl. Cochinch. $283(1790)=$ Paliurus, Tourn. (Rhamnac.).

ramosissima, Lour. 1. c. $=$ P. ramosissimus

AUBLETIA, Neck. Elem. i. $356 \quad(1790)=$ Ruellia Linn. (Acanth.).

AUBLETIA, Rich. in Pers. Syn. ii. $638(1807)=$ Mon nieria, Linn. (Rutac.)

trifoliata, Pers. 1. c. = M. trifolia.

AUBLETIA, Schreb. Gen. 353 (1789)=Apeiba, Anbl. (Tiliac.).

aspera, Willd. Sp. Pl. ii. $1156=$ Apeiba aspera. discolor, Spreng. Neue Entdeck. ii. $166=$ Apeiba discolor.

laevis, Willd. Sp. P1. ii. $1156=$ Apeiba glabra.

Petonma, Willd. 1. $\mathrm{c}_{\mathrm{r}}=$ Apeiba Petouma.

Tibourbou, Willd. 1. c. = Apeiba Tibourbou.

Tiburbu, Sw. F1. Ind. Occ. ii. $944=$ praec.

AUBRIFTIA, Adans. Fam. ii. 420 (1763) (Aubrieta) DC. in Mém. Mus. Par. vii. (1821) 232 ; Syst. ii. 293. CRUCIFERAE, Bentb. \& Hook. f. Gen. i. 73. canescens, Boiss. Fl. Orient. i. $252=$ deltoidea.

Columnae, Guss, Pl. Rar. 266.-Ital.

croatica, Schott, Nyman E Kotschy, Analect. Bot. 47. -Croatia.

deltoidea, DC. Syst. ii. 294.-Italia; Graecia ; As. Min. diffusa, Spreng. Syst. ii. $871=$ Heliophila diffusa.

edentula, Boiss. Fl. Orient. i. 254-Kurdistan.

erubescens, Griseb. Spicil. Fl. Rumel, i. 268.Graecia.

floribunda, Spach, Hist. Vég. Phan. vi. $469=$ deltoidea.

gracilis, Sprun. ex Boiss. Diagn. Ser. I. i. 74.-

Graecia.

graeca, Griseb. Spicil, F1. Rumel, i, $268=$ deltoiden

hesperidiflora, G. Don, ex Loud. Hort. Brit. $257=$ deltoider.

integrifolia, Fisch. \& Mey. in Ann. Sc. Nat. Sér. IV. i (1854) $35=$ deltoidea.

intermedia, Heldr. E Orph. ex Boiss. Diagn. Ser. II. i. 36.-Graecia.

\section{AUBRIFTIA :-}

Kotschyi, Boiss. E Hohen. Diagn. Ser. I, viii. 32.Persia.

italica, Boiss. F1. Orient. i. 252, in nota $=$ Columnae. lepidioides, Spreng. Syst, ii, $871=$ Heliophila diffusa libanotica, Boiss. E Hohen. Diagn. Ser. I. viii. 32.Mont. Libanus.

olympica, Boiss. Fl. Orient. i. 251.-Bithynia.

parviflora, Boiss. Diagn. Ser. I. vi. 14.-Persia.

Pinardi, Boiss, l. c. Ser. II i. 37-As. Min.

purpurea, DC. Syst. ii. $294=$ Arabis purparea.

AUBRYA, Baill. Adansonia, ii. 265 (1861-62) HUMIRIACEAE, Benth. $8 C$ Hook. f. i. 988. gabonensis, Baill. l. c. 266.-Afr. trop.

AUCHERA, DC. Coll. Mém. ix. t. 11; Prod. vi. 557 $(\mathbf{1 8 3 7})=$ Cousinia, Cass. (Compos)

floribunda, Regel, Cat. Pl. Hort. Aksakov. 13.-Hab.? orientalis, DC. Coll. Mém. ix. t. $11=\mathrm{C}$, orientalis.

AUCKLANDIA, Falc. in Trans. Linn. Soc. xix. (1845) 23 = Saussurea, DC. (Compos.)

Costus, Falc. 1. c. $=\mathrm{S}$. Lappa.

AUCUBA, Thunb. Nov. Gen.61 (1783), CORNA CEAE, Benth. \& Hook. f. i. 950 .

Eubasis, Salisb. Prod. 68 (1796)

chinensis, Benth. Fl. Hongk. 138.-China.

himalaica, Hook. $f$. E Thoms. Illustr. Himal. Pl. t. 12. -Reg. Himal.

japonica, Thunb. Nov. Gen. 61.-Japon.

AUCUBA, Cham. in Linnaea, v. (1830) 56, in syn.= ARUBA, Nees \& Mart. = Raputia, Aubl. (Rutac.).

AUCUBAEPHYLLUM, Ahlburg, in Bot. Zeit. xxxvi. (1878) 113. CORNACEAE.

lioukiense, Ahlburg, l. c.-Japon.

AUCUPARIA, Riv. ex Rupp. Fl. Jen. ed. Haller. 140 $(1745)=$ Pyrus, Linn. (Rosac.).

pinnata, Fourr. in Ann. Soc. Linn. Lyon, N. S. xvi. (1868) $378=$ P. Aacuparia.

sylvestris, Medic. Gesch. $86=$ P. Aucnparia.

AUDIBERTIA, Benth. in Bot. Reg. sub t. 1282 (1829)= Mentha, Linn. (Labiat.)

parviflora, Nym. Consp. $597=$ M. Requieni.

pusilla, Benth. in Bot. Reg. sub t. $1282=\mathrm{M}$. Requieni.

AUDIBERTIA, Benth, in Bot. Reg, t. 1469 (1831) LABLATAE, Benth. \& Hook. f. ii. 1197.

capitata, A. Gray, in Proc. Am. Acad. vii. (1868) 387. $\rightarrow$ Calif.

Clevelandi, A. Gray, l. c. x. (1874) 76.-Calif.

decurrens, Nutt. ex Benth. in DC. Prod. xii. $359=$ grandiflora.

Dorrii, Kellogg, in Proc. Calif. Acad. ii. (1863) 190.Calif.

grandifora, Benth. Lab. Gen. et Sp. 312,-Calif.

humilis, Benth. l. c. 313.-Calif

incana, Benth. in Bot.Reg. t. 1469.-Am. bor. occ

nivea, Benth. Lab. Gen. et Sp. 313.-Calif.

Palmeri, A. Gray, in Bot. Calif. i. 601.-Calif

polystachya, Benth. Lab. Gen. et Sp. 314.-Calif.

spinulosa, Nutt. ex Benth. in DC. Prod. xii. $359=$ stachyoides.

stachyoides, Benth. Lab. Gen. et Sp. 313.-Calif

Vaseyi, $T$. C. Porter, in Coult. Bot. Gasette,

(1881) 207.-Calif.

AUDOUINIA, Brongn. in Ann. Sc. Nat. viii. (1826) 384. t. 38. BRUNIACEAE, Benth. \& Hook. f. i. 673 Pavinda, Thunb. ex Bartl. Ord. 374 (1830).

capitata, Brongn. l. c.-Afr. austr.

AUGANTHUS, Link, Handb. i. $415(1829)=$ Primula, Linn.

praenitens, Link, 1. $c_{0}=\mathrm{P}$. sinensis.

AUGEA, Thunb. ex Retz. Obs. v. 3 (1799)=Lanaria, Ait. (Haemod.)

lanata, Thunb. ex Retz, 1, c. $=$ L. plamosa.

AUGEA, Thunb. Prod. PI. Cap. 80 (1794); et Nov. Gen. 182 (1798). ZYGOPHYLLEAE, Bentb. \& Hook. f. i. 265.

capensis, Thuns. ll. cc. 80 et 133.-Afr. austr.
AUGIA, Lour. Fl. Cochinch. 337 (1790). 'Genus igno. tum,' Benth. \& Hook. f. Gen. i. 418.

sinensis, Lour. 1. c. (=Calophyllum Augia ex Stend. Nom. ed. II. i. 171).-China.

AUGUSTA, Leandr. Sacram, in Denkschr. Akad. Muench. vii. (1819) 235. t. $14=$ Stiffíia, Mikan (Compos. grandiflora, Leandr. Sacram. 1. c. =S. chrysantha. parviflora, Leandr. Sacram. 1. c. =S. parvilfora.

AUGUSTA, Pohl, P1. Bras. Ic. ii. 1. t. 101-105. RUBIACEAE, Benth. \& Hook, f. ii. 51

Bonifacia, Manso, ex Steud. Nom. ed. II i. 216 $(1840)$

Schreibersia, Pohl, in Flora, viii. (1825) 183

attenuata, Pohl, Pl. Bras. Ic. ii. t. 104.-Bras.

glaucescens, Pohl, l. c. t. 105.-Bras.

lanceolata, Pohl, l. c. t. 101.-Bras.

oblongifolia, Pohl, l. c. t. 103.-Bras.

parvifolia, Pohl, l. c. t. 102.-Bras.

AUGUSTEA, DC. Prod. iv. $404(1830)=$ Augusta Poht (Rubiac.)

AUGUSTIA, Klotzsch, in Monatsb. Berl. Acad. (Maer, 1854) 124; et Abh. Akad. Berl. (1854) 80. t. 8. B. = Begonia, Linn.

caffra, Klotzsch, 11. ce, $124 \& 81=$ B. caffra.

Dregei, Klotzsch, 11. cc. $124 \& 80=$ B. Dregei.

natalensis, Klotzsch, 11. cc. $181 \& 80=\mathrm{B}$. natalensis

suffruticosa, Klotzsch, 11. cc. 124 \& $82=$ B. suffruticosa.

AUGUSTINEA, Karst. in Linnaea, xxviii. (1856) $395=$ Bactris, Jacq. (Palm.)

balanoidea, Oerst. in Kjoeb. Vidensk. Meddel. (1858 $39=$ B. balanoidea.

major, Karst. in Linnaea, xxvili. (1856) $395=\mathrm{B}$. major.

ovata, Oerst. in Kjoeb. Vidensk. Meddel. (1858) $38=$ B. ovata.

AUGUSTINEA, St. Hil. \& Naud. in Ann. Sc. Nat. Sér III. ii. (1844) $145=$ Miconia, Ruiz \& Pav. (Melast.) speciosa, St. Hil. \& Naud. 1. c. = M. speciosa.

AULACIA, Lour. Fl. Cochinch. $273(1790)=$ Clausena Burm. f. (Rutac.)

falcata, Lour. Fl. Cochinch. 273 (=Cookia falcata).Cochinch.

falcifolia, Stokes, Bot. Mat. Med. ii. $482=$ praec. punctata, Raeusch. Nom. ed. III. $119=\mathrm{Cl}$. Wampi.

AULACIDIUM, Rich, ex DC. Prod. iii. 112 (1828)= Macrocentrum, Hook. f. (Melast.)

cristatum, Rich。 ex DC. 1. c. $113=$ M. cristatum. fasciculatum, Rich. ex DC. 1, c. = M. fascicolatum.

AULACINTHUS, E. Mey, Comm. Pl. Afr. Austr. 155 (1835) = Lotononis, Eckl. \& Zeyh. (Legam.). gracilis, E. Mey. 1. c. = L. gracilis rigidus, E. Mey. 1. c. $=$ L. rigidus.

AULACOCALYX, Hook, $f$, in Hook. Ic. Pl, t, 1196 (1873). RUBIACEAE, Benth. \& Hook. f. ii. 109. jasminiflora, Hook.f.l. c.-Afr. trop.

AUIACOCARPUS, Berg, in Linnaea, xxvii. " 1854 345. MYRTACEAE, Benth. \& Hook. f. i. 720. crassifolius, Berg, l. c. $3 \pm 6$,-Ins. Gorgona.

qnadrangularis, Griseb. Fl. Brit. W. Ind. 299.-Iad, occ.

Sellowianus, Berg, in Linnaea, xrvii. ("1S54') 846.Bras.

Wrightii, Griseb. Cat. Pl. Cub. 90.-Caba,

AULACODISCUS, Hook of in Benth. \& Hook. Gien. ii. 71 (1873), non Ehrenb. quae Cryph). RL'BIA CEAE, Benth. \& Hook. ro ii. - il.

premnoides, Hook.f. l. c.-Malaya.

AULACOPHYLLUM, Regel, Gartenf. (15\%6) $141=$ Zamia, Lina. (Cyend.).

Lindeni, Kegel, l. $c_{0}=2$. Lindeni.

montanum, Kegel, 1. c. = Z. montana.

Ortgiesi, Reggel, 1. c. ca Z. Chigua.

Rocsli, Regel, 1. c. = Z. pseudo.parasicica.

Skinneri, Regel, l. c 14\$ $=$ Z. Skinneri.

Wallisii, Regel, I, c, = Z. Wallisii. 
AULACORHYNCHUS, Nees, in Linnaea, ix. 305 (1834); ib. x. 198 (1835). CYPERACEAE, Benth. \& Hook, f, Gen, iii. 1043.

criniflorus, Steud. Nom. ed. II. i. $171=$ seq.

crinifolius, Nees, in Linnaea, ix. 305; et x. 199.-Afr. austr.

AULACOSPERMUM, Ledeb. Fl. Alt, iv. 344 (1833)= Pleurospermum, Hoffm. (Umbell.).

anomalum, Ledeb. 1. c. 335.-Mont. Altai cuneatum, Ledeb. 1. c.-Mont. Altai.

multifidum, Meinsh. in Linnaea, xxx. (1859-60) 515. -Sibir.

simplex, Rupr. Sert. Tiansch. $49=$ P. stellatum.

tenuilobum, Meinsh. in Linnaea, xxx. (1859-60) 515. -Sibir.

AUlACOSTIGMA, Turcz in Bull. Soc. Nat. Mosc. $x_{\text {x }}$. (1847) I. $149=$ Rhynchotheca, Ruiz \& Pav. (Geran.) inerme, Turcz. 1. c. 150.- Reg. Andina.

AULAX, Berg. Descr. Pl. Cap. 33 (1767)。 PROTEACEAE, Benth. \& Hook, fo iii. 168. cneorifolia, Knight, Prot. 15.-Afr. austr. pinifolia, Berg. Descr. Pl. Cap. 33.-Afr. austr. umbellata, R. Br. in Trans. Linn. Soc。 X. (1810) $50=$ cneorifolia.

AULAXANTHUS, Ell. Sketch, i. 102 (1817)= Anthae nantia, Beauv. (Gramin.)

ciliatus, Ell. l. c $c_{0}=$ Anthaenantia villosa.

rufus, Ell. 1. c. t. $6=$ Anthaenantia rufa.

AULAXIA, Nutt. Gen. Am. i. 47 (1818)=Anthaenantia, Beauv. (Gramin.).

ciliata, Nutt. 1. c. = Anthaenantia villosa.

rufa, Nutt. 1. $\mathrm{c}_{\text {. }}=$ Anthaenantia rufa.

AULAXIS, Haw. Enum. Saxif。 46 (1821)= Saxifraga, Linn.

micranthifolia, Haw. I. c. $47=$ S. erosa.

nuda, Haw. 1. $\mathrm{c}_{\boldsymbol{}}=\mathrm{S}$. erosa,

AULAXIS, Steud. Nom, ed. II. i. 171 (1840)=AULAYIA, Nutt. = Anthaenantia, Beauv. (Gramin.)

AULAYA, Harv. Gen. Pl. Afr. Anstr. 249 (1838)= Harveya, Hook. (Scrophul.).

capensis, Harv. 1. c. $250=\mathrm{H}$. capensis.

coccinea, Harv. Thes. Cap. i, 23.-Afr. austr. grandiflora, Benth. in DC. Prod. x. 523.-Afr, austr. obtusifolia, Benth. 1. c. = H. obtusifolia. pauciflora, Benth. 1. c. 524.-Afr. austr. purpurea, Benth. 1. c. $523=$ H. purpurea. scarlatina, Benth. 1. c. 524.-Afr. austr. squamosa, Harv. Gen. PI. Afr。 Austr. $250=\mathrm{H}$. squamosa.

AULEYA, D. Dietr. Syn. Pl. iii. 539 (1843)= praec.

AULICA, Rafin. F1. Tellur. iv. $10(1836)=$ Hippeastrum, Herb. (Amaryll, ).

latifolia, Rafin. 1. c. $=$ H. aulicum.

platypetala, Rafin。 1. $\mathrm{c}_{0}=\mathrm{H}$. anlicum.

striata, Rafin. $l_{1} \mathrm{c}_{2}=\mathrm{H}$. anlicum.

AULIPHAS, Rafin. Sylva Tellur. 95 (1838)= Miconia, Ruiz \& Pav. (Melast.)

ligustrina, Rafin. 1. c. $=$ M. ligustrioides.

AULIZA, Salisb. in Trans. Hort. Soc. i. (1812) $294=$ Epidendrum, Linn. (Orchid.)

ciliaris, Salisb. 1. c. $=$ E. ciliare.

AULOMYRCIA, Berg, in Linnaea, xxvii. (1854) $35=$ Myrcia, DC. (Myrtac.).

Abrantea, Berg, 1. c. xxx. (1859-60) 659.-Bras.

acetosans, Berg, 1. c. 662 .-Ind. occ.

acrantha, Berg, in Mart. Fl. Bras. xiv. I. 71.-Bras,

acutata, Berg, 1. $c_{0}=$ M. acutata.

acutifolia, Berg, 1. c. $89,-$ Bras.

Aethusa, Berg, 1. c. 112.-Bras

alagoënsis, Berg, 1. c. $120=$ M. alagoënsis.

albo-tomentosa, Berg, in Linnaea, xxvii. (1.854) $62=$ M. albo-tomentosa.

alloiota, Berg, 1. c. 54.-Bras.

alternifolia, Berg, 1. с. $72=\mathrm{M}$. alternifolia.

amazonica, Berg, 1. c. $41=$ M. amazonica.

\section{AULOMYRCIA :-}

amethystina, Berg, in Mart. Fl. Bras. xiv. I. 108.-Bras.

andromedoides, Berg, in Linnaea, xxvii. (1854) $40=$ Myrcia andromedoides.

androsaemoides, Berg, 1. c. $\mathrm{xxx} .(1859-60)$ 661.Guiana.

angustifolia, Berg, in Mart. Fl. Bras. xiv. I, 135.Bras.

anomala, Berg, 1. c. $96=$ M. anomala.

apiocarpa, Berg, l. c. 64.-Bras.

atropilosa, Berg, 1. c. 101.--Bras.

atrovirens, Berg, 1. c. 121.--Bras.

aureo-lanata, Berg, in Linnaea, xxvii. (1854) 52.Bras.

badia, Berg, in Mart. F1. Bras. xiv. I. 547.-Bras.

bahiensis, Berg, 1. c. 113.-Bras.

bella, Berg, 1. c. $71=$ M. bella.

bicarinata, Berg, 1. c. 118.-Bras.

bicudoënsis, Berg, 1. c. 557.-Bras.

biformis, Berg, 1. c. 141.-Bras.

Billardiana, Berg, in Linnaea, xxvii. (1854) $51=\mathrm{M}$. Billardiana.

bimarginata, Berg, in Mart. Fl. Bras. xiv. I. 115.Bras.

Blanchetiana, Berg, 1. c. 65.-Bras.

bombycina, Berg, 1. c. 66.-Bras.

Botrys, Berg, 1. c. 116.-Bras.

bracteata, Berg, l. c. $554=$ M. bracteata.

breviramis, Berg, I. c. 66. - Bras.

bullata, Berg, 1. c. $96=$ M. bullata

buxifolia, Berg, 1. c. $80=$ M. buxifolia.

buxizans, Berg, in Linnaea, xxx. (1859-60) 664,Guiana.

caerulescens, Berg, in Mart. Fl. Braso xiv. I. 80_-Bras. caesia, Berg, 1. c. 83.-Bras.

calyptranthoides, Berg, 1. c. 67.-Bras.

Camaraeana, Berg, 1. c. $83=$ M. Camaraeana.

Cambessedeana, Berg, in Linnaea, xxvii. (1854) $40=$ M. Cambessedeana.

campestris, Berg, 1. c. $74=$ M. campestris

capitata, Berg, in Mart. FI. Bras. xiv. I. $554=$ M. capitata.

capivarhyensis, Berg, in Linnaea, xxvii. (1854) $36=$ M. capivarhyensis.

caracasana, Berg, 1. c. $53=$ M. caracasana.

cardiophylla, Berg, in Mart. F1. Bras. xiv. I. $103=$ M. cardiophylla.

cassinoides, Berg, in Linnaea, xxvii, (1854) $74=\mathrm{M}$. cassinoides.

castrensis, Berg, in Mart. F1. Bras. xiv, I, 111.-Bras. chapadensis, Berg, 1. c. 554,-Bras.

chilensis, Berg, in Linnaea, xxvii. (1854) $38=\mathrm{M}$. chilensis.

chrysophylla, Berg, in Mart. Fl. Bras, xiv. I. 125.Bras.

Clausseniana, Berg, 1. c. 118.-Bras.

collina, Berg, in Linnaea, xxvii. (1854) 40.-Bras.

comosa, Berg, in Mart. Fl. Bras, xiv, I. 133.-Bras.

conduplicata, Berg, in Linnaea, xxvii. (1854) 76.Guiana.

confusa, Berg, 1. c. 56.-Bras.

coriacea, Berg, 1. c. $70=$ M. coriacea.

corymbiflora, Berg, 1. c. 74.-Bras.

corymbosa, Berg, 1. c. $41=$ M. corymbosa

costata, Berg, in Mart. Fl. Bras, xiv. I. $79=$ M. costata.

Coumeta, Berg, in Linnaea, xxvii. (1854) $60=$ M. Coumeta.

crassicaulis, Berg, 1. c. $74=$ M, crassicaulis

crassifolia, Berg, in Mart. Fl. Bras, xiv. I. 128.-Bras. crenulata, Berg, 1. c. 141-Bras.

cuneata, Berg, in Linnaea, xxvii. (1854) 72,-Venezuela.

cuprea, Berg, in Mart. F1. Bras. xiv, I. 77.-Bras curatellaefolia, Berg, in Linnaea, xxvii. (1854) $55=$ M. curatellaefolia.

cymosa, Berg, in Mart. Fl. Bras. xiv. I. 552.-Bras,

daphnoides, Berg, in Linnaea, xxvii. (1854) $77=\mathrm{M}$. daphnoides.

dealbata, Berg, 1. c. $61=$ M. dealbata.

debilis, Berg, 1. c. $62=\mathrm{M}$. debilis.

decrescens, Berg, in Mart. Fl, Bras. xiv. I. 135.-Bras,

densa, Berg, in Linnaea, xxvii, (1854) $37=$ Calyptranthes densa.

desertorum, Berg, in Mart. F1. Bras. xiv. I, 556.Bras.

detergens, Berg, in Linnaea, xxvii. (1854) $46=\mathrm{M}$. detergens.
AULOMYRCIA :-

diaphana, Berg, in Mart. Fl. Bras. xiv. I. 82 -Bras.

dichroma, Berg, in Linnaea, xxvii. (1854) 65.-Guiana.

dictyophleba, Berg, in Mart. Fl. Bras. xiv. I. 560.Bras.

dictyophylla, Berg, 1. c. 72.-Bras.

dimorpha, Berg, 1. c. 101,-Bras.

divaricata, Berg, in Linnaea, xxvii. (1854) $58=\mathrm{M}$. divaricata.

Doniana, Berg, in Mart. Fl. Bras. xiv. I. 510=M. Doniana.

dumosa, Berg, in Linnaea, xxx. (1859-60) 656.Guiana.

edulis, Berg, 1. c. 657.-Guiana.

egensis, Berg, in Mart. Fl. Bras, xiv, I. 99,-Bras.

elaeodendra, Berg, in Linnaea, xxvii. (1854) $75=\mathrm{M}$. elaeodendra.

emarginata, Berg, in Mart. Fl. Bras. xiv. I. 134.Bras.

eumecophylla, Berg, 1. c. 98.-Bras.

exsucca, Berg, in Linnaea, xxvii. (1854) $79=$ M. exsucca.

Fenzliana, Berg, 1. c. $63=$ M. Fenzliana.

ferruginea, Berg, in Mart. Fl. Bras。 xiv. I. $552=\mathrm{M}$. ferruginea.

fragilis, Berg, 1. c. 117.-Bras.

Gardneriana, Berg, 1. c. $129=$ M. Gardneriana.

garopabensis, Berg, in Linnaea, xxvii. (1854) $47=\mathrm{M}$. garopabensis.

Gaudichaudiana, Berg, in Mart. Fl. Bras. xiv. I. 88.Bras.

gigantea, Berg, 1. c. 548.-Bras.

glabra, Berg, 1. c. 119.-Bras.

olandulosa, Berg, in Linnaea, xxvii. (1854) 79.-Bras. glauca, Berg, 1. C. $50=$ M. glauca.

glaucescens, Berg, in Mart. Fl. Bras. xiv. I. 81,-Bras. goyazensis, Berg, 1. c. $85=$ M. goyazensis.

grandiflora, Berg, 1. c. 113,-Bras.

grandifolia, Berg, l. c. $97=$ M. grandifolia.

hepatica, Berg, 1. c. 132.-Bras.

hirtiftora, Berg, in Linnaea, xxvii. (1854) $40=\mathrm{M}$ hirtiflora.

holosericea, Berg, in Mart. Fl. Bras. xiv. I. 99--Bras.

Hostmanniana, Berg, in Linnaea, xxvii. (1854) 42.Guiana.

hypericoides, Berg, 1. c. $62=$ M. hypericoides.

imbricata, Berg, 1. c. $61=$ M. imbricata.

insularis, Berg, in Mart. F1. Bras. xiv. I. $98=$ M. insularis.

intermedia, Berg, 1. c. 107.-Bras.

Facquiniana, Berg, in Linnaea, xxvii. (1854) 69=M. coriacea.

jequitinhonhensis, Berg, in Mart. Fl. Bras. xiv. I. 137. -Bras.

Klotzschiana, Berg, 1. c. 111= M. Klotzschiana

laciniosa, Berg, 1. c. 545.-Bras.

lancea, Berg, 1. c. 88,-Bras.

lancifolia, Berg, in Linnaea, xxx. (1859-60) 658.Guiana.

Langsdorffi, Berg, in Mart. Fl. Bras. xiv. I. $550=\mathrm{M}$. Langsdorffi.

lanuginosa, Berg, 1. c. 102=M. lanuginosa

laricina, Berg, 1, c.61.-Bras.

Laruottiana, Berg, in Linnaea, xxvii. (1854) $53=\mathrm{M}$ Laruottiana.

Laureola, Berg, in Mart. Fl. Bras. xiv. I. 110.-Bras.

lauriflora, Berg, in Linnaea, xxvii. (1854) $64=\mathrm{M}$ lauriflora.

Taurifolia, Berg, 1. c. = M. laurifolia.

laxiflora, Berg, in Mart. Fl. Bras. xiv. I. $114=\mathrm{M}$. laxiflora.

leptoclada, Berg, in Linnaea, xxvii. (1854) 40=M. leptoclada.

Leucadendron, Berg, 1. c. $64=$ M. Leucadendron.

leucantha, Berg, in Mart. Fl. Bras. xiv. I. 93.-Bras.

linearifolia, Berg, in Linnaea, xxvii. (1854) $35=\mathrm{M}$ linearifolia.

lineata, Berg, in Mart. F1. Bras. xiv. 1. 68.-Bras.

Lingua, Berg, in Linnaea, xxvii. (1854) 77.-Bras.

linguaeformis, Berg, in Mart. FI. Bras. xiv. I. 125.Bras.

longipes, Berg, in Linnaea, xxvii. (1854) 55.-Bras.

lucida, Berg, in Mart. Fl. Bras. xiv, I. 118.-Bras.

macrocarpa, Berg, in Linnaea, xxvii. (1854) $41=\mathrm{M}$. macrocarpa.

macrophylla, Berg, in Mart. Fl. Bras. xiv. I. $99=\mathrm{M}$. macrophylla.

Mansoni, Berg, 1. c. 121.-Bras. 
AULOMYRCIA :-

Maraguana, Berg, in Mart. F1. Bras. xiv. I. $120=$

Myrcia Maraguana.

maritima, Berg, 1. c. 553.-Bras.

Martiana, Berg, 1. c. $138=$ M. Martiana

Mathersiana, Berg, in Linnaea, xxvii. (1854) 45.Peruv.

micrantha, Berg, in Mart. Fl. Bras. xiv. I. 516.Bras.

microcárpa, Berg, 1. c. $81=$ M. microcarpa.

micropetala, Berg, in Linnaea, xxvii. (1854) $56 .-$ Bras.

montana, Berg, 1. c. $36=$ M. montana.

mugiensis, Berg, 1. c。= M. mugiensis.

multiflora, Berg, 1. c. $47=$ M. multiflora

mutabilis, Berg, in Mart. Fl. Bras. xiv. I. 70.-Bras.

myrtillifolia, Berg, in Linnaea, xxvii. (1854) $36=\mathrm{M}$ myrtillifolia.

Neesiana, Berg, 1. c. $36=$ M. Neesiana.

nigrescens, Berg, 1. c. $71=\mathrm{M}$. nigrescens

nigricans, Berg, in Mart. F1. Bras. xiv. I. 101.-Bras.

nigro-punctata, Berg, 1. c. 116.-Bras.

nivea, Berg, in Linnaea, xxvii. (1854) 61=M. nivea.

oblongata, Berg, 1. c. $37=\mathrm{M}$. oblongata.

obovata, Berg, 1. c. 72 .-Bras.

obscura, Berg, in Mart. Fl. Bras, xiv, 1. 132,-Bras.

obtecta, Berg, 1. c. 117.-Bras.

obtusa, Berg, in Linnaea, xxvii. (1854) $66=\mathrm{M}$. obtusa.

obtusata, Berg, 1. c. 39.-Bras.

orthophylla, Berg, in Mart. Fl. Bras, xiv. I. 549.Bras.

Ottonis, Berg, in Linnaea, xxvii. (1854) 55.-Guiana

ovalifolia, Berg, in Mart. F1. Bras. xiv. I. 81.-Bras.

ovalis, Berg, 1. c. 107.-Bras.

pachyclada, Berg, 1. c. 133.-Bras.

pallens, Berg, in Linnaea, xxvii. (1854) $73=$ M. pallens.

pallida, Berg, in Mart. FI. Bras. xiv. 1. 87.-Bras.

panicularis, Berg, 1. c. 84-Bras.

paniculata, Berg, in Linnaea, xxvii. (1854) 50.-Bras.

paraënsis, Berg, in Mart. FI. Bras. xiv, 1. 76.-Bras.

parnahibensis, Berg, 1. c. 135.-Bras.

pauciflora, Berg, 1. c. $560=$ M. pauciflora

perforata, Berg, 1. c. 83. -Bras.

pertusa, Berg, in Linnaea, xxvii. (1854) $47=\mathrm{M}$. pertusa.

piauhiensis, Berg, in Mart. Fl. Bras. xiv. I. 87.-Bras. pilantha, Berg, 1. c. 555.-Bras.

pinifolia, Berg, in Linnaea, xxvii. (1854) $35=\mathrm{M}$. pinifolia.

pirarensis, Berg, 1. c. 41.-Guiana.

platyclada, Berg, in Mart. Fl. Bras. xiv. I. $545=$ M. platyclada.

plumbea, Berg, 1. c. 142.-Bras.

Poeppigiana, Berg, in Linnaea, xxvii. (1854) 73.Bras.

Pohliana, Berg, in Mart. Fl. Bras, xiv. 1. 72.-Bras.

polyantha, Berg, 1. c. $82=$ M. Kunthiana.

polymorpha, Berg, in Linnaea, xxvii. (1854) 46.Bras.

pruinosa, Berg, in Mart. Fl. Bras. xiv, I. 114.-Bras.

prunifolia, Berg, in Linnaea, xxvii. (1854) $55=\mathbf{M}$. prunifolia.

puberula, Berg, 1. c. $54=$ M. puberula

pubiflora, Berg, 1, c. $40=$ M. pubiflora.

pulchra, Berg, in Mart. F1. Bras. xiv, 1. 68-Bras.

punctata, Berg, 1. c. $546=$ M. punctata.

pusilla, Berg, I. c. 140.-Bras.

pyrifolia, Berg, in Linnaea, xxvii. (1854) 44.-Bras

racemosa, Berg, 1, c. 52.-Bras

ramuliflora, Berg, in Mart. Fl. Bras. xiv. I. 64.-Bras.

ramulosa, Berg, in Linnaca, xxvii. (1854) $36=\mathrm{M}$.

ramulosa.

Regeliana, Berg, in Mart. Fl. Bras. xiv. I. 55\%.-Bras.

reticulata, Berg, 1. c. $108=$ M. reticulata.

reticulosa, Berg, in Linnaea, xxvii. (1854) $62=\mathrm{M}$. reticulosa.

retusa, Berg, in Mart. Fl. Bras. xiv. I. 142.-Bras.

Richardiana, Berg, in Linnaea, xxx. (1859-60) 664.Bras.

Riedeliana, Berg, in Mart. F1. Bras, xiv. 1. 551.Bras.

roraimensis, Berg, in Linnaea, xxvii. (1854) 68.Guiana.

rorida, Berg, in Mart. Fl. Bras, xiv. 1. 552.-Bras. rostrata, Berg, l. c. $544=\mathrm{M}$. rostrata.

rosulans, Berg, in Linnaea, xxvii. (1854) 54,-Bras,

rotundifolia, Berg, in Mart. F1. Bras. xiv, 1. 123.Bras.

\section{AULOMYRCIA :-}

rubella, Berg, in Linnaea, xxvii. (1854) $40=$ M. rubella rufa, Berg, in Mart. Fl. Bras, xiv. I. 65.--Bras.

rufipes, Berg, in Linnaea, xxvii. (1854) $77=$ M. rufipes. rugosa, Berg, in Mart. E1. Bras. xiv. 1. 110.-Bras.

Sagraea, Berg, in Linnaea, xxx. (1859-60) 655.-Cuba salicifolia, Berg, 1. c. xxvii. (1854) $78=$ M. salicifolia. Salsmanni, Berg, in Mart. F1. Bras, xiv, I, 116. Bras.

Schomburgkiana, Perg, in Linnaea, xxvii. (1854) 75.Bras.

Schrankiana, Berg, 1. c. $79=$ M. Schrankiana.

scrobiculata, Berg, in Mart. Fl. Bras. xiv. I. $137=$ M scrobiculata.

Sonderiana, Berg, 1. c. 110.-Bras.

spathulata, Berg, 1. c. 91 -Bras.

sphaerocarpa, Berg, in Linnaea, xxvii. (1854) $51=\mathrm{M}$. sphaerocarpa.

sphenoides, Berg, in Mart. Fl. Bras. xiv. I. 63.-Bras.

Spruceana, Berg, 1. c. 76.-Bras.

stenophylla, Berg, in Linnaea, xxx.(1859-60) 654.-

Paraguay.

stictophylla, Berg, in Mart. F1. Bras, xiv, I. 67.-Bras.

stricta, Berg, 1. c. 548.--Bras.

suaveolens, Berg, in Linnaea, xxvii. (1854) $78=\mathrm{M}$ suaveolens.

subalpestris, Berg, 1. c. $73=$ M. subalpestris.

subavenia, Berg, in Mart, Fl. Bras. xiv. I. 69.-Bras.

subcordata, Berg, in Linnaea, xxvii. (1854) $62=\mathrm{M}$ subcordata.

subobliqua, Berg, 1. c. 57.-Guiana.

subverticillaris, Berg, 1. c. 73.--Bras.

suffruticosa, Berg, in Mart. Fl. Bras. xiv. r. 136.-Bras.

supraaxillaris, Berg, 1, c. 69,-Bras.

surinamensis, Berg, in Linnaea, xxvii. (1854) 64=M surinamensis,

tenuifolia, Berg, in Mart. F1. Bras. xiv. I. 68.-Bras. ternifolia, Berg, 1. c. 134.-Bras.

thyrsiflora, Berg, in Linnaea, xxvii. (1854) 74.-Bras

torta, Berg, 1. c. $78=$ M. torta

tortuosa, Berg, in Mart. Fl. Bras, xiv. I. 558.-Bras,

trichantha, Wawra, in Oestr. Bot. Zeitschr. xxix. (1879) 215. - Bras.

triflora, Berg, in Linnaea, xxvii. (1854) $79=\mathrm{M}$. triflora.

trifolia, Berg, in Mart. Fl. Bras. xiv. 1. 107.-Bras.

undulata, Berg, 1. c. 89.-Bras.

vacciniffolia, Berg, 1. c. 140-Bras.

variabilis, Berg, in Linnaea, xxvii. (1854) $62=\mathrm{M}$ variabilis.

Vautheriana, Berg, 1. c。 xxx. (1859-60) $655=\mathrm{M}$. Vauthieriana.

velhensis, Berg, in Mart. Fl. Bras, xiv. I. 560.-Bras,

venulosa, Berg, in Linnaea, xxvii. (1854) $63=\mathrm{M}$. venulosa.

vestita, Berg, 1. c. $74=$ M. vestita.

virgata, Berg, in Mart. Fl. Bras. xiv. I. $136=$ M. virgata Widgreniana, Berg, 1. c. 70.-Bras.

Wullschlaegeliana, Berg, in Linnaea, xxvii. (1854) 48. -Guiana.

AULONEMIA, Goudot, in Ann. Sc. Nat. Sér. III. v. (1846) 76. t. $5=$ Arthrostylidium, Rupr. (Gramin.) Gueko, Goudot, 1. c.-N. Granat.

AULONIX, Rafin. Sylva Tellar. 25 (1838)=Cytisus, Linn. (Legumin.)

biflorus, Ratin. 1. $\mathrm{c}_{\mathrm{s}}=\mathrm{C}$. biflorus.

AULOSEMA, Walp. Rep. i. 694 (1842)=Astragalus,

Linn. (Legumin.).

eximium, Walp. 1. c. = Astr. hypogaeus.

AURANTIUM, Toum. ex Mill. Gard. Dict. ed. VI $(\mathbf{1 7 5 2})=$ Citrus, Linn. (Rutac.) acre, Mill. 1. c. ed. VIII. n. $1=$ C. Aurantium.

decumana, Mill. 1. c. n. $4=$ C. decumana.

humile Mill 1 . $5=\mathrm{C}$, bumilis

myrtifolium, Descourt. Fl. Med. Antill, iii. 308. t $219=$ C. Aurantium.

orientale, Mill. Gard. Dict. ed.VIII. n. $3=$ C. Aurantium. silvestre, Pritz. Ic. Ind. $127=\mathrm{C}$. Aurantiam.

sinense, Mill. Gard. Dict. ed. VIII. D. $2=\mathrm{C}$. Aurantium.

AURELIA, Cass. Bull. Soc. Philom. (1815) 175; et in Dict. Sc. Nat. xxxvii. $468\left(1816^{\circ}\right)=$ Grindelia, Willd. (Compos.)

amplexicaulis, Cass. 1. c. $=\mathrm{G}$. squarrosa.

decurrens, Cass. 1. $\mathrm{c} . \Rightarrow \mathrm{G}$. glutinosa.
AURELIA :-

glutinosa, Cass.CF. Bull. Soc. Philom. (1815) $175=$ Grindelia glutinosa.

squarrosa, Cass. ex Steud. Nom. ed. II. i. $171=\mathrm{G}$. quarrosa

AURELIA, J. Gay, in Ann. Sc. Nat. Sér. IV. x. (1858

$95=$ Narcissus, Toum. (Amaryll,

Broussonetii, J. Gay, 1. c. $96=$ N. Broussonetii.

AURELIANA, Lafit. ex Catesb. Nat. Hist. Carol. App. $16(1754)=$ Aralia, Linn

AURELTANA, Sendt. in Mart. Fl. Bras. x. 138. t. 19 $(1846)=$ Bassovia, Aubl. (Solan.) fasciculata, Sendt. 1 c. $140=$ B. fasciculata. glomuliflora, Sendt. 1. c. 138.-Bras. iucida, Sendt. 1. c. 139.-Bras.

tomentosa, Sendt. 1. c. $140=$ B. tomentosa velutina, Sendt. $\mathrm{I}_{\mathrm{c}} \mathrm{c}_{\mathrm{o}}=\mathrm{B}$. velutina.

AUREOLARIA, Rafin. New F1. Am. ii. 58 (1836) Gerardia, Linn. (Scrophul.)

cuneifolia, Rafin. 1. c. $59=$ Herpestis pubescens

glauca, Rafin. 1. c. $60=$ G. quercifolia.

levigata, Rafin. 1. c. $59=\mathrm{G}$. laevigata. reticulata, Rafin. I. c.-Am. bor.

rupestris, Rafin. 1. c. $60=\mathrm{G}$. rupestris.

villosa, Rafin. 1. c. $59=\mathrm{G}$. flava.

AURICULA, Tourn. ex Spach, Hist. Vég. Phan. ix. $350^{\circ}$ $(1840)=$ Primula, Tourn.

crenata, Spach, 1. c. $358=$ P. marginata.

glutinosa, Spach, 1. c. $359=$ P. glutinosa.

hortensis, Spach, 1. c. $357=$ P. Auricula.

integrifolia, Spach, 1. c. $359=\mathrm{P}$. integrifolia.

minima, Spach, 1. c. $360=$ P. minima.

Palinuri, Spach, 1. c. $357=\mathbb{P}$. Palinuri.

villosa, Spach, 1. c. $358=$ P. minima.

AURILA, Noronha, in Verh. Batav. Gen. v. (1790) ed. I. Art. IV. 1, nomen (Quid?

AURINIA, Desv. Journ. Bot. iii. (1813) 162=Alyssum Linn. (Crucif.)

capensis, Desv. 1. co = Heliophila diffusa

corymbosa, Griseb. Spicil. F1. Rumel. i. $271=\mathrm{Al}$ corymbosum.

edentula, Fisch. Mey. \& Trautv. Ind. Sem. Hort

Petrop. iii. $4=$ Al. gemonense

gemonensis, Griseb. Spicil. Fl. Rumel. i. $272=\mathrm{Al}$ gemonense.

media, Schur, Enum. PI. Transs. $61=\mathrm{Al}$. gemonense.

obcordata, Desv. Journ. Bot. iii. (1813) $162=$ Al. obcor datum.

orientalis, Griseb. Spicil. Fl. Rumel. i. $272=\mathrm{A}$ l. orientale.

petraeum, Fuss, F1. Transs, $64=\mathrm{Al}$. gemonense

saxatilis, Desv. Journ. Bot. iii. (1813) $162=$ Al. saxatile saxatilis, Griseb. Spicil. Fl. Rumel. i. $273=$ Al. orientale.

sinuata Griseb. 1. c. $271=$ Al. sinuatum.

AUROTA, Rafin. Fl. Tellar. iil. 61 (1836)=Curculigo, Gaertn. (Amaryll.).

latifolia, Rafin. 1. c. = C. latifolia.

AURORA, Noronha, in Verh. Batav. Gen, v. (1790) ed.

I. Art. IV. 1 = Quisqualis, Linn. (Combret.)

AUSTERIUM, Poit. ex DC. Prod. ii. 385 '1S:25)= Rhynchosia, Lour. (Legumin.)

AUSTRALINA, Gandich, in Freyc Voy, Bot $500^{\circ}$ (1826). URTICACEAE, Benth. \& Hook. fo iii. 394. ANaganthos, Hook. f. Fl. N. Zel. i. 226 ( 1554 . Didmotoca, E. Mey. Zwei PA. Docum. 175:1848. nomen.

acuminata, Wedd in Ann. Sc. Nat Sir. IV i 1854 212.-Afr. austr.

capensis, Wedd. b. co-Afr. austr.

Raccida, Wedd, in Arch. Mus. Par, viii. 1855-50 546 . t. $20 \mathrm{C}$. $=$ Schimperiana.

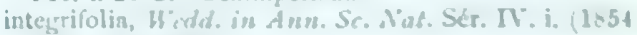
212. - A fro austr.

Muclleri, Wiold, in Arch. Mus. Par, viii. $1, \ldots$ : 545-Austral

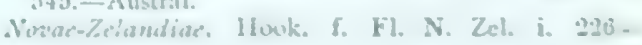
pusilla. 


\section{AUSTRALINA :-}

pusilla, Gaudich. in Freyc. Voy. Bot. 505.-Austral. N. Ze

Schimperiana, Wedd. in Ann. Sc. Nat. Sér. IV, i (1854) 212 -Abyss.

tasmanica, Hook. f. Fl. N. Zel. i. $226=$ pusilla.

AUSTROBUXUS, Miq. Fl. Ind. Bat. Suppl. 444 (1860) $=$ Sarcococca, Lindl. (Euphorb.)

nitidus, Miq. 1. c.-Sumatra.

AUTOGENES, Rafin. Fl. Tellur, iv. $20(1836)=$ Nar cissus, Tourn. (Amaryll.)

angustifolius, Rafin. $1 . \mathrm{c}_{0}=\mathrm{N}$. poëticus.

biflorus, Rafin. 1. c. $=\mathrm{N}$. biflorus.

poëticus, Rafin. 1. $c_{s}=\mathrm{N}$. poëticus

tenuior, Rafin. 1. c. $=$ N. gracilis.

AUXEMMrA, Miers, in Trans. Linn. Soc. Ser. II. i (1875) 23. t. 5. BORAGINEAE, Benth. \& Hook. f ii. 840 .

Gardneriana, Miers, l. c. 24. t. 5.-Bras.

AVELLANITA, Phil. in Linnaea, xxxiii. (1864-65 237. EUPHORBIACEAE, Benth. \& Hook. f. iii. 289.

Bustillosi, Phil. l. c. 238.-Chili

AVEILINIA, Parl. Pl. Nov. 59 (1842), GRA $M I N E A E$, Benth. \& Hook, f. iii. 1184

Michelii, Parl. l. c.-Italia.

Savi, Parl. l. c. 61.-Italia.

scabriuscula, Nym. Consp. $815=$ Koeleria scabriuscula.

tenuicula, Nym.l.c.-Hispan

AVENA, Hall. ex Scop. Introd. 74 (1777) = Agrostis, Linn. (Granin.).

AVENA, Linn. Syst, ed, I (1735). GRAMINEAE Benth. \& Hook. f. iii. 1160.

Elictotrichon, Bess. ex Andrz. Rys Botan. i. (1823) 9 .

Helicotrichum, Bess. in Reichb. Fl. Germ. Excurs. $140^{6}, \mathrm{n}, 352(1832)$

Heuffelia, Schur, Enum. PI. Transs. 760 (1866).

abyssinica, Hochst. ex A. Rich. Tent. Fl. Abyss. ii

415.--Abyss.

adsurgens, Schur, Enum. Pl. Transs. 762.-Hungar.

affinis, Bernh. ex Steud. Nom. ed. H. i. 171, 173=

sterilis.

agraria, Brot. Fl. Lusit, i. $105=$ strigosa

agraria-mutica, Brot. 1. c. $106=$ strigosa.

agraria-sesquialtera, Brot. 1. c. = strigosa

agropyroides, Boiss. Diagn. Ser. I. xiii. 50.-Graecia. agrostidea, Fries, Mant. iii. $3=$ Trisetum agrostideum, agrostoides, Griseb. Spicil. F1. Rumel. ii. $454=$ Trisetum myrianthum.

airoides, Koel. Gram. 208=Trisetum subspicatum

airoides, Pourr, ex Willd. in Ges. Naturf. Fr. Berl

Mag. ii. (1808) $290=$ Pourretii.

alba, Vahl, Symb. Bot. ii. 24.-Gall. austr.; Afr. bor.

albinervis, Boiss. Voy. Bot. Espagne, ii. 656.-

Hispan.

Alopecuros, Roth, Catalecta, iii. $20=$ Trisetum Alopecuros.

alpestris, DC. Fl. Fr. vi. $260=$ Trisetum pratense.

alpestris, Host, Gram. Austr. iii. 27. t. $39=\mathrm{T}$ alpestre.

alpina, [Honck.] Verz. Gew. Teutschl. $302=$ Aira montana?

alpina, Latour. Chlor. Lugd. $3=$ Scheuzeri

alpina, Sm. in Trans. Linn. Soc. x. (1811) $335=$ pratensis.

alpina, Trin. Fund. Agrost. $157=$ Deschampsia alpina.

alta, Cav. ex Roem. \& Schult. Syst. ii. $691=$ strigosa ambigua, Schoenb. ex Nym. Consp. $810=$ fatua. amethystina, $D C$. Fl. Fr. iii. 56 ; vi. $260 .-$ Gallia andropogoides, Steud. in Flora, xii. (1829) II. 486 . Afr. austr.

anglica, Hort. ex Roem. \& Schult. Syst. ii. $669=$ sativa.

antarctica, Roem. \& Schult. 1. c. $676=$ Trisetum antarcticum.

antarctica, Thunb. Prod. Pl. Cap. 22=Danthonia antarctica.

\section{A VENA}

arduensis, Lej. ex Steud. Nom. ed. II. i. $171=$ strigosa.

arenaria, Spreng. Syst. i. $333=$ Trisetum arenarium. argaea, Boiss. Fl. Orient. v. 546.-Cappadoc

argentoideum, Schur, in Oestr. Bot. Zeitschr. x. (1860) $74=$ Trisetum alpestre.

argentea, Willd. Enum. Hort. Berol. $125=$ Trisetum argenteum.

ariguensis, Steud. Syn. Pl. Gram. 233.-Chili.

aristidoides, Stend. in Flora, xii. (1829) II. 481, n. 23 $=$ Danthonia Thunbergii

aristidoides, Thunb. Prod. Pl. Cap. 22,-Afr. austr.

arundinacea, Delile, Fl. Egypte, 171. t. $12=$ Dan thonia Forskohlei.

arvensis, Salisb. Prod. $23=$ Bromus arvensis

aspera, Munro, ex Thw. Enum. Pl. Zeyl. 372.Zeylan.

atheranthera, Presl, Cyp. et Gram. Sic. $30=$ barbata.

atropurpurea, Link, Hort. Berol. i. $119=$ Aira atropurpurea.

aurata, All. Fl Pedem, ii. $255=$ setacea, Agrosti alpina.

australis, Parl. Fl, Ital, i, 285= pratensis

barbata, Brot. Fl. Lusit. i. 108.--Reg. Mediterr. ; As Min.; Arab.

barbata, Pott, ex Link, in Schrad. Fourn. ii. (1799) 315.-Lusitan.

baregensis, Nym. Consp. $813=$ Trisetum agrostideum Baumgartenii, Steud. Syn. Pl. Gram. 233-Hungar. Bellardi, Colla, Herb. Pedem. t. 93. f. 2.-Italia benghalensis, Schwaegr. ex Steud. Nom. ed, I. 94.Ind, or.

Besseri, Ledeb. Fl. Ross. iv. 415.-Ross. med

bifida, Beauv. A grost. 153, nomen-Hab.?

bipartita, Link, Hort. Berol. i. 113=Danthonia semiannularis.

Blavii, Aschers. \& Janka,-Cf. Aschers. \& Kan. Cat Coron. Serb. $9=$ compressa.

borbonia, Steud. Syn. Pl Gram 234.-Ins. Borbon. brevifolia, Host, Gram. iii. t. $40=$ Trisetum distichophyllum.

brevifolia, Spreng. Syst. i. $334=$ Trisetum rigidum.

brevis, Roth, Tent. Fl. Germ. i. 40.-Europ

bromoides, Gouan, Hort. Monsp. 52.-Reg. Mediterr. bromoides, Mert, \& Koch, in RoehI. F1. Deutschl. ed III, i. $570=$ pratensis.

Brownei, Spreng. Syst. i. $336=$ Danthonia pallida.

Bruhnsiana, Gruner, in Bull. Soc. Nat. Mosc. xli (1867) II. 458.--Reg. Casp.

bulbosa, Willd. in Ges. Naturf. Fr. Berl. Neue Schr. ii (1799) 116.t. 5. f. $1=$ Arrhenatherum avenaceum

Burnoufi, Nym. Syll. $413=$ Trisetum Bumoufii

byzantina, C. Koch, in Linnaea, xxi. (1848) $392=$ fatua.

caespitosa, Kuntze, Taschen-F1. Leipz. $45=$ Des champsia caespitosa.

calicina, Vill. Hist. Pl. Dauph. ii, $148=$ Danthonia provincialis.

callosa, Turcz, in Bull. Soc. Nat. Mosc. xxix. (1856) I. 36.-Sibir.

calycina, Lam. Illustr. i. $200=$ Danthonia calycina

calycina, Willd. Sp. Pl. i. 453, in syn.=Danthonia provincialis

canariensis, Nees, ex Steud. Nom. ed. II. i. 171.-Ins. Teneriff

Candollei, Nym. Consp. $812=$ Trisetum pratense. canescens, [Weber, in] Wigg. Prim. Fl. Hols. $9=$ Corynephorus canescens.

cantabrica, Lag, in Herrer. Agr. 141=filifolia.

capensis, Burm. f. Fl. Cap. Prod. 3=Anthistiria ciliata.

capensis, Linn. f. Suppl. $112=$ Aristida capensis

capensis, Steud. in Flora, xii. (1829) $481=$ Danthonia papillosa.

capillacea, Beauv. A grost. 153, nomen.-Hab.?

calllaris, Mert. E Koch, in Roehl. Deutschl. Fl. ed.

III. i. 573.-Europ.

Carmeli, Boiss. Diagn. Ser. I. xiii. 50.-Syria

caroliniana, Walt. F1. Carol. $81=$ Trisetum palustre.

carpatica, Host, Gram. Austr. iv. 18. t. $31=$ Trisetum carpathicum.

caryophyllea, Sibth. E Sm. Fl. Graec. Prod. 1. 67.Archip. Graec.

caryophyllea, [Weber, in] Wigg. Prim. F1. Hols. $10=$ Aira caryophyllea.

Cavanillesii, Hort. ex Roem. \& Schult. Syst. ii. 691 strigosa.

\section{A VENA :}

Cavanillesii, Koch, Syn. Fl. Germ. ed. I. $797=$ Tri. setum Cavanillesiı.

Cavanillesii, Lag. in Varied. Cienc. ii. IV. (1805) $39=$ Stipa arenaria.

cernua, Kunth, Enum. Pl. i. $306=$ Trisetum cernuum. chinensis, Fisch. ex Roem. \& Schult. Syst. ii. $669=$ nuda.

chlorantha, Link, in Linnaea, xvii. (1843) $401=$ Trisetum aureum.

ciliaris, Kit. ex Schult. Oestr. Fl. ed. II. i. $268=$ Trisetum carpathicum.

cinerea, Auct. ex Roem. \& Schult. Syst. ii. $669=$ sativa.

clauda, Dur. in Duch. Rev. Bot. i. (1845-46) 360.Graecia; As, Min. ; Afr. bor.

coarctata, Desf. Cat. Hort. Par. ed. III. (1829) $22=$ Gaudinia geminiflora.

colorata, Steud. in Flora, xii. (1829) II. 481. n. $11=$ Danthonia tortuosa.

compacta, Boiss. E Heldr. Diagn. Ser. I. vii. 122.Graecia ; Servia.

compressa, Heuff. in Flora, xviii. (1835) 244.Hungar.

condensata, Link, Enum. Hort. Berol. i. $82=$ Trisetum aureum, Tenore.

convoluta, Presl, Cyp. et Gram. Sic. 31.- Europ. austr. or.

coquimbensis, Roem. \& Schult. Syst. ii. $677=$ Hierochloë utriculata.

coronensis, Schur, Enum. Pl. Transs. 763.-Transsylv. corymbosa, Nym. Consp. 814.-Corsica.

cristata, Auct. ex Roem. \& Schult. Syst, ii. $758=$ Agropyron cristatum.

Cupaniana, Nym. Syll. 414.-Ital. ; Creta.

cuspidata, Willd. ex Kunth, Enum. Pl. i. $239=$ Calamagrostis cuspidata.

daenensis, Boiss. Diagn. Ser. I. vii. $123=$ Trisetum rigidum.

decora, Fanka, in Termész. Füzetek, viii. (1884) 28.Europ.

depauperata, Sieber, ex Trin. in Mém. Acad. Pétersb. Sér. VI. i. (1831) $68=$ Danthonia provincialis. desertorum, Less. in Linnaea, ix. (1834) 208.- Sibir.

deyeuxioides, H. B. \& K. Nov. Gen. et Sp. i. $147=$ Deyeuxia triflora.

dispermis, Mill. Gard. Dict. ed. VIII. n. 1 =sativa. distans, Schur, in Oestr. Bot. Zeitschr. xx. (1870) 22. -Europ.

disticha, Lam. Encyc. i. $330=$ Trisetum rigidum

distichophylla, Host, Gram. Austr. ii. 39. t. $53=$ Trisetum argenteum.

distichophylla, Vill. Prosp. 16; Pl. Dauph. ii. $144=$ Trisetum distichophyllum, rigidum.

dubia, Leers, F1, Herborn. $41=$ Gandinia tenuis.

Dufourei, Nym. Consp. $813=$ Trisetum Dufourei

dura, Salisb. Prod. $22=$ Festuca duriuscula.

elata, Forsk. Fl. Aegypt. Arab. 19.-Constantinop.

elata, Salisb. Prod. $23=$ Arrhenatherum avenaceum.

elatior, Linn. Sp. P1. $79=$ Arrhenatherum elatius

elegans, Aschers. in Verh. Bot. Ver. Brand, iii,-iv. (1861-62) $279=$ capillaris.

elephantina, Spreng. ex Steud. Nom. ed. II. i. $172=$ andropogoides.

elephantina, Thunb. Prod. P1. Cap. $23=$ Danthonia elephantina.

elongata, H. B. \& K. Nov. Gen. et Sp. i. $148=$ Trisetum elongatum.

eriantha, Dur. in Duch. Rev. Bot. i. (1845-46) 360.Afr. bor.

eriantha, Hack, in Oestr. Bot. Zeitschr. xxvii, (1877) 122.-Hispan.

fallax, De Not. Ind. Sem. Hort. Reg. Genuens, $24=$ sempervirens.

fallax, Pollini, F1. Vernon. iii. $773=$ pubescens.

fallax, Roem. \& Schult. Syst. ii. $692=$ montana

fallax, Tenore, Fl. Nap, iii. $96=$ convoluta.

fatua, Linn. Sp. Pl. 80.-Europ.; Oriens ; As. bor.

fatua, Schreb. Beschr. Graes. 109. t. 15= sterilis.

fatua, Viv. F1. Lib. Spec. $6=$ barbata.

fertilis, All. Auct. Pedem. $45=$ Gaudinia tenuis.

festucaeformis, Hochst. in Flora, xxxviii. (1855) 275.Afr. or.

filifolia, Lag. Gen. E Sp. Nov. 4.-Hispan.

fliformis, Forst. f. Prod. $9=$ Deyeuxia Forsteri

filiformis, Labill. Nov. Holl. Pl.i. 24. t. $31=$ Deyenxia Billardieri.

flava, Hort. ex Roem. \& Schult. Syst. ii. $669=$ sativa. 


\section{AVENA :-}

flavescens, Bout. ex Willk. \& Lange, Prod. Fl. Hisp. i. $72=$ Trisetum gallecicum

flavescens, Linn. Sp. Pl. $80=$ Trisetum pratense.

flexuosa, Mert. \& Koch, in Roehl. Deutschl. Fl. ed. III. i. $570=$ Deschampsia flexuosa.

flexuosa, Schrank, in Denkschr. Reg. Bot. Ges. ii. 7.Labrador.

Forskolei, Vahl, Symb. Bot. ii. $25=$ Danthonia Forskolei.

Forsteri, Kunth, Rev. Gram. i. $104=$ Deyeuxia Forsteri.

fragilis, Linn. Sp. P1. $80=$ Gaudinia fragilis.

Freita, Orteg. [ex Spreng.] Bot. Gart. Halle, $14=$ strigosa.

fusca, Ard. in Saggi Acc. Padov. ii. (1789) t. $4=$ sativa. fusca, Kit. ex Schult. Fl. Oestr. ed. II. i. $268=$ Trisetum carpathicum.

fusca, Schur, Enum. Pl. Transs. 756.-Hungar.

fuscoflora, Schur, l. c. = fusca

gallecica, Nym. Syll. Suppl. $71=$ Trisetum gallecicum. geminiflora, Kunth, Rev. Gram. 103, 299. t. $61=$ Gaudinia geminiflora.

Georgiana, Koem. \& Schult. Syst. ii. $669=$ sativa.

georgica, Boiss. olim ex F1. Orient. v. $540=$ Ventenata macra.

georgica, Zuccag. in Roem. Collect. $126=$ sativa.

gigantea, Salisb. Prod. $28=$ Bromus giganteus

glabra, C. Koch, in Linnaca, xix. (1847) $5=$ pubescens.

glabrata, Brot. ex Steud. Nom. ed II. i. $172=$ corymbosa.

glacialis, Boiss. Elench. 87; Voy. Bot. Espagne, ii. $654=$ Trisetum glaciale.

glauca, Lapeyr. Hist. Abr. Pl. Pyr. Suppl. 20= Scheuzeri.

glomerata, Steud. in Flora, xii. (1829) II. $483=$ Danthonia curvifolia.

glumosa, Ell. Sketch, 11.-Am, bor.

glumosa, Michx. Fl. Bor. Am. i. $72=$ Danthonia spicata.

gracilis, Moris, Stirp. Sard. Elench. fasc. i. $50=$ Trisetum Morisii.

Heldreichii, Parl. Fl. Ital, i. $275=$ convoluta.

heteromalla, Moench, Meth. $195=$ orientalis.

hexantha, Steud. in Flora, xii. (1829) II. 487. n. $87=$ Danthonia stricta.

hirsuta, Moench, Meth. Suppl. 64; Roth, Catalecta, iii. 19 = barbata.

hirta, Schrad. in Goett. Gel. Anz. (1821) II1. 2075.Afr. austr.

hirtifolia, Boiss. Diagn. Ser. II. iv. $128=$ pubescens.

hirtula, Lag. Gen. et Sp. Nov. $4=$ barbata.

hispanica, Ard. in Saggi Acc. Padov. ii. (1789) 112 = sativa.

hispanica, Hort. ex Roem. \& Schult. Syst. ii. $691=$ strigosa.

hispanica, Lange, in Kjoeb. Vidensk. Meddel. (1860) 41 = Arrhenatherum erianthum.

hispida, Linn. f. Suppl. 111= Tristachya leucothrix

hispida, Nym. Syll. Suppl. $71=$ Trisetum hispidum.

hybrida, Peterm. ex Reichb. Fl. Saxon. $17=$ fatua.

Hoppeana, Scheele, in Flora, xxvii. (1844) 57.Istria.

Hostii, Boiss. \&c Reat. Pugill. $121=$ Parlatorii.

Hugeninii, De Not. ex Steud. Syn. Pl. Gram.425.Italia.

hungarica, Luce, Topogr. Nachr. Oesel, 20.-Hungar.

hydrophila, F. Muell. ex Hook. f. F1. Tasm. i. 121 Amphibromus Neesii

intermedia, Lindgren, in Bot. Notiser (1841), $151=$ fatua.

intermedia, Guss. F1. Sic. Prod. Suppl. 16=corymbosa. involucrata, Schrad in Goett. Gel. Anz. (1821) III. $2075=$ Danthonia involucrata.

involuta, Presl, ex Steud. Nom. ed. II. i. $172=$ sempervirens.

japonica, Steud. Syn. Pl. Gram. 291 = hirsuta.

Janghubni, Buese, in Miq. Pl. Fungh. 345.Java.

Koenigii, Spreng. Syst. i. $336=$ Aristida arundinacea

Kotschyi, Steud. Syn. Pl. Gram. 235.-Persia.

lachnantha, Hook.f. in fourn. Linn. Soc. vii. (1864) 227. - Afr, trop.

laconica, Nym. Syll. Suppl. $71=$ Trisetum laconicum . laeta, Salisb. Prod. $22=$ Brachypodium pinnatum. laevigata, Schur, in Oestr. Bot. Leitschr. x. (1860) $72=$ pubescens.

lacvis, Hack, 1, c. xxvii. (1877) 46 =albinervis

\section{AVENA :}

anata, Koel, Gram, $303=$ Holcus lanatus.

lanata, Schrad, in Goett. Gel. Anz. (1821) III. 2075 $=$ Danthonia lanata

lanuginosa, Gilib. Exercit. ii. $539=$ fatua.

lasiantha, Link, in Linnaea, ix. (1834) $135=$ Bromus intermedius.

latifolia, Host, Gram. Austr. iv. 19. t. $32=$ planiculmis. lendigera, Salisb. Prod. $23=$ Gastriclium australe.

leonina, Steud. in Flora, xii. (1829) II. 484=Danthonia antarctica?

leptostachys, Hook. f. Fl. Antarct. 378.-Reg. Magellan.

levis, Nym. Consp. $811=$ albinervis.

lodunensis, Delastr. in 'Cat. Hort. Pict. $(1835)^{\text {' }}=$ sulcata.

Loeffingiana, Cav. Ic, i. t. 45. f. 1 =Trisetum Gaudinianum.

Loeffingiana, Geuns. ex Roem. \& Schult. Syst. ii. 370 = Aira praecox.

Loeflingiana, Balb. Misc. Bot. i. $12=$ Trisetum Cavanillesii.

Loeflingiana, Lian. Sp. P1. $79=$ Trisetum hispanicum. Loeflingiana, Lam. Encyc. 1. $332=$ Trisetum paniceum. longifolia, Req. in DC. \& Duby, Bot. Gall. i. $514=$ pratensis.

longifolia, Spreng. Syst. i. $336=$ Danthonia longifolia.

longifolia, Thore, Prom. Golf. fasc. $92=$ Arrhenatherum pallens.

longiglumis, Dur, in Duch. Rev. Bot. i. (1845-46) 359.-Afr. bor.

ucida, Bertol. F1. Ital. i. $701=$ pubescens.

ludoviciana, Dur. in Bull. Soc. Linn. Bord. xx. (1855) i. $41=$ sterilis.

Iupulina, Steud, in Flora, xii. (1829) II. $486=$ Danthonia lanata.

Iupulina, Thunb. Prod. Pl. Cap. $23=$ Danthonia lupulina.

lutea, Linn. $f$. Suppl. 112.-Ins. Martinic.

macilenta, Guss. Fl. Sic. Prod. Suppl.,i. $29=$ Koeleria macilenta.

macra, Hohen. Enum. P1. Elisabethpol. $214=$ rigida.

macra, Stev. in Bieb. Fl. Taur. Cauc. 1. $77=$ Ventenata macra.

macrocalycina, Steud. in Flora, xii. (1829) II. $482=$ Danthonia macrantha.

macrocarpa, Moench, Meth. 196=sterilis

macrostachya, Balansa E Dur. in Bull. Soc. Bot. Fr. i. (1854) 318.-Algeria.

magellanica, Beauv. Agrost. 153, nomen.-Reg. Magellan.

Mandoniana, Coss. \& Bal. in Bull. Soc. Bot. Fr. xv. (1868) 185 , nomen $=$ marginata

marginata, Lowe, in Trans. Camb. Phil. Soc. vi. (1888) 529. - Ins. Madera.

maxima, Presl, Fl. Sicul. p. xliv.-Sicilia.

mediolanensis, Balansa \& De Not. in Comoll, Fl. Comens, i. $147=$ Trisetum myrianthum.

Michelii, Guss. F1. Sic. Syn. 151=Koeleria macilenta mollis, Koel. Gram. $300=$ Holcus mollis

mollis, Michx. Fl. Am. Bor. i. $72=$ Trisetum subspicatum.

mollis, Salisb. Prod. $23=$ Bromus mollis.

montana, Brot. Fl. Lusit. i. $109=$ Arrhenatherum Thorei.

montana, Roem. \& Schult. Syst. ii. 674, in syn.= pratensis.

montana, Vill. Fl. Dauph. ii. 151.-Mont. Pyren.

montana, [Weber, in] Wigg. Prim. Fl. Holsat. $9=$

Deschampsia flexuosa.

multiculmis, Dum. Agrost. 121 = Aira caryophyllea.

muralis, Salisb. Prod. $22=$ Festuca Myurus.

muricata, Spreng. Neue Entdeck. i. 247=Aristida capensis, Danthonia papillosa.

mutica, Krock. Fl.Sil.Suppl. i. 187.-Europ.

myriantha, Bertol. Fl. Ital. i. $722=$ Trisetum myrianthum.

mysorensis, Spreng. Syst. i. 337.-Ind. or

nana, Kunze, ex Steud. Nom. ed. II. i. 172, $45=$ Air praecox.

Necsii, Hook. f. in Gourn. Linn. Soc, vii. (1864) 229. -Afr. trop.

neglecta, Bertol. Fl. Ital. i. $713=$ Trisetum Gandinianum.

neglecta, Savi, Fl. Pis. t. 1. 1. $4=$ Trisetum paniceum. nemoralis, Salisb. Prod. $23=$ Bromus asper, nervosa, Lam. Illustr. D. $1116=$ strigosa.

nervosa, R. Br. Prod, i. $178=$ Amphibromus Neesii.

\section{A VENA}

Neumeyeriana, Vis. F1. Dalm. iil. $339=$ compacta

nigra, Wallr. Beitr. Fl. Hercyn. 174 ; et in Linnaea, xiv. (1840) 544. - Europ.

nitida, Desf. Fl. Atlant. i. $102=$ Trisetum nitidum.

nodosa, Cullum, It. Scan. $251=$ Arrhenatherum avena ceum.

Noeana, Nym: Syll. Suppl. $71=$ Trisetum aureum, Tenore.

Totarisi, Parl. Fl. Ital. i. 279 ; ex Steud. Syn. PI.

Gram. $425=$ sempervirens.

nuda, Linn. Amoen. Acad. iii. 401.-Europ. austr

nuda, Thuill. Fl. Par. ed. II. i. $49=$ brevis.

nutans, St. Lag. Rech. Hist.-Cf. Bull. Soc. Bot.

Fr. xxxi. (1884) Bibl, $201=$ sterilis.

nutkaensis, 7 . Presl, in Rel. Haenk. i. 254.-Sisus Nootka.

occidentalis, Dur. Cat. Gr. Bord. (1864) 25.-Cf. Bull. Soc. Bot. Fr. xii. (1865) Bibl. 78, - Ins. Ferro. odorata, DC. Fl. Fr. iii. $42=$ Hierochloë australis. odorata, Pers. Syst. i. $100=$ Hierochloë borealis. oligostachya, Munro, ex Aitch. in Fourn. Linn. xviii. (1881) 108; xix. 193.t. 30.-Afghanist. orientalis, Schreb. Spicil. 52.-Europ. austr.; Oriens. ovata, C. C. Gmel. ex Kunth, Enum. Pl. i. $295=$ Trisetum ovatum.

ovina, Salisb. Prod. $22=$ Festuca ovina.

palaestina, Steud. Syn, Pl, Gram, 425,-Palnestina.

pallens, Link, in Schrad. Journ, ii. (1799) $314=$

Arrhenatherum pallens.

pallida, Salisb. Prod. $24=$ Hol cus lanatus

pallida, Thunb. Prod. Pl: Cap. $22=$ Danthonia pallescens.

patustris, Michx. F1. Bor. Am, i. 72 = Trisetom palnstre.

panicea, Hort. ex Roem. \& Scholt. Syst, ii. 625, 660 . Koeleria phleoides

panicea, Lam. Illustr. i. $202=$ Trisetum paniceum, papillosa, Schrad. in Goett. Gel. Anz. (1821) I11. 2075 =Danthonia papillosa.

papillosa, Steud. in Flora, xii. (1829) II. $434=\mathrm{Dan}$ thonia scabra.

paradensis, Kit. ex Kanitz, in Verh. Zool. Bot. Ges. Wien, xiii. (1863) 543 (Reliq. Kitaib. 119).-Europ. paradoxa, Willd. ex Kunth, Enum. Pl. i. $188=$ Aristid dichotoma.

Parlatorii, Woods, ex Dalla Torre, Atl. Alpenfl. 228.Italia.

parviflora, Desf. Fl. Atlant. i. $98=$ Trisetum parviflorum.

parviflora, Willd. in Ges. Naturf. Fr. Berl. Mag. ii. 1808) $289=$ Trisetum micranthum.

panciflora, Auct, ex Roem. \& Schult. Syst. ii. $660=$ Trisetum paniceum.

paupercula, Phil. in Linnaea, xxix. (1857-58) 94.Chili.

pendula, Gilib. Exercit. $539=$ sativa.

penicillata, Willd, ex Stend. Nom. ed. II. i. 172 ; it

$714=$ Trisetum rigidum

pennsylvanica, Muhl. Descr. Uber. $185=$ Arrhena. therum kentuckense.

pensylvanica, Forsk. Fl. Aegypt. Arab. 23= Danthonia Forskolei.

pensylvanica, Linn. Sp. Pl. 79.-Am. bor.

pensylvanica, Presl, Cyp, et Gram, Sic $\$ 0=$ maxima. persica, Steud. Syn. Pl. Gram. 230.-Persia.

peruviana, Hort. ex Willd. in Ges. Naturf. Fr. Berl.

Mag. ii. (1808) $290=$ Trisetum paniceum.

phleoides, Urv. in Mém. Soc. Linn. Par. iv. (1826 601 $=$ Trisetum phleoides.

pilosa, Ancher, ex Dur. in Duch. Rev. Bot. i. $(1845-16)$ $360=$ clauda

pilosa, Bieb. Fl. Taur. Cauc. iii. 84.-As. Min.; Syria Afr. bor.

pilosa, F. Presl, in Rel. Haenk. i. 253.-Chili.

pilosa, Scop. Fl Cartt, ed. II. i. 86.-Camiolin

planiculmis, Schrad. Fl. Germ. i. Ss1. ใ. 6. f. 2.-

Europ. : As. bor.

planiculmis, Sm. Engl. Bot. t. $2141=$ pratensis.

podolica, Pascal. ex Zuccagai, in Rocm. Collect. $120^{\circ}$ sativa.

Pourretii, Willd. in Ges. Nałurf. Fr. Berl. Mag. ii. (1808) 290. t. 8.-Hispan.

praccox, Beaur Aprost. \$9.-Lusitan.

praeusta, Reichb. Fl. Germ. Excurs. 140=pratensis

pratensis, Boiss Voy. Bot. Espagne, ii. 656 \& bro moides.

pratensis, Brot. Fl. Lusit. ii. $110=$ sulcats. 


\section{AVENA :-}

pratensis, Gouan, 'Hort. 53'; Kunth, Enum. Pl. i, $300=$ pubescens

pratensis, Linn. Sp. Pl. 80.-Europ.; As. bor.

pratensis, Sibth. \& Sm. Fl. Graec. Prod. i. $67=$ caryo phyllea.

precatoria, Thuill. F1. Par. ed. II. $58=$ Arrhenatherum avenaceum.

Preslii, Kunth, Enum. Pl. i. 304-Chili

provincialis, Nym. Syll. Suppl. $71=$ capillaris.

provincialis, Poir. Encyc. Suppl. i. $541=$ Danthonia provincialis

pseudolucida, Schur, in Oestr. Bot. Zeitschr. x. (1860) $72=$ pubescens.

pseudoviolacea, Kern. ex Dalla Torre, Atl. Alpenfl. 228.-Europ. alp.

puberula, Guss. in Tenore, Prod. F1. Nap. App. v. = Koeleria macilenta.

pubescens, Huds. Fl. Angl. 42,-Europ.; As. bor. pulchella, Beauv. Agrost. 154, nomen= Aira lendigera. pumila, Desf. Fl. Atlant. i. $103=$ Trisetum pumilum. pumila, Urv, in Mém. Soc. Linn. Par. i. (1822) 267 = Trisetum aureum, Tenore

purpurascens, DC. Cat, Hort. Monsp. $82=$ Trisetum pratense.

purpurascens, De Not, Ind. Sem. Genuen. (1847); Ann. Sc, Nat. Sér. III. ix. (1848) $323=$ Trisetum alpestre.

purpurea, Gueldenst. ex Ledeb. Fl. Ross. iv. 419.Rossia.

purpurea, Linn. f. Suppl. $112=$ Danthonia purpurea. pusilla, [Weber, in] Wigg. Prim. F1. Hols. 9= Aira praecox.

quadridentula, Doell, in Mart. Fl. Bras, ii. III, 100.Bras.

quadriseta, Labill. Nov. Holl. P1. i. 25. t. $32=$ Deyeuxia quadriseta,

quinqueseta, Steud. in Flora, xii. (1829) II. $485=$ Trisetum Steudelii.

racemosa, Thuill, Fl. Par, ed. II. 59-_Gallia.

Radula, Franch. E Sav. Enum. Pl. Fap. il. 174.Japon.

redolens, Pers. Syn. i. $100=$ Hierochloë redolens.

rigida, Bieb. F1. Taur. Cauc. I. $77=$ Trisetum rigidum,

rigida, Steud, in Flora, xii. (1829) II. 482.-Afr, austr

Rotae, De Not. ex Parl. Fl. Ital. i. $264=$ Trisetum argenteum.

rubra, Zuccagni, in Roem. Collect. $126=$ sativa

rupestris, J. F. Gmel. Syst. ? /4=Agrostis rupestris.

Ruprechtii, Ledeb. Fl. Rass. 1\%. 418.-Rossia arct.

sativa, Linn. Sp. Pl.79.-Terr. temp. (cult.).

scabriuscula, Lag. in Varied. Cienc. ii, IV. (1805) 212

$=$ Koeleria scabriuscula.

scabrivalvis, Trin, in Bull. Sc. Acad. Pétersb. i. (1836) 67.-Chili.

Schelliana, Hack. ex Trautv. in Act. Hort. Petrop. ix. (1884) 342.-Hab.?

Schenchzeri, All. Fl. Pedem. ii. 255.-Europ.; Reg. Caucas.

secalina, Salisb. Prod. $22=$ Bromus secalinus.

secunda, Salisb. 1. c.:=Arrhenatherum avenaceum.

sedenensis, DC. F1. Fr. iii. $719=$ montana.

segetalis, Bianca, ex Nym. Consp. $810=$ barbata.

sempervirens, Bory \& Chaub. Fl. Pélop. 7. n. $179=$ Heldreichii.

sempervirens, Host, Gram. iii. 28. t. $41=$ Parlatorii.

sempervirens, Bess. Enum. P1. Volh. $6=$ Besseri.

sempervirens, Lapeyr. ex Benth. Cat. PI. Pyr. $65=$ montana.

sempervirens, Ledeb. Fl. Alt, i. $89=$ desertorum. sempervirens, Vill. Prosp. 17.-Europ.; As. bor. sesquiflora, Ledeb. Fl. Ross. iv, 419.-As. or.

sesquitertia, Bieb. Fl. Taur. Cauc. i. $77=$ Trisetum rigidum,

sesquitertia, Comol. Prod. $18=1$ ucida.

sesquitertia, Host, Syn. Fl. Austr. $60=$ Trisetum alpestre.

sesquitertia, Hort. ex Steud. Nom. ed. I. $95=$ barbata.

sesquitertia, Linn. Mant. i. $34=$ pubescens.

sesquitertia, Tenore, ex Steud. Nom, ed. II. i. $173=$ sempervirens.

sesquitertia, Willd. Sp. P1. i. $448=$ Trisetum argenteum.

setacea, Baumg. ex Schur, Enum. P1, Transs. $735=$ Agrostis rupestris.

setacea, Baumg. 1. c. $753=$ Deschampsia flexuosa.

setacea, Parl. Fl, Ital. i. $133=$ Parlatorii.

\section{A VENA}

setacea, Muhl. ex Trin. in Mém. Acad. Pétersb. Sér.

VI. i. (1831) $87=$ Aristida dichotoma.

setacea, Vill. Prosp. 16.-Europ. austr.

setifolia, Brot. Fl. Lusit. $108=$ Arrhenatherum pallens

sibirica, Linn. Sp. P1. $79=$ Stipa sibirica

Sibthorpii, Nym. Syll. $412=$ bromoides,

sicula, Spreng. Syst. 1. $335=$ Trisetum aureum, Tenore

Smithii, Porter, ex A. Gray, Man. Bot. U. St. ed. V

640.-Am. bor.

spicaeformis, Auct. ex Roem. \& Schult. Syst. ii. $690=$ Danthonia spicaeformis

spicata, All. ex Kunth, Enum. P1. i. $312=$ Triodia decumbens, Danthonia provincialis.

spicata, Ell. Sketch, i. $174=$ Danthonia sericea.

spicata, Gilib. Exercit. $540=$ pratensis.

spicata, Linn. Sp. P1, $80=$ Trisetum subspicatum.

spicata, Willd. Sp. P1. i. 453, partim= Danthonia provincialis.

splendens, Boiss. Elench. $88=$ albinervis

splendens, Auct. Gall. ex Steud. Nom. ed. II. i. $173=$ pratensis.

splendens, Guss. F1. Sic. Prod. i. 126=Trisetum pratense.

squarrosa, Schrank, in Denkschr. Regensb. Ges. i. II (1818) 7.-Labrador.

sterilis, Delile, ex Boiss. Fl. Orient. v. $543=$ fatua.

sterilis, Linn. Sp. Pl. ed. II. 118.-Reg. Mediterr. Oriens.

stipaeformis, Linn. Mant. 34.-Afr. austr.

stipoides, Willd. ex Steud. Nom. ed. II. i. 173 ; ii. 146 $=$ Oryzopsis fimbriata.

striata, Lam. Encyc. i. $332=$ sempervirens.

striata, Trin. in Mém. Acad. Pétersb. Sér. VI, iv, II. (1838) $28=$ callosa

striata, Michx. Fl. Bor. Am, i. 73.-Am. bor,

striata, Schousb. ex Willk. Ev Lange, Prod. Fl. Hisp. i 60.-Hispan.

striata, Vis. Fl. Dalm. i. $70=$ convoluta

stricta, Host, Fl. Austr. i. $127=$ Danthonia provincialis.

strigosa, Schreb. Spic. 52.-Europ.; Reg. Casp.

strigosa, Vogler, Schediasma Bot. $22=$ Gaudinia tenuis.

subalpestris, Hartm. Handb. ed. III. ex ej. ed. IV. $29=$ Trisetum agrostideum.

subcylindrica, Ehrenb. ex Boiss. F1. Orient. v. $536=$

Trisetum glumaceum.

subspicata, [Clairv.] Man. Herb. 17=Trisetum subspi catum.

subulata, Lam. Illustr. n. $1113=$ setacea

subvillosa, Schur, Enum, PI. Transs, $763=$ convoluta.

sulcata, F. Gay, in Delastre, Fl. Vienne, 477. t. 4.Hispan.

sylvatica, Salisb. Prod. $24=$ Holcus mollis.

symphicarpa, Trin. ex Steud. Nom. ed. II. i. $173=$ hirta.

syriaca, Buiss. \& Bal. ex Boiss. Fl. Orient. v. $542=$ sterilis.

tatarica, Ard, in Saggi Acc. Padov, ii. (1789) 101. t. $1=$ orientalis.

taygetana, Steud. Syn. Pl. Gram, 233.-Graecia.

Tenorii, Nym. Consp. $814=$ corymbosa

tenuiflora, Bertol, ex Reichb.Ic.Fl, Germ. i. 41.n. 1688 - Italia.

tenuis, Moench, Meth. $195=$ Ventenata avenacea.

Thorei, DC. \& Duby, Bot. Gall. i. 514=Arrhena therum pallens.

tolucensis, H. B. \& K. Nov. Gen. et Sp. i. $148=$ Trisetum toluccense.

triaristata, Vill. Prosp. $17=$ Ventenata avenacea

trichophylla, C. Koch, in Linnaea, xxi. (1848) $393=$ fatua.

trichopodia, F. Presl, in Rel. Haenk. i. 254.-Mexic.

triseta, Thunb. Prod. P1. Cap. $22=$ Danthonia Thunbergii.

trisperma, Auct. ex Roem. \& Schult. Syst. ii. $669=$

triticoides, Lindl. in Mitch. Fourn. Austral. 365.Austral.

truncata, Dulac, F1. Hautes-Pyr, $83=$ bromoides.

tuberosa, Gilib. Exercit. ii. $538=$ Arrhenatherum avenaceum.

uniflora, Parl. Pl. Nov. 84.-Ins, Canar.

unilateralis, Brouss. ex Roem. \& Schult. Syst. ii. $669=$ orientalis.

valesiaca, Nym. Syll. $414=$ Trisetum Cavanillesii.

\section{AVENA}

varia, Schur, in Oestr. Bot. Zeitschr. x. (1860) 75 $=$ Trisetum carpathicum.

velutina, $N y m$. Consp. $812=$ Trisetum velutinum.

ventricosa, Balansa, in Bull. Soc. Bot. Fr. i. (1854) 14. -Algeria.

versicolor, Baumg. ex Steud. Syn. PI. Gram. $233=$ Baumgartenii.

versicolor, Vill. Prosu. $17=$ Scheuzeri

versicolor, St. Am. Fl. Agen. 48 = sulcata.

vilis, Wally. Beitr. Fl. Hercyn.173; et in Linnaea, xiv. (1840) 543.-German.

villosa, Bertol. Exc. de Re Herb. 6. n. $3=$ Trisetum villosum.

villosa, Lag, ex Roem. \& Schult. Syst. ii. $670=$ hirsuta. virescens, Regel, in Act. Hort. Petrop. vii. (1880) 635 -Turkestan.

viridis, H. B. \& K. Nov. Gen. et Sp. i. $147=$ Deyeuxia viridis, Fourn.

Wiestii, Steud. Syn. Pl. Gram. 231.-Aegypt.; Arab.; Persia.

Wilhelmsii, Spreng. Syst. i. $333=$ Trisetum rigidum.

AVENELLA, Koch, ex Steud. Nom. ed. II. i. $173(1840)$; Parl. Fl. Ital, i. 244 (1848)=Deschampsia, Beauv. (Gramin.).

cuprina, Schur, in Verh. Siebenb. Ver. Naturw. iv. (1853) $85=\mathrm{D}$. flexuosa.

flexuosa, Parl. F1. Ital. i. $246=$ D. flexuosa.

rubra, Jord. ex Nym. Consp. $808=$ D. flexuosa

uliginosa, Parl. F1. Ital, i. 246=D. uliginosa.

AVERRHOA, Linn. Syst. ed. I (1735). GERANIA. $C E A E$, Benth. \&c Hook. f. i. 277.

Carambola, Adans. Fam. ii. 508 (1763). acida, Linn. Sp. Pl. $428=$ Phyllanthus Cicca. acutangula, Stokes, Bot. Mat. Med.ii. $543=$ A. Carambola.

Bilimbi, Linn. Sp. Pl. 428.--Ind. or, ; China.

Carambola, Linn. Sp. Pl. 428.-Ind. or.; China.

frondosa, Salisb. Prod, $318=$ Phyllanthus Cicca,

obtusangula, Stokes, Bot. Mat. Med. ii. $542=$ A. Bilimbi.

pentandra, Blanco, Fl. Filip. ed. I. $392=$ Connaropsis philippica.

sinica, Hance, in Walp. Ann. ii. $241=$ Rourea microphylla.

AVERRHOIDIUM, Baill. Adansonia, xi, 244 (1874),

SAPINDACEAE.

Gardnerianum, Baill. l. c.-Bras.

AVERSIA, G. Don, Gen. Syst. iii. $92(1834)=$ ARVERSIA, Cambess $。$ = Polycarpon, Linn. (Caryophyll.).

AVICENNIA, Linn. Syst. ed. I (1735); Gen. ed. I. 27 (1737). VERBENACEAE, Benth. \& Hook, f. ii. 1160.

Bontia, Linn. Gen. ed. I. 180 (1737).

DonATIA, Loefl. Iter, 193 (1758).

Halodendrum, Thou. Gen. Nov. Madag. 8 (1806)

RACKA, J. F. Gmel. Syst. 245 (1791).

Sceura, Forsk. Fl. Aegypt. Arab. 37 (1778).

UpATA, Adans. Fam. ii. 201 (1763)

africana, Beauv. Fl. Owar. i. 80, t. $47=$ officinalis.

alba, Blume, Bijdr. $821=$ officinalis.

elliptica, Thunb. P1. Bras. Dec. iii. $37=$ officinalis floridana, Rafin. Atl. Journ. $148=$ officinalis. intermedia, Griff. in Trans. Linn. Soc. xx. (1846) $6=$ officinalis.

Lamarckiana, Presl, Bot. Bemerk. $99=$ officinalis. Meyeri, Miq. in Linnaea, xviii. (1844) $262=$ officinalis. nitida, Facq. Enum. Pl. Carib. 25.-Am. trop.; Afr. trop.

oblongifolia, Nutt, ex Chapm. F1. S. U. St. $310=$ officinalis.

obovata, Griff. Notul. iv. $\mathbf{1 8 9}=$ officinalis.

Oepata, Buch.-Ham. in Trans. Linn. Soc. xvil. (1837) $221=$ officinalis.

officinalis, Linn. Sp. Pl. 110.-Littora tropica.

resinifera, Forst. f. Pl. Escul. $72=$ officinalis.

tomentosa, Jacq. Enum. Pl. Carib. 25= officinalis.

AVICEPS, Lindl. Gen. et Sp. Orch. $345(1838)=$ Saty rium, Sw. (Orchid.)

pumila, Lindl. 1. c. $346=\mathrm{S}$. pumilum. 
AVICULARIA, Steud. Nom. ed. II. i. $174(1840)=$ Polygonum, Tourn.

indica, Didrichs. in Bot. Notiser, (1850) $187=\mathrm{P}$. plebeium.

maritima, Didrichs. 1. c. $=$ P. maritimum

vulgaris, Didrichs. 1. c. $=$ P. aviculare.

AVIUNCULUS, Fourr. in Ann. Soc. Linn. Lyon, N. S. xvi. (1868) $367=$ Coronilla, Linn. (Legum.). scorpioides, Fourr. 1. c. $=$ C. scorpioides.

AVORNELA, Rafin. Sylva Tellur. 24 (1838)=Genista, Linn. (Legum.).

canariensis, Rafin. 1. c. = G. canariensis. candicans, Rafin. 1. $\mathrm{c}_{\circ}=$ Cytisus candicans. linifolia, Rafin. 1. $c_{s}=$ Cytisus linifolia.

AWAYUS, Rafin. Sylva Tellur. 151 (1838)=Spiraea, Linn. (Rosac.).

japonicus, Rafin. 1. c. $151=\mathrm{S}$. japonica

AXANTHES, Blume, Bijdr. 1002 (1826)=Urophyllum, Wall. (Rubiac.)

arborea, Blume, 1. c. $1003=\mathrm{U}$. glabrum

Blumeana, Wight, in Calc. Journ. Nat. Hist. vii. (1847) $145=\mathrm{U}$. Blumeanum.

ceylanica, Wight, 1. c. $146=\mathrm{U}$. zeylanicum. corymbosa, Blume, Bijdr. $1003=\mathrm{U}$. corymbosum. elliptica, Wight, in Calc. Journ. Nat. Hist. vii. (1847) $144=\mathrm{U}$. ellipticum

enneandra, Wight, 1. c. $144=$ Aulacodiscus premnoides. Griffithiana, Wight, 1. c. $147=$ U. Griffithianum.

hirsuta, Wight, l, c. $148=\mathrm{U}$. hirsutum.

longifolium, Wight, I. c. $145=\mathrm{U}$. longifolium.

macrophylla, Blume, Bijdr. $1002=\mathrm{U}$. macrophyllum.

philippensis, Cham. \& Schlecht. ex Steud. Nom. ed. II. i. 174.-Ins. Luzon.

strigosa, Blume, Bijdr. $1003=\mathrm{U}$. strigosum.

timariensis, DC. Prod. iv. 441.-Ins. Timor.

tomentosa, Blume, ex DC. 1, c. $440=\mathrm{U}$, tomentosum.

zeylanica, Wight, Ic. t. $1163=\mathrm{U}$. zeylanicum.

AXANTHOPSIS, Korth. in Nederl. Kruidk. Arch. ii (1851) $195=$ Urophyllum, Wall. (Rubiac.)

elongata, Korth. 1. c. =U. elongatum.

AXENFELDIA, Baill. Etud. Gén. Euph. 419. (1858)= Mallotus, Lour. (Euphorb.)

intermedia, Baill. l. c.= M. muricatus.

AXIA, Lour. Fl. Cochinch. 35 (1790). VALERIANACEAE

cochinchinensis, Lour. l, c. 36.-Cochinch.

AXILLARIA, Rafin. in Am. Monthly Mag. (1818) 266 = Polygonatum, Adans. (Liliac.).

AXINAEA, Ruiz \& Pav. Prod. 68 (1794). MELASTOMACEAE, Benth. \& Hook. f. i. 749.

Chastenaea, DC. Prod. iii. 102 (1828)

bracteata, Zipp. ex Blume, in Flora, (1831) $519=$ Medinilla bracteata.

crassinoda, Triana, in Trans. Linn. Soc. xxviii. (1871) 69.-Peruv.

dependens, Ruir \& Pav. Fl. Per, iv, t. 411.-Peruv.

floribunda, Triana, in Trans. Linn. Soc. xxviii. (1871) 69.-Ecuador.

glandulosa, Ruis \& Pav. Fl. Per. iv. t. 412,-Peruv.

grandifolia, Triana, in Trans. Linn. Soc. xxviii. (1871) 69.-Venezuela.

lanceolata, Ruis \& Pav. Fl. Per. iv. 409 ; Syst. i. 122. -Peruv.

lepidota, Triana, in Trans. Linn. Soc. xxviii. (1871) bi.).-. Ecuador.

macrophylla, Triana, l. c.-Ecuador.

Merianiae, Triana, $l$.. .-Venezuela.

muricata, D. Don, in Mem. Wern. Soc. iv. (1823) 821 - Miconia muricata.

purpurea, Ruiz \& Pav, F1. Per, iv. 410 ; Syst. i. $122=$ Meriania radula.

Radula, Benth. Pl. Hartw. $130=$ Meriania Radula.

sclerophylla, Triana, in Trans. Linn. Soc. xxviii. (1871) 68.-Ecuador.

scutigera, Triana, l. c. 69,-N. Granat.

sessilifolia, Triana, l. c. 68.-Peruv.
AXINEA, Juss, in Dict. Sc. Nat. xxix. (1823) $508=$ praec.

AXINANDRA, Thw, in Hook. Kew Jourm, vi. (1854) 66. t. 1. C. LYTHRARIEAE, Benth. \& Hook.f. 784 .

alata, Baill. Adansonia, xii. (1876) 86.-Malaya.

Beccariana, Baill. l. c. 85.-Malaya.

coriacea, Baill. l. c.-Malaya.

Maingayi, C. B. Clarke, in Hook. f. Fl. Brit. Ind.ii. 581 - Malacca.

zeylanica, Thw. in Hook. Kew Fourn. vi. (1854) 67.Zeylan.

AXINANTHERA, Karst. in Linnaea, xxx. (1859-60)

$157=$ Bellucia, Neck. (Melast.)

Bellucia, Karst, l, $c_{.}=\mathrm{B}$. Axinanthera

macrophylla, Karst. 1. c. = B. superba?

AXINIPHYLIUM, Benth. in Hook. Ic. PI. xii. 16. t. 1118 (1872). COMPOSITAE, Benth. \& Hook. f. ii. 362 .

corymbosum, Benth. l. c.-Mexic.

tomentosum, Benth. l. c. sub t. 1118.-Mexic.

AXIRIS, Linn. Diss. Chen. $43(1751)=$ Axyris, Linn. (Chenop.).

AXOLOPHA, Alef. in Oestr. Bot. Zeitschr. xii. (1862) 258 = Lavatera, Linn. (Malvac.)

aegyptia, Alef. 1. c. $259=$ Malva aegyptia. althaeoides, Alef, 1. c.= Malva althaeoides. hirsuta, Alef. 1. c. = Althaea hirsuta.

Ludwigii, Alef. 1. c. = Althaea Ludwigii.

maritima, Alef. $1, c_{.}=\mathrm{L}$. maritima

Wigandi, Alef. l. c. =L. maritima.

AXOLUS, Rafin. Sylva Tellur. $61(1838)=$ Cepha lanthus, Linn. (Rubiac.).

angustifolius, Rafin. 1: c, =C. angustifolius.

AXONOPUS, Beauv. Agrost. $12(1812)=$ Paspalum Linn. (Gramin.).

aureus, Beauv. 1. $\mathrm{c}_{\mathrm{s}}=\mathrm{P}$. aureum.

cimicinus, Beauv. 1. c. = Panicum cimicinum.

compressus, Beany, l $\mathrm{c}=\mathrm{P}$ compressum.

corymbosus, Schult. Mant ii. 177 = Panicum corym bosum.

digitatus, Beauv. Agrost. $12=\mathrm{P}$. digitatum.

paniceus, Beauv. 1. c. $=$ Panicum filiforme.

Poiretii, Roem. \& Schult. Syst. ii. $318=$ P. com pressum.

savannarum, Schlecht. in Linnaea, xxvi, (1853-55) $132=\mathrm{P}$. savannarum.

AXONOTECHIUM, Fenzl, in Ann. Wien. Mus, i. (1836) $354=$ Orygia, Forsk. (Ficoid.).

trianthemoides, Fenzl, 1. c. $355=\mathrm{O}$. decumbens.

AXYRIS, Linn. Syst. ed. VI. Add. (1748); Amoen Acad. 24 (1751). CHENOPODIACEAE, Benth. \& Hook. f. iii. 56 .

amaranthoidos, Linn. Sp. Pl. 979.-As. bor

ceratoides, Linn. 1. c. $=$ Eurotia ceratoides

hybrida, Linn. 1. c. $980=$ amaranthoides.

Moorcroftiana, R. Br. in Wall. Cat. n. $6950=$ Eurotia ceratoides,

pentandra, Facq. Am. Select. 244.-Cuba.

prostrata, Linn. Sp. Pl. $980=$ amaranthoides?

sphaerosperma, Fisch. E Mey. Ind. Sem. Hort. Petrop. vi. (1839) 46-Mont. Altai.

triflora, Moench, Meth. Suppl. $120=$ amaranthoides.

villosa, Moq. in DC. Prod. xii. II. 117.-Afghan.

AYAPANA, Spach, Hist. Vég. Phan. x. $290(1811)=$ Eupatorium, Linn. (Compos).

officinalis, Spach, 1. c. =E. Ayapana.

AYDENDRON, Nees, in Linnaea, viii. (1833) 36 LAURINEAE, Benth. \& Hook. f. iii. 153. Endlicheria, Nees, in Linnaca, viii. (1893) 37. Goeppertia, Nees, Syst. Laurin. 365 (1836).

Schavera, Nees, in Lindl. Nat. Syst. ed. II. 202 in adnot. (1836)

aciphyllnm, Nees, in Linnaea, xxi. (1848) 496.-Guinna. affinis, Meissn. in DC. Prod. xv. 1. 92,-Bras. amazonicum, Meissn. l. c. 89.-Bras

argenteum, Griseb. Fl. Brit. W. Ind. 285,-Ind. occ.

bracteatum, Nees, Syst. Laurin. 256.-Ins. S. Vincent.

\section{AYDENDRON :-}

brasiliense, Meissn. in Mart. Fl. Bras, v. II. 180,-

Bras.

Cannella, Meissn. in DC. Prod. xv. 1. 90.-Guiana

cayennense, Meissn.l.c.95.-Guiana.

citrifolium, Griseb. Fl. Brit. W. Ind. $284=$ trinitatis.

citrifolium, Nees, Syst. Laurin. 257.-Bras.

cubense, A. Rich. Fl. Cub. Faner. ii. 187.-Cuba.

Cujumary, Nees, Syst. Laurin. 247-Bras.

curvirameum, Meissn. in DC. Prod. xy, I. 190.Guiana.

desertorum, Nees, Syst. Laurin. 260.-Bras.

firmulum, Nees, in Linnaea, viii. (1836) 36.-Bras.

floribundum, Meissn. in DC. Prod. xv. 1. 88.-Bras.

Gardneri, Meissn. l. c. 84.-Bras.

glaucum, Klotzsch E Karst. ex Meissn. l. c. 90.-N.

Granat.

goyazense, Meissn.l.c. 94.-Bras.

Hostmannianum, Nees, in Linnaea, xxi. (1818) 499.-

Guiana.

intermedium, Meissn, in DC. Prod. xv. I. 89-Bras.

laevigatum, Meissn. l. c. 88.-Bras.

Laurel, Nees, Syst. Laurin. 249.-Venezuela.

macrophyllum, Meissn. in DC. Prod. xv. I. 92.-N. Granat.

microbotryum, Nees, Syst. Laurin. 254.-Ins. Por-

torico.

Muca, Nees, in Linnaea, xxi. (1848) 498.-Peruv.

nitidum, Meissn. in DC. Prod.xv. I. 95.-Bras.

obtusifolium, Nees, Syst. Laurin. 258.-Am. austr.

pachycarpum, Meissn. in DC. Prod. xv. I. 95.

Guiana.

pallidum, Meissn. l.c. 93.-Bras.

panurense, Meissn. l. c. 89.-Bras.

parviflorum, Meissn. l. c. 90.-Bras.

permolle, Nees, Syst. Laurin. 216.-Bras.

piaubyense, Meissn. in DC. Prod. xv. 1. 93.-Bras.

riparium, Nees, in Linnaea, xxi. (1848) 497.-

Guiana.

robustum, Klotzsch Eै Karst. ex Meissn. in DC. Prod.

xv. I. 90.-N. Granat.

salicifolinm, Nees, Syst. Laurin. 252.-Ind. occ.

Guian.

Sellowii, Meissn. in DC. Prod. xv. I. 88.-Bras

sericeum, Griseb. Fl. Brit. W. Ind. 285.-Ind. oce.

suaveolens, Nees, in Linnaea, viii. (1833) 37-Bras.

tenellum, Meissn, in DC. Prod. xv. 1.93-Bras.

trinitatis, Meissn. l. c. 91 - Ins. 'Trinit

verrucosum, Nees, Syst. Laurin. 259.-Bras.

verticillatum, Meissn. in DC. Prod. xv. 1. 91.-Ins.

S. Vincent.

AYENIA, Loefl. It. 199 (1758). STERCULIACEAE,

Benth. \& Hook. f. i. 225

Cybiostigma, Turcz, in Bull. Soc. Nat. Mosc. xxv. (1852) II. 155.

DAYeNIA, Mill, Gard. Dict. ed. VII. (1759)

JuNGIA, Loefl. It. 199 (1758)

abatilifolia, Turcz, in Bull. Soc. Nat. Mosc xxxvi. (1863) 1. 569= magna.

acalyphifolia, Griseb. in Goett. Abh. xxiv. (1879) 50.Reg. Argent.

angustifolia, A. St. Hil. \& Naud in Antr. Sc. Vot.

Sér. II. xviii. (1842) 34.-Bras.

cardiopetala, Sesse, ex DC. Prod. i. $488=$ magna

cordifolia, Sesse, ex DC.l.c.-Mexic

cordobensis, Hieron. Ic. Pl. Argent. 50.-Reg. Argent.

euphrasiaefolis, Griseb. Cat. Pl. Cub. 29.-Cuba.

hirta. A. St. Hil. E Naud. in Ann. Sc. Not. Sér. II.

xviii. (1842) 34 --Bras.

inermis, Medic ex Steud. Nom ed. IL i. $17 t=$ pusilla.

laevigata, Sw. Prod. Veg. Ind. Occ. 97.-Ins. Jamaic,

lingulata, Griseb. in Goets. Ab/. xxiv. $18,-9)$ 50.Keg. Argent.

magna, Linn. Syst. ed. X. 1247.-Mexic

mexicana. Turcs, in Bull. Soc. Wal. Mose. xurvi. (1863) I. 569.-Mexic.

microphylla, A. Gray, in Smithson. Contr. iii. (185:) 24. -N. Mexic.

ovata, Hemst. Diag Pl Nion 4-Mexic.

pusilla, Linn. Syst. ed. ․ 1247.-Ins. Carib. ; Terus.

rotundifolia, Hemsl. Diak. Pl. Nor. h-Mexic.

sidacfolia, Hemsl. Biul. Centr. Am. Bot. i. 195 mexicana.

sidacfolia, DC. Prod. is $\$ \$ \$=$ tomentoea 


\section{AYENIA}

sidaeformis, Loefl. It $257=$ tomentosa.

stipularis, Planch. E Triana, in Ann. Sc. Nat. Sér. IV. xvii. (1862) 334.-N. Granat.

tomentosa, Linn. Syst. ed. X. 1247.-Venezuela.

AYLANTUS, Juss, Gen, $373(1789)=$ Ailanthus, Desf. (Simarub.).

AYLMERIA, Mart. Amaranth. 68 ; et in Nov. Act. Nat. Cur. xiii. (1826) $276=$ Polycarpaea, Lam. (Caryophyll.).

rosea, Mart. 11. cc. $=$ P. violacea.

violacea, Mart. Il. cc. $=\mathrm{P}$, violacea.

Zollingerii, Fenzl, in Zoll. Syst. Verz. Ind. Archip. 141.-Malaya.

AYPARIA, Rafin. Sylva Tellur. 154 (1838)= Symplocos, Linn. (Styrac.).

crenata, Rafin. 1. c. (=Dicalix cochinchinensis, Lour. $)$ -Cochinch.

AYTONIA, Linn. f. Suppl. 49, 303 (1781)=Aitonia, Thunb. (Sapind.).

AZADirachta, A. Juss, in Mém. Mus. Par, xix. (1830) 220 (Mél. 68) (1830)= Melia, Linn.

indica, A. Juss. 11. cc. $221,69=$ Melia Azadirachta.

AZALEA, Gaertn. Fruct.i. 301. t. 63 (1788), pro parte= Loiseleuria, Desv. (Ericac.).

AZALEA, Linn. Syst.. ed. I (1735)=Rhododendron, Linn. (Ericac.)

alba, Blume, ex DC. Prod. vii. $721=$ R. album

alba, Sweet, in Ann. Fromont, i. (1829) $104=$ R. ledifolium.

amoena, Lind1. in Paxt. Flow. Gard. ii. (1852) t. $89=$ $\mathrm{R}$. indicum.

arborea, Bart. ex Steud. Nom. ed. II. i. $174=\mathrm{R}$ arborescens.

arborea, Linn. Sp. Pl. $150=$ R. ponticum.

arborescens, Pursh, Fl. Am. Sept. i. $153=$ R, arborescens.

aurantiaca, Dietr. Darst. Vorz. Zierpfl. Heft i. 5. t. 1 $=\mathrm{R}$. calendulaceum.

Bealii, Fortune, ex C. Koch, Dendrol. ii. H. $_{175}=\mathrm{R}$. sublanceolatum.

bicolor, Pursh, F1. Am. Sept. i. $153=$ R. nudiflorum.

bullata, Forst. ex Steud. Nom. ed. II. i. $174=$ Lebetanthus americana.

Burgeri, Miq. Ann. Mus. Bot. Lugd. Bat. i. $34=\mathrm{R}$ indicum.

calendulacea, Hook. \& Arn. Bot. Beech. Voy. $361=\mathrm{R}$. occidentale.

calendulacea, Michx. Fl. Bor. Am. i. 151=R. calendulaceum.

californica, Torr. \& Gray, ex Durand, in Journ. Acad. Nat.. Sc. Philad. Ser, II. iii. (1855) $94=\mathrm{R}$ californicum.

calycina, Lem Jard: F1 iii. (1853) t. $257=\mathrm{R}$ indicum canescens, Michx. F1. Bor. Am. i. $150=$ R. nudiflorum. celebica, Blume, ex DC. Prod. viii. $725=\mathrm{R}$. malayanum.

chinensis, Steud. Nom. ed. II. i. $175=$ R. sinense. crispiflora, Hook. Bot. Mag, t. $4726=\mathrm{R}$, indicum. crocea, Hoffmgg, Verz. Pfl. Nachtr. iii. $22=\mathrm{R}$. calen dulaceum?

dahurica, C. Koch, Dendrol. ii. II. $181=$ R. dauricum. Danielsiana, Paxt, Mag. Bot. i. $129=\mathrm{R}$. indicum. decumbens, DC. Prod. vii. $718=\mathrm{R}$. indicum.

Farrerae, C. Koch, Dendrol. ii. II, $178=$ R. Farrerae. ferruginosa, Pall. Fl. Ross. ii. t. $70=$ R. Anthopogon. fimbriata, Dum.-Cours. Bot. Cult. ed. II. iii. 337.China.

flammea, Pritz. Ic. Ind. $131=\mathrm{R}$. calendulaceum.

flava, Hoffmgg. Verz. Pf. Nachtr. ii. $62=$ R. calendulaceum?

fragrans, Adams, in Mém. Acad. Pétersb. ii. (1808) $332=\mathrm{R}$. Anthopogon

fragrans, Rafin. Ann. Nat. $12=\mathrm{R}$, arborescens.

fulva, Michx. ex Lam. Journ. Hist. Nat. i. (1792) 410 $=\mathrm{R}$. nudiflorum.

gandavensis, Hort. ex C. Koch, Dendrol.iii. II. $185=$ R. ponticum.

glauca, Lam. Illustr. 493. t. $110=\mathrm{R}$, viscosum.

glauca, Meerb. Pl. Sel. Ic. t. $6=$ R. glaucum?
AZALEA :-

hispida, Pursh, Fl. Am. Sept, i. 154=R. viscosum.

indica-alba, Lindl. in Bot. Reg.t. $811(1824)=\mathrm{R}$ ledifolium.

indica, Linn. Sp. PI. $150=$ R. indicum.

japonica, A. Gray, in Mem. Am. Acad. N. S. vi. (1858-59) 400.-Japon.

javanica, Blume, ex DC. Prod. vii. $721=\mathrm{R}$. javanicum.

Fodogawa, Hassk. Cat. Hort. Bog. Alt. $162=$ R. Keiskei.

lapponica, Linn. Sp. P1. 151=R. lapponicum

lapponica, Pall. Fl. Ross. ii. 52. t. 70, f. $1=$ R. Antho-

pogon.

podifolia, Hook. Bot. Mag. t. $2901=$ R. ledifolium.

lilliflora, Poit, in Rev. Hortic. (1869) $299=\mathrm{R}$. ledifolium.

linariaefolia, Carr. 1. c. (1872) $100=$ seq.?

linearifolia, Hook. f. Bot. Mag. t. $5769=$ R. lineari. folium.

lucida, Meerb. Pl. Sel. Ic. $7=$ R. lucidum

Ludoviciae, Herb. in Bot. Reg. xxxi. 60.-Hab.?

lugens, Dum.-Cours. Bot. Cult. ed. II. iii. 337.China.

lutea, Linn. Sp. P1. $150=$ R. nudiflorum,

macrantha, Bunge, Enum. Pl. Chin. Bor. $41=$ R. indicum.

mollis, Blume, Bijdr. $853=$ R. molle.

Morterii, Sweet, ex Loud. Hort. Brit. Suppl. iii. $496=$ $\mathrm{R}$. calendulaceum.

Mortieriana, Hort. ex Spae, in Ann. Gand. ii. (1846) $325=\mathrm{R}$. calendulaceum

mucronata, Blume, Bijdr. $853=\mathrm{R}$. ledifolium

multiflora, Turcz. ex DC. Prod. vii. $715=\mathrm{R}$. Anthopogon.

myrtifolia, Champ. in Hook. Bot. Mag. Ixxvii. (1851) sub t. $4609=\mathrm{R}$, ovatum

narcissiflora, Fortune, ex Planch. in Rev. Hortic. Sér. IV. iii. (1854) $67=\mathrm{R}$. ledifolium.

nitida, Pursh, Fl. Am. Sept. i. $153=$ R. nitidum.

nivea, Dehnb. Cat. P1. Hort. Camald. ed. II. 17.$\mathrm{Hab}$ ?

nudiflora, Linn. Sp. Pl. ed. II. $214=$ R. nudiflorum.

obtusa, Lindl. in Journ. Hort. Soc. i. (1846) $152=\mathrm{R}$. indicum.

occidentalis, Torr. \& Gray, ex Torr. in Pacif. Rail. Rep. iv. $116=\mathrm{R}$. occidentale

ovata, Lindl. in Journ. Hort. Soc. i. (1846) $149=\mathrm{R}$. lapponicum.

pallida, Turcz. in Bull. Soc. Nat. Mosc. (1838) 96 ; xxi. (1848) II. 498.-Mont. Baical

periclymena, Pers. Syn. i. $213=\mathrm{R}$. nudiflorum.

periclymenoides, Michx. Fl. Bor. Am. i. $151=$ R. nudiflorum.

phaenicea, Hort. ex Planch. in FI. des Serres, Sér. I. ix. 1853-54) $79=\mathrm{R}$. puniceum.

pilosa, Michx. in Lam. Joum. Nat. Hist. i. (1792) 410 $=$ Menziesia globularis.

pontica, Linn. Sp. Pl. $150=$ R. ponticum.

procumbens, Linn. 1. c. 151 = Loiseleuria procumbens.

prolifera, Poit. in Ann. Fromont, i. (1829) 104=R. Simsii.

punctata, Lour. Fl. Cochinch. 113; ed. Willd.i. $139=$ R. Loureirianum.

punicea, Sweet, in Ann. Fromont, i. (1829) $104=\mathrm{R}$, sublanceolatum.

purpurea, Dam.-Cours. Bot. Cult. ed. II. iii. 337.Ind. or.

ramentacea, Lindl. Journ. Hort. Soc. iv. (1849) $291=$ $\mathrm{R}$. indicum.

Rawsonii, Paxt. Mag. Bot. ii. 121.-Hab. ?

retusa, Blume, ex Steud. Nom. ed. II. i, $175=$ R. retusum.

rosmarinifolia, Burm. f. Fl. Ind. $43=\mathrm{R}$. ledifolium rubra, Meerb. Pl. Sel. Ic. 8.-Hab.?

scabra, Lodd. ex A. Gray, Syn. F1. N. Am. ii. II. $41=$ R. viscosum.

serpyllifolia, A. Gray, in Perry, Jap. Exped.ii. $315=$ R. serpyllifolium.

Seymowri, Lindl. in Bot. Reg, t. $1975=$ R. Seymouri. sinensis, Lodd. Bot. Cab. t. $885=$ R. sinense.

speciosa, Willd. Enum. Hort. Berol. Suppl. $10=$ R. speciosum.

squamata, Lindl. in Journ. Hort. Soc. i. (1849) $152=$ R. Farrerae.

tomentosa, Duroi, ex Steud. Nom. ed. I. $97=$ Loiseleuria procumbens.

tubiflora, Blume, ex DC. Prod. vii. $725=$ R. malayanum.

\section{AZALEA :-}

verticillata, Bart. ex Lodd. Cab. t. 1632.-Am. bor. virens, Dum.-Cours. Bot. Cult. ed. II. iii. $335=\mathrm{R}$ viscosum.

viscosa, Linn. Sp. Pl. $151=$ R. viscosum

vittata, Dum.-Cours. Bot. Cult. ed. II. iii. $337=\mathrm{R}$. vittatum.

vittato-punctata, Lem. Illustr. Hortic. (1854) t. $20=$ praec.?

AZALTEA, Walp. Rep. i. $539(\mathbf{1 8 4 2})=$ Alzatea, Ruiz $\&$ Pav. (Celastr.).

AZAMARA, Hochst. ex Reichb. Nom. 145 (1841)= Schmidelia, Linn. (Sapind.).

trifoliata, Hochst. ex Baker, in Oliver, Fl. Trop. Afr. $421=$ S. africana

AZANZA, Alef. in Bot. Zeit. xix. (1861) $298=$ The spesia, Corr. (Malvac.).

acuminata, Alef. 1. c. $299=$ T. populnea

Lampas, Alef. 1. c. $297=$ T. Lampas.

Zollingeri, Alef. 1. c. 298.--Java.

AZANZA, Moç. \& Sessé, ex DC. Prod. i. 453 (1824)= Hibiscus, Linn. (Malvac.).

insignis, Moç. \& Sessé, 1. c. $454=\mathrm{H}$. Azanza.

AZAOLA, Blanco, Fl. Filip. 402 (1837)=Payena, A DC. (1844). (Sapot.).

Betis, Blanco, 1. c. = P. Betis

Leerii, Teijsm. \& Binn. in Tijdschr. Nederl. Ind. vi (1854) $116=$ P. Leerii.

AZARA, Ruiz \& Pav. Prod. 79. t. 36 (1799). BIXINEAE, Benth. \& Hook. f. i. 127

Myrtophyllum, Turcz. in Bull. Soe. Nat. Mosc. (1863) X. 604.

Silenia, Bert, in Merc. Chil. (1829) ex Bull. Féruss. xx. (1830) 108.

alpina, Poepp. En Endl. Nov. Gen. et Sp. ii. 30. t. 167 -Chili.

Berteroniana, Steud. in Flora, xxxix. (1856) 420.Chili.

celastrina, D. Don, in Edinb. N. Phil. Fourn. x. (Dec 1830) 119.-Chili.

chiloënsis, Hook. f. Fl. Antarct. 243.-Chili.

dentata, Ruiz \& Pav. Syst. 138.-Chili.

dubia, Steud. in Flora, xxxix. (1856) 418.-Chili.

Fernandesiana, C. Gay, F1. Chil. i. $196=$ serrata.

Gilliesii, Hook. Eo Arn. in Hook. Bot. Misc. iii. (1833) 144.-Chili.

hirtella, Miq. in Linnaea, xxv. (1852) 650.-Chili

integrifolia, Bert. ex Steud. in Flora, xxxix. (1856 $420=$ Berteroniana

integrifolia, Miq. ex Steud. 1. c. = Lechleriana.

integrifolia, Ruiz \& Pav. Syst. 138.-Chili.

intermedia, C. Gay, Fl. Chil. i. 194.-Chili

lanceolata, Hook. f. Fl. Antarct. 243.-Chili.

Lechleriana, Steud. in Flora, xxxix. (1856) 420. Chili.

Lilen, Bert. in Merc. Chil. (1829).—Cf. Bull. Férussac, xx. $(1830) \mathbf{1 0 8}=$ celastrina, sparsiflora.

microphylla, Hook. f. Fl. Antarct. 244.-Chili

salicifolia, Griseb. in Goett. Abh. xxiv. (1879) 20.Reg. Argent.

serrata, Bert. ex C. Muell. in Walp. Ann. vii. $226=$ dubia.

serrata, Ruiz \& Pav. Prod. 79. t. 36; Syst. 137.Chili.

sparsiflora, Steud. Nom. ed. II. i. 175.-Chili.

tomentosa, Bert. ex Steud. in Flora, xxxix. (1856) 419 -Chili.

umbellata, Phil. in Linnaea, xxviii. (1856) 610.-Chili

umbellata, Presl, Rel. Haenk. ii. $92=$ Laetia apetala.

Valdiviae, Lechler, ex Steud. in Flora, xxxix. (1856) 420.-Chili.

AZAROLUS, Borkh. Handb. Forstb. ii. 1224 (1803)=

Pyrus, Linn. (Rosac.)

alpina, Borkh. 1. c. $1234=\mathrm{P}$. alpina.

arbutifolia, Borkh. 1. c. $1225=\mathrm{P}$. arbutifolia.

Aria, Borkh. 1. c. $1229=$ P. Aria

Chamaemespilus, Borkh. 1. c. $1227=$ P. Chamaeme spilus.

crataegoides, Borkh. 1. c. $1253=$ Crataegus Azarolus.

heterophylla, Borkh. 1. c. 1248.-Hab.?

hybrida, Borkh. 1, c. $1239=\mathrm{P}$, rotundifolia.

intermedia, Borkh. 1. c. $1232=\mathrm{P}$, intermedia. 
AZAROLUS :-

maroccana, M. Roem. Syn. Rosifl. $133=$ Crataegus Azarolus.

Oliveriana, M. Roem. 1. c. = Crataegus pentagyna.

pinnatifida, Borkh. Handb. Forstb. ii. $1245=$ Pyrus pinnatifida.

platyphylla, M. Roem. Syn. Rosifl. $133=$ Crataegus pentagyna.

Pollvilleriana, Borkh. Handb. Forstb. ii. 1251=P. Pollveria.

pubescens, M. Roem. Syn. Rosiff. 134=Crataegus pubescens.

torminalis, Borkh. Handb. Forstb. ii. $1235=\mathrm{P}$. torminalis.

AZEDARA, Rafin. F1. Ludov. 135 (1817)= Melia, Linn.

speciosa, Rafin. 1. c. = M. Azedarach.

AZEDARAC, Adans. Fam. ii. $342(1763)=$ seq.

AZEDARACH, Tourn, ex Linn. Gen. ed. I. 127 (1737) $=$ Melia, Linn.

Commelini, Medic. Bot. Beobacht. (1782) 164=M. Azedarach.

deleteria, Medic. Maly, $115=$ M. Azadirachta. edule, Noronha, in Verh. Batav. Gen. v. (1790) ed. I. Art. IV. $5=$ Sandoricum indicum.

fraxinifolia, Moench, Meth. Suppl. 58=M. Azadirachta.

nigrum, Noronha, in Verh. Batav. Gen. v. (1790) ed. I. Art. IV. 5.-Malaya.

odoratum, Noronha, 1. c. = M. Azedarach. ramiflorum, Noronha, 1. c. = Epicharis cauliflora. recisum, Noronha, 1. c.-Malaya.

AZEREDIA, Arruda, ex Allemão, Desenb. cum Ic. (1846). BIXINEAE, Benth. \& Hook, f, i. 125. pernambucana, Allemão, $l$. c.-Bras.

AZIMA, Lam. Encyc. i. 343 (1789). SALVADORACEAE, Bentb. \& Hook. f. ii. 681.

Actegeton, Blume, Bijdr. 1143 (1826)

Kandena, Rafin. Sylva Tellur. 138 (1838)

Monetia, L'Hérit. Stirp. Nov. i. t. 1 (1784). angustifolia, $A$. $D C$. in $D C$. Prod. xvii. 29.-Madag. diacantha, Lam. Encyc. i. $343=$ Plectronia parviflora. nova, Blanco, Fl. Filip. ed. I. 68.-Ins. Philipp. nova, J. F. Gmel. Syst. $262=$ tetracantha. sarmentosa, Benth. E Hook. f. Gen. ii. 681.-Burma Malaya.

sarmentosa, Vill. ex Vidal, Sinops. t. 65. f. C $=$ tetracantha?

scandens, Baill. Hist. Pl. vi. $13=$ sarmentosa.

tetracantha, Lam. Encyc, i. 343.-Ind. or.

AZOPHORA, Neck. Elem.ii.361 (1790) = Rhizophora Linn.

AZORELLA, Lam. Encyc. i. 344 (1783), UMBELLIFERAE, Benth. \& Hook. f. i. 874 .

Bolax, Comm. ex Juss. Gen. 226 (1789)

Chamitis, Banks, ex Gaertn. Fruct. i. 94. t. 22 (1788).

Dichopetalum, F. Muell. in Hook. Kew Journ. vii. (1855) 378. t. 11.

Fragosa, Ruiz \& Pav. Prod. Fl. Per. 43. t. 34 (1794)

Microsciadium, Hook. f. in Hook. Lond. Joum.

Bot. vi. (1847) 468

Oschatzia, Walp. Ann. i. 340 (1849).

Pectophytum, H. B. \& K. Nov. Gen. et Sp. v. 28 t. $425(1821)$

Pozos, Lag. Gen, et Sp. Nov. 13 (1816).

apoda, A. Gray, Bot. U. St. Expl. Exped. i. 699.-

Chili.

aretioides, Willd. ex DC. Prod. iv. 77.-Ecuador.

biloba, Wedd. Chlor. And. ii. 196.-Bolivia.

bolacina, Clos, in C. Gay, Fl. Chil. iii. 80,-Chili.

bryoides, Phil. in Linnaea, xxviii. (1856) 695.-

Chili.

caespitosa, Cav. Ic. v. 57.t. 484.-Chili.

caespitosa, Vahl, Symb. Bot, iii, $48=$ glebaria.

Chamitis, Pers. Syn. i. $303=$ filamentosa.

cladorrhiza, Pers. l. c.-Peruy.

compressa, Labill. Nov. Holl. Pl. i. 75. t. $101=$ Siebera compressa.

corymbosa, Pers. Syn, i. 305.-Peruv.

crassifolia, Pers. 1, c. $303=$ caespitos

\section{AZORELLA :-}

crenata, Pers. Syn. 302.-Peruv.

cuneifolia, F. Muell. ex Benth. Fl. Austral. iii. 365.Austral.

daucoides, Urv. in Mém. Soc. Linn. Par. iv. (1826) 613 $=$ Oreomyrrhis andicola.

depauperata, Phil. Fl. Atac. 24.-Chili.

diapensioides, A. Gray, Bot. U. St. Expl. Exped. i. 702.-Peruv.

dichopetala, Benth. Fl. Austral. iii. 365.-Austral.

diversifolia, Clos, in C. Gay, Fl. Chil. iii. 86.-Chili.

filamentosa, Lam. Encyc. i. 344.-Terr. Magellan.

Gayana, Phil, in Linnaea, xxviii. (1856) 653.-Chili.

Gilliesii, Hook. E Arn. in Hook. Bot. Misc. iii. (1833) 347.-Chili.

glabra, Wedd. Chlor. And. 67.-Bolivia.

glebaria, A. Gray, Bot. U. St. Expl. Exped. i. 701.Chili.

gummifera, Poir. Encyc. Suppl. i. $551=$ caespitosa.

Hookeriana, Clos, in C. Gay, Fl. Chil. iii. 81= caespitosa.

incisa, Wedd. Chlor. And. ii. 197.-Bolivia

integrifolia, Raeusch. Nom. ed. III. $84=$ filamentosa

lanceolata, Labill. Nov. Holl. P1. i. 74. t. $69=$ Siebera Billardieri.

linearifolia, Cav. Ic. v. $57=$ Siebera linearifolia.

lycopodioides, Gaudich. in Ann. Sc. Nat. Sér. I. v. (1825) 105. t. 3.-Reg. Magellan.

madreporica, Clos, in C. Gay, Fl. Chil. iii. 79.Chili.

monantha, Clos, $l . c$-Chili.

Muelleri, Benth. Fl. Austral. iii. 364.-Austral.

multifida, Pers. Syn i, 303.-Peruy.

muscoides, Phil. in Linnaea, xxviii. (1856) 695.Chili.

nervosa, Phil. l. c. 696.-Chili

ovata, Labill. Nov. Holl. PI. i. 74. t. $100=$ Siebera Billardieri.

pedunculata, Willd: ex DC. Prod. iv, 78-Ecuador.

piligera, Phil. in Linnaea, xxviii. (1856) 652,-Chili.

pulvinata, Wedd. Chlor. And. ii. 194.-Ecuador.

Ranunculus, Urv. in Mém. Soc. Linn. Par. iv. (1826) 613.-Reg. Magell.

reniformis, Pers. Syn. 1. 303.-Peruv.

Saxifraga, Benth. Fl. Austral. iii. 365.-Austral.

Selago, Hook.f. Fl. Antarct. 284.-Terr. Magell.; Ins, Kerguelen.

sessilifiora, Phil. in Linnaea, xxviii. (1856) 652.Chili.

spinosa, Pers. Syn. i. 303.-Chili.

triscuspidata, Lam. Illustr. t. $189=$ caespitosa.

triscuspidata, Poir. Encyc. Suppl. i. $551=1$ ycopo dioides.

trifoliata, Walp. Ann. v. $62=$ trifoliolata

trifoliolata, Hook. f. Fl. N. Zel.i. (1853) t. 18.-N. Zel.

trifoliolata, Clos, in C. Gay, Fl. Chil. iii. 85. t. 30. f. 2. -Chili.

trifuscata, Hook. Ic. Pl. t. $539=$ seq

trifurcata, Pers. Syn. i. 303.-Reg. Magellan.

utriculata, Griseb. in Goett. Abh. vi. (1854) 122.--Reg. Magellan.

AZURHNIA, Fourr. in Ann. Soc. Linn. Lyon, N. S. xvii. (1869) $128=$ Veronica, Tourn. (Scrophul.).

aphylla, Fourr. 1. c. $128=\mathrm{V}$. aphylla.

\section{B}

BABACTES, DC, in Meissn. Gen. 302; Comm. 211 $(1840)$; et Prod ix. $260(1845)=$ Chirita, Buch.Ham. (Gesnerac.)

oblongifolia, DC. 1. c. = C. acuminata.

BABBAGLA, F. Muell. Rep. Babb. Exped, 21 (1858) CHENOPODIACEAE, Benth. \& Hook. f. iii. 61.

acroptera, F. Muell. E Tate, in Trans. Roy. Soc. S. Austral. vi, (1883) 108.-Austral.

dipterocarpa, F. Muell. Rep. Babb. Exped.21.-A ustral. pentaptera, F. Muell. E Tate, in Trans. Roy. Soc. S. Austral. vi. (1883) 108.-Austral.

scleroptera, F. Muell. in Wing, South Sc. Record, (Nov, 18S5), - Austral.
BABIANA, Ker-Gawl, in Bot. Mag t. 576 (1802) IRIDEAE, Benth. \& Hook, f. iii. 706 .

Acaste, Salisb. in Trans. Hort. Soc. i. (1812) 322. angustifolia, Sweet, Hort. Brit. ed. I. 396 ; Eckl. Verz 31.-Afr, austr.

atrocyanea, Eckl. Verz. 33.-Afr. austr.

atrodeltoidea, Eckl. l.c-Afr austr

Bainesii, Baker, in Fourn. Bot. xiv. (1876) 335.Afr. austr.

caesia, Eckl. Verz. 32.-Afr. austr.

caerulescens, Eckl. l. c.-Afr. austr.

cuneifolia, Baker, in fourn. Bot. xiv. (1876) 335. Afr. austr.

densiflora, Klatt, in Abh. Naturf. Ges. Halle, xii. 1882) 348.-Afr, austr.

disticha, Ker-Gavol, in Bat. Mag. t. 626.-Afr. austr.

Dregei, Baker, in Fourn. Bot. xiv. (1876) 336.-Afr austr.

Ecklonii, Klatt, in Abh. Naturf. Ges. Halle, xii. 1882) 348.-Afr. austr.

fmbriata, Baker, in Fourn. Linn. Soc. xvi. (1878) 166.-Afr. austr.

flabellifolia, Harv. ex Klatt, in Linnaea, xxxy. (186768) 380.-Afr。austr.

flavocaesia, Eckl. Verz. 32.-Afr. austr.

fragrans, Eckl. l. c. 31-Afr. austr.

Gladiola, Spreng, ex Steud. Nom. ed. II. i. 176.-Afr. austr.

hypogaea, Burch. Trav. ii. 589.-Afr. austr

lilacina, Eckl. Verz. 31.-Afr. austr.

lineolata, Klatt, in Abh. Naturf. Ges. Halle, xii. (1882) 347.-Afr. austr.

maculata, Klatt, l. c. 349.-Afr. austr.

mucronata, Ker-Gawl. in Kon. E Sims, Ann. Bot. (1805) 234.-Afr. austr.

multiflora, Klatt, in Abh. Naturf. Ges. Halle, xii 1882) 351 .-Afr. austr.

nana, Spreng. Syst. i. 156.-Afr. austr.

nervosa, Ker-Gawl. in Kon. \& Sims, Ann. Bot. i. (1805) $234=$ Antholyza nervosa

obtusifolia, Ker-Gawl. l.c.-Ins. Mascar

ochroleuca, Sweet, Hort. Brit. ed. I. 396.-Air. austr.

parviflora, Brehm, ex Klatt, in Abh. Naturf. Ges. Halle, xii. (1882) 350.-Afr, austr.

plicata, Ker-Gawl. in Bot. Mag. t. 576. -Afr. austr.

punctata, Klatt, in Abh. Naturf. Ges. Halle, xii. (1882 348.-Afr. austr.

punicea, Eckl. Verz. 32.-Afr. austr.

purpurea, Ker-Gawl. in Bot. Mag. sub t. $1019=$ villosa.

pygmaea, Spreng. ex Steud. Nom. ed. II. i. 176.-Afr. austr.

pygmaea, Baker, in Joum. Linn. Soc. xvi. (1878) $165=$ nana.

quadripartita, Klatt, in Abh. Naturf. Ges. Halle, xii. (1882) 350.-Afr. austr.

reflexa, Eckl. Verz. 33.-Afr. austr

reflexa, Ker-Gawl. Gen. Irid. $154=$ plicata

ringens, Ker-Gavl. in Kon. E Sims, Ann. Bot. i. 1805) 233.-Afr. austr.

rosea, Eckl. Ver:3. 32,-Afr. anstr.

rubro-coerulea, Pritz, Ind. Ic. $194=$ sea

rubrocyanea, Ker-Gawl in Kon. E Sims, Ann. Bot: 1805) 234. - Afr. austr.

sambucina, Ker-Gawl. l. c.-Afr. austr.

scabra, Brehm, ex Klatt, in Abh. Naturf. Ges. Halle, xii. (1882) 349.-Afr. austr.

secunda, Ker-Gavul. Gen. Irid. 154.-Afr. austr. socotrana, Hook. f. Bot. Mag. t. 6585.-Ins. Socotr. spathacea, Ker-Gazul. in Bot. Mag. to 688.-Afr. austr. Sprengelii, Baker, in Joum. Linn. Soc. xvi. (1878) 165 = pygmaea,

stellata, Eckl. Vers. 32.-Afr. austr.

stricta, Ker-Garol. in Bot. Mag. to 621, 687.-Afr.

sulphuren, Ker.Gavl. in Kon. E Sims, Ann. Bot. i. (1805) 23\%.-Afr. austr.

tenuiflora, Sweet, Hort. Brit. ed. I. 396, nomen.-Afr. austr.

Thunbergii, Ker-Gasl. in Kons. E Sims, Ann. Bot. i. (1805) 233. - Afre, nustr.

tubala, Swect, Hort. Brit. ed. I. $396 ;$ Eckl. Fors. 39. -Afr. austr.

tubitlom, Ker.Gawl. in Bot. Mag. t. 680.-Afr. ausir tubsulosa, Ker-Gawl. Gen. Irid. $15 \pm=$ cubirlora. undalato-venosa, Klatt, in Abh. Diaturf. Gis. Holle, sii $18 s 2) \$ 50,-$ Mro austr. 


\section{BABIANA :}

villosa, Ker-Gawl. in Bot. Mag. t. 583.-Afr. austr. villosula, Ker-Gawu. ex Steud. Nom. ed. II. i. 176. Afr. austr.

BABINGTONIA, Lindl. in Bot. Reg. (1842) t. $10=$ Baeckea, Linn. (Myrtac.).

Camphorosmae, Lindl. 1. c. = Baeckea Camphorosmae corynophylla, F. Muell. Fragm. iv, 74=Baeckea cory nophylla.

crispiflora, F. Muell. 1. c. = Baeckea crispiflora. densifolia, F. Muell. 1. c.=Baeckea densifolia gracilis, F. Muell. 1. c. = Baeckea polyandra. novo-anglica, F. Muell. 1. c. = Baeckea densifolia. ovalifolia, F. Muell. I. $\mathrm{c}=$ Baeckea ovalifolia. pentagonantha, F. Muell. 1. c. = Baeckea pentagonantha. pentandra, F. Muell. 1. c. = Baeckea pentandra. Preissiana, F. Muell. 1. c. = Baeckea pentandra robusta, F. Muell. 1. c. = Baeckea robusta. subcuneata, F. Muell. 1. c.=Baeckea subcuneata. virgata, F. Muell. 1, c. = Baeckea virgata.

BABIRON, Rafin. New Fl. Am. iv. $23(1836)=$ Daucus, Tourn. (Umbell.), \&c.

dichotomum, Rafin. 1. c. $24=$ Apium divaricatum. divaricatum, Rafin, 1. c. = Apium divaricatum. pusillum, Rafin. 1. c. $23=\mathrm{D}$. pusillus.

BACA, Rafin. Princ. Somiol. 25 (1814)=Boea, Commers. (Gesnerac.).

BACASIA, Ruiz \& Pav. Prod. Fl. Per. 105. t. 22 (1794) = Barnadesia, Mutis (Compos.).

corymbosa, Ruiz \& Pav. Syst. Veg. $189=$ Barn. corym bosa.

lanceolata, Ruiz \& Pav, ex DC. Prod. vii. $3=$ Barn lanceolata.

spinosa, Ruiz \& Pav. Syst. Veg. 188=Chuquiraga spinosa.

BACCAUREA, Lour. F1. Cochinch. 651 (1790) EUPHORBIACEAE, Benth. \& Hook. f. iii. 283. ADENOCREPIS, Blume, Bijdr. 579 (1825). Calyptroon, Miq. F1. Ind. Bat. Suppl. 471 (1860) Coccomelia, Reinw. in Syll. Ratisb. ii. (1828) 5. Hedycarpus, Jack, in Trans. Linn. Soc. xiv. (1825) 118

Microsepala, Miq. Fl. Ind. Bat. Suppl. 444 (1860)

Pierardia, Roxb. Hort. Beng. 28 (1814); Fl. Ind ii. $254(1832)$

acuminata, Muell. Arg. in DC. Prod. xv. II. 463.Sumatra.

affinis, Muell. Arg. 1. c. $459=$ parviflora.

Barteri, Muell. Arg. l. c. 464.-Afr. trop. occ.

borneensis, Muell. Arg. l. c. 460.-Borneo.

bracteata, Muell. Arg. l. c. 466.-Malaya

cauliflora, Lour. Fl. Cochinch. 661.-Cochinch.

costulata, Muell. Arg. in DC. Prod. xv. II. 464.-Sumatra.

courtallensis, Muell. Arg. l.c. 459.-Ind. or.

dasystachya, Muell. Arg. l. c. 458.- Java.

deflexa, Muell. Arg. l. c. 462.-Java.

dulcis, Muell. Arg. l. c. 460.-Sumatra.

flaccida, Muell. Arg. l. c. 459.-Burma.

Griffoniana, Muell. Arg. l. c. 464.-Afr. occ

javanica, Muell. Arg. l. c. 465.-Java.

lanceolata, Muell. Arg. l. c. 457-Malaya.

macrocarpa, Muell. Aro. l. c. 459.-Malaya.

macrophylla, Muell. Arg. l. c. 464.--Malaya.

macrostachya, Wight, Ic. Pl. t. $1913=$ sapida.

minutiflora, Muell. Arg. in DC. Prod.xv.11.463.-Java,

Motleyana, Muell. Arg. l. c. 461.-Malaya.

parviflora, Muell. Arg. l. c. 462.-Burma; Malaya.

propinqua, Muell. Arg. 1. c. $463=$ sapida.

pubera, Muell. Arg. l.c. 458.-Sumatra.

pyrrhadasya, Muell. Arg.l. c. 462.-Sumatra.

racemosa, Muell. Arg. l. c. 461.-Java

ramiflora, Lour. Fl. Cochinch. 661.-Cochinch

sapida, Bedd. FI. Sylv. t. $280=$ courtallensis

sapida, Muell. Arg, in DC. Prod. xv. II. 459.-Ind

or.; Malaya.

Seemanni, Muell. Arg. l. c. 462.-Ins. Pacif

stylaris, Muell. Arg. l. c. 465.-Ins. Pacif.

sumatrana, Muell. Arg. l. c. 466 -Sumatra.

sylvestris, Lour. Fl. Cochinch. 662.-Cochinch

taitensis, Muell. Arg, in DC. Prod. xv, II. 463.-Ins.

Pacif.

tetrandra, Muell. Arg. l. c. 465.-Ins. Philipp.

Wilkesiana, Muell. Arg. l. c. 461.-Ins. Pacif
BACCHARIOIDES, Linn. F1. Zeyl. $196(1747)=$ seq.

BACCHARIS, Linn. Hort. Cliff. 404 (1737). COM. POSITAE, Benth. \& Hook. f. ii. 286.

Achyrobaccharis, Sch. Bip. in Walp. Rep. ii. 952 (1843).

ARRhenaChne, Cass. in Dict. Sc. Nat, lii.,253 (1828).

Molina, Ruiz \& Pav. Prod. Fl. Per. 111. t. 24 (1794).

Pingraea, Cass. in Dict. Sc. Nat. xli. 57 (1826)

Polypappus, Less. in Linnaea, iv. (1829) 314.

Pterocladis, Lamb. ex G. Don, in Sweet, Hort. Brit. ed. III. 349 (1839).

SeRGILUS, Gaertn. Fruct. ii. 409. t. 174 (1791)

Stephananthus, Lehm. Ind. Sem. Hort. Hamb. (1826).-Cf. Flora, x. (1827) 96.

Tursenia, Cass. in Dict. Sc. Nat. xxxvii. 480 (1825) absinthioides, Hook. \& Arn. Bot. Beech. Voy. $57=$

Tessaria absinthioides.

acerosa, Turcz. in Bull. Soc. Nat. Mosc. xxiv. (1851) II. 67.-Ecuador

acutiloba, Sch. Bip. ex Baker, in Mart. F1. Bras. vi. III. $87=$ incisa.

adnata, Humb. \& Bonpl, ex Willd. Enum. Hort. Berol $870=$ Pluchea subdecurrens.

adscendens, Pers. Syn. ii. 424.-Peruv.

aegyptiaca, Forsk. ex DC. Prod. v. $450=$ Pluchea Dioscoridis.

affinis, DC. 1. c. $413=$ subopposita.

affinis, Spreng. ex Baker, in Mart. FI. Bras. vi. III. 94 = retusa.

Alamanni, DC. Prod. v. $402=$ glutinosa

alata, Hort. Berol. ex Loud. Hort. Brit. Suppl. ii. 612 $=$ genistelloides.

alaternoides, $H$. B. E $K$. Nov. Gen. et $S p$. iv. 51.Peruv.

alaternoides, Poepp. ex DC. Prod.v. $410=$ Poeppigiana albida, Hook. E Arn. in Hook. Fourn. Bot. iii. (1841) 41.- Reg. Argent.

alnifolia, Meyen E० Walp. in Nov. Act. Nat. Cur. xix. Suppl.i. (1843) 264.--Peruv.

alpestris, Gardn. in Hook. Lond. Fourn. Bot. iv. (1845) 122.-Bras.

alpestris, Mart. ex Baker, in Mart. Fl. Bras, vi. III. 64 $=$ rufescens.

alpina, $H . B$. $K$. Nov. Gen. et $S p$. iv. 48.-Peruv.

amplexicaulis, Wall. ex DC. Prod. v. $439=$ Laggera flava.

amygdalina, Griseb. in Goett. Abh. xix. (1874) $175=$ oxyodonta.

angulata, Griseb. l. c. xxiv. (1879) 180.--Reg. Argent. angustifolia, Desf. Cat. Hort. Par. ed. III. $163=\mathrm{B}$ Pingraea.

angustifolia, Michx. Fl. Bor. Am. ii. 125.-Am. bor.

anomala, DC. Prod. vo 403.-Bras.

aphylla, $D C . l . c .424$ - - Bras.

apiculata, Sch. Bip. ex Baker, in Mart. F1. Bras. vi. III. $74=$ trinervis.

arborea, Linn. Mant. 284.-Ins. Johann. (Afr. or.)

arborescens, Decne. in Nouv. Ann. Mus. Par. iii. (1834) $412=$ arborea

arbutifolia, Vahl, symb. Bot. iii. 97-Peruv.

arctostaphyloides, Baker, in Mart. Fl. Bras. vi. III. 88.-Bras.

arenaria, Baker, l. c. 62.-Bras.

aretioides, Sch. Bip. in Bonplandia, iv. (1856) 54, nomen.-Peruv.

aretioides, Turcz. in Bull. Soc. Nat. Mosc. xxiv. (1851) II. 67.-Ecuador

arguta, Gill. ex Hook. \& Arn. in Hook. Journ. Bot. iii. $(1841) 35=$ racemosa.

arguta, Pers. Syn. ii. $423=$ Psiadia trinervia.

artemisioides, Hook. E Arn. in Hook. Fourn. Bot. iii (1841) 41.-Reg. Argent

articulata, Pers. Syn. ii. 425.-Bras.

arunca, Schrank, ex DC. Prod. v. 381 = Conyza Gouani. asperifolia, Benth. F1. Hartw. $86=$ Conyza asperifolia asperula, Schau, in Linnaea, xix. (1847) 724.Mexic.

assuensis, H. B. E K. Nov. Gen. et Sp. iv. 67.-Ecuador

asteroides, Colla, in Mem. Acc. Torin. xxxviii. (1835)

14. t. 25. f. 1 (=Tripolium conspicuum ?).-Chili.

attenuata, D. Don, ex Hook. E' Arn. in Hook. Fourn. Bot. iii. (1841) 34.-Urugnay.

auriculata, Wall. ex DC. Prod. v. $442=$ Blumea hieracifolia.

avicenniaefolia, $D C$. l. c. 414.-Bras.

\section{BACCHARIS :-}

axillaris, DC. Prod. v. 407.-Bras

axillaris, Mart. ex Baker, in Mart. Fl. Bras. vi. III. 94 = halimimorpha.

bahiensis, Baker, l.c. 88.-Bahia.

Bairdii, Hook. E Arn. in Hook. Fourn. Bot. ii.. (1841)

30.-Uruguay.

Baldwinii, Griseb. in Goett. Abh. xxiv. (18\%9) $181=$ tridentata.

Baldwinii, Hook. \& Arn. in Hook. Journ. Bot. iii. (1841) $28=$ rufescens

balsamifera, Benth. Pl. Hartw. 202.-N. Granat

balsamifera, Stokes, Bot. Mat. Med, iv. 204=Blumea balsamifera.

banksiaefolia, Bert. in Merc. Chil. (1829).-Cf. Bull. Férussac, xx. (1830) $108=$ Tessaria absinthioides.

berberidifolia, Walp. in Linnaea, xiv. (1840) $314=$ brachylaenoides.

berberifolia, H. B. E K. Nov. Gen. et Sp. iv, 67.Ecuador.

Bezanilleana, Remy, in C. Gay, Fl. Chil. iv. 98.-Chili. bifrons, Baker, in Mart. Fl. Bras. vi. III. 54.-Bras.

Bigelovii, A. Gray, in Torr. Bot. Mex. Bound. 84.-

Am. bor.; Mexic.

Blanchetiana, DC. Prod. vii., $281=$ Moquinia flavescens, bogotensis, H. B. $\xi^{*} K$. Nov. Gen. et $S p$. iv. 61.-N. Granat.

brachylaenoides, DC. Prod. v. 421.-Bras

brachyphylla, A. Gray, Pl. Wright. ii. 83.-Am. bor.

bracteata, Hook. \& Arn. in Hook. Journ. Bot. ii (1841) $35=$ dracunculifolia.

bracteolata, $D C$. Prod. v. 418.-Hab.?

brasiliana, Linn. Sp. Pl. ed. II. $1205=$ Vernonia scabra

brevifolia, DC. Prod. v. 409.-Bras.

breviseta, DC. 1. c. $402=$ serrulata.

bryoides, Pers. Syn. ii, 425.-Reg. Magellan.

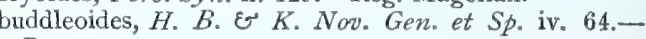
Peruv.

bupleuroides, Gardn. in Hook. Lond. Journ. Bot. vii. (1848) 86 = lignstrina

Burchellii, Baker, in Mart. Fl. Bras. vi. III. 44.-Bras. buxifolia, Pers. Syn. ii. 424.-Peruv.

cacalioides, Spreng. Nachr. i. Bot. Gart. Halle, 14.Hab. ?

caerulescens, DC. Prod. v. $402=$ glutinosa.

caespitosa, Pers. Syn. ii. 425.-Peruv.

calistemioides, Meyen E Walp. in Nov. Act. Nat. Cur. xix. Suppl.i. (1843) 265-Chili.

calliprinos, Griseb. in Goett. Abh. xix. (1874) 177.Reg. Argent.

calvescens, $D C$. Prod. v. 413.-Bras.

camporum, DC. l. c. 399.-Bras.

Candolleana, Steud. Nom. ed. II. i. 177.-Peruv

canescens, Spreng. Syst. iii. 466.-Reg. Argent.

capitata, H. B. \& K. Nov. Gen. et Sp. iv. 53.-Am. austr.

caprariaefolia, DC. Prod. v. 416.-Bras.

cassinefolia, DC. l. c. 412 .-Bras,

cassinoides, DC. l. $\mathrm{c}_{s}=$ cassinefolia.

cataphracta, Spreng. Syst. iii. 462-Peruv.

Cephalotes, DC. Prod. v. 421.-Bras.

Chilco, H. B. \& K. Nov. Gen. et $S p$. iv. 56.-N Granat.

chilensis, Weinm. in Syll. Ratisb. ii. (1828) $21=$ Podanthus ovatifolius.

chiloënsis, Sch. Bip. in Bonplandia, iv. (1856) $55=\mathrm{B}$. Chilquilla.

Chilquilla, DC. Prod. v. 419.-Chili.

chinensis, Lour. Fl. Cochinch. ii. $494=$ Blumea chinensis.

ciliata, Gard. in Hook. Lond. Fourn. Bot. iv. (1845) 122.-Bras.

cinerea, $D C$. Prod. v. 400.-Bras.

cinnamomifolia, H. B. E K. Nov. Gen. et Sp. iv. 65.Ecuador.

Clausseni, Baker, in Mart. Fl. Bras. vi. III. 99.Bras.

Clausseni, Sch. Bip. ex Baker, 1. c. $82=$ cassinefolia

cochinchinensis, Spreng. Syst. iii. 466.-Cochinch.

cognata, DC. Prod. v. 413,--Bras.

collina, Mart. ex Baker, in Mart. Fl. Bras. vi. III. $75=$ Lundii.

concava, Pers. Syn. ii. 425.-Peruv.; Chili.

conferta, H. B. \& $K$. Nov. Gen. et Sp. iv. 55.Mexic.

confertifolia, Colla, in Mem. Acc. Torin. xxxviii (1835) 15. t. 25. f. $2=$ B. Chilquilla 


\section{BACCHARIS :-}

congesta, DC. Prod. v, 410.-Mexic.

consanguinea, DC. 1. c. = pilularis.

conyzoides, $D C . l . c .403$.-Bras

coridifolia, DC. $l$. $c$. 422 .-Bras.

Corydalis, DC. ex Sch. Bip. in Linnaea, xxx. (1859 60) 181 = cassinefolia.

corymbosa, Meyen, Reise, i. 311.-Chili.

corymbosa, Pers. Syn. ii. 424.-Peruv.

crenulata, Spreng. Syst. iii. 465.-Bras.

crispa, Spreng. 1. c. $466=$ genistelloides.

cultrata, Baker, in Mart. Fl. Bras. vi. III. 93.-Bras

cuneata, DC. Prod. v. $408=$ conferta.

cuneifolia, DC. 1. c. $406=$ magellanica

cuneifolia, Moench, Meth. $574=$ halimifolia

cuneifolia, Wendl. ex Steud. Nom. ed. II. i. 177, $179=$

Wendlandii.

curvifolia, Gardn. in Hook. Lond. Journ, Bot. vii. (1848) $87=$ rufescens

cupressiformis, Pers. Syn. ii. $425=$ Lepidophyllum cupressiforme.

cylindrica, DC. Prod. v. $426=$ genistelloides.

daphnoides, Hook. \& Arn. in Hook. Journ. Bot. iii (1841) $34=$ cassinefolia.

Darwinii, Hook. EN Arn.l. c. 39.-Patagon.

deltoidea, Baker, in Mart. Fl. Bras. vi. III. 90.Reg. Argent.

densiflora, Wedd. Chlor. And i, 175-Bolivia.

denticulata, D. Don, in DC. Prod. vii. 282.-Patagon.

dentifolia, Mart. ex Baker, in Mart. Fl. Bras. vi. III. $66=$ recurvata.

dentosa, Mart. ex Baker, 1. c. $91=$ subopposita.

depauperata, Gardn. in Hook. Lond. Journ. Bot. iv, 1845) $120=$ serrulata

dependens, Pers. Syn. ii. 424.-Peruv.

dioica, Vahl, Symb. Bot. iii. 98.--Ins. Carib.

Dioscoridis, Bové, ex DC. Prod. v. $382=$ Conyza aegyptiaca.

Dioscoridis, Linn. Cent. Pl. i. 27 ; Amoen. Acad. iv. $289=$ Pluchea hirsuta

diptera, Sch. Bip. ex Baker, in Mart. Fl. Bras. vi. III. $38=$ articulata.

discolor, Baker, l. c. 48.-Bras.

discolor, Sch. Bip. ex Baker, 1. c. $54=$ B. Lychnophora

disticha, Sch. Bip. ex Baker, 1. c. $53=$ calvescens.

divergens, $D C$. Prod. v. 400.-Mexic

diversifolia, Spreng. ex Sch. Bip. in Walp. Rep. ii. $958=$ Erigeron Sprengelii.

Doniana, Hook. E Arn. in Hook. Fourn. Bot. iii. (1841) 26.-Bras.

Douglasii, DC. Prod, v. 400.-Calif.

dracunculifolia, $D C . l$.., 421 .-Bras.

effusa, Griseb. in Goett. Abh. xix. (1874) 177.-Reg. Argent.

elaeagnoides, Steud. ex Sch. Bip. in Linnaea, xxx. (1859-60) 181.-Bras.

elaeoides, Remy, in C. Gay, Fl. Chil. iv. 88.-Chili.

elegans, H. B. \& K. Nov. Gen, et Sp. iv. 60.t. 324.Mexic.

elliptica, Gardn. in Hook. Lond. Fourn. Bot. vii. (1848) 83.--Bras.

emarginata, Pers. Syn. ii. 424.-Peruv.

Lmoryi, A. Gray, in Torr. Bot. Mex. Bound. 83.-

Am. bor. occ.

ericoides, Pers. Syn. ii. $425=$ Liabum ericoides.

erigeroides, $D C$. Prod. v. 418.-Bras.

erioclada, $D C$. l. c. 415.-Bras.

erioptera, Benth. in Ann. Nat. Hist. ii. (1839) $441=$ Pterocaulon virgatum.

eupatorioides, Hook. E Arn. in Hook. Fourn. Bot. iii. (1841) 22.-Chili.

farinosa, Spreng. in Ersch \& Grub. Allgem. Encyc. vii. (1821) $27=$ glutinosa.

fasciculosa, Klatt, in Leopoldina, xx. (1884) 91.Mexic.

fastigiata, Baker, in Mart. Fl. Bras. vi. III. 39.-Bras. ferruginea, Pers. Syn. ii. 425.-Peruv.

Fevillei, DC. Prod. v, 403.-Peruv.

filifolia, Sch. Bip. ex Baker, in Mart. F1. Bras. vi, IIr $69=$ polyphylla.

flabellata, Hook. E Arn. in Hook. Fourn. Bot. iii. (1841) 28 - Chili.

flexuosa, Baker, in Mart. Fl. Bras, vi. III. 89.-Bras. flocculosa, Mart. ex Baker, 1. c. $53=$ calvescens.

floribunda, H. B. \& K. Nov. Gen. et Sp. iv. 64.N. Granat.

Aoribunda, Phil. in Linnaea, xxxiii. (1864-65) 145.Chili.

\section{BACCHARTS :-}

foetida, Linn. Sp. PI. $861=$ Pluchea camphorata.

foliosa, Gill. ex Hook. Eo Arn. in Hook. Fourn. Bot. iii. (1841) 30.-Chili.

frigida, H. B. E K. Nov. Gen. et Sp. iv. 49.-Peruv.

fuchsiaefolia, Gardn. in Hook. Lond. Fourn. Bot. vi (1848) $88=$ orgyalis.

fuliginea, H. B. \& K. Nov. Gen. et Sp. iv. $68=$ Bige lovia fuliginea.

fusca, Turcz. in Bull. Soc. Nat. Mosc. xxiv. (1851) II. 67.-Ecuador

Gaudichaudiana, DC. Prod. v. $424=$ articulata.

genistelloides, Pers. Syn. ii. 425.-Peruv.

genistelloides, Poepp. ex DC. Prod. v. $425=$ sagittalis.

genistifolia, DC. l. c. 423.-Bras.

Gibertii, Baker, in Mart. Fl. Bras. vi. IIr. 52.-Bras.

Gillesii, A. Gray, in Proc. Am. Acad.v. (1861) 123. Chili.

glabra, Spreng. Syst. iii. 466.-Reg. Argent

glauca, Meyen E Walp. in Nov. Act. Nat. Cur, xix. Suppl. i. (1843) 263.-Chili.

Glaziovii, Baker, in Mart. Fl. Bras. vi. III. 44.-Bras. glomeruliflora, Pers. Syn. ii. 423.-Am, bor.; Ins. Bermud.

glutinosa, Hook. \& Arn. Bot. Beech. Voy, $31=$ Douglasii ?

glutinosa, Pers. Syn. ii. 425.-Am. bor. et austr. occ. gnaphalioides, $D C$. Prod. v. 415.-Bras

gnaphalioides, Spreng. Syst. iii. $461=$ Lucilia acutifolia.

gnidiifolia, H. B. E K.Nov. Gen. et Sp. iv. 61.Ecuador.

gracilis, $D C$. Prod. v. 423.-Bras.

grandiflora, $H . B . \varepsilon^{\prime} K$. Nov. Gen, et Sp. iv. 58.Ecuador.

gratissima, Blume, ex DC. Prod. vi. $447=$ Blumea appendiculata.

graveolens, Sch. Bip. in Bonplandia, iv. (1856) 54, nomen.-Peruy.

grindeliaefolia, Wedd. Chlor. And. i. 177.--Peruv.

grisea, Baker, in Mart. Fl. Bras, vi. III. 65.-Bras.

Grisebachii, Hieron. in Bol. Acad. Nac. Cordova, iv. (1881) 36.-Reg. Argent.

guianensis, Schomb. Fauna \& Flora Guy. 1135.Guiana.

Haenkei, DC. Prod. v. $401=$ Douglasii.

halimifolia, Linn. Sp. Pl. 860.-Am. bor.; Ind. occ. halimifolia, Moench, Meth. Suppl. 235=Conyza ivaefolia.

halimimorpha, DC. Prod. v. 411.-Bras.

hambatensis, H. B. E K. Nov. Gen. et Sp. iv. 62.Ecuador.

Havardi, A. Gray, Syn. Fl. N.Am. i. II. 224.-Texas.

helichrysoides, $D C$. Prod. v. 415.-Bras.

hemiprionodes, Buek, Ind. Gen. DC. Prod. i. p. v.-Bras. heterophylla, H. B. E⿱ K. Nov. Gen. et Sp. iv. 62.Mexic.

heterophylla, Spreng. Syst. iii. 464, pro parte = seba stianopolitana.

hieracifotia, Lam. Encyc, i. $347=$ Conyza Gouani.

hieraciifolia, Hemsl. Biol. Centr. Am. Bot. ii. 129.Mexic.

hirta, DC. Prod. v. 405.-Bras.

hirtella, $D C$. $l$. c. 418.-Mexic

Hookeriana, DC. Prod,v. $\$ 14=$ Aplopappus Hookerianus.

humifusa, Banks \& Soland. ex Hook. f. Fl. Antarct. ii. $311=$ Melalema humifusa.

humifusa, H. B. \& $K$. Nov. Gen. et Sp. iv. 48. t. 322.Ecuador.

humilis, Sch. Bip. ex Baker, in Mart. Fl. Bras. vi. III. 92.-Bras.

Huydobriana, Remy, in C. Gay, Fl. Chil. iv. $90=$ B. Pingraea

hypericifolia, Baker, in Mart. Fl. Bras. vi. III. 69.Bras.

hyssopifolia, E. Mey. ex DC. Prod. v. $323=$ Nidorella foliosa.

ilicifolia, Lam. Encyc. 1. $845=$ Brachylaena dentata.

Ilinissae, Benth. Pl. Hartw. 202.-N. Granat.

ilinita, DC. Prod. v. 412,-Bras.

inamoena, Gardn. in Hook. Lond, Journ. Bot, vii. (1848) $81=$ trinervis

incarum, Wedd. Chlor. And. i. 170=microphylla

incisa, Hook. E Arn. in Hook. Gourn. Bot. iii. (1841) 29.-Reg. Argent

indica, Linn. Sp. Pl. $861=$ Pluchea indica.

intermedia, $D C$. Prod. v. 411.-Chili.

\section{BACCHARIS :}

intermixta, Gardn. in Hook. Lond. Fourn. Bot. vii (1848) 84.-Bras.

resinoides, H. B. E० K. Nov, Gen. et Sp. ir, 63.-N Granat.

ivaefolia, Blanco, Fl. Filip. ed. I. $627=$ Conyza viscidula.

ivaefolia, Linn. Sp. Pl. $860=$ Conyza ivaefolia.

juncea, Desf. Cat. Hort. Par. ed. III. 163.-Bras.

junciformis, DC. Prod. v. 426-Bras.

lacrymans, Mart. ex Baker, in Mart. FI. Bras. vi. III. $94=$ retusa

laevis, Spreng. Syst. iii. 466.-Cochinch

lanceolata, H. B. E K. Nov. Gen. et Sp. iv. 63Peruy.

lancifolia, Less. in Linnaea, ix. (1834) 266.-Mexic.

lanuginosa, Gardn. in Hook. Lond. Journ. Bot. vi (1848) 82 = helichrysoides.

lateralis, Baker, in Mart. Fl. Bras. vi. III. 100,-Bras.

latifolia, Pers. Syn. ii. 424.-Peruv.

laxa, Gardn. in Hook. Lond. Fourn. Bot iv. (1845) 121.-Bras.

Lechleri, Sch. Bip. in Lechl. Berŏ. Am. Austr. 53 , nomen.-Chili.

ledifolia, H. B. E K. Now. Gen. et Sp. iv. 50.-Perat

lepidophylla, DC. Prod.v. $427=$ Helichrysum baccha roides.

leptocephala, DC, 1, c. $413=$ rufescens

leptophylla, DC. 1. c. $423=$ rufescens.

leptospermoides, DC. 1. c. $421=$ dracunculifolia.

Lessingiana, $D C$. $l$. c. 414 . - Bras.

leucanthemifolia, Burm. fo ex DC. 1. c. $387=$ Conyza pinnatilobata.

leucolepis, Sch. Bip. in Linnaea, xxii. (1849) $570=$ helichrysoides.

leucopappa, DC. Prod. $\nabla .415=$ helichrysoides.

ligustrina, $D C . l . c .421$.-Bras.

limnophila, Sch. Bip. ex Baker, in Mart. F1. Bras. In. 60 = ligustrina

linearifolia, Pers. Syn. ii. $425=$ Psiadia trinervia

linearis, Pers. l. c.-Chili.

linearis, Poepp. ex Baker, in Mart. FL Bras. vi. Int $59=$ serrulata.

lingulata, Kunze, in Linnaea, vi. (1831) 147 = rosmarinifolia.

linifolia, DC. Prod. v. 420.-Mexic

linifolia, Meyen, Reise, i. $311=$ rosmarinifolia

linifolia, Phil. in Linnaea, xxxii. (1864-65; 145 Chili.

longifolia, DC. Prod. v. 402.-Mexic.

longipes, Kunze, ex DC. l.c. 401.-Chili.

loxensis, Benth. Pl. Hartw. 135.-Peruy.

lucida, Meyen, Reise, i. $460=$ Vermonia phylicae formis.

Lundii, DC. Prod. v. 404.-Bras.

Lychnophora, Gardn. in Hook. Lond. Fourn. Bot. vii. (1848) 85.-Bras.

lycioides, Remy, in C. Gay, Fl. Chil. iv. 99.-Chili.

lycopodioides, Pers. Syn. ii. $425=$ Eriotrix juniperifolia.

Macraei, Hook. E Arn. in Hook. Fourn. Bot. iii. (1841) 32.-Chili.

macrantha, H. B. \& K. Nov. Gen. et Sp. iv. 54.Ecuador.

macrodonta, DC. Prod. v. 416.-Bras.

madagascariensis, Pers, Syn, ii, $423=$ Psiadia mada gascariensis.

magellanica, Pers. l. c. 425.-Reg. Magell.

Mandonii, Sch. Bip. in Linnaea, uxxiv. (1865-66) 533. nomen.-Bolivia

marcetiaefolia, Benth. Pl. Hartw. 202.-Reg. Granal. marginalis, $D C$. Prod. y, 402 -Peruy, Chili.

maritima, Baker, in Mart. Fl, Bras, vi. 111.72 - Brys.

maxima, Baker, l. c. 80 .-Bras.

medullosa, DC. Prod. v. $\$ 05=$ serrulata.

megacephala, D. Don, ex Baker, in Mart. Fl. Bras, vi. III. $79=$ triplinervis.

megapotamica, Hook. \& Am. in Hook. Joum. Bot. iii. 1841) $38=$ rufescens.

megapotamica, Spreng. Syst. iii. 461.-Bms,

melastomaefolia, Hook. \& Am. in Iluok. Journ. liot iii. $(18+1) 25=$ oxyodonta.

mesoncure, DC. Prod. $\mathrm{v}_{0} 41 \cdot 2=$ retusa.

Meyeniana, Walp. in Noo. Act. Nat. Cur. xix. SuA i. (1843) 295.-P'cruy.

micrantha, H. B. E K. Ain. Gen. of So. iv. 61. Mexic.

microcephala, DC. Prod. ฯ. 425,-Bras

microdonta, $D C$. /. c. $\$ 10,-13$ rs. 


\section{BACCHARIS:-}

microphylla, DC. Prod. v, 406= Candolleana

microphylla, H. B. \& K. Nov. Gen. et Sp. iv. 53.N. Granat.

micropoda, Baker, in Mart. Fl. Bras. vi. III. 88.-Bras. microptera, Baker, l. c. 42,-Bras.

milleflora, DC. Prod. v. $426=$ genistelloides.

minutiflora, Mart. ex Baker, in Mart. Fl. Bras. vi. III. 69.-Bras.

mollis, H. B. \& $K$. Nov. Gen. et Sp. iv. 58.Ecuador.

monantha, Sch. Bip. ex Baker, in Mart. Fl. Bras. vi.

III. $69=$ minutiflora

montana, DC. Prod. v. $404=$ macrodonta.

montana Sch. Bip. ex Baker, in Mart. Fl Bras, vi. III. $78=$ Schultzii.

montevidensis, Sch. Bip. ex Baker, 1. c. $57=$ coridifolia. montevidensis, Spreng. Syst. iii. $460=$ Vernonia nitidula.

mucronata, Hook. \& Arn. Bot. Beech. Voy, $30=$ Aplopappus Hookerianus.

mucronata, $H . B$. E $K$. Nov. Gen. et Sp. iv, 60,Mexic.

Muelleri, Baker, in Mart. Fl. Bras. vi. III. 61.-Bras. multiflora, H. B. E K. Nov. Gen. et Sp. iv. 59. -Mexic.

multisulcata, Baker, in Mart. Fl, Bras. vi. III. 45.Bras.

myricaefolia, DC. Prod. $v_{*} 405=$ semiserrata.

myriocephala, Baker, in Mart. Fl. Bras. vi. III. 93.Bras.

myriocephala, DC. Prod. v. $426=$ genistelloides.

myrsinites, Pers. Syn. ii, 424, n. 25.-Ins. S. Doming myrsinoides, Hook, \& Arn, in Hook. Journ. Bot. iii. (1841) $32=$ brevifolia

myrtilloides, Griseb. in Goett. Abh. xix. (1874) 176.Reg. Argent.

nana, D. Don, ex Baker, in Mart. Fl. Bras, vi. III. 56. - Patagon.

Neaei, DC. Prod.v, 411.-Am. merid

neriffolia, Linn. Sp. P1. $860=$ Brachylaena nereifolia.

nervosa, DC. Prod. v. 399.-Ind. occ.

nitida, Pers. Syn. ii. 425.-Peruv.

nitida, Wall. Cat. n, $3043=$ Blumea chinensis.

nivalis, Sch. Bip. in Bonplandia, iv. (1856) 55, nomen. -Chili.

notosergila, Griseb. in Goett. Abh. xxiv. (1879) 183.Reg. Argent.

nuda, DC. Prod. v. $424=$ aphylla.

oblongifolia, Pers. Syn. ii. 424; Spreng. Syst. iii. 460. - Chili.

obovata, DC. Prod. v. 408.-Peruv

obovata, Hook. \& Arn. Bot. Beech. Voy. $30=$ umbelliformis.

obtusifolia, H. B. E K. Nov. Gen. et Sp. iv. 51.Peruy.

ochracea, Spreng. Syst. iii. 460.-Reg. Argent.

odorata, H. B. \& $K$. Nov. Gen. et Sp. iv. 52-N. Granat.

odorata, Spreng. in Ersch \& Grub. Allgem. Encyc. vii. (1821) $27=$ cassinefolia.

oleifolia, Gardn. in Hook. Lond. Journ. Bot. vii.

(1848) $86=$ calvescens.

oligantha, DC. ex Thoms, in Journ. Linn. Soc. ix. (1867) $343=$ Catamixis baccharoides.

oligophylla, Sch. Bip. ex Baker, in Mart. Fl. Bras, vi. III. $23=$ Pohlii.

opuntioides, Mart. ex Baker, l. c. 39.-Bras.

Orbignyana, Klatt, in Abh. Naturf. Ges. Halle, xv.

(1882) 327.-Chiquitos.

organensis, Baker, in Mart. Fl. Bras. vi. III. 74.-Bras orgyalis, DC. Prod. v. 416.-Bras.

orizabaënsis, Sch. Bip. ex Hemsl. Biol. Centr. Am.

Bot. ii. 130.-Mexic.

orizabaënsis, Klatt, in Leopoldina, xx. (1884) $91=$ resinosa.

oronocensis, DC. Prod. v. 422.-Peruv.

ovalis, Pers. Syn. ii. $424=$ Pluchea ovalis.

ovata, Hook. E Arn. in Hook. Fourn. Bot. iii. (1841)

22.-Chili.

ovata, Sieber, ex DC. Prod. v. $450=$ Pluchea ovalis.

oxyodonta, DC. l. c. 404,-Bras.

oxyphylla, DC. l. c. 400.-Peruv.

paniculata, $D C$. l. $c .420$.-Chili.

parviflora, Less, in Linnaea, v. (1830) 146.-Mexic

parviflora, Pers. Syn. ii. $425=$ marginalis

parviflora, Poir. Encyc. Suppl. i. $556=$ bracteolata.

parvifolia, DC. Prod. v. 424.-Peruv.

\section{BACCHARIS :-}

patagonica, Hook. Er Arn. in Hook. Fourn. Bot. iii. (1841) 29.-Reg. Magellan.

patens, Baker, in Mart. Fl. Bras. vi. III. 52.-Bras.

paucidentata, DC. Prod. v. $420=$ rufescens.

paucidentata, Sch. Bip. ex Baker, in Mart. Fl. Bras. vi. III. 71 = dracunculifolia

pauciflosculosa, DC. Prod. v, 413,--Bras

pedalis, Sch. Bip. ex Baker, in Mart. Fl. Bras. vi. III.

$64=$ rufescens

pedicellata, $D C$. Prod. v. 407.-Chili.

pentaptera, DC. l. c. 425.-Bras.

Pentlandii, $D C$. l. c. 416,-Bolivia.

pentziaefolia, Sch. Bip. ex Baker, in Mart. Fl. Bras. vi. III. 96.-Bras.

petiolata, DC. Prod. v. 418.-Chili

phagnaloides, Sch. Bip. ex Baker, in Mart. F1. Bras. vi. III. $59=$ microdonta.

philippensis, H. B. E K. Nov. Gen. et Sp. iv. 55.Ecuador.

phlogopappa, DC. Prod. v. 402.-Am. austr.

phylicaefolia, DC. l. c. 415.-Bras.

phylicaeformis, Meyen, Reise, ii. $31=$ Vernonia phylicaeformis.

phylicoides, H. B. E K. Nov. Gen. et Sp. iv. 49.Peruv.

phyteumoides, DC. Prod. v. 425.-Bras.

pilularis, $D C$. l. c. 407 - Am. bor. occ

Pingraea, DC. Prod. v. 420 -Chili.

Pingraea, Nutt. in Trans. Am. Phil. Soc. vii. (1841) $337=$ glutinosa.

pinnatifida, Klatt, in Abh. Naturf. Ges. Halle, xv, (1882) 327.--Patagon

platensis, Spreng. Syst. iii. 465.-Reg. Argent

platypoda, DC. Prod. v. 409.-Bras.

Plummerae, A. Gray, in Proc. Am. Acad. xv. (1880) 48.-Calif.

Poeppigiana, DC. Prod. v. 410.-Chili.

polifolia, Griseb. in Goett. Abh. xix. (1874) 176.-Reg. Argent.

polyantha, H. B. E K. Nov. Gen. et Sp. iv. 64.Peruv.?; Mont. Vid.?

polyantha, Spreng. Syst. ii. $464=$ helichrysoides.

polycephala, Wedd. Chlor. And. i. 173.--Bolivia.

polycephala, Sch. Bip. in Linnaea, xxx. (1859-60) 181 = vernonioides.

polygalaefolia, H. B. \& K. Nov. Gen. et Sp. iv. 49.Peruy.

polygona, Baker, in Mart. Fl. Bras. vi. III. 46.-Bras. polylepis, Sch. Bip. ex Baker, 1. c. $98=$ subcapitata.

polyneura, Sch. Bip. ex Baker, 1. c. $100=$ reticularia.

polyphylla, Gardn. in Hook. Lond. Fourn. Bot. vii. 1848) 87.-Bras.

polyphylla, Sch. Bip. ex Baker, in Mart. F1. Bras. vi. III. $69=$ minutiflora.

polyptera, $D C$. Prod. v. 426,-Bras.

potosina, A. Gray, in Proc. Am. Acad.xv. (1880) 33

-Mexic.

prenanthoides, Baker, in Mart. Fl. Bras. vi. III. 84.Bras.

prinoides, H. B. E K. Nov. Gen. et Sp. iv. 56.-Reg. Amazon.

prostrata, Baldw, in Hook. Journ. Bot. iii. (1841) $28=$ Baldwinii.

prostrata, Pers. Syn. ii. 424.--Peruv.

prunifolia, H. B. E K. Nov. Gen. et $S p$. iv. 63.Peray.

psilocalyx, Mart. ex Baker, in Mart. Fl. Bras. vi. III. $48=$ erioclada.

ptarmicaefolia, DC. Prod. v. $419=$ Bigelovii ?

Pterocaulon, Boj. ex DC. 1. c. $455=$ Pterocaulon Bojeri.

pteronioides, $D C$. l. c. 410,-N. Mexic.

puberula, DC. l. c. 401.-Bras.

pulchella, Sch. Bip. in Linnaea, xxxiv. (1865-66) 532 nomen.-Bolivia.

pulverulenta, Klatt, in Abh. Naturf. Ges. Halle, xv. (1882) 327.--Peruv.

punctigera, DC. Prod. v. $404=$ Lundii.

punctulata, DC. 1. c. $405=$ oxyodonta.

pyramidalis, Gardn. in Hook. Lond. Fourn. Bot. iv. (1845) 120.-Bras.

quadrangularis, Meyen, Reise, i. $460=$ Lepidophyllum Meyeni.

quadrinervia, Pers. Syn. ii, 423.-Am. austr.

quinquenervis, DC. Prod, v. 399.-Bras.

quitensis, H. B. E $K$. Nov. Gen. et Sp. iv. 57.Ecuador.

\section{BACCHARIS :}

racemosa, $D C$. Prod. v. 401 -Chili.

radicans, DC. 1. c. $416=$ gnaphalioides.

Radin, Phil. in Linnaea, xxxiii. (1864-65) 146. Chili.

ramiflora, A. Gray, in Proc. Am. Acad. xv. (1880) 33. -Mexic.

ramosissima, Gardn. in Hook. Lond. Journ. Bot. vii. (1848) $84=$ retusa.

ramulosa, A. Gray, Pl. Thurb. 301=pteronioides.

rapunculoides, E. Mey, ex DC. Prod. v. $323=$ Nidorella resedifolia.

recurvata, Gardn. in Hook. Lond. Fourn. Bot. vii. (1848) 86.--Bras.

refracta, Burch. ex Baker, in Mart. Fl. Bras. vi. III. 64.-Bras.

Regnellii, Sch. Bip. in Linnaea, xxii. (1849) 571.Bras.

resediflora, Less. ex Baker, in Mart. F1. Bras. vi. III. $58=$ erigeroides.

resiniflua, Steud. E Hochst. ex DC. Prod. vii. 282.Arab.

resinosa, Hook. \& Am. Bot. Beech. Voy. $31=$ concava. resinosa, H. B. $\Xi^{\circ} K$. Nov. Gen. et Sp. iv. 52,-Am. austr. retamoides, Phil. Sert. Mend. Alt. 22.--Chili.

reticularia, DC. Prod. v. 409.-Bras.

reticulata, Pers. Syn. ii. $425=$ genistelloides.

retusa, $D C$. Prod. v, 412 - -Bras.

revoluta, H. B. E K. Nov. Gen. et Sp. iv. 50.-Perav.

rhetinodes, Meyen E Walp. in Nov. Act. Nat. Cur xix. Suppl. i. (1843) 265.-Chili.

rhexioides, H. B. E K. Nov. Gen. et Sp. iv. 66.Peruv.; Bras.

rhomboidalis, Remy, in C. Gay, Fl. Chil. iv. 99.-Chili.

Riedelii, Sch. Bip. ex Baker, in Mart. Fl. Bras. vi. III. $82=$ cassinefolia

rigida, Hook. \& Arn. Bot. Beech. Voy. 57=oblongi-

riparia, H. B. E K. Nov. Gen. et Sp. iv. 65.-Ecuador. riparia, Poepp. ex DC. Prod. v. $418=$ sessilifolia.

rivularis, Gardn. in Hook. Lond. Journ. Bot. vii (1848) $83=$ macrodonta.

Rohriana, Spreng. in Ersch \& Grub. Allgem. Encyc. vii. (1821) $27=$ dioica.

Roraimae, Schomb. Fauna et Fl. Guy. 1078, nomen. -Guiana.

rosmarinifolia, Hook. E Arn. Bot. Beech. Voy. 30.Chili.

rotundifolia, Spreng. Syst. iii. 465--Reg. Argent.

rufescens, Spreng. l. c. iii. 464.-Reg. Argent.

rufidula, Sch. Bip. ex Baker, in Mart. F1. Bras, vi. III

$81=$ vernonioides.

rugosa, Willd. ex DC. Prod. v. $39=$ Vernonia patens.

rupicola, $H . B$. $\mathcal{G}^{\mathrm{K}} \mathrm{K}$. Nov. Gen. et $S p$. iv. $52, \mathrm{~N}$ Granat.

sagittalis, DC. Prod. v. 425.-Chili

salicifolia, Nutt. in Trans. Am. Phil. Soc. Ser. II. vii (1841) $337=$ salicina.

salicifolia, Pers. Syn. ii. 425.-Peruv.

salicina, Rothr. in Wheeler, Rep. vi. $156=$ Emoryi.

salicina, Torr. E Gray, Fl. N. Am. ii. 258.-Am. bor.

saligna, Mart. ex Baker, in Mart. Fl. Bras. vi. III. 60 $=$ ligustrina.

saltensis, Baker, l. c. 93.-Bras.

Salvia, Lour. Fl. Cochinch. ii. $494=$ Blumea balsami fera.

Salzmannii, DC. Prod. v. 409.-Bras.

sarophora, Phil in Anal. Univ. Chil. i. (1861) 52; et

in Linnaea, xxxiii. (1864-65) $147=$ Heterothalamus spartioides.

sarothroides, A. Gray, in Proc. Am. Acad. xvii. (1881-

82) 211 -Calif.

scabra, Pers. Syn. ii. 424.-Ecuador.

scandens, Less. in Linnaea, v. (1830) 146.-Mexic.

scandens, Pers. Syn. ii. 424,--Peruv.

Schiedeana, Oerst. in Kjoeb. Vidensk. Meddel. (1852) 83.-Bras.

Schlechtendalii, Mart. ex Baker, in Mart. Fl. Bras. vi. III. $50=$ tarchonanthoides

Schomburgkii, Baker, l. c. 89.-Guiana

Schultzii, Baker, l. c. 78.-Bras.

scolopendra, Hook. Ic. Pl. i. t. 68.-Ecuador. scoparia, Sw. Fl. Ind. Occ. iii, 1339.-Jamaica. scoparioides, Griseb. Cat. Pl. Cub. 150-Cuba. sculpta, Griseb. in Goett. Abh. xix. (1874) 175.-Reg. Argent. 


\section{BACCHARIS :-}

sebastianopolitana, Baker, in Mart. Fl. Bras. vi. III. 65.-Bras.

Seemanni, A. Gray, in Proc. Am. Acad. xv. (1880) 33.-Mexic

Selloi, Baker, in Mart. Fl. Bras. vi. In. 68.-Bras. semiserrata, DC. Prod. v. 404. n. $38=$ hemiprionodes. semiserrata, DC. 1. c. 419. n. $149=$ Sternbergiana. senegalensis, Pers. Syn. ii. $424=$ Vemonia senegalensis senicula, Mart. in Flora, xxi. (1838) II. Beibl. $61=$ cassinefolia

sergiloides, A. Gray, in Pacif. Rail. Rep. iv. 101.Am. bor. occ.

serraefolia, DC. Prod. v. 403.-Mexic.

serratifolia, H. B. E K. Nov. Gen, et Sp. iv. 59,-

Mexic. : Ind. oce.

serrulata, Pers. Syn. ii. 423.-Bras.

sessiliflora, Michx. Fl. Bor. Am. ii. $135=$ glomeruliflora.

sessiliflora, Vahl, Symb. Bot. iii. 97.-Bras.

sessilifolia, DC. Prod. v, 418.-Chili.

sinensis, Lour. Fl. Cochinch. ii. 604.-Cochinch

sinuata, H.B. \& K. Nov. Gen. et Sp. iv. 53.-Peruv.

Solierii, Remy, in C. Gay, Fl. Chil. iv. 98.-Chili.

Solisi, Phil. in Anal. Univ. Chil. (1865) ii.330.-Chili. sordescens, DC. Prod. v. 405.-Mexic.

spartea, Benth. Bot. Voy. Sulph. 114.-Am. centr.

spartioides, C. Gay, F1. Chil. iv. $102=$ Heterothalamus spartioides.

spathulata, Schau. in Linnaea, xix. (1847) 724.-

Mexic.

spathulata, Klatt, in Abh. Naturf. Ges. Halle, xv. (1882) 326.-Peruv.

speciosa, DC. Prod. v. 399.-Ins. Guadalup.

sphaerocephala, Hook. E Arn in Hook. Fourn. Bot. iii.

(1841) 25.-Chili.

spiropoda, F. Muell. Fragm. i. $34=$ Pluchea baccharoides. squarrosa, Baker, in Mart. Fl. Bras. vi. III. 50.-Bras. squarrosa, H. B. E' K. Nov. Gen. et Sp. iv. 67.-Mexic Steetzii, Anderss. Galap. Oarnes Veg, 177.-Ins. Galap.

stenocephala, Baker, in Mart. Fl. Bras, vi. III. 39.Bras.

stenoptera, Sch. Bip. in Linnaea, xxxiv. (1865-66) 533 = subalata.

Sternbergiana, Steud. Nom. ed. II. i. 179,-Peruv.

striata, Ruiz \& Pav. Syst. $207=$ Fevillei

Stroebeliana, Ces. in Atti Soc. Acc. Sc. Nap. v. (1873)

viI. 12.-Europ.

stylosa, Gardn. in Hook. Lond. Fourn. Bot. iv. (1845) 120.-Bras.

subalata, Wedd. Chlor. And: i. 174,-Bolivia.

subcapitata, Gardn. in Hook. Lond. Fourn. Bot. vii. (1848) 85.-Bras.

subdentata, DC. Prod. v. 408-Bras.

subopposita, $D C$. l. . . 413 .-Bras.

subpenninervis, Sch. Bip. in Linnaea, xxxiv. (1865-66) 532, nomen.-Bolivia.

subscandens, Sch. Bip. ex Baker, in Mart. Fl. Bras. vi. III. $76=$ conyzoides,

subspathulata, Gardn. in Hook. Lond. Journ. Bot. vii. (1848) $87=$ rufescens.

subulata, D. Don, in Hook. Fourn. Bot. iii. (1841) 39 -Patagon.

sulcata, DC. Prod.v. 419.-Mexic.

syncephala, Sch. Bip. in Bonplandia, iv. (1856) 54 ; et ex Baker, in Mart. FI. Bras. vi. III. $99=$ platypoda.

tarchonanthoides, $D C$. Prod. v, 414.-Bras.

teindalensis, H. B. E K. Nov. Gen. et Sp. iv. 417.-N Ciranat.

tenella, Hook. Er Arn. in Hook. Fourn. Bot. iii. (1841)

42.-Patagon.

tenuifolia, Linn. Sp. Pl. 860.-'Afr.'

tenuifolia, DC. Prod. v. $423=$ rufescens

teucrifolia, Hook. \& Arn. ex Baker, in Mart. Fl. Bras vi. 111.77 = anomala.

texana, A. Gray, Pl. Fendl. 75.-Texas.

thesioides, H. B. E K. Nov. Gen. et Sp. iv, 61.-

Mexic.; Arizona.

Thomasii, Klatt, in Abh. Naturf. Ges. Halle, xv. (1882) 326.-Mexic.

thymifolia, Hook. \& Arn. in Hook. Gourn. Bot. ii

(1841) 38.-Reg. Argent.

thymifolia, Miers, in Proc. Hort. Soc. (1869) $349=$ Weirii.

thyoides, Pers. Syn. ii. 425.-Peruv.

Tola, Phil. Fl. Atac. 30.-Chili

tomentosa, Steud. Nom. ed. II. i. $179^{\circ}=$ Moquinis polymorpha.

\section{BACCHARIS :-}

tomentosa, Pers. Syn. ii. 424.--Peruv.

trichoclada, DC. Prod, v, 400-Mexic.

trichotoma, Klatt, in Leopoldina, xx. (1884) 91.Mexic.

tricuneata, Pers. Syn. ii. $424=$ cuneata.

tridentata, Gandich. F1. Mal. $15=$ magellanica.

tridentata, Poepp. ex. DC. Prod. v. 411=concava.

tridentata, Vahl, Symb. Bot. iii. 98.-Bras.

trifurcata, Trevir. in Nov. Act. Nat. Cur. xiii. (1826)

$201=$ Conyza stricta.

trimera, DC. Prod, v. $425=$ genistelloides.

trinervis, Pers. Syn. ii. 423--Bras.

triplinervia, DC. Prod, v. $404=$ oxyodonta,

triplinervis, Baker, in Mart. Fl. Bras, vi. III. 79.Bras.

triptera, Mart. Mat. Med. Bras. $43=$ genistelloides.

tripterix, Poepp. ex Baker, in Mart. F1. Bras, vi. IIr. $42=$ sagittalis.

truncata, Gardn. in Hook. Lond. Fourn. Bot. vii.

1848) 82.-Bras.

truncata, Phil, in Linnaea, xxxiii. (1864) 148.-Chili.

tucumanensis, Hook. E Arn. in Hook. Fourn. Bot. iii.

(1841) 34.-Reg. Argent.

Tweediei, Hook. E Arn. l. c. $33=$ subopposita.

ulicina, Hook. E Arn.l. c. 38.-Patagon.

ulmifolia, Burm. f. Fl. Cap. Prod. $26=$ Conyza incisa

umbelliformis, DC. Prod. v. 410.-Chili.

nncinella, $D C$. l. c. 415 -Bras.

uniflora, Pers. Syn. ii. 425.-Peruy.

Urvilleana, Brongn. Bot.Voy.Coq. t. 61,-Reg. Magell,

ustulata, Benth. Pl. Hartw. 135.-N. Granat.

vaccinioides, Gardn. in Hook. Lond. Fourn. Bot. iv. 1845) 121.-Bras.

vaccinoides, $H, B$. E $K$. Nov. Gen, et Sp. iv, 50,Mexic.

Vahlii, DC. Prod. v. $411=$ dioica

valdiviana, Phil.in Linnaea, xxviii. (1856) 738.-Chili. varians, Gardn. in Hook. Lond. Journ. Bot. vii. (1848) $84=$ rufescens.

Vauthieri, DC. Prod.v. 409.-Bras.

velutina, DC. 1. c. $415=$ ochracea.

veneta, H. B. \& K. Nov. Gen. et Sp. iv. $68=$ Bigelovia veneta.

venosa, Pers. Syn. ii. 425.-Peruv.

venulosa, DC. Prod, $v_{-} 421$ = brachylaenoides

venusta, $H, B$. \& $K$. Nov. Gen, et Sp, iv, 66, - N Granat.

verbenaefolia, Hook. \& Am. in Hook. Journ. Bot. iii. (1841) $26=$ hirta

vernicosa, Hook. E Arn. in Hook. l. c. 28.-Uruguay.

vernonioides, $D C$. Prod. v. 422.-Bras.

villosa, Vahl, Symb. Bot. iii. 98.-Arabia.

viminea, $D C$. Prod.v. 400 -Calif.

vincaefolia, Baker, in Mart. Fl. Bras. vi. III. 83.Reg. Argent.

virgata, Boj. ex DC. Prod. v. $385=$ Conyza virgata.

viscosa, Hook. \& Arn. Bot. Beech. Voy. $352=$ Douglasii.

viscosa, Lam. Encyc. i. $345=$ Psiadia integerrima.

viscosa, Walt. F1. Carol. 202=Pluchea bifrons.

vismioides, DC. Prod. v. $412=$ vernonioides.

Volckmanni, Phil. in Linnaea, xxxiii. (1864-65) 147 -Chili.

volubilis, H. B. \& K. Nov. Gen. et Sp. iv. 417.-Peruy.

vulneraria, Baker, in Mart. Fl. Bras, vi. III. 75. - Bras.

Walpersiana, D. Dietr. Syn. P1. iv. $1447=$ brachylae noides.

Weddelli, Sch. Bip. ex Baker, in Mart. Fl. Bras, vi. III. $63=$ rufescens

Weirii, Baker, l.c. 67.-Bras.

Wendlandii, Sterd. Nom ed. II i. 179-Afr austr.

Wrightii, A. Gray, Pl. Wright. i. 101.-Am. bor. occ

Wrightii, Sch. Bip. in Seem. Bot. Voy. Herald, $303=$ Seemanni.

xalapensis, H. B. \& K. Nov. Gen. et Sp. iv. $56=$ conferta.

xerophila, Mart. in Flora, xxiv. (1841) II. Beibl. $11=$ sessiliftora.

xiphophylla, Baker, in Mart. Fl. Bras. vi. III. 68.Bras.

BACCHAROIDES, Moench, Meth, 578 (1794)= Vernonia, Schreb. (Compos.)

anthelmintica, Mocnch, 1. $\mathrm{c}_{\mathrm{n}}=\mathrm{V}$, anthelmintica.

BACKHOUSIA, Hook. \& Harv. in Bot. Mag.t. 4199 (1845). MYRTACEAE, Benth. \& Hook. f. i. 711 angustifolia, F. Muell. Fragm. i. 79 .-Austral.

\section{BACKHOUSIA}

citriodora, F. Muell. Fragm. i. 78.-Austral.

myrtifolia, Hook. E Harv. in Bot. Mag. 4. 4133.Anstral.

riparia, Hook. \& Harv. 1. c. sub t. $4133=$ myrtifolia. sciadophora, F. Muell. Fragm. ii. 26, 171.-Austral.

BACONIA, DC. in Ann. Mus, Par, ix, (1807) 219= Pavetta, Linn. (Rubiac.)

corymbosa, DC. 1. c. = P. Baconia.

montana, Hook. f, in Journ. Linn. Soc. vii. (1864) 196 $=$ P. Hookeriana.

BACOPA, Aubl. P1. Gui. i. 128. t. 49 (1775). SCRO. PHULARINEAE, Benth. \& Hook. f. ii. 952

aquatica, Aubl. l. c. 129. t. 49.-Guiana.

grandiflora, Mart. ex Benth. in Ann. Nat. Hist. î. (1839) $443=$ aquatica.

BACTRIS, Jacq. Stirp. Am. 271. t. 256 (1763) PALMAE, Benth. \& Hook. f. iii. 941.

AUGUSTINEA, Karst. in Linnaen, xxvii. (1856) 395

Guilielma, Mart. Palm. Fam.21 (1824); Hist.

Nat. Palm, ii. 81. tt. 66, 67 (1824).

Pyrenoglyphis, Karst. Fl. Columb. ii. 141. 174 (1869).

acanthocarpa, Mart. Hist. Nat. Palm. ii. 92. t. 70, 71. f. 2.-Bras.

acanthocarpoides, Barb.-Rodr. Enum. Palm. Nov. $31=$ acanthocarpa.

acanthocnemis, Mart, in Palmet. Orb, $67=$ simplicifrons. acanthophylla, Mart. l. c. 70.-Ins. Porto Rico.

acanthospatha, Trail, ex Drude, in Mart. Fl. Bras, iii. II. 354.-Bras

actinoneura, Drude \& Trail, ex Drude, in Mart. $L$ 344. - Bras.

aculeifera, Drude, l. c. 352 in obs.-Bras.

acuminata, Liebm. ex Mart. Hist. Nat. Palm. iii. 321 Mexic.

arenaria, Barb.-Rodr. Enum. Palm. Nov. $29=$ simplicifrons.

aristata, Mart. Hist. Nat. Palm. ii. 97. t. 73 a. f. $5 .-$ Bras.

armata, Barb.-Rodr. Enum. Palm. Nov. $27=$ chactospatha.

arundinacea, Trail, in Fourn. Bot. xv. (1577) 10.-

Reg. Amazon.

Aubletiana, Trail, l. c. xiv, (1876) 372.-Guiana.

baculifera, Karw. ex Mart. Hist. Nat. Palm. iii. 322 -Mexic.

balanoides, H. Wendl. in Kerch. Palm. 233.-Costa Rica.

balanophora, Sprece, in Fourn. Linn. Soc. xi. (1871) 146, 153. - Am. trop.

bicuspidata, Spruce, l. c. 146, 152.-Am. trop.

bidentula, Spruce; l. c. 146, 151.-Am. trop.

bifida, Mart. Hist. Nat. Palm. ii. 105. to 73 -Bras.

bifida, Oerst. in Kjoeb. Vidensk. Meddel. '1858) $44=$ Oerstediana.

brevifolia, Spruce, in Journ. Linn. Soc xi. (1S71) 144 $147=$ simplicifrons.

Brongniartii, Mart. in Palmet. Orb. 59. t. 7. \&. 2.Bolivia.

campestris, Poepp, in Mart. Hist. Nat. Palm, ii. $110^{\circ}$. -Bras.

capillacea, Trail, in Fourn. Bot. xr. (1877) 5.-Bras.

caracasana, Lodd. ex Linden, Illustr. Hortic. xritii. (1881) 16.--Venezuela.

Caravallana, Linden, Illustr. Hortic. xcriii. (1S\$1) 16.

caribaea, Karst. in Linnaea, xxviii. (1S56) 103.-Ind. occ.

carolensis, Spruce, in Journ. Linn. Soc xi. 18;1) 115, $149=$ simplicifrons.

caryotaefolia, Mart. Hist. . Vat. Palm. ii. 100. t. it. fo 3, 4.-Bras.

caryotifolia, Drude, in Mars. Fl Bras. iii. $11.33 \%-13$ ms.

Catel, Linden, Illustr. Hurtic, xxviii. (1ss1) 10.Venezuela.

chaetophylla, Mart, in Palmet. Orb. 71.-13ras. chactorhuchis, Mart. l. c. 181 a major.

chactospatha, Mart. Hist. Nis.Palm. ii. 147.-Bras,

chloracantha, Poepp. ins Mart. I. . 145.-Bras

ciliata, Mart. l. c. 95. 1. i1. f. \$.- Peruy.

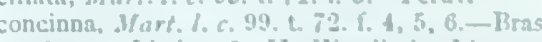

confluens, Linden \& H. Wendl. in Limnaca, xxriii.

$\left.1556^{\circ}\right) 847=$ acsunchospaths. 


\section{BACTRIS :-}

Constanciae, Barb-Rodr. Enum. Palm. Nov. 37.Bras.

Corossilla, Karst. in Linnaea, xxviii. (1856) 40\%.Venezuela.

Corazillo, Hort. ex H. Wendl. Cycl. Pand. Cycad. 5= praec.?

Cruegeriana, Griseb. \& Wendl. ex Griseb. Fl. Brit. W. Ind. 520.-Ind. occ.

cucullata, H. Wendl. in Kerch. Palm. 233, nomen.Hab.?

Cuesco, Crueg. ex Griseb. Fl. Brit. W.Ind. 520.--Ind. occ.

Cuesco, Engl. in Linnaea, xxxiii. (1864-65) 665.-N. Granat.

Curuena, Trail, in Journ. Bot. xv. (1877) $48=$ socialis. cuspidata, Mart. Hist. Nat. Palm. ii. 101. t. 73 B.Bras.

Cuvaro, Karst, in Linnaea, xxviii. (1856) 406.Venezuela.

cyagroides, Barb-Rodr. Enum. Palm. Nov. $33=$ syagroides.

elatior, Wallace, Palm Trees Amaz. 81. t. xxx.-Bras. elegans, Hort. ex H. Wendl. in Kerch. Palm. 233.Hab.?

elegans, Trait, in Fourn. Bot. xv. (1877) 3.-Bras.

ericetina, Barb. - Rodr. Enum. Palm. Nov, $26=$ bifida.

erosa, Mart. Hist. Nat. Palm. ii. 281.-Ind. occ.

eumorpha, Trail, in Fourn. Bot. xv. (1877) 9.t. 184. Bras.

exaltata, Barb.-Rodr. Enum. Palm. Nov. $32=$ major?

faucium, Mart. in Palmet. Orb. 60. t. 6. f. 2.Bolivia.

fissifrons, Mart. Hist. Nat. Palm. ii. 103. t. 73. b. f. 3, 4.-Bras.

flavispina, Hort. Belg. ex Heynh. Nom. ii. $57=$ pallidispina.

floccosa, Spruce, in Journ. Linn. Soc. xi. (1871) 146 , 151 = cuspidata.

fusca, Oerst. in Kjoeb. Vidensk. Meddel. (1858) 43.Costa Rica.

Gasipaës, H. B. \& K. Nov. Gen. et Sp. i. $302,-\mathrm{N}$. Granat.

Gaviona, Trail, in Journ. Bot. xv. (1877) $48=$ major. geonomoides, Drude, in Mart. Fl. Bras. iii. II. 325.Bras

glandulosa, Oerst. L'Amér. Centr. 15. t. 8. f. 1-15.Bras.

glancescens, Drude, in Mart. Fl. Bras. iii. II. 345.Bras.

Glazioviana, Drude, l. c. 348.-Bras

globosa, Gaertn. Fruct. i. $22=$ Acrocomia sclerocarpa.

gracilis, Barb.-Rodr. Enum. Palm. Nov. $27=$ simpli cifrons.

granariuscarpa, Barb.-Rodr. l. c. 37.-Bras.

granatensis, H. Wendl. ex Linden, Illustr. Hortic. xxviii. (1881) 16.-N. Granat.

guineensis, Steud. Nom. ed. I. 98, $99=$ minor.

hirta, Mart. Hist. Nat. Palm. ii. 105. t. 73. C. f. 3.Bras.

horrida, Oerst. in Kjoeb. Vidensk. Meddel. (1858) 41. -Nicaragua.

hylophila, Spruce, in Journ. Lirn. Soc. xi. (1871) 146, $152=$ pectinata.

incommoda, Trail, in Fourn. Bot. xv. (1877) 42.-Bras, inermis, Trail, ex Barb.-Rodr. Enum. Palm. Nov. 30 -Bras.

infesta, Mart. in Palmet. Orb. 54. t. 7. f. 1. Bolivia.

integrifolia, Wallace, Palm Trees Amaz. 91. t. xxxv= fissifrons.

interruptepinnata, Barb.-Rodr. Enum. Palm. Nov. 37. -Bras.

inundata, Mart. in Palmet. Orb. 58. t. 7. f. 3.-Bras.

juruënsis, Trail, in fourn. Bot. xv. (1877) 40.-Bras.

juruensis, Trail, in fourn. Bot. xv. (1877) 40.-Bras, N. Granat.

Liboniana, Linden, Illustr. Hortic. xxviii. (1881) 16.Bras.

linearifolia, Barb.-Rodr. Enum. Palm. Nov. $31=$ pectinata.

littoralis, Barb.-Rodr. l. c. 36.-Bras

longifrons, Mart. Hist. Nat. Palm. ii. 106.-Reg. Amazon.

longipes, Poepp. in Mart. l. c. 145. t. 73.-Bras.

Macanilla, Linden, Illustr. Hortic. xxviii. (1881) 16. Venezuela.

\section{BACTRIS}

macracantha, Mart. Hist. Nat. Palm. ii. 95. t. 73.Bras.

macroacantha, Mart. l. c.-Bras.

macrocarpa, Wallace, Palm Trees Amaz. 85. t. xxxii. -Bras.

major, Facq. Stirp. Am. 280. t. 171. f. 2.-N. Granat. Maraja, Mart. Hist. Nat. Palm. ii. 93. t. 71. f. 1.Bras.

Maraja-açu, Barb.-Rodr. Enum. Palm.Nov. 36.Bras.

Maraja-y, Barb.-Rodr. 1. c. ed. I. $29=$ cuspidata martineziaefolia, Hort. ex H. Wendl, in Kerch. Palm. $234=$ Martinezia corallina.

mexicana, Mart. in Palmet. Orb. 65.-Mexic

microcarpa, Spruce, in Journ. Linn. Soc. xi. (1871) 146 , $153=$ hylophila.

microspatha, Barb.-Rodr. Enum. Palm. Nov. $26=$ cuspidata.

minax, Miq. in Verh. Nat. Wet. Haarl. vii. (1851) 207. -Guiana.

minima, Gaertn. Fruct. ii. 269. t. 139. f. 5= Martinezia corallina.

minor, Gaertn. 1. c. i. t. 9. f. $1=$ Acrocomia lasiospatha? minor, Facq. Stirp. Am. 279. t. 171. f. 1.- Bras.; N Granat.

mitis, Mart. Hist. Nat. Palm. ii. 102 = cuspidata. monticola, Barb.-Rodr. Enum. Palm. Nov. 34.-Bras. negrensis, Spruce, in Journ. Linn. Soc. xi. (1871) 145, $147=$ simplicifrons.

nemorosa, Barb.-Rodr. Enum. Palm. Nov. 32.-Bras, Neromanni, Voigt, in Syll. Ratisb. ii. (1828) 51.Hab.?

obovata, H. Wendl. in Kerch. Palm, 234.-Hab.?

Oerstediana, Trail, in Fourn. Bot. xv. (1877) 43. Costa Rica.

oligocarpa, Barb.-Rodr. Enum. Palm. Nov. 28.Bras.

ovata, H. Wendl. in Kerch. Palm. 234.-Nicaragua. ovata, Stokes, Bot. Mat. Med, iv. $394=$ major.

pallidispina, Mart. in Palmet. Orb. 62.-Guiana.

palustris, Barb.-Rodr. Enum. Palm. Nov. 36 = bidentula paraënsis, Splitg. ex H. Wendl. in Kerch. Palm. 234. -Surinam.

paucijuga, Barb.-Rodr. Enum. Palm. Nov. 34-Bras. Pavoniana, Mart. in Palmet. Orb. 70.-Porto Rico.

pectinata, Mart. Hist. Nat. Palm. ii. 98. t. 60, 73. A. f. 1, 2.-Bras.

pilosa, Karst. in Linnaea, xxviii. (1856) $405 .-\mathrm{N}$. Granat.

Piritu, Wendl. ex H.Wendl. in Kerch. Palm. 234.-N Granat.

Piranga, Trail, in Fourn. Bot. xv. (1877) 41.-Bras. piscatorum, Wedd. ex Drude, in Mart. Fl. Bras. iii. II 354.-Bras.

Plumeriana, Mart. in Palmet. Orb. 64.-Ind. occ. praemorsa, Poepp. ex Mart. l. c. 66.-Peruv.

pulchra, Trail, in Fourn. Bot. xv. (1877) 4. t. 184. f. 2 , -Bras.

Puyamo, Linden, Illustr. Hortic, xxviii. (1881) 16.Reg. Granat.

riparia, Mart. Hist. Nat. Palm. ii. 97. t. 71. f. 4.Bras.

rivularis, Barb.-Rodr. Enum. Palm. Nov. 36.-Bras. rotunda, Stokes, Bot. Mat. Med. iv. $394=$ minor. Sanctae-Paulae, Engl. in Linnaea (1864-65), 667.-N Granat.

sciophila, Miq. in Verh. Nat. Wet. Haarl. vii. (1851) 208.-Guiana.

setipinnata, Barb.-Rodr. Ennm. Palm. Nov. $32=$ hylophila.

setosa, Mart. Hist. Nat. Palm. ii. 94. t. 72. f. 1-3.Bras.

setulosa, Karst. in Linnaea, xxviii. (1856) 408.Venezuela.

simplicifrons, Mart. Hist. Nat. Palm.ii. 103. t. 73. C. f. 1-2.-Bras.

simplicifrons, Spruce, in Journ. Linn. Soc. xi. (1869) $148=$ geonomoides.

socialis, Mart. in Palmet. Orb. 56. t. 14. f. $2=$ major. speciosa, Karst. in Linnaea, xxviii. (1856) 402.-N Granat.

sphaerocarpa, Trail, in fourn. Bot. xv. (1877) 8.Amazon.

subglobosa, H. Wendl. in Kerch. Palm.234.-Salvador. syagroides, Trail, in Fourn. Bot. xv. (1877) 76.Bras.

sylvatica, Barb.-Rodr. Enum. Palm. Nov. 30.-Bras.

\section{BACTRIS :-}

tenera, $H$. Wendl, in Kerch. Palm. 234-Hab.

tenerrima, Mart. ex Drude, in Mart. Fl. Bras, iii. II. 328.-Bras.

tenuis, Wallace, Palm Trees Amaz. 87. t. xxxiii. cuspidata.

tomentosa, Mart. Hist. Nat. Palm. ii. 100. t. 73. A. f. 3 , 4.- Bras.

Trailiana, Barb.-Rodr. Enum. Palm. Nov, 27.-Bras.

trichospatha, Trail, in Fourn. Bot. xv. (1877) 41, 42 -Bras.

turbinata, Spruce, in Journ. Linn. Soc. xi. (1871) 146 , $152=$ pectinata.

turbinocarpa, Barb.-Rodr. Enum. Palm. Nov. 33.Bras.

uaupensis, Spruce, in Journ. Linn. Soc. xi. (1871) 145 $150=$ cuspidata.

umbraticola, Barb.-Rodr. Enum. Palm. Nov. 34.Bras.

umbrosa, Barb.-Rodr. 1. c. $29=$ trichospatha.

utilis, Benth. \& Hook. f. ex Hemsl. Biol. Centr. Am. Bot. iii, 413,-Costa Rica.

varinensis, Hort. ex H. Wendl. in Kerch. Palm. 234.Hab.?

villosa, H. Wendl. ex Hemsl. Biol. Centr. Am. Bot iii. 413.-Costa Rica.

vulgaris, Barb.-Rodr. Enum. Palm. Nov. (1879) App. 42.-Bras.

xanthocarpa, Barb.-Rodr. 1. c. $30=$ simplicifrons ?

BACTYRILOBIUM, Willd. Enum. Hort. Berol. 439 $(1809)=$ Cassia, Linn. (Legumin.)

biflorum, Willd. ex Steud. Nom. ed. II, i, $179=$ C. billora.

ferrugineum, Schrad. in Goett. Gel. Anz. (1821) I. 713 $=\mathrm{C}$. ferruginea.

Fistula, Willd. Enum. Hort. Berol. $440=$ C. Fistula.

grande, Hornem. Hort. Hafn. i. $135=$ C. grandis.

latifolium, Steud. Nom. ed. I. 41= Anagyris latifolia. molle, Schrad. in Goett. Gel. Anz. (1821) I. $713=$ C. grandis.

BACULARIA, F. Muell. Fragm. vii. 103 (1870) PALMAE, Benth. \& Hook. f. iii. 903.

Linospadrx, H. Wendl. \& Drude, in Linnaea, xxxix (1874) 177 .

minor, F. Muell. l. c. xi. 58.-Austral.

monostachya, F. Muell. l. c. vii. 103 ; xi. 58.-Austral

BADAMIA, Gaertn. Fruct. ii. 90. t. 97 (1791)=

Terminalia, Linn. (Combret.).

Commersoni, Gaertn. 1. c. = T. Catappa.

BADAROA, Bert. ex Steud. Nom. ed. II. i. $179(1840)=$ seq.

BADEROA, Bert. ex Hook. Bot. Misc. iii. (1833) $324=$ Sicyos, Linn. (Cucurb.)

arenaria, Bert. ex Stend. Nom. ed. II. i. $179=$ seq. bryoniaefolia, Bert. ex Hook. 1. c.=S. bryoniae folius.

BADIERA, DC. Prod. i. 334 (1824). POLYGALEAE,

Benth. \& Hook. f. i. 137.

acuminata, $D C . l . c .335$-Mexic.

Berteriana, Spreng. Syst. iii, 172.-Ins. S. Doming

divaricata, $D C$. Prod. i. 335.-Bras.

diversifolia, $D C . l . c$. 334.-Jamaica.

domingensis, $D C . l$. c.-Ins. S. Doming.

Penaea, $D C$. l. c. 335.-Am. trop.

BADIERA, Hassk. Cat. Pl. Hort. Bogor. Alt. 227 (1844) $=$ Polygala, Linn

pulchra, Hassk. 1. c. $=$ P. venenosa.

venenosa, Hassk. $1 . c_{\text {, }}=\mathrm{P}$, venenosa.

BADULA, Juss. Gen. $420(1789)=$ Ardisia, Sw. (Myrsin.).

angustifolia, A. DC. in Trans. Linn. Soc. xvii. (1837)

$114=$ Embelia angustifolia.

arborea, Thou, ex A. DC. in DC. Prod. viii. $84=$ Embelia arborea.

Barthesia, A. DC. in Trans. Linn. Soc. xvii. (1837)

$113=$ A. Barthesia

Barthesia, Boj. Hort. Maurit. $196=$ A. insularis. borbonica, A. DC. in Ann. Sc. Nat. Sér. II. xvi. (1841)

90.-Ins. Borbon.

caribaea, A. DC. 1, c. $89=$ A. caribaea. 
BADULA :-

crassa, A. DC. in Trans. Linn. Soc. xvii. (1837) $114=$ Ardisia insularis.

cybianthoides, A. DC. in DC. Prod. viii. $107=$ Cybianthus philippinensis.

divaricata, Thou. ex A. DC. 1. c. $89=$ Oncostemum divaricatum.

excelsa, Thou. ex A. DC. 1. c. $113=$ (Monoporus paludosus).-Madag.

insularis, A. DC. in Trans. Linn. Soc. xvii. (1837) 113 $=\mathrm{A}$. insularis.

iteoides, Benth. Pl. Hartw. 217.-N. Granat.

Lamarkiana, A. DC, in DC. Prod. viii. $110=$ A laurifolia.

lanceolata, Boj. ex A. DC. 1. c. $90=$ Oncostemum Bojeranum.

lateriflora, Griseb. in Goett. Abh, vii. (1857) $237=\mathrm{A}$. laurifolia.

laurifolia, Boj. ex A. DC. in DC. Prod, viii. 108.Madag.

Lhotskyana, A. DC. 1. c. $111=$ A. Lhotskyana

Mameicillo, Schlecht. in Linnaea, xxvi. (1853-55) 671. $-\mathrm{N}$. Granat.

micrantha, Boj. Hort. Maurit. $196=\mathrm{A}$. insularis micrantha, A. DC. in Trans. Linn. Soc. xvii. (1837) 112.-Ins. Maurit

multiflora, A. DC. in Ann. Sc. Nat. Sér. II. xvi. (1841) $89=\mathrm{A}$. insularis.

myrtifolia, Thon. ex A. DC. in DC. Prod. viii. $90=$ Oncostemum myrtifolium.

nemorosa, Thou, ex A. DC. 1. c.=Oncostemum nemorosum.

nigricans, A. DC. in Ann. Sc. Nat. Sér. II. xvi. (1841) 89.-Bras.

ovalifolia, A. DC. in Trans. Linn. Soc. xvii. (1837) 114.-Ins. Maurit.

paludosa, Boj. ex A. DC, in DC Prod. viii. 113 (=Monosporus paludosus).-Madag.

pauciflora, Boj. ex A. DC. 1. c. $90=$ Oncostemum pauciflorum.

peruviana, A. DC. 1. c. $112=$ A. nigricans.

philippinensis, A. DC. 1. c. $108=$ A. subcuneata.

reticulata, A. DC, in Ann. Sc. Nat. Sér. II. xvi. (1841) $89=\mathrm{A}$. insularis

scandens, Boj. Hort. Maurit. $196=$ Embelia micrantha Schomburgkiana, A. DC. in Ann. Sc. Nat. Sér. II. xvi. (1841) 89.-Guiana.

Sieberi, A. DC. in Trans. Linn. Soc. xvii. (1837) 113. t. $\mathbf{5}=\mathbf{A}$. guadalupensis.

BADUSA, A. Gray, in Proc. Am. Acad. iv. 308 (1860) RUBIACEAE, Benth. \& Hook. f. ii, 42 . corymbiftora, A. Gray, l. c.-Ins. Pacif.

BADUSA Barthesia, Steud. Nom. ed. II. i. 98, in syn. (1840), sphalm. $=$ BADULA, Juss. = Ardisia Bar thesia.

BAEA, Comm. ex Juss. Gen. $121(1789)=$ Boea, Comm (Gesner.).

BAECKEA, Burm. f. Prod. Fl. Cap. $12(1768)=$ Brunia, Linn.

africana, Burm. f. l. c. $=\mathrm{Br}$. pinifolia.

cordata, Burm. f. $1 . \mathrm{c}=\mathrm{Br}$, racemosa

lancifolia, Eckl. \& Zeyh. Enum. $140=$ Br. racemosa

laurifolia, Sond. in Harv. \& Sond. F1. Cap. ii. 315, in syn. $=\mathrm{Br}$. racemosa

racemosa, Eckl. \& Zeyh. Enum. $140=$ Br. racemosa.

thyrsiflora, Harv. \& Sond. F1. Cap. ii. $604=$ Br. pini folia.

thyrsophora, Eckl. \& Zeyh. Enum. $140=$ Br. pinifolia.

BAECKEA, Linn. Sp. PI. 358 (1753). MYRTACEAE Benth. \& Hook, f i. 701.

Allostis, Rafin. Sylva Tellar. 104 (1888).

BABING'ONA, Lindl. in Bot. Reg. (1842) t. 10.

CAMPHOROMYRTUS, Schan. in Linnaea, xvii. (1843 240.

Cyathostemon, Turcz, in Bull. Phys.-Math. Acad. Pétersb. X. (1852) 331.

Ericomyrtus, Turcz. in Bull. Soc. Nat. Mosc, xx (1847) 1.154

Euryomyrtus, Schau. in Linnaea, xvii. (1843) 239.

HARMOGIA, Schau, in Linnaea, xvii. (1843) 288.

IMBricarIa, Sm, in Trans. Linn. Soc. iii. (1797) 257.

\section{BAECKFA}

JUNGIA, Gaertn. Fruct. i. 175. t. 35 (1788)

Mollia, J. F. Gmel. Syst. 420 (1791).

Murrinea, Rafin. Sylva Tellur. 104 (1838

Neufofia, Stokes, Bot. Mat. Med. i. 439 (1812).

OXYMYRRHINE, Schau. in Linnaea, xvii. (1843) 240.

RINZIA, Schau. 1. c, xvii. 239 (1843)

ScHidiomyrtus, Schau. 1. c. 237 (1843).

Tetrapora, Schau. 1. c. 238 (1843)

Tetraspora, Miq. in Nederl. Kruidk. Arch iv (1859) 150.

TJONGINA, Adans. Fam. ii. 234 (1763)

Triplarina, Rafin. Sylva Tellur. 104 (1838)

affinis, Endl. in Enum. P1. Hueg. 51=Astartea fascicu. laris.

affinis, Hook. Ic. Pl. t. $284 \mathrm{c}=$ diffusa

alpina, Lindl. in Mitch. Three Exped. ii. $178=$ diffusa arbuscula, R. Br. ex Benth. Fl. Austral. iii. 79.Austral.

astartioides, Benth. $l$. c. 80.-Austral

Behrii, F. Muell. Fragm. iv. 68.-Austral.

Blacketii, F. Muell. l.c. viii. 181.-Austra]

brevifolia, DC. Prod. iii. 230.-Austral.

calycina, Lindl. in Mitch. Three Exped. ii. $190=$

Thryptomene Mitchelliana.

camphorata, R. Br. in Bot. Mag. t. 2694.-Austral

Camphorosmae, Endl. in Enum. Pl. Hueg. 51.-

Austral.

capitata, F. Muell. Census, 54.-Austral.

carnulosa, Sieber, in Spreng. Syst. iv. Cur. Post. $149=$ brevifolia.

chinensis, Gaertn. Fruct i. 157=frutescens.

ciliata, F. Muell. Census, 54.-Austral.

cochinchinensis, Blume, Mus. Bot. Lugd. Bat. i. 69.-

Cochinch.

corymbulosa, Benth. Fl. Austral. iii. 87.-Austral.

corynophylla, F. Muell. Fragm. iv, 72-Austral.

crassifolia, Lindl. in Mitch. Three Exped. ii. 115.

Austral.

cresatifolia, F. Muell. Fragm. iv. 70.-Austral

crenulata, DC. Prod. iii. 230-Austral.

crispiflora, F. Muell. Fragm. iv. 72.-Austral.

cryptandroides, F. Muell. l. c. x. 29-Austral.

Cumingeana, Schau. in Walp. Rep. ii. $920=\mathrm{fr}$ tescens.

Cunninghamii, Benth. Fl. Austral. ii. 82.-Austral

densifolia, Sm. in Trans. Linn. Soc. iii. (1797) 260.Austral.

diffusa, Sieber, ex DC. Prod. iii. 230,-Austral.

dimorphandra, F. Muell. ex Benth. Fl. Austral. iii. 74. -Austral.

diosmifolia, Rudge, in Trans. Linn. Soc. viii. (1807) 298. t. 13.-Austral.

diosmoides, Sieber, ex DC. Prod, iii. $230=$ crenulata.

Drummondii, Benth. Fl. Austral, iix. 75 -Austral.

ericaea, F. Muell. Fragm. i, 31.-Austral

ericoides, Brongn. E Gris, in Bull. Soc. Bot. Fr. xi (1864) $184 .-\mathrm{N}$. Caled.

ericoides, Schlecht. in Bot. Zeit. iv. (1846) 724.Austral.

fasciculata, Sieber, in Spreng. Syst, iv. Cur, Post. $149=$ densifolia

floribunda, Benth. Fl. Austral. iii. 87.-Austral.

frutescens, Linn. Sp. Pl. 358.-Malaya; China

fumana, F. Muell. Fragm. iv. 68.-Austral

gracilis, A. Cunn. in Field, New South Wales, 349.Austral.

grandiflora, Benth. Fl. Austral. iii. 89.-Austral.

Gunniana, Schau. ex Walp. Rep, ii. 920.-Austral

involucrata, Endl. in Enum. Pl. Hueg. $170=$ Scholtzi obovata.

laxiflora, F. Muell. Census, 54.-Austral.

leptocaulis, Hook. f. in Hook.Ic. Pl. t. 298.-Tasmania. leptantha, F. Muell. Censys, 54.-Austral.

leptocalyx, F. Muell. Fragm. i. $30=$ Micromyrtus leptocalyx.

linifolia, Rudge, in Trans. Linn. Soc. viii. (1807) 297. Austral.

micrantha, DC. Prod, iii. $230=$ Thryptomene bacckeacea.

micrantha, Hook. f, in Hook. Ic. Pl, t. $309=$ Gun. niana.

microphylla, A. Cunn, ex Schau. in Linnaea, xvii. (1843 $288=$ Harmogia Cunninghami.

microphylla, Sieber, ex Spreng. Syst. iv. Cur. Post. 14 ? Micromyrtus micropleylla.

nelitrioides, Scem. in foum. Bot. ii. (1864) 74.N. Caled.
BAECKEA

nova-anglica, F. Muell, Fragm, iv. $71=$ densifolia.

obovata, DC. Prod. iii. 230 = Scholtzia obovata.

obtusifolia, Brongn. Eo Gris, in Bull. Soc. Bot. Fr. xi.

(1864) $185 .-\mathrm{N}$, Caled.

ochropetala, F. Muell. Fragm, x. 29.-Austral.

oligandra, F. Muell. Census, 54.-Austral.

oligomera, Radlk. in Ber. Deutsch. Bot. Ges. ii. (1884) 264.-Austral.

ovalifolia, F. Muell. Fragm. iv. 72.-Austral.

oxycoccoides, Benth. Fl. Austral. iii. 75.-Austral.

pachyphylla, Benth.. . c. 85.-Austral.

parviflora, F. Muell. Census, 54.-Austral.

parvula, DC. Prod. iii. $229=$ virgata.

pentagonantha, F. Muell. Fragm. iv. 73.-Austral

pentandra, F. Muell. l. C. 11. 31; iv. 72.-Austral.

phylicoides, A. Cunn. ex Schau. in Walp. Rep. ii. 921

= Kunzea peduncularis.

pinifolia, DC. Prod. iii. $229-\mathrm{N}$. Caled.

platystemona, Benth. Fl. Austral. iii. 74.-Austral.

plicata, F. Muell. Fragm. i. $30=$ Micromyrtus microphylla.

polyandira, $F$. Muell. l.c. iv. 72.-Austral.

polystemonea, F. Muell. lo c. ii. 124.-Austral.

prostrata, Hook. f. Ic. Pl. t. $284 \mathrm{~b}=$ diffusa,

pulchella, DC. Prod. iii. 230.-Austral,

pygmaea, R. Br. ex Benth. Fl. Austral. iii. \&6.Austral.

ramosissima, A. Cunn. in Field, New South Wales, 249.-Austral.

robusta, F. Muell. Fragm, iv, 72.-Anstral

saxicola, A. Cunn. ex Hook. Bot. Mag. t. 3160.Austral.

scholleraefolia, Lehm. Pl. Preiss. ü. 369.-Austral.

serpillifolia, F. Muell. Fragm. x. 30.-Austral.

sinensis, Gaertn. Fruct. i. t. 31 = frutescens.

speciosa, A. Cunn. ex Schan. in Linnaea, xvii. (1843'

$241=$ Hypocalymma strictum

spathulata, F. Muell. Census, 54.-Austral.

spinosa, Sieber, ex Spreng. Syst. iv. Cur. Post. 149.Austral.

stenophylla, F. Muell. Fragm. I. 13.-Austral.

subcuneata, F. Muell. L. G iv, 73.-Anstral.

sumatrana, Blume, Mus. Bot. Lugd. Bat. 69.Sumatra.

teretifolia, F. Muell. Census, 54.-Austral.

tetragona, F. Muell. ex Benth. Fl. Austral. iii. 77.Austral.

thymifolia, Hook. f. Ic. Pl. t. 284 a =diffusa.

trichophylla, Sieber, ex Spreng. Syst. iv. Cur. Post. $149=$ linifolia.

uberiflora, F. Muell. Census, 53.-Austral.

umbellata, F. Muell. Fragm. iv. $69=$ virgata

umbellifera, F. Muell. Census, 54-Austral.

unicinella, Benth. Fl. Austral, iii. 84.-Anstral.

utilis, F. Muell, ex Miq. in Neder. Kruidk. Arch, iv. 1859) $150=$ Gunniana.

virgata, Andr. Bot. Rep. 598.-N. Caled.

BAEICA, C. B. Clarke, in DC. Monog. Phan. v. 134 $(1883)=$ Boeica, C. B. Clarke (Gesner.).

BAEOBOTRYS, Forst. Char. Gen. 21. t. 11 $\left(17 \% 6^{\circ}\right)=$ Maesa, Forsk. (Myrsin.)

acuminata, Spreng. Syst. in Ind. $\nabla .89=$ M. ramentacea. acuminata, Wall. Cat, n. 2321=Gymnosporia acuminata.

argentea, Wall 1. c. n. $2316=$ Maesa argentea.

Bogota, Buch.-Ham, ex A. DC. in DC. Prod, viii. $81=$ M. macrophylla.

dubia, Wall. Cat. n. $2917=$ M. dubia.

fragrans, Wall. 1. c. n. $2322=$ M. ramentacea

fulvinervis, Kollm. ex A. DC. in DC. Prod, viii. $82=$

M. mollis.

glabra, Roxb. Hort. Beng. 16; Fl. Ind. i. $500=\mathrm{M}$. ramentaces.

indica, Roxb. 11. cc. $16,55 \pi=\mathrm{M}$. indica.

indica. Wall. Cat. $\mathrm{D} .2918$. A \& $\mathrm{B}=\mathrm{M}$. Chisia.

lanceolata, Blume, Bijulr. $865=$ M. Blumii.

lanceolata, Spreng. Syst. iv. Car. Post. $8 \$=M$. ramen. taces.

lanceolata, Vahl, Symb. Bot. i. $19=$ M. lanceolata.

latifolia, Blume, Bijdr. $865=\mathrm{M}$. indica.

lucida. Wall. Cnt. n. 2328.-Ind. or.

Intea. Roxb. ex sifcut. Nom. ed. 11. i. 1s0 M. lusea.

macrophylla, Wrall. Cat. n. $2825=$ M. macrophylla.

missionis, Wall. 1. c. D. 652 - M. ranacntacca i 
BAEOBOTRYS :-

mollis, Blume, Bijdr. 865 = Maesa mollis

mollissima, Blume, l. c. $866=$ M. mollissima.

Morsha, Buch.-Ham. ex A. DC. in DC. Prod, viii. 80 $=\mathrm{M}$. indica.

muscosa, Reinw。ex Blume, Bijdr。 866=M. membranacea.

nemoralis, Forst. Char. Gen. $22=$ M. nemoralis.

nemoralis, Roxb. Hort. Beng. 85 ; Fl. Ind. i. $559=$ M. indica.

ovata, Wall. Cat. n. $2324=$ M. ramentacea

paniculata, Wall. 1. c. n. $2320=$ M. paniculata.

picta, Hochst. ex Walp. Ann. iii. $964=$ M. lanceolata.

pubescens, Lodd. ex Lond. Hort. Brit. 71.-M. pubescens.

ramentacea, Roxb. Hort. Beng. 16 ; Fl. Ind. i. $558=$ M. ramentacea.

rufescens, E. Mey。 ex A. DC. in DC. Prod. viii. $81=$

M. lanceolata.

tetrandra, Roxb. Hort. Beng. 85; Fl. Ind. i. $560=$ M. tetrandra.

tomentosa, Buch.-Ham. ex Spreng. Syst. iv. Cur. Post. $83=\mathrm{M}$. macrophylla.

virgata, Blume, Bijdr. $866=$ M. indica.

BAFOMETRA, Salisb, in Trans. Hort. Soc. i. (1812) 330. LILIACEAE, Benth. \& Hook. f. iii. 823. JANIA, Schult. Syst. vii. II. p. xeviii. 1528 (1830). KolBEA, Schlecht, in Linnaea, i. (1826) 80. columellaris, Salisb. l. c.-Afr. austr.

BAEOTERPE, Salisb. Gen. PI. Fragm, $17(1866)=$ Hyacinthus, Linn. (Liliac.) brevifolia, Salisb. 1. c. $18=\mathrm{H}$. brevifolias, corymbosa, Salisb. 1. c. $=$ H. corymbosus.

BAEOTHRYON, Ehrh. Beitr. iv. 147 (1789)=Scirpus, Linn. (Cyperac.)

caespitosum, A. Dietr. Sp. Pl. ii. $89=$ =S. caespitosus. confervoides, A. Dietr. 1. c. $94=$ S. confervoides. crinitum, A. Dietr. 1. c. = Ficinia filiformis. festucoides, A. Dietr. 1. c. = Bulbostylis festucoides. fistulosum, A. Dietr. 1. c. = Eleocharis fistulosa. favescens, A. Dietr. 1. c. $91=$ Eleocharis ocreata Halleri, T. Nees, Gen. Germ. Ic. ii. $17=\mathrm{S}$, pauciflorus.

Hystrix, A. Dietr. Sp. Pl. ii. $92=$ Hypodiscus aristatus.

nanum, A. Dietr. 1. c. $91=$ S. nanus.

pauciflorum, A. Dietr. 1. c. $90=\mathrm{S}$. pauciflorus.

pusillum, A. Dietr. 1. c. $92=\mathrm{S}$. pusillus.

pygmaeum, A. Dietr. 1. c. = Eleocharis Chaetaria retroflexum, A. Dietr. 1. c. $93=$ Eleocharis Chaetaria. tenuiculum, A. Dietr. 1.c. = Eleocharis Rothiana, trichodes, A. Dietr. l. $c_{0}=$ Eleocharis trichodes. variegatum, A. Dietr。1. c. $92=$ Eleocharis variegata.

BAERIA, Fisch. \& Mey. Ind. Sem. Hort. Petrop. ii. 29 1835). COMPOSITAE, Benth. \& Hook. f, ii. 399.

Dichaeta, Nutt. in Trans. Am. Phil. Soc, N, S. VII. (1841) 383.

Ptilomeris, Nutt. in Am. Phil. Trans. N. S. vii. (1841) 381 .

affinis, A. Gray, in Proc. Am. Acad. xix. (1883) 23.-Calif

anthemoides, A. Gray, l.c. 23.-Calif.

carnosa, Greene, in Bull. Torrey Club, x. (1883) 86Calif.

chrysostoma, Fisch. Eoy. Ind. Sem. Hort. Petrop. ii. (1835) 29.-Calif.

Clevelandi, A. Gray, in Proc. Am. Acad. xix. (1883) 22,-Calif.

coronaria, A. Gray, l. c. 23.-Calif.

curta, A. Gray, l. c. 21.-Calif.

debilis, Greene, ex A. Gray, Syn. Flo N. Am.i. II. 325.-Calif.

Fremontii, A. Gray, in Proc. Am. Acad. vii. (1868) 358 ; ix. (1874) 196.-Calif.

gracilis, A. Gray, $l$. c. ix. (1874) 196.-Califo; Arizon. leptalea, A. Gray, Syn. Fl. N. Am.1. II. 325.-Calif. macrantha, A. Gray, in Proc. Am. Acad. xix. (1883) 21.-Calif.

maritima, A. Gray, l. c. ix. (1874) 196: Bot. Calif. i. 376.-Calif.

mutica, A. Gray, in Proc. Am. Acad. xix. (1883) 23. -Calif.

Palmeri, A. Gray, in Bot. Calif. i. 376.-Calif.

\section{BAERIA :-} platycarpha, A. Gray, in Proc. Am. Acad. ix. (1874)
196.-Calif.

tenella, A. Gray, l. c. xix. (1883) 23.-Calif.

tenerrima, A. Gray, l. c. ix. (1874) 196.-Calif

uliginosa, A. Gray, l. c.-Calif.

BAEUMERTA, Gaertn. Mey. \& Scherb. Fl. Wett. ii. $419(1800)=$ Nasturtium, R. Br. (Crucif.). Nosturtium, Gaertn. Mey. \& Scherb. 1. c. $467=$ N. officinale.

BAGALATTA, Roxb. ex Reichb. Consp. 86 (1828)= Tiliacora, Colebr. (Menisperm.) (T. racemosa).

BAGASSA, Aubl. Pl. Gui. Suppl. 15. t. 376 (1775). URTICACEAE, Benth. \& Hook. f. iii. 362.

LAUREA, Gaudich. Voy. Bonite, t. 88 (1826).

LoUreA, Kunth, in Linnaea, xiii. (1839) 562. guianensis, $A u b l . l . c .-G u i a n a$.

Sagotiana, Bur. ex Benth. E Hook.f. Gen. iii. 362.Guiana.

BAGNISIA, Becc. Malesia, i. 249. t. 12 (1878)。BURMANNIACEAE, Benth. \& Hook, f, iii. 459.

Sarcosiphon, Blume, Mus. Bot. Lugd. Bat. i. 65. t. $18(1849)$.

crocea, Becc. l. c.-Malaya.

BAHEL, Adans. Fam. ii. 210 (1763) = Hygrophila, R. Br. (Acanth.) (H. spinosa)

BAHIA, Lag. Gen. et Sp. Nov, 30 (1816), COM. POSITAE, Benth. \& Hook. f. ii. 402

Stylesia, Nutt. in Trans. Am. Phil. Soc. Ser. II. vii. (1841) 377.

Trichophyllum, Nutt. Gen. Am. ii. 160 (1818).

VirLETTA, Sck. Bip. ex Benth. \& Hook. f. Gen. ii. 402 (1873).

absinthifolia, Benth. Pl. Hartw. 18.--Texas; Mexic. achilleoides, DC. Prod. v。 $657=$ Eriophyllum caespitosum.

ambigua, A. Gray, in Bot. Calif. i. $382=$ Eriophyllum ambigunm.

ambrosioides, Lag. Gen. et Sp.Nov. 28, 30,-Chili angustifolia, DC. Prod. v, $656=$ Calea angustifolia. anthemoides, A. Gray, in Proc. Am. Acad. xv. (1880) 40-Mexic.

arachnoidea, Fisch. \& Avé-Lall, in Ind. Sem. Hort. Petrop. ix. $63=$ Eriophyllum caespitosum.

artemisiaefolia, Less. in Linnaea, iv. (1829) $160=$ Eriophyllum staechadifolium.

Bigelovii, A. Gray, in Torr. Bot. Mex. Bound. 96.Texas.

biternata, A. Gray, Pl. Wright. ii. 95.-Texas.

chrysanthemoides, A. Gray, in Proc. Am. Acad. xix. (1883) 28.-Am. bor. occ

confertiflora, DC. Prod. v. $657=$ Eriophyllum confertiflorum.

cuneata, Kellogg, in Proc. Calif, Acad. v. (1873) $49=$ Eriophyllum caespitosum.

dealbata, A. Gray, PI. Fend1. $99=$ absinthifolia.

Gilliesii, A. Gray, in Proc. Am. Acad. xix. (1883) 28. -Reg. Argent.

gracilis, Hook. \& Arn. Bot. Beech. Voy. $353=$ Eriophyllum gracile

integrifolia, DC. Prod. v. $656=$ Eriophyllum caespitosum.

lanata, DC. 1. c. $657=$ Eriophyllum caespitosum.

latifolia, Benth. Bot. Voy. Sulph. $30=$ Eriophyllum caespitosum.

latifolia, Lindl. in fourn. Hort. Soc. viii, (1853) 319 - Calif.

leucophylla, DC. Prod. v. $657=$ Eriophyllum caespitosum.

leucophylla, Eaton, Bot. King, Exped. 17, pro parte= Eriophyllum Watsoni.

multiflora, Nutt. in Trans. Am. Phil. Soc. Ser. II. vii (1841) $373=$ Eriophyllum caespitosum.

neo-mexicana, A. Gray, in Proc. Am. Acad. xix. (1883) 27.-N. Mexic.

nepetaefolia, A. Gray, 1. c. v. (1861) $184=$ sinuata nudicaulis, A. Gray, l. c. xix. (1883) 27.-Am. bor. occ oblongifolia, A.Gray, l. c.-Colorado.

oppositifolia, DC. Prod. v. 656.-Am. bor. occ.

Palmeri, A. Gray, Syn. Fl. N. Am. ii. I. 452.Calif.
BAHIA :

parviftora, A. Gray, in Bot. Calif. i. $382=$ Eriophyllum ambiguum.

pedata, A. Gray, Pl. Wright. i. 123.-Texas.

resinosa, DC. Prod. vi. $678=$ Galinsoga resinosa.

rubella, A. Gray, in Torr. Bot. Mex. Bound. 95= Eriophyllum Wallacei.

schkuhrioides, A. Gray, in Proc. Am. Acad. xix. (1883) 27.-Mexic.

sinuata, Less. in Linnaea, vi. (1831) 160.-Mexic.

staechadifolia, DC. Prod. v. $656=$ Eriophyllum staechadifolium.

tenuifolia, DC. l. . . 657.-Calif.

trifida, Nutt. in Trans. Am. Phil. Soc. Ser. II. vii (1841) $374=$ Eriophyllum confertiforum

trolliifolia, DC. Prod. v. 657.-.Mexic

Wallacei, A. Gray, in Pacif. Rail. Rep. iv. 105= Eriospermum Wallacei.

Wallacei, A. Gray, in Proc. Nat. Hist. Bost. vii. (1859-61) $145=$ Eriospermum ambiguum.

Woodhousii, A. Gray, in Proc. Am. Acad. xix. (1883) 28. - N. Mexic.

BAHIOPSIS, Kellogg, in Proc: Calif. Acad. Nat. Soc ii. (1863) $35=$ Viguiera, H. B. \& K. (Compos.).

lanata, Kellogg, l. $_{1}=\mathrm{V}$. nivea ?

BAIKAEA, Benth. in Benth. \& Hook. f. Gen, 581 (1865), LEGUMINOSAE, Benth. \& Hook, f. l.c insignis, Benth. in Trans. Linn. Soc. xxv. (1866) 314. t. 41.-Afr. trop.

minor, Oliver, Fi. Trop. Afr. ii. 309.-Afr, trop.

BAILEYA, Harv. \& Gray, ex Torr, in Emory, Notes Mil. Reconnois. 144 (1848). COMPOSITAE, Benth. \& Hook, f, ii, 423.

multiradiata, Harv. E Gray, ex Torr. l. co-Am. bor

pauciradiata, Harv. E Gray, ex A. Gray, Pl. Fendl 105.-Calif,

pleniradiata, Harv, \& Gray, ex A. Gray, 1. c. $=$ multiradiata.

BAILLIERIA, Aubl. Pl. Gui. ii. 804. t. $317(1775)=$ Clibadium, Linn. (Compos.)

aspera, Aubl. 1. c. $=$ C. surinamense.

Barbasco, H. B. \& K. Nov. Gen. et Sp. iv. $289=$ C Barbasco.

caroliniana, Spreng. Syst. iii. $625=$ Iva imbricata.

commelinoides, Less. Syn. Comp. $215=$ Ichthyothere Cunabi.

erosa, Poir. Encyc. Suppl. i. $563=$ C. erosum.

nereifolia, H. B. \& K. Nov。 Gen, et Sp. iv. $289=$ C nereifolium.

pedunculosa, Poir. Encyc. Suppl. i. $563=$ C. pedunculosum.

sylvestris, Aubl. Pl. Gui. ii. $807=$ C. surinamense.

terebinthacea, Poir. Encyc. Suppl. i. $563=$ C. terebin thaceum.

BAILLONTA, Bocq. ex Baill. Adansonia, ii. (1861-62) 251. t. 7. VERBENACEAE, Benth. \& Hook. f. ii. 1143

Diostea, Miers, in Trans. Linn. Soc. xxvii. (1870) 103. t. 28 .

amabilis, Bocq. ex Baill. l. c. 252.-Paraguay.

juncea, Benth. E Hook.f. Gen. ii. 1144.-Chili.

BAIMO, Rafin. Fl. Tellur. iv. 27 (1836)= Fritillaria Tourn. (Liliac.)

cirrhosa, Rafin. 1. c. $=$ F. japonica

BAISSFA, A. DC. Prod. viii. 424 (1844). APOCYNACEAE, Benth. \& Hook. f. ii. 719

CLEGHORNIA, Wight, Ic. t. 1310, 1312 (1850)

acuminata, Benth. ex Hook. f. Fl. Brit. Ind. iii. 663.Zeylan.

leonensis, Benth. in Hook. Niger Fl. 452 - Afr. trop. malaccensis, Hook. f. Fl. Brit. Ind. iii. 663.-Malacca. multifora, $A . D C$. in DC. Prod. viii. 424.-Afr. trop.

BAITARIA, Ruiz \& Pav. Prod. 63. t. $36(1797)=$ Calandrinia, H. B. \& K. (Portulac.).

acaulis, Ruiz \& Pav. Fl. Per. iv. t. 403 ; Syst. Veg. 111.-Peruv.

BAJAN, Adans. Fam. ii. $506(1763)=$ Amaranthus, Linn. 
BAKERIA, Seem. Journ. Bot. ii. (1864) $248=$ Plerandra, A. Gray (Araliac.).

vitiensis, Seem. 1 . c. $=$ P. vitiensis

BALAKA, Becc. in Ann. Jard. Buitenz. ii. (1885) 91 in obs. PALMAE.

perbrevis, Becc. l. c.-Ins. Fiji.

Seemanni, Becc.l. c.-Ins. Fiji.

BALANAULAX, Rafin. Alsog. Am. 28 (1838)= Quercus, Tourn. (Cupul.).

molucca, Rafin. 1. c. =Q. molucca.

Rumphi, Rafin。 1. c. = Q. molucea?

BALANGHAS, [Burm.] Rafin. Sylva Tellur. 72 $(1838)=$ Sterculia, Linn.

rubiginosa, Rafin. $1 . \mathrm{c}_{\mathrm{s}}=\mathrm{S}$. rubiginosa.

Telabo, Rafin. 1, c. $=$ S. Balanghas.

BALANGUE, Gaertn. Fruct. ii. 495 - t. 180. f. 3 (1791)。 7ASMINEAE?

Gaertneri, DC. Prod. viii, 316:-Madag.

BALANIA, Noronha, in Verh. Batav. Gen. v. $(1790)$ ed. I. Art. IV. 1 (Quid?).

BALANITES, Delile, Fl. Egypte, 221. t. 28. f. 1. (1813). SIMARUBEAE, Benth. \& Hook. f. i. 314. Agialid, Adans. Fam. ii. 508 (1763) aegyptiaca, Delile, l.c.-Afr. bor.; Arab.; Palaestin. aegyptica, Wall. Cat. n. $6855=$ Roxburghii.

ferox, $\mathrm{G}$. Don, Gen. Syst, i. $774=$ aegyptiaca.

Roxburghii, Planch. in Ann. Sc. Nat. Sér. IV. iv. (1854) 258. t. 2.-Ind. or.

BALANOCARPUS, Bedd. Forest. Man. Bot. 236 [bis] (1873). DIPTEROCARPEAE.

erosa, Bedd.l. c. 237.--Ind. or.

utilis, Bedd. l. c.-Ind. or.

BALANOPHORA, Forst. Char. Gen. t. $50(1776)$ BALANOPHOREAE, Benth. \& Hook. f. iii. 235. CYNOPSOLE, Endl. Gen. 74 (1838). SARCOCORDYLIS, Wall. Cat. n. 7249 (1831 ?) ScyNopsole, Reichb. Handb. 164 (1837)

abbreviata, Blume, Enum. Pl. Fav. i. 87.-Tava.

affinis, Griff. in Proc. Linn. Soc. i. (1849) 220; Trans.

Linn. Soc. xx. (1851) 94. t. $4=$ dioica.

alutacea, Jungh, in Nov. Act. Nat. Cur. xviii. Suppl. i. (1841) $205=$ abbreviata.

alveolata, Griff, in Proc. Linn. Soc. i. (1849) 220 ;

Trans, Linn. Soc, xx. (1851) 94=dioica.

Burmanniana, Griff, 11. cc. 219 et $93=$ dioica.

capensis, lickl. \& Zeyh. ex Eichl. in DC. Prod, xvii $125=$ Mystropetalon Thomii.

dioica, R. Br. in Wall. Cat. n. 7246.-Ind, or.; Burma.

dioica, Unger, in Ann. Wien. Mus. ii. (1838) t. 2. f. 1, $2=$ elongata.

elongata, Blume, Enum. Pl. Fav. i. 87.-Java.

elongata, Schott \& Endl. Melet. 13, partim = dioica

fungosa, Forst. Char. Gen. 99. t. 50.-Austral, ; N. Hebrid.

gigantea, Wall. Cat. n. $7249=$ globosa.

globosa, fungh. in Nov. Act. Nat. Cur. xviii. Suppl.i. (1841) 210 - - Burma; Java.

Harlandi, Hook. f. in Trans. Linn. Soc. xxii. (1859) 426.-Hongkong

Hildebrandtii, Reichb. f. in Fourn. Bot.xiv. (1876) 45. - Ins. Comoro.

indica, Wall Cat n. 7247.-Ind or

involucrata, Hook, fo Thoms, in Trans. Linn. Soc. xxii. (1859) 30 . - Reg. Himal

Lowii, Hook. f. l. c. 426 . to 75 C.-Borneo.

maxima, Jungh. in Nov, Act. Nat. Cur, xviii. Suppl, i. 1841) 209.t. $1=$ elongata.

picte, Griff. in Proc. Limn. Soc. i. (1849) 220 ; Trans. Linn. Soc. xx. (1851) $94=$ dioica.

picta, Miq. ex Eichl, in DC. Prod. xvii. $146=$ indica.

polyandra, Griff. in Trans. Linn. Soc。 Xx. (1851) 94. Reg. Himal,

reflexa, Becc. in Att. Soc. Ital. Sc. Nat. Milano, xi. 1868) 197.-Borneo.

Thwnitesii, Eichl, in DC. Prodo xvii. 146, in nota -Zeylan.

typhina, Wall. Cat, n. 7248=dioica。
BALANOPLIS, Rafin. Alsog. Amer. 29 (1838) = Quercus, Tourn. (Cupul.).

serrata, Rafin. 1. c. $30=Q$. cuspidata.

tribuloides, Rafin. 1. c. 29 =Castanopsis tribuloides.

BALANOPS, Baill. Adansonia, x. (1871) 117, 337 BALANOPSEAE, Benth. \& Hoolc. f. iii. 341, 1223. anstraliana, F. Muell. Fragm. x. 114.-Austral. Balansae, Baill. Adansonia, x. (1872) 338.-N. Caled. microstachya, Baill. l. c. $340 \ldots-\mathrm{N}$, Caled.

oliviformis, Baill. l. c. 337.-N. Caled.

Pancheri, Baill. l. c. 118.-N. Caled.

Theophrasta, Baill. l. c. 338.-N. Caled.

Vieillardi, Baill. l. c. 118. - N. Caled.

BALANOPSIS, Rafin. Sylva Tellur. 134 (1838) 든 Ocotea, Aubl. (Laurin.

acuta, Rafin. 1. c. (=Mespilodaphne cupularis)

Cassia, Rafin. 1. c. = Litsaea zeylanica?

cupulata, Rafin. 1. c. (=Mespilodaphne cupularis). elliptica, Rafin. 1. c.-Hab.?

BALANOPTERIS, Gaertn. Fruct. ii. 94. t. 98 (1791)= Heritiera, Ait. (Sterculiac.)

minor, Gaertn 1. c. t 98, f. $2=\mathrm{H}$. Fomes.

Tothila, Gaertn. 1. c. p. 94 . t. $99=\mathrm{H}$. littoralis.

BALANOSTREBLUS, Kurz, in Journ. As. Soc Beng. xlii. (1873) II. 247. t. 19. URTICACEAE Benth. \& Hook, f. iii. 377

ilicifolia, Kurz, l.c. 248.-Chittagong; Burma; Penang.

BALANSAEA, Boiss. \& Reut. Pugill. Pl. Nov。 49 (1852) Chaerophyllum, Linn. (Umbellif.).

Fontanesii, Boiss. \& Reut, 1. c. 50,-Hispan

glaberrima, Lange, Pugill. iv. 238 = Daucus glaberrimus,

BalantiuM, Desv. ex Ham. Prod. Fl. Ind. Occ, 34 $(1825)=$ Parinarium, Juss. (Rutac.)

cordifolium, Desv. 1. c.-Ind. occ.?

BALARDiA, Cambess, in A. St. Hil. F1. Bras. Mer. ii 180. t. $111(1829)=$ Spergularia, Presl Caryophyll.).

platensis, Cambess. 1. c. $=$ S. platensis.

BALAUSTION, Hook. Ic. Pl. t. 852 (1852)。MYRTACEAE, Benth. \& Hook. f. i. 702

Cheynia, J. Drumm. in Hook. Kew Journ. vii (1855) 56.

Punicella, Turcz. in Bull, Acad, Pétersb. x. (1852) 333.

pulcherrimum, Hook. Ic. Pl. t. 852.-Austral.

BALBISIA, Cav, in Anal. Cienc. Nat. vii. (1804) 62 t. 46. GERANIACEAE, Benth. \& Hook. f. i. 276. CruKshanksia, Hook. \& Arn, in Hook. Bot. Misc ii. (1831) 211. t. 90

LeDoCappon Desy in Mém. Mus. Par vi. (1818) 250 Meyeniana,Klotzsch, in Linnaea, x. (1836) 432 -. Peruv. peduncularis, D. Don, in Edinb. N. Phil. Fourn. xi (1831) 277 . - Chilli.

verticillata, Cav. in Anal. Cienc. Nat. vii. (1804) 62 t. 46.-Chili.

BALBISIA, DC in Guill. Archiv, Bot. ii. (1833) $333=$ Rhetinodendron, Meissn. (Compos.),

Berterii, DC. 1. c. $=$ R. Berteroi.

BALBISIA, Willd. Sp. Pl. iii. 2214 (1803)=Tridax Linn. (Compos.).

Caledoniae, Spreng. Fl. Hal. Mant. 52 = Olearia viscosa canescens, Rich ex Pers Syn ii $470=\mathrm{T}$, procumbens. divaricata, Cass. Opusc, iii. 91 ; ex DC. Prod, v. $679=$ T. procumbens.

elongata, Willd. Sp. P1. iii. $2214=\mathrm{T}$. procumbens pedunculata, Hoffmgg. Verz. PA. (1824) $228=\mathrm{T}$. procumbens.

suffruticosa, Dietr. ex DC. Prod. ₹. $267=$ Olearia viscosa.

BALBOA, Liebm. in Kjocb. Vidensk. Meddel. (1853) 100 Tephrosia, Pers. (Legumia.)

diversifolia, Liebm. 1. c. $107=\mathrm{T}$, madrensis,

BALBOA. Planch. \& Triann, in Ann. Sc. Nat. Sér. IY xiv, (1860) 252, GUTTIFERAE, Benth. \& Hook. S. i. 172 .

membranacea, Planch. \& Triana, h.c.-N. Granat.
BALDELLIA, Parl. Nuov. Gen. e Spec. 57 (1854 Alisma, Linn.

ranunculoides, Parl. 1. c. $58=\mathrm{A}$. ranunculoides.

BALDINGERA, Dennst. Schluess. Hort, Malab. 31 1818) = Premna , Linn. (Verben $)$

glandulosa, Dennst. l. $\mathrm{c}_{\mathrm{v}}=\mathrm{P}$. longifolia.

BALDINGERA, Gaertn. Mey。 \& Scherb. Fl. Wett. i. 43 $(1799)=$ Phalaris, Linn. (Gramin.

arundinacea, Dum. Obs. Gram. Belg. $130=$ P. arun dinacea.

colorata, Gaertn. Mey. \& Scherb. Fl. Wett. i. $96=$ P arundinacea.

BALDINGERIA, Neck. Elem. i. 88? $\left(1790^{\circ}\right)=$ Cotula Linn. (Compos.).

BALDINGERIA, F. W. Schmidt, Samml. Phys. Aufs, 277 (1795) = Leontodon, Linn. (Compos. pygmaea, F. W. Schmidt, 1. co $=$ L. hirtum urens, F. W. Schmidt, 1. co = Hypochoeris cretensis.

BALDWINIA, Nutt, Gen, Am, ii. 175 (1818 Balduina). COMPOSITAE, Benth. \& Hook. f. ii. 391 ACTINOSPERMUM, Ell. Sketch, ii. 448 (1817) ACTISPERMUm, Rafin. New Fl. Am. i. 61 (1836). ENDORIMA, Rafin. in Am. Monthly Mag. (1819) 195 MNESITEON, Rafin. Fl. Ludov, 67 (1817).

bicolor, Rafin. New Fl. Am. iv, 73.-Am, bor.

lutea, Rafin. $l$. $c$.-Am. bor.

multifora, Nutt. Gen. Am. ii. 175.-Am. bor.

uniflora, Nutt. l. c,-Am. bor.

BALDWINIA, Rafin, in Am. Monthly Mag.(1818) $26 \%$ Passiflora Linn.

peltata, Rafin. 1. c. = P. peltata.

BALENDASIA, Rafin. Fl. 'Tellur, iv. 105 (1836)= Pas serina, Linn. (Thymel.

ericoides, Rafin. I. $\mathrm{c}_{0}=\mathrm{P}$. ericoides

BALENERDIA, Comm. ex Steud. Nom. ed. I. 99 (1821 = Nanodea, Banks (Santal.).

BALESSAM, Bruce, Trav. v.t. $25(1790)=$ Balsamo dendron, Kunth, sec. Endl. Gen. 136 (Burserac.).

BALFOURIA, R. Br. in Mem. Wern. Soc. i. (1810) 70 $=$ Wrightia, R. Br. (Apocyn.).

saligna, R. Br. Prod. $467=\mathrm{W}$. saligna,

BALFOURODENDRON, Mello, ex Oliver, in Hook. Ic. Pl. xiii. 3. tt. 1203-04 (1877). RUTACEAE eburneum, Mello, l. c.-Bras.

BALFURIA, Reichb. Consp. 194 (1828)= BALFOURI. R. Br.=Wrightia, R. Br. (Apocyn。).

BALINGAYUM, Blanco, Fl. Filip. ed. I. 187 (1887) = Exythropalum, Blume (Olacin. decumbens, Blanco, 1. c.--Ins. Philipp.

BALIOSPERMUIM, Blume, Bijdr, 603 (1525) EUPHORBIACEAE, Benth. \& Hook. f. iii. 324.

angulare, Decne. ex Baill. Etud. Gén. Euph. $395=$ axillare.

axillare, Blume, Bijdr.604.-Ind. or.; Malaya. calycinum, Muell. Arg. in Flora, xlvii. 1004 ) 450. Reg. Himal.

indicum, Decne, in Jacquem. Voy, Bot, 15t. ᄂ. 155 axillare.

micranthum, Muell. Arg. in Linnaea, xxxiv. (1565-60 215. - Reg. Himal.

montanum, Muell. Arg, in DC. Prod. xv. 18. $1125=$ axillare.

Moritsianum, Baill. Etud. Gén. Euph. $\$ 95=$ axillare

polyandrum. Wight, Ic. t. $1 \times 85=2 x i l l a r c$,

reidioides, Kurs, in Flora, lviii. (1s75) $92 .-$ Siam.

sinuatum, Mrell. Arg. in Flora, xlvii. (1001) tio. Reg. Ilimal.

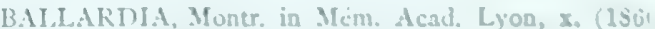
$204=$ Cloësia, Brongn. (Myrtac.).

elegans, Montr. 1. c. 2u5.-N. Calcu.

B.MLARION, Ratim, in Am. Monthly Mag. (1N? : Stellaria, Lim. Cargoplytll. 
BALLELA, Rafin. Fl Tellur, iv, $70(1836)=$ Cam panula?, Linn.

repens, Rafin. 1, c. $=$ C. repens.

BALLEXERDA, Comm. ex A. DC. Prod. xiv, 675 $(1857)=$ Nanodea, Banks $($ Santal. $)$.

BALLIERIA, Juss. Gen。 $188(1789)=$ BAILLIERIA, Aubl. = Clibadium, Linn. (Compos.).

BALLIMON, Rafin. New Fl. Am. iv. $28(1836)=$ Daucus, Tourn. (Umbellif.).

maritimum, Rafin. 1. c $=$ D. maritimus.

muricatulum, Rafin. 1. $\mathrm{c}=\mathrm{D}$. muricatus,

BALLOCHIA, Balf, f. in Proc. Roy. Soc. Edinb. xii. (1884) 86. ACANTHACEAE,

amoena, Balf. f. l. . . 87.-Ins. Socotr.

atro-virgata, Balf. f. l. c.-Ins, Socotr.

rotundifolia, Balf. f. l. c.-Ins. Socotr.

BALLOSPORUM, Salisb. Gen. Pl. Fragm. 142 (1866)= Gladiolus, Linn. (Irid.).

segetum, Salisb. 1. c. $=\mathrm{G}$. segetım.

BALLOTA, Linn. Gen. ed. I. 175 (1737). LABIATAE, Benth. \& Hook. f. ii. 1212.

ACANTHOPRASIUM, Spenn, in T. Nees, Gen. Fl. Germ. Gamop. i. (1843).

BERINGERIA, Neck. Elem. i. 312 (1790).

Pseudodictamnus, Toum. ex Adans. Fam. ii. 191 (1763).

acetabulosa, Benth. Lab. Gen. et Sp. 595.-Graecia; As. Min.

africana, Benth. l. c. 594.-Afr. austr.

africana, Colm. Apuntes, $121=$ hirsuta.

alba, Linn. Fl. Suec, ed. II. 206. n. 530_-Europ.

ampliata, Willd. ex Steud. Nom. ed. II. i. 181=nigra.

arabica, Hochst. \& Steud. ex Stend.1. c. = Leucas urticaefolia.

aristata, Reichb. Fl. Germ. Excurs. $325=$ nigra.

armena, Boiss. Diagn. Ser. II. iv. $54=$ rotundifolia,

Aucheri, Boiss. I. C. Ser. I, y, 39-_Kurdist. ; Persia

boreatis, Schweig. in Koenigsb. Arch. Naturw. i. (1812) $214=$ alba.

bracteosa, Ball, in Journ. Linn. Soc. xvi. (1878) $629=$ nigra.

bullata, Pomel, Nouv. Mat. Fl. Atl. 116.-Algeria.

cinerea, D. Don, Prod. Fl. Nep. 111 = Roylea elegans.

damascena, Boiss. Diagn. Ser. I. xii. 87.-Syria; Aegypt.

dictamnifolia, St. Lag. in Ann. Soc. Bot. Lyon, vii (1880) $120=$ pseudodictamnus.

disticha, Linn. Mant. 83= Anisomeles ovata.

disticha, Rodsch. Obs, $35=$ Hyptis pectinata.

foetida, Lam. Fl. Fr. ii. $381=$ nigra.

Forskahlei, Benth. Lab. Gen. et Sp. 599.-Arabia.

frutescens, Coss. ex Nym. Consp. $581=$ spinosa.

glandulifera, Trautv. in Act. Hort. Petrop. iii. II. (1875) $270=$ rotundifolia

Hildebrandtii, Vatke \& Kurtz, in Oestr. Bot. Zeitschr. xxv。 (1875) 95.-Afr. or.

hirsuta, Benth. Lab. Gen. et Sp. 595.-Hispan,; Afr. bor. hirsuta, Schult, ex Steud. Nom. ed. II. i. 181= nigra. hirta, Hort. Berol, ex Steud. 1. c. =nigra.

hispanica, Benth. Lab. Gen. et Sp. 597.-Europ, austr.

hispanica, Willk. \& Lange, Prod. Fl. Hisp. ii. 446, in syn, $=$ hirsuta

integrifolia, Benth. Lab. Gen. et Sp. 599.-Ins. Cyprus. italica, Benth. in DC. Prod. xii. $519=$ rupestris.

lanata, Linn. Sp. Pl. $582=$ Leonurus lanatus.

lanata, Willd, ex Ledeb. Fl. Ross. iii. $439=$ Eremostachys laciniata.

larendana, Boiss. \& Heldr. Diagn. Ser. I. xii. 88.-As. Min.

limbata, Benth. Lab. Gen. et Sp. $743=$ Otostegia limbata.

macrodonta, Boiss. Eo Bal. Diagn. Ser. II. iv. 54,Cappadoc.

mauritanica, Steud. Nom. ed. II. i. $181=$ seq.

mauritiana, Pers. Syn, ii. $126=$ Anisomeles ovata.

microphylla, Benth. Lab. Gen. et Sp. $596=$ Otostegia Schimperi.

mollissima, Benth. l. c. 595,-Hispan.

nigra, Linn. Sp. Pl. 582,-Europ,; Oriens; Afr. bor obliqua, Benth. Lab. Gen. et Sp. $596=$ saxatilis.

orbicularis, Lag. ex Willk. \& Lange, Prod. Fl. Hisp. ii. $446=$ hirsuta.

\section{BALLOTA}

orientalis, C. \& J. Presl, Delic. Prag. 80 (Sp. dubia negligenda, Boiss.).-As. Min.

persica, Benth. Lab. Gen. et Sp. $598=$ Otostegia macrophylla.

pilosa, Lour. F1. Cochinch. 364=Lencas Benthamiana. psendodictamnus, Benth. Lab. Gen. et Sp. 594.Graecia; Creta.

rotundifolia, C. Koch, in Linnaea, xxi. (1848) 697.Armenia.

royleoides, Benth. in DC. Prod. xii. 520_-Arab.

rubra, Schrad, ex Steud. Nom. ed. II. i. $182=$ nigra.

ruderalis, Sw. in Palmstr. Sv. Bot. t. 389 (1809)=nigra

rugosa, Benth. Lab. Gen, et Sp. $596=$ saxatilis.

rupestris, Vis. Fl. Dalm. ii. 216.--Dalmat.

Russeliana, Benth. Lab. Gen. et Sp. $597=$ saxatilis.

saxatilis, Guss. F1. Sic. Syn. ii. $82=$ rupestris.

saxatilis, Sieber, ex Benth. Lab. Gen.et Sp. 596.-

Syria; As. Min.

Schimperi, Benth. in DC. Prod. xii. $519=$ Otostegia Schimperi.

sepium, Paulet, in Pers. Syn, ii. $125=$ nigra

silvestris, Hoffmgg. \& Link, ex Willk. \& Lange, Prod.

Fl. Hisp. ii. $446=$ alba.

sordida, Salisb. Prod. $83=$ nigra.

spinosa, Link, Handb. 475.-Gallia.

stachydiformis, Hochst. in Flora, xxvii. (1844) 100.Abyss.

raveolens, Linn. Syst. ed. X. 1100 ; PI. Jam. Pugill. $15=$ Hyptis suaveolens.

suaveolens, Rodsch. Obs. $35=$ Hyptis pectinata.

undulata, Benth. Lab. Gen. et Sp. 595.-Syria; Arab.

urticaefolia, Ortim. ex Reichb. Ic. Bot. viiì. 30. t. 774 = nigra.

verticillata, Noronha, in Verh. Batav. Gen. v. (1790)

ed. I. Art, IV, 8,-Malaya

vulgaris, Hoffmgg. \& Link, Fl. Port. t. $115=$ nigra .

BALMEDA, Nocca, Hort. Ticin. 21 (1804)=Grewia, Linn. (Tiliac.)

corylifolia, Nocca, 1. $\mathrm{c},=\mathrm{G}$. corylifolia.

BALMISA,Lag. Gen. et Sp. Nov. 17 (1816)= Arisarum, Targ.-Tozz. (Aroid.).

vulgaris, Lag. 1. c. = A. vulgare,

BALOGHIA, Endl. Prod. F1. Norf. 84 (1833)。 EU. PHORBIACEAE, Benth. \& Hook, f. iii. 300 .

Steigeria, Muell. Arg, in Linnaea, xxxiv. (1865) 215.

alternifolia, Baill. Adansonia, ii. (1861-62) 216--N. Caled.

carunculata, Baill. l. c. 215,-N. Caled.

lucida, Endl. Prod. Fl. Norf. 84,-Ins. Norfolc

Pancheri, Baill. Adansonia, ii. (1861-62) 214.Austral.; N. Caled.

BALOSKION, Rafin. F1. Tellur. iv. 32 (1836)= Restio Linn.

dichotomum, Rafin. 1. $\mathrm{c} .=\mathrm{R}$, quadrifarius.

BALSAMARIA, Lour, Fl. Cochinch. ii. $469(1790)=$ Calophyllum, Linn. (Guttif.

Inophyllum, Lour. 1. c. $470=$ C. Inophyllum.

BALSAMEA, Gled, in Berl. Ges. Naturf. Fr. Schr. iii. (1782) 127 =BALSAMODENDRUM, Kunth = Commiphora, Jacq. (sec. Engler) (Burser). abyssinica, Engl, in Bot. Jahrb. i. (1881) $41=$ C. abyssinica.

africana, Baill. Hist. PI. v. $295=$ C. africana

Agallocha, Baill. 1. c. = C. Agallocha,

Berryi, Engl. in Bot. Jahrb. i. (1881) $41=$ C. Berryi

capensis, Engl. 1. c. $42=$ C. capensis.

caudata, Engl. 1. c. $=$ C. candata.

edulis, Baill, in Bull. Soc. Linn. Par. i. (1877) $122=$ C. edulis.

Harveyi, Engl. in Bot. Jahrb. i. (1881) $42=$ C. Harveyi.

Hildebrandtii, Engl. 1. c, = C. Hildebrandtii.

Kotschyi, Engl. 1. c. $41=$ C. africana.

madagascariensis, Engl. 1. c. $42=$ C. grandifolia.

meccanensis, Gled. in Berl. Ges. Naturf. Fr. Schr. iii (1782) $127=$ C. Opobalsamum.

mollis, Engl. in Bot. Jahrb. i. (1881) $42=$ C. mollis.

Mukul, Baill. Hist. Pl. v. $295=$ C. Mukul.

Myrrha, Baill. 1. c. $294=$ C. Myrrha.

pedunculata, Engl. in Bot. Jahrb. i. (1881) $42=$ C pedunculata

pilosa, Engl. l. c. $41=$ C. pilosa.
BALSAMEA :-

Roxburghii, Engl. in Bot. Jahrb. i. (1881) $41=$ C. Agallocha.

Schimperi, Engl. 1. c. $=$ C. Schimperi.

Stocksiana, Engl. 1. c. = C. Stocksiana.

zanzibarica, Baill. in Adansonia, xi。(1874) $180=$ C. zanzibarica.

BALSAMIFLUA, Griff. Notui. iv. $382(1854)=$ Po pulus, Linn. (Salicin.).

deltoides, Griff, $1, \mathbf{c}=\mathbf{P}$, euphratica.

BALSAMINA, Tourn. ex Scop. Fl. Carn. ed. II. ii. 183 (1772); Gaertn. Fruct. ii. 15I. t. $113(1791)=$ Impatiens, Linn. (Geraniac.).

angustifolia, Blume, Bijdr. $239=\mathrm{I}$. Balsamina.

bifida, DC. Prod, i, $686=$ I. flaccida.

capensis, DC, 1. c. $=$ I. capensis.

carnea, Noronha, in Verh. Batav. Gen, v. (1790) ed. I. Art. IV. 7.-Malaya.

chinensis, DC. Prod. i. $686=\mathrm{I}$. chinensis.

coccinea, DC. 1. c. $685=\mathrm{I}$. Balsamina.

cochleata, DC. 1. c. $686=\mathrm{I}$. cochleata

communis, Noronha, in Verh. Batav. Gen. v. (1790) ed.

I. Art. IV. 7.-Malaya.

comorensis, Boj. ex Baker, in Journ. Linn. Soc. xx.

(1884) $114=\mathrm{I}$. comorensis.

cornuta, DC. Prod. i. $686=\mathrm{I}$. Balsamina.

cristata, Ser. Cat. Gr. Jard. Lyon, (1853) = I. scabrida?

fasciculata, DC. Prod. i. $686=$ I. chinensis.

foeminea, Gaertn. Fruct. ii. $113=$ I. Balsamina.

fruticosa, Leschen. ex Steud. Nom。 ed. II. i. $182=$ I. fruticosa.

fulva, Ser. Fl. Jard. iii. $453=$ I. fulva.

glandulifera, Ser. Cat. Gr. Jard. Lyon, (1853)=I, glandulifera.

glandulifera, Lyall, ex Baker, in Journ. Linn. Soc. xx. (1884) $113=\mathrm{I}$. Lyallii.

heterophylla, G. Don, Gen. Syst. i. $749=\mathrm{I}$. chinensis. hirsuta, Blume, Bijdr. $240=\mathrm{I}$. hirsuta.

hortensis, Desp. in Dict. Sc. Nat. iii. $485=$ I. Balsamina. javensis, Blume, Bijdr. $240=\mathrm{I}$. javensis.

lacca, Medic, Malv. $71=\mathrm{I}$. Balsamina.

latifolia, DC. Prod, i. $686=\mathrm{I}$. latifolia.

Leschenaultii, DC. $l_{0} c_{0}=\mathrm{I}$. Leschenaultii.

longicornis, Ser. Fl. Jard. iii. $452=$ I. leptoceras?

lutea, Delarb. Fl. Auv, ed. II. 504=I. Noli-tangere.

macrochila, Ser. Fl. Jard. iii. $454=$ I. Roylei.

madagascariensis, DC. Prod. i. 686=I. madagascariensis.

Mastersiana, Paxt. Bot. Mag. vi. $75=$ I. Mastersiana.

micrantha, Blume, Bijdr. $240=\mathrm{I}$. leptoceras.

minor, DC. Prod. i. $686=$ I. Kleinii.

minutiflora, Span, in Linnaea, Xv。 (1841) $185=\mathrm{I}$. Balsamina.

mollis, G. Don, Gen, Syst. í. $749=$ I. Balsamina.

mutila, DC. Prod, i. $686=\mathrm{I}$. mutila.

mysorensis, DC. 1. c. =I. mysorensis.

Noli-tangere, Scop. Fl. Carn. ed. II. ii. 184=I. Nolitangere.

odorata, Buch.-Ham. ex D. Don, Prod: Fl. Nep. $203=$ I. Balsamina.

oppositifolia, DC. Prod. i. $686=\mathrm{I}$, oppositifolia. parviflora, Ser. Cat. Gr. Jard. Lyon, (1853) = I. parviflora? puberula, G. Don, Gen. Syst. i. $749=$ I. puberula. racemosa, Buch.Ham. ex D. Don, Prod. Fl, Nep. $203=\mathrm{I}$. Balsamina.

repens, Noronha, in Verh. Batav. Gen. v. (1790) ed. I. Art. IV. 8-Malaya.

rosmarinifotia, DC. Prod. i. $686=\mathrm{I}$, oppositifolia.

Roylei, Ser. Fl. Jard. iii. 455. t. $7=$ I. Roylei.

salicifolia, Boj. ex Baker, in Journ. Linn. Soc. xx. (1884)

$115=\mathrm{I}$, salicifolia.

scabriuscula, G. Don, Gen. Syst. i. $748=$ I. scabriuscula. setacea, Coleb. ex Hook. Exot. Flo ii. t. 137 =I. chinensis.

Tilo, DC. Prod. i. $686=$ I. tripetala ?

tricornis, Ser. Fl. Jard. iii. $452=$ I. scabrida.

BALSAMitA, Desf. in Act. Soc. Hist. Nat. Par. i. (1792) t. 1 =Chrysanthemum, Linn. (Compos.). ageratifolia, Desf. 1. c. $2=$ C. flosculosum.

annua, DC. Fl. Fr. iv. 187 = Tanacetum annuum. Audibertii, Req. in Ann. Sc. Nat. Sér. I. v. (1825) 382 $=$ Tanacetum Audiberti.

corymbosa, Salzm. in Flora, iv. (1821) $112=\mathrm{C}$ flosculosum.

dentata, Wall. Cat. n. $326=$ Myriactis Wallichii. 
BALSAMITA :-

flabelliformis, Pers. Syn. ii. $408=$ Pentzia flabelliformis grandiflora, Desf. in Act. Soc. Hist. Nat. Par, i. (1792) 1 (=Plagius grandiflorus).--Afr, bor.

major, Desf. 1. c. $8=$ C. Balsamita.

multifida, Roxas Clem. Ensay. Vid, $292=$ Tanacetum annuum.

suaveolens, Pers. Syn. ii. $408=$ C. Balsamita.

tridentata, Delile, Fl. Egypte, $273=$ Cotula tridentata. virgata, Desf. in Act. Soc. Hist. Nat. Par. i. (1792) 2 $=\mathrm{C}$. discoideum.

vulgaris, Willd. Sp. P1. iii. $1802=$ Chrysanthemum Balsamita.

BALSAMOCARPON, Clos, in C. Gay, Fl. Chil. ii. 226. t. $20(1846)=$ Caesalpinia, Linn. (Legumin.)

brevifolium, Clos, 1. c.-Chili.

BALSAMODENDRON, DC. Prod. ii. 76 (1825)=seq.

BALSAMODENDRUM, Kunth, in Ann. Sc. Nat. Sér. I ii. (1824) $348=$ Commiphora, Jacq. (Burser.). abyssinicum, Engl. in Bot. Jahrb. i. (1881) $41=$ C abyssinica.

africanum, Arn, in Ann. Nat. Hist, iii. (1839) $87=$ C. africana.

Agallocha, Wight \& Arn. 1. c. $86=$ C. Agallocha. Arnottianum, March. in Adansonia, vii. (1866-67) 266 $=\mathrm{C}$. pubescens,

Berryanum, Voigt, Hort. Suburb. Calc. $149=$ C Berryi.

Berryi, Arn。 in Ann. Nat. Hist. iii. (1839) $86=$ C Berryi.

capense, Sond. in Harv, \& Sond. Fl. Cap. i. $526=$ C. capense.

caudatum, March, in Adansonia, vii. (1866-67) 266= C. candata.

Ehrenbergianum, O. Berg, in Bot. Zeit. xx. (1862) 163 $=\mathrm{C}$. Opobalsamum.

gileadense, Kunth, in Ann. Sc. Nat. Sér. I. ii. (1824) $349=$ C. Opobalsamum.

habessinica, O. Berg, in Bot. Zeit. xx. (1862) $161=$ C. abyssinica

Kafal, Kunth, in Ann. Sc. Nat. Sér. I. ii. (1824) $349=$ C. abyssinica

Kataf, Kunth, 1. c. = C. Kataf.

Kotschyi, O. Berg, in Bot. Zeit. xx. (1862) $162=$ C africanum.

madagascariense, March. in Adansonia, viii. (1867-68) 71. t. $6=$ C. grandifolia

molle, Oliver, Fl. Trop. Afr. i. $326=$ C. mollis.

Mukul, Hook, ex Stocks, in Hook. Kew Journ. i. (1849) $259=$ C. Mukul.

Myrrha, T. Nees, Pl. Officin. t. 182 =C. Myrrha,

Opobalsamum, Kunth, in Ann. Sc. Nat. Sér. I. ii (1824) $348=$ C. Opobalsamum.

parvifolium, Balf, $f$. in Proc. Roy. Soc. Edinb. xi. (1882) 506,- - Ins. Socotra.

pedunculatum, Kotschy \& Peyr. Pl. Tinn. 11. t. 5 et Schweinf. Beitr. Fl. Aeth. $234=$ C. pedunculata.

planifrons, Balf, f. in Proc. Roy. Soc. Edinb. xi. (1882) 506. - Ins. Socotra.

Playfairii, Hook. f. ex Oliver, Fl. Trop. Afr. i. $326=$ C. Myrrha.

pubescens, Stocks, in Journ. As. Soc. Bomb. ii. (1848 395. t. $25=$ C. Stocksiana.

Roxburghianum, March. ex Baill. Adansonia, vii. $(1866-67) 266=$ C. candata.

Roxburghii, Arn。 in Ann. Nat. Hist. iii. (1839) $86=$ C Agallocha.

Roxburghii, Stocks, in Journ. As. Soc. Bomb. ii. (1848) $391=$ C. Mukul

Schimperi, O. Berg, in Bot. Zeit. xx. (1862) $162=\mathrm{C}$. Schimperi.

socotranum, Balf. f. in Proc. Roy. Soc. Edinb. xi. (1882) 505.-Ins. Socotr.

Wightii, Arn. in Ann. Nat. Hist. iii. (1839) $86=$ C. Mukul.

reylanicum, Kunth, in Ann. Sc. Nat. Sér. I. ii. (1824) 349 =Canarium zeylanicum.

BALSAMONA, Vand. Fasc. P1. 15 (1771)=Cuphea P. Br. (Lythrar.)

Pinto, Vand. 1. c. = C. Balsamona

BALSAMOPHLEOS, O. Berg, in Bot. Zeit. xx. (1862) $163=$ Commiphora, Jacq. (Burser.).

Katof, O. Berg, 1. c. $=$ C. Kataf
BAISA MIORHIZA Hook. FI. Bor Am. i. 310 (1833). COMPOSITAE, Benth. \& Hook. f. ii. 366.

EsPeletia, Nutt. in Journ. Acad. Philad. vii. (1834) 37. t. 4 .

Bolanderi, A. Gray, in Proc. Am. Acad. vii. (1868) 356.-Calif.

Careyana, A. Gray, Pl. Fendl. 81.-Am. bor, occ. deltoidea, Nutt. in Trans, Am. Phil. Soc. Ser. II. vii. (1841) 351.-Am. bor. occ

glabrescens, Benth. P1. Hartw. $317=$ deltoidea.

helianthoides, Nutt. in 'Trans. Am. Phil. Soc. Ser. II. vii. (1841) $351=$ sagittata.

hirsuta, Nutt. l.c. 349.-Am. bor. occ.

Hookeri, Nutt. l. c.-Am. bor, occ

incana, Nutt. 1. c. $350=$ Hookeri

macrophylla, Nutt.l.c.-Am, bor. occ

sagittata, Nutt. l.c.-Am. bor. occ

silphioides, Geyer, ex Hook. Lond. Journ. Bot. vi. 1847) $244=$ Silphium laeve.

terebinthacea, Nutt. in Trans. Am. Phil. Soc. Ser. II. vii. (1841) 349.-Am, bor. occ.

BALSAMUS, Stackh. De Liban. $11(1814)=$ Commi

phora, Jacq. (Burser.).

Kafal, Stackh. 1. c. $12=$ C. abyssinica

libanotus, Stackh. 1. c. $11=$ C. Opobalsamum?

meccanensis, Stackh. 1. c. $12=$ C. Opobalsamum.

Theophrasti, Stackh. 1. c. $11=$ C. Opobalsamum.

BALTIMORA, Linn. Mant. 158 (1771), COMPO

SITAE, Benth. \& Hook. fo ii. 348.

FoUGERIA, Moench, Meth. Suppl. 243 (1802)

Fovgerouxia, Cass, in Dict. Sc. Nat. liv. 461 (1829).

NiEBuHRia, Scop. Introd. 134 (1777)

Scolospermum, Less, in Linnaea, v. (1830) 152

Trmanthea, Salisb. Prod. 208 (1796)

alata, Meerb. Afb. t. $23=$ recta?

alba, Pers. Syn. ii. $489=$ recta.

recta, Linn. Mant. 288.-Mexic.

scabra, Pohl, ex Baker, in Mart. F1. Bras. vi. III. $258=$ Calea hymenolepis.

scolospermum, Steetz, in Seem. Bot. Voy. Herald, 154. -Panama.

trinervata, Moench, Meth, $592=$ recta.

BAMBOS, Retz. Obs. y. 24 (1789)=Bambusa, Schreb. (Gramin.)

arundinacea, Retz. Obs. v. $24=$ Bambusa arundinacea,

Arundo, Soland. Fl. Ins. Ocean. Pacif. $217=$ Schizostachyum glaucifolium.

quinqueflora, Stokes, Bot. Mat. Med. ii. 286 = Bambusa arundinacea.

stricta, Roxb. PI. Corom. i. 58. t. 80 (non text.) $=$ Oxytenanthera Thwaitesii, et Dendrocalamus strictus. verticillata, Poir. Encyc. viii. $703=$ Gigantochloa verticillata.

BAMBUS, J. F. Gmel. Syst. $579(1791)=$ seq

BAMBUSA, Schreb. Gen. PI. 236 (1789). GRAMI-

$N E A E$, Benth. \& Hook. fo iii. 1210.

Bambos, Retz. Obs. v. 24 (1789).

Bambus, J. F. Gmel. Syst. 579 (1791)

BeESHA, Kunth, Syn. i. 253 (1822).

IschurochloA, Buese, in Miq. Pl. Jungh. 389 (1854).

abyssinica, A. Rich. Tent. Fl. Abyss, ii. $439=$ Oxytenanthera abyssinica.

affinis, Munro, in Trans. Linn. Soc. xxvi. (1868) 93.Burma.

agrestis, Poir. Encyc. viii. 704.-Ind. or.; Cochinch alpina, Bory, Voy, i. 310, t. $12=$ Nastus borbonicus amahussana, Lindlo in Penny Cyclop. iii. 857 (1835). -Amboina.

amplexifolia, Schult. f. Syst. vii. $1348=$ Guadua amplexifolia.

andamanica, Kurs, in fourn. As. Soc. Beng. xxxix. (1870) Ir. 88.-Ins. Andam.

angulata, Munro, in Trans. Linn. Soc. xxvi. (1868) 94.-China.

Apus, Schult, f. Syst. vii. II. 1353. $\rightarrow$ Java.

argentea-striata, Regel, Gartenfl. (1865) 363.-Japon. aristata, Lodd. E Lindl. in Penny Cyc. iii. (1835) $\$ 5$ - Ind. or.

arundinacea, Humb. \& Bonpl. Pl. Aequin. i. $71=$ Nastus borbonicus.

\section{BAMBUSA}

arundinacea, Ait. Hort Kew ed. II. iL 316

Thonarsii.

arundinacea, Wight, ex Steud. Nom. ed. II. i. $183=$ orientalis.

arundinacea, Willd. Sp.Pl. ii, 245.-Ind. or.

Arundo, Nees, in Linnaea, ix. (1834) $471=$ arun dinacea

Arundo, Wight, ex Stend. Nom。 ed. II. i. $183=$ orientalis.

aspera, Schult. f. Syst. vii. II. 1352,-Amboina,

atra, Lindl, in Penny Cyc. iii. (1835) 357.-Amboina. attenuata, Thw. Enum. Pl. Zeyl. 375 = Teinostachyum attenuatum.

aurea, Hort. ex A. \& C. Rivière, in Bull. Soc, Acclim Sér. III. v. (1878) $716=$ Phyllostachys aurea,

aurea, Siebold, ex Miq. Ann. Mus. Bot. Lugd. Bat. ii 285.-Japon.

aureo-striata, Regel, Gartenfl. (1865) 362.-Japon.

auriculata, Kurz, in Journ. As. Soc. Beng. xxxix (1870) II. $86=$ vulgaris.

baccifera, Roxb. Hort. Beng. 25; Fl. Ind. ii. 197 = Melocanna bambusoides.

Balcooa, Roxb. Ul. cc. 25, 196.-Ind. or.

barbata, Trin. in Mém. Acad. Pétersb. Sér. VI. Sc. Nat. i. (1835) $627=$ Nastus barbatus.

Beecheyana, Munro, in Trans. Linn. Soc, xxvi. (1868, 108.-China.

bifolia, Siebold, ex Munro, 1. co $36=$ Phyllostachy bambusoides.

Bitung, Schult.f. Syst. vii. II. 1354,-Java.

Blancoi, Steud. Syn. Pl. Gram. 331.-Ins. Philipp.

Blumeana, Hook, \& Arn. Bot. Beech. Voy. 254 = tuldoides

Blumeana, Schult. f. Syst. vii, II. 1343.-Java

Brandisii, Munro, in Trans. Linn. Soc. xxvi. (1868 109.-Burma.

breviflora, Munro, l.c. 96.-China.

caesia, Sieb, \& Zucc ex Munro, 1. c. $89=$ nana

calostachya, Kurz, in fourn. As. Soc. Beng. xlii. (1873 II. 250.-Burma.

Cantori, Munro, in Trans. Linn. Soc. xxvi. (1868) 111 -China.

capensis, Rupr. in Mém. Acad. Pétersb. Sér. VI. v. (1839) 144.-Afr. austr.

capitata, Trin. 1. c. Sc. Nat. i. (1835) $626=$ Guadua capitata.

capitata, Wall. \& Griff. in Wall. Cat. n. $8913=$ Cephalo. stachyum capitatum.

capitata, Willdd. ex Rupr. in Mém. Acad. Pétersb. Sér VI. v. (1839) 43. - Madag.

China, Franch. E Sav. Enum. Pl. Fap. ii. 607.Japon.

Chusque, Poir. Encyc. Suppl. v. $494=$ Chusquea scandens.

cornuta, Munro, in Trans. Linn. Soc. xxvi. (1868) 113. - Java.

crinita, Thoms, ex Munro, 1. c. $157=$ nutans.

critica, Kurs, in fourn. As. Soc. Beng. xlii. (1873) It. 250.-Pegu.

dichotoma, Donn, Hort. Cantab. ed. IV. $78=$ Phyllostachys nigra.

diffusa, Blanco, Fl. Filip. ed. I. $269=$ Guadua distorta distorta, Nees, in Linnaea, ix. (1834) 470 - Bras.

diversistachya, Munro, in Trans. Linn. Soc. xxvi (1868) 126 = Gigantochloa beterostachya.

dumetorum, Hance, ex Walp. Ann. iii. $781=$ Schizostachyum dumetorum.

Duquilioi, Hort, ex Carr in Rev. Hortic. (1809) 292 m Phyllostachys Quilioi.

edulis, Carr.l.c. (1866) 380 - - China.

elegantissima, Hassk. P1. Jav. $42=$ Beesha elegantissima.

excelsa, Miq. Fl. Ind. Bat. iii. $418=$ maxima.

folcata, Hort, ex Vilm. Fl. Pl. Terre, ed. II. $98=$ Arundinaria falcata.

Falconeri, Munro, in Trans. Linns. $S$ x.xvi. 1900 95.-Reg. Himal,

Fax, Poir. Encyc. viii. $704=$ Melocanna humilis, fera, Miq. Fl. Ind. Bat, iii. 418. - Amboinn.

fistulosa, Royle, ex Munro, in Trans. Lint. Soc. xxvi Isós) 95 - Falconeri.

Ragellifera, Griff. ex Munro, I. c. 150 = Dendrocalamu ilingellifer.

flexuosa, M/unro, l. c. 101.-China.

Rexuosa, Hort. ex A. \& C. Riviere, in Bull. So Acclim. Ser. III, v, (18is) $755=$ Phyllustacl. thexuosa. 


\section{BAMBUSA :-}

floribunda, Zoll. E० Mor. ex Steud. Syn. Pl. Gram. 330 - Java.

floribunda, Munro, in Trans. Linn. Soc. xxvi. (1868) $34=$ Thamnocalamus Falconeri.

Fortunei, Van Houtte, Fl. des Serres, xv. (1863) t. 1535.-Japon.

fragilis, Spruce, ex Munro, in Trans. Linn. Soc. xxvi. 1868) $78=$ Guadua latifolia

gigantea, Wall. Cat. Bot. Gard. Calc. $79=$ Dendrocalamus giganteus.

glauca, Blume, ex Rupr. in Mém. Acad. Pétersb. Sér. VI. v. (1839) $162=$ Arundinaria glaucescens.

glauca, Lodd. ex Lindl. in Penny Cyclop. iii. 357 (1835) = nana.

glaucescens, Siebold, ex Munro, in Trans. Linn. Soc. xxvi. (1868) $89=$ nana

glaucifolia, Rupr. in Mém. Acad. Pétersb. Sér. VI. v. 1839) $147=$ Schizostachyum glaucifolium

globifera, Griseb. in Goett. Nachr. (1868) 72.-Ind. or

glomerata, Royle, ex Munro, in Trans. Linn. Soc. xxvi. 1868) $147=$ Dendrocalamus strictus.

gracilis, Hort. ex A. E C. Riviere, in Bull. Soc. Acclim. Sér. III. v. (1878) 682.-Hab.?

gracilis, Wall. Cat. n. $5033=$ Oxytenanthera nigrociliata.

Griffithiana, Munro, in Trans. Linn. Soc. xxvi. (1868) 99.-Burma.

Guadua, Humb. \& Bonpl. Pl. Aequin. 168. t. $20=$ Guadua angustifolia.

Helferi, Munro, in Trans. Linn.Soc. xxvi. (1868) 114 -Burma.

heterocycla, Carr. in Rev, Hortic. (1878) 354.-Hab.? hexandra, Roxb ex Munro, in Trans. Linn. Soc xxvi. (1868) $147=$ Dendrocalamus strictus.

Hookeri, A. E C. Rivière, in Bull. Soc. Acclim. Sér. III. v. (1878) $642 .-$ Hab. ?

Horsfieldii, Munro, in Trans. Linn. Soc. xxvi. (1868) 115.-Java.

humilis, Reichb. ex Rupr. in Mém. Acad. Pétersb. Sér. VI. v. (1839) $140=$ vulgaris.

khasiana, Munro, in Trans. Linn. Soc. xxvi. (1868) 97. -Reg. Himal.

kumasasa, Zoll. ex Steud. Syn. Pl. Gram. $331=$ Phyllostachys kumasaca.

latiflora, Kurz, in Fourn. As. Soc, Beng, xlii. (1873) II. 250.-Ind. or.

latifolia, Humb. \& Bonpl. P1. Aequin. i. 68. t. $21=$ Guadua latifolia.

levis, Blanco, Fl. Filip. ed. I. 272.-Ins. Philipp.

Lima, Blanco, $l . c .271$.-Ins. Philipp.

lineata, Munro, in Trans. Linn. Soc. xxvi. (1868) 118 -Ins. Ternate.

longinodis, Miq. Fl. Ind. Bat. iii. 418.--Malaya.

longispatha, Kurz, in fourn. As. Soc. Beng. xlii. (1873) II. 250.-Burma.

Luconiae, Munro, in Trans. Linn. Soc. xxvi. (1868) 115.--Ins. Philipp.

Lumampao, Blanco, Fl. Filip. ed. I. 272.-Ins. Philipp.

Mac-Clellandi, Munro, in Trans. Linn. Soc. xxvi. (1868) 114.-Burma

macra, Wall. ex Munro, 1. c. $34=$ Thamnocalamus spathiflorus.

macroculmis, A. Rivière, in Bull. Soc. Acclim. Sér. III. v. (1878) 624 . - Hab.?

Macala, Buch.-Ham. ex Munro, in Trans. Linn. Soc. xxvi. (1868) $91=$ Tulda.

madagascariensis, Hort. ex A. \& C. Rivière, in Bull Soc. Acclim. Sér. III. v. (1878) $631=$ vulgaris

marginata, Munro, in Trans. Linn. Soc. xxvi. (1868) 114.--Burma

Mastersii, Munro, l. c. 113.-Ind. or.

maxima, Buch.-Ham. in Wall. Cat. n. $5039=$ Dendrocalamus Hamiltonii.

maxima, Poir. Encyc. viii. 704.-Amboin.; China.

Maximowiczii, Hort. ex Munro, in Gard. Chron. (1876) II. $774=$ Arundinaria Fortunei.

Metake, Siebold, ex Miq. Anu. Mus. Bot. Lugd. Bat.ii. $284=$ Arundinaria japonica.

microphylla, Griff. Journ. i. 242, $259(1847)=$ Arun dinaria microphylla.

mitis, Blanco, F1. Filip. ed. I. 271 = Blancoi.

mitis, Hort. Paris. ex Munro, in Trans. Linn. Soc. xxvi. (1868) $18=$ Arundinaria japonica.

mitis, Poir. Encyc, viii. 704.-China.

mitis, Hort. ex Carr. in, Rev. Hortic. (1866) $380=$ edulis.

\section{BAMBUSA :-}

monogyna, Blanco, Fl. Filip. ed. I. 268,-Ins, Philipp. monogynia, Griff, Notul iii. $63=$ Dendrocalamus Hamiltoni.

multiplex, Raeusch. Nom. ed. III. 103; Schult. $f$ Syst. vil. II. 1350.-Cochinch.

nana, Roxb. Hort. Beng. 25; Fl. Ind. ii. 199.-Japon Neesiana, Arn. ex Munro, in Trans. Linn, Soc. xxyi. (1868) $103=$ arundinacea.

nigra, Lodd. Cat. (1823) ex Loud. Hort. Brit. $124=$ Phyllostachys nigra.

nigricans, Hort. ex Steud. Nom. ed. II. i. $183=$ Phyllostachys nigra.

nigro-ciliata, Buese, in Miq. P1. Jungh. $389=$ Oxy tenanthera nigro-ciliata.

nutans, Wall. ex Munro, in Trans. Linn. Soc. xxvi. (1868) 92.--Reg. Himal.

Oldhami, Munro, l. c. 109.-China

orientalis, Nees, in Linnaea, ix. (1834) 475.-Ind. or. pallida, Munro, in Trans.Linn. Soc. xxvi. (1868) 97. -Ind, or.

paniculata, Willd. ex Steud. Nom. ed. II. i. $183=$ Nastus borbonicus?

parviflora, Schult. f. Syst. vii. II. $1350=$ Arthrostylidium maculatum.

picta, Lindl. in Penny Cyclop. iii. 357 (1835).-Ins. Ceram.

picta, Sieb. \& Zucc. ex Munro, in Trans. Linn. Soc xxvi. (1868) $111=$ Fortunei.

polymorpha, Munro, l. c. 98.-Burma.

prava, Lindl. in Penny Cyclop. iii. 357 (1835).Amboina.

pseudoarundinacea, Steud. Syn. Pl. Gram. $330=$ Gigantochloa verticillata.

puberula, Miq. Ann. Mus. Bot. Lugd. Bat. ii. $285=$ Phyllostachys nigra.

pubescens, Doell, in Mart. Fl. Bras. ii. III. 189.-Bras, pubescens, Lodd. ex Lindl. Penny Cyclop. iii. 357 (1835) = Dendrocalamus strictus

pungens, Blanco, Fl. Filip. ed. I. $270=$ arundinacea.

pygmaea, Miq. Ann. Mus. Bot. Lugd. Bat. ii, 286.Japon.

quadrangularis, Fenzi, in Bull. Soc. Tosc. Ort. v. (1880) 401.-Japon.

Quilioi, Hort. ex A. \& C. Rivière, in Ball. Soc. Acclim.

Sér. III. v. (1878) $697=$ Phyllostachys Quilioi.

Ragamowskii, Hort.-Cf. Gard. Chron. (1876) II. 847 $=$ tessellata.

regia, Thoms. Cat. Hort. Bot. Calc. 79 ; ex Munro in Trans. Linn. Soc. xxvi. (1868) 116.-Ind. or. reticulata, Rupr, in Mém. Acad. Pétersb. Sér. VI, y. (1839) $148=$ Phyllostachys bambusoides

Ritcheyi, Munro, in Trans. Linn. Soc. xxvi. (1868) 113.- - Ind. or.

Rumphiana, Kurz, in fourn. As. Soc. Beng. xxxix. (1870) II. 86.--Ind. or.

ruscifolia, Siebold, ex Munro, in Trans. Linn. Soc xxvi. (1868) $157=$ Phyllostachys kumasaca

scandens, Blume, ex Nees, in Flora, vii. (1824) $291=$ Dendrocalamus Tjankorreh.

Schimperiana, Steud. Syn. Pl. Gram. $330=$ Oxytenanthera abyssinica.

schizostachyoides, Kurz, ex Munro, in Trans. Linn Soc. xxvi. (1868) $134=$ Melocanna Kurzii.

scriptoria, Dennst. Schluess. Hort. Malab. $31=$ Melocanna bambusoides.

senamensis, Franch. E Sav. Enum. Pl. Fap. ii. 606.Japon.

siamensis, Kurz, ex Munro, in Trans. Linn. Soc. xxvi 1868) $116=$ regia

Sieberi, Griseb. F1. Brit. W. Ind. $528=$ vulgaris.

Simoni, Carr. in Rev. Hortic. (1866) $380=$ Arundinaria Simoni.

spinosa, Nees, in Linnaea, ix. (1834) $475=$ arundinacea.

spinosa, Blume, ex Nees, in Flora, viii. (1825) $580=$ Blumeana.

spinosa, Roxb. Hort. Beng. 25; Buch.-Ham. in Trans Linn. Soc. xiii. (1822) 480.--Ind, or.

sterilis, Kurz, ex Miq. Ann. Mus. Bot. Lugd. Bat. ii $285=$ nana.

striata, Lodd. ex Lindl. Penny Cyclop. iii. 357 (1835), -China

stricta, Roxb. Hort. Beng. 25 ; Fl. Ind. ii. $193=$ Oxytenanthera Thwaitesii et Dendrocalamus strictus. stridula, Moon. Cat. 26.-Zeylan.

sulfurea, Carr. in Rev. Hortic. (1873) $379=$ Phyllostachys sulphurea.

\section{BAMBUSA:}

surinamensis, Rupr, in Mém. Acad, Pétersb. Sér. VI. v. (1839) $49=$ vulgaris

tabacaria, Poir. Encyc. viii. 705.-Amboina: Java. Tagoara, Nees, Agrost. Bras. $532=$ Guadna Tagoara. Teba, Miq. Fl. Ind. Bat. iii, 418.--Malaya; China. tenuis, Munro, in Trans. Linn. Soc. xxvi. (1868) 119. -Ins. Macass.

teres, Buch.-Ham. in Wall. Cat.n. 5026 B.-Ind, or. tessellata, Munro, in Trans. Linn. Soc. xxvi. (1868 110.-China.

textoria, Blanco, Fl. Filip. ed. I. 270.-Ins. Philipp.

Thouarsii, Kunth, Not. Gen. Bambusa, $3=$ vulgaris.

trigyna, Roxb. ex Munro, in Trans. Linn. Soc. xxvi. (1868) $91=$ Tulda.

Trinii, Nees, in Linnaea, ix. (1834) $469=$ Guadua Trinii.

Tulda, Benth. Fl. Hongk. $434=$ tuldoides

Tulda, Roxb. Hort. Beng. 25 ; Fl. Ind. ii. 193.-Ind. or. ; Burma.

tuldoides, Munro, in Trans. Linn. Soc. xxvi, (1868) 93. -China.

variegata, Siebold, ex Miq. Ann. Mus. Bot. Lugd. Bat. ii. $285=$ Fortunei

vasaria, Buch.-Ham, in Wall. Cat. n. $5025=$ Balcooa. vasaria, Munro, in Trans. Linn. Soc. xxvi. (1868) 122. - Malaya.

verticillata, Benth. FI. Hongkong. $434=$ Dendro calamus latiflorus.

verticillata, Rottler, ex Munro, in Trans. Iinn. Soc. xxvi. (1868) $147=$ Dendrocalamus strictus.

verticillata, Hook. \& Arn. Bot. Beech. Voy. $254=$ Beecheyana.

verticillata, Willd. Sp. P1. ii. 245 = Gigantochloa verticillata.

villosula, Kurz, For. Fl. Brit. Burma, ii. 553.Burma.

violascens, Carr. in Rev. Hortic. (1869) $292=$ Phyllostachys violascens.

virgata, Trin. in Mém. Acad. Pétersb. Sér. VI. 1. (1835) $624=$ Guadua virgata

viridi-glaucescens, Carr. in Rev. Hortic. (1869) $292=$ nana.

viridi-striata, Regel, Ind. Sem. Hort. Petrop. (1866) 77 = striata.

vulgaris, Nees, FI. Afr. Austr. $462=$ Balcooa

vulgaris, Schrad. in Wendl. Coll. Pl. ii. 26. t. 47. -Mexic.

Wightii, Munro, in Trans. Linn. Soc. xxvi. (1868) 111.-Ind. or.

BAMIA, [Linn.] R. Br. ex Wall. Pl. Asiat. Rar. i. 39 $(1830)=$ Hibiscus, Tourn. (Malvac)

Abelmoschus, R. Br. ex Wall. Cat. n. 1915=H. Abel. moschus.

angulosa, Wall. Cat. n. $1927=\mathrm{H}$. angulosus. betulifolia, Wall, 1. c. $1918=\mathbf{H}$. Abelmoschus. cancellata, Wall. 1. c. $1920=\mathrm{H}$. cancellatus. chinensis, Wall. 1. c, $1916=\mathrm{H}$. Abelmoschus? crinita, Wall. I. c. $1922=\mathrm{H}$. cancellatus. fusiformis, Wall. 1. c. $1921=\mathrm{H}$. cancellatus. magnifica, Wall. 1. c. $1919=\mathrm{H}$. hostilis. Manihot, Wall. 1. c. $1926=$ H. Manihot. multiformis, Wall. 1. c. $1917=\mathrm{H}$. Abelmoschus. pungens, Wall. 1. c. $1924=\mathrm{H}$. pungens. rugosa, Wall. 1. c. $1923=$ H. rugosus tetraphylla, Wall. 1. c. $1925=\mathrm{H}$. tetraphyllus.

BAMMIA, Rupp. Fl. Jen. ed. Hall. $39(\mathbf{1 7 4 5})=$ praec.

BANALIA, Moq. in DC. Prod, xiii, II. 278 (1849). AMARANT ACEAE, Benth. \& Hook. f. iii. 27. brasiliana, Moq. 1. c. (=Chamissoae sp.?).-Bras. occidentalis, Moq. 1. c. $279=$ Nitrophila occidentalis thyrsiflora, Moq. l. c. 278.-Ind. or.

BANARA, Aubl. Pl. Gui. i. 547. t. 217 (1775) SAMYDACEAE, Benth. \& Hook. f. i. 798.

AscrA, Schott, in Spreng. Syst. iv. Cur. Post. 407 (1827).

BocA, Vell. Fl. Flum. 232 (1825); v. t. 113 (1827). Christannia, Presl, Rel, Haenk. ii. 91. t, 67 (1830).

Prneda, Ruiz \& Pav, Prod. 76. t. 14 (1794).

Xyladenius, Desv. in Ham. Prod. Fl. Ind. Occ. 41 (1825).

brasiliensis, Benth. in Fourn. Linn. Soc. v. (1861) Suppl. ii. 93.-Bras. 
BANARA :-

brevifolia, Blanco, F1. Filip. ed. I. $426=$ Scolopia dasyanthera.

dioica, Benth. in Fourn. Linn. Soc. v. Suppl. ii. (1861) 94 -Mexic.

domingensis, Benth. l. c.-Ins. S. Doming.

fagifolia, Vahl, Symb. Bot. iii. 65 = guianensis.

glaberrima, Wright, ex Griseb. Cat. Pl. Cub. 8.-Cuba glauca, Benth. in Journ. Linn. Soc. v. Suppl. ii. (1861) $92=$ Kuhlia glauca.

grandiflora, Spruce, ex Benth. l. c. 93.-Peruv.

guianensis, Aubl. Pl. Gui. i. 548. t. 217.-Guiana; Bras.

ibaguensis, Tul. in Ann. Sc. Nat. Sér. III, vii. (1847) 291.-N. Granat.

incana, Benth, in Fourn. Linn. Soc. v. Suppl. ii. (1861) 94.-Peruy.

iaxiflora, Benth. l. c. 91.-Peruv.

mexicana, A. Gray, in Proc. Am. Acad. v. (1861) 174. -Mexic.

mollis, Tul. in Ann. Sc. Nat. Sér. III. vii. (1847) 290 , -N. Granat.

nitida, Spruce, ex Benth. in fourn. Linn. Soc. v, (1861) Suppl. ii. 93.-Peruv.

parviflora, Benth.l.c. 91.-Bras.

pubescens, Spruce, ex Benth. l.c. 92.-Ecuador. racemosa, Blanco, Fl. Filip. ed. I. 425.-Ins. Philipp.

reticulata, Griseb. Cat. Pl. Cub. 8.-Cuba.

Roxburghii, Spreng. Syst. ii. 479 (omnino dubia).Ind. or.

tomentosa, Clos, in Ann. Sc. Nat. Sér. IV. viii. (1857) 240.-Bras.

ulmifolia, Benth. in Journ. Linn. Soc. v. Suppl.

ii. (1861) $91=$ Kublia ulmifolia.

Vellozii, Gardn. in Hook. Lond. Fourn. Bot. ii. (1843) 331.-Bras.

BANCROFFTIA, Steud. Nom. ed. II. i. $183(1840)$, $=$ seq.

BANCROFTIA, Billb, in Linneska Samfund. Handl. i. 1832 (1833) 39= Arracacia, Bancr. (Umbell.). moschata, Billb. 1. $\mathrm{c}_{\mathrm{s}}=\mathrm{A}$, moschata. xanthorrhisa, Billb. 1. c.=A. xanthorrhiza.

BANCROFTIA, Macfad, Fl. Jamaic, i. 112 (1837) = Tovaria, Ruiz \& Pav. (Capparid.).

diffusa, Mactad. $1, c_{0}=\mathrm{T}$. pendula.

BANDEIRAFA, Welw. ex Benth. \& Hook. f. Gen. i. 577 (1865). LEGUMINOSAE, Benth. \& Hook. f. 1. c. simplicifolia, Benth. in Trans. Linn. Soc. xxv. (1866) 306 , in nota.-Afr. trop.

speciosa, Welw. ex Benth. l. c. 306. t. 40.-Afr. trop.

tenuiftora, Benth. l.c.307.-Afr. trop.

BANDEREIA, Baill. Hist. Pl. ii. $120(1870)=$ Ban deiraea, Welw. (Legum.).

BANDURA, Burm. Thes. Zeyl. 42. t. 17. (1737) = Nepenthes, Linn.

BANFFYA, Baumg. Enum. Stirp. Transs. i. 385 (1816)= Gypsophila, Linn. (Caryophyll.).

petraea, Baumg. 1. c. $=\mathrm{G}$. transsylvanica.

BANGLIUM, Buch.-Ham. ex Wall. Cat. sub n. 6579 $(\mathbf{1 8 8 2})=$ Alpinia, Linn. (Scitam.).

sulphureum, Buch.-Ham. 1.c. = A. Hamiltoniana.

BANIA, Becc. Malesia, i. (1877) 162, MENISPER$M A C E A E$.

thyrsiflora, Becc. l. c.-N. Guinea.

BANISTERIA, Linn. Syst. ed. II. 23 (1740), MALPI GHIACEAE, Benth. \& Hook. f. i. 257.

Anomalopteris, G. Don, Gen. Syst. i. 647 (1831). Holopetalon, Reichb. Nom. 207 (1841).

acanthocarpa, A. Guss. in Arch. Mus. Par. iii. (1843) 394.-Am. austr.

aculeata, Mill. Gard. Dict, ed. VIII. n. 6.-Mexic,

adamantium, Mart. ex A. Juss. in Arch. Mus. Par. iii. (1843) 406. - Bras.

adenopoda, A. Fuss. in St. Hil. Fl. Bras. Mer. iii. 40. -liras.

\section{BANISTERIA}

albicana, Griseb. in Kjoeb. Vidensk. Meddel. (1875) 131.-Bras.

albida, Willd, ex Steud. Nom. ed. II. i, $183=$ Gaudi chaudia albida.

allophila, Sieber, ex A. Juss. in Arch. Mus. Par. iii (1843) $356=$ Brachypterys borealis.

amoena, Mart. ex A. Juss. 1. c. $571=$ Hiraea Gaudi chaudiana.

angulata, Vell, Fl. Flum.191; iv. t. $160=$ Stigma phyllon affine.

angulosa, Linn. Sp. Pl. $427=$ Stigmaphyllon angu losum.

angustifolia, A. Fuss. in St. Hil. Fl. Bras. Mer. zii. 38 -Bras.

anisandra, Griseb, in Linnaea, xiii. (1839) $190=$ Clausseniana.

anisandra, A. Fuss. in St. Hil. Fl. Bras. Mer. ii. 47 -Bras.

antifebrilis, Ruiz, ex Griseb. in Einnaea, xxii. (1849) 15.--Peruv.

appendiculata, A. Fuss. in Arch. Mus. Par. iii. (1843) 413.-Ins. S. Vincent.

appendiculata, Lamb. ex DC. Prod. i. 592=Hetero pteris appendiculata.

argentea, Spreng. ex A. Fuss. in Arch. Mus. Par. iij (1843) 393.-Am. austr.

argyrophylla, A. Fuss, in St. Hil. Fl. Bras. Mer. iii. 45.-Bras.

atrosanguinea, A. Fuss. in Arch. Mus. Par. iii. (1843) 389.-Bolivia.

aurea, Vell. Fl. Flum. 192 ; iv. t. 167= Gardneriana. auriculata, Cav. Diss. ix. 428. t. $255=$ Stigmaphyllon auriculatum.

benghalensis, Linn. Sp. P1. $427=$ Hiptage Madablota.

Benthamiana, A. Fuss. in Arch. Mus. Par. iii. (1843) 390.--Peruy.

bicolor, Poepp. ex A. Fuss. l. c. 393.-N. Granat.

Billbergiana, Beurling, in Vet. Akad. Handl. Stockh. (1854) 118.-Panama.

Blanchetiana, A. Fuss. in Arch. Mus. Par. iii. (1843) 420.-Am, austr.

bogotensis, Bonpl. ex Triana \& Planeh. Prod. Fl. N Granat. 1. $318=$ Stigmaphyllon bogotense.

bonariensis, Hook. E Arn. in Hook. Bot. Misc, iii (1833) 157.-Reg. Argent.

brachiata, Linn. Sp. Pl. $428=$ Heteropteris brachiata

brachiata, Spreng. Syst. ii. $387=$ Heteropteris platy ptera.

brachiata, Willd. ex A. Juss. in Arch. Mus. Par. iii. (1843) $356=$ Brachypterys borealis

brachyptera, DC. Prod. i. $591=$ Brachypterys borealis. bracteata, DC. I. c. $590=$ Tetrapteris inaequalis

brevipes, Sesse, ex DC. Prod. i. 591=Gandichaudia brevipes.

Caapi, Spruce, ex Griseb. in Mart. Fl. Bras. xii. III. 43.--Bras.

caerulea, Lam. Encyc. i. $367=$ Heteropteris caerulea. Calcitrapa, Desv. in Ham. Prod. Fl. Ind. Occ. $40=$ Brachypterys borealis.

calocarpa, Miq. in Linnaea, xviii. (1844) 53.Guiana.

campestris, A. Fuss. in St. Hil. Fl. Bras. Mer. iii. 36. -Bras.

chrysophylla, Lam. Encyc. i. 368= Heteropteris chrysophylla.

ciliata, Lam. 1. c. $369=$ Stigmaphyllon ciliatum.

cinerascens, Griseb. in Linnaea, xxii. (1849) 18.Guiana.

Clausseniana, A. Fuss. in Arch. Mus. Par. iii. (1843) 422.-Bras.

coccinea, Vell. Fl. Flum, 191, iv, t. 161.-Bras

comans, Mart. ex A. Juss, in Arch. Mus. Par. iii. (1843) $406=$ stellaris

constricta, Griseb. in Mart. Fl. Bras. xii. IIr. 46.-Bras convolvulifolia, Cav. Diss. ix. 428 .t. $256=$ Stigma phyllon convolvulifolium.

cordata, Vell. Fl. Flum, 191 ; iv, t. $163=$ rotnndifolia

cordistipula, Mart. Herb. Fl. Bras. $556=$ Peixotoa cordistipula.

coriacea, G.Don, ex Griseb. in Mart. Fl. Bras, xii. III 94.-Bras.

cornifolia, Spreng, Syst. ii. 388.-N. Granat.

corymbosa, Griseb. in Mart. Fl. Bras! xii. III. 42, in nota.-13ras.

corymbosa, Griseb. in Linnaen, xxii, (1849) $18=$ cinerascens.

cristata, Griseb, f, co 16-Guiana.
BANISTERIA :-

crotonifolia, A. Fuss. in St. Hil. Fl. Bras, Mer, iii. 36. -Bras.

cujabensis, Griseb. in Linnaea, xiii. (1839) $194=$ Hiraea cujabensis.

deformis, Desv. in Ham. Prod. F1. Ind. Occ. $40=$ Stigmaphyllon angulosum.

dichotoma, Linn. Sp. P1. $427=$ Stigmaphyllon rotundifolium.

dichotoma, DC. Prod. i. $588=$ Stigmaphyllon con $=$ volvulifolium.

divaricata, A. Fuss. in Arch. Mus. Par.iii. (1843) 412. -Guiana.

diversifolia, Bert. ex DC. Prod, i. $588=$ variifolia.

diversifolia, H. B. E K. Nov. Gen. et Sp. v. 159.Cuba.

eglandulata, Vell. Fl.Flum. 190 ; iv. t. $155=$ Tetrapteris crebriflora.

eglandulosa, DC. Prod. i. 590 - Heteropteris suberosa.

eglandulosa, A. Fuss. in Arch. Mus. Par. iii. (1843) 410.-Bras.

elegans, Planch. Eo Triana, in Ann. Sc. Nat. Sér. IV. xviii. (1862) 322.-N. Granat.

elliptica, H. B. \& K. Nov. Gen. et Sp. v. $161=$ Stigmaphyllon ellipticum

emarginata, Cav. Diss. ix. 425. t. 249.-Am. austr.

erianthera, A. Fuss. in Arch. Mus, Par. iii. (1843) 411.-Bras.

fagifolia, DC. Prod. i. $590=$ Hiraea fagifolia.

ferruginea, Cav. Diss. ix. 424. t. 248.-Bras.; Guian,

ferruginea, Seem. Bot. Voy. Herald, 92 partim $=$ Tetrapteris Seemanni.

fimbriata, Vell. Fl. Flum. 192 ; iv. t. 165.-Bras,

fimbriata, Griseb. in Linnaea, xiii. (1839) $191=$ nigrescens.

Fischeriana, Regel E Koern. Ind. Sem. Hort. Petrop. 1858) 48.-Caba.

floribunda, DC. Prod. i. 589.-Bras

fruticosa, Vell. Fl. Flum. 192; iv. t. 164 $=$ Heteropteris umbellata.

fulgens, DC. Prod. i. 590=Stigmaphyllon puberam.

fulgens, G. F. W. Mey. Prim. Fl. Esseq. $181=$ ferruginea.

fulgens, Linn. Sp. Pl. 427.-Ins. Guadalup.

fulgens, Lam. Encyc. i. $368=$ Stigmaphyllon fulgens.

Gardneriana, A. Fuss. in Arch. Mus. Par. jii. (1843) 420.-Bras.

glandulosa, Pav. ex A. Juss.1. c. $478=$ Heteropteris rabiginosa.

glauca, Desf. Cat. Hort. Par, ed. III. $406=$ Stigma. phyllon ciliatum.

glaucophylla, Mart. ex A. Juss, in Arch. Mus. Par. iii (1843) $319=$ Verrucularia glaucophylla

grata, Griseb. in Mart. Fl. Bras. xii. IIx. 49.-Bras,

heterophylla, Willd. Sp. Pl. ii. $742=$ Stigmaphyllon fulgens.

heterostyla, A. Fuss. in Arch, Mus. Par. iii. (1843) 408.-N. Granat.

hexandra, Vell. Fl. Flum. 188 ; iv. t. $149=$ Schwannia elegans.

Humboldtiana, DC. Prod. i. 588=Stigmaphyllon Humbold tianum.

hypericifolia, A. Fuss. in St. Hil. Ft. Bres. Mer. iii. 42.-Bras.

intermedia, A. Juss, in Arch. Mus, Par. iii. (1843) $404=$ stellaris.

jasminellum, A. Fuss. l. c. 409.-N. Granat,

Kraussiana, Hochst. in Flora, xxvii. (1814) I. 296.Afr. austr.

laevifolia, A. Fuss, in St. Hil. Fl. Bras. Mer. iii. 38. -Bras.

lancifolia, West, ex Schlecht. in Linnaea, iv. (15:2) 81 - Heteropteris laurifolia

latifolia, A. Guss. in St. Hil. F. Bras. Mer. iii. 10 Bras.

laurifolia, Linn. Sp. Pl. ed. II. $611=$ Heteropteris Inurifolia.

laurifolia, Rich, ex A. Juss, in Arch. Mus, Par, iii, (1843) 850 - Stigmaphyllon periplocifolium.

laurifolia, Sieber, ex A. Juss, 1. Co $294=$ Bỹrsonima spicata.

ledifolia, H. B. E K. Nov. Gen. et Sp. v. 159.Cuba.

leiocarpa, A. Fruss, in Arch. Vus. Par. ii.. 11543895. -Peruv.

leonn, Cav. Diss. ix. $12 f$ (sp. lubin).-Afr. trop.

leptocarpa, Benth. in Hook. Losd. Gourn. Bot. vii, 1845) 130 - Guiana. 


\section{BANISTERIA :-}

lobulata, E. Mey. in Nov. Act. Nat. Cur. xii. II. (1825) 813.-Guiana.

longifolia, Sw. Prod. Veg. Ind. Occ. $75=$ Heteropteris platyptera.

lucida, Rich. in Act. Soc. Hist. Nat. Par. i. (1792) 109.-Guiana.

lupuloides, Linn. Sp. Pl. $427=$ Gouania domingensis.

lutea, Ruiz, ex Griseb. in Linnaea, xxii. (1849) 15. Peruv.

macradena, DC. Prod. i. 590.-Guiana

macrocarpa, Pers. Syn. i. $507=$ Heteropteris platyptera.

macrophylla, A. Fuss. in Arch. Mus. Par. iii. (1843) 418.--Bras,

macrostachia, Vell. Fl. Flum. 189 ; iv.t. $152=$ Clausseniana.

magnoliaefolia, Desv. ex Ham. Prod. F1. Ind. Occ. 40 = Heteropteris platyptera.

maracabensis, A. Juss. in Arch. Mus, Par. iii. (1843) 418 = comifolia.

maritima, Rich. in Act. Soc. Hist. Nat. Par. i. (1792) $109=$ Brachypterys borealis.

Martiniana, A. Fuss. in Arch. Mus. Par. ii. (1843) 413 -Guiana.

mediterranea, Vell. Fl. Flum. 191 ; iv. t. 162=Janusia muricata.

meoacarpos, Vell. 1. c. 189 ; iv. t. $189=$ Stigmaphyllon tomentosum.

megaphylla, A. Fuss. in Arch. Mus. Par. iii. (1843) 399.-Bras.

membranifolia, A. Fuss, in St. Hil. Fl. Bras. Mer. iii. 39.--Bras.

metallicolor, $A$. Fuss. $l$. $c .46$-Bras

microphylla, facq. Obs. iii. 7. t. 56-Carolin

Minarum, Mart. ex A. Juss, in Arch. Mus, Par, iii (1843) $403=$ schizoptera

monoptera, Vell. Fl. Flum. 189 ; iv. t. $153=$ Heteropteris chrysophylla.

montana, A. Juss, in St. Hil. Fl. Bras. Mer. iii. $3 \bar{\gamma}=$ campestris.

mucronata, DC. Prod. i. $589=$ Stigmaphyllon "ellipticum.

multialata, Vell. Fl. Flum. 189; iv. t. $154=$ Tetrapteris punctulata.

multiflora, Boj. ex A. Juss. in Arch. Mus. Par, iii 1843) $424=$ Sphedamnocarpus madagascariensis

multiflora, DC. Prod. i. $589=$ Heteropteris platyptera

multifoliolata, A. Fuss, in Arch. Mus. Par. iii. (1843) 402.-Bras.

muricata, Cav. Diss. ix. 423. t. 243. f. 2.-Peruv.

mutabilis, Vell. Fl. Flum. 193 ; iv. t. $168=$ Thryallis

brachystachys.

nigrescens, A. Fuss. in St. Hil. Fl. Bras. Mer. iii. 44 -Bras.

nitens, Griseb. in Linnaea, xiii. (1839) $198=$ argyrophylla.

nitida, Vell. F1. Flum. 188; iv. t, $148=$ Stigmaphyllon ciliatum

nitida, Lam, Encyc. i. $369=$ Heteropteris nitida

nitrosiodora, Griseb. in Goett. Abh. xxiv. (1879) 65.Reg. Argent.

nummifera, A. Fuss. in Arch. Mus. Par. iii. (1843) 391_-Bras.

ochnaefolia, Mart. ex A. Juss. 1. c. $464=$ Heteropteris byrsonimaefolia.

orinoccensis, H.B. E K. Nov. Gen. et Sp. v. 162.Venezuela.

ovata; Cav. Diss. ix. 429. t. 257. f. 1 =Brachypterys borealis.

oxyclada, A. Fuss. in Arch. Mus. Par. iii. (1843) 396. -Bras.

Pagua, Steud. Nom. ed. II. i. $184=$ Heteropteris syringaefolia.

palmata, Cav. Diss. ix. 430. t. 257. f. 2.-Am, austr

paniculata, DC. Prod. i. 591=Heteropteris Bee-

parvifora, A. Fuss. in Arch. Mus. Par. iii. (1843) 416. -Bras.

parvifolia, Vent. Choix, $51=$ Heteropteris parvifolia. patens, Griseb. in Linnaea, xiri. (1839) $200=$ Heteropteris patens.

pauciflora, $H . B . \& K$. Nov. Gen. et $S p$. v. 159.Cuba.

periplocaefolia, Desf. Tabl. ed. II. $160=$ Stigmaphyllon retusum.

picta, H. B. \& K. Nov. Gen. et Sp. v, $160=$ Brachypterys borealis.

\section{BANISTERIA :-}

platyptera, Griseb. in Linnaea, xxii. (1849) 17.Venezuela.

podadena, Turcz. in Bull. Soc. Nat. Mosc. (1858) I. 392.-Cuba

polita, Miq. in Verh. Nat. Wet. Haarl. vii. (1851) 80 t. 21. - Guiana.

praecox, Griseb. in Kjoeb. Vidensk. Meddel. (1875) 133.-Bras.

Pragua, Vell. Fl. Flum. 190 ; iv. t. 138=Heteropteris syringaefolia.

pruinosa, Mart. ex A. Fuss. in Arch. Mus. Par. iii. 1843) 392.--Bras.

pubera, Rich. in Act. Soc. Hist. Nat. Par. i. (1792) $109=$ Stigmaphyllon puberum.

pubiflora, DC. Prod. i. $591=$ Heteropteris laurifolia.

pubipetala, A. Fuss. in St. Hil. Fl. Bras. Mer. iii. 41 t. 169.-Bras

purpurea, Linn. Sp. Pl, $427=$ Heteropteris purpurea

Quapara, Aubl. Pl. Gui. i. 464. t. 186.-Guiana

Riedeliana, Regel, Ind. Sem. Hort. Petrop. (1855) 17 - Cuba.

rigida, A. Fuss. in Arch. Mus. Par. iii. (1843) 416.Bras.

sagittata, Cav. Diss. ix. 430. t. 257.-Ins. S. Doming.

salicifolia, DC. Prod. i. 590,-Bras.

schizoptera, A. Fuss, in St. Hil. Fl. Bras. Mer. iii. 43. -Bras.

Schlimii, Turcz. in Bull. Soc. Nat. Mosc. xxxvi. (1863) I. $584,-\mathrm{N}$. Granat.

Schomburgkiana, Benth. in Hook. Lond. Fourn. Bot. vii. (1848) 129.-Guiana.

schwannioides, Griseb. in Mart. Fl. Bras. xii. III. 54 -Bras.

scutellata, Griseb. in Kjoeb. Vidensk. Meddel. (1875) 131.-Bras.

Sellowiana, A. Fuss. in Arch. Mus. Par. ili. (1843) 419.-Bras.

sepium, Mart. ex A. Fuss. l.c. 414.-Bras,

sericea, Cav. Diss. ix. 429. t. $258=$ Heteropteris sericea ericea, Dombey, ex A. Juss, in Arch Mus. Par ii. (1843) 394 = acanthocarpa.

sinemariensis, Aubl. PI. Gui. i. 462. t. $185=$ Stigma phyllon puberum.

sinuata, DC. Prod. i. 588.-Guiana.

solitaria, Vell. Fl. Flum. 189 ; iv。 t. $151=$ Hiraea Salz manniana.

Spixiana, Mart. ex A. Juss. in Arch. Mus. Par. iii. (1843) $561=$ Heteropteris suberosa

splendens, DC. Prod. i. $588=$ Stigmaphyllon fulgens.

Spruceana, Griseb. in Mart. Fl. Bras, xii. III. 45. Bras.

stellaris, Griseb, in Linnaea, xiii. (1839) 192--Bras.

subcordata, Gardn. in Hook. Lond. Journ. Bot. ii (1843) $336=$ adenopoda.

suberosa, Willd. ex. Steud. Nom, ed. II. i. 184= Heteropteris suberosa.

temuis, Lindl, in Bot. Reg. (1838) Misc. $72=$ Heteropteris umbellata.

terminalis, Vell. Fl. Flum. 192; iv, t, 166_-Bras

ternata, Vell. l. c. 190 ; iv. t. $159=$ trifoliata.

ternata, Sesse, ex DC. Prod. i. 591=Stigmaphyllon ellipticum.

tetraptera, Sonner. Voy. Indes, iii. $270=$ Hiptage Madablota.

thyrsoidea, Griseb. in Linnaea, xiii. (1839) $199=$ Heteropteris thyrsoidea.

tiliaefolia, H. B. \& K. Nov. Gen. et Sp.v. $162=$ Stigmaphyllon Humboldtianum.

tiliaefolia, Vent. Choix, 50. t. 50.-Tava

timoriensis, DC Prod. i. 588.-Ins. Timor

tomentosa, Desf. Tabl. ed. II. 160= emarginata.

tomentosa, Salzm. ex A. Juss. in Arch. Mus. Par. iii. (1843) $383=$ Stigmaphyllon rotundifolium.

tomentosa, Schlecht. in Linnaea, $\mathrm{x}$. (1833) $244=$ Heteropteris Beecheyana.

triflora, Vell. Fl. Flum. 190; iv, t. $156=$ crotonifolia. trifoliata, Steud. Nom. ed. II. i. 184.-Bras.

tristellocarpa, Boj. ex A. Juss. in Arch. Mus. Par. ii (1843) $498=$ Tristellateia Bojeriana

umbellata, Sieber, ex A. Juss. 1. c. $356=$ Brachypterys borealis.

umbellulata, DC. Prod. i. 588.-Ins. S, Doming

umbellulata, Sieber, ex A. Juss. in Arch. Mus. Par. iii. (1843) $42=$ Byrsonima trinitensis.

unialata, Vell. F1. Flum. 190 ; iv. t. $157=$ B. ferruginea.

unicapsularis, Lam. Encyc, i. 367= Hiptage Madablota.

\section{BANISTERIA :-}

varia, Spreng. Syst. ii. $386=$ variifolia.

variifolia, DC. Prod. i. 588.-N. Granat.

velutina, A. Juss. in Arch. Mus. Par. iii. (1843) $401=$ crotonifolia

vernoniaefolia, Mart. ex A. Fuss. l. c. 398--Bras

verruculosa, Sw. Ann. Bot. Posth. 31.-Ind, occ.

virgultosa, Mart. ex A. Juss. in Arch. Mus. Par. iii,

(1843) $414=$ pubipetala.

vitifolia, Sesse, ex DC. Prod. i. 588=variifolia

volubilis, Endl. ex Heynh. Nom. ii. $59=$ Hiraea Sim siana.

zanzibarica, Boj. ex Steud. Nom. ed. II. i. $184=$ Acridocarpus zanzibaricus.

BANIUM, Ces, ex Boiss, Fl. Orient, ii. $882(\mathbf{1 8 7 2})=$ Carum, Linn. (Umbell.).

ligusticifolium, Ces. ex Boiss. 1. c. = C. multiflorum.

BANJOLEA, Bowdich, Madeira, 258 ACANTHACEAE? (Genus omnino dub.)

$(1825)$ violacea, Bowdich, l. c.-Madera.

BANKESIA, Bruce, Trav. ed. II. vii. 181 (1805)= Brayera, Kunth (Rosac.).

BANKSEA, Koen。 in Retz. Obs, iii. 75 (1783)=Costus, Linn. (Scitamin.).

speciosa, Koen. 1. c. = C. speciosus.

BANKSIA, Bruce, Trav. ed. II. vii. tt. $22,23=$ Brayera, Kunth (Rosac.).

abyssinica, 'Bruce', ex Steud. Nom. ed. II. i. $184=$ Brayera anthelmintica.

BANKSIA, Domb. ex DC. Prod. iii. 83 (1828)= Cuphea, P. Br. (Lythrar)

ciliata, Domb. ex DC. 1. c. $88=$ C. microphylla

glutinosa, Domb. ex DC. 1. c $=$ C cordata

BANKSIA, Forst. Char. Gen. 7.t. $4(1776)=$ Pimelea Banks (Thymel.).

Gnidia, Forst. 1. c. $8=$ P. Gnidia.

pilosa, Forst. f. in Nov. Act. Upsal. iii. (1780) $174=\mathrm{P}$ pilosa.

prostrata, Forst. Char. Gen. $8=$ P. prostrata

tomentosa, Forst. 1. $\mathrm{c} .=\mathrm{P}$. pilosa.

BANKSIA, Linn. f. Suppl. 15, 126 (1781). PROTEA$C E A E$, Benth. \& Hook. f. iii. 184

Isostylis, R. Br。 ex Steud. Nom. ed. II. i. 829 (1840).

aemula, $R$. Br. in Trans. Linn. Soc. x. (1811) 209.Austral.

aemula, Sieber, ex Meissn. in DC. Prod. xiv. $461=$ serrata.

aquifolia, Lindl. Swan Riv. App. $34=$ ilicifolia.

asplenifolia, Salisb. Prod. $51=$ integrifolia.

asplenifolia, Knight, Prot. $113=$ marcescens.

attenuata, R. Br. in Trans. Linn. Soc. x. (1811) 209 -Austral.

australis, R. Br. 1. c. $205=$ marginata.

barbigera, Meissn, in Lehm. Pl. Preiss. ii. $264=$ Goodii.

Baueri, R. Br. Prot. Nov. 35.-Austral.

Baxteri, R. Br. l.c. 36-Austral.

blechnifolia, F. Muell. Fragm, iv. $108=$ repens.

Brownii, Baxter, ex R. Br. Prot. Nov. 37.-Austral.

Caleyi, R. Br. i. c. 35.-Austral.

Candolleana, Meissn. in Hook. Kew Fourn. vii. (1855)

118. - Austral.

coccinea, R. Br. in Trans. Linn. Soc. x. (1811) 207.Austral.

collina, R. Br. l. c. 204.-Austral.

compar, R. Br. 1. c. $207=$ integrifolia

conchifera, Gaertn. Fruct, i. 221, t. $48=$ serrata.

cuneifolia, Hoffm. in Roem. \& Schult. Syst. iii. Mant. $379=$ integrifolia.

cuneifolia, Wendl. f. ex Hoffmgg. Verz. Pf. Nachtr. ii. 64.-Austral.

Cunninghamii, Sieber, in Spreng. Syst. iv. Cur. Post. $47=$ collina.

cylindrostachya, Lindl. Swan Riv. App. $34=$ attenuata. dactyloides, Gaertn. Fruct, i. 221. t. 47. f, $2=$ Hakea dactyloides.

dentata, Linn. f. Suppl. 127.-Austral.

dentata, Wendl. Hort. Herrenh. t. $8=$ serrata.

denticulata, Dum.-Cours. Bot. Cult. ed. II. vii. 108 spinulosa. 


\section{BANKSIA :}

depressa, R. Br. in Trans. Linn. Soc. x. (1811) $205=$ marginata.

dilleniaefolia, Knight, Prot. $113=$ latifolia

dryandroides, Baxter, in Sweet, Fl. Austral. t. 56.Austral.

elatior, R. Br. in Trans. Linn. Soc. x. (1811) $209=$ aemula.

elegans, Meissn. in Hook. Kew Fourn. vii. (1855) 119. -Austral.

ericaefolia, Linn.f. Suppl. 127.-Austral.

fagifolia, Hoffm. ex Roem. \& Schult. Syst. iii. Mant. $379=$ latifolin

ferrea, Vent. ex Spreng. Syst. i. $485=$ marginata

gibbosa, Sm, in White, Voy. 224, t. 22. f. $2=$ Hakea gibbosa.

glauca, Cav, in Anal. Hist. Nat. i. (1799) $230=$ integrifolia.

Goodii, $R$, Br. Prot, Nov, 36-Anstral.

grandidentata, Dum.Cours. Bot. Cult. ed. II. vii. 108 = speciosa.

grandis, Willd.Sp. Pl. i. 535.-Austral.

Guentheri, Regel, Ind. Sem. Hort. Petrop. (1857) 37 ; Gartenf. (1858) 50.-Austral.

Gunnii, Meissn. in Hook. Kew Joum. iv. (1852) 210 = marginata.

heterophylla, Hort, ex Meissn. in DC. Prod. xiv. $466=$ Hakea suaveolens.

Hookeri, Drumm. in Comp. Bot. Mag. (1848) $1=$ Solandri.

Hookeriana, Meissn. in Hook. Kew Fourn. vii. (1855) 119.-Austral.

Huegelii, R. Br. ex Endl. Gen. Suppl. iv. II. 89.Austral.

hypoleuca,Hoffmgg. Verz. Pf.Nachtr.ii. $66=$ marginata. ilicifolia, R. Br. in Trans. Linn. Soc, x. (1811) 211.Austral.?

insularis, R.Br.l.c. $206=$ marginata

integerrima, Dum-Cours. Bot. Cult. ed. II. ii. 421 ; vii 108.-Anstral.?

integrifolia, Labill. ex Meissn. in DC. Prod. xiv. 456 $=$ marginata.

integrifolia, Linn. f. Suppl. 127.-Austral.

integrifolia, Schlecht. in Linnaea, xx. (1847) $584=$ australis.

laevigata, Meissn. in Hook. Kew fourn. iv. (1852) 210 - - Austral.

latifolia, R. Br. in Trans. Linn. Soc. x. (1811) 208.Austral.

ledifolia, A. Cunn. ex Meissn. in DC. Prod, xiv. $454=$ Cunninghamii.

Lemanniana, Meissn: in Hook. Kew Fourn. iv. (1852) 210.-Austral.

Lindleyana, Meissn. l. c. vii. (1855) 120.-Austral.

littoralis, Lindl, in Bot. Reg, t. 1363=collina.

littoralis, R: Br. in Trans. Linn. Soc. x. (1811) 204.Austral,

longifolia, D. Dietr. Syn. i. $538=$ latifolia.

longifolia, Hort. ex Steud. Nom. ed. II. i. $184=$ oblongifolia.

longifolia, Don, ex F. G. Dietr. Vollst. Gaertn. Lexik. ii. $150=$ serrata.

macrophylla, Link, Enum. Hort. Berol. i. $116=$ integri folia.

marcescens, Bonpl. Jard. Malm. 116. t. $48=$ marginata marcescens, Hook. Bot. Mag. t. 2808 = australis.

marcescens, R. Br. in Trans. Linn. Soc. x. (1811) 208. - Austral.

marginata, Cav. in Anal. Hist. Nat. i. (1799) 227.Austral.

marginata, R. Br. in Trans. Linn. Soc. x. (1811) 204. -Austral.

media, Hook, f. F1. Tasm, i. $329=$ serrata.

media, R. Br. Prot. Nov, 35,-Austral.

Meissneri, Lehm. Pl. Preiss. i. 582.-Austral

Menziesii, R. Br. Prot. Nov. 36.-Austral.

microstachya, Cav, in Anal. Hist. Nat. i. (1799) $224=$ marginata.

mimosoides, Hort. Cantabr. ex F. G. Dietr. Vollst. Gaertn. Lexik. ii. 150.-Austral.

mitis, Knight, Prot. 112 = serrata.

musculiformis, Gaertn. Fruct. i. 221.-Austral.

nivea, Labill. Voy. i. 411. t. $24=$ Dryandra nivea

nutans, $R$. Br. in Trans. Linn. Soc. x. (1811) 203.Austral.

oblongifolia, Cav. Anal. Hist. Nat. i. (1799) 225.Austral.

oblongifolia, Lodd. Bot. Cab. t. $211=$ marginata.

\section{BANKSIA :-}

ccidentalis, $R, B r$ in Trans finn Soc. $\times$, (1811) 204.-Austral.

oleaefolia, Cav. in Anal. Hist. Nat. i. (1799) 228. t. $\mathbf{1 4}=$ integrifolia

oleaefolia, Salisb. Prod. $51=$ Hakea dactyloicles ornata, F. Muell. ex Meissn. in Linnaea, xxvi. (185355) 352.-Austral.

paludosa, R. Br. in Trans. Linn. Soc。 x. (1811) $207=$ integrifolia.

patula, R. Br. 1. c. $205=$ marginata

petiolaris, F. Muell. Fragm. iv, 109.-Austral

phylicaefolia, Salisb. Prod. $51=$ ericaefolia.

pinifolia, Meissn. in Hook. Kew Journ. vii. (1855) 118 = sphaerocarpa.

pinifolia, Salisb. Prod. $51=$ Hakea gibbosa

pinnata, Hort. Cels, ex Roem. \& Schult. Syst. iii. 444 $=$ Hakea pinnata.

pinnatisecta, F. Muell. Fragm. vii. $58=$ repens.

polypodiifolia, Knight, Prot. $113=$ repens.

praemorsa, Andr. Bot. Rep. t. $258=$ marcescens.

praemorsa, Hort. ex Dum.-Cours. Bot. Cult. vii. ed. II. $107=$ marginata

prionophylla, F. Muell. 1st Gen. Rep. $17=$ collina

prionotes, Lindl. Swan River App. 34.-Austral.

procumbens, Hort. ex Dum.-Cours. Bot. Cult。 ed. Is vii. $107=$ dentata.

prostrata, R. Br. Prot. Nov. 36.-Austral.

pubescens, Donn, ex Roem. EN Schult. Syst. iii. 444.Austral.

pulchella, R. Br. in Trans. Linn. Soc. x. (1811) 202.Austral.

pyriformis, Gaertn. Fruct. i. 220. t. 47=Xylomelum pyriforme.

quercifolia, R. Br. in Trans. Linn. Soc. x. (1811) 210 -Austral.

repens, Labill. Voy. i. 412. t. 23.-Austral.

reticulata, Hoffm, in Roem. \& Schult. Syst. Mant. iii. $379=$ integrifolia

reticnlata, Wendl. f. ex Hoffmgg. Verz. Pfl. Nachtr. ii. 67.-Austral.

Robur, Cav. in Anal. Hist. Nat. i. (1799) $226=$ latifolia salicifolia, Cav. 1. c. $230=$ integrifolia

Sceptrum, Meissn. in Hook. Kew fourn. vii. (1855) 120-Austral.

serraefolia, Knight, Prot. 112 =aemula.

serrata, Linn.f. Suppl. 126.-Austral.

serrata, Cav. Ic. vi. 27. t. $540=$ aemula.

serratifolia, Salisb. Prod. $51=$ aemula.

Solandri, R. Br. Prot. Nov. 36.-Austral.

speciosa, Lindl. in Bot. Reg. t. $1728=$ Victoriae.

speciosa, R. Br. in Trans. Linn. Soc, x. (1811) 210.Austral.

sphaerocarpa, R. Br. l. c. 203.-Austral.

spicata, Gaertn. Fruct. i. 221. t. $48=$ integrifolia.

spinulosa, Sm. New Holl. Pl. i. 13. t. 4.-Austral.

tenuifolia, Salisb. Prod. $50=$ Hakea acicularis.

teretifolia, Salisb. 1. c. $51=$ Hakea pugioniformis.

omentosa, F. Muell. in Hook. Kew Fourn. vii (1856) 327.-Austral.

tomentosa, Hort. ex Meissn. in DC. Prod. xiv. $454=$ littoralis.

tricuspis, Meissn. in Hook. Kew Fourn. vii. (1855) 118 . - Austral.

tridentata, Meissn. l. c. 120.-Austral.

uncigera, Knight, Prot. $112=$ latifolia

undulata, Lindl. in Bot. Reg. t. 1316=serrata.

verticillata, $R$. Br. in Trans. Linn. Soc. x. (1811) 207. -Austral.

Victoriae, Meissn. in Hook. Kew fourn. vii. (1855) 119.-Austral.

BANNISTERIA, Linn. Gen. ed. I. $377(\mathbf{1} 737)=$ Bani steria, Linn. (Malpig.).

BANNISTERIOIDES, Linn. Fl, Zeyl, $192(1747)=$ Pella, Gaertn. (Inc, sed.).

BAOBAB, Mill. Gard. Dict. ed. VI. $175(1752)=$ Adan sonia, Linn. (Malvac.).

BAPHIA, Afzel, ex Lodd. Bot. Cab. t. 367 1825 LEGUMINOSAE, Benth. \& Hook. f. i. 553 Bracteolaria, Hochst. in Flom, xxiv. (18.11) it 698.

Carporonra, G. Don, Gen. Syst i. 370 (1831)

Delarla, Desvo in Añ. Sc. Nat. Sér, 1. ix. $\left.1820^{\circ}\right)$ 406.

\section{BAPHIA}

angolensis, Welw, ex Baker, in Oliver, Fl. Trop. Afr. ii. 249,-Afr. trop.

haematoxylon, Hochst. ex Hook. Niger Fl. $321=$ nitida.

Heudelotiana, Baill. Adansonia, vi. (1866) 216.Afr. trop.

Kirkii, Baker, in Oliver, Fl. Trop. Afr, ii, 250 Afr. trop.

laurifolia, Baill. Adansonia, vi. (1866) $213=$ pubescens.

leptostemma, Baill. 1. c. $214=$ nitida.

maxima, Baker, in Oliver, Fl. Trop. Afr. ii. 250.Afr, trop.

nitida, Lodd. Bot. Cab. t. 367.-Afr trop.

pilosa, Baill. Adansonia, vi. (1866) 216.-Afr. trop.

polygalacea, Baker, in Oliver, Fl. Trop. Afr. ii. 248.Afr. trop.

pubescens, Hook. f. in Hook. Niger Fl. 320.-Aft trop.

pyrifolia, Baill. in Bull. Soc, Linn. Par. i. (1885) $445=$ polygalacea.

tacemosa, Hochst. in Flora, xxiv. (1841) 11. 638.Afr. trop.

spathacea, Hook.f. in Hook. Niger Fl. 320.-Afr. trop.

BAPHIOPSIS, Benth. ex Baker, in Oliver, Fl. Trop. Afr. ii. 256 (1871), LEGUMINOSAE

parviflora, Benth. ex Baker, l. c.-Afr. trop.

BAPHORHIZA, Link, Handb, i. $578(1829)=$ Alkanna Tausch (Borag.).

tinctoria, Link, l. c. $=$ A. tinctoria

BAPTISIA, Vent. Dec. Gen. Nov, 9 (1808). LEGU MINOSAE, Benth. \& Hook. fo i. 468.

Crotalodsis, Michx. ex DC. Prod. ii. 100, in syn (1825)

Eaplosia, Lasinia, Pericaulon, Ripasia, Rafí. New Fl. Am. ii. 48-51 (1836).

alba, Hook. Bot. Mag. t. $1177=$ leucantha.

alba, R. Br. in Ait. Hort. Kew. ed. II. iii. 6.Am, bor.

albiflora, Rafin. New Fl. Amo ii. 47.-Am, bor. auriculata, Sweet, Hort. Brit. ed, II. 123.-Am, bor. australis, Hort. ex Lehm. in Nov. Act. Nat. Cur. xi (1829) $803=$ minor.

australis, R. Br. in Ait. Hort. Kew. ed. II. iii, 6.Am. bor.

bracteata, Muhl ex Ell. Sketch, i. $469=$ leuco phaea.

caerulea, Eaton \& Wright, Man. N. Am. Bot. $154=$ australis.

calycosa, Engelm. in Coult. Bot. Gas.iii. (1878) 65.Florida.

confusa, Sweet, ex G. Don, Gen. Syst. ii. 113= australis ?

exaltata, Sweet, Brit. Flow. Gard. i. t. $97=$ australis.

fraxinifolia, Nutt. ex Torr. \& Gray, Fl. N. Am. i. 387 , in obs. $=$ Thermopsis fraxinifolia.

lanceolata, Ell. Sketch, i. 467-Am, bor.

Lecontii, Torr. \& Gray, Fl. N. Am. i. 386.-Florida.

leacantha, Torr. E Gray, l. c. 385.-Am. bor.

leucopbaea, Nutt. Gen. Am. i. 282.-Am. bot.

lupinoides, Burbidge, in Gard. Chron. (1\&81) I. \$27.-

Am. bor. ?

megacarpa, Chapm. ex Torr. Es Gray, Fl, N. An.

i. 386.-Florida.

microphylla, Nutt. in Fourn. Acad. Philad. vii. (1S3t) 97.-Florida.

minor, Lchm. in Nov. Act. Nat. Car. xiv. (18:24 sus s. australis.

mollis, DC. Prod. ii. $100=$ Thermopsis mollis

mollis, Nutt. Gen. Am. i. 281=Thermoursis fraxin. folia.

nepalensis, Hook. Exot. Fl. t. $191=$ Piptantbus nepalensis.

perfoliata, R. Br. in Ait. Hort. Rerar. ed. II. iii. 5. Am. bor.

retusa, Rafn. Neng Fl. Am, ïi. 4l.-Am, bor.

Serenae $M$. Curt

(1849) 406. - Am. bor.

simplicifolia, Croom, in .Am. Gourn. Sc. xxv, , $1 \$ 3 s^{\prime}$ : -Flurida.

sphacrocarpa, Nuts. in Fosurn. Acad. Phisad. vi LiSt: $97 .-\mathrm{T}$ exas.

sfipulacea, Ravenel, in Liliot Soc. Nat. His?. i. 1 sive $2=$ microphylla. 


\section{BAPTISIA :}

sulphurea, Engelm. in Coult. Bot. Gaz. iii. (1878) 65. -Am. bor.

texana, Buckl. in Proc. Acad. Sc. Philad. '1861' (1862) $452=$ anstralis?

tinctoria, R. Br. in Ait. Hort. Kew. ed. II. iii. 6.Am. bor.

uniflora, Spreng. Syst. ii. $347=$ lanceolata.

uniflora, Nutt. Gen. Am. i. 281, nomen=praec.?

versicolor, Lodd. Bot. Cab. t. $1144=$ australis?

versicolor, Rafin. New Fl. Am. iv. 107, nomen.-Am. bor.

villosa, Nutt. Gen. Am. i. 281.-Carolina.

BAPTISTONIA, Barb-Rodr. Orch. Nov. i. 95 (1877). ORCHIDEAE

echinata, Barb.-Rodr. l. c.-Bras.

BARANDA, Llanos, in Mem. Acad. Cienc. Madr. ii. (1859) $502=$ Barringtonia, Forst. (Myrtac.).

angatensis, Llanos, 1. c. = B. macrostachya.

BARATRANTHUS, Miq. Fl. Ind. Bat. i. I. 834 (1855 = Loranthus, Linn.

axanthus, Miq. 1. c.-Sumatra.

BARATtiA, A. Gray \& Engelm. in Proc. Am. Acad. i. (1848) $48=$ Encelia, Adans, (Compos.). calva, A. Gray \& Engelm. 1. c.=E. calva.

BARAULTIA, Spreng. Syst.ii. 313 (1825) = Barraldeia, Thou.

BARBACENIA, Vand. FI. Lusit. \& Bras. Spec. 21. t. 1 (1796). AMARYLLIDEAE, Benth. \& Hook. f. iii. 740 .

Campderia, H. B. \& K. Nov. Gen. et Sp, vii. 155 (1825).

Pleurostima, Rafin. Fl. Tellur. ii. 97 (1836).

RADIA, A. Rich. in Kunth, Syn. Pl. Aequin. i. (1822).

Visnea, Steud. ex Endl. Gen. 173 (1836).

Alexandrinae, Schousb. ex Hook. Lond. Fourn. Bot.s iv. (1845) 13.-Guiana

bicolor, Mart. Nov. Gen. et Sp. i. 19. t. 13.-Bras.

brasiliensis, Willd. Sp. Pl. ii. $227=$ Vandellii.

coccinea, Mart. in Schult. f. Syst. vii. 286.-Bras.

ensifolia, Mart. l. c.-Bras.

exscapa, Mart. Nov. Gen. et Sp. i. 21. t. 14.-Bras.

flava, Mart ex Steud. Nom, ed. II. i. 185-Bras

Gardneri, Seub. in Mart. Fl. Bras. iii. 1. 70. t. 8. f. 5 -Bras.

glauca, Mart. in Schult. f. Syst. vii. 238.-Bras.

gracilis, Hort. ex Baker, in Journ. Linn. Soc. xvii.

(1881) $239=$ Dasylirion acrotrichum.

ignea, Mart. in Schult. f. Syst. vii, 285.-Bras.

longiflora, Mart. Nov. Gen. et Sp. i. 19. t. 12.Bras.

luztulaefolia, Mart. in Schult. $f$. Syst. vii. 285. - Bras.

macrantha, Lem. Fard. Fl. iv. (1854) t. 390.-Bras.

purpurea, Hook. Bot. Mag. t. 2777.-Bras.

Rogierii x, Hort. ex Moore \& Ayres, Mag. Bot. ii (1850) $209 .-$ Bras.

rubro-virens, Mart. Nov. Gen. et Sp. i. 20. t. 14. f. 1.Bras.

schidigera, Lem Fard. Fl ii. (1852) t. 198-Bras, squamata, Lindl, in Bot. Reg. (1843) Misc. 64.-Bras. tomentosa, Mart. Nov. Gen. et Sp. 1. 18. t. 11.-Bras, tricolor, Mart. l. c. 18. t. 10.-Bras.

Vandelli, Schult. f. Syst. vii. $289=$ glauca

Vandellii, Pohl, ex Seub. in Mart. Fl. Bras. iii. 1. 72. -Bras.

3ARBA-JOVIS, Adans. Fam. ii. $321(1763)=$ Anthyllis, Linn. (Legumin.)

argyrophylla, Moench, Meth, $110=$ A. Barba-Jovis.

linearifolia, Moench, Meth. Suppl. $38=$ A. Her manniae.

montana, Moench, 1. c. $37=$ A. montana.

tragracanthoides, Medic in Vorles. Churpf. Phys. Ges. ii. (1787) $347=$ Astragalus armatus?

BARBARFA, Scop. Fl. Carn. ed. I. $522(1760)=$ Dentaria, Linn. (Crucif.).

BARBAREA, R. Br. in Ait. Hort. Kew. ed. II, iv. 109 (1812). CRUCIFERAE. Benth. \& Hook. f. i. 68. CAMpe, Dulac, FI. Hautes-Pyr, 199 (1867).

\section{BARBAREA :}

alpina, C. Koch, in Linnaea, xix. (1847) 319-As. Min.

altaica, Andrz. ex Steud. Nom. ed. II. i. $185=$ arcuata. arcuata, Andrz. ex DC. Prod. i. $141=$ taurica.

arcuata, Reichb. in Flora, v. (1822) 296.-Europ.; As.

Min.; As, bor.

augustana, Boiss. Diagn. Ser. I. i, $69=$ vulgaris.

australis, Hook. f. F1. N. Zel. i. $14=$ valgaris.

australis, Jord. Diagn. i. $103=$ praecox.

brachycarpa, Boiss. Diagn. Ser. I. v. 80.-As. Min.

bracteosa, Guss. Fl. Sic. Prod. ii. 257.-Sicilia.

brevicaulis, Jord. Diagn. i. $104=$ rupicola.

brevistyla, Jord. 1. c. $102=$ praecox.

cilicica, Schott \& Kotschy, ex Boiss. Fl. Orient. i. 185 $=$ minor

ciliifera, Steud. Nom. ed. II. i. 185, nomen.-Graecia.

elata, Hook. $f$. E' Thoms, in Fourn. Linn. Soc. v. (1861)

140.-Reg. Himal.

erysimoides, Schur, Enum. Pl. Transs. $41=$ praecox.

heterophylla, Willk, in Bot. Zeit. v. (1847) 217.Hispan.

hirsuta, Weihe, in Flora, xiii. (1830) 257 =vulgaris.

humilis, Presl, Fl. Sic. i. 45.--Sicilia.

iberica, DC. Syst. ii. $208=$ arcuata.

integrifolia, $D C$. l. C.-As. Mi

intermedia, Bor. Fl. Centr. Fr. ed. I. ii. $48(1840)=$ vulgaris.

Kayserii, Schur, in Verh. Siebenb. Ver. Naturw. iv. 1853) 57 = vulgaris.

Linnaei, Spenn. Fl. Friburg. iii. $929=$ praecox, vulgaris, taurica, \&c.

longisiliqua, Jord. Diagn. i. $103=$ praecox

lyrata, Aschers. in F1. Prov. Brandenb. i. $35=$ vulgaris minor, C. Koch, in Linnaea, xix. (1847) 55.-As. Min. Syria.

oligosperma, $C$. Koch, l. c.319.-Armenia. orthoceras, Ledeb. Hort. Dorp. (1824).-Sibir. altaic.

palustris, Hegetschw. Fl. Schw. $654=$ stricta

parviflora, Fries, Novit. ed. II. $207=$ stricta.

patula, Fries, Nov. Mant. iii. $76=$ praecox.

perennis, Pomel, Nouv. Mat. Fl. Atl. 375.-Algeria.

planisiliqua, C. A. Mey. in Middend. Reise (Fl. Ochot

14).--Sibir.

plantaginea, DC. Syst. ii. 208.-As. Min.; Persia.

praecox, R. Br. in Ait. Hort. Kerv. ed. II. iv. 109.Europ.

prostrata, J. Gay, in Ann. Sc. Nat. Sér. II. vi. (1836) $348=$ sicula.

pyrenaica, Jord. Diagn, i. $349=$ vulgaris.

rivularis, Martr. Fl. Tarn, $44=$ vulgaris.

rivularis, Panc. Elem. 14.-Servia.

rupestris, Steud. Nom. ed. II. i. $185=$ vulgaris

rupicola, Moris, Stirp. Sard. Elench. i. 55.-Sardinia.

sicula, Gren.\& Godr. Fl. Fr. i. $92=$ vulgaris.

sicula, C. F $^{\prime}$. Presl, Delic. Prag. 17.-Ital.; As Min.

stolonifera, Pomel, Nouv. Mat. Fl. Atl. 375.-Algeria.

stricta, Fellm. Pl. Vasc. Lapp. $6=$ orthoceras.

stricta, Andrz. in Bess. Enum.Pl. Volh. 72.-Ross.med

stricta, Willk, in Flora, xxxiv. (1851) $583=$ vulgaris.

sylvestris, Jord. Diagn. i. $100=$ vulgaris

taurica, DC. Syst. ii. $207=$ arcuata.

verna, Aschers. F1. Prov. Brandenb. i. $36=$ praecox.

vicina, Martr. Fl. Tarn, 45, in obs. = vulgaris.

vulgaris, R. Br. in Ait. Hort. Kew. ed. II. IV. 109.-

Europ.; As. temp.

BARBELLINA, Cass, in Dict. Sc. Nat. 1. 440 (1827)= Staehelina, Linn. (Compos.).

sericea, Cass. 1. $\mathrm{c}_{\mathrm{s}}=\mathrm{S}$. arborescens.

BARBERETTA, Harv. Gen. S. Afr. Pl. ed. II. 377 (1868). HAEMODORACEAE, Benth. \& Hook. f. iii. 674 .

aurea, Harv. l. c.-Afr. austr.

BARBERINA, Vell. Fl. Flum. 235 (1825); Ic. v. t. 117 (1827) =Symplocos, Linn. (Styrac.).

antillana, Miers, in Journ. Linn. Soc. xvii. (1880) 294 -Ind. occ

celastrinea, Miers, 1. c. =S. celastrinea

crenata, Miers, 1. c.-Bras.

cubensis, Miers, $1, \mathrm{c}_{\mathrm{n}}=\mathrm{S}$. cubensis.

estrellensis, Miers, 1. c. $293=\mathrm{S}$. estrellensis.

hirsuta, Vell. Fl. Flum. 235 ; v. t. $117=$ S. hirsuta

lanceolata, Mart. Herb. Fl. Bras. n. $723=$ S. lanceolata phaeoclados, Mart. 1. c. $724=\mathrm{S}$. phaeoclados.
BARBERINA :-

ramentacea, Miers, in Journ. Linn. Soc. xvii. (1880) $294=$ S. ramentacea

revoluta, Mart. Herb. Fl. Bras. n. 832 =S. revoluta, rhamnifolia, Miers, in Journ. Linn. Soc. xvii. (1880) $293=$ S. rhamnifolia

Spruceana, Miers, 1. c. 295.-Peruv.

tetrandra, Mart. Syst. Mat. Med. Bras. $49=$ S. tetrandra.

BARBEUIA, Thou. Gen. Nov. Madag. 6 (1806) PHYTOLACCACEAE, Benth. \& Hook. f. iii. 85 . madagascariensis, Steud. Nom. ed. II. i. 186.-Madag

BARBIERA, Spreng. Gen. ji. 587 (1831)=seq.

BARBIERIA, DC. Mém. Lég. 241. t. 39 (1825) LEGUMINOSAE, Benth. \& Hook. f. i. 495.

maynensis, Poepp. EN Endl. Nov. Gen. et Sp. iii. 58.Peruy.

pinnata, Baill. Hist. Pl. ii. $263=$ polyphylla

polyphylla, DC. Mém. Lég. vi. 249. t. 39.-Porto Rico.

BARBILUS, P. Br. Hist. Jamaic. $216(1756)=$ Tri chilia, Linn. (Meliac.).

BARBULA, Lour. Fl. Cochinch. $366(\mathbf{1 7 9 0})=$ Caryo pteris, Bunge (Verben.)

sinensis, Lour. I. $\mathrm{c}_{\mathrm{o}}=\mathrm{C}$. incana.

BARBYLUS, Juss. Gen. $430(1789)=$ Trichilia, Linn (Meliac.)

Brownii, J. F. Gmel. Syst. $611=$ T. hirta?

jamaicensis, DC. Prod. ii. $91=$ T. hirta?

BARCELLA, Drude, in Mart. Fl. Bras. iii. 459, t。 106 $(1881)=$ Elaeis, Jacq. (Palm.).

odora, Drude, 1. c. = E. odora.

BARCENA, Dugès, in Rev. Cienc. Mexic. Dec, (1879) 8, cum tab.; et in La Naturaleza, iv. (1879) 281. RHAMNEAE

guanajuatensis, Dugès, $l l, c c$.-Mexic.

BARCENIA, Dugès, in La Naturaleza, iv. (1879) $283=$ praec.

BARCKHAUSENIA, Menke, in Flora, xxvii. (1854) $723=$ seq.

BARCKHAUSIA, DC. FI. Fr. vi. $449(1815)=$ BARK HAUSIA, Moench = Crepis, Linn. (Compos.).

BARCLAYA, Wall. in Trans. Linn. Soc. xv. (1827) 442. t. 18. NYMPHAEACEAE, Benth. \& Hook. f i. 47 .

longifolia, Wall. l. c--Burma.

Mottleyi, Hook. f. in Trans. Linn. Soc, xxiii. (1862) 157. t. 21. f. 1-5.-Borneo.

oblonga, Wall. Cat. n. $599=$ longifolia.

BARDANA, Hill, Veg. Syst. iv. 28 (1762)= Arctium, Linn. (Compos.)

Arctium, Hill, Hort. Kew. $64=$ A. majus.

Lappa, Hill, Herb. Brit. i. $79=$ A. majus.

minor, Hill, Hort. Kew. $64=$ A. minus.

BARERIA, Juss, in Dict. Sc. Nat, iv. 64 (1804)= BARRERIA, Scop. = Poraqueiba, Aubl. (Olacin.).

BARGFMONTIA, Gaudich. Voy. Bonite, t. 8 . ("1839-46"). CONVOLVULACEAE, Benth. \& Hook. f. ii. 880 .

peruviana, Gaudich. l. c.-Peruv.

BARHAMIA, Klotzsch, in Seem. Bot. Voy. Herald, 104 $(1852$ ? $=$ Croton, Linn. (Euphorb.).

essequiboënsis, Klotzsch, 1. c. = C. populifolius. hispida, Klotzsch, 1. c. $=$ C. populifolius. macrostachya, Klotzsch, l. c. =C. populifolius. multispicata, Klotzsch, 1.c. =C. urticaefolius. ovalifolia, Klotzsch, 1. c. =C. ovalifolius, panamensis, Klotzsch, I. c. =C. populifolius. urticaefolia, Klotzsch, 1. c. $=$ C. urticaefolius. 
BARJONIA, Decne. in DC. Prod. viii. 512 (1844) ASCLEPIADEAE, Benth. \& Hook. f. ii. 771. chloraefolia, Decne. l. c.-Bras. cymosa, Fourn. in Mart. Fl. Bras. vi. IV. 206.Bras.

deltoidea, Decne. ex Fourn. 1. c. $205=$ racemosa.

linearis, Decne. in DC. Prod. viii. 512.-Bras.

obtusifolia, Fourn. in Mart. Fl. Bras. vi. IV. 206.Bras.

racemosa, Decne, in DC. Prod. viii. 512.-Bras.

Warmingii, Fourn, in Mart. Fl. Bras, vi, IV. 206.Bras.

BARKANIA, Ehrenb. [ex Reichb. Consp. 43 (1828)] in Abh. Acad. Berl. (1832) $429=$ Halophila Thou. (Hydroch.).

bullata, Ehrenb. in Abh. Acad. Berl. (1832) 42: = H. bullata.

punctata, Ehrenb. Symb. 5, ex Pritz. Ic. Ind. Suppl $42=\mathrm{H}$. ovata.

stipulacea, Zanard. in Mem. Ist. Venet. vii. (1857) $225=$ H. stipulacea

BARKERIA, Knowles \& Westc. Flor. Cab. ii. (1838) 7 . t. $49=$ Epidendrum, Linn. (Orchid.).

Barkeriola, Reichb. f. in Gard. Chron. (1884) II. 616 $=\mathrm{E}$. Barkeriola

cyclotella, Reichb. f. 1. c. (1880) I. $72=\mathrm{E}$. cyclo tellum.

elegans, Knowles \& Westc. Flor. Cab. ii. (1838) $7=$ E. elegans.

Lindleyana, Batem. ex Lindl. in Bot. Reg. (1842) Misc. $2=\mathrm{E}$. Lindleyanum

melanocaulon, A. Rich. \& Gal. in Ann. Sc. Nat. Sér III. iii. (1845) $22=\mathrm{E}$. melanocaulon.

Skinneri, Paxt. Mag. Bot. xv. (1849) $1=$ E. Skinneri. spectabilis, Batem. in Lindl. Bot. Reg. (1842) Misc. $43=$ E. spectabile.

Vanneriana, Reichb. f. in Gard. Chron. (1885) II. 678 $=\mathrm{E}$. Vannerianum.

BARKHAUSENIA, Schur, in Verh. Naturf. Ver. Bruenn, xv. II. (1877) $69=$ BORCKHAUSENIA, Gaert Mey. \& Scherb. $=$ Corydalis, Vent. (Papav.).

BARKHAUSIA, Moench, Meth. $537(1794)=$ Crepis, Linn. (Compos.)

aculeata, DC. Prod. vii. $159=$ C. aculeata.

adenothrix, Sch. Bip. ex A. Rich. Tent. Fl. Abyss. i $465=$ C. Rueppellii.

albida, Cass. in Iict. Sc. Nat. xxvi. $62=$ C. albida.

alpina, DC. Fl. Fr. ed. III. iv. $41=$ C. alpina.

amplexicaulis, Coss. \& Dur. ex Coss. in Ann. Sc. Nat. Sér. IV. i. (1854) 232.-Algeria.

amplexifolia, Godr. in Mém. Acad. Montp. (Sect. Méd.) i. (1853) $487=$ C. amplexifolia.

amygdalina, Lag, ex Stend. Nom. ed. II. i. $186=$ C. foetida.

apargioides, Spreng. Syst. iii. $652=$ Chondrilla Peltidium.

arenaria, Pomel, Nouv. Mat. FI. Atl. $4=$ C. arenaria? aspera, Reichb. in Moessl. Handb. ed. II. ii. $1405=$ C. aspera.

auriculifolia, Reichb. 1. c. 1410 , in nota = C. incarnata?

Balbisiana, DC. Prod, vii, $155=$ C. bursifolia.

balearica, Costa, Barcin. (1861) $6=$ C. balearica

bellidifolia, DC. Fl. Fr. v. $449=$ C. bellidifolia.

Bivoniana, Reichb. in Moessl. Handb. ed. II. ii. 1408 -Europ.

bursifolia, Spreng. Syst. iii. $653=$ C. bursifolia

byantina, DC. Prod. vii. $158=$ C. foctida.

caespitosa, Moris, F1. Sard, $92=$ C. caespitosa

Candollei, Spreng. Syst. iii. $657=$ C. foetida.

canescens, Spreng. 1. c. 653 , sub n. $16=$ C. bursi folia.

carbonaria, Sch. Bip, in Mus. Senck. iii. $54=$ C

caroliniana, Nutt. Gen. Am. ii. $126=$ Pyrrhopappus

carolinianus.
cermua, Reichb. in Moessl. Handb. ed. II. ii. $1406=$

C. neglecta.

chondrilloides, Bluff \& Fingerh. Comp. ii. $904=$ C.

foeniculacen.

chaetocephala, Bunge, in Mém. Sav. Etr. Pétersb, vii.

(1851) 384; (Lehm. Reliq. Bot. 208).-Turkest.

Clausonis, Pomel, Nouv. Mat. Fl. Atl. 4.-Algeria.

\section{BARKHAUSIA :-}

comata, Lowe, in Trans. Camb. Phil. Soc. iv. (1831) $27=$ C. comata.

cretica, Boiss. Diagn. Ser, I. xi. $53=$ C. cretica.

decumbens, Gren. \& Godr. F1. Fr. ii. $332=$ C. decumbens.

divaricata, Lowe, in Trans, Camb. Phil. Soc iv. (1831) $26=\mathrm{C}$. divaricata, Lowe

divaricata, Schur, Enum. Pl. Transs. $373=$ C. foctida dubia, Lowe, in Trans. Camb. Phil. Soc. iv. (1831) 27 -Ins, Madera.

echioides, Schur, Enum. PI. Transs. $373=$ C. foetida,

elata, Koch, in Linnaea, xxiii. $(1850) 684=C$ alpina.

elegans, Nutt, in Trans. Am. Phil. Soc. N. S. vii. 1841) $435=$ C. elegans

erucaefolia, Gren. \& Godr. Fl. Fr, ii, $331=$ C. erucaefolia.

flexuosa, DC. Prod. vii. $156=$ C. nana

floribunda, Pomel, Nouv. Mat. Fl. Atl. $260=$ C. floribunda.

foetida, F. W. Schmidt, Samml. Phys. Aufs. i. (1795) $283=$ C. foetida

glandulosa, Presl, Fl. Sic. p. xxxi=C. foetida.

gracilis, Dum. Fl. Belg. 61.--Belgium.

graveolens, Link, Enum. Hort. Berol. ii. $290=\mathrm{C}$. foetida.

Haensleri, Boiss. ex DC. Prod. vii. $153=$ C. taraxac folia.

heterocarpa, Boiss. Voy. Espagne, ii. $742=\mathrm{C}$. taraxaci folia.

hiemalis, Spreng. Syst. iii. $652=\mathrm{C}$. taraxacifolia.

hieracioides, Lowe, in Trans. Camb. Phil. Soc. iv (1831) $27=\mathrm{C}$. hieracioides.

hirsuta, Pomel, Nouv. Mat. F1. Atl, $260=$ C. hirsuta.

hirta, C. Koch, in Linnaea, xxiii. (1850) $688=\mathrm{C}$. foetida.

hispida, Link, Enum. Hort. Berol. ii. $290=$ C. setosa.

hyemalis, Bivona, Stirp. Rar. Sicil. i. [17] t. $2=$ C. taraxacifolia.

interrupta, Reichb. in Moessl. Handb. ed. II. ii. 1407, in nota $=\mathrm{C}$. Sieberi.

intybacea, Spreng. Syst. iii. $653=$ C. taraxacifolia

juvenalis, Delile, Ind. Sem. Hort. Monsp. (1856) $23=$

C. juvenalis.

Kotschyana, Boiss. Diagn. Ser. I. vii. $13=$ C. Kotschyana.

Kralikii, Pomel, Nouv. Mat. Fl. Atl. $5=$ C. Kralikii.

laciniata, Lowe, in Trans. Camb. Phil. Soc. iv. (1831) $25=$ C. laciniata

Leontodon, DC. F1. Fr. ed. III. n. $2950=$ C. leontodontoides.

leontodontoides, Spreng. Syst. iii. $653=$ C. leontodontoides.

Lessingii, Hook. \& Arn. Bot. Beech. Voy. i. $145=$ Troximon apargioides.

leucocephala, Bunge, in Mém. Sav. Etr. Pétersb. vii. 1851) 385 ; (Lehm. Reliq. Bot. 209),-As. centr.

leucorhodia, Reichb. in Moessl. Handb. ed. II. ii. 1409 $=$ C. bicolor.

macrocephala, Willk. in Bot. Zeit.v. (1847) $860=\mathrm{C}$. albida.

macrophylla, Spreng. Syst. iii. $652=$ C. macrophylla.

Marschallii, C. A. Mey. Verz. Pfl. Cauc. $57=$ C. Mar schallii.

melanocephala, Bunge, in Mém. Sav. Etr. Pétersb. vii (1851) 385; (Lehm. Reliq. Bot. 209).-As. centr. mucronata, Bertol. Fl. Ital, viii, $515=\mathrm{C}$. alpestris.

muricata, Spreng. Syst. iii. $651=$ C. aspera.

nana, DC. Prod. vii. $156=$ C. nana

nicaeensis, Link, ex Spreng. Syst. iii. $653=$ C. taraxacifolia.

nigricans, Viv. ex Coss. in Bull. Soc. Bot. Fr. xii. (1865) $278=$ C. nigricans

muda, Presl, ex Spreng. Syst. iii. $653=\mathrm{C}$. leontodon. toides.

nudiflora, Viv, ex Coss. in Bull. Soc. Bot. Fr. xii. (1865) $278=$ C. aspera.

numidica, Pomel, Nouv. Mat. F1. Atl. $261=$ C. numidica.

paludosa, Baumg, ex DC. Prod, vii. $170=$ C. paladosa. pinguis, Keichb. in Moessl. Handb. ed. II. ii. $1411=$ C. foetidn.

porrifolia, DC. Prod. vii. $157=$ Pterotheca bifida. praecox, Reichb. in Moessl. Handb. ed. II. ii. 1409 C. taraxacifolia.

prostrata, Dum. F1. Belg. Prod. $61=$ C. foetida.

purpurea, Bivona, Stirp. Rar. Man. iv. 22 Lagoseris purpurea.
BARKHAUSIA :-

radicata, Godr. in Mém. Acad. Montp. (Sect. Méd.) i. (1853) $436=$ Hypochoeris radicata.

raphanifolia, Chev, ex Steud. Nom. ed. II. i. $187=C$. taraxacifolia.

raphanifolia, Spreng. Syst. iii. $653=$ C. raphanifolia. recognita, DC. Prod. vii. $154=$ C. recognita.

reflexa, C. \& J. Presl, Delic. Prag. $111=$ C. taraxacifolia.

repens, Spreng. Syst. iii. 652.-China,

rhoeadifolia, Bieb. Fl. Taur. Cauc. iii, $538=$ C. foetida rodigioides, Sch. Bip. ex Tchihat. Asie Min. Bot. ii. $374=$ C. foetida.

Roylei, DC. Prod. vii, $157=$ C. bifida.

rubra, Moench, Meth. $537=$ C. rubra.

sardoa, Spreng, Syst. iv, Cur. Post. 304.-Sardin.

scapigera, Kunze, ex DC. Prod. vii. 152 (= Macro

rhynchus Poeppigii).-Chili.

scariosa, Moench, Meth. $537=$ C. alpina

scariasa, Reichb. Fl. Germ. Exc. i. $256=$ C. vesicaria

Schimperi, Sch. Bip. ex A. Rich. Tent. Fl. Abyss. i. $466=$ C. Schimperi.

Schultzii, Hochst. ex A. Rich. 1. c. $464=$ C. Schultzii. senecioides, Spreng. Syst. iii. $652=$ C. senecioides.

setosa, DC. FI, Fr. ed. III $\vee, 44=\mathrm{C}$. setosa.

spathulata, Spreng. Syst. iii. $651=$ C. spathulata.

Sprengelii, Steud. Nom. ed. II. i. $187=$ Troximon apargioides.

stricta, Reichb. in Moessl. Handb. ed. II. ii. $1406=\mathrm{C}$ neglecta.

Suffreniana, DC. Cat. Hort. Monsp. $83=$ C. Suffre. niana.

taraxacifolia, DC. Fl. Fr. iv. $43=$ C. taraxacifolia. taraxacifolia, Spreng. Syst. iii. $653=$ C. taraxacoides. taraxacoides, Reichb. in Moessl. Handb. ed. II. I

1408; DC. Prod. vii. $155=$ C. taraxacoides.

tenella, Benth, in Hook. Lond. Journ. Bot, i. (1842) $488=$ Lactuca versicolor

tenerrima, Sch. Bip. ex A. Rich. Tent. F1. Abyss.i. $464=\mathrm{C}$. carbonaria.

tenerrima, Tenore, in Ann. St. Nat. Bolog. iv. $252=\mathrm{C}$ leontodontoides.

tenuifolia, DC. Prod. vii. $155=$ C. tenuifolia.

triangularis, C. Koch, in Linnaea, xxiii. (1850) 687 C. foetida.

versicolor, Spreng. Syst. iii. $651=$ Lactuca versicolor. vesicaria, Spreng. 1. c. $652=\mathrm{C}$. vesicaria

zasinthia, Margot. \& Reut. Fl. Zanth. $62=$ C. foetida

BARKHUSENIA, Hoppe, in Flora, xii. (1829) $512=$ BARKHAUSIA, Moench=Crepis, Linn. (Comprs.

BARKLYA, F. Muell, in Journ. Linn. Soc. iii. (1859 158; Fragm. i. 109 (1859), LEGUMINOSAE, Benth. \& Hook. f. i. 559 .

syringifolia, F. Muell. ll. ccs-Austral.

BARLAEA, Reichb. fo in Linnaca, xli. (1877) $54=$ Habenaria, Willd. (Orchid.).

calcarata, Reichb. f. 1. c。 = H. calcarata.

BARLERIA, Linn. Gen, ed. I. 869 (1737), ACA THACEAE, Benth. \& Hook. f. ii. 1091.

Barleriacanthus, Barlerianthus, Barleri. OPSIS, BarleriosiphoN, BarLERITES, DICRAXA. CANTHUS, PRIONITIS et PSEUDOBARLERIA, Oerst. in Kjoeb. Vidensk. Meddel. (1854) 193-137.

BARRELIERA, J. F. Gmel. Syst. 959 (1791). Crabbea, Harv, Gen, Pl. Cap. ed. I. 276 (1835, Soubeyraxia, Neck. Elem. i. 365 (1790). WaHABIA, Fenal, in Flora, xxvii. (18t4) 312. acanthoides, Vahl, Symb. Bot. i. 47.-Amb. ; Aegypt. : Ind. bor. oce.

acanthophora, Nees, in DC. Prod. xi. 720.-Afr. urop aculeata, Balf. f. in Proc. Roy. Soc. Edinb. xii. Lsos 85. - Ins. Socotr.

acuminata, Wight, Ic. t. 450 ementosa.

adelensis, Delile, in Rochet, Sec. Voy. Choa. \$11.Afr. trop.

alnta, $S$ Moore, in Gourn. Bot, xwiii. ISs0: 2006 - Afr. trop.

alba, Lodd. Bot. Cab. iv. ?. $\$ 60=$ cristata.

anomala, Spreng. Syst. ii. \$2\$ - 13manisia floribunia arabica, Belang. ex Avers, in DC. Prodl. xi. i:25.Arabia.

argentea, Balf, fo in Proc. Roy. Soc. Edirb, xii. (1)st 6. - Ins. Socuts. 


\section{BARLERIA}

Arnottiana, Nees, in Hook. Comp. Bot. Mag. ii. (1836)

311.-Zeylan.; Burma.

Aucheriana, Nees, in DC Prod. xi. $234=$ Hochstetteri auriculata, Schum. Beskr. Guin. P1. 285=Hygrophila spinosa.

axillaris, Steud. Nom. ed. II. i. $187=$ Lepidagathis trinervis?

barbata, E. Mey. Zwei Pfl. Docum. 152=Gueinzii

Beddomei, T. Anders. ex Bedd. Ic. Ind. Or. i. $62=$ Lawii.

bispinosa, Hochst. ex A. Rich. Tent. Fl. Abyss. it $144=$ B. Prionitis

bispinosa, Vahl, Symb. Bot. i. 46.-Arab.

bispinosa, Nees, in Wall. P1. As. Rar. iii. $94=$ myso rensis.

bituminosa, Noronha, in Verh. Batav. Gen. v. (1790) ed. I. Art. IV. 8.-Malaya.

Boivinii, T. Anders. in Fourn. Linn. Soc. vii. (1864) 31.-Madag.

bracteata, Heyne, ex C. B. Clarke, in Hook. f. FI. Brit. Ind. iv. $490=$ nitida.

brasiliensis, Spreng. Neue Entdeck, iii. 26.-Bras.

brevispina, R Br in Salt, Abyss. App, $64=\mathrm{B}$. Prionitis .

Burchelliana, Nees, in DC. Prod. xi. $235=$ macrostegia.

Burkeana, Sond. in Linnaea, xxiii. (1850) $92=$ macrostegia.

buxifolia, Linn. Sp. Pl. 636.--Ind. or

buxifolia, Roxb. Hort. Beng. 45; F1. Ind. iii. $37=$ obovata.

buxifolia, Wall. Cat.n. $2504=$ mysorensis.

caerulea, Herb. Lamb. ex Nees, in DC. Prod. xi. $228=$ cristata.

caerulea, Roxb. Hort. Beng. 45 ; F1. Ind. iii. $39=$ strigosa

caerulea, Wall Cat n. 2509, partim = polytricha

candida, Nees, in DC. Prod. xi. 240.-Oriens.

capitata, Klotzsch, in Peters, Reise Mossamb. Bot. 210.-Afr. trop.

cardiocalyx, Solms, ex Schweinf. Beitr. Fl. Aethiop. 105. -Afr. trop.

Carruthersiana, S. Moore, in Fourn. Bot. xviii. (1880) 270 - - Afr. trop.

chegosa, Herb. Madr. ex Wall. Cat. n. $2506=$ cristata.

ciliata, E. Mey. ex Nees, in DC. Prod. xi. $230=$ Meyeriana.

ciliata, Roxb. Hort. Beng. 45 ; F1. Ind. iii. $38=$ cristata.

coccinea, Linn. Sp. Pl. $637=$ Ruellia coccinea

consanguinea, Klotzsch, in Peters, Reise Mossamb. Bot. 206.-Afr. trop.

conspicua, Nees, in Wall. Pl. As, Rar. iii. 92.-Ins, Penang.

cordifolia, Hochst. ex T. Anders. in Journ. Linn. Soc. vii. (1864) $29=$ parviflora

cornigera, Véry, ex Nees, in DC. Prod. xi. $248=$ Hygrophila spinosa.

courtallica, Nees, in Wight, Ic. iv. t. 1529.-Ind. or,

cristata, Lam. Encye. i. $380=$ noctiflora.

cristata, Linn. Sp.Pl. 636.-Ind. or. ; Burma.

cuspidata, Heyne, ex Nees, in Wall. Pl. As. Rar. iii. 93.--Ind. or.

cyanea, S. Moore, in Fourn. Bot. xviii. (1880) 265.Angola.

damarensis, T. Anders. in Fourn. Linn. Soc. vii. (1864) 29.-Afr. austr. trop.

Decaisneana, Nees, in DC. Prod. xi. 230-Madag

diacantha, Hochst. ex Nees, 1. c. $238=$ B. Prionitis

diandra, Heyne, ex Nees, in Wall. Pl. As. Rar. iii. 92 $=$ polytricha?

diandra, Hochst. \& Steud. ex Nees, in DC. Prod. xi. $231=$ Hochstetteri

diandra, Schlecht. ex Nees, 1. c. = obtusa

dianthera, Herb. Madr. ex Wall. Cat. n. $2391=$ Peristrophe montana.

dichotoma, Roxb. Hort. Beng. 45 ; Fl. Ind. iii. $39=$ cristata.

diffusa, Wight, ex C. B. Clarke, in Hook. f. Fl. Brit. Ind. iv. $518=$ Lepidagathis diffusa.

discolor, Nees, in Benth. Bot. Voy. Sulph. 146.Mexic.

echinata, St. Lag. in Ann. Soc. Bot. Lyon, vii. (1880) $120=$ B. Prionitis

elata, Dalz. in Hook. Kew Journ. iii. (1851) $227=$ involucrata.

eranthemoides, R. Br. in Salt, Abyss. App. $64=$ acanthoides.

fasciculata, Russ. ex Wall. Cat. n. $2509=$ polytricha?

\section{BARLERIA :}

fissiflora, Boj. ex Nees, in DC. Prod, xi. 238.Madag.

flava, Facq. Ecl. 67. t. 46.-Arab.

gentianoides, Desf. ex Nees, in DC. Prod. xi. $224=$ flava.

Gibsoni, Dalz. in Hook. Kew Fourn. ii. (1850) 339 .Ind. or.

glabra, Noronha, in Verh. Batav. Gen. v. (1790) ed. I. Art. IV. 8.-Malaya.

glabrata, Vahl, ex Nees, in DC. Prod. xi. $248=$ Hygrophila spinosa.

glandulosa, Hochst. ex Nees, 1. c. 243 = Lepidagathis glandulosa.

glauca, T. Anders. in Journ. Linn. Soc. ix. (1867) 493 - Gibsoni.

grandiflora, Dalz. in Hook. Kew Fourn. ii. (1850) 339. -Ind. or.

grandiflora, $R$. Br. in Salt, Abyss. App. 64.Abysin.

grandifolia, R. Br. ex T. Anders. in Journ. Linn. Soc. vii. (1864) 30 , sphalm. = grandiflora.

grandis, Hochst. ex Nees, in DC. Prod, xi. $233=$ grandiflora.

Grantii, Oliver, in Trans. Linn. Soc. xxix. (1875) 127 -Afr. trop.

Gueinzii, Sond. in Linnaea, xxiii. (1850) 91.-Afr. austr.

halimoides, Nees, in DC. Prod. xi. $231=$ Petalidium halimoides.

Hamierii, Solms, in Schweinf. Beitr. Fl. Aethiop. 106. -Afr. trop.

hexacantha, Bertol, in Ann. Stor. Nat. Bolog. fasc. ix. 445 ; Disq. Pl. Nov. $3(1832)=$ longifolia.

hexacantha, Moris, in Mem. Acc. Torm. xxxvi. (1833) 200. t. $7=$ Hygrophila spinosa

Hildebrandtii, S. Moove, in Fourn. Bot. xv. (1877) 69. - Afr. trop.

hirsuta, Herb. Madr. ex Wall. Cat. n. $2503=$ to mentosa.

hirsuta, Jacq. Obs. Bot. ii. $7=$ Gonzalea spicata.

hirsuta, Nees, Wall. P1. As. Rar. iii. 91; Cat. n. 7142 = polytricha.

Hochstetteri, Nees, ex DC. Prod. xi. 231.-Afr. bor. Arab. ; Scind

hypocrateriformis, Hochst. ex T. Anders. in Joum. Linn. Soc. vii.(1863) $28=\mathrm{B}$. Prionitis

Hystrix, Linn. Mant. i. $89=$ B. Prionitis

ilicina, E. Mey. ex T. Anders. in fourn. Linn. Soc. vii. (1864) 28.-Afr. austr.

inaequalis, Benth. in Flora, xxxii. (1849) $557=$ courtallica.

inaequalis, Hochst. ex A. Rich. Tent. Fl. Abyss. ii. 149 = Phaylopsis longifolia.

indica, Linn. ex T. Anders, in Journ. Linn. Soc, vii (1864) $115=$ cristata

involucrata, Nees, in Wall.Pl.As. Rar. iii. 92.-Ind. or irritans, Nees, in Linnaea, xv. (1841) 359.-Afr. austr. Kirkii, T. Anders. in fourn. Linn. Soc. vii. (1864) 30 - Afr. trop.

laciniata, Wall. P1. As. Rar. iii. 91; Cat. n. $7144=$ cristata.

lactea, Desf. ex Steud. Nom, ed. II. i. $187=$ cristata.

lancifolia, T. Anders. in Fourn. Linn. Soc. vii. (1864 28.-Afr, austr, trop.

Lawii, T. Anders. $l$. c. ix. (1867) 492.-Ind. or.

Lichtensteiniana, Nees, in DC Prod, xi. 235.-Afr. austr.

limnogeton, S. Moore, in Fourn. Linn. Soc. xv. (1877) 95. - Ins. Celebes.

longiflora, Linn. f. Suppl. 290,--Ind. or.

longifolia, T. Anders. in Journ. Linn. Soc, ix. (1867) $491=$ longiflora.

longifolia, Linn. Cent. Pl. ii. 22 ; Amoen. Acad. iv. 320 $=$ Hygrophila spinosa.

lupulina, Lindl. in Bot. Reg. t. 1483.-Ind. or.; Ins. Maurit.

Mackenii, Hook. f. Bot. Mag. t. 5866.-Afr. austr.

Macraei, Arn. in Hook. Comp. Bot. Mag. ii. (1836) 311.-Ind, or

macracantha, R. Br. in Salt, Abyss. App. $64=$ Hygro phila spinosa?

macrolemma, Peyr. in Sitzb. Acad. Wien. Math.-Nat. xxxviii. (1860) 574.-Afr. trop.

macrophylla, Heyne, ex C. B. Clarke, in Hook. f. Fl. Brit. Ind. iv. $489=$ strigosa,

macrostachya, Boj. Hort. Maurit. $260=$ lupulina macrostegia, Nees, in DC. Prod. xi. 235.-Afr. austr

\section{BARLERIA :-}

marginata, Oliver, in Trans. Linn. Soc. xxix. (1875) 127.-Afr. trop.

Meyeriana, Nees, in DC. Prod. xi. 230.-Afr. austr. micans, Nees, in Benth. Bot. Voy. Sulph. 146.N. Granat.

mitis, Ker-Gawl. in Bot. Reg. t. 191.--Ind. or. mollis, R. Br. in Salt, Abyss. App. 64.-Abyssin. monostachya, Boj. in Hook. Fourn. Bot. i. (1834) 356 -Ins. Maurit.

montana, Herb. Madr. ex Nees, in Wall. Pl. As. Rar. iii. 92.--Ind. or

montana, Wight \& Nees, ex C. B. Clarke, in Hook. f Fl. Brit. Ind. iii. 487, pro parte=Gibsoni multiflora, Hassk. Cat. Fl. Bogor. Alt. 149.-Hab. ? mysorensis, Heyne, in Roth, Nov. Sp. Pl. 313.Ind. or.

napalensis, Nees, in Wall, Pl. As, Rar. iii. $91=$ cristata.

nitida, Facq. ex Steud. Nom. ed. II. i. 187.-Am austr.

nitida, Nees, in Wall. Pl. As. Rar. iii. 91.-Ind. or. noctiflora, Hochst. ex A. Rich. Tent. F1. Abyss. ii $145=$ acanthoides.

noctiflora, Linn. f. Suppl. 290.-Ind. or. ; Arab

nuda, Nees, in Wall. Pl. As. Rar. iii. 92 = cristata.

nutans, Nees, in DC. Prod. xi. 227.-Zeylan.

obovata, Buch.-Ham. in Trans. Linn. Soc. xiv. (1825) $293=$ mysorensis

obtusa, Nees, in Linnaea, xv. (1841) 358.-Afr. austr. oenotheroides, Dum.-Cours. Bot. Cult. Cat, vii. 7 = flava opaca, Nees, in DC. Prod. xi. 230.-Afr. occ.

orbicularis, Hochst. ex Anders, in Fourn. Linn. Soc vii. (1864) 29.-Abyssin.

ovata, E. Mey. ex Nees, in DC. Prod. xi. 230.-Afr. austr.

paniculata, Herb. Madr. ex Nees, in Wall. Pl. As. Rar. iii. $92=$ tomentosa

papillosa, T. Anders. in Fourn. Linn. Soc. vii. (1864) 31.-Afr. austr.

parviflora, R. Br. in Salt, Abyss. App.65.-Abyssin. pentandra, Arn. ex Nees, in DC. Prod. xi. $232=$ involucrata et Arnottiana.

pilosa, Heyne, ex Nees, in Wall. Pl. As. Rar. iii. 93.Ind. or.

polyneura, S. Moore, in Fourn. Bot. xviii. (1880) 266. -Afr. trop.

polystachya, Hook. ex Nees, in DC. Prod. xi. $226=$ strigosa.

polytricha, Boj. ex Nees, 1. c. $286(=$ Polythrix stenanarium).-Madag.

polytricha, Wall. Pl. As. Rar. i. 72. t. 82.-Ind. or.

prinoides, Hort. Monsp. ex Nees, in DC. Prod. xi. 229 $=$ cristata.

Prionitis, Linn. Sp. Pl. 636.-As. et Afr. trop.

procumbens, Lour. Fl. Cochinch. 377.-China.

pubiflora, Benth. in Flora, xxxii. (1849) $558=\mathrm{B}$ Prionitis.

pumila, Hochst, ex Nees, in DC. Prod. xi. $372=$ Justicia simplex.

pungens, Heyne, ex Nees, in Wall. Pl. As. Rar. iii. 91 =polytricha?

pungens, Linn.f. Suppl. 290.-Afr. austr.

pungens, Thunb. Prod. Pl. Cap. $98=$ irritans.

pungens, Wall. Cat. n. $2498=$ Lepidagathis pungens.

purpurea, Lodd. Bot. Cab. iv. t. $344=$ montana.

pyramidalis, Lam. ex Nees, in DC. Prod. $243=$

Blechum Brownei.

quadrispinosa, Stokes, Bot. Mat. Med. iii. $411=\mathrm{B}$ Prionitis.

querimbensis, Klotzsch, in Peters, Reise Mossamb. Bot. 205.-Afr. trop.

racemosa, Herb. Madr, ex Wall. Cat. n. $2503=$ tomentosa.

ramosa, Buch.-Ham. in Trans. Linn. Soc. xiv. (1825 295 = noctiflora

repens, Nees, in DC. Prod. xi. 230.-Afr, austr.

rhynchocarpa, Klotzsch, in Peters, Reise Mossamb. Bot. 205.-Afr. trop.

Richardiana, Nees, in DC. Prod. xi. 225.-Madag. rigida, Spreng. in Zeyh. ex Schlecht. in Linnaea, xiv. (1840) $304=$ Pachypodium tomentosum

rigida, Willd. ex Nees, in DC. Prod. xi. 242.Afr, austr.

rubra, Buch.-Ham. in Trans. Linn. Soc. xiv. (1825) 296 (sp. dub.).-Ind. or

ruellioides, Rottl. ex Nees, in DC. Prod. xi. $240=$ nodiflora. 
BARLERIA :-

ruellioides, T. Anders. in fourn. Linn. Soc. vii. (1864) 30.-Afr. trop.

salicifolia, S. Moore, in Fourn. Bot. xviii. (1880) 268. -Afr. trop.

satureioides, Griseb. Cat. Pl. Cub. 195.-Cuba. senegalensis, Nees, in DC. Prod. xi. $224=$ flava.

senensis, Klotzsch, in Peters, Reise Mossamb. Bot. 209.-Afr. trop.

sepalosa, C. B. Clarke, in Hook. f. Fl. Brit. Ind. iv. 487.- Ind. or.

sericea, T. Anders, in Joum. Linn. Soc. vii. (1864) 115 =longiflora.

solanifolia, Linn. Sp. Pl, $637=$ Barleriola solanifolia somalensis, Franch, in Révoil, Comali, 51.-Afr. or. spicata, Roxb. Hort. Beng. $45=$ B. Prionitis.

Spina-ceylanica, Nees, in DC. Prod. xi. $242=$ mysorensis.

spinicyma, Nees, l. c. 240.-Arabia.

spinosa, Hook. ex Nees, 1. c. $247=$ Hygrophila spinosa.

spinosa, Wall. Cat. n. $2497=$ Lepidagathis spinosa

spinulosa, Klotzsch, in Peters, Reise Mossamb. Bot. 208.-Afr. trop.

squarrosa, Klotzsch, l. c. 207.-Afr. trop.

stellato-tomentosa, S. Moore, in Fourn. Bot. xviii. (1880) 268.-Afr. trop.

stenophylla, Kurz, in fourn. As. Soc. Beng. xlii (1873) II. 95.-Burma.

stimulans, E. Mey. ex Nees, in DC. Prod. xi. 241,Afr, austr.

Stocksii, T. Anders. in Fourn. Linn. Soc. ix. (1867) 493.-Ind. or

strigosa, Willd. Sp. Pl. iii. 379,-Ind. or.

terminalis, Nees, in DC. Prod, xi. $225=$ strigosa

tetracantha, Balf. $f$. in Proc. Roy. Soc. Edinb. xii. (1884) 85.-Ins. Socotr.

tomentosa, Roth, Nov. Sp. Pl. 314.-Ind. or.

tomentosa, Herb. Madr. ex Wall. Cat. n. $2503=$ acuminata.

triacantha, Hochst. ex Nees, in DC. Prod. xi. $240=$ acanthoides.

trinervis, Herb. Ham. ex Nees, 1. c. $243=$ Lepidagathis trinervis.

trispinosa, Vahl, Symb. Bot. i. 46.-Arab.

uitenagensis, Hochst. ex Nees, in DC. Prod. xi. $231=$ obtusa.

unilateralis, Buch.-Ham. ex Wall. Cat. n. $2509=$ polytricha.

ventricosa, Hochst.ex Nees, in DC.Prod.xi.230.-Abyss venulosa, Nees, 1. c. $228=$ cristata.

vestita, T. Anders, in Thw. Enum. Pl. Zeyl. 230.Zeylan.

villosa, S. Moore, in Fourn. Bot. xviii. (1880) 267.Afr. trop.

violascens, S. Moore, l. c. 265-Afr. trop.

Welwitschii, S. Moore, l. c. 267.-Afr. trop.

BARLERIACANTHUS, Oerst. in Kjoeb. Vidensk Meddel. (1854) $136=$ Barleria, Linn. (Acanth.) acanthoides, Oerst. 1. c. = Barleria acanthoides. noctiflora, Oerst. 1. c. = Barleria noctiflora.

BARLERTANTHUS, Oerst, in Kjoeb. Vidensk. Meddel (1854) $186=$ Barleria, Linn. (Acanth.).

grandis, Oerst. 1. c. = Barleria grandiflora.

BARLERIOLA, Oerst. in Kjoeb. Vidensk. Meddel. 1854) 186. ACANTHACEAE, Benth. \& Hook. f. ii. 1093. solanifolia, Oerst. l. c.-Ins. S. Doming.

BARLERIOPSIS, Oerst. in Kjoeb. Vidensk. Meddel (1854) 133 = Barleria, Linn. (Acanth.). discolor, Oerst. 1. c. $134=$ Barleria discolor glandulosa, Oerst. 1. $\mathrm{c}_{\mathrm{.}}=$ Barleria micans . micans, Oerst. 1. c. $=$ Barleria micans.

BARLERIOSIPHON, Oerst, in Kjoeb, Vidensk, Meddel. (1854) $136=$ Barleria, Linn. (Acanth.).

longiflora, Oerst. 1. c. = Barleria longiflora

BARLERITES, Oerst. in Kjoeb. Vidensk. Mcddel. (1854) 137 = Barleria, Linn. (Acanth.)

Hochstetteri, Oerst. 1. c. = Barleria Hochstetteri.

BARLIA, Parl. Nouv, Gen. Piant. Monocot. 5 (1858) Fl. Ital. iii. $445(1858)=$ Orchis, Lins.

longibracteata, Parl. 1. c. $6 ;$ Fl. Ital. iii. $447=0$. longibracteata.
BARNADESIA, Mutis, in Linn. f. Suppl. 55 (1781)

COMPOSITAE, Benth. \& Hook. f. ii. 484

Bacazia, Ruiz \& Pav, Prod. Fl, Per, 105, t 22 (1794).

Diacantha, Less, in Linnaea, v. (1830) 243.

Dolichostylis, Cass. in Dict. Sc. Nat. lvi. 139 (1828).

Fulcaldea, Poir. Encyc. Suppl.v. 375 (1817)

Penthea, Spacb, Hist. Vég. Phan. x. 9 (1841)

Rhodactinia, Gardn, in Hook. Lond. Journ. vi. (1847) 449

Turprnia, Humb. \& Bonpl. P1. Aequin. i. 113. t. 33 (1808)

VoIGTIA, Spreng. Syst. iii. $367(\mathbf{1 8 2 6})$

Xenophonta, Vell. Fl. Flum. 346 (1825)

arborea, H. B. E K. Nov. Gen. et Sp. iv. 16.Ecuador.

arborea, Sch. Bip. in Linnaea, xxii. (1849) $569=$ rosea. berberoides, Sch. Bip. in Lechl. Berb. Am. Austr. 57 -Peruv.

corymbosa, D. Don, in Trans. Iinn Soc. xyi. (1833) 278.-Peruv.

dianthiflora, Mart. ex Baker, in Mart. Fl. Bras. vi. IIY $365=$ rosea.

divaricata, Griseb. in Goett. Abh. xxiv. (1879) 209.Reg. Argent.

Dombeyana, Less. in Linnaea, v. (1830) 246.-Peruy.

flavescens, Meyen, Reise, i. 307.-Chili.

glochidiata, Mart. ex Baker, in Mart. Fl. Bras. vi. II $361=$ synacantha.

hirsuta, Sch. Bip. in Linnaea, xxxiv. (1865-66) 527, nomen.-Bolivia.

lanata, Meyen, Reise, i. 347.-Chili.

lanceolata, D. Don, in Trans. Linn. Soc, xvi. (1833) 277.- Peruv.

laxa, D. Don, 1. c. $280=$ rosea

media, D. Don, l. c. 276.-Peruv.

odorata, Griseb. in Goett. Abh. xxiv. (1879) $210 .-$ Reg. Argent.

parviflora, Spruce, ex Benth. E Hook. f. Gen. ii. 485. -Ecuador

polyacantha, Wedd. Chlor. And. i. 13.-Bolivia

reticulata, D. Don, in Trans. Linn. Soc. xvi. (1833) 277.-Peruv.

rosea, Lindl. in Bot. Reg. (1843) t. 29.-Am. austr. spinosa, Linn.f. Suppl. 348.-Peruv.; N. Granat

spinosa, Willd. ex DC. Prod, vii. $3=$ arborea

ulicina, Hook. \& Arn. Bot. Beech. Voy. $29=$ Chuquiraga ulicina.

BARNARDIA, Lindl. in Bot. Reg. t. 1029 (1826)= Scilla, Linn. (Liliac.)

indica, Wight, Ic. t. $2041=\mathrm{S}$. indica

japonica, Schult. f. Syst. vii. $555=\mathrm{S}$. japonica

scilloides, LindI. in Bot. Reg. t. $1029=\mathrm{S}$. chinensis

BARNEOUDIA, C. Gay, F1. Chil. i. 29. t. $1(1845)=$

Anemone, Linn, (Ranunc.).
chilensis, C. Gay, 1. c.-Chili.

Domeykoana, Leybold, in Anal. Univ. Chil. (1858) 159 et in Flora, xlii. (1859) 242,-Chili.

major, Phil. in Linnaea, xxviii. (1856) 609.-Chili.

BAROLA, Adans. Fam. ii. $344(1763)=$ Trichilia Linn. (Meliac.).

BAROLLAEA, Neck. Elem. ii. $322(1790)=$ Caryocar Linn. (Ternstroem.)

BARONIA, Baker, in Journ. Bot. xx. (1882) 6\% ANACARDIACEAE.

Taratana, Baker, l. c.-Madag.

BAROSMT A, Willd. Enum. Hort, Berol, 257 (1809) RUTACEAE, Benth. \& Hook. f. i. 290

BAR yosma, Roem. \& Schult. Syst. v. 448 (1819),

Bucco, Wendl. Collect. i. 13 (1808)

Parapetalifera, Wendl. Collect. t. 15, 34 (1808). acutata, Sond. in Harv. E Sond. Fl. Cap. i. 395.-Arr. austr.

alpina, Eckl. E Zeyh. Enum, 102.-Afr. austr.

angustifolia, Bartl. E Werdl. $f$. Diosm. 116.-Afr. austr

apiculata, Eckl. E Zey/h. Enum. 104.-Afr. austr.

betulina, Bartl. Eo Wendl. f. Diosm. 102.-Afr. austr.

bruniades, Hoffmgg. Verz. PA. Nachtr. i. 128 Aga-

thosma cuspiclata.

crenata, Eckl. E Zey/b. Enum. 102.-Afr. austr.

\section{BAROSMA}

crenat S Sweet Hort. Brit. ed, I, 89. -Afr. anstr. crenulata, Hook. Bot. Mag.t. 3413.-Afr. austr.

dioica, Bartl. \& Wendl. f. Diosm. 114.-Atr. austr.

Eckloniana, Bartl. in Linnaea, xvii. (1843) 363.-Afr. austr.

foetidissima, Bartl. Eo Wendl. f. Diosm. 118.-Afr. aust

gnidioides, Eckl. E Zeyh. Enum. 104,-Afr. austr.

graveolens, G. Don, Gen. Syst. i. 786.-Afr. austr.

Kraussiana, Meissn. in Flora, xxvii. (1844) 1. 303.Afr. austr.

lauceolata, Sond. in Harv. EN Sond. Fl. Cap. i. 397.

Afr. austr.

latifolia, Roem. Eo Schult. Syst. v. 449.-Afr, austr.

microcarpa, Sond. in Harv. \& Sond. Fl. Cap. i. 398.Afr. austr.

mucronata, Meissn. in Flora, xxvii. (1844) I. 303.Afr, austr.

Niveni, Sond.in Havv. E Sond. Fl. Cap. i. 398.-Afr. austr.

oblonga, Bartl. \& Wendl. f. Diosm. 112.-Afr. austr. odorata, Willd. Enum. Hort. Berol. $257=$ serratifolia. orbicularis, Hort, ex Sweet, Hort. Brit. ed. I. 89 betulina.

ovata, Bartl. E Wendl. f. Diosm. 109.-Afr. austr. paucifora, Eckl. Eo Zeyh. Enum. 103.-Afr, austr.

pulchella, Bartl. E Wendl. f. Diosm, 107.-Afr, austr. pulchra, Cham. in Linnaea, v. (1830) 53.-Afr. austr. pungens, E. Mey. ex Hary. E Sond. Fl. Cap. i. 397.Afr. austr.

scoparia, Eckl. Eo Zeyh. Enum. 103.-Afr. austr. serratifolia, Willd. Enum. Hort. Berol. 257.-Afr. austr.

sertuliflora, Delponte, in Mem. Acc. Torino, Ser. II xiv. (1854) 408. t. 9.- Hab.

ternata, Eckl. E Zeyh. Enum. 103.-Afr. austr. trichopodis, Bartl. \& Wendl. f.ex fuss. in Mém. Mu Par. xii. (1825) 474.-Afr. austr.

venusta, Eckl. E Zeyh. Enum. 102.-Afr. austr.

BARraldeiA, Thou. Gen. Nov. Madag. 24 (1809) Carallia, Roxb. (Rhizoph.

madagascariensis, Spreng. Syst. ii. 313 (Baraultia).Madag

BARRATtiA, A. Gray, in Proc. Am. Acad. i. (1848, $48=$ BARATTIA, A. Gray \& Engelm.=Encelia, Adans. (Compos.)

BARRELIERA, J.F. Gmel. Syst. 959 (1791)= Barleria, Linn. (Acanth.)

BARRERIA, Linn. Gen. ed. II. 131 (1742); (et BARRERA, Linn. Sp. Pl, ed, II. $393(1762)$ capensis, Linn. Sp. Pl. 274.-Afr. austr.

BARRERIA Willd. Sp. Pl, i. $1145(1798)=$ Pora queiba, Aubl. (Olacineae)

gujanensis, Raensch. Nom. ed. III. 259, nomen $=\mathbb{P}$ guianensis.

theobromaefolia, Willd. Sp. Pl. i. $1145=\mathrm{P}$. guianensis.

BARRINGTONIA, Forst. Char. Gen. 75.t. $28\left(1770^{\circ}\right.$ MYRTACEAE, Benth. \& Hook. f. i. 720.

Agasta, Miers, in Trans. Linn. Soc. Ser. II. Bot i. 59 (1875).

Baranda, Llanos, in Mem. Acad. Cienc. Madr. ii. (1859) 502

Botryoropis, Presl, Epim. Bot 220 (15 49 ).

ButonicA, Juss. Gen. 326 (1789).

Doxomma, Miers, in Trans. Linn. Soc. Ser. 1I. Bot i. $(1875) 98$

MEgadendroミ, Miers, 1. c. 109 (1S75 Menichea, Sonner. Voy. N. Guin. 1831776$)$

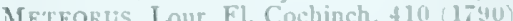

MiTrARIA, J F. Gmel. Syst. 799 (17i1).

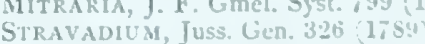

acuminata. Korth. in Nederl. Krusid. Arch. i. 1sts Zuir.-liwitis

acutangula, Gaertir. Fruct. ii. 97. ᄂ. 101.-Ins. Moluce alata. Il all. Cint. n. $\$$ iss = conoiden.

albo, Blume is 01 des Serres, Sir. I, vii 1551-5: 29. - Ins. Mnluce.

alba, Kostel. Allg. Med.-Phamn. F1. iv. $1586^{\circ}=$ racemosa asiatica, Kurz, in Joum. As Soa. Beng. xlv. (1s, $\left.b^{\circ}\right)$ il

181: xlvi. (1877:11. 70 spectos?

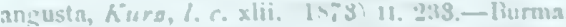

Butunion, Forst. Chas. Gen.t. SS. Ins. I"acil. 


\section{BARRINGTONIA}

calyptrata, R. Br. ex Benth. Fl. Austral. iii. 288, in nota $=$ speciosa?

Careya, F. Muell. Fragm. v. 183,-Austral.

ceylanica, Gardn. ex C. B. Clarke, in Hook. f. Fl. Brit. Ind. ii. 508.-Zeylan.

coccinea, Kostel. Allg. Med.-Pharm. Fl. iv. $1536=$ excelsa.

conoidea, Griff. Notul. iv. $656 ;$ Ic. Pl. As. t. $635,636$. f. 1.-Burma; Malacca.

costata, Miq. Fl. Ind. Bat. i. 489.-Archip. Sunda.

cylindrostachya, Griff. Notul. iv. $655=$ macrostachya.

edulis, Seem. Fl. Vit. 82.--Ins. Fiji.

elongata, Korth. in Nederl. Kruidk. Arch. i. (1848) 206. -Java.

excelsa, Blume, Bijdr. 1097.-Malaya.

Helferi, C. B. Clarke, in Hook.f. Fl. Brit. Ind. ii. 509 , -Burma.

Horsfieldi, Miq. Fl. Ind. Bat. i. 489.-Java.

inclyta, Miers, in Trans. Linn. Soc. Ser. II. Bot. (1876) $71 . \mathrm{t} .14=$ racemosa.

insignis, $\mathrm{Miq}$. Fl. Ind. Bat. i. 488.-Malaya.

intermedia, Vieill. in Bull. Soc. Linn. Normand. x. (1866) $98 .-\mathrm{N}$. Caled.

luzoniensis, Vidal, Phan. Cuming. Philipp. 13, 48, 113 -Ins. Philipp

macrocarpa, Hassk. Cat. Hort. Bogor. Alt. 263.-Java. macrophylla, Miq. Fl. Ind. Bat. i. 491 =speciosa macrostachya, Kurz, For. Fl. Brit. Burma, i. 498; et in Fourn. As. Soc. Beng, xlvi. (1877) II. 71.-Burma. Montrouzieri, Vieill. in Bull. Soc. Linn. Normand. x. (1866) 100-N. Caled.

neocaledonica, Vieill. $l$. c. $99 .-\mathrm{N}$. Caled.

nitida, Miq. Fl. Ind. Bat. i. 490.-Java.

pendula, Kurz, in fourn. As. Soc. Beng. xlvi. (1877) II. 71-Burma.

pterocarpa, Kurz, l. c. xlii. (1873) II 234.-Burma.

pubescens, Miers, in Trans. Linn. Soc. Ser. II. Bot. (1876) $83=$ acutangula.

racemosa, Roxb. Hort. Beng. 52 ; Fl. Ind. ii. 634.Ind. or. Malaya; Polynes.

Reinwardtii, Miq. Fl. Ind. Bat. i. 488.-Java.

reticulata, Mig. l. c. 490,-Borneo.

rigida, C. B. Clarke, in Hook. f. F1. Brit. Ind. ii. 510 $=$ Symplocos rigida.

rubra, Blume, in F1. des Serres, Sér. I. vii. (1851-52) 23 = racemosa.

samoënsis, A. Gray, Bot. U.St. Expl. Exped. i. 508.Ins, Fiji

sarcostachys, Miq. F1. Ind. Bat. i. $490=$ macrostachya.

Senequli, Fardin, in Bull. Soc. Linn. Normand. Sér. II. ix. (1875) 305 - - N. Caled.

serrata, Miq. Fl. Ind. Bat. i. 488.-Java.

speciosa, Linn. f. Suppl. $312=$ B. Butonica

speciosa, Wall. Cat. $\mathrm{n}$. $3632 \mathrm{~B}=$ racemosa.

spicata, Blume, Bijdr. 1097.- Java.

Stravadium, Blanco, F1. Filip. ed. I. $533=$ racemosa

sumatrana, Miq. Fl. Ind. Bat. Suppl.315.-Sumatra

timorensis, Blume, in Van Houtte, Fl. des Serres, Sér. I. vii. (1851-52) 23.-Ins. Timor.

Vriesei, Teijsm. E' Binn. in Tijdschr. Neêrl. Ind. ii. (1851) 308.- Java.

BARROËTIA, A. Gray, in Proc. Am. Acad. xv. (1880) 29. COMPOSITAE.

Pavonii, A. Gray, $l$. c. xvii. (1881-82) 206.-Mexic.

setosa, A. Gray, l. c. xv. (1880) 29.-Mexic.

subuligera, A. Gray, l. c.-Mexic.

BARROTIA, Gaudich. Bot. Voy. Bonite, t. 13 (1852?) $=$ Pandanus, Linn.

altissima, Brongn. in Ann. Sc. Nat. Sér. VI, i. (1875) $277=$ P. Minda

aragoënsis, Brongn. 1. c. $278=\mathrm{P}$. aragoënsis

Balansae, Brongn. 1. c. $281=\mathrm{P}$. Balansae.

decumbens, Brongn. 1 . c. $285=\mathrm{P}$. decumbens.

diodon, Gaudich. Bot. Voy. Bonite, t. 13. f. $9-14=\mathrm{P}$ furcatus.

Gaudichaudii, Brongn. in Ann. Sc. Nat. Sér. VI. i. (1875) $264=$ P. tetrodon

macrocarpa, Brongn. 1. c. $279=\mathrm{P}$. macrocarpus.

monodon, Gaudich. Bot. Voy. Bonite, t. 13. f. 15-24 $=\mathrm{P}$. monodon.

Pancheri, Brongn. in Ann. Sc. Nat. Sér. VI. i. (1875) $283=$ P. Pancheri.

sphaerocephala, Brongn. 1. c. $284=\mathrm{P}$. sphaerocephalus.

tetrodon, Gaudich. Bot. Voy. Bonite, t. 13. f. $1-8=$ P. tetrodon.
BARROWIA, Decne, in DC. Prod, viii. 629 (1844) ASCLEPIADEAE, Benth. \& Hook. f. ii. 779. jasminiflora, Decne. $l$. $c, 630$, - Afr. austr.

BARTERIA, Hook, f. in Journ. Linn. Soc. v. (1861) 14. t. 2. PASSIFLOREAE, Benth. \& Hook. f. i. 812. fistulosa, Mast. in Oliver, Fl. Trop. Afr. ii. 511.-Afr. trop.

nigritana, Hook. f. in fourn. Linn. Soc. v. (1861) 15 t. 2.-Afr. trop.

BARTHEA, Hook, f, in Benth. \& Hook. f. Gen. i. 751 (1867). MELASTOMACEAE, Benth. \& Hook. f. 1 , c.

chinensis, Hook. f. l. c.-Hongkong.

BARTHESTA, Comm. ex A. DC. in Trans. Linn Soc xvii. (1837) $112=$ Ardisia, Sw. (Myrsin.).

BARTHOLINA, R. Br. in Ait. Hort. Kew. ed, II, v. 194 (1813). ORCHIDEAE, Benth. \& Hook. f. iii. 623.

LAthrisia, Sw. Annot. Bot. 48 (1829).

Burmanniana, Ker-Gawl, in Brand. Journ. Sc. iv. (1818) 204.t. $5=$ pectinata.

Ethelae, Bolus, in Fourn. Linn. Soc. xx. (1884) 472.Afr. austr.

Lindleyana, Reichb. f. Otia Bot. Hamb. $119=$ pectinata. pectinata, R. Br. in Ait. Hort. Kerv. ed. II. v. 194.Afr. austr.

BARTHOLLESIA, Manso, Enum. $45(1836)=$ Berthol letia, Humb. \& Bonpl. (Myrtac.).

BARTHRATHERUM, Anderss, in Walp. Ann. iii. $799(1853)=$ BATHRATHERUM, Hochst. $=\mathbf{A r}$ thraxon, Beauv. (Gramin.).

BARTLetriA, A. Gray, in Mem. Am. Acad. Ser. II. v. (1855) (Pl. Nov. Thurb.) 323. COMPOSITAE, Benth. \& Hook. f. ii. 441.

scaposa, A. Gray, l. c.-Mexic.

BARTLINGIA, Brongn. in Ann. Se. Nat. Sér. I. x. (1827) $373=$ Pultenaea, Sm. (Legumin.).

obovata, Brongn. 1. c. $=$ P. obovata.

BARTLINGIA, F. Muell. ex Benth. F1. Austral. vii. 63 $(1878)=$ Laxmannia, R. Br. (Liliac.)

brachyphylla, F. Muell. Census, $119=\mathrm{L}$. brachyphylla. gracilis, F. Muell. Fragm, vii. $88=\mathrm{L}$, gracilis. grandiflora, F. Muell. Census, $118=\mathrm{L}$. grandiflora minor, F. Muell. 1. c. = L. ramosa.

ramosa, F. Muell. Fragm. vii. $88=\mathrm{L}$. ramosa

sessiliftora, F. Mnell. in Papers Roy. Soc. Tasm. (1877)

$116=\mathrm{L}$. sessiliflora

sessilis, F. Muell. Census, $119=\mathrm{L}$, sessilis

squarrosa, F. Muell. 1. c. $118=\mathrm{L}$, squarrosa.

BARTLINGIA, Reichb. in Flora, vii. (1824) $241=$ Plocama, Ait. (Rubiac.)

scoparia, Reichb. 1. $c_{\circ}=\mathrm{P}$. pendula.

BARTOLINA, Adans. Fam. ii. $124(1763)=$ Tridax, Linn. (Compos.).

BARTONIA. Muhl ex Willd in Ges. Naturf Freunde, Neue Schr. iii. (1801) 444. GENTIANEAE, Benth. \& Hook, f. ii. 818 .

ANĐREWSIA, Spreng. Syst. i. 428 (1825).

Centaurella, Michx. F]. Bor. Am. i.97.t. 12 (1803), Centaurium, Pers. Syn, i. 187 (1805).

Nuttalla, Rafin. in Am. Monthly Mag. (1818) 175. pubescens, Rafin. in Med. Repos. New York, v. (1808) $352=$ verna?

tenella, Muhl. ex Willd. in Ges. Naturf. Freunde, Neue Schr. iii. (1801) 445.-Am. bor.

uniflora, Rafin. in Med. Repos. New York, v. (1808) $352=$ verna?

verna, Muhl. ex A. Gray, in Chapm. Fl. S. U. St. 357. -Am, bor.

BARTONIA, Sims, Bot. Mag. t. 1487 (1804)= Mentzelia, Linn. (Loaseae)

albescens, Gill. \& Arn. in Edinb. Geog. Journ. ii. (1831) 273.-Chili.

albicaulis, Dougl. ex Hook. Fl. Bor. Am. i. $222=\mathrm{M}$. albicaulis.

aurea, Lindl, in Bot. Reg. t. 1831=M. Lindleyi.
BARTONIA :-

decapetala, Sims, Bot. Mag.t. $1487=$ Mentzelia ornata laevicaulis, Dougl, ex Hook. Fl. Bor. Am. i. 221. $69=$ M. laevicaulis

micrantha, Hook. \& Arn. Bot. Beech. Voy. $343=$ M. micrantha.

micrantha, Hook, in Lond. Journ. Bot. vi. (1847) 227 $=\mathrm{M}$. dispersa

multiflora, Nutt. in Journ. Acad. Sc. Phil. N. S. i (1847) $180=$ M. multiflora

nuda, Pursh, F1. Am. Sept. 328, $749=$ M. nuda.

ornata, Hook. Lond. Journ. Bot. vi. (1847) $226=\mathrm{M}$ laevicaulis.

ornata, Pursh, Fl. Am. Sept. $327=-$ M. ornata.

parviflora, Dougl. ex Hook. F1. Bor. Am. i. $221=$ M laevicaulis.

pumila, Nutt. ex Torr. \& Gray, F1. N. Am. i. $535=$ M. pumila.

sinuata, Presl, Rel. Haenk. ii. $38=$ albescens.

Wrightii, Walp. Ann. ii. $656=$ M. Wrightii.

BARTRAMIA, Linn. Diss. Dass. 17 (1747) ; Fl. Zeyl 77 (1747); Gaertn. Fruct. ii. 137. t. $111(1791)=$ Triumfetta, Linn. (Tiliac.).

angulata, Lam. Ill, t. 430 . f. $2=$ T. rhomboidea.

crispifolia, Stokes, Bot. Mat. Med. iii. 14=T. rhomboidea.

glandulosa, Lam. Ill. t. 400, f. 1=T. rhomboidea

indica, Linn. Sp. P1. $389=$ T. rhomboidea.

Lappago, Gaertn. Fruct. ii. 137 t. 111=T. rhomboidea

phombifolia, Stokes, Bot. Mat. Med. iii. 15=T. rhomboidea.

BARTRAMIA, Salisb. Prod. 99 (1796)= Penstemon Mitch. (Scrophular.)

concinna, Salisb. 1. c. = P. pubescens.

pulchella, Salisb. 1. $\mathrm{c}_{\mathrm{r}}=$ P. laevigata.

BARTSCHIA, Linn. Syst. ed. II. $26(\mathbf{1 7 4 0})=$ seq.

BARTSIA, Linn. Hort. Cliff, 325 (1737), SCRO. PHULARINEAE, Benth. \& Hook. f. ii. 977.

Alicosta, Dulac, Fl. Hautes-Pyr. 381 (1867).

Bellardia, All. F1. Pedem. i. 61 (1785).

Eufragra, Griseb. Spicil. F1. Rumel. ii. 13 (1844).

LAsioperA, Hoffmgg. \& Link, Fl. Port. i. 298 (1809)

ODontites, [Riv.] Hall. Enum. Stirp. Helv. ii. 627 (1742).

Parentucellia, Viv. Fl. Lib. Spec. 31. t. 21. f. (18:4)

Stae helinia, Hall. Enum. Stirp. Helv.ii. 624 (1742) Trixago, Stev. in Mém. Soc. Nat. Mosc. vi. (1823) 4. abyssinica, Hochst. ex A. Rich. Tent. F1. Abyss, ii.

$134=\mathrm{B}$. Trixago

acuminata, Pursh, Fl. Am. Sept. ii. $429=$ Castilleja pallida.

alpina, Linn. Sp. Pl.602.-Europ.; Am. bor.

aspera, Willk. E'Lange, Fl. Hisp. ii. 614, obs.-Hispan. Maroce.

bicolor, DC. Ic. Rar. t. $10=$ B. Trixago.

biloba, Wedd. Chlor. And. ii. 123.-Peruv.

breviflora, Benth. in DC. Prod. x. 545.-Calif

canescens, Wedd. Chlor. And. ii. 123.--Peruv. capensis, Spreng. Syst. ii. $773=$ B. Trixago. carnea, Griseb. Spicil. Fl. Rumel. ii. 12.-Macedon. chilensis, Benth. in DC. Prod. x. 547.-Chili. ciliolata, Wedd. Chlor. And ii. 123-Bolivia. coccinea, Linn. Sp. Pl. $602=$ Castilleja coccinea crenoloba, Wedd. Chlor. And. ii. 124.-Bolivia. decurva, Hochst. ex Benth. in DC. Prod. x. 545. Abysin.

densiflora, Benth. l. c. 548.-Peruv,

diffusa, Benth. l. c. 546.-Peruv.

elongata, Wedd. Chlor. And. ii. 127.-Am. merid. euphrasioides, Wedd. l. c. 130 --Ecuador.

Fagonii, Lapeyr. Hist. Abr. Pl. Pyr. $345=$ aspera.

filiformis, Wedd. Chlor. And.ii. 126.-Peruv.

Garideli, Ball, in Journ. Linn. Soc. xvi. (1878) $602=$ purpurea.

glanca, Poir. ex Steud. Nom. ed. II. i. 189= Lagotis glauca.

gracilis, Benth. in DC. Prod. x. 548.-N. Granat. granatensis, Ball, in Journ. Linn. Soc. xvi. (1878) 602 = purpurea.

grandiflora, Spreng. in Ersch \& Grub. Allgem. Encyc. vii. (1821) 461 = Castilleja sessiliflora.

Gymnandra, Linn. f. Suppl. $278=$ Lagotis glanca.

Gymnandra, Pursh, F1. Am. Sept. ii. $430=$ Synthyris rubra? 
BARTSIA :-

heterophylla, Wedd. Chlor. And. ii. 129.-N. Granat. hispida, Benth. in DC. Prod. x. 547,-Peruv.

humilis, Lapeyr. Hist. Abr. Pl. Pyr. 344=Euphrasia minima.

imbricata, Lapeyr. 1. c. = Euphrasia officinalis.

inaequalis, Benth. in DC. Prod. x. 547.-Peruv.; N. Granat.

integrifolia, Wedd. Chlor. And. ii, 131.-Peruy.

lanceolata, Reichb. f. Ic. Fl. Germ. xx. 57. t. 107.Europ.

laniflora, Benth. in DC. Prod. x. 546.-N. Granat.

laticrenata, Benth. 1. c. $547=$ santolinaefolia.

latifolia, Sibth. E Sm. Fl. Graec. vi. 69. t. 586.-Reg. Mediterr.; Reg. Cauc.; Persia.

laxiflora, Benth. in DC. Prod. x. 547.-N. Granat.

longiflora, Hochst. ex Benth. l. c. 545.-Abyss.

lutea, Reichb. f. Ic. Fl. Germ. xx. 56.-Europ.; As. Min.

maxima, Gren. \& Godr. Fl. Fr. ii, 611, in syn. $=$ viscosa.

maxima, Pers. Syn. ii. $151=$ B. Trixago.

melampyroides, Benth. in DC. Prod. x. 548.-Ecuador.

Meyeniana, Benth. l. c. 546.-Peruv.

mollis, Turcz. ex Herd. in Bull. Soc. Nat, Mosc, lviii. (1883). I. $397=$ Veronica ciliata.

mutica, Benth. l. c. 548,--Peruv.

Odontites, Huds. Fl. Angl. 268.-Europ.; Reg. Mediterr.

orthocarpiflora, Benth. in DC. Prod. x. 545.-Peruv.

pallida, Limn. Sp. Pl. $602=$ Castilleja pallida.

parviflora, Charpent. ex Benth. in DC. Prod. x. $544=$ alpina.

parviflora, Thom. Cat. Pl. Suisses (1837) $6=$ alpina, parvifolia, Benth in DC. Prod. x. 545,-N. Granat.

patens, Benth.l. c. 546.-Peruv.

pedicularoides, Benth. l. c-Ecuador

peruviana, Walp. in Nov. Act. Nat. Cur. xix. Suppl. i. 1843) 400 - - Peruy.

pumila, Benth. in DC. Prod. x. 546.-Peruv.

purpurea, Ball, in Fourn. Linn. Soc. xvi. (1878) 602. -Hispan.; Afr. bor.

purpurea, Duby, Bot. Gall. $354=$ latifolia.

rhinanthoides, Hochst. ex Benth. in DC. Prod. x. 543 B. Trixago.

mbricoma, Pall. Reise, iii. $34=$ Castilleja pallida. santolinaefolia, Benth. in DC Prod. x. 547.-Mexic.

scabra, Spreng. Syst. ii. 773.-Afr, austr.

scordifolia, Sterd. Nom. ed. II. i. 189.-Ins. Mader.

serotina, Bertol. Amoen. Ital. $33=$ B. Odontites.

sibirica, Pall. Reise, i1, 123 = Castilleja pallida.

spicata, Ramond, in Bull. Soc. Philom. ii. (1799-1801) $\approx$ aspera

stricta, Benth. in DC. Prod. x. 547.-Ecuador.

subinclusa, Benth. l. c.--Peruv.

subinclusa, Griseb. ex Wedd. Chlor. And. ii. $126=$ filiformis.

tenuifalia, Pursh, Fl. Am. Sept. ii. $429=$ Orthocarpus tenuifolius.

trichophylla, Wedd. Chlor. And. ii. 122.-Peruv.

trifida, Spreng. Syst. ii. $773=$ Bungea trifida.

Trixago, Linn. Sp. Pl. 602.-Europ.; Afr. bor.

verna, Reichb.f. Ic. Fl. Germ. xx. 57. t. 107.-Europ.

versicolor, Pers. Syn. ii. $151=B$. Trixago

viscosa, Linn. Sp. Pl. 602.-Europ.; Reg. Mediterr.

BARYA, Klotzsch, in Monatsb. Berl. Acad. (Maerz 1854) 122 ; et in Abl. Akad. Berl. (1854) 22. t. 2, B =Begonia, Linn.

monadelpha, Klotzsch, 11. cc. 122, $23=$ Begonia monadelpha.

BARYOSMA, Gaertn. Fruct. ii. 79. t. $93(1791)=$ Dipteryx, Schreb. (Legumin.)

oppositifolium, Pers. Syn, ii. $278=$ D. oppositifolia.

Tongo, Gaertr. Fruct. ii. t. $93=$ D. odorata.

BARYOSMA, Roem. \& Schult. Syst. v. 448 (1819)= Barosma, Willd. (Rutac.)

BARYSOMA, Bunge, Del. Sem. Hort. Dorpat. (1839) 7 ; et in Linnaen, xiv. (1840) Litt. $117=$ Heracleum, Linn. Umbellif.

villosum, Bunge, 11 . $\mathrm{cc} .=\mathrm{H}$. villosum.

BARYXYLUM, Lour. Fl. Cochinch. 266 (1790). LEGUMINOSAE?-Cr. Benth. \& IIook, f, i. 104 . rufum, Lour. l. co-China.
BASALTOGETON, Salisb. Gen. Pl. Fragm. $27(1866)=$ Scilla, Linn. (Liliac.)

peruvianum, Salisb. 1, c. $=\mathrm{S}$. peruviana.

BASANACANTHA, Hook, f, in Benth. \& Hook, f Gen. ii. 82 (1873). RUBIACEAE, Benth. \& Hook. f. $1 . c$.

armata, Hook. f. l. c. 83-Am. trop.

dioica, Hook. f. l. c.-N. Granat.

hebecarpa, Hook. f. l. c.-Am. trop.

Humboldtiana, Hook. f. l. c.-Am, trop.

monantha, Hook. f. l. c.-Guatemala.

reticulata, S. Wats. in Proc. Am. Acad. xviii. (188283) 98 -Mexic.

tetracantha, Hook. f. in Benth. E Hook. $f$. Gen. ii. 83. -Am. trop.

BASANANTHE, Peyr. in Bot. Zeit. xvii. (1859 101; et in Sitzb. Acad. Wien. Math. Nat. xxxviii. (1860) 569. PASSIFLOREAE, Benth. \& Hook, f. I 812.

littoralis, Peyr. 1l. cc.-Afr. trop.

Nummularia, Welw. in Trans. Linn. Soc. xxvii. (1869) 28. t. 9.-Angola.

BASELA,Linn. Gen. ed. VI. (Vindob. reimpr.) 151 (1767) $=\mathrm{seq}$

BASELLA, [Rheede] Linn. Diss. Dass. $12(1747)$ Amoen. Acad. i. 396. CHENOPODTACEAE, Benth. \& Hook. f. iii. 76.

Gandola, Rumph. ex Linn. Sp. Pl. ed. II. 390 (1762)

alba, Linn. Sp. Pl. $272=$ rubra.

cananifolia, Buch.-Ham. ex Wall. Cat. n. $6961=$ rubra cordifolia, Lam. Encyc. i. $382=$ rabra.

crassifolia, Salisb. Prod. $153=$ rubra.

diffusa, Ruiz \& Pav。 ex Moq, in DC. Prod, xiii. II. 226 (=Tandonia diffusa).-Peruv.

fliformis, Ruiz \& Pav. ex Moq. 1. c. 227 (=Tandonia filiformis).--Peruv.

Hookeriana, Moq. ex Moq. 1. c. $225=$ Toumonia Hookeriana.

japonica, Burm. f. Fl. Ind. 76. t. 39. f. $4=$ rubra. lucida, Linn. Syst. ed. X. 966 , n. $343=$ rubra.

marginata, H. B. \& K. Nov. Gen. et Sp. ii. 189 (=Tandonia marginata).-Ecuador. nigra, Lour. Fl. Cochinch. i. $183=$ rubra.

obovata, H. B. \& K. Nov. Gen. et Sp. ii. 189

Tandonia obovata).-N. Granat.

obtusifolia, Willd. ex Moq. in DC. Prod. xiii. II. 227

(=Tandonia obovata). - N. Granat.

ramosa, Jacq. $\mathrm{f}$, in Spreng. Syst. i. $950=$ rubra.

rubra, Linn. Sp. Pl. 272,-Reg. trop.

trifida, Willd. in Roem. \& Schult. Syst. vi. 695 (= Tandonia marginata) -Ecuador.

tuberosa, H. B. \& K. Nov, Gen. et Sp. ii. $189=$ Ullucus tuberosus.

vesicaria, Lam, Illustr. t. 215. f. 1=Anredera spicata

volubilis, Salisb. Prod. $153=$ rubra.

BASILAEA, Juss. ex Lam. Encyc. i. 382 (1783) ; et Gen $52(1789)=$ Eucomis, L'Hérit. (1788) (Liliac.).

bifolia, Mirb. Hist. Nat. Pl. viii. (1804) $339=$ Whiteheadia bifolia.

coronata, Lam. Encyc. i. $382=$ E, regia

nana, Mirb. Hist. Nat. Pl, viii. (1804) $339=$ E. nana punctata, Mirb. 1. c. ; Lam. Illustr. t. $289=$ E. punctata. regia, Mirb. 1. c. $338=\mathrm{E}$. regia.

undulata, Mirb. 1. c. = E. undulata.

BASILEOPHYTA, F. Muell. First. Gen. Rep. 16 (1853) = Fieldia, A. Cunn. (Gesnerac.)

Friderici-Augusti, F. Muell. 1. c. $=$ F. australis.

BASILICUM, Moench, Meth. Suppl. 149 (1802)= Ocimum, Tourn. (Labiat.)

polystachion, Moench, l. c. = O. Basilicum.

BASILLAEA, R. Hedw. Gen. 239 1809)= BASILAEA Juss, = Eucomis, L'Hérit. (Liliac.).

BASILIMA, Rafin. New Fl, Am. iii. 75 (1896)= Spiraea, Linn. (Rosac.)

pygmea, kiafin. 1. c. 76, -Am, bor

sorbifolia, Kafin. 1. c. $75=\mathrm{S}$. sorbifolia?
BASISTEMON, Turc. in Bull. Soc, Nat. Mosc. (1863) 214. SCROPHULARINEAE, Benth. \& Hook. f. ii. 1244 .

bogotensis, Turcz, l. c.-N. Granat.

peruviana, Benth. E Hook. f. Gen. ii. 1245.-Peruv.

BASKFRVILLA, Lindl. Gen. et Sp. Orch. 505 (1840) ORCHIDEAE, Benth. \& Hook. f. iii. 597

assurgens, Lindl. l. c.-Peruv.

BASONCA, Rafin. Fl. Tellur. iv. 68 (1836)= Martynia Linn. (Pedalín.).

longiflora, Rafin. 1. c. = M. longiftora.

BASSELINIA, Vieill. in Bull. Soc, Lina. Normand. Sér. II. vi. 1872 (1873) 230. PALMAE.

Deplanchei, Brongn. E Gris, lo co 232 , nomen.N. Caled.

gracilis, Brongn. Eo Gris, l. c. 231, nomen--N. Caled. kanaliensis, Vieill. l. c. 232 , nomen.-N. Caled. Lenormandii, Vieill. l. c. nomen.-N. Caled.

Pancheri, Brongn. Eo Gris, l. c. nomen.-N. Caled.

BASSIA, All. Misc. Taur. iii. 177. t. 4 (1766)

Chenolea, Thunb. (1781) (Chenopod.).

astracantha, F. Muell. Census, $140=$ C. astrocarpa. astrocarpa, F. Muell. Fragm. xii. $12=\mathrm{C}$. astrocarpa. bicornis, F. Muell. Census, $30=$ Sclerolacna bicomis. bicuspis, F. Muell. 1. c. = Anisacantha bicuspis. biflora, F. Muell. 1. c. = Sclerolaena biflora. Birchii, F, Mucll, 1. c $=$ Anisacantha Birchii. brevicuspis, F. Muell. 1. c. = Anisacantha brevicuspis. carnosa, $\mathrm{F}$. Muell l, $\mathrm{c}=\mathrm{C}$ carnosa.

Cornishiana, F. Muell, in Melb. Chem. \& Drug. (1885) -Austral.

Dallachyana, F. Muell. Census, $30=$ C. Dallachyana. diacantha, F. Muell. 1. c. =Sclerochlaena diacantha. divaricata, F. Muell. 1, c. = Apisacantha divaricata.

Drummondii, F. Muell, 1. c.=Anisacantha Drum mondii.

echinopsila, F. Muell. 1. c. = Anisacantha cchinopsila. enchylaenoides, F. Muell. 1. c. = C. enchylaenoides. Erskineana, F. Muell. in Melb. Chem. \& Drug. (Apr. 1885).-N. Guinea.

eurotioides, F. Muell. Census, $30=\mathrm{C}$. eurotioides Forrestiana, F. Muell. Fragm, xii. $12=$ C. Forrestiana glabra, F. Muell. Census, $30=$ Anisacantha glabra. hirsuta, Aschers. ex Nym. Consp. $625=\mathrm{C}$. hirsuta. lanicuspis, F. Muell. Census, $30=$ Sclerochlaena lani. cuspis.

micrantha, F. Muell. 1. $c_{s}=$ Enchylaena micrantha.

Muelleri, F Muell. 1. $\mathrm{c}=\mathrm{C}$. Muelleri.

muricata, All. Misc. Taur, iii, t. $4=\mathrm{C}$. hirsuta.

paradoxa, F. Muell. Census, $30=$ Sclerolaena para. doxa.

quinquecuspis, F. Muell. 1. c. = Anisacantha muricata salsuginosa, F. Muell. 1. c.=Threlkeldia salsuginosa. sclerolaenoides, F. Muell. 1. $\mathrm{c} .=\mathrm{C}$. sclerolaenoides. tricornis, F. Muell. 1. c. = C. tricomis.

tridens, F. Muell. Fragm. xiî. $12=\mathrm{C}$. tridens. uniflora, F. Muell. Census, $30=$ Sclerolaena miflora.

BASSIA, Koenig, ex Linn. Mant. ii. App. 555 (1771) SAPOTACEAE, Benth. \& Hook, f. ii. 658 .

Dasyaulus, Thw. Enum. Pl, Zeyl. 175 '1860

Illipe, F. Muell. Extra-trop. Pl. Am. ed. [5] is\& 181.

MADHUCA, J. F. Gmel. Syst. 799 '1791'.

albescens, Griseb. Cat. P1. Cub. 104 Labourdonnaisiae sp.).-Cuba occ.

amicorum, A. Gray, in Proc. Am. Acad. v. (1801-6? 327. - Ins. Pacif.

argentea, De Vriese Pl. Reins, 6" - Malacen.

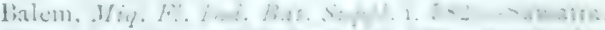

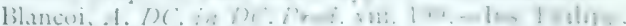

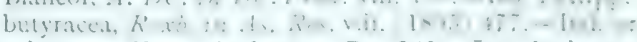
caloweura. Kurs. Andiman. Re- 141,-Ins. Andaman. canaliculata, Becld. Forest. Man. But. 111 = Dichuy canaliculata.

Cocco, Scheff, in Ann. Ford. Busterng. i. (1S:0̈) 34N. Guine:

cuneata, Blume, Bijalr. 3i5.-Malaya.

dubia, Gaertu. Fract. ii. 104. 1. 104.-Amtmin.

elliptica, Dalz. in Hook. Kew Joura. iii. lssi

Dichopsis elliptica.

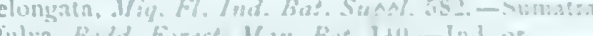




\section{BASSIA :-}

galactoxyla, F, Muell. Fragm. vi. $27=$ Lucuma galactoxylon.

grandis, Bedd. F1. Sylv. ii. t. $254=$ Dichopsis grandis hypoleuca, Miq. F1. Ind. Bat. Suppl. 582=Dichopsis obovata.

insignis, Radlk. in Sitzb. Math.-Phys. Acad. Muench xii. (1882) 309.-Ind. or.

Fussaei, Griseb. Fl. Brit. W. Ind. 402 (sphaIm.-Cf. Achras mammosa).-Ind. occ

Korthalsii, Pierre, ex Burck, in Ann. Fard. Buitenz. v. (1885) 45. - Sumatra.

Krantzil, Hance, in fourn. Bot. xiv. (1876) 260.Cambodia.

laevifolia, Bedd. Forest. Man. Bot. $\mathbf{1 4 1}=$ Dichopsis laevifolia.

lanceolata, Bedd. 1. c. = Dichopsis lanceolata.

lanceolata, A.DC. in DC. Prod. viii. 199.-Ins. Philipp

latifolia, Roxb. Pl. Corom. 1. 20. t. 19.-Ind. or.

Lobbii, C. B. Clarke, in Hook. f. Fl. Brit. Ind. iii. 546 -Burma.

lon gifolia, Linn. Mant. ii. App. 563.-Ind. or

malabarica, Bedd. Forest. Man. Bot. 140.-Ind. or.

microphylla, Hook. Ic. Pl. i. t. 74-Zeylan.

Moonii, Bedd. Forest. Man. Bot. 140.-Ind. or.

Mottleyana, C. B. Clarke, in Hook. f. Fl. Brit. Ind. iii.

546.-Malaya.

neriifolia, Bedd. Forest. Man. Bot. 140.-Ind. or.

obovata, Forst. f. Prod. n. 200.-Ins. Tanna.

oleifera, A. DC. in DC. Prod. viii. 199.-Ins. Philipp

pallida, Burck, in Ann. Fard. Buitenz. v. (1885) 44.Sumatra.

Parkii, G. Don, Gen. Syst. iv. $36=$ Butyrospermum Parkii.

parvifolia, A. DC. in DC. Prod.viii. 198=microphylla. panciflora, Bedd. Forest. Man. Bot. 141=Dichopsis pauciflora.

petiolaris, Bedd. l. c. 140,-Ind. or.

polyantha, Wall. Cat. n. $4166=$ Dichopsis polyantha.

rubiginosa, Bedd. Forest. Man. Bot. $141=$ Dichopsis rubiginosa.

sericea, Blume, Bijdr, 674.--Malaya.

villosa, Wail. Cat. n. $4165=$ latifolia.

Wightiana, Bedd. Forest. Man. Bot. $141=$ Isonandra Wightiana.

BASSOVIA, Aubl. PI. Gui. i. 217. t. 85 (1775) SOLANACEAE, Benth. \& Hook. f. ii. 892.

Aureliana, Sendt, in Mart. F1. Bras. x. 138. t. 19 (1846).

Witheringia, L'Hérit. Sert. Angl i. f. 1 (1788).

brachypoda, Dun. in DC. Prod. xiii. 411.-Peruv.

cornuta, Hiern, in Kjoeb. Vidensk. Meddel. (1877-78) 59.-Bras.

crassiflora, Dun. in DC. Prod. xiii, 409.-Bras.

fasciculata, Dun.l. c. 408.-Bras

Gardneri, Dun. l. c. 409.-Bras.

glomuliflora, Dun. $l$. c. 405-CBras.

hebepoda, Dun. l. c, $407=$ lucida?

laevis, Dun. l. c. 408.-Java.

leptopoda, Dun.l. c. 411.-Bras.

lucida, Dun. l. c. 406.-Guatemala.

pyraster, Dun. l. c. 408.--Bras.

Richardi, Dun. $l$. c. 406 -Guiana

silvatica, Blanco, Fl. Filip. ed. II. $95=$ Maesa indica.

solanacea, Benth. E Hook. f. Gen. ii. 891.-Hab.?

Spina-alba, Griseb. in Goett. Abhandl. xxiv. (1879)

248.-Am. bor.

sylvatica, $A u b l . P l$. Gui. i. 217.-Guiana.

tomentosa, Dun. in DC. Prod xiii. 409._Bras.

velutina, Dun. $l$. c, 410.-Bras.

Wallichii, Dun. 1. c. $409=$ Solanum crassipetalum.

BASTARDIA, H. B. \& K. Nov. Gen. et Sp. v. 254. t 472 (1821). MALVACEAE, Benth. \& Hook. f. i. 203. BogenHaRdiA, Reichb. Nom. 200 (1841)

angulata, Guill. \& Perr. Tent. F1. Seneg. 1. $65=$ Abrtilon intermedium.

aristata, Turcz. in Bull. Soc. Nat. Mosc. xxxi. (1858) i. $200=$ bivalyis.

bivalvis, $H . B$. \& $K$. Nov. Gen. et $S p$. v. 255 , in nota.Jamaica.

crispa, St. Hil. Fl. Bras. Mer. i. 194, in nota=Abutilon crispum.

foetida, Sweet, Hort. P-it. ed. II. $64=$ Abutilon foetidum. guayquilensis, Turcz. in Bull. Soc. Nat. Mosc. xxxi. (1858) I. $200=$ viscosa

hirsutiflora, PresI, Reliq. Haenk. ii. $112=$ viscosa.

\section{BASTARDIA :}

hirsutissima, Walp. Rep. i. $327=$ praec.

nemoralis, St. Hil. F1. Bras. Mer. i. $195=$ Abutilon crispum.

parvifolia, H. B. \& K. Nov. Gen. \& Sp. v. $255=$ viscosa.

spinifex, Triana \& Planch. in Ann. Sc. Nat. Sér. IV. xvii. (1862) $186=$ bivalvis.

viscosa, H. B. E' K. Nov. Gen. et Sp. v. 256.-Mexic.

BASTERA, J. F. Gmel. Syst. 1271 (1791)=BASTERIA, Houtt. $=$ Berkheya, Ehrh. (Compos.).

BASTERIA, Mill. Gard. Dict. ed. VII $(1759)=\mathbf{C a l y}$ canthus, Linn.

Calycanthus, Mill. 1. c. ed. VIII =C. floridus.

BASTERIA, Houtt. Nat. Hist. P1. vi. $158(\mathbf{1 7 7 6})=$ Berkheya, Ehrh. (Compos.).

aculeata, Houtt. 1. c. = Berkheya obovata

BASTIA, Steud. Nom. ed. II. i. 238, in syn. (1840), sphalm. = BUSTIA, Adans, = Buphthalmum, Linn (Compos.)

BATANTHES, Rafin. Atl. Journ. $145(1832)=$ Gilia, Ruiz \& Pav. (Polemon.)

aggregata, Rafin. 1. c.=G. aggregata

longiflora, Rafin. 1. c. = Collomia longiflora

pungens, Rafin. I. $\mathrm{c}_{.}=\mathrm{G}$. pungens.

BATATAS, Choisy, in Mém. Soc. Phys. Genèv. vi. (1833) 434 ; (Conv. Or. 52)=Ipomoea, Linn. (Convolv.). abyssinica, A. Rich. Tent. F1. Abyss. ii. $64=\mathrm{I}$. abys sinica.

acetosaefotia, Choisy, Conv. Rar. $124=\mathrm{I}$, carnosa. auriculata, Hochst. ex Choisy, in DC. Prod. ix. $350=$ I. cordofana.

betacea, Lindl. in Bot. Reg. (1839) Misc. 93 ; (1840) t. 56.-Guiana.

bignonioides, G. Don, Gen. Syst. iv. $261=\mathrm{I}$. bignonioides.

bombycina, Choisy, in DC. Prod. ix. $340=\mathrm{I}$. bombycina.

bonariensis, Lindl. in Bot. Reg. (1838) Misc. $55=\mathrm{I}$. ficifolia.

Cavanillesii, G. Don, Gen. Syst. iv. $262=\mathrm{I}$. Cavanillesii.

Choisyana, Wight, Ic. t. $491=$ Argyreia Choisyana.

cissoides, Choisy, Conv, Or. $55=\mathrm{I}$. cissoides.

crassicautis, Benth. Bot. Voy. Sulph. 134.-Guayaquil. edulis, Choisy, Conv. Or. $53=\mathrm{I}$. Batatas.

glaberrima, Hassk. Retzia, i. 65.-Hab.?

glabra, Benth. in Hook. Lond. Journ. Bot. v. (1846) $352=$ I. glabra

glaucifolia, G. Don, Gen. Syst. iv, $262=\mathrm{I}$, glaucifolia heterophylla, G. Don, l. c. $261=\mathrm{I}$. heterophylla

incurva, Benth. in Hook. Niger FI. $464=\mathrm{I}$. incurva?

insignis, G. Don, in Sweet, Hort. Brit. ed. III. $482=\mathrm{I}$ insignis.

Falapa, Choisy, Conv. Rar. $125=\mathrm{I}$. Jalapa.

littoralis, Choisy, 1. c. $124=$ I. carnosa.

Loureirii, G, Don, Gen. Syst. iv, $262=\mathrm{I}$. tuberosa

macrorhizos, G. Don, 1. c. $261=\mathrm{I}$. macrorhizos.

maritima, Boj. Hort. Manrit. $225=$ I. biloba.

multiflora, Boj. ex Choisy, in DC. Prod. ix. $371=\mathrm{I}$ staphylina.

paniculata, Choisy, Conv. Or. 54=I. digitata.

Papirin, G. Don, Gen. Syst. iv. $261=\mathrm{I}$. pubescens.

pareiraefolia, Choisy, Conv. Rar. $123=\mathrm{I}$. pareiraefolia

pentaphylla, Choisy, Conv. Or. $54=\mathrm{I}$. pentaphylla

pulchella, Boj. Hort. Maurit. 226=I. pulchella.

quinquefolia, Choisy, Conv. Rar. $127=\mathrm{I}$. quinquefolia

senegalensis, G. Don, Gen. Syst. iv. $261=\bar{I}$. palmata.

simuatus, Guss. Enum. PI. Ins. Inar. (1854) $210=\mathrm{I}$ stolonifera.

subtriloba, G. Don, Gen. Syst. iv. $261=\mathrm{I}$. pubescens.

ternata, G. Don, 1. c. $262=\mathrm{I}$. ternata.

tomentosa, Choisy, in DC. Prod. ix. 337 = I. tomentosa.

triloba, Choisy, Conv. Rar. 127 = I. triloba.

tuberosa, Boj. Hort Maurit. $226=\mathrm{I}$. tuberosa.

venosa, Boj. 1. $c_{.}=$I. cairica.

venosa, G. Don, Gen. Syst. iv. $261=\mathrm{I}$. venosa.

villosa, Choisy, in DC. Prod. ix. $337=\mathrm{I}$. villosa

viscida, Voigt, Hort. Suburb. Calc. 354.-Ind. or. ?

Wallii, Morr. in Ann. Gand. ii. (1846) 285 - I. Wallii.

Willdenorri, G. Don, Gen. Syst iv $261=\mathrm{I}$, hetero phylla.

xanthorhiza, Boj. Hort. Maurit. $225=\mathrm{I}$. Batatas.
BATEMANIA, Endl. Gen. 197 (1837)=seq.

BATEMANNIA, Lind1. in Bot. Reg. t. 1714 (1834) $O R C H I D E A E$, Benth. \& Hook. fo iii. 546.

apiculata, Reichb. f. in Linnaea, xli. (1877) 109.-N Granat.

armillata, Reichb. f. in Gard. Chron. (1878) I. 780 . Hab.?

Beaumontii, Reichb. f. in Walp. Ann. iii. 544.Bras.

Burtii, Endr. \& Reichb. f. in Gard. Chron. (1872) 1099 = Zygopetalum Burtii.

Colleyi, Lindl. Bot. Reg. xx. (1835) t. 1714.Guiana.

fimbriata, Linden $\sigma^{\circ}$ Reichb. f. in Bonplandia, ii. (1854) 280.-N. Granat.

grandiflora, Reichb. f. 1. c. iv. (1856) $323=$ Zygopetalum grandiflorum.

Gustavi, Reichb. f. in Linnaea, xli. (1877) 108.-N Granat.

Lalindei, Linden, Cat. (1873) n. 90.-N. Granat

lepida, Reichb. f. in Gard. Chron. (1878) I. 588. Bras.

Meleagris, Reichb. $f$. in Bonplandia, iii. (1855) 217.Bras.

Wallisii, Reichb. f. in Gard. Chron. (1880) I. $776 .-$ N. Granat.

BATERIUM, Miers, in Ann. \& Mag. Nat. Hist. Ser. III xiii. (1864) $124=$ Haematocarpus, Miers (1867) (Menisp.).

validum, Miers, 1. $\mathrm{c} .=\mathrm{H}$. Thomsoni.

BATESIA, Spruce, in Benth. \& Hook. f. Gen. i. 563 (1865). LEGUMINOSAE, Benth. \& Hook. f. 1. c. floribunda, Spruce, ex Benth. in Trans. Linn. Soc. Xxv. (1866) 303. t. 37.- Bras. bor.

BATHYSA, Presl, in Abh. Buehm. Ges. Folge V. iii. (1845) 514 ; (Bot. Bemerk. 84). RUBIACEAE Benth. \& Hook. f. ii. 49.

Schoenleinia, Klotzsch, in Hayne, Arzneigew. xiv. in nota ad $t .15(1846)$

VoIgTia, Klotzsch, 1. c. (1846)

stipulata, Presl, l. c.-Bras.

BATINDUM, Rafin. Sylva Tellur. 81 (1838)=Oftia Adans. (Myopor.)

jasmineum, Rafin. 1. c. $82=0$, africana.

BATIS, Linn. Syst. ed. X. 1380, n. 1172 (1759) BATIDEAE, Benth. \& Hook. f. iii. 88 .

americana, Linn. Mant. ii. 499.-Am. bor.

aurantiaca, Wall. ex Thw. Enum. Pl. Zeyl. $263=$ Plecospermum spinosum.

californica, Torr. in Smithson. Contrib. vi. (1854) $8=$ maritima.

fruticosa, Roxb. Hort. Beng. [71] ; F1. Ind. iii. $763=$ Cudrania javanensis et C. fruticosa

hermaphrodita, Blanco, Fl. Filip. ed. I. 791.-Ins. Philipp.

maritima, Linn. Syst. ed. X. 1380-Tamaica.

spinosa, Roxb. Hort. Beng. [71]; Fl. Ind. iii. $762=$

Plecospermum spinosum.

vermiculata, Hook. F1. Bor. Am. ii. $128=$ Sarcobatus vermiculatus.

BATOCARPUS, Karst. F1. Columb. ii. 67. t. 134 (1862?). URTICACEAE, Benth. \& Hook. f. iii. 376.

orinocensis, Karst. l. c.-Venezuela.

BATOCYDIA, Mart. ex DC. Prod. ix. $143(1845)=$ Bignonia, Linn.

capreolata, Mart. 1. c. $146=$ Bignonia capreolata. cuneifolia, Mart. 1. c. $157=$ Bignonia cuneifolia. exoleta, Mart. 1. c. $148=$ Bignonia exoleta.

Unguis, Mart. 1. c. $146=$ Bignonia Unguis-cati.

BATODENDRON, Nutt. in Trans. Am. Phil. Soc. Ser II. viii. (1843) $261=$ Vaccinium, Linn

arboreum, Nutt. $1_{0} c_{a}=$ V, arboreum.

BATRACHIUM, S. F. Gray, Nat. Arr. Brit. Pl. ii. 720 (1821) = Ranuneulus, Tourn.

admixtum, Nyl. in Nyl. \& Sael. Herb. Mus. Fenn. 35 $=\mathrm{R}$. confervioides.

aquatile, Wimm. F1. Schles. (1841) 8 -R. aquatilis. aspergillifolium, Dum, in Bull. Soc. Bot. Belg. ii. (1863) $218=\mathrm{R}$. trichophyllus. 
BATRACHIUM :-

Bachii, Wirtg. ex F. Scbultz, Arch. FI. Fr, et Allem, i. (1844) $292=$ Ranunculus fluitans.

Baudotii, F. Schultz, 1. c. $71=$ R. Baudotii.

bipontinum, F. Schultz, ex Gren. \& Godr. Fl. Fr. i. 24 $=\mathrm{R}$. trichophyllus.

biternatum, Bercht. \& Presl, Rostl. i. Ranunc. $49=\mathrm{R}$. biternatus.

caespitosum, S. F. Gray, Nat. Arr. Brit. Pl. ii. 722 $=\mathrm{R}$. circinatus.

caespitosum, F. Schultz, Arch. F1. Fr. et Allem. i (1844) $71=\mathrm{R}$. trichophyllus.

capillaceum, Bercht. \& Presl, Rostl. i. Ranunc. $49=$ R. trichophyllus.

carinatum, Schur, in Verh. Naturf. Ver. Bruenn, xv. II. (1877) $28=\mathrm{R}$. Baudotii.

circinatoides, Arv, in Soc. Ech. Dauph. iv. (1877) 105 $=\mathrm{R}$. aquatilis ?

circinatum, Spach, Hist. Vég. Phan, vii. $201=\mathrm{R}$.

circinatus.
coenosum, Nym, in Bot. Notiser (1852), 100 = R. coenosus.

confervoides, Fries, in Bot. Notiser (1845), $121=\mathrm{R}$.

coenosus.
confusum, Garcke, Fl, Deutschl. ed. V. $8=$ R. Petiveri.

confusum, Le Jolis, in Mém Soc. Sc. Nat. Cherb. vii. (1860) $257=\mathrm{R}$. confusus.

dichotomum, Schmalh. ex Trantv, in Act. Hort. Petrop.

ix. (1884) $363=\mathrm{R}$, aquatilis.

divaricatum, Wimm. H1. Schles. (1841) $10=\mathrm{R}$. divaricatus.

diversifolium, Nym. Consp. $15=\mathrm{R}$. diversifolius.

Drouetii, Nym. in Bot. Notiser (1852) $98=\mathrm{R}$. Drouetii.

elongatum, F. Schultz, in Billotia, i. $113=\mathrm{R}$. peltatus. eradicatum, Laest. ex Nym. Consp. $15=\mathrm{R}$. confervoides.

flaccidum, Rupr. Fl. Canc. $15=\mathrm{R}$. aquatilis.

floribundum, Dum. in Bull. Soc. Bot. Belg. ii. (1863) $216=\mathrm{R}$. floribundus

fluitans, Wimm. Fl. Schles. (1841) $9=\mathrm{R}$. fluitans.

fuviatile, S. F. Gray, Nat. Arr, ii. $722=$ R. fluviatilis

Friesii, Nym. Consp. $15=$ R. heterophyllus.

Godronii, Nym. 1. c. $16=\mathrm{R}$, diversifolius.

hederaceum, S. F. Gray, Nat. Arr. ii. $721=$ R. hederaceus.

heterophyllum, S. F. Gray, 1. c. = R. heterophyllus.

heterophyllum, Lange, Pugill. $251=\mathrm{R}$. peltatus.

hololeucum, Garcke, F1. Deutschl. ed. IV. $7=\mathrm{R}$. hololeucus.

intermedium, Nym. Syll. $175=\mathrm{R}$. intermedius.

Langei, F. Schultz, ex Nym. Consp. $16=$ R. tripartitus.

leiospermum, Hartm. f. Skand. Fl. ed. XIII. $165=$ R. hederaceus.

Lenormandii, F. Schultz, Arch. Fl. Fr. et Allem. i. (1844) $70=\mathrm{R}$. Lenormandi.

longirostre, F. Schultz, 1. c. $71=$ R. longirostris.

lutarium, Revel, in Act. Linn. Soc. Bord. xxv. (1864) 413. t. $4=\mathrm{R}$. Lenormandi.

luteolum, Revel.-Cf. Bull. Soc. Bot. Fr. xii. (1865) Bibliog. $258=\mathrm{R}$. heterophyllus.

lutulentum, Nym. Syll. Suppl. $29=$ R. trichophyllus, marinum, Fries, Nov. Mant. iii. $51=\mathrm{R}$. Baudotii.

minimum, Schur, in Verh. Naturf. Ver. Bruenn, xv. II. $(1877) 28=$ R. trichoph) llus

obtusiflorum, S. F. Gray, Nat. Arr. ii. $721=$ R. tripartitus.

ololeucos, [Bossch] Prod. F1. Bat. $7=$ R. hololeucus.

omoiophyllum, Nym. Consp. $16=\mathrm{R}$. hederaceus.

pantothrix, S. F. Gray, Nat. Arr. ii. $722=\mathrm{R}$. trichophyllus.

paucistamineum, F. Schultz, Arch. Fl. Fr, et Allem. (1844) $71=\mathrm{R}$. trichophyllus.

pectinatum, Nym. Consp. $15=\mathrm{R}$. trichophyllus.

peltatum, Bercht. \& Presl, Rostl. i. Ranunc. $49=\mathrm{R}$. peltatum.

penicillatum, Dum. in Bull. Soc. Bot. Belg, ii. (1863)

$216=\mathrm{R}$. peltatus.

Petiveri, F. Schultz, Arch. Fl. Fx. et Allem. 1. (1841) $71=$ R. Petiveri.

peucedanifolium, Dum. Fl. Belg. $127=\mathrm{R}$. Aluitans,

pseudofuitans, Nym. Consp. $16=\mathrm{R}$. peltatus.

pumilum, Nym. in Bot. Notiser (1852), 98=R. fluitans.

radians, Dum, in Bull. Soc. Bot. Belg. ii. (1863) $215=$ R. trichophyllus.
BATRACHIUM :-

radians, Revel, in Act. Linn. Soc. Bord. xix. (1853) $120=$ Ranunculus radians.

rhipiphyllum, Dum. in Bull. Soc. Bot. Belg. ii. (1863) $215=\mathrm{R}$. diversifolius

rigidum, Dum, Ft. Belg. $127=\mathrm{R}$. trichophyllus,

Rionii, Nym. in Bot. Notiser $(1850)=\mathrm{R}$. sceleratus.

tenellum, Dum. in Bull. Soc. Bot. Belg. ii. (1863) 211 R. tenellus.

trichophyllum, ['Bossch] Prod. F1. Bat. 7 ; Des Moul. in Act. Soc. Linn. Bord. xx. (1859) $456=\mathrm{R}$. trichophyllus.

trinacrium, Nym. Consp. $16=\mathrm{R}$. tripartitus

tripartitum, S. F. Gray, Nat. Arr. ii. $721=$ R. tripartitus.

triphyllos, Dum, in Bull. Soc. Bot. Belg. ii. (1863) 214 $=$ R. tripartitus.

truncatum, Dum, 1. c. $215=\mathrm{R}$, peltatus.

villosum, F. Schultz, ex Gren. \& Godr. F1. Fr. 1. $24=$ R. trichophyllus,

BATRATHERUM, Nees, in Edinb. N. Phil. Journ. $x$ viii. (1835) $180=$ Arthraxon, Beauv. (Gram.)

cuspidatum, Hochst. in Flora, xxxix. (1856) $178=\mathrm{A}$. cuspidatus.

echinatum, Nees, in Edinb. N. Phil. Journ. xviii. (1835) $181=$ A. lanceolatus.

lanceolatum, Nees, 1. c. = A. lanceolatus,

micans, Nees, 1. c. $182=\mathrm{A}$. cuspidatus.

molle, Nees, 1. c. $181=$ A. microphyllus.

nudum, Nees, ex Steud. Syn. Pl. Gram. $383=$ A. ciliaris.

plumbeum, [Munro, ex] Duthie, in Atkinson, Gazetteer, $640=$ A. ciliaris

rude, Nees, ex Steud. Syn. P1. Gram. $383=$ A. rudis.

Schimperi, Nees, ex Hochst. in Flora, xxxix. (1856) $179=\mathrm{A}$. microphyllus.

serrulatum, Hochst. ex A. Rich. Tent. Fl. Abyss, ii. $458=\mathrm{A}$. lanceolatus.

submuticum, Nees, ex Steud. Syn. Pl. Gram.382=A. ciliaris.

BATSCHIA, J. F. Gmel. Syst. ii. $315(1791)=$ Litho spermum, Linn, (Boragin.

albiflora, Rafin. New Fl. Am. iv, 19-Am. bor.

canescens, Michx. Fl. Am. Bor, i. 130, t, $14=\mathrm{L}$ canescens.

caroliniana, Roem. \& Schult. Syst. iv. $52=\mathrm{L}$. hirtum.

caroliniensis, J. F. Gmel. Syst. i. $315=\mathrm{L}$, hirtum, conspicua, R. Br. in Richards. App. Frankl. Journ. 732 $=\mathrm{L}$. canescens.

decumbens, Nutt. Gen. Am. i. $114=$ L. angustifolium disticha, G. Don, Gen. Syst. iv. $326=$ L. distichum. Gmelini, Michx. Fl. Am. Bor. i. 130=L. hirtum. longiflora, Pursh, Fl. Am. Sept. i. $132=$ L. angustifolium.

pilosa, G. Don, Gen. Syst. iv. $372=$ L. pilosum sericea, Roem. \& Schult. Syst, iv. $743=$ L. canescens

Torreyi, G. Don, Gen. Syst. iv. $372=$ L. pilosum.

BATSCHIA, Moench, Meth. 5007 (1794)= Eupatorium, Linn. (Compos.)

nivea, Moench, 1. c. = E. ageratoides.

BATSCHIA, Mutis, ex Thunb. in Nov. Act. Ups. v (1792) 120.t. $2=$ Abuta, Aubl. (Menisp.).

conferta, Miers, in Seem. Bot. Voy. Herald, i. $76=\mathrm{A}$. Seemanni.

conferta, DC. Prod. i. $103=$ A. spicata

racemosa, Thunb. in Nov. Act. Ups. v. (1792) $122=$ A racemosa.

spicata, Thunb. 1. c. = A. spicata.

BATSCHIA, Vahl, Symb. Bot. iii. 39. t. 56 (1794)= Humboldtia, Vahl (Legum.)

laurifolia, Vahl, 1. c. = H. laurifolia

BATTATA, Hill, Hort. Kew. $148(1768)=$ Solanum Linn.

tuberosa, Hill, 1. c. $=\mathrm{S}$. tuberosim

BAUCHEA, Fourn, ex Benth, in Journ. Linn. Soc, xix. (1881) 88. GRAMINEAE, Benth. \& Hook, fo iii. 1149

Karwinskii, Fourn.Mex. Pl. En. Gram. 87 ; ex Hemst. Biol. Centr. Am. Bot. iii. 550.-Mexic.
BAUDINIA, Lesch. ex DC. Prod. iii. 211 (1828)= Calothamnus, Labill. (Myrtac.)

BAUDINIA, Lesch. ex DC. Prod. vii. 511 (1839)= Scaevola, Linn. (Goodenoy)

humilis, Lesch, ex DC. 1. c. $511=\mathrm{S}$. striata.

BAUDOUINIA, Baill. Adansonia, vi. (1866) 193. t. 5 . LEGUMINOSAE, Benth. \& Huok. i. i. 1003. fluggeiformis, Baill. l. c. viii. (1868) 201.-Madag. sollyaeformis, Baill. l. c. vi. (1866) 194.-Madag.

BAUERA, Banks, ex Andr. Bot. Rep. t. 198 (1793). SAXIFRAGEAE, Benth. \& Hook. f. i. 655. Billardieri, D. Don, in Edinb. N. Phil. Jonrn, ix. (1830) $96=$ rubioides.

capitata, Ser. in DC. Prod. iv. 13.-Austral.

yalioides, Sieber, in Reichb. Ic. Exot. t. $7.7=$ rubioides. humilis, Sweet, Hort. Suburb. $124=$ rubioides.

juncea, Walp. Rep. ii. $375=$ Tetratheca juncea. microphylla, Sieber, ex DC. Prod. iv. $13=$ rubioidcs. rubiaefolia, Salisb. in Kon. \& Sims, Ann. Bot.

(1805) 514. t. $10=$ rubioides

rubioides, $A$ ndr. Bot. Rep. t. 198.-Austral.

sessiliflora, F. Muell. in Trans. Phil. Soc.

(1855) 41.-Austral.

BAUHINIA, Linn. Gen. ed, I. 126 (1737). LEGU.

MINOSAE, Benth, \& Hook, f, i. 575 .

Alvesia, Welw. Apont. 587. 0. 47 (1858)

Amaria, Mutis, ex Caldas, in Seman. Nuev. Gran.

II. (1810) 25 .

Binaria, Rafin. Sylva Tellur. 122 (1838)

CANSENIA, Rafin. 1. c. (1838)

Casparea, H. B. \& K. Nov. Gen. et Sp. vi. 317 (1823).

Caulotretus, Rich. ex Spreng. Syst. iv. Cur. Post. 406 (1827).

Elayuna, Rafin. Sylya Tellur. 145 (18:38)

LACARA, Spreng. Neue Entelek. iii. 56 (1822).

LAsiobema, Miq. Fl. Ind. Bat. i. 71 (1855)

Locellaria, Welw. Apont.

Mandarus, Rafin. Sylva Tellur. 122 (1838).

Monoteles, Rafin. 1. c. (1838)

Pauletia, Cav, Ic. v. $5 . t$. 409, 410 (1799).

Perlebia, Mart. Reise, i. 555 (1828.

Phanera, Lour. Fl. Cochinch. 37 (1790)

PileostigMa, Hochst. in Flora, xxix. (1846) 598.

Schnella, Raddi, in Mem. Mod. xviii. Fis, (1820

411.

Telestria, Rafin. Sylva Tellur. 122 (1838).

abyssinica, A. Rich. Tent. F1. Abyss. i. $253=$ reticulata.

acida, Reinw, in Flora, xxi. (1848) 578 = malabarica. aculeata, Linn. Sp. Pl. 37 . - Am. austr.

aculeata, Vell. Fl. Flum. 17 ; iv. t. $83=$ forficata

acuminata, Bruce, Trav. Abyss. App. 16\%. t. $18=\mathrm{B}$ Farec.

acuminata, Linn. Sp. Pl. 376.-Ind. or.; Malaya

China.

acuminata, Vell. Fl. Flum. 171; iv. t. 85.-Bras.

Acuruana, Moric Pl. Nouv. Rar. Am. 77 . 51. Bras.

Adansoniana, Guill. E Perr. Tent. Fl. Seneg. i. 265.Afr. trop.

aegopoda, St. Lag. in Ann. Soc. Bot. Lyon, vii. '1850 $69,120=$ B. Pes-caprae.

affinis, Vog. in Linnaeg, x. (1836) 594 --Bras.

Aimouta, Steud. Nom. ed. II. i. 191 (err. typ. 291), vide Outimouti.

alba, Buch.-Ham. ex Wall. Cat. sub D. $5790^{\circ}=$ rarie gata.

albicans, Vog. in Linnaca, xiii. (153:1) 304.-Bras. americuna, Delaun. H crb. Amat. t. 315-Am. anstr. ampla, Span. IC. 29; in Linnaea, xv. 15+1) 202. Timor.

anatomica, Link, Eumm. Hort. Beros. is $105 .-\mathrm{Am}$. austr.

Andrieuxii, Hemsl. Diag. Pl. Avs. 1S.-Mexic. anguing, Rorb. Hort. Berg. 81 ; Fo. Ind. ii. S2S.Ind. or.; Malays.

angulosa, iog, in Linnara, xiii. 159!0 312.-13ras,

armati, Orso, Pl. Bras. 25.- liras.

arficulata, Oliver, Fl. Trop. Ar. id. 290, err. typ. $=$ resiculata?

aurantiaca, Boj, in Ann. Sc. Vas. Ser. U. iv. 1s35

Qut.-Maday.

nurita, dif. Hurf. Ars. id. 1\$. -Jamaica. 


\section{BAUHINIA}

Bacuria, Buch.-Ham, ex Wall. Cat. sub n. $5793=$ malabarica.

bahiensis, Bong. in Mém. Acad. Pétersb. Sér. VI. iv. (1836) 114 = Langsdorffiana

Baueriana, Steud. Nom. ed. 1I. i. 191 (err.typ. 291)= malabarica.

Benthami, Bedd. Forest. Man. Bot. 93 ; Ic. Pl. Ind. Or. i. 22 = phoenicea.

Benzoin, Kotschy, ex Schweinf. Reliq. Kotsch. (1868) 12. t. 11.-Afr. trop.

bicolor, D. Dietr. Syn. Pl. ii. 1476.-Bras

bicuspidata, Benth. in Mart. Fl. Bras. Xv. II. 193.Am. trop.

bidentata, fack, in Malay. Misc. ii. (1822) n. vII. p. 76.-Malaya.

binata, Blanco, F1. Filip. ed. I. $331=$ Blancoi

binata, Naves, ex Villar, in Blanco, Fl. Phil. ed. III Nov. App. $72=$ tomentosa.

Blancoi, Benth. Fl. Austral. ii. 296, in nota; Baker, in Hook. f. Fl. Brit. Ind. ii, 278.-Siam; Ins. Philipp.

Bongardi, Steud. Nom. ed. II. i. 191 (err. typ. 291).Bras.

Bowkeri, Harv. in Harv. E Sond. Fl. Cap. ii. 596.Afr. austr.

brachycarpa, Wall. Cat. n. 5786.-Burma.

brachystachya, Walp. Rep. i. $852=$ cumanensis.

bracteata, R. Grah. in Wall. Cat. n. 5802.-Burma; Siam.

brasiliensis, Vog. in Linnaea, xiii. (1839) 302.-Bras.

Bredemeyeri, Vog.l. c.-Venezuela.

breviloba, Benth. in Mart. Fl. Bras. xv. II. 197.Bras.

brevipes, Vog. in Linnaea, xiii. (1839) $307=$ Bongardi. Buchanani, Desv. in Ann. Sc. Nat. Sér. I. ix. (1829) $430=$ diphylla

Burchellii, Benth. in Mart. Fl. Bras. xv. II. 186.Bras.

Burkeana, Benth. ex Harv. \& Sond. Fl. Cap. ii. $275=$ esculenta.

Cancara, Buch.-Ham. ex Steud. Nom. ed. II. i. 191 (err. typ. 291) = variegata

candicans, Benth. in Mart. Fl. Bras. xv. II. 201.Bras.

candida, Ait. Hort. Kew. ii. (1789) $49=$ acuminata.

candida, Roxb. Hort. Beng. [31]; F1. Ind. ii. $318=$ variegata.

Carronii, F. Muell. in Trans. Phil. Inst. Victoria, iii (1858) 49.-Austral.

castrata, Blanco, Fl. Filip. ed. I. 331,-Ins. Philipp.

castrata, Hassk. in Flora, xxv. (1842) Beibl. II. 54.Java.

Championi, Benth. Fl. Hongkong. 99.-Hongkong. cheilantha, D. Dietr. Syn. Pl. ii. 1476.-Bras.

chinensis, Vog. in Nov. Act. Nat. Cur. xix. Suppl. i. (1843) 42 = variegata.

choriophylla, Vog. in Linnaea, xiii. (1839) $307=$ rufa.

chrysophylla, Vahl, ex DC. Prod. ii. $517=$ macrophylla.

chrysophylla, Vog. in Linnaea, xiii. (1839) $313=$ splendens.

cinnamomea, DC. Prod. ii. 517.-Guiana.

cissoides, Welw. ex Oliver, Fl. Trop. Afr. ii. 287.-Afr. trop.

coccinea, DC. Prod. ii. 516.-Cochinch.

columbiensis, Vog. in Linnaea, xiii. (1839) $313=$ cumanensis.

compacta, Hort. ex Regel, Cat. Pl. Aksakov. 15.Hab. ?

confertiflora, Benth. in Mart. Fl. Bras. xv. Ir. 206.Bras.

cordata, Vog, in Linnaea, xi. (1837) $308=$ rufa.

cordifolia, Roxb. Hort. Beng. [90]; Fl. Ind. ii. $332=$ emarginata.

corniculata, Benth. in Mart. Fl. Bras. xv. II. 198.Bras.

cornifolia, Baker, in Hook, f. Fl. Brit. Ind. ii. 278.Ins. Penang.

coromandeliana, DC. Mém. Leg. xiii. 486; Prod. ii. $515=$ purpurea

coronata, Benth. in Mart. Fl. Bras. xV. II. 209.Bras.

corymbosa, Raxb. Hort. Beng. [31] ; Fl.Ind. ii. 329.China.

cucullata, Desw. Fourn. Bot.i. (1814) 74 (=variegata ?). -Ind. or.

cumanensis, H. B. $\Xi$ K. Nov. Gen. et Sp. vi. 321.Venezuela.

\section{BAUHINIA:-}

Cumingiana, Villar, in Blanco, Fl. Philipp. ed. III. Nov. App. 73.-Ins. Philipp.

Cunninghamii, Benth. Fl. Austral. ii. 295.-Austral.

cupulata, Benth. in Mart. Fl. Bras. Xv. II. 188. Bras.

curvula, Benth. l. c. 194.-Bras.

cuyabensis, Steud. Nom. ed. II. i. 191 (err, typ. 291).Bras.

debilis, Hassk. in Hoev. Eั De Vriese, Tijdschr. x. (1843) 149.-Tava.

dipetala, Hemsl. Diag. Pl. Nov. 48.-Mexic.

diphylla, Buch.-Ham. in Symes, Embassy, ed. II. ii. 311.-Burma; Malaya.

diptera, Blume, ex Miq. in Verh. Nederl. Inst. III. iii. (1850) 12.-Malaya.

divaricata, Hort. ex Steud. Nom. ed. II. i. 191 (err. typ. 291) = forficata.

divaricata, Lam. Encyc. i. $389=$ Lamarckiana.

divaricata, Linn. Sp. Pl. 374,-Am. austr

divergens, Baker, in Hook. f. Fl. Brit. Ind. ii. 282.Burma.

dodecandra, D. Dietr. Syn. $P l$. ii. 1475.-Bras.

dubia, G. Don, Gen. Syst. ii. 463.-Bras.

dubia, Vog. in Linnaea, xiii. (1839) $314=$ coronata

dumosa, Benth. in Mart. Fl. Bras. xv. 11. 194.-Bras. elongata, Korth. Verh. Nat. Gesch. Bot. (1839-42) 89.-Borneo.

emarginata, fack, in Malay. Misc. ii. (1822) n. vII. p. 75.- Sumatra.

emarginata, Mill. Gard. Dict. ed. VIII. ñ. 5.Mexic.

emarginata, Wall. Cat. n. $5792=$ retusa.

eriophora, Tenore, Ind. Sem. Hort. Neap. (1842) 12. -Hab.?

excelsa, Blume, ex Korth. Verh. Nat. Gesch. Bot. $90=$ ferruginea.

esculenta, Burch. Trav. ii. 589.-Afr. austr.

excisa, Hemsl. Biol. Centr. Am. Bot. i. 337.Panama.

eximia, Miq. Fi. Ind. Bat. i. I. 75.-Tava.

Farec, Desv. Fourn. Bot. i. (1814) 74.-Abyssin.

fassoglensis, Kotschy, ex Schweinf. Reliq. Kotsch. (1868) 14. t. 12.-Afr. trop.

ferruginea, D. Dietr. Syn. Pl. ii. $1476=$ Bongardi . ferruginea, Roxb. Hort. Beng. 90; Fl. Ind. i1. 331.Malaya.

Finlaysoniana, $R$ Grah, in Wall. Cat, n. 5801 Malaya.

flexuosa, Moric. Pl. Nouv. Am. 80. t. 53.-Bras floribunda, Desv. in Ann. Sc. Nat. Sér. I. ix. (1826) 430.-Bras.

forficata, Link, Enum. Hort. Berol. i. 404.-Bras.

foveolata, Dalz. in Journ. Linn. Soc. xiii. (1873) $188=$ Lawii?

fulva, Korth. Verh. Nat. Gesch. Bot. (1839-42) 91.Java.

furcata, Desv. in Ann. Sc. Nat. Sér. I. ix. (1826) 429. -Am. bor.

fusconervis, $D$. Dietr, Syn. $P l$. ii, 1476.-Bras

Gardneri, Benth. in Mart. Fl. Bras. xv. II. 186.Bras.

garipensis, E. Mey. Comm. Pl. Afr. Austr. i. 162.-

Afr, austr.

geminata, Vog. in Linnaea, xiii. (1839) 305 -Bras.

Gilesii, F. Muell. E Bailey, in Wing, South Sc. Record, ii. (1882) 151.-Austral.

glabra, Facq. Enum. Pl. Carib. 20.-N. Granat.

glabrifolia, Baker, in Hook. f. Fl. Brit. Ind. ii. 281.Burma.

glandulosa, DC. Prod. ii. 513.-N. Barcel.

glauca, Wall. Cat. n. 5785 ; Benth. Fl. Hongkong. 99. -Burma; Malaya; China.

glaucescens, DC. Prod. ii. 515.--Venezuela.

Grahami, Steud. Nom. ed. II. i. 191 (err. typ. 291) = rufa.

Grandidieri, Baill. in Bull. Soc. Linn. Par. i. (1883) 373.-Madag

grandiflora, Fuss. in Poir. Encyc. Suppl. i. 600.Peruv.

grandiflora, Blanco, F1. Filip. ed. I. 332 =variegata.

grandifolia, D. Dietr. Syn. Pl. ii. 1475.-Bras.

guianensis, Aubl. Pl. Gui. i. 377. t. 145.-Guiana.

heterandra, Benth, in Mart. Fl Bras, xy, II 196.Bras.

heterophylla, Kunth, Mim. t. 46.-Venezuela.

Hildebrandtii, Vatke, in Linnaea, xliii. (1880-82) 107. -Afr. trop.

\section{BAUHINIA :-}

hirsuta, Vog. in Linnaea, xiii. (1839) 300.-Bras.

hirsuta, Weinm. in Ratisb. Syll. ii. (1828) $9=$ acuminata.

hirta, Steud. Nom. ed. II. i. 191 (err. typ. 291).Bras.

holophylla, Steud. l. c.; D. Dietr. Syn. Pl. ed. II $1476,-.-$ Bras

Hookeri, F. Muell. in Trans. Phil. Inst. Vict. iii. (1859) 51.-Austral.

Hostmanniana, Miq. in Verh. Nat. Wet. Haarl. vii (1851) 10.-Guiana.

Humblotiana, Baill. in Bull. Soc. Linn. Par. i. (1883) 365.-Madag.

hymenaeaefolia, Triana, ex Hemsl. Biol. Centr. Am. Bot. i. 337.-Panama.

indica, Lodd. ex Loud. Hort. Brit. 165.-Ind. or

inermis, Forsk. Fl. Aegypt. Arab. 85=reticulata, tomentosa.

inermis, Pers. Syn. i. 455.-Am. austr.

integerrima, Mart. ex Benth. in Mart. Fl. Bras. xv. II. 197.-Bras.

integrifolia, Roxb. Hort. Beng. [90]; Fl. Ind. ii. 331. -Malaya.

intermedia, Vog. in Linnaea, xi. (1837) $309=$ rufa.

involucellata, Kurz, in Fourn. As. Soc. Beng. xli. (1873) II. 72.-Burma.

isopetala, Griff. Notul. iv. 451.--Burma.

japonica, Maxim. in Bull. Acad. Pétersb. xviii. (1873) 401.-Japon.

Kappleri, Sagot, in Ann. Sc. Nat. Sér. VI. xiii. (1882) 317.-Guiana.

khasiana, Baker, in Hook. f. Fl. Brit. Ind. ii. 281.Ind. or.

Kirkii, Oliver, Fl. Trop. Afr. ii. 288.-Afr. trop.

Kockiana, Korth. Verh. Nat. Gesch. Bot. (1839-42) 87 - Sumatra.

Krugii, Urban, in Berl. Deutsch. Bot. Ges. ili. (1885) 83.-Porto-Rico.

Kunthiana, Vog. in Linnaea, xiï. (1839) 312.-Am. austr.

Lamarckiana, DC. Prod. ii. 512.-Am, austr.

Langsdorffiana, Bong. in Mém. Acad. Pétersb. iv. (1836) 109.-Bras.

latifolia, Cav. Ic. v. 4. t. 405.-Mexic.

latisiliqua, Cav. l. c. 5.-Ins. Philipp.

Lawii, Benth. ex Baker, in Hook. f. Fl. Brit. Ind. ii. 277.-Ind. or.

Leichhardtii, F. Muell. in Trans. Phil. Inst. Victoria, iii. (1859) 50.-Austral.

leiopetala, Benth. in Mart. Fl. Bras. xv. II. 209... Bras. leptopetala, Moc. E Sessé, ex DC. Prod. ii. 513.-

Lingua, $D C$. L. c. 516.-Malaya.

longicuspis, Spruce, ex Benth. in Mart. Fl. Bras. xv. II. 185.-Bras.

longiflora, D. Dietr. Syn. Pl. ii. $1475=$ forficata.

longifolia, D. Dietr. l. c. 1476.-Bras.

longipetala, Walp. Rep. i. 852.-Guiana.

longistyla, Benth. in Mart. F1. Bras. Xv. II. $185=$ holophylla.

Iucida, Wall. Cat. n. $5779 \mathrm{~A}=$ emarginata.

lunaria, Caw. Ic. v. 4. t. 407.-Mexic

lunaroides, A. Gray, in S. Wats. Bibliog. Ind. N. Am. Bot. i. 205,-N. Mexic

macrantha, Oliver, Fl. Trop. Afr. ii. 289.-Afr, trop.

macranthera, Benth. ex Hemsl. Biol. Centr. Am. Bot. i. 338.-Mexic.

macrophylla, Poir. Encyc. Suppl. i. 600--Am. austr. macrostachya, Benth. in Hook. Fourn. Bot. ii. (1840) 96.-Guiana.

macrostachya, Wall. Cat. n. 5774.-Ind. or

maculata, Tenore, Cat. Hort. Neap. (1845) 79.Hab. ?

madagascariensis, Desथ. Fourn. Bot. i. (1814) 74.Madag.

malabarica, Roxb. Hort. Beng. [31]; Fl. Ind. ii. 321. -Ind. or.; Burma.

marginata, D. Dietr. Syn. Pl. ii. 1475.-Bras

Maximiliani, Benth. in Mart. Fl. Bras. xv. II. 203.Am. trop.

megalandra, Griseb. Fl. Brit. W. Ind. 213.-Ind, occ.

membranacea, Benth. in Mart. Fl. Bras. xv. II. 187.Bras.

mexicana, Vog. in Linnaea, xiii. (1839) 299.-Mexic. microphylla, Vog. l. c. 301-Am. austr. 


\section{BAUHINIA:}

mollis, D. Dietr. Syn. Pl. ii. 1475.-Bras.

mollissima, Wall. Cat. n. $5782=$ elongata

Mombassae, Vatke, in Oestr. Bot. Zeitschr, xxx. (1880) 279.-Afr. trop.

monandra, Kurz, in Fourn. As. Soc. Beng. xlii. (1873)

II. 73.-Burma.

mucora, C. Bolle, in Peters, Reise Mossamb. Bot. i, $22=$ tomentosa

multinervia, DC. Prod. ii. 515.-Venezuela,

natalensis, Oliver, in Hook. Bot. Mag. t. 6086.-Afr. austr.

nervosa, Wall. Cat.n.5777.--Ind. or.

nitida, Benth. in Mart. Fl, Bras. xv. II. 184-Bras.

notophila, Griseb. in Goett. Abh. xxiv. (1879) 116.

Reg. Argent.

obtusata, Vog. in Linnaea, xiii. (1839) 305,-Bras.

odoratissima, Moric. Pl. Nouv. Am.78. t. 52.-Bras,

odoratissima, Newm. ex G. Don, Gen. Syst. ii. 461.-

Bras.

Olfersiana, Vog. in Linnaea, xiii. (1839) 306.-Bras.

ornata, Kurz, in Fourn. As. Soc. Beng. xlii. (1873) II 72.-Burma

Outimouta, Aubl. Pl. Gui. i. 375. t. $144=$ guianensis, macrophylla.

ovata, Vog. in Linnaca, xiii. (1839) 300.-Bras.

panamensis, Spreng. Syst. ii. $384=$ B. Pauletia.

parviflora, Vahl, Symb. Bot. iii. $55=$ racemosa.

parvifolia, Hochst. ex Ficld. \& Gardn. Sert. t. $10=$ rufescens.

parvifolia, Seem. Bot. Voy. Herald, $113=$ B. Pauletia. parvifolia, Teijsm. E Binn. in Tijdschr. Nederl. Ind. xxix. (1867) 257-China.

Pauletia, Pers. Syn. i. 455.-Panama.

pentandra, Vog. ex D. Dietr. Syn. Pl. i.. 1475.Bras.

Persichii, F. Muell. in Wing, South Sc. Record (Feb. 1885), 25.-Austral.

Pervilleana, Baill. in Bull. Soc. Linn. Par. i. (1883) 374.- Madag.

Pes-caprae, Cav. Ic. v. 3. t. 404--Mexic.

Petersiana, C. Bolle, in Peters, Reise Mossamb. Bot. i 24.-Afr. trop.

petiolata, Triana, ex Hook. Bot. Mag. t. 6277.-N. Granat.

phoenicea, Heyne, in Wall. Cat. n. 5800.-Ind. or.

picta, DC. Prod. ii. 515,-N. Granat.

pinnata, Blanco, Fl. Filip. 334.-Ins. Philipp.

piperifolia, Roxb. Fl. Ind. ii. $327=$ anguina?

platisiliqua, Steud. Nom. ed. II. i. $192=$ reticulata.

platycalyx, Benth. in Mart. Fl. Bras. xv, II. 207.platycalys.

platypetala, Benth. ex Hemsl. Biol. Centr. Am. Bot. i. 339.-Mexic.

platyphylla, Benth. in Mart. Fl. Bras. xv. II. 185.Bras.

platyphylla, Zipp. ex Span. in Linnaea, xv. (1841) 201

= purpurea.
platysiliqua, Perr. ex DC. Prod. ii. $515=$ reticulata.

Poiteauana, Vog. in Linnaea, xiii. (1839) 309.Guiana.

polyantha, Vog.l.c. 310.-Bras.

polyacantha, Steud. Nom. ed. II. i. $192=$ polyantba.

polycarpa, Wall. Cat. n. 5787.-Burma.

porosa, Boivin, ex Baill. in Bull. Soc. Linn. Par. i. (1883) 373.-Madag.

porrecta, Sw. Prod. Veg. Ind. Occ. 66.-Ind. occ,

Pottsii, G. Don, Gen. Syst. ii. $462=$ ferruginea.

pruinosa, Voy. in Linnaea, xiii. (1839) 301.-Bras.

pubescens, DC. Lég. Mém. xiii. $483=$ aculeata.

pulchella, Benth. in Mart. Fl. Bras. xv. II. 190,-Bras.

punctata, Bolle, in Peters, Reise Mossamb. Bot. i. 28.-

Afr. trop.

punctata, Burch. ex Benth. in Mart. Fl. Bras. xv. II 211.-Bras.

purpurea, DC. ex Walp. Ann. ii. $448=$ malabarica.

purpurea, Linn. Sp. Pl. 375.-Ind, or.; Burma ; China

purpurea, Wall. Cat. n. $5797=$ acuminata, variegata.

pyrrhaneura, Korth. Verh. Nat. Gesch. Bot. (1839-42)

88.-Sumatra.

pyrrhocarpa, Hochst. in Flora, xxvii. (1844) $99=$ reticulata.

racemifera, Desf. Fourn. Bot. iii. (1814) 74.-Am, austr.

racemosa, Lam. Encyc. i. 390.-Ind. or.; Malaya China.

racemosa, Vahl, Symb. Bot, iii. 56. t. $62=$ Vahlii.

Raddiana, Bong. in Mém. Acad. Pétersb. Sér. VI. iv. 1896) 111.-Bras.

\section{BAUHINIA}

radiata, Vell. Fl. Flum, 170 ; iv t. 81 -Bras.

ramosissima, Benth. ex Hemsl. Biol. Centr. Am. Bot. 339.-Mexic

reniformis, Royle, ex Baker, in Hook. f. Fl. Brit. Ind. ii. $277=$ malabarica

reticulata, DC. Lég. Mém, xiii. 484.—Senegal.; Aegypt. retusa, Poir. Encyc. Suppl. i. $699=$ Lamarckiana, purpurea.

retusa, Roxb. Hort. Beng. [31]; Fl. Ind. ii. 322.-Reg. Himal.

rhodacantha, Desv. in Ann. Sc. Nat. Sér. I. ix. (1826) 429, - Bras.

Richardiana, DC. Prod. ii. 517-Guiana.

Riedeliana, Bong. in Mém. Acad. Pétersb. Sér. VI. iv. 1836) 113.-Bras

Riedelii, Baker, in Fourn. Linn. Soc. xv. (1877) 98. Celebes.

riparia, Mart. ex Benth. in Mart. Fl. Bras, Xv, II. 190 = pulchella.

rosea, Kurz, in Fourn. As. Soc. Beng. xlii. (1873) II. 72,-Burma

rosea, Miq. in Linnaea, xviii. (1844) 588.-Surinam.

rotundata, Mill. Gard. Dict. ed. VIII. n. 7.-N Granat.

rotundifolia, Pers. Syn. i. $455=$ subrotundifolia

Roxburghiana, Voigt, Hort. Suburb. Calc. $254=$ retusa rubescens, Pers. Syn. i. $455=$ rufescens.

rubiginosa, Bong. in Mém. Acad. Pétersb. Sér. VI. iv (1836) 112.-Bras.

rufa, R. Grah. in Wall. Cat. n. 5798.-Ind. or.

rufa, Steud. Nom. ed. II. 1. 192 ; et D. Dietr. Syn. Pl

ii. 1476.-Bras.

rufescens, Lam. Encyc. i. 391.-Afr. austr. et trop.

ruficarpa, Desv. in Ann. Sc. Nat. Sér. I. ix. (1826) 430 = phoenicea.

Rutenbergiana, Vatke, in Bremen Abh. vii. (1882) 249 -Afr, trop.

rutilans, Spruce, ex Benth. in Mart. Fl. Bras. xw. II 206. - Bras.

scandens, Blanco, Fl. Filip. ed. I. $332=$ Cumingiana

scandens, Burm. f. Fl. Ind. $94=$ corymbosa

scandens, Linn. Sp. Pl. $374=$ anguina.

scandens, Roxb. Hort. Beng. [31]; F1. Ind. ii, $326=$ macrostachya, racemosa.

Schlechtendaliana, Mart. \& Gal. in Bull. Brux. (1843) II. 308.-Mexic.

Sellowiana, Vog. in Linnaea, xiii. (1839) $306=$ cujabensis.

semibifida, Roxb. Hort. Beng. [31]; Fl. Ind. ii. 330.Burma; Malaya.

Serpae, Ficalho \& Hiern, in Trans. Linn. Soc. Ser. II. ii. (1881) 20.-Afr. trop.

smilacifolia, Burch. ex Benth. in Mart. Fl. Bras. xv. II. 183.-Bras.

smilacina, Steud. Nom. ed. II. i. 192.-Bras.

spathacea, Sesse, ex DC. Prod. ii. 512.-Mexic.

speciosa, Roxb. in Wall. Cat. n. $5791=$ tomentosa.

speciosa, Vog. in Linnaea, xiii. (1839) $314=$ superba

spicata, Koen. ex Wall. Cat. n. $5789=$ racemosa

spicata, Rottl. ex Spreng. Fl. Hal, Mant. 39 ; Syst. ii.

$333=$ racemosa

spicata, Vog. in Linnaea, xiii. (1839) 310.-Hab.

spinosa, Poir. Encyc. Suppl. i. $599=$ B. Pauletia.

splendens, H. B. E K. Nov. Gen. et Sp. vi. 319.-Am, austr.

Sprucei, Benth. in Mart. Fl. Bras. xv. II. 205.-Bras. stipularis, Korth. ex Verh. Nat. Gesch. Bot. (1839-42 92.-Sumatra.

suaveolens, H.B. E K.Non. Gen. et Sp, vi. 321.-Am. austr

subclavata, Benth. in Mart. Fl. Bras. xv. II, 188.Bras.

subrotundifolia, Cav.Ic. v. 4. t. 406.-Mexic superba, Steud. Nom ed. II i, 192-Guiana. tamarindacea, Delile, Voy. Méroé, $34=$ reticulata.

Teysmanniana, Scheff. in Ann. Fard. Buitens. i. (1876) 19.-N. Guinea.

Thonningii, Schum. Beskr. Guin. Pl. $208=$ reticulata. tenella, Benth. in Mart. Fl. Bras. xv. I1. 195.-Bras. tenuis, Span. Ic. 36 ; et in Lianaea, xv. (1841) 202 racemosa.

timoriana, Steud. Nom. ed. II. i. $192=$ seq

timorensis, Decne. in Nouv. Ann. Mus. Par. iii. (188 $466=$ racemosa

tomentosa, Linn. Sp. Pl. 375.-As. et Afr. trop.

tomentosa, Naves, ex Villar, in Blanco, I'l. l'hilipp. ed.

III. Nov. App. $72=$ acuminata.

\section{BAUHINIA}

tomentosa, Vell Fl Flum 171, iv t $84=\mathrm{Lang}$ dorffiana.

tomentosa, Wall. Cat. n. 5790. F \& G = malabarica triandra, Roxb. Hort. Beng. [31]; Fl. Ind. ii. $320=$ purpurea.

unguicularis, Benth. ex Hemsl. Biol. Centr. Am. Bot. i. 540.-Mexic.

unguiculata, Baker, in Hook. f. Fl. Brit. Ind. ii. 277 -Siam.

Ungula, Jacq. Fragm. 22. t. $15=$ aculeata.

Ungula, Willd. ex Steud. Nom. ed. II. i. 192

Bredemeyeri.

ungulata, Linn. Sp. Pl. 374.-'Amer.'

uruguayensis, Benth. in Mart. Fl. Bras. xv. Ir. 209.Bras.

Vahlii, Villar, in Blanco, Fl. Philipp. ed. III. Nov.

App. $72=$ Cumingiana

Vahlii, Wight E Arn. Prod. 1. 297.-Ind. or.

variegata, Linn. Sp. Pl. 375.-Ind. or.; IJurma; China

velutina, Wall. Cat. n. 5781.-Burma.

verrucosa, Vog. in Linnaea, xiii. (1839) 311.-Bras.

versicolor, Bertol. Hort. Bonon. Pl. Nov. i. 7.

Mexic.

viridescens, Desve in Ann. Sc. Nat. Sér. I ix. (1826, 429.-Ind. or.

Vogeliana, Steud. Nom. ed. II. i. $192=$ spicata.

Welwitschii, Oliver, Fl. Trop. Afr. ii. 287.-Afr. trop Williamsii, F. Muell. Descr. Pl. Papuan. iv, 61.N. Guinea.

xanthoneura, Korth. ex Mi. Fl. Ind. Bat. i. $63=$ pyrrhaneura.

BAUKEA, Vatke, in Linnaea, xliii.(1880-82) 104 LEGUMINOSAE.

insignis, Vatke, l. c.-Madag.

maxima, Baill. in Bull. Soc. Linn. Par. i. (1883) $383=$ insignis.

BAUMANNIA, DC in Mém. Soc. Phys. Genèv. iv $1833) 583$ (Not. Pl. Rar. Jard. Genèv. vi. 1. t. 1, 25 =Damnacanthus, Gaertn. (Rubiac). geminiflora, DC. $11 . \mathrm{cc}_{\mathrm{o}}=\mathrm{D}$. indicus.

BAUMANNIA, Spach, Hist. Vég. Phan. iv. 351 (183:) = Oenothera, Linn. (Onagrar.).

Douglasiana, Spach, 1, c. $352=0$. albicaulis

Nuttalliana, Spach, 1. c. = O. albicaulis.

pinnatifida, Spach, 1. c. $353=$ O. pinnatifida

BAUMEA, Gaudich. in Freyc. Voy. Bot.416. t. 29 (1826 = Cladium, P. Br. (Cyperac.)

acuminata, Regel, Cat. P1. Hort. Alssakov. 15.Hab.?

arthrophylla, Boeck. in Linnaea, xxxviii. (1874) 242 C. arthrophyllum.

Brownii, Boeck. 1. c. = C. glomeratum.

crassa, Thw. Enum. P1. Zeyl. $353=$ C. riparium.

Deplanchei, Boeck. in Flora, Ixi. (1878) 143-N Caled.

falcata, Nees, in Hook, Kew Journ. vi. (1S5t) 29.Ins. Philipp.

flexuosa, Boeck, in Bremen Abh, vii. (1580) 89. Madag.

glomerata, Gaudich. in Freyc. Voy. Bot. 416. t. 29.-

Ins. Miolucc.

ridifolia, Boeck, in Linnaer, ruxviii. 15it, 241 Madag.

laxa Boeck. l. c. $245=\mathrm{C}$. laxum.

loculata. Boeck. 1. c. $243=$ C. articulatum.

longifolia, Boeck. 1. c. $244=$ C. Filum.

mariscoides, Gaudich. in Freyc. Voy. Bot. $₫ 1 \overline{7}=\mathrm{C}$ mariscoides.

Meyenii, Kunth, Enum. Pl. ii. 814-Ins Sandric,

Preissii, Nees, in Lehm. Pl. Preiss, ii. $75=$ latissimum.

riparia, Boeck. in Linnaen, xxxviii. $(15 ; 1) 216=\mathrm{C}$ riparium.

rubiginosa, Bock. l. c. $211=$ C. glomeratum.

schoenoides, Boeck. 1. c. $2 \pm 10=$ C. sibocuoides,

BAUMGAKTENIA, Spreng. Aalcit ii. 3. 925 151; Syst ii. 91 (1825) - Borya, I-abill. Liliac) lucens, Stcud. Nom. ed. I1. i. 192 - Rorya nitida. rilida, Spreng. Syst. ii. 91 = Borya nitida. sphaerucrphala, Spreag. I. c. = Burna aitida. 
BAUMGARTIA, Moench, Meth. $650(\mathbf{1 7 9 4})=$ Coc culus, DC. (Menisp.)

scandens, Moench, 1. c. $=$ C. carolinus.

BAURSEA, Hort, ex Hoffmgg. Verz. Pfl. 42 (1824)= Philodendron, Schott (Aroid.).

glauca, Hoffmgg. 1. c.-Hab. ?

nervosa, Hort. Angl. ex Hoffmgg. 1. c. = P. Karstenianum?

BAURSIA, Schott, Syn. Aroid. i. $73(1856)=$ Philo dendron, Schott (Aroid.).

BAUSCHIA, Seub. ex Warm. in Kjoeb. Vidensk. Meddel. (1872) $123=$ Aneilema, R. Br. (Commel. $)$

bracteolata, Seub. ex Warm. 1. c. $124=$ A. ovato oblongum.

BAUXIA, Neck. Elem. iii. $160(1790)=$ Marica, Ker Gawl. (Irid.).

BAVERA, Poir. in Dict. Sc. Nat. iv. Suppl. 52 (1816)= Bauera, Banks (Saxif.)

BAXTERA, Reichb. Consp. 131 (1828) = Marsdenia, R. Br. (Asclep.).

loniceroides, Steud. Nom. ed. II. i. 192=M. Ioniceroides.

BAXTERIA, R. Br. ex Hook. Lond. Journ. Bot. ii. (1843) 494. t. 13-15. FUNCACEAE, Benth. \& Hook, f. iii. 866

australis, $R, B r . l . c$.-Austral.

BAZIASA, Steud. Nom. ed. II. i. $192(1840)=$ Sabazia, Cass. (Compos.).

humilis, Steud. 1. c, $=$ S. humilis.

microglossa, Steud. 1. c. $=\mathrm{S}$. microglossa.

sarmentosa Steud $1 \mathrm{c}=\mathrm{S}$ sarmentosa.

urticaefolia, Steud. 1. c. $=$ S. urticaefolia.

BDALLOPHYTON, Eichl. in Bot. Zeit. xxx. (1872) 709. t. $8=$ Cytinus, Linn.

Andrieuxii, Eichl. 1. c. 715 . t. $8=$ C. Andrieuxii.

ceratantherum, Eichl. 1. c, = C. americanus.

BEATONIA, Herb. in Bot. Mag. sub t. 3779 (1839)= Tigridia, Ker-Gawl. (Irid.)

atrata, Herb. in Lindl. Bot. Reg. (1843) Misc. $72=\mathrm{T}$ atrata.

bracteolata, Klatt, in Linnaea, xxxiv. (1865-66) 733.Bolivia.

coelestina, Klatt, 1. c. xxxi. (1861-62) 567.-Mexic. curvata, Herb. in Lindl. Bot. Reg. (1843) Misc. $74=$ T. curvata.

grandiflora, Klatt, in Abh. Naturf. Ges. Halle, xii (1882) $369=\mathrm{T}$. lntea.

Houttei, Klatt, 1. c. = T. Houttei.

lutea, Klatt, in Linnaea, xxxi. (1861-62) $566=\mathrm{T}$. Iutea. purpurea, Herb. in Bot. Mag, sub t. $3799=\mathrm{T}$. violacea.

BEATSONIA, Roxb. in Beats. St. Hel. App. 300 (1816) Frankenia, Linn.

portulacifolia, Roxb. 1. c。=F. portulacaefolia.

BEAUCARNEA, Lem. Jllustr. Hortic. viii. (1861) Misc. $59=$ Nolina, Michx. (Liliac.).

Bigelovii, Baker, in Journ. Bot. x. (1872) $326=\mathrm{N}$. Bigelovii.

erumpens, Baker, $\mathrm{l}_{\mathrm{c}} \mathrm{c}_{\mathrm{s}}=\mathrm{N}$. erumpens.

gracilis, Lem. Illustr. Hortic. viii. (1861) Misc. $61=$

N. Hartwegiana.

Hartwegiana, Baker, in Journ. Bot. x. (1872) $327=\mathrm{N}$. Hartwegiana.

Hookeri, Baker, 1. c. = Dasylirion Hookeri.

humilis, Baker, in Journ. Linn. Soc. xviii. (1881) $237=$ N. humilis.

Lindheimeriana, Baker, in Journ. Bot. x. (1872) 328 $=$ N. Lindheimeriana.

longifolia, Baker, 1. c. $324=\mathrm{N}$. longifolia.

microcarpa, Baker, in Journ. Linn. Soc. xviii. (1881) $236=\mathrm{N}$. microcarpa.

Palmeri, Baker, 1. c. $235=$ N. Palmeri.

parviflora, Baker, in Journ. Bot. x. (1872) $328=\mathrm{N}$. parviflora

recurvata, Lem. Illustr. Hortic. (1861) Misc. $59=$ N. recurvata.

stricta, Lem. 1. $c_{.}=$N. recurvata.
BEAUCARNEA :-

texana, Baker, in Journ. Linn. Soc. xviii. (1881) $236=$ Nolina texana.

Watsoni, Baker, 1. c. $=$ N. Watsoni

BEAUFORTIA, [R, Br, in ] Ait, Hort. Kew, ed, II. iv, $418(1812)$, MYRTACEAE, Benth. \& Hook. f. i. 705 .

Schizopleura, Endl, Gen. 1228 (1840)

anisandra, Schau. in Nov. Act. Nat. Cur. xxi. (1844) 13. t. 1.-Austral.

carinata, A. Cunn. ex Loud. Hort. Brit. 319.-Austral. cyrtodonta, Benth. Fl. Austral. iii. 167.-Austral.

Dampieri, A. Cunn. in Hook. Bot. Mag. t. 3272.Austral.

decussata, [R. Br. in] Ait. Hort. Kew. ed. II. iv. 418. -Austral.

elegans, Schau. in Nov. Act. Nat. Cur. xxi. (1844) 16. -Austral.

empetrifolia, Schau. 1. c. $17=$ micrantha

heterophylla, Turcz. in Bull. Phys.-Math. Acad Pétersb. x. (1852) 345.-Austral.

inops, Schau. in Nov. Act. Nat. Cur. xxi. (1844) $17=$ Regelia inops.

interstans, F. Muell. Fragm. x. 30.--Austral.

macrostemon, Lindl. Swan Riv. Bot. 10. n. 31.Austral.

micrantha, Schau. in Nov. Act. Nat. Cur. xxi. (1844) 18.--Austral

microphylla, Turcz. in Bull. Soc. Nat. Mosc, xxii (1849) II. 24.-Austral.

orbifolia, F. Muell. Fragm. iii. 110,-Austral.

pinifolia, Cels, Cat. (1817) $8=$ Calothamnus quadrifida.

puberula, Turcz. in Bull. Phys.-Math. Acad. Pétersb. x. (1852) 345.-Austral.

purpurea, Lindl. Swan Riv. Bot. 10. n. 30.-Austral.

Schaueri, Preiss, ex Schau. in Norv. Act. Nat. Cur. xxi. 1844) 14.- - Austral.

sparsa, [R. Br. in ] Ait. Hort. Kew. ed. II. iv. 418.Austral.

splendens, Baxter, in Loud. Hort. Brit. Suppl. i. $582=$ sparsa.

squarrosa, Schau. in Nov. Act. Nat. Cur. xxi. (1844) 11.-Austral

velutina, Turcz. in Bull. Phys.-Math. Acad. Pétersb. x. (1852) 345.-Austral.

BEAUHARNOISIA, Ruiz \& Pav. in Ann. Mus. Par. xi. (1808) 71. t. $9=$ Tovomita, Aubl. (Guttif.) fructipendula, Ruiz \& Pav. 1. c, = T. fructipendula.

BEAUMARIA, Deless. ex Stend. Nom. ed. II. i. 192 $(1840)=$ Aristotelia, L'Hérit. (Tiliac.).

Macqui, Deless. ex Steud, 1. c. = A. Macqui.

BEAUMONTIA, Wall. Tent. Fl. Nep. 14. t. 7 (1824) APOCYNACEAE, Benth. \& Hook. f. ii. 721. grandiflora, Wall. l. c. 15.t. 7.-Ind. or.

Jerdoniana, Wight, Ic. iv. t. 1314.--Ind. or.

khasiana, Hook. f. Fl. Brit. Ind. iii. 661.-Reg. Himal.

longiflora, Hook. f. 1. c. 660 , in syn. = grandiflora.

longifolia, Lodd. ex Loud. Hort. Brit. 67 ; Hook. Bot. Mag. sub t. $3213=$ grandiflora.

multiflora, Teijsm. \& Binn. in Nederl. Kruidk. Arch. iii. (1855) $393=$ khasiana.

Wallichii, Walp. Ann. iii. $39=$ Wrightia tomentosa.

BEAUMULIX, Willd. ex Poir. in Dict. Sc. Nat, iv. Suppl. 54 (1816) = Reaumuxia, Linn. (Tamariscin.).

BEAUPREA, Brongn, \& Gris, in Bull. Soc. Bot. Fr xviii. (1871) 243. PROTEACEAE, Benth. \& Hook f. iii. 175 .

Balansae, Brongn. Eo Gris, l. c. 245.-N. Caled. diversifolia, Brongn. \& Gris, l. $c .244 .-\mathrm{N}$. Caled. gracilis, Brongn. E Gris, l. c. 243.-N. Caled. Pancheri, Brong $n$. E Gris, $l . c .245$ - N. Caled. spathulaefolia, Brongn. E' Gris, l.c. 244.-N. Caled.

BEAUTEMPSIA, Gaudich. Voy. Bonite, t. 56 (1844 ?)= Capparis, Linn.

avicenniaefolia, Gaudich. 1. c.-Hab.?

BEBBIA, Greene, in Bull. Calif. Acad. i. (1885) 179 COMPOSITAE. atripliciflora, Greene, l. c. 181.--Calif. juncea, Greene, $l . c .179 .-$ Calif.
BECCABUNGA, Fourr. in Ann. Soc. Linn. Lyon, N. S. xvii. (1869) $128=$ Veronica, Tourn. (Scrophul.) Anagallis, Fourr. 1. c. $=$ V. Anagallis.

vulgaris, Fourr. 1. c. = V. Beccabunga.

BECHIUM, DC. Prod.v. $70(1836)=$ Vernonia, Schreb. (Compos.).

foliosum, Klatt, in Linnaea, xxxyii. (1871-73) 508.Madag.

rubricaule, DC. Prod. v. $70=\mathrm{V}$. Candollei.

scapiforme, DC. 1. c. 71,-Madag.

BECHONNERIA, Hort. ex Carr. in Rev. Hortic. (1867) $320=$ Beschorneria, Kunth (Amaryll.)

BECKEA, Pers. Syn. i. 234 (1805) = BAECKEA, Burm. $f_{.}=$Brunia, Linn.

BECKEA, St. Hil. in Dict. Sc. Nat. iv. 208 (1804)= Baeckea, Linn. (Myrtac.)

BECIUM, Lindl. Bot. Reg. (1842) Misc. 42= Ocimum, Tourn. (Labiat.)

bicolor, Lindl. 1. $c_{\circ}=$ O. filamentosum.

BECKERA, Fresen. in Mus. Senckenb. ii. (1837) 132. t. 8. GRAMINEAE,- Benth. \& Hook. f. iii. 1117.

dioica, Heynh. Nom, ii. $63=$ Panicum adoënse. glabrescens, Steud. Syn. Pl. Gram. 117.-Abyssin. gracilis, Hochst. in Flora, xxxviii. (1855) 199.Abyssin.

mutica, Hochst. l. c. xxvii. (1844) 514.-Abyssin.

nubica, Hochst. l. c. 512.-A byssin.

petiolaris, Hochst. l. c.-Abyssin.

Petitiana, A. Rich. Tent. Fl. Abyss, ii. 358-Abyssin.

polystachia, Fresen. in Mus. Senckenb. ii. (1837) 132 -Abyssin.

Schimperi, Hochst. in Flora, xxvii. (1844) 512.Abysin.

uniseta, Steud. Syn. Pl. Gram. 118=Pennisetum unisetum.

BECKERIA, Bernh. Syst. Verz. Erf. $20(1800)=\mathbf{M}$ elica, Linn. (Gramin.).

ciliata, Bernb. 1. c. $40=$ M. ciliata.

BECKERIA, Heynh. Nom. ii. $63(1846)=$ Beckera Fresen. (Gramin.).

BECKEROPSIS, Fig. \& De Not. in Mem. Acc. Torin. Ser. II. xiv. (1854) $365=$ Pennisetum, Pers. (Gramin.).

nubica, Fig. \& De Not. 1. c. 366.-Nubia.

petiolaris, Fig. \& De Not. 1. c. 368.-Abysin.

BECKIA, Rafin. Sylva Tellur. 103 (1838)=Osbeckia, Linn. (Melast.).

BECKMANNIA, Host, Gram. Austr. iii. 5. t. 6 (1805). GRAMINEAE, Benth. \& Hook. f. iii. 1099.

Bruckmannia, Nutt. Gen. Am. i. 48 (1818)

JoAchimia, Tenore, ex Roem. \& Schult. Syst. ii. 695 (1817)

erucaeformis, Host, l. c.-Europ.; As. temp.; Am. bor.

erucoides, Beauv. Agrost. t. 19. f. $6=$ erucaeformis.

BEClardiA, A. Rich. in Mém. Soc. Hist. Nat. Par. iv. (1828) 69=Cryptopus, Lindl. (Orchid.).

brachystachya, A. Rich. 1. c. $71=$ Aeonia brachystachya.

elata, A. Rich. 1. c. $69=$ C. elatus

macrostachya, A. Rich. 1. c. $70=$ Aeonia macrostachya.

BECQUERELA, Nees, in Linnaea, ix. (1834) $304=$ seq.

BECQUERELIA, Brongn. in Duperr. Voy. Coq. Bot. Phaner. 161. t. 27 (1829). CYPERACEAE, Benth. \& Hook. f. iii. 1069

cymosa, Brongn. l.c-Bras.

cymosa, Kunth, Enum. Pl. ii. $361=$ Merkeliana

discolor, Kunth, l. c. 362-Bras.

gigantea, Hochst. ex Steud. Syn. Pl. Cyp. 180.Guiana.

glomerata, Kunth, Enum. P1. ii. $364=$ seq. 


\section{BECQUERELIA :}

glomerulata, Brongn. in Duperr. Voy. Coq. Bot. Phan 163 = Calyptrocarya Palmetto

Merkeliana, Nees, in Mart. Fl. Bras. ii. I. 191.-Bras. muricata, Nees, l. c. 192.-Bras.

verruculosa, Nees, l. c. 191.-Bras.

BEDDOMEA, Hook. f. in Benth. \& Hook. f. Gen. 336 (1862). MELIACEAE, Benth. \& Hook. f. 1. indica, Hook. f. l. c.-Ind. or.

simplicifolia, Bedd. Fl. Sylv. i. t. 135.-Ind. or

BEDFORDIA, DC, in Guillem. Arch. Bot. ii. 332 (1833). COMPOSITAE, Benth. \& Hook. f. ii. 450. linearis, DC. l. c. 333 ; et Prod. vi. 441.-Tasmania salicina, $D C . l l . c c$. -Austral.

BEDOUSIA, Dennst. Schluess. Hort. Malab. 31 (1818) Casearia, Jacq. (Samyd.).

aromatica, Rafin. Sylva Tellur. $11=$ C. tomentosa malabarica, Dennst. Schluess. Hort. Malab. $31=$ C. tomentosa.

BEDUSIA, Rafin. Sylva Tellur. $11(1838)=$ praec

BEEHSA, Endl. Gen, 1354 (1841)=BEESHA, Kunth = Bambusa, Linn. (Gram.).

BEERA, Beauv, in Lestib. Essai Fam. Cyp. 43 (1819)= Hypolytrum, Rich. (Cyperac.).

caespitosa, Schrad, ex Kunth, Enum. Pl. ii. $270=\mathrm{H}$. strictum.

laxa, Schrad. ex Kuntli, 1. $\mathrm{c}_{0}=\mathrm{H}$. laxum.

silvatica, Schrad. ex Nees, in Mart. Fl. Bras. ii. I. $67=$ H. fuscum.

BEESHA, Kunth, Syn. i. 253 (1822)=Bambusa, Linn. (Gram.)

baccifera, Kunth, 1. c. = Melocanna bambusoides.

Fax, Schult. f. in Roem. \& Schult. Syst. vii. $1336=$ Melocanna humilis.

humilis, Kanth, Enum. Pl. i. 434=Melocanna humilis.

Rheedii, Kunth, Rev. Gram. i. $141=$ Melocanna bambusoides.

travancorica, Bedd. Forest. Man. Bot. $234=$ Melocanna travancorica.

BEESHA, Munro, in Trans. Linn. Soc, xxvi. 144 (1868) Ochlandra, Thw. (Gram.)

capitata, Munro, in Trans. Linn. Soc. xxvi. (1868) 145. -Madag.

elegantissima, Kurz, ex Munro, 1. c. 146.-Java.

stridula, Munro, 1. c. $145=0$. stridula.

BEETHOVENIA, Engl. in Linnaea, xxxiii. (1864-65 $677=$ Ceroxylon, Humb. (Palm.).

cerifera, Engl. 1. $\mathrm{c},=\mathrm{C}$. andicola.

BEFARIA, Mutis, ex Linn, Mant. ii. 152 (1771) ERICACEAE, Renth. \& Hook. f. ii. 599.

ACUNna, Ruiz \& Pav. Prod, 69. t. 12 (1794)

Bejaria, Zea, in Anal. Cienc. Nat. iii. (1801) 151, in nota; Vent. Jard. Cels $(\mathbf{1 8 0 0 )}$, sub t. 51.

Jurgensenia, Turcz. in Bull. Soc. Nat. Mosc. xx. (1847) I. 151.

aestuans, Linn. Mant. ii. 242.-N. Granat.

caxamarcensis, H. B. E K. Nov. Gen. et Sp. iii. 294.Peruv.

cinnamomea, Lindl, in Gard. Chron. (1848) 175.Peruy.

coarctata, Hook. Bot. Mag. t. $4433=$ Lindeniana.

coarctata, Humb. E Bonpl. Pl. Aequin. ii. 125. t. 121. -Peruv.

cubensis, Griseb. Cat. Pl. Cub, 52,-Cuba.

densa, Planch, ex Hirincq, in Rev. Hortic. Sér. III. iv. $(1850) 185 .-\mathrm{Hab}_{\text {. ? }}$

denticulata, Remy, in Ann. Sc. Nat. Sér. III. viii. (1847) 230 - Bolivia

discolor, Benth. Pl. Hartw, 65.-Mexic.

drymifolia, Linden, ex Hérinco, in Rev. Hortic. Sér. III. iv, (1850) 185-N. Gramat.

foribunda, Mart. \& Gal. in Bull. Acad. Brux. ix. 1842) $543=$ discolor

glabra, Mart. \& Gal. 1. c. = laevis

glaucn, Humb. G Bompl. Pl. Aequin. if. 118. 1. 117.N. Granat.

\section{BEFARIA}

grandiflora, Humb. \& Bonpl. Pl. Aequin ii. 222. t. 119.--Ecuador

guyanensis, Klotzsch, in Schomb. Fauna et Fl. Guy 1088.-Guiana

hispida, Poepp. E Endl. Nov. Gen. et Sp. i. 24. t. 39. -Chili.

laevis, Benth. Pl. Hartw. 65,-Mexic

lanceolata, Ruiz E Pav. Fl. Per iv. t. 413 , f b-Peruv.

ledifolia, Humb. E Bonpl. Pl. Aequin. ii. 124. t. 120, -N. Granat

Lindeniana, Hérincq, in Rev. Hortic. Sér. III. iv (1850) 181.-Venezuela.

mexicana, Benth. Pl. Hartw. 15. n. 92.-Mexic.

Mathewsii, Field. E Gardn. in Bot. Mag. t. 4981.Peruy,

microphylla, Paxt. \& Lindl. Flow. Gard. i. $86^{\circ}=$ densa.

myrtifolia, Hérincq, in Rev. Hortic. Sér. III. iv. (1850) 184.-N. Granat.

oblonga, Ruiz E Pav. Fl. Per, iv. t. 413 ; Pers. Syn. ii. 3.-Venezuela.

pallens, Remy, in Ann. Sc. Nat. Sér. III. viii. (1847) 229.-Peruv.

paniculata, Michx. Fl. Am. Bor. i. $280=$ racemosa.

parvifora, Benth. Pl. Hartw. 143.-Peruv.

phyllireaefolia, Benth. l. c. 225.-N. Granat.

racemosa, Vent. Fard. Cels, t. 51.-Am. bor.

resinosa, Linn. f. Suppl. 246.-N. Granat.

Schomburgkiana, Klotzsch, in Schomb. Fauna et Fl. Guy. 1088.-Guiana.

Sprucei, Meissn. in Mart.Fl. Bras. vii. 171.-Peruy. subsessilis, Benth. Pl. Hartw. 143.-Peruy.

tricolor, Linden, ex Hérincq, in Rev. Hortic. Sér. III iv. $(1850)$ 185. - N. Granat.

BEGONIA, [Tourn,] Linn. Gen. ed. II. 516 (1742) BEGONIACEAE, Benth. \& Hook. f. i. 841.

Augustia, Barya, Casparya, Cyathocnemis, DONALDIA, DORATOMETRA, Ewaldia, GaERdTIA Gireoudia, Gurltia, HaAgea, Huszia, IsoHTERIX, IsOPTERYX, KNESEbeckiA, LAUCHEA, Lepsia, 'Magnusia, Mitscherlichia, Mosch KOWITZIA, NEPHROMISCHUS, PETERMANNIA, Pilderia, Platycentrum, Pritzelia, Putzey Sia, Rachia, Reichenheimia, Reissia, Ross MANNIÄ, Sassea, SaUeria, ScheidWeIleria, Sterneria, Stibadotheca, Tittelbachia, Trachelanthus, Trendelenburgia, WageNERIA, et WEILBACHIA, Klotzsch, in Abh Akad. Berl. (1854) 17-134. tt. 1-12.

Cladomischus, Klotzsch, ex DC. 1. c. 278 (1864)

Diplocliniu M, Lindl. Veg. Kingd. 319 (1847)

Eupetalum, Lindl. Introd. Nat. Syst. ed. II. 440 (1836)

FalKeA, Koen. ex Steud. Nom. ed. II. i. 194, 625 (1840).

IrMA, Bout, ex A. DC. Prod. xy, I, 406 (1864).

MrTCHeRLICHIA, Klotzsch, in Monatsb. Berl. Acad. (Maerz 1854) 124.

Mezierea, Gaudich. Voy. Bonite, t. 32 (1839).

Platyclinium, T. Moore, in Moore \& Ayres, Gard. Mag. Bot. ii. (1850) 153.

SPHENDANTHERA, Hassk, in Versl, Kon, Akad, Wetensch.iv. (1855) 139

StiradothecA, Klotzsch, in Monatsb. Berl. Acad (Maerz 1854) 127.

Trachelocarpus, C. Muell. in Walp. Ann. iv. 909 (1857)

Tritomisa, Rafin. F1. Tellur. ii. 91 (1836)

Wagneria, Klotzsch, in Monatsb. Berl. Acad. Maerz 1854) 126.

acerifolia, H. B. E K. Nov. Gen. et Sp. vii. 186.Ecuador.

acetosa, Vell. Fl. Flum. x. t. 50.-Bras.

acida, A. DC. Prod. xv, 1. 364.-Bras.

acida, Vell. Fl. Flum, x. t. $49=$ prзec.?

aconitifolia, A. DC. in Ann. Sc. Nat. Sér. IV. xi. (1859) 127.-Bras.

aculeata, Walp. in Nov, Act. Nat. Cur. xix. Suppl.

(1843) $409=$ maculata.

acuminata, Dryand. in Trans. Linn. Soc. i. (1791)

166. t. 14.-Jamaica.

acutifolia, Balb. ex A. DC. Prod. Xv. I. $295=$ portori. censis.

acutifolia, Jacq. Coll, i. 122 = acuminata

acutifolia, Herb. Vindob. ex A. DC. P'rod. xv. 1. \$78

- dentatiloua.

\section{BEGONIA}

acutiloba, Liebm, in Kjoeb. Vidensk. Meddel. (1852) 14.-Mexic

adenopoda, Lem. Jard. Fleur. ii. Misc. $17=$ verticil lata.

aequata, A. Gray, Bot. U. St. Expl. Exped. i. 658.Ins. Luzon.

alaecida, C. B. Clarke, in Hook. f. Fl. Brit. Ind, ii. 637.-Burma.

albida-setulosa, Hassk. Cat. Hort. Bog. Alt. 313.Hab. ?

albiflora, Hort. ex Klotzsch, in Monatsb. Berl. Acad. (Maerz 1854) 126, nomen.-Hab. ?

albo-coccinea, Hook. Bot. Mag.t. 4172. -Ind, or.

alchemilloides, A. DC. in Ann. Sc. Nat. Sér. IV xi. (1859) 125 . - Bras.

alnifolia, A. DC. l. c. 132.-N. Granat

alto-peruviana, A. DC. l. c. 128.-Peruv

amabilis, Linden, Hort. Linden. (1859) 1,-Assam.

amoena, Wall. Cat. n. 3682.-Reg. Himal.

ampla, Hook. f. in Oliver, Fl. Trop. Afr. ii. 574.-Afr.

trop.

anaimalaiensis, Bedd. in Madr. Fourn. Sc. Ser. III. (1864) 48.--Ind. or.

anamalayana, Bedd. in Trans. Linn. Soc. xxy. (1866. $217=$ praec

andamensis, Parish, ex C. B. Clarke, in Hook. f. Fol. Brit. Ind. ii. 650 -Ind, or.

anemonoides, Arara, ex Steud. Nom. ed. II. i. 193.Hab. ?

angularis, Raddi, in Mem. Mod. xviii. Fis. $(1820,407$ -Bras.

angulata, Vell. Fl. Flum, x. t. 52.-Bras.

angustifolia, Blume, Enum. Pl. Fav. 97.-Tava.

angustiloba, $A . D C$ in $A n n$. Sc. Not. Sér. IV xi. (1859) 126.-Mexic

anisosepala, Hook. f. in Oliver, Fl. Trop. Afr. ii. 57t -Afr. trop.

annobonensis, A. DC in Ann. Sc. Nat. Sér. IV. xi. 1859) 127.-Afr. trop.

annulata, C. Koch, in Berl. Gartens. i. (1837) 76.Reg. Himal.

anodaefolia, $A . D C$. in $A n n . S_{c}$. Nat. Sér. IV. $x$ (1859) 126.-Mexic.

aptera, Blume, Enum. Pl. Fav. 97. -Ins. Celebes.

aptera, Roxb. Hort. Beng 104. Fl. Ind iii. 650-Ins.

Mascar.; Timor.; Ins. Philip.

arborescens, Raddi, in Mem. Mod. xviii. Fis. (1820 408.-Bras.

areolata, Miq. Pl. Fungh. 417.- Java.

argentea, Van Houtte, ex A. DC. Prod. xv. 1. \$18 maculata.

argyrocoelis, Hérinca, in Rez. Hortic Sér. III. (1847) 111, 165.-Hab.?

argyrostigma, Fisch. ex Link \& Otto, Ic. Sel. i. 23.

$10=$ maculata

Arnottiana, A. DC. Prod. xv, I. $322=$ cordifolia asarifolia, Liebm. in Kjoeb. Vidensk. Meddel. 185: (1853) 8 = hydrocotilifolia

ascotiensis, $\mathcal{F}$. B. Weber, in Rev. Hortic. (18; 1 ) 17.Hab. ?

aspleniifolia, Hook. f. ex A. DC. Prod. xv. 1. 392.-Afr.

atricha, Miq.ex A. DC. l. c. 321.-Sumatra.

attenuata, A. DC. L. c. 388 - - Bras.

attenuata, Klotzsch, ex Regel, Ind. Sem. Hort. Petrop. (1866) $101=$ hederacea

aucubaefolia, Hort. ex Klotzsch, in Monarsb. Berl. Acad. (Maerz 1854) 122 = incarnata.

aurantiaca, Hort ex Planch. in Fl. des Serres, Sér. I. v. $(18 \pm 9) 580=$ cinnabarina.

auriculata, Hook. f. in Oliver, Fol. Trop. Affr. ii. 577. Afr. trop.

auriformis, Hort. Berol. ex Klotzsch, in Abh. Akad Berl. (1855) $38=$ incana,

baccata, Hook. Bot. Mag. t. 555 t-Afr. trop.

Uahiensis, A. DC in Ante Sc. Aiat Ser. 11 . xi 1S5: 137.-Bras.

Balmisiann, Ruis, ex Klolsch, in Abh. Akad. Bert (1855) 38.-Mexic

barbata, Hall. Cot. D. 3679 , A. \& B. partim.-Int or. : Jurmn.

barbate. Miall, l. C = rubromenia.

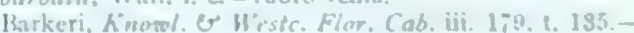
Mexic.

Reeldomei, Hork. f. Bot. Mage. t. 6;07.-Assam.

Ikernicrii. A. DC. in .tun. Si. . ist. Ser. IV. xi. ilsi. 130.-Madag. 


\section{BFGONIA :-}

besleriaefolia, Schott, in Spreng. Syst. iv. 408.-Bras. bidentata, Raddi, in Mem. Mod. xviii. Fis. (1820) 408 -Bras.

bipetala, Lodd. ex Otto E Dietr. Allg. Gartenz. ix. (1841) 58 - - Ind. or

biserrata, Lindl. in Fourn. Hort. Soc. ii. (1847) 313.Guatemala.

Boissieri, A. DC. in Ann. Sc. Nat. Sér. IV. xi. (1859) 126.-Mexic.

Boiviniana, $A$. DC. l. c. 130.-Madag.

boliviensis, $A, D C, l, c, 122$ - Bolivia

bombycina, Blume, Enum. P1. Jav, i. $97=$ isoptera

borneensis, A. DC. in Ann. Sc. Nat. Sér. IV. xi (1859) 128.-Borneo.

Boucheana, A. DC. Prod. xv. I. 373.-Venezuela.

Bowringiana, Champ. ex Benth. in Hook. Kew Journ. iv. (1852) $120=$ laciniata.

bracteata, Fack, in Malay. Misc. ii. (1822) vII. 13.Sumatra.

bracteosa, A. DC. in Ann. Sc. Nat. Sér. IV. xi. (1859) 132.--Peruv.

Brandisiana, Kurz, in Fourn. As. Soc. Beng. x1. (1871) II. 58 ; et in Flora, liv. (1871) 295.-Burma.

brasila, A. DC, in Mém. Soc. Phys. Genèv. vii. (1836) $295=$ hirtella

brasiliana, Schrank, ex Stend. Nom. ed. II. i. $193=$ praec.

brasiliensis, Klotzsch, in Monatsb. Berl. Acad. (Maerz 1854) 122, nomen.-Bras.

brevicaulis, $A$. DC in Ann. Sc. Nat. Sér. IV xi. 1859) 134.-Reg. Himal.

Bridgesii, A. DC. l. c. 132.-Bolivia.

Brongniartiana, Lem. Hort. Univ. v. 355.-Hab. ?

broussonetiaefolia, A. DC. in Ann. Sc. Nat. Sér. IV

xi. (1859) 133.-Guatemala

buddleiaefolia, $A, D C, l, c .141$ - - Peruy.

bulbifera, Hort. ex Vilm. Fl. Pl. Terre, ed. III. $155=$ discolor.

bulbifera, Lodd. ex Otto \& Dietr. Allg. Gartenz. ix 1841) $58=$ bulbillifera.

bulbillifera, Link $\mathcal{E}^{\prime}$ Otto, Ic. Pl. Rar. 89. t. 45.Mexic.

bulbillifera, Moric. ex A. DC. Prod. xv. I. $310=$ gracilis.

caespitosa, Fack, in Malay. Misc. ii. (1822) VII. 8.Sumatra.

caffra, Meissn. in Linnaea, xiv. (1840) $501=$ Dregei.

canarana, Miq. Anal. Bot. Ind iii. 18-Ind or.

candicans, A. DC. Prod. xv, I. 400, lapsu, vide Bignonia candicans.

capensis, Blanco, Fl. Filip. ed. I. 724=rhombicarpa

capensis, Linn. f. Suppl. $502=$ diptera.

cardiocarpa, Liebm. in Kjoeb. Vidensk. Meddel. 185. 1853) 13.-Nicaragua.

carminata $\times$, Hort. Fl. Mag. t. 551 (err. typ. 451)

carnosa, Teijsm. E Binn. Epim. Lugd. Bat. (1863) 4 - Malaya.

caroliniaefolia, Regel, Gartenfl. i. (1852) 259. t. 25.Mexic.

carpinifolia, Liebm. in Kjoeb. Vidensk. Meddel. 1852 (1853) 20.-Costa Rica.

castaneaefolia, Otto E Dietr. Allg. Gartenz. iv. (1836) 356. - Bras.

castaneaefolia, Schott, in Spreng. Syst. iv. App. $407=$ fruticosa.

Cathcartii, Hook. f. E' Thoms. Illustr. Pl. Himal. t. 13 -Reg. Himal.

ciliata, Hort. ex Steud. Nom. ed. II. i. 193, $194=$ insignis.

ciliata, H. B. \& K. Nov. Gen. et Sp. vii. $136=$ hirtella.

ciliata, Pav, ex A. DC. Prod. xy, I. $331=$ sub ciliata.

cinnabarina, Hook. Bot. Mag. t. 4483.-Bolivia

circumlobata, Hance, in Fourn. Bot. xxi. (1883) 203 -China.

cladocarpa, Baker, in Fourn. Bot. xx. (1882) 113.Madag.

Clarkei, Hook. f. Bot. Mag. sub t. 5663 et t. 5675. Bolivia.

clypeifolia, Hook. f. in Oliver, Fl. Trop. Afr. ii. 576 .Afr. trop.

coccinea, Hook. Bot. Mag. t. 3990.-Bras.

coccinea, Ruiz, ex Klotzsch, in Monatsh. Berl. Acad.

Maerz 1854) 127;A. DC. Prod. xv. I. 273. Perny.

columnaris, Benth. Pl. Hartw. 131.-Peruv,

\section{BEGONIA :-}

columnaris, Ruiz, ex Klotzsch, ia Monatsb. Berl. Acad. (Maerz 1854) $127=$ cordifolia

complicata, A. DC. Prod.xv. 1. 399.-Hab. ?

concanensis, A. DC. in Ann. Sc. Nat. Sér. IV. xi. (1859) 126.-Ind or

conchaefolia, A. Dietr. Allg. Gartenz. xix. (1851) 258. - Costa Rica.

concinna, Schott, in Spreng. Syst. iv. App. $408=$ peltata?

confertiflora, Gardn. in Hook. Lond. Journ. Bot. iv. (1845) $134=$ arborescens.

convolvulacea, A. DC. in Mart. Fl. Bras, iv, I, 367.Bras.

corallina, Carr. in Rev. Hortic. (1875) 89.-Bras

cordata, Vell. Fl. Flum. x. t. 34.--Bras.

cordifolia, Thw. Enum. Pl. Zeyl. 129.-Ind. or.

coriacea, A. DC. in Ann. Sc. Nat. Sér. IV. xi. (1859) 122.-Bolivia.

coriacea, Hassk. Cat. Hort. Bogor. Alt. $311=$ peltata. crassicaulis, Lindl. in Bot. Reg. (1842) Misc. 22.Guatemala.

crenata, Dryand. in Trans. Linn. Soc. i. (1791) 162. t. 14. f. 3.-Ind, or

crenata, Herb. Finlays. ex A. DC. Prod. xv, I. $401=$ prolifera?

crenatiflora, A. DC. Prod.xv. I. 306.-Mexic.

crenatifolia, Hemsl. Biol. Centr. Am. Bot. i. $494=$ crenatiflora.

crenulata, Schott, ex A. DC. in DC. Prod. xv. I. $358=$ angularis

crinita, Oliver, in Hook. Bot. Mag. t. 5897.-Peruv

cruenta, R. Grah. ex Steud. Nom. ed. II. i. 193.-Bras.

cubensis, Hassk. Cat. Hort. Bogor. Alt. $322=$ Wrighti ana.

cubincola, A. DC. in Ann. Sc. Nat. Sér. IV. xi. (1859) 124.-Cuba

cucullata, Ruiz, ex A. DC. Prod. xv, I. $274=$ columnaris.

cucullata, Willd. Sp. Pl. iv, 414.-Bras.

cucullifolia, Hassk. Cat. Hort. Bogor. Alt. $311=$ semperflorens.

Cumingii, A. Gray, Bot. U. St. Expl. Exped. i. $658=$

philippinensis.

Cummingiana, A. DC. Prod.xv. I. 320.-Ins. Fiji.

cuneata, Walp. Rep. ii. $214=$ spathulata.

cyathophora, Poepp. Ev Endl. Gen. et Sp. i. 7. t. 14.Peruy.

daedalea, Lem, Illustr. Hortic vii. (1860) 54. t, $269=$ strigillosa.

dasycarpa, A. DC. in Ann. Sc. Nat. Sér. IV. xi. (1859) 127.-Bras.

dasypoda, Meissn. ex A. DC. Prod. xv. I. $299=$ hirtella.

Daveauiana, Godefr, in Rev. Hortic. (1880) $290=$ Pellionia Daveauiana.

Davisii, Veitch, in Hook. f. Bot. Mag. t. 6252.-Peruv

dealbata, Liebm. in Kjoeb. Vidensk. Meddel. 1852 (1853) 5.-Mexic

decandra, Pav. ex A, DC in Ann. Sc. Nat. Sér. IV, xi. (1859) 122.-Mexic.

declinata, Vell. Fl. Flum. x. t. 44.-Bras.

delicatula, Parish, ex C. B. Clarke, in Hook. f. Fl. Brit. Ind. ii. 652.-Burma.

dentata, Pav. ex A. DC. Prod. xv. I. $307=$ angustiloba.

dentatiloba, A. DC. in Ann. Sc. Nat. Sér. IV, xi. (1859) 140.-Bras.

denticulata, H. B. E K. Nov. Gen. et Sp. vii. 182.Venezuela.

depauperata, Schott, in Spreng. Syst. iv. App. $408=$ rhizocarpa.

derycxiana, Lem. Hort. Univ. (1843-44) Misc. 355, fide A. DC. Prod. xv. I. $343=$ nelumbifolia.

Diadema, Linden, in Illustr. Hortic. xxix. (1882) 446.-Borneo.

dichotoma, Facq. Coll . iii 250.-Venezuela

digitata, Raddi, in Mem. Mod. xvii. Fis. (1820) 406.Bras.

Digwilliana, Carr. in Rev. Hortic. (1875) 420.Hab. ?

dimidiata, Vell. Fl. Flum. x. t. $46=$ arborescens.

dioica, Buch.-Ham. ex D. Don, Prod. Fl. Nep. $223=$ scutata?

dipetala, R. Grah. in Bot. Mag., t. $2849=$ malabarica.

diptera, Dryand. in Trans. Linn. Soc. i. (1791) 170.Bras.
BEGONTA :-

discolor, [R. Br. in] Ait. Hort, Kew. ed. II. v. $184=$ Evansiana.

disticha, Hort. Berol. ex Klotzsch, in Monatsb. Berl. Acad. (Maerz 1854) $122=$ suaveolens.

disticha, Link, Enum. Hort. Berol. ii. $396=$ stipulacea diversifolia, Knowl. E Westc. Flor. Cab, t. 14. i. (1837) 27.-Hab.?

diversifolia, R. Grah. in Edinb. N. Phil. Journ. (Jan.Apr. 1830) $183=$ gracilis.

domingensis, A. DC. in Ann. Sc. Nat. Sér. IV. xi (1859) 124.-Ins. S. Doming.

dominicalis, A. DC. Prod. xv. I. 366.-Ins. Dominica.

Donkelariana, Lem. Fard. Fleur. i. (1851) Misc. 34 -Mexic.

Dregei, Otto E Dietr. Allg. Gartenz. iv. (1836) 357.Bras.

dubia, Vell. Fl. Flum. x. t. 42,-Bras.

Dux, C. B. Clarke, in Hook. f. Fl. Brit. Ind. ii. 637.Burma.

echinata, Royle, Illustr. Bot. Himal. 313. t. 80. fig. 1 = picta.

echinosepala, Regel, in Act. Hort. Petrop. i. (1871) 91.--Bras.

elaeagnifolia, Hook. $f$. in Oliver, Fl. Trop. Afr. ii. 579 -Afr. trop.

elata, Klotzsch, in Monatsb. Berl. Acad. (Maerz 1854) 122.-Bras.

elatior, Hort. ex Steud. Nom. ed. II. i. $193=$ Dregei

elatostemmoides, Hook. f. in Oliver, Fl. Trop. Afr. ii 576. - Afr. trop.

elegans, H. B. Eे K. Nov. Gen. et Sp. vii. 182.-N Granat.

elliptica, H. B. \& K. 1. c. $138=$ scandens

elongata, Wall. Cat. n. $6291=$ sinuata.

Epibaterium, Mart.ex A. DC. in Mart. Fl. Bras. iv. I. 363.-Bras.

epiphytica, Hook. f. in Oliver, Fl. Trop. Afr. ii. 580.Afr. trop.

episcopalis, C. B. Clarke, in Hook. f. Fl. Brit. Ind. ii 644.- - Reg. Himal.

erecta, Vell. Fl. Flum. x. t. 43.-Bras.

eviocaulis, Vis. Orto Padov. (1842) $135=$ tomentosa.

eriocaulon, Neumann, in Rev. Horlic. Sér. III. i. (1847) $166=$ tomentosa?

Ermani, Klotzsch, in Abh. Akad. Berl. (1855) $35=$ uliginosa.

erminea, L'Hérit. Stirp. Nov. 97. t. 47.-Madag

erosa, Blume, Enum. Pl. Fav.i. 96.--Java.

erosa, Wall. Cat. n. 3688 , partim $=$ picta, amoena

erythrocarpa, A. DC. in Ann. Sc. Nat. Sér. IV. xi. (1859) 121.-Bras.

erythrophylla, Neuman, in Rev. Hortic. Sér. III. i (1847) 166.-Hab, ?

Evansiana, Andr. Bot. Rep. t. 627.-Malaya ; China

Japon.
excelsa, Hook. f. in Oliver, Fl. Trop. Afr. ii. 571.Afr. trop.

eximia, Hort. ex Lem. Illustr. Hortic. vii. (1860) t. 233.-Hab. ?

fagifolia, Fisch. in Otto \& Dietr. Allg. Gartenz. iv 1836) 356.-Bras.

fagopyroides, Kunth E Bouché, Ind. Pl. Hort. Berol. (1848).-Venezuela.

falcifolia, Hook. f. Bot. Mag. t. 5707.-Afr. trop.

falciloba, Liebm. in Kjoeb. Vidensk. Meddel. 185. 1853) 15.-Mexic.

fallax, A. DC. Prod. xv. I. 329.--Ind. or

fasciculata, Fack, in Malay. Misc. ii. (1822) vir. 12. - Sumatra.

ferruginea, Linn. f. Suppl. 419.-N. Granat.

fibrosa, C. B. Clarke, in Hook. f. Fl. Brit. Ind. ii. 652. -Burma.

filipes, Benth. Bot. Voy. Sulph. 101.-Panama

fimbriata, Liebm. in Kjoeb. Vidensk. Meddel. 1852 (1853) 18.-Mexic.

fimbristipula, Hance, in Fourn. Bot. xxi. (1883) 202.China.

Finlaysoniana, Wall. Cat. n. 3684= prolifera ?

Fischeri, Otto E Dietr. Allg. Gartenz. iv. (1836) 354. -Bras.

Fischeri, Schrank, Pl. Rar, t. $59=$ macroptera.

flaccidissima, Kurz, in Fourn. As. Soc. Beng. xl. (1872) II. 308.-Burma.

Alexuosa, A. DC. in Ann. Sc. Nat. Sér. IV. xi. (1859) 142.-Panama.

floccifera, Bedd. Ic. Pl. Ind. Or. i. 23.-Ind. or. floribunda, Carr. in Rev. Hortic. (1875) 420.-Hab. 
BEGONIA :

foliosa, H. B. $G$. Nov. Gen. et Sp, vii. 183. t. 642 N. Granat

foliosa, Poepp. ex A. DC. Prod. xv. I. $376=$ Poeppigiana.

Franconis, Liebm. in Kjoeb. Vidensk. Meddel. 1852 (1853) 21-Mexic.

frigida, A. DC. in Ann. Sc. Nat. Sér. IV. xi. (1859) 143. $-\mathrm{Hab}$ ?

Froebelii, A. DC. in Gard. Chron. (1874) II. 552.Ecuador.

fruticosa, A.DC. in Mart. Fl. Bras. iv. I. 377.Bras.

fusca, Liebm. ex Klotzsch, in Abh. Akad. Berl. (1855) 39.-Bras.

fuchsioides, Hook. Bot. Mag. t. 4281.-Mexic.

furfuracea, Hook. $f$. in Oliver, Fl. Trop. Afr. ii. 571.Afr, trop.

fusca, Liebm. in Kjoeb. Vidensk. Meddel. 1852 (1853) 7.-Mexic.

Galeotti, Hort. Berol. ex Klotzsch, in Abh. Akad, Berl. (1855) $39=$ lobata.

Galeottiana, Lem. Fard. Fleur. i. (1851) Misc. 14.Bras.

Gardneri, A. DC. in Ann. Sc. Nat. Sér. IV. xi. (1859 138.-Bras.

Gaudichaudii, Walp. Rep. v, 769.-Peruv.

gemmipara, Hook. f. E Thoms. Illustr. Him. Pl. t. 14 -Reg. Himal.

geniculata, Vell. Fl. Flum. x. t. 51=convolvulacea.

geniculata, Jack, in Malay. Misc. ii. (1822) viI. $15=$

isoptera.

geraniifolia, Hook. Bot. Mag. t. 3387.-Peruv.

geranioides, Hook. f. l. c. t. 5583 -Afr. austr.

gigantea, Wall. Cat. n. 3677.--Reg. Himal.

gigantea, Wall. 1. c, n. $3677 \mathrm{~B}=$ silhetensis.

glabra, Aubl. Pl. Gui. ii. $916=$ scandens,

Glabra, Ruiz, ex Klotzsch, in Monatsb. Berl. Acad. (Maerz 1854) 128.-Peruv.

glandulifera, Griseb. Fl. Brit. W. Ind. 304.-Ind. occ. glandulosa, A. DC. Prod. xv. I. 339.-Am. centr. glanca, Ruiz E Pav. ex A. DC. l. c. 330.-Peruv. goëgoënsis, N. E. Br. in Gard. Chron. (1882) II. 71.Sumatra.

goniotis, C. B. Clarke, in Hook. f. Fl. Brit. Ind. ii. 648.-Burma

Goudotii, A. DC. in Ann Sc. Nat. Sér. IV. xi. (1859) 130.-Madag.

gracilis, $H$. B. E K. Nov. Gen. et Sp. vii. 184.-

Mexico.

gracillima, A.DC. in Ann. Sc. Nat. Sér. IV. xi. (1859) 120.-Peruy.

Grahamiana, Wight, Ic. t. $1811=$ albo-coccinea

grandiflora, Jacq. Coll. i. $128=$ diptera.

grandiflora, Knowl. \& West. Flor. Cab. i. (1837) $51=$ octopetala.

grandis, Dryand. in Trans. Linn. Soc. i. (1791) 163 $=$ Evansiana.

grandis, Otto, ex A. DC. in Mart. F1. Bras. iv. I. $369=$ vitifolia.

Griffthii, Hook. Bot. Mag. t. 4984.--Reg. Himal.

grisea, A. DC. in Ann. Sc. Nat. Sér. IV. xi. (1859)

188.-Bras.

guaduensis, H. B. E K. Nov. Gen. et $S p$. vii. 178.N. Granat.

gunneraefolia, Linden E" André, Illust. Hortic, xxii (1875) 106. t. 212,-N. Granat.

guttata, Wall, Cat. n. 3671 A.-Malaya.

guttate, Wall. 1, c. n, $3671 \mathrm{~B}=$ sinuata.

guyanensis, A. DC. in Ann. Sc. Nat. Sér. IV. xi. (1859) 142.-Guiana

haematotricha, Boiss. ex A. DC. Prod. Xv. I. $298=$ humilis.

Hamiltoniana, Lehm. in E. Otto, Hamb. Allgem.

Gartenz, vi. (1850) $456=$ acuminata

Hasskarli, Zoll. E Mor. Syst. Verz. Zoll. 31,-Java.

Hasskarliana, Miq. ex A. DC. Prod. xv. I. 329.

Sumatra.

hastata, Vell. Fl. Flum x.t. $54=$ angularis.

Hatacoa, Buch. Ham. in D. Don, Prod. Fl. Nep. 223. - Nepal.

hederacea, A. DC. in Ann. Sc. Nat. Sér. IV. xi. (1859) 120.-N. Granat.

hederaefolia, Linden, ex A. DC. Prod. xv. I. 401.Mexic.

heracleifolia, Cham. E Schlecht. in Linnaea, v. (1830) 603.-Mexic.

herbacca, Vell. Fl. Flum. x. t. 58.-Bras.

\section{BEGONIA :}

hernandiaefolia, Hort. ex Klotzsch, in Monatsb. Berl. Akad. (Maerz 1854) $125=$ nelumbiifolia. hernandiaefolia, Hook. Bot. Mag. t. $4676=$ peltata. hernandiaefolia, Seem. ex A. DC. Prod. xv. I. $339=$ glandulosa.

heterophylla, Hort. Schoenb. ex Klotzsch, in Monatsb. Berl. Acad. (Maerz 1854) 122,-Mexic.

heteropoda, Baker, in fourn. Linn. Soc. xxi. (1884 347.--Madag.

Hilariana, A. DC. in Ann. Sc. Nat. Sér. IV. xi. (1859) 125.-Bras.

hirsuta, Aubl. Pl. Gui. ii. 913, t. 348-Guiana.

hirsuta, Hort. ex A. DC. Prod. xv. I. $298=$ humilis. hirsuta, Ruiz, ex Klotzsch, in Monatsb. Berl. Acad. (Maerz 1854) $127=$ cordifolia

hirsutula, Hook.f. in Oliver, Fl. Trop. Afr. ii. 575.Afr. trop.

hirtella, Link, Enum. Hort. Berol. ii. 296.-Bras. hispida, Schott, ex A. DC. Prod xy, 1. 363,-Bras. holosericea, Teijsm. E Binn. in Epim. Lugd. Bat. (1863) 5.- - Ins. Ternate

Holtonis, A. DC. in Ann. Sc. Nat. Sér. IV. xi. (1859 141.-N. Granat.

homonyma, Steud. Nom. ed. II. i. $194=$ Dregei.

Hookeri, Sweet, Hort. Brit, ed. II. 437 = nitida.

Hookeriana, Gardn. in Hook. Lond. Fourn. Bot. iv. (1845) 135.-Bras.

Horsfieldii, Miq.ex A. DC. Prod. xv. 1. 397.-Sumatra Hugelii, Hort. Berol. ex A. DC. I. c. 364 --Bras.

humilis, [Dryand.in] Ait. Hort. Kew. ed. I. iii. 353.Mexic.

humilis, Bonpl. ex Spreng. Syst. ii. $626=$ hirsuta. humilis, Dryand. in Trans. Linn. Soc, i. (1791) $166=$ flexuosa.

humilis, Ker-Gawl. in Bot. Reg, t. $284=$ diptera.

hydrocotylifolia, Otto, ex Hook. Bot. Mag. t. 3968.Mexic.

hydrophila, Miq. Anal. Bot. Ind. iii. $18=$ malabarica ignea, Warsc. in A. DC. Prod. xv. 1. 306.-Guatemala imperialis, Lem. Illustr. Hortic. vii. (1860) 53.Mexic.

incana, Linal. in Bot. Reg. (1841) Misc. 39.Mexic.

incarnata, Link \& Otto, Ic. Pl. Sel. 37. t. 19.Mexic.

incarnata, Pav. ex A. DC. Prod. xv. I. $273=$ cordifolia.

incarnata, Seem. Bot. Voy. Herald, $128=$ Seemanniana incisa, A. DC. in Ann. Sc. Nat. Sér. IV. xi. (1859) 129.--Ins. Philipp.

inciso-serrata, A. DC. Prod.xv. I. 371.-Bras.

inflata, C. B. Clarke, in Hook.f. Fl. Brit. Ind. ii. 636. -Reg. Himal.

insignis, R. Grah. in Bot. Mag. t. $2900=$ incarnata

integerrima, Spreng. Neue Entdeck, ii. 174.-Bras,

integrifolia, Dalz, in Hook. Kew Fourn. iii. (1851) 230 . -Ind. or.

involucrata, Liebm. in Kjoeb. Vidensk. Meddel. 1852 (1853) 15.-Costa-Rica.

isoptera, Dryand. in Sm.Ic. t. 43 ; et Trans. Linn. Soc. i. (1791) 160.-Java.

jamaicensis, A. DC in Ann. Sc. Nat. Sér. IV. xỉ. (1859) $124=$ acutifolia.

Jamesoniana, A.DC. l. c. 139.-Ecuador.

jatrophaefolia, Hort. ex Klotzsch, in Abh. Akad. Berl. (1855) $39=$ heracleifolia.

Josephi, A. DC. in Ann. Sc. Nat. Sér. IV. xi. 1859 126.-Reg. Himal.

Junghuhniana, Miq. Pl. Fungh.418.-Java.

Karwinskyana, A. DC. in Ann. Sc. Nat. Sér. IV. xi. (1859) 134.-Mexic.

khasiana, C. B. Clarke, in Hook. f. Fl. Brit. Ind. ii. 656.-Reg. Himal.

Kunthiana, Walp. Ann。 ii. 650,-Bras.

laciniata, Roxb. Hort. Beng. 68 ; Fl. Ind. iii. 649. Reg. Himal.; Burma; China.

laciniosa, A. DC. Prod. xv. I. $340 .-$ Am. centr. laetevirens, Van Houtte, ex A. DC. I. c. 400.-Hab.

lanceolata, Vell. Fil. Flume x t. 33.-Bras.

Langsdorfii, A. DC. in Ann. Sc. Nat. Sér. IV. xi. (1859) $140=$ biclentata

lantaniaefolia, $A . D C$. l. c. 141.-N. Granat

lanuginosa, $A . D C$. . $, c, 131 .-\mathrm{N}$. Granat.

laurina, Hort. ex A. DC. Prod. xv. I. $292=$ Ottonis,

Lasuli, Linden, in Belg. Hortic. viii. (1858) 106 xanthina.

lepida, Blume, Enum. Pl. Gav. 98.-Java.

\section{BEGONIA}

lepidota, Liebm. in Kjoeb. Vidensk. Meddel. $185^{\circ} 2$ (1853) $17=$ manicata.

leprosa, Hance, in Fourn. Bot. xxi. (1883) 202.-China.

Liebmannii, A. DC. Prod. xv. 1. 345.-Mexic.

Lindeniana, A. DC. in Ann. Sc. Nat. Sér. IV. xi. (1859) 123.-Cuba.

Lindleyana, Walp. Rep. ii. 209.-Guatemala.

Lindleyana, Warc. ex Klotzsch, in Monatsb. Berl. Acad. Maerz 1854) 122. - Am. calid.

lineata, N. E. Br. in Gard. Chron. (1882) II. 199.Java.

lobata, Schott, in Spreng. Syst. iv. App. $408=$ multinervia.

Lobbiana, A. DC. Prod. xv. I. 355=parviflora.

Lobbii, A. DC. l. c. 390.-Java.

lobulata, A.DC. l. c. 339 -Mexic.

locellata, A. DC. in Ann. Sc. Nat. Sér. IV. xi. (1859) 137.-Mexic.

longifolia, Blume, Cat. Gew. Buitenz. 102.-Java.

longipes, Hlook. Bot. Mag. t. 3001.-Mexic.

longipila, Lem. Illustr. Hortic. vii. $(1860) 307=$ heracleifolia.

longirostris, Benth. Pl Hartw. 185.-Ecuador.

longovillosa, A. DC. in Ann. Sc. Nat. Sér. IV. 1859) 130.-Ins. Philip.

loranthoides, Hook. f. in Oliver, Fl. Trop. Afr. ii. 580. -Afr. trop.

Lubbersii, E. Morr. in Belg. Hortic. xxxiii. (1883) 155. t. 13.-Bras.

lucida, Haw. Saxifr. Enum, $197=$ humilis.

lucida, Kunth \& Bouché, Ind. Sem. Hort. Berol. (1848) $16=$ Kunthiana

incida, Otto \&e Dietr. Allg. Gartenz. xvi. (1848) $162=$ scandens.

lucida, Parodi, in Anal. Soc. Cient. Argent. v. (1878) 208 ; Contrib. 57.-Paraguay.

ludicra, $A . D C$. in Ann. Sc. Nat. Sér. IV. xi. (1859) 133.-Mexic.

luxurians, Scheidw. in Otto \& Dictr. Allg. Gartenz. xvi. (1848) 131. - Bras.

Lyallii, A. DC. in Ann. Sc. Nat. Sér. IV. xi. (1859) 144.-Madag.

Lyncheana, Hook. f. Bot. Mag.t.6758.-N. Granat. macra, A. DC. in Ann. Sco Nat. Sér. IV. xi. (1859) 121. -N. Granat.

macrophylla, Dryand. in Trans. Linn. Soc. i. 1791) 164. - Jamaica.

macrophylla, Lam. Encyc. i. $394=$ diptera.

macroptera, Klotzsch, in Monatsb. Berl. Acad. Maerz 1854) 122.-Bras.

macrotis, Vis. in Act. Ist. Ven. Sc. Ser. III iv. (1858-59) 138. - Hab.?

maculata, Raddi, in Mem. Mod. xviii. Fis. (1820) 406. -Bras.

magnifica, Linden, in Belg. Hortic. vi. (1850) $5 .-$ N. Granat.

magnifica, Warsc. ex A. DC. Prod. xv. 1. $269=$ ferruginea.

magnifolia, Noronha, in Verh. Batav. Gen. v. (1790) ed. I. Art. IV. 8.-Malaya.

malabarica, Lam. Encyc. i. 393.-Ind, or

malabarica, Roxb. Hort. Beng. 68 ; Fl. Ind. iii. $648=$ Roxburghii.

malabarica, Buch.-Ham. in Wall. Cat. n. $3676 \mathrm{D}=$ megaptera.

malvacea, Klotasch, in Abh. Akad. Berl. (185i) 33.Bras.

manicata, Cels, ex Vis. Orto Pador. (1842) 195.Mexic.

manillensis, A. DC. in Ann. Sc. Nat. Ser. IV. xi. 1s59 129. - Ins. Philipp.

Mannii, Hook. f. Bot. Mag. t. 5434.-Afr. trop.

maracayuensis, Parodi, in Anal. Soc. Cient. Argene. v. (1878) 209; Conirib. 58 - Pamguay. marmorata, Van lloulte, ex l'lanch. in Fl. des Serres. ix. $(1853-54) 243$. t. $952-53=$ xanthina.

martabanica, A. DC. in Ann. Sc. Vat. Ser. IV. xi 1 1 $54 \%$ 186.-Burma.

MIartiana, Link E Otto, Lc. Pl. Select. Horf. Berot. th. -Mexic.

Martiana. Schlecht. in Linuatea, $\$ .15801604$ incamata.

martinicensis, A. DC. in Ann. Sc. Tas. Acr. IV. xi. (18:3) 123.-Ins. Martinic.

mascariensis, Roj. Hort. Marurit. 271.-Ins. Mascar

Maurandiae, A. DC. in Ans. S6. Diat. Ser. IV. si. (1559) $11 \%,-\mathbf{N}$. Granal. 


\section{BEGONIA :-}

maxima, Hort. Berol, ex Klotzsch, in Abh. Akad. Berl. (1855) 39.-Mexic.

maynensis, A. DC. in Ann. Sc. Nat. Sér. IV.xi. (1859) 126.-Peruv.

megaphylla, A. DC. l. c. 133.-Bras.

megaptera, A. DC. l. c. 134.-Reg. Himal, ; Burma.

Meissneri, Wall. Cat. n. 6294.-Ind. or.

membranacea, A. DC. in Ann. Sc. Nat. Sér. IV. xi. 1859) 139.-Bras.

meridensis, A. DC. l. c. 123.-Venezuela

metallica, L. Sm. in Floral Mag. (1876) t. $197=$ incarnata.

Meyeniana, Walp. in Nov. Act. Nat. Cur. xix. Suppl. i. (1843) 409 .-Bras.

Meyeri, Hook. Bot. Mag. t. 4100,-Mexic.

Meyeri, Otto \& Dietr. Allg. Gartenz. iv. (1836) $349=$ tomentosa.

micrantha, Steud. Nom. ed. II. i. 194=parviflora

micranthera, Griseb. in Goett. Abh. xix. (1874) 148. Reg. Argent.

microcarpa, A. DC. Prod. xv. I. 311.-Ecuador.

microphylla, A. DC. l.c. 375.-Reg. Granat.

microphylla, Willd. ex Klotzsch, in Abh. Akad. Berl.

$1854(1855) 62=$ foliosa.

microptera, Hook.f. Bot. Mag. t. 4974.-Borneo.

miniata, Planch. \& Linden, in Fl. des Serres, Sér. I. viii. (1852-58) $105=$ fuchsioides.

minima, Bedd. in Madr. Journ. Sc. Ser. III. i. (1864) 48 = crenata

minor, Jacq. Coll. i. $126=$ nitida

modesta, Liebm. in Kjoeb. Vidensk. Meddel. 1852 (1853) 20.--Mexic.

modestiflora, Kurz, in Flora, liv. (1871) 296.-Reg. Himal. ; Burma.

mollis, A. DC. Prod. xv. I, 391.-Java.

monadelpha, Ruiz E Pav.ex A. DC.l. c. 286.-Peruv. monophylla, Pav. ex A. DC. in Ann. Sc. Nat. Sér IV. xi. (1859) 121.-Mexic.?

monophylla, Pourr. ex A. DC. Prod, xv. r. 403 (est Orchidea)

monoptera, Link E Otto, Ic. Pl. Rar. t. 14.-Mexic.

Moritziana, Klotzsch, in Abh. Akad. Berl. (1854) 31 $=$ tovarensis.

Moritziana, Kunth \& Bouché, Ind. Sem. Hort. Berol. 1848) $16=$ scandens.

moulmeinensis, C. B. Clarke, in Hook. f. Fl. Brit. Ind.

ii. 643.--Burma.

multangula, Blume, Enum. Pl. Fav. 1. 96.-Java.

multibulbillosa, Mart. ex Steud. Norn. ed. II. i. 194 -Bras.

multiflora, Benth. Pl. Hartw. 185.-N. Granat

multinervia, Liebm. in Kjoeb. Vidensk. Meddel. 1852

(1853) 18.-Costa Rica.

muricata, Blume, Cat. Gew. Buitenz. $103=$ tuberosa

muricata, Scheidw. in Otto E Dietr. Allo. Gartenz. ix.

(1841) 156. Bras.

nana, L'Hérit. Stirp. Nov. 99. t. 48.-Madag.

natalensis, Hook. Bot. Mag. t. 4841.-Afr. austr.

neglecta, A. DC. in Ann. Sc. Nat. Sér. IV. xi. (1859)

139.-Вras.

nelumbiifolia, Cham. E Schlecht. in Linnaea, v. (1830) 604.-Mexic.

nemophila, Kurz, in Journ. As. Soc, Beng. xlvi. (1877) II. $106,108=$ Cathcartii.

neocomensium, A. DC. in Ann. Sc. Nat. Sér. IV, xi. (1859) 138.-Bras.

nervosa, [Desf.] Hort. Par, ex H. B, \&c K. Nov, Gen. et Sp. vii. $177=$ cucullata.

nigrescens, Van Houtte-Cf. Hamb. Gartenz. viii. (1852) 9.-Hab. ?

nigritarum, Steud. Nom. ed. I. 104 ; ed. II. i. $194=$ malabarica?

nigro-venia, Regel, Gartenfl. (1867) $163=$ glandulosa. nitida, [Dryand. in] Ait. Hort. Kew. ed. 1. iii. 352,Jamaica.

nossibea, A. DC. in Ann. Sc. Nat. Sér. IV. xi. (1859 130.-Ins. Nossibe.

Novo-Granatae, A. DC. Prod. xv. I. $517=$ rosacea

nivea, Parish, ex Kurz, in Fourn. As. Soc. Beng. xlii $(1873)$ II. 81. - Tenasserim.

nummulariaefolia, Putzeys.-Cf. Bot. Zeit. xi. (1853) 716-Hab. ?

oaxacana, A. DC. in Ann. Sc. Nat. Sér. IV. xi. (1859) 127.-Mexic.

obliqua, L'Hérit. Stirp. Nov. ii. $46=$ nitida

obliqua, Jacq. Obs. ex Steud. Nom. ed. II. i. $194=$ macrophylla.
BEGONIA :-

obliqua, Linn. Sp. Pl. $1056=$ acuminata

obliqua, Ruiz, ex A. DC. Prod. Xv. I. $333=$ cyathophora.

obliqua, Thunb. F1. Jap. $231=$ Evansiana

obliqua, Vell. Fl. Flum. x. t. 48.-Bras.

octopetala, L'Hérit. Stirp. Nov. 101.-Peruv.

odorata, Willd. Enum. Hort. Berol. Suppl. $64=$ diptera.

olbia, Kerchove, in Rev. Hortic. Belge (1883), $241-$ Bras.

oligophylla, Blume, ex Miq. Fl. Ind. Bat. i. 692.Java.

opuliflora, Putz. in Fl. des Serres, Sér. I. x. (1854-55) 71. t. $995,-\mathrm{N}$. Granat.

opulifolia, Loud. Encyc. Pl. $1540=$ praec.?

orbiculata, Fack, in Malay. Misc. ii. (1812) vII. 9. -Sumatra.

oregana, Hort. ex Klotzsch, in Monatsb. Berl. Acad.

(Maerz 1854) 126.-Bras.

Ottoniana $x, A . D C$. Prod. xv. I. 399.

Ottonis, Walp. Rep. ii, 212,-N. Granat.

ovatifolia, A. DC. in Ann. Sc. Nat. Sér. IV. xi. (1859)

132.--Reg. Himal.

oxyloba, Welw. ex Hook. $f$. in Oliver, Fl, Trop. Afr. ii. 573.-Afr. trop.

oxyphylla, A. DC. in Ann. Sc. Nat. Sér. IV. xi. (1859) 140.-Bras.

oxysperma, $A . D C$. l. c. 122.-As. trop.

paleacea, Kurs, in Flora, liv. (1871) 297.-Burma.

paleata, A. DC. in Ann. Sc. Nat. Sér. IV. xi. (1859) 137.-Bras.

palmaris, $A . D C . l . c .126 .-$ Mexic.

palmata, D. Don, Prod. F1. Nep. $223=$ laciniata?

palmata, Pav. ex A. DC. Prod. xv. I. $307=$ pal-

maris.

palustris, Benth. Pl. Hartw. 184. n. 1022.- N. Granat.

paniculata, Parodi, in Anal. Soc. Cient. Argent. v. (1878) 209 ; Contrib. 59.-Paraguay.

pantherina, Putz. ex Linden, Cat. n. 17 (1862) 2.Mexic.

papillosa, R. Grab. in Hook. Bot. Mag. t. $2846=$ incarnata.

papillosa, Lindl. Bot. Reg. (1841) Misc. 39.-Hab. ?

paraguayensis, Parodi, in Anal. Soc. Cient. Argent. (1878) 207; Contrib. 56.-Paraguay.

Parishii, C. B. Clarke, in Hook. f. Fl. Brit. Ind. ii. 651.-m Burma.

parviflora, Liebm. ex A. DC. Prod, xv. I. $383=$ Franconis.

parviflora, Poepp. E Endl. Nov. Gen. et Sp. i. 7. t. 12. -Chili.

parviflora, Steud. Nom. ed. II. i. $194=$ parvifolia.

parviflora, Wall. Cat, $\mathrm{n}, 3674=$ modestiflora

parvifolia, R. Grah. in Bot. Mag. t. 3720=Dregei.

parvifolia, Klotzsch, in Abh. Akad. Berl. (1855) 33.Bras.

parvifolia, Schott, in Spreng. Syst. iv. App. 408.Bras.

parvipeltata, A. DC. in Ann. Sc. Nat. Sér. IV. xi. (1859) 139.-Bras.

parvuliflora, A. DC. l. c. 136.-Burma

pastoënsis, A. DC. l. c. 121.-N. Granal.

patens, Griseb. ex A. DC. Prod. xv, I. $377=$ arbo-

rescens.

patula, Haw. Pl. Succ. Suppl. $100=$ macroptera.

pauciftora, Lindl. Bot. Reg. t. $471=$ macroptera.

paulensis, A. DC. in Ann. Sc. Nat. Sér. IV. xi. (1859)

125.-Bras

Pavoniana, A. DC. l. c. 142,-Peruv.

Pearcei, Hook. f. Bot. Mag. t. 5545.-Bolivia.

pedata, Liebm. in Kjoeb. Vidensk. Meddel. 1852 (1858) 10.-Mexic.

pedunculosa, Wall. Pl. As. Rar. i. 82. t. 97.-Reg Himal.

pedunculosa, Wall. Cat. n. $3672 \mathrm{~B}=$ khasiana.

peltata, Hassk. in Hoev. \& De Vriese, Tijdschr. $x$. (1843) $133=$ Hasskarlii.

peltata, A. DC in Ann. Sc. Nat. Sér. IV. xi. (1859) 138.--Bras.

peltata, Otto \& Dietr. Allg. Gartenz. ix. (1841) $58=$ incana.

peltifolia, Schott, in Spreng. Syst. iv. App. $408=$ parvipeltata.

pentaphylla, Walp. Rep, ii. $209=$ muricata.

peperomioides, Hook. f. in Oliver, Fl. Trop Afr. ii 575.-Afr. trop.
BEGONIA :-

peponifolia, Vis. Ind. Sem. Hort. Patav. (1847).-Cf Linnaea, xxiv. (1851) 180.--Jamaica.

perpusilla, A. DC. in Ann. Sc. Nat. Sér. IV. xi. (1859)

143.--Ins. Nossibé.

peruviana, A. DC. l. c. 133-Peruv.

petalodes, Lindl. Bot. Reg. t. 1757.-Bras

philippinensis, A. DC. in DC. Prod.xv。 I. 320.-Ins. Philipp.

phyllomaniaca, Mart. in Ann. Sc. Nat. Sér. III. xix (1853) 366 .-Bras.

physalifolia, Liebm. in Kjoeb. Vidensk. Meddel. 1852 1853) 19 = scandens.

picta, Hort. Henders. ex A. DC. Prod, xv, I. $350=$ Griffithii.

picta, Sm. Exot. Bot. ii. 81. t. 101.-Reg. Himal.

Pilderia, A. DC. Prod. xv. I. 380.-V'enezuela.

pilifera, $A . D C . l, c .337 .-$ Am. centr.

pilosa, Fack, in Malay. Misc. ii. (1822) vII. 13.Sumatra.

pinetorum, A. DC. in Ann. Sc. Nat. Sér. IV. xi. (1859) 131.--Mexic.

plagiata, Linden, ex A. DC. Prod. xv. I. $312=$ oaxacana.

plantanifolia, Schott, in Spreng. Syst. iv. App. 407.Bras.

plebeja, Liebm. in Kjoeb. Vidensk. Meddel. 1852 (1853) 8.-Nicaragua.

pleiopetala, A. DC. in Ann. Sc. Nat. Sér. IV. xi. (1859) 121.-Bras.

Plumieri, Kunth, in DC. Prod. xv. I. 295.-Ins. S. Doming.

poculifera, Hook. f. in Oliver, Fl. Trop. Afr. ii. 574.Afr. trop.

poecila, C. Koch, in C. Koch \& Fint. Wochenschr. (1858) 338,-Hab. ?

Poeppigiana, A. DC. Prod.xv. I. 376.-Bras.

Pohliana, Klotzsch, in Abh. Akad. Berl. (1855) $33=$ macroptera.

polygonata. Liebm. in Kjoeb. Vidensk. Meddel. 1852 (1853) 12.-Mexic.

polygonifolia, A. DC. in Mart. Fl. Bras. iv. I. 362.Bras.

polygonoides, Hook.f. in Oliver, Fl. Trop. Afr. ii. 571. -Afr. trop.

polypetala, A. DC.-Cf. 'Garden' (1878) 531.Peruv.

populifolia, H. B. E K. Nov. Gen. et Sp. vii. $142=$ Balmisiana.

populifolia, Klotzsch, in Abh. Akad. Berl. (1855) $30=$ tovarensis

populifolia, Schott, in Spreng. Syst. iv. App. $408=$ scandens.

populnea, A. DC. in Ann. Sc. Nat. Sér. IV. xi. (1859) 128.-Bras

Porteriana, Fisch. Mey. \& Avé-Lall. Ind. Sem. Hort. Petrop. viii. $51=$ humilis

portoricensis, A. DC. Prod. xv. I. 295.-Porto Rico

Prieurei, A.DC. in Ann. Sc. Nat. Sér. IV. xi. (1859) 142.-Guiana.

Princeps, Hort Berol. ex Klotzsch, in Abh. Akad. Berl. (1855) 39.-Bras.

prismatocarpa, Hook. Bot. Mag. t. 5307.-Afr. trop. procridifolia, Wall. Cat. n. 6242.-Burma.

procumbens, Vell. Fl. Flum.x. t. 36.-Bras

prolifera, A. DC. in Ann. Sc. Nat. Sér. IV. xi. (1859) 135.-Burma ; Malaya.

pruinata, A. DC. Prod. xv. I. 338.-Costa Rica

pulchella, Raddi, in Mem. Mod. xviii. Fis. (1820) 407. -Bras.

pulchra, Herb. Schreb. ex A. DC. Prod. xv. I. $293=$ nitida.

punctata, Hort. ex Steud. Nom. ed. II. i. $194=$ maculata.

punctata, Klotzsch, in Link, Klotzsch \& Otto, It. P1. Berol. i. $16=$ heracleifolia.

Purdieana, $A, D C$. in Ann. Sc. Nat. Sér. IV. xi. (1859) 124.-Jamaica.

purpurea, Sw. Prod. Veg. Ind. Occ. $85=$ nitida.

pusilla, A. DC. in Ann. Sc. Nat. Sér. IV. xi. (1859) 120.-Bolivia.

pustulata, Liebm. in Kjoeb. Vidensk. Meddel. 1852 (1853) 6.-Mexic.

Putzeysiana, A. DC. in Ann. Sc. Nat. Sér. IV. xi. (1859) 139.-Venezuela.

quercifolia, A. DC. l. c. 129.-Ins. Philipp.

racemosa, fack, in Malay. Misc. ii. (1822) vir. 14. -Sumatra. 
BEGONIA :-

radiata, R. Grah, in Edinb. N. Phil. Joum. (July 1833) $182=$ heracleifolia

radicans, Vell. Fl. Flum.x t. $39 .-$ Bras.

ramentacea, Paxt. Mag. Bot. x. 73.--Bras.

reniformis, Bedd. in Madr. Journ. Sc, xxi1. (1861) 7\% $=$ anaimalaiensis.

reniformis, Dryand. in Trans. Linn. Soc. i. (1791) 161

t. 14. f. $1-2=$ longipes

reniformis, Hook. Bot. Mag. t. $3225=$ vitifolia.

reniformis, Hort. Berol. ex Klotzsch, in Monatsb.

Berl. Acad. (Maerz 1854) $24=$ Dregei.

reniformis, Pav, ex A. DC. Prod. xv. I. $308=$ Balmisiana

reniformis, Vell. Fl. Flum. x. t. 40.-Bras.

repanda, Blume, Enum.Pl. Fav. i. 97.-Sumatra.

repens, Blume, 1. c. $95=$ mollis.

repens, Lam. Encyc. i. 394=rotundifolia.

repens, Hemsl. Biol. Centr. Am. Bot, i. $497=$ Liebmanni.

repens, Ruiz \& Pav. ex A. DC. Prod. xv. I. $333=$ Rossmanniae.

repens, Schott, ex A. DC. 1. c. $365=$ convolvulacea.

repens, Vell. Fl. Flum.x. t. 35.-Bras.

reptans, Benth. Pl. Hartw. 62.-Mexic.

reptans, Liebm. in Kjoeb. Vidensk. Meddel. 1852 (1853) 5 = Liebmanni.

reticulata, Gardn. in Hook. Lond. Fourn. Bot. iv. (1845) 134.-Bras.

Rex, Putz. in Fl. des Serres, ii. (1857) 141. t. 1255.Reg. Himal.

xhizocarpa, Fisch. ex A. DC. Prod.xv. I. 388.-Bras.

rhizocaulis, Hort. Berol. ex A. DC. l. c. 340 .-Am. centr.

rhombicarpa, A. DC. in Ann. Sc. Nat. Sér. IV. xi. (1859) 129. - Ins. Luzon.

Richardii x, [C.Moore] Cat. Bot. Gard.Sydney (1857), 9.-Hab.?

Richardsiana, T. Moore, in Gard. Chron. (1871) 1065. -Afr. austr.

Richardsoniana, Houll. in Rev. Hortic. (1872) 333.$\mathrm{Hab}$ ?

ricinifolia $\times$, A. Dietr. Allg. Gartenz. xv. (1847) 282

Riedelii, A. DC. in Ann. Sc. Nat. Sér. IV. xi. (1859)

137.-Bras.

rigida, Regel, ex A. DC. Prod.xv. I. 373.-Bras.

robusta, Blume, Enum. Pl. Fav. i, 96.-Java.

robusta, Zoll. ex A. DC. Prod. xv. I. $275=$ multangula.

Rodwelli, Hort.-Cf. Gard. Chron. (1867) 11.481.Hab?

Roesli, Regel, Gartenfl. (1876) 194; et in Act. Hort. Petrop. iv. (1876) $334=$ Lynchiana.

rosacea, Puts. in Belg. Hortic. vii. (1857) 196; et in Fl. des Serres, Sér. II. ii. (1857) 25. t. 1194. -N. Granat.

rosaeflora, Hook. f. Bot. Mag. t. 5680.-Peruv.

rosea, $A . D C$. Prod. xv. I. 299.-Am. centr.

rosea, Pav. ex A. DC. 1. c. $273=$ cordifolia.

Rossmannize, A. DC. l. c. 333.-Peruv.

rostrata, Welw. ex Hook. f. in Oliver, Fl. Trop. Afr. ii. 578.-Afr. trop.

rotata, Liebm. in Kjoeb. Vidensk. Meddel. 1852 (1853) $11=$ caroliniaefolia.

rotunda, Vell. Fl. Flum. x. t. 38.-Bras.

rotundifolia, Lam. Encyc. i. 394.-Ind. occ.

Roxburghii, A. DC. Prod. xv. I. 398.-Reg. Himal.; Burma.

Roylei, Linden, in Belg. Hortic. vii. (1857) 197.Ind or.

rubella, Buch.-Ham. ex D. Don, Prod. Fl. Nep. 223.Nepal.

mibella, Miq. Anal. Bot. Ind. iii. 18 = canarana.

rubella, Wall. Cat, n. $3687=$ scutata.

ruoicunda, Hort. Turic. ex A. DC. Prod. xv, 1. $384=$ Dregei.

rubra, Blume, Enum. Pl. Gav. i. 96.-Java,

rubricaulis, Hook. Bot. Mag. t. 4131.-Peruv.

rubru-nervia, Hort. ex Klotosch, in Abh. Akad. Berl. (1855) 40.-Ind. or.

robro-pilosa, A. DC. in Ann. Sc. Nat. Sér. IV. xi. (1859) 125.-Bras.

rubro-setulosa, A. DC. Prod. xv. 1. 390--Hab.?

rubro-venia, Hook. Bot. Mag. t. 4689.- Keg. Himal. rufa, Thunb. in Flora, iv. (1821) 330.-Bras.

rugosa, Hort. Schoenb. ex Klotosch, in Monatsb. Berl. Acad. (Maerz 1854) 126.-Hab.?

rupestris, Baxt. ex Loud. Hort. Brit. Suppl. iii. 498 -Bras.

\section{BEGONIA :}

rupicola, $\mathrm{Miq}$. Pl. Fungh. 418.-Java.

rutilans, Hort. Van-Houtte, ex A. DC. Prod. xv. I. 373.-Hab. ?

sagittata $\times$,Hort.-Cf. Gard. Chron. (1868) I. 1317.

salicifolia, A. DC. in Ann. Sc. Nat. Sér. IV. xí.(1859) 1.28. - Bras.

sandalifolia, C. B. Clarke, in Hook. f. Ft. Brit. Ind. ii 649.-Burma.

Sandersii, Hort. Kew. ex A. DC. Prod. xv. I. 400, nomen.-Hab.?

sanguinea, Raddi, in Mem. Mod. xviii. Fis. (1820) 409 -Bras.

sarcophylla, Liebm. in Kjoeb. Vidensk. Meddel. (1852) 12.-Mexic.

Sartorii, Liebm. 1. c. $14=$ praec

Satrapis, C. B. Clarke, in Hook. f. Fl. Brit. Ind. ii. 638 - Reg. Himal.

saxatilis, Blume, Enum. Fl. Fav. 95.-Ins. Philipp.

saxicola, A. DC. in Ann. Sc. Nat. Sér. IV. xi. 1859 144.-Bras.

Saxifraga, A.DC. l.c. 138.-Bras.

scabrida, A. DC. Prod. xv. 1. 367.- Venezuela

scandens, Vell. Fl. Flum. x. t. 41.-Bras,

scandens, Hort. Schoenb. ex Klotzsch, in Monatsb.

Berl. Acad. (Maerz 1854) $126=$ convolvulacea.

scandens, Sw. Prod. Veg. Ind. Occ. 86.-Am, austr.

scapigera, Hook. f. in Oliver, Fl. Trop. Afr. ii. 572.Afr. trop.

schizolepis, Liebm, in Kjoeb. Vidensk. Meddel. 1852 (1853) $17=$ manicata.

Schlumbergeriana, Lem. Illustr. Hortic. (1858) Misc. 61.-Bras.

Schmidti, Hort. ex Wien. Illustr. Gart. Zeit. (1880) $250=$ Schmidtiana.

Schmidtiana, Regel, Gartenf. (1879) 321.-Bras.

Schottiana, A. DC. in Ann.Sc. Nat. Sér. IV. xi. (1859) 140.-Bras.

scutata, Wall. Cat. n. 3686. partim.-Reg. Himal. scutata, Wall. 1. c. $\mathbf{A}=$ Josephi.

scutellata, Liebm. in Kjoeb. Vidensk. Meddel. 1852 (1853) $9=$ conchaefolia.

scutifolia, Hook. f. in Oliver, Fl. Trop. Afr. ii. 572.-

Afr. trop.

Scutulum, Hook. f. l. c. 575,-Afr. trop.

Sedeni $\times$,Hort.-Ci. Gard. Chron. (1870) 38

Secmanniana, A. DC. in Ann. Sc. Nat. Sér. IV. x (1859) 133.-Am. centr.

Selloi, Lodd. ex Steud. Nom. ed. II. i. 194-Bras.

Sellowii, Klotzsch, in Abh. Akad. Berl. (1855) $28=$ semperflorens.

semiovata, Liebm, in Kjoeb. Vidensk. Meddel. 1852 (1853) 22.-Am. centr.

semperflorens, Hook. Bot. Mag. t. $2920=$ Hookeri.

semperflorens, Link E Otto, Ic. Pl. Rar. t. 9-Bras,

sericoneura, Liebm. in Kjoeb. Vidensk. Meddel. 1852 (1853) 13.-Am. centr.

sericoneura, Seem. Bot. Voy. Herald, $128=$ pilifera.

serotina, A. DC. in Ann.Sc. Nat. Sér. IV. xi. (1859) 121.-Guayaquil.

sessilifolia, Hook. f. in Oliver, Fl. Trop. Afr. ii. 577

-Afr. trop.

setaria, Hort. Angl. ex A. DC. Prod. xv. 1. $293=$ semperflorens.

setifera, A.DC.l. c. 338.-Am. centr.

setosa, Klotzsch, in Abh. Akad. Berl. (1855) 31.-Bras. setulosa, Bertol. in Nov. Commr. Bon. iv. (1840) 437Guatemala.

sikkimensis, A.DC. in Ann. Sc. Nat. Sér. IV xi. (1S59) 134.-Reg. Himal.

silhetensis, C. B. Clarke, in Hook. f. Fl. Brit. Ind. ii. 636.-Reg. Himal.

sinensis, A. DC. in Ann. Sc. Nat. Sér. IV. xi. (1859) $125=$ Evansiana

sinuata, R. Grah, in Edinb. N. Phil. Joum. (Jan. 1835) $192=$ Dregei.

sinuata, E. Mey. in Otto E Dietr. Allg. Gartens. iv. (1836) 357.-Afr, austr.

sinuata, Wall. Cat. n. 3680,-Burma; Malaya,

smilacina, A. DC. in Ann. Sc. Nat. Sér. IV (1859) 197.-Bras.

socotrana, Hook. f. in Gard. Chron. (1881) 1. 8.-Ins, Socotr.

solananthera, A. DC. in Anr. Sc. Nat. Sér. IV. xi (1859) 128.-Bras.

sparsipila, Baker, in Sannd. Ref. Bot. 1. 340.-Am centr.?

spathulata, Lodd. Bot. Cab. t. 107 = cucullata.
BEGONIA .

speciosa, Hort. Van Houtte, ex A. DC. Prorl. Xv. I 293 - nitida

spilotophylla, F. Muell. Not. Papuan Pl. iv. 67.-N Guinea.

splendens, Hort. Turic. ex A. DC. Prod, xv, 1. $375=$

Putzeysiana.

splendida, Hort. Rollison, ex A. DC. 1. c. $275=$ robusta.

Spruceana, A. DC. in Ann. Sc. Nat. Sér. IV. xi. (1859)

142,-Peruv.

squamulosa, Hook. f. in Oliver, Fl. Trop. Afr. ii. 579 -Afr. trop.

squarrosa, Liebm. in Kjoeb. Vidensk. Meddel. 1852 (1853) 7--Mexic.

squarrosa, Seem. Bot. Voy. Herald, $128=$ stigmosa.

Stella, Regel, Gartenfl. (1875) 88.-Hab.

stenophylla, A. DC. in Ann. Sc. Nat. Sér. IV. xi. (1859) 137.-Bras.

stictopoda, Miq. ex A. DC. Prod. xv. 1. 391.-Sumatra.

stigmosa, Lindl. Bot. Reg. (1845) Misc. 32.Mexic.

stipulacea, Willd. Sp. PI. iv. $414=$ angnlaris

strigillosa, A. Dietr. Allg. Gartenz. xix. (1851) 330.Am. centr.

strigulosa, A. DC. Prod. xv, 1. 399.-Hat.

suaveolens, Haw in Lodd. Bot. Cab. t. $69=$ diptera.

suaveolens, Klotzsch, in Abh. Akad. Berl. (1855) 26 nitida.

subciliata, A. DC. in Ann. Sc. Nat. Sér. IV. xi. (1859) 132.-Peruv.

subhumilis, A. DC, l. c, 124-Guayaquil

sublobata, fack, in Malay. Misc. ii. (1822) n. vil. 10 , - Sumatra.

subovata, Wall. Cat. n. $3683=$ ovatifolia.

subpeltata, Regel, Ind. Sem. Hort. Petrop. (1866) 102 - incarnata

subpeltata, Wight, Ic. t. 1812.-Ind. or.

subperfoliata, Parish, ex Kurz, in Fourn. As. Soc. Beng. xlii. (1873) Ir. 81.-Burma.

subrotunda, Wall. Cat. n. $6293=$ sinuata.

subvillosa, Klotzsch, in Abh. Akad. Berl. (1855) 32.Bras,

suffruticosa, Meissn. in Linnaea, xiv. (1840) 502.Afr. austr.

suffruticosa, Pav. ex A. DC. Prod. Xv. I. $311=$ Boissieri.

sulcata, Scheidw. in Otto E Dietr. Allg. Gartenz. xvi. (1848) 130.-N. Granat.

surculigera, Kurz, in Flora, liv. (1871) 296.-Burma.

Sutherlandi, Hook. f. Bot. Mag. t. 5689,-Afr. austr.

sylvatica, A.DC. Prod. xv. I. 365 .-Bras,

sylvestris, A. DC. in Ann. Sc. Nat. Ser. IV. xi. (1859) 140.-Bras.

tanacetifolia, Hort, ex Steud. Nom, ed. II. i. 194 heracleifolia.

Telfariae, Steud. 1. c. sphalm. vide Bignonia Telfairiae. tenella, D. Don, Prod. Fl. Nep. $223=$ amoena.

tenera, Dryand. in Trans. Linn. Soc. i. (1791; 169. t. 16.-Zeylan.

tenuicaulis, A. DC. in Ann. Sc. Nat. Sér. IV, xi. (1859) 120.-Bolivia.

tenuifolia, Dryand in Trans. Linn. Soc i. (17y1) 100.2. t. 14.-Java.

tessaricarpa, C. B. Clarke, in Hook.f. Fl. Brit. Ind. ii. 636.-Assam

Teuscheri, Linden, ex André, in Illustr. Horlic. (187:4 137. t. 358.-Malaya.

Thomsonii, A. DC in Ant". Sc Aint. Sér. IV. xi. (1859) 184.-Reg. Himal.

Thwaitesii, Hook. Bot. Mag. t. $4692=$ tenera.

tomentosa, Schott, in Spreng. Syst. iv. App. tos. Bras.

torarensis, Klotssch, in Monatsb. Berl. Acad. Maesz 185.) 122 -Mexic

trachyptera, Benth. Pl. Hartw. 18t.-N. Granat.

trichocarpa, Dals. in Hook. Kiew Fourn. iij. (1851. 2su. -Ind. or.

trichopoda, Mig. Fl. Ind. Bat. i. I. 1093.-Sumatr.

tricuspidata, C. B. Clarke, in Hook. f. A\%. Brif. Ind.

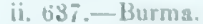

triradinta, C.B. Clarke, l, G.-Burma,

tropaculifolia, A. DC. in Ann. Sc. Afol. Sir. 11. xi. 1859) $120,-N$. Grannt.

truncata. Vell. 51 . Fitum. $x$. t. th $=$ tonantusa viti. folia.

puberasa, Herb. Wight, ex Wiall. Cat. n, Soin malatrarica. 


\section{BEGONIA :}

tuberosa, Heyne, ex A. DC. Prod. xv. I. $391=$ dipetala.

tuberosa, Lam. Encyc. i. 393.-Ins. Molucc.

tuberosa, Pav. ex A. DC. Prod. xv. I. $311=$ bulbillifera tuberosa, Ruiz, ex A. DC. 1. c. $281=$ geraniifolia.

uliginosa, Klotzsch, in Abh. Akad. Berl. (1855) 35.-Bras.

ulmifolia, Willd. Sp. Pl. iv. 418.-Venezuela.

umbellata, $H . B . G^{\prime} K$. Nov. Gen. et $S p$. vii. 143.-N Granat.

umbilicata, Hort. ex Planch. in Fl. des Serres, Sér. I. viii. $(1852-53)$ sub t. $810=$ hernandiaefolia.

umbrata, Hort ex A. DC. Prod. xv. I, 396.-Hab.

uncinata, Hort. ex Klotzsch, in Monatsb. Berl. Acad. (Maerz 1854) $124=$ Dregei.

undulata, Schott, in Spreng. Syst. iv. App. 408.-Bras

urophylla, Hook. Bot. Mag. t. 4855.-Mexic

Urticae, Linn. f. Suppl. 420.-N. Granat

urticaefolia, Sm. Ic. Fasc. ii. $45=$ tuberosa,

urticaefolia, Hort. ex Klotzsch, in Monatsb. Berl Acad. (Maerz 1854) $127=$ B. Pilderia.

urticifolia, F. G. Dietr. Vollst. Gartenlex, ii. $177=$ Urticae.

vaginans, Vell. Fl. Flum. x. t. 37.-Bras.

valdensium, A. DC in Anx. Sc. Nat. Sér. IV. xi. 1859) 138 - - Bras.

variana, A.DC. l. . . 135 .-Java.

Veitchii, Hook. f. in Gard. Chron. (1867) 734.Peruv.

vellerea, Klotzsch, in Monatsb. Berl. Acad. (Maerz 1854) 122 - Bras.

Velloziana, Walp. Rep. ii. $216=$ repens.

velutina, Hort. Vindob. ex Klotzsch, in Abh. Akad. Berl. (1855) $41=$ lobata.

velutina, Parish, ex Kurz, in Journ. As. Soc. Beng, xlii. (1873) II. $81=$ parvuliflora.

vernicosa, Hort. Berol. ex Klotzsch, in Abh. Akad. Berl. (1855) $40=$ lobata.

Verschaffeltiana $x$, Lem. Illustr. Hortic. ii. (1855) t. $68=$ Verschaffeltii.

Verschaffeltii x, Regel, Gartenfl. (1855) 248, t. 132

verticillata, Vell. F1. Flum. x. t. $45=$ digitata.

verticillata, Hook. Ic. Pl. t. 811.-Burma

villosa, Gardn. in Hook. Lond. Joum. i. (1842) $186=$ macroptera.

villosa, Klotzsch, in Monatsb. Berl. Acad. (Maer 1854) $122=$ subvillosa.

villosa, Lindl. Bot. Reg. t. $1252=$ hirtella.

violaefolia, A. DC in Ann. Sc. Nat. Sér. IV. xi (1859) 134.-Mexic.

viridiflora, A.DC.l. C. 132.- Peruv

vitifolia, Lindl. Bot. Reg. (1852) Misc. $21=$ Lind leyana.

vitifolia, Schott, in Spreng. Syst. iv. Cur. Post. 407.Bras.

Wras.
Wageneriana, Hook. Bot. Mag. t. 4988.-Bras.

Wallichiana, Steud. Nom. ed. II. i. 194; Lehm. in

Linnaea, xxiv. (1851) 213 (sp. dubia). - Ind. or.

Walpersii, Heynh. Nom. ii. 63.-Venezuela.

Warscerviczii, Neuman, in Rev. Hortic. Sér. III. i. (1847) 166 = conchaefolia.

Weddeliana, A. DC. in Ann. Sc. Nat. Sér. IV. xi (1859) 122-Bolivia.

weltoniensis $x$, Hort.-Cf. F. B. Weber, in Rev. Hortic. (1875) 105.

Wightiana, Wall. Cat, n- $3673=$ albo-coccinea,

Wrightiana, A. DC. in Ann. Sc. Nat. Sér. IV. xi. (1859) 123,-Cuba

xanthina, Hook. Bot. Mag. t. 4683 et t. $5107 .-\mathrm{Reg}$ Himal.

zebrina, Hort. Angl. ex Lond. Encyc. P1. Suppl. ii $1506=$ angularis.

Zollingeriana, A. DC. in Ann. Sc. Nat. Sér. IV. xi. (1859) 135.--Java.

BEGONIELLA, Oliver, in Trans. Linn. Soc. xxviii. (1873) 513, BEGONIACEAE.

angustifolia, Oliver, in Hook. Ic. Pl. t. 1487.-N. Granat.

Kalbreyeri, Oliver, l. c. t. 1352.-N. Granat.

Whitei, Oliver, in Trans, Linn. Soc. xxviii. (1873) 513.-N. Granat

BEHAIMIA, Griseb. Cat. Pl. Cub. 77 (1859). LEGUMINOSAE, Benth. \& Hook, f, i, 1002 cubensis, Griseb. l. c. 78,--Cuba.
BEHEN, Hill, Veg. Syst. iv, 41 (1762)=Vernonia

Schreb. (Compos.)

Facea, Hill, Hort. Kew. $68=$ Centaurea Jacea.

noveborascense, Hill, $1 . \mathrm{c},=\mathrm{V}$. noveboracensis.

praealtum, Hill, $1 . \mathrm{c}_{\mathrm{s}}=\mathrm{V}$. noveboracensis et altissima

BEHEN, Moench, Meth. $709(1794)=$ Silene, Linn. (Caryoph.).

angrestifolius, Schott, ex Steud. Nom. ed. II. i. $194=$ S. Cucubalus

glareosus, Fourr. in Ann. Soc. Linn. Lyon, N. S. xvi.

(1868) $343=\mathrm{S}$. Cucubalus?

puberulus, Fourr. 1. c. $=\mathrm{S}$. Cucubalns.

trachiatus, Fourr. 1. c. =S. Cucubalus

vesicarius, Fourr. 1. c. $=\mathrm{S}$. Cucubalus.

vulgaris, Moench, Meth. $709=\mathrm{S}$. Cucubalus.

BEHENANTHA, Schur, in Verh. Naturf. Ver. Bruenn, xv. II. (1877) $130=$ Silene, Linn. (Caryoph.)

Cserei, Schur, 1. c. $132=\mathrm{S}$. Cucubalus.

glaucescens, Schur, 1. $\mathrm{c}_{0}=\mathrm{S}$. Cucubalus.

inflata, Schur, 1. c. $131=$ S. Cucubalus.

saponariaefolia, Schur, 1. c. $133=\mathrm{S}$. Cucubalus.

BEHNIA, F. Didrichs, in Kjoeb. Vidensk. Meddel (1854) 182. LILIACEAE, Benth. \& Hook. f, iii 766.

Dictyopsis, Harv. in Bot. Mag. t. 5638 (186\%)

Hyionome, Baker, in Journ. Linn. Soc. xiv. (1875) 561.

reticulata, $F$. Didrichs. l. c. 183.-Afr. austr.

BEHRINIA, Sieber, ex Steud. Nom. ed. I. $105(1821)=$ BERINIA, Brign. = Crepis, Linn. (Compos.).

BEHURIA, Cham. in Linnaea, ix, (1834) 376. MELASTOMACEAE, Benth. \& Hook, f. i. 748 insignis, Cham. l. c. 377.-Bras.

BEILIA, Eckl. Verz. $43(1827)=$ Watsonia, Mill. (Irid.)

spicata, Eckl. 1. c. = W. spicata.

triticea, Eckl. 1,c. $=$ W. plantaginea

BEILSCHMIEDIA, Nees, in Wall. PI. As. Rar. ii. 69 (1831). LAURINEAE, Benth. \& Hook. f. iii. 152.

Bielschmeidia, Panch. \& Sebert, Not. Bois Nouv Caléd. 176 (1874).

Hufelandia, Nees, Prod. Laurin. ii. (1833); et

Laurin. Expos. (1836) 187, 674.

Nesodaphne, Hook. f. FI. N. Zel, i. 217 (1853)

assamica, Meissn. in DC. Prod. xv. I. 64.-Assam; Burma.

Baillonii, Panch. \& Sebert, Not. Bois Nouv. Caled 176.-N. Caled.

caloneura, Scheff. in Ann. Fard. Buitenz. i. (1876) 47. -N. Guin.

chinensis, Hance, in Fourn. Bot. xx. (1882) 79.China.

fagifolia, Nees, in Wall. Pl. As. Rar. ii. 69.-Ind. or.

globularia, Kurz, For. Fl. Brit. Burma, ii. 294.-

Burma.

javanica, Miq. Pl. Fungh. i. 176.-Java

lanceolata, Panch. E Sebert, Not. Bois Nouv. Caled 177.-Caled.

lancifolia, $M i q$. Pl. Fungh. 177.- Java.

macrophylla, Meissn. in DC. Prod. xv. I. 63.-Burm

Madang, Blume, Mus. Bot. Lugd. Bat. 1. 332.-Java. oppositifolia, Benth. E' Hook. f. Gen. iii. 152. -Zeylan. pendula, Hemsl. Biol. Centr. Am. Bot. iii. 70.Mexic.

Roxburghiana, Dalz. \& Gibs. Bomb. Fl, $222=$ fagifolia.

Roxburghiana, Nees, in Wall. Pl. As. Rar, ii. 61.Assam; Burma

Thomaea, Benth. E Hook. f. Gen. iii. 152.-Ind. oc undulata, Miq. Fl. Ind. Bat. i. I. 920.-Java.

Wightii, Benth. छ' Hook. f. Gen. iii. 152.-Ind. or

BEJARIA, Zea, in Anal. Cienc. Nat. iii. (1801) 151, in nota; Vent. Jard. Cels, sub t. $51=$ Befaria, Mutis (Ericac.).

BEJUCO, Loef. Itin. $314(1758)=$ Hippocratea, Linn. pendulus, Loefl. 1. c. $=$ H. scandens.
BELAIRIA, A. Rich. Ess, Fl, Cub. 511 t 40 (1845) LEGUMINOSAE, Benth. \& Hook. f. i. 558. mucronata, Griseb. in Mem. Am. Acad. N. S. viii (1861) 179.-Cuba.

spinosa, A. Rich. Ess. Fl. Cub. 513.-Cuba.

ternata, Wright, ex Griseb. Cat. Pl. Cub. 81.Cuba.

BELAMCANDA, Adans. Fam. ii. 60 (1763) (BelamCanda). IRIDIAE, Benth. \& Hook, f. iii. 697.

Pardanthus, Ker-Gawl, in Kon, \& Sims, Ann. Bot. i. (1805) 246

aristata, Moench, Meth. Suppl. 214=Sparaxis grandi flora.

bulbifera, Moench, 1. $\mathrm{c}_{\mathrm{o}}=$ Sparaxis bulbifera.

chinensis, [DC. in] Red. Lil. iii. t. $121=$ punctata

fenestrata, Moench, Meth. 529=Tritonia crocata

punctata, Moench, l.c.-China.

semiflexuosa, Moench, Meth. Suppl. $214=$ Sparaxi grandiflora.

tripedalis, Fisch. ex Roem. E Schult. Syst. i. Mant 306 (sp. dub.).

villosa, Moench, Meth. Suppl. $214=$ Babiana villosa

BELANGERA, Cambess. Cunon. Syn. Bras. Mer, 3 (1829). SAXIFRAGEAE, Benth. \& Hook. f. i. 650 .

Lamanonia, Vell. Fl. Flum. v. t. 104 (1827)

Polystemon, D. Don, in Edinb. N. Phil. Journ. ix $95(1830)$

cuneata, Cambess. l. c.-Bras.

denticulata, Moric. Pl. Nouv. Am. 153. t. 90.Bras.

glabra, Cambess. Cunon. Syn. Bras. Mer. (1829) 3.Bras.

intermedia, Mart. in Flora, xx. (1837) II. Beibl. 95.Bras.

Lamanonia, Steud. Nom ed. II, i, 195.-Bras.

Riedeliana, Casar. ex Eichl. in Mart. Fl. Bras. xiv. II $155=$ speciosa

speciosa, Cambess. Cunon. Syn. Bras. Mer. (1829) 4 -Bras.

tomentosa, Cambess. l. c.-Bras.

BELANTHERIA, Nees, in DC. Prod. xi. 96 (1847)= Brillantaisia, Beauv. (Gramin.)

Belvisiana, Nees, 1. c. $97=$ Brillantaisia owariensis.

BELENCITA, Karst. in C. Koch, Allg. Gartenz (1857) 25. CAPPARIDEAE.

Hagenii, Karst. l. c. 24.-N. Granat.

BELENIA, Decne. in Jacquem. Voy. Bot. 113. t. 120 $(1844)=$ Physochlaina, D. Don (Solanac.).

praealta, Decne. 1. c. 114 . t. $120=$ P. praealta.

BELENIDIUM, Arn. ex DC. Prod. vii. 292, in syn (1838) = Hymenatherum, Cass. (Compos.).

Candolleanum, Arn. ex DC. 1. c. = H. Belenidium.

BELEROPONE, C. B. Clarke, in Hook. f. Fl. Brit. Ind. iv. 524 (1885), sphalm. = Beloperone, Nees (Acanth.).

BELHARNOSIA, Adans. Fam. ii. $432(1763)=$ Sanguinaria, Linn. (Papav.).

BELIA, Steller, ex S. G. Gmel. F1. Sibir. iv. 88 (1769 = Claytonia, Gron. (Portulac.).

BELILLA, Adans. Fam. ii. $159(1763)=$ Mussaenda Burm. (Rubiac.).

BELIS, Salisb. in Trans. Linn. Soc. viii. (1807) 315 nomen prius = Cunninghamia, R. Br. $(1826$ (Conifer.).

jaculifolia, Salisb, 1. c. $=$ C. sinensis.

lanceolata, Sweet, Hort. Brit. ed. II. $475=$ C. sinensis.

BELLADONA, Adans. Fam. ii. $219(1763)=$ Atropa Linn. (Solanac.)

BELLADONNA, Sweet, Hort. Brit. ed. II. 506 (1830) = Amaryllis, Linn.

blanda, pallida, pudica, purpurascens, Sweet, 1. c. = A. Belladonna. 
BELLADONNA, [Tourn.] Rupp. Fl. Jen. ed. Hall. 252 $(1745)=$ Atropa, Linn. (Solanac.).

baccifera, Lam. Fl. Fr. ii. $255=$ A. Belladonna.

peruviana, Hort. Par. ex Adans. Fam. ii. $219=$ Nolana prostrata.

trichotoma, Scop. Fl. Carn。 ed. II. i. $160=$ A. Bella donna.

BELlardia, All. Fl. Pedem。 i. 61 (1785)= Bartsia, Linn. (Scrophul.).

Trixago, All. 1. c. $=$ Bartsia Trixago.

viscosa, Fisch. \& Mey. Ind. Sem. Hort. Petrop. ii. $4=$ Bartsia viscosa.

BELLARDIA, Colla, in Mem. Acc. Torin. xxxviii. (1835) 40. t. $34=$ Mieroseris, D. Don (Compos.). pusilla, Colla, 1. c. 42, t. 34.-Chili

BELLARDIA, Schreb.Gen. i. $790(1789)=$ Coccocipselum, R. Br. (Rubiac.).

mollis, Willd. ex DC. Prod. iv. $397=$ C. canescens. repens, Willd. Sp. Pl. i. $626=$ C. Tontanea.

Tontanea, Roem. \& Schult. Syst. iii. $305=$ C. Tontanea.

BELLENDENA, R. Bro in Trans. Linn. Soc. $x$. (1810) 166. PROTEACEAE, Benth, \& Hook. f. iii. 175 .

montana, R. Br. l. c. 48, 166.-Tasmania.

BELLENDENIA, Rafin. ex Endl. Gen. 169 (1837), in syn,$=$ Tritonia, Ker-Gawl. (Irid.).

BELLENDENIA, Endl. Gen. $340(1838)=$ Bellendena, R. Br. (Proteac.).

BeLlevalia, Delile, ex Endl. Gen. $231(1836)=$ Althenia, Petit (Naiad.).

australis, Delile, ex Parl. Fl. Ital. iii. $648=$ A. filiformis.

BELLEVAliA, Lapeyr. in Journ. Phys. 1xvii. (1808) $425=$ Hyacinthus, Tourn. (Liliac.)

abortiva, Gren. in Gren. \& Godr. Fl. Fr. iii. $217=\mathrm{H}$. trifoliatus.

aleppica, Boiss. Diagn. Ser. II. iv. $111=\mathrm{H}$, nervosus. appendiculata, Lapeyr. Hist. Abr. Pl. Pyr. $186=\mathrm{H}$ romanus.

atroviolacea, Regel, in Act. Hort. Petrop. viii. (1884) 654.-As. centr.

asurea, Boiss. Fl. Orient. v. $307=\mathrm{H}$. ciliatus.

Battandieri, Freyn, in Flora, Ixviii. (1885) 25.-Afr bor.

Boissieri, Freyn, 1. c. 95.-Graecia.

Bouviana, Heldr, ex Nym. Consp. 733.Graecia.

calandriniana, $\mathrm{Nym}$. Consp. $732=$ Muscari comosum.

caucasica, Griseb. Spicil. FI. Rumel. ii. $387=$ Muscari caucasicum

ciliata, T. Nees, Gen. 4. t. 8 ; Kunth, Enum. Pl. iv $308=$ H. ciliatus.

Clusiana, Griseb. Spicil, Fl, Rumel, ii. $387=$ H. dubius. comosa, Kunth, Enum. Pl, iv, 306 = Muscari comosum. Cupaniana, Nym. Consp. $733=$ Muscari Cupanianum. curta, Nym. 1. c. = Muscari Holzmanni.

cyanoleuca, St. Lag. in Ann. Soc. Bot. Lyon, vii. (1880 $121=\mathrm{H}$. romanus.

densiflora, Boiss. Diagn. Ser. I. vii, $109=\mathrm{H}$. densiflorus.

dubia, Reichb. F1. Germ. Excurs, $105=\mathrm{H}$. dubius, fallax, Pomel, Nouv. Mat. Fl. Atl. 254.-Algeria. flexuosa, Boiss. Diagn. Ser. I. xiii. $36=$ H. flexuosus.

Fontanesii, Nym. Consp. 783. - Creta.

glauca, Kunth, Enum. Pl. iv. $309=\mathrm{H}$. ciliatns.

graeca, Heldr. in Atti Congr. Bot. Firenze, 1874 (1876)

$228=$ Muscari graecum

graminifolia, Nym. Consp. 733.-Ins. Graec.

Gussoniana, Griseb. Spicil. Fl. Rumel. ii. 387.-Sicil.

Hackeli, Freyn, in Oestr. Bot. Zeitschroxxvii. (1877) 289.-Europ.

Haynei, Boiss. Fl. Orient. v. $308=$ H. Haynei.

Heldreichii, Boiss. Diagn. Ser. II. iv. $111=\mathrm{H}$ lineatus.

hispida, J. Gay, in Bull. Soc. Bot. Fr. iii. (1856) $240=$ H. hispidus.

Holsmanni, Heldr. in Atti Congr. Bot. Firenze, 1874 (1876). $228=$ Muscari Holzmanni.

lencophaea, Boiss. Fl. Orient. v. 305-H. leucophacus. lineata, Kunth, Enum. Pl. iv. $309=$ H. lineatus.

\section{BELLEVALIA :-}

macrobotrys, Boiss. Diagn. Ser. I. xiii. $35=$ Hyacinthus macrobotrys.

maritima, Kunth, Enum. Pl. iv. $307=$ Muscari mari timum.

mauritanica, Pomel, Nouv, Mat. Fl. Atl. 255.Algeria.

micrantha, Boiss. Diagn. Ser. I, v, $63=\mathrm{H}$. micranthus. monophylla, J. Gay, ex Boiss. Fl. Orient, v. $294=$ Muscari latifolium.

montana, Boiss. 1. c. $304=$ Muscari montanum. muscarioides, Mast. in Journ. Linn. Soc. iii. (1859) 113 $=$ Muscari latifolium.

nervosa, Boiss. Fl. Orient. v. $306=\mathrm{H}$. nervosus.

nivalis, Boiss. \& Kotschy, Diagn. Ser. II. iv. $110=\mathrm{H}$ nivalis.

operculata, Lapeyr. in Journ. Phys. Ixvii. (1808) 426 cum. tab. $=H_{\text {. }}$ romanus

pallens, Vis. in Mem. Ist. Venet. xvi. (1871) $67=\mathrm{H}$. dalmaticus.

paradoxa, Boiss. Fl. Orient. v. $308=\mathrm{H}$. paradoxus.

persica, Boiss. 1. $c_{\circ}=\mathrm{H}$. persicus

pharmacusana, Nym. Consp. $733=$ Muscari Sartoriantum.

Pinardi, Boiss. Diagn. Ser. I. v. $62=$ Muscari Pinardi.

pseudo-muscari, Boiss. \& Buhse, Diagn. Ser. II. iv. 110 $=\mathrm{H}$. paradoxus.

romana, Sweet, Hort. Brit. ed. I. 419 ; Reichb. Fl Germ. Excurs. $105=\mathrm{H}$. romanus.

Sartoriana, Nym. Consp. $733=$ Muscari Sartorianum. sessilifora, Kunth, Enum. Pl. iv. $309=$ H. sessiliflorus.

spicata, Boiss. Diagn. Ser. I. vii. $110=$ H. spicatus.

syriaca, Herb. in Lind1. Bot. Reg. (1844) Misc, $88=$ $\mathrm{H}$. trifoliatus.

tenuiflora, Nym. Consp. $732=$ Muscari caucasicum

theraea, Nym。1. c. 733 = Muscari thereum.

trifoliata, Kunth, Enum. Pl. iv. 308 = H. trifoliatus,

turkestanica, Franch.'in Ann. Sc. Nat. Sér. VI. xviit (1884) 256.-Turkest

variabilis, Freyn, in Flora, 1xviii. (1885) 29.Alger.

Webbiana, Parl. Nouv. Gen. e Spec. $19=$ Hyacinthus dubius.

Weissii, Freyn, in Oestr. Bot. Zeitschr. xxviii. (1878) $87=$ Muscari Weissii.

BELLIDASTRUM, Mich. ex Hall. Enum. Stirp. Hely. ii. $723(1742)=$ Aster, Tourn. (Compos.)

Michelii, Plan. Ensayo Fl. Gall. 259=Bellis sylvestris.

Michelii, Cass. in Dict. Sc. Nat. iv. $70=$ A. Bellidiastrum.

montanum, Hoppe, ex DC. Prod.v. $226=$ A. Bellidiastrum.

subalpinum, Schrank, Fl. Mon, iii. 251=A. Bellidiastrum.

BELLIDIASTER, Dum. Fl. Belg. 66 (1827)=Aster, Tourn. (Compos.).

montanus, Dum, 1, c. =A. Bellidiastrum.

BELLIDIASTRUM, [Vaill.] Less. Syn. Comp. 383 $(1832)=$ Osmites, Linn. (Compos.).

osmitoides, Less. 1. c. $384=\mathrm{O}$. Bellidiastrum.

BELLIDIASTRUM, Cass. in Bull. Soc. Philom. (1816) $199=$ BELLIDASTKUM, Mich. $=$ Aster, Tourn. (Compos.).

BELLIDISTRUM, Reichb. Consp. 109 (1828) = praec.

BELLIDIOPSIS, Spach, Hist. Vég. Phan. x. $25(1841)=$ Osmaites, Linn. (Compos.)

BELLIDIUM, Bertol. Fl. Ital. ix. 316 (1853)=Bellis, Tourn. (Compos.)

pappulosum, Bertol. I. $\mathrm{c}_{2}=$ Bellis sylvestris

rotundifolizm, Bertol, 1. c. = Bcllis rotundifolia.

BELLILLA, Rafin. in Ann. Gén. Sc. Phys, vi. (1820) $82=$ BELILLA, Rheede = Mussaenda, Burm. (Rubiac.).

BELLINIA, Roem. \& Schult. Syst. iv. $56(1819)=$ Saracha, Rujz \& Pav. (Solanac.)

biflora, Roem. \& Schult. 1. c. $689-$ S. procumbens.

contorta, Roem. \& Schult. I. c. $=$ S. contorta.

dentata, Roem. \& Schult. I. c. $=$ S. dentnen.

micrantha, Roem. \& Sichult. 1. c. $690=$ S. micrantha.

\section{BELIINIA :-}

peruviana, Steud. Nom. ed. I. $105=$ Saracha peruviana (nomen delendum)

procumbens, Roem. \& Schult. Syst. iv. $687=$ S. pro. cumbens.

pubescens, Roem. \& Schult. 1. c. $689=\mathrm{S}$. pubescens. punctata, Roem. \& Schult. 1. c. $688=$ S. punctata. umbellata, Roem. \& Schult. 1. c. =S. umbellata.

BELLIOPSIS, Pomel, Mat. Fl. At1. 7 (1860)=Bellium, Linn. (Compos.)

cordifolia, Pomel, Nouv. Mat. F1. At1. 286.-Algeria.

rotundifolia, Pomel, Mat. Fl. Atl. 7 = Bellium rotundifolium.

BELLIS, [Tourn.] Linn. Gen。 ed, I. 256 (1737). COM. POSITAE. Benth. \& Hook. f. ii. 265.

Astranthium, Nutt. in Trans. Am. Phil. Soc. Ser. II. vii. (1841) 312 .

KyberIA, Neck. Elem, i. 42 (1790).

Seubertia, H. Wats, in Hook. Lond. Journ. Bot. iii. $(1840) 602$.

aculeata, Labill. Nov. Holl. Pl. ii. 55. t. 206

Brachycome Billardieri.

alpina, Hegetschw. Fl. Schw, 821 - perennis.

americana, Mirb. ex Steud. Nom. ed. IL i. 195 integrifolia.

annua, Linn. Sp. Pl. 887.-Reg. Mediterr.

arabica, Raeusch. Nom. ed. III. 246, nomen.-Arabia

armena, Boiss. Fl. Orient. iii. 174.-Armenia.

atlantica, Boiss. Eo Reut. Pugill. 54.-Hispan.

azorica, Hochst. in Seub. Fl. Azor. 31. t. 9. fig. 1-3.Ins. Azores.

Bernardi, Boiss, E Reut. Pugill. 56.-Hispan.

caerulescens, Coss. E Bal. in Bull. Soc. Bot. Fr. xxii. (1875) 60, nomen..-Marocco.

campestris, Vell. Fl. Flum. viii. t. 124-Bras,

ciliaris, Labill. Nov, Holl. Pl. ii. 56. t. $209=$

Brachycome ciliaris.

ciliata, Rafin. New Fl. Am. ii. 24.-Am. bor.

cordifolia, Willk. Illustr. Fl. Hisp. 47.-Hispan.

dentata, DC. Prod. v. $304=$ annua,

droseraefolia, Gouan, Illustr. $69=$ Bellium bellidioides. dubia, Spreng. Syst. iii. 582.-Hab. ?

geifolia, Banks \& Soland. ex Hook. Fl. N. Zel. i. 125 = Lagenophora Forsteri.

glandulosa, Klatt, in Leopoldina, xix. 1 ins, $32=$ Brachycome glandulosa.

graminea, Labill. Nov. Holl. Pl. ii. 54. to 214 . Brachycome graminea.

hirta, Host, F1. Austr. ii. $501=$ sylvestris?

hortensis, Mill. Gard. Dict. ed. VIII. n. $8=$ perennis

hybrida, Tenore, F1. Nap. v. 239. t. $194=$ perennis

integrifolia, DC. in Lam. Encyc. v. 7 = perennis. integrifolia, Michx. Fl. Bor. Am, ii. 131.-Am. bor javanica, Blume, Bijdr. $917=$ Mrriactis Wightii.

longifolia, Boiss. \& Heldr. Diagn. Ser. I. xi. 1.-Ins. Creta.

longifolia, Orph. ex Nym. Consp. $390=$ sylvestris.

magellanica, DC. in Lam. Encyc. v. $7=$ Lagenophora Commersonii.

mexicana, A. Gray, Pl. Wright. i. 93.-Mexic

microcephala, Lange, in Kjoeb. Vidensk. Meddel. (1861) $66=$ annua

mossambicensis, Klatt, in Leopoldina, xix. (1889) $32=$

Brachycome mossambicensis.

nutans, Rafin. New Fl.Am. ii. 23.-Am. bor.

pappulosa, Boiss, ex DC. Prod. vii. $276=$ sylvestris.

parviflora, Rafin. New Fl. Am. ii. 23. - Am. bor.

pedunculata, Vell. Fl. Flum. viii. t. 125.-Bras.

perennis, Linn. Sp. Pl. 886.-Europ. occ.

pilosa, Banks \&c Soland. ex Hook. L Fl. N. Zel.i. 126 = Lagenophora lanata.

pilosa, Blume, Bijdr. 917 = Myriactis pilosit. prostrata, Pomsel, Nouv. Mat. Fl. At6.287.-Algeria racemosa, Steud. Nom. ed. I. 105, sphalm. = seg.

ramosa, Jacq. Enum. Pl. Carib. $28=$ Eclipta punctata. ramosa, Lam. Fl. Fr. ii. $122=$ annus.

repens, Lam. 1. $\mathrm{c}=$ annus.

rotundifolia, Bojss. E Reut. Pugill. 55.-Algeris.

scandens, Vell. Fl. Flum. viii. L. 126.-Bras.

scaposa, Gilib, k7. Lituan, i, $218=$ perennis.

stipitata, Labill. Nov. Holl. PI. î. 55. \&. $105=1$ a genophora Billardieri.

sylvestris, Cyrill. Pl. Rar. ii. 22. t. 4.-Reg. Medicert. velutina, Pomel, Nuwo. Nat. Fl. All. 35. - Alceria xanthocomoides, A. Gray, cx Hemsl. Biol. Crufr. of m. Buf. ii. 118. - Mesic. 
BELLIUM, Linn. Mant. 157 (1771). COMPOSITAE, Benth. \& Hook. f. ii. 265.

Belliopsis, Pomel, Mat. Fl. Atl. 7 (1860). bellidioides, Desf, Fl. Atlant. ii. $279=$ Bellis dentata. bellidioides, Linn. Mant. 285.--Reg. Mediterr.

bellidioides, Urv. in Mém. Soc. Linn. Par. i. (1822) $368=$ minutum.

bellioides, G. Don, in Sweet, Flow. Gard. ii. $175=$ bellidioides.

cordifolium, Kunze, in Flora, xxix. (1846) $703=$ Bellis rotundifolia.

crassifolium, Moris, Pl. Sard. Elench. i. 26.-Sardinia.

dentatum, Viviani, Fragm. 8. t. $10=$ Bellis annua.

droseraefolium, Labill. ex Steud, Nom. ed. I. $105=$ bellidioides.

giganteum, Cass. in Dict. Sc. Nat. xxxvii. $456=$ rotundifolium.

minutum, Linn. Mant. 286.-Archip. Graec.

nivale, Req. in Ann. Sc. Nat. Sér. I. v. (1825) $383=$ bellidioides.

pappulosum, Kunze, in Flora, xxix. (1846) $703=$ Bellis sylvestris.

pumilum, Salisb. Prod. $202=$ bellidioides.

rotundifolium, $D C$. Pro... v. 303,-Algeria.

BELLOA, Remy, in C. Gay, Fl. Chil. iii. 336. t. 38 (1849) = Gnaphalium, Linn. (Compos.)

chilensis, Remy, 1. c. 337. t. 38. f. 2.-Chili.

subspicata, Wedd. Chlor, And. i. 159.-Bolivia.

BELLONIA, [Plum.] Linn. Gen. ed. I. 50 (1737) GESNERACEAE, Benth. \& Hook. f. ii. 996.

BELONIA, Adans. Fam. ii. 158 (1763).

aspera, Linn. Sp.Pl.172.-Ind. occ.

spinosa, Sw. Prod. Veg. Ind. Occ. 41.--Ins. S Doming.

BELLOTA, C. Gay, Fl. Chil. v. 297. t. $59(1849)=$ Cryptocarya, R. Br. (Laurin.).

Miersii, C. Gay, 1. c. 298.-Chili.

nitida, Phil. in Linnaea, xxix. $(1857-58) 39=\mathrm{C}$ nitida.

pauciflora, Phil. in Anal. Univ. Chil. (1865) I. 649.Chili.

BELLOTA, A. Rich. ex Phil. in Linnaea, xxix. (185758) $40=$ Boldu, Nees (Laurin.).

BELLUCCIA, Adans. Fam. ii. $344(1763)=$ Ptelea, Linn. (Rutac.).

BELLUCIA, Meissn. Gen. Comm. 46, in syn. = praec.

BELIUCIA, Neck. Elem. ii. 142 (1790). MELASTOMACEAE, Benth, \& Hook. f. i. 768.

Apatitia, Desvo in Ham. Prod. Pl. Ind. Occ. 42 (1825).

AxinantherA, Karst. in Linnaea, xxx. (1859-60) 157.

Ischyranthera, Steud. ex Naud. in Ann. Sc. Nat. Sér. III. xvi. (1851) 102

Werera, J. F. Gmel. Syst. 820 (1790).

arborescens, Baill. Hist. Pl, vii. $34=$ Loreya arborescens.

Aubletii, Naud. in Ann. Sc. Nat. Sér. III. xvi. (1851) 102.-Guiana.

Aubletii, Seem. Bot. Voy. Herald, $122=$ superba.

Axinanthera, Triana, in Trans. Linn. Soc. xxviii. (1871) 142.-N. Granat.

brasiliensis, Naud. in Ann. Sc. Nat. Sér. III. xvi. (1851) 104.-Bras.

Cacatin, Sagot, l. c. Sér. VI. xv. (1883) 332.Guiana.

grossularioides, Triana, in Trans. Linn. Soc. xxviii. (1871) $141=$ Aubletii.

Hostmannii, Naud. in Ann. Sc. Nat. Sér. III. xvi. (1851) 103.-Guiana.

macrophylla, Triana, in Trans. Linn. Soc. xxviii. (1871) $142=$ superba.

multiflora, Karst. in Linnaea, xxx. (1859-60) $158=$ Aubletii.

nervosa, Rafin. Sylva Tellur. $93=$ Blakea trinervia.

pentamera, Naud. in Ann. Sc. Nat. Sér. III. xvi. (1851) 105.-Peruv.

pluricaulis, Spruce, ex Triana, in Trans. Linn. Soc. xxviii. (1871) $142=$ Hostmannii.

riparia, Spruce, I. $\mathrm{c}_{\mathrm{c}}=$ Hostmannii.

superba, Naud. in Ann. Sc. Nat. Sér. III. xvi. (1851) 104.-Mexic
BELLYNKXIA, Mnell. Arg. in Flora, lviii. (1875) $465=$ Appunia, Hook. f. (Rubiac.).

angulata, Muell. Arg. 1. $\mathrm{c}_{\mathrm{r}}=\mathrm{A}$. angulata.

BriLMONTIA, E. Mey, Comm. PI. Afr. Austr. 183 (1837). GENTIANEAE, Benth. \& Hook. f. ii. 804. EXochaenium, Griseb. in DC. Prod. ix. 55 (1845). Parasia, Rafin. F1. Tellur. iii. 78 (1836).

cordata, E. Mey. l. c. -Afr. austr.

gracilis, Welw. in Trans. Linn. Soc, xxvii. (1869) 47. -Afr. trop.

grandis, E. Mey. Comm. Pl. Afr. Austr. 183.-Afr austr.

Ohlendorffi, Griseb. in DC. Prod. ix. 54.-Afr austr.

spathulata, E. Mey.Comm. Pl. Afr. Austr. 183.-Afr austr.

BELOAKON, Rafin. F1. Tellur. iii. 87 (1836)= Phlomis, Linn. (Labiat.).

luteum, Rafin. 1. c. =P. fruticosa.

tomentosum, Rafin. $l . c_{s}=\mathrm{P}$. Samia.

BELOANTHERA, Hassk. in Flora, xxv, (1842) Beibl, ii. 55. 'GENUS DUBIUM.'

oppositifolia, Hassk. l. c.-Java.

BELOËRE, Shuttlew. ex A. Gray, Pl. Wright. i. 21 (1852) $=$ Abutilon, Gaertn. (Malvac.).

cistiflora, Shuttlew. ex A. Gray, 1. c. =A. indicum.

crispa, Shuttlew. ex A. Gray, l. c. in nota $=$ A. crispum.

BELONIA, Adans. Fam. ii. $158(1763)=$ Bellonia, Plum. (Gesner.).

BELONITES, E. Mey. Comm. PI. Afr. Austr. 187 (1837) $=$ Pachypodium, Lindl. (Asclep.).

bispinosa, E. Mey. l. c. $188=$ P. bispinosum.

succulenta, E. Mey. 1. c. $187=$ P. succulentum.

BELONOPHORA, Hook. f. Ic. Pl. t. 1127 (1873) RUBIACEAE, Benth. \& Hook. f. ii. 109 coffeoides, Hook. f. l. c.-Afr. trop.

BELOPERONE, Nees, in Wall. Pl. As. Rar. iii. 76 , 102 (1832). ACANTHACEAE, Benth. \& Hook, f. 1110 .

Beloperonides, Oerst. in Kjoeb. Vidensk. Meddel. (1854) 162 .

KUESTERA, Regel, Gartenfl. vi. (1857) 345 .

Simonisia, Nees, in Mart. Fl. Bras. ix. 144. t. 23 (1847).

Amherstiae, Nees, 1. c. $102=$ Dianthera nodosa.

appendiculata, Nees, in DC. Prod. xi. 423.-Peruv.

atropurpurea, Nees, in Mart. Fl. Bras. ix. 138.Bras.

aurantiaca, Benth. E Hook. f. Gen. ii. 1111.-Am. merid.?

auriculata, Nees, in Mart. Fl. Bras. ix. 138.-Bras.

bullata, Nees, l. c. 141.-Bras.

californica, Benth. Bot. Voy. Sulph. 38.-Am. bor. occ.

calycina, Nees, in Hook. Lond. Journ. Bot. iv. (1845) $637=$ Dianthera calycina.

caracasana, Fenzl, in Facq. Eclog. ii. 2, in obs.Venezuela.

carthaginensis, Benth. \& Hook. f. Gen. ii. $1111=$ violacea.

ciliata, Hook. Bot. Mag. t. $5888=$ Dianthera ciliata ciliata, Nees, in DC. Prod. xi. 422.-Peruv.

comosa, Nees, l.c. 416.-Mexic.

cordata, Mart. ex Nees, 1. c. $361 （=$ Sericographis cordata). - Bras.

cristata, Mart. ex Nees, 1. c. $419=$ Dianthera nodosa

denudata, Nees, l. c. 423.-Peruv.

diclipteroides, Nees, in Mart. Fl. Bras. ix. 136.Bras.

Eustachyana, Benth. E' Hook. f. Gen. ii. 1111.Ind. occ.

fimbriata, Nees, in DC. Prod. xi. 416.-Mexic.

formosa, Fenzl, in Facq. Eclog. ii. in Ind. (Fusticia, t. 102)-Venezuela

fragilis, Mart. ex Nees, in Mart. Fl. Bras, ix. 140.Bras.

fulgida, Hassk. Cat. Hort. Bog. Alt. $150=$ Clinacanthus Burmanni.

glandulosa, Nees, in DC. Prod. xi, 414.-Bras.

\section{BELOPERONE :}

glomerata, Nees, in Mart. Fl. Bras. ix. 137.-Bras.

hirsuta, Nees, l. c. 143.-Bras.

involucrata, Nees, $l$. c.-Bras.

Lamarckiana, Nees, in DC. Prod. xi. 415,-Ind. occ.

lanceolata, Mart. ex Nees, in Mart. Fl. Bras. ix. 141. -Bras.

longipetiolata, Nees, I. c. 137.-Bras.

macrantha, Benth. Er Hook. f. ex Hemsl. Biol. Centr. $A m$. Bot. ii. 516.-Mexic.

Mathewsiana, Nees, in DC. Prod. xi. 731.--Peruv.

Meyeniana, Nees, in Nov. Act. Nat. Cur. xix. Suppl. i. (1843) 381.-Bras.

microstachya, Nees, in Mart. Fl. Bras. ix. 137.Bras.

mollis, Nees, l.c. 142.-Bras.

monticola, Nees, l. c. - - Bras.

nemorosa, Nees, in DC. Prod. xi. 415=Adhatoda tetramera.

nodicaulis, Nees, in Mart. Fl. Bras. ix. 140,-Bras.

oblongata, Lindl. Bot. Reg. t. 1657.-Bras.

oblongata, Nees, in Wall. Pl. As. Rar. iii. $102=$ plumbaginifolia.

obtusifolia, Nees, I. c. $339=$ ovata.

plumbaginifolia, Nees, in Wall. Pl. As. Rar. iii. 102.Bras.

portoricensis, Nees, in DC. Prod. xi. 414.-Porto Rico.

pulchella, Linden, Cat. n. 17 (1862) 2; ex Regel, Gartenfl. xiv. (1865) $289=$ violacea.

Riedeliana, Benth. E Hook.f. Gen. ii. 1111.--Bras.

Rohrii, Nees, in DC. Prod. xi. 415 . - Am, austr.

rosea, Benth. E Hook. $f$. Gen. ii. 1111.-Bras.

Sehomburgkiana, Nees, in Hook. Lond. Fourn. Bot. iv. (1845) 636.-Guiana.

scorpioides, Nees, in DC. Prod.xi. 422,-Bras.

Selloviana, Nees, in Mart. Fl. Bras. ix. 136.Bras.

spathulata, Nees, l. c.-Bras.

sphaerosperma, Benth. E Hook. f. Gen. ii. 1111.Ind. occ.

strobilacea, Mart. ex «Nees, in DC. Prod. xi. 358 (= Amphiscopia strobilacea). - Bras.

surinamensis, Miq. Stirp. Surin. Sel. 130.-Guiana.

trifoliata, Nees, in Mart. Fl. Bras. ix. 141.-Bras.

villosa, Mart. ex Nees, in DC. Prod. xi. $417=$ hirsuta.

violacea, Planch. E Linden, Hort. Linden. i. 5. t. 3.Mexic.

BELOPERONIDES, Oerst. in Kjoeb. Vidensk. Meddel. (1854) $\mathbf{1 6 2}=$ Beloperone, Nees (Acanth.).

macrantha, Oerst. 1. c. = Beloperone macrantha.

BELOSPIS, Rafin. Fl. Tellur. iii. 90 (1836)=Salvia, Tourn. (Labiat.)

levigata, Rafin. 1. c, $91=\mathrm{S}$. involucrata.

BELOSTEMMA, Wall, ex Wight, Contrib. Bot. Ind. Or. 52 (1834) = Tylophora, R. Br. (Asclepiad.).

hirsutum, Wall, ex Wight, l. c. $=$ T. Belostemma.

BELOSYNAPSIS, Hassk. in Flora, liv. (1871) $259=$ Cyanotis, D. Don (Commelin.).

kewensis, Hassk. l. c. =C. kewensis.

BELOTIA, A. Rich. Ess. Fl. Cub. 207. t. 21 (1845) TILIACEAE, Benth. \& Hook. fo i. 233.

Adenodiscus, Tnrez. in Bull. Soc. Nat. Mosc. xix. (1846) II. 504.

Galleottii, Turcz. l.c.-Mexic.

greviaefolia, A. Rich. Ess. Fl, Cub. 209. t, 22.Cuba.

insignis, Baill. Adansonia, x. (1872) 182.-Mexic.

BELOU, Adans. Fam. ii. $408(1763)=$ Aegle, Correa (Rutac.).

BELOVIA, Bunge, in Mém. Sav. Etr. Pétersb. vii. (1852 $462=$ Suaeda, Forsk. (Chenopod.).

baccifera, Moq. in DC. Prod, xiii. II, $168=$ S. setigera. paradoxa, Bunge, in Mém. Sav. Etr. Pétersb. vii. (1852) $462=$ S. setigera.

BELTOKON, Rafin. Fl. Tellur. iii. 86 (1836) $=$ Origanum, Tourn. (Labiat.).

Tourneforti, Rafin. l. c. = O. Tournefortii. 
BELUTTA, Rafin. Fl. Tellur. iii. 39 (1836)=Allmania R. Br. (Amarant.).

peduncularis, Rafin. 1. c. =A. nodiflora.

sessilis, Rafin. 1. c. = A. albida, pyramidalis.

BELVALA, Adans. Fam. ii. 285 (1763)= Struthiola Linn. (Thymel.).

spicata, Rafin. F1. Tellur. iv. $105=$ S. virgata?

BELVALIA, Delile, sec. Flora, xiii. (1830) II. $455=$ Althenia, Petit (Naiad.)

australis, Delile, $\mathrm{l}_{\mathrm{n}} \mathrm{c}_{\mathrm{s}}=\mathrm{A}$. filiformis

BELVEDERE, Clayt. ex Gronov. Fl, Virgin. $25(1739)=$ Galax, Linn. (Diapens.).

BELVISIA, Desv. Journ. Bot. iv. (1814) $130=$ Napoleona, Beauv. (Myrtac.).

caerulea, Desv. 1. c. $=\mathrm{N}$, imperialis.

BEMBECODIUM, Lindl. Veg. Kingd. $712(1847)=$ BEMBYCODIUM, Kunze = Athanasia, Linn (Compos.).

BEMBICIA, Oliver, in Hook. Ic. Pl. t. 1404. SAMY$D A C E A E$.

axillaris, Oliver, l. c.-Malaya.

BEMBICIUM, Mart, ex Baker, in Mart. F1. Bras. vi. II. $341(1876)=$ Eupatorium, Tourn. (Compos.).

gracile, Mart. ex Baker, 1. c. $343=\mathbb{E}$. kleinioides.

BEMBIX, Lour. F1. Cochinch. 346 (1790). MALPIGHIACEAE?-Cf. Benth. \& Hook. f. Gen. i. 251. tectoria, Lour. l. c.-Cochinch.

BEMBYCODIUM, Kunze, in Linnaea, xvi. (1842) $316=$ Athanasia, Linn.(Compos.).

Athanasiae, Kunze, 1. c.-Afr. austr.

BEMSETIA, Rafin. Sylva Tellur. $12(1838)=$ Ixora, Linn. (Rubiac.).

paniculata, Rafin. 1. c. $=$ I. stricta.

BENAUREA, Rafin.Fl. Tellur.ii. 77 (1836)= Musschia, Dum. (Campan.).

sempervirens, Rafin. 1. c. $78=$ M. aurea.

BENCOMIA, Webb \& Berth. Phyt. Canar. ii. 10, t. 39 (1846). ROSACEAE, Benth. \& Hook. f. i. 624. caudata, Webb \& Berth. l. c. 11.-Ins. Canar.

Moquiniana, Webb E Berth. l.c.-Ins. Canar.

BENEDICTA, Bernh. Syst. Verz. Erf. $108(1800)=$ Carbenia, Adans. (Compos.). officinalis, Bernb. 1. c. $159=\mathrm{C}$. benedicta.

BENINCASA, Savi, in Bibl. Ital, ix, 158 (1818) (Mem. sopra Piant. Cucurb. i. (1818) 6). CUCURBITACEAE, Benth. \& Hook. f. i. 824.

cerifera, Savi, $\|$. cc.-As, et Afr. trop, (cult).

cylindrica, Hort. ex Ser. in DC. Prod. iii. $303=$ cerifera.

hispida, Cogn. in DC. Monog. Phan. iii. $513=$ cerifera.

BENITZIA, Karst. in Linnaea, xxviii. (1856) $420=$ Gymnosiphon, Blume (Burman.).

Poeppigiana, Karst. 1. c. 421.-Bras.

suaveolens, Karst. 1. c. 420.-Venczuela.

BENJAMINA, Vell. Fl. Flum. 93 (1825); ii. t. $189=$ Dietyoloma, DC. (Simarub.).

alata, Vell. 11. ec. $=$ D. incanescens

liENJAMINIA, Mart. ex Benj, in Mart. Fl. Bras, x. 255 (1847) = QUINQUELOBUS, Benj. (=Utricularia?).

glabra, Benj. in Linnaea, $\mathrm{xx} .(1847) 761=$ Limnophila Griftithii.

minor, Benj. 1. c. ( = Q. minor).-As. trop.

splendens, Benj, 1. c. $(=Q$. splendens $)$. As, trop.

utriculariacformis, Mart. ex Benj. in Mart. Fl. Bras. $256(=Q$. utricularioides $)$.-Bras.
BENKARA, Adans. Fam. ii. 85 (1763) = Melastoma,

Burm.

galia, Rafin. Sylva Tellur. 98.-Hab.?

BENNETIA, DC. Prod. vi. 531, in syn. (1837)= BENNETTIA, S. F. Gray = Saussurea, DC. (Compos.).

BENNETIA, Rafin. in Ser. Bull. Bot. i. (1830) 220 Sporobolus, R. Br. (Gramin.)

juncea, Rafin. 1. c. = S. junceus.

BENNETTIA, R. Br. in Benn. Pl. Jav, Rar. 249. t. 50 $(183.8)=$ Galearia, Zoll. (Euphorb.).

affinis, R. Br. 1. c. $251=\mathrm{G}$, affinis.

aristifera, Muell. Arg. in DC. Prod. xv. 11. $1039=\mathrm{G}$. aristifera

filiformis, Muell. Arg. in Linnaea, xxxiv. (1865-66) 204. -Ind. or.

Finlaysoniana, R. Br. in Benn. PI. Jav, Rar. $251=\mathrm{G}$. Finlaysoni.

fulva, Muell. Arg. in Linnaea, xxxiv. (1865-66) $205=$ G. fulva.

Fackiana, R. Br. in Benn. Pl. Jav. Rar. $251=\mathrm{G}$. Jackiana.

javanica, R. Br. 1. c. $249=\mathrm{G}$. pedicellata.

Lindleyana, Muell. Arg, in Linnaea, xxxiv. (1865-66) 205. - Ind. or.

pedicellata, R. Br. in Benn. P1. Jav. Rar. $251=\mathrm{G}$. pedicellata.

phlebocarpa, R. Br. 1. c. = G. phlebocarpa.

splendens, Muell. Arg. in Linnaea, xxxiv. (1865-66)

$205=\mathrm{G}$, splendens

subulato, Muell. Arg, in DC. Prod, XY. II. 1039.-Ins. Penang.

Wallichii, R. Br, in Benn. Pl. Jav. Rar. 251=G. Wallichii.

BENNETTIA, S. F. Gray, Nat. Arr. Brit. Pl. ii. 440 $(1821)=$ Saussurea, DC. (Compos.)

alpina, S. F. Gray, 1. c. =S. alpina.

BENNETTIA, Miq. Fl. Ind. Bat. i. I. 105 (1859). BIXINEAE, Benth. \& Hook. f. i. 128.

Horsfieldii, Miq. l. c.-Java.

BENTECA, Adans. Fam. ii. $166(1763)=$ Ambelania, Aubl. (Apocyn.)

odorata, Rafin. Sylva Tellur. $13=\mathrm{A}$. acida

BENTEKA, Adans. Fam. ii. 525 (1763).-Cf. praec.= Ambelania, Aubl. (Apocyn.).

Rheedi, Roem, \& Schult. Syst. iv. $706=$ 'Malabaria.'

BENTHAMIA, Lindl. Bot. Reg. t. 1579 (1838)= Cornus, Tourn.

fragifera, Lindl. 1. c. = C. capitata.

japonica, Sieb. \& Zucc. F1. Jap. j. 38 . t. $16=$ C. Kousa

BENTHAMIA, Lindl. Nat. Syst. ed. I. $241(1830)=$ Amsinckia, Lehm. (1831) (Boragin.)

lycopsoides, Lindl. ex A. DC. Prod. x. 118=A. lycopsioides.

BENTHAMIA, A. Rich. in Mém. Soc. Hist. Nat. Par. iv. (1828) 37. t. $7=$ Habenaria, Willd. (Orchid.) latifolia, A. Rich. 1. c. $38=\mathrm{H}$. chlorantha. spiralis, A. Rich. 1. c. $39=$ Spiranthes africana.

BENTHAMANTHA, Alef. in Bonplandia, x. (1862) 264 = Cracea, Benth. (Legum.)

glabrescens, Alef. 1. c. = C. glabrescens.

glandulifera, Alef. 1. c. = C. glandulifera.

Grayi, Alef. 1. c. $=$ C. sericea.

mollis, Alef. 1. c. $=$ C. mollis.

ochroleuca, Alef. 1. c. = C. ochrolenca.

BENTHAMIDIA, Spach, Hist, Vég, Phan, viii, 105 (1889) = Cornus, Tourn

florida, Spaçh, 1. c. $107=$ C. florida

BENTHAMTELLA, Speg, in Anal. Soc Cient Argent. xv. (1883) 109. SOLANACEAE patagonica, Speg. l. c. 110.-Reg. Argent.

BENTHECA, Neck. Elcm. ii. $54(1790)=$ BENTECA, Adans. ?= Ambelania, Aubl. (Apocyn.)
BENTHEKA, Neck, ex A. DC. Prod. viii. 321, in syn $(1844)=$ Willughbeia, Roxb. (Apocyn.).

BENTINCKIA, Berry, ex Roxb. [Hort. Beng. 68 (1814) et] F1. Ind. jii. 621 (1832). PALMAE, Benth. \& Hook, f, iii, 916.

KePpleria, Mart ex Endl, Gen, 251 (1838) ceramensis, Miq, in Verh. Kon. Akad. Wetensch. xi (1868) n. v. 8 = Cyrtostachys ceramica.

ceramica, H. Wendl. in Kerch. Palm. $235=$ praec.

Condapanna, Berry, ex Roxb. [Hort. Beng. $68 \mathrm{et}$ ] Fl. Ind. iii. 621.-Ind. or.

nicobarica, Becc. in Ann. Fard. Buitenz. ii. (1885) 165.-Ins. Nicob.

Renda, Mart. Hist. Nat. Palm. iii. $316=$ Cyrtostachys Renda.

BENZOIN, Hayne, Arzneigew. xi. t. $24(1829)=$ Styrax

Linn.
officinale, Hayne, 1. $\mathrm{c}_{\circ}=\mathrm{S}$. Benzoin.

BENZOIN, Nees, in Wall. Pl. As. Rar. ii. 63 (1831)= Lindera, Thunb. (Laurin.).

aestivale, Nees, Syst. Laurin. $495=\mathrm{L}$. Benzoin

citriodorum, Sieb. \& Zacc. in. Abh. Akad. Muench.

iv. III. (1846) 206, 78 (=Aperula citriodora).Japon.

Diospyrus, Sweet, Hort. Brit. ed. III. 581 = L. melissac. folia.

geniculatum, G. Don, in Sweet, 1. c. = L. genicnlata. glaucescens, Nees, ex Meissn. in DC. Prod. xv. I. 198 $=$ Litsea glaucescens

glaucum, Sieb. \& Zucc, in Abh. Akad. Muench. iv III. (1846) $205=$ L. glanca.

melissaefolium, Nees, Syst. Laurin. $494=\mathrm{L}$. melissac folia.

Neesianum, Nees, in Wall. Pl. As. Rar. ii. $63=\mathrm{I}$, Neesiana.

odoriferum, Nees, 1. c. $=$ L. Benzoin.

praecox, Sieb. \& Zucc. in Abh. Akad. Muench. iv. III. $(1846) 205=\mathrm{L}$. praecox.

sericeum, Hook. f. \& Thoms, ex Meissn. in DC. Prod. xv. I. $246=$ L. heterophylla.

sericeum, Sieb. \& Zucc. in Abh. Akad. Muench. iv. IIt. (1846) $204=$ L. sericea

Thunbergii, Sieb. \& Zacc. 1. c. = L. umbellata.

trilobum, Sieb. \& Zucc. 1. c. $202=\mathrm{L}$. triloba.

BENZOINA, Rafin. Sylva Tellur. $193(1838)=$ Styrax, Linn.

vera, Rafin. 1. c. $=$ S. Benzoin.

BENZONIA, Schum. in Schum. \& Thonn. Beskr. Guin. PI. 113 (1827). RUBIACEAE? Benth. \& Hook. f. ii. 29

corymbosa, Schum. l. c. 114.-Afr. trop.

BERARDIA, Brongn. in Ann. Sc. Nat. Sér. I. viii. (1826 380. t. $37=$ Nebelia, Neck. (Bruniac.)

affinis, Brongn. 1. c. $381=\mathrm{N}$. affinis.

affinis, Sond. in Harv. \& Sond. Fl. Cap. ii. 320.Afr. austr.

angulata, Sond. 1. c.-Afr. austr.

aspera, Sond. 1. c. 321.-Afr. austr.

Dregeana, Sond. 1. c-Afr. austr.

fragarioides, Schlecht. in Linnaea, vi. (18\$1) 190.Afr. austr.

globosa, Sond. in Harv. \& Sond. Fl. Cap. ii. 320.-Afr. austr.

laevis, E. Mey. ex Sond. 1. c. 819 -Afr. austr.

microphylla, Sond. 1. c. 320.-Afr. austr.

paleacea, Brongn. in Ann. Sc. Nac Ser. I. viii. (1820 $381=$ N. paleacca.

phylicoides, Brongn. 1. $\mathrm{c}=\mathrm{N}$. phylicoides.

sphaerocephalo, Sond. in Harr. \& Sond. Fl. Cap. ii. 319.-Afr. ausir.

BERARDIA, Vill. Prosp. $27(1779)$. CO.MPOSITAE

Benth. \& Hook, f. ii. tit

Arctio, Lam. lincyc. i. $235(1 ; 83)$.

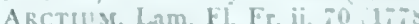

Vitaria, Guett. Mém. Mineral. Dauph. i. 109. ii. $19(1 ;-y)$

subacaulis, b'ill. /. 6. 28.-Callia.

BERBERIDOPSIS. Hook. \&. Bot. Mag. \& 584 (186i2). BERBERIDE.tE, Benth. S Hook. f. i. 984 corallina, Hook. f. b. $c_{0}-$ Chili. 
BERBERIS, [Tourn.] Linn. Gen. ed. I. 94 (1737). $B E R B E R I D E A E$, Benth. \& Hook. f. i. 43.

MaHonia, Nutt. Gen. Am, i. 211 (1818)

Odostemon, Rafin. in Am. Monthly Mag. (1817) 192

abortiva, Renault, F1. Dép. Orne, $179=$ vulgaris

acanthifolia, Wall. ex Walp. Rep. i. $103=$ nepalensis.

acida, Gilib. Exercit. i. $284=$ vulgaris

actinacantha, Mart. ex Schult. $f$. Syst. vii. 12.Chili.

acutifolia, Prantl, Ind. Sem. Wirceburg. (1873) 7.Hab. ?

aethnensis, Bourg. ex Willk. \& Lange, Prod. Fl. Hisp. iii. $901=$ vulgaris.

aetnensis, Presl, Fl. Sic. i. 28.-Cors.; Sardin.; Sicil.

affinis, G. Don, Gen. Syst. i. $115=$ aristata.

africana, Hebenstr. E Ludw. ex Schult. f. Syst. vii. 11. -Afr. austr.

agapatensis, Lechl. Berb. Am. Austr. 44.-Peruv.

altaica, Pall. F1. Ross. ii, $41, t .67=$ sibirica

amurensis, Rupr. in Bull. Phys.-Math. Acad. Pétersb. xv. (1857) 260.-Manchuria.

Andrieuxii, Hook. E' Arn. in Bot. Beech. Voy. 318, adnot.-Mexic.

angulosa, Wall. Cat. n. 1475.-Ind. or.

angustifolia, Benth. Pl. Hartw. 34, 270,-Mexic.

angustifolia, Roxb. Hort. Beng. [87]; FI. Ind. ii. 183

$=$ B. Lycium.

apyrena, Hort. ex C. Koch, Dendrol. i. $395=$ vulgaris.

Aquifolium, Pursh, Fl. Am. Sept. i. 219. t. 4.-Am, bor.

arborescens, Hort, ex C. Koch, Dendrol. i. $393=$ vulgaris.

aristata, Sims, Bot. Mag. t. $2549=$ umbellata

aristata, DC. Syst. ii. 8.--Ind. or.

articulata, Loisel. in Dict. Sc. Nat. 1xviii. 218.Gallia.

asiatica, Griff. Ic. Pl. Ind. Or. iv. t. $648=$ Wallichiana.

asiatica, Roxb. ex DC. Syst. ii. 13.--Reg. Himal.

asperma, Poit. \& Turp. in Duham. ed. Nov. iv. $12=$ vulgaris.

atrovirens, Wall, ex G. Don, Gen. Syst, i. $117=$

Wallichiana.

atroviridis, Steud. Nom. ed. II. i. $196=$ Wallichiana.

aurahuacensis, Lem. in Fl. des Serres, Sér. I. iv. (1848)

334.-N. Granat.

aurea, Tausch, in Flora, xvii. (1834) $495=$ vulgaris,

Bealei, Fortune, in Gard. Chron. (1850) 212.Japon.

bidentata, Lechl. Berb. Am. Austr. 11.-Chili

Bigelovit, Schrad. in Linnaea, xii. (1838) $362=$ vulgaris.

boliviana, Lechl. Berb. Am. Austr. 21.-Bolivia.

brachybotrys, Edgew. in Trans. Linn. Soc. xx. (1851) $29=$ vulgaris.

brachybotrys, C. Gay, Fl. Chil. i. 81.-Chili.

brachypoda, Maxim. in Bull. Acad. Pétersb. xxiii. (1877) 308-China.

brevifolia, Hort. ex C. Koch, Dendrol. i. $398=$ canadensis.

Bussmul, C. Koch, ex Miq. Ann. Mus. Bot. Lugd. Bat. i. $253=$ aristata.

buxifolia, Lam. Illustr. t. 253. f. 3 ; Poir. Encyc. viii, 619.-Reg. Magell.

calliobotrys, Bienert, ex Aitch, in Journ. Linn. Soc. xix (1882) $151=$ vulgaris

canadensis, Guimp. Abbild. Fremd. Holz. 79. t. $63=$ Guimpeli.

canadensis, Hayne, ex Steud. Nom. ed. II. i. $196=$ spathulata.

eanadensis, Mill. Gard. Dict, ed. VIII. n. $2=$ vulgaris.

canadensis, Pursh, Fl. Am. Sept. 219.-Am. bor.

caraganaefolia, Banks, ex DC. Syst. ii. $18=$ Caragana Chamlagu.

carinata, Lechl. Berb. Am. Austr. 41-Peruv.

caroliniana, Sweet, Hort. Brit ed. III 19=canadensis.

cerasina, Schrad. in Linnaea, xii. (1838) 379.-Am. bor.

ceratophylla, G. Don, Gen. Syst. i. $115=$ aristata

chilensis, Gill. in Hook. Bot. Misc. iii. (1833) 135.Chili.

\section{BERBERIS :--}

chinensis, Hort. ex C. Koch, Dendrol. i. $403=$ Guimpeli.

chinensis, Poir. Encyc. viii. $617=$ sinensis

Chitria, D. Don, Prod. F1. Nep. 204 =aristata

Chococa, Schlecht. in Bot. Zeit. xii. (1854) 652.Mexic

ciliaris, Lindl. in Fourn. Hort. Soc. v. (1850) 5, in adnot.-Bolivia.

coccinea, Hort. ex C. Koch, Dendrol i. $406=$ aristata coletioides, Lechl. Berb. Am. Austr. 38.-Chili

oncinna, Hook. f. Bot. Mag. t. 4744.-Reg. Himal.

conferta, H. B. E K. Nov. Gen. et Sp. v. 69. t. 430.Ecuador.

congestiflora, C. Gay, Fl. Chil. i. 75. t. 3.-Chili.

consanguinea, Fortune, in Fourn. Hort. Soc. vii. (1852) 226.-China.

coriacea, St. Hil. Fl. Bras. Mer. i. 46.-Bras.

coriaria, Royle, ex Lindl. Bot. Reg. xxvii. (1841) t. 46 $=$ aristata.

corymbosa, Hook. Arn. in Hook. Bot. Misc. iii. (1833) 135.-Ins. Juan. Fernand.

crataegina, DC. Syst. ii. $9=$ vulgaris.

crenulata, Schrad. in Linnaea, xii. (1838) $362=$ vulgaris.

cretica, Falk, Beitr. ii. $164=$ sibirica

cretica, Linn. Sp. Pl. $331=$ vulgaris

cretica, Thunb. Fl. Jap. $146=$ sinensis.

cretica, Viv. FI. Cors. $5=$ aetnensis.

crispa, C. Gay, Fl. Chil. i. 86.-Chili

cuneata, DC. Syst. ii. 16.-Am. austr.

cuneata, Hort. ex C. Koch, Dendrol. i. $415=$ empetrifolia.

Darwinii, Hook. Ic. Pl. t. 672,-Chili.

dasystachya, Maxim. in Bull. Acad. Pétersb. xxiii. (1877) 308.-China.

daurica, Lodd. ex Loud. Hort. Brit. 139.-Davuria.

dealbata, Lindl. Bot. Reg. t. 1750,-Mexic.

declinata, Schrad, in Linnaea, xii. (1838) 368.China?

densa, Planch. \& Linden, ex Triana \& Planch. in Ann. Sc. Nat. Sér. IV. xvii. (1862) $54=$ rigidifolia.

densiflora, Boiss. \& Buhse, in Nouv. Mém. Soc. Nat.

Mosc. xii. (1860) $9=$ vulgaris.

densiflora, Rafin. Sylva Tellur. 68,-Hab.

dentata, Tausch, in Flora, xxi. (1838) $729=$ vulgaris.

diaphana, Maxim. in Bull. Acad. Pétersb. xxiii. (1877) 309.-China.

diffusa, C. Gay, Fl. Chil. i. 80-Chili.

discolor, Turcz, in Bull. Soc. Nat. Mosc. xxvii. (1854) II. 287.-Venezuela.

discolor, Willd, ex Steud. Nom, ed. II. i. $197=$ rigidi folia

diversifolia, Steud. l. c.-Reg. Argent.

dulcis, Hort. ex C. Koch, Dendrol. i. $395=$ vulgaris.

dulcis, Sweet, Brit. Flow. Gard. Ser. I. ii. t. $100=$

buxifolia.

dumetorum, Gouan, Fl. Monsp. $312=$ vulgaris

edulis, Hort. ex C. Koch, Dendrol. i. $395=$ vulgaris.

Ehrenbergii, Kunze, in Linnaea, xx. (1847) 45.Mexic.

elegans, Hort. ex C. Koch, Dendrol. i. $409=$ aristata emarginata, Willd. Enum. Hort. Berol. $395=$ vulgaris. empetrifolia, Lam. Illustr. t. 253. f. 4.-Reg. Magellan. fascicularis, Sims, Bot. Mag. t. 2396= pinnata.

fasciculata, Schult. f. Syst. vii. $17=$ pinnata.

Fendleri, A. Gray, Pl. Fendl. 5.-Am. bor. occ.

ferox, C. Gay, Fl. Chil. i. 80.-Chili.

ferruginea, Lechl. Berb. Am. Austr. 9.-Bolivia.

Fischeri, Hort. ex C. Koch, Dendrol. i. $399=$ cana. densis.

flexuosa, Ruiz E Pav. Fl. Per. iii. 52. t. 281. f. A.Peruv.

floribunda, Wall. Cat. n. 1474; et G. Don, Gen. Syst. i. 115 = aristata

floribunda, Hort.Cf. Gard. Chron. (1869) 612= B. Aquifolium.

florida, Phil. in Linnaea, xxxiii. (1864-65) 5.Chili.

Fortunei, Lindl. in Fourn. Hort. Soc. i. (1846) 231 , 300.-China.

fraxinifolia, Hook. Ic. Pl. t. 329.-Mexic.

Fremontii, Torr. in Bot. Mex. Bound. 30.-Am. bor occ.

glauca, Benth. Pl. Hartw. 125. n. $710=$ Jamesoni.

glauca, DC. Syst. ii. $10 ; H . B$. \& K. Nov. Gen. et $S p$. v. 71.-N. Granat.
BERBERIS :-

glauca, Hort. ex C. Koch, Dendrol. i. $399=$ canadensis.

glaucescens, St. Hil. Fl. Bras. Mer. i. 45.-Bras.

globosa, Benth. Pl. Hartw. 158.-N. Granat.

glomerata, Hook. E Arn. Bot. Beech. Voy. 5.-Chili.

glumacea, Spreng. Syst. ii. $120=$ nervosa

Goudotii, Triana E Planch. in Ann. Sc. Nat. Sér. IV xvii. (1862) 52-N. Granat.

gracilis, Hort. ex Lindl. in Journ. Hort. Soc. v. (1850) $12=$ aristata.

gracilis, Hartw. ex Benth. Pl. Hartw. 34. n. 271.Mexic.

gracillima, C. Koch, in Miq. Ann. Mus. Bot. Lugd. Bat. i. $253=$ aristata

grandiflora, Turcs. in Bull. Soc. Nat. Mosc xxvii. 1854) II. 287.-Ecuador.

gratissima, Klotzsch, in Bot. Ergeb. Waldem. Reise, 130. - Himal.

Grevilleana, Gill. in Hook. Bot. Misc, iii. (1833) 136. Chili.

Grisebachii, Lechl. Berb. Am. Austr. 34.-Chili.

Guilache, Triana \& Planch. in Ann. $S_{c}$. Nat. Sér. IV. xvii. (1862) 54.-N. Granat.

Guimpeli, C. Koch E' Bouché, in App. Ind. Hort Berol. (1854) 13.-Am. bor.

Haenkeana, Presl, ex Schult. f. Syst. vii. 1616. -Chili.

Hartwegi, Benth. Pl. Hartw. 34. n. 272.-Mexic.

heterophylla, Hort. ex C. Koch, Dendrol. i. $395=$ vulgaris.

heterophylla, fuss. in Poir. Encyc. viii. 622.-Reg. Magellan.

heteropoda, Schrenk, Enum. Pl. Nov. $102=$ vulgaris

hispanica, Boiss. \& Reut. Pagill. Pl. Nov. (1852) $3=$ vulgaris.

Hookeri, Hort. ex Lem. Illustr. Hortic. vi. (1859) t. $207=$ Wallichiana.

horrida, C. Gay, Fl. Chil. i. 84.-Chili.

horrida, Jungh, in Nat. en Geneesk. Arch. Neêrl Indie, ii. (1845) $42=$ Wallichiana.

hypolenca, Lindl. in Journ. Hort. Soc. ii. (1847) $246=$ asiatica.

iberica, Sweet, Hort. Brit, ed. I. $13=$ vulgaris.

ilicifolia, Bert. ex Steud. Nom. ed. II. i. $197=$ glomerata, stipulacea.

ilicifolia, Booth, ex Steud. 1. c. = vulgaris

ilicifolia, Forst. in Comm. Gott. ix. (1789) 28.-Reg. Magellan.

ilicifolia, Hort. ex C. Koch, Dendrol. i. $402=$ aetnensis.

ilicifolia, Roxb. in As. Res. vi. (1799) $357=$ asiatica.

ilicifolia, Scheele, in Linnaea, xxi. (1848) $591=$ trifoliolata.

ilicina, Hemsl. Biol. Centr. Am. Bot. i. 23.-Mexic.

inermis, Pers. Syn. i. 387.-Reg. Magell.

innominata, Kielm. Dec. Rar. Pl. Tueb. $18=$ valgaris.

insignis, Hook. f. E Thoms. Fl. Ind. i. 226.--Reg. Himal.

integerrima, Bunge, in Linnaea, xviii. (1844) $149=$ vulgaris.

integerrima, Hort. ex C. Koch, Dendrol. i. $399=$ canadensis.

intermedia, Hort, ex C. Koch, 1. c. 404=Guimpeli.

intermedia, Hort. Angl,-Cf. Gard. Chron. (1869) 612 $=$ nepalensis.

irritabilis, Salisb. Prod. $213=$ vulgaris.

Facquini, Hort. ex C. Koch, Dendrol. i. $394=$ vaigaris.

Jamesoni, Turcz. in Bull. Soc. Nat. Mosc. xxvii. (1854) II. 286.-Ecuador.

Jamesonii, Lindl. in Fourn. Hort. Soc. v. (1850) 8; Lem. Illustr. Hortic. vi. (1859) t. 201.-Ecuador.

japonica, R. Br. in Tuckey, Congo Exped. App. 22.Japon.

japonica, Lindl. ex Lindl. \& Paxt. Flow. Gard. i. (1850-51) $11=$ Bealii.

kasgarica, Rupr. Sert. Tiansch. 38.-As. temp.

Klotzschiana, Warcz. in Otto E Dietr. Allg. Gartenz. xx. (1852) 292, nomen.-Bolivia.

kunawurensis, Royle, Illustr. Bot. Himal. $64=$ val. garis.

Knightii, Hort. ex C. Koch, Dendrol. i. $413=$ Bealei Lagenaria, Poir. Encyc. viii. $619=$ ilicifolia

lanceolata, Benth. Pl. Hartw. 34-Mexic.

latifolia, Ruiz \& Pav. Fl. Per. iii. 52. t. 282.-Peruv.

lavrina, Thunb. Pl. Bras. i. 8.-Bras. 


\section{BERBERIS :-}

laxa, Rafin, Sylva Tellur. 68,-Hab. ?

laxiflora, Schrad. in Linnaea, xii. (1838) $367=$

vulgaris.
Leschenaultiana, Wall. Cat. n. $1479=$ nepalensis.

Ligonii, Hort. ex C. Koch, Dendrol. ii. $411=$ concinna.

linearifolia, Phil. in Linnaea, xxviii, (1856) 663.Chili.

littoralis, Phil. Fl. Atac. 7.-Chili.

littoralis, Rupr. Fl Cauc. 49, in textu,-Reg. Caucas.

loxensis, Benth. Pl. Hartw. 125. - Peruv.

lucida, Schrad. in Linnaea, xii. (1838) 363.-Iberia.

lutea, Ruiz \& Pav. Fl. Per, iii. 51. t. 280.-Ecuador.

Lycium, Hort. ex C. Koch, Dendrol. i. $393=$ vulgaris.

Lycium, Royle, Illustr. Bot. Himal. 64.-Reg. Himal. macracantha, Hort. ex C. Koch, Dendrol. i. $400=$ canadensis.

macracantha, Schrad. in Linnaea, xii. (1838) $366=$ vulgaris.

macrocarpa, Schrad. 1. c. $370=$ canadensis.

macrophylla, Hort. ex Lindl. in Journ. Hort. Soc, v. (1850) 4 =Wallichiana.

macrophylla, Hort. ex C. Koch, Dendrol, i. 408= asiatica.

macrosepala, Hook. f. E Thoms. Fl. Ind. i. 228.-Reg. Himal.

macrotheca, Hort. ex C. Koch, Dendrol. i. $400=$ canadensis.

maderensis, Lowe, in Hook. Kew fourn. viii. (1856) 289.-Ins. Madera.

magellanica, Hort. ex C. Koch, Dendrol. i. $414=$ Bealei.

marginata, C. Gay, Fl. Chil. i. 88.-Chili.

marginata, Hort. ex C. Koch, Dendrol. i. $394=$ vulgaris.

Maximowiczi, Regel, Gartenfl. (1872) $238=$ vulgaris.

melanocarpa, Schau. Fahrb. Ges. Vat. Cult. xxviii. 180. - Am. bor.

Miccia, Buch.-Ham. in D. Don, Prod. Fl. Nep. $205=$ nepalensis.

microcarpa, Warcz. in Otto E Dietr. Allg. Gartenz. xx. (1852) 292.-Bolivia.

microphylla, F. G. Dietr. Vollst. Lex, Gaertn. ii. $184=$ vulgaris.

microphylla, Forst. in Comm. Gott. ix. (1789) $29=$ buxifolia.

microphylla, Hort, ex C. Koch, Dendrol, i. $399=$ canadensis.

minor, Forst. ex DC. Syst. ii. $15=$ buxifolia.

mitis, Schrad. in Linnaea, xii. (1838) $371=$ vulgaris.

monosperma, Hort. ex C. Koch, Dendrol. 1. $405=$ sinensis.

monosperma, Ruiz \& Pav. Fl. Per. iii. 52.-Peruv.

montana, C. Gay, Fl. Chil. i. 90.-Chili.

moranensis, Schult. f. Syst. vii. 17.-Mexic.

multifora, Benth. Pl. Hartw. 124.- Peruv.

mutabilis, Phil. in Anal. Univ. Chil. (1872) 665.Chili.

neglecta, Hort. ex Turcs. in Bull. Soc. Nat. Mosc. xxvii. (1854) II. 284-Hab, ?

nepalensis, Hort. ex C. Koch, Dendrol, i. $393=$ vulgaris.

nepalensis, Spreng. Syst. ii. 120.-Reg. Himal.

nervosa, Pursh, Fl. Am. Sept. 219. t. 5.-Am. bor. occ.

Nenberti $\times$, Hort. ex Lem. Illustr. Hortic. i. (1854)

Misc. 111. t. c.

nigra, Rafin. Sylva Tellur. 67.-Am. bor.

nitens, Hort. ex C. Koch, Dendrol. i. $399=$ cana densis.

nitens, Schrad. in Linnaea, xii. (1838) $382=$ valgaris.

nitida, Willd. ex Steud. Nom. ed. II. 1. $197=$ quin duensis.

Nummularia, Bunge, in Linnaea, xviii. (1844) $149=$ vulgaris.

obovata, Schrad. l. c. xii. (1888) $385=$ vulgaris.

orthobotrys, Bienert, ex Aitch. in fourn. Linn. Soc.

xix. (1882) 150.-Persia.

pallida, Hartw. ex Benth. Pl. Hartw. 34.-Mexic.

paniculata, H. B. \& K. ex DC. Syst. ii. $10=$ glauca.

paniculata, Fuss. ex DC. 1 . c. 12.-Peruv.

paniculata, Hemsl. Biol. Centr. Am. Bot. 1. 24.Costa-Rica.

paniculata, Phil. in Anal. Univ. Chil. (1872) 664.Chili.

\section{BERBERIS :-}

parviflora, Lindl. in Fourn. Hort. Soc. ii. (1847) 243. -Am. austr.

pauciflora, Salisb. Prod. $213=$ vulgaris.

Pearcei, Phil. in Linnaea, xxxiii. (1864-65) 4.Chili.

petiolaris, Wall. ex G. Don, Gen. Syst. i. 116=aristata.

pichinchensis, Turcz. in Bull. Soc. Nat. Mosc, xxvii. (1854) II. 286. -Ecuador.

pichinchensis, Wedd. Chlor. And. ii. 295 (= praec. ?).Ecuador.

pinnata, Banks, ex DC. Syst. ii. $20=$ B. Aquifolium.

pinnata, Buch, ex DC. 1. c. $21=$ nervosa

pinnata, H. B. \& K. Nov. Gen. et Sp. v. $434=$ moranensis.

pinnata, Lag. Elench. Hort. Madr. (1803) 6.Mexic.

pinnata, Roxb. Fl. Ind. ii. $184=$ nepalensis.

pisifera, Rafin. Sylva Tellur. $68=$ canadensis

polymorpha, Phil. in Linnaea, xxviii. (1856) 664.Chili.

polypetala, Phit. in Anal. Univ. Chil. (1872) 666.Chili.

provincialis, Audib. ex Schrad. in Linnaea, xii. (1838) $381=$ vulgaris.

psilopoda, Turcz. in Bull. Soc. Nat. Mosc. xxvii. (1854) II. 285.-N. Granat.

purpurea, Rafin. Sylva Tellur. 67.-Hab.?

quinduensis, $H . B . \&$ E. Nov. Gen. et $S p$. v. 70. t. 432 .

-Ecuador.

racemosa, Stokes, Bot. Mat. Med. ii. $296=$ vul

garis.
rariflora, Lechl. Berb. Am. Austr. 33.-Bolivia.

repens, Lindl. Bot. Reg. t. $1176=$ B. Aquifolium.

reticulata, Steud. Nom. ed. II. i. 197.--Chili.

retinervis, Triana E' Planch. in Ann. Sc. Nat. Sér. IV. xvii. (1862) 52.-N: Granat.

revoluta, Sm. ex DC. Syst. ii. $16=$ empetrifolia.

rigida, Willd. ex Steud. Nom. ed. II. i. $197=$ conferta.

rigidifolia, $H . B$. E K. Nov. Gen. et Sp. v. 70. t. 431 - Am. austr.

Roemeriana, Scheele, in Linnaea, xxii. (1849) $352=$ trifoliata.

rotundifolia, Poepp. Eo Endl. Nov. Gen. et Sp. ii. 63.Chili.

rotundifolia, Hort. ex Lindl. in Journ, Hort. Soc. v (1850) 2 =buxifolia.

rubra, Poit. \& Turp. in Duham. ed. Nov. iv. $12=$ vnlgaris.

ruscifolia, Lam. Illustr. t. 253. f. 2.--Reg. Argent.

sanguinea, Hort. ex C. Koch, Dendrol. i. $394=$ vulgaris.

sanguinolenta, Hort. ex C. Koch, l. c. = vulgaris

sanguinolenta, Schrad. in Linnaea, xii. (1838) 378. Hab. ?

saxicola, Lechl. Berb. Am. Austr. 42.-Peruv.

Schiedeana, Schlecht. in Bot. Zeit. xii. (1854) 654. Mexic.

serotina, Lange, Ind. Sem. Haun. (1872) 5, adnotHab. ?

serratifolia, Hort. ex C. Koch, Dendrol. i. $406=$ aristata.

serrato-dentata, Lechl. Berb. Am. Austr. 16.Chili.

serrulata, Rafin. Sylva Tellux, $68=$ canadensis.

sibirica, Hort. ex Schult. f. Syst. vii. $2=$ vulgaris

sibirica, Pall. Fl. Ross. ii. 42. t. 67.-Sibir. altaic

sicula, Jan, Elench. ex Schult. f. Syst. vii. $8=$ aetnensis.

Sieboldii, Miq. in Ann. Mus. Bot. Luyd. Bat. ii. 69.Japon.

sinensis, Desf. Tabl. ed. I. (1804) 150. - China.

sinensis, DC. Syst. ii. $6=$ Guimpeli.

spathulata, Schrad. in Linnaea, xii. (1838) 376Am. bor.

sphaerocarpa, Kar. \& Kir. in Bull. Soc. Nat. Mosc. (1841) $376=$ vulgaris

spinosa, Comm. ex Decne. in Bot. Voy. Astrol. \& Zíl. $65=$ buxifolia .

spinulosa, St. Hil. Fl. Bras. Mer. i. 45.-Bras,

stenophylla, Hance, in Fourn. Bot. xx. (1882) 257.China.

stenophylla $\times$, Hort.-Cf. Gard. Chron. (1864) 460 ; (1869) II. 612; (1882) 13. 466; C. Koch, Dendrol. i. $412=$ Darwinii.

stipulacea, Steud. Nom, ed. II. i. 197.-Chili.

\section{BERBERIS}

sulcata, C. Koch Eo Bouché, in App. Ind. Sem. Hort. Berol. (1854) 13.-Hab.

Swaseyi, Buckley, in Young, Fl. Texas. 152.Texas.

tenuifolia, Lindl. Bot. Reg. (1838) Misc. 64.-Mexic.

Thunbergii, DC. Syst. ii. $9=$ vulgaris.

tinctoria, Leschen. in Mém. Mus. Par。 ix. (1822) $306=$ aristata.

toluacensis, Hort.-Cf. Gard.Chron. (1868) 435.-Am. austr.

tolimensis, Planch. \& Linden, ex Triana O Planch. in Ann. Sc. Nat. Sér. IV. xvii. (1862) 52.-N. Granat.

tomentosa, Ruiz \& Pav. Fl. Per. iii. 52. t. 282 bChili.

tortuosa, Domb. ex DC. Syst. ii. $11=$ flexuosa.

tragacanthoides, DC. Syst. ii. 18.-Armenia.

tricuspidata, Sm. ex DC. l. c. 17 =heterophylla.

trifolia, Schult. f. Syst. vii. 1616.-Mexic.

trifoliata, Hartw。 ex Lindl. Bot. Reg. xxvii, (1841) Misc. $68=$ seq.

trifoliolata, Moric. Pl. Nouv. Am. 113. t. 69.Texas.

trifurca, Lindl. in Paxt. Flow. Gard. iii. 57 (1852-53) -China.

trigona, Kunze, in Poepp. E Endl. Nov. Gen。 et Sp. ii. 63. t. 187.-Chili.

truxillensis, Turcz. in Bull. Soc. Nat. Mosc, xxvii. (1854) II. 285, - Venezuela.

Tschonoskyana, Regel, in Act. Hort. Petrop. ji. (1873) 421.-Japon.

turcomannica, Kar. ex Ledeb. Fl. Ross, i. $79=$ vulgaris.

ulicina, Hook. f. E Thoms. Fl. Ind. i. 227.-Tibet. occ.

umbellata, Lindl. Bot. Reg. xxx. (1844) t. $44=$ aristata.

nmbellata, Phil. in Anal. Univ. Chil. (1872) 663.Chili.

umbellata, Wall. Cat. ฤ. 1475 ; et ex G. Don, Gen. Syst. i. 116.-Reg. Himal.

undulata, Hort. ex C. Koch, Dendrol. i. $408=$ asiatica.

undulata, Lindl. in fourn. Hort. Soc. v. (1550) 7.Peruv.

valdiviana, Phil. in Linnaea, xxviii. (1856) 609.Chili

verticillata, Turcz. in Bull. Soc.Nat. Mosc. xxvii. (1854) II. 288,-N. Granat.

violacea, Poit. \& Turp. in Duham, ed. Nov, iv, 12; Hort. ex C. Koch, Dendrol. i. $394=$ vulgaris

virgata, Hort. ex Lindl, in Journ. Hort. Soc. v. (1850), $6=$ parviflora.

virgata, Hort. ex C. Koch, Dendrol. i. $413=$ actinacantha.

virgata, Ruiz \& Pav. Fl. Per, iii. 51. to 281. f. B.Peruy.

vulgaris, Linn. Sp. Pl. 330._Europ.; As. temp. vulgaris, Vell. Fl. Flum. iii, t. $149=$ glancescens Wallichiana, DC. Prodo i. 107.-Reg. Himal.

Weddelli, Lechl. Berb. Am. Austr. 21_-Bolivia. xanthoxylon, Hassk. Cat. Hort. Bog. Alt $180=$ Wallichiana?

BERCHEMIA, Neck. Elem. ii. $122(1790$ RHAMNEAE, Benth. \& Hook. f. i. 377

OENOPLEA, Hedw. f. Gen。 i. $151\left(1806^{\circ}\right)$

OENOPLIA, Schult. ex Roem. \& Schult. Syst. v. 33: (1819)

affinis, Hassk. Hort. Bog. Desc. 117.-Malaya.

Burmanniana, DC. Prod. ii. 23.-Zeylan.

calophylla, G. Don, Gen. Syst. ii. $28=$ Zizyplos calophylla.

congesta, S. Moore, in Journ. Bot xiii. (1s75) 228 : Michrorhamnus franguloides.

corollata, F. Mnell. Census, $60=$ ccorollata

discolor, Hemsl, in Oliver, Fr. Trop. Afro. i. 381,-Afr. trop.

Edgeworthii, Lawson, in Hook. f. Fl. Brit. Ind. i. 6sS. -Reg. Himal.

ecorollatn, Fo Muell. Fragm, ix. 141. - Austral.

Havescens, Wall. Cas. n. 4255; Bromgn. in Amm Si Nat. Sér. I. x. (1827) 857.-Keg. Hima).

floribunda, Wall. Cat. n. $1250^{\circ} ;$ Bromgno l. co-Keg. limal.

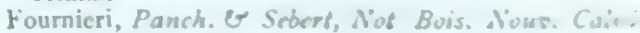
¿so, -N. Calod. 


\section{BERCHEMIA :-}

hamosa, Wall. Cat. n. $4253=$ Sageretia hamosa

laxa, Wall. 1. c. n. $4257=$ floribunda.

lineata, Benth. in Hook. Kew Journ. iv. (1852) 42 $=$ racemosa.

lineata, $D C$. Prod. ii. 23.-China.

Loureiriana, $D C$. l. $C$.-China

oppositifolia, Wall. Cat. n. $4254=$ Sageretia oppositifolia.

parviflora, Wall. 1. c. n. 4258 ; Wight, Ic. i. $19=$ Sageretia oppositifolia.

Poiretiana, DC. Prod. ii. $23=$ lineata.

polyphylla, Wall. Cat. n. 4259.-Burma.

pubiflora, Miq. Fl. Ind. Bat. i. 1. 645.-Malaya

racemosa, Sieb. E' Zucc. in Abh. Akad. Muench. iv. II. (1843) 147.-Japon.

repanda, Rafin. Sylva Tellur. 33.-Hab.

sessiliflora, Benth. Fl. Hongk. 68.--China.

trichantha, Miq. Fi. Ind. Bat. Suppl. i. 331.-Malaya.

undulata, Rafin. Sylva Tellur. 33.-Hab.?

volubilis, DC. Prod. ii. 23.-Am, bor.

BERCHTOLDIA, Presl, Rel. Haenk. 323. t. 43 (1830) $=$ Chaetium, Nees (Gramin.)

bromoides, Presl, 1. c. $324=\mathrm{C}$. bromoides.

holciformis, Fourn. ex Benth. in Journ. Linn. Soc. xix. (1881) $46=$ Oplismenus holciformis.

junciformis, Hemsl. Biol. Centr. Am. Bot. iii. 501, lapsu = Oplismenus holciformis

oplismenoides, Fourn. ex Benth. in Journ. Linn. Soc. xix. (1881) $46=$ Echinochloae sp.?

BERCKHEYA, Pers. Syn. ii. $480(1807) \doteq$ Berkheya, Ehrh. (Compos.).

BEREBERA, Baker, in Oliver, Fl. Trop. Afr. ii. 131 (1871), sphalm = BERREBERA, Hochst $=$ Millottia, Wight \& Arn. (Legumin.)

BERENDTIA, A Gray, in Proc. Am. Acad, vii. (1868) 379. SCROPHULARINEAE, Benth. \& Hook. f. ii. 942 .

Conlteri, A. Gray, l. c. 380.-Mexic

Ghiesbrechtii, A. Gray, 1, c. = rugosa.

rugosa, A. Gray, l. c.-Mexic.

BERENICE, Salisb. Gen. Pl. Fragm. $89(1866)=$ Allium, Linn. (Liliac.).

Victorialis, Salisb. $490=\mathrm{A}$. Victoria lis,

BERENICE, Tul, in Ann. Sc. Nat. Sér. IV. viii. (1857) 156. SAXIFRAGEAE, Benth. \& Hook. f. i. 646. arguta, Tul. l. c.-Ins. Borbon.

BERGENA, Adans. Fam. ii. $345(1763)=$ Lecythis, Linn. (Myrtac.)

BERGENIA, Moench, Meth. $664(1794)=$ Saxifraga,

biflora, Moench, 1. c. $=$ S. crassifolia.

cordifolia, Sternb. Rev. Sax. Suppl. ii. $2=$ S. crassifolia.

purpurascens, Engl. in Verh. Zool. Bot. Ges. Wien, xix. (1869) $549=\mathrm{S}$. purpurascens.

BERGENIA, Neck. Elem. ii. $108(1790)=$ Lythrum, Linn.

BERGENIA, Rafin. Sylva Tellur. $102(1838)=$ Cuphea, P. Br. (Lythrar.)

siphilitica, Rafin. 1. c.-Hab.?

BERGERA, Koen. ex Linn. Mant. ii. $563(1771)=$ Mur raya, Linn. (Rutac.)

compressa, Blanco, F1. Filip. ed. I. 360.-Ins. Philipp. inodora, Blanco, 1. c. 361.-Ins. Philipp.

integerrima, Buch.-Ham. ex Roxb. Hort. Beng. 32 ;

Fl. Ind. ii. $376=$ Micromelum pubescens.

intermedia, Zoll. \& Moritzi, Syst. Verz. Zoll. 24.-Java.

Koenigii, Linn. Mant. $565=$ Murraya Koenigii. nitida, Thw. Enum. Pl. Zeyl. $46=$ Clausena indica.

ternata, Blanco, F1. Filip. ed. I. $360=$ Glycosmis bilocularis.

villosa, Wall. Cat. n. $6372=$ Micromelum pubescens.

Wallichii, A. DC. ex Oliver, in Journ. Linn. Soc. $y$.

Suppl. ii. (1861) $35=$ Clausena Wallichii.
BERGERETIA, Desy. Jonrn. Bot. iii. (1813) $161=$ Clypeola, Linn. (Crucif.)

echinata, Desv. 1. c. = C. lasiocarpa.

BERGERIA, Koen. ex Steud. Nom. ed. II. i. 849, in syn. (1840) $=$ Koenigia, Linn. (Polygon.).

BERGERONIA, Micheli, in Mém. Soc. Phys. Genèv. xxviii. (1883) n. 7 (Contr. Fl. Parag. 38). LEGUMINOSAE.

sericea, Micheli, ll. cc. 39.-Paraguay.

BERGHAUSIA, Endl. Gen. Suppl. iii. 57 (1843) = Garnotia, Brongn. (Gramin.).

barbulata, Endl. ex Miq. Anal. Bot. Ind, 32.-Malaya. courtallensis, Nees, ex Miq. 1. c. $=\mathrm{G}$. courtallensis.

elata, Arn, ex Miq. 1. c.-Malaya.

Emodi, Endl. ex Miq. 1. c.-Malaya.

mutica, Munro, in Proc. Am. Acad. iv. (1864) 362 Hongkong.

pallens, Arn. ex Miq. Anal. Bot. Ind. 33.

patula, Munro, in Proc. Am. Acad.iv. (1864) $362=\mathrm{G}$. patula.

tenella, Arn. ex Miq. Anal. Bot. Ind. 34.-Malaya.

BERGHESIA, Nees, in Linnaea, xx. (1847) 701 RUBIACEAE?, Benth. \& Hook. f. ii. 29.

coccinea, Nees, l. c. 702 -Mexic.

BERGHIAS, Juss. in Mém. Mus. Par. vi. (1820) $399=$ BERGKIAS, Sonn.=Gardenia, Ellis (Rubiac.).

BERGIA, Linn. Mant. ii. 152. n. 1309 (1771), ELATINEAE, Benth. \& Hook. f. i. 163.

Bergieria, Neck, Elem ii, 237 (1790).

LANCRETia, Del. Fl. Egypte, 213. t. 25, f 1 (1813).

Merimea, Cambess, in St. Hil. Fl. Bras. Mer, ii 160. t. 107 (1829)

SPhondylococca, Willd. ex Roem. \& Schult. Syst. vi. p. Ixx. $799(1820)$

abyssinica, A. Rich. Tent. Fl. Abyss. 1. 49.-Abyss.

aestivosa, Steud. Nom ed II i. 198,-nnd. bor occ.

ammannioides, Roxb. Hort. Beng. 34 ; Fl. Ind. ii. 456. -As. Afr. et Austral. trop.

anagalloides, Walp. Rep. ii. 286.-Afr. austr.

aquatica, Roxb. P1. Corom. ii. 22.t. 142=verticillata.

arenaroides, Fenzl, in Denkschr. Baier. Bot. Ges, iii.

(1841) 183.-Bras.

capensis, Linn. Mant. 241.-Afr. austr

decumbens, Planch. ex Harv. Thes. Cap. i. 15. t. 24. -Afr. austr.

erecta, Guill. \& Perr. Tent. Fl. Seneg. 44.-Afr. trop.

glandulosa, Turcz. in Bull. Soc. Nat. Mosc. xxvii. (1854) XI. 371.-Ins. Luzon.

glomerata, Linn. f. Suppl. 243.-Afr, austr.

odorata, Edgew. in fourn. As. Soc. Beng. vii. (1838) 765.-Afr. trop.; Persia; Ind. bor. occ.

oryzetorum, Fenzl, ex Zoll. Syst. Verz. Ind. Archip. 62 -Malaya.

pedicellaris, F. Muell. Fragm. ii. 145.-Austral,

pentandra, Cambess. ex Guill, \& Perr. Tent. Fl. Seneg. 42. t. $12=$ ammanoides.

peploides, Guill. E Perr. l. c. 44.-Afr. trop.

perennis, F. Muell. Fragm. ii. 146.-Austral.

polyantha, Sond. in Linnaea, xxiii. (1850) 16.-Afr. austr.

pusilla, Benth. Fl. Austral. i. 180.-Austral.

repens, Blume, Bijdr.62--Java.
serrata, Blanco, Fl. Filip. ed. I. 387.-Ins. Philipp.

sessiliflora, Griseb. Cat. Pl. Cub. 40.-Cuba.

suffruticosa, Fenzl, in Denkschr. Baier. Bot. Ges. iii. (1841) $\mathbf{1 8 3}=$ odorata

texana, Seub. ex Walp. Rep. i. 285.-Texas.

trimera, Fisch. \& Mey. in Linnaea, x. (1836) $74=$ ammannioides.

tripetala, F. Muell. in Trans. Phil. Inst. Vict.ii. (1858)

66.-Austral

verticillata, Willd. Sp. $\mathrm{Pl}$. ii. $770=$ capensis.

BERGIERA, Neck. Elem. ii. $237(1790)=$ praec.

BERGINIA, Harv. ex Benth. \& Hook. f. Gen. ii. 1096 (1876). ACANTHACEAE, Benth. \& Hook. f. 1. c. virgata, Harv. ex Benth. E Hook. f. l. c. 1097.Calif.

BERGKIAS, Sonner. Voy. 48. t. $17(1776)=$ Gardenia, Ellis (Rubiac.).
BERGSMIA, Blume, Rumphia, iv, 23. t. 178 C. f." 2 (1848). BIXINEAE, Benth. \& Hook. f. i. 129 acuminata, Miq. Fl. Ind. Bat. Suppl. i. 389.-Sumatra. javanica, Blume, Rumphia, iv. 23.-Java.

sumatrana, Miq. Fl. Ind. Bat. Suppl. i. 389.Sumatra.

BERHARDIA, C. Muell. in Walp. Ann. v. $39(1845)$, sphalm. = Berardia, Vill. (Compos.).

BERIESA, Steud. Nom. ed. II. i. $199(\mathbf{1 8 4 0})=$ SIEBERA, Presl = Anredera, Juss. (Chenop.).

baselloides, Steud. 1. c. = A. spicata.

BERINGERIA, Neck, Elem, i, $312(1790)=$ Ballota Linn. (Labiat.).

acetabulosa, Neck. 1. c. = Ballota acetabulosa.

africana, Neck. 1. c, = Ballota africana.

cinerea, G. Don, in Sweet, Hort. Brit. ed. III. $545=$ Ballota hirsuta.

crispa, G. Don, l. c. = Ballota africana.

frutescens, Reichb. F1. Germ. Excurs. $325=$ Ballota spinosa.

hirsuta, Neck. Elem. $312=$ Ballota hirsuta.

hispanica, Neck. 1. $c_{\mathrm{n}}=$ Ballota hispanica.

mollissima, Heynh. Nom. ii. $66=$ Ballota mollissima orientalis, G. Don, in Sweet, Hort. Brit. ed. III. 548

Ballota orientalis (sp. dubia).

pseudodictamnus, Neck. Elem. i. 312 ; Link, Handb. $478=$ Ballota psetdodictamnus.

rugosa, Heynh. Nom. ii. $66=$ Ballota saxatilis.

BERINIA, Brignol. Pl. Forojul. $50(1810)=$ Crepis Vaill. (Compos.):

abyssinica, Sch. Bip. in Pollichia, xxii-xxiv. (1866) 315 $=\mathrm{C}$. abyssinica.

acuminata, Sch. Bip. 1. c. = C. acuminata.

alpestris, Sch. Bip. l. c. $=$ C. alpestris

andryaloides, Brignol. Pl. Forojul. 50=C. chondril loides.

aurea, Sch. Bip. in Pollichia, xxii-xxiv. (1866) $318=\mathrm{C}$. aurea.

auriculaefolia, Sch. Bip. 1. c. $315=$ C. auriculaefolia. biennis, Sch. Bip. 1. c. $318=$ C, biennis.

chondrilloides, Sieb, ex Sch. Bïp. 1. c. $315=$ C. chon drilloides.

chrysantha, Sch. Bip. 1. c. $318=$ C. chrysantba.

ciliata, Sch. Bip. 1. c. $317=$ C, ciliata.

crocea, Sch. Bip. 1. c. =C. crocea.

foetida, Sch. Bip. l. c. $315=$ C. foetida.

grandiflora, Sch. Bip. 1. c. $317=$ C. grandiflora.

heterantha, Sch. Bip. 1. c. = Lactuca Dubyaea.

heterotricha, Sch. Bip. 1. c $=$ C. heterotricha.

Facquinii, Sch. Bip. 1. c. $318=$ C. Froelichii?

jubata, Sch. Bip. 1. c. =C. jubata.

lacera, Sch. Bip. 1. c. $315=$ C. lacera.

nicaeënsis, Sch. Bip. 1. c. $318=$ C. nicaeënsis.

occidentalis, Sch. Bip. 1. c. $315=\mathrm{C}$. occidentalis.

oporinioides, Sch. Bip. 1. c. =C, oporinioides.

pannonica, Sch. Bip. 1. c. =C. rigida.

pinnatifida, Sch. Bip. 1. c. =C. pinnatifida.

polytricha, Sch. Bip. 1. c. $317=$ C. polytricha.

runcinata, Sch. Bip. 1. c. $315=$ C. runcinata.

Sibthorpiana, Sch. Bip. 1. c. =C. Sibthorpiana.

stricta, Sch. Bip. 1. c. $317=\mathrm{C}$. virens? vel tectorum.

tenuifolia, Sch. Bip. 1, c. $316=$ C. tenuifolia,

BERKHFYA, Ehrh. Beitr, iii, 137 (1788). COM

POSITAE, Benth. \& Hook. f. ii. 460.

AgriphylluM, Juss. Gen. 190 (1789).

A PULEIA, Gaertn. Fruct, ii. 439.t. 171 (1791)

Arelina, Neck. Elem. i. $83(1790)$.

ASPIDALIS, Gaertn. Fruct. ii. t. 171 (1791).

Basteria, Houtt. Nat. Hist. Pl. iv. 158 (1776).

Bastera, J. F. Gmel. Syst. 1271 (1791).

BerCKheya, Schreb, Gen. ii, 577 (1791)

Crocodiloides, Adans. Fam. ii. 127 (1763).

Cuspidia, Gaertn. Fruct. ii. 454. t. 171 (1791)

Evopis, Cass. in Bull. Soc. Philom. (Févr. 1818)

32 ; et in Dict. Sc. Nat. xvi. 65 (1820)

Gorteria, Linn. Sp. Pl. ed. II. 1282 (1763), pro parte; Lam. Illustr. t. 702 (1789?).

HeTERorachis,Sch. Bip. in Flora, xxvii. (1844) 775.

RoHria, Vahl, in Skr. Naturh,-Selsk. Kjoeb, ii (1793) 97 .

StobaeA, Thunb. Prod. P1. Cap. 141 (1800).

Zarabellia, Neck. Elem. i. 10 (1790). 
BERKHEYA :-

albida, Lichtst. ex DC. Prod. vii. $36=$ Dicoma capensis annectens, Harv. in Harv. \& Sond. Fl. Cap. iii. 509.Afr. austr.

bisulca, Pers. Syn. ii. $480=$ Cullumia bisulca.

canescens, DC. Prod. vi. 507.-Afr. austr.

carduiformis, $D C$. l. c.-Afr. austr.

carlinoides, Willd. Sp. Pl. iii. 2275.-Afr. austr.

carthamoides, Willd. $l_{0} c .2274$. -Afr. austr.

cernua, R. Br. in Ait. Hort. Kew. ed. II. v. $139=$ Didelta cernua.

ciliaris, Willd. Sp. Pl. iii. $2273=$ Cullumia ciliaris.

coriacea, Harv. in Harv. Es Sond. Fl. Cap. iii. 506.Afr. austr.

corymbosa, $D C$. Prod. vi. 507.-Afr. austr.

cruciata, Willd. Sp. Pl. 2276.-Afr. austr.

cuneata, Willd. l. c. 2270.-Afr. austr.

cynaroides, Willd. l. c. 2275.-Afr. austr.

decurrens, Willd. 1. c. $2276=$ Stephanocoma berkheyoides.

Dregei, Harv. in Harv, E Sond. Fl. Cap. iii. 507.Afr. austr.

Ecklonis, Harv. l. c. 504.-Afr. austr.

eryngiifolia, Less. Syn. Comp. 703.-Afr. austr.

fruticosa, Ehrh. Beitr. iii, 138.-Afr, austr.

gazanioides, Harv, in Harv. Er Sond. Fl. Cap. iii. 508 -Afr. austr

gorterioides, Oliver E Hiern, in Oliver, Fl. Trop. Afr. iii. 429,-Afr. trop

grandiflora, Willd. Sp. Pl. iii. 2271.-Afr. austr.

hirpicioides, Sond. in Harv. E Sond. Fl. Cap. iii, 509. -Afr. austr.

hispida, Willd. Sp. Pl. iii. $2274=$ Cullumia hispida

incana, Willd. 1. c. $2269=$ fruticosa.

Kraussii, Sch. Bip. in Flora, xxvii. (1844) $774=$ cynaroides.

lanceolata, Willd. Sp. Pl. iii. 2270,-Afro austr.

obovata, Willd. l.c. 2269.-Afr. austr.

palmata, Willd. l. c. 2271.-Afr. austr.

patula, Willd. 1. c. $2272=$ Cullumia patula

pectinata, Willd. 1. $\mathrm{c}_{\mathrm{c}}=$ Cullumia pectinata.

pinnata, Less. Syn. Comp. 75, -Afr, austr,

pungens, Willd. Sp. Pl. iii. 2275.-Afr, austr.

purpurea, Benth. है Hook. f. ex Mast. in Gard. Chron.

(1872) 1262.-Afr. austr.

scolymoides, DC. Prod, vi. 504,-Afr. austr.

seminivea, Harv. in Harv. E Sond. Fl. Cap. iii. 507. -Afr. austr.

setifera, DC. Prod. vi, 507.-Afr. austr

setosa, Willd. Sp. Pl, iii. $2273=$ Cullumia setosa

Spekeana, Oliver, in Trans, Linn. Soc. xxix. (1873) 100.-Afr. trop.

spinosissima, Willd. Sp. Pl. iii. 2270.-Afr. austr

squarrosa, Willd. 1. c. $2272=$ Cullumia bisulea.

stobaeoides, Harv. in Harv. E' Sond. Fl. Cap. iii. 505, -Afr. austr.

subulata, Harv. l. c. 507.-Afr. austr.

sulcata, Willd. Sp. Pl. 2271 = Cullumia sulcata.

umbellata, DC. Prod. vi. 507.-Afr. austr.

uniflora, Willd. Sp. Pl. iii. 2274.-Afr, austr

Zeyheri, Harv. E Sond. Fl. Cap. iii. 496.-Afr. austr.

BERLANDIERA, DC. Prod, v. 517 (1836), COMPOSITAE, Benth. \& Hook, f. ii. 350.

incisa, Torr. \& Gray, F1. N. Am. ii. $282=1$ yrata.

longifolia, Nutt. in Trans. Am. Phil. Soc, Ser. II. vii. (1841) $342=$ texana.

lyrata, Benth. Pl. Hartw. 18.-Am. bor. occ

pumila, Nutt. in Trans. Am. Phil. Soc. Ser. II. vii, (1841) $842=$ tomentosa.

subacaułe, Nutt. $t$. c. 343 - Florida.

texana, DC. in Deless. Ic. Sel. iv. t. 26.-Am. bor.

tomentosa, Nutt, in Trans. Am. Phil. Soc. Ser. II. vii. (1841) 343.-Am. bor

BERLIERA, Buch.-Ham, ex Wall. Cat, sub n. 6225 (1832 ?)= Myrioneuron, R. Br. (Rubiac.)。

nutans, Buch.-Ham, l. $c_{2}=$ M. nutans.

BERLINIA Soland, ex Hook, f. \& Benth in Hook, Nirer F1. $326(1849)$, LEGUMINOSAE, Benth. \& Hook. f. i. 579

acuminata, Soland. ex Hook。 f. \& Benth. l. c.Afr. trop.

angolensis, Welw. ex Benth. in Trans. Linn. Suc, xxy. (1866) 310. - Afr. trop.

auriculata, Benth. l. c. 309.-Afr. trop.

\section{BERLINIA :-}

bracteosa, Benth. in Trans. Linn. Soc. xxv. (1866) 309.-Afr. trop.

Heudelotiana, Baill. Adansonia, vi. (1865) 185.-Afr trop.

paniculata, Benth. in Trans. Linn. Soc. xxv. (1866) 311.-Afr. trop.

stipulacea, Benth. l. c. 310.-Afr. trop.

BERMUDIANA, ['Toum.] Linn. Syst. ed. I (1735)= Sisyrinchium, Linn. (Irid.)

graminea, Gaertn. Fruct. i. $32=$ S. Bermudiana.

graminifolia, Medic. Maly, $77=\mathrm{S}$, anceps

guttata, Stokes, Bot. Mat. Med. i. $109=$ Moraea chi nensis.

iridifolia, Medic. Malv. $77=$ S. Bermudiana

striata, Moench, Meth. Suppl. $113=\mathrm{S}$. striatum.

BERNARDIA, Endl. Gen. 459, in syn. $(1838)=\mathbf{B e}$ rardia, Vill. (Compos.).

BERNARDIA, Houst. ex P. Br. Nat. Hist. Jamaic 361 (1756). EUPHORBIACEAE, Benth. \& Hook. f. iii. 308 .

Alevra, Baill. Etud. Gén. Euph. 508 (1858)

Bivonia, Spreng. Neve Entdeck. ii. 116 (1821)

Passaea, Baill. Etud. Gén. Euph. 507. t. 18 (1858).

Phaedra, Klotzsch, in Endl. Gen. Suppl. iv. III. 88 (1847).

Polybaea, Klotzsch, 1. c. (1847)

Traganthus, Klotzsch, in Wiegm. Archiv, vii. (1841) 188, t. 9

TYRIA, Klotzsch, in Endl. Gen. Suppl. iv, 11.88 (1847).

axillaris, Muell. Arg. in Linnaea, xxxiv. (1865-66) 174. -Bras.

brevipes, Muell. Arg. l. c, 176.-Bras.

caperoniaefolia, Muell. Arg. in DC. Prod.xv. II. 920 -Reg. Argent.

capitellata, Muell. Arg. in Linnaea, xxxiv. (1865-66) $176=$ celastrinea.

carpinifolia, Griseb. Fl. Brit. W. Ind. 45.-Ind. occ.

celastrinea, Muell. Arg. in DC. Prod. xv. II. 921.Bras.

confertifolia, Muell. Arg. in Linnaea, xxxiv. (1865-66 $175 .-$ Bras.

corensis, Muell. Arg. l. c. 173.-Ind. occ.

crassifolia, Muell. Arg. in Mart. Fl. Bras. xi. II. 394 -Bras.

dichotoma, Muell. Arg. in Linnaea, xxxiv. (1865-66) 172. - Ind. occ.

fasciculata, S. Wats. in Proc. Am. Acad. xviii. (1882-83) 153.-Am, bor. occ.

gambosa, Muell. Arg. in Mart. Fl. Bras. xi. II. 391.Bras.

Gardneri, Muell. Arg. l. c. 394.-Bras.

grandifolia, Muell. Arg. in Linnaea, xxxiv. (1865-66) 173.-Guiana

hirsutissima, Muell. Arg. in DC. Prod. xv. I1. 922.Bras.

intermedia, Griseb. in Mem. Am. Acad. N. S. viii. (1861) $160=$ mexicana.

interrupta, Muell. Arg. in Linnaea, xxxiv. (1865-66) 171.-Mexic.

Jacquiniana, Muell. Arg. l. c. 173.-Venezuela.

leprosa, Muell. Arg. l. c. 172.-Ins. S. Doming.

Lorentzii, Muell. Arg. in fourn. Bot. xii. (1874) 229 -Reg. Argent.

megalophylla, Muell. Arg. in Linnaea, xxxiv. (1865-66)

$173=$ Adenophaedra megalophylla.

mexicana, Muell. Arg. l. c. 172.-Mexic

microphylla, Muell. Arg. l. c.-Cuba

multicaulis, Muell. Arg. l. c. 177.-Bras.

myricaefolia, Benth. Es Hook. f. Gen. iii. 308-Am. bor ligandra, Muell. Arg in Linnaea, xxiy, (1865-66)

$173=$ tamanduana

peduncularis, Muell. Arg. l. c. 176.-Bras.

pulchella, Muell. Arg. in Mart. Fl. Bras. xi. 11. 392.Bras,

scabra, Muell. Arg, l. c. 396.-Bras.

Sellowii, Muell. Arg. in Linnata, xxxiv. (1865-66) 177.-13ras.

sidoides, Muell. Arg. l. c.-Guiana.

spartioides, Muell. Arg. L. c.-Bras.

tamanduana, Muell. Arg. in DC. Prod. xv. 11. 920.Bras.

venosa, Griseb. in Mem. Am. Acad. N. S. viil. 1861 159. - Ind. occ.
BERNARDINIA, Planch, in Linnaea, xxiii. (1850)

412. CONNARACEAE, Benth, \&. Hook, f. i. 431.

fluminensis, Planch. l. C.-Bras.

BERNEUXIA, Decne. in Bull. Soc. Bot. Fro $x x$ (1873) 159. DIAPENSIACEAE, Benth. \& Hook. f. ii. 621 .

thibetica, Decne. l. c.-Tibet.

BERNIERA, DC. Prod. vii. $18(1838)=$ Gerbera Gronov. (Compos.)

nepalensis, DC. 1. C. = G. macrophylla

BERNIERIA, Baill. in Bull. Soc, Linn. Par. i. (1884 434. LAURINEAE.

madagascariensis, Baill. l. c.-Madag.

BERNOULLIA, Oliver, in Hook. Ic. Pl. t. 116 ' (1873). STERCULIACEAE

flammea, Oliver, l. c. t. 1169-70.-Guatemala.

BERREBERA, Hochst. in Flora, xxvii. (1844) 100 ; xxix. (1846) $597=$ Millettia, W ight \& Am. (Legrm.) caffra, Hochst. 11. cc, 100 et $598=$ M. caffra

ferruginea, Hochst. 11. cc. 100 et $597=$ M. ferruginea

BERRIA, Roxb. Hort. Beng. 42 (1814); Pl. Corom. iii. $60 . \mathrm{t} .264$ (1819), TILIACEAE, Benth. \& Hook f. i. 232 .

Espera, Willd. in Ges. Naturf. Fr. Ijerl. Neue Schr. iii. (1801) 449, nomen prius,

Hexagunófheca, Turcz in Bull. Soc. Nat Mosc. (1846) II. 505 .

Ammonilla, Roxb. Hort. Beng. 42 ; Fl. Ind. ii. 639.Zeylan.; Ind. or.

mollis, Wall. Cat. n. $1186=$ B. Ammonilla.

Vescoana, Baill. Adansonia, x. (1872) 240.-Ins. Tahiti.

BERRYA, DC. Prod. i. 517 (1824)=praec.

BERRYA, Klein, ex Willd. Sp. Pl. ii. 840, in syn. (1800 = Litsea, Lam. (Laurin.

chinensis, Klein, ex Willd. 1. c $=$ L. sebifera.

BERSAMA, Fresen. in Mus. Senckenb. ii. (1837) 280. 17. SAPINDACEAE, Benth, \& Hook, f, i. 412

Natalia, Hochst. in Flora, xxiv. (18\$1) 663.

Rhaganus, E. Mey. Zwei Pfl. Docum. 216 (1843).

abyssinica, Fresen. $l$. c. 281.-Abyss.

integrifolia, A. Rich. Tent. Fl. Abyss. i. 107.-Abyss.

maxima, Baker, in Oliver, Fl. Trop. Afr. 1. 434.-Afr. trop.

paullinioides, Baker, l. c. 435.-Afr. trop

serrata, A. Rich. Tent. Fl. Abyss, i. 107.-Abyss.

BERTERA, Steud. Nom. ed. II. i. $199(1840)=$ Gla diolus, Tourn. (Irid.)

BERTEROA, DC. in Mém. Mus. Par. vii. (1821) 232 et Syst. ii. $290(1821)=$ Alyssum, Toum. (Crucif.) escendens, Koch, in Linnaea, xv。 (1841) $257=\mathrm{A}$. mutabile.

graeca, Boiss. \& Heldr. Diagn. Ser. II. i. $35=$ A. mutabile

incana, DC. Syst. ii. $291=$ A. incanum.

mutabilis, DC. 1. c. $292=$ A. mutabile

obliqua, DC. 1. c. = A. mutabile.

orbiculata, DC 1. c. $293=$ A orbiculatum

peruviana, DC. 1. c.-Peruv.

Potanini, Maxim. in Bull. Acad. Pétersb. xxvi. (ISSu 432.-Mongolia.

procumbens, Portenschl. Enum. Pl. Dalm. $15=\mathrm{A}$ mutabile.

spathulata, C. A. Mey. in Ledeb. Fl. Alt. iii. $46=\mathrm{A}$. spathulatum.

stricta, Boiss. Diagn. Ser. II. i. $35=$ A. orbiculatum. thessala, Heldr. ex $\mathrm{Nym}$. Consp. $51=\mathrm{A}$. orbiculatum. viridis, Tausch, in syll. Ratisb. ii. $(1: 25) 245=A$ incruam.

BERTHELOTIA, DC. Prod, * $\$ 75\left(1530^{\circ}\right)=$ Pluchen, Cass. (Compos.)

lanccolato, DC. I. c $376^{\circ}=$ P. Ianceolata.

BERTHIERA, Vent. Tabl, ii. $5 \% 2(1 ; 0 !)$ - Bortiera. Aubl. (Kubiac).

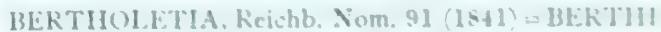
LUTIA, DC. = Pluchoa, Cass, Cormpos. 
BERTHOLETIA, Brongn Fnum Gen $123(1843)=$ Bertholletia, Humb. \& Bonpl. (Myrtac.).

BERTHOLLETIA, Humb. \& Bonpl. Pl. Aequin. i. 122. t. 36 (1808). MYRTACEAE, Benth. \& Hook. fo i. 723 .

ToNCA, Rich. Anal. Fruit. 84 (1811)

excelsa, Berg, in Mart. Fl. Bras. xiv. I. 478. t. $60,61=$ nobilis.

excelsa, Humb. \& Bonpl. Pl. Aequin. i. 122. t. 36.Bras.

nobilis, Miers, in Trans. Linn. Soc. xxx. (1874) 197.Guiana.

BERTIERA, Aubl. Pl. Gui. i. 180, t. 69 (1775). RUBIACEAE, Benth. \& Hook. fo ii. 77 .

Pomatium, Gaertn. f. Fruct. iii. 252. t. 225 (1805).

Zaluzania, Comm. ex Gaertn. fo Fruct, iii. 74. t. $192(1805)$.

aethiopica, Hiern, in Oliver, Fl. Trop. Afr. iii. 83.Afr. trop.

africana, Rich. in Mím. Soc. Hist. Nat. Par. v. (1830) 255.-Afr. trop.

angustifolia, Benth. Bot. Voy. Sulph. 103.-Ins. Cocos.

bistipulata, Boj. Hort. Maurit. $166=$ B. Zaluzania

borbonica, Rich. in Mém. Soc. Hist. Nat. Par. v. (1830)

$254=$ B. Zaluzania

bracteolata, Hiern, in Oliver, Fl. Trop. Afr. iii. 84.Afr. trop.

breviflora, Hiern, l. c. 85. -Afr. trop.

chrysantha, Hassk. Retzia, i. 30.-Java.

coccinea, G. Don, Gen. Syst. iii. $506=$ Mussaenda elegans.

ferruginea, Willd. ex Roem. \& Schult. Syst. v. $227=$ Psychotria rufescens.

gonzaleoides, Griseb. Cat. Pl. Cub. 124.-Cuba.

guianensis, Aubl. Pl. Gui. i. 180, t. 69.-Guiana.

lateriflora, Blume, Bijdr.987.-Java.

laxa, Benth, in Hook. Niger Fl. 394.-Afr. trop. macrocalyx, Hassk. in Nederl. Kruidk. Arch. iv. (1859) 7.-Malaya.

macrocarpa, Benth. in Hook. Niger Fl. 394.-Afr. trop.

montana, Hiern, in Oliver, Fl. Trop. Afr. iii. 83.Afr, trop.

mucronata, Comm. ex Gaertn. f. Fruct. iii. 74. t. 192 -Hab. ?

palustris, Rich. in Mém. Soc. Hist. Nat. Par.v. (1830) 254.-Guiana.

Pomatium, Benth. in Hook. Niger Fl, 394.-Afr trop.

rufa, Rich. in Mém. Soc. Hist. Nat. Par. v. (1830) $254=$ B. Zaluzania

subsessilis, Hiern, in Oliver, Fl. Trop. Afr. iii. 83.Afr. trop.

Zaluzania, Comm.ex Gaertn. f. Fruct. iii. 74. t. 192.Ins. Mascar.

BERTIERA, Blume, Bijdr. 987 (1826)= Adenosacme, Wall. (Rubiac.).

fasciculata, Blume, 1. $\mathrm{c}_{\mathrm{r}}=\mathrm{A}$. longifolia.

javanica, Blume, 1 . $\mathrm{c}_{\mathrm{s}}=\mathrm{A}$. longifolia.

lateriflora, Blume, 1. c.-Java.

BERTOLONIA, DC. in Ann. Mus. Par. xix. (1812) t. 5 (14) = Leuchéria, Lag. (Compos.).

purpurea, DC. 1. c. $=$ L. purpurea.

BERTOLONIA, Raddi, in Mem. Mod. xviii. Fis. 384 (1820). MELASTOMACEAE, Benth. \& Hook. f. i. 755.

Tribleman, R. Br. ex DC. Prod. iii. 113 (1828).

acaulis, Cham. in Linnaea, ix. (1834) $383=$ Eriocnema Hilariana.

acuminata, Gardn. in Hook. Lond. Fourn. Bot. ii (1843) 344.-Bras.

aenea, Naud, in Ann. Sc. Nat. Sér. III. xv. (1851) 318 $=$ marmorata.

guttata, Hook. f. Bot. Mag. t. $5524=$ Gravesia guttata

hirsuta, Benth. Bot. Voy. Sulph. $94=$ Triolaen hirsuta.

Houtteana, Van Houtte, in Fl. des Serres, Sér. II. x. (1874) 109-- Hab

leuzeana, DC. Prod. iii. 113.-Bras.

longifolia, Cham. in Linnaea, ix. (1834) $384=$ Salpinga longifolia.

\section{BERTOLONIA :-}

maculata, $D C$. Prod iii, 114-Bras.

margaritacea, Hort. Bull. ex Naud. in Fl. des Serres, xvi. (1865-67) $165=$ Salpinga margaritacea.

marmorata, Naud. in Ann. Sc. Nat. Sér. III. xv. (1851)

318.-Bras.

Mirandaei x, Van Houtte, in Fl. des Serres, xxi. (1875) 135.

nymphaeaefolia, Raddi, in Mem. Mod. xviii. Fis. (1820) 384. - Bras.

ovata, DC. Prod. iii. 113.-Bras.

primulaeflora, Hort. ex Triana, in Trans. Linn. Soc xxviii. (1871) $80=$ Monolena primulaeflora

cabra, Rafin. ex J. C. Schau. in DC. Prod, xi. $584=$ Lippia lanceolata.

scorpioides, Baill. Hist. Pl. vii. $11=$ Triolena scor pioides.

superbissima, Hort.-Cf. Gard. Chron. (1873) 5.Hab. ?

BERTOLONIA, Rafin. in Am. Monthly Mag. (1818) $267=$ Lippia, Linn. (Verben.)

BERTOLONIA, Moç. \& Sessé, ex DC. Prod. ii. 589 $(1825)=$ Cercocarpus, H. B. \& K. (Rosac.). guieroides, Moç. \& Sessé, l. c. =C. fothergilloides.

BERTOLONIA, Spinola, Cat. Jard. St. Sebast. (1809) 24 = Myoporum, Banks.

glandulosa, Spinola, 1. c. = M. viscosum.

BERTOLONIA, Spreng. Neue Entdeck. ii. 110. t. 1. f. 1 $(1821)=$ Chrysochlamys, Poepp. (Guttif.). paniculata, Spreng. 1. c.-Bras.

BERTUCHIA, Dennst. Schluess. Hort. Malab. 30 (1818) $=$ Gardenia, Ellis (Rubiac.).

speciosa, Denust. 1. c. - Ind. or.

BERTY A, Planch. in Hook. Lond. Journ, iv. (1845) 472. t. 16. EUPHORBIACEAE, Benth. \& Hook. f iii. 264

Cunninghamii, Planch. l. c. 473.-Austral.

dimerostigma, F. Muell. in Wing, South Sc. Record, ii. (1882) 98.-Austral.

Findlayi, F. Muell. Fragm. viii. 141.-Austral.

gummifera, Planch. in Hook. Lond. Fourn. Bot. iv. (1845) 473. t. 16.-Austral.

Mitchellii, Muell. Arg. in Linnaea, xxxiv. (1865-66) 63.-Austral.

oblongifolia, Muell. Arg. in Flora, xlvii. (1864) 471= pomaderrioides.

oleaefolia, Planch. in Hook. Lond. Fourn. Bot. iv, (1845) 473.-Austral.

oppositifolia, F. Muell. E O'Shanesy, in Wing, South Sc. Record, ii. (1882) 98.-Austral.

pedicellata, F. Muell. Fragm. iv. 143.-Austral. pinifolia, Planch. in Hook. Lond. Fourn. Bot. iv. (1845) 473.-Austral.

polymorpha, Baill. Adansonia, vi. (1865-66) 298.N. Zel.

pomaderrioides, F. Muell. Fragm. iv. 34.-Austral.

psiloclada, Muell. Arg. in Flora, xlvii. (1864) $471=$ Ricinocarpus psilocladus,

quadrisepala, F. Muell. Fragm. x. 52.-Austral. rosmarinifolia, Planch, in Hook. Lond. Fourn. Bot. iv. (1845) 473.-Austral.

rotundifolia, F. Muell. Fragm. iv. 34.-Austral. tasmanica, Muell. Arg. in Linnaea, xxxiv. (1865-66) $63=$ rosmarinifolia

BERULA, Hoffm. ex Bess. Enum. Pl. Volh. 44 (1822)= Sium, Tourn. (Umbellif.).

angustifolia, Mert. \& Koch, i Roehl. Deutschl. Fl. ii. $433=\mathrm{S}$, erectum.

lancifolia, Bess. Enum. Pl. Volh. $44=$ S. lancifolium,

BERYLLIS, Salisb. Gen. Pl. Fragm. $33(1866)=$ Ornithogalum, Tourn. (Liliac.).

pyrenaica, Salisb. 1. c. $=0$. pyrenaicum.

stachyoides, Salisb. 1. c. $=$ O. narbonense

BERZELIA, Brongn, in Ann. Sc. Nat. Sér. I vii (1826) 370. t. 35. BRUNIACEAE, Benth. \& Hook. f. i. 671 .

Heterodon, Meissn. Gen. 72 (1837).

RABENHORSTIA, Reichb. Nom. 159 (1841)

abrotanoides, Brongn. l. c. 371-Afr, austr.

\section{BERZELIA :-}

lopecurioides, Sond. in Harv. E Sond. Fl. Cap. ii 310.-Afr. austr.

arachnoidea, Eckl. E Zeyh. Enum. 138.-Afr. austr. brevifolia, Eckl. \& Zeyh. 1. c. =abrotanoides.

callunoides, Oliver, in Fourn. Linn. Soc. ix. (1867) 333.-Afr. austr.

commutata, Sond. in Harv. E Sond. Fl. Cap. ii. 310 -Afr. austr.

comosa, Eckl. \& Zeyh. Enum. $137=$ commutata.

cordifolia, Schlecht. in Linnaea, vi. (1831) 189.-Afr. austr.

ericoides, Eckl. \& Zeyh. Enum. $137=$ intermedia.

formosa, Eckl. \& Zeyh. 1. c. $138=$ abrotanoides.

globosa, G. Don, Gen. Syst. ii. 46 (=Berardia globosa Sond.).-Afr. austr.

intermedia, Schlecht. in Linnaea, vi. (1831) 188.Afr. austr.

lanuginosa, Brongn. in Ann. Sc. Nat. Sér. I. viii. (1826) 372. t. 35.-Afr. austr.

rubra, Schlecht. in Linnaea, vi. (1831) $189=$ squarrosa squarrosa, Sond. in Harv. E Sond. Fl. Cap. ii. 312.Afr. austr.

superba, Eckl. E Zeyh. Enum. 138.-Afr. austr.

Wendlandiana, Eckl, \& Zeyh. 1. c. $137=$ intermedia.

BERZELIA, Mart. in Nov. Act. Nat. Cur. xiii. (1826) $292=$ Hermbstaedtia, Reichb. (Amarant.).

glauca, Mart. 1. $\mathrm{c}_{\mathrm{.}}=\mathrm{H}$. glauca.

BESCHORNERIA, Kunth, Enum. Pl. v. $844(1850)$ AMARYLLIDEAE, Benth. \& Hook. f. iii. 738.

bracteata, Facobi, Index, 12 ; Baker, in Bot. Mag. t. 6641 - Mexic.

Decosteriana, Baker, in Bot. Mag. t. $6768=\mathrm{seq}$

Dekosteriana, C. Koch, Wochenschr. vii. (1864) 187. -Mexic.

dubia, Carr. in Rev. Hortic. (1877) 155.-Texas.

floribunda, Hort. ex C. Koch, Wochenschr. v. (1862) 199.-Hab. ?

Galleottii, Facobi, Index, 12, nomen.-Mexic.?

multiflora, Hort. ex C. Koch, Wochenschr. iii. (1860) 63.-Hab.?

Parmentieri, Facobi, in Hamb. Gartenz. xx. (1864) 503.-Hab.?

pumila, Facobi, Index, 12, nomen.-Hab.?

Toneliana, Jacobi, l. c. = seq.

Tonelii, Facobi, in Hamb. Gartenz. xx. (1864) 503 , nomen.-Mexic.

Schlechtendalii, Facobi, Index, 12, nomen.-Hab. ? tubiflora, Kunth, Enum. Pl. v, 844.-Mexic.

Verlindeniana, facobi, Index, 12, nomen.-Hab.? yuccoides, Hort. ex Hook. Bot. Mag. t. $5203=$ seq. yuccoides, C. Koch, Wochenschr. ii. (1859) 337; iii. (186 ) 63; vî. (1864) 186.-Mexic.

BESENNA, A. Rich. Tent. F1. Abyss. i. 253 (1847)= Albizzia, Durr. (Legumin.).

anthelmintica, A. Rich. 1. c. =A. anthelmintica.

BESHA, D. Dietr. Syn. i. $139(1839)=$ Ochlandra Thw. (Gramin.).

BESLERIA, Plum. ex Linn. Gen. ed. I. 181 (1737) GESNERACEAE, Benth \& Hook. f. ii. 1015

Crantzia, Neck. Elem. i. 366 (1790)

Cremosperma, Benth. Pl. Hartw. 234 (1846)

CyRTANThemum, Oerst. in Vidensk. Selsk. Skr. V v. (1861) 130

DruPina, Linn. Pl. Surin. 11 (1775) ; Amoen. Acad. viii. $259(1785)$

ERIPHIA, P. Br. Hist. Jamaic. 270 (1756)

Frimbrolina, Rafin. Sylva Tellur. 71 (1838)

Gasteranthopsis, Oerst. in Vidensk. Selsk. Skr. V v. (1861) 129 .

Gasteranthus, Benth. Pl. Hartw. 233 (1846).

Hematophyla, Rafin. Sylva Tellur. 71 (1838).

Parabesleria, Oerst. in Vidensk. Selsk. Skr. V v. (1861) 126

Pseudobesleria, Oerst. 1. c. 128 (1861).

acutifolia, Benth. Pl. Hartw. 237.-N. Granat

aggregata, Hanst. in Mart. Fl. Bras. viii. 400.Bras.

ampla, Vell. Fl. Flum. 262 ; vi. t. 84.-Bras.

arborea, Vell. $l i . c c .261$; vi. t. $82 .-$ Bras.

ardens, Decne. ex Linden, Cat. n. 5 (1850) 1.Venezuela. 


\section{BESIERIA :-}

barbata, Hanst. in Linnaea, xxxiv. (1865-66) 327.Peruv.

barbensis, Hanst. l. c. 319.-Costa Rica.

Berteriana, DC. Prod. vii. 538.- - Jamaica.

bicolor, H. B. E K. Nov. Gen. et Sp. ii. 398.-N.

Granat.

bicolor, Schott, in Oestr. Med. Jahrb. vi. II. $65=$

Alloplectus bicolor.

biflora, Forst. f. Fl. Ins. Austr. 43. n. $236=$ Cyrtandra biflora.

bivalvis, Linn. f. Suppl. 280 (=Picria surinamensis) -Guiana.

bonodora, Vell. Fl. Flum. 261 ; vi. t. $80=$ Brunfelsia latifolia.

caerulea, Aubl. Pl. Gni. ii. $631=$ violacea.

calcarata, H. B. E K. Nov. Gen. et Sp. ii. 399.-N Granat.

campanulata, Linden, Cat. n. 5. (1850) 2.-Venezuela. capitata, Poepp. E Endl. Nov. Gen. et Sp. iii. 2.Perny

coccinea, Aubl. P1. Gui. ii. $632=$ Alloplectus coccineus columneoides, Hanst. in Linnaea, xxxiv. (1865-66) 322.-Costa Rica.

costaricensis, Hanst. l. c. 330.-Costa Rica.

crassifolia, Schott, Neu. Bras. Pf. i. 7.-Bras.

cristata, Linn. Sp. Pl. $619=$ Alloplectus cristatus.

cristata, Moç. \& Sesse, ex DC. Prod. vii. $546,540=$ Alloplectus glaber.

cuneata, Gardn. in Hook. Lond. Fourn. Bot. i. (1842) 548.-Bras.

cymosa, Forst. f. Fl. Ins. Austr. 44. n. $237=$ Cyrtandra cymosa.

Cyrtanthemum, Hanst. in Linnaea, xxxiv. (1865-66) 321.-Mexic.

deflexa, Hanst. l. c.-Mexic

dichrus, Spreng. Syst. ii. $840=$ Alloplectus dichrous.

divaricata, Poepp. Ev Endl. Nov. Gen. et Sp. iii. 2.-

Peruv.

Drymonia, Stend. Nom. ed. II. i, $200=$ Drymonia calcarata.

elegans, H. B. E K. Nov. Gen. et Sp. ii. 397.-N. Granat. fasciculata, Wawra, in Oestr. Bot. Zeitschr. xiii (1863) 142.-Bras.

flavovirens, Mart. in Nov. Act. Nat. Cur. xi. (1823) 49.-Bras.

geminiflora, Gardn. in Hook. Lond. Fourn. Bot. i. (1842) 543.-Bras.

gibbosa, Hanst. in Mart. Fl. Bras, viii. 421.-Bras.

glabra, Hanst. in Linnaea, xxxiv. (1865-66) 325.Mexic.

grandiflora, H. B. E K. Nov. Gen. et Sp. ii. 401.-N.

Granat.

grandifolia, Schott, Neu. Bras. Pft. i. 5. n. 5.-Bras.

guadalupensis, DC. Prod. vii. 538.-Guadalup.

hirsuta, Hanst. in Linnaea, xxxiv. (1865-66) 326.Mexic.

hirtella, Schott, in Oestr. Med. Jahrb. vi. II. $66=$ Alloplectus sparsiflorus.

hispida, H. B. \& K. Nov. Gen, et Sp. ii. $39=$ Alloplectus hispidus.

Imray, Hook. Bot. Mag. t. 6341.-Ind, occ.

incarata Aubl. Pl. Gui ii 685-Guina.

inodora, Vell. Fl. Flum. 261 ; vi. t. $81=$ Brunfelsia pauciflora.

insignis, Mart. \& Gal. in Bull. Acad. Brux. ix. (1842) II. 37 = Solenophora insignis.

labiosa, Hanst. in Linnaea, xxxiv. (1865-66) $324 .-\mathrm{N}$. Granat.

laxiflora, Benth. in Hook. Lond. Fourn. Bot. v. (1846) 861.-Guiana.

leucostoma, Hanst. in Linnaea, xxxiv. (1865-66) 326. -N. Granat.

lucida, Poepp. \& Endl. Nov. Gen. et Sp. iii. 2.-Peruv. lutea, Linn. Sp. Pl. 619.-Ind, occ.

lutea, Spreng, Syst. ii. $841=$ Berteriana

luteo-virens, Mart. Nov, Gen. iii. $45=$ flavorirens.

melittifolia, Linn. Sp. Pl. $619=$ Episcia melittifolia.

mollis, Hook. ex Steud. Nom. ed. II. i. 200.-Am austr.

mollissima, Spreng. ex Steud. Nom. ed. I, $107=$ praec. ?

mucronata, Hanst. in Linnaca, xxxiv. (1865-66) 331 -N. Granat.

oncogastra, Hanst. l. c. 335.-Ecuador.

Patrisii, DC. Prod. vii. 598.-Guiana.

pendula, Hanst. in Linnaea, xxxiv. (1865-66) 399.-

N. Granat.

\section{BESLERIA :-}

pentaphylla, Vell. Fl. Flum. 262 ; vi. t. 83,--Bras.

Princeps, Hanst. in Linnaea, xxxiv. (1865-66) 317. Costa Rica.

pulchella, Donn, Hort. Cantab. 140, ex Sims, Bot. Mag. t. $1146=$ Tussacia pulchella.

quitensis, Hanst. in Linnaea, xxxiv. (1865-66) 334.Ecuador.

Rhytidophyllum, Hanst. l. c. 334.-N. Granat.

Riedeliana, Hanst. in Mart. Fl. Bras. viii. 399.Bras.

sanguinea, Pers. Syn, ii. 165=Alloplectus sanguineus. scandens, Moç. \& Sesse, ex D. Don, in Trans. Linn. Soc, xv, (1827) $349=$ Maurandia erubescens?

Selloana, Klotzsch \& Hanst. in Mart. Fl. Bras, viii. 398 - Bras.

serrilata, Facq. Hort. Schoenb. iii. 21. -Ind, occ.

solanoides, H. B. E K. Nov. Gen. et Sp. ii. 398.-Am. austr.

spectabilis, H. B. \& K. 1. c. $400=$ Drymonia spectabilis.

splendens, Hort. ex Steud. Nom, ed. II. 1. $200=$ Drymonia spectabilis.

surinamensis, Miq. in Linnaea, xxii. (1849) 471. Guiana.

Symphytum, Klotzsch Eั Hanst. ex Hanst. in Mart. Fl. Bras. viii. 399.-Bras.

tetrangularis, Ruiz, ex Hanst, in Linnaea, xxxiv. (1865-66) 331.-Peruv.

triflora, Hanst. l. c. 329.-Costa Rica.

umbellata, Herb. Banks, ex Sims, Bot. Mag. t. $1146=$ Episcia pulchella.

umbrosa, Mart. Nov. Gen. iii. 44. t. 218.-Bras.

violacea, $A u b l$. Pl. Gui. ii. 630 t 254-Griana

Wendlandiana, Hanst. in Linnaea, xxxiv. (1865-66) 318.-Costa Rica.

BESSER A, Schult. f. in Linnaea, iv. (1829) 121. LILIACEAE, Benth. \& Hook. f. iii. 801.

Pharium, Herb. in Bot. Reg. t. 1546 (1832).

elegans, Schult. f. l. c.-Mexic.

fistulosa, Pritz. Ic. Ind. $147=$ elegans.

Herberti, G. Don, in Sweet, Hort. Brit. ed. III. $694=$ elegans.

miniata, Lem. in Fl. des Serres, Sér. I. iv. (1848) t. $424=$ elegans.

multiflora, Mart. \& Gal. in Bull. Acad. Bras. ix. (1842) $($ reimpr. 14) $=$ elegans.

BESSERA, Schult. Obs. Bot. $27(1809)=$ Pulmonaria, Tourn. (Borag.)

azurea, Schult. 1. c. =P. azurea

BESSERA, Spreng. Pugill. ii. 90 (1815)=Xylosma, Forst. (Bixin.)

inermis, Spreng. 1. c.=Flueggia microcarpa. spinosa, Spreng. 1. c. $91=\mathrm{X}$. nitidum.

BESSERA, Vell. Fl. Flum. 147 (1825); iv.t. 2=Pisonia, Linn. (Nyctagin.).

calycantha, Vell. Il. cc. = P. Olfersiana

BESSIA, Rafin. Sylva Tellur, $13(1838)=$ Corypha Linn. (Palm.).

sanguinolenta, Rafin. 1. c. = C. umbraculifera.

BESTRAM, Adans. Fam. ii. 354 (1763)=Antidesma, Linn. (Euphorb.).

BETA, [Tourn.] Linn. Syst. ed. I (1735), CHENO. PODIACEAE, Benth. \& Hook, f, i, 52. alba, DC. F1. Fr. iii. $383=$ vulgaris. altissima, Hort. ex Steud. Nom. ed. II. i. $200=$ vulgaris.

bengalensis, Roxb. Hort. Beng. 21; F1. Ind. ii. $59=$ vulgaris.

Bourgaei, Coss. Notes Crit. 44.--Hispan.

campanulata, Coss. in Bull. Soc. Bot. Fr. xxii. (1875) 66.- Marocco.

carnulosa. Gren. in Gren. E Godr. Fl. Fr. iii. 16.Gallia.

chilensis, Hort.-Cf. Gard. Chron. (1870) 1. 449.Chili.

Cicla, Georgi, Beschr. Russ. Reich. iii. Iv. $8 \pm 8=$ trigyna.

Cicla, Linn. Syst. ed. XII. $195=$ vulgaris.

crispa, Tratt. Arch, vii. $117=$ vulgaris.

Cycla, Pall. Tabl. Taur. $48=$ trigyna.

decumbens, Mvelch, Meth. $392=$ vulgaris,

\section{BETA}

diffusa, Coss. Notes Crit. 178.-Hispan.

esculenta, Salisb. Prod. $152=$ vulgaris

foliosa, Ehrenb. ex Steud. Nom. ed. II. i. $200=$ valgaris.

hastata, Desf. Cat. Hort. Par. ed. III. (1829) $389=$ procumbens.

hortensis, Mill. Gard. Dict. ed. VIII. n. 2 =vulgaris.

hybrida, Andra. ex Trautv. in Act. Hort. Petrop. ix (1884) 124, nomen.- - Rossia

incarnata, Hort. ex Steud. Nom. ed. II. i. $200=$ vulgaris.

intermedia, Bunge, ex Boiss. Fl. Orient. iv. 900.Anatolia.

lomalogona, Fisch. E Mey. in Bull. Soc. Nat. Mosc. (1838) 360.-As. Min. ; Syria

longespicata, Moq. Chenop. Enum. 13 = lomatogona lutea, Hort. ex Steud. Nom. ed. II. i. $200=$ vulgaris, macrocarpa, Guss. Fl. Sicul. Prod. 1. $302=$ vulgaris. macrorhiza, Stev, in Mém. Soc. Nat. Mosc vii (1812) 257.-Reg. Caucas. ; Persia.

marina, Crantz, Inst. i. $120=$ valgaris.

maritima, Linn. Sp. P1. ed. II. $322=$ vulgaris

nana, Boiss. of Heldr. Diagn. Ser. I. vii. 82.Graecia.

Noèana, Bunge, ex Boiss. Fl. Orient. iv. $899=$ vulgaris prientalis, Roth, Nov. Pl. Sp. $181=$ valgaris

patellaris, Moq. in DC. Prod. iii. II. 57.-Ins. Tenerif.

patula, [Soland.in] Ait. Hort. Kew. ed. I. i. 315.-Ins Madera.

procumbens, Lange, in Willk. \&c Lange, Prod. Fl. Hiș i. $274=$ diffusa.

procumbens, Chr. Sm. in Hornem. Hort. Hafn. Suppl. 31.-Ins. Canar

pumila, Link, in Buch, Beschr. Canar. Ins. 141 Webbiana.

purpurea, Hort. ex Steud. Nom. ed. II. i. 200 vulgaris

Rapa, Dum. Fl. Belg. $21=$ vulgaris.

rapacea, Hegetschw. Fl. Schw. $256=$ vulgaris.

rosea, Hort. ex Steud. Nom. ed. II. i. $200=$ vulgaris.

rubra, Delile, Fl. Aeg. Illustr. 57.-Aegypt.

rubra, Noronha, in Verh. Batav. Gen. v. $(1790)$ ed. I.

Art, IV. 8.- Malaya.

sativa, Bernh. Syst. Verz. Erf. $162=$ vulgaris

stricta, C. Koch, in Linnaea, xxii. (1849) 180 vulgaris.

sulcata, Gasp. in Guss. F1. Sicul. Syn. ii. $800=$ vulgaris.

sylvestris, Hort. Panorm. ex Webb \& Berth. Phyt. Canar. iii. 197 = procumbens,

triflora, Salisb. Prod. $152=$ vulgaris.

trigyna, Waldst. \& Kit. Pl. Rar. Hung. 34. t. 35.Hungar.; As. Min.

vulgaris, Linn. Sp. Pl. 222.-Europ.; Afr. bor.; Oriens.

Webbiana, Moq. Chenop. Enum. 16.-lns. Canar.

BETCKEA, DC. Mém.Valer, 18; et Prod, iv. 64.2 (1829)= Plectritis, DC. (Rubiac)

cancasica, Boiss. Fl. Orient. iii. 94.-Reg. Cancas.

Gilliesii, Hook. \& Arn. in Hook. Bot. Misc. iii. (1533 366.-Reg. Argent.

heterophylla, Phil. in Linnaea, xxviii. (1856) 70tChili.

major, Fisch. \& Mey. Ind. Sem. Hort. Petrop. ii. $\$ 0=$ P. samolifolia.

samolifolia, DC. Prod. iv. $642=$ P. samolifolia.

samolifolia, Gill. ex Hook. \& Arn. in Hook. Bot. Misc. iii. (1833) $366=$ Gilliesii.

BETELA, Rafin. Sylva Tellur。 85 (1538) = Piper Linn. mastica, Rafin. 1. $c=$ P. Betle.

BETENCOURTIA, St, Hil. Voy. i. 376 (1s 39

Galactia, P. Br. (Legumin.)

rhynchosioides, St. Hil. 1. $c_{0}=G$. angustifolia

BETHENCOURTIA, Choisy, in Buch, Beschr. Canar. Ins. 148 (1825). = Senecio, Toum. (Compr. palmensis, Choisy, 1. $\mathrm{C}$ in obs, $=\mathrm{S}$. palmensis.

BETONICA. TToum.] Linn. Sist ed I 1795 Stachys, Tourn. I abiat.

afinis, Wender. in Flom, ix. 1 $1520^{2}, 359=5$. Betonic algeriensis, Not, in Bull. Soc. Bot. Fr. is (1856) 5s? $=\mathrm{S}$. Betonica.

Alopecuros, Lina. Sp. PL. 5i\$-S. Al : .: : 


\section{BETONICA :-}

alpestris, Jord. \& Fourr. Brev. Pl. Nov. fasc. ii. $93=$ Stachys densiflora.

alpigena, Schur, Enum. Pl. Transs. 540.-Hungaria.

alpina, Mill. Gard. Dict. ed. VIII. n. $3=$ S. Alopecuros. angustifolia, Jord. \& Eourr. Brev. Pl. Nov. fase. ii. 97 $=\mathrm{S}$. Betonica.

annua, Linn. Sp. P1. 573; Moench, Meth. $395=\mathrm{S}$. annua.

brachystachya, Jord. \& Fourr. Brev. Pl. Nov. fasc. ii. $98=$ S. Betonica

Brantii, Boiss. Fl, Orient. iv. $750=$ S. Brantii.

capensis, Burm. f. Fl. Cap. Prod. 16.-Afr. anstr.

Clementei, Perez-Lara, in Anal. Soc. Esp. Hist. Nat. xi. (1882) 400.-Hispan.

danica, Mill. Gard. Dict. ed. VIII, n. $2=$ S. densiflora. decumbens, Moench, Meth. $396=$ S. recta.

densifora, Schur, Enum. Pl. Transs. 890, Index $=$ S. densiflora.

divulsa, Tenore, Syll. Fl. Neapol. App. $614=$ S. Betonica.

drymophila, Jord. \& Fourr. Brev. P1. Nov. fasc. ii. $100=\mathrm{S}$. Betonica.

elongata, Willd. ex Steud. Nom. ed. II. i. $200=$ S. Betonica.

fava, St. Lag. in Ann. Soc. Bot. Lyon, vii. (1880) 120 $=\mathrm{S}$. Alopecuros.

foliosa, Presl, Fl. Sicul. 37 =S. Betonica.

foliosa, Rupr. Sert. Tiansch. 66.-As. centr.

frutescens, Bontekoe, Jav. 146= Justicia Betonica.

glabrata, C. Koch, in Linnaea, xxi. (1848) $684=\mathrm{S}$. Betonica.

graeca, Boiss. \& Sprun. Diagn. Ser. I. v. 27.Graecia.

grandiflora, Thuill. Fl. Par. ed. I1. $293=$ S. longifolia.

grandiflora, Steph. ex Willd. Sp. P1. iii. $96=\mathrm{S}$. grandiflora.

grandifolia, Jord. \& Fourr. Brev. Pl. Nov, fasc. ii. 101 $=\mathrm{S}$. Betonica.

heraclea, Linn. Mant. i. $83=$ S. integrifolia.

hirsuta, Linn. 1. c. ii. $248=$ S. densiflora.

hirsuta, C. A. Mey. Verz. PA. Cauc. 95=S. longifolia hirta, Leyss. Fl. Halens. $109=$ S. Betonica.

hirta, Linn. Cent. ii. 20 ; Gouan, Hort. Monsp. $276=$ S. recta.

hylebium, Jord. \& Fourr. Brev. P1. Nov. fasc. ii. $101=$ S. Betonica.

incana, Mill. Gard. Dict. ed. VIII. n. $5=$ S. densiflora Facquini, Gren. \& Godr. Fl. Fr. ii. $694=$ S. Alopecuros.

laevigata, D. Don, Prod. F1. Nep. $110=$ Nepeta spicata laxata, Jord. \& Fourr. Brev, PI. Nov。 fasc. ii. $96=\mathrm{S}$. Betonica.

leaitima, Link, Handb, $476=\mathrm{S}$. Betonica.

leiocalyx, Jord. \& Fourr. Brev. PI. Nov. fasc. ii. $95=$ S. Betonica.

intea, Lam. F1. Fr. ii. $404=$ S. Alopecurós

macrantha, C. Koch, in Linnaea, xxi. (1848) $683=\mathrm{S}$. grandiflora.

macrostachys, Wender. in Flora, ix. (1826) $353=\mathrm{S}$. densiflora.

Monnieri, Gouan, Illustr. $36=\mathrm{S}$. densiflora.

montana, Lej. F1. Spa, ii. $24=$ S. Betonica.

monticola, Jord. \& Fourr. Brev. Pl. Nov. fasc. ii. $95=$ S. Betonica.

nemorosa, Jord. \& Fourr, 1. c. $98=$ S. Betonica.

nivea, Stev. in Mém. Soc. Nat, Mosc. iii. (1812) $266=$ S. nivea.

nutans, Kit. ex Schult. Oestr, Fl. ed. II. ii. $146=$ S. Betonica.

occitana, Jord. \& Fourr. Brev. P1. Nov. fasc. ii. $97=$ S. Betonica.

officinalis, Linn. Sp. Pl. $573=$ S. Betonica.

orientalis, Linn. 1. $\mathrm{c}_{0}=\mathrm{S}$. longifolia,

orientalis, Thuill. Fl. Par. $293=\mathrm{S}$. grandiflora.

Orphanidea, Heldr. ex Boiss. Fl. Orient. iv. $750=\mathrm{S}$, Alopecuros.

parvula, Jord. \& Fourr. Brev. Pl, Nov, fasc. ii. $94=$ S. Betonica.

polyclada, Jord. \& Fourr. 1. c. $102=$ S. Betonica. pradica, Zanted. ex Nym. Consp. $577=$ S. densiflora. pratensis, Jord. \& Fourr. Brev. Pl. Nov. fasc. ii. $96=$ S. Betonica.

psilostachys, Jord. \& Fourr. 1. c. $97=$ S. Betonica. purpurea, Gilib. Fl. Lituan. i. $82=$ S. Betonica

p.yrenaica, Jord. \& Fourr. Brev. P1. Nov. fasc. ii. $94=$ S. Betonica.
BETONICA :-

recurva, Jord. \& Fourr. Brev. Pl. Nov. fasc. ii. $102=$ Stachys Betonica.

recurvidens, Peterm. Fl. Lips. Excurs. $444=\mathrm{S}$. Betonica.

rigida, Jord. \& Fourr. Brev. Pl. Nov, fasc. ii. $103=$ S. Betonica.

rosea, Hort. ex Heynh. Nom, ii. $67=$ S. grandiflora.

rubicunda, Wender. Ind. Sem. Hort. Marb. ex Benth. in DC. Prod. xii. $460=\mathrm{S}$, densiflora.

rusticana, Jord. \& Fourr. Brev. Pl. Nov. fasc. ii. $96=$ S. Betonica.

sabauda, Jord. \& Fourr. 1. c. $93=$ S. Betonica.

scardica, Griseb. Spicil. Fl. Rumel. ii. $136=$ S. graeca. serotina, Host, Fl. Austr. ii. 165=S. Betonica.

stricta, [Soland, in] Ait. Hort. Kew. ed. I. ii, $299=\mathrm{S}$. Betonica.

stricticaulis, Jord. \& Fourr, Brev, Pl. Nov, fasc. ii. $99=\mathrm{S}$. Betonica.

subcarnea, Jord. \& Fourr. I. c. $98=$ S. Betonica

sylvulicola, Jord. \& Fourr. 1. c. $100=$ S. Betonica. valdepubens, Jord. \& Fourr. 1. c. $103=$ S. Betonica. validula, Jord. \& Fourr, l. c. =S. Betonica.

virescens, Jord. \& Fourr. 1. c. $99=\mathrm{S}$. Betonica. virgultorum, Jord \& Fourr, 1. c. $100=\mathrm{S}$. Betonica. vulgaris, Rota, Prosp. Píant. Pav。 $272=\mathrm{S}$. Betonica

BETULA, [Tourn.] Linn. Syst. ed. I (1735). CUPULIFERAE, Benth. \& Hook. f. iii. 404.

Betulaster, Spach, in Ann. Sc. Nat. Sér. II. xv. (1841) 198.

acuminata, Ehrh. Beitr. vi. $98=$ alba.

acuminata, Wall. PI. As, Rar. ii. 7. t. $109=$ alnoides.

aetnensis, Rafin. Giorn. i. 17; J. \& C. Presl, Delic Prag. $144=$ alba.

affinis, Endl, Gen. Suppl. iv. $20=$ alnoides.

alba, Linn. Sp. Pl. 982.-Europ.; As, bor.; Am. bor. Alnobetula, Ehrh. Beitr. ii. $72=$ Alnus viridis.

alnoides, Buch.-Ham. in D. Don, Prod. Fl. Nep. 58. -Reg. Himal.

Alnus, Linn. Sp. Pl. 983= Alnus glutinosa.

Alnus, Thunb. Fl. Jap. $76=$ Alnus maritima.

Alnus-crispa, Steud. Nom. ed. II. i. $201=$ Alnus crispa.

Alnus-incana, Du Roi, Obs. Bot. $31=$ Alnus incana.

Alnus-rugosa, Du Roi, 1. c. $32=$ Alnus serrulata.

alpestris, Fries, Summ. Veg. Scand. i. 212.-Europ. bor.; Groenland.

alpina, Borckh. ex Reichb. Fl. Germ. Excurs. 1/4 = Alnus viridis.

ambigua, Hampe, ex Reichb. Ic. Fl. Germ. xii. $2=$ alba.

angulata, Hort. ex Steud. Nom. ed. II. i. 201.--Am. bor. antarctica, Forst. in Comm. Gott. ix. (1789) $45=$ Fagus betuloides.

arguta, Schlecht. in Linnaea, vii. (1832) $139=$ Alnus acuminata.

asplenifolia, Hort. ex Regel, in DC. Prod. xvi. II. 167 $=$ alba.

aurata, Borkh. Forstb. i. $378=$ alba.

aurea, Steud. Nom. ed. II. i. $201=$ alba.

Bhojpattra, Wall, Pl. As. Rar. ii. $7=$ utilis.

borealis, Spach, in Ann. Sc. Nat. Sér. II. xv. (1841) $196=$ pumila.

broccembergensis, Bechst. Forstb. $297=$ alba.

carpatica, Waldst. \& Kit. ex Willd. Sp. Pl, iv. $464=$ alba.

canadensis, Hort. ex C. Koch, Dendrol. ii. II. $656=$ alba.

carpinifolia, Ehrh. Beitr. vi. $99=$ lenta

carpinifolia, Sieb. E Zucc. in Abh. Acad. Muench. iv, Abth. III. 1846) 228.-Japon.

chinensis, Maxim. in Bull. Soc. Nat. Mosc. liv. (1879) I. 47.-China.

ciliata, Steud. Nom. ed. II. i. $201=$ Populus ciliata.

cordata, Loisel. Notul. 139= Alnus cordifolia.

cordifolia, Regel, in Nouv. Mém. Soc. Nat. Mosc. xiii. (1861) $86=$ alba.

coriifolia, Tausch, ex Regel, in DC. Prod. xvi. II. 168 $=$ alba.

corylifolia, Regel E Maxim. in' Bull. Soc. Nat. Mosc. xxxviii. (1865) II. 417.--Japon.

costata, Trautv. in Maxim. Prim. Fl. Amur. $253=$ ulmifolia.

crispa, [Dryand. in] Ait. Hort. Kew. ed. I. iii. $339=$ Alnus viridis.

cryptocarpa, Laestad. in Bot. Notiser, 1856 (1857) 109 $=$ alba.
BETULA :-

cuspidata, Schrad. ex Regel, in DC. Prod. xvi. II. 164 $=$ alba

cycoviensis, Steud. Nom. ed. I. 107, sphalm. $=$ oycoviensis.

cylindrostachya, Wall. Pl. As. Rar. ii. $7=$ alnoides. dalecarlica, Linn. f. Suppl. $416=$ alba.

davurica, Pall. Fl. Ross. i. 60. t. 39. fig. A.-Sibir. Am. bor.

dioica, Pall. Reise, iii. 321.-Sibir. transbaical.

divaricata, Ledeb, in Denkschr. Baier. Bot. Ges. iii. (1841) $59=$ fruticosa.

emarginata, Ehrh. Beitr. iv. 158= Alnus glutinosa.

Ermani, Cham. in Linnaea, vi. (1831) 537. t. 6. fig. D -As. bor. or

ethnensis, Rafin. ex Regel, in DC. Prod. xvi. II. $163=$ alba.

exaltata, S. Moore, in Fourn. Linn. Soc. xvii. (1880) 386. t. 16.-China

excelsa, [Dryand. in ] Ait. Hort. Kew. ed. I. iii. $337=$ papyracea?

excelsa, Hook. Fl. Bor. Am. ii. $156=$ lenta.

excelsa, Pursh, Fl. Am. Sept. ii. $621=$ lutea

Friesii, Larss. Fl. Verml. ed. II. ex Hartm. Scand. FI. ed. XIII, $376=$ alba

fruticans, Pall. Reise, iii. t. $\mathrm{kk}=$ fruticosa.

fruticosa, Fries, in Flora, xxxiii. (1850) $152=$ alpestris.

fruticosa, Pall. Fl. Ross. i. I. 62. t. 40. f. A. B. C.Europ.; As. bor.; Sibir.; Manchur.

fruticosa, Willd. Sp. Pl. iv, $467=$ humilis

fusca, Pall, Reise, iii. $173=$ fruticosa.

glabra, Dum. Fl. Belg. 11.-Belgia.

glandulosa, Michx. Fl. Am. Bor. ii. 180.-Am. bor

glauca, Wender. in Bot. Zeit. iv. (1846) $291=$ alba.

glutinosa, Lam. Encyc. i. $454=$ Alnus glutinosa.

glutinosa, Wallr. Sched. Crit. $497=$ alba.

Gmelini, Bunge, Verz. Suppl. Fl. Alt. $113=$ fruticosa

grandis, Schrad. in Ind. Sem. Hort. Gott. (1833) $2=$ alba.

Grayii, Regel, in Bull. Soc. Nat. Mosc. xxxviii. (1865) II. 406 = pumila.

grossa, Sieb. E Zucc. in Abh. Acad. Muench. iv. Abth. III. (1846) 228.- Japon.

gummifera, Bertol. Fl. Ital. x. $229=$ alba.

Hackelii, Opiz, ex Steud. Nom. ed. II. i. $201=$ alba

harcynica, Wender, ex Steud. 1. c = alba.

humilis, Fries, ex Regel, in DC. Prod, xvi. rI. $172=$ alpestris.

humilis, Schrank, Bayer. Fl. i. 420.-Europ. bor.; As. bor.; Am. bor.

hybrida, Blom, in Vet. Acad. Nya Handl. vii. (1786) 186. t. 6 . f. $13=$ alba.

hybrida, Regel, in Nouv. Mém. Soc. Nat. Mosc. xiii. 1861) 94.-Rossia.

incana, Roth, Tent. Fl. Germ. iii。 $477=$ Alnus incana. intermedia, Thomas, ex Reichb. Ic. Fl. Germ. xii. t. 624. fig. 1283.-Europ.

Facquemontii, Spach, in Ann. Sc. Nat. Sér. II. xv. (1841) $189=$ utilis.

japonica, Siebold, in Verh. Batav. Gen. xii. (1830) $25=$ alba.

kamtschatica, Buek, in DC. Prod. Ind. iv. $52=$ humilis.

laciniata, Blom, in Vet. Acad. Nya Handl. vii. (1786) 156. t. 6. f. $13=$ alba.

laciniata, Ehrh. Beitr. iii. $21=$ Alnus glutinosa.

laciniata, Thunb. Diss. Bet. $10=$ alba.

lagopina, Hartm. ex Regel, in DC. Prod. xvi. II. $173=$ alpestris.

lanulosa, Michx. Fl. Bor. Am. ii. $181=$ nigra.

latifolia, Tausch, in Flora, xxi. (1838) $751=$ alba.

lenta, Duroi, Harbk. Baumz, i. $92=$ alba.

lenta, Linn. Sp. Pl. 983,-Am. bor.

lenta, Regel, in Nouv. Mém. Soc. Nat. Mosc. xiii (1861) $125=$ carpinifolia.

leptophylla, Regel, in DC. Prod. xvi. II. 181=Alnus nepalensis.

leptostachya, Wall. Cat. n. $2799=$ Alnus nepalensis, Littelliana, Tuckerm. in Am. Journ. Sc. xlv. (1843) 30 $=$ glandulosa.

lobulata, Kit. in Linnaea, xxxii. (1863) 351.-Europ. longifolia, Bové, ex Spach, in Ann. Sc. Nat. Sér. II xv. (1841) $208=$ Alnus orientalis

lutea, Michx. Hist. Arb. ii. 153. t. 5.-Am. bor.

Maackii, Rupr. in Bull. Phys.-Math. Acad. Pétersb. xv. (1857) $380=$ davurica.

major, Gilib. Exercit. ii. $400=$ alba. 
BETULA:-

macrostachya, Schrad. ex Regel, in DC. Prod. xvi. 187 ; Spach, in Ann. Sc. Nat. Sér. II. xv. (1841) 7 $=$ alba.

Maximowicziana, Regel, in DC. Prod. xvi. $180=$ Maximowiczii.

Maximowiczii, Regel, in Bull. Soc. Nat. Mosc. xxxviii. (1865) II. 418.- -Japon.

Maximowiczii, Rupr, in Bull. Phys.-Math. Acad. Pétersb. xv。(1856) $139=$ davurica.

Maximowitschii, Rupr, in Bull. Phys.-Math. Acad. Pétersb. xv. (1856) $435=$ dahurica.

media, Laestad. in Bot. Notiser, 1556 (1857) $107=$ alba.

megalocarpa, Laestad. 1. c. $106=$ alba

Michauxii, Spach, in Ann. Sc. Nat. Sér. II. xv. (1841) 195. - Am. bor.

microphylla, Bunge, Verz. Suppl. Fl. Alt. 112; in Mém. Acad. Pétersb. (1835) 506.-Sibir. altaic.

Middendorffi, Trautv. E Mey. in Middend. Reise (Fl. Ochot. 84).- Manchuria.

Murithii, Gaudin, ex Regel, in DC. Prod. xvi. II. 168 =alba.

myrsinoides, Tausch, in Flora, xi. (1828) $753=$ humilis.

nana, Hook. F1. Bor. Am. ii. $156=$ glandulosa.

nana, Linn. Sp. Pl. 983.-Reg. bor

nana, Michx. F1. Bor. Am. ii. $180=$ Michauxii.

nigra, Duham. Arb. ed. Nov. iii. 203. t. $51=$ alba.

nigra, Duroi, Harbk. Baumz. 1. $93=$ lenta.

nigra, Linn. Sp. Pl. 982.-Am, bor.

nigra, Murith, Guide Bot, Valais, $55=$ intermedia.

nigricans, Wender. in Bot. Zeit. iv, (1846) $291=$

alba.

nitida, D. Don, Prod. Fl. Nep. $58=$ alnoides

oblongata, [Dryand. in] Ait. Hort. Kew. ed. I. iii. 338 $=$ Alnus glutinosa

occidentalis, Hook. Fl. Bor. Am. ii. 155.-Am. bor. occ.

odorata, Bechst. Forstb. 294=alba.

nvalifolia, Rupr. in Bull. Phys.-Math. Acad, Pétersb. xv. (1857) $378=$ humilis.

ovata, C. Koch, in Linnaea, xxii. (1849) $333=$ alba,

ovata, Schrank, Baier. Fl. i. $419=$ Alnus viridis.

oycoviensis, Bess. Prim. Fl. Galic. ii, $289=$ alba.

oycowiensis, Laestad. ex Regel, in DC. Prod. xvi. II.

$\mathbf{1 7 1}=$ intermedia.

oycarviensis, Reichb. Ic. F1. Germ. xii. t. 622. f. $1281=$ humilis.

palmaeformis, Laestad. in Bot. Notiser, 1856 (1857) $105=$ alba

palmata, Borkh. Handb. i. $500=$ alba

palustris, Rupr. in Bull. Phys.-Math. Acad. Pétersb. xv. (1857) $376=$ humilis.

palustris, Salisb. Prod. $395=$ Alnus glutinosa.

papyracea, [Dryand. in] Ait. Hort. Kew. ed. I. iii. 337.-Am. bor.

papyrifera, Michx. F1. Bor. Am. ii. $180=$ papyracea

pendula, Roth, Tent. Fl. Germ. i. $405=$ alba.

persicifolia, Hort. ex C. Koch, Dendrol, ii. II. $641=$ lutea.

pinnata, Landmark, in Vet. Acad. Nya Handl. Stockh

(1790) $131 . \mathrm{f} .5=$ Alnus incana.

pirifolia, Hort. ex C. Koch, Dendrol. ii. II. $646=$ papyracea

pontica, Desf. ex Steud. Nom, ed. II. i. 201.-As. Min.

pontica, Hort. ex Lond. Encyc. PI. $720=$ alba.

populifolia, [Dryand. in] Ait. Hort. Kew.ed. I. iii. 336 $=$ alba.

pubescens, Ehrh. Beitr. iv. 160 ; et vi. $98=$ alba.

pumila, Linn. Mant. i. 124.-Am. bor.

pumila, J. Vahl, ex Lange, Consp. F1. Groenl. i. 114 $=$ alpestris?

quebeccensis, Burg, in Ges. Naturf. Fr. Berl. Schr. v.

(1784) $196=$ humilis.

reticulata, Laestad, ex Regel, in DC. Prod.xvi. II. 169 = alba.

reticulata, Rupr. in Bull. Phys.-Math. Acad. Pétersb. xv. $(1857) 378=$ humilis.

vhombifolia, Tausch, in Flora, xxxvii. (1838) $752=$ alba.

rotundifolin, Regel \& Tiling, F1. Ajan. $118=$ Middendorffi.

rotundifolia, Spach, in Ano. Sc. Niat. Sér. II. xv,

(1841) $194=$ glandulosa.

rubra, Hort. ex Regel, in DC. Prod. xvi. II. 16t = alba.

\section{BETULA}

rubra, Michx. Hist. Arb. ii. 143. t. $3=$ nigra.

rugasa, Ehrh. Beitr, iii. $21=$ Alnus serrulata

rustica, Laestad. in Bot. Notiser, 1856 (1857) 104

alba.

Schmidtii, Regel, in Bull. Soc. Nat. Mosc. xxxviii.

(1865) Ir. 412.- Manchuria.

serrulata, [Dryand, in] Ait. Hort. Kew, ed, I. iii. 338 $=$ Alnus serrulata.

sibirica, Lodd. ex Regel, in DC. Prod. xvi. I1. 173 humilis.

silvatica, Laestad. in Bot. Notiser, 1856 (1857) $108=$ alba.

silvestris, Laestad. 1. c. $107=$ alba.

Socolowi, Jacq. f. ex. Regel, in DC. Prod. xvi. II. $173=$ humilis.

Sokolowii, Hort. Petrop. ex Regel, 1. c. $163=$ alba.

subaequalis, Latstad. in Bot. Notiser, 1856 (1857) 109 $=$ alba.

subalpina, Lacstad. I. c. $110=$ alba.

tianschanica, Rupr. Sert. Tiansch. 72.-As, centr.

tiliaefolia, Laestad. in Bot. Notiser, 1856 (1857) $106=$ alba.

tomentosa, Retz. \& Abel, Beschr. Holzarten, i. 17. t. $15=$ alba.

torfacea, Schleich. Cat. Pl. Helv, ed. IV. $9=$ alba.

tortuosa, Ledeb. F1. Ross. iii. $652=$ alba.

transsilvanica, Schur, in Verh. Siebenb. Ver. Naturw. iv. (1853) 68.-Hungar

triphylla, Thunb. Diss. Betul. 12,-Hab.

tristis, Wormsk. ex Link, Enum. Hort. Berol. ii. 401. -Kamtschat.

turfosa, Weigel. ex Reichb. F1. Germ. Excurs. $174=$ fruticosa.

ulmifolia, Sieb. E Zucc. in Abh. Akad. Muench. iv. III. (1846) 228.- Japon.

urticaefolia, Curtois, ex Steud. Nom. ed. II. i. $201=$ alba?

urticifolia, Regel, in Nouv. Mém. Soc. Nat. Mosc. xiii 1861) 115.-Suecia (cult.)

ntilis, D. Don, Prod. Fl. Nep. 58.-Reg. Himal. Japon.

verrucosa, Ehrh. Beitr. v. 161 ; vi. $98=$ alba.

virgata, Salisb. Prod. $395=$ alba.

virgultosa, Fries, ex Regel, in Nouv. Mém. Soc. Nat.

Mosc. xiii. (1861) $115=$ urticifolia.

viridis, Chaix, in Vill. Hist. Pl. Dauph. 1ii. $789=$ Alnus viridis.

BETULASTER, Spach, in Ann. Sc. Nat. Sér. II. xv.

(1841) 198 = Betula, Tourn. (Cupulif.)

acuminata, Spach, $1 . \mathrm{c}=$ = Betula alnoides

affinis, Spach, 1. c. $199=$ Betula alnoides.

cylindrostachya, Spach, 1. c. $198=$ Betula alnoides.

nitida, Spach, l. c. $200=$ Betula alnoides.

BEURERIA, Ehret, Pl. \& Pap. Rar. t. $13(1755)=$ Calycanthus, Linn.

BEURRERIA, Jacq. Enum, Pl. Carib. $2(1760)=$ Bour reria, P. Br. (Borag.).

BEVERNA, Adans, Fam. ii. $20(1763)=$ Iris, Tourn. ?

BEYERIA, Miq. in Ann. Sc. Nat. Sér. III. i. (1814) 350. t. 15. EUPHORBIACEAE, Benth. \& Hook. iii. 263.

Bryeriopsis, Muell. Arg. in Linnaea, xxxiv. (1865 56.

Calyptrostigma, Klotzsch, in Lehm. P1. Preiss, 175 (1844).

Backhousii, Hook. f. Fl. Tasm. i. $339=$ opaca

brevifolia, Baill. Adansonia, vi. (1865-66) 309.Austral.

cinerea, Baill. l. c.-Austral.

cyanescens, Benth. Fl. Austral. vi. 66.-Austral.

cygnorum, Brill. Adansonia, vi. (1865-66) 309.Austral.

Drummondi, F. Mucll. Census, 18.-Austral.

lasiocarpa, Muell. Arg. in Linnoea, xxxiv. (1865-66) 69.-Anstral.

latifolia, Baill. Adansonia, vi. (1865-66) 904.Austral.

ledifolia, Sond, in Linnaen, xxviii. (1856) $565=$ opaca.

lepidopetala, F. Muell. Fragm. i. 230.-Anstral.

Leschenaultii, Baill. Adansonia, vì. (1865-66) 307 oprca.

\section{BEYERIA :-}

loranthoides, Baill. Etud. Gén. Euph. 403.-Austral oblongifolia, Sond. in Linnaea, xxviii. (1856) $564=$ viscosa.

opaca, F. Muell. in Trans. Phil. Soc. Vict. i. (1855 16.-Austral.

similis, Baill. Adansonia, vi. (1865-66) 309-Austral. tristigma, F. Muell. Fragm. vi. 181.-Austral.

uncinata, F. Muell. ex Baill. Adansonia, vi. (1865-66) 306.-Austral.

viscosa, Miq. in Ann. Sc. Nat. Sér. III. i. (1844) 350. t. 15.-Austral.

BEYERIOPSIS, Muell. Arg. in Linnaea, xxxif. (1865) $56^{\circ}=$ Beyeria, Miq. (Euphorb.)

brevifolia, Muell. Arg. 1. c. $58=$ Beyeria brevifolia

cinerea, Muell. Arg. 1. c. $57=$ Beyeria cinerea.

cyanescens, Muell. Arg. in DC. Prod. Xv. II. 200

Beycria cyanescens.

cygnorum, Muell. Arg. in Linnaea, xxxiv. (1865) 56

Beyeria cygnorum.

Drummondi, Muell. Arg. 1. c. 58=Beyeria Drum mondi.

lasiocarpa, Muell. Arg. 1. c. $59=$ Beyeria lasiocarpa. latifolia, Muell. Arg. 1. c. $57=$ Beyeria latifolia.

lepidopetala, Muell. Arg. 1. c. = Beyeria lepidopetala

similis, Muell. Arg. 1. c. $58=$ Beyeria similis.

BEYRICHIA, Cham. \& Schlecht. in Linnaea, iii. (1828) 2I. SCROPHULARINEAE, Benth. \& Hook f. ii. 949

ACHETARIA, Cham. \& Schlecht. in Linnaea, ii. (1827) 566 , nomen prius.

ajugoides, Benth. Scroph. Ind. 9, in nota=ocy. moides.

floribunda, Benth. in DC. Prod. x. 379.-Bras.

ocymoides, Cham. E Schlecht. in Linnaea, iii. (1828) 21.-Bras.

scutellarioides, Benth. Scroph. Ind. 9, in nota. Bras

villosa, Benth. l. c.-Bras.

BEYTHEA, Endl. Gen. $1011(1840)=$ Elaeocarpus, Linn. (Tiliac.).

bifida, EndI. 1. c. = E. bifidus.

BEZANILLA, Remy, in C. Gay, F1. Chil, iv. 109. t. 46 $(1849)=$ Psilocarphus, Nutt. (Compos.) chilensis, Remy, 1. c. 110,-Chili.

BHESA, Buch.-Ham. ex Arn. in Edinb. Phil. Journ. xvi. (1834) $315=\mathbf{K}$ urrimia, Wall. (Celastr.), Moja, Buch.-Ham. 1. c. =K. pulcherrima. paniculata, Arn. 1. c. = K. paniculata.

BIA, Klotzsch, in Wiegm. Archiv, vii. $11541,1 \vee 0=$ Tragia, Linn. (Euphorb.)

alienata, F. Didr. in Kjoeb. Vidensk. Mcddel. (1557 $131=$ T. Sellowiana.

Lessertiana, Baill. Etud. Gén. Euph. 502=T. Lessertiana.

Lhotskyana, Klotzsch, in Wiegm. Archiv, vii. (18t1 $190=\mathrm{T}$. Sellowiana.

Sellowiana, Klotzsch, 1. $c_{-}=T$. Sellowiana.

BIANCAEA, Todaro, Nuov. Gen, 21 (1855)=Caesal pinia, Linn. (Legum.)

mimosoides, Tudaro, Hort. Bot. Panorm. $3=$ C. mimu soides.

Sappan, Todaro, $1, c_{0}=$ C. Sappan.

scondens, Todaro, Nuov, Gen, 22; et 1. c. 4. \& $1=$ C. sepiaria.

BIARUM, Schott, Melet. i. 17 (1:32). AROIDE.AE. Benth. \& Hook. f. iii. " $60^{\circ}$.

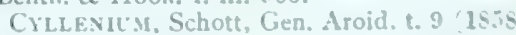

HomadD, Adans. Fam. ii. tio (1703), nomen

prius.

ISCHARUM, Blume, Rumphia, i. 14t. t. 29 (1\$35

Leprotetion, Schott, Gen. Aruid. t. 8 (185s).

STENuRus, Salisb. Gen, Pl. Fragm. t. 5 , $180^{\circ}$ abbreriatum, Schutt, Prod. Aroid. $62=$ enuifolium. aleraudrinum, Boiss. Dingn. Ser. I. xiii. 6 = Olivieri. Angruillarae, Schote, P'rod. Aroid. 62 - tenuilolium. amgustatum, N. E. Br. in fourn. Lines. Sic. xrut angustatum, $N$. E. Br. in Fot
lisul 255 . - Oriens; Syria.

arsudanum, Buiss. \& Reut. Pugill. $110=$ en enui. lulium. 


\section{BIARUM :}

Bovei, Blume, Rumphia, i. 114. t. 29.-Syria; As Min.

carduchorum, Engl. in DC. Monog. Phan. ii. 575.As. Min.; Syria.

constrictum, C. Koch, Ind. Sem. Hort. Berol. (1853)

$12=$ tenuifolium

eximium, Engl. in DC. Monog. Phan. ii. 576.Cilicia.

Fraasianum, N. E. Br. in Fourn. Linn. Soc. xviii (1880) 254.- Oriens.

gramineum, Schott, Melet. i. $17=$ tenuifolium.

Haenseleri, Willk, in Bot. Zeit. v, (1847) 49. t. 2.Hispan.

Homeid, Blume, Rumphia, i. 115.-Oriens.

Lehmanni, Bunge, in Mém. Sav. Etr. Pétersb. vii (1851) $327=$ Helicophyllum Lehmanni.

longifolium, Pomel, Nouv. Mat. Fl. Atl. 391.Algeria.

macroglossum, Pomel, l. c. 390,-Algeria.

numidicum, Parl. Fl. Ital. ii. 243.-Numidia.

Olivieri, Blume, Rumphia, i. 115.-Aegypt.

Pyrami, Engl. in DC. Monog. Phan. ii. 576.-Cilicia; Syria.

rhopalospadix, C. Koch, Ind. Sem. Hort. Berol. (1853) $12=$ Spruneri

rupestre, Pomel, Nouv. Mat. Fl. Atl. 391.-Algeria.

Russellianum, Schott, Prod. Aroid. 63.-Syria

Sewerzowi, Regel, in Act. Hort. Petrop. vi. (1879) 489 - Caucasus.

Spruneri, Boiss. Diagn. Ser, I. xiii. 5_-Graecia.

Spruneri, Schott, in Gen. Aroid, t. $7=$ abbreviatum.

tenuifolium, Heldr. ex Nym. Consp. 755=abbreviatum.

tenuifolium, Schott, Melet. i. 17.-Hispan

Zeleborii, Schott, in Oestr. Bot. Wochenbl. (1857) 245 $=$ tenuifolium

BIASLIA, Vand. Fl. Lusit. et Bras. Spec. 4. t. 1. f. 2 $(1788)=$ Mayaca, Aubl.

BIASOLETTIA, Koch, in Flora, xix. (1836) I. 163 Bertol. Fl. Ital. iii. $191(\mathbf{1 8 3 7})=$ Chaerophyllum, Linn. (Umbellif.)

congesta, Nym. Syll. Suppl. 28.-Graecia.

cretica, Nym. Consp. $303=$ C. creticum.

divaricata, Nym. Syll. Suppl. 28.-Graecia macrocarpa, Nym. Consp. 302.-Graecia. nodosa, Bertol. Fl. Ital. iii. $191=$ C. nodosum. parnassica, Nym. Syll. Suppl. 27.-Graecia. pumila, Nym. Consp. 302.-Graecia. tuberosa, Koch, in Flora, (1836) I. $163=$ Carum cylindricum?

BIASOLETTIA, Pohl, ex Baker, in Mart. FI. Bras, vi. II. $311=$ Eupatorium, Linn. (Compos.)

elliptica, Pohl, ex Baker, 1. c. = E. trixoides.

BIASOLETTIA, Presl, Rel. Haenk. ii. 141 (1840 ?)= Hernandia, Linn? (Laurin)

nymphaeaefolia, Presl, 1. c.-Ins. Marian.

BIASSOLETTIA, Endl. Gen. $1004(\mathbf{1 8 4 0})=$ BIASO LETTIA, Presl (= Hernandia, Linn.? Laurin.).

BIATHERIUM, Desv. Opusc. $72(1831)=$ Gymno pogon, Beauv. (Gramin.)

foliosum, Desv. 1. c. = G. foliosum

BICCHIA, Parl. Fl. Ital. iii. 396 (1858)= Habenaria Willd. (Orchid.).

albida, Parl. 1. c. $397=$ H. albida

BICHEA, Stokes, Bot. Mat. Med. ii. 564 (1812)= Cola Schott (Stercul.)

solitaria, Stokes, 1. c. $565=$ C. acuminata

BICHENIA, D. Don, in Trans. Linn. Soc. xvi. (1830 $236=$ Trichocline, Cass. (Compos.).

aurea, D. Don, 1. c. 237.-Chili.

auriculata, Wedd. Chlor. And. i. 26.-Bolivia.

Berteriana, Steud. Nom. ed. II. i. 202-aurea.

Cineraria, D. Don, in Phil. Mag. (1832) $391=$ T. Cineraria.

crenata, Remy, in C. Gay, F1. Chil. 302.-Chili.

dealbata, D. Don, ex Hook. Comp. Bot. Mag. i. (1835) $104=\mathrm{T}$. dealbata.

\section{BICHENIA :-}

plicata, D. Don, ex Wedd, Chlor. And, i. $26=$ Trichocline plicata.

reptans, Wedd. 1. c. 25.-Bolivia.

sinuata, D. Don, Phil. Mag. (1832) $391=$ T. incana

BICORNELLLA, Lindl. Bot. Reg. sub t. 1701 (1735). ORCHIDEAE, Benth. \& Hook. f. Gen. iii. 634 gracilis, Lindl. Gen. et Sp. Orch. 334.-Madag. longifolia, Lindl. l. c. 335.-Madag.

parviflora, Ridl. in fourn. Linn. Soc. xxi. (1885) 500. - Madag.

BICORONA, A. DC. Prod, viii. $330(1844)=$ Melo dinus, Forst. (Apocyn.).

phyllireoides, A. DC. 1. c. = M. phillyraeoides.

BICUCULLA, Borckh. in Roem. Arch. i. II. 46 (1797)= Adlumia, Rafin. (1808) (Papav.).

fumarioides, Borckh. 1. $\mathrm{c}_{\mathrm{o}}=\mathrm{A}$. cirrhosa.

BICUCULLARIA, Juss. ex Steud. Nom. ed. II. i. 202 (1840) = Dicentra, Bernh. (Papav.).

canadensis, Juss. ex Steud. 1. c. $201=$ D. Cucullaria.

BIDARIA, Decne, in DC. Prod. viii. $623(1844)=$ Gymnema, R. Br. (Asclep.)

elegans, Dalz. \& Gibs. Bomb. Fl. $151=$ G. montanum. elegans, Decne. in DC. Prod. viii. $623=\mathrm{G}$. elegans.

erecta, F. Muell. in Trans. Phil. Inst. Vict. iji. (1859)

$59=\mathrm{G}$. stenophyllum.

inodora, Decne. in DC. Prod. viii. 624 (Sp. dub.).Ind. or.

leptophylla, F. Muell. in Trans. Phil. Inst. Vict. iii. 1859) $60=$ Marsdenia leptophylla.

pergularioides, Thw. Enum. Pl. Zeyl. $198=$ G. pergularioides.

pubiflora, Miq. F1. Ind. Bat. ii. 497.-Java,

syringaefolia, Decne. in DC. Prod. viii. $623=$ Marsdenia syringaefolia.

tingens, Decne. $\mathrm{l}_{\mathrm{s}} \mathrm{c}=\mathrm{s}=\mathrm{G}$. montanum.

trinervis, Decne. 1. c. $624=\mathrm{G}$. trinerve.

BI.DENS, [Tourn.] Linn. Gen. ed. I. 248 (1737)= COMPOSITAE, Benth. \& Hook. f. ii. 387

Ceratocephalus, Vaill, ex Cass. in Dict. Sc. Nat. vii. 432 (1817)

DeLUCiA, DC Prod, v, 633 (1836)

EDwARSIA, Neck. Elem. i. 87 (1790).

Kerneria, Moench, Meth. 595 (1794).

Pluridens, Neck. Elem. i. 86 (1790).

Abadiae, DC. Prod. v. 601.-Peruy.

abortiva, Schum. \& Thonn. Beskr. Guin. Pl. 381= pilosa.

abyssinica, Sch. Bip. ex Walp. Rep. vi. $167=$ pilosa, quadriseta.

acaulis, Baker, in Mart. Fl. Bras. vi. III. 247.Paraguay.

Acmella, Lam. Encyc. i. $415=$ Spilanthes Acmella acmelloides, Berg. in Vet. Acad. Handl. xxix. II. (1768) $245=$ Spilanthes Acmella

adhaerescens, Vell. Fl. Flum. 348 ; viii. t. 88 .Bras.

alausensis, H. B. E K. Nov. Gen. et Sp. iv. 235.Ecuador.

alba, DC. Prod. v. $605=$ pilosa.

andicola, H. B. \& K. Nov. Gen. et Sp. iv. 237.Ecuador.

angustifolia, Lam. Encyc. i. $416=$ Spilanthes urens. angustifolia, Nutt. in Trans. Am. Phil. Soc, Str. II. vii. (1841) 369.-Ins. Sandvic.

angustissima, H. B. E $K$. Nov. Gen. et Sp. iv. 233.Mexic.

angustissima, Spreng. Syst. iii. $453=$ andicola.

anthriscoides, DC. Prod. v. 600.-Mexic.

apiifolia, Linn. Syst. ed. X. 1203 ; Pl. Jam. Pugill. 22 $=$ Chrysanthellum procumbens.

arborea, Roxb. in Beats. App. 301, 325=Petrobium arboreum.

arguta, H. B. \& K. Nov. Gen. et Sp. iv. $231=$ heterophylla.

artemisiaefolia, Poepp. E Endl. Nov. Gen. et Sp. iii. 49. -Pertiv.

atriplicifolia, Linn. Cent. ii.30 ; Amoen. Acad. iv. 329 = Isocarpha atriplicifolia.

atrosanguinea, Hort. ex Vilm. F1. Pl. Terre, ed. II. $269=$ Dahlia Zimapani.
BIDENS :-

atrosanguinea, Ortg. ex Regel, Gartenf. x. (1861) 406. t. $347=$ Cosmos diversifolius.

australis, Spreng. Syst. iii. $458=$ Coreopsis micrantha.

Bardanna, Wall. Cat. n. $3291=$ Chrysanthellum indicum.

Beckii, Torr. in Spreng. Neue Entdeck. ii. 135.-Am. bor.

Berteriana, Spreng. Syst. iii. $454=$ Cosmos caudatus.

Bigelovii, A. Gray, in Torr. Bot. Mex. Bound. 91.Am, bor. occ.

bimucronata, Turcz. in Bull. Soc. Nat. Mosc. xxiv. (1851) I. 184.-Ins. S. Doming.

bipinnata, Baill. Hist. Pl. viii. $50=$ Cosmos bipinnatus.

bipinnata, Hook. \& Arn. in Bot. Beech. Voy. i. $30=$ chilensis.

bipinnata, Linn. Sp. Pl. 832.-Reg. trop.

Bonplandii, Sch. Bip. in Seem. Bot. Voy. Herald, 308 $=$ Cosmos tenellus.

brachycarpa, DC. Prod. จ. 600.-Mexic.

Buchingeri, Sch. Bip. ex Schweinf. Beitr. Fl. Aethiop. $142=$ Schimperi.

bullata, Linn. Sp. Pl. 833.-Am. bor.; Europ.

californica, DC. Prod. v. $599=$ pilosa

calva, C. B. Clarke, Comp. Ind. $141=$ Cosmo sulphureus.

canescens, Bertol. Fl. Guatimal. 31.-Guatemala.

cannabina, Lam. F1. Fr. ii. $44=$ tripartita.

caracasana, DC. Prod. v, 600.-Venezuela.

carnea, Heer, Ind. Sem. Hort. Turic. (1842).Guiana.

carvifolia, Sch. Bip. in Seem. Bot. Voy. Herald, $308=$ Cosmos carvifolius

caucalidea, DC. Prod: v. 604,-Mexic.

caudata, Sch. Bip. in Seem. Bot. Voy. Herald, $308=$ Cosmos caudatus.

cernua, Linn. Sp. Pl. 832.-Reg. bor. temp.

Cervantesii, Baill. Hist. $\mathrm{Pl}$. viii. $305=$ Dahlia coccinea.

chilensis, DC. Prod. v. 603.-Chili

chinensis, Willd. Sp. Pl. iii. $1719=$ pilosa.

chrysantha, $D C$. Prod.v. 605.-Ind. occ-

chrysanthemoides, Michx. Fl. Bor. Am. ii. 136-Am bor.

cicutaefolia, Tausch, in Flora, xix. (1836) 395.Hab.?

ciliata, Hoffmgg. ex Fisch. \& Mey. Ind. Sem. Hort. Petrop. vi. 46.- Hab. ?

coccinea, Baill. Hist. Pl. viii. $49=$ Dahlia coccinea

connata, Muhl. in Willd. Sp. Pl. iii. 1718.-Am. bor.

consolidaefolia, Turcz. in Bull. Soc. Nat. Mosc. xxiv.

(1851) I. 185.--Peruv.

cordifolia, Sch. Bip. in Flora, xxxix. (1856) 361.-Ins. Pacif

coreopsidis, DC. Prod. v. 599=rubifolia

coronata, Fisch. ex Steud. Nom. ed. II. i. $202=$ Coreopsis coronata.

Cosmanthus, Griseb. in Goett. Abh. xix. (1874) 185.Reg. Argent.

costaricensis, Benth. ex Oerst. in Kjoeb. Vidensk. Meddel. (185i) 94.-Costa Rica.

crithmifolia, $H . B$. E K. Nov. Gen. et Sp. iv. 234.Cuba.

crocata, Cav. Ic. i. 66. t. $99=$ Verbesina crocata.

cynapifolia, H. B. E K. Nov. Gen. et Sp. iv. 235.Cuba.

daucifolia, DC. Prod. v. 601.-Mexic.

decolorata, H. B. E $\bar{K}$. Nov. Gen. et Sp. iv. 233.Mexic.

decomposita, Wall. Cat. n. $298=$ pilosa,

decussata, Pav. ex Steud. Nom. ed. II. i. $202=$ hispida.

delphinifolia, H. B. \& K. Nov. Gen. et Sp. iv. 234.Mexic.

denudata, Turcz. in Bull. Soc. Nat. Mosc. xxiv. (1851)

I. $183=$ Glossogyne tenuifolia .

dichotoma, Desf. Tabl. ed. I. (1804) 104-Bras.

Dilleniana, Hill, Veg. Syst. iii. 123.-Hab.?

diversifolia, Ortg. in Regel, Gartenft. (1861) 408. Mexic.

diversifolia, Hort. ex DC. Prod. v. $602=$ grandiflora. diversifolia, Sch. Bip. in Seem. Bot. Voy. Herald, 308 -Cosmos diversifolius.

diversifolia, Willd. ex DC. Prod. v. $602=$ alausensis.

dondiaefolia, Less. in Linnaea, v. (1830) 155.Mexic. 


\section{BIDENS :}

elongata, Tausch, in Flora, xix. (1836) 395.-Hab.? exaristata, DC. Prod. v. 600.-Mexic.

fastigiata, Michalet, in Mém. Soc. Emul. Doubs, Sér II. v. (1854) $29=$ tripartita.

ferulaefolia, $D C$. Prod. v. 603.-Mexic

ferulaefolia, Hemsl. Biol. Centr. Am. Bot. ii. 202 partim = procera.

fervida, Lam. Encyc. i. $415=$ Spilanthes Acmella.

fistulosa, Sch. Bip. ex Baker, in Mart. Fl. Bras. vi. III. 250.-Bras.

fixa, Hook. f. F1. Brit. Ind. iii. 307, sphalm. = fusca.

flagellaris, Baker, in Mart. Fl. Bras. vi. IIr. 248.-

Bras.

floribunda, $H . B . \in F$. Nov. Gen. et Sp. iv. 238.Ecuador.

foeniculifolia, DC. Prod. v. $603=$ procera?

foliosa, Willd. Enum. Hort. Berol. Suppl. 56, nomen. - Hab.?

frondosa, Buch.-Ham. ex Hook. f. Fl. Brit. Ind. iii. $309=$ tripartita

frondosa, Linn. Sp. Pl. 832.-Am. bor.

frutescens, Mill. Gard. Dict. ed. VIII. n. $4=$ Salmea grandiceps.

fruticosa, DC. Prod. v. 596.-Hab.?

fruticosa, Linn. Sp. Pl. $833=$ Wulffia stenoglossa.

fruticulosa, Meyen E Walp. in Nov. Act. Nat. Cur. xix. Suppl. i. (1843) 271.-Peruv.

fusca, Lam. Encyc. i. $416=$ Spilanthes Acmella.

Gardneri, Baker, in Mart. Fl. Bras. vi. III. 246. Bras.

glaberrima, DC. Prod. v. 601.-Am. austr.

glycinaefolia, Sch. Bip. ex Baker, in Mart. Fl. Bras, vi. III. 247.-Bras.

gracilis, Nutt. in Trans. Am. Phil. Soc. Ser. II. vii. (1841) 368.- Ins. Sand vic.

gracilis, Torr. in Ann. Lyc. N. York, ii. (1828) $215=$ Thelesperma gracile.

grandiflora, Balb. Cat. Hort. Taur. (1812) 19.-Am. austr.

graveolens, Mart. in Isis, (1824) 590.-Bras,

hawaiensis, A. Gray, in Proc. Am. Acad. v. (1861) 128. -Ins. Hawai.

helianthoides, H. B. \& K. Nov. Gen. et Sp. iv. $230=$ chrysanthemoides.

heterophylla, Orteg. Hort. Matr. 99, t, 12,-Am. bor. occ.: Mexic.

heterosperma, A. Gray, Pl. Wright. ii. 90.-Arizona.

hirsuta, Nutt. in Trans. Am. Phil. Soc. Ser. II. vii (1841) $369=$ pilosa.

hirsuta, Sw. Prod. Veg. Ind. Occ. 110=Salmea hirsuta.

hirta, Jord. in Gren. \& Godr. F1. Fr. ii. $168=$ bullata.

hirtella, H. B. $\in^{\prime} K$. Nov. Gen. et Sp. iv. 232.-Mexic

hispida, H. B. \& K. l. c. 237 .- Venezuela.

Humboldtii, Sch. Bip. in Seem. Bot. Voy. Herald, 307 $=$ Cosmos parviflorus.

humilis, H. B. E K. Nov. Gen. et Sp. iv. 234.Ecuador.

hybrida, Thuill. F1. Par. ed. II. 422 -tripartita

incisa, G. Don, in Sweet, Hort. Brit. ed. III. $360=$ rubifolia.

insipida, Lam. Encyc. i. $416=$ Spilanthes insipida.

intermedia, Opiz, ex Nym. Consp, $348=$ tripartita

Jardinii, Sch. Bip. in Flora, xxxix. (1856) 360 .-Ins. Pacif.

Kotschyi, Sch. Bip. ex Walp. Rep. vi. 168=bipinnata.

laciniata, Sch. Bip. ex Schweinf. Beitr. Fl. Aethiop. 283, nomen.-Afr. trop.

lantanoides, A. Gray, in Proc. Am. Acad. v. (1861) 128.-Ins. Pacif.

Lemmoni, A. Gray, Syn. Fl. N. Am. i. II. 297.Arizona.

leucantha, Poepp. ex DC. Prod, v. $604=$ chilensis.

leucantha, Willd. Sp. Pl. iii. $1719=$ pilosa.

leucorrhiza, DC. Prod. v. 605.-China.

Leyboldii, Phil, in Anal. Univ. Chil. ii. (1865) 938.Chili.

Lindleyi, Sch. Bip. in Seem. Bot. Voy. Herald, $307=$ Cosmos tenuifolius.

linearifolia, Sch. Bip. 1, c. $=$ Cosmos linearifolius.

lineariloba, Oliver, in Trans. Linn. Soc. xxix. (1879) 99. t. 60.-Afr. trop.

longifolia, DC. Prod. v. $597 \approx$ heterophylla

luxurians, Willd. Enum. Hort. Berol. 847-heterophylla.

macranthus, Griseb. in Goett. Abh. xix. (1874) 186.Reg. Argent.

\section{BIDENS :}

macrosperma, Fisch. Hort. Gorenk. (1808) 59 ; ed. II. 1812) $37=$ parvifor

marginata, Perr. ex DC. Prod, v. 631 - Chrysanthellum indicum.

megapotamica, Spreng. Syst. iii. 454.-Am. austr.

Messerschmidii, Turcz. ex Ledeb. F1. Ross. ii. $518=$ parviflora.

Meyeniana, Walp. in Nov. Act. Nat. Cur, xix. Suppl. i. (1843) 271.-China.

micrantha, Gaudich. Voy. Freyc. Bot. 464, $85=$ Coreopsis micrantha.

minima, Huds. Fl. Angl. $310=$ cernua.

mollis, Poepp. E Endl. Nov. Gen. et Sp. iii. 49.Ecuador.

monticola, Poepp \& Findl, 1. c. 49, t. $255=$ rubifolia multifida, Desf. Cat. Hort Par ed. III $186=$ parviflora. mutica, Nutt, in Trans. Am. Phil. Soc Ser. II vii (1834) $368=$ Coreopsis macrocarpa.

myrrhidifolia, Tausch, in Flora, xix. (1836) 394.-Hab.? nivea, Linn. Sp. P1. $833=$ Melanthera hastata

nivea, Sw. ex Steud. Nom. ed. II. i. $203=$ Mclanthera deltoidea.

nodiflora, Linn. Sp. Pl. 832. - Ind. or

Novae-Caledoniae, Forst. ex Schlecht. in Linnaea, (1835-36) 480 (Cf. Glossogyne pinnatifida). -N Hebrid.

mudiflora, Steud. Nom, ed. II, i. 203 sphalm. = nodiftora. acymifolia Lam. Encyc i. 416; Illustr. t. 668. \& $3=$ Spilanthes alba.

odorata, Cav. Ic. i. 9. t. 13.-Mexic.

odorata, Dum.-Cours. Bot. Cult. iv. 241; G. Don, in

Loud. Hort. Brit. $236=$ grandiflora.

oleracea, Cav. ex Steud. Nom. ed. II. i. $203=$

Spilanthes Acmella.

ostruthioides, Sch. Bip. in Secm. Bot. Voy. Herald, 308.-Mexic

oxyodonta, DC. Prod. v. 600.-Ins. S. Doming.

paleacea, Vis. in Nuav. Saggi Acc. Padov. v. (1840) 266. - Nubia.

paniculata, Hook. E Arn. Bot. Beech. Voy. 66.-Ins, Tahiti.

paradoxa, D. Don, ex Hook. EN Arn. in Hook. Fourn. Bot. iii. (1840) 319.-Chili.

parviflora, Willd. Enum. Hort. Berol.840.-Sibiria; China.

patula, Gardn. in Hook. Lond. Journ. Bot. vii. (1848) $405=$ rubifolia.

panciflora, Poir. Encyc. Suppl. i. $630=$ parviflora.

pectinata, Sch. Bip. in Linnaea, xxxiv.(1865-66) 528 nomen. - Bolivia.

peduncularis, Gaudich. Voy. Freyc. Bot. 464.-Ins. Sandvic.

perianthomega, Steud. Nom, ed, II. i. 203, sphalm. Bignonia perianthomega.

petiolata, Nutt. in Journ. Acad. Philad. vii. (1834) 99 = connata.

pilosa, Linn. Sp. Pl. 832,-Ind. occ. ; Am, austr. pinnata, Noronha, in Verh. Batav. Gen. v. $(1790)$ ed

I. Art. IV. 8.-Malaya.

pinnatifida, Forst. ex DC. Prod. v. $593=$ Coreopsis micrantha.

pinnatifida, Buch.-Elam, in Wall. Cat. n. $3190=$ Glossogyne pinnatifida.

platycephala, Oerst. Ind. Sem. Haun. (1859) 27 ; et in Linnaea, xxx.(1859-60) 753=tripartita

polycephala, Sch. Bip. in Flora, xxxix. (1856) 360.Ins. Pacif.

portoricensis, Spreng. in DC. Prod. v. 601.-Porto Rico.

procera, D. Don, in Bot. Reg. t. 684.-Mexic.; Arizona.

procumbens, H. B. \& K. Nov. Gen. et Sp.iv. 232.Mexic.

pulcherrima, Sch. Bip. in Linnaea, xxxiv. (1S65-66) 528 , nomen-Bolivia.

pumila, Stend. Nom. ed. I. $108=$ tripartita. purpurea, DC. Prod. v. $604=$ Cosmos purpureus. quadrangularis, DC. 1. c. $600=$ pilosa quadriaristata, DC. 1. c. $595=$ chrysanthemoides. quadriseta, Hochst. ex Oliver E Hiern, in Oliver, Fl Trop. Afr. iii. 393.-Alr. trop.

auingueradiata, Zea, ex Steud. Nom. ed. I. 108 grandiflora.

radiata, Thuill. Fl. Par. ed. II. $492=$ tripartita.

Ramtilla, Wall. Cat. n. $3191=$ Heliopsis platyglossa reflexa, Link, Enrum. Hort. Beroh. ii. 300.-Misic repens, D. Don, Prod. F1. Nep. $180=$ tripartita.

\section{BIDENS :}

reptans, G. Don, in Sweet, Hort. Brit. ed. III. $360=$ tripartita.

reptans, Sch. Bip. in Secm. Bot. Voy. Herald, $308=$ Cosmos diversifolius

rhombifolia, Sch. Bip. in Bonplandia, iv. (1856) 54.Peruv.

Riedelii, Baker, in Mart. Fl. Bras. vi. III. 246.-Bras. rigida, Hort. Calc. ex C. B. Clarke, Comp. Ind. 141 $=$ Glossogyne pinnatifida.

riparia, $H . B$. O $K$. Nov. Gen. et $S_{p}$. iv, 236.Venezuela.

rosea, Sch. Bip. in Seem. Bot. Voy. Herald, $308=$ Cosmos pílosus.

rubifolia, H. B. E K. Nov. Gen.et Sp. iv. 237. t. 381. -Ecuador.

rugulosa, Turcz. in Bull. Soc. Nat. Mosc. xxiv. (1851) 1. 184.-Peruy.

sambucifolia, Cav. Ic. iii. 15. t. 219.-Peruv, Mexic. sandwicensis, Less. in Linnaea, vi. (1831) 508= peduncularis.

Sartorii, Sch. Bip. in Seem. Bot. Voy. Herald, 307. Mexic.

scabiosoides, Ortg. in Regel, Gartenf. (1861) 408.Mexic.

scabiosoides, Sch. Bip. in Seem. Bot. Voy. Herald, 308 $=$ Cosmos scabiosoides.

scandens, Linn. Sp. Pl. $833=$ Salmea grandiceps,

scandicina, $H . B$. Eo $K$. Nov. Gen, et Sp. iv, 235 Ecuador.

Schimperi, Sch. Bip.ex Walp. Rep. vi 168.-Abyss.

scorzoneraefolia, Baker, in Mart. Fl. Bras. vi. III. 247. -Bras.

Seemannii, Sch. Bip. in Seem. Bot. Voy. Herald, 307. -Mexic.

serrata, Pav. ex DC. Prod. v. 597.-Peru

serrulata, Desf. Cat. Hort. Par. ed. III. (1829) 186 Coreopsis aurea.

serrulata, Sch. Bip. in Flora, xxxix. (1856) 361.-Ins. Pacif.

silvaticus, Sch. Bip. ex Baker, in Mart. Fl. Bras. vi. III. $245=$ rubifolia

speciosa, Gardn. in Hook. Lond. Fourn. Bot.iv. (1815) 126.-Bras.

squarrosa, H. B. E K. Nov. Gen. et Sp. iv. 238.Venezuela.

squarrosa, Less, in Linnaea, v, (1830) $156=$ rubifolis striata, Schott, ex Sweet, Brit. Flow, Gard. t. $23 i$ = pilosa.

subalternans, DC. Prod: v. $600=$ pilosa

sulphurea, Sch. Bip. in Seem. Bot. Voy. Herald, $308=$ Cosmos sulphureus.

sundiaca, Blume, Bijdr. $913=$ pilosa

tenella, Linn. Pl. Rar. Afr. 17; Amoen. Acad, vi. 96. -Afr. anstr.

tenuifolia, Labill. Sert. Austr. Caled. 44 . t. $45=$ Glossogyne tenuifolia.

tenuifolia, Tausch, in Flora, xix. (1836) 395.-Hab.

tenuisecta, A. Gray, Pl. Fendl. 86-Am, bor. occ.

tereticaulis, DC. Prod. v. $598=$ rubifolia.

tetragona, $D C$.. . c. 596.-Mexic.

tinctoria, Baill. Hist. Pl. viii. $305=$ Coreopsis tioctoria.

tridentata, Turcz. in Bull. Soc Nat. Mosc. xxiv.

(1851) I. $183=$ Glossogyne tridentata.

trifida, Roxb. F1. Ind iji. $411=$ tripartita

trifoliata, Gueldenst. ex Ledeb. Fl. Ross ii. $510^{\circ}=$

tripartita.

tripartita, Bigel. Fl. Bost. ed, II. 294=connala,

tripartita, Boj. Hort. Maurit. $183=$ pilosa.

tripartita, Linn. Sp. Pl. \$ $\$ 1$ - Europ ; Sibit.

triplinervia, H. B. E $K$. Non. Gen. et Sp. iv. 2s1-

Mexic.

tuberosa, Sch. Bip. in Linnaea, xxxiv. (1565-66) 528 nomen.-Bolivia.

yalladolidensis, Sch. Bip. in Seem. Bot. Voy. Herald, $308=$ Cosmos crithmifolius.

valparadisiaca, Colla, in Mem. Acc Torin, sxviii. 1895) 12. $24=$ chilensis.

cariabilis, Baill. Hisc. P'. viii. $905=\mathrm{N}$ ahlia variabilis. venosa, Gardn. in Hlook. Lond. Journ. But. vii. (1sts $405=$ graveolens.

verticillata, Baill. Hist. PI. viii. $\$ 05=$ Corcupsis verticillata.

verticillata, Linn. Sp. Pl. \$\$3.-Mexic

II allichii, DC. Prod. v. 505 - bipinnat.

lianzewiczinna, Regrel, in Flora, xxii. 1849; 1 s. Guntemala. 
BIDWILLIA, Herb. ex Lindl. Veg. Kingd. 205 (1847) nomen. (Liliac.), Benth. \& Hook. f. Gen. iii. 703.

BIEBERSTEINIA, Steph. ex [Fisch.] Hort. Gorenk. ed. I. 88 (1808); et in Mém. Soc. Nat. Mosc. í. (1811) 89. t. 9. GERANIACEAE, Benth. \& Hook. f. i. 271. DaYenia, Michx, ex Jaub. \& Spach, in Ann. Sc. Nat. Sér. III. vi. (1846) 137.

ambigua, Jaub. \& Spach, in Ann. Sc. Nat. Sér. III. vi, $(1846) \quad 141$ = multifida.

Aucheri, Jaub. \& Spach, Illustr. ii. $110=$ multifida. brachypetala, Jaub. \& Spach, 1. c. 113. to $192=$ multi. fida.

Emodii, faub. E Spach, l. c. 109.-Tibet. oec leiosepala. Faub. E Spach, l. c. 114. t. 193.-Persia. multifida, DC. Prod, i. 708.-Syria; Persia ; Soongaria. odora, Royle, Illustr. Bot. Himal. i. 153. t. $30=$ Emodii.

odora, Steph.ex [Fisch.] Hort. Gorenk. ed. I. (1808) 88; et ex Mém. Soc. Nat. Mosc. i. (1811) 89.-Persia. Orphanidis, Boiss. Diagn. Ser. II. i. 113.-Graecia Cilicia.

Rucheri, Walp. Ann. i. $153=$ multifida

BIELSCHMEIDIA, Panch. \& Sebert, Not. Bois Nouv. Caléd. $176(1874)=$ Beilschmiedia, Nees (Laurin.)

BIELZIA, Schur, Enum. Pl. Transs. $409(1866)=$ Cen taurea, Linn. (Compos.)

Schwarzenbergiana, Schur, 1. c. = C. ruthenica.

BIENERIA, Reichb. f. in Bot. Zeit. xi. (1853) 3. t. $1=$ Chloraea, Lindl. (Orchid.).

boliviana, Reichb. f. 1. c,-Bolivia

BIENERTIA, Bunge, in Act. Hort. Petrop. vi. (1879) II. 425 ; et in Boiss. Fl. Orient. iv. 945 (1879) CHENOPODIACEAE, Benth. \& Hook. f. iii. 68.

cycloptera, Bunge, ll. cc.-Persia.

BIFOLIUM, G. Gaertn. Mey. \& Scherb. Fl. Wett. i $175(1799)=$ Maianthemum, Wiggers (Liliac).

cordatum, G. Gaertn. Mey. \& Scherb. 1. c. $209=$ M. Bifolium.

BIFORA, Hoffm. Umb. Gen. ed. II. 191 (1816) UMBELLIFERAE, Benth. \& Hcok. f. i. 927.

Atkema, DC. Prod. iv. 250 (1830).

BiforIs, Spreng. Anleit. ii. I. 635 (1817) ; et in Roem. \& Schult. Syst. vi. $448(1820)$

Corion, Link \& Hoffmgg. Fl. Port. ii. 457 (1820).

americana, Benth. E' Hook.f.ex S. Wats. Bibl. Index, 415.-Am. bor.

benghalensis, Wall. [Cat. n. 588] ex DC. Prod. iv. 140 Oenanthe benghalensis.

dicocca, Hoffm. Umb.Gen. ed. II. 192.-Europ.; Oriens. flosculosa, Bieb. Fl. Taur. Cauc. iii. $234=$ dicocca.

glauca, Wall. Cat. n. $587=$ Oenanthe bengalensis.

Loureiri, Kostel. Allg. Med.-Pharm. Fl. iv. 1183.Cochinch.

radians, Bieb. Fl. Taur. Cauc. Suppl. 233.-Europ. austr.; Oriens.

testiculata, DC. Prod.iv. $249=$ dicocca.

testiculata, Roth, Enum. Pl. Phan. Germ. i. 888.Reg. Mediterr.

BIFORIS, Spreng. Anleit. ii. I. 635 (1817); et in Rnem. \& Schult. Syst. vi. $448 \quad(1820)=$ Bifora, Hoffm (Umbellif.).

BIFRENARIA, Lindl. Gen, et Sp. Orchid. 152 (1833). ORCHIDEAE, Benth. \& Hook. f. Gen. iii. 546.

Adre, Rafin. F1. Tellur. ii. 101 (1836).

Stenocoryne, Lindl. Bot. Reg. xxix. (1843) Misc. 68.

albiflora, Rodrig. Orch. Nov. ii. 212, nomen.-Bras. atropurvurea, Lindl. Gen. et Sp. Orch. 152-Bras. aurantiaca, Lindl. Bot. Reg. (1836) t. 1875. - Ind. occ aurea, Rodrig. Orch. Nov. ii. 212.-Bras. aureofulva, Lindl. Bot. Reg. (1843) Misc. 52.-Bras. bella, Lem. Jard. Fleur, iii. $(1852-53)$ t. $325=$ Coelia bella.

bicornaria, Reichb. f. in Hamb. Gartenz. xix. (1863) 12.-Bras.

\section{BIFRENARIA :}

chloroleuca, Rodrig. Orch. Nov, ii. 212, nomen.-Bras. calcarata, Rodrig. l. c. 213.-Bras.

clavigera, Reichb. f. in Hamb. Gartenz. xxi. (1865) 296.-Bras.

fragrans, Rodrig. Orch. Nov. ii. $213=$ inodora.

Hadwenit, Lindl. in Paxt. F1. Gard. ii. $67(1851-52)=$ Scuticaria Hadweni

Harrisoniae, Reichb. f. in Bonplandia, iii. (1855) 217.

inodora, Lindl. Bot. Reg. xxix. (1843) Mise. 48.Bras.

leucopetala, Rodrig. Orch. Nov. ii. 212, nomen.-Bras. leucorrhoda, Reichb. $f$. in Otto, Hamb. Gartenz. xy. (1859) 54.-Hab.?

longicornis, Lindl. Bot. Reg. (1838) Misc. 93.Guiana.

melanopoda, Klotzsch, in Otto E Dietr. Allg. Gartenz. xxiii. (1855) 105.-Bras.

mellicolor, Reichb. f. in Gard. Chron. (1858) I. 622.Bras.?

parvula, Reichb.f. in Walp. Ann. vi. 547.-Bras. racemosa, Lindl. Bot. Reg. (1843) Misc. 52.-Bras. sabulosa, Rodrig. Orch. Nor. i. 111.-Bras. vinosa, Rodrig. l. c. ii. 212, nomen.-Bras.

vitellina, Lindl. Bot. Reg. (1843) Misc. 52.-Bras.

tyrianthina, Reichb. f. Xenia, i. 61, 223.-Bras.

Wageneri, Reichb. $f$. in Bonplandia, ii. (1854) 17.Venezuela.

BIGAMEA, Koen. ex End1. Gen. 1183 (1840)=Ancistrocladus, Wall. (Dipterocarp.).

BIGELONIA, Rafin. in Journ. Phys. 1xxxix. (1819) 289 , sphalm. = BIGELOWIA, Rafin. = Arenaria, Rupp. (Caryoph.)

elongata, Rafin.1. c. = A. lanuginosa.

montana, Rafin. 1. c. = A. montana,

BIGELOVIA, Spreng. Syst. i. $366,404(182 \gamma)=$ Spermacoce, Linn. (Rubiac.)

alata, Bartl. ex Steud. Nom. ed. II. i. $203=$ S. latifolia, longifolia.

angustifolia, Span. in Linnaea, xv. (1841) $320=\mathrm{S}$. stricta?

commutata, Spreng. Syst. i. $404=$ Diodia maritima.

cornifolia, Heynh. Nom. i. $121=$ S. capitata.

corymbosa, Bartl. ex DC. Prod. iv. $550=\mathrm{S}$. corymbosa.

discolor, Bartl. ex DC. 1. c. 545 (=Borreria discolor)

distans, Hook. \& Arn. Bot. Beech. Voy. 295=S distans.

elata, Bartl. ex DC. Prod. iv. 544=S. latifolia, longifolia.

eryngioides, Hook. \& Arn. in Hook. Bot. Misc. iii. (1833) $360=\mathrm{S}$. diffusa.

gracilis, Spreng. Syst. i. $404=\mathrm{S}$. ocymoides

gracilis, Miq. in Verh. Nederl. Inst. Reeks III. v. (1852) $13-$ Malaya.

Kleinii, Wight \& Arn. Prod. $437=$ S. stricta.

laevicaulis, Miq. FI. Ind. Bat. ii. $335=\mathrm{S}$. ocymoides.

lasiocarpa, Wight \& Arn. Prod. $437=$ S. stricta.

linearis, Spreng. Syst. i. $405=$ Diodia hyssopifolia.

linifolia, Spreng. 1. c. $404=\mathrm{S}$. laevis.

mitracarpoides, Miq. Fl. Ind. Bat. ii. $334=$ S. stricta.

myriantha, Miq. 1. c. $=$ S. stricta.

ocymoides, Miq. 1. c. $335=\mathrm{S}$. ocymoides.

parviflora, Sieber, ex DC. Prod. iv. $542=$ S. ocymoides. parviflora, Spreng. Syst. i. $405=\mathrm{S}$. ocymoides.

psylloides, Bartl. ex DC. Prod. iv. $547=\mathrm{S}$. tenella.

pumila, Span. in Linnaea, xv. (1841) $320=\mathrm{S}$. pumila. pusilla, Spreng. Syst. i. $405=\mathrm{S}$. pusilla.

Roxburghiana, Wight \& Arn. Prod. $437=$ S. stricta.

Roxburghiana, Wight, 'Cat. n. 1360 '=S. ocymoides.

setidens, Miq. Fl. Ind. Bat. ii. $336=\mathrm{S}$. stricta

sociata, Span. in Linnaea, xv. (1841) 320,-Ins. Tímor.

striata, Span. 1. c. $321=\mathrm{S}$. stricta.

stricta, Blume, Bijdr. $945=\mathrm{S}$. stricta.

suaveolens, Spreng. Syst. i. $404=\mathrm{S}$. tenella.

tenera, Heynh. Nom. i. $122=$ S. tenera.

tenuis, Heynh. 1. $\mathbf{c}=\mathrm{S}$, tenuis.

umbellata, Spreng, Syst. i. 405.-Bras.

vaginata, Spreng. 1. c. $=\mathrm{S}$. laevis.

verticillata, Spreng. 1. c. $404=\mathrm{S}$. verticillata.

Zollingeriana, Miq. Fl. Ind. Bat. ii. 336.-Malaya.

BIGELOVIA, Spreng. Neue Entdeck. ii. 150 (1821)= Samyda, Linn brasiliensis, Spreng. 1. $c_{0}=\mathrm{S}$. Selloi.
BIGELOVIA, Sm, in Rees, Cyclop, xxxix $(1819)=$ Forestiera, Poir. (Oleac.)

acuminata, Sm. 1. c. = F. acuminata.

cassinoides, Sm. 1. c. = F. cassinoides

ligustrina, Sm. 1. c. $=$ F. ligustrina.

porulosa, Sm.1. c. = F. porulosa.

BIGELOWIA, DC. ex Ging. in DC. Prod. i. 290 (1824 $=$ Noisettia, H. B. \& K. (Violar.).

BIGELOWIA, DC. Prod.iv. $540(1830)=$ BIGELOVIA Spreng. = Spermacoce, Linn. (Rubiac.).

BIGELOWIA, DC. Prod. v. 329 (1836). COMPOSIT AE, Benth. \& Hook. f. ii. 1232.

Chrysothamnus, Nutt. in Trans. Am. Phil. Soc. Ser. II. vii. (1841) 323 .

Isocoma, Nutt. 1. c. 320 (1841).

Linosyris, Torr. \& Gray, Fl. N. Am. ii. 232 (1841) acradenia, Greene, in Bull. Torrey Club, x. (1883) 126. - Am. bor, occ

albida, M. E. Fones, ex A. Gray, in Proc. Am. Acad. xvii. (1881-82) 209,-Am. bor, occ.

arborescens, A. Gray, $l$. $c$. viii. (1873) 640.-Calif.

Bigelovii, A. Gray, l. c. xvii. (1881-82) 209.-N. Mexic.; Colorado.

Bolanderi, A. Gray, l.c. viii. (1873) 641--Calif

brachylepis, A. Gray, in Bot. Calif. i. 614.-Calif.

carnosa, Benth. \& Hook. f. Gen. ii. 1232, $255=$ Aster carnosus.

ceruminosa, A. Gray, in Proc. Am. Acad. viii. (1873) 643.-Calif.

Cooperi, A. Gray, l.c.640.-Calif.

coronopifolia, A. Gray, l.c. 638.-Texas.

depressa, A. Gray, l. c. 643 .-Am. bor. occ

diffusa, A. Gray, l. c. 640 --Calif

Douglasii, A. Gray, 1. c. $644=$ viscidiflora.

dracunculoides, DC. Prod. v, 329-Am, bor.

Drummondii, A. Gray, in Proc. Am. Acad. viii. (1873) 639 - Texas

Engelmanni, A. Gray, l.c.xi. (1876) 75.-Am. bor. occ fuliginea, A. Gray, l. c. viii. (1873) 638-Ecuador.

furfuracea, Greene, in Bull. Calif. Acad. i. n. 3 (1885) 87.-Calif.

graveolens, A. Gray, in Proc. Am. Acad. viii. (1873) $644=$ dracunculoides

Greenei, A. Gray, l. c. xi. (1876) 75.-Colorado.

Hartwegi, A. Gray, ex Hemsl. Biol. Centr. Am. Bot. ii. 115,-Mexic.

Howardi, A. Gray, in Proc. Am. Acad. viii. (1873) 641.-Colorado

hypolenca, A. Gray, l. c. 638.-Ecuador.

intricata, A. Gray, 1. c. xvii. (1881-82) 208=Aster carnosus.

juncea, Greene, in Coult. Bot. Gazette, vi. (1881) 184 -Arizona.

lanceolata, A. Gray, in Proc. Am. Acad. viii. (1873) $639=$ viscidiflora

leiosperma, A. Gray, Syn. Fl. N. Am. і. и. 139.Am. bor. occ.

Mandonii, Benth. E Hook. f. Gen. ii. 1232, 255.-Bolivia?

Menziesii, A. Gray, in Proc. Am. Acad. viii. (1873) 638.-Am. bor. occ

missouriensis, DC. Prod. $\nabla .329=$ dracunculoides.

mohavensis, Greene, ex A. Gray, Syn.Fl. N. Am. i. II. 138.-Am. bor. occ.

nepadensis, A. Gray, l. c. 136.-Calif

nudata, $D C$. Coll. Mém. ix. t. 5.-Am. bor. or.

oppositifolia, A. Gray, in Proc. Am. Acad. xv. (1880) 32.-Mexic.

paniculata, A. Gray, l.c. viii. (1873) 644.-Am. bor. occ Parishii, Greene, in Bull. Torrey Club, ix. (1882) 62 - Calif.

Parryi, A. Gray, in Proc. Am. Acad. viii. (1873) 642 - Colorado.

pluriflora, A. Gray, l. c. 639.-Colorado?

pulchella, A. Gray, l. c. 643.-Texas; N. Mexic.

ramulosa, Benth. E Hook. f. Gen. ii. 1232, 255.-Am. bor.

rupestris, Greene, in Coult. Bot. Gazette, vi. (1881) $183=$ Aplopappus cuneatus.

spathulata, A. Gray, in Proc. Am. Acad. xi. (1876) 7 = Aplopappus cuneatus.

teretifolia, A. Gray, $l$. c. viii. (1873) 644.-Calif, ; Arizona.

tridentata, Greene, in Bull. Torrey Club, x. (1883) 126 = veneta. 


\section{BIGELOWIA :}

uniligulata, DC. Prod. v, $329=$ Solidago neglecta.

Vaseyi, A. Gray, in Proc. Am. Acad. xii. (1877) 58. Colorado.

veneta, A. Gray, l. c. viii. (1873) 638.-Calif.; Mexic. virgata, DC. Prod. v. $329=$ nudata.

viscidiflora, $D C$. $l$. $c$. vii. 279.-Am. bor.

Wrightii, A. Gray, in Proc. Am. Acad. viii. (1873) 639 , -Am. bor. occ.

BIGGINA, Rafin. Alsog. Am. $14(1838)=$ Salix, Tourn.

angustata, Rafin. 1. $\mathrm{c}_{.}=\mathrm{S}$. cordata

argentea, Rafin. $1 . \mathrm{c} .=\mathrm{S}$, argentea.

conifera, Rafin. $1, \mathrm{c}=\mathrm{S}$, humilis.

BIGLANDUIARIA, Karst. in Linnaea, xxviii. (1856) 416. GENTIANEAE azurea, Karst. l. c. 417.-N. Granat.

BIGLANDULARIA, Seem. in Gard. Chron. (1868) 738 Sinningia, Nees (Gesnerac.).

conspicua, Seem. 1. c.-Bras.

BIGNONIA, [Tourn.] Linn. Syst. ed. I (1735 BIGNONIACEAE, Benth. \& Hook. f. ii. 1033. ANIsostichus, Bur. Monog. Bign. 48. t. 6 (1864). Clematitaria, Bur. 1. c. 44 (1864)

Cremastus, Miers, in Proc. Roy. Hort. Soc. iii. (1863) 187

Cupulissa, Rafin. Fl. Tellur. ii. 57 (1836).

Cydista, Miers, in Proc. Roy. Hort. Soc. iii. (1863) 191.

DoxanTha, Miers, 1. c. 188 (1863).

Endoloma, Rafin. Sylva Tellur. 79 (1838).

Hieranthes, Rafin. 1. c. (1838)

ODISCA, Rafin. 1. c. 80 (1888).

Panterpa, Miers, in Proc. Roy. Hort. Soc. iii. (1863) 195.

Paragonia, Bur. in Bull. Soc. Bot. Fr. xix. (1872) 17.

Pentelesia, Rafin. Sylva Tellur. 146 (1838)

Petastoma, Miers, in Proc. Roy. Hort. Soc. iii. 1863) 193

Phaedranthus, Miers, 1. c. 182 (1863)

Pleonotoma, Miers, 1. c. 184 (1863).

Pongelia, Rafin. Sylva Tellur. 78 (1838).

Proterpia, Rafin. 1. c. 80 (1838).

Pyrostegia, Presl, in Abh. Bochm. Ges. V. iii.

1845) 523 (Bot. Bemerk. 93).

SEREREA, Rafin. Sylva Tellur. 107 (1838)

STizophyllum, Miers, in Proc. Roy. Hort. Soc. iii. (1863) 197.

Temnocydi, Mart. ex DC. Prod. ix. 143 (1845).

acutiflora, Mart. ex DC. Prod. ix. 181=Lundia niticlula.

acutissima, Cham. in Linnaea, vii. (1832) 691,-Bras. acutistipula, Schlecht. l. c. xxyi. (1853-55) 375. Mexic.

adenophylla, Wall. Cat. n. 6502=Heterophragma adenophyllum.

adhatodaefolia, Facq. Fragm. 61.-Wenezuela.

aequinoctialis, Linn. Sp. Pl, 623.-Am, trop.

aequinoctialis, Sieber, ex DC. Prod, ix. $146=$ B. Unguiscati.

aesculifolia, H. B. \& K. Nov, Gen. et Sp. iii. $140=$ Tabebuia aesculifolia

Aesculus, Desf. Cat. Hort. Par. ed. III. $397=$ Tecoma Aesculus.

affinis, $G$. Don, Gen, Syst, iv, 217-Bras.

africana, Lam. Encyc. i. 424.-Afr, trop.

Agnusacastus, Cham. in Linnaea, vii. (1832) $673=$ Arrabidaea Agnus-castus.

alata, Pav, ex DC. Prod. ix. 224= Tecoma Guarume alba, Aubl. PI. Gui, ii, 653 = Spathodea bracteosa.

albida, Blume, in Verh. Bat. Gen, ix. (1825) $195=$

Aeschynanthus purpurascens.

albide, Stend. Nom. ed. II. i. 204=Aeschynanthus angustifolia.

albiflora, Salsm. ex DC. Prod. ix. 167.-Bras.

allamandacfora, Benth. ex Miers, in Proc. Roy. Hort.

Soc iii. (1863) 186, nomen.-Bras.

alliacea, Lam. Encyc. i. 421.-Guiana.

amara, Loud. Hort. Brit. 483 ; ex G. Don, Gen. Syst. iv. 222 - Stereospermum hypostictum.

amoena, Wall. Cat. n. 6512 ; et Pl. As. Rar. ii. 78. t.

$183=$ Stereospermum hypostictum.

anastomosans, DC. Prod. ix. 144.-Madag.

\section{BIGNONIA :}

Andrieuxii, DC. Prod. ix. 156,-Mexic

angrensis, Vell. Fl. Flum 246; vi. t. 23-Bras. angustifolia, Blume, Cat. Hort. Buitenz. $82=$ Aeschynanthus angustifolia

antisyphilitica, Mart. Reise Bras. i. $283=$ Cybistax antisyphilitica.

apurensis, H. B. E K. Nov. Gen. et Sp. iii. 138.-

Venezuela.

aquatilis, E. Mey, in Nov, Act. Nat. Cur. xii. (1825) $780=$ Tabebuia fluviatilis.

araliacea, Cham, in Linnaca, vii. (1832) 683=Tecoma araliacea.

argyrea, André, in Rev. Hortic. (1865) 251.-Hab.?

argyreo-violascens, Hort. ex Lem. Illustr. Hortic (1866) t. 469.-Hab.

Arrabidae, Steud. Nom. ed. II. i. 204.-Bras.

Arthrevion, Mart. Herb. Fl. Bras. 287=Distictis Arthrerion.

articulata, Desf. in Poir. Encyc. Suppl. i. $636=$ Phyllarthron Noronhianum.

arvensis, Vell. Fl. Flum. 250 ; vi. t. $40=$ Anemopaegma mirandum.

atrovirens, DC. Rev. Bign. ex Prod. ix. $171=$ Tecoma atrovirens.

atrovirens, Roth, Nov. Sp. $284=$ Dolichandrone falcata.

aurea, Manso, Enum. 40=Tecoma atrea,

auriculigera, Mart. ex DC. Prod, ix, $194=$ Pithecoctenium stipulacea

australis, Ait. Hort. Kew. ed. II. iv. $34=$ Tecoma anstralis.

Azedarachta, Kon. \& Sims, Ann. Bot. i. (1805) $578=$ Millingtonia hortensis.

Baclei, DC. Rev. Bign. ex Prod. ix. 171=Pithecoc tenium cynanchoides.

Balbisiana, DC.Prod. ix. 153.-Bras.

Banaibanai, Callery, ex Bur, in Baill. Adansonia, ii. 1861-62) $195=$ Sterospermum Banaibanai.

barbata, E. Mey. in Nov. Act. Nat. Cur, xii. (1825) $782=$ Tecoma barbata

Bellas, Sellow, ex Steud. Nom. ed. II. i. 204.-Bras,

bibracteata, Bert. ex DC. Prod. ix. $240=$ Bravaisia floribunda.

Bidwilliana, Regel, Cat. Pl. Hort. Aksakov. 19.$\mathrm{Hab}$ ?

bijuga, Vahl, Symb. Bot. ii. 68.-Madag.

binata, Thunb. Diss. P1. Bras. ii. 35. n. $27=$ Anemopaegma racemosum.

bipinnata, Salzm. ex DC. Prod. ix. $230=$ Jacaranda nitida.

Blanchetii, DC. l. c. 164.-Bras,

Bojeri, $D C$. l. c. 165.-Madag.

botryoides, Cham. in Linnaea, vii. (1832) $100=$ Pithecoctenium botryoides.

brachycalyx, Klotzsch, in Schomb. Fauna E Fl. Guy. 1085.-Guian.

brachypoda, $D C$. Prod. ix. 145.-Bras.

bracteata, Cham in Linnaea, vii. (1832) $692=$ Adeno calymna bracteatum.

bracteolata, DC. Prod. ix. 157.-Bras.

bracteosa, $D C . \dot{l}$. c. 165.--Madag

brasiliana, Lam. Encyc. i. $425=$ Jacaranda brasiliana. buccinatoria, Mairet, ex DC. Prod. ix. 195.-Mexic. caerulea, Linn. Sp. Pl, 625 = Jacaranda caroliniana. callistegioides, Cham. in Linnaea, vii. (1832) $712=$ Cuspidaria callistegioides.

calycina, $D C$. Prod. ix. 160-Bras.

campanulata, Cham. in Linnaen, vii. (1832) $711=$ Cuspidaria campanulata.

candicans, Rich. in Act. Soc. Hist. Nat. Par. i. (1792) $110=$ Arrabidaea candicans.

capensis, Thunb. Prod. PI. Cap. $105=$ Tecoma capensis.

capreolata, Linn. Sp. Pl.624.-Am. bor.

carichanensis, H.B. E K. Nov. Gen. et Sp. iii. 137.Venezuela.

Caroba, Vell. Fl. Flum. 250 ; vi. t. $43=$ Jacaranda Caroba.

Carolinae, Lindl. Bot. Reg. (18t2) sub t. 45.-Hab. caryophyllea, Bello, in Anal. Soc. Esp. Hist. Nat. x. (1881) 293.-Porto Rico.

cassinoides, Lam. Encyc. i. $\$ 18=$ Tabebuia cassinoides.

castaneacfolia, DC. Prod. ix. 145.-Peruv,

Catalpa, Linn.Sp. Pl. $622=$ Catalpa bignonioides.

Catharinae, DC. Rev. Bign. ex Prod, ix. $172=$ Pithe coctenium Catharine.

\section{BIGNONIA}

caudata, DC. Prod. ix, $166=$ Stereospermum caudatum.

caudata, Miq. ex C. B. Clarke, in Hook. f. Fl. Brit. Ind, iv. $382=$ Stereospermum chelonoides cauliflora, Sieber, ex DC. Prod. ix. $241=$ Colea flori-
bunda.

Chamberlaynii, Sims, Bot. Mag, t. 2148. -Bras.

chelonoides, Linn. f. Suppl, $252=$ Stereospermum chelonoides.

Cherere, Lindl. Bot. Reg. t. $1301=$ buccinatoria

Chica, Humb. \& Bonpl. Pl. Aequin. 1. 107. t. 31.Venezuela.

chinensis, Lam. Encyc. i, $423=$ Tecoma grardiflora, chondrogona, Miq. in Linnaea, xviii. (1814) 611. Guiana.

chrysantha, Jacq. Hort. Schoenb. ii. $45=$ Tecoma chrysantha.

chrysoleuca, H. B. E K. Nov. Gen. et Sp. iii. 134 -Venczuela.

Cicutaria, Koen. ex Mart. in Denkschr. Akad, Muench. vi. $(1820) 153=$ Millingtonia hortensis.

ciliata, Wawra, in Oestr. Bot. Zeitschr. xii. (186? 237.-Bras.

cinerea, DC. Rev. Bign. ex Prod. ix. $172=$ Pithecoc tenium cinereum.

cinnamomea, DC. Prod. ix, 164,-Bras.

citrifolia, Vitm. Summa Veg. iii. 511.-Hab.

Clematis, H. B. \& K. Nov. Gen, et Sp, iii. 141.

Venezucla.

coccinea, Steud. Nom. ed. T. $109=$ Tecoma radicans.

coccinea, Vell. Fl. Filum. 250 ; vi. t. 42.-Bras.

cognata, Cham. in Linnaea, vii. (1832, 703.-Bras.

Coito, Vell. Fl. Flum. 243 ; vi.t. $19=$ Spathodea Coito.

Colais, Buch.-Ham. ex Wall. Cat. sub n. $6501=$

Stereospermum chelonoides.

Colei, Boj. ex Hook. Bot. Mag. t. 2817 = Colea mauri tiana.

colorata, Poir. Encyc. Suppl. i. 634 - Arrabidata candicans.

comosa, Cham, in Linnaea, vii. (1832, $6933=$ Adeno. calymna comosum.

comosa, Roxb. Hort. Beng. [95]; Fl. Ind. iii. 103.Ins. Moluc

compressa, Lam. Encyc. i. $424=$ Colea decora.

conjugata, Vell. F1. Flum. 243 ; vi.t. $18=$ Arrabidaea conjugata.

conspicua, Rich. ex DC, Prod, ix, $221=$ Tecoma conspicua.

convoluta, Vell. Fl. Flum. 218; vi. t. 31 Cuspidaria puberula.

Copaia, Aubl. Pl. Gui. ii. 650 t $262=$ Jacaranda Copaia.

corallina, Facq. Fragm, 3\%.-Venezuela.

corchoroides, Cham. in Liunaea, vii. $1832,705^{\circ}=$ Arrabidaea corchoroides.

cordata, Vell. Fl. Flum. 247; vi. t. $29=$ Lundia cordata.

cordifolia, DC, Prod. ix, 162,-Bras.

coriacea, Sellow, ex Steud. Nom. ed. 1I. i. 20t, $205=$

Selloi.

corymbifera, Vahl, Ecl. Am. ii. 45. t. 17.-Am. austr.

craterophora, DC. Prod. ix. 147.-Bras.

crenata, Lodd. ex Loud. Hort. Brit. 212.-Ind. or.

crispa, Buch.-Ham, ex Roxb. Hort. Beng. $4 \tilde{j}$; Fl. Ind.

iii. $103=$ Dolichandrone crispa.

crucifera, Bert, ex DC. Prod, ix. $213=$ Tabebuia rufinervis.

crucigera, Linn. Sp. Pl. $624=$ capreolata

cujabana, DC. Prod. ix. 16t.-Bras.

cuncifolia, $D C$. $6.15 \pi$ - Babia.

cuprea, Cham. in Linnaea, vii. (1832 605.-Hms.

cupulata, Splitg. in Hoev. \& De l'rie'se, Ti ... in . $1 \mathrm{x}$

(1842) 6.-Brs.

curialis, Vell. Fl. Flum. 259 ; vi. t. $55=$ Jacnmanda curialis.

cuspidata, Boj. ex DC. l'rod. ix. $243=$ l'eriblema cuspidata.

Cymbalum, Cham, in Linnaea, vii. 1832 718.-1Bms cymosa, Vell. Fl. Flum. 249; vi. t. S6.-Bms

dasyantha, DC. Rev. Bign. ex A. I)C. Prod ix. 17: (= Pachyptera dasyantha).-Bras.

decipiens, Lodd. ex Lossd. Hort. Brit. 242. - Am. austr.

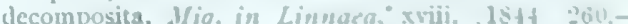
(ivians.

densiffora, Mart. ex DC. I'rud. ix. 181 = Lun ing densillura.

dentata, $D C$. I. c. 102 - liras 


\section{BIGNONIA :}

dichotoma, Facq. Enum. Pl. Carib. 25.-Am. austr. dichotoma, Vell. Fl. Flum. 248 ; vi. t. 32.-Bras. difficlis, Cham in Linnaea, vii, 1832$) 714$ - Bras. digitalis, Vell. F1. Flum. 251; vi. t. $47=$ Zeyheria montana.

digitata, E. Mey. in Nov. Act. Nat. Cur. xii. (1825) $\tau 82=$ Tecoma Meyeriana.

discolor, Boj. ex DC. Prod. ix. $165=$ Bojeri.

discolor, R. Br. in Salt, Voy. Abyss. App. 64, nomen. -Abyss.

discolor, Rich. Sert. Astrol. p. xxix = moluccana.

diversifolia, $H . B$. E K. Nov. Gen. et $S p$. iii. 133.Mexic.

dolichoides, Cham. in Linnaea, vii. (1832) 696.-Bras.

Dombeyana, DC. Rev. Bign. ex A. DC. Prod. ix. $172=$

Delostoma nervosum?

Doniana, DC. Prod. ix. 145.--Bras.

dubia, Linn. Pl. Surin.n.77; Amoen. Acad. viii. 258 - Guiana.

echinata, Aubl. Pl. Gui. ii. $648=$ Pithecoctenium Aubletii.

echinata, Jacq. Enum. Pl. Carib. 25=Pithecoctenium muricatum.

ehretioides, Cham. in Linnaea, vii.(1832) 704.-Bras.

elegans, Cham.l.c. 702.-Bras.

elegans, Vell. Fl. Flum. 247 ; vi. t. $27=$ exserta.

elliptica, Cham, in Linnaea, vii. (1832) $686=$ Tecoma

$$
\text { elliptica. }
$$

elliptica, Thunb. Diss. Pl. Bras. iii. 34.-Bras.

elliptica, Vell. 1. c. 250 ; vi. t. $44=$ Jacaranda elliptica.

elongata, Vahl. Ecl. ii. 45. t. 16.-Am. austr.

erubescens, DC. Prod. ix. 157.-Bras.

euphorioides, Boj. Hort. Maurit. $219=$ Stereospermum

euphorioides.

exoleta, Vell. Fl. Flum. 248 ; vi. t. 30.-Bras.

exselta, DC. Prod. ix. 158.-Bras.

extensa, Soland. ex Miers, in Proc. Roy. Hort. Soc. iii. (1863) 196 , nomen.-Bras

fagoides, Cham. in Linnaea, vii. (1832) 680.-Bras.

falcata, Koen. ex DC. Prod. ix. $206=$ Dolicliandron falcata.

falcata, Vell. Fl. Flum. 245; vi. t. 17.-Bras.

fallax, Cham. in Linnaea, vii. (1842) 717.-Bras.

farinosa, Salzm. ex DC. Prod. ix. $185=$ Arrabidaea

virescens.

fasciculata, Vell. Fl. Flum. 247 ; vi.t. $25=$ Arrabidaea fasciculata.

Ferdinandi, Welw. Apont. 584.-Afr. trop.

ferruginea, Tweedie, ex Miers, in Proc. Roy. Hort. Soc. iii. (1863) 190, nomen.-Reg. Argent.?

ficifolia, Steud. Nom. ed. II. i. 204, sphal. = filicifolia.

filicifolia, Anders. in Trans. Soc. Arts. xxv. (1807) 200 = Jacaranda filicifolia.

filiformis, A. Cunn. ex DC. Prod. ix. 209=Spathodea filiformis.

fimbriata, Wall. Cat. n. $6500=$ Stereospermum fimbriatum.

flava, DC. Prod. ix. 168,-Bras.

flavescens, Vell. FI. FIum. 252 ; vi. t. $51=$ Tecoma flavescens.

flavida, DC. Prod. ix. 168.-Bras.

floribunda, G. Don, Gen. Syst. iv, $216=$ Doniana.

floribunda, $H . B . E$ E Kov. Gen. et Sp. iii. 134.-

Mexic.

florida, Salisb. Prod. $106=$ Tecoma radicans

fluminensis, Vell. Fl. Flum. 246 ; vi. t. 24.-Bras.

fluviatilis, Aubl. Pl. Gui. ii. $655=$ Tabebuia fluvia tilis.

fluviatilis, H. B. \& K. Nov. Gen. et Sp. ii. 139= Tecoma barbata

funvatilis, G. F. W. Mey. Prim. Fl. Esseq. $212=$

Tecoma Meyeriana.

Fockeana, Miq. in Linnciea, xviii. (1844) 609.Guiana.

fraxinea, Desf. Cat. Hort. Par. ed. III. 398.-Hab.?

fraxinifolia, Spreng. Syst. ii. $833=$ Spathodea fraxinifolia.

fraxinoides, Perr. in Mém. Soc. Linn. Par, iii. (1824) 102.-Java.

frutescens, Mill. Gard. Dict. ed. VIII. n, 3=Tecoma stans.

fulva, Cav, Ic. iii. $58=$ Tecoma fulva

Gaudichaudi, DC. Rev. Bign. ex Prod. ix, 172=Lundia pubescens.

Ghorta, Buch.-Ham. ex Wall. Cat. n. $6510=$ Stereospermum Ghorta.

\section{BIGNONIA :-}

Giesbreghtii, Heller, ex Peyr. in Linnaea, xxx. (185960) 45.-Mexic.

gigantea, Noronha, in Verh. Batav. Gen. v. (1790) ed. I. Art. Iv. 8.- Malaya.

glaberrima, Cham. in Linnaea, vii. (1832) 677.Bras.

glabrata, H. B. E K. Nov. Gen. et Sp. iii. 135.Am. austr.

glandulosa, Mart. ex DC. Prod. ix. 149.-Bras.

glandulosa, Schum. Beskr. Guin. Pl. 274=Spathodea adenantha.

glauca, Decne. in Jacquem. Voy. Bot. 137. t. $142=$ Tecoma undulata.

glauca, Wall. Cat. n. 6506.-Burma.

glutinosa, $D C$. Prod. ix, 162,-Bras.

gnaphalantha, A. Rich. Fl. Cub. Fanerog. ii. 105.Cuba.

gracilis, Lodd. Bot. Cab.t. $1705=$ B. Unguis-cati.

grandiflora, Spreng. Syst. ii. $830=$ grandifolia,

grandiflora, Thunb. F1. Jap. $253=$ Tecoma grandiflora.

grandifolia, Facq. Hort. Schoenb. iii. 19. t. 287.-Am.

austr.

grandifolia, Vell. Fl. Flum. 247 ; vi. t. $28=$ Adenocalymna grandifolium et subsessilifolium.

gratissima, Koen. ex Wall. Cat. sub n. 6499 ; et DC,

Prod. ix. 211 = Stereospermum suaveolens.

Guarumé, Domb. ex A. DC. 1. c. $225=$ Tecoma Guarumé.

guayaquilensis, $D C$. l. c. 155.-Ecuador.

haemantha, Bert. ex Spreng. Syst. ii. $832=$ Tabebuia haemantha.

hebantha, Mart. ex DC. Prod. ix. $181=$ Lundia hebantha.

heptaphylla, Vell. F1. Flum. 251 ; vi. t. $48=$ Tecoma heptaphylla.

heterophylla. Willd. Sp. P1. iii, $298=$ B. Kerere

heteropoda, DC. Rev. Bign. ex Prod. ix. $173=$ Tecoma heteropoda.

heterotricha, DC. 1. c. = Tabebuia heterotricha.

hexagona, DC. 1. c.= Pithecoctenium hexagonum.

hibiscifolia, Cham. in Linnaea, vii. (1832) 705 . Bras.

hirsuta, Lam, Encyc, i. $222=$ Tecoma hirsuta.

hirta, Vell. Fl. Flum. 249 ; vi.t. 35 .-Bras

hispida, DC. Prod. ix. 152,-Bras.

hondensis, H. B. E K. Nov. Gen. et Sp. iii. 135.-N. Granat.

Hostmanni, E. Mey. in Nov. Act. Nat. Cur. xii. (1825) II. 779.-Guiana.

Hymenaea, DC. Prod. ix, 158.-Bras

ignea, Vell. Fl. Flum. 244 ; iv. t. 15.-Bras.

ilicifolia, Pers. Syn. ii. $170=$ Tabebuia ilicifolia.

inaequalis, $D C$. Prod. ix. 170.-Guiana.

Imperatoris-Maximiliana, Wawra, Bot. Ergeb. Maxim. Bras. 73.-Bras.

incarnata, Aubl. Pl. Gui. ii. 645. t. 261.-Guiana.

incisa, Hort. ex DC. Prod. ix. 224= Tecoma stans.

indica, Linn. Sp. Pl. $625=$ Oroxylum indicum

indica, Lour. Fl Cochinch. $460=$ Pajanelia multijuga

inflata, Griseb. in Goett. Abh. xxiv. (1879) 256.-Reg. Argent.

jasminifolia, H. B. E K. Nov. Gen. et Sp. iii. 141.Venezuela.

jasminoides, A. Cunn. ex DC. Prod. ix. $225=$ Tecoma jasminoides.

jasminoides, Thunb. Pl. Bras, iii, 36. n. 28.-Bras.

Kerere, Aubl. Pl. Gui. ii. 644.-Guiana.

labiata, Cham. in Linnaea, vii. (1832) 701.-Bras.

lactiflora, Vahl, Symb. Bot. iii. 80 . t. $66=$ Distictis lactiflora.

laeta, Wall. Cat, n. 6505-Burma.

lanata, Steud. Nom. ed. II. i. $205=$ discolor.

lanceolata, DC. Prod. ix. 163.-Bras.

lanuginosa, Hemsl. Biol. Centr. Am. Bot. ii. 491.Mexic.

laserpitiifolia, Mart. ex DC. Prod. ix. 168.-Bras,

latifolia, Rich, in Act. Soc. Hist. Nat. Par, i. (1792) $110=$ Callichlamys riparia.

latisiliqua, Poir. Encyc.Suppl. i. 632.-Gniana

laurifolia, Vahl. Ecl. Am. ii. 44.-Guiana.

lexiflora, DC. Rev. Bign. 21 ; Prod. ix. $173=$ Pithecoc tenium laxiflorum.

lenta, Mart. ex DC. Prod. ix. 159,-Bras.

lepidophylla, A. Rich. Fl. Cub. Fanerog. ii. 104.Ins. Pinet. (Ind. occ.).

lepidota, H. B. \& K. Nov. Gen. et Sp. iii. 139= Tecoma lepidota.

\section{BIGNONIA :}

lepidota, Seem. Bot. Voy. Herald, 197--Mexic.

leucantha, Vell. Fl. Flum. 251; vi. t. $49=$ Sparattosperma lithontripticum.

leucopogona, St. Lag. in Ann. Soc. Bot. Lyon, vii 1880) $121=$ seg

Leucopogon, Cham. in Linnaea, vii. (1832) 707.Bras.

leucoxylla, Vell. F1. Flum. 252 ; vi. t. $54=$ Tabebuia lencoxyla.

Lencoxylon, DC. Cat. Bign. ex Prod. ix. $173=$ Tecoma Salzmanni.

Leucoxylon, Linn. Sp. P1. 624=Tecoma Lencoxylon.

Lindleyi, DC. Prod. ix. 147.--Reg. Argent.

linearis, Cav. Ic. iii. 35. t. $269=$ Chilopsis saligna.

littoralis, $H . B$. E K. Nov. Gen. et Sp. iii. 139.Mexic.

longa, Vell. Fl. Flum. 249 ; vi. t. $37=$ Lundia longa.

longiflora, DC. Prod. ix. 206, sphalm. = Pajanelia Rheedii.

longiflora, Vell. Fl. Flum. 252; vi. t. 52=Tecoma speciosa.

longiflora, Cav. Ic. vi. 58. t. 581.-Guayaquil.

longifolia, Willd. Sp. Pl. iii. $306=$ Pajanelia Rheedii.

longisiliqua, Vell. F1. Flum. 247; vi. t. $26=$ Arrabidae.

longisiliqua, Bert. ex Spreng. Syst. ii. 830.-Venezuela

longissima, Jacq. Enum. Pl. Carib. $25=$ Catalpa longissima.

longissima, Lour. Fl. Cochinch. ii. $380=$ Dolichandrone Rheedii.

lucida, Lodd. ex Loud. Hort. Brit. 242.-Am. austr.

lugubris, Salisb. Prod. $106=$ Oroxylum indicum.

Lundii, DC. Rev. Bign. 21, ex Prod. ix. $173=$ Pithecoctenium Lundii.

macrophylla, Cham. in Linnaea, vii. (1832) $689=$ Adenocalymna macrophyllum.

macrostachya, Wall. Cat. n. 6504.-Burma

magnifica, Bull, in Gard. Chron. (1879) II. 73.-N Granat.

magnoliaefolia, H. B. ₹ K. Nov. Gen. et Sp. iii. 136.Venezuela.

Mansoana, DC. Prod. ix. 157.-Bras

maranhamensis, $D C$. l.c. 165.-Bras

marginata, Cham. in Linnaea, vii. (1832) $695=$

Adenocalymna marginatum.

marmoratum, Hort. ex André, in Rev. Hortic. (1865) 253.- - Hab. ?

Martini, $D C$. Prod.ix. 152.-Guiana

Martiusiana, $D C$. l. c. 156.-Bras.

megapotamica, Spreng. Syst. iv. 237.-Bras.

meonantha, Link, Enum. ii. $130=$ Tecoma australis.

meridionalis, Salisb. Prod, $106=$ Tecoma Leucoxylon.

Meyeniana, Schau. in Nov. Act. Nat. Cur. xix. Suppl. i. (1843) 366.-Peruv,

microcalyx, G. F. W. Mey. Prim. Fl. Esseq. 211.Guiana.

microphylla, Lam. Encyc. i. 418.-Ins. S. Doming.

Mina, Robin, Voy Louis, iii. 408.-Am. bor.

miranda, Cham. in Linnaea, vii. (1832) $687=$ Anemo paegma mirandum.

mollis, Vahl, Ecl. Am. ii. 46.-Guiana

mollissima, H. B. $\sigma^{\prime} K$. Nov. Gen. et Sp. iii. 133.-

Venezuela.

moluccana, DC. Prod. ix, 144,-Ins, Amboina.

moringaefolia, $D C . l$.c. 170 -Guiana

multifida, Lodd. ex Loud. Hort. Brit. 242.-Ind. or.

multiflora, Salzm. ex DC. Prod. ix. 160.-Bras

multijuga, Wall. Cat. n. 6503; Pl. Rar. As. i. 81.t. $95,96=$ Pajanelia Rheedii.

muricata, DC. Rev. Bign. 22, ex Prod. ix. $173=$

Pithecoctenium muricatum.

muricata, Herb. Madr. ex Wall. Cat. n. $6511=$ Stereospermum xylocarpum.

myriantha, Cham. ex Steud. Nom. ed. II. i. $205=$

Tecoma myriantha.

nematocarpa, Boj. Hort. Maurit. $219=$ Stereospermum nematocarpum.

nervosa, Domb. ex DC. Prod. ix. 198=Delostoma nervosum.

nigricans, Regel, Cat. Pl. Hort. Aksakov. 19.-Hab.? nitidissima, DC. Prod. ix. 160.-Venezuela.

nitidula, Mart ex DC 1 c. $181=$ Lundia nitidula. noctiflora, Buch.-Ham. ex Wall. Cat. sub n. $6499=$ Stereospermum suaveolens.

nodosa, Manso, Enum. Cat. Bras. 40.-Bras.

noterophila, DC. Prod. ix. 148.-Bras. 


\section{BIGNONIA}

obliqua, H. B. E K. Nov. Gen. et Sp. iii. 135.Venezuela.

obovata, Hook. \& Arn, Bot. Beech. Voy. $439=$ Stemmadenia pubescens.

obovata, Spreng. Syst. ii. $830=$ Spathodea obovata.

obovata, Vell. F1. Flum. 251 ; vi. t. . $45=$ Jacaranda subrhombea.

obtusifolia, Lam. Encyc. i. $418=$ Spathodea obtusifolia seu Tabebuia uliginosa.

occidentalis, Salzm. ex DC. Prod. ix. 160.--Bras.

odorata, Bello, in Anal. Soc. Esp. Hist. Nat. x. (1881)

293.-Porto Rico.

ophthalmica, Chisholm, ex Steud. Nom. ed. II. i. 205. -Guiana.

orbiculata, Jacq. Enum. Pl. Carib. $25=$ Anemopaegma orbiculatum.

ornata, Linden, Cat. n. 21 (1867) 1; E. Morr. Belg. Hortic. xvii. (1867) 102.-Bras.

oxyphylla, DC. Prod, ix. 169 (Cf. Fl. Brit. Ind. iv. $376)$. -Ind. or. ?

pachyptera, DC. Rev. Bign. 21 ; ex Prod. ix. 174 (= Pachyptera puberula).-Bras.

Pajanelia, Buch.-Ham. in Trans. Linn, Soc, xiii. (1822) $515=$ Pajanella Rheedii.

pallida, Lindl. Bot. Reg. t. 965.-Ind. occ

pandorana, Andr. Bot. Rep. t. $86=$ Tecoma australis.

Pandorea, Vent. Jard. Malm. to $43=$ Tecoma australis.

paniculata, Linn. Sp. Pl. $623=$ Amphilophum paniculatum.

pannosa, DC. Prod. ix. 148.-Peruv.

Parkeri, DC. l. c. 157.-Guiana.

parviflora, Rottl. ex Wall. Cat. sub n. $6501=$ Stereospermum chelonoides.

parvifora, Salzm。 ex DC. Prod. ix. 183=Arrabidaea Salzmanni.

patellifera, Schlecht. in Linnaea, viii. (1833) 516.Mexic.

Patrisiana, DC. Prod. ix. $174=$ Tecoma Patrisiana.

pedunculata, Vell. Fl. Flum. 250 ; vi. t. 41.-Bras.

pentandra, Lour. F1. Cochin. ii. $379=$ Oroxylum indicnm.

pentaphylla, Linn. Sp. Pl. ed. II. $870=$ Tabebuia pentaphylla.

pentaphylla, Salzm. ex DC. Prod. ix. $219=$ Tecoma Salzmanni.

perforata, Cham. in Linnaea, vii. (1832) 667.-Bras. perianthomega, Vell. Fl. Flum. 248; vi. t. 34.-Bras. peruviana, Linn. Sp. Pl. 625.-Peruv.

petiolaris, DC. Cat. Bign. 22; ex Prod. ix. $174=$ Tecoma Lencoxylon.

phaseoloides, Cham. in Linnaea, vii. (1832) 698.-Bras. physaloides, Cham.l.c. 668.-Bras.

picta, H. B. E K. Nov. Gen. et Sp. iii. 136. -Guiana picta, Lindl: Bot. Reg. (1842) t. $45=$ Lindleyi.

pilosa, Dietr. ex Stend. Nom. ed. II. i. $205=$ villosa.

pilulifera, Rich. in Act. Soc. Hist. Nat. Par. i. (1792) 111.-Guiana.

platyphylla, Cham. in Linnaea, vii. (1832) $679=$ brachypoda.

Poeppigii, DC. Rev. Bign. ex Prod. ix. 174=Anemopaegma Poeppigii.

populifolia, DC. Prod. ix. 159.-Bras.

Porteriana, Wall. Cat. n. $6509=$ Stereospermum glandulosum.

Prieurei, DC. Prod. ix. 154.-Guiana.

procera, Willd. Sp. Pl. iii. $307=$ Jacaranda Copaia.

pseudounguis, Desf. Cat. Hort. Par. ed. III. 397.-Ind. oce.

pterocarpa, Cham. in Linnaea, vii. (1832) $673=$ Cuspidaria trifoliata.

pubescens, Linn. Sp. Pl. ed. II. 870.-Mexic.

pubescens, Pav, ex DC. Prod, ix, $148=$ pannosa

pulchella, Cham in Linnaea, vii. (1832) 663.-Bras.

pulchra, Cham. . c. . 708,-Bras.

punctata, DC. Rev. Bign. ex Prod. ix, $160=$ occidentalis.

punicea, Mart. Herb. Fl. Bras. 255.-Bras.

purpurea, Lodd. ex Sweet, Hort. Brit. 283, nomen; Bot. Mag.t. 5800 -Am. austr.

pyramidata, Rich. in Act. Soc. Hist. Nat. Par. i. (1792) $110=$ Tabebuia pyramidata

quadrangularis, Lockart, ex Stend. Nom. ed. II. i. 205. -Ins. Trinitat,

quadrilocularis, Roxb. Pl. Corom. ii. 24. t. $145=$ Heterophragma Roxburghii.

quadripinnata, Blanco, Fl. Filip. ed. I. $499=$ Oroxylum indicum.

\section{BIGNONIA}

quadrivalvis, facq. Fragm. 37.--Venezuela. Quercus, Lam. Encyc. i. $417=$ Catalpa longissima. quinquefolia, Vell. Fl. Flum. 252 ; vi.t. $50=$ Cybistax antisyphilitica.

racemosa, Lam. Encyc. i. 424.-Madag.

radiata, Linn. Sp. Pl. 624=Argylia Feuillei

radicans, Linn. I. c. $=$ Tecoma radicans.

ramiflora, Decne, in Nouv. Ann. Mus. Par. iii. (1834) $381=$ Colea mauritiana.

Regnelliana, Sond. in Linnaea, xxii. (1849) 558.-Bras.

Rego, Vell. Fl. Flum. 249=Arrabidaea Sego.

reticulata, Hb. Madr. ex Wall. Cat. n. $6511=$ Sterospermum xylocarpum ?

Reveili, Hamon, in Bull. Soc. Hortic. Prat. Rhône, (1851) 149. t. 3.-Hab. ?

rhodosantha, Zipp. ex Blume, Rumphia, iv. 35.-N Guin.

rigescens, Jacq. Hort. Schoenb. ii. 44. t. $210=$ Distictis rigescens.

riparia, H. B. Er K.Nov. Gen. et Sp. iii. 138. - N. Granat rivularis, Hort. Kew. (1830) ex DC. Prod. ix. $199=$ Cybistax antisyphilitica.

rosea, DC. Rev, Bign. ex Prod. ix. $174=$ Arrabidaea rosea.

rosea, Pav. ex DC. Prod. ix. $198=$ Delostoma dentatum.

rotundata, DC. . . . . 163.-Bras.

rufescens, DC. Rev. Bign. ex Prod. ix. $174=$ Pithecoctenium rufescens.

rufinervis, Hoffmgg. ex DC. Prod. ix. 213 = Callichlamys riparia.

rugosa, Schlecht. in Linnaea, xxvi. (1853-55) 656.N. Granat.

rupestris, Gardn. in Hook. Lond. Fourn. Bot. i. (1842) 179. - Bras.

Sagraeana, DC. Prod.ix. 148,-Cuba.

salicifolia, Buch.-Ham. ex Wall. Cat. n。 $6498=$ Tecoma undulata.

salicifolia, H. B. E K. Nov. Gen, et Sp. iii. 133.Venezuela.

Salzmanni, DC. Rev. Bign. ex Prod. ix. $174=$ Adenocalymna Salzmanni.

samydoides, Cham. in Linnaea, vii. (1832) 669.-Bras. sambucifolia, Hort. ex Carr. Rev. Hortic. (1878) 50,Hab. ?

sarmentosa, Bertol. f. F1. Guatim. 25 =aequinoctialis. scandens, Vell. Fl. Flum. 246 ; vi. t. $22=$ Anemopaegma racemosum.

Sceptrum, Cham, in Linnaea, vii. (1832) 710_-Bras.

Sego, Vell. Fl. Flum. vi. t. $39=$ Arrabidaea Agnus

castus.
Selloi, Spreng. Syst. ii. 831.-Bras.

sempervirens, Linn. Sp. Pl. $623=$ Gelsemium semper virens.

serrata, Pav. ex G. Don, Gen. Syst. iv. $228=$ castaneaefolia.

serratifolia, Vahl, Ecl. Am. ii. $46=$ Tecoma serratifolia Serratula, Wall. ex DC. Prod. ix. $206=$ Stereospermum serrulatum.

serrulata, Steud. Nom. ed. II. i. 205, sphalm. praec.

Sieberi, DC. Rev. Bign. ex Prod. ix. 175=Arrabidaea Sieberi.

simplex, A. Rich. Fl. Cub. Fanerog, ii. 104.-Cuba. simplicifolia, Pav. ex DC. Prod, ix. $198=$ Delostoma integrifolium.

Sinclairii, Benth. Bot.Voy. Sulph. 129 = laurifolia. sorbifolia, Salisb. Prod. $106=$ Tecoma stans.

sordida, Klotssch, in Schomb. Fauna E Fl. Guy. 1158.-Guiana.

spathacea, Linn. f. Suppl. 283 = Dolichandrone Rheedii spathacea, Roxb. Pl. Corom. ii. 24. t. $144=$ Dolichandrone falcata.

speciosa, R. Grah, in Bot. Mag. t. 3888-Bras. spectabilis, Salisb. Prod. 106 = Catalpa bignonioides spectabilis, Vahl, Symb. Bot. iii. $80=$ aequinoctialis. spicata, Lockhart, ex Steud. Nom. ed. II. i. 205.-Ins. Trinitat.

Splendor-sylvae, Mart. ex DC. Prod. ix, 154.-Bras. squalus, Vell. Fl. Flum, 244; vi。 t. $13=$ Pithecoctenium

squalum.
squamelluilosa, DC. Rev. Bign, ex Prod. ix, 174 $=$ Tecoma squamellulosa.

staminea, Lam. Encyc. i. 421.-Ins. S. Doming.

stans, Linn, Sp. Pl. ed. II. $871=$ Tecoma stans.

stipulata, Roxb. Hort. Beng. 47 ; FI. Ind. iii. 108

Dolichandrone stipulata.

\section{BIGNONIA :}

striata, DC. Rev. Bign. ex Prod. ix. 174 (= Pachyptera striata). - Bras.

suaveolens, Roxb. Hort. Beng. 47 ; Fl. Ind, iii. 104 Stereospermum suaveolens.

suberosa, Roxb. 11, cc, 47, $111=$ Millingtonia hortensis subincana, Hemsl. Biol, Centr. Am. Bot. ii. 491. Panama.

subvernicosa, DC. Rev. Bign. ex Prod. ix. 229)= Tecoma subvernicosa.

Tababuya, Vell. Fl. Flum. 251; vi. t. $5 \xi=$ Tabebria uliginosa.

Tagada, Roxb. ex Wall. Cat. n. $6501=$ Stereospernum chelonoides.

tecomoides, DC. Prod. ix. $166=$ Tecoma mollis.

tenuiflora, $D C$. l. c. - Bolivia.

Telfairiae, Boj.ex Hook. Bot. Mag. t. 2976.-Madag

tenuisiliqua, $V a h l, E c l$. Am. ii. 43.-Am. austr.

ternata, G. Don, Gen. Syst, iv. 221 = maranbamensis.

ternata, Vell. Fl. Flum. 246; vi. t. 21.-Bras.

tetragona, Wall. ex DC. Prod. ix. $211=$ Stereospermur tetragonum.

tetragonocaulos, DC. Prod. ix. 169.-Bras

tetragonoloba, facq. Fragm. 36.-Venezuela.

tetraquetra, Cham in Linnaea, vii. (1832) 675.-Bras. thyrsoidea, DC. Prod. ix. 158.-Bras.

tiliaefolia, $H$. B. E K. Nov. Gen。 et Sp. iii. 136.-Am austr.

tinctoria, Arruda, in Koster, Trav. Braz. 497.Bras.

tomentosa, Pay, ex DC. Prod. ix $219=$ Tecoma heteropoda.

tomentosa, Rich. in Act. Soc. Hist. Nat. Par. i. (1796 $110=$ mollis.

tomentosa, Thunb. Fl. Jap. 252 = Paulownia imperiali. triantha, DC. Rev. Bign. ex Prod. ix. $148=$ exoleta.

trichoclada, DC. l. . . 158.-Bras

triflora, Pav, ex DC. 1. c. 148 (est Rubiacea).

triflora, Vell. Fl. Flum. 249 ; vi. t. 38--Bras

trifoliata, Vell. 1. c. 245 ; vi. to $16=$ Adenocalymn longeracemosum.

triphylla, Vell. 1. c. 244 ; vi. t. $14=$ triternata.

triphylla, Linn. Sp. Pl. ed. II. $870=$ Tabebuia triphylla. triphylla, Willd, ex DC. Prod. ix. $151=$ B. Chica

tripinnata, Noronha, in Verh. Batav. Gen。 v。 (1790 ed. I. Art. IV. 8.-Malaya.

triplinervia, Mart. ex DC. Prod. ix. 153.-Bras.

triternata, Steud. Nom. ed. II. i. 205.-Bras.

Tropaeolum, Jacquem. ex DC. Prod. ix. 223, in nota = Tecoma undulata.

tuberculata, Roxb, ex DC. Prod. ix。177=Oroxylum indicum.

tuberculosa, Vell. Fl. Flum. 251 ; vi. to $46=$ 'Leyheria montana.

tulipifera, Schum. Beskr. Guin. P1. $273=$ Spathodea tulipifera.

Tweediana, Lindl. Bot. Reg. (1840) t. 45.-Bras.

uliginosa, Gomez, Obs, ii. 7 . t. 2 ; Mem. Ac. Lisboa iii. (1812) Mem.dos Corresp. 57 - Tabebuia uliginosa ambellulata, $D C$. Prod. ix. 148.-Bras.

nmbrosa, H.B. E K. Nov. Gen. et Sp. iii. 188.-N Granat.

uncata, Andr. Bot. Rep, t. $530=$ Macfadyena uncinata uncata, Sims, Bot. Mag. t. $1511=$ Spathodea uncata.

uncinata, G. F. W. Mey. Prim. Fl. Esseg. $210=$ Mac fadyena uncinata.

undulata, Sm. Exot. Bot. i. $85=$ Tecoma undulata. unguiculata, Vell. Fl. Fium. 248 ; vi. t. 38.-Bras. unguiculato, St. Lag, in Ann. Soc. Bot. Lyon, vil.

(1880) $121=B$. Unguis-cati.

Unguis, Linn. Syst, ed. X. xiii. B. $\$=$ B. Unguis-cati.

Unguis-cati, Linn. Sp. Pl. 628.-Am. trop.

Vargasiana, DC. Rev. Bign. ex Prod. ix. 175 Anemo. paegma Vargasianum.

variabilis, focg. Hort. Schoenb. ii. 45, t. 212.-Venezuela.

variabilis, Mart. Herb. Fl. Bras. 250 = varians

variabilis, Sieber, ex E. Mey, in Nov. Act. Nat. Cur. xii. (1825) $779-$ Hostmanni.

varians, $D C$. Prod. ix. 149.-Bras

velutina $D C$. b e 160 - Bros.

venusta, Ker.Gowl, ins Bot. Reg. L. 219.-Bras

verrucifera, Schlecht. in Linnaea, xxvi. (1533-55) 655

N. Granat.

verrucosa, H. B. $\in$ $K$. Noc. Gem. ef Sp. iii. 137.-

Venezuela.

villasa, Bert. ex Spreng. Syst, ii, $\$ 90=$ IBnlbisiana.

villosa, Vahb, Ecl. Am. ì. 19. - Venezucla. 


\section{BIGNONIA}

viminalis, H. B. \& K. Nov. Gen. et Sp. iii, $132=$ Tecoma viminalis

violacea, DC. Prod. ix. 156.-Bolivia.

virginalis, Mart. ex DC. 1. c. $181=$ Lundia virginalis. viridiftora, Lodd. Bot. Cab. xi. (1825) t. $1026=$

Cybistax antisyphilitica.

Vitalba, Cham. in Linnaea, vii. (1832) $699=$ Pithecoctenium Vitalbae.

xylocarpa, Roxb. Hort. Beng. 47 ; Fl. Ind. iii. $108=$ Stereospermum xylocarpum.

BIKAI, Adans. Fam. ii. $67(1763)=$ Heliconia, Linn. (Scitam.).

BIHANIA, Meissn. in DC. Prod. xv. I. 96 (1861) = Eusideroxylon, Teijsm. (Laurin.)

borneensis, Meissn. 1. c.-Borneo.

BIKERA, Adans. Fam. ii. $130(1763)=$ Tetragonotheca, Dill. (Compos.).

BIKKIA, Reinw. ex Blume, Bijdr. 1017, in syn. (1826); et in Syll. Ratisb. ii. (1828) 8. RUBIACEAE, Benth. \& Hook. f. ii. 46.

Brkkiopsis, Brongn. \& Gris, in Bull. Soc. Bot. Fr. xii. (1865) 404 .

Cormigonus, Rafin. in Ann. Gén. Sc. Phys, vi. (1820) 83.

GrisIA, Brongn. in Bull. Soc. Bot. Fr. xii. (1865) 405 TATEA, Seem. Fl. Vit. $125(1866)$

australis, DC. Prod. iv, $405=$ grandiflora.

Forsteriana, Brongn. in Bull. Soc. Bot.Fr. xiii. (1866) 42 , - Ins. Fiji.

Gaudichaudiana, Brongn. l.c. 43.-N. Guinea.

grandiflora, Reinw. ex Blume, Bijdr.1017, in syn.; et in Syll. Ratisb. ii. (1828) 8.--Java; Ins. Amic. Guilloviana, Brongn。 in Bull. Soc. Bot. Fr. xiii. (1866) 42,-N. Guinea.

Hombroniana, Brongn. l. c. 43.-Ins. Pacif.

mariannensis, Brongn. l. c. 42.-Ins. Marian.

BIKKIOPSIS, Brongn. \& Gris, in Bull. Soc. Bot. Fr. xii. (1865) $404=$ Bikkia, Reinw. (Rubiac.).

Pancheria, Brongn. 1. c.-N. Caled.

BIKUKULLA, Adans. Fam. ii. 23 (1763)= Diclytra, Borckh. (Papav.).

BILABIUM, Miq. Fl. Ind. Bat. ii. 730 (1856). DIDY. MOCARPEAE, Benth. \& Hook. f. Gen. ii. 996. limans, Miq.l.c.-Malaya.

BILABRELLA, Lindl. Bot. Reg. sub t. 1701 (1835)= Habenaria, Willd. (Orchid.).

falcicornis, Lindl. 1. c. $=$ H. tetrapetala.

falciformis, Bolus, in Journ. Linn. Soc. xix. (1882) 340 $=$ praec.

salsicornis, Steud. Nom. ed. II. i. 205, sphalm. = praec.

BILAMISTA, Rafin. New Fl. Am. iv. $92(1836)=$ Gentiana, Tourn.

grandiflora, Rafin. 1. c. $93=\mathrm{G}$. grandiflora?

BILDERDYKIA, Dum. Florul. Belg. 18 (1827)= Polygonum, Tourn.

Convulvulus, Dum. 1. c. $=$ P. Convalvulus. dumetorkm, Dum. 1. $c_{0}=\mathrm{P}$. dumetorum.

BILITALIUM, Buch.-Ham. Journ. Mysore, 185 (1807), nomen.

farinosum, Buch.-Ham. 1. c. (Quid?),--Ind. or

BILLARDIERA, Moench, Meth. 369 (1794) = Verbena, Linn.

explanata, Moench, 1. c. = V. Aubletia.

BILLARDIERA, Sm. Bot. Nov, Holl. i. t. 1 (1793). PITTOSPOREAE, Benth. \& Hook, f. i. 132.

Labillardiera, Roem. \& Schult. Syst. v. p. xxyi. $330(1819)$

angustifolia, DC. Prod. i. $345=$ scandens.

brachyantha, F. Muell. ex Klatt, in Linnaea, xxviii. 1856) $571=$ scandens.

canariensis, Wendl. Beobacht. $43=$ scandens.

coriacea, Benth. Fl. Austral. i. 124.-Austral

cymosa, F. Muell. in Trans. Vict. Inst. i. (1855) 29. -Austral.

\section{BILLARDIERA :-}

cymosa, Klatt, in Linnaea, xxviii. (1856) $571=$ cymosa daphnoides, Knowles E Westc. Flor.Cab. ii. (1838) 60. -Austral.?

elegans, F. Muell. Pl. Vict. i. 78.-Austral

floribunda, F. Muell. in Wing, South Sc. Record, ii. (1882) 1.-Austral

fusiformis, Labill. Nov. Holl. Pl. t. $90=$ Sollya heterophylla.

grandiflora, Putterl. Stirp. Nov. Decad. $48=$ scandens. Hambruchiana, Seem. \& Schmidt, in Flora, xxvii. (1844) II. 496 = Sollya heterophylla.

latifolia, Putterl. Stirp. Nov. Decad. $47=$ scandens.

Lehmanniana, F. Muell. Pl. Vič. i. 78.-Austral.

longiflora, Labill. Nov. Holl. Pl. i. 64. t. 89.Tasmania.

macrantha, Hook. f. Fl. Tasm. i. $37=$ longiflora.

melocarpa, Hort. ex Steud. Nom. ed. II. i. 206.Austral.

mutabilis, Salisb. Parad. Lond. t. 48.-Austral. ovalis, Lindl. Bot. Reg, t. $1719=$ longiflora parviflora, DC. Prod. i. $346=$ Marianthus tenuis

pseudocymosa, Klatt, in Linnaea, xxviii. (1856) $571=$ cymosa.

rosmarinifolia, $D C$. Prod. i. 345.-Austral,

scandens, Sm. Exot. Bot. i, t. 1.-Austral.

sericophora, F. Muell. in Linnaea, xxv. (1852) $371=$ cymosa

variifolia, $D C$. Prod. i. 346.-Austral

versicolor, F. Muell. ex Klatt, in Linnaea, xxviii (1856) $751=$ cymosa:

BILLARDIERA, Vahl, Eclog. Am. i. 13. t. $10(1796)=$ Coussaria, Aubl. (Rubiac.)

paniculata, Vabl, 1. c. =C. Fruelichia.

BILLBERGIA, Thunb. Dec. P1. Bras. 30 (1823) BROMELIACEAE, Benth. \& Hook. f. iii. 664 .

CREMOBOTRYs, Beer, in Flora, xxxvii. (1854) 348

Eucallias, Rafin. F1. Tellur. iv. 25 (1836).

HELICODEA, Lem. Illustr. Hortic. xi. (1864) t. 421.

JoNGHEA, Lem. Jard. Fleur. ii. sub t. 180-181 (1852)

LiBonia, Lem. Illustr. Hortic. ii. (1855) t. 48 .

acaulis, Hort. ex Vis.-Cf. Otto \& Dietr. Allgem.

Gartenz, xvi. (1848) $29=$ Cryptanthus zonatus.

amabilis, Beer, Bromel. $118=$ vittata.

amoena, Lindl. Bot. Reg. sub t. $1068=$ speciosa.

angustifolia, C. Koch, Wochenschr. ix. (1866) 181.Hab.?

atro-rosea, Drapiez, Encyc. et Fl. des Serr. Angl. 1834) f. 1.-Bras.

Bakeri, E. Morr. in Belg. Hortic. xxx. (1880) 166. t. 8. -Bras.

Baraquiniana,Lem. Illustr. Hortic. (1864) 421=decora bicolor, Lodd. Bot. Cab. t. $1819=$ pyramidalis

bicolor, Schult. f. Syst. vii. $1255=$ Rhodostachys bicolor.

bifrons, Lindl. in Journ. Hort. Soc. viii. (1853) $54=$ Pitcairnea bracteata?

bivittata, Hook. Bot. Mag. t. $5270=$ Cryptanthus bivittatus.

Breauteana x, André, in Rev. Hortic. (1884) 117.

Brongniarti, Regel, Gartenfl. (1875) 166; et in Act.

Hort. Petrop. iii. II. (1875) $283=$ Portea kermesina.

Chantini, Carr. in Rev. Hortic. (1878) 112.-Bras.

chlorocyanea, De Vriese, Hort. Acad. Lugd. Bat. Pl Rar. (1854).-Cf. Linnaea, xxvi. (1853-55) $755=$ speciosa.

chlorostica, Hort. Saunders; ex Gard. Chron. (1871) $1425=$ Saundersii

clavata, Lindl. Bot. Reg. sub t. 1068=Aechmea bromeliaefolia.

coelestis, Hort, ex Morr, in Fl. des Serres, xxi. (1875) $1=$ Aechmea coelestis

Collevix, A. Van Geert, Cat. n. 81. p. 91; Belg. Hortic. xxxii. (1882) 334 .

commixta, C. Koch, Wochenschr。 iii. (1860) $146=$ zebrina?

contracta, Mart. ex Schult. f. Syst. vii. II. 1263 = Aechmea contracta.

corymbosa, Mart. ex Schult.f. l. c. 1268,-Bras.

Croyiana, De Jongh, ex Lem. Jard. Fleur. iv. (1854) t $413=$ pyramidalis.

cruenta, Hook. Bot. Mag. lvi. t. 2892.-Bras.

decora, Poepp. E Endl. Nov. Gen, 42.-Peruv.

discolor, Beer, Bromel. 121 = speciosa.

distichostachya, Lem. Jard. Fleur. ii. (1852) Misc. 96 =Aechmea distichantha.
BILIBERGIA :-

elegans, Mart. ex Schuit. f. Syst. vii. II. 1265 speciosa.

Euphemiae, E. Morr. Belg. Hortic. xxii. (1872) 1. t. 1.-Bras

excellens, Miq. in Fourn. Bot. Néerl. 1. (1861) 34.Guiana.

fasciata, Lind1. Bot. Reg. xiii, t. $1130=$ Aechmea fasciata.

fastuosa, Beer, Bromel. $110=$ thyrsoidea

filicaulis, Griseb. in Goett. Nachr. (1864) 13.-Venezuela.

Glasioviana, Regel, Gartenf. (1885) 260 = Quesnelia strobilispica.

Glymiana, De Vriese, Jaarb. der Kon. Ned. Maatsch.

Tuinb. (1853) $37=$ Morelii.

Glymiana, Beer, Bromel. $119=$ Morelii.

gracilis, Poepp. ex Beer, 1. c. $254=$ Aechmea tillandsioides:

granulosa, Brongn. in C. Koch, Wochenschr. iii. (1860) $145=$ decora

horrida, Regel, Ind. Sem. Hort. Petrop. (1856) 17 Gartenfl. (1857) 148.-Bras.

ianthina, Hort. ex E. Morr. Belg. Hortic. (1871) $2=$ Leopoldi.

incarnata, Schult. $f$. Syst. vii. II. 1261.-Peruv.

iridifolia, Lindl. Bot. Reg. t. 1068.-Bras.

Foinvillei, Van Houtte, ex E. Morr. in Belg. Hortic (1876) $161=$ Rhodostachys pitcairniaefolia

Foliboisi x, A. Van Geert, Cat. n. 81. p. 31; Belg Hortic. xxxii. (1882) 334.

lanuginosa, Hort. Hamb. ex C. Koch, Ind, Sem. Hort. Berol. (1856) App. $7=$ Aechmea nudicaulis,

latifolia, Hort. Belg. ex Heynh. Nom. ii. $69=$ Aechmeae sp.?

Legrelliana, Hort. ex Baker, in Saund. Ref. Bot. t. 285 $=$ Ortgiesiae sp.

Leopoldi, Linden, in Rev. Hortic. (1869) 87; E. Morr. in Belg. Hortic. xxi. (1871) 1.t. 1.-N. Granat. : Bras.

Leopoldii, Hort. Belg. ex C. Koch, Ind. Sem. Hort. Berol. (1856) $5=$ vittata.

Liboniana, De Fongh. Fourn. Hort. Prat. (Mars. 1851); et Lem. Fard. Fleur. ii. (1852) t. 197.-Bras.

Lietzei, E. Morr. in Belg. Hortic. xxxi. (1881) 97.t. 5-7.-Bras.

Loddigesii, Steud. Nom. ed. II. i. $206=$ pyramidalis.

longifolia, C. Koch \& Bouché, Ind. Sem. Hort. Berol. (1856) $5=$ thyrsoidea.

lutea, Schult. f. Syst. vii. $1258=$ Aechmea nudicaulis. macrocalyx, Hook. Bot. Mag. t. 5114.-Bras.

marmorata, Lem. Illustr. Hortic. ii. (1855) t. 48Bras.

Mertensii, Miq. in Linnaea, xviii. (1844) $376=$ Aechmea Mertensii.

Meyendorfi, Regel, Ind. Sem. Hort. Petrop. (1857) 27 Karatas Carolinae.

miniata-rosea, Lem. Illustr. Hortic. ii. (1855) Misc. 94 $=$ thyrsoidea.

mitis, Mart. ex Schult. f. Syst. vii, 1267.-Bras.

Moreliana, Brongn. ex Rev. Hortic. Sér. III. iii. (1849) $82=$ Morelii.

Moreliana, Lem. Jard. Fleur. ii. (1852) t. $138=$ vittata.

Morelii, Brongn. in Portef. Hort. ii. (1848) 97; et E. Morr. Belg. Hortic. x. (1860) 161.-Bras.

nudicaulis, Lindl. Bot. Reg. sub t. $1068=$ Aechmea nudicanlis.

nuptialis, Hort. ex E. Morr. in Belg. Hortic. (1871) 2 $=$ Leopoldi.

nutans, H. Wendl. in Regel, Gartenfl. (1869) 162.Bras.

Oberthuri X, A. Van Geert. Cat. n. 81. p. 92 ; Belg. Hortic. xxxii. (1882) 334.

oblonga, Mart. ex Schult. f. Syst. vii. 1256 (=Aechmeae sp.) -Bras.

odora, Miq. in Linnaea, xviii. (1844) $377=$ Aechmea odora.

olens, Hook. f. Bot. Mag. t. 5502=Karatas Carolinae pallescens, Baker, in Hook. f. 1. c. t. $6342=$ Bakeri.

pallescens, C. Koch \& Bouché, Ind. Sem. Hort. Berol (1856) App. $5=$ speciosa.

pallida, Beer, Bromel. $121=$ speciosa.

pallidiflora, Liebm. Ind. Sem. Hort. Hafn. (1854) 26.-Nicaragua.

paniculata, Mart. ex Schult. f. Syst. vii. II. $1268=$ Aechmea coelestis ?

parviflora, Mart. ex Schult. f. 1. c. $1270=$ Aechmea parviflora. 


\section{BILLBERGIA :-}

patentissima, Mart. ex Schult. f. Syst. vii. II. 1270 $=$ Aechmea patentissima.

Paxtonii, Beer, Bromel. $113=$ thyrsoidea.

polystachya, Lindl. \& Paxt. in Paxt. Flow. Gard. iii (1852-53) 33. t. $80=$ Aechmea distichantha.

Porteana, Brongn.ex Beer, Bromel. 115.-Bras

pulcherrima, C. Koch \& Bouché, Ind. Sem. Hort.

Berol. (1856) App. $6=$ vittata.

punicea, Beer, Bromel. 112.-Hab.?

purpurea, Beer, l. c. 126 (=Pitcairniae sp. ?).-Am. trop.

purpureo-rosea, Hook. Bot. Mag. t. $3304=$ Aechmea suaveolens.

pyramidalis, Forbes, Hort. Woburn. $64=$ Aechmea nudicaulis.

pyramidalis, Lindl. Bot. Reg. sub t. 1068.-Bras.

pyramidata, Beer, Bromel. $123=$ Aechmea nudicaulis.

Quesneliana, A. Brongn. in Ann.Sc. Nat. Sér. II. xv (1841) 371.-Guiana.

Rancougnei $x$, André, in Rev. Hortic. (1884) 524.

Reichardti, Wawra, in Oestr. Bot. Zeitschr. xxx. (1880) 115.-Bras.

rhedonensis $x$, A. Van Geert, Cat. n. 81. p. 92 ; Belg. Hortic. xxxii. (1882) 334 .

rhodocyanea, Lem. in F1. des Serres, Sér. I. iii. (1847) $207=$ Aechmea fasciata.

Rohaniana, De Vriese, in Linnaea, xxvi. (1853-55) $756=$ vittata.

rosea, Beer, Bromel. $128=$ Porteana.

roseo-marginata, Hort. ex C. Koch, Wochenschr. (1867) $141=$ Quesnelia rufa.

rubra-marginata, Hort. ex Carr. in Rev. Hortic. (1880

$70=$ Quesnelia rufa.

Sanderiana, E. Morr. in Belg. Hortic. xxxiv. (1884) 17

-Bras.

Saundersii, Hort. Bull, ex Floral Mag. N. S. t. 106.Bras.

saxatilis, Beer, Bromel. 127.-Bras,

Skinneri, Hort. ex Carr, in Rev. Hortic. (1880) $70=$ Quesnelia rufa.

speciosa, Thunb. Dec. Pl. Bras. iii. 30.-Bras.

sphacelata, Schult. f. Syst. vii. $1269=$ Greigia sphace lata.

splendida, Lem. Jard. Fleur. ii. (1852) t. 180-181= thyrsoidea.

tetrantha, Beer, Bromel. $127=$ Tillandsia tetrantha.
thyrsoidea, Mart. ex Schult. f. Syst. vii. 11. 1260.thyrsoidea,
Bras.

Bras.
tillandsioides, Mart. ex Schult. f. 1. c. $1269=$ Aechmea tillandsioides.

tinctoria, Mart. ex Schult. f. 1. c. $1256=$ Aechmea bromeliaefolis.

variegata, Schult. f. 1 . c. $1262=$ speciosa

variegata, Morr. in Belg. Hortic. xxxi. (1881) 78. Bras.

violacea, Beer, Bromel. 116.-Guiana.

viridiflora, $H$. Wendl. in Otto 6 Dietr. Allg. Gartenz. xxii. (1854) 154-Hab?

vittata, Brongn. ex Morel, Portef. Hortic. ii. (1848) 353.-Bras.

Wetherelli, Hook. Bot. Mag. t. 4835.-Bras.

zebrina, Lindl. Bot. Reg. sub t. 1068.-Bras.

sonata, Linden, Cat. n. 6 (1851) $20=$ vittata.

BILLIA, Peyr. in Bot. Zeit, xvi. (1858) 153 ; xvii. (1859) 221 = Aesculus, Linn. (Sapind.).

columbiana, Planch. \& Linden, ex Triana \& Planch. in Ann. Sc, Nat. Sér. IV. xviii. (1862) 367.-N Granat.

Hippocastanum, Peyr. in Bot. Zeit. xvi. (1858) $153=$ Aesculus mexicana.

BILLIOTIA, G. Don, Gen. Syst. iii. 560 (1884)= Billiottia, DC. (Rubiac.).

BILLIOTIA, Reichb. Nom, $176(1841)=$ BILLOTTIA, R. Br.=Ágonis, Lindl. (Myrtac.).

BILLIOTTIA, EndI. Gen, $1229(1840)=$ BILLOTTIA, $\mathrm{R} . \mathrm{Br} .=$ Agonis, Lindl. (Myrtac.)

BILLIOTTIA, DC. Prod. iv. 618 (1830), RUBIACEAE, Benth. \& Hook. f. ii. 80

Billiotia, G. Don, Gen. Syst. iii. 560 (1834).

Melanorsidium, Colla, Hort. Ripul. 88. t. 95 (1824).

\section{BILLIOTTIA :-}

Viviania, Colla, in Mém. Soc. Linn. Par. iv. (1826

$25, t 2$.

polytrichoides, Steud. Nom. ed. II. ii. 114, sphalm.

psychotrioides, DC. Prod.iv. 618.-Bras.

BILloTIA, G. Don, Gen. Syst. ii. 810,827 (1832) BILLOTTIA, R. Br.=Agonis, Lindl. (Myrtac.).

BILLOTIA, Sch. Bip. in Herb. \& Winck. Jahrb. Pharmac. iv. $(1841)$ in nota $155=$ Crepis, Linn. (Compos.)

alpina, Sch. Bip. 1. c. = C. alpina.

BILLOTTIA, R. Br. in Journ. Roy. Geogr. Soc. i. (1832) $19=$ Agonis, DC. (Myrtac.)

elliptica, Sweet, Hort. Brit. ed. III. $249=$ Leptospermum ellipticum.

flexuosa, R. Br. in. Journ. Roy. Geogr. Soc. i. (1832)

$19=$ A. flexuosa.

hypericifolia, Heynh. Nom. ii. $69=$ A. hypericifolia.

linearifolia, R. Br. in Journ. Roy. Geogr. Soc. i. (1832)

$19=$ A. linearifolia.

marginata, $\mathrm{R} . \mathrm{Br}, 1 . \mathrm{c}, 19=\mathrm{A}$. marginata.

ovatifolia, Sweet, Hort. Brit. ed. III. 249.-Austral.

saligna, Sweet, 1. c.-Austral

theaeformis, G. Don, ex Loud. Encyc. Pl. Suppl. ii $1380=$ A. hypericifolia.

BILLOTTIA, Colla, Hort. Ripul. 20. t. 23 (1824) Calothamnus, Labill. (Myrtac.)

acerosa, Colla, l. c. = C. quadrifida.

BIMA, Noronha, in Verh. Batav. Gen. v. (1790) ed. I. Art. IV. 1 (Quid?).

BINARIA, Rafin. Sylva Tellur. $122(1838)=$ Bauhinia, Linn. (Legumin.).

cumanensis, Rafin. 1. c. = Bauhinia cumanensis

BINDERA, Rafin. New Fl. Am. iv. 71 (1836)=Aster, Tourn. (Compos.)

ciliata, Rafin. 1. $\mathrm{c},=$ A. ciliatus.

BINECTARIA, Forsk. F1. Aegypt. Arab. $82(1775)=$ Imbricaria, Comm. (Sapot.)

BINNENDIJKIA, Kurz, in Tijdschr. Nederl. Ind. xxviii. (1865) $164=\mathbf{L}$ eptonychia, 'Turcz. (Sterculiac.) trichostylis, Kurz, 1. c. = L. glabra.

BIONDEA, Usteri, Ann. Bot. x. (Nene Ann. iv.) 90 $(1794)=$ BLONDEA, Rich. = Sloanea, Linn. (Tiliac.).

BIONIA, Mart, ex Benth. in Ann. Wien. Mus. ii. (1838 $130=$ Camptosema, Hook. \& Am. (Legumin.). acuminata, Benth. I. c. $=$ C. acuminatum. bella, Mart. in Walp. Rep. i. $764=\mathrm{C}$. bellum. coccinea, Mart. ex Benth. in Ann. Wien. Mus. ii. (1838) $380=\mathrm{C}$. coccineum.

coriacea, Benth. 1. c. $130=$ C. coriaceum. marginata, Mart. ex Benth. 1. c. = C. coriaceum. nitens, Benth. 1. c. $=$ C. coccineum.

rigida, Benth. 1. $\mathrm{c}_{\mathrm{s}}=$ C. coriaceum.

BIOPHYTUM, DC. Prod. i. 689 (1824). GERANIACEAE, Benth. \& Hook. f. i. 276 .

abyssinicum, Steud. ex A Rich. Tent. Fl. Abyss. i. 122. -Abyss.

adiantoides, Wight, ex Edgew, \& Hook. f. in Fl. Brit. Ind. i. 437.-Ind. or

Apodiscias, Edgew. E Hook. f. l. c.-Ind. or. Candolleanum, Wight, Ill. i. 161. t. 62 = sensitivum. castum, G. Don, Gen. Syst. i. $758=$ Oxalis casta. Cumingianum, Edgew. \& Hook, fo in Fl. Brit. Ind. 487 = sensitivum

Cumingit, Klotzsch, in Peters, Reise Mossamb. Bot $85=$ sensitivum

dendroides, DC. Prod. i. $680,-N$. Granat.

dormiens, G. Don, Gen. Syst. i. $753=$ Oxalis dormiens fruticosum, Blume, Bijdr. 242.-Java.

intermedium, Wight, Illustr. i. 162.-Zeylan.

mimosoides, G. Don, Gen. Syst. i. 758 = Oxalis mimo soides.

\section{BIOPHYTUM :-}

nervifolium, Thw. Enum. P1. Zeyl. $64=$ sensitivam. nudum, Edgew. E Hook. f. Fl. Brit. Ind. i, 438.Zeylan.

Petersianum, Klotzsch, in Peters, Reise Mossamb. Bot. 81. t. $15=$ sensitivam.

polyphyllum, Munro, in Wight, Illustr. i. 162. Ind. or.

poterioides, Edgew. ex Hook. f. Fl. Brit. Ind. i. $437=$ sensitivum.

proliferum, Edgew. E Hook. f. l. c. 438.Zeylan.

Reinwardtii, Klotzsch, in Peters, Reise Mossamb. Bot 85.-As. trop.

sensitivum, DC. Prod. i. 690.-Cosmopol. trop. sesbanioides, Edgew. ex Hook. f. Fl. Hrit. Ind. i, 437 = sensitivum.

sessile, Wall. Cat. n. $4344=$ B. Apodiscias.

somnians, G. Don, Gen. Syst. i. $758=$ Oxalis som nians.

Umbraculum, Welw. Apont. 590.-Afr. trop.

verticillatum, Wight, Illustr. i. $162=$ intermedium

BIOTA, D. Don, in Lamb. Pinet. ed. II. ii. 129 (1828

EndI. Conif. 46 (1847)= Thuya, Linn. (Conif.)

coraeana, Sieb. ex Gord. Pinet. Suppl. $17=\mathrm{T}$. orien talis.

dumosa, Hort. ex Carr. Conif. ed. II. $96=$ T. orientalis.

ericoides, Hort. ex Carr. 1, c. $141=\mathrm{T}$. occidentalis.

excelsa, Hort. ex Gord. Pinet. Suppl. $17=\mathrm{T}$. orien talis.

falcata, Hort. ex Carr. Conif. ed. II. $96=$ T , orien talis.

Fortunei, Hort. ex Carr. 1. c. $94=\mathrm{T}$, orientalis.

freneloides, Hort. Belg. ex Gord. Pinet. $35=T$, orien talis.

funiculata, Hort. ex Gord. 1. c. ed. II. $52=1$ orientalis.

glauca, Hort. ex Carr. Conif. ed. II. $100=$ T. orientalis.

gracilifolia, Knight, Syn. Conif, $16=\mathrm{T}$. orientalis. intermedia, Hort. ex Gord. Pinet. $35=T$. orientalis. japonica, Sieb. ex Gord. 1. c. $33=$ T. orientalis. macrocarpa, Hort. ex Gord. 1. c. ed. II. $422=$ I orientalis

meldensis, Laws. ex Gord. 1. c. $87=\mathrm{T}$. meldensis. nepalensis, Endl ex Gord. 1. c. $35=\mathrm{T}$. orientalis. orientalis, Endl. Conif. $47=\mathrm{T}$. orientalis.

pendula, Endl. 1. c. $49=\mathrm{T}$. orientalis.

prostrata, Hort. ex Gord. Pinet. ed. II. $401=1$ orientalis.

pyramidalis, Carr. Conif. ed. I. $96=$ T. orientalis semperaurea, Hort.Cf. Gard. Chron. (1874) $60=$ T. orientalis.

stricta, Lindl. \& Gord. in Journ. Hort. Soc. $\nabla .(1850$, $205=\mathrm{T}$. orientalis.

tatarica, Lindl. \& Gord. 1. $\mathrm{c}_{\mathrm{s}}=\mathrm{T}$. orientalis.

variegata, Hort. ex Gord. Pinet. $34=\mathrm{T}$. orientalis.

Wareana, Hort. ex Gord. 1. c. Suppl. 10t=T orientalis.

Zuccarini, Siebold, ex Carr. Conif. ed. II. $94=\mathrm{T}$ orientalis.

BIOTIA, Cass, in Dict. Sc Nat xxxiv, 308 (1825:= Madia, Molina (Compos.)

viscosa, Cass. 1. c. $309=$ M. viscosa

BIOTIA, DC. Prod. v. 264 (1856) = Aster, Toum

(Compos,

commixta, DC. Prod. v. $265=$ A. Herveyi.

corymbosa, DC. $\mathrm{L} . \mathrm{c}$. $=\mathbf{A}$. corymbosus.

crenata, Steud. Nom, ed. II. i. 15t, in syn. = Mairia crenata.

discolor, Maxim. Prim. Fl. Amur. $146=$ A. scabes. Thunb.

glomerata, DC. Prod. v. $265=$ A. macrophyllus.

japonica, Miq. Ann. Mus. Bot. Lugd. Bat. il. 170,Japon.

latifolia, DC. Prod, จ. 264 A. macrophyllas.

macropleylla, DC. 1. c. 265 A. macrophyllus.

Schreberi. DC. L c. 204 A. matrophyllus.

BIPINNULA. Comm. ex Juss. Gen. 65 (1;88

ORCHIDE.tE, Benth. \& Howk. fo iii. 613

bonariensis, Spreng. Syst. iij. 745. - Keg. Argent.

Commersonii, Lindl. in Quast. Journ. Roy. Inst. N. S i. $(1827) 52$ - bonariensis.

R I : 


\section{BIPINNULA :-}

Giberti, Reichb. $f$. in Linnaea, xli. (1877) 51.-Reg. Argent.

mystacina, Lindl. in Hook. Fourn. Bot. i. (1834) 5.-Chili.

plumosa, Lindl. in Quart. Fourn. Roy. Inst. N. S. i. (1827) 51. - Chili.

BIPONTINIA, Alef. in Pollichia, xxii-xxiv. (1866) 121 =Psoralea, Linn. Legumin.).

bituminosa, Alef. 1. c. $123=$ P. bituminosa.

corylifolia, Alef. 1 . c. $124=$ P. corylifolia.

BIPOREIA, Thou. Gen. Nov. Madag. 14. $(1806)=$ Samadera, Gaertn. (Simarub.).

BIRAMIA, Neraud, in Freyc. Voy. Bot. 28 (1826), nomen = Macleania, Hook. (Vaccin.). tuberosa, Auct. ex Walp. Ann. i. $478=$ M. insignis.

BIRCHEA, A. Rich. in Ann. Sc. Nat. Sér. II. xv. (1841) 66. t. $10=$ Luisia, Gaudich. (Orchid.). teretifolia, A. Rich. 1. c. 67 , t. $10=\mathrm{L}$. tenuifolia.

BIRIS, Medic. in Staatsw. Vorles. Churpf. Phys.-Oek. Ges. i. (1791) 257; et Phil. Bot. ii. 97 (1791)=Iris, Tourn.

sibirica, Medic. 11. cc. $=$ I. sibirica

BIRNBAUMIA, Kostel. Ind. Pl. Hort. Prag. (1844) $21=$ Anisacanthus, Nees (Acanth.).

quadrifida, Kostel, 1, c, = A. virgularia.

BIROLIA, Bell. in Mém. Acad. Turin, Ser. I. xviii. (1808) 403 . t. $11=$ Elatine, Linn. palludosa, Bell. 1. $\mathrm{c}_{.}=\mathrm{E}$. triandra.

BIROLIA, Rafin, Sylva Tellur. $163(1838)=$ Clusia, Linn. (Guttif,).

alba, Rafin. 1. c. $=$ C. alba.

BISCHOFTA, Blume, Bijdr. 1168 (1825)。 EUPHORBIACEAE, Benth. \& Hook. f. iii. 281.

MicroËLus, Wight \& Arn. in Edinb, N. Phil Journ. xiv. (1833) 298.

Stylodiscus, Benn. Pl. Jav. Rar. 133. t. 29 (1838).

Cummingiana, Decne. in Jacquem. Voy. Bot. $153=$

javanica, Blume, Bijdr. 1168.-Ind. or.; Malaya ; Ins. Pacif.

leptopoda, Muell. Arg. in DC. Prod. xv. II. 479.Ins. Pacif.

oblongifolia, Decne. in Jacquem. Voy. Bot. 152. t. 154 $=$ javanica.

Roperiana, Decne. l. c. $153=$ javanica.

Toui, Decne. 1. c. $=$ javanica.

trifoliata, Hook. Ic. PI. t. $844=$ javanica.

BISCUTELLA, Linn. Syst. ed. I (1735). CRUCIFERAE, Benth. \& Hook. f. i. 91 .

DiTHYREA, Harv. in Hook. Lond. Journ. Bot. iv. (1845) $7 \%$. t. 5 .

JondRaba, Medic. Pflanzeng. 27 (1792).

Thlaspidrum, Toum. ex Adans. Fam. ii. 422 (1763).

algeriensis, Jord. Diagn. i. $318=$ didyma

alpestris, Waldst. \& Kit. P1. Rar. Hung. iii. $253=$ laevigata.

alpicola, Jord. Diagn. i. $292=$ laevigata.

alsatica, Jord. 1. c. $300=$ laevigata.

ambigua, DC. Mon. Bisc. 9. t. 11. fo 1; Syst. ii. $415=$ laevigata.

anchusaefolia, Marz. ex Reichb. Fl. Germ. Excurs. 660 =laevigata.

anchusaefolia, Tenore, ex Steud. Nom. ed. II. i. 206 = sempervirens.

angulata, Steud. 1. c. = Megacarpaea angulata.

angustifolia, Schkuhr, Handb. ii. 238.-Enrop.

apetala, Walt. Fl. Carol. $174=$ Senebiera didyma.

apricorum, Jord. Diagn. i. $307=$ laevigata.

apula, Gaertn. Fruct. ii. $279=$ leiocarpa.

apula, Lam. Encyc. iii. $617=$ ciliata

apula, Linn, Mant. $254=$ didyma.

apula, Webb, ex Willk. \& Lange, Prod. Fl. Hisp. iii. 761 = scutulata.

\section{BISCUTELTA .}

arvernensis, Jord. Diagn. i. $298=$ laevigata.

auriculata, Herb. Un. ex Steud. Nom. ed. II. i. $207=$ cichoriifolia.

auriculata, Linn. Sp. Pl. 652 --Reg. Mediterr,

austriaca, Bonnet, in Bull. Soc. Dauph. fasc. vi. 222.

balearia, L'Hérit. ex DC. Syst. ii. $643=$ Succowia balearia.

balearica, Jord. Diagn. i. 325, $328=$ auriculata?

boetica, Boiss. \& Reut. Diagn. Ser. II. i. $42=$ laevigata.

Bourgaei, Jord. Diagn. i. $320=$ lyrata.

brevicaulis, Jord. 1. c. $303=$ laevigata.

Burseri, Jord. 1. c. $326=$ auriculata.

californica, Benth. E' Hook. f. ex S. Wats. Bot. Calif. i. 48 . - Calif.

Candollii, Jord. Diagn. i. $326=$ auriculata,

chilensis, Lag. ex DC. Mon. Bisc. 6=Cremolobus chilensis.

Chouletti, Jord. Diagn, i. $319=$ didyma.

cichoriifolia, Loisel. Add. Fl. Gall. 167.-Mont. Pyren.

ciliata, DC. Mon. Bisc. 6 ; Syst. ii. 410.-Ital. ; Hispan. collina, Jord. Diagn. i. $299=$ laevigata.

Columnae, Tenore, Prod. Fl. Nap. $38=$ didyma.

confusa, Pomel, Nour. Mat. Fl. AtI. 231.-Afr. bor. controversa, Bor. Fl. Centr. Fr. ed. III. $56=$ laevigata. coronaria, Ehrenb, ex Willk. in Ind. Sem. Dorpat. Adn. (1868),-Hab. ?

coronopifolia, Willd. Sp. PI. iii. $474=$ ciliata.

coronopifolia, Linn. Mant. ii. 255 ; All. Fl. Pedem. i. $247=$ laevigata.

cuneata, Lag. Cat. Hort. Madr. (1815) $20=$ Cremolobus chilensis.

depressa, Thom. ex DC. Syst. ii. $415=$ laevigata. depressa, Willd. Enum. Hort. Berol. $673=$ didyma. didyma, Linn. Sp. Pl. 653.-Reg. Mediterr.; Persia. didyma, Scop. Fl. Carn. ed. II. ii. $14=$ laevigata didyma, Willd. Enum. Hort. Berol. $673=$ ciliata. dilatata, Vis. Stirp. Dalm. $14=$ cichorifolia. divionensis, Jord. Diagn. i. 305 = laevigata. dubia, Steud. Nom. ed. II. i. $207=$ Cremolobus linearifolins.

erigerifolia, DC. Mon. Bisc. 4 ; Syst. ii. $408=$ auriculata.

eviocarpa, DC. Mon. Bisc. 7. t. 9. f. 2 ; Syst. ii. $411=$ didyma.

erucifolia, Reichb. Ic. Fl. Germ. vii. 5.-Europ.

flexuosa, Jord. Diagn. i. $300=$ laevigata.

frutescens, Coss. Notes Crit. ii. 27.-Hispan.

glabra, [Clairv.] Man. Herb. 216= laevigata.

glacialis, Jord. Diagn. i. $310=$ laevigata.

glareosa, Jord. 1. c. $304=$ laevigata.

granitica, Bor. ex Perar. in Bull. Soc. Bot. Fr. xvi. (1869) 352 = laevigata.

Guilloni, Jord. Diagn, i. $302=$ laevigata.

hispida, DC. Mon. Bisc. 4. t. i. f. 1; Syst. ii. $408=$ cichoriifolia.

incana, Tenore, Fl. Neap. Prod. App. $5^{\text {ta }}$. (1826).Italia.

intermedia, Gouan, Illustr. $42=$ laevigata.

intricata, Jord. Diagn, i. $308=$ laevigata.

laciniata, Willd. ex DC. Syst. ii. $417=$ Megacarpaea laciniata.

laevigata, Linn. Mant. 225.-Reg. Medit.

laevigata, Sibth. \& Sm. Fl. Graec. Prod. ii, 16= didyma.

Lamarckii, Jord. Diagn. i. $323=$ auriculata

Lamottii, Jord. 1. c. $302=$ laevigata.

laxa, Boiss. \& Reut. Diagn. Ser. II. i. 43.-Hispan.

laxiflora, Presl, ex Spreng. Syst. iv. Cur. Post. 239 didyma.

leiocarpa, DC. Mon. Bisc. 8 ; Syst. ii. 413.-Oriens

Lima, Reichb, Fl. Germ. Excurs, 661, sub n。 $4206=$ laevigata.

longa, Dulac, F1. Hautes-Pyr. $190=$ cichoriifolia.

longifolia, Vill. Prosp. $38=1$ laevigata.

lucida, Balb. ex DC. Mon, Bisc. 9. t. 7 ; Syst. ii. $414=$ laevigata.

lusitanica, Jord. Diagn. i, 315= laevigata,

lyrata, Linn. Mant. $354=$ didyma.

macrocarpa, Hort. ex DC. Syst. ii. $409=$ cichoriifolia.

macrocarpa, Bieb. ex Tauscher, in Mém. Soc. Nat. Mosc. iv. (1812) 232.-Transural.

major, Schkuhr, Handb. ii. 238. n. $1822=$ auriculata

marginata, Tenore, Prod. Fl. Nap. $38=$ didyma.

maritima, Tenore, 1. c: =didyma.

mauritanica, Jord. Diagn. i. 325 = auriculata.
BISCUTFLIA :-

maxima, Pall. ex DC. Syst. ii. $417=$ Megacarpaea laciniata.

mediterrannea, Jord. Diagn. i. $313=$ laevigata?

Megacarpaea, Boiss. \& Reut. Diagn. Ser. II. i. $44=$ laevigata.

megalocarpa, Fisch. ex DC. Mon. Bisc. 5. t. $3=$ Megacarpaea laciniata.

microcarpa, DC. 1. c. 7 ; Syst. ii. $411=$ didyma.

minor, Jord. Diagn. i. $297=$ laevigata.

mollis, Loisel. Not. $168=$ laevigata.

montana, Cav. Ic. ii. 59. t. $177=$ laevigata.

neustriaca, Ed. Bontrel, in Act. Soc. Dauph. (1879)

198 = laevigata

nicaeensis, Jord. Diagn. i. $314=$ Iaevigata?

obcordata, Reichb. Ic. F1. Germ. vii. 8. f, 615 = laevi gata.

obovata, Hort. Par. ex DC. Mon. Bisc. 8; Syst.ii. 413. -Hab.?

orcelitana, Lag. ex DC. Syst. ii. $408=$ auriculata.

oreites, Jord. Diagn. i. $294=$ laevigata.

orientalis, [Desf.] ex DC. Mon. Bisc. $8=$ leiocarpa.

patulipes, Jord. Diagn. i. $320=$ didyma.

perennis, Spach, Hist. Vég. Phan. vi. $571=$ ciliata,

laevigata, sempervirens.

peruviana, Lam. Encyc. iii. $620=$ Cremolobus pernvianus.

petraea, Jord. Diagn. i. 306= laevigata.

picridifolia, Lapeyr. Hist. Abr. Pl. Pyr. $375=$ cichoriifolia.

pinnatifida, Hort. ex Turcz. in Bull. Soc. Nat. Mosc. xxvii. (1854) II. $302=$ laevigata?

pinnatifida, Jord. Diagn. i. $311=$ praec.?

polyclada, Jord. 1. c. $312=$ laevigata.

pratensis, Timb. in Bull. Soc. Hist. Nat. Toul. iii. (1869) 114.-Gallia

pumila, Balb. ex DC. Mon. Bisc. 6; et Syst. ii. $411=$ didyma.

pyrenaica, Huet, in Ann. Sc. Nat. Sér. III. xix. (1853) 252.-Hispan

radicata, Coss. \& Dur. in Bull. Soc. Bot. Fr. xix. (1872) 224.-Afr. bor.; Hispan.

radicosa, Willk. \& Lange, Prod. Fl. Hisp. iii. $778=$ radicata.

raphanifolia, Poir. Voy. Barb. ii. $198=$ didyma.

rosularis, Boiss. E Reut. Diagn. Ser. II. i. 45.Hispan.

rupestris, Ehrh. Beitr. v. 177, nomen.-German.

saxatilis, Schleich. ex DC. Prod, i. 183=laevigata.

saxatilis, Endr. ex Willk. \& Lange, Prod. Fl. Hisp. iii. $765=$ pyrenaica.

scabra, Salisb. Prod. $268=$ didyma.

sclerocarpa, Revel, in Bull. Soc. Bot. Fr. xxv. (1878) Bibl. 78.-Gallia.

scutulata, Boiss. E Reut. Diagn. Ser. II. i.41.-Hispan. secunda, Jord. Diagn. i. $310=$ laevigata

sempervirens, DC. Syst. ii. $416=$ laxa.

sempervirens, Linn. Mant. 255.-Hispan.; Lusitan

sinuata, Jord. Diagn. i. $301=$ laevigata.

spathulata, DC. Prod. i. 183, in syn.=laevigata.

stenophylla, Dufour, in Ann. Gén. Sc. Phys. vii. (1820 $299=$ laevigata

stricta, Jord. Diagn. i. $312=$ laevigata

subspathulata, Lam. Encye. iii. $620=$ laevigata

suffrutescens, Coss. Notes Crit. 27.-Hispan.

suffruticosa, DC. Mon. Bisc. 5. t. 5=Cremolobus suffruticosus.

tergestina, Jord. Diagn. i. $295=$ laevigata.

tenuicaulis, Jord. I. c. $310=$ laevigata.

tomentosa, Lag. ex DC. Syst. ii. $416=$ laevigata.

tumidula, Lag. ex DC. 1. c. $411=$ didyma.

varia, Dum. Fi. Belg. Prod. $118=$ laevigata.

variabilis, Loisel. Fl. Gall. ii. $56=$ laevigata.

variegata, Boiss. \& Reut. Diagn. Ser. II. i. $44=$ laevígata.

verna, Matth. ex Nym. Consp. $59=$ laevigata.

virgata, Jord. Diagn. i. $309=$ laevigata.

Wislizeni, Benth. E' Hook. f. ex S. Wats. Bot. Calif.

i. 432 . $\mathrm{Am}$. bor. occ.

BISERRUI.A, Linn. Syst. ed. I (1735). LEGUMI-

NOSAE, Benth. \& Hook. f. i. 507.

Pelecinus, Tourn. ex Medic. in Vorles. Churpf. Phys. Ges. ii. (1787) 378.

leiocarpa. Hochst. ex A. Rich. Tent. F1. Abyss. i. 194 $=\mathrm{B}$. Pelecinus

pelecina, Lam. Fl. Fr. ii. $634=$ B. Pelecinus.

Pelecinus, Linn. Sp. Pl. 762.-Reg. Mediterr. 
BISMALVA, Medic. Malv. 39 (1787)= Malva, Tourn. Alcea, Medic. 1. c. $=$ M. Alcea.

fastigiata, Fourr. in Ann. Soc. Linn. Lyon, N. S. xvi. (1868) $350=\mathrm{M}$. Alcea.

laciniata, Fourr. 1. c. = M. moschata.

moschata, Medic. Malv. $39=$ M. moschata.

Tournefortiana, Fourr, in Ann. Soc. Linn. Lyon, N. S. xvii. $(1869) 195=$ M. Tournefortiana.

BISMARCKIA, Hildebr. \& H. Wendl. in Bot. Zeit. xxxix. (1881) 89, 90, 93. PALMAE, Benth. \& Hook. f. Gen. iii. 882.

nobilis, Hildebr. E' H. Wendl. l. c. 94.-Madag.

BISPHAERIA, Noronha, in Verh. Batav. Gen. v. (1790) ed. I. Art. IV. 1 (Gen. dub.).

BISTANIA, Noronha, in Verh. Batav. Gen. v. (1790) ed. I. Art. IV. 64 (1827) (Gen. dub.).

BISTELLA, Adans. Fam. ii. 226 (1763) (an Rubiacea?).

BISTELlA, Delile, in Caill. Voy. Méroé (Cent. Pl. Afr.) 97. t. $63(1826)=$ Vahlia, Thunb. (Saxifr.).

geminiflora, Caill. \& Delile, Voy. Méroé, 97. t. 2. f. 2 $=\mathrm{V}$. viscosa.

BISTORTA, [Tourn.] Linn. Syst. ed. I. (1735); Gen. ed. I. $115(1737)=$ Polygonum, Toum.

americana, Rafin. Fl. Tellur, iii. $12=\mathrm{P}$. viviparum? major, S. F. Gray, Nat. Arr. Brit. Pl. ii. $267=$ P. Bistorta.

officinalis, Rafin. Fl, Tellur. iii. 12=B. Bistorta.

vivipara, S. F. Gray, Nat. Arr. Brit. Pl. ii. $268=$ P. viviparum.

BISTROPOGON, Auct. ex Steud. Nom. ed. II. i. 207. $(\mathbf{1 8 4 0})=$ Bysteropogon, L'Hérit. (Labiat.).

BISW AREA, Cogn. in Comptes-rend. Soc. Bot. Belg. xxi. (1882) 16. CUCURBITACEAE.

WAREA, C. B. Clarke, in Journ. Linn. Soc. xv. (1876) 127.

tonglensis, Cogn. l. c.-Reg. Himal.

BIVINIA, Tul. in Ann. Sc. Nat. Sér. IV. viii. (1857) 78. SAMYDACEAE, Benth. \& Hook. f. i. 800

Jaubertia, Tul.l.c.-Madag.

BIVONAEA, DC. Syst. ii. 554 (1821). CRUCIFERAE, Benth. \& Hook. f, i. 88.

lutea, DC. Syst. ii. 555.-Sicil.

praecox, Bertol. Fl. Ital. x. 520.-Sicil.

Saviana, Caruel, Prod. Fl. Tosc. 47.-Ital.

BIVONAEA, Moç. \& Sesse, ex DC. Prod, iii. 372 (1828) $=$ Pentacaena, Bartl. (Illecebr.).

multicaulis, Moç. \& Sesse, ex DC. 1. c. $373=$ P. polycnemoides.

BIVONEA, Rafin. Fl. Ludov. 138 (1817)= Jatropha, Linn. (Euphorb.)

stimulosa, Rafin. 1. c. $=\mathrm{J}$. urens.

BIVONIA, Spreng. Nene Entdeck. ii. $116(1821)=$ Bernardia, P. Br. (Euphorb.).

axillaris, Spreng. 1. $\mathrm{c}_{0}=\mathrm{B}$. axillaris.

BIWALDIA, Scop. Introd. $232(1777)=$ Garcinia, Linn. (Guttif.).

BIXA, Linn. Coroll. Gen. 8 (1737). BIXINEAE, Benth. \& Hook. f. i. 125.

Urucu, Adans. Fan. ii. 881 (1763)

acuminata, Boj. Hort. Maurit. $20=$ Orellana.

americana, Poir. Encyc. vi. $229=$ Orellana.

odorata, Ruiz \& Pav. Fl. Per. vo to 460, ex G. Don, Gen. Syst. i. $295=$ Orellana?

Orellana, Linn. Sp. Pl. 512.-Am. austr.

orleana, Noronha, in Verh. Batav. Gen. v. (1790) ed, I. Art. Iv. $8=$ Orellana.

platycarpa, Ruiz \& Pav. Fl. Per. v. t. 459, ex G. Don, Gen. Syst, i. $294=$ Orellana.

purpurea, Sweet, Hort. Brit. ed. I. 33 ; G. Don, Gen. Syst. i. $295=$ Orellana?

sphaerocarpa, Triana, in Bull. Soc. Bot. Fr. v. (1858) $369 .-\mathrm{N}$. Granat.

tinctoria, Salisb. Prod. $369=$ Orellana.

Urucurana, Willd. Enum. Hort. Berol. 565 = Orellana.
BIXAGREWIA, Kurz, in Journ. Bot. xiii. (1875) $325=$ Trichospermum, Blume (Tiliac.)

nicobarica, Kurz, l. c.-Ins. Nicobar.

BLABEROPUS, A. DC. Prod. viii. $410 \quad(1844)=$ Alstonia, R. Br. (Apocyn.)

lucidus, A. DC. 1. c. $411=$ Trachelospermum fragrans. neriifolius, A. DC. I. c. = A. neriifolia.

Sebusi, Heurck \& Muell. Arg. in Heurck, Obs. Bot. ii. $188=$ A. neriifolia.

sericeus, A. DC. Prod. viii. $411=$ A. sericea.

venenatus, $\mathrm{A} . \mathrm{DC} . \mathrm{l}, \mathrm{c} .=\mathrm{A}$. venenata.

villosus, Miq. F1. Ind. Bat. ii. $440=\mathrm{A}$. villosa.

BLACHIA, Baill. Etud. Gén. Euph. 388. t. 19 (1858) EUPHORBIACEAE, Benth. \& Hook. f. iii. 301. calycina, Benth. in fourn. Linn. Soc, xwii. (1880) 226.- Ind. or.

denudata, Benth. l. c.-Ind. or,

Pentzii, Benth. l. c. - China.

reflexa, Benth. l. c.-Ind. or

umbellata, Baill. Etud. Gén. Euph. 387. t. 19. f. 18-20. -Ind, or.

BLACKBOURNEA, Kunth, in Ann. Sc. Nat. Sér. I. ii. (1824) $356=$ seq.

BLACKBURNIA, Forst, Char. Gen。 t. $6(1776)=$ Zanthoxylum, Linn. (Rutac.).

monadelpha, Roxb. Hort. Beng. [83]; F1. Ind, i. $415=$ Dobera Roxburghii.

oppositifolia, Planch, in Ann. Sc. Nat. Sér. III. (1848) $191=$ Dobera Roxburghii.

pinnata, Forst. Char. Gen. t. $6=Z$. Blackburnia.

BLACKIA, Schrank, ex DC. Prod. iii. $165(1828)=$ Myriaspora, DC. (Melastom.) egensis, Schrank, ex DC. 1. $\mathrm{c}_{\mathrm{r}}=$ M. egensis.

BLACKSTONIA, Huds. Fl. Angl. ed. I. 146 (1762) nomen prius $=$ Chlora, Ren。 ex Adans。 Fam。 ii. $503(1763)$

perfoliata, Huds, 1. c. $=$ C. perfoliata.

BLACKSTONIA, A. Juss. in Orbign. Dict. vi. 432 (1849) $=$ BLAKSTONIA, Scop. $=$ Moronobea, Aubl. (Guttif.).

BLACKWELLIA, Gaertn. Fruct. ii. t. 117 (1791) (Blakwellia, p. 169) (Genus dubium).

antarctica, Gaertn. 1. c.-Hab.?

BLACKWELliA, Comm. ex Juss. Gen。 343 (1789) (Blakwellia) $=$ Homalium, Jacq. (Samyd.)

acuminata, Wall, ex C. B. Clarke, in Hook. f. Fl. Brit. Ind. ii. $596=\mathrm{H}$. nepalense.

africana, Hook. f. in Hook. Niger Fl. $361=\mathrm{H}$. africanum.

austro-caledonica, Vieill. in Bull. Soc. Linn. Normand. x. (1866) $107=$ H. austro-caledonicum?

axillaris, Lam. Encyc. i. $428=\mathrm{H}$. axillare.

brachybotrya, F. Muell. in Trans. Phil. Inst. Vict. ii 1859) $48=\mathrm{H}$. brachybotrys.

brachystylis, Tul. in Ann. Sc. Nat. Sér. IV. viii. (1857) 59.-Madag.

caryophyllacea, Zoll. \& Mor. Syst. Verz. Zoll. 33=H. caryophyllaceum.

cerosifolia, Vent. Choix, 56. t. 56.-Madag.

ceylanica, Gardn. in Calc. Journ. Nat. Hist. vii. (1847) $452=\mathrm{H}$, zeylanicum.

chinensis, Lindl. ex Stend. Nom. ed. II. i. $208=$ H. fagifolium.

cochinchinensis, Blume, Mus, Bot. Lugd. Bat, ii. 27.Cochinchina.

dasyantha, Turce in Bull, Soc. Nat. Mosc. xxxvi. (1863) I. $610=\mathrm{H}$. Griffithianum.

decurrens, Vieill, in Bull. Soc. Linn. Normand. $x$. (1866) 105-N. Caled.

dentata, Harv, in Harv. \& Sond. Fl. Cap. ii. 585.Afro austr.

Deplanchei, Vieill. in Bull. Soc. Linn. Normand. (1866) 110.-N. Caled.

eriantha, Tul。 in Anu. Sc. Nat, Sér. IV. viii. (1857) 62.-Madag.

fagifolia, Lindl. in Trans. Hort. Soc. Lond. vi. (18:26) $269=$ H. fagitolium

foetida, Wall. Cat. n. $4899=$ H. foetidum.
BLACKWELLIA :

Fussieua, J. F. Gmel. Syst. $768=$ Homalium paniculatum

glauca, Vent. Choix, 55. t. $55=\mathrm{H}$. paniculatum.

gracilis, Blume, Mus. Bot. Lugd. Bat. ii. $26=\mathrm{H}$ axillare.

grandiflora, Lindl. ex Loud. Hort. Brit. 193=H fagifolium

Guillaini, Vieill. in Bull. Soc. Linn. Normand. $x$ 1866) $106 .-N$. Caled.

integrifolia, Lam. Encyc。 i. $428=\mathrm{H}$. paniculatum.

intermedia, Vieill. in Bull. Soc. Linn. Normand. (1866) 109.-N. Caled.

kanaliensis, Vieill. 1. c. 112,-N. Caled.

longiflora, Miq. Fl. Ind. Bat. lanthus.

Loureiri, Benth. in Hook, Lond. Jonm. Boto i. 1812 $482=\mathrm{H}$. fagifolium.

macrostachya, Turcz. in Bull. Soc. Nat, Mosc. (1863) $810=\mathrm{H}$. longifolium.

micrantha, Boiv, ex Tul, in Ann. Sc. Nat. Sér. IV viii. $(1857) 63=\mathrm{H}$. micranthum.

Mathieuana, Vieill. in Bull. Soc. Linn. Normand. (1866) $108,-\mathrm{N}$. Caled.

moluccana, Blume, Mus. Bot. Lugd. Bat. ii. 27.Ins. Molucc.

monostachya, Turcz. in Bull. Soc, Nat. Mosc。 xxxyi. 1863) 610 ,-Penang.

montana, Vieill. in Bull, Soc. Linn. Normand.

(1866) $110 .-\mathrm{N}$. Caled.

napaulensis, DC. Prod. ii. $54=\mathrm{se}$

nepalensis, Wall. P1. As. Rar. t. $179=$ H. nepalense.

padiflora, Lindl. Bot. Reg. t. $1308=\mathrm{H}$. fagifolium.

padifolia, Steud. Nom. ed. II. i. $208=$ H. fagifolium.

paniculata, Lam. Encyc. i. $428=$ H. paniculatum.

planiflora, Boiv, ex Tul, in Ann. Sc. Nat. Sér. IV. vił.

(1857) 64.-Madag.

polystachya, Vieill. in Bull. Soc. Linn. Normand, (1866) $107 .-\mathrm{N}$. Caled.

propinqua, Wall, Cat. n. $4898=\mathrm{H}$. propinquum. pubifora, Walp. Rep.i. $548=\mathrm{H}$. fagifolium.

purpurea, Steud. Nom. ed. II. i. 208, sphalm. $=$ H. propinquum.

rivularis, Vieill. in Bull. Soc. Linn. Normand, x. (1866 111.-N. Caled.

rubiginosa, Vieill. 1. c. 108.-N. Caled.

rufescens, Presl, Bot. Bemerk. $42=\mathrm{H}$. rufescens.

spiralis, Wall. in As. Res. xiii. (1820) $400=\mathrm{H}$.

tomentosum.

spiralis, Wall. Cat. B. 4897, partim $=$ H. propinquam.

tetrandra, Wight, Ic. v. t. $1851=$ H. zeylanicum.

Thouarsiana, Tul. in Ann. Sc. Nat. Sér. IV. viii. (1857 60.- - Madag.

tomentosa, Vent. Choix, 57.t. $57=\mathrm{H}$. tomentosum.

BLADHIA, Thunb. Nov. Gen. 6 (1781), nomen prius Ardisia, Sw. (1788) (Myrsin.)

crispa, Thunb. Fl. Jap. $97=\mathrm{A}$. crenata, Roxb.

glabra, Thunb, in Trans. Linn. Soc. ii. $(1794) 331=\mathrm{A}$. japonica.

japonica, Blanco, Fl. Filip. ed. I. $126=$ A. pyrami. dalis.

japonica, Thunb. Nov. Gen. $7=$ A. japonica.

villosa, Thunb. H1. Jap. $96=$ A. pusilla.

BLAERIA, Linn, Coroll. Gen。 \& (1737). ERJ-

CACEAE, Benth. \& Hook. f. ii. 592.

KolbIA, Adans. Fam. ii. 164 (1769)

aggregata, Wendl. ex Steud. Nom. ed. II. i. 208 ; ii. $589=$ Simocheilus multiflorus

articulata, Linn. Mant. ii. 198 articulatus).-Afr. austr.

articulata, Willd. ex Steud. Nom. ed. II. i. 2us Sympieza capitellata.

barbigera, G. Don, Gen. Syst. iii. S05.-Afr. austr.

bicolor, Klotzsch, in Linnaea, viii. (1\$\$3 680) (err. typ. $606)=$ Simucheilus bicolor.

bracteata, Wendl. Collect ii. 1. t. $87=$ Simpic 2.8 capitellata.

bruniaefolia, G. Don, Gen. Syst. iii. sos = Erica bruniacfolia.

caduca, Thunb. Diss. Blacrio, 10,-Air. auser. camproulata, Benth. in DC. Prod. vii. 698 - Afi

ausis.

carnea, Klotzsch, in Linnaca, viii. (1999) 600 l simocheilus carneus.

ciliaris, Linn. f. Suppl. 12.2-Grisebachia culiaris. 


\section{BLAERIA :-}

ciliciiflora, G. Don, Gen. Syst. ïi. $805=$ Grisebachia velleriflora.

coccinea, Klotrsch, in Linnaea, viii. (1833) 657.-Afr. austr.

condensata, Hochst. in A. Rich. Tent. Fl. Abyss. ii. $13=$ spicata

depressa, Drège, ex Benth. in DC. Prod. vii. $705=$ Sympieza Kunthii.

depressa, Lichst. ex Roem. \& Schult. Syst. iii. 168= Simocheilus depressus.

dumosa, Wendl. Collect. ii. 3. t. $38=$ purpurea. equisetifolia, G. Don, Gen. Syst. iii. $805=$ purpurea. eriantha, Willd. ex Steud. Nom. ed. II. i. 208 (=

Syndesmanthus articulatus).-Afr. austr.

ericoides, Linn.Sp. Pl. 162.-Afr. austr.

fasciculata, Willd. Sp. Pl. i. $629=$ Simocheilus glabellus.

fastigiata, Benth. in DC. Prod. vii. 697.-Afr. austr.

flexuosa, Benth. l. c. 698.-Afr. austr.

flosculosa, G. Don, Gen. Syst. iii. 805 (=Syndesmanthus paucifolius).-Afr. austr.

fuscescens, Klotzsch, in Linnaea, viii. (1833) 657.Afr. austr.

glabella, Drège, ex Benth. in DC. Prod. vii. $698=$ cam panulata.

glabella, Willd. Sp. Pl, i. $631=$ Simocheilus glabellus. glabra, Thunb. Diss. Blaeria, 10.-Afr, austr.

gracilis, Bartl. in Linnaea, vii. (1832) $650=$ Sympieza Kunthii.

hirsuta, Lichtst, in Roem. \& Schult. Syst. iii. 170 (= Syndesmanthus paucifolius).-Afr. austr.

hirsuta, Thunb. Diss, Blaeria, 8,-Afr austr.

incana, Bartl. in Linnaea, vii. (1832) $650=$ Grisebachia incana.

jucunda, Reichb. ex Steud. Nom. ed. II. i. $20 \dot{8}^{=}=$purpurea.

Kraussiana, Klotzsch, in Walp. Rep. ii. 728.-Afr. austr.

lencocephala, Bory, Voy, iii. 172,-Ins. Borbon.

multiflora, Klotzsch, in Linnaea, viii. (1833) $661=$

Simocheilus multiflorus.

muscosa, Ait. Hort. Kew. i. $150=$ Scyphogyne incon. spicua.

nodiflora, G. Don, Gen, Syst. iii. $805=$ Grisebachia plumosa.

nudiflora, Thunb. Diss. Blaeria, 6,-Afr. austr.

paniculata, Thunb. $l, c, 10$.-Afr. austr.

parviflora, Klotzsch, in Linnaea, viii. (1833) $665(=$ Codonanthemum parviflorum). - Afr. austr.

pauciflora, G. Don, Gen. Syst. iii. 804, sphalm.= paucifolia.

paucifolia, Wendl. Collect. ii. 17. t. $43(=$ Syndes manthus paucifolius).-Afr, austr.

ptilota, E. Mey. in Drège, ex Benth. in DC. Prod. vii. $701=$ Grisebachia hispida.

puberula, Klotzsch, in Linnaea, viii. (1833) 661 (= Codonanthemum puberulum).-Afr. austr.

purpurea, Berg. Desc.' Pl. Cap. $34=$ Simocheilus glabellus.

parpurea, Linn.f. Suppl. 122.-Afr. austr.

pusilla, Klotzsch, in Linnaea, viii. (1833) 659.-Afr. austr.

pusilla, Linn. Mant. 139 ('sp. dubia').-Afr. austr.

revoluta, Bartl. in Linnaea, vii. (1832) $650=$ barbigera.

rubra, Hort. ex Steud. Nom. ed. II. i. $208=$ ericoides

scabra, Drège, ex Benth. in DC. Prod. vii. $698=$ ericoides.

scabra, Willd. Sp. Pl. i. 629 (=Syndesmanthus scaber).-Afr. austr.

serrata, Thunb. Diss, Blaeria, 6-Afr, austr.

sessilifiora, Wendl. ex Steud. Nom. ed. II. i. $208=$ Simocheilus multiflorus.

spicata, Hochst. in A. Rich. Tent. Fl. Abyss. ii. 13.Abyss.

Thunbergii, G. Don, Gen. Syst. iii. $805=$ Grisebachia ciliaris.

trigona, Wendl. ex Steud. Nom. ed. II. i. $208=$ fuscescens.

turmalis, G. Don, Gen. Syst. iii. $805=$ Erica turmalis.

xeranthemifolia, G. Don, 1. c.= Eremia lanata.

BLAINVILLEA, Cass, in Dict. Sc. Nat. xxix. 493 (1823). COMPOSITAE, Benth. \& Hook. f. ii. 369 Calyptocarpus, Less. Syn. Comp. 221 (1833). EIsenManNIA, Sch. Bip. in Flora, xxv. (1842) II. 418.

\section{BIAINVILLEA :-}

Galophthalmum, Nees \& Mart. in Nov. Act. Nat. Cur. xii. (1824) 7.t. 2

OLIGOGYNe, DC. Prod v 629 (1837)

UCACEA, Cass, in Dict. Sc. Nat. xxvii. 9 (1823)

alba, Edgew. in Trans. Linn. Soc. xx. (1851) $70=$ rhomboidea.

amazonica, Benth. E Hook. f. Gen. ii. 370.-Reg. Amazon.

bahiensis, Baker, in Mart. Fl. Bras. vi. III. 177.Bras.

biaristata, DC. Prod. v. 492.-Bras

Gayana, Benth. in Hook. Niger F1. 434, in syn.= Aspilia Gayana.

Gayana, Cass. in Dict. Sc. Nat. xlvii. 90,-Afr. trop.

hispida, Edgew. in Trans. Linn. Soc. xx. (1851) $70=$ rhomboidea.

lanceolata, Baker, in Mart. Fl. Bras. vi. III. 176.Bras.

latifolia, DC. in Wight, Contrib. Bot. Ind. Or. $71=$ rhomboidea.

polycephala, Gardn. in Hook. Lond. Journ. Bot. vii. 1848) $89=$ rhomboidea

Prieureana, Benth. in Hook. Niger Fl. 433, in syn.= Aspilia Prieureana.

Prieureana, $D C$. Prod. v. 492. - Afr. trop.

racemosa, Gardn. in Hook. Lond. Journ. Bot. vii. (1848) $89=$ rhomboidea.

rhomboidea, Cass, in Dict. Sc. Nat. xxix. 493.-Cosmop. trop.; Ind, or.

synedrelloides, Benth. \& Hook.f. Gen. ii. 370.-Hab. tampicana, Benth. E Hook. l. c.-Cf. Hemsl. Biol Centr. Am. Bot. ii. 169.-Mexic.

tenuicaulis, Benth. E Hook. f. Gen. ii. 370.-Ins Galap.

BLAIRIA, Houst. ex Linn. Gen. ed. I. 334, in syn. (1737) $=$ Priva, Adans. (Verben.)

cordifolia, Moench, Meth. $423=\mathrm{P}$. hispida.

javanica, Gaertn. Fruct. i. t. 56=Lippia javanica.

lappulacea, Steud. Nom. ed. II. i. $208=$ P. echinata.

mexicana, Gaertn. Fruct. i. 265. t. 56. f. 1 =P. hispida

nodiflora, Gaertn. 1. c. 266 . t. $56=$ Lippia nodiflora.

BLAIRIA, Gled. in Mém. Acad. Berl. (1751) $125=$ Blaeria, Linn. (Ericac.).

BLAKBURNIA, J. F. Gmel. Syst. $258(1791)=$ BLACK BURNIA, Forst. = Zanthoxylum, Linn. (Rutac.).

BLAKEA, P. Br. Hist. Jamaic. 323 (1756). MELA STOM ACEAE, Benth. \& Hook. f. i. 770.

Pyxidanthus, Naud. in Ann. Sc. Nat. Sér. III. xviii. (1852) 150. t. 6

Valdesia, Ruiz \& Pav. Prod. 67 (1794).

brevipes, Naud. in Ann. Sc. Nat. Sér. III. xviri. (1852)

$144=$ repens

Cacatin, D. Don, in Mem. Wern. Soc. iv. (1823) 324 -Guiana.

caudata, Triana, in Trans. Linn. Soc. xxviii. (1871) 148.-N. Granat.

glabrescens, Benth. Bot. Voy, Sulph. 94.-Peruv.

gracilis, Hemsl. Diag. Pl. Nov. 13.-Costa Rica

granatensis, Naud, in Ann. Sc. Nat. Sér. III xviii

(1852) 143.-N. Granat.

grandiflora, Hemsl. Diag. Pl. Nov. 13,-Costa Rica.

hirsuta, O. Berg, ex Triana, in Trans. Linn. Soc. xxviii. (1871) 148. - Bras.

laevigata, D. Don, in Mem. Wern. Soc. iv. (1823) 327 = Topobea laevigata.

latifolia, $D$. Don, $l$. c. 325-Peruv.

laurifolia, Naud. in Ann. Sc. Nat. Sér. III. xviii. (1852) $143=$ pulverulenta

Lindeniana, Triana in Trans. Linn. Soc. xxviii.

(1871) 149.-Venezuela.

macrophylla, D. Don, in Mem. Wern. Soc. iv. (1823)

$326=$ Bellucia superba

mexicana, D. Don, 1. c. $325=$ repens.

multiflora, D. Don, 1. c. $326=$ Topobea multiflora.

ovalis, D. Don, l.c. 325.-Peruv.

ovalis, Griseb. ex Triana, in Trans. Linn. Soc. xxviii. (1871) $148=$ repens.

parasitica, D. Don, in Mem. Wern. Soc. iv. (1823) $327=$ Topobea parasitica.

podagrica, Triana, in Trans. Linn. Soc. xxviii. (1871) 149.-N. Granat.

pulverulenta, DC. Prod. iii. $196=$ Conostegia subhirsuta.

\section{BLAKEA :-}

pulverulenta, Vahl, Symb. Bot. iii. 61-Am. austr

pyxidanthus, Triana, in Trans, Linn. Soc. xxyii. (1871) $149 .-\mathrm{N}$. Granat.

quadrangularis, Triana, l. c.-N. Granat

quinquenervia, Aubl. Pl. Gui. i. 525. t. 210=Bellucia Aubletii.

repens, D. Don, in Mem. Wern. Soc, iv. (1823) 325. - Peruv.

repens, Griseb. ex Triana, in Trans. Linn. Soc. xxviii. 1871) $149=$ ovalis.

rosea, D. Don, in Mem. Wern. Soc. iv. (1823) 325.

rostrata, O. Berg, ex Triana, in Trans. Linn. Soc. xxyiii. (1871) 148.-Peruy.

rotundifolia, D. Don, in Mem.Wern. Soc. iv. (1823) 326.--Peruy.

Schlimii, Triana, in Trans. Linn. Soc. xxvii. (1871) 149.-Venezuela.

sessiliflora, Naud. in Ann. Sc. Nat. Sér. III. xviii. (1852) 144--Peruv.

sessiliflora, Poepp. ex Triana, in Trans. Linn. Soc. xxviii. (1871) $148=$ hirsuta.

subconnata, O.Berg, ex Triana, l. c.-Ecuador.

trinervia, Linn. Sp.Pl. ed. II. 635.-Jamaica.

trinervia, Pav. ex Triana, in Trans. Linn. Soc. xxviii. 1871) $149=$ Topobea laevigata.

trinervis, Pav. ex D. Don, in Mem. Wern. Soc. iv. (1823) $327=$ Topobea laevigata.

triplinervia, Linn. Amoen. Acad. viii. 257; Pl. Surinam. n. $59=$ Bellucia Aubletii.

BLAKSTONIA, Scop. Introd. $276(1777)=$ Moronobea, Aubl. (Guttif.).

BLAKWELLIA, Comm. ex Juss. Gen. 343 (1789) (Blackwellia, ex J. F. Gmel. Syst. $768(1791))=$ Homalium, Jacq. (Samyd.).

BLAKWELLIA, Gaertn. Fruct. ii. 170 (1791) (Blackwellia, t. 117) (Genus dubium).

BLAKWELLIA，Scop. Introd. $326(1777)=$ Aralia, Tourn.

BLANCHEA, Boiss. F1. Orient iii. 212, in syn. $(1875)=$ Iphiona, Cass. (Compos.)

iphionioides, Boiss. 1. c.-Syria.

BLANCHETIA, DC. Prod. v. 75 (1836). COMPOSITAE, Benth. \& Hook. f. ii. 226.

heterosticha, $D C$.. . c. - Bras.

BLANCKIA, Neck. Elem. i. $347(1790)=$ Conobea, Aubl. (Scrophul.).

BLANCOA, Blume, Rumphia, ii. $128(1836)=$ Didymosperma, H. Wendl. (Palm.).

BLANCOA, Blume, Rumphia, iii. 181 (1847)=Harpullia, Roxb. (Sapind.).

arborea, Blume, $1 . \mathrm{c} .=\mathrm{H}$. cupanioides.

BLANCOA, Lindl. Swan Riv. App. 45 (1839) HAEMODORACEAE, Benth. \& Hook. f. iii. 676 canescens, Lindl. l.c.-Austral.

BLANDFORDIA, Andr. Bot. Rep. t. 343 (1804)= Galax, Linn. (Diapens.)

caudata, Steud. Nom. ed. II. i. 209, sphalm. = seq.

cordata, Andr. Bot. Rep. t. $343=\mathrm{G}$. aphylla.

BLANDFORDIA, Sm. Exot. Bot. i. 5. t. 4 (1804) LILIACEAE, Benth. \& Hook. f. iii. 774.

aurea, Hook. f. Bot. Mag. t. 5809.-Austral.

Backhousii, Lindl. Bot. Reg. (1845) sub t. $18=$ grandiflora.

Cunninghamii, Lindl. 1. c. = grandiflora.

Cunninghamii, Van Houtte, F1. des Serres, t. 1829 flammea.

flammea, Lindl. in Fourn. Hort. Soc. v. (1850) 32.-

Austral.

grandiflora, R. Br. Prad. 296.-Tasmania.

grandiflora, Hook. f. Fl. Tasm. ii. $49=$ marginata. grandiflora, Lindl. Bot. Reg. t. $924=$ nobilis? intermedia, Herb. in Lindl. Bot. Reg. (1845) Misc. 64 - Tasmania.

marginata, Herb. l.c. (1842) Misc. 84.-Austral. 


\section{BLANDFORDIA :}

nobilis, Sm. Exot. Bot. i. 5, t. 4.-Austral.

Princeps, W. G. Smith, in Flor. Mag. N. S. (1875 t. $170=$ flammea.

punicea, Sweet, Hort. Brit. ed. II. $517=$ grandiflora . speciosa, Hort. Angl, ex Link, Enum. Hort. Berol. i. $330=$ grandiflora?

uniflora, Willd, ex Kunth, Enum. Pl. iv. $478=$ Milla biflora.

BLANDFORTIA, Poir. Encyc. Suppl. iv. $116(1814)=$ Blandfordia, Sm. (Liliac.).

BLANDINA, Rafin. Fl. Tellur. iii. 88 (1836)=Leucas, Burm. (Labiat.).

biflora, Rafin. 1, $\mathrm{c}_{\mathrm{c}}=\mathrm{L}$, biflora

chinensis, Rafin. 1. $\mathrm{c} .=\mathrm{L}$. chinensis.

BLANDOWIA, Willd. in Ges. Naturf. Fr. Berl. Mag. iii. (1809) 10. t. 4. f. 2 =A pinagia, Tul. (Podost.). Preissii, Wedd. in DC. Prod, xvii. $85=$ A. Preissii. striata, Corda, in Sturm, Deutschl. Fl. Abth. ii. Heft v-vi.p. 107. t. $33=$ A. Preissii.

striata, Lehm. ex Wedd. in DC. Prod, xvii, $71=$ Dicraea Wallichii.

striata, Willd. in Ges. Naturf. Fr. Berl. Mag. iii. (1809) 100. t. $4=\mathrm{A}$. Willdenowii.

BLANISIA, Pritz, Ind. Ic. 154 (1855), sphalm, $=$ POLANISIA, Rafin。 = Cleome, Linn. (Cappar.).

BLASTANIA, Kotschy \& Peyr. Pl. Tinn. 15. t. 7 (1865-66). CUCURBITACEAE.

CTENOLEPIS, Hook. f, in Benth. \& Hook. fo Gen. i. $832(1867)$.

Ctenopsis, Naud. in Ann. Sc. Nat. Sér. V. vi. (1866) 12.

fimbristipula, Kotschy \& Peyr.l.c.-Afr. trop.

Garcini, Cogn. in DC. Monog. Phan. iii. 629.-Ind, or.

BLASTEMANTHUS, Planch, in Hook, Lond. Journ. Bot. v. (1846) 644. OCHNACEAE, Benth. \&. Hook. f. i. 320.

gemmiflorus, Planch. l. c. 645.-Bras.

grandiflorus, Spruce, ex Engl, in Mart. Fl. Bras, xii. II. 355.-Bras.

BLASTOTROPHE, F. Didrichs. in Kjoeb. Vidensk. Meddel. (1854) 192 = Alafia, Thou. (Apocyn.) scandens, F. Didrichs, 1. c. 193.-Afr. trop.

BLASTUS, Lour. Fl. Cochinch. 526 (1790). MELASTOMACEAE, Benth. \& Hook. f. i. 752 cochinchinensis, Lour. l. c. 527.-Cochinch. Hindsii, Hance, in Journ. Linn. Soc. xiii. (1873) $103=$ Allomorphia pauciflora.

parviflorus, Triana, in Trans. Linn. Soc. xxviii. (1871) $74=$ cochinchinensis.

BLATTARIA, [Tourn.] Rupp. Fl. Jen. ed. Hall. 247 $(1745)=$ Verbascum, Linn. (Scrophul.).

alba, Medic. in Vorles. Churpf. Phys. Ges. iv. I. (1789) $230=\mathrm{V}$. Lychnitis.

Bastardi, Fourr. in Ann. Soc. Linn. Lyon, N. S. xvii. (1869) $125=\mathrm{V}$. Bastardi.

virgata, Fourr. 1. c. $=$ V. virgatum.

vulgaris, Fourr, 1. $\mathrm{c},=\mathrm{V}$. Blattaria.

BLATTI, Adans. Fam. ii. $88(1763)=$ Sonneratia, Linn. f. (Lythrar.).

BLAXIUM, Cass. in Dict. Sc. Nat. xxx. 328 (1824)= Dimorphotheca, Vaill. (Compos.)

decumbens, Cass. 1. c. = D. fruticosa.

BLEASDALEA, F. Muell. Fragm. v。 90 (1865)= Grevillea, R. Br. (Proteac.).

cupanoides, F. Muell. 1. c. $=$ G. Bleasdalea.

BLECHUM, P. Br。 Hist. Jamaic. 261 (1756) ACANTHACEAE, Benth. \& Hook. fo ii. 1082.

Alvarezia, Pav, ex Nees, in DC. Prod, xi. 465 (1847).

angustifolium, $R . B r$. Prod. i. 478. -Ind. oce. angustius, Nees, in DC. Prod. xi. 467.-N. Granat. anisophyllum, Juss, in Ann. Mus. Par, ix. (1807) $270=$

Pbaylopsis longifolia.

\section{BLECHUM :}

brasiliense, Mart. ex Nees, in DC. Prod. xi. $284=$ Stenandrium mandioccanum.

brasiliense, Lodd. Cat. ex G. Don, in Loud. Hort. Brit. 245.-Bras.

Brownei, Fuss. in Ann. Mus. Par. ix. (1807) 270Ind. occ.

Brownei, H. B. \& K. Nov. Gen. et Sp. ii. 238 Linnaei.

costaricense, Oerst, in Kjoeb. Vidensk. Meddel. (1854) 168.-Costa Rica.

grandiflorum, Oerst. l. c. - Am. centr.

Haenkei, Nees, in DC. Prod, xi. 467.-Mexic

hamatum, Klotzsch, in Peters, Reise Mossamb, Bot. 220.-Afr. trop.

laxiflorum, Fuss. in Ann. Mus. Par. ix. (1807) 270,Jamaica.

Linnaei, Nees, in DC. Prod. xi. 465.-Mexic.

Inzonium, Nees, 1. c. $466=$ Brownei

mexicanum, Oerst. in Kjoeb. Vidensk. Meddel. (1854) 169.-Mexic.

Sternbergii, Nees, in DC. Prod, xi. $468=$ Tetramerium nervosum.

trinitense, Nees, l. c. 466.-Ins. Trinit.

Tweedii, Nees, l.c.-Mexic.

BLEEKERIA, Hassk. Retzia, i. 38 (1855)= Ochrosia, Juss. (A pocyn.)

calocarpa, C. Muell. in Walp. Ann. v, $492=$ seq.

kalocarpa, Hassk. Retzia, i, $40=0$, elliptica

salubris, Hassk. 1. c. $41=\mathrm{O}$, borbonica.

BLEEKERIA, Miq. Fl. Ind. Bat. i. II. $40 \tau(1859)=$ Alchornea, Sw. (Euphorb.).

Zollingerii, Miq. 1. $\mathrm{c}_{\mathrm{s}}=\mathrm{A}$. villosa

BLEEKRODFA, Blume, Mus. Bot. Lugd. Bat. ii. 87 t. 28 (1852) [1856]. URTICACEAE, Benth. \& Hook. f. iii. 358 .

insignis, Blume, l. c. 88.-Borneo

madagascariensis, Blume, l.c.-Madag.

BLENCOCOËS, Rafin. Fl, Tellur. iii. $75 \quad(1836)=$ Nierembergia, Ruiz \& Pav. (Solanac.) filicaulis, Rafin. l. c. $76=\mathrm{N}$. linearifolia. longiflora, Rafin. 1. c.-Hab.?

BLENNODERMA, Spach, in Nouv. Ann. Mus. Par. iv. (1835) $406=$ Oenothera, Linn. (Onagrar.).

Drummondii, Spach, 1. c. $407=$ Oe. Spachiana.

BLENNODIA, R. Br. in Sturt, Exped. ii. App. 67 (1849). CRUCIFERAE, Benth. \& Hook. f. i. 82. alpestris, F. Muell. in Trans. Phil. Soc. Vict. i. $(1855$ 100.-Austral.

blennodes, F. Muell. l. c. =lasiocarpa.

brevipes, F. Muell. l. c. - Austral.

canescens, R. Br. in Sturt, Exped. ii. App. 67.-Austral. cardaminoides, Benth. Fl. Austral. i. 75.-Austral. Cunninghamii, Benth. l. c. 76.-Austral

curvipes, F. Muell. in Trans. Phil. Soc. Vict. i. (1855) 100.-Austral.

eremigera, Benth. Fl. Austral, i. 74-Austral.

filifolia, Benth. l. c. 73.-Austral.

lasiocarpa, F. Muell. in Trans. Phil. Soc. Vict. i. (1855) 100.-Austral.

nasturtioides, Benth. Fl. Austral, i. 74.-Austral.

trisecta, Benth. l. c.-Austral.

BLENNOSPERMA, Less. Syn. Comp. 267 (1832) COMPOSITAE, Benth. \& Hook, f, ii. 404

APALUS, DC. Prod. v. 507 (1836)

Coniothele, DC. Prod, v. 531 (1836)

UnxiA, Colla, in Mem. Acc. Torin. xxxviii. (1835) 37. t. 32.

californicum, Torr. E Gray, Fl. N. Am. ii. 272.-Calif. chilense, Less. Syn. Comp. 267.-Chili.

BLENNOSPORA, A. Gray, in Hook. Kew Journ. iii. (1851) $172=$ Calocephalus, $\mathrm{R}$. Br. (Compos.) Drummondii, A. Gray, 1. c. $179=$ C. Drummondii.

BLEPETALON, Rafin. Sylva Tellur. 80 (1838) Scutia, Comm. (Khamn.)

aculeatum, Rafin. I. c. $=$ S. Commersoni.
BLEPHANTHERA, Rafin, FI. Tellur, ii. $59(1836)=$ Bulbine, Linn. (Liliac.)

depressa, Rafin. 1. c。 = Bulbine bulbosa.

Hookeri, Rafin. 1. c. (= Anthericum Hookeri $)$.N. Zel.

BLEPHARACANTHUS, Nees, in Lind?. Introd, Nat Syst. ed. II. $444(1836)=$ Blepharis, Juss. (Acanth.) capensis, Nees, $1 . c_{.}=$Blepharis capensis.

carduifolius, Nees, ex Stend. Nom. ed. II. i. $209=$ Blepharis carduifolia.

furcatus, Nees, ex Steud. 1, c. = Blepharis furcata.

integrifolius, Nees, ex Steud. 1, c. = Blepharis satarejac folia.

procumbens, Nees, in Lindl. Introd. Nat. Syst. ed. II $444=$ Blepharis glomerata

verticillata, Steud. Nom. ed. II. i. $209=$ Cardanthera verticillata.

BLEPHARADEN, Dulac, Fl. Hautes-Pyr。 449 (1867)= Swertia, Linn. (Gentianac.)

perennis, Dulac, $1 . c_{0}=\mathrm{S}$. perennis

BLEPHARANDRA, Griseb, in Linnaea, xxii, (1849) 7. MALPIGHIACEAE, Benth. \& Hook, f, i, 254. bypoleuca, Griseb.l.c.-Guiana.

BLEPHARANTHEMUM, Klotzsch, in Link, Klotzsch \& Otto, Ic. Pl. $20(1841)=$ Plagianthus, Forst (Malvac.)

sidoides, Klotzsch, I. $\mathrm{c}_{\circ}=\mathrm{P}$, sidoides.

BLEPHARANTHES, Sm. Gramm. Bot. 188 (1821)= Modecea, Lam. (Passif.)

BLEPHARIGLOTIS, Rafin. Fl. Tellur。 ii. 38 (1836 = Habenaria, Willd. (Orchid.)

albiflora, Rafin. 1. co = H. albida?

bicolor, Rafin. I. c. 39.-Hab.?

cristata, Rafin, $1, c_{2}=\mathrm{H}$. cristata

flaviflora, Rafin. 1. c.-Hab.?

longicornis, Rafin, 1. c. $38=\mathrm{H}$. longicomis,

BLEPHARIPAPPUS, Hook. Fl. Bor. Am. i. 31 (1833). COMPOSITAE, Benth. \& Hook. f. ii. 392. Ptilonella, Nutt. in Trans, Am. Phil. Soc. Ser. If vii. (1841) 385

glandulosus, Hook. 1. c. = Layia glandulosa.

scaber, Hook. l. c. -Am. bor. occ.

BLEPHARIS, Juss. Gen。 103 (1789)。ACANTHA CEAE, Benth. \& Hook. f. ii. 1089.

ACnNThodium, Delile, Fl. Egypte, 241. t. 38 (1813)

Blepharacan'shus, Nees, in Lindl. Introd. Nat Syst. ed. II. 444 (1836).

ablephara, Nees, in DC. Prod. xi. 267.-Java.

abyssinica, Hochst. ex A. Rich. Tent. Fl. Abyss, it. $150=$ boerhaviaefolia

acanthodioides, Klotasch, in Peters, Reise Mossamb. Bot. 212.-Afr. trop.

angusta, T. Anders. in Fourn. Linn. Soc. vii. (18635.-Afr. austr.

arborea, Spreng. Syst. ii. 819.-Arabia.

asperrima, Nees, in DC. Prod. xi, 267. -Ind, or

boerhaavifolia, Roth, Nov. Sp. $320=$ seq.

boerhavizefolia, Pers. Syn. ii. 180.-Ind. or

calaminthaefolia, Pers. l. c.-Hab. ?

capensis, Pers. l. c.-Afr. austr.

carduifolia, T. Anders, in Fourn. Linn, Soc, vii, (186t

35.-Afr, austr.

cuanzensis, Wolw. ex S. Moore, in For rm. Bot xwiii 1880) 230.-Afr. trop

edulis, Pers. Syno ii. 180,-Arab.; Persia; Ind. bor occ.

furcata, Pers, l. co: T. Anders, in Gourn. Linn. Soc vii. 1864) 35 . - Afr. austr.

furcata, Eckl. ex Nees, in DC. Prod. xi. 276; et Zeyb. ex Nees, 1. c. $277=$ capensis.

glauca, $T$. Anders, in Gourn. Linn. Sor, vii. (186! 36.-Afr. austr.

glomerata, Poir, Encyco Supplo i. 89,-Afr. austr. glumaces, S. Moore, ins Yourn. Bup xvii. (1850) ag? -Afr. trop.

grossa, $T$. Anders, in Yourn. Linn. Soc. vii. 1 18vit 30.-Afr. austr.

Guiinzii. T. Anders. I. r. St.-Afr. nuste.

hintinervia. T. Amders. I. c. \$ö,-Air, austr. 


\section{BLEPHARIS :-}

integrifolia, E. Mey. in Drège, Zwei Pf. Docum. 168 = saturejaefolia.

involucrata, Solms, ex Schweinf. Beitr. Fl. Aethiop. 107.-Afr. trop.

linariaefolia, Pers. Syn. ii. 180.-Afr. trop.

maderaspatensis, Heyne, ex Roth, Nov. Sp. $320=$ boerhaviaefolia.

molluginifolia, Pers. Syn. ii. 180.-Ind. or.

Noli-me-tangere, S. Moore, in Fourn. Bot. xviii. (1880) 231.-Afr. trop.

pratensis, S. Moore, l.c. xv. (1877) 294.-Afr, trop.

procumbens, Heyne, ex Roth, Nov. Sp. $320=$ boerhaviaefolia.

procumbens, Pers. Syn. ii. $180=$ glomerata

procurrens, Nees, in DC. Prod. xi. $267=$ boerhaviaefolia. pungens, Klotzsch, in Peters, Reise Mossamb. Bot. 211.-Afr. trop.

repens, Roth, Nov. Sp. $321=$ molluginifolia

rubiaefolia, Schum. in Dansk. Vidensk. Selsk. Afh. iv. (1828) $66=$ boerhaviaefolia

saturejaefolia, Pers. Syn. ii. 180.-Afr. austr.

scindica, Stocks, ex T. Anders. in Journ. Linn. Soc. vii.

1864) $36=$ linariaefolia.

serrulata, Ficalho \& Hiern, in Trans. Linn. Soc. Ser. II. ii. (1881) 24.-Afr. trop.

setosa, Nees, in DC. Prod. xi. 265.-Afr. austr.

sindica, Stocks, ex T. Anders. in Journ. Linn. Soc. ix. (1867) $500=$ linariaefolia.

spathularis, T. Anders, l. c. vii. (1864) 35.-Afr. austr.

spiculifolia, Balf.f. in Proc. Roy. Soc. Edinb. xii. (1884) 85.-Ins. Socotr.

squarrosa, T. Anders. in Fourn. Linn. Soc. vii. (1864) 35.-Afr, austr.

Togodelia, Solms, ex Schweinf. Beitr. Fl. Aethiop. 108.-Abyss.

verticillata, Heyne, ex Wall. Cat. n. $2409=$ Cardanthera verticillata.

Welwitschii, S. Moore, in fourn. Bot. xviii. (1880) 231.-Afr. trop.

BLEPHARISPERMUM, Benth. in DC. Prod. vii. 709 $(\mathbf{1 8 3 9})=$ BLEPHAROPHYLLUM， Klotzsch $=$ Scy phogyne, Brongn. (Ericac.).

BLEPHARISPERMUM, Wight, ex DC. in Wight, Contrib. Bot. Ind. 11 (1834). COMPOSITAE, Benth. \& Hook. f. ii. 295

LeUCOBLePHARIS, Am. in Mag. Zool. \& Bot. ii. (1838) 422.

petiolare, $D C$. in Wight, l. c. 12.-Ind. or.

spinulosum, Oliver E Hiern, in Oliver, Fl. Trop. Afr. iii. 335.-Afr. trop.

subsessile, DC. in Wight, Contrib. Bot. Ind. 12.Ind. or.

zanguebaricum, Oliver E Hiern, in Oliver, Fl. Trop. Afr. iii. 336.-Afr. trop.

BLEPHARISTEMMA, Benth, in Wall, Cat. n. 6320 (1832). RHIZOPHOREAE, Benth. \& Hook. f. i. 682 .

corymbosum, Benth. $l_{*} c_{\text {. }}$-Ind. or.

BLEPHAROCALYX, Berg, in Linnaea, xxvii. (1854) 412 = Myrtus, Tourn.

acuminatissimus, Berg, 1. c. 413 ; et in Mart. F1. Bras. xiv. I. 421.-Reg. Argent.

acuminatus, Berg, 11. cc. 414, 426 (=Myrcia acuminala ?).-Bras.

affinis, Berg, in Mart. Fl. Bras. xiv. I. 605.-Bras.

amarus, Berg, 1. c. 422.--Reg. Argent.

angustifolius, Berg, 1. c. 421.-Bras.

angustissimus, Berg, 1, c--Bras.

apiculatus, Berg, 1, c. 425.-Bras.

brunneus, Berg, 1. c. 427 -Bras.

canescens, Berg, 1. c. 426.-Bras.

cisplatensis, Griseb. in Goett. Abh. xxiv. (1879) 126. -Reg. Argent.

cuspidatus, Berg, in Mart. Fl. Bras. xiv. I. 424.-Bras. depauperatus, Berg, in Linnaea, xxvii. (1854) 415; et in Mart. 1. c. 428. - Bras.

ellipticus, Berg, 1l. cc. 415 et $429,-$ Bras.

lanceolatus, Berg, in Mart. Fl. Bras. xiv. I. 422.-Bras longipes, Berg, 1. c. 423,-Bras.

parvifolius, Berg, 1. c. 606 .-Bras.

picrocarpus, Berg, 1. c. 427.-Bras.

pilosus, Berg, 1. c. $422,-N$. Granat.

ramosissimus, Berg, 1. c. 424.-Bras.
BLEPHAROCALYX :-

salicifolia, Berg, in Linnaea, xxvii. (1854) $413=$ Myrtus salicifolia.

Serra, Berg, in Mart. Fl. Bras. xiv. 1. 605.--Bras. sessilifolius, Berg, 1. c. 428.-Bras.

strictus, Berg, l. c. 423 . - Bras.

Tweediei, Berg, in Linnaea, xxvii. (1854) 415; et in

Mart. F1. Bras, xiv, I. 429. - Bras.

villosus, Berg, in Mart. Fl. Bras. xiv. I. 425.-Bras.

Widgreni, Berg, 1. c. 427.-Bras.

BLEPHAROCARYA, F. Muell. Fragm. ix。 15 (1878). SAPINDACEAE.

involucrigera, $F$. Muell. l. c. 16.-Austral.

BLEPHAROCHLAMYS, Presl, Epim. Bot. 245 (1849) = Mystropetalon, Harv. (Balanoph.).

capensis, Presl, 1. c. $246=$ M. Thomii.

BLEPHAROCHLOA, Endl. Gen. 1352 (1841) = Leersia, Sw. (Gramin.).

ciliata, Endl. 1. c. = L. ciliata?

BLEPHARODON, Decne. in DC. Prod. viii. 603 (1844). ASCLEPIADEAE, Benth. \& Hook. f. ii. 756 .

PTycholepis, Griseb, in Lechl. Berb. Am. Austr. 58 (1857)

ampliflorus, Fourn, in Mart. Fl. Bras. vi. IV. 304.Bras.

asparagoides, Decne, in DC. Prod. viii. 604.-Bras.

asterion, Fourn. in Mart. Fl. Bras. vi. IV. 307.Bras.

bicolor, Decne. in DC. Prod. viii. 604.-Bras.

bicuspidatus, Fourn. in Mart. Fl. Bras. vi. IV. 306.Bras.

bracteatus, Fourn. l.c. 307.-Bras

Decaisnei, Fourn. l. c. 305,-Bras.

diffusum, Decne in DC. Prod viii. 605.-Bras.

grandiflorum, Benth. Pl. Hartw. 215.-N. Granat.

laurifolium, Decne. in DC. Prod. viii. $603=$ Nephra denia laurifolia.

lineare, Decne. 1. c. $=$ Nephradenia linearis.

linearifolium, Benth. \& Hook. f. Gen. ii. 756, sphalm. =laurifolium.

longipedicellatum, Fourn. in Mart. Fl. Bras. vi. IV. 306.-Bras.

mucronatum, Decne. in DC. Prod. viii. 603.-Mexic nerifolium, Decne. 1. c- = Nephradenia neriifolia.

pallidum, Decne. $l . c$.-Bras.

salicinum, Decne.l. c. 604.-Bras.?

Spruceanum, Fourn. in Mart. Fl. Bras. vi. IV. 307.Bras.

triplinerve, Turcz. in Bull. Soc. Nat. Mosc. xxv. (1852) II. 319.-Venezuela.

BLEPHAROLEPIS, Nees, in Lindl. Introd. Nat. Syst. ed. II. $442(1836)=$ Polpoda, Presl (Ficoid.)

Zeyheriana, Nees, 1. $\mathrm{c}_{\mathrm{s}}=\mathbf{P}$. capensis.

BLEPHAROLEPIS, Nees, in Mart. Fl. Bras. ii. I. 91 (1843) = Scirpus, Linn. (Cyperac.).

leucoblepharis, Nees, 1. c.-Bras.

BLFPHAROPHYLLUM, Klotzsch, in Linnaea, xii. (1838) $216=$ Scyphogyne, Brongn. (Ericac.). divaricatum, Klotzsch, 1. c. $215=\mathrm{S}$. divaricata.

BLEPHAROSTEMMA, Fourr. in Ann. Soc. Linn. Lyon N. S. xvi. (1868) $398=$ Asperula, Linn. (Rubiac.). taurinum, Fourr. 1. $\mathrm{c}_{0}=\mathrm{A}$. taurina.

BLEPHILIA, Rafin. in Am. Monthly Mag. (1819) 190 ; et Journ. Phys. Ixxxix. (1819) 98. LABIATAE Benth. \& Hook. f. ii. 1198.

Becki, Rafin. in Atl. Fourn. 146.-Am. bor.

brevifolia, Rafin. New Fl. Am. iv. $96=$ ciliata.

brevipes, Rafin. l. c.-Am. bor.

ciliata, Rafin. in Am. Monthly Mag. (1819) 190.Am. bor.

heterophyla, Rafin. New Fl. Am. iv. $96=$ ciliata?

hirsuta, Benth. Lab. Gen. et Sp. 320.-Am. bor.

lanceolata, Rafin. New Fl. Am. iv. $96=$ hirsuta?

nepetoides, Rafin. 1. c. = hirsuta.

pratensis, Rafin. 1. c. = ciliata.

BLEPHILOMA, Rafin. Fl. Tellur. iii. 95 (1836)= Phlomis, Tourn, (Labiat.) amplifolia, Rafin. 1. c.-Hab. ?
BLEPHISTELMA, Rafin. F1. Tellur. iv. 103 (1836)=-

Passiflora, Linn.

aurantia, Rafin. $1, \mathrm{c}_{s}=\mathrm{P}$. aurantia

BLeTIA, Ruiz \& Pav. Prod. 119. t. 26 (1794) ORCHIDEAE, Benth. \& Hook. iii. 513.

Bletiana, Rafin, in Am. Monthly Mag. (1818) 268.

Bletilla, Reichb. fo in Fl. des Serres, viii. 1853 246.

Dilomilis, Rafin. F1. Tellur. iv. 43 (1836).

Gyas, Salisb. in Trans. Hort. Soc. i. (1812) 299.

Hecabe, Rafin. Fl. Tellur. iv. 44 (1836).

JIMENSIA, Rafin. 1. c. 38 (1836).

Thiebautia, Colla, Hort. Ripul. 139 (1824).

acaulis, Reichb. f. in Walp. Ann. vi. $435=$ Brassavola acaulis.

acuminata, Reichb. f. 1. c. $427=$ Laelia acuminata

acutipetala, Hook. Bot. Mag. t. $3217=$ verecunda.

adenocarpa, Reichb. $f$. in Bonplandia, iv. (1856) 216. -Mexic.

albida, Reichb. f. in Walp. Ann. vi. $428=$ Laelia albida amazonica, Reichb. 1. c. $434=$ Brassavola amazonica. amboinensis, Zipp. ex Blume, Mus. Bot. Lugd. Bat. ii. $180=$ Phaius amboinensis

anceps, Reichb. f. in Walp. Ann. vi. $418=$ Laelia anceps.

angustata, Gaudich. in Freyc. Voy. Bot. $421=$ spathoglottis plicata.

angustata, Reichb. f. in Walp. Ann. vi. $434=$ Brassavola angustata.

anomala, Rich. E' Gal. in Ann. Sc. Nat. Sér. III. i (1845) 23.-Mexic.

aphylla, Nutt. Gen. Am. ii. 194= Hexalectris aphylla attenuata, Reichb. f. Xenia Orchid. ii. 64.-Ind. occ.

autumnalis, La Llave \& Lex. Nov. Veg. Desc. fasc. ii. (Orch. Opusc.) $19=$ Laelia autumnalis.

bicallosa, D. Don, Prod. Fl. Nep. $30=$ Liparis bituberculata?

Boothiana, Reichb. f. Xenia Orchid. ii. 51=Laelia Boothiana.

bracteosa, Griff. Notul, iii. 326.-Ind. or.

campanulata, La Llave \& Lex. Nov. Veg. Desc, fasc. ii. (Orch.Opusc.) 17.-Mexic.

capitata, [R. Br. in] Ait. Hort, Kew. ed. II. v. 206 $=$ Elleanthus capitatus.

Casperiana, Reichb. f. in Walp. Ann. vi. $423=$ Laelia purpurata.

catenulata, Ruiz \& Pav. Syst. 229.-Peruv.

caulescens, Reichb. f. in Walp. Ann. vi. $431=$ Laelia caulescens.

Ceboletta, Reichb. f. 1. c. $435=$ Brassavola Ceboletta.

ciliata, Presl, Rel. Haenk. 99.-Peruv.

cinnabarina, Reichb. f. in Walp. Ann. vi. $430=$ Laelia cinnabarina.

cinnamomea, Reichb. f. l. c. 418= Laelia cinnamomea. coccinea, La Llave E" Lex. Nov. Veg. Desc. fasc. ii. (Orch. Opusc.) 16.-Mexic.

cordata, Reichb, f. in Walp. Ann. vi. $436=$ Brassavola nodosa.

crispa, Reichb. f. 1. c. $423=$ Laelia crispa

crispina, Reichb. f. l. c. $419=$ Schomburgkia crispa.

cucullata, Reichb. f. 1. c. $433=$ Brassavola cucullata.

Dabia, D. Don, Prod. Fl. Nep. $30=$ Eulophia campestris?

densiflora, Griff. Notul. iii. 328.-Ind. or

Digbyana, Reichb. f. in Walp. Ann. vi. $422=$ Laelia Digbyana.

domingensis, Reichb. f. l. c. $432=$ Broughtonia lilacina.

elegans, Reichb. f. 1. c. $427=$ Laelia elegans.

ensiformis, Ruiz \& Pav. Syst. 230.--Peruv.

Eulophiae, Reichb. f. in Walp. Ann. vi. $439=$ Tetramicra tenera.

euspatha, Reichb. f. 1. c. $424=$ Laelia euspatha.

flabellata, Reichb. f. 1. c. $422=$ Laelia xanthina.

flava, Reichb. f. 1. c. 431 = Laelia flava.

flava, Wall. ex Lindl. Gen. et Sp. Orch. $127=$ Phaius maculatus.

florida, [R.Br.in $]$ Ait. Hort. Kew. ed. II. v. 206.-Ind. occ.

fulgens, Reichb. f. in Bonplandia, iii. (1855) 221.Mexic.

furfurea, Reichb. f. in Walp. Ann. vi, $428=$ Laelia furfuracea.

gebina, Lindl. in Journ. Hort. Soc. ii. (1847) $307=$ hyacinthina.

glauca, Reichb. f. in Walp. Ann. vi. $423=$ Laelia glauca. 


\section{BLETIA}

gloriosa, Reichb. fo in Walp. Ann. vi. $419=$ Schomburgkia crispa.

gracilis, Lodd. Bot. Cab. t. 1977.-Mexic.

graminifolia, D. Don, Prod. F1. Nep. $29=$ Arundina bambusifolia.

grandiflora, La Llave \& Lex. Nov. Veg. Desc. fasc. ii. (Urch. Opusc.) $17=$ Laelia grandiflora.

grandis, Reichb. f. in Walp. Ann. vi. $424=$ Laelia grandis.

guineensis, G. Don, ex Sweet, Hort. Brit. ed. I. 492,

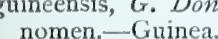

havannensis, Lindl. Bot. Reg. (1838) Misc. 28.-Cuba.

Humboldtii, Reichb, f, in Walp. Ann. vi. $430=$ Schom burgkia Humboldtii.

humilis, Link \&c Otto, Ic. Pl. Rar. 53. t. $27=$

Maxillaria gracilis.

hyacinthina, [R.Br.in] Ait. Hort. Kew. ed. II. v. 206. -China; Japon.

irrorata, Reichb. f. in Walp. Ann. vi. $426=$ Laelia irrorata

jucunda, Linden E Reichb. f. in Bonplandia, iii. (1855) 221.-Mexic.

Landsbergii, Reichb. f. in Nederl. Kruidk. Arch. iv. (1859) 317.-Am. trop

latifolia, Gaudich. Bot.Freyc. Voy. 421.-Ins. Molucc. lilacina, $A$. Rich. E Gal. in Ann. Sc. Nat. Sér. III. iii. (1845) 23.--Mexic.

Lindeni, Reichb. f. in Walp. Ann. vi. $431=$ Laelia Lindenii.

Lindleyana, Reichb. f. Xenia Orchid. ii. $65=$ Laelia Lindleyana.

lineata, Reichb. f. in Walp. Ann. vi. $436=$ Brassavola lineata.

lobata, Reichb. f. 1. c. $424=$ Laelia Boothiana

longipes, Reichb. f. Xenia Orchid. ii. $59=$ Laelia longipes.

Lundii, Reichb. f. \& Warm. in Otia Bot. Hamb. $92=$ Laelia Lundii.

Lyonsii, Reichb. fo in Walp. Ann. vi. $418=$ Schom-

burgkia Lyonsia.

marginata, Reichb. f. 1. c. $419=$ Schomburgkia marginata.

Martiana, Reichb. f. 1. c. $434=$ Brassavola Martiana.

Masuca, D. Don, Prod. Fl. Nep. $30=$ Calanthe Masuca

montana, Reichb. $f$. in Walp. Ann. vi. $445=$ Octadesmia serratifolia.

nipponica, Franch. \& Sav. Enum. Pl. Fap. ii. 511.Japon.

nodosa, Reichb. f. in Walp. Ann. vi. 437 = Brassavola nodosa.

obcordata, Lindl. Gen. et Sp. Orch. 123.--Ind. or.

Ortgiesiana, Reichb. f. in Otto, Hamb. Gartenz. xvi. (1860) 420 - - Hab?

pallida, Lodd. Bot. Cab. t. $629=$ florida

Parkinsonii, Hook. Bot. Mag. t. 3736.-Mexic

parviflora, Reichb. f. in Walp. Ana. vi. $439=$

Tetramicra parviflora.

parviflora, Ruis E Pav. Syst. Veg. 231.-Peruy.

patula, Hook. Bot. Mag. t. 3518.--Ins. S. Doming.

Paulinae, F. Muell. Fragm, vi. $95=$ Spathoglottis Paulinae.

peduncularis, Reichb. f. in Walp. Ann. vi. $426=$ Laelia peduncularis.

Perrinii, Reichb, f. 1, c. $421=$ Laelia Perrinii.

platyphylla, Reichb. f. ex Griseb. Cat. Pl. Cub. $264=$ sarcophylla.

praestans, Reichb. f. in Walp. Ann. vi. $425=$ Laelia praestans.

pratensis, Reichb. f. 1. c. $439=$ Tetramicra rigida.

pulchella, Hort.-Cf. Gard. Chron. (1850) 168 verecunds.

pumila, Reichb. f. in Walp. Ann。 vi. 421=Laelia pumila.

Pumilio, Reichb. f. 1. c. $499=$ Brassavola Pumilio.

punctata, La Llave E Lex. Nov. Veg. Desc. fasc. ii. (Orch. Opusc.) 15.-Mexic.

purpurata, A. Rich. \& Gal. in Ann. Sc. Nat. Sér. III. iii. $(1845) 23=$ Arethusa rosea.

purpurata, Reichb. f. in Walp. Ann. vi. $428=$ Laelia purpurata.

purpurea, DC. Huit. Not. P1. Rar. Jard. Genèv. 29 Everecunda.

reflexa, Lindl. Bot. Reg. xxi. (1896) t, 1760,-

Peruy.

repanda, Ruis \& Pav. Syst. Veg. 229.-Peruv.

retusa, Reicbb. fo in Walp. Ann. vi. $495=$ Brassavola retusa.

\section{BLETIA :}

rhopalorrhachis, Rcichb. f. I. c. $437=$ Brassavola rhopalorrhachis.

rigida, Reichb. f. 1, c. 438=Tetramicra rigida

Roezlii, Reichb. f. in Linnaea, xli. (1877) 7.-Mexic.

rosea, Reichb. f. in Walp. Ann. vi. $420=$ Schomburgkia rosea.

rubescens, Reichb. f. 1. c. $425=$ Laelia rubescens

rupestris, Reichb. f. 1. c. $431=$ Laelia rupestris.

sanguinea, Poepp. \& Endl. Nov. Gen. et Sp.i.56. t. 95 = catenulata.

sarcophylla, Reichb. f. in Flora, xlviii. (1865) 278.Ind. occ.

Schilleriana, Reichb. f. in Walp. Ann. vi. $424=$ Laelia Schilleriana.

schoenina, Reichb. f. 1. c. $439=$ Tetramicra schoenina

Schomburgkii, Reichb, f, l, c. $=$ Tetramicra rigida.

secunda, Lindl. Bot. Reg. (1840) Misc. 57.-Mexic.

Shepherdii, Hook. Bot. Mag. t. $3319=$ verecunda.

Sherrattiana, Batem. in Hook. l. c. t. 5646,-N. Granat

speciosa, H. B. \& K. Nov, Gen. et Sp. i. $342=$ Laelia grandiflora.

splendens, Linden, Illustr. Hortic. xxviii.(1881) 64 nomen.--Bras

stricta, C. Presl, Rel. Haenk. 98.-Ins. Luzon.

superbiens, Reichb. f. in Walp. Ann. vi. $418=$ Laelia superbiens.

sylvatica, Boj. Hort. Maurit. $318=$ Calanthe sylvatica.

Tankervilleae, R. Br. in Bot. Mag. t. $1924=$ Phaius grandiflorus.

tenera, A. Rich. Fl. Cub. Fanerog. ii. $242=$ Tetramicra tenera.

tibicinis, Reichb. f. in Walp. Ann. vi. $429=$ Schomburgkia tibicina.

tuberculata, Reichb. f. 1. c. $434=$ Brassavola tuberculata.

tuberculosa, Spreng. Syst. iii. $744=$ Phaius tuberculosus undulata, Reichb. f. in Walp. Ann. vi. $420=$ Schomburgkia undulata.

uniflora, Ruiz \& Pav. Syst. Veg. 230.-Peruv.

venosa, Reichb. $\mathrm{f}$. in Walp. Ann. vi. $438=$ Brassavola venosa.

verecunda, [R.Br. in] Ait. Hort. Kew. ed. II. v, 206. -Florida; Ind, occ.

villosa, Spreng. Syst, iii. 743 - Phaius villosus.

violacea, Reichb. f. in Walp. Ann. vi. $426=$ Laelia violacea.

Wagenerii, Reichb. f. in Bonplandia, ii. (1854) 22.Venezuela.

Wallisii, Reichb.f. in Linnaea, xli. (1877) 115.-N. Granat.

Wendlandi, Reichb. f. in Walp. Ann. vi. $431=$ Laelia Wendlandi.

Woodfordii, Hook. Bot. Mag. t. $2719=$ Phaius maculatus.

xanthina, Reichb. f. in Walp. Ann. vi. $425=$ Laelia xanthina.

BLETIANA, Rafin. in Am. Monthly Mag. (1818) $268=$ Bletia, Ruiz \& Pav. (Orchid.).

BLETILLA, Reichb, fo in Fl. des Serres, Sér. I. viii. (1851-53) $246=$ Bletia, Rriz \& Pav. (Orchid.).

forida, Reichb. f. 1. c. = Bletia florida.

Gebinae, Reichb, f. 1. c. = Bletia hyacinthina

BLETTI, Steud. Nom. ed. II. i. $210(1840)=$ BLATTI, Adans, = Sonneratia, Linn. f. (Lythrar.).

BLIGHIA, Kon. in Kon. \& Sims, Ann. Bot. ii. (1806). 571. t. 16, 17. SAPINDACEAE. [Benth. \& Hook. f. i. 399 ].

AKEA, Stokes, Bot. Mat. Med. ii. 353 (1812)

AKeEsia, Tussac, Fl. Ant, i. 66 (1808).

sapida, Kon. in Kon. E Sims, Ann. Bot. ii. (1806) 571. -Afr. ; Ind. occ.

unijugata, Baker, in Oliver, F1. Trop. Afr. i. 427.Afr. trop.

zambesiaca, Baker, l. c.-Afr. trop.

BLINKWORTHIA, Choisy, in Mém. Soc. Phys. Genèv, vi. (1833) 430. t. 4. CONVOLVULACEAE, Benth. \& Hook. f. ii. 869 .

lycioides, Choisy, l. c.-Burma.

BLITANTHUS, Reichb. Cat. Hort. Dresd. (1824) Handb. $235(1837)$ = Acroglochin, Schrad. (Chenopod.)

nepalensis, Reichb. II. cc, $=$ A. chenopodivides.
BLITUM, [Toum.] Linn. Gen. ed. I. $20(1737)=$ Cheno podium, Linn.

acuminatum, Schur, Enum. Pl. Transs。 $571=\mathrm{C}$ rubrum.

antarcticum, Hook. f. FI. Antarct. ii. $549=$ C. antarc ticum.

atriplicinum, F. Muell. in. Trans. Vict. Inst. (1855) $133=$ C. atriplicinum.

Bonus-Henricus, C. A. Mey. Fl. Alt. i. 11, nota $=$ C Bonus-Henricus.

botryoides, Drej. in Fl. Dan.t. $2894=$ C. rubrum californicum, S. Wats. in Proc. Am. Acad. ix. (1874 $101=$ C. californicum

capitatum, Linn. Sp. P1. 4 = C. capitatum

carinatum, C. A. Mey. in Ledeb. F1. Alt. i. 11 adnot.= C. carinatum.

chenopodioides, Bernh. ex Steud. Nom. el. II. i. 210 petiolare.

chenopodioides, Lam. Encyc. ii. $11=$ C. capitatum.

chenopodioides, Nutt. Gen. Am. i. $4=$ Monolepis cheno podioides.

crassifolium, Reichb. Fl. Germ. Excurs. $582=\mathrm{C}$ rubrum.

cristatum, F. Muell. in Trans, Phil. Inst. Vict. ii. (1858) $73=\mathrm{C}$. cristatum.

gangeticum, Moench, Meth. 359=Amaranthus gangeticus.

genuinum, Koch, ex Buek, Ind. DC. Prod. iii. 61 (es. sectio generis)

glandulosum, Moq. in DC. Prod. xiii. II. $82=C$ carinatum

glaucum, Koch, in Sturm, Deutschl. Fl. Heft $75=$ C glaucum.

graecizans, Moench, Meth. $359=$ Amaranthus Blitum. lividum, Moench, I. c. = Amaranthus lividus.

maritimum, Nutt. Gen. Am. ii. Add. post Ind. [12

C. rubrum.

maius, Scop. Fl. Carn. ed. II. ii. $237=$ Amaranthus Blitum.

melancholicum, Moench, Meth. $359=$ Amaranthus gangeticus.

Nuttallianum, Roem. \& Schult. Mant, i. $65=$ Mono. lepis chenopodioides.

oleraceum, Moench, Meth. $359=$ Amaranthus oleraceus petiolare, Link, Enum. Hort. Berol. i. 8.-Tataria! polymorphum, C. A. Mey. in Ledeb. F1. Alt. i. $13=$ C. rubrum.

Pumilio, C. A. Mey. 1. c. 11, adnot. =C. Pumilio. rubrum, C. A. Mey. 1. c. = C. rubrum.

Sanguisorba, Pritz. Ic. Ind. 155, sphalm.= Poterium Sanguisorba.

tataricum, Mill. Gard. Dict. ed. VIII. n. $3=$ C. capitatum.

tenue, Moq. in DC. Prod. xiii. II. $81=$ Roubieva multifida.

terminale, Stokes, Bot. Comment. i. $11=\mathrm{C}$. capitatum. virgatum, Linn. Sp. P1, $4=\mathrm{C}$. capitatum.

viride, Moench, Meth. $359=$ C. album.

BLOCHMANNIA, Reichb. Consp. 163 1828\}= Triplaris, Linn. (Polygon.)

peruviana, Poepp. ex Meissn. in DC. Prod. xir. $173=$ T. Poeppigiana.

Weigeltiana, Reichb. Consp. $163=\mathrm{T}$. surinamensis.

BLONDEA, Rich. in Act. Soc. Hist. Nat. Par. i. 174. $110=$ Sloanea, Linn. (Tiliac.).

latifolia, Rich. 1. c.-Guiana.

BLONDIA, Neck. Elem, ii, $115\left(1790^{\prime}=\right.$ Tiarella. Linn. (Saxifr.).

biternata, Rafin, F1. Tellur. ii. $75=$ Astilbe decandra. trifoliata, Rafin. 1. c. $=\mathrm{T}$. trifoliata.

BLOOMERIA, Kellomg, in Proc. Calif. Acad. ii. 11 (1863). LILIACEAE, Benth. \& Hook. f Gen. iii. 801 .

aurea, Kellogg, l. c.-Calif.

Clevelandi, S. Wats. in Proc. Am. Acad. xx. (1)s5 $\$ 76 .-$ Calif.

BLUFFlA, Delile, Sem. Hors. IIamb. 1895. (Cf. Lin nacn, $\left.x,\left(1896^{\circ}\right) 114\right)$; Nees, Fl. Afr. Austr. Gram $\left(1896^{\circ}\right)=$ Panicum, Linn. (Gramin

Ecklunsiana, Nees, in Lindl. Iatrod. Nat. Syst. ed. II. $4 \pi$. - Afr. austr.

BLUMLA, G. I)on, Gen. Syst i. 579 ;S\$1 - BI.LM1.1 Spreng. - Saurawa, Willd. (Ternstrocm.) 
BLUMEA, Reichb. Consp. 209 (1828) = Neesia, Blume (Malvac.).

altissima, Reichb. ex Steud. Nom. ed. II. i. $211=$ N. altissima.

BLUMEA, DC. in Guill. Arch. Bot. ii. (1833) 514. COMPOSITAE, Benth. \& Hook. f. ii. 289.

Doellia, Sch. Bip. in Walp. Rep. ii. 953 (1843).

Placus, Lour. Fl. Cochinch. 496 (1790).

abyssinica, Sch. Bip. ex A. Rich. Tent. Fl. Abyss. i. 392.-Abyss.

acutata, DC. in Nouv. Ann. Mus. Par. iii. (1834) $409=$ laciniata.

alata, DC. Prod. v, $448=$ Laggera alata.

amethystina, Hance, in Journ. Bot. vi. (1868) $173=$ glomerata.

amplectens, DC. in Wight, Contrib. Bot. Ind. 13.Ind. or.

amplectens, Thw. Enum. P1. Zeyl. 163=bifoliata

anagallidifolia, DC. in Wight, Contrib. Bot. Ind. $13=$ amplectens.

angustifolia, Thw. Enum. Pl. Zeyl. 164.-Zeylan.

appendiculata, $D C$. Prod. v. 447.- Java.

arenaria, DC. in Wight, Contrib. Bot. Ind. $13=$ amplectens.

arfakiana, Martelli, in Nuov. Giorn. Bot. xv. (1883) 292.-N. Guin

Arnottiana, Stend. Nom. ed. II. i. $210=$ Inula Cappa aromatica, DC. Prod. v. 446--Rer. Himal, ; Burma.

aurita, DC. in Wight, Contrib. Bot. Ind, $16=$ Laggera aurita.

axillaris, DC. Prod. v. $434=$ lacera

baccharoides, Sch. Bip. ex A, Rich. Tent. Fl. Abyss, i. $391=$ Pluchea Dioscoridis

balsamifera, DC. Prod. v. 447.-Ind, or.; Burma; Malaya.

harbata, DC. in Wight, Contrib. Bot. Ind. 14.Ind. or.

Belangeriana, DC. Prod. v. 444.-Ind. or.

bifoliata, DC. in Wight, Contrib. Bot. Ind. 14.Ind, or.; Burma ; Malaya.

Bovei, Vatke, in Linnaea, xxxix. (1875) $485=$ abyssinica.

bovina, Edgew. in Journ. As. Soc. Beng. xxi. (1853 $173=$ oxyodonta.

cernua, DC. Prod, v, $436=$ hieracifolia.

Chamissoniana, DC 1. c. $434=$ Wightiana.

chinensis, DC. l. c. 444.-Ind. or.; China; Java.

chinensis, Hook. \& Am. Bot. Beech. Voy. 195= Inula Cappa.

chinensis, Walp. in Nov. Act. Nat. Cur, xix. Suppl, i. (1843) $294=$ hieracifolia.

cichoriifolia, DC. ex Decne. in Nouv. Ann. Mus. Par. iii. (1834) $410=$ laciniata.

cinerascens, DC. Prod. v. $439=$ lacera

Clarkei, Hook. f. Fl. Brit. Ind. iii. $267=$ elongata.

Commersonii, Edgew. in Fourn. As. Soc. Beng. xxi. (1853) 38.-Ind. or

crassifolia, Sch. Bip. ex A. Rich. Tent. Fl. Abyss, i. 394.-Abyss.

crepidifolia, DC. Prod. v. $437=$ laciniata.

crinita, Arn. in Nov. Act. Nat. Cur. xviii. (1836) 348 -Zeylan.

crinita, Steetz, in Seem. Bot. Voy. Herald, $387=$ hieracifolia.

cuneifolia, DC. Prod. vo 441=lacera.

Cunninghami, DC. l. c. 435. - Austral.

densiflora, DC. l. c. 446.-Ind. or.; Malaya ; Ins. Pacif.

diffusa, R. Br. ex Benth. Fl. Austral. iii. 525.Austral.

diffusa, Kurz, in Fourn. As. Soc. Beng. xlvi. (1877) II. 187.-Burma.

Dregeana, $D C$. Prod. v. 436.-Afr. austr.

dregeanoides, Sch. Bip. ex A. Rich. Tent. Fl. Abyss. i. $392=$ lacera.

èlongata, DC. Prod. v. 445.-Reg. Himal,; Burma Penang.

eriantha, DC. in Wight, Contrib. Bot. Ind. 15.Ind. or.

excisa, DC. Prod. v. $446=$ densiflora.

fasciculato, DC, $\mathrm{V}, 442=$ lomerata.

fistulosa, Kurz, in Journ. As. Soc. Beng. xlvi. (1877) II. 187 = glomerata

flava, DC. Prod. v. $439=$ Laggera flava.

flexuosa, C. B. Clarke, Compos. Ind. 86.-Ind. or.

fontinalis, Edgew. in Journ. As. Soc. Beng. xxi. (1853) $173=$ lacera

\section{BIUMEA :-}

gariepina, $D C$. Prod. v. 448.-Afr. austr.

glandulosa, Benth. Fl. Hongk. 177 = laciniata.

glandulosa, DC. in Wight, Contrib. Bot. Ind. 14= lacera.

glandulosa, Thw. Enum. Pl.Zeyl. $163=$ membranacea

glomerata, DC. in Wight, Contrib. Bot. Ind. 15.Ind. or.; Malaya; China.

glutinosa, $D C$. Prod. v. 434.-Madag.

gracilis, DC. 1. c. $443=$ lacera.

grandiflora, Zipp. ex Span. in Linnaea, xv. (1841) 165

= Capparis spinosa.

grandis, DC. Prod. v. $447=$ densiflora

guineensis, DC. 1. c. $449=$ Laggera aurita

Hamiltoni, DC. 1. c. $439=$ hieracifolia.

Heyneana, DC. in Wight, Contrib. Bot. Ind. $15=$ lacera.

hieracifolia, $D C$. l. c. 15.--Ind. or.; Burma; Malaya.

hieracifolia, Hook. f. \& Thoms. ex FI. Brit. Ind. iii. $267=$ elongata.

hispidula, DC. ex C. B. Clarke, in Fl. Brit. Ind. iii. $672=$ membranacea.

holosericea, Dalz. \& Gibs. Bomb. F1. 126=glomerata.

holosericea, DC. Prod. v. $442=$ lacera.

Hookeri, C. B. Clarke, ex Hook. f. Fl. Brit. Ind. iii. 269.-Reg. Himal.

hymenophylla, DC. Prod. v. $440=$ membranacea.

integrifolia, DC. Prod. v. 433.-Austral.

Jacquemontii, Hook. f. Fl. Brit. Ind. iii. 265.Ind. or.

javanica, Zoll. \& Mor. in Nat. en Geneesk. Arch. Neêrl. Indie, ii. (1845) 239.-Java.

Kingii, C. B. Clarke, ex Hook. f. Fl. Brit. Ind. iii. 265. -Ind. or.

lacera, DC. in Wight, Contrib. Bot. Ind. 14.-Ind. or. Malaya; Ins. Mascax.

laciniata, $D C$. Prod. vo 436.-Ind, or.; Malaya; China.

lactucaefolia, DC. 1, c, $435=$ lacera.

lapsanoides, DC. in Wight, Contrib. Bot. Ind. $15=$ virens.

leptoclada, DC. Prod. v. $443=$ glomerata

leptoclada, Dalz. \& Gibs. Bomb. F1. $125=$ lacera.

Leschenaultiana, DC. Prod.v. $435=$ Wightiana.

lencanthema, DC. l. C. 436 (sp, dubia).-Nepal.

longifolia, DC. l. c. $446=$ myriocephala?

macrophylla, $D C . l$. c. 446.- Java.

macrostachya, DC. 1. c, $442=$ hieracifolia.

malabarica, Hook. f. Fl. Brit. Ind. iii. 267.-Ind. or.

Malcolmii, Hook. f. l. c. 266.-Ind. or.

manillensis, $D C$. Prod. v. 435 .- Ins. Luzon

membranacea, $D C$. $l$. c. 440.-Ind. or.; Malaya.

Metziana, Sch. Bip. ex Hook. f. F1. Brit. Ind. iii. 266 $=$ Belangeriana.

Milnei, Seem. in Bonplandia, ix. (1861) 257 ; F1. Vit. 141 = densiflora,

muralis, DC. Prod. v. $440=$ membranacea.

Musra, DC. 1. c. $435=$ lacera.

myriocephala, DC. l. c. 445.-Reg. Himal.; Burma myriocephala, Thw. Enum. PI. Zeyl. $163=$ spectabilis. napifolia, DC. 1. c. $440=$ lacera.

natalensis, Sch. Bip. in Walp. Rep. ii. 971.-Afr. austr.

neilgherrensis, Hook. f. Fl. Brit. Ind. iii. 261.Ind. or.

nitida, Wall. ex C. B. Clarke, Comp. Ind. $85=$ chinensis

nitida, Zoll. E๐ Mor. in Nat. en Geneesk. Arch. Neêrl. Indie, ii. (1845) 244.- - Java.

nodiflora, Hook. f. Fl. Brit. Ind. iii. 262,-Burma.

obovata, C. B. Clarke, Comp. Ind. $77=$ Jacquemontii

obovata, DC. Prod. v. 446. - Nepal.

oligocephala, DC. in Wight, Contrib. Bot. Ind. $13=$ bifoliata.

oloptera, DC. Prod. v. 448.-Afr. trop.

oxyodonta, DC. in Wight, Contrib. Bot. Ind. 15.-

Ind. or.; Burna; Malaya; China.

parvifolia, DC. Prod. v. $437=$ Wightiana

paucifolia, DC. 1. c. $440=$ membranacea.

Perrottetiana, DC. 1. c. $443=$ lacera.

Petitiana, A. Rich. Tent. Fl. Abyss. i. 395.-Abyss.

phagnaloides, A. Rich. 1. c. $393=$ Phagnalon scoparium.

phyllostachya, DC. Prod. v. $438=$ Wightiana.

procera, $D C$. l. c. 445 .-Ind. or.; Burma.

pterodonta, DC. in Wight, Contrib. Bot. Ind. $15=$

Laggera pterodonta.

pubiflora, DC. Prod. v. 434=amplectens.
BLUMEA :-

purpurascens, A. Rich. Tent. Fl. Abyss. i, $395=$ Laggera pterodonta.

purpurea, DC. Prod. v. $443=$ glomerata.

racemosa, DC. 1. c. $442=$ glomerata

riparia, DC. 1. c. $444=$ chinensis.

runcinata, DC. 1. c. $438=$ laciniata.

runcinata, Wall. Cat. n, $3087=$ lacera.

salvifolia, DC. Prod. v. 448.-Ins. Borbon.

salviodora, Zoll. E Mor in Nat. en Geneesk. Arch.

Neêrl. Indie, ii. (1845) 246.-Java.

saxatilis, Zoll. E Mor. l. c. 243.-Java.

semivestita, DC. Prod. v. $445=$ procera.

senecioides, DC. 1. c. $439=$ membranacea.

senecioides, Edgew. in Journ. As. Soc. Beng. xxi

(1853) $38=$ Pulicaria foliolosa

senegalensis, DC. Prod. v. $449=$ Conyza senegalensis sericans, Hook. f. Fl. Brit. Ind. iii. 262.-Burma.

sessiliflora, Decne. in Nouv. Ann. Mus. Par. ii. (1834) 410.-Ins. Timor.

sessilifolia, DC. Prod. v. $447=$ myriocephala

sikkimensis, Hook. f. Fl. Brit. Ind. iii. 268.-Reg.

Himal.

solidaginoides, DC. Prod. v. 443.-Afr, trop.

sonchifolia, DC. 1. c. $438=$ laciniata.

spectabilis, DC. l. C. 445 .--Ind. or.

spinellosa, DC. 1. c. $443=$ hieracifolia ?

squarrosa, C. B. Clarke, Comp. Ind. $87=$ myriocephala.

subcapitata, DC. Prod. v. 439.--Reg. Himal

subsimplex, DC. 1. c. $441=$ membranacea

sylvatica, $D C$. l. c. 447 .- Java.

tenella, DC, in Wight, Contrib. Bot. Ind. $13=$ bifoliata?

tetraptera, Rolfe, in Fourn. Linn. Soc. xxi. (1884) 313. -Ins. Philipp.

thyrsoidea, Sch. Bip. in Bot. Zeit. xxiv. (1866) $166=$ lacera.

timorensis, DC. ex Decne. in Nouv. Ann. Mus. Par.

iii. (1834) 411.-Ins. Timor.

tomentosa, A. Rich. Tent. Fl. Abyss. i. 394.-Abyss.

trichophora, DC. Prod. v. $436=$ Wightiana.

trigona, DC. 1. c. $437=$ lacera

trisulca, DC. 1. c. $440=$ Conyza stricta.

vernonioides, DC. 1. c. 447 = Laggera alata.

villosa, Sch. Bip. ex Hook, f. Fl. Brit, Ind. iii. $263=$ lacera.

viminea, $D C$. Prod. v. 442.-Ins, Timor.

virens, $D C$. in Wight, Contrib. Ind. Bot. 14.--Ind. or viscosula, DC. Prod. v. $441=$ membranacea

Wallichii, C. B. Clarke, Comp. Ind. 87.-Assam.

Wightiana, DC. in Wight, Contrib. Bot. Ind. 14.Geront. trop.

Zollingeriana, balsamifera.

C. B. Clarke, Comp. Ind. $90=$

BLUMENBACHIA, Koel. Gram. Gall. et Germ. 28 $(1802)$ = Sorghum, Moench (Gramin.).

haleppensis, Koel, 1. c. $29=$ S. halepense.

BLUMENBACHIA, Schrad. in Goett. Gel. Anz (1825) 1705 ; Blumenb. (1827) 6. t. 1. LOASEAE, Benth. \& Hook. f. i. 805.

CAJophora, Endl. Gen. 931 (1839)

GripideA, Miers, in Trans. Linn. Soc. xxv. (1866) 227. t. 28.

RAPHISANTHE, Lilja, in Linnaea, xv. (1841) 263.

carduifolia, Ball, in Fourn. Linn. Soc. xxii. (1885) 39. -Peruv.

cernua, Griseb. in Goett. Abh. xix. (1874) 152.-Reg. Argent.

chuquitensis, Hook.f. Bot. Mag. t. 6143.-Peruv.

contorta, Hook. f. 1. c. t. $6134=$ grandiflora.

coronata, Haage Es Schmidt, in Rev. Hortic. (1874) 58. - Chili.

Domeykoana, Phil. in Linnaea, xxxiii. (1864-65) 75 . -Chili.

Espigneera, C. Gay, Fl. Chit. ii. 434.-Chili.

grandiflora, G. Don, Gen. Syst. iii. 62.-Peru

Hieronymi, Urb. in Eichl. Fahrb. Berl. iii. (1884) 249 -Reg. Argent.

insignis, Schrad. in Goett. Gel. Anz. (1825) 1706. Reg. Argent

latifolia, Cambess. in St. Hil. Fl. Bras. Mer. ii. 209.Paraguay.

micrantha, G. Don, Gen. Syst. iii. 62.-Peruv.

multifida, Griseb. in Goett. Abh. xxiv. (1879) $139=$

Hieronymi. 
BLUMENBACHIA :-

multifida, Hook. Bot. Mag. t. 3599.-Reg. Argent. palmata, Cambess. in St. Hil. Fl. Bras. Mer. ii. 208.Paraguay.

parviflora, Gill. ex G. Don, Gen. Syst, iii. $62=$ insignis.

Prietea, C. Gay, Fl. Chil. ii. 485.-Chili. pterosperma, G. Don, Gen. Syst. iii. 62.-Peruv.

punicea, G. Don, l. c.-Peruy.

scandens, Meyen, Reise, i. 310 -Chili.

sepiaria, G. Don, Gen. Syst. iii. 62.-Peruy.

sylvestris, Poepp. Fragm. Syn. Fl. Chil. 25.-Chili.

BLUMEODENDRON, Kurz, in Journ. As. Soc. Beng. xlii. (1873) II. 245= Mallotus, Lour. (Euphorb.) Muelleri, Kurz, 1. c. = Paracroton pendulus.

Tokbrai, Kurz, 1. c.-Ins. Andaman.

BLUMIA, Nees, ex Blume, in Verh. Bat. Gen. ix. (1823 147 = Talauma, Juss. (Magnol.).

Candollii, Nees, 1. c. ; et in Flora, viii. (1825) $152=\mathrm{T}$. Candollii.

BLUMIA, Spreng. Syst. iii. 126 (1826)=Saurauja, Willd. (Ternstr.)

japonica, Steud. Nom. ed. II. i. 212, sphalm. $=$ seq.

javanica, Spreng. Syst. iii. $126=$ S. Blumia.

BLUTAPARON, Rafin. New Fl. Am. iv. 45 (1836) Philoxerus, R. Br. (Amarant.)

brevifolium, Rafin. 1. c. $=$ P. vermicularis.

repens, Rafin. 1. c. $46=\mathrm{P}$, vermicularis.

BLYSMUS, Panz. ex Roem. \& Schult. Syst. ii. Mant. 41 (1824) = Scirpus, Tourn. (Cyperac.).

Bonanni, Steud. Nom. ed. II. i. $212=$ Schoenus Bonanni.

brevifolius, Decne. in Jacquem. Voy. Bot. 173. t. 173 $=\mathrm{S}$. Caricis.

compressus, Panz. in Link, Hort, Berol, i. $278=\mathrm{S}$. Caricis.

rufus, Link, 1. c. $=$ S. rufus

BLYTTIA, Am. in Mag. Zool. et Bot. ii. 420 (1838)= Vincetoxicum, Moench (Asclep.)

arabica, Arn. 1. c. $=$ V. fruticulosum.

BLYTTIA, Fries, Novit. Fl. Suec. Mant. ii. $2(1839)=$ Cinna, Linn. (Gramin.)

suaveolens, Fries, 1. c. $=$ C. pendula.

BLYXA, Noronha, ex Thou. Gen. Nov. Madag. (1806). HYDROCHARIDEAE, Benth. \& Hook, f iii. 451 .

Drplosiphon, Decne. in Jacquem. Voy. Bot. 166. t. 167 (1844).

SarvalA, Jones, in As. Res, iv. (1799) 275

Aubertii, Rich. in Mem. Inst. Fr. (1811) 4.-Madag.

graminea, Thou. ex Steud. Nom. ed. II. i. 212. Madag,

javanica, Hassk. in Hoev. \& De Vriese, Tijdschr. x. (1843) 121.-Java

octandra, Planch. ex Thw. Enum. Pl. Zey. 332.Zeylan.

Roxburghii, Rich.in Mém. Inst. Fr. (1811) 77. t. 5.As. trop.; Austral.

Saivala, Steud. Nom. ed. II. i, 212,-Ind. or.

BOADSCHIA, All. Fl. Pedem. i. 248=BOHADSCHIA Crant $z=$ Peltaria, Linn. (Crucif.)

BOARIA, DC. Prod. viii. 299 (1844)= Maytenus, Molina (Celastr.)

Molinae, DC. 1. c. = M. Boaria.

BOBAEA, A. Rich, in Mém. Soc. Hist. Nat. Par, y. (1830) $215=$ Bobea, Gaudich. (Rubiac.)

BOBARTIA, Linn. Diss. Dass. 3 (1747); Fl. Zeyl $17(1747)$; Salisb. in Trans. Hort. Soc. i. (1812) 313 IRIDEAE, Benth. \& Hook. f. iii, 698.

Hecasta, Soland. ex Schum. in Skr. Naturk-Selsk. iii. (1793) 10

aphylla, Ker-Gavl. Gen. Irid. 30.-Afr. austr.

aurantiaca, Sweet, Hort. Brit. ed. III. $662=$ Homeria aurantiaca.

filiformis, Ker-Gazol. Gen. Irid. 30-Afr, austr.

\section{BOBARTIA :}

gladiata, Ker-Gawl. Gen.Irid. 30; Sweet, Hort. Brit ed. I. 395.-Afr. austr.

indica, Linn. Sp. Pl. 54-Afr. austr

juncea, Salisb. in Trans. Hort. Soc. 1. (1812) $313=$ indica.

Linnaei, Pritz. Ind. Ic. ii. 47 perperam =indica

spathacea, Ker-Gawl. Gen. Irid. $30=$ indica.

umbellata, Ker-Gawl. l.c. 31.-Afr. austr.

BOBEA, Gaudich. in Freyc. Voy. Bot. 473. t. 93 (1826)

RUBIACEAE, Benth, \& Hook. f. ii. 101

Bobaea, A. Rich. in Mém. Soc. Hist Nat. Par, v. (1830) 215.

Burneya, Cham. \& Schlecht. in Linnaea, iv. (1829) 190.

brevipes, A. Gray, in Proc. Am. Acad. iv. (1860) 36.-

Ins. Sandvic.

elatior, Gaudich. in Bot. Freyc. Voy. 473. t. $93=$ Timonius Gaudichaudi.

glabra, Korth. in Nederl. Kruidk. Arch. ii. (1851) II $211=$ Timonius Jambosella.

hirsutiuscula, Teijsm \& Binn, in Tijdschr. Nederl. Ind

xxix. (1867) $247=$ Polyphragmon sericeum.

inaequisepala, Miq. Fl. Ind. Bat. Suppl. 545.-Ins. Banca.

mutabilis, Korth. in Nederl. Kruidk. Arch. ii. (1851) II. 212 = Polyphragmon mutabile

putaminosa, F. Muell. Fragm. iv. $92=$ Guettardella putaminosa.

sericantha, Miq. Fl. Ind. Bat. ii. 355.-Malaya.

Wallichiana, Korth, in Nederl. Kruidk. Arch, ii

(1851) 1I. $211=$ Timonius Rumphii.

BOBU, Adans. Fam. ii. $88(1763)=$ Symplocos Linn. (Styrac.).

BOBUA, DC. Prod. iii. 23 (1828)=Symplocos, Linn (Styrac).

arborea, Miers, in Joum. Linn. Soc. xvii. (1879) $305=$ S. arborea.

atroviridis, Miers, 1. c. $304=\mathrm{S}$. spicata.

baptica, Miers, 1. c. $305=$ S. baptica.

caerulescens, Miers, $\mathrm{I}, \mathrm{c}_{\mathrm{a}}=\mathrm{S}$. caerulescens.

cerasifolia, Miers, 1. c. $304=\mathrm{S}$. cerasifolia.

glaucescens, Miers, 1. c. $305=\mathrm{S}$. glaucescens.

gracilis, Miers, 1. c. =S. gracilis.

japonica, Miers, 1. c. $306=\mathrm{S}$. japonica.

lancifolia, Miers, $\mathrm{I}, \mathrm{c},=\mathrm{S}$. lancifolia.

laurina, DC. Prod. iii. $24=$ S. spicata.

Lenormandiana, Miers, in Journ. Linn. Soc, xvii

(1879) $304=$ S. Lenormandiana.

leptostachya, Miers, 1. c. $306=\mathrm{S}$. lancifolia

lucida, Miers, 1. c. $305=\mathrm{S}$. lucida.

montana, Miers, $1 . \mathrm{c}_{\mathrm{s}}=\mathrm{S}$. montana.

myrtacea, Miers, 1. c. $306=\mathrm{S}$. myrtacea

neriifolia, Miers, $1, \mathrm{c},=\mathrm{S}$, neriifolin

nitida, Miers, 1. c. $305=\mathrm{S}$. nitida

oligostachya, Miers, 1. c. $304=\mathrm{S}$. spicata.

prunifolia, Miers, 1. c. $306=\mathrm{S}$. caudata.

rotundifolia, Miers, 1. c. $305=\mathrm{S}$. rotundifotia

stravadioides, Miers, 1. c. $304=\mathrm{S}$. stravadioides.

theophrastaefolia, Miers, 1, c. $306=\mathrm{S}$. theophrastae folia.

Vieillardi, Miers, 1. c. $305=\mathrm{S}$. Vieillardi.

BOCA, Vell. Fl. Flum. 232 ; v, t. $113(1825)=$ Banara Aubl. (Samyd.)

serrata, Vell. 11. cc. = Banara Vellozii

BOCAGEA, St. Hil. Fl. Bras. Mer, i. 41. t. 9 (1825), ANONACEAE, Benth. \& Hook. f. i. 29.

OXANDRA, A. Rich. Ess. F1. Cub. 45. t. 8 (1842)

SAgeraeA, Dalz, in Hook. Kew Journ. iii. (1851) 207

acuminata, Steud. Nom. ed. II. i. $212=$ Orophea acuminata.

alba, St.Hil. Fl. Bras, Mer. i, 42.-Bras.

aromatica. Triana E Planch. in Ann. Sc. Nat. Sẻr. IY. xvii. (1862) 36.-N. Granat.

canescens, Spruce, ex Benth, in Gourn, Linn. Soc.

(1861) 70 - Am, sustr.

celebica, Blume, Fl. Gav. Anon. 88.-Ins. Celebes.

coriacea, Hook. f. E Thoms. in Fl. Brit. Ind. i. 98

Zcylan.

corymbosa, Blume, Fl. Gav. Anon. 85.-Java.

\section{BOCAGEA :-}

Dalzelli, Hook. f. E Thoms. in Fl. Brit. Ind. i. 92.

Ind. or.

elliptica, Hook. f. E Thoms. l. c.-Burma; Malaya. enneandra, Spreng. Syst. iv. Cur. Post. 144.-Java.

espintana, Spruce, ex Benth. in Fourn. Linn. Soc. (1861) 71.-Peruy

Gaudichaudiana, Baill. Adansonia, viii. (1867-68 183-Cochinch.

heterantha, Baill. l. c. 173.-Madag.

hexandra, Blume, Fl. Jav. Anon. $83=$ javensis.

javensis, Spreng. Syst. iv. Cur. Post. 144,-Java.

latifolia, Blume, Fl. Fav. Anon. 89.-Java.

leucodermis, Spruce, ex Benth. in Fourn. Linn. Soc.

v. (1861) 71 - Bras.

longipedunculata, Mart. Fl. Bras. xiii. I. 45.-Bras.

lutea, Baill. Hist. Pl. i. $215=$ Alphonsea lutea.

multiflora, Mart. Fl. Bras. xiii. 1. 45.-Bras.

nervosa, Pierre, Fl. For. Cochin. sub t. $16=$ King

stonia nervosa.

obliqua, Hook. f. E Thoms. in Fl. Brit. Ind. i. 93.Zeylan.

philastreana, Pierre, Fl. For. Cochin.t. 16.-Cochinch. pisocarpa, Blume, Fl. Fav. Anon. 90. t. 45.-Java. polyandra, C. Prest, Rel. Haenk. ii. 77.-Ins. Luzon. polycarpa, Steud. Nom. ed. II, i. $212=$ Orophea poly carpa.

Thwaitesii, Hook. f. E Thoms. in Fl. Brit. Ind. i. 92. -Zeylan.

ventricosa, Baill. Hist. Pl. i. $215=$ Alphonsea ventri cosa.

verrucosa, Baill. 1. c. sphalm. = praec.

viridis, St. Hil. Fl. Bras. Mer. i. 42. t. 9.-Bras,

Weddelliana, Baill. Adansonia, viii. (1867-68) 170 Bras.

BOCCO, Steud. Nom. ed. I. 112 (1821) sphalm.= Bocoa Aubl.

BOCCONIA, Plum. ex Linn. Gen. ed. I. $32(1737)$ PAPAVERACEAE, Benth. \& Hook. fo i. 53

Macleaya, R. Br. App. Denh. \& Clapp. Trav. 218 in adnot. (1826)

cordata, Willd. Sp. Pl. ii. 841.-China; Japon.

ferruginea, Roezl, in Belg. Hortic. xxiv. (1874) 39.Peruv.

frutescens, Linn. Sp. Pl. 505.-Mexico; Peruy.

glauca, Salisb. Prod. $377=$ frutescens.

integrifolia, Humb. E Bonpl. Pl. Aequin. i. 119. t. 35 -Mexico; Perav.

japonica, Hort, ex André, in Rev. Hortic. (1866) $369=$ cordata.

jedoënsis, Carr. 1. c. $340=$ cordata.

quercifolia, Moench, Meth. Suppl. $122=$ frutescens

sinuatifolia, Stokes, Bot. Mat. Med. iii. 8 = frutescens subtomentosa, L'Hérit. ex Stahl, Estud. Fl. Puerto rico, Foll. ii. $34=$ frutescens.

BOCKIA, Scop. Introd. $106(\mathbf{1 7 7 7})=$ Mouriria, Juss (Melast.).

BOCOA, Aubl. Pl. Gui. Suppl, 38, t, 991 (1775:= Inocarpus, Forst. (Legum.)

edulis, Baill. Adansonia, ix. (1868-70) $237=1$. edulis. guianensis, Steud. Nom. ed. I. $112=$ seg. prouacensis, Aubl. Pl. Gui. Suppl. 38.-Guiana.

BOCQUILLONIA, Baill. Adansonia, ii. 225 (1861) 62). EUPHORBIACEAE, Benth. \& Hook. I. iii 313.

brachypoda, Baill. Adansonia, xi. (1573) 127.-N Caled.

brevipes, Muell. Arg. in Linnaea, xxxiv. (1\$05-66 $166^{\circ}-\mathrm{N}$. Caled.

grandidens, Baill. Adansonia, xi. (18;8) 128.-N Caled.

sessiliflora, Baill. l. c. ii. (1\$61-62' 220.-\$. Caled, spicata, Baill. 6. c. 22\%,-N. Caled.

BODWICHIA, Walp. Rep. i. 808 (1842), sphalm. Bowdichia, H. B. \& K. (Legum.)

BOEA, Comm. ex Lam. Fincyc i. 401 (1; 53 ). GES

NEKACEAE. licnth. E Howk. f. ii luas.

BAEA, Comm. ex Juss, Gen, 131 (1: $\$ 9$ :

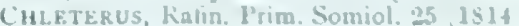


BOEA :

Dorcoceras, Bunge, Enum. Pl. Chin. Bor. 54 (1832).

alata, Pers. Syn. i, $15=$ Calceolaria petiolat is

amplexicaulis, Parish, ex C. B. Clarke, Comm. et

Cyrt. Beng. t. $84=$ Phylloboea amplexicaulis.

borneensis, Scheff. ex H. O. Forbes, in Journ. Linn.

Soc, xix. (1882) $298=$ Didymocarpus Schefferi

Cardwellia, F. Muell. ex C. B. Clarke, in DC. Monog.

Phan. v. $145=$ Commersonii.

cochinchinensis, C. B. Clarke, l. c. 143,-Cochinch.

Commersonii, R. Br. in Benn. Pl. Fav. 120.-China.

dictyoneura, Hance, in Fourn. Bot. xxi. (1883) 169.China.

flosculosa, C. B. Clarke, Comm. et Cyrt. Beng. t. $83=$ multiflora

Hancei, C. B. Clarke, in DC. Monog. Phan. v. 144 dictyoneura.

herbacea, C. B. Clarke, l. c. 142.-Ins. Formosa, bygrometrica, $R$. Br. in Benn. Pl. Far' 120.-China, hygroscopica, F. Muell. Fragm. iv, 146-Austral. magellanica, Lam. Illustr i. 53, t. 15=Commersonii Minahassae, Teijsm. E Binn. in Tijdschr. Nederl. Ind. xxv. (1863) 415.-Ins. Celebes.

multiflora, $R$. Br. in Benn. Pl. Fav. 120.-Ind. or. philippensis, C. B. Clarke, in DC. Monog. Phan. v. 146. - Ins. Philipp.

plantaginea, Pers. Syn, i. $15=$ Calceolaria plantaginea praliniana, J. St. Hil. Expos. i. $279=$ magellanica.

primuloides, Miq. in Ann. Mus. Lugd. Bat. iii. $190=$

Oreocharis primuloides.

prolixa, C. B. Clarke, in DC. Monog. Phan. v. 143.Burma.

punctata, Pers. Syn. i. $15=$ Calceolaria punctata.

rufescens, Franch in Bull. Soc. Linn Par. i. (1885)

449. - China.

Swinhoii, Hance, in Ann. Sc. Nat. Sér. V. v. (1866) 231.-China.

Treubii, H. O. Forbes, in fourn. Linn. Soc. xix. (1882) 297.-Sumatra.

triandro, Pers, Syn i. $15=$ Calceolaria triandra.

Urvillei, C. B. Clarke, in DC. Monog. Phan. v. 147.Ins. Waigiou.

violacea, Pers. Syn. i. $\mathbf{1 5}=$ Calceolaria violacea

Wallichii, R. Br. in Benn. Pl. Fav, 120.-Burma.

BOEBERA, Willd. Sp. P1. iii. 2125 (1803)=Dyssodia,

Cav. (Compos.)

alternifolia, Moç. \& Sessé, ex DC. Prod. v. $639=$ Adenophyllum Porophyllum.

Cavanillesii, Spreng. Syst. iii. $544=$ Adenophyllum coccineum

chrysanthemoides, Willd. Sp. P1. iii. 2125.-D. chrysanthemoides.

fastigiata, H. B. \& K. Nov. Gen, et Sp. iv. 198=D. chrysanthemoides.

glandulosa, Pers. Syn. ii. $459=$ D. chrysanthemoides, glandulosa.

incana, Lindl. Bot. Reg. t. $1602=\mathrm{D}$. pubescens.

Porophyllum, H. B. \& K. Nov. Gen. et Sp. iv. $198=$ Adenophyllum Porophyllum.

pubescens, Spreng. Syst. iii. $544=$ D. pubescens

subintegerrima, Spreng. $1 . c_{v}=\mathrm{D}$. subintegerrima

tagetiflora, Spreng. 1. c.=D. chrysanthemoides.

BOECKHIA, Kunth, Enum. Pl. iii. 448 (1841)= Hypodiscus, Nees (Restiac.).

laevigata, Kunth, 1. c. $450=\mathrm{H}$. albo-aristatus.

striata, Kunth, I. c. $449=$ H. striatus.

BOEHMERIA, Jacq, Enum. Pl, Carib, 9 (1760).

URTICACEAE, Benth. \& Hook. f. jii. 387.

Gymnogyne, F. Didr. Ind. Sem. Haun. (1850).Cf. Linnaea, xxix. (1857-58) 737 .

j)URETIA, Gaudich. in Bot. Freyc. Voy. 500 (1826).

Splitgerbera, Miq. Comm. Phytogr. 133. t. 14 (1840).

acalyphoides, Blume, Mus. Bot. Lugd. Bat. ii. $225=$ Pouzolzia acalyphoides.

acuminata, Hook. \& Arn. ex Wedd. in DC. Prod. xvi. I. $235=$ Pipturus albidus.

acuminata, Pers. Syn. ii. $556=$ Elatostema acuminatum.

acuminata, Wedd, in DC, Prod, xvi, I. $209-\mathrm{N}$ Caled.

albida, Hook. \& Arn. Bot. Beech. Voy. $96=$ Pipturus albidus.

alienata, Willd. Sp. Pl, iv, $341=$ Pouzolzia indica.

\section{BOEHMERIA}

amplissima, Blume, Mus. Bot. Lugd. Bat. ii. $219=$ stipularis.

ampullacea, H. B. \& K. Nov. Gen. et Sp. ii. $35=$ caudata.

angustata, Hassk. Cat. Hort. Bog. Alt. $79=$ Debregeasia velutina.

angustifolia, H. B. \& K. Nov. Gen. et Sp. ii, $34=$ Phenax angustifolius.

arachnoidea, Walp. in Nov. Act. Nat. Cur. xix. Suppl. (1843) $423=$ Pouzolzia macrura

arborea, Desf. Cat. Hort. Par. ed. III. 348=Gesnouinia arborea.

arborescens, Gardn. in Hook. Lond. Journ. Bot. i. 1842) $541=$ caudata

argentea, Guill. ex Wedd. in DC. Prod. xvi. I. 235 $=$ Pipturus argenteus.

argentea, Linden, in Belg. Hortic. viii. (1858) 166.Mexic

arguta, Mart. ex Miq. in Mart. Fl. Bras. iv. I. 186.Am. trop.

aspera, Blume, Mus. Bot. Lugd. Bat. ii. 206, in nota $=$ Pouzolzia aspera.

aspera, Wedd. in Arch. Mus, Hist. Nat. Par, viii 1855-56) 349. t. 11.-N. Granat.

australis, Endl. Prod. Fl. Norfolk. 38.--Ins. Norfolk.

ballotaefolia, H. B. \& K. Nov. Gen. et Sp. ii. $35=$ Phenax ballotaefolius.

bifida, Blume, Mus. Bot. Lugd. Bat. ii. $222=$ biloba, Wedd.

biloba, Miq. in Zoll. Syst. Verz. Ind. Archip. 100.Java.

biloba, Wedd. in Ann. Sc. Nat. Sér. IV. i. (1854) 199 -Japon.

Blumei, Wedd, in DC. Prod. xvi. I. 204.-Ins. Philipp. Boiviniana, Blume, Mus. Bot. Lugd. Bat. ii. $227=$ Pouzolzia Boiviniana.

boliviana, Blume, 1. c. 206, in nota=Pouzolzia Boi viniana.

brevirostris, Wedd. in Ann. Sc. Nat. Sér. IV. i. (1854) 201.-Peruv.

bullata, $H . B$, $\sigma^{\prime} K$. Nov, Gen et Sp, ii. 35-Ecuador. caerulea, Blume, Mus. Bot. Lugd. Bat. ii. $209=$ Cypholophus coeruleus.

calophleba, C. Moore E F. Muell. in F. Muell. Fragm viii. 11.-Austral.

candicans, Hassk. Pl. Jav. Rar. 203 ; Cat. Hort, Bog. Alt. $79=$ nivea

candidissima, Hassk. Cat. Hort. Bog. Alt. $79=$ Leucosyke javanica.

Candolleana, Gaudich. in Freyc. Voy. Bot. $499=$ Pipturus argenteus.

canescens, Wedd. in Ann. Sc. Nat. Sér. IV, i. (1854) $200=$ platyphylla

capensis, Spreng. Syst. iii. 844.-Afr. austr.

castaneaefolia, A. Cunn. ex Bureau, in DC. Prod. xvil $250=$ Pseudomorus Brunoniana

caudata, Poir. in Bonpl. Jard. Malm. t. 15= platyphylla caudata, Sw. Prod. Veg. Ind. Occ. 34.-Am, trop. caudigera, Wedd. in Ann. Sc. Nat. Sér. IV. i. (1854 $199=$ platyphylla.

celebica, Blume, Mus. Bot. Lugd. Bat. ii. 217.-Ins Celebes.

celtidifolia, $H . B . \xi{ }^{\circ} K$. Nov. Gen. et Sp. ii. 34.Ecuador

cephalida, Pers. Syn. ii. 556= Procris cephalida.

chinensis, Pers. l. c. $557=$ Procris cantonensis

cinerascens, Blume, Mus. Bot. Lugd. Bat. ii. $203=$ Pouzolzia cinerascens.

cinerascens, Hassk. Cat. Hort. Bog. Alt. $79=$ Pipturus argenteus.

clidemioides, Miq. Pl. Jungh, $34=$ platyphylla

cochinchinensis, Pers. Syn. ii. 557 = Procris cochinchinensis.

cochinchinensis, Spreng. Syst. iii. $844=$ Pouzolzia indica.

comosa, Wedd. in DC. Prod. xvi. I. 205= sidaefolia. compacta, Blume, Mus. Bot. Lugd. Bat. ii. 210.Java,

conglobata, Blume, 1. c. $204=$ Pouzolzia conglobata.

crenata, Blume, 1. c. $208=$ Cypholophus macro cephalus?

Cummingiana, Blume, 1. c. ii. $199=$ heterophylla

cuspidata, Blume, l. c. 216 (sp. dubia).-Nepal.

cuspidata, Wedd. in Arch. Mus. Hist. Nat. Par. viii $(1855-56) 345=$ ramiflora.

cylindrica, Hb. ex Blume, Mus. Bot. Lugd. Bat. ii. 218 = elongata.

\section{BOFHMERIA :-}

cylindrica, Sw. Prod. Veg. Ind. Occ. 34.-Am. bor. et

dasypoda, Miq. in Mart. F1. Bras. iv. I. 188=cylindrica . densiflora, Hook. E Arn. Bot. Beech. Voy. 271 China.

depauperata, Wedd, in Ann. Sc. Nat. Sér. IV. i. (1854) $202=$ malabarica

dichotoma, Hassk. Cat. Hort. Bog. Alt, $79=$ Debregeasia velutina.

didymogyne, Wedd. in DC. Prod. xvi, I. 204.-Burma

diffusa, Wedd. in Arch. Mus. Hist. Nat. Par, viii. (1855-56) $356=$ sidaefolia.

discolor, Poepp. ex Blume, Mus. Bot. Lugd. Bat. ii. $206=$ Pouzolzia discolor

diversiflora, Miq. in Zoll. Syst. Verz. Ind. Archip. 101 , $104=$ Zollingeriana

diversifolia, Miq. P1. Jungh. $34=$ Maoutia diversifolia. diversifolia, Wedd. in Ann. Sc. Nat. Sér. IV. i, (1854) $202=$ Pavonii.

Drummondiana, Wedd. 1. c. $201=$ cylindrica

elliptica, Wedd. 1. c. $200=$ platyphylla

elongata, Blume, Mus. Bot. Lugd. Bat, ii, 218-Hab. ? elongata, Hort. ex Steud. Nom. ed. II. i. 212 = platy. phylla.

elongata, Fisch. ex Jacq. Eclog. t. $135=$ Phenax vulgaris

erythropoda, Miq. in Zoll. Syst. Verz. Ind. Archip. 101, 104.-Malaya.

excelsa, Wedd. in Ann. Sc. Nat. Sér. IV. i. (1854) 202.-Ins. Juan Fernand.

fagifolia, Pers. Syn. ii. 556 = Elatostema fagifolium.

fallax, Wedd. in Arch. Mus. Hist. Nat. Par. viii. (1855-56) 346.-Peruv.

Fernandesiana, C. Gay, Fl. Chil. v. $360=$ Urtica glomerulaeflora.

flagelliformis, Liebm. in Vidensk. Selsk. Skr. V. ii. (1851) $310=$ caudata.

florida, Miq. in Mart. Fl. Bras. iv. I. 187.-Am. trop. formicaria, Poepp. ex Wedd. in Ann. Sc. Nat. Sér. IV. i. (1854) $201=$ Pouzolzia formicaria.

frondosa, D. Don, Prod. F1. Nep. $59=$ Pouzolzia viminea.

frutescens, D. Don, 1. c. = Maoutia Puya.

frutescens, Thunb. F1. Jap. 367. n. $98=$ Villebrunea frutescens:

glabra, Steud. Nom. ed. II. i. $192=$ Neraudia melastomaefolia.

glochidiata, Hassk. Pl. Jav. Rar. $206=$ Pouzolzia indica. glomerulifera, Miq. in Zoll. Syst. Verz. Ind. Archip. $101,104=$ malabarica.

grandifolia, Wedd. in Ann. Sc. Nat. Sér. IV. i. (1854) $199=$ platyphylla

greviaefolia, Presl, Bot. Bemerk. 110,-Hab.

guatemalana, Blume, Mus. Bot. Lugd. Bat. ii. $206=$ Pouzolzia guatemalana.

Hamiltoniana, Wedd. in Ann. Sc. Nat. Sér. IV. i. (1854) $199=$ platyphylla.

Harveyi, Seem. Fl. Vit. t. $62=$ Cypholophus heterophylla.

Helferii, Blume, Mus. Bot. Lugd. Bat. ii. 201.Burma.

heteroidea, Blume, l. c. 216 (sp. dubia).-Ind. or.

heterophylla, Blume, 1. c. $204=$ Blumei.

heterophylla, Wedd. in Arch. Mus. Hist. Nat. Par. viii. (1855-56) 351.-Ins. Philipp.

hirta, Roth, ex Blume, Mus. Bot. Lugd. Bat. ii. $231=$ Pouzolzia Rothiana.

hirta, Sw. Prod. Veg. Ind. Occ. $34=$ Phenax urticifolius.

hirta, Wedd. in Ann. Sc. Nat. Sér. IV. i. (1854) 202. -Peruv.

hispidula, Blume, Mus. Bot. Lugd. Bat. ii. 223.Sumatra.

holosericea, Blume, l. c. 221.-Japon.

Huegeliana, Blume, l.c. 218 (sp. dubia),-Ind, or.

humilis, Miq. Pl. Jungh. $33=$ platyphylla.

hypoleuca, Hochst. ex A. Rich. Tent. Fl. Abyss, ii. $264=$ Debregeasia hypoleuca.

incana, Hassk. Cat. Hort. Bog. Alt. $79=$ Pipturus velutinus.

interrupta, Guill. in Ann. Sc. Nat. Sér. II. vii. (1857) $182=$ platyphylla

interrupta, Willd. Sp. Pl. iv. $340=$ Fleurya interrupta.

Jacquiniana, Blume, Mus. Bot. Lugd. Bat. ii. 219.Hab.?

Fanatsi-itsigo, Siebold, in Verh. Bat. Gen. xii. (1830) $70=$ Debregeasia edulis. 


\section{BOFHMERIA :}

japonica, Miq. in Ann. Mus. Bot. Lugd. Bat. iii. 131. -Japon.

javanica, Hassk. Cat. Hort. Bog. Alt. $79=$ Fleurya interrupta.

laevis, Blume, Mus. Bot. Lagd. Bat. ii. 206 in nota = Pouzolzia virgata.

iateriflora, Muhl. ex Willd. Sp. Pl. iv. $342=$ cylindrica. latifolia, Blume, Mus. Bot. Lugd. Bat. ii. $207=$ Cypholophus latifolius.

Lindeniana, Blume, l. c. 226,-N. Granat.

littoralis, Sw. Prod. Veg. Ind. Occ. $34=$ cylindrica.

longispica, Steud. in Flora, xxxiii. (1850) $260=$ japonica.

lutescens, Blume, Mus. Bot. Lugd. Bat. ii. $209=$

Cypholophus lutescens.

macrocephala, Blume, 1. c. 208, in obs. $=$ Cypholophns macrocephalus.

macrophylla, Hornem. Hort. Hafn. ii. 890 .-Hab.?

macrophylla, D. Don, Prod. Fl. Nep. 60.-. Reg. Himal.; Burma.

macrophylla, Sieb. \& Zucc. in Abb. Akad. Muench, iv.

III. (1846) $215=$ japonica.

macrostachya, Wedd. in Ann. Sc. Nat. Sér. IV. i. (1854) $199=$ platyphylla.

macrothyrsa, Miq. in Zoll. Syst. Verz. Ind. Archip. $100,103=$ Laportia decumana.

maculata, Pers. Syn. ii. $556=$ Elatostema maculatum. malabarica, Wedd. in Arch. Mus. Hist. Nat. Par. viii. (1855-56) 355.-Ind. or.; Malaya.

massuriensis, Blume, Mus. Bot. Lugd. Bat. ii. $216=$ platyphylla.

mauritiana, Wedd. in Ann. Sc. Nat. Sér. IV. i. (1854)

$200=$ platyphylla.

melanocarpa, Blume, Mus. Bot. Lugd. Bat. ii. $210=$ Cypholophus melanocarpus.

melastomaefolia, Hook. \& Arn. Bot. Beech. Voy. $96=$ Neraudia melastomaefolia.

melastomoidea, Griff. Notul. iv. $386=$ Pouzolzia pentandra.

microcarpa, Wedd. in Ana. Sc. Nat. Sér. IV. i. (1854) 201 = platyphylla

microceltis, Miq. in Zoll. Syst. Verz. Ind. Archip. 100, $104=$ Pouzolzia viminea

mollicoma, Miq. in Zoll. l. c.-Java.

mollis, Wedd. in Ann. Sc. Nat. Sér. IV. i. (1854) 203 $=$ Cypholophus macrocephalus.

moluccana, Blume, Mus. Bot. Lugd. Bat. ii. $208=$ Cypholophus maerocephalus.

moluccana, Wedd. in Ann. Sc. Nat. Sér. IV. i. (1854) $201=$ Cypholophus macrocarpus.

monticola, Blume, Mus. Bot. Lugd. Bat. ii. 227.-

Sumatra.

nana, D, Don, Prod. Fl. Nep. $60=$ Ponzolzia indica.

neglecta, Blume, Mus. Bot. Lugd. Bat. ii. 200.Java.

nepalensis, Wedd. in Arch. Mus. Hist. Nat. Par. viii. $(1855-56) 383=$ Villebrunea frutescens.

nervosa, Madden, in Journ. As. Soc. Beng. xvii. (1848) I. $403=$ rugulosa

nivea, Gaudich. in Bot. Freyc. Voy. 499-As. trop. (cult.).

nudiflora, Willd. Sp. Pl. iv, 343.-Venezuela.

obliqua, Poepp. ex Blume, Mus. Bot. Lugd. Bat. ii. 206, adnot $=$ Pouzolzia obliqua

odontophylla, Miq. Pl. Jungh. $35=$ Maontia odonto-

phylla.
ourantha, Miq. 1. c. $83=$ platyphylla.

ovalis, Miq. in Zoll. Syst. Verz. Ind. Archip. $100=$ Pouzolzia viminen.

ovata, Blume, Mus. Bot. Lugd. Bat. ii. 206, adnot.=

Pouzolzia ovata.

ovata, Steud. Nom. ed. II. i. $212=$ Neraudia melastomaefolia.

palmata, Hassk. Cat. Hort. Bog. Alt. 79.-Hab.?

parvifolia, Wedd. in Ann. Sc. Nat. Sér. IV, i. (1854 $203=$ Droguetia diffusa.

pauciflora, Blume, Mus, Bot. Lugd. Bat. ii. $201=$

Droguetia diffusa.

Pavonii, Wedd. in Ann. Sc. Nat. Ser. IV. i. (1854) 202.-Peruy.

penduliflora, Wedd. 1. c. $199=$ macrophylla.

peruviana, Blume, Mus. Lugd. Bat. ii. $22 t=$ caudata.

petiolaris, H. B. \& K. Nov. Gen, et Sp, ii. $36=$ caudata phyllostachya, Miq. in Mart. Fl. Bras. iv. 1. 187= cylindrica.

pilosiuscula, Hassk. Cat. Hort. Bog. Alt. 79 = platy phylla.

\section{BOFHMERIA}

platanifolia, Franch. E Sav. Enum. Pl. Fap. i. 440,Japon.

platyphylla, D. Don, Prod. Fl. Nep. 60.-As. et Afr. trop.; Ins. Pacif.

polystachya, Wedd. in Ann. Sc. Nat. Sér. IV. i. (1854) 200.-Reg. Himal,; Burma,

procridioides, Blume, Mus. Bot. Lugd. Bat. ii. $204=$ Pouzolzia procridioides.

propinqua, Decne. Herb. Timor. 163 = Pipturus argenteus.

prostrata, Blume, Mus. Bot. Lugd. Bat, ii. $209=$ Cypholophus prostratus.

Puya, Hook. in Hook. Kew Journ. iii. (1851) $316=$ Maoutia Puya.

racemiflora, Forst. ex Blume, Rumphia, iv, 37 Phytocrene hirsuta.

radicans, Nees \& Mart. in Nov. Act. Nat. Cur. xi (1823) $35=$ Pilea rhizobola

ramiflora, Bedd. Forest. Man. Bot. t. 27. f. $2=$ malabarica.

ramiflo:a, Facq. Enum. Pl. Carib. 31.--Ind, occ.; Mexic

repanda, Hassk, Cat. Hort. Bog, Alt. $79=$ Pipturus repandus.

repens, Nees \& Mart, in Nov. Act. Acad. Nat. Cur. xi, (1823) $36=$ Pilea hirtella

repens, Wedd. in DC. Prod.xvi, 1. 201.-Cuba.

rhynchophylla, Wedd. in Ann. Sc. Nat. Sér. IV. i. (1854) 202.-Am, austr.

rigida, Benth. in Hook. Niger Fl. 519.-Afr. trop rotundifolia, D. Don, Prod. F1. Nep. $60=$ platyphylla.

rubescens, Hassk. Cat.Hort.Bog.Alt. $79=$ Villebrunea rubescens.

rubescens, Jacq. Fragm. 8=Gesnowinia arborea

rugosa, Pers. Syn. 1i. 556= Phenax ballotaefolius.

rugosissima, Miq. Pl. Jungh. i. $32=$ platyphylla.

rugosissima, Wedd. in Ann. Sc. Nat. Sér. IV. i. (1854) 200.- - Java.

rugulosa, Wedd.l. c. 200.-Reg. Himal.

salicifolia, D. Don, Prod. F1. Nep. $60=$ Debregeasia hypoletica.

sanguinea, Hassk. Cat. Hort. Bog. Alt. $79=$ Pou. zoizia viminea.

scabra, Hassk.l.c.-As. trop.?

scabrella, Gaudich. Bot. Freyc. Voy, $499=$ platyphylla.

scabrella, Hort. ex Blume, Mus. Bot. Lugd. Bat, ii. 215 = caudata.

sericea, Blume, Mus. Bot. Lugd. Bat. ii. 208 = Cypholophus moluccanus.

sidaefolia, Wedd. in Ann. Sc. Nat. Sér. IV. i. (1854) 203.-Reg. Himal.; Burma ; Java.

Sieboldiana, Blume, Mus. Bot. Lugd. Bat. ii. $220=$ platyphylla.

spicata, Thunb. in Trans, Linn. Soc. ii. (1794) $330=$ platyphylla.

spiciflora, Blume, Mus. Bot. Lugd. Bat. ii. 217 (sp. dubia) - Ind. or.

spicigera, Spreng. Syst. iii. 845.-Venezuela.

squamigera, Wedd. in Ann. Sc. Nat. Sér. IV. i. (1854) $203=$ Chamabainia cuspidata.

stipularis, Wedd. l. c. 200.-Ins. Mascar.

strigosa, Blume, Mus. Bot. Lugd. Bat. ii. $226=$ Pavonii.

strigosula, Blume, 1. c. $203=$ Pouzolzia viminea.

subperforata, Wedd. in Arch. Mus. Hist. Nat. Par. viii, (1855-56) 383 (sp. dubia).-Ind. or.

sumatrana, Miq. Pl. Jungh. $32=$ platyphylla.

sylvatica, Hassk. Cat. Hort. Bog. Alt. $79=$ Villebrunea sylvatica.

taitensis, Wedd, in Ann. Sc. Nat. Sér. IV. i. (1854) $200=$ platyphylla.

tenacissima, Gaudich. Bot. Freyc. Voy. $500=$ nivea. ternifolia, D. Don, Prod. Fl. Nep. $59=$ platyphylla. tomentosa, Wedd. in Ann. Sc. Nat. Sér. IV. i. (1854) $200=$ platyphylla

travancorica, Bedd. Forest, Man, Bot, 225=malabarica.

trinervata, Pers. Syn. ii. 556=Gyrotaenia trinervata. trinervis, Miq. Pl. Jungh. $86=$ Pipturus repandus,

uliginosa, Mor. ex Wedd. in DC. Prod. xvi. 1. $235^{37}$ Phenax uliginosus.

ulmifolia, Wedd, in Ann. Sc, Nat. Sér, IV. i. 1854) 202 = fallax.

urantha, Blume, Mus. Bot. Lugd. Bat. ii. 221 = platy phylla.

\section{BOEHMERIA}

urticaefolia, Pers. Syn. ii. $556=$ Phenax urticaefolius. urticaefolia, Spreng. Syst, iii. $844=$ Pilea rupipendia.

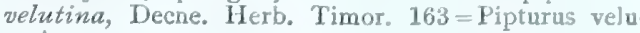
tinus.

vestita, Blume, Mus. Bot. Lugd. Bat. ii. $209=$ Cypholophus vestitus.

vialis, Casar. ex Wedd. in DC. Prod. xvi. 1. $235^{37}=$ Phenax Sonneratii.

viminea, Blume, Mus. Bot. Lugd. Bat. ii. 202 = Pouzolzia viminea.

wirgata, Guillem. in Ann. Sc. Nat. Sér. II. vii. (18:7 $182=$ platyphylla

Waitziana, Blume, Mus. Bot. Lugd. I3at. ii. $203=$ Pouzolzia viminea.

Wightiana, Blume, 1. c. $217=$ platyphylla

Zollingeriana, Wedd. in Ann. Sc. Nat. Sér. IV. i (1854) 201.-Java.

BOEICA, C. B. Clarke, Comm, et Cyrt. Beng. 118, tt 85 ad 87 (1874). GESNERACEAE, Bentb. \& Hook. f. ii. 1023.

BAEICA, C. B. Clatke, in DC. Monog. Phan. v. 134 (1883).

filiformis, C. B. Clarke, Comm. et Cyrt. Beng. 118 .

87.-Reg. Himal.

fulva, $C, B$. Clarke, $\%$. c. t. 85. - Reg. Himal.

Griffithii, C. B. Clarke, l. c.t. 86,-Assam.

hirsuta, C. B. Clarke, in DC. Monog. Phan. v. 136.Assam?

porosa, C. B. Clarke, l. c.-Burma.

BOELIA, Webb, Otia Hisp. 20, t. 15, 16 (1853)Genista, Linn. (Legumin.)

sphaerocarpa, Webb, l. c. =G. sphaerocarpa.

BOENNINGHAUSENIA, Reichb. Consp. 197 1828). RUTACEAE, Benth. \& Hook. f. i. 287. Ponostaurus, Jungh. in Nat. en Geneesk. Arch. Neêrl. Indie iî. (1845) 45

albiflora, Reichb. l. c.-Reg. Himal. ; Japon.

japonica, Sieb. ex Miq. Ann. Mus. Bot. Lugd. Bat. iii. $21=$ albiflora.

BOENNINGHAUSIA, Spreng. Syst. iii. 153, 245 (1826) $=$ Chaetocalyx, DC. (Legumin.)

vincentina, Spreng. 1. c. $245=\mathrm{C}$. vincentinus.

BOERHAVIA, Linn. Fl. Zeyl. $4(1747)=$ Boerhaavia, Vaill. (Nyctag.)

BOFRHAAVIA, Vaill ex Linn. Syst ed, I (1735) Linn. Gen, ed, I, 8 (1737). NYCTAGINEAE Benth. \& Hook. f. iii. 5.

adscendens, Willd. Sp. Pl. i. $19=$ repens

africana, Lour. Fl. Cochinch. i. 16.-Afr. trop.

aggregata, Pav, ex Choisy, in DC. Prod. xiii. II. 427 = Nyctaginia capitata.

angustifolia, Linn. Syst. ed. XII. 52 (sp. dubia'Hab.

angustifolia, Span. in Linnaea, xv. (1841) : ü? repens.

anisophylla, Torr in Bot. Mex. Bound. 171.-Texas arborea, Roem. \& Schult. Syst. i. $66=$ P'isonia hir tella.

arborescens, Lag. \& Rodr. in Anal. Cienc, Nat. iv. (1801) $257=$ Pisonia hirtella.

ascendens, Schum. Beskr. Guin, Pl. 17 rerens.

bastica, Buch.-Ham. ex Wall. Cat. sub n. $6769=$ repanda.

bicolor, Ehrenb. ex Schweinf. Beitr. Fl. Aethiop. 168 $169=$ repens.

bracteosa, S. Wats. in Proc. Am. Acad. xx. 1885) 370 - Texas.

Burchellii, Choisy, in DC. Prod. xiii. 18. 155.- Afr austr.

caribaea, Jacy. Obs, Bot. jv. $5=$ repens.

chaerophylloides, Willd. Sp. Pl. i. 22 Astrephia chaerophylloides.

coccintea, Mill. Gard. Dict. ed. VIII. n. $t=$ repens

Commersoni, Baill, in Bull. Sor. Linn. Par. i. (1ss.s.

484.- Maday.

cortensis, threnb ex Schweinf Beitr, fil. Acthiul.

168 - repens.

crispa, Hryne, in $15^{\circ}$ all. Cak. D. Bij1. - Ind. of

decumbers, Vahl, Lisum. i. $2 s t=$ paniculala. 


\section{BOERHAAVIA :-}

depressa, C.Sm. in Tuckey, Congo, 249, nomen.-Ins. Cap. Verd.

diandra, Aubl. Pl. Gui, i. $4=$ paniculata?

diandra, Burm. f. Fl. Ind, 3. t. $\mathbf{l}=$ erecta.

diandra, Linn. Sp. P1. $1194=$ hirsuta, paniculata.

dichotoma, Hochst. ex Walp. Ann. iii. 298.-Abyss.

dichotoma, Schimp. ex Oliver, in Trans. Linn. Soc.

xxix. (1875) $142=$ grandiflora.

dichotoma, Vahl, Enum. i. $290=$ plumbaginea

diffusa, Engelm. \& A. Gray, in Boston, Journ. Nat

Hist. v. (1847) $259=$ viscosa

diffusa, Linn. Sp. Pl. $3=$ repens.

diffusa, Sw. Obs. $10=$ paniculata.

discolor, H. B. E $K$. Nov. Gen. et Sp. ii. 215.Ecuador.

eglandulosa, Ehrenb. ex Schweinf. Beitr. Fl. Aethiop. $169=$ repens.

elegans, Choisy, in DC. Prod. xiii. II. 453.-Nubia ;

Arabia; Ind. bor. occ.

elongata, Salisb. Prod. $56=$ erecta.

erecta, Burm. f. F1. Ind. t. 3. f. $2=$ glutinosa

erecta, Ell. Sketch, i. $41=$ repens.

erecta, Linn. Sp. Pl. 3.-Am. bor.; Ind. occ.

eriosolena, A. Gray, in Am. Fourn. Sc. Ser. II. xv. (1853) 322.-Mexic.

excelsa, Willd. Phyt. 1. n. 5; Sp. Pl. i. $21=$ Oxybaphus micranthus?

fruticosa, Dalz. in Dalz. E Gibs. Fl. Bomb. 213.Ind. or.

fruticosa, Ehrenb. ex Schweinf. Beitr. F1. Aethiop. 167 $=$ plumbaginea.

gibbosa, Pav, ex A. Gray, in Am. Journ. Sc. Ser. II. xv. (1853) $323=$ Senkenbergia annulata.

gibbosa, Pav. ex Choisy, in DC. Prod. xiii. II. 457= Tinantia gypsophiloides.

glabrata, Blume, Bijdr. $733=$ repens

glandulosa, Anderss. Om Oarn. Galapagos. 64.--Ins, Galap.

glomerata, Klotzsch, in Schomb. Fauna et Fl. Guy. 1131, nomen-Guiana.

glutinosa, Miers, ex Bext. in Merc. Chil. (1829) $596=$ discolor.

glutinosa, Vahl, Enum. i. $287=$ diffusa?

Grahamii, A. Gray, in Am. Journ. Sc. Ser. II. xv. (1853) $323=$ scandens

grandiflora, A. Rich. Tent. Fl. Abyss, ii. $209=$ plumbaginea.

Helenae, Roem. \& Schult. Syst. Mant. i. 73 -verticillata.

hirsuta, Linn. Mant. 1170.-Ind. occ.; Am. bor.

hirsuta, Willd. Phyt. $1=$ repens.

insularis, Boj. Hort. Maurit. 264=repens.

laxa, Pers. Syn. i. $36=$ paniculata.

leiosolena, Torr. Bot. Mex. Bound. 172,-Texas.

libyca, Pomel, Nouv. Mat. Fl. Atl. 336.-Algeria

linearifolia, A. Gray, in Am. Fourn. Sc. Ser. II. xv. (1853) 322.-N. Mexic.

litoralis, H. B. E K. Nov. Gen. et Sp. ii. 216.Peruv.

maroccana, Ball, in Journ. Bot. xiii. (1875) $176=$ repens.

microphylla, Bory, ex Steud. Nom. ed. II. i. 213 (ordo ignot.).-Ins. Maurit.

minutiflora, Span. in Linnaea, xv. (1841) $342=$ repens.

mutabilis, R. Br. Prod. $422=$ repens.

nantocana, Schau. in Nov. Act. Nat. Cur. xix. Suppl. i. $(1843) 403=$ viscosa,

nudicaulis, Phil. in Linnaea, xxix. (1857-58) 37.Chili.

obtusifolia, Lam. Illustr, i. $10=$ patula

obtusifolia, Steud. Nom. ed. II. i. $213=$ paniculata.

Palmeri, S. Wats. in Proc. Am. Acad. xviii. (1882-83) 142.- Texas.

paniculata, Lam. Illustr. i. $10=$ hirsuta, erecta. paniculata Rich. in Act. Soc. Hist. Nat. Par. i. (1792) 105.-Texas: Mexic.

patula, Domb. ex Vahl, Enum. i. 287.-Peruv.

pedunculosa, A. Rich. Tent. Fl. Abyss. ii. 210.Abyss.

pentandra, Burch. Trav. i. $432=$ Burchellii.

periplocaefolia, Comm. ex Vahl, Enum. i. 290.Madag.

periplocifolia, Sieber, ex Choisy, in DC. Prod. xiii. II. $453=$ repens

plicata, Boj. 2 me Rapp. Soc. Hist. Nat. Maurit. 43 (sp. dub.).-Maurit?

\section{BOERHAAVIA :}

plumbaginea, Cav. Ic. ii. 7.t. 112.-Hispan.; Afr. trop. et austr. ; Syria.

polymorpha, Rich. in Act. Soc. Hist. Nat. Par. i. (1792) $105=$ caribaea, hirsuta, repens.

procumbens, Banks, ex Roxb. Fl. Ind. i. $146=$ repens.

pterocarpa, S. Wats. in Proc. Am. Acad. xvii. (1881-82) 376.-Am. bor.

pubescens, R. Br. Prod. i. $422=$ repens.

pulchella, Griseb. in Goett. Abh. xix. (1874) 88.-Reg. Argent.

pulverulenta, Dupuis, in Vahl, Enum. i. $291=$ dichotoma.

purpurascens, A. Gray, in Am. Fourn. Sc. Ser. II. xv. (1853) 321.-N. Mexic

Reboudiana, Pomel, Nouv. Mat. Fl. Atl. 335.Algeria.

repanda, Kotschy, ex Choisy, in DC. Prod. xiii. II. $454=$ verticillata.

repanda, Roxb. Hort. Beng. 2 ; in Beatson, St. Helena Tracts, $302=$ verticillata.

repanda, Willd. $S p . P l$. i. 22.-As. trop.; Austral.

repens, Linn. Sp. Pl. 3.-Cosmop. trop.

repens, Sieber. - Cf. Schweinf. Beitr. FI. Aethiop. 168 $=$ plumbaginea.

rhomboidea, Humb. in Spreng. Jahrb. Gew. i. III. $66=$

Cryptocarpus globosus.

Rottleri, Steud. Nom, ed. II. i. $213=$ crispa?

rubicunda, Steud. 1. c. = elegans.

rugosa, Rottl. ex Wall. Cat. sub n. $6771=$ crispa

rupestris, Ehrenb. ex Schweinf. Beitr. Fl. Aethiop. 169 = repens.

sarmentosa, Willd. Sp. Pl. i. $21=$ scandens.

scabrida, Steud. \& Hochst. ex Steud. Nom. ed. II. i. $213=$ discolor

scandens, Drège, ex Choisy, in DC. Prod. xiii. II. 455 $=$ Burchellii.

scandens, Forsk. Fl. Aegypt. Arab. $3=$ plumbaginea.

scandens, Gibs. Cat. Bomb. P1. $167=$ verticillata.

scandens; Linn. Sp.Pl. 3.-Am. bor.; Ind. occ

Schomburgkiana, Oliver, in Hook. Ic. Pl. t. 1225.Austral.

sessiliflora, Steud. Nom. ed. II. i. $213=$ repens.

spicata, Choisy, in DC. Prod. xiii. II. 456.-Am. bor, occ.

stellata, Boj. 2 me Rapp. Soc. Hist. Nat. Maurit. 43.-

Ins. Maurit.?

stellata, Wight, Ic, t. $875=$ verticillata.

suberosa, C. Sm. in Tuckey, Congo, $249=$ repens.

sumata, Zipp. ex Span. in Linnaea, xv. (1841) $342=$ repens.

surinamensis, Miq. 1. c. xviii. (1844) $244=$ repens.

tetrandra, Forst. f. Prod. 2. n. 5.-Ins. Societ.

tomentosa, Ehrenb. ex Schweinf. Beitr. Fl. Aethiop. $168=$ repens.

tuberosa, Lam. Illustr. i. 10.-Peruv.

umbellata, Wight, ex Hook. f. Fl. Brit. Ind. iv. $709=$ repanda.

undulata, Ehrenb. ex Schweinf. Beitr. F1. Aethiop. 168 $=$ repens.

verticillata, Boiss. F1. Orient. iv. $1044=$ plumba ginea.

verticillata, Poir. Encyc. v. 56.-Afr. trop.; Syria;

Ind. or.

verticillata, Rottl. in Wall. Cat. n. $6772=$ crispa.

virgata, $H . B . \&$. $K$. Nov. Gen. et Sp. ii. $215 .-\mathrm{N}$ Mexic.

viscosa, Fresen. in Mus. Senckenb. i. (1834) $75=$ repens.

viscosa, Lag. E" Rodr. in Anal. Cienc. Nat. iv. (1801) 256. n. 12.-Peruv.

viscosa, Ehrenb. ex Schweinf. Beitr. Fl. Aethiop. 167 =plumbaginea.

vulvariaefolia, Poir. Encyc. $\% .55=$ repens.

Wrightii, A. Gray, in Am. Fourn. Sc. Ser. II. xy (1853) $322 .-N$. Mexic.

BOGENHARDIA, Reichb. Nom. 200 (1841)=Abutilon, Tourn. (Malvac.).

crispa, Reichb. 1. c. in nota $=$ A. crispum.

BOHADSCHIA, Crantz, Stirp. Austr. ed. I. fasc. i. 2 (1762) ; ed. II. 5 (1769)= Peltaria, Linn. (Crucif.) alliacea, Crantz, $1 . \mathrm{c} .=\mathrm{P}$. alliacea.

BOHADSCHIA, Presl, Rel. Haenk. ii. 98. t. 68 (1831) = Turnera, Linn.

humifusa, Presl, 1. c $=$ T. diffusa.

microphylla, Griseb. Cat. P1. Cub. $114=$ T. diffusa.
BOHADSCHIA, F. W. Schmidt, Samml. Phys. Aufs. i. $279(1795)=$ Hyoseris, Linn. \&c. (Compos。). hirta, F. W. Schmidt, 1. c. $280=$ Leontodon hirtus. lucida, F. W. Schmidt, 1. c. $279=$ H. lucida.

BOHERA VIA, Parodi, in Anal. Soc. Cient. Argent. v. 210 (1878); Contrib. $59=$ Boerhaavia, Vaill. (Nyctag.).

BOISDUVALIA, Spach, Hist. Vég. Phan. iv. 383 (1835) = Oenothera, Linn. (Onagrar.).

andina, Phil. in Linnaea, xxxiii. (1864-65) $70(=0$. andina?).-Chili.

cleistogama, Curran, in Bull. Calif. Acad. (1884) 12.Calif.

concinna, Spach, Hist. Vég. Phan. iv. $384=$ O. concinna.

densiflora, S. Wats. Bot. Calif. i. $233=0$. densiflora.

Douglasii, Spach, Hist. Vég. Phan. iv. $385=$ O. densiflora.

glabella, Walp. Rep. ii. $89=$ O. glabella

Tocornalii, C. Gay, Fl. Chil. ii. 344.-Chili.

Torreyi, S. Wats. Bot. Calif. $233=0$. Torreyi.

Volckmanni, Phil. in Linnaea, xxx.(1859-60) 187.Chili.

BOISSIAEA, Lem. in Orb. Dict. ii. 638 (1842)= Bossiaea, Vent. (Legumin.).

BOISSIERA, Domb. ex DC. Syst. i. 512, in syn. (1818) = Lardizabala, Ruiz \& Pav. (Berberid.). trifoliata, Domb. ex DC. 1. c. $513=$ L. trifoliolata triternata, Domb. ex DC. 1. c. $512=$ L. biternata.

BOISSIERA, Haenseler, ex Willk. \& Lange, Prod. FI. Hisp. i. $218(1861)=$ Gagea, Salisb. (Liliac.).

baetica, Haenseler, $1 . \mathrm{c},=\mathrm{G}$. polymorpha.

BOISSIFRA, Hochst. \& Steud. in Flora, xxi. (1838) I. Intell. 25. GRAMINEAE, Benth. \& Hook. f. iii. 1175 .

Schnizleinla, Steud. Nom. ed. II. i. 213, in syn. (1840).

Wiestia, Boiss, F1. Orient. v, 559 (1884).

bromoides, Hochst. Eo Steud. l. c.; Syn. Pl. Gram 200.-Arab.; Syria; Persia; Affghan.

Danthoniae, A. Braun, Ind. Sem. Hort. Berol. (1857) $3=$ Bromus macrostachyus.

Pumilio, Stapf, in Denkschr. Acad. Wien, 1. (1885) 9.Persia.

BOJprIA, DC. Coll. Mém. ix. 18; et Prod. v. 94 (1836). COMPOSITAE, Benth. \& Hook. f. ii. 331.

glabra, Klatt, in Ann. Sc. Nat. Sér. V. xviii. (1873) 364.-Afr. trop.

speciosa, $D C$. Coll. Mém. ix. 18. t. 3.-Madag.

BOJERIA, Rafin. Fl. Tellur.iv. $50(1836)=$ Amomum Linn. (Scitam.).

magnifica, Rafin. 1. c. = A. magnificum.

BOLANDRA, A. Gray, in Proc. Am. Acad. vii. (1868) 341. SAXIFRAGEAE.

californica, A. Gray, l.c.-Calif.

oregana, S. Wats. l. c. xiv. (1879) 292.-Am. bor.

occ.

BOLANOSA, A. Gray, Pl. Wright. i. 82 (1852) COMPOSITAE, Benth. \& Hook. f. ii. 232. Coulteri, A. Gray, l. c.-Mexic.

BOLAX, Comm. ex Juss. Gen. $226(1789)=$ Azorella, Lam. (Umbell.)

angulatus, Presl, ex DC. Prod. iv. $80=$ Mulinum angulatum.

aretioides, Spreng. Umb. Sp. $11=\mathrm{A}$. aretioides.

caespitosus, Hombr. \& Jacquinot, ex Decne. Bot. Voy. Astrol. et Zél. $62=$ A. caespitosa.

caespitosus, Spreng. in Roem. \& Schult. Syst. vi. $358=$ A. aretioides.

cladorrhizus, Spreng. 1. c. $362=\mathrm{A}$. cladorrhiza.

complicatus, Spreng. Umb. Sp. 9, $10=$ A. caespitosa.

crenatus, Spreng. Syst. i. $880=A$. crenata.

Echinus, Presl, ex DC. Prod. vi. $79=$ Mulinum Echinus. 
BOLAX :-

filamentosus, Spreng. in Roem. \& Schult. Syst. vi. 359 $=$ A. filamentosa.

floccipes, Sieber, ex Benth. Fl. Austral. iii. $380=$ Astrotricha floccosa.

geraniifolius, Presl, ex DC. Prod. iv. $81=$ Huanaca geraniifolia.

Gilliesii, Hook. Bot. Misc. i. (1830) $325=$ A. Gilliesii. Glebaria, Comm. ex Lam. Encyc。 iii. $156=$ A. caespitosa.

gummifer, Spreng. Syst. i. $879=$ A. caespitosa.

integrifolius, Spreng. ex Steud. Nom. ed. II. i. $214=$ A. filamentosa.

ledifolius, Sieber, ex DC. Prod. v. $74=$ Astrotricha ledifolia.

lycopodioides, Spreng. in Roem. \& Schult. Syst. vi. 361 $=\mathrm{A}$. corymbosa.

multifidus, Spreng. Syst. i. $880=$ A. multifida.

pedunculatus, Spreng. Umb. Sp. $10=$ A. multifida.

pilifera, Turcz. in Bull. Soc. Nat. Mosc. xxii. (1849) II. 32.- Peruv.

prolifer, Spreng. in Roem. \& Schult. Syst. vi. $361=$ Mulinum proliferum.

spinosus, Spreng. 1. c. $362=$ Mulinum spinosum.

tridentatus, Spreng. Umb. Prod. $34=$ Hydrocotyle tridentata.

trifurcatus, Spreng. ex Steud. Nom. ed. II. i. $214=$ A. caespitosa.

trilobus, Spreng. Umb. Prod. $34=$ Hydrocotyle triloba.

BOLBIDIUM, Lindl. Veg. Kingd. 181 (1847), nomen (Orchid.). In Herb. Lindl. includit species Dendrobii (D. subacaule \& prasinum):

BOLBOPHYLLARIA, Reichb. f. in Bot. Zeit. x. (1852) $934=$ Bulbophyllum, Thon. (Orchid.).

aristata, Reichb. f. Beitr. Orch. Centr. Am. $60=$ Bulbophyllum aristatum.

biseta, Reichb. f. in Walp. Ann. vi. 242 = Bulbophyllum bisetum.

bracteolata, Reichb. f. in Bot. Zeit. x. (1852) $934=$ Bulbophyllum bracteolatum.

clavata, S. Moore in Baker, Fl. Maurit. $346=$ Bulbophyllum clavatum.

Oerstedii, Reichb. f. in Bonplandia, iii. (1855) $223=$ Bulbophyllum Oerstedii.

pachyrhachis, Reichb. fo in Walp. Ann. vi. $241=$ Bulbophyllum pachyrhachis.

sordida, Reichb. $\ell_{*}$ 1. c. $242=$ Bulbophyllum bracteolatum.

BOLBOPHYLLOPSIS, Reichb. f. in Bot. Zeit. x. (1852) $933=$ Cirrhopetalum, Lindl. (Orchid.).

maculosa, Reichb. f. in Walp. Ann. vi. $243=$ C. maculosum.

morphologorum, Reichb.'f. in Bot. Zeit. x. (1852) $983=$ C. maculosum.

BOLBOPHYLLUM, Spreng. Syst. iii. 681, $732(1826)=$ Bulbophyllum, Thou. (Orchid.).

BOLBORCHIS, Zoll. \& Moritzi, Syst. Verz. Zoll. 89 $(1845-46)=$ Coelogyne, Lindl. (Orchid.). crociformis, Zoll. \& Moritzi, 1. c. =C. javanica.

BOLBOSTYLIS, Gard̄n. in Hook. Lond. Journ. Bot. v. (1846) 467 = Eupatorium, Tourn. (Compos.).

BOLDEA, Juss, in Ann. Mus. Par. xiv. (1809) $134=$ Peumus, Molina (Monim.).

fragrans, C. Gay, F1. Chil. v. 353 ; et Tul. in Arch. Mus. Par. viii. (1855) 412. t. $31=$ P. Boldus.

BOLDOA, Endl. Gen. Suppl. i. 1378 (1841)=BOLDEA, Juss. $=$ Peumus, Molina (Monim.)

BOLDOA, Cav. Cat. Hort. Madr. (1803) t. 7 ; Lag Gen, et Sp. Nov, $10(1816)$, NYCTAGINEAE, Benth, \& Hook, fo iii. 8

Salpianthus, Humb. \& Bompl. Pl. Aequin, i. 154. t. 44 (1808).

lanceolata, Lag. Gen. et Sp. Nov. 10. - Mexic. ovatifolia, Lag. 1. c. = Cryptocarpus globosus. paniculata, Mart. \& Gal. in Bull. Acad. Brox. x. (1843) $356=$ Cryptocarpus globosus.

puerpurascens, Cav. Hort, Madr。 to $7=$ Cryptocarpus globosus.

repens, Spreng. Syst. i. 179.-Bras.
BOLDU, Feuill, ex Adans. Fam. ii. 446 (1763)= Peumus, Molina (Monim.).

BOLDU, Nees, Progr. 11 (1833); Syst. Laurin. 177 $(1836)=$ Cryptocarya, R. Br. (Laurin.). chilanum, Nees, Syst. Laurin. $178=$ Peumus Boldus chilense, Poepp. ex Meissn. in DC. Prod, xv. 1.67= praec.

nitidum, Meissn. 1. c. $506=$ C. nitida.

BOLDUCIA, Neck. Elem. kii. $82(1790)=$ Dipteryx, Schreb. (Legumin.).

BOLDUS, Schult. f. in Roem. \& Schult. Syst. vii. p. x $56(1829)=$ Peumus, Molina (Monim.)

chilensis, Schult. f. l. c. 56.-P. Boldus.

BOLELIA, Rafin. Atl. Journ. 120 (1832)= Downingia Torr. (Campan.).

BOLEUM, Desv。 Journ. Bot. iii. (1814) 163. t. 26. CRUCIFERAE, Benth. \& Hook. fo i. 98.

asperum, Desv. l. c. 163, 175.-Hispan.

BOLINA, Rafin. Sylva Tellur. 101 (1838) (Melastomac.). conferta, Rafin. 1. c. = Brachyotum confertum. divaricata, Rafin. 1. c. = Pterogastra divaricata. excelsa, Rafin. 1. c. = Centronia excelsa.

BOLIVARIA, Cham. \& Schlecht. in Linnaea, i. (1826). 207. t. 4 = Menodora, Humb. \& Bonpl. (Oleaceae) chlorargantha, Remy, in Ann. Sc. Nat. Sér. III. viii. (1847) 225.-Bolivia.

decemfida, Gill, ex Hook. Journ. Bot. i. (1834) 284. -Chili.

Grisebachii, A. Scheele, in Linnaea, xxv. (1852) $254=$ M. heterophylla.

integrifolia, Cham. \& Schlecht. I. c. i. (1826) $208=$ M. integrifolia.

mexicana, A. DC. Prod. viii. $315=$ M. mexicana.

pinnatifida, Schlecht. in Linnaea, xxvi. (1853-55) 474 $=$ M. pinnatifida.

robusta, Benth. in Hook. Lond. Journ. Bot. v. (1846) 190. t. $5=$ M. robusta.

trifida, Cham. \& Schlecht, in Linnaea, i. (1826) $209=$ M. trifida.

BOLLAEA, Parl. in Bull. Soc. Bot. Fr. v. (1858) $509=$ Paneratium, Linn. (Amaryll.).

canariensis, Parl. I. $_{0}=\mathrm{P}$. canariense.

BOLLEA, Reichb. f. in Bot. Zeit. x. (1852) $667=$ Zygopetalum, Hook. (Orchid.).

coelestis, Reichb. fo in Gard. Chron. (1876) I. $756=Z$ coeleste.

guianensis, Klotzsch, in Schomb. Fauna \& Fl. Guy. 1206, nomen.-Guiana.

Lalindei, Reichb. f. in Gard. Chron. (1874) II. $33=$ Z Lalindei.

Lazurenceana, Reichb. f. 1. c. (1878) II. $266=Z$. Lawrenceana.

pallens, Reichb. f. 1. c. (1881) I. 462,-Habo?

Patini, Reichb. f. l. c. $(1874)$ II. $34=Z$. Patini

pulvinaris, Reichb. f. in Linnaea, xli. (1877) $107=Z$ pulvinare.

violacea, Reichb, f. in Bot. Zeit. x. (1852) $668=$ Z violaceum.

BOLOPHYTA, Nutt. in Trans. Am. Phil. Soc. Ser. II vii. (1841) $347=$ Parthenium, Linn. (Compos.). alpina, Nutt. 1. c. $348=$ P. alpinum.

BOLOSIA, Pourr. ex Willk. \& Lange, Prod. Kl. Hisp. ii. $211(1870)=$ Hispidella, Bannad. (Compos.)

piloselloides, Pourr, ex Willk. 1. $\mathrm{c}_{2}=\mathrm{H}$. hispanica.

BOLTONIA, L'Hérit. Sert. Angl. 27 (1788). COMPOSITAE, Benth. \& Hook. f. ii. 269

Asteromoes, Blume, Bijdr. 901 (1827)

Dichaetophora, A. Gray, Pl. Fendl. 73 (1849).

Hisutsua, DC. Prod. vi. 44 (1897)

MADEA, L'Hérit. ex DC. Prod. v. 301 (1536)

asteroides, Sims, Bot. Mag. t. $255 t=$ difusa.

asteroides, L'Hérit. Sert. Angl. 27.-Am. bor. campestris, Hemsl. Biol. Centr. Am. Bot, ii. 120, Texas.

cantoniensis, Franch. \& Sav. Enum. Pl. Gap. ii. 398.Japon.

diffusa, Ell. Sketch, ii, 400, Am. bor.

\section{BOLTONIA}

glastifolia, L'Hérit. Sert. Angl. 27 = asteroides. incisa, Benth. Fl. Hongk. $173=$ Aster incisus. indica, Benth. I. c. $174=$ Aster indicus.

integrifolia, Benth. \& Hook. f. Gen. ii. $269=$ pekinensis.

japonica, Benth. EO Hook.f. l. co-Japon.

latisquama, A. Gray, in Am. Fourn. Sc. Ser. II. sxxiii (1862) 238.-Am. bor.

lautureana, Debeaux, in Act. Linn. Soc. Bord. xxxi. 1877) $215=$ Aster lautureanis.

pekinensis, Hance, in fourn. Bot. v. (1867) 370.-

China.

Seemannit, Benth. \& Hook. f. Gen。 ii。 $269=$ Achaetogeron Seemannii

BOLUSIA, Benth. in Hook. Ic. Pl. xii, 57. t. 1163 (1873). LEGUMINOSAE.

capensis, Benth. l. c.-Afr. austr.

BOMAREA, Mirb, in Hist. Nat. P1。 ix。 (1804) 71. AMARYLLIDEAE, Benth. \& Hook. f. iii. 736.

Collania, Herb. Amaryll. 103. t. 8 (1837).

Danbya, Salisb. Gen. PI. Fragm. 57 (1866

DODECASPERMa, Rafin. Fl. Tellar. iv. 35 (1836

Sphaerine, Herb. Amaryll. 106. t. 12, 18, 16, 18 (1837)

VANDESIA, Salisb, in Trans. Hort. Soc. i. (1812) 332.

Wichuraea, M. Roem. Syn. Ensat. 277 (1847)

acutifolia, Herb. Amaryll. 112.-Mexic.

affinis, Kunth, Enum. P1. v. $796=$ edulis.

amoena, M. Roem. Syn. Ensat. 274.-Peruv.

anceps, Herb. Amaryll. 116 = fimbriata

andimarcana, Baker, in Fourn. Bot. xx. (1882) 201.Peruv.

Andreana, Baker, l. c. 205.-N. Granat.

angulata, Benth. Pl. Hartw. 156,-Peruy.

angustifolia, Benth. l. c.-Peruv.

angustipetala, Baker, in fourn. Bot. xx. (1882) 202. N. Granat.

aurantiaca, Herb. Amaryll. 399. t. 46. f. 1.-Peray.

brachysepala, Benth.Pl. Hartw. 157.-Peruv.

bracteata, Herb. Amaryll. 112. t. 3. f. $3=$ edulis.

Brauniana, Schenk, in Mart. Fl. Bras. iii. I. 168 edulis.

Bredemeverana, Herb. Amaryll. $118=$ multiflora.

brevis, Baker, in Fourn. Bot. xx. (1882) 202. - Perav.

Caldasiana, Herb. Amaryll. 119.-Guatemala; Peray

caraccensis, Herb. 1. c. 111. t. 16. $1.2=$ edulis,

Carderi, Mast. in Gard. Chron. (1876) I. 793, 795. $-\mathrm{N}$. Granat.

chontalensis, Seem. in Gard. Chron. (18i1) 479 edulis.

coccinea, Baker, in Fourn. Bot. xx. (1882) 202.

Peruv.

conferta, Benth. Pl. Hartw. $259=$ patacocensis

cordifolia, Herb. Amaryll. 113.-Peruv.

cornigera, Herb. l. co 116. t. 17. f. 2.-Peruy

cornuta, Herb. l. c. 114. t. 17. f. $t=$ edulis.

crinita, Herb. l. c. 119. t. 15. f. 4.-Peruy.

crocea, Herb. I. c. 119.-Peruv.

cumbrensis, Herb. 1. c. 115. t. 18. f. $2=$ torta

declinata, Klotzsch, ex Kunth, Enam. P\}. マ. 802 dispar.

densiftora, Herb Amaryll. 399. t. 46. f. $4=1$ tomentosa.

diffracta, Baker, in Fourn. Bot. xx. (1852, 206. $\mathrm{N}$. Granat.

denticulata, Herb. Amaryll. 118.-Peruv.

dispar, Herb. l. G. 115. t. 17. fo 1-Percs

dissitifolia, Baker, in fourn. Bot. Xx. 1 ss:? 2(13.

Ecuador.

distichophylla, Baker, l. c. 202.-Peruy.

edulis, Herb. A maryll. 111.-Am. trop.

Fanningians, Herb. 1. c. 116. t. 16. f. \$: multitem.

fimbriata. Herb. l. c. 116.-Peruv.

floribuenda, Herb. 1. $c_{0}=$ fimbriata

formosissima Herb l c. 111 t. It f 4-Perus

froudea, Mast. in Gard. Chron. 1:82: 1. 688., Granat.

furcata, Klotzsch, ex Kunth, IEnum. P., $4,792=$ edulie

fuscata, Kilotesch, ins Sthomb. Fousura Es Fl. Guy

$11: 20$, nomen. Giviann.

glaucescens, Baker, in Fourn. Bot. xx. (1682 201

licundor.

glomerata, Herb. Amaryll. 115. t. 15. I. 1.- Peruv.

goniocaulon, Buter, in fourm. Bot. xx. 1682 IIIt.

Licuator. 


\section{BOMAREA :-}

gloriosa, M. Roem. Syn. Ensat, $269=$ edulis. granatensis, M. Roem. 1. c. $264=$ B. Salsilla. grandifolia, Herb. Amaryll. $113=$ edulis. Halliana, Herb. Amaryll. 117. t. 10. f. 3.-N. Granat Hartwegii, Baker, in Fourn. Bot. xx. (1882) 203.Ecuador.

hirsuta, Herb. Amaryll. 114.-N. Granat. hirta, Schenk, in Mart. Fl. Bras. iii. I. 169,-Bras. hirtella, Herb. Amaryll. $112=$ edulis.

hispida, Baker, in Fourn. Bot. xx. (1882) 202.-N Granat.

Hookeriana, Herb. Amaryll. 398. t. 46. f. 3.-Peruv.

involucrosa, Baker, in fourn. Bot. xx. (1882) 201. Peruv.

Jacquesiana, Kunth, Enum. Pl. v. 800.-Bras. janeirensis, M. Roem. Syn. Ensat. $267=$ edulis. Kalbreyeri, Baker, in Fourn. Bot. xx. (1882) 204.-N Granat.

lancifolia, Baker, l. c. 202.-Ecuador.

latifolia, Herb. Amaryll. $113=$ edulis

Lehmanni, Baker, in fourn. Bot. xxi. (1883) 373.-Am. austr.

linifolia, Baker, l. c. xx. (1882) 201.-N. Granat.

longipes, Baker, l. c. 204.-Ecuador

lutea, Herb. Amaryll. 120. t. 5.-Peruv.

lyncina, Herb. l. c. 398. t. 46. f. 8.-Peruv

Maakiana, Klotzsch, in Otto \& Dietr. Allg. Gartenz. xx. (1852) 337.-Venezuela.

Macleanica, Herb. in Lindl. Bot. Reg. (1842) Misc. $66=$ aurantiaca.

macrocarpa, Herb. Amaryll. $14=$ edulis

maranensis, Herb. l. c. 17.-Bras.

Martiana, Schenk, in Mart. F1. Bras. iii. 1. $170=$ edulis.

miniata, Kunth, Enum. PI. v. $792=$ edulis

minima, Baker, in Fourn. Bot. xx. (1882) $202 .-\mathrm{N}$. Granat.

Moritziana, Klotzsch, ex Kunth, Enum. Pl. v. $797=$ edulis.

multiflora, Mirb. Hist. Nat. Pl. ix. (1804) 72.-N. Granat.

multipes, Benth. Pl. Hartw. 156.-Peruv. nervosa, Baker, in fourn. Bot. xx. (1882) 202.-
Peruv.

nobilis, Herb. Amaryll. $422=$ ovata

obovata, Herb. 1. c. 112. t. 14. f. $2=$ edulis.

oculata, M. Roem. Syn. Ensat. $263=$ B. Salsilla

oligantha, Baker, in Gard. Chron. (1877) II. 648.Peruv.

ovata, Mirb. Hist. Nat. Pl. ix. (1804) 72.-Am. austr. pachyphlebia, Baker, in fourn. Bot. xx. (1882) 204.Ecuador.

pardina, Herb. Amaryll. 120, t. 14. f. 1.-N. Granat. paltarumensis, Herb. 1. c. 422 = fimbriata

patacocensis, Herb. l. c. 120. t. 14. f. 3.-Ecuador; N Granat.

pauciflora, Herb. 1. c. $112=$ edulis

platypetala, Benth. P1. Hartw. $156=$ uncifolia

podopetala, Baker, in Fourn. Bot. xx. (1882) 202.-

Ecuador:

polygonatoides, Baker, l. c.-Ecuador

praecipua, Herb. Amaryll. $422=$ B. Salsilla

pudibunda, Planch. E' Linden, Cat. n. 10. (1855) 4.-

N. Granat.

pumila, Griseb. in Lechl. Ber̀b. Am. Austr. 56, nomen. -Peruv.

punctata, Herb. in Lindl. Bot. Reg. (1842) Misc. 66. Peruv.

purpurea, Herb. Amaryll. 118, 399.-Peruv.

rosea, Herb. l. c. 118.-Peruv.

Salsilla, Mirb. in Hist. Nat. Pl. ix. (1804) 71Chili.

Salsilla, Vell. F1. Flum. iii. t. $20=$ edulis.

salsilloides, M. Roem. Syn. Ensat. $264=$ edulis.

secundifolia, Baker, in Fourn. Bot. xx. (1882) 202.

Peruv.

setacea, Herb. Amaryll. $117=$ tomentosa.

Shuttleworthii, Mast. in Gard. Chron. (1882) I. 76.-N. Granat.

simplex, Benth. P1. Hartw. 156= Hartwegii.

simplex, Herb. Amaryll. t. 15 ; et in Bot. Mag. t. 3863 = rosea.

spectabilis, Schenk, in Mart. F1. Bras, iii. I. $169=$ edulis. subfalcata, Herb. Amaryll. 422 ; Pritz. Ic. Ind. $158=$ B. Salsilla.

subglobosa, Herb. in Lindl. Bot. Reg. (1842) Misc. 66 = fimbriata.

\section{BOMAREA :-}

superba, Herb. Amaryll. 117. t. 6. f. 1.-Peruv,

Tatiana, Herb. 1. c. $423=$ ovata.

tomentosa, Herb. l. c. 117.--Peruv.

torta, Herb. l. c. 115.-Ecuador.

Turneriana, Herb. in Lindl. Bot. Reg. (1842) Misc. 66 = formosissima

uncifolia, Herb. l. c.-Peruv. vel Bolivia.

variabilis, Herb. 1. c. = rosea.

villosa, M. Roem. Syn. Ensat, $268=$ ovata.

vitellina, Mast. in Gard. Chron. (1882) I. 143.-N

Granat.

Williamsiae, Mast. l. c. (1882) II. 553.-N. Granat.

BOMARIA, Kunth, Enum. Pl. v. $787 \quad(1850)=$ Bomarea, Mirb. (Amaryll.).

BOMBAX, Linn. Sp P1. ed, I. 511 (1753), MALVA-

$C E A E$, Benth. \& Hook, f. i. 210

ERIotheca, Schott \& Endl. Meletem. 35 (1832)

Salmalia, Schott \& Endl. 1. c. (1852).

aculeatum, Vell. Fl. Flum. 289 ; vii. t. 56.-Bras.

aesculifolium, H. B. \& K. Nov. Gen. et Sp. v. $298=$

Eriodendron aesculifolium.

axillare, Moç. \& Sessé, ex DC. Prod. i. $479=$ Eriodendron aesculifolium.

Barrigon, Decne. in Fl. des Serres, Sér. II. xiii. (1880) 44.-Panama.

buonopozense, Beauv. Fl. Owar. ii. 42, t. 83.-Afr. trop. carolinoides, Donn, Cat. Hort. Cant. ed. IV. 156= Pachira minor.

carolinum, Vell. Fl. Flum. 289 ; vii. t. 57.-Bras.

Ceiba, Burm. f. FI. Ind. $145=$ malabaricum

Ceiba, Linn.Sp. Pl.511.-Am. austr

Congo, Burm. f. Fl. Ind. $145=$ Cochlospermum Gossypium.

coriaceum, Mart. Nov. Gen.et Sp. i. 93, in obs.-Bras, cumanense, H. B. E K. Nov. Gen. et Sp. v. 300.Veneznela.

decaphyllum, Decne. in Fl. des Serres, Sér. II. xiii. (1880) $44=$ endecaphyllum.

discolor, H. B. E\% K. Nov. Gen. et Sp. v. 299.-N.

Granat.

ellipticum, H. B. E K. l. c.-Mexic.

emarginatum, Decne in Fl. des Serres, Sér. II. xuii. (1880) 44.-Bras.

endecaphyllum, Vell. Fl. Flum, 288; vii. t. 50,-Bras, Erianthus, Cav. Diss. v. $294=$ Eriodendron leiantherum.

Fendleri, Benth. in Fourn. Linn. Soc. vi. (1862) 108. -Panama.

festivum, Wall. Cat. n. $1841=$ insigne.

glabrescens, St. Hil. E Naud. in Ann. Sc. Nat. Sér.

II. xviii. (1842) 211.-Bras.

globiferum, Raeusch. Nom. ed. III. 195=globosum

globosum, Aubl. Pl. Gui. ii. 701. t. 281,-Guiana.

Gossypium, Linn. Syst. ed. XII. $517=$ Cochlospermum Gossypium.

grandiflorum, Cav. Diss. v. $295=$ insigne.

grandiflorum, Sonner. Voy. Ind. ii. 235. t. $133=$ Cochlospermum Gossypium.

guineensis, Schum. \& Thonn. Beskr. Guin. Pl. 302 Eriodendron anfractuosum.

heptaphyllum, Cav. Diss. v. 296 ; Roxb. PI. Corom. iii.

43. t. 247 = malabaricum

heptaphyllum, Linn. Sp. Pl. $960=$ septenatum.

hexaphyllum, Vell. Fl. Flum. 288; vii. t. 52.-Bras.

hibiscifolium, Willd. ex Stend. Nom. ed. II. i. $215=$ Cochlospermum hibiscoides.

Hilarianum, Decne. in Fl. des Serres, Sér. II. xiii. (1880) 44.-Bras.

humile, Benth. in fourn. Linn. Soc. vi. (1862) 108.Bras.

insigne, Wall. Pl. As. Rar. i. 74. t. 79 et 80.-Ind. or. jasminodorum, Baill. Hist. P1. iv. $119=$ Eriodendron jasminodorum.

malabaricum, DC. Prod. i. 479.-Ind. or.; Malaya; China.

mediterraneum, Arruda, in Koster, Trav. Braz. 489. Bras.

mexicanm, Hemsl. Diag. Pl. Nov. 4.-Mexic.

mompoxense, H. B. E $K$. Nov. Gen. et Sp. v. 300.Venezuela.

Munguba, Mart. Nov. Gen. et Sp. i. 93.-Bras.

occidentale, Spreng. Syst. iii. $124=$ mompoxense ; Eriodendron caribaeum.

octophyllum, Vell. Fl. Flum. 288 ; vii. t. 51.-Bras.

orientale, Spreng. Syst. iii. $124=$ Eriodendron anfractuosum.

\section{BOMBAX:}

orinoccense, H. B. \& K. Nov. Gen. et Sp. v. $300=$ Cochlospermum orinoccense.

parviflorum, Mart. Nov. Gen.et Sp. i. 91. t. 57.-Bras. pentandrum, Jacq. Stirp. Am. $191=$ Eriodendron caribaeum.

pentandrum, Linn. Sp. PI. $511=$ Eriodendron anfrac tuosum.

pentaphyllum, Vell. Fl. Flum, 289; vii. t. 55.Bras.

plumosum, Noronha, in Verh. Batav. Gen. v. (1790) ed. I. Art. IV. $8=$ Eriodendron anfractuosum?

pubescens, Mart. Nov. Gen. et Sp. i. 91. t. 58.-Bras.

pyramidale, Cav. Diss. v. 294. t. $153=$ Ochroma lagopus.

pyramidatum, Steud. Nom. ed. I. $114=$ praec.

quinatum, Jacq. Stirp. Am. $192=$ B. Ceiba.

religiosum, Linn. Sp. Pl. $512=$ Cochlospermum Gossypium.

retusum, Mart. Nov. Gen. et.Sp. i. 92. t. 59.-Bras.

rubrinervis, Hoffmgg. Verz. Pf. Nachtr. ii. 69.Bras.

Samauma, Spreng. Syst. iv. Cur. Post. 259=Eriodendron Samauma.

septenatum, Facq. Enum. Pl. Carib. 26--N. Granat serrata, Desf. Cat. Hort. Par. ed. III. 407.-Hab.? sexdigitatum, Vell. Fl. Flum. 289 ; vii, t. 54.-Bras. tomentosum, A. Fuss. in A. St. Hil. Fl. Bras. Mer. i 263.-Bras.

ventricosum, Arruda, in Koster, Trav. Braz. $489=$ Chorisia crispiflora.

villosum, Mill. Gard. Dict. ed. VIII. n. 3.-Am. austr

vitifolium, Willd. Enum. Hort. Berol. $720=$ Cochlo spermum vitifolium.

BOMBIX, Medic. Malv. $44(\mathbf{1 7 8 7})=$ Hibiscus, Linn. (Malvac.).

phoenicea, Medic. 1. $\mathrm{c}_{\mathrm{s}}=\mathbf{H}$, phoeniceus.

BOMBYCELLA, Lindl. Veg. Kingd. 370 (1847)= Hibiscus, Linn. (Malvac.)

betulina, Bello, in Anal. Soc. Esp. Hist, Nat. $x$ (1881) 241 ( $=\mathrm{H}$. betulinus ?).--Porto Rico.

bicolor, Welw. Apont. 589.-Afr. trop

phoenicea, Bello, in Anal. Soc. Esp. Hist. Nat. x. (1881) $241=H$, phoeniceus.

BOMBYCIDENDRON, Zoll. \& Mor, in Nat. en Geneesk. Arch. Neêrl. Indie, ii. (1845) $14=$ Hibiscus, Linn. (Malvac.).

grewiaefolium, Zoll. \& Mor. 1. c. $=\mathrm{H}$. grewiaefolius.

BOMBYCOSPERMUM, Presl, Rel. Haenk. ii. 137. t. 71 $(1831)=$ Ipomoea, Linn. (Convolv.). mexicanum, Presl, l. c. $=1$. bombycina.

BOMByNIA, Noronha, in Verh. Batav. Gen. v. (1790 ed. I. Art. IV. 1; ed. II. 64 (1827) (Quid?).

BOMBYX, Moench, Meth. $616(1794)=$ Hibiseus, Linn. (Malvac.)

phoenicea, Moench, 1. c. $=\mathrm{H}$. phoeniceus.

BONA, Medic. in Vorles. Churpf. Phys. Ges. ii. (1787) 360 ; et Phil. Bot. i. $205(1789)=$ Vicia, Linn (Legumin.)

narbonensis, Medic.1. c. $360=\mathrm{V}$. narbonensis

speciosa, Medic. 1. c. $361=\mathrm{V}$, narbonensis.

BONAFIDIA, Neck. Elem. iii. $46^{\circ}(1790)=$ Amorpha, Linn. (Legumin.).

BONAFOUSIA, A. - DC. Prod, viii. $359(1844)=$ Tabernaemontana, Linn. (Apocyn.). attenuata, Miers, Apocyn. S. Am. 51.-Am. austr. guyanensis, Miers, $\mathrm{l}_{0} \mathrm{c}_{\mathrm{*}}=\mathrm{T}$. guyanensis latiflora, Miers, 1. c. $50=$ T. flavicans. obliqua, Miers, 1. c. 49.-Am. austr. oblongifolia, Miers, 1, c. 50=T. oblongifolia. olivacea, Miers, 1, c. $52=\mathrm{T}$, olivacea. Perrottetii, Miers, 1. c. $51=$ T. Perrottetii polyneura, Miers, 1. c. 53.--Am. austr. rariflora, Miers, 1. c.-Am. austr. rupicola, Miers, 1. c. $52=\mathrm{T}$. rupicola undulata, A. DC. Prod. viii. 359=T. undulata. 
BONAGA, Medic. in Vorles. Churpf. Phys. Ges, ii (1787) 345; Phil. Bot. $206(1789)=$ Ononis, Linn (Legumin.).

antiquorum, Medic. 1. c. $346=\mathrm{O}$. antiquorum. arvensis, Medic. Phil. Bot. $206=$ O. arvensis.

Columnae, Medic. in. Vorles. Churpf. Phys. Ges, ii. (1787) $346=$ O. Columnae

hircina, Medic. 1, $\mathrm{c}=\mathrm{O}$. hircina

minutissima, Medic. 1. c. $=\mathrm{O}$. minutissima.

mitis, Medic. l. ${ }^{\circ} .=0$, arvensis.

spinosa, Medic. 1. $\mathrm{c}_{\iota}=\mathrm{O}$. spinosa.

BONAMIA, A. Gray, in Proc. Am. Acad. v. (1862) 337 = Breweria, R. Br. (Convolv.).

aquatica, A. Gray, Man. Bot. N. U. St. ed. V. $376=$ Breweria aquatica.

humistrata, A. Gray, in Proc. Am. Acad. v. (1862) $337=$ Breweria humistrata.

Menziesii, A. Gray, 1. c.-Ins. Sandvic.

Pickeringii, A. Gray, Man. Bot. N. U. St, ed. V. 376 = Breweria Pickeringii.

BONAMTA, Thou. in Dict. Sc. Nat. v. 145 (1804); et Hist. Veg. Isl. Afr. 17. t. 8 (1805). CONVOLVULACEAE, Benth. \& Hook. f. ii. 877 .

madagascariensis, Poir. Encyc. Suppl. i. 677.Madag.

BONAMICA, Vell. F1. Flum, 21 (1825); i. t. $50=$ Linociera, Sw. (Oleac.)

filiformis, Vell. 1. c.-Bras.

BONANIA, A. Rich. F1. Cub. Fanerog. ii. 201. t. 68 (1853), EUPHORBIACEAE, Benth. \& Hook, f. iii. 385.

adenodon, Benth. E Hook. f. Gen, iii. 335.-Cuba cubana, A. Rich. Fl. Cub. Fanerog. ii. 201.-Cuba. cubensis, A. Rich. 1. c. t. $68=$ cubana.

emarginata, Wright, ex Griseb. in Goett. Nachr. (1865) 78.-Cuba.

erythrosperma, Benth. E Hook. f. Gen. iii. 335.Cuba.

myricifolia, Benth. E Hook.f.l. c.-Cuba.

BONANNIA, Guss. F1. Sic. Syn. i, 355 (1842) UMBELLIFERAE, Benth. \& Hook, f, i. 910. resinifera, Guss. l. c.-Sicilia.

resinosa, Strobl, in Oestr. Bot. Zeitschr. xxxiv. (1884) $174=$ resinifera.

BONANNIA, Presl, Fl. Sic. i. $99(1826)=$ Brassica, Linn. (Crucif.).

dissecta, Presl, 1. c. $100=$ Brassica dissecta

officinalis, Presl, 1. c. $99=$ Brassica alba.

BONANNIA, Rafin. Specchio, xv. $115(1814)=$ Blighia, Kon. (Sapind.).

nitida, Rafin. 1, c. $116=$ Blighia sapida.

BONANOX, Rafin. Fl. Tellur. $77(1836)=$ Ipomoea Linn. (Convolv.).

indica, Rafin. 1. c.-Ind. or.

muricata, Rafin. I. c. = I. Bona-nes.

orbiculata, Rafin. 1. $\mathrm{c}_{\mathrm{z}}=\mathrm{I}$, orbiculata.

riparia, Rafin. 1. c. $=$ I. riparia.

BONAPARTEA, Haw. Syn. Pl. Succ. 68 (1812)= Agave, Linn. (Amaryll.).

filamentosa, Boucen. in Rev. Hortic. (1868) $65=\mathrm{A}$ filifera.

flagelliformis, Henck. in Flora, iii. (1820) $45=\mathrm{A}$. geminiflora.

gracilis, Sweet, Hort. Brit. ed. II. $597=$ Dasylirion acrotichum.

Hystrix, Hort. ex Pasq. Cat. Orto Bot. Nap. $111=\mathrm{A}$. striat?.

junced, Haw. Syn. Pl. Succ. $68=$ A. geminiflora.

stricta, Hort. ex Vukot. in Rad. Jugos. Akad. Zagrab, xxvil. $(1874) 213=$ A. striata.

BONAPARTEA, Ruiz \& Pav, Fl. Per, iii. 98 (1802)= Tillandsia, Linn. (Bromel.).

juncea, Kuiz \& Pav. 1. c, = T. setacen.

strobilantha, Kuiz \& Pav, l, c, $39=$ T. strobilantha.

vittato, Mart. ex Schult. f. Syst, vii. II.1198 = T. vittata
BONAROTA, Adans. Fam.ii. $209(1763)=$ Paederota,

Linn. (Scrophul).

chamaedrifolia, Scop. FI. Carn. ed. II. i. $22=$ P. Ageria.

rotundifolia, Caruel, in Parl. F1. Ital. vi. $532=\mathrm{P}$ Bonarota.

BONATEA, Willd. Sp. Pl. iv, $43(1805)=$ Habenaria, Willd. (Orchid.)

Bilabrella, Lindl. Gen. et Sp. Orch. $328=\mathrm{H}$. tetrapetala Boltoni, Harv. Thes. Cap. i. 55. t. $88=\mathrm{H}$. Boltoni. cassidea, Sond. in Linnaea, xix. (1847) $81=\mathrm{H}$. cassidea cirrhata, Lindl. Gen, et $\mathrm{Sp}$. Orch, $327=\mathrm{H}$ cirrhata clavata, Lindl, in Hook. Comp. Bot. Mag. ii. (1836) $208=\mathbf{H}$. clavata

Darwinii, Weale, in Journ. Linn. Soc. x. (1869) $470=$ H. cassidea.

densiflora, Sond. in Linnaea, xix. (1847) $80=\mathrm{H}$ densiflora.

flexuosa, Lindl. Gen, et Sp. Orch. $328=\mathrm{H}$. flexuosa.

foliosa, Lindl. 1. c, $329=\mathrm{H}$, foliosa.

gracilis, Lindl. 1. c. $=\mathrm{H}$. gracilis.

herbacea, Wall. ex Lindl. 1. c. $307=\mathrm{H}$. digitata.

incarnata, Lindl. 1. c. $327=$ Disa incarnata.

macilenta, Lindl. ex Benth. in Hook. Lond. Journ.

Bot. ii. (1843) $673=\mathrm{H}$. macilenta.

micrantha, Lindl. Gen. et Sp. Orch. $329=\mathrm{H}$. arenaria panduana, Lindl. in Wall. Cat. n. $7063=\mathrm{H}$. digitata. pauciflora, Lindl. Gen. et Sp. Orch. $329=\mathrm{H}$. pauciflora pratensis, Lindl. 1. c. $328=\mathrm{H}$. pratensis.

speciosa, Willd. Sp. Pl. iv. $48=$ H. Lonatea

tetrapetala, Lindl, in Hook. Comp. Bot. Mag. ii (1836) $208=$ H. tetrapetala.

BONAVERIA, Scop. Introd. $310(1777)=$ Securigera DC. (1805) (Legum.)

Securidaca, Desv. Journ. Bot. i. (1813) $120=$ S. Coronilla.

Securigera, Endl. ex Heynh. Nom. ii. $73=$ S. Coronilla

BONDUC, Adans, Fam. ii. $318(1763)=$ Caesalpinia Linn. (Legum.)

canadense, Medic. Theod, $113=\mathrm{C}$. Bonduc,

majus, Medic, 1. c. $43=$ C. Bonduc.

minus, Medic. 1. c. $41=$ C. Bonducella.

BONELLIA, Bert. ex Colla, Hort. Ripul. 21 (1826)= Jacquinia, Jacq. (Myrsin.)

Cavanillesii, bert. 1. c. = J. macrocarpa.

BONGARDIA, C. A. Mey. Verz. Pf. Cauc. 17 (1831). BERBERIDEAE, Benth. \& Hook. f. i. 43 . chrysogonum, Boiss. Fl. Orient. i. $99=$ Rauwolfi.

Olivieri, C. A. Mey. Verz. Pf, Canc. $175=$ Rauwolfii Rauwolfii, $C$. A Mey, l. c. 174-Graecia; Oriens Afghan.

BONIFACIA, Manso, ex Steud. Nom, ed. II. i. 216 $(1840)=$ Augusta, Pohl (Rubiac.)

riparia, Manso, ex Steud. l. c.=A. lanceolata.

BONJEANEA, Reichb. F1. Germ. Excurs. 507 (1832)= Doryenium, Linn. (Legum.)

cinerascens, Jord. \& Fourr. Brev. P1. Nov. fasc. i. $12=$ D. hirsutum.

graeca, Griseb. Spicil. Fl. Rumel. i. $43=$ D. latifolium. hirsuta, Reichb. Ic. Fl. Germ. x. $32=$ D. hirsutum. hirta, Jord. \& Fourr. Brev. Pl. Nov, fasc. i. $11=\mathrm{D}$ hirsutum.

italica, Jord. \& Fourr. 1. c. $12=$ D. hirsutum.

Kotschyi, Boiss. \& Reut. ex Boiss. Fl. Orient. ii. $161=$ D. Kotschyi.

microphylla, Reichb. F1. Germ. Excurs. 507, in nota = Indigofera gracilis.

prostrata, Jord. \& Fourr Brey. Pl. Noy, fasc i. 11 [emend. fasc. ii. 183] = D. hirsutum

recta, Reichb. Fl. Germ. Excurs. $507=$ D. rectum,

sericea, Jord, \& Fours. Ic. Fl. Eur. i, 24. t. $61=\mathrm{D}$ hirsutum.

syriaca, Boiss. Diagn, Ser, I ix, $\$ 1=\mathrm{D}$. hirsutum.

venusta, Jord. \& Fourr. Brev, Pl. Nov, fnsc. i. $12=0$. hirsutum.

BONNAYA, Link \& Otto, Ic. PI. Sel. 25.t. $11(1820)$ SCROPHUL.ARINEAE, Benth. \& Hook. t. ii. $150^{\circ}$. alata, Spreng. Syst. i. 11 .-Ins. Molucc.

\section{BONNAYA}

alterniflora, Wright, in Sauv. Fl Cub 101-Cuba.

bifolia, Spreng. Syst. iv. Cur. Post. $15=$ Chirita bifolia brachiata, Link E Otto, Ic. Pl. Sel. ii. 25. t. 11.-Ind. or.; Malaya.

brachycarpa, Cham. \& Schlecht. in Linnaea, ii. (1827 $568=$ Ilysanthes capensis

bracteata, Griff. Notul iv, $107=$ veronicaefolia.

ciliata, Spreng. Syst. i. $41=$ reptans.

clausa, F. Muell. ex Benth. Fl. Austral. iv. 493.Austral.

cordifolia, Spreng. Syst. i. $42=$ Vandellia pedunculata, cyanea, Griff. Notul. iv. $107=$ veronicaefolia.

grandiflora, Spreng. Syst, i, $41=$ veronicaefolia.

hispidula, G. Don, Gen. Syst. iv, 538 (Gen. dubium).Ind. or.

humilis, Spreng. Syst. iv. Car. Post. $15=$ Chirita pumila.

hyssopioides, Benth. in Wall. Cat, n, $3866=1$ lysanthes hyssopioides.

integrifolia, Kostel. Allg. Med.Pharm. Fl. iii. $893=$ Vandellia erceta.

marginata, Spreng. Syst. i. 41 = veronicaefolia.

minima, G. Don, Gen. Syst. iv. 538=oppositifolia.

minima, Wight, Ic, iii. t. $858=$ Ilysanthes minima.

ocymifolia, G. Don, Gen. Syst. iv. 538 (= Vandelliae sp.).-Ind, or.

oppositifolia, Spreng. Syst. i. 41.-Ind. or.

origanifolia, Spreng. 1. c, $42=$ Vandellia diffusa.

parviflora, Benth. in Wall. Cat, n. $3867=11$ ysanthes parviflora.

peduncularis, Benth. in Wall.l. c. n. 3865 ; et Scroph. Ind. 34.-Ind or.

penicillata, Nees, in DC. Prod.xi. 161.-Japon.

personata, Hassk. in Flora, xlvii. (1864) 56 = bracbiata

procumbens, Benth. in Wail. Cat. ․ $3 \times 59=$ veronicatfolia.

pulegiifolia, Spreng. Syst. i. $41=$ veronicaefolia.

pumila, Spreng. Syst. iv. Cur. Post. $15=$ Chirita pumila.

punctata, G. Don, Gen. Syst. iv. $538=$ Limnophila conferta.

pusilla, Benth. in Wall. Cat. n. 3861 ; Scroph. Ind. 33 = brachiata.

pusilla, Griff. Notul. iv. $107=$ tenuifolia

pusilla, Oliver, in Trans. Linn. Soc. xxix. (1875) 121. -Afr. trop.

repens, G. Don, Gen. Syst. iv. $537=$ seq.

reptans, Spreng. Syst. i. 41.-Ind. or.; Malaya; Ins. Maurit.

rigida, Benth. in Wall. Cat. $n .3860=$ veronicrefoliz.

Rothii, A. Dietr, Sp. Pl. i, $556=$ veronicrefolia.

rotundifolia, Benth. Scroph. Ind. $34=$ Ilysanthes rotundifolia.

Roxburghiana, A. Dietr. Sp. Pl, i, 559 = veronicaefolia.

ruellioides, Spreng. Syst i. $41=$ reptans,

serrata, A. Dietr, Sp. Pl. i. 556 ; Griff. Notul. iv, 1(1y = brachiata.

tenuifolia, Spreng. Syst. i. 42.-Ind. or. ; China.

trichotoma, Oliver, in Trans. Linn. Soc, xxix (18;5 121.-Afr. trop.

Vahlii, G. Don, Gen. Syst, iv, $538=$ Vandellis scabm verbenaefolia, Spreng. Syst. i. $42=$ veronicaefolia

veronicaefolia, Spreng. l. c. 41.-Ind. or.; Malaya; China.

Wightii, Benth. in Wall. Cat. a. $3864=$ veronicnefulia

BONNETIA Mart, \& Zucc Nov, Gen et Sp, i. 114

t. 100 (1824), TERNSTROEVIJAEAE, benth i

Hook, f. i. 187

KiESERIA, Nees, in Neuwied, Reise nach Brasil. ii. $338(1 \mathrm{~s} 21)$

anceps, Mart. E Zuce. Not. Gen. et Sp. i. 115.irins.

bahiensis, Turcs. in Bull. Soc. Nat. Mose. xuxi, (19:s 1. 246. - Bras.

coriacea, Spreng. Syst. iv. Cur. Post. $207=$ Kielmeyen coriacua.

corymbosa, Spreng. 1. co = Kiclmeyera cormbosa

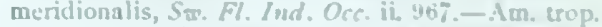

palustris, Yahl, Eclog. Am, ii, 12 meridionalis

paniculata, Spruce, ex Brnsh. in Yourn. Linn. Sor. 1Stil 68.-Peruy.

parviflua, Spruce, er Bensh. 1. c.-Peruv.

petiolaris, Spreng. Syst. iv. Cur. Post. 207 a Kic

mevera petiolacis.

rosera, Spreng. 1. c. - Kicloucyera rosea. 


\section{BONNETIA :-}

sessilis, Benth. in Hook. Lond. Fourn. Bot. ii. (1843) 363.-Guiana

stricta, Mart. in Nov. Act. Nat. Cur. xii. (1825) 87.Bras.

trifoliata, Auct. ex Walp. Rep. i. $499=$ Galipea offcinalis.

wariabilis, Spreng. Syst. iv. Cur. Post. 207=Kielmeyera variabilis.

venulosa, Mart. \& Zucc. Nov. Gen. et Sp. i. 115.Bras.

BONNETIA, Neck. Elem. i. $368(1790)=$ Buchnera Linn. (Scrophular.).

BONNETIA, Schreb. Gen. 363 (1789) = Mahurea, Aubl. (Ternstroem.)

palustris, J. F. Gmel. Syst. $814=$ M. palustris.

racemosa, Sw. F1. Ind. Occ. ii. $965=$ M. speciosa.

BONPLANDIA, Cav, in Anal. Hist. Nat. ii. (1800) 131. t. 20. POLEMONIACEAE, Benth. \& Hook. f ii 824

CALIDASIA, Willd. Hort. Berol. t. 71 (1807).

geminiflora, Cav.l.c. 132.-Mexic.

BONPLANDIA, Willd. in Mém. Acad. Berl. (1802) $24=$ Galipea, Aubl. (Rutac.).

Angostura, Rich. in Mém. Math.-Phys. Inst. Par. (1811) 82. t. $10=\mathrm{G}$. Cusparia.

Candolleana, Spreng. Syst. i. $781=$ G. Candolleana. cuneifolia, Spreng. 1. c. = G. cuneifolia.

Erythrochiton, Spreng. 1. c. $780=$ G. pentandra.

Fontanesiana, Spreng. 1. c. = G. Fontanesiana.

heterophylla, Spreng. 1. c. = G. heterophylla.

Lasiostemon, Spreng. l. c. = G. Lasiostemon.

pentagyna, Spreng. 1. c. =G. pentagyna.

resinosa, Spreng, 1, c, $=\mathrm{G}$, resinosa

trifoliata, Willd. in Mém. Acad. Berl. (1802) $35=$ G. Cusparia.

BONTIA, Linn, in Loefl. Iter, 193 (1758)= Avicennia, Linn. (Verbenac).

germinans, Linn. Sp. P1. ed. II. $891=$ A. officinalis.

BONTIA, Linn. Syst. ed.I (1735), MYOPORINEAE, Benth. \& Hook, fii. 1126.

daphnifolia, Salisb. Prod. $109=\mathrm{seq}$

daphnoides, Linn. Sp. Pl. 638.-Ind. occ.

minor, Gaertn. f. Fruct. iii. 169. t. 212. f. $3=$ daphnoides.

BONYUNIA, Schomb. Reise, iii. 1082, nomen Prog. in Mart. Fl. Bras. vi. I. 267. t. 72 (1868) LOGANIACEAE, Benth. \& Hook. f. ii. 796.

antoniaefolia, Prog. in Mart. Fl. Bras. vi. 1. 288.Bras.

superba, Schomb. Reise, iii. 1082.-Guiana.

BOOPHONE, Herb. App. 18 (1821)=Buphane, Herb Amaryll.).

BOOPIS, Juss. in Ann. Mus. Par. ii. (1803) 350. t. 58 CALYCEREAE, Benth. \& Hook. f. ii. 161

ACARPHA, Griseb. in Goett. Abh. vi. (1853-55) 125 Chronophila, Miers, ex Lindl. Veg. Kingd. 701 (1847).

Gamocarpha, DC. Prod, v, 2 (1836)

NASTAnthus, Miers, ex Lindl. Veg, Kingd. 701 (1847), nomen; et in Ann. \& Mag. Nat. Hist. Ser III. vi. $(1860) 185$.

acaulis, Phil. in Anal. Univ. Chil. (1861) 49.-Chili. alpina, Poepp. ex Less. in Linnaea, vi. (1831).258.Chili.

anthemoides, Fuss. in Ann. Mus. Par. ii. (1803) 350. - Keg. Argent.

araucana, Phil. in Anal. Univ. Chil. (1872) 736.Chili.

australis, Decne. Voy. Pôle Sud Bot. ii. 87. t. 18, B.Reg. Magell.

balsamitaefolia, Juss. in Ann. Mus. Par. ii. (1803) 350 $=$ Calycera balsamitaefolia

bellidifolia, Phil. in Anal. Univ. Chil. (1872) 736.Chili.

bupleuroides, C. A. Muell. in Mart. Fl. Bras. vi. iv. 355. - Bras.

\section{BOOPIS :-}

caespitosa, Phil, Fl. Atac. 26.-Chili.

compacta, Phil. in Linnoea, xxviii. (1856) 709. Chili.

crassifolia, A. Gray, in Proc. Am. Acad. v. (1861) 321. -Patagon.

Diazi, Phil. in Linnaea, xxxiii. (1864-65) 106.-Chili.

Gayana, Phil. l. c. xxviii. (1856) 709.-Chili.

gracilis, Phil. 1. c. $707=$ leucanthema

graminea, Phil. l. c-Chili.

laciniata, Ball, in Fourn. Linn. Soc. xxi. (1884) 220. -Patagon.

leucanthema, Poepp. ex Less. in Linnaea, vi. (1831) 259 -Chili.

multicaulis, Phil. in Linnaea, xxviii. (1856) 706.Chili.

pozoneformis, Phil. in Anal. Univ. Chil. (1872) 736. Chili.

pusilla, Phil. in Linnaea, xxxiii. (1864-65) 105. Chili.

rigidula, Miers, in Ann. E Mag. Nat. Hist. Ser. III. vi. (1860) 284,-Patag.

sanjuanina, Hieron. in Bol. Acad. Nac. Cordova, iv. 1881) 31.-Reg. Argent.

scapigera, Remy, in C. Gay, Fl. Chil. iii. 250.Chili.

spathulata, Phil. in Linnaea, xxviii. (1856) 708.Chili.

squarrosa, Miers, in Ann. \& Mag. Nat. Hist. Ser. III. vi. $(1860) 286=$ australis.

tribuloides, Spreng. Syst. iii. $674=$ Acicarpha tribuloides.

BOOTHIA, Dougl. ex Benth, in Trans, Hort. Soc. Ser. II. i. (1835) $405=$ Platystemon, Benth. (Papaverac.).

californica, Dougl. ex Loud. Encyc. PI. Suppl. i. 1214 $=P$. californicus

BOOTIA, Adans. Fam. ii. $320(1763)=$ Borbonia, Linn. (Legumin.).

BOOTIA, Bìgel. Fl. Boston. ed. II. $206(1824)=$ Potentilla, Linn. (Rosac.).

sylvestris, Bigel. 1. $\mathrm{c}_{\mathrm{c}}=\mathrm{P}$. arguta

BOOTIA, Neck. Delic. Gallo-Belg. i. $193(1768)=$ Saponaria, Linn. (Caryophyll.)

glutinosa, Neck. ex Reichb. Ic. F1. Germ. v. $41=\mathrm{S}$. glutinosa.

ocymoides, Neck, ex Reichb. 1. c. $=$ S. ocymoides

Saponaria, Neck, in Act. Acad. Theod. Pal. ii. (1770) $484=\mathrm{S}$, officinalis.

vulgaris, Neck. Delic. Gallo-Belg. i. $193=$ S. officinalis.

BOOTROPHIS, Steud. Nom. ed. II. i. 22 (1840) $=$ BOTROPHIS, Rafin. = Cimicifuga, Linn. (Ranunc.).

BOOTTIA, Ayres, ex Baker, F1. Maurit. $49(1877)=$ Pleurostylia, Wight \& Arn. (Celastrac.). obovata, Ayres, ex Baker, 1, c.= P. leucocarpa

BOOTTIA, Wall. Pl. As. Rar. i. 51. t. 65 (1829). HYDROCHARIDEAE, Benth. \& Hook. f. iii. 453. cordata, Wall. $l$. c.-Burma.

BOPUSIA, Presl, Bot. Bemerl.. $91(1844)=$ Graderia, Benth. (1846) (Scrophul.).

scabra, Presl, 1. c. = G. scabra.

BOQUILA, Decne. in Comptes Rend. (1837) 394 ; et in Arch. Mus. Par. i. (1839) 188. t. 11 B. BERBERIDEAE, Benth. \& Hook. f. i. 42.

discolor, Decne. in Ann. Sc. Nat. Sér. II. xii. (1839) 103.-Chili.

trifoliata, Decne. $l$. c:-Chili.

BORABORA, Steud. Syn. Pl. Cyp. 71 (1855) = Mariscus, Gaertn. (Cyperac.).

cyperoidea, Steud. 1. c. = M. macrophyllus.

BORAEVA, Boiss. in Ann. Sc. Nat. Sér. II. xvii. (1842) $382=$ Boreava, Jaub. \& Spach (Crucif.).
BORAGO, Linn. Sp. Pl. i. 137 (1753). BORA-

GINEAE, Benth. \& Hook, f. ii. 854.

Borrago, Tourn. ex Linn. Syst. ed. I (1735).

Buglossites, Moris, in Enum. Sem. Hort. Taur. (1845).-Cf. Ann. Sc. Nat. Sér. III. v. (1846) 365. advena, Gilib. F1. Lithuan. Suppl. $272=$ officinalis. africana, Linn. Sp. P1. 138= Trichodesma africanum. arabica, Ehrenb. ex Boiss. F1. Orient. iv. $281=$ Trichodesma Ehrenbergii.

aspera, Gilib. Fl. Lithuan. 1. $25=$ officinalis

constantinopolitana, Hill, Veg. Syst. vii. 45.-Oriens cordifolia, Moench, Meth. Suppl. $275=$ orientalis.

crassifolia, Vent. Jard. Cels, 100. t. 100=Caccinis glauca.

cretica, Willd. Sp. Pl. i. $778 \ldots$ Graecia.

gruina, C. Sm. in Tuckey, Congo, 250, nomen.-Ins Cap. Verd.

indica, Blanco, F1. Filip. ed. I. $81=$ Trichodesma zeylanicum.

indica, Linn. Sp. Pl. $137=$ Trichodesma indicum.

inflata, Salisb. Prod. $116=$ orientalis.

laxiflora, Willd. Enum. Hort. Berol. Suppl. 9.Corsica.

longifolia, Poir. Voy. Barb. ii. 119.-Afr. bor.

macranthera, [Soland. in] Russell, Aleppo, ed. II. ii. 246 = Caccinia Russellii.

officinalis, Linn. Sp. Pl. 137.-Europ.; Afr. bor.; As. $\mathrm{Min}$

orientalis, Linn. l. c. 138.-As. Min.; Reg. Caucas spinulosa, Roxb. Hort. Beng. [13]; Fl. Ind. i. $459=$ Trichodesma indicum.

verrucosa, Forsk. F1. Aegypt. Arab. $41=$ Trichodesma africanum

zeylanica, Burm. f. Fl. Ind. $41=$ Trichodesma zeylanicum.

BORAsSUs, Linn. Mus. Cliff. 13 (1736). PALMAE. Benth. \& Hook. f. iii. 939

LonTARUS, Adans. Fam. ii. 25 (1763)

gethiopium, Mart. Hist. Nat. Palm, iii. $221=$ flabellifer caudatum, Lour. F1. Cochinch. $760=$ Wallichia caudata dichotomus, White, in F. Grah. Cat. Bomb. Pl. (1839 226.--Ind, or.

flabellifer, Linn. Sp. Pl. 1187.--Ind. or.

flabelliformis, Murr. Syst. ed. XIII, $827=$ flabellifer.

Gomutus, Lour. Fl. Cochinch, ii. $618=$ Arenga saccharifera.

Ihur, Giseke, Linn. Prael. 87 = Pholidocarpus Ihur. madagascariensis, Boj. Hort. Maurit. 308.-Madag.

pinnatifrons, Jacq. Hort. Schoenb. ii. $65=$ Chamaedorea gracilis.

secundiflorus, Hort. ex H. Wendl. in Kerch. Palm. 235 , nomen.-Hab. ?

Sonnerati, Giseke, Linn. Prael. $86=$ Lodoicea sechellarum.

tunicata, Lour. F1. Cochinch. $618=$ Pholidocarpus tunicatus.

BORBONIA, Linn. Coroll. Gen. 12. n. 971 (1737) LEGUMINOSAE, Benth. \& Hook. f. i. 475 .

Bootia, Adans. Fam. ii. 320 (1763).

alata, Willd, Hort. Berol. i. $48=$ parviflora.

alpestris, Benth. in Hook. Lond. Fourn. Bot. ii. (1843) 461.-Afr, austr.

angustifolia, Lam. Encyc. i. 436.-Afr. austr.

axillaris, Lam. 1. c. $438=$ Amphithalea densa.

barbata, Lam.l.c. 436.-Afr. austr.

Candolleana, Eckl. E Zeyh. Enum. 163.-Afr. austr.

capitata, Poir. Encyc. Suppl. i. $680=$ Priestley capitata.

ciliata, DC. Prod. ii. $120=$ Candolleana

ciliata, Willd. Sp. Pl. iii. 923.-Afr. austr.

complicata, Benth. in Hook. Lond. Fourn. Bot. ii.

1843) 462.-Afr, austr.

cordata, Andr. Bot. Rep. t. $31=$ Rafnia triflora.

cordata, Linn. Sp. Pl. 707.-Afr. austr.

cordifolia, Lam. Encyc. i, $436=$ cordata.

crenata, Linn. Sp.Pl. 708.-Afr. austr.

crenata, Willd. ex Stend. Nom. ed. II. i. $217=$ parviflora.

decipiens, E. Mey. Comm. Pl. Afr. Austr. i. 15= lanceolata.

ericifolia, Linn. P1. Rar. Afr. 14 ; Amoen. Acad. vi. 92 $=$ Amphithalea ericaefolia.

graminifolia, Lam. Encyc. i. $437=$ Priestleya graminifolia.

hirsuta, Poir. Encyc. Suppl. i, 680=Priestleya hirsuta. laevigata, Linn. Mant. $100=$ Priestleya Thunbergii. 


\section{BORBONIA :-}

lanceolata, Linn. Sp, Pl 707.-Afr, austr.

latifolia, Benth. in Hook. Lond. Fourn. Bot. ii. (1843) 462.-Afr. austr.

monosperma, DC. Prod. ii. 120.-Afr. austr.

myrtifolia, Poir. Encyc. Suppl. i. $680=$ Priestleya

myrtifolia.

abcordata, Spreng. Syst. iv. Cur. Post. $267=$ Tephrosia obcordata.

ovata, Andr. Bot. Rep. t. $31=$ Rafnia triflora.

parviflora, Lam. Encyc. i. 437.-Afr. austr.

perfoliata, Lam, l. c. = ciliata.

perfoliata, Thunb. Prod. P1. Cap. $122=$ Rafnia

perfoliata.

perforata, Eckl. E Zeyh. Enum. 163,-Afr. austr.

perforata, Thunb. Prod. Pl. Cap. $122=$ ciliata.

pungens, Mundt, ex Benth. in Hook. Lond. Journ. Bot.

ii. (1843) $46 \mathrm{I}=$ trinervia.

ruscifolia, Sims, Bot. Mag. t. 2128 = parviflora.

sericea, Lam. Encyc. i. 438 = Priestleya sericea.

serrulata, Thunb. Diss, Borbonia, $6=$ parviflora.

sphaerica, Lam. Encyc, i, $437=$ Liparia sphaerica.

sphaerosperma, Spreng. Syst. iv. Cur. Post. 267

Requienia sphaerosperma.

tecta, Poir. Encyc. Suppl. i. $680=$ Priestleya tecta.

teres, Poir. 1. c. $=$ Priestleya teres.

tomentosa, Linn. Sp. Pl, $707=$ Priestleya villosa.

triflora, Anct. ex Steud. Nom. ed. II. i. $217=$ Rafnia triflora.

trinervia, E. Mey. Comm. P1. Afr. Austr, i. $15=$ lanccolata.

trinervia, Linn. Sp. Pl. $707=$ Cliffortia ruscifolia trinervia, Thunb. Prod. Pl. Cap. 122.-Afr. austr. umbellifera, Poir, Encyc. Suppl. i. 680.-Afr. austr. undulata, Thunb. Prod. Pl. Cap. 122.-Afr, austr. vestita, Poir. Encyc. Suppl. i. $680=$ Priestleya vestita villosa, Harv. in Harv. Eै Sond. Fl. Cap. ii. 28.-Afr. austr.

villosa, Thunb. F1, Cap. 560 -Priestleya angustifolia.

BORBONIA, Plum. ex Adans. Fam. ii. 341 (1763) (Laurin.).

carolinensis, J. S. Presl, Rostl. ii。 $57=$ Persea carolinensis.

cupularis, Gaertn. f. Fruct. iii. 225. t. $222(=$ Mespilodaphne cupularis).-Maurit.

exaltata, J. S. Presl, Rostl. ii. 57 -Nectandra exaltata.

foetens, J. S. Presl, 1. c. = Ocotea foetens.

globosa, Gaertn. f. Fruct. iii. 224. t. $222=$ Nectandra sanguinea.

indica, J. S. Presl, Rost1. ii. $57=$ Persea indica

martinicensis, J. S. Presl, 1. c. (=Oreodaphne Facquiniana).-Ind. occ

membranacea, J. S. Presl, 1. c. $=$ Nectandra membranacea.

peruviana, Juss. ex Steud. Nom. ed. II. i. 217 (= Mespilodaphne pretiosa).-Peruv.

JORBOYA; Rafin. Fl. Tellur. iii. $52(1836)=$ Hyacinthus, Tourn. (Liliac.).

spicata, Kafin. l. c. = H. spicatus.

BORCKHAUSENIA, Gaertn. Mey. \& Scherb. Fl. Wett. iii. $4(1801)$ = Corydalis, Vent. (1803) (Papav.). capnoides, Fuss, Fl. Transs, $42=$ C. capnoides.

cava, Gaertn. Mey. \& Scherb. Fl. Wett. iii. $17=$ C. bulbosa

lutea, Gaertn. Mey. \& Scherb. 1. c. $19=$ C. lutea ochroleuca, Fuss, F1. Transs, $42=\mathrm{C}$. ochroleuca. solida, Gaertn. Mey. \& Scherb. Fl. Wett. iii. $18=$ C. Halleri.

BORCKHAUSENIA, Roth, Cntalecta, fasc. ii. $56(1 \varepsilon 00)$ Teedia, Rudolphi (Scrophul.).

ucida, Roth, 1. c. = T. lucida

BORDEREA, Miégev. in Bull. Soc. Bot. Fr. xiii. (1866) $374=$ Dioscorea, Linn.

pyrenaica, Miégev. 1. c. $=$ D. pyrenaica.

BOREA, Zipp. ex Mackl, in Bijdr. Nat. Wet. v. (1830) 142 , nomen (absque descr.)

BoREA, Meissn. Gen. Comm. 221 (1836-42), sphalm. = BOVEA, Decne. = Lindenbergia, Lchm. (Scrophul.).
BOREAVA, Jaub. \& Spach, Illustr. i. 3. t. 2 (1841)

CRUCIFERAE, Benth. \& Hook, f. i. 95.

Martinsia, Godr in Mém. Acad. Stanislas, Sér. III. [xvii.] $1853(1854) 378$

aptera, Boiss. \& Heldr. Diagn. Ser. I. viii. 49.-As Min.

orientalis, Faub. or Spach, Illustr. i. 3.-As. Min. Syria.

BORELLIA, Neck. Elem. i. 275, $276(1790)=$ Cordia Linn. (Boragin.)

aspera, Rafin. Sylva Tellur, $41=$ C. aspera.

BORETTA, Neck. Elem. i. $212(1790)=$ Daboëcia D. Don (Ericac.)

BORISSA, Rafin. ex Stend. Nom. ed. II. i. $217(1840)=$ Lysimachia, Linn. (Primulac.)

Linum-stellatum, Rafin, ex Steud, I. co = L. Linumstellatum.

BORITH, Adans. Fam. ii. $262(1763)=$ Anabasis Linn. (Chenopod.)

BORKHAUSIA, Nutt. Gen. Am. ii. $125(1818)=$ BARK HAUSIA, Moench $=$ Crepis, Linn. (Compos.)

BORONELLA, Baill. Adansonia, x. (1872) 302 RUTACEAE

Pancheri, Baill. l. c. 303.-N. Caled.

BORONIA, Sm. Tracts, 288 (1798) ; et in Trans. Linn. Soc. viii. (1807) 285. t. 5-7. RUTACEAE, Benth. \& Hook. f. i. 291.

Cyanothamnus, Lindl Swan River Bot. 18 (1839). affinis, R. Br. ex Benth. Fl. Austral. i. 311.-Austral. alata, Sm. in Trans. Linn. Soc. viii. (1807) 283.Austral.

albiflora, R. Br. ex Benth. Fl. Austral. i. 317.Austral.

algida, F. Muell. in Trans. Phil. Soc. Vict. i. (1855 100.-Austral.

alulata, Soland. ex Benth. Fl. Austral. i. 313.Austral.

anemonifolia, A.Cunn. in Field, New South Wales, 330.-Austral.

anemonifolia, Paxt. Mag. Bot. ix, $123=$ Fraseri

anethifolia, A. Cunn. ex Endl. in Enum. Pl. Hueg. 10 = anemonifolia.

arborescens, F. Muell. Fragm. i. $100=$ Zieria Smithii.

artemisiaefolia, $F$. Muell. l. c. 66.-Austral.

artemisioides, F. Muell, in Hook. Kew Journ. ix. (1857) $196=$ praec

baeckeacea, F. Muell. Fragm. iv. 28.-Austral.

Barkeriana, F. Muell. l. c. xi. 96.-Austral.

bicolor, Turcz. in Bull. Soc. Nat. Mosc. xxv. (1852) II $163=$ tetrandra.

bipinnata, Lindl. in Mitch. Journ. Trop. Austr. $225=$ anemonifolia.

Bowmani, F. Muell. Fragm. iv. 135.-Austral

brachyphylla, F. Muell. 1. c. i. $99=$ oxyantha.

Busselliana, F. Muell. l.c. ix. 113.-Austral.

caerulescens, F. Muell. in Trans. Phil. Soc. Vict. i

(1855) 11.-Austral.

calophylla, Turcz in Bull. Soc. Nat. Mose. xxv. (1852) II. 160 - Austral

Candollii, G. Don, Gen. Syst. i. $793=$ alata.

capitata, Benth. Fl. Austral. i. 323.-Austral

chironiifolia, Bartl. in Lehm. PI. Preiss, i. $167=$ denticulata.

citriodora, Gunn, ex Hook. fo Fl. Tasm. i. $68=$ pinnata.

clavellifolia, F. Muell. in Trans. Phil. Soc. Vict. (1855) $12=$ inomata.

colorata, Lehm. Pl. Preiss。 ii. $226=$ viminea

crassifolia, Bartl. in Lehm. L. c. i. 169.-Austm.

crassipes, Bartl. l. c. 168.-Austral.

crenulata, Sm, in Trans, Linn. Soc, viii. (1807) 284.Austral.

cymosa, Endl. in Enum. Pl. Hueg. 16.-Austral,

defoliata, F. Muell. Fragm. ix. 118.-Austral.

denticulata, Sm. in Trans. Linn. Soc. viii. (1807) 284 -Austral.

dentigera, F. Muell. in Trans. Inst. Vict. i. (1855) $\$ 2$ = ancmonifolia.

dichotoma, Lind1. Bot. Reg. (1841) sub t. $47=$ spathu lata.

\section{BORONIA}

Orummondiz Planch in Fl des Serres, Sér. I. ix. 1853-54) 65. t. $881=$ pulchella.

Edwardsii, Benth. Fl. Austral. i. 312-Austral. elatior, Bartl. in Lehm. Pl. Preiss. 1. 170.-Austral. eriantha, Lindl. in Mitch. Fourn. Trop. Austr. 298. Austral.

ericifolia, Benth. Fl. Austral. i. 313.-Austral.

falcifolia, A. Cunn. in Lindl. Bot. Reg. (1841) sub t. 47.-Austral.

fasciculifolia, F. Muell. Fragm. i. $99=$ thymifolia

fastigiata, Bartl. in Lehm. Pl. Preiss. 1. 168.-Austral.

filicifolia, A. Cunn. ex Benth. Fl. Austral. i. 311.Austral.

filifolia, F. Muell. Fragm. i. 3.-Austral.

flexuosa, Bartl. in Lehm. Pl. Prciss, i. 166=spathulata.

floribunda, Sieber, ex Spreng. Syst. iv. Cur. Post. 14 pinnata.

Fraseri, Hook. Bot. Mag. t. 4052.-Austral.

gracilipes, F. Muell. Fragm. ii. 99.-Austral

grandisepala, $F$. Muell.l.c. i. 66--Austral.

granulata, F. Muell. 1. c. $101=$ Zieria granulata.

Gunnii, Hook. f. Fl. Tasm. i. $68 . t, 10=$ pinnata.

heterophylla, F. Mucell. Fragm. ii. 98.-Austral.

hirsuta, F. Muell. 1. c. i. 101=Zieria pilosa.

humilis, Turcz, in Bull. Soc. Nat. Mosc. 2xv. (185z)

11. $160=$ crassifolia

hypericifolia, Regel, Gartenfl. (1857) $152=$ fastigiata.

hyssopifolia, Sieber, in Spreng. Syst. iv. Car. Post. 14 polygalifolia.

inconspicua, Benth. Fl. Austral. i. 313.-Austral.

inornata, Turcz. in Bull. Soc. Nat. Musc. xxy. (185i

I1. 164.-Austral.

juncea, Bartl. in Lehm. Pl. Preiss, i. 166-Austral.

laevigata, F. Muell, Fragm. i. 101 - Zieria lacvigata.

lanceolata, $F$. Muell. l. c. 66.-Austral

laniflora, Bartl. in Lehm. PI. Preiss, i. $165=$ juncea.

lanuginosa, Endl. in Enum. Pl. Hueg. 16.-Austral.

ledifolia, F. Gay, in Mém. Mus. Par. vii. (1ל21, 450

in nota. - Austral.

ledophylla, F. Muell. Fragm, i. $67=$ ledifolia.

lepidota, Turcz. in Bull. Soc. Nat. Mosc. xxxvi. (186: I. 596.-Austral.

leptophylla, Turcz. 1. c. xxv. (1852) II. 164=inornats.

Machardiana, F. Muell. Fragm. ix. 115.-Austral.

macra, Bartl, in Lehm, Pl. Preiss, i. 16 = =spathulata

megastigma, Nees, ex Bartl, in Lehm. Pl. Preiss. 227.-Austral.

microphylla, Sieber, ex Spreng. Syst. iv. Cur. Post. 148.-Austral,

minutiflora, F. Muell. Fragm. i. $100=$ Zieria obcordats mollis, A. Cunn. in Lindl. Bot. Reg. (1841) sub t. 47 . -Austral.

multicaulis, Turcz. in Bull. Soc. Nat. Mosc. xxy. (18j2 II. $161=$ crassifolia ?

nana, Hook. Ic. Pl. t. $270=$ polygalifolia

nematophylla, F. Muell. Fragm。 ii. 100,-Austral.

ovata, Lindl. Bot. Reg. (1811) sub t. 47-Austral.

oxyantha, Turcz. in Bull. Soc. Nat. Mosc. rxv. (185:

II. 165 - Austral.

paleifolia, A. Cunn. in Enum. Pl. Hueg. $16=$ falcifolia

paradoxa, DC. Prod, i. $722=$ ledifolia.

parviflora, Sm. Tracts, 295. t. 6. -Austral.

penicillata, Benth. Fl. Austral. i. 32.2-Austm.

pilonema, Labill. Nor. Holl. Pl. i. $98,1.26^{\circ}=$ parvillora.

pilosa, Labill. l. c. 97. t. 124.-Austral.

pionata, Sm. Tracts, 290.-Austral.

platyrrhachis, F. Muell. Fragm. vii. 3\%.-Austral.

polygalifolia, Sm. Tracts, 297. t. 7.-Austral.

psoraleoides, DC. Prod. i. $721=$ elatior.

pteropoda, Turcz. in Bull. Soc. Naf. Mosc. rxmi.

(1863) I, 595.-Austral.

pubescens, Bartl. in Lehm. Pl. Preiss, ii. $227=$ lanuginosa

pulchella, Turcs. in Bull. Soc. Nas. Mose. xurv. 1:5: II. 162.-Austral.

ramosa, Benth. F\%. Austral. i. 320.-Austral.

rhomboiden, Hook, If. Pl, T.2.? - Austral.

Kinzii, Hueg. ex Heynh. Nom. ii. is, nomen. Austral.

rosmarinifolia, A. Cunn. ex Endl. in Enum. PL. Hue. $16=$ ledifulia,

rubiginosa, A. Cunn. ex Endl. 1. c. - ledifolin.

salicifolia, A. Curn, ex Hernh, dirm, ii, 7 s, nomen.-

Austral.

scabra, Lindl. Swan Rirer Afp. 76.-Austral.

semifertilis, F. Muell. liragm. i. 98 - elatior.

scrrulata, Sm. Tracts, 20.0. 8. 5.- Auseral 


\section{BORONIA :-}

spathulata, Lindl. Swan River App. 73.-Austral. spinescens, Benth. Fl. Austral. i. 319. -Austral. stricta, Bartl. in Lehm. Pl. Preiss. i. $169=$ lanuginosa. subcaerulea, F. Muell. Fragm. ii. $100=$ ramosa. subsessilis, Benth. Fl. Austral. i. 322.-Austral. tenuifolia, Bartl. in Lehm, Pl. Preiss. i. $168=$ viminea. tennis, Benth. Fl. Austral. i. 220.-Austral. teretifolia, Lindl. Swan River App, $75=$ cymosa. ternata, Endl. Nov. Stirp. Dec. 6.-Austral. tetrandra, Hook. Joum. Bot. ii. (1840) $419=$ pinnata. tetrandra, Labill. Nov. Holl. Pl. i. 98. t. 125.-Austral. tetrandra, Lindl. \& Paxt. Flow. Gard. i. $(1850-51) 35$. t. $8=$ pulchella.

tetrathecoides, DC. Prod. i. $723=$ polygalifolia.

thymifolia, Turcz. in Bull. Soc. Nat. Mosc. xxv. (1852) II. 165.-Austral.

triphylla, Sieber, ex Spreng. Syst. iv. Cur. Post. 148 $=$ ledifolia.

tristis, Turcz. in Bull. Soc. Nat. Mosc. xxv. (1852) II. $162=$ megastigma.

variabilis, Hook. Journ. Bot. i. (1834) $255=$ anemoni folia.

veronicea, F. Muell. in Trans. Phil. Soc. Vict. i. (1855) $11=$ Zieria veronicea

viminea, Lindl. Swan River App. 74.-Austral.

BORRAGINOIDES, Moench, Meth. $515(1794)=$ Trichodesma, R. Br. (Boragin.).

aculeata, Moench, 1. c. $516=$ T, africanum.

sagittata, Moench, 1. c. $=\mathrm{T}$. indicum.

BORRAGO, Tourn. ex Linn. Syst. ed. I $(1735)=$ Borago, Linn.

BORRERA, Spreng. Gen. i. $93(1830)=$ BORRERIA, G. F. W. Mey. = Spermacoce, Linn. (Rubiac.).

BORRERIA, G. F. W. Mey. Prim. Fl. Esseq. 79. t. 1 (1818) = Spermacoce, Linn. (Rubiac.).

adscendens, Cham. \& Schlecht. in Linnaea, iii. (1828) $340=\mathrm{S}$, adscendens.

advena, Fisch. \& Mey. Ind. Sem. Hort. Petrop. vi. 46 $=$ Diodia verticillata?

affinis, DC. Prod. iv. $546=\mathrm{S}$. diffusa.

alata, DC. 1. c. $544=\mathrm{S}$. alata.

alternans, Bello, in Anal. Soc. Esp. Hist. Nat. x. (1881) 283.-Porto Rico.

angustifolia, Cham. \& Schlecht. in Linnaea, iii. (1828) $330 .-$ Bras.

anthospermoides, DC. Prod. iv. 550.-Am. austr, aralioides, Cham. \& Schlecht. in Linnaea, iii. (1828) $339=$ umbellata?

aretioides, Griseb. Cat. Pl. Cub. 286.-Cuba. argentea, Cham. in Linnaea, ix. (1834) 215.-Bras. arida, DC. Prod. iv. 549.-Porto-Rico.

asclepiadea, Cham. \& Schlecht. in Linnaea, iii. (1828) $320=\mathrm{S}$. Poaya

aspera, Mart. \& Gal, in Bull. Acad. Brux. xi. I. (1844) $130=\mathrm{S}$, aspera.

asperula, DC. Prod. iv. $543=$ Diodia rigida ?

assurgens, Griseb. in Goett. Abh. xxiv. (1879) $156=$ Diodia dasycephala.

aturensis, Cham. \& Schlecht. in Linnaea, iii. (1828) $345=$ S. aturensis

Bartlingiana, DC. Prod. iv. $544=$ S. latifolia.

basalis, Anderss. Om Galap.-Oarnes Vegetat. 191.Ins. Galapag.

brachystemonoides, Cham. \& Schlecht. in Linnaea, iii. (1828) 314.-Bras.

capitata, DC. Prod. iv. $545=\mathrm{S}$, capitata.

capitellata, Cham. \& Schlecht. in Linnaea, iii. (1828) $319=\mathrm{S}$. laevis.

centranthoides, Cham. \& Schlecht. 1. c. 327.-Bras.

commutata, Spreng. Syst, i. $404=\mathrm{S}$, verticillata.

coriacea, Scheele, in Linnaea, xvii. (1843) $339=\mathrm{S}$. tenella.

cornifolia, DC. Prod. iv. $545=$ S. capitata.

corymbosa, DC. 1. c. $550=\mathrm{S}$. corymbosa

crassifolia, C. A. Mey. ex Heynh. Nom. ii. 74, nomen. -Am. austr.

cupularis, DC. Prod. iv, $543=$ S. pusilla.

cymosa, Cham. \& Schlecht. in Linnaea, iii. (1828) 323 $=\mathrm{S}$. cymosa.

densiflora, DC. Prod. iv. 542 =S. longifolia, L'Herit. dichatoma, Cham, \& Schlecht. in Linnaea, iii. (1828)

$340=$ Diodia glabra.

diffusa, DC. Prod. iv. $545=$ S. diffusa.
BORRERIA :-

discolor, Benth. in Hook. Kew Journ. iv. (1852) $199=$ Spermacoce semierecta

discolor, DC. Prod. iv. 545. - Ins. Philipp

dispersa, Hook. f. in Trans. Linn. Soc. xx. (1859) 217. -Ins. Galapag.

distans, Cham. \& Schlecht. in Linnaea, iii. (1828) 340 $=\mathrm{S}$. distans.

divaricata, Hook, f, in Trans. Linn. Soc, xx. (1859) 219. - Ins. Galapag

domingensis, Griseb. Cat. Pl. Cub. $141=$ S. ocymoides.

dubia, Cham. in Linnaea, ix. (1834) $216=$ valerianoides.

elongata, DC. Prod. iv. $547=$ S. capitata.

equisetoides, Cham. \& Schlecht. in Linnaea, iii. (1828) 338.-Bras.

ericaefolia, Hook. f. in Trans. Linn. Soc. xx. (1859) 218.-Ins. Galapag.

ericoides, Cham. \& Schlecht, in Linnaea, iii. (1828) 326

$$
=\mathrm{S} \text {. corymbosa. }
$$

eritrichoides, Griseb. Cat. Pl. Cub. 142.-Cuba

eryngioides, Cham. \& Schlecht. in Linnaea, iii. (1828) $316=\mathrm{S}$. diffusa.

eupatorioides, Cham. \& Schlecht. 1. c. 327.-Bras.

falcifolia, Hook, f. in Trans. Linn. Soc. xx. (1859) 219 , -Ins. Galapag

ferruginea, DC. Prod. iv. $547=$ S. capitata.

ferruginea, Mart. \& Gal. in Bull. Acad. Brux. Sér. I. xi. I. (1844) $128=$ Mitracarpum villosum.

flavescens, DC. Prod. iv. $548=\mathrm{S}$. Poaya.

Fockeana, Miq. in Linnaea, xviii. (1844) $299=\mathrm{S}$. latifolia.

globularioides, Cham. \& Schlecht. in Linnaea, iii. (1828) $312=\mathrm{S}$. verticillata.

gracitis, Miq. ex Hook. f. Fl. Brit. Ind. iii. $200=\mathrm{S}$. stricta.

gracilis, Scheele, in Linnaea, xvii. (1843) $340=\mathrm{S}$. tenella.

gracillima, DC. Prod. iv. $543=$ S. gracillima

graminifolia, Mart. \& Gal. in Bull. Acad. Brux. xi. I. $(1844) 129=\mathrm{S}$. verticillata.

gymnocephala, DC. Prod. iv. 549.-Bras.

Haenkeana, DC. 1. c. $547=\mathrm{S}$. tenella.

hebecarpa, Hochst. ex A. Rich. Tent. FI. Abyss. i. $347=$ S. stricta

humifusa, Mart. in Flora, xxiv. (1841) Beibl. II. 68.Bras.

Kleinii, Walp. Rep. ii. $464=$ S. stricta.

kohautiana, Cham. \& Schlecht. in Linnaea, iii. (1828) $311=\mathrm{S}$. verticillata

laevigata, Mart. \& Gal in Bull. Acad. Brux xi. I (1844) $130=\mathrm{S}$. laevigata

laevis, Griseb. in Goett. Abh. vii. (1857) $231=$ S. laevis. lasiocarpa, Walp. Rep. ii. $464=\mathrm{S}$. stricta

laxa, Cham. \& Schlecht. in Linnaea, iii. (1828) 337 Bras.

linearifolia, Hook. f. in Trans. Linn. Soc. xx. (1859) 217.-Ins. Galapag.

linifolia, DC. Prod. iv. 551=S. laevis.

linoides, DC. 1 . c. $548=\mathrm{S}$. tenella.

longiseta, Mart. \& Gal, in Bull. Acad. Brux. xi. I. (1844) $128=\mathrm{S}$. longiseta

lutescens, DC. Prod. iv. $547=\mathrm{S}$. tenella.

micrantha, Torr. \& Gray, Fl. N. Am. ii. $28=\mathrm{S}$, ocymoides.

microphylla, DC. Prod. iv. $546=$ S. ocymoides.

minima, DC. 1. c. $542=\mathrm{S}$. verticillata.

Neesiana, DC. 1. c. $542=$ S. Neesiana

neglecta, A. Rich. Tent. Fl. Abyss. i. 177.-Abyssin nervosa, DC. Prod. iv. 548=S. Poaya

oaxacana, Mart. \& Gal. in Bull. Acad. Brux. xi I. (1844) $130=\mathrm{S}$. verticillata.

ocymoides, DC. Prod. iv. $544=$ S. ocymoides.

organensis, Gardn. in Hook. Lond. Journ. Bot. iv.

(1845) 111,-Bras

ovalifolia, Mart. \& Gal. in Bull. Acad. Brux. xi. I. $(1844) 129=\mathrm{S}$. ocymoides.

ovalis, Anderss. Om Galap.-Oarnes Vegetat. 192.Ins. Galapag.

parviflora, G. F. W. Mey. Prim. Fl. Esseq. 83. t. $1=$ S. ocymoides.

parvifolia, Hook. f. in Trans. Linn. Soc. xx. (1859) 218.-Ins. Galapag.

patula, Mart. \& Gal. in Bull. Acad. Brux. xi. I. (1844)

$128=\mathrm{S}$. parviflora.

penicillata, Miq. in Verh. Nat. Wet. Haarl. vii. (1851) $176=$ S. latifolia.
BORRERIA :-

perpusilla, Hook, f. in Trans. Linn. Soc. xx. (1859) 218.-Ins. Galapag.

Perrottetii, DC. Prod. iv. $548=$ Spermacoce latifolia. platyphylla, DC. 1. c. $549=$ S. Poaya.

Poaya, DC. l. c. = S. Poxya,

podocephala, DC. 1. c. $542=$ S. verticillata.

Pohliana, DC. 1. c. $550=$ eupatorioides.

pratensis, DC. I. c. $548=\mathrm{S}$. Poaya

procera, Cham. in Linnaea, ix. (1834) $593=\mathrm{S}$. tenella prostrata, Mig. in Verh. Nat. Wet. Haarl. vii. (1851) $177=$ S. ocymoides.

psyllioides, DC. Prod. iv. $548=\mathrm{S}$. tenella. pterophora, Presl, Bot. Bemerk. 86.-Bras.

pumila, DC. Prod. iv. 543=S. pumila.

pusilla, DC. 1. c. $=\mathrm{S}$. stricta.

radiata, DC. 1. c. $542=\mathrm{S}$. radiata.

radicans, Griseb. Cat. Pl. Cub. $142=$ Nodocarpaea radicans.

ramisparsa, DC. Prod. iv, $544=\mathrm{S}$. ocymoides.

remotifolia, DC. $1 . \mathrm{c} .=$ Mitracarpum villosum

repens, DC. 1. c. $542=\mathrm{S}$. ocymoides.

Roxburghiana, Walp. Rep. ii. $264=$ S. stricta.

rubrostipulata, DC. Prod. iv. $546=\mathrm{S}$. tenella.

saponariaefolia, Cham. \& Schlecht. in Linnaea, iii. (1828) 325.-Bras.

saturejaefolia, Cham. \& Schlecht. 1. c. $313=\mathrm{S}$. tenella.

scabiosoides, Cham. \& Schlecht. 1. c. 318.-Bras.

scabrida, DC. Prod. iv. $548=\mathrm{S}$. latifolia.

scandens, DC. 1. c. $546=\mathrm{S}$. scandens.

setosa, Mart. \& Gal. in Bull. Acad. Brux. xi. I. (1844)

$131=\mathrm{S}$. setosa.

Sideritis, Cham. \& Schlecht. in Linnaea, iii. (1828)

$201=\mathrm{S}$. latifolia

simplex, Griseb. Fl. Brit. W. Ind. 350.-Jamaica.

sphaerica, DC. Prod. iv. $547=$ S. laevis.

spinosa, Cham. \& Schlecht. in Linnaea, iii. (1828) 340 $=\mathrm{S}$. spinosa.

squamosa, Griseb. Cat. P1. Cub. 142.-Cuba

stricta, G. F. W. Mey. Prim. F1. Esseq. 83. t. 1. f

$1-3=\mathrm{S}$. verticillata

strictissima, DC. Prod. iv. $547=$ S. tenella

strumpfioides, Griseb. Cat. PI. Cub. 142 -Cuba.

suaveolens, G. F. W. Mey. Prim. Fl. Esseq. 81. t.

$\mathbf{1}=\mathrm{S}$. tenella.

suberecta, Hook. f. in Trans. Linn. Soc. xx. (1859) 217.

-Ins. Galapag.

subulata, DC. Prod. iv. $543=$ Crusea subulata.

tampicana, DC. 1. c. 544 , pro parte $=\mathrm{S}$. laevis

tenella, Cham. \& Schlecht. in Linnaea, iii. (1828) 317 $=\mathrm{S}$. tenella.

tenera, DC. Prod, iv, $543=\mathrm{S}$, tenera

tenuis, DC. 1. C. $=\mathrm{S}$. tenuis.

tenuissima, Schweinf. ex Hiern, in Oliver, Fl. Trop

Afr. iii. $234=\mathrm{S}$. tenuissima.

tetracocca, Thw. Enum. Pl. Zeyl. $442=$ Fergusonia zeylanica.

tetraptera, Miq. in Linnaea, xvii. (1843) $70=\mathrm{S}$. latifolia.

thymifolia, Griseb. F1. Brit. W. Ind. 350.--Ind. occ.

thymocephala, Griseb. Cat. P1. Cub. $142=\mathrm{S}$. verticillata.

trichantha, Miq. in Verh. Nat. Wet. Haarl. vii. (1851) 178.-Guiana.

umbellata, Spreng. Neue Entdeck. ii. 144.-Bras.

vaginata, Cham. \& Schlecht. in Linnaea, iii. (1828) $340=\mathrm{S}$. laevis.

valerianoides, Cham. \& Schlecht. 1. c. 335.-Bras,

verbenoides, Cham. \& Schlecht. 1. c. 331 ; iv. (1829)

550.-Bras.

verticillata, G. F. W. Mey. Prim. Fl. Esseq. $83=$ S. verticillata.

virgata, Cham. \& Schlecht. in Linnaea, iii. (1828) 324 $=\mathrm{S}$. virgata

Wydleriana, DC. Prod. iv. 545.--Porto Rico.

BORRICHIA, Adans. Fam. ii. 130 (1763). COM. POSITAE, Benth. \& Hook. f. ii. 368.

Adelmannia, Reichb. Consp. 110 (1828).

Diomedea, Cass. in Bull. Soc. Philom. (1815) 175

Helicta, Cass. 1. c. (1818) 167.

Trimetra, Moç. ex DC. Prod. vii. 262 (1838).

arborescens, DC. Prod. v. 489.-Am. trop.

argentea, $D C$. l. c.-Am. trop.

demissa, $D C . l . c .-\mathrm{N}$. Granat.

frutescens, $D C$. l. c.-Am. bor.

peruviana, $D C$. l. $c$.-Peruv. 
BORSCZOWIA, Bunge, in Act. Hort. Petrop. v (1877) 643. CHENOPODIACEAE, Benth. \& Hook. f. iii. 68 .

aralo-caspica, Bunge, l.c.-Reg. Casp.

BORSZCZOWIA, Bunge, in Act. Hort. Petrop. vi. (1879) $424=$ praec.

BORYA, Labill. Nov. Holl. Pl. i. 81. t. 107 (1804) LILIACEAE, Benth. \& Hook. f. iii. 797.

Baumgartenia. Spreng. Syst. ii. 91 (1825).

Daviesia, Poir, Encye, Suppl.v. 480 (1817).

Cataractae, Endl. in Lehm. PI. Preiss. ii. $43=$ nitida.

gracilis, Endl. 1. c. $=$ nitida

lucens, Poir. Encyc. viii. $615=$ nitida.

nitens, Stend. Nom, ed. II. i. $192=$ seq.

nitida, Labill. Now. Holl. Hi. i. 81. t. 107.-Austral.

scirpoidea, Lindl. Swan River App. 57. t. $9=$ nitida.

septentrionalis, F. Muell. Fragm. v. 41.-Austral.

sphaerocephala, R. Br. Prod. $286=$ nitida.

sublanosa, F. Muell. ex Benth. Fl. Austral. vii. $71=$ nitida.

BORYA, Willd. Sp. Pl. iv. $711(1805)=$ Forestiera, Poir. (Oleac.).

acuminata, Willd. 1. $\mathrm{c}_{\mathrm{s}}=\mathrm{F}$. acuminata.

cassinoides, Willd. $1 . \mathrm{c}_{\mathrm{n}}=\mathrm{F}$. cassinoides

distichophylla, Nutt. Gen. Am. ii. $232=$ Buckleya distichophylla.

ligustrina, Willd. 1. c. = F. ligustrina.

nitida, Willd. Enum. Hort. Berol. Suppl. [66] nomen $=\mathrm{F}$. acuminata.

obovata, Desf. Cat. Hort. Par. ed. III. $88=$ F. prinoides. porulosa, Willd. Sp. Pl. iv. $711=$ F. porulosa.

prinoides, Willd. Lnum. Hort. Berol. Suppl. [66]; ex Spreng. Syst. iii. $900=$ F. prinoides.

retusa, Willd. 1 . c. $\lfloor 66]=\mathrm{F}$. retusa.

BOSCA, Vell. Fl. Flum. 150. (1825); iv, t. $11=$ Funi fera, Leandr.? (Thymel.).

stupacea, Vell. 1l. cc.-Bras.

BOSCHERIA, Carr. in Rev. Hortic. (1872) 199= BOSSCHERIA, De Vriese \& Teijsm. = Fieus, Tourn. (Urtic.).

BOSCEIA, Korth. Verh. Nat. Gesch. Bot. 257. t. 69 (1842). MALVACEAE, Benth. \& Hook. f. i. 213. Heteropyxis, Griff. Notul. iv. 524, t. 594 (1854). acutifolia, Mast. in Fourn. Linn. Soc. xiv. (1875) 503. -Borneo.

excelsa, Korth. Verh. Nat. Gesch. Bot. 258. t. 69.Sumatra.

grandiflora, Mast. in Fourn. Linn. Soc. xiv. (1875) 502.-Borneo

Griffithii, Mast. l. c. 508.-Malaya.

BOSCHNIAKIA, C. A. Mey.(Bong. Veg. Sitka, 41) in Mém. Acad. Pétersb. Sér. VI. ii. (1833). 157 OROBANCHACEAE, Benth. \& Hook. f. ii. 985. Stellara, Fisch. \& Reut. in DC. Prod. xi. 89 (1847). glabra, C. A. Mey. ex Bong. in Mém. Acad. Pétersb. Sér. VI. ii. (1893) 157.-Sibir : Japon. Am. bor.

himalaica, Hook. f. $\mathrm{g}^{\circ}$ Thoms. in Fl. Brit. Ind. iv. 327. -Reg. Himal.

Hookeri, Walp. Rep. iii. 479.-Am. bor. occ.

strobilacea, A. Gray, in Pacif. Rail. Rep. iv. 118.Calif.

BOSCIA, Lam. Illustr. t. 395 (1804?). CAPPARI. $D E A E$, Benth. \& Hook. f. i. 108.

PODORIA, Pers, Syn, ii. 5 (1807)

angustifolia, Harv. in Harv. \& Sond. Fl. Cap. i. Add. $19=$ Niebuhria angustifolia.

angustifolia, A. Rich. in Guill. E Perr. Tent. Fl. Seneg. i. 26.-Afr. trop.

caffra, Sond. in Linnaea, xxiii. (1850) 8.-Afr austr.

firma, Radlk. in Sitsb. Math.-Phys. Acad. Muench. xiv. [1884] 62 , in nota.-Afr. trop.

integrifolia, Brunn. in Flora, xxiii. (1840) Ir. Beibl. 32 = angustifolia.

intermedia, Hochst. ex A. Rich. Tent. Fl. Abyss. $i$. $27=$ angustifolia.

microphylla, Oliver, Fl. Trop. Afr. i. 93.-Afr. austr.

mossambicensis, Klotssch, in Peters, Reise Mossamb. Bot. 164.-Afr. trop.

\section{BOSCIA:-}

octandra, Fenzl, ex Radlk. in Sitzb. Math.-Phys. Acad. Muench. xiv, [1884] $62=$ firma.

octandra, Hochst, ex Radlk. l. c.-Afr. trop.

reticulata, Hochst. ex A. Rich. Tent. Fl. Abyss. i. 28. -Abyss.

salicifolia, Oliver, Fl. Trop. Afr. i. 93.-Afr. trop. senegalensis, Hochst. ex Walp. Ann. iii. $824=$ angustifolia.

senegalensis, Lam.Illustr.t. 395.-Afr. trop.

urens, Welw. in Oliver, Fl. Trop. Afr. i. 93.-Afr. trop.

BOSCIA, Thunb. Prod. Pt. Cap. $32(1794)=$ Toddalia, Juss. (Rutac.).

undulata, Thunb. 1, c. = T, lanceolata.

BOSEA, Linn, Coroll. 5 (1737) ; Bosia, Hort. Cliff. 84 (1737).] AMARANTACEAE, Benth. \& Hook. f. iii. 26.

Ronetia, Moq. in DC. Prod. xiii. 11. 323 (1849)

Amherstiana, Hook. f. Fl. Brit. Ind. iv. 716.-Keg Himal.

cannabina, Lour. Fl. Cochinch i. 176-Cochinch.

cypria Boiss. ex Hook. f. Fl. Brit. Ind. iv, 716, in nota -Cyprus.

humilis, Salisb. Prod. $154=\mathrm{B}$. Yervamora

trinervia, Roxb. Hort. Beng. 86 ; Fl. Ind. ii. $87=$

Celtis Wightii.

Yervamora, Linn. Sp. Pl. 225.-Ins. Canar.

BOSIsTOA, F. Muell. ex Benth. F1. Austral. i. 359 (1863). RUTACEAE, Benth. \& Hook, f. i. 990. euodiformis, F. Muell. Fragm. ix. 174.-Austral. pentacocca, Baill. Hist. Pl. iv. $470=$ sapindiformis. sapindiformis, F. Muell. ex Benth. Fl. Austral. i. 359 -Austral.

BOSQUIEA, Thou' ex Baill. Adansonia, iii. (1862-63) 338. t. 10. URTICACEAE, Benth. \& Hook. f. iii. 370 . Boiviuiana, Cord. ex Baill. l. c. iii. (1862-63) 340 . - Madlag.

gymnandra, Baker, Fl. Maurit. 283.-Ins. Mascar.

Phoberos, Baill. Adansonia, viii. (1867) 72,-Afr. trop.

Thouarsiana, Cord. ex Baill. l. co iii. (1862-63) 339.Madag.

BOSSCHERIA, De Vriese \& Teijsm, in Tijdschr. Nederl. Ind. xxiii. (1861) $213=$ Ficus, Tourn. (Urtic.).

Minahassae, De Vriese \& Teijsm. 1.c. $214=$ F. Minahassae.

BOSSIAEA, Vent. Jard. Cels, i. 7.t. 7 (1800). LEGU. MINOSAE, Benth. \& Hook. f. i. 473.

LALAGE, LindI. Bot. Reg. t. $1722(1834$

ScotteA, R. Br. in Ait. Hort. Kew.. ed..II. iv. 269 (1812).

aculeata, F. Muell. Fragm. ii. 120.-Austral.

Aquifolium, Benth. Fl. Austral. ii. 157.-Austral,

Armitii, F. Muell. Fragm, ix. 44-Austral

biloba, Benth. in Enum. Pl. Huseg. 36.-Austral.

bracteosa, F. Muell. ex Benth. Fl. Austral. ii. 166.Austral.

Brownei, Benth. l. c. 163.-Austral.

buxifolia, A. Cunn. in Field, N. S. Wales, 348.Austral.

calycina, Benth. Fl. Austral. ii. 159.-Austral.

carinalis, Benth. in Mitch. Fourn. Trop. Austr. 290. -Austral.

cinerea, R. Br. in Ait. Hort. Kew. ed. II. iv, 266.Austral.

coccinea, Bonpl. Jard. Malm. 128.t. $52=$ cinerea.

concinna, Benth. Fl. Austral. ii. 16L-Austral.

cordifolia, Sweet, F1. Austral.t. $20=$ cinerea.

cordigera, Benth. ex Hook. f. Fl. Tasm. i. 95. t. 15. Austral.

decumbens, F. Muell. Fragm. i. $9=$ buxifolia.

dentata, Benth. Fl. Austral ii, 156-Austral.

disticha, Lindl. Bot. Reg. (1841) Misc. 3S.-Austral.

distichoclada, F. Muell. in Trans. Phil. Soc. Vict. i. (1১55) $39=$ foliosa.

divaricata, Turcs. in Bull. Soc. Nat. Mosc. xxvi.

(1853) I. 285.-Austral.

egena, F. Muell. in Hook. Kew Gourn. viii. (1856) 43. -Austral.

Endlicheri, Meissn. in Lehn. Pl. Preiss. i. 83.Austral.

ensata, Hook. f. Fl. Tasman, i. $94=$ riparia.

\section{BOSSTAEA}

ensata, Meissn. in Lehm. P1. Preiss, i. $81=$ rufa. ensata, Sieber, ex DC. Prod. ii. 117-Austral. eriocarpa, Benth. in Enum. Pl. Hueg. 36.-Austral. foliosa, A. Cunn. in Field, N. S. Wales, 347.Austral.

Gilbertii, Turcz. in Bull. Soc. Nat. Mosc. xxvi. (1853) I. $286=$ eriocarpa.

Hendersoni, Hort. ex Regel, Gartenfl. (1866) 322. -Austral.

heterophylla, Vent. Fard. Cels, t. 7.-Austral.

humilis, Meissn. in Lehm. Pl. Pieiss. i. $85 \approx$ prostrata.

kiamensis, Benth. Fl. Austral. ii. 158.-Austral.

lalagoides, F. Muell. Fragm. iv..12=divaricata.

lanceolata, Sims, Bot. Mag. t. $1144=$ heterophylla.

lenticularis, Lodd. Bot. Cab. t. 1238 = rhombifolia

lenticularis, Sieber, ex DC. Prod. ii. 117.-Austral.

linnaeoides, G. Don, Gien. Syst. ii. $129=$ prostrata

linophylla, R. Br. in Ait. Hort. Kew. ed. U. iv. 268.Austral.

microphylla, Sm. in Trans. Linn. Soc. ix. (1808:303. - Austral.

neo-anglica, F. Muell. Fragm. v. 106.-Austral.

nervosa, Meissn. in Bot. Zeit. xiii. (1855; $31=$ erio. carpa.

Nummularia, Endl. Nov. Stirp. Dec. $27=$ prostrata.

ornata, Benth. Fl. Austral. ii. 158.-Austral.

ovalifolia, Endl. Nov. Stirp. Dec. $26=$ eriocarpa.

pvata, G. Don, Gen. Syst. ii. $128=$ heterophylla

ovata, Sm, in Trans, Linn. Soc. ix (1808)

prostrata.

oxyclada, Turcz in Bull. Soc. Nat. Mosc. xxvi. (1853) I. $284=$ rufa.

paucifolia, Benth. ex Lindl. Bot. Reg. (181I) Misc. 53 $=$ rufa.

peduncularis, Turcz. in Bull. Soc. Nat. Mosc. xxvi.

(1853) I. 287.-Austral.

phylloclada, F. Muell. in Trans, Phil. Inst. Vict. iij. 1859) 52.-Austral.

Preisii, Meissn. in Lehm. Pl. Preiss, i. 82.-Austral.

prostrata, R. Br. in Ait. Hort. Kew. ed. II iv, 268 .

Austral.

pulchella, Meissn. in Lehm. Pl. Preiss. i. 84 Austral.

rhombifulia, Siebor, ex D.C. Prod. ii. 117.-Anstral.

rigida, Turcz. in Bull. Soc. Nat. Mosc. xxvi. (1853) I.

$285=$ Preissii.

riparia, A. Cunn. ex Benth. Fl. Austral. ii, 166.Austral.

rosmarinifolia, Lindl. in Mitch. Three Exped. ii. 178 -Austral.

Rossii, F. Mnell. Fragm. iii. 94, $168=$ Templetonia sulcata.

rotundifolia, DC Prod, ii, $11 \%=$ rhombifolia.

rufa, $R$. Br, in Ait. Hort. Kew. ed. II. ix, 266.Austral.

rufa, Maund, Botanist, t. $81=$ ensata

rupicola, A. Cunn.ex Benth. Fl. Austra!. ii 10\%.Austral.

scolopendria, Sm. in:Trans. Linn.Soc. ix. (1808) 303. -Austral.

Scortechinii, F. Miuell. Census, 140, nomen.-Austra?. spinescens, Meissn. in Lehm. P1. Preiss. i. $\$ 2=$ rufa. stenophylla, F. Muell. Fragm. i. 9.-Austral. strigillosa, Benth.Fl. Austral. ii. 157.-Austral. sulcata, Meissn, in Lelm. Pl. Preiss. i. S1.-Austral. tenuicaulis, R. Grah, in Edinb. Y Phil. Joum, xxix.

(July 1840 ) $171=$ cinerea.

virgata, Hook. Bot. Mag. t. $3986=$ rufa.

Walkeri, F. Nuell. Fragm. ii. 120.-Austral.

lieblii,. F. Muell. in Melb. Chem. et Drug. Dec. 1882). - Austral.

l3OSSIENA, Pers. Syn. ii. 286 ; $180^{-}$Bossiaea. Vent. (Legum.)

BOSTRYCHANTHERA. Benth, in Benth. \& Hook. f. Gen. ii. $1210^{\circ}\left(18\right.$ OB $\left.^{\circ}\right)$ LABIATE, Benth. \& Hook. f. 1. c.

deflexa, Besth. l. c.-China.

BOSWELLIA. Roxb. cx Colebr. in As. Res ix. $1.50:$

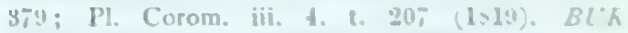
SERACEAE. Benth. N Hook. r. i. 92.2.

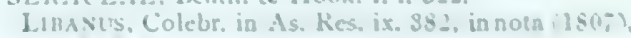
?. S. 1. 1 .

Ploessila, Endl. Nov, Stirp. Dec. 39 (153\%). 


\section{BOSWELLIA}

Ameero, Balf. $f$. in Proc. Roy. Soc. Edinb. xi. (1882) 505.-Ins. Socotra.

balsamifera, Spreng. Syst. ii. $313=$ glabra

Bhaw-Dajiana, Birdw. in Trans. Linn. Soc, xxvii. (1870) 144. t. 31.-Afr. trop.

Carterii, Birdw. l. c. 143.-Arabia

elongata, Balf. $f$. in Proc. Roy. Soc. Edinb. xi. (1882) 505.-Ins. Socotra.

Frereana, Birdw. in Trans. Linn. Soc. xxvii. (1870) 146. t. 31.-Afr. trop.

glabra, Roxb. Hort. Beng. 90 ; F1. Ind. ii. $384=$ serrata.

hirsuta, Sm. in Rees, Cyclc. xxxix, n. 2=Canarium hirsutum.

integra, Blanco, Fl. Filip. ed. II. $242=$ Bursera javanica.

javanica, Turcz. in Bull. Soc. Nat. Mosc. xxxvi. (1863) I. 612.-Java.

neglecta, $S$. Moore, in Fourn. Bot. xv. (1877) 67. t. 185.-Afr. trop.

papyrifera, Hachst. in Flora, xxvi. (1843) 81.Abyss.

sacra, Flneck. Lehrb. Pharmak. (1867) $31=$ Carterii.

serrata, Roxb. ex Colebr. in As. Res. ix. (1807) 379. t. 5.--Ind. or.

socotrana, Balf. f. in Proc. Roy. Soc. Edinb. xi. (1882) 505.-Ins. Socotra.

thurifera, Roxb. ex Flem. in As. Res. xi. (1810) $158=$ serrata.

BOTELUA, Lag, in Varied. Cienc. ii. IV. (1805) $134=$ Bouteloua, Lag. (Gramin.).

BOTHERBE, Steud. ex Klatt, in Linnaea, xxxi. (186162 ) $562=$ Calydorea, Herb. (Irid.).

bulbosa, Steud. ex Klatt, 1. c。 $=$ C. speciosa.

campestris, Klatt, i. c. $563=$ C. campestris

gracilis, Klatt, 1. c. $565=$ C. nuda.

longispatha, Klatt, 1. c. $564=$ Sphenostigma longispatha.

luteola, Klatt, 1. c. $563=$ C. 1uteola.

BOTHRIOCHILUS, Lem. Jard. Fleur. iii. (1852-53) t. 325 ; Illustr. Hortic. iii. (1856) Misc. $30,31=$ Coelia, Lindl. (Orchid.).

bellus, Lem. ll. cc. $=$ C. bella.

BOTHRIOCLINE, Oliver, ex Benth. in Hook. Ic. Pl. xii. 30. t. 1133 (1873). COMPOSITAE, Benth. \& Hook. f. ii. 226.

Schimperi, Oliver E Hiern, ex Benth. l. c.-Abyssin.

BOTHRIOSPFRMUM, Bunge, Enum. Pl. Chin. Bor. 47 (1832), BORAGINEAE, Benth. \& Hook. f. ii. 853 .

asperugoides, Sieb. \& Zucc. in Abh. Akad. Muench. iv. III. (1846) $150=$ tenellum.

bicarinatum, Bunge, ex Steud. Nom. ed. II. i. $219=$ seq.

bicarunculatum, Fisch. \& Mey. Ind, Sem. Hort. Petrop. i. (1835) $23=$ chinense.

chinense, Bunge, Enum. Pl. Chin. Bor. 47.-China bor.

chinense, Fisch. \& Mey. Ind. Sem. Hort. Petrop. 1. 23 = Kusnetzowii

Kusnetzowii, Bunge, ex DC. Prod. x. 116, cum cit. falsa.-Mongolia.

marifolium, A. DC. Prod. $x, 116=$ Heliotropium marifolium.

perenne, Miq. Ann. Mus. Bot. Lugd. Bat. ii. $95=$ tenellum.

secundum, Maxim. Prim. Fl. Amur, 202.—China.

tenellim, Fisch. E Mey. Ind. Sem. Hort. Petrop. i

(1835) 24.-China bor.

BOTHRIOSPORA, Hook. f. in Hook. Ic. P1. xi. 55. t. 1069 (1870). RUBIACEAE, Benth. \& Hook. f. ii. 76.

corymbosa, Hook.f.l.c.-Am. austr.

BOTOR, Adans. Fam. ii. 326 (1763)= Psophocarpus, Neck. (Legumin.).

BOTRIA, Lour. F1. Cochinch. $153(1790)=$ Vitis, Tuurn. (Ampel.).

africana, Lour. 1. c. $154=$ V. africana.
BOTROPHIS, Rafin. Med. Fl. i. $85(1828)=$ Cimicifuga, Linn. (Ranunc.)

actaeoides, Rafin. ex Fisch. \& Mey. Ind. Sem. Hort Petrop. i. $21=$ C. racemosa.

pumila, Rafin. Med. F1.i. $86=$ C. racemosa?

serpentaria, Rafin. 1. c. $85=$ C. racemosa.

BOTRYA, Juss. in Mém. Mus. Par. iii. (1817) $444=$ BOTRIA, Lour.=Vitis, Toum. (Ampelid.).

BOTRYADENIA, Fisch. \& Mey. Ind. Sem. Hort Petrop. ii. $30(\mathbf{1 8 3 5})=\mathbf{M}$ yriactis, Less. (Compos.) Gmelini, Fisch. \& Mey. 1. c. = M. Gmelini.

BOTRYANTHE, Klotzsch, in Wiegm. Archiv, ii. (1841) 190. t. $9=$ Plukenetia, Linn. (Euphorb.) concolor, Klotzsch, 1. c. 191.-Bras.

discolor, Klotzsch, 1. c.-Bras.

BOTRYANTHUS, Kunth, Enum. PI, iv. 310 (1843)= Muscari, Mill. (Liliac.)

albovirens, Tod. Nuovi Gen. $76=\mathrm{M}$. commutatum

alpestris, Jord. \& Fourr. Ic. PI. Eur, ii, $23=$ M. botryoides.

atlanticus, Nym. Consp. $734=\mathrm{M}$. racemosum

Aucheri, Boiss. Diagn. Ser. I. v. $63=$ M. Aucheri.

autumnalis, Heynh. Nom. ii. $75=$ M. parviflorum.

Boraeanus, Jord. \& Fourr. Ic. Pl. Eur. ii. $22=\mathrm{M}$. botryoides.

breviscapus, Tod. Hort. Panorm. t. 5.-Hab. ?

candidus, Jord. \& Fourr. Ic. Pl. Eur. ii. $23=$ M botryoides.

commutatus, Kunth, Enum, Pl. iv, $311=$ M. racemosum.

compactus, Jord. \& Fourr. Ic. Pl. Eur. ii. $24=$ M. botryoides.

conicus, Jord. \& Fourr. 1. c. = M. botryoides.

dilutus, Elwes, ex Baker, in Gard. Chron. (1878) I. $708=$ M. dilutum.

festinus, Jord. \& Fourr. Ic. PI. Eur. ii. $23=\mathrm{M}$. botryoides.

Gussonei, Tod. Ind. Sem. Panorm. (1872) 38 ; Nuov. Giom. Bot. v。 (1873) $157=$ M. Gussonii.

Heldreichii, Jord. \& Fourr. Ic. Pl, Eur, ii. $24=$ M. Heldreichii.

Kerneri, Marches,--Cf. Oestr. Bot. Zeitschr, xxxii. (1882) $339=$ M. botryoides.

Lelievrii, Jord. \& Fourr. Ic. P1. Eur. ii, $23=\mathrm{M}$. botryoides.

micranthus, Hort. Berol, ex Baker, in Gard. Chron. (1878) I. $799=$ M. micranthum.

Mordoanus, Nym. Consp. $734=$ M. Mordoanum

neglectus, Jord. \& Fourr. Ic. Pl. Eur. ii. $24=$ M. neglectum.

neglectus, Kunth, Enum. Pl. iv, $679=$ M. neglectum.

odorus, Kunth, 1. c. $311=$ M. racemosum.

pallens, Kunth, Enum. P1. iv. $312=$ M. pallens.

paradoxus, Kunth, 1. c. = Hyacinthus paradoxus.

parviflorus, Kunth, 1. c. = M. parviflorum.

pulchellus, Jord. \& Fourr. Ic. Pl. Eur. ii. $23=\mathrm{M}$ botryoides.

racemosus, Fourr. in Ann. Soc. Linn. Lyon, N. S. xvii. (1869) $160=$ M. racemosum

Sartorii, Tod. Hort. Panorm. t. $5=$ M. racemosum

Sauli, Jaub. \& Spach, Illustr. iv. $44=$ M. moschatum.

speciosus, Marches.-Cf. Oestr. Bot. Zeitschr. xxxii (1882) $339=$ M. neglectum.

stereophyllus, Herbich, Stirp. Rar. Bucov. 30 (1855)

182 = Hyacinthus leucophaeus.

Strangwaysii, Kunth, Enum. Pl. iv. $679=$ M. racemosum.

Szovitsianus, Hort. Bonn. ex Baker, in Gard. Chron.

(1878) I. $799=$ M. Szovitsianum

vulgaris, Kunth, Enum. Pl. iv. $311=$ M. botryoides.

BOTRYCARPUM, A. Rich. Bot. Méd. ii. 487 (1823), in adnot. $=$ Ribes, Linn. (Saxifrag.)

nigrum, A. Rich. 1. c. $490=$ R. nigrum.

BOTRYCERAS, Willd. in Ges. Naturf. Fr. Berl. Mag v. (1811) 396. ANACARDIACEAE, Benth. \& Hook. f. i. 426 .

DAPHNitis, Spreng. Syst. i. 370 (1825)

LaU Rophillus, Roem. \& Schnlt. Syst. iii. 30 (1818)

Laurophyllus, Thunb. Nov. Gen. vi. 104 (1792), nomen prius.

laturinum, Willd.l.c. 397.-Afr. austr
BOTRYCOMUS, Fourr. in Ann. Soc. Linn. Lyon, N. S. xvii. (1869) $160=$ Museari, Mill. (Liliac.).

vulgaris, Fourr. 1. $\mathrm{c}_{\mathrm{o}}=\mathrm{M}$. comosum.

BOTRYDIUM, Spach, Hist. Vég. Phan. v. 298 (1836)= Chenopodium, Linn.

aromaticum, Spach, 1. c. $299=$ C. Botrys.

Schraderi, Spach, 1. c = C. foetidum.

BOTRYIMORUS, Miq. F1. Ind. Bat. i. II. 282 (185\%), ARTOCARPEAE.

paniculata, Miq.l. c. 283.-Malaya.

BOTRYODENDRUM, Endl. Prod. Fl. Norf. 62 (1833) $=$ Meryta, Forst. (Araliac.).

angustifolium, Endl. 1. c. = M. angustifolia. capitatum, Endl. ex Heynh. Nom. ii. $75=$ Oreopanax capitatum.

coriaceum, Panch. ex Baill. Adansonia, xii. (1878) 153 $=$ M. coriace .

latifolium, Endl. Prod. Fl. Norf. $62=$ M. latifolia. macrophyllum, Rich, ex A. Gray, Bot. U. St. Expl. Exped. i. 732. t. $97=$ M. macrophylla.

Sinclairii, Hook. f. Fl. N. Zel. $97=$ M. Sinclairii. taitense, Guill. in Ann. Sc. Nat. Ser. II. vii. (1837) 349.-Ins. Tahiti.

BOTRYOLOTUS, Jaub. \& Spach, Illustr. i. 124. t. $63=$ Trigonella, Linn. (Legumin.).

cachemyrianus, Jaub. \& Spach, 1. c. $\mathbf{1 2 5}=$ T. Emodi.

persicus, Jaub. \& Spach, 1. c. 124. t. $63=$ T. elliptica.

BOTRYOPANAX, Miq. in Ann. Mus. Bot. Lugd. Bat. i. $5(\mathbf{1 8 6 3 - 6 4})=$ Polyscias, Forst. (Araliac.).

borbonica, Miq. 1. c. =Ins. Borbon.

BOTRYOPSIS, Miers, in Ann. Nat. \& Mag. Hist. Ser. II. vii. $43(1851)=$ Chondodendron, Ruiz \& Pav. (Menisperm.).

platyphylla, Miers, 1. c. =C. platyphyllum.

Spruceana, Eichl. in Flora, xlvii. (1864) $394=\mathrm{C}$ cretosum.

BOTRYOROPIS, Presl, Epim. Bot. $220(1849)$ = Barringtonia, Forst. (Myrtac.).

luzonensis, Presl, 1. c. = B. luzonensis.

BOTRYOSICYOS, Hochst. in Flora, xxvii. (1844) Bes. Beil. 3 = Dioscorea, Linn.

pentaphyllum, Hochst. 1. c. = D. pentaphylla.

BOTRYPHILE, Salisb. Gen. Pl. Fragm. $25(1866)=$ Muscari, Mill. (Liliac

botryoides, Salisb. 1. c. $=$ M. botryoides.

parviflorus, Salisb. 1. c. = M. parviflorum

racemosus, Salisb. 1. c. $=$ M. racemosum.

BOTRYS, Fourr. in Ann. Soc. Linn. Lyon, N. S. xvii (1869) 138 = Teucrium, Linn. (Labiat.)

chamaedryoides, Fourr. 1. $\mathrm{c}_{*}=\mathrm{T}$. Botrys.

BOTTIONEA, Colla, in Mem. Acc. Torin. xxxvii (1834) 43. t. 1. LILIACEAE,Benth. \& Hook.f. iii. 789 Endocoma, Rafin. FI. Tellur. ii. 57 (1836).

Trichopetalum, Lindl. Bot. Reg. t. 1535 (1832).

thysanthoides, Colla, l. c. 45. t. 1.-Chili.

BOU CEROSIA, Wight \& Arn. Contrib. Bot. Ind. 31 (1834). ASCLEPIADEAE, Benth. \& Hook. f. ii. 782. Apteranthes, Mikan, in Nov. Act. Nat. Cur. xvii. (1835) 593. t. 41

Desminochus, Reichb. Consp. 130 (1828).

DESMIDORCHIS, Ehrenb. in Linnaea, iv. (1829) 94.

Hutchinia, Wight \& Arn. Contrib. Bot. Ind. 34 (1834).

Hutschinia, D. Dietr. Syn. i. 579 (1839).

Aaronis, Hart, in Trans. Roy. Irish Acad. xxviii. (1885) 436.-Palaestin.

acutangula, Decne, in DC. Prod. viii. 648.-Afr. trop.

adscendens, Wall. Cat. n. 8146, partim= Caralluma edulis.

Aucheriana, Decne. in DC. Prod. viii. 649.-Arabia; Persia ; Ind, bor. occ.

campanulata, Wight, Ic. vi. t. $1287=$ umbellata.

crenulata, Wight \& Arn. Contrib. Bot. Ind. 34.Ind or. 
BOUCEROSIA :-

cylindrica, Brongn. in Bull. Soc. Bot. Fr. vii. (1860) 900.-Abyss.

Decaisniana, Lem. Herb. Gén. Amat. Sér. II. iv. t. 21 ; Decne. in DC. Prod. viii, 648.-Afr. trop.

diffusa, Wight, Ic. vi. t. 1287.--Ind, or.

edulis, Edgew. in Journ. Linn, Soc. vi. (1862) $205=$ Caralluma edulis.

Forskalii, Decne. in DC. Prod. viii. 648.-Arabia

Gussoniana, Hook. f. Bot. Mag. t. 6137 in textu.Algeria.

Hitchinia, Hook. f. Fl. Brit. Ind. iv. 78, lapsu=B. Hutchinia.

Hutchinia, Decne in DC. Prod. viii. 649.-Ind. or.

incarnata, N. E. Br. in Fourn. Linn. Soc. xvii. (1878) 166.-Afr. anstr.

lasiantha, Wight, Ic. vi. t. $1286=$ crenulata.

mammillaris, N.E. Br. in Fourn. Linn. Soc. xvii (1878) 165.-Afr. austr.

maroccana, Hook. f. Bot. Mag. t. 6137.-Marocco.

Munbyana, Decne. ex Munby, Fl. Alger. 25.-Algeria.

pauciflora, Wight, in Madras fourn. Sc. vi. (1837) t. ad p. 473 . - Ind, or.

quadrangula, Decne. in DC. Prod. viii. 664, in syn. $=$ Forskalii.

Russeliana, Courb. ex Brongn. in Bull. Soc. Bot. Fr. vii. (1860) 900.-Oriens.

sinaica, Decne in DC. Prod, viii. 649-Arabia.

socotrana, Balf. $f_{0}$ in Proc. Roy. Soc. Edinb. xii. (1884) 79.-Ins. Socotr.

Stocksiana, Boiss. F1. Orient. iv. $63=$ Caralluma edulis.

umbellata, Wight \& Arn. Contrib. Bot. Ind. 34.Ind. or.

BOUCHARDATIA, Baill. Adansonia, vii. (1867) $350=$ Melicope, Forst. (Rutac.)

australis, Baill. 1. c. 351. t. $10=\mathrm{M}$. neurococca.

neurococca, Baill. 1. c. ix. (1868) $110=$ M. neurococca.

BOUCHEA; Cham. in Linnaea, vii. (1832) 252. VERBENACEAE, Benth. \& Hook. f. ii. 1144.

Chascanum, E. Mey. Comm. Pl. Afr. Austr. 275 (1835).

Pleu rostigma, Hochst. ex Schnizl. in Flora, (1842) I. Beib. 144.

Plexipus, Rafin. Fl. Tellur. ii. 104 (1836).

adenostachya, Schau. in DC. Prod. xi. 560.-Afr. trop.

agrestis, Schau. l. c. 558.-Bras.

cernua, Schau. l. c. 559 -Afr. austr.

copiapensis, C. Gay, F1. Chil. v. 26. t. $55=$ Priva laevis.

cuneifolia, Schau. in DC. Prod. xi. 559.-Afr, austr.

Ehrenbergii, Cham. in Linnaea, vii. (1832) 253.-Ins

S. Doming.

garepensis, Schau. in DC. Prod. xi. 560.-Afr. austr.

Hanningtonii, Oliver, in Hook. Ic. Pl. t. 1446.-Afr trop.

hederacea, Sond. in Linnaea, xxiii. (1850) 36.-Afr. austr.

hyderabadensis, Walp. Rep. iv. 12.-Ind. or

incrassata, Lange, Ind. Sem. Haun. (1870) 31. Hab. ?

laetevirens, Schau. in DC. Prod. xi. 557.-Bras.

latifolia, Harv. Thes. Cap. ii. 57.-Afr. austr.

linifolia, A. Gray, in Am. foum. Sc. Ser. II. xvi (1853) 98.-N. Mexic.

marrubiifolia, Schau. in DC. Prod. xi. 558.-Afr. trop. Arab. : Scind.

pinnatifida, Schau. l. c. 560.-Afr. austr

pseudogervao, Cham. in Linnaea, vii. (1832) 252.Bras.

pterygocarpa, Schau. in DC. Prod. xi. 558.-Nubia.

pubescens, Schau. 1. c. $560=$ pumila.

pumila, Schau. l. c. -Afr. austr.

sessilifolia, Vatke, in Linnaea, xlii. (1880-82) 529.Afr. trop.

spathulata, Torr. Bot. Mex. Bound. 126.-Am. bor. occ.

BOUCHETIA, DC. ex Dun, in DC. Prod. xiii. I. 589 (1852). SOLANACEAE, Benth. \& Hook. f. ii. 908 LEUCANTHEA, Scheele, in Linnaea, xxy, (1852) 258 erecta, DC. ex Dun. l. c.-Texas; Mexic.

procumbens, $D C$. $e x$ Dun. l. c.-Mexic.
BOUEA, Meissn. Gen. 55 ; Cornm. 55 (1837). ANA

CARDIACEAE, Benth. \& Hook. f. i. 420

CambessejeA, Wight \& Arn. Prod, i, 170 (1834).

angustifolia, Blume, Mus. Bot. Lugd. Bat. i. 204.Borneo.

Brandisiana, Kurz, in Joum. As. Soc. Beng. xl. (1871)

II. $50=$ burmanica.

burmanica, Griff. Pl. Cantor, 14.-Burma; Malaya. diversifolia, Miq. F1. Ind. Bat. Suppl. i, 52: = micro phylla.

Gandaria, Blume, Mus. Bot. Lugd. Bat. i. $204=$ macrophylla?

macrophylla, Griff. Pl. Cantor, 15; Notul. iv. 420.Malaya.

microphylla, Griff. $l l . c c .15,423 .-$ Malaya.

myrsinoides, Blume, Mus. Bot. Lugd. Bat. i. 204 microphylla?

oppositifolia, Meissn. Gen. 75; Walp. Rep. i. $556=$ burmanica.

BOUGAIN VILLAFA, Comm, ex Juss, Gen. 91 (1789) Buginvillaea); Choisy, in DC. Prod, xiii. II. 437 (1849). NYCTAGINEAE, Benth. \& Hook. f. iii. 7 .

Josepha, Vell. F1. Flum. 154 (1825); iv, t. 16. bracteata, Pers. Syn. i, $418=$ spectabilis

brasiliensis, Lund, ex Choisy, in DC. Prod. xiii. II $437=$ virescens

brasiliensis, Raeusch. Nom. ed. III. 112 ; [Nees, in] Princ. Neuw. Reise, i. $44=$ spectabilis

frondosa, Griseb. in Goett. Abh. xix. (1874) 89.-Reg. Argent.

glabra, Choisy, in DC. Prod, xiii. II. 437.-Bras. infesta, Griseb. in Goett. Abh. xxiv. (1879) 40 - - Reg Argent.

patagonica, Decne. in Orbign. Voy. t. 8.-Patagon.

peruviana, Humb. Eั Bonpl. Pl. Aequin. i. 173. t. 49 -Peruv.

peruviana, Nees \& Mart. in Nov. Act. Nat. Cur. xi. (1823) $39=$ spectabilis.

pomacea, Choisy, in DC. Prod. xiii. II. 438.-Bras.

praecox, Griseb. in Goett. Abh. xxiv. (1879) 40.-Reg. Argent.

racemosa, Blanco, Fl. Filip. ed. I. $307=$ Pisonia excelsa.

rubicunda, Schott, ex Rohrb, in Mart. Fl. Bras, xiv, II. $351=$ glabra

speciosa, Schnizl. Jc. Fam. Nat. t. 104=spectabilis.

spectabilis, Willd. Sp. Pl. ii. 348.-Bras.

stipitata, Griseb. in Goett. Abh. xix. (1874) 88.-Reg. Argent.

virescens, Choisy, in DC. Prod. xiii. II. 437.-Bras,

BOUGAINVILLEA, Spach, Hist. Vég. Phan. x. 516 (1841) = Bougainvillaea, Juss. (Nyctag.).

BOUGUERIA, Decne, in Ann. Sc. Nat. Sér. II. (1836) 132. PLANTAGINEAE, Benth. \& Hook, f. ii. 1224 .

nubicola, Decne. l. c.-Peruv.; Boliv

BOULARDIA, F. Schultz, Arch. Fl. Fr, et Allem. 103 $(1847)=$ Orobanche, Tourn

latisquama, F. Schult. 1. c. 104.-Algeria.

BOUPHON, Lem, in Orb. Dict. ii. $686(1842)=\mathrm{seg}$

BOUPHONE, Lem. in Orb. Dict. ii. $778(1842)=$ Buphane, Herb. (Amaryll.).

BOURGAEA, Coss. Notes Crit. $39(1849)=$ Cynara,

Vaill. (Compos.).

humilis, Coss. I. $\mathrm{c},=\mathrm{C}$, humilis.

Tournefortii, Willk. in Linnaea, xxv. (1852) $39=\mathrm{C}$. Tournefortii.

BOURGIA, Scop. Introd, 158 (1777). BOR.AGIN.?

BOURJOTIA, Pomel, Nouv, Mat. Fl. Atl. 89 (187t)

Heliotropium, Linn. (Boragin.)

Kralikii, Pomel, l, $\mathrm{c}=\mathrm{H}$, Kralikii.

pterocarpa, Pomel, I. c. $90=\mathrm{H}$. pterocarpum,

BOURRERIA, P. Br. Hist. Jamaic, 168 (1756 BORAGINEAE, Benth. \& Hook. f. ii. 840 .

BeurRer1A, Jacq. Enum. Pl. Carib. 2 (1760).

Crimatoma, Miers, in Ann. \& Mag. Nat. Hist. Ser, IV, iii. (1869) 900

\section{BOURRERIA}

Hymenesthes, Miers, in Trans, Linn. Soc. Ser. II. i. $(1875) 26 . t .6$

Morelosia, La Llav, \& Lex. Nov. Veg. Descr. i. 1 (1824).

Andrieuxii, Hemsl. Biol. Centr. Am. Bot. ii. 369.Mexic.

aspera, G. Don, Gen. Syst. iv, $390=$ Ehretia laevis.

baccata, Rafin. Sylva Tellur. 42,-Hab.

calophylla, Griseb. in Mem. Am. Acad. N. S, viii. 1863) 528.-Cuba

cassinifolia, Griseb. l. c.-Cuba.

cestroides, Spreng. Syst. iv. Cur. Post. 66.-Am. austr.

clariuscula, Miers, in Ann. E Mag. Nat. Hist. Ser. IV. iii. (1869) 204.-Am. austr.

dichotoma, Rottl. ex G. Don, Gen. Syst. iv. $390=$ Ehretia laevis

divaricata, G. Don, l. c. 387.-Cuba.

domingensis, Griseb. in Mem. Am. Acad. N. S. viii. (1863) 528.- Ind. occ.

exsucca, Facq. Enum. Pl. Carib. 14.-Am. austr.

formosa, Hemsl. Biol. Centr. Am. Bot. ii. 369.-Mexic.

glabra, G. Don, Gen. Syst. iv. $390=$ Cordia Myxa.

grandifora, Bertol. Fl. Guatim. 10.-Guatemala.

havanensis, Miers, in Ann. $*$ Mag. Nat. Hist. Ser. IV. iii. (1869) 207.-Cuba.

Huanita, Hemsl. Biol. Centr. Am. Bot. ii. 370.Mexic.

laevis, G. Don, Gen. Syst. iv. $390=$ Ehretia laevis.

laxa, G. Don, l. c.-Ins. Mascar.

linearis, Miers, in Ann. \& Mag. Nat. Hist. Ser. IV. iii. (1869) 210.-Ind. occ.

microphylla, Griseb. Cat. Pl. Cub. 210.-Cuba

ovata, Miers, in Ann. E Mag. Nat. Hist. Ser. IV. iii.

(1869) 203.-Ind. occ.

punctata, G. Don, Gen. Syst. iv. $390=$ Ehretia lacvis.

Radula, G. Don, l. co-Ins. S. Doming.

recurva, Miers, in Ann. E Mag. Nat. Hist. Ser. I

iii. (1869) 203.--Ind. occ.

reticulata, Griseb. Cat. Pl. Cub. 210,-Cuba.

retusa, G. Don, Gen. Syst. iv. $390=$ Ehretia retusa

revoluta, H. B. \& $K$. Nov. Gen. et Sp. iii. 67.Mexic.

rigida, Miers, in Ann. \& Mag. Nat. Hist. Ser. IV. iii. (1869, 204.-Ind. oce.

setosa, G. Uon, Gen. Syst. iv. $390=$ Ehretia setosa

spathulata, Hemsl. Biol. Centr. Am. Bot. ii. 370.Mexic

spinifex, Griseb. in Mem. Am:Acad. N. S. viii. (1863. 528.-Cuba.

succulenta, Facq. Enum. Pl.Carib. 14.-Ind. occ. tomentosa, G. Don, Gen. Syst, iv, 390-Ind occ.

uniflora, G. Don, 1. $\mathrm{c}_{\mathrm{s}}=$ Ehretia unifiora.

virgata, G. Don, l. c. 389.-Ind. occ.

BOUSSINGAULTIA, H. B. \& K. Nov. Gen。 et Sp. vii. 194. t. 645 (1825). CHENOPODIACEAE, Benth. \& Hook. f. iii. 77

TAndoniA, Moq. in DC. Prod. xiii. II. 226 (1849) baselloides, H. B. E K. Nov. Gen. et Sp. vii. 196. t. $645 .-E c u a d o r$.

cordifolia, Tenore, Ind. Sem. Neap. (1852) ex Ann. Sc. Nat. Sér. III xix (1853 $355-\mathrm{Hab}_{\text {. }}$ ?

floribunda, Moq. in DC. Prod, xiii. II. 229N. Granat.

gracilis, Miers, in fourn. Bot. ii. (1S61) 161. t. 15.liras.

Lachaumei, Carr, int Rev. Hortic. $(1872): 7 \%$-Cuba. leptostachys, Moq. in DC. Prod, xiii. 11. 229=baselloides.

ramosa, Hemesl. Biol. Centr. Am. Bot. iii. 27.Guatemala.

BOUTELOU A, Lag in Paried. Ciene ii, IY (1Sus 134 (Botelua), GRAIMIVEAE, Benth. \& Houk. f iii. 1168.

Actrvochron, Willd. ex Roem. \& Schule. Syst, ij. $22,417(1815)$

Aristintes, Endl. Gen. 9t (1s96

Atheropocion, Mfuhl. in Willd. Sp, Pl. iv. :9i $1805)$

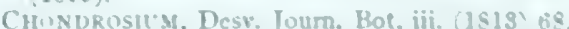

CoRETHRL', Vahl, io Skr. Naturk, Selsk. Kiolenth vi. (181(1) 85 .

I)ISEHRA, DC. Cat. Ilont. Mons, 104 (1sis), pro piapte.

LUTRIAsA, Trin. Fand. Asrost. 161 15:20! 


\section{BOUTELOUA :-}

Heterosteca, Desv. in Nov. Bull. Soc. Philom. ii (1810; 188 ; Desv. Journ. Bot. iii. (1813) 68

Heterostega, Kunth, in Mém. Mus. Far. ii. (1815) 73.

Nestlera, Willd. ex Steud. Nom. ed. II. ii. 192 (1841)

Polyodon, H. B. \& K. Nov. Gen. et Sp. i. 174. t 55 (1815).

TRIAENA, H. B \& K. 1, c. 178, t. 61 (1815).

Triathera, Desv. in Nov. Bull. Soc. Philom. ii (1810) 188.

Triplathera, Endl, Gen, 94 (1836)

aristidoides, Griseb. Fl. Brit. W. Ind. 537, in obs.Mexic.

barbata, Lag. Varied. Cienc. ii. IV. (1805) 141; Gen et Sp. Nov. 5.-Mexic.; Ins. Philipp.

brevifolia, Buckl. in Proc. As. Sc. Philad. ' 1862 (1863) $93=$ eriopoda.

bromoides, Lag. Gen. et Sp. Nov. 5.-Mexic.

Burkei, Scribn. ex S. Wats, in Proc. Am. Acad. xriii. (1883) 179.-Texas.

chrondrosioides, Benth. ex S. Wats. 1. c. =ovata.

ciliata, Griseb. in Goett. Abh. xxiv. (1879) 302.-Reg. Argent.

curtipendula, Torr, in Emory, Notes Mil. Reconnois. 153 = racemosa

disticha, Benth. in Fourn. Linn. Soc. xix. (1882) 105 -Am. trop.

elatior, Griseb. Fl. Brit. W. Ind. 537.-Ind. occ

eriopoda, Torr. in Pacif. Rail. Rep. iv. Bot. 155.--An bor.

foena, Bigelow, in Whipple Exped. Add. p. $\mathrm{ii}=$ hirsuta.

gracilis, Steud. Nom. ed. II. i. $219=$ oligostachya

gracilis, Vasey, in Wheeler, Exped. $287=$ aristidoides. Havardi, Vasey, ex.S. Wats. in Proc. Am. Acad. xviii (1883) 179.-Texas.

hirsuta, Lag. Varied. Cienc. ii. Iv. (1805) 141 ; Gen. et $S p$. Nov. 5.-Mexic

hirta, Hort. Madr, ex Lag. 1, c. 141 = hirsut

Humboldtiana, Griseb. in Mem. Am. Acad. N. S, viii (1863) $532=$ bromoides

humilis, Hieron. in Bol. Acad. Nac. Cordova, iv. (1881) 495.-Reg. Argent

juncifolia, Lag. Gen. et Sp. Nov. 5.-Mexic.; Ind. occ juncifolia, Vasey, Cat. Gr. Un. St. $62=$ bromoides.

litigosa, Lag. Gen. et Sp. Noy. $5=$ juncifolia.

lophostachya, Griseb. in Goett. Abr. xxiv. (1879) 302 -Reg. Argent.

melicaeformis, Hornem. ex Steud. Nom. ed. I. 91, in syn. = racemosa.

melicoides, Steud. 1. c. $115=$ racemosa

multiseta, Griseb. in Goett. Abh. xxiv. (1879) 303.Bras. ; Reg. Argent.

nana, Griseb. l. c.-Reg. Argent.

oligostachya, Torr. ex A. Gray, Man. ed. II. 553 ; et in Pacif. Rail. Rep. iv. Bot. 155.-Am. bor.

ovata, Lag. Gen. et Sp. Noz, 5,--Mexic.

pendula, Hort. Madr, ex Lag. in Varied. Cienc. ii. IV. (1805) $141=$ racemosa

pilosa, Benth. ex S. Wats. in Proc. Am. Acad. xviii. (1883) 179.-Ins. Galap.

polystachya, Torr. in Pacif. Rail. Rep. v, 366. t. 10.Am bor.

porphyrantha, Wright, in Sauv. Fl. Cub. $192=$ juncifolia.

prostrata, Lag. in Varied. Cienc. ii. IV. (1805) 141 Gen. et Sp.Nov. 5.-Mexic

pumila, Buckl. in Proc. Ac. Sc. Philad. ' 1862 ' (1863) $93=$ polystachya

pusilla, Vasey, in Bull. Torrey Bot. ‘Club, xi. (1884) 6.-N. Mexic

racemosa, Lag. in Varied. Cienc. ii. IV. (1805) 141 Gen. et Sp. Nov. 5.-Mexic.

Rothrockii, Vasey, Grasses U. St. 33, nomen.-Am. bor. scorpioides, Lag. Gen et Sp. Nov $5 ;$ s. Wats, in Proc. Am. Acad. xviii. (1883) 176.-Mexic.

simplex, Lag. in Varied. Cienc. ii. IV. (1805) 141. -Peruv:; Ins. Philipp.

tenuis, Griseb. in Goett. Abh. xxiv. (1879) 303.Mexic.; Reg. Argent.

texana, S. Wats. in Proc. Am. Acad. xviii. (1883) 196.-Texas.

Triathera, Benth. in Fourn. Linw. Soc. xix. (1882) 104.-Mexic.

trifida, Thurb. ex S. Wats. in Proc. Am. Acad. xviii. (1883) 177.-Mexic.
BOUTONIA, Boj. Hort. Maurit. 282 (1837)= Mallotus, Lour. (Euphorb.)

acuminata, Baill. Etud. Gén, Euphorb. $401=$ M. Baillonianus.

mascarensis, Boj. Hort. Maurit. $282=\mathrm{M}$. integrifolius.

BOUTONIA, DC. Rev. Bign. $18(1838)=$ Periblema, DC. (Birnon.)

cuspidata, DC. 1. c. = P. cuspidatum.

BOUTONIA, Hort. Erfurt. ex Steud. Nom. ed. II. i. 219 $(1840)=$ Goodenia, Sm.

pomifera, Hort. Erfurt. ex Stend. 1. c. $=$ G. paniculata.

BOUVARDIA, Salisb. Parad. Lond. t. 88 (1805) RUBIACEAE, Benth. \& Hook, f. ii. 36

Aeginetia, Cav. Ic. vi. 51.t. 572 (1801)

Bowvardia, Polak. in Linnaea, xli. (1877) 565.

angustifolia, H.B. E K. Nov. Gen. et Sp. iil. 384.Mexic.

bicolor, Kunze, in Linnaea, xx. (1847) 24,-Mexic.

candidissima x, Hort_-Cf. Gard, Chron. (1873) 714

Cavanillesii, $D C$. Prod. iv. 366.-Mexic.

chlorantha, Bert. ex Roem. E' Schult. Syst. iii. Mant, 116. - Am. austr.

chrysantha, Mart. Del. Sem. Hort. Monac. (1848) 4.Mexic.

coccinea, Link, Enum. Hort. Berol, i. $139=$ triphylla coccinea, A. Rich. in Mém. Soc. Hist. Nat. Par. (1834) 272.-Guiana.

cordifolia, DC. Prod. iv. 366.-Mexic

corymbosa, Oerst. in Kjoeb. Vidensk. Meddel. (1852) 46.-Nicarag.

crocata, Van Houtte, Cat. (1846).-Hab. ?

Davisoni, Hort.-Cf.Gard. Chron. (1872) 7.-Hab.?

discolor, Hook. \& Arn. Bot. Beech. Voy. 428 Rondeletia dubia.

ferruginea, A. Rich. in Mém. Soc. Hist. Nat. Par.v. (1834) 273.-Madag.

flava, Decne, in Van Houtte, Fl. des Serres, Sér. I. i. (1845) 90. t. 38.-Mexic.

glaberrima, Engelm. in Wisliz. Tour N. Mexico, 106. -Mexic.

glabra, Polak. in Linnaea, xli. (1877) 565.-Costa Rica.

Ravanensis, A. Rich, in Mim. Soc. Hist. Nat. Par. v. (1834) 272 .- Ind. occ.

hirsuta, A. Rich. l. c.-Ind. occ.

hirtella, H. B. \& K. Nov. Gen. et Sp. iii. 384.-Mexic. Houtteana, Schlecht. in Fl. des Serres, Sér. I. x. (1854-55) 149.-Mexic.

Humboldti, Hort.-Cf. Gard.Chron. (1873) 714, 716. -Hab. ?

hypoleuca, Benth. Pl. Hartw. 288.-Mexic.

facquini, H. B. \& K. Nov. Gen. et Sp. iii. $385=$ triphylla.

jasminiflora, Hort.-Cf. Gard. Chron. (1872) 215.Hab.

laevis, Mart. E Gal. in Bull. Acad. Brux. xi. (1844) 236. -Mexic

leiantha, Benth. Pl. Hartw. 85 ; Decne. in Rev. Hortic. Sér. III. v. (1851) 81.-Guatemala; Mexic. linearis, H. B. E K. Nov. Gen. et Sp. iii. 383.Mexic.

longiflora, H. B. \& K. 1. c. $386=$ Houstonia longiflora microphylla, Schlecht. in Linnaea, xxvi. (1853-55) 112 -Mexic.

mollis, Linden, Cat. (1848).-Cf. Schlecht. l. c.55.-

Mexic.

multiflora, Schult. in Roem. \& Schult. Syst. iii. 118 = Cavanillesii.

mutabilis, Hort. Berol. ex Walp. Ann. v. $127=$ versicolor.

myrtifolia, Schlecht. in Linnaea, xxvi. (1853-55) 121 -Mexic.

abovata, Benth. P1. Hartw, $16=$ scabra.

obovata, H. B. E K. Nov. Gen. et Sp. iii. 385.Mexic.

Oriana $x$, Pars. ex Van Houtte, Fl. des Serres, xii. (1857) 159, t. 1265

ovata, A. Gray, Pl. Wright. ii, 67.-N. Mexic

suberula, Decne. in F1. des Serres, Sér. I. i. (1845) 90 in deser. = flava.

quaterniflora, Stend. Nom. ed. II. i. 300, in syn. = seq quaternifolia, $D C$. Prod. iv. 365.-Mexic

quinqueflora, Dehnh. Revista Napol. i. III, 167.Mexic.

\section{BOUVARDIA :-}

racemosa, A. Rich. in Mém. Soc. Hist. Nat. Par. v. (1834).-Peruv.

rosea, Schlecht. in Linnaea, xxvi. (1853-55) 116.Calif.

scabra, Hook. E Am. Bot. Beech. Voy. 427.-Mexic. scabrida, Mart. E Gal. in Bull. Acad. Brux. xi. (1844) 237.-Mexic.

scandens, A. Rich. in Mém. Soc. Hist. Nat. Par. v. (1834) 272,-Hab. ?

Schiediana, Schlecht. in Linnaea, xxvi. (1853-55) 123 - Mexic.

splendens, R. Grah. in Bot. Mag. t. $3781=$ triphylla.

strigillosa, [Baxt. in] Loud. Hort. Brit. Suppl. 1ii. 502 $=\mathrm{seq}$. ?

strigosa, Benth. Pl. Hartw. $75=$ Rondeletia strigosa.

tenuiflora, Hort. Berol. ex Schlecht. in Linnaea, xxvi. (1853-55) 97.-Mexic.

ternifolia, Schlecht. 1. c. $98=$ triphylla.

tolucana, Hook. E" Arn. Bot. Beech. Voy. 427.-Mexic. triflora, H. B. \& K. Nov, Gen. et Sp. iii. 386. t. 288

$=$ Houstonia triflora

triphylla, Salisb. Parad. Lond. t. 88.--Mexic.

umbellata, Hort.-Cf. Gard.Chron. (1873) 714.-Hab. uniflora, Rich, in Mém. Soc. Hist. Nat. Par. v. (1834) 272.-Am. trop.

versicolor, Ker-Gawl. Bot. Reg. t. 245.-Am. austr.

viminalis, Schlecht. in Linnaea, xxvi. (1853-55) 120. -Mexic.

viperalis, Schlecht. l. c. 114.-Mexic

Vreelandi, Hort. ex Fl. et Pomol. (1872) 174=Davi soni.

xylosteoides, Hook. E Arn. Bot. Beech. Voy. 428,Mexic.

BOUZETIA, Montrous. in Mém. Acad. Lyon, x (1860) 192. RUTACEAE?, Benth. \& Hook. f, i. 989 .

maritima, Montrous. l. c.-N. Caled.

BOVF.A, Decne. in Ann. Sc. Nat. Sér. II. ii. (1834) $253=$ Lindenbergia, Lehm. (Scrophulac.).

sinaica, Decne. 1. $\mathrm{c}_{\mathrm{s}}=\mathrm{L}$ 。 sinaica

BOWDICHIA, H. B. \& K. Nov. Gen. et Sp. vi. 376 (1823). LEGUMINOSAE, Benth. \& Hook. f. i. 557 .

SEBIPIRA, Mart, Reise, 787 (1828).

brevipes, Benth. in Ann. Wien. Mus. ii. (1838) $89=$ virgilioides.

densiftora, Benth. 1. c. = virgilioides.

ferruginea, Walp. Rep. i. $808=$ virgilioides.

floribunda, Benth. in Ann. Wien. Mus, ii. (1838) $89=$ virgilioides.

major, Mart. Syst. Mat. Med. Bras. $53=$ virgilioides.

nitida, Spruce, ex Benth. in Mart. Fl. Bras. xv, I. 313. -Bras.

pubescens, Benth. in Ann. Wien. Mus. ii. (1838) $89=$ virgilioides.

Sebipira, Steud. Nom. ed. II. i. $220=$ virgilioides.

virgilioides, $H . B$, E $K$. Nov. Gen. et Sp, vi, 376.Am. austr.

BOWENIA, Hook. Bot. Mag. t. 5398 (1863) et 6008 . CYCADACEAE, Benth. \& Hcok. f. iii. 446.

spectabilis, Hook. l. c. 5398.-Austral.

BOWIEA, Hary, ex Hook. f. in Bot. Mag. t. 5619 (1867). LILIACEAE, Benth. \& Hook. f. iii. 786. volubilis, Harv. l. c.-Afr. austr.

BOWIEA, Haw, in Phil. Mag. 1xiv. (1824) $299=$ Aloë, Tourn. (Liliac.)

africana, Haw. 1. c. = A. Bourea.

myriacantha, Haw. 1. c, ; et N. S. i. $(1827) 122=$ A. myriacantha.

BOWKERIA, Harv. Thes. Cap. i. 24. t. 37 (1859), SCROPHULARINEAE, Benth. \& Hook. f. ii. 937. triphylla, Harv. l. c.-Afr. austr.

BOWLESIA, Ruiz \& Pav. Prod. Fl, Per. 44. t. 34 (1794). UMBELLIFERAE, Benth. \& Hook. f. i. 876 .

Drusa, DC. in Ann. Mus. Par. x. (1807) 466. t. 38 Ersneria, Walp. Nov. Act. Nat. Cur. xix. Suppl. i. (1843) 346.t. 8. 


\section{BOWLESIA :-}

Homalocarpus, Hook. \& Arn. in Hook. Bot. Misc iii. (1833) 348 .

acutangula, Benth. Pl. Hartw. 180.--Peruv. crenata, Desv. ex DC. Prod. iv, $70=$ Dysopis Gayana. dichotoma, Poepp. ex DC. l.c. 76.-Chili diversifolia, Meyen, ex Walp. Rep. v. $842=$ lobata. elata, Clos, in C. Gay, Fl. Chil. iii. 74,-Chili. elegans, Clos, l. c. 74. t. 30.-Chili.

flexilis, Meyen, Reise, i. 348.-Chili.

geniculata, Spreng. Umbellif. 14. t. $5=$ Angelica geniculata.

geraniifolia, Schlecht. in Linnaea, i. (1826) 382. Chili.

incana, Ruiz E Pav. Fl. Per. iii. 28.-Peruv.

integerrima, Turcz. in Bull. Soc. Nat. Mosc. xx. (1847) I. 170,-Chili,

lobata, Ruiz E Pav. Prod. 44. t. 34 ; Fl. Per. iii. 28. -Peruv.

multiradiata, Colla, in Mem. Acc. Torino, xxxvii. (1835) 81.-Chili

nigripetala, Clos, in C. Gay, Fl. Chil. iii. 71.-Chili. nodiftora, Presl, ex DC. Prod. iv. $75=$ tenera. oppositifolia, Buch, in Abh. Acad. Berl. 1816-17 (1819) 370.-Ins. Canar.

palmata, Ruiz E Pav. Fl. Per. iii. 28.-Peruv.

pulchella, Wedd. Chlor. And. ii. 188.-Peruv.; Boliv. rotundifolia, Phil. in Linnaea, xxviii. (1856) 651.Chili.

tenella, Meyen, Reise, i. 466.-Peruv.

tenera, Spreng. Syst. i. $880,-$ Bras.

tripartita, Clos, in C. Gay, Fl. Chil. iii. 76--Chili.

tropaeolifolia, Gill. \& Hook. in Hook. Bot. Misc. i. (1830) 325.-Chili.

uncinata, Colla, in Mem.Acc. Torino, xxxvii. (1835) 81. - Chili.

BOWMANIA, Gardn. in Hook. Ic. Pl. 519 (1843); et in Hook. Lond. Journ. Bot. ii. (1843) $9=$ Trixis,

P. Br. (Compos.).

verbascifolia, Gardn. 1l. cc. $519 ; 10=$ T. Bowmanii.

BOWRINGIA, Champ. ex Benth. in Hook. Kew Journ. iv. (1852) 75. LEGUMINOSAE, Benth. \& Hook, f. i. 553.

callicarpa, Champ. ex Benth. l.c.-Hongkong.

BOYKINIA, Nutt. in Journ. Acad. Philad. vii. (1834 113. SAXIFRAGEAE, Benth. \& Hook, f. i. 636 THEROFON, Rafin. New Fl. Am. iv. 66 (1836). aconitifolia, Nutt. l. c.-Am. bor.

humilis, Rafin. Aut. Bot. 9 ex S. Wats. Bibl. Ind. N. Am. Bot. i. $360=$ Ammannia humilis.

major, A. Gray, in S. Wats. Bot. Calif. i. 196.Calif.

occidentalis, Torr. E Gray, Fl. N. Am. i. 577.-Am. bor. occ.

ranunculifolia, A. Gray, in Am. Journ. Sc. Ser. I. xlii. (1842) $21=$ Saxifraga ranunculifolia.

Richardsoni, A, Gray, l. c.-Am. bor. occ.

rotundifolia, Parry, ex A. Gray, in Proc. Am. Acad. xiii. (1878) 371.-Calif

trispora, Nutt. ex Arn. in Hook. Journ. Bot. iii. (1840 $276=$ Cayaponia Boykinii.

BOYMIA, A. Juss, in Mém. Mus. Par. xii. (1825) 507 (Mem. Rut, 124) $=$ Evodia, Forst. (Rutac.).

glabrifolia, Champ. in Hook. Kew Journ. iii. (1851) $330=\mathrm{E}$. meliaefolia.

martinicensis, G. Don, Gen. Syst. i. 805.-Ins. Martinic.

rutaecarpa, A. Juss. in Mém. Mus. Par。 xii. (1825) $507=\mathrm{E}$. rutaecarpa.

BRABEJARIA, Burm. f. Fl. Cap. Prod. 30, err. typ. 26 (1768) (Gen. dub.)

verticillata, Burm. f. 1. c.-Afr. austr.

BRABEJUM, Linn. Gen. ed. I. 31 (1737)。 PROTEACEAE, Benth. \& Hook. f. iii. 177 BRABYLA, Linn. Mant. 137 (1767).

caliculatum, Blanco, F1. Filip. ed. II. $89=$ Loranthus Blancuanus.

concatenatum, Blanco, 1. c. $40=$ Alyxia laurina.

lucidum, Blanco, loco, =Alyxia stellata.

pinnatum, Blanco, 1. $\mathrm{c}_{.}=$Alyxia odorata.

stellatifolium, Linn. Sp. Pl. 121.-Afr. austr.

stellare, Knight, Proto 98 = stellatifolium.

\section{BRABEJUM :}

stellatum, Thunb. Prod. Pl. Cap. 91 = stellatifolium. stellulifolium, Murr. Syst. Veg. ed. XIII. $764=$ stellati"folium.

BRABXLA, Linn. Mant. $137(1767)=$ Brabejum, Linn. (Proteac.).

capensis, Linn. 1. $\mathrm{c}_{\circ}=$ Brabejum stellatifolium

BRACERA, Engelm. in Buchner, Rep. Pharm. Ixviii. 1839) $369=$ Brayera, Kunth (Rosac.)

BRACHANTHEMUM, DC. Prod. vi. 44 (1837) = Chry santhemum, Tourn. (Compos.)

fruticulosum, DC. 1. c. $45=$ C. fruticulosum.

BRACHATERA, Desv. in Nouv. Bull. Soc. Philom. ii. (1810) $189=$ Triodia, R. Br. (Gramis.

decumbens, Desv。 $1 . c_{0}=\mathrm{T}$. decumbens.

BRACHEILEMA, R. Br. in Salt, Abyss. App. 65 (1814) Vernonia, Schreb. (Compos.) paniculatum, R. Br. l. c. $=$ V. amygdalina.

BRACHIARIA, Griseb, in Ledeb. Fl. Ross。 iv. 469

$(1853)=$ Panicum, Linn. (Gramin.).
cruciformis, Griseb. 1. c. $=$ P. cruciforme

prostrata, Griseb. in Goett. Abh. vii. (1857) 263 = P. prostratum.

BRACHILOBOS et BRACHILOBUS, Desv. Journ. Bot. iii. $170(1814)=$ seq.

BRACHIOLOBOS, All. Fl. Pedem. i. $278(1785)=$ Nasturtium, R. Br. (Crucif.) amphibius, All. 1. $\mathrm{c}_{\mathrm{s}}=\mathrm{N}$. amphibium.

anceps, Link, Handb. ii. $311=$ N. anceps

armoracioides, Schur, Enum. Pl. Transs. $40=\mathrm{N}$. armoracioides.

austriacus, Schur, 1. c. $41=$ N. austriacum.

barbaraefolius, Desv. Journ. Bot. iii. (1814) $170=\mathrm{N}$. palustre.

brevistylus, Schur, Enum. Pl. Transs. $39=$ N. brevistylon.

domingensis, Desv. Journ. Bot. iii. (1814) $183=\mathrm{N}$. pyrenaicum.

hispidus, Desv. 1. c. $=$ N. palustre.

hybridus, Schur, Enum. Pl. Transs. $40=N$. austriacum. lippizensis, Link, Handb. ii. $311=$ N. lippizense.

palustris, [Clairv.] Man. Herb. 218; Schur, Enum. Pl.

Transs. $39=\mathrm{N}$. palustre

pyrenaicus, All. Fl. Pedem. i. $278=$ N. pyrenaicum.

riparius, Schur, Enum. Pl. Transs. $40=$ N. amphibium. sylvestris, All. F1. Pedem. i. $278=$ N. sylvestre.

tanacetifolius, Link, Handb. ii. $311=\mathrm{N}$. tanacetifolium.

BRACHIOLOBUS, Bernh. Syst. Verz. Erf. $181(1800)=$ praec.

BRACHIONIDIUM, Lindl. Fol. Orch, (1859) ORCHIDEAE, Benth. \& Hook. f. iii. 491.

concolor, Lindl. l. c.-Bolivia.

parvifolium, Lindl. l. c.-N. Granat.

tuberculatum, Lindl. l. c.-N. Granat.

BRACHISTUS, Miers, in Ann. \& Mag. Nat. Hist Ser. II. iii. (1849) 264. SOLANACEAE, Benth. \& Hook. f. ii. 892

Fregirardia, Dun. Ind. Sem. Monsp. (1849). Cf Ann. Sc. Nat. Sér. III. xii. (1849) 366.

SickLERA, Sendtn. in Flora, xxix。 (1846) 194 (err typ. 178), nomen prius.

ciliatus, Miers, l. c. 263.-N. Granat.

dimorphus, Miers, $l . c .267 .-\mathrm{N}$. Granat.

diversifolius, Miers, l. c. 268.-Mexic.

dumetorum, Miers, l. c. 265-N. Granat.

hebephyllus, Miers, l. c. 266.-N. Granat.

Hookerianus, Miers, l. c. 268.-Ecuador.

lanceaefolius, Miers, l. c. 267 -Peruy.

Linnaeanus, Miers, 1. c. $269=$ Physalis arborescens.

macrophyllus, Miers, l. c. 263.-N. Granat.

mollis, Miers, l.c. 264.-Peruv.

Neesianus, Miers, 1. c. $268=$ Physalis arborescens.

oblongifolius, Miers, l. c. 266.-N. Granat.

rhomboideus, Miers, l.c. 264.-N. Granat.

riparius, Miers, l. c. 265-N. Girnat.

solanaceus, Benth. E Hook. f. ex Hemsl. Biol. Contr. Am. Bot. ii. 42t. - Ntcragua.

stramonifolius, Miers, Illustr. S. Am. Plo ii。 i.Mexic.
BRACHTIA, Reichb. f. in Linnaea, xxii. (1849) $85 \%$ ORCHIDEAE, Benth. \& Hook. f. iii. 561.

ONCODIA, Lindl, Fol. Orch. (1853)

andina, Reichb. f. in Bonplandia, iv. (1856) 322,-N Granat

glumacea, Reichb. f. in Linnaea, xxii. (1849) 853 N. Granat

sulphurea, Reichb. f. in Bonplandia, ii. (1854) 14.N. Granat.

BRACHYACHYRIS, Spreng. Syst. iii. $574 \quad(1826)=$ BRACHYRIS, Nutt. = Gutierrezia, Lag. (Compos).

Euthamiae, Spreng. 1. cs = G. Euthamiae.

BRACHYACTIS, Ledeb, Fl. Ross, ii. 495 (1846) COMPOSITAE, Benth. \& Hook. f. ii. $27 \%$.

ciliata, Ledeb. $1_{0} c_{1}=$ Aster angustus.

frondosa, A. Gray, in Proc. Am. Acad。 viii. (1873 $647=$ Aster frondosus.

gyrnocephala, Rupr. Sert. Tiansch. 51.-As. centr. iliensis, Rupr. l. c.-As. centr.

indica, C. B. Clarke, Compos. Ind. $49=$ menthodora. menthodora, Benth. in Hook. Ic. Pl. t. 1106.-Reg. Himal.

obovata, Benth.l.c.sub t. 1106.-Oriens.

pubescens, Aitch. E Clarke, in fourn. Linn. Soc xviii. (1881) 68.-Ind. or

robusta, Bentho in Hook. Ic. Pl. sub to 1106,-Reg. Himal.

umbrosa, Benth. l.c.-Reg. Himal. ; As. centr.

wangtuensis, Hook. f. FI. Brit. Ind. iii. 253 umbrosa.

BRACHYANDRA, Naud, in Ann. Sc. Nat. Sér. III. ił $143(1844)=$ Pterolepis, Miq. (Melastom. perpusilla, Naud. I. $c_{0}=P$. perpusilla.

pusilla, Naud. 1. c. xiii. (1844) $360=\mathrm{P}$. perpusilla.

BRACHYANDRA., Phil. Fl. Atac. 34. t. 4 (1860) COMPOSITAE, Benth. \& Hook. f. ii. 244. macrogyne, Phil.l.c.-Chili.

BRACHYANTHES, Cham. ex Dunal, in DC. Prod. xiii I. $575(1852)=$ Petunia, Juss. (Solanac.)

nierembergiensis, Cham. ex Dunal, 1. c. $=$ P. parvi flora.

BRACHYBOTRYS, Maxim. ex Oliver, in Hook. Ic Pl. xiii. 43. t. 1254 (1878)。 BORAGINEAE. paridiformis, Maxim. ex Oliver, loc.-China.

BRACHYCARPAEA, DC. in Mém. Mus. Par. vii (1821) 247 ; et Syst. Veg. ii. 698 (1821). CRUCI FERAE, Benth. \& Hook. f. i. 87

laxa, Sond in Harv. Eo Sond. Fl. Cap. i. 33.-Afr. austr.

linifolia, Eckl. Eo Zeyh. Enum. 8.-Afr. austr. polygaloides, Eckl. Er Zeyh. .. c. 7.-Afr. austr. varians, $D C$. Syst. ii. 699.-Afr. austr.

BRACHYCENTRUM, Meissn. Gen. 114 (183\%) Centronia, D. Don (Melastom.

excelsum, Meissn. Gen. Comm. 81 = C. excelss.

BRACHYCHAETA, Torr. \& Gray, Fl, N. Am. ii. 194 (1841). COMPOSITAE, Benth. \& Hook. f, ii. $256^{\circ}$.

cordata, Torr. E Gray, l. co 195. -Am. bor.

BRACHYCHEILA, Harv, ex Eckl. \& Zeyh, in Linnaea. xx. (1847) $192=$ Euclea, Linn. (Ebenac pubescens, Harv, 1. $c_{2}=\mathrm{E}$, polyaudra.

BRACHYCHITON, Sehott \& Endl. Meletem. 3f is 1 s2 Sterculia, Lin

acerifolium, F. Muell. Fragm, i. $1=S$. acerifolin Bid willti, Hook. Bot. Mag. t. $5138=$ S. Bidwilli. Delabechei, F. Muell. Pl. Vict. i. $15 i=$ S. rupestris. discolor, F. Muell. Fragmo i. $1=$ S. disculur.

diversifolium, R. Br. in Benn. P1. Jav. Kar. $294=S$ enudata.

Gregorii, F. Mfucll. in Hook. Kew Journ. ir. (155i 1!9 - S. diversifolin.

incaurum, R. 13r. in Bena. PI. Jav. Kar. 29: $=3$ incourum,

Luridum, C. Moore, ex F. Mucll. Fragm. i. 1luricla.

parado.rum, Schout, Mlcietem. $\$ \$-S$. ramitlora 
BRACHYCHITON :-

platanoides, R. Br. in Benn. Pl. Jav. Rar. $234=$ Sterculia trichosiphon.

populneum, R. Br. 1. c. $=\mathrm{S}$. diversifolia.

ramiflorum, $\mathrm{R}$. Br. 1. $\mathrm{c}_{a}=\mathrm{S}$. ramiflora.

BRACHYCLADOS, D. Don, in Phil. Mag. (1832) 391. COMPOSITAE, Benth. \& Hook. f. ii. 495. lycioides, $D$. Don, $l$. $c-$-Chili.

BRACHYCODON, Prog. in Mart. F1. Bras. vi. I. 229. t. $42(1865)=$ Pagaea, Griseb. (Gentian.). pumilus, Prog. 1. c. 230.-Bras, ramosissimus, Prog. 1. c.-Bras.

BRACHYCOME, Cass. in Dict. Sc. Nat. xxxvii 491 (1825). COMPOSITAE, Benth. \& Hook. f. ii. 264.

Brachyscome, Cass, in Bull. Soc. Philom. (1816) 199.

Brachystephium, Less. Syn. Comp. 388 (1832).

Ctenosperma, F. Muell. ex Pfeiff. Nom. i. 936 (1874).

Panuerina, Cass. in Dict. Sc. Nat. xxxvii. 492 (1825)

Silphiosperma, Steetz, in Lehm. P1. Preiss. i. 433 (1844).

Steiroglossa, DC. Prod. vi. 38 (1838)

aculeata, Less. Syn. Comp. $192=$ Sieberi

angustifolia, A. Cunn. in DC. Prod. v. (1834) 306.Austral.

assamica, C. B. Clarke, Compos. Ind 40.-Assam.

basaltica, F. Muell. Fragm. 1.50.-Austral

bellidioides, Steetz, in Lehm. Pl. Preiss. i. $426=$ pusilla.

Billardieri, Benth. Fl. Austral. iii. 518.-Austral.

calocarpa, F. Muell. in Linnaea, xxv. (1852) 399. Austral.

capillacea, Walp. Rep. ii. $584=$ iberidifolia

cardiocarpa, F. Muell. ex Benth. Fl. Austral. iii. 517 -Austral.

cheilocarpa, F. Muell. in Wing, South Sc. Record, it. (1882) 172.-Austral.

chrysoglossa, F. Muell. in Trans. Phil. Soc. Vict. i (1855) $44=$ marginata

ciliaris, Less. Syn. Comp. 192.-Austral.

collina, Benth. Fl. Austral. iii. 521.-Austral,

debilis, Sond. in Linnaea, xxy. (1852) 477.-Austral.

decipiens, Hook. f. in Hook. Lond. Fourn. Bot. vi

(1847) 114-Austral.

discolor, C. Stuart, ex Benth. Fl. Austral. iii. 520.Austral.

diversifolia, Fisch. E Mey. Ind. Sem. Hort. Petrop. ii. 31.-Austral.

Drummondii, Walp. Rep. ii. $584=$ ciliaris

exilis, Sond. in Linnaea, xxv. (1852) 473.-Austral.

glabra, Benth. in Enum. PI. Hueg. $59=$ multifida

glandulosa, Benth. Fl. Austral. iii. 520.-Austral.

glauca, Walp. in Linnaea, xiv. (1840) $315=$ stricta.

goniocarpa, Sond. E F. Muell. in Linnaea, xxv. (1852 474.-Austral.

graminea, F. Muell. Fragm. i. 49.-Austral.

heterodonta, DC.Prod. v. 305.-Austral.

heterophylla, Benth. in Enum. Pl. Hueg. i. 50.Austral.

iberidifolia, Benth. l. c. 59.-Austral.

lanuginosa, Steetz, in Lehm. Pl. Preiss. i. $427=$ ciliaris.

latisquamea, F. Muell. Fragm. xi. 16.-Austral.

leptocarpa, F. Muell. in Trans. Phil. Soc. Vict. i. (1855) 43 - exilis.

leucanthemifolia, Benth. in Enum. Pl. Hueg. $60=$ stricta.

linearifolia, DC. Prod. v, 306.-A ustral.

linearifolia, Hook. f. Fl. Tasm, i, $185=$ cardiocarpa. marginata, Benth. in Enum. Pl. Hueg. 60.-Austral. melanocarpa, F. Muell. $\xi$ Sond. in Linnaea, xxy. (1852) 476.-Austral.

mexicana, Klatt, in Leopoldina, xix. (1883) $32=$ Bellis mexicana.

microcarpa, F. Muell. Fragm. i. 50,-Austral.

mossambicensis, Oliver E Hiern, in Oliver, Fl. Trop Afr. iii. 305.-Afr. trop.

Muelleri, Sond. in Linnaea, xxv. (1852) 475.Austral.

multicaulis, F. Muell, in Trans. Phil. Soc. Vict. i. (1855) 43 = ciliaris.

multifida, DC. Prod.v. 306.-Austral

\section{BRACHY COME :-}

aivalis, F Muell. in Trans. Phil. Soc. Vict. i. (1855)

43.-Austral.

oblongifolia, Benth. in Enum. Pl. Hueg. $60=$ stricta

odorata, Hook. f. Handb. N. Zeal. Fl. 138,-N Zel.

pachyptera, Turcz. in Bull. Soc. Nat. Mosc. xxiv. 1851) I. 175.-Austral.

parvula, Hook. f. Fl. Tasm. i. 185.-Austral.

pinnata, Hook. f. Handb. N. Zeal. Fl. 1381.-N Zel.

ptychocarpa, F. Muell. in Trans. Phil. Soc. Vict. i. (1855) 43.-Austral.

pumila, Walp. Rep. ii. $584=$ Billardieri

pusilla, Steetz, in Lehm. Pl. Preiss. i. 427.-Austral.

radicans, Steetz, l. c. 429.-Austral.

radicata, Hook. f. Fl. N.Zel. i. 127.-N. Zel.

scapiformis, DC. Prod. v. 306.-Austral.

scapigera, $D C$. $l$. $c$. viii. 277.-Austral.

segmentosa, F. Muell. Fragm. viii. 65 ; 144.-Ins.

Dom. Howe.

Sieberi, DC. Prod. v. 306.-Austral.

simplicifolia, Armst. in Trans. N.Z. Inst. xiii. (1881) 338.-N. Zel

Sinclairii, Hook. f. Handb. N. Zeal. Fl. 137,-N. Zel. squalida, Hook. f. in Hook. Lond. Journ. Bot. v

(1846) $115=$ ciliaris

stricta, DC. Prod v, 305.-Austral.

strongylospermoides, Walp. in Linnaea, xiv. (1840) $305=$ ciliaris

Stuartii, Benth. Fl. Austral. iii. 513.-Austral.

sylvestris, Klatt, in Leopoldina, xix. (1883) $32=$ Bellis sylvestris?

tenella, Turcz, in Bull. Soc. Nat. Mosc, xxiv. (1851) $176=$ collina

tenera, Benth. in Enum. Pl. Hueg. $59=$ multifida. tenuiscapa, Hook. fo in Hook. Lond. Journ. Bot. vi (1847) $114=$ scapiformis.

Thomsonii, T. Kirk, in Trans. N.Z. Inst. xvi. (1884) 372.-N. Zel.

trachycarpa, F. Muell. in Linnaea, xxv. (1852) 339.Austral.

xanthocomoides, Less. in Linnaea, ix. (1834) $265=$ Bellis xanthocomoides.

xeranthemoides, Less. ex Steud, Nom. ed. II. i. $220=$ Xanthocephalum Alamani.

BRACHYCOME, Gaudich. Freyc. Voy. Bot. 467 (1826 =Vittadinia, Rich. (Compos.)

dentata, Gaudich, 1. c. $468=$ V. australis ?

spathulata, Gaudich. 1. c. = V. australis.

triloba, Gaudich. 1. c. $467=\mathrm{V}$. australis

BRACHYCORYS, Schrad. Cat. Hort. Goetting. (1830).Cf. Linnaea, vi. (1831) Litt. $72=$ Lindenbergia, Linn. (Scrophular.).

parviflora, Schrad. 1. c. = L. urticaefolia.

BRACHYCORYTHIS, Lindi. Gen. et Sp. Orch. 363 (1838). ORCHIDEAE, Benth. \& Hook. f. iii. 632.

Bulbinella, Reichb. f. in Flora, 1. (1867) 116 (sphalm. 161). -Afr. austr.

Gerardi, Reichb. f, l. c-Afr, austr.

Kalbreyeri, Reichb. f. l. c. 1xi. (1878) 77.-Afr. trop.

Mac-Owaniana, Reichb.f. Otia Bot. Hamb. 104.-Afr. austr.

pleistophylla, Reichb. f. $l$. $c$-Afr. trop.

ovata, Lindl. Gen. et Sp. Orch. 363.-Afr. austr.

pubescens, Harv. Thes. Cap. I. 35.-Afr. austr.

Pumilio, Reichb. $f$. in Flora, lxv. (1882) 531.Afr. trop.

Schweinfurthii, Reichb. f. Otia Bot. Hamb. 59.-Afr. trop.

tenuior, Reichb. f. in Flora, xlviii. (1865) 183.Afr. trop.

Tysoni, Bolus, in Fourn. Linn. Soc. xx. (1884) 485.Afr. austr.

Welwitschii, Reichb.f. in Flora, 1. (1867) 99.-Afr. trop.

Zeyheri, Reichb. f. 1. c. $117=$ Schizochilus Zeyheri.

BRACHYDEREA, Cass. in Dict. Sc. Nat. xlviii. 429 (1827)=Crepis, Linn. (Compos.).

alpestris, Sch. Bip. ex Nym. Consp. $455=$ C. alpestris. aurea, Sch. Bip. in Pollichia, xxii-iv. (1866) $318=$ C. aurea.

biennis, Sch. Bip. 1. c. $=$ C. biennis.
BRACHYDEREA :-

chondrilloides, Sch. Bip. ex Nym. Consp. $456=$ Crepis chondrilloides.

grandiflora, Sch. Bip. ex Nym. 1. c. $455=$ C. grandiflora. heterantha, Sch. Bip. in Pollichia, xxii-iv. (1866) 318 = Lactuca Dubyaea.

Facquinii, Sch. Bip. 1. c. = C. Jacquinii

jubata, Sch. Bip. 1. c. =C. jubata.

nicaeënsis, Sch. Bip. 1. c. =C nicaeënsis.

rigida, Cass, in Dict. Sc. Nat. xlviii. $430=$ C. rigida

Rueppellii, Sch. Bip. in Schweinf, Beitr. Fl. Aethiop. $283=$ C. Rueppellii.

Schultzii, Sch. Bip. 1. c. =C. Schultzii.

tenerrima, Sch. Bip. I. c. $=$ C. carbonaria

tenuifolia, Sch. Bip. in Bonplandia, x. (1862) $331=$ C. tenuifolia.

xylorrhiza, Sch. Bip. ex Schweinf. Beitr. Fl. Aethiop. 284.-Afr. trop.

BRACHYELYTRUM, Beauv. Agrost. 39. t. 9. f. 2 1812). GRAMINEAE, Benth. \& Hook. f Gen. iii. 1144.

aristatum, Roem. \& Schult. Syst. ii. $413=$ erectum.

erectum, Beauv. Agrost. 39, 155.-Am. bor.

BRACHYGLOTTIS, Forst. Char. Gen. 91. t. 46 (1776). COMPOSITAE, Benth. \& Hook. f. ii. 444.

Bidwillit, Hook. f. Fl. N. Zel. ii. $342=$ Senecio Bidwillii.

Caledoniae, $D C$. Prod. v. 211.-N. Caled.

elaeagnifolia, Hook, f. Fl. N. Zel. t. $41=$ Senecio elaeagnifolius,

Forsteri, DC. Prod. v. 211.-N. Hebrid.

Forsteri, Hook. f. Fl. N. Zel. ii. $342=$ repanda

perdicioides, Hook. f. l. $\mathrm{c}_{*}=$ Senecio perdicioides

Rani, A. Cunn. in Ann. Nat. Hist. ii. (1839) $132=$ Olearia Cunninghami.

Rangiora, F. Buch. in Trans. N. Z. Inst. xiv. (1882) 357.-N. Zel.

repanda, Forst. Char. Gen.92.-N. Zel.

rotundifolia, Forst. 1. c. $=$ Senecio rotundifolius.

BRACHYGYNE, Cass, in Dict. Sc. Nat. 1. (1827) $493=$ Eriocephalus, Linn. (Compos.)

BRACHYLAENA, R. Br. in Trans. Linn. Soc. xii. (1816) 115. COMPOSITAE, Benth. \& Hook. f. ii. 288.

Oligocarpha, Cass. in Bull.Soc. Philom. (1817) 151, dentata, $D C$. Prod. v. 430.-Afr. austr.

discolor, $D C$. l. . . - Afr. austr.

elliptica, Less. Syn. Comp. 208.-Afr. austr.

grandifolia, DC. Prod v, 430-Afr austr.

natalensis, Sch. Bip. ex Walp. Rep. ii. $972=$ discolor. nereifolia, R. Br, in Trans, Linn. Soc. xii. (1816) 115 -Afr. austr.

racemosa, Less. Syn. Comp. 208.-Afr. austr

trinervia, Sond. in Linnaea, xxiii. (1850) 63.-Afr. austr.

unifora, Harv. in Harv. \& Sond. Fl. Cap. iii. 117.Afr. austr.

BRACHYLEPIS, Wight \& Am. Contrib. Bot. Ind 63 (1834). ASCLEPIADEAE, Benth. \& Hook. f. ii. 742.

nervosa, Wight EN Arn.l. c.-Ind. or.

BRACHYLEPIS, C. A. Mey, in Ledeb. Fl. Alt. i. 370 (1829) = Anabasis, Linn. (Chenopod.).

elatior, C. A. Mey. in Bull. Sc. Acad. Pétersb. viii. (1840) $341=$ A. phyllophora.

eriopoda, Schrenk, in Bull. Phys.-Math. Acad. Pétersb. i. (1843) $360=$ A. phyllophora.

hispidula, Bunge, in Act. Hort. Petrop. vi. (1879) 444 - Turkestan

humilis, Less. in Linnaea, ix. (1834) $198=$ salsa. intermedia, Kar. \& Kir. in Bull. Soc. Nat. Mosc. xv. (1842) $432=$ A. phyllophora.

jaxartica, Bunge, in Act. Hort. Petrop. vi. (1879) 443 -Reg. Casp.

salsa, C. A. Mey. in Ledeb. Fl. Alt. i. 372.-Reg. Casp.

truncata, Schrenk, in Bull. Phys.-Math. Acad. Pétersb. ii. $(18 \pm 4) 193=$ A. trunicata.

BRACHYLEPIS, Hook. \& Arn. in Hook. Journ. Bot (1834) $290=$ Melinia, Decne. (Asclep.)

Candolleana, Hook. \& Am. 1. c. $291=$ M. Canảolleana. 
BRACHYLOBOS, Desv. Journ. Bot. iii. (1814) $170=$ seq.

BRACHYLOBUS, Link, Handb. vii. 311 (1831) = BRACHIOLOBOS, All. = Nasturtium, R. Br. (Crucif.).

BRACHYLOBUS, Dulac, Fl, Hautes-Pyr. 279 (1867)= Melilotus, Tourn. (Legumin.)

officinatis, Dulac, 1. $c_{2}=$ M. officinalis.

BRACHYLOMA, Hanst. in Linnaea, xxvi. (1853) $203=$ Isoloma, Decne. (1848) (Gesnerac.).

elongatum, Hanst. 1. c. xxix。 (1857-58) 532.Ecuador?

erianthum, Hanst. 1. c. $530=$ I. erianthum.

hirsutum, Hanst. in Linnaea, xxvi. (1853) 203; xxix $1857-58) 526=\mathrm{I}$. hirsutum.

hondense, Hanst. 1. c. xxvi. (1853) 203, 213. t. f. $17=$ I. hondense.

incurvum, Oerst. in Vidensk. Selsk. Skr. V. v. (1861) $105=\mathrm{I}$. incurvum.

Karstenianum, Hanst. in Karst. Fl. Colomb. i. 101. t. 50.-N. Granat.

leucomallon, Hanst. in Linnaea, xxix. (1857-58) 528. $-\mathrm{N}$. Granat.

longiflorum, Hanst. 1. c. $530=\mathrm{I}$. longipes.

longifolium, Oerst. in Vidensk. Selsk. Skr. V. v. (1861) $104=\mathrm{I}$. longifolium.

longipes, Hanst. in Linnaea, xxix. (1857-58) $530=\mathrm{I}$. longipes,

molle, Hanst 1, c. $528=$ I. molle.

Moritzianum, Bouché \& Hanst. I. c. 524.-N. Granat.

petiolare, Hanst. 1. c. $534=$ I. petiolare.

pictum, Oerst. in Vidensk. Selsk. Skr. V. v. (1861) 104 $=1$. pictem.

pilosum, Oerst. 1. c. $103=$ I. pilosum.

rhodomallon, Hanst. in Linnaea, xxix, (1857-58) 526. - Venezuela.

rhynchocarpum, Oerst. in Vidensk. Selsk. Skr. V. v. (1861) $103=\mathrm{I}$. rhynchocarpum.

rubricaule, Hanst. in Linnaea, xxix. (1857-58) $526=$ I. rubricaule.

strictum, Oerst. in Vidensk. Selsk. Skr, V. v. (1861) $103=$ I. strictum.

Trianae, Hanst. in Linnaea, xxix. (1857-58) 532 I. Trianaei.

tubiflora, Oerst. in Vidensk: Selsk. Skr. V. v. (1861) $105=\mathrm{I}$. tubiflorum.

ventricosum, Hanst. in Linnaea, xxix. (1857-58) 528.Hab. ?

vestitum, Hanst. 1. c. $530=$ I. vestitum

BRACHYLOMA, Sond. in Lehm. Pl. Preiss, i. 304 (1845). EPACRIDEAE, Benth. \& Hook. f. ii. 613 ciliatum, Benth. Fl. Austral. iv, 173,-Austral. concolor, F. Muell. Fragm. vi. 39.-Anstral. daphnoides, Benth. Fl. Austral. iv. 173.-Austral. depressum, Benth. l.c.-Austral.

ericoides, Sond. in Linnaea, xxvi. (1853-55) 247.Austral.

Preissii, Sond. in Lehm. Pl. Preiss. i. 305.-Austral. Scortechinii, F. Muell. Fragm. xi. 121.-Austral.

BRACHYMERIS, DC. Prod, vi. 76 (1837)=Maras. modes, DC. (Compos.).

scoparia, DC. 1. C.-Afr. austr.

BRACHYNEMA, Benth. in Trans. Linn. Soc, xxii. (1859) 125. t. 22. EBENACEAE, Benth. \& Hook. f. ii. 666 .

ramiflorum, Benth. l. c. 126.-Bras.

BRACHYNEMA, Griff. Notul. iv. 176 (1854) = Sphenodesma, Jack (Verben.)

ferruginea, Griff. l. c. $=$ S. microstylis.

BRACHYNEMA, F. Muell. Fragm, iii. 90 (1862)= Abrophyllum, Hook. f. (Saxifrag.)

ornans, $\mathrm{F}$. Muell. l. $\mathrm{c}=\mathrm{A}$, ornans.

BRACHYOGLOTIS, Lam. Encyc, i, 459 (1783)= Brachyglottis, Forst.(Compos.).

BRACHYOLOBOS, DC. FI. Fr. v. $661(1805)=$ BRA CHIOLOBOS, All, = Nasturtium, R. Br. (Crucif.).
BRACHYOTUM, Triana, in Benth. \& Hook. f. Gen. i. 743 (1867). MELASTOMACEAE, Benth. \& Hook. f. l. c.

Alifana, Rafin. Sylva Tellur. 101 (1838)

Benthamianum, Triana, in Trans. Linn. Soc. xxviii. 1871) 49.-Peruy

campanulare, Triana, l. c. 48-Peruv.

campylanthum, Triana, l.c. 49.--Peruv

canescens, Triana, l. c. 48.-N. Granat.

cernuum, Triana, $l, c .-N$. Granat.

confertum, Triana, l.c. 49--Peruv.

floribundum, Triana, $l$. $c$,-Peruy.

gracilescens, Triana, l. c.-Peruv.

hermannioides, Triana, $l$. $c$. - Eolivia

Jamesonii, Triana, l. c.-Ecuador.

leclifolium, Triana, l. c. 48.-Peruy.

lutescens, Triana, $l$. $c$.-Peruv.

lycopodioides, Triana, l. c. 49.-Peray.

Microdon, Triana, l.c.-Bolivia.

microphyllum, Triana, loc.-Peruv.

Nandini, Triana, l. c. 48.-Ecuador.

Pentlandi, Triana, l. c. 49,-Bolivia,

quinquenerve, Triana, $l . c_{0}$ 48.--Peruv.

Radula, Trian $\alpha, l . c .-$ Peruv.

rosmarinifolium, Triana, $l$. c. 49--Peruv

rostratum, Triana, l. c. 48.-Peruv.

sanguinolentum, Triana, i. c. 49.-Bolivia

strigosum, Triana, l. c.-N. Granat.

trichocalyx, Triana, l. c. 48.-Ecuador.

BRACHYPAPPUS, Sch. Bip. in Flora, xxxviii. (1855 $119=$ Senecio, Tourn. (Compos.)

candicans, Sch. Bip. I. c. $120=$ S. candicans.

Smithii, Sch. Bip. 1. c. =S. Smithii.

BRACHYPODIUM, Beauv, Agrost. 100 partim 1812) GRAMINEAE, Benth. \& Hook, f, iii, 1201. DisticheiA, Ehrh. Beitr. iv. 148 (1789).

Hemibromus, Steud. Syn. Pl. Gram. 317 (1854)

TrachyNIA, Link, Hort. Berol, i. 42 (1827).

abbreviatum, Dum. Obs. Gram. Belg. 99.-Belgium.

Allionii, Presl, Fl. Sic. p. xlv, in nota $=$ ramosum. asperum, Roem. \& Schult. Syst. ii. $742=$ distachyon Barrelieri, Roem. \& Schult. 1. c. $741=$ pinnatum. biflorum, Kunth, Enum. Pl. i. 543 (Ind.) = Agropyron biflorum.

biunciale, Roem. \& Schult. Syst. ii. $746=$ Festuca Poa. Boissievi, Nym. Syll, $425=$ ramosa.

brevisetum, Roem. \& Schult. Syst. ii. $742=$ Triticum brevisetum.

caespitosum, Presl, Fl. Sic. p. xlv, nomen $=$ ramosum caespitosum, Roem. \& Schult. Syst. ii. $737=$ pinnatum. cenisium, Beauv. Agrost, 155, nomen = Poa cenisia. chinense, S. L. Moore, in fourn. Bot. xiii. (1875) 230 . -China

ciliatum, Beauv. Agrost. 101 = distachyum.

commutatum, Beauv, 1. c. = Bromus racemosus. contractum, Presl, Cyp. et Gram. Sic. $40=$ pinnatum. corniculatum, Lam. F1. Fr. v. $608=$ pionatum. dalmaticum, Vis.Fl. Dalm.Suppl.23.t.1.-Europ. austr. distachyum, Beauv. Agrost. 101.-Reg. Mediterr. Oriens.

distachyon, Roem. \& Schult. Syst. ii. $741=$ praec

divaricatum, Presl, Cyp. et Gram. Sic. $40=$ Festuca divaricata.

Festuca, Beauv. Agrost. 101.-Hab.?

festucoides, Beauv. 1. c. 155, nomen = Festuca Poa

festucoides, Link, Enum. Hort. Berol. i. $95=$ Festuca tenella.

Hexum, Nees, Fl. Afr. Gram. 456.-Afr. austr

Fontanesianum, Nees, 1. c. $457=$ ramosum.

fragile, Beauv. Agrost. 155 , nomen = Triticum fragile

geniculatum, C. Koch, in Linnaea, xxi. (1848) 4.22 distachyum.

genuense, Roem. \& Schult. Syst. ii. $742=$ Triticum genuense.

gracile, Beauv. Agrost. $101=$ sylvaticum

Halleri, Beauv, I. $\mathrm{c}=$ Festuce Poa.

hispanicum, Reichb. Fl. Germ. Excurs, 140= Festaca Pua

Hostii, Link, Hort, Berol. i. $40=$ ramosum

intermedium, Schur, in Verh. Sicbenb. Ver. Natura. iv. (1853) 89.-Transsylv.

interruptum, Roem. \& Schult. Syst. ii. $747=$ Aperd interrupta.

involutum, Buese, in Mig. Pl. Fungh. 34i., Malnyn.

japonicum, Moq. Ann. Mus. Bot. Lugd. Bat. ii. 286.Jap̧on.

\section{BRACHYPODIUM}

Kotschyi, Boiss, Fl. Orient. v. 659.-Cilicia

latifolium, Fourn. Mex. Pl. Enum. Gram. 125; ex Hemsl. Biol. Centr. Am. Bot. iii. 584.-Mexic.

littorale, Roem. \& Schult. Syst. ii. $740=$ ramosum.

loliaceum, Fries, Mant. iii. 15=Glyceria fluitans.

loliaceum, Link, Hort. Berol. i. 42 = Festuca elatior.

loliaceum, Roem. \& Schult. Syst. ii. 740=Demazeria loliacea.

longearistatum, Boiss. Diagn. Sér. I. vii, 127=Agropyron longearistatum.

longifolium, Beauv. Agrnst. $101=$ Bromus longifolius. macropodum, Hack. in Oestr. Bot. Zeitschr. xxvil (1877) 48.-Europ. austr.

macrostachyum, Bess. ex Roem. \& Schult. Syst, Mant. iii. $651=$ distachyum

maritimum, Roem. \& Schult. Syst. ii. $743=$ Cutandia maritima.

megastachyum, Bess. ex Roem. \& Schult. Syst. Mant. iii. 651 = distachyum.

mexicanum, Link, Hort. Berol. i. 41.-Mexic

monostachyum, Nym. Consp. $843=$ distachyum.

montanum, Nym. Syll. $426=$ Festuca montana.

mucronatum, Willk in Willk \& Lange, Prod. El. Hisp. i. 111.-Hispan.

Nardus, Beauv. Agrost. 155, nomen = Festuca tenuifora Nardus, Link, Lnum. Hort, Berol. i. $95=$ Festuca Poa nepalense, Nees, ex Steud. Syn. Pl. Gram. 316.

Ind. or.

nigricans, Roem. \& Schult. Syst. ii. $743=$ Triticum nigricans.

obtusifolium, Link, Enum. Hort. Berol. i. $95=$ ramosum.

patens, Nym. Syll. $425=$ Festuca loliacea

pentastachyum, Nym. Consp. 843 = distachyum.

peruvianum, Kunth, Enum. Pl. 543 (Ind.) = Agropyron peruvianum.

phleoides, Beauv. Agrost. 155, nomen $=$ Koeleria phleoides.

phoenicoides, Roem. \& Schult. Syst. ii. $740=$ ramosun. pinnatum, Beauv. Agrost. 101.-Europ.; Reg. Mediter. Plukenetii, Beauv. 1. c. ; Link, Hort. Berol. i. $40=$ ramosum.

Poa, Beauv. 1. c.; Roem. \& Schult. Syst. ii. $746=$ Festuca Poa.

psilanthum, Link, Gram. Europ. Austr. Obs. Bot. 398 = Festuca tenuiflora.

ramosum, S. F. Gray, Nat. Arr. Brit. Pl. ii. 113

Glyceria maritima?

ramosum, Roem. \& Schult. Syst. ii. $737 .-$ Reg. Mediterr.

retusum, Beauv. Agrost. $101=$ ramosum

rigidulum, Opiz E Bercht. Oek. Fl. Boekm. i. 392.Bohem.

rigidum, Link, Enum. Hort. Berol, i. $96=$ Triticum asperum.

Rottboellla, Beauv. Agrost. 155, nomen = ramosum. rupestre, Roem. \& Schult. Syst. ii. $730^{\circ}=$ pinnatum. sanctum, Fanka, in Oestr. Bot. Zeitschr. xxii. (187\% 181.-Macedon.

scaberrimum, Wight \& Arn, ex Steud. Nom, ed. II. i 221 = Triticum scaberrimum.

Schrenkianum, Ledeb. Fl. Ross. iv. 346.-Sibiria. setifolium, Schur, Enum. Pl. Transs. 800.-Hangas. strigosum, Schult. in Roem. \& Schult. Syst. Mant. 1i. $404=$ Triticum strigosum.

subtile, De Not. Prosp. F1. Ligust. $49=$ distachyom. subulatum, Fourn. Mex. Pl. Enum. Gram, 125: ea Hemsl. Biol. Centr. Am. Bot. iii. 58t.-Mexic. sylvaticum, Beawv. Agrost. 101.-Europ.; Uriens tataricum, Munro, ex Aitch. in Journ. Linn. Soc. 1880) $109=$ Agropyron longearistafum.

tenellum, Beauy. Agrost. $101=$ Festucs tenuiflors.

terellum, Roem, \& Schult. Syst. ii. $715=$ Festaca montana

Tenorianum, Schult. in Roera. \& Schult. Syst. Mant ii. $405=$ Triticum Barrelieri

tersue, Beauv, Agrost, 155, nomen Lolinm perenne. tenue, Tineo, ( al. Hort. Panorm. (152i) $13=$ Festuca incrassnta.

tenuiculsum, Roem. \& Schalt. Syst. ii. itt = Festuca P'on.

tensifforum, Roem. \& Schule. 1. c. $i 15=$ Festucs tenuiflura.

unilaterale, Beauv. Agrost. 155; Koem. \& Schul 1. c. $717=$ Triticum temuillorum.

uniolosides, Link. Enum. Ilort. Herol. i. 195 = Hema zeria sicula. 
BRACHYPTERUM, Benth. in Ann. Wien. Mus, ii. (1838) $\mathbf{1 0 1}=$ Derrîs, Lour. (Legumin.).

Benthamii, Thw. Enum. Pl. Zeyl. $93=$ D. paniculata. canarense, Dalz. \& Gibs. Bomb. Fl. $76=$ D. canarensis. elegans, Thw. Enum. P1. Zeyl. 93= D. parviflora. floribundum, Miq. Fl. Ind. Bat. i. $139=$ D. floribunda. microphyllum, Miq. Fl. Ind. Bat. Suppl. $296=$ D. microphylla.

polyphyllum, Miq. Fl. Ind. Bat. i. $139=$ D. polyphylla.

robustum, Dalz. \& Gibs. Bomb. Fl. $77=$ D. robusta scandens, Benth. in Ann. Wien. Mus. ii. (1838) $101=$ D. scandens.

timorense, Benth. in Miq. Pl. Jungh. i。 $255=\mathrm{D}$. timorensis.

BRACHYPTERYS, A. Juss. in Deless. Ic. Sel. iii. 20 (1837). MALPIGHIACEAE, Benth. \& Hook. f. i. 256 .

australis, A. Fuss. l. c.-Bras.

borealis, A. Fuss. in Arch. Mus, Par, iii. (1843) 356. t. 2. f. 16. - Am. centr.

BRACHYPUS, Ledeb. FI. Ross。 i. $133(1842)=$ Lunaria, Tourn, (Crucif.).

asper, Ledeb. 1. c. (=Fibigia suffruticosa).-Rossia.

BRACHYRAMPHUS, DC. Prod. vii. $176(1838)=$

Lactuca, Tourn. (Compos.).

caribaeus, DC. 1. c. $177=$ L. intybacea.

goraeënsis, DC. 1. c. $=\mathrm{L}$. goraeënsis.

Heyneanus, Wight, Ic. t. $1146=\mathrm{L}$. Heyneana

intybaceus, DC. Prod. vii., $177=\mathrm{L}$. intybacea.

lactucoides, T. Anders. in Journ. Linn. Soc. Bot. v. Suppl. i. (1860) $23=$ Heterachaena massaviensis. nudicaulis, Klatt, in Ann. Sc. Nat. Sér. V. xviii. (1873) $377=$ Launaea nudicaulis.

obtusus, DC. in Deless. Ic. Sel. iv. t. $96=$ Launaea nudicaulis.

ramosissimus, Benth. in Hook. Journ. Bot. i. (1834) $489=$ L. denticulata.

sinicus, Miq. in" Journ. Bot. Néerl, i. (1861) $105=$ L. denticulata.

sonchifolius, DC. Prod. vii. $177=$ L. remotiflora.

sonchifolius, Thw. Enum. Pl. Zeyl. 168=L. Hey. neana.

taraxacoides, DC. Prod. vii. $177=\mathrm{L}$. Heyneana.

BRACHYRHYNCHOS, Less. Syn. Comp. 392 (1832)= Senecio, Tourn. (Compos.)

albicaulis, DC. Prod. vi. $438=$ S. diversifolius, Harv cymbalarifolius, DC. 1. c. $=\mathrm{S}$. cymbalarifolius. diversifolius, DC. 1. c. $439=\mathrm{S}$. diversifolius, Harv.

elongatus, Less. Syn. Comp. $393=\mathrm{S}$. diversifolins, Harv.

eupatorioides, DC. Prod. iv. 439 (non seq.).-Afr. austr.

eupatorioides, Less. Syn. Comp. $393=$ S. othonnaeflorus.

junceus, Less. $1 . \mathrm{c}_{0}=\mathrm{S}$. junceus

trachycarpus, DC. Prod. vi. $438=\mathrm{S}$. incertus.

tuberosus, DC. $1 . \mathrm{c} .=\mathrm{S}$. incertus.

BRACHYRIS, Nutt. Gen. Am. ii. 163 (1818)= Gutier rezia, Lag. (Compos.)

californica, DC. Prod. v. $313=$ G. californica.

divaricata, Nutt. in Trans. Am. Phil. Soc. N. S. vii. (1841) $313=\mathrm{G}$. Enthamiae.

dracunculoides, DC. in Mém. Soc. Phys. Genèv. vii. (1836) II. 265. t. $1=$ Amphiachyris dracunculoides

Euthamiae, Nutt. Gen. Am. ii. 163=G. Euthamiae.

floribunda, Phil. in Linnaea, xxxiii. (1864-65) 137.Chili.

Gayana, Remy, in C. Gay, Fl. Chil. iv. 34.-Chili.

Iserni, Phil. in Anal. Univ. Chil. (1865) 1I. 335. Chili.

Mandonii, Sch. Bip. in Linnaea, xxxiv. (1865-66) 534.-Bolivia.

microcephala, DC. Prod. v. $313=$ G. Euthamiae.

microcephala, Hook. Ic. Pl. t. $147=$ G. texana.

Neaeana, DC. Prod. v. 313.--Mexic.

ovatifolia, DC. l. c. = Brachychaeta cordata.

paniculata, DC. 1. c. $=\mathrm{G}$. paniculata.

ramosissima, Hook. Ic. Pl. t. $142=$ Amphiachyris dracunculoides.

sectifolia, Ces. in Atti Soc. Acc. Sc. Nap. v. (1871) viI. 11.-Chili.

spathulata, Phil. in Anal. Univ. Chil. (1865) II. 336.Chili.
BRACHYSCOME, Cass. in Bull. Soc. Philom. (1816) 199.-Cf. Dict. Sc. Nat. v. Suppl. $63(1817)=$ Brachycome, Cass. (Compos.)

Billardieri, Cass. in Dict. Sc. Nat. v. Suppl. $63=$ Brachycome heterodonta.

BRACHYSCYPHA, Baker, in Journ. Linn. Soc. xi. (1871) 393 = Lachenalia, Jacq. (Liliac.) undulata, Baker, 1. c. $394=$ L. pusilla.

BRACHYSEMA, R. Br. in Ait. Hort. Kew. ed. II iii. 10 (1811). LEGUMINOSAE, Benth. \& Hook. f. i. 467

Burgesta, F. Muell. Fragm. i. 222 (1860?)

Kaleniczenkia, Turcz, in Bull. Soc. Nat. Mose. xxvi. (1853) I. 252

Leptosema, Benth. in Ann. Wien. Mus. ii. (1838) 84 acuminatum, Truff. in Rev. Hortic. (1866) 413.Hab. ?

aphyllum, Hook. Bot. Mag. t. 4481-Austral.

bossiaeoides, Benth. Fl. Austral. ii. 12.-Austral.

bracteolosum, F. Muell. Fragm. iv. 10.-Austral.

Celsianum, Lem. Hortic. Univ. v. n. 2. 33, ex Walp. Rep. v. $423=$ lanceolatum.

Chambersii, F. Muell. ex Benth. Fl. Austral. ii. 13.Austral.

daviesoides, Benth. l. c.-Austral.

lanceolatum, Meissn. in Lehm. Pl. Preiss. i. 24.Austral.

latifolium, R. Br. in Ait. Hort. Kerw. ed. II. iii. 10.Austral.

macrocarpum, Benth. Fl. Austral. ii. 13.-Austral. melanopetalum, F. Muell. Fragm. iv. 11 = undulatum. oxyloboides, Benth. Fl. Austral. ii. 12,-Austral. praemorsum, Meissn. in Lehm. Pl. Preiss. i. 25. Austral.

subcordatum, Benth. Fl. Austral. ii. 11.-Austral. tomentosum, Benth. l. c. 13.-Austral.

undulatum, Ker-Garel, in Bot, Reg, t. 642,-Austral.

uniflorum, R.Br.ex Benth.Fl. Austral. ii. 12.-Austral

BRACHYSIPHON, A. Juss. in Ann. Sc. Nat. Sér. III vi. (1846) 24. t. 2 =Sarcocolla, Linn. (Penaeac.). acutus, A. Juss. I. c. $25=$ S. acuta ericaefolius, A. Juss. 1. c. 24-Afr. austr. imbricatus, A. Juss. 1. c. $25=$ S imbricata. Mundii, Sond. in Linnaea, xxiii. (1850) 102.-Afr. austr.

rupestris, Sond. 1. c. $101=\mathrm{S}$. rupestris.

speciosus, Sond. 1. c. $103=$ S. speciosa.

BRACHYSPATHA, Schott, Syn. Aroid. $85(1856)=$ Amorphophalius, Blume (Aroid.)

consimilis, Schott, Prod. Aroid. $127=$ Hydrosme consimilis.

Konjac, C. Koch, in C. Koch \& Fint. Wochenschr. (1858); Gart. Nachr. n. 4. p. $13=$ A. Rivieri. Muelleri, Schott, Syn. Aroid. $36=$ A. Mulleri. sylvatica, Schott, l. c. $35=$ Synantherias sylvatica. variabilis, Schott, 1. c. =A. variabilis.

zeylanica, Schott, 1. c. $36=$ A. zeylanicus

BRACHYSTACHYS, Klotzsch, in Hook. Lond. Joum Bot. ii. (1843) 47 = Croton, Linn. (Euphorb.). hirta, Klotzsch, 1. c. =C. glandulosus.

BRACHYSTEGIA, Benth, in Benth. \& Hook. f. Gen. i. 582 (1865). LEGUMINOSAE, Benth. \& Hook. f. l. c.

appendiculata, Benth. in Trans. Linn. Soc. xxv (1866) 313. t. 42.-Afr. trop.

floribunda, Benth. in Hook. Ic. Pl. sub t. 1359.Afr. trop.

globiflora, Benth. l. c.-Afr. trop.

longifolin, Benth. l. c. t. 1359.-Afr. trop.

spicaeformis, Benth. in Trans. Linn. Soc. xxv. (1866) 312.-Afr. trop.

tamarindoides, Welw. ex Benth. l. c.-Afr. trop.

BRACHYSTELMA, $\mathrm{R}, \mathrm{Br}$, in Bot. Mag. t. 2343 1822). ASCLEPIADEAE, Benth. \& Hook. f. ii, 781.

Eriopetalum, Wight, Contrib. Bot. Ind. 35 (1834).

Micraster, Harv. Gen. P1. Afr. Austr. ed. II. 242 (1868).

Arnottii, Baker, in Saund. Ref. Bot. t. 9.-Afr austr.

\section{BRACHYSTELMA :}

attenuatum, Hook. $f$. Fl. Brit. Ind iv, 65.-Ind or. Barberiae, Harv. ex Hook.f. Bot. Mag. t. 5607.-Afr austr.

Beddomei, Hook. f. Fl. Brit. Ind. iv. 66.-Ind. or. caudatum, N. E. Br. in Journ. Linn. Soc. xvii. (1880) $169=$ crispum

circinnatum, E. Mey. Comm. Pl. Afr. Austr. 196.Afr. austr.

Comaru, E. Mey.l.c. 195.-Afr. austr.

crispum, R. Grah. in Edinb. Phil. Fourn. (1830) 170 -Afr. austr.

ellipticum, A. Rich. Tent. Fl. Abyss. ii. 49.-Abyssin. filiforme, Harv. Thes. Cap. i. 58. t. 93.-Afr. austr

Gerrardi, Havy l. c. ii, 61. t, 196-Afr, austr.

glabrum, Hook. f. Fl. Brit. Ind. iv. 65.-Ind, or.

hirsutum, E. Mey. Comm. Pl. Afr. Austr. 197.Afr. austr.

laevigatum, Hook. f. Fl. Brit. Ind. iv. 65.-Ind, or lineare, A. Rich. Tent. Fl. Abyss. ii. 49.-Abyssin. macrorrhizum, E. Mey. Comm. Pl. Afr. Austr, 197.Afr, austr.

maculatum, Hook. f. Fl. Brit. Ind. iv. 65.-Ind. or. micranthum, E. Mey. Comm. Pl. Afr. Austr. 196.Afr. austr.

ovatum, Oliver, in Saund. Ref. Bot. t. 226.-Afr. austr.

parviflorum, Hook.f. Fl. Brit. Ind. iv. 65.-Ind. or plocamoides, Oliver, in Trans. Linn. Soc. xxix. (1875) 112.-Afr. trop.

spathulatum, Lindl. Bot. Reg. t. 1113.-Afr. austr. tuberosum, $R$, Br. in Bot. Mag. t. 2343.Afr. austr. volubile, Hook. f. Fl. Brit. Ind. iv. 65.-Ind. or.

BRACHystem MA, D. Don, Prod. Fl. Nep. 216 (1288)

Arenaria, Rupp. (Caryophyll.)

calycinum, D. Don, $\mathrm{l}, \mathrm{c}=\mathbf{A}=\mathbf{A}$. nepalensis.

BRACHYSTEMUM, Michx, Fl. Bor. Am. ii. 5. t. 31, $32(1803)=$ Pycnanthemum, Michx. (Labiat.). lanceolatum, Willd. Enum. Hort. Berol. $623=\mathrm{P}$. lanceolatum.

linifolium, Willd. 1. c. $=$ P. linifolium.

muticum, Michx. Fl. Bor. Am. ii. 6. t. $32=$ P muticum.

verticillatum, Michx. 1. c. 6. t. $31=\mathrm{P}$. lanceolatum.

virginicum, Michx. 1. c. $6=\mathrm{P}$. lanceolatum.

BRACHYSTEPHANUS, Nees, in DC. Prod. xi. 511 (1847). ACANTHACEAE, Benth. \& Hook. f. ii. 1105 .

Lyallii, Nees, l. c.-Madag.

BRACHYSTEPHIUM, Less. Syn. Comp. $388(1832)=$ Brachycome, Cass. (Compos.).

leucanthemoides, Less. 1. c. $389=\mathrm{B}$, diversifolia.

scapigerum, DC. Prod. vi. $304=$ B. scapigera.

BRACHYSTEPIS, Pritz. Ind. Ic. 162 (1855) = Aeonia, Lindl. (Orchid.).

BRACHYSTYLIS, E. Mey. ex DC. Prod. vi. 76 (1837) Marasmodes, DC. (Compos.)

scoparia, E. Mey.' ex DC. Prod. vi. $76(=$ Brachymeris scoparia).-Afr, austr.

BRACHYSTYLUS, Dulac, Fl. Hautes-Pyr. 85 (1867)= Koeleria, Pers. (Gramin.).

cristatus, Dulac, 1. c. $=\mathrm{K}$. cristata.

setaceus, Dulac, 1. c. $=\mathrm{K}$. setacea.

BRACHYTOME, Hook. f. Ic. Pl, xi. 70, t. 1088 (1871). RUBIACEAE, Benth. \& Hook. f. ii. 87. Wallichii, Hook. f.ll. cc.-Reg. Himal.

BRACHYTROPIS, Reichb. Consp. 120 (1828) = Poly gala, Tourn.

microphylla, Willk. in Oestr. Bot. Zeitschr. xxix. (1879) $288=\mathrm{P}$. microphylla

BRACKENRIDGEA, A. Gray, Bot. U. St. Expl. Exped, i. 361. t. 42 (1854). OCHNACEAE, Benth. \& Hook. f. i. 318.

australiana, F. Muell. Fragm. v. 29.-Austral.

fascicularis, Villar, in Blanco, Fl. Phil. ed. III. Nov. $A p p$. 40.-Ins. Philipp: 


\section{BRACKENRIDGEA :-}

Hookeri, A. Gray, in Proc. Am. Acad iii. (1857) 51 -Ins. Fiji.

nitida, A. Gray, Bot. U. St. Expl. Exped. i. 362.Ins. Fiji.

zanguebarica, Oliver, in Hook. Ic. Pl. t. 1096.-Afr. trop.

BRACONOTIA, Godr. FI. Lorr. ed. I. iii. 191 (1844) [Ed. ii. (1861) Braconnotia.] = Agropyron, J.Gaertn. (Gramin.).

acuta, Godr. 1. c. $192=$ A. acutum.

elymoides, Godr. 1. c. $193=$ A. caninum.

glauca, Godr. 1. c. $192=$ A. glancum.

juncea, Godr. 1. c. = A. jnncenm.

officinarum, Godr. 1. c. =A. repens

pungens, Godr. 1. c. = A. pungens.

rigida, Godr. 1. c. = A. glancum et rigidum.

stricta, Godr. l. c. =A. strictum.

BRACTEARIA, DC. ex Steud. Nom. ed. II. i. $222(1840)$ = Tibouchina, Aubl. (Melast.).

Kappleri, Steud. ex Cogn. in Mart. F1. Bras. xiv. IIr. $375=\mathrm{T}$. aspera.

BRACTEOLARIA, Hochst, in Flora, xxiv. (1841) II. 658 = Baphia, Afzel. (Legum.)

polygalacea. Hook, f. in Hook. Niger Fl. $321=$ Baphia polygalacea.

racemosa, Hochst. in Flora, xxiv. II. (1841) $658=$ Baphia racemosa.

BRADBURIA, Torr. \& Gray, Fl. N. Am. ii. 250 (1841). COMPOSITAE, Benth. \& Hook. f. ii. 251 hirtella, Torr. E Gray, l. c.-Texas.

BRADBURIA, Spreng. Syst. iii. $255(1826)=$ seq.

BRADBURYA, Rafin. F1. Ludov. $104(1817)=\mathrm{W}$ is taria, Nutt. (Legumin.).

erecta, Rafin. 1. c. $105=$ W. speciosa

scandens, Rafin. 1. c. $104=$ W. speciosa.

BRADDLEYA, Vell. F1. Flum. 93 (1825); ii, t. 140 = Amphirrhox, Spreng. (Violar.)

legalis, Vell. I. c. 94 ; ii. t. $140=$ A. longifolia

BRADLAEIA, Neck. Elem. i. $169(1790)=$ Siler, Scop. (Umbellif.).

BRADLEA, Adans, Fam. ii. $324(1763)=$ Apios, Tourn. (Legumin.).

BRADLEIA, Banks, ex Gaertn. Fruct. ii. 127. t. 109 $(1791)=$ Glochidion, Forst. (Euphorb.)

acuminata, Wall. Cat. sub n. $7855=\mathrm{G}$. lanceo" larium.

arborescens, Steud. Nom. ed. II. i. $222=$ G. arborescens Blumei, Steud. 1. c. $=$ G. molle.

coccinea, Wall. Cat. n. $7868=\mathrm{G}$. coccineum.

coriacea, Wall. 1. c. $7872=$ Chaetocarpus castanocarpus.

coronata, Wall. 1. c. $7857=\mathrm{G}$. leiostylum.

dioica, Gaertn. ex Vahl, fide Baill. Adansonia, i. (1860)

$80=$ Flueggia microcarpa.

Finlaysoniana, Wall. Cat. n. $7860=$ G. superbum.

glauca, Labill. Sert. Austr. Caled. 76. t. $77=\mathrm{G}$. glaucum.

glaucophylla, Hassk. Cat. Hort. Bog. Alt. $242=$ G. glaucum.

Glochidion, Gaertn. Fruct. ii. 128. t. $109=$ G. ramiflorum.

hirsuta, Roxb. Hort. Beng. 104; F1. Ind. iii. $699=$ G. hirsutum.

impuber, Roxb. Il. cc. 104, $698=\mathrm{G}$. Lambertianum

Kipareh, Stend. Nom. ed. II. i, $222=$ G. glaucum.

laevigata, Wall. Cat. n.7859.-Ind. or.

lanceolaria, Roxb. Hort. Beng. 69 ; Fl. Ind. iii. $697=$ G. lanceolarium

lanceolaria, Wall. Cat. n. $7855=\mathrm{G}$. Hohenackeri et sphaerogynum.

littorea, Steud. Nom. ed. II. i. $222=$ G, littorale

lucida, Steud. 1. c. = G. lucidum.

lutescens, Steud. 1. c. = G. Iutescens.

macrocarpa, Steud. 1. c, = G. macrocarpum.

macrophylla, Labill. Sert. Austr. Caled. 77. t. $78=$ G. macrophyllum.

mollis, Steud. Nom. ed. II. i. $222=$ G. molle.
BRADLEIA :-

mollis, Wall. Cat. n. $7858=$ Glochidion hirsutum. moluccana, Steud. Nom. ed. II. i. $222=\mathrm{G}$. moluc canum.

multilocularis, Spreng. Syst. iii. $19 \Rightarrow$ G. multiloculare Nephroia, Steud. Nom. ed. I. $116=$ Cocculus Nephroia nitida, Roxb. Hort. Beng. 69 ; Fl. Ind. iii. $699=$ G. zeylanicum.

nitida, Wall. Cat. n. $7867=\mathrm{G}$, multiloculare.

obliqua, Spreng. Syst. iii. $19=$ G. zeylanicum.

obliqua, Wight, ex Wall. Cat. n. $7947=$ Phyllanthus Wightianus.

obtusa, Wall. 1. c. $7869=\mathrm{G}$. littorale

ovata, Wall. 1. c. $7052=\mathrm{G}$. velutinum.

philippensis, Buch.-Ham, in Wall. 1. c. $7871=$

$\mathrm{G}$, mutiloculare.

philippensis, Willd. Sp. P1. iv. $592=$ G. philippinense philippica, Cav. Ic. iv. 48, t. $371=\mathrm{G}$. philippinense pinnata, Roxb. Hort. Beng. 69 ; Fl. Ind. iii, $700=$ G. obscurum.

pubera, Roxb. 11. cc. 104; $698=\mathrm{G}$. multiloculare. rubra, Steud. Nom. ed. II. i. $222=$ G. rubrum.

sinensis, Siebold, ex Miq. Ann. Mus. Bot. Lugd. Bat. iii. $128=\mathrm{G}$. obovatum.

sinica, Gaertn. Fruct. ii. 127. t. 109. f. $1=$ G. sinicum. sinica, Hort. ex Muell. Arg. in DC. Prod. xv. 1I. $414=$

Phyllanthus nobilis.

timoriensis, Steud. Nom ed. II i $222=\mathrm{G}$, zeylanicum. Wightiana, Wall. Cat. n. $7862=\mathrm{G}$. ellipticum.

zeylanica, Gaertn. Fruct. ii. 128. t. $109=\mathrm{G}$. zeyla nicum.

zeylanica, Labill. Sert. Austr. Caled. 76. t. $76=$ G. philippinense.

zeylanica, Wall. Cat. n. 7855 G. $=$ G. lanceolarium.

BRAGANTIA, Lour. Fl. Cochinch. 528 (1790) ARISTOLOCHIACEAE, Benth. \& Hook, f. iii. 122. APAMA, Lam. Encyc. i. 91 (1783)

Asiphonia, Griff. in Trans. Linn. Soc. xix. (1845) 333. t. 37

Ceramium, Blume, Bijdr. 1134 (1826).

Cyclodiscus, Klotzsch, in Monatsb. Acad. Berl (1859) 591.

MUNNICKIA, Reichb. Consp. 85 (1828).

StrakaeA, Presl, Epim. Bot. 221 (1850)

TrimerizA, Lindl. Bot. Reg. sub t. 1543 (1832).

VAnHallia, Schult. f. Syst. vii. 18 (1829).

corymbosa, Griff. in Trans. Linn. Soc.xix. (1845) 335 -Malaya.

hispida, Thw. ex Duch. in DC. Prod. xv. I. $430=$ Wallichii.

khasiyana, Griff. in Trans. Linn. Soc. xix. (1845) 336 $=$ tomentosa.

latifolia, Lindl. Bot. Reg. sub t. $1543=$ Wallichii. melastomaefolia, Duch. in DC. Prod. xv. I. $429=$ corymbosa.

racemosa, Lour. Fl. Cochinch. 528,-China.

tomentosa, Blume, Enum. Pl. Fav. 82.-Ind. or. Malaya.

Wallichii, $R$. Br. in Wall. Cat. n. 7415.-Ind. or.

BRAGANTIA, Vand. Fasc. Pl. Nov. (1771) $6=$ Gomphrena, Linn. (Amarant.)

Vandelli, Steud. Nom. ed. II. i. $222=$ G. officinalis.

BRAHEA, Mart. Hist. Nat. Palm。 iii. 243, 319. t. 197 , 162 (1830?). PALMAE, Benth. \& Hook. f. iii. 926. armata, S. Wats. in Proc. Am. Acad. xi. (1876) $146=$ Erythea armata.

calcarata, Liebm. ex Linden, Cat. n. 87 (1871) sphalm. = seq. ?

calcarea, Liebm. in Mart. Hist. Nat. Palm. iii. 819.Mexic.

conduplicata, Linden, Illustr. Hortic. xxviii. (1881) 16. -Mexic.

dulcis, J. Cooper, in Smithson. Rep. (1860) $442=$ Washingtonia filifera.

dulcis, Mart. Hist. Nat. Palm. iii. 244. t. 137. 162.Peruv.

edulis, H. Wendl. ex S. Wals, in Proc. Am. Acad. xi (1876) $120,146=$ Erythea edulis.

filamentosa, Hort. ex S. Wats. 1. c. $147=$ Washingtoni filifera.

minima, H. Wendl, in Kerch. Palm. $285=$ Sabal Adansoni?

Roezli, Linden, Illustr. Hortic. xxviii. (1881) 38.Arizona

serrulata, H. Wendl. in Kerch. Palm. 235.-Georgia.

These ane

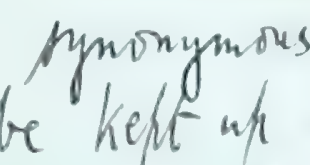

BRAMI, Adans. Fam. ii. $208(1763)=$ Herpestis Gaertn. f. (1805) (Scrophul.)

BRAMIA, Lam. Encyc. i. 459 (1783), nomen prius Herpestis, Gaertn. .. (1805) (Scrophul.

floribunda, F. Muell. Fragm, ix, $167=\mathrm{H}$, floribunda. indica, Lam. Encyc. 1. $459=$ H. Monniera

lanigera, G. Don, Gen. Syst. iv. $546=\mathrm{H}$. lanigera. semiserrata, Mart. Amoen. Monac. t. $8=\mathbf{H}$. gratio loides.

BRANCIONA, Salisb. Gen. Pl. Fragm. 36 (1866) Albuca, Linn. (Liliac.).

setosa, Salisb. 1. c. = A. setosa

BRANDESIA, Mart. Nov. Gen, et Sp. ii. 25.t. 125 (1826) Telanthera, R. Br. (Amarant.).

alba, Mart. ex Moq. in DC. Prod. xiii. II. $311=$ Achy ranthes alba.

echinocephala, Hook. f. in Trans. Linn. Soc. xx. (1851) $189=\mathrm{T}$. echinocephala.

elongata, Mart. Beitr. Amarant. 105. n. $4=$ T elongata.

lanceolata, Benth. P1. Hartw $247=T$. lanceolata.

Martiana, Gill. ex Moq. in DC. Prod. xiii. II. $363=\mathrm{T}$ philoxeroides.

mexicana, Schlecht. in Linnaea, vii. (1832) $392=\mathrm{T}$ mexicana.

porrigens, Mart. Beitr. Amarant. $106=\mathrm{T}$. porrigens.

puberula, Mart. Nov, Gen. et Sp. ii. $27=$ puberula.

pubiflora, Benth. in Bot. Voy. Sulph. $157=\mathrm{T}$ pubiflora.

pycnantha, Benth. 1. c. = T. pycnantha.

rufa, Mart. Nov, Gen, ii. 26, t, $125=\mathrm{T}$, rufa.

serpyllifolia, Mart. Beitr. Amarant. 106=T. serpylli-

folia.

villosa, Mart. Nov. Gen. et Sp. ii. 28. t. $128=$ T. Martii.

BRANDISTA, Hook. f. \& Thoms, in Journ, Linn. Soc. viii. (1865) 11. t. 4. SCROPHULARINEAE, Benth. \& Hook. f. ii. 938.

discolor, Hance, in Journ. Bot. xviii. (1880) $299=$ Hancei.

discolor, Hook. f. \& Thoms. in Fourn. Linn. Soc. viii, (1865) 11.-Burma

Hancei, Hook. f. Fl. Brit. Ind. iv. 257.-China.

BRANDONIA, Reichb. Consp. 127 (1828)= Pinguicula, Linn. (Lentibul.).

BRANDTIA, Kunth, Rev, Gram, ii. 511.t. 170 (1830) Arundinella, Raddi (Gramin.)

holcoides, Kunth, 1. c. = A. holcoides.

BRANICA, Endl. Ench. 339 (1841), sphalm.= BRAMIA, Lam, = Herpestis, Gaertn. f. (Scrophul.).

BRANICIA, Andrz, ex Trautv, in Act. Hort. Petrop. viii. (1883) $476=$ Senecio, Toum. (Compos.)

insignis, Andrz. 1. c. $=\mathrm{S}$, racemosus.

BRANDZEIA, Baill. Adansonia, ix. (1869) $21 \%$ LEGUMINOSAE.

filicifolia, Baill. l. c.-Ins. Mascar.

BRASENIA, Schreb. Gen. 372 (1789) PHAEACEAE, Benth. \& Hook. f. i. 46.

HYDROpElTIS, Michx. Fl. Bor. Am, i. 323. t, 29 $(1 \times 03)$

IxOD1A, Soland, ex DC. Syst. ii. 37 (1821).

Rondachine, Bosc; Encyc. Agric. vi. 1816) ISU (nomen gallicum, tamen citatur ab DC. Syst. et Steud.)

Hydropeltis, Muhl. Cat. 55; Rafin. Med. Fl. i. s0. f. $17=$ Schreberi.

nymphoides, Baill. Hist. Pl. iii. 82= Schreberi. peltata, Pursh, Fl. Bor. Am, ii. $889=$ Schreberi.

purpurea, Casp, in Jorn. Sc. Acad. Lisb. iv. (1879-it $312=$ Schreberi.

Schreberi, F. F. Gmel. Syst. 859.-Ind. or. : Japun; Austral.; Afr. trup.; Am, bor.

BRASILIASTRUM, Iam. Eacyc. i. 462 (1789) americamem. Lam. 1. c. - Comocladia Brasiliastrum et Picramaia Antiliesma.

BR.ASILILM, J. F. Gmel. Syst. 11; (1791) glabrum, J. F. Gincl. I. c. = I'icramuia Antillesina hirsufum, J. F. Gimel. 1. c. Comoclallia Brasiliastrom, 
BRASSAIA, Endl. Nov. Stirp. Dec. i. 89 (1839) $A R A L I A C E A E$, Benth. \& Hook. f. i. 943.

actinophora, Endl. l. c.-Austral.

actinophylla, F. Muell. Fragm. iv. 121.-Austral.

capitata, C. B. Clarke, in Hook. f. Fl. Brit. Ind.ii. 732 -Reg. Himal.; Burma.

littorea, Seem. in Fourn. Bot. ii. (1864) 244,Amboina.

macrostachya, Seem, l,c.-N. Guinea

palmata, Decne. \& Planch. in Rev. Hortic. Sér. IV. ii (1854) $106=$ Trevesia sundaica

sessilis, Seem. in fourn. Bot. ii. (1864) 244.-Sumatra

BRASSAIOPSIS, Decne. \& Planch. in Rev. Hortic Sér. IV. iii. (1854) 106. ARALIACEAE, Benth. \& Hook. f. i. 945 .

A RAliopsis, Kurz, in Andam. Rep. 39 (1870)

aculeata, Seem. in Fourn. Bot. ii. (1864) 293.-Reg. Himal.

alpina, C. B. Clarke, in Hook. f. Fl. Brit. Ind. ii. 736. -Reg. Himal.

confiuens, Seem. in Journ. Bot. ii. (1864) $292=\mathrm{B}$, Hainla et Trevesia palmata.

cyrtostyla, Seesz. l. c. 293.-Sumatra.

floribunda. Seem. l. c. $262=$ speciosa.

glomerulata, Regel, Gartenfl. (1863) 2\%5. t. $411=$ speciosa.

Griffithii, C. B. Clarke, in Hook. f. Fl. Brit. Ind. ii. 736.-Reg. Himal.

Hainla, Seem. in Fourn. Bot. ii. (1864) 291,-Reg. Himal.

hispida, Seem. l. c. 292.-Reg. Himal.

Hookeri, C. B. Clarke, in Hook. f. Fl. Brit. Ind. ii 737.-Reg. Himal.

mitis, C. B. Clarke, l. c. 736.-Reg. Himal.

palmata, Kurz, in Fourn. As. Soc. Beng. xxxix. (1870) II. 77.-Reg. Himal, ; Burma.

ricinifolia, Seem, in Journ. Bot. ii. (1864) $291=$ Acanthopanax ricinifolium.

simplicifolia, C. B. Clarke, in Hook. f. Fl. Brit. Ind. ii. 735. - Reg. Himal.

speciosa, Decne. E Planch. in Rev. Hortic. Sér. IV. iii. (1854) 106.-Reg. Himal.

BRASSAVOLA, Adans. Fam. ii.127 (17 $; 3)=$ Helenium, Linn. (Compos.)

BRASSAVOIA, R. Br. in Ait. Hort. Kew. ed. II. v. 216 (1813). ORCHIDEAE, B nth. \& Hook. f. iii. 533 .

Lysimnia, Rafin. F1. Tellur. i. 49 (1836)

Tulexis, Rafin. 1. c. $42(1836)$

acaulis, Lindl. E Paxt. Flow. Gard. ii. (1851-52) 152. f. 216.-Am. centr.

amazonica, Poepp. Eo Endl. Nov. Gen. et Sp.ii. 3.Bras.

angustata, Lindl. Bot. Reg. (1838) Misc. 41.-. Guiana.

appendiculata, A. Rich. \& Gal, in Ann. Sc. Nat Sér. III. iii. (1845) $23=$ cucullata.

Ceboletta, Reichb. f. in Bonplandia, iii. (1855) 221.Hab.?

cordata, Lindl. Bot. Reg.t. 1913.-Bras.

cucullata, $R$. Br. in Ait. Hort. Kerw. ed. II. v. 216 Ind. occ.

cuspidata, Hook. Bot. Mag. t. $3722=$ cucullata

Digbyana, Lindl. Bot. Reg. (1846) t. $53=$ Laelia Dig byana.

elegans, Hook. Bot. Mag. t. $3098=$ Tetramicra rigida

filifoli: Linden, Illustr. Hortic xxviii. (1881) 64 . N. Grarat.

flagellaris, Rodrig. Orch. Nov. ii. 161.-Bras.

fragrans, Lem. in Jard. Fleur. iii. (1853) Misc. $78=$ tubercnlata.

fragans, Rodrig. Orch. Nov. i. 65.-Bras.

Gibbsiana, Hort ex Nichols. Dict. Gard. i. $209=$ tuberculata.

glauca, Lindl. Bot. Reg. (1839) Misc. $47=$ Laelia glanca.

grandiflora, Lindl. I. c. $16=$ nodosa

lineata, Hook. Bot. Mag. t. 4734.-Am. centr.

Martiana, Lindl. Bot. Reg. (1836) sub t. 1914. Bras.

Mathieuana, Klotzsch, in Otto \& Dietr. Allg. Gartenz. xxi. (1853) $290=$ lineata.

nodosa, Hook. Bot. Mag. (1833) t. $3229=$ subuli. folia.

\section{BRASSA VOLA :-}

nodosa, Lindl. Gen. et Sp. Orch. 114.-Ind, occ odoratissima, Regel, Gartenf. (1852) 325. t. $33=$ cucullata.

Perninii, Lindl. Bot. Reg. t. 1561.-Bras.

Pumilio, Reichb. f. in Linnaea, xviii. (1844) 402.Mexic.

retusa, Lindl. Bot. Reg. (1847) sub t. 20,--Venezuela revoluta, Rodrig. Orch. Nov. ii. 161.-Bras.

rhopalorrhachis, Reichb. f. in Bot. Zeit. x. (1852) 855 . -Guatemala.

Sloanei, Griseb. F1. Brit. W. Ind. $620=$ subulifolia.

Sloanei, Lindl. ex Heynh. Nom. ii. 76, nomen nodosa?).-Jamaica.

suaveolens, Gal. ex Hemsl. in Gard. Chron. (1879) I. $235,236=$ Epidendri sp. ?

subulifolia, Lindl. Gen. et Sp. Orch. 115.-Ins. Nevis.

surinamensis, Focke, in Tijdschr. Nat. Wetens. iv. (1851) 17 = angustata.

tuberculata, Hook. Bot. Mag. t. 2878.-Bras.

venosa, Lindl. Bot. Reg. (1840) Misc. 20. t. 39.-N. Granat.

vomeriformis, Reichb. $f$. ex Griseb. Fl. Brit. W. Ind. 621.-Ind. occ.

BRASSAVOLAEA, Poepp. \& Endl. Nov. Gen. et Sp. ii. $3(1838)=$ praec.

\section{BRASSAVOLEA, Spreng. Syst. iii. $744(1826)=$ praec.}

BRASSENIA, Heynh. Nom. i. $130(1840)=$ Brasenia Schreb. (Nymphaeac.)

BRASSIA, R. Br, in Ait. Hort. Kew, ed. II, v, 215 (1813). ORCHIDEAE, Benth. \& Hook. f. iii. 564. angusta, Lindl. Bot. Reg. (1844) Misc. $5=$ Lawrenceana.

antherotes, Reichb. f. in Gard. Chron. (1879) II. 782, -Ecuador.

arachnoidea, Rodrig. Orch. Nov. i. 97.-Bras.

arcuigera, Reichb. f. in Gard. Chron. (1869) 388.Peruv.

aristata, Lindl. Bot. Reg. (1844) Misc. $7=$ verrucosa

bidens, Lindl. l. c. 6.-Hab.?

brachiata, Lindl. in Benth. Pl. Hartw. 94.-Guatemala.

brachypus, Reichb. f. in Gard. Chron. (1875) I. 136. Ecuador.

caudata, Lindl. Bot. Reg. t. 832.-Ind. occ

chloroleuca, Rodrig. Orch. Nov, i. 97-Bras

chlorops, Endr. E Reichb. f. in Gard. Chron. (1873) 542 - Costa Rica

cinnabarina, Linden, ex Lindl. Fol. Orchid. Brassia, 6.-N. Granat.

cinnamomea, Linden, ex Lindl. 1. c. $5=$ Keiliana.

Clowesii, Lind1. Bot. Reg. (1844) Misc. 7.-Bras.

cochleata, Knowl. \& Westc. Flor. Cab. ii. (1838) 23.t. $53=$ Lawrenceana

coryandra, Morr. in Ann. Gand, iv. (1848) 295. t. 212 = verrucosa

Cowani, Hort. ex Lindl. Fol. Orchid. Brassia, $4=$ verrucosa.

cryptophthalma, Reichb. f. in Gard. Chron. (1879) Ir. 554.-Peruv

elegantula, Reichb.f. l. c. (1885) Ir. 616.-Mexic. euodes, Reichb.f.l. c. (1880) I. 680 --N. Granat. farinifera, Linden E" Reichb. f. l. c. (1870) 923.Ecuador.

Gireoudiana, Reichb. f. E Warsc. in Otto E Dietr. Allg. Gartenz. xxii. (1854) 273.-Bras.

glumacea, Lindl. Orch. Linden. 17.-Venezuela.

guttata, Lindl, in Benth. Pl. Hartw. $94=$ maculata

Helenae, Reichb. ex Linden, Illustr. Hortic. xxvili. 1881) 64.-Ecuador.

hexodonta, Reichb. $f$. in Bonplandia, ii. (1854) 98.Peruv.

imbricata, Lindl. Fol. Orchid. Brassia, 5, -N Granat.

Josstiana, Reichb. f. in Regel, Gartenfl. iii. (1854) 309.-Bras.

Keiliana, Reichb: f. ex Lindl. Eo Paxt. Flow. Gard. iii. (1852-53) 114-N Granat.

Lanceana, Lindl. Bot. Reg. t. 1754.Guiana.

Lawrenceana, Lindl. l. c. (1841) Misc. 2. t. 18.Bras.

longicuspis, Reichb. f. Otia Bot. Hamb. 23.Ecuador.
BRASST.A :-

longiloba, DC, in Mém. Soc. Phys. Gerièv. xi. (1848) II. 427 . t. 1 = verrucosa.

macrostachya, Lindl. Sert. Orch. t. $6=$ Lanceana

maculata, R. Br. in Ait. Hort. Kew. ed. II. vo 215.Jamaica.

neglecta, Reichb. f. in Otto \& Dietr. Allg. Gartenz. xxiv. (1856) 322. Am. centr.

ocanensis, Lindl. Fol. Orch. Brassia, 5,-N. Granat. odontoglossoides, Klotzsch \& Karst. in Otto \& Dietr. Allg. Gartenz. xv. (1847) $330=$ verrucosa.

peruviana, Poepp. EN Endl. Nov。Gen, et Sp. ii. t. 117 -Peruv.

pumila, Lindl. Bot. Reg. (1845) Misc. 60=Lanceana.

signata, Reichb. f. in Gard. Chron. (1881) I1. 6.$\mathrm{Hab}$ ?

spathacea, Linden E Reichb. $f$. in Illustr. Hortic. xxviii. (1881) 64, nomen.-N. Granat.

thyrsodes, Reichb. f. in Gard. Chron. (1868) 842.Peruy.

verrucosa, Batem. Orch.t. 22.-Mexic

villosa, Lindl. Fol. Orchid. Brassia, 4.-Peruv

Wageneri, Reichb. f. in Bonplandia, ii. (1854) 14.-N Granat.

Warszewiczii, Reichb. f. in Bot. Zeit. x. (1852) 693.Ecuador.

Wrayae, Skinner, ex Hook. Bot. Mag. t. $4003=$ maculata.

BRASSICA, [Tourn.] Linn. Syst. ed. I (1735 CRUCIFERAE, Benth. \& Hook. f. i. 84

Agrosinapis, Fourr. in Ann. Soc. Linn. Lyon, N. S. xvi. (1868) 329 .

Brassicastrum, Link, Handb. ii. 318 (1:31)

Brassicella, Fourr, in Ann. Soc. Linn, Lyon, N. S. xvi. (1868) 330 .

Bonannia, Presl, Fl. Sic. i. 99 (1826).

Corynelobus, R. Roem. in Linnaea, xxv. (1852) 7

Erucastrum, Presl, Fl. Sic. i. 92 1826

GuENTHERA, Andrz. ex Bess. Enum. Pl. Volh. $8{ }^{\circ}$ (1822).

Heterocrambe, Coss, \& Dur. Ind. Sem. Hort Burdig. (1867) 25.

HirschFeldia, Moench, Meth, 264 (1794)

Melanosinapis, Schimp. \& Spenn. in Spenn. Fl Frib, iii. 944 (1829)

Micropodium, Reichb. Consp. 185 (1828).

Mutarda, Bernh. Syst. Verz. Erf. 184 (1800).

Napus, Schimp. \& Spenn. in Spenn. Fl. Frib. iii 939 (1829).

Ramphospermum, Andrz. ex Reichb. Moessl Handb, ed. II. i. p. lvii (1827).

Rapa, Toum. ex Linn. Syst. ed. I (1735).

Rhampiospermum, Andiz. ex Bess. Enum. Pl Volh. $83(1822)$

Sinapi, Dulac, Fl. Hautes-Pyr, 194 (1867).

SinAPIDENDRon, Lowe, in Trans. Camb. Phil. Soc, iv, $36(1831)$

Sinap1S, Linn. Syst. ed. I (1735)

Sinapistrum, Spach, Hist. Vég. Phan. vi. 343 (1838).

StRangalis, Dulac, F1. Hautes-Pyr. 195 (1867).

adpressa, Boiss. Voy. Espagne, ii. 38; Vis. Fl. Dalm

iii. 359.-Europ.; Reg. Mediterr

agrestis, Steud. Nom. ed. I. 116, $117=$ Conringia orientalis.

alba, Boiss. Voy. Espagne, ii. 39.-Europ.; Oriens ; Ind. or. (cult.)

alba, Gilib. F1. Lituan. ii. $63=$ Conringia orientalis.

Allionii, Moretti, Ind. Sem. Hort. Taur. (1829) (fide DC. sched,) = oleracea.

alpina, Linn. Mant. $95=$ Conringia alpina

amplexicaulis, Hochst. ex A. Rich. Tent. Fl. Abyss. 23. - Abyssin.

amplexicanlis, fanka, in Termész. Füzetek, vi. (1882 177.-Europ.

amplexicaulis, Pomel, Mat. Fl. Alt. 15.-Algeria.

antarctica, Molina, Sagg. Chile, ed. II. $292=$ magel lanica.

anticaria, Rouy E Fanka, in Termésg. Füzetek, vi. (1882) 177.-Europ.

apula, Fanka, l. c. 180.-Europ.

arborea, Steud. Nom, ed. I. 116, $117=$ campestris.

arenosa, Jord. Diag. i. $181=$ B. Cheiranthos.

armoracioides, Czern. ex Turcz. in Bull. Soc. Nat

Mosc. xxvii. (1854) II. 311.-Ucrania.

arvensis, Habl. Taur. $146=$ campestris. 


\section{BRASSICA :}

arvensis, Linn. Mant. $95=$ Moricandia arvensis. asperifolia, Lam. Encyc. i. $746=$ campestris. atlantica, Coss. \& Dur. ex Munby, Cat. Pl. Algér. $2=$ Gravinae.

Aucheri, Boiss. in Ann. Sc. Nat. Sér. II. xvii. (1842) $88=$ Raphanus Aucheri.

austriaca, Jacq. Fl. Austr. iii. $45=$ Conringia austriaca.

azurea, Uspensky, in Bull. Soc. Nat. Mosc, vii. (1834) 376, nomen.-Rossia.

balearica, Loisel. F1. Gall. ii. $69=$ Robertiana

balearica, Pers. Syn. ii. 206.-Ins. Balear

barbareaefolia, Ball, in Fourn. Linn. Soc. xvi. (1878) 328.-Marocco.

Barrelieri, Fanka, in Termész. Füzetek, vi. (1882) 179

Besseriana, Andrz. ex Trautv. in Bull. Soc. Nat Mosc. xxxiii. (1860) I. 134.-Rossia; As. temp.

Blancoana, Boiss. Diagn. Ser. II. i. 29.-Hispan.

boetica, Boiss. Voy. Espagne, ii. 38. t. 9.-Hispan.

Boissieri, Munby, in Bull. Soc. Bot. Fr. ii. (1855) 283. -Afr. bor.

botrytis, Mill. Gard. Dict. ed. VIII. n. $3=$ oleracea

Botteri, Vis. Fl. Dalm. iii. 135.-Dalmat.

brachyloma, Boiss. E Reut. Diagn. Ser. II. i. 30.Marocco.

bracteata, Fanka, in Termész. Füzetek, vi. (1882) 178. -Europ.

bracteolata, Fisch. E Mey. Ind. Sem. Hort. Petrop. iv. 33.-Aegypt.

brevipes, Syme, Engl. Bot. ed. III. i. $140=$ Diplotaxis muralis, viminea.

Briggsii, Varenne, in Journ. Bot. xix. (1881) $360=\mathrm{B}$. Rapa.

bullata, Pasq. Cat. Ort. Bot. Nap. $17=$ oleracea.

Bunias, DC. Syst. ii. 606.-Oriens.

cámpestris, Linn. Sp. Pl. 666.- Orb. Vet. (Cosmop. cult.).

campestris, Oed. in Fl. Dan. x. t. $550=$ Turritis glabra capitata, Hort. ex Pers. Syn. ii, 206, in syn.= oleracea.

carinata, A. Braun, in Flora, xxiv. (1841) 267.Abyss.

catholica, Brot. ex Willk. \& Lange, Prod, iii. $867=$ Diplotaxis catholica.

caulorapa, Pasq. Cat. Ort. Bot. Nap. $17=$ oleracea

cespitosa, Pomel, Nouv. Mat. Fl. Atl. 361.-Afi. bor.

cheiranthiflora, DC. Syst. ii. $60 \mathrm{i}=\mathrm{B}$. Cheiranthos

Cheiranthos, Vill. Prosp. 40; Hist.Pl. Dauph. iii. 332.

t. 36.-Europ. occ.; Afr. bor.

chinensis, Linn. Cent. 19 ; in Amoen. Acad. iv, $280=$ campestris.

coryneloba, Nym. Consp. 47.-Hispan.

Cossoneana, Boiss. \& Reut. Diagn. Ser. II. i. 31.Hispan.

crassifolia, Forsk. Fl. Aegypt. Arab. $118=$ Erucaria crassifolia.

cretica, Guss. Cat. Hort. Boccadif. (1821) $11=$ rupestris.

cretica, Lam. Encyc. i. 747.-Graecia.

cretica, Moris, Stirp. Sard. Elench. i. $3=$ insularis.

crispa, Rafin. Specch. ii. 69.-Sicilia

cyrenaica, Spreng. Syst. ii. 911.-Cyrenaic.

deflexa, Boiss. in Ann. Sc. Nat. Sér. II. xvii. 1842 87.- Syria; Persia.

densiflora, Jord. Diag. i. $186=$ B. Cheiranthos.

dimorpha, Coss. E Dur. in Bull. Soc. Bot. Fr. ii. (1855) 306. - Algeria.

dissecta, Boiss. Voy. Espagne, ii. 40,-Hispan.

elata, Ball, in Fourn. Bot. xi. (1873) 298.-Marocco.

elongata, Ehrh. Beitr. vii. 159.-Europ. or.; Reg Caucas.; Persia.

ensifera, Dum. Fl. Belg. Prod. 122.-Belgium

erosa, Turcz. in Bull. Soc. Nat. Mosc. xxvii. (1854) Il. 311.-Afr. austr.

Eruca, Boiss. Voy. Bot. Espagne, ii. $41=$ Eruca longirnstris.

Eruca, Linı. Sp. Pl. $667=$ Eruca sativa

Erucastrum, Poll. Pl. Palat. ii. $249=$ B. Cheiranthos.

Erucastrum, Linn. Sp. Pl. 667.-Europ.

erucoides, Boiss. Voy, Bot. Espagne, ii. $33=$ Diplotaxis erucoides.

erucoides, Roxb. Hort. Beng. [48] ; Fl. Ind. iii. $117=$ Eruca sativa.

erysimoides, Pourr. in Mém. Acad. Toul. uii. (1788)

$308=\mathrm{B}$. Cheiranthos.

erysimoides, Sieber, ex Spreng. Syst. ii. 912.-Aegypt.

\section{BRASSICA.}

fimbriata, Hort. ex Steud. Nom. ed. II i. $223=$

floridana, Rafin. Atl. Fourn. 147.-Am. bor.

foetida, Fanka, in Termész. Füzetek, vi. (1882) 177 Europ.

foliosa, Willd. Enum. Hort. Berol. $688=$ alba

Forskahli, Schult Obs 131. n 101 . Criens.

fragilis, Sieber, ex Spreng. Syst. ii. $912=$ Diplotaxis acris.

frutescens, Soland. ex DC. Syst. ii. 624.-Ins. Madera.

fruticulosa, Cyril. Pl. Rar, ii. 7.t. 1.-Reg. Mediterr. geniculata, Ball, in Journ. Linn. Soc, xvi. (1878) 327 =adpressa.

glaberrima, Pomel, Nouv. Mat. Fl. Atl. 364.Algeria.

glareosa, Jord. Diagn. i. $183=$ B. Cheiranthos. gongylodes, Mill. Gard. Dict. ed. VIII. n. $8=$ oleracea gracilis, Pomel, Nouv. Mat. Fl. Atl. 225.-Algeria. grandiflora, Balansa, ex Coss. in Ann. Sc. Nat. Sér.

IV.i. (1854) 221 = sabularia.

Gravinae, Tenore, Prod. Fl. Nap. 39. t. 62.-Ital. ; Afr bor.

Griffithii, Hook. f. \& Thoms, in Journ. Linn. Soc. (1861) $171=$ Diplotaxis Griffithii

Havardi, Pomel, Nouv. Mat. Fl. Atl. 363-Algeria.

heleniana, Burch. ex Loud. Hort. Brit. 264.-Ins. Helen.

heterophylla, Boiss. ex Nym. Syll. $197=$ adpressa.

hirta, Moench, Meth. Suppl. 84.-Hab.

hispida, Boiss. Voy. Espagne, ii. 40.--Hispan.; Afr

bor

hispida, Tenore, Prod. Fl. Nap. $39=$ Eruca sativa.

humilis, Boiss. Voy. Espagne, $35=$ latisiliqua.

humilis, DC. Syst. ii. 598.-Gallia.

hybrida, Tenore, Prod. Fl. Nap. 59.-Italia.

incana, Maly, Enum. Stirp. Austr. $272=$ Botteri

incana, Tenore, Prod. $\mathrm{Fl}$. Nap. 39.-Italia.

insularis, Moris, Fl. Sard. i. 168.-Sardinia

intricata, Fanka, in Termész. Füzetek, vi. (1882) 179. Europ.

japonica, Siebold, ex Miq. Ann. Mus. Bot. Lugd. Bat. ii. $74=$ auriculata?

juncea, Coss. in Bull. Soc. Bot. Fr. vi. (1859) 609.As, temp. et trop. (cult.)

laciniata, Steud. Nom. ed. I. 116, $117=$ oleracea.

laevigata, Lag. in Varied. Cienc. ii. Iv. (1805) 40.Hispan.

lanceolata, Lange, in Fl. Dan. t. 2658.-Dania.

lanceolata, Sauv. Fl. Cub. 2.-Cuba.

latisiliqua, Boiss. E Reut. Diagn. Ser. II. i. 30.Hispan.

lativalvis, Boiss. Diagn. Ser. I. vi. $72=$ Eruca lativalvis.

leptocarpa, Boiss. Fl. Orient. i. 392.-Persia.

leptopetala, Sond. in Harv. \& Sond. Fl. Cap. i. 31.-

Afr. austr.

leucantha, Boiss, ex Nym. Consp. $45=$ nivea.

loncholoma, Pomel, Nouv. Mat. Fl. Atl. 360.Algeria.

longirostra, Boiss. Voy. Espagne, ii. 40.-Hispan.

lutea, Gilib. Fl. Lituan. ii. $62=$ Conringia anstriaca

lyrata, Desf. Fl. Atlant. ii. 96. t. 166--Afr. bor macloviana, Ury, in Mém. Soc. Linn. Par. iv. (1826) $616=$ Arabis macloviana.

macrocarpa, Guss. in Presl, Fl. Sic. i. 92.-Sicilia.

macrorhiza, S. F. Gray, Nat. Arr. Brit. Pl. ii. $682=$ campestris.

magellanica, Gaudich. Freyc. Voy. Bot, i. 186 in nota = Arabis macloviana.

magellanica, Pers. Syn. ii. 207.-Reg. Magellan.

maritima, Tardent, Ess. Hist. Nat. Bessar. $79=$ oleracen. maurorum, Dur. in Duch. Rev. Bot. ii. (1847) 433. -Algeria.

mesopotamica, Bernh. ex Steud. Nom. ed. II. i. $223=$ B. Sinapis.

mollis, Vis. Fl. Dalm, iii. 359.-Europ. austr.

monensis, Huds. Fl. Angl. ed. II. 2!) 1.-Europ. occ

montana, DC. Fl. Fr. iv. $651=$ B. Cheiranthos.

montana, Rafin. Specch. ii. $69=$ rupestris.

Moricandia, Boiss. Voy. Espagne, ii. $841=$ Moricandia arvensis.

moricandoides, Boiss. Elench. $10=$ Moricandia Ramburci.

muralis, Huds. Fl. Angl. ed. II. $291=$ Diplotaxis

tenuifolia, murnti.

musscovita, Stcud. Nom. ed. 1. $117=$ oleraces.

\section{BRASSICA}

Napella, Chaix, in Vill. Hist. P1. Dauph. iii. 334 campestris.

napobrassica, Mill. Gard. Dict. ed. VIII. n. $2=\mathrm{cam}$

pestris.

Napus, Linn. Sp, P1, 666 = campestris

nervosa, Ball, in Fourn. Bot. xi. (1873) 299 (sp. dubia). - Marocco.

nigra, Koch, in Roehl. Deutschl. Fl. ed. III. iv. 713.Orb. vet. ; (Cosmop. cult.).

nivalis, Boiss. E' Heldr, in Boiss. Diagn. Ser. II. i. 32 -Graecia.

nivea, Boiss. E Sprun. l. c. Ser. 1. 1. 72,-Graecia

nudicaulis, Pomel, Nouv. Mat. Fl. Atl. 361.-Algeria.

obtusangula, Reichb. in Moessl. Handb. ed. II. ii. 118 -Europ.

obtusangulata, St. Lag. in Ann. Soc. Bot. Lyon, vii. (1880) $121=$ B. Erucastrum.

ochroleuca, Soyer-Willem. in Ann. Sc. Nat. ii. (1824)

$116=\mathrm{B}$. Cheiranthos

odorata, Schrank, ex Steud. Nom. ed. I. 117 -Europ.

oleifera, Moench, Meth. 253=campestris.

oleracea, Linn. Sp. Pl. 667.-Europ. occ. (Cosmop cult.).

oleracea, Lour. Fl. Cochinch. $396=$ campestris.

oleronensis. A. Savat, ex Foucaud, in Bull. Soc. Bot. Fir.

xxvi. (1879) 74.-Gallia.

rientalis, I inn. Sp. Pl. $666=$ Conringia oricntalis

ovalis, Viv. Fl. Libyc. Spec. 35. t. 16. f. 3.-Libya.

oxyrrhina, Coss. Notes Crit. ii. 26.-Hispan.

oxyrrhyncha, Coss. ex Regel, Ind. Sem. Hort. Petrop.

1856) $34=$ oxyr hina.

palustris, Bivona, Fl. Forojuliensis Syllab. (1855) 18 = elongata.

papillaris, Boiss. Elench. $10=$ sabularia.

pendula, Boiss. Voy. Espagne, ii. 35.-Hispan.

peregrina, Steud. Nom. ed. I. $117=$ oleracea.

perfoliata, Crantz, Stirp. Austr. ed. II. 37 ; Lam. Fl.

Fr. ii. $487=$ Conringia orientalis.

persica, Boiss. \& Hohen. Diagn. Ser. I. viii. $26=$ elongata.

petrosa, Jord. Diagn. i. $185=$ B. Cheiranthos.

pinnata, Spreng. Syst. ii. 911.-Afr. bor.

pinnatifida, Desf. Fl. Atlant. ii. 95. t. 165.-Hispan. Afr. bor.

Pollichii, Shuttl, in Mag. Zool. Bot, ii, (1838) $531=\mathrm{B}$ Cheiranthos.

polymorpha, Murr. in Nov. Comm. Gott. vii. (1777) 35. t. $6=$ juncea.

polymorpha, Syme, Engl. Bot ed. II. i. $183=$ cam pestris.

praecox, Waldst. \& Kit. ex DC. Syst. ii. $593=$ cam pestris.

Preslii, Fanka, in Termész. Füzetek, vi. (1882) 182Europ.

Prolongi, Boiss. Voy. Espagne, ii. 33.-Hispan.

propera, Jord. Diagn, i. $183=$ B. Cheiranthos.

pseudoerucastrum, Brot. Fl. Lusit. i. 581.-Lusitan.

psammophila, Pomel, Nouv. Mat. Fl. Atl. 3t3.Algeria.

purpurascens, [Soland.in] Russell, Aleppo, ed. II. ii. 258.-Syria.

purpurea, Mill. Gard. Dict. ed. VIII. D, $6=$ Moricandia arvensis.

pyrenaea, Jord. Diagn. i. $187=\mathrm{B}$. Cheiranthos.

quadrivalvis, Hook. f. \& Thoms. in Fourn. Linn. Soc. v. (1861) 170.-Ind. or. (cult.)

racemiflora, Jord. Diagn. i. $184=$ B. Cheiranthos

$R a p a$, Linn. Sp. Pl. $666^{\circ}=$ campestris.

rectangularis, Viv, in Limnaea, i. (1526) 502.-Corsica

recurvata, Jord. Diagn. i. $102=$ B. Cheiranthos

repanda, $D C$. Syst. ii. 598,-Gallia.

rerayensis, Ball, in Fourm. Bot. xi. (1579) 299.Mlarocco.

Richerii, Lange, in Fl. Dar xlv. t. $2058=$ lanceolata, Lange.

Richerii, Vill, Prosp \$0-Gallia.

Robertians, $\mathcal{F}$. Gay, in Anns. Sc. Nas. Sér. 1. vii. (1820 416. - Europ.

rostrata. Balf, $f$. in Proc. Roy. Soc. Edinb. xi. (1852 500.-Ins. Socutr.

Rouyana, fanka, in Termisg. Fiozelck, vi. (1582: 181 . -Europ.

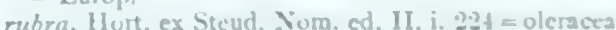
rupestris, Rafin. Carabferi, a. 191.-Sicil.

rupicula, Pomel, Nows. Mat. Fl. All. \$62.-Algeria subellica, llort. ex l'ens Syn. ii. $200^{\circ}$, in syo, = uleraces. subularia, Brot. 17. Lusip. I s.2.-Lusilan. A Ar. bur. 


\section{BRASSICA :}

sabularia, Willk. ex Willk. \& Lange, Prod. Fl. Hisp iii. $854=$ oxyrrhina.

Saruna, Siebold, in Verh. Bat. Gen. xii. (1830) $52=$ campestris?

Schimperi, Boiss. in Ann. Sc. Nat. Sér. II. xvii. (1842) 86.-Arabia.

scoposa, Fanka, in Termész. Füzetek, vi. (1882) 179.Europ.

sempervirens, Tenore, ex Schrank, Hort. Monac. t. 10 . -Europ. austr.

setigera, Willk. in Willk. E Lange, Prod. Fl. Hisp. iii. 857 . - Hispan.

sinaica, Boiss. in Ann. Sc. Nat. Sér. II. xvii. (1842) 85 = Moricandia sinaica.

Sinapistrum, Boiss. Voy. Espagne, ii. 39.-Europ.

Sinapis, Vis. Fl. Dalm. iii. 136.-Europ. (Cosmop. cult.).

sisymbrioides, Fisch. ex DC. Prod, i, $217=$ Tournefortii.

sphaerorhiza, S. F. Gray, Nat. Arr. Brit. P1. ii. $683=$ campestris.

spinescens, Pomel, Nouv. Mat. Fl. Atl. 364.Algeria.

Stocksii, Hook. f. \& Thoms. in Journ. Iinn. Soc. y (1861) $171=$ Tournefortii

stricta, Nestl. ex DC. Syst. ii. $593=$ campestris.

strigosa, $D C$. $l$. c. 603 .-Afr. austr.

subhastata, Willd. Sp. Pl. iii. $550=$ Sisymbrium orientale.

subspinescens, Fisch. \& Mey, in Bull. Soc. Nat. Mosc (1839) II. $145=$ Sisymbrium subspinescens.

subularia, Pers. Syn. ii. 207 (sphalm.) = sabularia.

suffruticosa, Desf. Fl. Atlant. ii. $94=$ Moricandia arvensis.

sylvestris, Mill. Gard. Dict. ed. VIII. n. 4,=oleracea.

taraxacifolia, Boiss. Elench. $11=$ Sisymbrinm crassi folium.

tenuifolia, Baill. Hist. P1. iii. $227=$ Diplotaxis tenui folia.

teretifolia, Desf. Fl. Atlant. ii. $94=$ Moricandia tereti folia.

Tigridis, Boiss. in Ann. Se. Nat. Sér. II. xvii. (1842) 87 = deflexa.

timoriana, F. Muell. Papuan Pl. ii. 4-Ins. Timor Tinei, Tod. Ind. Sem. Panorm. (1861) 32.-Hab.? torulosa, Dur. in Duch. Rev. Bot. ii. (1847) $434=$ Diplotaxis siifolia.

Tournefortii, Gouan, Illustr. 44. t 20, fo A.-Reg Mediterr.; Oriens; Ind, or

trilocularis, Hook. $f$. \& Thoms. in Fourn. Linn. Soc. v (1861) 169.-Reg. Himal.

trimestris, Boenn. Prod. Fl. Monast. $201=$ campestris.

tuberosa, Salisb. Prod. 272 = campestris.

turgida, Pers. Syn ii, $207=$ Ernca sativa.

Turrita, Weig. Obs. $32=$ Conringia orientalis.

Uechtritziana, Fanka, in Termész. Füizetek, vi. (1882) 182.-Europ.

valentina, DC. Syst. ii. 603.-Hispan.

varia, Dur. in Duch. Rev. Bot. ii. (1847) 484.-Afr. bor.

vesicaria, Linn. Sp. P1. $668=$ Eruca vesicaria

villosa, Bivon. ex Spreng. Syst. iv. Cur. Post. $243=$ incana.

viminea, Boiss. Voy, Espagne, ii. $33=$ Diplotaxis viminea.

violacea, Burm. f. Fl. Ind. $140=$ campestris.

violacea, Linn. Sp. Pl. 667 (sp. dub.).-China.

virgata, Boiss. Voy. Espagne, ii. $35=$ Diplotaxis virgata.

Washitana, Muhl. Cat. $63=$ Streptanthus maculatus.

Willdenovii, Boiss, in Ann. Sc. Nat. Sér. II. xvii. (1842) $88=$ juncea.

BRASSICARIA, Pomel, Mat. F1. Atl. $15(1860)=$ Brassica, Tourn (Crucifer.)

humilis, Lamotte, Prod. i. $87=\mathrm{B}$. humilis.

BRASSICASTRUM, Link, Handb. ii. 318 (1831) = Brassica, Tourn. (Crucifer.)

elongatum, Link, 1. c. $=$ B. elongata.

BRASSICELLA, Fourr, in Ann. Soc, Linn, Lyon, N. S. xvi. (1868) $330=$ Brassica, Tourn. (Crucifer.). arenosa, Fourr. 1. c. $=$ B. Cheiranthos. Cheiranthos, Fourr. 1. c. = B. Cheiranthos.
BRATHYDIUM, Spach, Hist. Vég. Phan, v, 442 (1836); et in Ann. Sc. Nat. Sér. II. v. (1836) $365=$ Hype ricum, Tourn.

canadense, Spach, 1. c. $446=\mathrm{H}$. pyramidatum?

Chamaerinum, Steud. Nom. ed. II. i. 224, sphalm.=

Chamaenerium, Spach, Hist. Vég. Phan. v. $445=\mathbf{H}$. sphaerocarpum

grandiflorum, Spach, 1. c. $443=\mathrm{H}$. dolabriforme

hyssopifolium, Spach, 1. c. $445=\mathrm{H}$. cistifolinm

sphaerocarpum, Spach, 1. c. $444=\mathrm{H}$. sphaerocarpum.

BRATHYS, Mutis, ex Linn. fo Suppl. $43(1781)=$ Hypericum, Tourn

acerosa, Spach, in Ann. Sc. Nat. Sér. II. v. (1836) 366 $=\mathrm{H}$. laricilolium.

acicularis, Spach, 1. c. $=\mathbf{H}$, aciculare

Billardieri, Spach, 1. c. $367=$ H. gramineum.

caespitosa, Blume, Mus. Bot. Lugd. Bat. ii. $20=$ H. japonicum.

canadensis, Spach, in Ann. Sc. Nat. Sér. II. v. (1836 $367=$ H. canadense.

caracasana, Spach, 1. c. $366=\mathrm{H}$. caracasanmm

connata, Spach, 1. c. = H. connatum.

debilis, Blume, Mus. Bot. Lugd. Bat. ii. $20=$ H. japonicum.

denticulata, Spach, in Ann. Sc. Nat. Sér. II. v. (1836) $367=\mathbf{H}$. denticulatum.

Drummondii, Spach, 1. $\mathrm{c}_{\mathrm{s}}=\mathrm{H}$. Drummondii

Erythraea, Spach, 1. c. $367=$ H. angulosum.

euphorbioides, Spach, 1. c. = H. mutilum?

Forsteri, Spach, 1. c. $=$ H. gramineum.

gentianoides, Spach, 1. c. = H. Sarothra.

humifusa, Spach, 1. c. = H. japonicum.

indecor $a$, Spach, 1. $\mathrm{c}_{\mathrm{s}}=\mathrm{H}$. thesiifolium.

japonica, Blume, Mus. Bot. Lugd. Bat. ii $19=\mathbf{H}$. japonicum.

juniperina, Linn. f. Suppl. $268=$ H. Brathys

lanceolata, Spach, in Ann. Sc. Nat. Sér. II. v. (1836) $367=\mathrm{H}$. angulosum.

laricifolia, Spach, 1. e. $366=$ H. laricifolium.

laxa, Blume, Mus. Bot. Lugd. Bat. ii, $19=\mathrm{H}$. japonicum.

linoides, Spach, in Ann. Sc. Nat. Sér. II. v. (1836) 367 $=\mathrm{H}$. angulosum

moranensis, Spach, 1. c. = H. moranense.

Mutisiana, Spach, 1. c. $366^{\circ}=$ H. mexicanum

nepalensis, Blume, Mus. Bot. Lugd. Bat. it. $19=\mathbf{H}$. japonicum.

oryzetum, Blume, 1. c. $20=\mathbf{H}$. japonicum

paniculata, Spach, in Ann. Sc. Nat. Sér. II. v. (1836) $367=\mathrm{H}$. paniculatum.

pauciflora, Spach, 1. c. = H. paucifiorum.

prolifica, Payer, Organ. 8. t. $\mathbf{1}=\mathbf{H}$. densiflorum.

quinquenervia, Spach, 1. c. = H. mutilum.

radicans, Blume, Mus. Bot. Lugd. Bat. ii. $20=$ H. japonicum.

struthiolaefolia, Spach, in Ann. Sc. Nat. Sér. II v. $(1836) 366=$ H. struthiaefolium.

tarquensis, Spach, l.c. $367=\mathrm{H}$. thesiifolium

thesiifolia, Spach, 1. c. $=\mathrm{H}$. thesiifolium.

thuyoides, Spach, 1. c. $366=\mathbf{H}$, thuyoides.

thymifolia, Spach, 1. c. = H. Humboldtianum.

tomentosa, Spach, 1. c. $367=\mathrm{H}$. setosum

BRAUNEA, Willd. Sp. P1. iv. 797 (1805), ex parte $=$

Tiliacora, Colebr. (Menisperm.).

menispermoides, Willd. 1. c. $=\mathrm{T}$. racemosa.

BRAUNERIA, Neck. Elem. i. $17(1790)=$ Echinacea Moench (Compos.)

BRAUNLOWIA, A. DC. Prod. xvii. 290 (1873) = Brownlowia, Roxb. (Tiliac.).

BRAVAISIA, DC. in Bibl. Univ. xvii. (1838) 124 (Rev. Bign. 16). ACANTHACEAE, Benth. \& Hook. f. ii. 1084 .

OnYchacanthus, Nees, in DC. Prod. xi. 217 (1847). floribunda, $D C$. Prod. ix. 240.-Mexic.

BRAVOA, Lex. in La Llave \& Lex. Nov. Veg. Desc. fasc i. 6 (1824). AMARYLLIDEAE, Benth. \& Hook. f iii. 737 .

Coztocapnia, Link \& Otto, Ic. Pl. Rar. 35 (1828). ZETOCAPNIA, Link \& Otto, l. c. i. t. 18 (sphalm. (1828).
BRAVOA :-

Bulliana, Baker, in Gard. Chron. (1884) II. 328.Am. austr.

Coetocapnia, M. Roem. Syn. Ensat. $245=$ geminiflora. geminiflora, Lex. in La Llave E Lex. Nov. Veg. Desc fasc. i. 6.-Mexic.

sessiliflora, Hemsl. Diag. Pl. Nov. 54.-Mexic.

BRAXIPIS, Rafin. Sylva Tellur. $72(1838)=$ Sterculia, Linn.

grandiflora, Rafin. 1. c. $=\mathrm{S}$. grandiflora.

nitida, Rafin. 1. c. $73=$ Cola acuminata.

BRAXIREON, Rafin. Fl. Tellur. iv. 23 (1836)= Tapei nanthus, Herb. (1837) (Amaryll.)

humile, Rafin. I. c. $=$ T. humile.

BRAXYLIS, Rafin. Sylva Tellur. $51(1838)=$ Ilex, Tourn.

obcordata, Rafin. 1. $c_{s}=$ I. obcordata.

BRAYA, Sternb. \& Hoppe, in Denkschr. Regensb. i. I. 1815) 65. CRUCIFERAE, Benth. \& Hook. f. i. 82 Aphragmus, Andrz. ex DC. Prod. i. 209 (1824) Eudema, Humb. \& Bonpl. Pl. Aequin. ii. 133. t. $135(1809)$, nomen prius.

OrEAS, Cham. \& Schlecht. in Linnaea, i. (1826) 29 t. 1 .

Orobium, Reichb. Consp. 185 (1828).

Platypetalum, R. Br. in Parry, Voy. App. 266 (1824).

aenea, Bunge, Del. Sem. Hort. Dorp. (1841) $8=$ alpina.

alpina, Sternb. E Hoppe, in Denkschr. Regensb. i. I. 1815) 66.-Alp. Europ.; Reg. arct.; Tibet.

arctica, Hook. in Parry, Voy. App. $387=$ alpina.

calycina, Wedd. Chlor. And. t. 85.-Reg. Andin.

dubia, R. Br. ex Hook. f. in Trans. Linn. Soc. xxiii. (1861) $319=$ alpina.

Eschscholtziana, Benth. E Hook. f. ex S. Wats. Bibl. Ind. N. Am. Bot. 51.-Am, arct.

falcata, Hochst. ex A. Rich. Tent. F1. Abyss. i. 17 Sisymbrium falcatum.

glabella, Richards. in Frankl. 1st Joum. $743=$ alpina.

imbricatifolia, A. Gray, Bot. U. St. Expl. Exped. i. $58=$ Sisymbrium imbricatifolium.

involucrata, Ledeb. Fl. Ross. i. 194.--Sibir. altaic.

Limosella, Bunge, Del. Sem. Hort. Dorp. (1841) $8=$ Sisymbrium Limosella.

limoselloides, Bunge, ex Ledeb. F1. Ross. i. $194=$ Sisymbrium L.imosella.

Meyeri, Bunge, ex Walp. Rep. ii. 755 (=Parryae sp.). - Sibir. altaic.

nana, Bunge, Del. Sem. Hort. Dorp. (1841) 8.-Sibir. baical.

Novae-Zelandiae, Hook. f. Handb. New Zeal. Fl. 13.N. Zel.

oregonensis, A. Gray, in Proc. Am. Acad. xvii. (188182) 199 -Am bor occ.

oxycarpa, Hook. f. \& Thoms. in Journ. Linn. Soc. y. (1861) $169=$ alpina

pilosa, Hook. Fl. Bor. Am. i. 65. t. 17.-As. et Am. aret.

pinnatifida, Koch, Syn. Fl. Germ. ed. I. $50=$ Sisymbrium pinnatifidum.

purpurascens, Bunge, ex Ledeb. F1. Ross. i. $195=$

pusilla, A. Gray, Bot. U. St. Expl. Exped. i. 57.Chili.

rosea, Bunge, Del. Sem. Hort. Dorp. (1841) 8.-As. arct.; Reg. altaic. et Himal.

Scharnhorsti, Regel \& Schmalh. in Act. Hort. Petrop v. (1877) 241. - Turkestan.

siliquosa, Bunge, Del. Sem. Hort. Dorp. (1839) 7.-Cf. Linnaea, xiv. 118.-Sibir, altaic.

supina, Koch, Syn. Fl. Germ. ed. I. 50=Sisymbrium supinum.

Thomsoni, Hook. f. in Journ, Linn. Soc. v. (1861) 168 $=$ alpina.

tibetica, Hook. f. E Thoms. l. c-Tibet. occ.

Tilingii, Regel \& Tiling, in Nouv. Mém. Soc. Nat. Mosc. xi. (1859) 61-_Ross, bor.

uniflora, Hook. $f$. E Thoms, in Fourn. Linn. Soc. y. (1861) 168. - Tibet. occ.

versicolor, Turcz. in Bull. Soc. Nat. Mosc. xv. (1842) 281.-Sibir. baical. 
BRAYFRA, Kunth, in Brayer, Not. Vermif. (1824) ROSACEAE, Benth. \& Hook. f. i. 622

Bankesia, Bruce, Travels, v. 22, $23(1790)$; Ed. II vii. 181 (1805).

Bracera, Engelm. in Buchner, Rep. Pharm. lxviii. (1839) 369.

HAGEA, Poir. in Dict. Sc. Nat. xii. 253 (1818).

HAGENIA, J. F. Gmel. Syst. 613 (1791).

anthelmintica, Kunth, l. c.-Abyssin.

BRAZORIA, Engelm. \& Gray, in Bost. Journ. Nat Hist. v. (Pl. Lindh.) 255 (1845). LABIATAE, Benth \& Hook. f. ii. 1204.

Roemeriana, Scheele, in Linnaea, xxii. (1849) 590.Texas.

scutellarioides, Engelm. E Gray, in Bost. Fourn. Nat. Hist. v. (1845) 257.-Texas.

truncata, Engelm. E Gray, l. c. 256.-Texas.

BREBISSONIA, Spach, in Ann. Sc. Nat. Sér. II. iv. (1835) 175 = Fuchsia, Linn. (Onagrar.).

microphylla, Spach, l. c. $=$ F. microphylla.

thymifolia, Steud. Nom. ed. II. i, $225=$ F. thymifolia.

BREDEMEYERA, Willd. in Ges. Naturf. Freunde Neue Schr. iii. (1801) 412. t. 6. POLYGALEAE, Benth. \& Hook. f. i. 138.

CATocoma, Benth. in Hook. Journ. Bot. iv. (1842) 101.

Hualania, Phil, in Linnaea, xxxiii. (1864-65) 18. acuminata, Klotzsch, ex A. W. Benn. in Mart. Fl. Bras. xiii. III. $51=$ myrtifolia.

acuminata, Poepp. ex Klotzsch, in Peters, Reise Mossamb. Bot. 117.-Afr. trop.

altissima, A.W. Benn. in Mart. Fl. Bras. xiii. III. 50. -Am. austr.

bracteata, Klotrsch, ex Hassk. in Miq. Ann. Mus. Bot. Lugd. Bat. i. 187.-Guiana.

brevifolia, Klotesch, ex A. W. Benn. in Mart. Fl. Bras. xiii. III. 49.-Bras.

cuneata, Klotrsch, ex Hassk. in Miq. Ann. Mus. Bot. Lugd. Bat. i. 187.-Guiana.

densiflora, A. W. Benn. in Mart. Fl. Bras. xiii. III. 52.-Bras.

floribunda, Willd. in Ges. Naturf. Freunde Neue Schr. iii. (1801) 412,-Am, austr.

Hilaireana, Klotzsch, ex A. W. Benn. in Mart. Fl. Bras. xiii. 111. $52=$ laurifolia.

Kunthiana, Klotzsch, ex A.W. Benn. l. c. 53.Bras.

la urifolia, Klotzsch, ex A. W. Benn. l. c. 52.-Bras,

Lhotzkyana, Klotzsch, in Peters, Reise Mossamb. Bot. 117 = floribunda.

lucida, A. W. Benn. in Mart. Fl. Bras. xiii. III. 51.Bras.

lucida, Klotzsch, ex Hassk. in Miq. Ann. Mus. Bot. Lugd. Bat. i. 189.-Guiana.

Mansonii, Klotzsch, in Peters, Reise Mossamb. Bot. $117=$ lucida

Martiana, A.W. Benn. in Mart. Fl. Bras, xiii. II. 49 -Bras.

microphylla, Hieron. in Roca, Exped. Rio-Negro, ii. 182.-Patagonia.

Moritziana, Klotzsch, ex Hassk. in Miq. Ann. Mus. Bot.Lugd. Bat. i. 188.-Guiana.

myrtifolia, A. W. Benn. in Mart. Fl. Bras, xiii. III 50.-Bras.

parviflora, A.W. Benn. l. c. 51,-Am. trop.

revoluta, $A$. W. Benn. l. c. 49.-Bras.

Sellowii, Hassk. in Miq. Ann. Mus. Bot. Lugd. Bat. i. 189.-Bras.

velutina, A. W. Benn. in Mart. Fl. Bras. xiii. xII. 58. -Bras.

BREDIA, Blume, Mus. Bot. Lngd. Bat. i. 24, f. 4 (1849). MELASTOMACEAE, Benth. \& Hook. f. i. 758.

hirsuta, Blume, l. c. 25.-Japon.

Oldhami, Hook. f. Ic. Pl. t. 1085.-Ins. Formosa.

BREEA, Less. Syn. Comp. $9(1832)=$ Cnicus, Linn. (Compos.).

dioica, Less. 1. c. $10=\mathrm{C}$. arvensis.

BREHMIA, Harv, in Hook. Lond. Journ. Bot. i. (1842) 25 - Strychnos, Linn. (Logan.) spinasa, Harv, 1. c. $26=\mathrm{S}$. spinosa.
BREHMIA, Schrank, in Syll. Ratisb. i. (1824) $85=$ Pavonia, Cav. (Malvac.)

arborescens, Schrank, 1. c. $=$ P. velutina

BREHNIA, Baker, in Journ. Linn. Soc. xiv. (1875) 561 sphalm.= Behnia, Didrichs. (Liliac.).

BREMONTIERA, DC. in Ann. Sc. Nat. Sér. I. iv 1825) 93. LEGUMINOSAE, Benth. \& Hook. f. i. 464 .

Ammoxylon, $D C$. $l$. $c_{0}$-Ins. Mascar.

BREONIA, A. Rich. in Mém. Soc. Hist. Nat. Par. v. (1830) 290. RUBIACEAE, Benth. \& Hook. f. ii. 32 madagascariensis, A. Rich. l. c.-Madag.

BREPHOCTON, Rafin. F1. Tellur, ii, 49 (1836) = Rochonia, DC. (Compos.)

cuneatum, Rafin. 1. c. =R. cuneata.

BRETEUILLIA, Buchoz, ex DC. Prod. vi. 503, in syn. $(\mathbf{1 8 3 7})=$ Didelta, Less. (Compos.).

BREVIGLANDIUM, Dulac, Fl. Hautes-Pyr. 423 (1867) = Hottonia, Linn. (Primul.)

palustre, Dulac, 1. c. $=$ H. palustris.

BREVOORTIA, Wood, in Proc. Acad, Sc. Philad, (1867) 81. LILIACEAE, Benth. \& Hook. f. iii. 800 . coccinea, S. Wats. in Proc. Am. Acad. xiv. (1879) 239 Ida-Maia.

Ida-Maia, Wood, in Proc, Acad. Sc. Philad. (1867) 82.-Calif.

BREWERIA, R. Br. Prod, 487 (1810), CONVOLVULACEAE, Benth. \& Hook. f. ii. 876.

Bonamia, A. Gray, in Proc. Am. Acad. v. (1862) 337

Calycobolus, Willd. ex Roem. \& Schult. Syst. v. 2 (1819).

Codonanthus, G. Don, Gen. Syst. iv. 166 (1856).

Dethardingia, Nees, in Nov. Act. Nat. Cur. xi (1823) 80 .

Dufourea, H. B. \& K. Nov, Gen. et Sp. iii. 113. t 214 (1818).

Prevostea, Choisy, in Ann. Sc. Nat. Sér. I. iv. (1825) 497

REINWARDTIA, Spreng. Syst. i. 527 (1825).

Seddera, Hochst. in Flora, xxvii. (1844) Bes. Beil 7.t. 5 .

STYlisma, Rafin. Neogenyt. 2 (1825)

TrichanTHA, Karst. \& Triana, in Linnaea, xxviii. (1856) 437.

WilBERForCiA, Hook. f. ex Planch. in Hlook. Ic Pl. t. 796 (1848).

abscissa, Choisy, in DC. Prod. ix. 438.-Madag. africana, Benth. Eo Hook. f. Gen, iii, 877.-Afr. trop. aquatica, A. Gray, Syn. Fl. N. Am ii. I 217.-Am bor.

brevifolia, Benth. Fl. Austral. iv. 436.-Austral Burchellii, Choisy, in Mém. Soc. Phys. Genev. vi. (1833) 493.-Bras.

Choisyana, Steud. Nom. ed. II. i. 224.-Ind. or. cordata, Blume, Bijdr. 722.-Ind. or.; Malaya.

elegans, Choisy, in Mém. Soc. Phys. Genez. vi. (1833) 494.-Burma.

evolvuloides, Choisy, 1. c.= Choisyana,

evolvuloides, R. Br. in Salt, Abyss. App. 65.-Abyss. fastigiata, Balf. $f$. in Proc. Roy.Soc. Edinb. xii. (1884 83.-Ins. Socotr.

ferruginea, Benth. E Hook. f. Gen. iii. 877.-Bras.

glomerata, Balf. f. l. c.-Ins. Socotr.

grandiflora, A. Gray, in Proc. Am. Acad.xv. (1880) 51 -Florida.

Hildebrandtii, Vatke, in Linnaea, xliii. (1880-82) 529. -Afr. trop.

hispida, Franch, in Revoil, Comali, 43.-Afr. trop.

humistrata, A. Gray, Syn. Fl. N.Am. ii. I. 217.-Am bor.

Langsdorffi, Meissn. in Mart. Fl. Bras. vii. 325 -Bras. latifolia, Benth. ex C. B. Clarke, in Hook. f. Fl. Brit Ind. iv, 224. -Afr. bor.; Arab.; Ind. bor. occ

linearis, $R$. Br. Prod. 488.-Austral.

linifolia, Spreng. Syst, i. $614=$ Wahlenbergia lina rioides.

madagascariensis, Choisy, in Mim. Soc. Phys. Genery. vi. (1893) 493.-Madag.

\section{BREWTRTA}

malvacea, Klotzsch, in Peters, Reise Mossamb. Bot. $245=$ Convolvulus malvaceus.

media, R. Br. Prod. 488.-Austral.

Menziesii, Benth. \& Hook. f. Gen. iii. 877.-Ins. Sandvic.

mexicana, Hemsl. Biol. Centr. Am. Bot. ii. 400.Mexic.

minima, A. Gray, in Proc. Am. Acad. xvii. (1881-82 228.-Calif.

ovalifolia, A. Gray, Syn. Fl. N. Am. ii. 1. 217.-Am bor, occ.

axycarpa, Hochst, ex A. Rich. Tent. Fl. Abyss. ii. 76 evolvaloides.

pannosa, R. Br. Prod. 488.-Austral.

parviflora, Arn. ex Steud. Nom. ed. II. i. 224

Convolvulus parviflorus.

pedunculata, Balf. f. in Proc. Roy. Soc. Edinb. xii. 1884) 83.--Ins. Socotr.

Pickeringii, A. Gray, Syn. Fl. N. Am. ii. I. 217.-Am. bor.

rosea, F. Muell. Fragm. i. 233.-Austral

Roxburghii, Choisy, in Mém. Soc. Phys. Genèv. vi, 1833) $493=$ cordata.

scoparia, Lindl. Fl. Med. 400.-Hab.?

secunda, Benth. in Hook. Niger Fl. 470 (err. typ. 70 -Afr. trop.

sericea, Griseb. in Goett. Abh. xix. (1874) 229.-Reg. Argent.

somalensis, Vatke, in Linnaea, xliii. (1880-82) 523.Afr. trop.

spectabilis, Choisy, in Mém. Soc. Phys. Genev. vi. 1833) 493.-Madag.

valerianoides, Villar, in Blanco, Fl. Phil. ed. III Nov. App. 143.-Ins. Philipp.

venulosa, Meissn in Mart. Fl. Bres. vii. 326.-Bras.

virgata, Vatke, in Linnaea, xliii. (1880 82) 523.Afr. austr.

BREWERINA, A. Gray, in Proc. Am. Acad, viii. (1872) $620=$ Arenaria, Rupp. (Caryophyll.). suffrutescens, A. Gray, 1. c。=A. congesta.

BREWSTERA, M. Koem. Syn. i. Hesp. 132, 141 $(1846)=$ Ixonanthes, Jack (Lineae)

crenata, M. Roem. 1. c. $141=\mathrm{I}$. icosandra.

BRFXIA, Noronba, ex Thon, Gen. Noy Madag. 2 (1806). SAXIFRAGEAE, Benth. \& Hook, f i 645 VENANA, Lam. Illustr. ii. 99.t. 131 (1800), nomeIl prius.

acanthifolia, Noronba, ex Tul. in Ann. Sc. Nat. Sér

IV. viii. (1857) $159=$ madagascariensis.

amplifolia, Noronha, 1. $\mathrm{c}_{\mathrm{s}}=$ madagascariensis.

caulifiora, Tul. l. c. 161.-Madag.

chrysophylla, Sweet, Hort. Brit. ed. I. $492=$ madagas cariensis.

digyna, Noronha, ex Tul. in Ann. Sc. Nat. Sér. IV. viii, 1857) $\mathbf{1 5 9}=$ madagascariensis.

heterophylla, Boj. Hort. Maurit. 52 =madagascariensis. Lucanana, Lubbers, Cat. Pl. Rar. 6.-Hab.?

madagascariensis, Thou. ex Ker-Gawl. in Bot. Reg.t. 730.-Madag.

microcarpa, Tul. in Ann. Sc. Nat. Sér. IV. viii. (185 160.-Ins. Seychell

ovatifolia, Noronha, ex Tul. 1. c. $159=$ madagas cariensis.

serrata, Presl, Rep. Bot. Syst. i. $190=$ madagacariensis.

spinosa, Lindl. in Bot. Reg. 1.872 = madagascariensi:

BREYNIA, Forst. Chat. Gen. 145, t. 79 (17\% EUPHORBIACEAE. Beath. \& Hook. f. iii. 276. Foersteria, Scop. Introd.98 (177\%) Mei.anthesa, Blume, Bijdr. 590 (18.25).

Melanthesiopsis, Muell. Arg. in Linnaea, xxxii (1863) 74.

acuminata, Muell. Arg. in DC. Prod. xv. It. 4t:... Ins. Philipp.

axillaris, Spreng. Pngill. ii. $92=$ disticha.

cernua, Muell. Arg. in DC. Prud. $5 \% .11 .499 .-$ Austrul.; Ins. Timor.

cinerascens, Baill. Adansonia, vi. (1S66) \$t1 oblongifoiia.

discigera, Macll. Arg. in DC. Prad. xv: 11. It1. Malayn.

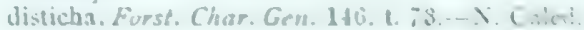




\section{BREYNIA :}

microphylla, Muell. Arg. in DC. Prod. xv. II. 442.Java.

Muelleriana, Baill. Adansonia, vi. (1866) $344=$ stipitata.

oblongifolia, Muell. Arg. in DC. Prod. xv, I1, 440.Anstral.

paniculata, Spreng. Pugill. ii. 93 (gen, dub.).-Ind. or racemosa, Muell. Arg. in DC. Prod. xv. II. 441.Java.

rhamnoides, Muell. Arg. l. c. 440.-As. trop.

rhynchocarpa, Benth. Fl. Austral. vi. 114.-Austral.

rubra, Muell. Arg. in DC. Prod. xv. II. 438.-Java.

stipitata, Muell. Arg.l.c. 442,-Austral.

virgata, Muell. Arg. l. c. 441,--Java.

BREYNIA, [Plum.] Linn. Gen. ed. I. $113(1737)=$ Capparis, Tourn.

indica, Linn. Sp. PI, $503=$ C. Breyniana.

BREZIA, Moq. in DC. Prod. xiii. II. $167(1849)=$ Suaeda, Forsk. (Chenop.).

heterophylla, Moq. 1. c. =S. heterophylla.

BRICKELLIA, Ell. Sketch, ii. 290 (1824). COM. POSITAE, Benth. \& Hook. f. ii. 247.

Bulbostyle, DC. Prod. v. 138 (1836).

Clavigera, DC. 1. c. 127 (1836).

Coleosanthus, Cass. in Bull. Soc. Philom. (1817) 67.

IsMARIA, Rafin. Sylva Tellur. 117 (1838)

Rosalesia, La Llav. \& Lex. Nov. Veg. Desc. i. 9 (1824).

atractyloides, A. Gray, in Proc. Am. Acad. viii. (1870) 290. - Am. bor. occ.

baccharidea, A. Gray, Pl. Wright. i. 87.-Texas; Arizona.

betonicaefolia, A. Gray, l. c. ii. 72.-N. Mexic.; Arizona.

brachyphylla, $A$. Gray, $l$. c. i. 84.-Am. bor. occ. californica, A. Gray, Pl. Fendl. 64.-Am. bor. occ.

Cavanillesii, A. Gray, Pl. Wright. i. 85-Mexic.

cedrosensis, Greene, in Bull. Torrey Club, x. (1883) 86.-Ins. Cedros.

cordifolia, Ell. Sketch, ii. 290.-Am. bor.

corymbosa, A. Gray, Pl. Wright. 1. 84.-Mexic.

Coulteri, A. Gray, l. c. 86.-Am. bor. occ.

Cumingii, Klatt, in Abh. Naturf. Ges. Halle, xv. (1882) $325=$ Chrysopsis oregana.

cylindracea, A. Gray, ex Engelm. in Proc. Am. Acad. i. (1846) 46.-Texas.

dentata, Sch. Bip. in Seem. Bot. Voy. Herald, 301.Texas; Arizona.

diffusa, A. Gray, Pl. Wright. i. 86.-Am. trop.

Fendleri, A. Gray, Pl. Fendl. 63.-N. Mexic.

floribunda, A. Gray, Pl. Wright. ii. 73.-Arizona.

frutescens, A. Gray, in Proc. Am. Acad. xvii. (1881-82) 207.-Calif.

Galeottii, A. Gray, Pl. Wright. i. 85.-Mexic.

grandiflora, Nutt. in Trans. Am. Phil. Soc. Ser. II vii. (1841) 287.-Am. bor. occ.

Greenei, A. Gray, in Proc. Am. Acad. xii. (1877) 58.Calif.

Hartwegi, A. Gray, Pl. Wright. i. 85.-Mexic.

hastata, Benth. Bot. Voy. Sulph. 21.-Calif.

hebecarpa, A. Gray, Pl. Wright. i. 85.-Mexic.

hymenochlaena, A. Gray, in Proc. Am. Acad.xv. (1880) 29.-Mexic

incana, A. Gray, l. c. vii. (1868) 350.-Calif.

laciniata, A. Gray, Pl. Wright. i. $87=$ dentata.

lanata, A. Gray. l. c. 84.-Mexic.

Lemmoni, A. Gray, in Proc. Am. Acad. xvii. (1881-82) 206. - Calif.

linearifolia, Klatt, in Abh. Naturf. Ges. Halle, xv, (1882) $325=$ Bigelowia Donglasii.

linifolia, Eaton, in Bot. King, Exp. 137. t. 15. f. 1-6. -Am. bor. occ.

longifolia, S. Wats. in Am. Natural. vii. (1873) 301.Am. bor, occ.

microphylla, A. Gray, Pl. Wright. i. 85.-Am. bor. occ.

mohavensis, A. Gray, Syn. Fl. N. Am. i. II. 104.Calif.

multiflora, Kellogg, in Proc. Calif. Acad. vii. (1877) 49.-Calif.

Nevinii, A. Gray, in Proc. Am. Acad. xx. (1885) 297. -Calif.

\section{BRICKELIIA :-}

oblongifolia, Nutt. in Trans. Am. Phil. Soc. Ser. II. vii. (1841) 288.-Am. bor. occ.

odontophylla, A. Gray, in Proc. Am. Acad. xvii. (1881-82) 206.-Mexic.

oliganthes, A. Gray, Pl. Wright. i. 84.-Arizona; Mexic.

Palmeri, A. Gray, in Proc. Am. Acad. xv. (1880) 30.Mexic.

Parryi, A. Gray, l. c. 31.-Mexic.

parvula, A. Gray, $\mathrm{Pl}$. Wright. i. 84.-Texas.

paucidentata, Klatt, in Abh. Naturf. Ges. Halle, xv, (1882) 326.--Ins. S. Cruc.

pendula, A. Gray, Pl. Wright. i. 85.-N. Mexic.

pinifolia, A. Gray, $l$. c. 84 --Bras.

Pringlei, A. Gray, in Proc. Am. Acad. xvii. (1881-82) 206.-Arizona.

reniformis, A. Gray, Pl. Wright. 1. $86=$ Wrightii.

Riddellii, A. Gray, l, c, 83.-Texas

Rosalesia, Benth. Eo Hook. f. ex Hemsl. Biol. Centr. Am. Bot. ii. 106.-Mexic

Rusbyi, A. Gray, Syn. Fl. N. Am. i. II. 106.N. Mexic.

scoparia, A. Gray, Pl. Wright. i. 84.-Mexic

secundiflora, A. Gray, l. c. 85 -Mexic.

Seemanni, A. Gray, in Proc. Am. Acad. xv. (1880) 30. - N. Mexic.

simplex, A. Gray, Pl. Wright. ii. 73.-Arizona.

spinulosa, A. Gray, l. c. i. 84.-Mexic.

squamulosa, A. Gray, in Proc. Am. Acad. xv. (1880) 30.-Mexic.

tenera, A. Gray, Pl. Wright. ii. $72=$ Wrightii

thyrsifiora, A. Gray, in Proc. Am. Acad. xv. (1880) 30 Mexic.

tomentella, A. Gray, Pl. Wright. i. 85.-Mexic

veronicaefolia, $A$. Gray, l. c.-Mexic.

Wislizeni, A. Gray, Pl. Fendl.64.-Arizona; Mexic.

Wrightii, Durand \& Hilg, in Pacif. Rail. Rep. v. $8=$

californica.

Wrightii, A. Gray, Pl. Wright. ii. 72.-Am. bor occ

BRICKELLIA, Rafin. in Med. Repos. New York, v (1808) $353=$ Gilia, Ruiz \& Pav. (Polemon.).

BRICOUR, Adans. Fam. ii. $423(1763)=$ Myagrum Tourn. (Crucifer.).

BRIDFLIA, Willd. Sp. Pl. iv. 978 (1805) (Briedelia) EUPHORBIACEAE, Benth. \& Hook. f. iii. 267. CANDElabria, Hochst. in Flora, xxvii. (1843) 79. Cluytia, Roxb. ex Steud. Nom. ed. II. 1. 225 (1840).

Pentameria, Klotzsch, ex Baill. Etud. Gén. Euph. 584 (1858).

Z.ARCOA, Llanos, in Bot. Zeit. Xv. (1857) 423.

acuminata, Wall, Cat. n. $7885=$ Phyllanthus bicolor. alnifolia, Griff. Notul. iv. 481.-Burma.

amoena, Wall. ex Baill. Etud. Gén. Euph. $584=$ retusa.

angolensis, Muell. Arg. in Seem. Fourn. Bot. ii. (1864) 327.-Afr. trop.

atroviridis, Muell. Arg. l. c.-Afr. trop.

attenuata, Wall. ex Voigt, Hort. Suburb. Calc. 156.Ind. or.

Berneriana, Baill. Adansonia, ii. (1861-62) 39,Madag.

Berryana, Wall. Cat. n. 7876, $7960=$ Phyllanthus indicus.

buxifolia, Baill. Adansonia, ii. (1861-62) 230.-

N. Caled.

cathartica, Bertol. f. in Mem. Acc.Sc. Bolog. v. (1854)

476.-Afr. trop.

chartacea, Wall. Cat. n. $7881=$ Cleistanthus chartaceus.

coccolobaefolia, Baker, in Fourn. Linn. Soc. xxi (1885) 441.-Madag.

collina, Hook. \& Arn. Bot. Beech. Voy. $211=$ Cleistanthus collinus.

crenulata, Roxb. Hort. Beng. 70 ; F1. Ind. iii. $734=$ retusa.

dasycalyx, Kurz, in Fourn. As. Soc. Beng. xlii. (1873) II. 241.-Burma.

diversifolia, Hook. E Arn. Bot. Beech. Voy. 211.Malaya.

elegans, Muell. Arg. in Seem. Fourn. Bot. ii. (1864) 327.-Afr. occ.
BRIDELIA :-

exaltata, F. Muell. Fragm. iị. 32,-Austral.

faginea, F. Muell. ex Benth. Fl. Austral. vi. 120.Austral.

ferruginea, Benth. in Hook. Niger Fl. 511.-Afr. trop. gambecola, Baill. Adansonia, i. (1860-61) 79.-Afr. trop.

glauca, Blume, Bijdr. 597.-Java.

glauca, Wall. Cat. n. $7875=$ praec. ? (Glochidionis sp.) -Penang.

Hamiltoniana, Wall. l. c. 7882.-Ind, or

heterantha, Wall. 1. c. $7873=$ Glochidion Wallichianum.

horrida, Dillw. Review Hort. Malab. 15=Scleropyron Wallichianum

insulana, Hance, in Fourn. Bot. xv. (1877) 337 . China.

lancaefolia, Roxb. Hort. Beng. 70 ; FI. Ind. iii. $737=$ tomentosa.

lanceolata, Kurz, ex Teijsm. E Binn. in Tijdschr. Nederl. Ind. xxvii. (1864) 45.-Malaya.

lancifolia, Buch.-Ham, in Wall. Cat. n. 7884= tomentosa.

laurina, Baill. Adansonia, ii. (1861-62) 229.N. Caled.

Leichardtii, Baill. Etud. Gén. Euph. 584=faginea.

Loureirii, Hook. \& Arn. Bot. Beech. Voy. $211=$ tomentosa.

melanthesoides, Klotzsch, in Peters, Reise Mossamb. Bot. 103.-Afr. trop.

micrantha, Baill. Adansonia, iii. (1862-63) 164.Afr. trop.

montana, Wall. Cat. n. $7879=$ retusa

montana, Willd. Sp. Pl. iv. 978.-Ind. or

Moonii, Thw. Enum. Pl. Zeyl. 279.-Zeylan

multiflora, Zipp. in Miq. Ann. Mus. Bot. Lugd. Bat. iv. 119.-Amboina.

oblongifolia, Hook. \& Arn. Bot. Beech. Voy. $212=$ Cleistanthus chartaceus.

ovata, Decne. in Nouv. Ann. Mus. Par. iii. (1835) 484.-Austra1.; Burma; Malaya; Ins. Timor.

patula, Hook. \& Arn. Bot. Beech. Voy. $212=$ Cleistanthus patulus.

Pervilleana, Baill. Adansonia, ii. (1861-62) 38.-Madag

polystachya, Baill. Etud. Gén. Euph. $584=$ Cleistanthus polystachyus.

pubescens, Kurz, in Fourn. As. Soc. Beng. xlii. (1873) II. 241.-Reg. Himal. ; Burma.

retusa, Baill. Etud. Gén. Euph. 584, nomen= Moonii retusa, A. Juss. Tent. Euphorb. 27. t. $7=$ stipularis.

retusa, Spreng. Syst. iii. 48.-Ind. or.; Malaya

rhamnoides, Griff. Notul, iv. $480=$ tomentosa.

rhomboidalis, Baill. Adansonia, ii. (1861-62) 37.Ins. Borbon.

rugosa, Miq. Fl. Ind. Bat. Suppl. 445.-Sumatra. scandens, Willd. Sp. Pl. iv. $979=$ stipularis

scleroneura, Muell. Arg. in Flora, xlvii. (1864) 515.Afr. trop.

sinica, J. Grah. Cat. Bomb. Pl, $179=$ Cleistanthus malabaricus?

speciosa, Muell. Arg. in Seem. Fourn. Bot. ii. (1864) 327.-Afr. trop.

spinosa, Hort. ex DC. in Mém. Soc. Phys. Genèv. vi. (1833) $563=$ Damnacanthus indicus.

spinosa, Willd. Sp. Pl. iv. $979=$ retusa.

stenocarpa, Muell. Arg. in Flora, xlvii. (1864) 515.Afr. trop.

stipitata, Baill. Adansonia, ii. (1861-62) 229.N. Caled.

stipularis, Blume, Bijdr. 597.-Ind. or.; Malaya; Afr. trop.

stipularis, Hook. \& Arn. Bot. Beech. Voy. $211=$ Cleistanthus stipularis.

tenuifolia, Muell. Arg. in Fourn. Bot. ii. (1864) 328 -Afr. trop.

tomentosa, Blume, Bijdr. 597.-Ind. or. ; Malaya; Austral.

Tulasneana, Baill. Adansonia, ii. (1861-62) 40.Madag.

urticoides, Griff. Notul. iv. $481=$ tomentosa?

Zollingeri, Miq. Fl. Ind. Bat. i. II. $364=$ stipularis.

BRIDGESIA, Bert. ex Cambess. in Nouv, Ann. Mus. Par. iii. (1834) 234. t. 13. SAPINDACEAE, Benth. \& Hook. f. i. 393

Tripterocarpus, Meissn. Gen. 52 (1837).

incisifolia, Bert. ex Cambess. l. c. 235.-Chili 
BRIDGESIA, Hook. Bot. Misc. ii. (1831) 222. t. $92=$ Polyachyrus, Lag. (Compos.).

echinopsoides, Hook. 1. c. $=$ P. sphaerocephalus.

BRIDGESIA, Hook. \& Arn. in Hook, Bot. Misc. iii. (1833) 168. t. $102=$ Ercilla, A. Juss. (Phytolacc.). spicata, Hook. \& Arn. 1. c. $169=\mathrm{E}$. volubilis.

BRIEDELIA, Willd. Sp. Pl. iv, 978 (1805)= Bridelia 'Willd,' (Euphorb.).

BRIGHAMIA, A. Gray, in Proc. Am. Acad, vii. (1867) 185. CAMPANULACEAE, Benth. \& Hook. f. ii. 545 .

insignis, A. Gray, l. c. - Ins, Hawaii.

BRIGNOLIA, Bertol. in Desv. Journ. Bot. ii. (iv.) (1815) $76=$ Kundmannia, Scop. (Umbellif.)

panacifolia, Heynh. Nom。 i. 131, sphalm. = seq.

pastinacifolia, Bertol. in Desv. Journ. ii. (iv.) (1815) $76=\mathrm{K}$. sicula.

BRIGNOLIA, DC. Prod. iv. 444. $(1830)=$ Isertia Schreb. (Rubiac.).

acuminata, DC. 1. c.-Ins. Trinit.

pubigera, Benth. in Hook. Journ. Bot. iii. (1840) 219. -Guiana.

BRILLANTAISIA, Beauv, Fl, Owar, ii. 67. t. 100 (1805). ACANTHACEAE, Benth. \& Hook. f. ii. 1076.

Belantheria, Nees, in DC. Prod. xi. 96 (1847). LEUCORHAPHIS, Nees, 1. c. 97 (1847).

alata, T. Anders. ex Oliver, in Trans. Linn. Soc. xxix. (1875) 125. - Afr. trop.

hirsuta, T. Anders, in Fourn. Agri-Hort. Soc. Ind. N. S. i. (1868) 267 - -Afr. trop.

Lamium, Benth. in Hook. Niger Fl. 477.-Afr. trop.

owariensis, Beauv. Fl. Owar. ii.68. t.100. f. 2.-Afr. trop.

patula, T. Anders. in fourn. Linn. Soc. vii. (1864) 21. -Afr. trop.

pubescens, T. Anders. ex Oliver, in Trans. Linn. Soc. xxix. (1875) 125.-Afr. trop.

Rutenbergiana, Vatke, in Bremen Abh. ix. (1885) 131. -Afr. trop.

Vogeliana, Benth. in Hook. Niger Fl. 477.-Afr. trop.

PRIMEURA, Salisb. Gen. Pl. Fragm. 26 (1866)= Hyacinthus, Tourn. (Liliac.)

amethystina, Salisb. I. $_{0}=\mathrm{H}$. amethystinus.

BRIMYS, Scop. Introd. 252 (1777) err. typ $=$ Drimys, Forst. (Magnol.).

BRINDONIA, Thou. in Dict. Sc. Nat. v. $339 \cdot(1804)=$ Garcinia, Linn. (Guttif.)

celebica, Thou. 1. c. $341=\mathrm{G}$, cornea?

cochinchinensis, Thou. $1 . \mathrm{c}_{\mathrm{n}}=\mathrm{G}$. cochinchinensis.

indica, Thou. 1. c. $340=\mathrm{G}$. indica.

BRISEGNOA, Remy, in C. Gay, Fl. Chil. v. 291 (1849) = Oxytheca, Nutt. (Polygon.).

chilensis, Remy, 1. c. $292=0$. dendroides.

BRISEIS, Salisb. Gen. Pl. Fragm. 92 (1866)=Allium, Tourn. (Liliac.)

triquetra, Salisb. I. c. $93=$ A. triquetrum.

BRISSONIA, Neck. Elem。 iii. 36 (1790); Desv. [Journ. i. (1814) 78]; in Ann. Sc. Nat. Sér. I. ix. (1826) 411 =Indigofera, Linn. et Tephrosia, Pers. (Legumin.).

caronillaefolia, Desv. Journ. i. (1814) 78 = T. coronillaefolia.

stipularis, Desv. 1. c. $=$ T. stipularis.

trapesicarpa, Desv. 1. c. = seq.?

trapesicarpa, Desv. in Ann. Sc. Nat. Sér. I. ix. (1826) $411=I$. senegalensis.

BRITOA, Berg, in Linnaea, xxvii. (1854) $485=$ Cam pomanesia, Ruiz \& Pav. (Myrtac.)

acida, Berg, 1. c. 436 ; et in Mart. Fl. Bras, xiv, Y. 461. -Bras.

-Bras.
dichotoma, Berg, 1l. cc. 436, 468--Bras.

eriantha, Berg, $\mathrm{H}_{\mathrm{c}} \mathrm{cc} .=\mathrm{C}$. eriantha.

psidioides, Berg, 11. cc. 436, 462.-Bras,

rugosa, Berg, in Mart. Fl. Bras, xiv, 1. 613.-Bras

Sellowiana, Berg, in Linhaea, xxpii. (1854) 487 ; et

in Mart. Fl. Bras. xiv. I. 468.-Bras,

sessilifiora, Berg, II. cc. 486, 461.-Brns.

iriftora, Berg, ll. cc. $436,462=$ C. triflora.
BRIZA, Linn. Syst. ed. I (1795), GRAMINEAE,

Benth. \& Hook. fo iii. 1194.

Calotheca el Chascolytrum, Desv, in Noy. Bull. Soc. Philom. ii. (1810) 190.

POA, Adans. Fam. ii. $34(1763$

Tremularia, Heist. Syst. 12 (1748)

anceps, Linn. ex Munro, in Journ. Linn. Soc. vi. (1862) $44=$ media

aspera, Knapp, Gram. Brit. t. $61=$ minor.

auriculata, Trev. ex Steud. Syn. PI. Gram. 283 =triloba. barbata, Trin. in Mém. Acad. Pétersb. Sér. VI. i (1831) 363.-Bras.

Berteroniana, Steud. Syn, Pl. Gram, 283.-Chili.

bipinnata, Linn. Syst. Nat. x. $875=$ Eragrostis cynosurioides.

canadensis, Michx. Fl. Bor. Am. i. 71,-Am. bor.

canadensis, Nutt. Gen. Am。 i。 69 pro parte $=$ Glyceria

nervata.

capensis, Schrank, Hort. Monac. t. $43=$ maxima,

capensis, Thunb. Prod. Fl. Cap. $21=$ Eragrostis brizoides.

caroliniana, Lam. Encyc. i. 465; Illustr. i. 187.t. 45 .

f. $3=$ Uniola paniculata.

caroliniana, Walt. Fl. Carol. $79=$ Eragrostis major.

Clusii, Schult. in Roem. \& Schult. Mant. ii. $294=$ media.

cynosuroides, Scop. Delic. Insub. ii. $21=$ Demazeri sicula.

deltoidea, Burm. f. Fl. Cap. Prod. 3.-Afr. austr.

disticha, Moench, Meth. $185=$ Demazeria sicula.

dura, Desv. Opusc. 105.-Am。austr.

elatior, Sibth. \& Sm. Fl. Graec. i. t. $75=$ media.

elegans, Doell, in Mart. Fl. Bras. ii. III. 135.-Bras.

Eragrostis, Desf. F1. Atlant. i. $78=$ Eragrostis minor

Eragrostis, Linn. Sp. Pl. $70=$ Eragrostis major.

erecta, Lam. Illustr. Gen. i. 187.-Reg. Argent.

flava, Desv. Opusc. 105.-Am. austr.

geniculata, Thunb. Prod. Pl. Cap. 21.-Afr. austr.

grandis, Salisb. Prod. $21=$ maxima

humilis, Bieb. Fl. Taur. Cauc, i. $66=$ spicata

imbricata, Steud. in Flora, xii. (1829) $489=\mathrm{Poa}$

Uniolae.

Lamarkiana, Cham. \& Schlecht. in Linnaea, vi. (1831) $39=$ rotundata.

Lamarckiana, Nees, Agrost. Bras. 481--Am, austr.

lutescens, [Foucault, in] Desv. Journ. iii. (1814) t. 24. f. $2=$ media

macrostachya, Steud. Nom. ed. II. i. 225.-Peruv. major, Desv. ex Kunth, Enum. Pl. i. $371=$ pulchella major, Presl, Cyp. et Gram. Sic. $42=$ maxima.

maxima, Linn. Sp. Pl. 70.-Reg. Mediterr.; Afr. austr.

media, Linn. l. c.-Europ.; Oriens; As. bor.

(Amphig. advent.).

megastachya, Hort, ex Steud. Nom. ed. II. i. $225=$ Eragrostis major.

microstachya, Steud. l. c.-Peruv.

minima, Hort. ex Nichols. Dict. Gard. i. $212=$ minor.

minor, Linn. Sp. Pl. 70.-Europ.; Oriens; As. bor. (Amphig, advent.).

monspessulana, Gouan, Hort. Monsp. $45=$ maxima. montana, Brouss. Cat. Monsp. (1804); Roem. Schult. Syst. ii. 521.-Teneriffa?

mucronata, Lam. Encyc。 i. 465 = Lamarckiana.

multiflora, Forst. ex Beauv. Agrost. 155, nomen.-Oriens.

Neesii, Doell, in Mart. Fl. Bras. ii. Irr. 132.-Bras

nigra, Burch. ex Stevid. Nom. ed. II. i. 225.-Afr. austr.

oblonga, Moench, Meth. $185=$ Eragrostis major. pauciflora, Schur, in Verh. Siebenb. Ver. Naturw.

(1853) 86. -Europ

pilosa, Schur, Enum. Pl. Transs. 766-Hangaria.

Poa, Nees, ex Steud. Syn. Pl. Gram. $283=$ Neesii.

pulchella, Kunth, Rev. Gram, i. 120,-Ins. Teneriff. purpurascens, Muhl. Descr. Uber. 154.-Carolina. reniformis, Steud. Nom. ed. II. i. 225.-Peruv. rotundata, Sterd. Syn. Pl. Gram. 281, - Mexic.

rubella, Steud. l. c. 282,-Afr. trop.

rubens, Poir. Suppl. i. $699=$ maxima.

rubra, Lam. Illustr, i. 187; ; Pers. Syn。 i. $98=$ maximn. rufa, Steud. Nom. ed. II. i. 225. - Perav.

scabra, Nees, ex Steud. Syn. Pl. Gram. 276. ฌ. 191 Neesii.

Sellowii, Nees, ex Steud. l. c. 284. n. 26.-Bms.

serotina, Dum. Obs. Gram. Belg. $110=$ media.

spicata, Burm. f. Fl. Cap. Prod. 3.-Afr. austr.

\section{BRIZA}

spicata, Lam. Encyc. i. $465=$ Poa Michauxii.

spicata, Sibth. Eo Sm. Fl. Graec. i. t. 77.-Graecia:

As. Min.

spicigera, Steud. Nom. ed. II. i. 225.-Peruv.; Chili

stricta, Steud. l. c.-Chili.

subaristata, Lam. Illustr. i. 187.-Reg. Argent.

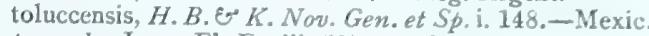

tremula, Lam. Fl. Fr. iii. $587=$ media.

trichotoma, Steud. in Flora, xxix. (1846) 20.-Japon

triloba, Nees, Agrost. Bras. 482.-Reg. Argent.

Uniolae, Nees, ex Steud. Syn. PI. Gram. $283=$ Eragrostis Uniolae.

violascens, Steud. 1. c. = subaristata.

virens, Linn. Sp. Pl. ed. II. $103=$ minor.

virens, Walt. Fl. Carol. $79=$ Poa obtnsa.

virens, Trin. in Mém. Acad. Pétersb. Sér. VI. i. (1831

$362=$ media

viridis, Pall. ex Steud. Nom. ed. II. i, 226=minor.

BRIZOPHILE, Salisb. Gen. Pl. Fragm, 34 (1866)=

Ornithogalum, Tourn. (Liliac.)

nutans, Salisb. 1. c. = O. nutans.

BRIZOPYRUM, Link, Hort. Berol. i. 159 (1827) Demazeria, Dum. (Gramin.).

siculum, Link, 1. c. $=$ D. sicula.

BRIZOPYRUM, J. Presl, in Rel. Haenk. 280 (1830)

Distichlis, Rafin. (Gramin.)

acutiflorum, Nees, Fl. Afr. Austr. $371=$ Eragrostis acutiflora.

alternans, Nees, 1. c. $369=$ Poa alternans.

americanum, Link, Hort. Berol. i. $160=$ Distichli maritima.

boreale, Presl, Rel. Haenk. $28=$ Distichlis maritima.

bromoides, Presl, I. c. $=$ Poa bromoides.

calycinum, Presl, 1. c. $281=$ Poa calycina

capense, Nees, Fl. Afr. Austr. $371=$ Poa Uniolae.

condensatum, Fourn. Mex, P1. Enum. Gram. 121

ex Hemsl. Biol. Centr. Am. Bot. iii. $578=$ Distichli condensata.

cyperoides, Nees, Fl. Afr. Austr. $374=$ Eragrosti: cyperoides.

Douglasii, Hook. \& Arn. Bot. Beech. Voy. $404=$ Po: Douglasii.

obtusiflorum, Fourn. Mex. Pl. Enum. Gram. 120; ex Hemsl. Biol. Centr. Am. Bot. iii. $579=$ Distichli: thalassica.

ovatum, Nees, ex Steud. Syn. Pl. Gram. 282,-Peruy.

pilosum, J. Presl, in Rel. Haenk. i. $280=$ Distichli thalassica.

prostratum, Benth. ex Fourn. Mex. Pl. Enum. Gram 120 ; ex Hemsl. Biol. Centr. Am. Bot. iii. 578

Distichlis prostrata.

scirpoideum, Steud. Syn. Pl. Gram. 282 = Schedonoru: scirpoideus.

spicatum, Hook. \& Arn. Bot. Beech. Voy. $408=$

Distichlis maritima.

subspicatum, J. Presl, in Rel. Haenk. $281=$ Po. subspicata.

BRIZULA, Hieron, in Bot. Zeit. xxx. (1872) 206 Aphelia, R. Br. (Centrolepid.

Drummondii, Hieron. in Abh. Natarf. Ges. Halle, xi. 1873) $206=\mathrm{A}$. Drummondii.

gracilis, Hieron. 1. c. $=$ A. gracilis

Muelleri, Hieron.1. c. $207=$ A. Brizula

Pumilio, Hieron. 1. c. $=$ A. Pumilio.

BROCCHIA, Mauri, ex Tenore, Cat. Ort. Napoli, 80 $(1845)=$ Simmondsia, Nutt. (Euphorb.)

dichotoma, Mauri, 1. c. $=\mathrm{S}$. californica.

BROCCHIA, Vis. Pl. Aeg. et Nab. $35\left(1590^{\circ}\right)=$ Cotula Linn. (Compos.)

cinerea, Vis. 1. $\mathrm{c}_{0}=\mathrm{C}$. cinereum.

Kotschyi, Schalt. ex Schweinf. \& Aschers. Enum. 293

C. Kotschyi.

BROCCHINIA Schult of Sytat vii 1.250 (1Ssu

BROMELIACE.AE, Benth. \& Mluok. R. Gen, iii. 06 ?

cordylinoides, Baker, in Fourn. Bot. xx. (1852) $\$ 80$.

Giuiana.

onniculata, Schulf. f. Syst. vii. 1250. - Bras

Plumierii, Griseb. Fl. Bris. W6. Ind. 593._lad. oce

reducts, Bater, in Gusurn. Bot. xx. (15s2) BS!

Guiana. 
BROCHOSIPHON, Nees, in DC. Prod. xi. 492 (1847) = Dicliptera, Juss. (Acanthac.)

australis, Nees, 1. c. $=$ D. glabra .

BRODIAEA, Sm. in Trans. Linn. Soc. x. (1811) 2. t. 1 . LILIACEAE, Benth. \& Hook. fo iii. 800. Calliprora, Lindl. Bot. Reg. t. 1590 (1833)。 Dichelostemma, Kunth, Enum. Pl. iv. 469 (1843). Gardinia, Bertero, 'in Merc. Chil. i. (1829)'.-Cf. Férussac, Bull, xx. (1830) 111

HESPEROSCORDU M, Lindl. Bot. Reg. sub t. 1293 (1829).

Hookera, Salisb. Parad. Lond. t. 98 (1808), nomen prins.

Scaduakintos, Rafin. Fl. Tellur. iv. 23 (1836)

Seubertia, Kunth, Enum. Pl. iv。 475 (1843).

ThemIs, Salisb. Gen. Pl. Fragm. 85 (1866).

Triteleia, Dougl. ex Lindl. Bot. Reg. sub t. 1293 (1829).

Veatchia, Kellogg, in Proc. Calif, Acad, ii. (1859? 11.

alliacea, Miers, ex Baker, in Journ. Linn. Soc. xi. (1871) $375=$ Leucocoryne alliacea.

Bridgesii, S. Wats. in Proc. Am. Acad. xiv. (1879) 237.-Calif.

californica, Lindl. ex Lem. in Fl, des Serres, Sér. I. v. (1849) $428 \mathrm{~b}=$ grandiflora.

capitata, Benth. Pl. Hartw. 339.-Am. bor. occ.

coccinea, A. Gray, in Proc. Am. Acad. vii. (1868) 389 -Calif.

congesta, Sm. in Trans. Linn. Soc. x. (1811) 3. t. 1.-

Am. bor. oce.

crocea, S. Wats. in Proc. Am. Acad. xiv. (1879) 238. -Calif.

Douglasii, S. Wats. l. c. 237.-Am. bor. occ.

filifolia, S. Wats. l. c. xvii. (1881-82) 381.-Calif.

gracilis, S. Wats. l. c. xiv. (1879) 238. - Calif.

grandiflora, Pursh, Fl. Am. Sept. i. $223=$ lactea.

grandiflora, Sm. in Trans. Linn. Soc. x. (1811) 2.-

Am. bor. occ.

grandiflora, Torr. in Stansb. Rep. $397=$ Douglasii.

Howellii, S. Wats. in Proc. Am. Acad. xiv. (1879) 301.-Am. bor.

ixioides, Sims, Bot. Mag. t. $2382=$ Leucocoryne ixioides.

ixioides, S. Wats. in Proc. Am. Acad. xiv. (1879) 238. -Am. bor. occ.

lactea, S. Wats. l. c.-Am. bor. occ.

laxa, S. Wats. l. c. 237.-Calif.

Lemmonae, S. Wats. l. c. xx. (1885) 376-mArizona.

minor, S. Wats. l. c. xiv. (1879) 236.-Am. bor. occ

multiflora, Benth. Pl. Hairtw. 339.-Am. bor. occ.

parviftora, Torr. \& Gray, in Pacif. Rail. Rep. ii (1854) $125=$ multiflora

peduncularis, $S$. Wats. in Proc. Am. Acad. xiv. (1879) 237.-Calif.

stellaris, S. Wats. l. c. xvii. (1881-82) 380.-Calif. terrestris, Kellogg, in Proc. Calif. Acad. ii. (1863) 6. -Calif.

Torreyi, Wood, in Proc. Acad. Sc. Philad. (1868) $172=$ terrestris.

volubilis, Baker, in Journ. Linn. Soc. xi. (1871) 3 i7 $=$ Stropholirion californicum.

BROGNIARTIA, Walp. Rep. ii. $994(1843)=$ Brong niartia, H. B. \& K. (Legumin.).

BROMBYA, F. Muell. Fragm. vo 4 (1865)。 RUTA$C E A E$, Benth. \& Hook. f. i. 991.

platynema, F. Muell. l. c.-Austral.

BROMELIA, [Plum.] ex Linn. Syst. ed. I (1735). BROMELIACEAE, Benth. \& Hook. f. iii. 660 .

Agallostachys, Beer, Bromel. 35 (1857).

ANANAS, Gaertn. Fruct. i. 30. t. 11 (1788)

Pinguin, [Dill.] Adans. Fam. ii. 67 (1763).

PSEDomelia, Neck. Elem. iii. 150 (1790).

Acanga, Linn. Syst. ed. XII. $232=$ B. Pinguin et Karatas Plumieri.

Acanga, Schult. fo Syst. vii. II. $1281=$ Araeococcus micranthus.

Acarna, Thunb. ex Schult. f. l. c. 1283, nomen.-Hab. ? acaulis, Stokes, Bot. Mat. Med. ii. $204=$ Karatas Plumieri.

agavaefolia, Brongn。 in Rev. Hortic. (1875) $247=$ Karatas agavaefolia.

agavoides, Carr.l.c. (1881) 31.-Hab.?

\section{BROMELIA :-}

albo-bracteata, Steud. in Lechl. Berb. Am. Austr. 53 nomen.-Chili.

albo-rosea, Lem. Illustr. Hortic. ii. (1855) Misc. $64=$ Aechmea suaveolens.

Ananas, Linn. Sp. Pl. $285=$ Ananas sativus.

antiacantha, Bertol. in Virid. Bonon. Veg. (1824) 4

Colla, Hort. Ripul. App. ii. $342=$ fastuosa.

aquilega, Salisb. Parad. Lond. t, $40=$ Aechmea aquilega.

arvensis, Vell. F1. Flum. 130 ; iii. t. $114=$ Quesnelia

rufa.

bicolor, Ruiz \& Pav, Fl. Peruv. Chil. iii. $33=$ Rhodostachys bicolor.

Binoti, Hort. Jacob-Makoy.-Cf. Gard. Chron. (1880) II. $151=\mathrm{B}$. Pinguin.

bracteata, Schult. f. Syst. vii. II. 1280, ex parte $=$ Aechmea laxiflora.

bracteata, Sw. Prod. Veg. Ind. Occ, $56=$ Aechme bracteata.

Caratas, Hill, Veg. Syst. vii, $19=$ Karatas Plumieri.

carnea, Beer, Bromel. $31=$ Rhodostachys andina.

Carolinae, Beer, 1. c. 29 ; Ortg. ex Regel, Gartenfl. vi. (1857) $361=$ Karatas Carolinae.

chrysantha, Facq. Hort. Schoenb. i. 28.-Am. austr. clandestina, Hort. ex Carr. in Rev. Hortic. (1880) $256=$ Greigia sphacelata.

comata, Beer, Bromel. 34.-Bras

Commeliniana, De Vriese, Del. Sem. Hort. Amst. 1844 ; ex Hoev. \& De Vriese, Tijdschr. xii. (1845) 49 = fastuosa.

comosa, Hill, Veg. Syst. vii. $18=$ Ananas sativus.

concentrica, Beer, Bromel. $29=$ Karatas Laurentii ?

crassa, Steud. in Lechl. Berb. Am. Austr. $53=$ Greigia Landbecki.

cruenta, R. Grah. in Edinb. N. Phil. Journ. (Oct.-Dec, 1828) $174=$ Billbergia cruenta.

denticulata, C. Koch, Wochenschr. ii. (1859) 151.Bras.

discolor, Lindl. Bot. Reg. (1838) Misc. 48.-Am. austr.

edulis, Salisb. Prod, $247=$ Ananas sativus.

elegans, Hort. Hamb. ex Schult. f. Syst. vii. II. 1283. -Hab.?

exsudans, Lodd. Bot. Cab. t. $801=$ Aechmea exsudans.

fastuosa, Lindl. Collect. 1.-N. Granat.

Fernandae, Morr. in Illustr. Hortic. xviii. (1871) 114. t. 65.-Bras.

gigantea, Hort. Vindob. ex Schult. f. Syst. vii. II, 1283.-Hab. ?

glabra, Schult. f. 1. c. $1286=$ Ananas sativus.

hemispherica, Lam. Encyc, i. $145=$ Karatas humilis.

Hookeri, Sweet, Hort. Brit. ed. I. 425=Aechmea nudicaulis.

humilis, Linn. Syst. ed. XII. 232; Jacq. Enum. Vindob. App. $306=$ Karatas humilis

ignea, Beer, Bromel. $35=$ B. Pinguin.

incarnata, Ruiz \& Pav. Fl. Per. iii. $32=$ Billbergia incarnata.

inermis, Steud. Nom. ed. II. i. $226=$ Ananas sativus.

iridifolia, Nees \& Mart. in Nov. Act. Nat. Cur, xi. (1823) $16=$ Billbergia iridifolia.

Itatiaiae, Wawra, in Oestr. Bot. Zeitschr. xxx. (1880) 114.-Bras.

Foinvillei, E. Morr. ex C. H. Morr. in Belg. Hortic xxvi. (1876) 161, t. $10,11=$ Rhodostachys pitcairniaefolia.

Karatas, Linn. Sp. Pl. $285=$ Karatas Plumieri.

laciniosa, Mart. ex Schult. f. Syst. vii. II. 1278.Bras.

laevis, Hort. Carlsruh. ex Schult. f. l. c. 1283.-Hab.? Landbecki, Lechl ex Phil in Linnaea, xxxiii. (1864-65) $246=$ Greigia Landbecki.

lanuginosa, Beer, Bromel. $32=$ Puya lannginosa.

lasiantha, Willd. ex Schult. f. Syst. vii. II. $1233=$ Puya lanata.

latifolia, Willd. ex Schult f. l. c. 1283.-Ins. Antigua.

Lindleyana, Lem. Jard. Fleur. iii. $(1852-53)$ t. 223, in obs, = Araeococcus micranthus.

lingulata, Linn. Sp. P1. $285=$ Aechmea lingulata.

longifolia, Lindl. in Paxt. Flow. Gard. ii, t. $65=$ Rhodostachys andina.

longifolia, Rudge, Gui. i. 31. t. 49.-Guiana.

longifolia, Klotzsch, in Schomb. Reise, iii. 903, nomen. -Guiana.

lucida, Willd. Enum. Hort. Berol. 345=Ananas sativus.

\section{BROMELIA}

lutea, G. F. W. Mey. Prim. Fl. Esseq. 145= Aechmea nudicaulis.

melanantha, Ker-Gawl. in Bot. Reg. t. $766=$ Aechmea bromeliaefolia.

Mertensii, G. F. W. Mey. Prim. Fl. Esseq. 144= Aechmea Mertensii.

mexicana, Nois, ex Schult. f. Syst. vii. II. 1283, nomen.-Mexic.

Moensi, Linden, Cat. (1873) n. I. 6.-Bras.

muricata, Arruda, Diss. Pl. Bras. 21 =Ananas bracteatus?

nudicaulis, Limn. Sp. Pl. $286=$ Aechmea nudicaulis.

nudicaulis, Reichb. Ic. Exot. 185 = Billbergia pyramidalis.

pallida, Ker-Gawl. in Bot. Reg. t. $344=$ Billbergia speciosa.

paniculata, J. F. Gmel. Syst. $529=$ Aechmea paniculigera.

paniculigera, Reichb. Ic. Exot. t. 239, 240=Aechmea exsudans.

paniculigera, Sw. Prod. Veg. Ind. Occ. $56=$ Aechmea paniculigera.

pauciflora, C. Koch, Wochenschr. ix. (1866) 183.$\mathrm{Hab}$ ?

Pinguin, Linn. Sp. Pl. 285.-Am. trop.

pitcairnifolia, C. Koch, Wochenschr. xi. (1868) $325=$ Rhodostachys pitcairniaefolia.

pumila, Hort. ex Schult. f. Syst. vii, II, 1283.-Hab.? pyramidalis, Sims, Bot. Mag. t. $1732=$ Billbergia pyramidalis.

pyramidata, Beer, Bromel. $34=$ Puya pyramidata.

Rohaniana, Walp. Ann. vi. $71=$ Billbergia vittata.

rubra, Hort. ex Schult. f. Syst. vii. II. $1285=$ Ananas sativus.

Sagenaria, Arruda, Diss. Pl. Bras. $14=$ Ananas bracteatus.

scarlatina, Hort. ex Hérincq, Hortic. Franç. (1869) $246=$ Distiacanthus scarlatinus

scarlatina, E. Morr. ex C. H. Morr. in Belg. Hortic xxxi. (1881) 164.-Bras.

Sceptrum, Hueg. Parad. Vind. fasc. viii. (sic) $=$ fastuosa.

semiserrata, Willd. Enum. Hort. Berol. $345=$ Ananas sativus.

sepiaria, Hort. ex Schult. f. Syst. vii. II. 1283.-Hab.?

Serra, Griseb, in Goett. Abh. xxiv. (1879) 328.-Reg. Argent.

sessiliflora, Lodd. ex Loud. Hort. Brit. 118.-Am. austr.

silvestris, Vell. Fl. Flum. 129; iii. t. 113=Ananas sativus.

sphacelata, Ruiz \& Pav, Fl. Per. iii. 32. t. $474=$ Greigia sphacelata.

spicata, Lam. Encyc. i. 146.-Ins. Martinic.

subspinosa, Wendl. ex Schult. f. Syst. vii. II. $1286=$ Ananas sativus.

surinamensis, Miq. in Linnaea, xviii. (1844) 378.Guiana.

sylvestris, Willd. ex Sims, Bot. Mag. t. 2392.-Am. trop.

thyrsifolia, Willd. ex Schult. f. Syst. vii. II. $1282=$ Aechmea spicata.

tinctoria, Mart. Reise Bras. ii. $554=$ Aechmea brome liaefolia.

tristis, Beer, Bromel. 30.-Bras.

variegata, Arruda, Diss. Pl. Bras. $7=$ Billbergia speciosa.

violacea, Hort. ex Schult. f. Syst. vii. II. $1285=$ Ananas sativus.

viridis, Hort. ex Schult. f. I. c. = Ananas sativus.

zebrina, Herb. in Bot. Mag. t. 2686=Billbergia zebrina.

BROMFELDIA, Neck. Elem. ii. $347(1790)=$ Ja tropha?, Linn. (Euphorb.).

BROMHEADIA, Lindl. Bot. Reg. (1841) App. 90 $O R C H I D E A E$, Benth. \& Hook. f, iii. 540.

aporoides, Reichb. f. Otia Bot. Hamb. 44.-Burma.

Finlaysoniana, Reichb. f. in Walp. Ann. vi. 630,882 = palustris.

palustris, Lindl. Bot. Reg. (1841) Misc. 89.Malaya.

BROMIDIUM, Nees \& Meyen, in Nov. Act. Nat. Cur. xix. Suppl. i. ; (Pl. Meyen.) 154 (1843) = Deyeuxia, Clar. (Gramin.). 
BROMIDIUM :-

anomalum, Doell, in Mart. F1. Bras. ii. III. 103.Bras.

brevifolium, Nees \& Meyen, in Nov. Act. Nat. Cur, xix. Suppl. i. $155=$ D. brevifolia

caespitosum, Nees \& Meyen, l. c. = Agrostis Preslii. hygrometricum, Nees \& Meyen, 1. c. 154.-Bras. lobatum, Nees, in Hook. Lond. Journ. Bot. ii. (1843) $415=\mathrm{D}$. quadriseta.

quadriseta, Nees, 1. c. $416=$ D. quadriseta.

rigescens, Nees \& Meyen, in Nov, Act. Nat. Cur. xix. Suppl. i. $155=$ Agrostis rigescens.

spectabile, Nees \& Meyen, 1. c. 156.--Peruv.

BROMOPSIS, Fourr. in Ann. Soe, Linn. Lyon, N. S xvii. (1869) $187=$ Bromus, Dill. (Gramin.).

aspera, Fourr. 1. c. = Bromus asper.

erecta, Fourr. 1. c. = Bromus erectus.

BROMUS, Dill. ex Linn. Syst, ed. I (1735), GRA. MINEAE, Benth. \& Hook. f. iii. 1200

Anisantha, C. Koch, in Linnaea, xxi. (1848) 394.

Bromopsis, Fourr, in Ann. Soc. Linn. Lyon, N. S. xvii. (1869) 187

CeratochloA, Beauv. Agrost. 75. t. 15. f. 7 (1812)

LASIOPOA, Ehrh. Beitr. iv. 147 (1789).

Libertia, Lej. in Nov. Act. Nat. Cur. xii. (1825)

755. t. 65 .

Michelaria, Dum. Obs, Gram. Belg. 77. t. 16 (1823):

Schedonorus, Beanv. Agrost. 99. t. 19. f. 2 (1812), partim.

Serrafalcus, Parl. Pl. Nov. 75 (1842).

Triniusa, Steud. Syn. PI. Gram. 328 (1854).

Zerna, Panz. in Denkschr. Acad. Muench. 1813 (1814) 296, partim.

abortiflorus, St. Amans, Fl. Agen. $44=$ tectorum.

adoënsis, Hochst. ex Steud. Syn. Pl. Gram. 326.Abyss.

aegyptiacus, Tausch, in Flora, xx. (1837) $124=$ brachystachys.

affinis, Dum. Obs. Gram. Belg. 118=mollis?

agrarius, Dum. 1. c. = diffusus.

agrarius, Hornung, ex Steud. Nom. ed. II. i. $226=$ racemosus.

agrestis, All. F1. Pedem. ii. $249=$ erectus.

albidus, Bieb. Fl. Taur. Cauc, iii. 79.-Reg. Cancas.

aleutensis, Trin. ex Ledeb. Fl. Ross. iv, 361.-Unalaska.

alopecuroides, Lag. Gen. et Sp. Nov. $4=$ Koeleria phleoides.

alopecuroides, Moris, ex Steud. Nom. ed. II. i. 226, 228 = intermedius

alopecuroides, Poir. Encyc. Suppl. i. $703=$ seq

Alopecuros, Poir. Voy. Barb. ii. 100; Vahl, Symb. Bot ii. 22,-Reg. Mediterr.

Alopecurus, Pers. Syn. i. $95=$ praec.

alpestris, Steud. in Lechl. Berb. Am. Austr. 52, nomen. -Chili.

altissimus, Gilib. Exercit. ii. $537=$ arvensis

altissimus, Pursh, Fl. Am. Sept. ii. 728.-Am. bor.

altissimus, [Weber, in] Wigg. Prim. Fl. Hols. $9=$ asper.

ambigens, Jord. ex Nym. Consp. $821=$ rigidus.

ambiguus, Cyrill. Pl. Rar. fasc. i. $10=$ Festuca

bromoides.

amplus, C. Koch, in Linnaea, xxi. (1848) $418=$ sterilis.

anatolicus, Boiss. \& Heldr. Diagn. Ser. I. xiii. $63=$ patulus.

angustifolius, Schrank, Baier. Fl. i. $366=$ erectus. angustifolius, Hornem. Hort. Hafn. Suppl. 13.-Hab. angustissimus, C. Koch, in Linnaea, xxi. (1848) $421=$ Biebersteinii.

anomalns, Rupr. in Bull. Acad. Brux. ix. II. (1842) 236. - Mexic.

antarcticus, Hook. f. F1. Antarct. $97=$ Danthoni bromoides.

aquaticus, Schrank, Baier. Fl. i, $367=$ Festuca gigantea.

arduennensis, Dum. Obs. Gram. Belg. 77,-Belgium.

arenaceus, Pourr. in Mém. Acad. Toul. iii. (1788) 308 $=$ tectorum.

arenarius, Labill. Nov. Holl. Pl i. 23, t. 28-Anstral. N. Zel.

arenarius, Thomine Desm, in Mém. Soc. Linn. Calv (1824) $40=$ mollis.

aristatus, Steud. Syn. Pl. Gram. 320,-Persia.

\section{BROMUS :}

armenus, Boiss. Fl. Orient. v. 642.-Armenia.

arrhenatheroides, Baker, in fourn. Linn. Soc. xx.

(1884) 301.-Madag.

arundinaceus, Roth, Tent. Fl. Germ ii $141=$ Festuca elatior.

arvensis, Knapp, Gram. Brit. t. $82=$ racemosus

arvensis, Lam, Fl. Fr. iii. $607=$ erectus.

arvensis, Linn. Sp.Pl. 77.-Europ. ; Oriens; As. bor.

arvensis, Oed. in Fl. Dan. t. $293=$ secalinus.

asper, Murr. Prod. Gotting. 42.-Europ. ; Oriens ; As. bor.

asper, Pall. Ind. Taur. ex Bieb. Fl. Taur. Cauc. i. $73=$ erectus.

asperipes, Jord. ex Nym. Consp. 821 =rigidus.

asperrimus, Tenore, Fl. Nap, t. 105 -Italia.

atticus, Steud. ex Nym. Consp, $823=$ mollis.

auleticus, Trin.ex Nees, in Mart. Fl. Bras. i1. 468.Reg. Argent.

auriculatus, Rasp. in Ann. Sc. Nat. Sér. I. v. (1825 $439=$ arduennensis.

australis, R. Br. Prod. i. $178=$ arenarius.

avenaceus, Lam, lllustr, i. 194 =tectorum.

avenaeformis, Steud. Syn. Pl, Gram. $326=$ Trisetum flavescens.

avenoides, Baker, in Fourn. Linn. Soc. xx. (1884 302.-Madag.

badensis, C. C. Gmel. Fl. Bad, iv. 75. t. $5=$ secalinus barbatus, Savi, Bot. Etrusc. ii. $61=$ Festuca Alope curos.

Baumgartenii, Steud. Syn. Pl. Gram. $320=$ rigidus.

Berterianus, Colla, in Mem. Acc. Torin. xxxix. (1835) 25.-Chili.

bicuspis, Nees, ex Steud. Syn. P1. Gram. 322.-Chili.

Biebersteinii, Roem. \& Schult. Syst. ii. $638=$ albidus.

bifidus, Thunb. Fl. Jap. $53=$ Trisetum cernuum

Billotii, Sch. Bip. in Flora, xxxii. (1849) $233=$ secalinus.

bohemicus, F. W. Schmidt, ex Mert. \& Koch, in Roehl. Deutschl. Fl, ed. III. i. $638=$ Festuca Myurus.

Boraei, Jord, ex Nym. Consp. $821=$ rigidus.

brachyantheca, Doell, in Mart. Fl. Bras. ii. III, 110.Bras.

brachystachys, Hornung, in Flora, xvi. (1833) II. 417 -Oriens; Aegypt.

breviaristatus, Buckl. in Proc. Acad. Sc. Philad. ' 1862 ' (1863) 98.-Am. bor. occ

brevis, Steud. Syn. Pl. Gram. 326,-Mendoza.

brevisetus, Dum. Fl. Belg. 155.-Belgium.

brizaeformis, Fisch. E Mey. Ind. Sem. "Hort. Petrop. iii. 30.-Reg. Cancas.; Persia.

brisaeformis, Willk. ex Willk. \& Lange, Prod. Fl Hisp. i. $101=$ squarrosus.

brizioides, Lam. Illustr. i. 193. n, $1060=$ Briza La. marckiana.

brizoides, Willd. ex.Steud. Nom. ed. II. i. $227=$ Briza rotundata.

Brongniartii, Kunth, Enum. Pl. i. 421.-Bras.

Buxbaumii, Tenore, ex Steud. Nom, ed. II. i. $227=$ Brachypodium distachyum.

caerulescens, Kunth E Bouché, Ind. Sem. Hort. Berol 1845) 9.-Hab.

caespitosus, Host, Gram. Austr. iv. t. 18 = Brachypodium pinnatum.

caespitosus, Steud. Nom. ed. I, $119=$ Brachypodium ramosum.

Caldasii, H. B. \& K. Nov. Gen. et Sp. i. 151=Festuca Caldasii.

canadensis, Michx. Fl. Bor. Am. i. $65=$ ciliatus.

canariensis, Zuccagni, Cent. n. 27; in Roem. Coll, $125=$ lanceolatus

canescens, Viv. F1. Lyb. Spec. $5=$ rubens

canus, Willd. ex Steud. Nom, ed. 1I, i, 227 = Festuca mollis.

capensis, Stend, in Flora, xii. (1829) $491=$ vestitus.

capillaris, Moencb, Meth. $194=$ Leptochloa domingensis.

capillaris, Vahl, ex Hornem. Hort. Hafn, i, 101.Hab. ?

capillifolia, Dufour, ex Roem. \& Schult. Syst. ii. 795. -Hispan.

cappadocicus, Boiss. E Bal. in Bull. Soc. Bot. Fry. iv. 1857) 306.-As. Min.

caprearum, Hack, in Oestr. Bot. Zeitschr, xxix. (1879) $209=$ caprinus

caprinus, Kerner, ex Hack. l. c.-Italia.

carinatus, Hook. E Arn. Bot. Becch. Voy. Suppl. 408.Am. bor. vec

\section{BROMUS}

catharticus, Vahl, Symb, Bot, ii. $22=$ unioloides.

caucasicus, Fisch. ex Steud. Nom. ed. II. i. 227.-Reg. Caucas.

caudatus, Brot. Phyt. Lusit. t. 99,-Lusitan.

Cavanillesii, Willk. ex Willk. \& Lange, Prod. Fl Hisp. i. 101.-Hispan.

Cebadilla, Steud. Syn. Pl. Gram. 321.-Chili.

Chiapporianus, De Not. ex Nym. Consp. $824=$ patulus.

chilensis, Trin. in Linnaea, x. (1836) 304.-Chili.

chloroticus, Bieb. ex Kunth, Enum. PI. i. $420=$ albidus.

Chrysopogon, Viv. F!. Lyb. Spec. 4. t. 2=scoparius.

ciliatus, Huds. Fl. Angl. ed. I. $40=$ madritensis.

ciliatus, Lam. Fl. Fr. nii. $609=$ Brachypodium distachyom.

ciliatus, Linn. Sp. Pl. 76.-Am. bor

ciliatus, Muhl. Desc. Gram. $169=$ Kalmi

cinereus, S. G. Gmel, ex Trin, in Bull. Sc. Acad. Pétersl.

i. (183B) $66=$ Trisetum Gmelini.

cincinnatus, Tenore, Lez, Bot. iv, I. 52; Fl. Nap iil. $85=$ Avena bromoides.

circinnatus, Kunth, Enum. Pl. i. $423=$ praec

coarctatus, Hornem. ex Kanth, 1. c. $308=$ Gaudini geminiflora.

cognatus, Steud. Syn. Pl. Gram. 321.-Abyssin,

collinus, Phil. in Linnaea, xxix. (1857-58) 101.Chili.

coloratus, Baumg. ex Nym. Consp. $824=$ squarrosus.

coloratus, Steud. Syn. Pl. Gram. 429.- Reg. Ma gellan.

commutatus, Bieb. Fl. Taur, Cauc, iii. $77=\mathrm{pa-}$ tulus.

commutatus, Guss, ex Steud. Syn. Pl. Gram, $325=$ scabratus.

commutatus, Schrad. F1. Germ. i. $353=$ racemosus.

compactus, Hort. ex Steud. Nom. ed. II. i. $227=$ mollis.

compressus, Lag. Elench. $4=$ ciliatus

condensatus, Hack. in Oestr. Bot. Zeitschr, xxix. (187) 209.-Europ

confertus, Bieb. Fl. Taur. Cauc. i. $71=$ scoparius

confertus, Bor. Fl. Centr. Fr. ed. II. $586=$ molliforzais.

confinis, Nees, ex Steud. Syn. Pl. Gram. 320.Ind, or.

conformis, Steud. l. c. 323.-Japon.

contortus, Desf, Fl. Atlant. i. $95=$ B. Alopecuros.

corniculatus, Lam. Fl. Fr. iii. 608=Brachypodium pinnatum.

crinitus, Boiss. \& Hohen. Diagn. Ser. I. xiii. 64.-

Pers.; Afghan. : Turkest.

cristatus, Linn. Sp. Pl. $78=$ Agropyron cristatum.

cristatus, Spreng. Nachr, i. Bot, Gart. Halle, $15=$ Koeleria phleoides.

cultus, Steud. Syn. Pl. Gram. 323.-Europ.

cylindracens, Brot. Phyt. Lusit, 98-Lusitan.

Cyri, Trin, in C. A. Mey. Verz. Pfl. Cauc $24=$ patulo dactyloides, Roth, Nov, Sp, $60=$ Koeleria phleoides,

Danthoniae, Trin. in C. A. Mey. Verz. PA. Cauc 24 macrostachys.

decipiens, Hort. Madr. ex Steud. Nom. ed. II. i. 22 ; madritensis.

decolorans, Reichb. Fl. Germ. Excurs, $44=$ Festuca elatior.

decumbens, Koel. Gram. $242=$ decumbens.

denseciliatus, Steud. Syn. Pl. Gram. 422.-'Terra nova.'

depauperatus, f. Presl, in Reh Haenk. in 203.-Am. bor. occ.

dertonensis, All. Fl. Pedem, ii. $249=$ Festuca bro. moides.

diandrus, Curt. Fl. Lond. fasc. vi. t. $5=$ madritensis.

diandrus, Roth, Bot. Abh. $4 t=$ pilosus.

diffusus, Dum. Obs. Gram. Belg. 118.-Belgium.

digitatus, Roir. ex Beauv. Agrost. $150^{\circ}=$ madri

dilatatus, Lam. Encyc, i. $468=$ madritensis.

dissitiflorus, Baker, in Yowrn. Linw. Sor. $\mathrm{xx}$. (1:St 901.-Mailag.

distachyos, Linn. Cent. ii. 8 ; Amocn. Acad. iv. 304 Brachypodium distachyum.

distichus, lieongi, Bemerk. Keise Kuss. Reich. i. 19i Agropyron cristatum.

distichus. Monch. Meth. 1:1] - sterilis.

diraricatus, Khode, ex Loiscl. in Desw. Joum. liot. i (1s0!) $21 t=$ macros(achys. 


\section{BROMUS}

dortonensis, Kunth, Enum. Pl. i. 397, in syn.= Festuca bromoides

dumetorum, Lam. Fl. Fr. iii. $605=$ asper.

dumosus, Vill. Hist. Pl. Dauph. ii. $119=$ Brachypodium sylvaticum.

Ehrharti, Gand. in Roem. Collect. $19=$ secalinus elatior, Koel. Gram. $214=$ Festuca elatior.

elatior, Spreng. Syst. 1. 359=Festuca arundinacea .

elatus, Gueldenst. ex Ledeb. F1. Ross. iv. $353=$ Festuca elatior.

elongatus, Gaud. Agrost. i. $305=$ racemosus.

erectus, Huds. Fl. Angl. ed. I. 39.-Europ.; As Min.

erectus, Moris, Stirp. Sard. Elench. i. $50=$ scoparius.

erectus, Ledeb. F1. Ross. iv. $358=$ inermis.

exaltatus, Bernh. in Linnaea, xy. (1841) Litt. 90.Mexic.

fascicularis, Tenore, F1. Nap. iv. 17, 161 = fasciculatus

fasciculatus, Presl, Cyp. et Gram. Sic. 39.-Reg Mediterr. or.

Ferronii, Mabelli, in Act. Soc. Linn. Bord. xxv. (1864) 613.-Cf. Bull, Soc. Bot. Fr. xiv. (1867) Bibl. 138 $=$ mollis.

festucoides, Link, in Schrad. Fourn. ii. (1799) 315. Lusitan.

fibrosus, Hack. in Oestr. Bot. Zeitschr. xxix. (1879) 209.-Europ. or

flabellatus, Hack. ex Boiss. Fl. Orient. v. 648.Palaestin.

flavescens, Tausch, in Flora, xx. (1837) 1. 124.Sicilia.

Fonki, Phil. in Linnaea, xxix. (1857-58) 102.Chili.

fragilis, Schrank, Baier. F1, i. $370=$ Brachypodium pinnatum.

fragilis, Schur, in Verh. Siebenb. Ver. Naturw. iv. (1853) 90.-Europ

frigidus, Ball, in Fourn. Linn. Soc. xxii. (1885) 63.Peruv.

frigidus, Boiss. E Haussk. ex Boiss. Fl. Orient.v. 645. -Persia.

Gaudini, Roem. \& Schult. Syst. ii. $632=$ racemosus. geniculatus, Linn. Mant. i. 33= Festuca genieulata. geniculatus, Steud. Syn. Pl. Gram. 218.-Oriens. giganteus, Leers, Fl. Herborn. $38=$ Festuca elatior

giganteus, Linn. Sp.Pl. 77.-Europ. ; Sibir.

giganteus, Vill. Hist. Pl. Dauph. il. $118=$ asper.

Gilliesii, Nees, ex Steud. Syn. Pl. Gram. 328.Chili.

glaber, Reich. F1. Franco-Moen. i. $19=$ Festuca gigantea.

glaber, Scop. F1. Carn. ed. II. i. 84= Agropyron repens glaber, Willd, ex Steud. Nom, ed. II i. $227=$ pitensis.

glaberrimus, C. Koch, in Linnaea, xxi. (1848) $420=$ erectus.

glaucus, Hort. ex Reichb. Fl. Germ. Excurs. $38=$ Festuca ovina.

glaucus, Lapeyr. Hist. Abr. Pl. Pyr. t. $53=$ erectus.

glaucus, Spreng. in Link, Hort. Berol. i. $170=$ Festuca rubra.

glomeratus, Scop. Fl. Carn. ed. II. i. $76=$ Dactylis glomerata.

glomeratus, Tauseh, in Flora, xx. (1837) $124=$ mollis.

gracilis, Leyss. F1. Hal. 26. n. $116=$ Brachypodium pinnatum.

gracilis, Weigel, Obs. $15=$ Brachypodium sylvaticum.

gracillimus, Bunge, in Mém. Sav. Etr. Pétersb. vii. 1851) $527=$ crinitus.

grandiflorus, C. Koch, in Linnaea, xxi. (1848) 419 (sp.

dub.).-Pontus.

grandiflorus, Weigel, Obs, $9=$ sterilis, tectorum.

grossus, DC. F1. Fr. iii. $68=$ secalinus.

grossus, Desf. in C. C. Gmel. Fl. Bad. iv. t. $2,3=$ velu tinus.

Gussoni, Parl. Pl. Nov. $66=$ rigidus .

gyganteus, Crantz, Inst. i. $390=$ giganteus.

gynandrus, Roth, in Roem. \& Ust. Mag. iv. 10tes St. (1790) $20=$ madritensis.

Haenkeanus, Kunth, Enum. Pl, i, $416=$ unioloides

Haussknechtii, Boiss. Fl. Orient. v. 648.-Mesopotam.

hirsutissimus, Cyrill, ex Roem. \& Schult. Syst. ii. 643 = asper.

hirsutus, Curt. F1. Lond. fasc. ii. t. $8=$ asper.

hirsutus, Schrank, in Denkschr. Bot. Ges. Regensb. (1818) 161 = squarrosus.

hirtus, Lichtst. in Roem. \& Schult. Syst. ii. 654.Afr. austr.

\section{BROMUS :}

hispidus, Savi, Bot. Etrusc. ii. $62=$ Koeleria hispida Hohenackeri, Hochst. ex Ledeb. Fl. Ross. iv. $416=$ Ventenata macra.

holciformis, Steud. E' Hochst. ex Steud. Syn. Pl. Gram 324. - Chili.

Hookeri, Fourn. Mex. Pl. En. Gram. 127 ; ex Hemsl Biol. Centr. Am. Bot. iii. $583=$ ciliatus.

Hookerianus, Thurber, in Bot. U. St. Expl. Exped. ii. $493=$ virens

hordeaceus, C. C. Gmel. Fl. Bad. iv. $68=$ secalinus. hordeaceus, Linn. Sp. Pl. $77=$ racemosus, mollis.

hordeiformis, Lam. Illustr. i. $195=$ Festuca bromoides Hughi, Tod. ex Nym. Consp. $823=$ intermedius. humilis, Cav. Ic. vi. $65=$ scoparius.

hyalinus, Schur, in Verh. Siebenb. Ver. Naturw. iv (1853) $90=$ arvensis.

hybridus, Schur, Enum. Pl. Transs. 801-Transsylv. imperialis, Hort. ex Steud. Nom. ed. II. 1. $227=$ ciliatus incrassatus, Lam. Encyc. i. 468=rigidus, Festuca geniculata.

indicus, Hort. ex Steud. Nom. ed. II. i. $227=$ rigidus. inermis, Leyss. Fl. Hal. 16; Linn. Mant. ii. 186.Europ.; Reg. Caucas. ; As. bor.

inermis, Stev, in Mém. Soc. Nat. Mosc. iii. (1812) 252 $=$ albidus.

insignis, Buese, in Miq. Pl. Fungh. 347.-Java intermedius, Guss. Fl. Sic. Prod. 1. 114.-Reg. Mediter intermedius, Zumag. Fl. Pedem. i. 166--Pedemont.

japonicus, Thunb. Fl. Fap. 51.t. 11.-Japon.

jubatus, Tenore, F1. Nap. $10=$ sterilis.

jubatus, Vill. Hist. Pl. Dauph. ii. 118.-Gallia.

Kalmii, A. Gray, Man. 600.-Am. bor.

Kochii, C. C. Gmel. Fl. Bad. iv. 76, t. $6=$ patulus.

Krausei, Regel, in Act. Hort. Petrop. vii. (1880) 600 -As. centr.

lanatus, H. B. \& K. Nov. Gen. et Sp. i, $150=$ Festuca mollis.

lanceolatus, Roth, Catalect. i. 18=macrostachys lanuginosus, Poir. Encyc. Suppl. i. 703=macrostachys lateripronus, St. Lag, in Ann. Soc. Bot. Lyon, vii. (1880) 121 = tectorum.

latifolius, Kar. E' Kir. in Bull. Soc. Nat. Mosc. (1841) 865.--Sibir.

laxiflorus, Spreng. in Zeyh. ex Steud. Nom. ed. II. i 228. - Afr. austr.

laxus, Hornem. Hort. Hafn, ii. $954=$ erectus.

laxus, Reichb. Ic. F1. Germ. i. 32. t. 77. f. 1605= inermis.

lenis, F. Pressl, in Rel. Haenk. i. 262.-Peruv.

leptoclados, Nees, Fl. Afr. Austr. Gram, i. 453.-Afr austr.

leptostachys, Ehrenb. ex Boiss. Fl. Orient. v. $654=$ brachystachys.

leptostachys, [Yieri,] in Ionios Anthol. iii. (1834) 680 =squarrosus.

leptostachyus, Steud. Syn. Pl. Gram. 324.-Gallia.

ligusticus, All. Fl. Pedem. ii. $249=$ rubens, scoparius, Festuca geniculata.

lithobius, Trin. in Linnaea, x. (1836) 303.-Chili.

littoralis,Steud. Syn. Pl. Gram. 325.- 'Austr. littoralis'

littoreus, Georgi, Beschr. Russ. Reich. Nachtr. $257=$ inermis.

littoreus, Retz. Fl. Scand. Prod. ed. I. 19= Festuca elatior.

lividus, H. B. \& K. Nov. Gen. et Sp. i. $150=$ Festuca livida.

loliaceus, Tenore, F1. Nap. iii. $91=$ Triticum Barrelieri. longe-aristatus, Gilib. Exercit. ii. $536=$ sterilis

longiflorus, Spreng. Pugill. ii. $23=$ tectorum.

longifolius, Schousb. Vextr. Marokko, 44.-Marocco.

longipilus, Kummer \& Send, in Flora, xxxii. (1849) $757=$ tectorum

luzonensis, J. Presl, in Rel. Haenk. i. $262=$ Triticum luzonense.

macranthes, Meyen, Reise, i. 311, nomen = setifolius

macranthos, E. Desv. in C. Gay, Fl. Chil. vi. $443=$ praec.

macrocladus, Boiss. Diagn. Ser. I. xiii. $64=$ arvensis

macrostachys, Desf. Fl. Atlant. i. 96. t. 19.-Reg Mediterr.

macrostachyus, Guss. F1. Sic. Prod. $115=$ lanceolatus madritensis, Cav, ex Kunth, Enum, Pl. i. 419 maximus.

madritensis, Linn. Cent. Pl. i. 5; Amoen. Acad. iv. 265.-Europ.; Afr. bor. ; Oriens.

malacanthus, Trin. ex Ledeb. Fl. Ross. iv. $361=$ ciliatus.

\section{BROMUS}

Mango, E. Desv. in C. Gay, Fl. Chil. vi. 440.-Chili. marginatus, Steud. Syn. PI. Gram. $322=$ ciliatus. massiliensis, Forsk. Fl. Aegypt. Arab. 203.-Massilia. matritensis, 'Linn.' ex Roem. \& Schult. Syst. ii. 651 $=$ madritensis.

matritensis, Cav. Ic. vi. $67=$ rigidus.

Matthewsii, Steud. Syn. Pl. Gram. 323.-Peruv maximus, Desf. Fl. Atlant. i. 95. t. 26=rigidus. maximus, Gilib. Exercit. ii. $535=$ secalinus. maximus, Roth, N. Beitr. i. $114=$ pilosus.

megapotamicus, Spreng. Syst. iv. Cur. Post. 36.Bras.

mexicanus, Hort. ex Steud. Nom. ed. II. i. $228=$ Triticum mexicanum.

Micheli, Savi, Bot. Etrusc. i. $78=$ festucoides, Avellinia Micheli.

modensis, Steud. Syn. Pl. Gram. 324-Graecia.

molliformis, Lloyd, Fl. Loire-Inf. 315.-Gallia.

mollis, Linn. Sp. Pl. ed. II. 112.-Europ.; Afr. et As. bor.

mollis, Thunb. Prod. Pl. Cap. $22=$ vestitus

mollissimus, Hornem. Hort. Hafn. Suppl. 13.Hab.?

monostachyus, Steud. Nom. ed. II. i. $228=$ Brachypodium distachyum.

montanus, Gaertn. Mey. \& Scherb. F1. Wett. ex Kunth,

Enum. Pl. i. $418=$ erectus.

montanus, Scop. F1. Carn. ed. II. i. $82=$ asper.

montanus, Retz. Prod. Scand. 124.-Europ, bor.

mucronatus, Willd. ex Steud. Nom. ed. II. i. $228=$ unioloides.

multiflorus, Host, Gram. Austr. 1. t. $11=$ patulus.

multiflorus, Kar. \& Kir. in Bull. Soc. Nat. Mosc.

1841) $865=$ macrostachys.

multiflorus, Roth, Tent. Fi. Germ. i. $47=$ racemosus.

multiflorus, Sm, in Trans. Linn. Soc. iv. (1798) $283=$ secalinus.

multiflorus, Weigel, Obs, 2. t. 1. f. 1 =arvensis

multiflorus, Willd. Sp. Pl. i. $4: 28=$ commutatus.

multispicatus, Roem. \& Schult. Syst. ii. $650=$ madritensis.

Munroi, Boiss. Fl. Orient. v. 643.-Afghanist

muralis, Huds. Fl. Angl, ed. II. i. 50=madritensis

murorum, Bernh. ex Roem. \& Schult. Syst. ii. $651=$ pilosus, tectorum.

mutabilis, $F$, Schultz, in Flora, xxxii. (1849) 234.Europ.

nanus, Weigel, Obs. $8=$ mollis

neglectus, Nym. Syll. $419=$ racemosus.

nemoralis, Huds. Fl. Angl. ed. II. i. 51=asper.

nemorosus, Vill. Hist. Pl. Dauph. ii. $117=$ asper.

nitidus, Clarke, Trav, ii. $260=$ rigidus.

nitidus, Dum. Obs. Gram. Belg. $119=$ secalinus

Noëanus, Boiss. Diagn. Ser. II. iv. $141=$ squarrosus

nototropus, Rupr. Sert. Tiansch. 73.-As. centr.

odoratus, Gouan, Herbor. 11 = erectus.

oranensis, Steud. Syn. Pl. Gram. 319.-Afr. bor.

Orcuttianus, Vasey, in Coult. Bot. Gaz. x. (1885) 223.

-Am. bor.

ovatus, Cav. Ic. vi. $67=$ Trisetum ovatum

ovatus, J. Gaertn. in Nov. Comm. Acad. Petrop. xiv (1770) 537. t. 19. f. 1 = scoparius.

ovinus, Seop. FI. Carn. ed. II. i. $77=$ Festuca ovina,

oxyodon, Schrenk, Enum. Pl. Nov. ii. $1=$ macrostachys.

oxyphloeus, Payne, Palest. Expl. Rep. (1874) $128=$ macrostachys

pallens, Cav. Ic. vi. 66. t. 591. f. 1.-Ins. Philipp.

pannonicus, Kummer E' Sendt. in Flora, xxxii. (1849)

757.-Hungar.

paradoxus, Presl, Fl. Sicul. i. p. xlv, in nota = pentastachyus.

parviflorus, Desf. Cat. Hort. Par. ed. III. 387.Hab.?

patagonicus, Phil. in Anal. Univ. Chil. (1873) 577.-Chili.

patentissimus, Weigel, Obs. $12=$ Festuca sylvatica.

patulus, Mert. E' Koch, in Roehl. Deutschl. Fl. i. 685 -Europ.; Oriens ; Afghanist.

pauciflorus, Schum. in Fl. Dan. t. 1383.-Island.

pauciflorus, Willd. ex Steud. Nom. ed. II. i. $228=$ Festuca mollis.

pauper, J. F. Gmel. Syst. $191=$ Brachypodium distachyum.

pauper, Schrank, Baier. Fl. i. $370=$ Brachypodium sylvaticum.

pectinatus, Thunb. Prod. Pl. Cap. 1. 22.-Afr. anstr 
BROMUS :

pendulinus, Desf. ex Steud. Nom. ed. I. 119, $120=$ commutatus.

pendulinus, Hort. ex Schrad. N. Journ. iv. (1810) $70=$ ciliatus.

pendulus, Schur, in Verh. Siebenb. Ver. Naturw. iv

(1853) $90=$ patulus.

pentastachyus, Tineo, Pl. Rar. Sic. Pugill. i. $4=$ Brachypodium distachyum.

perennis, Vill. Hist. Pl. Dauph. ii. $122=$ erectus.

persicus, Boiss. Diagn. Ser. I. xiii. 66 ; Ledeb. Fl Ross. iv. $357=$ tomentosus.

Petitianus, A. Rich. Tent. Fl. Abyss. ii. 438.-Abyss.

phleoides, J. F. Gmel, Syst. $190=$ Koeleria phleoides.

phoenicoides, Steud. Nom. ed. I. $120=$ Brachypodium pinnatum.

Phoenix, F. F. Gmel. Syst. 190,-Hab.?

phrygius, Boiss. Diagn. Ser. II. iv. $140=$ patulus.

pictus, Hook. f. Fl. Antarct. 387.-Chili.

pilosus, F. G. Dietr. Vollst. Lex. Gaertn. i. 558. -Europ. austr.

pilosus, Willd. in Spreng. Syst, i. $358=$ trichodes.

pinnatus, Linn. Sp. Pl. $78=$ Brachypodium pinnatum.

pinnatus, Oed. in F1. Dan. t. 164=Brachypodium sylvaticum.

pitensis, H. B. E K. Nov. Gen. et $S p$. i. 152.-

platystachys, Desf. Cat. Hort. Par. ed. III. $387=$ arduennensis.

platystachyus, Lam. Illustr. i. 195=Brachypodium distachyum.

Pluckenetii, All. Fl. Pedem. ii. $250=$ Brachypodium ramosum.

poaeformis, Forsk. Fl. Aegypt. Arab. 23.-Aegypt.

poaeformis, Spreng. Nachr. i. Bot. Gart. Halle, 15; F1

Hal. Mant. $34=$ Diplachne fascicularis.

poaeformis, Vahl, ex Hornem. Hort. Hafn. i. 102.Hab.?

polymorphus, Hohen. Enum. Taluesch, $19=$ patulus.

polymorphus, Hort. ex Steud. Nom. ed. II. i. $228=$ arvensis.

polymorphus, Scop. Fl. Carn. ed. II. i. 79; Huds. F1. Angl. ed. Il. i. $48=$ mollis, racemosus, secalinus.

polystachios, Forsk. F1. Aegypt. Arab. 23=Diplachue fusca.

polystachyus, DC. Fl. Fr. vi. $276=$ madritensis.

polystachyus, Kunth, Enum. P1. i, $447=$ Brachypodium distachyum, Triticum ciliatum.

polystachyus, Stend. Nom. ed. II. i. $228=$ arduennensis.

pratensis, Ehrh. Beitr. vi. 84 , nomen = racemosus.

pratensis, Lam. Encyc. i. $468=$ erectus.

pratensis, Spreng. Syst. i. $359=$ Festuca elatior.

Preslii, Kunth, Enum. Pl. i. 416.-Peruv.

procerus, H. B. \& K. Nov. Gen. et Sp. i. $150=$ Festuca eminens.

procerus, Spreng. Syst. i. $357=$ quitensis.

propendens, Jord. ex Nym. Consp. $821=$ rigidus.

pseudoarvensis, Koel. Gram. $241=$ erectus.

pseudoasper, Schur, Enum. Pl. Transs. $804=$ asper.

pseudoinermis, Schur, in Verh. Siebenb. Ver. Naturw.

iv. (1853) 90 .-Transsylv.

pubescens, C. Koch, in Linnaea, xxi. (1848) $420=$ variegatus.

pubescens, Muhl. in Willd. Enum. Hort. Berol. $120=$ ciliatus.

pubescens, [Pieri,] in Ionios Anthol. ii. (1834) $680=$ squariosus.

pulchellus, Fig. \& De Not.Agr. Fragm. 16 (sp. dub.). -Arabia.

purgans, Linn. Sp. PI. $76=$ ciliatus.

purgans, Torr. F1. N. York. ii. $468=$ Kalmii.

purpurascens, Delile, Fl. Aeg. Illustr. $52=$ rubens

purpurascens, Turcz. ex Ledeb. F1. Ross. iv. $357=$

inermis.

quitensis, Willd. ex Steud. Nom, ed. II. i, 228.Ecuador.

racemiferus, Steud. Syn. Pl. Gram. 323,-Japon.

racemosus, Linn. Sp. Pl. ed. II. 114.-Europ.

ramosus, Linn. Mant. i. $34=$ Brachypodium ramosum

ramosus, Huds. Fl. Angl. $40=$ asper.

ramosus, Schousb. Vextr. Marok. $44=$ Brachypodium pinnatum.

repens, Borb. ex Nym. Consp. $822=$ vernalis.

Requieni, Loisel. F1. Gall. i. $90=$ intermedius

retusus, Pers. Syn. i. 96 = Brachypodium ramosum.

Richardsoni, Link, Hort. Berol. ii. 281.-Am. bor.

rigens, Linn. Mant. $93=$ rigiclus.

\section{BROMUS :}

rigens, Vandelli, in Roem. Script. Pl. Hisp. $49=$ Koeleria phleoides

rigidus, C. A. Mey. Verz. PA. Cauc. $23=$ rigidus. rigidus, Reichb. Ic. F1. Germ. i. 31 . n. $1586=$ rubens. rigidus, Roth, in Roem. E Ust. Mag. Bot. iv. (1790)

21.-Europ.; Reg. Mediterr. et Caucas.

riparius, Rehm. Notiz. Veg. Gest. Schwarz. Meer.8.Rossia.

Rochelianus, Opiz, Natural. n. 9 (1825) $119=$ madritensis.

rotundatus, H. B. \& K. Nov. Gen. et Sp. i, $152=$ Briza rotundata.

rubens, Cav. Ic. i. t. $45=$ scoparius.

rubens, Delile, Fl. Aeg. Illustr. $52=$ fasciculatus,

rubens, Desv. ex Willk. \& Lange, Prod. Fl. Hisp. i. 98 $=$ madritensis

rubens, Host. Gram. Austriac. i. t. 18 =rigidus.

rubens, Linn. Cent. i. 5.-Reg. Mediter.

rupestris, Host, Gram. Austriac. iv, t. $17=$ Brachy

podium pinnatum.

sabulosus, Guss. Fl. Sic. Prod. i. 120.-Sicilia

sardous, Spreng. Syst. iv. Cur. Post. 36.-Sardin.

scaberrimus, Tenore, Fl. Nap. iii. $89=$ madritensis.

scabratus, Link, in Linnaea, xvii. (1843) 402, - Italia

scabridus, Hiook. $f$. in fourn. Linn. Soc. vii. (1864)

231. - Afr. trop.

scabriflorus, Opiz, Natural, n. 9 (1825) $119=$ tectorum

Scheuchzeri, C. C. Gmel. Fl. Bad. iv. 79. t. 7

Festuca gigantea.

Schraderi, Kunth, Enum. Pl. i. $416=$ unioloides

sclerophyllus, Boiss. Diagn. Ser. I. xiii. 65.-Lydia

scoparius, Guss, F1. Sic. Prod, $10=$ alopecuroides.

scoparius, Linn. Cent. Pl. i. 6; Amoen. Acad. iv, 266.

-Reg. Mediterr.; As. Min.; Persia.

secalinus, Bieb. Fl. Taur. Cauc. i. $71=$ patulus.

secalinus, Linn. Sp, Pl. 76.-Lurop.; Reg. Mediterr. As. bor.

secalinus, Savi, Fl. Pis, i. $120=$ arvensis.

secundus, 7. Presl, in Rel. Haenk, i. 263-Sinus

Nootka.

segetalis, A. Braun, ex Nym. Consp. $822=$ secalinus

segetum, Cham. \& Schlecht, in Linnaea, vi. (1831) 38 $=$ ciliatus.

segetum, H. B. E K. Nov. Gen. et Sp. i, 152.-Am austr.

sericeus, Tenore, F1. Nap. Prod. $10=$ alopecuroides.

serotinus, Beneken, in Bot. Zeit. iii. (1845) $724=$ aspe

setareus, Buckl. in Proc. Acad. Sc. Philad. ' 1863

(1863) $98=$ sterilis.

setifolius, F. Presl, in Rel. Haenk. i. 261.-Chili Mexic.

Sewerzowi, Regel, in Act. Hort. Petrop. vii. (1880)

601.-As. centr.

silvaticus, J. F. Gmel. Syst. $190=$ sylvaticus.

simplex, Gaud. Agrost. Helv. i. $296=$ racemosus.

simplex, Pers. Syn.i. 96.-Hab.?

simplicissimus, Cesati, ex Nym. Consp. $823=$ mollis

sipyleus, Boiss. Diagn. Ser. I. xiii. 65.-As. Min

sitchensis, Bongard, Veget. Ins. Sitcha, 173.-Ins. Sitcha.

speciosus, Nees, Fl. Afr. Austr. i. 454.-Afr. austr.

spicatus, Nees, in Mart. Fl. Bras. ii. $471=$ Diplachne simplex.

spiculitenuata, Knapp, Brit. Gram. t. 81 = arvensis.

squarrosus, Brot. Fl. I.usit. i. $112=$ macrostachys.

squarrosus, Linn. Sp. Pl. 76.-Europ. austr.; Oriens As. bor.

squarrosus-muticus, C. A. Mey. Verz. Pf. Cauc. $24=$ briziformis.

stachyoides, Link, Hort. Berol. ii. 285.-Hab. ?

stamineus, E. Desv, in C. Gay, Fl. Chil. vi. $440=$ unioloides.

stenophyllus, Link, Enum. Hort. Berol. i. $94=$ erectus. stenostachyus, Boiss. Fl. Orient. v. 648.-Afghanist. sterilis, Guss. FI. Sic Prod, i. $118=$ madritensis, sterilis, Lang, ex Kumm. \& Sendt. in Flora, xxxiii. (1849) $758=$ tectorum

sterilis, Linn. Sp. Pl.77.-Europ.; Oriens; As, bor.

Steudelii, Frank, ex Steud. Nom. ed. II. i. $229=$ ciliatus.

stipoides, Linn. Mant ii. $557=$ Festuca geniculata

strictus, Brongn. in Duperr. Voy. $\mathbf{1 5}=$ Brongniartii.

strictus, Kunth, Rev. Gram. i. 134.-Ins. Borbon.

strictus, Scop. Fl. Carn. ed. II. i. $79=$ Diplachne serotina.

strictus, Hall. fo in Roem. Arch. i. 11. $10=$ Brachypodium pinnatum ?

\section{BROMUS}

strigosus, Bieb, Fl. Taur. Cauc iii. $81=$ Triticum strigosum.

strigosus, Lam. Illustr. 191. n, $1063=$ Festuca gigantea.

subalpinus, Rupr. in Bull. Acad. Brux. ix. (1842) 2, $236=$ exaltatus

submuticus, Steud. Syn. Pl. Gram, 321-Missouri.

subulatus, Griseb. in Ledeb. F1. Koss. iv. 358 Melica acuminata.

Suksdorfii, Vasey, in Coult. Bot. Gaz. x. (1885) 223. Am, bor.

sylvaticus, Pollich, Hist. P1. Palat. i. $118=$ Brachy podium sylvaticum.

sylvaticus, Vogler, Schediasma, $13=$ asper

syriacus, Boiss. \& Blanche, Diagn. Ser. II. iv. 139 erectus.

Tacna, Steud, in Lechl. Berb. Am. Austr. 56 Peruv.

subrectus, Fries, Mant. iii. $181=$ erectus.

tectorius, Dulac, Fl. Hautes-Pyr. $96=$ tectorum.

tectorum, Linn. Sp. Pl. 77.-Europ.; Oriens bor.

temulentus, Bernh. Syst. Verz. Erf. 47 = Lolium temulentum.

Tenorianus, Roem. \& Schult. Syst. Mant. ii. 360, obs sterilis.

tenuiflorus, Viv. F1. Lyb. Spec. 5.t.'1. f. 1 = fascicu latus.

tenuis, F. Presl, in Rel. Haenk. i. 262.-Peruv.

tenuis, Tineo, Rar. Pl. Sic. Pugill. i. $3=$ Festuca incrassata.

Thominii, Ard. ex Nym. Consp. $823=$ mollis

Tigridis, Boiss. \& Noé, Diagn. Ser. II. iv. 141 = brachystachys.

tigurinus, Suter, F1. Helv. i. $65=$ Brachypodium pinnatum.

tomentellus, Boiss. Diagn. Ser. I. vii. 126.-Graecia As. Min. ; Persia.

tomentosus, Rohde, in Schrad. N. Journ, iii. (1809) 42 $=$ macrostachys

tomentosus, Trin. in Mèm. Acad. Pétersb. (1813-14) 9.-Persia.

tortilis, Presl, ex Steud. Nom. ed. II. i. 229_-Europ. austr.

transsilvanicus, Schar, in Oestr. Bot, Zcitschr. 1860) 227 = fibrosus

transylvanicus, Steud. Syn. Pl. Gram. $320=$ praec.

triaristatus, Loisel. Fl. Gall. i. $89=$ arduennensis.

trichodes, Kunth, Rev. Gram. i. 135.-Ins. Mascar.

trichopodus, A. Rich. Tent. Fl. Abyss, ii, 43i.Abyss.

trifiorus, Ehrh. Beitr. i. $90=$ Festuca sylvatica.

triflorus, Linn. Sp. Pl. ed. II. $115=$ Festuca gigantea.

triflorus, Pollich, Hist. Pl. Palat. i. $119=$ Ventenata avenacea.

Trinianus, Schult. Mant. ii. 254.-Persia

Trinii, E. Desv. in Co Gay, Fl. Chil. vi. 441 Chili.

trisetoides, Trin. ex Steud. Nom. ed. II. i. 229, nomen. - Hab. ?

triticeus, Raeusch. Nom. ed. III. 27.-Helvet.

trivialis, Savi, Fl. Pis. 1. $124=$ Koeleria phleoides.

truncatus, Scop. Fl. Cam.ed. II. i $85=$ Agropyron junceum.

tunicatus, Phil. in Linnaea, xxxiii. 1864-65) 298.Chili.

turgidus, Pers. Syn. i. 95= macrostachvs,

unilateralis, Schur, in Verh. Siebenb. Ver. Nalurw. iv. 1858) $90=$ patulus.

unioloides, $H . B$. E K. Noo. Gens et Sp, i. 151.Am. calid.

valdivianus, Phil. in Lirnnea, xxix. (155i-58 101.Chili.

variegatus, Fl. Danub. ex Boiss. Fl. Orient. v. 045 fibrosus.

variegatus, Bieb. Fl. Taur. Caus, iii. $79-\mathrm{kek}$ Caucas, : Persia.

varius, Brot. Fl. Lusit. i. $118=$ rigidus.

velutinus, Suthrad. Fi. Germ. i. 34?. \&. B. f. 8 secalinus.

Vintolara. Hurt. ex Stcud. Nom. ed. II. i. 220 e race. musus.

lentolara, Schleich. ex Stcud, 1. c, = anensis.

veraalis, Pant, ex Hack, in Oestr. Bot. Zrissinir. x.my (1s79) 205 . - Eurup.

rersicolor, Pollich, Hist. PI. Palat. i. 190 e arvensos

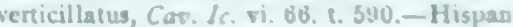




\section{BROMUS:}

vestitus, Schrad. in Goett. Gel. Anz. (1821) III. 2074. -Afr. austr.

villiferus, Steud. Syn. P1. Gram. $326=$ japonicus

villosulus, Steud. l. c. 327.-Graecia

villosus, Forsk. Fl. Aegypt. Arab. $23=$ madritensis, rigidus.

villosus, C. C. Gmel. Fl. Bad. i. $229=$ squarrosus

villosus, Scop. Fl. Carn. ed. II. 1. 83=Agropyron repens.

virens, Buckl. in Proc. Acad. Sc. Philad. '1862' (1863) 98.-Am. bor. occ

virgatus, F. Presl, in Rel. Haenk. i. 263.-Peruv, Mexic

vitiosus, Weigel, Obs. 4 =secalinus.

Willdenorvi, Kunth, Rev. Gram. i. 134=unioloides wolgensis, Willd. Enum. Hort. Berol. Suppl. 9 ; Jacq. Ecl. Gram. 20.t. $15=$ squarrosus.

BROMUS, Scop. Introd. $74(1777)=$ Triticum, Linn (Gramin.).

BRONGNIARTIA, Blume, Bijdr. 435 (1825)=Kibara Endl. (Monim.)

coriacea, Blume, 1. $c_{n}=\mathbf{K}$. coriacea

BRONGNIARTIA, H. B. \& K. Nov. Gen. et Sp. vi. 465. t. 587 (1823). LEGUMINOSAE, Benth. \& Hook. f, i. 495 .

Megastegia, G. Don, Gen. Syst. ii. 468 (1832) Peraltea, H. B. \& K. Nov. Gen. et Sp. vi. 469. t $589(1823)$

Benthamiana, Hemsl. Biol. Centr. Am. Bot. i, 252 - Mexic.

foliolosa, Benth. ex Hemsl. Diag. Pl. Nov. 7.Mexic.

galegoides, Presl, Symb. Bot. ii. 21. t. 67.-Am. trop.

glabrata, Hook. E Arn. Bot. Beech. Voy. 238.-

Mexic.

gracilis, Hemsl. Biol. Centr. Am. Bot. i. 253.Mexic.

intermedia, Moric. in Mém. Soc. Phys. Genèr. vii. (1836) 253.--Mexic

magnibracteata, Schlecht. in Linnaea, xii. (1838) 338 -Mexic.

minutifolia, S. Wats in Proc. Anv. Acad xx. (1885) 360.-Texas.

mollis, H. B. ह K. Nov. Gen. et Sp. vi. 465. t. 587.Mexic.

obliqua, Schlecht. in Linnaea, xii. (1838) 339.Mexic.

oligosperma, Baill. Adansonia, ix. (1868-70) 240.Mexic.

oxyphylla, Hemst. Biol. Centr. Am。Bot. i. 254.Mexic.

Parryi, Hemsl. l. c.-Mexic.

podalyrioides, H. B. E K. Nov. Gen. et Sp, vi. 465. t. 588.-Mexic

retusa, Benth, in Hemsl. Diag, Pl, Nov, 8.-Mexic.

robinioides, Kunth, Ind. Sem. Hort. Berol. (1845) 12.-Chili.

sericea, Schlecht. in Linnaea, xii. (1838) 338.Mexic.

stipitata, Hemsl. Diag. Pl. Nov. 8.-Mexic.

thermoides, Spreng. Syst. iv. Cur. Post. 287.Mexic.

vicioides, Mart. \& Gal. in Bull. Acad. Brux. x (1843) 49.-Mexic.

BRONNIA, H. B. \& K. Nov, Gen. et Sp, vi. 83, t. 528 $(1823)=$ Fouquieria, H. B. \& K. (Tamarisc.)

spinosa, H. B. \& K. 1. c. = F. spinosa.

BROOKEA, Benth. in Benth. \& Hook. f. Gen. ii. 939 (1876). SCROPHULARINEAE, Benth. \& Hook. f. 1 c

dasyantha, Benth. in Hook. Ic. Pl. xii. 84. t. 1197.Borneo.

tomentosa, Benth. l. c.-Borneo

BROSIMUM, Sw, Prod. Veg. Ind. Occ, 12 (1788) URTICACEAE, Benth, \& Hook, f, iii. 369

Galactodendrum, Humb. Relat. Hist. ii. 108 (1819).

Piratinera, Aubl. Pl. Gui. ii. 888. t. 340 (1775), nomen prius.

Alicastrum, Sw. l. c.-Am, trop.

\section{BROSIMUM :}

Aubletii, Poepp. E Endl. Nov. Gen. et Sp. ii. 34. t. 148. f, a. -Am. trop.

costaricanum, Liebm. in Vidensk. Selsk. Skr. V. ii (1851) 334.-Costa Rica.

discolor, Schott, in Spreng. Syst. iv. Cur. Post. 403.Bras.

echinocarpum, Poepp. Ev Endl. Nov. Gen. et Sp. ii. 34 . t. 148.-Peruv.

Galactodendron, D. Don, ex Sweet, Hort. Brit. ed. II 462.-Guiana

Gaudichaudii, Trécul, in Ann. Sc. Nat. Sér. III. viii (1847) 139.-Bras

Humboldtii, Carr. in Rev. Hortic. (1874) 314. f. 42 , $43=$ B. Galactodendron.

microcarpum, Schott, in Spreng. Syst. iv. Cur. Post. $403=$ B. Alicastrum.

refractum, Mart. ex Miq. in Mart. Fl. Bras. iv. I. 108 $=$ Gaudichaudii.

spurium, Sw. Prod. Veg. Ind. Occ. 12.-Jamaica.

turbinatum, Spruce, ex Baill. Adansonia, xi, (1875) 299.-Bras.

BROSSAEA, [Plnm.] Linn. Gen. ed. I. $366(1737)=$ Gaultheria, Kalm. (Ericac)

anastomosans, Griseb, Fl. Brit. W. Ind. $142=\mathrm{G}$ anastomosans.

coccinea, Linn. Sp. Pl. $1190=$ G. cordifolia.

BROSSARDIA, Boiss。 in Ann. Sc. Nat. Sér. II. xvii (1842) 183. CRUCIFERAE, Benth. \& Hook. f. i. 91 .

papyracea, Boiss. l. c. 184.--Persia.

retusa, Boiss. Fl. Orient. i. 336.-Persia.

BROTERA, Cav, in Anal. Cienc. Nat. i. (1800) 33 ; Ic v. 19.t. 433 . (1799) = Melhania, Forsk. (Sterculiac.) bracteosa, Guill. \& Perr. F1. Seneg. Tent. i. $86=$ M Denhami.

Leprieurii, Guill. \& Perr. 1. c. = Pentapetes Leprieurii. ovata, Cav. Ic. v. $20=$ M. abyssinica.

BROTERA, Spreng. in Schrad. Journ. Bot. iv. (1800) t. $\mathbf{5}=$ Flaveria, Juss. (Compos.).

Contrayerba, Spreng. 1. $\mathrm{c} .=\mathrm{F}$, repanda

Sprengelii, Cass. in Dict. Sc. Nat. xxxiv. $306=\mathrm{F}$ repanda.

trinervata, Pers. Syn. ii. $498=$ F. repanda.

BROTERA, Spreng. Nachr, i. Bot. Gart. Halle, (1801) 15 ; et in Trans. Linn. Soc. vi. (1802) 151. t. $12=$ Hyptis, Jacq. (Labiat.).

persica, Spreng. 11. cc. $=$ H. pectinata.

BROTERA, Vell. Fl. Flum. 322 (1825) ; vii. t. 163 $(1827)=$ Luhea, Willd. (Tiliac.).

maritima, Vell. 11. cc. $323 ;$ t. $163=\mathrm{L}$. speciosa

mediterranea, Vell. 11. cc. 323 ; t. $164=\mathrm{L}$. divaricata.

BROTERA, Willd. Sp. Pl. iii. $2399(1803)=$ Cardopatium, Juss. (Compos.).

corymbosa, Willd. 1. c. =C. corymbosum.

BROTERoA, DC. Prod. v. $635(1836)=$ Flaveria, Juss. (Compos.)

trinervata, DC. i. c. $636=\mathrm{F}$. repanda.

BROUGHTONIA, R. Br. in Ait. Hort. Kew, ed. II. v. 217 (1813). ORCHIDEAE, Benth. \& Hook. f. iii. 531.

alba, Spreng. Syst: iii. $735=$ Maxillaria alba.

aurea, Lindl. Bot. Reg. (1840) Misc. $19=$ Epidendrum aurantiacum.

chinensis, Lindl, in Hook. Lond. Journ, Bot. i. (1842) $492=$ Epidendrum nonchinense.

coccinea, Hook. Bot. Mag. t. 3536=sanguinea.

grandiflora, Spreng. Syst. iii. $735=$ Maxillaria grandiflora.

lilacina, Henfr. in Moore E Ayres, Gard. Mag. Bot. iii. (1851) 201.--Ind. occ. ?

maculata, Spreng. Syst. iii. $735=$ Maxillaria maculata sanguinea, R. Br. in Ait. Hort. Kew. ed. II. v. 217.Ind. occ.

tetragona, Spreng. Syst. iii. $734=$ Phajus tetragonus violacea, Hort. ex Moore \& Ayres, Gard. Mag. Bot. iii. (1851) $201=$ lilacina
BROUGHTONIA, Wall. ex Lindl. Gen. et Sp. Orch. 35 $(\mathbf{1 8 3 0})=$ Otochilus, Lindl. (Orchid.).

amoena, Wall. l. c. $=$ O. fusca.

nitida, Herb. ex Sweet, Hort. Brit, ed. III. 641, nomen (=Coelogynes sp. ?).-Hab.?

linearis, Wall. 1. c. $42=$ Coelogyne ovalis.

pendula, Wall. 1. c. $35=$ O. alba.

pilosa, Hook. ex Steud. Nom. ed. II. i. 230.-Ind. or.

BROUSSAISIA, Gaudich. Freyc. Voy. Bot. 479. t. 69 (1820). SAXIFRAGEAE, Benth. \& Hook. f. i. 641. (1826). SAXIFRAGEAE, Benth.
arguta, Gaudich. l. c.-Ins. Sandvic.

pellucida, Gaudich. Bot. Voy. Bonite, t. 9.-Ins Sandvic.

BROUSSONETIA, Orteg. Hort. Matr. 61. t. 7 (1798)= Sophora, Linn. (Legumin.)

secundiflora, Orteg. 1. c. $=\mathrm{S}$. secundiflora

speciosa, Orteg. 1. c. t. $7=\mathrm{S}$. secundiflora.

BROUSSONETIA, L'Hérit. ex Vent. Tabl. Regn. Veget. iii. 547 (1799). URTICACEAE, Benth. \& Hook. f. iii. 361 .

PAPYRIUS, Lam. Illustr. t. $762(1798)$

Stenochasma, Miq. Pl. Jungh, i. 45 (1850).

Billardii, Carr. in Rev. Hortic. (1878) $375=$ papyrifera.

brasiliensis, Mart. in Flora, xxiv. (1841) Beibl. $10=$ Maclura brasiliensis.

cordata, Blume, Mus. Bot. Lugd. Bat. ii. 87.-China. cordata, Hort. ex C. Koch, Dendrol. ii. II. $440=$ papyrifera.

cucullata, Hort. ex Steud. Nom. ed. II. i. $230=$ papyrifera.

dissecta, Hort. ex Bur. in DC. Prod. xvii. $225=$ papyrifera.

elegans, Hort. ex C. Koch, Dendrol. ii. II. $440=$ papyrifera.

integrifolia, Buch.-Ham. in Trans. Linn. Soc. xvii. 1837 195. - Ind. or

Kaempferi, Siebold, in Verh. Bat. Gen. xii. (1830) 28. -Japon.

Kazi, Siebold, ex Blume, Mus. Bot. Lugd. Bat. ii. $86=$ papyrifera.

Kazinoki, Siebold, in Verh. Bat. Gen. xii. (1830) 28.Japon.

Iozonica, Bur. in DC. Prod. xvii. 224.-Ins. Philipp. luzoniensis, Blanco, Fl. Filip. ed. II. $488=$ Allaeanthus luzonicus.

maculata, Hort. ex Steud. Nom. ed. II. i. $230=$ papyrifera.

monoica, Hance, in Fourn. Bot. xx. (1882) 294.China.

navicularis, Lodd. ex C. Koch, Dendrol. ii. II. $440=$ papyrifera.

nana, Hort. ex Bur, in DC. Prod. xvii. $225=$ papyri fera.

navicularis, Lodd. ex Bur. 1. c. = papyrifera.

navifolia, Hort, ex Steud. Nom. ed. II. i. $230=$ papyrifera.

papyrifera, Vent. Tabl. Regn. Veget. iii. 547.Malaya; Ins. Pacific.

Plumerii, Spreng. Syst. iii. 901=Chlorophora tinctoria.

Sieboldii, Blume, Mus. Bot. Lugd. Bat. ii. $86=\mathrm{B}$. Kazinoki.

spathulata, Hort. ex Steud. Nom. ed. II. i. $230=$ papyrifera.

tinctoria, Blanco, F1. Filip. ed. II. $488=$ Cudrania javanensis.

tinctoria, H. B. \& K. Nov. Gen. et Sp. ii. $32=$ Chlorophora tinctoria.

tinctoria, Spreng. Syst. ii. $901=$ Maclura tinctoria.

tricolor, Hort. ex C. Koch, Dendrol. ii. II. $440=$ papyrifera.

xanthoxylon, Mart, in Flora, xxiv. (1841) Beibl. $10=$ Maclura xanthoxylon.

BROUVALEA, Adans, Fam. ii. 211 (1763)=seq.

BROVALLIA, Linn. Orb. Nat. $(1764)=$ seq.

BROWATIIA, Linn, Gen ed. I 348 (1737), SOLA-

NACEAE, Benth. \& Hook. f. ii. 910.

abbreviata, Benth. Bot. Voy. Sulph. 144.-Peruv. alienata, Linn. Syst. ed. X. $1118=$ Ruellia paniculata americana, Linn. Sp. Pl. $631=$ demissa . cordata, G. Don, Gen. Syst. iv. 478.-Peruv. 
BROWALLIA :-

demissa, Linn. Syst. ed. X. 1118.-Am. austr.

elata, Linn. 1. c. = demissa.

elongata, H. B. \& K. Nov. Gen. et Sp. ii. $372=$ demissa.

grandiflora, R. Grah. in Edin. N. Phil. Fourn. "Fan.-

Apl. 1830' [1829].--Peruv.

grandiflora, Lindl. Bot. Reg. t. $1384=$ cordata.

humifusa, Forsk. Fl. Aegypt. Arab. $112=$ Striga lumifusa.

Jamesonii, Benth. in DC. Prod. x. 197.--Peruv.; N. Granat.

lactea, Hort. ex G. Don, in Sweet, Hort. Brit. ed. III. $508=$ demissa.

Linnaeana, Spreng. Syst. ii, $808=$ demissa.

nervosa, Miers, in Ann. \& Mag. Nat. Hist. Ser. II. v. 1850) $206=$ demissa.

peduncularis, Benth. Bot. Voy. Sulph. 143.-Peruy.

pulchella, Hort. ex Vilm. F1. Pl. Terre, ed. III. $176=$ viscosa.

pulchella, Lehm. in Hamb. Gartenz. x. (1854) 375 . Hab.?

speciosa, Hook. Bot. Mag. t. 4339.-N. Granat.

tenella, Miers, in Ann. E Mag. Nat. Hist. Ser. II. v. (1850) 205.-Bras.

texana, Torr. Bot. Mex. Bound. $156=$ Nierembergia viscosa.

viscosa, H. B. \& K. Nov. Gen. et Sp.ii. 373.-Am. austr.

BROWNEA, Jacq. Enum. Pl. Carib. 6 (1760) (Brownaea). LEGUMINOSAE, Benth. \& Hook. f. i. 577 .

Hermesias, Loefl. Iter, 278 (1758).

antioquensis, Linden, Cat. (1869) 3 =macrophylla.

Ariza, Benth. Pl. Hartw. 171.-N. Granat.

Ariza, Lindl. \& Paxt. Flow. Gard. ii. 107. t. $59=$ grandiceps.

Birschellii, Hook. f. Bot. Mag. t. 5998,-Venezuela. capitella, Facq. Fragm. 26. t. 18, 19.-Venezuela. cauliflora, Poepp. E Endl. Gen. et Sp. Pl. Chil. iii. 32. -Chili.

Loccinea, facq. Enum. Pl. Carib. 26.-Venezuela. coccinea, Loef. ex Griseb. Fl. Brit. W. Ind. $212=$ B. Rosa-de-monte

erecta, Hort. Belg. ex Planch. in Fl. des Serres, vi. (1850-51) 154 (= Theophrasta pinnata).

grandiceps, facq. Collect. iii. 287. t. 22.-Am. austr.

guianensis, Klotzsch, in Schomb. Faun. E Fl. Guy

1209, nomen.-Guiana.

latifolia, facq. Fragm. 25. t. 17.-Venezuela.

leucantha, facq. l. c. 26.-Venezuela.

macrophylla, Linden, Cat. n. 18 (1863) 11; Mast. in Gard. Chron. (1873) 777. f. 149.-N. Granat.

negrensis, Benth. in Mart. Fl. Bras. xv. 11. 212.-Bras.

pauciflora, Willd. Sp. Pl. ii. $716=$ Palovea guianensis.

Princeps, Linden, ex Otto, in Otto \& Dietr. Allg. Gartenz. xxiii. (1855) $147=\mathrm{B}$. Ariza.

racemosa, facq. Fragm. 25. t. 16.-Venezuela.

Rosa, Pers. Syn. ii. $237=$ B. Rosa-de-monte.

Rosa-de-monte, Berg. in Phil. Trans. (1771) 171. t. 8, 9.-Am. austr.

rosea, Otto, in Otto \& Dietr. Allg. Gartenz. xxiii. (1855) $147=$ B. Rosa-de-monte speciosa, Reichb. ex DC. Prod. ii. $477=$ B. Rosa-de-
monte.

BROWNETERA, Rich. in Ann. Mus. Hist. Nat. Par. xvi. (1810) 299 = Phyllocladus, Rich. (Conifer.). aspleniifolia, Rich. $1 . \mathrm{c}_{\mathrm{v}}=\mathrm{Ph}$. rhomboidalis.

BROWNLEEA, Harv, ex Lindl. in Hook. Lond. Journ. Bot. i. (1842) i6. ORCHIDEAE, Benth. \& Hook. f, iii. 631 .

caerulea, Harv. ex Lindl. l. c.-Afr. anstr.

macroceras, Sond. in Linnaea, xix. (1847) $106=$ cacrulea.

parviflora, Harv. ex Lindl. in Hook. Lond. Fourn. Bot. i. (1842) 16.-Afr. austr.

recurvata, Sond. in Linnaca, xix. (1847) 107.-Afr. austr.

BROWNLOWIA, Roxb. Pl. Corom. iii. 61.t. 265 (1819). TILIACEAE, Benth. \& Hook. f. i. 281. Humes, Roxb. Fl. Ind, ii. 640 (1832).

argentata, Kurg, in fourn. As. Soc. Beng. xxxix. (1870) II. 67.-Ind or

elata, Roxb. Pl. Corom. iii. 61. t. 265.-Ind. or.; Burma. lanceolata, Benth. in fourn. Linn. Soc. v. Suppl. ii. (1861) 57.--lnd. or.; Burma.

peltata, Benth. b. c. 56.-Borneo.

\section{BROWNLOWIA}

Riedelii, Hemsl. Bot. Voy. Challenger, i. II. 128.ins. Moluce.

BRUCEA, J. S. Mill, Fasc. t. 25 (1780), SIMARU $B E A E$, Benth. \& Hook, f, i. 31 .

GonUs, Lour. F1. Cochinch, ii. 658 (1790)

Nima, Buch.-Ham, ex A. Juss, in Mém. Mus. Par xii. $516(1825)$

abyssinica, Spreng. Pugill. ii. 90, in obs, =ferruginea

antidysenterica, Lam. in Mém. Acad. Par. (1784) 342

Encyc. i. 471 = ferruginea.

dubia, Stend. Nom. ed.II. i. $230=$ Picrasma nepalensis

ferruginea, L'Hérit. Stirp. Nov. 19. t. 10.-Abyss.

glabrata, Decne. in Nouv. Ann. Mus. Par. iii. (1834)

447. - Ins. Timor.

gracilis, DC. Prod ii. $88=$ sumatrana

guineensis, G. Don, Gen. Syst. i. $801=$ paniculata.

macrophylla, Oliver, Fl. Trop. Afr. i. 310.-Afr. trop.

mollis, Wall. Cat. n. 8483.-Reg. Himal.

paniculata, Lam. Encyc. i. 472.-Afr. trop.

quercifolia, Seem. Fl. Vit. 83.-Ins. Fiji.

sumatrana, Roxb. Hort. Beng, 12; Fl. Ind i. 449 As. trop.; Austral.

sumatrensis, Spreng. Pugill, ii. $90=$ sumatrana.

trichotoma, Spreng. Syst. i. 441.--Cochinch

trifoliata, Spreng. 1. c. iv. Cur. Post. $43=$ Evodia drupacea.

virginica, Hornem. ex Steud. Nom. ed. I. 122, nomen. -Virginia.

BRUCHMANNIA, Nutt. Gen. Am. i. 48 (1818) Beckmannia, Host (Gramin.).

erucaeformis, Nutt. l. c $=$ Beckmannia erucaeformis.

BRUCKENTHALIA, Reichb. Fl. Germ. Excurs. 414 (1831). ERICACEAE, Benth. \& Hook. f.ii. 591 spiculifolia, Reichb. l. c.-Europ. austr. or.; As. Min.

BRUEA, Gauclich. in Freyc. Voy. Bot. 511 (1826) URTICACEAE? (Gen. dubium) Benth. \& Hook. f. iii. 351 .

bengalensis, Gaudich. l. c. (= Laportea terminalis?) -ind. or.

BRUECKEA, Klotzsch \& Karst. in Karst, Ausw. Gew. Venez. 31. t. $10(1848)=$ Aegiphila, Jacq. (Verbenac.)

grandifolia, Klotzsch \& Karst. 1. c. $32=$ A. verrucosa,

BRUENNICHIA, Willd. Sp. Pl. ii. 751 (1800)= Brun nichia, Banks (Polygon.).

BRUGMANSIA, Blume, in Van Hall, Bijdr. Nat Wet. ii. (1828) 422. CYTINACEAE, Benth. \& Hook. f. iii. 119.

Mycetanthe, Reichb. Nom.61 (1841)

Zrppelia, Reichb, ex Endl. Gen. Suppl, ii. 6 (1842)

Lowi, Becc, in Atti Soc, Ital. Sc. Nat. xi. (1868) 198= Zippelii.

Zippelii, Blume, in Van Hall, Bijdr. Nat. Wet. ii. (1828) 422.-Java.

BRUGMANSIA, Pers. Syn. i. $216(1805)=$ Datura, Linn. (Solanac.).

arborea, Steud. Nom. ed. II. i. $230=$ D. arborea.

aurantiaca, Hort. ex Walp. Rep. iii. $934=$ Juanulloa parasitica.

bicolor, Pers. Syn. i. $216=$ D. sanguinea.

candida, Pers. 1. c. = D, arborea.

floribunda, Paxt. Mag. Bot. ix. $3=$ Juanulloa aurantiaca. Knightii, Hort. ex Dan, in DC. Prod. xiii. I. $690=\mathrm{D}$, cornigera.

parvifiora, Hort. ex Walp. Rep. iii. $934=$ Juanulloa parasitica.

sanguinea, D. Don, in Sweet, Brit. Fl. Gard. Ser. II. t. $272=$ D. sanguinea.

suaveolens, Bercht. \& Presl, Kostl. i. Solaneac. $45=$ D. suaveolens.

Waymanni, Paxt. Mag. Bot. 1v. $241=$ D. fastuosa.

BRUGUIERA, Lam. Encyc. iv. 696 (1796). RHI. ZOPHOREAE, Benth. \& Hook. f. i. 679

KanIl.IA, Blume, Mus. Bot. Lugd. Bat. i. 140 (1849).

Paletuviera, Thou, ex DC. Prod, iii. $82(1828)$

Arnottiana, Wight, ex Am, in Ann. Nat. Hist. (1838) $364=$ Ceriops Candollenna.

australis, A. Cunn, ex Arn. 1. c. $868=$ Rheedii

Candel, Stcud. Nom. ed. II. i, $281=$ Krndelia Rheedii.

\section{BRUGUIERA}

capensis, Blume, Mus. Bot. Lugd. Bat. i. $137=$ gymnor rhiza.

caryophyllaeoides, Blume, Enum. Pl. Fav. i. 93.-Ind. or.; Malaya.

cylindrica, Blume, 1. c. i. $91=$ caryophyllaeoides, mala barica.

decangulata, Griff. Notul.iv. $669=$ Rhizophora Mangle eriopetala, Wight \& Arn. in Ann. Nat. Hist. (1838) 368.-As, trop.

gymnorrhiza, Lam. Illustr. t. 397; Blume, Mus. Bot. Lugd. Bat. i. 136.-Geront. trop.

malabarica, Arn. in Ann. Nat. Hist. i. (1838) 369.Ind. or.

nemorosa, Blanco, Fl. Filip. ed. II. $275=$ Carallia integerrima.

nubicola, Prit». Ic. Ind. ii. 51, sphalm. = Bougueria nubicola.

obtusa, Steud. Nom. cd. II. i. 231 (= Problastes cuneifolia).-Java.

oxyphylla, Miq. Fl. Ind. Bat. Suppl. i. 324.-Sumatra. parietosa, Griff. Notul. iv. 670 ; Ic. PL. Asiat. t. $641=$ eriopetala.

parviflora, Wight E Arn. Prod. 311.-Ind. or. ; Malaya. Rheedii, Blume, Enum. Pl. Fav. i. 92.-Geront. trop. Rumphii, Blume, Mus. Bot. Lugd. Bat. i. 138= Rheedii.

sexangula, Poir. Encyc. Suppl. iv. $262=$ Rhizophora scxangula.

sexangularis, Spreng. Syst. ii. $602=$ Rhizophora sexangula.

timoriensis, Wight \&e Am. Prod. $311=$ Ceriops Can dolleana

Wightii, Blume, Mas. Bot. Lugd, Bat. i. $138=$ gymnorrhiza.

Zippelii, Blume, 1. c. $139=$ Rheedii.

BRUGUIERA, Thou. Gen. Nov. Madag. 21 (1806) Lumnitzera, Willd. (Combret.

littorea, Steud. Nom. ed. II. i. $231=$ L. coccinea.

madagascariensis, DC. Prod. iii. $23=\mathrm{L}$. racemosa.

BRUGUIERA, Rich. ex. DC. Prod. iii. 173, in syo, $(1828)=$ Conostegia, D. Don (Melastom.)

BRUINSMANIA, Miq. in Linnaea, xvii. (18t3) $72=$ Isertia, Schreb. (Rubiac.)

isertioides, Miq. 1. c. 73.-Guiana.

BRUNELLA, Tourn, ex Linn. Syst, ed, I $(1735)=$ Prunella, Linn. (Labiat.).

BRUNFILIA, Ruiz \& Pay, Prod, Fi, Per, 71, t. 12 1794). SIMARUBEAE, Renth. \& Hook. f. i. 313. aculeata, Ruiz \& Pav. Fl. Per. iv. 71. t. 415 ; Syst. 127.--Peruv.

acutangula, Humb. E Bonpl. Pl. Aequin. i. 216, t. 62 $-\mathrm{N}$. Granat.

comocladifolia, Humb. Eo Bonpl. l. c. i. 211. t. 59.Peruv.

Funkiana, Tul. in Ann. Sc. Nat. Sér. III. vii. (1847 267.-N. Granat.

Goudotii, Tul. l. c. 270.-N. Granat.

inermis, Ruis E Pav. Fl. Per. iv. 71. t. 414; Syst. 127 -Peruv.

ovalifolia, Humb. E Bonpl. Pl. Aequin. i. 216. t. 61 -Peruv.

propinqua, H. B. E K. Nov. Gen. et Sp. vii. 45.-Am austr.

quadrilocularis, Hook. E Arn. Bot. Beeck. Voy. 282.Mexic.

racemifera. Tul. in Ann. Sc. Nat. Sér. III. vii. 1st7 $269 .-\mathrm{N}$. Granat.

rugosa, Turcs. in Bull. Soc. Nat. Mosc. xxxii. (1859) i. 274 . - Bras.

sandwicensis, Gaudich. Freyc. Voy. Bot. 99; ex Hook. \& Arn. Bot. Beech. Voy, s0= Pelea sandwicensis.

tomentosa, Humb. E Bonpl. Pl. Aequin. 211. 1. 60.Am. austr.

BRUNFELSIA. Plum. ex Linn. Hort. Ciift. 5 (1737) (Brunstelsia); Gen. ed, L. 992. SOLAWACEAE, Benth. \& Hook. f. ji. 911.

pranciscea, Pohl, Pl. Bras, Ic. i. 1. \&. $1-7$ RANCISCEA
(1S27).

acuminata. Benth, in DC. Prod, $x_{0} 199=$ ramosissuma americana, Linn. Sp.Pl. 191.-Am. trop. 


\section{BRUNFELSIA}

australis, Benth. in DC. Prod. x. $200=$ Hopeana bahiensis, A. DC. Prod. x. 590_-Am. austr. calycina, Benth. in DC. Prod. x. $199=$ pauciflora. capitata, Benth. l. c. 198.-Bras.

cestroides, A. Rich.Fl. Cub. Fanerog. ii. 151.-Cuba confertiflora, Benth. in DC. Prod. x. $199=$ ramosissima.

cuneifolia, F. A. Schmidt, in Mart. Fl. Bras. viii. 259 -Bras.

eximia, Bosse, Handb. Blumeng. $524=$ macrophylla. falcata, Regel, Cat. Pl. Hort. Aksakov, 21.-Hab.?

fallax, Duchass. ex Griseb. in Goett. Abh. vii. (1857) 242. - Ind. occ.

gracilis, Regel, Cat. Pl. Hort. Aksakov.21.-Hab.? grandiflora, D. Don, in N. Edin. Phil. Fourn. (Apr.

Oct. 1829) 86--Peruv.

guianensis, Benth. in DC. Prod.x. 200.-Guiana.

Hopeana, Benth. l. c.-Bras.

hydrangeaeformis, Benth. l. c. 198.-Bras.

inodora, Mart. Del. Sem. Hort. Monac. (1847).-Cf Linnaea, xxiv. (1851) 180.-Bras.

jamaicensis, Griseb. Fl. Brit. W. Ind. 432.-Ind. occ latifolia, Benth. in DC. Prod. x. 199.-Bras.

latifolia, Hort. ex Steud. Nom, ed. II. i. $231=$ americana.

Lockharti, Hort. Belg. ex Heynh. Nom. ii. 79, nomen. - Ins. Trinitat.

longiflora, Regel, Cat. Pl. Hort. Aksakov. 21.-Hab.

longituba, Lem. Fard. Fleur. iv. (1854) Misc. 61.Cuba.

macrophylla, Benth. in DC. Prod. x. 198.-Bras.

maritima, Benth. l. c. 200.-Bras.

montana, Lodd. ex Loud. Hort. Brit. 253, nomen.Ind. occ.

multiflora, Regel, Cat. Pl. Hort. Aksakov. 21.-Hab. mutabilis, Poit. in Rev. Hortic. Sér, II. i. (1842) 261 -Hab.?

nitida, Benth. in DC. Prod. x. 201.-Am. trop.

obovata, Benth. l. c. 199.--Bras.

parviftora, A. Rich. Fl. Cub. Fanerog. ii. $327=$ seq.

parvifotia, A. Rich. 1. c. $151=$ nitida.

pauciflora, Benth. in DC. Prod. x. 199.-Bras

purpurea, Griseb. in Mem. Am. Acad. N. S. viii.

(1863) 523.--Ind. occ

ramosissima, Benth. in DC. Prod. x. 199.-Bras

Schomburgkiana, Klotzsch, in Schomb. Fauna et Fl.

Guy. 1155, nomen.-Guiana.

Sieberi, Regel, Cat. Pl. Hort. Aksakoz. 21.-Hab.?

sinuata, A.Rich.Fl. Cub. Fanerog. ii. 151.-Am. trop.

spinosa, facq. Enum. Pl. Carib. 14.-Ind. occ.

Spruceana, Mart. ex J. A. Schmidt, in Mart. Fl. Bras

viii. $258=$ maritima.

terminalis, Salisb. Prod. $109=$ americana.

undulata, Sw. Prod.Veg. Ind. Occ. 90.-Tamaica

uniflora, D. Don, in Edinb. N. Phil. Fourn. (Apr.-Oct. 1829) 85.-Hab. ?

vinciflora, Griseb. in Mem. Am. Acad. N. S. viii

(1863) 523.-Ind. occ.

violacea, Lodd. Bot. Cab. t. 792.-Am. austr.

BRUNIA, Linn. Syst. ed. I (1375)。 BRUNIACEAE Benth. \& Hook. f. i. 671

Baeckia, Burm. f. Prod. Fl. Cap. 12 (1768).

abrotanifolia, F. G. Dietr. Vollst. Lex. Gaertn. ii. 320

$=$ Berzelia abrotanoides.

abrotanoides, Linn. Sp. P1. $199=$ Berzelia abrotanoides

alopecuroides, Brongn, in Ann. Sc. Nat. Sér. I. viii. (1826) 375.-Afr. austr.

alopecuroides, Thunb. Prod. Pl. Cap. $187=$ Berzelia alopecuroides.

arachnoidea, Wendl. Coll ii $62=$ Berzelia squarrosa

brevifolia, D. Dietr. Syn. P1. i. $848=$ Berzelia abrota noides.

candicans, Hort. ex Steud. Nom. ed. II. i. 231.-Afr. austr.

capitata, Desf. Tabl. Hort. Par. ed. II. $232=$ Staavia capitella

capitella, Thunb. Diss. Brun. $5=$ Staavia capitella.

capitellata, E. Mey. ex Harv. \& Sond. Fl. Cap. ii. 316 $=$ staavioides.

ciliata, Linn. Sp. Pl. 199.-Afr. austr.

comosa, Thunb. in Hoffm. Phytogr. Blaetter, i. (1803)

$17=$ Berzelia lanuginosa.

cordata, Walp. Rep. i. $544=$ racemosa

cordifolia, D. Dietr. Syn. Pl. i. $848=$ Berzelia cordifolia. coronata, Linn. Mant. ii. 210 , in syn. = Staavia glutinosa cupressina, Linn. I. c. ii. $343=$ Diosma cupressina

\section{BRUNIA :-}

deusta, Thunb. Prod. Pl. Cap. 187.-Afr. austr.

deusta, Willd. in Denkschr. Acad. Muench. (1808)

127. t. 7. f. $2=$ Nebelia phylicoides

Dregeana, Presl, Bot. Bemerk. 39.-Afr. austr.

elegans, Dum.-Cours. Bot. Cult. ed. I. iii. 616.-Afr. austr.

ericoides, Wendl. Coll. ii. $57=$ Berzelia squarrosa.

flagelliformis, Hort. ex Steud. Nom. ed. II. i. 231 (quid?).-Hab.?

formosa, D. Dietr. Syn. Pl. i. $848=$ Berzelia abrotanoides.

formosa, Dum.-Cours. Bot. Cult. ed. I. iii. 616.-Afr. austr

fragarioides, Willd.Sp. Pl.i.1143 (=Berardiaglobosa) -Afr. austr.

glabrata, Thunb. in Hoffm. Phytogr. Blaetter, i. (1803) 18.-Afr, austr.

globosa, Eckl. \& Zeyh. Enum. $139=$ laevis.

globosa, Thunb. Diss. Brun. 4 (=Berardia globosa).Afr. austr.

glutinosa, Berg. Desc. P1. Cap. $57=$ Staavia glutinosa hirsuta, Thunb. in Hoffm. Phytogr. Blaetter, i. (1803) 19.-Afr. austr.

imbricata, Sweet, Hort Brit ed. II 115-racemosa.

imbricata, Wendl. f. ex Hoffm. Verz. Pfl. Nachtr. i. 228 , ii. \& iii. 26,71.-Afr, austr.

intermedia, D. Dietr. Syn. Pl. i. $848=$ Berzelia intermedia.

laevis, Thunb. Prod. Fl. Cap. 187.-Afr. austr.

lancifolia, Walp. Rep. i. 544.-Afr, austr.

lanuginosa, Linn. Sp. Pl. $199=$ Berzelia lanuginosa

lanuginosa, Thunb. Prod. PI. Cap. $41=$ Berzelia squarrosa.

laurifolia, Sond. in Harv. \& Sond. Fl. Cap. ii. $315=$ lancifolia

laxa, Thunb. Prod. Pl. Cap, $187=$ Tittmannia laxa.

Levisanus, Linn. Sp, Pl. $199=$ Leucadendron Levisanu

macrocephala, Willd. in Denkschr. Acad. Muench. (1809) 152.-Afr. austr.

microcephala, E. Mey. ex Harv. \& Sond. Fl. Cap. ii. $320(=$ Berardia sphaerocephala).-Afr. austr.

microphylla, Thunb. Prod. P1. Cap. 187 (=Berardia microphylla).-Afr, austr.

nodiflora, Linn. Sp. Pl. 199,-Afr. austr.

paleacea, Berg. Desc. P1. Cap. $56=$ Nebelia paleacea paleacea, Wendl. Coll. $\mathrm{t}, 2=$ Berzelia intermedia.

passerinoides, Schlecht. in Linnaea, vi. (1831) 190.-

Afr, austr.

phylicoides, E. Mey. ex Harv. \& Sond. F1. Cap. ii. 321 (=Berardia Dregeana).-Afr. anstr.

phylicoides, Thunb. in Hoffm. Phytogr. Blaetter, i. (1803) $18=$ Nebelia phylicoides

pinifolia, Brongn. in Ann. Sc. Nat. Sér. I. viii. (1826) 374.-Afr. austr.

plumosa, Lam. Encyc. 1. $475=$ Berzelia squarrosa.

pragarioides, DC. Prod. ii. 45 , err. typ.=fragarioide Protea, Crantz, Inst. i. $357=$ Berzelia abrotanoides. racemosa, Brongn. in Ann. Sc. Nat. Sér. I. viii. (1826) 374.-Afr, austr

racemosa, Sond. in Harv. \& Sond. F1. Cap. ii. $315=$ lancifolia.

radiata, Berg. Desc. PI. Cap. $58=$ Staavia glutinosa.

radiata, Linn. Mant. ii. $209=$ Staavia radiata

rubra, Willd, in Denkschr. Acad. Muench. i. (1809)

131. $t .7=$ Berzelia squarrosa

sericea, Hort ex Dum.-Cours. Bot. Cult, ed. II vii. $329=$ Berzelia superba.

speciosa, Hort. ex Dum.-Cours. 1. c. vi. 279 ; vii. $329=$ Berzelia superba.

squalida, Sond, in Harv. E Sond. Fl. Cap, ii. 315.Afr. austr.

squarrosa, Sw, ex Harv. \& Sond. 1. c. $311=$ Berzelia abrotanoides.

squarrosa, Thunb. Diss. Brun. $5=$ Berzelia squarrosa.

staavioides, Sond. in Harv. E Sond. Fl. Cap. ii. 316. -Afr. austr.

superba, Donn, Ind. Hort. Cantab. 25 = Berzelia lanu. ginosa.

superba, Krauss, ex Harv. \& Sond. Fl. Cap. ii. $314=$ laevis.

tenuifolia, Willd. in Denkschr. Acad. Muench. i.

1809) $129=$ Berzelia lanuginosa

teres, Oliver, in Fourn. Linn. Soc. ix. (1867) 333.Afr. austr.

Thunbergiana, D. Dietr. Syn. Pl. i. $849=$ Nebelia paleacea.

thyrsophora, Walp. Rep. i. 544.-Afr, austr.
BRUNTA :

uniflora, Linn. Sp. PI. 199= Diosma copressina.

verticillata, E. Mey. ex Harv. \& Sond. Fl. Cap. ii $322=$ Staavia nuda

verticillata, Linn. f. Suppl. 156_-Afr. austr.

verticillata, Thunb. Prod. P1. Cap, $41=$ virgata.

villosa, E. Mey. ex Harv. E Sond. Fl. Cap. ii. 315.Afr. austr.

virgata, Brongn. in Ann. Sc. Nat. Sér. I. viii. (1826 376.-Afr. austr.

BRUNIERA, Franch, in Billotia, (1864) $25=$ Wolffia Horkel. Lemnac.)

vivipara, Franch. 1. c. $=$ W. Michelii.

BRUNNERA, Stev. in Bull, Soc. Nat. Mosc. (1851) I. $582=$ Anchusa, Linn. (Boragin.).

myosotidiflora, Stev. I. c. = A. myosotidiflora

sibirica, Stev, 1. c.-Sibir.

BRUNNICHIA, Banks, ex Gaertn. Fruct. i. 213.' t. 45 (1788). POLYGONACEAE, Benth. \& Hook. f iii. 103 .

Faltopia, Adans. Fam. ii. 274, 277 (1763)

Rajania, Walt. Fl. Carol. 247 (1788).

africana, Welw. in Trans. Linn. Soc. xxvii. (1872) 61 -Afr. trop.

cirrhosa, Gaertn. Fruct. i. 214. t. 45.-Am. bor.

BRUNONIA, Sm. in Trans. Linn. Soc. x. (1811) 365 t. 28, 29. GOODENOVIEAE, Benth. \& Hook. f. ii. 541.

australis, Sm. l. c. 367.t. 28.-Austral.

sericea, Sm. 1. c. 367 . t. $29=$ australis.

simplex, Lindl. in Mitch. Trop. Austr. $82=$ australis.

BRUNSFELSIA, Plum. ex Linn. Hort. Cliff. 5 (1737)= Brunfelsia, Linn. (Solanac.).

BRUNSVIA, Neck. Elem. iii. $337(\mathbf{1 7 9 0})=$ Croton Linn. (Exphorb.)

BRUNSVIGIA, Heist. Beschr. Brunsv. Braunschweig (1755), 3, cum ic. AMARYLLIDEAE, Benth. \& Hook. f. iii. 728 .

albiflora, Eckl. Topogr. Verz. 7, nomen.-Afr. austr. Burchelliana, Herb. Amaryll. t. 22. f. $2=$ radulosa. ciliaris, [Ker-Gawl. in] Bot. Reg. sub t. 192, $193=$ Buphane disticha.

Cooperi, Baker, in Saund. Ref. Bot. t, 330.-Afr, austr. coranica, Sweet, Hort. Brit. ed. I. 404.-Am. austr.

disticha, Sweet, 1. $c_{.}=$Buphane disticha.

falcata, [Ker-Gawl.in] Bot. Mag.t. 1443. -Afr. austr

fulva, Steud. Nom. ed. II. i. $231=$ Stenomesson incarnatum.

gigantea, Heist. Beschr. Brunsv. Braunschweig, 3, cum ic. fide Schult. f. Syst. vii. 844 (nobis latet).-Afr. austr.

glauca, Salisb. Gen. Pì. Fragm. $117=$ Josephinae.

grandiflora, Lindl. Bot. Reg. t. 1335.-Afr. austr.

Josephinae, [Ker-Gawl. in] Bot. Reg. t. 192, 193.Afr. austr.

laticoma, Sweet, Hort. Brit, ed. I, $404=$ Nerine lucida lucida, Herb. App. $16=$ Nerine lucida .

magnifica, Linden \& Rodigas, in Illustr. Hortic. xxxii (1885) t. $552=$ Crinum Forbesianum

marginata, Ait. Hort. Kew. ed. II. ii. $230=$ Nerine marginata.

minor, Lindl. Bot. Reg. t. 954.--Afr. austr.

multiflora, Ait. Hort. Kew. ed. II. i. $230=$ gigantea orientalis, Ait. ex Eckl. Topog. Verz. $7=$ gigantea. Radula, Ait. Hort. Kew. ed. II. ii. 230.-Afr. austr. radulosa, Herb. Amaryll. 281. t. 22. f. 2.-Afr. austr rubricaulis, M. Roem. Syn. Ensat. 57 = gigantea. Slateriana, Benth. E' Hook. f. Gen. iii. 727.-Afr. austr striata, Ait. Hort. Kew. ed. II. ii. 231.-Afr. austr. toxicaria, [Ker-Gawl. in] Bot. Reg. t. $567=$ Buphane disticha.

vaginata, Schult. f. Syst. vii. $852=$ Hessea vaginata.

BRUSCHIA, Bertol, in Mem. Acad. Sc. Bolog. viii. (1857) 238 (Misc. Bot. xviii. 16. t. 2) = Nyetanthes, Linn. (Oleac.).

macrocarpa, Bertol. 11. cc. $238 ; 17=$ N. Arbor-tristis.

BRUXANFuIA, Dennst. Schluess. Hort. Malab. 31 (1818). RUBIACEAE? (Gen. dub.).

indica, Dennst. l. c.-Ind, or. 
BRYA, Vell. Fl. Flum. 146 (1825); iv. t. $1(1827)=$ Hirtella, Linn. (Rosac.).

racemosa, Vell. li. cc. 147; iv. t. 1.-Bras.

BRYA, P. Br. Hist. Jamaic. 299, t。 31 (1756)。 LEGUMINOSAE, Benth: \& Hook, f. i. 514.

Ebenus, $D C$. Prod. ii, 421 . -Ind. occ.

leonensis, Lodd. ex Loud. Hort. Brit. 285, nomen.Afr. trop.

nicaraguensis, Oerst. in Kjoeb. Vidensk. Meddel. 1853) 13.-Nicaragua.

parviflora, DC. Prod. ii. 421.-Bras.

BRYANTEA, Rafin. Sylva Tellur. 165 (1838)=Litsea, Lam. (Laurin.).

dealbata, Rafin. $l_{0} c_{0}=$ L. dealbata.

BRYANTHUS, S. G. Gmel. Fl. Sibir. iv, 133. t. 57 f. 3 (1769). ERICACEAE, Benth, \& Hook. f. ii. 595 aleuticus, A. Gray, in Proc. Am. Acad. vii. (1868) 368.-As. bor. or.; Am. bor. occ.

Breweri, A. Gray, l. c. 367.-Calif.

empetriformis, A. Gray, l. c.-Am. bor. occ.

erectus $\times$, Lindl. \& Paxt. Flow. Gard. i. (1850-51) 97. glanduliflorus, A. Gray, in Proc. Am. Acad. vii. (1868) 368.-Am. bor. occ.

Gmelini, D. Don, in Edinb. N. Phil. Fourn. xvii (July 1834) 160.-Sibir。; Kamtsch.

intermedius, A. Gray, in Proc. Am. Acad. vii. (1868) $367=$ empetriformis.

Stelleri, D. Don, in Edinb. N. Phil. Journ. xvii. (July 1834) $160=$ Cassiope Stelleriana.

taxifolius, A. Gray, in Proc. Am. Acad. vii. (1868) 368.-Reg. bor, frigid.

BRYANTIA, Webb, ex Gaudich. Bot. Voy. Bonite, t. 20 (1844 ?); Brongn. in Ann. Sc. Nat. Sér. VI. i. (1875) 287. t. $15=$ Pandanus, Linn.

butyrophora, Webb, $1 . \mathrm{c}_{0}=\mathrm{P}$. butyrophorus.

oblonga, Brongn. in Ann. Sc. Nat. Sér. VI. i. (1875) 288 ; in Comptes-Rendus, lxxx。(1875) $1196=\mathrm{P}$. oblongus.

wiscida, Brongn. 11. cc. $287 ; 1196=$ P. viscidns.

BRYIKINIA, F. Schmidt, Reisen Amurl. 199. t. 8 (1868). GRAMINEAE, Benth. \& Hook. f. iii 1192.

caudata, F. Schmidt, l. c.-Japon; Ins. Sachal.

BRYOBIUM, Lindl. Introd. Nat. Syst. ed. II. 446 (1836) =Eria, Lindl. (Orchid.).

pubescens, Lindl. Bot. Reg. (1838) Misc. $79=\mathrm{E}$. retusa.

BRYOCARPUM, Hook. f. \& Thoms. in Hook. Kew Journ, ix. (1857) 200. t. 5. PRIMULACEAE, Benth. $\&$ Hook. f. ii. 634 .

himalaicum, Hook. f. E Thoms. l. c.-Reg. Himal.

BRYOCLES, Salisb. in Trans. Hort. Soc. i. (1812) $335=$ Funkia, Spreng. (Liliac.).

ventricosa, Salisb. 1. $\mathrm{c} .=\mathrm{F}$, ovata.

BRYODES, Benth. in DC. Prod. x. 433 (1846), SCROPHULARINEAE, Benth. \& Hook. f. ii. 957. micrantha, Benth.l. c.-Ins. Maurit.

BRYOMORPHA, Kar. \& Kir. in Bull. Soc. Nat. Mosc xv. (1842) $172=$ Thylacospermum, Fenzl (Caryophyli.).

rupifraga, Kar. \&c Kir. 1. c. =T. rupifragum.

BRYOMORPHE, Harv. Thes, Cap. ii. 33. t. 15 (1863), COMPOSITAE, Benth. \& Hook. f. ii. 324. Zeyheri, Harv. l. c.-Afro austr.

BRYONIA, Linn. Syst. ed. I (1735), CUCURBITACEAE, Benth. \& Hook. f. i. 829.

abyssinica, Goualt, in Rev。 Hortic. (1853) $61=$ Maximowiczin Lindheimeri.

abyssinica, Lam. Encyc. i. $497=$ Coccinia abyssinica. acerifolia, D. Dietr. Sya. Pl. v. $367=$ Coccinia indica. acuta, Desf. Fl. Atlant. ii. $360=$ dioica.

acutangula, Thunb. Prod. Pl. Cap. $13=$ (Senecionis

affinis, Endl. Prod, Fl. Norfolk, $125=$ Bryonopsis affinis, End

\section{BRYONIA}

africana, E. Mey. Zwei Pfl. Docum, 169=Kedrostis grossulariaefolia.

africana, Linn. Sp. Pl. $1013=$ Kedrostis africana africana, Thunb. Prod. Pl. Cap. $13=$ Kedrostis nana. agrestis, Raeusch. Nom. Bot. ed. II. $283=$ Blastania Garcini.

alba, Bull. Herb. t. $55=$ dioica,

alba, Linn. Sp. Pl. 1012,-Europ.; Reg. Caucas. Persia.

alceaefolia, Willd. in Ges. Naturf. Freunde, Neue Schr. iv. (1803) $223=$ Coccinia indica.

althaeoides, Ser。 in DC. Prod, iii. $306=$ Melothria maderaspatana.

americana, Descourt. F1. Antill. ii, 281, t. $136=$ Melothria pervaga.

americana, Lam. Encyc。 i. $498=$ Cayaponia americaria.

amplexicaulis, Lam. 1. c. $496=$ Melothria amplexicaulis.

angulata, Thunb. Prod. PI. Cap. $13=$ Melothria punctata.

arguta, Zipp. ex Span. in Linnaea, xv. (1841) 206.Malaya.

aspera, Stev, in Cat. Hort. Gorenk. (1812) $32=$ alba.

asperifolia, Presl, Bot. Bemerk, $72=$ Cayaponia american

attenuata, Hook. \& Am. Bot. Beech. Voy. Suppl. 424 $=$ Cayaponia attenuata.

barbata, Buch.-Ham. ex Cogn. in DC. Monog. Phan iii. $530=$ Coccinia indica.

biflora, Buch.-Ham. in Wall. Cat. n. $6707=$ Melothria odorata.

Blumei, Ser. in DC. Prod. iii. $305=$ Melothria Rumphiana.

bonariensis, Mill. Gard. Dict. ed. VIII. n. $6=$ Cayaponia ficifolia.

Boykinii, Torr. \& Gray, Fl. N. Am. i. $540=$ Cayaponia Boykinii.

Cabocla, Vell. Fl. Flum. x. t. $88=$ Cayaponia globosa

callosa, Heyne, ex Wall. Cat. sub n. $6708=$ Melothria maderaspatana.

callosa, Rottl. in Ges. Naturf. Freunde, Neue Schr. iv. (1803) 210 ; Wall. Cat. no $6710=$ Cucumis trigonus.

capillacea, Schum. \& Thonn. Beskr. Guin. P1. $430=$ Melothria triangularis.

cheirophylla, Wall. Cat. $\mathrm{n}, 6715 \mathrm{~A}=\mathrm{Luffa}$ aegyptiaca. ciliata, Moench, Meth. $653=$ Kedrostis africana.

cissoides, Wall. Cat, n. $6698=$ Melothria perpusilla

cochinchinensis, Lour. F1. Cochinch. 595= Gymnopetalum cochinchinense.

collosa, Rottl. in Ges. Naturf. Freunde, Neue Schr. iv. 1803) $210=$ sphalm. vide callosa.

convolvulifolia, Schlecht. in Linnaea, xxvi. (1853-55) $640=$ Melothria guadalupensis.

convolvuloides, A. Rich. Tent. Fl. Abyss, i. $288=$ Coccinia adoènsis.

cordata, Thunb. F1. Cap. $149=$ Melothria cordata cordatifolia, Goday Torres, in Patriota, iii. n. 37 (1814) 71 = Cayaponia Taynya.

cordifolia, Walp. Rep. ii. $199=$ praec

cordifolia, Linn. Sp. Pl. $1012=$ Coccinia indica

cordifolia, Russ. ex Steud. Nom. ed. II. i. $232=$ Melothria maderaspatana.

cretica, Linn. Sp. Pl. 1013.--Graecia et Ins. Creta.

cucumeroides, Ser, in DC. Prod. iii. $308=$ Trichosanthes cucumeroides.

deltoidea, Arn. Pugill. 19 ; in Nov. Act. Nat. Cur. xviii. (1836) $337=$ Melothria zeylanica.

deltoidea, Schum. \& Thonn. Beskr. Guin. Pl. $429=$ Melothria deltoidea.

dentata, E. Mey. Zwei Pf. Docum. $169=$ Melothria punctata.

digitata, Thunb. Prod. Pl. Cap. $13=$ Kedrostis digitata.

digyna, Pomel, Nouv. Mat. Fl. Atl. $155=$ dioica.

dioica, Bieb. Fl. Taur. Cauc, iii。 $625=$ alba.

dioica, Boj. Hort. Maurit. $148=$ Bryonopsis laciniosa

dioica, Facq. Fl. Austr. ii. 59. to 199 (err. typ. disica) - Lurop. Reg. Mediterr.

dissecta, Thunb. Prod. Pl. Cap. 13 - Kedrostis africana.

divisa, Willd. ex Sterd. Nom。 ed. II. i. 292, nomen.Hab.?

epigaea, Blume, Bijdr. 925 = Mclothria Rumphiana.

epigrea, Rottl, in Gies. Naturf, l'reunde, Neae Schr. iv. (1803) 223 = Corallocarpus epigacus.

\section{BRYONIA}

ficifotia, Descourt. Fl. Antill. vi. 39.t. $391=$ Cayaponia americana.

ficifolia, Lam. Encyc, i. $498=$ Cayaponia ficifolia filicaulis, Wall. Cat. n, 6713= Kedrostis rostrata. filifolia, Spreng. Syst. iii. 16 = Cayaponia ficifolia. filiformis, Roxb. Hort. Beng. 70; F1. Ind. iii. $727=$ Melothria heterophylla?

fimbristipula, Fenzl, ex Hook. f. in Oliver, Fl. Trop. Afr. ii. $558=$ Blastania fimbristipula.

fuminensis, Vell. Fl. Flum, x, t. $87=$ Cayaponia fluminensis.

foetidissima, Schum. \& Thonn. Beskr. Guin, P1, $428=$ Kedrostis foetidissima.

Garcini, Willd. Sp. Pl. iv. $623=$ Blastania Garcini

geminata, Blume, Bijdr. 924= Melothria indica.

glabra, Roxb. Hort. Beng. $104=$ Corallocarpus epigaeus.

glandulosa, Gill. in Hook. Bot. Misc, iii. (1833) 324.Chili.

glandulosa, Poepp. \& Endl. Nov. Gen. et Sp. ii. 56. t. 175 = Cayaponia glandulosa.

gracilis, Wall. Cat. n. $6714=$ Melothria madera spatana.

grandis, Linn. Mant. i. $126=$ Coccinia indica.

grandis, Wall. Cat. n. $6700 \mathrm{~K}=$ Gymnopetalum cochinchinense.

grandis, Wall. 1. c. $\mathrm{L}=$ Momordica dioica.

grossularifolia, E. Mey. Zwei Pf. Docum. 169 Kedrostis grossulariaefolia.

guadalupensis, Spreng. Syst. iii. 15=Melothria pervaga.

guineensis, G. Don, Gen. Syst. iii. 32 (sp. dub.),-Afr. trop.

hastata, Lour. Fl. Cochinch. ii. $594=$ Melothria heterophylla.

hederaefolia, Jacq. Fragm. 73. n. 230. t. $113=$ verucosa.

heterophylla, Blume, Bijdr. $925=$ Melothria Rum. phiana.

heterophylla, Raeusch. Nom. ed. III. 282; Stend. Nom. ed. I. $123=$ Melothria heterophylla.

heterophylla, Wall. Cat. n, $6704=$ Melothria mar. ginata?

hispida, Salisb. Prod. $158=$ Melothria maderaspatana. Hookeriana, Wight \& Arn. Prod. $345=$ Melothria

perpusilla.
japonica, Thunb. F1. Jap. $325=$ Melothria japonica

jatrophaefolia, A. Rich. Tent. Fl. Abyss. i. $289=$ Coccinia jatrophaefolia.

Fohnstoni, Cuzent, ex Seem. in Journ. Bot. ii. (1864) $47=$ Melnthria Grayana.

laciniosa, Linn. Sp. P1. $1013=$ Bryonopsis laciniosa.

laevis, Thunb. Prod. P1. Cap. $13=$ Melothria velutina lagenaria, E. Mey. Zwei Pfl. Docum. 169=Coccinia sessilifolia.

latebrosa, [Dryand. in] Ait. Hort. Kew. ed. I. iii. 384 = Cayaponia latebrosa.

leiosperma, Wight \& Arn. Prod. $345=$ Melothria leio sperma.

leucocarpa, Blume, Bijdr. $924=$ Melothria odorata.

Lhotzkyana, Cogn. in Mart. Fl. Bras. vi. IV. $83=$

Cayaponia Lhotzkyana.

lutea, Bast. ex Ser. in DC. Prod. iii. $307=$ dioica.

macrophylla, Kotschy, ex Boiss. Fl. Orient. ii. 761 Armenia.

macrophylla, Ser. in DC. Prod. iii. $\$ 08$ (sp. dub.).Hab.?

maderaspatana, Berg. Desc. Pl. Cap. $851=$ Melothria punctata.

maderaspatana, Lam. Encyc. i. 4900 Melothris maderaspatana.

marginata, Blume, Bijdr. 924=Melothria Rumphiann. maysorensis, Wall. Cat. n. $6702=$ Melothria mucroaata. maysorensis, Wight, Ic. iii. t. $7581=$ Melothria perpusilla.

Melothria, Crantz, Inst. i. 179= Melothria pendula. nicrantha, Hoiss. Diagn. Ser. 1. x. $7=$ suriaca. micrantha, Hochst. ex Cogn. in DC. Monog. Phan. iii. $6^{2} 29=$ Melothria maderaspatana.

micropoda, E. Mey. Zwei PH. Docum. 169 - Melochris maderaspatann

Moimoi, Ser in DC, Prod, iii, $\$ 05=$ Coucinea Morhadd. msucromata, Blume, Bijdr. $193=$ Melochris mucronata. multifida, E. Mey. Zwei PH. Docum. $189=$ Kecirostis atricans.

multiflora, Boiss. \& Heidr. Diagn. Ser. I. x. 8.Oricns: Ind. bor. oc: 


\section{BRYONIA :-}

mysorensis, Miq ex C. B. Clarke, in Hook. f. Fl. Brit. Ind. ii. $623=$ Melothria leiosperma.

mysorensis, Walp. Rep. ii. $198=$ Melothria mucro. nata.

mysorensis, Wight \& Arn. Prod. i. $345=$ Melothria perpusilla

nana, Lam. Encyc. i. $497=$ Kedrostis nana

nepaulensis, Ser. in DC. Prod. iii. $307=$ Melothria heterophylla.

nigra, Gilib. F1. Lituan. i. $60=$ alba,

nitida, Link, Enum. Hort. Berol, ii, $404=$ dioica.

obtusa, A. Rich. Tent. Fl. Abyss, i. 288=Mukia scabrella.

obtusiloba, E. Mey. Zwei Pfl. Docum. 169= Melothria obtusiloba.

odorata, Buch.-Ham, ex Wall. Cat. n. 6706 B, C= Melothria odorata.

odorata, Wall. Cat. n, $6706 \mathrm{D}=$ Melothria Wallichii.

oxyphylla, Wall. Cat, n. $6698=$ Melothria perpusilla

palmata, Linn. Sp. P1. 1012= Bryonopsis laciniosa.

palmata, Wall. Cat. n. $6711 \mathrm{~A}, \mathrm{~B}, \mathrm{C}=$ Coccinia indica.

palmata, Wall. 1. c. $\mathrm{D}=$ Corallocarpus epigaeus.

Pancheri, Naud. in Ann. Sc. Nat. Sér. IV. ix. (1858)

$398=$ Bryonopsis affinis.

pectinata, E. Mey. Zwei Pfl. Docum. $169=$ Trochomeria pectinata.

pedata, Hassk, in Flora, xxv. (1842) Beibl. $42=$ Bryonopsis laciniosa.

pedunculosa, Ser. in DC. Prod. iii. $306=$ Herpetospermum caudigerum

perpusilla, Blume, Bijdr. $926=$ Melothria perpusilla

Perrottetiana, Ser. in DC. Prod. iii. $304=$ Kedrosti foetidissima.

pilosa, Vell. FI. Flum. x. t. $86=$ Cayaponia diffusa.

pilosa, Roxb. Hort. Beng. 104; F1. Ind. iii. $726=$

Kedrostis rostrata.

pinnatifida, Vell. F1. Flum. x。 t. $90=$ Cayaponia diversifolia.

pinnatifida, Burch. Trav. i. $547=$ Kedrostis africana.

pinnatiloba, M. Roem. Syn. fasc. ii. Pepon. $40=$ Cayaponia diversifolia.

prostrata, D. Dietr. Syn. P1. v. $363=$ Kedrostis rostrata.

polymorpha, Fensch. ex Trautv in Act. Hort. Petrop. viii. (1883) 352, nomen.-Hab.?

pubescens, Poir. Encyc. Suppl. i. 731 (sp. dub.).Oriens.

punctata, Buch.-Ham. ex Wall. Cat. sub n. $6708=$ Melothria maderaspatana

punctata, Thunb. Prod. Pl. Cap. $13=$ Melothria punctata.

quinquefolia, Noronha, in Verh. Batav. Gen. v. (1790) ed. I. Art. IV. $48=$ Bryonopsis laciniosa.

quinqueloba, Thunb. Prod. P1. Cap. $13=$ Coccinia quinqueloba.

racemosa, Mill. Gard. Dict. ed. VIII n, 4-Ind, oce.

racemosa, Poepp. \& Endl. Nov. Gen. et Sp. ii. $56=$ Cayaponia Poeppigii.

racemosa, Sw. Prod. Veg. Ind. Occ. $=$ Cayaponia racemosa.

reniformis, Roxb. ex Wight \& Am. Prod. $344=$ Blastania Garcin

repanda, Blume, Bijdr. $923=$ Melothria punctata.

Rheedei, Blume, 1. c. $925=$ Melothria heterophylla

rostrata, Rottl, in Ges. Naturf. Freunde Neue Schr. iv. (1803) $212=$ Kedrostis rostrata.

Rottleri, Spreng. Syst. iii. 15=Melothria maderaspatana.

nuderalis, Salisb, Prod, $158=$ dioica.

ruderalis, Zipp. ex Span. in Linnaea, xv. (1841) 206, nomen.-Malaya

sagittata, Blume, Bijdr. 925 = Melothria heterophylla

scabra, Rottl. ex Wight \& Arn. Prod. i. $345=$ Melothria maderaspatana.

scabra, Thunb. Prod. Pl. Cap. $13=$ Melothria punctata scabrata, Blume, Bijdr. 923 = Melothria perpusilla. scabrella, Linn. f. Suppl. $424=$ Melothria maderaspatana scabrella, Sieber, ex Cogn. in DC. Monog. Phan. iii $786=$ Cayaponia americana

scabrella, Wall. Cat, n. $6708=$ Melothria leiosperma

scarlatina, Dum. Fl. Belg. $54=$ dioica.

scrobiculata, Hochst. ex A. Rich. Tent. F1, Abyss. i. $287=$ Melothria scrobiculata.

septemlobata, Vell. Fl. Flum.x. t. 85.-Bras.

sicula, Guss. Fl. Sic. Syn. ii. $621=$ dioica.

sinuata, Wall. Cat. n. $6711 \mathrm{D}=$ Corallocarpus epigaeus. sinuosa, Wall. Cat. n. $6716=$ Coccinia indica et Melothria heterophylla.

\section{BRYONIA :-}

Solena, Mirb, ex Steud. Nom ed. II i, $233=$ Melothri heterophylla.

stipulacea, Willd. Sp. Pl. iv. $620=$ Blastania Garcini

subpinnata, Stend. Nom. ed. II. i. $232=$ Cayaponia diversifolia.

syriaca, Boiss. Diagn. Ser. II. ii. 59.-Syria; Palaestin. Tayuya, Mart. in Linnaea, xii. (1838) Litt. $86=$ Cayaponia Martiana.

Tayuya, Vell. F1. Flum. x, t. $89=$ Cayaponia Tayuya Teedonda, Roxb. ex Willd. Sp. PI. iv, $618=$ Melothria heterophylla.

tenella, Roxb. Hort. Beng. 70; F1. Ind. iii. $725=$ Melothria indica.

tenuifolia, Gill. in Hook. Bot. Misc. iii. (1833) $323=$ Abobra tenuifolia.

tenuifolia, Poepp. Eo Endl. Nov. Gen. et Sp. ii. 56.Chili.

tenuis, Klotzsch, in Peters, Reise Mossamb. Bot. 150 - Bryonopsis laciniosa.

ternata, Vell. Fl. Flum. x. t. 91=Cayaponia ternata

Thunbergiana, Dietr. ex Steud. Nom. ed. I. $123=$ Melothria cordata.

Tinei, Huet, ex Cogn. in DC. Monog. Phan. iii. 471 $=$ dioica.

tomentosa, Noronha, in Verh. Batav. Gen. v. (1790) ed. I. Art. IV. 8.-Malaya

tricuspidata, Leschen. ex Steud. Nom. ed. II. i. $275=$ Passiflora Leschenaultii.

triflora, Wall. Cat. n. $6707=$ Melothria leucocarpa

triloba, Lour. F1. Cochinch. ii. 595=Blastania Garcini

triloba, Thunb. Prod. Pl. Cap. $13=$ Kedrostis nana

trilobata, Ser. in DC, Prod. iii. $307=$ Kedrostis nana

tubiflora, Wight \& Arn. Prod. $347=$ Gymnopetalum Wightii.

umbellata, Klein, ex Willd. Sp. PI. iv. $618=$ Melothria heterophylla.

umbellata, Wall. Cat. $\mathrm{n}, 6705 \mathrm{D}=$ Trichosanthes cucumerina.

umbellata, Wall. 1. c. K, $\mathrm{L}=$ Melothria amplexicaulis. variegata, Mill. Gard. Dict. ed. VIII. n. $5=$ Bryonopsis laciniosa.

verrucosa, [Dryand. in] Ait. Hort. Kew. ed. I. iii. 385.Ins. Canar.

vitifolia, Hort. Belo, ex Heynh. Nom. ii. 79, nomen.Hab. ?

vittata, Zipp. ex Span. in Linnaea, xv. (1841) 206 nomen.-Malaya.

vulgaris, Gueldenst. ex Ledeb. F1. Ross. ii. $1401=$ alba Wallichiana, Ser. ex DC. Prod. iii. 309=Melothria heterophylla.

Wightiana, Wall. Cat. n. $6703=$ Melothria leiosperma

BRYONOPSIS, Am. in Hook. Journ. Bot. iii. (1841) 274. CUCURBITACEAE, [Benth. \& Hook. f. 1.274] affinis, $\operatorname{Cog} n$. in DC. Monog. Phan. iii. 479.-Ins. Norfolk.

Bonnettii, Miq. Fl. Ind. Bat. i. I. $657=$ Cerasiocarpum zeylanicum.

courtallensis, Arn. in Hook. Journ. Bot. iii. (1841) 274 = laciniosa.

erythrocarpa, Naud. in Ann. Sc. Nat. Sér. IV. xviii. (1862) $194=$ laciniosa.

laciniosa, Naud. $l$. c. Sér. V. vi. (1866) 30,-As. Afr. et Austral. trop.

leucocarpa, Miq. Fl. Ind. Bat. i. I. 657 =Melothria odorata.

Pancheri, Naud, in Ann. Sc. Nat. Sér. V. vi. (1866) $30=$ affinis

pedata, Hassk. Cat. Pl. Hort. Bog. Alt. 189=laciniosa.

BRYOPHTHALMUM, E. Mey. Preuss. Pflanzeng. 101 $(\mathbf{1 8 3 9})=$ Moneses, Salisb. $($ Ericac $)$

uniflorum, E. Mey. 1. $\mathrm{c}_{\mathrm{s}}=\mathrm{M}$. uniflora.

BRYOPHYLLUM, Salisb. Parad. Lond. t. 3 (1805). CRASSULACEAE, Benth. \& Hook. f. i. 658. Physocalycium, Vest, in Flora, iii. (1820) 409 Crassuvia, Comm. ex Lam. Encyc. ii. 141 (1786) calycinum, Salisb. $l$. $c_{\mathrm{n}}-$ Mexic.

cochleatum, Lem. Illustr. Hortic. vi. (1859) Misc. 100 =Kalanchoë cochleatum.

crenatum, Baker, in fourn. Linn. Soc. xx. (1884) 139 - Madag.

germinans, Blanco, Fl. Filip. ed. II. $220=$ calycinum pinnatum, Kurz, in Journ. As. Soc. Beng. xl. (1871) II. $52=$ calycinum

proliferum. Bowie, ex Hook. Bot. Mag. t. 5147.-Afr. austr.

\section{BRYOPHYITUM :}

serratum, Blanco, F1. Filip. ed. II. 220=Kalancho laciniata.

triangulare, Blanco, 1. c. $221=$ Kalanchoë spathulata tubiflorum, Harv. in Harv. E Sond. Fl. Cap. ii. 380 - Afr, austr.

BUBALINA, Rafin. in Ann. Gén. Sc. Phys. vi. 1820 $86=$ Burchellia, R. Br. (Rubiac.).

BUBANIA, Girard, in Mém. Acad, Montp. (Sect. Sc.) (1848) 182 = Iimoniastrum, Moench (Plumbagin.) Feei, Girard, 1. c. $185=\mathrm{L}$. Guyonianum.

monopetala, Girard, 1. c. $183=\mathrm{L}$. articulatum

BUBON, Linn. Gen. ed. I. $339(1737)=$ Seseli, Linn (Umbellif.)

aphyllus, Cham. \& Schlecht. in Linnaea, i. (1826) 389 (=Deverra tortuosa).-Aegypt.

buchtormensis, Spreng. Pugill. ii. $55=\mathrm{S}$. buchtormense. capensis, Sond. in Harv. \& Sond. F1. Cap. iii. 561.Afr. austr.

cuneifolius, Spreng, Syst. i. $900=\mathrm{S}$. cuneifolium.

dichotomus, Link, Enum. Hort. Berol. i. (1821) 278

$\mathrm{S}$. dichotomum.

eriocephalus, Pall. ex Spreng. Syst. i. $900=$ S. Lessingianum.

Galbanum, Hort. ex Steud. Nom. ed. II. i. 233 (= Mela noselinum decipiens).-Madera.

Galbanum, Linn. Sp. P1.253= Peucedanum Galbanum garganicus, Tenore, FI. Nap. i. $123=$ Athamanta sicula.

glaucus, Spreng. Umb. Spec. $\mathbf{1 3 6}=\mathrm{S}$. petraeum

globosus, Stev. ex Ledeb. F1. Ross, ii. $274=$ S. rigidum gummifer, Linn. Sp. PI. $254=$ S. gummiferum.

humilis, Salisb. Prod. Stirp, $165=$ Athamanta macedonica.

hypolencus, Meissn. in Hook. Lond. Journ. Bot. ii. (1840) 536.-Afr. austr.

laevigatus, Ait. Hort. Kew. ed. II. v. i. 352.-Afr. anst latifolius, Salisb. Prod, $165=$ laevigatus.

Libanotis, Dum. Fl. Belg. $79=$ S. Libanotis.

macedonicus, Linn. Sp. P1. $253=$ Athamanta macedonica.

montanus, Sond. in Harv. \& Sond, F1. Cap. iii. 560,Afr. austr.

multiflorus, Moench, Meth. $95=$ Athamanta macedonica.

persicus, Pall, ex Ledeb. Fl. Ross. ii. $329=$ Zosima orientalis.

peucedanifolius, Spreng. Syst. i. $900=$ S. rigidum.

pimpinellifolizis, Eckl. \& Zeyh. Enum. 353-Afr. austr.

prolifer, Burm. f. F1. Cap. Prod. 7=Lichtensteinia pyrethrifolia.

pyrenaicus, Dum. F1. Belg. $79=\mathrm{S}$. vulgare.

rigidior, Linn. Sp. Pl. 254=Ferula communis

rigidus, Spreng. Pugill. ii. $53=\mathrm{S}$. gummiferum

rigidus, Spreng. Syst. i. $900=\mathrm{S}$, rigidum.

siculus, Spreng. in Roem. \& Schult. Syst. vi. $499=$ Bocconi.

tenuifolius, Salisb. Prod. $165=\mathrm{S}$. gummiferum.

tenuifolius, Sond. in Harv. \& Sond. Fl. Cap. ii. 560.Afr. austr.

tortuosus, Desf. Fl. Atlant. i. 257 (=Deverra tortuosa). -Afr. bor.

BUBONIUM, Hill; Veg. Syst. ii. 74 (1761); Hort. Kew. 13 (1769) (Compos.).

aquaticum, Hill, 1l. cc. $=$ Odontospermum aquaticum arborescens, Hill, Hort. Kew, $13=$ Borrichia arbore cens.

frutescens, Hill, Veg. Syst. ii. 74 ; Hort. Kew. $13=$ Borrichia frutescens.

maritimum, Hill, Hort. Kew. 13=Odontospermum maritimum.

spinosum, Hill, Veg. Syst. ii. $74=$ Pallenis spinosa.

BUBROMA, Schreb. Gen. 513 (1791)=Guazuma Plum. (Sterculiac.).

crinitum, Steud. Nom, ed. II. i. $233=$ G. crinita. grandiflorum, Willd. ex Steud. 1. c. $=$ G. grandiflora. Guazuma, Willd. Sp. Pl. iii. $1423=$ G. ulmifolia. Invira, Willd. Enum. Hort. Berol. $806=\mathrm{G}$. ulmifolia polybotryum, Willd. 1. c. =G. polybotrya.

tomentosum, Spreng. Syst. iii. $332=\mathrm{G}$. nlmifolia.

BUCAFER', Adans, Fam. ii. 469 (1763)=Ruppia, Linn. (Naiad.). 
BUCANION, Stev, in Bull. Soc. Nat. Mosc. (1851) 1. $568=$ Heliotropium, Tourn. (Boragin.) Srovitsii, Stev, 1, $\mathrm{c}_{2}=\mathrm{H}$. Szovitsii.

BUCCAFERREA, Bubani, in Nuovo Giorn. Bot. Ital. v. (1873) $316=$ Potamogeton, Tourn. (Naiad.). Hornemanni, Bubani, 1. c. = P. Hornemanni. obtusifolia, Bubani, 1. c. $317=\mathrm{P}$. obtusifolius.

BUCCAFERREA, Mich. ex Petagna, Inst. Bot. v. 1826 $(\mathbf{1 7 8 7})=$ Ruppia, Linn. (Naiad.).

cirrhosa, Petagna, 1. c。 = R. maritima

BUCCO, Wendl. Coll. 13, tt. 2, 3, 13, 28, $77(1808)=$ Agathosma, Willd. (Rutac.).

acuminata, Wendl. Coll. i. t. $28=$ A. imbricata

barbata, Roem. \& Schult. Syst. v. $445=$ Macrostylis lanceolata.

betulina, Roem. \& Schult. 1. c. $443=$ Barosma betulina brevifolia, Roem, \& Schult. 1. c. $446=$ A, erecta. Cerefolium, Roem. \& Schult. 1. c. $439=$ A. Cerefolium. crenata, Roem, \& Schult. 1, c. $444=$ Barosma crenata cuspidata, Wendl. Coll. iii. 17.t. $81=\mathrm{A}$. cuspidata. erecta, Wendl. 1. c. i. 17. t. $3=$ A. erecta.

hamata, Wendl. ex Bartl. \& Wendl. f. Diosmeae, 114 = Barosma dioica.

hirta, Roem. \& Schult. Syst. v. $446=$ A. hirta hispida, Roem. \& Schult. 1. c. = A. hispida.

imbricata, Wendl. Coll. i. 33 . t. $9=\mathrm{A}$. imbricata.

Lamarckiana, Roem. \& Schult. Syst. v. $447=$ A. virgata.

linifolia, Lichtst. in Roem. \& Schult. 1, c. $448=$ A. linifolia.

obtusa, Wendl. Coll. i. $45=$ A. obtusa.

obtusata, Wendl. 1. c. iii. 7. t. $76=$ A. imbricata.

ovata, Roem. \& Schult. Syst. v. $442=$ Barosma ovata

prolifera, Wendl. Coll. iii. t. $77=$ A. prolifera.

pulchella, Roem. \& Schult. Syst. v. $442=$ Barosma pulchella.

rubra, Roem. \& Schult. 1. c. $441=$ Diosma vulgaris.

scabra, Wendl. ex Bartl. \& Wendl, f. Diosmeae, $156=$ A. ciliata.

serpyllacea, Roem. \& Schult. Syst, v, $447=$ A. serpy llacea.

spicata, Roem. \& Schult. 1. c. $448=$ A. spicata.

tetragona, Roem. \& Schult. 1. c. $444=$ Acmadenia tetragona.

Ventenatiana, Roem. \& Schult. 1. c. $442=$ A. Ventena tiana.

vestita, Roem. \& Schult. 1, c, $447=$ A. imbricata.

villosa, Wendl, Coll. i. 14. t. $2=\mathrm{A}$, villosa.

BUCCULINA, Lindl. in Hook. Comp. Bot. Mag. ii (1886) $209=$ Holothrix, Rich. (Orchid.). aspera, Lindl. 1. c. $=$ H. aspera.

BUCEPHAT,ANDRA, Schott, Gen, Aroid, t. 56 (1858). AROIDEAE, Benth, \& Hook, f, iii. 984 Mottleyana, Schott, l. c.-Borneo.

BUCEPHALON, [Plum.] Linn. Gen. ed. I. 375 (1737) = Trophis, Linn. (Urtic.)

racemosum, Linn. Sp. P]. $1190=$ T. americana

BUCERAS, Hall, ex All. F1. Pedem. i. 313 (1785)= Trigonella, Linn. (Legumin.)

corniculata, All. Fl. Pedem, i. $313=$ T. comiculata. elliptica, Moench, Meth. $143=$ T. monspeliaca.

Foenum-graecum, Ali. F1. Pedem. ‥ $313=$ T. Foenumgraecum.

grandiflora, Moench, Meth. $143=\mathrm{T}$. corniculata monspeliaca, All. Fl. Pedem. i. $313=$ T. monspeliaca. mutica, Moench, Meth. $142=\mathrm{T}$. polycerata. odoratissima, Medic. in Vorles. Churpf. Phys, Ges, ii (1787) $883=$ T. F oenum-graecum.

platycarpos, Moench, Meth. Suppl. 51=Mcdicago platycarpos.

polyceration, All. Fl. Pedem. i. $313=$ M. polycerata spinosa, Moench, Meth. $143=$ T. spinosa torosa, Moench, Meth. Suppl. $51=$ T. striata. tortuosa, Steud. Nom. ed. II. i. $233=$ T. striata.

13UCERAS, P. Br. Hist. Jamaic. t. $29(1756)=$ Terminalia, Linn. (Combretac.).

Bucida, Crantz, Inst. i. $133=$ T. Catappa.

BUCEROSIA, Lind1. Gen. 598 (1898)= Boucerosia, Wight \& Arn. (Asclep.).
BUCETUM, Parneli, Grasses of Scotl. 104-109 (1842)= Festuca, Tourn. (Gramin.).

elatius, Parnell, 1.c. $107=\mathrm{F}$. elatior

giganteum, Parnell, 1. c. $108=\mathrm{F}$. gigantea

loliaceum, Pornell, 1. c. $104=\mathbf{F}$. loliacea

pratense, Parnell, 1. c. $105=\mathrm{F}$. elatior.

BUCHANANIA, sm. Exot. Bot. ii, tab. solum, 115 $(1805)=$ Colebrookea, Sm. (Labiat.)

oppositifolia, Sm. 1. c $=$ C. oppositifolia

BUCHANANIA, Spreng, in Sihrad. Journ. (1800) II. 234; Roxb. Pl. Corom, iii. 79. t 282 (1819). ANACARDIACEAE, Benth. \& Hook, f, i. 421. Cambessedea, Kunth, in Ann. Sc Nat, ii. (1824) 366 Coniogeton, Blume, Bijdr. 1156 (1.826)

LANZana, Stokes, Bot. Mat. Med。 ii. 543 (1812) Launzan, Buch.-Ham. in As. Res. v. (1799) 123. LAUNZEA, Endl. Ench. 599 (1841)

LundiA, Puer, ex DC. Prod, ii. 64, in syn. (1825). Iuminata Turcs in Bull. Soc. Nat Mosc (1858)i.

472.-Burma; Malaya

acuminata, Wall. Cat. n. $981=$ lanceolata

amboinensis, Miq. in Ann. Mus. Lugd. Bat. iv. 117 -Amboina.

angustifolia, Benth. Fl. Austral. i. 490= Mnelleri. angustifolia, Roxb. Hort. Beng. 32 ; FI. Ind. ii. 386 B. Lanzan.

arborescens, Blume, Mus. Bot. Lugd. Bat. i. $183=$ florida.

arborescens, F. Muell. Fragm. vii. 23=Muelleri. auriculata, Blume, I.c. $185=$ Campnosperma auriculata. bancana, Miq. Fl. Ind. Bat. Suppl. i. $523=$ florida,

ferruginea, Enol. in DC. Monog. Phan, iv. 194. Ind. or.

florida, A. Gray, in Bot. U. St. Expl. Exped. i. $366=$ vitiensis

florida, Schau. in Nov. Act. Nat. Cur. xix. Suppl. i (1843) 481.-As. trop.; Malaya.

glabra, Wall. Cat. n. 984-Burma.

Halmaheirue, Miq. in Ann. Mus. Lugd. Bat. iv. 117. -Malaya.

insignis, Blume, Mus. Bot. Lugd. Bat. i. 184.Borneo.

intermedia, Wight, Ic. i. t. $81=$ florida.

lanceaefolia, Roxb. Hort. Beng. $32=$ lancifolia.

lanceolata, Wight, Ic. i. t. 237.--Ind. or

lancifolia, Roxb. Fl. Ind. ii. 386.-Ind. or.; Burma

Lanzan, Spreng. in Schrad. Fourn. (1800) II. 234.Ind or.

latifolia, Roxb. Hort. Beng. 32; Fl. Ind. ii. 385.Ind. or.; Burma.

laxiflora, Kurz, in Fourm. As. Soc. Beng. xli.(1872) II. 304.-Burma

longifolia, Blume, Mus. Bot. Lugd. Bat. i. $184=$ florida longifolia, Span. in Linnaea, xv. (1841) 188,-Ins. Timor.

Incida, Blume, Mus. Bot. Lugd. Bat. i. 184=florida. macrophylla, Blume, 1. c. $185=$ Campnosperma ma crophylla.

mangoides, F. Muell. Fragm. vii. 23.-Ins. Pacif,

microphylla, Engl, in DC. Monog. Phan. iv. 185.-

Ins. Philipp.

Muelleri, Engl. l. c. 190,-Austial.

nitida, Engl. l. c. 193.-Ins. Philipp

obovata, Engl. l. c. 187.-Austral

oxyphylla, Miq. Fl. Ind. Bot. Suppl. i. 522.-Sumatra oxyrhachis, Miq. 1. c. $524=$ Campnosperma oxyrhachis. Plume, Mus, Bot, Lugd, Bat, i 186= florida.

paniculata, Roxb. ex Steud. Nom. ed. II. i. $233=$ Amoora cucullata.

petiolaris, Miq. Fl. Ind. Bat, i. II, 637 = florida

platyneura, Kurs, in fourn. As. Soc. Beng, xly. (1876) II. 125. - Ins. Nicobar.

polybotrya, Mig. Fl. Ind, Bat, i. II. $638=$ florida. racemiflora, Miq. Fl. Ind. Suppl. i. $529=$ Campnosperma macrophylla.

reticulata, Hance, in fourn. Bot. xv. (1877) 332.Cochinch,

sessilifolia, Blume, Mus. Bot. Lugd. Bat. i. 184.Malaya.

siamensis, Mig. in Ann. M/us. Lugd. Bat. iv. 118. Siam

spicata, Roxb. ex Wall. Cat. D. $4895=$ Amoor cucullat?.

splendens, Mig. M. Ind. Bat. Suspl. i. 524-Sumatra, subobouata, Grift. Notul, iv, $419=$ florida.

\section{BUCHANANIA}

itiensis, Engl. in DC. Monog. Phan。 iv, 186.-Ins. Fiji.

zeylanica, Blume, Mus, Bot. Lugd, Bat. i. $185=$ Mangifera zeylanica.

BUCHAREA, Rafin. Fl. Tellur. iv. $84(1836)=$ Con volvulus, Tourn.

atlantica, Rafin. 1. c.-Afr. bor.

maderensis, Rafin. 1. c.-Ins. Madera.

BUCHENAVIA, Eichl, in Flora, xlix, (1866) $164=$

Terminalia, Linn. (Combret.)

capitata, Eichl. 1. c. $165=$ T. Hilariana

macrophylla, Eichl. 1. c, 166-T. macrophylla.

megalophylla, Heurck \& Muell. Arg. in Heurck,

Bot. 211-Am. trop.

ochroprumna, Eichl. in Flora, xlix, (1866) 165.

Am. trop.

oxycarpa, Eichl. 1. c. $166=$ T. oxycarpa

punctata, Eichl. 1. c. =1. punctata, Spruce.

reticulata, Eichl. 1. c.-Am. trop.

suaveolens, Eichl. 1. c. $=$ T. suaveolens.

tomentosa, Eichl. 1. $c_{1}=$ T tomentosa, Mart.

BUCHENROEDERA, Eckl, \& Zeyh. Enum. 19 1836). LEGUMINOSAE, Benth. \& Hook. fo i. 478 . Colobotus, E. Mey, Comm. Pl, Afr. Austr, 156 . $(1836)$

alpina, Eckl. E Zeyh. Enum. 195.-Afr. austr.

caerulescens, Presl, Bot. Bemerk. 47.-Afr. austr. gracilis, Eckl. E Zeyh. Enum. 195.-Afr. austr. holosericea, Benth. in Hook. Lond. Fourn. Bot.

(1848) 581.-Afr. austr.

lanceolata, Presl, Bot. Bemerk. 47.-Afr. austr.

Meyeri, Presl, $l$ G-Afr anstr.

multiflora, Eckl. E Zeyh. Enum. 195.-Afr, anstr.

spicata, Harv. in Harv. E Sond. Fl. Cap. ii. 93.-Af. austr.

tenuifolia, Eckl. E Zeyh. Enzım. 196.-Afr. austr. teretifolia, Eckl. \& Zeyh. L. c.= Aspalathus armata. trichodes, Presl, Bot. Bemerk. 47.-Afr. anstr. umbellata, Hav, in Harv. \& Sond. F. Cap. ii. 98. Afr. austr.

viminea, Presl, Bot. Bemerk. 47.-Afr. austr.

BUCHERIA, Heynh. Nom. ii. $80(1846)=$ Thryp. tomene, Endl. (Myrtac).

saxicola, Heynh. 1. $\mathrm{c}_{\mathrm{n}}=\mathrm{T}$, saxicola.

BUCHIA, D. Dietr. Syn. P1. iii. $370(18 \pm 3)=$ Bouchea Cham. (Verbenac.)

BUCHIA, H. B. \& K. Nov, Gen, et Sp. ii. 20\%. t. 13: (1817) = Perama, Aubl. (Rubiac.)

plantaginea, H. B. \& K. 1. c. 270。 t $132=1$ ? dichotoma.

BUCHINGERA, Boiss, \& Hohen. Diagn. Ser. I. vii 29 (1849). CRUCIFERAE, Benth. \& Hook. I. i. 72 axillaris, Boiss. E Hohen. l. c.-Persia.

BLCHINGERA, F. Scioltz, in Jahrb. Pharm. Mar. 1847) - Cf Bot Zeit, vi. (1848) $760=$ Cuscuta, Lin. (Convolv.)

suaveolens, F. Schult $2,1 . \mathrm{c} .=\mathrm{C}$. racemosa

BUCHLOE, Engelm. in Trans. Acad. Sc. St. Louis (1859), 432. t. 12, 14. GR.AMTMEAE, lesth. S Hook. f. iii. 1173.

Bulbuls, Rafin in Joum. Phys Irxix $(1819$ 20

CALANTHERA, Nutt ex Hook. Kev Jourd, viii. (1S56) 18.

Seslerla, Nutt. Gen. Am. i. 64 (1\$1S

dactyloides, Ergelm. I. c.-Texas; Mexic

BUCHNER A, Linn, Hort. Cliff. $50117 \%$ PHLTARINEAE, Bench. \& IIouk. f. ii. 908 BonxeT1A. Neck. Elem. i. 368 1,90

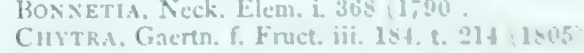
Micalia, Rafin. Fi. Tellur. ii. $1041836^{\circ}$. PIRIPEA. Aubl. PI. (iui. ii, 62- . 2. 259 1:-5) qethiopica, Iinn. Mant. ii. 251 e Chacnostumn acthiu. picum.

plewm. Linn. P. Afr. Kas. 18; in Aruoco. Alad, if 88 - Trixago Apula americana, Linu. Sp. Pl. $690 .-$ Am. hor.

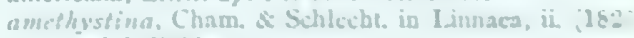
iss = lubclicieles. 


\section{BUCHNERA :-}

angustifolia, D. Don, Prod. F1. Nep. 91=Striga euphrasioides.

angustifolia, Rafin. New Fl. Am. ii. 32.-Am. bor. aquatica, Wight, ex Steud. Nom. ed. II. i. $234=$ Striga lutea.

arguta, Decne, in Nouv. Ann. Mus. Par. iii. (1834) $374=$ ramosissima

asiatica, Linn. Sp. PI. 630; Vahl, Symb. Bot. iii. $81=$ Striga densiflora.

aspera, Schum. \& Thonn. Beskr. Guin. P1. $280=$ Striga aspera.

asperata, R. Br. Prod. $438=$ linearis.

aurantica, Burch. Trav. i. $388=$ Lyperia multifida.

aurea, Banks, ex Benth. in Hook. Comp. Bot. Mag. i. 1835) $372=$ Polycerena aurea

bifida, Buch.-Ham. in Wall. Cat. n. $3872=$ Striga euphrasioides.

bilabiata, Thunb. Prod. Pl. Cap. $100=$ Striga Thun bergii.

canadensis, Linn. Mant. $88=$ Verbena Aubletia

capensis, Linn. 1. $\mathrm{c}_{\mathrm{s}}=$ Polycarena capensis

capillaris, Desv. in Ham. Prodr. Fl. Ind. Occ. 46.-

Griana.

capitata, Benth in DC. Prod. x. 495.-Madag.

capitata, Burm. f. Fl. Cap. Prod. 17.-Afr. austr

cernua, Houtt. Handleid. ix. $542=$ Bouchea cuneifolia

cernua, Linn. Mant. ii. $251=$ Bouchea cernua.

coccinea, Benth. Scroph. Ind. $40=$ Striga lutea.

coccinea, Scop. Delic. Insub. ii. $10=$ Achimenes coccinea,

cordifolia, Linn. f. Suppl. $287=$ Streptium asperum. cruciata, Buch.-Ham. in D. Don, Prod. Fl. Nep. 91. As. trop.; Malaya.

cuneifolia, Thunb. Prod. Pl. Cap. $100=$ Bouchea cuneifolia.

curviflora, R. Br Prod, $438=$ Striga curviflora

densiflora, Benth. Scroph. Ind. $41=$ Striga densiflora

densiflora, Hook. \& Arn. Bot. Beech. Voy. $203=$ cruciata.

denticulata, Buch.-Ham. ex Wall. Cat. n. $3872=$ Striga euphrasioides.

disticha, $H . B$. $\boxminus$ $K$. Nov. Gen. et Sp. ii. 340.-

N. Granat.

divaricata, Linn. ex Walp. Rep. iii. $308=$ Zaluzianskya pusilla.

dura, Benth. in Hook. Comp. Bot. Mag. i. (1835) 366. -Afr., austr.

elegans, D. Dietr. Syn. PI. iii. $525=$ Striga elegans. elongata, [Benth.] ex Griseb. F1. Brit. W. Ind. $428=$ longifolia.

elongata, Sw. Prod. Veg. Ind. Occ. 92.-Am. calid

erinoides, Farosz, Pl. Nov. Cap. 19.-Afr. austr.

euphrasioides, Vahl, Symb. Bot. iii. $81=$ Striga enphrasioides.

exserta, Fawuc, in H. O. Forbes, Nat. Wand. East. Archip. 512.-Ins. Timor.

foetida, Andr. Bot. Rep. t. $80=$ Chaenostoma hispidum.

foetida, Jacq. Hort. Schoenb. iv. 23. t. $448=$ Chaenostoma foetidum.

foetida, Schrad. Fourn. 1800. II (1801) 196- - Hab. ?

Forbesii, D. Dietr. Syn. Pl, iii. $526=$ Striga Forbesii

gesnerioides, Willd. Sp. PI. iii. $338=$ Striga oroban choides.

glabrata, Benth. in Hook. Comp. Bot. Mag. i. (1835) 366.-Afr. austr.

gracilis, R. Br. Prod. 437.-Austral.

grandiflora, Linn. f. Suppl. $287=$ Escobedia scabrifolia.

Hermonthica, Delile, F1. Egypte, 245. t. $34=$ Striga Hermonthica

Heyneana, D. Dietr. Syn. Pl. iii. $525=$ Striga densi flora.

hirsuta, Wall. Cat. n. $3869=$ Striga euphrasioides.

hispida, Buch.-Ham. in D. Don, Prod. Fl. Nep. 91.Ind. or. ; Afr. trop.

humifusa, Vahl, Symb. Bot. iii. $81=$ Striga humifusa.

hydrabadensis, Roth, Nov. Sp. Pl. $292=$ Striga oroban choides.

juncea, Cham. E Schlecht. in Linnaea, ii. (1827) 590. -Bras.

lavandulacea, Cham. \& Schlecht. 1. c. $589=$ rosea

leptostachya, Benth. in DC. Prod.x. 497.-Afr. trop.

levicaulis, Rafin. New Fl. Am. ii. 39.-Am. bor

lilacina, Zipp. ex Span, in Linnaea, xv. (1841) $331=$ ramosissima.

linearifolia, Schum. \& Thonn. Beskr. Guin. Pl. 279.-

Afr. trop.

linearis, R. Br. Prod. 437.-Austral.
BUCHNERA :-

lithospermifolia, H. B. \& K. Nov. Gen. et Sp. ii. 341 = elongata.

lobelioides, Cham. E Schlecht. in Linnaea, ii. (1827) 589.-Bras.

longiflora, Arn. in Nov. Act. Nat. Cur. xviii. (1836) $356=$ Rhamphicarpa longiflora.

longifolia, H. B. \& K. Nov. Gen. et Sp. Pl. ii. $340=$ elongata.

longifolia, Klotzsch, in Peters, Reise Mossamb. Bot 225.-Afr. trop.

macrantha, Benth. in Hook. Comp. Bot. Mag. i. (1835) 366. - A fr, trop.

macrocarpa, A. Rich. Tent. Fl. Abyss. ii. 128.Abyssin.

macrocarpa, H. B. E K. Nov. Gen. et Sp. ii. 342.N. Granat.

major, Polak. in Linnaea, xli. (1877) 588.-Costa Kica.

Masuria, Buch.-Ham. ex Benth. Scroph. Ind. $41=$ Striga Masuria.

mexicana, Hemsl. Biol. Centr. Am. Bot. ii. 457.Mexic.

missurica, Rafin. New Fl. Am. ii. 32.-Am. bor.

montevidensis, Spreng. ex Walp. Rep. iv. $27=$

Verbena venosa

Moouria, Steud. Nom. ed. II. i. 234=Striga Masurea.

mossambicensis, Klotzsch, in Peters, Reise Mossamb

Bot. 224.-Afr. trop.

multiflora, D. Dietr. Syn. Pl. iii. 525; F. Muell. Census, $98=$ Striga multiflora.

nigrescens, Span. Ic. 69; et in Linnaea, xv. (1841) $331=$ arguta.

obliqua, Benth. in DC. Prod. x. 498.-Mexic.

oppositifolia, Hort. ex Steud. Nom. ed. II. i. $234=$

Chaenostoma hispidum.

orobanchoides, R. Br. in Salt, Abyss. App. $64=$ Striga orobanchoides.

palustris, Spreng. Syst. ii. 805.-Guiana.

parviflora, R. Br. Prod. 438 = Striga parviflora.

pedunculata, Andr. Bot. Rep. t. $84=$ Lyperia peduncalata.

Peripea, Stend. Nom. ed. I. $124=$ palustris

phoenicea, Wall. in Benth. Scroph. Ind. $41=$ Striga lutea.

pilosa, Benth. Bot. Voy. Sulph. 144=elongata.

pinnatifida, Linn. f. Suppl. $288=$ Bouchea pinnatifida

Piripea, Raeusch. Nom. ed. III. $179=$ palustris.

pubescens, Benth. in Hook. Comp. Bot. Mag. i. (1835)

$365=$ ramosissima

pusilla, $H . B$. E K. Nov. Gen. et Sp. ii. 340.N. Granat.

ramosissima, $R$. Br. Prod. 438,-Austral

rosea, H. B. E K. Nov. Gen. et Sp, ii. 342.-Venezuela.

rupestris, Sw. Fl. Ind. Occ. ii. $1063=$ Rachicallis rupestris.

Schimperiana, Hochst. ex A. Rich. Tent. Fl. Abyss. ii. $128=$ hispida.

stricta, Benth, in Hook. Comp. Bot. Mag。 i. (1835) 367 $=$ cruciata.

sumatrana, Miq. Fl. Ind. Bat. ii. $702=$ cruciata,

tenella, R.Br.Prod. 437.-Austral.

ternifolia, H. B. $\varepsilon^{\prime} K$. Nov. Gen. et Sp. ii. 340.-Am. austr.

tetragona, R. Br. Prod. 437.-A Austral.

tetrasticha, Wall. Cat. n. 3878 ; et in Benth. Scroph Ind. 41.-Assam; Burma

Thunbergii, D. Dietr. Syn. Pl. iii. $525=$ Striga Thunbergii.

timorensis, Fawc. in H. O. Forbes, Nat. Wand. East. Archip. 512.--Ins. Timor.

tinctoria, Bertol. Fl. Guatim. 26.-Guatemala.

tomentosa, Blume, Bijdr. 741.- - Java

urticifolia, R.Br. Prod. 437.-Austral.

usuiensis, Oliver, in Trans. Linn. Soc. xxix. (1875) 121.-Afr. trop.

verbenoides, Klotzsch, in Peters, Reise Mossamb. Bot. 226.-Afr. trop.

virgata, $H . B$. \& $K$. Nov. Gen. et Sp. ii. 342.N. Granat.

viscosa, [Soland, in] Ait. Hort. Kew. ed. I. ii. $357=$ Sphenandra viscosa.

Wallichii, Benth, in Wall. Cat. n. $3876=$ Striga Masuria.

BUCHOLTZIA, Meissn. Gen. 318, ; Comm. 230 (1841) $=$ BUCHOLZIA, Mart. = Telanthera, P. Br. (Amaranth.).
BUCHOLZIA, Mart. Nov. Gen. et Sp. ii. 49. t. 147 (1826) = Telanthera, R. Br. (Amaranth.)

brachiata, Schrad. ex Seub. in Mart. F1. Bras, v. I. 173 $=\mathrm{T}$. ficoidea.

diffusa, Mart. Nov. Gen. et Sp. ii. tt. 149, $151=\mathrm{T}$ polygonoides.

ficoidea, Mart. 1. c. $52=$ T, ficoidea.

filifolia, Hook. f. in Trans. Linn. Soc. xx. (1851) 192 $=\mathrm{T}$. filifolia.

frutescens, Mart. Nov. Gen. et Sp. ii. 52, in obs, $=T$ frutescens.

glaucescens, Hook, f, in Trans, Linn. Soc, xx. (1851) $191=$ T. glaucescens.

lupulina, Mart. Beitr. Amarant. 108=T. lupulina

maritima, Mart. Nov. Gen. et Sp. ii. 50. t. $147=$ T. maritima.

nudicaulis, Hook. f. in Trans. Linn. Soc. xx. (1851) $191=$ T. nudicaulis.

oborata, Mart. \& Gal. in Bull. Acad. Brux. x. (1843) $348=\mathrm{T}$. obovata

philoxeroides, Mart. Beitr. Amarant. 107. n. $5=$ T. philoxeroides.

polygonoides, Mart. Nov. Gen. et Sp. ii. $51=\mathrm{T}$. polygonoides.

spinescens, Gill. ex Moq. in DC. Prod. xiii. II. $359=$ Alternanthera Achyrantha.

BUCHOLZIA, Stadtm. ex Willem. in Ust. Ann. Bot xviii. (1796) 54=Combretum, vel Terminalia, Linn.

BUCHOZIA, L'Hérit, ex Juss, in Dict. Sc. Nat. v. (1804 409 ; et in Mém. Mus. Par. vi. (1820) $395=$ Serissa Comm. (Rubiac.)

coprosmoides, L'Hérit. ex DC. Prod. iv. $575=\mathrm{S}$. foetida.

BUCHOZIA, Vell. Fl. Flum. $33(1825)=$ Heteran thera, Ruiz \& Pav. (Ponteder.)

aquatica, Vell. 1. c. 33 ; i. t. $80=$ H. reniformis.

BUCIDA, Linn. Syst. ed. X, $1025(\mathbf{1 7 5 9})=$ Terminalia Linn. (Combret.)

angustifolia, DC. Prod. ii. $10=$ T. Buceras.

angustifolia, Spruce, ex Eichl. in Mart. FI. Bras. xi II. $96=$ T. Hilariana

Buceras, Linn. Syst, ed. X. $1025=$ T. Buceras.

Buceras, Sieber, ex Presl, in Oken, Isis, xxi. (1828) 272 $=\mathrm{T}$. Catappa

Buceras, Vell. Fl. Flum. 172 ; iv. t. $87=$ Laguncularia racemosa.

capitata, Vahl, Eclog. Am. i. 50, t. $8=$ T. Hilariana.

Comintana, Blanco, Fl. Filip. ed. I. $856=$ T. Chebula meorapotamica, Spreng. Syst. iv, Cur, Post. 177.-Bras. nitida, Hassk. in Flora, xxvii. (1844) 605.-Ins. Sandvic.

BUCKINGHAMIA, F. Muell. Fragm. vi. 248 (1868) PROTEACEAE, Benth. \& Hook. f. iii. 182. celsissima, F. Muell. l. c.-Austral.

BUCKLANDIA, R. Br. in Wall. Cat. n. 7414 (1832) HAMAMELIDEAE, Benth. \& Hook. f. i. 668 .

populifolia, Hook. f. \& Thoms. in Joum. Linn. Soc. ii. 1858) $86=$ populnea.

populnea, R. Br. in Wall. Cat. n. 7414.-Reg. Himal.

BUCKLEYA, Torr, in Am. Journ. Sc. xly, (1843) 170. SANTALACEAE, Benth. \& Hook. f. iii. 226. DArbya, A. Gray, in Am. Journ. Sc. Ser. II. i. (1846) 388.

Nestronia, Rafin. New Fl. Am. iii. 12 (1836).

QUAdriala, Sieb. \& Zucc. in Abh. Akad. Muench.

iv. II. (1845) 194 ; (Fam. Nat. Fl. Jap. i. 86. t. 2) distichophylla, Torr. l. c.-Am. bor.

BUCKNERA, Michx. Fl. Bor. Am. ii. 18 (1804)= Buchnera, Linn. (Scrophul.).

BUCQUETIA, DC. Prod. iii. 110 (1828), MELASTOMACEAE, Benth. \& Hook, f. i. 736 .

glutinosa, $D C$, l. $c_{0}-\mathrm{N}$. Granat.

nigritella, Triana, in Trans. Linn. Soc. xxviii. (1871) 23.-Ecuador. 
BUDA, Adans. Fam. иi. 507 (1763); Dum. Fl. Belg. 110 (1827) = Spergularia, C. \& J. Presl (1817) (Caryoph.).

marina, Dum. Fl. Belg. $110=\mathrm{S}$. marina.

media, Dum. 1. c. =S. marina.

rubra, Dum. 1. c. $=\mathrm{S}$, rubra.

BUDDLEIA, Houst ex Linn. Gen, ed. I. 26 (1737) LOGANIACEAE, Benth. \& Hook. f, ii. 793.

Adenople., Radlk. in Bremen Abh. viii. (1883) 406.

Romana, Vell. F1. Flum. 54, pro parte (1825)

abbreviata, $H . B . \&$ G. Nov. Gen. et Sp. ii. 353.Mexic.

acuminata, R. Br. in Salt, Abyss, App. $62=$ polystachya.

acuminata, H. B. \& K. 1. c. $349=$ Humboldtiana

acuminata, Poir. Encyc. Suppl. i. 745. -Ind. or.

acuminatissima, Blume, Bijdr. $743=$ asiatica.

alpina, Oerst. in Kjoeb. Vidensk. Meddel. (1853) 25.Costa Rica.

alternifolia, Maxim. in Bull. Acad. Pétersb. xxvi. (1880) 494.-China.

americana, H. B. \& K. Nov. Gen, et Sp. ii. $351=$ spicata.

americana, Linn. Sp. Pl. 112.-Am. austr

angustata, Benth. in DC. Prod. X. $443=$ vetula.

araucana,Phil.in Anal. Univ. Chil. (1873) 525.-Chili.

arborea, Meyen, Reise, i. $478=$ pichinchensis.

aromatica, Remy, in Ann. Sc. Nat. Sér. III. viii.

(1847) 227.-Bolivia.

asiatica, Lour. Fl. Cochinch.72.-As, trop.; Malaya.

auriculata, Benth. in Hook. Comp. Bot. Mag. ii

(1836) 60.-Afr. austr.

australis, Vell. Fl. Flum. 41; i. t. 104=brasiliensis.

axillaris, Willd. in Roem. \& Schult. Syst. iii. $97=$

Adenoplusia Willdenowii.

barbata, Kunth E Bouche, Ind. Sem. Hort. Berol.

(1847) 12.-Mexic.

betonicaefolia, Lam. Illustr. i. 291.-Peruv.

brachiata, Cham. $E$ Schlecht. in Linnaea, ii. (1827)

599. - Bras.

brasiliensis, facq. f. Eclog. t. 158.-Bras.

brevifolia, Willd. ex Roem. \& Schult. Syst. iii. Mant.

$97=$ abbreviata

bullata, H. B. E K. Nov. Gen. et Sp. ii, 348.-

Ecuador.

callicarpoides, H. B. \& K. 1. c. $350=$ americana

calycina, Benth. in DC. Prod. x. 440.-Ecuador.

campestris, Walp. Rep. iii. 330.-Bras.

cana, Willd. ex Roem. \& Schult. Syst. iii. Mant. $94=$ verbascifolia.

capitata, Jacq. Ic. Rar. ii. 9 ; Coll. ii. $332=$ globosa. carnea, Carr. in Rev. Hortic. (1879) $90=$ curviflora. cestriflora, Cham. in Linnaea, viii. (1833) 20.-Bras.

Colvilei, Hook. f. Illustr. Himal. Pl. t. 18.-Reg Himal.

comorensis, Baker, in Fourn. Linn. Soc. xx. (1884) 206. - Ins, Comor.

connata, Mart. ex J. A. Schmidt, in Mart. Fl. Bras viii. $283=$ brasiliensis.

connata, Ruiz E Pav, Fl, Per. i. 52, t. 18.-Peruv.

cordata, H. B. \& K. Nov. Gen. et Sp. ii. 348. t. 185 . -Mexic.

cordobensis, Griseb. in Goett. Abh. xix. (1874) 213.Reg. Argent.

coriacea, Remy, in Ann. Sc. Nat. Sér. III. viii. (1847)

226.-Bolivis.

crispa, Benth. in Wall. Cat. n. 6404; et Scroph. nd 43 = paniculata.

crotonoides, A. Gray, in Proc. Am. Acad. v. (1861) 165.-Calif.

cuneata, Cham. in Linnaea, viii. (1833) 17.--Bras.

curviflora, Hook. E Arn. Bot. Beech. Voy. 267.-

China.

curvifolia, Hort. ex Carr. in Rev. Hortic. (1866) 339 -Hab.?

decurrens, Cham. \& Schlecht. in Linnaea, v. (1830) $105=$ americana.

densiflora, Blume, Bijdr. 743.-Java.

dentata, H. B. छ $K$. Nov. Gen. et Sp. ii. 352.Venezuela.

diffusa, Ruis E Pav, Fl. Per, i. 53. t. 80.-Peruv.

discolor, Roth, Nov. Pl. Sp. $83=$ asiatica

diversifolia, Vahl, Symb. Bot. iii. $15=$ Nicodemia diversifolia.

elegans, Cham. E Schlecht. in Linnaea, ii. (1827) 594.-Bras.

\section{BUDDLEIA}

eliptica, Mart. Es Gal. in Bull. Acad. Brux. xii. II. (1845) 24.-Mexic

ferruginosa, Pohl, ex J.A. Schmidt, in Mart. F1. Bras $284=$ elegans.

floccosa, Kunth, in Ind. Sem. Hort. Berol. (1844) -Cf. Linnaea, xvii. (1844) 501.-Mexic.

floribunda, H. B. E K. Nov. Gen, et Sp. ii. 352.Mexic.

foliata, R. Br. ex Benth. in DC. Prod. x. $446=$ polystachya.

fusca, Baker, in Fourn. Linn. Soc. xx. (1884) 205.Madag.

Gayana, Benth. in DC. Prod. x. 442.-Chili.

glaberrima, Hort. Amat. Cat. Hort. Taurin. $13=$ Freylinia cestroides.

glabra, Hort. ex C. Koch, Dendrol. ii. II. $295=$ curviflora.

glabrata, Spreng. Syst, i, $431=$ Cephalanthus Sarandi. globifera, Mirb. in Duham. Arb. ed. Nov. i. t. $25=$ globosa.

globosa, Hope, in Verh. Harlem. xx. II. (1782) 417. t. 11.-Chili ; Peruv.

glomerata, Wendl. ex Benth. in DC. Prod. x, 447 , nomen.-Afr. austr.

gracilis, Kunth, in Ind. Sem. Hort. Berol. (1844)

-Cf. Linnaea, xviii. (1844) 500--Mexic.

grandiflora, Cham. \& Schlecht. in Linnaea, ii. (1827) 596. - Bras.

gajanensis, Roxb. Hort. Beng. [10], nomen.-Am. austr

heterophylla, Lindl. Bot. Reg. t. $1259=$ madagascariensis.

Humboldtiana, Roem. E Schult. Syst. iii. 93.-Texas; Mexic.

incana, Ruiz E Pav. Fl. Per. i. 52. t. 80.-Peruv.

incompta, Linn. f. Suppl. 123.-Afr. austr.

indica, Lam. Encyc. i. $513=$ Nicodemia diversifolia.

insignis, A. Van Geert, Cat. n. 78 (1879-80), 8; Carr. in Rev. Hortic. (1878) 330.-Hab.?

integrifolia, Willd. ex Roem. \& Schult. Syst. iii. Mant. $96=$ abbreviata

intermedia, $H . B$. E $K$. Nov. Gen. et Sp. ii. 350.Mexic.

intermedia, Lorenz, in Roca, Exped. Rio-Negro, ii. 255, nota.-Patagon.

interrupta, Buch.-Ham. ex Wall. Cat. sub n, $6401=$ asiatica.

interrupta, H. B. E K. Nov. Gen. et Sp. ii. 348.Ecuador.

Jamesonii, Benth. in DC. Prod. x. 441.-Ecuador.

japonica, Linden, Cat. n. 19 (1865).-Japon.

Janata, Benth, in DC. Prod. x. 441--Peruv.

lanceolata, Benth. Pl. Hartw. 48.-Am, centr.

lanceolata, Heyne, ex Wall. Cat. sub n. $6401=$ asiatica.

Lindenii, Benth. in DC. Prod. X. 438.-N. Granat.

Lindleyana, Fortune, in Lindl. Bot. Reg. (1844) Misc. 25.-China,

longifolia, H. B. E K. Nov. Gen. et Sp. iv. 349.Peruv.

Lucae, Niederl. in Roca, Exped. Rio-Negro, ii. 254.Patagon.

macrantha, Mart. ex J. A. Schmidt, in Mart. Fl. Bras. viii. 285 = grandiflora.

macrophylla, Kunth, in Ind. Sem. Hort. Berol. (1844).-Cf. Linnaea, xviii. (1844) 500.-Hab.?

macrostachya, Benth. in Wall. Cat. n. 6407 ; et Scroph. Ind. 42.-Reg. Himal.

madagascariensis, Lam. Encyc. i. 518.-Ins. Mascar.; Madag.

marrubiifolia, Benth. in DC. Prod. x. 441.-Texas; Mexic.

Martii, J. A. Schmidt, in Journ. Bot. vi. (1868) $228,245=$ macrostachya.

melliodora, Kunth E Bouché, Ind. Sem. Hort. Berol. (1845) 10,-Mexic.

mendozinensis, Gill. ex Berth, in DC. Prod. x. 443.Chili.

microphylla, H. B. E K. Nov. Gen. et Sp. ii. 35\$.Mexic.

Missionis, Benth. in Wall. Cat. n. 6405 ; et Scroph.Ind. 43.-Ind. or.

mollis, $H, B$, E $K$ Non, Gen et Sp, ii. 349,Ecuador.

Nappii, Lorens, in Roca, Exped. Rio-Negro, ii. 254.Patagon.

Neemda, Buch.-Ham. in Wall. Cat. n. $6401=$ asiatica.

Neemda, Hort, ex Link, Enum. Hort. Berol. i. $125=$ brasiliensis.

\section{BUDDLEIA :}

nepalensis, Colla, in Mem. Acc. Torin, xxxv, (1835 $182=$ paniculata

nitida, Benth. in DC. Prod. x. 437.-Mexic

oblonga, Benth. .. c. 442.-Bras.

obtusifolia, Mart. \& Gal. in Bull. Acad. Brux, xii I1. (1845) 25 = microphylla.

occidentalis, Linn. Sp. Pl. ed. II. 162,-Jamaic. Peruv.

occidentalis, Ruiz \& Pav. Fl. Per. i. 53. t. 82. f. a = americana.

officinalis, Maxim. in Bull. Acad. Pétersb. xxvì. (1880) 496.-China.

otophylla, Hassk. in Versl. en Med. Kon. Akad. Wetensch. v. (1857) 97.-Malayn.

ovalifolia, Kunth, in Ind. Sem. Hort. Berol. (1844) -Cf. Linnaea, xviii. (1844) 500--Mexic

paniculata, Wall. Cat. n. 6403; et in Roxb. Fl. Ind.ed. Carey, i. 412.-Reg. Himal. ; Burma.

parviflora, H. B. E K. Nov. Gen. et Sp. ii. 353.Mexic.

parvifolia, Willd, ex Roem. \& Schult. Syst. iii. Mant $96=$ microphylla

perfoliata, H. B. \& K. Nov. Gen. et Sp. ii. 346.Mexic.

pichinchensis, H.B. E K. l. c.-Ecuador.

Poiretii, Spreng. Syst. i. 430.-Ind. or.

polycephala, H. B. E K. Nov. Gen. et Sp. ii. 346.Peruv.

polystachya, Fresen. in Flora, xxi. (1838) 605.Abyssin.

Pringlei, A. Gray, in Proc. Am. Acad. xix. (1883) 86. -Arizona.

propinqua, Kunth, Ind. Sem. Hort. Berol. (1844). -Cf. Linnaea, xviii. (1844) 501.-Mexic.

pseudoverticillata, Mart. \& Gal. in Bull. Acad. Brux. xii. II. (1845) $24=$ sessiliflora.

racemosa, Torr. Bot. Mex. Bound. 121.-Texas,

rondeletiaeflora, Benth. in DC. Prod. x, 445.-Ins. Comor.

rufa, Fresen. in Flora, xxi. (1838) 606.-Abyss.

rufescens, Willd. ex Roem. \& Schult. Syst. iii, Mant. $97=$ americana.

rugosa, H. B. E $K$. Nov. Gen, et Sp. ii. $347 .-\mathrm{N}$ Granat.

salicifolia, Jacq. Hort. Schoenb. i. $12=$ Chilianthu: arboreus.

salicifolia, Vahl, Symb. Bot. iii. $14=$ thyrsoidea.

salicina, Lam. Illustr. i. 291 = asiatica.

saligna, Willd. Enum. Hort. Berol. 159= Chilianthas arboreus.

Saltiana, Steud. Nom. ed. II. i. $235=$ polystachya.

salvifolia, Lam. Encyc. i. 513.-Afr. austr.

scordioides, H. B. \& K. Nov. Gen. et Sp. ii. 34 J t. 183.-Texas; Mexic.

serrulata, Roth, Nov. Pl. Sp. $82=$ asiatica.

sessilifiora, H. B. E K. Nov. Gen. et Sp. ii. 345. t. 18.

-Mexic.

sinuata, Willd. ex Roem. \& Schult. Syst. Mant. ii. 97.-Madag.

spectabilis, Kunth E Bouché, Ind. Sem. Hort. Berol. (1845) 11.-Mexic.

sphaerantha, Cham. \& Schlecht, in Linnaea, v. (1830 $104=$ perfoliata

sphaerocephala, Baker, in fourn. Linn. Soc. xi. (1885) 425.-Madag

spicata, Ruiz \& Pav.Fl. Per. i. 53. t. 81-Peruv. stachyoides, Cham. E Schlecht. in Linnoea, ii. (152) 597.-Bras.

snaveolens, Kunth Eo Bouché, Ind. Sem. Hort. Berc. (1845) 11.-Chili.

subserrata, Buch.-Ham. ex D. Don, Prod. F1. Nep. $92=$ asiatica.

sundaica, Blume, Bijdr. 743.-Tava.

tenuifolia, Griseb. in Goeth. Abh. xix. (18\%t) 213.-

Am. austr.

temata, Lour. Fl. Cochinch. 72.-Cochinch.

thapsoides, Desf. Cat. Hort. Par. ed. III. $100^{\circ}=$ brasi. liensis.

thyrsoides, Lam. Illustr. i. 291.-Reg. Argent.

tubiflora, Benth. in DC. Prod. x. 1t3. - Bras.

cucumanensis, Griseb. ing Goett. Abh. xix. 18 it 218.

Tucuman.

venusta, Kunth, in Ind. Sem. Hort. Berol. (1514).-Cf Linnaea, xviii. (1S \$4) 500.-Mexic.

Verbasci, Yers. Syn. 1. $185=$ amcricana.

verbascifolia, H. B. Є K. Nov. Gen. et Sp. ï. $\$ 31 .-1$

Grmat. 


\section{BUDDLEIA}

verticillata, $H . B$ g K. Nov. Gen. et Sp. 346. t. 184.-Mexic.

vetula, Cham. in Linnaea, viii. (1833) 18.--Bras.

virgata, Blanco, Fl. Filip. ed. I. $57=$ asiatica.

virgata, Linn. f. Suppl, 123=Gomphostigma scoparioides.

volubilis, Lam. Illustr. i. 291.-Ins, Mascar.

BUECHNERIA, Roth, Nov. Pl. Sp. 292 (1821) = Buchnera, Linn. (Scrophul.).

BUECKIA, A. Rich. in Orb. Dict. ii. 759 (1842)= BUEKIA, Nees=Elynanthus, Linn. (Cyperac.).

BUEKIA, Giseke, Prael. Linn. 199, 204 (1792) = Alpinia, Linn. (Scitamin.).

malaccensis, Raeusch. Nom, ed. III. 1=A. malaccensis.

BUEKIA, Nees, in Linnaea, ix. (1834) $300=$ Elynanthus, Linn. (Cyperac.).

punctoria, Nees, $\mathrm{l}_{0} \mathrm{c}_{\mathrm{v}}=\mathrm{E}$. punctorius.

BUELOWIA, Schum. \& Thonn. Beski: Guin. P1. 246 (1827) = Smeathmannia, Soland. (Passiflor.).

illustris, Schum. \& Thonn. 1. c. $247=\mathrm{S}$. pubescens.

BUENA, Cav. in Anal. Hist. Nat. ii. (1800) 278 ; Ic. vi. $49=$ GONZALAGUNIA, Ruiz \& Pav.=Gonzalea, Pers. (Rubiac.).

panamensis, Cav. 11. cc. 279 ; $50=\mathrm{G}$. panamensis.

BUENA, Pohl, Pl. Bras. Ic. i. 8 (1827); Wedd. in Journ. Linn. Soc. xi. (1869) $185=$ Cosmibuena, Ruiz \& Pav, et Cascarilla, Wedd. (Kubiac.).

acuminata, DC. Prod, iv. $356=$ Cosmibnena acuminata.

acutifolia, Wedd. in Journ. Linn. Soc. xi. (1869) $186=$ Cascarilla acutifolia.

bullata, Wedd. 1. c. $187=$ Cascarilla bullata.

calycina, Wedd. 1. c. = Cascarilla calycina

Carua, Wedd. 1. $\mathrm{c}_{\mathrm{n}}=$ Cascarilla Carua.

citrifolia, Wedd. 1. c. = Cascarilla citrifolia.

crassifolia, Wedd. l. c. = Cascarilla calyptrata.

Gaudichaudiana, Wedd. 1. c. =Cascarilla Gaudichandiana.

heterophylla, Wedd. 1. c. $186=$ Cascarilla heterophylla.

hexandra, Pohl, P1. Bras. Ic. i. 10. t. $8=$ Cascarilla hexandra.

Hookeriana, Wedd. in Journ. Linn. Soc. xi. (1869) 187 = Cascarilla Hookeriana.

Lambertiana, Wedd. 1. c.= Cascarilla Lambertiana.

latifolia, Benth. Pl. Hartw, $191=$ Cosmibuena latifolia macrocarpa, Benth. Bot. Voy. Sulph. 104. t. $38=$ Cosmibuena macrocarpa.

macrocarpa, Wedd. in Journ. Linn. Soc. xi. (1869) 187 - Cascaillla macrocarpa.

magnifolia, Wedd. 1. c. $186=$ Cascarilla magnifolia. muzonensis, Wedd. 1. c. $187=$ Cascarilla muzonensis. nitida, Wedd. 1. c. $186=$ Cascarilla nitida.

obtusifolia, DC. Prod. iv. $356=$ Cosmibuena obtusifolia.

Pavonii, Wedd, in Journ, Linn. Soc. xi. (1869) $186=$ Cascarilla Pavonii.

Riedeliana, Wedd, 1, c. = Cascarilla Riedeliana.

Riveroana, Wedd. 1. c.=Cascarilla magnifolia.

Roraimae, Wedd. 1. c. $187=$ Cascarilla Roraimae.

Skinneri, Oerst. in Kjoeb. Vidensk. Meddel. (1852) 48 =Cosmibuena Skinneri.

stenocarpa, Wedd, in Journ. Linn. Soc. xi. (1869) 186 = Cascarilla stenocarpa.

triflora, Benth. in Hook. Journ. Bot. iii. (1841) $216=$ Cosmibuena triflora.

undata, Wedd. in Journ. Linn. Soc, xi. (1869) $187=$ Cascarilla undata.

BUERGERIA, Miq. Ann. Mus. Bot. Lugd. Bat. iii. 53 $(\mathbf{1 8 6 7})=$ Cladrastis, Rafin. (Legumin.).

floribunda, Miq. I. c, $=$ C. amurensis.

BUERGERIA, Sieb. \& Zucc. in Abh. Akad. Muench. iv. II. (1845) 186. t. 2 (F1. Jap. Fam. i. 78, t. 2) = Talauma, Juss. (Magnol.).

obovata, Sieb. \& Zucc. 11. cc, $187=$ Magnolia obovata. salicifolia, Sieb. \& Zucc. 1. c. =T. salicifolia. stellata, Sieb. \& Zucc. 1. c. $186=$ T. stellata.
BUETTNERA, J. F. Gmel. Syst. ii. 404 (1791)=seq.

BUETTNERIA, Loefl. Iter Hisp. 313 (1758) (Byttneria); Linn. Syst. ed. X. ii. 939 (1759). STERCULIACEAE, Benth. \& Hook. f. i. 225.

BytTne Ria, Loefl. Iter Hisp. 313 (1758).

Chaetaea, Jacq. Enum. Pl. Carib. 2 (1760)

Heterophyllum, Boj.ex Hook. Bot. Misc. i. (1830) 291.

Pentaceros, G. F. W. Mey. Prim. Fl. Esseq. 136 (1818).

Telfairia, Newm. ex Hook. Bot. Misc. i. (1830) 291.

abutiloides, St. Hil. \& Naud. in Ann. Sc. Nat. Sér. II, xviii. (1842) $31=$ hirsuta

aculeata, Domb. ex Lam. Encyc. i. $523=$ cordata

aculeata, Jacq. Stirp. Am. $76=$ carthagenensis.

acuminata, Bred. ex Roem. Eo Schult. Syst. v. 470.Venezuela.

affinis, Pohl, P1. Bras. ii. $73=$ melastomaefolia

africana, Mast. in Oliver, Fl. Trop. Afr. i. 239.-Afr. trop.

andamanensis, Kurz, in Fourn. As. Soc. Beng. i.. (1871) 47 ; et Flora, liv. (1871) 277.-Burma. angulata, Hassk. Cat. Pl. Hort. Bog. 204.-Java. aspera, Colebr, in Roxb. Fl. Ind. ed. Carey, ii. 383. Reg. Himal.; China.

australis, Sieber, ex Steud. Nom. ed. II. i. $241=$ pannosa.

austratis, St. Hil. F1. Bras. Mer. i. $145=$ tereticaulis.

biloba, Baill. Adansonia, x. (1872) 178.-Madag.

brasiliensis, Spreng. Syst. i. 790-Bras.

brevipes, Benth. Pl. Hartw. 115-Am. trop.

caledonica, Turcz. in Bull. Soc. Nat. Mosc. (1863) I. 568.-N. Caled.

carthagenensis, Facq. Stirp. Am. Piot. 41.-N. Granat.

catalpaefolia, Facq. Hort. Schoenbr. i. 21.-Am. trop.

catalpifolia, Wall. Cat n, $1152=$ crenulata?

celtoides, St. Hil. Fl. Bras. Mer. i. 141.-Bras.

corchorifolia, Turcz. in Bull. Soc. Nat. Mosc. xxv. (1852) II. 152.-Am. austr.

cordifolia, Sagot, in Ann. Sc. Nat. Sér. VI. xi. (1881) 155.-Guiana.

cordata, Lam. Encyc. i. 523.-Peruy.

corylifolia, Humb. Eं Bonpl. ex Roem. E Schult. Syst. v. 470. - Am. austr.

crenulata, Wall. Cat. n. 1150.-Reg. Himal.; Burma

dasyphylla, J. Gay, in DC. Prod. i. $486=$ Rulingia pannosa.

dentata, Pohl, Pl. Bras. ii. 79.-Bras.

discolor, Benth. in Hook. Kew Fourn. iii. (1851) 165. -Bras.

divaricata, Benth. in Hook. Fourn. Bot. iv. (1842) 124. -Guiana.

echinata, Wall. Cat, n. $1149=$ crenulata?

elliptica, Mast. in Hook. f. Fl. Brit. Ind. i. 377 .Malacca.

elliptica, Pohl, PI. Bras. ii. $71=$ melastomaefolia.

flaccida, Span. Ic. n. 18; in Linnaea, xv. (1841) 174. -Ins. Timor.

fulva, Poepp. E Endl. Nov. Gen. et Sp. iii. 37.-Bras.

Gayana, St. Hil. Fl. Bras. Mer, i. 145.-Bras.

geminifolia, Turcz. in Bull. Soc. Nat. Mosc. xxv. (1852) II. 153,--Ecuador.

genistella, Triana Es Planch. in Ann. Sc. Nat. Sér. IV. xvii. (1862) 333.-N. Granat.

glabrescens, Benth. Bot. Voy. Sulph. 71.-Am. trop.

Grandidieri, Baill. in Bull. Soc. Linn. Par. i. (1885) 502.-Madag.

grandifolia, DC. Prod. i. $486=$ aspera.

herbacea, Roxb. Pl. Corom. i. 28. t. 29.-Ind, or.

hermanniaefolia, J. Gay, in DC. Prod. i. $486=$

Rulingia hermanniaefolia.

heterophylla, Hook. Bot. Misc. i. (1830) 291Madag.

hirsuta, Ruiz \& Pav. Fl. Per. iii. 10.-Peruv.

hypoleuca, Turcz. in Buil. Soc. Nat. Mosc. xxxi. (1858 I. $207=$ Commersonia platyphylla.

inodora, J. Gay, ex DC. Prod. i. $486=$ Rulingia pannosa.

Jackiana, Wall. in Roxb. Fl. Ind. ed. Carey, ii. 386. -Ins. Penang.

jaculifolia, Pohl, Pl. Bras. ii. 77.-Bras.

javanica, Spreng. ex Miq. Illustr. F1. Ind. Arch. $91=$ angulata.

laevigata, Schott, in Spreng. Syst. Veg. iv. App. $404=$ Gayana.

lanceolata, Sesse, ex DC. Prod. i. 487.--Mexic.

\section{BUETNERIA}

lancifolia, Hook. $f$. in Trans. Linn. Soc. xxiri. (1862 158.-Borneo

lancifolia, St. Hil. E Naud. in Ann. Sc. Nat. Sér. II. xviii. (1842) 32.--Bras.

lateralis, Presl, Rel. Haenk. ii. 145.-Mexic.

lobata, Baill. in Bull. Soc. Linn. Par. i. (1885) 503. -Madag.

longicuspis, Baill. l. c. 502.-Madag.

longifolia, Turcz. in Bull. Soc. Nat. Mosc. xxv. (1852) II. 154,-Venezuela.

macrophylla, H. B. ש K. Nov. Gen. et Sp. v. 315.-N. Granat.

Maingayi, Mast. in Hook. f. Fl. Brit. Ind. i. 377.Malacca.

melastomaefolia, St. Hil. Fl. Bras. Mer. i. 144.-Bras melastomoides, G. Don, Gen. Syst. i. $524=$ praec.

microphylla, facq. Hort. Vindob. i. 10. t. 29; Linn. Mant. 209.-Ind. occ.

mollis, H. B. E K. Nov. Gen. et Sp. v. 314. t. 481 et b.-N. Granat.

morifolia, Triana \& Planch. in Ann. Sc. Nat. Sér. IV. xvii. (1862) 332,-N. Granat.

nepalensis, Turcz. in Bull. Soc. Nat. Mosc. (1858) I. $207=$ aspera.

obliqua, Benth. in Hook. Fourn. Bot. iv. (1842) 124. -Guiana.

oblongata, Pohl, Pl. Bras. ii. 73.-Bras.

ovata, Lam. Encyc, i. 522.-Peruv.

pannosa, Bauer, ex Steetz, in Lehm. Pl. Preiss. ii. 350 $=$ Keraudrenia Hookeriana.

pannosa, DC. Prod. i. $486=$ Rulingia pannosa

parviflora, Benth. Pl. Hartw. 114.-Ecuador.

peruviana, Turcz. in Bull. Soc. Nat. Mosc. xxxi. (1858) I. 20\%.-Peruy.

pilosa, Roxb. Hort. Beng. 18 ; Fl. Ind. i. 618.-Ind. or. : Burma.

Pohliana, Steud. Nom, ed. II i. 242-Bras.

palyacantha, Wall. Cat. n. $1151=$ crenulata?

ramosissima, Pohl, Pl. Bras. ii. $75=$ scabra.

Reinwardtii, Korth. in Nederl. Kruidk. Arch. (1848) i 310.-Borneo.

reticaulis, Cav. Diss. 292, sphalm. $=$ tereticaulis.

rhamnifolia, Benth. in Hook. Kew Fourn. iii. (1851) 164.-Bras.

rivularis, Gardn. in Hook. Lond. Fourn. Bot. ii. (1843) 333.-Bras.

rubricaulis, Presl, Rel. Haenk. ii. 145.-Mexic.

sagittaefolia, St. Hil. Fl. Bras. Mer. i. 142. t. 27.-Bras. salicifolia, Humb. Eo Bonpl. ex Roem. Eo Schult. Syst. v. 470.-Venezuela.

salicifolia, Presl, Rel. Haenk. ii. 144.-Mexic.

scabra, Linn. Syst. ed. X. 197.-Am, austr.

scabra, Pohl, Pl. Bras. ii. $81=$ Pohliana.

scalpellata, Pohl, 1. c. $78=$ scabra

scorpiura, Wright, ex Griseb. Cat. Pl. Cub. 29.-Cuba sidaefolia, St. Hil. F1. Bras. Mer. i. $146=$ catalpaefolia. sulcata, Ruiz E Pav. Fl. Per. 1ii. 10.-Peruv.

tahitensis, Nadeaud, Enum. Pl. Tahiti, 68.-Ins. Tahiti.

tereticaulis, Lam. Encyc. i. 523.-Peruv.

tiliaefolia, Presl, Rel. Haenk. ii. 144.-Mexic.

uncinata, Mast. in Hook. f. Fl. Ind. i. 377.-Malacca.

velutina, Wall. Cat. nn. 1148, 1925= pilosa.

virgata, Pohl, Pl. Bras. ii. $80=$ scabra.

vitifolia, Baill. Adansonia, x. (1872) 177.-Madag.

Voulily, Baill. in Bull. Soc. Linn. Par. i. (1885) 502. -Madag.

BUFFONEA, Koch, Syn. Fl. Germ. ed. I. 108 (1836)= Bufonia, Linn. (Caryophyll.).

BUFONIA, Sauv. ex Linn. Diss. Dass. 2 (1747) Amoen. Acad. i. 386 (1749). CARYOPHYLLEAE, Benth. \& Hook. f. i. 151.

alsinoides, Hill, Veg. Syst. xi. $27=$ annua?

angustifolia, Cav. ex Willk. \& Lange, Prod. Fl. Hisp. iii. $605=$ tenuifolia.

annua, DC. Fl. Fr. iv. $768=$ tenuifolia et macrosperma.

brachyphylla, Boiss. Feldr. Diagn. Ser. I. viii. 94. -Graecia et Ins.

calyculata, Boiss. E Bal. l. c. Ser. II. v. 58.Cilicia.

Duvaljouvii, Batt. E Trab. in Bull. Soc. Bot. Fr. xxvi (1879) 56.-Afr. bor.

elata, Boiss. Diagn. Ser. I. i. $44=$ macrocarpa.

enervis, Boiss. l. c.-Persia. 
BUFONIA :

hebecalyx, Boiss. Diagn. Ser. I. i. 45.-Persia. Kotschyana, Boiss. l. c. Ser. II. i. 84.-Persia. macrocarpa, Ser. in DC. Prod. 1. 388.-Persia; Afghan.

macropetala, Willk. in Flora, xxxiv. (1851) 604 ; et Ic. Pl. Hisp. 112.-Hispan.

macrosperma, F. Gay, in Mutel, Fl. Dauph. ed. II. 88. -Europ.; As. Min, ; Syria.

multiceps, Decne. in Ann. Sc. Nat. Sér. II. iii. (1835) 259.-Arabia.

Oliveriana, Ser, in DC, Prod. i. 388.-Mesopot.; Persia : Afghan.

paniculata, Dubois, in Delarb. F1. Auvergne, ed. II. $300=$ tenuifolia.

parviftora, Griseb. Spicil. F1. Rumel. i. $197=$ tenuifolia. perennis, Pourr. in Mém. Acad. Toul. vii. (1788) 309.Gallia.

rotundifolia, Buch.-Ham. ex Steud. Nom, ed. II. i. $235=$ Drymaria cordata.

spicata, Delarb. Fl. Auvergne, ed. II. $299=$ macrosperma.

tenuifolia, Linn. Sp. $P l .123$. - Europ. austr. Marocco; Reg. Caucas.

tenuifolia, Moc. \& Sessé, ex DC. Prod. i. $390=$ Hymenella moehringioides.

tenuifolia, Vill. Hist. Pl. Dauph. iii. $650=$ macrosperma.

virgata, Boiss. Fl. Orient. i. 665.-As. Min. ; Syria.

Willkommiana, Boiss. Diagn. Ser. II. i. $83=$ perennis.

BUFORRESTIA, C. B. Clarke, in DC. Monog. Phan. iii. 233. t. 6, 7 (1881). COMMELINACEAE, Benth. \& Hook. f. Gen. iii. 850

Candolleana, C. B. Clarke, l. c. 233.-Guiana.

imperforata, C. B. Clarke, l. c. 234.-Afr. trop.

Mannii, C. B. Clarke, l. c. 233.-Afr. trop.

tenuis, C. B. Clarke, l. c. 234.-Afr. trop.

BUGENVILLEA, Endl. Gen. 312 (1837)=seq.

BUGINVILLAEA, Comm. ex Juss. Gen. 91 (1789)= Bougainvillaea, Juss. (Nyctag.).

BUGLOSSA, S. F. Gray, Nat. Arr. Brit. Pl. ii. 351 (1821) = Lycopsis, Linn. (Boragin.).

arvensis, S. F. Gray, 1. c. $=\mathrm{L}$ arvensis.

sempervirens, S. F. Gray, 1. c. $352=$ Anchusa sempervirens.

BUGLOSSITES, Moris, in Enum. Sem. Hort. Taur. (1845).-Cf. Ann. Sc. Nat. Sér. III. v. (1846) $365=$ Borago, Linn.

laxiflora; Moris, 1. c. = Borago laxiflora.

BUGLOSSOIDES, [Riv.]. Moench, Meth. 418 (1794)= Lithospermum, Linn. (Borag.)

ramosissima, Moench, 1. $\mathrm{c}_{\diamond}=\mathrm{L}$. tenuiflorum.

BUGLOSSUM, [Toum.]. Adans. Fam, ii. 178 (1763) Gaertn. Fruct. i. 322. t. $67(1788)=$ Anchusa, Linn. (Baertn. Frin.).

amoenum, Gaertn. 1. c.=A. italica

angustifolium, All. F1. Pedem. i. $47=$ A. undulata.

angustifolium, Moench, Metb. $418=\mathrm{A}$. angustifolia.

aspermum, Gilib. F1. Lituan. i. $21=$ Anchusa officinalis. Barrellieri, All. F1. Pedem, i, $48=\mathrm{A}$. Barrelieri.

caeruleum, Pers. Syn, i. $159=$ A. italica.

echinatum, Tausch, in Flora, vii. (1824) $230=\mathrm{A}$. strigosa.

elatum, Moench, Meth. $418=$ A. italica.

italicum, Tausch, in Flora, vii. (1824) $230=\mathrm{A}$. italica.

officinale, Lam. Fl. Fr. ii. $278=$ A. officinalis

paniculatum, Tausch, in Flora, vii. (1824) $228=\mathrm{A}$ italica.

sempervirens, All. Fl. Pedem, i. 48=A. sempervireas,

syriacum, Tausch, in Flora, vii. (1824) $281=\mathrm{A}$. strigosa.

tinctorium, Lam, Fl. Fr. ii. $278=$ Alkanna tinctoria.

vulgare, Tausch, in Flora, vii. (1824) $229=\mathbf{A}$ italica.

BUGRANOPSIS, Pomel, Nouv. Mat. F1, Atl, 171 (1874) = Ononis, Linn. (Legumin.)

alopecuroides, Pomel, 1. c. $172=0$. alopecuroides.

cephalantha, Pomel, 1. c. $=0$. cephalantha

\section{BUGRANOPSIS :-}

crinita, Pomel, Nouv. Mat. F1. Atl, $171=0$. crinita. euphrasiaefolia, Pomel, 1. c. $172=0$. euphrasiaefolia megalostachys, Pomel, 1. c. $171=0$. megalostachys. mitissima, Pomel, 1. c. $172=0$. mitissima.

rosea, Pomel, 1, c. $171=0$. rosea.

Salzmaniana, Pomel, 1. c. $172=0$. Salzmanniana.

stricta, Pomel, l, $\mathrm{c}_{\mathrm{c}}=\mathrm{O}$, stricta

Tournefortii, Pomel, 1. c.=O. Toumefortii

variegata, Pomel, $1, c_{n}=\mathrm{O}$. variegata.

BUGULA, Tourn. ex Mill. Gard. Dict. ed. VI. $(1752)=$ Ajuga, Linn. (Labiat.)

alpina, All. Fl. Pedem. i. $45=$ A. genevensis

arvensis, S. F. Gray, Nat. Arr. Brit. Pl. ii. $368=$ A.

Chamaepitys.

Chamaepithys, Scop. Fl. Carn. ed. II. i. $416=\mathrm{A}$

Chamaepitys.

decumbens, Mill. Gard. Dict. ed. VIII, n, $2=\mathrm{A}$. reptans.

densiflora, Benth. in DC. Prod. xii. 595, in syn. = A reptans.

genevensis, Crantz, Inst. i. $518=\mathrm{A}$. genevensis.

nana, Gilib. Fl. Lituan, i. $94=$ A pyramidalis.

obliqua, Moench, Meth. $381=$ A. orientalis.

orientalis, Crantz, Inst. i. $518=\mathrm{A}$. orientalis.

pyramidalis, Crantz, l. c. = A. pyramidalis

reptans, Crantz, 1. c. $=$ A. reptans.

tomentosa, Gilib. Fl. Lituan. 1. 94=A. genevensis,

villosa, Steud. Nom. ed. II. i. $235=$ A. pyramidalis

BUHSIA, Bunge, Del. Sem. Hort. Dorpat. (1859) 41.Cf. Linnaea, xxx. $(1859-60) 752=$ Cleome, Linn. (Capparid.)

coluteoides, Bunge, 11. $\mathrm{cc} .=\mathrm{C}$. coluteoides.

BUINALIS, Rafin. New Fl. Am. iv. $40 \quad(1836)=$

Paronychia, Linn. (Illecebrac.).

floridana, Rafin. 1. c. = P. Baldwinii

BUJACIA, E. Mey. Comm. P1. Afr. Austr. 127 (1835)= Glycine, Linn. (Legumin.).

anonychia, E. Mey. 1. c. = G. javanica.

gampsonychia, E. Mey. 1. c. = Teramnus labialis.

BULBEDULIS, Rafin. F1. Tellur. ii. 26 (1836) = Camassia, Lindl. (Liliac.).

BULBILIS, Rafin. in Am. Monthly Mag. (1819) 190, nomen prius; et in Journ. Phys. Ixxxix. (1819) $262=$ Buchloë, Engelm. (Gramin.).

dactyloides, Rafin. in Am. Monthly Mag. (1819) $190=$ Buchloë dactyloides.

BULBILLARIA, Zucc, in Abh. Akad. Muench. iii. (1843) 229. t. $2=$ Gagea, Salisb. (Liliac.)

gageoides, Zucc. 1. c. $=\mathrm{G}$. persica.

BULBINE, Linn. Hort. Cliff. 122 (1737); Gen. Pl ed. I. 95 (1737). LILIACEAE, Benth. \& Hook, f. iii. 784 .

Blephanthera, Rafin. Fl. Tellur. ii. 59 (1836). NeMOPOGON, Rafin. 1. c. 27 (1836)

abyssinica, A. Rich. Tent. Fl. Abyss. ii. $334=$ asphodeloides.

acaulis, Linn. Sp. PI. ed. II. $446=$ alooides.

alooides, Willd. Enum. Hort. Berol. 372 -Afr austr. annua, Willd. l. c.-Afr, austr.

asiatica, Gaertn. Fruct. i. 42. t. $13=$ Crinum asiaticum

asphodeloides, Spreng. Syst. ii. 85.-Afr. austr.

australis, Spreng. Syst. ii. $86=$ bulbosa .

bisulcata, Haw, in Phil. Mag. (Feb. 182\%) 121.Afr. austr.

brevifolia, Schalt. f. Syst. vii. $450=$ Anthericum brevifolium.

bulbosa, Haw. Rev. Pl. Succ. 38.-Austral,

canaliculata, Spreng. Syst. ii. $86=$ Anthericum cana-

liculatnm.

Cauda-felis, Schult. f. Syst. vii. $450=$ Bulbinella caudata.

caudata, Spreng. Syst. ii. $86=$ Bulbinella caudata. caulescens, Linn. ex Steud. Nom. ed. I. 125 ; ed. II. $236=$ frutescens.

ciliata, Link, Enum. Hort. Berol. i. 329 = Anthericum ciliatum.

crispa, Spreng. Syst. ii. $86=$ Chlorophytum crispum.

densiflora, Baker, in Fourn. Linn. Soc. xv. $1870^{\circ}$ 347.-Afr. austr.

\section{BULBINE}

dubia, Schult. f. Syst. vii. 450,-Afr. austr

falcata, Schult. f. 1. c. 451 = Anthericam falcatum

favosa, Schult. f. l. c. 444.-Afr. austr.

filifolia, Baker, in Fourn. Linn. Soc. x. . (1876) 344 .

- Afr. austr.

floribunda, Schrad. ex Benth. F1. Austral. vii. $35=$

semibarbata.

Fraseri, Kunth, Enum. Pl. iv. $565=$ bulbosa.

frutescens, Willd. Enum. Hort. Berol. 372.-Afr austr.

graminea, Haw, Revis. PI. Succ. $33=$ asphodeloides.

hispida, Sweet, Hort. Brit. ed. I. $416=$ Anthericum

hispidum.

Hookeri, Kunth, Enum. Pl. iv. $566=$ bulbosa.

incurva, Spreng. Syst. ii. $86=$ rostrata.

latifolia Spreng. $l$. $c$.-Afr anstr.

laxiflora, Baker, in Fourn. Linn. Soc. xv. (1876) 347

- Afr, austr

longiscapa, Willd. Enum. Hort. Berol. 372.-Afr.

Mackenii, Hook. f. Bot. Mag. t. $5955=$ Eriospermum Mackenii.

macrophylla, Salm-Dyck, Hort. Dyck. 333 = lati folia.

mesembryanthemoides, Hav. in Phil. Mag. (July 1825) 31.-Afr. austr.

Mettinghii, Tenore, Syll. $563=$ longiscapa.

minima, Baker, in Fourn. Linn. Soc. xv. (1876) 344 -Afr, austr.

narcissifolia, Salm-Dyck, Hort. Dyck. 334-Afr austr.

nutans, Spreng. Syst. ii. 86.-Afr. austr.

nutans, Zeyh. ex Baker, in Journ. Linn. Soc. $x$ (1876) $347=$ Zeyheri.

pallida, Baker, in Fourn. Bot. xiv. (1876) 184.Afr, austr.

planifolia, Spreng. Syst. ii. $86=$ Simethis bicolor. praemorsa, Spreng. l. c.-Afr. austr.

pugioniformis, Link, Enum. Hort. Berol. i. 389.-Afr austr.

rostrata, Willd. Enum. Hort. Berol. 372.-Afr. austr.

scabra, Spreng. Syst. ii. $86=$ Anthericum scabrum. semibarbata, Haw. Revis. Pl. Succ. 33.-Anstral. semibarbata, Hook. Bot. Mag. t. $3129=$ bulbosa. suavis, Lindl. Bot. Reg. (1838) Misc. $45=$ bulbosa. subbarbata, Steud. Nom. ed. II. i. 74, sphalm. bulbosa.

triquetra, Spreng. Syst. ii. $86=$ Bulbinella triquetra uncinata, Moench, Meth. $641=$ Crinum americanum. undulata, Spreng. Syst. ii. $86=$ Anthericum undulatum. unifolia, Schult. f. ex Baker, in Journ. Linn. Soc. xy (1876) $263=$ Eriospermum abyssinicum.

urgineoides, Baker, l. c. $\$ 48$-Afr austr.

Zeyheri, Baker, l. c. 347.-Afr. austr.

BULBINELLA, Kunth, Enum. Pl. iv. 569 (1843) LILIACEAE, Benth. \& Hook. f. iii. 781.

Chrysobactron, Hook. f. Fl. Antarct. i. 72. t. 4 (1845).

brevifolia, Kunth, 1, c. $573=$ Anthericum brevifolinm Burkei, Benth. E Hook. f. Gen. iii. 784.-Afr. austr. capillaxis, Kunth, Enum. Pl. iv. $572=$ triquetra.

caudata, Kunth, l. c.-Afr. austr.

ciliolata, Kunth, l. c. 570.-Afr. austr.

filiformis, Kunth, 1. c. $572=$ triquetra.

gracilis, Kunth, l. c. 571.-Afr, anstr.

latifolia, Kunth, l. c. 572.-Afr. austr.

ornithogaloides, Kunth, l. c. 693.-Afr. austr.

peronata, Kunth, l.c. 570.-Afr. austr.

robusta, Kunth, l. c. 571-Afr. austr.

setifolia, Kunth, 1. c. $569=$ triquetra.

squamea, Kunth, 1. c. $573=$ Anthericum hispidum

triquetra, $K u n t h, l . c$.-Afr. austr.

BULBISPERMA, Reinw, ex Blume. Cat. Gew. Buitenż $59[1829]=$ Peliosanthes, Andr. (Haemod.). ovigera, Reinw. 1. $c_{\text {. }}=$ P. javanica.

BULBOCAPNOS, Bemh. in Linnaea, viii. (1\$93) 46 ?

Corydalis, Vent. (Papaverac.)

bracteatus, Bernh. 1. c. = C. bracieata.

caves, Bernh. 1, c. $=$ C.

digitatus, Bernh. 1. $c_{0}=$ C. Halleri.

fabacers, Bernb. 1. $c=$ C. fabacea.

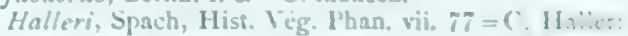

longiforus, Bernh. in Linnaca, riii. (1899) $169=1$ longiflora. 


\section{BULBOCAPNOS:-}

Marschallianus, Bernh. in Linnaea, viii. (1833) $469=$ C. Marschalliana.

nobitis, Bernh. 1. c. = C. nobilis

tuberosus, Spach, Hist. Vég. Phan. vii. $78=$ C. cava.

BULBOCASTANUM, Lag. Amen. Acad. Madr. 99 (1821) = Conopodium, Koch (Umbellif.).

majus, Lag. 1. $\mathrm{c}_{\mathrm{f}}=\mathrm{C}$. denudatum.

BULBOCASTANUM, Schur, Enum. Pl. Transs. 249 (1866) = Carum, Rupp. (Umbellif.)

daucoides, Nym. Consp. $304=$ C. daucoides.

ferulaceum, Nym. 1. c. 303,-Europ.

incrassatum, Lange, in Willk. \& Lange, Prod. Fl. Hisp. iii. $88=\mathrm{C}$. incrassatum.

Linnaei, Schur, Enum. PI. Transs. $249=$ C. Bulbocastanum.

mauritanicum, Willk. in Linnaea, xl. (1876) $84=\mathrm{C}$ mauritanicum

BULBOCODIUM, Linn. Coroll. Gen. 6 (1737). LILIACEAE, Benth. \& Hook. f. iii. 821.

ABANDIUM, Adans. Fam. ii. 54 (1763).

alpinum, Mill. Gard. Dict. ed. VIII. n. 1=Lloydia alpina.

atticum, Nym. Syll. $379=$ Merendera attica.

antumnale, Lapeyr. Hist. Abr. P1. Pyr. 202=Merendera Bulbocodium.

balearicum, Nym. Syll, $379=$ Merendera filifolia

Broteri, Welw. ex Baker, in Journ. Linn. Soc. xvii.

(1880) $441=$ Merendera Bulbocodium.

caucasicum, Endl. ex Heynh. Nom. ii. $81=$ Merendera caucasica.

colchicoides, Nym. Syll. $379=$ Merendera Bulbocodium dentatum, Schur, in Verh. Siebenb. Ver. Naturw. ii (1851) 166.-Transsylv

edentatum, Schur, in Oestr. Bot. Zeitschr. x. (1860) $355=$ ruthenicum.

Eichlevi, Regel, in Act. Hort. Petrop. v. (1877) $638=$ Merendera Eichleri.

Fontanesii, Heynh. Nom. ii. 81.-Ins. Majorc. ; Algeria. hastulatum, Friwald. in Flora, xix. (1836) $434=$ Merendera sobolifera.

lusitanicum, Heynh. Nom. ii. 81.-Lusitania.

montanum, Fisch. Ind, Pl. Hort. Gorenk. (1812) 10 $=$ ruthenicum.

persicum, Regel, Gartenfl. xxx. (1881) 294. t. 1058.Persia.

robustum, Bunge, ex Regel, in Act. Hort. Petrop. vi. (1879) 491.-Turkestan

ruthenicum, Bunge, in Del. Sem. Hort. Dorpat. (1837)

11.-Transylv.; Reg, Cancas.

serotinum, Linn. Sp. PI, 294=Lloydia alpina

soboliferum, Heynh. Nom. ii. $81=$ Merendera sobolifera.

trigynum, Nym. Syll. 379= Merendera sobolifera.

trigynum, Adam, in Weber \& Mohr, Cat. i. 49 ex Schult. f. Syst. vii. $1524=$ Merendera caucasica.

trigynum, Griseb. Spicil. F1. Rumel.ii. 380= Merendera sobolifera.

vernum, Bieb. Fl. Taur. Cauc. i. $261=$ ruthenicum. vernum, Desf. F1. Atlant. i. $284=$ Merendera filifolia vernum, Linn. Sp. Pl. $294=$ ruthenicum.

versicolor, Spreng. Syst. ii. 40.--Rossia austr.

BULBOPHYLIARIA, S. Moore, in Baker, F1. Maurit. 344 (1877), sphalm. = BOLBOPHYLLARIA, Reichb. $\mathrm{f}_{\mathrm{s}}=$ Bulbophyllum, Thou. (Orchid.).

BULBOPHYLLUM, Thou. Orch. Iles Afr. Tab. Esp. 3 et Ic. t. 93-97 (1822). ORCHIDEAE, Benth. \& Hook. f. iii. 501

Anisopetalum, Hook. Exot. Fl, t. 149 (1825).

Bolbophyllaria, Reichb. $f$. in Bot. Zeit. x. (1852) 934.

Bolbophyllum, Spreng. Syst. iii. 681 (1826).

Cochlia, Blume, Bijdr. 320 . t. 59 (1825).

Didactyle, Lindl. Fol. Orch. (1852)

Diphyes, Blume, Bijdr. 310. t. 66 (1825)

EPICRANTHES, Blume, 1, c. 306. t. 9 (1825)

EPICRIanthes, Blume, Fl. Jav. Praef. p. vii (1828).

GERsinIA, Neraud, in Gaudich. Bot. Freyc. Voy. 27 (1826).

IONE, Lindl. Fol. Orch. (1853).

LyraeA, Lindl. Gen. et Sp. Orch. $46(1830)$

MACrolepis, A. Rich. Sert. Astrol. 25. t. 19 (1833).

Malachadenia, Lindl. Bot. Reg. (1839) Misc. 67.

\section{BULBOPHYLLUM:}

Odontostyles, Breda, Orch. Kuhl et Hass. t. sine n. (1827).

OXYSEPAlA, Wight, Ic. v. 17. t. $1736(1852)$

Sarcobodium, Beer, Prakt. Orch. 306 (1854).

Sestochilos, Breda, Orch. Kuhl et Hass. t. sine n. (1827).

Taurostalix, Reichb. f. in Bot. Zeit. x. (1852) 933.

Tribrachia, Lindl. Bot. Reg. sub t. 832 (1824)

XIPHIzUsa, Reichb. f. in Bot. Zeit. x. (1852) 919

abbreviatum, Reichb. f. in Gard. Chron. (1881) II. 70 $=$ Cirrhopetalum abbreviatum.

acutiflorum, A. Rich. in Ann. Sc. Nat. Sér. II. xv. (1841) 18 (Cirrhopetali sp.).--Ind. or.

adenopetalum, Lindl. Bot. Reg. (1842) Misc. 85.Malaya.

affine, Lindl. in Wall. Cat. n. 1982.-Reg. Himal.

alcicorne, Par. E Reichb. f. in Trans. Limn. Soc. xxx. (1874) 151.-Burma.

alopecurum, Reichb. f. in Gard. Chron. (1880) II. 70. -Burma.

amplebracteatum, Teijsm. E Binn. in Tijdschr. Nederl. Ind. xxiv. (1862) 307.-Malaya.

amplum, Reichb. f. in Walp. Ann. vi. $244=$ Dendrobium amplum.

Andersonii, Kurz, Rep. Andam. 51, nomen.-Ins. Andam.

andongense, Reichb. $f$. in Flora, xlviii. (1865) 184.Afr. occ.

angustifolium, Lindl. Gen. et Sp. Orch. 57.-Tava.

antenniferum, Reichb. fo in Walp. Ann. vi. 250.Ins. Philipp.

antenniferum, Reichb. f. 1. c. $248=$ geraënse.

apetalum, Lindl. in Fourn. Linn. Soc. vi. (1862) 127. -Afr. trop.

apiferum, Batem. ex Steud. Nom. ed. II. i.241.-Afr. trop.

argyropus, Reichb. f. in Linnaea, xli. (1877) 42.-Ins. Norfolc.

aristatum, Hemsl. Biol. Centr. Am. Bot. iii. 213.-Am. centr.

atropurpureum, Rodrig. Orch. Nov. i. 41.-Bras.

aurantiacum, F. Muell. Fragm. iii. 39.-Austral.

aurantiacum, Hook. $f$. in Fourn. Linn. Soc. vii. (1864) 219. - Afr. trop

auratum, Reichb. f. in Walp. Ann. vi. 261.-Manilla. auricomum, Lindl. in Wall. Cat. n. 1985.-Burma.

Baileyi, F. Muell. Fragm. ix. 5.-Austral.

balaeniceps, Reichb. f. in Hamb. Gartenz. xix, (1863) $208=$ Napelli

barbatum, Rodrig. Orch. Nov. ii. 119.-Bras.

barbigerum, Lindl. Bot. Reg. xxiii. (1837) t. 1942.

-Afr. trop.

Baronii, Ridl. in Fourn. Linn. Soc. xxi. (1885) 463

Beccarii, Reichb. f. in Gard. Chron. (1879) 1. 41.Borneo.

Berenicis, Reichb.f. l. c. xiv. (1880) II. 588.-Hab. ?

Betchei, F. Muell. in Wing, South. Sc. Record, i (1881) 173.-Ins. Samoa.

bicolor, Lindl. Gen. et Sp. Orch. 49.-China

bifarium, Hook. f. in Fourn. Linn. Soc. vii. (1864) 219 -Afr. trop.

biflorum, Teijsm. E Binn. in Nederl. Kruidk. Arch. iii. (1855) 397.- Java.

bisetum, Lindl. in Ann. E Mag. Nat. Hist. x. (1842) 186.--Reg. Himal.

Blepharistes, Reichb. f. in Flora, Iv. (1872) 278 (Cirrhopetali sp.).-Burma.

Boukettae, F. M. Bailey, in Proc. Roy. Soc. Queensl. i. (1884) 89.-Austral.

bootanense, Par. \& Reichb. f. in Trans. Linn. Soc. xxx. (1874) $153=$ Cirrhopetalum bootanense.

Bowringianum, Reichb. f. in Gard. Chron. (1881) I. 814.-Assam.

braccatum, Reichb. f. in Linnaea, xli. (1877) 117.-

Ins. Philipp.

bracteolatum, Lindl. Bot. Reg. xxiv. (1838) 57.Guiana.

Bufo, Reichb. f. in Walp. Ann. vi. $258=$ Megaclinium Bufo.

caespitosum, Thou. Orch. Afr.t. 103.-Ins. Borbon, calamarium, Lindl. Bot. Reg. (1843) Misc. 70.-Afr

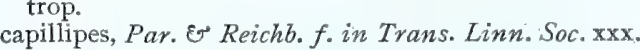
(1874) 150.-Burma.

capitatum, Lindl. Gen. et Sp. Orch. 56.-Malaya.

\section{BULBOPHYLLUM :-}

Careyanum, Spreng. Syst. iii. 732.--Reg. Himal cariniflorum, Reichb. fo in Walp. Ann. vi. $253=$ bisetum.

caudatum, Lindl. in Wall. Cat. n. 1983.-Reg. Himal. cernuum, Lindl. Gen. et Sp. Orch. 48.-Tava.

Cheiri, Lindl. Bot. Reg. (1844) Misc. 44.-Manilla

chinense, Reichb. f. in Walp. Ann. vi. 260.-China.

chloroglossum, Reichb. $f$. in Gard. Chron. (1871) 1195. -Bras.

chloropterum, Reichb. f. in Linnaea, xxii, (1849) 835 -Bras.

ciliatum, Lindl. Gen. et Sp. Orch. 48.-Java.

cirrhopetaloides, Griff. Notul. iii. $290=$ bisetum

clandestinum, Lindl. Bot. Reg. (1841) Misc. 77.-Ind. or. ; Malaya.

Clausseni, Reichb. f. in Linnaea, xix. (1847) 371.Bras.

lavatum, Thou. Orch. Afr. t. 99.-Ins. Mascar.

clavigerum, F. Muell. Census, Suppl. i. 3.--Austral.

cochleatum, Lindl. in Fourn. Linn. Soc. vi. (1862) 125.-Afr. trop.

cocoinum, Batem. ex Lindl. Bot. Reg. xxiii. (1837) t. 1964.-Afr. trop.

colubrinum, Reichb. f. in Walp. Ann. vi. $257=$ Megaclinium colubrinum.

comatum, Lindl. in Fourn. Linn. Soc. vi. (1862) 128. -Afr. trop.

Commersonii, Thou. Orch. Afr. t. 97.-Ins. Borbon.

compressum, Teijsm. E Binn. in Tijdschr. Nederl. Ind. xxiv. (1862) 307.--Sumatra.

conchiferum, Reichb. $f$. in Walp. Ann. vi. 253.-Reg. Himal.

conicum, Thou. Orch. Afr. Tab. Esp. $3=$ clavatum conitum, Thou, 1. c. t. $100=$ clavatum.

cornutum, Reichb. f. in Walp. Ann. vi. $247=$ Cirrhopetalum cornutum.

coriscense, Reichb. f. Otia Bot. Hamb. 118.-Afr. trop. crassifolium, Thw. ex Trimen, in Fourn. Bot. xxiii. (1885) 244 .-Zeylan

croceum, Lindl. Gen. et Sp. Orch. 57.-Java.

Cumingii, Reichb. f. in Walp. Ann. vi. 261.-Ins, Philipp.

cupreum, Hook. Bot. Mag. t. 5316=Careyanum.

cupreum, Lindl. Bot. Reg. (1838) Misc. 95.-Burma.

cuspidilingua, Reichb. $f$. in Walp. Ann. vi. 264.-Ins. Philipp.

cylindraceum, Lindl. Gen. et Sp. Orch. 53.--Reg. Himal.

Dayanum, Reichb. f. in Gard. Chron. (1865) 434.Burma.

delitescens, Hance, in Journ. Bot. xiv. (1876) $44=$ Cirrhopetalum delitescens.

densum, Thou. Orch. Afr. t. 108.-Ins. Mascar,; Madag.

distans, Lindl. in Fourn. Linn. Soc. vi. (1862) 125.Afr. trop.

Drallei, Reichb. f. in Regel, Gartenfl. (1885) 20.Afr. trop.

elaidium, Lindl. in Fourn. Linn. Soc. vi. (1862) $12 \%$. -Afr. trop.

elegans, Gardn. ex Thw. Enum. Pl. Zeyl. 298.Zeylan.

Elisae, F. Muell. Fragm. vi. 120.-Austral.

Elliae, Reichb. f. in Walp. Ann. vi. $263=$ Cirrhopetalum Wightii.

elongatum, Hassk. Cat. Hort. Bog. Alt. 39.-Malaya. epiphytum, Rodrig. Orch. Nov. i. 40.-Bras.

erectum, Thou. Orch. Afr. t. 96.-Madag.

eublepharum, Reichb. f. in Walp. Ann. vi. 252.-Reg Himal.

exaltatum, Lindl. in Ann. \& Mag. Nat. Hist. x. (1842) 186.-Guiana.

exiguum, F. Muell. Fragm. ii. 72.-Austral.

falcatum, Reichb. f. in Walp. Ann, vi. $258=$ Mega clinium falcatum.

falcipetalum, Lindl. in Fourn. Linn. Soc. vi. (1862) 128.--Afr, trop.

fimbriatum, Reichb. f. in Walp. Ann. vi, $260=$ Cirrhopetalum fimbriatum.

flavescens, Lindl. Gen. et Sp. Orch. 54.-Java.

flavidum, Lindl. Bot. Reg. (1840) Misc. 83.-Afr. trop. foenisecii, Par. ex Reichb. f. in Bot. Zeit. xxiii. (1865) 99 =auricomum.

fuscescens, Reichb. f. Walp. Ann. vi. $244=$ Dendrobium fuscescens.

fusco-purpureum, Wight, Ic. v. t. 1651.--Ind. or. fuscum, Lindl. Bot. Reg. (1839) Misc. 3.-Afr, trop. 


\section{BULBOPHYLLUM}

Gabonis, Linden छ Reichb. f. in Flora, xlviii. (1865) 185.-Afr. occ.

galeatum, Lindl. Gen. et Sp. Orch. 57.-Afr. trop.

geraënse, Reichb. f. ex Rodrig. Orch. Nov. ii. 125.-

Bras.

gibbosum, Lindl. Gen. et Sp. Orch. 54.-Java.

gladiatum, Lindl. in Ann. E' Mag. Nat. Hist. x. (1842) 185.-Bras.

gracile, Lindl. Gen. et Sp. Orch. 50.-Java.

gracile, Thou. Orch. Afr, t. $101=$ Thouarsii.

gracile, Par. E Reichb. f. in Trans. Linn. Soc, xxx.

(1874) 152.-Burma.

grandiflorum, Blume, Rumphia, iv. 42.-N. Guinea.

grandiflorum, Griff. Notul. iii. $293=$ reptans.

granulosum, Rodrig. Orch. Nov. i. 41.-Bras.

gravidum, Lindl. in Fourn. Linn. Soc. vi. (1862) 126.

-Afr. trop.

Griffithianum, Par. \& Reichb. f. in Trans, Linn. Soc.

xxx. (1874) $153=$ Cirrhopetalnm gamosepalum.

Griffithii, Reichb. f. in Walp. Ann. vi. 247.-Reg. Himal.

Henshallii, Hort. ex Gard. Chron. (1852) $422=$ Lobbii.

herminiostachys, Reichb. f. in Walp. Ann. vi. 254.-

Afr. trop.

Hildebrandtii, Reichb. f. Otia Bot. Hamb. 74; et in Bot. Zeit. xxxix. (1881) 449.-Madag.

hirsutum, Lindl. Gen. et Sp. Orch. 49.-Java

hirtum, Lindl. in Wall. Cat. n. 1989.--Reg. Himal.

imbricatum, Griff. Notul. iii. $289=$ cylindraceum.

imbricatum, Lindl. Bot. Reg. (1841) Misc. 37.-Afr.

trop.

inaequale, Lindl. Gen. et Sp. Orch. 49.-Java.

incurvum, Thou. Orch. Afr. t. 95.-Ins. Mascar. Madag.

iners, Reichb. f. in Gard. Chron. (1880) 1. 776.Assam?

inops, Reichb.f. l. c. (1880) 1I. 620.-Hab.?

insectiferum, Rodrig. Orch. Nov. ii. 120.-Bras.

intertextum, Lindl. in Fourn. Linn. Soc. vi. (1862) 127.-Afr. trop.

javanicum, Miq. Fl. Ind. Bat. iii. 650.-Java.

kaitiense, Reichb. f. in Walp. Ann. vi. $262=$ Cirrhopetalum nilgherense.

khasyanum, Griff. Notul. iii. $284=$ cylindraceum

khasyanum, Reichb. fo in Trans. Linn. Soc. xxx. (1874) $138=$ repens.

lasianthum, Lindl. in Gard. Chron. (1855) 53.Sumatra.

lasiochilum, Par. E Reichb. f. in Trans. Linn. Soc. xxx. (1874) 153.-Burma.

laxiflorum, Lindl. Gen.et Sp. Orch. 57.-Java.

lemniscatum, Par. ex Hook. f. Bot. Mag. t. 5961.Burma.

leopardinum, Lindl. in Wall. Cat. n. 1981.-Reg. Himal.

lichenastrum, F. Muell. Fragm. vii. 60.-Austral

limbatum, Lindl. Bot. Reg. (1840) Misc. 74.Singapora.

limbatum, Par. E"Reichb. f. in Trans. Linn. Soc. xxx. (1874) 152 (non Lind1.).-Burma.

Lindleyanum, Griff. Notul. iii. 287.-Burma.

Lobbii, Lindl. Bot. Reg. (1847)' t. 29.-Burma; Malaya.

longiflorum, Thou. Orch. Afr. t. $98=$ Cirrhopetalum Thouarsii.

longipes, Reichb. f. in Walp. Ann. vi. 253,-Burma.

Luckraftii, F. Muell. in Wing, South. Sc. Record, ii. (1882) 71.-Ins. Solomon.

Lundianum, Reichb. f. E Warm, in Otia Bot. Hamb. 94.-Bras.

Inpulinum, Lindl. in Fourn. Linn. Soc. vi. (1862) 126. -Afr. trop.

Macraei, Reichb. f. in Walp. Ann, vi. $263=$ Cirrhopetalum Wightii.

macranthum, Lindl. Bot. Reg. (1844) t. 13,-Singapora.

macroceras, Rodrig. Orch. Nov. ii. 118.-Bras.

maculatum, Boxall, ex Naves, in Blanco, Fl. Philipp. ed. III. Nov. App. 235.-Ins. Philipp.

Makoyanum, Reichb. $f$. in Gard. Chron. (1879) I. 294 in nota.-Bras.

mandibulare, Reichb. f. l. c. (1882) 1. 366.-Borneo

Mannii, Hook. f. in Gourn. Linn. Soc. vii. (1864) 218 -Afr. trop.

Mannii, Reichb. fo in Flora, 1v. (1872) 275 (=Cirrhopetali sp.).-Reg. Himal.

maxillare, Reichb. f. in Walp. Ann, vi. 248,-Ins. l'hilipp.

\section{BULBOPHYLLUM}

maximum, Reichb. f, in Walp. Ann. vi. $259=$ Mega clinium maximum.

Medusae, Reichb. f. in Walp. Ann. vi. 262.-Malaya. megalanthum, Griff. Notul. iii. 286-Malaya.

megalonyx, Reichb. f. Otia Bot. Hamb. 74 ; et in Bot. Zeit. xxxix. (1881) 449-Ins. Comor.

melanorrhachis, Reichb, f. in Gard. Chron. (1875) $162=$ Megaclinium melanorrhachis .

Melleri, Reichb. f. in Flora, lxi. (1878) $78=$ Megaclinium Melleri.

membranaceum, Teijsm. EN Binn. in Nederl.Kruidk. Arch. iii. (1855) 397.-Java.

mentosum, Rodrig. Orch. Nov, i. 42 -Bras.

merguense, Par. \& Reichb. f. in Trans. Linn. Soc. xxx. 1874) 154 (=Cirrhopetali sp.).-Burma.

meridense, Reichb. f. in Linnaea, xxii. (1849) 836.Venezuela.

micranthum, Rodrig. Orch. Nov. i. 39.-Bras.

micropetalum, Lindl in Fourn. Linn. Soc vi. (1861) 127.-Afr. trop.

micropetalum, Rodrig. Orch. Nov. ii. 121.-Bras.

microtepalum, Reichb. f. in Walp. Ann. vi. 253.Burma.

minutum, Thou. Orch. Afr.t. 110,-Madac.

minntissimum, $F$. Muell. Fragm, xi. 53. - Austral.

moniliforme, F. Muell. in Gard. Chron. (1878) II. 818. - Austral.

moniliforme, R. King, in Gard. Chron. (1879) I. 55, $149=$ minutissimum.

moniliforme, Par. EN Reichb. f. in Trans. Linn. Soc. xxx. (1874) 151.-Burma.

monosepalum, Rodrig. Orch. Nov. ii. 121.-Bras.

monticolum, Hook. f. in Foum. Linn. Soc. vii. (1864) 219.-Afr. trop.

moulmeinense, Reichb. f. in Walp. Ann, vi. $249=$ Trias picta.

mucronatum, Lindl. Gen. et Sp. Orch. 50.--Java. mucronifolium, Reichb. f. \& Warm. in Otia Bot.

Hamb. 94.-Bras.

multiflorum, Ridley, in Fourn. Linn. Soc. xxi. (1885) 463.-Madag.

muscicolum, Reichb. f. in Flora, lv. (1872) $275=$

Cirrhopetalum Wallichii.

mutabile, Lindl. Gen. et Sp. Orch. 48.-Java.

Napelli, Lindl. in Ann. E' Mag. Nat. Hist. x. (1842) 185.--Bras.

nasutum, Reichb. f. in Gard. Chron. (1871) 148.Burma.

neilgherrense, Wight, Ic. v. 1, t. 1680 -Ind. or. nematopodum, F. Muell. Fragm. viii. 30.-Anstral.

nutans, Thou. Orch. Afr. t. 107.-Ins. Mascar. Madag.

nutans, Reichb. $f$. in Walp. Ann. vi. 260.-Ins. Philipp.

nutans, Thou. Orch. Afr. 63. t. 8. n. 2 = variegatum.

oblongum, Reichb. f. in Walp. Ann. vi. $249=$ Trisa oblonga.

obtusum, Lindl. Gen. et Sp. Orch. 56.-Java.

occidentale, Spreng. Syst. iii. $732=$ Epidendrum poly bulbon.

occlusum, Ridley, in Fourn. Linn. Soc. xxi. (1885) 464.-Madag.

occultum, Thou. Orch. Iles Afr. t. 93.-Ins. Mascar

oculatum, Teijsm. E' Binn. in Tijdschr. Nederl. Ind xxiv. (1862) 309.-Malaya.

odoratissimum, Lindl. in Wall. Cat. n. 1987.-Reg.

Himal. ; Burma.

odoratum, Lindl. Gen, et Sp. Orch. 54.-Tava.

Oerstedii, Hemsl. Biol. Centr. Am. Bot. iii. 213.Nicaragua.

oligoglossum, Reichb. f. in Hamb. Gartens. xxi (1865) 297.-Burma.

oreonastes, Reichb. f. Otia Bot. Hamb. 118.-Afr. trop. ovalifolium, Lindl. Gen. et Sp. Orch. 49.-Java.

oxypterum, Reichb. $f$ in Walp. Ann. vi. $258=$ Megaclinium oxypterum.

pachyrrhachis, Griseb. Fl. Brit. W. Ind. 613.-Ind

Pahudi, Reichb. f in Wals, Ann. vi. 264-Malays.

paleaceum, Benth. E Hook. f. Gen. iii. 503.-Reg. Himal.

Pangerangi, Reichb. f. in Bonplandia, v. (1857) 57.Malaya.

parviflorum, Par. \& Reichb. f. in Trans. Linn. Soc xxx. (1874) 152,-Burms.

parvulum, Lindl. Gen. et Sp. Orch. 49.-Java

\section{BULBOPHYITUM :-}

pavimentatum, Lindl. in Fourn Linn. Soc. vi. (1861) 128.-Afr. trop

pendulum, Thou. Orch. Afr.t. 104.-Ins. Mascar

Penicillium, Par, E Reichb. $f$. in Trans. Linn. Soc xxx. (1874) 151.-Burma.

petiolare, Thw. Enum. Pl. Zevl. 298.-Zeylan.

pictum, Par. \& Reichb, $f$ in Trans, Linn. Soc, $x x x$ (1874) $150=$ Drymoda picta.

picturatum, Reichb. fo in Walp. Ann. vi. $262=$ Cirrhopetalum picturatum.

pileatum, Lindl. Bot. Reg. (1844) Misc. 73.-Malaya.

Pipio, Reichb. f. in Linnaea, xli. (1877) 92.-Afr irop.

polyrrhizum, Lindl. Gen. et Sp. Orch. 53.-Reg. Himal.

Prenticei, F. Muell. in Wing, South. Sc. Record, i. 1881) 173.-Austral.

prismaticum, Thou. Orch. Afr. t. 102,-Ins, Mascar.

psittacoglossum, Reichb. f. in Bot. Zeit. xxi. (1863) 236.-Burma.

Psychoon, Reichb. f. in Gard. Chron. (1878) II 170.-Assam.

Pumilio, Par. E Reichb. f. in Trans. Linn. Soc. xxx.

(1874) $153=$ Cirrhopetalum Pumilio.

pumilum, Lindl. Gen. et Sp. Orch. 54.-Afr. trop.

punctatum, Fitzgerald, in Fourn. Bot. xxi. (1883) 205.-Austral.

punctatum, Rodrig. Orch. Nov. i. 40.-Bras.

purpurascens, F. M. Bailey, in Proc. Roy. Soc. Queensl.i. (1884) 88.-Austral.

purpurascens, Teijsm. E Binn, in Tijdschr. Nederl. Ind. xxiv. (1862) 308-Jaya.

purpureum, Thw. Enum. Pl. Zeyl. 298.-Zeylan. pusillum, Thou. Orch. Afr. t. 102.-Ins. Maurit pygmaeum, Lindl. Gen. et Sp. Orch. 58.-N. Zeland. quadrisetum, Lindl. in Hook. Lond. Fourn. Bot. ii. (1843) 670.-Guiana.

radiatum, Lindl. in Wall. Cat.n. 1986.-Burma; China. recurvum, Lindl. Gen. et Sp. Orch. 53.-Afr. trop.

refractum, Reichb. f. in Walp. Ann, vi. $259=$ Cirrbope talum refractum.

Regnelli, Reichb. f. in Linnaea, xxii. (1849) 835.Bras.

Reinwardtii, Reichb. $f$ in Walp. Ann. vi. 246.-

Malaya.

repens, Griff. Notul. iii. 293.-Reg. Himal.

reptans, Lindl. in Wall. Cat. n. 1988.-Reg. Himal. reticulatum, Batem. in Hook. f. Bot. Mag. t. 5605. Borneo.

retusiusculum, Reichb, f in Gard, Chron. (1869) 1182 = Cirhopetalum retusinsculum.

Rhizophorae, Lindl. in fourn. Linn. Soc. vi. (1861 125.-Afr. trop.

rigens, Reichb. f. in Hamb. Gartens. xxi. (1865) $290^{\circ}$ -Burma.

rostriceps, Reichb. f. Otia Bot. Hamb. 55.-Ins. Fiji.

rotundatum, Reichb. fo in Walp. Ann. vi. $244=$ Dendrobium rotundatum.

Roxburghii, Reichb. f. 1. c. 263 = Cirrhopetalum Roxborghii.

rufinum, Reichb. f. Xenia Orch. iii. 45.-Barma

rupicola, Rodrig. Orch. Noo. i. 39-Bras.

rupincola, Reichb. f. in Flora, xlviii. (1865) 184.-Af. trop.

salaccense, Reichb. f. in Bonplandia, v. (1857) 57.Java.

saltatorium, Lindl. Bot. Reg, xxiii. (1897) t. 1970.Afr. trop.

Sandersoni, Reichb. in Flora, lxi. (18;8) $78=$ Megaclinium Sandersoni.

sarcoscapum, Teijsm. E Binn, in Tijdschr. Nederl. Ind. xxix. (1867) 242.-Java.

scabratum, Reichb. f. in Walp. Ans. vi. $259=$ Cirshopetalum caespitosnm.

Sceptrum, Reichb. f. l. c. 254.-Ins. Sunda.

Schillerianum, Reichb. f. in Hamb. Gartenz xvi. (1Eòu $423=$ Shepherdi

Schmidtianum, Reichb. f. l. co xxii. (150i5) 357 . Ind. or.

sciadanthum, F. Muell. in W'ing, Sonth. Sc. Record. ii. (185\%) 95--Ins simoa.

serpens, Liadl. Gen. et Sp. Oreh. $57=$ nutans.

setigerum, Lindl. Bot. Rez. (1s38) Misc. 21. Cuin: Seychellarum, Reichb. f. in Linnaea, xli. (157i; :... Ins. Mascar.

Shepherdi, F. Mucll. Frogm. iii. 10.-Austral. 


\section{BULBOPHYLLUM:-}

siamense, Reichb. f. in Gard.Chron. (1867) $572=$ Lobbii. sicyobulbon, Par, E Reichb. $f$. in Trans. Linn. Soc. xxx. (1874) 152.-Burma.

Sillemianum, Reichb. f. in Gard. Chron. (1884) II 166. -Burma

simillinum, Par. \& Reichb. f. Otia Bot. Hamb. $49=$ Cirrhopetalum simillinum.

sordidum, Lindl. Bot. Reg. (1840) Misc, $89=$ bracteolatum.

stenobulbon, Par. E Reichb. f. in Trans. Linn. Soc xxx. (1874) 153.-Burma

striatum, Reichb. f. in Walp. Ann. vi. 257.-Reg. Himal.

suave, Griff. Notul. iii. $292=$ hirtum

sulcatum, Lindl. Gen, et Sp. Orch. 57.-Java.

taeniophyllum, Par. \& Reichb. f. in Journ. Bot. xii. (1874) 198 ("=Cirrhopetali sp).-Moulmein

tahitense, Nadeaud, Enum. Pl. Tahiti, 36.--Ins, Pacif.

Taylori, F. Muell. Fragm. viii. 150.-Austral

tenellum, Lindl. Gen et Sp. Orch. 49,-Java.

tentaculigerum, Reichb. f. in Flora, 1xi. (1878) $77=$

Megaclinium tentaculigerum.

tenuicaule, Lindl. in Fourn. Linn. Soc. vi. (1861) 126. -Afr. trop.

tenuifolium, Lindl. Gen. et Sp. Orch. 50.-Java.

tetragonum, Lindl. l. c. 53.-Afr. trop.

Thompsonii, Ridley, in Fourn. Linn. Soc. xxi. (1885) 464.-Madag.

Thouarsii, Steud. Nom. ed. II. i. 214.-Ins. Maurit.

Thwaitesii, Par. \& Reichb. f. in Journ. Bot. xii (1874) 199 (=Cirrhopetali sp.).-Zeylan.

tigridum, Hance, in fourn.Bot. xxi. (1883) 232.-China tortuosum, Lindl. Gen. et Sp. Orch. 50.-Java.

tremulum, Wight, Ic. v. t. 1749.-Ind. or.

triadenium, Reichb. f. in Walp. Ann. vi. 257.-Tava.

trigonopus, Reichb. f. in Gard. Chron. (1881) II. $71=$ Cirrhopetalum abbreviatum.

tripetalum, Lindl. in Ann. E Mag. Nat. Hist.x. (1842) 185.-Bras.

tripudians, Par. \& Reichb. $\mathrm{f}$ in Trans. Linn. Soc xxx. (1874) $154=$ Cirrhopetalum refractum.

trisetosum, Griff. Notul. iii. $283=$ clandestinum.

triste, Reichb. f. in Walp. Ann. vi. 253.-Burma.

tuberculatum, Colenso, in Trans. N. Z. Inst. xvi (1884) $336 .-\mathrm{N}$. Zel.

umbellatum, Lindl. in Wall. Cat, n, 1984=Cirrhopetalum maculosum.

unguiculatum, Reichb. f. in Linnaea, xxii. (1849) 836. - Java.

uniflorum, Griff. Notul. iii. 293.-Reg. Himal

uniflorum, Hassk. Cat. Hort. Bogor. Alt. 39.-Malaya. yaginatum, Reichb. $f$. in Walp. Ann. vi. $261=$ Cirrhopetalum vaginatum.

variegatum, Thou. Orch. Afr.t. 105, 106.-Ins. Borbon velutinum, Reichb. f. in Walp. Ann. vi. $258=$ Mega clinium velutinum.

violaceum, Lindl. Gen. et Sp. Orch. 50.-Java.

vittatum, Reichb. f. E Warm. in Otia Bot. Hamb. 95. -Bras.

vittatum, Teijsm. E Binn. in Tijdschr. Nederl. Ind. xxiv. (1862) 308.-Java.

Wallichii, Reichb. f. in Walp. Ann. vi. $259=$ Cirrhopetalum Wallichii.

Weddelii, Reichb.f.l. c. 251.-Bras.

Wightii, Reichb. f. 1. c. $262=$ Cirrhopetalum grandiflorum.

xylophyllum, Par. E Reichb. f. in Trans. Linn. Soc. xxx. (1874) 151.-Burma.

BULBOSPERMUM, Blume, Enum. Pl. Jav. 15 (1828)= Peliosanthes, Andr. (Haemodor.)

javanicum, Blume, l. c. = P. javanica.

BULBOSTYLIS, DC. Prod. v. 138 (1836)=Brickellia, E1I. (Compos.).

annua, Nutt. in Journ. Acad. Philad. Ser. II. i. (1847)

$179=$ Psathyrotes annua.

californica, Torr. \& Gray, Fl. N. Am. ii. 79 = Brickellia californica

Cavanillesii, DC. Prod, v. 138=Brickellia californica. diffusa, DC. 1. c. vii. $268=$ Brickellia diffusa.

glabra, DC. 1. c. v. $139=$ Eupatorium Vauthierianum.

glabriuscula, C. Koch, in App. Sem. Hort. Berol.

(1855) 13.-Am. trop.

hastata, Walp. Rep. Ind. p. $279=$ Brickellia hastata.

hebecarpa, DC. Prod. v. $138=$ Brickellia hebecarpa.

\section{BULBOSTYLIS :-}

lanata, DC. Prod. vii. $268=$ Brickellia lanata

microphylla, Nutt. in Trans. Am. Phil. Soc. Ser. II.

vii. (1841) $286=$ Brickellia microphylla.

nepetaefolia, DC. Prod, v. 139=Brickellia californica

oliganthes, DC. 1. $\mathrm{c}_{\mathrm{s}}=$ Brickellia oliganthes

pauciflora, DC. l. $\mathrm{c}_{\star}=$ Eupatorium paneiflorum.

pedunculosa, DC. in Deless. Ic. Sel. iv. t. $17=$ Eupa-

torium longipes.

pendula, DC. Prod. v, $138=$ Brickellia pendula.

reticulata, DC I. c vii. $268=$ Brickellia reticulata.

rigida, Hook. \& Arn. Bot. Beech. Voy. $297=$ Brickellia lanata.

scorodoniaefolia, Kunth, Ind. Sem. Hort. Berol. (1846) $12=$ Brickellia californica?

secundiflora, DC. Prod. v. $138=$ Brickellia secundiflora.

spinaciaefolia, DC. 1. c. $139=$ Eupatorium spinaciae

folium.

subuligera, S. Schan. in Linnaea, xix. (1847) $718=$

Barroetia subuligera.

triangularis, DC. Prod. vii. $268=$ Carphephorus triangularis.

veronicaefolia, DC. 1. c. v. $139=$ Brickellia veronicae folia.

BULBOSTYLIS, Gardn. in Hook. Lond. Journ. Bot. v. (1846) $467=$ Eupatorium, Tourn. (Compos.)

Cassiniana, Gardn. 1. c. $471=\mathrm{E}$. Vauthierianum

deltoides, Buckl. in Proc. Acad. Sc. Philad. 1861 (1862)

$456=\mathrm{E}$. ageratifolium.

elegans, Gardn. in Hook. Lond. Journ. Bot. v. (1846)

$467=\mathrm{E}$. elegans?

glandulosa, Gardn. 1. c. $469=$ E. amygdalinum

micrantha, Gardn. 1, c. $449=\mathrm{E}$. amygdalinum.

microcephala, Gardn. 1. c. $468=\mathrm{E}$. amygdalinum.

oblongifolia, Gardn. 1. c. $469=\mathrm{E}$. trixoides.

pumila, Gardn. 1. c. $470=\mathrm{E}$ amphidictyum.

ramosissima, Gardn. 1. c. = E. ramosissimum.

scandens, Gardn. 1. c. = E. Vitalbae.

tomentosa, Gardn. l. c. $468=\mathrm{E}$. amygdalinum.

BULBOSTYLIS, Kunth, Enum.P1. ii. 205 (1837) = Fimbristylis, Vahl (Cyperac.).

capillaris, Nees, in Mart. Fl. Bras. ii. I. 84, in obs. $=$ F. capillaris.

ciliata, Presl, ex Nees, 1. c. 84 , in obs.-Hab. ?

consanguinea, Nees, 1. c--Bras.

hirtella, Nees, 1. c. 85 .-Bras.

paradoxa, Nees, 1. c. 82.-Bras.

tenuifolia, Nees, 1. c. 83.--Bras.

trifida, Nees, 1, c. 84 , in obs。 $=\mathrm{F}$. capillaris

BULboSTyLIS, Stev. in Mém. Soc. Nat. Mosc.v. (1814)

$355=$ Eleocharis, R. Br. (Сурегас.)

capitatus, Stev. 1. c. $=$ E. capitata

geniculatus, Stev. 1. c. = E. geniculata.

maculosus, Stev. 1. c $=$ E. maculosa.

ovatus, Stev. 1. $\mathrm{c}_{\mathrm{c}}=\mathrm{E}$. ovata.

palustris, Stev. 1. c. = E. palustris.

tuberculatus, Stev. 1. c. = E. tuberculosa.

BULLIARDA, DC. in Bull. Soc. Philom, iii. (1801) n. 49. p. 1 = Tillaea, Mich. (Crassul.).

abyssinica, A. Rich. Tent. Fl. Abyss. i. $306=\mathrm{T}$. aquatica.

alpina, Harv, in Harv. \& Sond. Fl. Cap. ii. 330,-Afr. austr.

aquatica, DC. in Bull, Soc. Philom. (1801) n. 49. p. $2=\mathrm{T}$. aquatica

bonariensis, DC. 1. c. $=$ T. peduncularis.

brevifolia, Eckl. \& Zeyh. Enum. 290.-Afr. austr.

capensis, DC. in Bull. Soc. Philom. (1801) n. 49. p $2=\mathrm{T}$, capensis.

decumbens, DC. 1. c. $=$ T. decumbens.

Dregei, Harv. in Harv. \& Sond. Fl. Cap. ii. $330=$ Crassula prostrata, E. Mey.

elatinoides, Eck1. \& Zeyh. Enum. 290.-Afr. austr.

filiformis, Eckl. \& Zeyh. 1. c. =T. filiformis

Linnaei, Spreng. Syst. i. $497=$ T. aquatica.

magellanica, Comm. ex DC. in Bull. Soc. Philom.

(1801) n. 49. p. $2=$ T. moschata.

moschata, Urv. in Mém. Soc. Linn. Par. iv. (1826) 618 $=\mathrm{T}$. moschata.

pedunculata, St. Lag. in Ann. Soc. Bot. Lyon, vii. (1880) $144=\mathrm{T}$. Vaillantii.

perfoliata, DC. in Bull. Soc. Philom. (1801) n. 49. p. $2=T$. capensis.

prostrata, DC. 1. c. $=$ T. prostrata.
BULLIARDA :-

prostrata, Weinm. Fl. Petrop. $21=\mathrm{T}$. aquatica.

recurva, Hook. f. in Hook. Lond. Journ, Bot. vi. (1847)

472 [bis] $=$ T. recurva

Schkuhrii, Spreng. Syst. i. $498=$ T. prostrata.

Sieberi, Spreng. Syst. iv. Cur. Post. $48=$ T. verticillata

trichotoma, Eckl. \& Zeyh. Enum. $290=$ T. decumbens.

Vaillantii, DC. in Bull. Soc. Philom. (1801) n. 49. p. $1=\mathrm{T}$. Vaillantii.

Vaillantii, Schimp. ex Britten, in Oliver, Fl. Trop. Afr. ii. $388=$ T. aquatica.

BULLIARDA, Neck. Elem. ii. $321(1790)=$ Unona, Linn. f. et Xylopia, Linn. (Anonac.).

BUINESIA, C. Gay, Fl. Chil. i. 474. t. 15 (1846) ZYGOPHYLLEAE, Benth. \& Hook, f. i. 268.

Gonoptera, Turcz, in Bull. Soc. Nat. Mosc. xx. (1847) r. 150

bonariensis, Griseb. in Goett. Abh. xix. (1874) 105.Reg. Argent.

chilensis, C. Gay, Fl. Chil. i. 475.-Chili.

foliosa, Griseb. in Goett. Abh. xix. (1874) 106.-Reg. Argent.

macrocarpa, Phil. Sert. Mend. Alt. 9.--Chili.

Retamo, Griseb. in Goett. Abh. xix. (1874) 106.Reg. Argent.

Sarmienti, Lorentz, ex Griseb. l. c. xxiv. (1879) 75.Reg. Argent.

Schickendanzii, Hieron. ex Griseb. l. c.-Reg. Argent.

BULOWIA, Hook. Bot. Mag. sub t. 4364 (1848)= BUELOWIA, Schur = Smeathmannia, Soland (Passifl.).

BULWERIA, F. Muell. Fragm.iv. $147(1864)=$ Diplan thera, R. Br. (Bignon.).

nobilissima, F. Muell. 1. c. $=$ D. tetraphylla.

BUMALDA, Thunb. Nov. Gen. 62 (1783)=Staphylea Linn. (Sapind.)

trifolia, Thunb. 1, c. $63=$ S. Bumalda.

BUMELIA, Sw. Prod. Veg. Ind. Occ. 49 (1788) SAPOTACEAE, Benth. \& Hook. f. ii. 660 .

SCle ROCladus et SPONDOgona, Rafin. Sylva Tellur 35 (1838).

ambigua, Tenore, ex A. DC. in DC. Prod. v. $189=$ lycioides.

angustifolia, Nutt. Sylv. Am. iii. 38. t. 93.-Am. bor.; Mexic.

arachnoidea, Rafin. New Fl. Am. iii. 28 =lanuginosa. arborea, Buckl. in Proc. Ac. Sc. Philad. 1861 (1862) $461=$ lanuginosa

argentea, Roem. \& Schult, in Ges. Naturf. Fr. Berl. Mag, iii. (1809) 57 ; Syst, iv, $499=$ Heeria argentea. Anzuba, Roem. \& Schult. Syst. iv. 499.-Ins. S Doming.

borbonica, Lodd. ex Loud. Hort. Brit. 69,-Ins. Borbon.

buxifolia, Roem. \& Schult. Syst. iv, $802=$ obtusifolia. buxifolia, Willd, ex H. B. \& K. Nov. Gen, et Sp, vii.

t. 147.-Am, austr

celastrina, $H . B . \varepsilon \cdot K$. l. c. 212.-Mexic.

chrysophylloides, Wats. Dendrol. i. $10=$ tenax.

crenulata, Spreng. Syst. i. 665.-Porto Rico.

Cruegerii, Griseb. Fl. Brit. W. Ind. 401.-Ind. occ

cubensis, Griseb. Cat. Pl. Cub. 164.-Cuba.

cuneata, Sw. Fl. Ind. Occ, i. $496=$ Sideroxylon obo vatum, Lam.

cuneifolia, Rudge, Pl. Guian. i. -30 . t. $47=$ Chrysophyllum cuneifolium.

denticulata, Rafin. New Fl. Am iii. 29-Am bor. dulcifica, Schum. \& Thonn. Beskr. Guin. Pl. 130 Sideroxylon dulcificum.

Dunantii, A. DC. in DC. Prod. viii. 191.-Am. austr. egensis, Poepp. ex A. DC. 1. c. $182=$ Sideroxylon rugosum.

excelsa, A. DC. 1. c. $192=$ obtusifolia

ferox, Cham. E Schlecht. in Linnaea, vi. (1831) 392. - Mexic.

ferruginea, Nutt. Sylv. Am. 33 = lannginosa.

foetidissima, Willd. Sp. Pl. i. $1086=$ Sideroxylon foetidissimum.

glomerata, Griseb. in Mem. Am. Acad. N. S. viii. (1863) 518. - Ind. occ.

Hayesii, Hemsl. Biol. Centr. Am. Bot. ii. 297.Guatemala. 
BUMELIA

horrida, Griseb. Cat. Pl. Cub. 165.-Cuba.

laete-virens, Hemsl. Biol. Centr. Am. Bot. ii. 298.Mexic.

lanuginosa, Pers. Syn. i. 237.-Am. bor

lucida, Roem. \& Schult. Syst. iv. $499=$ Sideroxylon lucidum.

lycioides, Willd. Enum. Hort. Berol. 249.-Am. bor. macrocarpa, Nutt. Sylva Am. iii. $37=$ lanuginosa? Manglillo, Willd. Sp. P1. i. $1087=$ Myrsine Manglilla. Mastichodendrum, Roem. \& Schult. Syst. iv. $493=$ Sideroxylon Mastichodendron.

micrantha, Willd. ex Roem. \& Schult. 1. c. $802=$ Ardisia micrantha.

inicrophylla, Griseb. Cat. Pl. Cub. 165.-Cuba

montana, Sw. Prod. Veg. Ind. Occ. $49=$ Dipholis montana.

monticola, Buckl. in Bull. Torrey Club, x. (1883) 91.Texas.

multiflora, Roem. \& Schult. Syst. iv. 498 (non Sapotacea).-Afr. austr.

myrsinifolia, A. DC. in DC. Prod. viii. 192 = Sideroxylon obovatum, Lam.

nervosa, Vahl, Eclog. Am. i. $28=$ Lucuma Rivicoa.

niora, Bert. ex Griseb. Fl. Brit. W. Ind. $400=$ Dipholis salicifolia.

nigra, Sw. Prod. Veg. Ind. Occ. $49=$ Dipholis nigra. oblongifolia, Nutt. Gen. Am. i. $135=$ lanuginosa. obovata, A. DC. in DC. Prod. viii. 191.-Am, austr. obtusifolia, Roem. E' Schult. Syst. vi. 802.-Bras.

obtusifolia, Willd. ex Steud. Nom. ed. II. i. $237=$ rotundifolia.

occidentalis, Hemsl. Biol. Centr. Am. Bot. ii. 298.Mexic.

pallida, Sw. Prod. Veg. Ind. Occ. $49=$ Sideroxylon Mastichodendron.

parvifolia, A. DC in DC. Prod, viii. 190,-Ind. occ. parvifolia, Chapm. F1. S. U. St. $275=$ angustifolia.

pauciflora, Engelm. ex A. Gray, Syn. Fl. ii. Ir. $68=$ lanuginosa.

pauciflora, Roem. \& Schult. Syst. iv. $493=$ Sideroxylon pauciflorum.

pentagona, Sw. Prod. Veg. Ind. Occ. $50=$ Dipholis salicifolia.

persimilis, Hemsl. Biol. Centr. Am. Bot. ii. 298.Mexic.

pubescens, Tenore, Sem. Hort. Neap. (1827)= lycioides.

punctata, Roem. \& Schult. Syst. iv. $498=$ Myrsine Rapanea?

reclinata, Torr. Bot. Mex. Bound. $109=$ angustifolia

reclinata, Vent. Choix, 22.-Am. bor.

retusa, Balbis, ex A. DC. Prod. viii. $194=$ Ilicis sp.

retusa, Sw. Prod. Veg. Ind. Occ. 49.-Ind. occ

rhamnoides, Casar. Stirp. Bras. Dec. $64=$ obtusifolia.

rotundifolia, H. B. \& K. Nov. Gen, et Sp. iii. $237=$ obtusifolia.

rotundifolia, Sw. Prod. Veg. Ind. Occ. 50.-Ind. occ.

rufa, Rafin. New Fl. Am. iii. 29.-Am, bor.

salicifolia, Bert, ex A. DC. in Trans. Linn. Soc, xvii

1837) $108=$ Myrsine salicifolia.

salicifolia, Sw. Prod. Veg. Ind. Occ. $50=$ Dipholis salicifolia.

sartorum, Mart. Herb. Fl. Bras. 233.-Bras.

serrata, Pursh, Fl. Am. Sept, i, $155=$ Prunus caroliniana.

serrulata, Rafin. New Fl. Am, iii, 29.-Am. bor.

spiniflora, A. DC. Prod. viii. 191,-Mexic

spinosa, $A . D C . l . c .-$ Mexic.

spinosa, S. Wats. in Proc. Am. Acad. xviii. (1883) 112 =languinosa.

strigosa, Spreng. Syst. i. 655.-Hab. ?

subsessiflora, Hemsl. Biol. Centr. Am. Bot. ii. 299.Mexic.

tenax, Willd. Sp. Pl. i. 1085-Am. bor.

texana, Buckl. in Bull. Torrey Club, x. (1883) $90 .-$ Texas.

tomentosa, A. DC. Prod. viii. $190=$ lanuginosa.

tortuosa, Wright, in Sauv. Fl. Cub. 87.-Cuba.

undulata, Rafin. Nevv Fl. Am, iii. 28,-Am, bor.

I3UNBURIA, Harv. Gen. S. Afr. Pl. ed. I. $416(1838)=$ Vincetoxicum, Moench (Asclep.).

elliptica, Harv. 1. c. 417.-Afr. austr.

BUNBURYA, Meissn, ex Hochst, in Flora, xxvii. (1844) $553=$ Tricalysia, A. Rich. (Rubiac.)

capensis, Meissn. ex Hochst. 1. c.-Afr. austr.
BUNCHOSIA, Rich. ex Juss, in Ann. Mus. Par. xviii (1811) 481. MALPIGHIACEAE, Benth. \& Hook f. i. 252 .

MalacmaEa, Griseb. in Linnaea, xiii. (1839) 248. acutifolia, A. Fuss. in Arch. Mus. Par. iii. (1843) 336. -Mexic.

angustifolia, A. Fuss. l. c. 331.-Peruy.

argentea, $D C$. Prod. i. 582.-Venezuela.

armeniaca, $D C$. l. c.-Peruv.

bilocellata, Hemsl. Biol. Centr. Am. Bot. i. $147=$ seq

biocellata, Schlecht. in Linnaea, x. (1836) 241.Mexic.

Bonplandiana, A. Fuss. in Arch. Mus. Par. iii. (1843) 332.-Am. trop.

bracteosa, Juss. in St. Hil, Fl. Bras. Mer. iii. $79=$

Dicella bracteosa.

canescens, DC. Prod. i. 582,-Ind. occ.

cornifolia, H. B. E $K$. Nov. Gen. et Sp. v, 154.-N Granat.

cumanensis, G. Don, in Loud. Hort. Brit. 170.Venezuela.

deflexa, Triana Es Planch. in Ann. Sc. Nat. Sér. IV xviii. (1862) 310-N Granat.

discolor, Turcz. in Bull. Soc. Nat. Mosc. xxxii. (1859) $266=$ biocellata

eglandulosa, A. Fuss. in Arch. Mus. Par. iii. (1843) 336.- Hab.

lliptica, Tod. Ind. Sem. Hort. Panorm. (1877) 38.Hab. ?

emarginata, Regel, Ind. Sem. Hort. Petrop. (1856) 35. -Cuba.

fluminensis, Griseb. in Mart. Fl. Bras. xii. I. 31.Bras.

Gaudichaudiana, A. Juss. in Arch. Mus. Par. iii.

(1843) $334=$ fluminensis.

g]andulifera, H. B. ह K. Nov. Gen. et Sp. v. 154.Venezuela.

glandulosa, DC. Prod. i. 581.-Am. trop.

glauca, $H . B$. E $K$. Nov. Gen. et $S p$. v. $155 .-\mathrm{N}$. Granat.

glauca, Seem. ex Hemsl. Biol. Centr. Am. Bot. i. 147 = cornifolia.

grandifolia, A. Fuss. in Arch. Mus. Par. iii. (1843) 341.-Ins. Martinic.

Hartwegiana, Benth. Pl. Hartw. 164.-N. Granat

holosericea, Mart. ex A.Juss. in Arch. Mus. Par. iii.

(1843) $344=$ Dicella holosericea.

Hookeriana, A. Fuss. l. c. 337.-Peruv.

hypoleuca, Miq. Stirp. Surin. Sel. 77.-Guiana.

lanceolata, Turcz. in Bull. Soc. Nat. Mosc. xxxii (1859) I. $266=$ discolor.

laxiflora, Gardn. in Hook. Lond. Journ. Bot. i. (1842) 168 = Tetrapteris Guilleminiana.

Lindeniana, A. Fuss. in Arch. Mus. Par, iii. (1843) 335. -Am. trop.

Martiana, A. Juss. 1. c. $334=$ fluminensis.

media, DC. Prod. i. 581. - Ind. occ.

mollis, Benth. in Hook. Lond. Fourn. Bot. vii. (1848)

127.-Guiana.

mollis, Seem. ex Hemsl. Biol. Centr. Am. Bot. i. 148 pilosa.

montana, A. Fuss. in Arch. Mus. Par. iii. (1843) 340 - Mexic

multiflora, Hook. E Arn. in Hook. Bot. Misc. iii (1833) 157.-Am. austr.

nitida, Fuss. in Ann. Mus. Par. xviii. (1811) 481 - Mexic. Peruv ; Ind occ.

odorata, $\mathscr{f} u s s . l$. $c_{0}-\mathrm{N}$. Granat.

palustris, Poepp. ex A. Juss. in Arch. Mus. Par. iii. (1843) 311 = Burdachia prismatocarpa.

paniculata, DC. Prod. i. $582=$ Triopteris ovata.

pilosa, H. B. E $K$. Nov. Gen. et Sp. v. 154.-N Granat.

polystachya, DC. Prod. i. 581.-Ind. occ.

retusa, Triana É Planch. in Ann. Sc. Nat. Sér. IV xviii. (1862) $311 .-\mathrm{N}$. Granat.

rhombifolia, Turcs. in Bull. Soc. Nat. Mosc. xxxyi. (1863) I. 582,-Venezuela.

sessilifolia, DC Prod, i. 582-Mexic

sphaerocarpa, A. Guss. in Arch. Mus. Par, iii. (1843) 319.-Bras.

squarrosa, Griseb. in Linnacs, xxii. (1849) $11=$ Tetrapterys squarrosa.

strigosa, Schlecht. in Linnaed, x. (1836) 242.Mexic.

Swartziana, Griseb. Fl. Brit. W. Ind. 115.-Jamnic.

tuberculata, $D C$. Prod. i. 581.-Venezuela.
BUNGEA, C. A. Mey. Verz. PA. Canc. 108 (1831) SCROPHULARINEAE, Benth. \& Hook. f. ii 976.

Sheareri, S. Moore, in Fourn. Bot. xiii. (1875) 229.China.

trifida, C. A. Mey. Verz. Pfl. Cauc. 108.-As. Min. Persia.

turkestanica, Maxim. in Mém. Acad. Pétersb. Sér. VII. xxix. No. III. 61.-Turkestan.

BUNIAS, [Tourn:] Linn. Syst. ed. I. (1735). CRU CIFERAE, Benth. \& Hook. f. i. 97.

Erucago, Tourn, ex Adans. Fam. ii. 423 (1763).

LaeliA, Adans. Fam. ii. 423 (1763); Desv. Journ Bot. iii. (1813) 160

aegyptiaca, Linn. Syst. Nat. ed. XII. $231=$ Ochthodium aegyptiacum.

altaica, Schang. ex DC. Syst. ii, 388=Hutchinsia calycina.

americana, Rafin. Med. Fl. ii. $202=$ Cakile maritima.

arvensis, ford. Cat. Gr. Fard. Dijon (1848) 18.Gallia.

aspera, Retz. Obs. ii. $21=$ B. Enucago.

balearica, Linn. Syst. Nat. ed. XII. $446=$ Snccowia balearica.

Cakile, Linn. Sp. P1. $670=$ Cakile maritima.

cochlearioides, Bieb. F1. Taur. Caac. ii. $87=$ Calepin Corvini.

cochlearioides, Murr. in Comm. Gott. viii. (1777) 42

t. 3.-Sibir. altaic.

cornuta, Linn. Sp. PI. $669=$ Pugioninm cornutum

cristata, Desv. Joum. Bot. iii. (1813) $163=$ B. Erucago

edentula, Bigel. FI. Bost. ed. III. $267=$ Cakile maritima.

Erucago, Linn.Sp. Pl.670.-Europ. austr.; As. Min. Syria.

glomerata, Lapeyr. Hist. Abr. Pl. Pyr, 362=Senebier

Coronopus.

littoralis, Salisb. Prod. $273=$ Cakile maritima.

macroptera, Reichb. Fl. Germ. Excurs, $654=\mathbb{H}$ Erucago.

myagroides, Linn. Mant. i. $96=$ Erucaria aleppica.

orientalis, Linn. Sp. Pl. 670-Europ. or.; As. Min.

ovalis, Viv. Fl. Lib. Spec. t. $16=$ Cakile cyrenaica.

paniculata, L'Hérit. ex DC. Syst. ii. $520=$ Neslia paniculata.

paradoxa, Banks, ex DC. 1. c. $677=$ Chamira comuta perennis, Moench, Meth. Suppl. $91=$ orientalis.

perennis, Sibth. \& Sm. Fl. Graec. Prod. ii. $2=$ Rapistrum perenne.

prostrata, Desf. Fl. Atlant. ii. $76=$ Muricaria pro strata.

pyramidata, Fisch. Hort. Gorenk. ed. II. (1812) 4! nomen.-Hab.

raphanifolia, Sibth. \& Sm. Fl. Graec. t. $612=$ Rapi strum orientale.

rostrata, L'Hérit. ex DC. Syst. i̊. $422=$ Euclidium syriacum.

sibirica, Linn. Amoen. Acad. viii. S.-Sibir

spinosa, Linn. Mant. 96 = Zilla myagroides.

syriaca, Gaertn. Fruct, ii. $290=$ Euclidium syriacum.

tatarica, Willd. Sp. P1 iii. $413=$ Euclidium tataricum.

tcheliensis, Debeaux, in Actes Linn. Soc. Bord. xxxii. (1879) 35.-China.

tenuifolia, Sibth. \& Sm. Fl. Graec. Prod. ii. 3 (=Dide: mus tenuifolius).-Graecia.

Tonernefortii, Sibth, ex DC. Syst. ii. 659 (=Didesmus tenuifolius).-Graecia.

tricornis, Lange, in Kjoeb. Vidensk. Meddel. (1S65 s. - Hispan.

verrucosa, Moench, Meth. $27 \pi=$ Rapistrum orientale

virgata, Sibth. \& Sm. Fl. Graec. t. $613=$ Ochthodium aegyptiacum.

algaris, Andrz, ex Stend. Nom. ed. II. i, 237, 238

B. Erucago.

Winterli, Schult. Obs, $121=$ orientalis

BUNION, St. Lag. in Ann. Soc. Lyon, vii. 85 (1s\$0 seq.

BUNIUM, Koch, Syn. F]. Germ. ed. II. 315 (18t3) Pimpinella, Kiv. (Umbellif.)

montanum, Koch, 1. c.-Lurop.

BUNIUM, Linn. Gen. ed. I. 72 , 1;3i = Carum, Lirn. ('mbellif.).

acaule, Bieb. Fl. Taur. Cauc. i. 212 = Chanacsei. dium acaule. 


\section{BUNIUM:-}

alpinum, Waldst. \& Kit. Pl. Rar. Hung. ii. 199. t. 182 $=$ C. alpinum

ammoides, Cesati, in Linnaea, xi. (1837) $323=\mathrm{C}$. ammoides.

ammoides, Link, ex Spreng. Syst. i. $903=$ Conopodium denudatum.

aphyllum, Jan, ex DC. Prod. iv. 117.-Sicilia.

arcuatum, Griseb. ex Pantoc. in Oestr. Bot. Zeitschr. xxiii. (1873) 267.-Europ.

aromaticum, Linn. Mant. $218=$ C. copticum

brevifolium, Lowe, in Trans. Camb. Phil. Soc. vi (1838) Repr. 21.-Ins. Mader.

Bulbocastanum, Bert. ex DC. Prod. iv. $668=$ Diposis Bulbocastanum.

Bulbocastanum, Huds. Fl. Angl. 122=Conopodium denudatum.

Bulbocastanum, Linn. Sp. PI. $243=$ C. Bulbocastanum.

bulbosum, Dulac, F1. Hautes-Pyr, $351=$ C. Bulbocastanum.

butinioides, Boiss. \& Reut. ex Boiss. Voy. Bot. App. 736. - Hispan

capillifolium, Bertol. Fl. Ital. iii. 219.-Italia.

capillifolium, Kar. \& Kir. in Bull. Soc. Nat. Mosc. (1841) $428=$ Carum setaceum.

Carvi, Bieb. F1. Taur. Cauc. i. $211=$ C. Carvi

carvifolium, DC. Prod, iv. $116=\mathrm{C}$. flexuosum.

cassium, Boiss. Diagn. Ser. I. x. $24=$ C. elegans

cilicicum, Fenzl, in Tchihat. Asie Min. Bot. i. $411=\mathrm{C}$

Pestalozzae.

collinum, Albert, in Bull. Soc. Sc. Draguign. (1884) repr. 23.-Europ.

copticum, Spreng. Prod, Umb. $28=$ C. copticum

corydalinum, DC. Prod. iv, 117.--Ins. Corsic.

creticum, Mill. Gard. Dict. ed. VIII. n. $2=$ C. ferulaefolium.

creticum, Urv. in Ball. Soc. Linn. Par. i. (1822) 287 (=Conopodii sp.).-Graecia ; As. Min. ; Syria.

cynapioides, Bertol. Fl. Ital. iii. $217=\mathrm{C}$. cylindricum? denudatum, DC. Fl. Fr. iv. $525=$ Conopodium denudatum.

divaricatum, Bertol. Fl. Ital. iii. 222 (=Pimpinellae sp.).-Ital.

divaricatum, Cesati, in Linnaea, xi. (1837) $314=\mathrm{C}$

ferulaefolium

Falcaria, Bieb. Fl. Taur. Cauc. i. $211=$ Falcaria Rivini.

ferulaceum, Sibth. \& Sm. Fl. Graec. Prod. i. $186=$ C ferulaefolium.

ferulaefolium, Desf. in Ann. Mus. Par. xi. (1808) 275 Choix, 55. t. $43=$ C. ferulaefolium

flexuosum, Brot. FI. Lusit. i. $437=$ Conopodium capillifolium.

flexuosum, With. Bot. Arr. Brit. Pl. ed. II. $276=$ Conopodium denudatum.

glaberrimum, DC. Prod. iv. 118.-Algeria

glaucescens, DC. 1. c. 117 (=Scatigeria glaucescens) -Armenia; Persia

glaucocarpum, Boiss. Diagn. Ser. I. x. $25=$ C Pestalozzae.

junceum, Margot \& Reut. in Mém. Soc. Phys. Genèv. viii. (1839) $300=$ C. creticum.

ligusticifolium, Cesati, ex Boiss. FI. Orient. ii. $882=$ C. multiflorum

luteum, Hoffm. Gen. Umb. 108 = Muretia tanaicensis.

Macuca, Boiss. Elench. 44; Voy. Espagne, ii. 239. t. $66=$ C. Macuca

majus, Bieb. Fl. Taur. Cauc, i; $210=$ C ferulaefolium.

majus, Gouan, Illustr. $10=$ Conopodium denudatum.

majus, S. F. Gray, Nat. Arr. Brit. Pl. ii. $514=\mathrm{C}$.

Bulbocastanum

minus, Gouan, Illustr. $10=\mathrm{C}$. Bulbocastanum.

minus, S. F. Gray, Nat. Arr. Brit. Pl. ii. $514=$ Cono podium denudatum.

minutifolium, Janka, in Oestr. Bot. Zeitschr. xxii. (1872) $177=$ Peucedanum vittijugum.

napiforme, Willd. ex Roem. \& Schult. Syst. vi. $539=$ C. creticum.

nepalense, Jacquem. ex Walp. Rep, ii, 422 = Chaerophyllum capnoides.

nivale, Boiss. Elench. 45; Voy. Espagne, ii. 240.t $67=$ C. nivale.

paucifolium, DC. Prod. iv. $117=$ C. elegans.

Pestalozzae, Boiss. Diagn. Ser. I. x. $24=$ C. Pesta. lozzae.
BUNIUM :-

petraeum, Loisel. Fl. Gall. ed. II. i. $195=$ cory dalinum.

petraeum, Tenore, Prod. Fl. Neap. p. lix $=$ Carum alpinum.

peucedanoides, Bieb. Fl. Taur. Cauc i. 211 = Silaus carvifolius.

peucedanoides, DC. Prod. iv. 116.--Reg. Caucas.

pilosum, Willd. ex Roem. \& Schult. Syst. vi. $500=$ Conopodium denudatum.

pityranthon, Spreng. Syst. i. $901=$ Pituranthus denudatus.

pumilum, Sibth. \& Sm. Fl. Graec. iii. 67. t. 274 ( = Biasolettia pumila).-Graecia.

pyrenaeum, Loisel. Fl. Gall. 161. t. 5=Conopodium denudatum.

rigens, Spreng. in Roem. \& Schult. Syst. vi. 500.-Afr. austr.

rigidulum, Caruel, Prod. F1. Tosc. $272=$ C. rigidulum saxatile, Mill. Gard. Dict. ed. VIII. n, $3=\mathrm{C}$. alpinum.

strictum, Griseb. Spicil. Fl, Rumel, i. $344=\mathrm{C}$. strictum.

subcarneum, Boiss. \& Reut. Diagn. Pl. Nov. Hisp. 14 $=$ Conopodium subcarneum.

tenuifolium, Salzm. ex DC. Prod. iv. 118=Conopodium capillifolium.

tenuisectum, Griseb. ex Pantoc. in Oestr. Bot. Zeitschr. xxiii. (1873) 267.-Europ.

ternatum, Pers. Syn. i. $308=$ Conopodium denudatum. thalictrifolium, Boiss. Elench. 45.-Hispan.

verticillatum, Gren. \& Godr. Fl. Fr. i. $729=$ C. verticillatum.

virescens, DC. in Mém. Soc. Phys. Genèv. iv. (1828) $197=$ Silaus carvifolius

BUNNYA, F. Muell. Fragm. v. 36. to $39(1865)=$ Cyanostegia, Turcz. (Verbenac.).

cyanocalyx, F. Muell. 1. c. = C. Bunnyana.

BUNOPHILA, Willd. ex Roem. \& Schult. Syst. iii. Mant. 128, et Ind. (1827) (Ord. Nat. ?).

PuNophila, Willd. 1. c. $8(1827)$

lycioides, Willd. 1. c. 128.-Am. austr.

BUONAPARTEA, G. Don, in Sweet, Hort. Brit. ed. III. $706(1839)=$ BONAPARTEA, Ruiz \& Pav. Tillandsia, Linn. (Bromel.).

BUPHANE, Herb, in Bot. Mag. sub t. 2578 (1825); et Amaryll. 239.t. 22, 36. f. 7, 8 (1825); prius Boophane, ejusd. App. 18 (1821); serius Buphone in Bot ejusd. App. 18 (1821); serius Buphone in Bot.
Mag. sub t. 2593 in nota (1825). AMARYLLI$D E A E$, Benth. \& Hook. f. iii. 730.

Crossyne, Salisb, Gen. Pl. Fragm. 116 (1866). amaryllidea, M. Roem. Syn. Ensat. $61=$ ciliaris. angolensis, Baker, in Journ. Bot. xvi. (1878) $197=$ Crinum angolense

ciliaris, Herb. App. 18 (Boophane).-Afr. austr. disticha, Herb. in Bot. Mag. sub t. 2578.-Afr. austr guttata, Herb. Amaryll. 240. t. 22. f. $1=$ ciliaris. intermedia, M. Roem. Syn. Ensat. $59=$ disticha. toxicaria, Herb. App. 18 (Boophane)=disticha.

BUPHTHALMUIM, Linn. Syst. ed. I (1735). COMPOSITAE, Benth. \& Hook. f. ii. 338.

Athalmum, Neck. Elem. i. 20 (1790)

BustiA, Adans, Fam ii. 127 (1763).

Molpadia, Cass. Dict. Sc. Nat, xxiii. 565 (1822

TelekiA, Baumg. Fl. Transsylv. iii. 149 (1816).

angustifolium, Pursh, F1. Am. Sept. ii. 564=Marshallia angustifolia

aquaticum, Linn. Sp. Pl, 903 = Odontospermum aquaticum.

arabicum, Delile, in Laborde, Voy. Arab. Pétr, $84=$ Anvillea Garcini.

arborescens, Linn. Syst. ed. X. $1227=$ Borrichia arborescens.

arvense, Vell. Fl. Flum. viii. t. 133.-Bras.

asperrimum, Spreng. Neue Entdeck. ii. 140 (=Anomostephium buphthalmoides).-Guadelup.

asperum, Hornem. Hort. Hafn. Suppl. $102=$ Wedelia hispida.

asteriscoides, Baill. Hist. PI. viii. $301=$ Osmites asteriscoides.

asteroideum, Viv. F1. Lib. Spec. 57.t. 25.f. $2=$ Pallenis spinosa.

australe, Spreng. F1. Hal. Mant. 52=Wedelia aristata.

\section{BUPHTHATMUT :}

aureum, Salzm. ex Steud. Nom. ed. II. i. $238=$ Pallenis spinosa.

bipinnatum, Gilib. F1. Lituan. i. 213=Anthemis tinctoria.

bonariense, Pers, Syn. ii. $474=$ Acicarpha spathulata?

canum, L'Hérit. ex DC. Prod. v. $489=$ Borrichia argentea,

capense, Linn. Syst. ed. X. $1227=$ Oedera prolifera.

chrysanthemoides, Poir. Encyc. Suppl. i. $747=$ Odon tospermum imbricatum.

cordifolium, Waldst. \& Kit. Pl. Rar. Hung. ii. $117=$ speciosum.

coriaceum, Hort. ex Loud. Hort. Brit. $357=$ Jasonia laevigata

crassifolium, Rafin. Specch. $191=$ Odontospermum maritimum.

dentatum, Baill. Hist. PI, viii. $301=$ Osmites dentata. diffusum, Vahl, ex DC. Prod. v, 491=Eclipta erecta

durum, Linn. Sp. Pl. ed. II. $1275=$ Osteospermum spinosum.

elegans, Brouss. ex Willd. in Ges. Naturf. Fr. Berl. Mag. i. (1807) $138=$ Odontospermum imbricatum.

equinum, Vell. F1. Flum. viii. t. 131.-Bras.

flexile, Bertol. Fl. Ital. ix. 413,-Ital.

flosculosum, Vent. Jard. Cels, $25=$ Anvillea Garcini.

frutescens, Linn. Sp. P1. 903=Borrichia frutescens.

Garcini, Burm. f. Fi. Ind. t. $60=$ Anvillea Garcini.

grandiflorum, Linn. Sp. Pl. $904=$ salicifolium.

graveolens, Forsk. Fl. Aegypt. Arab. 151=Odontospermum graveolens.

graveolens, Schimp, ex Boiss, Fl, Orient. iii. 180 (=Asteriscus Schimperi).-Arab.

Gussoni, Pasquale, Notizie, (1878) 2.-Sicil.?

helianthoides, Forst. f. Prod. $57=$ Wedelia aristata

helianthoides, Linn. Sp. PI. $904=$ Heliopsis laevis.

heterophyllum, Willd. ex DC. Prod. v. $484=$ Wedelia pedunculosa.

imbricatum, Cav. in Anal. Cienc. Nat. iv. (1801) $94=$ Odontospermum imbricatum.

incanum, Mill. Gard. Dict. ed VIII. n. 10=Borrichia frutescens.

inuloides, Moris, Sard. App. (1828).-Sardinia.

laevigatum, Brouss, ex Willd, in Ges. Naturf. Fr. Berl. Mag. i. (1807) $138=$ Jasonia laevigata.

leucoifolium, Burm. f. Fl. Cap. Prod. 27.-Afr. austr.

lineare, Willd. Sp. Pl. iii. $2230=$ Borrichia frutescens.

littorale, Vell. Fl. Flum. viii. t. 134.-Bras.

longipes, Comm. ex Cass. in Bull. Soc. Philom. (1822) 144.-Madag.

maritimum, Linn. Sp. P1. $903=$ Odontospermum maritimum.

mediterraneum, Vell. Fl. Flum. viii. t. 135.-Bras.

melissoides, Poir, Encyc. Suppl. i. $747=$ Heliopsis scabra.

melitense, Forsk. Fl. Aegypt. Arab. 218, nomen.Ins. Melita.

nutans, Vitm. Summa Veg. v. $123=$ Bidens cernua

odorum, Schousb. Vextr. Marokko, $199=$ Odontospermum odorum.

oleraceum, Lour. Fl. Cochinch. ii. 506.-China.

Ortegae, Spreng. Nachr. i. Bot. Gart. Halle, 16, nomen - Hab?

peruvianum, Lam. Encyc. i. $515=$ Borrichia peruviana pratense, Vahl, Symb. Bot. i. $75=$ Ceruana pratensis. procumbens, Desf. ex Steud. Nom. ed. I. $127=$ Wedelia carnosa.

ramosum, Forsk. Fl. Aegypt. Arab. 151.-Arab.

Ramtilla, Buch.-Ham. ex Wall. Cat, sub n. $3191=$ Guizotia oleifera

repens, Lam. Encyc. i. $515=$ Wedelia carnosa. sagittatum, Pursh, Fl. Am. Sept. ii. 564=Balsamo rhiza sagittata.

salicifolium, Linn. Sp. Pl. 904.--Europ. austr.

scabrum, Cav. Ic. ii. $53=$ Wedelia hispida .

scandens, Vell. Fl. Flum. viii. t. 132.-Bras

scandens, Schum. \& Thonn. Beskr. Guin. PI. $392=$ Melanthera Brownei.

sericeum, Linn. f. Suppl. $379=$ Odontospermum sericeum.

sessile, Mill. Gard. Dict. ed. VIII. n. $5=$ Odontospermum maritimum.

silphioides, Hornem. ex Steud. Nom. ed. II. i. 239.Hab.?

speciosissimum, Ard. Spec. i. 26; Linn. Mant. i. 117 -Earop.

speciosum, Schreb. Dec, 11. t. 6-Oriens.

spinosum, Linn. Sp. Pl. $904=$ Pallenis spinosa. 


\section{BUPHTHALMUM :-}

stenophyllum, Link, in Buch, Beschr. Canar. Ins. $150=$ Odontospermum sericeum.

strigosum, Spreng. Neue Entdeck, ii. $140=$ Wedelia pedunculosa.

succisaefolium, Britting, in Flora, xxiv. (1841) I. 138 $=$ salicifolium

tenuifolium, Burm. $f$. Fl. Cap. Prod. 28.-Afr. austr. trifolium, Poepp. ex DC. Prod. v. $577 \approx$ Oyedaea buphthalmoides.

uniflorum, Forst. f. Prod. $541=$ Wedelia Forsteriana

BUPLEUROIDES, [Boerh.] Moench, Meth. 294 (1794) =Phyllis, Linn. (Rubiac.).

Nobla, Moench, 1. c. $=$ P. Nobla

BUPLEURUM, [Tourn.] Linn. Syst. ed. I (1735) UMBELLIFERAE, Benth. \& Hook. f. i. 886.

Agrostana, Hill, Veg. Syst. v, 32 (1772).

Buprestis, Spreng. Pl. Umb. Prod. 27 (1813).

Diaphyllum, Hoffm. Gen. Umb. 115 (1814).

Dratropa, Dum. Fl. Belg. 76 (1827).

IsopHyllum, Hoffm. Gen. Umb. 115 (1814).

OdonteA, Fourr. in Ann. Soc. Linn. Lyon, N. S. xvi. (1868) 391

ODoNTites, Spreng, in Ges. Naturf. Fr. Berl. Mag. vi. (1812) 258.

Perfoliata, Fourr. in Ann. Soc. Linn. Lyon, N. S. xvi. (1868) 390.

Tenoria, Spreng. Pl. Umb. Prod. 32 (1813).

Trachypleurum, Reichb. Consp. 143 (1828).

acerosum, E. Mey. in Drege, Zwei Pf. Docum. 170 , nomen.-Afr. austr.

aciphyllum, Webb E" Berth. Phyt. Canar. ii. 154. t. 77. -Ins. Canar.

acutifolium, Boiss. Elench. $47=$ paniculatum.

aegyptiacum, Willd. ex Steud. Nom. ed. II. i. $239=$ protractum.

aeneum, Boiss. E Huet, Diagn. Ser. II. ii. 85.Armenia.

affine, Sadl. Fl. Pesth. 204.-Europ. anstr.; Tauria. aleppicum, Boiss. in Ann. Sc. Nat. Sér. III. i. (1844) 148.-Syria.

alpigenum, Jord. \& Fourr. Brev. P1. Nov. fasc. i. $35=$ falcatum.

alpinum, Nym. Consp. $311=$ falcatum

altaicum, Pall, ex Roem. \& Schult. Syst, vi. 367, $368=$ triradiatum.

amplexicaule, [Clairv.] Man. Herb. 87=pyrenaicum.

angulosum, Cham. \& Schlecht. in Linnaea, i. (1826) $383=$ ranunculoides

angulosum, Linn. Sp. Pl. 236.-Reg. arct.

angustifolium, Ledeb. Fl. Ross. ii. 265.-Sibir. altaic.

angustifolium, Pall. Reise Statth. Russ. Reich. i. 345

-Reg. Caucas.

apiculatum, Boiss. in Ann. Sc. Nat. Sér. III. i. (1844)

147 = semidiaphanum.

apiculatum, Friwald. in Flora, xviii. (1835) 335.Oriens.

arborescens, Jacq. Coll. ii. $343=$ gibraltaricum.

arborescens, Thunb. Prod. Pl. Cap. 50=Heteromorpha arborescens.

aristatum, Bartl. in Reichb. Ic. Fl. Germ. ii. 70. t. 178.

-Europ.; Reg. Caucas.

armenum, Boiss. \& Kotschy, ex Boiss. Fl. Orient. ii. $845=$ kurdicum.

asperuloides, Heldr. in Boiss. Diagn. Ser. II. vi. 76.Graecia.

Aucheri, Boiss. in Ann. Sc. Nat. Sér. III. i. (1844) $148=$ brevicaule.

aureum, Fisch. in Hoffm. Gen. Umb. 115.-Sibir.

australe, Jord. Pugill. $72=$ Gerardi.

badium, Rochel \& Lang, ex Sant. in Flora, ix. (1826) $177=$ junceum.

Balansae, Boiss. \& Reut. Diagn. Ser. II. ii. 83.-Afr. bor.

baldense, Host, Syn. 141.-Europ.; Oriens.

baldense, Turr. in Giorn, Ital. i. (1765) $120=$ aristatum.

baldense, Waldst. \& Kit. Ic. Pl. Hung, Rar. iii. 285. t. $257=$ junceum.

Barcelloi, Coss. ex Willk. in Linnaea, xl. (1876) 83.Afr. bor.

Baumgartenianum, Schur, Enum. P1. Transs. $252=$ petraeum.

bicalyculatum, Bell. Stirp. Nov. 4. t. 2 =stellatum.

bicaule, Helm. in Mém. Soc. Nat. Mosc. ii. (1809) 108. t. $8=$ baldense

\section{BUPLEURUM}

Bourgaei, Boiss. E Reut. Diagn. Ser. II. ii. 84.Hispan.

brachiatum, C. Koch, ex Boiss. Fl. Orient. ii. 844.As. Min.

Brasianum, Timb. in Mém. Acad. Toulouse, Sér. VIII iv. (1882) 128.-Gallia.

brevicaule, Schlecht. in Linnaea, xvii. (1843) 124.Syria.

Burserianum, Willd. Enum. Hort, Berol. Suppl. $14=$ angulosum.

canalense, Wulf. ex Spreng. in Roem. \& Schult. Syst. vi. $371=$ ranunculoides.

canariense, Spreng. Syst. i. $882=$ Astydamia cana riensis.

Candollii, Wall. Cat. n. 552.-Reg. Hima].

canescens, Schousb. Vextr. Marokkko, 127.-Marocco. capillare, Boiss. E Heldr, Diagn. Ser, II. ii. 82.Graecia.

capitatum, Thunb. Prod. Pl. Cap, $50=$ Hermas capitata.

cappadocicum, Boiss. in Ann. Sc. Nat. Sér. III. i (1844) 146.-As. Min.; Syria.

caricifolium, Willd. Sp. Pl. i. $1373=$ ranunculoides caricinum, Reichb. Ic. Crit. ix. f. 1109, 1110 ranunculoides.

cernuum, Tenore, App. i. Cat. Hort. Neap. ; DC. Prod. iv. 131 = baldense

chinense, Franch. in Nouv. Arch. Mus. Par. Sér. II vi. (1883) 18. - China.

chinense, DC. Prod. iv. $128=$ falcatum.

chlorocarpum, Timb. E Feanb. in Mém. Acad. Tou louse, Sér. VI. v. (1867) 471, nomen.-Gallia.

Chouletti, Pomel, Nouv. Mat. Fl. Atl. 140.Algeria.

ciliatum, Thunb. Prod. Pl. Cap. $50=$ Hermas ciliata. citrinum, Hochst. in Lorent, Wanderungen, 337.Armenia.

collinum, D. Dietr. Syn. P1. ii. 951=Heteromorpha arborescens.

coloratum, Schur, Enum. PI. Transs. $254=$ aureum.

Columnae, Gass. Fl. Sic. Prod. $70=$ tenuissimum

commutatum, Boiss. E Bal. Diagn. Ser. II. vi. 75.-

Macedon.; As. Min.

compositum, Spreng. in Ges. Naturf. Fr. Berl. Mag. vi. (1812) 258.-Hab. ?

corbariense, Timb. in Mém. Acad. Toulouse, Sér. VIII. v. II. (1883) 139.-Mont. Pyren.

coriaceum, L'Hérit. Stirp. Nov. 139. t. $67=$ gibraltaricum.

corsicum, Coss. E Kral. Notes Crit. 56.-Corsica

croceum, Fenzl, Pugill. Pl. Nov. Syr. 16.-As. Min. Syria.

uspidatum, Bunge, in Mém. Acad. Pétersb. vii. (1854) 299; (Lehm. Rel. 123)= linearifolium.

dahuricum, Fisch. E' Mey, ex Turcz. in Bull. Soc. Nat. Mosc. xvii. (1844) 720,721-Dahnria.

densiflorum, Rupr. Sert. Tiansch. 47.-As. centr.

denticulatum, Bellard, ex Spreng. in Roem. \& Schult. Syst. vi. $396=$ petraeum.

dianthifolium, Guss. Suppl. Fl. Sic. Prod. i. 71,Sicilia.

dichotomum, Boiss, Diagn Ser. I x. 28.-Syria.

dichotomum, Stev. in Bull. Soc. Nat. Mosc. xxix. (1856) II. 342 , in textu $=$ Gerardi.

difforme, Linn. Sp. Pl. 238.-Afr. austr.

dilatatum, Schur, Enum. PI. Transs. $253=$ falcatum.

distichophyllum, Wight \& Arn. Prod. i. 970.Ind. or.

divaricatum, Lam. F1. Fr. iii. $410=$ B. Odontites

divaricatum, Steph. ex Ledeb. Fl. Ross. ii. $262=$ gracile.

diversifolium, Rochel, Banat. 68. t. $28=$ baldense.

dumosum, Coss. E Bal. in Bull. Soc. Bot. Fr. xx. (1873) 249 ; xxii. (1875) 59.-Marocco.

elatum, Guss, Fl. Sic. Prod. i. 316.-Sicil.

erubescens, Boiss. Fl. Orient. ii. 841.-Lycia.

exaltatum, Bieb. Beschr. Casp. $156=$ baldense.

exaltatum, Schur, Enum. P1. Transs. $258=$ subfalcatum.

falcatum, Berg. Desc. P1. Cap. 76, partim = Mundtii.

falcatum, Dalz. \& Gibs. Bomb. Fl. $108=$ mucronatum.

falcatum, Linn. Sp. Pl. 287.-Europ.; Oriens; As. bor,; Reg. Himal.

falcatum, Turcz. in Bull. Soc. Nat. Mosc. xvii. (1844) $721=$ dahuricum.

filicaule, Brot. Fl. Lussit. i. 452-Lusitan.

\section{BUPLEURUM}

flavicans, Boiss. \& Heldr. Diagn. Ser. II. vi. 74.Aetolia.

flavum, Forsk. Fl. Aegypt. Arab. 205 (sp. dub.) glumaceum?

flexuosum, Ledeb. Fl. Ross, ii. 267.-Dahuria.

flexuosum, Moench, Meth. 88 = falcatum.

flexuosum, Wall. Cat, n. $554=$ tenue

foliosum, Salzm. ex DC. Prod. iv. 133.-Marocco

Fontanesii, Guss. Ind. Sem. Hort. Boce. $(1825)=\mathrm{B}$ Odontites.

frutescens, Hill, Veg. Syst, vi. $21=$ fruticosum.

fruticans, Steud. Nom. ed. I. $128=$ difforme.

fruticescens, Bourg. ex Nym. Consp. $310=$ foliosum.

fruticescens, Linn. Cent. Pl. i. 9.-Reg. Mediterr. occ

fruticosum, Linn. Sp. Pl. 238.-Reg. Mediterr.

Gerardi, Colm. ex Nym. Consp. $312=$ junceum

Gerardi, Gaertn. Mey. \& Scherb. Fl. Wett. i. $403=$ tenuissimum.

Gerardi, Facq. Fl. Austr. iii. 31, t. 256.--Europ.austr. Oriens.

Gerardi, Pollini, Ving. Lag. Gard, 15, $81=$ B. Odontite

Gerardi, Sibth. \& Sm. Fl. Graec. t. $262=$ trichopodum.

Gerhardi, Georgi, Beschr. Russ. Reich. iii. Iv. 828 Gerardi.

gibraltaricum, Lam. Encyc. i. 520.-Lusitan.; Marocco.

giganteum, Thunb. Prod. Pl. Cap. $50=$ Hermas gigantea.

glaucum, Rabill. \& Cast. ex DC. Fl. Fr. Suppl. 515Reg. Mediterr.

glumaceum, Sibth. EN Sm. Fl, Graec, Prod i. 177. Graecia ; As. Min.

gracile, DC. Prod. iv, $128=$ Marschallianum.

gracile, Urv. in Mém. Soc. Linn. Par. i. (1822) $28=$ glumaceum.

gracillimum, Klotzsch, in Bot. Ergeb. Waldem. Reise, $148=$ falcatum

gramineum, Vill. Prosp. $23=$ baldense.

graminifolium, Favre, in Bull. Soc. Morith. v. (1875) $85,250=$ stellatum

graminifolium, Georgi, Beschr. Russ. Reich. iii. IV, $828=$ exaltatum

graminifolium, Lapeyr. Hist. Abr. Pl. Pyr. $139=$ ranunculoides.

graminifolium, Salisb. Prod. $160=$ B. Odontites,

graminifolium, Vahl, Symb. Bot. iii. $48=$ petraeum.

Haussknechtii, Boiss. Fl. Orient. ii. 843.-Kurdistan.

Heldreichii, Boiss. \& Bal. Diagn. Ser. II. vi. 75.As. Min.

heterophyllum, Jacquem. ex C. B. Clarke, in Hook. f. Fl. Brit. Ind. ii. $675=$ jucundum.

heterophyllum, Link, Enum. Hort. Berol. i. $262=$ protractum.

heterophyllum, Kochel, Banat. t. 28 = baldense

himalayense, Klotzsch, in Bot. Ergeb. Waldem. Reise, $146=$ longicaule.

hispanicum, Pers. Syn. i. $305=$ fruticescens.

Hoffmeisteri, Klotzsch, in Bot. Ergeb. Waldem. Reise $147=$ falcatum

humile, Vest, ex Reichb. Ic. Fl, Germ, ii. $71=$ aris tatum.

imaicolum, Kern, in Ber. Naturry, Ver. Innsbruck, i.

(1870) 115 (Nov. Pl. Sp. Dec. ii. 19)=falcatum.

incurvum, Bell. A pp. Fl. Pedem. 77. t. $11=$ petraeum. intermedium, Stead. Nom. ed. I. $128=$ protractum. irregulare, Boiss. \& Kotschy, ex Boiss. Fl. Orienl. ii. $850 .-$ Syria.

Facquinianum, Jord. Pugill. $71=$ Gerardi.

jucundum, Kurg, in fourn. Bot. v。 (156i) 24u.

Himal. bor. occ.; Reg. Amur.

junceum, Bieb. Fl. Taur. Cauc. i. $204=$ affine.

junceum, Linn. Sp. Pl, ed. II. 348.-Europ. austr. jenceum, Pall. Ind. Taur. ex Bieb. Beschr. Casp. ltiti =exaltatum.

junceum, Pollich, Fl. Palat i. $264=$ tenuissimum.

Kargli, Vis. Fl. Dalm. iii. 85.-Dalmat.

Koechelii, Fensl, Pugill. Pl. Now. Syr. 17.-A Min.

kokanicum, Reget \& Schmalh. ex Ragel, Pl. Nir Fedsch. 29-As, centr.

Kotschyanum, Boiss. Dingn. Ser. I. x. $29=$ linearifolium.

kurdicum, Boiss. in Ann. Sc. Nat. Ser. III. i. (18t4 146.-As. Min.; Syria; Persia.

lanceolatum, Hall. Cat. D. 551.-Reg. Himal.

lancifolism, Hornem. Cat. Hort. Hafn. i. $26^{\circ}$ protractura. 


\section{BUPLEURUM}

laricense, Gaut. Eg Timb, in Mém. Acad. Toulouse, Sér. VIII. iv. (1882) 130.-Gallia.

lateriflorum, Coss. in Bull. Soc. Bot. Fr. xxii. (1875) 59.-Marocco.

leucocladum, Boiss. in Ann. Sc. Nat. Sér. III. i. (1844) 144.-Assyria.

libanoticum, Boiss. E" Blanche, Diagn. Ser. II. ii. 82. -Syria.

linearifolinm, DC. Prod. iv. 131.-Persia; Arab.; Turkest.

longepetiolatum, Weiss, in Verh. Zool.-Bot. Ges. Wien, xvi. (1866) $581=$ Kargli.

longeradiatum, Turcz, in Bull. Soc. Nat. Mosc. xvii (1844) 719.-Sibir. baical.

longicaule, Wall. Cat.n. 557.-Reg. Himal.

longifolium, Falk, Beitr. ii. 144=aureum.

longifolium, Linn. Sp. Pl. 237.-Europ.

lophocarpum, Boiss. E Bal. Diagn. Ser. II. v. 97.Cilicia.

Maddeni, C. B. Clarke, in Hook. f. Fl. Brit. Ind. ii. 678.-Reg. Himal

mareoticum, Delile, ex DC. Prod. iv. $129=$ nodi florum.

marginatum, Wall. Cat. a. $566=$ falcatum

Marschallianum, C. A. Mey. Verz. Pfl. Cauc. 123.Graecia; As. Min.; Persia.

minimum,Clarke, Trav. ii. 644 ; Spreng. Neue Entdeck. iii. $163=$ nodifforum

montanum, Coss. E Dur. in Bull. Soc. Bot. Fr. iii. (1856) 706.-Algeria.

mucronatum, Brouss. ex Spreng. in Roem. \& Schult. Syst. vi. $377=$ fruticescens.

mucronatum, Wight \& Arn. Prod. 370.-Ind. or

multinerve, DC. in Mém. Phys. Soc. Genèv. iv. (1828) 500.-Sibir. altaic.

Mundtii, Cham. E Schlecht. in Linnaea, i. (1826) 384. -Afr. austr.

nanum, Poir. Encyc. Suppl. i. $750=$ nodiflorum.

nebulosum, Haussk, ex Boiss. Fl. Orient, ii. $847=$ cappadocicum.

neglectum, Cesati, in Linnaea, xi. (1837) $314=$ baldense.

nervosum, Boiss. \& Buhse, in Nouv. Mém. Soc. Nat. Mosc. xii. (1860) $97=$ polyphyllum.

nervosum, Moon, Cat. 22= mucronatnm.

nervosum, Schousb. ex Ball, in Journ. Linn. Soc. xvi. (1878) $464=$ paniculatum.

nervosum, Trev. Symb. Phytol. i. $22=$ multinerve

nigrocarpa, Jacquem. ex C. B. Clarke, in Hook. f. Fl, Brit. Ind. ii. $676=$ falcatum

nodiflorum, Sibth. E Sm. Fl. Graec. t. 260-Graecia; Syria ; Aegypt

Nordmanniantm, Bal. ex Boiss. F1. Orient. ii. $851=$ polyphyllum

Nordmannianum, Ledeb. Fl. Ross. ii. $265=$ baldense. nudum, [Soland. in] Ait. Hort. Kerv. ed. I. i. 331.Afr, austr.

obliquatum, Schousb. ex Ball, in Journ. Linn. Soc. xvi. (1878) $466=$ foliosum.

obliquum, Vahl, Symb, Bot.i. $24=$ gibraltaricum.

oblongifolium, Ball, in fourn. Linn. Soc. xvi. (1878) 466 - Marocco.

obtusatum, Lapeyr. Hist. Abr. PI. Pyr. Suppl. ii. 42 = angulosum.

obtusifolium, Tenore, Prod. Fl. Nap. p. xviii = baldense.

octoradiatum, Bunge, in Mém. Sav. Etr. Pétersb. ii. (1830) 106. - China bor.

Odontites, Linn. Sp.Pl. 237-Europ. : Reg. Mediterr

Odontites, Sm. Engl. Bot. t. 2468 (1812); Lapeyr. Hist. Abr. P1. Pyr. 141 (1813)= aristatum.

odontitum, St. Lag, in Ann. Soc. Bot. Lyon, vii. (1880) $67,121=\mathrm{B}$. Odontites.

oligactis, Boiss. Diagn. Ser. II. ii. 84.-Hispan. Marocco.

olympicum, Boiss, in Ann. Sc. Nat. Sér. III. i. (1844) $149=$ baldense

opacum, Lange, in Willk. \& Lange, Prod. Fl. Hisp, iii. 71 = aristatum

oppositifolium, Lapeyr. Hist.Abr. Pl. Pyr. 141.-Mont. Pyren.

pachnospermum, Panč. Fl. Princ. Serbiae (1874) 329. - Banat.

panacifolium, Hornem. ex Steud. Nom. ed. II. i. 240 $=$ heterophyllum.

paniculatum, Bourg. ex Willk. \& Lange, Prod. Fl. Hisp. iii, $74=$ Bourgaei

\section{BUPLEURUM :}

paniculatum, Brot. Fl. Lusit. i. 455.-Lusit. ; Marocco. paniculatum, Willk. ex Willk. \& Lange, Prod. Fl. Hisp. iii. $74=$ rigidum.

papillosum, DC. Prod. iv. 127.-Mesopotam.

pauciradiatum, Fensl, in Tchihat. Asie Min. Bot. i 418.-Cilicia.

perfoliatum, Lam. F1. Fr. iii. 405=rotundifolium.

persicum, Boiss. in Ann. Sc. Nat. Sér. III. i. (1844) 150 $=$ baldense.

petiolare, Lapeyr. Hist. Abr. P1. Pyr. 141 = falcatum. petraeum, Geners. ex DC. Prod. iv. $131=$ angulosum. petraeum, Georgi, It. i. $204=$ exaltatum.

petraeum, Linn. Sp. Pl. 236.-Europ.

petraeum, Wulf, in Jacq. Coll. ii. $209=$ graminifolium. petrogenes, Jord. ex Nym. Consp. $311=$ falcatum. petroselinoides, Spreng. Pl. Umb. Prod. $39=$ Carum peregrinum.

plantagineum, Desf. Fl. Atlant. i. 233. t. 57.Marocco.

plantaginifolium, Wight, Ic, i. t. 281.-Ind. or

Pollichii, C. C. Gmel. Fl. Bad. 1. $613=$ tenuissimum

polyphyllum, Ledeb. in Mém. Acad. Pétersb. v. (1815) 528.-Reg. Caucas.

procumbens, Desf. F1. Atlant, i. 230.t. $56=$ tenuissimum proliferum, Delile, Fl. Egypte, 205. t. 22 =nodiflorum prostratum, Ledeb. ex Loud. Hort. Brit. Suppl. ii. 615. -Sibir, altaic.

protractum, Hoffmgg. E Link, Fl. Port. ii. 387.-

Reg. Mediterr. or.

provinciale, Huet, ex Timb. in Mém. Acad. Toulouse, Sér. VIII. iv. (1882) 131-Gallia.

pruinosum, Cesati, ex Boiss. Fl. Orient. ii. $849=$ baldense.

pulchellum, Boiss. E Heldr. Diagn. Ser. I. x. 27.Pamphylia.

pyrenaeicum, Willd. Sp. Pl. i. $1371=$ angulosum

pyrenaeum, Gonan, Illustr 8, t. 4 =angulosum.

quinqueden $[$ ta $]$ tum, Thunb. Prod. P1. Cap. $50=$

Hermas quinquedentata.

quinqueradiatum, Steud. Nom. ed. II. i. 240, sphalm. = praec.

ramosissimum, Wight \& Am. Prod. $370=$ mucronatum. ramosum, Gaut. ex Timb. in Mém. Acad. Toulouse, Sér. VIII. iv. (1882) 136.-Gallia.

ranunculiformis, St. Lag. in Ann. Soc. Bot. Lyon, vii. 1880) $67=$ seq.

ranunculoides, Linn. Sp. Pl. 237.-Reg. bor. temp.

ranunculoides, Sibth. \& Sm. FI. Graec. Prod. i. 178=

baldense.

repens, Lapeyr. Hist. Abr. Pl, Pyr. $140=$ ranunculoides. rigidum, Frey, ex Reichb. Ic. FI. Germ. xxi. $21=$ baldense.

rigidum, Georgi, Beschr. Russ. Reichb. iii. IV. $828=$ Gerardi.

rigidum, Linn. Sp. Pl.238.-Gall. austr.

Rissoni, Rich. ex DC. Prod. iv. $128=$ affine

rotundifolium, Linn. Sp. Pl. 236.-Europ.; Reg Cancas.; Persia.

rotundifolium, Schousb. Vext. Marokko, $126=$ protractum.

rupestre, Edgew. in Trans. Linn. Soc. xx. (1851) $52=$ longicaule.

rupestre, Rafin. in Med.Repos. N. York, v. (1808) 352, nomen.-Hab.?

sachalinense, F. Schmidt, Reisen Amurl. $135=$ jucundum.

salicifolium, Soland. ex Lozve, in Trans. Camb. Phil. Soc, vi. (1838) repr. 21.-Ins. Madera.

Savignonii, De Not. in Mem. Acc. Tor. ix. (1848) 208. -Italia.

saxatile, Pall. Reise, ii. $676=$ baldense

scabrum, Griseb. Spicil. Fl. Rumel. i. $348=$ brevicaule. Schefferi, Hampe, ex Nym. Consp. $313=$ filicaule.

Schimperi, Boiss. in Ann. Sc. Nat. Sér. III. i. (1844)

$151=$ linearifolium.

scorzoneraefolium, Willd. Enum. Hort. Berol. Suppl. $30=$ falcatum.

semicompositum, Hochst. \& Steud. ex Steud. Nom. ed.

II. i. $240=$ aristatum.

semicompositum, Linn. Amoen. Acad. iii. 405.-Europ. austr.

semicompositum, Pall. Ind. Taur. ex Bieb. Fl. Taur.

Cauc. i. $205=$ junceum

semicompositum, Sibth. \& Sm. Fl. Graec. Prod. i. 176 = glaucum.

semidiaphanum, Boiss. Diagn. Ser. II. vi. 73.Graecia et Ins.
BUPLEURUM :-

semiperfoliatum, Griseb. Spicil. FI. Rumel. i. $350=$ croceum.

setaceum, Fenzl, in Tchihat. Asie Min. Bot. i. 418.Bithynia; Himal. bor. occ.

sibiricum, Vest, ex Roem. \& Schult. Syst. vi. $368=$ angulosum.

Sibthorpianum, DC. ex Boiss. F1. Orient. ii. $849=$ linearifolium

Sibthorpianum, Sibth. \& Sm. F1. Graec. Prod. i. $179=$ baldense.

spinosum, Gouan, Illustr. 8.-Hispan. ; Afr. bor. occ Sprunerianum, Hampe, in Flora, Xxv. (1842) I. $63=$ B. Odontites.

stellatum, Lapeyr. Hist. Abr. Pl. Pyr. $139=$ angulosum.

stellatum, Linn. Sp.Pl. 236.-Europ. austr.

striatum, Steph. ex Roem. \& Schult. Syst. vi. $367=$ multinerve.

subfalcatum, Schur, Enum. Pl. Transs, 253.Transsylv.

subovatum, Link, ex Spreng. Sp. Umb. $19=$ protractum. subpinnatum, Ledeb, in Eichw. P1. Nov. Casp. Cauc. 13. t. $11=$ Carum segetum.

subrubeum, Dulac, F1. Hautes-Pyr. $346=$ ranunculoides. subuniflorum, Boiss. E" Heldr. Diagn. Ser. I. x. 28. -Pamphylia.

sulcatrm, Steud. Nom. ed. II. i. $240=$ Mundtii.

sulphureum, Boiss. E" Bal. Diagn. Ser. II. vi. 74.As. Min.

telonense, Gren. ex Nym. Consp. 311=ranunculoides. tenue, Buch.-Ham. ex D. Don, Prod. Fl. Nep. 182.Reg. Himal,

tenue, Salisb. Prod. $160=$ tenuissimum

tenuifolium, Pourr. ex Nym. Consp. 311 = baldense.

tenuissimum, Linn.Sp. Pl. 238.-Europ.; Afr. bor

terminale, Salisb. Prod. $160=$ fruticosum.

Thomsoni, C. B. Clarke, in Hook. f. Fl. Brit. Ind. ii. 675.-Reg. Himal.

tortnosum, Schousb. ex Ball, in Fourn. Linn. Soc. xvi (1878) 466.-Marocco.

transsilvanicum, Schur, Enum. Pl. Transs. $253=$ baldense.

trichopodum, Boiss. E Sprun. in Ann. $S_{C}$. Nat. Sér.

III. i. (1844) 145.-Graecia ; As. Min.

trifidum, Tenore, Prod. F1. Nap. $18=$ junceum.

trifoliatum, Wendl. \& Bartl. Beitr. ii. $\mathbf{1 3}=$ Heteromorpha trifoliata.

triradiatum, Adams, ex Hoffm. Umb. 115.-Sibir.

vapincense, Vill. Prosp. $23=$ longifolium.

Vanheurckii, Muell. Arg. in Heurck, Obs. Bot. 207.-

China.

veronense, Turra, F1. Ital. Prod. $64=$ B. Odontites.

verticale, Orteg. Fl. Esp. ex DC. Prod. iv. $133=$ gibraltaricum.

villosum, Linn. Sp. PI $238=$ Hermas villosa.

virgatum, Brot. ex Steud. Nom. ed. II. i. $240=$ fruticescens.

virgatum, Cav. Desc. i. $121=$ Gerardi.

virgatum, Wall. Cat. n. $555=$ falcatum

virgatum, Wight \& Arn. Prod. $370=$ mucronatum

Wittmanni, Stev. in Bull. Soc. Nat. Mosc. xxix. (1856)

II. $342=$ rotundifolium.

BUPRESTIS, Spreng. in Ges. Naturf. Fr. Berl. Mag, vi.

(1812) $258=$ Bupleurum, Tourn. (Umbell.).

arborescens, Spreng. 1. c. $259=$ Heteromorpha arborescens.

coriacea, Spreng. 1. c. = B. gibraltaricum.

difformis, Spreng. 1. $\mathrm{c}_{\mathrm{c}}=\mathbf{B}$. difforme

exaltata, Spreng. 1. c. = B. baldense.

frutescens, Spreng. 1. c. = B. fruticescens.

fruticosa, Spreng. 1. c. = B. fruticosum.

Gerardi, Spreng. 1. c. = B. Gerardi

gigantea, Spreng. 1. c. = Hermas gigantea

juncea, Spreng. 1. c. = B. junceum.

latifolia, Spreng. 1. $\mathrm{c}_{n}=$ Astydamia canariensis

BURAEAVIA, Baill. Adansonia, xi. (1873) 83 EUPHORBIACEAE, Benth. \& Hook. f. iii. 280 . carunculata, Baill. l. c. 84.-N. Caled.

clusiacea, Baill. l. c.-N. Caled.

BURASAIA, Thou. Gen. Madag. 18 (1806); et in Roem. Collect. 209 (1809); DC. Syst. Veg. i. 514 (1818). MENISPERMACEAE, Benth. \& Hook. f i. 39,960 . 
BURASAIA :-

Congesta, Decne in Ann. Sc. Nat. Sér. II. xii. (1839) 108.--Madag.

gracilis, Decne. l. c.-Madag.

madagascariensis, DC. Syst. i. 514.-Madag.

Vitis, Mello, in Fourn. Linn. Soc. xiv. (1875) 4.-

Bras.

BURBIDGEA, Hook. f. Bot. Mag. t. 6403 (1879). SCITAMINEAE, Benth. \& Hook. f. iii. 647. nitida, Hook. f. l. c.-Borneo.

BURCARDA, J. F. Gmel. Syst. $514(1791)=$ seq.

BURCARDIA, Schreb. Gen. i. $530(1789)=$ Piriqueta, Aubl. (Turnerac.)

aromatica, Rafin. Sylva Tellur. 106.-Hab.?

grandiflora, Rafin. 1. c.-Hab.?

villosa, J. F. Gmel. Syst. ii. $514=$ P. villosa.

BURCHARDIA, [Heist.] Duham, Arb. i, 111, t. 44 $(\mathbf{1 7 5 5})=$ Callicarpa, Linn. (Verbenac.) americana, Duham. $1 . \mathrm{c}_{\mathrm{s}}=\mathrm{C}$. americana. Callicarpa, Crantz, Inst. ii. $360=$ C. americana.

BURCHARDIA, R. Br. Prod. 272 (1810), LILIA $C E A E$, Benth. \& Hook. f. iii. 82? congesta, Lindl. Swan River App. $58=$ umbellata multiflora, Lindl. l. c. =umbellata.

umbellata, $R$. Br. Prod.273.-Austral.

BURCHELLIA, R, Br, in Bot. Reg. t, $466(1820)$ RUBIACEAE, Benth. \& Hook. f. ii. 85.

Bubalina, Rafin. in Ann. Gén. Sc. Phys. vi. (1820) 86.

Bubalina, Sims, Bot. Mag. t. $2339=$ capensis. capensis, R. Br. in Bot. Reg. t. 466.-Afr. austr. Kraussii, Hochst. in Flora, xxv. (1842) $237=$ capensis. inajor, Hort. ex Heynh. Nom. ii. 83 = capensis. parviflora, Lindl. Bot. Reg. t. $891=$ capensis. speciosa, Hort. ex Heynh. Nom. ii. $83=$ capensis.

BURDACHIA, Mart, ex A. Juss. in Ann. Sc. Nat Sér. II. xiii. (1840) 329. MALPIGHIACEAE, Benth. \& Hook. f. i. 252

macrocarpa, Benth. ex Griseb. in Mart, F1. Bras. xii 1. $23=$ Glandonia macrocarpa.

prismatocarpa, Mart. ex A. Fuss. in Ann. - S6. Nat. Sér. II. xiii. (1840) 330 .- Bras.

pyramidata, Mart. ex Griseb. in Mart. F1. Bras. xii. 1. $23=$ prismatocarpa.

sphaerocarpa, A. F $\iota s s$. in Ann. Sc. Nat. Sér. II. xiii. (1840) $330 .-$ Bras.

BUREAVA, Baill, Adansonia, i. $71(1860-61)=$ Com bretum, Linn.

crotonoides, Baill. 1. c. $72=$ C. altum.

BURGESIA, F. Muell. Fragm. i. $222(1859)=$ Brachy sema, R. Br.

homaloclada, F. Muell. 1. c. = Brachysema aphyllum.

13URGHARTIA, Scop. Introd. $229(1777)=$ Piriqueta, Aubl. (Turnerac.)

villosa, J. F. Gmel. Syst. $514=$ P. villosa.

BURGLARIA, Wendl. ex Steud. Nom. ed. I. 129 (1821) = Ilex, Tourn.

incida, Wendl. 1. c. = I. salicifolia.

BURGSDORFIA, Moench, Mtth. $392(1794)=$ Sideritis, Tourn. (Labiat.).

montana, Reichb. Fl. Germ. Excurs. $327=$ S. montana.

rigida, Moench, Meth. $392=$ S. romana.

romana, Hoffmgg. \& Link, Fl. Port. i. $97=$ S. romana.

BURKEA, Benth. in Hook. Ic, Pl. t. 593 (1843) LEGUMINOSAE, Bench. \& Hook. f. i. 587. africana, Hook. l. c. tt. 593, 594.-Afr. anstr. Caperangan, Baill. Hist. Pl. ii. 167.-Afr. trop.

BURKHARDIA, Benth. \& Hook. f. Gen. i. 1007 (1867) BURGHARTIA, Scop. = Piriqueta, Aubl.
BURLINGTONIA, Jindl. Bot. Reg. t. 1927 (1837) Rodriguezia, Ruiz \& Pav. (Orchid.

Batemani, Linden, 1llustr. Hortic. xxviii. (1881) $64=$ R. Batemanni.

candida, Lindl. Bot. Reg. xxiii. (1837) sub t. $1927=$ R. candida.

carnea, Lindl, ex Linden, Illustr. Hortic, xxviii. (1881 $80=\mathrm{R}$, carnea.

decora, Lem. Jard. Fleur. ii. (1852) Misc. $96=\mathrm{R}$ decora.

fragrans, Lindl. Bot. Reg. xxiii. (1837) sub t. 1927 $=\mathrm{R}$. fragrans.

granadensis, Lindl. Orchid. Linden, $24=$ R. grana densis.

maculata, Lindl. Bot. Reg. xxv. (1839) $44=\mathrm{R}$. maculata.

obtusifolia, Lindl. Sert. Orch. (1840) sub t. $36=\mathrm{R}$. obtusifolia.

pubescens, Lindl. \& Paxt. Flow. Gard. i. (1851) 158 $=$ R. pubescens.

refracta, Lindl. ex Linden, Illustr. Hortic. xxviii. (1881) $80=\mathrm{R}$. refracta.

gida, Lindl. ex Lem. in Fl. des Serres, i. (1845) 11

t. $2=\mathrm{R}$. rigida.

rubescens, Lindl. Bot. Reg. xxiii. (1837) sub t. 1927.-Peruv.

scintillulans, Lem. Jard. Fleur. iii. (1852-53) Misc. 66. -Bras.

venusta, Lindl. ex Lem. Illustr. Hortic. v. (1858) t. $188=\mathrm{R}$. venusta.

BURMANNIA, Linn. Syst, ed. I (1735). BUR $M A N N I A C E A E$, Benth. \& Hook. f. ii. 457.

CyananTHUS, Miers, in Wall. Cat. nn. 9007-8(1849) Cyanotis, Miers, 1, c. n. 9006 (1849)

Cryptonema, Turcz. in Bull, Soc. Nat. Mosc. xxi (1848) I. 590

Gonianthes, Blume, Cat. Gew. Buitenz. (1823) 19 Maburnia, Thou. Gen. Nov. Madag. 4 (1806)

NePhrocoelium, Turcz. in Bull. Soc. Nat. Mosc (1853) I. 287.

TETrAPterA, Miers, in Lind1, Veg. Kingd. 172 (1847).

Tripteranthus, Wall. ex Miers, 1. c. (1847)

Tripterella, Michx. Fl. Bor. Am, i. 19.t. 3 (1803

Vogelia, J. F. Gmel. Syst. 107 (1791).

alba, Mart. Nov. Gen. et Sp. i. 12.-Bras.

azurea, Griff. Notul. iii. $236=$ coelestis

bancana, Miq. Fl. Ind. Bat. Suppl. 617.-Ins. Banca.

bicolor, Mart. Nov. Gen. et Sp. i. 10. t. 5.-Bias.

billora, Linn. Sp. Pl. 287.-Am. bor.

brachyphylla, Willd. ex Schult. $f$. Syst. vii. I1. p. Ixxv. - Venezuela.

brachystachya, Miq. in Linnaea, xix. (1847) 141.Guiana.

capensis, Mart. Nov. Gen. et Sp. i. 12.-Afr. austr

capitata, Mart. l. c.-Am. bor.

Championii, Thw. Enum. Pl. Zevl. 325.Zeylan.

coelestis, D. Don, Prod. F\%. Ncp. 44.-As. trop.

Austral.

dasyantha, Mart. Nov. Gen. et Sp. i. 11.-Bras.

distachya, R. Br. Prod. $265=$ disticha.

disticha, Linn. Sp. Pl. 2ऽ7.-As. trop. ; Austral

flava, Mart. Nov. Gen. et Sp. i. 11. t. 5. f. 2.-Bras.

flavula, Wright, in Sauv. Fl. Cub. 165.-Cuba

Geelvinkiana, Becc. Malesia, i. (1878) 244.-Malavn.

javanica, Blume, Enum. Pl. Fav. fasc. i. 28 - Java

juncea, Soland. ex R. Br. Prod. 265.-Austral.

Kalbreyeri, Oliver, in Hook. Ic. Pl.t. 1357.-N. (irnat.

longifolia, Becc. Malesia, i. (1878) 244.-Malaya.

lutescens, Becc. l. c. 246. - Malaya.

madagascariensis, Baker, in Fourn. Linn. Soc. $x x$

(1884) 268.-Madag.

madagascariensis, Mart. E Zucc. Nov. Gen. et Sp. 12.- Madag.

paniculata, Willd. ex Schult.f. Syst. vii. II. p. Ixxiv

- Madag.

pusilla, Thw. Enum. Pl. Zoyl. 325.-Zeylan.

quadriflora, Willd. ex Schult. f. Syst. vii. 72.

Ixxiv. -Guians.

selebica, Becc. Malesia, i. (1878) 243.-Ins. Celetes

Sellowiana, Seub. in Mart. Fl. Bras. iii. 57. t. 7. f. 2. -Bras.

sphagnoides, Becc. Malesia, i. (18;8) 246,-Malaya sumatrana, Miq. Fl. Ind. Bat. Suppl, 617 = disticha. tenella, Benth. in Hook. Kex fourn. vii. (1855) 12 -Bras

tridentata, Becc. Malesia, i. (1878) 246.-Malaya,

\section{BURMANNIA:}

triflora, Roxb. Hort. Beng. [87]; F1. Ind. ii. 117 coelestis.

tuberosa, Becc. Malesia, i. (1878) 245.-Malaya. uniftora, Rottl. ex Spreng. Syst. iv. Cur. Post. $23=$ coelestis.

BURMEISTERA, Karst. \&c Triana, in Linnaea, xxvii. (1856) 444. CAMPANULACEAE, Benth. \& Hook. f. ii. 547 .

acuminata, Karst. l. c. 445-N. Granat.

glabrata, Benth. E Hook. f. Gen. ii. 547.-N. Granat.

ibaguensis, Karst. in Linnaea, xxviii. (1856) 444.-N Granat.

lacerata, Karst. l. c. 445,-N. Granat

Matthiaei, Benth. E Hook. f. Gen. ii. 547.-Peruv.

marginata, Karst. in Linnaea, xxviii. (1856) 445.-N Granat.

pomifera, Karst. l. c.-N. Granat.

succulenta, Karst. l. c.-N. Granat

tomentosula, Karst. l. c. $-\mathrm{N}$. Granat

virescens, Benth. E Hook. f. Gen. ii. 547.-Guatemala.

BURNATIA, Micheli, in DC. Monog. Phan. jii. 81 (1881). ALISMACEAE, Benth. \& Hook. fo iii 1007.

enneandra, Micheli, l. c.-Nubia

BURNETTIA, Lind]. Gen. et Sp. Orch. 517 (1840 ORCHIDEAE, Benth. \& Hook. f. iii. 612

cuneata, Lindl. l. $c$. 518.-Tasmania.

BURNEYA, Cham. \& Schlecht, in Linnaea, iv. (1829) $189=$ Timonius, Romph. et Bobea, Gaudich. (Rubiac.)

Forsteri, Cham. \& Schlecht. 1. c. $=$ T. Forsteri.

Gaudichaudii, Cham. \& Schlecht, 1. c. $190=$ B. Gaudi. chaudi.

BURRIELIA, DC. Prod. v. 663 (1836). COMPO SITAE, Benth. \& Hook. f. ii. 398

anthemoides, A. Gray, in Torr. Bot. Mex. Bound. 97 -Am. bor.

chrysostoma, Torr. \& Gray, F1. N. Am. ii. $379=$ Baeria chrysostoma.

Fremonti, Benth. Pl. Hartw. $317=$ Baeria Fremontii. gracilis, DC. Prod. v. $664=$ Baeria gracilis

hirsuta, Nutt in Trans. Am. Phil. Soc. Ser. II vii. (1841) $381=$ Baeria gracilis.

lanosa, A. Gray, in Pacif. Rail. Rep. iv. $107=$ Erio phyllum lanosum.

leptalea, A. Gray, in Proc. Am. Acad. vi. (1864-65 $546^{\circ}=$ Baeria leptalea

loncifolia, Nutt. in Trans. Am. Phil. Soc. Ser. II. vil. 1841) $380=$ Baeria gracilis.

maritima, A. Gray, in Proc. Am. Acnd, vii. (1865) $358=$ Baeria maritima.

microglossa, DC.Prod. v. 664.-Calif.

nivea, D. Eaton, in Bot. King, Exp. 174=Eatonella nivea.

parviflora, Nutt. in Trans. Am. Phil. Soc. Ser. II vii. 1811) $381=$ Baeria gracilis.

platycarpha, A. Gray, in Torr. Bot. Mex. Bound. $97=$ Baeria platycarpha.

tenerrima, DC. Prod. v. $664=$ Baeria gracilis ?

BURSA, [Weber, in] Wigg. Prim. Fl. Hols. 47 (1750) Capsella, Medic. (1792) (Crucif.

astoris, [Weber, ] 1. c. = C. Bursa-pastoris

BURSA-PASTORIS, [Toum.] Rupp. Fl. Jen. 77. ed. Hall. (1745) 87 = Capsella, Medic. (1792) (Crucif.

BURSAIA, Steud, Nom. ed. II. i. 211 (1810) sphalm. Burasaia, Thon. (Menisp.)

BURSARIA, Cav, Ic. iv. $\$ 0, \$ 50(179 \%)$ PITTO. SPOREAE, Benth. \& Hook. f. i. 132.

diosmoides, Putterl. Syn. Pittosp. $20=$ Marianthus pro cumbens.

incana, Lindl. in Mitch. Journ. Trop. Austral. 224 spinosi.

inermis, Blanco, Fl. Filip. ed. II. 124.-Ins. Philipp.

procumbens, Putterl. Syn. Pittusp. $20=$ Mraianthu. procumbens.

spinosn, Cav. Ic. iv. 30. t. $350 .-$ Austral.

Stuartiana. F. Muell, ex Klatt, in Linnaea, xxvii $1856^{\circ}, 580^{\circ}=$ Marianthus prucumbens 
BURSERA, 'Jacq. 'ex Linn. Sp. Pl. ed. Ii. 471 (1762) BURSERACEAE, Benth. \& Hook. f. i. 324.

Busseria, Cramer, Disp. Syst. 144 (1803).

Dammara, Gaertn. Fruct. ii. 100. t. 103 (1791).

Elaphrium, Jacq. Enum. Pl. Carib. 3 (1760); Stirp.

Am. i. 105. t. 71 (1763), nomen prius.

IcrCA, Aubl. Pl. Gui. i. 337. t. 130 ad 135 (1776)

Marignia, Comm, ex Kunth, in Ann. Sc. Nat. Ser. I. ii. (1824) 351 .

acuminata, Willd. Sp. P1. iv. $1120=$ Dacryodes hexandra.

acutifolia, Sieber, ex Steud. Nom. ed. II. i. $241=$ Sorindeia madagascariensis.

Aloëxylon, Engl. in DC. Monog. Phan. iv, 52.Mexic.

altissima, Baill. Hist. Pl. v. 297.-Guiana

angustata, Griseb. Cat. Pl. Cub. 65.-Cuba.

bahiensis, Salzm. ex Engl, in DC. Monog. Phan. iv $277,537=$ Tapiria guianensis

balsamifera, Pers. Syn. i. $413=$ Hedwigia balsami fera.

bicolor, Engl. in DC. Monog. Phan. iv. 53.-Mexic.

bipinnata, Engl.l. c. 49.-Mexic.

caudata, Turcz. in Bull. Soc. Nat. Mosc. xxxvi. (1863)

I. $614=$ Protium Sagotianum.

cinerea, Engl. in DC. Monog. Phan. iv, 43.-Mexic

cuneata, Engl. l. c. 56.-Mexic.

decandra, Baill. Hist. Pl. v. 262, 297.-Guiana.

Delpechiana, Poiss. ex Engl. in DC. Monog. Phan, iv. 53.-Mexic.

excelsa, Engl. l. c. 57.-Mexic.

fagaroides, Engl. l.c. 48-Mexic

Galeottiana, Engl.l. c. 47.-Mexic.

glabra, Triana E Planch. in Ann. Sc. Nat. Sér. V. xiv (1872) 304 -N. Granat

glauca, Griseb. Cat. Pl. Cub. 66.-Cuba.

gracilis, Engl. in DC. Monog. Phan. iv. 50.-Mexic

grandifolia, Enst.l.c. 45.-Mexic.

graveolens, Triana Eे Planch. in Ann. Sc. Nat. Sér.

V. xiv. (1872) 303.-Peruv.

guianensis, Baill. Hist. Pl. v. 297.-Guiana.

gummifera, Linn. Sp. Pl. ed. II. 471.-Am. trop.

heptaphylla, Wright, in Sauv. Fl. Cub. 20.-Cuba.

heterophylla, Engl. in DC. Monog. Phan. iv. 46.-

Mexic,

Hindsiana, Engl. l. c. 58.-N. Granat.

Icicariba, Baill. Hist. Pl. v. 297.-Bras.

integerrima, Triana E Planch. in Ann. Sc. Nat. Sér

V. xiv. (1872) 303.-N. Granat

javanica, Baill. Hist. Pl. v. 297.-Java.

jorullensis, Engl. in DC. Monog. Phan. iv. 57.Mexic.

Karsteniana, Engl. l. c. 41.-Venezuela.

Karwinskii, Engl. l. c.-Mexic.

Kerberi, Engl. l. c-Mexic.

lancifolia, Engl. l. c. 42-Mexic

lanuginosa, Engl. l. c. 58.-Mexic

leptophloeos, Mart. in Flora, xi. (1828) II. 393.Bras.

macrostachya, Turcz. in Bull. Soc. Nat. Mosc. xxxvi. (1863) I. 613.-Guiana:

Martiana, Enol. in Mart. Fl. Bras. xii. II. 253.Bras.

mexicana, Engl. in DC. Monog. Phan. iv. 51.Mexic.

microphylla, A. Gray, in Proc. Am. Acad.v. (1861) 155.-Mexic.

multijuga, Engl. in DC. Monog. Phan. iv. 42.Mexic.

obovata, Turcz. in Bull. Soc. Nat. Mosc. xxxvi. (1863) I. 614-Mexic.

obtusifolia, Lam. Encyc. ii. $768=$ Protium obtusifolium.

orinocensis, Engl. in Mart. Fl. Bras. xii. II. 254.Bras.

ovalifolia, Engl. in DC. Monog. Phan. iv. 40.Mexic.

paniculata, Lam. Encyc. ii. $768=$ Canarium mauritianum.

pannosa, Engl. in DC. Monog. Phan. iv. 54.Mexic.

penicillata, Engl. l. c. 52--Mexic

Schiedeana, Engl.l.c. 57.-Mexic.

Schlechtendalii, Engl. l. c. 41.-Mexic.

Sellowii, Turcz. in Bull. Soc. Nat. Mosc. xxxvi. (1863) I, 613.-Bras.

serrata, Wall. ex Coleb. in Trans. Linn. Soc. xv. (1827 361. t. 4 = Protium serratum.
BURSERA :-

sessiliflora, Engl. in DC. Monog. Phan. iv. 55.Mexic.

simplicifolia, $D C$. Prod. ii. 78.-Tamaic.

submoniliformis, Engl. in DC. Monog. Phan. iv. 55.Mexic.

Tacahamaca, Baill. Hist. Pl. v. 297 = Protium heptaphyllum.

Tatamaco, Triana E Planch, in Ann. Sc. Nat. Sér. V. xiv. (1872) 303.-N. Granat

tomentosa, Triana \& Planch. l. c. 304,-N. Granat.

BURSERIA, Loef. It. Hisp. $194(1758)=$ Verbena, Linn.

BURSERIA, Jacq. Stirp. Am. 94. t. 65 (1763)= Bursera, Linn.

BURSHIA, Rafin. in Med. Repos. N. York, v. (1808) $357=$ Myriophyllum, Linn. (Halorag.).

humilis, Rafin. 1. c. et vi. (1808) $422=$ M. ambiguum.

BURSINOPETALUM, Wight, Ic. t. $956(\mathbf{1 8 4 7})=$ Mastixia, Blume (Cornac.).

arboreum, Wight, 1. $\mathrm{c}_{\mathrm{s}}=\mathrm{M}$. arborea.

tetrandrum, Wight, ex Thw. Enum. PI. Zeyl. $42=$ M. tetrandra.

BURTONIA, R. Br. in Ait. Hort. Kew. ed. II. iii. 12 (1811). LEGUMINOSAE, Benth. \& Hook. f. i.

Weinea, Reichb, Consp, $212^{\mathrm{b}}$ (1828).

conferta, DC. Prod. ii. 106.-Austral.

diosmaefolia, Benth. Enum. Pl. Hueg. $82=$ Latrobea diosmifolia.

foliolosa, Benth. Fl. Austral. ii. 50.-Austral.

gompholobioides, F. Muell. Fragm. x. 34.-Austral.

Hendersonii, Benth. Fl. Austral. ii. 51.-Austral.

minor, DC. Prod. ii. $106=$ Gompholobium minus

polyzyga, Benth. Fl. Austral. ii. 51.-Austral.

pulchella, Meissn. in Lehm. Pl. Preiss. i. $41=$ scabra.

scabra, R. Br. in Ait. Hort. Kew. ed. II. iii. 12. Austral.

sessilifolia, DC. Prod. ii. $106=$ scabra

solanacea, Hort. ex Steud. Nom ed. II i. 241 Austral.

subalpina, F. Muell. in Trans. Phil. Soc. Victoria, i. (1855) $39=$ Pultenaea rosea.

subulata, Benth. Fl. Austral. ii. 50,-Austral.

tenella, Meissn. in Lehm. Pl. Preiss. i, $42=$ Latrobea tenella.

villosa, Meissn. l. c. 41.-Austral.

BURTONIA, Salisb. Parad. Lond. t. $73(\mathbf{1 8 0 7})=$ Hibbertia, Andr. (Dillen.).

grossulariaefolia, Salisb. 1. c. $=$ H. grossulariaefolia

BUSBECKEA, Endl. Prod. Fl. Ins. Norf. 64 (1833) = Capparis, Tourn.

arborea, F. Muell. Fragm. i. $163=\mathrm{C}$. nobilis.

canescens, F. Muell. 1 c. v $104=\mathrm{C}$. canescens corymbiflora, F. Muell. 1. c. vii. $163=$ C. lucida humistrata, F. Muell. 1, c. v. $156=$ C. humistrata. lorantifolia, F. Muell. l. c. i. $164=$ C. loranthifolia. Mitchellii, F. Muell. I. c.; et Vict. PI. i. $53=$ C. Mitchellii.

nobilis, Endl. Prod. Fl. Ins. Norf. $64=\mathrm{C}$, ornans.

ornans, F. Muell. Fragm. v. 104=C. ornans.

Shanesiana, F. Muell. 1. c. x. $94=$ C. Shanesiana.

Thozetiana, F. Muell. l. c. v. $104=$ C. Thozetiana.

umbonata, F. Muell. 1. c. i. 164 ; v. $104=$ C. um.

bonata.

BUSBECKEA, Mart. Cat. Hort. Monac. (1829) $69=$ Salpichroa, Miers (Solanac.).

radicans, Mart. 1. c. $=$ S. rhomboidea.

BUSBEQUIA, Salisb. Gen. PI. Fragm. $25(1866)=$ Hyacinthus, Tourn. (Liliac.) ciliaris, Salisb. 1. $c_{0}=\mathrm{H}$. ciliatus.

BUSEA, Miq. F1. Ind. Bat. ii. $732(1856)=$ Cyrtan dromoea, Zoll. (Gesnerac.).

acuminata, Miq. 1. c. $733=\mathrm{C}$. Miqueliana.

angustifolia, Miq. 1. c. $734=$ C. angustifolia.

asperifolia, Miq. 1. c. $733=$ Dichrotrichum asperifolium.
BUSEA :-

decurrens, Miq. Fl. Ind. Bat. ii. $733=$ C. decurrens. subsessilis, Miq. 1. c, =C. acuminata.

BUSIPHO, Salisb. Gen. Pl. Fragm. $76(1866)=$ Aloë Toum. (Liliac.)

ferox, Salisb. 1. c. = A. ferox.

BUSSERIA, Cramer, Disp. Syst. $144(1803)=$ Bursera Jacq.

BUSTAMENTA, Alam. ex DC. Prod. v. 166 (1836) = Fupatorium, Tourn. (Compos.)

cordata, Alam, ex DC. 1. c. = E. petiolare.

ovata, Mairet, ex DC. 1. c. $168=\mathrm{E}$. Bustamenta.

BUSTELINA, Fourn, in Mart. F1. Bras. ví. IV. 288 (1885). ASCLEPIADEAE.

Warmingii, Fourn. l. c.-Bras.

BUSTIA, Adans. Fam.ii. 127 (1763)=Buphthalmum, Linn. (Compos.).

BUSTILlOSIA, Clos, in C. Gay, F1. Chil. iii, 106. t. 32 $(1847)=$ Asteriscium, Cham. (Umbellif.) chilensis, Clos, 1. c. $108=$ A. chilense.

BUTEA, Koen. ex Roxb. Pl. Corom, i. 22. t. 21 (1795) LEGUMINOSAE, Benth. \& Hook. f. i. 533.

Megalotropis, Griff. Notul. iv. 441 (1854).

MeIzotropis, Voigt, Hort. Suburb. Calc. 239 (1845).

Plaso, Adans. Fam. ii. 325 (1763).

acuminata, Wall. Cat. n. $5443=$ Spatholobus actminatus.

Braamiana, DC. Prod. ii. 415.-China

frondosa, Roxb. Pl. Corom. i. 21.-Ind. or.; Burma.

frondosa, Wall. Cat. n. 5569 , partim = superba.

gyrocarpa, R. Grah. in Wall. 1. c. n. $5442=$ Spatholobus gyrocarpus.

Loureirii, Spreng. Syst. iii. 186. - Cochinch.

minor, Buch.-Ham. ex Wall. Cat. n. 5439.--Reg.

Himal.

parviflora, Roxb. Hort. Beng. $53=$ Spatholobus Rox burghii.

peltata, Pers. Syn. ii. $279=$ Rudolphia peltata.

sericophylla, Wall. Cat. n. $5441=$ Spatholobus Rox. burghii.

superba, Roxb. Pl. Corom i. t 22,-Ind or

volubilis, Pers. Syn. ii. $279=$ Rudolphia volubilis,

BUTERAEA, Nees, in Wall. Pl. As. Rar. iii. 75, 196 (1832) = Strobilanthes, Blume (Acanthac.).

rhamnifolia, Nees, in DC. Prod. xi. $725=\mathrm{S}$. rhamnifolius.

ulmifolia, Nees, in Wall. P1. As. Rar. iii. $84=\mathrm{S}$. rufescens.

BUTINIA, Boiss. Elench. $53(1838)=$ Conopodium Koch (Umbellif.)

bunioides, Boiss. 1. c. $54=$ Conopodium butinioides. capnoides, Decne. in Jacquem. Voy. Bot. $70=$ Chaerophyllum capnoides.

cretica, Boiss. \& Heldr. Diagn. Ser. I. x. 50=Carum creticum

glaucescens, Boiss. in Ann. Sc. Nat. Sér. III. ii. (1844) 61 (=Elaeosticta glaucescens).-Persia.

libanotica, Boiss. 1. c. 62 (=Elaeosticta meifolia).Syria.

macrocarpa, Boiss. \& Sprun. in Ann. Sc. Nat. Sér. III. ii. (1844) $62=$ Carum macrocarpum.

nodosa, Boiss. I. c. 61 (=Elaeosticta nodosa).Persia.

parnassica, Heldr. ex Nym. Consp. 302 (=Biasolettia parnassica).-Graecia

stylosa, Boiss, in Ann. Sc. Nat. Sćr. III. ii. (1814) 63 $(=$ Freyera stylosa $)$.-Graecia.

BUTNERIA, Duham. Arb. i. 113. t. $45(1755)=$ Caly canthus, Linn.

BUTOMISSA, Salisb. Gen. Pl. Fragm. 91 (1866)= Allium, Tourn. (Liliac.)

tatarica, Salisb. 1. c. = A. tataricum.

BUTOMOPSIS, Kunth, Enum. Pl. iii. 164 (1841) ALISMACEAE, Benth. \& Hook. f. iii. 1008.

Tenagocharis, Hochst. in Flora, xxiv. (1841) 369. cordofana, Kunth, ex Walp. Ann. i. $769=$ lanceolata. 


\section{BUTOMOPSIS :}

lanceolata, Kunth, Enum. Pl. vii. 165.-Austral. latifolia, Kunth, 1. c. = lanceolata.

BUTOMUS, Linn. Syst. ed. I (1735). ALISMACEAE, Benth. \& Hook. f. iii. 1008.

Caesalpini, Neck. Delic. Gallo-Belg. i. $189=$ umbellatus.

floridus, Gaertn. Fruct. i. 74. t. 19. f. $3=$ umbellatus

junceus, Turcz. in Bull. Soc, Nat. Mose. (1837) n. vII

157; (1838) 101, nomen; et xxvii. (1854) II. $60=$ umbellatus.

lanceolatus, Roxb. Hort. Beng. 89 ; Fl. Ind. ii. $315=$ Butomopsis lanceolata.

latifolius, D. Don, Prod. Fl, Nep. $22=$ Butomopsis lanceolata.

umbellatus, Linn. Sp. Pl. 372.-Europ. ; As. temp. vulgaris, Gueldenst. Iter, ii. $22=$ umbellatus.

BUTONICA, Lam. Encyc. i. 515 (1783) ; Juss, Gen. 326 $(\mathbf{1 7 8 9})=$ Barringtonia, Forst. (Myrtac.). acutangula, Lam. 1. c. $591=$ Barringt. acutangula. alata, Miers, in Trans. Linn. Soc. Ser. II. i. (1875) 70 $=$ Barringt. conoidea.

$a l b a$, Miers, 1. c, $65=$ Barringt. racemosa.

apiculata, Miers, 1. c. 78.-Madag.

caffra, Miers, 1. c. $77=$ Barringt. racemosa

calyptrata, Miers, 1. c. $76=$ Barringt. speciosa

ceylanica, Miers, 1. c. $77=$ Barringt. ceylanica.

edulis, Miers, 1. c. $76=$ Barringt. edulis.

inclyta, Miers, 1. c. $71=$ Barringt. racemosa.

intermedia, Miers, 1. c. $73=$ Barringt. intermedia.

procera, Miers, 1. c. 74 .- Ins. Pacif。

racemosa, Juss. Gen. 326 ; Miers, 1. c. $65=$ Barringt. racemosa.

rosata, Miers, 1. c. 72.-Ins. Philipp.

rubra, Miers, 1. c. $70=$ Barringt. racemosa.

Rumphiana, Miers, 1. c. $68=$ Barringt. Butonica.

samoënsis, Miers, 1. c. $75=$ Barringt. samoënsis.

speciosa, Lam. Encyc. i. 521 = Barringt. speciosa.

terrestris, Miers, in Trans. Linn. Soc. Ser. II. i. (1875) $69=$ Barringt. elongata.

BUTTNERIA, Duham. Arb. ed. II. 217. t. $47(1801)=$ Calycanthus, Linn.

BUTTNERIA, Schreb. Gen, i. $145(1789)=$ Buettneria Loefl.

BUTTONIA, MacKen, ex Benth. in Hook. Ic. P1. xi, 63. t. 1080 (1871). SCROPHULARINEAE, Benth. \& Hook. f. ii. 970

natalensis, MacKen, ex Benth. in Hook. l. c.-Afr. austr.

natalis, MacKen, ex Benth. in Hook, 1. c. = natalensis.

BUTYROSPERMUM, Kotschy, in Sitzb. Acad. Wien, Math. Nat. 1. Abth. I. (1865) 357. SAPOTACEAE, Benth. \& Hook. f. ii. 661 .

Micadania, R. Br. in Denh, et Clapp. Voy. App. $239(1826)$.

Kirkii, Baker, in Oliver, Fl. Trop. Afro iii. 504.-Afr. trop.

niloticum, Kotschy, in Sitzb. Acad. Wien, Math. Nat. 1. Abth. I. (1865) 858. t. 1. $=$ seq

Parkii, Kotschy, l. c. 359. t, 2,-Afr. trop.

BUXUS, Linn. Syst. ed. I (1735), EUPHORBIA$C E A E$, Benth. \& Hook, f, iii. 266.

Crantzia, Sw. Prod. Veg. Ind. Occ. 38 (1788).

Tricera, Schreb. Gen. 630 (1791) ; Sw. Fl. Ind Occ. 331. t. 7 (1797).

acuminata, Muell. Arg. in DC. Prod, xvi. I, 15.-Cuba angustifolia, Mill. Gard. Dict. ed. VIII. n. 2 = sempervirens.

aquartiano, Rich. ex Baill. Monog. Bux. $69=$ citrifolia.

arborescens, Mill. Gard. Dict. ed. VIII. n. 1 ; Lam. F1. Fr. ii. $203=$ sempervirens.

argentea, Hort. ex Steud. Nom. ed. II. i. $242=$ sempervirens.

aurea, Hort. ex Stend, 1. c. = sempervirens.

australis, A. Cunn, ex Stend. l. C.-Austral.

halearica, Lam. Encye, i. 511,-Ins. Balear.

californica, Hort. ex Baill, Monog. Bux. 66-Simmondsia californica

\section{BUXUS :-}

caucasica, Hort. ex C. Koch, Dendrol ii. II. $476=$ sempervirens.

chinensis, Link, Enum. Hort. Berol, ii. $386=$ Simmondsia californica.

citrifolia, Spreng. Syst. iii. 847.-Am. austr.

cordifolia, Spreng. Syst. iii. $847=$ Tricera cordifolia.

coriacea, Spreng. Syst. iv. Cur. Post. $314=$ Sarcococc pruniformis.

crispa, Hort. ex C. Koch, Dendrol. ii. II. 476 sempervirens.

cruciata, Rich. ex Baill, Monog. Bux, $67=$ Vahlii.

cubana, Baill. l.c. 71.-Cuba.

cucullata, Hort. ex C. Koch, Dendrol. ii. 1I. $476=$ sempervirens.

dioica, Forsk. Fl. Aegypt. Arab. $159=$ Myrsine bottensis.

elegantissima, Hort. ex C. Koch, Dendrol. ii. II. $477=$ sempervirens.

Fortunei, Carr. in Rev. Hortic. (1870-71) 519.China.

glomerata, Muell. Arg. in DC. Prod. xvi. I. 17.Cuba.

gonoclada, Muell. Arg. l. c. 16.-Cuba.

haleppica, Hort. ex C. Koch, Dendrol. ii, Ir. $477=$ longifolia.

Handsworthii, Hort. ex C. Koch, 1. c. $476=$ semper virens.

Harlandi, Hance, in Fourn. Linn. Soc. xiii. (1873) 123.-China.

Hildebrandtii, Baill. Adansonia, xi. (1873-76) 268.Afr. trop.

japonica, Muell. Arg。 in DC. Prod. xvi. I. 20.Japon

laevigata, Spreng. Syst. iii. 847.-Jamaic.

longifolia, Boiss. Diagn. Ser. I. xii. 107.-Syria.

madagascarica, Baill. Monog. Bux. 65.-Madag.

marginata, Hort. ex Stend. Nom. ed. II. i. $242=$ sempervirens.

microphylla, Sieb. \& Zucc. in Abh. Akad. Muench. iv. II. (1846) $142=$ japonica.

mucronata, Hort. ex Baill. Monog. Bux. $62=$ semper virens.

myrtifolia, Lam. Encyc. i. 511=sempervirens.

obcordata-variegata, Fortune, in Gard. Chron. (1861) $735=$ microphylla.

ovalifolia, Siebold, ex C. Koch, Dendrol, ii. 11, $479=$ microphylla.

pulchella, Baill. Monog. Bux. 68.-Jamaic

Purdieana, Baill. l. c. 70 (1859),-Jamaic.

retusa, Muell. Arg, in DC. Prod, xvi. I, 16. - Cnba. rosmarinifolia, Hort. ex Baill. Monog. Bux. $62=$ sempervirens.

rotundifolia, Hort. ex C. Koch, Dendrol, ii. II. $479=$ microphylla.

salicifolia, Hort. ex C. Koch, 1. c. $476=$ sempervirens.

saligna, D. Don, Prod. Fl. Nep. $63=$ Sarcococca pruniformis.

sempervirens, Linn. Sp. Pl. 983.-Europ.; Oriens As. temp.

sempervirens, Thunb. Fl. Jap. 77 =japonica.

stenophylla, Hance, in Fourn. Bot. vi. (1868) 331.China.

subcolumnaris, Muell. Argo in DC. Prod.xvi. I. 14-Ind. occ.

suffruticosa, Mill. Gard. Dict. ed. VIII. n. $3=$ semper virens.

tenuifolia, Hort. ex Baill. Monog. Bux. 61 = sempervirens.

Vahlii, Baill. Monog. Bux. 67.-Ind. occ

variegata, Hort. ex Stend. Nom. ed. II. i. $242=$ sempervirens.

virens, Thunb. Fl. Jap. $77=$ microphylla,

Wallichiana, Baill. Monog. Bnx, $63=$ sempervirens.

Wrightii, Muell. Arg. in DC. Prod. xvi. 1. 17.-Cuba

BYBLIS, Salisb. Parad. Lond. t. 95 (1808), DROSE RACEAE, Benth. \& Hook. f. i. 664.

caerulea, R. Br. ex Planch, in Ann. Sc. Nat. Sér. III. ix. (1848) $306=$ linifolia.

filifolia, Planch. 1. c. $305=$ linifolia

gigantea, Lindl. Swan River App.92,-Austral.

Lindleyano, Planch, in Ann. Sc, Nat. Sér. III ix. (1848) $307=$ gigantea.

liniflora, Salisb. Parad. Lond. t, 95.-Austral.

BYGNONIA, Barcena, in La Naturaleza, ii. (18\%3) 173 Bignonia, linn.
BYRONIA, Endl. in Anr. Wien. Mus. i. (1836) 184 ILICINEAE, Benth, \& Hook. f. i. 357.

Polystigma, Meissn. Gen. 252 ; Comm. 161 (1839

arnhemensis, F. Muell. Fragm. ii. 119.-Austral.

Hookeri, Steud. Nom. ed. II. i. $242=$ seq.

sandwicensis, Endl. in Ann. Wien. Mus. i. (1836) 184.-Ins. Sandvic.

taitensis, A. Gray, Bot. U. St. Expl. Exped. i. $297 . t .25$. -Ins. Tahiti.

BYRSA, Noronha, in Verh. Batav. Gen. v. (1790) ed. I Art. IV. i. (Gen. ignot.)

BYRSANTHES, Presl, Prod. Monog. Lobel. 41 (1836) Siphocampylus, Pohl (Campanul.

Halliana, Presl, 1. c. $42=$ S. Hallianus

Humboldtiana, Presl, I. c. $=S$. niveus.

nivea, A. DC. in DC. Prod. vii. $408=$ S. niveus.

BYRSANTHUS, Guillem, in Deless. Ic. Sel, iii, 30 t. 52 (1837). SAMYDACEAE, Benth. \& Hook of 800 .

Anetra, Endl. Gen. 923 (1839).

Brownii, Guillem. l.c.-Afr. trop.

epigynus, Mast. in Oliver, Fl. Trop. Afr. ii. 499.-Afr. trop.

BYRSOCARPUS, Schum. \& Thonn. Beskr. Guin, PI 226 (1827). CONNARACEAE, Benth. \& Hook. f, 431

Boivinianus, Baill, Adansonia, vii. (1866) $231=$ Rourea Boiviniana.

coccineus, Schum. E Thonn. Besker. Guin. Pl. 226.Afr. trop.

maximus, Baker, in Oliver, Fl. Trop. Afr. i. 453.Afr. trop.

orientalis, Baill. Adansonia, vii. (1866)230,-Afr. tror. ovatifolius, Baker, in Oliver, Fl. Trop. Afr. i. 452.Afr. trop.

parviflorus, Baill. Adansonia, vii. (1866) $229=$ coccineus.

parvifolius, Planch. in Linnaea, xxiii. (1850) $412=$ coccineus.

Pervilleanus, Baill. Adansonia, vii. (1866) $232=$ Rourea Pervilleana.

puniceus, Schum. \& Thonn. Beskr. Guin. PI, $227=$ coccineus.

BYRSONIMA, Rich. ex Juss. in Ann. Mus. Par, xviti. (1811) 481. MALPIGHIACEAE, Benth. \& Hook. f. i. 251 .

adenophylla, Triana Ê Planch. in Ann. Sc. Nat. Sér IV. xviii. (1862) 314.--N. Granat.

Aerugo, Sagot, l. c. Sér. VI. xii. (1881) 178.-Guiana. altissima, DC. Prod. i. 579.-Guian3.

amazonica, Griseb. in Mart. Fl. Bras, xii. I. 14Bras.

angustifolia, H.B. E K.Nov. Gen. et Sp. v. 153. t. 449.-Venezuela.

arbutifolia, Griseb, in Mart. Fl. Bras, xii. I. 14Bras.

arthropoda, A. Juss. in Arch. Mus. Par. iii. (1813) \$07 $=$ laxiflora.

basiloba, A. Fuss. l. c. 279.-Bras.

Berteroana, A. Juss. 1. c. $293=$ spicata

bicorniculata, A. Fuss. l. c. 284-Bras

biflora, Griseb. in Mem. Am. Acad. N. S. viii. (1861 167.-Cuba.

Blanchetiana, Miq. in Linnaea, xxii. (1819) $799=$ bicorniculata.

brachystachya, DC. Prod. i. 581.-Bras.

brachystachya, Poepp. ex Griseb. in Mart. Fl. Bras. xii. 1. $10=$ crispa.

bracteolaris, Benth. in Hook. Lond. Gourn. Bot, vì (1848) 128.-Guiana.

brasiliensis, Griseb. in Linasea, xiij. 1899 255 serices.

bumeliaefolia, A. Guss, in St. Hil. Fy. Bras. Mer. iii, 79.-Bras

ceranthera, Benth, in Hook. Lond. Fourn. Bot. vil 18.8) 121.-Guiana.

chrysophylla, H. B. E K. Nov. Gen. ef Sp. จ. 1:ip.Venezuela.

chrysophylla, A. Juss in St. Mil. Fl. Bras. Mer. iỉ. \$1 serices.

cineren, DC. Prod, i, 580-Am, trop

Claussenians, A. Fuss, in Arch. Mrus. Par. iii. (18ts 251 - Hras. 


\section{BYRSONTMA :}

coccolobaefolia, H. B. E K. Nov. Gen. et Sp. v. 148. Am. austr.

coleostachya, Griseb. in Linnaea, xxii. (1849) 3.Guiana.

concinna, Benth. in Hook. Lond. Fourn. Bot. vii. (1848) 122.-Guiana.

coniophylla, A. Fuss. in Arch. Mus. Par. iii. (1843) 310 -Bras.

coriacea, DC. Prod. i. 580 = spicata

correaefolia, A. Fuss. in St. Hil. Fl. Bras. Mer. iii. 78 -Bras.

cotinifoiia, Benth. Pl. Hartw. $277=$ oaxacana

cotinifolia, H. B. \& $K$. Nov. Gen. et Sp. v. 152. t. 447. - Mexic.

crassifolia, H. B. E K. Nov. Gen. et Sp. Pl. v. 149.Guiana.

crassifolia, Lunan, ex Griseb. F1. Brit. W. Ind. $114=$ cinerea.

crassifolia, Steud. Nom, ed. IJ. i. $242=$ verbascifolia. crispa, A. Fuss, in Arch. Mus. Par.iii. (1843)306.-Bras. cujabensis, A. Fuss, ex Mart. Herb. Fl. Bras. 344. n. 657 , nomen.-Bras.

cubensis, A. Fuss. in Arch. Mus. Par. iii. (1843) 292. -Cuba.

Cumingiana, A. Juss, 1. c, $282=$ crassifolia. cuprea, Griseb, in Mart. Fl. Bras. xii. I. 19.-Bras.

cydoniaefolia, A. Zuss, in St. Hil. Fl. Bras. Mer. ii 77.-Bras

cydoniaefolia, Mart. in Flora, xxiv. (1841) Beibl. $104=$ Clausseniana

dealbata, Griseb. in Linnaea, xiii. (1839) 253.-Bras. densa, DC. Prod. i. 580.-Guiana.

diphylla, $D C . l . c .581 .-\mathrm{N}$. Granat.

dispar, Griseb. in Mart. Fl. Bras. xii. I. 10.-Bras.

eglandulosa, A. Juss. in Arch. Mus. Par. iii. (1843 $273=$ sericea

elegans, DC. Prod. i. 580.-Gniana.

eriopoda, $D C$. c c. 579-Am austr.

fastigiata, Mart. in Flora, xxiv. (1841) II. Beilıl. 61 = laevigata.

Fendleri, Turcz. in Bull. Soc. Nat. Mosc. xxxvi 1863) I. 582.-Panama.

ferruginea, H. B. \& K. Nov. Gen. et Sp. v. $151=$ crassifolia.

frondosa, Mart. ex A. Fuss, in Arch. Mus. Par. iii. (1843) 303.-Guiana.

Gardnerana, A. Fuss. l. c. 296.-Bras.

guadalupensis, G. Don, Gen. Syst. i. 637.-Ind. occ.

Guilleminiana, A. Fuss, in Arch. Mus. Par. iii. (1843) 276.-Bras,

gymnocalycina, A. Fuss. l. c. 304-Guiana.

Hostmanni. Benth. in Hook. Lond. Fourn. Bot. vid. (1848) 120.-Guiana.

hypargyrea, Planch. ex Linden, Cat. n. 8 (1853) 2.-

ypolenco Turcz in Bull. Soc. Nat. Mosc. xxxi. (1858) I. 391.-N. Granat.

intermedia, A. Fuss. in St. Hil. Fl. Bras. Mer. iii. 82. -Bras.

inundata, Benth. in Hook. Lond. Fourn. Bot. vii. (1848) 122.-Bras.

japurensis, A. Fuss. in Arch. Mus. Par. iii. (1843) 305.-Bras.

Karwinskiana, A. Fuss. l. c. 288.-Mexic

laevtgata, DC. Prod. i. 580.-Guiana.

lanceolata, DC. 1. c. = crassifolia.

lancifolia, A. Fuss. in Arch. Mus. Par. iii. (1843) 275. -Bras.

laurifolia, H. B. ๒ K. Nov. Gen. et Sp. v. 147.Venezuela.

laxiflora, Griseb. in Linnaea, xiii. (1839) 256.-Bras.

leucophlebia, Griseb. in Mart. Fl. Bras. xii. 1. 15. Bras.

ligustrifolia, A. Fuss. in St. Hil. Fl. Bras. Mer. iii. 82. -Bras.

ligustrifolia, Mart. Herb. Fl. Bras. n. 1176=intermedia.

linearifolia, A. Fuss. in Arch. Mus. Par. iii. (1843) 279.-Bras.

longibracteata, A. Juss. ex Mart. in Flora, xxiv. (1841) II. Beibl, 61 = stipulacea.

Iucida. DC. Prod. i. 580.-Am, bor. ; Ind. oce.

Martiana, A. Fuss. in Arch. Mus. Par. iii. (1843) 286. -Bras.

microphylla, A. Fuss. l. c. 298.-Bras.

mollis, DC. Prod. i. 581.-Guiana

montana, H. B. \& K. Nov, Gen, et Sp. v. $149=$ crassifolia.

\section{BYRSONIMA :-}

monticola, A. Juss. \& Mart. ex Griseb. in Mart. Fl. Bras. xii. 1. $17=$ coccolobaefolia.

Moritziana, Turcz in Bull. Soc Nat. Mosc. xxxi. 1858) 391.- - Venezuela.

Moureila, Loud. Hort. Brit. $182=$ crassifolia

myricifolia, Griseb. in Kjoeb. Vidensk. Meddel. (1875)

125.-Bras.

nervosa, DC. Prod. i. 579.-Bras.

nitida, D. Don, Gen. Syst. i. 636,-Peruv,

nitidifolia, A. Fuss. in Arch. Mus. Par. iii. (1843) 296.-Bras.

nitidissima, H. B. E K. Nov. Gen. et Sp. v, 152.-. Venezuela.

oaxacana, A. Fuss. in Arch. Mus. Par. iii. (1843) 283. -Mexic.

oblongifolia, A. Fuss. l. c. 300--Bras.

obversa, Miq. Stirp. Surin. Sel. 76.-Guiana.

Orbignyana, A. Fuss. in Arch. Mus. Par. ii. (1843) 284.-Bolivia.

oxyphylla, A. Fuss. in St. Hil. Fl. Bras. Mer. iii, 84.-

pachyphylla, Griseb. in Linnaea, xiii. (1839) $250=$ verbascifolia.

pachyphylla, A. Fuss. in St. Hil. Fl. Bras. Mer. iii. 77.--Bras.

pallida, DC. Prod. i. 581,-Guiana.

panamensis, Beurling, in Vet. Akad. Handl. Stockh. (1854) 117.--Panama.

Paulista, A. Fuss, in St. Hil. Fl. Bras. Mer. iii. 85.Bras.

perseaefolia, Griseb. in Linnaea, xiii. (1839) 257.Bras.

peruviana, A. Fuss. in Arch. Mus. Par. iii. (1843) 289 -Peruv.

phlomoides, G. Don, Gen. Syst. i. 636-Bras.

piauhensis, A. Juss, in Arch. Mus. Par. iii. (1843) 274 = sericea

pinetorum, Griseb. Cat. Pl. Cub. 42.-Cuba

Poeppigiana, A. Fuss, in Arch. Mus. Par. ili. (1843) 308. Bras.

propinqua, Benth. in Hook. Lond. Fourn. Bot. vii. (1848) 120.-Guiana.

psilandra, Griseb. in Linnaea, xiii. (1839) 251.-Bras. pulchra, DC. Prod. i. 580--Mexic.

punctulata, A. Fuss. in Arch. Mus. Par. iii. (1843) 309.-Bras.

reticulata, DC. Prod. i. $581=$ Heteropteris platyptera.

reticulata, Klotzsch \& Karst. ex Griseb. in Linnaea, xxii. (1849) 6.-N. Granat.

hombilolia, A. Fuss. in Arch. Mus. Par. iii. (1843) 290 .-Bras.

rhopalaefolia, H. B. \& K. Nov, Gen. et Sp. v. $148=$ crassifolia

rigida, A. Fuss, in Arch. Mus. Par. iii. (1843) 298.Bras.

rotunda, Griseb. in Mart. Fl. Bras. xii. I. 20.-Bras, rufescens, Bertol. Fl. Guatim 18.-Guatemala.

rugosa, Benth. in Hook. Lond. Fourn. Bot. vii. (1848) 118.-Guiana.

Salzmanniana, A. Fuss. in Arch. Mus. Par. iii. (1843) 277.-Bras.

Schomburgkiana, Benth. in Hook. Lond. Fourn. Bot. vii. (1848) 123.-Guiana.

sericea, DC. Prod. i. 580.-Bras.

sessilifolia, Benth. in Hook. Lond. Fourn. Bot. vii (1848) 124.-Guiana.

sparsibilis, Turcz. in Bull. Soc. Nat. Mosc. (1858) I. 391.-Bras.

spicata, Rich. ex Fuss, in Ann. Mus. Par. xviii (1811) 481; DC.Prod. i. 580.-Am. trop.

spicata, Poepp. ex Spreng. Syst. ii. $383=$ Heteropteris platyptera.

stigmatophora, Schlecht. in Linnaea, x. (1836) 241. Mexic.

stipulacea, A. Fuss. in Arch. Mus. Par. iii. (1843) 287.-Bras.

trinitensis, A. Fuss. l. c. 296.-Ind. occ.

triopterifolia, A. Fuss. l. c. 298.-Am. austr

umbellata, Mart. ex A. Fuss. l. c.301.-Bras.

vacciniaefolia, A. Fuss, in St. Hil. Fl. Bras. Mer. i. 84. - Bras.

variabilis, $A$. Fuss. l. $c$. $78,-$ Bras

verbascifolia, Rich. ex fuss. in Ann. Mus. Par. xviii. (1811) 481; DC. Prod. i. 579.-Am. trop. viminifolia, A. Fuss. in St. Hil. Fl. Bras. Mer. ii. 83. -Bras.

volubilis, DC. Prod i. $581=$ Hiraea Simsiana.
BYRSOPHYLLUM, Hook, f. in Benth. \& Hook. f. Gen. ii. $83(1873)$. RUBIACEAE, Benth. \& Hook. f. l. c.

ellipticum, Hook. f. l. c.-Zeylan.

tetrandrum, Hook.f.l.c.; Bedd. Forest. Man.134/2.Ind. or.

BYSTROPOGON, L'Hérit. Sert. Angl. 19, t. 22, 23 1788). LABIATAE, Benth. \& Hook. f. ii. 1184. Astemon, Regel, Ind. Sem. Hort. Petrop. (1860) 30. Mintostachys, Spach, Hist. Vég. Ihan. ix. 164 (1840).

bipinnatus, Roth, Nov. Pl. Sp. $225=$ Lavandula Burmaun

canariensis, L'Hérit. Sert. Angl. 20.-Ins. Canar.

canus, Benth. Lab. Gen, et Sp. 326.-Peruv.

coarclatus, Thonn. E Schum. in Vidensk. Selsk. Skr. iv. (1828) $34=$ Hyptis pectinata.

confertus, Willd. ex Steud. Nom. ed. II. i. $243=$ Mentha mollis.

dentatus, Poir. Encyc. Suppl. i. 755.-Peruv.

erianthus, Benth. Lab. Gen. et.Sp. $727=$ Cuminia eriantha.

glabrescens, Benth. Pl. Hartw. 145.-Peruv.

graveolens, Blume, Bijdr. $824=$ Hyptis suaveolens.

maderensis, Webb \& Berth. Phyt. Canar. iii. 66.-Ins.

Madera.

marifolius, Juss, ex Steud. Nom. ed. II. i. $243,521=$

Micromeria marifolia.

Meridiani, C. Bolle, in Bonplandia, viii. (1860) 281.Ins. Canar.

mollis, H. B. E K. Nov. Gen. et $S p$. ii. $317 .-\mathrm{N}$. Granat.

mollis, Salisb. Prod. $80=$ canariensis

odoratissimus, C. Bolle, in Bonplandia, viii. (1860 281.-Ins. Canar.

origanifolius, L'Hérit. Sert. Angl. 20.-Ins. Canar. pectinatus, L'Hérit. 1. c. $19=$ Hyptis peclinata.

piperitus, Lowe, in Hook. Kew fourn. viii. (1856) 299. - Ins. Madera.

plumosus, L'Hérit. Sert. Angl. 20. t. 22.-Ins, Canar. punctatus, L'Hérit. l. c. 20. t. 23.--Ins. Madera. reticulatus, Willd. ex Steud. Nom. ed. II. 1. 243 Mentha mollis.

serrulatus, Webb E Berth. Phyt. Canar. iii. 65. t. 151 -Ins. Canar.

sidaefolius, L'Hérit. Sert. Angl. $19=$ Hyptis polyantha.

Smithii, Webb \& Berth. Ihyt. Canar. iii. $281=$ punctata.

spicata, Benth. Lab. Gen. et Sp. 326.-Peruv.

suaveolens, L'Hérit. Sert. Angl, $19=\mathrm{Hyp}^{\mathrm{t}}$ is suaveolens. Lomentosus, Benth. Lab. Gen. et Sp. 326.--Peruv.

BYTHOPHYTON, Hook. f, Fl. Brit. Ind, iv, 286 (1884). SCROPHULARINEAE. indicum, Hook. f. l. c.-Reg. Himal.

BYTNERIA, Jacq. Hort. Vindob. i. $10(1770)=$ seq

BYTTNERIA, Loefl. Iter Hisp. $313(1758)=$ Buett neria, Loef. (Stereuliac.).

BYTTNERIA, Steud. Nom, ed. II. i. $243(1840)=$ Calycanthus, Linn.

\section{O}

CAAPEBA, Plum. ex Adans. Fam. ii. $357(1763)=$ Cissampelos, Linn. (Menisp.)

CABAlleria; Ruiz \& Pav, Prod. Fl. Per. et Chil. 141. t. $30(1794)=$ Myrsine, Linn.

coriacea, G. F. W. Mey. Prim. Fl. Esseq. $118=$ M foribunda.

dentata, Ruiz \& Pav. Syst. Veg. $281^{\circ}=$ M. dentata dependens, Ruiz \& Pav. l. c. = M. dependens.

ferruginea, Ruiz \& Pav. i. c. $250=$ M. ferruginea latifolia, Ruiz \& Pav. 1. c. $279=$ M. latifolia. myrtifolia, Ruiz \& Pav. ex DC. Prod. viii. $102=$ M dependens.

oblonga, Ruiz \& Pav. Syst. Veg. $280=$ M. Manglilla. pellucida, Ruiz \& Pav. 1. c. = M. pellucida.

venosissima, Ruiz \& Pav. 1. c. 282=M, venosissima. 
CABANISIA, Klotzsch, ex Schlecht. in Abh. Naturf. Ges. Halle, vi. (1862) $176=$ Eichhornia, Kunth (Ponted.).

caracasana, Schlecht. 1. c. = E. paradoxa.

Martiana, Schlecht. l. $c_{0}=$ E. paniculata.

CABOMBA, Aubl. Pl. Gui. i. 321. t. 124 (1775) NYMPHAEACEAE, Benth. \& Hook. f. i. 46.

NECTRIS, Schreb. Gen. i. 237 (1789).

VILLAa RIA, Neck. Elem. ii. 110 (1790)

aquatica, Aubl. $l . c .-$ Mexic.

aquatica, DC. Syst. ii. $36=$ caroliniana.

Aubletii, Michx. Fl. Bor. Am. i. $206=$ caroliniana.

australis, Speg. in Anal. Soc. Cient. Argent. x. (1880)

219.-Reg. Argent.

caroliniana, A. Gray, in Ann. Lyc. N. York, iv. (1848) 46.-Am. bor.

furcata, Schult. f. Syst. vii. 1379.-Bras.

peltata, F. Muell. Native Pl. Vict. $15=$ Braseni peltata.

piauhiensis, Gardn。 in Hook. Ic. Pl. vii. t. 641.Bras.

pinnata, Schult. $f$. Syst. vii. $1379=$ caroliniana.

Warmingii, Casp. in Mart. Fl. Bras. iv. II. 142.Bras.

CABRAlEA, A. Juss, Mém. Mus, Y’ar. xix. (1830) 229. t. 16. MELIACEAE, Benth. \& Hook. fo i. 33. affinis, A. Juss. 1. c. $230=$ polytricha.

Burchellii, C. DC. in Mart. Fl. Bras. xi, x. 171.Bras.

Cangerana, Saldanha, in Ann. Sc. Nat. Sér. V. xix. (1874) 210.-Bras.

Clausseniana, C. DC. in Mart. Fl. Bras. xi, I. 173.Bras.

corcovadensis, C. DC. l.c. 177.-Bras.

coriacea, C. DC. l. c. 181.--Bras.

Eichleriana, C. DC. l. c. 174,-Bras.

estrellensis, $C$. DC. l. c. 171.-Bras.

Gaudichaudii, C. DC. l. c. 172,-liras.

glaberrima, A. Fuss. in Mém. Mus. Par. xix. (1830) 270.-Bras.

Glaziovii, C. DC. in Mart. Fl. Bras. xi. I. 172.Bras.

inaequilatera, Casar. Decad. Nov. Stirp. Bras, ii. 22.Bras.

Jussiaeana, C. DC. in Mart. Fl. Bras. xi. 1. 171.Bras.

laevis, C. DC. l.c. 176. t. 53.-Bras.

lagoènsis, C. DC. l. . . 178 .-Bras.

Lundii, $C . D C$. l. c. 180.-Bras.

macrophylla, C. DC. l. c. 144.-Bras.

montana, C. DC.l. c. - Bras.

multijuga, $C . D C$. l. c. 175 .-Bras.

oblongiflora, C. DC. l. c. 180.-Bras.

oligotricha, A. Juss. in Mém. Mus. Par, xix. (1830) $230=$ polytricha

pallescens, C. DC. in Mart. Fl. Bras, xi. 1. 175. t. 52. -Bras.

pedunculata, C. DC. l. . . 172,-Bras

pilosa, $C . D C . l . c .177$. - Bras.

Poeppigii, C. DC. in DC. Monog. Phan. i. 471.Am. trop.

polytricha, A. Fuss. in Mim. Mus. Par. xix. (1830) 230.-Bras.

Richardiana, C. DC. in Mart. Fl. Bras, xi. I. 176.Bras. (vel Cuba).

Riedelii, C. DC. l. c. 180,--Bras.

rubiginosa, $C . D C$. $l_{0} c_{0} 179$. - Bras.

Selloi, C. DC. l. c. 176.-Bras.

silvatica, C. DC. l. c. 173.-Bras

sulcata, $C . D C$. i. $C$. 171.-Bras

tomentosa, Casar. Decad. Nov. Stirp. Bras, ii. $22=$ polytricha.

Warmingiana, C. DC. in Mart. Fl. Bras. xi. 1. 178.Bras.

CABRERA, Lag. Gen. et Sp. Nov. $5(1816)=$ Pas. palum, Linn. (Gramin.)

hrysoblepharis, Lag. 1. c. = P. exasperatum.

CACABUS, Bernb. in Linnaea, xiii. (1839) 360. SOLANACEAE, Benth. \& Hook. f. ii. 896.

DictYocalyx, Hook, $f$ in Trans, Linn. Soc, xx, (1847) 202

STREptostigma, Regel, Gartenf. (1853) 323. t. 68.

THinogeton, Benth. Bot. Voy. Sulph. 142 (184t)

\section{CACABUS}

inflatus, Miers, in Ann. E Mag. Nat. Hist. Ser. II iv. (1849) 255 . - Peruy

maritimus, Benth. E Hook. f. Gen。 ii. 897.-N Granat.

mexicanus, S. Wats. in Proc. Am. Acad. xviii. 1882-83) 127.-Mexic

nolanoides, Miers, in Ann. Eo Mag. Nat. Hist. Ser. II. iv. (1849) 255 .- - Peruy.

prostratus, Bernh. in Linnaea, xiii. (1839) 360 Peruv.

CACALIA, Linn. Sp. Pl. $834(1753)=$ Senecio, Toum (Compos.).

abyssinica, $\mathrm{R}$. Br. in Salt, Abyss, Alp. $65=\mathrm{S}$. abyssinicus.

abyssinica, Walp. Ann. ii. $908=\mathrm{S}$. tuberosus.

acaulis, Linn. f. Suppl. $364=$ S. acaulis, Sch. Bip

acerifolia, Siebold, ex Maxim. in Bull. Acar. Pétersb. xix. (1874) 487, nomen.-Japon.

acetosellaefolia, Jacq. ex Steud. Nom. ed. II. ii. 243

S. articulatus

aconitifolia, Bunge, Ennm. Pl. Chin. Bor. $37=S$. aconitifolius.

aconitifolia, Miq. ex Maxim. in Bull. Acad. P'étersb. xix. (1874) $487=\mathrm{S}$. adenostyloides.

acuminata, Fisch. ex Herd. in Bull. Soc. Nat. Mose. xliii. (1870) I. 215 (=Mulgedium hastatum).

adenostyloides, Franch. \& Sav, ex Maxim. in Bull. Acad. Pétersb. xix. (1874) 486=S. adenostyloide

albida, Cass. ex Schur, Enum. Pl. Transs. $301=$ Adenostyles alba.

albifrons, Linn. f. Suppl. $353=$ Adenostyles alba.

Alliariae, Gouan, Illustr. $65=$ Adenostyles alba.

alliariaefolia, Lam. Encyc. i. $532=$ Adenostyles viridis.

alliariaefolia, Poir。Voy, Barb。 ii. $235=$ Petasites fragrans.

alpina, Linn. Sp. Pl. $836=$ Adenostyles viridis.

alpina, Mill. Gard. Dict. ed. VIII. n, 1 = Adenostyles alba.

amplifolia, DC. Prod. vi. $328=$ S. amplifolius

angulata, Vahl, Symb. Bot. iii. $92=$ Emilia angulata.

angulata, Vell. Fl. Flum. 336 ; viii. t. $55=$ Mikania cordifolia.

angulosa, Wall. Cat. n. 3152=Gynura angulosa.

ancustifolia, H. B. \& K. Nov. Gen. et Sp. iv, $159=\mathrm{S}$.

Humboldtianus.

angustifolia, Wall. Cat. n. $3163=$ Emilia prenanthoidea.

Anteuphorbium, Linn. Sp. Pl. $834=$ S. Antenphorbium

appendiculata, Linn. f. Suppl. $352=$ S. populifolius arborea, H. B. \& K. Nov, Gen. et Sp. iv. 163 Psacalium arboreum),- $\mathrm{Am}$. austr.

arbuscula, Thunb. Prod. Pl. Cap. $142=$ Othonna arbuscula.

arenaria, H. B. \& K. Nov. Gen. et Sp. iv. $165=\mathrm{S}$. sabulosus.

articularis, Salisb. Prod. $187=$ seq

articulata, Linn. f. Suppl. $364=$ S. articulatus.

asarifolia, Steud. Nom. ed. II. i. $243=$ Faujasia reticulata.

asclepiadea, Linn. f. Suppl. $352=$ S. asclepiacleus. atriplicifolia, Linn. Sp. Pl. $835=$ S. atriplicifolius. aurantiaca, Blume, Bijdr. 908 = Gynura aurantiaca aurantiaca, Wall. Cat. n. $3146=$ Gynura nepalensis auriculata, DC. Prod. vi. $329=$ S. dahuricus. baccharidifolia, Poepp. ex Phil. f. Cat. Pl. Vasc. Chil. $156=\mathrm{S}$. baccharidifolius.

Berlandieri, DC. Prod. vi. $3 \geq 8=$ S. desertorum.

bicolor, Roxb. Hurt. Beng. 61; FI. Ind. iii. $412=$ Gynura bicolor.

bipinnata, Linn. f. Suppl. $353=$ S. bipinnatus,

bulbosa, Lour. Fl. Cochinch. 485= Gyaura ovalis.

cancellata, Rudolphi, in Ledeb. Diss. Pl. Doming. $(\mathbf{1 8 0 5})=\mathrm{S}$. cancellatus.

candicans, Poepp. ex DC. Prod, vi. $325=$ Culcitiun Poeppigii.

candicans, Vahl, Symb. Bot, iii. $91=\mathrm{S}$, candicans. canescens, Poepp. ex I)C. Prod, vi. $414=\$$. Nenei canescens, Willd. Enum. Hort. Berol. Suppl. $42 \bar{\gamma}=$

Haworthii.

Calliariae, Gouan, Illustr. $65=$ Adenostyles alpina carnosa, Ait. Hort. Kew, iii. $156=$ S. clegans. caucasica, Hoffm. Hort. Mosq. (1808) n. 598 platyphyllus.

cervariaefolia, DC. Prod, vi. $328=$ S. cervariaefolius,
CACALIA ;-

chiapensis, A. Gray, in Proc. Am. Acad. xix. (1883 $53=$ Senecio chiapensis.

cinerarioides, H. H. \& $\mathrm{K}$. Nov, Gen, et Sp, iv, $166=4$. Bonplandianus.

cirsiifolia, Hook. \& Arn. Bot. Beech. Voy, $436=\mathrm{S}$ cirsiifolius.

cissampelina, DC. Prod. vi. $331=$ S. cissampelinus.

citrina, Boj. ex DC. l. c. $302=1$ milia citrina.

Clematites, Poir。 Encyc. Suppl。 ii. $4=$ Faujasia flexuosa.

coccinea, Sims, Bot. Mag. t. $564=$ Emilia flaminea

cordata, Vell. Fl. Flum. 336 ; viii. to $53=$ Mikania cordifolia.

Cor-Fesu, Vell. 1. c. 340 ; viii. t. $71=$ Mikania officinalis.

cordifolia, H. B. \& K. Nov. Gen. et Sp。 iv, 168, t. 360 S. cardiophyllus.

cordifolia, Linn. f. Suppl. $351=$ Mikania cordifolia cordiformis, Lam. Fl. Fr. ii. $75=$ Adenostyles alpina. crassissima, Wall. Cat. n. $3155=$ Notonia crassissima crenata, Vell. Fl. Flum. 335 ; viii. t. 51.-Bras. cuneifolia, Liın. Mant. i. $110=S$. cuneifolins.

Cusimbua, D, Don, Prod。 Fl. Nep. $179=$ Gynura angulosa.

cuspidata, Bertol. Fl. Guatimal. $32=$ S. guatimalensis cuspidata, Klatt, in Ann. Sc. Nat. Sér. V, xviii. 1873 374.-Ins. Borbon.

cylindrica, Lam. Encyc, i, $529=$ Othonna cylindrica cylindriflora, Wall, Cat. n. $3150=$ Gybura sarmentosa decomposita, A. Gray, P1. Wright. ii. $99=$ S. Gray anus.

decurrens, Vell. Fl. Flum. 340 ; viii. t. $72=$ Bacchari genistelloides.

delphiniffolia, Sieb. \&c Zucc. in Abh. Acad, Muench. iv. III. (1846) $190=$ S. Zuccarinii.

denticulata, Hook. \& Arn. Bot. Beech. Voy. $29=\$$ denticulatus.

dichroa, Boug. Nov, Comp. Bras. 40. t. 7 ? dichrous.

discolor, Griseb. Cat. PI. Cub. 157=S. discolor.

disticha, Heyne, ex DC. Prod. v. $384=$ Conyza Wallichii.

diversifolia, Torr. \& Gray, Fl. N. Am. ii. $435=\mathrm{S}$. floridanns.

dulcis, Salisb. Prod. $187=$ S, ficoides.

echinata, Linn. f. Suppl. $353=S$. echinatus.

elata, Spreng. ex DC. Prod. vi. $314=$ S. Ligularia.

emarginata, Vell. F1. Flum. 336 ; viii. t. 52 -Bras.

farfaraefolia, Sieb. \& Zucc. in Abh. Acad. Muench. xiI. (1846) $190=\mathrm{S}$. farfaraefolius.

ficoides, Linn. Sp. Pl. $834=\mathrm{S}$. ficoides.

fimbrillifera, Cass, in Dict. Sc. Nat. xlviii. $460=\$$. deltoideus.

Finlaysoniana, Wall. Cat. n. $3162=$ Gynura sarmentosa.

flexuosa, Wall. Cat. n. $3160=$ Faujasia flexuosa.

Alexuosa, Willd. ex DC. Prod, vii, $69=$ Trixis divaricata.

floridana, A. Gray, in Proc. Am. Acad. xix. (1883) 5.? $-\mathrm{S}$. floridanus.

foetens, Wall. Cat. n. $3156=$ Gynura nepalensis.

frutescens, Vell. Fl. Flum. 338 ; viii. t 64 - Bras.

gigantea, Nees, Del. Sem. Hort. Vrat. (18t1) $3=\mathrm{S}$. atriplicifolins.

glabra, Ledeb. Ind. Sem. Hort. Dorpat. (1S20 16 -S. sagittatus.

glabra, Heyne, in Wall. Cat. v. $3145=$ Emii ia sonchifolia.

glabra. Mill. Gand. Dict, etl. VIII. n. 2 = Adenosenles alpina.

glabra, Vill. Prosu, $30=$ Adcnostyles viridis.

glabrata, H. B. \& K. Nov. Gen. el Sp. iv, 161 (= Psacalium glabratum) - Am. trop.

glandulosa, Salisb. Prod. $18 \%=P^{\prime}$ orophyyllum rai'te rale.

glauca, Salisb. 1. c. =S. succulentus, Sch. Bia.

gracilifora, Wall. Cal in $\$ 1+9=\mathbf{4}$, graciliflorus.

gracilis, Hoj. ex DC. P'rod, vi. 30\% = Emila gracilis,

grandiffora, Wall. Cal, D. $\$ 1$ ti $=$ Notonas grandiBora.

hastata, Linn. Sp. R1. $835=$ S. sugiteneus.

Hasworthii, Swect, in Loud. Hort 13rit. $393=$ Haworthit.

Actercgansa, Bienth. ex Merst, in Kineb. Viticnsk Mecldel. (1852) $10_{0}^{-}=5$. beterensmus.

keferophylla. l'ueple ex DC. I'rud, vi. $t 14=S$. pill. yuensis. 
CACALIA :-

hieracioides, Willd. Sp. Pl. iii. 1731 = Gynura auriculata.

hirsuta, Vill. Prosp. 31 = Adenostyles alba.

humifusa, Boj. ex DC. Prod. vi. $302=$ Emilia humifusa.

humilis, H. B. \& K. Nov. Gen. et Sp. iv. $166=$ Senecio humilis.

hybrida, Stend. Nom. ed. II. i. $244=$ Adenostyles alpina, etc.

iatrophoides, H. B. \& K. Nov. Gen. et Sp. iv. $169=\mathrm{S}$. jatrophoides.

ilicifolia, H. B. \& K. 1. c. $163=$ S. scrobicarius, incana, Bosc, ex DC. Prod. vi. $330=$ S. Boscianius. incana, Linn. Sp. Pl. ed. II. $1169=$ Gynura nitida .

indica, Lam. Encyc. i. 530.-Ind. or.

involucrata, H. B. \& K. Nov. Gen. et Sp. iv. $166=\mathrm{S}$. involucratus.

Kleinia, J. Grah. Cat. Bomb.Pl. $98=$ Notonia balsamica, Kleinia, Herb. Madr. ex C. B. Clarke, Comp. Ind. 176 $=$ Notonia grandiflora.

Kleinia, Linn, Sp. Pl. $834=$ S. Kleinia

Kleiniana, Hill, Veg. Syst. iii. $144=$ praec.

kieinioides, H. B. \& K. Nov. Gen. et Sp. iv. 164 (= Psacalium kleinioides).-Am. trop.

laciniata, Jacq. Ic. Rar. 1. t. $68=\mathrm{S}$, articulatus.

laciniata, Wall. Cat. n. $3153=$ Gynura lycopersicifolia.

laeta, Vell. Fl. Flum. 341; viii, t. 76.-Bras.

lanata, H. B. \& K. Nov. Gen。 et Sp. $162=$ S. lanatus. lanceolata, Nutt. Gen. Am. ii. $138=$ S. Boscianus. laurifolia, Linn. f. Suppl. $351=$ Mikania laurifolia.

ledifolia, H. B. \& K. Nov. Gen. et Sp. iv. $162=\mathrm{S}$. ledifolius.

leucopappa, DC. Prod. vi. $330=$ S. leucopappus,

leucophylla, Willd. Sp. Pl. iii. $1736=$ Adenostyles candidissima.

Linaria, Cav. Ic. iii. 29. to $257=$ Porophyllum Linaria.

linearis, Labill, Nov, Holl. Pl, ii. 36. t. 178 - Bedfordia linearis.

linifolia, Heyne, ex DC. Prod. v. $25=$ Vernonia cinerea.

linifolia, Linn. Mant. $109=$ Porophyllum linifolium

lobata, Moris, in Flora, xv. (1832) Lit, ii, 79. Chili.

longifolia, Haw. Rev. P1. Succ. $193=$ S. pugioniformis, lutea, Mill. Gard. Dict. ed. VIII. n. 10.-Ins, st Helena.

Lycopersicum, Heyne, ex DC. Prod. vi. $301=$ Gynura lycopersicifolia.

macrophylla, Bieb. Fl. Taur. Cauc. ii. $286=$ S. platyphyllus.

macrophylla, Rafin. in Med. Repos. N. York, v. (1808) 354, nomen.-Hab. ?

maculata, Buch.-Ham. ex Steud. Nom. ed. II. i. $244=$ Gynura sinuata.

Mentrasto, Vell. Fl. Flum. 339 ; viii. t. $69=$ Ageratum conyzoides.

mikaniaefolia, DC. Prod. vi. $328=$ S. mikaniaefolia.

mucronata, Heyne, in Wall. Cat. n. $3161=$ Emilia flammea.

multiflora, Auct. ex Walp. Rep. vi. $266=\mathrm{S}$, multi Alorus.

napeaefolia, DC. Prod.vi. $328=$ S. napeaefolius.

napellifolia, S. Schan. in Linnaea, xix. (1847) $732=\mathrm{S}$. napellifolius.

Nardosmia, A. Gray, in Proc. Am. Acad. vii. (1868) $361=$ Cacaliopsis Nardosmia.

nepalensis, Spreng. ex DC. Prod.vi. $300=$ Gynura nepalensis.

nipponica, Miq. Ann. Mus. Bot. Lugd. Bat. ii. 181.Japon.

nitida, H. B. \& K. Nov. Gen. et Sp. iv. $162=\mathrm{S}$ nitidus.

nitida, Vell. Fl. Flum. 337 ; viii. t. 59,-Bras.

nizea, Kunze, ex DC, Prod. vi. $325=$ Culcitium Poeppigii.

obsoleta, Vell. Fl. Flum. 337 ; viii. t. $57=$ Mikania biformis.

dodora, Forsk. Fl. Aecypt. Arab. $146=$ S. odorus.

odorata, Desf. Cat. Hort. Par, ed. III. 165, $400=\mathrm{S}$. odoratus.

oligocephala, Scheele, in Linnaea, xviii. (1844) 480 .Hab.?

oppositifolia, Poir. Encyc. Suppl. ii. $7=$ Porophyllum oppositifolium.

ovalifolia, Salisb. Prod. 186 =S. Anteuphorbium.
CACALIA :-

ovalis, Ker-Gawl, in Bot. Reg.t. 101 = Gynura psendochina.

ovata, Walt. Fl. Carol. $196=$ Senecio Walteri

pachyphylla, Sch. Bip. ex Seem. Bot. Voy. Herald, 310 $=\mathrm{S}$. sclerophyllus.

paniculata, Rafin. Ann. Nat. (1820) $14=$ S. Nuttallii. papillaris, Linn. Sp. Pl. $834=$ S. papillaris.

parasitica, Sch. Bip. ex Hemsl. Biol. Centr. Am.

Bot. ii. $244=$ S. parasiticus.

patens, H. B. \& K. Nov. Gen. et Sp. iv. $164=\mathrm{S}$. patens.

pedunculata, Vell. Fl. Flum. 339 ; viii. t. $68 .-$ Bras.

peltata, H. B. \& K. Nov. Gen. et Sp. iv. 170. t. $361=$ S. peltiferus.

pendula, Forsk Fl Aegypt Arab, 145=S, pendulus. penduliftora, A. Gray, in Proc. Am. Acad. xix. (1883) $53=$ S. subpeltatus, Sch. Bip.

penicillata, Cass. in Dict. Sc. Nat. xiviii, $460=$ S penicillatus.

Petasites, Lam. Encyc. i. $531=$ Adenostyles alba. peucedanifolia, Jacq. Coll. Suppl, $149=$ S. paniculatus. pilosa, Vell. Fl. Flum. 338; viii. t. $61=$ Mikania cordifolia.

pinnata, Willd. Enum. Hort. Berol. $850=\mathrm{S}$. Othonnae.

pinnatifida, Berg. Desc. P1. Cap. $230=$ S. pinnatifidus.

pinnatifida, Linn. Mant. ii. $281=$ S. bipinnatus.

pinnatifida, Lour. Fl. Cochinch. ii. $486=$ Gynura pinnatifida.

pinnatifida, Wight, ex DC. Prod. vi. $301=$ Gynura lycopersicifolia.

Porophyllum, Linn. Sp. Pl. $834=$ Porophyllum ruderale.

praestans, Baker, in Mart. F1. Bras. vi. III. 384, sphalm. $=$ Trixis mollissima.

prenanthoides, H. B. \& K. Nov. Gen。 et Sp. iv. 167 = S. albiflorus.

prenanthoides, Sieber, ex DC. Prod. vi. $302=$ Emilia sonchifulia.

procumbens, Lour. F1. Cochinch. ii. $485=$ Gynura sarmentosa.

Pteranthus, Rafin. Ann. Nat. (1820) 14=S. Nuttallii.

pubescens, Rafin. FI. Ludov, $61=$ Eupatorium lndovicianum.

pugioniformis, Salzm. ex Link, Enum. Hort. Berol. ii. $510=\mathrm{S}$. pugioniformis.

pulchella, H. B. \& K. Nov. Gen, et Sp. iv, $160=\mathrm{S}$. pulchellus.

pumila, Boj. ex DC. Prod. vi. $302=$ Emilia pumila. punctulata, Vell, Fl, Flum, 339 ; viii. t. 66 .-Bras.

pungens, H. B. \& K. Nov。 Gen. et Sp. iv. $160=\mathrm{S}$. pungens.

purpurascens, Wall. Cat. n. $3157=$ Gynura purpurascens.

quinqueloba, Thunb. Prod. Pl. Cap. $142=$ S. quinquelobus.

racemosa, DC. Prod. vi. $330=$ S. exsertus.

racemosa, Sch. Bip. ex Hemsl. Biol. Centr. Am. Bot. ii. $241=\mathrm{S}$. helodes,

radicans, Linn. f. Suppl. $354=$ S, radicans.

radulaefolia, H. B. \& K. Nov. Gen, et Sp. iv, $169=\mathrm{S}$, radulaefolius.

ramosa, Spreng. ex DC. Prod. vi. $368=$ S. triligulatus.

reclinata, Roxb. Hort. Beng. 101; Fl. Ind. iii. 412... Ins. Molucc.

reclinata, Wall. Cat. n. $3151=$ Gynura sarmentosa. regia, Baker, in Mart. Fl. Bras. vi. III. 384, sphalm.= Trixis divaricata.

reniformis, Lam. F1. Fr. ii. $75=$ Adenostyles viridis.

reniformis, Muhl. in Willd. Sp. Pl. iii. $1735=\mathrm{S}$, Muehlenbergii.

repens, Linn. Mant. $110=$ S. succulentus.

reticulata, Vahl, Symb. Bot. iii. 91 = Faujasia reticulata.

reticulata, Vell. F1. Flum. 337 ; viii. t. 60.-Bras.

rhombifolia, Willd. Enum. Hort. Berol. $850=\mathrm{S}$. platyphyllus.

rigida, Thunb. Prod. Pl. Cap. $142=$ S. spinescens.

Ros-marinus, Vell. Fl Flum. 339 ; viii. t. $67 .-$ Bras.

rotundifolia, Willd. Phyt. 11. t. 6. f. $1=$ Vernonia cinerea.

ruderalis, Sw. Prod. Veg. Ind. Occ. $110=$ Porophyllum ruderale.
CACALIA :-

runcinata, H. B. \& K. Nov. Gen. et Sp. iv, $168=$ Senecio roseus.

runcinata, Lam. Encyc. i. $529=$ S. articulatus.

sagittaria, Heyne, in Wall. Cat. n. $3159=$ Gynura pseudochina.

sagittata, Vahl, Symb. Bot. iii. $91=$ Emilia flammea. sagittifolia, Mertens, in Linnaea, v. (1830) 63, nomen. -Ins. Koragin.

salicina, Labill. Nov. Holl. P1. ii, 37.t. $179=$ Bedfordia salicina.

sarmentosa, Blume, Bijdr. $907=$ Gynura sarmentosa sarmentosa, Lesch. ex Hook. f. Fl. Brit. Ind. iii. $352=$ S. candicans.

Sarracenia, Blanco, Fl. Filip. ed. I. $618=$ Gynura angulosa.

sarracenica, Linn. Sp. Pl. ed. II. $1169=$ S. Cacaliaster

scabra, Vahl, Symb. Bot. iii. $92=$ Trixis brasiliensis

scandens, Ait. Hort. Kew, iii. 157.-Afr. austr.

scandens, Thunb. Prod. Pl. Cap. $142=$ S. deltoideus.

scandens, Zeyh. ex DC. Prod. vi. $404=\mathrm{S}$. volubilis.

Schaffneri, A. Gray, in Proc. Am. Acad. xix. (1883) 53.-Mexic.

sempervirens, Spreng. ex DC. Prod. vi. $442=$ Notonia grandiflora.

sempervirens, Vahl, Symb. Bot. iii. $92=\mathrm{S}$. semper-

semperviva, Forsk. Fl. Aegypt. Arab. $146=$ S. sempervivus.

senecioides, H. B. \& K. Nov. Gen. et Sp. iv. $163=\mathrm{S}$. assuayensis.

septemnata, Vell. Fl. Flum. 338 ; viii. t. 63.-Bras.

sessilifolia, Hook. \& Arn. Bot. Beech. Voy. $436=\mathrm{S}$. sessilifolius.

sessilis, Vell. Fl. Flum. 341 ; viii. t. $73=$ Baccharis articulata.

sinuata, Cerv, in La Llave \& Lex. Nov, Veg. Desc. fasc, i. $25=$ S. albo-lutescens.

sonchifolia, Forsk. Fl. Aegypt. Arab. p. cxix = Emilia angulata.

sonchifotia, Hort. ex Steud. Nom. ed. II. i. $244=$ Emilia sagittata.

sonchifolia, Linn. Sp. Pl. 835 = Emilia sonchifolia

sonchifolia, Wall. Cat. $\mathrm{n} .3144 \mathrm{D}=$ Lactuca remotiflora.

spathulata, Moç. \& Sesse, ex D. Don, in Trans. Linn. Soc. xvi. (1830) $250=$ Chaptalia spathulata.

suaveolens, Linn. Sp. Pl. $835=$ S, suaveolens.

suffruticosa, Linn. Mant. i. $109=$ Porophyllum linifolium.

tabularis, A. Gray, in Proc. Am. Acad. xix. (1883) 52 $=$ S. tabularis

tenuissima, Boj. in Rapp. Soc. Maur. vi. 27 = Emilia gracilis.

teres, Wall. Cat. n, 3164=Emilia prenanthoidea.

teretifolia, H. B. \& K. Nov. Gen, et Sp. iv. $159=$

S. teretifolius.

terminalis, Salisb. Prod. $187=$ S. Kleinia.

ternata, Vell. F1. Flum. 336 ; viii. t. $56=$ Mikania apiifolia.

thyrsoidea, Spreng. ex DC. Prod. vi. $368=$ S. alatus

toluccana, DC. Prod. vi. $328=$ S. callosus.

tomentosa, Eck1. ex DC. 1. c. $403=$ S. scaposus.

tomentosa, Haw. Misc. 189=S. Haworthii.

tomentosa, Jacq. Fl. Austr. iii. $20=$ Adenostyles alba.

tomentosa, Linn. f. Suppl. $353=$ S, oliganthus.

tomentosa, Vell. Fl. Flum. 341 ; viii. t. 75. - Bras.

tomentosa, Vill. Prosp. 31 = Adenostyles candidissima.

triangularis, Vell. Fl. Flum. 338 ; viii. t. $62=$ Mikania cordifolia.

trilobata, Vell. 1. c. 336 ; viii. t. $54=$ Mikania glomerata.

trinervia, Vell. l. c. 338 ; viii. t. 65 -Bras.

triphylla, Vell. 1. c. 341 ; viii. t. 74 --Bras.

tuberosa, Bosc, ex DC. Prod. vii. 89 = Krigia Dandelion.

tuberosa, Delile, in Ferr. \& Gall. Voy. Abyss. iii. 142 $=\mathrm{S}$. tuberosus.

tuberosa, Nutt. Gen. Am, ii, $138=\mathrm{S}$. Nuttallii?

tussilaginoides, H. B. \& K. Nov. Gen。 et Sp. iv. 168 $=\mathrm{S}$. farfarus.

unifiora, Schum. \& Thonn. Beskr. Guin. P1. $382=$ Gynura cernua.

vaccinoides, H. B. \& K. Nov. Gen. et Sp. iv. 162 $(=$ Psacalium vaccinoides $)$. $\mathrm{Am}$. trop. 
CACALIA :-

verbascifolia, Sibth. \& Sm. Fl. Graec, ix. $35=$ Senecio thapsoides.

villosa, Jacq. Coll. ii. $347=$ S. purpureus.

villosa, Vell. Fl. Flum. 337 ; viii, t. 58,-Bras.

volubilis, Blume, Bijdr. $903=\mathrm{S}$. araneosus.

volubilis, Buch.-Ham. ex DC. Prod, vi. $370=\mathrm{S}$. Buimalia.

Wightiana, Wall, ex DC. Prod. vi. $370=$ S. scandens.

CACALIOPsIs, A. Gray, in Proc. Am. Acad, xix. (1883) 50. COMPOSITAE.

Nardosmia, A. Gray, l.c.-Am. bor. occ.

CACAO, Tourn, ex Mill. Gard. Dict. ed. VI. $(1752)=$ Theobroma, Linn. (Sterculiac.)

bicolor, Poir. Encyc. Suppl, ii. $7=$ T. bicolor. guianensis, Aubl. P1. Gui, ii. $683=$ T. Cacao minor, Gaertn. Fruct. ii. $190=$ T. Cacao. sativa, Aubl. Pl. Gui. ii. $689=$ T. Cacao. sylvestris, Aubl. 1. c. 687 = Genipa Merianae. Theobroma, Tussac, Fl. Med. Ant. t. $13=$ T. Cacao

CACARA, Rumph. ex Thou. in Dict. Sc. Nat. vi. 35 (1805) = Pachyrhizus, Rich. (Legumin.).

CACATALI, Adans. Fam. ii. $213(1768)=$ Pedalium, Royen (Pedalin.).

CACCINIA, Savi, Cose Bot. 1. t. I (1832)。 BORAGINEAE, Benth. \& Hook. f. ii. 846. Anisanthera, Rafin. Fl. Tellur. iii. 80 (1836). Actinobole, Bunge, Helioc, 8.-Persia.

Celsii, Boiss. Diagn. Ser. I, xi. $133=$ glauca. dubia, Bunge, Lehm. Rel. (1847) 242.-As. centr. glauca, Savi, Cose Bot.1. t. 1. f. 1-6 (1832).-Persia; Beluchist.

Kotschyi, Boiss. Diagn. Ser. I. vii. 31.-Persia.

Rauzvolfi, A. DC. in DC. Prod, x, $167=$ Russellii.

Rauwolfii, C. Koch, in Linnaea, xvii. (1843) 303.-As. Min.; Persia

Russellii, Boiss. Diagn. Ser. I. xi. 134.-Syria. strigosa, Boiss. l. c.-Persia.

CACHRIS, D. Dietr. Syn. Pl. i. $586(1839)=$ Cachrys, Tourn. (Umbellif.).

CACHRYDIUM, Link, Handb. i. 339 (1829) = Hippomarathrum, Link (Umbellif.)

Libanotis, Link, Handb. i. $339=\mathrm{H}$. Libanotis.

CACHRYS Linn. Syst. ed. I (1735) ; Gen. ed. I. 75 (1737). UMBELLIFERAE, Benth. \& Hook. f. i. 904. abyssinica, Hochst. ex A. Rich. Tent. Fl. Abyss. i. 333 $=$ Diplolophium africanum.

acaulis, DC. Prod. iv. 238 = Prangos Szovitzii.

alata, Hoffm. Umb. i. 176 ; Bieb. Fl. Taur. Cauc, i. $217=$ Prangos ferulacea.

alpina, Bieb. l. c-Tauria.

ambigua, Salzm. ex DC. Prod. iv. 241= Magydaris panacina.

amplexifolia, Pritz. Ind. Ic. $179=$ seq.

amplifolia, Ledeb. in Eichw. Casp. 6. t. $9=$ Hippomarathrum crispum.

athamanthoides, Bieb. F]. Taur. Cauc. iii. $217=$ Rumia athamanthoides

callosperma, Pall, Reise, iii, $663=$ odontalgica cheilanthifolia, Boiss. Fl. Orient. ii. 936.-Persia.

cretica, Lam. Encyc. i. 259 = Lecokia cretica.

crispa, Pers. Syn. i. $311=$ Hippomarathrum crispum.

crispata, Pomel, Nouv. Mat. Fl. Atl. 151.-Algeria.

cristata, DC. Prod. iv. 238 = Hippomarathrum cristatum.

cylindracea, Guss. ex DC. 1. c. $239=$ Prangos cylindracea.

decursiva, Hornem. Hort. Hafn. ii. 960. Add. = Siler caucasicum.

dichotoma, Spreng. P1. Umb. Prod. 21 = Capnophyllum dichotomum.

didyma, Regel, in Act. Hort. Petrop.v. (1877) 601.Turkestau.

echinophora, Guss. Fl. Sic. Syn. i. $347=$ Hippomarathrum cristatum.

eriantha, DC. Prod. iv. 238.-Persia.

goniocarpa, Boiss. Diagn. Ser. I. x. 58.-Syria

Herderi, Regel, in Act. Hort. Petrop. v. (1877) 601.-

Turkest.

hirta, Bertol. Disquisit. de Pl. Nov. 6.-Hab.?

\section{CACHRYS :}

humilis, Schousb. Vextr. Marokko, 133-Marocco.

hungarica, Mill. Gard. Dict. ed. VIII. n. $5=$ Magydaris panacina.

involucrata, Pall: ex Willd. fide Roem. \& Schult. Syst. vi. $447=$ Polylophirm orientale.

Korolkowi, Regel \& Schmalh. in Act. Hort. Petrop. v. (1877) 602,-Turkestan

laevigata, Brouss. ex Ball, in Journ. Linn. Soc, xvi. (1878) $463=$ Hippomarathrum cristatum

laevigata, Lam. Encyc. i. 256.-Lusitan.

lanata, Hort. ex Steud. Nom. ed. II. i. $245=$ Magydaris panacina, tomentosa.

latifolia, Bieb. F1. Taur. Cauc. i. $219=$ Siler caucasicum.

Libanotis, Georgi, Beschr. Russ. Reich. iii. IV. $845=$ odontalgica.

Libanotis, Gouan, Illustr. $12=$ laevigata.

Libanotis, Guss. FI. Sic. Prod, i. 358=Prangos ferulacea.

Libanotis, Linn. Sp. PI. $346=$ Hippomarathrum Libanotis.

Libanotis, Salzm. ex Ball, in Journ. Linn. Soc. xvi. (1878) $463=$ Hippomarathrum cristatum

Linearia, Mill. Gard. Dict. ed. VIII. n. $4=$ Hippomarathrum Libanotis.

littoralis, Spreng. Umbell. Prod. iv. $20=$ Daucus bessarabicus.

longiloba, DC. Prod. iv. $237=$ Hippomarathrum crispum.

macrocarpa, Ledeb. Fl. Alt. i. 364.-Sibir. altaic maritima, Spreng. in Ges. Naturf. Fr. Berl. Mag. vi (1812) $259=$ Crithmum maritimum.

microcarpa, Bieb. Fl. Taur. Cauc. i. $218=$ Hippomarathrum crispum.

Morisoni, All. Auctuar. F1. Pedem. 23 = laevigata.

nudicaulis, Godet, ex DC. Prod. iv. $237=$ Hippo. marathrum crispum.

odontalgica, Pall. Reise, iii. 720 -Reg. Caucas. ; Sibir. panacifolia, Vahi, Symb. Bot. i. 25= Magydaris panacina.

panax-siculum, Ucria, in Roem. Arch, i.68 = Magy daris tomentosa.

papillaris, Boiss. in Ann. Sc. Nat. Sér. III. ii. (1844) 75.-Mesopotam.

pastinacea, Lam. Encyc. i. $260=$ Magydaris panacina. peregrina, Spreng. in Ges. Naturf. Hr. Berl. Mag. vi (1812) 259 = Capnophyllum dichotomum.

peucedanoides, Desf. Fl. Atlant. i. 250 -Afr. bor.

prangoides, Boiss. in Ann. Sc. Nat. Sér. III. ii. (1844) 76.-Persia.

pterochlaena, DC. Prod. iv. $237=$ Hippomarathrum pterochlaenum.

pungens, Jan, ex Guss. Fl. Sic. Prod. i. App. $7=$ Hippo marathrum cristatum

seseloides, Bieb. F1. Taur. Cauc. iii. $217=$ Rumia seseloides.

sibirica, Steph. ex Fisch, in Cat. Sem. Hort. Petrop. (1823) = Phloidicarpos dahuricus

sibirica, Turcz. ex Ledeb. Fl, Ross. ii. $331=$ Phloidi carpos villosus.

sicula, Gueldenst. ex Ledeb. Fl. Ross. ii. $357=$ Hippo marathrum crispum.

sicula, Guss. Fl. Sic. Prod. i. $359=$ Hippomarathrum cristatum.

sicula, Linn. Sp. P1. ed. II. 355= Hippomarathrum pterochlaenum.

sicula, Urv. in Mém. Soc. Linn. Par. i. (1822) $287=$ Hippomarathrum Bocconi.

sphaerocarpa, Tenore, Prod. Fl. Nap. xix.; Syn. $120=$

Hippomarathrum Libanotis.

taurica, Wilid. Sp. Pl. i. $1410=$ Rumia taurica.

tomentosa, Desf. F1. Atlant. 1. $249=$ Magydaris tomen tosa.

tortuosa, Webb \& Berth. Phyt. Canar. iii. $281=$ Ferula tomentosa.

trifida, Mill. Gard. Dict. ed. VIII. n. 1= laevigata.

triquetra, Sprengo in Ges. Naturf. Fr. Berl. Mag. vi (1812) $259=$ Prangos triquetra.

vaginata, Ledeb. F!. Alt. i. $366=$ Hippomarathrum vaginatum.

CACHYRIS, Zumag. Fl, Pedem, i. 99, $\$ 25$ (1849) praec.

CACONAPEA, Cham, in Linnaea, viii. (1893) 2s

Herpestis, Gaertn. (Scrophulanin.

sratioloides, Cham. 1. c. $29=$ H. gratiuloides.
CACONOBEA, Walp. Rep, iii, $281(1845)=$ praec

CACOSMANTHUS Miq. Fi. Ind, Bat, ii. $1040(1856)=$ KAKOSMANTHUS, Hassk. = Payena, Linn Sapotac.)

CACOSMIA, H. B. \& K. Nov. Gen. et Sp, iv. 289. 04 (1820). COMPOSITAE, Benth. \& Hook. f. ii. $396^{\circ}$ Clairvillea, DC. Prod. v. 636 (1836)

Xantholepis, Willd. ex Less. in Linnaea, iv. (1829) 338

quinquenervia, Steud. Nom, ed. II. i. 377, in syn. =sec rugosa, H. B. E K. Nov. Gen. et Sp. iv. 289.-Perwv.

CACOTANIS, Rafin. New Fl. Am. ii. $43(1836)=$ Eclipta, Linn.? (Compos.)

ciliata, Rafin. 1. c. 44.-Am, bor.

CACOUCIA, Aubl. Pl. Gui. i. 450, t. $179(1775)$ COMBRETACEAE, Benth. \& Hook. f. i. 688. HAMBERGERA, Scop. Introd. 106 (1777).

SCHOUSBOEA, Willd. Sp. Pl. ii. 578 (1799)

bracteata, Laws, in Oliver, Fl. Trop. Afr. ii. $434_{0}-$ Afr. trop.

chinensis, A. Fuss. ex DC. Prod. iii. 22.-China

coccinea, Aubl. Pl. Gui. i. 450. t. 179.-Guiana.

cordifolia, Walp. Rep. ii. 68-Afr. trop.

exannulata, O. Hoffm. in Linnaea, xlii. (1880-82, 132. - Afr. trop.

lucida, Hassk. in Flora, xxvii. (1844) I1. $607=$ Com bretum trifoliatum.

paniculata, Laws, in Oliver, Fl. Trop. Afr. ii. 431.Afr. trop.

platyptera, Welw. in Trans. Linn. Soc, xxvii. (186!) 24.-Afr. trop.

trifoliata, DC. Prod. iii. $22=$ Combretum trifoliatum.

velutina, S. Moore, in Fourn. Bot. xviii. (1850) 2.Afr. trop.

villosa, Lazus, in Oliver, Fl. Trop. Afr.ii. 433.-Afr. trop.

CACTUS, Linn. Syst. ed. I $(1735)=C A C T E A E$ Benth. \& Hook. f. Gen. 1. 1008.

abnormis, Willd. Enum. Hort. Berol. Suppl. $31=$

Cereus peruvianus.

Ackermanni, Haw. in Bot. Reg. t. $1331=$ Phyllocactu Ackermanni.

aculeatissimus, Zeyh. ex Steud. Nom. ed. I. 13 (quid ?).

alatus, Hook. Bot. Mag. t. $2820=$ Rhipsalis pa chyptera.

alatus, Sw. Prod. Veg. Ind. Occ. $77=$ Rhipsali Swartziana.

alatus, Willd. Enum. Hort. Berol. Suppl. $35=$ Phyllo cactus phyllanthoides.

albisetosus, Haw. ex Spreng. Syst, ii. $\$ 96=$ Cereu: albisetosus.

albisetus, Steud, Nom, ed. II. i. $245=$ praec.

ambiguus, Bonpl. Jard. Malm. t. $30^{\circ}=$ Cereus am biguus.

ambiguus, Gill. exLoud. Hort. Brit. 194 = Mammillaria ambigua.

americanus, Vitm. Summa Pl. iii. 209 (quid ?).

anisogonus, Hort. Angl. ex Foerst. Handb. Cact. ed. II i. $764=$ Cereus triangularis.

arboreus, Vell. Fl. Flum. 207 ; v. t. $28=$ Upuntia arborea.

aurantiaca, Gill.ex I.oud. Hort. Brit. Suppl. ii. $65.2=$ Opuntia aurantiaca.

aurantifformis, Thiery, ex Stend Jiom, ed. I. 131; ed. II. i. 245 (quid?)

aureus, Meyen, Reise. i. $\$ 47=$ Echinocsctas aureus.

bicolor, Berland. ex Engelm. Cact. Mex Bound. 2] $=$ Echinocactus uncinatus.

Bleo, H. B. \& K. Nov. Gen. et Sp. vi. 69y=Pereskis Bleo.

Bleo, Torr in Ann, Lyc. N. Jork, 1i. (18.23) 20.2 Opuntia arborescens.

bolivianus, Lem. Cact. 88.-Bulivia.

Bonplandis, H. B. \& K. Nor. Gen. et Sp. vi. $6:=$ Opuncia Tuna.

bradypes. Lehm. Ind. Sem. Hort. Hamb. $1520^{\circ}: 17=$ Cereus senilis.

brasiliensis, Willd. Enum. Hort. Berol. Suppl. \$ Opuneia brasiliensi:

bubissinus, Lem. Cact, 85.-11ab, ?

califurnicus, Torr. \& Gray. Fil. N. An.

(i)uutia serpentina ! 


\section{CACTUS :-}

campechianus, Thiery, ex Stcud. Nom. ed. 1. 131 ; ed. II. i. 243 (quid?).

canescens, Moę. \& Sesse, ex DC. Prod. iii. $459=$ Mammillaria lanifera.

caripensis, H. B. \& K. Nov. Gen. et Sp. vi. $66=$ Cereus caripensis.

cassythoides. Moç. \& Sesse, ex DC. Prod. iii. $476=$ Rhipsalis Cassytha.

caudata, Gill. ex Loud. Hort. Brit. 194= Mammillaria caudata.

chiloënsis, Colla, ex Steud. Nom. ed. II. i. $245=$ Cerens chiloënsis.

chinensis, Roxb. Hort. Beng. [37]; Fl. Ind. 1i. $476=$ Opuntia Dillenii.

chlorocarpus, H. B. \& K. Nov. Gen. et Sp. vi. $67=$ Cereus chlorocarpus.

clavatus, Lem. Cact. $88=$ Opuntia clavata, Engelm .

coccinellifer, Stend. Nom. ed. I. 131, vide cochenillifer,

coccineus, Gill. ex Loud. Hort. Brit. 194= Mammillaria coccinea.

cochenillifer, Linn. Sp. Pl. $468=$ Nopalea coccinellifera. cochenillifer, Moc. \& Sesse, ex DC. Prod. iii. $474=$ Opuntia Hernandesii.

columnaris, Moc. \& Sesse, ex DC. Prod. iii. $459=$ Mammillaria acanthophlegma.

communis, Steud. Nom. ed. II. i. $245=$ Melocactus communis.

compressus, Salisb. Prod. $348=$ Opuntia vulgaris.

coquimbanus, Molina, Saggio Chile, $170=$ Cereus eburneus.

cornigerus, Moc. \& Sesse, ex DC. Prod. iii. $461=$ Echinocactus cornigerus.

coronarius, Cav. Desc. $490=$ Cereus cylindricus

coronatus, Lam. Encyc. i. $537=$ Melocactus communis.

coronatus, Willd. Enum. Hort. Berol. Suppl. $30=$ Mammillaria coronaria.

corrugatus, Gill. ex Loud. Hort. Brit. $194=$ Echinocactus corrugatus.

crispatus, Moç. \& Sesse, ex DC. Prod. iii. $462=$ Echinocactus arrigens.

cruciformis, Vell. F1. Flum. 207; v. t. 29=Cereus cruciformis.

curassavicus, Linn. Sp. Pl. $469=$ Opuntia curassavica

curvispinus, Bert. in 'Merc. Chil. 1829.'-Cf. Bull. Férussac, xx. (1830) 108.-Chili.

cylindricus, James, Cat. $182=$ Opuntia arborescens.

cylindricus, Lam. Encyc. i. $539=$ Opnntia cylindrica

cylindricus, Orteg. Hort. Matr, 128. t. 16= Mammil-

laria coronaria.

cylindricus, Vell. Fl. Flum. 207 ; v. t. $31=$ Rhipsalis cylindrica.

decumanus, Willd. Enum. Hort. Berol. Suppl. $34=$ Opuntia decumana.

depressus, DC. Cat. Hort. Monsp. $84=$ Mammillaria discolor.

depressus, Haw. Syn. PI. Succ. $173=$ Echinocactus depressus.

Dillenii, Ker-Gawl. in Bot. Reg. t. $255=$ Opuntia Dillenii.

divaricatus, Lam. Encyc. i. $540=$ Cereus divaricatus.

eburneus, Link, Enum. Hort. Berol. ii. 22-Cereus eburneus.

eburneus, Salm. ex Spreng. Syst. ii. $494=$ Cereus eburneus.

echinocarpus, Lem. Cact. 88.-Hab.?

elatior, Willd. Enum. Hort. Berol. Suppl. $34=$ Opuntia elatior.

elegans, Link, Enum. Hort. Berol. ii. $25=$ Phyllocactus phyllanthoides.

elongatus, Willd. Enum. Hort. Berol. Suppl. $34=$ Optutia decumana?

Emoryi, Lem. Cact. $88=$ Cereus Emoryi.

ensiformis, Biden, in Gard. Chron, xx. (1883) 53.Hab. ?

Epidendrum, Linn. Amoen. Acad. viii. $257=$ Rhipsalis undulata?

erinaceus, Haw. Suppl. $74=$ Cerens erinaceus.

euphorbioides, Spreng. Syst. ii. $496=$ Cereus euphorbioides.

fascicularis, Meyen, Reise, i. $447=$ Echinocactus fascicularis.

fasciculatus, Willd. Enum. Hort. Berol. Suppl. $33=$ Rhipsalis fasciculata.

ferox, Nutt. Gen. Am. i. $296=$ Opuntia missouriensis.

ferox, Willd. Enum. Hort. Berol. Suppl. $35=$ Opuntia ferox.
CACTUS :-

Ficus, Thunb. F1. Jap. 198-seq

Ficus-indica, Linn. Sp. P1. $468=$ Opuntia Ficus-indica, decumana.

fimbriatus, Desc. Fl. Antill. vi. $160=$ Cereus Swartzii. fimbriatus, Lam. Encyc. i. $539=$ Cereus fimbriatus.

fimbriatus, Moç. \& Sesse, ex DC. Prod. iii. $475=$

Pereskia lychnidiflora.

flagelliformis, Linn. Sp. Pl. $467=$ Cereus flagelliformis flavescens, DC. Cat. Hort. Monsp. $83=$ Mammillaria flavescens.

flavispinus, Colla, Hort. Rip. $24=$ Cereus flavispinus.

foliosus, Gill. ex Loud. Hort. Brit. 194=Echinocactus foliosus.

foliosus, Willd. Enum. Hort. Berol. Suppl. $35=$ Opuntia foliosa.

fragilis, Nutt. Gen. Am. i. $296=$ Opuntia fragilis.

frutescens, Moç. \& Sesse, ex Pfeiff. Enum. Diag. Cact. $178=$ Pereskia rotundifolia.

fulvispinosus, Spreng. Syst. ii. $497=$ Cereus Royeni.

funalis, Spreng. 1. c. $479=$ Rhipsalis funalis.

garipensis, Kunth, Syn. Pl. Aeq. iii. $370=$ Cereus caripensis.

gibbosus, Haw. in Bot. Reg. t. $137=$ Echinocactus gibbosus.

glomeratus, Lam. Encyc. i. $257=$ Mammillaria glomerata.

grandiflorus, Linn. Sp. Pl. $467=$ Cerens grandiflorus.

grandifolius, Link, Enum. Hort. Berol. ii. $25=$ Pereskia grandifolia.

Haworthii, Spreng. Syst. ii. $495=$ Cereus Haworthii.

Helicteres, Moc. \& Sesse, ex DC. Prod. iii. $460=$

Mammillaria Helicteres.

heptagonus, Linn. Sp. P1. $466=$ Cereus heptagonus

heptagonus, Vell. Fl. Flum. 205 ; v. t. 19.-Bras.

heterogonus, DC. Prod. iii. 470 , sphalm. = praec.

hexagonus, Lam. Encyc. i. 538=Melocactus monoclonos.

hexagonus, Linn. Sp. Pl. $466=$ Cereus hexagonus.

hexagonus, Vell. Fl. Flum. 205 ; v. t. 18.-Bras.

Histrix, Salm-Dyck, Obs. Bot. (1822) = Cereus Hystrix.

horridus, H. B. \& K. Nov. Gen. et Sp. vi. $70=$ Pereskia horrida.

horridus, Salisb. Prod. $348=$ Opuntia Tuna .

Humboldtii, H. B. \& K. Nov. Gen. et Sp. vi. $66=$ Cereus Humboldtii.

humifusus, Rafin. Ann. Nat. (1820) 15=Opuntia vulgaris.

humilis, Desf. ex Steud. Nom. ed. II. i. $246=$ Opuntia vulgaris.

humilis, Haw. Misc. $187=$ Opuntia Tuna

humilis, Lag. Gen. et Sp. Nov. $16=$ Opuntia foliosa

hybridus, Hort. Angl. ex P. C. Van Geel, Sert. Bol. iv. (1832) t. 118.-Hab. ?

hyptiacanthus, Lem. ex Steud. Nom. ed. II. i. $246=$

Echinocactus hyptiacanthus.

icosagonus, H. B. \& K. Nov. Gen. et Sp. vi. $67=$ Cereus icosagonus.

imbricatus, Lem. Cact. 88.-Hab. ?

indicus, Roxb. Hort. Beng. [37]; F1. Ind. ii. [475]= Opuntia Dillenii.

intortus, Mill. Gard. Dict. ed. VIII. n. $2=$ Echinocactus intortus.

italicus, Tenore, ex Steud. Nom. ed. II. ii. 246 (quid?)

famacaru, Kostel. Allg. Med.-Pharm. Fl. iv. 1393= Cereus Jamacaru.

Kageneckii, Gmel. ex Salm-Dyck, fide DC. Prod. iii. $463=$ Cereus multangularis.

laetus, H.B. \& K. Nov. Gen.et Sp.vi. $68=$ Cereus laetus.

Lamarkii, Colla, Hort. Ripul. App. iii. 15. t. $\tau=$ Melocactus communis.

lanatus, H. B. \& K. Nov. Gen. et Sp. vi. $68=$ Cereus lanatus.

lanceolatus, Haw. Misc. $188=$ Opuntia lanceolata.

Langsdorfii, Lehm. Ind. Sem. Hort. Hamb. $(1826)=$ Echinocactus Langsdorfií.

lanuginosus, Linn. Sp. Pl. $467=$ Cereus repandus.

latispinus, Haw. in Phil. Mag. lxiii. (1824) $41=$ Echinor cactus latispinus.

Lecchii, Colla, Hort. Ripul. App. iv. 6. t. $2=$ Cereus Lecchii.

Lemarii, Monvill. ex ' Lem. Cact. Gen. 105' = Echinocactus Lemarii.

Linkii, Lehm. Ind. Sem. Hort. Hamb. (1827) $16=$ Cereus Linkii.

lucidus, Salisb. Prod. $349=$ Pereskia aculeata.

luteus, Thiery, ex Steud. Nom. ed. I. 132; ed. II. i. 246 (quid?).
CACTUS:-

lyratus, Vell. Fl. Flum. 205; v. t. $21=$ Rhipsalis salicornoides,

macracanthus, Salm-Dyck, Obs. (1820) 1=Melocactus macracanthus.

magnimamma, Salm-Dyck, ex Steud. Nom. ed. II. i. $246=$ Mammillaria magnimamma.

Mallisoni, Hort. ex Loud. Encyc. Pl. Suppl. i. $1202=$ Cereus Smithii.

mammillaris, Linn. Sp. Pl. 466=Mammillaria simplex.

mammillaris, Nutt. Gen. Am. i. 295= Mammillar a missourensis.

melocactoides, Hoffmgg. Verz. Pfl. Nachtr. iii. $24=$ Melocactus melocactuides.

Melocactus, Linn. Sp. Pl. $466=$ Melocactus communis. mensarum, Thiery, ex Steud. Nom. ed. I. 132 ; ed. II i. 246 (quid?).

meonacanthus, Lem. ex Steud. Nom. ed. II. i. $246=$

Echinocactus meonacanthus.

micranthus, H. B. \& K. Nov. Gen. et Sp. vi. $65=$ Rhipsalis micrantha.

microdasys, Lehm. Ind. Sem. Hort. Hamb. (1827) 16 $=$ Opuntia microdasys.

microthele, Spreng. Syst. ii. $494=$ Mammillaria parvimamma.

monacanthos, Willd. Enum. Hort. Berol. Suppl. $33=$ Opuntia monacantha.

moniliformis, Lam. Encyc. i. $541=$ Cereus moniliformis.

moniliformis, Linn. Sp. Pl. 468=Opuntia monili formis.

multangularis, Moc. \& Sesse, ex DC. Prod. iii. $462=$

Echinocactus melocactiformis.

multangularis, Voigt, ex Steud. Nom. ed. I. $132=$ Echinocactus recurvus.

multangularis, Willd. Enum. Hort. Berol. Suppl. $33=$

Cereus multangularis.

nanus, H. B. \& K. Nov. Gen. et Sp. vi. $68=$ Cerents nanus.

nanus, Hort. ex Steud. Nom. ed. II. ii. $246=$ Opuntia vulgaris.

Napoleonis, Hort. ex Loud. Encyc. Pl. Suppl. i. 1202 $=$ Cereus Napoleonis.

neglectus, Dehnhardt, Revist. Napol. i. III. 166 (=Pereskiae sp.)

niger, Spreng. Syst. ii. $495=$ Cereus niger.

nigricans, Haw. Misc. $187=$ Opuntia nigricans.

nobilis, Haw. Syn. Pl. Succ. $174=$ Cereus reductus.

nobilis, Lam. Encyc. i. $537=$ Echinocactus intortus.

nobilis, Linn. Mant. $243=$ Echinocactus recurvus.

nudus, Moç. \& Sesse, ex DC. Prod. iii. 460= Mammillaria nuda.

obvallatus, Moç. \& Sesse, ex DC. 1. c. $462=$ Echino cactus obvallatus.

octogonus, Page, ex Steud. Nom. ed. II. i. $246=$ Cerens hexagonus.

Opuntia, Blanco, Fl. Filip. ed. I. $414=$ Nopaleo coccinellifera.

Opuntia, Guss. Fl. Sicul. Prod. 559=Opuntia Ficusindica.

Opuntia, Linn. Sp. Pl. $468=$ Opuntia vulgaris.

opuntiaeflorus, Moc. \& Sesse, ex Pfeiff. Enum. Diag. Cact. $178=$ Pereskia opuntiaeflora.

ottonis, Lebm. Ind. Sem. Hort. Hamb. (1827) $16=$ Echinocactus Ottonis.

ovatus, Gill. ex Loud. Hort. Brit. $195=$ Cereus ovatus. ovoides, Lem. Cact. 88.-Hab. ?

oxypetalus, Moç. \& Sesse, ex DC. Prod. iii. $470=$ Phyllocactus latifrons.

paniculatus, 1 am. Encyc. i. $540=$ Cereus paniculatus. paradoxus, Hornem. Hort. Hafn. ii. 443 -Upuntia brasiliensis.

parasiticus, Lam. Encyc. i. $\mathbf{5 4 1}=$ Rhipsalis fasciculata.

parasiticus, Linn. Syst. ed. X. 1054=Rhipsalis undulata. Parryi, Lem. Cact. 88-Hab.?

parvifolius, Ehrh. ex F. G. Dietr. Vollst. Lex. Gaertn ii. 416.-Hab.?

parvispinus, Haw. Suppl. $73=$ Echinocactus parvispinus.

pendulinus, Sieber, ex DC. Prod. iii. $476=$ Rhipsalis Cassyta.

pendulus, Sw. Prod. Veg. Ind. Occ. $77=$ Rhipsalis Cassutha.

pentagonus, Linn. Sp. Pl. $467=$ Cereus pentagonus.

pentagonus, Vell. F1. Flum. 205 ; v. t. 22 -Bras.

Pentlaudi, Lem. Cact. 88.-Hab.? 
CACTUS :-

Pereskia, Linn: Sp. Pl. $469=$ Pereskia aculeata. peruvianus, DC. Pl. Grasses, t. $58=$ Cereus haxagonus, peruvianus, Linn. Sp. P1. $467=$ Cereus peruvianus. peruvianus, Willd. Enum. Hort. Berol. Suppl. $32=$ Cereus eburneus.

phyllanthoides, DC. Hort. Monsp. $84=$ Phyllocactus phyllanthoides.

Phyllanthus, Linn. Sp. P1. $469=$ Phyllocactus Phyllanthus.

Phyllanthus, Vell. Fl. Flum. 208; v, t. 33.-Bras.

Pitajaya, Blanco, F1. Filip. ed. II. $289=$ Cereus triangularis.

Pitajaya, Jacq. Enum. P1. Carib. $23=$ Cereus variabilis. placentiformis, Lehm. Ind. Sem. Hort. Hamb. (1826)

17 = Melocactus placentiformis.

polyanthos, Sims, Bot. Mag. t. 2691=Opuntia polyantha.

polygonus, Lam. Encyc. i. $539=$ Cereus polygonus.

polymorphus, Gill. ex Loud. Hort. Brit. $195=$ Cereus polymorphus.

portulacaefolius, Linn. Sp. Pl. $469=$ Pereskia portulacaefolia.

prismaticus, Desf. Tabl. Hort. Par. 165=Cerens triqueter.

prismaticus, Willd. Enum. Hort. Berol. Suppl. 32= Cereus pentagonus, prismaticus.

prolifer, Willd. ex Pfeiff. Enum. Diagn. Cact. $9=$ Mammillaria parvimamma.

proliferus, Mill. Gard. Dict. ed. VIII. n. 6= Mammil laria prolifera.

proteiformis, Desf. Tabl. Hort. Par. ed. II. $192=$ Cereus proteiformis.

pruinosus, Monvill. ex Steud. Nom. ed. II. i. $246=$ Echinocactus pruinosus.

pseudococcinillifer, Bertol. 'Exc. 11 virid. (1824) 4'; ex DC. Prod.'iii. $473=$ Opuntia nigricans.

pseudomammillaris, Desf. Tabl. Hort. Par. ed. II. 191 $=$ Mammillaria discolor.

Pseudotuna, Hort. ex Steud.' Nom. ed. II. i. $246=$ Opuntia Pseudotuna

pubescens, Lem. Cact. 87.-Hab.?

pusillus, DC. Cat. Hort. Monsp. 184= Mammillaria pusilla.

pusillus, Haw. Misc. $188=$ Opuntia fragilis.

pyramidalis, Salm-Dyck, Obs. (1820) $4=$ Melocactus pyramidalis.

quadrangularis, Haw. Syn. Pl. Succ, $181=$ Cereus caripensis.

quadratus, Gill. ex Loud. Hort. Brit. 194= Mammillaria quadrata.

recurvus, Mill. Gard. Dict. ed. VIII. n. $3=$ Echinocactus recurvus.

reductus, Link, Enum. Hort. Berol. ii. $21=$ Echinocactus gibbosus.

regalis, Spreng. Syst. ii. $496=$ Cereus regalis.

repandus, Linn. Sp, Pl, $467=$ Cerens gracilis.

reptans, Salm-Dyck, ex DC. Prod. iii. $468=$ Cereus pentagonus.

reptans, Willd. Enum. Hort. Berol. Suppl. $33=$ Cereus radicans.

reticulata, Desc. Fl. Antill, i. t. 68.-Ind. occ.

Rosa, Vell. Fl. Flum. 206 ; v. t. $27=$ Pereskia grandifolin.

rotundifolius, Moç. \& Sesse, ex DC. iii, $475=$ Pereskia rotundifolia.

Royeni, Linn. Sp. Pl. $467=$ Cereus Royeni.

Royeni, Willd. Enum. Hort. Berol. Suppl. $32=$ Cereus crenulatus.

salicornoides, Steud. Nom. ed. II. i. $246=$ Rhipsalis salicomoides.

Salmianus, Lem. Cact. 87.-Hab.?

Scopa, Link, Enum. Hort. Berol. ii. $21=$ Cereus Scopa.

senilis, Haw. in Phil. Mag. Ixiii. (1824) $41=$ Cereus senilis.

sepium, H. B. \& K. Nov. Gen. et Sp. vi. $66=$ Cereus sepium.

sericeus, Gill. ex Loud. Hort. Brit. 196=Opuntia sericea.

serpens, H. B. \& K. Nov. Gen. et Sp. vi. $68=$ Cereus serpens.

serpentinus, Lag, \& Rodr. in Anal Cienc. Nat. iv. (1801) $261=$ Cereus serpentinus.

serpentinus, Pers. Syn. ii. $23=$ Cereus fagclliformis.

solitarius, Gill. ex Loud. Hort. Brit. 194=Mammillaria solitaria.

speciosissimus, Desf. in Mém. Mus. Par, iii. (1817)

193. t. $9=$ Cereus speciosissimus.
CACTUS :-

speciosus, Cav. in Anal. Cienc. Nat. vi. (1803) $339=$ Cereus speciosissimus.

speciosus, Desf. Tabl. Hort. Par. 191=Phyllocactus phyllanthoides.

speciosus, Gill. ex Sweet, Hort. Brit. ed. II. 235 = Mammillaria speciosa.

speciosus, Hook. Bot. Mag. t. $2820=$ Rhipsalis Swartriana.

Spinii, Colla, Antol. vi. 501= Mammillaria discolor.

spinosissimus, Martyn, Cat. Hort. Cant. $88=$ Opuntia spinosissima.

spinosus, Gill. ex Loud. Hort. Brit. 194= Mammillaria spinosa.

stellaris, Salm-Dyck, Hort. Dyck. ed. II. $7=$ Mammillaria pusilla.

stellatus, Willd. Enum. Hort. Berol. Suppl. $30=$ Mammillaria pusilla.

stramineus, Spreng. Syst. i. $494=$ Mammillaria flavescens.

strictus, Haw. Misc. $188=$ Opuntia stricta

strictus, Willd. Enum. Hort. Berol. Suppl. $32=$ Cereus strictus.

subinermis, Link, ex Steud. Nom. ed. II. i. $246=$ Opuntia coccinellifera.

subquadriflorus, Moç. \& Sesse, ex DC. Prod. iii. $471=$ Opuntia rosea.

subrepandus, Spreng. Syst. ii. $495=$ Cereus subrepandus. sulphureus, Gill. ex Loud. Hort. Brit. 196=Opuntia sulphurea.

sylvestris, Thiery, ex Steud, Nom. ed. I. 132 ; ed. II. i 246 (quid?).

tenuis, Schott, ex DC. Prod, iii, $469=$ Cereus tenuis.

teres, Vell. F1. Flum. 207 ; v. t. $30=$ Rhipsalis fasciculata.

tetragonus, Linn. Sp. P1. $466=$ Cereus tetragonus.

tomentosus, Link, Enum. Hort. Berol. ii. $24=$ Opunti tomentosa.

torquatus, Hort. Lugd, ex Walp. Rep. ii. $342=$ Rhipsalis rhombea.

triacanthos, Willd. Enum. Hort. Berol. Suppl. $34=$ Opuntia triacantha.

triangularis, Linn. Sp. Pl. $468=$ Cereus compressus, trigonus.

triangularis, Vell. F1. Flum. 206; v. t. 24=Cereus triangularis.

trichotomus, Tenore, ex Steud. Nom. ed. II. i. 246 (quid?)

triqueter, Haw. Misc. $189=$ Cerens triqueter

triqueter, Vell. Fl. Flum. 206; v. t. $25=$ Cereus Arrabidae.

triqueter, Willd. Enum. Hort. Berol. Suppl. $33=$ Cereus trigonus.

truncatus, Link, Enum. Hort. Berol. ii. $24=$ Epiphyllum Altensteinii ?

tuberculatus, Willd. Enum. Hort. Berol. Suppl. $34=$ Opuntia tuberculata.

Tuna, Linn. Sp. Pl. 468=Opuntia Tuna.

Tuna-elatior, Roxb. Hort. Beng. [37] nomen.-Am. austr.

Tuna-major, Roxb. 1. c.-Am, austr.

tunicatus, Lehm. Ind Sem. Hort. Hamb. (1827) $17=$ Opuntia tunicata.

undulosus, Kostel. Allg. Med.-Pharm. Flora, iv. 1393 $=$ Cereus variabilis.

Urumbeba, Vell. Fl. Flum. 207 ; v. t. $32=$ Opuntia triacantha.

Unumbella, Stend. Nom. ed. II. i. $246=$ praec.

verticillatus, Brot. ex Heynh. Nom. ii. 103, nomen (quid?).

viviparus, Nutt. Gen. Am. i. 295=Mammillaria vivipara.

sinniaeflorus, Moç. \& Sesse, ex DC. Prod. iii. $475=$ Pereskia zinniacflora.

CACUCIA, J. F. Gmel. Syst. 693 (1791)= Cacoucia Aubl. (Combret.).

CACUVALluM, Medic. in Vorles. Churpf. Phys. Ges ii. (1787) $399=$ Mucuna, Adans. (Legum.).

altissimus, Medic. l. c. $400=$ M. urens.

CADABA, Forsk. F1. Aegyit. Arab. 67 (1775), CAP PARIDEAE, Benth. \& Hook. f. i. 108

Desmocarpus, Wall. Cat. n. $6278(1832)$

Macromerum, Burch. Trav, i. 888 (1522); ii. 615 .

SichePpERIA, Neck. Llem. iii. 67 (1790)

STROEMERIA, Roxb. lil. Ind, ii. 78 (183:).

Stroemia, Vahl, Symb. Bot. i, 19 (1790)

\section{CADABA :-}

capparoides, DC. Prod. i. 244.-Ins. Molucc.

dubia, DC. 1. co = farinosa.

farinosa, Forsk. Fl. Aegypt. Arab. 68.-Ind. bor. occ.

Arab.; Afr. trop.

glandulosa, Forsk. l. c.-Arabia.

glandulosa, Miq. in Verh. Neder1. Inst. III. v. (1852) $2=$ Miqueliana.

heterotricha, Stocks, in Hook. Ic, PI. t. 839.-Sindh.

indica, Lam. Encyc, i. 544.-Ind. or

juncea, Harv. Gen. S. Afr. Pl. ed. II. 13,-Afr. austr.

Kirkii, Oliver, Fl. Trop. Afr. i. 90.-Afr. trop.

longifolia, DC. Prod. i. 244 .-Abyss.

madagascariensis, Baill. in Bull. Soc. Linn. Par.

(1885) 464.-Madag.

Miqueliana, Turcz, in Bull. Soc. Nat. Mosc. xxvii. (1854) II. 321.-Malaya.

monopetala, Edgew. in Journ. As. Soc. Beng. xvi (1847) 1212 = glandulosa

natalensis, Sond. in Linnaea, xxiii. (1850) 8.-Natal. rotundifolia, Forsk. Fl. Aegypt. Arab. 68.-Arab. Abyss.

somalensis, Franch. in Revoil, Comali, 12.Afr. trop.

trifoliata, Wight Eै Arn. Prod. 24.-Ind. or.

trinervia, DC. Prod. i. $244=$ Cleome coluteoides.

triphylla, Wight, in Hook. Bot. Misc. iii. (1833) 296 $=$ trifoliata.

virgata, Boj. in Ann. Sc. Nat. Sér. II. xx. (1843) 58.Madag.

Cadalvena, Fenzl, in Sitz. Akad. Wien, Math. Nat. li. Abth. II. (1865) $139=$ Kaempferia, Linn. (Scitamin.

spectabilis, Fenzl, 1. c. 140.-Afr. trop.

CADAMBA, Sonner. Voy. ii. 228. t. $128(1782)=$ Guettarda, Limn. (Rubiac.)

jasminiflora, Sonner. 1. c. ii. t. 128 ; iii. $253=\mathrm{G}$. speciosa.

CADELARI, Adans. Fam. ii. $268(1763)=$ Pupalia, Juss. (Amarantac.)

lappacea, Medic. Malv. 92=P. atropurpurea.

CADELARIA, Rafin. Fl. Tellar, iii. 39 (1836)= Achyranthes, Linn. (Amarantac.)

indica, Rafin. 1. c. = A. aspera.

punctata, Rafin. 1. c. = A. aspera

sicula, Rafin. 1. c. = A. aspera.

CADELIUM, Medic. in Vorles. Churpf. Phys. Ges. in (1787) 352; Phil. Bot. i. $206(1789)=$ Phaseolus, Tourn. (Legumin.)

nigrum, Medic. 1. c. $352=$ P. Max

viride, Medic 1. $\mathrm{c}_{\mathrm{o}}=\mathrm{P}, \mathrm{Max}$.

CADELLIA, F. Muel1. Fragm, ii. 25 (1860). SIMA. RUBEAE, Benth. \& Hook. f. i. 313

Guilfoylia, F. Muell. Fragm. viii. 33 (1873).

monostylis, Benth. Fl. Austral, is 3\% - Austral.

pentastylis, F. Muell. Fragm. ii. 26. t. 12.-Austral

CADETIA, Gaudich. in Freyc. Voy. Bot. 422 . t. 93 (1S20" = Dendrobium, Sw. Orchid.

angustifolia, Blume, Rumphia, iv. $39=\mathrm{D}$. angustifolium

biloba, Blume, Mus. Bot. Lagd. Bat. i. (1S49 90 D. bilobum.

recurvata, Blume, 1. c.-N. Guinea.

similis, Blume, Rumphia, iv. 29, in obs. - 1 . Guinea.

umbellata, Gaudich. in Freyc. Voy. Bot. 422. L $\$ S=$ D. umbellatum.

CADIA, Forsk. Fl. Aegypt. Arab. 90 (1755). LEGL MINOSAE. Benth. \& Hook. f. i. 50 i i. Panclatica, Picciv. Hort. Hanciat, 9 (1;-89) SPAENDONCEA, Desf. Dec. Phil. vii, 25!; et in Usteri, N. Ann, xiii, $\left(1 ; 90^{\circ}\right) 15$.

anomala, Vatke, in Linuac\%, xliii. (1SSO-S2 $397 .-$ Madag.

arabica, Kaeusch. Nom. ed. III. $117=$ purpuren.

Commersoniana, Baill. in Bull. Sor. Lign. Par. i. (1888) 370. -Madag.

Ellisiann, Baker, in fourn. Linn. Soc. ex (1854) 185. - Madag.

pedicellata, Baker, 1. c. 39S.-Mailag.

pubescens, Boj. ex Baker, in Olieer, Fl. Trop. Afro ii. 256.-Mata. M. Mar.

purpuren, Forsk. Fl. Arevest. Arah. 90,-Arab. felix

iaria, L'Herit. Diss in Mag. Enc. $\vee .29=$ purpurea. 
CAdiscus, E. Mey. ex DC Prod. vii. 254 (1838). COMPOSITAE, Benth. \& Hook. f. ii. 408 aquaticus, E. Mey. l.c. 255. -Afr. austr.

CADSURA, Spreng. Syst. ii. $642(1827)=$ Kadsura, Juss. (Magnoliac.)

CAELESTINA, Cass. in Dict. Sc. Nat. vi. Suppl. 8. t. $93(1817)=$ Ageratum, Linn. (Compos.).

ageratoides, H. B. \& K. Nov. Gen. et Sp. iv. $151=$ A. corymbosum.

albida, DC. Prod. v, $107=$ A. albidum.

caerulea, Cass. in Dict. Sc. Nat. vi. Suppl. $8=$

A corymbosum.

cordata, Pohl, ex Baker, in Mart. Fl. Bras. vi. II. 345

=Eupatorium macrophyllum.

corymbosa, Benth. Bot. Voy. Sulph. $111=$ A. salicifolium.

corymbosa, DC. Prod. v. $108=A$. corymbosum.

Hartwegi, Walp. Rep. ii. $545=$ Eupatorium Hartwegi.

hastata, Pohl, ex Baker, in Mart. F1. Bras, vi. II. 363 = Eupatorium betonicaeforme.

isocarphoides, DC. Prod. v. $107=\mathrm{A}$. isocarphoides.

latifolia, Benth. ex Oerst. in Kjoeb. Vidensk. Meddel. 1852) $71=$ A. latifolium.

Lessingiana, Klotzsch, ex Walp. Rep. ii. $545=$ A. corymbosum.

linearifolia, Sch. Bip. ex Baker, in Mart. Fl. Bras. vi. II. 191 = Alomia polyphylla.

longifolia, Pohl, ex Baker, 1. c. $361=$ Eupatorium organense.

maritima, Torr, \& Gray, Fl. N. Am. ii, $64=$ A. littorale.

micrantha, Spreng. Syst. iii. $446=\mathrm{A}$. coelestinum.

microcarpa, Benth. ex Oerst. in Kjoeb. Vidensk. Meddel. (1852) $72=\mathrm{A}$. microcarpum.

paleacea, J. Gay, ex DC. Prod. v. $107=$ A. paleaceum. parvifolia, DC. 1. c. 108.-Am. austr.

petiolata, Hook. \& Arn. Bot. Beech. Voy. $433=$ A. petiolatum.

Pohlii, Sch. Bip. ex Baker, in Mart. Fl. Bras. vi. II. $190=$ Alomia Pohlii.

repanda, Pohl, ex Baker, 1. c. $309=$ Eupatorium viridiflorum.

repens, Sch. Bip. in Schomb. Fauna et Flora Guy. 1138.-Guiana.

scab̉riuscula, Benth. ex Oerst. in Kjoeb. Vidensk. Meddel. (1852) $72=\mathrm{A}$. scabriusculum.

suffruticosa, Sweet, Hort. Brit. ed. I. $229=$ A. corymbosum.

tomentosa, Benth. ex Oerst. in Kjoeb. Vidensk. Meddel. (1852) $71=\mathrm{A}$, tomentosum.

urticaefolia, Pohl, ex Baker, in Mart. FI. Bras. vi. II. $362=$ Eupatorium betonicaeforme.

viscosa, Pohl, ex Baker, 1. c. = Eupatorium apiculatum.

CAELIA, G. Don, in Sweet, Hort. Brit. ed. III. 637 $(1839)=$ Coelia, Lindl

CAELOCLINE, Auct. ex Steud. Nom. ed. II. i. 247 $(\mathbf{1 8 4 0})=$ COELOCLINE, A. DC. = Xylopia, Linn. (Anonac.).

CAELODEPAS, Benth. \& Hook. f. Gen. iii. 313 (1880) = Coelodepas, Hassk. (Euphorb.).

CAELOGLOSSUM, Steud. Nom. ed. II. i. $247(1840)=$ COELOGLOSSUM, Lindl. = Habenaria, Willd. (Orchid.).

CAELOGYNE, Wall. ex Steud. Nom. ed. II. i. 247 $(1840)=$ Coelogyne, Lindl. (Orchid. $)$.

CAELOSPERMUM, Blume, Bijdr. 994 (1826), vide Coelospermum, Blume.

CAENOTUS, Rafin. Fl. Tellur. ii. 50(1836)=Erigeron, Linn. (Compos.).

canadensis, Rafin. 1. c. = E. canadensis.

longifolius, Rafin. 1. c. = E. longifolius?

pusillus, Rafin. 1. $\mathrm{c}_{.}=\mathrm{E}$. camadensis.

CAESAlPINA, Plum. ex Linn. Gen. ed. I. $363(1753)=$
CAFSALPINTA, Linn. Sp. Pl. 380 (1753). LEGU

MINOSAE, Benth. \& Hook. f. i. 565.

Balsamocarpon, Clos, in C. Gay, Fl. Chil. ii. 226. t. $20(1846)$

Biancaea, Todaro, Nuov, Gen. 21 (1858).

BonduC, Adans. Fam. ii. 318 (1763).

CAMPecia, Adans. 1. c. (1763).

Cinclidocarpus, Zoll, in Nat. en Geneesk. Arch.

Neêrl. Indie, iii. (1846) 81

Cladotrichium, Vog. in Linnaea, xi. (1837) 401.

Coulteria, H. B. \& K. Nov. Gen. et Sp. vi. 328 . t. 568 (1823).

ErYTHRostemon, Klotzsch, in Link, Klotzsch \& Otto, Ic. Pl. i. 97. t. 39 (1841).

Guilandia, P. Br. Hist. Jamaic. 228 (1756).

Guilandina, Linn. Gen. ed. I. 124 (1737).

Libidibia, Schlecht. in Linnaea, v. (1830) 192.

Pomaria, Cav. Ic. v. 1. t. $402(1799)$.

TARA, Molina, Saggio Chile, ed. II. 153 (1810).

TiCanto, Adans, Fam, ii. 319 (1763)

acanthobotrya, Miq. Fl. Ind. Bat. Suppl. i. 292.Sumatra.

acinaciformis, Mart. ex Steud. Nom. ed. II. i, 247.-

Bras.

affinis, Hemsl. Diag. Pl. Nov. 8.-Guatemala.

angulicaulis, Clos, in C. Gay, Fl. Chil. ii. 223.Chili.

angustifolia, Salisb. Prod. $326=$ C. Sappan.

arborea, Zoll. ex Miq. Fl. Ind. Bat. i. $112=$ Peltophorum ferrugineum.

Arista, Mill. Gard. Dict. ed. VIII. n. 2, sphalm. = Crista.

armata, R. Grah. in Wall. Cat. n. $5840=$ mimosoides.

axillaris, DC. Prod. ii. $481=$ C. sepiaria? et Mezoneurum cucullatum.

bahamensis, Lam. Encyc. i. $461=$ Crista.

Barbon, Bert. in 'Merc. Chil. (1829)'; et in Bull. Férussac, xx. (1830) 109.-Chili.

Berterii, Spreng. ex DC. Prod. ii. $482=$ bijuga

bijuga, Sw. Obs. 166.-Ind, occ.

bijuga, Wall. Cat. п. $5833=$ C. Nuga.

Bonduc, Roxb. Hort. Beng. 32 ; Fl. Ind. ii. 362.Cosmop. trop.

Bonduc, Wight \& Arn. Prod. $280=$ C. Bonducella.

Bonducella, Fleming, in As. Res. xi. (1810) 159.Cosmop. trop

bracteosa, Tul. in Arch. Mus. Par. iv. (1844) 141.Bras.

brasiliensis, Linn. Sp. Pl. 380--Am. trop.

Brea, Gill. ex Steud. Nom. ed. II. i. $247=$ praecox.

brevifolia, Baill. Hist. Pl. ii. 168.-Chili

Cacalaco, Humb. E Bonpl. Pl. Aeq. ii. 173. t. 137.Mexic.

calycina, Benth. in Mart. Fl. Bras. xv. II. 71.-Am trop.

cassioides, Willd. Enum. Hort. Berol. 444.-Am austr.

Cavanillesii, Spreng. Syst. v. Ind. $123=$ bijuga.

chinensis, Roxb. Hort. Beng. 32 ; F1. Ind. ii. $361=$ C Nuga.

Cinclidocarpus, Miq. Fl. Ind. Bat. i. 110.-Ind. or.;

Malaya.

coluteifolia, Griseb. in Goett. Abh. xxiv. (1879) 111.-

Reg. Argent.

compressa, D. Dietr. Syn. Pl. ii. 1494-Mexic. Peruv.

coriacea, Poit: in Rev. Hortic. Sér. II. ii. (1843-44) 269 $=$ coriaria

coriaria, Willd. Sp. Pl. ii. 532.-Am, austr.

corymbosa, Benth. Pl. Hartw. 117.-Guayaquil.

coulterioides, Griseb. in Goett. Abh. xxiv. (1879) 113 - Reg. Argent.

Courboniana, Baill. Adansonia, x. (1871) 103.-

Mare rubrum.

Crista, Linn. Sp. Pl. 380.-Ind, occ.

Crista, Thunb. F1. Jap. $179=$ sepiaria

cucullata, Roxb. Hort. Beng. 32 ; Fl. Ind. ii. $358=$ Mezoneurum cucullatum.

dasyrachis, Miq. Fl. Ind. Bat. Suppl. i. $292=$

Peltophorum dasyrachis.

desertorum, Mart. ex G. Don, Gen. Syst. ii. $431=$ bracteosa.

digyna, Rottl. in Ges. Naturf. Freunde Neue Schr. iv. (1803) 200.-Ind. or.; Malaya.

dubia, Spreng. Syst. ii. $343=$ Peltophorum Vogelianum

Ebano, Karst. Fl. Columb. ii. 57. t. 129.-N. Granat.

echinata, Lam. Encyco-i. 461.-Bras.

elata, Sw. Obs. $166=$ Poinciana elata.

\section{CAFSALPINTA :}

enneashylla, Roxb. Hort. Beng. 32 ; Fl. Ind. ii. $363=$ Mezoneurum enneaphyllum.

eriostachys, Benth. Bot. Voy. Sulph. 88.-Am. centr.

exilifolia, Griseb. in Goett. Abh. xix. (1874) 128.-Reg Argent.

exostemma, Moc. E' Sesse, ex DC. Prod. ii. 483.Nicaragua.

ferox, Hassk. Ind. Sem. Hort. Amst. (1841); Pl. Jav Rar. $400=$ sepiaria.

ferox, Hohen. ex Baker, in Hook. f. Fl. Brit. Ind. ii. $261=$ Wagatea spicata.

ferrea, Mart. Reise Bras. ii. 611.-Bras,

ferruginea, Decne. in Nouv. Ann. Mus. Par. iii. (1834) $462=$ Peltophorum ferrugineum.

fimbriata, Tul. in Arch. Mus. Par. iv. (1844) 145.Bolivia.

Finlaysoniana, R. Grah. in Wall. Cat. n. $5971=$ Peltophorum dasyrachis.

Fischeri, Regel E Koern. in Gartenfl. (1858) 251.Ind. or.?

flavicans, R. Grah. in Wall. Cat. n. 5825=digyna

floribunda, Tul. in Arch. Mus. Par. iv. (1844) 140.Bras.

furfuracea, Wall. Cat. n. $5835=$ Mezoneurum glabrum. Gardneriana, Benth. in Mart. Fl. Bras. xv. II. 68.Bras.

Gilliesii, Wall. ex Hook. Bot. Misc. i. (1830) 129.Am. austr.

glabrata, H. B. E K. Nov. Gen. et Sp. vi. 326.-Peruv. glandulosa, Bert. ex DC. Prod. ii. $482=$ bijuga.

Gleniei, Thw. Enum. Pl. Zeyl. $414=$ Peltophorum ferrugineum.

gracilis, Benth ex Hemsl. Diag. Pl. Nov. 9.-Mexic.

gracilis, Miq. Fl. Ind. Bat. i. $110=$ digyna.

grandis, Heyne, in Wall. Cat. n. 5830-Ind. or.

Heyneana, Steud. Nom. ed, II. i. $247=$ Wagatea spicata.

Hildebrandtii, Baill. in Bull. Soc. Linn. Par. i. (1883) 371.-Afr. trop.

hispida, D. Dietr. Syn. Pl. ii. 1495.-Mexic

horrida, Herb. Madr. ex Wall. Cat. n. $5836=$ mimosoides.

horrida, A. Rich. Ess. Fl. Cub. $411=$ sepiaria

horrida, Spreng. Syst. iv. Cur. Post. 169.-N. Granat. hymenocarpa, Wall. Cat. n. $5832=$ Mezoneurum pubes-

cens,
ignota, Blanco, F1. Filip. ed. I. $336=$ Mezoneurum pubescens.

inermis, Roxb. Hort. Beng. [90]; F1. Ind. ii. $367=$ Peltophorum ferrugineum.

insignis, Steud. Nom. ed. I. 133 ; D. Dietr. Syn. Pl. ii. 1494.-Reg. Amazon.

japonica, Sieb. \& Zucc. in Abb. Akad. Muench. iv. II (1845?) $117=$ sepiaria.

kavaiensis, H. Mann, in Proc. Am. Acad. vii. (1867) 164.-Ins. Hawaii.

Kilaroe, Span. in Linnaea, xv. (1841) $200=$ Peltophorum ferrugineum.

lacerans, Roxb. Hort. Beng. [90]; FI. Ind. ii. $367=$ Pterolobium indicum.

languida, Hoffmgg. Verz. Pfl. Nachtr. ii. 72.-Ind. or. latifolia, Salisb. Prod. $326=$ vesicaria.

laxa, Benth. Pl. Hartw. 60.-Mexic.

laxiflora, Tul. in Arch. Mus. Par. iv. (1844) 143.Bras.

lebbekkioides, DC. Prod. ii. $483=$ Albizzia Millettii.

ligulata, Heyne, ex DC. Prod. ii. 484=Pterolobium lacerans.

Macklottii, Zipp. ex Miq. F1. Ind. Bat. i. 112 = Pelto. phorum ferrugineum.

macrantha, Delile, Ind. Sem. Hort. Monsp. (1838) 3. -Chili.

marginata, Tul. in Arch. Mus. Par. iv. (1844) 147.Bras.

melanocarpa, Griseb. in Goett. Abh. xix. (1874) $12 S$. -Reg. Argent.

Melanosticta, Spreng. Syst. iv. Cur. Post. $169=$ Melanosticta Burchellii.

mexicana, A. Gray, in Proc. Am. Acad. v. (1861) 157. -Mexic.

microphylla, Buch.-Ham. in Wall. Cat. n. $5826=$ C, Cinclidocarpa.

microphylla, Mart. Reise Bras. ii. 611.-Bras.

Millettii, Hook. E Arn. Bot. Beech. Voy. 182. China.

mimosifolia, Griseb. in Goett. Abh. xix. (1874) 128. -Reg. Argent. 
CAESALPINIA :-

mimosoides, Heyne, in Wall. Cat. n. $5837=$ Wagatea spicata.

mimosoides, Lam. Encyc. i. 452.-Ind. or.; Burma. Minax, Hance, in Fourn. Bot. xxii. (1884) 365.China

mollis, Spreng. Syst. iv. Cur. Post. 169.-Am. trop. monosperma, Buch.-Ham, ex Wall. Cat. sub n, $5828=$ Mezoneurum cucullatum.

monosperma, Tul. in Arch. Mus. Par. iv. (1844) 148. -Ind. occ.

mucronata, Willd. Enum. Hort. Berol. 444.-Bras.

nitida, Hassk. Cat. Hort. Bog. Alt. 285.-Malaya.

Nuga, Ait. Hort. Kew. ed. II. iii. 32.-As. trop.; Austral.; Polynes.

obliqua, Vog. in Linnaea, xi. (1837) $407=$ echinata. oleosperma, Roxb. Hort. Beng. 32 ; Fl. Ind. ii. $357=$ digyna.

Paipae, Ruiz E Pav. Fl. Per. iv. t. 375.-Peruv.

paniculata, Desf. Tabl. Hort. Par. ed. II. $210=$ C Nuga.

Parahyba, Allem. in Trab. Soc. Vell. 56=Schizolobium excelsum.

parvifolia, Steud. Nom. ed. II. i. $247=$ C. Cinclidocarpa.

pauciflora, Benth. E Hook. f. ex Chapm. Fl. S. U. St. Suppl. 18.-Am. bor.; Ind. occ.

pectinata, Cav. Desc. 467 = tinctoria.

pellucida, Vog, in Linnaea, x. (1836) 601.-Ins. S, Doming.

peltophoroides, Benth. in Mart. Fl. Bras. xv. II. 72.Bras.

pilosa, Benth. l. c. 73.-Bras.

pluviosa, DC. Prod. ii, 483.-Bras.

polyphylla, Roxb. Hort. Beng. 32, nomen.-Pegu.

porcina, Mart. ex Steud. Nom. ed, II. i. 247.-

Bras.

praecox, Ruiz E Pav. Fl. Per. iv. t. 376.-Chili.

procera, Poepp. ex Spreng. Syst. ii. 343.-Cuba.

pubescens, Buch.-Ham. ex Wall. Cat. sub n. $5834=$ sepiaria.

pulcherrima, Sw. Obs. 166.-Cosmop, trop.

Pumilio, Griseb. in Goett. Abh. xxiv. (1879) 113.Reg. Argent.

punctata, Willd. Enum. Hort. Berol. 445.-Bras.

pyramidalis, Tul. in Arch. Mus. Par. iv. (1844) 139.Bras.

regia, D. Dietr. Syn. P1. ii. $1495=$ Poinciana regia

resupinata, Roxb. Hort. Beng. 32 ; F1. Ind. ii. $362=$

mimosoides.

Roxburghii, D. Dietr. Syn. P1. ii. 1494 = Peltophorum ferrugineum.

rubicunda, Benth. in Mart. Fl. Bras. xv. II. 73.Bras:

Sapang, Noronha, in Verh. Batav. Gen. v. (1790) ed. I. Art. IV. $12=$ C. Sappan.

Sappan, Linn. Sp. Pl. 381.-As. trop.

scandens, Heyne, ex Roth, Nov。 Pl. Sp. 209. Ind. or.

scandens, Koen. ex Baker, in Hook, f. Fl. Brit. Ind. ii $255=$ Nuga

Selloi, G. Don, Gen. Syst. ii. $431=$ Peltophorum Vogelianum

sepiaria, Roxb. Hort. Beng. 32 ; 'Fl. Ind. ii, 360 .-As. trop.

sepiaria, Wall. Cat. n. $5834 \mathrm{H}_{\mathrm{.}}=$ Mezoneurum enneaphyllum.

Simora, Buch.-Ham. ex Roxb. Hort. Beng. 32 ; Fl. Ind. ii. $359=$ mimosoides.

smilacea, Hort. ex Steud. Nom. ed. II. i. $248=$ Cocculus carolinus.

spicata, Dalz. in Hook. Kew Journ. iii. (1851) $89=$

Wagatea spicata.

stipularis, Benth. in Mart. Fl. Bras. xv. II. 72.-Bras

suberosa, Lodd, ex Loud. Hort. Brit. 167.-Ind. or.

sumatrana, Roxb. Hort. Beng. $32 ; \mathrm{Fl}$. Ind. ii. $366=$

Mezoneurum sumatranum.

sumatrana, Wall . Cat. n. $5831 \mathrm{~B}, \mathrm{C}=\mathrm{Nuga}$.

Tara, Ruiz \& Pav. Fl. Per, iv, t. 374.-Peruv.

thomaea, Spreng. Syst. ii. $343=$ coriaria.

tinctoria, Domb. ex DC. Prod. ii. 481.-N. Granat.

torquata, Blanco, Fl. Filip. ed. I. $396=$ Mezoneurum glabrum.

tortuosa, Roxb. Hort. Beng. 32 ; Fl. Ind. ii. 365.-

Burma; Malaya; Sumatra.

tortuosa, Wall. Cat. n. 5827. D = C. Cinclidocarpus,

trichocarpa, Griseb. in Goett. Abh, xxiv. (1879) 112.Reg. Argent.

\section{CAESALPINIA :}

ulosperma, Hort. ex Steud. Nom. ed. II. i. 248.Hab.?

ventricosa, Griseb. F1. Brit. W. Ind, $205=$ bijuga.

vernalis, Champ.ex Benth. in Hook. Kew Fourn. iv. (1852) 77.-China

vesicaria, Lam. Encyc. i. $461=$ bijuga

vesicaria, Linn. Sp. Pl. 381.-Bras.

vesicaria, Vell. F1. Flum. 172 ; iv. t. $89=$ echinata

wynaadensis, Heyne, ex Wall. Cat. sub n. $5830=$ grandis.

CAESAREA, Cambess. in Mém. Mus. Par. xviii. (1829) 373. t. $18=$ Viviania, Cav. (Geraniac.)

albiflora, Cambess. 1. c. 374.-Bras.

grandiflora, St. Hil. ex Steud. Nom. ed. II. i. 248.Bras.

hypoleuca, Mart. ex Steud. 1.c.-Bras.

lanceolata, Klotzsch, in Linnaea, x. (1836) 437.-Bras. monteridensis, Klotzsch, 1. c. 436.-Reg. Argent.

ovata, Klotzsch, 1. c.-Bras.

petiolata, Klotzsch, 1. c. 437.-Bras.

nubriflora, Cambess. in Mém. Mus. Par. xviii. (1829) 374.-Bras.

CAESIA, R. Br. Prod. 277 (1810), LILIACEAE Benth. \& Hook. f, iii. 792.

acanthoclada, F. Muell. Fragm. i. $215=$ Corynotheca acanthoclada.

africana, Baker, in Trans. Linn. Soc. xxix. (1875) 160.

-Afr. trop

alpina, Hook. f. FI. Tasm. ii. $373=$ Chlorophytum alpinum.

asparagoides, Eckl. ex Steud. Nom. ed. II. i. 248.-Afr. austr.

chlorantha, F. Muell. Fragm. i. $63=$ vittata.

coarctata, Spreng. Syst. ii. $88=$ Eccremis coarctata

comosa, Spreng. 1. c. = Chlorophytum comosum

corymbosa, R. Br. Prod. 277= Chamaescilla corymbosa.

cyanea, A. Cunn. ex Baker, in Journ. Linn. Soc. xv. (1876) $358=$ vittata.

dichotoma, F. Muell. Fragm, i. 215=Corynotheca dichotoma.

Dregeana, Kunth, Enum. P1. iv. $611=$ Anthericum Dregeanum.

Eckloniana, Schult. f. Syst. vii. 1691 = Aathericum scilliflorum.

Helleri, Hueg. ex Heynh. Nom. ii. 103, nomen.Austral.

hirsuta, Lindl. Swan Riv. App. 57. n. $273=$ Agrostocrinum stypandroides.

lateriflora, R. Br. Prod. $277=$ Corynotheca lateriflora. micrantha, Lindl. Swan Riv. App. $57=$ parviflora.

occidentalis, R. Br. Prod. $277=$ parvillora

paradoxa, Endl. in Lehm. Pl. Preiss. ii. $34=$ Chamae silla spiralis?

parviflora, R. Br. Prod. 277.-Austral.

physodes, Spreng. Syst. ii. $88=$ Urginea physodes.

pusilla, Spreng. l. c. = Urginea pusilla.

rigidifolia, F. Muell. Fragm。x.48.-Austral.

scabra, Baker, in Journ. Linn. Soc. xv. (1876) $359=$ Agrostocrinum stypandroides.

setifera, Baker, l. c.-Austral.

spiralis, Endl. in Lehm. Pl. Preiss. ii. $34=$ Chaemae scilla spiralis.

Thunbergii, Schult. f. Syst. vii. $1692=$ Anthericum contortum.

versicolor, Lindl. Swan Riv, App. $57=$ Cbamaescilla corymbosa.

vittata, R. Br. Prod. 277.-Austral

CAESIA, Vell. F1. Flum. 107 (1825); iii. t. $23(1827)=$ Cormonema, Reissek (Rhamneae).

spinosa, Vell. 1. c. - = C. spinosum.

CAEsulia, Roxb. Pl. Cотоm. i. 64. t. 93 (1759) COMPOSITAE, Benth. \& Hook, f. ii. 31.8.

axillaris, Roxb. l. c.-Ind. or.

lancifolia, Sweet, Hort. Brit. ed. II. 288 (quid ?),Ind, or.

radicans, Willd. Sp. PI. iii. $1797=$ Cryphiospermum repens.

scandens, Poepp. ex DC. Prod. ₹. $564=$ Wulffia scandens.

CAETA, Steud. Nom. ed. II. i. $218(1810)=$ Torenia Linn. (Scrophular.).
CAETOCAPNIA, End1. Gen. $180(1837)=$ COETOCAPNIA, Link \&c Otto= Bravoa, Lex.

CAFFEA, Noronha, in Verh. Batav. Gen. v. (1790) ed. I. Art. IV. 12, an Coffea, Linn.

CAHOTA, Karst. in Linnaea, xxviii. (1856) $448=$ Clusia, Linn. (Guttifer.)

carachensis, Karst. 1. c.-Venezuela.

CAIDBEJA, Forsk. FI. Aegyit. Arab. 82 (1775) = Forskohlea, Linn. (Urticac.

adhaerens, Forsk. 1. c. $=\mathrm{F}$. tenacissima

CAILLIEA, Guillem. \& Perr. Tent. FI. Seneg. 23 (1833) = Dichrostachys, DC. (Legumin.) dichrostachys, Guillem. \& Perr. 1. c. $240=$ D. nutans macrostachya, Steud. in Flora, xxvi. (1843) $759=$ Pentaclethra filamentosa.

CAINA, Panch. ex Baill. in Bull. Soc. Linn. Par. (1880) 264 = Couthovia, A. Gray (Loganiac.) erratica, Panch. ex Baill. 1. c. =C. corynocarpa.

CAINITO, Plum. ex Adans. Fam. ii. 166 (1763); Tuss Fl. Antill. iii. 41. t. $9(1824)=$ Chrysophyllum Linn. (Sapotac.)

pomiferum, Tuss. Fl. Antill, iii. 41. t. $9=$ Chryso phyllum Cainito.

CAIOPHORA, Presl, Rel. Haenk. ii. 41. t. 56 (1831) =

Blumenbachia, Schrad. (Loas.)

absinthiifolia, Presl, 1. c. $42=\mathrm{B}$, coronata.

carduifolia, Presl, 1. c. $=$ B. carduifolia.

cirsiifolia, Presl, 1. c. t. 56.-Peruy.

contorta, Presl, 1. c. $42=$ Loasa compressa.

coronata, Hook. \& Arn. in Hook. Bot, Misc. iil. (1833) $327=\mathrm{B}$. coronata.

Herbertix, G. Don, ex Lour. Encyc. Pl. Suppl. i. 1438.- - Hab.

lateritia, Benth. in Maund. \& Hensl. Botanist, 111. 119.-Chili.

Pentlandii, G. Don, ex Loud. Encyc. Pl. Suppl. ii. 1438.-Peruv.

scandens, Mey, \& Klotzsch, in Nor, Act. Nat. Cur. xix. Suppl. i. (1843) $339=$ B. scandens.

CAJAN, Adans. Fam. ii. $326(1763)=$ Cajanus, DC (Legumin.).

inodorum, Medic. in Vorles. Churpe. Phys. Ges, ii. (1787) $363=$ Cajanus indicus.

scarabaeoides, Thou. in Dict. Sc. Nat. vi. $167=$ Atylosia scarabaeoides.

CAJANUM, Rafin. Sylva Tellur. $25(1838)=\mathrm{seq}$. Thora, Rafin. 1. c. = Cajanas indicus.

CAJANUS, DC. Cat. Hort. Monsp. 85 (1S13) LEGUMINOSAE, Benth. \& Hook of i. 541

albicans, R. Grah. in Wall. Cat. B. 5552=Atylosia albicans.

argenteus, Spreng. Syst. iii. $248=$ Argyrolobium Linnaeanum.

bicolor, DC. Cat. Hort. Monsp. $85=$ indicas. candicans, Wall. Cat. n. 5576 = Rhynchosia arensis. cinereus, F. Muell. Censics, 41.-Austral.

confertiflorus, F. Muell. Pl. Fitsalan, 9.-Austral. flavus, DC. Cat. Hort. Monsp. $85=$ indicus.

glandulosus, Dalz. \& Gibs. Bomb. Fl. $73=$ Atylosia mollis.

goënsis, Dalz, in Hook. Kew Journ. ii. (1550) 264 Atylosia barbata.

grandifolius, F. Muell. Pl. Fit=olan, 9-Austral. helvolus, Spreng. Syst. iii. $24 \mathrm{~S}=$ Glycine belvola. indicus, Spreng. \%. c.-Ind, or.

kulnensis, Dalz. in Hook. Kew Joura. ii. 1550 -60t= Atylosia kulnensis.

lineatus, R. Grah. in Wall. Cat. D. $55,8=$ Atylosia lineata.

Iuterus, Bello, in Anal. Soc Esp. Hist. Tac $x, 15 s]$ $260=$ inclicus

marmoratus, F. Mfuell. Census, 41.-Austral. megalanthus, Spreng. ex DC. Prod. ii. $218=$ Astri. galus megralantbus.

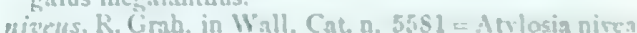
guinquepelalus, Blanco, 11. bilip. ed. 11. $11 \%$ - Dci mudium Cepbalotes. 


\section{CAJANUS :-}

reticulatus, F. Muell. Census, 41.-Austral.

scarabaeoides, Thou. ex R. Grah. in Wall. Cat. n. 5580 $=$ Atylosia scarabaeoides.

striatus, Boj. Hort. Maurit. $109=$ indicus

suaveolens, R. Grah. in Wall. Cat. n. $5579=$ Rhynchosia suaveolens.

volubilis, Blanco, Fl. Filip. ed. II. $417=$ Atylosia mollis.

Wightianus, R. Grah. in Wall. Cat. n. $5583=$ Atylosia albicans.

wolgaricus, Spreng. ex Steud. Nom. ed. II. i. $248=$ Calophaca wolgarica.

CAJU-PUTI, Adans. Fam. ii. 84 (1763)= Melaleuca, Linn. (Myrtac.).

CAKILF, Linn. Syst. ed. I (1735), CRUCIFERAE, Benth. \& Hook. f. i. 99

aegyptia, Spreng. Syst. ii. $852=$ Didesmus aegyptiacus. aegyptiaca, Willd. Sp. Pl. iii. $417=$ maritima. requalis, L'Hérit. ex DC. Syst. ii. $430=$ maritima. americana, Nutt. Gen. Am. ii. 62 = maritima bipinnata, Spreng. Syst. ii. $852=$ Didesmus bipinnatus. clavata, Spreng. 1. c. = Rapistrum clavatum. crenata, Jord. Diagn. i. $346=$ maritima. cubensis, H. B. \& K. Nov. Gen. et Sp. v. $75=$ maritima. cyrenaica, Spreng. Syst. ii. 852,-Cyrenia.

domingensis, Tuss. Fl. Ant. i. $119=$ maritima.

edentula, Hook. Fl. Bor. Am. i. $59=$ maritima

hispanica, L'Hérit. ex DC. Syst. ii. $619=$ Brassica incana.

hispanica, Jord. Diagn. i. $345=$ maritima.

latifolia, Poir. Encyc. Suppl. ii. $88=$ maritima.

littoralis, Jord. Diagn, i. $345=$ maritima

maritima, Scop. Fl. Carn. ed. II. ii. 35.-Europ.; Afr. bor.; Am. bor

monosperma, Lange, Pl. Nov. Hisp. fasc. i. 5. t. 7.Hispan.

myagroides, Poir. Encyc. Suppl. ii. $88=$ Erucaria aleppica.

perennis, L'Hérit. ex DC. Syst. ii. $431=$ Rapistrum perenne.

perfoliata, L'Hérit. ex DC. 1. c. $575=$ Conringia orientalis.

pinnatifida, Stokes, Bot. Mat. Med.iii. 484=maritima.

rugosa, L'Hérit. ex DC. Syst. ii. $432=$ Rapistrum rugosum.

Serapionis, Gaertn. Fruct. ii. $287=$ maritima.

sinuatifolia, Stokes, Bot. Mat. Med. iii. $485=$ maritima.

striata, L'Hérit. ex DC. Syst. ii. 659 = Didesmus tenuifolius.

CALACANTHA, T. Anders. ex Benth. \& Hook. f. Gen, ii. 1088 (1876). ACANTHACEAE, Benth. \& Hook. f. 1. c.

Dalzellianus, T. Anders. ex Benth. E Hook. $f$. l. $c_{\mathrm{s}}$-Ind. or.

grandiflorus, Radlk. in Sitzb. Math.-Phys. Acad, Muench. xiii. ' 1884 ' (1883) $279=$ praec.

CALACINUM, Rafin. Fl. Tellur. ii. 33 (1836)= Muehlenbeckia, Meissn. (Polygon.)

adpressum, Rafin. 1. c. $34=\mathrm{M}$. adpressa.

australis, Rafin. 1. c. $=$ M. australis.

CALADENIA, R. Br. Prod. 323 (1810). ORCHI$D E A E$, Benth. \& Hook, f. iii. 612 .

Leptoceras, Lindl. Gen. et Sp. Orch. 415 (1840). alata, R. Br. 1. c. $324=$ carnea.

alba, R. Br. 1. c. $323=$ carnea

angustata, Hook. f. Fl. Tasm. ii. 30, t. $125=$ carnea angustata, Lindl. Gen. et Sp. Orch. 420=testacea. antarctica, Reichb. f. Beitr. Syst. Pf. $67=$ Lyperanthus antarcticus.

aphylla, Benth. Fl. Austral. vi. 387.-Austral. arenaria, Fitzg. Austral. Orch. i. vit t. 1-Austral Barbarossa, Reichb. f. Beitr. Syst. Pft. 64.-Austral. barbata, Lindl. Gen. et Sp. Orch. $418=$ deformis. Behrii, Schlecht. in Linnaea, xx. (1847) $569=$ Patersoni.

bifolia, Hook. f. Fl. Nov. Zel. i. 247.-N. Zel.

Brunonis, Reichb. Beitr. Syst. Pfl. $67=$ Glossodia Brunonis.

caerulea, R. Br. Prod. 324.-Anstral.

Cairnsiana, F. Muell. Fragm. vii. 31.-Austral.

carnea, R. Br. Prod. 324.-Austral.

\section{CALADENIA :-}

clavigera, A. Cunn. ex Lindl. Gen. et Sp. Orch. 422. -Austral.

concolor, Fitzg. Austral. Orch. i. vir. t. 1.-Austral. congesta, R. Br. Prod. 324. - Austral.

cornuta, Reichb. f. Beitr. Syst, Pfl, $67=$ Chiloglottis cornuta.

cucullata, Fitzg. Austral. Orch. i. I1.t. 4.-Austral.

cuneata, Reichb. f. Beitr. Syst. Pf. $67=$ Burnettia cuneata

deformis, R. Br. Prod. 324.-Austral.

denticulata, Lindl. Swan Riv. App. $52=$ filamentosa.

dilatata, R. Br. Prod. $325=$ Patersoni.

dimorpha, Fitzg. Austral. Orch. i. I. t. 3.-Austral.

diphylla, Reichb. f. Beitr. Syst. Pfl. $67=$ Chiloglottis diphylla.

discoidea, Lindl. Swan Riv. App. 52,-Austral.

Drummondii, Benth. Fl. Austral. vi. 383.-Austral.

elliptica, Reichb. f. Beitr. Syst. Pfl. $67=$ Lyperanthus ellipticus.

elongata, Lindl. Swan Riv. App. $52=$ latifolia.

emarginata, Reichb. f. Beitr. Syst. Pfl. $67=$ Glossodia emarginata.

filamentosa, Lindl. Gen. et Sp. Orch. 421=Patersoni.

filamentosa, R. Br. Prod. 324.-Austral.

filifera, Lindl. Swan Riv. App. $52=$ filamentosa.

fimbriata, Reichb. f. Beitr. Syst. Pfl. 65.-Austral

flava, R. Br. Prod. 324-Austral.

gemmata, Lindl. Swan Riv. App. 52.-Austral.

Gigas, Reichb. f. in Linnaea, xli. (1877) 56.-N. Caled.

gracilis, $\mathrm{R} . \mathrm{Br}$. Prod. $324=$ testacea.

Gunnii, Reichb. f. Beitr. Syst. Pfl. $67=$ Chiloglottis Gunnii.

hirta, Lindl. Swan Riv. App. 52.-Austral.

ixioides, Lindl. $l$. c.-Austral.

javanica, Benn. ex Ridl. in H.O. Forbes, Nat. Wand. East. Archip. 518.-Timor.

latifolia, R. Br. Prod. 324,--Austral.

leptochila, Fitzg. in Gard. Chron. (1882) I. 462.Austral.

lobata, Fitzg. l. c. 461.-Austral.

longicauda, Lindl. Swan Riv. App. 52. t. $8=$ Patersoni.

Lyallii, Hook.f. Fl. Nov. Zel. i. 247.-N. Zel.

macrophylla, R. Br. Prod, $325=$ Menziesii

macrostylis, Fitzg. in Gard. Chron. (1882) I. 462.Austral.

major, Reichb. f. Beitr. Syst. Pfl. $67=$ Glossodia major.

marginata, Lindl. Swan Riv. App. 51=latifolia.

Menziesii, $R . B r$. Prod. 325.-A ustral

minor, Hook. f. Fl. Nov. Zel. i. 247.-N. Zel.

minor, Reichb. f. Beitr. Syst, Pfl. $67=$ Glossodia minor.

mollis, Endl. in Lehm. P1. Preiss. ii. $8=$ hirta.

mollis, Lindl. Swan Riv. App. $51=$ latifolia.

multiclavia, Reichb. f. Beitr. Syst. Pfl. 64.-Austral.

nana, Endl. in Lehm. Pl. Preiss. ii. $7=$ reptans

nigricans, Reichb. f. Beitr. Syst. Pfl. $67=$ Lyperanthus nigricans,

Nortoni, F. Muell. Census, 113.-Austral.

oblonga, Reichb. f. Beitr. Syst. Pf. $67^{\circ}=$ Cyrtostylis oblonga

ochreata, Lindl. Swan Riv. App. 51=latifolia.

pallida, Lindl. Gen. et Sp. Orch. 421= Patersoni

paniculata, Fitzg. in Gard. Chron. (1882) I. 461.Austral

Patersoni, R. Br. Prod. 324.-Austral.

pellita, EndI. in Lehm. Pl. Preiss. ii. $8=$ gemmata.

plicata, Fitzg. in Gard. Chron. (1882) I. 461.Austral.

Preissii, Endl. in Lehm. Pl. Preiss. ii, $7=$ reptans.

pulcherrima, F. Muell. Fragm, v, $93=$ Patersoni.

reniformis, Reichb. f. Beitr. Syst. Pf. 67 = Cyrtostylis reniformis.

reptans, Lindl. Swan Riv. App. 52-Austral.

reticulata. Fitrg, in Gard. Chron. (1882) I. 462.Austral.

Roei, Benth. Fl. Austral. vi. 383.-Austral.

rotundifolia, Reichb. f. Beitr. Syst. Pfl. $67=$ Cyrtostylis rotundifolia.

saccharata, Reichb. f. l. c. 63.-Austral.

sericea, Lindl. Swan Riv. App. 52.-Austral.

serrata, Reichb. f. Beitr. Syst. Pfl. 67.-Austral.

suaveolens, Reichb.f.l. c.-Austral.

sulphurea, A. Cunn. in Field, N. S. Wales, $361=$ suaveolens.

\section{CALADENIA :-}

tentaculata, Schlecht. in Linnaea, xx. (1847) $571=$ Patersoni.

tenuis, Fitzg. in Gard. Chron. (1882) I. 462.Austral.

tessellata, Fitzg. Austral. Orch. i. II. t. 3.-Austral.

testacea, R. Br. Prod. 324.-Austral.

unguiculata, Lindl. Swan Riv. App. $51=$ deformis. unita, Fitzg, in Gard. Chron. (1882) I. 461.Austral.

variegata, Colenso, in Trans. N. Z. Inst. xvii. (1885) 248.-N. Zel.

CALADIUM, Vent. in Roem. Arch. ii. (1800) 347. AROIDEAE, Benth. \& Hook. f. iii. 976.

Arosma, Rafin. Fl. Tellur. iii. 66 (1836)

Cyrtospadix, C. Koch, Ind. Sem. Hort. Berol. (1853).

acre, R. Br. Prod. $336=$ Colocasia antiquorum

aculeatum, G. F. W. Mey. Prim. Fi. Esseq. 274.Guiana.

acuminatum, F. G. Dietr. Vollst. Lexik. Gaertn, i. $616=$ Xanthosoma belophyllum

albo-punctatissimum, J. Makoy, ex Karst. in C. Koch \& Fint. Wochenschr. (1858) $331=$ bicolor?

amabile, Versch. Cat. n. 70 (1862) 2.-Bras.

amoenum, Hort. ex Engl. in DC. Monog. Phan. ii. $461=$ bicolor.

appendiculatum, Hort. ex Engl. 1. c. $476=$ Xanthosoma atrovirens.

Appunianum, Hort. ex Engl. 1. c. $466=$ picturatum.

arborescens, Vent. Fard. Cels, sub t. 30 ; Willd. Sp. Pl. iv. 490.-Ind. or.

arboreum, H. B. E K. Nov. Gen. et Sp. i. 80.N. Granat.

argyrites, Lem. in Illustr. Hortic. (1858) t. 185. f. 3. Misc. $57=$ Humboldtii.

argyrospilum, Lem. 1. c. $59=$ bicolor.

argyrostigma, Sihott, Melet. i. 18, nomen.-Am. trop.

asperulum, Schott, in Oestr. Bot. Wochenbl. (1853) $313=$ smaragdinnm

auritum, Vent. Jard. Cels, sub t. 30 ; Willd. Sp. Pl. iv. $491=$ Syngonium auritum.

Baraquini, Hérincq, in F1. des Serres, Sér. II. iii. (1858) $163=$ bicolor.

Barilletii, Hort.-Cf. Gard. Chron. (1867) 461.Hab.?

Bauersii, Reichb. Hort. Bot. t. 160.-Bras.

Belleyenei, Hort. Chantin, ex Lem. in Illustr. Hortic. (1860) t. $252=$ picturatum.

belophyllum, Wiild. Enum. Hort. Berol. $987=$ Xanthosoma belophyllum.

bicolor, Vent. Fard. Cels, t. 30.-Am. austr.

Bongniartii, C. Koch \& Fint. Wochenschr. (1858) 287, sphalm, = bicolor.

Bowei, Steud. Nom. ed. II. i. $249=$ Biarum Bovei.

brasitiense, Desf. Cat. Hort. Par. ed. III. 7, $386=$

Xanthosoma hastifolium.

Brongniartii, Lem, in Illustr. Hortic. (1858) Misc. 58 $=$ bicolor.

caracasanum, Engl. in DC. Monog. Phan. ii. 666, Index =Xanthosoma belophyllum.

Chantinii, Lem. in Illustr. Hortic. (1858) Misc. $58=$ bicolor.

Colocasia, Schott, ex Wight, Ic. t. $787=$ Alocasia cucullata.

colocasioides, Brongn. in Nouv. Ann. Mus. Par, iii. 156 $=$ Colocasia antiquorum.

concolor, C. Koch, in Berl. Allg. Gartenz. (1857) 135.

-Venezuela.

Connaertii, Hort. ex Engl. in DC. Monog. Phan. ii. 461 = bicolor.

cordatum, Hort. Versch. ex Engl. 1. c. $455=$ Schomburgkii.

crassipes, Hort. ex Engl. 1. c. $369=$ Philodendron cannaefolium.

cucullatum, Pers. Syn. ii. $575=$ Alocasia cucullata.

cupreum, C. Koch \& Bouché, Ind. Sem. Hort, Berol. (1854) $6=$ Alocasia cuprea.

Curwadlii, Hort. ex Engl. in DC. Monog. Phan. ii. 461 $=$ bicolor.

Devosianum, Lem. in Illustr. Hortic. (1862) t. 322, f. 1 =bicolor.

digitatum, Blanco, Fl. Filip. ed. II. 459.-Ins. Philipp. discolor, Hort. ex Engl. in DC. Monog. Phan. ii. 462 = bicolor.

Duchartrei, Hort, ex Engl. I. c. = bicolor. 
CALADIUM:-

Eckhartii, Lem. ex Engl, in DC. Monog. Pban. ii. 463 $=$ bicolor.

edule, G. F. W. Mey. Prim. Fl. Esseq. 272 = Xanthosoma edule.

Engelii, Karst. in C. Koch E Fint. Wochenschr. (1858) 330.-Venezuela

Enkeanum, C. Koch, Wochenschr. (1861) $267=$ bicolor. erythropus, Mart. ex Engl. in Mart. F1. Bras. iii. II. $172=$ Adelonema erythropus.

esculentum, Vent. Jard. Cels, sub t. 30 ; et in Roem. Arch. ii. III, $351=$ Colocasia antiquorum.

firmulum, Schott, in Oestr. Bot. Wochenbl. (1854) 417 = bicolor.

fragrantissimum, Hook. Bot. Mag. t. $3314=$ Philodendron fragrantissimum.

Gaerdtii, C. Koch \& Fint. Wochenschr. (1858) $288=$ bicolor.

giganteum, Blume, Cat. Gew. Buitenz. $103=$ Colocasia indica.

glycyrrhizum, Fraser, in Hook. Bot. Misc. i. (1830) $259=$ Alocasia macrorrhiza

grandifolium, Sims, Bot. Mag. t. $2643=$ Philodendron Simsii.

grandifolium, Willd. Sp. Pl. iv. $490=$ Philodendron grandifolium.

griseo-argenteum, Hort. ex Engl. in DC. Monog. Phan. ii. $463=$ bicolor

guttiferum, Poepp. ex Kunth, Enum. Pl. iii. $52=$ Philodendron guttiferum.

Haageanum, C. Koch, Wochenschr. (1862) $136=$ bicolor.

haematostigma, Kunth, Enum. P1. iii. $42=$ bicolor.

hastatum, Lem. in Illustr. Hortic. (1858) Misc. $61=$ picturatum.

hastatum, Willd. ex Engl. in DC. Monog. Phan. ii. $279=$ Urospatha Poeppigiana.

hastifolium, Steud. Nom. ed. II. i. 249 = Xanthosoma hastifolium

helleborifolium, Vent. Jard. Cels, sub t. 30 ; et in Roem. Arch. ii. III. 351 = Xanthosoma helleborifolium.

Hendersoni, Hort. ex Engl. in DC. Monog. Phan. ii. $461=$ bicolor.

heterophyllum, Presl, Reliq. Haenk. ii. 148.-Ins. Luzon.

Houbyanum, Hort. ex Engl. in DC. Monog. Phan. ii. $464=$ bicolor.

Houlletii, Lem. in Illustr. Hortic. (1858) $59=$ bicolor.

Humboldtii, Schott, in Oestr. Bot. Wochenbl. (1854) 417.--Bras.

Imbe, Hort. ex Kunth, Enum. Pl. iii. $50=$ Philodendron Imbe.

indica, Hort. ex C. Koch, Berl. Allg. Gartenz. (1857)

$136=$ Alocasia indica.

Ketteleri, Hort. ex Engl, in DC. Monog. Phan. ii. 461 $=$ bicolor.

Kochii, Hort. Versch. ex C. Koch, Wochenschr. v. (1862) 185 = bicolor.

Kramerianum, Hort. ex Engl, in DC. Monog. Phan.

ii. $459=$ bicolor

lacerum, Willd. Sp. Pl. iv, $491=$ Philodendron lacerum.

Laucheanum, C. Koch, Wochenschr. (1861) $266=$ bicolor.

Lemaireanum, Barraq. in Illustr. Hortic. (1862) t. 311 $=$ picturatum.

Leopoldii, Hort. Versch. ex Engl. in DC. Monog. Phan. ii. $460=$ bicolor

Lindeni, Hort. ex Engl. 1. c. $462=$ bicolor

liniferum, Nees, in Neuwied, Reise nach Brasil. ii

398.-Bras.

lividum, Lodd. Bot. Cab. t. $1590=$ Staurostigma concinnum.

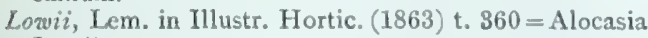
Lowii.

luridum, Kunth, Enum. PI. iii. $50=$ Staurostigma concinnum.

macrophyllum, Lem. in Illustr. Hortic. (1862) t. $\$ 16$, 322 = bicolor.

macropus, Hort. Petrop. ex Kunth, Enum. Pl. iii. $47=$ acropus, Hort. Petrop. ex Ku
Philodendron cannacolium.

macrorrhigon, R. Br. Prod. $386=$ Alocasia macrorrhiza. macrotites, Schott, in Oestr. Bot. Wochenbl. (1855) 20. -Bras.

maculatum, Lodd. Bot. Cab. t. $608=$ Dieffenbachia Seguine.

\section{CALADIUM}

Mafaffa, Hort. ex Engl. in DC. Monog. Phan. ii. 471 - Xanthosoma Mafaffa.

marantaefolium, Zipp. ex Kunth, Enum. P1. iii. $55=$ Aglaonema marantifolinm.

narginatum, C. Koch \& Bouché, Ind. Sem. Hort. Berol. (1854) $6=$ bicolor

marmoratum, L. Math. ex C. Koch, l. c.-Ecuador

Martersteigianum, Hort. ex Engl. in DC. Monog Phan. ii. $461=$ bicolor.

metallicum, Hamburg. Gart. Blumenzeit. (1853) $517=$

Alocasia cuprea.

metallicum, Hort. ex Engl, 1, c. 502 = Alocasia indica mirabile, Lem. Illustr. Hortic. (1863) t. $354=$ bicolor.

Mooreanum, Hort. ex Engl. in DC. Monog. Phan. ii. $462=$ bicolor

myriostigma, C. Koch, Wochenschr. v. (1862) $135=$

Humboldtii.

Neumanni, Lem. in Illustr. Hortic. (1858) $58=$ bicolor.

nymphaeaefolium, Vent. Jard. Cels, sub t. 30 ; Willd. Sp. Pl. iv. $488=$ Colocasia antiquorum.

odoratissimum, Hort. ex C. Koch, Berl. Allg. Gartenz (1857) $20=$ Alocasia odora.

odoratum, Lodd. Bot. Cab. t. 416= Alocasia macrorrhiza.

odorum, Lindl. Bot. Reg. t. $641=$ Alocasia macrorrhiza Ottonis, Hort. ex Engl. in DC. Monog. Phan. ii. $464=$ bicolor.

ovatum, Vent. Jard. Cels, sub t. 30 ; et in Roem. Arch. ii. IIr. $351=$ Lagenandra toxicaria.

pallidinervium, Hort. ex Engl. in DC. Monog. Phan. ii. $463=$ bicolor

pallidum, C. Koch \& Bouché, Ind. Sem. Hort. Berol. (1853) $13=$ smaragdinum.

pedatum, Hook. Exot. Fl. t. $206=$ Philodendron laciniatum.

pellucidum, DC.' in Pl. Jard. Genèv. (1826) $38=$ bicolor.

pendulinum, Manso, Enum.21.-Bras.

pendulum, Blume, Cat. Gew. Buitenz. 103.-Malaya. Perrieri, Lem. in Illustr. Hortic. (1858) $59=$ bicolor.

petiolatum, Hook. Bot. Mag. t. 3428=Anehomanes difformis.

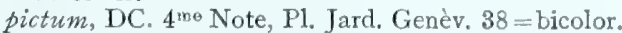
pictum, Lodd. Bot. Cab. t. $608=$ Dieffenbachia picta.

picturatum, C. Koch E Bouché, Ind. Sem. Hort. Berol. 1854) 6.-Am. austr.

pinnatifidum, Willd. Sp. Pl. iv. $487=$ Philodendron pinnatifidum.

platynervium, Hort. ex Kunth, Enum. Pl. iii. 47= Philodendron crassinervium.

platynevron, Salm-Dyck, Hort. Dyck. (1834) 334.Bras.

plumbeum, C. Koch, Berl. Allg. Gartenz. (1857) $136=$ Alocasia cuprea.

poecile, Schott, Melet. i. $18=$ bicolor

porphyroneuron, C. Koch, Wochenschr. จ. (1862) $135=$ picturatum.

Princeps, Hort. ex Kunth, Enum. Pl. iii. 55=Aglaonema simplex.

pumilum, D. Don, Prod. F1. Nep. $21=$ Gonatanthas sarmentosus.

punctatissimum, Hort. ex Engl, in DC. Monog. Phan. ii. $461=$ bicolor

punctatum, Desf. Tabl. Hort. Par. ed. II. 6, nomen.Hab.?

Purdieanum, Schott, in Oestr. Bot. Zeitschr. (1859) 38 $=$ bicolor.

pusillum, C. Koch, in Fl. des Serres, Sér. II iii. (1858) $110=$ bicolor.

regale, Lem. in Illustr. Hortic. (1862) t. $316=$ bicolor

Reichenbachianum, Stange, ex Engl. in Mart. F1. Bras. iii. II. $182=$ bicolor

reticulatum, Desf. Tabl. Hort. Par, ed. II. 6, nomen. - Hab.?

Rougieri, [Versch.].-Cf. Gard. Chron. (1864) 414.Bras.

rubellum, C. Koch \& Fint. Wochenschr. (1858) $288=$ bicolor.

rubricaule, Hort ex Lem, in FI des Serres, Sér. II. iii. (1858) $109=$ bicolor.

rubrovenium, Hort. ex Lingl. in DC. Monog. Phan. it $460=$ bicolor.

rugosum, Desf. Cat. Hort. Par. ed. III. $\$ 86=$ Alocasia cucullata.

sagittaefolium, Sieber, ex Engl. in DC. Monog. I'han. ii. $164=$ bicolor.

\section{CALADIUM}

sagittaefolium, Vent. Jard. Cels, sub t. 30 ; et in Roem. Arch. ii. IIr. 351 = Xanthosoma sagittifolium.

sarmentosum, Hort. ex Kunth, Enum. Pl, iii. $36=$ Gonatanthus sarmentosus.

scandens, Willd. Sp. Pl. iv. $489=$ Culcasia scandens.

Schmitzii, Lem. I1lustr. Hortic. (1861) t. 297. f. $3=$ Schomburgkii.

Schoelleri, Lem. 1. c. f. 2 =Schomburgkii.

Schomburgkii, Schott, in Oestr. Bot. Wochensch. (1858) 122.-Guiana.

seguinum, Vent. Jard. Cels, sub t, 30 ; Willd. Sp. Pl iv. $490=$ Dieffenbachia Seguine.

Sieboldii, Hort, ex Engl, in DC. Monog. Phan. ii. 461 $=$ bicolor.

simplex, Blume, Cat. Gew. Buitenz. 103 = Aglaonema simplex.

Simsii, Hook. Bot. Mag. t. $3345=$ Philodendron Simsii.

smaragdinum, C. Koch Es Bouché, Ind. Sem. Hort. Berol. (1853) 13.-Am, trop.

sororium, Schott, in Oestr. Bot. Zeitschr. ix. (1859) 38.-Bras.

splendens, C. Koch \& Fint. Wochenschr. (1858) 288

bicolor.

splendidum, Versch. Cat.n. 70 (1862) 4.-Bras.

Spruceanum, Schott, in Oestr. Bot. Zeitschr, ix. (1859) $38=$ bicolor.

Stangeanum, C. Koch, Wochenschr. (1861) 136 bicolor.

steudneriaefolium, Engl. Bot. Fahrb. vi. (1885) $284 .-$ N. Granat.

striatipes, Schott, Syn. Aroid. 51.-Bras.

subrotundum, Lem, in Illustr. Hortic. (1858) Misc. 60 $=$ Schomburgki.

surinamense, Miq. Hort. Amstelod. (1853)= bicolor.

Thelemanni, Versch. Cat. n. 72 (1863) 2.-Hab.

thripedestum, Lem, in lllustr. Hortic. v. (1858) Misc. 59 $=$ marmoratum.

trifoliatum, Desf. Cat. Hort. Par. ed. III. $386=$ seq.

tripartitum, Willd. Sp. Pl. iv. $491=$ Philodendron tripartitum.

Troubetzkoyi, Hérincq, in Fl. des Serres, Sér. II. iii. 1858) $164=$ picturatum.

undulatum, Steud. Nom. ed. II. ii. $219=$ Peltandra undulata.

utile, Hort. ex Engl. in DC. Monog. Phan. ii. $469=$ Xanthosoma sagittifolium.

variegatum, Desf. Cat. Hort. Par. ed. III. 7, $385=$

Xanthosoma helleborifolium.

Veitchii, Henders, ex Hook. f. Bot. Mag. to $5370^{\circ}=$

Alocasia Lowii.

Veitchii, Lindl. in Gard. Chron. (1859) $740=$ Alocasia cuprea.

Vellozianum, Schott, in Bonplandia, vii. (1859) $163=$ bicolor.

Verschaffeltii, Lem. in Illustr. Hortic. (1858) 59. ᄂ. 18 u =bicolor.

violaceum, Desf. Cat. Hort. Par. ed. III. $7=$ seq. ?

violaceum, Hort. ex Engl. in DC. Monog. Phan. $492=$ Colocasia antiquorum

virginicum, Hook, Exot. F1. t, 1 2 $2=$ Peltandra undulata.

viviparum, Neés, in Schott, Melet. i. 18; Lodd. Bot. Cab. t. $281=$ Remusatia vivipara.

Wagneri, Hort. ex Engl. in DC. Monog. Phan. ii. $46 \pm$ = bicolor.

Wightii, Lem. Illnstr. Hortic (1861) 294=bicolor. ranthorrison, Boos, Cat. $348=$ Xanthosoma Jac. quini.

xanthorrhisum, Willd. Sp. Pl. iv. $490=$ Xianthosoma sagittifolium.

amiaefolium, Lodd. Bot. Cab. t. $1108=$ Zamioculca: Loddigesii.

CALAENA, Schlecht. in Linnaza, ii. (1S:7' 5:8, sphalun. Caleana, R. Br. (Orclait.)

CALAIS, DC. Prod, vii. $85(1 \$ 39)=$ Microseris, D.

Don (Compos.)

aphantocarpha, A. Gray, in Proc Am. Acad. yi. (1864-65) $55^{2}=\mathrm{M}$. aphantocarpha.

Bigelorit, A. Giny, ß'acif. Kail. Kep. iv. 119-M. Bigeluvii.

Bolanderi, A. Gray, in Proc. Am. Acad. vii. (1sis): . $=$ M. I3olanders.

geclacarpha, A. Gray, in Pacif. Rail. Rep. iv, 113 = 11. Uouglasii. 


\section{CALAIS :-}

Douglasii, DC. Prod. vii. $85=$ Microseris Douglasii. eriocarpha, A. Gray, in Proc. Am. Acad. vi. (1864-65) $552=$ M. Douglasii.

glauca, A. Gray, 1. c. vii. (1868) $364=$ M. procera gracililoba, Kellogg, in Proc. Calif. Acad. v. (1878) 48 Mi major.

laciniata, A. Gray, in Pacif Rail. Rep。 iv. 119=M. laciniata.

Lindleyi, DC. Prod. vii. $85=$ M. Lindleyi.

linearifolia, DC. 1, c. = M. linearifolia.

macrochaeta, A. Gray, Pl. Fendl. $112=$ M. macrochaeta.

major, A. Gray, in Pacif. Rail. Rep. iv. $113=\mathrm{M}$. major.

nutans, A. Gray, 1. c. = M. nutans

Parryi, A. Gray, l. c. $112=$ M. Parryi.

platycarpha, A. Gray, 1. c. $113=$ M. platycarpha

sylvatica, A. Gray, 1. c. $114=$ M. sylvatica.

tenella, A. Gray, 1. c. = M. aphantocarpha.

CALAMAGROSTIS, Adans. Fam. ii. 31 (1763) GRAMINEAE, Benth. \& Hook. f. iii. 1150

Amagris, Rafin. Princ. Somiol. 27 (1814); et in Am. Monthly Mag. (1819) 190.

Athernotus, Dulac, Fl. Hautes-Pyr. 74 (1867)

LECHLERA, Steud. Syn. Pl. Gram. 101, in nota (1855).

Pteropodium, Willd. ex Steud. Nom. ed. II. ii. 414 (1841)

abietina, Schur, in Oestr. Bot. Zeitschr. ix. (1859) 155 $=$ Deyeuxia acutiflora.

acrathera, Peterm. in Flora, xxvii. (1844) 225.Saxonia.

acutiflora, DC. F1. Fr. v. $255=$ Deyeuxia acutiflora aemula, Steud. Nom. ed. II. i. 249; Syn. Pl. Gram. 192 $=$ Deyeuxia Forsteri.

agapatea, Steud. in Lechl. Berb. Am. Austr. 56.Peruv.

agrostoides, Boiss. Fl. Orient. v. 522.-Reg. Caucas. agrostoides, Spreng. Syst. i. 252=Deyeuxia canadensis airoides, Steud. Nom. ed. II. i. $249=$ Arundo airoides. alba, Steud. l. c.-Peruy.

albicans, BuckI, in Proc. Acad. Sc Pbilad ' 1862 ' (1863) $92=$ Deyeuxia aleutica.

aleutica, Bong. Veg. Ins. Sitcha, $171=$ Deyeuxia aleutica.

alpina, Host, Gram. iv. t. $51=$ tenella.

altissima, Host, Fl. Austr. i. 101=Arundo mauritanica.

ambigua, Hartm. Skand. Fl. ed. V.-Scandin.

andina, Nutt. in Fourn. Acad. Sc. Philad. N. S. i. (1847) 187.-Calif.

anomala, Steud. in Lechl. Berb. Am. Austr. 56.Peruy.

anthoxanthoides, Regel, in .Act. Hort. Petrop. vii (1880) 640.--Turkestan.

Antoniana, Steud. in Lechl. Berb. Am. Austr. 56.Peruv.

arenaria, Roth; Tent. Fl. Germ. i. 34=Ammophila arundinacea.

argentea, DC. F1. Fr. iii. $25=$ Stipa Calamagrostis

arundinacea, Roth, Tent. Fl. Germ. i. $33=$ Deyeuxia sylvatica.

arundinacea, Wibel, Prim. F1. Werth, $122=$ Deyeuxia acutiflora.

Arundo, J. F. Gmel. Syst. $\mathbf{1 7 1}=$ Stipa Calamagrostis. Arundo, Roth, Tent. F1. Germ, i. 33=Aira caespitosa. australis, Butese, in Miq. Pl. Fungh. 343.-Malaya.

azorica, Steud. Syn. Pl. Gram. $189=$ Agrostis pallida.

Balansae, Boiss. Fl. Orient. v. 522.-Pontus.

baltica, "Trin. Gram. Unifl. 227 ; Hartm. Skand. F1. ed. II. $20=$ Ammophila baltica.

Beyrichiana, Nees, ex Doell, in Mart. Fl. Bras. ii. III. 53.-Bras.

bicolor, J. F. Gmel. Syst. i. $172=$ Ampelodesma bicolor.

Billardieri, Stend. Nom. ed. II. i. $249=$ Deyeuxia Billardieri.

Bolanderi, Thurb in S. Wats. Bot. Calif ii. $280=$ Deyeuxia Bolanderi.

borealis, Laest. Bidr. Vaextl. Torn. Lappm. Ups. $44=$ Deyeuxia neglecta.

brachytricha, Steud. Syn. Pl. Gram. 189.-Japon.

brevifolia, Steud. Nom. ed. II. i. $249=$ Deyeuxia brevifolia.

brevipilis, Beck, Bot. N. \& Mid. St. $401=$ Ammophila brevipilis.

\section{CALAMAGROSTIS}

Breweri, Thurb. ex Boland. in Trans. Calif. Agr. Soc. $(1864-65) 136=$ Deyeuxia Breweri.

bromoides, Nutt. Gen. Am. i. $44=$ Stipa Aristella. caespitosa, Stend. Syn. Pl. Gram. $189=$ Agrostis pallida.

canadensis, Beauv. Agrost. 157, nomen = Deyeuxia canadensis.

canadensis, Nutt. Gen. Am. i. $46=$ Deyeuxia Nuttal liana.

canescens, Beauv, ex Steud. Nom. ed. II i. $249,250=$ Epigeios.

capillaris, Nees, ex Steud. Nom. ed. II. i. 219; Syn

Pl. Gram. 188.-Bras.

caucasica, Trin. in C. A. Mey. Verz. Pf. Cauc. $15=$ Deyeuxia acutiflora.

chalybaea, Fries, Summa Pl. 241.-Norveg.

Chamissonis, Steud. Nom. ed. II. i. $250=$ Deyeuxia Chamissonis.

chilensis, Phil. in Linnaea, xxix. (1857-58) 89.Chili.

chrysantha, Steud. Nom. ed. II. i. $250=$ Deyeuxia chrysantha.

ciliata, Steud. Syn. Pl. Gram. 193.-Nepal.

cinnoides, Spreng. Syst. i. $252=$ Deyeuxia Nuttalliana

Clarionis, Loisel. F1. Gall. $719=$ Deyeuxia Halleriana coarctata, Stend. Nom. ed. II. i. $250=$ Deyeuxi coarctata.

coarctata, Torr. Fl. N. York, ii. $444=$ Deyeuxia Nuttalliana.

colorata, Nutt. Gen. Am. i. $46=$ Phalaris intermedia colorata, Sibth. F1. Oxon $37=$ Phalaris arundinacea, columbiensis, Nutt. ex A. Gray, in Proc. Acad. Sc. Philad. ' 1862' (1863) $334=$ Deyeuxia Langsdorfii. compressa, Doell, in Mart. Fl. Bras. if. HI. 56.--Bras confinis, Nutt. Gen. Am. i. 47.-Am. bor.

conspicua, Bergetet, Fl. Pyr. i. 60=Stipa Calamagrostis.

conspicua, J. F. Gmel. Syst. $172=$ Arundo conspicua

crassiglumis, Thurb. ex S. Wats. in Bot. Calif. ii. 281 = Deyeuxia crassiglumis.

contracta, Dum. Obs. Gram. Belg. $126=$ stricta ?

cuspidata, Spreng. Syst. i. 253.-Mexic

densiflora, C. Muell. in Walp. Ann. vi. $986=$ phragmitoides.

densiflora, Steud. Nom. ed. II. i. $250=$ Deyeuxia densiflora.

deschampsioides, Trin. Ic. Gram. iii. t. 354=Deyeuxia deschampsioides.

dioica, Steud. Syn. Pl. Gram. 193,-Cochinch

donaciformis, Loisel, Fl. Gall. i. 53=Arundo Pliniana

dubia, Bunge, Lehm. Rel. (1847) 348.-As. centr.

effusa, Steud. Nom. ed. II. i. $250=$ Deyeuxia effusa.

elata, Blytt, Norges F1. i. $92=$ phragmitoides .

eminens, Steud. Nom. ed. II. i. $250=$ Deyeuxi eminens.

emodensis, Griseb. in Goett. Nachr. (1868) 80,-Reg. Himal.

epigeios, Huds. F1. Angl. 43 ; ed. II. $54=$ lanceolata. epigeios, Kar. \& Kir. in Bull. Soc. Nat. Mosc. (1842) $529=$ laxa

epigeios, Roth, Tent. Fl. Germ. i. 34.-Europ.; As. temp.

epigeios, Steud. Nom. ed. II. i. 250, sphalm. = Saccharum cylindricum.

eriantha, Steud. Syn. Pl. Gram. $190=$ Deyeuxia eriantha.

Falklandiae, Steud. l.c. 192.-Ins. Falkland.

farcta, F. F. Gmel. Syst. 172-Guiana.

filiformis, Griseb. in Goett. Nachr. (1868) 79.Ind. or.

flexuosa, Rupr. Beitr. Pfl. Russl, iv. $34=$ phragmitoides.

Forsteri, Stend. Nom, ed. II. i. $250=$ Deyeuxia Forsteri Funckii, Steud. Syn. Pl. Gram. 192.-Venezuela.

fuscata, Steud. Nom. ed, II. i. $250=$ Deyeuxia fuscata Gaudiniana, Reichb. F1. Germ. Exc. $27=$ lanceolata. georgica, C. Kach, in Linnaea, xxi. (1848) $387=$ epigeios.

glauca, Hohen. Enum. Taluesch. 14=laxa.

glauca, Reichb. Fl. Germ. Excurs. 27=epigeios.

glauca, Steud. Nom. ed. II. i. $250=$ Deyeuxia Nuttal liana.

glauca, Stend. Syn. Pl. Gram. 187=littorea.

glaucescens, C. Muell. in Walp. Ann. vi. $986=$ phragmitoides

glomerata, Boiss. \& Buhse, in Mém. Soc. Nat. Mosc. xii. (1860) $229=$ epigeios.
CATAMAGROSTIS:-

gracilescens, Blytt, Norges Fl. i. 88.-Norveg. gracilis, Seenus, Reise Istr. $73=$ Stipa Aristella. gracilis, Schumach. ex Nym. Consp. $800=$ lanceolata. groenlandica, Kunth, Rev. Gram. i. 75.-Groenl.; Labrad.

hakonensis, Franch. E Sav. Enum. Pl. Fap. ii. 599.Japon.

Halleriana, DC. F1. Fr. Suppl. 256=Deyeuxia Halleriana.

Halleriana, Fries, Summa Veg. $240=$ gracilescens. Hartmaniana, Fries, 1. c. $241=$ ambigua

hirtigluma, Steud. Syn. Pl. Gram. 188.-Am. bor.

holciformis, Faub̆. E' Spach, Illustr. iv. 61.-Tibet.

Hookeriana, Steud. Syn. Pl. Gram. 192.-Zeylan.

Howelli, Vasey, in Coult. Bot. Gaz. vi. (1881) $271=$ Deyeuxia Howellii.

Huebneriana, Reichb. Fl. Germ. Excurs. $27=$ epigeios.

Humboldtiana, Steud. Nom. ed. II. i. $250 .-\mathrm{N}$. Granat.

hyperborea, Lange, in Fl. Dan. t. 2942.-Groenl. inexpansa, A. Gray, ex Torr. F1. N. York, ii. 445. t. $152=$ Deyeuxia confinis.

intermedia, Lindeb. ex Nym. Consp. $799=$ Hartmaniana.

intermedia, Steud. Nom. ed. II. i. $250=$ Deyeuxia intermedia.

Jamesoni, Steud. Syn. Pl. Gram. 191.-Ecu dor

javana, Steud. l. c. 193.-Java.

junciformis, Steud. Nom. ed. II. i. $250=$ Deyeuxia junciformis.

Karka, J. F. Gmel. Syst. $172=$ Arundo Karka.

laguroides, Regel, in Act. Hort. Petrop. vii. (1880) 641. -Turkestan.

Lagurus, Koel. Desc. Gram, $112=$ Imperata arundinacea.

lanceolata, Roth, Tent. Fl. Germ. i. 34.-Europ.; As. temp.

lanceolata, Stokes, in With. Arr. Brit. P1. ed. III. ii. $122=$ epigeios.

lanceolata, Trin. ex Steud. Nom. ed. II. i. $250=$ purpurea.

Langsdorffi, Auct. ex Nym. Consp. $799=$ phragmitoides.

Langsdorffi, Trin. Gram. Unifl. 225. t. 4. f. 10 = Deyeuxia Langsdorffi.

lapponica, Hartm. Scand. F1. ed. I. 46 ; Trin. Gram. Unif. $226=$ Deyeuxia lapponica

lapponica, Hook. Brit. FI. ed. IV. $34=$ Deyeuxia neglecta.

latifolia, Blytt, Norges Fl. i. $90=$ phragmitoides.

laxa, Hegetschw. Fl. Schw. 65.-Helvet.

laxa, Host, Gram. iv. $25=$ littorea.

laxior, C. Muell. in Walp. Ann. vi. $1115=$ Deyeuxia Hartmanniana.

Leersii, Koel. Desc. Gram. $107=$ Deschampsia juncea. Leersii, Trin. ex Steud. Nom. ed. II. i. 850 , ii. $643=$ Stipa Calamagrostis.

lenkoranensis, Steud. Syn. Pl. Gram. 188.--Reg. Caucas.

leucantha, Delile, ex Steud. Nom. ed. II. i. $250=$ Stipa Calamagrostis.

lithuanica, Bess. in Roem. \& Schult. Add. ad Mant. ii. $602=$ phragmitoides.

littorea, $D C$. $F l$. Fr. vi. 255.-Europ.; As. temp.

longearistata, Fisch. ex Ledeb. Fl. Ross.iv. 433, nomen. -Hab.?

longifolia, Hook. Fl. Bor. Am. ii. 241=Ammophila longifolia.

macloviana, Steud. Syn. Pl. Gram. 192,-Ins. Falkl.

maritima, Kunth, Rev. Gram. 1. 75.-Scania.

mauritanica, Spreng. Syst. i. $252=$ Arundo mauritanica.

megapotamica, Steud. Syn. P1. Gram. 192=Andro pogon laguroides.

mexicana, Kunth, Syn. iv. $473=$ Muehlenbergia calamagrostidea.

mexicana, Nutt. Gen. Am. i. 46 (excl. syn.) = Deyeuxia canadensis.

Michauxii, Trin. ex Steud. Nom. ed. II. i. $250=$ Deyeuxia canadensis.

montana, DC. Fl. Fr. vi. 254.-Germ. ; Austr. ; Gall. montana, Host, Gram. t. $146=$ Deyeuxia sylvatica. montevidensis, Nees, in Mart. Fl. Bras. ii. 401.-Reg. Argent.

Munroana, Boiss. Fl. Orient. v. 523.-Afghan.

Munroi, Boiss. l. c, 526.-Afghan.

mutica, Steud. in Lechl. Berb. Am. Austr. 56.-Peruv. 


\section{CALAMAGROSTIS}

Neesii, Steud. Nom. ed. II. i. 250; Syn. Pl. Gram. 193 -Ind, or.

neglecta, Gaertn. Mey. E Scherb. Fl. Wett. 1. $94=$ Deyeuxia neglecta.

nepalensis, Nees, ex Steud. Syn. Pl. Gram. 193.Nepal.

nigricans, Mérat, FI. Paris, ed. II. ii. $33=$ Phragmites communis

nipponica, Franch. E Sav. Enum. Pl. Fap. ii. 599.Japon.

xutans, Saut. ex Reichb. F1. Germ. Exc. $26=$ Deyeuxia Halleriana.

nutkaënsis, Steud. Syn. Pl. Gram. 190=Deyenxia nutkaënsis.

Nuttalliana, Steud. Nom. ed. II. i, $251=$ Deyeuxia Nuttalliana.

obscura, Downar, in Bull. Soc. Nat. Mosc. xxxv. (1862) I. 605.-Podol.

obtusata, Trin. Gram. Unifl. 225. t. 4. f. 11.-Sibir.

obtusata, Turez. in Bull. Soc. Nat. Mosc. (1838) 104; xxix. (1856) I. $26=$ Deyenxia deschampsioides.

odessana, Bess. ex Andrz. Rys Botan. ii. (1830) 26.Tauria.

olympica, Boiss. Diagn. Ser. I. v. 70.-Reg. Caucas.; Persia.

Onaei, Franch. E Sav. Enum. Pl. Fap. ii. 598.Japon.

oregonensis, Buckl. in Proc. Acad. Sc. Philad. ' 1862 ' (1863) $92=$ Deyeuxia Langsdorffii.

Orizabae, Steud. Syn. Pl. Gram. $193=$ Deyenxia Orizabae.

ovata, Steud. Nom. ed. II. i. $251=$ Deyeuxia ovata.

pallens, Steud. 1. c. = Deyeuxia pallens.

pallida, C. Muell. in Walp. Ann, vi. $986=$ phragmitoides.

pallidiflora, C. Muell. 1. c, = phragmitoides.

parviflora, Rupr. in Beitr. Pf. Russ. Reich. iv, $36=$

Deyeuxia sylvatica.

patula, Steud. Syn. Pl. Gram. 422.-Chili.

persica, Boiss. Diagn. Ser. I. vii. $120=$ littorea.

phalaroides, Regel, in Act. Hort. Petrop. vii. (1880) 641 , in textu. - Turkestan.

phleoides, Steud. Nom. ed. II. i. 251.-Am. austr. ?

phragmitoides, Hartm. Scand. Fl. ed. IV. 25.-Reg. bor

Pickeringii, A. Gray, Man. Bot. U. St. ed. I. $547=$ Deyeuxia Pickeringii.

piscatoria, Steud, Syn. Pl. Gram, 193,-Cochinch.

planifolia, Trin. ex Steud. Nom. ed. II. i. 251= Deyeuxia planifolia.

Plinii, J. F. Gmel. Syst. $172=$ Arundo mauritanica.

plumosa, Spreng. Syst. i. $253=$ Stipa papposa.

poaeoides, Steud. Syn. Pl. Gram. 423.-Reg. Magell.

poaeoides, Trin. ex Steud. Nom. ed. II. i. $251=\mathrm{Poa}$ subuniflora.

Porteri, A. Gray, in Proc. Am. Acad. vi. (1862) $79=$ Deyeuxia Porteri.

Pseudophragmites, Aschers. Fl. Brandenb. $821=$ littorea.

Pseudophragmites, Blytt, Norges F1. i. $89=$ phragmi toides.

Pseudophragmites, Link, ex Reichb. FI. Germ. Exc. 26 = Deyeuxia Halleriana.

Pseudophragmitis, Koel. Desc. Gram. 106=littorea

pulchella, Blytt, Norges F1. i. $93=$ phragmitoides

pulchella, Griseb. in Goett. Nachr. (1868) 78.-

Ind. or.

pulchella, Saut. ex Reichb. F]. Germ. Excurs. $26=$ Deyeuxia Halleriana.

pumila, Hook. f. in Trans. Linn. Soc. xx. (1851) 176 - Ins. Galap.

purpurascens, R. Br. in Richards. App. Frankl. Journ. $S=$ Deyeuxia sylvatica.

purpurea, Trin. Gram. Unifl. 219.-Sibir. baical. pyramidalis, Host, Gram. iv. t. $49=$ Deyenxia sylvatica. quadriseta, Spreng. Syst. i. $253=$ Deycuxia quadriseta. quitensis, H. B. \& K. Nov. Gen. et Sp. i. $133=$

Muehlenbergia calamagrostidea.

romosa, Host, Gram. 1v, t. $44=$ lanceolata.

rariflora, C. Muell. in Walp. Ann. vi. $986=$ Deyeuxia Halleriana.

rarifora, Schur, in Oestr. Bot. Zeitschr. ix. (1859) 156 Deyeuxia sylyatica.

rocta, Trin. ex Steud. Nom. ed. II. i. $251=$ Deyeuxia recta.

retrofracta, Link, ex Steud. 1. c $c_{s}=$ Deyeuxia Forsteri.

rigens, Fries, Summa Veg. $240=$ epigeios.

\section{CALAMAGROSTIS:-}

rigida, Trin. ex Stend. Nom. ed. II. i. $251=$ Deyenxia rigida.

robusta, C. Muell. in Walp. Ann. vi. $985=$ Deyeuxia Halleriana.

robusta, Franch. E Sav. Enum. Pl. Fap. ii. 600.Japon.

Royleana, Steud. Nom. ed. II. i. 251.-Ind. or

Roylei, Steud. Syn. Pl. Gram. $193=$ praec

rubella, Boiss. FI. Orient. v. $525=$ littorea.

rubescens, Buckl. in Proc. Acad'. Sc. Philad. ' 1862 (1863) $92=$ Deyeuxia rubescens.

rubicunda, Blytt, Norges F1. i. 91=phragmitoides.

rubra, Bosc, ex Kunth, Enum. Pl. 478=Erianthus saccharoides.

rudis, Steud. Syn. P1. Gram. 192=Deyetxia scabra rupestris, Trin. ex Steud. Nom. ed. II. 1. 251, nomen Doell. in Mart. Fl. Bras. ii. III. 53,-Bras.

sachalinensis, F. Schmidt, Reisen Amurl. 202.-Terr. Amur.

scabra, Presl, Rel. Haenk. i. 234.-Sinus Nootka. scabrescens, Griseb. in Goett. Nachr. (1868) 79.Ind, or.

Schiedeana, Steud. Syn. Pl. Gram. 198=Deyeuxia Schiedeana.

Schimperiana, Hochst. in Flora, xxxviii. (1855) 202. -Afr. trop.

Schleicheri, Bess. Prim. Fl. Galic. i. $69=$ lanceolata.

Schwabii, Spreng. Syst i. $253=$ Gastridium australe

sciuroides, Franch. E Sav. Enum. Pl. Fap. ii, 600.Japon.

sedenensis, Loisel. Fl, Gall. ed. II. i. $54=$ varia

sesquitriflora, Steud. Syn. P1. Gram. 190=Deyenxia tolucensis.

simplex, Boiss. Fl. Orient. v, 523.-Reg. Caucas.

sitchensis, Trin. ex Ledeb. Fl. Ross. iv. 433.-Ins Sitcha.

speciosa, Host, Gram. iv. t. $45=$ Stipa Calamagrostis. spicigera, Steud. Nom. ed. II. i. $251=$ Deyeuxia spicigera.

splendens, Steud. l. c.-Ins. Catharin.

stricta, Koel. Desc. Gram. $105=$ Deyeuxia neglecta?

stricta, Trin. Gram. Unif. 226.Europ.; Am. bor.

strigosa, Hartm. Skand. Fl. ed. I. $46=$ Deyeuxi strigosa.

subalpina, Schur, Enum. Pl. Transs. $740=$ Deyeuxia sylvatica.

subspicata, Desv. Opusc. $60=$ Trisetum subspicatum?

subulata, Dum. Agr. Belg. t. 9. f. $36=$ montana.

subulate, Stend. Nom, ed. II. i. 251 = varia.

sylvatica, Bess. Prim. Fl. Galic, i. 70.-Europ.

sylvatica, DC. Fl. Fr. v. $253=$ Deyeuxia arundinacea.

sylvatica, Host, Gram, iv. t. 48 =varia

sylvatico-stricta, Kuehlew. ex Ledeb. Fl. Ross. iv. 429

$=$ Deyeuxia neglecta.

tenella, Host, Gram. iv. t. 50.-Eur. med. ; As. bor

tenuifolia, H. B. \& K. Nov. Gen. et Sp. i. $134=$

Muehlenbergia tenuifolia.

thrysoidea, C. Koch, in Linnaea, xxi. (1848) $388=$ epigeios.

tianschanica, Rupr. Sert. Tiansch. 34.-Turkestan.

toluccensis, Trin. ex Steud. Nom. ed. II. i. $250=$

Deyeuxia tolucensis.

transsylvanica, Schur, in Oestr. Bot. Zeitschr. ix (1859) $154=$ laxa.

Trinii, Rupr. in Beitr. Pf. Rnss. Reich. iv. $36=$

Deyenxia acutiflora.

varia, Beauv. Agrost. 157.-Europ.; As. bor.

varia, Boland. ex Bot. Calif. ii. $280=$ Deyeuxi

Bolanderi.

varia, Gren. \& Godr. Fl. Fr. iii. $477=$ montana.

varia, Host, Gram. iv, t. $47=$ Deyeuxia Hallerians.

variegata, With. Bot. Arr. Brit. PI. ed. III. ii. $124=$

Phalaris arnndinacea.

variflora, C. Muell. in Walp. Ann. vi. $1115=$

Deyeuxia Halleriana.

velutina, Steud. Nom. ed. II. i. 251.-Chili

villosa, J. F. Gmel. Syst. $172=$ Deyeuxia sylvatica.

villosa, Mutel, Fl. Fr. iv, $41=$ Deyeuxia Halleriana.

vilnensis, Bess, ex Roem. \& Schult. Add. ad Mant. ii

$602=$ phragmitoicles.

vinealis, Baumg. ex Steud. Syn. Pl. Gram. 188.Transsylv.

viridescens, Steud. 1. c. $192=\mathrm{seq}$.

viridifavescens, Stcud. Nom. ed. II. i. 251=Deycuxis viridiflavescens.

Willdenowii, Steud. Syn. Pl. Gram. i. 192=Dcyeuxia Forsteri.
CALAMINA, Beauv. Agrost. 128. t. 23. f. 1. $(1812)=$ Apluda, Linn. (Gramin.).

gigantea, Beauv. 1. c. 129= Apluda mutica.

gigantea, Roem. \& Schult. Syst. ii. $810=$ Anthistiria gigantea.

humilis, Presl, Rel. Haenk. i. $344=$ Apluda mutica. imberbis, Beauv. Agrost. $129=$ Anthistiria imberbis mutica, Beauv. 1. c. = Apluda mutica.

Sehima, Beauv. 1. c, $157=$ Ischaemum laxum.

Themeda, Beauv. 1. c. = Anthistiria imberbis.

CALAMINTHA, Adans. Fam. ii. $192(1763)=$ Nepeta Linn. (Labiat.).

CALAMINTHA, [Tourn.] Lam, Fl. Fr。 ii. 393 (1778). LABIATAE, Benth. \& Hook. f. ii. 1190. Acrinos, Moench, Meth. 407 (1794).

Clinopodium, Tourn. ex Linn. Gen. ed, I. 170 (1737), nomen prius.

Fadcibarba, Dulac, Fl. Hautes-Pyr. 402 (1867)

abysinica, A. Rich. Tent. Fl. Abyss. i1. 191.-A byssin acinoides, Nym. Consp. $589=$ suaveolens.

Acinos, [Clairv.] Man. Herb. 197 (err. typ. 917).-

Europ.; Reg. Caricas.

acuminata, Frivald, in Flora, xviii. (1835) 332 suaveulens.

adscendens, Willk. \& Lange, Prod. Fl. Hispan. i. $413=$ officinalis.

aegyptiaca, Lam. ex Schur, Enum. Pl. Transs, $531=$

C. Clinopodium.

aetnensis, Strobl, in Oestr. Bot. Zeitschr. xxiv. (1874)

$29=$ alpina

alba, Lam. ex Steud. Nom. ed. II. i. $251=$ Melissa alpina.

alba, Reichb. F1. Germ. Exc. $328=$ Micromeria rupestris.

alpina, Lam. Fl. Fr. i. 394.-Europ. austr.; Reg. Mediterr.

annua, Schrenck, in Bull. Sc. Acad. Pétersb. x. 1842 353.-Rossia.

arundana, Benth. in DC. Prod. xii. 233.-Hispan.

arvensis, Lam. F1. Fr. ii. $394=$ C. Acinos.

ascendens, Jord. Obs. Pl. Crit. iv. (1846) 8=officinalis.

athonica, Reichb. Fl. Germ. Exc. $329=$ C. Nepeta.

atlantica, Ball, in Joum. Bot. xiii. (1875) $175=\mathrm{C}$.

Clinopodium.

atlantica, Coss. in Bull. Soc. Bot. Fr. ix. (IS62) $176=$ grandiflora.

baetica, Boiss. \& Reut. Pugill. Pl. Nov. (1852) 92 officinalis.

betulifolia, Boiss, \& Bal. Diagn. Ser. II iv. 14.Cilicia.

Biebersteiniz, C. Koch, ex Ledeb. Fl. Ross. iii. $355=$ umbrosa.

byzantina, C. Koch, in Linnaea, xxi. (1848) $672=$ C. Nepeta.

caerulescens, Wedd. Chlor. And ii. 149. 62-X Granat.

cana, Auct. ex Heynh. Nom, ii. $104=$ graveolens. candidissima, Munby, ex Benth. in DC. Prod. xii. 22 -Algeria.

canescens, Presl, F1. Sicul. $37=$ C. Nepeta.

canescens, Torr. \& Gray, ex Benth in DC. Prod xil. $229=$ Conradina canescens.

caroliniana, Sweet, Hort. Brit. 409.-Am. bor.

chinensis, Benth. in DC. Prod. xii. 233.-Chin

Clinopodium, Benth. $l$. c.-Reg. bor. temp.

coccinea, Benth. l. c. 229,-Am. bor.

confinis, Hance, in fourn. Bot. vi. (1868) 381.China.

corsica, Benth. in DC. Prod. xii. 231.-Ins. Corsica.

cretica, Benth. l. C. 227.-Ins. Creta.

cretica, Lam. Fl. Fr. ii. $395=$ Micromeria marifolia.

croatica, Host, Fl. Austr. ii. 192 = Micromeria

Piperella.

cryptantha, Vatke, in Linnaca, xxxvii. (1571-79) 92s. -Abyss.

debilis, Benth. in DC. Prod. xii, 292.-Sibiria.

dentata, Chapm. Fl. S. U. St. 318.-Florida.

depauperata, Bunge, Lab. Pers S\$-Peria.

dilatate, Schrad. Ind, Sem. Hork Goesting, $15^{\prime}: 5^{\circ}$

C. Nepeta,

Einscleana, F. Schults, Arch. Fl. Fr. et Alsem. 1:8.Europ.

exigua, Nym. Consp. 5s! graveolens.

Fervlii, Vis. Revis. 1"l. Min. Cogn. (1855) $7=$ subn ds.

florida, Buiss. Diasn. Ser. I. xii. 59.-Cilicia.

foliosn, Opis, Vutural. iii. (1223) [20]. Lliurop. 


\section{CAIJAMINTHA :-}

fruticosa, Steud. Nom, ed. II. i. $251=$ Micromeria marifolia.

glabella, Benth. in DC. Prod. xii. 230.-Am. bor.

glabella, A. Gray, Man. ed. II. $307=$ Nuttallii.

glabrescens, Boiss. F1. Orient. iv. $580=$ staminea

glandulosa, Benth. Lab. Gen. et Sp. 387.-Corsica.

glomerulosa, Boiss. \& Heldr. ex Benth. in DC. Prod. xii. $234=$ origanifolia

gracilis, Benth. l. c. 232.-Java.

granatensis, Boiss. \& Reut. Pugill. P1. Nov. $94=$ alpina. grandiflora, Moench, Meth. 408.-Europ.

grandiflora, Pursh, F1. Am. Sept. ii. $414=$ caroliniana

graveolens, Benth. in DC. Prod. xii. 231.-Reg. Mediterr.; As. Min.

graveolens, Coss. ex Willk. \& Lange, Prod. FI. Hispan.

ii. $415=$ umbrosa

Gussonei, Tod. ex Nym. Consp. 588=C. Nepeta.

Haussknechti, Bunce, Lab. Pers. 36.-Persia

hederacea, Scop. F1. Carn. ed. II. i. $423=$ Nepeta Glechoma.

Herba-barona, Heynh. Nom. i. $144=$ Thymus Herbabarona.

heterophylla, Heynh. 1. c. =C. Acinos.

heterotricha, Boiss, E Reut. Pugill. Pl. Nov. 93,Hispan.

hispidula, Boiss. E Reut. l. c.-Hispan.

ilicifolia, A. Gray, in Proc. Am. Acad. viii. (1873) $368=$ Acanthomentha ilicifolia.

incana, Boiss. ex Benth. in DC. Prod. xii. 226.-Graecia et Ins.; Syria.

Jahniana, Simk. in Termész. Füzetek, ix. (1885) 25.-

Europ.
Langei, Nym. Consp. $589=$ suaveolens.

longicaulis, Benth. in DC. Prod.xii. 234.--Reg. Himal.

macrostema, Benth l. c. 229-Mexic.

marifolia, Steud. Nom. ed. II. i. 251=Micromeria marifolia.

maritima, Benth. in DC. Prod. xii. 231.-Thracia.

menthaefolia, Host, F1. Austr. ii. $129=$ officinalis.

meridionalis, Nym. Consp. $589=$ alpina.

mimuloides, Benth. Pl. Hartw. 331.-Calif.

mollis, Jord. ex Lamotte, Prod ii. 599=C. Nepeta

moluccana, Miq. Fl. Ind. Bat. ii. 968.-Ins. Molucc.;

Timor.

montana, Lam. Fl. Fr. ii. $396=$ officinalis.

multicaulis, Maxim. in Bull. Acad. Pétersb. xx. (1875) 466.-Japon.

mebrodensis, Kern. \& Strobl, in Oestr. Bot. Zeitschr.

xxiv. (1874) $171=$ alpina

neglecta, Opiz, Natural. iii. (1823) [20].-Europ.

nepalensis, Fisch. \& Mey. Ind. Sem. Hort. Petrop. xi.

$53=$ umbrosa

Nepeta, Savi, Fl. Pis. (179.8) 197.-Europ.; Afr. bor.; Oriens.

Nepeta, Willk, in Flora, xxxv. (1852) 277 =officinalis nepetoides, Jord.Obs. Pl. Crit.iv. (1846) $16=$ C. Nepeta nervosa, Pomel, Nouv. Mat. Fl. Atl. 307.-Afr. bor. nivea, Boiss. in Ann. Sc. Nat. Sér. IV. ii. (1854) 253. -As. Min.

Nuttallii, Benth, in DC. Prod. xii. 230.-Am. bor.

obliqua, Host, Fl. Austr. ii. $131=$ C. Nepeta.

officinalis, Moench, Meth. 409.-Europ.; Oriens.

origanifolia, Boiss. Diagn. Ser. I. xii. 50.-As. Min. ; Syria.

origanifolia, Host, Fl. Austr, ii. $130=$ Micromeria Pulegium.

origanifolia, Vis. Fl. Dalm. ii. $199=$ Micromeria origanifolia.

Palmeri, A. Gray, in Proc. Am. Acad. xi. (1876) 100. -Calif.

pamphylica, Boiss. E Heldr. Diagn. Ser. I. xii. 52.Pamphylia.

paradoxa, Vatke, in Linnaea, xxxvii. (1871-73) 327.Abyssin.

parviflora, Lam. F1. Fr. ii. $396=$ C. Nepeta

patavina, Heldr. ex Nym. Consp. 588=suaveolens.

patavina, Host, Fl. Austr. ii. 133.-Oriens; Europ.

austr. or.

Piperella, Reichb. F1. Germ. Excurs. 328=Thymus Piperella.

Piperella, Schloss. \& Vukot. Syll. Fl. Croat. $80=$ Micromeria croatica.

piperelloides, Stapf, in Denkschr. Acad. Wien, 1. (1885) 95--Lycia.

Pulegium, Reichb. f. Ic. F1. Germ. xviii. 45 . f. $1278=$ Micromeria Pulegium.

purpurascens, Benth. in DC. Prod. xii. 231.-Hispan.

\section{CALAMINTHA}

repens, Benth. 1. c. $233=$ umbrosa.

rotundifolia, Benth. 1. c. $232=$ umbrosa.

rotundifotia, Ces. Pass. \& Gib. Comp. Fl. Ital. $303=$ alpina.

rotundifolia, Host, Fl. Anstr. ii. $131=$ C. Nepeta.

rotundifolia, Losc. \& Pard Ser. Inconf. 82=

Zizyphora acinoides,

rotundifolia, Reichb. Ic. Fl. Germ. xviii. $43=$ patavina.

mpestris, Host, FI. Austr. ii. $131=$ Micromeria rupestris.

simensis, Benth. in DC. Prod. xii. 230.-Abyssin.

spicigera, C. Koch, in Linnaea, xxi. (1848) $671=$

Micromeria serpyllifolia.

Spruneri, Boiss. Diagn. Ser. I. xii. $53=$ C. Nepeta.

staminea, Boiss. l. c.51.-Kurdistan

stenostoma, Stapf, in Denkschr. Acad. Wien, 1. (1885)

95.-Lycia.

stricta, Reichb. Ic. F1 Germ, xviii. $44=$ officinalis

suaveolens, Boiss. Diagn. Ser. I. xii. 54,-Graecia

subnuda, Host, Fl. Anstr. ii. $130=$ Micromeria Pulegium.

subnuda, Reichb. Fl. Germ. Excurs. $329=$ thymifolia.

sylvatica, Bromf. in Engl. Bot. Suppl. t. $2897=$ officinalis.

thymifolia, Host, Fl. Austr. ii. 132.-Carniola

thymifotia, Reichb. Fl. Germ. Excurs. $328=$ Micromeria rupestris.

trichotome, Moench, Meth. $409=$ C. Nepeta

umbrosa, Fisch. E Mey. Ind. Sem. Hort. Petrop. vi. 6 ; ix. Suppl. 8.-Oriens; Ind. or.

umbrosa, Reichb. Fl. Germ. Excurs, $329=$ officinalis

ussuriensis, Regel \& Maack, in Regel, Tent. Fl. Ussur 116.-Reg. Amur.

vulgaris, [Clairv.] Man. Herb. 197 (err. typ. 9I7) =C. Nepeta.

CATAMOCHIOA, Fourn, in Bull. Soc, Bot. Fr xxiv. (1877) 178. GRAMINEAE, Benth. \& Hook. f. iii. 1178.

filifolia, Fourn. l. c--Mexic

CALAMOCHLOË, Reichb. Consp. 52 (1828)=Arundinella, Raddi (Gramin.).

CALAMOSAGUS, Griff. in Calc. Journ. Nat. Hist. v. (1845) $22=$ Korthalsia, Blume (Palm.)

harinaefolius, Griff. Palms Brit. E. Ind. 29. t. $184=\mathrm{K}$. wallichiaefolia.

laciniosus, Griff. in Calc. Journ. Nat. Hist. v. (1845) $23=\mathrm{K}$. laciniosa,

ochriger, Griff. Palms Brit. E. Ind. 31. t. $216=\mathrm{K}$. polystachys.

polystachys, H. Wendl. in Kerch. Palm. 235, sphalm. $=\mathrm{K}$. polystachys.

scaphiger, Griff. Palms Brit. E. Ind. 30. t. $148 \mathrm{a}=\mathrm{K}$

scaphigera.
wallichiaefolius, Griff. in Calc. Journ. Nat. Hist. v. (1845) $24=\mathrm{K}$. wallichirefolia.

CALAMPELIS, D. Don, in Edinb, N. Phil. Journ. vii. (1829) $89=$ Fccremocarpus, Ruiz \& Pav. (Big-

noniac.).
scaber, D. Don, 1. c. $=$ E. scaber.

CALAMUS, Auct. ex Linn. Gen. ed. I. 104 (1737)= Acorus, Linn. (Aroid.)

aromaticus, Gueldenst. ex Ledeb. Fl. Ross: iv. $13=$ Acorus Calamus.

CALAMUS, Linn. Sp. PI. 325 (1753). PALMAE,

Benth. \& Hook. f. iii. 931

Rotang, Adans. Fam. ii. 24 (1763).

Rotanga, Boerh. ex Crantz, Inst. i. 127 (1766)

acanthopis, Griff. Palms Brit. E. Ind. t. $216=$ Daemonorops malaccensis.

acanthospathus, Griff. in Calc. Fourn. Nat. Hist. v.

(1845) 39.-Reg. Himal.

accedens, Miq in Verh. Kon. Akad, Wetensch. xi. (1868) n. v. $28=$ Daemonorops Draco.

adspersus, Blume, Rumphia, iii. $40=$ Daemonorops adspersus.

albus, Pers. Syn. i. 383.-Amboina.

amarus, Lour. Fl. Cochinch. $210=$ tenuis?

amboinensis, Mig in Verh. Kon. Akad. Wetensch. xi

(1868) n. V. $20=$ Daemonorops calapparius.

americanus, Hort: ex Steud. Nom. ed. II. 1. $252=$

Desmoncus americanus.
CATAMUS:-

amplectens, Becc. Malesia, ii. (1884) 78.-Borneo anceps, Blume, Rumphia, iii. 65 . t. $149=$ melanoloma andamanicus, Kurz, in Fourn. As. Soc. Beng. xliii. (1874) Ir. 211.-Ins. Andaman.

angustifolius, Griff. in Calc. Fourn. Nat. Hist. y. 1845) $89=$ Daemonorops angustifolius.

arborescens, Griff. l. c. 33.-Burma.

asperrimus, Blume, in Schult. f. Syst. vii. 1327.-Java. assamicus, Linden, Illustr. Hortic. xxviii. (1881) 16, nomen.-Assam.

aureus, Reinw. ex Mart. Hist. Nat. Palm. iii. $341=$ ornatus.

australis, Mart. l. c. 342.-Austral.

barbatus, Macklot, in Bijdr. Nat. Wetensch. v. (1830) 178, nomen ; Blume, Rumphia, iii. $42=$ Daemonorops barbatus.

Blancoi, Kunth, Enum. Pl. iii. 595.--Ins. Philipp.

borneensis, Miq. Anal. Bot. Ind. $4=$ javensis

brevifrons, Mart. Hist. Nat. Palm. iii. $338=$ Blancoi.

buroènsis, Mart. l. c. 336.-Ins. Buro.

caesius, Blume, Rumphia, iii. 57.-Malaya.

calapparius, Mart. Hist. Nat. Palm. ed. prior, 209 (iii. 331 ) Daemonorops calapparius

calicarpus, Griff, in Calc. Journ. Nat. Hist. v. (1845) $92=$ Daemonorops calicarpus.

calolepis, Miq. P1. Jungh. $159=$ melanoloma

caryotoides, A. Cunn. ex Mart. Hist. Nat. Palm. iii. 338.--Austral.

castaneus, Griff. in Calc. Fourn. Nat. Hist. v. (1845) 28.-Malaya.

Cawa, Blume, Rumphia, iii. 31-Amboina.

ciliaris, Blume, in Schult. f. Syst. vii. 1330.-Malaya. cochleatus, Miq. in Verh. Kon. Akad. Wetensch. xi. (1868) n. v. $29=$ Daemonorops cochleatns.

collinus, Griff. in Calc. Fourn. Nat. Hist. v. (1845) 31.-Ind. or.

concinnus, Mart. Hist. Nat. Palm. iii. 332. t. 116.Burma.

crinitus, Miq. Anal. Bot. Ind. $6=$ Daemonorops crinitus. cuspidatus, Mann \& H. Wendl. in Trans. Linn. Soc. xxiv. (1864) 434. t. 41=Eremospatha cuspidata.

dealhatus, Hort. ex H. Wendl. in Kesch. Palm. $236=$ Acanthophoenix rubra.

deerratus, Mann E H. Wendl. in Trans. Linn. Soc. xxiv. (1864) 429.-Afr. trop.

delicatulus, Thw. Enum. Pl. Zeyl. 330.-Zeylan.

depressiusculus, Teijsm. E Binn. Cat. Hort. Bog. 74.

-Sumatra.

Diepenhorstii, Miq. Fl. Ind. Bat. Suppl. 594.Malaya.

dioieus, Lour. Fl. Cochinch. 211.-Cochinch.

discolor, Mart. Hist. Nat. Palm. iii. $341=$ siphonospathus?

Draco, Willd. Sp. Pl ii. $203=$ Daemonorops Draco.

elegans, Hort. ex H. Wendl. in Kerch. Palm. 236. Hab.?

elongatus, Miq. Anal. Bot. Ind. $6=$ Daemonorops elongatus.

epetiolaris, Mart. Hist. Nat. Palm. iii. 336.-Java.

equestris, Blume, in Schult. f. Syst. vii. $1330=$ javensis.

equestris, Willd. Sp. Pl. ii. 204.-Ins. Molucc.

erectus, Roxb. Hort. Beng. 72; Fl. Ind. iii. 774.-Reg Himal.

exilis, Griff. ex Mart. Hist. Nat. Palm. iii. 333.Malaya.

extensus, Mart. Hist. Nat. Palm. iii. 200, partim, t. 116 f. 4 . = viminalis

extensus, Roxb. Hort. Beng. 73; FL. Ind. iii. $777=$ palustris?

farinosus, Linden, in Illustr. Hortic. xix. (1872) t. 109 - Sumatra.

fasciculatus, Roxb. Hort. Beng. 72 ; F1. Ind. iii. $779=$ viminalis.

Fernandezii, H. Wendl. in Kerch. Palm. 236= Oxleyanus.

fissus, Miq. Anal. Bot. Ind. $6=$ Daemonorops fissus.

Flagellum, Griff. ex Mart. Hist. Nat. Palm. iii. $333=$ polygamus.

floribundus, Griff. in Calc. Fourn. Nat. Hist. v. (1845) 56.-Reg. Himal.

Gaudichaudii, H. Wendl. in Kerch. Palm. $236=$ Daemonorops Gaudichandii.

geminiflorus, Griff. ex Mart. Hist. Nat. Palm. iii. 338 $=$ Plectocomia geminiflora

geniculatus, Griff. in Calc. Journ. Nat. Hist. v. (1845) $67=$ Daemonorops geniculatus. 
CALAMUS

glaucescens, Blume, Rumphia, iii. $65=$ caesius

glaucescens, D. Dietr. Syn. P1. ii. $1064=$ Ceratolobus glaucescens.

gracilipes, Miq. in Verh. Kon. Akad. Wetensch. xi. (1868) n. v. $28=$ Daemonorops longipes, $M i q$.

gracilis, Blanco, Fl. Filip. ed. I. $267=$ Blancoi.

gracilis, Roxb. Hort. Beng. 73 ; Fy. Ind. iii. 781.-Reg. Himal.

gracilis, Thwaites, Enum. P1. Zeyl. $330=$ pachystemonus.

graminosus, Blume, Rumphia, iii. 31.-Amboina.

grandiflorus, Steud. Nom. ed. II. i. 252, sphalm. =

Ancistrophyllum secundiflorum.

grandis, Griff. in Calc. Journ. Nat. Hist. v. (1845) 84 $=$ Daemonorops grandis

Griffithianus, Mart. Hist. Nat. Palm. iii. 332.Malaya.

Guruba, Buch.-Ham. ex Kunth, Enum. Pl. iii. 210.Reg. Himal.; Burma.

Haenkeanus, Mart. Hist. Nat. Palm. iii. $337=$ mollis.

Helferianus, Kurz, in fourn. As. Soc. Beng. xlii. (1874) II. 213.-Burma.

Heliotropium, Buch.-Ham. ex Kunth, Enum. P1. ii. $210=$ tenuis.

heteracanthus, Macklot, in Bijdr. Nat. Wetensch. v. (1830) 178.-N. Guinea.

heteroideus, Blume, Rumphia, iii. $46=$ Reinwardtii. hirsutus, Miq. in Verh. Kon. Akad. Wetensch. xi. (1868) n. v. $28=$ Daemonorops Hystrix.

Hookeri, Mann \& H. Wendl. in Trans. Linn. Soc. xxiv. (1864) $434=$ Eremospatha Hookeri.

horrens, Blume, Rumphia, iii. 43.-Java.

hostilis, Wall. ex Voigt, Hort. Suburb. Calc. 639 ; Miq. F1. Ind. Bat. iii. 113, nomen $=$ arborescens.

Huegelianus, Mart. Hist. Nat. Palm. ii. 338.Malabar.

humilis, Roxb. Hort. Beng. 72; F1. Ind, iii, $773=$ latifolius?

hygrophilus, Griff. Palms Brit. Ind. t. $213 \mathrm{C}=$ Daemonorops hygrophilus.

hypoleucus, Kurz, in Fourn. As. Soc. Beng. xliii. (1874) II. 208.-Burma.

Hystrix, Griff, in Calc. Journ, Nat. Hist. v. (1845) 70 $=$ Daemonorops Hystrix

inermis, T. Anders, in Journ. Linn. Soc. xi. (1871) 11 $=$ latifolius.

insignis, Griff. in Calc. Fourn. Nat. Hist. v. (1845) 59. - Malaya.

intermedius, Griff. 1. c. $86=$ Daemonorops intermedius.

javensis, Blume, Rumphia, iii. 62.-Malaya.

Fenkinsianus, Griff, in Calc. Joum. Nat. Hist. v (1845) $81=$ Daemonorops Jenkinsianus.

fenkinsianus, Griff. Palms Brit. Ind. 40. t. 186 A. f. 3 (non p. 89) = polygamus.

Korthalsii, Miq. Anal. Bot. Ind. i. 6=Daemonorops Korthalsii.

laevigatus, Mart. Hist. Nat. Palm. iii. 339.Malaya.

laevis, Mann \& H. Wendl. in Trans. Linn. Soc. xxiv. (1864) 430, t. 38 (Ancistrophylli sp.).-Afr. trop.

latifolius, Kurz, in Journ. As. Soc. Beng. xliüi. (1874) II. 20. t. 31. A. = palustris.

latifolius, Roxb. Hort. Beng, 73; Fl. Ind. iii. 775.Burma.

latispinus, Miq. in Verh. Kon. Akad. Wetensch. xi. (1868) n. v. 29 .- Sumatra.

leptopus, Griff. in Calc. Journ. Nat. Hist. v. (1845) 73 = Daemonorops leptopus.

leptospadix, Griff. l. c. 49.-Reg. Himal.

Lewisianus, Griff. 1. c. $87=$ Daemonorops Lewisianus.

Lindeni, Rodigas, in Illustr. Hortic. xxx. (1883) t. 499

- Malaya.

litoralis, Blume, Rumphia, iii. $43=$ viminalis

longipes, Griff. in Calc. Journ. Nat. Hist, v. (1845) 68 - Daemonorops longipes, Mart.

longisetus, Griff. l. c. 36.-Burma.

macracanthus, T. Anders. in Jouru. Linn. Soc. xi. (1871) $10=$ latifolius.

macrocarpus, Griff. ex Mart. Hist. Nat. Palm, iii. 333 = erectus.

macrocarpus, Mann \& H. Wendl. in Trans. Linn. Soc. xxiv. (1864) 435 - Eremospatha macrocarpa.

macropterus, Miq. in Verb. Kon. Acad. Wetensch. xi. (1868) n. v. 19.-Ins. Celebes.

Manan, Miq. Fl. Ind. Bat. Suppl. 595.-Sumatra.

\section{CALAMUS:}

manicatus, Teijsm. \& Binn. ex Miq. F1. Ind. Bat. iii. $135=$ Daemonorops crinitus

manillensis, H. Wendl. in Kerch. Palm. 237.-Ins Philipp.

Mannii, H. Wendl. in Trans. Linn. Soc. xxiv. (1864) $436=$ Oncocalamus Mannii.

Margaritae, Hance, in Fourn. Bot. xii. (1874) 266.China.

marginatus, Mart. Hist. Nat. Palm. ini. 342.Borneo.

maritimus, Blume, Rumphia, iii. 31, in adnot.Java.

Mastersianus, Griff. in Calc. Journ. Nat. Hist. v. (1845) $76=$ C. Guruba

maximus, Blanco, F1. Filip. ed. I. $266=$ manillensis?

maximus, Reinw. ex Schult. f. Syst. vii. $1333=$ Plectocomia elongata.

melanacanthus, Mart. Hist. Nat. Palm. iii. 339. t. 116. f. 13.-Burma.

melanochaetes, Miq. in Verh. Kon. Akad. Wetensch. xi. (1868) n. v. $28=$ Daemonorops melanochaetes. melanolepis, H. Wendl. in Kerch. Palm. $237=$ Huegelianus.

melanoloma, Mart. Hist. Nat. Palm. iii. 209, 339. t.

116. f. 3.-Java.

Metzianus, Schlecht. in Linnaea, xxvi. (1853-55) 727. -Ind. or.

Meyenianus, Schau. in Nov. Act. Nat. Cur. xix. Suppl. i. (1843) 425.-Ins. Philipp.

micracanthus, Griff. in Calc. Fourn. Nat. Hist. v. (1845) 62.-Malacca.

micranthus, Blume, Rumphia, ii. 53.-Malaya.

mirabilis, Mart. ex Kunth, Enum. Pl. iii. $213=$ Daemonorops mirabilis.

mishmeensis, Griff. in Calc. Journ. Nat. Hist. v. (1845) $55=$ floribundus.

mollis, Blanco, Fl. Filip. ed, I, 264.-Ins. Philipp. monoecus, Roxb. Hort. Beng. 73 ; Fl. Ind. iii. $783=$ C. Rotang.

montanus, T. Anders. in Journ. Linn. Soc. xi. (1871) 9 = acanthospathus,

monticolus, Griff. in Calc. Journ. Nat. Hist. v. (1845) 90 $=$ Daemonorops monticolus.

Muelleri, H. Wendl. E Drude, in Linnaea, xxxix (1875) 193. - Austral.

niger, Willd. Sp. Pl. ii. $203=$ Daemonorops niger.

nitidus, Mart. Hist. Nat. Palm. iii. 334.-Burma

Ind, or.

nivalis, Thw. ex Trimen, in Journ. Bot. xxiii. (1885) 268 , sphalm. $=$ rivalis

nutantiflorus, Griff. in Calc. Journ. Nat. Hist. v. 1845) $79=$ Daemonorops Jenkinsianus.

oblongus, Reinw. in Schult. f. Syst. vii. 1323.Java.

obstruens, F. Mnell. Fragm. v. $48=$ australis

ochreatus, Miq. in Verh. Kon. Akad. Wetensch. xi. (1868) n. V. 29.-Sumatra.

opacus, Blume, Rumphia, iii. 50.-Sumatra.

opacus, Mann \& H. Wendl. in Trans. Linn. Soc. xxiv. (1864) 431.t. 41=Laccosperma opaca.

ornatus, Blume, ex Schult. f. Syst. vii. 1326.Malaya.

ovatus, Reinw. ex Kunth, Enam. Pl. iii. $205=$ ornatus.

ovoideus, Thw. ex Trimen, in Fourn. Bot. xxiii. (1885) 269.-Zeylan.

Oxleyanus, Teijsm. G Binn. Cat. Hort. Bog. 75, nomen.-Malaya.

pachystemonus, Thw. Enum. Pl. Zeyl. 431.-Zeylan. palembrnicus, Miq. in Verh. Kon. Akad. Wetensch. xi. (1868) n. v. $29=$ Daemonorops palembanicus. pallens, Blume, Rumphia, iii. $51=$ Reinwardtii. palustris, Griff. in Calc. Gourn. Nat. Hist. v, (1845) 60.-Burma.

paniculatus, Roxb. Hort. Beng. [105], nomen.Penang.

paradoxus, Kurs, in fourn. As. Soc. Beng. xliii. (1874) Ir. 213. t. 29, 30.-Burma.

penicillatus, Roxb. FI. Ind. iii. $781=$ javensis ? periacanthus, Miq, in Verb. Kon. Akad. Wetensch, xi (1868) D. v. $28=$ Docmonorops periacanthus.

petiolaris, Griff. in Calc. Journ. Nat. Hist. v. (1845) $93=$ Daemonorops petiolaris.

petraeus, Lout. Fl. Cochinch. 209.-Cochinch.

philippensis, Linden, Illustr. Hortic xxviii. (1881) 16, nomen.-Ins. Pbilipp.

\section{CALAMUS:}

pisicarpus, Blume, Rumphia, iii. 39,-Ins. Molucc. platyacanthos, Mart. ex Kunth, Enum. P1. iii. $205=$ oblongus.

platyspathus, Mart. ex Kunth, l. c. 209.-Burma

plicatus, Blume, Rumphia, iii. 67.-Ins. Celebes.

polygamus, Roxb. Hort. Beng. 73 ; Fl. Ind. iii. 780.Reg. Himal.

Pseudo-Rotang, Mart. ex Kunth, Eunm. P1. iii. $207=$ viminalis.

pulcher, Miq. Anal. Bot. Ind. i. 3.-Borneo.

quinquenervius, Roxb. Hort. Beng. 73; Fl. Ind. ii. 777.-Reg. Himal.

radiatus, Thw. Enum.Pl. Zeyl. 431.-Zeylan.

radicalis, $H$. Wendl. E Drude, in Linnaea, xxrix. (1875) 195.-Austral.

ramosissimus, Griff. in

Reinwardtii, Mart. Hist. Nat. Palm. iii. 208. t. 112.Malaya.

Rheedei, Griff. in Calc. Fourn. Nat. Hist. v. (1845 73, nota._Malabar.

rhomboideus, Blume, in Schult. f. Syst. vii. 133.Malaya.

Riedelianus, Miq. in Verh. Kon. Akad. Wetensch. xi (1868) n. V. 18.--Ins, Celebes.

rivalis, Thw. ex Trimen, in fourn. Bot. xxiii. (1885) 386, 268.-Zeylan.

Rotang, Linn. Sp. Pl. 325.-Ind. or

Roxburghii, Griff. in Calc. Journ. Nat. Hist. v. (1845 $43=\mathrm{C}$. Rotang.

Royleanus, Griff. I. c. $40=$ tenuis.

ruber, Reinw, ex Kunth, Enum. Pl. iii. $208=$ Daemonorops Draco.

rudentum, Lour. Fl. Cochinch. 209.-Cochinch.

rudentum, Mart. Hist. Nat. Palm. iil. $340=$ rivalis.

rudentum, Roxb. Hort. Beng. 72; Fl. Ind. iii. $776=$ albus.

Rumphii, Blume, Rumphia, iii. $38=$ Daemonorops Rumphii.

Salakka, Willd, ex Steud. Nom. ed. II. i. $252=$

Zalacca edulis.

schistocanthos, Blume, Rumphia, iii. 49.-Sumatra.

schizospathus, Griff. in Calc. Journ. Nat. Hist. v. (1845) $32=$ erectus.

Scipionum, Lam. Encyc. vi. $304=$ C. Rotang.

Scipionum, Lour. Fl. Cochinch.210.-Malaya.

secundiflorus, Beauv. FI. Owar. i. 15. t. 9, $10=$ Ancistrophyllum secundiflorum.

siphonospathus, Mart. Hist. Nat. Palm. iii. 342.Ins. Philipp.

spectabilis, Blume, Rumphia, iii. 55.-Sumatra.

stoloniferus, Teijsm. \& Binn. Cat. Hort. Bog. 75 horrens.

strictus, Miq. in Verh. Kon. Akad. Wetensch. xi. (1865) n. V. $28=$ Daemonorops longipes.

subangulatus, Miq. Fl. Ind. Bat. Suppl. 594Sumatra.

symphysipus, Mart. Hist. Nat. Palm, iii. $396^{\circ} .-$ Ins. Celebes.

tenuis, Roxb. Hort. Beng. 73; Fl. Ind. iii. 780.-Reg Himal.; Burma ; Cochinch.

tetradactylus, Hance, in Fourn. Bot. xiii. (1575) 259 . -China.

tetrastichus, Blume, Rumphia, iii. $62=$ jarensis.

thysanolepis, Hance, in Fourn. Bot. xii. (187t) 265.China.

tigrinus, Kurz, in Journ. As. Soc. Beng. xliii. 1 $1 \tilde{i}_{t}$ II. $211 . \mathrm{t} .25=$ longisetus.

trichrous, Miq. in Verh. Kon. Akad. Wetensch, xi. (1868) n. v. $28=$ Daemonorops trichrous.

nnifarius. H. Wendl. in Bot. Zeit. xvii. 185!1 158.Ins. Nicobar. ; Java.

usitatus, Blanco, Fl. Filip. ed. I. $205=$ Dsemonorops Gaudichaudii.

usitatus, Mart. Hist. Nat. Palm. iii. $940=$ Blancoi.

Verschaffelti, Hort. ex H. Wendl, in Kerch. Palm. 299 = Acanthophoenix crinita.

verticillaris, Griff. in Calc. Joum. Nat. Hist. v. (15 45 $63=$ Daemonorops verticillaris.

verus, Lour. Fl. Cuchinch. $210=$ pisicarpus.

viminalis, Reinav. ex Mart. Vas. Hist. Pazlm. iii. 39 .

t. U. 111-Culebes: Jam?

viminalis, Willd. Sp. Pl. ii. 20S.-Ind. or. : Malava.

Walkeri, Hance, in Gourn. Bot. xii. (18it) $26^{\circ}$. China.

Wightii, Ciriff. Palms Brit. Ind. 102. t. $210^{\circ} \mathrm{G}=$ Hacte. lianus. 


\section{CALAMUS:-}

Zalacca, Gaertn. Fruct. ii. 267. t. $139=$ Zalacca edulis.

Zalacca, Roxb. Hort. Beng. 72 ; Fl. Ind. iii. $773=$ Zalacca Wallichiana.

CALANCHOË, Pers. Syn. i. 445 (1805)= Kalanchoë Adans. (Crassulac.).

CALANDARIUM, Juss. ex Stend. Nom. ed. II. i. 252 $1840)=$ seq.

CAIANDRINIA, H. B. \& K. Nov. Gen. et Sp. vi. 77. t. 526 (1823). PORTULACEAE, Benth. \& Hook. f. i. 158 .

Baitaria, Ruiz \& Pav. Prod. 63, t. 36 (1794). Cistanthe, Spach, Hist. Vég. Phan. v. 229 (1833) Cosmia, Domb. ex Juss. Gen. 312 (1789).

Diazia, Phil. Fl. Atac. 22. t. 1 E (1830)

Geunsia, Moç. \& Sesse, ex DC. Prod. iii. 358 (1828) Phacosperma, Haw. in Phil. Mag. i. (1827) 124.

Rhodopsis, Lilja, Fl. Sverig. Suppl. i. 42 (1840).

Tegneria, Lilja, F1. Sverig. odl. Vext. 76 (1839).

acaulis, H. B. E $K$. Nov. Gen. et Sp. vi. 78.Ecuador.

acuta, Meyen, ex Walp. in Nov. Act. Nat. Cur. xix. Suppl. i. (1843) $340=$ biflora.

adscendens, Hort. ex Phil. f. PI. Vasc. Chil. $85=$ pilosiuscula.

affinis, Gill. ex Arn. in Cheek, Edinb. Fourn. iii. (1831) 355.-Chili

alba, DC. Prod. iii. 359.-Peruv.

amoena, Vis, in Nuov. Sagg. Padov. vi. (1847) 94.Hab. ?

andicola, Gill. in Hook. Bot. Misc. iii. (1833) 332.Chili.

Andrewsii, Sweet, Hort. Brit. ed. II. 219.-Ind. occ

Andrewski, Hort. ex Vilm. Fl. Pl. Terre, ed. I. $865=$ Talinum patens.

angulata, Hort. ex Fisch. \& Mey. Ind. Sem. Hort

Petrop. xi. $53=$ procumbens.

arenaria, Cham. in Linnaea, vi. (1831) 563.-Chili.

aurea, Barn. in C. Gay, Fl. Chil. ii. 510.-Chili.

axilliflora, Barn. l. c. 486.-Chili.

balonensis, Lindl. in Mitch. Fourn. Trop. Austral. 148.-Austral.

Berteroana, Phil. in Linnaea, xxviii. (1856) 643.Chili.

biflora, Meyen, Reise, i. 349,-Chili

brevipedata, F. Muell. Fragm. x. 69.-Austral.

Breweri, S. Wats. in Proc. Am. Acad. xi. (1876) 124 -Am. bor. occ.

Buridgii, Hort. ex Regel, Gartenfl. (1855) 4.-Am. austr.

cachinalensis, Phit. Fl. Atac. 20.-Chili.

caespitosa, Gill. ex Arn. in Cheek, Edinb. Fourn. iii. (1831) 356.-Chili.

calycina, Phit. in Linnaea, xxxiii. (1864-65) 75.Chili.

calycotricha, Phil. l. c. xxx. (1859-60) 188.-Chili. calyptrata, Hook. f. in Ic. Pl. t. 296.-Austral.

capitata, Hook. E Arn. in Hook. Bot. Misc. iii. (1833) 334.-Chili.

caulescens, H. B. E K. Nov. Gen. et Sp. vi. 78. t. 526 -Ecuador: Peruy.

Chamissoi, Barn. in C. Gay, Fl. Chil. ii. 497.-Chili

chromantha, Griseb. in Goett. Abh xxiv. (1879) 30 . Reg. Argent.

ciliata, DC. Prod. iii. 359.-Peruv.

cistiflora, Gill. ex Arn. in Cheek, Edinb. Fourn. iii (1831) 355.-Chili.

colchaguensis, Barn. in C. Gay, Fl. Chil. ii. 483.Chili.

compacta, Barn. l. c. 481.-Chili

composita, Benth. Fl. Austral. i. 175.-Austral

compressa, Schrad. ex DC. Prod. iii. 359.-Chili.

conferta, Gill. ex Arn. in Cheek, Edinb. Fourn. iii (1831) 356.-Chili.

coquimbensis, Barn. in C. Gay, Fl. Chil. ii. 483.Chili.

corrigioloides, F. Muell.ex Benth.Fl. Austral.i. 175.-Austral.

corymbosa, Walp. in Nov. Act. Nat. Cur. xix. Suppl. i. (1843) 341.-Chili.

Cotyledon, S. Wats. in Proc. Am. Acad. xx. (1885) 355.-Calif.

Cumingii, Hook. E Arn. in Hook. Bot. Misc. iii. (1833) 334.-Chili

\section{CALANDRINIA :-}

curvifolia, Hort. ex Heynh. Nom, ii. $105=$ procumbens.

demissa, Phil. in Linnaea, xxviii. (1856) 644.-Chili densiflora, Barn. in C. Gay, Fl. Chil. ii. 503.-Chili. densiflora, Phil. in Linnaea, xxviii. (1856) 642. densiflor

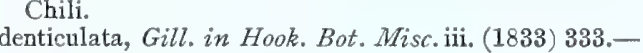
Chili

dianthoides, Phil. in Anal. Univ. Chil. (1872) 717. -Chili.

diffusa, Gill. ex Arn. in Cheek, Edinb. Fourn. iii. (1831) 355.-Chili.

discolor, Lindl. Bot. Reg. (1839) t. $4=$ Lindleyana.

discolor, Schrad. in Linnaea, viii. (1833) Lit. 22.Chili.

elegans, Hort. ex Vilm. Fl. PI. Terre, ed. I. $149=$ discolor.

elegans, Spach, Hist. Vég. Phan. v. $232=$ Menziesii.

erythrocoma, Phil. in Linnaea, xxxiii. (1864-65) 76. Chili.

fasciculata, Phil. l. c. xxviii. (1856) 645.-Chili

Fenzlii, Barn. in C. Gay, Fl. Chil. ii. 493.-Chili.

ferruginea, Barn. l. c. 513.-Chili.

floribunda, Phil. in Linnaea, xxxiii. (1864-65) 78.Chili.

frigida, Barn. in C. Gay, Fl. Chil. ii. 495.-Chili. fruticulosa, Kunze, ex Walp. in Nov. Act. Nat. Cur. xix. Suppl. i. (1843) $340=$ trifida.

Gaudichaudii, Barn. in C. Gay, Fl. Chil. ii. 490.Chili.

Gayana, Bam. 1. c. $503=$ biflora.

Gilliesii, Hook. E Arn. in Hook. Bot. Misc, iii. (1833) 333.-Chili.

glandulosa, Hort. ex Steud. Nom. ed. II. i. $253=$ procumbens.

glauca, Schrad. ex DC. Prod. iii. $359=$ grandiflora.

glomerata, Phil. in Linnaea, xxviii. (1856) 644. Chili.

gracilis, Benth. Fl. Austral. i. 173.-Austral.

graminifolia, Phil. in Linnaea, xxviii. (1856) 690.Chili.

grandiflora, Lindl. Bot. Reo.t. 1194.-Chili.

granulifera, Benth. Fl. Austral. i, 176.-Austral.

hirtella, Phil. in Linnaea, xxviii. (1856) 691.-Chili

Landbeckii, Phil. l. c. xxxiii. (1864-65) 77.-Chili.

Leana, Porter, in Coult. Bot. Bull. i. (1876) 49. Calif.

Lehmanni, Endl. in Lehm. Pl. Preiss, ii. 235.Austral.

leucocephala, Phil. Fl. Atac. 21.-Chili.

leucotricha, Phil. in Anal. Univ. Chil. (1861) 91.Chili.

Lindleyana, Hort. ex Vilm. Fl. Pl. Terre, ed. II. 162 $=$ discolor.

Lindleyana, Walp. Rep. ii. 235.-Hab. ?

linearifolia, $D C$. Prod. iii. 359.-Mexic.?

lingulata, DC. l. c. 358.--Peruy.

lingulata, Hort. ex Steud. Nom. ed. II. 1. $253=$ procumbens.

liniflora, Fenzl, in Enum. Pl. Hueg. 52.-Austral.

litoralis, Phil. Fl. Atac. 20,-Chili.

Llavea, Loud. Hort. Brit. Suppl. i. 616, sphalm. Cuphea Llavea.

Lockharti, Sreet, Hort. Brit. ed. II. 219.-Ins. Trinit. longiscapa, Barn. in C. Gay, Fl. Chil. ii. 492.-.Chili. macilenta, Barn. l. c. 488.-Chili.

maritima, Nutt. ex Torr. E Gray, Fl. N. Am. i. 197.Calif

megarhiza, Hemsl. Diag. Pl. Nov. 23.--Guatemala

Menziesii, Torr. \& Gray, Fl. N.Am. i. 197.-Am. bor. occ.

Meyeniana, Walp. in Nov. Act. Nat. Cur. xix. Suppl. i. (1843) 341, - Chili.

micrantha, Schlecht. in Linnaea, xiii. (1839) Lit. 97. -Mexic.

minima, Bert. ex Steud. Nom, ed. II. i. 253.-Chili

minutissima, Barn. in C. Gay, Fl. Chil. ii. 504.Chili.

modesta, Phil. Fl. Atac. 20.-Chili.

monandra, DC. Prod, iii. $359=$ Monocosmia corrigioloides.

mucronulata, Meyen, Reise, i. 314.-Chili.

multicaulis, Phil. in Linnaea, xxviii. (1856) 641.Chili.

nevadensis, A. Gray, in Proc. Am. Acad. viii. (1873) 623. -Am. bor. occ.

nitida, $D C$. Prod. iii, 359,-Chili.

\section{CALANDRINIA :-}

oblongifolia, Barn. in C. Gay, Fl. Chil. ii. 482.Chili.

occulta, Phil. Fl. Atac, 20.-Chili.

oppositifolia, S. Wats. in Proc. Am. Acad. xx. (1885) 355.-Calif.

paniculata, $D C$. Prod. iii. 358.-Peruv

parviflora, Hort. 'ex Steud. Nom. ed. II. i. $253=$ procumbens.

Phacosperma, DC. Prod. iii. 359.-Peruy.

Pickeringii, A. Gray, Bot. U. St. Expl. Exped. i. 144 -Chili.

picta, Gill. ex Am, in Cheek, Edinb. Journ. iii. (1831 $356=$ arenaria

pilosiuscula, DC. Prod. iii. 359.-Chili

pleiopetala, F. Muell. Fragm.x. 70.-Austral.

Poeppigiana, Walp. in Nov. Act. Nat. Cur. xix. Suppl. i. (1843) 340 - Chili.

pogonophora, F. Muell. Fragm. x. 69.-Austral polyandra, Benth. Fl. Austral. i. 172.-Austral. polycarpoides, Phil. in Linnaea, xxviii, (1856) 644.Chili.

polyclados, Phit. l. c. xxxiii. (1864-65) 77-Chili polypetala, Fenzl, in Enum. Pl. Hueg. 51.-Austral, potentilloides, Barn. in C. Gay, Fl. Chil. ii. 512.Chili.

procumbens, Moris, in Mem. Acc. Tor. xxxvii. (1834) 100.-Chili

prostrata, Phil. in Linnaea, xxxiii. (1864-65) 76 .Chili.

ptychosperma, F. Muell. Fragm, iv. 137.-Austral.

pulchella, Lilja, in Linnaea, xvii. (1843) $109=$ Menziesii.

pumila, F. Muell. Fragm. x. 68.-Austral.

pusilla, Barn. in C. Gay, Fl. Chil. ii. 485,-Chili.

pusilla, Lindl. in Mitch. Trop. Austral. 360.-Austral.

pygmaea, A. Gray, in Proc. Am. Acad. viii. (1873) 623. -Am. bor. occ

pygmaea, F. Muell. Fragm. i. 175.-Austral

quadrivalvis, $F$. Muell. l. c. 176.-Austral.

racemosa, Steud. Nom. ed. II. i. $253=$ arenaria.

ramosissima, Hook. Eo Arn. in Hook. Bot. Misc, iii (1833) 334.-Chili.

rupestris, Barn. in C. Gay, Fl. Chil. ii. 485.-Chili.

salsoloides, Barn. l. c.502.-Chili

Saxifraga, Barn. l. c. 506.-Chili.

sericea, Hook. E Arn, in Hook. Bot. Misc. iii. (1833) 334.- Chili.

sericea, Poepp. ex Walp. in Nov. Act. Nat. Cur. xix. Suppl. i. (1843) $340=$ Poeppigiana.

setosa, Phil. in Linnaea, xxvii. (1856) 690.-Chili. speciosa, Lehm. in Linnaea, vi. (1831) Litt. $74=$ discolor speciosa, Lindl. Bot. Reg. t. $1598=$ Menziesii spectabilis, Otto E Dietr. Allg. Gartenz. i. (1833) 161 - Chili.

spergularina, F. Muell. Fragm. i. 175.-Austral.

spicata, Phil. Fl. Atac. 21.-Chili

splendens, Barn. in C. Gay, Fl. Chil. ii. 499,-Chili strophiolata, F. Muell. Fragm.xi. 82,-Austral.

tenella, Hook. Bot. Beech. Voy, $24=$ pilosiuscula.

tenuifolia, Phil. in Linnaea, xxviii. (1856) 691-Chili tricolor, Phil. l. c. 642.-Chili.

trifida, Hook. E' Arn. in Hook. Bot. Misc. iii. (1833) 333.-Chili.

tuberosa, Benth. Pl. Hartw. 9.-Mexic.

umbellata, $D C$. Prod iii. 358-Chili.

umbellata, Gill. ex Hook. \& Arn. in Hook. Bot. Misc. iii. (1833) $334=$ Gilliesii.

uniflora, F. Muell. in Trans. Phil. Inst. Vict. iii. (1859) 41.-Austral.

venulosa, Hook. \& Arn. in Hook. Bot. Misc. iii. (1833) $336=$ arenaria

venusta, Steud. Nom, ed. II i. $253=$ arenaria.

vinulosa, Walp. Rep. iii. $236=$ arenaria.

virgata, Phil. in Linnaea, xxviii. (1856) 642.-Chili volubilis, Benth. Fl. Austral. i. 174.-Austral

CALANTHE, R. Br. in Bot. Reg. sub t. 573 (1821) $O R C H I D E A E$, Benth. \& Hook, f. iii. 520

AmblyglotTis, Blume, Bijdr. 369. t. 64 (1825),

Centrosis, Thou. Orch. Iles Afr. t. 35, 36 (1822)

Ghiesbreghtia, A. Rich. in Ann. Sc. Nat. Sér. III iii. (1845) 28.

Preptanthe, Reichb. f. in Fl. des Serres, Sér. I. viii. (1853) 245

Styloglossum, Breda, Orch. Kuhl et Hass. (1827) Zeduba, Buch.-Ham. ex Meissn. Gen. Comm. 280 (1842). 
CALANT்HE :-

abbreviata, Lindl. Gen. et Sp. Orch, 251,-Java. alismaefolia, Lindl. Fol. Orchid. Calanth. 8.-Reg. Himal.

alpina, Hook. f. ex Lindl. l. c. 4.-Reg. Himal. alta, Reichb. f. Otia.Bot. Hamb. 53.-Ins. Fiji. anchorifera, Reichb. f. in Gard. Chron. (1883) II. 166. -Polynesia.

angraeciflora, Reichb. $f$, in Linnaea, xli. (1877) 75 . N. Caled.

angusta, Lindl. Fol. Orchid. Calanth. 7.-Reg Himal.

angustifolia, Lindl. Gen. et Sp. Orch. 250.-Malaya. aristulifera, Reichb. f. in Bot. Zeit. xxxvi. (1878) 74.Japon.

australis, Ait. ex Lond. Hort. Brit. Suppl. ii. $615=$ Spiranthes australis.

Barberiana x, Reichb. f. in Gard. Chron. (1881) I. 136. bella $\times$, Reichb. f. 1. c. 234

bicolor, Lindl. Sert. Orch. sub t. $9=$ striata.

biloba, Lindl. Fol. Orchid. Calanth. 3-Reg. Himal.

bracteosa, Reichb. f. in Flora, lxv. (1882) 533.-Ins.

Samoa.

brevicornu, Lindl. in Wall. Cat. n. 7338.-Reg. Himal.

catilligera, Reichb.f. in Bonplandia, v. (1857) 37.-

Java

Ceciliae, Hort. Low.Cf. Gard. Chron. (1883) I. 432.-Malaya.

chloroleuca, Lindl. Fol. Orchid. Calanth. 10.-Reg. Himal.

citrina, Scheidw. in L'Hortic. Belge, v. (1838) 185. t. 104.-Hab.?

clavata, Lindl. in Wall. Cat. n. 7343.-Reg. Himal, ; Burma.

colorans, Reichb.f. in Gard. Chron. (1885) II. 360.Hab.?

comosa, Reichb. f. in Linnaea, xix. (1847) $374=$ veratrifolia.

conspicua, Lindl. Fol. Orchid. Calanth. 4,-Malaya.

corymbosa, Lindl. in Fourn. Linn. Soc. vi. (1862) 129 -Afr. trop

curculigoides, Lindl. in Wall. Cat. n. 7340.-Malaya.

Curtisii, Reichb. f. in Gard. Chron. (1884) II. 262.

-Ins. Sondaic.

densiflora, Lindl in Wall. Cat. n. 7344,-Reg. Himal dipteryx, Reichb. f. in Gard. Chron. (1884) II. 394

-Ins. Sondaic.

discolor Lindl. Sert. Orch. sub t. 9.-Japon.

Dominii x, Lindl. in Gard. Chron. (1858) 4.

emarginata, Lindl. Gen. et Sp. Orch. 249.-Java.

Hava, Morr. in L'Hortic. Belge, ii. (1834) 238, t. 46.Java.

Foerstermanni, Reichb. f. in Gard. Chron. (1883) 814.-Burma.

fulgens, Lindl. Fol. Orchid. Calanth. $10=$ C. Masuca furcata, Batem. ex Lindl. Bot. Reg. (1838) Misc. 28. -Ins. Luzon.

galeata, Lindl. Fol. Orchid. Calanth. 5=chloroleuca.

Gebina, Lodd. Cat. ex Lindl. 1. c. $11=$ Bletia hyacinthina.

gracilis, Lindl. in Wall. Cat. n. 7341.-Reg. Himal. ;

China.

gracillima, Lindl. Fol. Orchid. Calanth. 8.-Ins.

Carolin.

granatensis, Reichb.f. in Bonplandia, iv. (1856) 322. N. Granat.

grandiflora, Nadeaud, Enum. Pl. Tahiti, 37.-Ins

Pacif.

Griffithii, Lindl. in Paxt. Fl. Gard. iii. (1852-53) 37. -Reg. Himal.

herbacea, Lindl. Fol. Orchid. Calanth. 10.-Reg. Himal.

hololeuca, Reichb.f. in Seem. Fl. Vit. 298.-Ins. Fiji.

japonica, Blume, in Miq. Ann. Mus. Bot. Lugd. Bat.

ii. 205.-Japon.

Jusnerii, Boxall, ex Naves, in Blanco, Fl. Filip. ed. III. Nov. App. 247.-Ins. Philipp.

labrosa, Reichb. f. in Gard. Chron. (1883) 1. 44.Burma.

Langei, F. Muell. in Wing, South Sc. Record, N. S. i. $(1885)-\mathrm{N}$. Caled

lentiginosa X, Reichb, $f$ in Gard, Chron. (1883) I. 44. lyroglossa, Reichb. f. Otia Bot. Hamb. 53.-Afr. trop.

Masuca, Lindl. in Wall. Cat. n. 7387.--Ind. or. Malays.

mexicana, Reichb. f. in Linnaea, xviii. (1844) 406.Mexic.

\section{CALANTHE}

natalensis, Reichb. f. in Bonplandia, iv. (1856) 322Afr. austr.

nivalis, Boxall, ex Naves, in Blanco, Fl. Filip. ed. III. Nov. App. 247.-Ins. Philipp.

occidentalis, Lindl. Fol. Orchid. Calanth. $3=$ tricarinata.

odora, Griff. Notul. iii. 365.--Reg. Himal.

parviflora, Lindl. in Paxt. Fl. Gard. iii. (1852-53) 37, sub t. 61.-Java.

Perrottetii, A. Rich. in Ann. Sc. Nat. Sér. II. xy. 1841) $68=$ veratrifolia

Petri, Reichb. f. in Gard. Chron. (1880) II. 326.Polynesia.

phajoides, Reichb. f. in Bonplandia, v. (1857) $37=$ angustifolia.

pilosa, Lindl. Fol. Orchid. Calanth. 11.-Sumatra.

plantaginea, Griff. Notul. iii. $368=$ Griffithii.

plantaginea, Lindl. in Wall. Cat. n. 7346.-Reg. Himal.

pleiochroma, Reichb. f. in Gard. Chron.(1871) 938. -Japon.

porphyreax, Reichb. f. 1, c. (1884) r. 76

proboscidea, Reichb.f.l. c. 476 . - Ins. Sondaic.

puberula, Lindl, in Wall. Cat. n. 7342,-Reg. Himal.

pulchra, Lindl. Gen. et Sp. Orch. 250.-Java.

purpurea, Lindl. l.c. 249.-Zeylan.

reflexa, Maxim. in Bull. Acad. Pétersb. xviii. (1873) 68.-Japon.

Regnieri, Reichb.f. in Gard. Chron. (1883) I. 274.Cochinch.

rosea, Benth. in Fourn. Linn. Soc. xviii. (1880) 309.Burma.

Sandhurstiana x, Gosse, ex Reichb. f. in Gard. Chron. (1881) I. 395 .

Sedeni x, Reichb. f. 1. c. (1878) I. 168

Sieboldi, Decne. ex Regel, Ind. Sem. Hort. Petrop. (1868) 80.-Japon.

speciosa, Lindl.Gen. et Sp. Orch. 250.-Java.

speciosa, Vieill. in Ann.Sc. Nat. Sér, IV. xvi. (1861) 44.-N. Caled.

Stevensiana, Régnier, ex Reichb. $f$. in Gard. Chron. (1883) I. 274, in nota.-Java?

striata, $R$. Br. in Bot. Reg. 573, in nota.-China; Japon.

sulphurea, Hort. Hueg. ex Heynh. Nom. ii. 105, nomen. -Ind. or.

sumatrana, Blanco, ex Boerl. in Hasselt E Boerl. Bijdr. Midd. Sum. 33.-Sumatra.

sylvatica, Lindl. Gen. et Sp. Orch. 250.-Madag.

sylvestris, Lindl. ex Steud. Nom. ed. II. i. $253=$ sylvatica.

tahitensis, Nadeaud, Enum. Pl. Tahiti, 37.-Ins, Tahiti.

Textori, Miq. Ann. Mus. Bot. Lugd. Bat. ii. 204.Japon.

triantherifera, Nadeaud, Enum. Pl. Tahiti, 38.-Ins, Tahiti.

tricarinata, Lindl. in Wall. Cat. n. 7339.-Reg. Himal.

'Turneri, Reichb. f. in Gard. Chron. (1883) I. 274. - Java?

uncata, Lindl. Fol. Orchid. Calanth. 6.-Reg. Himal

vaginata, Lindl. l. c. 7.-Assam.

variegata, Scheidw, in L'Hortic. Belge, v. (1838) 185. t. 105. - Hab.?

Veitchiix, Hort.-Cf. Gard. Chron. (1859) 1016

Ventilabrum, Reichb. f. in Seem. Fl. Vit. 298, -Ins, Fiji.

veratrifolia, R. Br. in Bot. Reg. sub t. 573.-Ind. or.; Malaya; Austral

veratrifolia, Hook. Bot. Beech. Voy. 71 = gracillima versicolor, Lind1. Sert. Orch. $42=$ C. Masuca.

vestita, Lindl. in Wall. Cat.n. 7345.-Burma; Malaya. viridi-fusca, Hook. Bot. Mag. to $4669=$ Tainia viridifusca

Wightii, Reichb. f. in Walp. Ann. vi. $932=$ C. Masuca. Zollingeri, Miq. Fl. Ind. Bat. ii. 711.-Java.

Zollingeri, Reichb. f. in Bonplandia, v. (1857) 88.Java.

CALANTHERA, Kunth (?), ex Hook. Kew Journ. viii. (1856) 18 = Buchloë, Engelm. (Gramin.). dactyloides, Kunth, l. c. = Buchloè dactyloides.

CALANTHUS, Oerst. in Vidensk. Selsk, Ser. V. v. 1861) 121 ; (Gesa. Centr. Am. 47. t. 4) = Alloplectus, Mart. (Gesnerac.)

multiforus, Oerst. 1. c. $=$ A. multiflorus.
CALANTICA, Jaub. ex Tul, in Ann. Sc. Nat. Sér. IV. viii. (1857) 74. SAMYDACEAE, Benth. \& Hook. f. i. 799 .

cerasifolia, Tul. l.c. 76.-Madag.

grandiflora, faub. ex Tul. l. c. 75,-Madag.

Falberti, Baill. Hist. Pl. iv. $277=$ Bivinia Jabertia

CALASIAS, Rafin, Fl. Tellur, iv. 64 (1836) (nom. prius) = Anisotes, Nees (Acanthac.)

bracteata, Rafin. $1, \mathrm{c}_{\mathrm{o}}=\mathrm{A}$. trisulcus.

CaLATheA, G, F. W. Mey. Prim. Fl. Esseq. 6 (1818). SCITAMINEAE, Benth. \& Hook, fo iii 65

Endocodon, Rafin. Fl. Tellur iv, 49 (1836)

Goeppertra, Nees, in Linnaea, vi. (1831) 337

Monostiche, Koem. in Regel, Gartenfl. (1858) 88

Psydaranta? Neck. Elem. iii. 145 (1790).

Zelmira, Rafin. Fl. Tellur. iv. 50 (1836).

Ackermanni, Koern. in Bull. Soc. Nat. Mosc. xxxu.

(1862) I. 138.-Bras.

aemula, Koern. l. c. 131.-Bras

albicans, A. Brongn. ex Gris, in Ann. Sc. Nat. Sér. IV. xii. (1859) 193.-Hab.?

affinis, Fenzl, ex Regel, Gartenfl. (1879) 294.Bras.?

Allouga, Steud. Nom. ed. II. i. $253=$ C. Allouia

Allonia, Lindl. Bot. Reg. sub t. 1210.-Guiana.

altissima, Horan. Prod. Scitam. 13; Koern. in Bull. Soc. Nat. Mosc. xxxv. (1862) I. 141.-Am. trop. angustifolia, Koern. in Regel, Gartenfl. (1858) 87. -Am. trop.

applicata, 7. Makoy, ex E. Morr. in Belg. Hortic. xxiv. (1874) 228. - Bras.

argyraea, Koern. in Bull. Soc. Nat. Mosc. xxxv. (1862) I. 142.-Bras.

Arrabida, Koern. l.c. 144.-Bras.

arrecta, Lindl. E André, in Illustr. Hortic. (1871) 174. t. 77.-Ecuador.

Backemiana, E. Morr. in Belg. Hortic. xaxv. (1875) 271. f. 4.-Bras

bambusacea, Poepp. \& Endl. Nov. Gen. et Sp. ii. $23=$ Ischnosiphon bambusacea.

bella, Regel, Gartenfl. (1879) 297.-Hab.

bellula, Linden, Cat. n, 89 (1872) 2-Reg. Amazon.

bicolor, Steud. Nom. ed. II. i. $253=$ Maranta bicolor.

blanda, Steud. l. c.-Bras.

brasiliensis, Koern. in Bull. Soc. Nat. Mosc. xxxy. (1862) I. 118.-Bras.

brevipes, Koern. l. c. 140.-Bras.

Cachibou, Lindl. ex Horan. Prod. Scitam. $12=$ lutea.

capitata, Lindl. Bot. Reg. t. 1210.-Peruv.

Cassupito, G. F. W. Mey. Prod. Fl. Esseq. 10.Venezuela.

chrysantha, Horan. Prod. Scitam. 13.-Bras.

chimboracensis, Linden, Illustr. Hortic. (1870) t. 6.Ecuador.

chlorosticta, Hort. Vind. ex Regel, Garten f. (1879) 294 $=$ angustifolia.

chrysoleuca, Koern. in Bull. Soc. Nat. Mosc. xxxy. (1862) I. 142.-Peruv.

cinerea, Regel, Gartenfl. (1876) 2.-Reg. Amazon.

colorata, Benth. Eo Hook, $f$. Gen. iii. 654-Bras.

comosa, Lindl. Bot. Reg. sub t. 1210. -Ind. occ.

composita, Klotzsch, in Schomb. Brit. Guian. iii. $918=$ Ischnosiphon Parkeri.

conferta, Benth. in Benth. E Hook. f. Gen. iii. 653.Afr. trop.

crocata, E. Morr. E Foriss. in Belg. Hortic. xur. (18\% 141. t. 8.-Bras.

densa, Regel, Ind. Sem. Hort. Petrop. (1866) 83.Bras.

dicephala, Koorn. in Bull. Soc. Nat. Mosc. Axxv. (1862) I. 127.-Peruv.

discolor, G. F. W. Mev. Prim. F7. Esseg.7.-Guians

dubia, Lindl. Bot. Reg. sub t. $1210=1$ schnosiphon spicatus.

eximia, Koern, ex Regel, in Gartenfi. (155s) 87.-Am. trop.

exscapa, Koern. in Bull. Soc. Nat. Mose. xxxv. (180? 1. 122.-Peruy.

fasciata, Reget \& Kiern. in Gartenf?. (155\$) \$18.Bras.

fasciculata, Presl, Reliq. 1laenk. i. 108. to $10^{\circ}=$ Phrgnium fasciculatum.

Alavescens, Lindl. Bot. Rrg. L. 982-Bras. 


\section{CALATHEA:-}

Glaziovi, Benth。 in Benth. E' Hook.f. Gen. iii. 654.Bras.

grandifolia, Lindl. Bot. Reg. t. 1210.-Bras.

hieroglyphica, Linden E André, Illustr. Hortic. (1873) 63. t. 123.-N. Granat.

Jagoriana, Regel, Gartenfl. (1879) 297.-Bras.

juncea, Spreng. Syst. i. $8=$ Ischnosiphon Arouma.

Kappleriana, Koern。 ex Horan. Prod. Scitam. 12.Bras.

Koernickeana, Horan. 1. c. = brasiliensis.

Koernickiana, Regel, Gartenfl. (1874) 33-Bras.

Kummeriana, E. Morr. in Belg. Hortic, xxv。 (1875) 270. t. 15-17. f. 1.-Bras.

lanceolata, Koern. in Bull. Soc. Nat. Mosc, xxxv. (1862) I. $134=$ longifolia

lateralis, Lindl. Bot. Reg. sub t. 1210.-Peruv.

latifolia, Klotzsch, in Schomb. Faun. et Fl. Guian. 918.-Guiana.

laxa, Poepp. \& EndI. Nov. Gen. et Sp. ii. 22. t. $130=$ Ischnosiphon plurispicatus.

Legrelliana, Regel, Gartenf. (1879) 301.-Ecuador

leopardina, Regel, l. c. (1877) 35. t. 893.-Bras.

leucocephala, D. Dietr. Syn. Pl. i. 7 = Ischnosiphon leucophaeus.

leuconeura, Hort. ex Nichols. Dict. Gard. i. $237=$ Maranta leuconeura.

leucophaea, Poepp. \& Endl. Nov. Gen. et Sp. ii. 21. t. 129 = Ischnosiphon leucophaeus.

lencostachys, Hook. f. Bot. Mag. t. 6205.-Costa Rica.

Lietzei, E. Morr. in Belg. Hortic. xxv。 (1875) 273. f。 8.-Bras.

Lindeni, Wallis \& André, Illustr. Hortic. (1871) 211. t. $82=$ seq.

Lindeniana, Wallis, in Belg. Hortic. xvi. (1866) 200.Peruv.

littoralis, Koern. in Bull. Soc. Nat.Mosc. xxxv. (1862) I. 144.-Bras.

longibracteata, Lindl. Bot. Reg. t. 1020,-Bras.

longifolia, Klotzsch, ex Koern. in Bull. Soc. Nat. Mosc xxxv. (1862) I. 134, -Bras.

lutea, G. F. W. Mey. Prod. Fl. Esseq. 10.--Venezuela macilenta, Lindl. Bot. Reg, sub t. 1210,--Bras.

macrostachya, Griseb. in Goett. Abh. xxiv. (1879) 335. -Reg. Argent.

macrostachya, Klotzsch, in Schomb. Faun. et Fl.

Brit. Guian. $918=$ Ischnosiphon obliquus.

Makoyana, E. Morr. in Belg. Hortic. xxii. (1872) 321. t. $24 \& 25$, - Bras.

Mandioccae, Koern.in Bull. Soc, Nat. Mosc. xxxv. (1862) I. 138.-Bras.

Mannii, Benth. in Benth. \& Hook. f. Gen. iii. 653.Afr. trop.

Mansonis, Koern. in Bull. Soc. Nat. Mosc. xxxv, (1862) I. 119.-Bras.

marantina, C. Koch, Allg. Gartenz. (1857) $163=$ C. Casupito.

medio-picta, Makoy, ex E. Morr. in Belg. Hortic. xxiv. (1874) 228.-Bras.

metallica, Koern. ex Regel, Gartenfl. (1858) 88.Hab. ?

micans, Koern. l. c. 87.-Peruv.

microcephala, Koern. in Bull. Soc. Nat. Mosc. xxxv. (1862) I. 125. - Peruv.

mirabilis, Makoy, ex E. Morr. in Belg. Hortic. xxiv. 1874) 228. - Bras.

modesta, A. Brongn. ex Gris, in Ann. Sc. Nat. Sér. IV. xii. (1859) 193.-Hab?

monophylla, Koern. in Bull. Soc. Nat. Mosc. xxxv. (1862) I. 144.-Bras.

Myrosma, Koern. in Regel, Gartenfi. (1858) 87.Guiana.

nigro-costata, Linden Es André, Illustr. Hortic. xx. (1873) t. 144.-N. Granat.

nobilis, Koern. in Bull. Soc. Nat. Mosc. xxxv, (1862) I. $144,-\mathrm{Hab}$. ?

oblonga, Koern. l. c. 138.-Bras.

olivaris, Hort. ex Nichols. Dict. Gard. i. $238=$ Makoyana.

Oppenheimiana, E. Morr. in Belg. Hortic. xxv. (1875) 271. f. 3.-Bras.

orbiculata, Lodd. Bot. Cab. t. 1879.-Ind. occ.

ornata, Koern. in Regel, Gartenfl. (1858) 87. $\rightarrow$ Am, trop.

ovata, Lindl. Bot. Reg. sub t. 1210.-Bras.

pachystachya, Koern. in Bull. Soc. Nat. Mosc, xxxy. (1862) 1. 142.-Peruv.

pacifica, Linden E André, Illustr. Hortic. xix. (1872) t. 101,-Peruv,

\section{CALATHEA}

pardina, Planch. \& Linden, in $\mathbf{F l}$. des Serres, Sér. II. i. (1856) $53=$ villosa.

Parkeri, Poepp. \& EndI. Nov. Gen. et Sp. ii. $22=$ Ischnosiphon Parkeri.

Pavonii, Koern. in Bull. Soc. Nat. Mosc. xxxv. (1862)

I. 116.--Peruy.

pavonina, C. Koch E Linden, Belg. Hortic. xv. (1865) 99.-Bras.

peruviana, Koern. in Bull. Soc. Nat. Mosc. xxxv. (1862) I. 128.-Peruv.

picturata, C. Koch E Linden, ex C. Koch, Wochenschr. vi. (1863) 346.-Bras.

polyphylla, Poepp. \& Endl. Nov. Gen. et Sp. ii. 23. t. $131=$ Ischnosiphon polyphyllus.

Princeps, Regel, Gartenfi. (1879) 302.--Reg. Amazon. propinqua, Koern. in Bull. Soc. Nat. Mosc. xxxv. (1862) I. 122.-Peruv.

pulchella, Koern. in Regel, Gartenfl. (1858) 87.Bras.

pumila, Koern. in Bull. Soc. Nat. Mosc. xxxv. (1862) I. 138. - Bras.

Riedeliana, Paull, ex Regel, in Act. Hort. Petrop, iii. (1875) II. $284=$ Koernickiana.

rosea-picta, Regel, Ind. Sem. Hort. Petrop. (1869) 12 .Am. trop.

Rossii, Koern. in Bull. Soc. Nat. Mosc. xxxv. (1862) I. 144. - Bras

rotundifolia, Koern. l. c. 125.-Hab. ?

rotundifolia, Poepp. \& Endl, Nov. Gen, et Sp. ii. 23 $=$ Ischnosiphon rotundifolius.

rufibarba, Fenzl, in Regel, Gartenfl. (1879) 294.Bras.?

Sellowii, Koern. in Bull. Soc. Nat. Mosc. xxxv. (1862) I. 120.-Bras.

smaragdina, Linden E' André, Illustr. Hortic. (1870) 78.-Ecuador?

spicata, Steud. Nom. ed. II. i. 253.-Guiana; Bras

strobilifera, Miq. in Linnaea, xxii. (1849) 79.Surinam.

taeniosa, G. Foriss. in Belg. Hortic, xxvi. (1876) 83. t. 5.-Bras.

trifasciata, Koern. in Regel, Gartenfl. (1858) 86.Guiana.

tuberosa, Koern. in Bull. Soc. Nat. Mosc. xxxv. (1862) I. 124.-Bras.

tubispatha, Hook. Bot. Mag. t. 5542.-Bolivia.

umbrosa, Koern. in Bull. Soc. Nat. Mosc. xxxv. (1862) I. 137.-Bras.

undulata, Regel, Illustr. Hortic. xix. (1872) t. 98.Ecuador.

Vandenheckei, Regel, Ind. Sem. Hort. Petrop. (1869) 14.-Hab.?

varians, C. Koch E Math. in App. Cat. Sem. Hort. Berol. (1855) 12.-Am. trop.

variegata, Koern. in Regel, Gartenfl. (1858) 88.-Am. trop.

Veitchiana, Veitch, ex Hook. f. Bot. Mag. t. 5535.Bolivia?

velutina, Koern. in Bull. Soc. Nat. Mosc. xxxy. (1862) I. 127.-Peruy

vestita, Baker, in Saund. Ref. Bot. v. t. 311.-Bras.

villosa, Lindl. Bot. Reg. (1834) Misc. 61.-Guiana.

violacea, Lindl. l. c. sub t. $932 ;$ t. $962,-$ Bras.

virginalis, Linden, ex Regel, Gartenfl. (1879) 299.Bras.

vittata, Koern. l.c. (1858) 88.-Wab. ?

Wallisi, Regel, Ind. Sem. Hort. Petrop. (1869) 14.Reg. Amazon.

Warscewiczii, Koern. in Regel, Gartenfl. (1858) 87.Am. trop.

Widgreni, Koern. in Bull. Soc. Nat. Mosc. xxxv. (1862) I. 117.-Bras.

Wiotiana, Makoy, ex E. Morr. in Belg. Hortic. xxiv. (1874) 228.-Bras.

zebrina, Lindl. Bot. Reg. sub t. 1210.-Bras.

zingiberina, Koern. in Bull. Soc. Nat. Mosc. xxxv. 1862) I. 122.-Bras.

CALATHIANA, Delarb. Fl. Auv. ed. II. i. $28(1800)=$ Gentiana, Tourn.

nivalis, Delarb. 1. $\mathrm{c}_{.}=\mathrm{G}$. nivalis.

CALATHINUS, Rafin. Fl. Tellur. iv. $21(1836)=$ Narcissus, Tourn. (Amaryllid.).

cernuus, Rafin. 1, c. $=$ N, calathinus. multiflorus, Rafin. 1. c. =N. Tazetta? serotinus, Rafin. 1. c. $=\mathrm{N}$, serotinus.
CALATHODES, Hook. f. \& Thoms. Fl. Ind. i. 40 (1855). RANUNCULACEAE, Benth. \& Hook. f. i. 7 .

palmata, Hook.f. \& Thoms. l. c. 41.-Reg. Himal

CALATHOSTELMA, Fourn. in Mart. F1. Bras. vi. IV, 219 (1885).ASCLEPIADEAE

ditassoides, Fourn. l. c.-Bras.

CALBOA, Cav. Ic. v. 51. t. 476 (1799) =Ipomoea, Linn. (Convolvul.).

globosa, Lindl, in Journ. Hort. Soc. v. (1850) $82=\mathrm{I}$. Llaveana.

vitifolia, Cav. Ic. v. 51. t. $476=$ I. peduncularis.

CALCALIA, Krock. Fl. Siles. ii. II, 381=CACALIA, Linn, = Adenostyles, Cass. $($ Compos. $)$.

alpina, Krock. 1. c. = A. glabra.

CALCARUNIA, Rafin。 Med. Fl. ii. 106 (1830)= Pontederia, Linn

hastata, Rafin. 1. c. = P. cordata.

CALCATRIPPA, Heist. Syst. $8(1748)=$ Delphinium, Linn. (Ranunculac.).

CALCEARIA, Blume, Bijdr. 417. t. 33 (1825) = Cory santhes, R. Br. (Orchid.).

fornicata, Blume, $1 . \mathrm{c} .=$ Cor. fornicata.

picta, Blume, 1. $\mathrm{c}_{.}=$Cor. picta.

CALCEOLARIA, Heist. Syst. $5(1748)=$ Cypripe dium, Linn. (Orchid.)

CALCEOLARIA, Linn. Mant. ii. 143 (1771) SCROPHULARINEAE, Benth. \& Hook。 fo ii, 929.

FAgelia, Schwencke, in Verh. Bat. Gen. Roterd. i. (1774) 474. t. 13

Jovellana, Ruiz \& Pav. Fl. Per. i. 12 (1798) adscendens, Lindl. Bot. Reg. t. 1215.-Chili. alba, Ruiz E Pav. Fl. Per. i. 19. t. 27.-Chili. alternifolia, $C a v . I c$. v. 28. t. 445. f. 2,-Peruv. ambigua, Phil. in Linnaea, xxix. (1857-58) 32.Chili.

amplexicaulis, H. B. \& K. Nov. Gen. et Sp. ii. $384_{\text {。 }}-$ Ecuador.

andina, Benth. in DC. Prod. x. 219,-Chili.

angustiflora, Hook. Bot. Mag. t. $3094=$ verticillata.

angustiflora, Ruiz Eo Pav. Fl. Per.i. 17, 28, t. 28-

Ecuador.

angustifolia, Sweet, Hort. Brit. ed. II. $396=$ integrifolia.

anomala, Pers. Syn. i. $16=$ crenatiflora.

aquatica, A. Br. \& Bouché, Ind. Sem. Hort. Berol. (1852) 2.-Hab.?

arachnoidea, R. Grah. in Edinb. N. Phil. Fourn. (Sept. 1828) 371; et Bot. Mag. t. 2874. - Chili.

araucana, Phil. in Linnaea, xxix. (1857-58) 33.Chili.

argentea, $H . B$. \& $K$. Nov. Gen. et Sp. ii. 387. t. 170 . -Peruv.

Atkinsiana, Sweet, Brit. Flow. Gard. Ser. II. t. 168 bartsiaefolia, Wedd. Chlor. And. ii. 134.-Bolivia. bellidifolia, Gill. ex Benth. in DC. Prod. x. 207.Chili.

bellidifolia, Salisb. Prod. $89=$ Fothergillii

Benthami, Phil. in Anal. Univ. Chil. (1873) 583.Chili.

Bergii, Hieron. in Bol. Acad. Nac. Cordova, iii. (1879) 363.- Reg. Argent.

Berterii, Colla, in Mem. Acc. Tor. xxxix. (1836) 138 -Chili.

bicolor, Ruiz E Pav. Fl. Per. i. 16. t. 25.-Peruv.

bicrenata, Ruiz \& Pav. l.c. 15. t. 23.-Peruv.

bifida, Willd. ex Link, in Spreng. Jahrb. i. III. (1820) $53=$ graminifolia.

biflora, Lam. IIl. i. 52 ; Encyc. i. $556=$ plantaginea,

biflora, Ruiz \& Pav. Fl. Per, i. 16. t. $20=$ ovata.

bipinnatifida, Phil. Fl. Atac, 46.-Chili.

brachiata, Willd. ex Link, in Spreng. Jahrb. i. III (1820) $52=$ flexuosa

brevistyla, Clos, in C. Gay, Fl. Chil.v. 175.-Chili. Bridgesii, Kunze, in Linnaea, xx. (1847) 35.-Chili calycina, Benth. in DC. Prod, x. 211.-Peruv.

cana, Cav. Ic. v. 27. to 443. f. 2.-Chili.

candicans, Willd, ex Link, in Spreng. Jahrb, i. III

(1820) $53=$ argentea

canescens, Humb. ex Link, 1. c. $54=$ hyssopifolia. 
CATCFOTARIA :-

canescens, Willd. ex Roem. E Schult. Syst. Mant. i. 165.-Am. austr.

Cavanillesii, Pers. ex Steud. Nom. ed. I. $135=$ Fothergillii.

Cavanillesii, Phil. in Anal. Univ. Chil. (1873) 532. -Chili.

cerasifolia, Benth. in DC. Prod. x. 218.-Peruv.

chelidonioides, H. B. E K. Nov. Gen.et Sp. ii. 378.Ecuador.

chiloënsis, Lindl. Bot. Reg.t. $1476=$ dentata.

chimboracensis, Willd. ex Link, in Spreng. Jahrb. i. III. (1820) $52=$ saxatilis.

collina, Phil. in Linnaea, xxix. (1857-58) 30.-Chili. concinna, Willd. ex Link, in Spreng. Jahrb. i. III. (1820) $51=$ chelidonioides.

connata, Hook, ex R. Grah. in Edinb. N. Phil. Journ.

(Sept. 1828) $372=$ petiolaris.

corymbosa, Ruiz \& Pav. Fl. Per. i. 14. t. 20.-Chili.

crassifolia, Phil. in Anal. Univ. Chil. (1873) 532.

Chili.

crenata, Bot. Reg. t. $790=$ adscendens.

crenata, Lam. Encyc. i. 556.-Ecuador.

crenatiflora, Cav. Ic. v. 28. t. 446.-Ins. Chiloe.

cuneiformis, Ruiz E Pav. Fl. Per. i. 19.t. 27.Ecuador.

Cunninghamii, Vatke, in Linnaea, xl. (1876) 222. Chili.

Darwinii, Benth. in DC. Prod. x. 207.-Reg. Magellan.

deflexa, Ruiz E Pav. Fl. Per, i. 18, t. 30-Ecuador.

deflexa, Willd. ex Link, in Spreng. Jahrb. i. HI. (1820 $52=$ padifolia

densifolia, Phil. in Linnaea, xxxiii. (1864-65) 216. Chili.

dentata, Ruiz \& Pav. Fl. Per. i. 18. t. 29,-Chili.

denticulata, Willd, ex Link, in Spreng. Jahrb. i. III (1820) $53=$ stricta.

dichotoma, Lam. Illustr. i. $32=$ ovata.

diffusa, Lindl. Bot. Reg..t. $1374=$ bicolor.

dilatata, Benth. in DC. Prod. x. 211.-Ecuador.

divaricata, H. B. E K. Nov. Gen. et Sp. ii. 381.-

Peruv.

elatior, Griseb. in Goett. Abh. xxiv. (1879) 237.-Reg. Argent.

elliptica, Wedd. Chlor. And. ii. 137.-Peruv, ; Boliv.

ericoides, Fuss. ex Vahl, Enum. i. 190.-Ecuador.

erioclada, Benth. in DC. Prod. x. 215.-Ecuador.

excelsa, Hort. ex Court. in Mag. Hortic. i. (1833) 64

- Hab. ?

exoniensis $\times$, Hort. Angl. ex Steud. Nom. ed. II. i. 254

extensa, Benth. in DC. Prod. x. 214.-Peruv.

fasciculata, Willd. ex Link, in Spreng. Fahrb. i. III (1820) 53.-Peruv.

ferruginea, Cav. Ic, y, 27, t. 445, f. 1-Chili.

ferruginea, Colla, in Mém. Acc. Tor. xxxviii. (1835) 137.t. 46 =integrifolia.

ferruginosa, Kunze, ex Walp. \& Schau, in Nov. Act.

Nat. Cur. xix. Suppl. i. (1843) $397=$ integrifolia.

filicaulis, Clos, in C. Gay, Fl. Chil. v. 181.-Chili.

flexuosa, Ruiz \& Pav. Fl. Per. i. 17, 26.-Peruv.

floribunda, H. B. E K. Nov. Gen. et Sp. ii. 385.Ecuador.

floribunda, Hook. Bot. Mag. t. $4154=$ crenata.

foribunda, Lindl. Bot. Reg. t. $1214=$ petiolaris.

foliosa, Griseb. in Goett. Abh. xix. (1874) 210.-Reg. Argent.

foliosa, Meyen, ex Walp. \& Schau. in Nov. Act. Nat. Cur, xix. Suppl. i. (1843) $395=$ cuneiformis.

foliosa, Phil. in Anal. Univ. Chil. (1873) 531.-Chili.

Fothergillii, [Soland. in] Ait. Hort. Kew. ed. I. i. 30 t. 1.-Ins. Falkl.

fuchsiaefolia, Hort.-Cf. Gard. Chron. (1881) I. 269. -Hab.?

Gellandana, Lindl. ex Steud. Nom. ed. II. i, $254=$ seq. Gellaniana, Penny, in Loud. Hort. Brit. Suppl. i. $583=$ purpurea.

gemelliflora, Cav. Ic. v. 30, t. 450. f. 1.-Peruv.

glabrata, Phil. in Linnaea, xxix. (1857-58) 31.-

glacialis, Wedd. Chlor. And, ii. 143.-Bolivia

glandulosa, Bentb. in DC. Prod. x. $210=$ pseudoglandulosa.

glandulosa, Poepp. ex Benth.l.c.-Chili.

glauca, Ruiz E Pav. Fl. Per. i. 17. t. 27.--Peruv.

glutinosa, Heer \& Regel, Ind. Sem. Hort Turic

(1848) 4.-Cf. Linnaea, xxiy. (1851) 196.-Guateroala.

\section{CALCEOLARIA}

gnidiifolia, Willd. ex Link, in Spreng. Jahrb, i. III. 1820) $54=$ lavandulaefolia.

gossypina, Benth. in DC. Prod. x. 223.-N. Granat. gracilis, H. B. E K. Nov. Gen. et Sp. ii. 379.Ecuador.

gracilis, Willd. ex Link, in Spreng. Jahrb. i. III. (1820) $52=$ ovata.

graminifolia, H. B. E K. Nov. Gen. et Sp. ii. 386.Ecuador.

guttata, Willmore, ex Knowules E Westc. Flor. Cab. i. (1837) 21.-Hab.?

Hartwegii, Benth. Pl. Hartw. 147.--Peruv.

helianthemoides, $H . B$. $E K$. Nov. Gen. et Sp. ii. 387 (err. typ. helianthoides).-Peruv.

Henrici, Hook. f. Bot. Mag. t. 5772.-Ecuador.

Herbertiana, Lindl. Bot. Reg. t. $1313=$ racemosa

heterophylla, Ruiz \& Pav. Fl. Per. i. 16. t. 21.Peruy.

heterophylla, Willd. Enum. Hort. Berol. $29=$ scabiosae.

folia.
hians, Penny, ex G. Don, Gen. Syst. iv. $603=$ corymbosa?

hispida, Benth. in DC. Prod. x. 212.-Peruv.

Hopeana, Morrison, ex G. Don, Gen. Syst. iv, $606=$ corymbosa?

Hoppeana, Morrison, ex Loud. Hort. Brit. Suppl. i. 583 $=$ plantaginea.

hypericina, Poepp. ex Benth: in DC. Prod. x. 222.Chili.

hypoleuca, Benth. l. c.-Ecuador

hypoleuca, Meyen, Reise, i. 224; Walp. E Schau. in Nov. Act. Nat. Cur. xix. Suppl. i. (1843) 396.Chili.

hyssopifolia, H. B. E K. Nov. Gen. et Sp. ii. 386.Ecuador.

inflexa, Ruiz \& Pav, Fl. Per, i, 16, t. $25=$ serrata.

integrifolia, Linn. f. Suppl, $86=$ ovata

integrifolia, Murr. Syst. ed. XIII. 61.-Chili.

involuta, Ruiz Es Pav. Fl. Per. i. 15. t. 23.-Ecuador.

Kellyana, Hort.-Cf. Gard. Chron. (1883) II. 12.-

Hab.?

knypersliensis, Hort. ex Stend. Nom. ed. II. i. $254=$ crenatiflora.

lamiifolia, H. B. E K. Nov. Gen. et Sp. ii. 383.Ecuador.

lanata, $H . B . \& \sigma . K$. .. . -Ecuador.

lanceolata, Cav. Ic. v. 27. t. 144. f. 2.-Patagon

lancifolia, Link, in Spreng. Jahrb. i. III. (1820) $5=$ lamiifolia.

Landbeckii, Phil. in Linnaea, xxxiii. (1864-65) 215.Chili.

lanigera, Phil. in Anal. Univ. Chil. (1884) reimpr. 9. -Chil

latifolia, Benth. in DC. Prod. x. 212,-Chili. lavandnlaefolia, $H, B$, \& $K$, Nov. Gen et Sp, ii. 386. -Ecuador.

laxa, Benth. in DC. Prod. x. 223.-Peruv

linearis, Ruiz \& Pav. Fl. Per. 1. 19.-Peruv.

linifolia, Willd. ex Link, in Spreng. Jahrb. i. III (1820) $54=$ hyssopifolia.

lobata, Cav. Ic. y. 26. t 443. f 1-Peruy

Lorentzii, Griseb. in Goett. Abh. xix. (1874) 210.

Martineauae x, Low, ex Sweet, Brit. Fl. Gard. Ser. II. t. 162

Matthewsii, Benth. in DC. Prod. x. 207.-Peruv.

melissaefolia, Benth. l. c. 214.-Peruv.

mendocina, Phil, in Anal. Univ. Chil. (1862) II. 404. -Chili.

mexicana, Benth. Pl. Hartw. 47.-Mexic

Meyeniana, Phil. in Linnaea, xxix. (1857-58) 82.Chili.

mimuloides, Clos, in C. Gay, Fl. Chil. v. 174.Chili.

mirabilis, Knowl. \& Westc. Flor. Cab. i. (1837) 25 = crenatiflora.

mollissima, Walp. in Nov. Act. Nat. Cur, xix. Suppl. i. (1843) 396 - integrifolia.

monanthos, Poir. Encyc: Suppl. ii, $24=$ uniflora

montana, Cav. Ic. v, 2\%. t. 444. f. 1.-Chili

Morisii, Walp. Rep. iii. 157.-Chili.

Morrisoni, G. Don, in Sweet, Hort. Brit. ed. III. 521 = plantaginea.

multiflora, Cav. Ic. v. 29, t. 149.-Peruv.

Nabuelbutae, Phil. in Anal. Univ. Chil. (1873) 591 -Chili.

nana, Sm. Ic. Ined. d. 1. t. 1.-Reg. Magelln.

Neeana, Spreng. Syst. i. $44=$ Fothergillii.

\section{CALCEOIARIA}

nitida, Colla, in Mem. Acc. Tor. xxxix. (1836) 138 $=$ adscendens.

nivalis, H. B. E K.Nov. Gen. et Sp. ii. 381.-Chili. nivalis, Steud. \& Hochst. ex Benth. in DC. Prod. $x$. $219=$ adscendens

nudicaulis, Benth. l. c. 208-Chili.

mudicaulis, Meyen, ex Walp. \& Schau in Nov. Act.

Nat. Cur. xix. Suppl. i. (1843) $397=$ plantaginea.

obovata, Stokes, Bot. Comment. i. $119=$ Fothergillii.

oblonga, Ruiz E Pav. Fl. Per. i. 15. t. 24-Peruv.

abtusifolia, Kunze, ex Walp. \& Schau, in Nov. Act.

Nat. Cur. xix. Suppl. i. (1843) $397=$ plantaginea.

oligantha, Phil. in Linnaea, xxxiii. (1864-65) 216. Chili.

ovata, Sm. Ic. Ined. i. 3. t. 3.-Peruv.

padifolia, H. B. E K. Nov. Gen. et Sp. ii. 380.-Perav. Palpe, Steud. \& Hochst. ex Benth, in DC. Prod, x. $219=$ thyrsiflora

panicea, Roem, \& Schult. Syst. i. 181, sphalm。=punicea paniculata, Herb. ex G. Don, Gen. Syst. iv. $606=$ petiolaris.

paniculata, Willd. ex Link, in Spreng. Jabrb. i. III

1820) $53=$ floribund $a$.

pannosa, Phil. in Linnaea, xxxiii. (1864-65) 219. Chili.

paposana, Phil. Fl. Atac. 46.-Chili.

paralensis, Spreng. Syst. i. $45=$ seq.

paralia, Cav. Ic. v, 29. $t$. 447.-Chili

paralia, Hook. Exot. Fl. t. $75=$ corymbosa.

pardantherax, W. Baxt. ex Loud. Hort. Brit. Suppl. ii. 616

parviflora, Gill. ex Benth. in DC. Prod. x. 207.-Chili.

parvifolia, Wedd. Chlor. And. ii. 134.-Boliv.

Pavonii, Benth. in DC. Prod. x. 211.-Peruv.

pendula, Sweet, Brit. Flow. Gard. Ser. II. $155=$ crenatiflora.

perfoliata, Linn. f. Suppl. 86.-N. Granat.

perfoliata, Ruiz \& Pav. Fl. Per. i. 15. t. 21. f. a = Pavonii.

petioalaris, Cav.Ic. v. 30, 451.-Ecuador.

petiolaris, Vahl, Enum, i. $186=$ praec.

picta, Phil. in Linnaea, xxix. (1857-58) 34,Chili.

pinifolia, Cav. Ic. v. 26. t. 442. f: 2.-Chili.

pinnata, Linn. Mant. 171.-Peruv.

pinnata, Ruiz \& Pav. FI. Per. i. 14. t. $19=$ scabiosae folia.

pisacomensis, Meyen, Reise, $\dot{i} ; 469$-Peruy

plantaginea, Sm. Ic. Ined. i. 2. t. 2.-Reg. Magellan.

plectranthifolia, Walp, in Nov. Act. Nat. Cur. xix. Suppl. i. (1843) 394.-Peruy.

polifolia, Hook. Bot. Mag. t. 2897.-Chili.

polyantha, Penny, ex Loud. Hort. Brit. Suppl. i. 583 $=$ petioalaris

polyırhiza, Cav. Ic. v. 25. t. 441.-Patagon.

pratensis, Phil in Linnaea, xxix. (1857-58) 33. - Chili.

pseudoglandulosa, Clos, in C. Gay, Fl. Chil. v. 175.Chili.

pulchella, Salisb. Prod. $89=$ pinnata.

pulverulenta, Ruiz \& Pav. Fl. Per.i. 19.-Peruv.

punctata, Vahl, Enum. i. 177.-Peruy.

puncticulata, Phil. in Linnaea, xxix. $(1857-58)$ 36.Chili.

punicea, Ruis E Pav. Fl. Per. i. 15. t. 24.-Perav.

purpurea, R. Grah. in Bot. Mag. t. 2775.-Peruv.

quadriradiata, Phil. in Linnaea, xxix. (1857-58) 31.Chili.

racemosa, Cav, Ic. v, 29. t 448.-Patagon.

refugens, Sweet, Brit. Flow. Gard. Ser. II. t. 227 arachnoidea.

repens, Hook. f. Fl. Nov. Zel. i. 187.-N. Zel.

robusta, A. Dietr. in Otto \& Dietr. Allg. Gartenz i.

1838) 73 =integrifolia

rosmarinifolia, Lam, Encyc i. 556.-Ecuador.

rotundifolia, $H . B . E K . N o v$. Gen et Sp.ji. 352.-Peruy.

rugosa, Hook. Exot. Fl. t. $99=$ adscendens.

rugosa, Ruiz \& Pav. Fl. Per. i. 19. t. 28; Lodd. Bot.

Cab. t. 942 = integrifolia.

salicifolia, Colla, in Mem. Acc. Tor. xxxix. (1830 $139=$ sessilis ?

salicifolia, Ruic \& Pat. F7. Per. i. 18. ᄂ. 19.-Perux: salviaefolia, Pers. Syn. i. 17 integrifulis.

saxatilis, H. B. G K. Nos. Gon. et Sp. ii. $38 s .-$ Ecuador.

scabiosaefolia, Nees, ex G. Don, Gen. Syst. iv. $600^{\circ}$ rugrosa. donivides. 


\section{CALCEOLARIA :-}

scabiosaefolia Sims, Bot. Mag. t. 2405-Peruv. scabra, Ruiz \& ${ }^{\circ}$ Pav. Fl. Chil. i. 19. t. 29.-Peruv, scapiflora, Benth. in DC. Prod. x. 206.-Peruv. Segethi, Phil. in Linnaea, xxix. (1857-58) 29.-Chili. serrata, Lam.Encyc. i. 555.-Ecuador.

sessilis, Ruiz E Pav. Fl. Per. i. 18.-Chili.

sibthorpioides, H.B. E K. Nov. Gen. et Sp. ii. 382.Peruv.

Sinclairii, Hook. Ic. Pl. t. 561,-N. Zel.

sparsiflora, Kunze, in Linnaea, xxiv, (1851) 228. -Boliv.

spectabilis, Kunze, ex Walp. \& Schau. in Nov. Act.

Nat. Cur. xix. Suppl. i. (1843) $396=$ dentata.

Standishix, Paxt. Mag, ix. t. 75.

stricta, H. B. \& $K$. Nov. Gen. et Sp. ii. $380 .-\mathrm{N}$. Granat.

tenella, Poepp. E Endl. Nov. Gen. et Sp. iii. 76. t. 287. -Chili.

tenera, Phil. in Linnaea, xxix. (1857-58) 34.-Chili.

tenuis, Benth. in DC.Prod. x. 205.-Chili.

terniflora, Cav. Ic. v. 30. t. 450. f. 2.-Peruv.

tetragona, Benth. in DC. Prod. x. 218.-Peruv.

tetraphylla, Phil. in Linnaea, xxix. (1857-58) 35.Chili.

teucrioides, Griseb. in Goett. Abh. xix. (1874) 212.Am. austr.

thyrsiflora, R. Grah. in Edinb. N. Phil. Fourn. (Sept. 1828) 372 (err. typ. 272).-Chili.

tinctoria, Gill. ex G. Don, Gen. Syst. iv. 606 = arachnoidea.

tomentosa, Ruiz \& Pav. Fl. Per, i. 15. t. 22.-Peruv. tracheliifolia, Mart. \& Gal in Bull. Acad. Brux, xii 1845) reimpr. $2=$ mexicana.

triandra, Vahl, Enum. i. 181.-Peruy

trifida, Ruiz \& Pav. Fl. Per. i. 17. t. 26.-Peruv

trilobata, Hemsl. Biol. Centr. Am. Bot. ii. 439. Guatemala.

tripartita, Ruiz os Pav. Fl. Per. i. 14. t. 20,-Peruy. umbellata, Wedd. Chlor. And. ii. 142.-Boliv.

undulata, Benth. in DC. Prod. x. 212.-Chili.

uniflora, Lam. Tabl. Meth. i. $52=$ nana.

uniflora, Ruiz \& Pav. Fl. Per. i. 16. t. 20.-Peruv.

utricularioides, Hook. ex Benth. in DC. Prod.x. 213. -Peruv.

valdiviana, Phil. in Linnaea, xxix. (1857-58) 35.-

Chili.

verbascifolia, Phil.l.c. 30.-Chili.

verbascifolia, Bert, in 'Merc. Chil. 1829' in Bull.

Férussac, xx. (1830) 109, nomen.-Chili.

vernicosa, Phil. in Linnaea, xxix. (1857-58) 29.-Chili.

verticillata, Ruiz E Par. Ft. Per. i. 17.-Ecuador.

violacea, Ca7. Ic. v. 31. t. 452.-Chili.

virgata, Ruiz \& Pav. Fl. Per. 1. 20. t. 31.--Peruv

viscosa, Ruiz \&o Pav.l.c. 18. t. 30.-Peruv.

viscosissima, Lindl. Bot. Reg.t. 1611.-Chili.

Volckmanni, Phil. in Linnaea, xxxiii. (1864-65) 218. -Chili.

Wheeleri, Sweet, Brit. Flow. Gard. Ser. II. t. $130=$ corymbosa.

Youngiix, Lindl. Bot. Reg. t. 1448.

CALCEOLUS, [Tourn.] Adans. Fam, ii. 70 (1763) = Cypripedium, Linn. (Orchid,)

alternifolius, St. Lag. in Ann. Soc. Bot. Lyon, vii. (1880) $62,124=\mathrm{C}$. Calceolus.

Marianus, Crantz, Stirp. Austr. ed. II. fasc. vi. $454=$ C. Calceolus.

CALCITRAPA, Hall. Enum. Stirp. Helv, ii. 689 (1742) = Centaurea, Linn. (Compos.)

Adami, Schur, Enum. Pl. Transs, $409=$ Cent. solstitialis.

aegyptiaca, Sweet, Hort. Brit. ed. I. 218, nomen =

Cent. aegyptiaca.

altissima, Lam. F1. Fr. ii. $31=$ Mierolonchus salman ticus.

aspera, Cass. in Dict. Sc. Nat. viii. $252=$ Cent. aspera.

Balsamita, Sweet, Hort. Brit. ed. I. $218=$ Cent Balsamita.

benedicta, Sweet, 1. $\mathrm{c}_{\mathrm{s}}=$ Carbenia benedicta

brevispina, Moench, Meth. $563=$ Microlonchus salman ticus.

Calcitrapa, Hill, Hort. Kew. $62=$ Cent. Calcitrapa.

calcitrapoides, Hill. 1, c. = Cent. calcitrapoides.

centauroides, Sweet, Hort. Brit. ed. I. 218=Cent.

centaurioides.

cichoracea, Lam. Fl, Fr. ii. $32=$ Cent. Seridis.

\section{CALCITRAPA :-}

collina, Lam, Fl. Fr. ii. $33=$ Centaurea collina conferta, Moench, Meth. $564=$ Cent. melitensis. cucullata, Moench, 1. c. $563=$ Cent. Crocodylium. elongata, Moench, 1. c. = Volutarella muricata. eriophora, Moench, 1. c. $564=$ Cent, eriophora. ferox, Moench, Meth. Suppl. $229=$ Cent. ferox.

fusca, Moench, Meth. $564=$ Cent. sicula.

Galactites, Lam. Fl. Fr. ii. $30=$ Galactites tomentosa heterophylla, Moench, Meth. Suppl. $230=$ Cent. aspera Hippophaestrum, Gaertn. Mey. \& Scherb. Fl. Wett. iii $178=$ Cent. Calcitrapa

hybrida, Sweet, Hort. Brit. ed. I. $218=$ Cent. Calcitrapa.

Hypophaestum, Gaertn. Fruct. ii. t. $163=$ Cent. Calcitrapa.

iberica, Trev. ex Spreng. Syst. iii. $406=$ Cent, iberica lanceolata, Lam. Fl. Fr. ii. $34=$ Cent. calcitrapoides. lanuginosa, Steud. Nom. ed. II. i. $845=$ Kentrophyllum lanatum.

lanuginosa, Lam. F1. Fr. ii. 35=Carbenia benedicta longifolia, Willk. \& Lange, Prod. F1. Hisp. ii. 141, sphalm. $=$ Cent. sonchifolia

lutea, Delarb. Fl. Auv. ed. II. $199=$ Cent. solstitialis.

myacantha, Cass. in Dict. Sc. Nat. viii. $251=$ Cent.

Calcitrapa.

napifolia, Moench, Meth. $564=$ Cent. napifolia.

nudicaulis, Lam. Fl. Fr, ii. 30 = Serratula nudicaulis. parviflora, Lam. 1. c. $32=$ Cent. aspera.

patibilcensis, H. B. \& K. Nov. Gen. et Sp. iv. $23=$ Cent. americana.

phoenicea, Sweet, Hort. Brit. ed. I. $218=$ Cent. calcitrapoides.

pubescens, Sweet, 1. c. = Cent. incana

reflexa, Sweet, $1 . c_{-}=$Cent. reflexa.

rigida, Sweet, l. c. = Cent. rigida.

rupestris, Sweet, 1. c. = Cent. rupestris,

sessiliflora, Lam. Fl. Fr. ii. $35=$ Cent. melitensis.

solstitialis, Lam. 1. c. $34=$ Cent. solstitialis.

sonchifolia, Lam. 1. c. 32 ; Moench, Meth. 564=Cent sonchifolia.

sordida, Sweet, Hort. Brit. ed. I. $218=$ Cent. sordida stellaris, Hill, Herb. Brit. i. $76=$ Cent. Calcitrapa. stellata, Lam. Fl. Fr. ii, $34=$ Cent. Calcitrapa subspinosa, Moench, Meth. Suppl. $228=$ Cent. diluta. Verutum, Moench, Meth. $563=$ Cent. Verutum. vulgaris, Bernh. Syst. Verz. Erf. 158=Cent. Calcitrapa.

CALCOA, Salisb. Gen. Pl. Fragm. $67(1866)=$ Geitono plesium, A. Cunn. (Liliac.).

CALDASIA, Lag. Amen. Nat. ii. $98(1821)=$ Oreo myrrhis, Endl. (Umbellif.

andicola, Lag. ex DC. Coll. Mém. v. t. $2=$ O. andicola, argentea, Hook. f. in Hook. Ic. Pl. iii. t. $300=$ O. andicola.

brachycarpa, Hook. f. 1. c. nota $=$ O. andicola.

chaerophyllaea, DC. Prod. iv. $229=0$. andicola.

chaerophylloides, Lag. Amen. Nat. ii. $99=$ O. andicola.

daucoides, Hook. f. F1. Antaret. ii. t. $101=0$. andicola.

eriopoda, DC. Coll. Mem.v. 60 t. 2 ; et Prod. iv. $229=$ $\mathrm{O}$. andicola.

eriopus, DC. Coll. Mém. v. $75=\mathrm{O}$. andicola.

lasiopetala, Lag. ex DC. Prod. iv. $229=\mathrm{O}$. andicola,

CALDASIA, Mutis, ex Caldas, in Seman. Nuov. Gran. II. $26(1810)=$ Helosis, Rich. (Balanoph.

cayennensis, Mutis, ex Steud. Nom. ed. II. i. $255=$ H. guyanensis.

fungiformis, Mutis, ex Eich1. in DC. Prod. xvii. $136=$ H. guyanensis.

CALDASIA, Willd. Hort. Berol. t. $71(1807)=$ Bon

plandia, Cav. (Acanthac.).

heterophylla, Willd. 1. c. = B. geminiflora.

CALDCLUVIA, D. Don, in Edinb. N. Phil. Journ, ix. (1830) 92. SAXIFRAGEAE, Benth. \& Hook. f. i. 653 .

Dieterica, Ser. in DC. Prod, iv, 8 (1830).

paniculata, D. Don, l. c.-Chili.

CALDEnBaCHIA, Pohl, ex Nees, in DC. Prod. xi. $281(1847)=$ Stenandrium, Nees (Acanthac.) elegans, Pohl, ex Nees, 1. c. $283=$ S. Pohlii. macrogranum, Nees, 1. c. $282=$ S. dulce.
CALDESIA, Parl, F1, Ital. iii. $598(1858)=$ Alisma Linn.

parnassifolia, Parl. 1. c. $599=$ A. parnassifolium.

CALEA, Linn. Sp. Pl. ed. II. 1179 (1763)。 COMPOSITAE, Benth. \& Hook. f. ii. 390

Allocarpus, H. B. \& K. Nov. Gen. et Sp. iv. 291 t. $405(1820)$

Alloispermum, Willd, in Ges. Naturf. Fr. Berl. Mag. i. (1807) 139.

AMPHICALEA, Gardn. in Hook. Lond: Journ. Bot. vii. (1848) 411.

Caleacte, $\mathrm{R}, \mathrm{Br}$. in Trans. Linn. Soc. xii. (1818) 109

Calebrachys, Cass. in Dict. Sc. Nat. 1v. 277 (1828),

Calydermos, Lag. Gen. et Sp. Nov. 24 (1816).

Lemmatium, DC. Prod. v. 669 (1836).

Leontophthalmum, Willd. in Ges. Naturf. Fr. Berl. Mag, i. (1807) 140

Meyeria, DC. Prod. v. $670(1836)$

Mocinna, Lag. Gen. et Sp. Nov. 31 (1816)

Oteiza, La Llave, Reg. Trim. Mex. (1832) 41.

StenopHylum, Sch. Bip. ex Benth. \& Hook. f. Gen. ii. 391 (1873).

TETRACHYRon, Schlecht. in Linnaea, xix. (1847) 744.

acaulis, Baker, in Mart. Fl. Bras. vi. III. 266.-Bras. aculeata, Labill. Nov. Holl. Pl. ii. 41. t. $185=$ Cassinia aculeata.

albida, A. Gray, in Proc. Am. Acad. xv. (1880) 38.Mexic.

Amellus, Linn. Sp. Pl, ed. II. $1179=$ Salmea scandens, angustifolia, Gardn. in Hook. Lond. Journ. Bot. vii (1848) $417=$ multiplinervia.

angustifolia, Sch. Bip. ex Baker, in Mart. Fl. Bras. vi. III. 256.-Bras.

aspera, Jacq. Collect. ii. $290=$ Melananthera deltoidea axillaris, DC. Prod. v. 673.-Mexic

Berteriana, DC. l. c. 672-N. Granat.

brachiata, DC. l. c. 673-Panama.

cacosmoides, Less. in Linnaea, v. (1830) 157.Mexic.

Candolleana, Baker, in Mart. Fl. Bras. vi. III. 256.Bras.

caroliniana, Walt. Fl. Carol. 200.-Am. bor

Clausseniana, Baker, in Mart. Fl. Bras. vi. III. 265. Bras.

clematidea, Baker, l. c. 262.-Bras.

collina, Klatt, in Leopoldina, xx. (1884) 95 . N. Granat.

cordata, Lour. Fl. Cochinch, ii. 488.-China.

cordifolia, Sw. F1. Ind. Occ. iii. $1326=$ jamaicensis

coriacea, DC. Prod. v. 675.-Peruv.

crenata, Sch. Bip. ex Baker, in Mart. Fl. Bras. vi. Irr. 256 - Candolleana

cuneifolia, DC. Prod. v, 674_--Bras.

cymosa, Less. in Linnaea, v. (1830) 158.-Bras.

densiflora, Klatt, in Leopoldina, xx. (1884) 96.Peruv.

discolor, A. Gray, in Proc. Am. Acad.xv. (1880) 38.Mexic.

divaricata, Benth. in Hook. Fourn. Bot. ii. (1840) 44 -Guiana.

divergens, Sch. Bip. ex Baker, in Mart. Fl. Bras. vi. III. 262. - Bras.

elegans, $D C$. Prod. v. 674.-Mexic

elongata, Baker, in Mart. Fl. Bras. vi. IIt. 255.-Bras. eupatorioides, Gardn. in Hook, Lond. Journ. Bot, vii 1848) $417=$ serrata

ferruginea, Baker, in Mart. Fl. Bras. vi. III. 261.Bras.

fruticosa, Benth. \& Hook.f. Gen. ii. 390= rotundifolia. Gardneriana, Baker, in Mart. Fl. Bras. vi. III. 255.Bras.

gentianoides, DC. Prod, v. $672=$ Geissopappus gentianoides.

glabra, $D C . l$. c. 674.-Bras.

Grayii, Klatt, in Leopoldina, xx. (1884) 96.-Peruv.

hispida, Baker, in Mart. Fl. Bras. vi. III. 261-Bras. hymenolepis, Baker, l. c. 258.-Bras.

hypericifolia, Baker, $l$. $c .-$ Bras.

integrifolia, Hemsl. Biol. Centr. Am. Bot. ii. 205.Mexic.

jamaicensis, Linn. Sp. Pl. ed. II. 1179.-Jamaica.

lantanoides, Gardn. in Hook. Lond. Fourn. Bot. vii (1848) 416.-Bras.

lemmatioides, Sch. Bip. ex Baker, in Mart. Fl. Bras. vi. III. 252,-Bras. 
CALEA :

Leontophthalmum, Less. Syn. Comp. 241.-Peruv. leptophylla, Forst. f. Prod. $55=$ Cassinia leptophylla lobata, Sw. Prod. Veg. Ind. Occ. $113=$ Neurolaen lobata.

longifolia, Baker, in Mart. Fl. Bras. vi. III. 260.Bras.

longifolia, Gardn. in Hook. Lond. Journ. Bot. vii. (1848) $418=$ multiplinervia

manicata, Benth. E Hook. f. ex Hemsl. Biol. Centr.

Am. Bot. ii. 206.-Mexic.

Martiana, Baker, in Mart. Fl. Bras. vi. III. 256.Bras.

martinicensis, Hort. ex Steud. Nom. ed. II. i. 255.Ins. Martinic.

melissaefolia, Baker, in Mart. Fl. Bras. vi. III. 257.Bras.

microphylla, Baker, l. c. 259.-Bras.

montana, Klatt, in Leopoldina, xx. (1884) 96-Peruv. multiplinervia, Less. in Linnaea, v. (1830) 159.-Bras. myrtifolia, Benth. E Hook. f. Gen. ii. 391 ; Baker, in Mart. Fl. Bras. vi. III. 259.-Bras.

nitida, Less. in Linnaea, v. (1830) 158.-Bras.

oligocephala, DC. Prod. v. 675.-Bras.

oppositifolia, Linn. Sp. P1. ed. II. $1179=$ Isocarpha oppositifolia.

oxylepis, Baker, in Mart. Fl. Bras. vi. III. 354.Bras.

parvifolia, Baker, l. c. 259-Bras

paucidentata, Sch. Bip. ex Benth. \& Hook. f. Gen. ii $391=$ myrtifolia

peduncularis, H. B. E K. Nov. Gen. et Sp. iv. 295. t. 408.-Mexic.

pedunculosa, DC. Prod. v. $673=$ uniflora,

perforata, Klatt, in Leopoldina, xx. (1884) 95.-N Granat.

phyllolepis, Baker, in Mart. Fl. Bras, vi. III. 260.Bras.

pilosa, Baker, l.c. 257.-Bras.

pinifolia, Forst. f. Prod. 55. n. $288=$ Ozothamnus pinifolius.

pinnatifida, Banks, ex Steud. Nom ed. I 136-Bras. platylepis, Sch. Bip.ex Baker, in Mart. Fl. Bras. vi. III. 267.-Bras

Pohliana, Sch.Bip. ex Baker, l. c. 266.-Bras.

prunifolia, H. B. E K. Nov. Gen. et Sp. iv. 294.t. 406 -N. Granat.

ramosissima, Baker, in Mart. Fl. Bras. vi. III. 257.Bras.

reticulata, Gardn. in Hook. Lond. Fourn. Bot. vii (1848) 416.-Bras.

rotundifolia, Benth. Eo Hook. f. Gen. ii. 390 ; Baker, in Mart. Fl. Bras. vi. III. 253.-Bras

rugosa, Hemsl. Biol. Centr. Am. Bot. ii. 206.-Mexic sabazioides, Hemsl. l. $c$-Mexic.

salmiaefolia, Hemsl. l. c.-Mexic.

scaberrima, Sch. Bip. ex Baker, in Mart. Fl. Bras. vi III. $255=$ elongata.

scabrifolia, Benth. EN Hook. f. Gen. ii. 391.-Mexic. scandens, Griseb. in Goett. Abh. xxiv. (1879) 199.Reg. Argent.

scoparia, Linn. Syst. Nat. ed. XII. $234=$ Baccharis scoparia.

senecioides, Baker, in Mart. Fl. Bras. vi. Mr. 258.Bras.

Senecionis, Benth. \& Hook. f. Gen. ii. $391=$ praec.

serrata, F. G. Dietr. Vollst. Lex Gaertn, i. $642=$ cordifolia.

serrata, Less. in Linnaea, v. (1830) 158.-Bras.

sessiliflora, Less. l. c.-Mexic.

sessiliftora, Stokes, Bot. Mat. Med. iv. $172=$ Pacourina edulis.

solidaginea, H. B. E K. Nov. Gen. et Sp. iv. 295 -Venezuela; Ind. occ.

spectabilis, Labill. Nov. Holl. Pl. i. 42. t. $186=$ Apalochlamis spectabilis.

stenophylla, Baker, in Mart. Fl. Bras. vi. III. 255.Bras.

subrotunda, Gardn. in Hook. Lond. Journ. Bot. vii. (1848) $415=$ lantanoides.

Suriani, Cass. in Dict. Sc. Nat, vi. Suppl. $32=$ Neuroleana integrifolia.

terrifolia, $H . B$. \& K. Nov. Gen. et Sp. iv. 294.N. Granat.

teucriifolia, Baker, in Mart. Fl. Bras, vi. III. 259.Bras.

tomentosa, Gardn. in Hook. Lond. Gourn. Bot. vii (1848) $418,-$ Bras.
CALEA :-

tomentosa, A. Gray, in Proc. Am. Acad. xv. (1880) 38.-Mexic.

trifida, Moench, Meth. $581=$ jamaicensis.

uniflora, Less, in Linnaea, v. (1830) 159.-Bras.

urticaefolia, DC. Prod. v. 674.-Mexic.

verbenaefolia, $D C$. l. c. 673 .-Am. trop.

villosa, Sch. Bip. ex Baker, in Mart. Fl. Bras. vi. III 262.-Bras.

Zacatechichi, Schlecht. in Linnaea, ix. (1834) 589.Mexic.

CALEA, Sw. Prod. Veg. Ind. Occ. $113(1788)=$ Neurolaena, R. Br. (Compos.)

lobata, Sw. 1. c, = N. lobata

CALEACTE, R. Br. in Trans. Linn. Soc, xii. (1818) 109 Calea, Linn. (Compos.)

pinnatifida, R. Br. 1. c。 = Calea pinnatifida.

rotundifolia, Less, in Linnaea, vo. (1830) $158=$ Calea rotundifolia.

urticifolia, R. Br. in Trans. Linn. Soc. xii. (1818) 109 $=$ Calea urticaefolia

CALEANA, R. Br. Prod. 329 (1810), ORCHIDEAE, Benth. \& Hook. f. iii. 610 .

Caleya, R. Br. in Ait. Hort. Kew, ed. II. v, 204 (1813).

major, R. Br. Prod. 329.-Austral.

minor, $R . B r . l$. c. - Austral

nigrita, Lindl. Swan Riv. App. 54.-Austral.

CALEBRACHYS, Cass. in Dict. Sc. Nat. 1v. 277 (1828) = Calea, Linn. (Compos.)

peduncularis, Cass. 1. c. = Calea peduncularis.

CALECTASIA, R. Br. Prod i. 263. (1810); et in Flind. Voy. ii. 609. t. 9 (1814), FUNCACEAE, Flind. Voy. 1i. 609. t.

Benth. \& Hook. f. iii. 866.
HutTra, Preiss, ex Hook. Bot. Mag. t. 3834 (1840) cyanea, R. Br. Prod. 264.-Austral.

grandiflora, Preiss, in Lehm. Pl. Preiss. ii. $53=$ cyanea. intermedia, Sond. in Linnaea, xxviii. (1856) $222=$ cyanea.

CALENDULA, Linn. Syst. ed. I (1735). COMPOSITAE, Benth. \& Hook. f. ii. 454

Caltha, Tourn. ex Adans. Fam. ii. 126 (1768)

aegyptiaca, Desf. Tabl. Hort. Par. ed. I, 100.-Reg. Mediterr. or. ; Mesopot.

algarbiensis, Boiss. Diagn. Ser. II. vi. $106=$ suffruticosa. algeriensis, Boiss. E Reut. in Boiss. l. c. 109.Algeria.

americana, Mill. Gard. Dict. ed. VIII. 1. 10,-Mexic amplexicaulis, Thunb. Prod. P1. Cap. 164=Tripteris amplexicaulis.

amplexifolia, Reichb. in Flora, xiii. (1830) $382=$ arvensis.

anemoneflora, Breit. ex DC. Prod. vi. 454, nomen.Hab.?

arborescens, Jacq. Collect. iii. $167=$ Tripteris arbores cens.

arragonica, Fisch. ex Steud. Nom. ed. II. i. 256.Hispan.

arvensis, Bieb. Fl. Taur. Canc. iii. $596=$ persica.

arvensis, Boiss. Voy. Bot. Espagne, ii. $338=$ aegyp= tiaca.

arvensis, $\operatorname{Linn}$. Sp. Pl. ed. II. 1303.-Europ. ; Oriens. aspera, Thunb. Prod. Pl. Cap. $164=$ Osteospermum asperum.

Asterias, Fisch. \& Mey. Ind. Sem. Hort. Petrop. ii. 31 = stellata.

aurantiaca, Kotschy, ex Boiss. Diagn. Ser. I. vi, $96=$ sinuata.

aurea, Hort. ex Steud. Nom, ed. II. i. 256.-Afr. austr.

Balansae, Boiss. E Reut. Diagn. Ser. II. vi. 107.Hispan.

bicolor, Rafin. Caratt. 82. ‥ $199=$ arvensis.

brachyglossa, Rupr. in Ind. Sem. Hort. Petrop. (1852) ex Bull. Phys. -Math. Acad. Pétersb. xiv. (1856) $230=$ arvensis.

byrantina, DC. Prod, vi. $453=$ arvensis.

cariensis, Boiss. Diagn. Ser. I. x. 82.-As. Min.

ceratosperma, Viv, Fl. Lib. Spec, $59, t, 20=$ palestina.

chrysanthentifolia, Vent. Jard. Malm. $56=$ Dimorphotheca chrysanthemifolia.

cornuta, Poir. Encyc. vii. $277=$ stellata.

\section{CALENDULA}

Cristagalli, Viv. Fl. Lib. Spec. 59. t. 26. f. $2=$ sicula stellata.

cuneata, Thunb. Prod. PI. Cap. 164=Dimorphotheca cuneata.

Dalgesirum, Hort. ex DC. Prod. vi. $452=$ marginata

decumbens, Mill. Gard. Dict. ed. VIII. n. 9.Mexic.

decurrens, Thunb. Prod. PI. Cap. $163=$ Dimorphotheca pluvialis.

dentata, Hort. ex Steud. Nom. ed. I, 136=denticulata.

denticulata, Schousb. in Willd. Enum. Hort. Berol 936.-Maurit

diffusa, Salisb. Prod. $209=$ Dimorphotheca fruticosa echinata, DC. Prod. vi. $453=$ arvensis

eriocarpa, $D C$. l. c.- - Hab. ?

flaccida, Vent. Jard. Malm. $20=$ Dimorphothec auran-

tiaca.

Forskohleana, Hort. ex Steud. Nom. ed. II. i. $256=$ stellata.

fruticosa, Hort. ex DC. Prod. vi. 452 = suffraticosa.

fruticosa, Linn. P1. Afr. Rar. 25 (Amoen. Acad. v. 25 = Dimorphotheca fruticosa.

fulgida, Rafin. Caratt. 83. n. $200=$ suffroticosa

glabrata, Thunb. Prod. Pl. Cap. $163=$ Osteospermum glabratum.

glauca, Salisb. Prod. 209.-Hab.

gracilis, DC. Prod. vi. $453=$ persica.

graminifolia, Linn. Sp. Pl. $922=$ Dimorphotheca gra. minifolia.

grandiflora, Hort. ex Steud. Nom. ed. II. i. 256.-Afr austr

hispanica, Hort. ex DC. Prod. vi. 452 suffraticosa hispida, Thunb. Prod. Pl. Cap. $164=$ Aster hispidas. hybrida, Linn. Sp. Pl. $921=$ Dimorphotheca hybrida.

hybrida, Sweet, Brit. Flow Gard, i. t. $39=$ Dimorphotheca pluvialis.

incana, Willd. Sp. Pl. iii $2341=$ suffruticosa

incanescens, Schrad. ex Steud. Nom. ed. II. i 256.Hab. ?

linifolia, Wendl. ex DC. Prod. vi. 454, nomen.$\mathrm{Hab}$ ?

lusitanica, Boiss. Diagn. Ser. I. x, $83=$ suffruticosa maderensis, $D C$. Prod. vi. 454-Ins. Madera.

magellanica, Willd. Sp. Pl. iii. $2344=$ Lagenophora Commersonii.

malacitana, Boiss. \& Reut. Pugill. (1852) $61=$ aegyptiaca.

malvaecarpa, Pomel, Nouv. Mat. Fl. Atl. 33.Algeria.

marginata, Willd. Enum. Hort. Berol. $935=$ suffru ticosa.

maritima, Guss. Ind. Sem. Hort, Bocc. (1825)Sicilia.

maritima, Lowe, ex DC. Prod, vi. 454=maderensis.

maroccana, Ball, in Fourn. Bot. xi. (1873) 365. Maroceo.

micrantha, Boiss. \& Noé, Diagn. Ser. II. vi. $111=$ aegyptiaca.

micrantha, Tineo \& Guss. Fl. Sic. Syn. ii. $8 \pi t=$ arvensis.

microcephala, Kral. ex Reichb. Ic. Fl. Germ. xv. 99. $891=$ aegyptiaca

microcephala, Lange, ex Ficalho, in Bol. Soc. Broter. i. (1883) $51=$ suffruticosa

microphyla, Lange, ex Ficalho, l. c.-Hispan.

Monardi, Boiss, \& Reut. Diagn. Ser. II. vi 108.Hispan.

monstrosa, Burm. f. F1. Cap. Prod. $28=$ Tripteris scariosa.

muricata, Thunb. Prod, PI. Cap. 164=Tripteris arborescens.

Nö̈ana, Boiss. Fl. Orient iii. $416=$ soffroticosa.

nudicanlis, Linn. Sp. Pl. $922=$ Dimorphotheca nudi caulis.

officiralis, Hohen. in Bull. Soc. Nat. Mosc. (1\$38) $250^{\circ}$ = persica.

officinalis, Limn. SP. Pl. 921-Europ, anstr.

oppositifolia, Ait. Hort. Kew, iii. $272=$ Dimorphotheca oppositifolis.

palestina, Boiss. Diagn. Ser. I. х. \$\$.-Palestin. Mesoputarn.

pariflera, DC. partim, ex Boiss. Fl. Oriene iii. $\$ 12$. aegylutiace.

parififora, Rafin. Caratt. 83. n. $201=$ stcllala.

parriflora, Thunb. I'rod. Pl. Cap $169=$ Oligocarpus calondniacus. 


\section{CALENDUIA :-}

persica, C. A. Mey. Verz. Pf. Cauc. 72.-Reg. Caucas. Persia; Afghan.

pinnata, Thunb. Prod. PI. Cap. 164= Chrysanthemum lidbeckioides.

platycarpa, Coss, in Bull. Soc. Bot. Fr. iii. (1856) 655 $=$ stellata.

pluvialis, Linn. Sp. Pl. $921=$ Dimorphotheca pluvialis pluvialis, Thunb. Fl, Cap. $704=$ Dimorphotheca clandestina.

prolifera, Hort. ex Stend. Nom, ed. II. i. $256=$ officinalis.

pumila, Forst. f. Prod. $57=$ Lagenophora Commersoni1.

pusilla, Thou. F1. Trist. Acun. $40=$ Lagenophora Commersonii.

repanda, Boiss. \&z Noé, Diagn. Ser. II. vi. $110=$ pale stina.

rigida, [Dryand. in] Ait. Hort. Kew. ed. I. iii. $271=$ Tripteris arborescens.

rosmarinifolia, Houtt. Handl. xi. 84 =Osteospermum polygaloides.

sancta, Linn. Sp. Pl. ed. II. $1304==$ aegyptiaca?

scabra, Berg. Desc. Pl. Cap. $310=$ Dimorphotheca pluvialis.

sicula, DC. Prod. vi. 452 (pl. aegypt.) = aegyptiaca.

sicula, Cyrill, ex Balb. Hort. Taur. $(1800)=$ stellata.

sicula, Poir. Encyc. vii. $277=$ praec. ?

sinuata, Boiss. E Gaill. Diagn. Ser. II. vi. 109.Syria; Persia.

spatulata, Hoffmgg. Verz. Pfl. Nachtr. iii. $24=$ stellata.

stellata, Cav. Ic. i, 3, t. 5.-Reg. Mediterr

stellata, Lowe, ex DC. Prod. vi. $454=$ maderensis.

stipitata, Spreng. Syst. iii. $624=$ Lagenophora Billardieri.

subinermis, Pomel, Nowv. Mat. Fl. Atl. 34.-Algeria. sublanata, Reichb. f. Ic. Fl. Germ. xv. 99. t. $891=$ arvensis.

suffruticosa, Vahl, Symb. Bot. ii. 94.-Règ. Mediterr. occ

thapsiaecarpa, Pomel, Nouv. Mat. Fl. Atl. 34.Algeria.

tomentosa, Desf. F1. Atlant. ii. 305. t. 245=suffruticosa.

tomentosa, Thunb. Prod. P1. Cap. 163=Tripteris tomentosa

Tragus, Ait. Hort. Kew. iii. 271 ; Jacq. Hort. Schoenb. ii. 14. t. $153=$ Dimorphotheca Tragus.

Tragus, Curt. Bot. Mag. t. $408=$ Dimorphotheca aurantiaca.

tripterocarpa, Rupr. in Ind. Sem. Hort. Petrop. (1853); ex Bull. Phys.-Math. Acad. Pétersb. xiv. (1856) 231.-Mesopot.

undulata, J. Gay, ex Gand. Fl. Helv. v. $417=$ arvensis.

undulata, Rafin. Caratt. 81, n. 198=stellata

versicolor, Salisb. Prod, $209=$ Dimorphotheca hybrida viscosa, Andr. Bot. Rep. t. $412=$ Dimorphotheca cuneata.

CALEPIN A, Adans. Fam. ii. 423 (1763); DC. Syst. Veg. ii. 648. CRUCIFERAE, Benth. \& Hook. f Veg.

i. 96 .
cochlearioides, Dum. Fl. Belg. $121=$ Bunias cochlearioides.

Corvini, Desv. Fourn. Bot. iii. (1814) 158.-Europ med,; Reg. Caucas, ; Persia.

prostrata, Spreng. Syst. ii. $850=$ Muricaria prostrata.

CALESIA, Rafin. Princ. Somiol. $29(1814)=$ seq

CALESIAM, Adans, Fam. ii. $446(1763)=$ Odina Roxb. (Anacard.).

CALETIA, Baill. Etud. Gén. Euph. 553.t. 26 (1858) = Mierantheum, Desf. (Euphorbiac.).

divaricatissima, Muell. Arg, in Linnaea, xxxii. (1863) $79=$ Pseudanthns divaricatissimus.

hexandra, Muell. Arg. in DC. Prod. xv. II. $194=$ M. hexandrum.

linearis, Muell. Arg. in Linnaea, xxxii. (1863) $79=$ Pseudantbus orientalis.

micrantheoides, Baill. Etud. Gén. Euph. 554. t. 26. f. $1=\mathrm{M}$. bexandrum.

orientalis, Baill. Adansonia, vi. (1865-66) $327=$ Pseudanthus orientalis.
CALETIA :-

ovalifolia, Muell. Arg. in Linnaea, xxxiv. (1865-66) 55 Pseudanthus ovalifolius.

Wilhelmi, F. Muell. ex Muell. Arg. in DC. Prod. xv II. $194=$ Pseudanthus ovalifolius.

CALEyA, R. Br. in Ait. Hort. Kew. ed. II. v. 204 $(1813)=$ Caleana, R. Br. (Orchid.).

major, R. Br. l, c. = Caleana major.

minor, Sweet, Hort. Brit. ed. I. $385=$ Caleana minor. Sullivani, F. Muell. in Melb. Chemist (1882) 44.Austral.

CALIBRACHOA, Cerv. in La Llave \& Lex. Nov. Veg. Desc. fasc. ii. (1825) $3=$ Petunia, Juss. (Solanac.). mexicana, Lex. 1. $c_{0}=$ P. parviflora.

procumbens, Cerv. l. $\mathrm{c}_{\mathrm{o}}=\mathrm{P}$. viscidula

\section{CALICERA, Cav. Ic. iv. 34. t. $358(1797)=$ Calycera;} Cav.

CALICOREMA, Hook. f. in Benth. \& Hook. f. Gen. iii. 34 (1880). AMARANTACEAE, Benth. \& Hook. f. 1. c.

capitata, Hook. fo l. c. 35.-Afr. austr.

CALICOTOME, Link, in Schrad. Neues Journ. ii.(1808) II. $50=$ Calycotome, Link (Legumin.).

CALIGULA, Klotzsch, in Linnaea, xxiv. (1851) $28=$ Agapetes, G. Don (Vacciniac.)

odontocera, Klotzsch, ' l. c. = A. variegata.

pulcherrima, Klotzsch, 1. c. = A. variegata.

CALIMERIS, Nees, Gen. et Sp. Ast. $225(1833)=$ Aster, Tourn. (Compos.)

Alberti, Regel, Gartenfl. (1884) 130.-Turkestan.

altaica, Nees, ex Fisch. Mey. \& Avé-Lall. Ind. Sem.

Hort. Petrop. viii. $52=$ A. altaicus.

alyssoides, DC: Prod. v. $259=\mathrm{A}$. alyssoides.

amplexifolia, Sieb. \& Zucc. in Abh. Akad. Muench, iv. III. $(1846) 182=\mathrm{A}$. trinervius.

biennis, Ledeb. F1. Ross. ii. $483=$ Heteropappus hispidus.

biennis, Nees, Gen. et Sp. Ast. $231=$ A. altaicus.

canescens, Nees, 1. c. $229=\mathrm{A}$. altaicus.

cassiarabica, G. Don, in Sweet, Hort. Brit. ed. III $343=$ Aster cassiarabicus.

chinensis, Sch. Bip. in Flora, xxxv. (1852) $48=$ A altaicus.

ciliata, A. Gray, in Mem. Am. Acad. N. S. vi (1858-59) $394=$ A. altaicus.

ciliosa, Turcz. in Bull. Soc. Nat. Mosc. xxiv. (1851) II. $61=\mathrm{A}$. altaicus

cordata, Sch. Bip. in Zoll. Syst. Verz. Ind. Archip. 126, nomen.-Malaya.

coronata, Sch. Bip. in Flora, xxxv. (1852) $48=\mathrm{A}$ altaicus.

distortus, Turcz. in Bull. Soc. Nat. Mosc. xix. (1846) II. $152=\mathrm{A}$. altaicus.

exilis, Lindl, ex DC. Prod, $v, 259=\mathrm{A}$. altaicus.

fastigiata, Sch. Bip. in Zoll. Syst. Verz. Ind. Archip. $126=$ A. fastigiatus.

flexuosa, Royle, ex Lindl. in DC. Prod. v. 258=A Thomsoni.

hispida, Lindl. 1. c. $259=$ A. altaicus.

hispida, Nees, Gen. et Sp. Ast. $227=$ Heteropappus hispidus.

incisa, DC. Prod. v. $258=\mathrm{A}$. incisus.

indica, Sch. Bip. in Zoll. Syst. Verz. Ind. Archip. 125 = Boltonia indica

integrifolia, Turcz. in DC. Prod. v. 259.-Reg. Amur.

japonica, Sch. Bip. in Zoll. Syst. Verz. Ind. Archip. $126=$ A. fastigiatus

microcephala, Miq. Ann. Mus. Bot. Lugd. Bat. ii. 169. - Japon.

platycephala, Nees, Gen. et Sp. Ast. $226=$ A. incisus.

rosea, DC Prod. v, $259=\mathrm{A}$, roseus.

tatarica, Lindl. ex DC. Prod. v. $259=$ Heteropappus hispidus.

CALINEA, Aubl. Pl. Gui. i. 556. t. $221(1775)=$ Doliocarpus, Boland. (Dilleniac.).

scandens, Aubl. 1. c. = D. Calinea.

CALINUX, Rafin. in Med. Repos. New York, v. (1808) $352=$ Pyrularia, Michx. (Santalac.).
CAIIPHRURIA, Herb, in Bot. Reg. (1844) Misc. 87. AMARYLLIDEAE, Benth. \& Hook. f. iii. 731. Hartwegiana, Herb. l. c.-N. Granat.

subedentata, Baker. in Bot. Mag. t. $6289=$ Eucharis subedentata.

CALIPOGON, Rafin. Atl. Journ. 148 (1832)= Calo pogon, R. Br. (Orchid.).

CALISAYA, Hort. ex Pav. Nuev. Quinol. sub t. 5. p. 6 (1862) ; Howard, Quinol. E. Ind. $86(1869)=$ Cinchona, Linn. (Rubiac.)

anglica $\times$, Hort. ex Howard, 1. c. 87.

javanica, Hort. ex Howard, 1. c. $86=$ Cinch. Calisaya.

CALISPERMUM, Lour. Fl. Cochinch. $157(1790)=$ Embelia, Juss. (Myrsin.).

scandens, Lam. l. c. = E. Ribes

CALISTA, Ritg. in Marb. Ges. Schrift. ii. 128 (1831) = CALLISTA, Lour. = Dendrobium, Sw. (Orchid.).

CALISTACHYA, Rafin. in Med. Repos. New York, v. (1808) $352=$ Veronica, Tourn. (Scrophular.). alba, Rafin. 1. c. $=$ V. virginica.

CALIUS, Blanco, Fl. Filip. ed. I. 698 (1837) =Streblus, Lour. (Urticac.).

lactescens, Blanco, 1. c. $=\mathrm{S}$. asper,

CALIXNOS, Rafin. FI. Tellur. iv. 82 (1836) (quid ?). trinervius, Rafin. 1. c.= Convolvulus trinervis; 'non Convolvulacea,'sec. Choisy.

CALLA, Linn. Syst. ed. I (1735). AROIDEAE, Benth. \& Hook. f. iii. 989

Callaria, Rafin. in Am. Monthly Mag. (1818) 267. HOUTTrNiA, Neck. Elem iii. 291 Provenzalia, Adans. Fam. ii. 469 (1763). aethiopica, Gaertn. Fruct. ii. 20. t. $84=$ palustris. aethiopica, Linn. Sp. Pl. $968=$ Zantedeschia aethiopica ambigua, Salisb. Prod. $262=$ Zantedeschia aethiopica. angustifolia, Jack, in Malay. Misc. i. (1820) n. 1.p. 24 = Chamaecladon angustifolium

aromatica, Roxb. Hort. Beng. 65 ; Fl. Ind. iii. $513=$ Homalomena aromatica.

Badian, Blanco, F1. Filip. ed. I. $658=$ Alocasia indica. calyptrata, Roxb. Hort. Beng. 65 ; Fl. Ind. iii. $514=$ Schismatoglottis calyptrata.

cordifolia, Stokes, Bot. Mat. Med. iv. $326=$ palustris

Dracontium, G. F. W. Mey. Prim. Fl. Esseq. $197=$ Monstera pertusa.

Gaby, Blanco, Fl. Filip. ed. I. 659.-Ins. Philipp. humilis, Jack, in Malay. Misc. i. (1820) n. I. p. $22=$ Chamaecladon humile.

maxima, Blanco, Fl. Filip. ed. I. 658.--Ins. Philipp. montana, Blume, Cat. Gew. Buitenz. $62=$ Anadendrum montanum vel Rhaphidophora montana.

moschata, Moench, Meth. $346=$ Richardia elliptica.

nitida, Jack, in Malay. Misc. i. (1820) n. I. p. $24=$ Aglaonema nitidum.

oblongifolia, Roxb. Hort. Beng. 65 ; Fl. Ind. iii. $516=$ Aglaonema marantifolium.

occulta, Lodd. Bot.Cab.t. xii. = Homalomena aromatica occulta, Lour. F1. Cochinch. ii. $532=$ Zantedeschia occulta.

oculata, Lindl, in Gard. Chron. (1859) $788=$ Richardia melanoleuca.

orientalis, Linn. Sp. P1.'ed. II. $1373=$ Biarum Bovei. ovatofolia, Gilib. Exercit. ii. $452=$ palustris.

palustris, Linn. Sp. Pl. 968.-Europ.; As. bor. ; Am. bor.

pertusa, Kunth, Syn. i. $129=$ Monstera pertusa.

picta, Roxb. Hort. Beng. 65; Fl. Ind. iii. 516 Aglaonema pictum.

polyphylla, Blanco, Fl. Filip. ed. I. 659.--Ins. Philipp radicans, Ruiz \& Pav, ex Engl. in DC. Monog. Phan. ii. $377=$ Philodendron deltoideum.

rubescens, Roxb. Hort. Beng. 65 ; F1. Ind. iii. $515=$ Homalonema rubescens.

sagittifolia, Michx. Fl. Bor. Am. ii. 187 = Peltandra alba.

sylvestris, Blume, Cat. Gew. Buitenz. 62 = Rhaphidophora angustifolia.

virginica, Michx. Fl. Bor. Am. ii. $187=$ Peltandra virginica.

virosa, Roxb. Hort. Beng. 65 ; F1. Ind. iii. $517=$ Colocasia virosa. 
CALLAEOCARPUS, Miq. Pl. Jungh. $13(1851-55)=$ Castanopsis, Spach (Cupulif.). rhamnifolia, Miq. Fl. Ind. Bat. Suppl. $353=$ Cast. rhamnifolia.

sumatrana, Miq. Pl. Jungh. $14=$ Cast. sumatrana.

CALLAEOLEPIUM, Karst. Fl. Colomb. ii. 123. t. 165 (1869?) = Fimbristemma, Turcz. (Asclepiad.). Warscewiczii, Karst. I, c. $=$ F. Warscewiczii.

CALLANTHUS, Reichb. Consp. $44(1828)=$ Watsonia, Mill. (Irid.).

CALLARIA, Rafin. in Am. Monthly Mag. (1818) $267=$ Calla, Linn. (Aroid.).

CALLERYA, Endl. Gen. Suppl. iii. 104 (1843)= Milletia, Wight \& Arn. (Legumin.) tomentosa, Endl. 1. c. = M. nitida.

CALLIACHYRIS, Torr. \& Gray, in Journ. Bost. Soc. Nat. Hist. v. (1844) $110=$ Layia, Hook. (Compos.). Fremontii, Torr. \& Gray, 1. c. = L. Fremontii.

CALlianassA, Webb \& Berth. Phyt. Canar. iii. 143 $(1836-50)=$ Isoplexis, Lindl. (Scrophularin.). canariensis, Webb \& Berth. 1. c. $144=\mathrm{I}$. canariensis. Isabelliana, Webb \& Berth. 1. c. 145.-Ins. Canar.

CALLIANDRA, Benth, in Hook, Journ. Bat. ii (1840) 138. LEGUMINOSAE, Benth. \& Hook. f. i. 596.

Anneslia, Salisb. Parad. Lond. t. 64 (1.807), nomen prius.

Clelia, Casar. Nov. Stirp. Dec. 83 (1842).

CoDonANDRA, Karst. Fl. Colomb. ii. 43. t. 122 (1862?).

abbreviata, Benth. in Hook. Lond. Fourn. Bot. iii. (1844) 108.-Bras.

aculeata, Spruce, ex Benth. in Trans. Linn. Soc. xzxx (1875) 541.-Ecuador.

aeschynomenoides, Benth. in Mart. Fl. Bras. xv. II. 415. - Am. trop.

alba, Benth. in Hook, Lond. Journ. Bot. i. (1842) 527 $=$ portoricensis.

alternans, Benth. in Trans. Linn. Soc. xxx. (1875) 548 - Madag.

amazonica, Benth. in Hook. Lond. Fourn. Bot. iii. (1844) 94.-Bras.

angelica, Benth. l. c. 100.-Mexic.

angustifolia, Spruce, ex Benth. in Trans. Linn. Soc. xxx. (1875) 539.-Am. trop.

asplenioides, Benth. in Hook. Lond. Journ. Bot. i. (1842) $527=$ mertensioides.

axillaris, Benth. in Mart. Fl. Bras. xv. II. 415.-Bras. bella, Benth. in Hook. Lond. Fourn. Bot. iii. (1844) 110.-Am. trop.

bicolor, Benth. in Hook. Fourn. Bot. ii. (1840) 139.Bras.

Blancheti, Benth. in Hook. Lond. Fourn. Bot. iii. (1844) 102,-Bras.

bombycina, Spruce, ex Benth. in Trans. Linn. Soc. xxx. (1875) 538.-Am. trop.

bracteosa, Benth, in Hook. Lond. Fourn. Bot. v. (1846) 104.-Bras.

brevicanlis, Micheli, in Mém. Soc. Phys. Genèv, xxviii. (1883) n. VII. 61.-Paraguay.

brevipes, Benth. in Hook. Fourn. Bot. ii. (1840) 140.Bras.

californica, Benth. Bot. Voy. Sulph. 14. t. 11.Calif.

Callistemon, Benth. in Hook. Lond. Fourn. Bot. i. 1842) 527.-Mexic.

calothyrsus, Meissn. in Linnaea, xxi. (1848) 251.Cuiana.

calycina, Benth. in Mart. Fl. Bras. xv, 11. 419.-Am. trop.

canescens, Benth. in Hook. Lond. Fourn. Bot, iii. (1844) 96 - Mexic.

capillata, Benth. l. c. 98.-Mexic.

caracasana, Benth. in Trans. Linn. Soc. xxx. (1875) 543.-Am. trop.

carbonaria, Benth. in Hook. Lond. Fourn. Bot. iii. (1844) $95 .-\mathrm{N}$. Granat.

Chamaedrys, Engelm. ex A. Gray, P1. Fendl. $39=$ eriophylla.

chilensis, Benth. in Hook. Lond. Fourn. Bot. iii. (1844) 103.-Cbili.

\section{CALLIANDRA}

clavellina, Karst. Fl. Colomb. i. 159. t. $79=$ Purdiaei.

Codonandra, Benth. in Trans. Linn. Soc. xxx. (1875) 547.-Am. trop.

colletioides, Griseb. in Mem. Am. Acad. N. S. viii. (1861) 180.-Cuba

comosa, Benth. in Hook. Lond. Fourn. Bot. v. (1846) 104.-Am. trop.

conferta, Benth. in A. Gray, Pl. Wright. i. 63.-Am. bor. occ.

coriacea, Benth. in Hook. Lond. Journ. Bot. iii. (1844) $95=$ emarginata.

coroënsis, Karst. F1. Colomb. ii, $41=$ purpurea.

Coulteri, S. Wats. in Proc. Am. Acad. xvii. (1881-82) 352.-Am. bor. occ.

crassipes, Benth.in Trans. Linn. Soc. xxx. (1875) 555. -Am. trop.

Crugerii, Griseb. Fl. Brit. W. Ind. 224.-Ind. occ.

Cumingif, Benth. in Hook. Fourn. Bot. ii. (1840) 140. -N. Granat.

cylindrocarpa, Benth. in Hook. Lond. Journ. Bot. ii.. (1844) $96=$ Harrisii.

cynometroides, Bedd. Fl. Sylv. t. $317=$ Inga cynome troides.

dasyantha, Walp. Rep. i. 926, sphalm. = dysantha. depauperata, Benth. in Trans. Linn. Soc. xxx. (1875) 546.-Am. trop.

diademata, Lem. Jard. Fleur. iii. (1852-53) t. $305=$ bicolor.

dysantha, Benth. in Hook. Fourn. Bot. ii. (1840) 138. -Bras.

emarginata, Benth. in Hook. Lond. Fourn. Bot. iii. (1844) 95.-Mexic.

eriophylla, Benth. l. c. 105.-N. Mexic.

expansa, Benth. in Trans. Linn. Soc. xxx. (1875) 549. -Am. trop.

falcata, Benth. in Hook. Lond. Fourn. Bot. iii. (1844) 97.-Am. cent.

fasciculata, Benth. in Hook. Fourn. Bot. ii. (1840) 140. -Bras.

filipes, Benth. l. c. 139.-Am. trop.

foliolosa, Benth. in Hook. Lond. Fourn. Bot. iii. (1844) 110.-Am. trop.

foliosa, Benth. l. c.-Bras.

formosa, Benth. l. c. 98.-Am. trop.

Gardneri, Benth. l. c. 108.-Bras.

geminata, Benth. in Trans. Linn. Soc. xxx. (1875) 548

Pithecolobium geminatum.

glomerulata, Karst. Fl. Colomb. ii. 5. t. 103.-N. Granat.

glyphoxylon, Spruce, ex Benth. in Trans. Linn. Soc xxx. (1875) 539.-Ecuador.

gracilis, Griseb. in Mem. Am. Acad. N. S. viii. (1861 $180=$ formosa.

gracilis, Klotzsch, ex Baker, in Saund. Refug. Bot.t. 294.-Am. trop.

grandiflora, Benth. in Hook. Fourn. Bot. ii. (1840) 139 -Am. trop.

Griffithii, Beñth. in Trans. Linn. Soc. xxx. (1875) 537. - Reg. Himal.

Guildingii, Benth. in Hook. Lond. Fourn. Bot. iii. (1844) 96.-Bras.

haematocephala, Hassk. Retzia, 216.-Hab. ?

haematomma, Benth. in Hook. Lond. Fourn. Bot. iii. (1844) 103.-Am. trop.

Harrisii, Benth. l. c. 95.-Mexic

herbacea, Engelm. ex A. Gray, Pl. Fendl. $39=$ humilis.

Hildebrandtii, Vatke, in Linnaea, xliii. (1880-82) 110 -Ins. Mascar.

hirsuta, Benth. in Trans. Linn. Soc. xxx. (1575) 554. - Mexic.

hirtiflora, Benth. l. c. 550.-Am. trop.

Hookeriana, Schomb. in Linnaea, xx. (1847) $754=$ rigida.

Houstoni, Benth. in Hook. Fourn. Bot. ii. (1840) 139 -Mexic.

humilis, Benth. in Hook. Lond. Fourn. Bot. v. (1846) 108.-N. Mexic.

hymenaeoides, Benth. in Trans. Linn. Soc. xxx. (1875) 537.-Am, trop.

Hystrix, Griseb. Cat. Pl. Cub. $83=$ Pithecolobium Hystrix.

Kinthii, Benth. in Hook. Journ. Bot. ii. (1St0) $199=$ grandiflora.

Lambertiana, Benth, in Hook. Lond. Goum. Bot. iii, (1814) $100 .-$ Mexic.

\section{CALLIANDRA :-}

lanata, Benth. in Trans. Linn. Soc. xxx. (1875) 553. Am. trop.

lasiopus, Griseb. F1. Brit. W. Ind. $711=$ Pithecolobium cauliflorum.

latifolium, Griseb. 1. c, $225=$ Pithecolobium latifolium.

laxa, Benth. in Trans. Linn. Soc. xxx. (1875) 551.Am. trop.

leptopoda, Benth. in Hook. Lond. Fourn. Bot. iii. (1844) 101.-Bras.

linearis, Benth. l. c.v. (1846) 103.-Bras,

longipes, Benth. in Trans. Linn. Soc. xxx. (1875) 53 - Bras.

longipinna, Benth. lo c. 546.-Am. trop.

macrocephala, Benth. in Hook. Fourn. Bot. ii. (1840) 140.-Bras

Magdalenae, Benth. in Hook. Lond. Fourn. Bot. y. (1846) 102.-Am. trop.

malacophylla, Benth. l. c. iii. (1844) 100.-Mexic.

marginata, Benth, in Trans. Linn. Soc. $x \times x$. (1875) $586=$ Pithecolobium marginatum.

marginata, Griseb. Fl. Brit. W. Ind. $710=$ formosa. mertensioides, Benth. in Hook. Lond. Fourn. Bot. iii. (1844) 106.-Am. trop.

metrosideriflora, Benth. l. c. i. (1842) 527.-Mexic

microphylla, Benth. in Hook. Fourn. Bot. ii. (1840, 139.-Bras.

mollissima, Benth. in Hook. Lond. Fourn. Bot. iii. 1844) 97.-Bras.

myriophylla, Benth. l. c. 111.-Bras.

obovata, Benth. 1. c. $101=$ Pithecolobium lusorium,

obtusifolia, Karst. F1. Colomb. î. 41. t. $121=$ purpurea.

Pacara, Griseb. in Goett. Abh. xxiv. (1879) 123.-Reg. Argent.

pallens, Benth. in Hook. Lond. Journ. Bot. v. (1846) $102=$ Pithecolobium albicans.

parviflora, Benth. l. c. iii. (1844) 112.-Bras.

Patrisii, Sagot, in Ann. Sc. Nat. Sér. VI. xiii. (1882, 324.-Guiana.

pauciflora, Griseb. Cat. Pl. Cub. 284.-Cuba.

Peckoltii, Benth. in Trans. Linn. Soc. xxx. (1875) 555 -Bras.

pedicellata, Benth. in Hook. Lond. Fourn. Bot. iii. (1844) 102.-Ins. S. Doming.

portoricensis, Benth. l. c. 99.- Am. bor.; Ind. occ.

prehensilis, Wright, in Sany. Fl. Cub. $35=$ Pithecolobium prehensile.

prostrata, Benth. in Trans. Linn. Soc. vxx. (1875) 554.-Peruv.

Purdiaei, Benth. in Hook. Lond. Fourn. Bot. v. (1846 104.-N. Granat.

purpurea, Benth. l.c. iii. (1844) 104.-Am. trop. quadrangularis, Walp. Rep. i. $927=$ tetragona.

reticulata, A. Gray, Pl. Wright. ii. 53. -N. Mexic.

revoluta, Griseb. Cat. Pl. Cub. $83=$ Pithecolobium obovale.

rigida, Benth. in Hook. Lond. Fourn. Bot. v. 1846 103.-Guiana.

Rntenbergiana, Vatke, in Bremen Abh: vii. (1S\&2) 250.-Madag.

Saman, Griseb. Fl. Brit. WV. Ind. $225=$ Pithecolobium Saman.

Sancti-Pauli, Hassk. Retzia, i. 214=Tweedii.

Schottii, Torr, ex S. Wats. in Proc. Ans. Acad. xx. (1885) 364.-Arizona.

scritellifera, Benth. in Hook. Fourn. Bot. ii. (1940) 139.-Am. trop.

Seemanni, Benth. in Seem. Bot. Voy. Herald, 116. t. 22.-Venezuela.

sessilis, Benth. in Hook. Fourn. Bot. ii. ISt01 141.Bras.

Spruceana, Benth. in Tmas. Linn. Soc. xxx. (1575) 593 $=$ Pithecolobium parvifolium.

squarrosa, Benth. in Hook. Land. Gourn. Bob. iii. (1\$44) $104 .-$ Am. trop

stenophylla, Wamra, in Oestr. Bot. Terilschr. xxix. (1s79) :15. - Bras.

stipulacea, Benth. in Hook. Fourn. Bot. ii. (18t0) 18: -Guiana.

subnervosa, Benth. in Trizhs. Linn. Sor. xxx. $18 \mathrm{~s}$ 5\$0.-An. trop.

subspicata, Benth.l. c, 5563. -Am. trop.

surinamensis, Bersth. in Hook. Lond. Fourn. Bop. iii.

(18.t4) 105.-Guians

taxifulia, Bensh. l. 6. 104.-N. Gramat. 


\section{CALLIANDRA :}

tenuiflora, Benth. in Trans. Linn. Soc. xxx. (1875) 547. - Am, trop.

tergemina, Benth. in Hook. Lond. Fourn. Bot. iii. (1844) 96.-Am. trop.

tetragona, Benth. in Hook. Fourn. Bot. ii. (1840) 139. -Am. trop.

tetraphylla, Benth. in Trans. Linn. Soc. xxx. (1875) 544.-Mexic

Thouarsiana, Baill. in Bull. Soc. Linn. Par. i. (1883) 365.-Madag.

trinervia, Benth. in Hook. Lond. Fourn. Bot. iii. (1844) 94.-Bras.

tubulosa, Benth. 1. c, $101=$ Pithecolobium Saman.

turbinata, Benth. l. c. 109.-Bras.

Tweedii, Benth. in Hook. Fourn. Bot. ii. (1840) 140.Bras.

umbellifera, Benth.l.c.141.-Bras.

umbrosa, Benth. in Benth. \& Hook. f. Gen. i. 597.Ind. or. ; Penang.

ungulata, Benth. in Hook. Lond. Journ. Bot. i. (1842) $527=$ portoricensis.

vespertina, Benth. 1. $\mathrm{c}_{\mathrm{s}}=$ portoricensis.

virgata, Benth. in Hook. Fourn. Bot. ii. (1840) 140.Bras.

viridiflora, Benth. in Hook. Lond. Fourn. Bot. iii. 1844) 98.-Bras.

viscidula, Benth. l. c. 109.-Bras.

Wendlandi, Benth. in Trans. Linn. Soc. xxx. (1875) 556.-Guatemala.

xalapensis, Benth. in Hook. Lond. Journ. Bot. iii. (1844) $105=$ laxa.

CALLIANIRA, Miq. Syst. Pip. $344(1843)=$ Piper, Linn.

melastomoides, Miq. 1. c. $345=$ P. melastomoides,

CALLIANTHEMUM, C. A. Mey, in Ledeb. Fl. Alt. ii. 336 (1830). RANUNCULACEAE, Benth. \& Hook. f. i. 5 .

anemonoides, Endl. ex Heynh. Nom. ii. $106=$ rutae folium.

bipinnatum, Dulac, Fl. Hautes-Pyr. 216=rutae folium

cachemirianum, Cambess. in facquem. Voy. Bot. 5. -Reg. Himal

coriandrifolium, Reichb. F1. Germ. Excurs, $727=$ rutaefolium.

Endlicheri, Walp. Rep. i. $33=$ Oxygraphis polypetala. pimpinelloides, Royle, Illustr. Bot. Himal. 45 (Hook. f. \& Thoms. Fl. Ind. 26)= cachemirianum.

rutaefolium, C. A. Mey. in Ledeb. Fl. Alt. ii. 336.Sibir.

rutaefolium, Reichb. F1. Germ. Excurs. $727=$ Ranunculus anemonoides.

semiverticillatum, Phil. in Linnaea, xxxiii. (1864-65) 3.-Chili.

CALlias, Cass. in Dict. Sc. Nat. xxiv. 327 (1822) $=$ KALLIAS, Cass $s=$ Heliopsis, Pers. (Compos.).

CALLICARPA, Linn. in Act. Soc. Ups. (1741) 80. VERBENACEAE, Benth. \& Hook. f. ii. 1150.

Aganon, Rafin. Sylva Tellur. 161 (1838).

Amictonis, Rafin. 1. c. (1838).

Burchardia, [Heist.] Duham. Arb. i. 111. t. 44 (1755).

ILlA, Adans. Fam. ii. 446 (1763).

Johnsonia, T. Dale, ex Mill. Gard. Dict. ed. VI App. 75 (1752).

PoRPHYRA, Lour. Fl. Cochinch. $69(1790)$

SpondylococcA, Mitch. in Act. Phys.-Med. Acad.

Nat. Cur. viii. (1748) 218.

TomeA, Linn. Diss. Dass. 5 (1747) (Amoen. Acad. i. 389 ).

aculeolata, Schau. in DC. Prod. xi. 642.-Ins. S. Doming.

acuminata, H. B. E K. Nov. Gen. et Sp. ii. 252.-N Granat.

acuminata, Roxb. Hort. Beng. [10] ; Fl. Ind. i. 394.Ind. or.

acuminatissima, Teijsm. \& Binn. in Tijdschr. Nederl. Ind. xxy. (1863) $409=$ Geunsia farinosa. acutidens, Schau. in DC. Prod.xi. 645.-Cochinch. adenanthera, R. Br. Prod. $513=$ cana. albida, Blume, Bijdr. 818.- -Java. americana, Blanco, Fl. Filip. ed I. $517=$ Blancoi americana, Linn. Sp. Pl. 111.-Am. bor. americana, Lour. Fl. Cochinch. $70=$ cana.

\section{CALLICARPA :}

ampla, Schau. in DC. Prod. xi. 642.-Jamaica, angusta, Schau. l. c.--Ins. Philipp.

arborea, Miq. ex C. B. Clarke, in Hook. f. Fl. Brit Ind. iv. 567 = lanata.

arborea, Roxb. Hort. Beng. [10]; Fl. Ind. i. 390.-

As, trop.

arborea, Wall. Cat. n. 1826 , partim $=$ vestita

attenuata, Wall. 1. c. n. $1835=$ longifolia.

bicolor, Juss. in Ann. Mus. Par. vii. (1806) $77=$ cana.

bicolor, F. Vill. in Blanco, Fl. Philipp. ed. III. Nov. App. $158=$ Blancoi.

Blancoi, Rolfe, in Fourn. Linn. Soc. xxi. (1884) 315. -Ins. Philipp.

Blumei, Zoll. \& Moritzi, Syst. Verz. Zoll. 53.Malaya.

Bonplandiana, Schult. Mant. iii. $50=$ acuminata.

breviceps, Hance, in Journ. Linn. Soc. xiii. (1873) 116 $=$ brevipes.

brevipes, Hance, in Ann. Sc. Nat. Sér. V. v. (1866) 233.-China.

cana, Dalz. \& Gibs. Bomb. FI. $200=$ lanata.

cana, Gamble, Darjeeling List, 60 ; Ind. Timbers, $283=$ macrophylla

cana, Linn. Mant. ii. 198.-As. trop.; Austral.

cana, Wall. Cat. n. $1834=$ pedunculata et longifolia

cinerea, A. Rich. Fl. Cub. Fanerog. ii. 145.Cuba.

cordifolia, Ruiz \& Pav. F1. Per. i. 50. t. 57. f. $a=$ Aegiphila Mutisii.

Cumingiana, Schau, in DC. Prod, xi. $644=$ Geunsi Cumingiana.

cuspidata, Roxb. Hort. Beng. 83; F1. Ind. 1. $394=$ pedunculata.

dentata, Roth, Nov. Pl. Sp. 81; Wall. Cat. n. $6319=$ pedunculata.

dentata, Roxb. ex Wall. 1. c. p. 87. n. $1834=$ cana

dentata, Wall. 1. c. n. 6319 , partim =longifolia.

dichotoma, Raeusch. Nom. ed. III. $37=$ purpurea

discolor, Willd. ex Steud. Nom, ed. II. i. $257=$

Aegiphila arborescens.

erioclona, Schau, in DC. Prod. xi. $643=$ cana.

farinosa, Roxb. ex C. B. Clarke, in Hook. f. FI. Brit

Ind, iv, $567=$ lanata.

ferruginea, Sw. Prod. Veg. Ind. Occ. 31.-Jamaica

formosana, Rolfe, in fourn. Bot. xx. (1882) 358.-.Ins Formosa.

fulva, A. Rich. Fl. Cub. Fanerog, ii. 145.-Ins. Cuba.

globiflora, Ruiz E Pav, Fl, Per, i. 49, t. 57. f. b.-

Am. austr.

gracilis, Sieb. E Zucc. in Abh. Akad. Muench. iv. III. (1846) 154.-Tapon.

hexandra, Teijsm. \& Binn. in Tijdschr. Nederl. Ind xxv, $(1863) 410=$ Geunsia farinosa?

Heynii, Roth, Nov. Pl. Sp. $82=$ cana

Horsfieldi, Turcz. in Bull. Soc. Nat. Mosc. xxxvi. (1863) II. 217.-Java.

incana, Roxb. Hort. Beng. [10]; F1. Ind. i. $393=$ macrophylla.

integerrima, Champ. ex Benth. in Hook. Kew fourn. v. (1853) 135.-China

integrifolia, Jacq. Enum. Pl. Carib. 12=Aegiphila arborescens.

japonica, Thunb. Fl. Fap. 60.-Japon

lanata, Gamble, Darjeeling List, $60=$ vestita.

lanata, Lam. ex Steud. Nom. ed. I. 137=Premna lanata (sp. ignot.)

lanata, Linn: Mant. ii. 331.-Ind. or.

lanata, Schau. in DC. Prod. xi. $644=$ pedunculata

lanceolaria, Roxb. Hort. Beng. [10]; F1. Ind. i. $395=$ longifolia.

latifolia, Zipp. ex Span. in Linnaea, xv. (1841) 330 , nomen.-Ins. Timor.

lobata, C. B. Clarke, in Hook. f. Fl. Brit. Ind. iv 566.-Reg. Himal

longifolia, Lam. Encyc. i. 563.-Malaya; Austral. macrocarpa, Raeusch. Nom. ed. III. $37=$ cana? macrophylla, Vahl, Symb. Bot. iii. 13. t. 53.-Ind, or magna, Schau, in DC. Prod. xi. 641.-Ins. Philipp. micrantha, Vidal, Phan. Cuming. Philipp. 187.-Ins. Philipp.

Mimurazaki, Hassk. Cat. Hort. Bog. Alt. $136=$ japonica.

mollis, Sieb. E Zucc, in Abh. Akad. Muench. iv. III. (1846) 155.-Japon.

mollis, Willd. ex Schau. in DC. Prod. xi. $644=$ acuminata, $H . B$. $\xi K$.
CALLICARPA :-

mudiflora, Hook. \& Arn. Bot. Beech. Voy. $206=$ Reevesii.

oblongifolia, Hassk, Cat. Hort. Bog. Alt. $136=$ longifolia.

paniculata, Lam. Encyc. i. $563=$ Chilianthus arboreus. parvifolia, Hook. E Arn. Bot. Beech. Voy. 305.-

Mexic.

pedunculata, R. Br. Prod. 513.-Malaya; Austral.

pentandra, Roxb. Hort. Beng. 83; Fl. Ind. i. $395=$ Geunsia farinosa.

psilocalyx, C. B. Clarke, in Hook. f. Fl. Brit. Ind. iv. 569.-Reg. Himal.

purpurea, Fuss. in Ann. Mus. Par, vii. (1806) 67.China.

Reevesii, Wall. Cat. n. 1830.-China.

reticulata, Poepp. ex Walp. Rep. iv. $72=$ Petitia Poeppigii.

reticulata, Sw. Prod. Veg, Ind. Occ. 31.-Jamaica.

Rheedii, Kostel. Allg. Med.-Pharm. F1. iii. $829=$ cana.

rhynchophylla, Miq. Fl. Ind. Bat. ii. 888.-Malaya.

Roxburghiana, Schult. Mant. iii. $54=$ longifolia

Roxburghii, Wall. Cat. n. $1833=$ macrophylla.

rubella, Lindl. Bot. Reg. t. 883.-Reg. Himal.; China.

Schlimii, Turcz. in Bull. Soc. Nat. Mosc. xxxvi. (1863) I. 217.-N. Granat.

serrata, Moench, Meth. $468=$ americana.

sessilifolia, Wall. Cat, n. $1837=$ rubella.

sinensis, Hort. ex Steud. Nom. ed. II. i. $257=$ cana.

subintegerrima, H. B. \& K. Nov. Gen. et Sp. ii. 25 = acuminata, $H . B . \& K$

subpubescens, Hook. E Arn. Bot. Beech. Voy, 305.Mexic.

sumatrana, Miq. Fl. Ind. Bat. ii. $888=$ cana.

tectonaefolia, Wall. Cat. n, $1827=$ arborea.

tenuiflora, Champ. ex Benth. in Hook. Kew Journ. (1853) $135=$ rubella

tiliaefolia, Teijsm. \& Binn. ex C. B. Clarke, in Hook f. Fl. Brit. Ind. iv. $569=$ pedunculata.

tomentosa, Koen. ex Vahl, Symb. Bot. iii. $13=$ macrophylla.

tomentosa, Lam. Encyc, i. $562=$ cana

tomentosa, Murr. Syst. Veg. ed. XIII. $153=$ lanata.

tomentosa, Willd. Enum. Hort. Berol. 158; Hook. E Arn. Bot. Beech. Voy. 305.-China.

Tomex, Poir. Encyc. Suppl. ii. $32=$ lanata.

triloba, Lour. $\mathrm{Fl}$. Cochinch. 70,-Cochinch.

umbellata, Lour, l. c-Cochinch.

velutina, Presl, Bot. Bemerk. 98.-Bras.

vestita, Wall. ex C. B. Clarke, in Hook. f. Fl. Brit. Ind. iv. 567.-Reg. Himal.

viburnifolia, Salisb. Prod. $53=$ americana.

villosa, Roxb. Hort. Beng. [10]= arborea.

villosa, Vahl, Symb. Bot. ii. 14,-Ind. or. ?

Walichiana, Walp. Rep. iv. $125=$ lanata.

Zollingeriana, Schau. in DC. Prod. xi. $640=$ mollis.

CAlliCephalus, C. A. Mey. Verz. Pf. Canc. 66 1831) = Centaurea, Linn. (Compos.)

nitens, C. A. Mey. 1. c, = Cent. nitens.

CALLICHLAMYS, Mig. in Linnaea, xviii. (1844) 254. BIGNONIACEAE, Benth. \& Hook. f. ii. 1039. riparia, Miq. l. c.-Panama.

rubiginosa, Miers, in Proc. Roy. Hort. Soc. iii. (1863) $201=$ riparia.

rufinervis, Miers, 1. c. $201=$ riparia.

splendida, Miers, 1. c. = riparia.

CALLICHLOË, Pfeiff. Nom, i. $536(1871)=$ seq.

CALLICHLOEA, Spreng. ex Steud. Nom. ed. II. i, 257 $(1840)=$ Elionurus, Humb. \& Bonpl. (Gramin.). elegans, Spreng. 1. c. = E. elegans.

CALliCHROA, Fisch. \& Mey. Ind. Sem. Hort. Petrop ii. 31 (1835)=Layia, Hook. \& Arn. (Compos.) anoustifolia, Walp. Rep. ii. $632=\mathrm{L}$. platyglossa. angustifolia, Walp. 1. c. iii. $396=$ Castilleja angustifolia.

Bradburii, Walp. 1. c. = Castilleja Bradburii.

Douglasii, Torr. \& Gray, F1. N. Am. ii. $396=\mathrm{L}$ Douglasii.

hirsuta, Walp. Rep. ii. $632=\mathrm{L}$. platyglossa.

platyglossa, Fisch. \& Mey. Ind. Sem. Hort. Petrop. ii $31=\mathrm{L}$. platyglossa. 
CALLICOCCA, Schreb. Gen. i. $126(1789)=$ Cephaëlis, Sw. (Rubiac.).

alba, J. F. Gmel. Syst. $371=$ Ceph. alba.

elata, J. F. Gmel, 1. c. $372=$ Ceph. elata.

glabra, J. F. Gmel. 1. c. = Ceph. glabra.

guianensis, J. F. Gmel. 1. c. = Ceph. involucrata

Ipecacuanha, Brot. in Roem. Arch. iii. MII. $455=$

Psychotria Ipecacuanha

muscosa, Steud. Nom. ed. II. i. $257=$ Ceph. muscosa

purpurea, J. F. Gmel. Syst. $371=$ Ceph. purparea.

tomentosa, J. F. Gmel. I. c.=Psychotria tomentosa

CALLICOMA, Andr. Bot. Rep.t. 566 (1809). SAXI

FRAGEAE, Benth. \& Hook, f i. 649

Calycomis, R. Br. in Flind. Voy. App. 549 (1814).

Stutzeria, F. Muell. Fragm. v. 31 (1865)

Billardieri, D. Don, in Edinb. N. Phil. Fourn. (Apr.

June 1830) 94.-Austral.

ferruginea, D. Don, 1. c. = serratifolia.

serratifolia, Andr. Bot. Rep.t. 566.-Austral.

Stutzeri, F. Muell. Fragm. v. 34.-Austral.

ternata, Montr. in Mém. Acad. Lyon, x. (1860) 211.N. Caled.

CALLICORE, Link, Handb. i. 193 (1829)= Amaryllis, Linn.

crocata, Link, 1. c. = Hippeastrum rutilum.

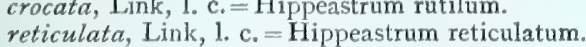

rosea, Link, l. c. = A. Belladonna.

rutila, Link, 1. c. $194=$ Hippeastrum rutilum.

CALLICORNIA, Burm. f. Prod. Fl. Cap. 24 (1768)=

Leyssera, Linn. (Compos.).

gnaphaloides, Burm. f. 1. c. =L. gnaphaloides.

tenuifolia, Burm. f. l. c.-Afr. austr.

triflora, Burm. f. 1. c.-Afr. austr.

CALlicysthus, Endl. Prod. F1. Norf. 90 (1833)= Vigna, Savi (Legumin.)

volubilis, Endl. 1. c.-Ins, Norfolk.

CALLIDRYNOS, Neraud, in Freyc. Voy. Bot. 29 (1829), nomen (Sapind.).

CALLIGLOSSA, Hook, \& Am. Bot. Beech. Voy. 356 $(1840)=$ Layia, Hook. \& Arn. (Compos.)

Douglasii, Hook. \& Arm. 1. c. = L. Calliglossa.

CALIIGONUM, Linn. Gen. ed. I. 345 (1737) POLYGONACEAE, Benth. \& Hook. f. iii. 95.

Calliphysa, Fisch. \& Mey. Ind. Sem. Hort. Petrop. i. $24(1835)$.

Ginsonia, Stocks, in Proc. Linn. Soc. i. (1848) 367.

PALI ASIA, Linn. f. Suppl. 37 (1781)

Pterococcus, Pall. Reise, i. App. 738. t. 5 (1776);

Reise, ii. App. 43 (1777).

Traxilisa, Rafin. Sylva Tellur. 161 (1838).

acanthopterum, Borszcz. Aralo-Casp. Callig. 34.-Reg.

Aral. Casp.

anfractuosum, Bunge, in Mém. Sav. Etr. Pétersb. vii. (1851) 487 (Lehm. Rel. 311). - As. centr.

aralense, Borszcz. Aralo-Casp. Callig. 31.-Reg. Aral. Casp.

esperum, Lour. F1. Cochinch. $342=$ Tetracera sarmen$\operatorname{tos} 2$.

bucocladum, Bunge, in Mém. Sav. Etr. Pétersb. vii. (1851) 485 (Lehm. Rel. 809).-As. centr.

Bungei, Boiss. Fl. Orient. iv. 999.-Persia.

Calliphysa, Bunge, Del. Sem. Dorpat. (1839) 8.-Reg. Casp.; Turkest.

canescens, Pursh, Fl. Am. Sept. ii. $370=$ Atriplex cancscens.

Caput-Medusae, Schrenk, Enum. Pl. Nov. i. 9.Soongaria.

colubrinum, Borsacz. Aralo-Casp. Callig. 38.-Reg. Aral. Casp.

comosum, L'Hérit. in Trans, Linn. Soc. i. (1791) 180. -Aegypt. ; Arab.; Persia.

crinitum, Boiss. Diagn. Ser. II. iv. 77.-Beluchist.

crispum, Bunge, Del. Sem. Dorp. (1839) 8.-Hab. ?

cristatum, Bunge, in Mém. Sav.Etr. Pétersb. vii. (1851)

485 (Lehn. Rel. 309).-As, centr.

densum, Borszcz. Aralo-Casp. Callig. 36.-Reg. Aral. Casp.

denticulatum, Bunge, ex Boiss. Fl. Orient. iv. 999.Persia.

erinaceum, Borszcs. Aralo-Casp. Callig. 87.-Reg. Aral. Casp.

\section{CALLIGONUM:-}

eriopodum, Bunge in Mém. Sav, Etr. Pétersb. vii 1851) 485, 486 (Lehm. Rel. 309, 310).--Turkest.

flavidum, Bunge, Del. Sem. Dorp. (1839) 8.-Hab.?

gobicum, Bunge, ex Meissn. in DC. Prod. xiv. $29=$ mongolicum.

horridum, Borszcz. Aralo-Casp. Callig. 32,-Reg. Aral. Casp.

leucocladum, Bunge, in Mem. Sav. Etr. Petersb. (1851) 485 (Lehm. Rel. 309).-As, centr.

macrocarpum, Borszcz. Aralo-Casp. Callig. 35.-Reg. Aral. Casp.

medusecephalum, St. Lag, in Ann. Soc. Bot. Lyon, vii, (1880) 69-C. Caput-Medusae

microcarpum, Borsacz. l.c. 41.-Reg. Aral, Casp

mongolicum, Turct, in Bull. Soc. Nat. Mosc.v. (1832) 204.-Mongolia.

Murex, Bunge, in Mém. Sav. Etr. Petersb. vii. (1851) 485, 486 (Lehm. Rel. 309, 310).-As. centr.

Pallasia, L'Herit. in Trans. Linn. Soc. i. (1791) 180. -Reg. Casp.; Turkest.

Panderi, Fisch. ex Sweet, Hort. Brit. ed. II. 440, nomen, -Reg. Casp.

paniculatum, Borszcz. Aralo-Casp. Callig. 42,-Reg. Aral. Casp.

persicum, Boiss. Fl. Orient. iv. 999.-Persia.

platyacanthum, Borszcz. Aralo-Casp. Callig. 37.-Reg. Aral. Casp.

polygonoicles, Linn. Sp. Pl. 530.-Armenia; Persia; Ind, bor. occ.

polygonoides, Pall. Reise, iii. $530=$ C. Pallasia.

Rotula, Boszca. Aralo-Casp. Callig. 35.-Reg. Aral. Casp.

rubicundum, Bunge, Del. Sem. Dorp. (1839) 8.Hab. ?

songaricum, Endl. Gen. Suppl. iv. II. 50.-Soongaria. stenopterum, Bunge, ex Boiss. Fl. Orient. iv. 999. Persia; Afghan.

tetrapterum, Faub. Es Spach, Illustr. v. 80, t. 471.Mesopotam.

tripterum, Bunge, ex Boiss. Fl. Orient. iv. $999=$ Bungei.

CALLIGONUM, Lour. Fl. Cochinch. $342(1790)=$ Tetracera, Linn. (Dilleniac.).

asperum, Lour. 1. c. $=\mathrm{T}$. sarmentosa.

CALLILEPIS, DC. Prod. v。 671 (1836). COMPOSITAE, Benth. \& Hook. f. ii. 339.

glabra, $D C$. l. c.-Afr. austr.

hispida, $D C$. $l, c$.-Afr. austr.

Laureola, $D C . l_{\text {. }}$. . $-\mathrm{Afr}$. austr.

leptophylla, Harv. in Harv. E Sond. Fl. Cap. iii. 136. -Afr. austr.

salicifolia, Oliver, in Hook. Ic. Pl. t. 1482,-Afr, austr.

CALLIOPEA, D. Don, in Edinb. N. Phil. Journ. (182829) $309=$ Crepis, Linn. (Compos.)

aurea, D. Don, 1. c. = Crepis aurea.

CALLIOPSIS, Reichb. Ic, et Desc. P1. t. $70(1824)=$ Coreopsis, Linn. (Compos.)

Atkinsoniana, Hook. Fl. Bor. Am. i. $310=$ Cor. Atkinsoniana.

atropurpurea, Hort. ex Steud. Nom. ed. II. i. $258=$ Cor, tinctoria.

basalis, A. Dietr. in Otto \& Dietr. Allgem. Gartenz. iii. (1835) 330.-Am. bor.

bicolor, Reicbb. Ic. et Desc. P1. t. $70=$ Cor, tinctoria cardaminefolia, DC. Prod. v. 568=Cor, cardamine. folia.

Drummondi, D. Don, in Sweet, Brit. Flow. Gard. Ser. II. t. $315=$ Cor. Drummondii.

fimbriata, Lange, Sem. Hort. Haun. Adn. (1866) 5. Hab.?

nudata, Spreng. Syst. iii. $611=$ Cor. nudata.

palmata, Spreng. 1. c. = Cor. palmata.

rosea, Spreng. 1. $c_{0}=$ Cor. rosea.

tinctoria, DC. Prod. v. $56 \mathrm{~s}=$ Cor. tinctoria.

CALLIPELTIS, Stev, in Mém. Soc. Nat. Mosc, vii. (1829) 275 (Obs, Pl. Ross. 69). RUBIACEAE, Benth. \& Hook, f, ii. 148

aperta, Boiss. G Buhse, in Nouv. Mém. Soc. Nat. Mosc, xii. (1860) 110.-Acgypt.; Persia.

Cacullaria, Stev, in Mém. Soc. Nat. Mosc. vii. (1S29) 275. - Oriens; Reg. Mediter.

microstegia, Boiss. F\%. Orient. iii. 84-Persia.
CALLIPHYSA, Fisch. \& Mey. Ind. Sem. Hort. Petrop. i. $24(1835)=$ Calligonum, Linn. (Polygonac.). juncea, Fisch. \& Mey. I. c. = Calligonum Calliphysa. polygonea, C. A. Mey, ex Borszcz. Aralo-Casp. Callig $43=$ Calligonum Calliphysa.

CALLIPRENA, Salisb, Gen. Pl. Fragm. 89 (1855 Allium, Tourn. (Liliac.)

cernua, Salisb. $1 . c_{0}=\mathrm{A}$. cernuum.

CALLIPRORA, Lindl. Bot. Reg. t. 1590 (1833)= Bro diaea, Sm. (Liliac.)

aurantea, Kellogg, in Proc. Calif. Acad. ii. (1863) 20 $=$ B. ixioides.

flava, Hort. ex Steud. Nom. ed. II. i. $258=\mathrm{B}$. ixioides.

lutea, Lindl. Bot. Reg. t. $1590=$ B. ixioides.

CAIIIPSYCHE, Herb, in Bot. Reg, (1842) Misc. 49. AMARYLLIDEAE, Benth. \& Hook. f. iii. 731. aurantiaca, Baker, in Saund. Ref. Bot. t. 167.Ecuador.

auratum, Hort, ex Gard, Chron. (1871) 6=praec eucrosioides, Herb. in Bot. Reg. (1842) Misc. 50. Ecuador.

mexicana, M. Roem. Syn. Ensat. $155=$ eucrosioides

mirabilis, Baker, in Saund. Ref. Bot. t. 168, Peruv.

CAILIRHOË, Nutt, in Journ. Acad. Philad, ii. (1821 181. MALVACEAE, Benth. \& Hook, f. i. 201.

Monolix, Rafin, Cat. 14 (1824).

Nuttallia, Bart. Fl. N. Am. ii. 74. t. 62 (1822)

alcaeoides, A. Gray, Pl. Fendl. 18.-Am. bor.

digitata, Nutt. in Fourn. Acad. Philad. ii. (1821) 181

-Am. bor. occ.

involucrata, A. Gray, Pl. Fendl. 16.-Am. bor. occ.

lineariloba, A. Gray, in Proc. Am. Acad. xix. (1883 74.-Am. bor.

macrorrhiza, A. Gray, Pl. Fendl. $18=$ alcaeoides. palmata, Buckl. in Proc. Acad. Sc. Philad. ' 1861

(1862) $449=$ involucrata.

Papaver, A. Gray, Pl. Fendl.17.-Am. bor. occ.

pedata, A. Gray, l. c.-Am. bor. occ.

spicata, Regel, Gartenf. (1872) 291. t. $737=$ Sidalcea malvaeflora.

triangulata, A. Gray, Pl. Fendl. 16.-Am. bor.

verticillata, Groenl. in Rev. Hortic, (1862, $171=$ involucrata.

CALLIRRHOË, A. Gray, P1. Fendl. 16 (1819) praec.

CALLISACE, Fisch, in Hoffm. Gen. Umb. ed. II. $170=$ Angelica, Linn. (Umbellif.)

cantabrigiensis, Hoffm. ex Steud. Nom.ed. I. 763 $138=$ Peucedanum palustre.

dahurica, Fisch. in Hoffm. Gen. Umb. ed. II. 170= A. dahurica.

ruthenica, Fisch. 1. c. = Peucedanum ruthenicum?

Schiefereckii, Hoffm, 1. c.= Peucedanum palustre,

CALlisemA, Stend. Nom. ed. II. i. $258(1840)=$ seq.

CALLISEMAEA, Benth, in Ann. Wien. Mus, ii. (1 $\$ 3:$ $105=$ Platypodium, Vog. (Legumin.) elegans, Walp. Rep.i. $802=$ P. elegans. grandiflora, Benth. in Ann. Wien. Mus, ii. (1ss8) 105 $=\mathrm{P}$. grandiflorum.

probescens, Benth. 1. c, = P. elegans.

sericea, Benth. 1. c. = P. elegans,

viridis, Walp. Kep. i. $802=$ P. viride.

CALIISIA, Linn, in Inefl. It. Hisp, $\$ 05$ (175: COHUELVVACEAE, Benth. \& Hook. r. iii. 85 t. Haralaxtmus, Jacq. Stirp. Am. 11. t. 11 (176s ciliata, H. B. \& K. Nov. Gen. et Sp, i. $261=$ Tradcscantia clongrta.

cilista, Pers. Syn. i, $56=$ renens.

delicatula. Kunth, Enum, I"l. iv. $69=$ ambellulata. diffusa, Pohl, ex Seub. in Mart. Fl. Bras. iii. 1. 251 Tradescantia cffusa.

glandulosa, Pobl, cx Seub. I. c. 255 Dithyracarpus flandulosus.

insignis, C. B. Clarke, in Hewsl. Diagm. Pl. Mex. $50^{\circ}$ Mexic. 


\section{CALLISIA :}

Martensiana, C. B. Clarke, in DC. Monog. Phan. iii. 312.-Mexic.

meiandra, Wright, in Sauv. Fl. Cub. $159=$ Tradescantia cordifolia.

monandra, Schult. f. Syst. vii. $1179=$ umbellulata

orientalis, Buch.-Ham. ex Wall. Cat, n. $5222=$ Aneilema Hamiltonianum.

repens, Linn. Sp. Pl. ed. II. 62.-Am. austr.

rosea, Pohl, ex Seub. in Mart. Fl. Bras. iii. I. $252=$ Tradescantia Gaudichaudiana.

umbellulata, Lam. Illustr. 1. 130. t. 35. f. 2.-Ins. Martinic.

CALLISTA, Lour. F1. Cochinch, $519(1790)=$ Dendrobium, Sw. (Orchid.)

amabilis, Lour. 1. c.-Cochinch.

CALlista, D. Don, in Edünb. N. Phíl. Journ. xvii. (1834) $154=$ Frica, Tourn.

acuminata, G. Don, Gen. Syst. iii. $813=$ E. Massoni. armata, G. Don, i. c. =E. Sparmanni.

Bandonia, G. Don, 1. c. =E. Irbyana.

Bedfordiana, G. Don, I. c. $814=$ E. Massoni

blanda, G. Don, I. c. $815=\mathrm{E}$. blanda.

Broadleyana, G. Don, 1. c. $813=$ E. Broadleyana

buccinaeflora, G. Don, 1. c. $=\mathrm{E}$. Massoni.

calostoma, G. Don, 1. c. $815=\mathrm{E}$. Massoni

Celsiana, G. Don, 1. c. $813=$ E. Thunbergii.

Cliffortiana, G. Don, 1. c. $815=\mathrm{E}$. tenuifora

comosa, D. Don, in Ediab. N. Phil. Journ. xvii. (1834)

$155=\mathrm{E}$. comosa.

Comptoniana, G. Don, Gen. Syst. iii. 813 = E. curvifolia.

Coventryana, G. Don, 1. c. $815=\mathrm{E}$. pavettaeflora.

daphniflora, G. Don, 1. c. = E. daphniflora.

daphnoides, G. Don, I. c. $=\mathrm{E}$. praestans.

denticulata, D. Don, in Edinb. N. Phil. Journ. xvii.

(1834) $155=\mathrm{E}$. denticulata.

fastigiata, G. Don, Gen. Syst. iii. $814=$ E. fastigiata

ferruginea, G. Don, 1. c. $813=\mathrm{E}$. squarrosa

fragrans, D. Don, in Edinb. N. Phil. Journ. xvii. (1834 $155=\mathrm{E}$. fragrans.

Humeana, G. Don, Gen. Syst. iii. $813=$ Erica fastigiata. hyacinthoides, G. Don, 1. c. $814=\mathrm{E}$. praestans.

inflata, G. Don, 1. c. = E. inflata.

infundibutiformis, G. Don, 1. c. $813=\mathrm{E}$. pavettaeflora.

Fuliana, G. Don, 1. c. =E. Walkeriana.

Lawsoniana, G. Don, 1. c. = E. Lawsoniana.

magnifica, G. Don, l. c. $813=$ E. Massoni.

metulaeflora, G. Don, I. c. = E. Massoni.

moschata, G. Don, 1. c. $815=\mathrm{E}$. Muscari.

mundula, G. Don, l. c. = E. fastigiata.

Muscari, G. Don, 1. c. $814=$ E. Muscari.

nidifiora, G. Don, 1. c. $815=$ E. Muscari.

Parmentieri, G. Don, 1. c. $=$ E. praestans.

pavettaeflora, G. Don, 1. c. $=\mathrm{E}$. pavettaeflora.

pellucida, D. Don, in Edinb. N. Phil. Journ. xvii.

(1834) $155=\mathrm{E}$. Walkeriana.

pellucida, G. Don, Gen. Syst. iii. $814=$ E. venusta.

praegnans, G. Don, 1. c. $813=\mathrm{E}$. ventricosa

praestans, G. Don, 1. c. $815=\mathrm{E}$. praestans.

primuloides, G. Don, 1. c. $816=$ E. fastigiata.

quadrangularis, G. Don, 1. c. = E. Massoni.

rigida, G. Don, 1. c. $815=$ E. Massoni.

Russeliana, G. Don, 1. c. =E. Russeliana.

Sainsburiana, G. Don, 1. c. $813=\mathrm{E}$. inflata

stellifera, G. Don, I. c. $815=\mathrm{E}$. Massoni.

struthiolaeflora, G. Don, 1. c. $=$ E. teretiuscula.

Srainsoniana, G. Don, 1. c. $816=\mathrm{E}$. Massoni.

Templeana, G. Don, 1. c. $814=$ E. Massoni.

tenuiflora, G. Don, 1. c. $812=\mathrm{E}$. tenuiflora.

tetragona, G. Don, 1. c. = E. tetragona.

thymifolia, Steud. Nom. ed. II. i. $258=$ E. thymifolia.

trossula, G. Don, Gen. Syst. iii. $815=$ E. Muscari.

undulata, G. Don, 1. c. $813=\mathrm{E}$. Massoni.

varia, $\mathrm{G}$. Don, 1. c. = E. varia.

ventricosa, D. Don, in Edinb. N. Phil. Journ. xvii

(1834) $155=\mathrm{E}$, ventricosa.

venusta, G. Don, Gen. Syst. iii. $815=\mathrm{E}$. venusta

verecund $a, \mathrm{G}$. Don, 1 , c.=E. Meuroni

Walkeria, G. Don, 1. c. $814=$ E. Walkeriana.

CALLISTACHYA, Rafin. in Med. Repos. New York v. (1808) $60=$ Veronica, Tourn. (Scrophular.). sibirica, Rafin. $1 . c_{0}=V$. sibirica

virginica, Rafin. 1. c. = V. virginica.
CALLISTACHYA, Sm. in Trans. Linn. Soc。 ix. (1808) $267=$ CALLISTACHYS, Vent.

CALLISTACHYS, Heuffel, in Flora, xxvii. (1844) 528 $=$ Carex, Linn. (Cyperac.).

pyrenaica, Heuffel, 1. c. $=\mathrm{C}$. pyrenaica.

CALLISTACHYS, Vent. Jard. Malm. 115. t. 115 (1803) =xylobium, Andr. (Legumin.)

carinata, Meissn. in Lehm. Pl. Preiss. i. $27=0$. carinatum.

cuneata, Heynh. Nom. i. $148=$ Isotropis stricta. cuneifolia, Sm. in Trans. Linn. Soc. ix. (1808) $266=$ Isotropis striata.

elliptica, Vent. Jard. Malm. $115=0$. ellipticum. lanceolata, Vent. 1. c. = O. Callistachys.

linariifolia, Hort. Mackay, ex Sweet, Hort. Brit. ed. I. 474, nomen $=0$. lineare

linariaefolia, G. Don, Gen. Syst. ii. $117=0$. lineare linearis, Benth. in Enwm. PI. Hueg, $27=0$. lineare. longifolia, Paxt. Mag. viii. $31=0$. Callistachys. ovata, Sims, Bot. Mag. t. 1925=O. Callistachys. oxylobioides, Meissn. in Lehm. PI. Preiss. i. $27=0$. capitatum.

parviflora, Benth. in Enum. Pl. Hueg. $27=0$. ineare.

purpurea, Van Houtte, ex Heynh. Nom. ii. $107=$ O. ellipticum.

retusa, Lodd. Bot. Cab. t. $1983=$ O. Callistachys.

sparsa, A. Cunn, ex Benth. in Ann. Wien. Mus. ii.

(1838) $69=$ O. Pultenaea.

spathulata, Meissn. in Lehm. Pl. Preiss. ii. $208=0$. spathulatum.

tetragona, Turcz. in Bull. Soc. Nat. Mosc. xxvi. (1853) I. $249=$ O. retusum.

CALLISTEMMA, Boiss. F1. Orient. iii. $-146(1875)=$ Scabiosa, Tourn. (Dipsac.).

brachiata, Boiss. 1. c. $=$ S. brachiata.

Sibthorpianum, Nym. Consp. $341=$ S. brachiata.

CALLISTEMMA, Cass. in Dict. Sc. Nat. vi. Suppl. 45 (1817), nomen prius $=$ Callistephus, Cass. (Compos.).

capitatum, Reichb. Hort. Bot. i. t. 84, sphalm.= Callistemon capitatus.

hortense, Cass, in Dict. Sc. Nat. vi. Suppl. 45; et Bull. Soc. Philom. (1817) $32=$ Callistephus chinensis.

indicum, G. Don, in Loud. Hort. Brit. $348=$ Boltonia indica.

CALLISTEMON, R. Br. in App. Flind. Voy. ii. 547 (1814). MYRTACEAE, Benth. \& Hook. f. i. 704.

acerosus, Miq. in Nederl. Kruidk. Arch. iv. (1859) 141 $=$ brachyandrus.

acerosus, Tausch, in Flora, xix. (1836) $411=$ pinifolius.

amoenus, Lem. in Illustr. Hortic. vii. t. 247.-Hab.?

arborescens, $\mathrm{F}$. Muell in Iinnaea, $\mathrm{xxy}$ (1852) $388=$ brachyandrus.

brachyandrus, Lindl. in Fourn. Hort. Soc. iv. (1849) 112.-Austral.

capitatus, Reichb. Ic. Exot. i. 59. t. $84=$ Kunzea capitata.

coccineus, F. Muell. Fragm. i. 13.-Austral.

Cunninghami, Hort. Berol. ex 'C. Koch, Wochenschr. vi. (1863) 294.-Austral.

flavescens, Regel, Gartenfl. (1861) 51.-Austral.

glaucus, Sweet, Fl. Austral. sub t. $29=$ speciosus.

Hainesii, F. Muell. 1. c. iii. $153=$ Kunzea Baxteri.

hybridus, $D C$. Prod. iii. 224.-Austral.

intermedius, Hort. Berol. ex Steud. Nom. ed. II. 1. 259. -Austral.

juniperinus, Heynh. Nom. i. 148.-Austral.

lanceolatus, Sweet, Fl. Austral. sub t. $29 ; D C$. Prod. iii. 223.-Austral.

leptostachyus, Sweet, 1. c. = salignus.

linearis, DC. Prod. iii. 223. - Austral.

linearifolius, DC. 1. c. = rigidus.

lophanthus, Sweet, F1. Austral. t. $29=$ salignus.

macrostachyus, Lindl. Bot. Reg. (1838) t. $7=$ Kunzea Baxteri.

marginatus, Sweet, Hort. Brit. ed. I. 155 ; DC. Prod. iii. $224=$ lanceolatus.

macrostachyus, Lindl. Bot. Reg. (1838) t. $7=$ Kunzea Baxteri.

\section{CALLISTEIMON}

nervosus, Lindl. in Mitch. Journ. Trop. Austral. $235=$ Melaleuca Leucadendron.

pallidus, DC. Prod. iii. $223=$ salignus

paludosus, F. Muell. Fragm. i. $14=$ salignus.

Pancheri, Brongn. Er Gris, in Bull. Soc. Bot. Fr. xi. (1864) 183; in Ann.Sc. Nat. Sér. V. ii. (1864) 138. -N. Caled.

pendulus, Regel, Gartenfl. (1859) 288.--Austral.

Phoeniceus, Lindl. Swan River App. 10.-Austral.

pinifolius, Sweet, Hort. Brit. ed. I. $155 ; D C$. Prod

iii. 223.-Austral.

pithyoides, Miq. in Nederl. Kruidk. Arch. iv. (1859 142 (sp. dub.).-Austral.

pungens, G. Don, ex Loud. Hort. Brit. 197.-Austral rigidus, $R$. Br. in Bot. Reg. t. 393.-Austral. rugulosus, DC. Prod. iii. $223=$ rigidus.

rugulosus, Miq. in Nederl. Kruidk. Arch. iv. (1859) $141=$ coccineus.

salignus, Sweet, Fl. Austral. sub t. $29 ; D C$. Prod. iii. 223.-Austral.

scaber, Lodd. Bot. Cab.t. $1288=$ lanceolatus.

semperflorens, Lodd. l. c. t. 523.-Austral.

Sieberi, DC. Prod. iii. 223 = salignus.

speciosus, $D C$. . . c. 224.-Austral.

suberosus, Brongn. Eั Gris, in Bull. Soc. Bot. Fr. xi. (1864) 183. - N. Caled

teretifolius, F. Muell. in Linnaea, xxv. (1852) 387.Austral.

viminalis, G. Don, ex Loud. Hort, Brit. $197=$ rigidus,

viridiflorus, Sweet, Hort. Brit. ed. I. $\mathbf{1 5 5}=$ salignus.

CALLISTEPHANA, Fourr. in Ann. Soc. Linn. Lyon, N. S. xvi. (1868) $367=$ Coronilla, Linn. (Legumin.) varia, Fourr. 1. c. = C. varia.

CALLISTEPHUS, Cass. in Dict. Sc. Nat. xxxvii. 491(1825). COMPOSITAE, Benth. \& Jook. f, ii. 270. Callistemma, Cass. 1. c. vi. Suppl. 45 (1817) nomen prius.

biennis, Lindl. ex DC. Prod. v. $275=$ Heteropappus hispidus.

chinensis, Nees, Gen. et Sp. Ast. $222=$ hortensis

concolor, DaIz. in Hook. Kew Journ. ii. (1850) $344=$ Pulicaria angustifolia.

Heyneanus, DC. Pród. v. $275=$ Pulicaria Wightiana.

hortensis, Cass. in Dict. Sc. Nat. xxxvii. 491.Sibiria; China.

indicus, DC. Prod. v. $275=$ Boltonia indica.

Wightianus, DC. 1. c.=Pulicaria Wightiana.

CAILISTHENE, Mart. Noy. Gen. et Sp. i. 123. t. 75, 76 (1824). VOCHYSIACEAE, Benth. \& Hook. f. i. 976 .

Blanchetii, Warm. in Mart. Fl. Bras, xiii. II, 26.-Am. trop.

erythroclada, Warm. l. c. 28.-Am. trop.

fasciculata, Mart. Nov. Gen. et Sp. i. 126.-Bras.

major, Mart. l. c. 124.t. 75.-Bras.

microphylla, Warm. in Mart. Fl. Bras. xiii. II. 28.Am. trop.

minor, Mart. Nov. Gen. et Sp. ii. 126. t. 76.-Bras.

mollissima, Warm. in Mart. Fl. Bras. xiii. II. 26.-

Am. trop.

CALLISTHENIA, Spreng. Gen. i. $8(\mathbf{1 8 3 0})=$ praec.

CALLISTROMA, Fenzl, in Flora, xxvi.. (1843) 457 ; Endl. Gen. Suppl. ili. $82(1843)=$ Oliveria, Vent. (Umbell.).

erubescens, FenzI, 1. c. $=$ O. orientalis.

CALLITHAMNA, Herb. Amaryll. 225 (1837) = Stenomesson, Herb. (Amaryllid.).

angustifolium, Herb. in Bot. Mag. t. 3866. f. b= S. viridiflorum

Hartwegianum, Van Houtte, ex Heynh. Nom. ii. 108, nomen $=\mathrm{S}$. aurantiacum ?

spathulatum, Herb. Amaryll. 225.-'Truxillo.'

viridiflorum, Herb. 1. $\mathrm{c} .=\mathrm{S}$. viridiflorum.

CALIITRICHE, Linn. Syst. ed. VI. 82 (1748), HALORAGEAE, Benth. \& Hook. fo i. 676.

Stellaria, Hall. Enum. Stirp. Helv. i. 198 (1742). Stellina, Bubani, in Nuov. Giorn. Bot. Ital. v (1873) 318.

aestivalis, Thuil, F1. Par. 2 =stagnalis 
CALLITRICHE :

alpina, Schur, in Oestr. Bot. Zeitschr. (1858) $403=$ verna. amblyocarpa, Scheidw. ex Hegelm. Monog. Callit. 61 =truncata.

androgyna, Linn. Cent. Pl. Rar. i. $31=$ verna. angustifolia, Gilib. Exercit. ii. $421=$ autumnalis. angustifolia, Hoppe, Taschenb. (1792) $160=$ verna. antarctica, Engelm. ex Hegelm. in Verh. Bot. Ver. Brandenb. ix. (1867) 20.-Reg. Antarct. aquatica, Huds. F1. Angl, ed. II. $439=$ verna?

Asagraei, Hegelm. Monog. Callit. 54. t. 3. f. 9.Am. bor.

attenuata, Delastre, Fl. DÉ. Vienne, 144.-Gallia. autumnalis, A. Gray, ex Hegelm. Monog. Callit. 55 = Asagraei.

autumnalis, Kuetz. in Linnaea, vii. (1832) $186=$ hamulata.

autumnalis, Bertol. ex Steud. Nom. ed. II. i, $259=$ Berteroniana.

autumnalis, Brot. ex Steud. 1. c. =latifolia.

autumnalis, Linn. Fl. Suec. ed. II. n. 4.-Europ. ; Am. bor.

autumnalis, Michx. F1. Bor. Am, i. 2= Peplis diandra. autumnalis, Pollich, F1. Palat. $3=$ verna.

Berteroniana, Steud. Nom. ed. II. i. 259.-Chili

Bolanderi, Hegelm. in Verh. Bot. Ver. Brandenb. x.

(1868) 116.-Am. bor. occ

brachycarpa, Hegelm. l.c. 115.-Austral

brevifolia, Pursh, Fl. Am. Sept. i. 8.-Am. bor:

brutia, Petagna, Inst. Bot. ii. $10=$ hamulata.

capillaris, Parl. Fl. Ital. iv. 423. - Italia.

cespitosa, Schultz, Prod. Fl. Stargard. 2 = verna.

confervoides, Thuil. ex Link, in Spreng. Jahrb. Gew.

iii. $30=$ autumnalis.

connata, Rafin. in Med. Rep. New York, Ser. III. ii.

(1811) 4,08 = hamulata.

cophocarpa, Sendtn. ex Hegelm. Monog. Callit. $55=$ verna.

cruciata, Lebel, ex Hegelm. in Verh. Bot. Ver. Bran-

denb. ix. (1867) $38=$ truncata.

cruciata, Rafin. in Med. Rep. New: York, Ser. III. ii (1811) 408.-Am. bor.

cuneifolia, A. Br. ex Hegelm. in Verh. Bot. Ver Brandenb. ix. (1867) $21=$ verna.

cyclocarpa, Hegelm.l. c. x. (1868) 116.-Austral.

decussata, Link, in Spreng. Jahrb. Gew. iii. $30=$ autumnalis.

decussata, Schur, Enum. Pl. Transs. $217=$ hamulata.

deflexa, A. Br. in Hegelm. Monog. Callit. 58. t. 3.Am. bor. et austr.

dioica, Petagn. Inst. Bot. ii. 10.-Italia.

dioica, Schur, in Verh. Siebenb. Ver. Naturw. (1859) 98 $=$ stagnalis.

Drummondi, Hegelm. Monog. Callit. 60.-Austral.

dubia, Hoffm. Obs. Bot. n. 1 ; ex Roth, Tent. Fl. Germ. i. $389=$ verna,

euautumnalis, Syme, Engl. Bot. ed. III. viii. $122=$ autumnalis.

euverna, Syme, 1. c. $119=$ verna

foliosa, Rafin, in Med. Repos. New York, V. (1808) 354 = autumnalis.

fontana, Scop. Fl. Carn. ed. II. ii. 251 = verna

genuina, Ducommun, Taschenb. 243 = hamulata

glomerata, Thuill. ex Link, in Spreng. Jahrb. Gew. iii

$30=$ autumnalis.

graminea, Link, 1. c. = truncata

hamulata, Kuets. ex Koch, Syn. Fl. Germ. ed. II. 271. -Europ.

hermaphrodita, Linn. Cent. P1. Rar. i. $31=$ verna.

heterophylla, Pursh, F1. Am. Sept. i. $3=$ verna.

heteropoda, Engelm, ex Hegelm. in Verh. Bot. Ver.

Brandenb. ix. (1867) 40.-Am. anst:

intermedia, Hoffm. Fl. Germ. (1791) 2 = hamulata.

intermedia, Hoppe, Taschenb. (1792) $159=$ verna.

japonica, Engelm. ex Hegelm. in Verh. Bot. Ver.

Brandenb. x. (1868) 113.-Japon.

K"uetringi, Rupr. Fl. Ingric. $378=$ stagnalis.

latifolia, Gilib. Exercit. it. 421 = hamulata vel verna.

latifolia, Link, ex Steud. Nom. ed. II. i. 259.-Lusitan.

linearis, Pursh, Fl. Am. Sept. i. 3 =autumnalis.

macropteryx, Hegelm. Monog. Callit. 59.-Austral.

marginata, Torr. in Pacif. Rail. Rep. iv, 135.-Calif. Chili.

Mandonis, Heurck or Muell. Arg. in Heurck, Obs. Bot. 136.-Ecuador.

microcarpa, Engelm. ex Hegelm. in Verh. Bot. Ver.

Brandenb. x. (1868) 118. - Cuba.

minima, Hoppe, Taschenb. (1792) $157=$ verna.

\section{CALLITRICHE :-}

minor, Bellynck, Fl. Namur (1855), $232=$ stagnalis

Muelleri,Sond. in Linnaea, xxviii. (1856) 229.-Austral. Nuttallii, Torr. in Pacif. Rail. Rep. iv. 135.-Am. bor. obtusangula, Le Gall, ex Hegelm. Monog. Callit. 54 -Europ.

occidentalis, Hegelm. l. c. 57. t. iv, 5.-Cuba:

ovata, Rafin. in Med. Rep. New York, Ser. III. di

1811) 408.-Am. bor.

pallens, Bieb. Fl. Taur. Cauc. iii. $6=$ hamulata.

pallens, Goldb. in Mém. Soc. Nat. Mosc. v. (1817)

$118=$ verna.

palustris, Linn. Sp. Pl. 969=autumnalis.

pedunculata, DC. Fl. Fro iv. $415=$ hamulata.

pedunculata,A. Gray, Man. ex Hegelm. Monog. Callit.

$58=$ deflexa.

pendunculata, F. Muell. ex Hegelm. l. c. $61=$ truncata.

pedunculosa, Nutt. in Trans. Am. Phil. Soc. N. S. v.

(1837) 140.-Am. bor

peploides, Nutt. \%.c. 141.-Am. bor.

platycarpa, Kuetz, in Linnaea, vii (1832) $174=$ stagnalis.

plena, Rafin. in Med. Rep. New York, Ser. III. ii

(1811) 408.-Am. bor.

polymorpha, Loennroth, Obs. Crit. Pl. Suec. 19 (1854). -Scania.

refiexa, Lange, in Cutanda, F1. Matrit. $292=$ hamulata. sepulta, S. Wats. in Proc. Am. Acad. xiv. (1879) 298. -Am. bor. occ.

sessilis, DC. F1. Fr. iv, $414=$ autumnalis, verna

Sonderi, Hegelm. in Verh. Bot. Verh. Brandenb. ix. (1867) 18.-Austral.

spuria, Rafin. in Med. Repos. New York, v. (1808) 354.-Am. bor.

stagnalis, Scop. Fl. Carn. ed, II. ii. 251.--Europ Ind or.

Stellaxia, Rafin. in Med. Rep. New York, Ser. III. ii. (1811) $408=$ autumnalis.

stenocarpa, Hegelm. in Verh. Bot. Ver. Brandenb. x

(1868) 114.-Calif.

stellata, Hoppe, Taschenb. (1792) $158=$ verna

tenuifalia, Fries, Novit. F1. Suec. $280=$ hamulata

tenuifolia, Gennari, ex Parl. F1. Ital.iv. 424=capillaris.

tenuifolia, Thuil. ex Pers. Syn. i. $6=$ verna.

terrestris, DC. Prod. iii. $71=$ deflexa.

terrestris, Muhl. ex Rafin. l.c. Ser. III. ii. (1811) 408.

-Am. bor.

terrestris, Rafin. in Med. Repos. New York, v. (1808) $358=$ brevifolia.

transsilvanica, Schur, Enum. Pl. Transs. $216=$ stagnalis. truncata, Guss. Pl. Rar. 4.-Italia.

turfosa, Bert.. in Am. Fourn. Sc. xix. (1831) 308,

nomen; Hegelm. Monog. Callit. 59.-Chili.

turfosa, Schur, Enum. Pl. Transs. 216.-Transsylv.

umbonata, Hegelm. in Verh. Bot. Ver. Brandenb. ix

(1867) 19.-Tasmania.

verna, Hook. f. Fl. Antarct. i. 11 =antarctica.

verna, Linn.Fl. Suec, ed. II. ii. n. 3.-Europ.; Am. bor.

verna, Linn. l. c. partim $=$ polymorpha.

verna, Savi, Fl. Pis, i, $4=$ stagnalis.

vernalis, Kuetz, in Linnaea, vii. (1832) $175=$ verna

virens, Goldb. in Mém. Soc. Nat. Mosc。 v. (1817) 119

$=$ autumnalis

Wightiana, Wall. Cat. n. $7008=$ stagnalis.

CALIITRIS, Vent. Decad. (1808) 10. CONIFERAE Benth. \& Hook. f. iii. 424

Frenela, Mirb. in Mém. Mus. Par. xiii. (1826) 30

Fresnelia, Steud. Nom, ed. II. i. 648 (1840)

LEICHHARDTIA, Sheph, Cat. Pl. Cult. Sydn. (1851) 15

PACHYlepis, Brongts, in Ann. Sc. Nat. Sér. I. Xx. (1833) 189 .

OCtoclinis, $\mathrm{E}$. Muell, in Trans. Phil. Inst. Vict. (1858) 21

Parolinia, Endl. Gen. Suppl. i. 1372 (1841)

WIDDRINGTONIA, Endi. 1. c. ii. 25 (1842)

Actinostrobus, F. Muell. Rep. Burdek. Exp. 19=

Actinostrobus pyramidalis.

acuminata, F. Muell. Census, 109.-Austral.

arborea, Schrad. ex E. Mey. Zwei Pfl. Docum. 79 nomen.-Afr. austr.

arenosa, Sweet, Hort. Brit. ed. II. 478, nomen $=$ rhomboidea.

articulata, Hort. ex Gord. Pinet. ed. II. 117=rhom boidea.

australis, Swcet, Hort. Brit. ed. II. $474=$ rhomboiden. calcarata, R. Br. ex Mirb. in Mim. Mus. Par. xiii (1825) 74.-Austral.

capensis, Schrad. ex Gord. Pinet. $393=$ cupressoides.

\section{CALLITRIS:-}

columellaris, F. Mnell. Fragm, v. 198=robusta. conglobata, Sieber, ex Heynh. Nom. i. 148.-Austral. cupressiformis, Vent. Decad. $10=$ rhomboidea. cupressoides, Schrad. ex E. Mey. Zwei Pfl. Docum. 126.-Afr. austr.

Drummondii, Benth. E Hook. f. ex F. Muell. Census, 109.-Austral.

elegans, Sieber, ex Heynh. Nom. i. 149.-Austral Fothergillii, Loud. Encycl. Trees, $1072=$ australis. fruticosa, R. Br. ex Rich. Conif. $49=$ calcarata. glauca, R. Br. ex Mirb. in Mém. Mus. Par. xiii. (1825) $74=$ robusta

Gunnii, Hook, f. in Hook. Lond. Joum. iv, 1845 147 = australis.

Hugelii, Knight, Syn.Conif. 14.-Austral.

Macleayana, F. Muell. in Rep. Burdek. Exped. 17 Extra-Trop. Pl. Am. ed. (1884) 65.-Austral. macrostachya, Hort. ex Steud. Nom. ed. II. i. $260=$ quadrivalvis.

montana, Sieber, ex Heynh. Nom. i. 149.-Austral.

Muelleri, Benth. E Hook. f. ex F. Muell. Census, 105 - Austral.

oblonga, Rich. Conif. 49. t. 18. f. 2.-Austral.

Parlatorei, F. Muell. Fragm, v, 186.-Austral.

Preissiz, Miq. in Lehm. P1. Preiss. i. $643=$ robusta.

propinqua, R. Br. ex Endl. Syn. Conif. $38=$ robusta.

pyramidalis, Sweet, Hort. Brit. ed. II. $473=$ calcarata

quadrivalvis, Vent. Decad. 10.-Afr. bor.

rhomboidea, R. Br. in Rich. Conif. 47.t. 18.-Austral.

robusta, $R$. Br ex Mirb, in Mém. Mus. Par xiil.

(1825) 74.-Austral.

Roei, Benth. E Hook.f. ex F. Muell. Census, 109.Austral.

stricta, Schrad, ex Carr. Conif. ed. I. $66=$ cupressoides triquetra, Hort ex Loud. Encyc. Trees, $1072=$ quadrivalvis ?

tuberculata, R. Br. ex Endl. Syn. Conif. $38=$ robusta.

Ventenatii, R. Br. ex Mirb. in Mém. Mus. Par. xiii. (1825) $74=$ rhomboidea.

verrucosa, R. Br. ex Mirb. 1. c. = robusta.

CALLIXENE, Comm. ex Juss. Gen. 41 (1789)=Luzuriaga, Ruiz \& Pav. (Liliac.)

magellanica, Raeusch. Nom. ed. III. $98=$ L. marginata.

marginata, Lam. Illustr. t. $248=\mathrm{L}$. marginata.

melantha, Colenso, in Trans. N. Z. Inst. xvii. (1885 $250 .-\mathrm{N}$. Zel.

parviflora, Hook. f. in Hook. Ic. PI. t. $632=\mathrm{L}$. parviflora.

polyphylla, Hook. 1. c. t. $674=$ L. erecta,

CALlopisma, Mart. Nov. Gen. et Sp. ii. 107. t. 183, $184(1827)=$ Deianira, Cham, \& Schlecht (Gentian.)

amplexifolizm, Mark. 1. c. $109=$ D. nervosa

cordifolium, Lhotsky, ex Griseb. in DC. Prod. ix. $45=$

D. erubescens.

perfoliatum, Mart. Nov. Gen. et Sp. ii. $10 s=\mathrm{D}$. crubescens.

CALlosmIA, Presl, Bot. Bemerk. $103(1544)=\mathbf{A n}$ neslea, Wall. (Temstroem.).

fragrans, Presl, l, c. = A. fragrans.

CALLOSTYLIS, Blume, Bijdr. 340. t. $i \pm(1525)=$ Eria Lindl. (Orchid.)

rigida, Blume, 1. c. $=$ E. palchella.

CALlOTROPIS, G. Don, Gen. Syst. ii. 228 '1932" = Galega Linn. (Legumia.)

tricolor, G. Don, I. c. $=\mathrm{G}$. officinalis.

CALLUNA. Salisb, in Truns, Linn. Soc, vi. (1s(1.2) 317. ERICACEAE. Benth. \& Hook. f. ii. 599 . allanica, Secm. in Journ. Hot. iv. (1506), S00 rulgaris.

ciliaris, Schur, Enum. Pl. "Trans, $f t \bar{t}=$ ralgaris.

Erica, DC. Fl. Fr. iii. $6 \$ 0=$ vulgaris.

germing, Ducommun, Taschenb. 491 = val caris

sibritacfulia, S. F. Gray, Nat. Arr. ii. $999=$ val caris.

rulgaris, Salisb. in Trans. Limm. Sor. vi. (1s02, \$1\%.kurop.; Ams, bor. 
CALOBOTA, Eckl, \& Zeyh. Enum. $192(1836)=$ Lebeckia, Thunb. (Legumin.)

cytisoides, Eckl. \& Zeyh. 1. c. 191=L. cytisoides.

decipiens, Bentb. in Ann. Wien. Mus. ii. (1838) $142=$ L. decipiens.

decutiens, Benth, 1, c. $=$ L. decutiens.

flexuosa, Benth. 1. c. = L. flexuosa.

multiflora, Benth. 1. c. $=$ L. multiflora.

pulchella, Eckl. \& Zeyh. Enum. 191=L. cytisoides.

'AlobotryA, Spach, in Ann. Sc. Nat. Sér. II. iv (1835) 21 =Ribes, Linn. (Saxifr.).

sanguinea, Spach, $1 . \mathrm{c} .=\mathrm{R}$. sanguineum.

CALOCEDRUS, Kurz, in Journ. Bot. xi. (1873) 196. t. 133 = Libocedrus, Endl. (Conifer.)

macrolepis, Kurz, 1. c. = L. macrolepis.

CALOCEPHALUS, R. Br. in Trans. Linn. Soc, xii. (1817) 106. COMPOSITAE, Benth. \& Hook. f. ii. 520 .

Achrysum, A. Gray, in Hook. Kew Journ, iv. (1852) 228 .

BlenNospora, A. Gray, 1. c. iii. (1851) 172.

Leucophyta, R. Br. in Trans. Linn. Soc. xii (1817) 106.

Pachysurus, Steetz, in Lehm. Pl. Preiss. i. 441 (1845)

aeruoides, Benth. Fl. Austral, iii. 576.-Austral. angianthoides, Benth. l. c.575.-Austral

Brownii, F. Muell. Rep. Babb. Exp. 13.-Austral.

chrysanthus, Schlecht in Linnaea, xx. (1847) $592=$ Craspedia chrysantha.

citreus, Less. Syn. Comp. 271.-Austral.

Drummondii, Benth. Fl. Austral. iii. 574,-Austral.

Francisii, Benth.l. c. 576.-Austral.

gnaphalioides, Hook, in Mitch. Journ. Trop. Austral. $378=$ Helipterum moschatum.

lacteus, Less. Syn. Comp. 271.-Austral.

multiforus, Benth. Fl. Austral. iii. 576.-Austral.

platycephalus, Benth. l. c.-Austral.

Sonderi, F. Muell. 2nd Gen. Rep. (1854); et Rep. Babb. Exp. 13.-Austral.

\section{CALOCHILUS, R. Br. Prod. 320 (1810)。 ORCHI-} $D E A E$, Benth, \& Hook. f. iii. 614

campestris, $R . B r . l$. c.-Austral.

herbaceus, Lindl. Gen. et Sp. Orch. $459=$ campestris. paludosus, R. Br. Prod. 320.-Austral

Robertsoni, Benth. Fl. Austral. vi. 315.-Austral.

CALOCHLAMYS, Presi, Bot. Bemerk. 148 (1844)= Congea, Roxb. (Verbenac.)

capitata, Presl, 1. c. $149=$ Congea tomentosa.

CALOCHORTUS, Pursh, Fl. Am. Sept. i. 240 (1814) LILIACEAE, Benth. \& Hook. f. iii. 820 .

Cyclobothra, G. Don, in Sweet, Brit. Flow. Gard, t. $273(1829)$.

albus, Dougl. ex Benth. in Maund E Hensl. Botanist, t. 98.-Calif.

apiculatus, Baker, in fourn. Linn. Soc, xiv. (1875) 305.-Am. bor. occ.

aureus, S. Wats. in Am. Natural. vii. (1873) 303.Calif.

Barnardi, Dougl.ex Steud. Nom, ed. II. i. 260.-Am. bor, occ.

Benthami, Baker, in Fourn. Linn. Soc. xiv. (1875) 304.-Calif.

Bonplandianus, Schult. f. Syst. vii. 1532.--Mexic

caeruleus, S. Wats. in Proc. Am. Acad. xiv. (1879)

263.-Calif.

Catalinae, S. Wats. l. c. 268.-Calif.

citrinus, Baker, in Bot. Mag. t. 6200.-Calif.

clavatus, S. Wats. in Proc. Am. Acad. xiv. (1879) 265. -Calif.

Douglasianus, Schult. f. in Van Hall, Bijdr. iv. 127. - Am. bor. occ.

elegrans, Baker, in Journ. Linn. Soc. xiv. (1875) $305=$ lilacinus, nudus et Tolmiei

elegans, Hook. f. Bot. Mag.t. $5976=$ Maweanus elegans, Pursh, Fl. Am. Sept. i. 240-Am. bor. occ. eurycarpus, S. Wats. in Bot. King, Exp. $348=$ nitidus. flavus, Schult.f. Syst. vii. 1535.-Mexic.

flexuosus, S. Wats. in Am. Natural vii. (1873) 303.Am. bor. occ.

fuscus, Schult.f. Syst. vii. 1534.-Mexic.

\section{CALOCHORTUS :-}

Ghiesbreghtianus, S. Wats. in Proc. Am. Acad. xiv. (1879) 268.-Mexic.

glaucus, Regel, Gartenfl. (1875) 260 ; et in Act. Hort. Petrop. iii. II. (1875) $285=$ caeruleus.

Greenei, S. Wats. in Proc. Am. Acad. xiv. (1879) 264 -Am. bor. occ.

Gunnisoni, S. Wats. in Bot. King, Exp. 348.-Am bor. occ.

Hartwegii, Benth. Pl. Hartw. 26.-Mexic.

Kennedyi, Porter, in Coult. Bot. Gaz. ii. (1877) 79.Calif

Leichtlinii, Hook. f. Bot. Mag. t. $5862=$ Nuttallii.

lilacinus, Kellogg, in Proc. Calif. Acad. ii. (1863) 5.Calif.

longebarbatus, S. Wats. in Proc. Am. Acad. xvii (1881-82) 381.-Am. bor. occ.

Iuteus, Dougl. ex Kunth, Enum. Pl. iv. 233.-Calif.

luteus, Nutt, in Journ. Acad. Phil. vii. (1834) $53=$

Nuttallii.

Lyallii, Baker, in Journ. Linn. Soc. xiv. (1875) $305=$ elegans.

macrocarpus, Dougl. in Trans, Hort. Soc. vii. (1830) 276. t. 8.-Am. bor. occ.

Maweanus, Leichtl. ex Baker, in Fourn. Linn. Soc. xiv. (1875) 305.-Am, bor. occ

monophyllus, Lem. in Fl. des Serres, Sér. I. v. (1849) 430 b.-Calif.

nitidus, Dougl. in Trans. Hort Soc. vii. (1830) 277. 9.-Calif.

nitidus, Torr. Pacif. Rail. Rep. iv. $146=$ Benthami.

nudus, S. Wats. in Proc. Am. Acad. xiv. (1879) 263.Calif.

Nuttallii, Torr. E Gray, in Pacif. Rail. Rep. ii. 124 -Am, bor. occ.

Palmeri, S. Wats. in Proc. Am. Acad. xiv. (1879) 266 -Calif.

pallidus, Schnlt. f. Syst. vii. $1533=$ flavus.

parviflorus, Nutt. ex Baker, in Journ. Linn. Soc. xiv. (1875) $306=$ Nuttallii.

pulchellus, Dougl. ex Benth. in Trans. Hort. Soc Ser. II. i. (1835) 412.-Calif.

purpureus, Baker, in Journ. Linn. Soc. xiv. (1875) 308 , pro parte $=$ Bonplandianus

pusillus, Dougl. ex Steud. Nom. ed. II, i. 260.-Am. bor, oce.

spatulatus, S. Wats. in Proc. Am. Acad. xiv. (1879) 267.-Mexic.

splendens, Dougl. ex Benth. in Trans. Hort. Soc. Ser II. i. (1835) 411 . t. 15.-Calif.

Tolmiei,Hook. E Arn. Bot. Beech. Voy, 398--Calif. umbellatus, Wood, in Proc. Nat. Sc. Philad. (1868) $168=$ lilacinus.

uniflorus, Hook. Er Arn. Bot. Beech. Voy. Suppl. 398 -Calif.

uniflorus, Hook. f. Bot. Mag. t. 5804=lilacinus.

venustus, Dougl. ex Benth. in Trans. Hort. Soc. Ser.

II. i. (1835) 412 t. 15. f. 3-Calif.

vestitus, Benth. ex Steud. Nom. ed. II. i. 260.Calif.

Weedii, Wood, in Proc. Nat. Sc. Philad. (1868) $169=$ luteus

CALOCOCCUS, Kurz, ex Teijsm, \& Binn. in Nat. Tijdschr. Nederl. Ind. xxvi. (1864) $48=$ Phyllanthus, Linn. (Euphorbiac.).

sundaicus, Kurz, 1. c. = P. sundaicus.

CALODENDRUM, Thunb. Nov. Gen. ii. 41 (1782). RUTACEAE, Benth. \& Hook. f. i. 288.

Partasia, Houtt. Handleid. ii. 382 (1775).

capensis, Thunb. l. c. 43 ; et Prod. Pl. Cap. 44.Afr. austr.

CALODIUM, Lour. F1. Cochinch. $247(1790)=$ Cas sytha, Linn. (Laurin.)

cochinchinensis, Lour. 1. c. = Cas. filiformis

CALODONTA, Nutt. in Trans. Am. Phil. Soc. Ser. II. vii. (1841) $448=$ Tolpis, Adans. (Compos.).

azarica, Nutt. l. $\mathrm{c}_{.}=\mathrm{T}$, virgata.

CALODRACON, Planch. in Fl. des Serres, Sér. I. vi. (1850-51) 132, $137=$ Cordyline, Comm. (Liliac.) heliconiaefolia, Planch. 1. c. = Cord. heliconiaefolia. Facquini, Planch. 1. c. = Cord. Jacquinii.

nobilis, Planch. 1 , c. vii. (1851-52) 105. t. 682, 683.-

Japon.
Sieberi, Planch. 1. c. vi. $(1850-51) 132=$ Cord. Sieberi.
CALODRACON :-

Sieboldii, Planch. in Fl des Serres, Sér. I. vi. 137=

Dracaena Sieboldii.

terminalis, Planch. 1. c. $=$ Cord. terminalis

venusta, Planch. 1 . c. $132=$ Dracaena venusta.

CALODRYUM, Desv. in Ann. Sc. Nat. Sér. I. ix. (1826) 401. t. $51=$ Quivisia, Comm. (Meliac.).

tubiflorum, Desv. 1. c. $=$ Q. lanceolata.

CALOGYNE, R. Br. Prod. 579 (1810). GOODENOVIEAE, Benth. \& Hook. f. ii. 539

Distylis, Gaudich, in Freyc. Voy. Bot, 460. t. 80 (1826).

Berardiana, F. Muell. Fragm. vi. 7.-Austral.

chinensis, Benth. in Fourn. Linn. Soc. v. (1861) 78.China.

distylis, F. Muell. Fragm, vi, 6= Berardiana.

heteroptera, $F$. Muell. Fragm x: 43.-Austral

pilosa, R. Br. Prod. 579.-Austral.

purpurea, F. Muell. Fragm. viii. 57.-Austral,

CALOMECON, Spach, Hist. Vég. Phan. vii. 7 (1839) = Papaver, Tourn.

bracteatum, Spach, l. c. $9=$ P. bracteatum.

orientale, Spach, 1. $\mathrm{c}_{\mathrm{.}}=\mathrm{P}$. orientale.

CALOMERIA, Vent. Jard. Malm. 73. t. $73(1804)=$ Humea, Sm. (Compos.)

amaranthoides, Vent. 1. c。 $=$ H. elegans.

CALOMORPHE, Kunze, ex Walp. Rep.i. 680 (1840)= Lennea, Klotzsch (Legumin.)

Ehrenbergiana, Kunze, ex Walp. 1. c. = L. robinioides.

CALOMYRTUS, Blume, Mus. Bot. Lugd. Bat. i. 76, in obs. $(1849)=$ Myrtus, Tourn.

excelsa, Blume, l. $\mathrm{c} .=\mathrm{M}$. excelsa

ovalifolia, Blume, 1. c. = M, ovalifolia.

CALONNEA, Buchoz, Icon. (1786) t. $126=$ Gaillardia, Fonger. (Compos.).

pulcherrima, Buchoz, 1. c. = G. pulchella.

CALONYCTION, Choisy, in Mém. Soc. Phys. Genèv. vi. 441 (1833) (Conv. Or. 59) = Ipomoea, Linn. (Convolvul.).

acanthocarpum, Choisy, in DC. Prod. ix. $346=$ I. acanthocarpa.

asperum, Choisy, Conv. Or. $60=\mathrm{I}$. grandiflora.

Bona-nox, Boj. Hort. Maurit. $228=\mathrm{I}$. Bona-nox.

capillatum, Miq. F1. Ind. Bat. ii. $598=$ I. capillata.

chenopodifolium, Mart. \& Gal. in Bull. Acad. Brux.

xii. II. (1845) $269=$ I. chenopodifolia

clavatum, G. Don, Gen. Syst. IV. 264.-Ecuador.

comorensis, Boj. Hort. Maurit. $228=\mathrm{I}$. grandiflora.

comespermum, Boj. I. c. = I. grandiflora.

diversifolium, Hassk. Pl. Jav. Rar. 523 = I. tricho-

sperma.

dubium, Mart. \& Gal. in Bull. Acad. Brux. xii. II (1845) $268=\mathrm{I}$. dubia

Galeottii, Martens, ex Mart. \& Gal. 1. c.-Mexic.

grandiflorum, Choisy, Conv. Or. $60=\mathrm{I}$. grandiflora.

Facquinii, G. Don, Gen. Syst, iv, 264=I. grandiflora. longiflorum, Hassk. PI. Jav. Rar. $523=$ I. grandiflora. mantholewcum, Colla, N.Sp Calon $15=$ - B Bona-nox. macranthum, Van Houtte, ex Poit. in Rev. Hortic. Sér. II. iv. (1845-46) 409.-Hab. ?

megalocarpum, A. Rich. FI. Cub. Fanerog. ii. $129=$ I. Bona-nox.

mollissimum, Zoll. Syst. Verz. Ind. Archip. 128, 131. - Java.

muricatum, G. Don, Gen. Syst. iv. $264=$ I. Bona-nox. muticum, Decne, in Nouv. Ann. Mus. Par. iii. (1834) $390=$ I. grandiflora

noctolucum, G. Don, in Sweet, Hort. Brit. ed. III. 482 $=$ I. latiflora.

proximum, Mart. \& Gal, in Bull. Acad. Brux, xii. II. (1845) $268=\mathrm{I}$. proximum.

pseudomuricatum, G. Don, Gen. Syst. iv. $264=$ I. grandiflora.

pteripes, G. Don, 1. c.-Ecuador.

pterodes, Choisy, in DC. Prod. ix. $346=$ praec

pulcherrimum, Parodi, Contrib. 12.-Paraguay.

Rheedi, Colla, N. Sp. Calon, $15=\mathrm{I}$. Bona-nox.

Roxburghii, G. Don, Gen. Syst. iv. $263=\mathrm{I}$. Bona-nox. sanguineum, Hort.-Cf. Gard. Chron. (1865) 934= Lettsomia Kurzii.

sanguinolentum, Guillon, in Rev. Hortic. (1880) 20. -Hab. ? 


\section{CALONYCTION :-}

speciosum, Choisy, Conv. Or. $59=\mathrm{I}$. Bona-nox, trichospermum, Choisy, 1. c. $60=\mathrm{I}$. trichosperma. Tuba, Colla, Nov. Sp. Calon. $15=\mathrm{I}$. grandiflora? venustum, Mart. \& Gal. in Bull. Acad. Brux, xii. II. (1845) $269=$ I. venustum.

CALOPAPPUS, Meyen, Reise, i. $315(1834)=\mathbf{N a s s a u}$ via, Juss. (Compos.)

acanthifolius, Remy, in C. Gay, Fl. Chil. iii. 298.Chili.

acerosus, Meyen, Reise, i. $315=\mathrm{N}$, acerosa.

CALOPETALON, J. Drum. ex Harv. in Hook. Kew Journ. vii. (1855) $52=$ Marianthus, Hueg. (Pittospor.).

ringens, J. Drum. 1. c. $53=\mathrm{M}$. ringens.

CALOPHACA, Fisch. Hort. Gorenk. ed. II. 67 (1812); et in DC. Prod. ii. 270 (1825). LEGUMINOSAE, Benth. \& Hook. f. i. 505

ChesNeya, Lind1. in Endl. Gen. 1275 (1840)

Hovenii, Schrenk, Enum. Pl. Nov. 74.-Soongaria

juncea, Steud. Nom. ed. II. i. 260, sphalm.= Caligo num Calliphysa.

soongorica, Kar. \& Kir. in Bull. Soc. Nat. Mosc. (1841) $401=$ Hovenii.

wolgarica, Fisch. Hort. Gorenk. ed. II. (1812) 68.Ross, austr.

CALOPHANES, D. Don, in Sweet, Brit. Flow. Gard. Ser. II. t. 181 (1833). ACANTHACEAE, Benth, \& Hook. f. ii. 1077 .

Chaetacanthus, Nees, in Lindl. Introd. Nat. Syst. ed. II. 444 (1836).

DyschORISTE, Nees, in Wall. Pl. As. Rar. iii, 75 1832), nomen prius.

LiNostyles, Fenzl, in Linnaea, xxiii. (1850) 94

adscendens, Hochst. ex Nees, in DC. Prod. xi. 111.Abyss.

amoenus, Nees, Mart. Fl. Bras. ix. 27.-Bras.

angustus, A. Gray, Syn. Fl. N.Am. ii. I. 456.-Florida.

angustifolius, Hemsl. Biol. Centr. Am. Bot. ii. 502.-

Mexic.

biflorus, Shuttlew. ex Nees, in DC. Prod. xi. $107=$ oblongifolius.

bilabiatus, Seem. Bot. Voy. Herald, 324. t. 65.Mexic.

Buchenavii, Vatke, in Bremen Abh. ix. (1885) 131.Madag.

Burkei, T. Anders, in fourn. Linn. Soc. vii. (1864) 24. -Afr. austr.

capitatus, Oerst. in Kjoeb. Vidensk. Meddel. (1854) 121. - Mexic.

Clarkei, Vatke, in Bremen Abh. ix. (1885) 132.-Ins. Mascar.

ciliatus, Nees, in DC Prod. xi. 110.-Peruy

costatus, T. Anders. in Fourn. Linn. Soc. vii. (1864) 23.-Afr. austr.

crinitus, Nees, in Mart. Fl. Bras. ix. 26.-Bras

cubensis, A. Rich. Fl. Cub. Fanerog. ii. 160.-Cuba.

Dalzellii, T. Anders, ex Bedd. Ic. Ind. Or. i. 60.Ind, or.

decumbens, A. Gray, Syn. Fl. N.Am. ii. 1. 325.Arizon.; Mexic.

depressus, T. Anders. in Thw. Enum. P1. Zeyl. $225=$ Nagchana.

gracilis, Nees, in DC. Prod. xi. 111.-Madag.

Heudelotianus, Nees, L. c. 112. - Afr, trop.

Hildebrandtii, S. Moore, in fourn. Bot. xviii. (1880) 8, 197.-Afr. trop.

hirsutissimus, Nees, in DC. Prod. xi. 109-Mexic.

hirsutus, Oerst. ex Hiern, in Kjoeb. Vidensk. Meddel. (1877-78) 71.-Mexic.

humistratus, Shuttlew, ex Nees, in DC. Prod. xi. 108. -Am. bor.

hygrophyloides, Nees, in Mart. Fl. Bras. ix. 26.Bras.

hyssopifolius, Nees, in DC. Prod. xi. 111.-Abyss.

Jasminum-mexicanum, Nees, l. c. 110-Mexic.

lavandulaceus, Nees, in Mart. Fl. Bras. ix. 27.-Bras.

linenris, A. Gray, Syn. Fl. N.Am. ii. I. 324.-Texas ; Mexic.

littoralis, T. Anders. in Thw. Enum. Pl. Zeyl.225.Ind. or.

madagascariensis, Nees, in DC. Prod. xi. 112.-

Madag.

Maranhonis, Nees, in Mart. Fl. Bras. ix. 25.-Bras.

\section{CALOPHANES :-}

mauritianus, T. Anders, in Joum. Linn. Soc. vii.(1864) 23, nomen $=$ Hypoëstes serpens.

microphyllus, Nees, in DC. Prod. xi. 113.-Mexic.

multicaulis, $T$. Anders. in Fourn. Linn. Soc. vii.

(1864) 23.-Abyss.

Nagchana, Nees, in DC. Prod. xi. 109.-Ind. or.

natalensis, T. Anders, in Fourn. Linn. Soc. vii. (1864)

23. -Afr. austr.

oblongifolius, D. Don, in Sweet, Flow. Gard. t. 181 -Am. bor.

oblongifolius, Torr. Bot. Mex. Bound. $122=$ decumbens uvatus, Benth. Pl. Hartw. $89=$ linearis.

Perrottetii, Nees, in DC. Prod xi. 111.-Afr, trop

Persoonii, T. Anders. in Fourn. Linn. Soc. vii. (1864) 23.-Afr. anstr

Pulegium, Nees, in Mart. Fl. Bras. ix. 25.-Bras.

quadrangularis, Oerst. in Kjoeb. Vidensk. Meddel.

(1854) 120.-Mexic

quitensis, Nees, in DC. Prod.xi. 110.-Ecuador.

radicans, T. Anders. in Fourn. Linn. Soc. vii. (1864) 23.--Afr. trop.

repens, Nees, in DC. Prod. xi. 109.-Peruy.

rigidus, Dalz. ex C. B. Clarke, in Hook. f. Fl. Brit. Ind. iv. $411=$ Dalzellii.

Schiedeanus, Nees, in DC. Prod.xi. 111.-Mexic.

Serpyllum, Nees, in Mart. Fl. Bras. ix. 26.-Bras.

setosus, Nees, in DC. Prod. xi. 112.-Afr. austr.

siphonanthus, Nees, $l$. c.-Madag

thunbergiaeflora, S. Moore, in Fourn. Bot. xviii. (1880)

8, 197.-Afr, trop.

trichocalyx, Oliver, in Trans. Linn. Soc. xxix. (1875)

126.-Afr. trop.

Tweedianus, Nees, in DC. Prod. xi. 108.-Reg. Argent. vagans, Wight, Ic. xi. t. 1526.--Ind. or.

verticillaris, $T$. Anders, ex Oliver, in Trans. Linn.

Soc. xxix. (1874) 126, in nota.-Afr. trop.

CALOPHTHALMUM, Reichb. Nom. 82 (1841) GALOPHTHALMUM, Nees \& Mart.

CALOPHYLICA, Presl, Bot. Bemerk. 39 (1844)= Phylica, Linn. (Rhamn.),

gnidioides, Presl, 1. c. = P. gnidioides.

juniperifolia, Presl, 1. c. = P. gnidioides.

CALOPHYLLOIDES, Smeathm. ex DC. Prod. iii. 272 (1828) = Eugenia, Mich. (Myrtac.)

iucida, Smeathm. 1. c. =E. Calophylloides.

CALOPHYLLUM, Linn. Gen. ed. I. 154 (1737) GUTTIFERAE, Benth. \& Hook. f. i. 175.

Apoterium, Blume, Bijdr. 218 (1825).

Augia, Lour..Fl. Cochinch. 337 (1790)

acuminatum, Lam. Encyc. i. 553 = spectabile.

acuminatum, Willd. in Ges. Naturf. Fr. Berl. Mag. v. (1811) $80=$ Rheedia acuminata

Akara, Burm. f. F1. Ind. $121=$ Tetracera laevis. amoenum, Wall. Cat. n. $4849=$ retusum.

amplexicaule, Choisy, ex Planch. E Triana, in Ann Sc. Nat. Sér. IV. xv..(1861) 281.-Ins. Philipp. angustifolium, Roxb. Hort. Beng. 41; Fl. Ind. ii. 608 -Penang.

apetalum, Blanco, Fl. Filip. ed. II. 429.-Ins. Philipp apetalum, Willd. in Ges. Naturf. Fr. Berl. Mag. v. (1811) $79=\mathrm{C}$. Inophyllum?

Augia, Steud. Nom. ed. II. i. 260.-China.

bancanum, Miq. Fl. Ind. Bat. Suppl. i. $499=$ pulcherrimum.

Bingator, Roxb. Hort. Beng. 41 ; Fl. Ind. ii. 607 C. Inophyllum

Blancoi, Planch. E Triana, in Ann. Sc. Nat. Sér. IV. xv. (1861) 272.-Ins. Philipp.

Blumei, Wight, Illustr. i, 128.-Java,

bracteatum, Thw. Enzum. Pl. Zeyl. 51.-Zcylan.

brasiliense, Camb. in St. Hil. Fl. Bras. Mer, i, 321. 67. - Bras.

Burmanni, Wight, Illustr. i. $129=$ C. Calaba, Linn.

Calaba, Facq. Am. 269. t. 165.-Ins. Carib.

Calaba, Linn. Sp. Pl. 514.-Zeylan.

calaboides, G. Don, Gen. Syst. i. 622.-Ind. or.

caledonicum, Vieill, ex Planch. E Triano, ins Anns.

Sc. Nat. Sér. IV. xv. (1861) 291.-N. Caled.

canum, Hook. f. Fl. Brit. Ind. i. 271.-Malacca.

chinense, T. Anders. in Hook. f. FI. Brit. Ind. i. $270=$

Ochrocarpus longifolius.

cordato-oblongum, Thw. Ensm. Pl. Zeyl. 407.Zeylan.

\section{CALOPHYILUM}

Cumingii, Planch. E Triana, in Ann. Sc. Nat. Sér IV. xv. (1861) 259.-Ins. Philipp.

cuneifolium, Thw. Enum. Pl. Zeyl. 51, 407.-Zeylan.

Cupi, H. B. \&c K. Nov, Gen. et Sp, v. 203 = Rheedia

Cupi.

Cussi, G. Don, Gen. Syst, i. $623=$ praec

cymosum, Miq. FI. Ind. Bat. Suppl. i. $497=$ specta bile.

dasypodium, Miq. Fl. Ind. Bat. i. I1. 511.-Java. decipiens, Thw. Enum. Pl. Zeyl. $51=$ Thwaitesii. decipiens, Wight, Illustr. 128 ; Ic. i. $106=$ Wightianum. Diepenhorstii, Miq. Fl. Ind. Bat. Suppl. i. 497.Sumatra.

dongnaiense, Pierre, Fl. For. Cochinch. t. 108.Cochinch.

dryobalanoides, Pierre, l.c. . t. 108.-Cochinch.

dubium, Steud. Nom. ed. II. i. 261=Ochrocarrus longifolius.

edule, Seem. Bot. Voy. Herald, $89=$ Rheedia edulis.

elatum, Bedd..Fl. Sylv. i.-t. 2 =tomentosum.

excelsum, Zoll, \& Morr. in Nat. en Geneesk. Arch.

Neerl. Indie, ii. (1845) $582=0$ chrocarpus oval folius.

floribundum, Hook. f. Fl. Brit. Ind. i. 272.-Malacca.

gracile, Miq. F1. Ind. Bat. Suppl.. i. $498=$ pulcherrimum.

Griffithii, T. Anders. in Hook. f. Fl. Brit. Ind. i. 273 -Malacca.

Hasskarlii, Teijsm. \& Binn. ex Planch. E Triand. in Ann. Sc. Nat. Sér. IV. xv. 1861) 273. Java.

hexapetalum, Hook. $f_{\text {。 }}$ (1862) 163.-Borneo.

hirtellum, Miq. Pl. Fungh. 291.-Java.

Inophyllum, Lam. Encyc. i. $552=$ C. Tacamahaca.

Inophyllum, Linn.Sp. Pl. 513.-Geront. trop. Inophyllum, Sieber, ex Presl, in Oken, Isis, xxi. (1828

$274=$ C. Calaba, Facq

javanicum, Miq. Pl. Fungh.292,-Java

lanceolarium, Roxb. Hort. Beng. 41; FI. Ind. ii. Gu $=\mathrm{C}$. Tacamahaca.

lanceolatum, Blume, Bijdr. $217=\mathrm{C}$. Tacamahaca.

lanceolatum, Teijsm. E Binn. in Nederl. Kruidh.

Arch. iii. (1855) 395-Java.

lanigerum, Miq. Fl. Ind. Bat.. Suppl-i. 498.-Ins Banca.

longifolium, Wall. Cat. n. $4851=$ Ochrocarpas longi folius.

longifolium, Willd. Ges. Naturf. Fr. Berl. Mag. v. (1811) $80 .-\mathrm{N}$. Granat.

Lowei, Planch. E Triana, in Ann. Sc..Nat. Sér. IV. xv. (1861) 271.-Borneo.

lucidum, Benth. in Hook. Lond. Fourn. Bot. ii. (1843 370.-Guiana.

macrocarpum, Hook. f. Fl. Brit.Ind. i. 273.-Malacca. macrophyllom, Scheff, in Tijdschr. Nederl. Ind, xxxij. (1871) 405. Malaya.

Madruño, H. B. \& K. Nov. Gen. et Sp. v. $202=$ Rheedia Madruno.

marginatum, Wall. Cat.n. 4845 (sp...?).-Ins. Penang Mariae, Planch. E Triana, in Ann. Sc. Nat. Sér. It xv. (1861) 251. - Am. austr.

membranaceum, Gardn. \& Champ. in Hook. Ken Fourn. i. (1849) 309.-China.

mesuaefolium, Wall. Cat. $\mathrm{n} .4850=$ pulcherrimum. microphyllum, T. Anders. in Hook. f. Fl. Brit. Ind. i.

272.-Malaya.

microphyllum, Planch. \& Triana, in Ann, Sc. Nat. Sér. IV. xv. (1861) $282=$ parvifolium

microphyllum, Scheff. in Tijdschr. Nederl. Ind. xxxii. (1871) 406.-Ins. Gebeh.

montanum, Vieill. ex Planch. Ee Triana, in Ann. Sc. Nat. Sér. IV. xv. (1861) $292,-\mathrm{N}$. Caled.

Moorii, WVight, Illustr i. 109 - strectabile.

Nagassarium, Burm. f. Fl. Ind. 121 = Mesua ferrea. obovale, Mig. Fl. Ind. Bat. Suppl. i. 19s.-Sumatra. odoratissimum. Noronha, in Verh. Batav. Gea. (1790) ed. I. Art. 1v. 12 - speetabile. ovatifolium, Noronha, 1. c. $13=$ C. Inophyllum, pachyphyllum, Planch. E Triana, in Anm. Se. Sias Sir. IV xy, (1801) 255 -Bras parvillorum, Buj.ex Baker, Fl. diasurit. 18. - Ins. Maui i: parvifolium, Choisy, in Mrm. Sor. Kist. . Vat. Par. 1823) 2029 - Ins. Muluce.

pisiferum, Planch. Se Triana, in An. Sc. Xat. Scr. IV

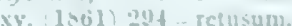

plicipes, Miy. Fl. Ind. BaL Suppl. i. t:9 pulcherrimum. 


\section{CALOPHYLLUM:}

polyanthum, Wall. Cat.n. 4844; Planch. E Triana, in Ann. Sc. Nato Sér. IV. xv, (1861) 278.-Ind, or pseudotacamacha, Planch. \& Triana, l. c. $270 .-$ Ind, or.

pulcherrimum, Wall. Cat. n. 4848 ; Planch. E Triana, l. c. 274 . - Malaya.

retustum, Wall. Cat. n. 4846; Planch. E Triana, l.c. 265,-Malaya.

rigidum, Miq. Fl. Ind. Bat. Suppl. i. 497.-Sumatra.

saigonense, Pierre, Fl. For. Cochinch. t. 105.-Cochinch.

Soualatti, Burm.f. F1. Ind. 121 = spectabile.

spectabile, Hook. \& Arn. Bot. Beech. Voy. $174=$ membranaceum.

spectabile, Willd. in Ges. Naturf. Fr. Berl. Mag.v

(1811) 80.-Malaya; Polynes.

spurium, Boj. Hort. Maurit. $52=$ parviflorum

spurium, Choisy, in Mém. Soc. Hist. Nat. Par. i. (1823) $229=\mathrm{C}$. Inophyllum.

Suriga, Buch.-Ham. ex Roxb. Hort. Beng. [93]; Fl. Ind. ii. 608.-1nd. or.

Surinoa, Buch.-Ham. ex Stend. Nom. ed. II. i. $261=$ praec.

Tacamahaca, Willd. in Ges. Naturf. Fr. Berl. Mag. v. (1811) 79.-Borbon. ; Madag.

tetrapetalum, Roxb. Hort. Beng. [93]; F]. Ind. ii. $608=$ spectabile.

tetrapetalum, Wall. Cat. n. $4843=$ Wallichianum.

tetrapterum, Miq. Pl. Fungh. 291.-Sumatra.

Teysmanni, Miq. Fl. Ind. Bat. Suppl. i. 499.Sumatra.

Teysmannii, Zoll. ex Planch. \& Triana, in Ann. Sc. Nat. Sér. IV. xv. (1861) 275 =lanceolatum.

thuriferum, Poepp. E Endl. Nov. Gen, et Sp. iii. 16.Peruy.

Thorelii, Pierre, Fl. For.Cochinch.t. 103.-Cochinch. Thwaitesii, Planch. E Triana, in Ann. Sc. Nat. Sér. IV. xv. (1861) 260.-Zeylan.

tomentosum, Wight, Illustr. i. 128.-Ind. or trapezifolium, Thw. Enum. Pl. Zeyl. 51.-Zeylan.

venulosum, Zoll. Syst. Verz. Ind. Archip. 149, 150.Java.

Walkeri, Wight, Illustr. i. 128.-Ind. or

Wallichiana, Planch. E Triana, in Ann. Sc. Nat. Sér. IV. xv. (1861) 277.-Malaya.

Wightianum, Wall. Cat. n. 4847 ; Planch. E Triana, in Ann. Sc. Nat. Sér. IV. xv. (1861) 256.-Ind. or.

CALOPHYSA, DC. Prod. iii. 166 (1828). MELASTOMACEAE, Benth. \& Hook. f. i. 766.

ciliata, Triana, in Trans. Linn. Soc. xxviii. (1871) 140.-Am. trop.

dentata, Triana, l. c--Peruv.

dispar, Triana, l. c. 141.-Peruv.

flexuosa, Triana, l. $c$-Venezuela.

heterophylla, Triana, l. c. 140--Peruy

pilosa, Triana, l. c.-Am. trop.

setosa, Triana, in Fourn. Bot. v. (1867) 209 Nicaragua.

testiculata, Triana, in Trans. Linn. Soc. xxviii. (1871) 140.-N. Granat

tococoidea, DC. Prod. iii. 166.-Bras

vesiculosa, Triana, in Trans. Linn. Soc. xxviii. (1871) 140.--Mexic.

CALOPLECTUS, Oerst. in Vidensk. Selsk. Skr. V. v. (1861) $119=$ Alloplectus, Mart. (Melastom.)

macrophyllus, Oerst. 1. $\mathrm{c}_{0}=\mathrm{A}$. macrophyllus.

CAIOPOGON, R. Br. in Ait. Hort. Kew, ed. II, y. 204 (1813). ORCHIDEAE, Benth. \& Hook. f. iii. 204.

Cathea, Salisb. in Trans. Hort. Soc. i. (1812) 300, nomen prius.

Lessonii, Brongn. Bot. Voy. Coquille, 188. t. $37=$ Pogonia tetraphylla.

multiflorus, Lindl. Gen, et Sp..Orch. 425.-Am. bor. pallidus, Chapman, Fl S. U. St. 457 -Am. bor.

parviflorus, Lindl. Gen. et Sp. Orch. 424.-Am. bor.

parviflorus, Rafin. Atl. Fourn. 148 (= praec. ?).-Am. bor

pulchellus, R. Br. in Ait. Hort. Kew. ed. I. v. 204.Am. bor.

CALOPOGONIUM, Desv. in Ann. Sc. Nat. Sér. I. ix. (1826) 423. LEGUMINOSAE, Benth. \& Hook. f. i. 534 .

Cyanostremma, Benth. ex Hook. \& Arn. Bot. Beech. Voy. 415 (1841).

\section{CALOPOGONIUM}

Stenolobium, Benth. in Ann. Wien. Mus. ii. (1838) 125.

brachycarpum, Benth. ex Hemsl. in Biol. Centr. Am. Bot. i. $300=$ mucun oides.

caeruleum, Hemsl.l. c. 301.-Mexic

galactoides, Benth. ex:Hemsl. l. c.-Mexic,

mucunoides, Desv. in Ann. Sc. Nat. Sér. I ix (1826) 423.-Guiana.

CALOPSIS, Beauv, ex Juss. in Dict. Sc. Nat. xlv, 272 (1827); et ex Desv. in Ann. Sc. Nat. Sér. I. xili (1828) 44 .t. $3=$ Leptocarpus, R. Br. (Restiac.) chilensis, Steud. Syn. P1. Cyp. 258 =L. chilensis.

festucacea, Kunth, Enum. Pl. iii. $425=\mathrm{L}$. incurvatus.

hirtella, Kunth, I. c. $426=\mathrm{L}$. peronatus.

incurvata, Kunth, 1. c. $427=\mathrm{L}$. incurvatus

neglecta, Hochst. in Flora, xxviii. (1845) $338=\mathrm{L}$ neglectus.

oxylepis, Kunth, Enum. Pl. iii. $427=$ L. oxylepis.

paniculata, Desv, in Ann. Sc. Nat. Sér. I. xiii. (1828)

44. t. 3. f. $2=$ L. paniculatus.

peronata, Kunth, Enum. Pl. iii. $426=$ Restio ocreatus et $\mathrm{L}$. peronatus.

ramiflora, Kunth, 1. c. $423=$ L. paniculatus.

triticea, Kunth, 1. c. $424=$ Restio triticeus.

CALOPTILIUM, Lag. Amen. Nat. i. 34 (1811) = Nassauvia, Juss. (Compos.).

Lagascae, Hook. \& Arn. in Hook. Comp. Bot. Mag. i. (1835) $36=$ N. Lagascae.

CALOPYXIS, Tul, in Ann. Sc. Nat. Sér. IV. vi. (1856) $86=$ Combretum, Linn

alata, TuI. 1. c. 89.-Madag

eriantha, Tul. 1. c. 90.-Madag.

oxygonia, Tui. 1. c. 88.-Madag.

sphaeroides, Tul. 1. c. 86.-Madag

velutina, Tul. 1. c. 87.-Madag.

CATORCHIS, Rodrig. Orch. Nov. i. 195 (1877) $O R C H I D E A E$

phaenoleuca, Rodrig. l. c. 196.-Bras.

CALORHABDOS, Benth. Scroph. Ind. 44 (1835) SCROPHULARINEAE, Benth. \& Hook, f. ii 963.

Brunoniana, Benth. l. c.-Reg. Himal

cauloptera, Hance, in fourn. Bot.xv. (1877) 298.China.

CALOROPHUS, Labill. Nov. Holl. Pl. ii. 78. t. 228 $(1806)=$ Hypolaena, R. Br. (Restiac

asper, Nees, in Lehm. Pl. Preiss. ii. $67=$ Restio Loxocarya.

crispatus, Nees, 1. c. $=$ Restio crispatus

densus, Nees, 1. c. $=$ H. densa.

dentatus, Nees, 1. c.-Austral.

elongatus, Labill. Nov. Holl. Pl. ii. 78. t. $228=\mathrm{H}$. elongata

elongatus, F. Muell. Fragm. viii. $86=\mathrm{H}$. elongata

elongatus, Nees, in Lehm. Pl. Preiss. ii. $68=\mathbf{H}$ gracillima.

flexuosus, Nees, in Lehm. P1. Preiss. ii. $68=\mathrm{H}$. flexuosa.

minor, Hook, f. Fl, N. Zel. i. $267=$ H. elongatai

Sieberianus, Steud. Syn. PI. Cyp. $265=$ Restio fastigiatus.

CALOSACME, Wall. Cat. nn. 800-806 (1829)= Chirita, Buch.-Ham. (Gesnerac.).

acuminata, Wall. 1. c. n. $802=$ Ch. acuminata et Didymocarpus acuminata.

amplectens, Wall. 1. c. n. $806=$ Ch. bifolia

dimidiata, Wall. 1 , c, n. $803=\mathrm{Ch}$. dimidiata

flava, Wall. 1. c. n. $801=$ Ch. pumila.

grandiflora, Wall. 1. c. n. $800=$ Ch. urticaefolia.

macrophylla, Wall. 1, c. n. $805=$ Ch. macrophylla

polycarpa, Wall. 1. c. n. $804=$ Lysionotus serrata.

CALOSANTHES, Blume, Bijdr. $760(1826)=$ Oroxy lum, Vent. (Bignoniac.)

indica, Blume, $1 . \mathrm{c}_{s}=\mathrm{O}$. indicum.

CALOSANTHOS, Reichb. in Moessl. Handb. ed. II. i $50(1827)=$ KALOSANTHES, Haw $=$ Rochea, DC. (Crassul.).
CALOSCIADIUM, Endl. Gen. Suppl. iv. III. 7 (1850)= Aciphylla, Forst. (Umbellif.)

antipodum, Endl. ex Walp. Ann. ii. 702.-N, Zel

latifolium, Endl. ex Walp. 1. c.-N. Zel.

CALOSCILLA, Jord. \& Fourr. Ic. FI. Eur. ii. 14. t. $245(1869)=$ Scilla, Linn. (Liliac.).

Clusii, Jord. \& Fourr. 1. c. $=\mathrm{S}$. peruviana.

elegans, Jord, \& Fourr. 1. c. 16. t. $250=\mathrm{S}$. peruviana.

flaveola, Jord. \& Fourr. 1. c. 17. t. $254=$ S. peruviana. grandiflora, Jord. \& Fourr. 1. c. 16. t. $252=\mathrm{S}$ peruviana.

hipponensis, Jord. \& Fours. 1. c. 17. t. $255=\mathrm{S}$ peruyiana.

Hughii, Jord. \& Fourr. 1. c. 15. t. $246=$ S. peruviana. livida, Jord. \&c Fourr. 1. c. $=\mathrm{S}$. peruviana.

pallidiflora, Jord. \& Fourr. 1. c. t. $248=\mathrm{S}$. peruviana.

subalbida, Jord. \& Fourr. 1. c, 16.t. $253=\mathrm{S}$. peruviana. subcarnea, Jord. \& Fourr. l. c. t. $250=\mathrm{S}$. peruviana. venusta, Jord. \& Fourt. 1. c. 15, t. $247=\mathrm{S}$. peruviana.

CALOSCORDUM, Herb. in Linḋ. Bot. Reg. (1844) Misc. $66=$ Nothoscordum, Kunth (Liliac.) neriniflorum, Herb. 1. c. $67=\mathrm{N}$. neriniflorum.

CALOSERIS, Benth. P1. Hartw. 88 (1841)=Onoseris, DC. (Compos.)

rupestris, Benth. 1. c. $=$ O. isotypus.

CALOSMON, J. S. Presl, Rostl. ii. 71 (1823)=Lindera, Thunb. (Laurin.)

aestivale, Kostel. Allg. Med.-Pharm. Fl. ii. $478=\mathrm{L}$ Benzoin.

Benzoin, J. S. Pres1, Rostl. ii. $71=$ L. Benzoin.

Neesianum, Kostel. Allg. Med.-Pharm. F1. ii. $478=$ L. Neesiana.

CALOSPHACE, Rafin. F1. Tellur iii. 91=Salvia, Tourn. (Labiat.)

CALOSTELma, D. Don, in Sweet, Brit. Fl. Gard. Ser II. sub t. 184 (1833)= Liatris, Schreb. (Compos.). elegans, D. Don, 1. c. = L. elegans.

CALOSTEMTMA, R. Br. Prod. 297 (1810) AMARYLLIDEAE, Benth. \& Hook. f. iii. 735 .

album, $R$. Br.l. c. 298.-Austral. aureum, Link, Enum. Hort. Berol. i. $312=$ luteum. candidum, Lindl. in Mitch. Three Exped. i. $54=$ luteum.

carneum, Lindl, I. c. ii. $39=$ purpureum.

Cunninghami, Ait. ex Loud. Hort. Brit. Suppl. ii. 616. -Austral.

luteum, Sims, Bot. Mag. t. 2101.-Austral.

purpureum, R. Br. Prod. 298.-Austral.

CATOSTEPHANE, Benth, in Hook. Ic. Pl. t. 111 (1872). COMPOSITAE, Benth. \& Hook, f. ii. 335 divaricata, Benth. $l_{\text {. }} c_{0}-$ Afr. trop.

CALOSTtgmA, Decne. in Ann. Sc. Nat. Sér. II. ix (1838) 343. t. 12. ASCLEPIADEAE, Benth. \& Hook. f. ii. 752 .

Burchelli, Fourn, in Mart. Fl. Bras, vi, IV, 286.Bras.

glabrum, Decne. in DC. Prod. viii. 581.-Bras.

Glaziovii, Fourn. in Mart. Fl. Bras. vi. IV. 286.Bras.

Guilleminianum, Decne, in DC. Prod. viii. 581.Bras.

insigne, Decne. in Ann. Sc. Nat. Sér. II. ix. (1838) 343.-Bras.

CALOSTIGMA, Schott, Melet. Bot. 19 (1832)= Philo dendron, Schott (Aroid.) Imbe, Schott, l. c. = P. Imbe.

CALOSTIMA, Rafin. Fl. Tellur. iii. $47(1836)=$ Urera Gaudich. (Urtic.).

aculeata, Rafin. 1. c. $48=\mathrm{U}$. baccifera

CALOSTROPHUS, F. Muell. Fragm. viii. 86 (1873)= Hypolaena, R. Br. (Restiac.)

elongatus, F. Muell. 1. $\mathrm{c}$. $=$ H. longissima

elongatus, Mast. in DC. Monog. Phan. i. $378=\mathrm{H}$ lateriflora. 
CALOSTROPHUS :-

exsulcus, F. Muell. Census, $124=\mathrm{H}$. exsnlca.

fastigiatus, F. Muell. in Papers Roy. Soc. Tasm

(1878) $117=\mathrm{H}$. fastigiata.

gracillimus, F. Muell. Fragm. viii. $88=\mathrm{H}$. gracillima.

lateriflorus, F. Muell. 1. c. $87=\mathrm{H}$. lateriflora.

Sieberianus, Mast. in DC. Monog. Phan. i. $378=\mathrm{H}$. lateriflora.

CALOTHAMNUS, Labill. Nov, Holl. Pl. ii. 25. t 164 (1806). MYRTACEAE, Benth. \& Hook. f. i. 704.

BAudinia, Leschen. ex DC. Prod. iii. 211 (1828).

Billotira, Colla, Hort. Ripul. 20. t. 23 (1824).

affinis, Turcz. in Bull. Phys.-Math. Acad. Pétersb. $\mathrm{x} .(1852) 346=$ microcarpus ?

asper, Turcz. in Bull. Soc. Nat. Mosc. xxii. (1849) II 25,-Austral.

Baxteri, Hort. Angl. ex Klotzsch, in Otto \& Dietr. Allg. Gartenz. iv. (1836) $115=$ Kunzea Baxteri. blepharantherus, F. Muell. Fragm. iii. 112.-Austral.

blepharospermus, F. Muell.l.c. 111.-Austral.

chrysanthereus, F. Muell. l. c. 112.-Austral.

clavatus, Mackay, ex Lodd. Bot. Cab. t. $1447=$ quadrifidus.

eriocarpus, Lindl. Swan River App. $9=$ sanguineus.

gibbosus, Benth. Fl. Austral. iii. 175.-Austral.

Gilesii, F. Muell. Fragm. x. 31.-Austral.

gracilis, $[R, B r . i n]$ Ait. Hort. Kew, ed. II. iv. 418.Austral.

homalophyllus, F. Muell. Fragm. iii. 111.-Austral.

Huegelii, Schau. in Nov. Act. Nat. Cur. xxi. (1845) 30 = lateralis.

Knightii, Hort. ex Schau. 1. c. 23 =robusta.

laevigatus, Schau. 1.c. $26=$ quadrifidus,

lateralis, Lindl. Swan River App.9.-Austral.

laxus, Kunze, in Linnaea, xx. (1847) $58=$ Preissii.

Lehmanni, Schau. in Nov. Act. Nat. Cur. xxi. (1845) 27.-Austral,

longifolius, Lehm. Del. Sem. Hort. Hamb. (1842) $7=$ lateralis.

longissimus, F. Muell. Fragm. iii. 112.-Austral. microcarpus, F. Muell. l. c. 113.-Austral.

nodosus, Turcz. in Bull. Soc. Nat. Mosc. xx. (1847) I. $168=$ lateralis

Oldfieldii, F. Muell. Fragm. iii. 113.-Austral. pachystachyus, Benth. Fl. Austral. iii. 173.-Austral. pinifolius, F. Muell. Fragm. iii. 153.-Austral.

planifolius, Lehm. Del. Sem. Hort. Hamb. (1842) 7.Austral.

plumosus, Turcz. in Bull. Soc. Nat. Mosc. xx. (1847) I. $168=$ Lehmanni.

Preissii, Schau. in Nov. Act. Nat. Cur. xxi. (1845) 27. -Austral.

purpureus, Endl, in Enum. Pl. Hueg. 48 =quadrifidus quadrifidus, [R.Br. in ] Ait. Hort. Kew. ed. Il. iv. 418.Austral.

robustus, Schau. in Nov. Act. Nat. Cur. xxi. (1845) 2 ? $=$ villosus

rupestris, Schau. l. c.-Austral.

sanguineus, Labill. Nov. Holl. Pl. ii. 25. t. 164.Austral.

Schaueri, Lehm. Del. Sem. Hort. Hamb. (1842) 7.Austral.

schoenophyllus, Schau, in Nov, Act. Nat. Cur. xxi. (1845) $29=$ Schaueri.

spathulatus, Hort. ex Stend. Nom. ed. II. i. $261=$ Kunzea Baxteri.

suberosus, Schav, in Lehm. Pl. Preiss. i. 156=Mela leuca exarata.

torulosus, Schau, in Nov. Act. Nat. Cur, xxi. (1845) 21.-Austral.

villosus, $[R . B r$. in $]$ Ait. Hort. Kew. ed. II. iv. 418.Austral.

CALOTHECA, Spreng. Anlcit. ii. I. 167 (1817) Syst. i. $347(1825)=$ Aeluropus, Trin. (Gramin.) arabica, Spreng. Syst. i. $348=$ A. arabicus.

cuspidata, Spreng. 1. c. $=$ Poa rufescens.

litoralis, Spreng. 1. c. $347=$ A. littoralis

massariensis, Hochst. \& Steud. ex Steud. Nom. ed. II

i. $261=$ A. littoralis.

mucronata, Spreng. Syst. i. $348=$ Poa mueronulata.

riliaca, Spreng. 1. c. - A. nilincus.

poaeformis, Spreng. 1. c.=Briza Lamarckiana.

pungens, Spreng. 1. c. = Sesleria echinata

purpurascens, Spreng. 1. c。 = Briza purpurascens

repens, Spreng. 1. c. $347=$ A. villosus.
CALOTHECA, Desv, in Nov, Bull. Soc. Philom, ii (1810) $190=$ Briza, Linn. (Gramin.).

barbata, Nees, Agrost. Bras. $477=\mathrm{B}$. barbata.

brizoidea, Beauv. Agrost. 86. t. 17. f. $6=$ B. erecta.

brizoidea, Desv: Journ, Bot. i. (1813) $71=\mathrm{B}_{0}$ Lamarckiana.

bromoidea, Lejeune, Messager des Sciences (1823); et in Nov. Act. Nat. Cur. xil. (1825) 757 = Bromus arduennensis.

dilatata, Link, Hort. Berol. i. $157=$ B. erecta.

elegans, Beauv. Agrost. 157. t. $17=$ B. elegans.

macrostachya, Presl, Rel. Haenk. 1. $268=\mathrm{B}$. macrostachya.

microstachya, Presl, l. $\mathrm{c}_{\mathrm{s}}=\mathrm{B}$. microstachya

montevidensis, Spreng. ex Steud. Nom, ed. II. i. 261, $225=$ B. subaristata

reniformis, Presl, Rel. Haenk. i, 268 = B, reniformis.

rotundata, Roem. \& Schult. Syst. ii. $632=$ B. rotun data.

sabulosa, Steud. in Flora, xii. (1829) II. 488 - Sporo bolus virginicus.

stricta, Hook. \& Ain. Bot. Beech. Voy. $50=$ B. stricts triloba, Kunth, Enum. Pl. i. $374=$ B. triloba.

CALOTHYRSUS, Spach, in Ann. Sc. Nat. Sér. II, ii 1834) $62=$ Aesculus, Linn. (Sapindac.)

californica, Spach, I. c. = A. californica.

CALOTIS, R. Br. in Bot. Reg. t. 504 (1820), COMPOSITAE, Benth. \& Hook. f. ii. 267.

Cheiroloma, F. Muell. in Linnaea, xxv。(1852) 401.

Goniopogon, Turcz. in Bull. Soc. Nat. Mosc xxiv (1851) I. 173

HUENEFELDIA, Walp, in Linnaea, xiv. (1840) 307. anthemoides, F. Muell. in Trans. Phit. Soc. Vict. i. (1855) 44.-Austral.

breviseta, Benth. in Enum. Pl. Hueg. 60.-Austral.

cuneifolia, R. Br. in Bot. Reg. t. 504.-Austral

cymbacantha, F. Muell. in Linnaea, xxv. (1852) 400 . -Austral.

dentex, R. Br. in Bot. Reg. t. 504.-Austral.

dilatata, A. Cunn. in DC. Prod. v. $302=$ cuneifolia.

erinacea, Steetz, in Lehm. Pl. Preiss. i. 424.

Austral.

glandulosa, F. Muell. in Trans. Vict. Inst. (1855) 129. -Austral.

hispidula, F. Muell. l. c. 130.-Austral

Kempei, F. Muell. in Trans. Roy. Soc. S. Austral. iv. (1881) 112.-Austral.

lappulacea, Benth. in Enum. Pl. Hueg. 60.Austral.

microcephala, Benth. Fl. Austral. iii. 504.-Austral, microphylla, Benth. in Enum. Pl. Hueg. 60.Austral.

Muelleri, Sond. in Linnaea, xxv, (1852) $4 \% 0=$ scabiosifolia.

palmata, A. Gray, in Proc. Am. Acad. v. (1861) 121. -Austral.

plumulifera, F. Muell, in Trans. Phil. Inst. Vict. iii. (1859) 57.-Austral.

polyseta, Sond. ir Linnaea, xxv. (1852) $470=$ lappu-

lacea.

porphyroglossa, F. Muell. ex Benth. Fl. Austral. iii. 505.-Austral.

pterosperma, R. Br. ex Benth. l. c.-Austral.

scabiosifolia, F. Muell. in Linnaea, xxv. (1852) 471.Austral.

scapigera, Hook. in Mitch. Fourn. Trop. Austral. 75. - Austral.

tropica, F. Muell. in Trans, Phil. Inst. Vict. iii. (1859) $58=$ breviseta.

CALOTRoPIS, R. Br, in Mem. Wem. Soc. i. (1809) 39. ASCLEPIADEAE, Benth. \& Hook. fo ii. 754. Acia, Buch-Ham, in Trans. Linn. Soc xiv, (182:) 247. -Ind. or.

gigantea, [Dryand. in] Ait. Hort. Kew. ed. II. ii. 78 -Ind. or.

Hamiltoni, Wight, Contrib. Ind, Bot. $58=$ procera.

herbacea, Wight, 1. c. $54=$ C. Acia.

heterophylla, Wall. Cat. $\mathrm{n} .8217=$ procera.

procera, [Dryand. in] Ait. Hort. Ken. ed. II. ii. 78.-

Peruv.; Afr. trop.; Ind. or.

Sussuela, G. Don, Gen. Syst. iv. $147=$ Hoya impet

rialis?

Wallichii, Wight, Contrib. Ind. Bot. $5 \$=$ procera.
CALPANDRIA, Blume, Bijdr. 178 (1625)=Camellia, Linn. (Ternstroem.).

lanceolata, Blume, $1 . \mathrm{c}_{0}=$ Cam. lanceolata.

Ouiscosaura, Korth. in Verh. Nat. Gescls. Bot. $149=$ Cam. Quinosaura.

CALPICARPUM, G. Don, Gen. Syst. iv. 100 (1837 Kopsia, Blume (A pocyn.).

albiflorum, Teijsm. \& Binn. in Tijdschr. Nederl. Ind. xxv. (1863) 402.-Malaya.

Lamarkii, G. Don, Gen. Syst iv. $100=$ K. fruticosa.

Roxburghii, G. Don, 1. c。=K. fruticosa.

CALPIDIA, Thou. Hist. Vég. Isles Afr. Austr. (180 37. t. $10=$ Pisonia, Linn. (Nyctagin.

costata, Boj. Hort. Maurit. $265=\mathrm{P}$. costata

lanceolata, Thou. Hist. Vég. Isles Afr. Austr. 37. t. 10 $=\mathrm{P}$. Calpidia

macrophylla, Boj. Hort. Maurit. $265=\mathrm{P}$. macrophylla. ovalifolia, Boj. 1. $\mathrm{c}_{\mathrm{o}}=$ P. Calpidia.

CALPIGYNE, Blume, Mus. Bot. Lugd, Bat. ii. 193 (1856). EUPHORBIACEAE, Benth. \& Hook. f. iii, 323.

frutescens, Blume, l. c.-Borneo.

CALPURNIA, E Mey, Comm, P1. Afr. Austr. (1835). LEGUMINOSAE, Benth. \& Hook, f. 554.

aurea, Baker, in Oliver, Fl. Trop. Afr. ii. 252.-Air. trop.

aurea, Benth. in Ann. Wien. Mus, ii. (1840) $90=$ lasiogyne.

capensis, Steud, Nom, ed. II. i. $262=$ Virgilia capensis. floribunda, Harv, in Harv. E Sond. Fl. Cap. ii. 267. -Afr. austr.

intrusa, E. Mey. Comm. Pl. Afr. Austr. 2.-Afr. austr.

lasiogyne, E. Mey. l. c. 3.-Afr. austr

robinioides, E. Mey, L. c-Afr. austr.

sericea, Harv. in Harv. E Sond. Fl. Cap. ii. 267.Afr. austr.

sylvatica, E. Mey. Comm. Pl. Afr. Austr. 2.-Afr. austr.

villosa, Harv. in Harv. Eo Sond. Fl. Cap. ii. 268.-Afr. austr.

CALSIAMA, Rafin. Sylva Tellur. $12(1838)=$ Odina, Roxb. (Anacard.)

malabarica, Rafin. 1, $c_{s}=0$. Wodier.

CALTHA, Tourn. ex Adans. Fam. ii, 126 1763; Calendula, Linn. Compos.

arvensis, Moench, Meth. $585=$ Calend. arrensis. dentata, Moench, Meth. Suppl. $238=$ Calend. stellato graveolens, Gilib. Fl. Lituan. i. 212 = Calend. arvensis officinalis, Moench, Meth. $585=$ Calend. officinalis. officinalis, Scop. F1. Carn. ed. II. ii. 147-Lalend. arvensis.

stellata, Moench, Meth. Suppl. 238 = Calend. stellata.

CALTHA, [Rupp.] Linn. Syst. ed, I (1735;. RA. I'L:): CULACEAE, Benth, \& Hoolis fo is $b$.

Psychrophila, Bercht. \& Presl, Rostl. i. Ranunc. SO (18:3)

Psycrophila, Rafin. Atl. Journ. 144 (1832)

Thacla, Spach, Hist. Vég. Phan. vii. 205 ; 1839 alba, Jacquem. Voy. Bot. $6=$ palustris.

alpestris, Schott, Nym. St Kutschy, Analect, Bot. $39=$ palustris.

alpina, Schur, Fnum. Pl. Transs. $25=$ palustris

andicola, C. Gay, Fl. Chil. i. 49. t. 2.-Chili.

apperdiculata, Lechl. ex C. Mucll. in Walp. Ann. vii. $26=$ limbata.

appendiculata, Pers. Syrs. ii. 10i.-Keyg. Magell.

arctica, R. Br. m Parry, Ist Vov. App. $205=$ palustris. asqrifolia, DC Sist i suy a palustriz baicalensis, Demid. ex Steud. Xum. ed. 11. i. 26:2. natians.

biflora, IC. Syst. i. $310=$ palustris

Bisma, Buch.-Han. in Krewst. Edinb. Journ. Sc. i 1s.24) $251=$ Aconitum palmatum.

cambschatica, Spreng. Syst. ii. $6000=($ xygraptis glacialis.

Codua, liuch.-Ham. in Bawst. Eihnb. Juum. S: 15:21) $251=$ Acoutiuas ferox 


\section{CALTHA:}

cornuta, Schott, Nym. \& Kotschy, Analect. Bot. $31=$ palustris.

coronata, Schur, Enum. Pl. Transs. 25.--Transsylvan. dentata, Muhl. Cat. ed. II. $56=$ palustris.

De-Ranco, Steud. in Flora, xxxix. (1856) 407.De-Ranco,
Chili.

dioneaefolia, Hook. f. in Hook. Lond. Fourn. Bot. ii. (1843) 306.-Reg. Magell.

emodorum, Spreng. Syst. iv. Cur. Post. $220=$

palustris,
ficarioides, Pursh, F1. Am. Sept. ii. $289=$ palustris.

flabellifolia, Pursh, 1. c. 390. t. 17=palustris.

glabra, Gilib. F1. Lituan. ii. $279=$ palustris.

glacialis, Spreng. Syst. ii. $660=$ Oxygraphis glacialis.

Govaniana, Wall. Cat. n. $4710=$ palustris.

grosse-serrata, Pantoc. in Verh. Ver. Naturw. Heilk.

Presb. ii. (1871-72) $86=$ palustris.

Guerangerii, Bor. in Billot, Annot. $11=$ palustris.

himalensis, D. Don, Prod. F1. Nep. $195=$ palustris.

holophylla, Leyb.in Anal. Univ. Chil. (1859) 678. Chili.

integerrima, Pursh, Fl. Am. Sept. ii. 390=palustris.

intermedia, Schott, Nym. \& Kotschy, Analect. Bot. $32=$ palustris.

introloba, F. Muell. in Trans. Phil. Soc. Vict. i. (1855) 98.-Austral.

kamtschatica, Spreng. Syst. ii. $666=$ camtschatica.

laeta, Schott, Nym. \& Kotschy, Analect. Bot. $32=$ palustris.

lasopetala, Steud. Nom. ed. II. 1. 139, sphalm. = leptosepala.

latifolia, Schott, Nym. \& Kotschy, Analect. Bot. $32=$ palustris.

leptosepala, DC. Syst. i. 310.-Am. bor. occ.

leptostachya, G. Don, Gen. Syst. i. $44=$ praec.

limbata, Schlecht. in Linnaea, xxviii. (1854) 556.Chili.

major, Mill. Gard. Dict. ed. VIII. n. 1=palustris.

minor, Mill. 1. c. n. 2 =palustris.

multicapsularis, Sond. ex DC. Prod. i. $44=$ sagittata.

natans, Pall. Reise, iii. 248.-Reg. bor.

Nirbisia, Buch.-Ham. in Brewst. Edinb. Journ. Sc. i. (1824) $251=$ Aconitum ferox.

Novae-Zelandiae, Hook, f. Fl. Nov. Zeal. i. 12. t. 6.N. Zel.

orthorhyncha, Rupr. Fl. Caucas. 28.-Reg. Caucas.

pallidiflora, Martr, in Bull. Soc. Bot. Fr. (1862) $130=$ palustris.

palustris, Linn. Sp. Pl. 558.--Reg. bor. temp. et arct. paniculata, Wall. Cat. n. $4711=$ palustris.

paradoxa, T. F. Forst. in Trans. Linn. Soc. viii. (1807) $324=$ appendiculata

parnassifolia, Rafin. in Med. Rep. New York v. (1808) $361=$ palustris

polypetala, Hochst. in Lorent, Wanderungen, 339.As. Min. : Persia.

Populago, Gouian, Hort. Monsp. $268=$ palustris.

pumila, Schur, Enum. PI. Transs. $26=$ palustris

radicans, T. F. Forst. in Trans. Linn. Soc. viii. (1807) 324. t. 17.- Scotia.

ranunculoides, Schur, Ennm. PI. Transs. $26=$ palustris.

riparia, G. Don, Gen. Syst. i, $44=$ palustris.

sagittata, Cav. Ic. v. 8, 456. t. 414. -Reg. Magell.

scaposa, Hook. f. \& Thoms. Fi. Ind. i. 40.-Reg. Himal. vulgaris, Pall. ex Stend. Nom. ed. II. i. $262=$ palustris.

vulgaris, Schott, Nym. \& Kotschy, Analect. Bot. $33=$ palustris.

CALTHOIDES, B. Juss. ex DC. Prod. vi. $473(1837)=$ Othonna, Linn. (Compos.).

CALUCECHINUS, Hombr. \& Jacquinot, ex Decne. Bot. Voy. Astrol. et Zél. 19 (1853) = Fagus, Tourn. (Cupulif.).

antarctica, Hombr. \& Jacquinot, I. c. $=$ F. antarctica. Montagnei, Hombr. \& Jacquinot, 1. c. =F. antarctica.

CALUSIA, Bert. ex Steud. Nom. ed. II. i. $262(1840)=$ Myrospermum, Jacq. (Legumin.).

emarginata, Bert. ex. Steud. 1. c. ii. $175=$ M. frutescens.

CALUSPARASSUS, Hombr. \& Jacquinot, ex Decne. Bot. Voy. Astrol. et Zél. 20 (1853)= Fagus, Tourn. (Cupulif.).
CALUSPARASSUS :-

betuloides, Hombr. \& Jacquinot, ex Decne. Bot. Voy. Astrol, et Zél. $20=\mathrm{F}$. betuloides.

Forsteri, Hombr. \& Jacquinot, 1. c. = F. betuloides.

Pumilio, Hombr. \& Jacquinot, 1. c. $21=\mathrm{F}$. betuloides.

CALVARIA, Comm. ex Gaertn. f. Fruct. Suppl. 116. t. 200, 201 (1805) (Gen. dub.).

cerebellina, Comm. ex Gaertn. f. 1. c.-Hab.?

globosa, Gaertn. f. 1. c. 117.-Hab.?

hexangularis, Gaertn. f. 1. c.-Hab.?

major, Gaertn. f. 1. c. $116=$ cerebellina?

CALVELIA, Moq. in DC. Prod. xiii. II. 167 (1849)= Suaeda, Forsk. (Chenopod.) pterantha, Moq. 1. c. 168.-Soongar.

CALVOA, Hook: f. in Benth. \& Hook. f. Gen. i. 755 (1867) MELASTOMACEAE, Benth. \& Hook. f. l. c. crassinoda, Hook. f. ex Triana, in Trans. Linn. Soc. xxviii. (1871) 78.-Afr. trop.

hirsuta, Hook. f. ex Triana, l. c.-Afr. trop.

sinuata, Hook. f. ex Triana, l. c.-Afr. trop.

CALYCADENIA, DC. Prod. v. $695(1836)=$ Hemi zonia, DC. (Compos.).

Cephalotes, DC. 1. c.= H. multiglandulosa.

Fremontii, A. Gray, in Torr. Bot. Mex. Bound. 101, in nota $=\mathrm{H}$. multiglandulosa.

Harrisii, Lem. Illustr. Hortic. (1855) Misc. $9=$ Odontadenia speciosa.

mollis, A. Gray, in Proc. Am. Acad. vii. (1868) $360=$ H. mollis.

multiglandulosa, DC. Prod. v. $695=\mathrm{H}$. multiglandulosa.

pauciflora, A. Gray, in Torr. Bot. Mex. Bound. 101, in nota $=H$. pauciflora

plumosa, Kellogg, in Proc. Calif. Acad. v. (1873) $49=$ H. plumosa.

tenella, Torr. \& Gray, Fl. N. Am. ii. $402=$ H. tenella truncata, DC. Prod. v. $695=\mathrm{H}$. truncata.

villosa, DC. 1. c. $=$ H. Douglasii

CALYCAMPE, Berg, in Linnaea, xxvii. (1854) $129=$ Myrcia, DC. (Myrtac.).

angustifolia, Berg, 1. c. $131=$ M. hebepetala.

latifolia, Berg, 1. c. 130.-Guiana.

CALYCANDRA, Lepr. ex A. Rich. in Guill. \& Perr Fl. Seneg. Tent. 30 et 232. t. $9(1832)=$ Cordyla Lour. (Legumin.)

pinnata, A. Rich. 1. c. 31 . t. $9=$ Cord. africana.

CALYCANTHEMUM, Klotzsch, in Peters, Reise Mossamb. Bot. 243, t. $40(1861)=$ Ipomoea, Linn (Convolvul.)

leucanthemum, Klotzsch, 1. c. 244.--Afr. trop.

CALYCANTHUS, Linn. Syst. ed. X. 1066 (1759) CALYCANTHACEAE, Benth. \& Hook. f. i, 16.

Basteria, Míll. ex Adans. Fam. ii. 294 (1763)

Beureria, Ehret, Pl. et Pap. Rar. t. 13 (1755).

Butneria, Duham. Arb. i. 113, t. 45 (1755).

Pompadoura, Buchoz, ex DC. Prod. iii. 2 (1828).

acuminatus, Hort. ex C. Koch, Hort. Dendrol. $183=$ floridus.

asplenifolius, Hort. ex C. Koch, Dendrol. i. $365=$ floridus.

bullatus, Hort. ex C. Koch, 1. c. = floridus

ferax, Michx. F1. Bor. Am. i. $305=$ laevigatus.

fertilis, Andr. Rep. viii. t. $539=$ laevigatus.

fertilis, Walt. Fl. Carol. 151= glaucus.

floridus, Linn. Syst. ed. X. 1066.-Am. bor.

glaucus, Willd. Enum. Hort. Berol. 559.-Am. bor.

inodorus, Ell. Sketch, i. $576=$ laevigatus.

laevigatus, Willd. Hort. Berol. t. 80; Enum. Hort.

Berol. 559.-Am. bor.

macrophyllus, Hort. ex C. Koch, Dendrol. i. $364=$ occidentalis.

mollis, Rafin. Alsog. Am. 7.-Am. bor.

nanus, Loisel. in Duham. ed. Nov. i. $219=1$ aevigatus

oblongifolius, Loud. Hort. Brit. 214.-Am. bor.

occidentalis, Hook. E Arn. Bot. Beech. Voy. 340. t. 84.-Calif.

pensylvanicus, Lodd. in Loud. Hort. Brit. 214.--Am. bor.

\section{CALYCANTHUS :-}

philadelphicus, Nois. ex Steud. Nom. ed. II. i. 262.Am. bor.

praecox, Linn. Sp. P1. ed. II. $718=$ Chimonanthus fragrans.

prunifolins, Sweet, Hort. Brit. ed. II. 195, nomen.Carolina.

reticulatus, Rafin. Alsog. Am. 7.-Am. bor.

steritis, Walt. Fl. Carol. $151=$ floridus.

suaveolens, Salisb. Prod. $379=$ Chimonanthus fragrans tomentosus, Rafin. Alsog. Am. 7.-Am. bor.

verrucosus, Rafin.l.c. 8.-Am. bor.

versicolor, Regel, Cat. Pl. Hort. Aksakov. 25.-Am. bor.

CALYCERA, Cav. Ic. iv. 34. t. 358 (1797) (Calicera). CALYCEREAE, Benth. \& Hook. fo ii. 162 .

Anomocarpus, Miers, in Ann. \& Mag. Nat. Hist. Ser. III. vi. (1860) 351 ; Contrib. Bot. ii. 28

Discophytum, Miers, ex Lindl. Veg. Kingd. 701 (1847).

Gymnocaulus, Phil. in Linnaea, xxviii. (1856) 705.

Leucocera, Turcz. in Bull. Soc. Nat. Mosc. xxi. (1848) I. 582.

balsamitaefolia, Rich. in Mem. Mus. Par. vi. (1820) 77.-Chili.

Calcitrapa, Griseb. in Goett. Abh. xix. (1874) 163.Reg. Argent.

Cavanillesii, Rich, in Mem. Mus. Par. vi. (1820) $77=$ herbacea.

eryngioides, Remy, in C. Gay, Fl. Chil. iii. 254.-Chili.

herbacea, Cav. Ic. iv. 34. t. 358,-Chili

intermedia, Phil. in Anal. Univ. Chil. (1870) ii. 174.-Chili.

involucrata, Phil. Sert. Mend. Alt. 16.-Chili.

nudicaulis, Phil. ex Miers, in Ann. \& Mag. Nat. Hist. Ser. III. vi. (1860) $399=$ viridiflora.

pūlvinata, Remy, in Ann. Sc. Nat. Sér. III. vi. (1846) 352.-Bolivia.

sessilifora, Phil. in Linnaed, xxviii. (1856) 706.Chili.

sinuata, Miers, in Ann. E Mag. Nat. Hist. Ser. III. vi. (1860) 398.-Chili.

spinulosa, Gill. ex Miers, l. c. 399.-Chili.

squarrosa, Miers, l. c. 398.-Chili.

tenuifolia, Phil. ex Miers, l. c. 356.-Chili.

ventosa, Meyen, Reise, i. 356.-Chili

viridiflora, Miers, in Ann. \& Mag. Nat. Hist. Ser. III. vi. (1860) 399.-Chili.

CALYCIUM,EIl. Sketch, ii. 339 (1824)= Heterotheca,

Cass. (Compos.).

divaricatum, Ell. 1. c. 339, 338= H. Lamarckii

scabrum, Ell. 1. c. $339=$ H. Lamarckii.

CALYCOBOLUS, Willd. ex Roem. \& Schult. Syst. v. 2 (1819) = Breweria, R. Br. (Convolvul.)

emarginatus, Willd. 1. c. 4-N. Granat.

pulchellus, Willd. 1. c.-N. Granat.

CAIYCOCARPUM, Nutt. ex Torr. \& Gray, Fl. N. Am. i. 48 (1838). MENISPERMACEAE, Benth. \& Hook. f. i. 35 Lyonii, Nutt. ex A. Gray, Gen. Am. Bor. i. 76.-Am.
bor.

CALYCOCORSUS, F. W. Schmidt, Samml. Phys. Aufs. i. $271(1795)=$ Chondrilla, Linn. (Compos.). hieracioides, F. W. Schmidt, 1. c. = Ch. Peltidium.

CALYCODAPHNE, Boj. Hort. Maurit. 273 (1837) = Ocotea, Aubl. (Laurin.).

cupularis, Boj. 1. c. $=$ O. floribunda.

dysoxylon, Boj. 1, c. $=$ O. floribunda.

floribunda, Boj. 1. c. $=$ O. floribunda.

CALYCODON, Nutt. in Journ. Acad. Phil. Ser. Ir. i. $186(1847)=$ Muehlenbergia, Schreb. (Gramin.). montanum, Nutt. 1. c. = M. gracilis.

CALYCOGONIUM, DC. Prod. iii. 168 (1828) MELASTOM ACEAE, Benth. \& Hook. f. i. 761.

Calycopteris, Rich. ex DC. Prod. iii. 168 (1828). angulatum, Griseb. Cat. Pl. Cub. 93.-Cuba.

clidemioides, Griseb. l. c. 94.-Cuba.

cubense, Griseb. 1. c. $93=$ stellatum. 


\section{CALYCOGONIUM :}

cubense, A. Rich. Ess. Fl. Cub. $555=$ Pachyanthus Poiretii.

echinatum, Griseb. in Mem. Am. Acad. N. S. viii. (1861) 184 .-Cuba

ellipticum, Sauvalle, Fl. Cub. 50.-Cuba

glabratum, DC. Prod. iii. 168.-Jamaic.

Grisebachii, Triana, in Trans. Linn. Soc. xxviii. 1871) 97 - Cuba

heterophyllum, Naud. in Ann. Sc. Nat. Sér. III. xvi. (1851) 85.-Cuba.

heterotrichum, Triana, in Trans. Linn Soc. xxviii. (1871) 96.-Cuba.

hypoglaucum, Wright, ex Griseb. Cat. Pl. Cub. 94.Cuba.

involucratum, Griseb. in Mem. Am. Acad. N. S. viii. (1861) $184=$ Ossaea involucrata.

lanceolatum, Griseb. Cat. P1. Cab. $93=$ glabratum.

Lima, Griseb. 1. c. $95=$ Oxymeris asperifolia.

Lindenianum, Naud. in Ann. Sc. Nat. Sér. III. xvi. (1851) 84.-Cuba.

microphyllum, Sauvalle, F1. Cub. $50=$ glabratum. muricatum, Griseb. Cat. Pl. Cub. 95= Octopleura muricata.

pauciflorum, Triana, in Trans. Linn. Soc. xxviii. (1871) $96=$ echinatum.

plicatum, Griseb. Cat. Pl. Cub. 94.-Cuba.

productum, Sauvalle, Fl. Cub. $49=$ heterophyllum.

rhamnoideum, Griseb. Cat. Pl. Cub. $93=$ glab-

rhamnoideum, Griseb. Cat. Pl. Cub. $93=$ glab-

ratum. (1851) 85.-Jamaic.

rosmarinifolium, Griseb. Cat. $\mathrm{Pl}$. Cub. 93.-Cuba.

stellatum, DC Prod. iii. 168,-Ins. S. Doming.

stellatum, Griseb. in Mem. Am. Acad. N. S. viii. (1861) $183=$ Grisebachii

verrucosum, Griseb. Cat. Pl. Cub. 95.-Cuba

Wrightianum, Griseb. in Mem. Am. Acad. N. S. viii. (1861) $184=$ glabratum.

CALXCOLPUS, Berg, in Linnaea, xxvii. (1854) 378. MYRTACEAE, Benth. \& Hook. f. i. 718.

calophyllus, Berg, in Mart. Fl. Bras. xiv. I. 412.-Bras,

glaber, Berg, l. c. 411.-Peruv.

Goetheanus, Berg, l. c. 412.-Bras.

Kegelianus, Berg, in Linnaea, xxvii. (1854) 381.Guiana.

ovalifolius, Berg, l. c. 379.-Ind. occ.

parviflorus, Sagot, in Ann.Sc. Nat. Sér. VI. xx. (1885)

181.-Guiana.

revolutus, Berg, in Linnaea, xxvii. (1854) 383.Guiana.

Schomburgkianus, Berg, l. c. 380,-Guiana.

Warscewiczianus, Berg, l. c. 382.-N. Granat.

CALYCOMELIA, Kostel. Allg. Med..Pharm. Fl. iii. $1003(1834)=$ Fraxinus, Linn. (Oleac.).

acuminata, Kostel. 1. c. $1004=$ F. americana.

alba, Kostel. Ind. Hort. Prag. $26=\mathrm{F}$. alba.

americana, Kostel. Allg. Med.-Pharm. Fl. iii. 1004=

F. americana.

caroliniana, Kostel. Ind. Hort. Prag. $26=$ F. platycarpa.

elliptica, Kostel. 1. c. $=$ F. elliptica.

epiptera, Kostel. 1. c. = F, epiptera.

expansa, Kostel. 1. c. $=$ F. pubescens.

juglandifolia, Kostel. Allg. Med.-Pharm. Fl. iii. $1004=\mathrm{F}$. americana.

lancea, Kostel. Ind. Hort. Prag. $26=$ F. lancea.

nigra, Kostel. 1. c. = F. nigra.

orata, Kostel. 1. c, $=$ F, ovata.

pallida, Kostel. 1. c. = F. pallida

platycarpa, Kostel. 1. c. $=F$. platycarpa.

pubescens, Kostel. 1. c。 $=$ F. pubescens.

quadrangulata, Kostel. Allg. Med.-Pharm. FI. iii $1004=\mathrm{F}$, quadrangulata.

Richardi, Kostel. Ind. Hort. Prag. $26=$ F. Richardi. tomentosa, Kostel. Allg. Med.-Pharm. Fl. iii. $1004=$ F. pubescens.

viridis, Kostel. Ind. Hort. Prag. $26=$ F. viridis.

CALYCOMIS, R. Br. in Flind. Voy. App. 549 (1814)= Callicoma, Andr. (Saxifrag.).

CALYCOMIS, D. Don, in Edinb. N. Phil. Journ. ix (1830) 93 = Acrophyllum, Benth. (Saxifr.) verticillatum, D. Don. 1. c, $=\mathrm{A}$. venosum.
CALYCOMORPHUM, Presl, Symb. Bot. i. 50 (1830) = Trifolium, Toum. (Legumin.).

globosum, Presi, 1. c, = T. globosum.

subterraneum, Presl, 1. c. = T. subterraneum.

CALYCOPEPLUS, Planch. in Bull. Soc. Bot. Fr. viii. (1861) 30. EUPHORBIACEAE, Benth. \& Hook. f. ii. 261 .

ephedroides, Planch. l. c. 31.-Austral.

marginatus, Benth. Fl. Austral. vi. 53.-Austral

paucifolius, Baill. Adansonia, vi. (1865-66) $319=$ ephedroides.

CALYCOPHYLLUM, DC. Prod. iv. 367 (excl. sp. 2 \& 3) (1830). RUBIACEAE, Benth. \& Hook. f. ii 38.

EUKxLISTA, Benth. in Hook. Kew Journ. v. (1853) 280.

candidissimum, DC. Prod. iv, 367.-Am. austr. coccineum, DC. 1. c. $=$ Warscewiczia coccinea. grandiflorum, Meyen, Reise, ii. 234=Mussaenda grandiflora.

multiflorum, Griseb. in Goett. Abh. xxiv. (1879) 155.Reg. Argent.

Stanleyanum, Schomb. in Hook. Lond. Fourn. Bot. iii (1844) 622.-Guiana.

tubulosum, DC. Prod, iv, 367 (Pogonopi sp.),-Bras. tubulosum, Seem. Bot. Voy. Herald, $135=$ Pogonopus exsertus.

CALYCOPHYSUM, Karst. \& Triana, in Linnaea, xxviii. (1856) 427. CUCURBITACEAE, Benth. \& Hook. f. i. 828

gracile, Cogn. in Bull. Acad. Belg. Sér. II. xlix. (1880) 191.-N. Granat.

pedunculatum, Karst. E Triana, in Linnaea, xxvili. (1856) 428.-N. Granat.

CALYCOPLECTUS, Oerst. in Vidensk. Selsk. Skr. V. v (1861) $120=$ Alloplectus, Mart. (Gesner.) concolor, Oerst. 1. $c_{0}=\mathrm{A}$. dichrous.

dichrous, Oerst. 1, c. = A, dichrous

Pinelianus, Oerst. 1. c. $=$ A. Pinelianus.

CALYCOPTERIS, Lam. Ilinstr. t. 357 (1794?) COMBRETACEAE, Benth. \& Hook. f. i. 686. Getonia, Roxb. Pl. Corom. i. 61.t. 87 (1795) floribunda, Lam. Tabl. Encyc. ii. 485.-Ind. or. Malaya.

nutans, Kurz, in Joun. As. Soc. Beng. xlvi. (1877) II. $59=$ floribunda.

CALYCOPTERIS, Rich. ex DC. Prod. iii. 168 (1828)= Calycogonium, DC. (Melastom.)

CALYCORECTES, Berg, in Linnaea, xxvii. (1854 317. MYRTACEAE, Benth. \& Hook. f. ¿. 720 Schizocalyx, Berg, 1. c. 319 (1854). cubensis, Griseb. Cat. Pl. Cub. 90.-Cuba. grandifolius, Berg, in Linnaea, xxvii. (1854) 317.Guiana.

Langsdorff, Berg, in Mart. Fl. Bras. xiv. 1. 597.-Bras. latifolius, Berg, in Linnaea, xxx. (1859-60) 701Guiana.

Martianus, Berg, in Mart. Fl. Bras. xiv. I. 596.-Bras mexicanus, Berg, in Linnaea, xxvii. (1854) 318.Mexic.

protractus, Griseb. Cat. Pl. Cub. 284-Cuba.

Riedelianus, Berg, in Mart. Fl. Bras. xiv. 1. 596.Bras.

Schottianus, Berg, l. c. 357.-Bras.

Sellowianus, Berg, l. c. 856. - Bras.

CALYCOSERIS, A. Gray, Pl. Wright. ii. 104. t. 14 (1853), COMPOSITAE, Benth. \& Hook, f. ii. 523. Parryi, A. Gray, in Torr. Bot. Mex. Bound. 106.Californ.

Wrightii, A. Gray, Pl. Wright. ii. 104. t. 14.-N. Mexic.

CALYCOSORUS, Endl. Gen, 499, in syn. (1898)= CALYCOCORSUS, F. W. Schmidt=Chondrilla, Linn. (Compos.).

CALYCOSIA, A. Gray, in Proc. Am. Acad. iv (1860) 47. RUBIACEAE, Benth. \& Hook. f. ii. 123. Hunteri, Horne, ex Baker, in Gourn. Linn. Soc. $x x$. (18S4) 864. -Ins, Fiji.
CAIYCOSIA :-

Milnei, A. Gray, in Proc. Am. Acad. iv. (1860) 307 . Ins. Fiji.

petiolata, A. Gray, l. c. 48.-Ins. Fiji.

pubiflora, A. Gray, l. c. 306.-Ins, Fiji.

sessilis, A. Gray, l. c. 48.-Ins. Samoa.

CALYCOSTEGIA, Lem. in Orb. Dict. iii. 86 (1849) Calystegia, R. Br. (Convolv.)

CALYCOSTEMMA, Hanst. in Linnaea, xxix. (1857-58 $506=$ Isoloma, Decne. (Gesnerac.)

Lindenii, Hanst. 1. c. 516.-N. Granat.

CALYCOTHRIX, Meissn. Gen.107 (1837)= Calythrix Labill. (Myrtac.)

CALYCOTOME, E. Mey. Comm. Pl. Afr. austr. 113 (1835) = Dichilus, DC. (Legumin.)

pusilla, E. Mey. 1. c. $114=\mathrm{D}$. gracilis

CALYCOTOME, Link, in Schrad. Neues Journ. (1808) I1.50 (Calicotome). LEGUMINOSAE, Benth. \& Hook. f.i. 481.

cretica, Presl, ex Nym. Consp. $158=$ villosa.

infesta, Guss. Fl. Sic. Syn. ii. 247.-Dalmatia.

intermedia, Boiss. ex Keichb. f. Ic. Fl. Germ. xxii. 33 t. $2094=$ villosa.

spinosa, Link, Enum. Hort. Berol. ii. 225-Lusitan. villosa, Link, in Schrad. Neues fourn. ii. (1808) II. 51. -As. Min.

CALYCOTOMON, Hoffmgg. Verz. PA. 166 (1824)= Calicotome, Link (Legumin.).

CALYCOTOMUS, Rich, ex DC. Prod, iii. 173 (1828) Conostegia, D. Don (Melastom.)

CALYCOTROPIS, Turcz. in Bull. Soc. Nat. Mosc. XXXY. (1862) II. 327. PARONYCHIEAE vel ELATINEAE? Benth. \& Hook. f. Gen. i. 978. minuartioides, Turcz. l. c. 328.-Mcxic.

CALYDERMOS, Lag. Gen. et Sp. Nov. 21 (1816 Calea, Linn. (Compos.)

atriplicifolius, Spreng. Syst. iii. $457=$ Isocarph 2 atriplicifolia.

jamaicensis, Spreng. Syst. iii. $457=$ Eupatorium Dalea.

longifolius, Lag. Gen. et Sp. Nov. $2 t=$ Calea peduncularis.

peduncularis, DC. Prod, v, $669=$ Calea peduncularis. repens, Spreng. Neue Entdeck. i. $278=$ Oiospermum involucratum.

rugosus, DC. Prod. v. $670=$ Calea ragosa

salmeaefolius, DC. 1. c. = Calea salmiaefolia.

scaber, Lag. Gen. et Sp. Nov. $24=$ Calea pedunculari spilanthoides, Griseb. in Mem. Am. Acad. N. S. riil. (1863) 514.-Cuba

CALYDERMOS, Rniz \& 12ar, Fl. Per, ii. 43 1-9y)= Nicandra, Adans. (Solanac.)

erosus, Ruiz \& Pav. 1. $\mathrm{c}_{\mathrm{n}}=\mathrm{N}$. physalodes.

CALYDOREA, Herb, in Lindl. Bot. Reg. 1843 Misc. 85. IRIDEAE, Benth. \& Hook. f. iii. 695. BOTHERBE, Stcud. ex Klatt, in Linnaea, xrxi. ISÜu 61) 562

ROTERBE, Klatt, in Mart, Fl. Bras, iii. 1. 543, t. (18:1).

azurea, Klatt, in Abh. Naturf. Ges. Hable, xii. 'ISE? 387.- Hab.

campestris, Baker, in Fourn. Boto xiv. (1Si0) 158.Am. trop.

cipuroides, Klatt, in Abh. Naturf. Gers. Halle, xi. (1:82) 387 - - Hob ?

furcata, Boker, in Fourn. Buf. xix. (18; $\left.0^{\circ}\right)$ 1S0.-Keg. Argent.

Gardneri, Baker, 1. c.-Bras.

longispatha, Baker, l. $C_{\mathrm{e}}=$ Sphenostignaa lungispacha. luteola. Baker, I. c.-liras.

nuda, Baker, 6. G- - Keg. A

pallens, Griseb. in Goxth. Albh. xxiv. (1979 $824-\mathrm{Rcg}$ Argene.

punctuta, Raker, in Joum. Bot xir. $\left(15 ; 0^{\circ}\right)$ 1S: Vicmastylis punctat?.

speciosa, Herb. in Bob. Reg. (1Et3) Afise. 83.-Chili texana, Baker, in Fourn. Bot. xir. $(15 ; 6) 189 .-T e x a c$. 
CALYGoGoniuM, G. Don, Gen. Syst. ii. 731 (1832)= Calycogonium, DC. (Melastom.).

CALYGONIUM, D. Dietr. Syn. ii. $1376(1840)=$ praec.

CALYLOPHIS, Spach, in Ann. Sc. Nat. Sér. II. iv. (1835) $272=$ Oenothera, Linn. (Onagrar.). Berlandieri, Spach, 1. c. $273=$ Oe. serrulata? Drummondiana, Spach, l. c。 $=$ Oe. serrulata. Drumondii, Spach, ex Steud. Nom. ed. II. i. $262=$

praec,
Nuttallii, Spach, Hist. Vég. Phan. iv. $350=$ Oe. serrulata.

CALYlOPHUS, Spach, Hist. Vég. Phan. iv. $351=$ praec.

CALYMenIA, Pers. Syn. i. $36(1805)=$ Oxybaphus, Vahl (Nyctagin.)

aggregata, Pers. Syn. i. $37=$ O. aggregatus.

albida, Nutt. Gen. Am. i. $26=0$. aggregatus.

angustifolia, Nutt. in Fras. Cat. (1813); Gen. Am. i. $26=0$. angustifolius.

Cervantesii, Heynh. Nom, ii. $110=0$. Cervantesii.

chilensis, Heynh. $\mathrm{I}, \mathrm{c}=\mathrm{O}$. chilensis.

corymbosa, Pers. Syn. î. $37=$ O. glabrifolius.

decumbens, Nutt. Gen. Am. i. $26=0$. decumbens.

expansa, Pers. Syn. i. $36=0$. expansus.

hirsuta, Nutt, Gen. Am. i, $26=$ O. hirsutus.

linearis, Nutt. 1. c. $=\mathrm{O}$. angustifolius.

nyctaginea, Nutt. $1_{\mathrm{n}} \mathrm{c}_{\mathrm{o}}=\mathrm{O}$. nyctagineus.

ovata, Pers. Syn. i. $36=0$, ovatus.

paniculata, Heynh. Nom. ii. $110=\mathrm{O}$. glabrifolius.

pilosa, Nutt. Gen. Am. i. $26=$ O. ovatus.

prostrata, Pers. Syn. i. $36=$ O. prostratus.

viscosa, Pers. 1. $\mathrm{c}_{。}=\mathrm{O}$, viscosus.

CALYMMANDRA, Torr. \& Gray, Fl. N. Am. ii. 262 $(1841)=$ Evax, Gaertn. (Compos.).

candida, Torr. \& Gray, 1. c. = E. candida.

CALYMNANDRA, Lindl. Veg. Kingd. $710(1847)=$ praec.

CALYNUX, Rafin. in Journ. Phys. 1xxxix. 257 (1819)= Pyrularia, Rich. (Santalac.).

CALYPleCtus, Ruiz \& Pav. Prod. 73. t. $13(1794)=$ Lafoensia, Vand. (Lythrar.).

acuminatus, Ruiz \& Pav. FI. Per. iv. t. $423=\mathrm{L}$. acuminata.

adenophyllus, Schott, ex Steud, Nom. ed. II. i. $263=$ L. replicata.

dependens, Ruiz, ex Koehne, in Engl. Bot. Jahrb. iii. (1882) $155=\mathrm{L}$, acuminata.

punicaefolius, Bert. ex Koehne, I. c. $154=$ L. punicaefolia.

speciosus, H. B. \& K. Nov. Gen。 et Sp. vi. 183. t. 548 $=\mathrm{L}$. speciosa.

CALYPSO, Salisb. Parad. Lond. t. 89 (1806) ORCHIDEAE, Benth. \& Hook. f. iii. 496.

Cytherea, Salisb. in Trans. Hort. Soc. i. (1812) 301.

NORNA, Wahlenb. Fl. Suec. 561 (1826)

Orchidium, Sw. in Svensk Bot. t. 518 (1819).

americana, R. Br. in Ait. Hort. Kew, ed. II. v. $208=$ borealis.

borealis, Salisb. Parad. Lond. t. 89.-Reg. bor. temp. bulbosa, Reichb. f. Ic. Fl. Germ. xiii. 158. t. $137=$ borealis?

CALYPSO, Thou. Hist. Vég. Afr. Austr. i. 33. t. 6 (1805) = Salacia, Linn. (Celastr.).

africana, G. Don, Gen. Syst. i. $629=$ S. africana.

campestris, Cambess. in St. Hil. F1. Bras. Mer. ii. 111. t. $104=\mathrm{S}$. campestris.

debilis, G. Don, Gen. Syst. i. $629=$ S. debilis.

erecta, G. Don, $1 . c_{0}=\mathrm{S}$. erecta.

madagascariensis, Cambess. in St. Hil. Fl. Bras.

Mer. ii. 111. t. $104=S$. madagascariensis.

pyriformis, G. Don, Gen. Syst. i. $629=\mathrm{S}$. pyriformis.

salacioides, Thou. ex Cambess。 in St. Hil. FI. Bras.

Mer。 ii. 111. t. $104=$ S. Calypso.

senegalensis, Cambess. $1 . c_{.}=\mathrm{S}$. senegalensis.

sylvestris, Mart, in Flora, XX。(1837) II. Beibl. $96=\mathrm{S}$. sylvestris.
CALYPSODIUM, Link, Handb。 i. 252 (1829) = Calypso, Salisb. (Orchid.)

boreale, Link, l. c. $=$ Calypso borealis

CALYPSOGYNE, Neraud, in Freyc. Voy. Bot. 25, 26 (1826), nomen.

CALYPTERIOPETALON, Hassk. in Flora, xl. (1857) $531=$ Croton, Linn. $($ Euphorbiac.).

brasiliensis, Hassk. 1. c. $=$ Croton urticaefolius.

CALYPTERIS, Zipp. ex Mackl, in Alg. Konst. en Letter-bode, i. (1829) 298 (Ord. Nat. ?)

miniata, Zipp. ex Mackl. l.c. nomen.-Hab. ?

CALYPTHRANTES, Raeusch. Nom. ed. III. 144 $(1797)=$ Calyptranthes, Sw. (Myrtac.).

CALYPTOCARPUS, Less. Syn. Comp. $221(1832)=$ Blainvillea, Cass. (Compos.).

bahiensis, Sch. Bip. in Bot. Zeit. xxiv. (1866) $165=$ B. bahiensis.

Burchellii, Sch. Bip. 1. c. = B. rhomboidea.

megapotamica, Sch. Bip. 1. c. = B. biaristata.

vialis, Less. Syn. Comp. $221=$ B. tampicana.

Wendlandii, Sch. Bip. in Bot. Zeit. xxiv. (1866) 165. - Costa Rica.

CALYPTRANTHes, Sw. Prod. Veg. Ind. Occ. 79 (1788). MYRTACEAE, Benth. \& Hook. f, i. 717. Chytralia, Adans. Fam. ii. 80 (1763).

Mitranthes, Berg, in Linnaea, xxvii. (1854) 316.

Suzygium, P. Br. ex Adans. Fam. ìi. 244 (1763).

affinis, Berg, in Mart. Fl. Bras. xiv. I. 43.-Bras.

anceps, Berg, l. c. 40.-Bras.

aromatica, Blnme, Bijdr. 1092 (=Caryophyllus antisepticus).

aromatica, St. Hit. Pl. Us. Bras. fasc. iii. t. 14Bras.

axillaris, Berg, in Mart. Fl. Bras, xiv, I. 53.-Bras.

bimarginata, Berg, l. c. 543.-Bras.

bipennis, Berg, in Linnaea, xxxi. (1861-62) 248.Peruv.

Blanchetiana, Berg, in Mart. Fl. Bras. xiv. I. 40,Bras.

brasiliensis, Spreng. Syst. ii. 499.-Bras.

bullata, DC. Prod. iii. 258,-Honduras.

calyptrata, Griseb. in Mem. Am. Acad. N. S. viii. (1861) 181.-Cuba.

capitellata, Buch.-Ham. ex Wall, Cat, n. 3560 B= Eugenia Jambolana.

caryophyllata, Pers. Syn. $32=$ Eugenia caryophyllaea. caryophyllifolia, Willd. in Usteri, Ann. xvii. (1796) 22 = Eugenia Jambolana.

caudata, Gardn. in Hook. Lond. Fourn. Bot. iv. (1845)

102-Bras.; N. Granat.

cephalantha, Berg, in Mart. Fl. Bras, xiv. 1. 46.Bras.

Chytraculia, Sw. Prod. Veg. Ind. Occ. 79.-Jamaica.

clusiaefolia, Berg, in Mart. Fl. Bras. xiv. I. 39,Bras.

concinna, $D C$. Prod. iii. 258.-Bras.

cordata, Berg, in Mart. Fl. Bras. xiv. 1. 48.-Bras.

cordifolia, Moon, Cat. P1. Ceyl. $39=$ Eugenia Neesiana vel cordifolia.

corymbosa, Blume, Bijdr. 1091 (=Syzygium corymbosum).

costaricensis, Berg, in Linnaea, xxvii. (1854) 20.Costa Rica.

costata, Buch.-Ham. in Wall. Cat. n. $3556=$ Eugenia operculata.

cubensis, Berg, in Linnaea, xxix. (1857-58) 215.Ind. occ.

Cumini, Pers. Syn. ii. $32=$ Eugenia Jambolana.

cuminodora, Stokes, Bot. Mat. Med. iii. $67=$ Eugenia caryophyllifolia.

cuneata, Buch.-Ham. ex Wall. Cat. n. $3557=$ Eugenia operculata.

cuprea, Berg, in Linnaea, xxx. (1859-60) 653.Cuba.

cuspidata, Mart. ex DC. Prod. iii. 258.-Bras.

Danca, Buch.-Ham. ex Wall. Cat. n. $3560=$ Eugenia Heyneana.

decandra, Griseb. in Mem. Am. Acad. N. S. viii.

(1861) 181.-Cuba.

densa, DC. Prod. iii. 257.-Bras.

densiflora, Poepp. ex Berg, in Linnaea, xxvii. (1854) 30.-Peruv.
CALYPTRANTHES :-

dichotoma, Casar. Decad. Nov. Stirp. Bras. v. 47.Bras.

enneantha, Wright, in Sauv. Fl. Cub. 40.-Cuba.

eriopoda, DC. Prod. iii. 257.-Bras.

eugenioides, Cambess. in St. Hil. Fl. Bras, Mer, ii. 370.-Bras.

eugenioides, Seem. Fl. Vit. 81.-Ins. Fiji.

fasciculata, Berg, in Linnaea, xxvii. (1854) 31.Guiana.

fastigiata, Berg, in Mart. Fl. Bras. xiv, I. 50.-Bras.

fastigiata, Blume, Bijdr. 1090 (=Caryophyllus fastigiatus',

floribunda, Blume, 1. c. $1091=$ Eugenia floribunda.

Forsteri, Berg, in Linnaea, xxvii. (1854) 23.-Ins. S. Lucia.

fragrans, Ruiz, ex Berg, 1. c. $20=$ paniculata.

glomerata, Cambess. in St. Hil. Fl. Bras. Mer. î. 371. -Bras.

gracilipes, Wright, in Sauv. Fl. Cub. 39.-Cuba.

grandiflora, Berg, in Mart. Fl. Bras. xiv. I. 542.Bras.

grandifolia, Berg, l. c. 48.-Bras.

grandis, Buch.-Ham. ex Wall. Cat. n. $3554=$ Eugenia operculata.

guineensis, Willd. Sp. Pl. ii. 974,--Afr. trop.

Fambolana, Moon, Cat. Pl. Ceyl. $39=$ Eugenia sylvestris.

Fambolana, Willd. in Usteri, Ann. xvii. (1796) $23=$ Eugenia Jambolana.

jambolifera, Stokes, Bot. Mat. Med. iii. 68 = Eugenia Jambolana.

Karwinskyana, Berg, in Linnaea, xxix. (1857-58) 214. -Mexic

lanceolata, Berg, in Mart. Fl. Bras. xiv. X. 51.-Bras. Langsdorff, Berg, l. .. 539.-Bras,

lateriftora, DC. Prod. iii. $258(=$ Rubachia lateriflora $)$ -Bras.

latifolia, Poir. Encyc. Suppl. ii. 43.-Ins. Maurit.

laxiflora, Blume, Bijdr. 1090,-Java.

Lindeniana, Berg, in Linnaea, xxix. (1857-58) 213.Mexic.

longifolia, Berg, in Mart. Fl. Bras. xiv. I. 46.-Bras. loranthifolia, DC. Prod. iii. 258.-Bras.

lucida, Mart. ex DC. l. c.-Bras.

macrophylla, Berg, in Mart. Fl. Bras. xiv. I. 45.Bras.

Makal, Raeusch. Nom. ed. III. 144 (= Syzygium Makul).

Makul, Blanco, Fl. Filip. ed. I. 419 = Eugenia operculata.

malabarica, Dennst. Schluess. Hort. Malab. $31=$ Eugenia zeylanica.

mangiferifolia, Hance, ex Walp. Ann. ii. $629=$ Eugenia operculata.

Martiusiana, DC. Prod. iii. 257.-Bras.

maschalantha, Berg, in Mart. Fl. Bras, xiv. I. 53.Bras.

melanoclada, Berg, $l$. c. 50 -Bras,

micrantha, Wright, ex Griseb. Cat. Pl. Cub. 85.Cuba.

multiflora, Poepp. ex Berg, in Mart. Fl. Bras, xiv. I. 42.-Bras

musciflora, Berg, l. c. 54.-Bras.

mutabilis, Berg, l. c. 540.-Bras.

myrtoides, Seem. Fl. Vit. 81.-Ins. Fiji

nigricans, $D C$. Prod. ili. 258.-Bras.

nitida, Raeusch. Nom. ed. III. $144=$ Syzygium lucidum.

Nummularia, Berg, in Linnaea, xxx. (1859-60) 652. -Ins. S. Doming.

obscura, DC. Prod. iii. 257.-Bras.

obscura, Mart. in Flora, xx. (1837) Beibl. ii. $87=$ tuberculata.

obtusa, Benth. in Hook. Fourn. Bot. ii. (1840) 319.Guiana.

obtusa, Miq. in Linnaea, xxii. (1849) $172=$ Marlierea suffruticosa.

obtusifolia, Buch.-Ham. ex Wall. Cat. n, 3600 B = Eugenia inophylla.

obversa, Berg, in Mart. Fl. Bras. xiv. I. 51.-Bras.

oleina, Wight, Illustr. ii. $15=$ Eugenia myrtifolia.

Ottonis, Wright, in Sauv. Pl. Cub. 40.-Cuba.

ovalifolia, Cambess. in St. Hil. Fl. Bras. Mer. ii. 371. -Bras.

ovata, Berg, in Mart. Fl. Bras, xiv. I. 50, - Bras.

pallens, Griseb. in Goett. Abh. vii. (1857) 215.Ind, occ. 


\section{CALYPTRANTHES :-}

paniculata, Raeusch. Nom. ed. III. $144=$ Eugenia paniculatum.

paniculata, Ruiz E Pav. Fl. Per. iv. t. 424; Syst. 131.-Peruv.

paniculata, Spreng. Neue Entdeck, ii. $170=$ brasiliensis. pauciflora, Berg, in Mart. Fl. Bras, xiv. 1. 543.Bras.

pendula, Berg, in Linnaea, xxvii. (1854) $21=$ C. Chytraculia.

platyphylla, Berg, in Mart. Fl. Bras. xiv. I. 539.Bras.

Poeppigiana, Berg, l. c. 45.-Bras.

Pohliana, Berg, l. c. 42 -Bras

pollicina, Willem. in Usteri, Ann. xviii. (1796) $39=$

Eugenia obovata.

polyantha, Berg, in Mart. Fl. Bras. xiv. 1. 541.-Bras. pteropoda, Berg, l. c. 47.-Bras.

pulchella, DC. Prod. iii. 257.-Bras.

punctata, Griseb. in Mem. Am. Acad. N. S. viiii. (1861) 181.-Cuba.

pyrifolia, Blume, Bijdr. $1090=$ Eugenia pyrifolia.

racemosa, Blume, 1. c. 1089 (= Sysygium race mosum).

ramiflora, Blanco, Fl. Filip. ed. I. $420=$ Eugenia bracteata.

Regeliana, Berg, in Mart. Fl. Bras. xiv. 1. 542.-Bras. rigida, Macf. ex Griseb. F1. Brit. W. Ind. $233=\mathrm{C}$ Syzygium.

rigida, Sw. Prod. Veg. Ind. Occ, 80.-Tamaic.; Cuba. rigida, Tussac, $\mathrm{Fl}$. Antill. iii. t. $26=$ Tussaceana.

rostrata, Blume, Bijdr. 1092 (= Syzygium rostratum), rostrata, Griseb. in Mem. Am. Acad. N. S. viii

(1861) 181.-Cuba.

rotundata, Griseb. l. c.-Cuba.

rufa, Berg, in Mart. Fl. Bras, xiv, I, 541.-Bras.

Ruiziana, Berg, in Linnaea, xxvii. (1854) 22,-Peruv.

Schiediana, Berg, l. c. 28.-Mexic.

Schlechtendaliana, Berg, I. c. 29.-Mexic.

scoparia, Berg, l. c. xxxi. (1861-62) 247.-Bras.

Seemanni, Seem. Fi. Vit. 81--Ins. Fiji.

sericea, Griseb. Fl. Brit. W. Ind. 233.-Ind. occ.

speciosa, Sagot, in Ann. Sc. Nat. Sér. VI. xx. (1885) 187.-Guiana.

Spruceana, Berg, in Mart. Fl. Bras. xiv. I. 45.-Bras. strigipes, Berg, l. r. 540.-Bras.

Syzygium, Sw. Fl. Ind. Occ, ii. 919.-Ind. occ.

Tatna, Buch.-Ham. ex Wall. Cat. n. $3555=$ Eugenia operculata.

tenuis, Buch.-Ham. ex Wall. 1. c. sub n. $3570=$ Eugenia tenuis.

tetraptera, Berg, in Mart. Fl. Bras. xiv. I. 53.-Bras.

Thomasiana, Berg, in Linnaea, xxvii. (1854) 26. Ind. occ.

tuberculata, Berg, in Mart. Fl. Bras. xiv. I. 52.Bras.

Tussaceana, Berg, in Linnáea, xxvii. (1854) 25. Ind. occ.

unifora, Spreng. in Flora, xx. (1837) Beibl. ii. 87.-

Bras.
variabilis, Berg, in Mart. Fl. Bras. xiv. I. 49.-Bras.

variabilis, Berg, in Mart. Fl. Bras.
Widgreniana, Berg, l. c. 39 - - Bras.

Wilsonii, Griseb. Fl. Brit. W. Ind. 233.-Ind. occ.

Zuzygium, Blanco, Fl. Filip. ed. II. 293=Eugenia operculata.

Zusygium, Sw. Prod. Veg. Ind, Occ. $79=$ C. Syzygium.

CALYPTRANTHUS, Thou. Obs. Pl. Isles Afr. 26 (1811) Capparis, Tourn.

CALYPTRANTHUS, Blume, Bijdr, 1089 (1826) = Eugenia, Mich. (Myrtac.).

CALYPTRANTHUS, Juss, in Dict. Sc. Nat. vi. 274 (1817) = Calyptranthes, Sw. (Myrtac.).

CALYPTRARIA, Naud. in Ann. Sc. Nat. Sér. III. xviii. (1852) 132 =Centronia, D. Don (Melastom.).

africana, DC. Prod. ix. 469 , in $\mathrm{syn} .=$ Varronia abyssinica.

brachycera, Naud. in Ann. Sc. Nat. Sér. III. xviii. (1852) $134=$ Cent. brachycera.

eximia, Naud. 1. c. $133=$ Cent. eximia.

haemantha, Planch. \& Linden, in $\mathrm{Fl}$. des Serres, Sér. I ix. (1853-54) t. 924=Cent. haemantha.

insignis, Naud, in Ano. Sc. Nat. Sér. III. xviii. (1854) $193=$ Cent. insignis

Mutisii, Naud, 1. c. $182=$ Cent Mutisii.
CALYPTRELLA, Naud, in Ann. Sc. Nat. Sér. III. xviii. (1852) 115. MELASTOMACEAE, Benth. \& Hook. f. i. 750 .

cucullata, Triana, in Trans. Linn. Soc. xxviii. (1871) 72.--Peruy

Galeotti, Naud. in Ann. Sc. Nat. Sér. III. xviii. (1852) 115.-Mexic

gracilis, Triana, in Trans. Linn. Soc. xxviii. (1871) 72 -Peruv.

tristis, Triana, l. c.-Peruy.

CALYPTRIDIUM, Nutt. ex Torr. \& Gray, Fl. N. Am, i. 198 (1838). PORTULACEAE, Benth. \& Hook, f. i. 159.

monandrum, Nutt. l. c.-Calif.

quadripetalum, S. Wats. in Proc. Am. Acad. xx. (1885) 356.-Cakif.

roseum, S. Wats. in Bot. King, Exp. 44. t. 6.Calif.

CALYPTRION, Ging, in DC. Prod. i. $288(1824)=$ Corynostylis, Mart. (Violac.)

Aubletii, Ging. 1. c. $289=$ Cor. Hybanthus.

Berterii, Ging. 1. c. = Cor. Berterii.

citrifolium, Ging. 1. c.= Cor. Loeflingii.

diandxum, Ging. 1. c. = Cor, diandra.

frangulaefolium, Ging. 1. c.-Peruv.

nitidum, Benth. in Hook. Journ. Bot, iv. (1842) $106=$ Cor. Hybanthus.

orinocense, H. B. \& K. Nov. Gen. et Sp. v. 384.Venezuela.

pyrifolium, Sweet, ex Steud. Nom. ed. II. i. $263=$ Anchietea pyrifolia.

CALYPTRIOPETALUM, Hassk. ex Muell. Arg. in DC Prod. xv. II. $513(1866)=$ Croton, Linn. (Euphorb.)

CALYPTROCALYX, Blume, Rumphia, ii. 103. t. 102 D, 118, 161 (1836). PALMAE, Benth. \& Hook. f. Gen. iii. 902

Laccospadix, H. Wendl. \& Drude, in Linnaea, xxxix. (1875) 205.

australasicus, Scheff. in Ann. Fard. Bot. Buitenz. i. (1876) 132, 140.-Austral.

spicatus, Blume, Rumphia, ii. 103.-Amboina.

CALYPTROCARPUS, Reichb. Nom. 82 (1841) = CALYPTOCARPUS, Less, = Blainvillea, Cass. (Compos.).

CALYPTROCARYA, Nees, in Linnaea, ix. (1834) 304. CYPERACEAE, Benth. \& Hook. f. Gen. ii 304.

angustifolia, Nees, l. c.-Guiana.

bicolor, Nees, l. c. = Poeppigiana

brevicaulis, Nees, l. c. 365.-Guiana.

fragifera, Nees, l. c. 304.-Am. trop.

longifolia, Boeck. in Linnaea, xxxyiii. (1874) $431=\mathrm{C}$. Palmetto.

longifolia, Kunth, Enum. Pl. ii. 365.-Guiana.

Martii, Nees, in Mart. Fl. Bras. ii. 1. 195.-Bras.

Palmetto, Nees, l. c.-Am. trop.

Poeppigiana, Kunth, Enzım. Pl. ii. 364.-N. Granat.

Schottmuelleriana, Boeck. in Engl. Bot. Fahrb. y. (1884) 509.-Bras.

CALVPTROCORYNE, Schott, in Oestr. Bot. Wochen schr. (1857) 262= Theriophonum, Blume (Aroid.) cochinchinensis, Schott, Prod. Aroid. $105=$ T. Wightii.

minuta, Schott, 1. c. = T. Wightii.

Wightii, Schott, in Oestr. Bot. Wochenschr. (1857) $262=$ T. Wightii.

CALYPTROGYNE, H. Wendl, in Bot. Zeit. xvi. (1859) 72. PALMAE, Benth. \& Hook. f. iii. 914.

Calyptronom, Griseb. Fl. Brit. W. Ind. 518 (1864).

Ghiesbrechtiana, H. Wendl. l. c.-Mexic.

Ghiesbreghti, H. Wendl. in Kerch. Palm. $298=$ Ghies. brechtiana.

glauca, $H$. Wendl. l. c.-Nicamgua

sarapiquensis, $H$. Werdl. l. c.-Costa Ricr.

spicigera, H. Wendl. in Bot. Zcit. xvii. (1859) 72.Guatemala.
CALYPTROLEPIS, Steud. Syn. P1. Cyp. 151 (1855)= Rynchospora, Vahl (Cyperac.)

junciformis, Steud. 1. c. = R. oligantha.

CALYPTROMYRCIA, Berg, in Linnaea, xxvii. (1854 $34=$ Myreia, DC. (Myrtac.).

cordata, Berg, in Mart. Fl. Bras. xiv. r. $56=$ M. corclata. costata, Berg, 1. $\mathrm{c}_{\mathrm{v}}=\mathrm{M}$, costata.

cymosa, Berg, 1. c. 58.-Bras.

elegans, Berg, 1. $c_{n}=$ M. elegans.

eugenioides, Berg, 1. c. $56=\mathrm{M}$. eugenioides.

paniculata, Berg, l. c. 57.-Bras.

puberula, Berg, 1. c. = M. puberula.

Spixiana, Berg, 1. с. $59=$ M. Spixiana.

venosa, Berg, 1. c. 57.-Bras.

CALYPTRONOMA, Griseb. F1. Brit. W. Ind. 518 (1864) Calyptrogyne, H. Wendl. (Palm.)

dulcis, H. Wendl. in Kerch. Palrn. 238 (=Geonomu dulcis).

intermedia, H. Wend1. 1. c. nomen.-Hab. ?

robusta, Traill, in Journ. Bot. xiv. (1876) 330. I'ras.

Schwartzii, H. Wendl. in Kerch. Palm, $238=\mathrm{seg}$

Swartzii, Griseb. Fl. Brit. W. Ind. 518 (=Geonoma

Swartzii).

CALYPTROON, Miq. Fl. Ind. Bat. Suppl, 471 (1860)

Baccaurea, Lour. (Euphorbiac.)

sumatranum, Miq. 1. c. $472=\mathrm{B}$, sumatrana.

CALYPTROPSIDIUM, Berg, in Linnaea, xxyii. (1854 $349=$ Psidium, Linn. (Myrtac.).

Friedrichsthalianum, Berg, 1. c. 350.-Guatemala.

CALyptrospatha, Klotzsch, ex Baill. Etud. Gien. Euph. 440 (1858); et in Peters, Reise Mossamb. Bot. t. $18(1861)=$ Acalypha, Linn. (Euphorb.). pubiflora, Klotzsch, 1. c. 97 . t. 18=A. pubiflora.

CALYPTROSPERMUM, A. Dietr. Sp. P1. i. 226 (1831)

= Menodora, Humb. \& Bonpl. (Oleac.

integrifolium, A. Dietr. 1. c. $227=\mathrm{M}$. integrifolia.

trifidum, A. Dietr. 1. c. $=$ M. trifida.

CALYPtrostegia, C. A. Mey. in Bull. Phys.-Math. Acad. Pétersb. iv. (1845) 72 pro parte = Pimelea Banks (Thymel.

angustifolia, C. A. Mey. 1. c. $74=$ P. angustifolia. argentea, C. A. Mey. 1. c. $=$ P. argenten. brevifolia, C. A. Mey. 1. c. = P. brevifolia.

cernua, C. A. Mey, 1, c. = P. spathulata.

cluytioides, Walp. Ann. iii, $324=\mathrm{P}$. serpyllifolia.

Cornucopiae, Endl. Gen. Suppl, iv. 11. $60=$ Cornucopiae.

curviflora, C. A. Mey. in Bull. Phys.-1Math. Acad. Pétersb. iv. (1845) $74=\mathrm{P}$. curviflora,

Drummondii, Turcz, in Bull. Soc. Nat. Mosc, xiv.

(1852) II. $178=\mathrm{P}$. suaveolens.

fava, Endl. Gen. Suppl. iv, 11. $60=$ P. flava.

glauca, C. A. Mey. in Bull. Phys-Math. Acad. Pétersb. iv. (1845) $74-$ P. glauca.

graciliflora, Endl. Gen. Suppl. iv. 1I. $61=\mathbb{P}$. sylvestris, gracilis, End1. 1. c. = P. carvillora

hypericina, C A. Mey, in Bull. Phys-Math. Acad Pétersb. iv. (1845) $74=\mathrm{P}$. ligustrina.

intermedia, C. A. Mey. 1. C. = P. glanca.

lanata, Endl. Gen. Suppl. iv. 11. $61=$ P. hispida,

latifolia, Endl. l. $c_{\text {. }}=$ P. Iatifolia.

Lehmanniana, Endl. 1. c。 = P. Lehmanniana.

ligustring, C. A. Mey, in Bull. Phys-Math. Acal

''étersb.jv. $(1545) 74=1$ '. ligustrina,

linifolia, C. A. Mey, 1. c. = P. linifolia.

linoides, Endl. Gen. Suppl. iv. 11.61 1'. linifolia.

longiflora, Endl. l. c $=$ P. longiliors.

macrocephala, Whalp. Ann. iii. $\$ \geq 5=$ P. suaveolens,

Menkeana, Endl. (jon. Supyl, iv, 11. 81 = P. suaveulens.

microcephala, Endl. I. C. P. microcephals.

myrianfha, Endl. I. c. = P. angentea.

nana. Lindl. 1. c. $=$ P. imbricata.

nerrosa, Walp. Ann. iii. $\$ 2 t=\mathbb{P}$. nervosa.

phylicovides, Walp. I. $c$ = I". phvlicnides

pursicen, Endl. (ien. Suppl. iv. $11.60=5$. punices.

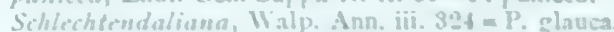

spathulala, C. A. Mev, in Hull. Phrs.-Math. Aczi.

P'etersb. iv. $(1 s+5)$ it - P. spathulata.

spicafa, Endl. Gen. Suppl. iv. 11. 61 - P. spicata. 


\section{CAIYPTROSTEGIA :-}

suaveolens, Endl. Gen. Suppl. iv。 II. $61=$ Pímelea suaveolens.

sulphurea, Walp. Ann. iii. $325=$ P. sulphurea

sylvestris, C. A. Mey, in Bull. Phys.-Math. Acad.

Pétersb. iv. (1845) $74=$ P. sylvestris.

tinctoria, Endl. Gen. Suppl. iv. II. $61=$ P. suaveolens. trichostachya, Walp. Ann. iii. $325=$ P. trichostachya. villifera, Walp. 1. c. $324=\mathrm{P}$. villifera.

villosa, Turcz, in Bull. Soc. Nat. Mosc. xxv. (1852) II $178=\mathrm{P}$. longiffora

CALyPTROSTIGMA, Klotzsch, in Lehm. PI. Preiss, i $175(1844)=$ Beyeria, Miq. (Euphorbiac.).

ledifolium, Klotzsch, 1. c. $176=\mathrm{B}$. Drummondit

oblongifolium, Klotzsch, 1. e. = B. viscosa.

viscosum, Klotzsch, 1. c. = B. viscosa。

CALyptrostigma, Trautv。 \& Mey. in Middend. Reise $($ Fl. Ochot, 46$)(1847)=$ Diervilla, Tourn (Caprifol.).

Middendorffinum, Trautv. \& Mey. 1. c. = D. Middendorffiana.

CALYPTROSTYLIS, Nees, in Linnaea, ix. (1834) $295=$ Rynchospora, Vahl (Cyperac.).

articulata, Nees, in Hook. Joum. Bot. ii. (1840) 394 in obs. $=\mathrm{R}$, aurea

asperula, Nees, in Mart. Fl. Bras. ii. I. $139=$ R。 aurea capitata, Nees, l. c. $140=$ R. minarum.

divergens, Nees, 1. c. $139=$ R. aurea.

fascicularis, Nees, 1. c. $139=\mathrm{R}$, aurea.

florida, Nees, 1. c. $138=\mathrm{R}$, aurea.

Gaudichaudii, Nees, in Linnaea, ix. (1834) $295=$ R. aurea.

gigantea, Nees, in Mart. Fl. Bras. ii. 'T. $137=$ R. gigantea.

longirostris, Nees, in Hook. Journ. Bot. ii. (1840) 394 $=\mathrm{R}$. amazonica.

paniculata, Liebm. in Vidensk. Selsk. Skr. V. ii. (1851) $252=\mathrm{R}$. Schiedeana.

Rudrei, Nees, in Linnaea, ix. (1834) $295=\mathrm{R}$, gigantea. Schiedeana, Liebm. in Vidensk. Selsk. Skr. V. ii (1851) $252=R$. Schiedeana.

terminalis, Nees, ex Steud. Syn. PI. Cyp. $143=$ R. minarum.

zeylanica, Nees, in Hook. Journ. Bot. ii. (1840) 394, in obs. $=\mathrm{R}$, triflora

CALYSACCION, Wight, Illustr. i.. $130(1840)=$ Ochrocarpus, Thou. (Guttifer.)

chinense, Walp. in Bot. Zeit. ix. (1851) 368=O. Iongifolius.

Horstii, Teijsm. \& Binn. Cat. Hort. Bog. 205. Borneo.

longifolium, Wight, Illustr. i. $130=$ O. longifolius.

obovale, Miq. F1. Ind. Bat. Suppl. i. $500=0$. ovali folius.

ovalifolium, Choisy, Guttif. Ind. $45=\mathrm{O}$. ovalifolia. siamense, Miq. in Ann. Mus. Bot. Lugd. Bat. i. 7, 209 $=0$. siamensis.

tinctorium, Seem. Fl. Vit. 13.-Ins. Fiji

CALYSERICOS, Eckl. \& Zeyh. ex Meissn. in DC. Prod. xiv. $573(1856-57)=$ Cryptadenia, Meissn. (Thymelaeac.).

argentea, Eckl, \& Zeyl. L. c. $582=$ Gnidia Cephalotes, ranaliculata, Eckl \& Zeyh. 1. c. $573=\mathrm{Cr}$. grandiflora. grandiflora, Eckl. \& Zeyh. 1. c. =Cr. grandiflora. linarifolia, Eckl. \& Zeyh. 1. c. $583=$ Gnidia linoides parviflora, Eckl. \& Zeyh. 1. c. $574=$ Cr. breviflora. subulata, Eckl. \& Zeyh. 1. c. =Cr. breviflora. tabularis, Eckl, \& Zeyh. 1. c, $=$ Cr breviflora typica, Eckl. \& Zeyl.1. c. 581=Gnidia pubescens. uniflora, Eckl. \& Zeyh. 1. c. 573= Gnidia uniflora

CALYSPHYRUM, Bunge, in Mém. Sav. Etr. Acad. Pétersb. ii. (1835) 107 ; Enum. Pl. Chin. Bor. $33=$ Diervilla, Toum. (Caprifol.).

floridum, Bunge, 1. c. $=\mathbf{D}$. florida.

pauciflorum, Bunge, in Walp. Rep. ii. $450=$ D. florida. roseum, C. A. Mey, in Bull. Phys.-Math. Acad, Pétersb. xiii. (1855) $220=\mathrm{D}$, rosea

CALYSTegia, R. Br. Prod. 483 (1810)。CON. OLVULACEAE, Benth. \& Hook, f. ii. 874 .

Milmania, Rafin. Fl. Tellur. iv. 71 (1836).

Volvulus, Medic. in Staatsw. Vorles. Churpf. Phys. Oek. Ges. i. (1791) 202 .

\section{CALYSTEGIA:-}

acetosifolia, Turcz. F1. Baic, Dahur, ii. II. $289=$ hederacea.

affinis, Endl. Prod. Fl. Norf. 51.-Ins. Norfolk.

asarifolia, S. F. Gray, Nat. Arr. Brit. Pl. ii. $344=$ C. Soldanella.

barbara, Pomel, Nouv. Mat. Fl. Atl. 83.-Afr, bor

Basniniana, Turcz. ex Ledeb. Fl. Ross. iii. $95=$ pellita.

Catesbeiana, Pursh', Fl. Am. Sept. Suppl.ii. 729.-Am. bor.

chinensis, Baill. in Bull. Soc. Linn. Par. i. (1881) 284. -China.

dahurica, Choisy, in DC. Prod, ix. $433=$ pellita.

dahurica, Fisch. ex Planch. in Fl. des Serres, x. (1854 55) 245 , t. 1075.-Sibir.

grandiflora, G. Don, Gen. Syst. iv. 297.-Ind, or.

Hantelmanni, Phil. in Linnaea, xxx. (1859-60) 196.Chili.

hederacea, Wall. Cat. n。 1328.-Ind. or.; China; Afghan.

inflata, G. Don, in Sweet, Hort. Brit. ed. III. $486=$ sepium.

japonica, Choisy, in Zoll. Syst. Verz. Ind. Archip. 130 , 132.-Japon.

Keriana, Sweet, Hort. Brit. ed. I. $287=$ Hewittia bicolor.

Krauseana, Phil. in Linnaea, xxxiii. (1864-65) 184.Chili.

Iucana, G. Don, Gen. Syst. iv. $296=$ sylvestris.

marginata, R.Br.Prod. 484.-Australas.

Maximiliana, Nees, in Newwied, Reise Nord. Am. ii. 443.-Am. austr.

mucronata, Spreng. ex Choisy, in DC. Prod. ix. $430=$ Ipomoea martinicensis.

mutabilis, Rafin. F1. Ludov. $46=$ sepium

obtusa, Pomel, Nouv. Mat. Fl. Atl.295.-Afr. bor.

ochroleuca, Boj. Hort. Maurit. 231. -Afr. trop.

palmato-partita, Benth. \& Hook, f. Gen. ii., $874=$ seq

palmato-pinnata, Meissn, in Mart. F1. Bras. vii. 317

Ipomoea palmato-pinnata.

paradoxa, Pursh, Fl. Am. Sept. Suppl. ii. $729=$ Convolvulus hirsutus.

pellita, G. Don, Gen. Syst. iv. 296.-Sibir, baical.

physoides, Pomel, Nouv. Mat. Fl. Att. 294,-Afr. bor. pubescens, Lindl. in Journ. Hort. Soc. i. (1846) 70 hederacea.

reniformis, R. Br. Prod. $483=$ C. Soldanella.

riparia, Rafin. New Fl. Am. ii. 29.-Am. bor.

rosea, Phil. in Linnaea, xxix. (1857-58) 15.-Chili

rugosa, Ledeb. Ind. Hort. Dorp. (1821) 4.-Hab.?

sagittata, Turcz. in Bull. Soc. Nat. Mosc. xxii. (1849)

II. 356 . -Am. bor.

Scammonia, Pritz. Ind. Ic. ii. $58=$ Convolvulus Scam monia.

sepium, R. Br. Prod. 483.-Cosmop. temp.

setifera, Meissn. in Mart. Fl. Bras. vii. $316=$ Ipomoea setifera.

silvatica, Choisy, in DC. Prod. ix. 483.- Europ. austr. or. ; Reg. Caucas, ; Afr. bor.

Soldanella, R. Br. Prod. 483.-Cosmop. temp. spithamaea, Pursh, Fl. Am. Sept. i. 143.-Am. bor stans, Steud. Nom. ed. II. i. $264=$ spithamaea ? subacaulis, Hook. E Arn. Bot. Beech.Voy. 363.-Calif subvolubilis, G. Don, Gen. Syst. iv. $296=$ pellita. sylvestris, Roem. \& Schult. Syst. iv. 183.-Oriens. tomentosa, Pursh, Fl. Am. Sept. i. $143=$ spithamaea tuguriorum, R. Br. ex Hook. Fl. Nov. Zel. i. 183. t. 47.- -N. Zeland.; Chili.

valdiviana, Miq. in Lechl. Berb. Am. Austr. 54._Chili. villosa, Kellogg, in Proc. Calif. Acad. v. (1873) 17.Calif.

villosa, Rafin. Ft. Ludov. 45.-Am. bor.

CALYTHRIX, Labill. Nov. Holl. PI. ii. 8. t. 146 (1806) (Calytrix). MYRTACEAE, Benth. \& Hook f. i. 699 .

Calycothrix, Meissn. Gen. 107 (1837).

Trichocalyx, Schau. Myrt. Xetoc. 86, adnot. (1840).

achaeta, F. Muell. in Trans, Phil. Vict. Inst. ii (1859) 43.-Austral.

angulata, Lindl. Swan River App. 6.--Austral.

arborescens, F. Muell. in Trans. Phil. Vict. Inst. iii. (1859) 42.-Austral.

asperula, Schau, in Lehm. Pl. Preiss, i. 104-Anstral. aurea, Lindl. Swan River App.5. t. 3.-Austral.

Baueri, Schau. in Nov. Act. Nat. Cur. xix. Suppl ii. (1841) $261=$ tetragona.
CATYTHRIX :-

Behriana, Schlecht. in Linnaea, xx. (1847) $650=$ tetragona.

Billardieri, Schau. in Nor. Act. Nat. Cur. xix. Suppl. ii. (1841) 245 = tetragona.

Birdii, F. Muell. Fragm. x. 26.-Austral.

brachychaeta, F. Muell. in Trans. Phil. Inst. Vict. iii (1859) 43.-Austral

brachyphylla, A. Cunn。 ex Steud. Nom. ed. II. i. 264. -Austral.

brachyphylla,Turcz. in Bull. Soc.Nat. Mosc. xx. (1847) I. 161-Austral.

brevifolia, Meissn. in Fourn. Linn. Soc. i. (1857) 46 -Austral.

breviseta, Lindl. Swan River App. 5.-Austral.

Brownii, Schau, in Nov. Act. Nat. Cur. xix. Suppl. ii. (1841) $260=$ tetragona.

brunioides, A. Cunn. in Bot. Mag. sub t. 3323 =tetragona.

Candolleana, Schau, in Nov. Act. Nat. Cur. xix. Suppl. ii. (1841) $260=$ C. decandra.

ciliata, Turcz. in Bull. Soc. Nat. Mosc. xx. (1847) I. $161=$ empetroides

conanthera, F. Muell. Fragm. i. 146=decandra.

conferta, A. Cunn. in Bot. Mag, sub t. 3323.Austral.

Creswelli, F. Muell. Fragm. x. 27.-Austral.

cupressifolia, A. Rich. Sert. Astrol. 41. t. 16=microphylla.

cupressoides, A. Rich. 1, c. $43=$ microphylla

curtophylla, A. Cunn. in Bot. Mag. sub t. $3323=$ flavescens.

curtophylla, Schau. in Nov. Act. Nat. Cur. xix. Suppl. ii. (1841) $242=$ Leschenaultii.

cuspidata, Turcz, in Bull. Soc. Nat. Mosc. xx. (1847) I. $162=$ breviseta

decandra, DC. Prod. iii. 208.-Austral.

depressa, Turcz. in Bull. Soc. Nat. Mosc. xx. (1847) I. 162.-A nstral.

diversifolia, Turcz. in Bull. Phys.-Math. Acad. Pétersb. x. (1852) 328,-Austral

Drummondii, Meissn. in Journ. Linn. Soc. i. (1857) 47 $=$ flavescens.

empetroides, Schau. in Nov. Act. Nat. Cur. xix. Suppl. ii. (1841) 254 . - - Austral.

ericoides, A. Cunn, in Field, N. S. Wales, $350=$ tetragona.

exstipulata, DC. Prod, iii. 208 = microphylla.

flavescens, A. Cunn. in Bot. Mag. sub t. 3323.Austral.

Fraseri, A. Cunn. l. c.-Austral.

glabra, R. Br. in Bot. Reg. t. $409=$ tetragona

glutinosa, Lindl. Swan River. App. 5.-Austral.

gracilis, Benth. Fl. Austral. iii, 45.-Austral.

granulosa, Benth. l. c. 49,-Austral.

laricina, R. Br. ex Benth. l. c. 52.-Austral

lasiantha, Meissn. in Journ. Linn. Soc. 1. (1857) $46=$ strigosa.

lasiostachya, F. Muell. Fragm. i. $224=$ sapphirina

leptophylla, Benth. Fl. Austral. iii. 50.-Austral.

Leschenauliii, Schau, in 'Lehm. PI. Preiss, i. 104.Austral.

leucantha, Miq. in Nederl. Kruidk. Arch. iv. (1859) 117 $=$ tetragona.

longiflora, F. Muell. Fragm. i. 12.-Austral.

luteola, Schau. in Lehm. Pl. Preiss. i. $106=$ flavescens. megaphylla, F. Muell. Fragm. i. 146.-Austral.

microphylla, A. Cunn. in Bot. Mag. sub t. 3323.Austral.

monticola, Miq. in Nederl. Kruidk. Arch. iv. (1859) 118 =tetragona.

Muelleri, Miq. 1. c. $119=$ tetragona.

muricata, F. Muell. Fragm.i. 224.-Austral.

Oldfieldii, Benth. $\mathrm{Fl}$. Austral. iii. 46.-Austral.

plumulosa, F. Muell. Fragm. x. 27.-Austral.

propinqua, A. Cunn. ex Walp. Rep. ii. $158=$ tetragona.

puberula, Meissn. in Fourn. Linn. Soc. i. (1857) 48.Austral.

pubescens, Sweet, ex Loud. Hort. Brit. $199=$ tetragona

pulchella, Turcz. in Bull. Phys.-Math. Acad. Pétersb. x. (1852) 328.-Austral.

rosea, Meissn. in Journ. Linn. Soc. i. (1847) $46=$ tenuifolia.

rosea, Miq. in Nederl. Kruidk. Arch. iv. (1859) $117=$ tetragona.

sapphirina, Lindl. Swan River App. 5.--Austral.

scabra, DC. Prod. iii. $208=$ tetragona. 


\section{CALYTHRIX}

Schlechtendahlii, Miq. in Nederl. Kruidk. Arch. iv. (1859) $116=$ tetragona.

simplex, Lindl. Swan River App. 5.-Austral.

sparsa, A. Cunn, ex Walp. Rep. ii. $160=$ strigosa.

squarrosa, Miq. in Nederl. Kruidk. Arch. iv. (1859)

$118=$ tetragona.

strigosa, A. Cunn. in Bot. Mag. sub t. 3323.-Austral.

Sullivani, F. Muell. Fragm. ix. 1.-Austral.

tenella, Meissn. in Journ. Linn. Soc. i. (1857) $47=$

flavescens.

tenuifolia, Meissn. l. c. 46.-Austral.

tenuiramea, Turcz. in Bull. Soc. Nat. Mosc. xxii. (1849) II. 20.-Austral.

tetragona, Labill. Nov. Holl. Pl. ii. 8. t. 146.Austral.

tetragonophylla, Meissn. in Journ. Linn. Soc. i. (1857) $47=$ flavescens.

tetraptera, DC. Prod. iii. $208=$ tetragona

variabilis, Lindl. Swan River App. 5.-Austral.

virgata, A. Cunn. in Bot. Mag. sub t. $3323=$ tetragona.

CALYTRIPLEX, Ruiz \& Pav. Prod. 96 (1794)= Herpestis, Gaertn. (Scrophular.)

obovata, Ruiz \& Pav. Syst. Veg. $165=$ H. Monniera.

CALYXHymeniA, Orteg. Hort. Matr. Dec. 5. t. 1 (1798)= Oxybaphus, Vahl (Nyctagin.).

aggregata, Orteg. 1. c. 81 . t. $11=\mathrm{O}$. aggregatus.

Cervantesii, Desf. Cat. Hort. Pax, ed. III. $390=$ O.

Cervantesii.

chilensis, Desf. ex Steud, Nom. ed. II. i. $264=$ O. chilensis.

expansa, Ruiz \& Pav. Fl. Per. i. $45=$ O. expansus.

glabrifolia, Orteg. Hort. Matr. 5. t. $1=0$. glabrifolius.

ovata, Ruiz \& Pav, F1. Per, i. $45=0$, ovatus.

paniculata, Desf. Cat. Hort. Par, ed. III. $390=$ O. ovatus.

pilosa, Choisy, in DC. Prod. xiii. II. $433=0$. angustifolius.

prostrata, Ruiz \& Pay. Fl. Per. i. $46=$ O. prostratus.

viscosa, Orteg. Hort. Matr. Dec. i. 6, in obs $=0$. viscosus.

CAMACUM, 'Adans.' ex Steud. Nom. ed. II. ii. 174, in syn. $(1841)=$ Myristica, Linn.

CAMAION, Rafin. Sylva Tellur. 75 (1838)= Helicteres, Linn. (Sterculiac.).

hirsuta, Rafin. 1. c. $=$ H. hirsuta.

undulata, Rafin, 1. c. = Sterculia lanceolata.

CAMARA, Plum. ex Linn. Syst, ed. I (1735); Adans, Fam. ii. 199 (1763) = Lantana, Linn. (Verbenac.). tiliaefolia, Benth. in Hook. Journ. Bot. ii. (1840) $53=$ L. tiliaefolia.

vulgaris, Benth. Bot. Voy. Sulph. 154=L. Camara.

CAMAREA, St. Hil. in Bull. Soc. Philom. (1823) 133. MALPIGHIACEAE, Benth. \& Hook. f. i. 261.

affinis, St. Hil. Pl. Rem. 57.-Bras.

axillaris, St. Hil. in Bull. Soc. Philom. (1823) 133.Bras.

discolor, Griseb. in Mart. Fl. Bras. xii. I. 105.Bras.

ericoides, St. Hil. in Bull. Soc. Philom. (1823) 133.Bras.

hirsuta, St. Hil. L. c.-Bras.

juncea, Griseb. in Mart. Fl. Bras, xii. I. 105.-Bras.

lincarifolia, St. Hil. in Bull. Soc. Philom. (1823) 133. - Bras.

phylicoides, Mart. ex Walp. Rep. v. $851=$ axillaris.

pulchella, Griseb. in Mart. Fl. Bras. xii. I. 105.-

Bras.

sericea, St. Hil. in Bull. Soc. Philom. (1823) 139.Bras.

triphylla, A. Fuss. in Arch. Mus. Par. iii. (1843) 601. -Bras.

CAMARIDIUM, Lindl. Bot. Reg. sub t. 844 (1824). ORCHIDEAE, Benth. \& Hook. f. Gen. iii. 556.

Amarinium, Hort. ex Lubbers, Cat. Pl. Rar. San Donato, $15(1880)$

alatum, Lindl, in Benth. Pl. Hartw. 153.-Ecuador.

Arbuscula, Lindl. l. c.-Ecuador.

brevifolium, Lindi. 1. c. 154.-N. Granat.

\section{CAMARIDIUM}

graminifolium, Reichb. f. in Linnaea, xxii. (1849) 857. -Peruv.

inflexum, Lindl. in Ann. Nat. Hist. v. (1840) 116.-

Ins. Dominica.

lancifolium, Reichb. f. in Linnaea, xxii. (1849) 857.Peruy.

longibracteatum, Lindl. in Benth. Pl. Hartw. 154.Peruv.

luteo-rubrum, Lindl. Orch. Linden. 22.-Venezuela.

lutescens, Reichb. f. in Walp. Ann. vi. 541.-Bras.

ochroleucum, Lindl. Bot. Reg. x. (1824) $844=$ Maxil. laria Camardii.

pendulum, Rodrig. Orch.Nov. i. 123.-Bras

purpuratum, Lindl. Orch. Linden. 22.-Venezuela.

purpureum, Spreng. Syst. iii. $735=$ Cymbidium vestitum.

robustum, Rodrig. Orch. Nov. ii. 210.-Bras.

vestitum, Lindl. in Ann. \& Mag. Nat. Hist. Ser. III.

i. (1858) $333=$ Ornithidium vestitum.

CAMARILLA, Salisb. Gen. Pl. Fragm. 91 (1866)= Allium, Tourn. (Liliac.)

obliqua, Salisb. 1. $\mathrm{c}_{\mathrm{r}}=\mathrm{A}$, obliquum.

CAMAROTIS, Lindl. Gen. et Sp. Orch. $219(1833)=$ Sarcochilus, R. Br. (Orchid.).

apiculata, Reichb. fo in Bonplandia, v. (1857) 39.Malaya.

cochinchinensis, Reichb. f, in Gard. Chron. (1876) II. 740.-Cochinch

obtusa, Lindl. Bot. Reg. xxx. (1844) Misc, $71=$ S. obtusus.

pallida, Lindl. in Journ. Linn. Soc. iii. (1859) $37=$ S. pallidus.

philippinensis, Lindl. 1. c. $=\mathrm{S}$. philippinensis

purpurea, Lindl. in Wall. Cat. n. $7329=\mathrm{S}$. pur pureus.

rostrata, Reichb. f. in Walp. Ann. vi. $881=\mathrm{S}$. purpureus.

CAMASSIA, Lindl. Bot. Reg. t. 1486 (1832). LILIA-

$C E A E$, Benth. \& Hook. f. iil. 815

Bulbedulis, Rafin. Fl. Tellur. ii. 26 (1836)

Cyanotris, Rafin. in Am. Monthly Mag. (1811)

356 ; 1819) 192, nomen prius.

Lemotris, Rafin. Fl. Tellur. ii. 26 (1836)

Quamasia, Rafin. Cat. 15 (1824); Quamassia

Rafin. F1. Tellur, ii, 25 (1836)

Sitocodium, Salisb. Gen. Pl. Fragm. 27 (1866).

alba, Hort.-Cf. Gard. Chron. (1875) I.662=Leichtlinii

esculenta, Lindl. Bot. Reg. t. 1486,-Am. bor. occ.

Fraseri, Torr. in Rep. Pacif. Rail. iv. 91.-Am. bor. occ.

Leichtlinii, S. Wats. in Proc. Am. Acad. xx. (1885) 376.-Calif.

CAMAX, Schreb. Gen, i. $144(1789)=$ Ropourea, Aubl. (Verbenac.?)

fraxinea, Willd. Sp. Pl. i. $1117=\mathrm{R}$. guianensis.

guianensis, J. F. Gmel. Syst. $403=$ R. guianensis.

CAMBANIA, Comm. ex M. Roem. Syn. Hesper. 83, 102 $(1846)=$ Dysoxylum, Blume (Meliac.).

Fraseriana, M. Roem. 1. c. $102=$ D. Fraseranum

CAMBDERIA, Steud. Nom. ed. II. ^. 264 (1840) CAMPDERIA, Rich. = Vellozia, Vand. $($ Amaryll $)$

CAMBEA, Endl. Gen. 1234, in Syn. (1840) sphalm.= CUMBIA, Buch.-Ham.= Careya, Roxb. (Myrtac.).

CAMBESSEDEA, Wight \& Am. Prod. i. 170 (1834)

Bouea, Meissn. (Anacard.)

oppositifolia, Wight \& Arn. 1. c. = B. burmanica.

CAMBESSEDEA, Kunth, in Ann. Sc. Nat. Sér. I. ii. 396 (1824) = Buchanania, Roxb. (Anacard.).

axillaris, Kunth, $1, \mathrm{c}_{\mathrm{a}}=\mathrm{B}$. angustifolia.

CAMBESSEDESIA, DC. Proxl。 iii. 110 (1820) MELASTOMACEAE, Benth. \& Hook. f. i. 787 . Acipetalum, Turez. in Bull. Soc. Nat. Mose. xxi. (1848) I. 577, pro parte.

adamantium, DC. Prod. iii. 111.-Bras.

adamantium, Miq. in Linnaca, xxii. (1849) 58\%

ilicifolia.

arenaria, Cogn. in Marl. F\% Bras. xiv. I11. 15.-Bras.

\section{CAMBFSSEDFSTA}

balsamifera, DC. Prod, iii, $110=$ Microlicia balsamifera.

bidentata, DC. I. c. $111=$ Hilariana

corymbosa, DC. l. c. 110.-Bras.

corymbosa, Naud. in Ann. Sc. Nat. Sér. III. xv. (1851) $61=$ rugosa.

crenulata, DC. Prod. iii. $111=$ Microlicia crenulata.

Lichleri, Cogn. in Mart. Fl. Bras. xiv. 11. 11.-Bras.

Espora, DC. Prod. iii. 111.-Bras.

Espora, Naud. in Ann. Sc. Nat. Sér. III. xv. (1851) 62 =ilicifolia.

Hilariana, DC. Prod. iii. 111.-Bras.

ilicifolia, Triana, in Trans. Linn. Soc. xoxiii. (1871

24.--Bras.

intermedia, Mart. Herb. Fl. Bras. n. $940=$ rugosa.

latevenosa, DC. Prod. iii. 110.-Bras.

membranacea, Gardn. in Field. Sert. Pl. t. BA.Bras.

paraguayensis, Hook. f. Bot. Mag. t. 6604-Paraguay.

purpurata, DC. Prod. iii. 110,-Bras

Regnelliana, $\operatorname{Cogn}$, in Mart. Fl. Bras. xiv. III. 19.Bras.

rugosa, Cogn. l. c. 14.-Bras.

setacea, Cogn. l. c. 23.-Bras,

sincorensis, DC. Prod, iii. $111=$ Microlicia sincorensi. terminalis, Naud. in Ans. Sc. Nat. Sér. III. xv. (18j] $61=$ Hilariana,

Weddelii, Naud. l. c.-Bras.

CAMBOGIA, Linn. Pl. Mart. Burser. (1745); Diss. Dass 18 (1747) (Amoen. Acad, i. 171, 402) = Garcinia Linn. (Guttifer.)

Binucao, Blanco, Fl. Filip. ed. I. $434=$ G. Cambogia crassifolia, Blanco, 1. c. ed. II. $304=\mathrm{G}$. Cowa.

Gutta, Linn. Gen, ed. V. Add. Fin.=G. Cambogie.

solitaria, Stokes, Bot. Mat. Med. iii. $175=\mathrm{G}$. Cama bogia.

venulosa, Blanco, El. Filip. ed. I. $435=\mathrm{G}$. venulosa.

CAMDENIA, Scop. Introd. $190(1777)=$ Evolvulus Linn. (Convolvul.).

CAMDERIA, Dum. Anal. Fam, $80 \quad(1829)=$ Lach nanthes, Ell. (Haemod.)

CAMELINA, Crantz, Stirp. Anstr, ed. I. fase i. Is (1762); ed. II. 18 (1769), CRUCIFERAE, Benth. \& Hook. f. i. 83.

Chamaelinum, Host, Fl. Austr. ii. $22 \pm$ (1831) Linostrophum, Schrank, Fl. Prim. Salisb. 163 (1792).

Sinistrophorum, Schrank, ex Endl. Gen. 88: $(1840)$.

albiflora, Kotschy, ex Boiss. F1. Orient. i. 312 sylvestris.

ambigua, Bess, ex. Steud, Nom, ed. II. i. 201 sativa.

anomala, Boiss. E Haussk. ex Boiss. Fl. Oricut. i. 913 - Syria.

aquatica, Brot. Fl. Lusit. i. $560=$ Nasturtium amphi bium.

armeniaca, Desv. Journ. Bot. iii. (1๖11) $192=$ sylvestris.

austriaca, Pers. Syz. ii. $191=$ Nasturtium austriacum. barbaraefolia, DC. Syst. ii. 517 ( $=$ Tetrapoma borbaracfolium.

Caisir, Wall. Cat. n. $480^{2}=$ Cochlearia fara.

Camisir. Buch.-Ham. ex Steud. Nom. ed. II. i. 204 sphalm. = praec.

campestris, Schimp. \& Spenn. in Spenn. Fl, Friburg. ii. $959=$ sylvestris.

doutato l'ers. Syp ii. $191=$ sativa.

edentula, Desv. Joum. Bot. iij. (1014) $170=$ Alyssum edentulum.

foetida, Fries, Nos. Mans. iii. 70,-Europ. grandiflura, Boiss. Diagn. Ser. I. ช.. S2.-As. Min. kirsuta, Bernb. Syst. Verz, Liff 190 - sqtiva! hispida, Boiss, in Ann. Sc. Nat. Serr. 11. xvii. ISt? 1iti.-Armenia: Persia.

lnsicuarpa, Buiss. E Bal. ex Buiss. F7. Orimt. i. $\$ 12$. syrua.

laxi, C. A. Mry. Hers. Pf. Caruc. 199.-As. Min, P'ersial

linicola, schimp. G SArnn. in Spenn. Fl. Friósups.... \$5s. - Europ? 


\section{CAMELINA :}

macrocarpa, Wierzb. ex Reichb. Ic. F1. Germ. ii, $10=$ sativa.

microcarpa, Andrz. ex DC. Syst. ii. $517=$ sylvestris. myagrodes, Moretti, in Giorn. Fis. Pav. (1820) $279=$ Cochlearia saxatilis.

binnatifida, Hornem. Hort. Hafn. ii. $598=$ foetida. sagitiata, Moench, Meth. $265=$ sativa.

sativa, Boiss. Voy. Bot. Espagne, $49=$ sylvestris. sativa, Crantz, Stirp. Austr. ed. I. fasc. i. 14 ; ed. II 18.-Europ.; As, temp.

saxatilis, Pers. Syn. ii. 191=Cochlearia saxatilis.

sylvestris, Wallr. Sched. Crit. 347.-Europ,; As. Min.

CAMELII A, Linn. Syst. ed. I (1735). TERNSTROE. MIACEAE, Benth. \& Hook. f. i. 187

CAlPANDRIA, Blume, Bijdr. 178 (1825)

Desmitus, Rafin. Sylva Tellur. 139 (1838)

DruPIFERA, Rafin. 1. c. 140 (1838).

KeMELIA, Rafin. 1. c. 138, 139 (1838).

SAI.CEDA, Blanco, Fl. Filip. ed. II. 374 (1854).

SAsAnqua, Nees, in Flora, iv. (1834) Lit. 144.

THEA, Linn. Gen, ed. I. 154 (1737).

Theaphylla, Rafin. in Loud. Gard. Mag. vii (1832) 246.

TsiA, Adans. Fam. ii. 450 (1763).

TsUBAKI, Adans. 1. c. 399 (1763)

assimilis, Champ. ex Benth. in Hook. Kew Fourn. iii (1851) 309.-Hongkong.

axillaris, Roxb. ex Ker-Gawl. in Bot. Reg.t. 349; et

Sims, Bot. Mag. t. 2047=Gordonia anomala

axillaris, Wall. Cat. $\mathrm{n} .158=$ Adinandra acuminata.

Bohea, Lindl, in Loud. Encycl. Pl. 592 ; Griff. Notul

iv $553=\mathrm{C}$. Thea

caudata, Griff. Notul. iv. $559=$ drupifera.

caudata, Wall. Cat.n. 978.-Reg. Himal.

Chamgota, Buch.-Ham. ex Wall. in As. Res. xiii. (1820) $429=$ C. Sasanqua

drupifera, Lour. Fl. Cochinch. ii. 411.-Reg. Himal.; Burma ; China.

Edithae, Hance, in Ann. Sc. Nat. Sér. IV. xv. (1861) 221.-China,

euryoides, Lindl. Bot. Reg. t. 983.-China.

Rorida, Salisb. Prod. $370=$ japonica

fraterna, Hance, in Ann. Sc. Nat. Sér. IV. xviii. (1862) 218.-China.

grandifora, Forsk. Fl. Aegypt. Arab. 126.-Arab.

Grijsii, Hance, in Fourn. Bot. xvii. (1879) 9.-China.

hongkongensis, Seem. in Trans. Linn. Soc. xxii. (1859) 342. t. 60.-China.

integrifolia, Choisy, in Mém. Soc. Phys. Genèv. xiv. (1855) $150=$ Actinodaphne chinensis.

japonica, Champ. in Hook. Kew Journ. iii. (1851) 309 $=$ hongkongensis.

japonica, Linn. Sp. Pl. 698.--Japon.

japonica, Wall. Cat. n. $3667=$ Adinandra integerrima.

Kaempferia, Reboul, in Atti $3^{a}$ Reun. Sc. Ital. (1841) 494.-Hab. ?

Keina, Buch.-Ham, in D. Don, Prod. F1. Nep. $224=$ drupifera.

$K$ issi, Wall. in As. Res, xiii. (1820) $429=$ drupifera.

lanceolata, Seem. in Trans. Linn. Soc. xxii. (1859) 345. - Malaya.

lutescens, Dyer, in Hook. f. Fl. Brit. Ind. i. 293.-Reg. Himal.

maliflora, Lindl. Bot. Reg. t. $1078=$ rosaeflora.

Mastersia, Griff. Notul. iv. $559=$ drupifera.

mutabilis, Paxt. Mag. Bot. ii.t. $122=$ japonica.

oleifera, Abel, Journ. in China, $174=\mathrm{C}$. Sasanqua.

oleifera, Wall. Cat. n. $976=$ drupifera.

oleosa, Lour. F1. Cochinch. $339=$ C. Sasanqua.

planipetala, Lem. Illustr. Hortic. (1865) t. $426=$ japonica.

Quinosaura, Seem. in Trans. Linn. Soc. xxii. (1859) 345.-Java.

reticulata, Lindl. Bot. Reg. t. 1078.-China.

rosaeflora, Hook. Bot. Mag. t. 5044.-China.

salicifolia, Champ. ex Benth. in Hook. Kew Fourn. iii. 1851) 309.-Hongkong.

Sasanqua, Blanco, FI. Filip. ed. I. $530=$ drupifera,

Sasanqua, Thunb. Fl. Fap. 273, t. 30-Japon.; China.

Scottiana, Choisy, Mém. Ternstr. $90=$ Adinandra dumosa.

Scottiana, Wall. Cat. n. $3668=$ C. Thea

simplicifolia, Griff. Notul. iv. 560, t. 604 , f, $2=$ drupifera.

\section{CAMELIIA:}

spectabitis, Champ. ex Benth. in Hook. Kew. Journ. iii. (1851) $310=$ reticulata.

ymplocifolia, Griff. Itin. Notes, 40. n. $652=$ drupifera. Thea, Link, Enum. Hort. Berol. ii. 73.--China. theifera, Griff. Notul. iv. 558. t. 601. f. $1,3=$ C. Thea. theiformis, Hance, in Ann. Sc. Nat. Sér. IV.xv. (1861) $221=$ euryoides.

Tsubakki, Crantz, Inst. ii. $172=$ japonica

viridis, Link, Enum. Hort. Berol. ii. $73=$ C. Thea.

CAMERARIA, Dill. ex Moench, Meth. $520(1794)=$ Miontia, Linn. (Portulac.)

fontana, Moench, l. c. = M. fontana

CAMERARIA, [Plum.] Linn. Syst. ed. I (1735). APOCYNACEAE, Benth. \& Hook. f. ii. 701. angustifolia, Linn.Sp. Pl. 210.-Am. austr. dubia, Sims, Bot. Mag. t. $1646=$ Wrightia dubia. guianensis, Aubl. Pl. Gui. i. $262=$ Malouetia Tamaquarina.

latifolia, Linn. Sp. Pl. 210.-Ind. occ.

lutea, Lam. Encyc. i. $573=$ Malouetia Tamaquarina.

obesa, Spreng. Syst. i. $641=$ Adenium obesum.

retusa, Griseb. Fl. Brit. W. Ind. 410.-Ind. occ.

Tamaquarina, Aubl. P1. Gui. i. 256=Malouetia Tama quarina.

zeylanica, Retz. Obs. iv. $24=$ Hunteria corymbosa.

zeylanica, Wight, ex Wall. Cat. n. $4459=$ Strophanthus Wightianus.

CAMERIDIUM, Reichb. f. in Linnaea, xxii. (1849) 857 , sphalm. = Camaridium, Lind1. (Orchid.).

CAMFOROSMA, Spreng. Syst, i. $453(1825)=$ Campho rosma, Linn. (Chenop.).

CAMIRIUM, Gaertn. Fruct. ii. 194. t. $125(1791)=$ Aleurites, Forst. (Euphorbiac.)

cordifolium, Gaertn. 1. c. $195=$ A. moluccana.

oleosum, Reinw. ex Blume, Cat. Gew. Buitenz, $104=$ A. moluccana.

CAMISSONIA, Link, in Jahrb. Gew. i. (1818) I. $186=$ Oenothera, Linn. (Onagrar.)

flava, Link, 1. c. =O. dentata.

CAMMARUM, Fourr. in Ann. Soc. Linn. Lyon, N. S. xvi. (1868) $327=$ Aconitum, Tourn. (Ranuncul.). paniculatum, Fourr. 1. c. =A. paniculatum.

CAMOCLADIA, Linn. Syst. ed. X 861 (1756)= Comocladia, P. Br. (Anacard.).

CAMOFNSIA, Welw. ex Benth. \& Hook. f. Gen. 557 (1865). LEGUMINOSAE, Benth. \& Hook. f 557
1. c.

brevicalyx, Benth. in Trans. Linn. Soc. xxv. (1866) 30\%.-Afr. trop.

maxima, Welw. ex Benth. l. c. 302. t. 36.-Afr. trop.

CAMOMILLA, Gilib. Exercit. i. $178(1792)=$ Matri caria, Toum. (Compos.)

deflexa, Gilib. l. c. $179=$ M. suaveolens

inodora, Gilib. 1. c. = M. inodora.

patens, Gilib. 1. c. $178=$ M. Chamomilla.

CAMONEA, Rafin. F1. Tellur. iv. 81 (1836)=Ipomoea Linn. (Convolval.).

bifida, Rafin. 1. c. = I. cymosa.

CAMPANEA, Decne. in Rev. Hortic. (1849) 241. 13. GESNERACEAE, Benth. \& Hook. f. ii. 1003 grandiflora, Decne. l. c.-N. Granat.

Humboldtii, Hanst. in Linnaea, xxvi. (1853) 214. t. 1. f. 24.-Costa Rica.

Oerstedii, Oerst. in Vidensk. Selsk. Skr. V. v. (1861) 108.-Costa Rica.

CAMPANULA, [Tourn.] Linn. Syst. ed. I (1735) Gen, ed. I. 46 (1737). CAMPANULACEAE, Benth. \& Hook. f, ii. 561

APENULA, Neck. Elem. i. 234 (1790)

Ballela, Rafin. Fl. Tellur. iv. 70 (1836).

ČněKIA, Opiz, Seznam, 27 (1852).

DECAPRISMA, Rafin. 1. c. ii. 78 (1836).

Depierrea, Anon. ex Schlecht. in Linnaea, xvi. (1842) 374.
CAMPANUIA :

Drymoconon, Fourr, in Ann. Soc. Linn. Lyon, N. S. xvii. (1869) 111.

ERINia, Noulet, F1. Sous-Pyr. 407.

Hecale, Rafin. Fl. Tellur. ii, 79 (1836).

Heterocodon, Nutt. in Trans. Am. Phil. Soc. Ser. II. viii. (1843) 255.

LACARA, Rafin, Fl. Tellur. iv. 70 (1836).

LOREIA, Rafin. 1. c. iii. 82 (1836).

Marianthemum, Schrank, in Denkschr. Regensb. Ges. ii. (1822) 34

Medium, [Tourn.] Fisch. ex A. DC. Monog. Camp. $213(1830)$.

Nenningia, Opiz, Seznam, 68 (1852).

Pentropis, Rafin. Fl. Tellur. ii. 80 (1836).

Quinouelocularia, C. Koch, in Linnaea, xxiii (1850) 630

Rapunculus, Fourr. in Ann. Soc. Linn. Lyon, N. S. xvii. (1869) 111.

RoNCELIA, Willk. in Willk. \& Lange, Prod. Fl Hisp. ii. $289(\mathbf{1 8 7 0})$

Roucelia, Dum. Comm. Bot. 14 (1822).

SykoraeA, Opiz, Seznam, 94 (1852).

Syncodon, Fourr. in Ann. Soc. Linn. Lyon, N. S xvii. (1869) 111.

Talanelis, Rafin. Fl. Tellar. iv. 70 (1836)

Tracheliopsis, Opiz, Seznam, 98 (1852).

WEITENWEBERA, Opiz, 1, c. 104 (1852).

abietina, Griseb. E Schenk, in Wiegm. Archiv, xv (1852) I. 333.-Europ.

acuminata, Michx. F1. Bor. Am. i. 108=americana.

acutangula, Leresche E Levier, in Fourn. Bot. xvii. (1879) 198.-Hispan.

acutiloba, Vatke, in Linnaea, xxxviii. (1874) 709.Kurdistan.

Adami, Bieb. Fl. Taur. Cauc. i. $153=$ bellidifolia.

Adami, Willd. ex Steud. Nom. ed. II. i. $265=$ lasiocarpa.

adhaerens, Ehrenb. ex Boiss. Fl. Orient. iii, $943=$ retrorsa.

adpressa, Linn. f. Supp1. $140=$ Wablenbergia adpressa adscendens, Vest. ex Roem. E Schult. Syst. v. 90.Sibir.

adsurgens, Leresche $\sigma^{\circ}$ Levier, in Fourn. Bot. xvii (1879) 199.-Hispan.

affinis, Fisch, ex Rupr. in Bull. Acad. Pétersb, xi (1867) $205=$ Aucheri

affinis, Reichb. ex Nym. Consp. $480=$ Portenschlagiana affinis, Roem. E Schult. Syst. v. 140.--Hispan.

afganica, Pomel, Nouv. Mat. Fl. Atl. 257.-Afr. bor.

afra, Cav. in Anal. Cienc. Nat. iii. (1801) $21=$ dichotoma.

aggregata, Willd. Enum. Hort. Berol. Suppl. $10=$ glomerata.

agrestis, Wall. Cat. n. $1292=$ Wahlenbergia gracilis

Aizoon, Boiss. Es Sprun. Diagn. Ser. I. iv. 34.-Graecia ajugaefolia, Sestini, ex Spreng. Syst. i. 732 (sp. dub.). -As. Min.

alata, Desf. Fl. Atlant. i. 178. t. 50,-Afr. bor.

Alberti, Trautv. in Act. Hort. Petrop. vi. (1879) 83.Turkestan.

albiflora, C. Koch, in Linnaea, xxiii. (1850) $634=$ sarmatica.

alburnica, Brigant. Pempt. - i. 3. t. $2=$ Phyteuma amplexicaule.

algida, Fisch.ex A. DC. Monog. Camp. $338=$ làsiocarpa. alliariaefolia, Reichb. Pl. Crit. Cent. iii. $345=$ Symphyandra pendula.

alliariaefolia, Willd. Sp. Pl. i. 910.-Reg. Caucas,; As. Min.

Allionii, Lapeyr. Hist. Abr. Pl. Pyr. $107=$ speciosa.

Allionii, Vill. Fl. Delph. 18 ; Prosp. 22.-Europ.

allophylla, Rafin. ex A. DC. Monog. Camp. 282 rotundifolia.

alopecuroides, Willd, ex Steud. Nom, ed. II. i. $265=$ Phyteuma Sibthorpianum.

alpestris, All. Fl. Pedem. 113. t. 6. f. 3 =Allionii

Alphonsii, Wall. Cat. n, 1296.--ind. or.

alpigena, C. Koch, in Linnaea, xxii. (1849) $638=$ Aucheri.

alpina, Facq. Enum. Vind. $36 ; 210$.-Europ.

Alpini, Linn. Sp. Pl. ed. II. 1669=Adenophora lilifolia.

Alpini, Pichl. ex Vis. FI. Dalm. Suppl. $74=$ Phyteuma amplexicaule.

alsinoides, Hook. $f$. E Thoms. in Fourn. Linn. Soc. ii. 1858) 24 - Reg Himal.

altaica, A. DC. Monog. Camp. 229, t. 10=pilosa. 
CAMPANULA :-

altaica, Ledeb. Ind. Sem. Hort. Dorpat. (1824) $2=$ Steveni.

altiflora, Pers. Syn. i. $192=$ Prismatocarpus altiflorus. americana, Hoit, ex Steud. Nom. ed. II. i. $266=$ Phyteuma canescens.

americana, Linn. Sp.Pl. 164.-Am. bor.

americana, Mill. Gard. Dict, ed. VIII. n. $13=$ planiflora.

amplexicaulis, Boiss. Diagn. Ser. I. xi. $77=$ Phyteuma amplexicaule.

amplexicaulis, Michx. Fl. Am. Bor, i, $108=$ Specularia perfoliata.

amygdalifolia, Salisb. Prod. $126=$ persicaefolia. anagalloides, Royle, Illustr. Bot. Himal. $253=$ Cepha lostigma hirsutum.

anchusiflora, Sibth. E Sm. Fl. Graec. Prod. i. 141. -Archip. Graec.

andina, Rupr. in Bull. Acad. Pétersb. xi. (1867) $215=$ gumbetica.

Andrewsii, A. DC. Monog. Camp. $220=$ tomentosa. androsacea, D. Dietr. Syn. Pl. i. $753=$ Wahlenbergia androsacea.

angulata, Rafin. Fl. Ludov. $55=$ Specularia perfoliata. angustifolia, Lam. Tabl. Encyc. ii. $53=$ linifolia

anticensis, Kunze, ex A. DC. in DC. Prod. vii. $491 \Rightarrow$ Specularia perfoliata.

antirrhina, Schleich. Cat. Pl. Helv, ed. III. $10=$ caespitosa, rotundifolia.

aparinoides, Pursh, Fl. Am. Sept. i. 159.-Am. bor, appendiculata, A. DC. Prod. vii. $462=$ tomentosa.

arborescens, P. Br. (err. R. Br.) ex Steud. Nom. ed. TI. i. $266=$ Hamelia ventricosa.

arcuata, Schur, in Verh. Siebenb. Ver. Naturw. x.

1859) 138 -rotundifolia.

ardonensis, Rupr. in Bull. Acad. Pétersb. xi. (1867) 212.-Reg. Caucas.

argaea, Boiss. E Bal. Diagn. Ser. II. vi. 119.Cappadoc.

argentea, Lam. Encyc. i. 584.-Armenia.

argunensis, Rupr. in Bull. Acad. Pétersb. xi. (1867) $209=$ Aucheri.

argyrotricha, Wall. Cat. n. 7138.-Reg. Himal

arida, H. B. \& K. Nov. Gen, et Sp. iii. $301=$ Wahlenbergia linarioides.

aristata, Wall. Cat. n. 1291; et in Roxb. Fl. Ind. ed. Carey, ii. 98.--Reg. Himal.

armena, Stev, in Mém. Soc. Nat. Mosc. iii. (1812) 236 = Symphyandra armena.

arvatica, Lag. in Varied. Cienc. ii. IV. (1805) $40=$ Wahlenbergia hederacea.

arvensis, Pers. Syn. i. $193=$ Specularia Speculum.

aspera, Boiss. Diagn. Ser, I. xi. $77=$ Phyteuma asperum.

aspera, Donn, ex A. DC. Monog. Camp. $290=$ aparinoides.

aspera, Moench, Meth. Suppl. 188.-Hab. ?

asperrima, Zuccagni, in Roem. Collect. 128=ajugaefolia.

asteroides, Lam. Tabl. Encyc, ii. $55=$ americana.

athoa, Boiss. \& Heldr. Diagn. Ser. II. iii. $110=$ C. Trachelium.

attenuata, Ledeb. ex Spreng. Syst. i. $729=$ persicifolia attica, Boiss. \& Heldr. Diagn. Ser. I. xi, $67=$ drabaefolia.

Aucheri, A. DC. in DC. Prod. vii. 460.-Reg. Caucas.; As. Min.

aurea, Linn. f. Suppl. $141=$ Musschia aurea.

axillaris, Boiss. E Bal. Diagn. Ser. 1I. iii. 109.Cilicia.

asurea, Soland. \& Banks, ex Sims, Bot. Mag. t. 551= rhomboidca.

baicalensis, Pall. ex A. DC. Prod. vii. $479=$ silenifolia.

Balansae, Boiss. E Haussk. Fl. Orient. iii. 931.Cappadoc.

baldensis, Balb. Cat. Hort. Taur. (1813) $20=$

ramosissima.

Banksiana, D. Dietr. Syn. Pl. i. $754=$ Wablenbergia Banksiana.

barbata, Lapeyr. Hist. Abr. Pl. Pyr. $107=$ speciosa.

barbata, Linn. Syst. ed. X. 927.--Europ.

barbata, Spreng, Fl. Halens. $77=$ glomerata.

Bartelieri, Marnock, Floric. Mag. i. (1896) 161. t. 12.

-Italia.

Barrelieri, Presl, Symb. Bot. 80. t. $19=$ fragilis.

Baumgartenii, Becker, Fl. Francof, i. $264=$ rotundiiolia.
CAMPANULA :-

Bayerniana, Rupr. in Bull. Acad. Pétersb. xi. (1867) 214.--Reg. Caucas.

Bellardi, All. F1. Pedem. i. $108=$ caespitosa.

bellidifolia, Adam, in Web. EN Mohr, Beitr. i. (1805) 47.-Reg. Caucas.

bellidifolia, Frivald. ex Nym. Consp. $476=$ Orpha nidea.

bellidifolia, Lapeyr. Hist. Abr. Pl. Pyr. Suppl. $36=$ patula.

Benthamii, Wall. Cat. n. $1290=$ canescens.

Bergiana, D. Dietr. Syn. Pl. i. $757=$ Prismatocarpus subulatus.

betonicaefolia, Biehl. Pl. Nov. Hort. Spreng. $14=$ sarmatica.

betonicaefolia, Gilib. Fl. Lituan. i. $53=$ glomerata.

betonicaefolia, Sibth. E Sm. Fl. Graec. Prod. i. 141 .

As. Min.

betulaefolia, C. Koch, in Linnaea, xxiii. (1850) 635.Armenia.

bicaulis, Lapeyr. Hist. Abr. Pl. Pyr. 107. t. $7=$ speciosa.

bicolor, Boiss. F1. Orient. iii. $931=$ camptoclada

Biebersteiniana, C. A. Mey. Verz. Pfl. Cauc. 83, pro parte $=$ Aucheri

Biebersteiniana, Roem. \& Schult. Syst, v, $147=$ tridentata.

Bielsii, Schur, in Verh. Siebenb. Ver. Naturw. iv (1853) 47 =rotundifolia

biflora, Ruiz \& Pav. F1. Per. ii. 55=Specularia biflora.

Billardieri, A. DC. Monog. Camp. 303.t. $13=$ C. Cymbalaria.

biserrata, C. Koch, in Linnaea, xix. (1847) $29=$ lactiflora.

bithynica, A. DC. in DC. Prod. vii. $460=$ tridentata.

Bocconi, J. F. Gmel. Syst. $348=$ rhomboidea.

Bocconi, Vill. Hist. Pl. Dauph. ii. $502=$ pusilla.

Boissieri, Sprun. ex Boiss. Fl. Orient. iit. $915=$ radicosa

Boissieri, Vatke, in Linnaea, xxxviii. (1874) $703=$ Phyteuma asperum.

Bolosii, Vayr. in Anal. Soc. Esp. Hist. Nat. viii. (1879) 451.- Hispan.

bononiensis, Linn. Sp. Pl. 165.--Europ. austr.; Reg. Caucas.; Sibir.

brachiata, Salzm. ex A. DC. Prod, vii. $462=$ dichotoma.

brachiata, Seidl, ex Opiz, Boeheims Gew. 168 . Natural. ii. (1823) [6] = patula.

brachysepala, Vukot. in Linnaea, xxvi.(1853-55) 325 =cenisia.

bracteata, Thunb. in Hoffm. Phytogr. Blaett. i. (1803) $20=$ Roella bracteata.

brevibracteata, D. Dietr. Syn. Pl. i. $757=$ Microcodon glomeratum.

Broussonetiana, Roem. \& Schult. Syst. v. 104= Loeflingii.

Brunonis, Wall. Cat. n. $1285=$ latifolia.

Buchii, D. Dietr. Syn. Pl. i. $753=$ Wahlenbergia pilosa.

caespitosa, Scop. Fl. Carn. ed. II. i. 143. t. 4.-Europ.

calamenthifolia, Aucher, ex A. DC. Prod. vii. $462=$ tomentosa.

calamenthifolia, Lam. Encyc. i. 585.-Ins. Naxos,

calaminthifolia, Griseb. Spicil. Fl. Rumel. i. $286=$ orphanidea.

calycantha, Turcz. ex Herd. in Act. Hort. Petrop. i. 1873) 288 , $296=$ pilosa, silenifolia.

calycina, Boeber, ex Roem. \& Schult. Syst. v. $104=$ C. Rapunculus.

camptoclada, Boiss, Diogn. Ser. I. xi. 63.-Syria. camatschatica, Pall. ex Roem. E Schult. Syst. v. 152.Kamtschat.

cana, Wall. Cat. D. 1284 ; et in Roxb. Fl. Ind.ed. Carey, ii. 101.-Reg. Himal.

canaria, Schrank, ex Stewd. Nom. ed. II. i. 266.-Ins. Canar.

canariensis, Linn. Sp. Pl. 168= Canarioa campanulata. candida, A. DC. Monog. Camp. 234.-Kurdistan.

Candolleana, D. Dietr. Syn. Pl. i. $756=$ Prismatocarpus Candollennus.

canescens, Roth, Enum. Pl. Phan. Germo. i. 716 Phyteuma canescens.

crnescens, Wall. Cat. n. 1289.-Ind, or.; Afghan.

capensis, Linn. Sp. Pl. $169=$ Wablenbergia capensis.

caperonoides, Klotzsch, in Bot. Ergeb. Waldem. Reise, $79=$ sylvatica.

\section{CAMPANULA:}

capillacea, Thunb. Prod. P1. Cap. $38=$ Wahlenbergia capillacea.

capillaris, Lodd. Bot. Cab. t. $1406=$ Wahlenbergia gracilis.

capitata, Schur, in Verh. Siebenb. Ver. Naturw. iii,

(1852) $88=$ C. Cervicaria.

capitata, Sims, Bot. Mag, t. 811 = lingulata.

cappadocica, Boiss. Diagn. Ser. I. xi. $73=$ Phyteuma cappadocica?

cariensis, A. DC. in DC. Prod. vii, $459=$ betonicaefolia.

carnica, Schiede, ex Mert.E Koch, Deutschl. Fl. ii. 158. - Carniola.

carnosa, Wall. Cat. n. 1282 ; et in Roxb. Fl. Ind, ed, Carey, ii. $102=$ Peracarpa carnosa.

carpatica, Facq. Hort. Vind. i. 22. t. 57.-Hangar.

cashmiriana, Royle, Illustr. Bot. Himal. i. 254. 62 Reg. Himal.

caucasica, Bieb: Casp. 140 ; App. n. $14=$ sibirica?

caudata, Vis. Fl. Dalm. ii. 136. t. 33.-Dalmat.

Cavolini, Tenore, F1. Nap. t. $213=$ fragilis.

celebica, D. Dietr. Syn. P1, i, 758=Campanumoea celebica.

Celsii, A. DC. Monog. Camp. $217=$ tomentosa

celtidifolia, Boiss. Diagn. Ser. II. iii. $111=$ lactiflora.

cenisia, Linn. Sp. Pl. ed. II. Suppl, 1669.-Europ.

cephalantha, Fisch. ex A. DC. Monog. Camp. 254 glomerata.

Cephalaria, Vukot. in Linnaea, xxvi. (1853-55) 333.Hungar.

Cephalotes, Fisch. ex A. DC. Monog. Camp. $254=$ glomerata.

cernua, Hort. ex Hornem. Hort. Hafn. $201=$ sibirica.

cernua, Thunb. Prod. Pl. Cap. $39=$ Wahlenbergia cernua.

cerviana, Pall. Reise, iii. $687=\mathrm{C}$. Cervicaria.

Cervicaria, Linn.Sp. Pl. 167.--Europ.

cervicarioides, Roem. \& Schult. Syst. v. $128=$ glomerata.

Cervicina, D. Dietr. Syn. Pl. i. $754=$ Wahlenbergia Cervicina.

chilensis, Bert. ex Steud. Nom. ed. II. i. 266 = Wahlenbergia hirsuta, reflexa.

chilensis, Molina, Sagg. Chile, ed. II. $281=$ Wahlen bergia linarioides.

chondrophylla, D. Dietr. Syn. P1. i. $753=$ W chondrophylla.

cichoracea, Sibth, \& Sm. Fl. Graec. t. $209=$ lin gulata.

cichoriformis, Boiss. Diagn. Ser. I. xi. $77=$ Phyteuma cichoriforme.

ciliaris, Salisb. Prod. 127 = Roella ciliata

ciliata, Patr, ex A. DC Prod. vii, $479=$ silenifolia.

ciliata, Ster, in Msm. Soc. Nat. Mosc iii. (1812) 256.

-Reg. Caucas.

ciliata, Thunb. Fl. Cap. ii. $24=$ Lightfootia tenella

cilicia, Boiss. Diagn. Ser. I. xi. $77=$ Phyteuma am plexicaule.

cinerea, Linn. f. Suppl. $139=$ Lightfootia orisea

circaeoides, F. Schmidt, Reisen Amurl. 154.-Japon.

cissophylla, Boiss. E Haussk. ex Boiss. Pl. Or. Nor.

Dec. 1, 2.-Kurdistan.

clisophylla, Moretti, ex Reichb. Ic. Fl. Germ. xix. 1611.-Hab. ?

clivosa, Banks, ex A. DC. Monog. Camp, $161=$

Wablenbergia clivosa.

clivosa, Herb. Roxb. ex A. DC. Prod, vii. $486^{\circ}=$ Wahlenbergia linifolia.

coa, D. Dietr. Syn. Pl. i. $758=$ Specularia pentagonia. coarctata, Gilib. Fl. Lituan. i. $48=$ C. Kapuaculas. coccinea, Sieber, ex A. DC. Prod. vii. $\$ 50^{\circ}$ (quid ?).-

Ins. Maurit.

cochlearifolia, Lam. Encyc. i. 5i8= caespitosa.

cochlearifolia, Vahl, Symb. Bot. $18=$ fragiliz.

collina, Bieb. Fl. Taur. Cauc. i. 152.-Reg. Caucas, coloradoénse, Buckl. in Proc. Acad. Sc. Philad. ' $156^{\circ} 1$ 1862) $460=$ Specularia Lind heimen.

colorata, Wall. in Roxb. Fl. Ind. ed. Carry, it. 101.-

Ind. or, ; Afghan.

commutata, Kuem. \& Schult. Syst. v. 113= sarmatica. compacta, Boiss. G Heldr. Diagn. Ser. I. xi. 71.Pisidia.

conferta, A. DC. Prod. vii. tös.-Cappadoc.

confertifolia, Keut. $c x$ Nivm. Consp. $179=$ rotundifolia.

congesta, Rocm. \& Schuil. Syst. v, 125 - glomerats.

conglomerata, Gucldenst, ex Ledeb. F1. Kuss, ii. s\$0 glomerata. 


\section{CAMPANUTA :-}

consanquinea, Schott, Nym. Kotschy, Analect. Bot. 8.-Europ.

contracta, Mutis, ex Nym. Consp. $478=$ rapunculoides.

controversa, Boiss. Diagn. Ser. II. iii. $115=$ Phyteuma rigidum.

cordata, Peterm. Fl. Lips. Excurs. 187.-Saxonia.

cordata, Tausch, in Flora, xxv. (1842) I. $288=$ Adenophora cordata.

cordata, Vis. Stirp. Dalm. 5=Specularia Speculum.

cordifolia, C. Koch, in Linnaea, xix. (1847) $29=$ rapun

culoides.

cordifolia, Vukot. in Linnaea, xxvi. (1853) 328.Europ.

coriacea, Boiss. \& Kotschy, ex F1. Orient. iii. $910=$ C. Radula.

coronata, Ker-Gaw1. in Bot. Reg. t. 149= Adenophora marsupiiflora.

coronopifolia, Fisch. ex Roem. \& Schult. Syst. v. $157=$ Adenophora coronopifolia.

corymbifera, Poir. Encyc. Suppl. ii. $64=$ seq.

corymbosa, Desf. in Ann. Mus. Par. xi. (1808) $139=$ pelviformis.

corymbosa, Tenore, Prod. F1. Nap. $15=$ versicolor,

Costae, Willk. in Willk. \& Lange, Prod. Fl. Hisp. ii. $294=$ patula.

crassifolia, Nees, in Syll. Ratisb. i. (1824) $6=$ fragilis.

crassipes, Heuff. in Oestr. Bot. Zeitschr. viii. (1858) 27 -Europ.

crenata, Link, Enum. Hort. Berol. i. 214 =rapunculoides.

cretica, D. Dietr. Syn. Pl. i. 758--Ins. Creta.

crispa, Banks, ex A. DC. Prod. vii. $444=$ Prismatocarpus crispus.

crispa, Lam. Encyc. i. 581.-Armenia.

Cymbalaria, Sibth. E Sm. Fl. Graec. Prod. i. 139 -As. Min.; Syria.

dalmatica, D. Dietr. Syn. i. $752=$ Wahlenbergia dalmatica.

dalmatica, Tausch, in Flora, x. (1827) $246=$ C. Cervicaria.

damascena, Labill. Ic. Pl. Syr. Dec. v. 7. t. 5.-Syria.

dasyantha, Bieb. F1. Taur Cauc, iii $147=$ pilosa.

dasycarpa, Kit. ex Schult. Oestr. Hl. ed. II. $404=$ persicifolia.

dasycarpa, Schur, Enum. Pl. Transs. $440=$ carpatica.

davurica, Siev. in Pall. N. Nord. Beitr. vii. 218. Sibir.

debilis, D. Dietr. Syn. P1. i. $752=$ Wahlenbergia debilis.

decipiens, Roem. \& Schult. Syst. v. $142=$ dichotoma

declinata, Moench, Meth. Suppl. $187=$ americana.

Decloétiana, Ortm. in Weitenw. Beitr. iii. (1838) $220=$ rotundifolia.

decumbens, A. DC. Monog. Camp. 334. t. $11=$ Loeflingii.

decurrens, Linn. Sp. P1. $164=$ patula, persicaefolia.

decurrens, Thore, Ess. Chlor. $64=\mathrm{C}$. Rapunculus.

decurrens, Zuccagni, in Roem. Collect. $128=$ peregrina.

dehiscens, Roxb. Hort. Beng. 85 ; F1. Ind. i. $505=$

Wahlenbergia gracilis.

delicatula, Boiss. Diagn. Ser. I. xi. 67.-As. Min.

delicatula, Jord. ex Nym. Consp. $479=$ caespitosa.

denticulata, Boiss. \& Huet, Diagn. Ser. II. iii. $107=$ betulaefolia.

denticulata, Burch. Trav. i. 538 = Lightfootia capillaris.

denticulata, Spreng. Syst. i. $735=$ Adenophora tricuspidata.

denudata, D. Dietr. Syn. P1. i. 753 = Wahlenbergia denudata.

desertorum, Weinm. in Bull. Soc. Nat. Mosc. (1837) n. VII. 58.- Ruthenia

dichotoma, Linn. Cent. Pl. ii. 10; (Amoen. Acad.iv. 306).-Reg. Mediterr, occ.

diffusa, Banks, ex A. DC. Prod. vii. $436=$ Wahlenbergia nudicaulis.

diffusa, D. Dietr. Syn. i. 752, $756=$ Microcodon lineare.

diffusa, Vahl, Symb. Bot. i. $48=$ fragilis.

dilecta, Schott, Nym. \& Kotschy, Analect. Bot. $8=$ rotundifolia.

dimorphantha, Schweinf. Beitr. Fl. Aethiop. 140.Aegypt.

dissoluta, Schott \& Kotschy, ex Boiss. Fl. Orient. iii. $943=$ retrorsa

\section{CAMPANULA :-}

divaricata, Michx. Fl. Bor. Am. i. 109.-Am. bor divergens, Willd. Enum. Hort. Berol, i. $212=$ sibirica.

diversifolia, D. Dietr. Syn. Pl. i. $752=$ Wahlenbergia diversifolia

diversifolia, Dum. F1. Belg. $58=$ rotundifolia.

Draba, Burm. f. Fl. Cap. Prod. 5.-Afr. austr.

drabaefolia, Frivald. ex Boiss. Fl. Orient. iii. $932=$ scutellata.

drabaefolia, Sibth. E' Sm. Fl. Graec. iii. 11. t. 215.Graecia.

drabaefolia, Steud. Nom. ed. II. i. $267=$ fastigiata.

dracunculifolia, Boiss. \& Kotschy, Fl. Orient. ii $952=$ Phyteuma rigidum.

dubia, A. DC. Monog. Camp. $286=$ rotundifolia.

dulcis, Decne. in Ann. Sc. Nat. Sér. II. î. (1834) 258. -Arab.

dumetorum, Boiss. Fl. Orient. iii. 922 =rapunculoides. Dunantii, D. Dietr. Syn. Pl. i. $754=$ Wahlenbergia Dunantii.

Duriaei, Boiss. Voy. Bot. Espagne, 401=Loeflingii echifolia, Gilib. Fl. Lituan. i. $56=\mathrm{C}$. Cervicaria. Ecklonii, D. Dietr. 'Syn. P1. i. $753=$ Wahlenbergia Ecklonii.

edulis, Forsk. Fl. Aegypt. Arab. 106.-Arab,

elatina, Hill, Veg. Syst, viii, $13=\mathrm{C}$. Elatines

Elatines, Bout. ex Willk. \& Lange, Prod. Fl. Hisp. ii. $295=$ specularioides

Elatines, Linn. Syst. ed. X. 927.--Europ. austr

Elatines, Petag. Inst. Bot. ii. $367=$ garganica.

Elatines, Pollini, Fl. Veron, i. 278=elatinoides.

elatinoides, Moretti, in Brugnat. Giorn. Fis. II. v. (1822) 110.-Italia

elatior, Link \& Hoffmgg. F1. Port. ii. 11. t. $80=$ C. Rapunculus.

elegans, Roem. E Schult. Syst. v. 105.-Sibir

elliptica, Kit. in Schult. Oestr. F1. ed. II. $410=$ glomerata.

elongata, Banks, ex A. DC. Prod. vii. $436=$ Wahlenbergia nudicaulis.

elongata, Portensch. ex A. DC. Monog. Camp. $277=$ rapunculoides.

elongata, Willd. Enum. Hort. Berol. Suppl. $10=$ Wahlenbergia capensis.

ensifolia, Lam. Encyc. i. 582=Heterochaenia ensifolia.

ephesia, Boiss. Fl. Orient. iii. 898.--Lydia.

eriantha, Hampe, in Flora, xxv. (1842) I. $76=$ tomentosa.

ericoides, Lam. Tabl. Encyc, ii. $63=$ Prismatocarpus paniculatus.

erinoides, Cav, in Anal. Cienc. Nat. iii. (1800) $20=$ Loeflingii.

erinoides, Linn. Mant. i. 44.-Hisp. ; Afr. bor.

erinoides, Muhl. Cat. n. 22=aparinoides.

Erinus, Linn. Sp, Pl 169-Reo. Mediter

eriocarpa, Bieb. Fl. Taur. Cauc. i. 149 =latifolia

erysimoides, Vest, ex Roem. \& Schult. Syst. V. $102=$ Adenophora Gmeliui.

esculenta, A. Rich. Tent. Fl. Abyss. ii. 4.-Abyssin.

esculenta, Salisb. Prod. $126=\mathrm{C}$. Rapunculus.

euclasta, Boiss, Diagn. Ser. I xi, 70-Syria.

evolvulacea, Royle, Illustr. Bot. Himal. i. $254=$ cachemiriana.

excisa, Schleich. ex Murith, Guide Val. 33, 35.Helvet.

exilis, D. Dietr. Syn. Pl, i. $754=$ Wahlenbergia exilis. expansa, Frituald in Flora, xix. (1836) II. 434. Thessalia; Macedon

expansa, Rudolph, in Mém. Acad. Pétersb. iv. (1809) 340. t. 2. f. $1=$ Wahlenbergia homallanthina

Exul, Schott, Nym. E Kotschy, Analect. Bot. 9.Austria.

falcata, Roem. \& Schult. Syst. v. $154=$ Specularia falcata.

fallax, Rupr. in Bull. Acad. Pétersb. xi. (1867) 205, in textu $=$ Aucheri.

farinosa, Andrz. ex Bess. Enum. PI, Volh. $10=$ glomerata.

fasciculata, Linn. f. Suppl. 139 = Lightfootia fasciculata.

fastigiata, Dufour, ex A. DC. Monog. Camp. 340. t. 12. Hispan.; Afr, bor.; Reg. Caucas.

fastigiata, S. G. Gmel. Iter, i. 153. t. $33=$ C. Rapuncrilus.

Fedtschenkiana, Trautv. in Act. Hort. Petrop. vi. (1879) 77.-As. temp.

\section{CAMPANULA :-}

fernandeziana, D. Dietr. Syn. Pl. i. $744=$ Wahlenbergia fernandeziana.

ficarioides, Timb. in Mém. Acad. Toulouse, Sér. V. vi. (1862) $33=$ linifolia.

filicaulis, Dur. Expl. Algér. t. 62.-Algeria.

filiflora, Kellogg, in Proc. Calif. Acad. ii. (1863) $5=$ prenanthoides.

filiformis, Gilib. F1. Lituan. i. $53=$ rotundifolia

filiformis, Moretti, in Brugnat. Giorn. Fis. II. ix. (1826) $155=$ Morettiana

filiformis, Ruiz \& Pav. Fl. Per. ii. 55 = Wahlenbergia linarioides.

firma, Boiss. Diagn. Ser. I. xi. $77=$ Phyteuma Aucheri.

Firmiana, Vand. Fasc. Pl. 9 = barbata.

Fischeri, Roem. \& Schult. Syst. v. $116=$ Adenophora communis.

Fischeriana, Spreng. Syst. iv. Cur. Post. $77=$ Adenophora coronopifolia.

flaccida, D. Dietr. Syn. Pl. i. $752=$ Wahlenbergia flaccida.

flaccidula, Vatke, in Linnaea, xxxviii. (1874) 712:Mesopot

flagellaris, H. B. \& K. Nov. Gen. et Sp. iii. t, $265=$ Specularia perfoliata.

Alexuosa, Michx. Fl. Bor. Am. i. 109=divaricata

flexuosa, Waldst. \& Kit. P1. Rar. Hung. ii. $145=$ Waldsteiniana.

floribunda, Viv. Fl. Lib. Spec. $67=$ isophylla.

florida, Salisb. Prod. $127=$ C. Medium

floridana, S. Wats. ex A. Gray, Syn. Fl. N. Am. ii. I 13. - Florida.

foliosa, Tenore, Fl. Nap. i. 71. t. 18.-Italia

Fontanesiana, Boiss. Diagn. Ser. I. xi. $76=$ Phyteuma lanceolatum.

Foudrasi, Jord. Pugill. Pl. Nov. (1852) 124 = caespitosa.

fragilis, Cyrill. Pl. Fasc. i. 32. t. 11. f. 2.-Italia.

frigida, Pall ex A. DC. Prod, vii. 461=pilosa.

Frivaldskyi, Steud. Nom. ed. II. i. $567=$ expansa.

fruticosa, Banks, ex A. DC. Prod. vii. $444=$ Prismatocarpus fruticosus.

fruticosa, Hill, Syst. Veg. viii, t. 8 = Prismatocarpus paniculatus.

fruticosa, Linn. Sp. P1. $168=$ Lightfootia subulata.

fulgens, Wall. Cat. n. 1283 ; et in Roxb. Fl. Ind. ed. Carey, ii. 99 .-Ind. or.

garganica, Tenore, Cat. Sem. Hort. Nap. (1827) 3 ; ex Fl. Nap. iii. 203.-Italia; Graecia.

Gautieri, Jeanb. \& Timb. in Bull. Soc. Sc. Phys. et Nat. Toul. iii. $(1875-76) 621=$ Schenchzeri

gentianoides, Lam. Encyc. i. 181=Platycodon grandi florum.

ghilanensis, Pall. ex Roem. \& Schult. Syst. v. $154=$ Specularia ghilanensis.

ghilanensis, Schlecht. ex Boiss. Fl. Orient. iii. 943.Persia.

Gieseckiana, Vest, ex Roem. \& Schult. Syst. v. $89=$ uniflora.

gilanica, Rupr, ex Boiss. Fl. Orient. iii. $905=$ Ruprechtii. Gisleri x, Bruegg, in Fahresb: Naturf. Ges. Graub. II xxiii-xxiv. (1880) 104.-Europ.

glabrata, Banks, ex A. DC. Prod. vii. $435=$ Wahlenbergia undulata.

glabricarpa, Schleich. Cat. P1. Helv. ed. IV. $10=$ rapunculoides.

glacialis, Shuttl. in Mag.Zool. E Bot. ii. (1838) 188.-m HeIvetia.

glandulosa, Banks, ex A. DC. Monog. Camp. $326=$ C. Rapunculus.

glareosa, Huet, ex Nym. Consp. $480=$ caespitosa glauca, Thunb. Fl. Fap. 88.-Japon.

glaucophylla, Schloss. \& Vukot. in Rad Jugos. Akad. Zagreb. xxxi. (1875) 111 = glomerata.

glomerata, Linn. Sp. Pl. 166.-Europ.; As. temp.

Gmelini, Roem. \& Schult. Syst. v. $103=$ Adenophora marsupiiflora.

Gmelini, Spreng. F1. Hal. Mant. $36=$ Adenophora Gmelini.

gracilis, Boiss. Diagn. Ser. I. xi, $77=$ Phyteuma lobelioides.

gracilis, Bert. ex Colla, in Mem. Acc. Tor. xxxviii. (1835) $119=$ Wahlenbergia Berteroi.

gracilis, Forst. f. Prod. $\mathbf{1 5}=$ Wahlenbergia gracilis. gracilis, Jord. Pugill. PI. Nov. (1852) $122=$ caespitosa.

graminifolia, Host, Fl. Austr. i. $268=$ Wahlenbergia tenuifolia. 
CAMPANULA:

graminifolia, Linn. Sp. Pl. $166=$ Wablenbergia graminifolia.

graminifolia, Waldst. \& Kit. P1. Rar. Hung. ii. $166=$ Wahlenbergia Kitaibelii.

graminifolia, Willerm. ex A. DC. Monog. Camp. 254 = glomerata.

grammosepala, Vukot. in Linnaea, xxvi. (1853-55) $323=$ spp. pluximi.

grandiflora, Jacq. Hort. Vindob. iii. $4=$ Platycodon grandiflorus.

grandiflora, Lam. Fl. Fr. iii. $334=$ C. Medium.

grandiflora, Pourr. ex Nym. Consp. $476=$ speciosa.

grandis, Fisch. \& Mey. Ind. Sem. Hort. Petrop. v. 34 $=$ latiloba.

Griffithii, Hook. f. E Thoms. in Fourn. Linn. Soc. ii (1858) 22.-Afghan.

Grossekii, Heuff. in Flora, xvi. (1833) I. 353.Hungar.

gumbetica, Boiss. Fl. Orient. iii. 914.-Reg. Caucas.

gummifera, Willd, ex Roem, \& Schult. Syst. v. $144=$ sarmatica.

Gundelia, C. Koch, in Linnaea, xxiii. (1850) $634=$ sibirica.

hagielia, Boiss. Fl. Orient iii. 899-Ins, Rhodos.

hastaefolia, Salisb. Prod. $127=$ Canarina campanulata

Hauryi, Schott, Nym. \& Kotschy, Analect. Bot. $10=$ rotundifolia.

Hausmanni $\times$, Reichb. f. in Flora, 1x. (1877) 31.

haylodgensis, Hort.-Cf. Gard.Chron. (1885) II.147.$\mathrm{Hab}$ ?

hederacea, Linn. Sp. Pl. $169=$ Wahlenbergia hederacea hederaefolia, Salisb. Prod. $127=$ Wahlenbergia hederacea.

hemschinica, C. Koch, in Linnaea, xxiii. (1850) 644 -As. Min.

Hendersoni, Hort.-Cf. Gard. Chron. (1882) II. 502.Hab. ?

Herminii, Bory \& Chaub. ex Boiss, Fl. Orient. iii. $937=$ Spruneri.

Herminii, Hoffmgg. E' Link, Fl. Port. ii. 9. t. 79.Lusitan.

hesperidifolia, Boiss. Diagn. Ser. I. xi. $76=$ Phyteuma lobelioides.

heterodoxa, Bong. Veg. Sitcha, 144=rotundifolia.

heterodoxa, Vest, in Roem. \& Schult. Syst. v. $98=1$ inifolia.

heterophylla, Baumg. F1. Transs. Suppl. iii. $342=$ Wanneri.

heterophylla, S. F. Gray, Nat. Arr. Brit. Pl. ii. $408=$ rotundifolia.

heterophylla, Linn. Sp. Pl. ed. I. errata, et 169 (sine nom. triv.),-Archip. Graec.

hierosolymitana, Boiss. Diagn. Ser. I. xi. 62.Palaestin.

Hilsenbergi, Boj. ex A. DC. Prod, vii. $429=$ Wahlen bergia Hilsen bergii.

himalayensis, Klotzsch, in Bot. Ergeb. Waldem. Reise, $73=$ colorata

hirsuta, Guss. Syn. F1. Sic. 1. 250, in syn.=Specularia Speculum.

hirsuta, Pantot. in Verh. Ver. Natur-u. Heilk. Presb. ii. $(1871-72)$ 54.-Europ.

hirsutissima, Guss. ex A. DC. Monog. Camp. $316=$ peregrina.

hirta, Roem. \& Schult. Syst. v. $153=$ Specularia Speculum.

hispanica, Willk. in Willk. E Lange, Prod. Fl. Hisp. ii 291 - Hispan.

hispida, Eckl. ex A. DC. Prod. vii. $421=$ Microcodon glomeratum.

hispida, Fisch. ex Hornem. Hort. Hafn. 199 = lactiflora.

hispida, Lejenne, F1. Spa, Suppl. ii. $298=$ persicifolia.

hispida, Portensch. ex A. DC. Monog. Camp. $304=$ Morettiana.

hispida, Spreng. ex Steud. Nom. ed. II. 1. $268=$ ciliata

hispidissima, Hochst. in Lorent, Wanderungen, 381 = propinqua.

hispidula, Eckl. ex A. DC. Monog. Camp. 127=

Microcodon glomerat

hispidula, Link, Enum. Hort. Berol. i. 215=Micro= cocton sparsillorum.

hispidula, Linn. f. Suppl. 142 = Microcodon depressum. Hochstetteri, Schott, Nym. \& Kotschy, Analect. Bot. 12 = caespitosa.

Hoffmeisteri, Klotzsch, in Bot. Ergeb. Waldem. Reise, $74=$ colorata.

\section{CAMPANUIA :}

Hohenackeri, Fisch, Mey, \& Avé-Lall. Ind. Sem. Hort. Petrop. ix. Suppl. $9=$ sibirica.

homallanthina, Ledeb, in Mém. Acad. Pétersb. iv. (1811) $340=$ Wahlenbergia homallanthina.

Hornungiana, Schur, Enum. Pl. Transs. 442,Transsylv.

hortensis, Meerb. PI. Sel. $10=$ rapunculoides,

Hostii, Baumg. Enum. Stirp. Transs. iii. $342=$ rotundifolia.

humilis, D. Dietr. Syn. Pl. i. $753=$ Wablenbergia humilis.

humilis, Schur, Enum. Pl. Transs, $438=$ persicifolia.

humillima, A. DC. Prod vii. 474-Persia.

hungarica, Pers. Syn. i. 191 = lingulata.

hybrida, Bout. ex Willk. \& Lange, Prod. Fl. Hisp. ii. $295=$ Loeflingii.

hybrida, Linn. Sp. Pl. $168=$ Specularia hybrida .

hybrida, Rodigas.-Cf. Illnstr. Hortic. Xxx. (1883) 118

t. $499=$ Van-Houttei

hygrophila, Rupr. in Bull. Acad. Pétersb. xi. (1867) $209=$ Ancheri.

hypopolia, Trautw. in Act. Hort. Petrop. iv. (1876) 389.-As. temp.

hyrcania, Wettstein, ex Stapf, in Denkschr. Acad. Wien, 1, (1885) 69.-Persia.

illinoënsis, Fresen. Ind. Sem. Hort. Franc. (1836)= americana.

imbricata, Hayne, ex A. DC. Monog. Camp. $284=$ caespitosa.

imeretina, Rupr. in Bull. Acad. Pétersb. xi. (1867) 217.-Reg. Caucas.

incanescens, Boiss. Diagn. Ser. I. vii. 16.-Persia.

inconcessa, Schott, Nym. \& Kotschy, Analect. Bot. 10 Scheuchzeri.

inconspicua, Banks, ex A. DC. Monog. Camp. $157=$ Wahlenbergia lobelioides.

incurva, Aucher, ex A. DC. Prod, vii. 464=Lentweinii. indica, D. Dietr. Syn. Pl. i. $753=$ Wahlenbergia indica. infundibuliformis, Sims, Bot. Mag. t. $2632=$ rapunculoides.

Infundibulum, Reichb. Ic. P1. Crit. i. t. 75 . f. $158=$ silenifolia.

Infundibulum, Vest, ex Roem. \& Schult. Syst. v. 106 - Steveni.

integerrima, Buch.-Ham. ex D. Don, Prod. Fl. Nep. $155=$ sylvatica.

intermedia, Engelm. ex Nutt. in Trans. Am. Phil. Soc, N. S. viii. (1843) $256=$ biflora.

intermedia, Roem. \& Schult. Syst, v. $110=$ Adenophora communis.

interrupta, Pers. Syn. i. 192=Prismatocarpus inter ruptus.

Intybus, Schott \& Kotschy, ex Tchihat. Asie Min. Bot. ii. $402=$ trachyphylla

invulucrata, Aucher, ex A. DC. Prod. vii. 467.-As. Min.; Persia.

isophylla, Moretti, in Brugnat. Giorn. Fis. II. vii. (1824) 44, 98 (App. Schomb. Fl. Ital. 22).-Italia.

Jacobaea, C. Sm. ex Hook. Niger Fl. 148. t. 12.-Ins. Cap. Verd.

facquini, A. DC. Monog. Camp. 251=Trachelinm Jacquini.

japonica, Vatke, in Linnaea, xxxviii. (1874) $705=$ Phyteuma japonicum.

jasionefolia, A. DC. in DC. Prod. vii. $463=$ stricta.

Jaubertiana, Timb. in Bull. Soc. Bot. Fr. xv. (1868) p. xlviii.-Gallia

javanica, D. Dietr. Syn. Pl. i. $759=$ Campanumoea javanica.

juncea, D. Dietr. 1. c. $757=$ Lightfootia juncea.

juncea, Hill, Veg. Syst. viii. 14.-German.

juncea, Hort. ex A. DC. Monog. Camp. $157=$ Wablenbergia lobelioides.

juncea, Wettstein, in Stapf, in Denkschr. Acad. Wien,

1. (1885) 117.-Lycia.

juncifolia, Hort. ex A. DC. Monog. Camp. $157=$ Wahlenbergia lobelioides.

jurjurensis, Pomel, Nouv. Mat. Fl. Atl. 257.-Afr. bor. kamtschatica, Pall. ex Ledeb. Fl. Ross. ii, 889. camtschatica.

kashmiriana. Royle, ex Hook. f. \& Thoms. in Journ. Linn. Soc. ii. (1858) $24=$ cashmiriana.

khasiana, Hook. f. E Thoms. l. c. 25.-Reg. Himal

Kitaibeliana, Rocm. E' Schult. Syst. v, 90,-Banatus.

kolenatiana, C. A. Mey. ex Rupr. in Bull. Acad.

Pétersb.xi. (1867) 216.-Reg. Cnucas.

Kotschyana, A. DC. Prod. vii. 481.-Cilicia.

\section{CAMPANUTA}

Krebsi, D. Dietr. Syn. P1. i. $753=$ Wahlenbergia Zeyheri.

Kremeri, Boiss, \& Reut. Pugill. PI. Nov. $75=$ dichotoma kryophila, Rupr. in Bull. Acad. Pétersb. xi. (1867) 211 $=$ ardonensis.

laciniata, Andr. Bot. Rep. t. $385=$ tomentosa.

laciniata, Linn. Sp. Pl. 165.-Archip. Graec.

lactiflora, Bieb. Fl. Taur. Cauc, i. 153.-Reg. Caucas.

Lamarckii, D. Dietr. Syn. PI. i. $755=$ Adenophora Lamarkii.

Lambertiana, A. DC. Monog. Camp. $327=$ C. Rapun. culus.

lamiifolia, Bieb. F1. Taur. Canc. i. $154=$ alliariaefolis lanata, Frivald. in Flora, xix. (1836) 434-Thracia. lanceolata, Boiss. \& Rent. ex Willk. \& Lange, Prod. F1. Hisp. ii. $291=$ hispanica.

lanceolata, Lapeyr. Hist. Abr. Pl. Pyr. 105.-Mont. Pyren.

lanceolata, Pall. ex A. DC. Monog. Camp. $321=$ Steveni.

lanceolata, J. \& C. Presl, Fl. Čech. 49 =persici folia.

lanceolata, Schur, in Verh. Siebenb. Ver. Naturw. iv. (1853) $47=$ rotundifolia

lancifolia, Roxb. Fl. Ind. ed. Carey, ii. $96=$ Campanumoea celebica.

lancifolia, Schur, Enum. PI. Transs. $445=$ rotundifolia

Langsdorfiana, Fisch. ex A. DC. Monog. Camp. 279 =linifolia.

Langsdorffiana, A. Gray, in Am. Journ. Sc. Ser. II. xxxiv. (1862) 254= Parryi.

lanifora, Hornem. ex Steud. Nom. ed. II. i. 268.Hab. ?

lanuginosa, Hort, ex Steud. 1. c. = divergens.

lanuginosa, Lam. Encyc. i. $584=$ peregrina.

lanuginosa, Willd. Enum. Hort. Berol. $213=$ rupestris.

Larreinii, Bert, ex Colla, in Mem. Acc 'Tor xxcyiii. (1835) 118 t. $35=$ Wahlenbergia fernandeziana.

lasiocarpa, Cham. in Linnaea, iv. (1829) 39.-Am. bor. occ.

latifolia, Linn.Sp.Pl. 165.-Earop.; Oriens; As. temp. latiloba, A.DC. Prod. vii. 478.-Bithynia.

lavandulaefolia, Reinw. ex Blume, Bijdr. $726=1 \mathrm{~K}$ ah lenbergia gracilis.

Ledebouriana, Trautv. in Act. Hort. Petrop. ii. (1873) 477.-Armenia.

Ledebourii, Boiss. Fl. Orient. iii. $905=$ praec.

Lehmanniana, Bunge, in Lehm. Reliq. Bot. 211.Turkestan.

leptocarpa, Engelm. ex A. Gray, in Proc. Am. Acad. xi. $(1876) 82=$ Specularia leptocarpa.

leptopetala, Ebrenb. ex Boiss. Fl. Orient. iii. $952=$ Phyteuma rigidum.

lencanthemifolia, Pourr. in Mém. Acad. Toul. iii. (1788) $309=$ caespitosa

leucoclada, Boiss. Diagn. Ser. II. iii. 109._Afghan.

leucosiphon, Boiss. E Heldr. Diagn. Ser. I. xi. 6t.As. Min.

Leutweinii, Heldr. in Ann. Sc. Nat. Sér. IV. xiii. 1860) 379.-Graecia.

libanotica, A. DC. Prod. vii. 463.-Syria.

ligularis, Lam. Encyco i. 585.-Europ.

ligulata, Pers. Syn. i. 191 = lingulata.

ligulata, Steud. Nom. ed. II. i. $268=$ C. Cervicaria.

liliflora, Roth, Enum. Pl. Phan. Germ. i. $715=$ Adeno. phora communis.

lilifolia, Lam. Encyc, i. $581=$ Adenophora Lamarkii.

lilifolia, Linn. Sp. P1, $165=$ Adenophora communis.

limonia, Murr. Syst. Veg. ed. NIII. 175 = seq.

limonifolia, Linn. Sp. Pl. ed. II. $239=$ Phyteumn limonifolium.

linarioides, Lam. Encyc. i. $580=1$ ahlenbergia lins. rioides.

linearifolia, D. Dietr. Syn. PI. i. $756=$ Prismntocarpus campanuloides.

linearis, Linn. f. Suppl. $110=$ Microcodon lineare. lingulata, Reichb. Ic. Pl. Crit. vi. 12 = C. Cervicaria. lingulata, Waldst. E Kit. Pl. Ror. Hong. i. 05. t. ot -Europ. austr. or.

linifolia Scop. Ann. ii. Hist. Nat. 17.-Europ.

linifolia, Schrank, I'rim. Fl. Sal. iO - rotumécisclia,

liniplaylla, Pall. ex A. DC. Monog. Camp. 369= Acenophora marsupiifulia.

linnacilolia, A. Gray, in Proc. Am. Arad. vii. 1560 Süb.-Calit.

incides, Presl, ex A. DC. Monog. Camp. $155=11$ ah. leaberyia liaarioides.

$3 \mathrm{~F}_{2}$ 


\section{CAMPANULA:}

littoralis, Labill. Nov. Holl. P1. i. 49. t. $70=$ Wahlenbergia gracilis.

lobata, Schloss. E Vukot. in Rad,Fugos. Akad. Zagreb. xxxi. (1875) 105.--Europ.

lobelioides, Linn. f. Suppl. $140=$ Wahlenbergia lobelioides.

lobelioides, Spreng. Syst. i. $736=$ Wahlenbergia nutabunda.

lobelioides, Vatke, in Linnaea, xxxviii. (1874) $704=$ Phyteuma lobelioides.

Loeflingii, Brot. Fl. Lusit. i. 287 ; Phyt. Lusit. i. 41. t. 18.-Lusitan.; Marocco.

longebracteata, D. Dietr. Syn. P1. i. $757=$ Treichelia longebracteata.

longifolia, Lapeyr. Hist. Abr. PI. Pyr. $107=$ speciosa.

longipes, Coss. ex Nym. Consp. $482=$ Loeflingii.

longirostris, Banks, ex A. DC. Monog. Camp. $168=$ Prismatocarpus crispus.

Loreyi, A. Blanco, ex Nym. Consp. $282=$ Loeflingii

Loreyi, Pollini, Elem. Bot. ii. 149 (Lorei),-Europ. austr.

Lostritti, Tenore, Syll. 96.--Italia.

lourica, Boiss. Diagn. Ser. I. xi. 70.-Persia.

Iudoviciana, Torr。 ex A. Gray, Syn. Fl. N. Am. ii. I. $11=$ Specularia biflora

lunariaefolia, Reichb. Ic. F1. Germ. vi. $750=$ rapunculoides.

lunariaefolia, Willd. ex Roem. \& Schult. Syst. v. 92= Phyteuma campanuloides.

lusitanica, Linn, in Loef. It. Hisp. 111, $126=$ Loeflingii.

Lychnitis, Hornem. Hort. Hafn. i. $199=$ bononiensis. lycia, Boiss. Diagn. Ser. I. xi. $77=$ Phyteuma lycium.

Iyraefolia, Salisb. Prod.127 = Michauxia campanuloides.

lyrata, Bourg. ex Nym. Consp. $476=$ hagielia.

lyrata, Lam. Encyc. i. 588.-As. Min.; Reg. Caucas

macedonica, Boiss. Fl. Orient. iii. 932 =scutellata.

macedonica, Boiss, \& Orph. ex Boiss. 1. c. $925=$ multiflora.

macrantha, Fisch. ex Hornem. Hort. Hafn. Suppl. 23 $=$ latifolia

macrocalyx, Schur, Enum. P1. Transs. $441=$ pulla.

macrocephala, Willd. ex Steud. Nom. ed. II. i. $268=$ Wahlenbergia tenuifolia.

macrochlamys, Boiss. \& Huet, Diagn. Ser. II. iii. 111. -Armenia.

macrophylla, Sims, Bot. Mag. t. $912=$ alliariaefolia

macrorhiza, Vukot. in Linnaea, xxvi. (1853-55) $329=$ spp. plurim.

macrorrhiza, F. Gay, ex A. DC. Monog. Camp. 302.Gallia.

macrostachya, Panz. ex Roem. \& Schult. Syst. v. 121= rapunculoides.

macrostachya, Willd. Enum. Hort. Berol, i. $213=$ multiflora.

macrostyla, Boiss. Ev Heldr. Diagn. Ser. I. xi. 65.Pisidia.

madagascariensis, D. Dietr. Syn. P1. i. $752=$ Wahlen. bergia oppositifolia.

Malyi, Schott, Nym. \& Kotschy, Analect. Bot. 11= rotundifolia.

marginata, Thunb. Fl. Jap. $89=$ Wahlenbergia gracilis. maroccana, Ball, in Fourn. Linn. Soc. xvi. (1878) 554.-Marocco.

Marschalliana, Boiss. Diagn. Ser. I. xi. $77=$ Phyteuma campanuloides.

marsupiiflora, Fisch. ex Roem. \& Schult. Syst. v. 116 $=$ Adenophora marsupiiflora.

Massonii, D. Dietr. Syn. Pl. i. $754=$ Wahlenbergia Massonii.

Mathoneti, Jord. ex Gren. \& Godr. Fl. Fr. ii. $418=$ caespitosa.

matritensis, A. DC. Monog. Camp. $332=$ Loeflingii.

mauritanica, Pomel, Nouv. Mat. Fl. Atl. 3.-Afr. bor

Medium, Lapeyr. Hist. Abr. Pl. Pyr. $107=$ speciosa.

Medium, Linn. Sp. Pl. 167.-Europ. austr.

Meyeriana, Rupr. in Bull. Acad. Pétersb. xi. (1867) $207=$ Aucheri

michauxioides, Boiss, Diagn. Ser. I. iv. 35-Caria.

micrantha, Schur, Enum. Pl. Transs. $438=$ bononiensis.

Microcodon, D. Dietr. Syn. P1. i. $757=$ Microcodon glomeratum.

microphylla, Cav. in Anal. Cienc. iii. (1800) $19=$ mollis.

microphylla, Kit. ex Schult. Oestr. Fl. ed. II. $400=$ Kitaibeliana.

Minae, P.G. Stroebl, in Flora, 1xvi. (1883) 549.-Sicil.

\section{CAMPANULA:}

minor, [Honck.] Verz. aller Gew. Teutschl. $617=$ caespitosa.

minor, Lem. Fl. Fr. iii. $339=$ rotundifolia

minuta, Agardh, ex Roem. \& Schult. Syst. v. $87=$ Jasione foliosa.

minuta, Savi, Cent. ii. F1. Etrusc, $54=$ rotundifolia.

minutissima, Schur, in Verh. Siebenb. Ver. Naturw. iv. (1853) 47.-Transs.

mixta, Hegetschw. Fl. Schw. 231.-Helvet.

modesta, Hook. f. E Thoms. in Fourn. Linn. Soc. ii. (1858) 24--Reg. Himal.

modesta, Schott, Nym. \& Kotschy, Analect. Bot. $13=$ caespitosa.

mollis, Linn. Sp. Pl. ed. II. 237.-Reg. Mediterr. occ monadelpha, Pall. ex A. DC. Monog. Camp. $363=$ Adenophora coronopifolia.

monantha, Schur, in Verh. Siebenb. Ver. Naturw, iv. (1853) 47 = Scheuchzeri.

monanthos, Pantor. in Verh. Ver. Natur- u. Heilk. Presb. 1i. $(1871-72) 54=$ praec.?

monocephala, Trautv. in Act. Hort. Petrop. vi. (1879) 64.-Turkestan.

montana, Delarb. Fl. Auvergne, ed. II. 40-Gallia.

montevidensis, Spreng. Syst. 1. $738=$ Specularia biflora

Moorcroftiana, Wall. Cat. n. 1288 = colorata.

Morettiana, Reichb. Ic. Fl. Germ. iv. 18.-Dalmat.

morifolia, Salisb. Prod. $126=$ rapunculoides

multicaulis, Boiss. Diagn. Ser. I. vii. 19 (=Podan-

thum persicum).-Persia.

multiflora, Hort. ex A. DC. Monog. Camp. 271= bononiensis.

multiflora, Waldst. E Kit. Pl. Rar. Hung. iii. 292.Hungar.

multiflora, Willd. ex Roem. \& Schult. Syst. v. $130=$ polyantha.

muralis, Portenschl. ex A. DC. Monog. Camp. $303=$ Portenschlagiana.

musarum, Heldr. ex Nym. Consp. $477=$ rupicola.

myosotidifolia, Boiss, in Tchihat. Asie Min. Bot. ii. $392=$ argentea.

muscosa, [Pieri,] in Ionios Anthol. v. 204.-Ins. Corcyra.

myrtifolia, Boiss. \& Heldr. Diagn. Ser. I. xi. $69=$ Trachelinm myrtifolium.

nana, Lam. Encyc. i. $585=$ Allionii.

napuligera, Schur, Enum. Pl. Transs. $444=$ rotundifolia.

neglecta, Bess. Cat. Hort. Cremen. (1816) 28 = rapunculoides.

neglecta, Downar, in Bull. Soc. Nat. Mosc. xxxiv (1861) I. $182=$ praec.?

neglecta, Roem. \& Schult. Syst. v. $104=$ patula.

nemorosa, A. DC. Monog. Camp. $274=$ rapunculoides. nervosa, Royle, Illustr. Bot. Himal. $253=$ colorata.

nicaeensis, Risso, ex A. DC. Monog. Camp. $302=$ macrorrhiza.

nicaeensis, Roem. \& Schult. Syst. v. 126=glomerata. nitida, [Soland. in] Ait. Hort. Kew. 1. $346=$ planiflora nobili-macrantha, Regel, Ind. Sem. Hort. Petrop. (1869) 14.-- Hab.?

nobilis, Lindl. in Journ. Hort. Soc. i. (1846) $232=$ punctata.

notata, Schott, Nym. \& Kotschy, Analect. Bot. $13=$ caespitosa.

nudicaulis, D. Dietr. Syn. P1. i. $753=$ Wahlenbergia nudicaulis.

numidica, Dur. Expl. Algér. t. 62.-Afr. bor.

nutabunda, Guss. in Tenore, Append. v. ad F1. Nap. Prod. $8=$ Wahlenbergia nutabunda.

nutans, Lam. Fl. Fr. ii. $336=$ rapunculoides.

nutans, Sieber, ex A. DC. Monog. Camp. $366=$ Symphyandra cretica,

nutans, Vahl, ex Hornem. Hort. Hafn. $201=$ sibirica. Nuttallii, Penny, ex Loud. Hort. Brit. Suppl. i. 583.Am. bor.

obliqua, Jacq. Hort, Schoenb. iii. $47=$ americana. obliquifolia, Tenore, Fl. Nap. Prod. 15 =bononiensis, odontosepala, Boiss. Diagn. Ser. I. xi. 66.-Persia oenipontana, Moretti, ex A. DC. Monog. Camp. 269 = rapunculoides.

oligosantha, Schur, Enum. P1. Transs. $436=$ C. Trachelium.

Olivieri, A. DC. Monog. Camp. 233.t. $9=$ calamenthifolia.

olympica, Boiss. Diagn. Ser. I. iv. 34.--As. Min.

orbelica, Panč. Elem. 48.-Europ.

\section{CAMPANULA:-}

oreadum, Boiss. \& Heldr. Diagn. Ser. II. iii. 107.Thessalia.

oreophila, Schur, Enum. Pl. Transs. $441=$ carpatica. orientalis, Steud. Nom. ed. II. i. $269=$ peregrina? Orphanidea, Boiss. Fl. Orient. iii. 897.-Macedon. ossetica, Bieb. Fl. Taur. Cauc. iii. $145=$ Symphyandra ossetica.

Ottoniana, Roem. \& Schult. Syst. v. $115=$ Lightfootia oxyococcoides.

ovata, Spreng. Syst. iv. Cur. Post. $78=$ Wahlenbergia ovata.

oxyphylla, Vukot. in Linnaea, xxvi. (1853-55) $331=$ spp. plurim.

paenina, Reut. ex Tissière, Bot. Gr. St. Bernard, 63.Helvet.

Pallasiana, Roem. \& Schult. Syst. v. $138=$ pilosa

pallida, Wall. in As. Research. xiii. (1820) $375=$ colorata.

paniculata, Linn. f. Suppl. $139=$ Wahlenbergia paniculata.

paniculata, Pohl, ex A. DC. Monog. Camp. $244=$ sibirica.

paniculata, Sm. ex A. DC. 1. c. $154=$ Wahlenbergia Banksiana.

paniculata, Turra, ex Sacc. in Atti Ist. Venet. Ser. III, ix. (1863-64) 486.-Italia.

paniculata, Wall. Cat. n. $1295 \mathrm{~A}, \mathrm{~B}=$ Cephalostigma paniculatum.

pannonica, Bernh. ex Schrank, in Denkschr. Regensb. Ges. ii. (1822) $34=$ sibirica.

parnassica, Boiss. E Sprun. Diagn. Ser. I. vii. 17.Graecia.

Parryi, A. Gray, in Syn. Fl. N. Am. ii. I. 395.-Am. bor. occ.

parviflora, Lam. Encyc. i. $588=$ sibirica.

parviflora, St. Lag. in Ann. Soc. Bot. Lyon, vii. (1880) $121=$ C. Erinus.

parviflora, Salisb. Prod. $126=$ Wahlenbergia lobelioides.

parvula, Jord. Pugill. Pl. Nov. (1852) 123 = caespitosa.

patens, Gueldenst. ex Ledeb. Fl. Ross. ii. $887=$ patula. patula, Linn. Sp. Pl. 163.-Europ.

patula, Sibth. \& Sm. F1. Graec. Prod. i. $137=$ Spruneriana.

pauciflora, Desf. Choix Pl. 36. t. 26=Spruneriana. pauciflora, Lam. ex Steud. Nom. ed. II. i. $269=$ planiflora, Lam.

peduncularis, Wall. Cat. n. $7139=$ Wahlenbergia peduncularis.

pedunculata, J. F. Gmel. Syst. $352=$ Wahlenbergia paniculata.

peirescifolia, Spreng. Syst. i. $735=$ Adenophora latifolia.

pelviformis, Lam. Encyc. i. 586.-Ins. Creta.

pendula, Bieb. FI. Taur. Cauc. i. $154=$ Symphyandra pendula.

pennica, Reut. ex Payot, in Bull. Soc. Bot. Fr. xxix. 1882) - - Cf. Bibl. $43=$ seq.

pennina, Reut. in Comptes-Kend. Soc. Hallér.(1854-56) $115=$ rotundifolia.

Pentagonia, Linn. Sp. Pl. $169=$ Specularia Pentagonia. pentagonophylla, Vukot. in Linnaea, xxvi. (1853-55) $325=$ Wahlenbergia hederacea.

peregrina, Hoffmgg. \& Link, F1. Port. ii. 15. t. $83=$ primulaefolia.

peregrina, Linn. Mant. ii. 204.-As. Min.; Syria

Pereskia, Fisch. ex A. DC. Monog. Camp. $357=$ Adenophora latifolia.

pereskiaefolia, Fisch. ex Roem. \& Schult. Syst. v. $116^{\circ}$ $=$ Adenophora latifolia.

perfoliata, Linn. Sp. P1. $169=$ Specularia perfoliata.

periplocifolia, Lam. Encyc. i. $580=$ Adenophora periplocaefolia.

perneglecta, Schott, Nym. E Kotschy, Analect. Bot. 11.-Austria.

Perpentiae, Moretti, ex A. DC. Monog. Camp. $305=$ Rainerii.

perpusilla, A. DC. Prod. vii. 474.-Persia

persepolitana, Kotschy, ex Boiss. Diagn. Ser. I. vii. 19. -Persia.

persica, A. DC. Prod. vii. 483 (= Podanthum persicum). -Persia.

persicifolia, Linn. Sp. Pl. 164.-Europ.; As. bor. Pestalozzae, Boiss. Diagn. Ser. I. xi. $62=$ propinqua. petiolata, A. DC. Monog. Camp. $278=$ rotundifolia. petraea, All. Fl. Pedem. 1. $112=$ glomerata. 


\section{CAMPANUI,A:-}

petraea, Habl. Taur. 157 = bononiensis

petraea, Kutschy, ex A. DC. Prod. vii. $467=$ involu. crata.

petraea, Linn. Syst. ed. X. 927.-Italia

petraea, Zanted. ex Moretti, in Syll. Ratisb. i. (1824)

$154=$ elatinoides.

petrophila, Rupr. in Bull. Acad. Pétersb. xi. (1867) 212. - Reg. Caucas.

phrygia, Faub. E Spach, Illustr. Pl. Or, iii. 42.Macedon.; As. Min.

phyctidocalyx, Boiss. Eڤ Noé, Diagn. Ser. II. iii. 114.Armenia.

phyteumoides, Sibth. ex Zuccagni, in Roem. Collect. $128=$ Phyteuma limoniifolium.

Pichleri, Vis. in Mem. Ist. Venet. xvi. (1871) $106=$ Phyteuma amplexicaule.

pilosa, Less. ex Ledeb. F1. Ross. ii. $894=$ Adenophora tricuspidata.

pilosa, Pall. ex Roem. E Schult. Syst. v. 148.Sibir.; Am. bor. occ.

pinifolia, Vulkot. in Rad Jugos. Akad. Zagreb. Ivii. (1881) $92=$ patula.

planiflora, Engelm, in Coult. Bot. Gaz. vii. (1882) $5=$ Parryi.

planiflora, Lam. Encyc. i. $580=$ pyramidalis ?

planiflora, Willd. Enum. Hort. Berol. 210 =versicolor.

plicata, Pers. Syn, i. $193=$ Prismatocarpus crispus.

plicatula, Dum. Fl. Belg. $58=$ C. Trachelium.

podanthoides, Boiss. E Haussk. ex Boiss. Fl. Orient.

iii. 938.-Cataonia.

podocarpa, Boiss. Diagn. Ser. I. xi. 68-Pamphylia.

polyantha, Roem. E' Schult. Syst. v. 130.-Sibiria.

polymorpha, Banks \& Soland. ex A. DC. Monog. Camp. $142=$ Wahlenbergia gracilis

pomponiifolia, Fisch. ex A. DC. 1. c. $363=$ Adenophora Gmelini.

porosa, Thunb. Prod. P1. Cap. $39=$ Salmolus Valerandi.

Portenschlagiana, Rocm. \& Schult. Syst. v. 93.Dalmatia.

portensis, Linn. in Loefl. It. Hisp. 111, $127=\mathrm{C}$. Erinus.

Pourreti, Feanb. E Timb. in Bull. Soc. Sc. Phys. et Nat. Toul. vi. (1883-84) 153.-Gallia.

pratensis, Lapyl. ex A. DC. Monog. Camp. $287=$ rotundifolia.

pratensis, Reut. ex Nym. Consp. $478=$ C. Trachelium.

precatoria, Timb. in Mém. Acad. Sc. Toul. Sér. VII. v. $(1873) 271=$ lanceolata.

Preissii, De Vriese, in Lehm. Pl. Preiss. ii. $241=$ Wahlenbergia gracilis.

prenanthoides, Durand, in fourn. Acad. Nat. Sc. Philad. Ser. II. iii. (1855) 93,-Calif.

primulaefolia, Brot. Fl. Lusit. i. 288-Lusitan.

Prismatocarpus, L'Hérit. Sertum, t. $3=$ Prismatocarpus nitidus.

procumbens, Linn. f. Suppl. $141=$ Wablenbergia procumbens.

propinqua, Fisch. E Mey. Ind. Sem. Hort. Petrop. ii (1835) 32.-As. Min.; Persia.

pruinosa, [Pievi] in Ionios Anthol. v. 204.-Ins. Corcyra.

prostrata, Dulac, F1. Hautes-Pyr. $457=$ Scheuchzeri.

pseudo-carpatica, Schur, Enum. Pl. Transs. $441=$ reniformis

pseudolanceolata, Pantoč. in Magyar Növent. Lapok, vi. (1882) 162.-Hungar.

pseudo-pulla, Schur, Enum. Pl. Transs. $441=$ pulla.

pseudo-valdensis, Schur, in Verh. Siebenb. Ver Naturw. iv. (1853) $47=$ rotundifolia.

psilostachya, Boiss. E Kotschy, Diagn. Ser. II. iii. 113. -Cilicia.

ptarmicaefolia, Lam. Encyc. i. 570.-As. Min.

pubescens, Reichb. ex Nym. Consp. $479=$ rotundifolia.

pubescens, Schmidt, FI. Boëm. Cent. ii. $67=$ caespitosa.

pubiflora, Rupr. in Bull. Acad. Pétersb. xi. 207= Aucheri.

pulchella, Boiss. Diago. Ser. I. xi. $76=$ Phyteuma pulchellum.

pulchella, Jord. Pugill. Nov. Pl. (1852) $126=$ caes= pitosa.

puelchella, Salisb. Prod. $127=$ Specularia Speculam.

pulcherrima, Schrank \& Zeyh. ex Steud. Nom. ed. II

i. 269 - II ab. ?

\section{CAMPANULA:}

pulla, Baumg. ex Stead. Nom. ed. II. i, 268, $269=$ linifolia.

pulla, Gueldenst. It. ii. 24 ; ex Ledeb. Fl. Ross. ii. 891 -Reg. Caucas.

pulla, Linn. Sp. Pl. 163,-Europ.

pulla, Parol. ex Pollini, F1. Ver, i, 268=Morettiana.

pumila, Curt. Bot. Mag, t. $512=$ caespitosa

pumila, Schmidt, F1. Boem. ii. $71=$ persicifolia

Pumilio, Portenschl. ex Roem. \& Schult. Syst. v. $136=$ Wahlenbergia Pumilio.

punctata, Lam. Encyc. i. 586.--Sibir.; Japon.

punduana, D. Dietr. Syn. Pl. i. $757=$ Campanumoea parviflora.

purpurea, Spreng. Syst. iv. Cur. Post. $78=$ Codonopsis purpurea.

pusilla, Haenke, in Jacq. Collect. ii. $79=$ caespitosa.

pygmaea, D. Dietr. Sp. Pl. i. $757=$ Microcodon glomeratum.

pygmaea, Lam. ex DC, Fl, Fr, iii. $705=$ Borago laxifora.

pyramidalis, Gilib. Fl. Lituan. i. $52=$ bononiensis.

pyramidalis, Linn. Sp. Pl. 164.-Europ

pyramidata, Gilib. Hist. Pl. Eur. ii. $209=$ praec.

pyramidiflora, Reichb. Cat. Sem. Hort. Dresd. (1822)

$=$ rapunculoides.

pyrenaica, A.DC. Monog. Camp. 324-Mont. Pyren.

pyrenaica, 'Hecht. Willd.' ex Steud. Nom. ed. II. $\mathrm{i}$ $269,270=$ rhomboidea

quadrifida, R. Br. Prod. $561=$ Wablenbergia gracilis

Quartiniana, A. Rich. Tent. Fl. Abyss. ii. 5.-Abyss.

Rabelaisiana, Roem, \& Schult. Syst. v. $158=$ Adenophora Gmelini.

racemosa, S. G. Gmel. It. i. $9=$ sibirica.

racemosa, Opiz, ex Steud. Nom. ed. II. i. $269=$ rapunculoides.

racemosa, Vukot. in Linnaea, xxvi. (1851) $332=$ spp.

plurim.
Raddeana, Trautw. in Bull. Acad. Pétersb. x. (1866) 395.-Reg. Caucas.

radicosa, Bory \& Chaub. Fl. Pélop. 14. t. 7.Graecia.

Radula, Fisch. ex Tchihat. Asie Min. Bot. i1. 395.Kurdistan.

Rainerii, Perpent. in Bibl. Itat. v. (1817) 134. - Italia ramosissima, Griseb. Spicil. Fl. Rumel. ii. $282=$ phrygia.

ramosissima. Host, F1. Austr. i. $264=$ Loreyi.

ramosissima, Sibth. EN Sm. Fl. Graec. Prod. i. 137.Graecia.

ramosissima, Sprun. ex Nym. Consp. $481=$ Spruneriana ramosissima, Willd. ex Steud. Nom. ed. II. i. $269=$ Loeflingii.

ramulosa, Wall. Cat. n. 1286; in Roxb. Fl. Ind. ed. Carey, ii. $100=$ colorata.

ranunculoides, Uspensky, in Bull. Soc. Nat. Mosce vii. (1834) 369 = rapunculoides.

rapuncula, St. Lag. in Ann. Soc. Bot. Lyon, vii. (1880) $121=$ C. Rapunculus.

rapunculoides, Linn.Sp. Pl. 165.-Europ.; As. temp. rapunculoides, Pall. ex Steud. Nom. ed. II. i. $270=$ bononiensis.

Rapunculus, Linn. Sp. Pl. 164.-Europ.; Oriens; Afr. bor.: As. bor.

Rapunculus, O. F. Muell. Fl. Dan. t. $855=$ rotundifolia. Raveyi, Boiss. Diagn. Ser. I. iv. 32.-Caria.

Reboudiana, Gren. \& Godr. Fl. Fr. ii. $415=$ rotundifolia.

Reboudiana, Pomel, Nouv. Mat. Fl. Atl. 2.-Algeria

recta, Dulac, Fl. Hautes-Pyr. $458=$ linifolia.

Redowskiana, Cham. \& Schlecht. in Linnaea, iv. (1829) 41 = Wablenbergia homallanthina.

Redoruskyi, Fisch. ex Herd. in Act. Hort. Petrop. (1873) $288=$ pilosa

redux, Schott, Nym. \& Kotschy, Analect. Bot. $9=$ Scheuchzeri.

reflexa, Hausm. ex Nym. Consp. $480=$ carnica

reflexa, Schur, in Verh. Siebenb. Ver. Naturw. iv. (1853) $47=$ caespitosa.

remotiflora, Sieb. E Zucc, in Ab/s. Akad. Muench, iv. III. (1846) 180.-Japon.

reniformis, Schur, Enum. Pl. Transs. 441. - Transsylv. repanda, Boiss. Diagn. Ser. I. xi. $76=$ Phyteuma limonifolium.

repens, Hort. ex Steud. Nom. ed. II. i. $270=$ Wiahlen. bergia procumbens.

repens, Lour. Fl. Cochinch. 139.-Cochinch.

retrorsa, Labill. Ic. Ml. Syr. Deco v. 5.-Syria; Cillcia

\section{CAMPANULA}

Reverchoni, A. Gray, Syn. Fl. N.Am. ii. 1. 396.Texas.

Renteriana, Boiss. E Bal. Diagn. Ser. II. iii. 108..-As Min.; Persia.

Reyneri, D. Dietr. Syn. PI. i. $749=$ Rainerii.

rhodensis, A. DC. Monog. Camp. $297=$ drabaefolia

Rhodii, Loisel. F1. Gall. ed. II. i. $140=$ linifolia.

rhomboidalis, Anct. ex Steud. Nom. ed. II. i. $270=$ lanceolata,

rhomboidalis, Gorter, Fl. Ingr. $34=$ rapunculoides.

rhomboidalis, Linn. Sp. Pl. 165.-Europ.

rhomboidalis, Schur, Enum. P1. Transs, $445=$ arcuata

rhomboidea, Endr. ex Willk. \& Lange, Prod. Fl. Hisp. ii. 291 = lanceolata.

rhomboidea, Murr. Syst. ed. XIII. 173.-Europ.

rigescens, Pall. ex Koem. \& Schult. Syst. vo 102

silenifolia.

rigida, Boiss. Diagn. Ser. I. xi. $76=$ Phyteuma rigridum.

rigida, Gilib. F1. Lituan. i. $51=$ rapunculoides.

rigidipila, Steud. \& Hochst. ex A. Rich. Tent. Abyss. ii. 3.-Abyss.

rimarum, Boiss. Fl. Orient. iii. 931-Lycia

riparia, Boj. ex A. DC. Prod. vii. $432=$ Wahlenbergia emirnensis.

riparia, Leprieur \& Perr. ex A. DC. 1. c. $435=$ Wahlen bergia riparia.

Rochelii, Schur, in Oestr. Bot. Zeitschr. (1861) 45 Steveni.

roëlloides, Juss. ex A. DC. Monog. Camp. $165=$ Prismatocarpus paniculatus.

Roezli, Regel, Gartenf. (1872) 239 ; et in Act. Hort. Petrop. ii. (1873) $310=$ prenanthoides.

Rohdii, Loisel. Fl. Gall. ed. II. i. 140, t. $24=$ linifolia Rosani, Tenore, FI. Nap. iii. 205. t. $120=$ versicolor.

rosea, Noronha, in Verh. Batav. Gen. v. $(1790$ ) ed. I. Art. IV, 12.-Malaya.

rosulata, Vukot. in Linnaea, xxvi. (1853-55) $326=$ cenisia.

rotunda, Gilib. F1. Lituan, i, $46=$ rotundifolia

rotundifolia, All. ex Steud. Nom. ed. II. i. $270=$

rhomboidea.

rotundifolia, Boiss. Voy. Espagne, $399=$ macrorrhiza

rotundifolia, Ledeb. F1. Alt. i. $238=$ linifolia.

rotundifolia, Linn. Sp: Pl. 163.-Reg. bor. temp.

rotundifolia, Pall. ex A. DC. in DC. Prod. vii. $484=$ adscendens.

rubioides, Banks, ex A. DC. Monog. Camp. $137=$

Microcodon lineare.

rubra, Hort. Journ. \& Fl. des Jard. (1832) 120. t. 124 $=$ rhomboidalis

ruderalis, Aitch. E Hemsl. in Fourn. Linn. Soc. xix. (1882) 174.-Afghan.

rumeliana, Vatke, in Linnaea, xxxviii. (1874) 705.Rumel.

rupestris, Adams, ex Ledeb. Fl. Ross. ii. $876=$ telli difolia.

rupestris, Bieb. Fl. Taur. Cauc. i. $154=$ Biebersteiniana.

rupestris, Host, Fl. Austr. i. $263=11$ aldsteiniana.

rupestris, Risso, ex A. DC. Monog. Camp. $902=$ macrorrhiza.

rupestris, Sibth. \& Sm. Fl. Gmec. Prod, i. 142 = tomentosa.

rupestris, Sprun. ex Nym. Consp. $477=$ rupicola.

rupicola, Boiss. E Sprun. Diagr. Ser. I. vii, 17,-

Graecia.

Ruprechtii, Boiss. Fl. Orient, iii. 905-Persia.

ruscinonensis, Timb. in Mim. Acad. Sc. Toul. Ser. VIJ. v. (1873) $275=$ linifolia.

Russeliana, Roem. \& Schult. Syst. v. $1 \pm 2=$ strigosa. ruthenica, Bieb. Fl. Taur. Cauc. i. $151=$ benoniensis. sabatia, De Not. Prosp. Fl Ligusp. 52. Italia. sajanensis, [Fisch.] Hort. Gorenk, ed. I. 1su8) 5\%= Adenophora marsupiitiora.

sajanensis, Spreng. ex Stcud. Nom. ed. IJ. i. 270 lasiocarpa.

salicifolia, Boiss. Diagn. Ser. I. xi. $76=$ Phvteuma

salicifolin Boiss. Se Kolschy, ex Boiss Fl. Orient. ii $949=1$ hytcuma amplexicaule.

salicifolia, Juss. ex 1 .edeb. Fl. Ross. ii. \$!t = Adenophora coronopifolia.

sanensis, Fisch. Cnt. II ort. Goresk. (Istas) ex A. IC. in Prod. vii. 461 a pilosi.

sarmatica, Ker-Gaxe in Buf. Res. to 23i.-Key. Caucas. 


\section{CAMPANULA :-}

sarmentosa, Hochst. ex A. Rich. Tent. Fl. Abyss. ii. 4. -Abyssin.

sarmentosa, Fenzl \& Vukot. in Rad Jugos. Akad. Zagreb. xxxi. (1875) $105=$ lobata.

Sartorii, Boiss. E Heldr. ex Boiss. Fl. Orient. iii. 919. -Archip. Graec.

saxatilis, Georgi, Beschr. Russ. Reich. iii. IV. 776 (sp. dub.).-Rossia.

saxatilis, Linn. Sp. Pl. 167.-Ins. Creta.

saxicola, R. Br. Prod. $561=$ Wahlenbergia saxicola

Saxifraga, Bieb. Fl. Taur. Cauc.,i. 155.-Reg. Caucas.

scabrella, Engelm. in Coult. Bot. Gazette, vi. (1881) 237.-Am. bor. occ.

scabrida, Hochst. in Lorent, Wanderungen, 331.Mesopotam.

scandens, Pall. ex Roem. E' Schult. Syst. v. 120.Sibir.

Scheuchzeri, A. Gray, Syn. F1. N. Am. ii. I. $12=$ Parryi.

Scheuchzeri, Lodd. Bot. Cab. t. $485=$ rotundifolia

Scheuchzeri, Vill Prosp. 22-Mont. Pyren.

Schimperi, Vatke, in Linnaea, xxxviii. (1874) $712=$ rigidipila.

Schleicheri, Suter, F1. Helv. i. 124 = linifolia.

Schotti, Hort.-Cf. Gard. Chron. (1885) II. 147.Hab.?

sclerotricha, Boiss Diaon. Ser I. xi. 66.-Persia.

Scouleri, Hook. ex A. DC. Monog. Camp. 312.-Am. bor. occ.

scutellata, Griseb. Spicil. Fl. Rumel. ii. 282.-Macedon.

secunda, Schmidt, F1, Boëm. ii. $74=$ rapunculoides.

secundiflora, Vis, \& Panc, in Mem. Ist. Venet. $x$. (18bi) $442=$ rapunculoides

seminuda, Vest, in Roem. \& Sehult. Syst. v. $91=$ Steveni

serpyllifolia, Vis. Fl. Dalm. ii. 136. t. 15.-Dalmatia. serratifolia, Vukot. in Linnaea, xxvi. (1853-55) 335 C. Trachelium, latifolium.

sessiliflora, Boiss. Fl. Orient. iii. 947.-Armenia.

sessilifiora, D. Dietr. Syn. P1. i. $756=$ Prismatocarpus campanuloides.

sessiliflora, C. Koch, in Linnaea, xix. (1847) $30=$ latiloba.

sessiliflora, Linn. f. Supp1. $139=$ Lightfootia longifolia subulata.

sessiliflora, Vukot. in Linnaea, xxvi. (1853-55) $327=$ Rainerii.

sessilis, D. Dietr. Syn. P1. i. $756=$ Prismatocarpn sessilis.

setacea, D. Dietr. 1. c. $754=$ Wahlenbergia capillacea.

setosa, Fisch. ex DC. Monog. Camp. $269=$ rapuncu loides.

setosa, Wendl. Beobacht. 42.-Hab.?

Sewerzowi, Regel, in Bull. Soc. Nat. Mosc. xl. (1867) II. 188.-As, temp.

sibirica, Linn. Sp. Pl. 167.-Europ.; As. temp.

Sibthorpiana, Boiss. Diagn. Ser. 1. xi. $77=$ Phyteuma Sibthorpianum.

sidoniensis, Boiss. Elanche, Diagn. Ser. II. iii. 114 -Syria.

Sieberi, D. Dietr. Syn. P1, i. $753=$ Wahlenbergia gracilis.

silenifolia, Fisch. ex A. DC. Monog. Camp. 320.As. bor.

silenifolia, Host, Fl. Austr. i. 268=Wahlenbergia Pumilio.

simplex, Lam. ex DC. Fl.'Fr. iii. $730=$ bononiensis.

simplex, Stev, in Mém. Soc. Nat. Mosc. iii. (1812) 255 $=$ Steveni.

Sinai, Boiss. Diagn. Ser. I. xi. $76=$ Phyteuma lanceolatum.

sinensis, D. Dietr. Syn. PI. i. $755=$ Adenophora sinensis.

singarensis, Boiss, E Haussk. ex Boiss. Pl. Or. Nov. Dec. i. 2.-Mesopotam.

sparsiflora, D. Dietr. Syn. Pl. i. $757=$ Microcodon sparsiflorum.

spathulaefolia, Sprun. ex Nym. Consp. $483=$ ramosis sima.

spathulata, Ehrenb. ex Boiss. F1. Orient. iii. 918= trichopoda.

spathulata, Sibth. \& Sm. F1. Graec. Prod. i. $137=$ Spruneriana

spathulata, Waldst. \& Kit. PI. Rar. Hung. ii. 286. t. $258=$ sibirica

speciosa, Gilib. F1. Lituan, i, $50=$ persicifolia.

\section{CAMPANULA:-}

speciosa, Hornem. Hort. Hafn. ii. 957, Add.=glomerata.

speciosa, Pourr. in Mém. Acad. Sc. Toul. iii. (1788) 09.-Mont. Pyren

speciosa, Willd. ex Spreng. Syst. i. $729=$ elegans,

specularioides, Coss. Notes Crit. 41.-Hispan.

Speculum, Linn. Sp. Pl. $168=$ Specularia Speculum.

sphaerothrix, Griseb. Spicil. F1. Rumel. ii. $280=$ expansa.

spicata, Linn. Sp. Pl. 166.-Europ.

spicata, Geners. Elench. Scepus. n. 192 ; ex Wahlenb. Fl. Carp. $62=$ C. Cervicaria.

spinulosa, D. Dietr. Syn. Pl. i. $754=$ Wahlenbergia spinulosa.

spreta, Roem. \& Schult. Syst. v. 123=Adenophora communis.

Spruneri, Boiss. F1. Orient. iii. $937=$ seq

Spruneriana, Hampe, in Flora, xxv. (1842) I. 76.Graecia et Ins.

spuria, Pall. ex Roem. \& Schult. Syst. v. $154=$ Specularia hybrida

St.-Helenae, D. Dietr. Syn. Pl. i. $755=$ Wahlenbergia linifolia.

stellarioides, D. Dietr. 1. c. $753=$ Wahlenbergia stellarioides.

stellaris, Boiss. Diagn. Ser. T. xi. 63.-Syria; Palestin. stellata, Thunb. in Hoffm. Phyt. Blaett.i. (1803) 20.Afr. austr.

Stelleri, Steph, ex Herd. in Act. Hort. Petrop. i. (1873) $299=$ lasiocarpa.

stenanthina, Ledeb. in Mém. Acad. Pétersb. v. (1814) $525=$ Adenophora marsupiiflora.

stenocarpa, Trautv. E Mey, in Middend. Reise (Fl. Ochot. 61).-As. temp.

stenocodon, Boiss. \& Reut. Diagn. Ser. II. iii. $112=$ rotundifolia.

stenophylla, Boiss. \& Heldr. 1. c. Ser. I. xi. $77=$ Phyteuma linifolium.

stenosiphon, Boiss. \& Heldr. I. c. vii. $18=$ glomerata

stenosiphon, Reichb. f. ex Nym. Consp. $479=$ rotundifolia.

Steveni, Bieb. Fl. Taur. Cauc. iii. 138.-Reg. Caucas. ; Persia.

Steveniana, Roem. \& Schult. Syst. v. $91=$ praec.

stolonifera, Mign. in Bull. Soc. Bot. Fr. xii. (1865) 312.- Hispan.

stricta, Labill. Ic. P1. Syr. Dec. v. $6=$ libanotica.

stricta, Linn. Sp. Pl. ed. II. 238.-As. Min.

stricta, Sibth. \& Sm. F1. Graec. Prod. i. $140=$ lyrata.

stricta, Wall. in As. Research, xiii. (1820) $374=$ sylvatica.

strigillosa, Boiss. in Ann. Sc. Nat. Sér. IV. Ii. (1854) 251.-Cappadocia.

strigosa, [Soland. in] Russ. Aleppo, ed. II. ii. 246.Cilicia; Syria.

strigosa, Vahl, Symb. Bot. iii. 34.-As. Min.

stylidioides, Boiss. Diagn. Ser. I. 'xi. $77=$ Phyteuma lobelioides.

stylosa, Bess. Cat. Hort. Crem. $(1816)=$ Adenophora communis.

stylosa, Lam. Encyc. i. $580=$ Adenophora stylosa

styriaca, Schott, Nym. \& Kotschy, Analect. Bot. $9=$ Scheuchzeri.

suanetica, Rupr. in Bull. Acad. Pétersb. xi. (1867) 215. -Reg. Caucas.

suaveolens, Gilib. FI. Lituan. i. $50=$ Adenophora communis.

suaveolens, Wender, ex Steud. Nom. ed. II. i. 270 Hab.?

subalpina, Delponte E Gras, Ind. Sem. Hort. Taurin. (1873) 35.-Hab. ?

subpyrenaica, Timb. in Mém. Acad. Toul. Sér. IV. v. (1855) 387.-Hispan

subramulosa, Jord. in Gren. \& Godr. F1. Fr. ii. $418=$ caespitosa.

subulata, Beauv, ex A. DC. Prod. vii. $478=$ americana.

subulata, Spreng. Syst. i. $809=$ Lightfootia subulata.

subulata, Thunb. Prod. P1. Cap. $38=$ Prismatocarpus subulatus.

subuniflora, Lam. Tabl. Encyc, ii. $53=$ liniflora.

sulphurea, Boiss. Diagn. Ser. I. xi. 64.-Syria.

swellendamensis, D. Dietr. Syn. P1. i. $753=$ Wahlenbergia swellendamensis.

sylvatica, Wall. Cat. n, 1293 ; et in Roxb. Fl. Ind. ii. 97.-Reg. Himal
CAMPANUTA :-

syngenesiflora, Pall. ex A. DC. Monog. Camp. $363=$ Adenophora marsupiiflora

syriaca, Ehrenb. ex Boiss. Fl. Orient. iii. $928=$ stellaris.

syriaca, Willd. ex Roem. \& Schult. Syst. .. $133=$ Specularia falcata.

syspirensis, C. Koch, in Linnaea, xxiii. (1850) 639.Armenia.

tauricola, Boiss. \& Bal. Diagn. Ser. II. iii. $116=$ Phyteuma rigidum.

telephioides, Boiss. E Haussk. ex Boiss. Pl. Or. Nov. Dec. i. 1.-Cataonia.

tenella, Jord. Pugill. P1. Nov. (1852) $125=$ caespitosa. tenella, Lange, ex Nym. Consp. $479=$ hispanica.

tenella, Linn. f. Suppl. $141=$ Lightfootia tenella Thunbergiana.

tenerrima, D. Dietr. Syn. Pl. i. $757=$ Prismatocarpus tenerrimus.

Tenorii, Moretti, Prosp. Geogr. Bot. Ital. Schouw, 19 $=$ versicolor.

tenuiflora, Schur, Enum. P1. Transs. $438=$ bono niensis.

temuiflora, Tenore, Fl. Nap. iii. 207. t. $210=$ lingulata.

tenuifolia, Hoffm. F1. Germ. i. 100=rotundifolia.

tenuifolia, Waldst. \& Kit. Pl. Rar. Hung. ii. $168=$ Wahlenbergia tenuifolia.

tetraphylla, Thunb. Pl. Jap. $87=$ Adenophora verticillata.

teucrioides, Boiss. Diagn. Ser. I. iv. 33.-Lydia.

Teymonsii, Hort.-Cf. Gard. Chron. (1885) II. 147, 182.-Hab.

Thaliana, Wallr. Sched. Crit. $86=$ bononiensis.

thalictriflora, Spreng. Syst. iv. Car. Post. $77=$ Codonopsis thalictrifolia.

Thomasii, Tenore, ex A. DC. Monog. Camp. $309=$ versicolor.

Thomsonii, Hook, fo in Journ. Linn. Soc. ii. (1858) 25 $=$ Phyteuma Thomsoni.

Thunbergii, Roem. \& Schult. Syst. v. $135=$ Lightfootia ciliata.

thyrsoidea, Lapeyr. Hist. Abr. Pl. Pyr. $107=$ speciosa

thyrsoides, Linn. Sp. Pl. 167.-Europ.

tomentosa, Lam. Encyc. i. 584.-As. Min.

tomentosa, Vent. Hort. Cels, 18.-Graecia et Ins.

Tommasiniana, Koch, ex F. Schultz, Arch. Fl. Fr. et

Allem. 229 ; Reut. in Cat. Genev. (1865) $4=$ Waldsteiniana.

trachelioides, Bieb. F1. Taur. Canc. i. 150 = rapunculoides.

trachelioides, Munby, in Bull. Soc. Bot. Fr. ii. (1855) 285. - Afr. bor.

Trachelium, Brot. Fl. Lusit. i. $287=$ primulaefolia.

Trachelium, Bull. Herb. Fr. t. $319=$ rapunculoides.

Trachelium, Linn. Sp. Pl. 166.-Europ.; As, temp.

Afr. bor.

Trachelium, Thunb. Fl. Jap. $88=$ punctata

trachyphylla, Schott \& Kotschy, ex Boiss. Fl. Orient. iii. 926.-Cilicia.

transsilvanica, Schur, ex Andrae, in Bot. Zeit. xiii. (1855) 328.-Transsylv.

trichocalycina, Tenore, F1, Nap, i. 67.t. 16=Phyteuma amplexicaule.

trichopoda, Boiss. Diagn. Ser. I. xi. 68.-Syria.

tricuspidata, Fisch. ex Roem. \& Schult. Syst. v. $158=$ Adenophora denticulata.

tridens, Rupr. in Bull. Acad. Pétersb. xi. (1867) $204=$ tridentata.

tridentata, Schreb. Ic. 3. t. 2; Linn. Mant. i.44.-As. Min.

trigona, Ehrenb. ex Boiss. F1. Orient. iii. $959=$ Specularia Speculum.

trilocularis, Turra, Prod. Fl. Ital, 64=Allionii.

triphylla, Thunb. Fl. Jap. $87=$ Adenophora triphylla.

truncata, D. Dietr. Syn. P1. i. $757=$ Campanumoea celebica.

tubiflora, Tausch, ex Ledeb. Fl. Ross. ii. $880=$ glomerata.

tubulosa, Lam. Encyc. i. 588.-Ins. Creta.

turbinata, Schott, Nym. \& Kotschy, Analect. Bot. 14 = carpatica.

tyrolensis, Schott, Nym. \& Kotschy, 1. c. $12=$ caes-

pitosa.
ucranica, Bess. Cat. Hort. Cremen. (1816) $28=$ rapunculoides.

umbellifera, Vukot, in Linnaea, xxvi. (1853-55) $333=$ pyramidalis. 


\section{CAMPANULA}

umbrosa, F. G. Dietr. Vollst. Lex. Gaertn. i. $675=$ Adenophora communis. undulata, Linn. f. Suppl. 142=Wahlenbergia undulata undulata, Moench, Meth. Suppl. $189=$ sibirica. unidentata, Linn. f. Suppl. $139=$ Lightfootia unidentata.

uniflora, Georgi, Beschr. Russ. Reich. iii.. IV. $772=$ silenifolia.

uniflora, Gorter, Fl. Ingr. $33=$ rotundifolia uniflora, Honck. Syn. Pl. Germ. ii. $251=$ cenisia. uniflora, Linn. Sp. Pl. 163.--Reg. Arctic.

uniflora, Schult. Oestr. Fl. ed. II. $400=$ caespitosa. uniflora, Vill. Prosp. 22 =linifolia.

urticaefolia, All. Fl. Pedem. i. $110=$ latifolia. urticaefolia, Gilib. Fl. Lithuan. i. $52=$ bononiensis. urticaefolia, Turra, Prod. Fl. Ital, $64=$ rapunculoides. urticifolia, Schmidt, Fl. Boëm. ii. $73=$ C. Trachelium. valdensis, All. Fl. Pedem. i. $109=$ linifolia.

Van-Houttei, Carr. in Rev. Hortic. (1878) 420.-Hab.? Vandesi, G. Don, ex Loud. Hort. Brit. 77.-Hab.? variifolia, Salisb. Prod. $126=$ rotundifolia.

Vayredae, Leresche $\sigma^{\circ}$ Levier, in fourn. Bot. xvii. (1879) 199.-Hispan.

velata, Pomel, Nouv. Mat. Fl. Atl. 2.-Algeria.

velebica, Borb.-Cf. in Oestr. Bot. Zeitschr. xxxiii. (1883) 201.-Austria.

velutina, Desf. F1. Atlant, i. 180, t. $51=$ mollis

venosa, Willd. Enum. Hort. Berol. Suppl. $10=$ rhomboidalis.

venusta, Schur, Enum. Pl. Transs. $442=$ caespitosa.

verbenaefolia, Sieber, in Ann. Fr. Pom.. (1838) 375.Hab. ?

veronicifolia, Hance, in Fourn. Bot. ix. (1871) 133.China.

verruculosa, Hoffmgg. \& Link, F1. Port. ii. 12. t. $81=$ C. Rapunculus.

versicolor, Sibth. \& Sm. Fl. Graec. Prod. i. 138.Italia ; Graecia.

verticillata, Guss. Pl. Rar, $92=$ versicolor.

verticillata, Hill, Veg. Syst. viii. 10.-Am. bor.

verticillata, Pall. Reise, iii. $719=$ Adenophora verticillata.

vesula, All. Fl. Pedem. i. $108=$ persicifolia

Vidalii, H. C. Wats. in Hook. Ic. Pl. t. 684.-Ins. Azores.

vincaeflora, Vent. Jard. Malm. 12 = Wablenbergia gracilis.

gracilis.
Violae, Pers. Syn. i. $192=$ seq.

violaefolia, Lam. Encyc. i. 587.-Sibiria.

virgata, A. DC. Prod. vii. $483=$ C. Rapunculus.

virgata, Labill. Ic. Pl. Syr. Dec. ii. 11. t. 6=-Phyteuma limonifolium.

virgata, Rafin. ex Roem. \& Schult. Syst. v. $100=$ divaricata, linifolia.

viridis, Spreng. Syst. iv. Cur. Post. $78=$ Codonopsis viridis.

Vitinghofiana, Roem. \& Schult. Syst. v. $102=$ Steveni,

persicifolia.
Vlachovae, Orphan. ex Boiss. Fl. Orient. iii. $927 .=$ glomerata.

volubilis, Willd. ex Roem. \& Schult. Syst. v. $98=$ lactiflora.

vulgaris, Gueldenst. It. ii. 10, ex Ledeb. Fl. Ross. ii. 891.- Reg. Cancas.

Waldsteiniana, Roem, E Schult. Syst. ₹. 99.Croatia.

Wanneri, Rochel, P1. Banat. Rar. 41. t. 5. f. $12=$ Symphyandra Wanneri.

Welandi, Heuff, in Oestr. Bot. Wochenschr. (1857) $118=$ expansa.

Willdenorviana, Roem. \& Schult. Syst. จ. $107=$ versicolor.

Willdenowit, Boiss, Diagn. Ser. II. iii, $117=$ Phyteuma Jobelioides.

Zeyheri, D. Dietr. Syn. P]. i. $753=$ Wahlenbergia Zeyheri.

Zoysii, Wulf. in facq. Collect. ii. 122.-Europ. austr.

CAMPANULOIDES, Hort. Kew. ex A. DC. Monog. Camp. $107(1890)=$ Lightfootia, L'Herit. (Campan.).

subulata, Hort. Kew, ex A. DC. 1. c. = L. subulata.

CAMPANULOPSIS, Zoll. \& Mог. in Nat. en Geneesk. Arch. Neîrl. Indie, i. (1844) 484, nomen. CAMPANULACEAE?

cyanea, Zoll. E Mor. l. c.-Malaya.
CAMPANUMOEA, Blume, Bijdr. 726. (1825) CAMPANULACEAE, Benth. \& Hook.f. ii. 557. Cyclocodon, Griff. Notul, iv. 277 (1854)。

celebica, Blume, l. c. 727.-Ind. or.; Malaya; China. cordata, Maxim. in Bull. Acad. Pétersb.xii. (1868) 68 $=$ javanica

inflata, C. B. Clarke, in. Hook, f. Fl. Brit. Ind. iii. 436. - Reg. Himal.

japonica, Maxim. in Bull. Acad. Pétersb. xii. (1868) 67.- Japon.

japonica, Siebold, ex Morr. Belg. Hortic. (1863) $937=$ lanceolata?

javanica, Blume, Bijdr. 726.--Reg. Himal.; Java.

lanceolata, Sieb. \& Zucc. Fl. Japon. i. 174. t. 91.= Codonopsis lanceolata.

leucocarpa, C. B. Clarke, in Hook. f. Fl. Brit. Ind. iii. $436=$ celebica

parviflora, Benth. E Hook. f. Gen. ii. 558.-Reg. Himal.

pilosula, Franch. Pl. Davidian. i. (1884) 192.Mantchur.

truncata, Endl. Gen. Plant. i. 515 ; C. B. Clarke, in Hook. f. Fl. Brit. Ind. iii. $436=$ celebica.

CAMPBELLIA, Wight, Ic. iv. 5. t. 1424, 1425 (1850) Christisonia, Gardn. (Orobanch.).

albida, Benth. \& Hook. f. Gen. ii. $967=$ Christisonia albida.

aurantiaca?, Wight, Ic. iv.t. $1424=$ Chr. neilgherrica cytinoides, Wight, 1. c. $1425=\mathrm{Chr}$. neilgherrica.

Lawii, Benth. \& Hook. f. Gen. ii. $967=$ Chr. Lawii.

subacaulis, Benth. \& Hook. f. 1. c. = Chr. subacaulis.

CAMPDERIA, Benth. Bot. Voy. Sulph. 159. t. 52. (1844). POLYGONACEAE, Benth. \& Hook f iii. 102 floribunda, Benth. l.c. 160.-Guatemala.

gracilis, Meissn. in Mart. Fl. Bras. v. I. 23.-Bras. Lindeniana, Benth. E Hook. f. Gen. iii. 103.-Mexic mexicana, Meissn. in DC. Prod.xiv, $171=$ floribunda. nematostachya, Griseb. in Bonplandia, vi. (1858) 4.Panama.

CAMPDERTA, Lag. Amen, Nat, ii. 99 (1821) = Kundmannia, Scop. (Umbellif.).

sicula, Lag. 1. c. $=\mathbf{K}$. sicula.

CAMPDERIA, A. Rich. in Bull. Soc. Philom. (1822) 79 - Barbacenia, Vand. (Amaryllid.).

CAMPE, Dulac, F1.Hautes-Pyr. $199($ 1867) = Barbarea, R. Br. (Crucifer.)

praecox, Dulac, 1, c. $=$ B. praecox.

vulgaris, Dulac, $1 . \mathrm{c}=\mathrm{B}$, vulgaris.

CAMPECARPUS, H. WendI. ex Benth. \& Hook. f. Gen. iii. 893 (1883)=Cyphophoenix, H. Wenda.(Palm.) fulcitus, H. Wendl. 1. c。=Cyph. fulcita.

CAMPECIA, Adans. Fam.ii. 567 (1763)= Caesalpinia Linn. (Legumin.).

CAMPELEPIS, Falc. in Trans. Linn. Soc. xix. (1845) 101 = Periploca, Linn. (Asclepiad.).

viminea, Falc. 1. $\mathrm{c}_{\mathrm{s}}=\mathrm{P}$. aphylla.

CAMPELIA, Kunth, Enum. PI. i. 286, 287 (1833) = CAMPELLA, Link.

CAMPELIA, Rich. Anal. Fruit. 46 (1808)。COMME LINACEAE, Benth. \& Hook. f. iii. 855 .

GoNATANDRA, Schlecht in Linnaea, xxiy. (1851) 659 SARCOPERIS, Rafin. Fl. Tellur, ii. 16 (1886)

Zavonia, [Plum.] Cram. Diss. Syst. 75 (1808).

bibracteata, Wied-Neuwied, Beitr. Bras. 15. t. 2. f. = C. Zanonia.

Boucheana, Schult. f. Syst. vii. $1180=$ C. Zanonia. fastigiata, Schlecht. in Linnaea, xxv. (1852) $188=$

Zanonia.

Fendleri, Hassk, in Flora, xiviii. (1865) $102=\mathrm{C}$ Zanonia.

glabrata, Hassk. in Miq. Pl. Jungh. $15 t=$ Forrestia glabrata.

glabrata, Kunth, Enum. Pl. iv, $109=$ C. Zanonia. Hofmanni, Hassk. in Flom, xlviii. (1865) $105=\mathrm{C}$. Zanonia.

marginata, Blume, Enum. Pl. Jav. i. $7=$ Forrestia marginata

marginata, Wall. Cat. n. $8977=$ Forrestia, Ilookeri.

\section{CAMPELIA:}

mexicana, Mart. ex Kunth, Enum. P1. iv. $109=\mathrm{C}$ Zanonia

mollissima, Blume, Enum. Pl. Jav. i. $7=$ Forrestia mollis.

Pseudo-Zanonia, Kunth, Enum, P1. iv. $108=\mathrm{C}$. Zanonia.

scandens, Hassk. in Flura, xlviii. (Isfí, 103.-T'erur.

Zanonia, H. B. \& K. Nov. Gen. et Sp.i. 264.-Am. austr.

CAMPELLA, Link, Hort. Berol. i, 122 1827)

Deschampsia, Beauv. (Gramin.)

caespitosa, Link, 1. c. $122=$ D. caespitosa.

media, Link, 1. c. $123=$ D. juncea.

CAMPHORA, [Banh.] Linn. Syst. ed. I (1735); Nees, Syst. Laurin. 87 = Cinnamomum, Tourn. (Laurin.) angustifolia, Rafin. Sylva.Tellur, 136.-Hab. chinensis, Nees, in Otto, Gartenz. (1833) 91; Syst. Laurin. 92 = Cinn. Parthenoxylon.

glandulifera, Nees, in Wall. Pl. As. Rar. ii. $72=$ Cinn. glanduliferum.

glauca, G. Don, in Swect; Hort. Brit. ed. III. $582=$ Litsea glauca.

inodora, Blume, ex Miq. Fl. Ind. Bat. i. 904.-Arch. Sunda.

inuncta, Nees, in Wall. P1.As. Rar. iii. $32=$ Cinn. inunctum.

japonica, Rafin. Sylva Tellur. $136=$ Cinn. pedunculatum officinalis, Steud. Nom. ed. II. i. 271 = Cinn. Camphora. offinarum, Nees, ex. Mall. Pl. As. Rar, ii. $72=$ Cinn. Camphora.

Parthenoxylon, Nees, 1. $\mathrm{c}=$ = Cinn. Parthenoxylon.

porrecta, Voigt, Hort. Suburb. Calc. $308=$ Cinr. Parthenoxylon.

Pseudo-Sassafras, Miq. in Zoll. Syst. Verz. Ind, Archip.

$113,114=$ Cinn. Parthenoxylon.

sumatrana, Miq. Pl. Jungh. 174.-Sumatra

vera, Rafin. Sylva Tellux. $136=$ Cinn. Camphora.

CAMPHORATA, Toum. ex Crantz, Inst. i. 113 (1766 Camphorosma, Linn. (Chenopod.)

acuta, Crantz, 1. c. $114=$ Halimocnemis juniperina.

glabra, Crantz, 1. c $c_{b}=$ Camphorosma glabrum.

hirsuta, Moench, Meth, $700=$ Camphorosma mons peliacum.

monspeliensium, .Crantz, Inst. i. $114=$ Camphorosma monspeliacum.

CAMPHORINA, Noronha, in Verh. Batav. Gen. v. (1790 ed. I. Art. IV. 1 = Cinnamomum, Tourn. ? (Laurin.)

CAMPHOROMOEA, Nees, Laurid. Expos. 16 (1833) = Ocotea, Aubl. (Laurin.)

divaricata, Nees, Syst. Laurin. 467.-Bras.

laxa, Nees, 1. c. 468,-Bras.

litsaeifolia, Meissn, in DC. Prod, xy. I. 145.-Bras. ovalifolia, Meissn. 1. c. 144,-Bras.

rhamnoides, Meissn. 1. c. 145.-Bras.

subtriplinervia, Nees, Syst. Laurin. 466 .-Bras. surinamensis, Meissn. in DC. Prod. xr. L. 145.Guinea.

tenuiflora, Meissn. 1. c. 144.-Bras.

venulosa, Nees, Syst. Laurin, 469.-Bras.

sisyphoides, Meissn. in DC. Prod. xv. 1. 145.-Bras.

CAMPHOROMYRTUS, Schau. in Linnaea, xvii. (1 49 $240=$ Baeckia, Lina. (Myrtac)

Behrii, Schlecht. 1. c. xx. (1st7; $651=$ B. Behrii

Brownii, Schau. 1. c. xvii. $(1843240=13$. cam 2 ? $=$ B. virgata.

pluriftora, F. Mucll. 1. C. B. rirgata

CAMPHOROSMA, Linn. Niss HWE (IT!) (Amoen. Acad. i. 39

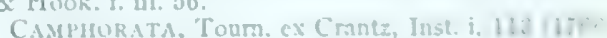
acutum. Falk, theitr. ii. 120 \}

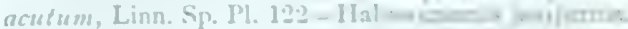

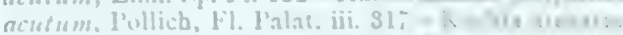

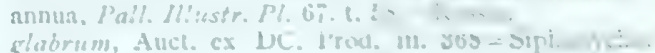
Slabrum, Auch.

glabrum, Linn. SP. PI. 322-Mcluetia, hirsubums. Stokes 13os. Mat. Med. i.29: = monspe!iseun

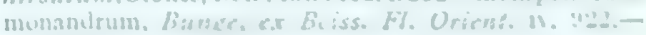
Alghan. 


\section{CAMPHOROSMA :}

monspeliacum, Linn. Sp. Pl. 122.-Reg. Mediterr. monspeliacum, Pall. Reise, ii. $471=$ ruthenicum. monspeliacum, Pollich, Fl. Palat. i. 165=Kochia arenaria.

monspeliense, Murr. Syst. Veg. ed. XIII. $139=$ monspeliacum.

ovatum, Biasol. ex Moq. in DC. Prod. xiii. II. 126= monspeliacum.

ovatum, Waldst. E Kit. Pl. Rar. Hung. i. 64. t. 63.-Europ. austr. or

ovatum, Bong. \& Mey. Suppl. ii. F1. Alt. 68. n. $274=$ annuum.

paleaceum, Linn. f. Suppl. $128=$ Monetia paleacea.

perennis, Pall. Illustr. Pl. iii. 66. t. 57.-Reg. Caucas. ;

Persia.

polygamum, Bunge, ex Boiss. Fl. Orient. iv. 921.Afghan.

Pteranthus, Linn. Mant, i. $41=$ Pteranthus echinatus. ruthenicum, Bieb. Fl. Taur. Cauc. iii. Suppl. 112.Europ. austr. or.; As. bor.

sabulosa, Kit. ex Moq. in DC. Prod. xiii. II. 126.Hungar.

songoricum, Bunge, in Act. Hort. Petrop. vi. (1879) 415. - Sibir.

vingintimilleis, Tineo, Cat. Hort. Panorm. 277.Sicil.

CAMPHUSIA, De Vriese, in Nederl. Kruidk. Arch. ii (1850) $148=$ Seaevola, Linn. (Goodeniac.). glabra, De Vriese, 1. c. 149.-Malaya.

CAMPHYLEIA, Spreng. Gen. ii. 486 (1831)=Striga Lour. (Scrophulac.).

CAMPIA, 'Domb.' ex Endl. Ench. 91, in syn. (1841)= CAPIA, Juss.= Lapageria, Ruiz \& Pav. (Liliac.).

CAMPILOSTACHYS, A. Juss, in Orb. Dict. xi. 38 (1849) = Campylostachys, Kunth (Verbenac.).

CAMPNOSPERMA, Thw, in Hook. Kew Journ. vi. (1854) 65. t. 1. ANACARDIACEAE, Benth. \& Hook. f. i. 425.

auriculata, Hook. f. Fl. Brit. Ind. ii. 41.-Ind. or.

Griffithii, March. Rev. Anac. 174.-Penang.

gummifera, March. l. c. 173.-Bras.

macrophylla, Hook. f. Fl. Brit. Ind. ii. 41.-Malacca.

Micranteia, March. Rev. Anac. 173.-Madag.

oxyrhachis, Engl. in A. DC. Monog. Phan. iv. 319.Sumatra.

seychellarum, March. Rev. Anac. 173.-Ins. Mascar

zeylanica, Thw. in Hook. Kew Fourn. vi. (1854) 65.Zeylan.

CAMPOMANESIA, Ruiz \& Pav. Prod. 72. t. 13 (1797). MYRTACEAE, Benth. \& Hook. f. i. 712.

AbbeVillea, ACrandra, BritoA, Lacerdaea, Berg, in Linnaea, xxvii. (1854) 425-437.

adamantium, Blume, Mus. Bot. Lugd. Bat. i. 73.Bras.

affinis, Berg, in Mart. Fl. Bras. xiv. I. 446.-Bras.

aprica, Berg, l. c. 459.-Bras.

arenaria, Berg, l.c. 448.-Reg. Argent.

aromatica, Griseb. Fl. Brit. W. Ind. 242.-Ind. occ.

anrea, Berg, in Mart. Fl. Bras. xiv. I. 454.-Bras.

australis, Berg, l. c. 445.-Bras.

caerulea, Berg, l. c. 455 .-Bras.

caerulescens, Berg, l.c. 612.-Bras.

Cambessedeana, Berg, l.c. 457.-Bras

campestris, Blume, Mus. Bot. Lugd. Bat. i. 72.Bras.

cerasoides, A. Gray, Bot. U. St. Expl. Exped. i. 549.-Bras.

ciliata, Berg, in Mart. Fl. Bras. xiv. I. 453.-Bras

coaetanea, Berg, l. c. 444.-Am. trop.

cornifolia, H.B. \& K. Nov. Gen. et Sp. vi. 150. t. 147. -N. Granat.

corymbosa, Blume, Mus. Bot. Lugd. Bat. i. 72.Bras.

crassifolia, Benth. Bot. Voy. Sulph. 97. t. 37.N. Granat.

crenata, Berg, in Mart. Fl. Bras. xiv, I. 456.-Bras.

cuneata, Berg, l. c. 446.-Bras.

cyanea, Berg, l. c. 454. - Bras.

dentata, Berg, l. c. 457.-Bras.

desertorum, Berg, l. c. 450 .-Bras

dimorpha, Berg, l. $c .609$-Bras.

discolor, Berg, l. c. 439.-Bras.

\section{CAMPOMANESIA :-}

eriantha, Blume, Mus. Bot. Lugd. Bat. i. 72.Bras.

eugenioides, Blume, $l$. c.-Bras,

fruticosa, Berg, in Mart. Fl. Bras, xiv. I, 458,-Bras.

fusca, Berg, l. c. 447 .- -Bras.

Gardneriana, Berg, l. c. 455 --Bras.

glabra, Benth. in Hook. Journ. Bot. ii. (1843) $319=$ Calycolpus glaber.

glabra, Berg, in Mart. Fl. Bras. xiv. I. 450.-Bras.

Goetheana, Hemsl. Biol. Centr. Am. Bot. i. $407=$ Calycolpus glaber.

grandiflora, Sagot, in Ann. Sc. Nat. Sér. VI. xx. (1885) 182. - Guiana.

Guaviroba, Benth. E Hook. f. Gen. i. 712,-Bras

guazumaefolia, Blume, Mus. Bot. Lugd. Bat. i. 72.Bras.

heterophylla, Berg, in Mart. Fl. Bras. xiv. I. 440.Bras.

hirsuta, Gardn. in Hook. Lond. Fourn. Bot. ii. (1843) 353.--Bras.

Houlletii, Berg, in Mart. Fl. Bras. xiv. 1. 449.Bras.

lanceolata, Berg, l. c. 612.-Bras.

Langsdorffi, Berg, l. c. $610 .-$ Bras.

lanrifolia, Gardn. in Hook. Lond. Fourn. Bot. ii. (1843) 353.-Bras.

lineatifolia, Ruiz E Pav. Fl. Per. iv. t. 422; Syst. 128. -Peruv.

malifolia, Berg, in Mart. Fl. Bras. xiv. I. 452.Bras.

Martiana, Berg, l. c. 610.-Bras.

mediterranea, Berg, l. c. 458.-Bras.

microcarpa, Berg, l. c. 455-Bras.

multiflora, Blume, Mus. Bot. Lugd. Bat. i. 72.Bras.

obscura, Berg, in Mart. Fl. Bras. xiv. I. 451.-Bras.

obversa, Berg, l. c. 445 .-Bras.

ovalifolia, Berg, l. c. 452.--Bras.

Pohliana, Berg, l. c. 441.-Bras.

Poiteati, Berg, in Linnaea, xxvii. (1854) 432.-Bras.

pubescens, Berg, in Mart. Fl. Bras, xiv. I 443.-Bras.

racemosa, Berg, l. c. 458.-Bras.

repanda, Berg, l. c. 456 .-Bras.

reticulata, Berg, l. c. 439.-Bras.

rhombea, Berg, l. c. 453.-Bras.

rhytidophylla, Berg, l. c. $608,-$-Bras

Riedeliana, Berg, l. c. 610.-Bras.

rugosa, Berg, l. c. 439 . - Bras.

salviaefolia, Berg, l. c. 442 .-Bras.

suaveolens, Blume, Mus. Bot. Lugd. Bat. i. 72.-Bras.

suffruticosa, Berg, in Mart. Fl, Bras, xiv. I. 448.Bras.

synchrona, Berg, l. c. 444--Bras.

tenuifolia, Berg, l. c. 452.-Bras.

tomentosa, $H . B$. \& $K$. Nov. Gen. et Sp. vi. 151, t. 147.-N. Granat.

transalpina, Berg, in Mart. Fl. Bras. xiv. 1. 459.Bras.

triflora, Baill. Hist. Pl. vi. 342.-Bras.

vaccinioides, Berg, in Mart. Fl. Bras. xiv. I. 450. Bras,

velutina, Blume, Mus. Bot. Lugd. Bat. i. 72.-Bras.

virescens, Berg, in Mart. Fl. Bras. xiv. I. 611.-Bras.

Widgreniana, Berg, l. c. 447.-Bras.

xanthocarpa, Berg, l.c. 451.--Bras.

CAMPSANTHUS, Steud. Nom. ed. II. i. $272(1840)$, sphaIm. = COMPSANTHUS, Spreng. = Tricyrtis, Wall. (Liliac.).

CAMPSIANDRA, Benth. in Hook. Journ. Bot. ii. (1840) 93. LEGUMINOSAE, Benth. \& Hook. f. i. 563.

angustifolia, Spruce, ex Benth. in Mart. Fl. Bras. xv. II. 55. - Am. trop.

comosa, Benth. in Hook. Fourn. Bot. ii. (1840) 93.Guiana.

laurifolia, Benth.l. c. 94.-Bras.

rosea, Poepp. E Endl. Nov. Gen. et Sp. iii. 62.--Bras.

CAMPSIDIUM, Seem, in Bonplandia, x. (1862) 147 ; in Ann. \& Mag. Nat. Hist. Ser. III. x. (1862) $32=$ Tecoma, Juss. (Bignon.).

chilense, Reiss. \& Seem. in Bonplandia, x. (1862) 147. Chili.

filicifolium, A. Van Geert. Cat. n. 71 (1874); Fl. et Pom. (1874) 280.-Ins. Fiji.
CAMPSIS, Lour. F1. Cochinch. $377(1790)=$ Tecoma Juss. (Bignon,).

adrepens, Lour. 1. c. = Incarvillea sinensis.

amboinensis, Seem. in Journ. Bot. v. (1867) $374=$ $T$, amboinensis.

Curtisii, Seem. 1. c. $37 \mathbf{1}=\mathrm{T}$. radicans?

dendrophila, Seem. 1. c. $373=\mathrm{T}$. dendrophila.

Fortunei, Seem. 1. c.-China.

Haussmannii, F. Muell. Fragm. iv. $148=$ Haussmannia jucunda.

radicans, Seem. in Journ. Bot. v. (1867) $372=$ $T$, radicans.

CAMPTEDERIA, Steud. Nom. ed. II. i. 272 (1840) sphalm.= CAMPDERIA, A. Rich.

CAMPTOCARPUS, Decne in DC. Prod, viii. (1844) 493. ASCLEPIADEAE, Benth. \& Hook. f. ii. 744. Bojerianus, Decne. l. c. 494.-Madag.

crassifolius, Decne. l. c.-Madag.

linearis, Decne. l. c.-Madag.

mauritianus, Decne.l. c. 493.-Ins. Borbon.

CAMPTOCARPUS, C. Koch, in Linnaea, xvii. (1842) $304=$ Alkanna, Tausch (Boragin.).

orientalis, C. Koch, 1. c. $=\mathrm{A}$. orientalis.

CAMPTOLOIMA, Benth. in DC. Prod. x. 430 (1846) SCROPHULARINEAE, Benth. \& Hook. f. ii. 960 . rotundifolia, Benth. l. c. 431.-Afr. austr.

villosa, Balf. f. in Proc. Roy. Soc. Edinb. xii. (1884) 84.-Ins, Socotra.

CAMPTOPUS, Hook. f. Bot. Mag. t. 5755 (1869)= Cephaëlis, Sw. (Rubiac.)

Manniz, Hook. f. 1. c. = Cephaëlis Mannii.

CAMPTOSEMA, Hook. \& Arn. in Hook. Bot. Misc iii. (1833) 200. LEGUMINOSAE, Benth. \& Hook. f. i. 536 .

Bronla, Mart, ex Benth, in Ann. Wien, Mos. ii (1838) 130.

acuminatum, Benth. in Mart. Fl. Bras. xv. 1. 155.Am. austr.

bellum, Benth. $l$. c. 156.-Am. austr.

coccineum, Benth. l. c. 154.-Am. austr.

coriaceum, Benth. l. c. 155-Am austr.

erythrinoides, Benth. l. c. 156.-Am. austr.

grandiflorum, Benth. in Linnaea, xxii. (1849) 516.Bras.

pedicellatum, Benth. in Hook. Fourn. Bot. ii. (1840) 60.-Guiana

pinnatum, Benth. in Mart. Fl. Bras. xv. I. 325.-Bras. rubicundum, Hook. E Arn. in Hook. Bot. Misc. ii (1833) 201.-Reg. Argent.

tomentosum, Benth. in Mart. Fl. Bras. xv. I. 155.Am. austr.

CAMPTOSTEMON, Mast. in Hook. Ic. PI. xii. 18 t. 1119 (1872), MALVACEAE.

Schultzii, Mast. l. c.-Austral.

CAMPTOTHECA, Decne, in Bull. Soc. Bot. Fr, xx (1873) 157. CORNACEAE.

acuminata, Decne.

CAMPUlEIA, Thou. Gen. Nov. Madag. 7 (1806)= Striga, Lour. (Scrophularin.).

coccinea, Hook. Exot. Fl. 3. t. $203=$ S. lutea.

coerulea, Boj. ex Benth. in DC. Prod. x. 501=S orobanchioides.

rosea, Boj. ex Benth. 1. c. $=\mathrm{S}$. orobanchioides

CAMPUloA, Desv. Journ. Bot, i. (1813) $69=$ Ctenium Panz. (Gramin.)

brachystachya, Nees, ex Doell, in Mart. Fl. Bras. ii. III. $73=\mathrm{Ct}$. brachystachyum.

chapadensis, Trin. ex Doell, 1. c. $74=\mathrm{Ct}$. chapadense. elegans, J. Gay, ex Kunth, Rev. Gram. i. $93=\mathrm{Ct}$. elegans.

gracilis, Desv. Journ. Bot. i. (1813) $69=\mathrm{Ct}$. caro. linianum.

hirsuta, Desv. 1. c. (=Campulosus falcatus),-Afr. austr.

monostachya, Roem. \& Schult. Syst. ii. $516=$ Ct. carolinianum. 
CAMPULOCLINIUM, DC. Prod. v. $136(1836)=\mathbf{E u}$ patorium, Tourn. (Compos.).

alternifolium, Gardn. in Hook. Lond. Journ. Bot. vi. (1847) $438=$ Ageratum alternifolium

arenarium, Gardn. l. c. v. (1846) 467.-Bras. ascendens, Sch. Bip. ex Baker, in Mart. F1. Bras. vi. II. $363=\mathrm{E}$. betonicaeforme.

corymbosum, Sch. Bip. ex Baker, 1, c. $356=\mathrm{E}$. Burchellii.

crenatum, Schlecht. in Mart. Herb. F1. Bras. n. $668=$ E. sordescens.

decumbens, Sch. Bip. ex Baker, in Mart. Fl. Bras. vi. II. $344=$ E. decumbens.

frutescens, Bartl. Ind. Sem. Hort. Goett. (1843).-

Hab.?

hirsutum, Gardn. in Hook. Lond. Journ. Bot. v. (1846) $438=$ E. hirsutum.

kleinioides, DC. Prod. v. $137=$ E. kleinioides

macrocephalum, DC. 1. C. $=\mathrm{E}$. macrocephalum

palustre, DC. in Deless, Ic. Sel. iv. t. $16=$ E. palustre.

Pohlianum, Sch. Bip. ex Baker, in Mart. Fl. Bras, vi. II. $358=$ E. macrocephalum.

polyphyllum, Sch. Bip. ex Baker, 1. c. $354=$ E. megacephalum.

siegesbeckioides, Sch. Bip. ex Baker, 1. c. $359=\mathrm{E}$.

hirsutum.

strigosum, Sch. Bip. ex Baker, 1. c. $358=$ E. macrocephalum.

subpaniculatum, DC. Prod. $\mathbf{v} .137=$ E. sordescens

surinamense, Miq. in Linnaea, xvii. $(1843) 69=\mathrm{E}$. Vitalbae.

turbinatum, Sch. Bip. ex Baker, in Mart. F1. Bras. vi. II. $357=\mathrm{E}$. chlorolepis.

urticaefolium, DC. Prod. v. $137=$ E. urticaefolium.

viridiflorum, Bartl, ex Baker, in Mart. Fl. Bras, vi. $\mathbf{I}$. $309=\mathrm{E}$. viridiflorum.

CAMpulosus, Desy, in Nouv, Bull, Soc. Philom, ii. (1810) $189=$ Ctenium, Panz. (1814) (Gramin.)

aciculatus, Trin. Sp. Gram. iii.t. $301=$ Ct. elegans

aromaticus, Trin. ex Steud. Nom. ed. II. i. $272=\mathrm{Ct}$. carolinianum.

brachystachyus, Nees, Agrost. Bras. $417=$ Ct. brachystachyum.

chapadensis, Trin. Sp. Gram. iii. 26. t. $303=$ Ct. chapadense.

cirrhosus, Nees, Agrost. Bras. $416=$ Ct. cirrhosum.

concinnus, Steud. Nom. ed. II. i. $272=\mathrm{Ct}$. concinnum.

dolichostachys, Trin. ex Steud. 1. c.-Hab.?

falcatus, Beauv. Agrost. 64.-Afr. austr.

gracilior, Desv, in Nouv. Bull. Soc. Philom. ii. (1810) $189=\mathrm{Ct}$. carolinianum.

gracilis, Bertol. in Mem. Acad. Sc. Bolog. ii. (1850) 602.-Am. bor.

hirsutus, Desv, in Nouv. Bull. Soc. Philom, ii. (1810) $189=$ falcatus.

macrostachys, Steud. Nom. ed. II. i. $29=\mathrm{Ct}$. carolinianum.

monostachyos, Beauv. Agrost. 64. t. 13. f. $1=\mathrm{Ct}$. carolinianum.

planifolius, Presl, Reliq. Haenk. i. $287=\mathrm{Ct}$. planifolium

tricorys, Trin. ex Steud. Nom. ed. II. i. 272.-Hab.?

CAMPYDORUM, Salisb. Gen. P1. Fragm. 64 (1866)= Polygonatum, Adans. (Liliac.)

verticillatum, Salisb, 1. c. $=\mathrm{P}$, verticillatum.

CAMPVLANDRA, Baker, in Journ. Linn. Soc. xiy. (1875) 582. t. 20 = Tupistra, Ker-Gawl. (Liliac.). aurantiaca, Baker, 1. c. $582=\mathrm{T}$. aurantiaca. dasystachys, Welw. ex Baker, in Trans. Linn. Soc. Ser. II. i. (1878) $256=$ Dasystachys campanulata.

CAMPYLANTHERA, Hook. Ic. PI. t. $82(1837)=$ Pronaya, Hueg. (Pittospor.).

ericoides, Lindl. in Mitch. Three Exped. ii. $277=$ Marianthus procumbens.

Fraseri, Hook. Ic. Pl. t. $82=$ P. elegans.

CAMPYLANTHERA, Schott, Melet. $35(1832)=$ Erio dendron, DC. (Malvac.)

Samauma, Schott, 1. c. = E. Samauma.

CAMPYLANTHUS, Roth, Nov. Pl. Sp. 4 (1821) SCROPHULARINEAE, Benth. \& Hook, f. ii. 961

Benthamii, Webb, in Hook. Niger Fl. 163.-Ins. Cap. Verd.

\section{CAMPYLANTHUS :}

glabra, Benth in DC Prod x. 508. - Ins. Cap. Verd. junceus, Edgew. in Fourn. As. Soc. Beng. xvi. (1847) 1217. - Ind. or

ramosissimus, Wight, $I c$. iv. to 1416.--Ind. or, Beluchist.

salsoloides, Roth, Nov. Pl. Sp. 4.-Ins. Teneriff.

salsoloides, Stocks, ex Boiss, F1. Orient. iv, $433=$ ramosissimus.

salsoloides, Webb, Phyt. Canar. iii. $126=$ Benthamii. spinosus, Balf. f. in Proc. Roy. Soc. Edinb. xii. (1884) 84.-Ins. Socotra.

CAMPYLEIA, Spreng. Syst. iv. Cur, Post. 222 (1831)= CAMPULEIA, Thou,=Striga, Lour. (Scrophular.).

CAMPYLIA, Lindl. ex Sweet, Geran, sub t. $43(1820)=$ Pelargonium, L'Hérit. (Geraniac.)

blattaria Sweet, Geran. t, $88=$ P. ovale.

cana, Colv, ex Sweet, 1. c. t. $114=$ P. ovale

capillaris, Eckl. \& Zeyh. Enum. $74=$ P. capillare.

carinata, Lindl. ex Sweet, Geran. sub t. $43=\mathrm{P}$. carinatum.

cartilaginea, Eckl. \& Zeyh. Enum. 74=P. cartilagineum.

coronopifolia, Sweet, Hort. Brit. ed. I. $75=$ P. coronopifolium.

elata, Eckl. \& Zeyh. Enum. $74=$ P. elatum. elegans, Colv. ex Sweet, Geran. t. $222=\mathrm{P}$. elegans.

eriostemon, Eckl. \& Zeyh. Enum, $73=$ P. ovale.

holosericea, Sweet, Geran. t. $75=\mathrm{P}$. ovale.

laciniata, Sweet, 1. c. t. $[401]=$ P. laciniatum

Oenotherae, Sweet, Hort. Brit. ed. I. $75=$ P. Oenotherae.

staticephylla, Eckl. \& Zeyb. Enum. $74=$ P. staticaefolium.

tricolor, Eckl. \& Zeyh. 1. c.=P. violaceum. variegata, Sweet, Geran. t. $266=\mathrm{P}$. marginatum verbasciflora, Sweet, 1. c. ii. t. $157=\mathrm{P}$. ovale veronicaefolia, Eckl. \& Zeyh. Enum. $73=$ P. veronicaefolium.

CAMPYLOBOTRYS, Lem. in Fl. des Serres, Sér. I. iii. (1847) sub t. $260=$ Hoffmannia, Sw. (Rubiac.) argyroneura, Linden, in Belg. Hortic. viii. (1858) 166. -Mexic.

discolor, Hook. Bot. Mag. t. $4530=$ seq.

discolor, Lem. in Fl. des Serres, Sér. I. iii. (1847) sub t. $260=\mathrm{H}$. discolor.

Ghiesbreghtii, Lem. Illustr. Hortic. viii. (1861) t. 279 $=\mathrm{H}$. Ghiesbreghtii.

pyrophylla, Linden, Cat. n. 16 (1861) 2.-Mexic. regalis, Linden, 1. c. n. $15(1860)=\mathrm{H}$. regalis.

CAMPYLOCARYUM, DC. ex A. DC. in Prod. x. 97 in syn. $(1846)=$ Alkanna, Tausch (Boragin. smyrnaeum, Boiss. ex A. DC. Prod. x. $98=$ A. Pinardi. syriacum, Boiss. Fl. Orient. iv. $226=\mathrm{A}$. syriaca. syriacum, Boiss. \& Hohen. ex A. DC. Prod. x. $101=$ A. strigosa.

verrucosum, Boiss, ex A. DC. 1. c. $102=$ A. incana。

CAMPYLOCENTRON, Benth. in Journ. Linn. Soc xviii. (1881) $33 \%$. ORCHIDEAE, Benth. \& Hook. f iii. 585 .

TODAROA, A. Rich, in Ann. Sc. Nat. Sér. III. iii (1845) 28

Schiedei, Benth. ex Hemsl. Biol. Centr. Am. Bot. iii 292.-Mexic.

CAMPYlocera, Nutt. in Trans. Am. Phil. Soc. Ser. II. viii. (1843) $257=$ Specularia, Heist. (Campanul.).

leptocarpa, Nutt. 1. c. $=$ S. leptocarpa.

CAMPYLOCHINIUM, End1. Gen. $369(1838)=$ CAM PULOCHINIUM, DC. = Eupatorium, Tourn (Compos.).

CAMPYLONEMA, Poir. Illustr. 598 (1823); Schult. f. Syst. vii. $96,1507(1830)=$ Campynema, Labill. (Amaryllid.)

lineare, Schult, f, 1. c. = Campynema lincare.

CAMPYLOP'TERA, Boiss. in Ano. Sc. Nat. Sér. II. xvii. (1841) $194=$ Aethionema, R. Br. (Crucif.)

heterocarpa, Baill. Hist. 11. iii. $291=$ Ae. campylo

pterum.
syriaca, Boiss, in Ann. Sc. Nat. Sér. II. xvii. (1S11) $194=$ Ae. campylopterum.
CAMPYLOPUS, Spach, in Ann. Sc. Nat. Sér. II. v. (1836 $360=$ Hyperieum, Tourn.

cerastioides, Spach, Hist. Vég. Phan. v。 $412=\mathbf{H}$ rhodopeum.

CAMPYLOSTPHON, Benth, in Hook. Ic. Pl. t 1384 (1882). BURMANNIACEAE, Benth. \& Hook. f. iii. 458 .

purpurascens, Benth. l. c.-Am. austr.

CAMPYLOSIPHON, St. Lag. in Ann. Soc. Bot. Lyon, vii. (1880) $135=$ Siphocampylus, Pohl (Campanul.)

lycioideus, St. Lag. 1. c. $=\mathrm{S}$. lycioides.

CAMPYLOSPORUS, Spach, in Ann. Sc. Nat. Sér. II. v (1836) $363=$ Hypericum, Toum

angustifolius, Spach, Hist. Vég. Phan。 v。 $425=\mathrm{H}$ lanceolatum.

madagascariensis, Spach, 1. c. $426=\mathrm{H}$. madagas cariense.

reticulatus, Spach, 1. c. $424=\mathrm{H}$. lanceolatum

CAMPYLOSTACHYS, Kanth, in Abh. Akad. Berl. (183I) 206. VERBENACEAE, Benth. \& Hook. f. ii. 1137

CAMpilostachys, A. Juss, in Orb, Dict. xii. 38 (1849).

abbreviata, E. Mey. Comm. Pl. Afr. Austr. i. 279.Afr. austr.

cernua, Kunth, in Abh. Akad. Berl. (1831) 201.Afr, austr.

cernua, Zeyh. ex DC. Prod. xii. $607=$ Stilbe pinastra. phylicoides, Sond in Linnaea, xix. (1847) 202 = Stilbe phylicoides.

CAMPYLOSTACHYS, E. Mey. in Drège, Zwei PA. Docum. $83(1843)=$ Fimbristylis, Vahl (Cyperac.) abbreviata, E. Mey. 1, $c_{0}=\mathrm{F}$. ferruginea.

CAMPYLOSTEMON, E. Mey。 in Drège, Zwei Pfl.Docum. 170 (1843), nomen = Justicia, Linn. (Acanthac.). campanulatus, E. Mey. 1. c. (=Leptostachya Cam pylostemon).-Afr. austr.

paniculatus, Nees, in DC. Prod. ix. $378=$ praec.

CAMPYLOSTEMON, Welw. in Benth. \& Hook. If Gen. i. 998 (1862). CELASTRINEAE, Benth. \& Hook. f. 1. c.

angolense, Welw. ex Oliver, in Fourn. Linn. Soc. $x$ (1869) 44.-Afr. trop.

CAMPylothecA, Cass. in Dict. Sc. Nat. li. 470 $(1827)=$ Coreopsis, Linn. (Compos.)

angustifolia, Walp. Rep. ii. $618=$ Bidens angustifolia australis, Less. in Linnaea, vi. (1831) $509=$ Cor. micrantha.

gracilis, Walp. Rep. ii. $618=$ Bidens gracilis.

grandiftora, DC. Prod. v. 598. - Ins Sandvic.

micrantha, Cass. in Dict. Sc. Nat. lix. $321=$ Cor. micrantha

mutica, Walp. Rep. ii. $618=$ Bidens mutica.

CAMPYLOTROPIS, Bunge, Pl. Mongholico-Chin. $(1835)=$ Lespedeza, Michx. (Legumin.) chinensis, Bunge, 1. c. 7 = L. macrocarpa. cytisoides, Benth. in Pl. Jungh. i. 230.-Java. macrostyla, Lindl. ex Miq. Fl. Ind. Bat. i. $290=\mathrm{L}$ eriocarpa.

virgata, Miq. 1. c. $230=$ L. virgata.

CAMPYLUS, Lour. Fl. Cochinch. 113 (1790 Genus dub.

sinensis, Lour. l. c.-China.

CAMPYNEMA, Labill. Nov. Holl. Pl. i. 98. ᄂ. 12 (1804), AMARYLLIDEAE, Benth. \& Hook. f. Gen iii. 716 .

CuMprlovey, Poir Illustr, 595 (1823: ; Sebull.

f. Syst. vii. 96,1507 , 1630 ).

lincare, Labill. l. c,-Ins. Tasman.

pygmaeum, $F$. Musll. ex Benth. Fl. Austral. vi 115 . Ins. Tasman. ; Austral.

CAMUNIUM, Adans. Fam. ii. $100(1763)$-Aglaia Lour. Mcliac). bengalense, Buch.Ham. ex Wall. Cat. D. 12:9=A. exlulis.

chinense, Roxb. Hort. Beng. 18; Fl. Ind. i. 6\$6 - A olurala. 
CAMUTIA, Bonat. ex Steud. Nom. ed. II. i. 273 (1840) = Melampodium, Linn. (Compos.).

perfoliata, Bonat. ex Steud. 1. c. = M. perfoliatum.

CANABIS, Roth, Tent. Fl. Germ. i. 422 (1788), sphalm. =Cannabis, Tourn. (Urtic.).

CANAHIA, Steud. Nom. ed. I. 146.(1821)=Kanahia R. Br. (Asclepiad.)

laniflora, Steud. 1. $\mathrm{c}_{*}=\mathrm{K}$. laniflora.

CANALA, Pohl, Pl. Bras. Ic. ii. 62. t. 142 (1831)= Spigelia, Linn. (Loganiac.). heliotropioides, Pohl, 1. c. 63 . t. $142=\mathrm{S}$. Olfersiana. macrophylla, Pohl, 1. c. $64=$ S. macrophylla. rubiaefolia, Pohl, 1. c. $65=$ S. Schlechtendaliana.

CANAlia, F. W. Schmidt, Neue u. Selt. Pfl. 30 $(1793)=$ Gnidia, Linn. (Thymel.)

daphnoides, F. W. Schmide, l, c. $=\mathrm{G}$. pinifolia.

CANANGA, Aubl. P1. Gui. i. 607. t. 244 (1775)= Guatteria, Ruiz \& Pav. (1794) (Anonac.) Candolleana, Warm. in Kjoeb. Vidensk. Meddel. (1873) $145=\mathrm{G}$. Candolleana.

Klotzschiana, Warm. 1. c. = G. Klotzschiana

lancea, Poit. ex DC. Syst. i. 506=G. virgata.

Ouregon, Aubl. Pl. Gui: i. $608=\mathrm{G}$. Ouregon.

pseudolancea, Poit. ex DC. Syst. i. $507=$ G. 1aurifolia.

Schomburgkiana, Baill. Hist. P1. i. $204=\mathrm{G}$. Schomburgkiana.

Sellowiana, Warm. in Kjoeb. Vidensk. Meddel. (1873) $144=\mathrm{G}$. Sellowiana.

villosissima, Warm, 1. $\mathrm{c}_{*}=\mathrm{G}$. villosissima

CANANGA, Rumph. ex Hook. f. \& Thoms. Fl, Ind. i 129 (1855). ANONACEAE, Benth. \& Hook. f. i. 24. monosperma, Hook. f. E Thoms. in Fl. Brit. Ind. i. 57.-Malacca.

odorata, Hook. f. Eo Thoms. Fl. Ind. i. 130,-Burma; Malaya.

virgata, Hook. f. E Thoms. in Fl. Brit. Ind. i. 57.Malaya.

CANARIA, Linn. Mant. ii. $148(1767)=$ Canarina, Linn. (Campanul.)

campanulata, Linn. 1. $c_{\mathrm{s}}=$ Canarina campanulata.

CANARINA, Linn. Mant. 588 (1767). CAMPANULACEAE, Benth. \& Hook f. ii. 558. Canaria, Linn. Mant. ii. 148 (1767). Pernetya, Scop. Introd. 150 (1777). Campanula, Lam. Encyc. i. $598=$ seq. campanulata, Linn. Mant. ii. 225.-Ins. Canar. laevigata, G. Don, ex Loud. Hort. Brit. $139=$ campanulata.

moluceana, Roxb. Hort. Beng. 87, nomen.-Ins. Molucc.

Zanguebar, Lour. Fl. Cochinch, 195.-Afr. trop.

CANARION, St. Lag. in Ann. Soc. Bot. Lyon, vii. 121 $(1880)=$ Canarium, Rumph. (Burserac.). pimelum, St. Lag. 1. $\mathrm{c}_{\mathrm{r}}=$ Canarium Pimela.

CANARIOPSIS, Miq. F1. Ind. Bat. i. II. 651 (1859)= Canarium, Rumph. (Burserac.).

altissima, Miq. I. c. = Canarium altissimum. angustifolia, Miq. 1. c. $653=$ Canarium angustifolium. aspera, Miq. 1. c. $653=$ Canarium asperum. decumana, Miq. 1. c.=Canarium decumanum. denticulata, Miq. 1. c. $654=$ Canarium denticulatum glabra, Miq. 1. c. $652=$ Canarium balsamiferum. hirsuta, Miq. 1, c. $653=$ Canarium hirsutum. hispida, Miq. 1. c. = Canarium hispidum. paucijuga, Miq. ]. c.-Ins. Molucc.

villosa, Miq. 1. c. $652=$ Canarium villosum.

CANARIUIM, [Rumph.] Linn. Herb. Amboin. 9 (1754) (Amoen. Acad. iv. 121); Mant. 127 (1767). 'BUR SERACEAE, Benth. \& Hook, f, i. 324.

Canariopsis, Miq. Fl. Ind. Bat. i. II. 651 (1859).

Cenarium, Linn. Amoen. Acad. iv. 121, in nota (1759).

Colophonia, Comm. ex Kunth, in Ann. 'Sc. Nat. Sér. I. ii. (1824) 352 .

Mehenbethene, Besl. ex Gaertn. Fruct. ii. 98

(1788); Walp. Ann. ii, 291 (1851).

\section{CANARIUM :-}

Pachylobus, G. Don, Gen. Syst. ii. 89 (1832).

Pimela, Lour. Fl. Cochinch, 407 (1790).

Scutinanthe, Thwaites, in Hook. Kew Journ. viii. (1856) 267. t. 8 .

acutum, Engl. in DC. Monog. Phan. iv. 113.Borneo

album, Blanco, F1. Filip. ed. I. 793=1nzonicum

album, Raeusch. Nom. ed. III. 287 ; DC. Prod.ii. 80. -Cochinch.

altissimum, Blume, Bijdr. 1163.-Java.

altissimum, Korth. ex Blume, Mus. Bot. Lugd. Bat. i $211=$ Santiria laevigata.

angustifolium, Miq. Ann. Mus. Bot. Lugd. Bat. it

117.-N. Guin.

sperum, Benth. in Hook. Lond. Fourn. Bot. ii. (1843)

215 -N. Guin.

australianum, F. Muell. Fragm. iii. 15.-Austral.

Balansae, Engl. in DC. Monog. Phan. iv. 117.-N Caled.

balsamiferum, Moon, Cat. $68=$ zeylanicum

balsamiferum, Willd. Sp. Pl. iv. 760.-Ins. Molucc.

Beccarii, Engl. in DC. Monog. Phan. iv, 107.Borneo.

bengalense, Roxb. Hort. Beng. 49 ; Fl. Ind. iii. 136.Ind. or.

Bennettii, Engl. in DC. Monog. Phan. iv. 119.-

Burma : Malacca.

Boivini, Engl. l. c. 110.-Madag.

brunneum, Bedd. Fl. Sylv. t. 127.-Zeylan.

coccineo-bracteatum, Kurz, in Fourn. As. Soc. Beng

xli. (1872) II. 296.-Ins. Andaman.

Colophania, Baker, F1. Maurit. $44=$ mauritianum.

commune, Blanco, FI. Filip. ed. I. $791=$ Cumingii

commune, Linn. Mant. i. 127.-Ins. Molucc.

commune, Wight \& Arn. Prod. $175=$ zeylanicum.

Cumingii, Engl. in DC. Monog. Phan. iv. 132.-Ins. Philipp.

decumanum, Gaertn. Fruct. ii. 99. t. 102.-Ins. Molucc. denticulatum, Blume, Bijdr, 1162.-Java.

dichotomum, Miq. Fl. Ind. Bat. i. II. 648. -Sumatra.

divergens, Engl. in DC. Monog. Phan. iv. 143.Borneo.

edule, Hook. f. in Hook. Niger Fl. 285.-Afr. trop.

euphyllum Kurz, in fourn. As. Soc. Beng. xli. (1872) II. 295---Ins. Andaman.

eupteron, Miq. Fl. Ind. Bat.i. II. 648.-Sumatra.

fissistipulum, Miq. l. c. Suppl. 525.-Sumatra.

fragile, Engl. in DC. Monog. Phan. iv. 138.-Borneo.

fuscum, Engl. l. c. 116.-Java.

giganteum, Engl.l.c. 106.-Borneo.

gilvescens, Miq. Fl. Ind. Bat. i. II. $650=$ Santiria rostrata.

glaucum, Blume, Mus. Bot. Lugd. Bat. i. 219.-

Sumatra.

gracile, Engt. in DC. Monog. Phan. iv. 140.-Ins.

Philipp.

grandiforum, A. W. Benn. in Hook. f. Fl. Brit. Ind. i. 533.-Malacca.

Harami, Boj. Hort. Maurit. 83.-Madag.

Harveyi, Seem. Fl. Vit. 35.--Ins. Tonga.

hirsutum, Willd. Sp. Pl. iv. 760.-Ins. Molucc.

hirtellum, A. W. Benn. in Hook. f. Fl. Brit. Ind. i. 534.-Penang.

hispidum, Blume, Bijdr. 1163.-Java

Horami, Engl. in DC. Monog. Phan. iv. $150=$ Harami.

incurvatum, Engl. l. c. 138.-Borneo.

Kadondon, A. W. Benn. in Hook. f. Fl. Brit..Ind. i. 535.-Malacca.

Kipella, Miq. Fl. Ind. Bat. i. II. 646.-Java.

Kitenga, Miq. l. c. 647.-Java.

Korthalsii, Miq. 1. c. 645 =Santiria tomentosa

laevigatum, Miø. 1. c. $648=$ Santiria laevigata.

laxiflorum, Decne. in Nouv. Ann. Mus. Par. iii. (1834)

$477=$ mictocarpum

laxiforum, Zipp. ex Blume, Mus. Bot. Lugd. Bat. i. 221.-Ins. Moluce.

laxum, A.W. Benn. in Hook. f. Fl. Brit. Ind. i. 535 - Malacca.

legitimum, Miq. Fl. Ind. Bat. i. II. 647.-Ins. Amboina.

littorale, Blume, Bijdr. 1164.--Java.

longiflorum, Zipp. ex Miq. Fl. Ind. Bat. i. II. 647.Ins. Molucc.

Iuxurians, Engl. in. DC. Monog. Phan. iv. 146.--Ins.

Philipp.

luzonicum, Miq. Fl. Ind. Bat. i. II. 651.-Ins. Philipp.

\section{CANARIUM:-}

macrophyllum, Oliver, Fl. Trop. Afr.'i. 327.-Afr. trop. madagascariense, Engl. in DC. Monog. Phan. iv. 111. - Madag.

Mahassan, Miq. Fl. Ind. Bat. Suppl.526.-Sumatra. mauritianum, Blume, Mus. Bot. Lugd. Bat. i. 217.Ins. Maurit.

Mehenbethene, Gaertn. Fruct. ii. 98. t. 102,-Ins. Molucc.

microcarpum, Willd. Sp. Pl. iv. 760.-Ins. Molucc

minutiflorum, Engl. in DC. Monog. Phan. iv. 123.Ins. Philipp.

molle, Engl. l. c. 109.-Ins. Borbon.

moluccanum, Blume, Mus. Bot. Lugd. Bat. i. $216=\mathrm{C}$.

Mehenbethene.

montanum, Korth. ex Blume, 1. c. 212 = Santiria montana.

Motleyanum, Engl. in DC. Monog. Phan. iv. 133.Borneo.

multiflorum, Engl. l. c. 128.-Madag.

multipinnatum, Llanos, Fragm. 107.-Ins. Philipp.

nigrum, Roxb. Hort. Beng. 49 ; Fl. Ind. iii. 138.-Ins,

Amboina.

nitidum, A.W. Benn. in Hook. f. Fl. Brit. Ind. i. 533. - Malaya.

oblongifolium, Miq. Fl. Ind. Bat. i. II. $645=$ Santiria oblongifolia.

odontophyllum, Miq. l. c. Suppl. 525.-Sumatra.

oleiferum, Baill. Adansonia, x. (1871-72) 341,-N. Caled.

ovatum, Engl. in DC. Monog. Phan. iv. 110.-Ins. Philipp.

paniculatum, Benth. ex Engl. 1. c. $124=$ mauritianum.

parvifolium, A. W. Benn. in Hook. f. Fl. Brit. Ind. i. 536.-Malacca

patentinervium, Miq. Fl. Ind. Bat. Suppl. 526.Sumatra.

pilosum, A. W. Benn. in Hook. f. Fl. Brit. Ind. i. 533. -Malacca.

Pimela, Blanco, Fl. Filip. ed. II. $545=$ villosum.

Pimela, Blume, Bijdr. $1162=$ C. Kipella.

Pimela, Kon. in Kon. EN Sims, Ann. Bot. i. (1805) 361.-China.

Pimela, Zoll. ex Engl. in DC. Monog. Phan. iv. $127=$ Zollingeri.

pruinosum, Engl. l. c. 106.-Borneo

purpurascens, A. W. Benn. in Hook. f. Fl. Brit. Ind. i, 532.-Malacca.

Riedelianum, Engt. in DC. Monog. Phan. iv. 130.Ins. Celebes.

rigidum, Zipp. ex Miq. Fl. Ind. Bat. i. II. 648,-N. Guinea

rostratum, Zipp. ex Blume, Mus. Bot. Lugd. Bat. i. 221.--Ins. Molucc.

rostriferum, Miq. Fl. Ind. Bat. Suppl. $526-$ Sumatra.

rubiginosum, A. W. Benn, in Hook̈. f. Fl. Brit. Ind. i. 535.-Malacca.

mubiginosum, Miq. F1. Ind. Bat. i. II. 651=Santiria rubiginosa.

rufescens, Miq. 1. c. $650=$ Santiria rufescens.

rufum, A.W. Benn, in Hook. f. Fl. Brit. Ind. i. 533. -Malacca.

mugosum, Miq. F1. Ind. Bat. i. Ir. $649=$ Santiria rugosa.

Sajiga, Buch,-Ham. ex Wight \& Arn. Prod. $175=$ Turpinia pomifera.

samoënse, Engl. in DC. Monog. Phan. iv. 134.-Ins. Samøa.

Schweinfurtii, Engl. l. c. 145.-Afr, trop.

secundum, A. W. Benn, in Hook, f. Fl, Brit. Ind i. 532.-Malaya.

serricuspe, Miq. Fl. Ind. Bat. i. I1. 649.-Sumatra.

serrulatum, Miq.l.c.646.-Java.

simplicifolium, Engl. in DC. Monog. Phan. iv. 146.Ins, Amboina.

spectabile, Miq. Ann. Mus. Bot. Lugd. Bat. iv. 116.Sumatra.

strictum, Roxb. Hort. Beng. 49 ; Fl. Ind. iii. 138.-Ind.

subrepandum, Miq. Fl. Ind. Bat. Suppl. 525.Sumatra.

subtruncatum, Engl. in DC. Monog. Phan. iv. 109.Java.

sylvestre, Gaertn. Fruct. ii. 99. t. 102.-Ins. Amboina. tomentosum, Blume, Mus. Bot. Lugd. Bat. i. 219.Malaya.

triandrum, Engl. in DC. Monog. Phan. iv. 145.Malaya. 


\section{CANARIUM:}

trifoliolatum, Engl. in DC. Monog. Phan. iv. 124.-N Caled.

villosum, Benth. E Hook. f. ex Naves, in Blanco, Fl. Philipp. ed. III. App. 40.--Ins. Philipp.

virgatum, Miq. Fl. Ind. Bat. i. II. $650=$ Santiria virgata.

vitiense, A. Gray, Bot. U. St. Expl. Exped. i. 373.Ins. Fiji.

Vrieseanum, Engl. in DC. Monog. Phan. iv. 142.-Ins. Celebes.

sephyrinum, March. in Baill. Adansonia, viii. (1867-68) $58=$ commune

zeylanicum, Blume, Mus. Bot. Lugd. Bat. i. 218.Zeylan.

Zollingeri, Engl. in DC. Monog. Phan. iv. 127.Java.

CANAVALI, Adans. Fam. ii. 325 (1763); Thou. in Desv. Journ. Bot. i. (1813) 77 =Canavalia, DC. (Legumin.)

CANA VALIA, DC. Mém, Lég。ix. 375; Prod, ii 403 (1825). LEGUMINOSAE, Benth. \& Hook. f. i. 537.

Canavali, Adans. Fam. ii. 325 (1763); Thou. in Desv. Journ. Bot. i. (1813) 77.

Crementea, Cav, in Anal. Cienc. Nat. vii. (1804) 63. t. 47.

Malocchia, Savi, in Nuov. Giom. Pisa, viii. (1824) 113.

WENDERothiA, Schlecht. in Linnaea, xii. (1838) 330 .

altissima, Macfad. Fl. Famaic. i. 292.-Jamaica.

Baueriana, Endl. Prod. F1. Norf. $91=$ obtusifolia.

bonariensis, Lindl. Bot. Reg. t. 1199.-Bras.

Bouquete, Montr. in Mém. Acad. Lyon, x. (1860) 197. - N. Caled.

brasiliensis, Mart. ex Benth. in Ann. Wien. Mus. ii. (1838) $135=$ ensiformis.

cathartica, Thou. in Desv. Fourn. Bot. i. (1813) 81.Madag.

cryptodon, Meissn. in Hook. Lond. Journ. Bot. ii. 1843) $96=$ bonariensis.

cubensis, Griseb. in Mem. Am. Acad. N. S. viii. (1861) 178.-Cuba.

dolichoides, Kurz, in Journ. As. Soc. Beng. xliii. (1874) Ir, $\mathbf{1 8 5}=$ Vigna dolichoides.

emarginata, G. Don, Gen. Syst. ii, $362=$ obtusifolia

ensiformis, DC. Prod. ii. 404.-Cosmop. trop.

Finlaysoniana, R. Grah. in Wall. Cat. n. 5535.Siam.

galeata, Gaudich. Freyc. Voy. Bot.486.-Ins. Sandvic.

Gaudichaudii, Endl. in Ann. Wien. Mus. i. (1836) 186 = galeata.

gladiata, DC. Prod. ii, 404=ensiformis.

grandiflora, Benth. in Ann. Wien. Mus. ii. (1838) 135 - Bras

grandis, Kurz, in Journ. As. Soc. Beng. xliii. (1874) Ir. $185=$ Phaseolus velutinus.

incurva, DC. Prod, ii. $404=$ ensiformis

incurva, Thou. in Desv. Journ. Bot. i. (1813) $80=$ ensiformis.

lenta, Benth. in Ann. Wien. Mus. ii. (1838) 135.Bras.

lineata, DC. Prod, ii. $404=$ obtusifolia.

Loureirii, G. Don, Gen. Syst. ii. $363=$ ensiformis.

lucens, Kurz, in Journ. As. Soc. Beng. xliii. (1874) II. $185=$ Vigna lucens.

machaeroides, Steud. Nom. ed. II. i. $273=$ cathartica. maritima, Thou. in Desv. Journ. Bot. i. (1813) $80=$ obtusifolia.

maxima, Thou, $\%$, - -Ind or.

miniata, DC. Prod, ii. $404=$ obtusifolia.

mollis, Wall. Cat. n. $5583=$ ensiformis.

moneta, Welw. Apont. 588. n. 62.-Afr. trop.

monodon, E. Mey. Comm. Pl. Afr. Austr. $149=$ bonariensis.

multiflora, Hook, \&e Arn. Bot. Beech. Voy, $416=$ villosa.

obcordata, Voigt, Hort. Suburb. Calc. $285=$ obtusifolia, obtasifolia, DC. Prod. ii. 404-Cosmop. trop.

paranensis, Benth. in And. Wien. Mus. ii. (1838) 135 = parviflora.

paranensis, Hook. \& Am. in Hook. Bot. Misc. iii (1838) $200=$ bonariensis.

parviflora, Benth. in Mart. Fl. Bras. xv, 1. 177.-Am. trop.

\section{CANAVALIA :-}

picta, Mart. ex Benth. in Ann. Wien. Mus. ii. (1838) 135.-Bras.

polystachya, Schweinf. Rel. Kotsch.25, t. $20=$ ensiformis.

pubescens, Hook, \& Arn. Bot. Beech. Voy, $81=$ galeata.

rosea, DC. Prod. ii. $404=$ obtusifolia

rostrata, Benth. in Ann. Wien. Mus. ii. (1838) $135=$ villosa.

rutilans, DC. Prod, ii. $404=$ obtusifolia.

sericea, A. Gray, Bot. U. St. Expl. Exped. i. 440.-Ins. Fiji.

Stocksi, Dalz. \& Gibs. Bomb. F1. $69=$ ensiformis turgida, R. Grah, in Wall. Cat, n. 5534=ensiformis villosa, Benth. in Ann. Wien. Mus. ii. (1838) 135.Mexic

virosa, Naves, ex Villar, in Blanco, Fl. Philipp. ed III. Nov. App. 64.--Ins. Philipp.

virosa, Wight \& Am. Prod. $253=$ ensiformis.

CANBYA, Parry, ex A. Gray, in Proc. Am. Acad. xii. (1877) 51. PAPAVERACEAE.

candida, Parry, ex A. Gray, L. c.-Calif.

CANCELLARIA, Sch. Bip. ex Oliver, Fl. Trop. Afr. iii. $321(1877)=$ Adelostigma, Steetz (Compos.) senegalensis, Sch. Bip. ex Oliver, $1_{0} \mathrm{c}_{0}=\mathrm{A}$. sene galensis.

CANCRINIA, Kar. \& Kir. in Bull. Soc. Nat. Mosc xv. (1842) 124. COMPOSTTAE, Benth. \& Hook. f. ii. 424 .

chrysocephala, Kar. Eo Kir. l. c. 125.As. centr.

CANDARUM, Schott, Melet, i. 17 (1832)=Amorpho phallus, Blume (Aroid.

Hookeri, Schott, 1. c。=A. campanulatus.

Roxburghii, Schott, 1. c.=A. campanulatus

Rumphii, Schott, 1. $\mathrm{c}=$ A. campanulatus.

CANDELABRIA, Hochst. in Flora, xxvi. (1843) $79=$ Bridelia, Willd. (Euphorbiac.)

micrantha, Hochst. 1. c. $=$ B. micrantha.

polystachya, Planch. in Ann. Sc. Nat. Sér. IV. ii

1854) $264=$ Cleistanthus polystachyus.

CANDIDEA, Tenore, in Atti Acc. Nap. iv. (1839) 104 t. 1, 2=Vernonia, Schreb. (Compos.). senegalensis, Tenore, $1, c_{\circ}=\mathrm{V}$. Tenoreana.

CANDJERA, Decne, in Ann. Sc. Nat. Sér, II, xix. (1843) 37, sphalm. $=$ Cansjera, Juss. (Olacin.).

CANDOLLEA, Baumg. Cat. Hort. Bollw. (1810) Menziesia, Sm. (Ericac.)

azaleoides, Baumg. 1. c.= M. globularis,

CANDOLleA, Labill. in Ann. Mas. Par, vi. (1805 453. t. $63=$ Stylidium, Sw.

adnata, F. Muell. Census, $86=\mathrm{S}$. adnata.

adpressa, F. Muell. 1. c. =S. adpressa.

alsinoides, F. Muell. 1. c, $=\mathrm{S}$. alsinoides

amoena, F. Muell. 1. c. $=\mathrm{S}$. amoena.

Armeria, Labill. in Ann. Mus. Par, vi. (1805) $455=\mathrm{S}$. graminifolium.

articulata, F. Muell. Census, $86=\mathrm{S}$. articulata.

assimilis, F. Muell. 1. c. $=\mathrm{S}$. assimilis.

Barleei, F. Muell, 1. c. =S. Barleci.

brachyphylla, F. Muell. 1. c. =S. brachyphylla.

breviscapa, F. Muell. 1. c. $=$ S. breviscapa.

Brunoniana, F. Muell. $\mathrm{l}$. $\mathrm{c} .=\mathrm{S}$. Brononiana.

bulbifera, F. Muell. 1. c, =S. balbifera.

caespitosa, F. Muell. 1. c. $=\mathrm{S}$. caespitosa

calcarata, F. Muell. 1. c. $=$ S. calcarata

canaliculata, Steud. Nom. ed. II. i. $273=$ S. cana. liculata.

capillaris, F. Muell. Census, $86=\mathrm{S}$. capillaris.

carnosa, F. Muell. l. c. $85=\mathrm{S}$. carnosa

ciliata, F. Muell. 1. c. $86=\mathrm{S}$. ciliata.

corymbosa, F. Muell. 1. $\mathrm{c}_{\mathrm{c}}=\mathrm{S}$. corymbosa

crassifolia, F. Muell. 1. c. $=\mathrm{S}$. crassifolia.

crossocephala, F. Muell. I. c. $85=\mathrm{S}$. crossocephala.

debilis, F. Muell. l. c. $86=\mathrm{S}$. debilis

despecta, F. Muell. 1. c. $=$ S. despecta.

dichotoma, F. Mucll, $1 . \mathrm{c}_{\mathrm{o}}=\mathrm{S}$. dichotoms.

diffusa, F. Muell. 1. c, $=\mathrm{S}$. diffusa

disperma, F. Muell. $\mathrm{I}, \mathrm{c}_{\mathrm{a}}=\mathrm{S}$. disperma.

\section{CANDOLLEA}

diuroides, F. Muell. Census, 86 = Stylidium dinroides diversifolia, F. Muell. 1. c.=S. diversifolia.

eglandulosa, F. Mue11. 1. $\mathrm{c}_{\mathrm{v}}=\mathrm{S}$. eglandulosa.

elongata, F. Muell. 1. c. $85=$ S. elongata.

emarginata, F. Muell. 1. c. $86=\mathrm{S}$. emarginata.

eriorrhiza, F. Muell. 1. c. $=\mathrm{S}$. eriorthiza.

falcata, F. Muell. 1. c. = S. falcata.

fasciculata, F. Muell. 1. c. = S. fasciculata

filifera, F. Muell, 1. c. = S. filifera.

fissiloba, F. Muell, 1. c. =S. fissiloba

Floodii, F. Muell. 1. ce = S. Floodii.

floribunda, F. Muell. 1. c. = S. floribunda.

glandulosa, F. Muell. 1. c.=S. glandulosa.

glauca, Labill. in Ann. Mus. Par. vi. (1605) $454=$

glaucum.

graminifolia, F. MuelL Census, $85=$ S. gramini-

folia.

guttata, F. Muell. 1. c. $=$ S. guttata.

hirsuta, F. Muell. 1. $\mathrm{c}_{0}=\mathrm{S}$. hirsuta.

imbricata, F. Muell. 1. c. $86=\mathrm{S}$. imbricata.

juncea, F. Muell. 1. c. $85=\mathrm{S}$. juncea.

laricifolia, F. Muell. L c. $86=$ S. laricifolia.

lepida, F. Muell. 1. $\mathrm{c}_{\mathrm{v}}=\mathrm{S}$. lepida.

leptophylla, F. Muell. 1. c. =S. leptophylla.

leptorrhiza, F. Muell. 1. c.=S. leptorrbiza.

limbata, F. Muell. 1. co = S. limbata.

linearis, F. Muell 1. c. $85=\mathrm{S}$. linearis.

lineata, F, Muell. 1. c, $86=$ S. lineata.

lobuliflora, F. Muell. 1. c, $=$ S. lobuliflora

longituba, F. Muell. $1 . c_{v}=S$. longituba.

lutea, $\mathrm{F}$. Muell. I. $\mathrm{c}_{\mathrm{n}}=\mathrm{S}$. Intea.

musicola, F. Muell. 1. $\mathrm{c},=\mathrm{S}$. musicola

pachyrrhiza, F. Muell. 1. $\mathrm{c}_{\mathrm{s}}=\mathrm{S}$. pachyrrhiza.

pedunculata, F. Muell. 1. c. = S. pedunculata.

perpusilla, F. Muell. 1. c. $=S$. perpusilla.

petiolaris, F. Muell. 1, c $=\mathrm{S}$, petiolaris.

pilosa, Labill. in Ann. Mus. Par. vi (1805) $453=\mathrm{S}$ pilosum.

Preissii, F. Muell. Census, $86=$ S. Preissii.

pubigera, F. Muell. 1. c. =S. pubigera.

pulchella, F. Muell 1, $c_{0}=$ S. pulchella.

pychnostachya, $\mathrm{F}$, Muell. 1. $\mathrm{c}_{0}=\mathrm{S}$. pychnostachya.

pygmaea, F. Muell. 1. c. =S. pygmaea.

reduplicata, F. Muell. 1. c. $85=\mathrm{S}$. reduplicata.

repens, F. Muell. $1 . \mathrm{c}_{\mathrm{o}}=\mathrm{S}$. repens.

rhynchocarpa, F. Muell. 1. c. $86^{\circ}=$ S. rhynchocarpa.

rotundifolia, F. Muell. $1 . \mathrm{c}_{0}=\mathrm{S}$. rotundifolia.

rupestris, $\mathrm{F}$. Muell, $1 . \mathrm{c}_{0}=\mathrm{S}$, rupestris.

scabrida, F. Muell. $85=\mathrm{S}$. scabrida.

scandens, F. Muell. 1. c. $86=\mathrm{S}$. scandens.

schizantha, F. Muell. 1. c.=S. schizantha.

serrulata, Labill. in Ann. Mus. Par. vi. :1805) $454=$

S. graminifolium.

setacea, Labill. 1. c. $455=\mathrm{S}$. spinulosum?

sobolifera, F. Muell. Census, $86=\mathrm{S}$. sobolifera.

spathulata, F. Muell. 1. c. =S. spathulata.

spinulosa, F. Muell. 1. c. $85=\mathrm{S}$. spinulosa.

squamellosa, F. Muell. 1. c. $86=\mathrm{S}$. squamellosa.

streptocarpa, F. Mucll. 1. c. =S. streptocarp.

striata, $\mathrm{F}$. Muell. 1. $\mathrm{c}_{0}=\mathrm{S}$. striata

tenerrima, $\mathrm{F}$. Iuell, $\mathrm{l}, \mathrm{c}=\mathrm{S}$, tenerrima.

trichopoda, F. Muell. I. c. $=$ S. trichopoda.

uliginosa, F. Muell. 1. c. =S. uliginosa,

umbellata, Labill. in Ann. Mus. Par. vi. 1505: $450^{\circ}=$

S. graminifolium.

uniftora, F. Muell. Census, $86=\mathrm{S}$. uniflora.

utricularioides, F. Mucll, $\mathrm{l}_{\mathrm{c}} \mathrm{c}_{\mathrm{s}}=\mathrm{S}$. utricularioides.

verticillata, F. Muell. $1 . \mathrm{c}_{\mathrm{S}}=\mathrm{S}$. verticillata.

violacea, F. Muell. 1. $\mathrm{c}_{0}=\mathrm{S}$. violacen.

CANDOLLEA, Labill. Nov. Holl. Pl. ii. 39 1..1: (1806) DIILENIACEAE, Benth. S. Hook. f i. 1 t assimilis, Steud. in Lethm. P1. Preiss, i. $279=$ pedup. culata.

calycina, Steud. 1. c. $2 \% \downarrow=$ tetrandra.

cuneiformis, Labill. Noos. Holl. Pl. ii. \$4. 6. 170.Austral.

Cunminghems, Benth. in Maund, Bot. ii. t. \$5

Hibbertia Cunninghamii.

cygnorum, Stesad. in Lehm. Pl. Preisso i. 985.

Austral.

desmophylla, Bensh. Fl. Alustral. i. 13.-Austral. exasperata, Sicud. in Lehm. Pl. Preiss. I. 276.-

iustral.

fisciculata, R. Br. ex DC. Syst, i. 424. - A astsart

glaberrima, Sirand. in Lehm. Pl. Preiger. Lo dit

Austral. 


\section{CANDOLLEA :}

glomerosa, Benth. Fl. Austral. i. 43.-Austral.

helianthemoides, Turcz. in Bull. Soc. Nat. Mosc. xxii. (1849) II. 8.-Austral.

Huegelii, Benth. in Enum. Pl. Hueg. 4.-Austral.

kochioides, 'Turcz. in Bull. Soc. Nat. Mosc, xxii. (1849)

II. $7=$ fasciculata

latifolia, Steud. in Lehm. P1. Preiss. i. $273=$ tetrandra pachyrrhiza, Benth. Fl. Austral. i. 44.-Austral. parviflora, Steud. in Lehm. Pl. Preiss. i. $276=$ pedunculata.

pedunculata, $R$. Br. ex DC. Syst. i. 424.-Austral.

Preissiana, Steud. in Lehm. Pl. Preiss, i. 274.Austral.

racemosa, Endl. in Enum. Pl. Hueg. $5=$ pedunculata. rupestris, Steud. in Lehm. Pl. Preiss. i. $275=$ glaber rima.

striata, Steud. in Lehm. P1. Preiss. i. $274=$ Huegelii. subvaginata, Steud. 1. c. $275=$ glaberrima.

teretifolia, Turcz. in Bull. Soc. Nat. Mosc. xxii. (1849) II. 6.-Austral.

tetrandra, Lindl. Bot. Reg. (1842) Misc. 40.-Austral. tridentata, Turcz. in Bull. Soc. Nat. Mosc. xxv. (1852) II. $140=$ pedunculata.

uncinata, Benth. Fl. Austral. i. 46.-Austral

vaginata, Benth. l. c. 45.-Austral.

CANDOLLEA, Steud. Nom. ed. II. i. $273(1840)=$ DECANDOLIA, Bast. = Agrostis, Linn. (Gramin.)

CANELLA, P. Br. Hist. Jamaic. 275 t. 27. f. 3 (1756); Sw. in Trans. Linn. Soc. i. (1791) 96, t. 8. CANEL LACEAE, Benth. \& Hook. f. i. 121.

Winterania, Linn. Hort. Cliff. 488 (1737) ; et Syst. ed. X. (1759) 1045 (Wintirania)

alba, Murr. Syst. ed. XIV.443.-Ind. occ.

alba, Nees, P1. Officin. t. $418=$ Cinnamodendron corticosum

axillaris, Nees \& Mart. in Neuwied, Reise nach Brasil. ii. $336=$ Cinnamodendron axillare.

laurifolia, Lodd. Cat ex Sweet, Hort. Brit. $65=$ alba obtusifolia, Miers, in Ann. E Mag. Nat. Hist. Ser. III. i. (1858) 348.-Venezuela.

Winterana, Gaertn. Fruct. i. t. $77=$ alba.

CANEPHORA, Juss. Gen. 208 (1789). RU. $B I A C E A E$, Benth. \& Hook. f. ii. 74 .

axillaris, Willd. Sp. P1. i. $976=$ madagascariensis. capitata, Willd. 1. c. = Burchellia capensis.

madagascariensis, f. F. Gmel. Syst. 372.-Madag.

CANICIDIA, Vell. F1. Flum. 184 (1825); iv. t. 139 (1827) = Connarus, Linn

rostrata, Vell. 11. cc.= Connarus cymosa.

CANIDIA, Salisb. Gen. P1. Fragm. $92(1866)=$ Allium, Tourn. (Liliac.).

magica, Salisb. 1. c. = A. magicum .

CANIRAM, Thou, ex Steud. Nom. ed. II. i. 274 (1840) =Strychnos, Linn. (Loganiac. $)$.

CANISTRUM, E. Morr. Belg. Hortic. (1873) 257.t. 15 $=$ Aechmea, Ruiz \& Pav. (Bromeliac.) aurantiacum, E. Morr. 1. c. = A. aurantiaca. eburneum, E. Morr. 1. c. xxix. (1879) 168. t. 13, 14.Bras.

fuscum, E. Morr. 1. c. xxxiii. (1883) 195.-Bras. purpureum, E. Morr. 1. c.-Bras.

roseum, E Morr. 1. c, xxix, (1879) 301.-Bras.

viride, E. Morr. ex Ch. Morr. 1. c. xxiv. (1874) 376. $\mathrm{t}$. $16=$ A. viridis

CANKRIENIA, De Vriese, in Jaarb. Nederl. Maatsch. Tuinb. $(1850)=$ Primula, Tourn.

chrysantha, De Vriese, 1. c. $30=\mathrm{P}$. imperialis farinosa, Zoll. Syst. Verz. Ind. Archip. 59.-Java.

CANNA, Linn. Syst. ed. I (1735); Gen. ed. I. 1 (1737). SCITAMINEAE, Benth. \& Hook. f. iii.

ACHIRIdA, Horan. Prod. Scitam. 18. t. 2 (1862).

CANNACORUS, Tourn. ex Medic, in Act. Acad.

Theod. Palat. vi, Phys. (1790) 378.

Distemon, Bouché, in Linnaea, xviii. (1844) 494.

Eurystylus, Bouché, 1. c. (1844) 485.

\section{CANNA:}

Katubala, Adans. Fam. ii. 67 (1763).

Xyphostylis, Rafin. F1. Tellur. iv. 52 (1836).

Achiras, Gill. in Bot. Reg, t. 1358.-Chili

Altensteinii, Bouché, in Linnaea, xi. (1837) 326.Am, austr.

angustifolia, Linn. Sp. Pl. 1.-Bras.

angustifolia, Walt. F1. Carol. $59=$ flaccida.

aurantiaca, Rosc. Scit. t. $21=$ lutea.

aurantiaca $x$, Tineo, ex Tod. in Ann. Sc. Nat. Sér. IV xi. (1859) 377 .-Hab.?

aurea, Hort. ex Horan. Prod. Scitam. 18, nomen.Hab. ?

aureo-vittata, Lodd. Bot. Cab. t. $449=$ limbata.

barbadica, Hort. ex Bouché, in Linnaea, viii. (1833) $145=$ occidentalis.

bidentata, Bertol. in Mem. Acc. Sc. Bolog. x. (1859) 33.-Afr. trop.

bifida, Herb. ex Roem. \& Schult. Syst. i. Add. I. $69=$ speciosa.

brasiliensis, Hort. Vind. ex Bonché, in Linnaea, xii. (1838) $148=$ Jacquini.

brasiliensis, Rosc. ex Spreng. Syst. iv. Cur. Post. 5.Bras.

Buekii, Weinm. in Syll. Ratisb. i. (1824) 119 ; Flora, vii. (1824) $10=$ pedunculata.

caripensis, Hort. ex Horan. Prod. Scitam. 18, nomen. - Hab. ?

carnea, Rosc. Scit. t. 15.-Bras.

chinensis, Willd. in Ges. Naturf. Fr. Berl. Mag. ii. (1808) $170=$ orientalis

cinnabarina, Bouché, in Linnaea, xviii. (1844) 490.Mexic.

coccinea, Link, Enum. Hort. Berol. i. $1=$ patens.

coccinea, Mill. Gard. Dict. ed. VIII. n. 3.-Ind. or.

commutata, Bouché, in Linnaea, viii. (1833). 147= lutea.

compacta, Hort. ex Bouché, 1. c. $145=$ occidentalis

compacta, Rosc. Scit. t. 22.-Hab.?

concinna, Bouché, in Linnaea, xviii. (1844) 491.-Am trop.

crocea, Lag. ex Reichb. Hort. Bot. t. 148.-Hab. ?

crocea, Roem. \& Schult. Syst. i. $11=$ patens.

curviflora, Hort. ex Horan. Prod. Scitam. 18.-Am centr.

densifolia, Bouché, in Linnaea, xviii. (1844) 489. China.

denudata, Rosc. Scit.t. 23.-Bras.

discolor, Lindl. Bot. Reg. t. 1231.-Ins. Trinitat.

edulis, Ker-Gawl. in Bot. Reg. ix. t. $775-\mathrm{Am}$ trop.

Ehrenbergii, Bouché, in Linnaea, viii. (1833) 150.Ins. S. Thomas.

elegans, Rafin. Fl. Ludov, 143 = flaccida?

ellipticifolia, Stokes, Bot. Mat. Med. 1. 2=indica.

esculenta, Lodd. Cat. ex Loud. Hort. Brit. $1=$ edulis.

excelsa, Lodd. Bot. Cab. n. 743*. - Bras.

exigua, Bouché, in Linnaca, xviii. (1844) 490.Nepal.

eximia, Hort. ex Horan. Prod. Scitam. 18.-Bras.

Fintelmanni, Bouché, in Linnaea, xviii. (1844) 487.Hab. ?

flaccida, Rosc. in Trans. Linn. Soc. viii. (1807) 339.Am. bor

flava, Michx. ex Lam. in Journ. Nat. Hist. Par. i. (1792) $416=$ flaccida

flavescens, Link, Handb. i. 226.-Ind. or

floribunda, Bouche, in Linnaea, xviii (1844) 489 . $\mathrm{Hab}$ ?

formosa, Bouché, l. c. 491.-Bras.

fulgida, Bouché, l. c. 490.-Ins. S. Barthol

gemella, Nees \& Mart. in Nov. Act. Nat. Cur. xi.

(1823) $\mathbf{2 2}$ = gigantea.

gigantea, Desf. Tabl. Hort. Par. ed. I. 32.-Bras

glauca, Linn. Sp. Pl. 1.--Ind. occ.; Mexic.

glauca, Walt. Fl. Carol. $59=$ flaccida.

heliconiaefolia, Hort. Berol. ex Bouché, in Linnaea, viii. (1833) 164.-.Mexic

humilis, Bouché, l. c. 153.-China.

indica, Curt. Bot. Mag. t. $454=$ patens.

indica, [DC. in] Red. Liliac. t. $201=$ speciosa

indica, Linn. Sp. Pl.1.-Cosmop. trop.

indica, Rosc. in Trans. Linn. Soc. viii. (1807) $338=$ orientalis.

indica, Ruiz \& Pav. Fl. Per. (1820) i. $1=$ edulis.

iridiflora, Ruiz Es Pav. l. c.-Peruv

iridiflora, Willd. Enum. Hort. Berol. Suppl. 1= gigantea.
CANNA:-

Jacquini, Bouché, în Linnaea, xii. (1838) 148. Bras.

juncea, Retz. Obs, fasc. i. 9.-China.

latta, Bouché, in Linnaea, xviii. (1844) 489.-Hab.?

lagunensis, Lindl. Bot. Reg. t. $1311=$ lutea.

Lamberti, Lindl. l. c. t. 470.--Ind, occ. : Guiana.

lanceolata, Lodd. ex Loud. Hort. Brit. 1.-Bras.

lanuginosa, Rosc. Scit. t. 16.-Am, trop.

latifolia, Mill. Gard. Dict. ed. VIII. n. 2.-Am. bor.

latifolia, Rosc. Scit. t. $4=$ gigantea.

leptochila, Bouché, in Linnaea, viii. (1833) 152.Hab. ?

leucocarpa, Bouché, l. c. xviii. (1844) 493.-Am austr.

liliiflora, Warscew. ex Planch. in Fl. äes Serres, Sér. I. $\mathrm{x} .(1854-55) 211$. Am. centr

limbata, Rosc. Scit. t. 9.-Bras.

Linkii, Bouché, in Linnaea, viii. (1833) 166.-Bras.

liturata, Link, ex A. Dietr. Sp. Pl. i. $12=$ glauca.

longifolia, Bouché, in Linnaea, xviii. (1844) 386. Mexic

lutea, Mill. Gard. Dict. ed. VIII. n. 4,-Am. trop.

macrocarpa, Hort. ex Horan. Prod. Scitam. 18, nomen.-Am. trop.

macrophylla, Hort. ex Horan. l. c-Am, trop.

maculata, Link, Handb. i. 227.-Am. trop.

maxima, Lodd. ex Rosc. Scit. t. 2 = Lamberti

mexicana, A. Dietr. Sp. Pl. i. $11=$ glauca

miniata, Bouché, in Linnaea, viii. (1833) 165.Bras.

montana, Blume, Enum. Pl. Fav. 35.-Java.

Moritziana, Bouché, in Linnaea, xviii. (1844) 492.Venezuela.

napalensis, Wall. Cat. n. $6622=$ indica

neglecta, Hort. ex Steud. Nom. ed, II. i. $274=$ lanuginosa.

neglecto, Weinm. in Flora, iii. (1820) 607 = gigantea. nepalensis, Hort. Par. ex D. Dietr. Syn. Pl. i. $4=$ indica nudata, Lodd. Cat. ex Steud. Nom. ed. II. i. 274.$\mathrm{Hab}$.

occidentalis, Rose. in Bot. Reg. t. 772.-Ind. occ.

orientalis, Bouché, in Linnaea, viii. (1833) $152=$ pulchra.

orientalis, Rosc. Scit. t. 12.-Ind. or

Ottonis, Bouché, ex Heynh. Nom. ii. 116, nomen.Venezuela.

ovata, Hort. ex Horan. Prod. Scitam. 18, nomen.Hab?

pallida, Rosc, Scit. t. $19=1$ utea.

paniculata, Ruiz \& Pav. Fl. Per. I. 1.-Peray.

patens, Hook. Exot. F1. t. $228=$ limbata.

patens, Rosc. in Trans. Linn. Soc. viii. (1807) 338.Hab.?

pedicellata, Presl, Reliq. Haenk. 106.-Chili.

pedunculata, Sims, Bot. Mag.t. 2323.-Am. trop. pentaphylla, D. Dietr. Syn. P1. i. $5=$ platyphylla. petiolata, Wall. ex Horan. Prod. Scitam. 17, nomen - Hab. ?

platyphylla, Nees E Mart. in Nov. Act. Nat. Cur. xi. (1823) 22. -Bras.

Poeppigii, Bouché, in Linnaea, xii. (1838) 143.Bras.

polyclada, Wawra, in Oestr. Bot. Zeitschr. xiii (1863) 7.-Bras.

polymorpha, Lodd. ex Loud. Hort. Brit. 1; Bouché, in Linnaea, viii. (1833) 151.-Am. austr.

portoricensis, Bouché, l.c. xii. (1838) 147-Porto Rico. pruinosa, Hoffmgg. Verz. Pfl. Nachtr. ii. 79.-Bras. pulchra, Bouché, ex Horan. Prod. Scitam. 16.-Ind. or pulchra, Hassk. Cat. Bogor. Alt. 52 ; et Pl. Fav. Rar. i. 140.-Java.

recurvata, Bouché, in Linnaea, xviii. (1844) 488.Hab. ?

reflexa, Nees, ex D. Dietr. Syn. P1. i. 4 =pedunculata.

Reevesii, Lindl. Bot. Reg. t. 2004.-China.

Roscoeana, Hort. Berol. ex Bouché, in Linnaea, viii 1833) 146.-Am, trop.

rotundifolia x, E. André, in Rev. Hortic. (1862) 371. rubra, Willd in Ges. Naturf. Fr. Berl. Mag, ii. (1808) $169=$ coccinea.

rubricaulis, Link, Enum. Hort. Berol. 1. 1=edulis sanguinea, Hort. Angl. ex Bouché, in Linnaea, viii (1833) $154=$ speciosa.

sanouinea, Warsz. ex Otto \& Dietr. Allg. Gartenz. xix. (185I) $290=$ Warszewiczii.

saturate-rubra, Bouché, ex C. Koch, Allg. Gartenz. (1858) 386.-Hab.? 
CANNA :-

Schlechtendaliana, Bouché, in Linnaea, xviii. (1844) 487.-Hab. ?

Schubertii, Hort. ex Horan. Prod. Scitam. 18.Venezuela.

Sellowi, Hort. Berol. ex Bouché, in Linnaea, viii. (1833) 162.-Bras.

speciosa, Herb. ex Sims, Bot. Mag. t. $2317=$ coccinea. speciosa, Rosc. Scit. t. $17=$ indica.

spectabilis, Bouché, in Linnaea, xviii. (1844) 487.Hab.?

stolonifera, [Hort. Berol. ex] A. Dietr. Syn. Pl. i. 11 . -Reg. Argent

stricta, Bouché, in Linnaea, xii. (1838) 144.-Hab. ?

sulphurea, Hort. ex Bouché, 1. c. viii. (1833) $150=$

lutea.

surinamensis, Bouché, in Linnaea, xviii. (1844) 491.Guiana.

sylvestris, Rosc. Scit. t. 10.-Am. austr.

tenuiflora, Bouché, in Linnaea, viii. (1833) 150.-Ind. occ.

thyrsiflora, Hegetschw. Comm. Bot. t. 1. f. $8=$ patens.

Tinei, Tod. Cat. Hort. Panorm. (1858) 25.-Hab.? tubiflora, Regel, Cat. Pl. Hort. Aksakov. 27.-Hab.? variabilis, Willd. in Ges. Naturf. Fr. Berl. Mag. ii. (1808) $169=$ camea.

variegata, Bouché, in Linnaea, xviii. (1844) 487.Hab.?

ventricosa, Bouche, l. c. 488-Bras.

violacca, Bouché, l. c. xii. (1838) 146.-Hab.

vitellina, Hort. ex Horan. Prod. Scitam. 18, nomen.Hab.?

Warszewiczii, Hort. ex Otto E Dietr. Allg. Gartenz. xix. (1851) 289.-Am. centr.

xalapensis, Hort. Berol. ex Bouché, in Linnaea, viii. (1833) $163=$ patens.

CANNABINA, Tourn. ex Medic. Phil. Bot. i. 53 (1789) = Datisca, Gaertn.

laevis, Moench, Meth, $363=$ D. Cannabina.

CANNABTS, [Tourn.] Linn. Syst. ed. I (1735); Gen. ed. I. 304 (1737). URTICACEAE, Benth. \& Hook. ed. 1 ii. 357 .

chinensis, Delile, Ind. Sem. Hort. Monsp. $(1849)=$ sativa.

erratica, Siev. in Pall. N. Nord. Beitr. vii. $174=$ sativa.

foetens, Gilib. Exercit. ii. $450=$ sativa.

indica, Lam. Encyc. i. $695=$ sativa.

Lupulus, Scop. F1. Carn. ed. II. ii. $263=$ sativa.

macrosperma, Stokes, Bot. Mat. Med. iv. $539=$ sativa.

sativa, Linn. Sp. Pl. 1027.-As. centr.; Himal. bor. occ.

CANNACORUS, Tourn, ex Medic. in Act. Acad. Theod, Palat. vi. Phys. (1790) $378=$ Canna, Linn. (Scitamin.).

indicus, Medic. 1. c. $379=$ Canna indica.

ovatus, Moench, Meth. $526=$ Canna indica.

CANNELLA, Schott, ex Meissn. in DC. Prod.xv. I. 103, in syn. $(1864)=$ Ocotea, Aubl. (Laurin.)

Sassafras, Schott, 1. c. $=0$. indecora.

CANNOMOIS, Beauv, ex Desv. in Ann. Sc. Nat. Sér. I. xiii. (1828) 43. t. 3. f. 1. RESTIACEAE, Benth \& Hook, f. iii. 1036.

Cucullifera et Mesanthus, Nees, in Lindl. Introd. Nat. Syst. ed. II. 451 (1836).

Cephalotes, Beauv. l. c.-Afr. austr.

robustus, Hochst. in Flora, xxviii. (1845) $340=\mathrm{C}$. Cephalotes.

scirpoides, Hochst. l. c.; Mast. in Gourn. Linn. Soc x. (1869) 236.-Afr. austr.

simplex, Kunth, Enum. Pl. iii. 448,-Afr. austr.

strictus, Hocbst. in Flora, xxviii. (1945) $340=$ simplex?

virgata, Hochst. 1. $\mathrm{c}_{ }=\mathrm{C}$. Cephalotes.

CANONANTHUS, G. Don, Gen. Syst. iii. 718 (1834)= Siphocampylus, Pohl (Campanulac.)

campanulatus, G. Don, 1. c. $719=\mathrm{S}$. campanulatus.

CANOPHOLIS, G. Don, Gen. Syst. iv. 684 (1837) sphalm. = Conopholis, Wallr. (Orobanch.).
CANOPUS, Presl, Epim. Bot. 248 (1849)=Exocarpus, Labill. (Santalac.)

luzonensis, Presl, $\mathrm{I}_{0} \mathrm{c}_{\mathrm{n}}=\mathrm{E}$. latifolius.

CANSCHI, Adans. Fam. ii. $443(1763)=$ Trewia, Linn. (Euphorb.).

CANOTHUS, Rafin. in Med. Repos. New York, v. (1808) $360=$ Ceanothus, Linn. (Rhamn.).

CANOTIA, Torr. in Pacif. Rail. Rep. iv. 68 (1856), RUTACEAE, Benth. \& Hook. f. i. 164, 616. holacantha, Torr. l. $c$ - -Calif.

CANSCORA, Lam. Encyc. i. 601 (1783)。 GENTIANEAE, Benth. \& Hook. f. ii. 811.

Combamba, Blanco, Fl. Filip. 510 (1837)

Flemingia, Raxb. ex Steud. Nom.ed. II. i. 643 (1840)

Heterocanscora, C. B. Clarke, in Joum. Linn. Soc. xiv. (1875) 431.

Orthostemon, R. Br. Prod. 451 (1810)

Phyllocyclus, Kurz, in Journ. As. Soc. Beng, xlii, (1873) II. 235

Pladera, Soland. ex Roxb. Fl. Ind. ed. Carey, i. $400(1832)$

PootiA, Dennst. Schluess. Hort. Malab. 37 (1818) alata, Wall. Cat. n. $4363=$ perfoliata.

andrographioides, Griff. ex C. B. Clarke, in fourn.

Linn. Soc. xiv. (1875) 431.-Reg. Himal.; Burma.

concanensis, C. B. Clarke, in Hook. f. Fl. Brit. Ind. iv. 104.-Ind, or.

decurrens, Dalz. in Hook. Kew Fourn. ii. (1850) 136. -Ind. or.

decussata, Schult. Mant. iii. 229.-Ind. or. ; Afr. trop. diffusa, R. Br. Prod. 451 .-Geront. trop.

diffusa, Wall. Cat. n. $4361 \mathrm{~K}=$ andrographioides.

divaricata, Miq. ex C. B. Clarke, in Hook. f. Fl. Brit. Ind. iv, $\mathbf{1 0 3}=$ decurrens.

foliosa, D. Don, in G. Don, Gen. Syst. iv. $199=$ diffusa?

grandiflora, Wight, Ic, iv, t. $1326=$ perfoliata.

Helferiana, Wall. ex C. B. Clarke, in fourn. Linn. Soc. xiv. (1875) 432.-Burma.

justicioides, Griff. ex Voigt, Hort. Suburb. Calc. 520. -Ind. or.

lancifolia, Miq. ex C. B. Clarke, in Hook. f. F1. Brit. Ind. iv, $103=$ pauciflora.

Lauri, C. B. Clarke, in Journ. Linn. Soc. xiv. (1875) $430=$ pauciflora

Lawii, Wight, Ic. iv. t. $1327=$ diffusa

macrocalyx, Miq. ex C. B. Clarke, in Hook. fo Fl

Brit. Ind. iv. $104=$ perfoliata

macrocalyx, Miq. Fl. Ind. Bat. ii. 558.-Java.

Parishii, Hook.f. Bot. Mag. t. 5429,-Burma.

pauciflora, Dals. in Hook. Kew Fourn. ii. (1850) 136. -Ind. or.

perfoliata, Lam. Encyc. i. 601.-Ind. or,

perfoliata, Wall. Cat. n. $4365=$ Wallichii

pusilla, Roem. \& Schult. Syst, iii. $301=$ Hoppea dichotoma.

Roxburghii, Arn. ex Miq. Anal. Bot. Ind. iii. 11.Ind. or.

Schultesii, Wall. Cat. n. 4368.-Burma.

sessiliflora, Schult. Mant. iii. 230.-Ind. or.

tenella, Wall. Cat. n, 4362; Wight, Ic. t. 1327 diffusa.

ventricosa, J. F. Gmel. Syst. $262=$ perfoliata.

Wallichii, C. B. Clarke, in Hook. f. Fl. Brit. Ind. iv. 105.-Ind. or.

CANSENIA, Rafin. Sylva Tellur. $122(1838)=$ Bau hinia, Linn. (Legumin.)

angulosa, Rafin. 1. $\mathrm{c}_{\mathrm{o}}=\mathrm{B}$. angulosa

tomentosa, Rafin. 1, $\mathrm{c},=\mathrm{B}$, tomentosa.

CANSJERA, Juss. Gen. 448 (1789). OLACINEAE, Benth. \& Hook. f. i. 349.

Octoplis, Rafin. F1. Tellur, iv, 105 (1836)

grossularioides, Blanco, Fl. Filip. ed. I. 78.-Ins,

Philipp.
lanceolata, Benth. in Hook. Lond. Journ. Bot. i. (1842) $491=$ Rheedii.

leptostachya, Benth.l.c. ii. (1843) 231.-Austral

madagascariensis, Spreng. Syst. i. $453=$ Potameia Thouarsii.

malabarica, Lam. Encyc. iii. 489 - Rheedii.

manillana, Blume, Mres. Bot. Lugd. Bat, i. 216.-Ins. Philipp.

\section{CANSJERA}

martabanica, Wall. Cat. n. $7266=$ Rheedii.

monostachya, M. Roem. Syn. Hesper. 10 = Rheedii.

parvifolia, Kurz, in fourn. As. Soc. Beng. xli. (1872)

ii. 298.-Burma.

pentandra, Blanco, F1, Filip, ed, I, $73=$ Antidesma Cumingii.

pentandra, Naves, ex Villar, in Blanco, Fl. Philipp. ed. III. Nov. App. $190=$ Antidesma Ghesaembilla. polystachya, M. Roem. Syn. Hesper. $144=$ Rheedii.

Rheedii, Blanco, Fl. Filip. ed. I. $73=$ Antidesma Ghaesembilla.

Rheedii, F. F. Gmel. Syst. i. 280.-As. et Austral. trop.

Rheedii, Naves, ex Villar, in Blanco, Fl. Philipp. ed. III. Nov. App. $190=$ Antidesma Cumingiana scandens, Roxb. Pl. Corom. ii. [2]. t. $103=$ Rheedii. timorensis, Decne. Bot. Vénus, 12. t. 4.-Ins. Timor. zizyphifolia, Griff. in Calc. Joum. Nat. Hist. 1844) $236=$ Rheedii.

CANTALEA, Rafin. Sylva Tellur. 54 (1838)= Lycium, Linn. (Solanac.).

CANTHAROSPERMUM, Wight \& Am. Prod. 255 $(1834)=$ Atylosia, Wight \& Arn. (Legumin.) albicans, Wight \& Arn. 1. c. $256=$ A. albicans. calycinum, Miq. Anal. Bot. Ind. i. 8.-Borneo. distans, Royle, ex Baker, in Hook. f. Fl. Brit. Ind. ii, $216=\mathrm{A}$. platycarpa

nervosum, Royle, ex Baker, 1. c. = A. scarabaeoides,

pauciflorum, Wight \& Arn. Prod. 255=A. scara. baeoides.

sarabeoideum, Baill. in Bull. Soc. Linn. Par. i. (1883. $384=$ A. scarabaeoides.

CANTHIOPSIS, Seem. Fl. Vit. 166. t. $46(1865-73)$ Randia, Linn. (Rubiac)

odorata, Seem. 1. c.-Ins. Fiji.

CANTHIUM, Lam. Encyc, i. $602(1783)=$ Plectronia, Linn. (Rubiac.)

acuminatum, D. Dietr. Syn. P1. i. $779=$ P. acuminata. acutiflorum, Hiern, in Oliver, Fl. Trop. Afr. iii. 136.Afr. trop.

Afzelianum, Hiern, 1. c. 142.-Afrotrop

angulosum, Wall. Cat. n. $8285=$ Randia longiflora.

angustifolium, Roxb. Hort. Beng. 85 ; Fl. Ind. i. 533 $=\mathrm{P}$. angustifolia.

anomocarpum, DC. Prod. iv. 475.-Guiana.

anonaefolium, Webb, in Hook. Kew Joum, ii. '1850 370.-Ins. Cap. Verd.

approximatum, Korth. in Nederl. Kruidk. Arch. ii. II. 1851) 234.-Borneo.

arboreum, Vidal, Phan. Cuming. Philipp. 181.-Ins. Philipp.

attenuatum, R. Br, ex Benth. Fl. Austral. iii. 121 . Austral.

Balansae, Baill. Adansonia, xii. (1878) 184.-N Caled.

barbatum, Seem. Fl. Vit. 132 - Ins, Societ.

Barteri, Hiern, in Oliver, Fl. Trop. Afr. iii. 113.Afr. trop.

Beecheyi, Steud. Nom. ed. II. i. 275.-Ins. Socich.

Benthamianum, Baill. Adansonia, xii. (18i8; $190=$

Vangueria canthoides.

bibracteatum, Hiem, in Oliver, Fl. Trop. Afr. iü. $145=$ P. bibracteatum.

Billardieri, D. Dietr. Syn. PI. i. $\quad 779=$ Coprosma Billardicri.

Breoni, Baill. Adansonia, xii. (1S /8' 221.-Madag

buxifolium, Benth. Fl. Austral iii. $422=8$. buxifolia.

camparulatum, Thw. Enom. Pl. Zeyl. 152 = P campanulatum.

cardiocarpum, Baill. Adansonia, xii. (1S;s) 185.-N) Caled.

caudatiflorum, Hiern, in Oliver, Fl. Trop. Afr. iii. 137.- Afr. trop.

celastroides. Baill. Adansonia, xii. (18-5) $190=l^{\prime}$ celastroides:

chinense, Pers. Syn. i. 200 - Randia dumetorum. confertism. Kurtb. in Nederl. Kiruidk. Arch. it

(1851) 285 - Bumco.

congense, Hiern, in Oliver, Fl. Trup. Afr. iii. 1+1 Afr. trop.

cuprosmovides, F. Mucll. Fragm. ii. 191-rusi 


\section{CANTHIUM :-}

Cornelia, Cham. \& Schlecht. in Linnaea, iv. (1829) 14.-Afr. trop

cornelianum, St. Lag. in Ann. Soc. Bot. Lyon, vii (1880) $121=$ praec.

coronatum, Lam. Encyc..i. $602=$ Randia dumetorum. corymbosum, D. Dietr. Syn. Pl. i. $779=\mathrm{P}$. ventosa Celastrus Plectronia.

corymbosum, Pers. Syn. i. $200=$ Webera corymbosa.

crassum, Hiern, in Oliver, F1. Trop. Afr. iii. 145.-

Afr. trop.

cymosum, Pers. Syn. i. $200=$ P. didyma

Deplanchei, Baill. Adansonia, xii. (1878) $183,186=$ Cyclophyltum Deplanchei.

didymum, Gaertn. f. Fruct. iii. 94. t. $196=\mathrm{P}$ didyma.

discolor, Baill. Adansonia, xii. (1878) $191=$ Vangueria lasiantha.

discolor, Benth. in Hook. Niger FI. 409.-Afr. trop.

dubium, Lindl. Bot. Reg. t. $1026=$ Diplospora viridiflora.

edule, Baill. Adansonia, xii. (1878) $191=$ Vangueria edulis.

ellipticum, Hochst. ex Delile, in Ferr. \& Galin. Voy Abyss. iii. $136=$ Feretia apodanthera.

erythroxyloides, Baill. Adansonia, xii. (1878) 220.Madag.

evonymoides, Baill. 1. c. $189=$ Vangueria euonymoides. fasciculatum, Blume, Bijdr. 967.-Java.

ficiforme, Hook. f. Fl. Brit. Ind. iii. 133.--Ind. or.

favidum, Seem. Fl. Vit. 132.-Ins. Fiji.

floribundum, Wall. ex Voigt, Hort. Suburb. Calc. 389 nomen.-Hab.?

foetidum, Hiern, in Oliver, F1. Trop. Afr. iii. 142.Afr. trop.

fraternum, Miq. Fl. Ind. Bat. ii. 253.-Malaya.

furcatum, Miq. 1. c. 252.-Malaya.

Gaertneri, Steud. Nom.ed. II.i. 275=Damnacanthus indicus.

glabriflorum, Hiern, in Oliver, F1. Trop. Afr. iii. 140.Afr. trop.

glabrum, Blume, Bijdr. $967=$ = P.glabra

glaucum, Hiern, in Oliver, Fl. Trop. Afr. iii. 134.Afr. trop.

glomeratum, C. B. Clarke, in Hook. f. Fl. Brit. Ind. ii. 565 (sphalm. glomerulatum) $=$ seq.

glomerulatum, Miq. F1. Ind. Bat. Suppl. 545= confertum.

gracile, Hiern, in Oliver, FI. Trop. Afr. iii. 139.-Afr. trop.

gracilipes, Kurz, in Journ. As. Soc. Beng. xli. (1872) II $314=P$. gracilipes.

Guenzii, Sond. in Linnaea, xxiii. (1850) 54.-Natal.

Gynochthodes, Baill. Adansonia, xii. (1878) 199.-Ins. Philipp.

hebecladum, DC. Prod. iv. 474.m-Ins. Luzon.

Henriettae, Baill. Adansonia, xii. (1878) 186.-N. Caled.

Feudelotii, Hiern, in Oliver, Fl. Trop. Afr. iii. 139.-

Afr. trop.

hispidum, Benth, in Hook. Niger F1. i. 409.-Afr. trop. horizontale, Benth. 1. c. 408=Afzelianum.

horizontale, Hiern, in Oliver, Fl. Trop. Afr. iii. 137.Afr. trop.

horridum, Benth. FI. Hongk. $159=\mathrm{P}$. parvifolia

horridum, Blume, Bijdr. $966=\mathrm{P}$. horrida.

indicum, D. Dietr. Syn. Pl. 1. $779=$ Damnacanthus indicus.

infaustum, Baill. Adansonia, xii. (1878) 191=Vangueria infausta.

Korthalsianum, Miq. Ann. Mus. Bot. Lugd. Bat. iv. 252.-Sumatra.

laeve, Teijsm. \& Binn. in Tijdschr. Nederl. Ind. xxvii (1864) 32.--Ins. Banca.

lagoênse, Baill. Adansonia, xii. (1878) $190=$ Vangueria euonymoides?

lamprophyllum, F. Muell. Fragm. ii. 133=lucidum.

lanceolatum, Arn. in Nov. Act. Nat. Cur. xviii. (1836) $342=\mathrm{P}$ didyma

lanciflorum, Hiern, in Oliver, F1. Trop. Afr. iii. 146. -Afr. trop.

lasianthoides, Miq. F1. Ind. Bat. ii. 253.--Java.

latifolium, F. Muell. ex Benth. Fl. Austral. iii. 421.Austral.

Leschenaulti, Wight \& Am. Prod. $426=$ P. angustifolia.

leucophloeum, Baill. Adansonia, xii. (1878) $191=$ Fadogia leucophloea.
CANTHIUM :-

lividum, Hiern, in Oliver, Fl. Trop. Afr. iii. 144.Afr. trop.

lucidulum, Miq. Ann. Mus. Bot. Lugd. Bat. iv. $254=$ Plectronia didyma.

lucidum, R. Br. in Salt, Abyss. App. 1xii.-Abyssin.

lucidum, Hook. \& Arn. Bot. Beech. Voy. 65 Beecheyi.

lucidum, Schlecht. ex Hook. f. F1. Brit. Ind. iii. $132=$ P. umbellata?

lycioides, A. Rich. in Mém. Soc. Hist. Nat. Par. vo (1834) 188.-Ins. Philipp.

macrocalyx, Baill. Adansonia, xii. (1878) $191=$ Vangueria macrocalyx.

macrocarpum, Boiv. ex Baill. 1. c. $226=$ pallens

macrocarpum, Thw. Enum. P1. Zeyl. $152=$ P. macrocarpa.

Mannii, Hiern, in Oliver, F1. Trop. Afr. iii. 143.-Afr. trop.

microphyllum, F. Muell.Fragm. ii.134=vaccinifolium. mite, Bartl. in DC. Prod. iv. 474.-Ins. Luzon.

moluccanum, Roxb. Hort. Beng. 85 ; Fl. Ind. i. 536.Ins. Molucc.

mombarense, Baill. Adansonia, xii. (1878) 188.Afr. trop.

monoflorum, Blanco, Fl. Filip. ed. I. $166=$ pedunculare.

montanum, Thw. Enum. Pl. Zeyl. 152.-Zeylan.

multiflorum, Hiern, in Oliver, F1. Trop. Afr. iii. 144. -Afr trop.

Mundtianum, Cham. \& Schlecht. in Linnaea, iv (1829) $131=$ P. Mundtiana.

neglectum, Hiern, in Oliver, F1. Trop. Afr. iii. 135.Afr. trop.

neilgherrense, Wight, Ic. t. 1064 bis $=$ P. neilgherrensis, nervosum, Hiern, in Oliver, Fl. Trop. Afr. ii. 143.

Afr. trop.

nitens, DC. Prod, iv. 474--Ind, or

nitens, Hiern, in Oliver, Fl. Trop. Afr. iii. 135.Afr. trop.

obovatum, Klotzsch, in Eck1. \& Zeyh. Enum. 361.Afr. anstr.

odoratum, Seem, F1, Vit, 132,-Ins, Fiji.

oleifolium, Hook. in Mitch. Journ. Trop. Austr. 397.Austral.

oligocarpum, Hiern, in Oliver, Fl. Trop. Afr. iii. 138. -Afr. trop.

pallens, Baill. Adansonia, xii. (1878) 226.-Ins. Nossibe.

Pancheri, Baill. 1. c. 186.-N. Caled

parviflorum, Bartl. ex DC. Prod. iv. $474=$ hebecladum. parviflorum, Lam. Encyc. i. $602=$ P. parviflora.

parviflorum, Schlecht. ex Hook。f. Fl. Brit. Ind. iii. $111=$ Randia malabarica.

parvifolium, Baill. Adansonia, xii. (1878) $191=$ Vangueria parvifolia.

parvifolium, Roxb. Hort. Beng. 15; F1. Ind. 1. $534=$ P. parvifolia.

pauciflorum, Baill. Adansonia, xii. (1878) $189=\mathrm{P}$. pauciflora.

pauciflorum, Blanco, F1. Filip, ed, I, 165=P, horrida pedunculare, Cav. Ic. v. 21. t. 436.-Ins. Philipp.

Pervilleanum, Baill. Adansonia, xii. (1878) 197.Madag.

phyllanthoideum, Baill. 1. c. 220.-Afr. trop.

polyanthum, Miq. F1. Ind. Bat. Suppl. 545. - Sumatra. polycarpum, Schweinf ex Oliver, Fl. Trop. Afr. iii. 139. - Afr. trop.

puberulum, Thw. ex Hook. f. Fl. Brit. Ind. iii. 134. Zeylan.

pyrifolium, Klotzsch, ex Eckl. \& Zeyh. Enum. 361.-

Afr. austr.

quadrifidum, Labill. Nov. Holl. Pl. i. $69=$ Coprosma Billardieri.

recurvum, Wall. Cat. n. $8284=$ Randia malabarica.

Rheedii, DC. Prod. iv. $474=$ P. Rheedii.

rubens, Hiern, in Oliver, FI. Trop. Afr. iii. 142,-Afr. trop.

ruminatum, Baill. Adansonia, xii. (1878) 200.-Afr. trop.

sagittatum, Baill. 1. c. 184.-N. Caled.

scandens, Blume, Bijdr. 966.-Java.

Schimperianum, A. Rich. Tent. Fl. Abyss. i. $350=$ P Schimperi.

senegalense, A. Rich. in Mém. Soc. Hist. Nat. Par. v. (1834) $188=$ P. hirsuta.

sessilifolium, A. Gray, in Proc. Am. Acad. iv. (1860) 39.-Ins. Fiji.
CANTHIUM :-

setiflorum, Hiern, in Oliver, F1. Trop. Afr. iii. 134.Afr. trop.

setosum, Hiern, 1. c. 141.-Afr. trop.

spirostylum, Miq. Ann. Mus. Bot. Lugd. Bat. iv. 251. - Sumatra.

subcordatum, DC. Prod. iv. 473.-Afr. trop.

sumatranum, Miq. Fl. Ind. Bat. ii. 254. - Sumatra.

tetraphyllum, Baill. Adansonia, xii. (1878) $192=$ Vangueria tetraphylla.

Thonningii, Benth. in Hook. Niger F1. 410.-Afr. trop.

Thunbergianum, Cham. \& Schlecht. in Linnaea, iv. (1829) $130=$ Wendlandia thyrsoidea.

thyrsoideum, Roem. \& Schult. Syst. vi. $207=$ Wendlandia Notoniana.

tomentosum, D. Dietr. Syn. Pl. i. 779 (=Gynopachis tomentosa).--Malaya.

travancoricum, Bedd. Ic. Pl. Ind. Or, t. $239=$. travancorica

triacanthum, Webb, in" Hook. Kew Journ. ii. (1850) 371. -Ins. Cap. Verd.

umbellatum, Wight, Ic. t. 1034; Spicil. Neilgh. i. 81.

t. $97=$ P. umbellata.

umbelligerum, Miq. Ann. Mus. Bot. Lugd. Bat. iv. 252. - Borneo.

umbellulatum, Korth. in Nederl. Kruidk. Arch. ii. Ir. (1851) 235.-Borneo.

undulatum, Champ. ex Benth. in Hook. Kew Journ.

iv. $(1852) 198=\mathrm{P}$. didyma.

acciniffolium, F. Muell, in Trans. Phil. Inst. Vict. iii (1859) 47.-Austral

vanguerioides, Hiern, in Oliver, Fl. Trop. Afr. ii. 146. - Afr. trop.

Vatkeanum, Hiern, 1. c. 136.-Afr. trop.

venosum, Hiern, 1. c. 144.-Afr. trop.

venulosum, Boiv. ex Baill. Adansonia, xii. (1878) 221. -Ins. Comor.

Vieillardi, Baill. 1. c. 185.-N. Caled,

Villarii, Vidal, Phan. Cuming. Philipp. 182.-Ins. Philipp.

violaceum, Zoll. \& Moritzi, Syst. Verz. Zoll. 64.Java.

viridiflorum, D. Dietr. Syn. Pl. i.780= Diplospora viridiflora.

zanzibaricum, Klotzsch, in Peters, Reise Mossamb. Bot. $291=\mathrm{P}$. zanzibarica

zizyphinum, Wall. Cat, n. 8288 A, C =P. horrida.

CANTHOPSIS, Miq. Fl. Ind. Bat. ii. 256 (1856) RUBIACEAE, Benth. \& Hook. f. ii. 113.

pubitora, Miq. l. c. 257.-Ins. Timor.

CANTUA, Juss. Gen. 136 (1789), POLEMONIA$C E A E$, Benth. \& Hook, f, ii. 824.

Periphragmos, Ruiz \& Pav, Prod. 26. t. 24 (1794)

aggregata, Pursh, Fl. Am. Sept. i. 147=Gilia aggregata.

bicolor, Lem. in Fl. des Serres, Sér. I. iii. (1847) 242 , verso.-Bolivia.

breviflora, Juss, in Ann. Mus. Par, iii. (1804) $119=$ Gilia laciniata.

brevifolia, Steud. Nom. ed. II. i. $275=$ praec.

buxifolia, Lam. Encyc. 1. 603.-Peruv.

caerulea, Poir. Encyc. Suppl. ii. $80=$ Loeselia caerulea. coccinea, Poir. 1. c. = Loeselia coccinea.

cordata, Fuss. in Ann. Mus. Par. iii. (1804) 119.Peruy.

coronopifolia, Willd. Sp. PI. 1. $879=$ Gilia coronopifolia cuneifolia, Fuss. ex Roem. Ë Schult. Syst. iv. 369.Hab.?

dependens, Pers, Syn. i. $187=$ buxifolia.

elegans, Poir. Encyc. Suppl.ii. $80=$ Gilia coronopifolia. fasciculata, Humb. ex Roem. \& Schult. Syst. iv. 369 $=$ Fouquiera spinosa.

flexnosa, Pers. Syn. i. $187=$ pyrifolia.

floridana, Nutt. ex A. Gray, Syn. Fl. N. Am. ii. I. 145 $=$ Gilia coronopifolia

foetida, Pers. Syn. i. $187=$ Vestia lycioides

glandulosa, Poir. Encyc. Suppl. ii. $80=$ Loeselia glandulosa.

glomeriflora, Juss, in Ann. Mus. Par. iii. (1804) $119=$ Collomia Cavanillesiana.

glutinosa, Presl, Epim. Bot. 213.-Chili.

Hoitzia, Willd. Sp. Pl. i. $878=$ Loeselia coccinea.

laciniata, Poir. Encyc. Suppl. ii. $81=$ Gilia laciniata.

ligustrifolia, Juss. in Ann. Mus. Par. iii. (1804) $118=$ Vestia lycioides. 
CANTUA:

longiflora, Torr. in Ann. Lyc. N. York, iii. (1828) 221 $=$ Collomia longifora.

loxensis, Willd. ex Roem. \& Schult. Syst. iv. $369=$ pyrifolia.

megapotamica, Spreng. Syst. iv. Cur. Post. 64 (quid?). -Bras.

ovata, Cav. Ic. iv. 43.-Peruv.

parviflora, Pursh, Fl. Am. Sept. ii. $730=$ Gilia parviflora.

peruviana, J. F. Gmel. Syst. $347=$ pyrifolia.

pinnatifida, Lam. Illustr. i. $473=$ Gilia coronopifolia.

pungens, Torr. in Ann. Lyc. N. York, ii. (1828) $221=$ Gilia pungens.

pyrifolia, Fuss. in Ann. Mus. Par. iii. (1804) 11\%,Peruv.

quercifolia, fuss. l. c. 118.-Peruv.

theaefolia, D. Don, in Edinb. Phil. Fourn. (Apl:-Oct. 1822) 289,-Pernv.

thyrsoidea, Juss. in Ann. Mus. Par, iii. (1804) $119=$ Gilia coronopifolia.

tomentosa, Cav. Ic. iv. $43=$ buxifolia:

tuberosa, Roem. \& Schult. Syst. iv. $793=$ Ipomoea muricata.

uniflora, Pers. Syn. i. $187=$ ovata.

CANTUFFA, J. F. Gmel. Syst. 677 (1791)= Ptero lobium, R. Br. (Legumin.).

exosa, J. F. Gme1. 1. $c_{2}=$ P. lacerans.

CAOUTCHOUA, J. F. Gmel. Syst. 1007 (1791)= Hevea, Aubl. (Euphorbiac.).

elastica, J. F. Gmel, i. c。 = H. guianensis.

CAPANEA, Decne. in Van Houtte, Fl. des Serres, t. $499(1850)=$ Campanea, Decne. (Gesnerac.).

CAPANEMIA, Rodrig. Orch. Nov. i. 137 (1877). ORCHIDEAE

carinata, Rodrig. l. c. ii. 243.-Bras.

micromera, Rodrig. l. c. i. 138.-Bras.

Therasiae, Rodrig. l. c. ii. 244.-Bras.

uliginosa, Rodrig. l.c. i. 137:-Bras.

CAPASSA, Klotzsch, in Peters Reise Mossamb. Bot. 27. t. $5(1861)$ =Lonchocarpus, Humb. \& Bonpl. (Legumin.).

violacea, Klotzsch, 1. c. $28=\mathrm{L}$. violaceus.

CAPELLENIA, Hassk. Cat. Hort. Bog. Alt. 178 (1844)= CAPELLIA, Blume $=$ Wormia, Rottb. (Dilleniac.).

CAPELLENIA, Teijsm. \& Binn. in Tijdschr. Nederl. Ind. xxix. (1866) $239=$ Endospermum, Benth. (Euphorb.)

moluccana, Teijsm. \& Binn. 1. c.-Ins. Molucc.

CAPELLIA, Blume, Bijdr. 5 (1825)=Wormia, Rottb. (Dilleniac.).

biftora, A. Gray, Bot. U. St. Expl. Exped. i.15. t. $1=$ W. biflora.

membranifolia, A. Gray, 1. c. $17=$ W. membranifolia.

multiflora, Blume, Bijdr. 5. - Java

pauciftora, Zoll. \& Moritzi, Syst. Verz. Zoll. 35.-Java.

CAPERONIA, St. Hil. Pl. Rem. Bras. 244 (1824). EUPHORBIACEAE, Benth. \& Hook. f. iii. 304. ANDROPHORANTHUS, Karst. in C. Koch \& Fint. Wochenschr. (1859) 5

Cavanilla, Vell. Fl, Flum. 226 (1825).

LEPIDOCOCCA, Turcz, in Bull. Soc. Nat. Mosc. xxi (1848) I. 588 .

METERANA, Rafin. Sylva Tellur. 65 (1898).

acalyphifolia, Griseb. in Goett. Abh. xxiv. (1879) 58. -Reg. Argent.

aculeolata, Muell. Arg. in Linnaea, xxxiv. (1865-66) 152.-Bras.

angustissima, Klotosch, in Hook. Lond. Fourn. Bot. ii. (1843) 50,-Guiana.

bahiensis, Muell. Arg. in Mart. Fl. Bras. xi. It. 325.Bras.

buettneriacer, Muell. Arg.l.c. 320.-Bras.

castaneaefolia, Miq. in Linnea, xxi. (1848) $478=$ corchoroidles.

castaneaefolia, St. Hil. Pl. Rem. Bras, 245,-Java.

corchoroides, Muell. Arg. in Limnaca, xxxiv, (1865-66)

153.-Guiana

cordata, St. Hil. Pl. Rem. Bras. 2\$5.-Bras.

\section{CAPERONIA}

Gardneri, Muell. Arg. in Mart. Fl. Bras, xi. I1. 321. -Bras.

heteropetala, Fo. Didr. in Kjoeb. Vidensk. Meddel. (1857) 148,-Bras.

heteropetaloides, Muell. Arg, in Linnaea, xxxiv. (1865-66) 152.-Bras.

Langsdorffi, Muell. Arg. in Mart. Fl. Bras. xi. II. 319.-Bras.

linearifolia, St. Hil. Pl. Rem. Bras. 246.-Bras.

multicostata, Muell. Argo in Mart. Fl. Bras. xi. II 323. - Bras.

nervosa, A. Rich. Fl. Cub. Fanerog. ii. $213=$ castaneae folia. paludosa, Klotzsch, in Hook. Lond. Fourn. Bot. ii.
(1843) 51.-Mexic.

palustris, St. Hil. Pl. Rem. Bras. 245, -Ind, acc. Mexic.

palustris, H. B. \& K. Nov. Gen, et Sp. ii. $71=$ castaneaefolia.

panamensis, Klotzsch, in Seem. Bot. Voy. Herald, 103 = paludosa.

Regnellii, Muell. Arg. in Mart. Fl. Bras.xi.. II. 321.Bras.

Rutenbergii, Muell. Arg, in Bremen Abh. vii. (1880) 25.-Madag.

senegalensis, Muell. Arg. in Linnaea, xxxiv. (1865-66) 153.-Afr. trop.

serrata, Baill. in Adansonia, i. (1860-61) $66=$ senegalensis.

serrata, Presl, Epim. Bot. 213.-Afr. trop.

stenophylla, Muell. Arg. in Mart. Fl. Bras. xi. I1. 326. -Bras.

Velloziana, Muell. Arg. b.c. 323.-Bras.

CAPIA, Domb. ex Juss. in Dict. Sc. Nat. vi, 500 (1805) Lapageria, Ruiz \& Pav. (Liliac.).

CAPIRONA, Spruce, in Journ. Linn. Soc. iii. (1859) 200. RUBIACEAE, Benth. \& Hook. f. ii. 39. Boiviniana, Baill. in Bull. Soc. Linn. Par. i. (1880) 270.-Madag.

decorticans, Spruce, in Fourn. Linn. Soc. iii. (1859) 200.-Peruv.

CAPITELlaria, Naud. in Ann. Sc. Nat. Sér. III, xviii. (1852) 103 = Sagraea, DC. (Melastom.)

Benthami, Naud. 1. $c_{0}=$ S. capitata.

CAPNITES, Dum.Fl. Belg. 117 (1827) (err. typ. 177) $=$ Corydalis, Vent. (Papaverac.)

alpestris, Rupr. Fl. Caucas. $59=$ Cor. pauciflora. angustifolia, Rupr. 1. c. $57=$ Cor. angustifolia. araratica, Rupr. 1. c. 61--Armenia.

Bayerniana, Rupr. 1. c. 59. t. $4=$ Cor. pallida. caucasica, Rupr. 1.c. $56=$ = Cor. caucasica.

cava, Dum. Fl. Belg. 117 (err. typ. 17/ $)^{\circ}=$ Cor. tuberosa, bulbosa.

conorhiza, 'Ledeb.' ex Rupr. F1. Caucas. $61=$ Cor, conorhiza.

digitata, Dum. Fl. Belg. 117 (err. typ. 177) = Cor. solida.

Emanueli, Rupr. Fl. Caucas. $58=$ Cor. pauciflora.

fabacea, Dum. Fl. Belg. 117 (err. typ. 177) =Cor. fabacea.

macrosepala, Rupr. Fl. Caucas. 61.-Reg. Caucas.

Marschalliana, Rupr. 1. c. $55=$ Cor. Marschalliana.

ochroleuca, Rupr. 1..c. $61=$ Cor. lutea.

pallidiflora, Rupr.1. c. $58=$ Cor. pallida

roseo-purpurea, Rupr. 1. c. 288.-Reg. Caucas.

solida, Fourr, in Ann. Soc. Linn, Lyon, N. S. xvi (1868) $329=$ Cor. solida.

CAPNITIS, E. Mey. Comm. Pl. Afr. Austr. 81 (1835)= Lotononis, Eckl. \& Zeyh. (Legumin.)

clandestina, E. Mey. I. co = L。 clandestina

porrecta, E. Mey. 1. co = L, porrecta.

CAPNOCYSTIS, Juss, in Ann. Mus, Par, xviii, (1811) $473=$ CXSTICAYNOS, Boerh, $=$ Corydalis, Vent. (Papaverac.).

CAPNOGONIUM, Bernh. Ind. Sem. Hort. Erfurt. (184. ex Endl. Gen. Suppl. ii. $10 \%=$ Corydalis, Vent. (Papaverac.)

nobile, Bernh. 1. c. $=$ Cor, nobilis.
CAPNOIDES, Tourn。 ex Adans, Fam. ii. 431 (1763)= Corydalis, Vent. (Yapaverac.).

albida, Bernh. ex steud. Nom. ed. II. i. $276=$ Cor lutea.

cava, Moench, Meth. $52=$ Cor. tuberosa

glauca, Moench, $1 . c_{2}=$ Cor. glauca.

lutea, Gaertn. Fruct. ii, $163=$ = Cor. lutea.

minor, Schum, ex DC. Syst. ii. $119=$ Cor, fabacea

nobilis, Moench, Meth. $52=$ Cor, nobilis.

rigidula, Bernh. ex Steud. Non, ed. II. i. $276=$ Cor

ochroleuca.

scandens, Moench, Meth. Suppl. $215=$ Adlumia cirrhosa.

sempervirens, Borckh. in Roem. Arch. i.. II. $44=$ Cor. glauca.

solida, Moench, Meth. $52=$ Cor. tuberosa.

CAPNOPHYLLUM, Gaertn. Fruct. ii, 32, t. 85 (1791). UMBELLIFERAE, Benth. \& Hook. f. i. 908.

Acrinocladus, E. Mey. Ind. Sem. Hort. Regiom. (1846).

Krubera, Hoffm. Gen. Umb. 103 (1814).

Sclerosciadium, Koch, in DC. Coll. Mém. v. 43 (18:9); Prod. iv, 140 (1836)

UloSPERMUM, Link, Enum. Hort. Berol. i. 207 (1822).

africanum, Gaertn. Fruct. ii. 32, t. 85.-Afr. austr. dichotomum, Lag. Gen. et Sp. Nov.13.- Reg. Mediters. Jacquini, $D C$. Prod. iv. 187.-Afr. austr.

peregrinum, Lange, in Willk. \&: Lange, Prod. Fl. Hisp. iii. 33 = diclrotomum.

simplex, Lag. Gen.et Sp. Nov. $19=$ africanum.

CAPNORCHIS, Borck. in Roem. Arch. i. Ir. 46 (1797) =

Dicentra, Bernh. (Papaverac.)

chrysantha, Planch. in Fl. des Serres, Sir. Io viii.

(1852-53) 193. t. $820=\mathrm{D}$. chrysantha.

Cucullaria, Planch. 1, c. 193=D. Cucullaria.

eximia, Planch..1. c. $=$ D. eximia.

formosa, Planch. $1 . \mathrm{c}=\mathrm{D}$. formosa.

spectabilis, Borck. in Roem. Arch. i. 11, $46=$ ]). spectabilis.

CAPNOREA, Rafin. F1. Tellur. iii. $7 \pm(1836)=$ Nicotiana, Linn. (Solanac.).

nana, Rafin. 1. c. $75=$ N. nana.

CAPPARIS, [Tourn.] Linn. Syst. ed. I (1795) CAPPARIDEAE, Benth. \& Hook. f. i. 108.

BeAutempsia, Gaudich. Bot. Voy. Bonite, t. 30 (1844?)

Busbeckia, Endl. Prod. Fl. Ins. Norf. $6 \pm$ (1833)

Calyptranthus, Thoul Obs. Pl. Tsles Afr. 26 (1811).

Colicodendron, Mart. Herb. Fl. Bras. 201 (133i.

Destruguezia, Gaudich. Bot. Voy. Bonite, to 57 (1844?).

HombaK, Adans, Fam。 ii. 408 (1763)

Intutis, Marsesina, Octanema, Oligloron,

Olofuton, Pleuteron, Triclanthera, Rafin.

Sylva Tellur. 108-112 (1838)

LiNDACKERA, Sieber, ex Endl. Gen, 893, in syn. (1841).

Petersia, Klotzsch, in Peters, Reise Mossamb. Bot. 168. t. $30(1861)$

Quadrella, Meissn. Gen. 15 (1867).

SODADA, Forsk. Fl. Aegypt. Arab. 81 (1-T/3).

UTERVERIA, Bertol. Pl: Nov. Hort. Bunon. (1839).

aculeata, Steud. Nom. ed. I. 147=spinosa

acuminata, I.indl. Bot. Reg. t. 18:0 = acurifolia. acuminata, Roxb. Hort. Beng. 11 ; Fl. Ind. ii. 5000 zeylanica.

acuminata, Willd. Sp. Pl, ii, 1181.-Ind, or. acuminata, Willd. ex Wall. Cat. n. $6.990 C^{\circ}=$ horricis. acutifolia, Sacet, Horf. Brit. ed. II. 5s5.-Chiala. aceyplia, Lam. Encyc i. 605 = spinosa acyyptia, Sieber, ex Presl, in Olen, Isis, xxi. (15.s $274=$ Fontanesii.

Afsclii, DC. Prod, i. 240 = erythrocamos

Asmba, Banks, ex DC. Prod. i. 21s - Koxburyhii.

albitrunca, Eurch. Trav, i. 913. - Afr. austr.

ambigua, Kiure, for. F\%. Brit. Burma, i. 65-Ins. Amian.

amplissimn, Lam. Encyco i, $60 \%$.-Ind, ooc.; Mexic. amygutalifolia, Facq. Ensupe. Pl. Carib. 24.-Ind. ox amygrdalina, Griseb. in Mcrn. An. Acad. X. S. 17 (1)tis 155 - Lisiselanchii. 


\section{CAPPARIS}

amygdalina, Lam. Encyc. i. $608=$ Capparis Breynia. angulata, Ruiz E Pav. Fl. Per. t. 431 ex DC. Prod. i. 253 - Ecuador.

angustifolia, H. B. E K. Nov. Gen. et Sp. v. 96. t. 438. -Mexic.

antanossarnm, Baill. in Bull. Soc. Linn. Par. i. (1885) 462.-Madag.

apetala, Roth, Sp. Pl. Nov. $238=$ Niebuhria linearis.

aphylla, Roth, l. c.-Afr. bor.; Arab.; Ind. or

arborescens, Mill. Gard. Dict. ed. VIII. n. $3=$ pulcher rima.

Arrabidae, Steud. Nom. ed. II. i. 276.-Bras.

artensis, Montr. in Mém. Acad. Lyon, x. (1860) $177 .=$ N. Caled.

asperifolia, Presl, Rel. Haenk. ii. 86.-Mexic

assamica, Hook. f. E" Thoms, in Fl. Brit. Ind. i. 177. -Assam.

aurantioides, Presl, Rel. Haenk. ii. 86.-Ins. Luzon.

avicennifolia, $H . B$. \& K. Nov. Gen. et Sp. v. 94.Am, austr.

Baducca, Blanco, F1. Filip. ed. I. $438=$ spinosa

Baducca, Linn. Sp. P1. $504=$ zeylanica?

barcellonensis, H. B. \& K. Nov. Gen. et Sp. v. $92=$ Breynia.

Billardieri, DC. Prod. i. 247.-Ins. Moluce

bisperma, Roxb. Hort. Beng. [93] ; F1. Ind. ii. $568=$ grandis.

bisperma, Wight, ex Hook. f. Fl. Brit. Ind. i, $176=$ Roxburghii

brachyscias, Turcz. in Bull. Soc. Nat. Mosc. xxvii. (1854) II. 323. - Java.

brasiliana, DC. Prod. i. 249.-Bras.

Brassii, DC. l, c. 248 , - Am austr.

brevipes, Benth. Bot. Voy. Sulph. $65=$ verrucosa.

brevis, Spreng. F1. Hal. Mant. $43=$ eustachiana.

brevisiliqua, Mo६. É Sessé, ex DC. Prod.i. 251.-Mexic.

brevispina, DC. Prod. i. $246=$ zeylanica

brevispina, Wight \& Arn. Prod. $24=$ divaricata.

Breynia, H. B. \& K. Nov. Gen, et Sp. v. $97=$ odoratissima.

Breynia, Linn. Syst. ed. X. 1071; Facq. Am. Select. 161. t. 103.-Am, austr

caerulea, Heyne, ex Wall. Cat. n. $6986=$ diversifolia.

callophylla, Blume, Bijdr. 53.-Java.

callosa, Blume, l, $\mathrm{c}=$ micracantha.

canescens, Banks, ex DC. Prod. i. 246.-Austral.

canescens, G. Don, Gen. Syst, i, $281=$ Doniana.

cantoniensis, Lour. Fl. Cochinch. 330.-China.

capensis, Thunb. Prod. Pl. Cap. $92=$ citrifolia

Carandas, Burm. f. Fl. Ind. 118,-Ind. or.

cardiophylla, Turcz. in Bull. Soc. Nat. Mosc. xxvii.

(1854) II. 325.-Venezuela.

cartilaginea, Decne. in Ann. Sc. Nat. Sér. II. iii. (1835) $273=$ galeata

celebica, Miq. Illustr. Fl. Arch. Ind. 26.-Ins. Celebes.

cerasifolia, A. Gray, Bot. U. St. Expl. Exped. i. 71.-

Archip. Sulu.

chinensis, G. Don, Gen. Syst, i. $278=$ acutifolia

chrysomeia, Boj. in Ann. Sc. Nat. Sér. II. xx. (1843) 59.-Madag.

citrifolia, Lam. Encyc, i. 606.-Afr. austr.

clutiaefolia, Burch. ex DC.Prod. i. 248.-Afr. austr.

coccolobifolia, Mart. ex Eichl. in Mart. Fl. Bras, xiii. I. 281-Am. trop.

coluteoides, Boiss. Diagn. Ser. I. xiii. $83=$ Cleome coluteoides.

commutata, Spreng. Neue Entdeck. iii. $57=$ frondosa.

comosa, Facq. Enum. Pl. Carib. 23.-Ins, S. Doming. conferta, Mill. Gard. Dict. ed. VIII. n. $8=$ laurifolia.

conspicua, Wall. Cat. n. $6991=$ micracanth

cordata, Ruiz \& Pav. Fl. Per.t. 432; ex DC. Prod. i. 251 $=$ crotonoides.

cordifolia, Lam. Encyc. i. $609=$ spinosa

coriacea, Burch. ex DC. Prod. i. 248.--Afr. austr

corymbifera, E. Mey. ex Harv. Eo Sond. Fl. Cap. i. 6

- Afr. austr.

corymbosa, Lam. Encyc. i. 605.-Afr. trop.

carymbosa, Roxb. Hort. Beng. [93]; F1. Ind. ii. $569=$ Roxburghii.

crassifolia, A. Gray, Bot. U. St. Expl. Exped.i. 71.Archip. Sulu.

crassifolia, Kurz, in Fourn. As. Soc. Beng. xlii. (1873) II. 227 -Burma.

crotonoides, $H . B$. E K. Nor. Gen. et $S p$. v. 95, t. 437 . - N. Granat.

cuneata, DC. Prod. i. $249=$ frondosa

Cynophallophora, Linn. Sp. PI. ed. I. $504=$ jamaicensis.

\section{CAPPARIS :}

Cynophallophora, Linn. Sp. Pl. ed. II. 721 ; facq. Am. Select. t. 98.-Am austi.

Dahi, Forsk. Fl. Aegypt. Arab. 212 (Zygophylli sp.?) - Arab.

dasypetala, Turcz. in Bull. Soc. Nat. Mosc. xxvii. 1854) II. 322.-Java.

dealbata, $D C$. Prod. i. 246.--Ins. Timor

decidua, Edgew. in Journ. Linn, Soc. vi. (1862) $184=$ aphylla.

declinata, Vell. F1. Flum. 230 ; v. t. $111=$ C. Cynophallophora

detonsa, Triana $\varepsilon^{~ P l a n c h . ~ i n ~ A n n . ~ S c . ~ N a t . ~ S e ́ r . ~ I V . ~}$ xvii. (1862) 80.-N. Granat.

didymobotrys, Ruig E Pav. Fl. Per. t. 423 ; ex DC Prod. i. 253.-Ecuador.

disperma, Walp. Rep. i. $199=$ grandis

disticha, Kurz, in fourn. As. Soc. Beng. xliii. (1874) II. 70.-Burma.

divaricata, Lam. Encyc. i. 606. ; Klein, ex Wall. Cat. n. $6988 \mathrm{~A}=$ diversifolia.

diversifolia, Wight Eे Arn. Prod. 27.-Ind. or

domingensis, Spreng, ex DC. Prod. i. 253.-Ins. S. Doming.

Doniana, D. Dietr. Syn. Pl. iii. 227.-Afr. trop.

Eichleriana, Urban, in Linnaea, xliii.(1880-82) 265 -Bras.

elaeagnifolia, Facq. Enum. Pl. Carib. 23.-Ind. occ.

elegans, Mart in Flora, xxii. (1839) I, Beibl. 24.-Bras

elliptica, Span. in Linnaea, xv. (1841) $166=$ Rox burghii ?

emarginata, Presl, Reliq. Haenk. ii. 85.-Ins. Luzon. emarginata, A. Rich. Ess. Fl. Cub. $78=$ jamaicensis. emarginata, Zipp. ex Span. in Linnaea, xv. (1841) 166 = sepiaria.

erythrocarpos, Isert, in Ges. Naturf. Fr. Berl. Schrift. ix. (1789) 334. t. 9.-Guiana.

erythrodasys, Miq. P1. Jungh. $397=$ horrida.

eustachiana, facq. Enum. Pl. Carib. 23.-Ins. S. Eustach.

exstipulata, J. F. Gmel. Syst. $807=$ inermis ?

falcata, Lour. F1. Cochinch. $330=$ Crataeva falcata.

fascicularis, DC. Prod. i. $248=$ corymbosa

ferruginea, Linn. Syst. ed. X. 1071.-Ind, occ.

ferruginea, Sieber, ex Eichl. in Mart. Fl. Bras, xiii, I.

$271=$ C. Breynia.

ferruginea, Willd ex Eichl. 1. c. =odoratissima

Finlaysoniana, Wall. Cat. n. 6992 B.-Malaya.

Finlaysoniana, Wall. 1. c. A=micracantha.

flavicans, Wall. l.c. n. 7003.-Burma.

flexicaulis, Hance, in Fourn. Bot. vi. (1878) 225.China.

Alexuosa, Blume, ex Hassk. Pl. Fav. Rar. 179.-Tava.

flexuosa, Linn. Sp. Pl.ed. II. $722=$ C. Cynophallophora.

flexuosa, Vell. F1. Flum. 230 ; v. t. $108=$ Arrabidae.

floribunda, Lepr. ex Walp. Rep. i. $197=$ tomentosa.

floribunda, Wight, Illustr. Ind. Bot. i. 35. t. 14.-Ind.

or. : Ins. Plilipp.

foetida, Blume, Bijdr. 52.-Java.

Fontanesii, DC. Prod. i. 245.-Ins. Maurit

formosa, Dalz. in Hook. Kew Journ. ii. (1850) $40=$ Heyneana.

formosa, Wall. Cat. n. $6982 \mathrm{~A}=$ horrida

Forsteniana, Miq. Illustr. Fl. Arch. Ind. 32.-Malaya

frondosa, Faco. Enum. Pl. Carib. 24; Linn. Sp. Pl. ed. II. App. 1674.-Am. austr.

fruticosa, Mill. Gard. Dict. ed. VIII. n. 7.-Am. austr.

furfuracea, Ruiz E Pav. ex DC. Prod. i. 252.-Mexic.

galeata, Fresen. in Mus. Senckenb. ii. (1837) 111.Aegypt.

Gaudichaudiana, Eichl, in Mart. Fl. Bras, xiii. I. 273. -Peruv.

glandulosa, Desf. Cat. Hort. Par. ed. III. 405.-Hab. ?

glauca, Wall. Cat. n. 7005.-Burma.

globifera, Delile, in Rochet, Sec. Voy. Choa, 340.-Afr. trop.

Gomeziana, Steud. Nom. ed. II. i. $277=$ pumila

Grandidiera, Baill. in Bull. Soc. Linn. Par. i. (1885) 463.-Madag.

grandiflora, Wall. Cat. n, 6984.-Ind. or

grandis, Linn. f. Suppl.263.-Ind. or. ; Burma.

grandis, Russ. ex Wall. Cat n. $7001=$ Russeliana

Grisebachii, Eichl. in Mart. Fl. Bras, xiii. I. 275.Cuba.

guayaquilensis, H. B. \& K. Nov. Gen. et Sp. v. $89=$ C. Cynophallophora.

Guenezii, Sond. in Harv. E Sond. Fl. Cap. i. 62.Afr, austr.

\section{CAPPARIS :-}

Hasseltiana, Miq. Illustr. Fl. Arch. Ind. 24. t. 13.Java.

hastata, Jacq. Enum. Pl. Carib, $23=$ C. Cynophallophora.

hastigera, Hance, in Journ. Bot. vi. (1868) $296=$ Swinhoii.

herbacea, Willd. Enum. Hort. Berol. $560=$ spinosa.

heteracantha, DC. Prod. i. 246.-Mesopotam.

heteroclita, Roxb. Hort. Beng. 41; Fl. Ind. ii. $570=$ Maerua arenaria.

heterogenea, Roxb. ex Steud. Nom. ed. II. i. $277=$ Maerua oblongifolia.

heterophylla, Ruiz \& Pav. ex DC. Prod. i. 250.Ecuador.

Heyneana, Wall. Cat. n. 6985,-Ind, or.

horrida, Banks, ex Wight \& Arn. Prod. $25=$ stylosa

horrida, Linn.f. Suppl. 264.-As. trop.; Malaya.

Humbloti, Baill. in Bull. Soc. Linn. Par.i. (1885) 463. - Madag.

humistrata, F. Muell. Fragm. v. 156.-Austral.

hypericoides, Hochst. in Flora, xxvii. (1844) i. 290.Afr, occ.

hypoleuca, Presl, Rel. Haenk. ii. 87.-Peruv.

incana, $H . B$. \& $K$. Nov. Gen. et Sp. v. 94.-Am. austr.

incanescens, DC. Prod. i, $247=$ sepiaria

inermis, Forsk. Fl. Aegypt. Arab. 100.-Arab.

intermedia, H. B. \& K. Nov. Gen. et Sp. v. $98=$ odoratissima.

isthmensis, Eichl. in Mart. Fl. Bras. xiii. I. 269.-Am. trop.

Jacobinae, Moric. ex Eichl.l. c. 277.-Bras.

jamaicensis, Facq. Enum. Pl. Carib. 23.-Jamaica.

Karwinskiana, Schlecht. in Linnaea, x. (1836) 237.Mexic.

Kirkii, Oliver, Fl. Trop. Afr. i. 98.-Afr. trop.

Korthalsiana, Miq. Illustr. Fl. Arch. Ind. 31.-Borneo.

laeta, H. B. \& K. Nov. Gen, et Sp. v. $88=$ verrucosa.

laetevirens, Mart. in Flora (1839) I. Beibl. $23=\mathrm{C}$. Cynophallophora.

laevigata, Mart. 1. c. $21=$ C. Cynophallophora.

lanceolaris, Lesch. ex Steud. Nom. ed. II. i. 277.-Java. lanceolata, Ruiz \& Pav. F1. Per. t. 423; ex DC. Prod. i. $249=$ C. Cynophallophora.

lasiantha, $R$. Br. ex $D C$. Prod. i. 247.-Anstral.

lasiopodia, Turcz, in Bull. Soc. Nat. Mosc, xxvii. (1854) II. 322.-Ins. Luzon.

laurifolia, Mill. Gard. Dict. ed. VIII. errat.-N. Granat.

laurina, H. B. E K. Nov. Gen. et Sp. v. 93,-Am. austr.

leucophylla, DC. Prod. i. $246=$ spinosa.

linearifolia, Hook. f. in Hook. Niger F1. $217=$ Thonningii.

linearifolia, Linden, ex Turcz. in Bull. Soc. Nat. Mosc. xxvii. (1854) II. 324.-Venezuela.

linearis, Blanco, Fl. Filip. ed. I. $438=$ viminea.

linearis, facq. Enum. Pl. Carib. 24.-Am, austr.

lineata, Pers. Syn. ii. 60.-Bras.

linifolia, Roxb. Hort. Beng. $41=$ Niebuhria linearis

Lobbiana, Turcz. in Bull. Soc. Nat. Mosc. xxvii. (1854 II. 323.-Singapore.

Loddigesii, Steud. Nom. ed. II. 1. 277.-Hab. ?

longifolia, Sw. Prod. Veg. Ind. Occ. 81.-Ind, occ.

longispina, Hook. $f$. E Thoms. in Fl. Brit. Ind. 1. 176. -Burma.

loranthifolia, Lindl. in Mitch. Trop. Austral. 220.Austral.

lucida, Banks, ex DC. Prod.i. 254.-Austral.

luzonensis, Turcz. in Bull. Soc. Nat. Mosc. xxvii. (1854) II. 324. - Ins. Luzon.

macrocarpa, Ruiz \& Pav. ex DC. Prod. i. $250=$

petiolaris.
macrophylla, H. B. E K. Nov. Gen. et Sp. v. 91.-N. Granat.

macrosperma, Delile, in Rochet, Sec. Voy. Choa, 344 -Afr. trop.

magna, Lour. F1. Cochinch. $330=$ Crataeva magna.

malabaria, Wight, ex Steud. Nom. ed. II. i. $277=$ Heyneana.

malabarica, Wall. Cat. n. $7000=$ floribunda

mariana, Jacq. Hort. Schoenbr. 1. 57. t. 109=spinosa

maxima, Roth, Sp. PI. Nov, $237=$ grandis.

membranacea, Gardn. E Champ. in Hook. Kew Fourn. i. (1849) 241.-China.

membranifolia, Kurz, in fourn. As. Soc. Beng. xliii

(1874) II. 70.-Burma.

micracantha, $D C$. Prod. 1. 247.-Burma; Malaya. 


\section{CAPPARIS}

micracantha, Teijsm. ex Miq. Illustr. Fl. Arch. Ind. 33 $=$ Forsteniana

micrantha, A. Rich. Tent. Fl. Abyss. i. 31.-Abyss.

Mitchellii, Lindl. in Mitch. Three Exped. i. 315.Austral.

mithridatica, Forsk. Fl. Aegypt. Arab. 99,-Arabia.

mollis, H. B. $\sigma^{\circ} K$. Nov. Gen. et Sp. v. 88.-Peruv.

molliuscula, Wall. Cat. n. 7006 (=Cansjerae sp.).Ind, or.

Moonii, Wight, Illustr. Ind. Bot. 1. 35.-Zeylan.

Morisonia, Sw. Obs. $272=$ Morisonia americana.

mucronifolia, Boiss. Diagn. Ser. I. i. $3=$ spinosa.

multiflora, Hook. f. E Thoms. in Fl. Brit. Ind. i. 178. -Reg. Himal. ; Burma.

Murrayana, J. Grah. in Cat. Pl. Bomb. $9=$ spinosa.

Murrayi, Stew. ex Dalz. in Journ. Linn. Soc. xiii. (1873) $74=$ spinosa?

nectaria, Vell. Fl. Flum. 280 ; v. t. 107.-Bras.

nemorosa, Blanco, Fl. Filip. ed. I. 438.-Ins. Philipp.

nemorosa, facq. Enum. Pl. Carib. 24.-N. Granat.

nepaulensis, DC. Prod. i. 246 ; Wall. Cat. n. $6979=$ spinosa.

neriifolia, Radlk. in Sitzb. Math.-Phys. Acad. Muench. xiv. (1884) 180-Hab. ?

nigricans, Span. in Linndea, xv. (1841) 165.-Ins, Timor.

nitida, Ruiz \& Pav. ex DC. Prod. i. 252.-Peruy.

nobilis, F. Muell. ex Benth. Fl. Austral. i. 95.Austral.

noctiflora, Spreng. ex Eichl, in Mart. F1. Bras. xiii. 1. $285=$ nitida.

nummularia, DC. Prod. i. 246.-Austral.

oblongifolia, Forsk. Fl. Aegypt. Arab. 99.-Arabia.

obovata, Buch.-Ham, ex DC. Prod. i, $248=$ grandis

obovata, Royle, Illustr. Bot. Himal. 73 =spinosa.

obovatifolia, H. B. \& K. Nov. Gen. et Sp. v. $92=$ tenuisiliqua.

obtusa, Rafin. Sylva Tellur. $109=$ C. Cynophallophora. octandra, Jacq. Am. Select. 160. t. $100=$ ferruginea

adorata, Blanco, Fl. Filip. ed. I. 439.-Ins. Philipp.

odoratissima, facq. Hort. Schoenb. t. 110.-Venezuela

olacifolia, Hook. f. E Thoms. in Fl. Brit. Ind. 1. 178. -Reg. Himal.

oleoides, Burch, ex DC. Prod. i. 248,-Afr. austr.

oligandra, Griff. Notul. iv. $577=$ Aloribunda.

orbiculata, Wall. ex Hook. $f$. E Thoms, in Fl. Brit.

Ind. i, 176.-Burma.

ornans, F. Muell. ex Benth. Fl. Austral. i. 95.Austral.

ovalifolia, Ruiz \& Pav. Fl. Per. t. 432, ined. ex DC. Prod. i. $253=$ avicennifolia.

ovalis, Risso, Fl. Nice, 44 = spinosa.

ovata, Bieb. Fl. Taur. Cauc. ii. $1=$ spinosa.

ovata, Desf. Fl. Atlant. i. $404=$ Fontanesii.

oxyphylla, Miq. Pl. Fungh. 397.-Java.

oxyphylla, Wall. Cat. n. $6997=$ tenera.

oxysepala, Wright, ex Radlk. in Sitzb. Math.-Phys.

Acad. Muench. xiv. (1884) 172.-Nicarag.

Pachaca, H. B. E K. Nov. Gen. et Sp. v. 93.-Venezuela.

panduriformis, Lam. Encyc. i. $609=$ Thylachium panduriforme.

panduriformis, Thou. Obs. Afr. Austr. 26=Thylachium heterophyllum.

paradoxa, Jacq. Hort. Schoenb. i. $58=$ Steriphoma paradoxum.

parviflora, Boiss. Diagn. Ser. I. i. $4=$ spinosa

parviflora, Hook. f. E Thoms, in Fl. Brit. Ind. i. 176 -Ind. or.

pauciflora, H, B. \& K. Nov. Gen, et Sp, v. $89=$ C. Cynophallophora.

pauciflora, Presl, Rel. Haenk. ii. $86=$ incana

pedancularis, C. E $\mathcal{F}$. Presl, Delic. Prag. i. 20.Sicilia.

pedunculosa, Wall. Cat. n. 6999.-Ind. or.

peltata, G. Don, Gen. Syst. i. 285.-Ins. Trinitat.

pendula, Triana E Planch. in Ann. Sc. Nat. Sér. IV. xrii. (1862) 76.-N. Granat.

persicaefolia, A. Rich. Tent. F1. Abyss. i. $81=$ tomentosa.

petiolaris, Banks, ex DC. Prod. i. $249=$ frondosa.

petiolaris, H. B. \& K. Nov. Gen. et Sp. v. 91.Guayaquil,

platyacantha, Turcz. in Bull. Soc. Nat. Mose. xxvii. (1854) 11. 323.-Java.

pluvialis, Mart. in Flora, xxii. (1839) I. Beibl. 22 =C. Cynophallophora.

\section{CAPPARIS :-}

polyantha, Triana E Planch. in Ann. Sc. Nat. Sér. IV. xvii. (1862) 76, - N. Granat.

polymorpha, Kurz, in fourn. As. Soc. Beng. xlii. (1873) II. 227.-Burma

polymorpha, Rich. in Guill. \& Perr. Fl. Seneg. Tent. i. $24=$ tomentosa.

populifolia, Willd. ex Eichl, in Mart. Fl. Bras, xiii, I $274=$ crotonoides

pruinosa, Griseb. in Goett. Abh. xxiv. (1879) 18.-Reg. Argent.

puberula, DC. Prod. i. $248=$ tomentosa.

pubiflora, $D C$. ᄂ. c. 246.-Malaya.

pulcherrima, Facq. Enum. Pl. Carib. 24.-N. Granat. pumila, Champ. ex Benth. in Hook. Kew Fourn.

iii. (1851) 260.-China; Ind, or.

punctata, Burch. Trav. i. 492.-Afr. austr.

punctata, Wall. Cat, n. $7002=$ pumila

pyracantha, Boj. in Ann. Sc. Nat. Sér. II. xx. (1843) 59.-Madag.

pyrifolia, Lam. Encyc. i. 606.-Ind. or

pyrifolia, Wight \& Am. Prod. $25=$ grandiflora.

quadriflora, DC. Prod. i. $247=$ horrida.

quiniflora, $D C$. l. c. - Austral

quinqueflora, Steud. Nom. ed. II. is = quiniflora.

racemifera, DC. Prod. i. $248=$ grandis.

racemosa, Mill. Gard. Dict. ed. VIII. n. 5.-Mexic.

racemulosa, $D C$. Prod. i. 248.-Afr. austr.

radiatiflora, Ruiz \& Pav. Fl. Per. v. t. $433=$ Crataeva radiatiflora.

reflexa, Thonn. E Schum. in Dan. Vid. Sel. Afh. iv. (1828) 11.-Guinea.

reticulata, Klein, ex Wall. Cat. n. $6986=$ diversifolia.

retusa, Griseb. in Goett. Abh. xxiv. (1879) 18.-Am. austr.

retusella, Thw. Enum. P1. Zeyl. 16, 400=sepiaria.

Rheedii, DC. Prod. i. $246=$ zeylanica.

Richardi, Baill. in Bull. Soc. Linn. Par.i. (1885) 463. - Madag.

Richii, A. Gray, Bot. U. St. Expl. Exped. i. 69.Ins. Fiji.

rosea, Oliver, Fl. Trop. Afr. i. 99.-Afr, trop.

Rothii, Oliver, $l$. $c_{.} 97$.-Afr, trop.

rotundifolia, Rottl. in Ges. Naturf. Fr. Neue Schr. iv. 1803) $185=$ zeylanica.

Roxburghii, $D C$. Prod. i. 247.-Ind, or

roydsiaefolia, Kurz, in Fourn. As. Soc. Beng, xxxix.

(1870) Ir. 62.-Burma

rufescens, Turcz. in Bull. Soc. Nat. Mosc. xxvii. (1854) II. 321.-Ins. Sumbawa.

rugulosa, Turcz. l.c. 326.-Venezuela.

rupestris, Sibth. \& Sm. Fl. Graec. t. $487=$ spinosa.

Russeliana, Wall. Cat n. 7001--Ind. or.

sabiaefolia, Hook. f. E Thoms. in Fl. Brit. Ind.i. 179. - Reg. Himal.

salaccensis, Blume, Bijdr. 54.-Java

salicifolia, Griseb. in Goett. Abh. xxiv. (1879) 17.Reg. Argent.

saligna, Vahl, Symb, Bot. iii. $66=$ C. Cynophallophora sandwicensis, Walp. Rep. v. $54=$ seq.

sandwichiana, DC. Prod. i. $245=$ spinosa.

sarmentosa, A. Cunn. ex Benth. Fl. Austral. i. 95.Austral.

sativa, Pers. Syn. ii. $59=$ spinosa.

saxatilis, $H . B$. E $K$. ex DC. Prod. i. 250.-Venezuela

scabrida, H. B. E K. Nov. Gen. et Sp. v. 95.-Am. austr.

scandens, Vell. F1. Flum. 280 ; v. t. $109=$ lineata.

Schimperi, Steud. Nom. ed. II. i. 278.-Arab

sciapkila, Hance, in Ann. Sc. Nat. Sér. V. v. (1866) 206 $=$ pumila.

secaridacea, Triana E Planch, l, c. Sér. IV, xvii (1862) $77 .-\mathrm{N}$. Granat.

sepiaria, Linn. Syst. ed. X. 1071.-Ind. or.; Malaya. sepiaria, Wall. Cat. n. $6993 \mathrm{G}=$ pedunculosa.

sessilis, Banks, ex DC. Prod. i. 249.-N. Granat.

Shanesiana, F. Muell. Fragm, x. 94-Austral.

siamensis, Kurs, fior. Fl. Brit. Burma, i. 63,Burma.

sicula, Duham. Arbr. i. $159=$ spinosa

sidaefolia, Ruiz \& Pav. ex DC. Prod. i. $252=$ crotonoides.

sikkimensis, Kurg, in fourn. As. Soc. Beng. xliii. (1874) II. 181-Reg. Himal.

siliquosa, Linn. Syst. ed. X. $1071=$ jamaicensis.

Sinclairii, Berth. Bot. Voy. Sulp/s. 65. t. 27.-Am. austr.

\section{CAPPARIS}

singalensis, Korth. ex Miq. Illustr. Fl. Arch. Ind. $28=$ pubiflora.

Sodada, R. Br. in Denh. Clapp. \& Oudn. Trav. $225=$ aphylla.

solanoides, Boj. in Ann. Sc. Nat. Sér. II. xx. (1843) 59 = chrysomeia.

speciosa, Griseb. in Goett. Abh. xxiv. (1879) 18.-Reg.

Argent.

speciosa, Moric. ex Eichl. in Mart. Fl. Bras. xiii. $1.27 \%$ $=\mathrm{C} . \mathrm{Yco}$

spinosa, Linn. Sp. Pl. 503.-Reg. Mediterr.; Ind. or. Oriens.

Sprucei, Eichl. in Mart. Fl. Bras. xail. 1. 281.Perav

stylosa, DC. Prod, i. 246 = divaricata

subacuta, Miq. Fl. Ind Bat. i. I. 101 -Bomeo

subbiloba, H. B. \& K. Nov. Gen. et Sp. v. $90=$ C. Cynopballophora.

subcordata, Span. in Linnaea, xv. (1811) 166.-Ins Timor.

subspinosa, Roxb. Hort. Beng. [93] ; Fl.Ind. ii. 568.Ins. Molucc.

Swinhoii, Hance, in fourn. Bot. vi. (1868) 296. China.

tarapotensis, Eichl. in Mart. Fl. Bras. xiii. I. 284.Peruy.

tenera, Dalz. in Hook. Kew fourn. ii. (1850) 41.Ind, or.

tenuiflora, Fl. Brit. Ind. i. 178 , sphalm. $=$ terniflora.

tenuifolia, J. F. Gmel. Syst. 1519, sphalm.= seq.

tenuisiliqua, facq. Enum. Pl. Carib. 24.-N. Granat.

terniflora, DC. Prod. i. $247=$ horrida.

tetrasperma, Thw. Enum. Pl. Zeyl. $15=$ tenera.

Thonningii, Schum, in Schum. EO Thonn. Beskr. Guin.

Pl. 236.-Afr, trop.

Thozetiana, F. Muell. Fragm. v. 104.-Austral.

tomentosa, Lam. Encyc. i. 606.-Afr. trop.

torulosa, Griseb. ex Hemsl. Biol. Centr. Am. Bot. i. 44 = odoratissima.

torulosa, Sw. Prod. Veg. Ind. Occ. 81 = jamaicensis,

trapeziflora, Span. in Linnaea, xv. (1841) 165.-Ins.

Timor.

triflora, Mill. Gard. Dict. ed. VIII. n. $10=$ frondosa.

trifoliata, Roxb. Hort. Beng. 41 ; Fl. Ind. ii. $571=$

Crataeva religíosa.

trifoliata, Spreng. ex DC. Prod. i. $243=$ Crataeva tapioides.

trinervia, Hook. f. \& Thoms. in Fl. Brit. Ind. i. 175. -Barma.

triphylla, Thunb. Prod. Pl. Cap. 92.-Afr. austr.

Tweediana, Eichl. in Mart. Fl. Bras. xiii. 1. 273.-

Reg. Argent.

tylophylla, Spreng. Syst. iv. Cur. Post. 204. -Java.

uberiflora, F. Muell. Fragm. ix. 172-Austral.

umbellata, $R$. Br. in DC. Prod. i. 247.-Austral.

umbellata, Willd. ex Eichl. in Mart. Fl. Bras. xiii. $273=$ angustifolia

umbonata, Lindl. in Mitch. Fonrn. Trop. Austrab. 257.-Austral.

uncinata, Edgew, in Joum. As, Soc Beng. xyi.

(1847) II. $1219=$ spinosa.

uncinata, Lodd. ex Eichl, in Mart. F1. Bras. xiii. 1. 270 = jamaicensis.

uncinata, Wall. Cat. n. $6998=$ tenera.

undulata, Lodd, ex Loud, Hort, Brit. 215 = Loddigesii.

undulata, Zeyh. ex Eckl. E Zeyh. Enum. 14.-Afr, austr.

variabilis, Wall. Cat. n. 7004 (non Capparid.).Ind. or.

Vellosiana, Mart, in Flora, xxii. (1S99) 1. Beibl. $23=$ C. Cynophallophora.

verrucosa, Facq. Enum. Pl. Carib. 23.-Ind. oce; . V. Granat.

verriccosa, Wight, ex Wall. Cat. n. 6980 - stylose

versicolor, Griff. Notul. iv. 577.-Barma.

verticillaris, Turc\%. in Bull. Soc. Wias. Mosc. (186.3) 55:- - Bras.

viminea, Hook. f. E Thoms, in Fl. Brit. Ind. i. 179.Keg. Himal. : Burma.

viridiflora, H. B. \& K. Nov. Gen. et Sp. r. 92tenuisiliqua.

Cilhmeria, DC. Prost. i. atz. Afr. austr.

I! . . . . Hiana, Wight \& Am. Prod, $35=$ zeylanica

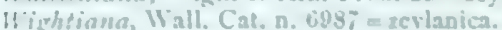

Yco, Mart. Rrise, ii, 5y9; Marb. G Eoihl in Marr. Fl. Bras, xiii. 8. 2i:-liras. 


\section{CAPPARIS :-}

Zeyheri, Turcz. in Bull. Soc. Nat. Mosc, xxvii. (1854) II. 324,-Afr. austr.

zeylanica, Linn. Sp. Pl. ed. II. 720--Ind. or.

zeylanica, Roxb. Hort. Beng. 47 ; Fl. Ind. ii. $567=$ horrida.

zeylanica, Wight \& Arn. Prod. $25=$ acuminata.

Zippeliana, Miq. Illustr. Fl. Arch. Ind. 25. t. 14.-N. Guinea.

CAPRAEA, Opiz, Seznam, 25 (1852)=Salix, Tourn. acuminata, Opiz, 1. c. =S. acuminata

aurita, Opiz, 1. $\mathrm{c}_{\mathrm{s}}=\mathrm{S}$. aurita.

cinerea, Opiz, l. $\mathrm{c}_{\circ}=\mathrm{S}$. cinerea.

grandifolia, Opiz, $\mathrm{l}_{1} \mathrm{c}_{\mathrm{.}}=\mathrm{S}$. grandifolia.

vulgaris, Opiz, 1. $\mathrm{c}_{\mathrm{s}}=\mathrm{S}$. Caprea.

CAPRARIA, [Tourn.] Linn. Gen. ed. I. 28, 75 (1737). SCROPHULARINEAE, Benth. \& Hook. t. ii. 959

Pogostoma, Schrad. Ind. Sem. Hort. Goett. (1831)

Xuarezia, Ruiz \& Pav. Prod. 24. t. 4 (1794)

aegrptiaca, Steud. \& Hochst. ex Endl. Nov. Dec. $23=$ Anticharis arabica.

arabica, Steud. \& Hochst. ex Steud. Nom. ed. II. i $278=$ Anticharis arabica.

biflora, Linn. Sp. Pl. 628.-Am. trop.

calycina, A. Gray, in Proc. Am. Acad. vi. (1862) $49=$ Myoporum debile.

crustace, Linn. Mant. $87=$ Vandellia crustacea

cuneata, [R. Br. in] Ait. Hort. Kew. ed. II. iv. $45=$ saxifragaefolia.

diffusa, Roxb. Hort. Beng. 47; F1. Ind. iii. $93=$ Ebermaiera thysoidea.

dissecta, Delile, F1. Egypte, 239. t. 32. f. $2=$ Sutera glandulosa.

durantifolia, Linn. Syst. ed. X. 1116=Stemodia durantaefolia.

gratioloides, Linn. 1.c. $1117=$ Ilysanthes gratioloides gratissima, Roxb. Hort. Beng. 47 ; F1. Ind. iii. $92=$

Limnophila Roxburghii.

hirsuta, H. B. \& K. Nov. Gen. et Sp. ii. $355=$ saxifragaefolia.

humifusa, Buch.-Ham. ex Wall. Cat. n. $3883=$ Centranthera humifusa.

humilis, [Soland. in] Ait. Hort. Kew. ed. I. ii. $354=$ Stemodia parviflora.

integerrima, Miq. in Linnaea, xxii. (1849) 476. Guiana.

integrifolia, Mart. E Gal. in Bull. Acad. Brux. xii. II. (1845) 20.-Mexic.

lanceolata, Hort. ex Stend. Nom. ed. II. 1. $278=$ salicifolia.

lanceolata, Linn. f. Suppl. $284=$ Freylinia lanceolata

Janceolata, Vahl, Ecl. Am, ii, 47-N. Granat

lucida, [Soland. in] Ait. Hort. Kew. ed. I. ii. $353=$ Teedia lucida.

mexicana, Moric ex Benth. in DC. Prod. x. $429=$ biflora.

Monnieria, Roxb. Hort. Beng. $47=$ Herpestis Monnieria.

multifida, Michx. F1. Bor. Am. ii. 22. t. $35=$ Conobea multifida.

multiflora, Steud. Nom. ed I. 148=Conobea multifida peruviana, Benth. in DC. Prod. x. $430=$ biflora.

pusilla, Tors. in Ann. Lyc. N. York, i. (1824) $36=$ Mimulus floribundus.

rigida, Buch.-Ham. ex Hook. f. F1. Brit. Ind. iv. $301=$ Centranthera hispida.

rigida, Thunb. Prod. Pl. Cap. 103.-Afr. austr.

salicifolia, Link \& Otto, Ic. Pl. Rar. Hort. Berol. 11. t. $4=$ Freylinia cestroides.

salicifolia, Salisb. Prod. $94=$ Freylinia lanceolata

saxifragaefolia, Cham. E Schlecht. in Linnaea, (1830) 105.-Mexic.

semiserrata, Vahl, Ecl. Am. ii. 47.-Am. mer.

undulata, Linn. f. Suppl. 284.-Afr. austr.

uniflora, Burm. f. Fl. Ind. 133.-Ind, or.

CAPRIFICUS, Gasp. Nov. Gen. Fic. 6 (1844)=Ficus, Tourn. (Urticac.)

gigantea, Gasp. Ric. Caprif. $80=$ F. fulva.

insectifera, Gasp. Nov. Gen. Fic. $6=$ F. Carica

lencocarpa, Gasp. Ric. Caprif. 80. t. 2, 3=F. albescens.

oblongata, Gasp. 1. c. $=$ F. neapolitana.

pedunculata, Gasp. 1. c. $=$ F. pedunculata, Miq.

rugosa, Gasp. 1. c. = F. rugosa, Miq.

sphaerocarpa, Gasp. 1. c.=F. globosa, $M i q$.
CAPRIFOLIUM, Toum. ex Linn. Syst. ed. I (1735) = Lonicera, Linn. (Caprifol.).

alpigenum, Gaertn. Fruct. i. 136=L. alpigena.

alpinum, Lam. F1. Fr. iii. $367=\mathrm{L}$. alpigena.

arboreum, Noronha, in Verh. Batav. Gen. v. (1790) ed

I. Art. IV. 9.-Malaya.

atropurpureum, Hort. ex C. Koch, Dendrol. ii. II. $8=$ L. Caprifolium.

balearicum, Dum.-Cours. Bot. Cult. ed. II. iv. $358=\mathrm{L}$ implexa.

bracteosum, Michx. F1. Bor. Am. i. 105=L. glauca.

caeruleum, Lam. FI. Fr. iii. $366=\mathrm{I}$. caerulea

chinense, Wats. ex Loud. Hort. Brit. $79=\mathrm{L}$. japonica

ciliosum, Pursh, Fl. Am. Sept. i. $160=\mathrm{L}$. ciliosa.

cristatum, Noronha, in Verh. Batav. Gen. v. (1790)

ed. I. Art. IV.9.-Malaya.

dentatum, Rafin. Atl. Journ. 151.-Am. bor.

dioicum, Roem. \& Schult. Syst. v. $260=$ L. glauca.

distinctum, Moench, Meth. $501=\mathrm{L}$. Periclymenum

Douglasii, Lindl. in Trans. Hort. Soc. Lond. vii (1830) $244=\mathrm{L}$. hirsuta.

dumetorum, Lam. FI. Fr. iii. $367=$ L. Xylosteum.

etruscum, Roem. \& Schult. Syst. v. $261=$ L. etrusca.

frovum, Ell, Sketch, i. $271=\mathrm{L}$. flava.

flexuosum, Hort. ex Stend. Nom. ed. II. i. $278=\mathrm{I}$ japonica.

Fraseri, Pursh, F1. Am. Sept. i. $160=$ L. flava.

germanicum, Delarb. Fl. Auv. ed. II. $128=\mathrm{L}$. Caprifolium.

germanicum, Quer, Fl. Esp. t. $79=\mathrm{L}_{\mathrm{e}}$ etrusca

germanicum, Roehl. Deutschl. Fl. i. 175 = L. Pericly. menum

glaucum, Moench, Meth. 502=L. glauca.

gratum, Pursh, Fl. Am. Sept. i. $161=$ L: grata.

hirsutum, Denson, ex Loud. Hort. Brit. Suppl. iii. $509=$ L. hirsuta.

hispidulum, Dongl. ex Lindl. Bot. Reg. t. $1761=\mathrm{I}$. hispidula.

hortense, Lam. Fl. Fr, iii. $365=$ L. Caprifolium.

implexum, Roem. \& Schult. Syst. v. $261=$ L. implexa.

italicum, Medic. Pfl. Anat. $97=$ L. Caprifolium

japonicum, D. Don, Prod. Fl. Nep. $140=$ L macrantha

japonicum, Roem. \& Schult. ex Steud. Nom. ed. II. $278=\mathrm{L}$. longiflora.

javanicum, Blume, Bijdr. $653=\mathrm{L}$. javanica

longiflorum, Sabine, in Bot. Reg. t. $1232=\mathrm{L}$. longiflora.

Loureiri, Blume, Bijdr. $653=\mathrm{L}$. confusa.

macranthum, D. Don, Prod. F1. Nep. $140=\mathrm{L}$. macrantha.

nopalense, G. Don, ex Loud. Hort. Brit. $79=\mathrm{L}$. macrantha.

oblongifolium, Sweet, Hort. Brit. ed. II. 259=L. oblongifolia.

occidentale, Lind1. Bot. Reg, t. 145 $\overline{7}=\mathrm{L}$. ciliosa.

ovatum, Noronha, in Verh Batav Gen. v. (1790) ed. I

Art. IV. 9 =Clerodendron serratum.

pallidum, Schur, Enum. Pl. Transs. $243=$ L. Caprifolium.

paniculatum, Noronha, in Verh. Batav. Gen. v. (1790) ed. I. Art. IY. 9.-Malaya.

parviflorum, Pursh, Fl. Am. Sept. i. $161=\mathrm{I}$. glauca.

perfoliatum, Roehl. Deutschl.Fl.i..175 = L.Caprifolium.

Periclymenum, Delarb. Fl. Auv. ed. II. $129=$ L. Periclymenum.

pilosum, H. B. \& K. Nov. Gen. et Sp. iii. 427. t. 298 $=\mathrm{L}$. pilosa.

pubescens, Goldie, in Edinb. Phil. Journ. (Apr. 1822 $323=\mathrm{L}$. hirsuta

pyrenaicum, Lam. Fl. Fr. iii. $366=\mathrm{L}$. pyrenaica.

quercifolium, Meigen, Syst. Verz. $35=$ L. Periclymenum.

reclinatum, Noronha, in Verh. Batav. Gen. v. (1790) ed. I. Art. IV. 9.-Malaya.

roseum, Lam. Fl. Fr. iii. $368=$ L. japonica.

rotundifolium, Moench, Meth. $501=\mathrm{L}$. Caprifolium.

rubrum, Rafin. Fl. Ludov. 78.-Am. bor

nupestris, Rafin. New F1. Am. iii. 17.-Am. bor.

scarlatinum, Noron'a, in Verh. Batav. Gen. v. (1790)

ed. I. Art. IV 9.-Malaya

sempervirens, Moench, Meth. Suppl. $194=$ L. sem-

pervirens.
sericeum, Noronha, in Verh. Batav. Gen. v. (1790)

ed. I. Art. IV. 9.-Malaya.

sylvaticum, Lam. Fl. Fr. iii. $365=\mathrm{L}$. Caprifolium.

viticifolium, Noronha, in Verh. Batav. Gen. v, (1790)

ed. I. Art. IV. 9.-Malaya.

vulgare, Medic. Pfl. Anat. $387=\mathrm{L}$. Caprifolium.

Xylosteum, Gaertn. Fruct. i. $135=$ L. Xylosteum
CAPRIOLA, Adans. Fam. ii. $31(1763)=$ Cynodon, Pers. (Gramin.).

CAPROXYLON, Tussac, Fl. Antill. iv. t. $30(1827)=$ Hedwigia, Sw. (Burserac.)

Hedwigii, Tussac, 1. c. = H. balsamifera.

CAPSELLA, Medic: Pflanzeng. i. 85 (1792) CRUCIFERAE, Benth. \& Hook. f. i. 86.

Bursa, [Web. in] Wigg.. Prim. Fl. Holsat. $47(1780)$. Bursa-PASTORIS, [Tourn.] Rupp. Fl. Jen. ed. Hall. $87(1745)$, nomen prius.

Hymenolobus, Nutt. ex Torr. \& Gray, Fl. N. Am. i. 117 (1838).

MarsypocarPus, Neck. Elem. iii. 91 (1790),

Microlepidium, F. Muell. in Linnaea, xxv. (1852) 371.

acutifolia, Rafin. New Fl. Am. ii. 27=C. Bursapastoris?

agrestis, Jord. Diagn. i. $339=$ C. Bursa-pastoris

agrestisurubella, Paill. in Mém. Soc. Emul. Doubs, Sér. IV. ví. (1872) $80=$ C. Bursa-pastoris

amblodes, Rafin. New Fl. Am, ii. $28=$ C. Bursa-pastoris,

Andraeana, F. Muell, in Wing, South. Sc. Record (March, 1885).-Austral.

antipoda, F. Muell. in Trans. Phil. Soc. Vict. i. (1855) 34.--Austral

antipoda, F. Muell. Pl. Vict. i. $44=$ australis.

apetala, Opiz, in Flora, v. (1822) $269=\mathrm{C}$. Bursapastoris.

australis, Hook. f. ex Benth. Fl. Austral. i. 81.Austral.

Berengeriana, Hort. Petrop. ex Bull. Phys.-Math. Acad. Pétersb. xiv. (1856) $234=$ procumbens.

bifida, Rafin. New Fl. Am. ii. $28=\mathrm{C}$. Bursa-pastoris?

blennodina, F. Muell. Pl. Vict. i. $42=$ Blennodia alpestris.

Bursa, Rafin. New Fl. Am. ii. $28=$ C. Bursa-pastoris.

Bursa-pastoris, Medic. Pflanzeng. 85.-Reg. temp.

ceratocarpa, Moench, Meth. $271=$ Thlaspi ceratocarpon.

cochlearina, F. Muell. Pl. Vict. i. 51-Austral.

cornigera, Medic. Pflanzeng. $86=$ Thlaspi ceratocarpon

dentata, Rafin. New Fl. Am. ii. $28=$ C. Bursapastoris?

divaricata, Walp. Rep. i. 175.-Am, bor, occ.

Drummondii, F. Muell. Fragm. xi. 26.-Austral.

elliptica, C. A. Mey, in Ledeb. Fl. Alt. iii. $199=$ procumbens.

erecta, Walp. Rep. i. $175=$ divaricata.

furcata, Rafin. New Fl. Am. ii. $28=$ C. Bursapastoris ?

gracilis, Gren. in Mém. Soc. Emul. Doubs, Sér. III. ii, (1858) $403=$ C. Bursa-pastoris.

grandiflora, Boiss. Diagn. Ser. I. i. 76.-Archip. Graec.

humistrata, F. Muell. Fragm. xi. 25.-Austral,

hybrida, Albert, in Bull. Soc. Sc. Draguignan (1884) [reimpr. 9].-Gallia.

integrifolia, Rafin. New F1. Am. ii, 27=C. Bursapastoris.

mexicana, Hemsl. Diagn. Pl. Nov. 19.-Mexic.

pastoris, Rupr. F1. Caucas, $128=$ C. Bursa-pastoris.

pauciflora, Koch, in Sturm, Deutschl. H1. Heft x. $66=$ Hutchinsia pauciflora.

pastoralis, Dulac, Fl. Hautes-Pyr, 189=C. Bursapastoris.

pilosula, F. Muell. Vict. Pl. i. 44.-Austral.

polymorpha, Cav. Desc. $411=$ C. Bursa-pastoris.

poimenobalantion, St. Lag. in Ann. Soc. Bot. Lyon, vii. (1880) $71=\mathrm{C}$. Bursa-pastoris.

praecox, Jord. Diagn. i. $342=$ C. Bursa-pastoris.

procumbens, Fries, Novit. Fl. Suec, Mant. i. 14.Reg. temp.

pubens, Benth. E Hook. f. ex S. Wats. Bibliog. Ind. N.Am, 52.-Am. bor, occ.

puberula, Rupr. Fl. Caucas. 129.-Reg. Caucas.

rubella, Reut. in Comptes-Rend. Soc. Hallér. (1853-54) 18.-Europ.

rubello-agrestis, Paill. in Mém. Soc. Emul. Doubs, Sér. IV. vi. (1872) $80=$ C. Bursa-pastoris.

rubescens, Personnat, in Bull. Soc. Bot. Fr. vii. (1860) $511=$ rubella.

ruderalis, Jord. Diagn. i. $340=$ C. Bursa-pastoris.

sabulosa, Jord. 1. c. $341=$ C. Bursa-pastoris?

Schaffneri, S. Wats. in Proc. Am. Acad. xvii. (188182) 322.-Mexic

spinosa, Moench, Meth. Suppl. $89=$ Lepidium spinosum 
CAPSELLA :-

stenocarpa, Timb. in Bull. Soc. Hist. Nat. Toulouse, iii. (1869) 115.-Gallia.

tasmanica, F. Muell. Fragm. xi. 26.-Ins. Tasman

Thomsoni, Hook. f. in fourn. Linn. Soc. v. (1861) 172.-Tibet, occ

triangularis, St. Lag. in Ann. Soc. Bot. Lyon, vii. (1880) $69=\mathrm{C}$. Bursa-pastoris.

virgata, Jord. Diagn, i. $339=$ C. Bursa-pastoris.

CAPSICUM, [Tourn.] Linn. Syst. ed. I (1735). SOLANACEAE, Benth. \& Hook, f. ii. 892.

abyssinicum, A. Rich. Tent. Fl. Abyss, ii. 96.Abyssin.

aggregatum, Willd.ex Roem. Ev Schult. Syst. iv. 809. -Am. bor.

angulosum, Mill. Gard. Dict. ed. VIII.n. $4=$ annuum ? angustifolium, Dun. in DC. Prod. xiii. 1. 420 .Ind. or.

annuum, Linn. Sp. Pl. 188.-Reg. trop.

anomalum, Franch. Es Sav. Enum. Pl. Fap. ii. 452.Japon.

Axi, Vell. F1. Flum, 61 ; ii. t. $6=$ annuum

baccatum, Hort. Genev. ex Dun. in DC. Prod. xiii. I. $420=$ angustifolium

baccatum, Buch.-Ham. ex Wall. Cat. n. $2644=$ minimum.

baccatum, H. B. \& K. Nov. Gen. et Sp. iii. $39=$ cumanense.

baccatum, Linn. Mant. i. 46.--Reg. trop

baccatum, Rodsch. Obs. $38=$ globiferum.

baccatum, Vell. Fl. Flum. 60 ; ii. t. $3=$ frutescens.

Bauhini, Dun. in DC. Prod, xiii. I. 428.-Hab.?

bicolor, Jacq. Fragm. 66. t. 99, f. $1=$ nigrum.

caerulescens, Bess. Cat. Hort. Crem. 27.-Hab.?

campylopodium, Sendt. in Mart. Fl. Bras. x. 144.Bras.

cerasiflorum, Link, Enum. Hort. Berol, i. 190.Hab.?

cerasiforme, Fort. ex Dun. in DC. Prod. xiii. I. $420=$ baccatum

cerasiforme, Mill. Gard. Dict, ed. VIII. n. $5=$ annuum?

cerasiforme, Willd. Enum. Hort. Berol. i. $242=$ grossum.

ceratocarpum, Fingerh. Monog. 22.- Hab. ?

cereolum, Bertol. Hort. Bonon. PI. Nov, i. 6. t. $2=$ frutescens.

chamaecerasus, Nees, in Trans. Linn. Soc. xvii. (1837) 65 = grossum.

chinense, Facq. Hort. Vindob. iii. 38. t. 67.-Hab. ?

chlorocladum, Dun. in DC. Prod. xiii. I. 415. Mexic.

ciliare, Willd, Enum. Hort. Berol. $243=$ microcarpum.

Comarim, Vell. Fl. Flum. 60 ; ii. t. $2=$ frutescens.

conicum, Lam. Illustr, n. $2390=$ conoideum

conicum, G. F. W. Mey. Prim. Fl. Esseq. 112.Guiana

conicum, Vell. F1. Flum, ii. t. $9=$ baccatum

conoides, Roem. \& Schult. Syst. iv. $562=$ frutescens.

conoideum, Mill. Gard. Dict. ed. VIII, n. 1 = annuum

cordiforme, Mill. 1. c. n. 2 =annuum?

crispum, Dun. in DC. Prod. xiii. x. 415.-Ins. Maurit.

cumanense, Fingerh. Monog. 17.-Venezuela.

curvipes, Dun. in DC. Prod. xiii. I. 423.-Guiana

cydoniforme, Hort. ex Roem. \& Schult. Syst. iv. $561=$ tetragonum

dichotomum, Vell. Fl. Flum. 61; ii. t. 9-Bras.

dalce, Hort. ex Dun, in DC. Prod. xiii. 1. 428.-Reg. trop.

fastigiatum, Blume, Bijdr. $705=$ minimum.

flexuosum, Sendt. in Mart. Fl. Bras. x. 143,-Bras.

frutescens, Linn. Sp. Pl. 189.-Reg. trop

frutescens, Rodsch. Obs. $38=$ conicum.

glandulosum, Dun . in DC. Prod. xiii. I. 417.-Bras,

globiferum, G. F. W. Mey. Prim. Fl. Esseq. 113.-

Guinns.

globosum, Bess. Cat. Hort. Crem. 27=gro sum.

gracilipes, Dun. in DC. Prod. xiii. 418.-Bras.

grossum, Linn. Mant. i. 47 ; Roxb. Hort. Beng. 17 ;

Fi. Ind. i. 574 --Reg. trop.

grossum, Willd. Enum. Hort. Berol. $241=$ annunm.

Hamiltonii, G. Don, Gen. Syst. iv, $447=$ nigrum.

havanense, $H . B . \sigma^{\circ} K$. Nov. Gen. et $S_{p}$, iii. $49 .-\mathrm{Am}$. austr

hispidum, Dun. in DC. Prod. xiii. 1. 419,-Texas.

Homemanni, Dun, l. c. 429 - Hab. ?

\section{CAPSICUM}

inaequale, Vell. Fl. Flum, 61; ii, t, 5.-Bras.

laurifolium, Dun. in DC Prod xiii 1, 418 - Ind occ.

Bras.

lencocarpon, Mill. ex Fingerh. Monog. 32.-Hab.

longum, Bouton, ex Dun. in DC. Prod. xiii. I. 414 conoides.

longum, DC. Cat. Hort. Monsp. (1813) 86=annuum. luteum, Lam. Illustr. n. 2392.-Ind. or.

Maximowiczii, Regel \& Rach, Ind. Sem. Hort. Petrop. 1858) 40 .- Hab. ?

micranthum, Link, Enum. Hort. Berol. i. 190.-Bras

microcarpum, Cav. Desc. 371; DC. Cat. Hort. Monsp. 86.--Ind. occ.

microphyllum, Dun. in DC. Prod. xiii. 1. 421 baccatum.

Milleri, Roem. \& Schult. Syst. iv. $563=$ annuum

minimum, Blanco, Fl. Filip. ed. I. 133.-Ins. Philipp.

minimum, Mill. Gard. Dict. ed. VIII. n. $10=\mathrm{bac}$ catum, microcarpum.

minimum, Roxb. Hort. Beng. 17; Fl. Ind. i. 574.Reg, trop.

mirabile, Mart. Fl. Bras. x. 144,-Bras.

Narunca, Hort. Matr. ex Dun. in DC. Prod. xiii. I. $414=$ nigrum.

nigrum, Willd. Enum. Hort. Berol. 242.-Hab. ?

odoratum, Steud. Nom. ed. II. i. $279=$ frutescens.

odoriferum, Vell. Fl. Flom, 61 ; ii, t. 8 =frutescens.

olivaeforme, Mill. Gard. Dict. ed. VIII. n. 6 annuum?

ovatum, DC. Cat. Hort. Monsp. (1813) 86.-Hab.

oxycarpum, Dun. in DC. Prod. xiii. I. 426.-Bras.

parvifolium, Sendt. in Mart. Fl. Bras. X. 145.Bras.

pendulum, Willd. Enum. Hort. Berol. i. 242.Cuba.

pomiferum, Mart. ex Steud. Nom. ed. II. i. 279 grossum.

pubescens, Dun. in DC. Prod. xiii. I. $415=$ chlorocladum.

pubescens, Ruiz \& Pav. Fl. Per. ii. 30-Perny.

pulchellum, Salisb. Prod. $134=$ baccatum.

purpureum, Vahl, ex Hornem. Hort. Hafn. i. $224=$ grossum.

pyramidale, Mill. Gard. Dict. ed. VIII. n. 7.Aegypt.

quitense, Willd, ex Roem. \& Schult. Syst, iv. $809=$ violaceum.

Rabenii, Sendt. in Mart. Fl. Bras. x. 145.-Bras.

salicifolium, Dun, in DC. Prod. xiii. I. 418.-Bras

Schottianum, Sendt. in Mart. Fl. Bras. x. 143.Bras.

silvestre, Vell. Fl. Flum. 60 ; ii. t. $1=$ annumm

sinense, Murr. Syst. ed. XIV.226= chinense

sphaerium, Willd. Enum. Hort. Berol. i. $241=$ annuum?

strictum, Fingerh. Monog. 21.-Am. austr.

testiculatum, Vis. ex Dun. in DC. Prod.xiii. I. 424.- Hab. ?

tetragonum, Mill. Gard. Dict. ed. VIII, n. $3=$ annuum?

tomatiforme, Fingerh. ex Steud. Nom. ed. II. i. $279=$ dulce.

torulosum, Hort. Matr. ex Hornem. Hort. Hafn. Suppl. $27=$ pyramidale

torulosum, Vell, Fl. Flum, 60 ; ii t. 4-Bras.

Tournefortii, Bess. Cat. Hort. Crem. (1811) $27=$ annuum.

toxicarium, Poepp. ex Fingerh. Monog. $32=$ frutescens, umbilicatum, Vell. F1. Flum. 61 ; ii. t. 7 =annuum. nstulatum, Paxt. Mag. Bot. v. 197.-Chili.

villosum, Sendt. in Mart. Fl. Bras. x. 14t.-Bras.

violaceum, Desf. Tabl. Hort. Par. ed. I. 70 ; Desv. in Ham. Prod. $25=$ nigrum

violaceum, H. B. E K. Nov. Gen. et $S p$. iii. $49 .-$ Ecuador.

CAPURA, Blanco, Fl. Filip. ed. I. 264 (err. typ. 64t) SAPINDACEAE, Benth. \& Huok. ro i. 405.

Otolepis, Turcz, in Bull. Soc. Nat. Mose, xxi. (1848) I. 572.

OTOPHORA, Blume, Rumphia, iii. 142 (1850)

nigrescens, Vidal, Sinops. 1. S4. f. E = pinnata.

pinnata, Blanco, Fl. Filip.ed. I. 264.-Ins. Philipp.

CAPURA, Linn. Mant. ii. $149(1771)=$ Wikstroemia Endl. (Thymelac.)

purpurata, Linn. 1. c. $225=W$, indica.
CAQUEPIRIA, J. F. Gmel. Syst. 651 (1791) $=$ Gar. denia, Ellis (Rubiac.).

Bergkia, J. F. Gmel. 1. c. $=$ G. Thunbergia

CARACALLA, Tod. Ind. Sem. Hort. Panorm. (1861) 32 et in Lem. Yllustr. Hortic. ix. (1862) Misc. 13 Phaseolus, Tourn. (Legumin.)

pulcherrima, Tod, 11. cc. = P. Caracalla.

CARACHERA, Juss. in Dict. Sc. Nat. vii. 11 (1817) = Charachera, Forsk. (Inc, sed.)

CARADESIA, Rafin. New F1. Am, iv, 80 (1836) Eupatorium, Tourn. (Compos.)

pauciflora, Rafin. I. c. =E. pauciforum, Rafin.

CARAGANA, Lam. Encyc。 i. 615 (1783). LEGU MINOSAE, Benth. \& Hook. f. i. 505.

acaulis, Baker, in Fourn. Linn. Soc. xviii. (1881) 44 -Afghanist.

Altagana, Poir. Encyc. Suppl. ii. $89=$ microphylla.

ambigua, Stocks, in Hook. Kew fourn. iv. (1852) 145 - Beluchist.

arborescens, Lam. Encyc. i. 615.-Sibir.

arenaria, Donn, ex Sims, Bot. May. t. 1886 - Sibir.

argentea, Lam. Encyc. i. $616=$ Halimodendron argentenm.

brevispina, Benth. in Royle, Illustr. Bot. Himal. 198 - Reg. Himal.; Afghan.

Bungei, Ledeb. Fl. Alt. iii. 264.-Sibir. alt.

Chamlagu, Lam. Encyc. i. 616.-China.

chinensis, Turcz. ex Maxim. Prim. Fl. Amur, $470=\mathrm{C}$. Chamlagu.

conferta, Benth. ex Baker, in Hook. f. Fl. Brit. Ind. ii.

116.- Tibet. occ.

crassicaulis, Benth. ex Baker, l. c. 117.-Reg. Himal.

cuneata, Baker, l. c.--Reg. Himal.

cuneata, Moench, Meth, $135=$ frutescens.

digitata, Lam. Encyc. i. $616=$ frutescens.

ferox, Lam. 1. c. $315=$ spinosa

fava, Poir. Encyc. Suppl. ii. $90=$ Robinia flava.

frutescens, Medic. in Vorles. Churpf. Phys. Ges. Ii.

(1787) 365.--Reg. Caucas.; Soongaria

frutex, C. Koch, Dendrol. i. $48=$ seq. ?

fruticosa, Bess. Cat. Hort. Crem, $11 b^{\circ}=$ arborescens.

Gerardiana, Benth. in Royle, Illustr. Bot. Himel. 198.-Reg. Himal.

glomerata, Hort. ex C. Koch, Dendrol. i. $48=$ microphylla.

gracilis, Hort. ex C. Koch, l. c. 52.-Hab. ?

grandiflora, DC. Prod. ii. 268.-As. Min.; Reg. Casp.

Halodendrum, Hoffmgg. Verz. PA.46= Halimodendron argenteum.

inermis, Moench, Meth. 185 = arborescens.

jubata, Poir. Encyc. Suppl. ii. 89.-Sibir.

microphylla, Lam. Encyc. i. 615.-Sibir. alt.

mollis, Bess. Enum. Pl. Volh. $29=$ fratescens.

mongolica, Fisch. ex Steud. Nom. ed. II. i. 27 -

Mongolia.

mongolica, Hort. ex C. Koch, Dendrol. i. $47=$ arborescens.

Moorcroftiana, Benth. in Royle, Illustr. Bot. Himal. $198=$ Sophora Moorcroftiana.

nubigena, Bunge, Monog. Astrag. $210=$ crassicaulis.

parvifolia, Hoffmgg. Preise. Pf. viii. An/. 39 ; es

Walp. Rep. i. $651 .-\mathrm{Hab}$. ?

polyacantha, Benth. in Royle, Illustr. Bot. Himat.

198. - Reg. Himal.

pygmaea, DC. Prod. ii. 268,-Reg. Himal.; As. bor. quadrifolia, Medic Pfl.-Anat. $62=$ frutescens.

Redowskii, DC. Mém. Ĺg. 94. t. 11.f. 45.-Sibir.

rosea, Turcz. ex Maxim. in Prim. Fl. Amur. tio frutescens.

sibirica, Medic. in Vorles. Churff. Phys. Ges. .

(1787) 365.-Sibir.

sophoraefolia, Hort, ex C. Kich, Dendrol. i. ti

arberescen:

sophoraefulia, Tausch, in Flora, xxi. (1s9s) I. Bribl. ii. - IInb. ?

spinosn, DC. Prort. ii. 269 - - Sibir.

spirrosa, Rich. $\mathrm{ex}$ I)C. l. c. $91 \mathrm{t}=$ Picfelia squamata.

spinosissima, Bench, in Royle, Illuetr. Kot Jlimal.

$198=$ Gerardians.

lenuis, Hoffmgg. Prrist. PH. viii. Anh. 10; ex Wials. Rep.i. B81.-Hiab. 1

cortumensis. Boiss. ex Trhihal. Asis Min. Bod. i. 1? numen - As Mlin.

3 II 2 


\section{CARAGANA :-}

tragacanthoides, Poir. Encyc. Suppl. ii 90-Sibir. triflora, Lindl. Bot. Reg. (1845) Misc. $41=$ brevispina ? ulicina, Stocks, in Hook. Kew Fourn. iv. (1852) 145.Beluchist.

versicolor, Benth. in Royle, Illustr. Bot. Himal. 198. t. $34=$ pygmaea

CARAGUATA, [Plum.] Lindl. Bot. Reg. sub t. 1068 (1827). BROMELIACEAE, Benth. \& Hook. f. iii, 668.

Devillea, Bert. ex Schult. f. Syst. vii. p. Ixvii. 1229 (1830).

Massangra, E. Morr. in Belg. Hortic. (1877) 59, 199. t. 8.

Andreana, E. Morr. in Rev. Hortic. (1884) 247.-N. Granat.

angustifolia, Baker, in Gard. Chron. (1884) I1. 616. N. Granat.

Augustae, Benth. E Hook. f. Gen. iii. 668.-Guiana.

Berteroniana, Schult. f. Syst. vii. Ir. 1229.-Porto Rico.

cardinalis, E. André, in Illustr. Hortic. xxvii. (1880) t. 374 ; Rev. Hortic. (1883) $12=$ lingulata.

coriostachya, Griseb. in Goett. Nachr. (1864) 21.Venezuela.

fulgens, Griseb. l. c.-Venezuela.

Fuerstenbergiana, Kirch E Wittm, in Berl. Gartenzeit. (1883) 299.-Ecuador.

latifolia, Beer, Bromel. $78=$ lingulata.

lingulata, Lindl. Bot. Reg. sub t. 1068.-Am. trop.

macrostachya, Bello, in Anal. Soc. Esp. Hist. Nat. xii. (1883) 122...Porto Rico.

musaica, E. André, in Illustr. Hortic. xxiv. (1877) t. 268.-N. Granat.

nitida, Griseb. in Goett. Nachr. (1864) 21.-Venezuela.

Osyana, E. Morr, in Belg. Hortic. xxxv. (1885) 254. Ecuador.

Peacockii, E. Morr. l. c. 82.-Reg. Andin. ?

sanguinea, E. André, in Rev. Hortic. (1883) 468.-N, Granat.

serrata, Hort. Petrop. ex Antoine, Bromel. $46=$ Karatas Scheremetiewii.

serrata, Schult. f. Syst. vii. II. $1231=$ Tillandsia serrata.

sphaerocephala, Gaudich. Bot. Voy. Bonite, t. 61.Hab.?

splendens, Hort. ex Planch. in Fl. des Serres, (1856) 31. t. $1091=$ lingulata.

Van-Volxemi, E. André, in Illustr. Hortic. xxv. (1878)

t. 326.-N. Granat.

Zahnii, Hook. f. Bot. Mag. t. 6059.-Am. centr.

CARAIPA, Aubl. Pl. Gui. i. 561 (1775), ex parte. TERNSTROEMIACEAE, Benth. \& Hook. f. i. 188. africana, Oliver, $\mathrm{Fl}$. Trop. Afr. i. 172.-Afr, trop. angustifolia, $A u b l$. $P l$. Gui. i. 561.-Guiana.

calophylla, Benth. in fourn. Linn. Soc. v. (1860) 61. -Bras.

calophylla, Spreng. ex Choisy, in Mém. Soc. Phys. Genèv. xiv. (1855) $166=$ glabrata

costata, Spruce, ex Benth. in Fourn. Linn. Soc. v. (1860) 61-Ám, austr.

densiflora, Mart. Nov. Gen. et Sp. i. 105.--Bras.

fasciculata, Cambess. in Mém. Mus. Par. xvi. (1828) 416.-Guiana.

glabrata, Mart. Nov. Gen. et Sp. i. 105.-Bras.

grandiflora, Mart. l. $c$.-B-Bras.

latifolia, Aubl. Pl. Gui, i. 561-Guiana.

laurifolia, Spruce, ex Choisy, in Mém. Soc. Phys. Genèv. xiv. (1855) 166.-Bras.

laxiflora, Benth. in Hook. Lond. Fourn. Bot. ii. (1843) 364.-Guiana.

leiantha, Benth. l.c.-Guiana.

longifolia, $A u b l$. Pl. Gui, i, 561-Guiana.

myrciaefolia, Spruce, ex Benth. in Journ. Linn. Soc. v. (1860) 61 = fasciculata.

paniculata, Mart. Nov. Gen. et Sp. i. 104.-Bras

parvifolia, Aubl. Pl. Gui. i. 561.-Guiana.

racemosa, Cambess. in Mém. Mus. Par. xvi. (1828) 415. t. 3.-Bras.

Richardiana, Cambess. l. c. 414.-Guiana.

Sellowii, Turcz. in Bull. Soc. Nat. Mosc. xxxvi. (1863) I. 578.-Bras.

suaveolens, Planch. ex Benth. in Fourn. Linn. Soc. v. (1860) 61.-Guiana.

surinamensis, Miq. Stirp. Surin. Sel. 75.-Guiana.

\section{CARAIPA :-}

tereticaulis, Tul. in Ann.Sc. Nat. Sér. III. viii. (1847)

$341 .-G u i a n a$.
variabilis, Cambess. in Mém. Mus. Par. xvi. (1828) 416.-Guiana.

CARAJAEA, Wedd. in DC. Prod. xvii. $84(1873)=$ Castelnavia, Tul. (Podostemac.).

orthocarpa, Wedd. 1. c. $85=$ Castelnavia orthocarpa.

CARALIIA, Roxb, ex R. Br. in Flind. Voy. ii. 549 (1814). RHIZOPHOREAE, Benth. \& Hook. f. i. 680 .

Barraldeia, Thou. Gen. Nov. Madag. 24 (1809). Baraultia, Spreng. Syst. ii. 313 (1825)

Catalium, Buch.-Ham. ex Wall. Cat. sub n. 4880 (1831?).

Demidofia, Dennst. Schluess. Hort. Malab. 31 (1818).

Diatoma, Lour. Fl. Cochinch. 296 (1790), nomen prius.

KARE-KANDEL, Adans. Fam. ii. 88 (1763).

Petalotoma, DC. Prod. iii. 294 (1828).

Symmetria, Blume, Bijdr 1130 (1826).

Baraldeia, Arn. in Ann. Nat. Hist. i. (1838) 371.Madag.

calycina, Benth. in Fourn. Linn. Soc. iii. (1859) 75.Zeylan.

celebica, Blume, Mus. Bot. Lugd. Bat. i. 131.Ins. Celebes.

cerisopsifolia, Miq. Anal. Bot. Ind. iii. $8=$ integerrima ceylanica, Am. in Ann. Nat. Hist. i. (1838) $371=$ integerrima.

confinis, Blume, Mus. Bot. Lugd. Bat. i. 129=lanceaefolia.

corymbosa, Arn. in Ann. Nat. Hist. i. (1838) $37 \mathrm{I}=$ integerrima.

cuspidata, Blume, Mus. Bot. Lugd. Bat. i. 129.Borneo.

densiflora, Griff. Notul. iv. 668.-Burma

integerrima, $D C$. Prod. iii. 33.-As, et Austral. trop.

lanceaefolia, Roxb. Hort. Beng. [37]; Fl. Ind. ii. 481 .

-Burma; Malaya.

lanceolaria, Wall. Cat. n. $4881=$ lanceaefolia

lucida, Roxb. ex Kurz, For. FI. Brit. Burm. i. $451=$ integerrima.

lucida, Roxb. Hort. Beng. [92] ; Fl. Ind. ii. $481=$ lanceaefolia.

madagascariensis, Tul. in Ann. Sc. Nat. Sér. IV. iv. (1856) 117. t. 6.-Madag.

multiflora, Blume, Mus. Bot. Lugd. Bat. i. 131.Borneo.

multiflora, Miq. F1. Ind. Bat. i. I. 594=floribunda.

obcordata, Wight, ex Walp. Rep. ii. $71=$ integerrima.

octopetala, F. Muell. P1. Austr. Trop. Occid. ex Benth. in Journ. Linn. Soc. iii. (1859) $74=$ integerrima.

sinensis, Arn. in Ann. Nat. Hist. i. (1838) $371=$ integerrima.

symmetria, Blume, Mus. Bot. Lugd. Bat. i. $130=$ integerrima.

timorensis, Blume, 1. c. $128=$ integerrima

Tulasnei, Baill. Adansonia, iii. (1862-63) 20.-Ins Marian.

zeylanica, Am. in Wight, Illustr. Ind. Bot. t. $90=$ integerrima.

CARAILUMA, R. Br. in Mem. Wern. Soc. i. (1809) 25. ASCLEPIADEAE, Benth. \& Hook. f. ii. 782.

adscendens, $R, B r . l$. $c$.-Ind, or.

attenuata, Wight, $I c$, iv. 15. t. 1268.-Ind, or.

crenulata, Wall. Pl. As. Rar. i. 6.t. $7=$ Boucerosia crenulata.

edulis, Benth. ex Hook. f. Fl. Brit. Ind. iv. 76.Ind. or.

fimbriata, Wall. Pl. As. Rar. i. 7. t. 8.-Ind. or.; Burma.

subulata, Decne. in Ann. Sc. Nat. Sér. II. ix. (1838) 267.-Arabia.

umbellata, Haw. Syn. Pl. Succ. $47=$ Boucerosia umbellata.

CARAMANICA, Tineo, Pl. Rar. Sic. $3(1847$ ?)= Taraxacum, Linn. (Compos.).

taraxacoides, Tineo, 1. c. $4=$ T. minimum.

CARAMBOLA, Adans. Fam. ii. 508 (1763)=Averrhoa Linn. (Oxalid.).
CARANDA, Gaertn. Fruct. ii. 17.t. 83.f. 5 (1791) (Gen. dub, fructu deformato)

pedunculata, Gaertn. 1. c.-Zeylan.

CARANDAS, Rumph. ex Adans. Fam. ii. $171(1763)=$ Carissa, Linn. (Apocyn.).

CARANGA, Vahl, Enum, i. $100(1805)=$ Curanga Juss. (Scrophular.)

amara, Vahl, 1. c. = Curanga amara

CARAPA, Aubl. Pl. Gui. ii. Suppl. 32. t. 387 (1775), MELIACEAE, Benth. \& Hook, f. i. 338.

Persoonia, Willd. Sp. Pl. ii. 331 (1800).

RACAPA, M. Roem. Syn. Hesper, 123 (1846)

Touloucouna, M. Roem. 1. c. (1846).

Xylocarpus, Koen. ex A. Juss. in Mém. Mus. Par. xix. (1830) 243

ZeLeA, Hort. ex Tenore, in Atti $3^{a}$ Reun. Sc. Ital (1841) 504

ZURLOA, Tenore, 1. c. 503 (1841).

cauliflora, Poepp. \& Endl. Nov. Gen. et Sp. iii. $38=$ Gaurea Poeppigii.

guianensis, Aubl. Pl. Gui. Suppl. 32.t. 387.-Guiana ; Afr. trop.

guineensis, Sweet, Hort. Brit. ed. I. 72 ; Juss. in Mém Mus. Par. xix. (1830) $242=$ procera.

guyanensis, Oliver, Fl. Trop. Afr i. $336=$ procera.

indica, A. Juss, in Dict. Sc. Nat. vii. $31=$ moluccensis, latifolia, Willd. ex C. DC. in DC. Monog. Phan. i. $718=$ guianensis.

moluccensis, Lam. Encyc, i. 621.-Geront. trop.

nicaraguensis, C. DC. in DC. Monog. Phan. 1.717.Am. centr.

obovate, Blime, Bijdr. i. $179=$ moluccensis.

procera, DC. Prod. i. $626 .-$ As. et Afr. trop.

Rumphii, Kostel. Allg. Med.-Pharm. Fl. v. 1988 moluccensis?

sericea, Poepp. \& Endl. Nov. Gen. et Sp. iii. 39. t. 245 $=$ Guarea trunciflora.

surinamensis, Miq. Stirp. Surin. Sel. 75. t. 19.-Guiana. Touloucouna, Guill. \& Perr. F1. Seneg. Tent. i. $128=$ procera.

trijuga, Willd. ex C. DC. in DC. Monog. Phan. i. 564 $=$ Guarea humilis.

CARAPICHEA, Aubl. Pl. Gui. 167. t. $64(1775)=$ Cephaëlis, Sw. (Rubiac.)

Aubletii, DC. Prod. iv. 536=Ceph. involucrata. guianensis, Aubl. Pl. Gui. i. 168=Ceph. involucrata. Kappleri, Miq. Stirp. Surin. Sel. 181.-Guiana. Patrisi, DC. Prod, iv. $536=$ Ceph. Patrisii.

CARARA, Medic. Pflanzeng. $34(1792)=$ Senebiera DC. (1799) (Crucifer.).

Coronopus, Medic. 1. c. $35=\mathrm{S}$. Coronopus.

CARAXERON, Vaill. ex Rafin. Fl. Tellur. iii. 38 (1836) =Philoxerus, R. Br. (Amarantac.).

brasiliense, Rafin. 1. c.=Telanthera dentata

conicus, Rafin. 1, c. $=$ P. conicus.

diffusus, Rafin. 1. c. = Gomphrena diffusa.

vermicularis, Rafin. 1 . c. $=\mathrm{P}$, vermicularis

CARBENIA, Adans. Fam. ii, 116 (1763) (Carbeni) COMPOSITAE, Benth. \& Hook. f, ii. 482 Benedicta, Bernh. Syst. Verz. Erf. 108 (1800).

benedicta, Adans. l. c. 116.--Reg. Mediterr, et Caucas.

CARCIA, Raeusch. Nom. ed. III. $275(1797)=$ Garcia Rohr. (Euphorb.).

CARDA, Noronha, in Verh. Batav. Gen. v. (1790) ed. I Art. IV. 2 (Quid ?)

CARDAMINDUM, Tourn. ex Adans. Fam. ii. 388 (1763) Tropaeolum, Linn. (Geraniac.) majus, Moench, Meth. Suppl. $20=$ T. majus. minus, Moench, 1. c. $21=$ T. minus.

CARDAMINE, [Tourn.] Linn. Syst. ed. I (1735); Gen. ed. I. 176 (1737). CRUCIFERAE, Benth. \& Hook. f. i. 69.

DENTARIA, [Tourn.] Linn. Syst. ed. I (1735).

Heterocarpus, Phil. in Bot. Zeit. xiv. (1856) 641. KARDANOGLYPHOS, Schlecht. in Linnaea, xxviii (1856) 472.

Pteroneuron, DC. Prod. i. 150 (1824). 


\section{CARDAMINE :-}

acaulis, Berg, in Bot. Zeit. xiv. (1856) 874.-German. acris, Griseb. Spicil. Fl. Rumel. i. 253.-Macedon.; Armen.

affinis, Hook. E Arn. in Hook. Bot..Misc. iii. (1833) 137.-Chili.

africana, Linn.Sp. Pl. 655.-Ind. or. ; Afr.; Japon.

allevia, Comm. ex DC. Syst. ii. $252=$ africana.

alpina, Willd. Sp. Pl. iii. 481.-Europ.

amara, Bieb. Fl. Taur. Cauc. ii. $109=$ uliginosa

amara, Lam. Encyc. ii. $\mathbf{1 8 5}=$ pratensis.

amara, Linn. Sp. Pl. 656,-Europ, ; As. bor.

amplexicaulis, Haensel. in Bot. Zeit. iv. (1846) 312.-

Hispan.

angulata, Hook. Bot. Misc. i. (1830) 343. t. 69.-Am. bor. occ.

angulata, Regel, in Bull. Soc. Nat. Mosc. xxxiv. (1861)

II. $172=$ hirsuta.

angulata, Torr. in Pacif. Rail. Rep. iv. 65, $77=$ paucisecta.

angustifolia, Rafin. Fl. Ludov. 84.-Eouisiana.

anteniquana, Burch. ex DC. Syst. ii. $252=$ africana.

antiscorbutica, Banks, ex Griseb. in Goett. Abh. vi.

(1854) $115=$ glacialis

apetala, Gilib, Fl, Lituan. ii. $67=$ impatiens.

apetala, Moench, Meth. $259=$ hirsuta.

appendiculata, Franch. E Sav. Enum. Pl. Fap. ii. 281. -Japon.

arenosa, Roth, Man. Bot. $926=$ Arabis arenosa.

armoracioides, Turcs. in Bull. Soc. Nat. Mosc, xxvii.

(1854) II. 293.-Veneznela.

articulata, Pursh, Fl. Am. Sept. ii. $430=$ Parrya nudicaulis.

asarifolia, Linn. Sp. Pl. 654.-Europ.

auriculata, S. Wats, in Proc. Am. Acad. xvii. (1881-82 319. - Calif.

axillaris, Wedd. in Ann. Sc. Nat. Sér. V. i. (1864) 290-Bolivia.

ballidifolia, Hill, Herb. Brit. ii. 275 = bellidifolia.

belgaumensis, Dalz, ex Hook. in Hook. Kew Journ. iv. (1852) $294=$ subumbellata.

bellidifolia, All. FI. Pedem. i. 260. t. 18. f. $3=$ alpina. bellidifolia, Linn. Sp. Pl.654.-Reg. bor. et arct. Bergeriana, Andrz. ex DC: Syst. ii. $266=$ glauca Berro, Steud. Nom. ed. II. i. 280.-Ins. Juan. Fern.

bicolor, Opiz, ex J. \& C. Presl, Fl. Čech. $136=$ amara.

Bielzii, Schau, in Verh. Siebenb. Ver. Naturw. iv. (1853) $64=$ amara.

Bocconi, Vis. Prod. Fl. Cors. App. $4=$ thalictroides.

bonariensis, Juss. ex Pers. Syn. ii. 195=flaccida.

borbonica, Boj. Hort. Maurit. $11=$ hirsuta.

borbonica, Pers. Syn. ii. $195=$ africana.

borealis, Andrz. ex DC. Syst. ii. $256=$ prorepens.

borealis, Laest. ex Nym. Consp. $37=$ amara.

Boryi, Boiss. Elench. $9=$ Sisymbrium pinnatifidum.

brachycarpa, Franch. in Bull. Soc. Bot. Fr. xxvi.

(1879) 88.-Japon.

brachycarpa, Opiz, Natural. xi. $(1826) 411=\mathrm{im}$ patiens.

bracteata, S. Moore, in Fourn. Bot. xvi. (1878) 130.-

Japon.

brasiliensis, D. Dietr. Syn. Pl. iii. 698.-Bras.

Breweri, S. Wats. in Proc. Am. Acad. x. (1875) 339 -

Am. bor. oce.

buchtormensis, Willd. ex DC. Syst, ii. 258=- pratensis

bulbifera, [R.Br. in] Ait. Hort. Kew. ed. II. iv, 101.

-Europ.

Burchellii, Spreng. Syst. ii. $886=$ africana

calabrica, Archang. in Nuov. Giorn. Bot. x. (1878) 163.-Italia.

calbucana, Phil. in Anal. Univ. Chil. (1872) 668.Chili.

caldeirarum, Guthn. in Seub. Fl. Azor. 43.-Ins. Azores.

camosa, Waldst. E Kit. Pl. Rar. Hung. ii. 197. t. 129. -Thesșalia.

caucasica, Willd, ex Ledeb. F1. Ross. i. $126=$ uliginosa.

chelidonia, S. G. Gmel. It. iv, $108=$ impatiens,

chelidonia, Lam. Encyc. ii. $183=$ latifolia.

chelidonia, Linn. Sp. Pl. 655.-Italia; Hungar.

chelidonia Pall. Reise, iii. $84=$ macrophylla.

chelidonioides, S. Moore, in Fourn. Bot. xvi. (1878) 130.- Japon.

chenopodifolia, Pers. Syn。 ii, 195.-Am. austr.

chilensis, $D C$. Syst. ii. 254.-Chili.

circreoides, Hook. f. E' Thoms. in Gourn. Linn. Soc. v. (1861) 144.- Reg. Himal.

\section{CARDAMINE}

Clematitis, Shuttl. ex S. Wats. Bibliog. Ind. N. Am. Bot. i. 53.-Am. bor.

cognata, Steud. in Flora, xxxix. (1856) 409.-Chili.

colchaguensis, Barn, in C. Gay, Fl. Chil. i. 115.-Chili.

cordata, Barn.l.c. 109.-Chili.

cordifolia, A. Gray, Pl. Fendl. 8.-N. Mexic.

corsica, Jord. ex Nym. Consp. $38=$ graeca.

corsica, Sieber, ex Turcs. in Bull. Soc. Nat. Mosc. xxvii. (1854) II. 293.-Ins. Corsica.

corydaloides, Guss. ex Spreng. Syst. ii. $888=$ glauca.

corymbosa, Hook. fo in Ic. Pl. 七. $686=$ hirsuta.

crassifolia, Opiz, Natural. xi. (1826) $412=$ amara.

cretica, Nym. Consp, $38=$ graeca

croatica, Schott, Nym. \& Kotschy, Analect. Bot. $46=$ carnosa.

cuneata, Greene, in Bull. Calif. Acod.n. 3 (1885) 74.

-Calif.

Cupani, Jord. ex Nym. Consp. $38=$ graeca.

curvisiliqua, Shuttl. ex Chapm. Fl. S. U. St. Suppl. 205.-Florida.

dalmatica, Nym. Consp. $38=$ maritima

dasycarpa, Bieb. F1. Taur. Cauc. iii. $437=$ C. impatiens.

dasyloba, Bernh. ex Steud. Nom. ed. II. i. $280=$ macrophylla.

debilis, Banks, ex DC. Syst. ii. $265=$ hirsuta.

debilis, D. Don, Prod. F1. Nep. $201=$ hirsuta.

decumbens, Barn. in C. Gay, Fl. Chil.. i. 109.-Chili.

decurrens, Zoll. E Moritzi, Syst. Verz. Zoll. 35. - Java.

demissa, Triana E Planch. in Ann. Sc. Nat. Sér. IV. xvii. (1862) 60.-N. Granat.

dentariaefolia, Royle, ex Hook. f. \& Thoms. in Journ.

Linn. Soc, v. (1861) $145=$ macrophylla

dentata, Schult. Obs. $126=$ pratensis.

depressa, Hook. f. Fl. Antarct. 6.-N. Zel.

dictyosperma, Hook. Fourn. Bot. i. (1834) 246.Austral.

digitata, Richards. in Frankl. Narr. 1st Journ. $743=$ pratensis?

diphylla, Wood, Bot. E Fl. 37.-Am. bor

divaricata, Hook. f. F1. N. Zel. i. 13=stylosa.

diversifolia, Sternb. \& Hoppe, in Denkschr. Bot. Ges,

Regensb. i. (1815) 156. t. $2=$ Arabis Halleri.

drymeja, Schur, Enum. P1. Transs, 47 =hirsuta

duraniensis, Revel, ex Des Moul. in Actes Linn. Soc. Bord. xx. (1855) 466.-Gallia.

elegantula, Hook. f. ET Thoms. in Fourn. Linn. Soc. v. (1861) 146.-Reg. Himal.

Engrelmanniana, Ind. Sem. Hort. Berol. (1840); ex Heynh. Nom. ii. $118=$ Arabis lndoviciana.

enneaphylla, [R. Br.in] Ait. Hort. Kew. ed. II. iv. 101. -Europ.

Eschscholtziana, Andrz. ex Ledeb. F1. Ross. i. $128=$ purpursa.

eustylis, F. Muell, in Trans. Vict. Inst. i. (1854) 114. -Austral.

faëroënsis, Hornem. in Fl. Dan. t. $1392=$ Arabis petraea.

fagetina, Schur, Enum. Pl. Transs. $47=$ mmbrosa. fastigiata, Hook. f. Handb. New. Zeal. Fl. 13.-

flaccida, Bert. ex C. Muell. in Walp. Ann. vii. 100 macrorrhiza.

flaccida; Cham. E Schlecht. in Linnaea, i. (1826) 21. -Chili.

flavescens, Phil. in Anal. Univ. Chil. (1872) 667.Chili.

Alexuosa, With. Bot. Arr. Brit. Pl. ed. III. iii. $578=$ sylvatica.

fluminensis, Eichl. in Kjoeb. Vidensk. Meddel. (1870) 185. t. \&-Bras.

foliosa, Wall. Cat, n, $4779=$ macrophylla

fontana, Lam. Fl. Fr. ii. $499=$ Nasturtium officinale.

fontinalis, Schur, Enum. Pl. Transs. $48=$ pratensis.

fossicola, Godet, Suppl. Fl. Jura, $13=$ pratensis.

Gambellii, S. Wats. in Proc. An. Acad. xi. (1876) 147.-Calif.

gelida, Schott, in Oestr. Bot. Wochenbl. (1855) 145.Tyrol.

geraniifolia, DC. Syst. ii. 268.-Reg. Magellan,

gilanensis, Willd. ex DC. 1. c. 26.2 = impatiens.

glacialis, $D C$. l. c. 264 -Reg. Magellan.

glandulosa, Blanco, Fl. Filip. ed. I. 521.-Ins. Philipp.

glauca, Sprene, ex DC. Syst, ii. 260.-Calabria.

glaucescens, Reichb. Ic. Pl. Crit. จ. Index, 4 (Quid ) -Europ.
CARDAMTNF :

Gmelini, Tausch, in Flora, xix. (1836) $402=$ macrophylla.

gongylodes, Phil. in Linnaea, xxviii. (1856) 664.Chili.

graeca, Janka, ex Nym. Consp. $38=$ longirostris.

graeca, Linn. Sp. Pl. 655.--Keg. Mediterr. or.

grandiflora, Hallier, in Bot. Zeit. xxiv. (1866) 209 pratensis.

grandiflora, Turcz. in Bull. Soc. Nat. Mosc. xv。 (1842 238 = tenuifolia, Turcz.

grandis, Schur, Enum. Pl. Transs, $49=$ amara.

granulata, Phil. in Linnaea, xxxiii. (1864 65) 8.Chili.

granulosa, All. Auct. Fl. Pedem. $16=$ pratensis. Griffithii, Hook. f. E Thoms. in Fourn. Linn. Sod (1861) 146.- keg. Himal.

Hamiltonii, G. Don, Gen. Syst. i. 167=hirsuta.

hamulosa, Bertol. Mant. Fl. Alp. Apuan. 43 = resedi. folia.

hastata, Willd, ex Ledeb. Fl. Ross. i. 125=uliginosa hastulata, Sm. Engl. Bot. t. $469=$ Arabis petraea. hastulata, Steud. Nom. ed. II. i. $280=$ resedifolia. hederacea, DC. Syst. ii. $264=$ thalictroides. herbivaga, Jord. Diagn. i. $129=$ pratensis.

heterophylla, Bory, in Ann. Sc. Gén. Phys. iii. (1820 $6=$ Sisymbrium pinnatifidum

heterophylla, Hook. Comp. Hot. Mag. i. (1835) $273=$ hirsuta?

heterophylla, Host, Syn. Pl. Austr. 366 = resedifolia. heterophylla, Lapeyr. Hist. Abr. Pl. Pyr. 377.-Mont. Pyren.

heterophylla, Wood, Bot. Fo Flor. 38.-Am. bor.

Heyneana, Welw. ex Reichb. F1. Germ. Excurs. 678 pratensis.

Hilariana, Walp. Rep. i. 137.-Bras.

hirsuta, Linn. Sp. Pl. 655.- - Reg. temp. et subtrop.

hirsuta, Oed, in Fl. Dan, t. 148=amara.

hirsuta, Pall. ex DC. Syst. ii. $256=$ prorepens.

Huetii, Boiss. Diagn. Ser. II. v. $18=$ Sisymbriam Huetii.

humilis, Kit. in Linnaea, xxxii. (1863) 496.Hungar.

ibaguense, Triana Es Planch. in Ann. Sc. Nat. Sér. IV xvii. (1862) 60.-N. Granat.

impatiens, Linn. Sp. Pl. 655.-Europ.; As. bor.; Reg. Himal.

impatiens, O. F. Muell. in Fl. Dan. t. $735=$ hirsuta. indica, Burm. f. Fl. Ind. 140. - Java.

integrifolia, Gilib. Fl. Lituan. ii. $68=$ pratensis.

intermedia, Hook. Ic. Pl. t. $258=$ tenuifolia ?

intermedia, Stend. in Flora, xxxix. (1856, 410,-Chili.

Jamesoni, Hook. Lond. Fourn. Bot. vi. (1847) 293.Ecuador.

javanica, Miq. Illustr. Fl. Archip. t. 10.-Java.

Keckii x, A. Kern. in Zeitschr. Ferdinand. Tirol. III. xv.

(1870) 280.-Europ.

kopaonikensis, Panc. ex Nym. Consp. 37 = glauca.

laciniata, F. Muell. in Trans. Phil. Soc. Vict. (1855) 34.-Austral.

laciniata, Steud. Nom. ed. II. i. $281=$ Thelypodium laciniatum.

laciniata, Wood, Bot. \& Flor. 38.-Am, bor.

Lamontii, Hance, in Fourn. Bot. xiv. (15i6) 363.China.

latesiliqua, Cheesem. in Trans. N. Z. Inst. xv. $18 \div 3$ $298 .-$ N. Zel.

latifolia, Lej. Fl. Spa, ii. $348=$ pratensis.

latifolia, Vajl, Symb. Bot. ji. 77 . Eirop. austr.

laxa, Benth. Pl. Hartw. 158.-N. Granat.

Lechleriana, Steud. in Flora, xxix. (1S56 in!Chili.

legionensis, Reut. Ind. Sen. Hort. Genew. (1801) t.Hispan.

lenensis, Andrz. in Ledeb. Fl. Alt. jii. $39=$ bellidifolia.

Libertiana, Lej. Rev. Fl. Spa, $135=$ amara.

lilacira, Hook. Comp. Bot. Mag. i. (1895) 278 tenuifulia.

litoralis, Phil. in Anab. C'nir. Chil. ISo's, ii. \$11.chili.

Uobate Yoench, Yeth. $200=\mathrm{P}$ - graeca.

longirostris, Funka, Asias. Mastar. 164. - Cf. Yus: biot. Fusheso. (18;0 1061.-Lanat.

lucorum, Boiss. \& Iluel, ex Hoiss. Fl. Oricnt. i. 161 pectinata.

A desiciarsa, Hook. Joura. Hot. i. (1534) 191 - Aral ludoviciana. 


\section{CARDAMINE:-}

Lunaria, Linn. Sp. Pl. $656=$ Ricotia Lunaria

lyrata, Bunge, in Mém. Sav. Etr. Pétersb. ii. (1835) 573.-China.

macrophylla, Schur, Enum. Pl. Transs. $49=$ amara

macrophylla, Willd. Sp. Pl. iii. 484.-Reg. HimaI. Sibir.; Japon.

macrorrhiza, Bert. ex Steud. Nom. ed. II. i. 281.Chili.

magellanica, Phil. in Anal. Univ. Chit. (1872) 666.-

Chili.

marginata, Phil. l. c. (1865) ii. 324.-Chili

maritima, Portenschl. Enum. Pl. Dalm. 15.Dalmat.

Matthioli, Moretti, ex Comol. F1. Com. v. 157= pratensis.

maxima, Wood, Bot. E Flor. 38.-Am. bor.

melananthera, Steud. Nom. ed. II. i. $280,281=$ seq.

melanthera, Stokes, Bot. Mat. Med. iii. $445=$ amara.

Menziesii, DC. Syst. ii. $267=$ Sisymbrium canescens

micrantha, Spenn. FI. Frib. iii. $922=$ hirsuta.

microphylla, Adams, in Mém. Soc. Nat. Mosc. v.

(1817) 111-Sibir. or.

microphylla, J. \& C. Presl, Delic. Prag. $15=$ thalic troides.

minima, Steud. in Flora, xxxix. (1856) 410.-Peruy.

minuta, Willd ex DC. Prod. i. $150=$ microphylla.

monticola, Timb, in Bull. Soc. Hist. Nat. Toulouse,

iii. (1869) 112,-Gallia

multicaulis, Hoppe, ex Schur, Enum. P1. Transs. $47=$ hirsuta.

multifida, Pursh, F1. Am. Sept. ii. $440=$ Sisymbrium canescens.

multifida, Wood, Bot. Er Flor. 38.-Am. bor.

muscosa, Vahl, ex DC. Syst. ii. $260=$ hirsuta

nana, Barn. in C. Gay, Fl. Chil. i. 108.-Chili

nana, C. Muell. in Walp. Ann. vii. 106.--Peruv.

nasturtiana, Thuill. Fl. Par. ed. II. i. $330=$ amara.

Nasturtii, Spreng. Syst. iv. Cur. Post. $241=$ nastur-

tiodes, D. Don.

nasturtiifolia, Stend. Nom. ed. II. i. $281=$ nastur tioides, Bert.; C. Berro.

nasturtioides, Bert. in 'Merc. Chil. (1829)'; Bull Férussac, xx. (1830) 109; Barn. in C. Gay, Fl. Chil. i. 113.-Chili.

nasturtioides, Camb. in St. Hil. Fl. Bras. Mer. ii. $89=$ Hilariana.

nasturtioides, D. Don, Prod. Fl. Nep. 201.-Nepal.

nasturtioides, Schur, Enum. Pl. Transs. $48=$ pratensis

Nasturtium, Wallr. Beitr. F1. Hercyn. 235 = amara?

nemophila, Phil. in Linnaea, xxx. (1859-60) 186. Chili.

nemorosa, Lej. Fl. Spa, ii. 62.-Belgium.

nevadensis, Turcz. in Bull. Soc. Nat. Mosc. xxvii (1854) II. 295.-Hispan.

nilagirica, Schlecht. ex Hook. f. \& T. Anders. in Fl

Brit. Ind i. $138=$ subumbellata.

nipponica, Franch. E' Sav. Enum. Pl. Fap. i. 281.Japon.

nivalis, Gill. ex Hook. Bot. Misc. iii. (1833) 136.Chili.

nivalis, Pall. Reise, ii. $740=$ Macropodium nivale

nivalis, Schur, Enum. P1. Transs. $46=$ resedifolia.

nivea, Hook. Comp. Bot. Mag. 1. (1835) 273 = dictyosperma.

nudicaulis, Linn. Sp. P1. $654=$ Parrya macrocarpa.

nudicaulis, Pall. ex DC. Syst. ii. $454=$ Macropodium nivale.

nudicaulis, S. Wats. Bibl. Ind. N. Am. Bot. $54=$ Parrya nudicaulis.

obliqua, Hochst. ex A. Rich. Tent. Fl. Abyss. 1. 19.Abyssin.

occulta, Hornem. Hort. Hafn. Suppl. 71.-China

oligosperma, A. Gray, in Proç. Am. Acad. viii. (1873)

$376=$ Breweri

oligosperma, Nutt. in Torr. E" Gray, Fl. N, Am. i. 85. Am. bor occ.

olympica, Boiss. Diagn. Ser. I. viii. $19=$ uliginosa

Opićii, C. \& J. Presl, F1. Čech. $136=$ amara.

orophila, Timb. in Bull. Soc. Hist. Nat. Toulouse, iii.

(1869) 112.-Gallia.

ovata, Benth. Pl. Hartw. 158,-N. Granat.

oxycarpa, Boiss. in Ann. Sc. Nat. Sér. II. xvii. (1842)

$56=$ pectinata

oxyphylla, Andrz. ex Ledeb. Fl. Ross. 1. $128=$ pratensis? paludosa, Knaf, in Flora, xxix. (1846) $293=$ pratensis

palustris, Peterm. in Rabenh. Bot. Centralbl. i. (1846)

$47=$ pratensis

\section{CARDAMINE:-}

paradoxa, Hance, in Foum. Bot. vi. (1868) 111.China

parviflora, Linn. Syst. ed. X. $1131=$ hirsuta.

parviflora, Suter, F1. Helv. ii. $59=$ tetrandra.

paucijuga, Turcz. in Bull. Soc. Nat. Mosc. xxvii. (1854) II. $295=$ hirsuta

paucisecta, Benth. Pl. Hartw. 297.-Calif.

pectinata, Pall ex DC. Syst ii. $264=$ impatiens.

pedata, Regel Ev Tiling, in Nouv. Mém. Soc. Nat. Mosc. xi. (1859) 47.- Sibir.

pensylvanica, Muhl. Cat. 60, ex Willd. Sp. Pl. iii. 486 =hirsuta.

pentaphylla, [R. Br. in] Ait. Hort. Kew. ed. II. iv. 101 $=$ pratensis

pentaphylla, Phit. in Linnaea, xxxiii. (1864-65) 6.Chili.

petiolaris, DC. Syst. ii. $264=$ graeca.

petraea, Linn. Sp. Pl. $654=$ Arabis petraea

petraea, Townson, Trav. Hung. 490, 348=Arabis arenosa.

picta, Hook. Lond. Journ. Bot. vi. (1847) 292.t. $12=$ Porphyrocodon pictum.

pilosa, Willd. ex DC. Syst. ii. $256=$ prorepens.

pinnata, [R.Br.in] Ait. Hort. Kew. ed. II. iv. 101. -Europ.

Plumieri, Vill. Prosp. $38=$ thalictroides.

polyphylla, D. Don, Prod. Fl. Nep. $201=$ macrophylla

praecox, Pall. ex Ladeb. Fl. Ross. i. $127=$ hirsuta

pratensis, Hook. f. Fl. Tasm, i. $19=$ tenuifolia.

pratensis, Linn. Sp. Pl. 656.-Reg. temp.

praticola, Jord. Diagn. i. $128=$ pratensis.

propinqua, Carm. in Trans. Linn. Soc. xii. (1819) 507 = hirsuta.

prorepens, Fisch. ex DC. Syst. ii. 256.-Sibir.

psendopratensis, Schur, ex Nichols. in Journ. Bot. xviii. $(1880) 200=$ pratensis.

pubescens, Stev. ex DC. Syst. ii. $256=$ prorepens.

punicea, Turcz. in Bull. Soc. Nat. Mosc. xxvii. (1854)

II. 295.-Venezuela.

purpurea, Cham. E" Schlecht. in Linnaea, i. (1826) 20.-Am. bor. occ.

purpurea, Torr. \& Gray, F1. N. Am. i. $667=$ paucisecta.

pusilla, Hochst. ex A. Rich. Tent. Fl. Abyss. i. 18.-Abyssin.

pusilla, Phil. in Linnaea, xxviii. (1856) 665.-Chili.

pusilla, Schur, Enum. Pl. Transs. $47=$ hirsuta

radicata, Hook. f. in Ic. Pl. t. 882.-Tasman.

ramosissima, Steud. in Flora, xxxix. (1856) 409.-. Chili.

raphanifolia, Pourr. in Mém. Acad. Toul. iii. (1788) $310=$ latifolia.

reflexa, Rafin. Fl. Ludov. 84.-Am. bor.

Regetiana, Miq. Ann. Mus. Bot. Lugd. Bat. ii. $73=$ hirsuta.

reniformis, Phil. in Anal. Univ. Chil. (1865) ii. 313. -Chili.

repanda, Sm. ex DC. Syst. ii. 251; Prod. i. $150=$ flaccida.

resedifolia, Linn. Sp. Pl. 656-Europ.

rhomboidea, DC. Syst. ii. 246.-Am. bor

rhomboidea, Durand, F1. Utah, $159=$ cordifolia.

rigida, Bieb. Fl. Taur. Cauc. iii. 439.--Reg. Caucas,

rivularis, Schur, in Verh. Siebenb. Ver. Naturw. iv 1853) $61=$ pratensis.

rostrata, Griseb. in Goett. Abh. vi. (1854) 115.-Chili.

rotundifolia, Bigel. Fl. Bost. ed. II. $252=$ bellidifolia

rotundifolia, Torr. \& Gray, Fl. N. Am. i. 83, pro parte $=$ rhomboidea.

rubifolia, Sm. ex DC. Syst. ii. 252; Prod. i. $150=$ flacçida.

runcinata, Pourr. in Mém. Acad. Toul. iii. (1788) 310 =latifolia, Sisymbrium pinnatifidum.

sarmentosa, Forst. f. Prod. App. 92, nomen.-Ins. Pacif.

saxatilis, Salisb. Prod. $269=$ impatiens.

scaposa, Franch. Pl. Davidian. i. (1884) 33.Mongol.

scaturiginosa, Wahlenb. ex Steud. Nom. ed. II. i. 281

Schaffneri, Hook. f. in Hemsl. Diagn. Pl. Nov. $2=$
pratensis. Gambelii.

scutata, Thunb. in Trans. Linn. Soc. ii. (1794) 339.Japon.

senanensis, Franch. E Sav. Enum. Pl. Fap. ii. 280.Japon.

\section{CARDAMINE:-}

serbica, Panc. ex Aschers. \& Kan. Cat. Corm. Serb. 76 = carnosa.

setigera, Tausch, in Flora, xix. (1836) 404.-Hab. ? silvatica, Anct. vide sylvatica.

simensis, Hochst. ex Oliver, Fl. Trop. Afr. i. 61.Abyssin.

Solisi, Phil. in Anal. Univ. Chil. (1856) 410.-Chili. spathulata, Michx. Fl. Bor. Am. ii. 29-Carolina.

stellata, Hook. f. Fl. Antarct. 7.t. $4 \mathrm{~A}=$ depressa.

stolonifera, Scop. Fl. Carn. ed. II. ii. $22=$ Arabis stolonifera.

stolonifera, Tausch, Cat. $5=$ pratensis

strictula, Steud. in Flora, xxxix. (1856) 410.-Reg. Magell.

stylosa, $D C$. Syst. ii. 248.-Austral.; N. Zel.

sublyrata, Miq. Ann. Mus. Bot. Lugd. Bat. ii. $73=$ Nasturium sublyratum.

subumbellata, Hook. ex Hook. f. E T. Anders. in Fl.

Brit. Ind. i. 138.-Ind. or.

sylvatica, Bess. Primit. Fl. Galic. ii. $76=$ pratensis

sylvatica, Link, in Hoffm. Phyt. Blaett. i. (1803) $50=$ hirsuta.

Tanakae, Franch. \& Sav. Enum. Pl. Fap. i. 36.Japon.

tenella, Clark, Trav. ii. $117=$ hirsuta

tenera, Boiss. in Ann. Sc. Nat. Sér. II. xvii. (1842) 56 $=$ pectinata

tenera, S. G. Gmel. ex C. A. Mey. Verz. Pfl. Cauc 179.-Reg. Caucas.; Persia.

tenuifolia, Hook. Fourn. Bot. i. (1834) 247.-Austral.

tenuifolia, Turcz. in Bull. Soc. Nat. Mosc. xy. (1842) 238.-Sibir.

tenuirostris, Hook. E" Arn. Bot. Beech. Voy. 6.-Chili.

teres, Michx. Fl. Bor. Am. ii. $29=$ Nasturtium tanacetifolium.

ternata, Bory, ex DC. Syst. ii. $252=$ africana.

tetrandra, Hegetschw. Fl. Schw. 641.-Helvet.

thalictroides, All. Fl. Pedem. i. 261.-Europ. austr.

tolimensis, Planch. Er. Linden, in Ann. Sc. Nat. Sér. IV. xvii. (1862) 59.-N. Granat.

trichocarpa, Hochst. ex A. Rich. Tent. Fl. Abyss. i. 18 = graeca.

trifolia, Linn. Sp. Pl. 654.-Europ. austr.

trifolia, Pall. Reise, iii. $316=$ amara.

trifolia, Thunb. F1. Jap. $260=$ scutata

trifolia, Wablenb. Fl. Lapp. $179=$ amara

trifoliolata, Hook. f. E Thoms. in fourn. Linn. Soc. v. 1861) 145.-Reg. Himal

triphylla, Pall. Reise, ii. $35=$ amara

tuberosa, Bert. ex Steud. in Flora, xxxix. (1856) $409=$ cognata.

tuberosa, DC. Syst. ii. 254.-Chili

udicola, Jord. Diagn. i. $130=$ pratensis.

uliginosa, Bieb. Fl. Taur. Cauc. iii. 438.-Ross. austr. Qriens.

umbrosa, Andrz. in DC. Syst. ii. 260.-Volhynia.

umbrosa, Lej. F1. Spa, ii. $63=$ amara

unalaschcensis, Andrz. ex Ledeb. Fl. Ross. i. 127= hirsuta.

undulata, Laramb. E Timb. in Bull. Soc. Bot. Fr. xiv. 1867) 62.-Gallia

unifora, Michx. F1. Bor. Am. ii. $29=$ Leavenworthia Michauxii.

valdiviana, Phil. in Anal. Univ. Chil. (1865) II. 314. -Chili.

variabilis, Phil. in Linnaea, xxxiii. (1864-65) 5.Chili.

violacea, Wall. Cat. n. 4782.-Reg. Himal

virginica, Linn. Sp. P1. $656=$ Arabis ludoviciana

virginica, Michx. Fl. Bor. Am. ii. $29=$ birsuta

viscosa, S. G. Gmel. ex DC. Syst. ii. $216=$ Arabis albida.

Volckmanni, Phil. in Linnaea, xxxiii. (1864-65) 7.Chili.

vulgaris, Phil. 1. c. xxviii. (1856) $665=$ pratensis

Wiedmanniana, Boiss. Fl Orient. i. 162-Anatolia.

Wightiana, Wall. Cat. n. $4780=$ africana.

Willdenowit, Tausch, in Flora, xix. (1836) $403=$ macrophylla.

yezoënsis, Maxim. in Bull. Acad. Pétersb. xviii. (1873) 277.- Japon.

Zollingeri, Turcz. in Bull. Soc. Nat. Mosc, xxvii. (1854 II. 294.-Java?

CARDAMINUM, Moench, Meth. $262(\mathbf{1 7 9 4})=\mathbf{N a}$ sturtium, $\mathrm{R}$. Br. (Crucifer.)

Nasturtium, Moench, 1, c $=$ N, officinale. 
CARDAMOMUM, Noronha, in Verh. Batav. Gen. v. (1790) ed. I. Art. IV. 2 ; Salisb. in Trans. Hort. Soc. i. (1812) $282=$ Elettaria, Maton (Scitamin.). malabaricum, Pritz. Ic. Ind. $207=\mathrm{E}$. Cardamomum medium, Schult. Mant. 24=Amomum costatum. officinale, Salisb. in Trans. Hort. Soc. i. (1812) $282=$ E. Cardamomum

CARDAMON, Fourr. in Ann. Soc.. Linn. Lyon, N. S. xvi. (1868) $338=$ Lepidium, Linn. (Crucif.).

sativum, Fourr. 1. c. = L. sativum.

CARDANTHERA, Buch.-Ham, ex Nees, in DC. Prod. xi. 67 (1847). ACANTHACEAE, Benth. \& Hook. f. ii. 1074 .

Adenosma, Nees, in Wall. Pl. As. Rar. iii. 75 (1832).

SYNNEMA, Benth. in DC. Prod. x. 598 (1846), nomen prius.

africana, Benth. E Hook. f.Gen. ii, 1075.-Afr. trop. avana, Benth. ex C. B. Clarke, in Hook. f. Fl. Brit Ind. iv. 405.-Burma.

balsamica, Benth.l.c. 404.--Ind. or.

glutinosa, Buch.-Ham. ex Nees, in DC. Prod. xi. $68=$ triflora.

Griffithii, Benth.ex C.B. Clarke, in Hook. f. Fl. Brit. Ind. iv. 404.-Assam; Burma.

justicioides, S. Moore, in fourn. Bot. xviii. (1880) 6:Afr. trop.

longifolia, Buch.-Ham. ex Nees, in DC. Prod. xi. $90=$ Hygrophila phlomoides.

pinnatifida, Benth. ex C. B. Clarke, in Hook. f. Fl. Brit. Ind. iv, 405 .-Ind. or.

Thwaitesii, Benth. E' Hook. f.Gen. ii. 1075.-Zeylan. triflora, Buch-Ham. ex Nees, in DC. Prod. xi. 68.Ind. or. : Malaya.

uliginosa, Buch.-Ham, l. c. 69,-Ind, or.

verticillata, Benth. ex C. B. Clarke, in Hook.f. Fl. Brit. Ind. iv. 405 . - Ind. or

CARDARIA, Desv.. Joum. Bot. iii. (1813) $163=$ Lepidium, Linn. (Crucif.).

amplexicaulis, Spach, Hist. Vég. Phan. vi. $544=\mathbf{L}$ amplexicaule.

brachypetala, Opiz, Seznam, $26=$ L. Draba

cochlearia, Spach, Hist. Vég. Phan. vi. $542=\mathrm{I}$ Draba.

crassifolia, Spach, 1. c. $545=$ L. crassifolium.

Draba, Desv, Journ. Bot. iii. (1813) $163=\mathrm{L}$. Draba

latifolia, Spach, Hist. Vég. Phan. vi. $546=\mathrm{L}$ latifolium.

CARDERINA, Cass. in Dict. Sc. Nat. xxxv. 272 (1825) = Senecio, Toum. (Compos.

reclinata, Cass, 1. c. xlviii。 $447=\mathrm{S}$. reclinatus.

CARDIA, Dulac, F1. Hautes-Pyr. 387 (1867)= Veronica, Tourn. (Scrophularin.). agrestis, Dulac, 1. c. $388=\mathrm{V}$. agrestis. alpina, Dulac, 1, c, $391=\mathrm{V}$, alpina. amplexicaulis, Dulac, 1. c. $390=$ V. Anagallis aphylla, Dulac, 1. c. =V. aphylla. aphylla, Dulac, 1. c. $=V$. aphylla.
arvensis, Dulac, 1. c. $388=\mathrm{V}$.arvensis arvensis, Dulac, 1. c. $388=V$.arvensis.
Beccabunga, Dulac, 1. c. $890=$ V. Beccabunga. ciliata, Dulac, 1. $\mathrm{c}=\mathrm{V}$. Cbamaedrys. didyma, Dulac, 1. c. $388=\mathrm{V}$. didyma elliptica, Dulac, 1.c. $390=\mathrm{V}$. nnagalloides. filiformis, Dulac, 1. c. $389=\mathrm{V}$. Tournefortii fruticulosa, Dulac, l. c. $391=\mathrm{V}$. fruticulosa latifolia, Dulac, 1. c. $390=\mathrm{V}$. latifolia. montan $\alpha$, Dulac, 1. c. $389=\mathrm{V}$. montana multiflora, Dulac, 1. c. $391=\mathrm{V}$. serpyllifolia. Nummularia, Dulac, 1, c. $392=\mathrm{V}$. Nummularis. obtusifolia, Dulac, l. c. $391=V$. bellidioides, officinalis, Dulac, 1. c. $390=\mathrm{V}$. officinalis. orbicularis, Dulac, 1. c. $388=\mathrm{V}$. acinifolia plana, Dulac, 1. c. $391=$ V. Tencrium. praecox, Dulac, 1. c. $389=\mathrm{V}$. praecox. prostrata, Dulac, l. c. $391=\mathrm{V}$, prostrata quadriloba, Dulac, 1, c $389=\mathrm{V}$. hederaefolia scutellata, Dulac, 1. $\mathrm{c},=$ V. scutellats. serrata, Dulac, 1.c. $3: 1=$ V. Ponae. spicata, Dulac, 1. c. $392=$ V. spicata. verna, Dulac, 1.c. $388=\mathrm{V}$. verna.

CARDIACA, [Tourn.] Linn. Syst. ed I (1735) = Leonurus, Linn. (Labiat.)

arvensis, Lam. K1. Ir. ii. $388=$ Stachys arvensis.

\section{CARDIACA :-}

crispa, Moench, Meth. $401=$ Leonurus Cardiaca glabra, Gilib. Fl. Lituan, i. $85=\mathrm{L}$. tatarícus. Marrubiastrum, Medic. Beobacht. (1783) $127=\mathrm{L}$ Marrubiastrum.

quinquelobata, Gilib. Fl. Lituan. i. $84=$ L. Marrubiastrum.

Stachys, Medic. Beobacht. (1783) $126=\mathrm{L}$. Cardiaca.

sylvatica, Lam. Fl. Fr, ii. 384 Lamilum Galeobdolon trilobata, Lam. 1. c. $383=\mathrm{L}$. Cardiaca.

vulgaris, Moench, Meth. $401=\mathrm{L}$. Cardiaca:

CARDIACANTHUS, Schau. in Linnaea, xx. (1847) 714 ; et in DC. Prod. xi. 381 (1847)=Jacobinia Moric. (Acanthac.)

Neesianus, Schau. 1.c. $715=$ J. Neesiana

CARDIANDRA, Sieb. \& Zucc: F1. Jap. 119, t. 65 , 66 (1835). SAXIFRAGEAE, Benth. \& Hook, f. 643 .

alternifolia, Sieb. E Zucc. l.c. 121.-Japon

CARDIANTHERA, Hance, in Journ. Linn. Soc, xiji (1873) 114 , sphalm. = Cardanthera, Buch.-Ham.

CARDINALIS, Rupp. Fl. Jen. ed. Hall, $248(1745)=$ Lobelia, Linn.

CARDIOCARPUS, Reinw, in Syll. Ratisb. ii. (1828) 14 = Soulamea, Lam. (Simarub.)

amarus, Reinw. l, $\mathrm{c}_{*}=\mathrm{S}$, amara

CARDIOCHIAMYS, Oliver, in Hook. Ic. Pl. 1403 (1883). CONVOLVULACEAE. madagascariensis, Oliver, l. c.-Madag.

CARDIOCRINUM, Lindl, Veg. Kingd. 205 (1847)= Lilium, Tourn

CARDIOGYNE, Bur, in DC, Prod, xpii. $232(1873)=$ Plecospermum, Tréc. (Urticac.). africana, Bur. 1. c. 233.-Afr. trop.

CARDIOLEPIS, Rafin. Neogen. $1(1825)=$ Rhamnus, Tourn

nigra, Rafin. 1. c. $1=$ R. lanceolata

obtusa, Rafin. Sylva Tellur. $28=\mathrm{R}$. Purshiana

rubra, Rafin. Neogen. $\mathbf{I}=\mathrm{R}$. lanceolata.

spinosa, Rafin. 1. c.-Am. bor.

CARDIOLEPIS, Wallr. Sched. Crit. 340 (1822)= Lepidium, Linn. (Crucif.) dentata, Wallr. 1. c. = L. Draba

CARDIOLOCHIA, Rafin. ex Reichb. Consp. 85 (1828) $=$ Aristolochia, Tourn.

CARDIOLOPHUS, Griff. in Madr. Journ. Sc. iv. (1836) $376=$ Herpestis, Gaertn. (Scrophular.) decussata, Griff. 1 , c. $=$ H. Hamiltoniana.

CARDIONEMA, DC. Prod, iii. $372(1828)=$ Pen tacaena, Bartl. (Illecehrac.). multicaule, DC. 1. c. = P. polycnemoides.

CARDIOPETALUM, Schlecht. in Linnaea, ix. (1834) $328=$ Duguetia, St. Hil. (Anonac). calophyllum, Schlecht. 1. c.-Bras.

CARDIOPHORA, Benth. in Hook. Lond. Journ. Bot. ii. (1843) 216 = Soulamea, Lam. (Simarub.). Hindsii, Benth. 1, c, =S. amara.

CARDIOPTERIS, Wall, Cat. מ.. 8033 (1836?) OLACINEAE, Benth. \& Hook. f. i. 355 .

PERIPTERYGIUM, Hassk, in Hoev. \& De Vriese, Tijdschr..x. (1843) 142

Sroja, Buch.-Ham. ex Lindl. Introd. Nat. Syst. Bot. ed. II. 82 (1836)

hamulosa, Griff Notul. iv. 542 ; Ic. Pl. Asiat. 1. 598 lobata.

javanica, Blume, Rumphia, jii. $206=$ lobata.

lobata, Wall. Cat. n. 8083.-Ind. or.

moluccana, Blume, Rumphia, iii. $207=$ lobata. quinqueloba, Hassk. Retzia, i. bit =lobata. Rumphis, Baill. Adansonia, x. (1871-72) $280=$ lobata. subhamata, Wall. ex Baill. in DC. Prod. xvii. $20^{\circ}$ lubata.
CARDIOSPERMUM, Linn. Syst. ed. I (1735)

SAPINDACEAE, Benth. \& Hook. f, i. 393.

acuminatum, Miq. in Linnaea, xvii. (1843) $579=$ microcarpum.

altissimum, Poepp. En Endl. Nov. Gen. et Sp. iii. 38.Hras.

anomalum, Cambess, in St. Hil. Fl, Bras, Mer, i. 351 - Bras.

barbicaule, Baker, in Oliver, Fl. Trop. Afr. i. 418.Afr. trop.

canescens, Wall. Pl. As. Rar. i. 14.-As. et Afr. trop.

clematideum, A. Rich. Tent. Fl. Alyss. i. 100 -Abyss.

coluteoides, H.B. E K. Nov. Gen, et Sp. v, 100.-Am. austr.

Corindum, Linn.Sp. Pl. $526=$ C. Halicacabum

corycodes, Kunze, in Linnaea, xviii. (1844) 359.Cutua.

Duarteanum, Cambess, in St. Hil. Fl. Bras. Mer. i. 34: -Bras.

elegans, H. B. E K. Nov. Gen. et Sp. v. 99.--Peruv. ferrugineum, A.Rich. Ess. Fl. Cub. 276.-Cuba. glabrum, Schum. \&e Thonn. Beskr. Guin. Pl. 197 C. Halicacabum.

grandiflorum, Sw. Prod. Veg. Ind.Occ.64.-Jamaica.

Halicacabum, Linn. Sp. Pl. 366.-Reg. trop.

hirsutum, Willd. Sp. Pl, iii, 467.-Afr. occ

hispidum, H. B. E K. Nov. Gen. et Sp. v. 100.-Am. austr.

inflatum, Salisb. Prod. $279=$ C. Halicacabum.

inflatum, Vell. Fl. Flum. 158 ; iv. t. 22.-Uras.

integerrimum, Radlk in Sitsb. Math-Phys. Acad. Muench. viii. (1878) 260.-Bras.

Leuarthianum, G. Don, Gen. Syst. i. 657, sphalm.= Duarteanum.

loxense, H. B. E K. Nov. Gen. et Sp. v. 104.-Peruv. macrolophum, Radlk, in Sitzb. Math.-Phys. Acad. Muench, viii. (1878) 261. - Venezuela.

macrophyllum, H. B. E K. Nov. Gen. et Sp. v. 100.Venezuela.

microcarpum, H. B. \& K. 1. c. 104=C. Halicacabum. microspermum, E. Mey. in Drège, Zwei Pf. Docum. $170=\mathrm{C}$. Halicacabum

molle, Hochst. ex A. Rich. Tent. Fl. Abyss, i. $100=$ clematideum.

molle, H. B. \& K..Nov. Gen. et Sp. v. 104.-Mexic

moniliferum, Sw. ex Steud. Nom. ed. II. i. 150.-Ind. occ.

oblongum, A. Rich. Tent. Fl. Abyss. i. $101=$ canescens. ovatum, Wall. Cat. n. $8031=$ canescens.

parviflorum, Cambess. in St. Hil. Fl. Bras. Mer. i. 351 -Bras.

pilosum, Vell. Fl. Flum. 159; iv. t. 26.-Bras.

pilosum, Turcz. in Bull. Soc. Nat. Mosc. xxci. (1858 I. 395.-Bras.

procumbens, Radlk. in Sitsb. Math.-Phys. Acad. Muench, viii. (1878) 262.-Bras.

pubescens, Griff. Journ. $108=$ canescens.

pubescens, Lag. Gen. et Sp. Nov. $14=$ molle.

Schmiedelia, Dalz. \& Gibs. Bomb. Fl. $34=$ Schmiedelia villosa.

strictum, Radlk, in Sitzb. Math.-Phys. Acad. Muench. viii. (1878) 262-Bras.

tortuosum, Benth. Bot. Voy. Sulph, 9-Calis.

triphyllum, Vell. Fl. Flum. 159 ; iv, t. 25 .-Bras.

truncatum, A. Rich. Tent. Fl. Abyss. i. $101=$ C Halicacabum.

velutinum, Hook. E Arn. in Hook. Bot. Misc. iii. (1539 158.-Bras.

vesicarum, Humb. Rel. Hist. i. $\$ 9=$ coluteoides

villosum, Dalz. \& Gibs. Bomb. Fl. $\$ 4=$ Schmiedelia villosa.

villosum, Macfad. Fl. Famaic. i. 154.-Ind. oce

villosum, Mill. ex DC. Prod. i. $602=\mathrm{C}$. Halicacaburn.

CARDIOSTEGIA, Presl, Lipim. Bot. 249 1s 4 ) Melhania, Forsk. (Sterculiac.

Kotschyi, Presl, 1. c. $249=$ M. Denhami.

CARDJOSTIGMA, Baker, in Journ. Linn. Soc xy 1878) 102 - Sphenostigma, Baker (Irid.)

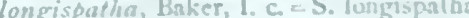
urda Klalk, in Abb. Naturf. Ges. Halle, xii. (1ss? SSS $=$ Calydorea nuda.

CARDIOTIIE A, Ehrent, ex Secud Nom. ed. II. i. 2s: $15 f(0)=$ Anarrhinuon, I)es. (Scrophularin.? probescens, Lihrenb. ex Sicud. I. c. A. pubereas rirgata, lihreab. ex Boiss. Fil. Orient. iv. $30^{2}=A$ orictutale. 
CARDOPATIUM. Tuss. in Ann. Mas. Par. vi. (1805) 324 in adn. COMPOSITAE, Benth. \& Hook. $f$ ii. 463.

Brotera, Willd. Sp. Pl. Hii. 2399 (1803). amethystinum, Spach, in Ann. Sc. Nat. Sér. III. v. (18t6) 242.-Afr. bor.

apulum, Spach, 1. c. $240=$ corymbosum.

Billardieri, Spach, 1. c. $247=$ corymbosum.

Boryi, Spach, l. c. 245.-As. Min.

corymbosum, Pers. Syn. ii. 500.-Reg. Mediterr. or. As. Min.

Fontanesii, Spach, in Ann. Sc. Nat. Sér. III. F. (1846) 244.-Reg. Tunetan.

orientale, Jaub, \& Spach, Illustr. t. $426=$ corymbosum orientale, Spach, in Ann. Sc. Nat. Sér. III. v. (1816) 237.-Graecia.

Vrionis, Heldr. in Boiss. F1. Orient. iii. $443=$ eorymbosum.

CARDUNCELLUS, Adans, Fam, ii, 116 (1763) COMPOSITAE, Benth. \& Hook. f. ii. 483 ,

LAMotTeA, Pomel, Mat. Fl. Atl. 3 (1860?). ONobroma, Gaerta. Fruct. ii. 380. t. 160 (1791). acaulis, Presl, Fl. Sic. i. p. xxx=pinnatus. araneosus, Boiss. E Reut. Pl. Nov. Hisp. Diagn. 18.Hispan.

aröorescens, Sweet, Hort. Brit. ed. I. $216=$ Carthamus arborescens.

atlanticus, Coss. E Dur. ex Coss. in Ann. Sc. Nat. Sér IV. i. (1854) 240 .-AIgeria.

atractyloides, Coss. E Dur. ex Pomel, Nout. Mat. Ft Atl. 278.-Algeria.

caeruleus, Less. Syn. Comp. 6.-Reg. Mediter.

calpus, Boiss. \& Reut. Pugill. 64.-Afr. bor.

dianius, Webb, Iter Hisp. $33=$ caerulens

eriocephalus, Boiss. Diagn. Ser. I. x. 100.-Afr. bor.

inispaniczes, Boiss, ex DC. Prod, vii. $304=$ caeruleus.

ilicifolius, Pomel, Nouv. Mat. Fl. Atl. 277.-Afr. bor.

lucens, Ball, in Fourn. Bot. xi. (1si3) 370.-Marocco. mitissimas, DC. Fl. Fr. iv. 7 g.-Gallia.

monspeliensis, St. Lag. in Ann. Soc. Bot. Lyon, vil. 1880) $121=\mathrm{sec}$

monspeliensium, All. Fl. Pedem, i. 154.-Gall austr.

pectinatus, $D C$. Prod. vi. 615.-Afr. bor.

pinnatus, $D C . l . c .614$ - - Oriens.

plumosus, Pomel, Nour. Mat. Fl. Atl. 277.-Afr. bor. rhaponticoides, Coss. E Dur. ex Ponel, Nouv. Mat. Fl Aitl. 278.-Algeria.

tingitanus, DC, ex Dubr, Bot. Gall, i, 281=caerulens.

vulgaris, Loud. Hort. Brit. $332=$ monspeliensium.

CARDUUS, [Toarn.] Linn. Syst. ed. I (1735), COMPOSITAE, Benth \& Hook, f. ii. 467 .

Alfredia, Cass. in Bull. Soc. Philom. (1815) 175.

Clavena, DC. Prod. vi. 633 (I837)

ONopyxus, Bubani, in Nuor. Giom. Bot. Ital. $\mathrm{v}$ (1873) 319.

Polfacantha, Hill, Herb. Brit. i. 69 (17 9).

PTervix, Hill, Veg. Syst. iv. 16 (1762)

abyssinicus, Sch. Bip. in Linnaea, xix. (1847) 332.Abyssin.

acanthifolius, Lam. Encyc. i. $703=$ Cnicas oleracens.

Acantlium, Baill. Hist. Pl. viî. $289=$ Onopordon Acanthium.

acanthocephalus, C. A. Mey.Verz. Pf. Cauc. 71.-Reg. Caucas.

acanthoides, Gren. \& Godr. Fl. Fr. ii. 231, sec. Nym. Consp. 411 = nutans.

acanthoides, Hornem. in Fl. Dan. t. 1341 = Cnicus palustris.

acanthoides, Huds. Fl. Angl. ed. II. ii. $351=$ pycnocephalus.

acanthoides, Linn. Sp. PI.821.-Europ.; Reg. Cancas. acanthoides, Pall. ex Bieb. F1. Taur. Cauc. ii. $268=$ hamalosus.

acanthoides, Urr. in Mém. Soc, Linn, Par. i. (1822) 361 =nutans.

acantholepis, Benth. in Benth. E Hook. f. Gen. ii. 468. -As.centr.

Acarna, Linn. Sp. Pl. $820=$ Cnicus Acarna.

acaulis, Linn. 1. c. $1199=$ Cricus acaulis.

acaulis, Thunb. F1. Jap. $306=$ Cnicus japonicus.

acicularis, Bertol. in Ann. Sc. Nat. Sér. I. i. (1829) 27 t. Italia

acuminatus, Gaud. ex Reichb. Ic. F1. Germ. xr. 90. t. $872=$ acanthoides.

adpressus, C. A. Mey. Verz. Pfl. Cauc. 71.-Reg. Caucas.

\section{CARDUUS :}

afer, Jacq. Hort. Schoenb. ii. $10=$ Cnicus afer. affinis, Guss. Pl. Rar. 334. t. 57.-Neapol. aggregatus, Schieich. Cat. PI. Helv. ed. IV. $11=$ natans

agrestis, Presl, Fl. Sicul. p. xxx, in nota = corymbosus. Aitonit, Raeusch. Nom. ed. III. 229 (Quid?)

alatus, D. Don, Prod. Fl. Nep. $167=$ Jurinea alata.

albidus, Bieb. Fl. Taur. Cauc. ii. $269=$ pycnocephalus albidus, Lam. Fl. Fr. ii. $18=$ praec.?

algeriensis, Munby, in Bull. Soc. Bot. Fr. ii. (1855) 285. -Algeria.

alpestris, Waldst. \& Kit. P1. Rar. Hung, iii. 296. t. 267 $=$ arctioides.

altaicus, Patrin, ex S. G. Gmel. Fl. Sib.t. 39. f. $2=$ Serratula glauca.

altissimus, Gilib. Fl. Lituan, iii. 186 = Cnicus palnstris.

altissimus, Linn. Sp. P1. $824=$ Cnicus altissimus. ambiguns, Pers. Syn. i. $389=$ Cnicus heterophyllus

ammophilns, Hoffmgg. E Link, Fl. Port. ii. 187.Lusitan.

amplexicaulis, Noronha, in Verh. Batav. Gen. F. (1790)

ed. I. Art. IV. 11-Malaya.

Amsteinii x, Bruegg. in Jahresb. Naturf. Ges. Graub. II. xxiii,-xxiv, (1880) 106.-Helvet.

anglicus, Lam. Encyc. i. $705=$ Cnicns pratensis angustifolius, Lam. l. c. 703.-Hab. ?

antarcticus, Auct. ex Steud. Nom. ed. I. $152=$ autareticus.

appeninus, Jan, ex DC. Prod. vi. $622=$ nutans.

arabicus, Jacq. Coll. i. $56=$ prcnocephalus

arachnoideus, Bieb. ex Steud. Nom. ed. II. i. $283=$ Cnicus arachnoideus.

araneosus, Stend. Nom. ed. I. $151=$ Cnicus araneosus. arctioides, Vill. Hist. P1. Dauph. ii. $22=$ Personata.

arctioides, Willd. Sp. Pl. iii. 1656.-Europ.

arenarius, DC. Fl. Fr. vi. $45 \overline{7}=$ Candollei

arenarius, Desf. Fl. Atlant.ii. 99.-Afr. bor.

Argemone, Pourr. in Lam. Encjc. i. $700=$ carlinae folins.

argentatus, Linn. Mant. ii. 280.-Reg. Mediterr, or. Iresopot.

argentatus, Willd. ex Steud. Nom. ed. II. i. $283=$ pycnocephalus.

argiroa, Nrm. Consp. $413=$ argyroa.

argutus, Sweet, Hort. Brit. ed. I. 213 = Serratnl tinctoria.

argyracanthus, Wall. Cat. n. $2903=$ Cnicns Tallichii argyroa, Birona, Stirp. Rar. Sicil. i. [7].-Sicilia.

argyroa, Kunze, in Flora, xxix. (1846) $760=$ malaci tanus.

armatus, Boiss. \& Heldr. Diagn. Ser. I. Vi. $104=$ cronias.

armatus, Steud. Nom. ed. I. $151=$ Cnicus armatus.

armenzs, Boiss. Fl. Orient. iii, $516=$ nutans.

arvensis, Robs. Brit, Fl, $168=$ Cnicus arrensis.

Aschersonianus x, Ruhm. in Eichl. Fahrh. Berl. i (1\&81) 239 -German

astracanicus, Spreng. Fl. Hal. Mant. 49-Astracan.

stlanticas, Pomel, Nour, Mat. Fl. Atl. 22,-Afr, bor

atriplicifolius, Trevir. Hort. Wratisl, $1820=$ Serratula atriplicifolia.

auriculatus, Wall. Cat. n. 2899 = Saussurea hypoleuca.

auroficus, Chaix, ex Vill. Fl. Delph. 90 sphalm.= seo.

aurosicus, Vill. Hist. Pl. Daush iii 7.-Gallia.

australis, Jord. Gr. Rec. Bot. Gren. (1849) $14=$ rivariensis.

australis, Linn. f. Suppl. $348=$ pscnocephalus.

autareticus, Vill. Hist. PI. Dauph. iii, $12=$ Cnicus heterophyllus.

axillaris, Gaud. Fl. Helr, ii. $169=$ acanthoides.

baeocephalus, Webb \& Berth. Phyt. Canar. ii. 373,-

Ins. Canar.

baeticus, Boiss. Ô Reut. Pugill. Pl. Nov. (1852) 63.Hispan.

Balansae, Boiss. Diagn. Ser. II. iii. 44.-Algeria.

Ballii, Hook. fo in Fourn. Bot. xi. (1873) 368.Marocco.

Barrelieri, Bertol. ex Nym. Consp. 411.-Liguria.

benedictus, Auct. ex Steud. Nom. ed. I. $151=$ Carbenis benedicta.

bicolor, Visiani, F1. Dalm. ii. 48. t. 49. fig. $2=$ argrroa.

bihariensis $\times$, Simk. in Termész. Fïzetek, v. (1881) 51. -Transsyly

\section{CARDUUS}

Bonjarti, Pill. \& Mitterp. Iter Poseq. i. 143. t. $13=$ Cnicus arachnoideus.

Boujarti, Savi, F1. Pis. ii. $243=$ Cnicus ferox.

Bourgaeanus, Boiss. \& Reut. Pugill. P1. Nov. (1852) $62=$ Reuterianos

Bourgeaenus, Sch. Bip. ex Boiss, Diagn. Ser. II. iii. 44. -Ins. Canar.

brachycephalus, Schur, in Verh. Siebenb. Ver. Naturw. x. (1859) $68=$ collinus

bulbosus, Lam. Encyc. i. $705=$ Cnicus tuberosus. caeruletus, Brot. Fl. Lusit. i. 342,-Lusitan.

caesius, Andrz. ex Trauto. in Act. Hort. Petrop. riii. (1883) 498, nomen,-Rossia.

Cafischii x, Bruegg. in Jahresb. Naturf. Ges. Graub. II xxiii,-xxir. (188U) 106.-Helret.

callosus, Steud. Nom, ed. II. i. 283.-Hab. ? camporum, Boiss. Diagn. Ser. II. iii. 45.-Rumel.

canaliculatus, Dulac, Fl. Hautes-Pyr. 522 = carlinaefolius.

candicans, Waldst. \& Kit. Pl. Rar. Hung. i. t. $83=$

collinus.
Candollei, Moretti, Pl. Ital. Dec. ii. 10.-Gallia; Ital. canus, Linn. MIant. $105=$ Cnicus canus.

Canduelis, Gren, in Billotia, i. (1864) 14=arctioides. carlinaefolius, Lam. Encyc. i. 700.-Europ.

carlinaefolizs, Nym. Consp. $412=$ defloratus.

carlinaefolius, Tenore, Prod. FI. Neap. $48=$ chrysacanthus.

carlinoides, Dur. ex DC. Prod. vi. $625=$ confertus,

carlinoides, Gouan, Illustr. 62, t. 23.-Mont. Pyren.

carlinoides, Steud. Nom. ed. II. i. $283=$ Cnicus carlinoides.

carlinoides, Tenore, Prod. F1. Neap. $48=$ chrysacanthus.

carniolicus, Pers. Syp. ii. $388=$ Cnicus rufescens.

carolinianus, Walt. Fl. Carol. 195 = Cnicus muticus,

Carolonum $x$, Horvie \& Tenner, in Trans. Bot. Soc. Edinb. ix. (1868) 260.-Scotia.

carpetanus, Boiss. \& Reut. Diagn. P1. Hisp. 19. п. 35 = Gayanus.

carthamoides, Steud. Nom, ed. I. $151=$ Leuzea earthamoides.

Casabonae, Linn. Sp. Pl. $823=$ Cnicus Casabonae.

caucasicus, Adam, in Weber \& Mohr, Beitr. i. $64=$ Cnicus horridus.

caulescens, Pers. ex Sterd. Nom. ed. I. $151=$ Cnicus acaulis.

centauroides, Buch.-Ham. ex DC. Prod, vi. $563=$ Volntarella divaricata.

centauroides, D. Don, Prod. Fl. Nep. $167=$ Serratula centauroides.

centauroides, Hoppe, ex DC. Prod. vi. $628=$ arctioides.

centauroides, Linn. Sp. Pl. ed. II. 1148 (=Cnicus cynaroides).

cephalanthus, Viv. Fl. Cors. Sp. Nov. 14.-Sardin,

cerinthifolizes, Vill. Prosp. $30=$ Serratula nudicaulis

cerinthoides, Willd. Sp. Pl. iii. $1660=$ Serratula nudicaulis.

cernuus, Bertol. Fl. Guatimal. 31.-Guatemal.

cernuus, Steud. Nom. ed. I. 151.-Sibir.

Chailleti, Godr. Fl. Lorr. ii. $42=$ Cnicus palustris.

chamaecephalas, Oliver \& Hiern, in Oliver, Fl. Trop. Afr. iii. 434.-Abyssin.

chinensis, DC. Prod. ri. $629=$ Cnicus chinensis.

chius, Facq. Hort. Vindob. iii. 7.-Ins. Chios.

chrysacanthus, Tenore, Sem. Hort. Neap. (1825) 12.Hispan. ; Italia.

cichoracens, Cyr. P1. Rar. Neap. Fasc. ii. 17. t. $7=$

Serratula cichoracea.

ciliatus, Murr. in Comm. Gott. (1784) 35. t. $5=$ Cuicus ciliatus.

ciliatus, Pours, ex Willk. \& Lange, Prod. Fl. Hisp. if. $198=$ Gavanus

citiatus, Vill. Préc. Vor, 45=Cricos spathulatus,

cinerascens, Hort. Huber, in Rev. Hortic. (1872) 60 -Am. bor. ?

cinereus, Bieb. Fl. Taur. Cauc. ii. $270=$ pycnocephalus.

cirsiformis, Vukot. in Rad 千ugos. Akad. Zagreb. xxxix. (18i7) 206.--Europ.

cirsioides, Vill. Prosp. $30=$ defloratus.

Cirsium, Mill. Gard. Dict. ed. VIII. n, $5=$ Cnicus dissectus.

claralatus, Link, in Buch, Beschr. Canar. Ins. 147.-

Ins. Canar.

collinus, Waldst. E Kit. Pl. Rar. Hung, iii. 25\%. t. 232.-Europ. austr. or. 


\section{CARDCCS:-}

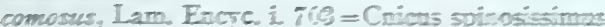
confertus, Bong, ex Willk, a Lange, Hrod. FL Hisp ii. $154=$ testicrs

confertics, Moris, Eleach, PL. Seril. ii. $5=$ mrria. cantios:

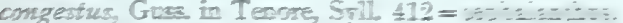

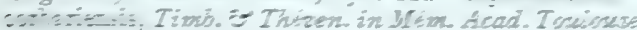
Ser. TII ri 187 , O4t7-Europ.

cononato, D. Don, Prod FL Sep. 15i=Serratia csecuszas.

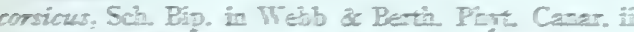
$3-5=$ ciari a

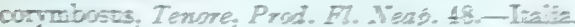

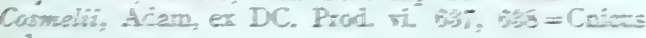
lapracens.

crassifoisus, Minid. Erum. Hott Perol Ės = cetora:s

creticus, Lam. Exerc i ioll=Cricas phagen

crispus, Gouan, FL Morsp. 32\% = resulfors.

crispus, Gtir ex Nym Cossp. $413=$ Reterians

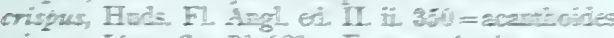

crispes, Linn Sp. Pl. $\$ 21$ - Europ.; A bor.

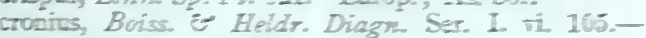

Grascia: As Min

crancides, I inn SP. PL 829 = Twinea cranoidec

Crancides, Pail Fieise, ifi $594=$ Juri-ea poirciocus

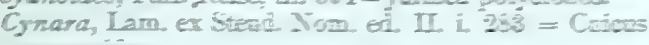
ran.

gratoides, I2m. Ectge i i $2=$ Cnions cyarices,

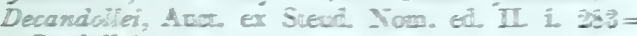

Carcicie

ceforame, Linn Syst. ed X 1200-Europ

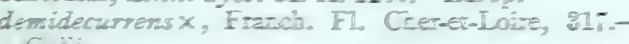
$\mathrm{G}=1 \mathrm{il}=\mathrm{s}$

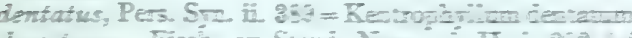

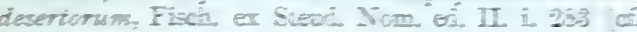
Cirsium decerismus - 5

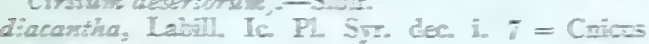
diacatis

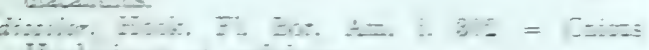

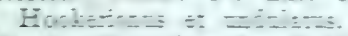

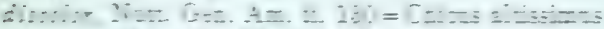

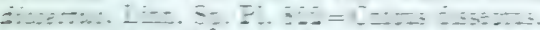

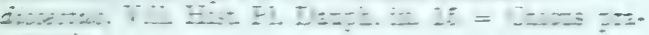
:Es:

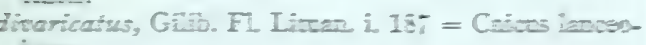
ist:s.

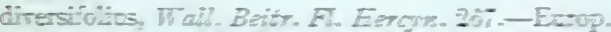

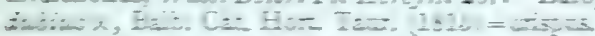

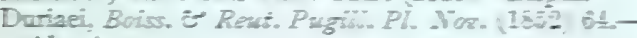
Algeria

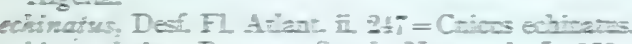

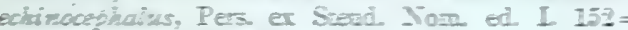

Crivos eñisocerhales,

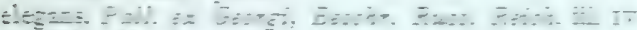
1-1 - Thes:

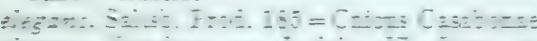

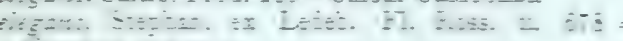

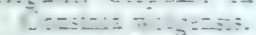

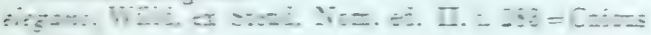
$-1-2=0.0$

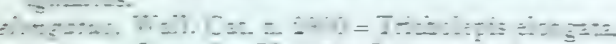

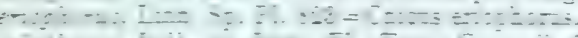

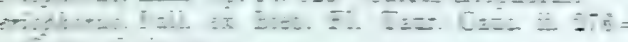
$C=0=-2 . \cdots=$

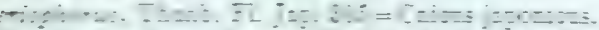

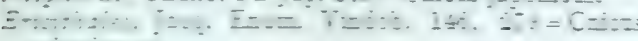

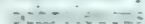

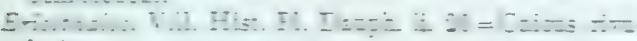
intis.

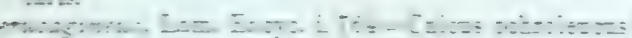

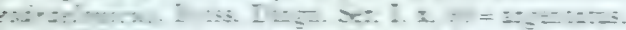

actera-s.

$(10-1,-\infty$

-

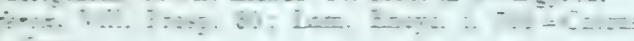
tern.

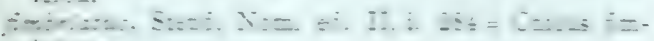

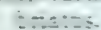

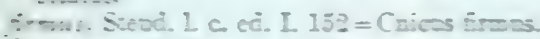

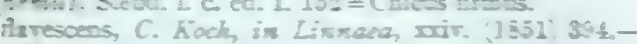
incis.

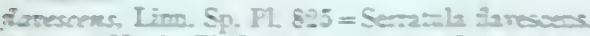

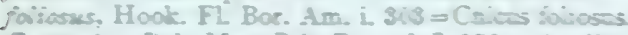

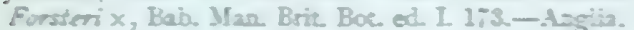

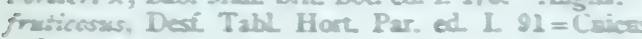
iresionses.

\section{CARDUUS}

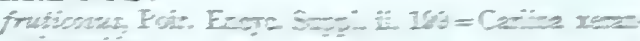
inemesict

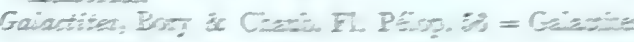

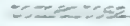

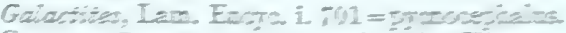

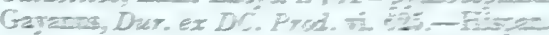

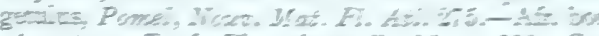

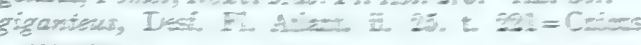
$\overline{\varepsilon-\varepsilon}=-\mathrm{e}=\mathrm{s}$.

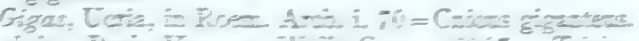

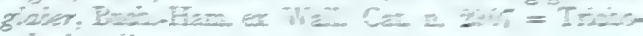
iepis rateas.

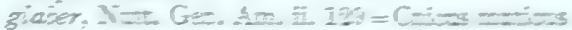

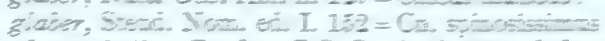

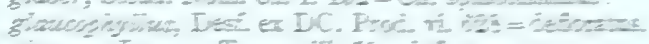

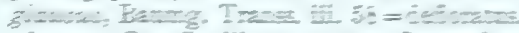

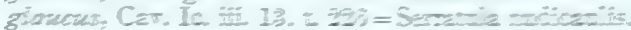

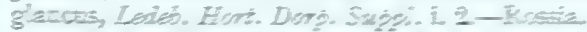

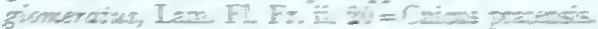

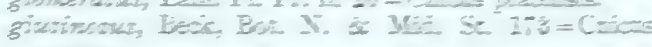
$=2=\ldots$.

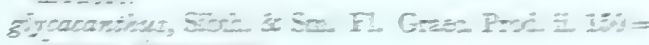
-

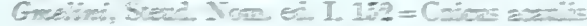

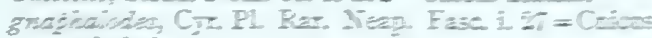
grapaiores

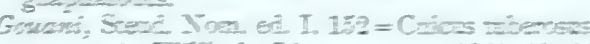

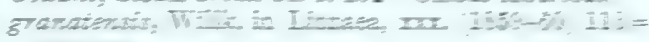

z $=1-2=$

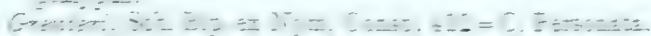

and 2ross

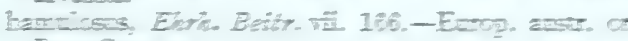
Feg. Catcas

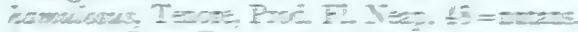

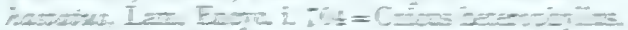

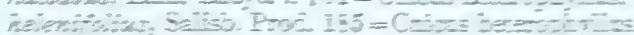

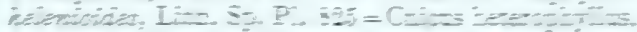

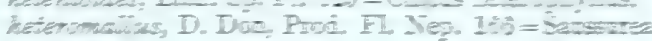
carivase

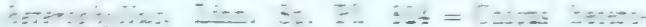

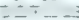

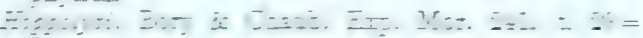
$C=-2=-2$

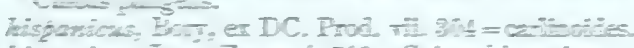

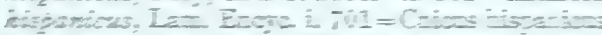

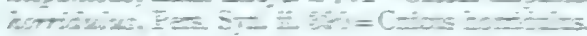

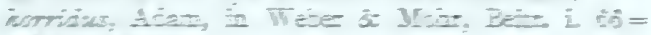
C:-:- = = =

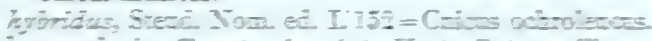

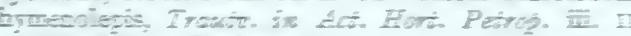

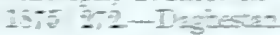

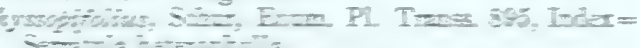

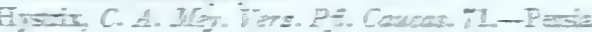

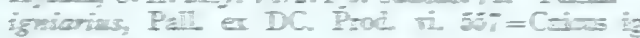

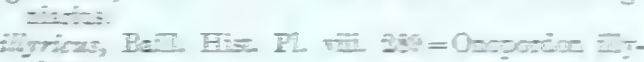
r....

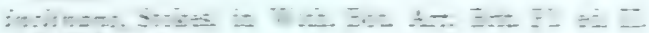
$-1-10=$

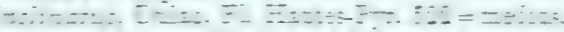

$0 \quad 1=-00=0+\cdots$

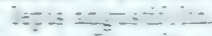

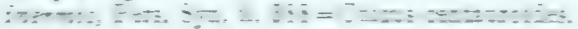

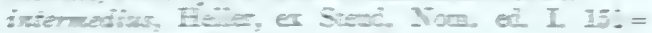
$C=x s i n=0$

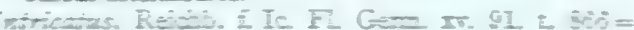
Cectile

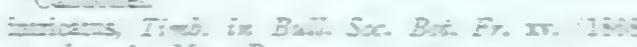

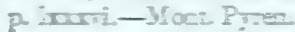

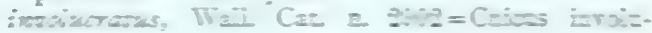

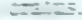

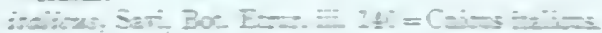

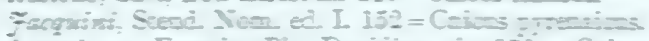

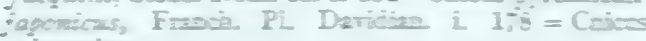
int.

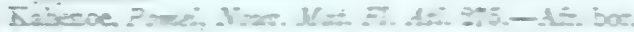

$\mathrm{K}$ insi $x, B$ -

II. xi -

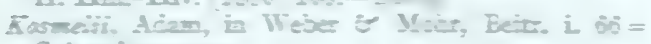
Caios isprears

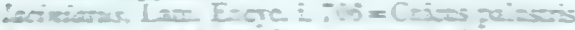

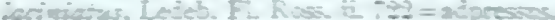

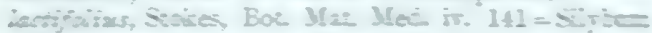
Visise

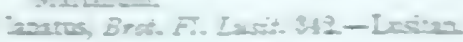

CAPปपTE

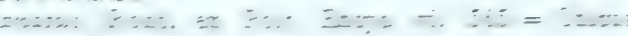
$=\ldots . .$.

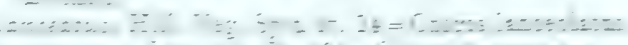

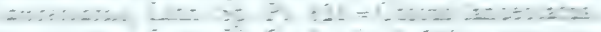

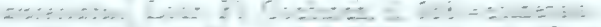

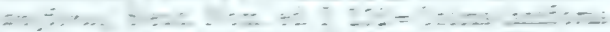

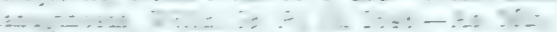

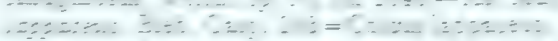

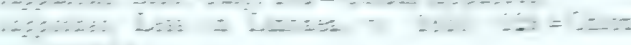

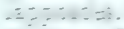

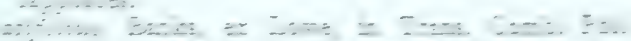

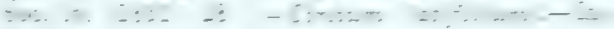

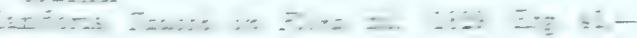
$\therefore+\ldots$

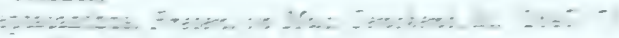
$-\therefore \ldots$

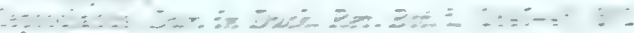

- $=1-3=$

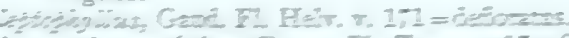

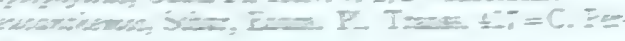
sien:a

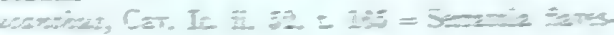
$z=-$

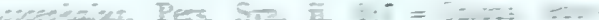
sepezite.

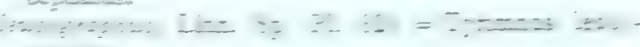

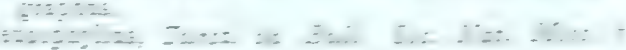

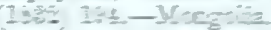

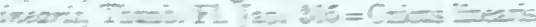

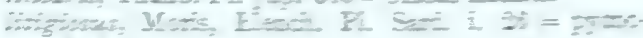

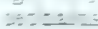

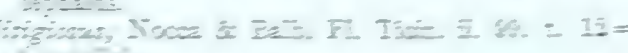

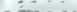

들. A : $\quad \therefore-2=?$

-

and

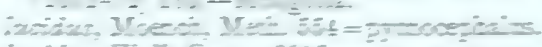

:

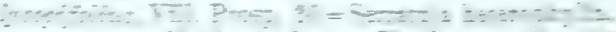

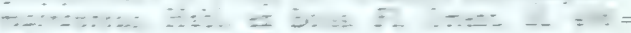

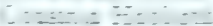

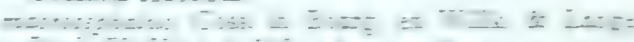

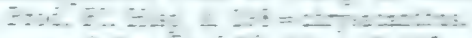

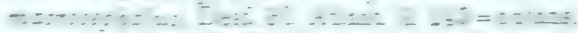

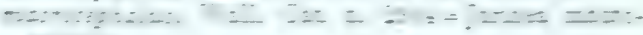

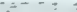

$=-\cdots$

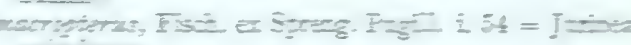
C........

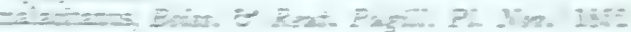
F- Hise:

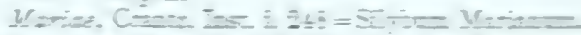

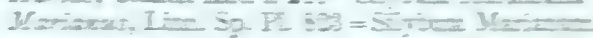

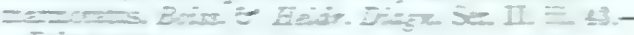

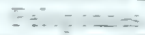

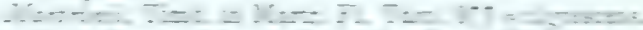

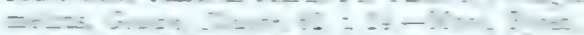

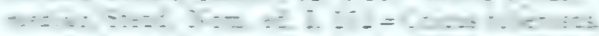

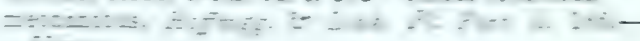
$\exists=:$.

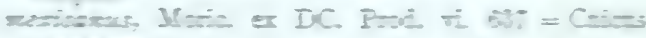

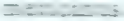

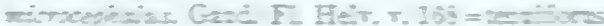

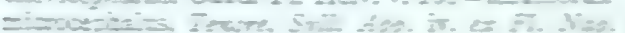

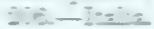

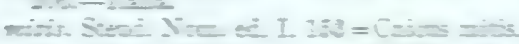

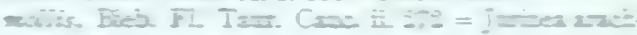
$=2.0$

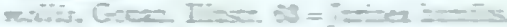

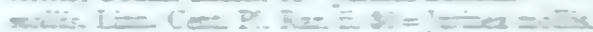

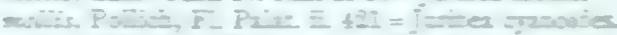

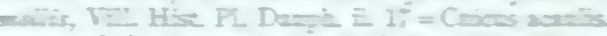

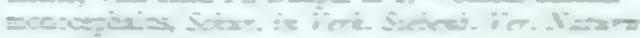
E $1350^{\circ}-\mathrm{B}-\mathrm{E}=0$

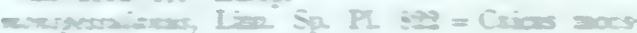
pesse isas.

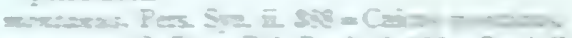

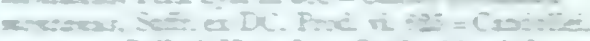

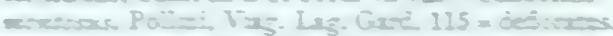

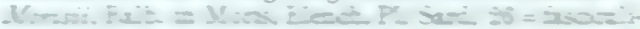
nots

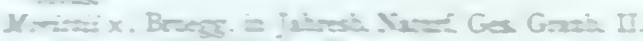

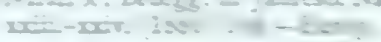




\section{CARDUUS:-}

moschatus, Guss, Ind. Sem. Hort. Boccadif. $(1825)=$ Jurinea mollis.

multifiorus, Gaud. Fl. Helv. v. 166=acanthoides multiflorus, Panc. ex Nym. Consp. $414=$ Pancicii multijugus, C. Koch, in Linnaea, xxiv. (1851) 392 adpressus.

muticus, Pers. Syn, ii. $386=$ Cnicus muticus.

myriacanthus, Boiss. Voy. Bot. Espagne, ii. $361=$ Reuterianus.

myriacanthus, Salzm. in DC. Prod. vi. 624.--Reg Mediterr. occ.

Naegeli $x$, Bruegg. in Jahresb. Nat. Ges. Graub. II xxiii-xxiv. (1880) 107.-Europ.

neglectus, Steud. Nom. ed. I. $153=$ Cnicus uliginosus. meglectus, Tenore, Ind. Sem. Hort. Neap. (1830) $14=$ acicularis.

nepalensis, Spreng. ex DC. Prod. vi. 542=Jurinea nacrocephala.

nervosus, C. Koch, in Linnaea, xvii. (1843) 42.Armenia.

nidulans, Rupr. Sert. Tiansch. 55.-As. centr.

nigrescens, Mutel, ex Nym. Consp. 412 =vivariensis.

nigrescens, Vill. Prosp. 30.-Europ.

nitidus, Waldst. \& Kit. Pl. Rar. Hung. i. $52=$ Serratula heterophylla.

nitidus, Wall. Cat. n, 2908=Tricholepis angustifolia niveus, Benth. in Benth. E Hook. f. Gen. ii. 468.-As. centr.

nudicaulis, Pers. Syn. ii. $386^{\circ}=$ Serratula nudicaulis numidicus, Coss. E' Dur. Explor. Pl. Algér. t. 49.Algeria.

utans, Boiss, ex Nym. Consp. $411=$ platypus

nutans, Linn. Sp. Pl. 821.-Europ. ; As. temp.

bvallatus, Bieb. ex Willd. Enum. Hort. Berol. 842.

Reg. Caucas.

obvallatus, Steud. Nom. ed. I. $153=$ Cnicus obvallatus obvallatus, Wall. Cat, n. 2095 = Saussurea obvallata. occidentalis, Nutt. in Trans. Am. Phil. Soc. N. S. vii

(1841) $418=$ Cnicus occidentalis

ochroleucus, Pers. Syn. ii. $389=$ Cnicus ochroleucus.

odoratus, Muhl. Cat. Darl. F1. Cestr. $85=$ Cnicus pumilus.

oleraceus, Vill. Hist. Pl. Dauph. iii. $21=$ Cnicus olera ceus.

olympicus, Boiss. Diagn. Ser. II. iii. 43-As. Min. onopordoides, Fisch ex Bieb. Fl. Taur Cauc. iii. 552 -Reg. Caucas.

Onopyxos, Hill, Veg.Syst. iv. 13.-German.

orgyalis, Steud. Nom. ed. I. $153=$ Cnicus orgyalis orientalis, Adam, in Weber \& Mohr, Beitr. i. $63=$ Cousinia carduiformis.

prientalis, Pers. Syn. ii. $387=$ Galactites tomentosa orthocephalus $\times$, Wallr. Beitr. Fl. Hercyn. 268 ; et in Linnaea, xiv. (1840) $86=$ acanthoides.

osseticus, Adam, in Weber \& Mohr, Beitr. i. $65=$ Cnicus fimbriatus.

palatinus $\times$, Sch. Bip. ex Nym. Consp. $413=$ acanthoides.

palustris, Linn. Sp. PI. $822=$ Cnicus palustris

palustris, Savi, Bot. Etrusc. iii. $141=$ Cnicus polyanthemus.

Pancicii, Sch. Bip. ex Nym. Consp. 414.-Serbia. paniculatus, Ait. Hort. Kew. ed. I. iii. 143.-Europ. paniculatus, Dulac, Fl. Hautes-Pyr, $522=$ carlinoides. paniculatus, Vahl, Symb. Bot. i. $68=$ Cnicus flavispinus. pannonicus, Linn. f. Suppl. $348=$ Cnicus pannonicus. pannonicus, Schleich. ex DC. Prod. vi. $629=$ tenuifolius.

pannosus, Trautv. in Act. Hort. Petrop. iii. Ir. (1875) 271.-Armenia.

parviflorus, Buch, Beschr. Ins. Canar. $147=$ pycnocephalus.

parviflorus, Linn. Mant. $279=$ Cnicus parviflorus.

pauciflorus, Pers. Syn. ii. $388=$ Cnicus pauciforus.

pectinatus, Linn. Mant. $279=$ defloratus.

pedemontanus, Pers. Syn. ii. $389=$ Cnicus tuberosus.

peregrinus, Retz. Obs. i. $27=$ pycnocephalus

Personata, Facq. Fl. Austr. iv. 25. t. 348.-Europ.

personatus, Gaertn. Fruct. ii. $378=$ praec.

petrophilus, Timb. in Bull. Soc. Bot. Fr. xv. (1868)

p. Ixxxyii.-Mont. Pyren.

pinnatifidus, Cav. Ic i. 58, t. $83=$ Serratula pinnatifida Pitcheri, Steud. Nom. ed. II. i. $284=$ Cnicus Pitcheri platylepis, Sauter, in Flora, xiii. (1830) $410=$ nutans platypus, Lange, Ind. Sem. Hort. Haun. (1857) 26.Hispan.

podacanthus, DC. Fl. Fr. iii. $80=$ aurosicus.

\section{CARDUUS :-}

poliochrus, Trautv. in Act. Hort. Petrop. iii. II. (1875) 272 .-Reg. Caucas.

polvacanthos, Curt. Fl Lond fasc. vi t. $54=$ acanthoides. polyacanthus, Lam. F1. Fr. ii. $20=$ Cnicus Casabonae. polyanthemos, Hegel, ex Heer, Fl.Schw. 801.-Helvet polyanthemos, Schur, Enum. Pl. Transs. $417=$ collinus. polyanthemus, Boeber, in Pall. N. Nord. Beitr. vi. 261 Bieb. Casp. App. 210 (=Cirsium elodes).--Reg. Caucas.

polyanthemus, Linn. Mant. i. 109=Cnicus polyanthemus.

polyanthemus $\times$, Schleich. Spicil. $15=$ nutans

polyanthos, Boiss. F1. Orient. iii. 548, $988=$ Cnicus pungens.

polyanthos, Schreb. Spicil. 15=acanthoides

polyclonos, Willd. Sp. Pl iii. $1655=$ Jurinea polyclonos polymorphus, Lapeyr. in Mém. Acad. Toulouse, (1782) 217. t. 19, 20= Cnicus heterophyllus

Pontederae, Steud. Nom. ed. 1. $153=$ Cnicus rivularis.

Poolii x, Bruegg. in Jahresb. Nat. Ges. Graub. II. xxiiixxiv. (1880) 107.-Europ.

pratensis, Huds. FI. Angl. ed. II. 353 ; Lam. Encyc. i. $700=$ Cnicus pratensis.

pseudosyriacus, Lojac. in Natural. Sicil. iv. (1885) 109.-Sicil.

ptarmicaefolius, Mill, Gard. Dict. ed. VIII. n. $1=$

pteracanthus, Dur, in Duch. Rev. Bot, i. (1845-46) $362=$ Reuterianus

pterocaulos, Steph. ex DC. Prod, vi. $553=$ Cousinia arachnoidea.

pulcher, Clark, Trav. i. 739, nomen.-Tauria.

pumilus, D. Don, Prod. Fl. Nep. 167-Nepal.

pumilus, Hook. F1, Bor. Am. i. $302=$ Cnicus Drummondii.

pumilus, Nutt. Gen. Am, ii. $130=$ Cnicus pumilus.

pumilus, Vill. Hist. Pl. Dauph. ii. $17=$ Cnicus heterophyllus.

punctatus, Herb. Madr. ex Wall. Cat. n. $2907=$ Tricholepis radicans.

pungens, Pers. ex DC. Prod. vi. $643=$ Cnicus pungens. purpureus, Vill. Fl. Delphin. 90.-Gallia.

pycnocephalus, Linn. Sp. Pl. ed. II. 1151; facq. Hort. Vind. i, 17. t. 44.-Europ.; Reg. Mediterr.; Oriens. pycnocephalus, Spreng. Syst. iii. $385=$ cephalanthus.

pycnocephalus-alatus, Stev, ex DC Prod. vi. $553=$ Cousinia arachnoidea.

pygmaeus, Jacq. Enum. Vindob. 147, $282=$ Saussurea pygmaea.

pyrenaicus, Gouan, Illnstr. $63=$ Cnicus pyrenaicus.

pyrenaicus, Facq. Obs. Bot. Iv. 11. t. 95.-Mont. Pyren

pyrochros, Less. in Linnaea, v. (1830) $130=$ Cnicus conspicuus.

quinquefolius, D. Don, Prod. Fl. Nep. $167=$ Serratula quinquefolia.

radiatus, Waldst. \& Kit. Pl. Rar. Hung. i. $9=$ Serratula radiata.

radicans, Roxb. Hort. Beng. 60 ; F1. Ind. iii. $408=$

Tricholepis radicans.

ramosus, Roxb. 1l. cc. 101, $407=$ Volutarella divaricata

ramosissimus, Panč. Elench. Crna-Gora, 51.-Monteneg.

recurvatus, Jord. ex Bor. Fl, Cent. Fr. ed. III. ii. 359 , in obs, = nigrescens.

recurvatus, Willk. in Linnaea, xxx. (1859-60) $113=$ granatensis.

remotifolius, Hook. Fl. Bor. Am. i. $302=$ Cnicus remotifolius.

repandus, Pers. Syn, ii. $386=$ Cnicus repandus.

Reuterianus, Boiss, Diagn. Ser. II vii. 44--Hispan.

rhaeticus, Dalla Torre, Atl. Alpenfl. 138.-Europ.

rheginus, Steud. Nom. ed. I. $153=$ Cnicus strictus.

rigens, [Dryand. in] Ait. Hort. Kew. ed. I. iii. $144=$ Cnicus rigens.

rigens x, Godr. Fl. Lorr. ii. 40,-Gallia.

rivularis, Jacq. F1. Austr. i. $57=$ Cnicus rivularis

Rosenii, Vill. Fl. Delphin. $91=$ Cnicus acaulis.

ruderalis, Tausch, ex Nym. Consp. $412=$ acanthoides.

rufescens, Pers. Syn. ii. $389=$ Cnicus rufescens

salinus, Bieb. ex Steud. Nom. ed. II. i. $353=$ Centaurea serratuloides.

salisburgensis, Pers. Syn. ii. $388=$ Cnicus rivularis

samniticus, Tenore, Sem. Hort. Neap. (1825) $12=$ Cnicus italicus.

Sanctae-Balmae, Loisel. Nouv. Not. $34=$ Candollei.

sardous, DC. Prod. vi. $626=$ pycnocephalus.

scaber, Poir. Voy. Barb. ii. $231=$ Cnicus giganteus.

\section{CARDUUS :}

Schimperi, Sch. Bip. in Linnaea, xix. (1847) 334.Abyssin.

Schulzeanus $\times$, Ruhm, in Eichl. Jahrb. i. (1881) 240 Europ.

Scolymus, Baill. Hist. P1. viii. 7, 289 = Cynara Cardunculus.

Scordium, Stokes, Bot. Mat. Med. iv. $142=$ Serratula Scordium.

segetum, Franch. Pl. Davidian. i. $178=$ Cnicus segetum. seminudus, Bieb. Fl. Taur.Cauc. ii. 271.-Reg. Caucas. et Casp.

semipectinatus, Lam. Encyc. i. $705=$ Cnicus semipectinatus.

semipinnatus, Desf. ex Steud. Nom. ed. I, $153=$ Cnicus pratensis.

serratuloides, Jaca. Fl. Austr. $127=$ Cnicus pannonicus serratuloides, Linn. Sp. Pl. $825=$ Cnicus serratuloides. serratuloides, Neck. Delic. Gallo-Belg. $338=$ Cnicus arvensis.

serrulatus, Steud. Nom. ed. I. 154 ; ed. I1. i. $285=$ Cnicus serrulatus.

setosus, Bab. in Gard. Chron. (1844) $718=$ Cnicus arvensis?

simplicifolius, Sang, in Atti Acc. Pont. Lincei, Ser, I. xviii. (1865) t. 2.-Italia.

sinuatus, Gilib. Fl. Lituan. i. $187=$ acanthoides.

Spachianus, Dur. in Duch. Rev. Bot. i. (1845-46) 361. - Afr. bor.

spinigerus, Jord. Obs. Pl. Crit. iii. (1846) $215=$ hamulosus.

spinosissimus, Gueldenst. ex Ledeb. F1. Ross. ii. $743=$ Cnicus acaulis.

spinosissimus, C. A. Mey, in Beitr. Pfl. Russ. Reich. iv. $43=$ Cnicus esculentus.

spinosissimus, Steud. Nom. ed. II. i. $285=$ Cnicus echinocephalus.

spinosissimus, Vill. Hist. Pl. Dauph. iii. $11=$ Cnicus spinosissimus.

spinosissimus, Walt. FL Carol, 194=Cnicus horridulus spinulosus, Bertol. Amoen. Ital. $41=$ defloratus.

spinosus, Gueldenst. ex Ledeb. Fl. Ross. ii. $743=$ Cnicus acaulis.

spurius, Linn. Hort. Ups. $249=$ Cnicus eriophorus. squarrosus, DC. ex Lowe, in Trans. Camb. Phil. Soc. vi. (1838) reimpr. 18.-Madera.

Stangii, Buek, ex Nym. Consp. $411=$ nutans.

stellatus, Linn. Sp. Pl. $823=$ Cnicus stellatus

stenolepis, Benth. in Benth. E Hook. f. Gen. ii. 468.As. centr.

strictus, Steud. Nom. ed. I. $154=$ Cnicus strictus.

strigosus, Bieb. Tabl. Casp. $194=$ Cnicus strigosus.

suaveolens, Benth. in Benth. E Hook. f. Gen. ii. 468

-As. centr.

subcoriaceus, Less. in Linnaea, v. (1830) $130=$ Cnicus subcoriaceus.

subdecurrens, Bertol. Fl. Ital. viii. 623.-Liguria. sumanus, Pollini, in Brugnat. Giorn. Fis. ix. (1816) $96=$ defloratus.

syncephalus, Reichb. f. Ic. Fl. Germ. xv. 87. t. $864=$ pycnocephalus.

syriacus, Linn. Sp. P1. $823=$ Notabasis syriaca. tataricus, Lam. Encyc. i. $703=$ Cnicus rigens. tataricus, Linn. Sp. Pl. $825=$ Cnicus oleraceus ? tauricus, Boeber, ex Georgi, Beschr. Russ, Reich. iii. IV. $1224=$ Cnicus echinocephalus.

taygeteus, Boiss. \& Heldr. Diagn. Ser. II. iii. $42=$ nutans.

tectus, Wall. Cat. n, $2906=$ Saussurea obvallata

tenuiflorus, Curt. Fl. Lond, fasc. vi. t. 55=pyenocephalus.

tenuifolius, Gaud. F1. Helv. v, 174=defloratus.

thessalus, Boiss. \& Heldr. Diagn. Ser. II. iii. $46=$ acanthoides.

Thoermeri, Weinm, in Bull. Soc. Nat. Mosc. (1837) n. vIr. $69=$ nutans.

Thomsoni, Hook. f. Fl. Brit. Ind. ii, 361.-Tibet. occ. Timbali, Martr. Fl. Tarn, $377=$ nigrescens.

tinctorius, Falk, Beitr. ii. $237=$ Carthamus tinctorius, tinctorius, Scop. F1. Carn. ed. II. ii. $132=$ Serratula tinctoria.

tmoleus, Boiss. Diagn. Ser. I. iv. 21.-As. Min. tomentosus, Gilib. Fl. Lituan i. $188=$ Cnicus eriophorus. transalpinus, Suter, F1. Helv. $172=$ defloratus tricephaloides, Lam. Encyc. i. $704=$ Cnicus rivularis. trichocephalus, Wall. Cat. n. $2901=$ Tricholepis furcata. trilobatus, Buch.-Ham. ex DC. Prod. vi. $639=$ Cnicus involucratus. 


\section{CARDUUS:}

tuberosus, Georgi, It. i. 228 (=Cirsium setigerum). tuberosus, Jacq. F1. Austr. $280=$ Cnicus canus. tuberosus, Linn. Sp. Pl. $824=$ Cnicus pratensis tuberosus, Vill. Hist. Pl. Dauph. iii. $15=$ Cnicus tuberosus.

uliginosus, Hort. ex Steud. Nom. ed. I. 154=Cnicus Willdenowii.

uliginosus, Steud, 1. c. = Cnicus uliginosus.

uncinatus, Bieb. Fl. Taur. Cauc. iii. 553.-Reg. Caucas. ; Tauria.

undulatus, Nutt. Gen. Am. ii. $130=$ Cnicus undulatus. uniflorus, Turcz, ex Ledeb. Fl. Ross. ii. $758=$ Serratula glauca.

valentinus, Boiss. E Reut. Diagn. Ser. II. iii. 45.Hispan.

Verdii, Carr, in Rev. Hortic. (1870-71) 520.-Hispan versicolor, Salisb. Prod. $185=$ Silybum Marianum.

virginianus, Bose, ex DC. Prod. vi. $651=$ Cnicus Nuttallii.

virginianus, Linn. Sp. Pl. $824=$ Cnicus virginianus. virginianus, Walt. Fl, Carol. $195=$ Cnicus repandus. viridis, A. Kern. Sched. Fl. Exsicc. i. 74.-Europ. vivariensis, ford. Obs. iii. 212.-Gallia.

vulgaris, Savi, Fl. Pis. ii. $241=$ Cnicus italicus.

Winklerianus $\times$, Dalla Torre, in Lotos, xxvii. 1877 (1878) 45.-Europ.

wolgensis, Bieb. ex Willd. Enum. Hort. Berol. $839=$ Cousinia wolgensis.

xanthacanthus, Freyn, in Flora, lxiv. (1881) 211.Lusitan.

xeranthemoides, Sweet, Hort. Brit. ed. I. $213=$ Serratula xeranthemoides.

CARDWFLLIA, F, Muell. Fragm, v, 23 (1865) PROTEACEAE, Benth. \& Hook. f. iii. 182. sublimis, F. Muell. l. c. 24, 38, 73.-Austral.

CARELIA, Adans. Fam. ii. $123(1763)=$ Ageratum, Linn. (Compos.)

CARELIA, Less. Syn. Comp. 156 (1832), COMPOSITAE, Benth. \& Hook. f. ii. 241.

cistifolia, Less. l. c.-Bras.

CAREX, [Dill.] Linn. Syst. ed. I (1735), CYPERA$C E A E$, Benth. \& Hook. f. iii. 1073.

Callistachys et CRYproglochin, Heuff, in Flora, xxvii. (1844) 528 .

CARICELLA, Ehrh. Beitr. iv. 146 (1789).

Distinax, Rafin. ex Stend. Nom. ed. II. i. 521 (1840).

Dornera, Heuff, ex Schur, Enum. Pl. Transs, 697 (1866)

DRYMEIA, Ehrh. Beitr. iv. 148 (1789).

Genersichia, Heuff. in Flora, xxvii. (1844) 528.

Heleonastes, Ehrh. Beitr. iv. 147 (1789).

LEPTOSTACHYS, Ehrh. 1. c. (1789).

Leucoglochin, Heuff. in Flora, xxvii. (1844) 528.

LIMONAETES, Ehrh. Beitr. iv. 148 (1789)

MAUksChIA, Heuff. in Flora, xxvii. (1844) 527.

Mondo, Adans. Fam, ii. 496 (1763).

Neilreichia, Kotule, in Spraw. Kom. Fis. Krakow, xvii. (1883) 136.

Phyliostachys, Torr. ex Steud. Nom. ed. II, i. 297, in syn. 1840$)$; ii. 328.

Physiglochis, Neck. Elem, iii. 245 (1790).

Polyglochin, Ehrh. Beitr. iv. 146 (1789).

Pseunocarex, Miq. in Ann. Mus. Lugd. Bat. ii. 146 (1866).

PSYLLOPHORA, Ehrb. Beitr. iv. 146 (1789).

Ptacosera, Ehrh. 1, c. 147 (1789).

Schelmammeria, Moench, Meth. Suppl. 119 (1802).

ScURIA, Rafin. in Journ. Phys. Ixxxix. (1819) 106.

Trasus, S. F. Gray, Nat. Arr. Brit. Pl. ii. 53 (1821)

Trionus, Rafin, in Journ. Phys, Ixxxix. (1819) 106.

TrRiplima, Rafin. in Am. Monthly Mag, (1819) 195

Ulva, Hall. Enum. Stirp. Helv. 1. 242 (1742).

Uva, Stend. Nom. ed. II. i. 285 (1840)

VignanTHA, Schur, Enum. PI. Transs. 705 (1866).

Vignes, Beanv, in Lestib. Essai Fam. Cyp. 22 (1819).

abbreviate, Presc ex Boott, in Ann. Nat. Hist. xvii (1846) $57=$ Torreyi

abjiciens, Steud. Syn. Pl. Cyp. 209.-Missouri.

acaulis, Urv. in Mém. Soc. Linn. Par. iv. (1826) 599. -Ins. Falk1.

\section{CAREX:}

acicularis, Boott, in Hook. Fl. N. Zel. 280. t. 63.Austral.; N. Zel.

acicularis, Turcz ex Steud. Nom ed. II i 285 . Sibir.; Reg Caucas.

acroandra, Schur, Enum. Pl. Transs. 699.-Transsylv acrolepis, Ledeb. in Denkschr. Baier. Bot. Ges. iii. 1841) $56=$ Gmelini

acrolepis, Liebm. in Vidensk. Selsk. Skr. V. ii. (1851) 271.-Costa-Rica.

acuminata, Reichb. Ic, Fl, Germ, viii, 28, t. $267=$ nutans.

acuminata, Willd. Sp. P1. iv. $300=$ glauca

acuta, All. F1. Pedem, ii. $247=$ riparia.

acuta, Curt. Fl. Lond. t. $281=$ paludosa

acuta, Darling. Florul. Cestric $98=$ virginiana.

acuta, Dewey, ex Hook. Fl. Bor. Am. ii. $218=$ angustata.

acuta, Linn. Sp. Pl. 978.--Reg. bor. temp.; Austral.

acuta, Muhl. Cat. 84 ; ed. (1818) 85, nomen = commutata.

acuta, Suter, Fl. Helv, ii. $261=$ glauca

acutaeformis, Brot. F1. Lusit. i. $66=$ echinata,

acutata, Boott, in Proc. Linn. Soc. i. (1846) 287.-Am austr.

acutiformis, Ehrh. Beitr. iv. $43=$ paludosa

acutissima, Déségl. in Loisel. Fl. Gall.ed. I. $628=$ pyrenaica.

Aederi, Desv. Fl. Anj. 74, sphalm, =Oederi

adusta, Boott, in Hook. Fl. Bor. Am. ii. 215.-Am. bor.

adusta, Carey, ex Boott, Illustr. Carex, iii. $118=$ foenea.

aematorhyncha, Dest. in C. Gay, F1. Chil. vi. $224=$ filiformis.

aemulans, Liebm. E Drej. in Flora, xxii. (1839) 142 $=$ stricta.

aequabilis, Boott, Illustr. Carex, i. 66. t. 178.-Ins. S. Helena.

aequata, Nees, ex Boott, 1. c. ii. $83=$ myosurus.

aestivalis, $M$. A. Curt. ex A. Gray, in Am. Fourn. Sc. xlii. (1842) 28.-Am. bor

aethiopica, Schkuhr, Riedgr. i.107. t. Z. f. 83.-Afr. bor. aethostachya, Schkuhr, 1. c. ii. $53=$ atrata.

affinis, R. Br. in Richards. in Frankl. Narr. 1st Journ.

$750=$ obtusata

agastachys, Linn. f. Supp1. $414=$ pendula .

Aitchisoni, Boeck. in Flora, 1xiii. (1880) $456=$ fissirostris.

alascana, Boeck, in Engl. Bot. Fahrb. vii. (1885) 277 -Am. bor. occ.

alata, Torr. in Ann. Lyc. N. York, iii. (1836) $396=$

alba, Bast. Ess. F1. Maine-et-Loire, $338=$ Bastardiana. alba, Dewey, in Am. Journ. Sc. vii. (1824) $266=$ eburnea.

alba, Scop. Fl. Carn. ed. II. ii. 216.-Europ.; Am. bor. albata, Miq. in Ann. Mus. Bot. Lugd. Bat. iii. 193, nomen.-Japon.

albescens, F. Nyland. Spicil. Pl. Fenn. ii. n. $90=$ gracilis.

albicans, Willd. ex Spreng. Syst. iii. 818.-Am. bor.

albo-atra, Willd. ex Kunth, Enum. Pl, ii. 432 , in obs. $=$ fusca.

albo-lutescens, Schwein. in Ann. Lyc. N. York, i. 1828) $66=$ straminea

algida, Turcz. in Bull. Soc. Nat. Mosc. (1838) 104 ; xxviii. (1855) I. 341.- Sibir. baical.

alligata, Boott, Illustr. Carex, iv. 129.-Ins. Sandvic allomacros, Steud. Syn. Pl. Cyp. 189.-Chili.

alopecoidea, Tuckerm. Enum. Caric. 18.-Am. bor.

alopecuroides, D. Don, in Trans. Linn. Soc. xiv.

1825) 332; Prod. Fl. Nep. 43,-Reg. Himal.

Alopecurus, Lapeyr. Hist. Abr. P1. Pyr. Suppl. $141=$ Eriophorom latifolium.

alpestris, All. Fl. Pedem. ii. $270=$ Halleriana.

alpestris, Dewey, in Am. Journ. Sc. vii. (182t) $268=$ varia.

alpestris, Gaud. Etrennes Fl. 179= sempervirens

alpestris, Lam. Encyc. iii. $389=$ caespitosa

alpigena, Kern. ex Dalla Torre, Atl. Alpenfl. 224 ferruginea.

alpina, Honck. Syn. Pl. Germ. i. $374=$ vulgaris.

alpina, Hoppe, ex Kunth, Enum, Pl, ii. 466 ferruginea.

alpina, Schrank, Baier. Fl. i. $29 S=$ sempervirens.

alpina, Sw. ex Wablenb. Vet. Akad. Nya Handl. Stockh. (1803) $160=$ Vahlii.

\section{CAREX:}

alsophila, F. Muell. Fragm. viii, 257.-Austral. alta, Boott, in Proc. Linn. Soc. i. (1849) 254; et in Trans. Linn. Soc. xx. (1846) 130.-Java. alveata, Boott, Illustr. Carex, i. 21. t. 56.-Texas. ambigua, Link, in Schrad. Fourn. ii. (1799) 308. Lusitan.; Marocc.

ambigua, Moench, Meth. 324=actita.

ambleocarpa, Willd. Sp. I'l. iv. $307=$ glauca.

amblyolepis, Trautv. \& Mey. in Middend. Reise (F. Ochot. 99).-Sibir

ambusta, Boott, lllustr. Carex, i. 64, t. 172.Alaska.

amgunensis, F. Schmidt, Reisen Amurl. 69.-Reg Amur.

amicta, Bontt, Illustr. Carer, iv, 131.-N. Granat

ammophila, Willd. Sp. Pl. iv, $226=$ divisa

amoena, Boott, Illustr. Carex, iii. 106.-Ind. or amphibola, Steud. Syn. Pl. Cyp.234.-Am. bor. amphilogos, C. Koch, in Linnaea, xxi. (1848) $615=$ incurva.

amphora, Franch. \& Sav. Enum. Pl. Fap. ii. 566.Japon.

amplifolia, Boott, in Hook. Fl. Bor. Am. ii. 228.Am. bor.

ampullacea, Good. in Trans. Linn. Soc. ii. (1794) 207. Reg, bor. temp.

ampullacea, Wulf ex Wahlenb, in Vet. Akad. Nya Handl. Storkh. (1803) $155=$ Michellii.

anceps, Muhl. ex Schkuhr, Riedgr. ii. 66. t. F.ff. fig. 128. -Am. bor.

anceps, Willd. ex Kunth, Enum. Pl, ii. $457=$ grisea. Andersoni, Boott, in Hook. f. Fl. Antarct. $364=$ decidua.

Andoiniana, De Not. Sem. Hort. Genov. (1817); ex Steud. Syn. Pl. Cyp. 233.-Europ.

androgyna, Balb. Elencho, $97=$ bicolor

Angarae, Steud. Syn. Pl. Cyp. 190.-Sibir.

anguillata, Drej. in F1. Dan. t. 2846; Revis. Caric. 36 = aquatilis.

angustata, Boott, in Hook. Fl. Bor. Am. ii. 218 stricta.

angustifolia, Linn. ex Steud. Nom. ed, I, 156 filiformis.

angustifolia, Seguier, ex Boott, Illustr. Carex, iv. 199 = Schreberi.

angustifolia, Sm. Engl. Fl. iv. 127 = vulgaris.

anisostachys, Liebm, in Vidensk. Selsk. Skr. V. it. (1851) 266.-Mexic

anomala, Boott, ex Perry, Jap. Exp. ii. 327 gibba.

anomala, fanka, in Linnaea, xxx. (1859-60) 609.-

Europ. austr.

anomala, Pall. ex Kunth, Fonm. Pl. i $479=$

Halleriana.

anomala, Steud. Syn. Pl. Cyp. 230.-Abyssin.

anthericoides, Presl, Rel. Haenk. iii. 204.-Am. bor. occ.

anthoxanthera, Presl, l. c. 203.-Alaska.

antucensis, Kunze, ex Kunth, Enum. Pl, ii, $412=$ vulgaris.

aperta, Boott, in Hook. Fl. Bor. Am. ii. $218=$ stricts.

aphanandra, Franch. G Sav. Ensm. Pl. Gap. ii. 56 . - Japon.

aphanolepis, Franch. E Sav. l. c. 580.-Japon.

aphylla, Kunth, Enum. Pl. ii. 421.-Chili.

aporandra, Kunze, ex Bnott, Illustr. Carex, ii. 92

Shortiana.

appressa, R. Br. Prod. $242=$ paniculata

approximata, All. Fl. Pedem. ii. $267=$ ericetoram.

approximata, Hoppe, ex DC. Fl. Fr. Suppl. $390=$

lagopina.

approximata, Willd. ex Kunth, Enam. Pl. ii. 111

caespitosa.

aprica, Turcs. ex Bess. in Flora, xvii. (18\$\$) 1. Bribl. 27.-Sibir. baical.

aquatilis, Tenore, Fl. Nap, iv. $189=$ microcarpa.

aquatilis, Wahlenb. in Vet. Akad. Nya Handl. Storkh. (1808) 165. - Keg. bo:

Archeri. Boott, in Hook. f. FI. Tasm. ii. 98. t. 150 acicularis.

arcta, Boutt, Illustr. Carex, iv. $155=$ canescens arctata, Boots, in Hook. F\%. Bor. Am. ii. $23 \%$-Am. bor.

arcica, Deinb, in Fl. Man. 2. 101: Fries, Somm.

Seand. i. $2 \cdot 2 \cdot 2=$ stenophylla.

arctica, Dewey, in Am. Jours. Sc xrvil. (15s5; S9! - Parrana. 


\section{CAREX:-}

arctophila, Nyland. ex Fries, Summ. Scand. 561= aquatilis.

Ardoiniana, De Not. in Ann. Sc. Nat. Sér. III. ix. (1848) $324=$ olbiensis.

arenaria, Dubois, ex Steud. Nom, ed. II. i. $286=$ praecox.

arenaria, Lapeyr. ex Kunth, Enum. Pl. ii. $389=$ paniculata.

arenaria, Leers, Fl. Herborn. 195, t. 14, f。 $2=$ disticha.

arenaria, Linn. Sp. Pl. 973.-Reg. bor. temp.

arenaria, Mohr, ex Boott, Illustr. Carex, iv. $210=$ incurva.

arenicola, F. Schmidt, Reisen Amurl. 195.-Ins Sachalin.

argentea, J. F. Gmel. Syst. $143=$ alba.

argentea, Vill, Fl. Hist. Pl. Dauph, ii. $206=$ bumilis.

argunensis, Turcz. ex Ledeb. Fl. Ross. iv. 267.Dahuria.

argyrantha, Tuckerm. ex Boott, Illustr, Carex, iii. 119 = adusta.

argyroglochin, Hornem, in Fl. Dan. x. 7. t. $1710=$ leporina.

argyrolepis, Maxim. in Franch. \& Sav. Enum. Pl Jap. i. $126=$ albata.

arida, Schleich. ex Kunth, Enum. P1. ii. $464=$ semper virens.

arida, Schwein. \& Torr, in Ann. Lyc. N. York, i. (1824) 312. t. $24=$ muskingumensis

aristata, R. Br. in Richards. in Frankl. Narr. 1st Journ 751 = trichocarpa.

aristata, Clairv. ex Steud. Nom. ed. II. i. $286=$ Uncinia microglochin.

aristata, Dewey, in Am. Journ. Sc. vii. (1824) 277. t. A. f. $1=$ Davisii.

aristata, Honck. Syn. PI. Germ. $361=$ praecox.

aristata, Siegert, ex Wimm. Fl. Schles. ed. III. (1857) $72=$ hirta.

aristata, Urv, in Mém. Soc. Linn. Par. iv. (1826) 599 = trifida

armena, Boiss, Fl. Orient. v, $426=$ fulva

Arnottiana, Boott, in Ann. E Mag. Nat. Hist. xvii. (1846) 56.-Ind. or.; Malaya.

aspera, Willd. Prod. Fl. Berl. $32=$ glauca

asperifolia, Steud. Syn. Pl. Cyp. 195.--Ins. Borbon.

asperula, Nees, in Wight, Contrib. 124.-Reg. Himal

asperula, Turcz. in Bull. Soc. Nat. Mosc. (1838) 104 ; xxviii. (1855) I. $347=$ Meyeriana.

assimilis, Steud. Syn. Pl. Cyp. 195.-Ins. Maurit.

assiniboinensis, Boott, in Coult. Bot. Gaz. ix. (1884)

91.-Am. bor.

astracanica, Willd, ex Kunth, Enum. PI. ii. 385 muricata.

asturica, Boiss. Pugill. Pl. Nov. 117.-Hispan.

aterrima, Hoppe, in Denkschr. Bot. Ges. Regensb.

(1815) t. 3. f. o, p, q. -Alp. Europ.

aterrima, Koch, Syn. Fl. Germ. ed. II. $874=$ atrata

atherodes, Frank, ex Kunth, Enum, Pl, ii, 498 stenolepis.

atherodes, Spreng. Syst. iii. $828=$ aristata

athrostachya, Olney, in Proc. Am. Acad, viii. (1868) 393.-Am. bor. occ.

atrata, Banks, ex Boott, in Proc. Linn. Soc. i. (1849) $257=$ Banksii.

atrata, Linn. Sp. Pl. 976.-Reg. bor. et arct.

atrofusca, Schkuhr, Riedgr. $106=$ ustulata.

atrofusca, Sieber, ex Kunth, Enum. Pl. ii. $435=$ fuliginosa.

atrofusca, Stev. in Mém. Soc. Nat. Mosc. iv. (1813) 67 = atrata.

atrofusca, Willd. ex Steud. Nom. ed. II. i. $286=$ pichinchensis.

atropicta, Steud. Syn. Pl. Cyp. 204.-Reg. Magell.

atropurpurea, Boeck. in Linnaea, xxxix. (1875) 150. Am. austr.

atropurpurea, Fisch, ex Trevir, in Bull. Soc. Nat. Mosc. xxxvi. (1863) I. $538=$ atrata

atrorufa, Willd, ex Kunth, Enum. Pl. ii. $392=$ pichinchensis.

attenuata, $\mathrm{R} . \mathrm{Br}$, in Richards, in Frankl. Narr. 1st Journ. $750=$ rupestris.

anrea, Nutt. Gen. Am. ii, 205-Am, bor.

aureolensis, Steud. Syn. Pl. Cyp. 223.-Am. bor.

austriaca, Schkuhr, Riedgr. ii. 10. t. 2 qq. f. $157=$ divisa.

\section{CAREX:-}

axillaris, Good. in Trans. Linn. Soc. ii. (1794) 151. t. 19. f. 1.-Europ.

axillaris, Link, Enum. Hort. Berol. ii. $329=$ diluta.

axillaris, Linn. Sp. Pl. ed. II. $1382=$ remota

axillaris, Schrank, ex Steud. Nom. ed I 155= loliacea.

azorica, f. Gay, in Ann. Sc. Nat. Sér. II. xi. (1839) 185.-Ins. Azoric.

baazasana, Steud. Syn. Pl. Cyp. 236.-Texas.

baccans, Nees, in Wight, Contrib. 122,-Ind. or.

Backiana, Dewey, in Am. Journ. Sc. xxix. (1836) $250=$ obtusata.

Backii, Boott, in Hook. Fl. Bor, Am. ii. 210.Am. bor.

badia, Pers. Syn, ii. $541=$ canescens.

baetica, Auersw. ex Willk. in Bot. Zeit. vi. (1848) 414 - distans.

Balbisii; Schkuhr, ex Spreng. Pugill. ii. $86=$ extensa, punctata.

baldensis, Linn. Cent. Pl. ii. 32.--Europ.

baldensis, Vill. Hist. Pl. Dauph. ii. $196=$ foetida.

Baldwinia, Dewey, in Am. Journ. Sc. xxvi. (1834) 107. t. T. f $61=$ Elliottii

Baldwiniana, Steud. Nom. ed. II. i. $286=$ praec.

Baltzellii, Chapm. List of Florida Pl. (1845).Am. bor.

banata, Sm. in Rees, Cyclop. xxxix, =incurva,

banatica, Heuff. in Verh. Zool.-Bot. Ges. Wien, viii. (1858) 222.-Banat.

Banksii, Boott, in Trans. Linn. Soc. xx. (1851) 119; ex Hook. f. Fl. Antarct. 465. t. 142.-Reg. Magell.

Barbarae, Dewey, ex Torr. in Bot. Mex. Bound. $231=$ Prescottiana.

barbata, Boott, Illustr. Carex, i. $68=$ Gunniana

Baroni, Baker, in fourn. Linn. Soc. xxi. (1885) 451.Madag

Bárratti, Torr. ex Schwein. in Ann. Lyc. N. York, i. (1824) $361=$ littoralis.

basiantha, Steud. Syn. Pl. Cyp. 232,-Am. bor.

basilaris, Ford. Obs. Pl. Crit. iii. (1846) 246.-Europ. austr. occ. ; Marocco.

Bastardiana, DC. Fl. Fr. vi. $293=$ pilulifera

Beckeri, C. A. Mey. ex Claus, in Beitr. Pfl. Russ. Reich. viii. 55.-Rossia.

Beechyana, Boott, Illustr. Carex, i. $67=$ Hookeri

Bellardi, All. Fl. Pedem. ii. $264=$ Elyna spicata.

Bella-Villa, Dewey, in Am. Fourn. Sc. Ser. II. xli. 1866) 229 - Am. bor

bengalensis, Roxb. Hort. Beng. 103; Fl. Ind. iii. 572. -Ind. or.

Benthamiana, Boott, in Royle, Illustr. Bot. Himal. Pref.) ex Boott, Illustr. Carex, $8=$ notha.

beringiana, Cham. ex Steud. Syn. Pl. Cyp. 229.Alaska.

bermudiana, Hemsl. in Fourn. Bot. xxi. (1883) 260.Ins. Bermuda.

Berteroana, Desv. in C. Gay, F1. Chil. vi. $198=$ aphylla?

Berteroana, Hohen. ex Boott, Illustr. Carex, iv. $149=$ setifolia.

Berteroniana, Steud. in Flora, xxv. (1842) 604.-Ins. Juan. Fernand

Bertolonii, Schkuhr, Riedgr. ii. 5. t. D. f. $18=$ divisa.

Beyrichiana, Boeck. in Linnaea, xli. (1877) 239.Am. bor.

Bichenoviana, Boott, in Hook. f. Fl. Tasm. ii. 101.Tasmania.

bicolor, All. Fl. Pedem. ii. 267.-Europ. ; Am. bor.

bicolor, Nyland. ex Nym. Consp. $776=$ salina.

bicostata, Olney, Car. Bor. Am. 9.-Am. bor.

bifida, Boott, in Proc. Am. Acad. vii. (1868) 394.Am. bor. occ.

bifida, Roth, ex Steud. Nom. ed. I. 155.-Hab. ?

bifurca, Moench, Meth. $326=$ riparia.

bifurca, Schrank, Baier. Fl. i. 304=ampullacea.

Bigelowii, Torr. \& Schwein. ex Boott, Illustr. Carex, iv, $167=$ vulgaris.

biligularis, DC. F1. Fr. v, $296=$ laevigata

bina, Schkuhr, Riedgr. i. $36=$ distachya

binata, Poir. Encyc. Suppl. iii. 257.-Afr, bor.

binervis, Dewey, in Am. Journ. Sc. xxx. (1836) $61=$ laevigata.

binervis, Sm. in Trans. Linn. Soc. v. (1800) 268.Europ.

binervis, Wahlenb. ex Kunth, Enum. Pl. ii. $451=$ fulya.

binervis, Willd, ex Kunth, 1. c. 447 = extensa.

\section{CAREX}

bipartita, All. Fl. Pedem. ii. 265. t. 89. f. $3=$ Kobresia caricina.

bipartita, F. G. Dietr. Vollst. Lex. Gaertn. Nachtr. ii. $16=$ bifida, Roth

bispicata, Hook. \& Arn. in Bot. Beech. Voy. 118.t. 28 $=$ longerostrata.

blanda, Dewey, in Am. Journ. Sc. x. (1826) $45=$ laxiflora.

blepharophora, A. Gray, in Ann. Lyc. N. York, iii. (1835) $235=$ flexilis.

Blyttii, F. Nyland. Spicil. Pl. Fenn, ii. $35=$ tenella.

Boenninghauseniana, Kunth, Enum. Pl. ii. $404=$ axillaris.

Boenninghausiana, Weihe, in Flora, ix. (1826) $759=$ axillaris.

bohemica, Schreb. Beschr. Graes. ii, $52=$ cyperoides.

Boissieri, Steud. Syn. Pl. Cyp. 215.-Afr. bor

Bolanderi, Olney, in Proc. Am. Acad. vii. (1868) 393. -Calif.

bolina, Lang, in Linnaea, xxiv. (1851) $551=$ vulgaris

boliviensis, Heurck \& Muell. Arg. in Heurck, Obs. Bot. 32.-Bolivia

Bolliana, Boeck, in Flora, lxi. (1878) 40.-Am. bor.

bonariensis, Desf. in Poir. Encyc. Suppl. iii. 250.Reg. Argent

bonariensis, Schlecht. in Linnaea, x. (1836) $116=$ involucrata.

Bongardi, Boott, in Proc. Linn. Soc. i. (1846) 260.Ins. Loo-choo.

Bongardiana, C. A. Mey, in Middend. Reise (Fl. Ochot. 101). - Sibir. or

Bonplandii, Kunth, Enum. Pl. ii. 380.-Am. bor. oce. et austr.

Boottiana, Benth. ex Boott, in Bost. Journ. Nat. Hist. v. (1845) $112=$ picta

Boottiana, Hook, \& Arn. Bot, Beech. Voy. $273=$ Bongardi.

borbonica, Lam. Encyc. iii. 387.--Ins. Mascar.

borealis, Lang, in Flora, xxvi. (1843) $142=$ aquatilis.

borotalicola, Regel, in Act. Hort. Petrop. vii. (1880) 566. - As. centr.

Boryana, Schkuhr, Riedgr. ii. 43.-Ins. Mascar.

Boscii, Willd. ex Spreng. Syst. iii. 812.-Am. bor.

brachycalama, Griseb. in Goett. Abh. xxiv. (1879) 315 -Reg. Argent.

brachycephala, Poepp. ex Boott, Illustr. Carex, i. $67=$ indecora

brachylepis, Turcz. ex Steud. Nom. ed. II. i. 286 ; et ex Boott, 1. c. iii. $113=$ alpina.

brachyphylla, Turcz. in Bull. Soc. Nat. Mosc. (1838) 104 ; xxviii. $(1855)$ I. $346=$ ericetorum.

brachyrhyncha, Gsaller, in Oestr. Bot. Zeitschr. xx. (1870) 199, 292.-Europ.

brachystachys, Schrank, Baier, FI i. $294=$ tenuis.

bracteata, Giesecke, ex Boott, Illustr. Carex, iv. $160=$ salina.

bracteata, Suter, F1. Helv. ii. $250=$ mucronata.

bracteosa, Kunze, in Schkuhr, Riedgr. Suppl. 12.Chili.

bracteosa, Schwein. in Ann. Lyc. N. York, i. (1824) 65 = vulpinoidea.

brasiliensis, St. Hil. Voy. Bras, i. $369=$ procera

brazatana, Boeck. in Flora, xxxix, (1856) $321=$ baazasana.

Breutelii, Schnizl, ex Lange, Consp, F1. Groenl. i.136 $=$ canescens.

brevicaulis, Thou. ex Steud. Nom. ed. II. i. 287.--Ins. Trist. d'Acunna.

brevicollis, $D C$. Fl. Fr. vi. 295.-Europ. austr.; As Min.

breviculmis, R. Br. Prod. 242.-Reg. Himal.; Japon. Australas.

breviculmis, Thw. Enum. Pl. Zeyl. $356=$ Thwai tesii.

brevifolia, Host, Gram. iv. 50. t. $89=$ ferruginea.

breviglumis, Le Gall, Fl. Morb. 658.-Gallia.

brevipes, S. Wats. in Bot. Calif. ii. 246.-Calif.

brevirostrata, Poir. Encyc. Suppl. iii, $273=$ obesa.

brevirostris, Blytt, in Bot. Notiser, (1857) 133.Europ.

brevirostris, Cederstr. in Vet. Akad. Oefv. Stockh. xiv. (1857) $199=$ incurva.

Breweri, Boott, Illustr. Carex, iv. 142. t. 455.-Am. bor, occ.

brizoides, Geners. Elench. n. $857=$ leporina.

brizoides, Huds. Fl. Angl. 349 ; ed. II. $406=$ canescens. 
CAREX :-

brizoides, Lam. Encyc. iii. $382=$ praecox.

brizoides, Linn. Cent. Pl. i. 31.-Europ.

brizoides, Pall. ex Boott, Illustr. Carex, iv, $199=$

Schreberi.

Brizopyrum, Kunze, in Schkuhr, Riedgr. Suppl, i. 169 t. $43=$ alta.

bromoides, Dubois, ex Boott, Illustr. Carex, iv. $199=$ Schreberi.

bromoides, Schkuhr, Riedgr. ii. 8.-Am. bor.

Brongniartii, Kunth, Enum. Pl. ii. 380.-Chili.

Brownei, Steud. Syn. Pl. Cyp. $209=$ longifolia.

Brownii, Tuckerm. Enum. Car. 21 = lacistoma.

brunnea, Thunb. Fl. Fap. 38. - Reg. bor. et anstr.

brunnescens, Poir. Encyc. Suppl. ii. $286=$ Gebhardi.

Buchanani, Berggr. in fourn. Bot. xviii. (1880) 104:-

N. Zel.

Buckleyi, Dewey, in Am. Journ. Sc. xlviii. (1845) 143 canescens.

Buekii, Wimm. Fl. Schles. ed. III. (1857) $81=$ stricta.

bufonia, Gueldenst. ex Ledeb. Fl. Ross. iv. 320.-Ross. austr.

bulbosa, Boeck. in Flora, xxxviii. (1855) 597.-Am. bor.

bullata, Ell. Sketch, ii. $556=$ striata

bullata, Dewey, in Am. Journ. Sc. ix. (1825) $71=$ Tuckermani.

bullata, Rudolph, ex Georgi, Besch: Russ. Reich. iii: v. 1286.-Tauria.

bullata, Schkuhr, Riedgr: ii. 85.-Am, bor.

Bungeana, Debeaux, in Act. Linn. Soc. Bord. xxxiii. (1879) 68.-China.

Burchelliana, Boeck. in Linnaea, xli. (1877) 234.-Afr. austr.

Buxbaumii, Wahlenb. in Vet. Akad. Nya Handl.

Stockh. $(1803) 163=$ fusca.

caduca, Boott, Illustr. Carex, iv. 157.-Am. austr.

caesia, Griseb. Spicil. Fl. Rumel, ii. $412=$ tomentosa.

caespititia, Nees, in Wight, Contrib. 127.-Reg. Himal. caespitosa, Good. in Trans. Linn. Soc: ii. (1794) 195. t.

$21=$ vulgaris .

caespitosa, Hook. Fl. Scot, 286 =saxatilis.

caespitosa, Huds. Fl. Angl. ed. II. 412=stricta.

caespitosa, Ledeb. F1. Ross. iv. $310=$ eleusinoides.

caespitosa, Linn. Sp. Pl. 978,-Reg. bor. et austr

caespitosa, Soland. ex Boott, Illustr. Carex, i. $63=$

deciclua.

caespitosa, Tenore, Viaggio in Calab. $129=$ frigida.

caespitosa, Thunb. F1. Jap. $39=$ Thunbergii?

Cafischii x, Bruegg. in Jahresb. Nat. Ges. Graub. II xxiii-xxiv. (1880) 119.-Europ.

campestris, Hort. ex Boott, Illustr. Carex, i. 161= obesa.

campestris, Host, Gram. iv. t. $38=$ supina.

Camposii, Boiss. E Reut. Pugill. Pl. Nov. 117.Hispan.

Campyloxys, Steud. Syn. Pl. Cyp. 213.-Reg. Magell.

camtschatcensis, Kunth, Enum. Pl. ii. $477=$ longero strata.

canadensis, Dewey, in Am. Fourn. Sc. Ser. II. xli. (1866) 229.-Am, bor.

canescens, Host, Gram. i. t. $57=$ paradoxa.

canescens, Huds. Fl. Angl. ed. II. $405=$ divulsa.

canescens, Leers, Fl. Herbora. 712. t. 14. f. $3=$ muricata.

canescens, Linn. Sp. Pl. 974.-Reg. temp. bor. et austr.

canescens, Poll. Palat. Hist. Pl.ii. $571=$ elongata.

capensis, Schkuhr, Riedgr. ii. 39.-Afr. austr.

capensis, Thunb. Prod. Pl. Cap. $14=$ Schoenoxyphium Thunbergii.

capillacea, Boott, Illustr. Carex, i. 44. t. 110.-Reg.

Himal.; Austral.

capillaris, Leers, Fl. Herborn. t. 15. f. 2 =sylvatica.

capillaris, Linn. Sp. Pl. 977.-Reg. bor. temp. et arct. capillaris, Willd. ex Kunth, Enum. Pl. ii. $464=$ firma. capillata, Schkuhr, ex Kunth, 1. c. $430=$ hirsuta.

capillipes, Drej. in Fl. Dan. t. 2844 ; Revis. Caric. 50. -Ins. Island.

capitata, All. F1. Pedem. ii. $264=$ Davalliana.

capitata, Linn. Syst. ed. X. 1261.-Europ.; Am. bor.

capitate, F. Muell. Fragm, viii. $251=$ Cephalotes.

capitata, Oed. in F1. Dan, t. $372=$ Eleocharidis Sp.

capitata, Suter, ex Bookt, Illustr. Carex, iv, $143=$

dioica.

capitellata, Boiss. E Bal. ex Boiss. Fl. Orient. v. 399

-As. Min.

\section{CAREX :}

cardiolepis, Nees, in Wight, Contrib. 127.--Reg. Himal.

Careyana, Torr. ex Dewey, in Am. Fourn. Sc. Ser. I. xxx. (1836) 60,-Am. bor.

Carlantoniana, J. Gay, in Ann. Sc. Nat. Sér. II 1838) $293=$ enervis.

carltoniana, Dewey, in Am. Fourn. Se. Ser. I. xxviii, 1835) 238 - Am. bor

caroliniana, Buckley, l. c. xlv. (1848) 173.-Am. bor.

caryophyllaea, J. F. Gmel. Syst. $142=$ seq.

caryophyllata, Kunth, Enum. Pl. ii. 437 =emarginata.

oaryophyllea, Latour. Chlor. $27=$ praecox

Castanea, Ell. Sketch, ii. $546=$ Elliottii.

Castanea, Mielich. in Flora, xxxii. (1849) $665=$ capillaris.

Casteriana, Heer, ex Boott, Mllustr. Carex, iv, $143=$ dioica.

cataractae, $\mathrm{R} . \mathrm{Br}$. Prod. 242 - flava

cancasica, Stev. in Mém. Soc. Nat. Mosc. iv. (1813) 68. -Reg. Caucas

celsa, Boott, Illustr. Carex, iii. 108.-Reg. Himal.

cenisia, Balb. in Roem. Arch. iii. $137=$ bicolor.

cephaloidea, Dewey, ex Boott, Illustr. Carex, iii. 123.

-Am. bor.

cephalophora, Muhl. ex Schkuhr, Riedgr, ii.4.-Am. bor

Cephalotes, F. Muell. in Trans. Phil. Soc. Vict. i. (1855) 110.-Austral.

cerina, Dum. Fl. Belg. 147 ; Boott, Illustr. Carex, iv. $170=$ vulgaris.

cernua, Boott, l. c. 171.-Reg. Himal. ; Japon.

cernux, Phil. in Linnaea, xxix. (1857-8) 83.-Chili.

cernua, Raeusch. Nom. ed. III. 270.- 'Helvet.'

ceylanica, Boeck. in Linnaea, xl. (1876) 341.--Ind. or

Chaberti, F. Schult. in Flora, liv. (1871) $21=$ divulsa.

chaetophylla, Steud. Syn. Pl. Cyp. $187=$ divisa.

chaetorhiza, Franch. \& Sav, Enum, Pl. Fap, ii. 552Japon

chalaros, Steud. Syn. Pl. Cyp. 231.-Am. bor

Chamissoi, Boeck. in Linnaea, xli. (1877) 145.Hab. ?

Chapmani, Torr. ex Boott, Illustr. Carex, i. $16=$ Baltzellii.

Chapmanni, Sartwell, ex Dewey, in Am. Journ. Sc. Ser. II. xix. (1855) $254=$ tenax.

Chapmanni, Steud. Syn. Pl. Cyp. 222.-Florida,

Cheesemanii, Petrie, in Trans. N.Z. Inst. xv. (1883) 358.-N. Zel.

cherokeensis, Schwein. Eo Torr in Ann. Lyc. N. York, i. (1824) 369. t. 25. f. 1.-Am. bor

chilensis, Brongn. in Duperr. Voy. Bot. $156=$ riparia. chillanensis, Phil. in Anal. Univ. Chil. II. (1862) 38 -Chili.

chinensis, Retz. Obs, iii. 42.-China.

chlorantha, R. Br. Prod. 242,-Austral.

chlorocarpa, Wimm. in Flora, xxxiii. (1849) $620=$ vulgaris.

chlorocarpos, Iiebm. in Vidensk. Selsk. Skr. V. i (1851) $265=$ Liebmanni

chlorocystis, Boeck. in Engl. Bot. Fahrb. v. (1884) 520 -Hongkong.

chlorolepis, Steud. Syn. Pl. Cyp. 204,-Chili

chlonostachys, D. Don, in Till. Mag. (Dec. 1823) 45 = japonica.

chlorostachys, Stev. in Mêm. Soc. Nat. Mosc. iv. (1819) $68=$ sempervirens.

chordalis, Liebm. in Vidensk. Selsk. Skr. V. ii. (1851) 269.-Mexic

chordorrhiza, Linn.f. Suppl. 414.-Europ. "Am. bor Christyana, Boott, in Bost. Journ. Nat. Hist. v. (1847 $114=$ cherokeensis.

chrysolepis, Franch. E Sav. Enum. Pl. Fap. ii. 571:Japon.

ciliata, Willd. in Mém. Aond. Berol. 1794 (1797) 47 . l. 3. f, 2 =ericetorum.

cilicica, Boiss. Diagn. Ser. II. iv. 124.-Cilicia.

cinerea, Poll. Hist. Pl. Palat. ii. $571=$ canescens

cinnamomea, Boott, in Proc. Linn. Soc. i. (1846) 257

Trans. Linn. Soc, xx. (1851) $196=$ nivalis.

cinnamomes, Cheesm, in Trans. N. Z. Lust. xiv. (185.) 301.-N. Zel

cinnamomea, Olney, in Proc. Ans. Acad. vii. (1868 396.-Calif.

circinnata, C. A. Mey. in Mim. Sav. Etr. Pdtersb. 1831) 209. t. 6.-Unalaschka.

cirrhosa, Bergg, in Minneskr. Fising. Sallks. Luned (1877) n. VII. 29,-N. Zel.

\section{CAREX :-}

cirrhulosa, Nees, in Hook. Kew Fourn. vi. (1854) 29 -Ins. Philipp.

cladostachya, Wahlenb. in Vet. Akad. Nya HandL Stockh. (1803) $149=$ polystachya

clandestina, Good, in Trans, Linn. Soc. ii. (1794) 167 $=$ humilis.

clavaeformis, Hoppe, in Sturm, Deutschl. Fl. Heft 61 (1833).-Carinthia.

clavata, Thunb.Prod. Pl. Cap. 14.-Afr. austr

coacta, Boott, in Proc. Linn. Soc. i. (1846) 285 ; et

Trans. Linn. Soc, $x x,(18 \neq 6) 133=$ curaica.

coarctata, Kit. in Linnaea, xxxii. (1863) 319. Hungar.

cognata, Kunth, Enum. Pl. ii. 502,-Afr. aust

colchica, J. Gry, in Ann. Sc. Nat. Sér. II. x. (1838) 308 = arenaria.

Colensoi, Boott, in Hook.f.Fl, N.Zeal. 281. t. 63.-N. Zel.

collata, Boott, in Hook. Lond. Jonrn. Bot. iii. (1844, $417=$ virgata

collecta, Dewey, in Am. Fourn. Sc. xi. (1826) 314

tab. N. fig. 44.-Am. bor.

collina, Willd. Sp. Pl. iv. $260=$ montana.

Collinsiz, Nutt Gen. Am ii, $205=$ subulata

columbiana, Dewey, ex Torr. in Ann. Lyc. N. York, ii. (1836) $406=$ Mertensii.

comans, Bergg. in Minneskr. Fisiog. Sallk. Lund (1877) n. vıI. p. 28.-N. Zel.

Commersoniana, Sieber, ex Kunth, Enum. Pl. ii. $3 y \mathrm{l}=$ brunnea.

commixta, Steud. Syn. Pl. Cyp. 207.-Java

commutata, F. Gay, in Ann. Sc. Nat. Sér. II. xi. (1839) 198.-Am. bor.

commutata, Turcz. in Bull. Soc. Nat. Mosc. xxrii. 1854) I. 205--Soongaria.

comosa, Boott, in Trans. Linn. Soc. xx. $(1846) 117=\mathrm{C}$. Pseudo-cyperns.

compacta, R. Br. in App. Ross, Voy. 163.-Am. arct.

compacta, Krock. ex Hoppe, Caric. 37 = vulgaris

compacta, Lam. Fl. Fr. ii. $172=$ valpina.

compacta, Poir. Encyc. Suppl. iii. $282=$ Uncinia compacta.

compacta, Wimm in Flora, vxuiii. (1850) 618 . Europ.

complanata, Torr, in Ann..Lyc. N. York, iii. ' 183$)^{\prime}$ $408=$ triceps

composita, Boott, lllustr. Carex, i. 3.-Reg. Himal.

compressa, Gaud. Etiennes Fl. $111=$ stricta.

compressa, Hose, in Usteri, Ann. Bot. xxi. 1797) 38. Europ.

compressa, Kit. ex Willd. Sp. Pl. iv. $276=$ brachy stachys.

compressa, Vahl, ex Kunth, Enum. P1. ii. 3is bonariensis

concinna, R. Br. in Richards. Frankl. Narr. 1st fourn. 751 -Am. arct.

concolor, R. Br. in Parry, Voy. App. 283.-Am. arct. concolor, Nees, in Wight, Contrib. $125=$ speciosa. condensata, Nees, in Wight, Contrib. 123.-Reg. Himal.

conferta, Hochst. ex A. Rich. Tent. Fl. Abyss. ii. 512. -Abyssin.

confertiflora, Boott, in Mem. Am. Acad. N. S. vi, (1858-59) 418.-Japon.

congesta, C. A. Mey. ex Boott, Illustr. Carex, i. $17=$ Hoodii.

conglobata, All. Fl. Pedem ii. $268=$ montana. conglobata, Kit. in Willd. Sp. Pl. iv. $2 s 1=$ obese conica, Boott, ex Perry, Fap. Exped. ii. 325.-Japon. conjugata, Willd, ex Kunth, Enum. PL ii. Syl Commersoniana.

conjuncta, Boott, Illustr. Carex, iii. 122.-Am. bor. conoidea, Muhl. Desc. Gram. Uber. $245=$ laxillora. conoiden, Schkuhr, Riedgr, ii. 6i.-Am. bor. consanguinea, Kunth, Enum. PI. ii. $37 t=$ divisa consocialis, Sterd. Syn. Pl. Cyp. 2*2.2-Japon. contigua, Hoppe, in Sturm, Deutschl. F'. Heft 6] 1339! = muricata.

contracta, F. Afuell. Fragm. viii. 25s.-Austral. convexa, Rif. in Linnara, xxii. (1503) 91\%.Hungaria.

Cooleyi, Wewey, in Ann. Joura. Sc. Ser. 1. xlviii. 1S15 14=hystericina.

coriophora, Fisch. \& Mcy. ex Kuntb, Enum. Pl. ii. 169 - ustulata.

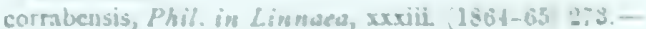
C'bili. 


\section{CAREX}

corsica, Degl. ex Loisel. F1. Gall. 1i. $307=$ microcarpa.

corsicana, Link, Enum. Hort. Berol. i. $358=$ punctata.

Cortesii, Liebm. in Vidensk. Selsk. Skr. V. ii. (1851) 268.-Mexic

corynophora, Peterm. in Flora, xxvii. (1844) $335=$ acuta.

costata, F. E C. Presl, Fl. Čech. 191.-Bohemia.

costata, Schwein. in Ann. Lyc. N. York, i. (1824) $67=$ virescens.

costata, Turcz. ex Ledeb. Fl. Ross. iv. 305= obesa.

Coulteri, Boott, ex Hemsl. Biol. Centr. Am. Bot. iii. 473.-Mexic.

courtallensis, Nees, ex Boott, Illustr. Carex, i. 52.Ind. or.

crassa, Ehrh. Beitr. iv. 43 = riparia.

crassipes, Boeck. in Linnaea, xl. (1876) 329.Ind. or.

Crawei, Dewey, ex Torr. Fl. N. York, ii. 408.-Am. bor

crinalis, Boott, in Proc. Linn. Soc. i. (1846) 256.-N. Granat.

crinigera, Boott, Illustr. Carex, ii. 102.-Ins. Borbon. crinita, Lam. Encyc. iii. 393.-Am, bor.

cristata, [Clairv.] Man. Herb, 291 = ferruginea.

cristata, Schwein. in Ann. Lyc. N. York, i. (1824) 66 $=$ tribuloides.

cruciata, Nees, ex Wight, Contrib. 123.-Ind. or.

cruciata, Wahlenb. in Vet. Akad. Nya Handl. Stockh. (1803) $149=$ ramosa.

cruenta, Nees, in Wight, Contrib. 128.-Reg. Himal.

Crus-corvi, Shuttl. ex Kunze, in Schkuhr, Riedgr. Suppl. 128. t. 32.-Am. bor.

cryptandra, Franch. \& Sav. Enum. Pl. Jap. ii. $148-$ macroglossa.

cryptocarpa, Cheesem. in Trans, N. Z. Inst. xvi. 1884) 412.-N. Zel.

cryptocarpa, C. A. Mey. in Mém. Sav. Etr. Pétersb. i. 1831) $226=$ halophila.

cryptostachys, Brongn. in Duperr. Voy. Bot. 152.-N, Guinea.

Csetzii, Nym. Consp. $773=$ Czetzii.

Cumingiana, Steud. Syn. Pl. Cyp. 206.-Ins. Philipp.

Cunninghamii, Boott, Illustr. Carex, iv. 171. t. $579=$ acuta.

curaica, Franch. \& Sav. Enum. P1. Jap. ii. $252=$ chaetorhiza.

curaica, Kunth, Enum. P1. ii, $375=$ vulpinaris.

curta, Good, in Trans. Linn. Soc. ii. (1794) $145=$ canescens.

curvata, Boott, Illustr. Carex, i. 2.-Reg. Himal. curvata, Knaf, in Flora, xxx. (1847) $184=$ Schreberi curvicollis, Franch. E Sav. Enum. PL. Fap. ii. 579 Japon.

curvirostra, Hartm. Skand. F1. ed. II $221=$ vaginata.

curvirostris, Kunze, in Schkuhr, Riedgr. Suppl. 79, t. 20 = baccans.

curvula, All. Fl. Pedem. ii. 264. t. 92. f. 3.-Europ.

curvula, Lam. Encyc. iii. $380=$ Schreberi.

curvula, Stev. in Mém. Soc. Nat. Mose. vi. $(1823) 67=$ Elyna schoenoides.

curvula, Willd. ex Kunth, Enum. Pl. ii. $269=$ Davalliana.

cuspidata, Bertol. in Mem. Soc. Med. Emul. Gen. ii. (1803) $145=$ divisa.

cuspidata, Degl, in Loisel. Fl Gall. 294=echinata.

cuspidata, Host, Gram. i. 71. t. $97=$ glauca.

cuspidata, Wahlenb. in Vet. Akad. Nya Handl. Stockh. 1803) $164=$ salina.

Custoriana, Heer, ex Hegetschw. F1. Schw. $906=$ dioica.

cylindrica, Mielich. ex Kunth, Enum. P1. ii. $434=$ atrata.

cylindrica, Schwein. in Ann. Lyc. N. York, i. (1824) $71=$ bullata

cylindrica, Tuckerm. ex Boott, in Hook. Lond. Journ. Bot. v. (1846) $74=$ Tuckermani.

cyperoides, Dewey, in Am. Journ. Sc. Ser. II. iii

(1847) $171=$ sychnocephala.

cyperoides, Murr. in Linn. Syst. ed. XIII. 703.Europ.; As. temp.

Czetzii, Fanka, in Oestr. Bot. Zeitschr. viii. (1858) 93.-Europ.

dacica, Heuff. in Flora, xviii. (1835) $247=$ caespitosa.

Daltonii, Boott, Illustr. Carex, i. 5.-Ind. or.

\section{CAREX :}

Darlingtonii, Schwein. ex M. A. Curt. in Am. Journ. Sc. Ser. II. vii. (1849) $410=$ aestivalis.

Darwinii, Boott, in Proc. Linn. Soc. i. (1845) 261.Reg. Magell.

dasycarpa, Muhl. Desc. Gram. Uber, 236.-Am. bor.

Davalliana, Dewey, ex Steud. Nom. ed. II. i. $288=$ pyrenaica.

Davalliana, Sm. in Trans. Linn. Soc. v. (1800) 266. Reg. bor. temp.

Davalliana, Willd. ex Kunth, Enum. P1. ii. $368=$ dioica.

Davidi, Franch. Pl. Davidian. i. (1884) 319.China.

Davisii, Dewey, in Am. Journ. Sc. x. (1826) $279=$ varia.

Davisii, Schwein. E Torr. in Ann. Lyc. N. Yark, i. (1824) 326.-Am. bor.

debilis, Boiss. \& Bal. ex Boiss. Fl. Orient. v. $410=$ transylvanica.

debilis, Forst. f. Prod. $92=$ Forsteri

debilis, Michx. Fl. Bor. Am. ii. 172.-Am. bor.

debilis, Soland. ex Boott, Illustr. Carex, i. $65=$ Solandri.

decidua, Boott, in Proc. Linn. Soc. i. (1845) 255.Calif. ; Reg. Magell.

decipiens, J. Gay, in Ann. Sc. Nat. Sér. I. xxvi. (1832) $209=$ macrostyla.

decipiens, Turcz. in Bull. Soc. Nat. Mosc. (1838) 102 xxviii. $(1855)$ I. $323=$ obtusata.

declinata, Boott, Illustr. Carex, iv. 171. t. 580.Austral.

decolorans, Wimm, in Flora, xxxiii. (1850) $622=$ vulgaris.

decomposita, Muhl. Descr. Gram. Uber, 264.-Am bor.

decora, Boott, Illustr. Carex, i. 5. t. 15--Reg. Himal decumbens, Ehrh. Beitr. vi. $82=$ pilulifera.

leflexa, Hornem. in Fl. Dan. t. 3051-Am, bor Groenl.

Deinholliana, J. Gay, in Ann. Sc. Nat. Sér. II. xi (1839) 183 = stenophylla.

Dematranea, Lagger, in Flora, xxxviii. (1855) 207.Europ.

demissa, Hornem. in Fl. Dan. t. 1342.-Europ.

densiflora, Presl, Rel. Haenk. iii. 204.-Ins. Marian

denudata, Lapeyr. ex Steud. Nom. ed. I. $160=$ pyrenaica.

depauperata, Good. in Trans. Linn. Soc. ii. (1794) 181. -Europ.; As. bor.

depauperata, Hornem. Plantelaere, ii. $829=$ vaginata

depressa, Link, in Schrad. Journ. ii. (1799) $309=$

Halleriana.

depressa, Willd, ex Kunth, Enum. Pl, ii, $479=$ alpes tris.

desponsa, Boott, Illustr. Carex, ii. 82,-Reg. Himal.

Despreauxif, Steud. Syn. Pl. Cyp. 237.-'Terra nova,'

devia, Cheesem. in Trans. N. Z. Inst. xv. (1883) 301. - N. Zel.

Deweyana, Schwein. in Ann.Lyc. N. York, i. (1824) 65, 310. Am. bor.

Dianae, Steud. Syn. Pl. Cyp. 238.-Ins. S. Helena.

diandra, Roth, Tent. Fl. Germ. ii. II. $437=$ paniculata.

diandra, Schrank, in Act. Acad. Mogunt. (1782) 49 (err. typ. 57) = teretiuscula.

diaphana, Boott, Illustr. Carex, iv, 156.-Austral.

Tickinsii, Franch. E' Sav. Enum. Pl. Fap. ii. 581.Japon.

diclina, Phil. in Linnaea, xxxiii. (1864-65) 271.Chili.

Dietrichiae, Boeck. in Flora, lviii. (1875) $122=$ fissilis?

digitalis, Schwein. \& Torr. in Ann. Lyc. N. York, i. (1824) 324.t. $27=$ gracillima

digitalis, Willd. Sp. Pl. iv. 298.-Am. bor.

digitata, Linn. Sp. Pl. 975.-Europ.; As. temp.

dilatata, Hohen. ex Boiss. F1. Orient. v. 425, sphalm.

diluta, Bieb. Fl. Taur. Cauc. ii. 388.-Europ. austr. As. temp.

dimorpha, Brot. F1. Lusit. i. $64=$ Linkii.

dimorpholepis, Steud. Syn. P1. Cyp. $214=$ pruinosa dimorphotheca, Stschégl. in Bull. Soc. Nat. Mosc.

(1854) 206,-Sibir. altaic.

dioica, Carey, ex Boott, Illustr. Carex, iv. $143=$ chordorrhiza.

\section{CAREX:-}

dioica, Host, ex Steud. Nom. ed. II. i. $288=$ Davalliana.

dioica, Lam. ex Steud. 1. c. = Elyna spicata

dioica, Linn. Sp. Pl.972.-Reg, bor.

dioicotrigona, St. Lag. in Ann. Soc. Bot. Lyon, vii. (1880) 121 = Davalliana

dioiscostrongyla, St. Lag. 1. c. = dioica

dipsacea, Bergg. in Minneskr. Fisiog. Sallks. Lund $1877)$ n. VIII. p. 28. -N. Zel.

discoidea, Boott, in Mem. Am. Acad. N. S. vi. (185859) $419=$ breviculmis.

discolor, Boeck. in Engl. Bot. Fahrb. v. (1884) 519.Japon.

discolor, F. Nyland. Spicil. P1. Fenn. iii. n. 12 = salina. discolor, Reinw. ex De Vriese, P1. Ind. Bat. Reinw. 143, partim $=$ virgata.

dispalatha, Boott, in Perry, Ұap. Exp. ii. 325.Japon.

disperma, Dewey, in Am. Journ. Sc. viii. (1820) 266.t. A. f. $3=$ tenella

disperma, Herb. Un. It. ex Kunth, Enum. Pl. ii. $480=$ Steudelii.

dissimilis, F. F. Gmel. Syst. 144,-Helvet.

dissita, Soland. ex Hook. f. Fl. N. Zel. 284,-N. Zel.

distachya, Desf. Fl. Atlant. ii. 336=Linkii.

distachya, Willd. Sp. Pl. iv. $220=$ atrata.

distans, Bert. ex Steud. Nom. ed. II. i. $288=$ indecora.

distans, Host, Gram. i. 57.t. $77=$ fulva.

distans, Lightf. F1. Scot. ii. $561=$ binervis.

distans, Linn. Syst. ed. X. 1263.-Europ.; As. occ. Am. bor.

distans, Willd. ex Kunth, Enum. Pl, ii. 488=nutans distenta, Kunze, ex Kunth, 1. c. $449=$ indecora.

disticha, A. Gray, Man. N. U. St. ed. V. $574=$ Sart wellii.

disticha, Huds. Fl. Angl. ed. I. 347.-Europ.

divergens, Thuill. Fl. Par. ii. $481=$ elongata.

diversicolor, Crantz, Inst. i. 405. -Italia

diversiflora, Host, Gram. i. 53. t. $70=$ Halleriana

divisa, Huds. Fl. Angl. ed. I. 348 ; ed. II. $405 .-\mathrm{Reg}$ bor. temp.

divisa, Oed. in Fl. Dan. t. $371=$ flava.

divulsa, Gaud. Fl. Helv. vi. $47=$ muricata.

divulsa, Good. in Trans. Linn. Soc. ii. (1794) 160.Reg. bor. temp.

Doenitzii, Boeck. in Flora, lxv. (1882) 61.-Japon.

Doniana, Spreng. Syst. iii. $825=$ japonica.

Douglasii, Boott, in Hook. Fl. Bor. Am. ii. 213.-Am, bor. occ.

Dregeana, Kunth, Enum. Pl. ii. 511.-Afr. austr.

Drejeri, Lange, in Flora, xxv. (1842) $548=$ caespitosa Drejeriana, Lange, in Fl. Dan. t. 2975.-Groenl.

Drummondiana, Dewey, in Am. Journ. Sc. xxix. (1836) 251. t. Y. f. $82=$ rupestris.

Drymeia, Linn, f. Suppl. $414=$ sylvatica.

drymophila, Turcz. in Bull. Soc. Nat. Mosc. (1838) 104.-Sibir

dubia, Gaud. Etrennes F1. 178=atrata.

dubia, Hose, in Usteri, Ann. Bot. xxi. (1797) 34.Europ.

dubia, Sibth. in Sibth. \& Sm. F1. Graec. Prod. i. $53=$ Sesleria alba.

dubitata, Dewey, ex Boott, Illustr. Carex, iv. $167=$ vulgaris.

Dufourei, Lapeyr. Hist. Abr. Pl. Pyr. Suppl. $140=$ rupestris.

dura, Boott, in Proc. Linn. Soc. i. (1845) 255 = pichinchensis.

Durieui, Steud. Nom. ed. II. i. 289.-Hispan.

duriuscula, C. A. Mey. in Mém. Sav. Etr. Pétersb. i. 1831) 214 . t. $8=$ stenophylla,

Duvaliana, Franch. \& Sav. Enum. Pl. Fap. ii. 568.Japon.

ebracteata, Phil. in Linnaea, xxxiii. (1864-65) 271.Chili.

ebracteata, Trautv. in Act. Hort. Petrop.v. (1877) 125. -Sibir.

eburnea, Boott, in Hook. Fl. Bor. Am. ii. 226.-Am. bor.

echinata, Lam. Fl. Fr. ii. $177=$ flava.

echinata, Murr. Prox. Stirp. Gotting. 76,-Reg. bor. temp.; Austral.

echinata, Roth, Tent. F1. Germ. i. $395=$ stellulata.

echinochloe, Kunze, in Schkuhr, Riedgr. Suppl. 47 t. 12.-Abyssin.

Ecklonei, Nees, in Linnaea, x. (1836) 203.-Afr. austr. 


\section{CAREX :}

efflata, Laestad, ex Ledeb. Fl. Ross. iv, $291=$ panicea. eggytera, Steud. Syn. PI. Cyp. $220=$ breviculmis.

Ehrenbergiana, Boeck. in Linnaea, xli. (1877) 175.Mexic.

Ehrhartiana, Hoppe, ex Boott, Illustr. Carex, iv. 145 $=$ teretiuscula.

elata, All. Fl. Pedem, ii: $272=$ stricta

elata, Lowe, in Trans. Camb. Phil. Soc. iv. (1831) 11. -Ins. Madera.

elata, Turner, ex Boott, Illustr. Carex, i. $66=$ praelata. elatior, Boeck. in Bremen Abh. vii. (1880) 41.Madag.

elegans, Willd. Prod. Fl.. Berl. 34=limosa

eleopsammodes, Steud. Syn. Pl. Cyp. $213=$ Darwinii.

eleusinoides, Turcz. ex Kunth, Enum. Pl. ii. 407.-

Sibir, baical.

Elliottii, Torr. in Ann. Lyc. N. York, i. (1824) 357.Am. bor.

elongata, Leers, FÍ. Herborn. 197. t. 14. f. $7 .=$ canescens.

elongata, Linn. Sp. Pl. 974,-Europ.; Sibir.

elytroides, Fries, in Bot. Notiser, (1846) $106=$ saxatilis.

emarcida, Suter, Fl. Helvet. ii. $263=$ sylvatica.

emarginata, Willd. Sp. Pl. iv. $262=$ montana.

eminens, Nees, in Wight, Contrib. 122.-Reg. Himal.

emimensis, Baker, in Fourn. Bot. xxi. (1883) 129.

Madag.

Emmonsii, Dewey, in Ann. Lyc. N. York, iii. (1836) $411=$ varia

emodorum, Spreng. Syst. iii. $818=$ alopecuroides.

Emoryi, Dewey, ex Torr. Bot. Mex. Bound. 230.-Am. bor. occ.

enervis, Dulac, F1. Hautes-Pyr, $53=$ brizoides.

enervis, C. A. Mey. in Ledeb. Fl. Alt. iv, 209.-Sibir. altaic.

ensifolia, Turcz. ex Ledeb. Fl. Ross. iv. $309=$ saxatilis.

epigejos, Fries, Summa, $223=$ salina

erecta, DC, Fl. Fr. iii. $120=$ sempervirens.

erecta, Gilib. Exercit. ii. $549=$ caespitosa.

ericetorum, Poll. Hist. Pl. Palat. ii. 580.-Europ. As. temp.

erinacea, Cav. Ic, v. $40=$ Uncinia erinacea.

erinacea, Muhl. ex Steud. Nom. ed. II. i. $288=$ hystericina.

eriophora, Fisch. ex Steud. l. c. 289.-Dahuria

erythraea, Schrad. in Linnaea, xi. (1837) 87.-Reg Himal.

erythrorrhiza, Boeck. in Linnaea, xxxix. (1875) 103.Abyss.

erythrorrhiza, Steud. Syn. P1. Cyp. 194=Koestlini.

erythrostachys, Hoppe, in Sturm, Deutschl. Fl. Heft $69(1835)=$ glauca

erythrostachys, Kral. ex Nym. Consp. $774=$ serrulata.

Esenbeckiana, Boeck. in Linnaea, xl. (1876) 372. Afr, austr.

Esenbeckii, Kunth, Enum. Pl. ii. 522.-Reg. Himal.

Essenbeckii, Boott, Illustr. Carex, i. 52 =linearis.

evoluta, Hartm. in Vet. Akad. Handl..Stockh. (1818) 156.-Europ.

exaltata, Kit. in Linnaea, xxxii. (1863) 322.-Hungaria.

exaltata, Peterm, in Flora, xxvii. (1844) $340=$ riparia.

excelsa, Poepp. ex Kunth, Enum. P1. ii. $502=$ C. Pseudo-

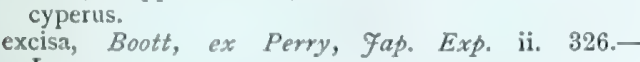
Japon.

excurrens, Cham. ex Steud. Syn. P1. Cyp. $228=$ podocarpa.

excurva, Boott, Illustr. Carex, i, 57.-Reg. Himal.

exigua, Boeck. in Engl. Bot. Gahrb. v. (1884) 514. Zeylan.

exilis, Dewey, in Am. Fourn. Sc. xiv. (1828) 351.Am. bor.

extensa, Good, in Trans. Linn. Soc, ii. (1794) 175.

t. 2 L. f. 7.-Reg. temp. bor. ; Am, austr.

extensa, C. A. Mey. Verz. PA. Cauc. $31=$ diluta.

Fabri, Hance, in fourn. Linn. Soc. xiii. (1873) 90.China.

falcata, Turcz, in Bull. Soc. Nat. Mose. (1838) 104 ; xxviii. (1855) 1. $898=$ saxatilis.

fallax, Sterd. Syn. Pl. Cyp. 189.-Java.

familiaris, Sterd. l. c. 226.-Texas.

fascicularis, Sicvers, ex Trevir. in Bull. Soc. Nat. Mosc. xxxvi. $(1863)$ I. $543=$ crespitosa.

\section{CAREX:}

fascicularis, Soland. ex Hook. f. Fl. N. Zel, i. $283=$ C. Pseudocyperus.

fasciculata, Link, in Schkuhr, Riedgr, i. $119=$ echinata. fasciculata, Willd. Sp. Pl. iv. 248.-Lusitan

Fauriae, Franch. in Bull. Soc. Bot. Fr. xxvi. (1879) 89.-Japon.

fecunda, Steud. Syn. Pl. Cyp. 194.-Am. trop.

Fedia, Nees, ex Wight, Contrib. $129=$ Wallichiana.

feminea, Steud. ex Boott, Illustr. Carex, iv. $138=$ acutata.

Fendleriana, Boeck. in Linnaea, xxxix. (1875) 135.Am. bor.

ferax, Raeusch. Nom, ed. III. $270=$ erecta.

ferruginea, Schkuhr, Riedgr. i. $92=$ sempervirens.

ferruginea, Scop. Fl. Carn. ed. II, ii. 225.-Europ.

ferruginea, Stev. in Mém. Soc. Mat. Mosc. iv. (1813) $68=$ sempervirens.

festiva, Dewey, in Am. Fourn. Sco xxix. (1835) 246.Reg. bor.; Ins. Sandvic.

festucacea, Schkuhr, Riedgr. ii. $23=$ straminea.

fibrillosa, Franch. E Sav. Enum. Pl. Fap. ii. 564.Japon.

filicina, Nees, in Wight, Contrib. 123.--Ind. or. Malaya.

filiculmis, Franch. E Sav. Enum.Pl. Fap. ii. 563.Japon.

filifolia, J. Gay, in Ann. Sc. Nat. Sér. II. vi. (1836) $125=$ Durieui.

filifolia, Nutt. Gen. Am. ii. 204=Uncinia breviseta

fliformis, Leers, F1. Herborn. t. 16. f. $5=$ praecox.

filiformis, Linn. Sp. Pl. 976.-Europ.; Am. bor. e austr.; As. bor.

filiformis, Thuill. Fl. Par, $440=$ tomentosa

filiformis, Vahl, in Fl. Dan. t. 1048=pilulifera.

flipendula, Drej. 1. c. t. $2370=$ halophila.

filipes, Franch. E' Sav. Enum. Pl. Fap. ii. 57\%.-Japon.

fimbriata, Schkuhr, Riedgr. ii. 61.-Europ.

finitima, Boott, Illustr. Carex, i. 44.-Reg. Himal.

firma, Host, Syn. 509.-Europ.

Fischeriana, J. Gay, in Ann. Sc. Nat. Sér. II. x. (1838) $286=$ chordorrhiza

fissilis, Boott, Illustr. Carex, ii. 86. t. 245.-Austral. N. Caled.

fissirostris, Ball, in Fourn. Bot. xiii. (1875) 206. Marocco; Afghanist.

flacca, Carey, ex Boott, Illustr. Carex, i. $69=$ Barrattii.

flacca, Schreb. Spicil. $669=$ glanca

flaccida, Sw. ex Kunth, Enum. Pl. ii. $150=$ clado stachya.

flaccidula, Steud. Syn. Pl. Cyp. 199.-Am. bor.

flacciformis, Hoflmgg. ex Kunth, Enum. Pl. ii. 493= laevigata.

flaccosperma, Dewey, in Am. Fourn. Sc. Ser. II. ii (1846) 245.-Am. bor.

flagellifera, Colenso, in Trans. N. Z. Inst. xvi. (1884) 342, -N. Zel,

Flagellum, J. F. Gmel. Syst. $138=$ Scleria Flagellum. flava, Boiss. Voy. Espagne, ii. $631=$ Oederi

flava, Linn. Sp. Pl. 975.-Reg. bor. temp.; Tasman.

flavescens, Host, Gram. iv. 53. t. $96=$ fulva

flavicans, F. Nyland. Spicil. Pl. Fenn. iii. $15=$ salina.

flavocuspis, Franch. E Sav. Enum. Pl. Fap. ii. 574. Japon.

flavo-fulva, Beurl, in Bot. Notiser (1853) $37=$ flava.

flectens, Boott, Illustr. Carex, iv. 171.-Japon.

flexilis, D. Don, in Till. Mag. (Dec. 1823) $455=$ gracilis

flexilis, Rudge, in Trans. Linn. Soc. vii. (1804) 98. $10=$ castanea

Aexuosa, Muhl ex Schkuhr, Riedgr ii. $74=$ debilis.

floresiana, Hochst. ex Seub. Fl, Azor, 22. t. 3. f. $1=$

Vulcani.

floribunda, Boeck. in Linnaea, x1. (1876) 335.Reg. Himal.

floridana, Schwein. in Ann. Lyc. N. York, i. (1824) 66. - Florida.

fluviatilis, Boott, Illustr. Carex, iv, 172.-Burma.

foeminea, Steud. Syn. Pl. Cyp. $20 \mathrm{~S}=$ acutata.

foenea, Muhl. ex Torr. in Ann. Lyc. N. York, iii, (1836) 315.-Am. bor.

foenea, Willd. Enum. Hort. Berol. ii. $95 \%$ =straminea. foetida, All. Fl. Peden. ii. 265.-Europ.

foliose, All. 1. c, $270=$ fava, crespitosa

foliosa, D. Don, Prod. F7. Nep. 42.-Reg. Himal,

foliosissima, F. Schmidi, Reisen Amurl. 195.- Reg. Amur.

\section{CAREX}

folliculacea, Crantz, Inst. i. 405.-Hab.?

folliculata, Ell. Sketch, ii. $545=$ turgescens.

folliculata, Linn. Sp. Pl. 978.-Am, bor.

folliculata, Wahlenb. in Vet. Akad. Nya Hand1. Stockh. (1803) $152=$ intumescens

Fonki, Phil. in Linnaea, xxix. (1857-58) 83.-Chili.

Fontanesiana, DC. Fl. Fr. iii. $102=$ pyrenaica.

Fontanesii, Poir. Encyc. Suppl. 1ii. 257 = divisa.

Forficula, Franch. Es Sav. Enum. Pl. Fap, ii. 557 Japon.

formosa, Dewey, in Am. Fourn. Sc. viii. (1824) 98. t. B. fig. 6.-Am. bor.

Forsteri, Wahlenb. in Vet. Akad. Nya Handl. Stockh. 1803 $154=$ C. Pseudo-cyperus.

fragilis, Boott, Illustr. Carex, i. 7.-Reg. Himal.

Frankii, Kunth, Enum. Pl. ii. $498=$ stenolepis.

Frankii, Steud. Nom. ed. II. i. 290, Am. bor.

Franklinii, Boott, in Hook. Fl. Bor. Am. ii. 217.-Am. bor.

Fraseri, Andr. Bot. Rep. t. 639.-Am, bor.

Fraseriana, Ker-Gawl, in Bot. Mag, to 1391

Fraseri.

fraterna, Rupr. Symb. Pl. Ross. 208.-Rossia.

Fridrichsthaliana, Steud. Syn. Pl. Cyp. 211 =caes pitosa.

frigida, All. Fl. Pedem. ii, 270.-Reg. bor.

frigida, Vill. Hist. Pl. Dauph. ii. $215=$ ferroginea.

frigida, Wahlenb. in Vet. Akad. Nya Handl. Stockh.

(1803) $154=$ fuliginosa.

frigida, Willd. ex Kunth, Enum. Pl. ii. 464, $465=$ firma, fimbriata.

frisica, H. Koch, in Flora, xxix, (1846) $273=$ trinervis.

fuirenioides, Gaudich. Freyc. Voy. Bot. 112 -Ins. Marian.

fuliginosa, Host, Gram. iv. 52. t. $93=$ fimbriata

fuliginosa, Schkuhr, Riedgr. i. 91.-Lappon.

fulva, Boiss. Voy. Bot. Espagne, ii. $631=$ Hom schuchiana.

fulva, Gaertn. Mey. \& Scherb. EL. Wett. iii. $330=$ distans.

fulva, Good. in Trans. Linn. Soc, ii. (1794) 177. t. 20 . f. 6.-Europ.; Am. bor.

fulva, Hornem. in Fl. Dan, t. 1768 = binervis

fulva, Host, Gram. iv. 53. t. $95=$ varia.

fulva, Muhl. Desc. Gram. Uber. $246=$ Elliotii.

fulia, Thuill. Fl. Par. 45:3 - teretiucula, am

fulvicoma, Dewey, in Am. Journ. Sc. Aaix. 1:3*j 24 =chordorrhiza.

funiformis, [Clairv.] Man. Herb. 287 =chordorrhiza.

furcata, Ell. Sketch, ii. $552=$ comosa.

furcata, Lapeyr. Hist. Abr. Pl. Pyr. 568.-Mont. Pyrea.

furculata, Peterm。 in Flora, xxvii. (1844) 329 muricata.

furva, Webb, It. Hisp. 5 =lagopina.

fusca, All. Fl. Pedem. ii. $269=$ caespitosa

fusca, Schkubr, Riedgr. i. $64=$ pulla.

fusca, Soland. ex Boott, Illustr. Carex, iv. $217=$ pumila.

fuscescens, Boeck. in Engl.Bot. Fahrb. v. (1881) $51 \%$ -Japon.

fuscescens, Willd. ex Kunth, Enum. Pl. ii. $378=$ divisa.

fuscoatia, Boeck. in Linnaea, xl. (18;6) 878.Peruv,

fuscula, Urv. in Mém. Soc. Lina. Par. iv. (1526) 599 indecorn.

fusiformis, Chapm. ex Boott, Illustr. Carex, i. 97 laxillora.

fusiformis, Nees, in Wight, Contrib. 128-Reg. Himal.

gaimardioides, Desv. in C. Gay, Fl. Chil. vi 202Chili.

Galeottiana, C. A. Mey. in Bull. Acad. Brux. ix, 1st2 11. $248=$ Jamesoni.

Gasparrinii, Parl. Fl. Ital, ir. 149.-Italia.

Gaudichaudiana, Kanth, Enum. Pl. ii. $11 \%=$ rulgaris.

Gaudiniana, Guthrick, in Flore, xv. (1:3:2) 241.Ilctvet.

Gayana, Dess. in C. Gay, 15\%. Chil. vi. 205,-Chili. Gaviana, Steud. Nom. ed. II. i. 290 asturica. Gebhardi, IVilld. Sp. Pl. iv. 2t0; Scblubr, Riedgr. ii $2: 2$ = elongata.

Gebhardii, Hoppe, Caric. e. $\$ 0=$ canescens

Gebieri, Prescolt, cx Boolt, in Pruc. Lino. Soc. i. $1940^{\circ}$ 235 - songarica. 


\section{CAREX :-}

gemella, Hochst. ex Steud. Syn. Pl. Cyp. 214. Ind. or.

geminata, Schkuhr, Riedgr. i. $65=$ ternaria geniculata, Host, Gram. iv. 52, t. $94=$ frigida. geniculata, Schleich. ex Kunth, Enum. Pl. ii. $466=$ ferruginea.

genuensis, DC. Cat. Hort. Monsp. $87=$ glauca.

georgiana, Dewey, ex.Steud. Syn. Pl. Cyp. 225.Am. bor.

germana, Boott, in Hook. f. Fl. Antarct. 466.-Chili. Gersneri, Suter, Fl. Helv. ii. $248=$ humilis.

Geyerii, Boott, in Trans. Linn. Soc. xx. (1846) 118.Am. bor. occ.

gibba, Wahlenb, in Vet. Akad. Nya Handl. Stockh. (1803) 148.--Japon.

Gibsoni, Bab. in Jard. Ann. Nat. Hist. xi. (1843) 168. t. $5=$ vulgaris.

gigantea, Rudge, in Trans. Linn. Soc.vii. (1804) 99. t. 10. f. 2.-Am. bor.

Gilliesii, Phit. in Anal. Univ. Chil. (1873) 556.Chili.

Giraudiana, Steud. Syn. Pl. Cyp. 209.-Ins. Borbon. glabra, Boott, Illustr. Carex, ii. $93=$ venusta.

glandulosa, Ell. ex Boott, 1. c. $89=$ glancescens,

glareosa, Schkuhr, ex Wahlenb. in Vet. Akad. Nya

Handl. Stockh. (1803) 146.-Scandinav.

glauca, Bosc, ex Boott, Illustr. Carex, ii. $89=$ glaucescens.

glauca, Scop. Fl. Carn. ed. II. ii. 223.-Europ. ; Afr. bor.; Am. bor

glaucescens, Ell. Sketch, ii. 553.-Am, bor

glaucina, Boeck. in Linnaea, xl. (1876) 353.-Ind.or

glaucodea, Tuckerm. ex Olney, in Proc. Am. Acad. vii. (1868) 395.-Am. bor.

Glazioviana, Boeck. in Flora, 1xv. (1882) 59.-Bras.

Glehni, F. Schmidt, Reisen Amurl. 194.-Reg. Amur.

globosa, Bootk, in Proc. Linn. Soc, i. (1846) 259.Calif.

globularis, Leyss. ex Kunth, Enum. Pl. ii. $439=$ praecox.

globularis, Linn. Sp. Pl. 976.-Scandinav.

globularis, Oed. in F1. Dan. t. $443=$ panicea.

globularis, Roth, Tent. Fl. Germ. i. $397=$ obesa.

globularis, Suter, Fl. Helv ii. $249=$ ericetorum.

globularis, Vahl, in Skr. Naturh. Selsk. ii. I. (1792) 45 $=$ rotundata.

globularis, Vill. Hist. Pl. Dauph. ii. $211=$ canescens .

globularis, Willd. in Ges. Naturf. Fr. Neue Schr, i.

(1794) 45 . t. 2. f. $1=$ montana.

glomerata, Gilib, Exercit, ii. $545=$ vulpina

glomerata, Host, Gram. i. t. $44=$ stenophylla.

glomerata, Schkuhr, Riedgr. i. 79. t. 1. f. $41=$ obesa.

glomerata, Thunb. Prod. Pl. Cap. 14.-Afr. austr. Am. bor. et austr.

Gmelini, Hook. E' Arn. in Bot. Beech. Voy. 118. t. 27. -Kamtschatka.

Godefrini, Willem. Phyt. iii. $1114=$ laevigata.

Goodenowii, J. Gay, in Ann. Sc. Nat. Sér. II. xi. (1839) $191=$ vulgaris.

Goyeni, Petrie, in Trans. N. Z. Inst. xiv. (1882) 363. - N. Zel.

gracilescens, Hartm. ex Anderss. Cyp. Scand. $16=$ riparia.

gracilescens, Steud. Syn. Pl. Cyp. 226.-Am. bor

gracilipes, Miq. Ann. Mus. Bot. Lugd. Bat. ii. 151.Japon.

gracilis, $R$. Br. Prod. 242.-Austral.

gracilis, Curt. Fl. Lond. fasc. iv, t. $60=$ acuta

gracilis, Ehrb. Beitr. vi. 83, nomen; Schkuhr, Riedgr. i. $48=$ loliacea

gracilis, A. Gray, in Am. Journ. Sc. Ser. II. iv. (1847) $19=$ tenella

gracilis, Honck. Syn. Pl. Germ. i. $368=$ mucronata gracilis, Moench, Meth. $323=$ montana.

gracilis, Wimm. in Jahresb. Schles. Ges. (1849) 79 ; et in Flora, xxxiii. (1850) $620=$ stricta.

gracillima, Hoppe, ex Nym. Consp. $775=$ panicea

gracillima, Schwein. in Ann. Lyc. N. York, i. (1824) 66.-Am. bor.

gracillima, Steud. \& Hochst. ex Steud. Nom. ed. IJ. i. $290=$ ferruginea.

Graeffeana, Boeck. in Flora, 1viii. (1875) 123.-Ins. Fiji.

Grahami, Boott, in Proc. Linn. Soc. i. (1843) 180; et Trans, Linn. Soc. xix. (1845) $215=$ saxatilis.

granularioides, Schwein. in Ann. Lyc. N. York, i. 1824) $69=$ conoidea

\section{CAREX :}

granularis, Muhl.ex Schkuhr, Riedgr. ii. 67.-Am, bor. Grasmanniana, Rabenh. Fl. Lusat.; ex Steud. Syn. P Cyp. $218=$ tomentosa.

Grayana, Dewey, in Am. Journ. Sc. xxv. (1834) $141=$ livida.

Grayii, Carey, in A. Gray, Man. Bot. U. St. ed. I. 563 - Am bor.

Greeniana, Dewey, in Am. Joum. Sc. xxx. (1836) $61=$ fulva.

Greenii, Boeck. in Flora, xli. (1858) 649.-Am. bor.

Griffithii, Boott, in Proc. Linn. Soc. 1. (1846) 286.Afghan

Grioletti, Roem. in Schkuhr, Riedgr. ii. $76=$ grisea. grisea, Viv. Ann. Bot. i. 186.-Reg. Caucas. ; Persia. grisea, Wahlenb. in Vet. Akad. Nya Handl. Stockh (1803) 154.-Am. bor.

Grosseckii, Heuff. ex Boott, Illustr. Carex, iv. $148=$ pyrenaica.

Grypos, Schkuhr, Riedgr, ii. $18=$ echinata

guestphalica, Boenn. ex Koch, Syn. Fl. Germ. ed. II $867=$ muricata

Gunniana, Boott, in Proc. Linn. Soc. i. (1846) 258.Austral.

Guthnickiana, J. Gay, in Ann. Sc. Nat. Sér. II. x. (1838) $289=$ decipiens.

gynandra, Schwein. in Ann. Lyc. N. York, i. (1824) 70 - Am. bor.

gynandra, Sieber, ex Kunth, Enum. P1. ii. $478=$ Linkii.

gynobasis, Vill. Hist. Pl. Dauph. ii. 206=Halleriana Eormsk in Drej. Rev, Caric 16 chordorrhiza.

gynodynama, Olney, in Proc. Am. Acad. vii. (1868) 394-Calif.

Gynomane, Bertol. Pl. Rar. Ital. Dec. ii. $43=$ Linkii.

Haastiana, Boeck. in Flora, 1xi. (1878) 168.-N. Zel.

haematolepis, Drej. in Fl. Dan. t. $2370=$ salina.

haematostoma, Nees, in Wight, Contrib. 125.-Nepal. Reg. Himal.

Haenkeana, Presl, Rel. Haenk. iii. 203=C. Pseudo cyperus.

Hailstoni, Gibs. in Phytol. i. (1841) $870=$ axillaris.

hakonensis, Franch. E Sav. Enum. Pl. Fap. ii. 550.Japon.

Haleana, Olney, Car. Bor. Am.6.-Am. bor.

Halei, Dewey, in Am. Joum. Sc. Ser. II. ii. (1846) $248=$ C. Crus-corvi.

Halei, Carey, in Chapm. Fl. S. U. St. 543--Am. bor Halleri, Vest, ex Steud. Nom. ed. II. i. 290.-Cf. Suteri

Halleriana, Asso, ex Hanck. Syn. i. 372.-Europ.; Reg Casp.; Marocco.

Halliana, L. Bailey, in Coult. Bot. Gaz. ix. (1884) 117. -Am. bor. occ.

Hallii, Olney, in Hayden, Rep. (1871) 496.-Am. bor, occ.

halmaturina, Boeck, in Linnaea, xxxix. (1875) $100=$ paniculata, tereticaulis.

halophila, Heuff. in Linnaea, xxxi. (1861-62) .695= fulva.

halophila, F. Nyland. Spicil. Pl. Fenn. ii. n. 50.Lappon.

Halseyana, Dewey, in Am. Journ. Sc. xi. (1826) $313=$ polymorpha.

hamata, Forst. ex Steud. Nom. ed. II. i. $290=$ Forsteri hamata, Sw. Prod. Veg. Ind. Occ. 18=Uncinia jamaicensis.

Hancockiana, Maxim. in Bull. Soc. Nat. Mose, liv. (1879) x. 66.-China.

Harlandi, Boott, Illustr. Carex, ii. 87. t. 255.-Hongkong.

Hartii, Dewey, in Am. Fourn. Sc. Ser. II. xli. (1866) 226. - Am. bor.

Hartwegii, Boott, in Benth. Pl. Hartw. 96.-N. Granat.

Haydeniana, Olney, in Bot. King, Exp. 366.-Am. bor. occ

Haydenii, Dewey, in Am. Journ. Sc. Ser. II. xwiii. (1854) $103=$ aperta.

hebecarpa, Hook. \& Arn. Bot. Beech. Voy. $50=$ Hookeri

hebecarpa, C. A. Mey. in Mém. Sav. Etr. Pétersb. i. (1831) 223. t. 12.-Reg. Himal.

hebetata, Boott, Illustr. Carex, iv. 172.-Am. austr.

Heleonastes, Ehrh. ex Linn. f. Suppl. 414.-Europ.

Heleonastes, Liljebl. in Vet. Akad. Nya Handl Stockh. (1793) $73=$ glareosa.

\section{CAREX :-}

Helferi, Boeck, in Linnaea, xl. (1876) 365.-Burma

helodes, Link, in Schrad. Journ. ii. (1799) $309=$ laevigata.

helvola, Blytt, in Fries, Bot. Notiser (1849), 58.Norveg

helvetica, Honck. Syn. Pl. Germ. 1. $375=$ frigida.

helvetica, Schleich. ex Kunth, Enum. Pl. ii. $448=$ punctata.

Hepburnii, Boott, in Hook. F1. Bor. Am. ii. 209. t. $207=$ nardina.

heptastachys, Boeck. in Linnaea, xxxix. (1875) 114.Am. trop.

hermaphrodita, J. F. Gmel. Syst. $138=$ Elyna spicata. hermaphrodita, Jacq. Coll. iv. $174=$ Mariscus Jacquini. heterolepis, Bunge, Enum. Pl. Chin. Bor. 69.-China. heteroneura, S. Wats. in Bot. Calif. ii. 240.-Calif

heterophylla, Krock. ex Steud. Nom. ed. II. i. 290.Silesia.

heterosperma, Wahlenb, in Vet. Akad. Nya Handl. Stockh. (1803) $151=$ anceps.

heterostachya, Bunge, Enum. P1. Chin. Bor. $69=$ nutans. heterostachya, Torr. in Am. Journ. Sc. Ser. II. ii. 1846) $248=$ Crawei.

hians, Steud. Syn. Pl. Cyp. 236.-Hab. ?

Hilairei, Boott, Illustr. Carex, iv. 146.-Bras.

Hildebrandtiana, Boeck. in Engl. Bot. Fahrb. v. (1884) 516.-Madag.

Hilgendorfiana, Boeck. l. c. 518.-Japon.

hirsuta, Suter, FI. Helv. ed. II. ii. $324=$ Halleri

hirsuta, Willd. Sp. Pl. iv. $252=$ triceps.

hirta, Linn. Sp. Pl. 975.-Europ.; As. temp.

hirta, Oed. in Fl. Dan. t. $379=$ filiformis.

hirtaeformis, Pers. Syn. ii. $547=$ hirta.

hirtella, Drej. Symb. 21.-Afghan. ; Reg. Himal.

hirtella, J. F. Gmel. Syst. $138=$ Scleria hirtella.

hirtissima, S. Wats. in Bot. Calif. ii. 247.-Calif

hispida, Gaud. Agrost. Helu. ii. 136.-Helvet.

hispida, Link, Hort. Berol. ii. $331=$ lasiochlaena.

hispida, Willd. ex Schkuhr, Riedgr. i. $63=$ echinata.

hispidula, Gaud. Agrost. Helv. $136=$ fimbriata.

Hitchcockiana, Dewey, in Am. Fourn. Sc. x. (1826) 274.-Am. bor.

Hochstetteri, Frank, ex Steud. Nom. ed. II. i. $291=$ polytrichoides.

Hochstetteriana, F. Gay, ex Seub. Fl. Azor. 22. t. 2. f. 2.-Ins. Azoric

holostoma, Drej. in Fl. Dan. t. 2428.-Groenl.

homalocarpa, Peterm. in Flora, xxvii. (1844) $333=$ vulgaris.

homoiolepis, Franch. \& Sav. Enum. Pl. Fap. ii. 567. -Japon.

Hoodii, Boott, in Hook. Fl. Bor. Am. ii. 211.Am. arct.

Hookerana, Dewey, in Am. Fourn. Sc. xxix. (1836) 248.-Am. arct

Hookeri, Kunth, Enum. Pl. ii. 490-Chili.

Hoppneri, Boott, in Hook. Fl. Bor. Am. ii. $219=$ salina.

hordeiformis, Wahlenb. in Vet. Akad. Nya Handl. Stockh. (1803) $152=$ hordeistichos.

hordeistichos, Vill. Prosp. 18.-Europ.; As. temp.

Hornschuchiana, Hoppe, in Flora, vii. (1824) 599.Europ.

Horsfieldii, Boott, in Proc. Linn. Soc. i. (1845) 257.Java.

Hosteana, DC. Cat. Hort. Monsp. $88=$ fulva.

Hostii, Hoppe, ex Kunth, Enum. Pl. ii. $372=$ divisa

Hostii, Schkuhr, Riedgr. Nachtr. $7=$ stenophylla.

Houghtonii, Torr. in Ann. Lyc. N. York, iii. (1836) 413.-Am. bor. occ

Huetiana, Boiss, Diagn. Ser. II. iv. 123.-Reg. Caucas.

huitensis, Steud. Syn. Pl. Cyp. $223=$ indecora.

Humboldtiana, Steud. l. c. 208-N. Granat.

humilis, Leyss. Fl. Hal. 175.-Europ.; Reg. Caucas.

humilis, Willd. ex Kunth, Enum. Pl. ii. $411=$ caespi tosa.

hyalina, Boott, in Bost. Journ. Nat. Hist. v. (1847) 112 = straminea.

hyalinolepis, Steud. Syn. Pl. Cyp. 235.-Am. bor.

hybrida, Belev. ex Lam. Encyc. iii. $382=$ divisa.

hybrida, Schkuhr, ex Kunth, Enum. PI. ii. $533=$ Kobresia caricina.

hydrophila, Dum. F1. Belg. $146=$ echinata.

hymelayensis, Steud. Syn. Pl. Cyp. 204.-Reg. Himal. hymenina, Nees, ex Boott, Illustr. Carex, i. 67.Chili. 
CAREX :

hymenocarpa, Drej, in Fl. Dan, t. $2849=$ ampullacea hymenolepis, Nees, in Wight, Contrib. $126=$ setigera. hypandra, F. Muell. Fragm. viii. 259.-Austral. hyperborea, Drej. Revis. Caric. $43=$ salina. hypoxanthos, Steud. Syn. Pl. Cyp. $193=$ Brongniartii. hypsophila, Miq. Fl. Ind. Bat. iii. 354.-Malaya. hystericina, Muhl. ex Schkuhr, Riedgr. ii. 69.-Am. bor.

Hystrix, A. Gray, ex Boott, Illustr. Carex, i. $26=$ Cruscorvi

Idzuroei, Franch. \& Sav. Enum. Pl. Fap. ii. 583.Japon.

ignota, Dewey, in Am. Journ. Sc. Ser. II. viii. (1849) 348 = laxiflora.

illegitima, Cesati, in Frieder. Reise, 271.-Dalmat. ; Graecia.

illinoënsis, Dewey, in Am. Fourn. Sc. Ser. II. iv. 1847) 245.-Am. bor.

illustranda, Steud. Syn. P1. Cyp, $190=$ bracteosa

Ilseana $\times$, Ruhm. in Eichl. Jahrb. i. (1881) 258.Europ.

impunctata, Boott, Illustr. Carex, iii. 107.-Java. inaequalis, Raeusch. Nom. ed. III. $270=$ caespitosa? inanis, Kunth, Enum. Pl. ii. 522.-Reg. Himal. incerta, Steud. Syn. Pl. Cyp. $210=$ saxatilis incisa, Boott, in Perry, Fap. Exp. ii. 327.-Japon.

incisodentata, Lechl, ex Boott, Illustr. Carex, i. $26=$ festiva.

incisodentata, Steud. Syn. Pl. Cyp. 189.-Reg. Magellan.

inclusa, Turcz. ex Boott, Illustr. Carex, iv. $177=$ alba inconspicua, Steud. Syn. P1. Cyp. 221 = indecora.

incrassata, Schlecht. in Linnaea, x. (1836) $119=$ riparia.

incrassata, Soland. ex Boott, Illustr. Carex, iv. 138 $=$ trifida.

incurva, Lightf. Fl. Scot. ii. 544. t. 24.-Reg, bor.

temp. et arct.

incurva, Sibth. \& Sm. Fl. Graec. Prod, i. $227=$ divisa.

indecora, Kunth, Enum. Pl. ii. 448.-Ins. Falk.

indica, Koen. ex Willd. Sp. Pl. iv. $315=$ Scleria tessellata.

indica, Linn. Mant. ii. 574.--Ind. or.; Malaya.

indica, F. Muell, ex Benth. Fl, Austral, vii, 441 = fissilis indica, Schkuhr, Riedgr. i. $37=$ Uncinia spartea.

indica, Wahlenb. in Vet. Akad. Nya Handl. Stockh. (1808) $149=$ Wahlenbergiana

inflata, Huds. F1. Angl. ed. I. $354=$ vesicaria.

inflata, Suter, Fl. Helvet. ii. $265=$ ampullacea.

infuscata, Nees, in Wight, Contrib. $125=$ alpina

innocua, Wallr. Beitr. Fl. Hercyn. 299,-Europ.

inops, Kunze, in Schkuhr, Riedgr. Suppl. 131 = tenella.

inornata, Turcz. ex Ledeb. Fl. Ross. iv. 303, nomen $=$ ericetorum.

insignis, Boott, Illustr. Carex, i. 5.-Reg. Himal.

instlaris, Carmich. in Trans. Linn. Soc. xii. (1818) 508. - Ins. Trist. d'Acunha.

intermedia, Good. in Trans. Linn. Soc. ii. (1794) 154 $=$ disticha.

intermedia, Miégev. in Bull. Soc. Bot. Fr. x. (1863) 83 =vulgaris.

intermedia, Retz. F1. Scand. $178=$ muricata.

intermedia, Suter, F1. Helvet. ii. 261, 262= paludosa.

intermedia, Urv. in Mém. Soc. Linn. Par. i. (1822) $378=$ arenaria.

interrupta, Boeck, in Linnaea, xl. (1876) 432.-Am. bor.

intricata, Tineo, in Guss. Fl. Sic. Syn. ii. $574=$ vulgaris. intumescens, Rudge, in Trans. Linn. Soc vii. (1804) 97. f. 3.-Am. bor.

inundata, Willd. ex Kunth, Enum. Pl. ii. $492=$ glaucescens.

inversa, $R$. Br. Prod. 242,-A ustral.; N. Zeland.

involucrata, Boeck. in Flora, xxxviii. (1855) 594.Texas.

involucrata, Boott, Illustr. Carex, ii. 76.-Am. austr. iridifolia, Kunth, Enum. Pl. ii. 492 =aethiopica.

irregularis, Schwein. in Ann. Lyc. N. York, i. (1824) $66=$ flava.

irrigua, Sm. in Hoppe, Caric. t. 92.-Reg. bor. temp. et arct.

ischnantha, Steud. Syn. Pl. Cyp. 204=brunnea.

ischnostachya, Steud. l. c. 222.-Japon.

Jackiana, Boott, in Proc. Linn. Soc. i. (1846) 260.-Java,

jamaicensis, Poir. Encyc. iii. $246=$ Uncinia jamaicensis,

Gamesii, Schwein. in Ann. Lyc. N. York, i. (1824) 67 =Steudelii.

\section{CAREX :-}

Jamesii, Torr, in Ann. Lyc. N. York, iii. (1836) 398 -Am, bor.

Jamesoni, Boott, in Proc. Linn. Soc. i. (1845) 258.Ecuador.

japonica, Fisch. ex Boott, 1. c. $259=$ breviculmis

japonica, Thunb. Fl. Fap. 38.-Japon.

juncea, Scop. FI. Carn, ed. II. ii. $227=$ fulva.

juncea, Willd. Enum. Hort. Berol. Suppl. 63.-Am bor.

juncella, T. M. Fries, in Bot. Notiser, (1857) $207=$ vulgaris.

juncifolia, All. F1. Pedem. ii. 264=incurva.

juncifolia, J. F. Gmel. Syst. $142=$ mucronata

juncifolia, Host, Syn. $504=$ stenophylla.

juncoides, F. $\sigma^{\circ}$ C. Presl, Fl. Cech. 190-Bohemia

jungenda, Steud. Syn. Pl. Cyp. $210=$ saxatilis

kaloides, Petrie, in Trans. N.Z. Inst. xiii. (1881) 332.-N. Zel.

Kanitzii, Floriano, in Magyar Növent. Lapok, ix (1885) 131.-Europ.

kattegatensis, Fries, Ind. Sem. Hort. Upsal. (1857).Cf. Hartm. Skand. Fl. ed. XIII. $466=$ salina.

Keiskei, Miq. Ann. Mus. Bot. Lugd. Bat. ii. 148.Japon.

Kelloggii, S. Wats, Bot. Calif ii. 240,-Calif

Kelvingtoniana, Steud. Syn. Pl. Cyp. 215.-Am. bor.

Kerneri, Kohts, in Oestr. Bot. Zeitschr. xx. (1870) 164 -Europ.

kiotensis, Franch. E Sav. Enum. Pl. Fap. ii. 556.Japon.

Kirilowii, Turcz. in Bull. Soc. Nat. Mosc. xxviii. (1855) I. 340 . - As. centr

Kneiskernii x, Dewey, in Am. Journ. Sc. xxxii. (1846) 247.-Am. bor.

Kochiana, DC. Cat. Hort. Monsp. $8=$ paludosa.

Kochiana, Schueb. F1. Wuerttb. $601=$ evoluta.

Koestlini, Hochst. ex Steud. Syn. Pl. Cyp. 193.Abysin.

Kotschyana, Boiss. \& Hohen. Diagn. Ser. I. xiii. $38=$ vulgaris.

Krameri, Franch. E Sav. Enum. Pl. Fap. i. 551.Japon.

Krullii, Boeck. in Flora, lxv. (1882) 59.--N. Zel.

Kunzei, Olney, ex A. Gray, in Proc. Am. Acad. viii. (1872) 406.-Am. bor.

Lachenalii, Schkuhr, Riedgr. i. $51=$ lagopina

lachnosperma, Wall. Cat, n. $3379=$ gracilis.

laciniata, Boott, Illustr. Carex, iv. 175.-Calif.

lacistoma, R. Br. Prod. 243.-Austral.

lacustris, Balb. ex Kunth, Enum. Pl. ii. $533=$ Elyna caricina.

lacustris, Schkuhr, Riedgr. ii. 84.t. 600. f. 152.-Europ

lacustris, Willd. Sp. Pl. iv. $306=$ riparia.

laeta, Boott, Illustr. Carex, i. 69.-Reg. Himal.

laevicaulis, Hochst. in Seub. Fl. Azor. $21=$ punctata.

laevi-conica, Dewey, in Am. Fourn. Sc. xxiv. (1857) 47. - Am. bor.

laevigata, Boiss. Voy. Bot. Espagne, ii. $631=$ Camposii laevigata, Sm. in Trans. Linn. Soc. v. (1799) 272.Europ.

laevigata, Wahlenb. in Vet. Akad. Nya HandI. Stockh. (1803) $153=$ aethiopica.

laevirostris, Anderss. Cyp. Scand. 17 =rhynchophysa. laevis, J. F. Gmel. Syst. $138=$ Scleria laevis. laevis, Hoppe, Taschenb. (1800) $243=$ dioica.

laevis, Kit ex Willd. Sp. Pl iv, 292,Enrop austr. or. Laggeri, Wimm, in Flora, xxxvil. (1854) $161=$ repens.

lagopina, Wahlenb. in Vet. Akad. Nja Handl. Stockh. (1808) 145.-Reg. bor.

lagopodioides, Schkuhr, Riedgr. ix. $20=$ tribuloides.

Lagopus, Muhl. Desc. Gram. Uber. $265=$ Fraseri.

Lamarckii, [W. Wood] in Rees, Cycl, vi. n. $103=$ obesa.

Lambertiana, Boott, ex Hook. f. Fl. N. Zel. 284.-N. Zel.

lanceata, Dewey, in Am. Journ. Sc. xxix. (1836) 249 salina.

lanceolata, Boott, in Perry, Fap. Exp. ii. 326.Japon.

lanescens, Follm. in Bull. Soc. Nat. Mosc. viii. (1835) 283.-Lappon.

Langii, Steud. Syn. Pl. Cyp. 227.-Norreg.

Langsderffi, Boott, in Proc. Linn. Soc. i. (1845) $259=$ leucochlora.

lanosa, Gueldenst. It. i. 107; ex Ledeb. Fl. Ross. iv. 320,-Ross, austr.

lanuginosa, Michx. Fl. Bor. Am. ii. 175.-Am, bor.

\section{CAREX:}

lapponica, Lang, in Linnaea, xxiv. (1851) $539=$ canescens.

lasiocarpa, Ehrh. in Hann. Mag. $9^{\text {tes }}$ Stuick (1784), 132 $=$ filiformis.

lasiochlaena, Kunth, Enum. Pl. ii. 485.-Sardinia.

latifolia, Boiss. E Bal. in Boiss. Fl. Orient. $\nabla .421$ Pontus.

latifolia, J. F. Gmel. Syst. $138=$ Scleria latifolia.

latifolia, Moench, Meth. 324 = plantaginea.

latifolia, Soland. ex Boott, Illustr. Carex, i. $52=\mathrm{C}$ Pseudo-cyperus

laxa, Dewey, in Am. Joum. Sc. xxvi. (1834) $376 \Rightarrow$ limosa.

laxa, Sw, ex Kanth, Enum. P1. ii. 513 = scabrella.

laxa, Wahlenb. in Vet. Akad. Nya Handl. Stockh. 1803) 156.-Lappon.

laxiculmis, Schwein. in Ann. Lyc. N. York, i. (1824 70.-Am. bor.

laxiflora, Ell. Sketch, ii. $549=$ grisea.

laxiflora, Lam. Encyc. iii, 378-Am, bor

laxula, Tineo, ex Boott, Illustr. Carex, iv. $202=$ sylvatica.

lazica, Boiss. \& Bal. in Boiss. Fl. Orient. v. $424=$ sempervirens.

Leavenworthii, Dewey, in Am. Journ. Sc, Ser. II. ii. $\left(1846^{\circ}\right) 246=$ cephalophora.

Lechleri, Phil. in Linnaea, xxix. (1857-58) 83.-Reg. Magellan.

Lechleri, Steud. Syn. Pl. Cyp. 234.-Chili.

Ledebouriana, C. A. Mey. ex Trevir, in Bull. Soc. Nat. Mosc. xxxvi. (1863) 1. $540=$ capillaris.

Ledebourii, Boiss, \& Buhse, in Nouv. Mém. Soc. Nat. Mosc. xii. (1860) $222=$ natans.

Leersii, F. Schult. in Flora, liii. (1870) 455, \& liv. (1871) $25=$ muricata.

Leersii, Willd. Prod. Fl. Berl. $28=$ stellulata.

Lehmanniana, Boott, ex Walp. Ann. i. 910=Lemanniana.

Lehmannii, Drej. Symb. 13. t. 2.-Ind, or

leiocarpa, J. Gay, in Aas. Sc. Nat. Sér. II. vi. (1836 $351=$ asturica.

leiocarpa, C. A. Mey. in Mém. Sav. Etr. Pétersb. i. (1831) 208. t. 5.-Unalask

leiorhyncha, C. A. Mey, in Mém. Sav. Etr. Pétersb. (1831) 217. t. 9.-Dahuria.

Lemanniana, Boott, in Proc. Linn. Soc. i. (1846) 256 - Am. austr.

Lemmoni, W. Boott, in Coult. Bot. Gaz. ix. (1884) 93. -Am. bor. occ.

lenta, D. Don, ex Spreng. Syst. iii. 811, sphalm.= gracilis.

lenticularis, Dewey, in Am. Journ. Sc. vii. (182*) 263 ix. (1825) 263 =-magellanica.

lenticularis, D. Don, in Trans. Linn. Soc. xiv. (1825) $331=$ phacota.

lenticularis, Michx, El, Bor. Am ii. 172-Am bor.

leonura, Wahlenb. in Vet. Akad. Nya Handl. Stockh. (1803) $161=$ crinita, hystericina.

lepida, Boott, Illustr. Carex, iv. 211.-Perav.

lepidocarpa, Tausch, in Flora, xvii. (1834) $179=$ flavs. leporina, Linn. Sp. Pl. 973.-Reg. bor. temp.

leporina, Michx. Fl. Bor. Am. ii. $170=$ scoparia

leporina, Oed. in Fl. Dan. t. 294=lagopina.

leporina, Pall. ex Kunth, Enum. Pl. ii. $393=$ divisa.

leporina, Schkuhr, ex Ledeb. Fl. Ross. iv. $279=$ C. He leonastes.

leptalea, Wahlenb. in Vet. Akad. Nya Handl. Stockh. (1803) $139=$ polytrichoides.

leptophylla, Hewff, in Linngea, xxxi, 1861-62) -208. t. 5.-Europ.

leptostachya, Boiss. F1. Orient. $v .41 \mathrm{~s}=\mathrm{seq}$

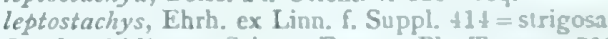

Lerchenfeldiana, Schur, Enum. Pl. Transs, $711=$

hordeistichos.

Lessoniana, Steud. Nom. cd. II. i. 292.-N. Zeh.

lencantba, Arr. ex Boott, in Proc. Linn. Soc. i. 1545 357 .- Ind. or.

leucantha, Schur, Enum. Pl. Tronss. 711.-Europ.

leucocarpa, Boeck. in Flora, xxix. (1856) 227. Am. hor.

lencocarpa, Phil. in Linnoeg, xxix. $(185 \%-59)$ 82.Chili.

lencochlora, Bunge, in Mém. Sav. Etr. Peitersb. ii. 1535) 142 = breviculmis.

leucoglochin, Ehrh. ex Wahlenb, is Vet. Akad. Nva Handl. Stockh. (180) $139,1 \neq 0=0$ obtusata.

lencoglochin, Linn. f, Suppl. $f 13=$ pauciflora . 


\section{CAREX :-}

leucolepis, Turcz. ex Steud. Nom. ed. II. i. $292=$ tenuiflora.

leucorhizia, Dulac, Fl. Hantes-Pyr, 452=Davalliana Lhotrkiana, Nees, ex Steud. Nom. ed. II. i. $292=$ Fintelmannia restioides.

Liddoni, Boott, in Hook. Fl. Bor. Am. ii. 214.Am. bor.

Liddoni, Carey, in A. Gray, Man. Bot. U. St. ed. I. 545 $=$ pallida.

Liebmanni, Walp. Ann. iii. 705-Mexic.

ligata, Boott, ex Benth. Fl. Hongk. 402.-China

ligerica, J. Gay, in Ann. Sc. Nat. Sér. II. x. (1838) 360 = arenaria.

ligerina, Guep. ex Bor. in Mém. Soc. Acad. Maine-etLoire, vi. (1859) $171=$ praec

ligulata, Nees, in Wight, Contrib. 127.-Ind. or

limosa, Engelm. ex Steud. Syn. Pl. Cyp. $209=$ abjiciens.

limosa, Linn. Sp.Pl. 977.-Europ.; Am. bor.

limosa, Scop. Fl. Carn. ed. II. ii. $222=$ ustulata

limula, Fries, Summa Veg. $229=$ vulgaris.

Lindleyana, Nees, in Wight, Contrib. 121.-Ind, or.

linearis, Boott, Illustr. Carex, i. 51.-Reg. Himal.

linearis, Clairv. ex Boott, 1. c. iv. 204=tenuis.

lineola, Fries, in Bot. Notiser (1844), 53.-Lappon.

Linkii, Willd. ex Schkuhr, Riedgr. ii. 39.-Reg.

Mediterr.

Linnaeana, Host, Gram. iii. $77=$ dioica.

Linnaei, Dégl. in Loisel. Fl. Gall. $627 \doteq$ dioica.

liparocarpus, Gaud. Etrennes F1. $153=$ obesa.

lipsiensis, Peterm. F1. Lips. Excurs. $58=$ flava

lithophila, Turcz. in Bull. Soc. Nat. Mose. (1838) 104 ; xxviii. (1855) I. 328.-Sibir.

lithosperma, Forst. f. Prod. $65=$ Scleria margaritifera.

lithosperma, Linn. Syst. ed. XII. $706=$ Scleria Flagellum.

lithosperma, Walt. Fl. Carol. $227=$ Scleria reticu. laris.

littoralis, Krock. ex Steud. Nom. ed. II. i. $292=$

stricta.
littoralis, Petrie, in Trans. N. Z. Inst. xv. (1883) 358. -N. Zel.

littoralis, Schwein. in Ann. Lyc. N. York, i. (1824) 70 -Am. bor.

littorea, Labill. Nov. Holl. Pl. ii. 69. t. $219=$ pumila.

livida, Willd. Sp. Pl. iv. 285.-Reg. bor. temp.

lobata, Bell. App. Fl. Pedem. $42=$ curvula.

lobata, Lam. Encyc. iii. 379 ; Schkuhr, Riedgr. i. $28=$ divisa.

lobata, Schleich. ex Steud. Nom. ed. II. i. $293=$ microstyla.

lobata, Vill. Hist. Pl. Dauph. ii. $197=$ foetida.

lobata, Wahlenb. ex Steud. Nom. ed. II. i. $292=$ curvula.

lobata, Willd. ex Kunth, Enum. Pl. ii. 533=Elyna caricina.

lobolepis, F. Muell. Fragm, viii. 258.-Austral.

lobulirostris, Drej. Symb. 27. t. 14.-Zeylan.

loliacea, Linn. Sp. Pl. 974.-Reg. bor. et arct.

loliacea, Schkuhr, Riedgr, i. $22=$ tenella.

loliacea, Sclureb. ex Steud. Nom. ed. II. i. $292=$ divulsa.

loliacea, Steph. ex Boott, Illustr. Carex, iv. $187=$ elongata.

loliacea, Thuill. ex Boott, Illustr. Carex, iv. $192=$ muricata.

lonchicarpa, Willd. ex Kunth, Enum. Pl. ii. $500=$ folliculata.

longearistata, Bivona, in Sicil. Sponte Prov. Desc. iv. 8. t. 2 = echinata.

longebrachiata, Boeck. in Linnaea, xli. (1877) 282.Austral.

longebracteata, Steud. Syn. Pl. Cyp. 205.-Java.

longerostrata, C. A. Mey. in Mém. Sav. Etr. Pétersb. i. (1831) 220.-Kamtschatka.

longibracteata, Dulac, F1. Hautes-Pyr. $57=\mathrm{C}$. Pseudocyperus.

longibracteata, Schleich. Cat. PI. Helv. ed. IV. $11=$ intermedia.

longicaulis, Boeck. in Flora, 1xv. (1882) 62.-Mexic

longicruris, Nees, in Wight, Contrib. 124--Ind, or.

longiculmis, Petrie, in Trans. N. Z. Inst. xiv. (1882) 363.-N. Zel.

363.-N. Zel.
longifolia, R. Br. Prod. 242.-Austral.

longifolia, Burch. ex Hemsl. Bot. Challeng. Exped. i. II. 87 =aequabilis.

\section{CAREX:}

longifolia, Host, Gram. iv. t. $85=$ praecox.

longifolia, Thuill. Fl. Par, i. $490=$ ampullacea.

longipes, D. Don, in Trans. Linn. Soc. xiv. (1825) 329.

-Ind. or.

longirostris, Krock. ex Kunth, Enum. P1. ii. $493=$ laevigata.

longirostris, Torr. ex Schwein. in Ann. Lyc. $N$. York, i. (1824) 71.-Am. bor.

longiseta, Brot. Fl. Lusit. i. 63.-Lusitan.

Lorentziana, Griseb. in Goett. Abh. xix. (1874) 271.Reg. Argent.

Loscosi, Lange, in Kjoeb. Vidensk. Meddel. (1877-78) 223.-Hispan.

lucida, Boott, in fourn. Linn. Soc. xx. (1884) 377.N. Zel.

lucida, Dicks. ex Stend. Nom. ed. II. i. $292=$ Elyna spicata.

lucorum, Sartw. ex Boott, Illustr. Carex, ii. $99=$ nigromarginata.

lucorum, Willd. Enum. Hort. Berol, Suppl.63.-Am bor.

ludibunda, F. Gay, in Ann. Sc. Nat. Sér. II. x. (1838) 357.-Gallia.

lupuliformis, Sartw. ex Dewey, in Am. Journ. Sc. Ser. II. ix. (1850) $29=$ Iupulina

lupulina, Muhl. ex Schkuhr, Riedgr. ii. 54.-Am. bor.

lurida, Wahlenb. in Vet. Akad. Nya Handl. Stockh.

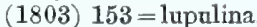

lusitanica, Schkuhr, Riedgr. ii. $23=$ paniculata.

lutensis, Kunth, Enum. Pl. ii. 487.-Afr. austr. luteola, Nees, ex Boott, Illustr. Carex, iv. $181=$ bracteosa.

luzulaefolia, S. Wats. in Bot. Calif. ii. 250.-Calif.

luzulina, Olney, in Proc. Am. Acad. vii. (1868) 395.Calif.

Lyallii, Boott, Illustr. Carex, iv. 150.-Am. bor. occ Lyngbyei, Hornem. in FI. Dan. t. $1888=$ maritima.

Lyoni, Boott, in Hook. Fl. Bor. Am. ii. 209.-Am. bor.

Maackii, Maxim. Prim. Fl. Amur. 308.-Reg. Amur macella, Kunth, Enum. Pl. ii. 482.-Reg. Argent. macilenta, Fries, Summa Veg. $224=$ gracilis. macloviana, Urv. in Mém. Soc. Linn. Par. v. (1826) $599=$ leporina.

Macounii, Dewey, in Am. Fourn. Sc. Ser. II. xli. (1866) 228.-Am. bor.

macra, Steud. Syn. Pl. Cyp. $212=$ vulgaris.

macrocarpa, Phil. in Linnaea, xxix. (1857-58) 86.Chili.

macrocephala, Willd. ex Kunth, Enum.Pl.ii. 428.Sibir.; Japon.

macrochaeta, C. A. Mey. in Mém. Sav. Etr. Pétersb. i. (1831) $224, t .13=$ podocarpa.

macroglossa, Franch. E Sav. Enum. Pl. Fap. ii. 576. -Japon.

macrogyna, Turcz. in Bull. Soc. Nat. Mosc. (1838) 104 $=$ ferruginea.

macrokolea, Steud. Syn. Pl. Cyp. 223.-Am. bor

macrolepis, DC. Cat. Hort. Monsp. 89.-Italia ; Graecia.

macrolepis, D. Don, in Till. Mag. (Dec. 1823) $455=$ longipes.

macrophylla, Hochst. ex Steud. Syn. Pl. Cyp. 207.Ind. or.

macrorhyncha, Kar. \& Kir. in Bull. Soc. Nat. Mosc. xv. (1842) $521=$ parva

macrosolen, Steud. Syn. Pl. Cyp. 210.-Reg. Magell macrostachyos, Link, in Schrad. Fourn. ii. (1799) 311. - Lusitan.

macrostachys, Bertol. Amoen. Ital. $421=$ ferruginea.

macrostyla, Lapeyr. Hist. Abr. P1. Pyr. $562=$ decipiens.

macrothrysa, Miq. Fl. Ind. Bat. iii. 351.-Malaya.

maculata, Boott, in Trans. Linn. Soc. xx. (1851) 128.

-Zeylan; As, or. ; Austral.

maculata, Liebm. in Vidensk. Selsk. Skr. V. ii. (1851)

$268=$ spilocarpa.

maculata, Turcz. ex Ledeb. Fl. Ross. iv. $295=$ ustulata.

maculata, Turcz. ex Steud. Nom. ed. II. i. $292=$ coriophora.

madagascariensis, Boeck. in Engl. Bot. Fahrb. v. (1884) 517.-Madag.

magellanica, Banks, ex Boott, in Proc. Linn. Soc. i. (1884) $257=$ Banksii.

magellanica, Lam. Encyc. iii. 385.-Reg. bor. et austr.
CAREX:

Mairii, Coss. E Germ. Obs. Pl. Crit. 18.-Mont. Pyren.

malaena, Steud. Syn. P1. Cyp. 211=vulgaris.

manca, Boott, ex Benth. Fl. Hongk. 402.-Hongkong.

manostachys, Spreng. Syst. iii. 824, sphalm. = macrostachys.

Marchandiana, Lapeyr. ex Spreng. 1. c. $806=$ pyrenaica.

marcida, Boott, in Hook. Fl. Bor. Am. ii. 212.-Am. bor. occ.

marcida, Raeusch. Nom. ed. III. 270 (quid?).Helvet.

margaritifera, Steud, Nom. ed. II. i. $292=$ Scleria Flagellum.

marginata, Gort. F1. Belg. $247=$ divisa, intermedia.

marginata, Muhl, ex Schkuhr, Riedgr. ii. $49=$ pensylvanica.

marina, Dewey, in Am. Journ. Sc. xxix. (1836) $247=$ C. Heleonastes

maritima, O.F. Muell. in Fl. Dan. t. 703.-Reg. bor. et arct.

Marssoni, Auersw. in Bot. Zeit. x. (1852) $409=$ flava.

Maubertiana, Boott, Illustr. Carex, i. 45.-Cochinch. mauritanica, Boiss. \& Reut. Pugill. Pl. Nov. 116.Afr. bor.

mauritanica, Steud. Syn. Pl. Cyp. 204.-Ins. Maurit.

maxima, Scop. F1. Carn. ed. II. ii. $229=$ pendula.

Maximowiczii, Boeck, in Linnaea, xli. (1877) 237 Reg. Amur.

Maximowiczii, Miq. Ann. Mus. Bot. Lugd. Bat. ii. 180 $=$ picta.

Maximowiczii, F. Schmidt, Reisen Amurl. 71.-As. temp.

Meadii, Dewey, in Am. Journ. Sc. xliii. (1842) $90=$ tetanica.

media, R. Br. in Richards. in Frankl. Narr. 1st Journ. $750=$ alpina

meiogyna, Nees, in Wight, Contrib. $123=$ filicina.

melaena, Wimm. in Flora, xxxiii. (1850) $619=$ vulgaris.

melanantha, C. A. Mey. in Ledeb. Fl. Ross. iv. 216.As. centr.

melanocarpa, Cham. in Middend.Sibir. Reise, i. II. 21 - Sibiria.

melanocephala, Turcz. ex Kunth, Enum. Pl. ii. $437=$ alpina.

melanochloros, Thnill. Fl. Par. i. $488=$ stricta.

melanocystis, Desv. in C. Gay, Fl. Chil. vi. $203=$ incurva.

melanosperma, Liebm. in Vidensk. Selsk. Skr. V. ii. (1851) 270.-Mexic

melanostachya, Willd. Sp. Pl. iv. $299=$ nutans

melanostylis, Desv. in. C. Gay, Fl. Chil. vi. t. 73.Chili.

melastoma, Fisch. ex Boott, Mllustr. Carex, ii, $100=$ Tolmiei.

membranacea, Hook. in Parry, 2 Voy. App. $406=$ vesicaria.

membranacea, Hoppe, Ic. t. 71 = ericetorum.

mendocinensis, Olney, in S. Wats. Bot. Calif. ii. 249. -Calif.

Menziesiana, Sm. ex Boott, Illustr. Carex, i. 27= macrocephala.

mercarensis, Hochst. ex Steud. Syn. Pl. Cyp. 194.Ind. or.

Mertensii, Presc. ex Bong. Vég. Sitcha, 51.-Alaska,

mertensis, Weihe, ex Kunth, Enum. Pl. ii. $383=$ vulpina.

Metteniana, Lehm. ex Schur, Enum. P1. Transs. $697=$ dioica.

mexicana, Presl, Rel. Haenk, i. 204=polystachya.

Meyeni, Nees, in Nov. Act. Nat. Cur. xix. (1843) Suppl. i. $123=$ brunnea.

Meyeriana, Kunth, Enum. Pl. ii. 438.-Sibir. alt.

micans, Boott, in Mem. Am. Acad. N. S. vi. (1858-59) $419 \approx$ maculata

Michauxiana, Boeck. in Linnaea, xli. (1877) 336.Am. bor.

Michauxii, Dewey, in Am. Journ. Sc. x. (1826) 273 = subulata.

Michauxii, Schwein. in Ann. Lyc. N. York, i. (1824) $64=$ scirpoidea

Micheliana, Sm. in Trans. Linn. Soc. v. (1800) 270 = glauca.

Michelii, Host, Syn. Pl. Austr. 507.-Europ. austr.; As. temp. 
CAREX :

microcarpa, Bertol. ex Moris, Stirp. Sard. Elench. 48. -Sardinia.

microcephala, C. A. Mey. in Ledeb. Fl. Alt. iv, $205=$ obtusata.

microdontos, Torr. in Ann. Lyc. N. York, iii. (1836) 428. - Texas.

microglochin, Wahlenb. in Vet. Akad. Nya Handl. Stockh. (1803) 140.- - Reg. bor. et arct.

microlepis, Boeck. in Linnaea, xli. (1877) 269.Hab.?

micropoda, C. A. Mey. in Mém. Sav. Etr. Pétersb. i. (1831) 210.-Unalaschk

microsperma, Steud. Syn. Pl. Cyp. 231.-Texas.

microsperma, Wahlenb. in Vet. Akad. Nya Handl.

Stockh. (1803) $144=$ vulpinoidea.

microstachya, Ehrh, in Hannov. Mag. $9^{\text {tes }}$ Stück

(1784), 132.-Europ. bor.

microstachya, Michx. Fl. Bor. Am. ii. $169=$ polytrichoides.

microstyla, F. Gay, in Gaud. Fl. Helv. vi. 37.-Alp Helv.

Middendorffi, F. Schmidt, Reisen Amurl. 70.-Reg. Amur.

Mielichhoferi, Schkuhr, Riedgr. ii. $66=$ ferruginea.

Mielichhoferi, Sm. Engl. Bot. t. 2293 = vaginata

Mielichhoferi, Willd. ex Kunth, Enum. Pl. ii. $465=$

brachystachys, fimbriata.

miliacea, Muhl, ex Schkuhr, Riedgr. ii. $77=$ prasina.

miliacea, Schrank, Baier. Fi. i. $300=$ distans.

miliaris, Michx. Fl. Bor. Am. ii. 174.-Am. bor.

minima, Boullu, in Ann. Soc. Bot. Lyon, v. (1878) 88 -Gallia.

mirabilis, Dewey, in Am. Journ. Sc. xxx. (1836) $63=$

straminea.

mirabilis, Host, Gram. iv. t. $78=$ Elyna caricina.

mirabilis, Schleich. Cat. (1821) ex Gaud. F1. Helv. vi. $63=$ curvula.

mirata, Dewey, in Ar. Fourn. Sc. Ser. II. xxxix. (1865) 71.-Am. bor.

misandra, R. Br. in Parry, Voy. App. 283.-Am. arct.

miser, Buckl. in Am. Joum. Sc. xlv. (1843) $173=$ juncea.

misera, Phil. Fl. Atac. 53.-Chili.

Mitchelliana, M. A. Curt. in Am. Fourn. Sc. xliv. (1843) 84.-Am. bor.

mitis, J. F. Gmel. Syst. $138=$ Scleria mitis.

mixta, J. F. Gmel. l. c. $146=$ stricta, paludosa.

mixta, Miégev. in Bull. Soc. Bot. Fr. xii. (1865) 343. -Gallia. modesta, J. Gay, in Ann. Sc. Nat. Sér. II. x. (1838)
$304=$ disticha.

Moenchiana, Wender. in Flora, vi. (1823) $718=$ acuta. moesta, Kunth, Enum. Pl. ii. 482.-Reg. Argent.

mollicula, Boott, Illustr. Carex, iv, 192.-Ins. Loochoo.

mollis, Gilib. Exercit. ii. $546=$ leporina

mollis, Host, Gram. iv, 46. t. $82=$ praecox.

monadelpha, Boott, in Perry, Jap. Exped. ii. $323=$ tristachya.

Moniezi, Timb. in Bull. Soc. Bot. Fr. iv. (1857) 164.Gallia.

monile, Tuckerm. ex Boott, in Hook. Lond. Fourn. Bot.v. (1846) 69.-Am, bor.

monilifera, Thuill. F1. Par. i. $490=$ depauperata.

Moniziana, Lowe, ex Boott, Illustr. Carex, iv. 174. Ins. Mader.

monostachya, A. Rich. Tent. Fl. Abyss. ii. 512.Abysin.

montana, Leers, F1. Herborn. 716. t. 16. f. $6=$ ericetorum.

montana, Linn. Sp. Pl, $975=$ pilulifera.

montana, Linn. Fl. Suec. ed. II. 328.-Europ. ; Reg.

Caucas.; Japon.

montana, Poll. ex Lightf. Fl. Scot. ii. $551=$ praecox.

montana, Scop. Fl. Carn. ed. I. ii. $219=$ tomentosa.

monticola, Dewey, ex Torr. Bot. Mex. Bound. $229=$

triquetra.

Moorcroftii, Falc. in Proc. Linn. Soc. i. (1846) 288.-

Reg. Himal.

Morrowii, Boott, in Perry, Fap. Exp. ii. 326,-Japon.

Motoskei, Miq. in Ann. Mus. Bot. Lugd. Bat. ii. 148 -Japon.

mucronata, All. Fl. Pedem. ii. 268.-Europ. med. Reg. Caucns.

Muehlenbergi, Brongn. Voy. Duperr. Bot, $151=$ Brongniartii.

Muehlenbergii, Schkuhr, Riedgr. ii. 12.-Am. bor.

\section{CAREX}

Muelleri, Steud. Syn. P1. Cyp. 204=Linkii

Muhlenbergii, Kunth, ex Boott, Illustr. Carex, iii. 125 $=$ vulpinoidea.

multicaulis, L. Bailey, in Coult. Bot. Gaz. ix. (1884) 118. - Calif.

multiceps, Gaud. Etrennes F1. $78=$ elongata.

multiculmis, Ehrh. Beitr. vi. $83=$ elongata

multiflora, Muhl. ex Schkuhr, Riedgr. ii. $14=$ vulpinoidea.

multiformis, Thaill. Fl. Par, i. $479=$ disticha

multinervis, Boeck, in Flora, xxxviii. (1855) 596.Texas.

multinervis, Krock. ex Steud. Nom. ed. II. i. $293=$ binervis.

multispicata, Kunze, in Schkuhr, Riedgr. Suppl. 42.

$$
\text { t. 10.-Chili }
$$

munda, Boott, Illustr, Carex, i, 7-Reg. Himal.

muricata, Desf. F1. Atlant. ii. $335=$ divulsa

muricata, Huds. F1. Angl. $406=$ echinata,

muricata, Jungh. in Linnaea, vi. (1831) $29=$ glomerata

muricata, Leers, F1. Herborn. t. 13. f. $8=$ stellulata

muricata, Linn. Sp. Pl. 974.- Reg. bor, temp.

muricata, Schlecht. in Linnaea, vi. (1831) $29=$ Brongniartii.

musei, Steud. Syn. Pl. Cyp. 205.-Ins, Borbon

muskingumensis, Schwein. in Ann. Lyc. N. York, i.

1824) 66.-Am. bor

mutabilis, Willd. Prod. Fl. Berl. $37=$ pendula

mutans, Boott, ex C. B. Clarke, in Journ. Linn. Soc.

xx. (1883) $383=$ Hemicarex. Hookeri.

mutica, R. Br. in Richards, in Frankl. Narr. 1st Journ. $751=$ aurea.

myosuroides, Lowe, in Trans. Camb. Phil. Soc. iv.

(1833) 10.-Ins. Azoric.

myosuroides, Vill. Prosp. $17=$ Elyna spicata

myosurus, Nees, in Wight, Contrib. 122.-Ind. or

nana, Boott, in Mem. Am. Acad. N. S. vi. (1858-59) 418.-Japon.

nana, Cham. ex Steud. Syn. Pl. Cyp. 228.-Alaska.

nana, Lam. Encyc. iii. $389=$ ferruginea

nardifolia, Wahlenb, in Vet. Akad. Nya Handl.

Stockh. (1803) $165=$ aquatilis.

nardina, Fries, Nov. Mant. ii. 55.-Europ. et Am. bor. et arct.

Naufragii, Hochst. \& Steud. Nom. ed. II. i. 293 ; Syn, Pl. Cyp. $206=$ illegitima.

Naumanniana, Boeck. in Engl. Bot. Fahrb. v. (1884) 518.- Japon.

nebrascensis, Dewey, in Am. Journ. Sc. Ser. II. xviii. (1854) $102=$ Jamesii.

Neesiana, Arn. ex Boott, in Proc. Linn. Soc. i. (1845) $260=$ lobulirostris.

Neesiana, Endl. Prod. Fl. Norf. 24.-Ins. Norfolk. neglecta, Degl. in Loisel. Fl. Gall. ii. $298=$ distans,

neglecta, Peterm. in Flora, xxvii. (1844) $331=$ vulgaris.

neglecta, Tuckerm. Enum. 19; et in Am. Journ. Sc. xlv. (1843) $40=$ rosea.

nematosperma, Willd. ex Kunth, Enum. Pl. ii. $456=$ anceps.

nemorensis, J. F. Gmel. Syst. $143=$ pilosa

nemorosa, J. F. Gmel. 1. c. $1520=$ pilosa.

nemorosa, Hort. Berol. ex Kunth, Enum. Pl. ii. $388=$ leiorhyncha.

nemorosa, Lumnitz. ex Honck. Syn. i. 355=muricata. nemorosa, Rebent. ex Boott, Illustr. Carex, iii. $122=$ vulpina.

nemorosa, Schrank, Baier. Fl. i. $291=$ alba.

nemostachys, Steud. in Flora, xxix. (1846) 23.Japon.

nepalensis, Spreng. Syst, iii. $811=$ longipes

nervata, Franch. E" Sav. Enum. Pl. Fap, ii. 566.Japon.

nervina, L. Bailey, in Coult. Bot. Gas. x. (1885) 203. -Calif.

nervosa, Desf. Fl. Atlant, ii. $\$ 37=$ extensa.

nervosa, Willd. ex Kunth, Enum, PI. ii. $449=$ distans

neurocarpa Maxim. Prim. Fl. Amur. \$06-Reg. Amur.

neurochlamys, F. Muell. Fragm. viii. $258=$ maculata. nevadensis, Boiss. \& Reat. Pugill. Pl. Nov. 118 Oederi.

nexa, Boott, ex Benth. Fl. Hongk. 402,-China

nigella, Boott, ex Hook. Fl. Bor. Ams, ii. 225.-Am. bor.

nigra, All. Fl. Pedem, ii. $267=$ strata.

nigra, Reich. F1. Moeno-Franc. ii. $96=$ acuta

nigra, Schkuhr, Kiedgr. i. $38=$ aterrima.

\section{CAREX}

nigra, Schwein. ex Torr. in Ann. Lyc. N. York, i (1824) $336=$ vulgaris.

nigra, Siev. in Pall. N. Nord. Beitr, vii. 198.-Sibir baical.

nigricans, Dewey, in Am. Journ. Sc. xxix. (1836) 249 = dioica

nigricans, Hombr. ex Boott, Illustr. Carex, iv. $156=$ Darwinii.

nigricans, Kit. in Linnaea, xxxii. (1863) 320.-Earop. nigricans, $C$. A. Mey in Mém. Sav. Etr. Pétersb. (1831) 210.t. 7.-Unalaschk

nigritella, Drej. in Fl. Dan. t. $2369=$ stylosa nigrolutea, Gaud. Agrost. Helv。 ii. $196=$ glanca.

nigro-marginata, Schwein. in Ann. Lyc. N. York, i.

1824) 68.-Am. bor.

nikoënsis, Franch. E Sav. Enum. Pl. Fap. ii. 558.Japon.

nilagirica, Hochst. ex Steud. Syn. Pl. Cyp. 207.Ind or.

nipponica, Franch. in Bull. Soc. Bot. Fr. xxri. (1879 89.- Japon.

nitens, Phil. in Anal. Univ. Chil. (1873) 557.-Chili.

nitida, Hoppe, Taschenb. (1800) $198=$ mucronata

nitida, Host, Gram. i. 71.-Europ.

nitida, Willd. ex Kunth, Enom. Pl. ii. $411=$ caes pitosa.

nivalis, Boott, in Proc. Linn. Soc. 1. (1845) 256 . Reg. Himal.

nivalis, Cham, ex Steud. Syn. Pl. Cyp. 184=micropoda.

nivicola, G. Don, ex Boott, Illustr, Carex, iv. $149=$ vaginata.

nobilis, Boott, l. . . i. 4.-Reg. Himal.

nodiflora, Boeck. in Engl. Bot. Fahrb. v. (1884) 516.-

Ins. Philipp.

norvegica, Willd. ex Schkuhr, Riedgr. 1. 50.-Europ et Am. bor.

notha, Kunth, Enum. Pl. ii. 421--Reg. Himal.

notoleia, Nees, in Wight, Contrib. $121=$ foliosa.

Novae-Angliae, Schwein. in Ann. Lyc. N. York, 1824) 67.-Am. bor.

Novae-Selandiae, Boeck, in Flore, 1xi. (1878) 169. N. Zel.

nubigena, D. Don, in Trans. Linn. Soc. xiv. (1825) 326. - Ind. or.

nuda, Lam. Fl. Fr. ii. 172 =leporina.

nudata, S. Wats, Bot. Calif, ii. 241.-Calif.

nuptialis, Boott, Illustr. Carex, iv, 175,-Ins. Sandvic.

nutans, Host, Gram. i. 61. t. 83.--Europ.; Japon.

nutans, Raeusch. Nom, ed. III. $270=$ erecta.

Nuttallii, Dewey, in Am. Fourn. Sc. xliii. (1842) 92.Am. bor. occ.

Oakesiana, Torr. in Ann. Lyc. N. York, iii. (1836) $421=$ oligosperma

obesa, All. Fl. Pedem. ii. 270.-Europ.; Tauria.

obesa, Schleich. ex Kunth, Enum. Pl. ii. $411=$ caes pitosa.

obliqua, Turcz. in Bull. Soc. Nat. Mosc. (1838) $10 t=$ pediformis.

oblita, Steud. Syn. Pl. Cyp. 231.-Am. bor.

oblonga, F. F. Gmel. Syst. 146.-German.

obovata, Goldb. ex Ledeb. Fl. Ross. iv. $290=$ pedi formis.

obscura, Nees, in Wight, Contrib. 126.--Reg. Himal.

obtusa, Kit. in Linnaea, xxxii. (1863) 319.-Hungar.

obtusangula, Ehrh. Beitr vi. $82=$ ampullacea.

obtusangula, Hort. Berol. ex Kunth, Enum. Pl. ii 459 = glauca.

obtusangula, Salzm. ex Boott, Illastr. Carex, iv. 206 = echinata.

obtusangula, Salzm, ex Nym. Consp. 77t: i.i: i....,

obtusata, Liljeb. in Vet. Aked. Nya Handl $\therefore$. B

(1793) 69. t. 4.-Reg. bor. et arct.

ochroleuca, Cham. ex Steud. Syn. Pl. . 2. 21,Alaskn.

odontolepis, Phil. in Linnaea, xxix. (1\$57-58) 8\%. Chili.

Oederi, Rets. ex Ehrh. Beribr. vi. (1\%1) 83.-Reg. bor. temp.

Oederi, Willk. in Flora, xxxv. (1552) $521=$ nevadensis. oedipostyla, Duvab-7onse, in Mcm. Acad. Mansp. (Sect. Sc.) vii. (1S69) \$\$2. Gallia.

Dedocarpa, Anderss. Cyp. Seand. $28=$ Oederi.

Oerstedii, Liebm. in l'julensk. Selsk. Str. V. ü. 185L $27^{2}$, - Costa Rica.

ohiotica, Hochst. E Strud. ex Strud. Nom. ed. II. i 293. - Am. bor. 


\section{CAREX :-}

Ohmuelleriana, Lang, in Flora, xxvi. (1843) $240=$ arenaria.

Okesiana, Dewey, in Am. Journ. Sc. xiv. (1828) $351=$ oligosperma?

olbiensis, Ford. Obs. Pl. Crit. iii. (1846) 241.-Europ Olgae, Regel, Pl. Nov. Fedsch. 83.-As. centr.

oligandra, F. Muell, ex Boott, Illustr. Carex, iv. $136=$ Buxbaumii.

oligantha, Boott, $l . c .174$. t. 589-Am. austr.

oligantha, Steud. Syn. Pl. Cyp. 203.--Reg. Caucas.

oligocarpa, Hornem. ex Boott, Illustr. Carex, iv. $161=$ obesa.

oligocarpa, Muhl. Descr. Gram. Uber. 242; ex Boott, 1. c, i, $40=$ digitalis.

oligocarpa, Schkuhr, Riedgr. ii. 58.-Am, bor

oligogyna, Less. ex Kunth, Enum. Pl. ii. $442=$ globularis.

oligosperma, Michx. Fl. Bor. Am. ii. 174-Am. bor. oligostachya, Nees, in Hook. Kew Fourn. vi. (1854) 29.-Ins. Philipp.

olivacea, Boott, in Proc. Linn. Soc. i. (1845) 286. Reg. Himal.

olivacea, Liebm. in Vidensk. Selsk. Skr. V. ii. (1851) 267.-Mexic.

Oliveri, Boeck. in Flora, lxiii. (1880) 455.-Afghanist.

Oliveriana, J. Gay, ex Boiss. Fl. Orient. v. $408=$ illegitima.

Olneyi x, Boott, Illustr. Carex, i. 15.-Am. bor. olyssiponensis, Steud. Syn. Pl. Cyp. $204=$ Linkii omiana, Franch. E Sav. Enum. Pl. Fap. ii. 554.Japon.

Onoei, Franch. Es Sav. l. c. i. 551.-Japon.

ontakensis, Franch. E' Sav. l. c. 550.-Japon.

orbicularis, Boott, in Proc. Linn. Soc. i. (1845) $254=$ vulgaris.

oreades, C. A. Mey. in Bull. Acad. Brux. ix. II. (1842) $248=$ festiva

oregonensis, Olney, ex A. Gray, in Proc. Am. Acad. viii. (1872) 407.-Am. bor occ.

oreophila, C. A. Mey. Verz. Pfl. Cauc. 29.-Reg. Caucas.; As. Min

Orizabae, Liebm. in Vidensk. Selsk. Skr. V. ii. (1851 $263=$ festiva.

ornithopoda, Willd.Sp. Pl. iv 255.-Europ.; As. bor ornithopodioides, Hausm. in Flora, xxxvi. (1853) 225 $=$ ornithopoda.

ornithorhyncha, Boott, Illustr. Carex, i. $26=\mathrm{C}$. Crus corvi.

Orsiniana, Tenore, Fl. Nap. v. $244=$ muricata

orthostachys, C. A. Mey. in Ledeb. Fl. Alt. iv. $231=$ aristata.

orthostachys, Trev. ex Nym. Consp. $769=$ hirta.

ovalis, Good. in Trans. Linn. Soc. ii. (1794) $148=$ leporina

ovalis, Willd. ex Kunth, Enum. Pl. ii. $397=$ scoparia. ovata, Burm. f. Fl. Ind. 194 (err. typ. 294).-Java.

ovata, Honck. Syn. i. $341=$ Halleri.

ovata, C. A. Mey, in Ledeb. Fl. Alt. iv, $207=$ curaica.

ovata, Rudge, in Trans. Linn. Soc. vii. (1804) 96. t. 9 f. 1 = atrata.

oxylepis, Torr. E Hook. in Ann. Lyc. N. York, iii (1836) 409.-Texas.

pachygyna, Franch. E' Sav. Enum. Pl. Fap. ii. 560.Japon.

pachystachya, Cham. ex Steud. Syn. Pl. Cyp. 197.Alaska.

pachystylis, J. Gay, in Ann. Sc. Nat. Sér. II. x. (1838) $301=$ stenophylla.

pacifica, Drej. Revis. Car. $292=$ caespitosa

Pairaei, F. Schultz, in Flora, li. (1868) $303=$ divulsa.

paleacea, Wahlenb. in Vet. Acad. Nya Handl. Stockh 1803) $164=$ maritima

paleata, Boott, in Trans. Linn. Soc. xx. (1846) 127.Ins. Juan Fermandez.

pallescens, Linn. Sp. Pl. 977.--Reg. bor, temp.

pallida, C. A. Mey. in Mem. Sav. Etr. Pétersb. i. (1831) $215=$ siccata

pallida, Salisb. Prod. $29=$ pallescens

pallidior, Degl, in Loisel. Fl. Gall. ii. $299=$ punctata.

paludosa, Good. in Trans. Linn. Soc. ii. (1794) 202 -

Reg. bor. temp.

palustris, Suter, F1. Helvet. ii. $261=$ paludosa

panicea, Carey, in A. Gray, Man. Bot. U. St. ed. I. 521 $=$ Meadii.

panicea, Bunge, ex Boott, in Proc. Linn, Soc. i. (1845) $288=$ tenuissima?

\section{CAREX :-}

panicea, Linn. Sp. Pl. 977.- Reg. bor. temp. paniculata, Linn. Cent. Pl. i. 31 (Amoen. Acad. iv. 294).-Reg. temp. bor. et austr.

paniculata, Wahlenb. in Vet. Akad. Nya Handl. Stockh. (1803) $143=$ paradoxa

paniculata, Willd. ex Kunth, Enum. P1. ii. $390=$ teretiuscula.

panormitana, Guss, Fl. Sic, Syn ii. $575=$ acuta.

papillosa, Nees, in Hook. Fourn. Bot. ii. (1840) 398.Guiana

papulosa, Boott, in Mem. Am. Acad. N. S.vi. (1858-59) 418.- Japon.

paradoxa, Benth. Cat. Pl. Pyr. $67=$ divisa

paradoxa, J. F. Gmel. Syst. $145=$ seq. ?

paradoxa, Willd. in Schrift. Naturf. Fr. Berl. (1794)

30. t. 1.-Europ.; As. bor.

parallela, Laest. in Vet. Akad. Nya Handl. Stockh. (1822) $338=$ dioica

parciflora, Boott, in Mem. Am. Acad. N. S. vi. (185859) 418.- Japon.

Parkeri, Petrie, in Trans. N. Z. Inst. xiii. (1881) 332. - N. Zel.

Parryana, Dewey, in Am. Fourn. Sc. xxvii. (1835) 239.-Am. bor.

parva, Nees, in Wight, Contrib. 120.-Reg. Himal parvibracteata, Nees, l. c. 125.-Reg. Himal. parviflora, Gaud, Etrennes Fl. 84=lagopina. parviflora, Host, Gram. i. 2, 221=atrata.

parviflora, C. A. Mey. Verz. Pf. Cauc. $30=$ alpina. patula, Host, Gram. i. 2, 221. t. $64=$ flava. patula, Huds. F1. Angl. ed. II. ii. $402=$ pauciflora. patula, Schkuhr, Riedgr. i. 115. t. B. bb. f. $16=$ laevigata.

patula, Scop. Fl. Carn. ed. II. ii. $226=$ sylvatica. pauciflora, Balb. ex Boott, Illustr. Carex, iv. 174 microglochin.

pauciflora, Lightf. Fl. Scot. ii. 543. t. 6. f. 2.-Reg. bor. temp.

pauciflora, Usteri, ex Schkuhr, Riedgr. i. $83=$ firma

paupercula, Michx. F1. Am. Bor. ii. $172=$ magel lanica.

pedata, All. Fl. Pedem. ii. 168=ornithopoda

pedata, Linn. Sp. Pl. ed. II. 1384.-Europ, arct.

pediformis, C. A. Mey. in Mém. Sav. Etr. Pétersb. i. (1831) 219 t. 10 -As. bor

peduncularis, Wall. ex Boott, Illustr. Carex, i. $53=$ speciosa.

pedunculata, Muhl. ex Schkuhr, Riedgr. ii. 39.-Am. bor.

pedunculata, Willd. ex Roxb. in Beats. St. Helena Tracts, $302=$ praealta

pelia, Lang, in Linnaea, xxiv. (1851) $575=$ panicea.

pellita, Muhl. ex Schkuhr, Riedgr. ii. $84=$ lanuginosa.

pellucida, Turcz. ex Boott, Illustr. Carex, iv. $196=$ pediformis.

pendula, Geners. Elench. n. $871=$ capillaris.

pendula, Huds. Fl. Angl. ed. I. 352 ; ed. II. 411.Europ.; As. bor.

pendula, Moench, Meth. $324=$ vesicaria

pennsylvanica, Torr. in Am. Lyc. N. York, iii. (1836) $410=$ varia

pensylvanica, Lam. Encyc, iii. 388-Am. bor

pentacarpa, Boeck. in Flora, lviii. (1875) 265.-Java.

pentastachys, Fisch. ex Steud. Nom. ed. II. i. 294. Kamtschatka.

peregrina, Link, Hort. Berol. i. 334.-Afr. trop.

perennis, Krock. ex Steud. Nom. ed. II. i. $294=$ marginata.

Perraudieriana, F. Gay, in Bull. Soc. Bot. Fr. iii. (1856) 685 , nomen.-Ins. Teneriff.

Personii, Schkuhr, ex Kunth, Enum. Pl. ii. $509=$ Wahlenbergiana.

Persoonii, Lang, in Flora, xxv. (1842) $748,767=$ canescens.

Persoonii, Sieber, ex Koch, Syn. Fl. Germ. ed. II. 871 = elongata, Gebhardi.

peruviana, Domb. ex Boott, Illustr. Carex, iv. $138=$ acutata.

peruviana, Presl, Rel. Haenk. i, $205=$ extensa.

petasata, Dewey, in Am. Journ. Sc. xxix. (1836) $246=$ leporina.

Petersii, C. A. Mey. ex F. Schmidt, Reisen Amurl. 194 $=$ falcata.

Petitiana, A. Rich. Tent. Fl, Abyss. ii. 513.-Abyssin. petraea, Wahlenb. in Vet. Akad. Nya Handl. Stockh. (1803) $139=$ rupestris.
CAREX :-

petricosa, Dewey, in Am. Fourn. Sc. xxix. (1836) 246. -Am. bor.

Petriei, Cheesem in Trans. N.Z. Inst, xvi. (1884) 413 - N. Zel.

phacota, Spreng. Syst. iii. 826.-Ind. or.; Malaya

phaecostachya, Sm. Engl. Bot. Suppl. t. $2731=$ vaginata.

phalaroides, Kunth, Enum. Pl. ii. 482.-Bras.

pharensis, Vis. Fl. Dalm. iii. $346=$ illegitima.

phleoides, Cav. Ic. v. $40=$ Uncinia phleoides

phyllomanica, S. Wats. Bot. Calif. ii. 233.-Calif.

phyllophora, Kunth, Enum. Pl. ii. $424=$ pauciflora.

phyllostachys, C. A. Mey. Verz. Pf. Cauc. 30.-Reg.

Cauc. ; Persia.

physema, Dewey, in Am. Fourn. Sc. Ser. II. xxix. (1860) 347. - Am. bor.

physocarpa, Nees, ex Boott, in Proc. Linn. Soc i. (1846) $287=$ acutala.

physocarpa, Presl, Rel. Haenk. iii, 202.-Am, aret.

physodes, Bieb. in Mém. Soc. Nat. Mosc. ii. (1809) 104 t. 7.-Reg. Caucas.; As. bor.

physorhyncha, Steud. Syn. Pl. Cyp. 719.-Mexic

pichinchensis, $H, B . \& K$. Nov. Gen. et Sp. i. 233.Ecuador.

picta, Boott, in Mem. Am. Acad. N. S. vi. (1858-59) 418.- -Japon.

picta, Steud Syn. Pl. Cyp. 184-Am bor.

Pierotii, Miq. Ann. Mus. Bot. Lugd. Bat. ii. 148.Japon.

pilosa, Scop. Fl. Carn. ed. II. ii. 226.-Italia.

pilosiuscula, Boeck. in Flora, lxv. (1882) 61.-Am. bor

pilosiuscula X, Gobi, in Fust, Fahresb. iv. (1876) 1078.Rossia

pilulifera, Geners. ex Boott, Illustr. Carex, iv. 216 = praecox.

pilulifera, Linn. Sp. Pl. 976.-Europ.; Japon.

pilulifera, Willd. ex Kunth, Enum. Pl. ii. 439.-Reg.

bor, et arct. ?

pinetorum, Liebm. in Vidensk. Selsk. Skr. V. ii. (1851) $263=$ festiva.

pinetorum, Willd. ex Kunth, Enum. Pl. ii. $381=$ Muehlenbergii.

piniaria, Bosc, ex Boott, Illustr. Carex, iii. $124=$ Muehlenbergii.

pinnata, Moench, ex Reichb. F1. Germ. Excurs. $59=$ elongata.

piptolepis, Desv. in C. Gay, F1. Chil. vi. 201 = seti folia.

pisiformis, Boott, in Perry, Ұap. Exped. ii. 324.Japon.

Pissisi, Phil. in Linnaea, xxxiii. (1864-65) 272.Chili.

planata, Franch. \& Sav. Enum. Pl. Fap. ii. 555.Japon.

planifolia, Kohts, in Oestr. Bot. Zeitschr. xx. (1870 141.-Europ.

planostachys, Kunze, in Schkuhr, Riedgr. Suppl. 138 t. $35=$ Halleriana

plantaginea, Lam. Encyc. iii. 392.-Am. bor

plantaginea, Muhl. Descr. Gram. Uber. 235 = laxiflora.

platycarpa, Hochst. ex Steud. Syn. P1. Cyp. $214=$ phacota.

platyphylla, Carey, in Am. Fourn. Sc. II. iv. (1847) 23.-Am. bor.

platyrhyncha, Franch. E Sav. Enum. Pl. Fap. ii. 582 -Japon.

platystachys, Tenore, FI. Nap, iv. $133=$ macro lepis.

plumbea, Willd. Sp. Pl. iv. $308=$ riparia

poaeformis, J. F. Gmel. Syst. $138=$ Scleria poaeformis.

pocilliformis, Boott, Illustr. Carex, iv. 175--Japon.

podocarpa, $R$. Br. in Richards. in Frankl. Narr. 1st Fourn.751.-Am. arct.

podogyna, Franch. E Sav. Enum. Pl. Fap. ii. 557.Japon.

podostachys, Steud. Syn. Pl. Cyp. 232.-Am. bor.

Poireti, J. F. Gmel. Syst. $140=$ Fuirena pubescens. polyandra, Schkubr, Riedgr. i. $59=$ caespitosa.

polyantha, Franch. \& Sav. Enum. Pl. Fap. ii. 556.Japon.

polyantha, F. Muell. in Trans. Phil. Soc. Vict. i. (1855) $110=$ acuta.

polycephala, Boott, Illustr. Carex, i. 4.-Reg. Himal. polygama, Schkuhr, Riedgr. i. $84=$ Buxbaumii. 
CAREX :

polymorpha, Muhl. ex Boott, Illustr. Carex, i. 21. t. 57 - Am. bor.

polymorpha, Schwein. ex Boott, 1. c. iii. $125=$ vulpinoidea.

polymorpha, Torr. in Ann. Lyc. N. York, iii. (1836) $413=$ striata.

polyphylla, Kar. E Kir. in Bull. Soc. Nat. Mosc. (1841) 859.-As. centr.

polyrrhisa, Wallr. Sched. Crit. $492=$ praecox

polystachya, Lesson \& A. Rich. Voy. Astrol. $118=$ Lessoniana.

polystachya, A. Rich. Voy. Astrol. 111. t. $21=$ ternaria, polystachya, Sw. ex Wahlenb. in Vet. Akad. Nya Handl. Stockh. (1803) 149.-Am. trop.

polysticha, Boeck. in Kjoeb. Vidensk. Meddel. (1869) 157.-Bras.

polytrichoides, Muhl. ex Schkuhr, Riedgr. ii. 34.-Am. bor.

Porteri, Olney, Car. Bor. Am. 12.-Am. bor.

potamostauros, Steud. in Lechl. Berb. Am. Austr. 52. -Chili.

potosina, Hemsl. Biol. Centr. Am. Bot. iii. 474.Mexic.

praealta, Boott, Illustr. Carex, i. 66.-Ins. S. Helen.

praeceps, Borck. ex Reichb. Fl. Germ. Excurs. $64=$

praecox.

praecox, Facq. Fl. Austr. v, 23,-Reg, bor. temp.

praecox, Jundz. Fl. Lithuan. n. $889=$ brizoides.

praecox, Poll. ex Steud. Nom. ed. II. i. $294=$ emarginata.

praecox, Schreb. Spicil. $63=$ Schreberi

praegracilis, W. Boott, in Coult. Bot. Gas, ix. (1804)

87.-Am, bor.

Praetutiana, Parl. Fl. Ital. ii. $182=$ glauca

prairea, Dewey, ex Woods, Bot. $750=$ teretiuscula.

prasina, Wahlenb. in Vet. Akad. Nya Handl. Stockh. (1803) $161=$ miliacea.

pratensis, Drej. Revis. Caric. $24=$ adusta.

pratensis, Hose, in Usteri, Ann. Bot. xxi. (1797) 35.Europ.

pratensis, Phil. in Linnaea, xxix. (1857-58) 81.Chili.

Preissii, Nees, in Lehm. Pl. Preiss. ii. 94.-Austral.

Prescottiana, Boott, in Proc. Linn. Soc. i. (1845) 286. -Calif.; Ins. Hawaii.

Preslii, Steud. Syn. Pl. Cyp. 242.-Sinus Nutka.

Princeps, Kunth, Enum. Pl, ii. $439=$ praecox.

procera, Kunth, l. c. 491.-Bras.

prolifera, Kit. in Linnaea, xxxii. (1863) 320.-

Hungar.

prolixa, Fries, Nov, Mant. iii. $228=$ acuta.

prolixa, Sshur, Enum. Pl. Transs. $707=$ stricta.

propinqua, Nees \& Meyen [Reise, i. 116], ex Kunth, Enum. Pl. ii. $\$ 96=$ festiva

prostrata, All. F1. Pedem. ii. $267=$ humilis.

prostrata, J. F. Gmel. Syst. $142=$ pilosa

protracta, Steud. Syn. Pl. Cyp. 234.-Am. bor.

provincialis, Degl. in Loisel. Fl. Gall. ii. $307=$ echinata.

pruinosa, Boott, in Proc. Linn. Soc. i. (1845) 255.Java.

psammogaea, Steud. Syn. P1. Cyp. $187=$ incurva.

psammophila, Schur, Enum. Pl. Transs. $700=$ brizoides.

pseudo-arenaria, Pers. Syn. ii. 536=disticha.

pseudo-arenaria, Reichb. Ic. F1. Germ, viii. 8. t. $208=$ arenaria.

pseudo-brizoides, Chavaud, in Bull. Soc. Pharm. Bord. xiii. (1873) 156.-Gallia.

pseudo-Buxbrumii, Winkler, in Oestr. Bot. Zeitschr. xviii. (1868) 72.-Europ.

pseudo-conica, Franch. ES Sav. Enum. Pl. Fap. ii. 570 - Japon.

pseudo-curaica, F. Schmidt, Reisen Amurl. 67.-Reg.

Amur.

Pseudo.cyperus, R. Br. Prod. $243=$ fascicularis,

Pseudo-cyperus, Linn. Sp. Pl. 978.-Keg. temp. bor. et austr.

pseudo-flava, Schur, Enum. Pl. Transs. 712.Transsyly.

pseudo-loliacen, F. Schmidt, Reisen Amurl. 193.-Ins. Sachalin.

pseudo-nutans, Bor. ex Martin, Cat. Romor. 309.Gallia.

pseuda-paradoxa, S. Gibson, in Phytol. i. (1844) $778=$

teretiuscula.

pseudo-praecox, Schur, Enum. Pl. Transs. 716 - praecox.

\section{CAREX}

psilostachya, Kit. ex Willd. Sp. Pl. iv. $289=$ sylvatica, psilostachys, Steud. Syn. Pl. Cyp. 215.-Chili

psychrophila, Nees, in Wight, Contrib. 127.-Reg. Himal.

psyllophora, Hartm. ex Reichb. F1. Germ. Excurs. 61 = pauciflora.

psyllophora, Linn. f. Suppl. $413=$ pulicaris.

pteroloma, Kunze, ex. Steud. Syn. Pl. Cyp. $242=$ gibba.

pterygocarpa, Steud. l. c. 222.-Chili.

ptychocarpa, Link, in Sichrad. Journ. ii. (1799) $309=$ alpestris

ptychocarpa, Steud. Syn. Pl. Cyp.234.Am. bor.

puberula, Boott, in Perry, Jap. Exp. ii. 324

breviculmis.

pubescens, Gilib. Exercit. ii. $547=$ montana,

pubescens, Muhl. ex Schkuhr, Riedgr. ii. 60. t. Eee. fig. 126. - Am. bor

pubescens, Poir. Voy. Barb. ii. $254=$ Furrena pubescens.

pulchella, Bergg. in Minneskr. Fisiog. Sallks. Lund

(1877) n. VIII. $29 .-\mathrm{N}$. Zel.

pulchella, Nyland. ex Trevir, in Bull. Soc. Nat. Mosc. xxxvi. (1863) I. $537=$ gracilis.

pulchra, Boott, Illustr. Carex, i. 4.-Reg. Himal.

pulicarioides, Ramond, ex DC. F1. Fr. iii. $101=$ pyrenaica.

pulicaris, All. ex Boott, Illustr. Carex, iv. $174=$ microglochin.

pulicaris, Linn. Sp. Pl. 972.-Europ.; As. bor

pulicaris, Linn. f. ex Boott, Illustr. Carex, iv. $196=$ pauciflora.

pulla, Good. in Trans. Linn. Soc. iii. (1797) 78. t. $14=$ saxatilis.

pulla, Soland, ex Boott, Illustr. Carex, i. $64=1$ lucida pullulans, Dulac, Fl. Hautes-Pyr. $57=$ Oederi.

pumila, Honck. Syn. Pl. Germ i. $373=$ montana?

pumila, Thunb. Fl. Fap. 39.-China; Japon; Reg. austr, temp.

punctata, Gaud. Agrost. Helv. ii. 152.-Europ.; Afi, bor.

punctata, Nees, ex Wight, Contrib. $127=$ notha.

punctulata, Leers, Fl. Herborn. 713. t. 14. f. $4=$ paniculata.

punctulata, Lesson, ex A. Rich. Voy. Astrol. Bot. 119

t. $21=\mathrm{C}$. Pseudo-cyperus.

pungens, Boeck. in Linnaea, xxxix. (1875) 46.-Chili.

Purdiei, Boott, Illustr. Carex, i. $26=$ Bonplandii.

purpurea, Boott, l. c. iv. 157. t. 514.-Hab.?

purpureovaginata, Boeck. in Kjoeb. Vidensk. Meddel. (1879-80) 30.-Bras.

pusilla, Pers. Syn. ii. $536=$ bicolor.

pycnostachya, Desv. in C. Gay, Fl. Chil. vi. 204.Chili.

pycnostachya, Kar. \& Kir. in Bull. Soc. Nat. Mosc. xv. 1842) $522=\mathrm{C}$. Curaica.

pygmaea, Boeck. in Linnaea, xl. (1876) $379 .-\mathrm{N}$. Granat.

pyrenaica, F. Muell. Fragm. viii. $251=$ acicularis.

pyrenaica, Wahlenb. in Vet. Akad. Nya Handl. Stockh.

(1803) 139.-Europ.; Reg. Caucas。; Am.bor.; N. Zel. pyriformis, F. Schultz, in Pollichia, xv. (1855) $122=$

pyriformis, Tausch, in Schultz, Arch. Fl. i.. $285=$ flava.

quadrangulata, Colenso, in Trans. N. Z. Inst. xvii. (1885) 254, -N. Zel.

quaternaria, Spreng. Syst. iii. $809=$ loliacea

quinata, Raeusch. Nom. ed. III. $270=$ caespitosa?

radicalis, Boott, Illustr. Carex, i. 56.-Reg. Himal.

Raeana, Boott, in Richardson, Arctic Exp. ii. 344.Am. bor.

Rafflesiana, Boott, in Proc. Linn. Soc. i. (1845) 285. Java.

Ramondiana, DC. Fl. Fr. iii. $101=$ pyrenaica.

ramosa, Eckl. ex Kunth, Enum. PI. ii. $531=$ Schoenoxiphium Sickmannianum.

ramosa, Schkuhr, Riedgr. ii. 40.-Ind. or.; China.

Rasulii, Boott, in Hook. f. Fl. N. Zeal. 28s.-N. Zel.

raphidocarpa, Nees, ex Wight, Contrib. 122.-Ind. or.

rara, Boott, in Trans. Linn. Soc. xx. (1st6) 19y.Zeylan.

rariflora, Sm. Engl. Fl. iv, 100.-Reg, bor. et arct.

laynoldsii, Dewey, in Am. Fourn. Sc. Ser. II. xxii. (1861) 39.-Am. bor.

reclinata. Facch, in Ambr. Fir. Mer. i. (1854) $333,82 \mathrm{~S}$ $=$ ornithopoda.

recto, Boott, in Hook. Fl. Bor. Am, ii. 220 -salina.
CAREX

recurva, Huds. FI. Angl, ed. II, $413=$ glauca. recurva, Mubl. Desc. Gram. Uber, n. $55=$ cherokensis.

recurva, Schkuhr, Riedgr. i. $120=$ C. Pseudo-cyperus. recurva, Willd. ex Kunth, Enum. PI. ii. $413=$ acuta.

ecurvirostra, Hall, f. ex Stend. Nom. ed. I. $156=$ Davalliana.

recurvirostra, Kunze, in Schkuhr, Riedgr. Suppl. 79 2. 20.-Java.

Redowskiana, C. A. Mey. in Mém. Sav. Etr. Pétersb. i (1831) 207.t. 4 = chordorrbiza.

reducta, Drej. Revis. Caric. $36=$ salina.

reflexa, Dietr. ex Kunth, Enum. Pl。 ii. $384=$ glomerata

reflexa, Gaud. Etrennes Fl. $53=$ Davalliana.

reflexa, Hoppe, Caric. $65=$ praecox.

refracta, Roth, Tent. Fl. Germ. ii. II. $451=$ praecox

refracta, Schkuhr, Riedgr. ii. 62.-Mons Cenis.

Reinii, Franch. E Sav. Enum. Pl. Fap. ii. 55\%.-

Japon.

remota, Linn. Cent. Pl. i. 31.-Reg. bor, temp. et arcr. remota, Richards. in Frankl. Narr. 1st Journ. $750=$ Deweyana.

remota, Thunb. F1. Jap. $37=$ gibba.

remotiuscula, Wahlenb. in Vet. Akad. Nya Handl Stockh. (1803) $147=$ cristata.

Renschiana, Boeck, in Engl. Bot. Fahrb. v. (1884) 515 - Madag.

Remyi, Boeck. in Flora, Iviii. (1875) 264=brunnea.

repens, Bell. App. Fl. Pedem. 42,-Italia.

repens, Schleich. ex Kunth, Enum. Pl. ii. $376=$ disticha.

reticulosa, Peterm. in Flora, xxvii. (1844) 333.Saxonia.

retrocurva, Dewey, in Am. Journ. Sc. Ser. II. xlii. (1866) $243=$ laxiculmis

retroflexa, Muhl. ex Schkuhr, Riedgr. ii. $11=$ rosea

retrorsa, Nees, in Linnaea, x. (1835-36) $204=$ cognata.

retrorsa, Schwein. in Ann. Lyc. N. York, i. (1824) 71 -Am. bor.

retusa, Degl, in Loisel. F1. Gall. 307 . t. $30=$ echinata. Retsii, Nees, in Wight, Contrib. $128=$ chinensis.

Reuteriana, Boiss, \& Reut. in Fl. Orient. v. 411

Huetiana.

Reuteriana, Boiss. Pugill. Pl. Nov. 116.-Hispan.

reversa, Gilib. Exercit. ii. $549=$ C. Pseado-cyperus.

reversa, Spreng. Syst. iii. $827=$ retrorsa.

rhaphidocarpa, Kunth, Enum. Pl. ii. $512=$ raphido carpa.

whizantha, J, F. Gmel. Syst, $144=$ alpestris,

rhigodes, Blytt, ex Boott, Illustr. Carex, iv, $196=$ pediformis.

rhisomatose, Steud. Syn. Pl. Cyp. $206=$ Cumingiana

rhynchocarpa, Heuf. in Flora, xvi. (1833) $\$ 65=$ brevicollis.

rhynchophysa, Fisch. Mey. E Avé-Lall. Ind. Sem. Hort. Petrop. ix. Suppl. 9.-Europ. et As. bor.

rhynchophyse, Liebm. in Vidensk, Selsk. Skr. V. ii. (1851) $264=$ physorhyncha.

rhynchosporoides, Steud. Syn. Pl. Cyp. 195.-Ins. Borbon.

Richardi, Michx. Fl. Bor. Am. ii. $170=$ tribuloides.

Richardi, Thuill. Fl. Par, i. $t \delta 2=$ canescens.

Richardsonii, R. Br. in Richards. in Frankl. Narr. 1st Fourn. 751, 35.-Am, aret.

rigens, L. Bailey, in Coult. Bot. Gas. ix. (1851) 11\%.Am. bor.

rigens, Boott, in Mem. Am. Acad. N. S. vi. 1 1s58-59

$419=$ Brownii.

rigens, Thuill. Fl. Par. i. $488=$ paludusa, stricta.

rigida, Clairv. ex Sicud. Num. ed. II. i. $295=$ caespitosa.

rigida, Good. in Trans. Lino. Soc. ii. (1794 193. t. 22 = vulgaris.

rigida, Schrank, Brier. Fl, i. $290=$ firma

rigida, Tuckerm, Lnum, Caric. 11 =stylosa.

rigidifolia, Hochst. ex Scub. Fl. Azor. 21 = punctata.

Kinggoldiana, Boot, in Mrm. Am. Acad. N. S. vi (1s5y-59:419.-Japon.

ripasia, Curt. F\%. Lond. Fase, iv. t. 60.-Reg. bor. eq

riparia, Geners. Elench. n. $\$ 7 t=$ paludusa

riparia, Muench, ex Sicud. Nom. ed. II. i 295 acuta.

riparia, Muhl. Mesc Ciram. Uher. 259 - Iacustris

riparia, Poir. Lincyc Suppl. iii. $282=$ Locinia riparia 


\section{CAREX:-}

rivalis, Willk. \& Lange, Prod. F1. Hisp. i. $130=$ divisa.

rivularis, Koch, ex Kunth, Enum. Pl. ii. $487=$ paludosa.

rivularis, Schkuhr, Riedgr. i. $30=$ divisa.

robusta, F. Nyland, Spicil. Fenn. sub n. $33=$ rhynchophysa.

Rochebruni, Franch. E Sav. Enum. Pl. Fap. ii. 555. -Japon.

Roemeriana, Scheele, in Linnaea, xxii. (1849) 346.Texas.

Romanzowiana, Cham. ex Steud. Syn. Pl. Cyp. 216.Alaska.

rosea, Schkuhr, Riedgr. ii. 15.-Am. bor.

Rossii, Boott, in Hook. Fl. Bor. Am. ii. 222.-Am. bor. occ.

rostellata, Gay, ex Boott, Illustr. Carex, i. $8=$ notha. rostrata, Hoppe, ex Schkuhr, Riedgr, i, $99=$ Michelii. rostrata, Michx. F1. Bor. Am. ii. $173=$ Michauxiana. rostrata, Muhl. ex.Schkuhr, 1. c. ii. $54=$ tentaculata. rostrata, Stokes, in With. Bot. Arr. Brit. Pl. ed. II. ii $1059=$ ampullacea.

Rotae, De Not. Ind. Sem. Hort. Gen. (1848) $24=$ paniculata.

rotundata, Wahlenb. in Vet. Akad. Nya Handl. Stockh. (1803) 153.-Lappon.

Royleana, Nees, in Wight, Contrib. $127=$ breviculmis

rubella, Boott, Illustr. Carex, iv. 176.-Zeylan.

rubescens, Boeck. in Flora, lxv. (1882) 60.-Japon.

rudis, Wimm, in Flora, xxxiii. (1850) 619.-Silesia.

rufa, Lam. Fl. Fr. ii. $184=$ paludosa.

rufa, Schrank, Baier. F1, i. $305=$ paludosa.

rufidula, Steud. Syn. Pl. Cyp. 220.-Am. bor.

rufina, Drej. Revis. Crit. Car. 28.-Norveg.

Rugeliana, Kunze, in Linnaea, xx. (1847) $8=$ juncea.

Ruiziana, Boeck. in Linnaea, xxxix. (1875) 30.Peruv.

rupestris, All. Fl. Pedem. ii. 264. t. 92. f. 1.Europ.

rupestris, Turcz. ex Ledeb. Fl. Ross. iv. $267=$ argunensis.

Rutenbergiana, Boeck. in Bremen Abh. vii. (1880) 40. -Abyssin.

sabuletorum, Bieb. ex Boott, Illustr. Carex, iv. $178=$ arenaria.

sabulosa, Turcz. ex Kunth, Enum, Pl. ii. 432.-Sibir.

baical.

sabynensis, Less. ex Kunth, 1. c. $440=$ praecox.

sachalinensis, F. Schmidt, Reisen Amurl. 194.-Ins. Sachalin.

Sachapata, Steud. in Lechl. Berb. Am. Austr. 56.Peruv.

sagittifera, Lowe, in Camb. Phil. Soc. Trans. vi. (1838) $531=$ macrostyla.

salina, Boott, in Hook. Fl. Bor. Am. $219=$ cryptocarpa.

salina, Bongard, ex Ledeb. F1. Ross. iv. $281=$ canescens.

salina, Wahlenb. in Vet. Akad. Nya Handl. Stockh. (1808) 165.--Norveg.

salinoides, Beurl. in Bot. Notiser, (1853) $35=$ salina.

Salisiana $\times$, Bruegg. in Jahresb. Nat. Ges. Graub. II. xxiii-xxiv. (1880) 120._Europ.

Sampsoni, Hance, in Fourn. Bot. vi. (1868) 89.China.

sandwicensis, Boeck. in Flora, lviii. (1875) 265.Ins. Pacif.

sanguinea, Boott, in Trans. Linn. Soc. xx. (1846) 137. -Afghanist.

sarda, Link, Hort. Berol. ii. $328=$ Linkii.

Sartwelliana, Dewey, in Am. Journ. Se. xliii. (1842) $90=$ disticha.

Sartwelliana, Olney, in Proc. Am. Acad. vii. (1868) 396.-Calif.

Sartwellii, Dewey, ex J. Carey, in A. Gray, Man. Bot. U. St. ed. I. $539=$ Sartwelliana.

saskatschawana, Boeck. in Linnaea, xli. (1877) 159.Am. bor.

satsumensis, Franch. E Sav. Enum. Pl. Fap. ii. 558. -Japon.

saxatilis, Huds. Fl. Angl. $408=$ praecox.

saxatilis, Linn. Sp. Pl.976.-Europ.

saxatilis, Matusch. ex Kunth, Enum. Pl. ii. $450=$ fulva. saxatilis, Oed. in F1. Dan. t. $\mathbf{1 5 9}=$ vulgaris.

saxatilis, Scop. Fl. Carn. ed. II. ii. $221=$ atrata

saxatilis, Suter, ex Boott, Illustr. Carex, iv. $218=$ sempervirens.

\section{CAREX :-}

scaberrima, Scheele, in Linnaea, xxii. (1849) 345.Texas.

scabra, Hoppe, Taschenb. (1800) $242=$ Davalliana scabrata, Schwein. in Ann. Lyc. N. York, i. (1824) 69. -Am. bor.

scabrella, Wahlenb. in Vet. Akad. Nya Handl. Stockh. (1803) 149.-Ind. occ

scabrifolia, Steud. Syn. Pl. Cyp. 237.--Java.

scabrior, Sartwell, ex Boott, Illustr. Carex, iii. $125=$ vulpinoidea.

scariosa, Lam. Encye. iii. $388=$ humilis.

Schaffneri, Boeck. in Flora, lxi. (1878) 39.-Mexic.

Schaffneri, W. Boott, ex S. Wats. in Proc. Am. Acad. xviii. $(1882-83) 172=$ potosina.

schedonautos, Steud. Syn. Pl. Cyp. 189--Reg. Magell.

Scheuchzeri, Gaud. ex Boott, Illustr. Carex, iv. $204=$ tenuis.

Scheuchseri, J. F. Gmel. Syst. $144=$ paludosa?

Schiedeana, Kunze, in Schkuhr, Riedgr. Suppl. 119 t. 30 .-Mexic.

Schimperiana, Boeck. in Linnaea, xl. (1876) 373.Abyssin.

Schkuhrii, Willd. Sp. P1. iv. $264=$ obesa.

Schmidtii, Boeck. in Flora, Ixv. (1882) 63.-Ins. Sachalin.

Schmidtii, Meinshaus. Nachr. Wilni-Geb. 224.Manchuria.

schoenoides, DC. F1. Fr. iii. 104=intermedia

schoenoides, Desf. Fl. Atlant. ii. $336=$ divisa.

schoenoides, Schrank, Baier. Fl. i. 274.-Europ.

schoenoides, Thuill. Fl. Par. 480.-Gallia.

Schottii, Boiss. Diagn. Ser. II. iv. $123=$ sempervirens.

Schottii, Dewey, ex Torr. Bot. Mex. Bound. 231.Calif

Schraderi, Schkuhr, Riedgr. ii. $81=$ laevigata.

Schreberi, Desv. Fl. Auv. 73 (Scherberi)=arenaria

Schreberi, Schrank, Baier. Fl. i. 278.-Europ.; As. bor.

Schreberi, Tenore, ex Boott, Illustr. Carex, iv. 186= divisa.

Schreberi, Willd. in Mém. Acad. Berl. 1794 (1797) 38 $=$ praecox.

Schrenkiana, C. A. Mey. ex Ledeb. F1. Ross. iv. $317=$ vesicaria.

Schummelii, Siegert, in Verh. Bot. Brandenb. (1860) 112.-Europ.

Schweinitzii, Dewey, in Am. Fourn. Sc. ix. (1825) 68 -Am. bor.

scirpina, Tuckerm. ex Boott, Illustr. Carex, iv. $150=$ scirpoidea.

scirpoidea, Michx. Fl. Bor. Am. ii. 171.-Am. bor.

scirpoides, Schkuhr, Riedgr. ii. $19=$ echinata.

scitula, Boott, Illustr. Carex, iv. 177.-Reg. Himal.

scoparia, Schkuhr, Riedgr. ii. 20.-Am. bor.

scoparia, Torr. in Ann. Lyc. N. York, iii. (1836) $394=$ arida.

Scopoliana, Willd. Sp. Pl. iv. $292=$ ferruginea.

Scopolii, Gaud. Agrost. Helv. ii. $168=$ ferruginea

scotica, Spreng. Syst. iii. $819=$ vaginata.

Scouleri, Torr. in Ann. Lyc. N. York, iii. (1836) $398=$ cryptocarpa.

secale, Ledeb. Fl. Ross. iv. $300=$ hordeistichos

secalina, Lapeyr. Hist. Abr. P1. Pyr. ii. $576=$ riparia.

secalina, Wahlenb. in Vet. Akad. Nya Handl. Stockh.

(1803) $151=$ hordeistichos.

secta, Boott, in Hook. f. Fl. N. Zel. i. 281.-N. Zel.

seditiosa, Steud. in Lechl. Berb. Am. Austr. 56. Peruv.

Sellowiana, Schlecht. in Linnaea, x. (1836) 117.Bras.

semicylindrica, Kit. l. c. xxxii. (1863) 319.-Hungar. sempervirens, Ell. ex Kunth, Enum. Pl. ii. $460=$ commutata?

sempervirens, Schwein. in Ann. Lyc. N. York, i. (1824) $70=$ glaucescens

sempervirens, Vill. Hist. Pl. Dauph. ii. 214.-Europ. Sendtneriana x, Bruegr in Jahresb. Nat. Ges. Graub.

II. xxiii-xxiv. (1880) 119.-Europ.

senta, Boott, Illustr. Carex, iv. 174, in nota.-Calif.

serotina, Tenore, F1. Nap. iv. $133=$ muricata

serratodens, S. Wats. Bot. Calif. ii. 245.-Calif.

serrulata, Bivona, ex Spreng. Syst. iii. $827=$ glauca

serrulata, Mutel, FI. Fr. $395=$ echinata.

setacea, Dewey, in Am. Journ. Sc. ix. (1825) 61. t. B f. $5=$ vulpinoidea.

setacea, Frank, ex Kunth, Enum. Pl. ii. $382=$ stipata.
CARFX:-

setacea, Froel. ex Kunth, Enum. P1. ii. $409=$ mucronata.

setariaeformis, Turcz. ex Boott, Illustr. Carex, iv, 189 =leiorhyncha.

seticulmis, Boeck. in Kjoeb. Vidensk. Meddel. (1869) 156.-Bras.

setifolia, Godr. in Mém. Soc. Emul. Doubs, Sér. II. v. (1854) $14=$ divisa

setifolia, Kunze, Syn. Pl. Am. Austr. 26.-Chili.

setigera, D. Don, Prod. Fl. Nep. 43.-Reg. Himal.

setosa, Boott, Illustr. Carex, iii. 108-Reg. Himal

setosa, Franch. \& Sav. Enum. P1. Jap. $142=$ homoio lepis.

sexspicata, Colenso, in Trans. N.Z. Inst. xvi. (1884) 342.-N. Zel.

Shortiana, Dewey ह Torr. in Am. Fourn. Sc. xxx. (1836) 60.-Calif.

Shortii, Steud. Syn. Pl. Cyp. $202=$ stenolepis.

Shortii, Torr. in Ann. Lyc. N. York, iii. (1836) 407 = Shortiana.

sibirica, Willd, ex Kunth, Enum. Pl. ii. $406=$ loliacea. sicaeformis, Boott, in Bost. Fourn. Nat. Hist. v. (1845) 113.-Am, bor.

siccata, Dewey, in Am. Fourn. Sc. x. (1826) 27.-Am. bor.; As. bor. or.

sicula, Presl, ex Boott, Illustr. Carex, iv. $185=$ distans.

sicula, Tineo, Pl. Rar. Sicil. 30.-Sicilia.

sicyocarpa, Lebel, Obs, Pl. Manche (1848) $18=$ praecox.

siderosticha, Hance, in Fourn. Linn. Soc. xiii. (1873) 89.-China.

Sieberi, Nees, ex Kunth, Enum. Pl. ii. $118=$ Mariscus flavus.

Sieberiana, Opiz, Natural. xi. (1826) $413=$ Davalliana.

Sieboldi, Miq. Ann. Mus. Bot. Lugd. Bat. ii. 150.Japon.

Siegertiana, Uechtritz, ex Garcke, Fl. Deutschl. ed. VIII. $435=$ hirta.

sikokiana, Franch. E' Sav. Enum. Pl. Fap. ii. 573.Japon.

silicea, Olney, in Proc. Am. Acad. vii. (1878) 393.Am. bor.

simensis, Hochst, ex A. Rich. Tent. Fl. Abyss. ii. $514=$ aethiopica.

similis, Urv. in Mém. Soc. Linn. Par. iv. (1826) $599=$ curta.

simplicissima, F. Muell. Fragm. ix. 191=capillacea

simpliciuscula, Wahlenb. in Vet. Akad. Nya Handl. Stockh. (1803) 141 (Quid ?).-Anglia.

Sinai, Boott, in Trans. Linn. Soc. xx. (1851) 146.Arab.

sinaica, Nees, ex Steud. Syn. Pl. Cyp. $223=$ distans sinensis, J. F. Gmel. Syst. $144=$ chinensis

sitchensis, Presc. ex Bong. Veg. Sitcha, 51.-Alaska Am. bor. occ.

Smithii, Tausch, in Flora, iv. (1821) $559=$ vaginata. socia, Boott, in Proc. Linn. Soc. i. (1845) 254= Arnottiana.

sociata, Boott, in Mem. Am. Acad. N. S. vi. (1858-59) 420.-China.

Solandri, Boott, in Hoo㞼 f. Fl. N. Zel. 284.-N Zel

Soleirolii, DC. \& Duby, Bot. Gall. ii. $498=$ echinata. songorica, Kar. E Kir. in Bull. Soc. Nat. Mosc. xy. (1842) 525.-Afghanist.; Soongar.

sordida, Heurck \& Muell. Arg. in Heurck, Obs. Bot. 33.-Kamtschatka.

sororia, Kunth, Enum. Pl. ii. 379.-Reg. Argent.

sororia, Meinsh. Fl. Ingr. $404=$ aperta

Spachiana, Boott, Illustr. Carex, i. 43.-China.

spadicea, Gilib. Exercit. ii. $546=$ arenaria.

spadicea, J. F. Gmel. Syst. $144=$ firma.

spadicea, Host, Gram. iv. 51. t. 91 ; DC. Fl. Fr. ii $120=$ ferruginea

spadicea, Roth, Tent. F1. Germ. ii. II. $461=$ paludosa spadicea, Schkuhr, Riedgr. i. $90=$ frigida.

spaniocarpa, Steud. Syn. P1. Cyp. $225=$ obesa.

sparganioides, Le Conte, ex Kunth, Enum. Pl. ii. $382=$ stipata.

sparganioides, Muhl. ex Schkuhr, Riedgr. ii. 14.-Am. bor.

sparsiflora, Steud. Nom. ed. II. i. $296=$ vaginata.

spartea, Wahlenb. in Vet. Akad. Nya Handl. Stockh. (1803) $149=$ Uncinia spartea. spatiosa, Boott, Illustr. Carex, ii.86.-Cochinch. 
CAREX :

speciosa, Kunth, Enum. Pl. ii. 504,-Ind, or spectabilis, Dewey, in Am. Journ. Sc. xxix. (1836) 248. t. X. f. $76=$ podocarpa.

speirostachya, Sw. ex Sm. Engl. Fl. iv. 98=fulva. sphaerica, Lapeyr. Hist. Abr. Pl. Pyr. 570.-Mont. Pyren.

sphaerocarpa, Ehrh. Beitr. vi. $83=$ tomentosa. sphaerocarpa, Willd. Sp. Pl. iv. $265=$ obesa.

sphaerogyne, Baker, in fourn. Bot. xxi. (1883) 129.Madag.

sphaerostachya, Dewey, in Am. Fourn. Sc. xlix. (1845)

44. t. Ee. f. 110.-Am. bor.

spicata, Brot. ex Kunth, Enum. P1. ii. $373=$ divisa

spicata, Huds. Fl. Angl. ed. I. $353=$ muricata.

spicata, Lam. Encyc. iii. 381; Pollich, Palat. ii. 562 = disticha.

spicata, Schkuhr, Riedgr. i. $11=$ obtusata

spicata, Thuill. Fl. Par. $480=$ vulpina.

spicigera, Nees, in Wight, Contrib. 121.-Zeylan.

spiculata, Boott, in Trans. Linn. Soc. xx. (1851) 139. -Reg. Himal.

spiculosa, F. Nyland. Spicil. Pl. Fenn. ii. n. $49=$ salina.

spilocarpa, Steud. Syn. Pl. Cyp. 195.-Mexic

spinirostris, Colenso, in Trans. N. Z. Inst. xv. (1883)

$335 .-\mathrm{N}$. Zel.

splendens, Thuill. ex Pers. Syn. iii. $536=$ divisa.

splendida, Willd. Prod. Fl. Berl. $33=$ filiformis.

Sprengelii, Boeck. in Linnaea, xl. (1876) 371.-Afr. austr.

Sprengelii, Dewey, ex Spreng. Syst. iii. $837=$

longirostris.

spreta, Steud. Syn. Pl. Cyp. $212=$ caespitosa.

squarrosa, Linn. Sp. Pl. 973.-Am. bor.

stans, Drej. Revis. Caric. $40=$ aquatilis.

Steenstrupii, Liebm. in Forhand. Scand. Naturf. (1840) 321. - Islandia.

stellulata, Bieb. Fl. Taur. Cauc, ii. $383=$ muricata.

stellulata, Good, in 'Trans. Linn. Soc, ii. (1794) $144=$ echinata.

stenantha, Franch. E Sav. Enum. Pl. Fap. ii. 573.Japon.

stenocarpa, Turcz. ex Steud. Nom, ed, II. i. $296=$ frigida.

stenolepis, Less. ex Steud. l. c.-Norveg.

stenolepis, Torr. in Am. Fourn. Sc. xxx. (1836) 59.Am. bor.

stenophylla, Thien. ex Boott, Illustr. Carex, iv, $210=$ incurva.

stenophylla, Wahlenb. in Vet. Akad. Nya Handl.

Stockh. (1803) 142.-Reg. bor. temp.

stenostachys, Franch. E' Sav. Enum. Pl. Fap. ii. 569. -Japon.

sterilis, Schkuhr, Riedgr. ii. 3.-Am. bor.

Sterdelii, Kunth, Enum. Pl. ii. $480=$ Jamesii.

Steudneri, Boeck. in Linnaea, xl. (1876) 364.Abyssin.

stictocarpa, Sm. Engl. Bot. t. $2772=$ glauca.

stipata, Muhl. ex Schkuhr, Riedgr. ii. 12.-Am. bor.

stipitata, Boeck. in Linnaea, xxxix. (1875) $85=$ stipata.

stolonifera, Ehrh. Beitr. vi. $83=$ praecox.

stolonifera, Hoppe, Ic. n. 41 = vulgaris.

straminea, Willd. ex Schkuhr, Riedgr. i. 49.-Am. bor.

striata, R. Br. Prod. $243=$ lacistoma.

striata, Gilib. Exercit. ii. $550=$ riparia.

striata, Michx. Fl. Bor. Am. ii. 174.-Am. bor.

striata, Torr. ex Boott, Illustr. Carex, i. $22=$ poly. morpha.

striatula, Michx. F1. Bor. Am. ii. $179=$ laxiflora.

stricta, Good. in Trans. Linn. Soc. ii. (1794) 196. t. 21. f. 9.-Europ.; Am. bor.

stricta, Lam. Encyc. iii. $387=$ angustata.

strictifolia, Opiz, ex Nym. Consp. $777=$ acuta.

strictior, Dewey, ex Wood, Cl. Book. $755=$ stricta.

strigosa, All. F1. Pedem. ii. $270=$ tenuis.

strigosa, Huds. Fl. Angl. 411.-Europ.; Reg. Cancas.

strigosa, Suter, ex Boott, Illustr. Carex, iv. $208=$

firma.

strigosa, Willd. ex Kunth, Enum, Pl. ii. $470=$ sylvatica.

stygia, Fries, Mant. iii. $141=$ rariflora.

stylofexa, Buckl. in Am. Journ. Sc. xlv. (1843) $174=$

laxiflora.

stylosa, C. A. Mey. in Mém. Sav. Etr. Petersb. i. (1881) 222. t. 12.-Unalaschka.

subanceps, Boeck. in Engl. Bot. Fahrb. v. (1884) 520. -Japon.

\section{CAREX:-}

subbiflora, Steud. Syn. Pl. Cyp. 234.-Am. bor. subcompressa, Steud. l. c. 221.-Am, bor

subdola, Boott, in Proc. Linn. Soc. i. (1845) 255.N. Zel

suberea, Boott, Illustr. Carex, iv, $165=$ Pierotii,

subfusca, S. Wats. in Bot. Calif. ii. 234.-Calif.

subglobosa, Mielich. in Flora, xxii. (1839) $256=$ Oederi.

sublivida, Norrl. in Notis. Saellsk. Fauna et Fl.

Fenn. II. Haeft x. 51.-Europ. bor.

subramosa, Willd. ex Kunth, Enum. Pl. ii. $385=$ echinata.

subrotunda, Serres, in Bull. Soc. Bot. Fr. iv. (1857)

440.-Gallia.

subsalsa, Nym. Syll. Suppl. $69=$ fulva.

subspathacea, Wormsk. in Fl. Dan. ix. 4. t. $1590=$ salina.

subulata, J. F. Gmel. Syst. $138=$ Scleria subulata.

subulata, Michx Fl Bor. Am ii 173-Am bor.

subulata, Schum. ex Steud. Nom. ed. II. i. 296

Buxbaumii.

subulata, Wahlenb. in Vet. Akad. Nya Handl, Stockh. (1803) $152=$ Boryana.

subuniflora, Steud. Syn. Pl. Cyp. 234.-Am. bor subvillosa, Bieb. Fl. Taur. Cauc. ii. $386=$ tomentosa. sudetica, Opiz, Natural. xi. (1826) $413=$ atrata.

sudetica, Presl, ex Kunth, Enum. Pl. ii. $451=$ vaginata.

suilla, J. Fellm. in Bull. Soc. Nat. Mosc. viii. (1835) $285=$ pulla?

sulcata, Schur, in Verh. Siebenb. Ver. Naturz. iv. (1853) 80.-Transsyly.

Sullivantii x, Boott, in Am. Journ. Sc. xlii. (1842) 29 -Am. bor.

supina, Wahlenb. in Akad. Vet. Nya Handl. Stockh. (1803) 158.-Reg. bor. temp.

Suteri, Kunth, Enum. Pl. ii. 523.-Europ.

sychnocephala, Carey, in Am. Fourn. Sc. Ser. II. x. (1847) 24.-Am. bor.

sylvatica, Dewey, 1. c. Ser. I. x. (1826) $40=$ arctata.

sylvatica, Huds. Fl. Angl. ed. I. 353.-Europ.; As. temp.

sylvatica, Maxim. ex Boeck. in Linnaea, xli. (1877)

238 = Maximowiczii.

tabina, Steud. in Lechl. Berb. Am. Austr. 56.-Am. austr.

tabularia, M. A. Curt. ex Boott, Illustr. Carex, i. $54=$ aestivalis.

tartarea, Ridl. in Fourn. Bot. xxi. (1883) 262.Sumatra.

tauricola, Boiss. F1. Orient. $\nabla .415=$ atrata.

teinogyna, Boott, Illustr. Carex, i. 60.-Reg. Himal.

tenebrosa, Boott, l. c. 88. t. 256.-China.

tenax, Bergg. in Minneskr. Fisiog. Sallks. Lund (1877), n. VIII. p. 27.-N. Zel.

tenax, Chapm. ex Dewey, in Am. Fourn. Sc. Ser. II. xix. (1855) 254-Am, bor.

tenax, Reut. in Comptes-Rend. Soc. Hallér. (1854-56) 130.-Europ

tenella, Ehrh. Beitr. vi. $83=$ canescens.

tenella, Froel. ex Kunth, Enum. Pl. ii. $445=$ supina.

tenella, Poir. Encyc. Suppl, iii. $282=$ Uncinia tenella

tenella, Schkuhr, Riedgr.i. 23.-Am. bor.

tenella, Thuill. Fl. Par. i. $429=$ praecox

tenera, Dewey, in Am. Journ. Sc. viii. (1824) $97=$ straminea.

Tenorii, Kunth, Enum. Pl. ii. $437=$ macrolepis.

tentaculata, Muhl. ex Willd. Sp. Pl. iv. 266.-Am. bor.

tenuiflora, Hartm, ex Kunth, Enum. P1. ii. $405=$ loliacea.

tenviflora, Wahlenb. in Vet. Acad. Nya Handl. Stockh. (1803) 147.-Europ.; Am. bor.

tenuifolia, Poir. Voy. Barb. ii. $254=$ Scirpus pubescens tenuirostris, Olney, in Am. Natural. viii. (1874) 214 -Am. bor.

tenuis, Gmel. ex Steud. Nom. ed. II. i. 296 = Scleria tenuis

tenuis, Host, Gram. Austr. iv. 51. t. 92.-Europ. austr.

tenuis, Nees, in Wight, Contrib. 128 - hirtella.

tenuis, Rudge, in Trans. Linn. Soc vii. (1804) 97. t. 9 . f. $2=$ debilis

tenuis, Schleich. ex Steud. Nom. ed. II. i. $296^{\circ}=$ leporina.

tenuispica, Boeck, in Flora, xxix. (1856) 225 tristicha, Boeck.

\section{CAREX:}

tenuispica, Steud. Syn, Pl. Cyp. 319.-Ins. Borbon. tenuissima Boott in Proc Linn Soc i. (1845) 288 Japon.

teres, Boott, Illustr. Carex, i. 62.-Reg. Himal.

tereticaulis, F. Muell. Fragm. viii. 256.-Austral

teretiuscula, Good. in Trans. Linn. Soc. ii. (1794)

163.-Europ.; Am. bor.

teretiuscula, Willd, ex Kunth, Enum. Pl. ii. $389=$ paniculata.

teretiuscula, Willk, in Bot. Zeit. vi. (1848) $414=$ chordorrhiza.

tergestina, Hoppe, ex Boott, Illustr. Carex, iv. $193=$ muricata.

ternaria, Forst. f. Prod. 92.-N. Zel

testacea, Soland ex Boott, in Hook. f. Fl. N. Zel. 282.-N. Zel.

tetanica, Reichb. Fl. Germ. Excurs, $83=$ vaginata

tetanica, Schkuhr, Riedgr. ii. 68.-Groenl,; Am. bor.

tetanica, Schwein. \& Torr. in Ans. Lyc. N. York, i, (1824) $347=$ conoidea.

tetrastachya, Scheele, in Linnaea, xxii. (1849) $347=$ straminea.

tetrastachya, Traunst. in Flora, xxxiii. (1850) 366.Europ.

Textori, Miq. Ann. Mus. Bot. Lugd. Bat. ii. $151=$ incisa.

thecata, Boott, in Trans. Linn. Soc. xx. (1851) $143=$

Preissii.

thermarum, Phil. in Anal. Univ. Chil. xxi. (1862) II 385.-Chili.

Thomsonii, Boott, Illustr. Carex, i. 1.-Reg. Himal

Thouarsii, Carmich, in Trans, Linn. Soc. xii. (1818)

508.- Ins. Tristan. D'Acunha

Thunbergii, Stend. in Flora, xxix. (1846) 23.Japon.

Thurberi, Dewey, ex Torr. Bot. Mex. Bound. 232.-

Am, bor. occ.

thuringiaca, Willd. Sp. Pl. iv. $250=$ glauca

Thwaitesii, Hance, in Fourn. Bot. vo (1867) 235.Zeylan.

thyrsiflora, Boott, Illustr. Carex, i. 12. t. \$4.Ind. or.

tokioënsis, Boeck. in Flora, 1xv. (1882) 68.-Japon.

Tolmiei, Boott, in Hook. Fl. Bor. Am. ii. 224.-Am. bor. occ.

tomentosa, Hornem. in Fl. Dan. t. 1404=globularis.

tomentosa, Lightf. Fl. Scot. $553=$ filiformis.

tomentosa, Linn. Mant. 123.-Europ.; Reg. Cancas. tomentosa, C. A. Mey. Verz. Pf. Cauc. $192=$ grisea.

torfacea, J. F. Gmel. Syst. $145=$ ampullacea

Torreyana, Dewey, in Am. Journ. Sc. x. (1826) $47=$ Davisii.

Torreyi, Tuckerm. Enum. Caric. 21.-Am. bor.

torta, Boott, ex Tuckerm. l.c. 11.-Am. bor.

Touranginiana, Bor. Fl. Cent. Fr. ed. II. $532=$ acuta.

trachyantha, Dorner, ex Heuff. in Verh. Zool. Bot. Ges. Wien, viii. (1858) $219=$ praecox.

trachycarpos, Link, in Schrad. Journ. ii. (1799 $310=$ glauca.

trachycystis, Griseb. in Goett. Abh. xxiv. (1879) 311.Reg. Argent.

traiziscana, Fo Schmidt, Reisen Amurl. 192.-Ins. Sachalin.

transversa, Boott, in Hook. Fl. Bor. Am. ii. 215. L 216 - Japon.

transwersa, Miq. Ann. Mus. Bot. Lugd. Bat. ii. 148 = rigens.

transsilvanica, Scbur, in Verb. Siebenb. Ver. Ninturw. iv. (1853) $80=$ Halleriana?

triandra. Gromow, ex Trauty, in Act. Hort. Petrop. ix. (1884) 911, nomen.-Rossia.

triangularis, Boeck. in Flora, xxix. (1856) 226.Texas.

tribuloides, Wahlenb. in Vet. Akad. Nya Handl. Srock h. (1SO8) $145=$ lagopodioides.

tricephala, Boeck. in Flora, lviii. (1875) 283.Malaya.

triceps, Michx. Fl. Bor. Am. ii. 170.-Am. bor. triceus, Schrank, Baier. Fl. i. 257.-Eurap. trichocarpa, Mahl. ex Schbuhr, Rinder. ii. 17, 81.Am. bor.

trichocarpa, Schur, Enum. Pl. Transs, $709=$ semper. virens.

trichodes, Strud. in Linnara, xxxix. (18\%5) 29. l'cruv. 


\section{CAREX :-}

trichostachya, Fisch. ex Boott, Illustr. Carex, iv. 198= podocarpa.

trichostyles, Franch. E Sav. Enum. Pl. Fap. ii. 581. -Japon.

tricostata, Fries, Novit. Mant. iii. $152=$ vulgaris

trifida, Cav. Ic. v. 41. t. 465.-Reg. Magell.

triflora, Schkuhr, Riedgr. i. 94 , ii. $66=$ depauperata.

triflora, Vahl, ex Kunth, Enum. Pl. ii. $460=$ vaginata.

trigona, All. Fl. Pedem. ii. $269=$ fulva

trinervis, Degl. in Loisel. Fl. Gall. ii. 731.-Gallia.

trinervis, Nees, in Wight, Contrib. $120=$ Esenbeckii.

tripartita, All. Fl. Pedem. ii. $265=$ curvula.

tripartita, Lam. Encyc. iii. $339=$ divisa.

tripartita, Suter, Fl. Helv. ii. $241=$ lagopina

triquetra, Boott, in Trans, Linn. Soc. xx. (1851) 126 -Calif.

trisperma, Dewey, in Am. Fourn. Sc. ix. (1825) 63.Am. bor.

trisperma, A. Gray, ex Boott, Illustr. Carex, ii. 81 rosea.

tristachya, Thunb. $F$. Fap. 38,-Tapon.

tristicha, Boeck. in Flora, xli. (1858) 651.-Am. bor

tristicha, Spruce, ex Boott, Illustr. Carex, iv. 153.Ecuador.

tristis, Bieb. F1. Taur. Cauc. iii. $615=$ sempervirens.

triticea, Wahlenb. ex Steud. Nom. ed. II. i. $299=$ clavata.

truncata, Boeck. in Flora, xli. (1858) 649.-Am. bor.

truncata, Fenzl, in Friederichsthal, Reise Griechenl. 278.-Graecia.

truncatula, Kit. in Linnaea, xxxii. (1863) 318.Hungar.

tuberculata, Liebm. in Vidensk. Selsk. Skr. V, ii. 1851) 270 - - Mexic.

tuberculata, Nees, ex Boott, Illustr. Carex, ii. $76=$ bonariensis.

tuberosa, Blanco, F1. Filip. ed. I. $35=$ Eleocharis tuberosa.

tuberosa, Degl. in Loisel. F1. Gall. ii. 629=Linkii,

tubulata, Schum. ex Boott, Illustr. Carex, iv. $136=$ Buxbaumii

Tuckermanni, Boott, in Hook. Lond. Fourn. Bot. v. (1846) 73.-Am. bor.

tumida, Beilschmid, in Hornsch. Archiv Skand. ii. 214 $=$ vulgaris.

tumida, Boott, Illustr. Carex, i. 66.--Reg. Himal.

tumidicarpa, Anderss. in Bot. Notiser (1849); et Flora, xxxiii. (1850), 297.- Scandinav.

turbinata, Liebm. in Vidensk. Selsk. Skr. V. ii. (1851) 265 - Mexic

Turczaninofii, Steud. ex Boott, Illustr. Carex, iv. 161 $=$ obesa.

turfacea, Auct. vide torfacea.

turfosa, Fries, Bot. Notiser (1846), 104, $107=$ caespitosa.

turfosa, Fries, Summa, $228=$ vulgaris.

turgescens, Dewey, in Am. Journ. Sc. Ser. II. iii. (1847) $356=$ Halei.

turgescens, Torr. in Ann. Lyc. N. York, iii. (1836) 419. -Am, bor.

turkestanica, Regel, in Act. Hort. Petrop, vii. (1880) 570. - Turkestan.

Tweediana, Nees, in Hook. Fourn. Bot. ii. (1840) 398. -Reg. Argent

typhina, Michx. F1. Bor. Am. ii. 169=squarrosa,

typhinoides, Schwein. in Ann. Lyc. N. York, i. (1824) $66=$ squarrosa.

typhoides, Bory, Voy. iii. $24=$ Boryana.

uda, Maxim. Prim. Fl. Amur. 303.-Reg. Amur.

uetliaca, Suter, F1. Helv. i. 251 = flava

uliginosa, Linn. Sp. Pl. $973=$ Scirpus Caricis.

umbellata, Schkuhr, Riedgr. ii. 75.-Am. bor.

umbrosa, Host, Gram. i. 52. t. $69=$ praecox.

uncifolia, Cheesem. in Trans. N. Z. Inst. xvi. (1884)

$$
\text { 412.-N. Zel. }
$$

uncinata, Linn. f. Suppl. $413=$ Uncinia australis

uncinata, Schkuhr, ex Steud. Nom. ed. II. i. $297=$ Uncinia jamaicensis.

uncinioides, Boott, Illustr. Carex, i. 8.-Reg. Himal.

undulata, Kunze, in Schknhr, Riedgr. Suppl. 23, n. 8 .

t. 4 . f. $2=$ pallescens.

undulata, Schur, Enum. Pl. Transs. $714=$ leucantha.

Urbani, Boeck. in Engl. Bot. Fahrb. vii. (1885) 280 . Alaska.

ursina, Dezvey, in Am. Fourn. Sc. xxvii. (1835) 240.Am, arct.
CAREX :-

Urvillei, Brongn. in Duperr. Voy. Bot. $157=$ pumila.

ustulata, Wahlenb. in Vet. Akad. Nya Handl. Stockh. (1803) 156.-Europ.

utriculata, Boott, in Hook. Fl. Bor. Am. ii. 221.-Am. bor.

vacillans, Soland. ex Boott, in Hook. f. Fl. N. Zel. i. 285.-N. Zel

vacillans, Steud. Syn. P1. Cyp. $235=$ riparia.

vaginata, Tausch, in Flora, iv. (1821) 557.-Europ.

Vahlii, Schkuhr, Riedgr. i. 87.-Reg. bor. et arct.

valdiviana, Phil. in Linnaea, xxix. (1857-58) 84. Chili.

valesiaca, Suter, F1. Helv. $259=$ tenuis.

valesiaca, Wahlenb. in Vet. Akad. Nya Handl. Stockh. 1803) $155=$ ambigua.

valida, Nees, in Wight, Contrib. 123.-China; Zeylan.

vallicola, Dewey, in Am. Fourn. Sc. Ser. II. xxxii. (1861) 40.-Calif

Vanheurckii, Muell. Arg. in Heurck, Obs. Bot. 30.Kamtschatka.

varia, Host, Gram. i. 59. t. $80=$ sempervirens

varia, Muhl. ex Schkuhr, Riedgr. ii. 48.-Am. bor.

variegata, Lam. Encyc. iii. $389=$ sempervirens.

variegata, Scheele, in Linnaea, xxiii. (1850) 565.-Am. bor.

Vaseyi, Dewey, in Am. Journ, Sc. Ser. II. xxix. (1860) $347=$ monile.

ventricosa, Curt. F1. Lond. fasc. vi. t. $68=$ depauperata. venusta, Dewey, in Am. Fourn. Sc. xxvi. (1834) 107.Am. bor.

verna, Chaix \& Vill. Hist. P1. Dauph. i. 312 , ii. $204=$ praecox.

verna, Lam. Fl. Fr. ii. 185, partim=glauca

verna, Schkuhr, Riedgr. i. $89=$ obesa.

verna, Torr. ex Kunth, Enum. Pl. ii. $439=$ praecox.

verrucosa, Muhl. Desc. Gram. Uber. 261= glaucescens.

verrucosa, Schwein. ex Torr, in Ann. Lyc. N. York, iii 1836) $400=$ commutata

versicolor, Dum. Fl. Belg. 148.-Belgium

verticillata, Boott, Illustr. Carex, i. 67.-Am. bor

verticillata, Zoll. E Moritzi, Syst. Verz. Zoll. 98.Java.

vesicaria, Bunge, ex Boott, in Proc. Linn. Soc. i. (1845) $261=$ songorica

vesicaria, Dewey, ex Stend. Nom. ed. II. i. $297=$ bullata.

vesicaria, Leers, F1. Herborn. t. 16. f. 2. 1=riparia.

vesicaria, Lightf. F1. Scot. ii, 566=ampullacea.

vesicaria, Linn. Sp. Pl. 979.-Reg, bor. temp.

vesicaria, Thunb. Prod. Pl. Cap. $14=$ clavata.

vesiciformis, Peterm. in Flora, xxvii. (1844) 339.Saxonia.

vesiculosa, Boott, Illustr. Carex, iii. 107.-Ind. or.

vestita, Willd. Sp. $P$ l. iv, 263.-Am bor.

vexilis, Wormsk, ex Boott, Illustr. Carex, iv, $191=$ Michelii.

vicinalis, Boott, l. c. 133.-Ind. or

victorialis, Nees, in Wight, Contrib. $126=$ notha.

Villarsii, Schkuhr, Riedgr. ii. 5.-Gallia.

villosa, Boott, in Perry, fap. Exped. 1i. 327.-Tapon.

villosa, Franch \& Sav. Enum. Pl. Jap. ii. $142=\mathrm{D}$ valiana.

villosa, Stokes, Bot. Mat. Med. iv. $346=$ hirta.

virens, Lam. Encyc. iii. $384=$ muricata.

virens, Thuill. $\mathrm{Fl}$, Par, i, $489=$ acuta

virescens, Muhl. ex Schkuhr, Riedgr. ii. 45.-Am. bor.

virescens, Willd. ex Kunth, Enum. Pl. ii. $430=$ triceps. virgata, Miq. Fl. Ind. Bat. iii. 351.-Java.

virgata, Soland. ex Hook. f. Fl. N, Zel. i. $282=$ paniculata.

virginiana, Woods, in Rees, Cycl. vi. n. $100=$ acuta.

virginica, Steud. Syn. Pl. Cyp. $217=$ praec.

viridis, Honck. Syn. Pl. Germ. i. $372=$ flava

viridis, Petrie, in Trans. N. Z. Inst. xiii. (1881) 332 $-\mathrm{N}$. Zel.

viridis, Schlecht. EN Cham. in Linnaea, vi. (1831) 30. -Mexic.

viridis, Spenn. Fl. Friburg. i. 48.-Europ.

viridula, Franch. E Sav. Enum. Pl. Fap. ii, 579.Japon.

viridula, Michx. Fl. Bor. Am. ii. 170-Am. bor.

viridula, Schwein. \& Torr, in Ann. Lyc. N. York, i.

(1824) $320=$ triceps

\section{CAREX}

vitilis, Fries, Novit. Mant. iii. $137=$ canescens

Vleckii, Schwein. in Ann. Lyc. N. York, i. (1824) $69=$ oligocarpa.

Vulcani, Hochst. ex Seub. Fl. Azor. 22. t. 3. f. 2Ins. Azoric.

vulgaris, Fries, Nov. Mant. iii. 153.-Reg. temp. bor. et austr.

vulpina, Carey, ex Dewey, in Am. Journ. Sc. Ser. II. viii. (1849) $348=$ conjuncta.

vulpina, Hohen. in Bull. Soc. Nat. Mosc. (1833) 259 = muricata.

vulpina, Linn. Sp. Pl. 973.-Europ.; As, temp.

vulpina, Nees, in Hook. Journ. Bot. ii. (1840) $398=$ bonariensis.

vulpinaeformis, Tuckerm. Enum. $9=$ vulpinoidea.

vulpinaris, Nees, in Wight, Contrib. 121.-Reg.

Himal.; As. bor

vulpinoidea, Michx. Fl. Bor. Am. ii, 169.-Reg Cauc.; Am. bor.

vulpinoidea, Torr. in Ann. Lyc. N. York, i. (1824) $390=$ stipata

Wahlenbergiana, Boott, Illustr. Carex, ii. 101. t. 301 -Ins. Maurit.

wahuensis, C. A. Mey. in Mém, Sav. Etr. Pétersb. i. (1831) 218. t. 10.-Ins. Oahu; Japon.

Wakatipu, Petrie, in Trans. N. Z. Inst. xiv. (1882 $363,-N$. Zel.

Walkeri, Arn. ex Boott, in Proc. Linn. Soc. i. (1845) 257.-Zeylan.

Wallichiana, Presc. in Wall. Cat. n. 3380.-Reg Himal.

Wallichiana, Spreng. Syst. iii. $812=$ foliosa.

Washingioniana, Dewey, in Am. Journ. Sc. x. (1826) $272=$ vulgaris

Watsoni, Boott, Illustr. Carex, iv. $203=$ Vulcani

Watsoni, Olney, in Bot. King, Exp. 370.-Am. bor. occ

Watsoniana, Steud. Syn. Pl. Cyp. 215.-Am. bor.

Wazmanni, Schrank, Baier. Fl. i. 297.-Europ.

Weiheana, Boeng. ex Kunth, Enum. P1. i1. $439=$ praecox?

Welwitschi, Boiss. ex Steud. Syn. Pl. Cyp. 230.Lusitan.

Whitneyi, Olney, in Proc. Am. Acad. vii. (1868) 394 -Calif.

Wichurai, Boeck. in Engl. Bot. Fahrb. v. (1884) 519. -China.

Wightiana, Nees, in Wight, Contrib. 122.-Ind. or,

Wilkesii, Olney, in Bot. U. St. Expl. Exped. ii. 477. t. 17. - Hab.?

Willdenowii, Schkuhr, Riedgr. ii. 33.-Am. bor.

wiluica, Meinsh. ex Maack, Vilyuisk. Okruge Yakutsk. Obl. II. 308.-Sibir.

Wimmeri, Steud. Syn. Pl. Cyp. 215.-Silesia

Winkleri, Lange, in Kjoeb. Vidensk, Meddel. (187778) 224 .- - Hispan.

Witheringii, S. F. Gray, Nat. Arr. Brit. PI. ii. $48=$ arenaria.

Wormskioldiana, Hornem. in FI. Dan. t. $1528=$ scirpoidea.

Wormskioldii, Drej. Revis. Caric. $18=$ scirpoidea

Woodii, Dewey, in Am. Journ. Sc. Ser. II. ii. (1846) $249=$ tetanica

Wrightii, Dewey, ex Torr. Bot. Mex. Bound. 232.Am. bor. occ.

xalapensis, Kunth, Enum. Pl. ii, $380=$ Brongniartii.

xanthophysa, Wahlenb. in Vet. Akad. Nya Handl. Stockh. (1803) $152=$ folliculata.

xerocarpa, S. H. Wright, in Am. Fourn, Sc. Ser. II xlii. 1866) 334, in nota.-Am. bor.

yodoënsis, Boeck, in Engl. Bot. Fahrb. v. (1884) 515 -Japon.

Zollingeri, Kunze, ex Steud. Syn. Pl. Cyp. $221=$ nemostachys.

gonata, F. Nyland. Spicil. Pl. Fenn. ii. 19=vulgaris ?

CAREYA, Roxb. Hort. Beng. 52 (1814) ; Fl. Ind. ii. 636 (1832). MYRTACEAE, Benth. \& Hook. f. i. 721.

Cumbea, Wight \& Arn. Prod. i. 334 (1834).

Cumbia, Buch.-Ham. Mysore, iii. 187 (1807)

arborea, Roxb. ll. cc.-Ind. or.

australis, F. Muell. Fragm. v. $183=$ Barringtonia Careya.

herbacea, Roxb. Hort. Beng. 52 ; Fl. Ind. ii. 638.Ind. or.

macrostachya, Jack, in Malay Misc. i. n. v. $47=$ Barringtonia macrostachya. 
CAREY A :-

orbiculata, Miers, in Trans. Linn. Soc. Ser. II. i. (1875) $98=$ arborea

pendula, Griff. Notul. iv, $66 \mathrm{l}=$ Barringtonia macrostachya.

sphaerica, Roxb. Hort. Beng. 52 ; Fl. Ind. ii. 636.-Ind, or.

valida, Kurz, in Fourn. As. Soc. Beng. xlvi. (1877) II. 72.-Ins. Andam.

CARGILLA, Adans. Fam. ii. $130(1763)=$ Chrysogonum, Linn. (Compos.)

CARGilliA, R. Br. Prod. 526 (1810)=Diospyros, Lam. (Ebenac.).

arborea, A. Cunn. ex Hiern, in Trans. Camb. Phil. Soc. xii. (1873) $239=\mathrm{D}$. pentamera.

australis, R. Br. Prod. $526=\mathrm{D}$. Cargillia.

laxa, R. Br. 1. c。= D. maritima.

mabacea, F. Muell. Fragm. v. $162=$ D. mabacea.

maritima, Hassk. Cat. Hort. Bog. Alt. $159=$ D maritima.

megalocarpa, F. Muell. Fragm, v, $163=$ D. maritima.

pentamera, F. Muell, 1. c. iv. $82=$ D, pentamera.

CARICA, Linn. Gen. ed. I. 309 (1737). PASSIFLOREAE, Benth. \& Hook. f. i. 815.

Mocinna, Cerv, ex La Llave, in La Naturaleza, vii. (1885) Apénd, 70

Papaya, Tourn. ex Linn. Syst. ed. I (1735).

Vasconcellea, A. St. Hil. Mém. Resed. ii. 13 (1837).

Boissieri, Hemsl. Biol. Centr.-Am. Bot. i. 481.-Mexic. candamarcensis, Hook. f. Bot. Mag. t. 6198.-Ecuador candicans, A. Gray, Bot. U. St. Expl. Exped. i. 640. -Peruv.

cauliflora, Facq. Hort. Schoenb. iii. 33. -Venezuela.

citriformis, Facq. $f$. ex Spreng. Syst. iii. 905.-Afr trop.

cundinamarcensis, J. Linden, Cat. n. $87(1871)=$ candamarcensis.

digitata, Spreng. Syst. iii. $906=$ spinosa .

dodecaphylla, Vell. Fl. Flum. x. t. 132.-Bras.

erythrocarpa, Linden Eे André, Illustr. Hortic. xviii.

(1871) t. 51.-Ecuador.

glandulosa, Pav.ex A. DC. in DC. Prod. xv. 1. 417.Peruv,

gossypifolia, Griseb. in Goett. Abh. xxiv. (1879) 137. - Reg. Argent

heptaphylla, Vell. Fl. Flum. x. t. $133=$ spinosa.

hermaphrodita, Blanco, F1. Filip. ed. I. $205=$ C.

Papaya.

heterophylla, Poepp. E Endl. Nov. Gen. et Sp. ii. 60. -N. Granat.

Mamaya, Vell. Fl. Flum. x. t. 131.-Bras.

microcarpa, Facq. Hort. Schoenb. iii. 32.-An. austr

monoica, Desf. in Ann. Mus. Par. i. (1802) 273. t.

18.-Peruv.

nana, Benth. Pl. Hartw. 288.-Mexic.

Papaya, Linn. Sp. Pl. 1036.-Am. trop.

peltata, Hook. Eo Arn. Bot. Beech. Voy. 425. t. 98.Nicaragua.

Posopora, Linn. Sp. Pl. 1036,-Peruv,

pubescens, Lenne \& $C$. Koch, in Ind. Sem. Hort Bot. Berol. (1854) 12.-Guatemala.

pyriformis, Willd. Sp. Pl. iv. $815=$ C. Posopora.

scandens, A. Gray, Bot. U. St. Expl. Exped. i. 640.Peruv.

spinosa, Aubl. Pl. Gui. ii. 908.-Guian.; Bras.

CARICELLA, Ehrh. Beitr. iv, $146(1789)=$ Carex Dill.

CARICTERTA, Scop. Introd. $104(1777)=$ Corchorus Tourn. (Tiliac.).

CARIGOLA, Rafin. Fl. Tellur, ii. $10(1836)=$ Mono choria, Presl (Pontederac.)

hastata, Rafin. 1. c. = M. hastaefolia.

CARIMA, Rafin. Fl. Tellur. iv. $62(1836)=$ Adhatoda, Nees (Acanthac.)

sulcata, Rafin. l. c. $=$ A. sulcata.

CARINIANA, Casar. Nov. Stirp. Bras. 85 (1842)= Couratari, Aubl. (Myrtac.).

brasiliensis, Casar. 1. c. = Couratari legalis.
CARINIANA :- -

domestica, Miers, in Trans. Linn. Soc. xxx. (1874) 286 = Couratari domestica.

excelsa, Casar. Nov. Stirp. Bras. $46=$ Couratari estrellensis.

exigua, Miers, in Trans. Linn. Soc. xxx. (1874) 289 . Ind. oce.

pyriformis, Miers, 1. c. 290.-Bolivia.

rubra, Miers, 1. c. $288=$ Couratari rubra.

uahupensis, Miers, 1. c. = Couratari uaupensis,

CARIONIA, Naud. in Ann. Sc. Nat. Sér. III. xv (1851) 311. t. 15. MELASTOMACEAE, Benth. \& Hook, f. i. 759

elegans, Naud.l. c. 312.-Ins. Philipp.

triplinervia, Rolfe, in fourn. Linn. Soc. xxi. (1884) 310.-Ins. Philipp.

CARISSA, Linn. Mant. i. 7 (1767). APOCYNACEAE, Benth. \& Hook. f. ii. 695 .

Antura, Forsk. Fl. Aegypt. Arab. 63 (1775)

ARDuina, Mill Ic. 300 (1759); Lino. Mant, (1767).

abyssinica, R. Br. in Salt, Abyss. App. p. Ixiv, nomen. -Abyss.

acuminata, A. DC. Prod. viii. 335.-Afr. austr.

africana, $A, D C . l, c .332$ - Afr. trop.

Arduina, Lam. Encyc. i. 555.-Afr. austr.

axillaris, Roxb. Hort. Beng. 84 ; Fl. Ind. i. 691.-Ins. Molucc.

bispinosa, Desf. Tabl. ed. I. $78=$ C. Arduina.

Brownii, F. Muell. Fragm. iv. 45 = lanceolata, ovata, et

scabra.
Candolleana, Faub. E Spach, Illustr. v. 107. t. 497.-

Abysin.

Carandas, Linn. Mant. 52.-Ind. or. ; Malaya.

Carandas, Lodd. Bot. Cab. t. $663=$ paucinervia

Carandas, Lour. Fl. Cochinch. $155=$ africana.

congesta, Wight, Ic. iv. t. $1289=\mathrm{C}$. Carandas.

coriacea, Wall. Cat. n. 1680.-Ind, or.

cornifolia, Faub. E' Spach, Illustr. v. 108. i. 498.Abyssin.

cryptophlebia, Baker, in fourn. Linn. Soc. xx. (1884) 204.-Madag.

Dalzellii, Bedd. Forest. Fl. Anal. Gen. 156 ; Man. Bot. $157=$ macrophylla.

densiflora, Baker, in fourn. Linn. Soc. xx. (1884) 204 - Madag

diffusa, Roxb. Hort. Beng. 19; Fl. Ind. i. $689=$ spinarum.

diffusa, Wall. Cat, n. 1678, partim= paucinervia.

dulcis, Schum. \& Thonn. Beskr. Guin. Pl. $146=$ edulis

edulis, Vahl, Symb. Bot. i. 22.-Aegypt.

erythrocarpa, A. DC. Prod. viii. 335.-Afr. austr.

ferox, $A . D C$. $l$.. .-Afr, austr

grandiflora, $A . D C$. l. c.-Afr, anstr.

grandis, Bert. ex A.DC.l.c. 336.-Ins. Tahiti.

haematocarpa, $A . D C . l . c_{0}-$ Afr, austr.

hirsuta, Roth, Nov. PI. Sp. $128=$ spinarum

inermis, Vahl, Symb. Bot. iii. $43=$ macrophylla

lanceolata, $R . B r$. Prod. 468.-Austral.

lanceolata, Dalz. in Dalz. \& Gibs. Bomb. F1. $143=$

macrophylla.

laxiflora, Benth. Fl. Austral. iv, 305.-Austral.

macrocarpa, A. DC. Prod. viii. 336.-Afr. austr.

macrophylla, Wall. Cat. n. 1679.-Ind. or.

madagascariensis, Thou. Obs. Pl. Iles Afr. Austr. 80 - Madag.

mitis, Heynh. ex A. DC. Prod. viii. $332=$ macrophylla.

mitis, Vahl, Symb. Bot. iii. $44=$ Holnrrhena mitis

myrtoides, Desf. Cat. Hort. Par. ed. III. 398.-Hab. ?

oblongifolia, Hochst. in Flora, xxvii. (1844) ii. 827.Afr. austr.

ovata, R. Br. Prod. 468.-Austral.

paucinervia, A. DC. Prod. viii. 389.-Ind. or.

pubescens, A.DC. l. c. 334.-Afr. trop.

Richardiana, Jaub. \& Spach, Illustr. v. 106 t. 496 edulis.

salicina. Lam. Encyc, i. $554=$ spinarum?

scabra, R. Br. Prod. 468. - Austral.

Schimperi, A. DC. Prod. viii. 675.-Abyssin

sechellensis, Baker, Fl. Maurit. 222.-Ins. Seychell.

spinarum, Linn. Mant. t. 559 .-Ins. Molucc.

spinarum, Lodd. ex A. DC. I'rod. viii. $936^{\circ}$ Damna canthus indicus.

suavissima, Bedd. ex Hook. f. Fl. Brit. Ind. iii. 632.Ind, or.
CARISSA :

tomentosa, A. Rich. Tent. Fl. Abyss. ii. 30.Abyssin.

villosa, Ruxb. Hort. Beng, 19; Fl. Ind. 1. $690=$ spinarum.

Xylopicron, Thou. Obs. Pl. Iles Afr. Austr. 80. t. 2.Ins. Mascar.

CARLEA, Presl, Epim. Bot. $216(1849)=$ Symplocos Linn. (Styrac.).

oblongifolia, Presl, 1. c. $217=$ S. oblongifolia.

CARLEMANNIA, Benth, in Hook. Kew Journ. y (1853) 308. RUBIACEAE, Benth. \& Hook. f. ii 63.

congesta, Hook. f. Fl. Brit. Ind. iii. 85.-Reg. Himal.

Griffithii, Benth. in Hook. Kew Fourn. v. (1853) 308 - Reg. Himal.

tetragona, Hook. f. Fl. Brit. Ind. iii. 85,-Reg. Himal.

CARLINA, Linn. Syst. ed. I (1735). COMPOSITAE Benth. \& Hook. f. ii. 465.

ATHAmus, Neck. Elem, i. 85 (1790)

CarlowlzIa, Moench, Meth. Suppl. 225 (1802).

Chromatolepis, Dulac, Fl. Hautes-Pyr. 525 (1867)

Mitina, Adans. Fam. ii, 116 (1763)

acanthifolia, All. Fl. Pedem. i. 156.t.51.-Reg. Mediterr Acarna, Bieb. Fl. Taur. Canc. ii. $282=$ Caicu. Acarna.

acaulis, Lam. Encyc. i. 623 - acanthifolia.

acaulis, Linn. Sp. Pl. 828.-Europ.

acaulis, Stokes, Bot. Mat. Med. iv, $156=$ Cnicus acaulis.

aculeata, Burm. f. Fl. Cap. Prod. 23 (=Stobaea rigida -Afr. anstr.

aggregata, Willd. Sp. Pl, iii. $1694=$ acaulis

alpina, Jacq. Enum. Stirp. Vindob, $274=$ acaulis.

atlantica, Pomel, Nouv. Mat. Fl. Atl. 19,-Algeria.

atractyloides, Linn. Sp. Pl. 1161 (=Stobaea atractyloides). - Afr. austr.

Biebersteinii, Bernh. ex Homem. Hort. Hafn. Suppl. $94=$ vulgaris

bracteata, J. \& C. Presl, Delic. Prag. $103=$ sicula. caulescens, Gilib. Fl. Lituan. iii. $195=$ vulgaris.

caulescens, Lam. Fl. Fr. ii. $7=$ acaulis.

Chamaeleon, Vill. Hist. Pl. Dauph. iii. $30=$ acaulis Chardousse, Vill. Prosp. $27=$ acanthifolia. complanata, Schur, Enum. Pl. Transs. $413=$ vulgaris. corymbosa, Linn. Sp. Pl. 828.--Reg. Mediterr.

corymbosa, Scop. ex Steud. Nom, ed. II. i. $299=$ vulgaris.

Curetum, Heldr. in Boiss. Fl. Orient. iii. $449=$ corymbosa.

Cynara, Pourr. ex DC. Fl. Fr. iv. 123=acanthirolia.

discolor, Soleir, ex Nym. Consp. $400=$ macrocephala.

Echinus, Bieb. Fl. Taur. Cauc. ii. 288.-Reg. Cauc. (=Cirsium scleranthum).

elatior. Wallr. in Linnaea, xiv. (1810) 636 ; et Beitr. Fl Hercyn. $266=$ acaulis.

foliosa, Hoiss. \& Haussk. in Boiss. Fl. Orient. iii. $450=$ oligocephala.

Fontanesii, DC. Prod, vi $5 \$ 8=$ Atractylis macroce. phala.

frigida, Boiss. E Heldr. Diagn. Ser. I. vi, 109.Graecia.

gorterioides, Lam. Encyc. i. 625 := Berkheyze sp.).Afr, austr.

graeca, Heldr. \& Sart. ex Boiss. Fl. Orient. iii. $449=$ corymbosa.

grandiflora, Moench, Meth. $558=$ acaulis

gummifera, Less. Syn. Comp. $12=$ Atractylis gummifera.

hispanica, Lam. Encyc, i. $624=$ corymbosa

internedia, Schur, linum. Pl. Tronss. $418=$ ralgaris.

involuerata, Poir. Voy. Barb. ii, 234.-Reg. Mediters.

lanata, Habl. Taur. $160=$ vulgaris.

lanata, Linn. Sp. Pl. 828.-Keg. Meditert.

lanata, Pall. ex DC. Prod. vi. $540=$ gulgaris

libanolica, Boiss. Diagn. Ser. I. x. $95=$ con mbusa.

Lobrliana, Tausch, in Flora, xii. (1829) Érs. 11 -

corymbusa.

longifolia, Reichb. Ic. Fl. Germ. viii. $25=$ rulgaris

longifolia, Viv. Fl. Lib. Spec. $68=$ corn mbosa.

lyrnta, Thunb. Prod. Pl. Cap. 111.-Áfr. aussr.

macrocephola, Less. Syn. Comp. 12 = Atractylis macrocephala. 


\section{CARLINA.}

macrocephala, Moris, Elench. Sard. ii. 5.-Reg. Mediterr.

macrophylla, DC. Prod. vi. $548=$ Atractylis macro phylla.

nebrodensis, Guss. in DC. Prod. vi. 546.--Sicilia.

nebrodensis, Koch, ex Nym. Consp. $401=$ vulgaris.

oligocephala, Boiss. E' Kotschy, Diagn. Ser. II. iii. 51.

-As. Min.; Syria.

onopordifolia, Bess. ex DC. Prod. vi. $545=$ acanthifolia orophila, Lamotte, Prod. ii. $443=$ vulgaris.

patula, Burm. f. Fl. Cap. Prod. 23 (=Stobaeae sp.).-

Afr. austr.

Pola, Hacq. Pl. Alp. Carn. 29. t. 4. f. $3=$ lanata.

pyrenaica, Linn. Sp. P1. $829=$ Carduus carlinoides.

racemosa, Gilib. Chlor. Grodn. $34=$ vulgaris.

racemosa, Gouan, Illustr. $64=$ corymbosa.

racemosa, Linn. Sp. Pl. 829.-Reg. Mediterr. occ.

radiata, Viv. F1. Lib. Spec. $68=$ corymbosa.

Rebondiana, Pomel, Nouv. Mat. Fl. Atl. 273.-

Algeria.

Rothii, Heldr. \& Sart. ex Boiss. F1. Orient. iii. $449=$ corymbosa.

salicifolia, Cav. in Anal. Cienc. Nat. iv. (1801) 81 ;

Less, in Linnaea, vi. (1831) 88. - Ins. Madera.

scabra, Burm. f. Fl. Cap. Prod. $23=$ Tripteris arborescens.

sicula, Tenore, Cat. Hort. Neap. App. (1819).Sicilia.

simplex, Waldst. \& Kit. P1. Rar. Hung. ii. 164. t. 152 =acaulis.

subacaulis, DC. F1. Fr. iv, $122=$ acaulis.

sulphurea, Desf. F1. Atlant. ii. $251=$ racemosa.

tragacanthifolia, Klatt, in Leopoldina, xx. (1884) 94.Ins. Rhodus.

transsilvanica, Schur, in Verh. Siebenb. Ver. Nat. iv.

(1853) $34=$ acanthifolia.

tristis, Salisb. Prod. $185=$ vulgaris.

Utzka, Hacq. Pl. Alp. Cam. 7. t. 1 = acanthifolia.

vulgaris, Linn.Sp. Pl. 828.-Europ.; As. bor

xeranthemoides, Linn.f. Suppl. 349.-Ins. Tenerif

CARLOTEA, Arruda, ex Koster, Trav. 493 (1816) (Gen. ignot.).

formosissimum, Arruda, 1. c.-Pernambuc.

speciosa, Arruda, 1. c.-Pernambuc.

CARLOWIZIA, Moench, Meth. Suppl. $225(1802)=$ Carlina, Linn. (Compos.)

corymbosa, Cass. in Dict. Sc. Nat. xxv. $53=$ Carlina salicifolia.

saticifolia, Moench, Meth. Supp1. 226=Carlina salicifolia.

CARIOWRIGHTIA, A. Gray, in Proc. Am. Acad. xiii. (1878) 364. ACANTHACEAE.

arizonica, $A$. Gray, $l$. $c$.-Arizona.

linearifolia, A. Gray, l. c.-Texas.

CARLUDOVICA, Rniz \& Pav. Prod, 146. t, 31 (1794). CYCLANTHACEAE, Benth. \& Hook. f. iii. 953.

Evodianthus, Oerst. in Kjoeb. Vidensk. Meddel. (1875) 194.

Ludovia, Pers. Syn. ii. 576 (1807).

Salmia, Willd. in Ges. Naturf. Fr. Berl. Mag. v. $(1811) 399$.

Sarcinanthus, Oerst. in Kjoeb. Vidensk. Meddel. (1875) 196.

acuminata, Poepp. \& End1. Nov. Gen. et Sp. ii. $37=$ divergens.

acuminata, Ruiz \& Pav. Syst. 293--Am, austr

angustifolia, Ruiz \& Pav. 1. c. $292=$ Cyclanthus Plumerii.

atrovirens, H. Wendl. Ind. Palm. (1854) 67.-N. Granat.

brachypus, Drude, in Mart. Fl. Bras. iii, I. 237.-Bras.

chelidonura, Drude, l. c. 238.-Bras.

disticha, Poit. in Rev. Hortic. Sér. III. i. (1847) 86.Guiana.

divergens, Drude, in Mart. Fl. Bras. iii. II. 241.-Bras. Drudei, Mast. in Gard. Chron. (1877) II. 714.-Bras. ensiformis, Hook. f. Bot. Mag. t. 6418.-Costa Rica.

funifera, Kunth, Enum. Pl. iii. 106-Guiana.

Gardneri, Hook. Fourn. Bot. ii. (1840) 29. t. 3, 4.Bras.

heterophylla, Mart. ex Drude, in Mart. Fl. Bras. iii. II. 242.-Bras.

\section{CARLUDOVICA :}

humilis, Poepp. E Endl. Nov. Gen. et Sp. ii. 37.Peruv.

imperialis, Linden \& André, Illustr. Hortic. xxi. (1874) t. 165.-Ecuador.

incisa, H. Wendl. Ind. Palm. (1854) 67.-Am. centr. insignis, Duchass. ex Griseb. Fl. Brit. W. Ind. 513. Ind. oce.

Kegeliana, Lem. Illustr. Hortic. ii. (1855) Misc. 23.Guiana

latifolia, Ruiz E Pav. Syst. 292.-Ind. occ.

latifrons, Drude, in Mart. Fl. Bras. iii. Ir. 237.-Bras. longicrura, Drude, l. c. 240.-Bras.

macropoda, Klotzsch, in Linnaea, xx. (1847) 469.N. Granat.

microphylla, Oerst. in Kjoeb. Vidensk. Meddel. (1857) 197.-Costa Rica.

Moritziana, Klotzsch, in Linnaea, xx. (1847) 468.-N. Granat.

Oerstedii, Hemsl. Biol. Centr. Am. Bot. iii. 416.Costa Rica.

palmata, Griseb. in Groett. Abh. vii. (1857) $259=$ insignis.

palmata, Ruiz \& Pav. Syst. 291.-Am. austr.

plicata, Klotzsch, in Linnaea, xx. (1847) 468.N. Granat.

plicata. Linden, ex H. Wendl. Ind. Palm. (1854) $67=$ atrovirens.

Plumerii, Kunth, Enum. Pl. iii. 106.-Ins. Martinic. Plumieri, Griseb. Fl. Brit. W. Ind. $513=$ gracilis purpurascens, J. Linden, Illustr. Hortic. xxviii. (1881) 64.-N. Granat.

rupestris, Klotzsch, in Linnaea, xx. (1847) 469.-N. Granat.

sarmentosa, Sagot, ex Drude, in Mart. Fl. Bras. iii. II. 239.-Guiana.

Sartoni, Teijsm. Ev Binn. Cat. Hort. Bog. 381, nomen. - Hab. ?

schizophylla, Drude, in Mart. Fl. Bras. iii. II. 235.Bras.

speciosa, Linden.-Cf. Gard. Chron. (1877) II. 753 $=$ Drudei.

subacaulis, Kunth, Enum.Pl. iii. 107.-Guiana,

tetragona, $H . B$. E $K$. Nov. Gen et Sp. i. $79, \mathrm{~N}$ Granat.

tetragonopus, Mart. ex Drude, in Mart. Fl. Bras. iii. II. 238.-Bras.

Trailiana, Drude, l.c. 241.-Bras.

trigona, Ruiz E Pav. Syst. 293.-Am, austr.

utilis, Benth. E" Hook, f. ex Hemsl. Biol. Am. Centr. Bot. iii. 416.-Costa Rica.

Wallisi, Regel, Gartenfl. (1879) 325.-N. Granat.

CARMELITA, C. Gay, ex DC. Prod. vii. $14(1838)=$ Chaetanthera, Ruiz \& Pav. (Compos.)

formosa, C. Gay, 1. c. $15=$ Chaet. villosa.

CARMENTA; Noronha, in Verh. Batav. Gen. v. (1790) ed. I. Art. IV. 2 (Quid?).

CARMICHAELA, Reichb. Nom, $147(1841)=$ seq.

CARMICHAELIA, R. Br. in Bot. Reg. xi. t. 912 (1825). LEGUMINOSAE, Benth. \& Hook. f. i. 502 australis, $R . B r \cdot l, c .-\mathrm{N} . \mathrm{Zel}$.

compacta, Petrie, in Trans. N. Z. Inst. xvii. (1885) 272.- N. Zel

corrugata, Colenso, l. c. xv. (1883) 320.-N. ZeI

crassicanlis, Hook. f. Handb. New Zeal. Fl. 48.-N Zel

Cunninghamii, Raoul, Choix, 29.-N. Zel.

Enysii, T. Kirk, in Trans. N, Z. Inst. xvi. (1884) 379. $-\mathrm{N}$. Zel.

Exsul, F. Muell. Fragm. vii. 126.-Ins. Dom. Howe.

flagelliformis, Colenso, in Hook. f. Fl. N. Zel. i. 51.N. Zel.

gracilis, Armst. in Trans. N. Z. Inst. xiii. (1881) 336 -N. Zel.

grandiflora, Hook. f. Handb. New Zeal. Fl. 49,--N. Ze1.

juncea, Colenso, ex Hook. f. Fl. N. Zel. i. 51.-N Zel.

Kirkii, Hook. f. Ic. Pl. t. 1332,-N. Zel.

Munroi, Hook. f. Handb. Nerv Zeal. Fl. 49.-N. Zel.

nana, Colenso, ex Hook. f. $l_{0} c .-\mathrm{N}$. Zel.

odorata, Colenso, ex Hook. f. Fl. N.Zel. i. 50,-N. Zel

pilosa, Colenso, ex Hook. f. l. c.-N. Zel.

stricta, Lehm. in Ind. Hort. Bot. Hamb. (1852) 8.

-Cf. Hamb. Gartenz. viii. (1852) 372.-Hab.
CARMICHAFIIA :-

uniflora, F. Buch. in Trans. N.Z. Inst. xvi. (1884) 394.-N. Zel.

uniflora, T. Kirk, in Gard. Chron. (1884) I. 512; Trans. N. Z. Inst. xvi. (1884) 379.-N. Zel.

Williamsi, T. Kirk, in Trans. N. Z. Inst.xii. (1880) 394.-N. Zel.

CARMINATIA, Moç. ex DC. Prod. vii. 267 (1838). COMPOSITAE, Benth. \& Hook. f. ii. 243.

tenuiflora, DC. l. c.; et in Deless.' Ic. Sel. iv. t. 98.Mexic.

tenuifolia, Steud. Nom. ed. II. i. 299, sphalm.= praec.

CARMONA, Cav. Ic. v. 22. t. $438(1799)=$ Fhretia Linn. (Borag.)

heterophylla, Cav. 1. c. $23=\mathrm{E}$. buxifolia.

lycioides, G. Don, Gen. Syst. iv. $391=$ E. lycioides microphylla, G. Don, 1. c. = E. buxifolia.

viminea, G. Don, 1. c. $=$ Rhabdia lycioides.

CARMONEA, Pers. Syn. i. $290(1805)=$ praec.

CARMOREA, Steud. Nom. ed. II. i. 299 (1840) sphalm. $=$ praec.

CARNARVONIA, F. Muell. Fragm. vi. 80. t. 55 56 (1867). PROTEACEAE, Benth. \& Hook. f. iii. 182.

araliaefolia, F. Muell. l. c. 81.-Austral.

CAROLI-GMELINA, Gaertn. Mey. \& Scherb. Fl. Wett. ii. $419(1800)=$ Nasturtium, R. Br. (Crucif.)

lancifolia, Gaertn. Mey. \& Scherb. 1. c. $468=\mathrm{N}$, amphibium.

palustris, Gaertn. Mey. \& Scherb. 1. c. $470=\mathrm{N}$. amphibinm.

sylvestris, Gaertn. Mey. \& Scherb. 1. c. $470=$ N. syl. vestre.

CARoLineA, Linn. f. Suppl. $51(1781)=$ Pachira Aubl. (Malvac.)

affinis, Mart. Nov. Gen. et Sp. i. $85=$ P. affinis.

alba, Lodd. Bot. Cab. t. $752=\mathrm{P}$. alba.

arenaria, G. Don, Gen. Syst. i. $510=$ P. arenaria campestris, Mart. Nov. Gen. et Sp. i. $86=\mathrm{P}$. campestris.

emarginata, D. Dietr. Syn. Pl. iv, $861=$ P. emarginata fastuosa, Sesse, ex DC. Prod, i. $478=$ P. fastuosa. grandifiora, Spach, Hist. Veg. Phan. iil. 426 ; xiv. $206=$ P. grandiflora.

insignis, Sw. Prod. Veg. Ind. Occ. $101=\mathrm{P}$. insignis.

longiflora, Mart. Nov. Gen. et Sp. i. $86=$ P. longiflora.

macrantha, G. Don, Gen. Syst. i. $510=$ P. macrantha. macrocarpa, Cham. \& Schlecht. in Linnaea, vi. (1831) $423=$ P. macrocarpa

marginata, G. Don, Gen. Syst. i. $511=$ P. marginata. minor, Sims, Bot. Mag. t. $1412=$ P. minor.

pompalis, Moc. \& Sesse, ex DC. Prod. i. $478=$ P. minor. Princeps, Linn. f. Suppl. $314=$ P. aquatica

robusta, Lodd. ex Steud. Nom. ed. II. i. 299.-Am. austr.

tomentosa, Mart. Nov. Gen. et Sp. i. $84=$ P. tomentosa. villosa, Mart. ex Steud. Nom. ed. II, i. $300=$ P. tomentosa.

CAROMBA, Steud. Nom. ed. II. i. 300 (1840) sphalm. = Cabomba, Aubl. (Nymph.).

CAROPYXIS, Benth. \& Hook. f. Gen. i. 688 (1865) sphalm. = CALOPYXIS, Tul. = Combretum, Linn.

CAROSELINUM, Griseb. Spicil. Fl. Rumel. i. 374 (1843) $=$ Peucedanum, Linn. (Umbellif.).

Chabraei, Griseb. 1. co = P. carvifolium.

distans, Griseb. 1. c. = Johrenia graeca.

CAROTA, Rupr. Sert. Tỉansch. 49 ; in Mém. Acad. Pétersb. Sér. VII. xiv. $(1869)=$ Daucus, Tourn. (Umbellif.)

sativa, Rupr. Fl. Ingric. $468=$ D. Carata.

sylvestris, Rupr. Sert. Tiansch. $49=$ D. Carota.

CAROXYLON, Thunb. Nov. Gen. ii. $37(1782)=$ Salsola, Linn. (Chenopod.)

acutifolium, Moq. in DC. Prod. xiii. II. $173=$ S. Auricula. 
CAROXYLON :-

articulatum, Moq. in DC. Prod.xiii. II. $175=$ Haloxylon articulatum.

Auricula, Moq. 1. c. $172=$ S. Auricula.

Bottae, Moq. in DC. 1. c. 178.-Afr. austr.

brevifolium, St. Lag, in Ann. Soc. Bot. Lyon, vii. (1880) $121=\mathrm{S}$. aphylla.

divaricatum, Moq. in DC. Prod. xiii. II. $177=$ S. longifolia.

foetidum, Moq. 1. c. $178=\mathrm{S}$. foetida.

glaucum, Moq 1 c $173=$ S glauca.

Griffithii, Moq. 1. c. $175=$ Haloxylon Griffithii.

hispidulum, Bunge, Lehm. Reliq. Bot. $293=\mathrm{S}$. hispidula.

imbricatum, Moq. in DC. Prod. xiii. II. $177=\mathrm{S}$. gemmascens.

indicum, Wight, Ic. t. $1794=$ Haloxylon recurvum.

lancifolium, Boiss. Diagn. Ser. I. xii. $98=$ S. lancifolia.

nodulosum, Moq. in DC. Prod. xiii. II. $177=$ S. gemmascens.

recurvum, Moq. 1. c. $175=$ Haloxylon recurvum saiicornicum, Mog. 1. c. 174= Haloxylon salicornicum. Salsola, Thunb. Diss. Med. Afric. $8=\mathrm{S}$, aphylla. subaphyllum, Moq. in DC. Prod. xiii. II. $173=\mathrm{S}$. subaphylla.

tamariscifolium, Moq. 1. c. $174=\mathrm{S}$. genistoides.

tamariscinum, Moq. 1. $\mathrm{c}_{0}=\mathrm{S}$. tamariscina.

tetragonum, Moq. l. c. $176=\mathrm{S}$. tetragona.

tuberculatum, Moq. 1, c. $178=\mathrm{S}$. tuberculata

verrucosum, Moq. $\mathrm{l}_{\text {. }} \mathrm{c}=\mathrm{S}$. tuberculata.

Zeyheri, Moq. 1. c. 176.-Afr. austr.

CARPACOCE, Sond, in Harv, \& Sond. Fl. Cap. iii. 32 (1864-65). RUBIACEAE, Benth. \& Hook. f. ii. 141 .

141. (1843).

scabra, Sond. l. c. 33.-Afr, austr.

Spermacoce, Sond. l. c.-Afr. austr.

CARPENTARIA, Becc. in Ann. Jard. Buitenz. ii. (1885) 128. PALMAE

acuminata, Becc. l. c.-Austral.

CARPENTERIA, Torr. in Smithson. Contrib, vi. 12. t. 7 (1854). SAXIFRAGEAE, Benth. \& Hook. f. i. 643.

californica, Torr. l. c.-Calif.

CARPENTIERA, Steud. Nom, ed. IT. i. 344 in syn. (1840) sphalm. = Charpentiera, Gaudich. (Amarant.).

CARPESIUM, Linn. in Act. Soc. Upsal. (1741) 80 COMPOSITAE, Benth. \& Hook f ii. 336 Con xzordes, Toum. ex DC. Prod. vi. 281 (1837) abrotanoides. Linn. Sp. Pl. 860.-Europ.; As. temp. cernuum, Linn. l. c. 859.-Europ.; As. temp. ciliatum, Wall. Cat. n. $3214=$ cernuum.

divaricatum, Sieb. E Zucc. in Abh. Akad. Muench. iv. III. (1846) 187.-Japon.

glossophyllum, Maxim. in Bull. Acad. Pétersb. xix (1874) 475.-Japon.

macrocephalum, Franch. \& Sav. Enum. Pl. Fap. ii 408.- Japon.

nepalense, Less. in Linnaea, vi. (1831) $234=$ cernuum.

pedunculosum, Wall. Cat. n. $3200=$ cernuum.

pubescens, Wall. 1. c. n. $3199=$ cernuum

racemosum, Wall. 1. c. n. $3201=$ abrotanoides

rosulatum, Miq. Ann. Mus. Bot. Lugd. Bat. ii. 179.Japon.

scandens, Schult. f. ex Miq. 1. c. 172=Rhynchospermum verticillatum.

Thunbergianum, Sieb. E Zucc. in Abh. Akad. Muench. iv. III. (1845) 187.-Japon.

trachelifolium, Less. in Linnaea, vi. (1831) 233.-Reg. Himal.

triste, Maxim. in Bull. Acad. Pétersb. xix. (1874) 479.

-Japon.
Wulferianum, Schreb. ex DC. Prod. vi. 282 = abrota. noides.

CARPEZIUM, Gouan, Fl. Monsp. $465(1765)=$ praec.
CARPHA, Banks \& Soland. ex R. Br. Prod. 230 (1810), pro parte. CYPERACEAE, Benth. \& Hook. fo iii. 1061.

alpina, R. Br. Prod. 230.-Austral.; N. Zel.; Patag. andina, Phil. in Anal. Univ. Chil. (1873) $555=$ pani culata.

arundinacea, Brongn. in Duperr. Voy. Bot. 169. t. $30=$ Schoenus arundinaceus

Aubertii, Nees, in Linnaea, ix. (1834) $300=$ Cyclo campe Aubertei.

avenacea, R. Br. Prod. $230=$ Cyathochaete avenacea. capensis, Martens, ex Steud. Nom. ed. II. i. $300=$ Ecklonea capensis

capitellata, Boeck. in Linnaea, xxxviii. (1874) 266.Afr. austr.

clandestina, R. Br. Prod. 281 = Cyathochaete clande stina.

deusta, R. Br, 1. c. $230=$ Mesomolaena deusta.

diandra, R. Br. 1. c. $231=$ Cyathochaete diandra

elongata, Boeck. 1, c. xxxviii. (1874) $273=$ Astero chaeta elongata.

glomerata, Nees, 1. c. vii. (1832) $529=$ Asterochaete glomerata.

hexandra, Nees, i. c. ix. (1834) 300 ; x. (1835-36) 193 = Macrochaetium Uregei.

junciformis, Boeck. in Linnaea, xxxviii. (1874) $267=$ Cladium undulatum.

nivicola, F. Muell. in Trans. Phil. Soc. Vict. i. (1855) 111 = alpina.

paniculata, Phil. in Linnaea, xxix. (1857-58) 80.Chili.

schoenoides, Banks \& Soland. ex Hook. f. Fl. Antarct. 362. t. $148=$ alpina

Schweinfurthiana, Boeck. in Flora, lxii. (1879) 569.Afr. trop.

Urvilleana, Gaudich. ex Nees, in Linnaea, ix. (1834) $300=$ Asterochaete arundinacea.

CARPHALEA, Juss. Gen. 198 (1789). RUBIA$C E A E$, Benth. \& Hook. f. ii. 52

angulata, Baill. in Bull. Soc. Linn. Par. i. (1878) 188

angulata, $B a$

corymbosa, Willd. Sp. Pl. i. 583.-Madag.

Kirondron, Baill. in Bull. Soc. Linn. Par. i. (1878) 188.--Madag.

madagascariensis, Lam. Illustr. i. 258. t. $59=$ corymbosa.

Pervilleana, Baill. in Bull. Soc. Linn. Par. i. (1878) 188. - Madag.

pubiflora, Moç. \& Sesse, ex DC. Prod. iv. $365=$ Bouvardia quaternifolia.

CARPHEPHORUS, Cass. in Bull. Soc. Philom. (1816) 198. COMPOSITAE, Benth. \& Hook. f. ii. 249.

atriplicifolius, A. Gray, in Proc. Am. Acad. v. (1861) 159.-Calif

baicalensis, DC. Prod. v. $132=$ Saussurea pycnocephala.

bellidifolius, Torr. E Gray, Fl. N. Am. ii. 66.Am. bor.

coridifolius, DC. Prod, vii, $267=$ Brickellia pinifolia.

corymbosus, Torr. \& Gray, Fl. N.Am. ii. 67.Am. bor.

junceus, Benth. Bot. Voy. Sulph. 21.-Calif.

junceus, Durand, in Pacif. Rail. Rep. v. $8=$ Linosyris squamata.

Pseudo-liatris, Cass. in Bull. Soc. Philom. (1816) 149. -Am. bor.

revolutifolius, $D C$. Prod. v. 133.-Mexic.

tomentosus, Torr. E Gray, Fl. N.Am. ii. 66.-Am. bor.

triangularis, A. Gray, Pl. Wright. i. 86.-Mexic.

CARPHOBOLUS, Schott, in Spreng. Syst. iv. Cur Post. 409 (1827) = Piptocarpha, R. Br. (Compos.) asterotrichius, Sch. Bip. in Pollichia, $\mathrm{xx}_{*}=\mathrm{xxi}$. (1863) $426=\mathrm{P}$. Vauthieriana

axillaris, Sch. Bip. 1. c. $417=\mathrm{P}$. axillaris

Blanchetianus, Sch. Bip. 1. c. $423=$ P. Lundiana,

cinereus, Sch. Bip. 1. c. $419=$ P. cincrea

cuneifolius, Sch. Bip. 1. c. $413=$ P. oblonga.

latifolius, Sch. Bip.1.c. $426=\mathrm{P}$. opaca,

Lechleri, Sch. Bip 1. c. $428=$ P. Lechleri.

lepidotus, Sch. Bip. 1. c. $414=$ P. oblonga.

leprosus, Sch. Bip. 1. c. $419-$ P. leprosi.

lucidus, Sch. Bip. 1. c. $413=$ P. lucida.

\section{CARPHOBOLUS :-}

Lundianus, Sch. Bip. in Pollichia, xx.-xxi. (1863) 421 = Piptocarpha Lundiana.

macropodus, Sch. Bip. 1. c. $418=$ P. macropoda. neurophyllus, Sch. Bip, 1. c. $414=$ P. pyrifolia. notatus, Sch. Bip. 1. c. $420=\mathrm{P}$, notata.

oblongus, Sch. Bip. 1, c. $416=\mathrm{P}$. oblonga.

opacus, Sch. Bip. 1. c. $427=$ P. polycephala. oxyphyllus, Sch. Bip. 1. c. $415=$ P. oxyphylla. pellucidus, Sch. Bip. I. c. $420=\mathrm{P}$. pellncida.

Poeppigianus, Sch. Bip. 1. c. $422=$ P. Poeppigiana

pyrifolius, Sch. Bip. l. c. $415=\mathrm{P}$. pyrifolia.

ramiflorus, Sch. Bip. 1. c. $429=$ P. ramiflora

Regnellii, Sch. Bip. 1. c. $417=$ P. axillaris.

Riedelii, Sch. Bip. 1. c. $425=$ P. Riedelii.

rotundifolius, Sch. Bip. 1. c. $424=\mathrm{P}$. rotundifolia.

Sellovii, Sch. Bip. 1. c, $421=$ P. Sellowi.

semiserrulatus, Sch. Bip. 1. c. $416=\mathrm{P}$. axillaris.

sessiliflorus, Schott, in Spreng. Syst. iv. Cur. Post. 405 $=$ P. lucida.

tereticaulis, Sch. Bip. in Pollichia, xx.-xxi. (1863) 422 $=$. tereticaulis

umbellulatus, Schott, in Spreng. Syst. iv. Cur. Post. $409=$ P. umbellulata

CARPHOCHAETE, A. Gray, Pl. Fendl. 65 ; in Mem Am. Acad. N. S. iv. (1849). COMPOSITAE, Benth \& Hook. f. ii. 247 .

Bigelovii, A. Gray, Pl. Wright. 1. 89.-N. Mexic.

Grahami, A. Gray, ל. c.-Mexic

Wislizeni, A. Gray, Pl. Fendl. 65.-Mexic

CARPHOLOMA, D. Don, in Mem. Wern. Soc. (1826) $555=$ Lachnospermum, Willd. (Compos.) rigidum, D. Don, I. c. $=$ L. ericaefolium.

CARPHOPAPPUS, Sch. Bip. in Walp. Rep. ii. 954 , 973 (1843) = Iphiona, Cass. (Compos.)

baccharidifolius, Sch. Bip. 1. c. $974=1$. baccharidi. folia

CARPHOSTEPHIUM, Cass, in Dict. Sc. Nat. xliv. 62 $(1826)=$ Tridax, Linn,$($ Compos $)$

trifidum, Cass. 1, c. $=$ T. trifida.

CARPIDOPTERIX, Karst. Fl. Columb. ii. 45. t. 123 (1862?) = Thouinia, Poit. (Sapindac.)

macroptera, Karst. l. c. =T. macroptera.

CARPINUS, Linn. Gen, ed. I. 292 (1737)

LIFERAE, Benth. \& Hook. f. iii. 405

Carpinum, Rafin. in Am. Monthly Mag. (1818) 268

Distegocarpus, Sieb. \& Zucc. Fam. Nat. Fl. Jap.

ii. 1U2. t. $3(1846)$

americana, Michx. Fl. Bor. Am, ii. $201-\mathrm{Am}$, bor.

Betulus, Linn. Sp. Pl. 998.-Europ.; Reg. Cauc Persia.

caroliniana, Walt. Fl. Carol. $236=$ americana.

Carpinisga, Kit. in Host, Fl. Austr. ii. $626=$ C. Betulus.

compressus, Gilib. Exercit. ii. $399=$ C. Betulus

cordata, Blume, Mus. Bot. Lugd. Bat. i. 309. Japon.

duinensis, Scop. FI. Carn. ed. II. ii. 243. t. 60 orientalis.

edentulus, Kit. in Rochel, Pl. Banat. Rar. nomen.Banat.

erosa, Blume, Mus. Bot. Lugd. Bat. i. 308.-Japon.

faginea, Lindl. in Wall. Pl. As. Rar. ii. 5.-Reg. Himal.

intermedia. Wierzb. ex Reichb. Ic. Fl. Germ. xii. 4. t. $633=$ C. Betulus.

italica, Scop. ex Steud. Nom. ed. II. i, $300=$ Ostrya carpinifulia.

japonica, Blume, Mus. Bot. Lugd. Bat. i. S08.Japon.

laxiflora, Blume, l.c. 309 - Japon.

minor, Pall. Reise, ii 95. - Tauria.

nervata, Dulac, Fl. Hautes-Pyr. $1+1=$ C. Betulus.

nigra, Moench, Verz. Ausl. liseume, $19=$ orientalis.

orientalis, Mill. Gard. Dict. ed. VIII. n. \$.-Euron.

austr.

Ostrya, Linn. Sp. Pl. 998 = Ostrua virginica.

ostryoides, Rafin. in Med. Kepois N. York, Ser. III. ii 1s11) $\$ 33$ - americana?

quercifolia, Desf. ex Sicud. Nom. ed. II. i. $\$ 00=C$. lectulus. 


\section{CARPINUS}

setium, Lam. Fl. Fr, ii. $212=$ C. Betulus.

triflora, Moench, Meth. $694=$ Ostrya virginica.

Tschonoskii, Maxim. in Bull. Acad. Pétersb. xxvii. (1881) 534.-Japon.

Turczaninovii, Hance, in fourn. Linn. Soc, x. (1869) 203.-China.

ulmifolia, Salisb. Prod. $392=$ C. Betulus.

ulmoides, S. F. Gray, Nat. Arr. Brit. Pl. ii. $245=$ C Betulus.

viminea, Wall. ex Lindl. in Wall. Pl. As. Rar. ii. 4. t. 106.-Reg. Himal.

virginiana, Michx. Hist. Arb. For. iii. 57. t. $8=$ americana.

virginiana, Mill. Gard. Dict. ed. VIII. n. 4; Lam. Encyc. i. $708=$ Ostrya virginiana.

vulgaris, Mill. 1. c. n. $1=$ C. Betulus.

yedoënsis, Maxim. in Bull. Acad. Pétersb. xxvii. (1881) 535.-Japon.

CARPIPHEA, Rafin. Sylva Tellur. $39(1838)=$ Cordia, Tourn. (Boragin.).

dentata, Rafin. I. $\mathrm{c}_{\mathrm{c}}=$ Cordia dentata

CARPOCALYMNA, Zipp. in Alg. Konst, en Letterbode, i. (1829) $297=$ Fpithema, Blume (Gesnerac.). monophylla, Zipp. ex Span. in Linnaea, xv. (1841) 331 $=\mathrm{E}$. difformis.

CARPOCERAS, Link, Handb.ii. 289 (1831) = Thlaspi, Tourn. (Crucif.)

cappadocicum, Boiss. Diagn. Ser. II. vi. 19.Cappadoc.

cilicicum, Boiss. \& Kurz, ex Boiss. Fl. Orient. i. 332. -Cilicia.

Griffithianum, Boiss. Diagn. Ser. II. i. $40=$ T. alpestre. hastulatum, Boiss. 1. c. Ser. I. viii. $38=$ T. hastulatum oxyceras, Boiss. 1. c. $37=$ T. oxyceras.

sibiricum, Link, Handb. ii. $289=\mathrm{T}$. ceratocarpon.

stenocarpum, Boiss. Diagn. Ser. I. viii. $38=$ T. stenocarpum.

CARPOCERAS, A. Rich. Elem. Bot. (1846) $706=$ Martynia, Linn. (Pedalin.)

longiflora, A. Rich. 1. c. = M. diandra.

CARPODETES, Herb. App. 41 (1821) = Stenomesson, Herb. (Amaryllid.).

recurvata, Herb. 1. $\mathrm{c}$. $=\mathrm{S}$. recurvatum.

CARPODFTUS, Forst: Char. Gen. 33. t. 17 (1776) SAXIFRAGEAE, Benth. \& Hook, f i. 646 dentatus, Poir. Encye. Suppl. îi. $120=$ serratus. Forsteri, Roem. \& Schult. Syst. v. $\ddot{B} 04=$ serratus. serratus, Forst. Char. Gen. 34. t. 17 A.-N. Zel.

CARPODINUS, R. Br. ex Sabine, in Trans. Hort. Soc. v. (1823) 455. APOCYNACEAE, Benth. \& Hook. f ii. 693

acida, Sabine, l. c. 456.-Afr. trop.

dulcis, Sabine, $l_{0} c_{0} 455$. -Afr. trop.

CARPoDIPTERA, Griseb. in Mem. Am. Acad. N. S. viii. (1861) 163. TILIACEAE, Benth. \& Hook. f. i. 232 .

africana, Mast. in Oliver, Fl. Trop. Afr. i. 241.-Afr. trop.

Boivini, Baill. Adansonia, x. (1872) 180. - Ins. Comor.

cubensis, Griseb. in Mem. Am. Acad. N. S. viii. (1861) 164.-Cuba.

Schomburgkii, Baill. Adansonia, x. (1872) 181.Guiana.

CARPODON, Spreng. Syst. ii. $634(1825)=$ seq.

CARPODONTOS, Labill, Voy。 ii. 16. t. $18(1798)=$ Eucryphia, Cav. (Rosac.).

lucida, Labill. 1. c. $=$ E. Billardieri.

CARPolobia, G. Don, Gen. Syst. i. 370 (1831), partim, POLYGALEAE, Benth. \& Hook. f. i. 139, 553.

Afzeliana, Oliver, $\mathrm{Fl}$. Trop. Afr. i. 136.-Afr. trop.

alba, G. Don, Gen. Syst. i. 370.-Afr. trop.

dubia, G. Don, l. c. = Baphia polygalacea.

lutea, G. Don, l. $c$.-Afr. trop.

versicolor, $\mathrm{G}$. Don, l. $\mathrm{c}_{\mathrm{c}}=$ Baphia nitida.
CARPOLIZA, Steud. Nom. ed. II. i. $300(1840)=$ seq.

CARPolyzA, Salisb. Parad. Lond. t. 63 (1807). AMARYLLIDEAE, Benth. \& Hook. f. iii. 721. HESSEA, Berg, ex Schlecht. in Linnaea, i. (1826) 252, non Herb.

spiralis, Salisb. Parad. Lond. t. 63.-Afr. austr.

stellaris, Heynh. Nom. ii. $122=$ Hessea stellaris, Herb.

CARPONEMA, Eckl. \& Zeyh. Enum. 8 (1835). CRUCIFERAE, Benth. \& Hook. f. i. 102. aggregata, Eckl. \& Zeyh, 1. c. = Heliophila gracilis. filiformis, Eckl. E Zeyh. l. c.-Afr. austr.

CARPOPHILLUS, Neck. Elem. ii. $84(\mathbf{1 7 9 0})=$ Pereskia, Plum.? (Cacteae)

CARPOPHORA, Klotzsch, in Bot. Ergeb. Waldem. Reise, 139.t. 32 (1862) =Silene, Linn. (Caryophyll.). Hoffmeisterii, Klotzsch, 1. c. =S. Griffithii.

CARPOPHYLLUM, Miq. Fl. Ind. Bat. Suppl. i. 401 $(1860)=$ Sterculia, Linn

macropodum, Miq. 1. c.-Sumatra.

CARPOPHYLLUM, Neck. Elem. iii. 402, $411(1790)=$ CARFOPHILLUS, Neck.

CARPOPODIUM, Eckl. \& Zeyh. Enum. i. $13(1835)=$ Heliophila, Linn. (Crucif.)

carnosum, Eckl. \& Zeyh. 1. c. = H. carnosa.

cleomoides, Eckl. \& Zeyh. 1. c. $=$ H. glauca

Thunbergii, Eckl. \& Zeyh, l. c. $=$ H. Thunbergii.

CARPOPOGON, Roxb. Hort. Beng. 54 (1814); Fl. Ind iii. $283(1832)=$ Mueuna, Adans. (Legumin.).

anguineum, Roxb. ex Baker, in Hook. f, Fl. Brit. Ind.

ii, $185=$ M. monosperma.

atropurpureum, Roxb. Hort. Beng. 54 ; Fl. Ind. iii. $287=\mathrm{M}$. atropurpurea.

bracteatum, Roxb. Hort. Beng. $54=$ M. bracteata.

capitatum, Roxb. 1. c. [98]; Fl. Ind. iii. $284=$ M. capitata.

giganteum, Roxb. 11. cc. 54, $287=$ M. gigantea,

imbricatum, Roxb. Hort. Beng, $54=$ M. imbricata

monospermum, Roxb. 1. c。; Fl. Ind。 iii. $283=\mathrm{M}$. monosperma.

niveum, Roxb. 11. cc. $54,285=\mathrm{M}$, nivea.

pruriens, Roxb. 11. cc. 54, $283=$ M. pruriens.

volubilis, Roxb. ex Stend. Nom. ed. II. i. $300=$ M volubilis.

CARPOTHALIS, E. Mey. in Drège, Zwei Pfl. Docum. $170(1843)=$ Kraussia, Harv. (Rubiac. $)$

lanceolata, E, Mey. I, c. = K. lanceolata.

CARPOTRICHE, Reichb. Nom. 189 (1841)=seq.

CARPOTROCHE, Endl. Gen. 918 (1839). BIXINEAE, Benth. \& Hook. f. i. 125.

brasiliensis, Endl.l. c.-Bras.

denticulata, Benth. in Hook. Fourn. Bot. iv. (1842) 115.-Guiana.

grandifora, Spruce, ex Eichl. in Mart. Fl. Bras. xiii. I. 437.-Bras.

laxiflora, Benth. in Hook. Fourn. Bot. iv. (1842) 114. -Guiana.

longifolia, Benth. in Fourn. Linn. Soc. v. Suppl. ii. (1861) 82.-Bras.; Peruv.

paludosa, Benth. in Hook. Fourn. Bot. iv. (1842) 114. -Guiana.

CARPOXIS, Rafin. New Fl. Am. iii, $89(1836)=$ Forestiera, Poir. (Oleac.).

inermis, Rafin. 1. c. 92,-Am. bor.

nitida, Rafin. I. c. $91=$ F. acuminata.

prinoides, Rafin. 1. c. $92=\mathrm{F}$. prinoides,

retusa, Rafin. 1. c. $=$ F. retusa.

spinosa, Rafin. 1. c.-Am. bor.

CARPOXYLON, H. Wendl. \& Drude, in Kerch. Palm. 238 (1878), nomen. PALMAE. macrospermum, $H$. Wendl. E Drude, l.c.-Hab.?
CARPunYA, Presl, Epim. Bot. $228(1849)=$ Piper, Linn.

Lessertiana, Presl, 1. c. $229=$ P. Carpunya.

oblongata, Presl, 1. c. = P. oblongatum.

peruviana, Presl, 1. c. $=$ P. Carpunya.

CARPUPICA, Rafin. Sylva Tellur. 85 (1838)=Piper, Linn.

odorata, Rafin. 1. c. = P. Carpunya.

CARRADORIA, A. DC. Prod, xii. 610 (1848)= Globularia, Linn. (Selagin.)

incanescens, A. DC. 1. $\mathrm{c}_{\mathrm{o}}=\mathrm{G}$. incanescens.

CARREGNOA, Boiss. Voy. Bot. Espagne, ii. 605 (1842) = Tapeinanthus, Herb. (Amaryllid.).

dubia, Perez-Lara, in Anal. Soc. Esp. Hist. Nat. xi. (1882) $399=$ Narcissus serotinus?

humilis, J. Gay, in Ann. Sc. Nat. Sér. IV. x. (1858) 98 $=\mathrm{T}$. humilis

lutea, Boiss. Voy. Bot. Espagne, ii. $605=$ T. humilis.

CARRIA, Gardn. in Calc. Journ. Nat. Hist. vii. (1847) $6=$ Gordonia, Ellis (Ternstroem.).

speciosa, Gardn. 1. c. $7=$ G. speciosa.

CARRICHTERA Adans. Fam. ii. 421 (1763); DC. Syst. Veg, ii.641. CRUCIFERAE, Benth. \& Hook. f. i. 86 .

Vella, $D C$. l. c. 642.-Hispan

CARROA, Presl, Symb. Bot. ii. 25 (1858)= Dalea, Linn. (Legumin.).

diffusa, Presl, 1. c. = D. diffusa.

grandulosa, Presl, 1. c. =D. diffusa.

CARRONIA, F. Muell. Fragm. ix. 171 (1875). MENISPERMACEAE.

multisepalea, F. Muell. l. c.-Austral.

CARRUTHERSiA, Seem. Fl. Vit. 155. t. 30 (1865-73). APOCYNACEAE, Benth. \& Hook. f. ii. 718.

pilosa, Villar, in Blanco, Fl. Philipp. ed. III. Nov. App. 132.--Ins. Philipp.

scandens, Seem. Fl. Vit. 156. t. 30.-Ins. Fiji.

CARTALINIA, Szov. ex Kunth, Enum. Pl. v. 119 (1850) $=$ Paris, Rupp. (Liliac.).

CARTERETIA, A. Rich. Sert. Astrol. 10. t. $4(1834)=$ Doritis, Lindl. (Orchid.)

paniculata, A. Rich. 1. c.=D. paniculata.

CARTESIA, Cass. in Bull. Soc. Philom. (1816) $198=$ Stokesia, L'Hérit. (Compos.).

centauroides, Cass. 1. c. = S. cyanea.

CARThAMUS, [Tourn.] Linn. Syst. ed. I (1735). COMPOSITAE, Benth. \& Hook. f. ii. 483.

Durandoa, Pomel, Mat. Fl. Atl. 2 (1860)

Heracantha, [Hoffmgg. \&] Link, Fl. Port. ii. 205 (1820).

HeteraCantha, Steud. Nom. ed. II. i. 755 (1840).

HOHENWARTHA, Vest, in Flora, iii. (1820) 1.

Kentrophyllum, Neck. Elem. i. 86 (1790).

Onobroma, DC. Prod. vi. 613 (1837).

PHONUS, Hill, Veg. Syst. iv. 5 (1762).

acaulis, Presl, ex Stend. Nom. ed. II. i. $300=$ Carduncellus pectinatus.

africanus, Lam. Encyc, i. $640=$ Berckheya grandiflora. albus, Desf. Tabl. ed. I. 92.-Oriens.

araneosus, Sch. Bip. in Webb \& Berth. Phyt. Canar. ii. $363=$ Carduncellus araneosus.

arborescens, Linn. Sp. Pl. 831.-Hispan.

armenus, Willd. Enum. Hort. Berol, $845=$ flavescens. baeticus, Nym. Consp. $419=$ lanatus.

brasiliensis, Vell. Fl. Flum. 342 ; viii. t. 77.-Bras. caeruleus, Linn. Sp. Pl. $830=$ Carduncellus caerulens. cancellatus, Lam. Fl. Fr. ii. $10=$ Atractylis cancellata. canescens, Lam. l. c. $=$ Cnicus Acarna.

canescens, [Soland. in] Russell, Aleppo, ed. II. ii. 262. -Aleppo.

Carduncellus, Linn. Sp. P1. 831 = Carduncellus monspeliensium.

carolinianus, Walt. Fl. Carol. $194=$ Elephantopus carolinianus? 


\section{CARTHAMUS:}

corymbosus, Linn. Sp. Pl. ed. II. $1164=$ Cardopatium corymbosum.

creticus, Linn. 1. c. $1163=$ lanatus.

creticus, Nym. Consp. $419=$ glaucus .

cyaneus, Banks, ex Steud. Nom. ed. II. i. $300=$ Stokesia cyanea.

cynaroides, Bieb. Tabl. Casp. 195=Cousinia cynaroides.

dentatus, Vahl, Symb. Bot. i. 69.-As. Min.

dianius, Sch. Bip. in Webb \& Berth. Phyt. Canar. ii.

$363=$ Carduncellus caeruleus

elatus, Nym. Consp. 419.-Italia.

ferox, Lam. Fl. Fr. ii. $11=$ Cnicus ferox. ferox, Lam. Willd. $S_{p}$. Pl. iii. 1706.-As. Min.;
Syria.

fluminensis, Vell. Fl. Flum. 342 ; viii. t. 78.-Bras.

glaber, Burm. f. Fl. Cap. Prod.23.-Afr. austr.

glaucus, Bieb. Fl. Taur. Cauc. ii. 284.-Aegypt.; As. Min.; Persia.

gummiferus, Lam. Encyc. i. $639=$ Atractylis gummifera.

helenioides, Desf. Fl. Atlant. ii. 258. t. 230.Algeria.

hircinus, Lag. ex Spreng. Syst, iii, $391=$ arborescens.

hispanicus, Sch. Bip. in Webb \& Berth. Phyt. Canar. ii. $363=$ Carduncellus caeruleus.

humilis, Lam. Encyc. i. $638=$ Carduncellus pinnatus.

integrifolius, Hort. ex Webb \& Berth. Phyt. Canar. ii $344=$ Carlina salicifolia.

involucratus, Lam. Fl. Fr. ii. 12=Cnicus spinosis. simus.

laevis, Hill, Hort. Kew. $57=$ Stokesia cyanea

lanatus, Linn. Sp. Pl. 830.-Europ.; Oriens.

leucocaulos, Sibth. E Sm. Fl. Graec. t. 842.-Archip. Graec.

linearifolius, Molina, Sagg. Chile, ed. II. 294.Chili.

maculatus, Lam. Encyc. i. $638=$ Silybum Marianum.

magellanicus, Lam. l. c. 640.-Reg. Magellan.

mareoticus, Delile, Fl. Egypte, 276.-Aegypt.

mitissimus, Linn. Sp. Pl. $831=$ Carduncellus mitissimus.

multifidus, Desf. Fl. Atlant. ii. $256=$ Carduncellus caeruleus.

nitidus, Boiss. Fl. Orient. iii. 708.-Syria.

Oxyacantha, Bieb. Fl. Taur. Cauc, ii. 283.-Reg. Caucas.; As. occ.

pectinatus, Desf. Fl. Atlant. ii. $257=$ Carduncellus pectinatus.

persicus, Desf. ex Willd. Sp. Pl. iii. $1707=$ flavescens

persicus, Willd. ex Boiss. Fl. Orient. iii. $708=$ leucocaulos.

pinnatis, Cntand. Fl. Madrit. $412=$ Carduncellus monspeliensium.

pinnatus, Desf. F1. Atlant. ii, $258=$ Carduncellus pinnatus.

polyacantha, Bieb. Tabl. Casp. 58.-Transcauc.

pterocaulos, C. A. Mey. Verz. Pf. Cauc. $67=$ Cousinia Hystrix.

rigidus, Burm. f. Fl. Cap. Prod. 23.-Afr. austr.

rigidus, Willd. Enum. Hort. Berol. $845=$ arborescens.

salicifolizes, Linn, f. Suppl. $350=$ Carlina salicifolia

tauricus, Bieb. F1. Taur. Cauc. ii. $285=$ lanatus.

Teneriffae, f. F. Gmel. ex Steud. Nom. ed. I. 164. -Ins. Teneriffa.

tinctorius, Linn. Sp. Pl. 830.-Geront. cult.

tingitanus, I.inn. 1. c. ed. II. $1163=$ Carduncellus caerulets.

tomentosus, J. F. Gmel. Syst. 1521. Index (quid?)

turbinatus, Nym. Consp. 419.-Sicilia.

CARTODIUM, Soland. ex R. Br. in Trans. Linn. Soc. xii. (1817) $106=$ Craspedia, Forst. f. (Compos.)

CARTONEMA, R. Br. Prod. 271 (1810). COMMELINACEAE, Benth. \& Hook. f. iii. 852.

brachyantherum, Benth. Fl. Austral. vii. 92.-Austral. parviflorum, Hassk, in Flora, lii. (1869) 365. Austral.

philydroides, F. Muell. Fragm. i. 62 = spicatum

spicatum, R. Br. Prod. 271.-Anstral.

spicatum, F. Muell. Fragm, i. 62 = parviforum.

tenue, Caruel, in Nuov. Giorn. Bot. xi. (1879) 216. Austral.

trigonospermum, C. B. Clarke, in DC. Monog. Phan. iii. 264.-Austral.
CARTREMA, Rafin, Sylva Tellur, $184(1838)=$ Osmanthus, Lour. (Oleac.).

americana, Rafin. 1. $c_{\circ}=\mathrm{O}$. americanus

CARUELIA, Parl; Nuov. Gen. e Spec, 21 (1854)=

Ornithogalum, Tourn. (Liliac.). arabica, Parl. 1. c. $22=$ O. arabicum

CARUM, Rup. ex Linn. Syst. ed. I (1735)。 UMBEL LIFERAE, Benth. \& Hook. f. i. 890 .

Anis Actis, Dulac, Fl. Hautes-Pyr. 347 (1867).

Ataenia, Hook. \& Arn. Bot. Beech. Voy. 349 $(1840)$.

Bulbocastanum, Schur, Enum. Pl. Transs. 249 (1866)

BuniUM, Linn. Gen. ed. I. $72(1737)$

Chamarea, Eckl. \& Zeyh. Enum. iii. 346 (1837).

Euosmia, Nutt. in Torr. \& Gray, Fl, N. Am. i. 612 (1840)

ELWENDIA, Boiss. in Ann. Sc. Nat. Sér. III. i. (1844 140 .

Froriepia, C. Koch, in Linnaea, xvi. (1842) 362.

Geocaryum, Coss. \& Dur. Pl. Nouv. et Crit. Esp $112(1851)$

HLADNIKIA, Reichb. Ic Pl Crit. ix, 9 (1831); et F1. Germ. Excurs. 476 (1832)

Huetia, Boiss. Diagn. Ser. II. ii. 103 (1856).

Petroselinum, Hoffm. Umb. i. 78 (1514).

Phymatis, E. Mey. in Drège, Zwei Pfl. Docum. 211 $(1843$

Ptychoris, Koch, in Nov, Act. Nat. Cur. xii. 1. (1824) 124.

RidolfiA, Moris, Ind. Sem. Hort. Taur. (1841) Fl. Sard. ii. 212 (1842)

Selinopsis, Coss. \& Dur. ex Munby, Cat. Pl. Alg ed. II. $13(1859)$, nomen.

Sympouium, C: Koch, in Linnnea, xvi (1842) 356.

TrachySPERMUM, Link, Enum. Hort. Berol, i. 26' (1<21).

Trachyssiadium, Eckl. \& Zeyh. Enum. 341 (1837)

Wydleria, DC. Coll. Mém. v. 36 (1829)

ZrzIA, Koch, in Nov. Act. Nat. Cur, xii. I. (1824) 128

Ajowan, Benth. \& Hook. f. Gen. i. $891=$ copticum.

allioides, Franch, in Ann. Sc. Nat. Sér. VI. xyi. (1883) 294.-Turkest.

alpinum, Benth. \& Hook. f. Gen. i. 891,-Europ. Persia.

ammoides, Benth. E Hook.f.l. c. 892.-Reg. Mediterr anethifolium, Benth. $\varepsilon$ Hook. f. l. c. 891.-Reg. Himal Anisum, Baill. Hist. Pl. vii. 119, $178=$ Pimpinell Anisum.

apiculatum, Kar. E Kir. in Bull. Soc. Nat. Mosc. xv (1842) 358.-As, centr.

armenum, Boiss. in Ann. Sc. Nat. Sér. III. i. (1844)

137.-Reg. Caucas.

aromaticum, Salisb. Prod. $168=\mathrm{C}$. Carvi.

atrosanguineum, Kar. Es Kir. in Bull. Soc. Nat. Moso xv. (1842) 359.-As. centr.

avromanum, Boiss. E Haussk. ex Boiss. Fl. Orient. ii 888.-Persia.

aureum, Benth. \& Hook. f. Gen. i. $891=$ Thaspium aureum.

Bourgaei, Boiss. Fl. Orient. ii. 885.-As. Min

brachycarpum, Boiss. Diagn. Sér. I. x. $23=$ ferulae folium

Bulbocastanum, Koch, in Nov. Act. Nat. Cur. xii. I

(1824) 121-Europ; As. bor.

Bunius, Linn. Syst. Nat. ed. XII. 733.-Europ

bupleuroides, Schrenk, ex Fisch. E Mey. in Bull. Phys.-Math. Acad. Pétersb. iii. (1845) 305. - Soongar.

buriacticum, Turcs. in Bull. Soc. Nat. Mosc. xvi. (1844) 713 -Sibir. baical

calcicolum, Balf. $f$. in Proc. Roy. Soc. Edinb. xi. (1882) 514.- Ins. Socotra.

capense, Sond. in Harv. E Sond. Fl. Cap. ii. 538.Afr. austr.

Capusi, Franch. in Ann. Sc. Nat. Sér. VI. xvi. (1SSצ) 293.-Turkestan.

Carvi, Linn. Sp. Pl. 263.-Europ, ; Oriens; As. bor, carvifolium, Benth. E Hook. f. Gen. i. 892.-Afr. austr.

caucasicum, Boiss. Fl. Orient. ji. 880.-Reg. Caucas, chacrophylloides, Regel of Schmalh. in Act. Hort. Petrop. v. (18:7) 505.-Turkest.

copticum, Benth G Hook. fo Gen. i. 891.-Europ. Afr. bor. : As. bor.

cordatum, Benth. \& Hook. f. 1. c. 891, 913 Thaspjum trifoliatum.

\section{CARUM :}

cornigerum, Boiss. E Haussk. ex Boiss. Fl. Orient. î 887.-Kurdistan.

creticum, Benth. E" Hook. f. Gen. i. 891.-Creta

cylindricum, Boiss. \& Haussk. Diagn. Ser. I. x, 23.-

Persia ; Beluchist.

daucoides, Boiss. in Ann. Sc. Nat. Sér. III. i. (1844 139.-Macedon. ; Lydia.

decussatum, Gilib. F1. Lituan, ii. $3 \uparrow=\mathrm{C}$. Carvi

dichotornum, Benth. E Hook. f. Gen. i. 891.-Reg.

Mediterr. occ.

didymum, Benth. E' Hook, f. L c.-Afr austr.

dissectum, Baill. Hist. Pl. vii. $179=$ Pimpinella magna divaricatum, Koch, Syn. Fl. Germ, 315=ferulaefolium.

divergens, Boiss. Eo Huet, Diagn. Ser. II. ii. 80Armenia.

diversilolium, C. B. Clarke, in Hook. f. Fl. Brit. Ind. ii. 681.-Reg. Himal.

elegans, Fenzl, Pugill. Pl. Nov. Syr. 16.-Oriens.

Elvendia, Boiss. Fl. Orient. ii. 888.-Persia.

Falcaria, Lange, in Willk. E Lange, Prod. Fl. Hisp. iii. 92.-Hispan.

falcarioides, Boiss. \& Buhse, in Nouv. Mém. Soc. Nat. Mosc. xii. (1860) $96=$ elegans.

Falconeri, C. B. Clarke, in Hook. Fl. Brit. Ind. ii. 683 -Reg. Himal.

ferulacfolium, Boiss, Diagn. Ser. I. x. 22.-Reg. Mediterr. or.

flexuosum, Fries, Summa Veg. Scand. 24, $180=$ Conopodium denudatum.

ftexuosum, Nym. Consp. 307.-Italia.

Gairdneri, A. Gray, in Proc. Am. Acad. vii. (1868) 344. - Am. bor. occ.

gracile, Lindl. in Royle, Illustr. Bot. Himal. 232.Ind, or

graecum, Boiss, E Heldr. Diagn. Ser. I, vi. 58-Graevia; Serbia

Hallii, S. Wats. Bibliog. Ind. N. Am. Bot. 416.Calif.

Heldreichii, Boiss. Diagn. Ser. II. ii. 78.-Graecia. heterophyllum, Regel \& Schmalh. in Act. Hort. Petrop. v, (1877) 586,-As, temp.

hispanicum, Mill. Gard. Dict. ed. VIII. n. 2.-Hispan. hispidum, Benth. E Hook. f. Gen. i. 8y1.-Afr. austr. Huetii, Boiss. Diaun. Ser. II. ii. 81 = Bourgaei.

humile, Boiss. \& Bal. ex Boiss. F1. Orient. ii. $881=$ caucasicum.

incrassatum, Boiss. Voy. Bot. Espagne, ii. 239, 731.Hispan.

indicum, Regel E Herd. in Bull. Soc. Nat. Mosc. xxxix. (1866) ir. 72.-Soongaria.

inodorum, Siev. in Pall. N. Nord. Beitr. vii. 229.Rossia.

intermedium, Benth. \& Hook. f. Gen. i. $892=$ inundatum.

inundatum, Lespin. in Act. Soc. Bord. xiv. (1845) 270 - Eurup.

involucratum, Baill. Hist. Pl. vii. $179=$ Rox burghianum.

Kelloggii, A. Gray, in Proc. Am. Acad. rii. $186 \mathrm{~s}$ 344 - Calif

khasianum, C. B. Clarke, in Hook f. Fl Brit. Ind. ii. 682.-Rey. Himal.

latifolium, Benth. E Hook. f. Gen. i. 892.-Europ.

leucocolcon, Boiss. E Huet, Diagn. Ser. II. ii. 80.Armenia.

lomato

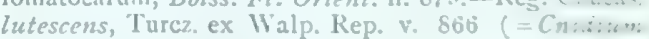
multicaule).-.Sibir.

macrovarpum, Benth. E Hook. f. Gers. i., $1 .-$ Graecia.

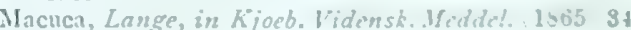
- Hispan.

magnuen, Waill, Hist. Pl, vii, 173= Pimpinclla magna mauritanicum, Boiss. E Reut. Pugill. $\left\{155^{2} ?^{\prime} 49\right.$. - Af lior. oc:

meifolium, Boiss, Fl. Orient. ii. $\$ s 0=$ amenum.

Meum, Stokes, Bot. Mat. Met, ii. 13s = Meum atba. manticum.

microcurpum, Buiss, in Ann. Se, Sinf Sir. III i (18+4) 18:- Lydia.

multuflorum, Boiss. Fl. Orient. ii. \$\$\&.-Graccia; As. IIn

neuruphyllum, Franch. \& Sass. Enam. Pl. Gas. i. $18 \mathrm{a}$ -Japon

nigrum, Baill. Hist. Pl. vii. 1/5=l'smpinclla saw iraga. 


\section{CARUM:--}

nivale, Lange, in Kjoeb. Vidensk. Meddel. (1865) 34. - Hispan.

Noëanum, Boiss, Diagn. Ser. II, ii. $77=$ elegans.

nothum, C. B. Clarke, in Hook. f. Fl. Brit. Ind. il 681.-Zeylan.?

officinale, S. F. Gray, Nat. Arr. Brit. P1. ii. $515=$ C Carvi.

oreganum, S. Wats. in Proc. Am. Acad. xx. (1885) 368.-Am, bor. occ.

Panatjan, Baill. Hist. PI. vii. $178=$ Pimpinella Panat jan

Pansil, Griseb. in Goett. Abh. xxiv. (1879) 146.-Reg. Argent.

paucifolium, DC. Prod. iv. $117=$ elegans.

peregrinum, Linn. Diss. Dem. Pl. in Amoen. Acad. iii. 406.-Peruv?

persicum, Boiss. in Ann. Sc. Nat. Sér. III. i. (1844) 138.-Persia.

Pestalozzae, Boiss. Fl. Orient. ii. 886,-Persia; Beluchist.

Petroselinum, Benth. E Hook.f.Gen. i. 891.-Geront. cult.

pimpinelloides, Balf. $f$. in Proc. Roy. Soc. Edinb. xi. (1882) 514.-Ins, Socotra

Podagraria, Roth, Enum. Pl. Phan. Germ. i. $946=$ Aegopodium Podagraria.

polyphyllum, Boiss. Ë Bal. ex Boiss. Fl. Orient. ii. 881.--Syria.

purpurascens, Boiss. in Tchihat. Asie Min. Bot. i. 411 = elegans.

rectangulum, Boiss. E Haussk. ex Boiss. Fl. Orient. ii 884.-Persia

Ridolfia, Benth. EN Hook. f. Gen. i. 891.-Reg. Mediterr.; Oriens.

rigidulum, Koch, in DC. Prod. iv. 115.-Italia.

rigidum, Steud. Nom. ed. II. i. $301=$ rigidulum.

Roxburghianum, Benth. E Hook. f. Gen. i. 891.--Ind or.; Malaya.

rupestre, Boiss, E Heldr. Diagn. Ser. II. ii. 79.Graecia

Saxifraga, Baill. Hist. Pl, vii. 178=Pimpinella Saxifraga.

Saxifraga, Benth. \& Hook. f. Gen. i. $892=$ C. Bunius. segetum, Benth. छ Hook. f. l. c.-Europ.

setaceum, Schrenk, Enum. Pl. Nov. 61.-Soongaria

Sewerzowi, Regel, in Act. Hort. Petrop. v. (1877) 587 , 588.-Turkestan.

simplex, Steph. ex Willd. Sp. Pl. i, $1470=$ Seseli annuum. Sisarum, Baill. Hist. P1. vii. $179=$ Sium Sisarum.

stictocarpum, C. B. Clarke, in Hook. f. Fl. Brit. Ind. ii. 681 .- -Ind. or

strictum, Boiss. Fl. Orient ii. 887.-Macedon.

sulcatum, Steud. Nom, ed, I. 164, $49=$ Selinum Carvifolia.

sylvestre, Baill. Hist. Pl. vii. 179.-Ind. or.

Tanakae, Franch. E Sav. Enum. Pl. Fap. ii. 371. Japon.

tenuifolium, Benth. E Hook.f. Gen. i. 891.-Hispan. ; Marocco.

Thorei, Benth. \& Hook. f. 1. c. 888 , in obs. = inundatum trichophyllum, Schrenk, Enum.Pl.Nov.61.-Soongaria. verticillatum, Koch, in Nov.Act. Nat. Cur. xii. I. (1824) 122.-Europ.

CARUMBIUM, Kurz, For. F1. Brit. Burma, ii. 411 $(1877)=$ Sapium, P. Br. (Euphorb.).

baccatum, Kurz, 1. c. $412=\mathrm{S}$. baccatum.

insigne, Kurz, 1. c.-Burma.

sebiferum, Kurz, 1. c. =S. sebiferum.

CARUMBIUM, Reinw. Elench. Sem. Hort, Leid. ex Isis (1823) 319; et in Syll. Katisb. ii. (1828) $6=$ Homalanthus, A. Juss. (Euphorb.).

acuminatum, Muell. Arg. in DC. Prod. xv. II. 1144. -Ins. Pacif.

amboinicum, Miq. Fl. Ind. Bat. i. II. 413.-Malaya.

fastuosum, Muell. Arg, in DC. Prod, xv. II. 1144=H. fastuosus.

giganteum, Muell. Arg. ex Miq. FI. Ind. Bat. i. II. 687 $=\mathrm{H}$. giganteus.

Moerenhoutianum, Muell. Arg. in DC. Prod. xv. Ix 1146. - Ins. Pacif.

nutans, Muell. Arg. 1. c. $=$ H. nutans.

pallidum, Muell. Arg. in Linnaea, xxxii. (1863) $85=$ H. Leschenaultianus.

pedicellatum, Miq. F1. Ind. Bat. i. II. $414=$ H. pedicellatus.

\section{CARUMBIUM :-}

platyneuron, Muell. Arg. in DC. Prod. xv. II. $1145=$ Homalanthus Leschenaultianus.

polyandrum, Hook. f. Handb. New Zeal. Fl. 248.N. Zel.

populifolium, Reinw. in Blume, Cat. Hort. Buitenz. $105=$ H. Leschenaultianus.

populneum, Muell. Arg. in DC. Prod. xv. II. 1144= praec.

Sieberi, Muell. Arg, in Linnaea, xxxii. (1863) $85=\mathrm{H}$. Leschenaultianus.

stillingiaefolium, Baill. Adansonia, vi. (1865-66) 325 $=$ H. stillingiaefolius.

CARUNCULARIA, Haw. Syn. Pl. Succ. $333(1812)=$ Stapelia, Linn. (Asclepiad.)

aperta, Sweet, Hort. Brit. ed. II. $359=$ S. aperta.

Facquini, Sweet, 1. $c_{0}=\mathrm{S}$. pedunculata.

Massoni, Sweet, 1.c. $=$ S. pedunculata.

pedunculata, Haw. Syn. Pl. Succ. $334=$ S. pedunculata. penduliflora, Sweet, Hort. Brit. ed. II. $359=$ S. penduliflora.

serrata, Decne. in DC. Prod. viii. 658, sphalm. =seq.

serrulata, G. Don, Gen. Syst. iv. $122=$ Piaranthus serrulatus.

Simsii, Sweet, Hort. Brit. ed. II. $358=$ S. pedunculata.

CARVI, [Tourn.] Bernh. Syst. Verz. Erf. 114 (1800) Selinum, Tourn. (Umbellif.)

sulcatum, Bemh. 1. c. $169=\mathrm{S}$. Carvifolia.

CARvifoliA, C. Banh. ex Vill. Hist. Pl. Dauph. ii. $629(1787)$ Selinum, Tourn. (Umbellif.).

CARYA, Nutt, Gen. Am. ii. 220 (1818). $L A N D E A E$, Benth. \& Hook. f. iii. 398.

Hicorius, Rafin. Fl. Ludov. 109 (1817).

Scoria, Rafin. in Med. Repos. N. York, v. (1808) 352 , nomen prius.

alba, Nutt. L. c. 221. -Am. bor.

amara, Nutt. l. c. 222.-Am. bor

angustifolia, Sweet, Hort. Brit, ed. I. $97=$ olivaeformis.

aquatica, Nutt. Gen. Am. ii. 222.-Am. bor.

compressa, G. Don, in Loud. Hort. Brit. $384=$ alba.

cordiformis, C. Koch, Dendrol. 1. $597=$ sulcata.

glabra, Sweet, Hort. Brit. ed. I. $97=$ porcina.

illinoënsis, C. Koch, Dendrol, i. $593=$ olivaeformis integrifolia, Spreng. Syst. iii, 849.-Louisian. laciniosa, Loud. Hort. Brit. 384, nomen=sulcata mexicana, Engelm. ex Hemsl. Biol. Centr. Am. Bot iii. 162.-Mexic.

microcarpa, Nutt. Gen. Am. ii. 221.-Am. bor.

myristicaeformis, Nutt. l. c. 222.-Am. bor.

obcordata, Sweet, Hort. Brit. ed. I. $97=$ porcina

olivaeformis, Nutt. Gen. Am. ii. 221.-AAm. bor.

ovata, C. Koch, Dendrol. i. $598=$ alba.

porcina, Nutt. Gen. Am. ii. 222.-Am. bor.

pubescens, Sweet, Hort. Brit. ed. I. $97=$ sulcata

sulcata, Nutt. Gen. Am, ii. 221.-Am. bor.

tetraptera, Liebm. in Kjoeb. Vidensk. Meddel. (1850) $80=$ olivaeformis

texana, C. DC. in Ann. Sc. Nat. Sér. IV. xviii. (1862) 34.--Texas.

tomentosa, Nutt. Gen. Am. ii. 221.-Am. bor.

CARYOCAR, Linn. Mant. ii. 247, n. 1314 (1771) TERNSTROEMIACEAE, Benth. \& Hook. f. i. 180. ACAntacaryx, Arruda, ex Koster, Trav. Braz. 49$]$ (1816).

Barollaea, Neck, Elem. ii. 322 (1790)

Pekea, Aubl. Pl. Gui. 594 (1775).

Rhizobolus, Gaertn, ex Schreb. Gen. 369 (1789);

et Fruct. ii. 93. t. 98 (1791).

Saouari, Aubl. Pl. Gui. 599 (1775).

amygdaliferum, $C a v . I c$. iv. 37.tt. 361, 362,-N. Granat amygdaliforme, Ruiz \& Pav. Fl. Per, v. t. 570.Peruy.

barbinerve, Miq. in Linnaea, xxii. (1849) 802.-Bras brasiliense, St. Hil. Fl. Bras. Mer. 1. 322.-Bras. butyrosum, Willd. Sp. Pl. ii. 1243.-Guiana.

edule, Casar. Decad. Nov. Stirp. Bras. viii. 67.Bras.

glabrum, Pers. Syn. ii. 84.-Guiana

nuciferum, Linn. Mant. ii. 247.-Guiana.

tomentosum, Willd. Sp.Pl. ii. 1244.-Guiana.

tuberculosum, Baill. Hist. Pl. iv. $251=$ tomentosum.

villosum, Pers. Syn. ii. 84.-Guiana.
CARYOCHLOA, Spreng. Syst. iv. Cur. Post. 22 (1827)= Oryzopsis, Michx. (Gramin.)

chilensis, Spreng. ex Trin. in Mém. Acad. Pétersb. Sér VI. iii. II. (1835) 123 (=Stipa Caryochloa) montevidensis, Spreng. Syst. iv. Cur. Post. 30 (=Stipa setifolia).-Reg. Argent.

refracta, Spreng. ex Trin. in Mém. Acad. Pétersb. Sér

VI. iii. II. (1835) $124(=$ Stipa Caryochloa).

CARYOCHLOA, Trin. Gram. Panic. Diss. ii. 54 (1826) $=$ Luziola, Juss. (Gramin.

bahiensis, Steud. Syn. Pl. Gram. 5.-Bras.

brasiliensis, Trin. ex Nees, Agrost. Bras. 299.-Bras caudata, Trin. ex Steud. Nom. ed. II. i. 301.-Bras.

CARYOCOCCA, Willd, ex Roem, \& Schult. Syst. iii. Mant. 131 (1827)= Gonzalea, Pers. (Rubiac.).

dependens, Willd. ex Roem. \& Schult. 1. c. $=\mathrm{G}$. pendula.

multiflora, Willd. ex Roem. \& Schult. 1. c. $132=$ G. pendula.

CARYODAPHNE, Blume, ex Nees, Syst. Laurin. 225 $(1836)$ = Cryptocarya, R. Br. (Laurin.)

australis, A. Br. Ind. Sem. Hort. Berol. (1851) App. $13=$ Crypt. australis.

Browniana, Nees, Syst. Laurin. $230=$ Crypt. triplinervis.

costata, Miq. in Zoll. Syst. Verz. Ind. Archip. 113, $115=$ Crypt. costata.

densiflora, Blume, ex Nees, Syst. Laurin. $228=$ Crypt. densiflora.

laevigata, Blume, 1. c. $227=$ Crypt. laevigata

CARYODENDRON, Karst, F1, Colomb, i, 91, t. 45 (1858). EUPHORBIACEAE, Benth. \& Hook. f iii. 314 .

Centrodiscus, Muell. Arg, in Mart. Fl. Bras. xi. II. 325. t. $102(1874)$.

orinocense, Karst. l. c.-N. Granat.

CARYOLOBIS, Gaertn. Fruct. i. 215. t. $45(1788)=$ Doona, Thw. (Dipteroc.)

indica, Gaertn. 1. c. = D. cordifolia?

CARYOLOBIUM, Stev, in Bull. Soc. Nat. Mosc. iv. (1832) $266=$ Astragalus, Tourn. (Legumin.). macrocarpos, Stev. 1. c。 $=$ A. macrocarpus.

CARYOLOPHA, Fisch, \& Trauty, Ind. Sem. Hort. Petrop. iii. 31 (1837)=Anchusa, Linn. (Boragin.) sempervirens, Fisch. \& Trautv. I. c. $=$ A. sempervirens.

CARYOPHYLLATA, Tourn. ex Scop, Fl. Carn. ed. II. i. $364(1772)=$ Geum, Tourn. (Rosac.).

alba, Moench, Meth. $660=\mathrm{G}$, album.

aquatica, Lam. Fl. Fr. iii. $123=\mathrm{G}$. rivale. kamtchatica, Lam. Encyc. i. $400=\mathrm{G}$. anemonoides montana, Scop. Fl. Carn. ed. II. i. $365=\mathrm{G}$. montanum nutans, Lam. Encyc. i. $399=G$, nutans.

nutans, Moench, Meth, $661=\mathrm{G}$, rivale.

obliqua, Moench, l. c. Suppl. $280=$ G. obliquum. officinalis, Moench, Meth. $660=\mathrm{G}$. urbantum. potentilloides, Lam. Encyc. i. $400=$ Coluria geoides. prolifera, Gilib. Fl. Lituan. 416.-Europ. reptans, Lam. Fl. Fr. iii. $122=$ G. reptans. rivalis, Scop. Fl. Carn, ed. II. i. $365=\mathrm{G}$, rivale, urbana, Scop. 1. c. $364=\mathrm{G}$. urbanum

virginiana, Iam. Encyc. i. $399=\mathrm{G}$. virginianum. vulgaris, Lam. Fl. Fr. iii. 122 = G. urbanum.

CARYOPHYLLEA, Opiz, Seznam, 27 (1852)= Aira, Linn. (Gramin.)

airoides, Opiz, 1. c. = A. caryophyllea

praecox, Opiz, l. c. =A, praecox.

CARYOPHYLLUS, Linn. Syst. ed. I $(1735)=$ Eugenia, Linn. (Myrtac.).

acutangulus, Stokes, Bot. Mat. Med. iii. $75=$ Barringtonia acutangula.

adenolepis, Miq. F1. Ind. Bat. i. 466.-Java. antisepticus, Blume, ex DC. Prod. iii. 262.-Java. aromaticus, Linn. Sp. Pl $515=\mathrm{E}$ caryophyllata

baladensis, Brongn. \& Gris, in Bull. Soc. Bot. Fr。 xii (1865) 185.-N. Caled.

corticosus, Stokes, Bot. Mat. Med. nii. $75=$ E. Jambolana. 
CARYOPHYLLUS :-

cotinifolius, Mill. Gard. Dict. ed. VIII. n. 4=Myrcia coriacea.

elegans, Brongn. \& Gris, in Bull. Soc. Bot. Fr. xii. (1865) $184 .-\mathrm{N}$. Caled.

ellipticus, Labill. Sert. Austr. Caled. 64. t. 63.-N. Caled.

fastigiatus, Blume, ex DC. Prod. iii. 262.-Java.

floribundus, Blume, ex DC. 1. c.- Java.

fruticosus, Mill. Gard. Dict. ed. VIII. n. $3=\mathrm{E}$, biflora.

Fambos, Stokes, Bot. Mat. Med. iii. $73=$ E. Jambos.

hortensis, Noronha, in Verh. Batav, Gen. v. (1790) ed. I. Art. IV. $11=$ E. caryophyllata?

malaccensis, Stokes, Bot. Mat. Med. iii. $72=\mathrm{E}$, malaccensis.

Pimenta, Mill. Gard. Dict. ed. VIII. n. $2=$ Pimenta officinalis.

pterocarpus, Vieill, ex Panch. \& Sebert, Not. Bois. Nouv. Caléd. 256.-N. Caled.

racemosus, Mill. Gard. Dict. ed. VIII. n. $5=\mathrm{E}$. acris.

racemosus, Stokes, Bot. Mat. Med. iii. $76=$ Barring tonia racemosa.

CARYOPHYLLUS, Tourn. ex Moench, Meth. 58 (1794) = Dianthus, Lino. (Caryophyll.).

aridus, Moench, Meth. 59=D. prolifer.

armerius, Moench, $1 . \mathrm{c}_{0}=\mathrm{D}$. Armeria.

atrorubens, Moench, Meth. Suppl. $23=$ D. atrorubens.

barbatus, Moench, Meth, $59=$ D. barbatus.

Carthusianorum, Moench, 1. c. = D. Carthusianorum.

deltoides, Moench, 1. c. $=\mathrm{D}$. deltoides.

glaucus, Moench, 1. $c_{t}=\mathrm{D}$. deltoides.

plumarius, Moench, $1 . \mathrm{c} .=\mathrm{D}$. plumarius

superbus, Moench, 1. c。 = D. superbus.

CARYOPTERIS, Bunge, P1, Mongholico-Chin, 27 (1835). VERBENACEAE, Benth. \& Hook. fo ii. 1157 .

BARbula, Lour. Fl. Cochinch. 366 (1790), nomen prius.

Mastacanthus, Endl. Gen. 638 (1839).

divaricata, Maxim. in Bull. Acad. Pétersb. xxiii. (1877) 390.-Japon.

grata, Benth. \& Hook. f. Gen. ii. 1158.-Reg. Himal. incana, Miq. Ann. Mus. Bot. Lugd. Bat. ii. 97.Japon.

Mastacanthus, Schau. in DC. Prod. xi. 625.-China.

mongholica, Bunge, Fl. Mongholico-Chin. 28.-China bor.

nepetaefolia, Maxim. in Bull. Acad. Pétersb. xxiii. (1877) 390.-China.

ovata, Miq. in Fourn. Bot. Néerl. i. (1861) 114.China.

paniculata, C. B. Clarke, in Hook. f. Fl. Brit. Ind. iv. 597.-Reg. Himal.

tangutica, Maxim. in Bull. Acad. Pétersb. xxvii. (1881) 525.-China

terniflora, Maxim. in Bull. Soc. Nat. Mosc. liv. (1879) I. 40.-China.

Wallichiana, Schau. in DC. Prod. xi. 625.-Reg. Himal.

CARYOSPERMUM, Blume, Mus. Bot. Lugd. Bat. i. $175(1850)$. CELASTRINEAE, Benth. \& Hook. f. i. 367 .

arborescens, F. Muell. Fragm. viii. 279,-Austral

moluccanum, Blume, Mus. Bot. Lugd. Bat. i. 176.Ins. Molluce.

serrulatum, Miq. Fl. Ind. Bat. i. II. 592.-Java.

CARYOTA, Linn. Mus. Cliff. 12 ; et Gen, ed. I. 355 (1737). PALMAE, Benth. \& Hook. f. iii. 918

Alberti, F. Muell. ex H. Wendl. in Linnaea, dxxix (1875) 221 = Rumphiana.

Cumingii, Lodd. ex Mart. Hist. Nat. Palm. iii.315.Ins. Philipp.

clegans, Hort. ex H. Wendl. in Kerch. Palm. 238, nomen.-Hab.

excelsa, Hort. ex H. Wendl. l. c. nomen.-Hab.?

furfuracea, Blnme, in Mart. Hist. Nat. Palm. iii. 195 $=$ mitis.

Grifithii, Becc. in Nuov. Giom. Bot. iii. (1871) $15=$ mitis.

horrida, Jacq. Fragm, $20=$ Bactris caryotaefolia.

\section{CARYOTA :-}

humilis, Reinw. ex Kunth, Enum. Pl. iii. 193 = Didy mosperma porphyrocarpa.

javanica, Zipp. ex Miq. Fl. Ind. Bat. iii. $41=$ mitis majestica, Linden, Illustr. Hortic. xxviii. (1881) 16. Ins. Philipp.

maxima, Blume, in Mart. Hist. Nat. Palm iii. 195.Java.

mitis, Lour. Cochinch.697.-Malaya ; Cochinch. nana, Linden, Illustr. Hortic. xxviii. (1881) 16.-Ins. Philipp.

nana, Wall. Cat. n. $8595=$ mitis.

Nó, Becc. in Nuov. Giorn. Bot. iii. (1871) 12.Borneo.

obtusa, Griff. in Calc. Fourn. Nat. Hist. v. (1845) 480.-Reg. Himal.

obtusidentata, Griff. Palms Brit. Ind. t. $236 \mathrm{~A}, \mathrm{~B}=$ praec.

ochlandra, Hance, in Journ. Bot. xvii. (1879) $174=$ obtusa?

onusta, Blanco, F1. Filip. ed. I. $741=$ Arenga saccharifera.

Palindan, Blanco, 1. c. ed. I. 714; ed. II. $513=$ Orania regalis.

Princeps, Voigt, in Syll. Ratisb. ii. (1828) 51.$\mathrm{Hab}$ ?

propinqua, Blume, in Mart. Hist. Nat, Palm. iii. $195=$ mitis

Rumphiana, Mart. l. c.-Malaya; Austral.

sobolifera, Wall. in Mart. 1. c. 194. t. 107. f. $2=$ mitis.

speciosa, Linden, Illustr. Hortic. xxviii. (1881) 16.Ins. Philipp.

tremula, Blanco, Fl. Filip. ed. I. $744=$ Didymosperma tremula.

urens, Blanco, 1. c. $740=$ Cumingii.

urens, Jacq. Fragm, 20. t. 12. f. $1=$ mitis.

urens, Linn. Sp. Pl. 1189.-As, trop.

CARYOTAXUS, Zucc. ex Endl. Syn. Conif. 240 (1847) = Torreya, Arn. (Conif.).

grandis, Henk. \& Hochst. Nadelhoelz. $367=\mathrm{T}$. grandis.

Myristica, Henk. \& Hochst. 1. c. $368=$ T. californica. nucifera, Zacc. ex Endl. Syn. Conif. $241=\mathrm{T}$, nucifera. taxifolia, Henk. \& Hochst. Nadelhoelz. $367=T$, taxi axifolia,
folia.

CASAlEA, St. Hil. Fl. Bras. Mer, i. 8.t. $1(1825)=$

Ranunculus, Tourn.

ascendens, St. Hil. 1. c. $11=\mathrm{R}$. cordifolius.

biternata, St. Hil. 1. c. 9 , in obs. $=\mathrm{R}$. biternatus.

breviscapa, St. Hil. 1. c. $=$ R. breviscapus.

chilensis, St. Hil. 1. c. = R. chilensis.

ficarifolia, St. Hil. 1. c. $10=\mathrm{R}$. bonariensis.

flagelliformis, St. Hil. 1. c. $11=\mathrm{R}$, flagelliformis

hederacea, Mart. ex Eichl. in Mart. F1. Bras. xiii. $156^{\circ}=\mathrm{R}$. sessiliflorus.

phyteumaefolia, St. Hil. Bras. Mer. i. $9=$ R. bonariensis. sessilifiora, St. Hil. 1. c. = R. platensis.

CASARETTOA, Walp. Rep. iv. $91 \quad(1844)=$ Vitex, Linn. (Verbenac.).

diversifolia, Walp. 1. c. $92=\mathrm{V}$. triflora.

mollissima, Walp. 1. c. $91=\mathrm{V}$. polygama.

CASASIA, A. Rich. Fl. Cub. Fanerog. ii. 9. t. 49 (1853). RUBIACEAE, Benth. \& Hook. f. ii. 84. calophylla, A. Rich.l. c.-Cuba.

CASCABELA, Rafin. Sylva Tellur, 162 (1538)= Cerbera, Linn. (Apocyn.) peruviana, Rafin. 1. c.= Cerb. peruviana.

CASCAliLLA, Adans, Fam。ii. $355(1763)=$ Croton Linn. (Euphorbiac.)

aromatica, Rafin. Sylva Tellur. $62=$ Crot. aromaticus discolor, Rafin. 1. c. = Crot. discolor.

linearis, Rafin, 1. $c_{2}=$ Crot. linearis.

officinalis, Ratin. 1. c. = Crot. Cascarilla.

CASCARILLA, Ruiz, ex Steud. Nom. ed, I. 165 (1S21 Cinchona, Linn. (Kubiac.)

pallida, Steud. 1. c. = Cinch, cordifolia,

CASCARILLA, Wedd. in Ann. Sc. Nat. Sér. III. (1848) 10, 77. RUBIACEAE, Bcnth. \& Hook. f. ii 3.2 .
CASCARIIIA.

Buena, Pohl, ex Wedd, in Journ. Linn. Soc. xi (1871) 185

LADENBERGIA, Klotzsch, in Hayne, Arzn. Gew, xiv. in not. ad t. 15 (1846)

acutifolia, Wedd. in Ann.Sc. Nat. Sér. III. x. (1848) 11.-Peruv.

bullata, Wedd. l. c. 11.-Perav.

caduciflora, Wedd.l. c. 10.-Peruv.

calycina, Wedd. l. c. $12,-\mathrm{N}$. Granat.

calyptrata, Wedd.l.c. 13.-Peruv.

Carua, Wedd.l.c. 12.-Peruy

citrifolia, Wedd. l. c. 11.-Venezuela.

Gaudichaudiana, Wedd. l. c. 12.-Bras.

gavanensis, Schlecht. in Linnaea, xxvi. (1853) 730.Peruy.

grandiflora, Linden, in Belg. Hortic. vii. (1857) 197. -N. Granat.

heterophylla, Wedd. in Ann. Sc. Nat. Sér. III. x. (1848) 10.-N. Granat

hexandra, Wedd. l. c. 12.-Bras.

Hookeriana, Wedd. Hist. Nat. Quinq. 91.-N. Granat Lambertiana, Wedd. l. c. 85.-Bras.

macrocarpa, Wedd. in Ann. Sc. Nat. Sér. III. x. (1848) 13.-N. Granat. ; Peruv.

magnifolia, Wedd. l. c. 10.-Bolivia.

muzonensis, Wedd. l. c. 11.-N. Granat.

nitida, Wedd. l. c. 11.-Venezuela.

oblongifolia, Wedd. 1. c. 12 = magnifolia

officinalis, Ruiz, Quinol. 56.-Pernv.

Pavonii, Wedd. in Ann. Sc.Nat.Sér, III. x. (1848) 11. -Peruv.

Riedeliana, Wedd. l. c. 12.-Bras.

Riveroana, Wedd. l. c. 11.-Peruv.

Roraimae, Wedd.l.c. 12.-Guiana.

rostrata, Wedd.l. c. 10.-Boliv.; Peruv.

stenocarpa, Wedd. Hist. Nat. Ouing. 81.-Perap.

undata, Wedd. in Ann. Sc. Nat. Sér. III. x. (1848) 12.-Venezuela.

CASCARONIA, Griseb. in Goett. Abh. xxiv. (1879) 100. LEGUMINOSAE

astragalina, Griseb. l.c.-Reg. Argent.

CASCOELYTRUM, Beauv. Agrost. $85(1812)=$ CHAS COLYTRUM, Desv, = Briza, Linn. (Gramin.)

CASEARTA, Jacq. Enum. Pl. Carib. 4 (1760). SAMY$D A C E A E$, Benth. \& Hook. f.i. 796.

ANAVINGA, Lam. Encyc. 1. 147 (1783).

ANTIGONA, Vell. Fl. Flum. iv. t. 145 (1827)

ATHENAEA, Schreb. Gen. i. 259 (1789).

Bedusia, Rafir. Sylva Tellur, 11 (1838)

Chaetucrater, Ruiz \& Pav. Prod. Fl. Per. 61. $36(1794)$

CHetockater, Rafin. Sylva Tellur. 149 (1838).

Clasta, Comm, ex Vent. Choix, sub t. 47 (1803).

Corizospermum, Zipp. ex Blume, Mus. Bot. Lagd. Bat. i. $255(1850)$.

Crateria, Pers. Syn. i. 485 (1805)

GuIDONIA, Griseb. Fl. Brit. W. Ind. 24 (1864).

IROUCANA, Anbl. Pl. Gui, i $328,1,127(1775)^{\circ}$

L.NGLFiA, Scop. Introd. 231 1:\%

Lindleya, Kunth, Malv, 10 (1822

Melistaurum, Forst. Char. Gen. 143. t. 72 (1776\%

Moelleria, Scop. Introd. $335(1777)$

PIPAREA, Aubl. Pl. Gui. ii. App. 30 . t. $\$ \$ 6$ 1775)

Prtumba, Aubl. 1. c. 29. t. $\$ 85(17-5)$

ThIODIA, Griseb. Fl. Brit. IW. Ind. 22 1864.

Valentinia, Sw. Prod. Veg. Ind. Occ. 63 (1;88)

VARECA, Gaertn. Fruct. i. 290. t. 6001785

ZuELANIA, A. Rich. Ess, Fl. Cub. 88. t. 12 1845)

aculeat $\alpha$, Jacq. Enum. P1. Carib. $21=$ spinosa.

acuminata, $D C$. Prod, ii. 50,-Guiana,

acuminato, Wall. Cat. D. jlys (non Cascaria:Ind. or.

acuminatissima, A. Gray, Bot. U. St. Expl. Exped. i. 80.-Ins. Fiji.

adamantium, Cambess, in .4.St. Hil. Fl. Bras. Mer, iो. 230.- - Bras.

adstringens, Mart. Mat. Med. I'es. Brazs. 51.-Bras.

aftinis, Garda. in Hook. Lond. Joura. Bor. i 1842

$5: 9=$ sylvestris.

alba, A. Rich. Ess. Fl. Cub. sss.-Cuba

albicans. Wiall. Cat. n, i197.-Malay.

amplissima, Tsel. in Ann. Sc. Nat. Ser. V. ir 1=60

8.2. - Madag.

Amasinga, Dalz s Gibs. Bomb. Fl. 11-comentusa. 


\section{CASEARIA:}

Anavinga, Pers. Syn. i. $485=$ ovata.

angustata, Teijsm. E Binn. in Nederl. Kruidk. Arch. iii. (1855) 409.-Java.

aquifolia, Sauv. Fl. Cub. 6. Cuba.

arguta, H. B. \& K. Nov. Gen. et Sp. v. $363=$ parvifolia.

astyla, Turcz. in Bull. Soc. Nat. Mosc. xxxvi. (1863) 608.-Ind. or.

avellana, Miq. ex Eichl, in Mart. Fl. Bras. xiii. I. 463 = spinosa.

Barteri, Mast. in Oliver, Fl. Trop. Afr. ii. 494.-Afr. trop.

Benthamiana, Miq. in Ann.Sc. Nat. Sér. III. i. (1844) 38.-Bras.

Berteriana, Turcz. in Bull. Soc. Nat. Mosc. xxxi. (1858) 461.-Porto Rico.

Blanchetiana, Miq. in Linnaea, xxii. (1849) 801.Bras.

brasiliensis, Eichl. in Mart. Fl. Bras. xiii. I. 477.Bras.

brevipes, Benth. in Hook. Fourn. Bot. iv. (1842) 110. - Guiana ; Ind, occ.

Cambessedesii, Eichl, in Mart. Fl. Bras, xiii. I. 475 Bras.

Canziala, Buch.-Ham. in Wall. Cat. n. $7192=$ tomentosa.

capitata, Spreng. Syst. ii. $355=$ sylvestris.

capitellata, Blume, Mus. Bot. Lugd. Bat. i. 254.Borneo.

carpinifolia, Benth. in Hook. Journ. Bot. iv. (1842) $112=$ parvifolia.

celastroides, Klotssch, in Schomb. Faun. et Fl. Guy. 1167 , nomen.-Guiana.

celtidifolia, H. B. E K. Nov. Gen. et Sp. v. 362... Venezuela.

Championi, Thw. Enum. PI. Zeyl. $19=$ esculenta.

cinerea, Turcz. in Bull. Soc. Nat. Mosc. xxxi. (1858) $462=$ grewiaefolia.

Clausseniana, Miq. in Linnaea, xix. (1847) 441.Bras.

clutiaefolia, Blume, Mus. Bot. Lugd. Bat. i. 255-N. Guinea.

combaymensis, Tul. in Ann. Sc. Nat. Sér. III. vii. (1847) 362.-N. Granat.

Commersoniana, Cambess. in St. Hil. Fl. Bras. Mer. ii. 235 -Bras.

comocladifolia, Vent. Choix, t. 44.--Ins. S. Doming.

congestiflora, Turez. in Bull. Soc. Nat. Mosc. xxxvi. (1863) I. 608.-Bras.

contermina, Miq. Fl. Iwä. Bat. i. I. 707.-Java.

coriacea, Thw. Enum. Pl. Zeyl. 20.-Zeylan.

coriacea, Vent. Choix, t. 45.--Java.

coriacea, Wall. Cat. n. $¥ 196=$ Chaetocarpus castanocarpus.

corymbosa, H. B. K. Nov. Gen. et Sp. v. 366.-N. Granat.

cuspidata, Blume, Mus. Bot. Lugd. Bat. i. 255.Sumatra.

Dallachii, F. Muell. Fragm. v. 107=tomentosa

decandra, Jacq. Enum. PI. Carib, $21=$ parvifolia

densiflora, Benth. in Hook. Fourn. Bot. iv. (1842) 113. -Guiana.

dentata, Moc. E Sesse, in DC. Prod. ii. 51.-Mexic.

disticha, A. Gray, Bot. U. St. Expl. Exped. i. $81=\mathrm{C}$. Melistaurum.

dubia, Moc. E Sesse, in DC. Prod. ii. 51.-Mexic

elliptica, Klotzsch, in Schomb. Faun. Er Fl. Guy. 1167, nomen.-Guiana.

elliptica, Willd. Sp. Pl. ii. $628=$ tomentosa.

emarginata, Griseb. Cat. Pl. Cub. 10.-Cuba.

eriophora, Wright, ex Griseb. l. c. 11-Cuba.

esculenta, Roxb. Hort. Beng. [90]; Fl. Ind. ii. 422.As. trop.; Austral.

fallax, Miq. in Linnaea, xix. (1847) 128.-Guiana.

fasciculata, Boj. Hort. Maurit. 71 =fragilis.

flavovirens, Blume, Mus. Bot. Lugd. Bat. i. 254.Java.

Fockeana, Miq. in Ann. Sc. Nat. Sér. III. i. (1844) 39.-Guiana.

fragilis, Vent. Choix, 47, verso.-Ins. Mascar.

fuliginosa, Blanco, Fl. Filip. ed. II. 262.-Ins. Philipp.

glabra, Kurz, ex C. B. Clarke, in Hook. f. F1. Brit. Ind. ii. $591=$ glomerata.

glabra, Roxb. Hort. Beng. 33; F1. Ind. ii. $421=$ tomentosa.

glabrata, Blume, Mus. Bot. Lugd. Bat. i. 253.-Java.

\section{CASEARIA :-}

gladiiformis, Mast. in Oliver, Fl. Trop. Afr. ii. 493.Afr. trop.

glomerata, Roxb. Hort. Beng. 33 ; Fl. Ind. ii. 419.Ind. or.

gonocarpa, Miq. Fl. Ind. Bat. i. I. 1093.-Sumatra.

grandiflora, Cambess. in St. Hil. Fl. Bras. Mer. i, 232. -Bras.

grandifolia, Miq. Fl. Ind. Bat. i. I. 712.-Sumatra

graveolens, Dalz. in Hook. Kew Fourn. iv. (1852) 107. -Ind. or.

grewiaefolia, Vent. Choix, 48.-Malaya.

Guidonia, Benth. in Journ. Linn. Soc. v. Suppl. ii. (1861) $89=$ brevipes

guineensis, G. Don, Gen. Syst. ii. 53.-Afr. trop

Hamiltonii, Wall. Cat. n. $7195=$ graveolens.

hexagona, Decne, in Ann. Nouv. Mus. Par. iii (1834) 429.-Ins. Timor

hirsuta, Sw. Fl. Ind. Occ. ii. 755.-Ind. occ

hirta, Sw. l. c. 756.-Ind. occ.

Hostmanniana, Steud. ex Griseb. Fl. Brit. W. Ind. 23 = stipularis.

hypoleuca, Mart. in Flora, xx. (1837) Beibl. ii. 128.Bras.

icosandra, Planch. Eo Triana, ex Hemsl. Biol. Centr. Am. Bot. i. 469.-Panama.

ilicifolia, Vent. Choix, t. 44.-Ins. S. Doming.

impunctata, Hook. E' Arn. Bot. Beech. Voy. 61.-Ins. Societat.

inaequilatera, Cambess. in A. St. Hil. Fl. Bras. Mer. ii. 237.-Bras.

integrifolia, Vah1, ex DC. Prod. ii. $49=$ sylvestris

javitensis, H. B. E K. Nov. Gen. et Sp. v. 366.-Am. austr.

Kurzii, C. B. Clarke, in Hook. f. Fl. Brit. Ind. ii. 594. -Burma.

laevigata, Dalz. in Hook. Kew Journ. iv. (1852) 108 = esculenta.

lanceolata, Miq. in Linnaea, xviii. (1844) $753=$ stipularis.

lasiophylla, Eichl. in Mart. Fl. Bras, xiii. I. 468.-Bras. lasiosperma, Triana Er Planch, in Ann. Sc. Nat. Sér. IV. x vii. (1862) 113,-N. Granat.

laurifolia, Benth. in Hook. Fourn. Bot. iv. (1842) 113. - Guiana.

laurina, Blume, Mus. Bot. Lugd. Bat. i. 253.-Malaya, leucolepis, Turcz. in Bull. Soc. Nat. Mosc. (1858) I. 463.-Malaya

Lingua, Cambess. in St. Hil. F1. Bras. Mer, ii. $236=$ sylvestris.

Lobbiana, Turcz. in Bull. Soc. Nat. Mosc. xxxi. (1858) I. 463.-Burma ; Malaya.

lucida, Tul. in Ann. Sc. Nat. Sér. V. ix. (1868) 325.Madag.

lucida, Wall. Cat. n. 7199 (Euphorbiac.).-Ind, or. macrocarpa, C. B. Clarke, in Hook. f. Fl. Brit. Ind. ii 593.-Penang.

macrogyna, Turcz. in Bull. Soc. Nat. Mosc. (1858) I. $463=$ graveolens

macrophylla, Vahl, Eclog. Am. ii. 32.-Guiana.

Mannii, Mast. in Oliver, Fl. Trop. Afr. ii. 494.-Afr. trop.

mariquitensis, H. B. E K. Nov. Gen. et Sp. v. 363.N. Granat.

Mathewsii, Turcz. in Bull. Soc. Nat. Mosc. xxxvi. (1863) I. 608--Peruy.

Maximiliana, Eichl. in Mart. Fl. Bras, xïi. I. 487.Bras.

meliodora, Eichl. l. c. 469.-Bras.

Melistaurum, Spreng. Syst. ii. 354.-Ins. Pacif

membranacea, Hance, in Fourn. Bot. vi. (1868) 113.China.

micrantha, G. Don, Gen. Syst. ii. $52=$ parvifora.

microdon, Miq. Fl. Ind. Bat. Suppl. 333.-Sumatra.

microphylla, Eichl. in Mart. Fl. Bras. xiii. I. 474.Bras.

mollis, H. B. \& K. Nov. Gen. et Sp. v. 362. t. $480=$ hirsuta.

moluccana, Blume, Mus. Bot. Lugd. Bat. i. 255.Amboina.

montana, Gardn. in Hook. Lond. Journ. Bot. ii. (1843) 335 = inaequilatera

multiflora, Spreng. Pugill. ii. 61.-Ind. or.

myriantha, Turcz. in Bull. Soc. Nat. Mosc. xxxvi. (1863) 609.--Panama.

negrensis, Eichl. in Mart. Fl. Bras. xiii. I. 466.-Bras. nigrescens, Tul. in Ann. Sc. Nat. Sér. V. ix. (1868) 326. - Madag.

\section{CASEARIA:-}

nitida, Facq. Enum. Pl. Carib. 21.-N. Granat.

nitida, Sieber, ex Griseb. Fl. Brit. W. Ind. $23=$ parvifolia.

obliqua, Spreng. Syst. ii. $355=$ inaequilatera.

oblongifolia, Cambess, in St. Hil. Fl.Bras. Mer. ii. 234. -Bras.

obovalis, Poepp. ex Griseb. in Goett. Abh. ix. (1860) 27 = obovata.

obovata, Poepp. ex Eichl. in Mart. Fl. Bras. xiii. I. 472. -Peruv.

obovata, Schlecht. in Linnaea, xiii. (1839) 434.Mexic

odorata, Macfad. Fl. Jamaic. i. $216=$ ramiflora.

odorata, Teijsm. E' Binn. in Nederl. Kruidk. Arch. iii. (1855) 408.- Java.

oligantha, Eichl. in Mart. Fl. Bras. xiii. I. 476.Bras.

ovata, Roxb. Hort. Beng. [90]; Fl. Ind. ii. $420=$ tomentosa.

ovata, Wall. Cat. n. $7192 \mathrm{E}=$ glomerata.

ovata, Willd. Sp. Pl. ii. 629.-Ind. or.

paniculata, Gardn. ex Thw. Enum. Pl. Zeyl. $20=$ Osmelia zeylanica.

parviflora, J. F. Gmel. Syst. $700=$ parvifolia.

parviflora, Willd. Sp. Pl. ii. $627=$ sylvestris.

parvifolia, Willd. l. c. 628.-Ind. occ.

panciflora, Cambess, in St. Hil. Fl. Bras. Mer. i. 235 -Bras.

petiolaris, Poepp. ex Eichl. in Mart. Fl. Bras. xiii. I. 471.-Peruy.

petraea, Benth. in Hook. Fourn. Bot. iv. (1842) 111.Guiana.

Pitumba, DC. Prod. ii. 50, in syn $=$ macrophylla

Poeppigii, Eichl. in Mart. Fl. Bras. xii. I. 475.Bras.

Pohliana, Eichl. l. c. 474.-Bras.

praecox, Griseb. Cat. Pl. Cub. 10.-Cuba.

prismatocarpa, Mast. in Oliver, Fl. Trop. Afr. ii. 494. - Afr, trop.

propinqua, Blume, Mus. Bot. Lugd. Bat. i. 253.Java.

prunifolia, H. B. E K. Nov. Gen. et Sp. v. 362.-Am. austr.

prunifolia, Tul. in Ann. Sc. Nat. Sér. III. vii. (1847) $363=$ spinosa.

pubiflora, Benth. Bot. Voy. Sulph. $66=$ parvifolia. punctata, Spreng. Nene Entdeck. ii. $154=$ parvifolia punctata, Spreng. Syst. ii. 355.-Am. trop.

quinduensis, Tul. in Ann. Sc. Nat. Sér. III. vii. (1847) 360.-Ecuador.

ramiflora, Seem. Bot. Voy. Herald, $98=$ hirsuta

ramiflora, Vahl, Symb. Bot. ii. 50.-Am. trop.

ramosissima, Griseb. Cat. Pl. Cub. 10,-Cuba

resinifera, Spruce, ex Eichl. in Mart. Fl. Bras. xiii. 466.-Bras.

Richii, A. Gray, Bot. U. St. Expl. Exped. i. 82.-Ins. Fiji.

rubescens, Dalz. in Hook. Kew Fourn. iv. (1852) 108. -Ind. or.

rufescens, Cambess, in St. Hil. Fl. Bras. Mer. ii. 231 -Bras.

rufidula, Triana E Planch. in Ann. Sc. Nat. Sér. IV xvii. (1862) 107.-N. Granat.

rufinervis, Turcz. in Bull. Soc. Nat. Mosc. xxxi. (1858) I. 462.-Cuba

rugulosa, Blume, Mus. Bot. Lugd. Bat. i. 255.Malaya.

rupestris, Eichl. in Mart. Fl. Bras, xiii. I. 468.-Bras. salacioides, Blume, Mus. Bot. Lugd. Bat. i. 252.-N Guinea.

salicifolia, Turcz. in Bull. Soc. Nat. Mosc. xxxi. (1858) I. 460.-Mexic.

Samyda, DC. Prod. ii. 51.-Porto Rico.

Selloana, Eichl. in Mart. Fl. Bras. xiii. I. 483. Bras.

Serrata, Macfad. Fl. Jamaic i. 215 = serrulata. serrulata, Sieber, ex Griseb. F1. Brit. W. Ind. $23=$ parvifolia.

serrulata, Sw. Fl. Ind. Occ. ii. 754.-Ind. occ.

sessilifiora, Cambess. in St. Hil. Fl. Bras. Mer, ii. 231 -Bras.

singularis, Eichl. in Mart. Fl. Bras. xiii. I. 473:Guiana.

spinescens, Griseb. Cat. Pl. Cub. 10,-Cuba.

spinosa, Willd. Sp. Pl. ii. $626=$ ramiflora.

Spruceana, Benth. ex Eichl. in Mart. Fl. Bras. xiii. I 486 . - Bras. 


\section{CASFARIA :-}

squarrosa, Klotzsch, in Schomb. Faun. et Fl. Guy. 1167, nomen.-Guiana.

stipitata, Mast. in Oliver, Fl. Trop. Afr. ii. 493.-Afr trop.

stipularis, Cambess. in St. Hil. FI. Bras. Mer. ii. $169=$ brasiliensis.

stipularis, Vent. Choix, 46. t. 46.-Am. austr

subciliaris, Klotzsch, in Schomb. Faun. et Fl. Guy. 984 nomen,-Guiana.

subcuneata, Miq. F1. Ind. Bat. i. $706=$ grewiaefolia.

subopaca, Planch. E Triana, in Ann. Sc. Nat. Sér. IV

xvii. (1862) 110 - N. Granat.

subrhombea, Hance, in fourn. Bot. xxiii. (1885) 323. -China.

sylvestris, Sw. Fl. Ind. Occ. ii. 752.--Ind. occ

tinifolia, Vent. Choix, 47. t. 47.-Hab.?

tomentosa, Roxb. Hort. Beng. [90]; Fl. Ind. ii. 421.-

As. trop. ; Austral.

truncata, Blume, Mus. Bot. Lugd. Bat. i. 252.-

Malaya.

tuberculata, Blume, l. c. 254.-Java

tuberculata, Blume, l. c. 255.-Sumatra.

ulmifolia, Cambess. in St. Hil. Fl. Bras. Mer, ii. $169=$ Cambessedesii.

ulmifolia, Vahl, ex Vent. Choix, 46, verso = serrulata

uniflora, Decne, in Nouv. Ann. Mus. Par, iii. (1834) 428.-Ins. Timor.

Vareca, Roxb. Hort. Beng. 33; Fl. Ind. ii. 418.--Reg.

Himal.; Burma.

variabilis, Blume, Mus. Bot. Lugd. Bat. 1. $252=$ grewiaefolia.

varians, Thw. Enum. Pl. Zeyl, $19=$ esculenta

velutina, Blume, Mus. Bot. Lugd. Bat. i. 253.Sumatra.

viridiflora, DC. Prod. ii. 51.-Ind. or.

viridiflora, Lam. Encyc. vi. $493=$ leucolepis

wynadensis, Bedd. Ic. Pl. Ind. Or. i. 34.-Ind, or.

zeylanica, Thw. Enum. Pl. Zeyl. $19=$ esculenta.

zizyphoides, H. B. E K. Nov. Gen. et Sp. v. 362.Am. austr.

CASEOLA, Noronha, in Verh. Batav. Gen. v. (1790) ed. I. Art. IV. 2 (Quid ?).

CASIMIRA, Scop. Introd. $233(1777)=$ Melicocca, Linn. (Sapind.).

CASIMIROA, La Llave, in La Llave \& Lex. Nov. Veg. Desc. fasc. ii. 2 (1825). RUTACEAE, Benth. \& Hook. f. i. 302

edulis, La Llave, l. c.-Mexic.

Sapota, Oerst. in Kjoeb. Vidensk. Meddel. (1857) 187. -Nicaragua.

tomentosa, Domb. ex Miers, in Journ. Linn. Soc, xvii. (1880) $79=$ Cervantesia tomentosa.

CASINGA, Griseb. in Goett. Abh. ix. (1861) 27, $29=$ Laetia, Linn. (Olacin.).

procera, Griseb. Fl. Brit. W. Ind. $710=$ L. procera.

suaveolens, Griseb. in Goett. Abh. ix. (1861) $27=$ L. suaveolens.

CASIOSTEGA, Rupr. ex Galeotti, in Bull. Acad. Brux. ix. II. (1842) 232, nomen = Opizia, Presl (Gramin.). anomala, Rupr. 1. c. $=\mathrm{O}$. stolonifera.

dactyloides, Fotirn. in Bull. Soc. Bot. Belg. xv. (1876) $470=$ Buchloë dactyloides.

Hookeri, Rupr. ex Fourn. 1. c. $471=$ Buchloë dactyloides.

humilis, Rupr. [ex Munro] in Benth. Pl. Hartw. $347=$ = Buchloë dactyloides.

CASPAREA, H. B. \& K. Nov. Gen. et Sp. vi. 317 (1823) = Bauhinia, Linn. (Legumin.)

acuminata, Heynh. Nom. ii. $123=$ B. acuminata aurita, Griseb. F1. Brit. W. Ind. $213=$ B. aurita. castrata, Hassk. Cat. Hort. Bogor. $288=\mathrm{B}$. castrata. divaricata, H. B. \& K. Nov. Gen, et Sp. vi. $317=$ B. divaricata.

furcata, Desv. in Ann. Sc. Nat. Sér. I. ix. (1826) 429 $=\mathrm{B}$. furcata.

latifolia, H. B. \& K. Nov. Gen. et Sp. vi. $317=$ B. latifolia.

Iunaria, H. B. \& K. l. c. = Bauhinia lunaria.

Pes-caprae, H. B. \& K. 1. c. $318=$ B. Pes-caprae.

porrecta, H. B. \& K. I. c. $317=$ B. jorrecta.

subrotundifolia, H. B. \& K. 1. $\mathrm{c}_{2}=\mathrm{B}$, subrotundifolia.
CASPARYA, Klotzsch, in Monatsb. Berl. Acad. (Maerz 1854) $127=$ Begonia, Linn

antioquensis, A DC in Ann. Sc. Nat. Sér. IV xi. (1859) 116.-N. Granat.

brevipetala, A. DC. 1. c. 118.-Venezuela.

coccinea, Klotzsch, in Monatsb. Berl. Acad. (1854) 127

$=$ B. columnaris

columnaris, Klotesch, 1. $\mathrm{c}_{2}=\mathrm{B}$, colnmnaris.

cordifolia, A. DC. in DC. Prod. xv. 1. $273=$ hirta.

crassicaulis, A. DC. in Ann. Sc. Nat. Sér. IV. xi. 1859) 119.- - Java.

elegans, Klotzsch, in Monatsb. Berl. Acad. (1854) 127 $=\mathrm{B}$, elegans.

erosa, A. DC. in DC. Prod. xv, I. $276=\mathrm{B}$, erosa.

ferruginea, A. DC. 1, c. $269=\mathrm{B}$, ferruginea

fuchsiaeflora, A. DC. in Ann. Sc. Nat. Sér. IV. xi. (1859) 116.-Ecuador.

grewiaefolia, A. DC. 1. c. 117.-N. Granat.

hirta, Klotzsch, in Monatsb. Acad. Berl. (1854) 127.Peruy.

longirostris, A. DC. in DC. Prod. xy, I. $272=\mathrm{B}$. longirostris.

montana, A. DC. in Ann. Sc. Nat. Sér. IV. xi. (1859) 118.-Venezuela.

multiangula, A. DC. in DC. Prod. xv, 1, $275=\mathrm{B}$. multiangula.

oligocarpa, A. DC, in Ann. Nat. Sér. IV. xi. (1859) $118=\mathrm{B}$. Roxburghii.

polycarpa, A. DC. 1. c. = B. Roxburghii.

robusta, A. DC, in DC. Prod, xv. 1. $275=$ B. robusta.

silhetensis, A. DC. 1. c. $277=$ B. silhetensis.

Teysmanniana, Miq. ex A. DC. 1. c. 276.-Sumatra.

trachyptera, A. DC. l. c. $274=$ B. trachyptera.

Trianaei, A. DC in Ann. Sc. Nat. Sér. IV, xi. (1859) 117.-N. Granat.

trispathulata, A. DC. 1. c.-N. Granat.

trisulcata, A. DC. 1. c. 119,-Java.

umbellata, A. DC. in DC, Prod. xv. I. $270=\mathrm{B}$ umbellata.

Urticae, A. DC. 1. c. $274=$ B. Urticae.

CASPIA, Pison. ex Scop. Introd. $276(1777)=$ Vismia, Vell. (Hypericin.)

CASSANDRA, D. Don, in Edinb. N. Phil. Journ. xvii. (1834) 158. ERICACEAE, Benth. \& Hook. fo ii. 584

Dipearia, Rafin. ex DC. Prod. vii. 610 (1839). angustifolia, D. Don, 1. c. = calyculata

calyculata, D. Don, l. c. 158.-Europ.; As. et Am. bor.

racemosa, Spach, Hist. Vég. Phan. ix. $478=$ Leucothoë racemosa.

CASSEBEERIA, Denust. Schluess. Hort. Malab. 35 (1818) = Sonerila, Roxb. (Melast.) maculata, Dennst. 1. $\mathrm{c}_{\mathrm{s}}=\mathrm{S}$. Wallichii.

CASSELIA, Dum. Comm. Bot. $21(1822)=$ Mertensia Roth (Boragin.)

bracteata, Dum. 1. c. $25=$ M. sibirica.

davurica, Dum. 1. c. $22=\mathrm{M}$, dahurica.

denticulato Dum 1 c $23=$ M sibirica.

diversifolia, Regel, Ind. Sem. Hort. Petrop. (1857) 46 -Hab.?

gracilis, Dum. Comm. Bot. $23=$ M. dahurica

lanceolata, Dum. 1. c. $24=$ M. lanceolata

maritima, Dum. 1. c. $25=$ M. maritima.

paniculata, Dum. I. c. $22=$ M. paniculata.

parviflora, Dum, 1. c. $25=$ M, maritima.

sibirica, Dum. 1. c. $28=$ M. sibirica

simplicissima, Dum. 1. c. $24=\mathrm{M}$. simplicissima.

villosula, Dum. 1. c. $23=$ M. villosula.

virginica, Dum. 1. c. $24=$ M. pulmonarioides.

CASSEliA, Nees \& Mart. in Nov. Act. Nat. Cur. xi.

(1823) 73. t. 6. VERBENACEAE, Benth. \& Hook. f. ii. 1148 .

chamaedryfolia, Cham, in Linnaea, vii. (1892) 365.Bras.

interrifolia, Nees E Mart. in Now. Act. Acad. Nat. Cur. xi. (1823) 70.--Bras.

Mansoi, Schau. in Mart. Fl. Bras. ix. 175.--Bras,

serrata, Nees Es Mart. in Nov. Act. Acad. Nat. Cur.

xi. (1523) 75.-13ras.

reronicaefolia, Cham, in Linnaea, vii. (1832) 364 Bras.
CASSIA Tourn, ex Linn, Syst ed, I (1735) LE

GUMINOSAE, Benth. \& Hook, f, i. 571

Adipera, Dialanthera, Diallobus, DisteREPTA, Diplotax, Ditremexa, EMELISTA, Hepteireca, Herpetica, Isandrina, Nicti teida, Octelisia, OpHIOcaulon, Panisia, Peiranisia, Scolodia, Tagera, Xamacrista, Rafin. Sylva Tellur. 127-129 (1838)

BACTYRILOBIUM, Willd, Enum. Hort. Berol. 439 (1809)

Cassiana, Rafin. in Am. Monthly Mag. (1818) 266.

Cathartocarpus, Pers. Syn. i. 459 (1805)

Chamaecrista, Moench, Meth. 272 (1794).

Chamaefistula, G. Don, Gen. Syst. ii. 451 (1832).

Grimaldia, Schrank, in Denkschr. Akad. Muench. (1808) 103. t. 3.

Macleaya, Montrouz. in Mém. Acad. Lyon, z (1860) 198.

SENNA, Tourn. ex Mill. Gard. Dict. ed. VIII (1768)

abbreviata, Oliver, Fl. Trop. Afr. ii. 271.-Afr. trop.

Absus, Aubl. Pl. Gui. i. $381=$ hispidula.

Absus, Linn. Sp. Pl. 376.-Cosmop. trop.

acanthoclada, Griseb. in Goett. Abh. xxiv. (1879) 116 - Reg. Argent.

acapulcensis, H. B. \& K. Nov. Gen. et. Sp. vi. $353=$ biflora.

acclinus, F. Muell. Fragm. iv. $13=$ glauca

aciphylla, Benth. ex A. Gray, Bot. U. St. Expl. Exped. i. $465=$ australis, Sims

acisperma, Schrank, in Colla, Hort. Ripul. App. ii 343.-Hab?

acosmifolia, Mart. ex Benth. in Mart. Fl. Bras. xv. II 133.-Bras.

aculeata, Pohl, ex Benth. l. c. 128.-Bras

acuminata, Moench, Meth. $273=$ marylandica.

acuminata, Willd. Sp. Pl. ii. $517=\mathrm{C}$. Aponcouita.

acuruensis, Benth. in Mart. Fl. Bras, xv, II. 122. Bras.

acuta, Meyen, Reise, i. $376=$ Cumingii

acutifolia, Delile, Fl. Egypte, 219. t. 27.-Aegrpt.

aculisepala, Benth. in Mart. Fl. Bras. xv. II. 97.-

Am, trop.

adenantha, Zoll. \& Moritz. Syst. Verz. Zoll. $2=$ divaricata.

adenensis, Benth. in Trans. Linn. Soc. xxvii. (1871) 553.-Arab.

adenopoda, Miq. in Linnaea, xix. (1847) $436=\mathrm{C}$ Apoucouita.

adiantifolia, Spruce, ex Benth. in Mart. Fl. Bras. s5. II. 130.-Bras.

advena, Willd. ex Vog. Syn. Cass, $18=$ bicapsu. laris.

aegyptiaca, Willd. Enum. Hort. Berol. $442=\mathrm{C}$. Sophera.

Aeschynomene, DC. in Collad. Hist. Cass. 127. t. 1\% mimosoides.

aethiopica, Guibourt, Hist. Drogues, ed. III. iii. 219.Aegypt.

affinis, Benth, in Mart. Fl. Bros, xv. 11. 98-Am. trop.

Afzeliana, Vog. in Linnaea, xv. (1841) $70=$ podo carpa.

alata, Linn. Sp. Pl. 378.-Cosmop. trop.

albida, Orteg. Hort. Matr. Dec. 92 = tomentosa.

Alcaparilla, H. B. \& K. Nov. Gen. et Sp. vi. $355=$ bicapsularis.

Alcaparra, Plit. in Linnoea, xxxiii. (1S0 $1-65) 61-$ Chili.

amoena, Buch.-Ham. in Wiall. Cat. n. $5821=$ mimosoides.

ampliflora, Steud. in Flora, xxvi. (1\&43) ii. $760=$ maltijuga.

anceps, Benth. in Mart. Fl. Bras. xy. 11. 168-Am. trop.

andina, Pbil. in Linnaea, xxviii. (1\$56) $6 \$ 5=$ Arnottiana.

Andrieuxii. Benth. in Trans. Linn. S. $x \times$ vii. '15: I 548.-Mexic.

andromeden. Mart. ex Bcuth, in Mart. Fl. Brass xr. 11. 196. - Am. trop.

angulata, Fog. Syru. Cass. 16.-Bras.

angustifulia, Vahl, Symb. Bot. i. 29.-Afr. trop.

angustisiliqua, Lam. Encyc. i. 6\$9 = biflora.

angustisiliqua, Torr. \& Gray, F. N. Am. i. $396=$

bahamensis. 


\section{CASSI.A :-}

angustissima, Lam. Encyc. 1. $650=$ mimosoides. annulata, Willd. ex Klotzsch, in Schomb. Faun. E F Gui. 1207, nomen.-Guiana.

aphylla, Cav. Ic. vi. 41. t. 561.-Reg. Argent.

apiculata, Mart. \& Gal. in Bull. Acad. Brux. x. II.

(1843) $304=$ crotalarioides

Apoucouita, Aubl. Pl. Gui. i. 379. t. 146.-Guiana.

appendiculata, Vog. Syn. Cass. 24.-Bras.

applanata, Anderss. Galap.-Oames Vegetat. $254=$ picta.

aprica, Vell. FI. Flum. 169 ; iv. t. $76=$ cathartica.

arachoides, Burch. Trav, i. $341=$ obovata.

arayatensis, Llanos, Fragm. $71=$ timoriensis.

arayatensis, Naves, ex Villar, in Blanco, Fl. Philipp.

ed. III. Nov. App. $71=$ alata

arborea, Macfad. Fl. Jamaic, i. $343=$ siamea

arborescens, Mill. Gard. Dict, ed, VIII. n, $15=$ emarginata.

arborescens, Vahl, Symb. Bot. iii. $56=$ glauca.

arenaria, H. B. \& K. Nov. Gen, et Sp. vi. $370=$ flexuosa.

arequipensis, Meyen, in Vog. Syn. Cass. 43.-Peruv.

Arereh, Delile, Cent. Pl. Afr. 29.-Aegypt.

argentea, H. B. E K. Nov. Gen. et Sp. 358.-Mexic.

aristata, Benth. in Mart. Fl. Bras. xv. II. 170.-

Bras.

aristata, Willd. ex Walp. Rep. i. $836=$ patellaria

armata, S. Wats. in Proc. Am. Acad. xi. (1876) 136.Calif.

Arnottiana, Gill. in Hook. Bot. Misc. iii. (1833) 211.Chili.

Arnottiana, Wight, ex Benth. in Trans. Linn. Soc. xxvii. (1871) 577 =nigricans

arowana, Schomb. Faun. Eo Fl. Gui. 1206.-Guian.

artemisioides, Gaudich. ex DC. Prod. ii. 495.Austral.

Aschrek, Forsk. Fl. Aegypt. Arab. 86.-Arab.

aspera, Muhl. Cat. ex Ell. Sketch, $474=$ nictitans.

astroites, Willd. ex Cham. \& Schlecht. in Linnaea, ii.

(1827) $597=$ villosa

atomaria, Linn. Mant. 68.-Am. austr.

atropurpurea, Benth. in Trans. Linn. Soc. xxvii. (1871) 533 , sphalm. = seq.

atroviridis, Span. in Linnaea, xv. (1841) $201=\mathrm{C}$ Sophera.

aurantia, Ruiz \& Pav. ex G. Don, Syst. ii. 442.Peruy.

aurata, Roxb. Hort. Beng. 32, nomen = laevigata.

auricoma, R. Grah. in Wall. Cat. n. $5322=$ mimosoides.

auriculata, Linn.SP. Pl. 379.-Ind. or.

aurita, Collad. Hist. Cass. 131.-Bras.

aurivilla, Mart. ex Benth. in Mart. Fl. Bras. xv. II. 152.-Am. trop.

australis, Reinw. ex Steud. Nom. ed. II. i. 303, nomen -Java.

australis, Sims, Bot. Mag.t. 2676.-Austral.

australis, Vell. FI. Flum. 166 ; iv. t. $65=$ appendiculata.

aversiflora, Hook. Bot. Mag. t. 2138=biflora.

bacillaris, Linn. f. Suppl. 231.-Am. trop.

bacillaris, Willd. ex Steud. Nom. ed. II. i. $303=$ sclerocarpa.

Bacillus, Gaertn. Fruct. ii. $313=$ javanica.

bahamensis, Mill. Gard. Dict. ed. VIII. n. 9.-Am. trop.

barbata, Mart. E Nees, in Nov. Act. Nat. Cur. xii. (1824) 32.-Bras.

Barclayana, Sweet, FI. Austral. t. $32=$ C. Sophera.

Barrenfieldii, Colla, Hort. Ripnl. App. ii. $343=$ australis.

basifolia, Vog. Syn. Cass. 56.-Bras.

batramensis, Steud. Nom. ed. II. i. 303, sphalm. =bahamensis.

bauhiniaefolia, Kunth, Mimos, 123. t. $37=$ rotundifolia.

bauhinioides, A. Gray, in Bost. Fourn. Nat. Hist. vi. (1850) 180 - Texas; N. Mexic.

Berlandieri, Benth. in Trans. Linn. Soc. xxvii. (1871) 520.-Mexic

Berryana, Voigt, Hort. Suburb. Calc. $249=$ montana

Berteriana, Balb. ex DC. Prod. ii. $496=$ biflora.

Berterii, Colla, Hort. Ripul. 30. t. $24=$ bicapsularis.

bicapsularis, Linn. Sp. Pl. 376.-Am. trop.

bifida, Zoll. \& Mor. in Nat. en Genesk. Arch. Neerl.

Ind. iii. (1846) $68,80=$ divaricata.

biflora, Griseb. Cat. Pl. Cub. $79=$ robiniaefolia.

biflora, Linn, Sp. Pl. 378.-Am. trop.
CASSIA :

biflora, Mill. Gard. Dict. ed. VIII. n. 14 (=Aeschynomenes sp.).-Ind. occ.?

bifoliolata, DC. in Collad. Hist. Cass. 120. t. $9=$ ro tundifolia.

biglandulosa, Bertol. in Bologn. Opusc. Sc. iii. (1819) $409=$ patellaria.

bijuga, Vog. Syn. Cass. $17=$ speciosa.

bimarginata, Griseb. in Bonplandia, vi. (1858) 5.Panama.

birostris, Domb. ex Vog. Syn. Cass. 43,-Chili

Blancheti, Benth. in Hook. Fourn. Bot. ii. (1840) 78 . -Bolivia.

bonariensis, Hort. ex Colla, Hort. Ripul. $88=$ corymbosa.

Bonplandiana, DC. Prod, ii. $490=$ C. Fistula,

borbonioides, Vog. Syn. Cass. $53=$ Langsdorffi

borneensis, Miq. Anal. Bot. Ind. i. 9.-Borneo

Botteriana, Benth. in Trans. Linn. Soc, xxvii. (1871) 541.-Mexic.

brachypoda, Benth. in Mart. Fl. Bras. xv. II. 172.Am. trop.

brachystachya, Benth. in Hook. Fourn. Bot. ii. (1840) 78.-Bras.

brachystachya, Moc. \& Sesse, ex DC. Prod. ii. $500=$ panciflora.

bracteata, Linn. f. Suppl. 232=alata.

bracteolata, Vog. Syn. Cass. 52.-Bras.

bracteosa, Welw. ex Oliver, Fl. Trop. Afr. ii. $277=$ didymobotrya.

brasiliana, Lam. Encyc. i. $649=$ grandis.

brasiliana, Saldanha, Descr. Rio Madeiras Jan. $43=$ ferruginea.

brevicalyx, Benth. in Mart. Fl. Bras, xv. II. 134.Bras.

brevifolia, Lam. Encyc. i.'651.-Madag.

brevipes, $D C$. in Collad. Hist. Cass. 119. t. 9,-Panama.

Brewsterii, F. Muell. 4th Ann. Rep. 17.-Austral

Brongniartii, Gaudich. Bot. Voy. Bonite, t. 10.-Hab.

Browniana, Kunth, Mimos. 135. t. $41=$ polyantha.

Buchanani, Kostel. Allg. Med.-Pharm. F1. iv. 1333= obovata.

Burchellii, Benth. in Mart. Fl. Bras, xv, II. 165.-Bras.

Burmanni, DC. Prod. ii. $502=$ capensis?

Burmanni, Wight, in Madras Journ. Sc. vi. (1837) t $5=$ obovata.

caespitosa, Benth. in Mart. Fl. Bras. 'xv. II. 136,-Bras. calliantha, G. F. W. Mey. Prim. Fl. Esseq. 169= multijuga.

calycioides, DC. in Collad. Hist. Cass. 125. t. 20 B.Am. trop.

camporum, Benth. in Hook. Journ. Bot. ii. (1840) $79=$ pauciflora.

cana, Nees Es Mart, in Nov. Act. Nat. Cur xii. (1824) 34.-Bras.

cana, Schrank, ex Steud. Nom. ed. II. i. $304=$ tomen tosa.

cana, Wender. in Linnaea, xii. (1838) $22=$ holosericea. canaliculata, R. Br. in Sturt, Centr. Austral, ii. 611 =eremophila.

Canca, Cav. Desc. $132=$ C. Sophera

candenatensis, Dennst. Schluess. Hort. Malab. $32=$ C Tora.

Candolleana, Vog. Syn. Cass. 42 = bicapsularis.

canescens, H. B. \& K. Nov. Gen. et Sp. vi. $357=$ emarginata.

capensis, Thunb. Prod. Pl. Cap. 79.-Afr. austr.

caracasana, Jacq. Hort. Schoenb. iii. $11=$ hirsuta.

cardiosperma, F. Muell. Fragm. x. 50.-Austral.

caroliniana, Walt. F1. Carol. $135=$ occidentalis

carthaginensis, Willd, ex Steud. Nom. ed. II. 304= bacillaris.

Castigitonia, Collad. Hist. Cass. $121=$ C. Chamaecrista.

cathartica, Mart. Reise, Bras. i. 548.-Bras

centijuga, Wawra, in Flora, xlvii. (1864) $248=$ verru$\operatorname{cosa}$

cernua, Balb. Cat. Hort. Taur. (1813) $22=$ sulcata

Chamaecrista, Boj. Hort. Maur, 122 = glandulosa.

Chamaecrista, Linn. Sp. Pl. 379.-Am. bor. et austr.

Chamaecrista, Mill. Gard, Dict. ed. VIII. n. $17=$ procumbens.

Chamaecrista, Mill. ex Benth. in Trans. Linn. Soc. xxvii. (1871) $576=$ virgata.

chamaecristoides, Collad. Hist. Cass. $134=$ procumbens, Linn. Herb.

Chatelainiana, Gaudich. in Freyc. Voy. Bot. 485. t. 111.-Austral.

\section{CASSIA :}

chinensis, Jacq. Coll. i. $64=$ C. Sophera.

chinensis, Lam. Encyc, i. 644 = bicapsularis

choriophylla, Vog. Syn. Cass. 56.-Bras.

chrysocarpa, Desv. Fourn. Bot. iii. (1814) 72 -Bras.

chrysogyne, Miq. in Linnaea, xviii. (1844) $579=$ chryso carpa.

chrysoloma, De Not. Ind. Sem. Hort. Gen. $(1840)=$

bicapsularis.

chrysophylla, A. Rich. Ess. Fl. Cub. 500=emarginata. chrysotricha, Collad. Hist. Cass. 99, t. $13=$ chrysocarpa. chrysotricha, Mart. Herb. Fl. Bras. $103=$ angulata. ciliaris, Collad. Hist. Cass, $98=$ C. Tagera.

ciliata, Hoffmgg. Verz. Pf. Nachtr. i. $208=$ sericea.

ciliata, Rafin. FI. Ludov. $100=$ occidentalis.

ciliolata, Benth. in Mart. Fl. Bras. Xv, II. 146.-Bras. cinerascens, Vog. Syn. Cass. 60.-Bras.

cinerea, Cham. E Schlecht. in Linnaea, v. (1830) 599 -Mexic.

circinnata, Benth. in Mitch. Fourn. Trop. Austral. 384.-Austral.

Clausseni, Benth. in Hook. Fourn. Bot. ii. (1840) 79. -Bras.

coccinea, Wall. Cat. n. $5315=$ C. Absus.

Collae, G. Don, Gen. Syst. ii. $442=$ bicapsularis.

coluteoides, Collad. Hist. Cass. 102.t. $12=$ bicapsularis comosa, Vog. Syn. Cass. 65.--Afr. austr.

concinna, Benth. Fl. Austral. ii. 291.-Austral.

conferta, Benth. in Mart. Fl. Bras. xv. Ir. 142.Bras.

conjugata, Ruiz E Pav. ex Benth. in Trans. Linn. Soc. xxvii. (1871) 540.-Am. trop.

conspicua, Vog. Syn. Cass. $47=$ Sieberiana

contorta, Vog. 1. c. $17=$ C. Tora.

coquimbensis, Vog. l. c. 27.-Chili

cordistipula, Mart. ex Benth. in Mart. Fl. Bras. xv. II. 164.-Bras.

coriacea, Bong. ex Benth. in Hook. Fourn. Bot. ii. 1840) 78.-Bras.

corifolia, Benth. in Mart. Fl. Bras. xv. II. 120.-Am. trop.

corneliana, Vatke, in Oestr. Bot. Zeitschr. xxx. (1880) 79.-Afr. trop.

caromandeliana, Jacq. Fragm. 67. t. $100=$ C. Sophera coronilloides, A. Cunn. ex Benth. in Mitch. Journ Trop. Austral. $384=$ australis.

corymbosa, Lam. Encyc. i. 644.-Am. calid.

corymbosa, Orteg. Hort. Matr. Dec. 124=laevigata.

cotinifolia, G. Don, Gen. Syst, ii. 445.-Bras.

Covesii, A. Gray, in Proc. Am. Acad. vii. (1868) 399. -Calif.

crassifolia, Orteg. Hort. Matr. Dec. $122=$ corymbosa. crassiramea, Benth. in Hook. Ic. Pl. t. 1063.-Bolivia. crassisepala, Benth. in Linnaea, xxii. (1849) $527=$ bicapsularis.

crenulata, Benth. in Hook. Fourn. Bot. ii. (1840) 80. -Bras.

Crista, Jacq. Coll. i. $82=$ biflora.

crotalarioides, Kunth, Mimos. 132. t. 40.-Am. austr.

Cruikshanksii, Hook. छٌ Arn. in Hook. Bot. Misc. iii. (1833) 210.-Chili

cubensis, Hoffmgg. Verz. Pf. Nachtr. i. $209=$ corymbosa.

cultrifolia, H. B. E $K$ Nov. Gen. et Sp. vi. 363.Venezuela.

Cumingii, Hook. E. Arn. in Hook. Bot. Misc. iii. (1833) 211.-Chili

cuneata, DC. in Collad. Hist. Cass. 121.-Am. austr. cuneata, Griseb. Cat. Pl. Cub. $80=$ lineata.

cuneifolia, Vog. Syn. Cass. $49=$ viscosa.

curvifolia, Vog. l.c. 55.-Bras.

cuspidata, Willd. Enum. Hort. Berol. $443=$ pistaciae folia.

cytisoides, DC. in Collad. Hist. Cass. 116. t. 14.Bras.

dalbergiaefolia, Benth. in Mart. Fl. Bras. xv. II. 149. -Am. trop.

debilis, Vog. Syn. Cass. 53.-Bras.

decipiens, Desv. Journ. Bot. iii. (1814) 72 = angustifolia.

decipiens, Griseb. Cat. P1. Cub. $79=$ stenophylla. decrescens, Benth. in Hook. Fourn. Bot. i1. (1840) 80. -Bras.

decumbens, Benth. l. c. 79.-Am. trop.

delagoënsis, Harv. in Fl. Cap. ii. 272.-Afr. austr.

densiflora, Mart. E Gal. in Bull. Acad. Brux. xii II. (1845) 304.-Mexic. 
CASSIA :-

densifolia, Benth. in Hook. Fourn. Bot. ii. (1840) 80.Bras.

dentata, Vog. Syn. Cass. 49.-Bras.

Deplanchei, Benth. in Trans. Linn. Soc. xxvii. (1871) 554.-N. Caled.

desertorum, Mart. ex Benth. in Mart. Fl. Bras. xv. II 133. - Bras.

desolata, F. Muell. in Linnaea, xxv. (1852) 389.Austral.

Desvauxii, Collad. Hist. Cass. 131.-Am. trop. didymobotrya, Fresen. in Flora, xxii. (1839) 53. Abysin.

diffusa, DC. in Mém. Soc. Phys. Genèv. ii. (1824) 130 Prod. ii. $504=$ nictitans.

dimidiata, Klein, ex Wall. Cat. n. $5328=$ Kleinii.

dimidiata, Roxb. Hort. Beng. 32 , nomen $=$ mimosoides

diphylla, Linn. Sp. Pl. 376.-Am. trop.

disadena, Steud. in Flora, xxvi. (1843) II. $760=$ glandulosa.

discolor, Desv. Journ. Bot. iii. (1814) $73=$ glauca.

dispar, Willd. Enum. Hort. Berol. 441,-Am. austr.

disperma, Vell. Fl. Flum. 167 ; iv. t. $69=$ Peltophorum Vogelianum.

distichoclada, Mart. ex Benth. in Mart. Fl. Bras. xv. II. 168.-Am. trop.

divaricata, Nees, in Syll. Ratisb. i. (1824) 94.-As. trop.; Malaya.

Dombeyana, Vog. Syn. Cass. $28=$ aurantia.

domingensis, Spreng. Neue Entdeck. iii. 55.Ind. occ.

dormiens, Vell. Fl. Flum, 16\%; iv. t. 67 = bicapsularis. drepanophylla, Benth. in Mart. Fl. Bras. xv. II. 170. -Bras.

dumetorum, Bert, ex DC. Prod, ii. $499=$ reticulata, dysophylla, Benth. in Mart. Fl. Bras. xv. II. 117.Am. trop.

echinocarpa, Benth. l. c. 136.-Am. trop.

edulis, Posada, in Baill. Adansonia, x. (1872) 187.N. Granat.

eglandulosa, Dum-Cours, Bot. Cult. ii. vi, 34-Hab. Ehrenbergii, Bisch. in Bot. Zeit. ii. (1844) $51=$ angustifolia.

elegans, H. B. \& K. Nov. Gen, et Sp. vi. $342=$ laevigata.

elegans, Voigt, in Syll. Ratisb. ii. (1828) 55.-Hab. ?

elliptica, H. B. \& K. Nov. Gen. et Sp. vi. $356=$

emarginata.

elongata, Lemaire-Lis. in Journ. Pharm. vii. (1821) 345 $=$ angustifolia.

emarginata, Bert. ex Steud. Nom. ed. II. i. 304, $305=$ atomaria.

emarginata, Clos, in C. Gay, Fl. Chil. ii. 237 = bicapsularis.

emarginata, Linn. Sp. Pl. 376.-Am. trop.

emarginata, Mill. Gard. Dict. ed. VIII. n. $13=$ pilosa.

enneaphylla, Koen. ex Wight \& Arn. Prod. $289=$ glauca.

ensiformis, Vell. Fl. Flum. 170 ; iv. t. $79=$ C. Apoucovita.

erecta, Willd. ex Steud. Nom. ed. II. i. $303=$ glandulosa.

eremophila, A. Cunn. ex Vog. Syn. Cass. 47.Austral.

ericifolia, Benth. in Mart. Fl. Bras. xv. II. 145.-Ain. trop.

esculenta, Roxb. Hort. Beng. [31], nomen $=\mathrm{C}$. Sophera.

exaltata, Reinw. in Blume, Cat. Gew. Buitenz. 68 ; Span. in Linnaea, xv. (1841) 201.-Ins. Timor.

excelsa, H. B. \& K. Nov. Gen. et Sp, vi. $339=$ C. Fistula.

excelsa, Schrad. in Goett. Gel. Ans. i. (1821) 717.Bras.

exigua, Roxb. Hort. Beng. [31], nomen $=$ C. Absus.

exsuduns, Benth. in Hook. Fourn. Bot. ii. (1840) 80.Bras.

fabaginifolia, H. B. \& K. Nov. Gen. et Sp. vi. $363=$ rotundifolia.

fagifolia, Bertol. Fl. Guatim. 14=oxyphylla.

fagonioides, Vog. Syn. Cass. $50=$ hispidula.

falcata, Dum.-Cours. Bot. Cult. ed. II. vi. $\$ 5=$ corym. bosa.

falcato, Linn. Sp. Pl, $377=$ occidentalis

falcinella, Oliver, Fl. Trop. Afr. ii. 281.-Afr. trop

fasciculata, Michx. Fl. Bor. Am. i. $262=$ C. Chamaecrista.

\section{CASSIA :-}

fastigiata, Nees, in Flora, iv. (1821) $303=$ excelsa. fastigiata, Vahl, Symb. Bot. iii. $57=$ glauca

fastuosa, Willd. ex Vog. in Linnaea, xi. (1837) 654.Am. trop.

felipensis, H. B. \& K. Nov. Gen, et Sp. vi. $368=$

C. Chamaecrista.

ferruginea, Schrad. ex DC. Prod. ii, 489.-Am, trop Fieldii, Colla, Hort. Ripul. App. iv. 23. t. $11=$ australis.

filicifolia, Mart. ex Benth. in Mart. Fl. Bras, xv. II. 148.-Bras.

filipendula, Boj. Hort. Maurit. $122=$ mimosoides

filipes, Benth. in Hook. Jaurn. Bot. ii. $(1840) 81=$ rotundifolia.

fimbriata, Noronha, in Verh. Batav. Gen. v. (1790)

ed. I. Art. IV. 9.-Malaya.

Fistula, Herbb, ex Oliver, Fl. Trop. Afr, $271=$ C. Arereh.

Fistula, Linn. Sp. Pl. 377.-As. trop.

fistuloides, Collad. Hist. Cass. 87. t. $\mathbf{1}=$ C. Fistula.

flaccida, Clos, in C. Gay, Fl. Chil. ii. $238=$ coquimbensis.

flavicoma, Benth. PI. Hartw. $171=$ tristicula.

flavicoma, H. B. E K. Nov. Gen. et Sp. vi. 366 . Venezuela.

flexuosa, A. DC. Not. $7^{\text {me }}$ Pl. Rar. Jard. Genèv. 34. t $4=$ bicapsularis.

flexuosa, Burm. f. Fl. Cap. Prod. $12=$ capensis.

flexuosa, Linn. Sp. Pl. 379.-Bras,

flexuosa, Mill. Gard. Dict. ed. VIII. n. I6=serpens.

floribunda, Cav. Desc. 132 = laevigata.

floribunda, Collad. Hist. Cass, 88. t. $11=$ corymbosa,

floribunda, Griseb. ex Benth. in Trans. Linn. Soc.

xxvii. (1871) $549=$ racemosa.

florida, Vahl, Symb. Bot. iii. $57=$ siamea.

fuminensis, Vell. F1. Flum. 168; iv, t. $72=$ Dimor

phandra exaltata.

Fockeana, Miq. in Linnaea, xviii. (1844) $579=$ bacil. laris.

foetida, Ruiz \& Pav. ex G. Don, Gen. Syst. ii. $443=$ stipulacea

foetida, Salisb. Prod. $325=$ C. Tora

foetida, Willem. in Usteri, Ann. Bot. xviii. (1796) $32=$ occidentalis

foetidissima, Ruiz \& Pav. ex G. Don, Gen. Syst. ii. $441=$ mexicana

foliolosa, Benth. in Trans. Linn. Soc. xxvii. (1871)

544.-Guatemala.

foliolosa, Steud. Nom. ed. II. i. $305=$ seq.

foliosa, G. Don, Gen. Syst. ii. $746=$ tenella?

foliosa, Phil. in Anal. Univ. Chil. (1862) II. 379.Chili.

Fraseri, A, Cunn, ex Vog, Syn. Cass。 $48=$ anstralis.

fraxinifolia, H. B. \& K. Nov. Gen. et Sp. vi. $349=$ pistaciaefolia.

frondosa, Hook. \& Arn. in Hook. Bot. Misc. iii. (1833) $210=$ bicapsularis.

frondosa, [Soland. in] Ait. Hort. Kew. ed. I. ii. $53=$ biflora.

frutescens, Mill. Gard, Dict. ed, VIII. n. $2=$ C. Sophera.

fruticescens, Bert. ex Spreng. Syst. ii. $335=$ viminea

fruticosa, Mill. Gard. Dict. ed. VIII. ․ 10 = bacillaris.

fulgens, Macfad. Fl. Jamaic. i. $342=$ biflora.

fulgens, Wall. Cat. n. $5310=$ multijuga.

fuscescens, Benth. in Mart. Fl. Bras. xv. 1I. 153.-Am. trop.

galegaefolia, Linn. Syst. Nat. ed. X. $1017=$ bifora.

Galeottiana, Martens, in Bull. Acad. Brux. x. II. (1843) 305.-Mexic.

gallinaria, Collad. Hist. Cass, $96=\mathrm{C}$. Tora

Gardneri, Benth. in Mart. Fl. Bras. xv. 11. 120.-Bras.

Gaudichaudii, Hook. E Arn. Bot. Beech. Voy. 81.--Ins.

Sandvic.

gemina, Vell. Fl. Flum. 169 ; iv. t. $74=$ C. Chamae-

crista

geminata, Benth. in Mart. Fl. Bras. Xv. II. 135.Bras.

geminata, Vahl, ex DC. Prod. ii. $505=$ mimosoides.

geminitora, Collad. Hist. Cass. t. 8.-Mexic.

geminiflora, Moç. \& Sesse, in Collad. Hist. Cass. 109

t. $3=$ biflora.

geminiflora, Schrank, Hort. Monac. t. $26=$ occidentalis.

geniculata, Ruiz \& Pav. ex G. Don, Gen. Syst. ii. 410 - villosa.

\section{CAssia}

gigantea, Bert, ex DC. Prod. ii. $492=$ siamea

glabra, Collad. Hist. Cass. $131=$ cytisoides.

glandulifera, Reinw. ex Stend. Nom. ed. II. i. $305=$

seq.

glanduliflora, Reinw. in Blume, Cat. Gew. Buitenz. 68 = bicapsularis.

glandulosa, Hook. Bot. Mag. t. $3485=$ virgata.

glandulosa, Linn. Syst. Nat, ed. X. 1017.-Am. trop.

glauca, Lam. Encyc. i. 647.-As, trop.; Austral.; Polynes.

glaucescens, Benth. in Trans. Linn. Soc. xxvii. (1871) 539.-Chili.

glaucescens, Hoffmgg. Verz. Pfl. Nachtr. i. 209.Cuba.

glutinosa, $D C$. Prod. ii. 495-Austral.

goënsis, Dalz. in Hook. Kew Fourn. iv. (1852) 112 -Ind. or.

gonioides, A. Cunn. ex Benth. in Hook. Ic. Pl. xi. 48. t. 1061.-Austral.

gonoclada, Benth. in Mart. Fl. Bras. xv. II. 169.Bras.

gonoclada, Benth. in Trans. Lins. Soc. xxvii. (1871) $572=$ choriophylla.

goratensis, Fresen. in Flora, xxii. (1839) 53.Abyssin.

gracilis, Kunth, Mimos. 120.t. 36.-Am, trop.

gracillima, Benth. in Mart. Fl. Bras. xv. 11. 143.Bras.

gracillima, Welw. Apont. $590=$ mimosoides

grammica, Spreng. Noue Entdeck. iii. 55.-Am. trop.

grandiflora, Dest Cat. Hort. Par. ed. III. $302=$ laevigata.

grandiflora, Pers. Syn, i. $457=$ bicapsularis

grandis, Linn. f. Suppl. 230.-Panama.

grandistipula, Vog. Syn. Cass. $58=$ rotundata.

Grantii, Oliver, Fl. Trop. Afr. ii. 279.-Afr. trop.

graveolens, Colla, Hort. Ripul. App. ii. $343=$ atomaria.

Greggii, A. Gray, Pl. Wright. i. 59.-Mexic.

grisea, A. Rich. Ess. Fl. Cub. 493 =emarginata

guineensis, G. Don, Gen. Syst. ii. $449=$ mimosoides.

Hartwegi, Benth. Pl. Hartw. $117=$ oxyphylla.

hecatophylla, DC. in Collad. Hist. Cass. 124, t. 18 mimosoides.

hedysaroides, Vog. Syn. Cass. 52.-Bras.

heptanthera, F. Muell. Fragm. x. 8.-Austral.

Herbertiana, Lind]. Bot. Reg, t. $1422=$ laevigata.

herpetica, Jacq. Obs. Bot. ii. 24. t. 45. f. 2 = alata.

heteroloba, Lindl. in Mitch. Three Exped. Austral. ed. II. ii. (1839) $122=$ eremophila.

heterophylla, Walp. Rep. i.838, sphalm. = mimosoides. Hibbertiana, Steud. Nom, ed. II. i. 305, sphalm.= Herbertiana.

Hilariana, Benth. in Mart. Fl. Bras. xv. 11. 108.-Am. trop.

Hildebrandtii, Vatke, in Oestr. Bot. Zeitschr. xxx. (1880) 80.-Afr. trop.

birsuta, Linn. Sp. Pl. 378.-Am. trop.

hirsuta, Vell. F1. Flum. 170 ; iv, t. $80=$ cathartica

hirta, Willd. Enum. Hort. Berol. Suppl. 23.-Hab. ?

hispida, Collad. Hist. Cass. $118=$ hispidala.

hispidula, Vahl, Eclog. Am. iii. 10.-Mexic.

Hoffmanseggit, Mart. ex Benth. in Mart. Fl. Bras. Xv. II. 104.-Bras.

holosericen, Fresen, in Flora, xxii. (1839) I. 51Abyssin.

homophylla, Hoffngg. Vers. Pf. Nachtr. i. 209.Hab.?

Hookeriana, Gill. in Hook. Bot. Misc. iii. (1\$\$S) 210. -Chil.

Hornemanni, DC. Prod, ii. $50 \pi-$ C. Chamacerista.

Horsfieldii, Mig. Fl. Ind. Bal. i. $99=$ glauca.

Houstoniana, Collad. Hist. Cass. $192=$ biflora, Mill.

Humboldtiana, DC. Prod. ii. $\$ 89=$ spectabilis.

humilis, Collad. Hist. Cass. $96=$ C. Tora.

humilis, Willd. ex Steud. Nom. ed. II. i. $\$ 05=$ C.

$$
\text { Tagera. }
$$

lybrida, Tenore, Cat. Hort. Neap. 80 =lacrigata.

bymentaefolia, Benth. in Mart. F\%. Bras. xr. II. 130. -Am. trop.

hypnotica, Vell. Fl. Flum. 169 ; iv. L. 75 - C. Chamaccrista.

hypoleuca, Mart. ex Bensh. in Mart. Fl. Bras. xr. II. $117 .-1 \mathrm{~ms}$.

inacquilatera, Falb. ox DC. Prod. ii. 190.-N. Granat. incana, bog. Syn. Cass. 52.-Bres.

; M : 


\section{CASSIA :}

incarnata, Pav. ex Benth. in Trans. Linn. Soc. xxvii. (1871) 545.-Peruv

incurvata, Benth. in Mart. Fl. Bras. xv. II. 137.Am. trop.

indecora, H. B. \& K. Nov. Gen, et Sp. vi. $313=$ bicapsularis.

indica, Poir. Encyc. Suppl. ii. 126=C. Sophera.

inflata, Spreng. Syst. ii. $336=$ bicapsularis.

Isidorea, Benth. in Mart. Fl. Bras. xv. II. 154.Bras.

italica, Lam. ex Steud. Nom. ed. I. 166, $167=$ C. Senna.

itambana, Mart. ex Benth. in Mart. Fl. Bras. Xv. II. 151.-Am. trop.

Jacobinea, Benth. in Mart. l. c. 132.-Am. trop.

javanica, Aubl. Pl. Gui. i. $382=$ grandis.

javanica, Linn. Sp. Pl. 379.-Malaya.

javanica, Sieber, ex Benth, in Trans. Linn. Soc, xxvii. (1871) $517=$ Sieberiana.

javanica, Vell. Fl. Flum. 168 ; iv. t. $73=$ ferruginea

Johannae, Vatke, in Oestr. Bot Zeitschr. xxx. (1880) 77.-Afr. trop.

Ketschta, Hasselq. It. Palaest. 469.-Palaest.

Kirkii, Oliver, Fl. Trop. Afr. ii. 281.-Afr. trop.

kituiensis, Vatke, in Oestr. Bot. Zeitschr. xxx. (1880) 81.-Afr, trop.

Kleinii, Wight छे Arn. Prod. 293.-Ind. or.; Malaya.

Kotschyana, Oliver, Fl. Trop. Afr. ii. 271.-Afr. trop.

Kunthiana, Cham. \& Schlecht. in Linnaea, v. (1830) $598=$ C. Tagera

lactea, Vatke, in Oestr. Bot. Zeitschr. xxx. (1880) 78 - Madag.

laeta, $H$. . B. \& $K$. Nov. Gen. et Sp. vi. $340,-\mathrm{N}$ Granat.

laevigata, Willd. Enum. Hort. Berol. 441.-Cosmop. trop.

lamprosperma, Mart. ex Benth. in Mart. Fl. Bras. xv. II. 146.-Am, trop.

lanceolata, Collad. Hist. Cass. 93. t. 15=acutifolia.

lanceolata, Forsk. F1. Aegypt. Arab. 85=C. Sophera

lanceolata, Pers. Syn. i. $456=$ uniflora.

lanceolata, Wight \& Am. Prod. 288=angustifolia.

Langsdorffi, Kunth, ex Vog. Syn. Cass. 55.-Bras.

latifolia, G. F. W. Mey. Prim. Fl. Esseq. 166.Guiana.

latistipula, Benth. in Mart. Fl. Bras. Xv. II. 156.Bros.

latopetiolata, Domb. ex Vog. Syn. Cass. 70.-Peruv.

lavradioides, Benth. in Mart. Fl. Bras. xv. II. 137.Am. trop.

laxiflora, Benth. Fl. Austral. ii. 283.-Austral.

leiandra, Benth. in Mart. Fl. Bras. xv. II. 94.Bras.

leiantha, Benth. in Hook. Journ. Bot. ii. (1840) $78=$ hispidula.

leiophylla, Vog. Syn. Cass. 25.-Bras.

lenitiva, Bisch. in Bot. Zeit. viii. (1850) $885=$ acutifolia.

lentiscifolia, Benth. in Mart. Fl. Bras. xv. II. 144.Am. trop.

leptocarpa, Benth. in Linnaea, xxii. (1849) 528.-N Mexic.

leptoclada, Benth. Fl. Austral. ii. 290.-Austral.

leptophylla, Vog. Syn. Cass. 13.-Bras.

Leschenaultiana, DC. in Mém. Soc. Phys. Genèv, ii (1824) $132=$ mimosoides.

Leschenaultii, Wall. Cat. n. 5325 = mimosoides.

leucoxylon, Klotzsch, in Schomb. Faun. E Fl. Gui. 1207 , nomen.-Guiana.

Liebmannii, Benth. in Trans. Linn. Soc. xxvii. (1871) 549 - Mexic.

ligustrina, Forsk. ex Benth. 1. c. $533=$ C. Sophera.

ligustrina, Linn. Sp. Pl. 378.-Am. trop.

ligustrina, Mill. Gard. Dict. ed. VIII. n. $12=$ obovata.

ligustrinoides, Schrank, in Denkschr. Akad.Muench.vi, (1816-17) $179=$ angustifolia.

limensis, Lam. Encyc. i. $643=$ bicapsularis.

Lindheimeriana, Schlecht. in Linnaea, xxi. (1848) 457 -Texas.

Lindleyana, Gardn. in Hook. Lond. Journ. Bot. ii. (1843) $341=$ multijuga.

linearifolia, G. Don, Gen. Syst. ii. 446.-Bras.

linearis, Michx. F1. Bor. Am, i. 261=occidentalis.

lineata, Sw. Prod. Veg. Ind. Occ. 66.-Am. trop.

\section{CASSIA}

omatopoda, Benth. in Mart. Fl. Bras. Xv. II. 146.Bras.

longeglandulosa, Benth. l. c. 119.-Am. trop

longicuspis, Benth. l. c. 150.-Am. trop.

longifolia, Steud. Nom. ed. II. i. 304, in syn. = angusti-

longiracemosa, Vatke, in Oestr. Bot. Zeitschr. xxx. (1880) 80.-Afr, trop.

longisiliqua, Blanco, F1. Filip. ed. I. $338=$ hirsuta

longisiliqua, Linn. f. Suppl. $230=$ occidentalis.

Lorentzii, Niederl. in Roca, Exped. Rio Negro, ii. 210. - Patagon.

lotoides, H. B. \& K. Nov. Gen. et Sp. vi. $361=$ hispidula.

lucens, Vog. Syn. Cass. $46=$ racemosa.

lucida, Dehnh. Cat. Pl. Hort. Camald. ed. II. 18.$\mathrm{Hab}$ ?

Lundii, Benth. in Mart. Fl. Bras. xv. II. 143.Am. trop.

lutescens, G. Don, Gen. Syst. ii. $442=$ tomentosa

machaeriifolia, Benth. in Mart. Fl. Bras. xv. II. 151.Am. trop.

macradenia, Collad. Hist. Cass. 132.-Bras.

macranthera, $D C$ in Collad l. c. 99. t. 8-Bras.

macrocarpa, Micheli, in Mém. Soc. Phys. Genèv. xxviii.

(1883) n. vir. 43.- Paraguay.

macrophylla, Kunth, Mimos. 126. t. 38.-N. Granat

macrophylla, Ruiz \& Pav, ex Benth, in Trans. Linn.

Soc. xxvii. (1871) $520=$ Ruiziana.

madagascariensis, Boj. Hort. Maurit. 120.-Madag.

madagascariensis, Poir. ex Desv. in Ann. Sc. Nat. Sér.

I. ix. (1826) $424=$ Swartzia madagascariensis.

magnifica, Mart. Herb. F1. Bras. 106=multijuga

magnifolia, F. Muell. Fragm. i. 166.-Austral.

malacophylla, Vog. Syn. Cass. 55.-Bras.

Mandoni, Benth. in Trans. Linn. Soc. xxvii. (1871) 540 - -Peruy.

Manni, Oliver, Fl. Trop. Afr. ii. 272.-Afr. trop.

marginata, Roxb. Hort. Beng. [31] ; Fl. Ind. ii. 338. -Ind, or.

marginata, Willd. Enum. Hort. Berol. $443=$ poly= phylla.

Marimari, Aubl. Pl. Gui. $382=$ biflora

maritima, Willd. ex Vog. Syn. Cass. $23=$ pilifera

Martiana, Benth. in Mart. Fl. Bras. xv. II. 127.-Am. trop.

marylandica, Linn. Sp. $P l$. 378.-Am. bor.

medellinensis, Posado, in Baill. Adansonia, x. (1872)

187.-N. Granat.

medica, Forsk. Fl. Aegypt. Arab. p. cxi =angustifolia.

medica, Vell. Fl. Flum. 166; iv. t. $62=$ quinquangulata.

medicinalis, Bisch.' in Bot. 'Zeit. viii. (1850) $887=$ angustifolia.

megalantha, Decne. Herb. Tim. Descr. 136.-Ins. Timor.

melanocarpa, Bert. ex DC. Prod. ii. 491 - viminea.

mexicana, facq. Hort. Schoenbr. ii. t. 203.-Am. trop. micans, Nees, in Flora, iv, (1821) $303=$ speciosa

micrantha, Guill. \& Perr. Fl. Seneg. Tent. i. $262=$ nigricans.

microphylla, Willd. Sp. Pl. ii. $529=$ mimosoides.

Milleri, Collad. Hist. Cass. $132=$ pilosa.

Mimosa, Noronha, in Verh. Batav. Gen, v. (1790) ed.

I. Art. IV, 9.-Malaya.

mimosoides, DC. Prod. ii. $503=$ Kleinii

mimosoides, Linn. Sp. Pl. 379.-Cosmop. trop.

misera, Phil. Fl. Atac. 17.-Chili.

mollis, Vahl, Symb. Bot. iii. $57=$ grandis.

mollissima, Humb. \& Bonpl. ex Willd. Enum. Hort.

Berol. $440=$ atomaria

monaden, Vell. F1. Flum. 166 ; iv. t. $63=$ splendida.

monantha, DC. Prod. ii. $506=$ sericea.

monophylla, Vell. Fl. Flum. 166 ; iv, t. $61=$ rotundi folia.

montana, Heyne, in Roth, Nov. Sp. Pl. 214.Ind. or.

montana, Naves, ex Villar, in Blanco, Fl. Philipp. ed.

III. Nov. App. $71=$ timoriensis.

montana, Vell. Fl. Flum. 169 ; iv. t. 77.-Bras.

monticola, Mart. ex Benth. in Mart. Fl. Bras. xv. II.

134.-Am. trop.

moschata, Benth. in Hook. Journ. Bot, ii, (1840) $75=$ leiandra.

moschata, $H . B . \varepsilon K$. Nov. Gen, et $S p$. vi. 358.-Am. austr.
CASSIA :-

mucronata, Spreng. Syst, ii. 341.-Bras.

mucronifera, Mart. ex Benth. in Mart. Fl. Bras. xv. II 116.-Bras.

multiflora, Mart. Et Gal. in Bull. Acad. Brux. x. II. (1843) 307.-Am. trop.

multiflora, Scheele, in Linnaea, xvii. (1843) $337=$ excelsa.

multiflora, Vog. Syn, Cass. $39=$ macranthera.

multiglandulosa, Jacq. Ic. Rar, i. t. $72=$ tomentosa.

multijuja, Rich. in Act. Soc. Hist. Nat. Par. i. (1792) 108.-Guiana.

multinervia, Mart. ex Benth. in Mart. Fl. Bras. xy. II. 166.-Am. trop.

multiseta, Benth. l. c. 141.-Am, trop.

multisitiqua, J. F. Gmel. Syst. 1521 (quid?).

Mutisiana, Kunth, Mimos. 142. t. 43.-Am. trop.

myriophylla, Wall. Cat. n. $5326=$ mimosoides

nana, Benth. in Mart. Fl. Bras. xv. II. 110.-Am. trop.

Neesiana, Mart, ex Benth. l. c. 148.-Bras.

neglecta, Vog. in Linnaea, x. (1836) 394.-Bras.

nemophila, Walp. Rep. i. 827, sphalm.=eremophila.

nemorosa, H. B. \& K. Nov. Gen, et Sp. vi. $358=$ biflora.

nervosa, Vog. Syn. Cass. $39=$ speciosa.

nicaraguensis, Benth. in Trans. Linn. Soc. xxvii. (1871) 552.-Am. trop.

nictitans, Linn. Sp. Pl. 380.-Am, bor, et austr.

nictitans, Wydl. ex Steud. Nom. ed. II. i. $303,306=$ mimosoides.

nigricans, Vahl, Symb. Bot. i. 30.-Geront. trop

nitida, Rich. in Act. Soc. Hist. Nat. Par. i. (1792) 108 $=$ viminea.

nodosa, Buch.-Ham. ex Roxb. Hort. Beng. [31]; Fl. Ind. ii. 336.-As. trop.

notabilis, F. Muell. Fragm, iii, 28-Austral.

nummularia, Vahl, ex DC. Prod. ii. $501=$ rotundifolia.

nummulariaefolia, Benth, in Mart. Fl. Bras. xv. II. 143. -Bras.

nutans, Collad. Hist. Cass. 113. t. $4=$ atomaria.

obcordata, Sw. ex Wickstr. in Vet. Acad. Handl. (1825 $429=$ lineata

obliqua, Ruiz E Pav. ex G. Don, Gen. Syst. ii.. 451 -Peruv.

obliquifolia, Schrank, in Denkschr. Bot, Ges. Regensb. ii. (1822) $40=$ occidentalis.

oblongifolia, Vog. Syn. Cass. 23.-Bras,

obovata, Collad. Hist. Cass. 92. t. 15.-Geront. trop.

obtecta, Benth. in Mart. Fl. Bras. xv. II, 136.-Am. trop.

obtusa, Clos, in C. Gay, FI. Chil. ii. $235=$ bicapsularis obtusa, Roxb. Hort. Beng. [31] ; Wight, Ic. t. $757=$ obovata.

obtusata, Hayne, Arzneig. ix. t. $43=$ obovata

obtusata, Hochst. \& Steud. Nom. ed. II. i. $306=$ holosericea.

obtusifolia, Linn. Sp. Pl. 377 = C. Tora,

occidentalis, Hort. ex Steud. Nom. ed. II i. $306=$ homophylla.

occidentalis, Linn. Sp. Pl. 377.-Cosmop. trop. occidentalis, Naves, in Blanco, Fl. Philipp. ed. III. $t$ $73=$ C. Sophera.

ochnacea, Vog. Syn. Cass. 51,-Bras.

odorata, Morris, Fl. Conspic, t. 57.-Austral.

olesiphylla, Vog. Syn. Cass. 68.-Bras.

oligoclada, F. Muell. Fragm. iii. 49.-Austral.

oligophylla, $F$. Muell. l. c.--Austral.

oligosperma, Mart. ex Benth. in Mart. Fl. Bras. xv. II. 147.-Bras.

opaca, R. Grah. ex Vog. Syn. Cass. $42=$ stipulacea. orbiculata, Benth. in Hook. Fourn, Bot. ii. (1840) 79 -Bras.

orinocensis, Spruce, ex Benth, in Mart. Fl. Bras. xv. II. 150.-Bras.

orientalis, Pers. Syn. i. $457=$ acutifolia.

ornata, Bernh, ex Benth, in Trans, Linn. Soc. xxvii (1871) $522=$ latifolia.

ornata, Klotzsch, in Schomb. Faun. EF Fl. Gui. 1104, nomen.-Guiana.

ornithopodioides, Steud. Nom. ed. I. $166=$ seq.

ornithopoides, Lam. Encyc. i. $644=$ sericea.

Otterbeynii, G. F, W. Mey. Prim. Fl. Esseq. $169=$ glandulosa.

ovalifolia, Mart. \& Gal. in Bull, Acad, Brux, x. Ir. (1843) $305=$ bicapsularis. 


\section{CASSIA :}

ovata, Mérat E Lens, ex Geiger, Pharm. Bot. ed. II. ii. 1125.-Arab

oxyadena, DC. Prod. ii. $495=$ biflora.

oxyphylla, Kunth, Mimos. 129. t. 39.-N. Granat.

pachycalyx, Vog. Syn. Cass. $52=$ cathartica.

pachyphylla, Mart. ex Benth. in Mart. Fl. Bras. xv. II. 166.-Bras.

pallida, Vahl, Eclog. Am. iii. $12=$ biflora.

palmata, Wall. Cat. n. 5306=timoriensis.

paniculata, Benth. in Mart. Fl. Bras. xv. II. 153.-

Am. trop.

paposana, Phil. Fl. Atac. 17.-Chili.

papulosa, Hoffmgg. Verz. Pfl. Nachtr. ii. 81.-Bras.

paradyction, Vog. Syn. Cass. 45.-Bras.

paraguensis, Micheli, in Mém.Soc. Phys. Genèv. xxviii.

(1883) n. VIr. 44.-Paraguay.

Parahyba, Vell. Fl. Flum. 168 ; iv, t. $71=$ Schizolobium excelsum.

paramariboènsis, Miq. in Bot. Zeit. i. (1843) 461.Guian.

paratyensis, Vell. Fl. Flum. 168; iv. t. 70.-Bras

Parkeriana, DC. Prod. ii. $504=x$ iparia.

parvifolia, Wender, in Syll. Ratisb, i. (1824) $65=$ glandulosa.

parvistipula, Benth. in Mart. Fl. Bras. xv. II. 170.Am. trop.

pascuorum, Mart. ex Benth. l. c. 165.-Am. trop.

patellaria, DC. in Collad. Hist. Cass. 125. t. 16.-Am.

trop.

patula, [Soland. in] Ait. Hort. Kew, ed. I. ii. $51=$ C. Sophera.

pauciflora, $H: B$. E K. Nov. Gen. et Sp. vi. 360.-Am trop.

Pavoniana, G. Don, Gen. Syst. ii. $447=$ glandulosa.

Pearcii, Benth. in Trans. Linn. Soc. xxvii. (1871) 552 -Bolivia.

pedicellaris, DC. Prod. ii. 504.-Ins. S. Doming

pendula, Willd. Enum. Hort. Berol. $440=$ bicapsularis

pentagonia, Mill. Gard. Dict. ed. VIII. n. 18.-Am.

trop.

pentandra, Raddi, in Mem, Mod. xviii. Fis. (1820)

$399=$ rotundifolia.

peralteana, H. B. \& K. Nov. Gen. et Sp. vi. 356,Mexic.

Persoonii, Collad. Hist. Cass. $119=$ uniflora

peruviana, Vog. Syn. Cass. $39=$ obliqua.

Petersiana, Bolle, in Peters, Reise Mossamb. Bot. 13 $=$ delagoënsis.

phyllodinea, R. Br. App. Sturt, Centr. Austral. 15.Austral.

phyllostachya, Benth. in Mart. Fl. Bras. xv. II. 150. -Am. trop.

picta, G. Don, Gen.Syst. ii. 444.-Ecuador; Ins. Galap. pilidens, Steud. Nom. ed. II. i. $307=$ nictitans.

pilifera, Vog. Syn. Cass. 23.-Bras.

pilosa, Linn. Syst. Nat. ed. X. 1017.-Am. trop.

pinnata, Hort. ex Voigt, in Syll. Ratisb. ii. (1828) 55 $=$ elegans.

pistaciaefolia, $H$. B. $K$. Nov. Gen. et Sp. vi, 349.-

N. Granat.

planisiliqua, Burm. f. Fl. Ind. $96=$ Albizzia Lebbek.

planisiliqua, Linn. Sp. Pl. $377=$ occidentalis.

planisiliqua, Lam. Encyc. i. 645.-Ins. Guadelup.

platypoda, R. Br. in Sturt, Centr. Austr. ii. 78 = eremophila.

pleurocarpa, F. Muell. Fragm. i. 228.-Austral

Plumieri, DC. Prod. ii. 506.-Ins. Guadelup.

plumosa, Vog. Syn. Cass. $64=$ mimosoides.

podocarpa, Guill. E Perr. Fl. Seueg. Tent. 259.-Afr

trop.

Pohliana, Benth. in Hook. Fourn. Bot. ii. (1840) 80.Bras.

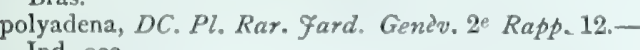
Ind, occ.

polyantha, Mof. E Sesse, ex Collad. Hist. Cass. 112. t 2.-Mexic.

polyphylla, Gacq. Coll. iv. 104 ; Ic. Rar. t. 460.-Ind. occ.

polystachya, Benth. in Hook. Fourn. Bot. ii. (1840) 77. - Guiana.

porturegalensis, Bancroft, ex Macf. Fl. Jamaic. i. 340 =obovata.

Potentilla, Mart. ex Benth, in Mart. Fl. Bras. xv. I1. 168.-Am. trop.

praetexta, Vog. Syn. Cass. 67.-Am. trop.

procumbens, Forsk. Fl. Aegypt. Arab. p. cxi=nigricans.

procumbens, Linn. Sp. Pl, ed. I. $380=$ nictitans.
CASSIA.

procumbens, Linn. Sp. Pl. ed. II. 543, pro parte, et Herb.-Am. bor.

procumbens, Mill. Gard. Dict. ed. VIII. n, $20=$ hispidula.

procumbens, Thunb. F1. Jap. $179=$ mimosoides prominens, D. Dietr. Syn. Pl. ii. $1479=$ macranthera. propinqua, Cham. \& Schlecht. in Linnaea, v. (1830) $599=$ tristicula

propinqua, H. B. \& K. Nov. Gen. et Sp. vi. $369=$ glandulosa.

prostrata, Humb. \& Bonpl. ex Willd. Enum. Hort Berol. $441=$ serpens

prostrata, Koen. ex Roxb. Hort. Beng. $32=$ pumila.

pruinosa, F. Muell. Fragm. iii. 48.-Austral.

seudo-nictitans, Hance; in Journ. Linn. Soc. xi.

1871). 79 =nictitans.

sammophila, Bênth. in Trans. Linn. Soc. xxvii. (1871) $571=$ cordistipula

psilocarpa, Welw. Apont. 587. n. $40=$ Sieberiana.

puberula, H. B. \& K. Nov. Gen, et Sp. vi. $341=$ bacil laris.

pubescens, R. Br, in Salt, Abyss. App. $64=$ holosericea.

pubescens, Ehrenb. \& Hempr. ex Benth. in Proc. Linn.

Soc. ii. (1855) 283 = holosericea.

pubescens, Facq. Fragm. 46. t. 57.-Bras

pubescens, Ruiz \& Pav. ex G. Don, Gen. Syst. ii. $442=$ tomentosa.

pubigera, Lag. Gen. et Sp. Nov, $14=$ hirsuta.

pudibunda, Mart. ex Benth. in Mart. Fl. Bras, xv. II. 102.-Bras.

pulchella, Boj. Hort. Maurit. 122.-Ins. Maurit.

pulchella, Salisb. Prod. $326=$ C. Chamaecrista.

pulcherrima, Dehn. Rivista Nap. i. III. 174.-Guiana.

pulchra, H. B. \& K. Nov. Gen. et Sp. vi. $362=$

Desvanxii.

pumila, Lam. Encyca i. 651.-Cosmop. trop.

pumila, Mart. \& Gal. in Bull. Acad. Brux. x. II. (1843) $307=$ leiophylla.

pumila, F. Muell. Fragm. iii. $47=$ concinna.

Pumilio, A. Gray, Pl. Lindh. 180.-Am. bor. occ

punctata, Scheele, in Linnaea, xvii. (1843) $336=$ sylvestris.

punctata, Vog. Syn. Cass. 51.-Bras.

punctulata, Hook. \& Arn. Bot. Beech. Voy, $420==$ pauciflora.

purgans, Steud. Nom. ed. II. i. 307.-Chili.

purpurea, Roxb. Hort. Beng. [31] = C. Sophera

pygmaea, DC. Prod. ii. $502=$ procumbens, Linn. Herb.

quadrangularis, Zoll. \& Mor. Syst. Verz. Zoll. 2= laevigata,

quadriflora, Vog. Syn. Cass, $47=$ glutinosa

Quebracho, Steud. '1833' ex Nom. ed. II. i. 307, 304 = bicapsularis

quinquangulata, Rich. in Act. Soc. Hist. Nat. Par. (1792) 108.-Am. trop.

racemosa, Mill. Gard. Dict. ed. VIII. n. 19.-Bras

ramiflora, Vog. Syn. Cass. $48=$ C. Apoucouita.

ramosa, Vog. 1. c. $55=$ uniflora.

ramosissima, H. B. \& K. Nov. Gen。 et Sp. vi. 366 glandulosa.

reflexa, Salisb. Prod. $326=$ marylandica

Reinwardtii, Hassk. in Hoev. E De Vriese, Tijdschr. v. (1838-39) 269.-Java.

reniformis, G. Don, Gen. Syst. ii. 440.-Bras.

renigera, Wall. Cat. n. 5307.-Burma.

repens, Vog. Syn. Cass. 60 -Bras,

reticulata, Willd. Enum. Hort. Berol. 443.-Am. austr.

retusa, Soland, ex Vog. in Linnaea, Xv. (1841) 72.Austral.

revoluta, F. Muell. in Trans, Vict. Inst. (1855) $120=$ australis.

rhombifolia, Roxb. Hort. Beng. [31] ; F1. Ind. ii. $334=$ C. Fistula.

Richardiana, Kunth, Mimos. 139. t. $142=$ multijuga.

Riedelii, Benth. in Mart.Fl. Bras, xv. II. 122.-Am, trop.

rigidifolia, Benth. l. c. 142.-Bras.

riparia, $H, B . G^{\circ} K$. Nov. Gen. et $S p$. vi. $369 .-A m$. trop.

robiniaefolia, Benth, in Trans. Linn. Soc, xxvii. (1871) 545.-Am. trop.

robinioides, Willd. Enum. Hort, Berol. $443=C_{\text {. }}$ Sophera.

Roemeriana, Scheele, in Linnaea, xvi. (1842) 457.Texas,

\section{CASSIA :}

Roraimae, Benth. in Trans. Linn. Soc. xxvii. (1871) 574.-Guiana.

rostrata, Voigt, in Syll. Ratisb. ii. (1828) $55=$ biflora.

rotundata, Vog. Syn. Cass. 58.-Bras.

rotundifolia, Pers. Syn. i. 456-Mexic

Roxburghiana, R. Grah. in Wall. Cat. n. $5323=$ mimosoides.

Roxburghii, DC. Prod. ii. $489=$ marginata.

Roxburghii, Steud. Nom. ed. II. i. 307, sphalm. $=$ Roxburghiana.

rufa, Mart. E Gal. in Bull. Acad. Brux. 工 II (1843 306.-Mexic.

rugosa, G. Don, Gen. Syst. ii. 440.-Bras.

Ruiziana, Vog. Syn. Cass. 40.-Am. trop.

rupicola, Benth. in Trans. Linn. Soc. xxvii. (1871) 57 t $=$ olesiphylla.

rusa, Mart. \& Gal, in Bull. Acad. Brox. x. II. (1848) $306=$ tristicula

ruscifolia, Jacq. Ic. Rar. i. t. $71=$ C. Sophera

Sabak, Delile, Cent. Pl. Afr. 28.-Aegypt.

Sagera, Lam. Encyc. i. $643=$ C. Tora.

Sagotiana, Benth. in Mart. Fl. Bras. xv. Ir. 93.Guiana.

Saltiana, Stend. Nom, ed. II. i. $307=$ holosericea

sapindifulia, Vog. Syn. Cass. 34.-Bras.

savannensis, Miq. in Bot. Zeit. i. (1843) $461=$ nniflora.

scabra, Pohl,ex Benth. in Mart. Fl. Bras. xv. II. 135. -Am. trop.

scabrella, Hoffmgg. Verz. Pf. Nachtr. ii. 81.-Bras.

scandens, Ruiz E' Pav. ex G. Don, Gen. Syst. ii. 440 -Ecuador.

Schimperi, Steud. Nom. ed. II. i. $307=$ holosericea

schinifolia, A. DC. $7^{\circ}$ Not. Pl. Rar. Hort. Genèv. $35=$ C. Sophera.

Schlimii, Benth, in Trans, Linn. Soc, vovii. (1871) 571. - Am, trop.

Schomburgkii, Klotzsch, ex Schomb. Faun. E Fl. Gui 1207, nomen.-Guiana.

Schultesii, Colla, Hort. Ripul. App. ii. $343=$ australis. sclerocarpa, Vog. Syn. Cass. 15.-Bras.

secunda, Benth, in Mart. Fl. Bras, xy, II, 148.Bras.

Selloi, G. Don, Gen. Syst. ii. $442=$ multijuga.

Selloi, Spreng. ex Vog. Syn. Cass. $39=$ specios

semifalcata, Vell. Fl. Flum. 167 ; iv. t. $68=$ multijuga.

semperflorens, DC. Cat. Hort. Monsp. $90=$ biflora

Senna, Linn. Sp. Pl. $377=$ obovata, acutifolia.

sennoides, Jacq. Coll. i. $74=$ bicapsularis.

sensitiva, Jacq. 1. c. ii. $367=$ sericea,

sensitiva, Roxb. Hort. Beng. $32=$ mimosoides.

septemtrionalis, Viv. Elench. Pl. Hort. Dinegro, 14.-

$\mathrm{Hab}$ ?

septentrionalis, Zuccagni, in Roem. Collect. 141

laevigata.

sericea, $S_{w} . \mathrm{Fl}$. Ind. Occ. 724.-Am. trop.

serpens, Griseb. Cat. Pl. Cub. $80=$ strigillosa

serpens, Lint. Syst. Nat. ed. X. 1018.-Am. trop.

sessilis, Benth. in Mart. Fl. Bras. xv. II. 135, in syd. andromedea.

setigera, DC. Prod. ii. $499=$ montana.

setosa, Vog. Syn. Cass. 51.-Bras,

siamea, Lam. Encyc. 1.648.-Ind. or.; Malava

Sieberi, Presl, in Oken, Isis, xxi. (1828) $272=$ glancm.

Sieberiana, DC. Prod. ii. 489.-Afr. trop.

silvestris, Vell. Fl. Flum, 169; iv, to 78,-Bras.

simplicifolia, Desv. Joum. Bot iii. (1814) $72 i=D_{c}$

laria ovalifolia).-Bras.

sinensis, J. F. Gmel. Syst. $669=$ chinensis.

singueana, Delite, in Caill. Voy. Meroè, Bot. iv. 27

Cent. Pl. Aft. 28) = goratensis.

Skinneri, Benth. in Trans. Linn. Soc, xxvii. 18;1

542.-Guatemal.

smaragdisa, Macfad. Fl. Jamaic. i. $\$ 47=$ nictitans.

Sophera, Linn. Sp. Pl. 379.-Geront. trop.

Sophere, Wall. Cat. n. $5317=$ occidentalis.

sopheroides, Collad. Hist. Cass. $199=$ C. Sophera.

Sophora, Auct. $=$ C. Sophera.

sophoroides, Mart.ex Brnth. in Mart. Fl. Bras. Xv. II. 15:-Am. trop.

speciosa, H. B. \& K. Nov. Gea. et Sp, ri. 958 = spec tabilis.

speciosa, Roxb. Hort. Beng. [\$1], nomen = glauca.

speciosa, Schrad. in G.ptt. Gol. Ane. i. (1821) i18.

lims.

spectabilis, DC. Cas. Murt. Monsp. 90, -Am. trop. 


\section{CASSTA :-}

spinescens, Hoffmgg. ex Vog. Syn. Cass. 27.-Bras.

splendida, Vog. l. c. 17.-Bras.

Spruceana, Benth. in Mart. Fl. Bras. xv. II. 92.Bras.

staminea, Vog. Syn. Cass. $14=$ ferruginea.

stenocarpa, Vog. l. c. 68.-Bras.

stenophylla, Benth. in Trans. Linn. Soc. xxvii. (1871) 535.-Cuba.

stipulacea, [Soland. in] Ait. Hort. Kerv. ed. II. ii. 52. - Chili

stipulata, G. Don, Gen. Syst. ii. 448 =flavicoma.

striata, Vog. Syn. Cass. $39=$ splendida.

stricta, Schrank, Hort. Monac. t. $34=\mathrm{C}$. Chamaecrista.

stricta, Steud. Nom. ed. II. i. 308.-Afr. austr.

strictifolia, Benth. in Mart. Fl. Bras. Xv. II. 145.Bras.

strigillosa, Benth. in Trans. Linn. Soc. xxvii. (1871)

581 - Ind, occ

strobilacea, H. B. \& K. Nov. Gen. et Sp. vi. $347=$ reticulata.

Sturtii, R. Br. in Sturt, Centr.Austral. App. 14.Austral.

subtriflora, Mart. ex Benth. in Mart. Fl. Bras, xv. II. 176. - Bras.

subulata, Griseb. in Goett. Abh. xix. (1874) 130.-Am austr.

succedana, Bell. ex DC. Prod. ii. 498=marylandica suffruticosa, Koen. ex Roth, Nov. Sp. Pl. $213=$.glauca. sulcata, Blanco, Fl. Filip. ed. II. $236=$ hirsuta. sulcata, DC Cat Hort Monsp. 90-Am. austr. sulphurea, DC. ex Collad. Hist. Cass. $84=$ glauca. sumatrana, Roxb. Hort. Beng. [31], nomen= siamea Sunsub, Forsk. Fl. Aegypt. Arab. $86=$ C. Tora. supplex, Mart. ex Benth. in Mart. Fl. Bras. Xv. II. 163.-Bras.

surattensis, Burm. f. F1. Ind. $97=$ glauca

surinamensis, Dehnh. Cat. Pl. Hort. Camald. ed. II. 18.-Guiana.

Swainsoni, Benth. in Mart. Fl. Bras. Xv. II. 167.-Bras.

Swartzii, Wikst. in Vet. Akad. Handl. (1825) $430=$ virgata.

sylvestris, Auct. $=$ silvestris

Tagera, Lam. Encyc. i. $643=$ C. Tora

Tagera, Linn.Sp.Pl. 376.-Am. trop.

Tala, Desv. Journ. Bot. iii. (1814) 23. t. $73=$ C. Tora.

Tarantan, H. B. \& K. Nov. Gen. et Sp. vi. $348=$ reticulata.

tarda, Noronha, in Verh. Batav. Gen. v. $(1790)$ ed. I. Art. IV. 9.-Malaya.

tecta, Vog. Syn. Cass. 56.-Bras.

Telfairiana, Wall. Cat. n. $5324=$ mimosoides

tenella, H. B. E K. Nov. Gen. et Sp. vi. 365.Venezuela.

tenella, Roxb. Hort. Beng. 32, nomen =mimosoides tenuifolia, Vog. Syn. Cass. 16.-Bras.

tenuisepala, Benth. in Mart. Fl. Bras. xv. II. 164.Am. trop.

tenuissima, Linn. Sp. P1. $378=$ biflora.

tephrosiaefolia, Benth. in Mart. Fl. Bras. Xv. II. 153.

-Am. trop.

teretifolia, A. Cunn. ex Lindl. in Ann. Sc. Nat. Sér. II. xv. (1841) 60.-Austral.

teretifolia, Lind1. in Mitch. Three Exped. i، $289=$ artemisioides.

teretiuscula, F. Muell. in Linnaea, xxv. (1852) $389=$ artemisioides.

tetrafoliata, Desv. in Ann. Sc. Nat. Sér. I. ix. (1826) 428 = Langsdorffi.

tetraphylla, Collad. Hist. Cass. $130=$ hispidula.

tetraphylla, Desv. Journ. Bot. iii. (1814) $72=$ Desvauxii.

tettensis, Bolle, in Peters, Reise Mossamb. Bot. 14.

-Afr. trop.

texana, Buckl. in Proc. Acad. Sc. Philad. ' 1861 1862) $452=$ procumbens, Linn. Herb.

Thonningii, DC. Prod. ii. $500=\mathrm{C}$. Absus.

Thunbergiana, Blume, ex Miq. Ann. Mus. Bot. Lugd. Bat. iii. $54=$ mimosoides.

timorensis, DC. Prod. ii. 499.-As. trop.; Austral

tomentosa, Ehrenb. \& Hempr. ex Benth. in Proc. Linn Soc. ii. (1855) $283=$ holosericea.

tomentosa, Linn. f. Suppl.231.-Am. trop.

tomentosa, Wall. Cat. n. $5304=$ hirsuta.

Tora, Linn. Sp. Pl. 376.-Cosmop. trop.

toroides, Roxb. Hort. Beng. [31], nomen $=$ C. Tora

torosa, Cav. Desc. $131=$ C. Sophera.

torulosa, Poir. Encyc. Suppl. ii. $127=$ C. Sophera

trachycarpa, Vog. Syn. Cass. 52.-Bras.
CASSIA :-

trachypus, Mart. ex Benth. in Mart. Fl. Bras. xv. II. 122.-Bras

tragacanthoides, Mart. ex Benth.l. c. 166.-Am. trop. trichopoda, Benth.l.c. 163.-Am. trop.

triflora, Jacq. Hort. Schoenb. iv. $40=$ C. Chamaecrista.

triflora, Vahl, Eclog. Am. iii. 11.-Ins. S. Cruc

trinitatis, Benth. in Hook. Journ. Bot. ii. (1840) $77=$ racemosa.

trinitatis, Reichb. ex DC. Prod. ii. $489=$ spectabilis.

tristicula, H. B. \& K. Nov. Gen. et Sp. vi. 367.-Am. austr.

tropica, Vell. Fl. Flum. 166; iv. t. $64=$ laevigata.

tuberculata, Collad. Hist. Cass. 133.-Bras.

Tula, Desv. ex Steud. Nom. ed. II. i. $308=$ C. Tora

umbellata, Reichb. Ic. Exot. t. 206 = australis.

undulata, Benth. in Hook. Fourn. Bot. ii. (1840) 76. -Am. trop.

uniflora, Mill. Gard. Dict. ed. VIII. n. $5=$ sericea.

uniflora, Spreng. Neue Entdeck. i. 291.-Am. trop.

Urmenetae, Phil. in Anal. Univ. Chil. (1872) 708. Chili.

ursina, Mart. ex Benth. in Mart. Fl. Bras. xv. II. 151. -Am. trop.

Vauthieri, Benth. l. c. 138.-Am, trop.

velutina, Vog. Syn. Cass. 24.-Bras.

venenifera, Rodsch. in G. F. W. Mey. Prim. Fl. Esseq. $167=$ hirsuta

venosa, Castigl. ex Zuccagni, in Roem. Collect. $140=$ C. Chamaecrista

venosa, Desv. Journ. Bot. iii. (1814) $72=$ cytisoides,

venulosa, Benth. in Mart. Fl. Bras. xv. II, 170.-Bras.

venusta, F. Muell. Fragm. i. 165.-Austral.

venustula, H. B. \& K. Nov. Gen.et Sp. vi, $358=$ biflora

vernicosa, Clos, in C. Gay, F1. Chil. ii. $244=$ laevigata.

verrucosa, Vog. Syn. Cass, 38.-Bras.

versicolor, Benth. Pl. Hartw. $128=$ incarnata

versicolor, Meyen, in Vog.Syn. Cass. 29 ; et Pl. Meyen, 39.-Peruv.

vestita, Vog. Syn. Cass. 60.-Bras.

viciaefolia, Benth. in Trans. Linn. Soc. xxvii. (1871) 544.-N. Granat.

villosa, Mill. Gard Dict. ed. VIII n 4-Mexic.

viminea, Linn. Syst. Nat. ed. X. 1016.-Am. trop.

virgata, Rich. in Act. Soc. Hist. Nat. Par. i. (1792) $108=$ chrysocarpa.

virgata, Sieber, ex Steud. Nom. ed. II. i. $308=$ glandulosa.

virgata, Sw. Prod. Veg. Ind. Occ. 66.-Ind. occ.

viscida, Zoll. E Mor. in Nat. en Geneesk. Arch. Neerl. Indie, iii. (1846),80.-Malaya.

viscosa, H. B. E K. Nov. Gen. et Sp. vi. 360.-N Granat.

viscosa, Schum, \& Thonn. Beskr. Guin. Pl. 205=C. Absus.

viscosopilosa, Steud. in Flora, xxvi. (1843) 11. 760= viscosa.

Vogeliana, Schlecht. in Linnaea, xii. (1838) 342.Mexic.

vulgaris, Roxb. ex Steud. Nom. ed. II. i. 308.-Ind. or. Wallichiana, DC. in Mém. Soc. Phys. Genèv. ii. (1824) $132=$ mimosoides.

Wightiana, R. Grah. in Wall. Cat. n. $5329=$ tomentosa.

Wislizeni, A. Gray, Pl. Wright, i. 60,-N. Mexic.

Wrightii, A. Gray, l. c. ii. 50.-Mexic.

xanthocoma, Miq. Anal. Bot. Ind. i. 10.-Borneo,

xiphoidea, Bertol. Fl. Guatim. $14=$ biflora.

zambesica, Oliver, Fl. Trop. Afr. ii. 280.-Afr. trop.

zanzibarensis, Vatke, in Oestr. Bot. Zeitschr, xxx.

1880) 77.-Afr. trop.

zygophylla, Benth. in Mitch. Journ. Trop. Austral. 288 =eremophila.

CASSIANA, Rafin. in Am. Monthly Mag. (1818) 266 = Cassia, Linn. (Legumin.).

CASSIDA, Tourn. ex Adans, Fam. ii. $188(1763)=$ Scu telleria, Herm. (Labiat.).

alpina, Moench, Meth. Suppl. $144=$ S. alpina.

altissima, Moench, 1. c. $145=\mathrm{S}$. altissima

galericulata, Scop. F1. Carn. ed. II. i. $430=$ S. galericulata.

hastifolia, Scop, 1. $\mathbf{c}=\mathrm{S}$. hastifolia

lateriflora, Moench, Meth. Suppl, $145=\mathrm{S}$. lateriflora major, Gilib. Fl. Lituan, i. $90=\mathrm{S}$. galericulata. minor, Gilib. 1. c. $91=\mathrm{S}$. minor.

racemosa, Moench, Meth. $414=\mathrm{S}$. peregrina.
CASSIDOCARPUS, Presl, ex DC. Prod. iv. $82(1830)=$ Asteriscium, Cham. \& Schlecht. (Umbellif.) chilensis, Presl, 1. c. $=$ A. chilense.

CASSIERA, Raeusch. Nom. ed. III. 42 (1797) sphalm. Cansjera, Juss. (Olacin.)

CASSINE, Linn. Gen. ed. I. 338 (1737), CELA STRINEAE, Benth. \& Hook. f. i. 363.

Maurocenza, Linn. Gen. ed. I. 85 (1737)

aethiopica, Eckl. \& Zeyb. Enum. $128=$ capensis.

aethiopica, Thunb. Fl. Cap. ii. 227.-Afr. austr.

affinis, Sond. in Harv. E' Sond. Fl. Cap. i. 465.-Afr. austr.

albanensis, Sond. l. c. 467.-Afr. austr.

articulata, E. Mey. ex Sond. 1. c. $457=$ Celastrus procumbens.

Barba, Murr. Syst. Veg. ed. XIII. 243, sphalm. = seq.

barbara, Linn. Mant. ii. 220.-Afr, austr.

capensis, Linn. l. c.-Afr. austr.

caroliniana, Lam. Encyc. 1. $652=$ Ilex Cassine

caroliniana, Walt. Fl. Carol. $242=$ Ilex ambigua.

Colpoon, Eckl. \& Zeyh. Enum. $128=$ affinis.

Colpoon, Thunb. Prod. P1. Cap. $52=$ capensis.

concava, Lam. Encyc. i. $652=$ Celastrus lucidus.

Congonha, St. Hil. in Guill. Arch. Bot. i. (1832) $31=$

Villaresia mucronata.

corymbosa, Mill. Gard. Dict. ed. VIII. n. $1=$ Ilex Cassine.

crocea, Presl, Bot. Bemerk. $37=$ Elaeodendron capense discolor, Wall. in Roxb. Fl. Ind. ed. Carey, ii. $378=$ Microtropis discolor.

domingensis, Spreng. Syst. i. 939.-Ins. S. Doming.

excelsa, Wall. in Roxb. Fl. Ind. ed. Carey, ii. $376=$ Ilex excelsa.

Gongonha, Mart. Reise Bras. i. 285=Ilex Gongonha.

humilis, Hort. ex Steud. Nom. ed. II. i. $308=$ Celastrus lucidus.

ilicifolia, Hochst. ex Sond. in Harv. \& Sond. Fl. Cap. i. $474=$ Cassinopsis capensis.

integrifolia, Salisb. Prod. $173=$ C. Maurocenia.

Kraussiana, Bernh. ex Harv. \& Sond. Fl. Cap. i. 466 $=$ capensis.

Kraussiana, Hochst. in Flora, xxvii. (1844) I. 305. Afr. austr.

laevigata, Lam. Encyc. i. 652 - Pterocelastrus rostratus.

latifolia, Eckl. \& Zeyh. Enum. 129.-Afr. austr. magellanica, Lam. Illustr. ii. 92. D. 2690= Maytenus magellanicus.

Maurocenia, Linn. Sp. Pl. ed. II. 385.-Afr. austr.

mucronata, Turcz. in Bull. Soc. Nat. Mose. (1858) I. $455=$ Cassinopsis capensis.

oleifolia, Pers. Syn. i. $327=$ Celastrus oleoides.

oleoides, Lam. Encyc. i. $652=$ Celastrus oleoides

oppositifolia, Mill. Gard. Dict. ed. VIII n. 3-Hab.

parvifolia, E. Mey. ex Harv. \& Sond. Fl. Cap. i $468=$ Elaeodendron croceum.

parvifolia, Sond. l. c. 466.-Afr. austr.

Peragua, Linn. Mant. ii. $220=$ Ilex Cassine.

ramulosa, Rafin. F1. Ludov. $110=$ Ilex Cassine.

scandens, Eckl. E' Zeyh. Enum. 128.-Afr. austr.

serratifolia, Salisb. Prod. $173=$ capensis.

sphaerocarpa, Cels, ex Steud. Nom. ed. II. i. $308=$ capensis.

xylocarpa, Vent. Choix, $23=$ Elaeodendron xylocarpum.

CAssinIA, R. Br. in Trans. Linn. Soc. xii. (1817) 126. COMPOSITAE, Benth. \& Hook. f. ii. 313.

Achromolaena, Cass. in Dict. Sc. Nat. lvi. 222 (1828).

Apalochlamys, Cass. 1, c. 223 (1828)

Chromochiton, Cass. 1. c. 220 (1828).

RHyNeA, DC. in Deless. Ic. Sel. iv. t. 52 (1837)

aculeata, R. Br. in Trans. Linn. Soc. xii. (1817) 127 -Austral.

aculeata, A. Cunn. ex DC. Prod. v. $156=$ Cunninghami.

aduncá, F. Muell. in Linnaea, xxv. (1852) $496=$ aculeata

affinis, R. Br. in Trans. Linn. Soc. xii. (1817) $127=$ aculeata.

arcuata, $R, B r, l, c$-Austral.

argophylla, DC. Prod. vi. $155=$ Helichrysum ferru-

gineum. Austral. 


\section{CASSINIA}

aurea, R. Br. in Ait. Hort. Kew, ed. II. v. (1813) $185=$ Angianthus tomentosus.

berberifolia, A. Cunn. ex DC. Prod. vi. $155=$ denticulata.

cinerea, Banks \& Soland. ex Hook. f. Fl. N. Zel. i. 132 = leptophylla.

compacta, F. Muell. Fragm. i. 18.-Austral.

cuneifolia, A. Cunn. ex DC. Prod. vi. 155=Helichrysum Backhousii.

Cunninghami, DC. Prod. vi. $156=$ Helichrysum Cunninghamii.

cuprea, F. Muell. Fragm. iii. $139=$ Helipterum polycephalum.

denticulata, R. Br. in Trans. Linn. Soc. xii. (1817) 127.-Austral.

fulvida, Hook. f. Handb. New Zeal. Fl. 145,-N. Zel.

glossophylla, Cass. in Dict. Sc. Nat. 1vi. 219.Anstral.

hygrophila, A. Cunn. in DC. Prod. vi. $156=$ quinquefaria.

Iaevis, R. Br. in Trans. Linn. Soc. xii. (1818) 127. Anstral.

laevis, End1. ex DC. 1. co=longifolia

ledifolia, A. Cunn. ex DC. Prod. vi. $155=$ Helichrysum ledifolium.

leptocephala, F. Muell. Fragm. iii. 138.-Austral.

leptophylla, $R$. Br. in Trans. Linn. Soc. xii. (1817) 126.-N. Zel.

longifolia, R. Br. L, c. 127-Austral.

obovata, A. Cunn. in DC. Prod. vi. $155=$ Helichrysum obcordatum.

paniculata, Behr \& F. Muell. in Linnaea, xxv. (1852) $496=$ arcuata.

patens, A. Cunn. ex DC. Prod. vi. $156=$ Helichrysum Cunninghami.

pholidota, F. Muell. Fragm. ii. 131= Helichrysum pholidotum.

quinquefaria, R. Br. in Trans. Linn. Soc. xii. (1817) 127.-Austral.

quinquefaria, Sond. in Linnaea, xxv. (1852) $496=$

Humea punctulata.

retorta, A. Cunn. ex DC. Prod. vi. 154-N. Zel.

rosmarinifolia, A. Cunn. ex DC. 1. c. $156=$ laevis.

spathulata, Endl. ex Steud. Nom. ed. II. i. $309=$ spectabilis.

spectabilis, R. Br. in Trans. Linn. Soc.xii. (1817) 128. -Austral.

subtropica, F. Muell. Fragm. i. 17.-Austral.

tenuifolia, Benth. Fl. Austral. vii. 585.-Austral.

Theodori, F. Muell. Fragm. v. 148.-Austral.

uncata, A. Cunn. in DC. Prod. vi. $156=$ aculeata

Vauvilliersii, Hook. f. Fl. N. Zel. 133.-N. Zel.

CASSINIOLA, F. Muell. Fragm. iii. 139 (1863) = Helipterum, DC. (Composi).

cuprea, F. Mnell. 1. c. = H. polycephalum.

CASSINOPSIS, Sond. in Harv, \& Sond. Fl. Cap. i. 473 (1860). OLACINEAE, Benth. \& Hook, i. 354.

capensis, Harv. E Sond. l. c. 474.-Afr. austr.

ciliata, Baker, in Fourn. Linn. Soc. xx. (1884) 118.Madag. madagascariensis, Baill. Adansonia, xi. (1873-76) 180.

tinifolia, Harv. Thes. Cap. ii. 44.-Afr, austr.

CAssioPE, D. Don, in Edinb. N. Phil. Journ. xvii. (1834) 157. ERICACEAE, Benth. \& Hook, f. ii. 584.

ericoides, D. Don. $l$. c. 158.-Sibiria

fastigiata, $D$. Don, $l_{\text {. c. }}$ 156.-Reg. Himal.

hypnoides, $D$. Don, l. c. 158,-Reg. arct. et subaret.

lycopodioides, D. Don, l. . . 158. - Sibiria; Am. subarct.

occ.

Mertensiana, G. Don, Gen. Syst. iii. 829 -Am. bor. occ.

oxycoccoides, A. Gray, in Proc. Am. Acad. xx. (1885) 300.-Kamtschat.

Redowskii, G. Don, Gen. Syst. iii. 829,-Sibir, or. Ross.

selaginoides, Hook. f. \& Thoms, in Hook. Kew fourn. vii. (1855) 126. t. 4.-Reg. Himal.

Stelleriana, DC. Prod. vii. 611 . - Alaska.

tetragonn, D. Don, in Edinb. N. Phil. Gourn. xvii. (1834) 158. - Reg. arct. et subarct.
CASSIPOUREA, Aubl. Pl. Gui. i. 528. t. 211 (1775). RHIZOPHOREAE, Benth. \& Hook. f. i. 682.

Legnotis, Sw. Prod. Veg. Ind. Occ. 84 (1788).

TitA, Scop. Introd. 219 (1777).

africana, Benth, in Hook. Niger Fl. $341=$ Weihea africana.

alba, Griseb. in Goett. Abh. vii. (1857) 223.-Ind. occ. congensis, R. Br. in Tuckey, Voy. Congo, 18.-Afr. trop.

elliptica, Poir. Encyc. Suppl. ii. 131.-Tamaica.

guianensis, $A$ ubl. Pl. Gui. i. 529. t. 211.-Am. anstr.

gummifuna, Tul. in Ann. Se. Nat. Sér. IV. vi. (1856)

$123=$ Dactylopetalum sessiliflorum

lanceolata, Tul. l. c. 121.-Ins. Mascar.

leptoclada, Tul.l. c. 125.-Ins. Mascar.

macrophylla, DC. Prod. iii. 34.-Bras.

madagascariensis, $D C . \ell_{0} C_{0}-\mathrm{Madag}$.

microcarpa, Tul. in Ann.Sc. Nat. Sér. IV. viii. (1857) 162.-Ins. Mascar

microphylla, Tul.l.c. vi. (1856) 124.-Madag.

myriocarpa, Tul. l. c. viii. (1857) 162,-Madag.

ovata, Tul. l. c. vi. (1856) 121.-Ins. Comor.

phaeotricha, Tul. l. c. 122.-Madag.

quadrilocularis, Spruce, ex Benth. in Mart. Fl. Bras. xii. II. $429=$ guianensis.

serrata, Benth. in Hook. Fourn. Bot. ii (1840) 223. Guiana.

Spruceana, Benth. in Mart. Fl. Bras. xii.. II. 429.Am. trop.

CASSITHA, Hill, Veg.. Syst.ix. 17 (1765)= Cassytha, Linn. (Laurin.)

CASSUMBIUM, Benth. \& Hook.f. Gen. i.. 404 (1862) $=$ CUSSAM BIUM, Rumph. = Schleichera, Willd. (Sapind.).

CASSUMUNAR, Colla, Nov. Scit. Gen. $9(1830)=$ Zingiber, Adans. (Scitamin.)

Roxburghii, Colla, 1. c. $10=\mathrm{Z}$. Cassumunar.

CAssurA, Humb. \& Bonpl. P1. Aequin. i. 43. t. 12 (1808). RUBIACEAE, Benth. \& Hook. f. ii. 65. laevis, Triana, in Ann. Sc. Nat. Sér. IV. ix. (1858) 44. - N. Granat.

verrucosa, Humb. E Bonpl. Pl. Aequin. i. 43. t. 12,Mexic.

CASsutha, [J. Bauh.] Des Moul. Etud. Org. Cusc. 66 (1853) $=$ Cuscuta, Linn. (Conyolvui)

americana, Des Moul. 1. c. $70=$ Cusc. americana. arabica, Des Moul. 1. c. $72=$ Cusc. arabica. chrysocoma, Des Moul. 1. c. $71=$ Cusc. australis. suaveolens, Des Moul. 1.c. $66=$ Cusc. racemosa.

CASSUVIUM, Lam. Encyc. i. $22(1783)=$ Ana. cardium, Rottb.

pomiferum, Lam. 1. c. = A. occidentale

reniforme, Blanco, Fl. Filip. ed. I. $322=\mathrm{A}$. occidentale. solitarium, Stokes, Bot. Mat. Med. ji. $475=\mathrm{A}$. occidentale.

CASSYTA, Linn. Gen. ed. VI. $291(1764)=$ Cassytha, Linn. (Laurin.).

CASsy THA, S, F. Gray, Nat. Arr. Brit. Pl. ii. 345 (1821) = Cuscuta, Tourn. (Convolvul.)

major, S. F. Gray, 1, c. $346=$ Cusc. europaea.

CASSYTHA, Linn. Sp. Pl. ed. I. 35 (1753), LAURINEAE, Benth. \& Hook. f. iii. 164

Calodium, Lour. Fl. Cochinch. 247 (1790).

OzARTHRIS, Rafin. Fi. Tellur, iv, 92 (1836)

Rombut, Rumph. ex Adans. Fam. ii. 284 (1763).

Rumputris, Rafin. Fl. Tellur. iv. 92 (1836).

Vocutella, Forsk. Fl. Aegypt. Arab. 84 (1775)

americana, Nees, Syst. Laurin. $6 \pm 4=$ filiformis.

aphylla, Raeuscb. Nom, ed. III. $116=$ filiformis

brasiliensis, Mart. ex Nees, Syst. Laurin. $648=6$ fili-

formis.

capensis, Mcissn. in DC. Prod. xv. 1. 254.-Afr. austr capillaris, Meissn. l. c. 252.-Zeylan.; Borneo. Casuarinae, Nees, in Lehm. PI. Preiss, i, $619=$ glabella ceratopoda, Meissn. in DC. Prod.xv. I. $257=$ pomi formis.

ciliolata, Nees, Syst. Laurin. 616.-Afr. anstr.

comiculata, Burm. f. Fl. Ind. 93. - Ind. or.

coronata, Nees, in Lelm. Pl. Preiss. i. 620.-Austral,

digitata, Nces, l, c. = racemosa.

\section{CASSYTHA :-}

dispar, Schlecht, in Linnaea, xx. (1847) 578=glabella dissitiflora, Meissn. in Kjoeb.Vidensk. Meddel. (1870 145.-Bras.

filiformis, Linn. Sp. Pl. 35.-Cosmop. trop.

filiformis, Thunb. Prod. P1. Cap. $78=$ glabella.

flava, Nees, in Lehm. Pl. Preiss. i. 620.-Austral.

glabella, R. Br. Prod. 404.-Austral

glabella, Sieber, ex Meissn. in DC. Prod. xv. I. 256 paniculata.

guineensis, Schum. \& Thonn. Beskr. Guin. Pl. $199=$

filifurmis.

melantha, R. Br. Prod. 404.-Austral.

micrantha, Meissn. in DC. Prod. xv. I. 256.-Austral.

microcephala, Meissn. 1. c. $253=$ glabella.

Muelleri, M issn. I. c. $257=$ racemosa.

multiflora, Nees, in Lehm, Pl. Preiss, i. $621=$ pomi-

formis.

nodiflora, Meissn. in DC. Prod. xv. I. 252.-Austral

paniculata, R. Br. Prod. 404.-Austral.

phacolasia, F. Muell. Fragm.v. 167.-Austral

piligera, Schlecht. in Linnaea, xxi. (1848) $446=$ pubescens.

poniformis, Nees, in Lehm. Pl. Preiss. i. 620.Austral.

pubescens, R. Br. Prod. 404. - Austral.

racemosa, Nees, in Lehm. Pl. Preiss. i. 621.-Austral. remotiflora, F. Muell. ex Meissa. in DC. Prod. xv, I. $256=$ paniculata.

robusta, Meissn. 1. c. $255=$ melantha

rubiginosa, E. Mey. in Drege, Zwei Pf. Docum. 171, nomen.-Afr. austr.

rugulosa, Meissn, in DC. Prod. xv. I. $255=$ pubescens. subcapitata, Meissn. 1. c. $253=$ pomiformis, racemosa. tasmanica, Meissn. 1, c. $252=$ pubescens.

triflora, E. Mey. in Drège, Zwei PA. Docam. 171=

capensis.
umbellata, Meissn. in DC. Prod. xv. I. $257=$ racemosa zeylanica, Gaertn. Fruct. i. $134=$ filiformis

CASSYTHA, Mill. Gard. Dict. ed, VIII (1768) =

Rhipsalis, Gaertn. (Cacteae)

baccifera, Mill. ex DC. Prod, iii. 476=sec

fliformis, Mill. Gard. Dict. ed. VIII = R. Cassytha.

polysperma, Ait. ex Gaerta. Fruct. i. $137=\mathrm{R}$. Cassytha

CASTALIA, Salisb. Parad. Lond, i. t. 14 (1805); et in

Kon. \& Sims, Ann. Bot. ii. (1806) $71=\mathbf{N y m p h a e a ~}$

Linn.

ampla, Salisb. 1l. cc. t. $14,73=\mathrm{N}$. ampla.

caerulea, Tratt. in Flora, v. (1822) $604=\mathrm{N}$. stellata.

edulis, Salisb. Parad. Lond. i. sub t. 14; et in Kon.

\& Sims, Ann. Bot. ii. (1806) $73=$ N. Lotus.

Lotus, Tratt. in Flora, v. (1822) $598=\mathrm{N}$. Lotus.

magnifica, Salisb. Parad. Lond. i, t. $14=$ N. Lotus.

mystica, Salisb. 1. c. ; et in Kon. \& Sims, Ann. Bot. ii.

1806) $73=$ N. Lotus.

pubescens, Blume, Bijdr. $48=\mathrm{N}$. Lotus.

pudica, Salisb. in Kon. \& Sims, Ann. Bot. ii. (18015) $72=N$. odorata.

bygmaea, Salisb. Parad. Lond. (1806) i. 2. t. $68=\mathrm{N}$ tetragona.

rubra, Tratt. in Flora, v. (1822) $595=\mathbf{N}$. Lotus.

Rudgeana, Tratt. 1. c. $599=\mathrm{N}$. tetragona.

sacra, Salisb. Parad. Lond. i. sub t. $14=\mathbf{N}$. Lotus.

scutifolia, Salisb. 1. c. ; et in Kon. \& Sims, Ann. Bot. ii. (1806) $72=\mathrm{N}$. stellata.

speciosa, Salisb. in Kon. \& Sims, Ann. Bot. ii. 1 silt $72=$ N. alba.

stellaris, Salisb. Parad. Lond. i. sub t. $14=\mathrm{N}$. stellats. stellata, Blume, Bijdr. $49=\mathrm{N}$. stellata.

versicolor, Tratt. in Flora, $\vee .(1 S 22) 600=\mathrm{N}$. stellata.

CASTALIS, Cass, in Dict. Sc. Nist. xxx. 392, 182f)= Dimorphotheca, Moench (Compos.)

Ventenati, Cass. 1. c. = D. aurantinen.

CASTANEA, Tourn. ex Linn. Srst, ed, I (1785 CUPCLIFER.AE, Benth. \& Hook. \& jii. to:

Castanophortis, Neck. Elem. iij. $25 \%$ (1790i (Casnnuphorum)

acuminatissima, Blume, Mus. Bot. Logu. Bat. i. $2 s \$=$ Quercus Junghuhnit.

alnifolia, Nutt. Gen. Am. ij. 21\% - pumila.

americand, G. Don, in Siweet, Hort. Brit. ed. III. Gitt - stiva.

americana, Ratin. Fl. Ludor. 194; New Sylra, \&? sativa.

argensea, Blume, Lijjur. $525=$ Castanopsis agrentea. 


\section{CASTANEA :}

argyrophylla, Buek, in DC. Prod. Index, iv. $67=$ Castanopsis argentea.

brevicuspis, Miq. F1. Ind. Bat. i. I. $866=$ Castanopsis javanica.

Bungeana, Blume, Mus. Bot. Lugd. Bat. i. $284=$ sativa.

buruana, Oerst. in Vidensk. Selsk. Skr, V. ix. (1873) $377=$ Castanopsis buruana.

castanicarpa, Oerst. 1. c, = Castanopsis castanicarpa

Chincapin, Hort. ex C. Koch, Dendrol. ii. II. $24=$ pumila.

chinensis, Hassk. Cat. Hort. Bog. Alt. $73=$ sativa.

chinensis, Spreng. Syst. iii. $856=$ Castanopsis tribuloides.

chrysophylla, Dougl. ex Hook. F1. Bor. Am. ii. $159=$ Castanopsis chrysophylla.

concinna, Champ. ex Benth. in Hook. Kew Journ. vi. $(1854) 115=$ Castanopsis concinna

cooperta, Oerst. in Vidensk. Selsk. Skr. V. ix. (1873) 379.-Ins. Philipp.

costata, Blume, Mus. Bot. Lugd. Bat. i. $284=$ Castanopsis javanica.

crenata, Sieb. \& Zucc, in Abh. Akad. Muench, iv. III. (1846) $324=$ sativa

divaricata, Oerst. in Vidensk. Selsk. Skr. V. ix. (1873) $379=$ Castanopsis argentea.

diversifolia, Kurz, in fourn. As. Soc. Beng. xliv. (1875) II. 198.-Ind. or.

echidnocarpa, Hook. fo et Thoms, ex A. DC. in Prod. xvi. II. $112=$ Castanopsis tribuloides.

Fagus, Scop. Fl. Carn. ed. II. ii. $242=$ Fagus sylvatica Falconeri, Hance, in Jouri. Bot. xiit. (1875) $367=$ Castanopsis armata.

furfurella, Miq. F1. Ind. Bat. Suppl. 352=Castanopsis Hystrix.

glomerata, Blume, Mus. Bot. Lugd. Bat. i. $283=$ Castanopsis sumatrans.

Hystrix, Hook. f. \& Thoms. ex Miq. in Ann. Mus. Bot. Lugd. Bat. i. $119=$ Castanopsis Hystrix.

indica, Roxb. Hort. Beng. 68; Fl. Ind. iii. $643=$ Castanopsis indica.

inermis, Lindl, in Wall. Pl. As. Rar. ii. $6=$ Castanopsis sumatrana.

japonica, Blume, Mus. Bot. Lugd. Bat. i. $284=$ sativa.

javanica, Blume, Bijdr. $525=$ Castanopsis javanica

lanceaefolia, Kurz, For. Fl. Brit. Burma, ii. $482=$ Quercus lanceaefolia.

latifolia, Blume, Bijdr. 526.-Java

martabanica, Wall. Cat. n. 2764 ; P1. As. Rar. ii. t. 107 = Castanopsis argentea.

microcarpa, Lindl. ex Wall. Cat. n. $3735=$ Castanopsis tribuloides.

mollissima, Blume, Mus. Bot. Lugd. Bat. i. 286.China.

montana, Blume, Bijdr. $526=$ Castanopsis javanica

nana, Muhl. Cat. $86=$ pumila.

pumila, Hassk. Cat. Hort. Bog. Alt. $73=$ sativa.

pumila, Mill. Gard. Dict. ed, VIII, n. 2-Am. bor.

pumila, Siebold, ex Blume, Mus. Bot. Lugd. Bat. i $286=$ Castanopsis tribuloides

purpurella, Miq. Fl. Ind. Bat. Suppl. $352=$ Castanopsis Hystrix

regia, Hance, in Ann. Sc. Nat. Sér. IV. xviii. (1862) $230=$ Quercus fissa.

rhamnifolia, Kurz, For. F1. Brit. Burma, ii. $481=$ Castanopsis rhamnifolia.

rhamnifolia, Oerst. in Vidensk. Selsk. Skr. V. ix. (1873) 378.-Am. centr.

Roxburghii, Lindl. in Wall. Pl. As. Rar. ii. $6=$ Castanopsis castanicarpa.

sativa, Mill. Gard. Dict. ed. VIII. n. 1.-Europ. Japon.; Am. bor.

sempervirens, Kellogg, in Proc. Calif. Acad. i. 71, ed. II. $(1873) 75=$ Castanopsis chrysophylla

sessi[li] folia, Blume, Mus. Bot. Lugd. Bat. i. $284=$ Quercus Junghuhnii.

Sloanea, Mill. Gard, Dict. ed, VIII, n, 3=Sloanea dentata.

spectabilis, Miq. F1. Ind. Bat. i. I, $866=$ Castanopsis sumatrana.

sphaerocarpa, Lindl. in Wall. P1. As. Rax. ii. $5=$ Castanopsis armata.

stricta, Sieb. \& Zucc. in Abh. Akad. Muench. iv. III (1846) $225=$ sativa

sumatrana, Oerst. in Vidensk. Selsk. Skr. V. ix. (1873) $378=$ Castanopsis sumatrana.

\section{CASTANEA}

tribuloides, Lindl in Wall. Pl. As. Rar, ii. $6=$ Casta nopsis tribuloides.

tribuloides, Wall. Cat. n. 2765 B. $=$ Quercus lanceaefolia.

Tungurrut, Blume, Bijdr. 525 = Castanopsis Tungurrut. vesca, Gaertn. Fruct, i. 181. t. 37 = sativa.

vulgaris, Lam. Encyc. i. $708=$ sativa.

CASTANELLA, Spruce, ex Benth. \& Hook. f. Gen. i. 394 (1862). SAPINDACEAE, Benth. \& Hook. f. 1. c.

granatensis, Planch. \& Linden, in Ann. Sc. Nat. Sér. IV xviii. (1862) $365=$ Paullinia granatensis. paullinioides, Spruce, ex Radlk. Monog. Serjan. 75. - Bras.

riparia, Spruce, ex Radlk. l.c.-Peruv

CASTANOCARPUS, Sweet, Hort. Brit. ed. II. 589 $(1830)=$ Castanospermum, A. Cunn (Legumin.) australis, Sweet, 1. c. = Castanosp. australe.

CASTANOLA, Llanos, in Mem. Acad. Cienc. Madr. ii. (1859) $503=$ Connarus, Linn.

trinervis, Llanos, 1. $\mathrm{c}_{\mathrm{s}}=$ Conn, monocarpus.

CASTANOPHORUM, Neck. Elem. iii. $257(1790)=$ Castanea, Tourn. (Cupulif.).

CASTANOPSIS, Spach, Hist. Vég. Phan. xi. 185 1842). CUPULIFERAE, Benth. \& Hook. fiii. 409 Callakocarpus, Miq. Pl. Jungh. i. 13 (1851).

acuminatissima, A. DC. ex Hance, in Journ. Bot. i. (1863) $182=$ Quercus lanceaefolia.

argentea, A. DC. in Fourn. Bot. i. (1863) 182.Burma: Malaya.

armata, Spach, Hist. Vég. Phan. xi. 185.-Reg. Himal.; Burma.

brevicuspis, A. DC. ex Hance, in Journ. Bot. i. (1863) $183=$ javanica

buruana, Miq. Ann. Mus. Lugd. Bat. i. 120.-Ins. Molucc.

castanicarpa, Spach, Hist. Vég. Phan. xi. 185.-Reg. Himal.

caudata, Franch. Pl. Davidian. i. 277.-Mongol.

chinensis, Hance, in Journ. Linn. Soc. X. (1869) 199 $=$ tribuloides.

chrysophylla, A. DC. in Fourn. Bot. i. (1863) 182.Am. bor. occ.

concinna, A.DC. l.c.-Hongkong.

costata, A. DC. 1. c. = javanica.

discocarpa, Hance, 1. c. xvi. (1878) $201=$ Quercus discocarpa.

echidnocarpa, A. DC. 1. c. i. (1863) $182=$ tribuloides. echinocarpa, Miq. in Ann. Mus. Bot. Lugd. Bat. 119 , sphalm. $=$ praec.

Fabri, Hance, in Fourn. Bot. xxii. (1884) 230,-China. Falconeri, Hance, 1. c. xiii. (1875) $368=$ armata. ferox, Spach, Hist. Vég. Phan. xi. $185=$ tribuloides.

Fordii, Hance, in Fourn. Bot. xxii. (1884) 230.China.

Hystrix, A. DC. l. c. i. (1863) 182.-Reg. Himal. Malaya.

indica, $A . D C$. l. c.-Reg. Himal.

inermis, Benth. \& Hook. f. Gen. iii. $409=$ sumatrana.

javanica, A. DC. in Fourn. Bot. i. (1863) 182.-

Malaya.

jucunda, Hance, l. c. xxii. (1884) 230.-China

Lamontii, Hance, $l$. $c$. xiii. (1875) 369.-China.

lanceaefolia, Kurz, For. Fl. Brit. Burma, ii. $482=$ Quercus lanceaefolia.

mitifica, Hance, in Journ. Bot. xvi. (1878) $200=$ sumatrana.

Pierrei, Hance, l. c. xiii. (1875) 369.-Cambodia.

rhamnifolia, A. DC. Prod. xvi. II. 113.-Burma; Sumatra.

Schefferiana, Hance, in Fourn. Bot. xvi. (1878) 200. - Sumatra.

sessilifolia, A. DC. 1. c. i. (1863) $182=$ Quercus Junghuhnii.

spectabilis, A. DC. 1. c. = javanica.

sumatrana, A. DC. l. c.-Burma; Malaya.

tibetana, Hance, l. c. xiii. (1875) 367.-Tibet; China.

tribuloides, A. DC.l.c. i. (1863) 182.-Reg. Himal.; Burma.

trisperma, Scheff. in Tijdschr. Nederl. Ind. xxxi. (1870) 362 ; in Flora, liii. (1870) $252=$ javanica

Tungurrut, A. DC. in Fourn. Bot. i. (1863) 182.-
CASTANOSPERMUM, A. Cunn in Hook. Bot Misc. i. (1830) 241. t. 51. LEGUMINOSAE, Benth. \& Hook. f. i. 556.

Castanocarpus, Sweet, Hort. Brit. ed. II. 589 (1830).

Viellardia, Montr. in Mém. Acad. Lyon, x. (1860) x. 196.

australe, A.Cunn. E Fraser, in Hook. l. c.-Austral.

CASTANOSPORA, F. Muell. Fragm. ix. 92 (1875). SAPINDACEAE.

Alphandi, F. Muell. l. c.-Austral.

CASTELA, Turp in Ann. Mus. Par, vii, (1806) 78, t 5. SIMARUBEAE, Benth. \& Hook. f. i. 310

alaternifolia, Planch. in Hook. Lond. Fourn. Bot. v. (1846) 569.-Chili.

coccinea, Griseb. in Goett. Abh. xix. (1874) 107.-Reg. Argent.

depressa, Turp. in Ann. Mus. Par. vii. (1806) 79. t. 5 A.-Ins, S. Doming.

erecta, Turp. l. c. 80. t. 5 B.-Ind. occ.

Galapagei, Hook. f. in Trans. Linn. Soc. xx. (1851) 229. - Ins. Galap.

laevigata, Zipp. ex Span. in Linnaea, xv. (1841) 186, nomen,-Hab. ?

lychnophoroides, Liebm. in Kjoeb. Vidensk. Meddel. (1853) 111.-Mexic.

Nicholsoni, Hook. Bot. Misc. i. (1830) 271. t. 56.Ind. occ.

retusa, Liebm. in Kjoeb. Vidensk. Meddel. (1853) 110. -Mexic.

tortuosa, Liebm. l.c. 108.-Mexic

Tweediei, Planch. in Hook. Lond. Fourn. Bot. v. (1846) 569.--Reg. Argent.

CASTELIA, Cav. in Anal. Cienc. Nat. iii. (1801) 134 = Priva, Adans. (Verbenac.).

cuneato-ovata, Cav. I. c. $135=$ laevis.

CASTELIA, Liebm. in Kjoeb. Vidensk. Meddel. (1853) $108=$ Castela, Turp. (Simarub.).

CASTELLIA, Tin, Pl. Rar. Sicul. 17 (1817)= Festuca, Linn. (Gramin.).

tuberculata, Tin. 1 , c. $18=$ F. tuberculata.

CASTELNAVIA, Tul. \& Wedd, in Ann. Sc. Nat. Sér. III. xi. (1849) 108. PODOSTEMACEAE, Benth. \& Hook, f. iii. 114.

Carajaea, Wedd. in DC. Prod. xvii. 84 (1873), fimbriata, Tul. E Wedd. l. c.-Bras.

fluitans, Tul. \& Wedd. l. c. 109.-Bras.

fruticulosa, Tul. E Wedd. l. c. 110.-Bras. monandra, Tul. E Wedd. l. c. 109.-Bras. multipartita, Tul. E Wedd. l. c.-Bras. ortbocarpa, Tul. \& Wedd.l. c. 110.-Bras Princeps, Tul. \&o Wedd.l. c. 108.-Bras. pusillina, Tul. \&o Wedd. l. c. 109.-Bras. serpens, $T u l$. $\xi W e d d$. l. c.-Bras.

CASTIGLIONIA, Ruiz \& Pav. Prod. 139. t. 37 (1794) =Jatropha, Linn. (Euphorbiac.).

lobata, Ruiz \& Pav. 1. c. ; Syst. Veg. $277=$ J. Curcas.

CASTILLA, Cerv. in Supl. Gaz, Lit. Mexico (Jul. 2, 1794), 7 = Castilloa, 'Cerv.' (Urticac.).

CASTILLEJA, Mutis, ex Linn. f. Suppl. 47 (1781). SCROPHULARINEAE, Benth. \& Hook. f. ii. 973. Euchroma, Nutt. Gen. Am. ii. 54 (1818).

acuminata, Spreng. Syst. ii. $775=$ pallida.

acuminata, Turcz, in Bull, Soc. Nat. Mosc. xxiv. (1851) II. 321 = pallida.

affinis, Benth. PI. Hartw. $329=$ stenantha. affinis, Hook. E Arn. Bot. Beech. Voy. 154,-Calif. ambigua, Hook. \& Arn. 1. c. =Orthocarpus australis. angustifolia, G. Don, Gen. Syst. iv. $616=$ parviflora. angustifolia, A. Gray, in Torr. Bot. Mex. Bound. 118 =integra.

angustifolia, Mart. E Gal. in Bull. Acad. Brux. xii. II. (1845) 29.-Mexic.

anthemidifolia, Benth. in DC. Prod. x. $528=$ tenuiflora. arvensis, Cham. E' Schlecht. in Linnaea, v. (1830) 103.-Mexic

Bradburii, G. Don, Gen. Syst. iv. $616=$ parviflora breviflora, Benth. in DC. Prod. x. 534.-Venezuela. breviflora, A. Gray, in Am. Fourn. Sc. Ser. II. xxxiv 1862) 250.-Am. bor. occ. 
CASTILIEJA :-

candens, Durand \& Hilg. in Pacif. Rail. Rep. v. $12=$ linariaefolia.

canescens, Benth. in DC. Prod. x. 533.-Mexic

cinerea, A. Gray, in Proc. Am. Acad. xix. (1883) 93.Calif.

coccinea, Dougl. in Lind1. Bot. Reg. t. $1136=$ parviflora. coccinea, Spreng. Syst. ii. 775.-Am. bor

communis, Benth. in DC. Prod. x. 529.-Am. trop.

coronopifolia, Vent. Choix, 59.-N. Granat.

desertorum, Geyer, in Hook. Kew Journ. v. (1853) $258=$ parviflora.

divaricata, Benth. in DC. Prod. x. 534.-Venezuela

Douglasi, Benth. 1. c. $530=$ parviflora.

fissifolia, Linn. f. Suppl. 293.-N. Granat.

flava, S. Wats. in Bot. King, Exped. 230.-Am. bor.

foliolosa, Hook. E Arn. Bot. Beech. Voy. 154,-Calif. fulgens, Nutt. ex A. Gray, in Torr. Bot. Mex. Bound. $119=$ linariaefolia ?

gracilis, Benth. in DC. Prod. x. 528.-Mexic

grandiflora, Spreng. Syst. ii. $755=$ sessiliflora.

hirsuta, Mart. E' Gal. in Bull. Acad. Brux. xii. II. (1845) 29.-Mexic.

hispida, Benth. in Hook. Fl. Bor. Am. ii. $105=$ parviflora.

hyssopifolia, Willd. ex G. Don, Gen. Syst. iv. $615=$ lithospermoides.

indivisa, Engelm. in Engelm. \& $A$. Gray, Pl. Lindh. i. 47 . - Texas.

integra, A. Gray, in Torr. Bot. Mex. Bound. 119.-N. Mexic.

integrifolia, H. B. \& K. Nov. Gen. et Sp. ii. $330=$ canescens.

integrifolia, Linn. f. Suppl. 293.-Am. trop.

irasuensis, Oerst. in Kjoeb. Vidensk. Meddel. (1853) 27. - Costa Rica.

laciniata, Hook. Eo Arn. Bot. Beech. Voy, 60.-Chili.

lanata, A. Gray, in Torr. Bot. Mex. Bound. 118.-N. Mexic.

latifolia, Hook. E' Arn. Bot. Beech. Voy. 154.-Calif.

laxa, A. Gray, in Torr. Bot. Mex. Bound. 119.-N. Mexic.

Lemmoni, A. Gray, Syn. Fl. N. Am. ii. I. 297.-Calif.

linariaefolia, Benth. in DC. Prod. x. 532.-Mexic.

Lindheimeri, A. Gray, Syn. Fl. N. Am. ii. I. 298.Texas.

linoides, A. Gray, l. c. 299-Am. bor. occ

lithospermoides, H. B. E K. Nov. Gen. et Sp. ii. 331. t. 164.-Mexic.

longibracteata, Mart. $\xi$ Gal. in Bull. Acad.Brux. xii. II. (1845) 28.-Mexic.

longiflora, Kunze, in Linnaea, xvi. (1842) 312.Mexic.

macrocarpa, Benth. Scroph. Ind. 13 = latifolia.

miniata, Dougl. in Hook. Fl. Bor. Am. ii. 106.-Am. bor. occ.

minor, A. Gray, Bot. Calif. i. 573.-Am. bor. occ.

moranensis, H. B. E K. Nov. Gen, et Sp. 329.Mexic.

nubigena, H.B. E K. l. c. 330 -Ecuador.

oblongifolia, A. Gray, Syn.Fl. N.Am. ii. I. 296.Calif.

obovata, Benth. in DC. Prod. x. $528=$ hirsuta.

occidentalis, Torr, in Ann. Lyc. N. York, ii. (1828) $230=$ pallicla

Orisabae, Benth. in DC. Prod. x. 533= pectinata.

pallida, Kunth, Syn. Pl. Aequin. ii. 100.-Sibir.; Am. bor.

pallida, Spreng. Syst. ii. $774=$ septentrionalis, sibirica. parviflora, Bong in Mím. Acad. Pétersb. Sér. VI, v. II. (1840) 157.-Am. bor. occ.

pectinata, Mart. E Gall. in Bull. Acad. Brux. xii. II (1845) 27.-Mexic.

plagiotoma, A. Gray, in Proc. Am. Acad. xix. (1883) 93.-Calif.

pumila, Wedd. Chlor. And t. $61=$ fissifolia.

purpurea, G. Don, Gen. Syst, iv, 615-Am. bor, occ

Schaffneri, Hemsl. Biol. Centr. Am. Bot. ii. 462 Mexic.

scorzoneracfolia, H. B. E K. Nov. Gen. et Sp. ii. 331. -Mexic.

septentrionalis, Lindl. Bot. Reg. t. 925.-Am. bor.

serrata, Hort. ex Loud. Hort. Brit. Suppl. iii. 511 Hab. ?

sessilifiora, Pursh, Fl. Am. Sept. ii. 798.-Am. bor. ace.

sibirica, Lindl. Bot. Reg. t. 925 - pallida.

\section{CASTILIEJA :-}

speciosa, Mart. \& Gal. in Bull. Acad. Brux. xii. II (1845) $30=$ scorzoneraefolia.

stenantha, A. Gray, Syn. Fl. N. Am. ii. I. 295.-Am bor occ

stricta, Benth. in DC. Prod. x. 534.-Ecuador.

tenuiflora, Benth. Pl. Hartw. 22,-Mexic.

tenuifolia, Mart. E Gal. Bull. Acad. Brux. xii. II (1845) 30.-Mexic,

toluccensis, Cham. \& Schlecht, in Linnaea, ii. (1827) $579=$ parviflora ?

toluccensis, H. B. E० K. Nov. Gen. et Sp. ii. 329.Mexic.

tomentosa, A. Gray, in Torr. Bot. Mex. Bound. $118=$ integra.

trifida, Willd. ex Walp. Rep。 iii. $394=$ nubigena.

viscidula, A. Gray, Syn. Fl. N.Am. ii. I. 297.-Am bor. occ.

CASTILLOA, Cervant. in Supl. Gaz. Lit. Mexic. (Jui. 2, 1794) 7 (Castilla). URTICACEAE, Benth. \& Hook. f. iii. 372.

costaricana, Liebm. in Vidensk.Selsk.Skr. V.ii. (1851) 319.-Costa Rica.

elastica, Cerv. in Supl. Gaz. Lit. Mexico (Jul. 2, 1794) 7.-Mexic.

Markhamiana, Collins, Rep. Caoutch. Comm. 12. t. 3 -Am. trop.

CASTRA, Vell. Fl. Flum. 242 (1825); viii. 79-81= Trixis, P. Br. (Compos.)

illustris, Vell. Fl. Flum. 343 ; viii. t. $81=$ T. brasiliensis.

nobilis, Vell. 1. c. 344 ; viii. t. $81=$ T. glaberrima,

praestans, Vell. 1. c. 343 ; viii. t. $80=$ T. mollissima

regia, Vell. 1. c. 343 ; viii. t. $79=$ T. divaricata

CAstratelLA, Naud. in Ann. Sc. Nat. Sér. III xiv. (1850) 139. MELASTOMACEAE, Benth. \& Hook. f. i. 736 .

piloselloides, Naud. l. c.-N. Granat.

CASTREA, A. St. Hil. Morphol, $451(1840)=$ Phora dendron, Nutt. (Loranthac.).

falcata, St. Hil. 1. c.-Bras.

CASTRONIA, Noronha, in Verh. Batav. Gen. v。 (1790 ed. I. Art. IV, 2 = Helicia, Lour. (Proteac.)

CAsU ARINA, Linn. Amoen. Acad. iv, 143, nomen (1759); Adans. Fam. ii. 481 (1763); Forst. Char Gen. 103. t. $52(1776)$, CASUARINEAE, Benth. \& Hook. f. iii. 402 .

acuaria, F. Muell. in Fourn. Bot. v. (1867) 212.Austral.

acutivalvis, F. Muell. Fragm. x, 61.-Austral.

africana, Lour. Fl. Cochinch. ii. $549=$ equisetifolia.

angulata, Poiss. in Nouv. Arch. Mus. Par. Sér. I. x. (1874) $49 .-\mathrm{N}$. Caled

Baxteriana, Miq. Rev. Crit. Casuar. 37. t. $3 \mathrm{C}=$ distyla.

bicuspidata, Benth. Fl. Austral. vi. 202.-Austral.

Brunoniana, Miq. Rev. Crit. Casuar. (1848) 21. t. 1. C. -Java.

Chamaecyparis, Poiss, in Nouv. Arch. Mus. Par. Sér. I. x. $(1874) 52 \cdots \mathrm{N}$. Caled.

collina, Poiss. ex Panch. E" Sebert, Not. Bois Nout. Caléd. 174.-N. Caled.

corniculata, F. Muell. Fragm. x. 62.-Austral.

cristata, Miq. Rev. Crit. Casuar. 70. to 10. $\mathrm{A}=$ stricta.

Cunninghamiana, Miq.l. c. 56.t. 6 A.-Austral.

Decaisneana, F. Muell. Fragm. i. 61.-A ustral.

decussata, Benth. Fl. Austral. vi. 200.-Austral.

Deplancheana, Miq. in DC. Prod. xvi. II. 342.N Caled.

distyla, Vent. Fard. Cels, 62. t. 62.-Austral.

Drummondiana, Miq. Rev. Crit. Casuar. 26. t. 1 D.-

Austral.

dumosa, A. Cunn. ex Miq. in DC. Prod. xvi. xi. $998=$ distyla.

cchinata, R. Br. ex Benth. F1. Austral. vi. $202=$ thuyoides.

equisetifolia, Blanco, Fl. Filip. ed. I. $661=$ sumatrana.

equisetifolia, Linn. Amoen. Acad. iv. 148; Forst. Char. Gen, 108. 6. 52.-Malaya; Lns. Pacif.

\section{CASUARINA:}

xcelsa, Dehnhardt, ex Miq. Rev. Crit. Casuar. 23. t. 1 $\mathbf{F}=$ equisetifolia.

excelsa, Salisb. Prod. $2=$ stricta.

Fraseriana, Miq. Rev. Crit. Casuar. 59. t. 6. D.Austral.

glauca, Sieber, in Spreng. Syst. iii. 803.-Austral.

Gunnii, Hook. f. ex Miq. in Neder. Kruidk. Arch. iv

(1859) $100=$ stricta.

hexagona, Dehnhardt, in Revista Napolitana, i. III

$176^{\circ}$ - - Austral.

Huegeliana, Miq. in Lehm. Pl. Preiss. i. 640.Austral.

humilis, Otto \& Dietr. Allg. Gartenz, ix. (1841) $163=$ Fraseriana.

incana, A. Cunn. ex Benth. Fl. Austral. vi. 197= equisetifolia.

indica, Pers. Syn. ii. $531=$ equisetifolia

inophloia, F. Muell. E Bailey, in Melb. Chemist (Apr 1882),-Austral.

Junghuhniana, Miq. Pl. Fungh. 7.-Malaya.

lateriflora, Poir. Encyc. Suppl. ii. $658=$ equisetifolia.

Lehmanniana, Miq. in Lehm. Pl. Preiss, i. $639=$ humilis.

lepidophloia, F. Muell. Fragm. x. 115.-Austral,

leptoclada, Miq. Rev. Crit. Casuar. 41. t. 4. C suberosa.

leucodon, Poiss. in Nouv. Arch. Mus. Par. Sér. I. x. (1874) 52.-N. Caled.

littoralis, Salisb. Prod. 2 = equisetifolia.

lucida, Dehnhardt, in Revista Napolitana, i. III. 175 -Austral.

lugubris, Salisb. Prod. $2=$ torulosa.

macrocarpa, A. Cunn. ex Miq. in DC. Prod. xvi. Ir. $335=$ stricta.

Mertensiana, Rupr. ex Miq. 1. c. $339=$ equisetifolia.

microstachya, Miq. in Lehm. Pl. Preiss. i. 642.Austral.

Miquelii, Hook, f. ex Miq. in DC. Prod. xvi. II. $337=$ suberosa.

moesta, F. Muell, ex Miq. in Neder. Kruidk. Arch. iv (1859) $98=$ suberosa.

montana, Leschen. ex Miq. in Zoll. Syst. Vers. Ind. Archip. 86.-Malaya.

Muelleriana, Miq. in Neder. Kruidk. Arch. iv. (185y) $99=$ distyla.

muricata, Herb. Paris. ex Miq. in DC. Prod. xvi. II. $335=$ montana.

muricata, Roxb. Hort. Beng. 66 ; Fl. Ind. iii. $519=$ equisetifolia.

nana, A. Cunn. ex Benth. Fl. Austral, vi. $200=$ humilis.

nana, Schlecht. in Linnaea, xx. (1847) $574=$ Fraseriana nana, Sieber, ex Spreng. Syst. iii. 804.-Austral.

nodiflora, Forst. f. Prod. Fl. Ins. Austr. 64.-Ins. N. Hebrid.

obesa, Miq. in Lehm. Pl. Preiss. i. $643=$ Huegeliana.

obtusa, Hort. ex Miq. in DC. Prod. xvi. 11. 384

glauca.

axyclada, Miq. 1. c. $344=$ acuaria.

paludosa, Sieber, ex Spreng. Syst. iii. $\$ 08=$ distyla

Pauper, F. Muell. ex Miq. in Neder. Krwidk. Arch. iv. (1859) 100.-Austral.

Preissiana, Miq. in Lehm. Pl. Preiss, i. $6 \pm 0=$ humilis.

pumila, Otto \& Dietr. in Allg. Gartenz. ix. (18\$1) 162 $=$ distyla.

quadridentata, Desf. Tabl. Cat. Hort. Par. ed. II. 240 = quadrivalvis.

quadrivalvis, Labill. Nov. Holl. Pl. ii. 67. t. $218=$ stricta.

ramuliftora, Otto \& Dietr. Allg. Gartenz. ix. (15 $\$ 1$ ) $163=$ humilis.

repers, Hort. ex Hoffmgg. Verz. PA. Nachtr. $88=$ equisetifolia

rigida, Miq. in DC. Prod. xvi. 11. $937=$ distrla.

rigida, Miq. Rev. Crit. Casuar. 61. 4 7. D

suberosa.

rugosa, Ruxb. Hort. Beng, oit, nomen.-Ind. or.

Kumphiana, Miq. in Flora, xlviii. (1s03) 23, 38.Amboiun.

selaginardes, Miq. in Ithm. Pl. Preiss. i 613 humilis.

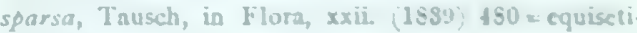

folin!

stricin, [Dryand. in] Afl. Horl. Rnes. ed. I. iii. \$20. Ausiral.

sfricta, Miq. in DC. Prod, xvi. 11. $\$ 90^{\circ}$ - distyla. 


\section{CASUARINA}

suberosa, Otto E Dietr. Allg. Gartenz. (1841) 155.Austral.

sumatrana, Fungh. in Hoev. E De Vriese, Tijdschr. xi. (1844) 115.-Sumatra.

tenuissima, Sieber, ex Spreng. Syst. iii. $804=$ torulosa. tephrosperma, Lehm. Hort. Hamb. ex Miq. Rev. Crit. Casuar. $31=$ humilis

thuyoides, Miq. in Lehm. Pl. Preiss. i. 641.-Austral. tortuosa, Henry, in Nov. Act. Nat. Cur. xx. I. (1847) 217. t. 19= stricta?

torulosa, [Dryand. in] Ait. Hort. Kew. ed. I. iii. 320. -Austral.

torulosa, Miq. Rev, Crit, Casuar, 75. t. $11 \mathrm{~B}=$ glauca. torulosa, Miq. in Lehm. Pl. Preiss. i. $639=$ Fraseriana. trichodon, Miq. l. c. 641.-Austral.

truncata, Willd. Enum. Hort. Berol. Suppl. $63=$ equisetifolia?

verticillata, Lam. Encyc. ii. $502=$ nodiflora.

Webbiana, Miq. in Flora, xlviii. (1865) 33.-Borneo; N. Caled.?

CATABRosA, Beauv, Agrost. 97. t. 19. f. 8 (1812), GRAMINEAE, Benth, \& Hook. f. iii. 1186.

agrostidea, Presl, F1. Sicul. p. xliv $=$ Airopsis agros* tidea.

algida, Fries, Nov. F1. Suec. Mant. iii. $174=$ Phippsia algida.

altaica, Boiss. Fl. Orient. v. $579=$ Colpodium altaicum.

antarctica, Hook. f. Fl. Antarct. 102.-N. Zel.

aquatica, Beauv. A grost. 97.t. 19. f. 8.-Reg. bor. temp

Balansae, Boiss, in Bull. Soc. Bot. Fr. xxi. (1874) 15. -As. Min.

Capusii, Franch. in Ann. Sc. Nat. Sér. VI. xviii. (1884) 272.- Turkest.

concinna, T. Fries, in Ofver. Vet. Akad. xxvi. (1869) $140=$ Phippsia algida?

distans, Link, ex Heynh. Nom. ii. $126=$ Glyceria distans.

elodes, Auct. $=$ helodes

Engelmanni, Link, ex Heynb. 1. $\mathrm{c}_{\mathrm{c}}=$ Glyceriae sp. ? -Hab.?

fibrosa, Boiss. Fl. Orient. v. 577.-Armenia.

frigida, Phil. Fl. Atac. 55.-Chili.

glaucescens, Phil. in Anal. Univ. Chil. (1873) $569=$ $=$ Glyceria glaucescens

helodes, Roem. \& Schult. Syst. ii. $696=$ Poa nemoralis humilis, Trin. Fund. Agrost. 136.-Persia; Reg. Casp.

latifolia, Fries, Summ. Veg. Scand. i. 245=Arctagrostis latifolia.

magellanica, Hook. f. F1. Antarct. $387=$ Glyceria magellanica.

micrantha, Hochst. ex A. Rich. Tent. FI. Abyss. ii.

$426=$ Eragrostis interrupta

minuta, Trin. Fund. Agrost. $136=$ Aira minuta. ochroleuca, Dum. Obs. Gram. Belg. $108=$ aquatica. parviflora, Boiss. Fl. Orient. v. 578.-Persia.

pontica, Balansa, in Bull. Soc. Bot. Fr. xxi. (1874) 15. -As. Min.

pumila, Roem. \& Schult. Syst. ii. $696=$ Poa annua. scabra, Kunth, Rev. Gram i. 119.-Hab. ?

stricta, Link, ex Steud. Nom. ed. II. i. 310.--Hab.?

tenuifolia, F. Presl, in Rel. Haenk. i. 256.-Chili.

vacillans, T. Fries, in Ofver. Vet. Akad. Stockh. xxvi.

(1869) $142=$ Phippsia algida.

variegata, Boiss. Diagn. Ser. i. v. 71.-As. Min.

versicolor, Boiss. FI. Orient. v. $579=$ Colpodium Steveni.

verticillata, Beauv. Agrost. 157, nomen.-Hab.?

vilfoidea, Anders. ex Malm. in Ofver.Vet. Akad. Stockh. xix. (1562) $254=$ Glyceria vilfoidea.

violacea, Boiss, Diagn. Ser. I. vii. $126=$ Colpodium violaceum.

viridula, Roem. \& Schult. Syst. ii. $697=$ Aira viridula.

CATABROSIA, Roem. \& Schult. Syst, ii. 696 (1817)= Catabrosa, Beauv. (Gramin.).

CATACHAENIA, Griseb. in Goett. Abh.ix. (1861) 54

= Miconia, Ruiz \& Pav. (Melastom.).

alternifolia, Griseb. I. c. $55=$ M. Grisebachii.

parviflora, Griseb. Cat. Pl. Cub. $102=$ M. Grisebachii. rufa, Griseb. 1. c. $=$ M. rufa.

CATACHAETUM, Hoffmgg. Verz. Orch. 22 (1842); ex Linnaea, xvi. (1842) Litt. 231 = Catasetum, Rich. (Orchid.)
CATACLINE, Edgew, in Journ. As. Soc. Bengal, xvi. (1847) $1214=$ Tephrosia, Pers. (Legumin.). sericea, Edgew. 1. c. $=$ T. sericea:

CATACOMA, Walp. Rep.i. 243 (1842)=CATOCOMA, Benth.=Bredemeyera, Willd. (Polygal.).

CATAGYNA, Beauv. in Lestib. Essai Fam. Cyp. 26 1819) = Exiospora, Hochst. (Cyperac.).

CATAKIDOzamia, T. Hill, in Gard. Chron. (1865) $1107=$ Macrozamia, Miq. (Cycad.).

Hopei, T. Hill, 1. c. = M. Perowskiana.

Macleayi, Hort, ex Miq. in Verh. Akad. Wetensch. II. iii. (1869) $56=$ M. Perowskiana.

CATALrum, Buch.-Ham, ex Wall. Cat. sub n. 4880 $(1831$ ?) = Carallia, Roxb. (Rhizoph.).

nitidum, Buch.-Ham, 1. c.=Carallia lanceaefolia

CATALPA, Scop. Introd. 170 (1777). BIGNO. NIACEAE, Benth. \& Hook. f. ii. 1041.

Catalpium, Rafin. Princ. Somiol. 27 (1814); Fl. Ludov, 139 (1817)

Cumbalu, Adans. Fam. ii. 199 (1763).

bignonioides, Walt. Fl. Carol. 64.-Am. bor.

Bungei, C. A. Mey. in Bull. Sc. Acad. Pétersb. ii. (1837) 51.-China.

cassinoides, Spreng. Syst. i. 70.-Bras.

communis, Dum.-Cours. Bot. Cult. ed. II. iii. $242=$ bignonioides.

cordifolia, Jaume, in Duham. Arb. ed. Nov, ii. 13. t. $5=$ bignonioides.

hirsuta, Spreng. Syst. i. 70.-Bras.

Kaempferi, Sieb. E Zucc. in Abh. Akad. Muench.iv. III. (1846) 142.-Japon.

longisiliqua, Cham. in Linnaea, vii. (1832) $720=$ longissima.

longissima, Sims, Bot. Mag. sub t. 1094.-Ind. occ. microphylla, Spreng. Syst. i. 70.-Ins. S. Doming.

ovata, G. Don, Gen. Syst. iv, $230=$ Kaempferi.

Pottsii, Seem. in Otto \& Dietr. Allg. Gartenz. xix. (1851) 321.-Mexic.

punctata, Griseb. Cat. Pl. Cub. 192.-Cuba

purpurea, Griseb. l. c.-Cuba.

speciosa, Warder, ex Engelm. in Coult. Bot. Gaz. v. (1880) 1.-Am, bor.

syringaefolia, Bunge, Enum. Pl. Chin. Bor. $45=$ Bungei.

syringifolia, Sims, Bot. Mag. t. $1094=$ bignonioides

ternifolia, Cav. Dese. 26 = bignonioides.

CATALPIUM, Rafin. Princ. Somiol. 27 (1814); F1 Ludov. $139(1817)=$ Catalpa, Scop. (Bignoniac.). amena, Rafin. Fl. Ludov. $139=$ Catalpa bignonioides.

CATAMIXIS, Thoms. in Journ. Linn. Soc. ix. (1865 342. t. 4. COMPOSITAE, Benth. \& Hook. f. ii 494 .

baccharoides, Thoms. l. c. 343, t. 4.-Himal bor occ.

CATANANCHE, Linn. Syst. ed. I (1735), COM POSITAE, Benth. \& Hook. f. ii. 505.

Piptocephalum, Sch. Bip. in Bonplandia (1860) 369.

arenaria, Coss. E Dur. in Bull. Soc. Bot. Fr. ii. (1855) 253.-Algeria.

caerulea, Georgi, Beschr. Russ. Reich. iii. IV. $1217=$ Centaurea pulchella.

caerulea, Linn, Sp. Pl. 812--Reg. Mediterr. occ.

crespitosa, Desf. Fl. Atlant. ii. 238.-Afr. bor.

carpholepis, Nym. Consp. $472=$ caerulea.

graeca, Bory \& Chaub. Nouv. Fl. Pélop. $55=$ Hymeno nema laconicum.

graeca, Linn. Sp. Pl. $813=$ Hymenonema Tournefortii.

Iutea, Linn. l. c.812.-Reg. Mediterr.

montana, Coss. E Dur. in Bull Soc. Bot. Fr. iii. (1856) Bibl. 743.-Afr. bor

propinqua, Pomel, Nouv. Mat. Fl. Atl. 19.-Algeria.'

Webbii, Sch, Bip. in Bonplandia, viii. (1860) $369=$ montana.

CATANGA, Steud. Nom. ed. II. i. 311 (1840), sphalm. =Cananga, Aubl.
CATAPODIUM, Link, Hort. Berol. i. 380, 44 (1827)= Festuca, Linn. (Gramin.)

aquaticum, Willk. in Willk. \& Lange, Prod. F1. Hisp. i. $77=$ Catabrosa aquatica

durum, Link, in Linnaea, xvii. (1843) $399=$ Sclerochloa dura.

fusiforme, Nees, ex Benth. in Journ. Linn. Soc. xix. (1881) $128=$ Tripogon bromoides.

Halleri, Reichb. Fl. Germ. Excurs. $140=$ F. Poa.

loliaceum, Link, Hort. Berol. i. $45=$ Desmazeria loliacea.

nepalensis, Link, ex Steud. Nom. ed.II. i. 311 (quid ?).

pungens, Boiss. Fl. Orient. v. 635.-Afghan.

Salsmanni, Boiss. I. c. 634.-Reg. Mediterr.

siculum, Link, Hort. Berol.ii. $194=$ Desmazeria sicula. tuberculosum, Moris, in Atti 2da Riun. Sc. Ital. (1841) $481=\mathrm{F}$. tuberculosa

CATAPPA, Gaertn. Fruct. ii 206. t. $127(1791)=$ Terminalia, Linn. (Combretac.).

Benzoin, Gaertn. 1. c. $206=\mathrm{T}$. angustifolia

brasiliensis, Raddi, in Mem. Mod. xviii. Fis. (1820) $405=\mathrm{T}$. januarensis.

guyanensis, Gaertn. f. Fruct. iii. $207=$ T. mauritiana guyanensis, Gaertn. f. 1. c. t. $217=$ T. Tanibouca mauritiana, Gaertn f. I. c. $207=$ T. mauritiana.

CATAPUNTIA, Muell. Arg. in DC. Prod. Xv. II. 1020 (1866), sphalm. = seq.

CATAPUTIA, Ludw. Gen. 81 (1760) = Ricinus, Tourn (Euphorbiac.)

major, Ludw. Ectyp.t. $7=\mathrm{R}$. communis. minor, Ludw. Gen. $8 \mathrm{I}=\mathrm{R}$. communis.

CATARIA, Adans. Fam. ii. $192(1763)=$ Nepeta, Linn. (Labiat.)

canescens, Moench, Meth. $388=\mathrm{N}$. orientalis.

Nepetella, Moench, 1. c. $=$ N. Nepetella.

nuda, Moench, l. c. $=$ N. nuda.

paniculata, Moench, Meth. Supp1. $134=$ N. nuda. tomentosa, Gilib. F1. Lituan. i. $78=$ N. Cataria.

violacea, Moench, Meth. $388=\mathrm{N}$. nuda.

vulgaris, Moench, 1. c. $387=\mathrm{N}$. Cataria.

CATAS, Domb. ex Lam. Encyc。 ii. 354 (1786)=Embothrium, Forst. (Proteac.)

grandiflora, Juss. ex Lam. Encyc. ii. $354=$ E. grandiflorum.

parviflora, Juss. 1. c. $355=\mathrm{E}$, coccineum,

CATASETUM, Rich. ex Kunth, Syn. P1. Aequin. i. 330 (1822), ORCHIDEAE, Benth. \& Hook. f. iii. 551.

Catachaetum, Hoffmgg. Verz. Orch. $22(1842)$. Cf. Linnaea, xvi. (1842) Litt. 231.

Clowesia, Lindl. Bot. Reg. xxix. (1843) Misc. 25. t. 39.

Cuculina, Rafin. Fl. Tellur. iv. 49 (1836).

Monachanthus, Lindl. Bot. Reg. sub t. 1538 (1832).

Myanthus, Lindl. Bot. Reg. sub t. 1538 (1832), abruptum, Hook. Bot. Mag. t. 3929.-Bras.

adnatum, Steud. Nom. ed. II. i. 311, sphalm.= atratum.

albovirens, Rodrio. Orch. Now, i. 129-Bras.

atratum, Lindl. Bot. Reg. (1838) Misc. 61.-Bras.

Baraquinianum, Lem. Illustr. Hortic. ix. (1862) Misc. 81.-Bras.

barbatum, Lindl. Bot. Reg. (1844) Misc. 38.-Bras.

bicolor, Klotzsch, in Otto \& Dietr. Allg. Gartenz. xxii. (1854) 337.-N. Granat.

calceolatum, Lem. Fard. Fleur. i. (1851) Misc. 45.Guatemala.

callosum, Linal. Bot. Reg. (1840) Misc.77.-Venezuela.

carunculatum, Reichb. f. E Warsc. in Otto E Dietr. Allg. Gartenz. xxii. (1854) 274.-Peruv.

cassideum, Linden छ Reichb. f.Xen. Orch. ii. 171.Bras.

cernuum, Reichb. f. in Walp. Ann. vi. 570.-Bras.

Christyanum, Reichb. f. in Gard. Chron. (1882) I. 588. -Hab.?

ciliatum, Rodrig. Orch. Nov. i. 130.-Bras.

Claveringi, Lindl. ex Van Geel, Sert. Bot. ii. (1829) t. $3=$ macrocarpum.

cornutum, Lindl. Bot. Reg. (1840) Misc. 77.Guiana. 


\section{CATASETUM:-}

craniomorphum, Hoffmgg. ex Heynh. Nom. ii. 126, nomen.-Hab.?

cristatum, Lindl. Bot. Reg. t. 966.--Bras.

deltoideum, Lindl. l. c. xxvii. (1840) Misc. 157.Guiana.

dilectum, Reichb. f. Beitr. Orch. Centr. Am. 73.Costa Rica.

discolor, Lindl. Bot. Reg. (1844) Misc. 34.-Bras. expansum, Reichb. f. Otia Bot. Hamb. 9.-Ecuador. fimbriatum, Lindl. E Paxt. Flow. Gard. i. (1850-51) 124.-Hab. ?

fimbriatum, Reichb. f. in Saund. Refug. Bot. t. 83 $=$ discolor.

floribundum, Hook. Exot. F1. ii. 151=macrocalpum. fuliginosum, Lindl. Bot. Reg. (1841) Misc. 78.-Hab.? glaucoglossum, Reichb. f. in Gard. Chron. (1885) II. 552.-Mexic.

globiflorum, Hook. Bot. Mag. t. 3942.-Bras

Gnomus, Linden E' Reichb. f. Xen. Orch. ii. 171.Bras.

heteranthum, Rodrig. Orch. Nov, $127=\mathrm{C}$. Gnomus,

Hookeri, Lindl. Bot. Reg. sub t. 840.-Bras.

inapertum, Steud. Nom. ed. II. i. 31., sphalm.= purum.

incurvum, Klotzsch, in Otto $\Xi$ Dietr. Allg. Gartenz. xxii. (1854) 178.-Peruv.

integerrimum, Hook. Bot Mag. t. $3823=$ maculatum.

labiatum, Rodrig. Orch. Nov. ii. 218.-Bras.

laminatum, Lindl. in Ann. Nat. Hist. iv. (1840) 384. -Mexic.

lanciferum, Lindl. Bot. Reg. xxvii. (1841) 5. f. 5.-Bras,

Landsbergii, Lindl. E' Paxt. Flow. Gard. i. (1850-51) 156. - Venezuela.

lituratum, Hoffmgg. Vers. Orch. 22 ; ex Linnaea, xvi. (1842) Litt. 231.--Bras.

longifolium, Lindl. Bot. Reg. (1839) Misc. 94.Guiana.

luridum, Lindl. Gen. et Sp. Orch. 156.-Bras.

macrocarpum, Rich, ex Kunth, Syn. Pl. Aequin. i 330.-Guiana.

macroglossum, Reichb. f. in Gard. Chron. (1877) II. 552.-Ectiador

maculatum, Kunth, Syn. Pl. Aequin. i. 331.-N. Granat.

medium, Reichb. f. in Gard. Chron. (1885) II. 6.Hab.?

mentosum, Lem. Fard. Fleur, iii. (1852-53) Misc.65.Bras.

micranthum, Rodrig. Orch. Nov. ii. 219.-Bras.

Milleri, Lodd. ex Lindl. Bot. Reg. (1838) Misc. 80. -Bras.

Naso, Lindl. Bot. Reg. (1843) Misc. 71.-Venezuela.

ochraceum, Lindl. l. c. (1844) Misc. 44.-N. Granat.

Oerstedii, Reichb. $f$. in Bonplandia, iii. (1855) 218.-

Nicaragua.

ollare, Linden, Illustr. Hortic. xxviii. (1881) Misc. 80 . -Bras.

pallidum, Klotssch, in Otto $\xi$ Dietr. Allg. Gartenz. xxiii. (1855) 217.--Bras.

Phasma, Reichb. f. in Gard. Chron. (1877) II. 488.Bras.

pileatum, Reichb. f. l. c. (1882) I. 492.Venezuela. planiceps, Lindl. Bot. Reg. (1843) t. 9.-Guiana.

poriferum, Lindl. l. c. (1838) Misc. 89.-Guiana.

proboscideam, Lindl. l. c. (1839) Misc. 86.-Bras.

purpurascens, Hoffmgg. ex Heynh. Nom. ii. 126,

nomen.-Bras.

purum, Nees E Sinning, Pl. Hort. Bonn. Nutrit. i. 1. -Bras.

recurvatum, Link, Klotosch E Otto, Ic. Pl. ii. 105. t. 42.-Guiana.

Regnellii, Rodrig. Orch.Nov. ii. 219.-Bras.

rivularium, Rodrig, l. c. i. 180 -Bras.

roseo-album, Lindl. Bot. Reg. (1840) Misc. $65=$ discolor.

roseum, Reichb. f. in Gard. Chron. (1872) 1003.-Bras. roseum, Rodrig. Orch. Nov. i. 128.-Bras.

Russellianum, Hook. Bot. Mag. t. 3777.-Guatemala. saccatum, Lindl. Bot. Reg. (1840) Misc. 76.-Peruv. sanguineum, Lindl. E Paxt.Flow. Gard. ii. (1851-52) 168. - Am. centr.

Scurra, Reichb. fo in Gard. Chron. (1872) 1003.Guiana.

semiapertum, Hook. Exot. Fl. iii, 213 = purum.

serratum, Lindl. Bot. Reg. (1847) t. $24=$ viridi-flavum. spinosum, Lindl. 1. c. (1840) Misc. 65 - barbatum?

\section{CATASETUM}

qualidum, Hoffmgg.Verz. Orch. 23 ; ex Linnaea, xvi (1842) Litt. 231.-Bras.

tabulare, Lindl. Bot. Reg. xxx. (1840) Misc, 40,-N. Granat.

tigrinum, Reichb. f. in Gard. Chron. (1881) I. 40.Hab.

thylaciochilum, Lem. Illustr. Hortic. iii. (1856) Misc. 90.-Mexic.

tricolor, Reichb. f. in Hamb. Garten\%. xiii. (1857) 313.-Guatemal.

tridentatum, Hook. Exot. F1, ii. 90, 91 = macrocarpum trifidum, Hook. Bot. Mag. t. 3262.-Ind. occ.

trimerochilum, Lem. Illustr. Hortic. ix. (1862) t. $374=$ Mormodes lineatum.

triodon, Reichb. f. in Otto, Hamb. Gartenz. (1857) 313. Guatemal.

triste, Reichb. fo in Bonplandia, iii. (1855) $218=$ Hookeri

Trulla, Lindl. Bot. Reg. (1840) Misc.75.-Am. trop. turbinatum, Hoffmgg, ex Heynh. Nom. ii. 126, nomen. -Bras.

umbrosum, Rodrig. Orch. Nov. i. 129.-Bras.

variabile, Rodrig. i. c. ii. 217.-Bras

violascens, Reichb. f. $\%$ Warsc. in Bonplandia, ii (1854) 97 - -N. Granat.

viride, Lindl. Bot. Reg. (1841) Misc. 79.-Bras.

viridi-flavum, Hook, Bot. Mag, t. 4017.-Am. centr.

Wailesii, Hook. 1. c. t. $3937=$ maculatum

Warczewitzii, Lindl. E Paxt. Flow. Gard. i. (1850-51) 45. f. 29.-Panama.

CATATEROPHORA, Steud. Nom. ed. II. i. 311 (1840), sphalm. $=$ seq

CATATHEROPHORA, Steud, in Flora, xii. (1829) 465 Pennisetum, Pers. (Gramin).

hordeiformis, Steud. l. c. = P. macrourum.

CATENARIA, Benth. in Miq. Pl. Jungh. 217, 220 (1852) $=$ Desmodium, Desv. (Legumin.).

laburnifotia, Benth. 1. c. =D. laburnifolium.

CAEPHA, Leschen. ex Reichb. Handb. 221 (1837)= Platysace, Bunge (Umbell.)

CATESBAEA, Linn. Gen. ed. I. 336 (1737)。 RUBIA $C E A E$, Benth. \& Hook. f. ii. 78.

campanulata, Sagra, ex DC. Prod. iv. 401.-Cuba

elliptica, Spreng. ex. DC. 1. c. = Exostemma Vavassori erecta, Moc. ES Sesse, ex DC. l. c.-Mexic.

Grayii, Griseb. in Mem. Am. Acad. N. S. viii. (1863) 503.-Cuba.

holacantha, Griseb. Cat. Pl. Cub. 122.-Cuba

inermis, Spreng. Syst. i. $416=$ Rondeletia buxifolia.

latifolia, Lindl. Bot. Reg. t. 858.-Ind. occ.

Lindeniana, Baxt. ex Loud. Hort. Brit. Suppl. tii.

511 , nomen.-Hab.

Iongiflora, Sw. Prod. Veg. Ind. Occ. $30=$ spinosa.

longispina, A. Rich. Fl. Cub. Fanerog. ii. 12.-Cuba.

macrantha, A. Rich. 1. c. =spinosa?

macrantha, Wright, in Sauv. Fl. Cub. 59.-Cuba.

parahybensis, Vell. Fl. Flum. 54; i. t. 145.-Bras,

parviflora, Griseb. Cat. Pl. Cub. $122=$ Scolosanthus

parviflorus.

parviflora, Lam. Tabl. 1. 288. n. $1481=$ Scolosanthus versicolor.

parviflora, Spreng. ex Stend. Nom. ed. II. 1. $311=$ Rondeletia buxifolia.

parviflora, Sw. Prod. Veg. Ind. Occ. 30.-Jamaic

parvifolia, DC Prod. iv, 401.-Ins. S. Doming

phyllacantha, Griseb. Cat. Pl. Cub. $122=$ Phyllacantha Grisebachiana.

spinosa, Linn. Sp. Pl. 109.--Ind. occ.

strigosa, Willd. ex Steud. Nom, ed. II. i. $311=$ Randia tetrandra.

triacantha, Spreng, Neue Entdeck. iii. $47=$ Scolo santhus triacanthus.

Vavassorii, Spreng. Syst. i. $416=$ Exostemma Vavassorii.

CATEVALA, Medic. Theodora, $67(1786)=$ Aloö Linn. (Liliac.).

arachnoidea, Medic. 1. c. 68 Haworthin arachnoides. arborescens, Medic. 1. c. $67=\mathrm{A}$. arborescens. atroviridis, Medic. 1. c. $69=$ Hnworthia atrovirens. humilis, Medic. 1, $\mathrm{c}_{\mathrm{v}}=\mathrm{A}$. humilis.

retusa, Medic. 1. c. $68=$ Haworthia retusa.
CATHA, Forsk. Fl. Aegypt. Arab. 63 (1775). CELASTRINEAE, Benth. \& Hook. f. i. 361.

MethysCophyluum, Eckl. \& Zeyh. Enum. 152 (1836)

TrigonothecA, Hochst. in Flora, xxiv. (1841) 662 edulis, Forsk. l. c.-Afr. trop.

Forskalei, A. Rich. Tent. Fl. Abyss. i. $134=$ edulis.

inermis, J. F. Gmel. Syst. $411=$ edulis.

spinosa, Forsk. Fl. Aegypt. Arab. $64=$ Celastrus parviflorus.

CATHA, G. Don, Gen. Syst. ii. 11 (1832)=Celastrus,

Linn.

acuminata, Presl, Bot. Bemerk. $33=$ Cel. acuminatus. alaternifolia, Tul. in Ann. Sc. Nat. Sér. IV. viii. (1857) 98,-Ins. Comor.

articulata, G. Don, Gen. Syst. ii. $10=\mathrm{Cel}$. articulatus. Benthami, Gardn. \& Champ. in Hook. Kew Journ. i (1849) $310=$ Cel. Championi.

buxifolia, G. Don, Gen. Syst, ii. $10=$ Cel. buxifolius. campestris, Presl, Bot. Bemerk. $34=$ Cel. pyracanthus. cassinoides, Webb \& Berth. Phyt. Canar. ii. $142=\mathrm{Cel}$ cassinoides.

crenata, A. Gray, Bot. U. St. Expl. Exped, i. 288 in textu $=\mathrm{Cel}$, crenatus.

Cunninghamii, Hook. in Mitch. Journ. Trop. Austral. $387=$ Cel. Cunninghamii.

cymosa, G. Don, Gen. Syst. ii. $10=$ Cel, buxifolius.

decolor, Webb, Fragm. F1. Aethiop. $60=$ Gymnosporia montana.

Dryandri, Lowe, Man. F1. Madeir. i. 107.-Ins. Madera.

emarginata, G. Don, Gen. Syst. ii. 9 = Gymnosporia emarginata.

europaea, Boiss. Voy. Espagne, ii. $725=$ Gymnosporia montana.

excisa, G. Don, Gen. Syst. ii. $9=$ Cel. excisa.

fasciculata, Tul. in Ann. Sc. Nat. Sér. IV. viii. (1857 98.-Malaya

flexuosa, G. Don, Gen. Syst. ii., $10=$ Cel. flexuosus.

fruticosa, Thw. Enum. Pl. Zeyl. $72=$ Gymnosporia emarginata.

Grossulariae, Tul. in Ann. Sc. Nat. Sér. IV. viii. (1857) 98.-Madag.

heterophylla, Presl, Bot. Bemerk. $33=$ Cel. heterophyllus.

Heyneana, Walp. Rep. i. $532=$ Gymnosporia Hey. neana.

integer, G. Don, Gen. Syst. ii. $9=$ Cel. pyracanthus.

integrifolia, G. Don, 1. $\mathrm{c}_{\mathrm{n}}=$ Cel. integrifolius.

lanceolata, Presl, Bot. Bemerk. $33=$ Cel. linearis?

leptopus, Tul. in Ann. Sc. Nat. Sér. IV, viii. (1557

100.-Madag.

linearis, G. Don, Gen. Syst. ii. $9=$ Cel. linearis.

monosperma, Benth. in Hook. Lond. Journ. Bot. i. 483 $=$ Cel. monospermus.

montana, G. Don, Gen. Syst. ii. 10=Gymnosporia montana.

multiflora, G. Don, 1. c. = Cel. multiforus.

ovata, Walp. Rep. i. $582=$ Gymnosporia ovata

paniculata, Scheidw. in Otto \& Dietr. Allg. Gartenz $\mathrm{x} .(181-2) 275=\mathrm{Cel}$. paniculatus.

sarviflora, G. Don, Gez. Syst. ii. $10=$ Cel. parvi. florus.

parvifolins, Presl, Bot. Bemerk. $34=$ Cel. parvifolius.

patens, Presl, 1. c. $33=$ Cel. patens.

Pyracantha, G. Don, Gen. Syst. ii. $10=$ Cel. pyra. canthus.

rigid $\alpha$, G. Don, l. c. $9=$ Cel. rigidus.

Rothirma, Walp. Rep. i. 532=Gymnosporia Rothiana. roturdifolia, G. Don, Gen. Syst, ii, $10=$ Doryalis celastroides.

nufa, G. Don. 1. c. = Gymnosporia rufa.

rupestris, Presl, Bot. Bemerk, $39=\mathrm{Cel}$. acuminatus. seregalensis, G. Don, Gen. Syst. ii. 10 Gymnosporia montana.

senegalersis, Webb, Framm. Fl. Aethiop, $61=\mathrm{Cel}$. senconlensis.

spathulata, Turcz in Bull. Soc. Nat. Mosc. xxxii. (155y) i. 275.-Ind. or.

spathyphylla, Presl, Bot. Bemerk. $\$ 9=$ Cel. buxifolins. trigyra, Presl, 13ot. Bemerk. \$ - Gymnosporia irigyna.

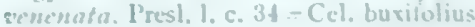
vitiensis, A. Gray, Bot. U. St. Expl. Exped. i. 257. ?. 2S.-Ins. Fiji.

Hallichii, G. Don, Gea. Syst. ii. 10 Gymnosporis Wallichiana.

ecylanica, Ci. Don, 1. c. $=$ Scutia Commersunii.

$3 \mathrm{~N}$ 
CATHANTHES, Rich, in Mém. Mus. Par. i. (1815) 365 $=$ Tetroncium, Willd. (Naiad.).

CATHARANTHUS, G. Don, Gen. Syst. iv. 95 (1836) =Vinca, Linn. (A pocynac.).

pusillus, G. Don, $1 . \mathrm{c}_{.}=\mathrm{V}$. parviflora.

roseus, G. Don, l. c. $=$ V. rosea.

CATHARTOCARPUS, Pers. Syn. i. 459 (1805) = Cassia, Linn. (Legumin.)

Atteleh, G. Dun, Gen, Syst. ii. $453=$ Cassia Arereh.

bacillaris, Pers. Syn. i. $459=$ Cassia bacillaris.

Bacillus, Lindl. Bot. Reg. t. 881 = Cassia baciliaris.

brasilianus, Jacq. Fragm. 59. t. 85 . f. $3=$ Cassia grandis.

Brewsteri, F. Muel1. Fragm. i. $110=$ Cassia Brewsteri. conspicuus, G. Don, in Loud. Hort. Brit. $167=$ Cassia Sieberiana.

excelsus, G. Don, Gen. Syst. ii. $453=$ Cassia Fistula

ferrugineus, $\mathrm{G}$. Don, 1. c. = Cassia ferruginea.

Fistula, Pers. Syn. i., $459=$ Cassia Fistula.

fistuloides, G. Don, in Loud. Hort. Brit. $167=$ Cassia Fistula.

grandis, Pers. Syn. i. $459=$ Cassia grandis.

Humboldtianus, Loud. Hort. Brit. $167=$ Cassia spectabilis.

javanicus, Pers. Syn. i. $459=$ Cassia javanica.

laetus, G. Don, Gen. Syst. ii. $454=$ Cassia laeta.

marginatus, G. Don, l. c. $453=$ Cassia marginata.

moschatus, G. Don, $\mathrm{l}_{\mathrm{c}} \mathrm{c} .=$ Cassia moschata.

nodosus, S.eud. Nom. ed. II. i. $311=$ Cassia nodosa.

rhombifolius, G. Don, Gen. Syst. ii. $453=$ Cassia Fistula.

Roxburghii, Loud. Hort. Brit. $167=$ Cassia marginata.

Sieberianus, G. Don, Gen. Syst. ii. 453 = Cassia

Sieberiana.

speciosus, G. Don, 1. $\mathrm{c}_{\mathrm{.}}=$ Cassia spectabilis.

Trinitatis, G. Don, in Loud. Hort. Brit. 167=Cassia spectabilis.

CATHARTOLINUM, Reichb. Handb. 306 (1837) = Linum, Linn.

agreste, Reichb. 1. c. $307=\mathrm{L}$. angustifolium.

alternum, Reichb. 1. $\mathrm{c}_{0}=\mathrm{L}$. strictum.

bicolor, Reichb. 1. c. $=$ L. bicolor.

corymbulosum, Reichb. 1. c. = L. strictum.

gallicum, Reichb 1. $_{0}=\mathrm{L}$. gallicum.

pratense, Reichb. 1. $c_{2}=\mathrm{L}$. catharticum.

salsoloides, Reichb. 1. c. $=$ L. salsoloides.

sardoum, Reichb. 1. c. = L. Mnelleri.

spicatum, Reichb. Ic. Fl. Germ. xvi. $62=$ L. strictum.

strictum, Reichb. l.c. xvi. t. $327=\mathrm{L}$. strictum.

suffruticosum, Reichb. Handb. $307=\mathrm{L}$. suffruticosum.

tenuifolium, Reichb. 1. c. = L. tenuifolium.

virginianum, Reíchb. $\mathrm{l}_{\text {. }}$. $=\mathrm{L}$. virginianum.

CATHASTRUM, Turcz, in Bull. Soc, Nat. Mosc, xxxi. (1858) r. 448. CELASTRINEAE, Benth, \& Hook. f. i. 362 .

capense, Turcz. $l_{0} c_{0}$-Afr. austr.

CATHCARTIA, Hook. fo in Bot. Mag. t. 4596 (1851). PAPAVERACEAE, Benth. \& Hook. f. i. 52.

integrifolia, Maxim. in Bull. Acad. Pétersb. xxiii. (1877) 310.-China.

villosa, Hook. f. in Bot. Mag. t. 4596.-Reg. Himal.

CATHEA, Salisb, in Trans. Hort. Soc. i. (1812) $300=$ Calopogon, R. Br. (Orchid.).

pulchella, Salisb. 1, c, =Calop. pulchellus.

CATHEDRA, Miers, in Ann. Nat. Hist. Ser. II. vii. (1851) 452, 457. OLACINEAE, Benth. \& Hook. f. i. 348 .

DIPLOCRATER, Benth. in Hook. Kew Journ. iii. (1851) 367

acuminata, Miers, $l . c$. Ser. III. iv. (1859) 361.-Bras.

crassifolia, Miers, l. c.-Bras.

Gardneriana, Miers, l. c. Ser. II. vii. (1851) 459,-Bras. rubricaulis, Miers, l. c. 458.--Bras.

CATHESTECUM, J. Presl, in Rel. Haenk. i. 294. t. 42 (1830). GRAMINEAE, Benth. \& Hook. f. iii. 1122 .

erectum, Vasey E Hack. in Bull. Torrey Bot. Club. xi. (1884) $3 \%$. t. 45 ,-Mexic.

prostratum, F. Presl, in Rel. Haenk. i. 295. t. 42.-
CATHETOSTEMMA, Blume, Rumphia, iv. 30 (1848)= Hoya, R. Br. (Asclepiad.)

laurifolium, Blume, $\mathrm{l}_{0} \mathrm{c}_{\mathrm{o}}=\mathrm{H}$. laurifolia.

CATHETUS, Lour. Fl. Cochinch. $607(1790)=$ Phyllanthus, Linn. (Euphorbiac.).

fasciculata, Lour. 1. c. $608=$ P. cochinchensis.

CATHISSA, Salisb. Gen. Pl. Fragm. $34(1866)=$ Ornithogalum, Tourn. (Liliac.).

concinna, Salisb. 1. c. $=$ O, unifolium

unifolia, Salisb. 1. c. $=$ O. unifolium.

CATHORMION, Hassk. Retzia, i. $231(1855)=$ Pithe colobium, Mart. (Legumin.).

funghuhnianum, Hassk. 1. c. $232=$ P. Junghnhnianum.

moniliferum, Hassk. 1. c. $231=$ P. moniliferum.

CATIMBiUM, Juss. Gen.62 (1789) = Alpinia, Linn (Scitamin.).

erectum, Juss, ex Lestib. in Ann. Sc. Nat. Sér. II. xv, (1841) $342=$ A. calcarata

exaltatum, Mirb. ex Steud. Nom. ed. II. i. $311=$ Renealma exaltata.

nutans, Juss, ex Lestib. in Ann. Sc. Nat. Sér. II. xv. (1841) $342=$ A. nutans.

CATINGA, Aubl. Pl. Gui. i. 511, t. $203(1775)=$ Eugenia, Linn。 (Myrtac.).

aromatica, Aubl. 1. c. f. $2=$ E. aromatica

moschata, Aubl. 1. c. f. $1=$ E. Catinga.

CATOBLASTUS, H. Wendl. in Bonplandia, viî (1860) 104, 106. PALMAE, Benth. \& Hook. f. iii. 901.

maynensis, Drude, in Mart. Fl. Bras. iii. II. 544.Peruv.

praemorsus, H. Wendl. in Bonplandia, viii. (1860) 104.-N. Granat.

pubescens, $H$. Wendl. l. c.-Bras.

CATOCOMA, Benth. in Hook. Journ. Bot. iv. (1842) $101=$ Bredemeyera, Willd. (Polygal.).

altissima, Poepp. \& Endl. Nov. Gen. et Sp. iii. 65. t $273=$ B. altissima .

brevifolia, Benth. in Hook. Journ. Bot. iv. (1842) 102 $=\mathrm{B}$. brevifolia.

emarginata, Spruce, ex A. W. Benn. in Mart. Fl. Bras, xiii. IIf, $50=$ B. altissima.

floribunda, Benth. in Hook. Journ. Bot. iv. (1842) 102 $=$ B. fluribunda.

Kunthiana, Benth. 1. c. $103=$ B. Kunthiana,

laurifolia, Benth. 1. c. = B. laurifolia.

lucida, Benth. 1. c. $101=$ B. lucida

Mansonii, Klotzsch, ex A. W. Benn. in Mart. Fl. Bras. xiii. III, $51=$ B. lucida.

mollis, Triana \& Planch. in Ann. Sc. Nat. Sér. IV. xvii。 (1862) V. $133=$ B. altissima.

myrtifolia, Spruce, ex A. W. Benn. in Mart. Fl. Bras. xiii. III. $51=$ B. myrtifolia.

parviflora, Spruce, ex A. W. Benn. 1. c. $51=$ B. parviflora.

CATOCORYNE, Hook. f. in Benth. \& Hook. f. Gen. i. 765 (1867). MELASTOMACEAE, Benth. \& Hook. f. l. c.

linneoides, Hook. f.l. c.-Peruv.

CATODIACRUM, Dulac, Fl. Hautes-Pyr. $369(\mathbf{1 8 6 7})=$ Orobanche, Tourn.

cruentum, Dulac, 1. c. $371=0$. cruenta.

foetidum, Dulac, 1. c. $=$ O. foetida.

incurvum, Dulac, 1. c. $370=0$. caryophyllacea.

luteum, Dulac, 1. $c_{2}=$ O. Hederae.

pallidiflorum, Dulac, 1. c. = O. pallidiflora.

rubidum, Dulac, 1. c. $=$ O. Teucrii.

sparsiftorum, Dulac, 1. c. = O. Epithymum.

variegatum, Dulac, l. $\mathrm{c} .=\mathrm{O}$. variegata.

CATONIA, P. Br. Hist. Jamaic. 148 (1756); Juss. Gen. 441 (1789). INC. SED.

Brownei, Roem. E' Schult. Syst. iii. 480.-Jamaica. marginata, Jaume St. Hil. Expos. ii. $347=$ Brownei.
CATONIA, Moench, Meth. $535(1794)=$ Crepis, Linn. (Compos.).

blattarioides, Cass. in Dict. Sc. Nat. v. 274; xxvi. $9=$ Crepis blattarioides.

cordifolia, Moench, Meth. 536 = Hieracium amplexicaule.

crocea, Reichb. ex Steud. Nom. ed. II. i. $311=$ Crepis Columnae.

sagittata, Moench, Meth. $536=$ Crepis blattarioides.

CATONIA, Rafin. Fl. Tellur. ii. 36 (1836) (Quid?). lantanoides, Rafin. 1. c.-Hab.?

CATONIA, Vahl, in Skrivt. Nat. Hist. Selsk. Kiobenh. vi. (1810) 98 =Erycibe, Roxb. (Convolvulac.). elliptica, Vahl, 1. c. $101=\mathrm{E}$. paniculata

glauca, Vahl, 1. c. $98=$ E. paniculata.

CATONIA, Vell. Fl. Flum. 155 (1825); t. iv. t. 18 ('Oct. Mon.' Quid ?).

rustica, Vell. 1. c.-Bras.

CATOPHERIA, Benth, in Benth, \& Hook, f, Gen. ii 1173 (1876). LABIATAE, Benth. \& Hook. f. 1.c. capitata, Benth. l. c.-Mexic.

chiapensis, A. Gray, ex Benth. in Hook. Ic. Pl. sub t. 1215.-Mexic.

spicala, Benth. l. c. t. 1215.-N. Granat.

CATOPHRACTES, D. Don, in Proc. Linn. Soc. i. 4 (1839); Trans. Linn. Soc。 xviii. (1841) 306. t. 22. BIGNONIACEAE, Benth. \& Hook. f. ii. 1048.

Alexandri, D. Don, $I l . c c .4 ; 307$.-Afr. austr.

Kolbeana, Harv. Gen. S. Afr. Pl. ed. II. 276.-Afr. austr.

Welwitschii, Seem. in Fourn. Bot. iii. (1865) 331.Afr. trop.

CATOPHylLUM, Pohl, ex Baker, in Mart. Fl. Bras. vi. II. 222 (1876)=Mikania, Willd. (Compos.), deltoideum, Pohl, ex Baker, I. $c_{0}=$ M. officinalis. tropaeolifolium, Pohl, ex Baker, 1. c. = M. officinalis.

CATOPODIUM, Link, Hort. Berol, i. 44 (1827), sphalm, Catapodium, Link (Gramin.).

CATOPSIS, Griseb. in Goett. Nachr. 1864 (1865) 21. BROMELIACEAE, Benth. \& Hook. fo iii, 670.

Pogospermum, Brongn. in Ann. Sc. Nat. Sér. V. i. (1864) 237

Tussacia, Klotzsch, ex Beer, Bromel. 99 (1856). fulgens, Griseb. l. c. 21.-Am. trop.

nitida, Griseb. Fl. Brit. W. Ind. 599.-Ind, occ.

nutans, Griseb. l. c.-Ind. occ.

CATOSPERMA, Benth. in Hook. Ic. Pl. t. 1028 (1868), GOODENOVIEAE, Benth. \& Hook. f, ii. 539.

Careyi, F. Muell. in Melb. Chemist (Apr. 1884).Austral.

Muelleri, Benth. in Hook. Ic. Pl. t. 1028.-Austral

CATOSTEMMA, Benth, in Hook. Lond. Journ. Bot. ii. (1843) 365. MALVACEAE, Benth. \& Hook. f. i. 724 .

fragrans, Benth. l. c- - Guiana.

CATTLEYA, Lindl. Collect. Bot, tt. 33, 37 (1824), ORCHIDEAE, Benth. \& Hook. f. iii. 531.

Maelenia, Dum. in Mém. Acad. Brux. ix, (1835) 13. t. 10 .

Acklandiae, Planch. in Fl. des Serres, Sér. I. vii. (185152) $83=$ seq.

Aclandiae, Lindl. Bot. Reg. xxvi. (1840) t. 48.Bras.

acuminata, Beer, Prakt. Orch. $208=$ Laelia acuminata. atbida, Beer, 1. c. = Laelia albida.

alutacea, Rodrig. Orch. Nov. ii. 157.-Bras.

amethystina, Morr. in Ann. Gand. iv. (1848) 217. t. $201=$ intermedia.

amethystoglossa, Linden \& Reichb. fo ex Warner, Sel. Orch. Ser. I. t. 2 = guttata.

anceps, Beer, Prakt. Orch. $208=$ Laclia anceps.

Arembergii, Scheidw. in Otto \& Dietr. Allg. Gartenz. xi. (1843) $109=$ Loddigesii.

Aucklandiae, Heynh. Nom. ii. 126, sphalm. $=$ Aclandiae. 
CATTLEYA :-

Auclandii, Beer, Prakt. Orch. 208, sphalm. = Aclandiae. aurantiaca, P. N. Don, in Florist's Journ. (1840) $185=$ Epidendrum aurantiacum.

aurea, Linden, Illustr. Hortic. xxx. (1883) t. 493.-N. Granat.

autumnalis, Beer, Prakt. Orch. 208 = Laelia autumnalis. bicolor, Lindl. Bot. Reg. (1836) sub t. 1919.-Am. austr.

Bluntei, Hort. ex Gard. Chron. (1876) I. 735.-Hab.

bogotensis, Linden, in Belg. Hortic. Xv. (1865) $102=$ labiata.

Bowringiana, Veitch, ex Gard. Chron. (1885) II. 683. Honduras.

Brabantiaex, Veitch.-Cf. Gard. Chron. (1864) 413 ; et Floral Mag. vi. (1867) t. 360

Brymeriana x, Reichb. f. in Gard. Chron.(1883) II. 492 Brysiana, Lem. in Jard. Fleur. iii. $(1852-53)$ t. $275=$ Laelia purpurata.

bulbosa, LindI. Bot. Reg. (1847) t. $42=$ Walkeriana

calummatax, André, in Rev. Hortic. (1883) 564.

candida, Williams, in Gard. Chron. (1851) $453=$

Loddigesii.

Carrierei, Houllet, in Rev. Hortic. (1876) $250=$ labiata

cernua, Beer, Prakt. Orch. $209=$ Sophronitis cernua.

Chamberlainiana x, Reichb. f. in Gard. Chron. (1881)

Ir. 427.

chlorantha, Beer, Prakt. Orch. $209=$ Sobralia macro. phylla.

chocoënsis, Linden, in Illustr. Hortic, xvii. (1870) $37=$

labiata.

cinnabarina, Beer, Prakt. Orch. $209=$ Laelia cinna-

barina.

citrina, Lindl. Coll. Bot. sub t. 37.-Mexic.

coccinea, Lindl. Bot. Reg. sub t. $1919=$ Sophronitis grandiflora.

crispa, Beer, Prakt. Orch. $209=$ Schomburgkia crispa.

crispa, Lindl. Bot. Reg. t. $1172=$ Laelia crispa.

Dawsoni, Warner, Sel. Orch. P1. i. t. $16=$ labiata

Deckeri, Klotzsch, in Otto \& Dietr. Allg. Gartenz.

xxiii. 1855) $81=$ Skinneri.

decora, Beer, Prakt. Orch. $209=$ Sobralia decora.

devoniensis $\times$, Hort. ex Floral Mag. N.S. (1881) sub t. $437=$ Laelia elegans ?

dolosa, Reichb. f. Xenia Orchid. ii. 224, in synon.Bras.

domingensis, Lindl. Gen, et Sp. Orch. $118=$ Broughtonia lilacina

Dominiana $\times$, Lindl. in Gard. Chron. (1859) 948.

Dormanianax, Reichb. f. in Gard. Chron. (1882) I. 216.

Dowiana, Batem. l. c. (1866) 922.-Costa Rica.

elatior, Lindl. Gen, et Sp. Orch. $117=$ guttata.

Eldorado, Linden, in Fl. des Serres, Sér. II. viii. (1869-

70) 13. t. $1826=$ labiata

elegans, Morr. in Ann. Gand. iv. (1848) 93. t. $185=$ Laelia elegans.

elegantissima, Linden, Illustr. Hortic. xxviii. (1881)

80. - Venezuela.

elongata, Rodrig. Orch. Nov. i. 72.-Bras.

eximia, Rodrig. i.c. 70.-Bras.

exoniensis $\times$, Reichb. f. in Gard. Chron. (1867) 1144.

fausta $\times$, Reichb. f. 1. c. (1873) 289.

felix $x$, Reichb. f. 1. c. (1876) II. 68

flava, Beer, Prakt. Orch. $210=$ Laelia flava.

Ravida, Klotzsch, in Otto \& Dietr. Allg. Gartenz. xxiv. (1856) $73=$ luteola

Forbesii, Lindl. Coll. Bot. sub t. 37.-Bras.

fragrans, Rodrig. Orch. Nov. i. 72.-Bras,

furfuracen, Beer, Prakt. Orch. $210=$ Laelia furfuracea

fulva, Beer, \&. 210- Hab?

Galeottiana, Beer, I. c. = Epidendrum Galeottianum.

Gardneriana, Reichb. f. in Gard. Chron. (1870) 1373,

in nota $=$ Walkeriana

Gaskelliana, Hort. Sander, 1. c. (1883) I. 243, $310=$ labiata.

gigantea, Hort. ex P. N. Don, in Florist's fourn.

(1840) 187.-Hab.?

Gigas, Linden \& André, Illustr. Hortic. xx. (1873) 70 $=$ labiata.

gloriosa, Carr. in Rev. Hortic. (1885) $339=$ labiata.

Grahami, Lindl. Gen. et Sp. Orch. $116=$ Laelin

majalis.

grandifora, Beer, Prakt, Orch. 209=Sophronitis grandiflora.

granulosa, Liradl. Bot. Reg. (1842) t. 1.-Am. austr.

guatemalensis, T. Moore, in Flor. Mag. (1861) t. 61.

Ginatemala.

\section{CATTLEYA}

guttata, Lindl. Bot. Reg. t. 1406.-Bras.

Hardyana, Hort. Sander.-Cf. Gard. Chron. (1883) I.

243 = labiata.

Harrisoniae, Paxt. Mag. Bot. iv. (1838) $247=$ Loddigesii.

Harrisoniana, Batem. ex Lindl. in Bot. Reg. sub t. $1919=$ Loddigesii.

Harrisonii, Hort. ex Duchartre, in Journ. Soc. Hort. Fr. iii. (1857) 725. t. $7=$ praec

hybrida ×, Veitch, in Gard. Chron. (1863) 602.

ianthina, Hort. ex Gard. Chron. (1853) 247, nomen = intermedia?

imperialis, J. O'Brien, in Gard. Chron. (1883) IT. $404=$ labiata.

intermedia, R. Grah. in Bot. Mag. t. 2851.-Bras.

intricata, Reichb. f. in Gard. Chron. (1884) II. 7.Hab,

iricolor, Reichb.f. l.c. (1874) II, 162.-Hab.?

Isabclla, Reichb. f in C. Koch E Fint. Wochenschr. (1859) 336.-Hab.?

isopetala, Beer, Prakt. Orch. 211.-Hab. ?

Karwinskii, Mart. Ausw. Merkw. Pf. 14. t. $10=$ citrina.

labiata, Lindl. Coll. Bot. t. 33.-Am. trop.

laelioides, Lem. Jard. Fleur. iii. (1852-53) Misc. 42, $50=$ Skinneri.

Lawrenceana, Reichb. f. in Gard. Chron. (1885) I. 338.-Guiana.

Lawrenceana, Warsc. ex Reiclıb. fo in Gard. Chron. (1883) I. $243=$ Dowiana.

Leeana, Hort. Sander.-Cf. Gard. Chron. (1883) I. 43 $=$ labiata.

Lemoniana, Lindl. Bot. Reg. (1846) t. $35=$ labiata.

Leopoldii, Hort. Versch. ex Illustr. Hortic. i. (1854) Misc. 68 ; ii. $(1855)$ t. $69=$ guttata.

Liliastrum, Beer, Prakt. Orch. $212=$ Sobralia Liliastrum.

Lindleyana, Reichb. f. in C. Koch, Allg. Gartenz. 1857) 118.-Bras.

lobata, Lindl. Gard. Chron. (1848) $403=$ Laelia Boothiana.

Loddigesii, Lindl. Coll. Bot. t. 37.--Bras.

Lucieniana x, Reichb. fo in Gard. Chron. (1885) II. 456.

Luddemanniana, Reichb. f. Xenia Orch. i. $29=$ labiata.

Iuteola, Lindl. in Gard. Chron. (1853) 774.-Bras. macrantha, Beer, Prakt. Orch. 212 = Sobralia macrantha. majalis, Beer, 1. c. = Laelia majalis.

Manglesii x, Reichb. f. in Gard. Chron. (1880) \x. 556

Mardellii x, Seden, ex Reichb. f. 1. c. (1879) r. 234

marginata, Beer, Prakt. Orch. $212=$ Schomburgkia marginata.

marginata, Paxt. Mag. Bot. x. (1843) 265=Laelia pumila.

maritima, Lindl. Bot. Reg. (1836) sub t. $1919=$ intermedia.

Marstersoniae x, Seden, ex Reichb. f. in Gard. Chron. (1878) II. 556.

Massangreana, Reichb, f. in Gard. Chron. (1883) I. $242=$ labiata

maxima, Lindl. Gen et Sp. Orch. 116.-Peruv.

Mendelli, Hort.-Cf. Gard. Chron. (1883) II. 404.Hab.?

Meyeri, Regel, in Ind. Sem. Hort. Petrop. (1855) 17.

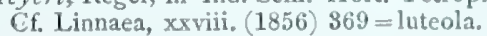

Mitchellix, Reichb. fo in Gard. Chron. (1876) I. 386.

Morganae, Warner, Orch. Album, i. (1882) t. $6=$ labiata.

Mossiae, Parker, in Hook. Bot. Mag. t. $3669=$ labiata.

Nalderiana, Reichb, fo in Gard. Cliron. (1885) I. $750^{\circ}$ =labiata.

nobilior, Reichb, fo in Illustr. Hortic. xxx. (1883) t. $485=$ Walkeriana.

odoratissima, P. N. Don, in Florist's Journ. (1840) 185 $=$ Sobralia violacea?

ovata, Lindl. Bot. Reg. sub t. $1919=$ intermedia.

pallida, Lindl. \& Paxt. Flow. Gard. ii.(1851-52) 51 = labiata.

paludosa, Beer, Prakt. Orch. $215=$ Sobralia paludosa, papeiansiane, Morr, in Ann. Gand, i. (1845) 57. t. $=$ Loddigesii.

peduncularis, Beer, Prakt. Orch. $213=$ Laclia peduncularis.

Peetersii, Andre, in Rev. Hortic. (1885) 271=labiata.

Percivaliana, Hort.-Cf. Gard. Chron. (18s\$) I1. 404 labiats.

\section{CATTLEYA:}

Perrini, Endl, in Harting. Parad. Vindob. t. $20=$ labiata.

Perrinii, Lind1. Bot. Reg. (1838) t. $2=$ Laelia Perrinis picturatax, Reichb, f. in Gard. Chron. (1877) II. 584

Pinellii, Hort. ex Lindl. in F1. des Serres, Sér. I. vil. (1851-52) $43=$ Laelia pumila.

piperita, Hort.-Cf. Gard. Chron. (1850) 168, nomen. - Hab.?

porphyroglossum, Linden E Reichb. fo in Otto E Dietr. Allg. Gartenz. xxiv, (1856) 98.-Bras.

porphyrophlebia x, Reichb. f. in Gard. Chron. (1885 ]1. 552 .

Princeps, Rodrig. Orch. Nov. i. 68.-Bras

pterocarpa, Beer, Prakt. Orch. 20!= Sophronitis ptero.

carpa.

pumila, Hook. Bot. Mag. t. $3656=$ Laelia pumila.

purpurata, Beer, Prakt. Orch. $213=$ Laelia purpurata.

purpurina, Rodrig. Orch. Nov. ii. 158.-Bras.

quadricolor, Lindl. in Paxt. Flow. Gard. i. $6=$ labiata.

Quindois, Hort.-Cf. Gard.Chron. (1853) 247, nomen. - Hab.

quinquecolor $\times$, Dombr, in Floral Mag. to 511

reflexa, Parment. ex Walp. Ann. vi. $423=$ Laelia crispa

reoralis, Hort.-Cf. Gard. Chron. (1883) II. 404=

labiata?

Regnellii, Warner, Sel. Orch. Ser. II. t. $22=$ Schil leriana.

Reineckiana, Reichb. f. in Bonplandia, iv. (1856) 237 =laliata.

resplendens x, Reichb.f. in Gard. Chron. (1885) I. 692.

Roezlii, Reichb. f.-Cf. Gard. Chron. (1882) II. $457=$ labiata.

Rollissonii, T. Moore, in Floral Mag. i. (1861) t. $8=$

labiata.

rubescens, Beer, Prakt. Orch. $214=$ Laelia rubescens.

Ruckeri, Linden, in Belg. Hortic. xv. (1865) 102.-N

Granat.

Rueckerii, Beer, Prakt. Orch. $214=$ Sobralia Rueckeri Sanderiana, Hort. Low:-C. Gard. Chron. (1882) II $151=$ labiata .

Schilleriana, Reichb. f: in C. Koch, Allg. Gartens. (1857) 335.-Bras.

Schofieldiana, Reichb. $f$. in Gard. Chron. (1882) Ir. 808.- Hab.?

Schroederiana, Reichb.f. l. c. (1883) II. 102.-Hab. ?

Scita x, Reichb. f. l. c. (1885) II. 489.

sessilis, Beer, Prakt. Orch. $214=$ Sobralia sessilis.

Skinneri, Batem. Orch. Mex. \& Guat. t. 13.-Guatemala.

peciosissima, Hort.Cf. Gard. Chron. (1868) 404, in nota $=$ labiata.

spectabilis, Hort.-Cf. Florist (1850) $91=$ marginata

sphenophora, Mort. Ann. Gand. iv. (1848) 17. t. $175=$ guttata.

sulfurina, Lem. Illustr. Hortic. i. (1854) Mise. $2=$

citrina.

superba, Schomb. ex Lindl. Sert. Orch, t. $22=$

violacea.

superbiens, Beer, Prakt. Orch. $21 t=$ Laelia superbiens

tibicinis, Beer, 1. c. $215=$ Schombargkia tibicinis

tichotoma, Beer, 1. c. = Sobralia dichotoma.

tigrina, A. Rich. ex Beer, l. c. 215,-Hab. ?

Trianaei, Linden \& Keichb. f. in Bot. Zeit. svii. (1860 $74=$ labiata

Trianaei, Linden G Reichb. f. in C. Koch, Wochenschr. iii. (1860) 67.-N. Granat.

trichopiliochila, Rodrig. Orch. Nov.i. 70.-Bras.

trilabiata, Rodrig. l. c. 69.-Bras.

triophthalma x, Reichb. f. in Gard. Chron. (15\$3) Il.

tuberculata, Hort. ex Reichb. f. in Walp. Anns. xi. $8 \geqslant 0$. Hab. ?

undulata, Beer, Prakt. Orch. $215=$ Schomburgki. undulata.

Feitchi, Hort. ex Pfitz, Verg. Morph. Orch 124 seq.

Fritcliana $\mathrm{Cf}$ Gard. Chron. (15it) I, $\$ \$ 5,560^{\circ}=$ Laclia Veitchiana.

relutina, Reichb. f. in Gard. Chron. 18;0) 140, 13:s. -llab. ?

vestalis, Hoffmge. Verz-Ce. Bor. Zcit, i. (1St\$) 831 Forbesii.

violacea, Beer, Prakt. Orch. 209 = Sophmonitis violaces. vivlacea, Beer, l. c. 215 Suthralia violaces.

pirginalis, Lindeo \& André, Hlluser. Honic. xxiu 1si(i) $8.25 i=$ latrata. 


\section{CATTTEYA}

Wageneri, Reichb. fo in Bonplandia (1854) $21=$ labiata.

Walkeriana, Gardn. in Hook。 Lond. Fourn. Bot. ii. (1843) 662.-Bras。?

Wallisii, Linden, in Gard. Chron. (1882) I. $557=$ labiata.

Warneri, T. Moore, ex Warner, Orch. Sel, Ser. I. t. 8 $=$ labiata.

Warscerviczii, Reichb. f. in Bonplandia (1854) $112=$ labiata.

Whitei, Hort. Lozw.-Cf. Gard. Chron. II. (1882) 151, 586.-Hab. ?

Wilsoniana, Reichb. f. in Gard. Chron. (1877) II. 72.Am. austr.

CATTLEYOPSIS, Lem. Jard. Fleur. iv. (1854) Misc. 59. ORCHIDEAE

delicatula, Lem. l. c.-Cuba.

CATU-ADAMBOE, Adans. Fam. ii. 85 (1763)=Lagerstroemia, Linn. (Lythrar.) (L. hirsuta).

CATU-NAREGAM, Adans. Fam. ii. 85 (1763) Randia, Houst. (Rubiac.) (R. virosa).

CATURUS, Linn. Mant. i. 19 (1767)=Acalypha, Linn. (Euphorbiac.).

ramiflorus, Linn. 1. c. $127=$ Boehmeria ramiflora

sessilis, Thou. ex Baill. Adansonia, i. (1860-61) $267=$ A. integrifolia.

spiciflorus, Jacq. f. ex Wedd.in DC. Prod. xvi. I. $214=$ Boehmeria spiciflora.

spiciflorus, Linn. Mant. i. $127=$ A. hispida

pedunculatus, Thou. ex Baill. in Adansonia, i. (1860-61) $267=$ A. arborea

CATURUS, Lour. Fl. Cochinch. $612(1790)=$ Malaisia, Blanco (Urtic.)

scandens, Lour. 1. c. $=$ M. tortuosa.

acuminatus, Cunninghamii, Deplanchei, fagifolius, oblongatus, pelagicus, torulosus, virescens, Seem. F1. Vit. $254=$ M. tortuosa

CATYONA, Lind1. Veg. Kingd. 715 (1847), sphalm.:= GATYONA, Cass. = Crepis, Linn. (Compos.).

CAUCALT.S, Linn. Syst. ed. I (1735); Gen. ed. I. 71 (1737). UMBELLIFERAE, Benth. \& Hook. f. i. 928.

Agrocharis, Hochst, in Flora, xxvii. (1844) 19. Daucalis, Pomel, Nouv. Mat. Fl. Ati. 148 (1874). Glochinotheca, Fenzl, in Russegg. Reise, i. II 970, obs. (1843).

Lappularia, Pomel, Nouv, Mat. Fl, Atl. 149 (1874).

LrSAEA, Boiss. in Ann. Sc. Nat. Sér. III. ii. 54 (1844).

ToRILIS, Adans. Fam. ii. 99 (1763)

Turgenda, Hoffm. Gen. Umb. 59 (1814).

Turgeñorsis, Boiss, in Ann. Sc. Nat. Sér. III, ii. $53(1844)$.

abyssinica, Hochst. ex A. Rich. Tent. Fl. Abyss, i. $331=$ Dancus abyssinicus

aequicolorum, All. Fl. Pedem. ii. $33=$ Anthriscus vulgaris.

africana, Crantz, Cl. Umb. Emend. 109=Capnophyllum africanum.

africana, Thunb. Prod. P1. Cap. $49=$ capensis.

angustifolia, Forsk. Fi. Aegypt. Arab. Suppl. 206.Arabia.

Anthriscus, Huds. Fl. Angl. 99.-Europ.

arvensis, Huds. l. c. 98.-Europ.; As. temp.

aspera, Lam. Fl. Fr. iii. $424=$ C. Anthriscus.

aspersa, Savi, Fl. Pis. i. $290=$ arvensis.

bifrons, Coss. Ev Dur. ex Ball, in Fourn. Linn. Soc. xvi. (1878) 478.-Algeria.

caerulescens, Boiss. Elench. 93. p. 53.-Hispan, ; Marocco.

canadensis, Crantz, Cl. Umb. Emend. $109=$ Sanicula canadensis.

capensis, Lam. Encyc, i。651.-Afr, austr.

capitata, Stokes, Bot. Mat. Med. ii. $64=$ Sanicula europaea.

carnosa, Roth, Tent. Fl. Germ. i. $119=$ Dancus Carota.

Carota, Huds. Fl. Angl. ed. II. $114=$ Daucus Carota. coniifolia, Wall, ex DC. Prod。iv. $220=\mathrm{C}$. Anthriscus.

\section{CAUCALIS :}

cretica, Salzm. ex Boiss. F1. Orient, ii. $1071=$ Daucus maritimus.

daucoides, Linn. Sp. Pl. 241.-Europ.; As. temp. Daucus, Crantz, Stirp. Austr. ed. I. fasc. iii. 125 ; ed. II. $227=$ Daucus Carota.

divaricata, Heller, Fl. Wirceb. ed. I. $169=$ arvensis.

elata, D. Don, Prod. Fl. Nep. $183=$ C. Anthriscus

elongata, Link, ex Steud. Nom. ed. I. $169=$ leptophylla.

erythrotricha, Boiss. Es Haussk. ex Boiss. Fl. Orient. ii. 1085.-Cilicia.

fallax, Boiss. E Balansa, ex Boiss. l. c. 1086.--Syria; Persia.

Gaillardoti, Boiss. l. c. 1085.-Syria.

Gerardi, Schwaegr, ex Steud. Nom. ed. I. 169.Europ.

Gingidium, Crantz, Cl. Umb. Emend. 113=Daucus Gingidium.

glabra, Forsk. Fl. Aegypt. Arab. $206=$ Daucus littoralis.

glochidiata, Poir. Encyc. Suppl. ii. $137=$ Daucus brachiatus.

grandiflora, Linn. Sp. Pl. 240.-Daucus grandiflorus.

helvetica, Jacq. Hort. Vindob. iii. 12. t. $16=$ arvensis.

heterophylla, Guss. Fl. Sic. Prod. i. 326.-Reg Mediterr.

hispanica, Crantz, Cl. Umb. Emend. $113=$ Daucus mauritanicus.

hispanica, Lam. Encyc. i. $658=$ Daucus Durieui.

hispida, Desf. Cat. Hort. Par, ed. III 205=Laserpitium hispidum.

humilis, Jacq. Hort. Vindob. ii. 92. t. $195=$ leptophylla.

humilis, Viv. ex Coss. in Bull. Soc. Bot. Fr. xii. (1865) $277=$ nodosa.

infesta, Curt. Fl Lond, ii fasc. vi. t. $23=$ arvensis,

infesta, Vest, Ench. 495; ex DC. Prod. iv. 219.Europ.

japonica, Houtt. Handleid. viii. 42.-Japon.

lappulacea, Poepp. ex DC. Prod. iv. $219=$ nodosa.

latifolia, Lam. FI. Fr. iii. $426=$ daucoides.

latifolia, Linn. Syst. Nat. ed. XII, ii. 205.-Europ.; As, temp.

leptophylla, Crantz, Stirp. Austr. ed. I. fasc. iii. 121; ed. II. $225=$ daucoides.

leptophylla, Linn. Sp. Pl. 242.-Europ.; Reg, Mediterr. Ind

leptophylla, Viv. Fl. Lib. Spec. $16=$ nodosa

linearifolia, Requien, ex DC. Prod. iv. 219.-Europ. austr.

littoralis, Bieb. F1. Taur, Cauc. i. $208=$ Daucus bessarabicus.

marilandica, Crantz, Cl. Umb. Emend, $110=$ Sanicula marilandica.

maritima, Gouan, Hort. Monsp. $135=$ Daucus maritimus.

mauritanica, Linn.Sp. Pl.241.-Afr. bor

melanantha, Benth. E Hook. f. Gen. i. 929-Afr. trop.

microcarpa, Hook. Ë Arn. Bot. Beech. Voy. 348.-. Calif.

muricata, Crantz, Cl. Umb. Emend. $114=$ daucoides. nodiflora, Lam. F1. Fr. iii. $424=$ nodosa.

nodosa, Scop. Fl. Carn. ed. II. i. 192-Europ.

orientalis, Linn. Sp. Pl. $241=$ Daucus pulcherrimus.

orientalis, Lour, Fl. Cochinch. $177=\mathrm{C}$. Anthriscus.

parviflora, Lam. Encyc. i. $657=$ leptophylla.

platycarpos, Linn. Sp. Pl, 241 = daucoides.

pulcherrima, Willd. Enum. Hort Berol. $303=$ Daucus

pulcherrimus.

pumila, Forsk. Fl. Aegypt. Arab. 206.-Arab.

pumila, Gouan, F1. Monsp. $285=$ Daucus pumilus.

pumila, Lam. Fl. Fr. iii. $425=$ leptophylla.

pumila, Linn. Syst. ed. X. $955=$ arvensis.

pumila, Willd. Sp. Pl. i. $1385=$ Daucus maritimus.

purpurea, Tenore, F1. Nap. t. $131=$ infesta.

Royeni, Crantz, Cl. Umb. Emend. $109=$ daucoides.

Sanicula, Crantz, Stirp. Austr. ed. I. fasc. iii. 125; ed. II. $228=$ Sanicula europaea

scandicina, Roth, Tent. Fl. Germ. i. $121=$ C. Anthriscus.

Scandix, Scop. F1. Carn.ed. II. i. $191=$ C. Anthriscus. segetalis, Stend. Nom. ed. II. i. $312=$ arvensis. segetum, Thuill. F1. Par. ed. II. $136=$ arvensis. siifolia, RoehI. ex Steud. Nom. ed. II. i. $312=$ Heracleum austriacum.
CAUCALIS :-

Stocksiana, Boiss. Diagn. Ser. II. vi. 89.-Persia; Beluchist.

strigosa, [Soland. in] Russell, Aleppo, ed. II. ii. 248. -Syria; Mesopotam.

tenella, Delile, Fl. Egypt, 202. t. 21. f. 3.-Syria; Persia; Aegypt.

tenerrima, Scheele, in Linnaea, xxy. (1852) $256=$ nodosa.

tenuifolia, Salisb. Prod. $161=$ daucoides.

trichosperma, Delile, in Steud. Nom. ed. II. i. 312.Syria.

tuberculata, Poir. Encyc. Suppl. ii. 137=Pimpinella peregrina.

virgata, Poir. Voy. Barb. ii. 133=Daucus laserpitioides.

xanthotricha, Stev. in Bull. Soc. Nat. Mosc. xxix. (1856) II, $353=$ leptophylla.

CAUCANTHUS, Forsk. F1. Aegypt. Arab. 91 (1775). $M A L P I G H I A C E A E$ ?

arabicus, Lam. Encyc. i. 658.-Arabia

Forskahlei, Raeusch. Nom. ed. III. 132=arabicus.

platanifolia, Rafin. Sylva Tellur. $72=$ Sterculia platani folia.

CAULANTHUS, S. Wats. Bot. King, Exped. 19, 27 (1871). CRUCIFERAE.

amplexicaulis, S. Wats. in Proc. Am. Acad. xvii. (188182 ) 364 -Calif.

Coulteri, S. Wats. in Bot. King, Exped. 27.-Calif. crassicaulis, $S$. Wats, $l$. $c$-Calif

glancus, S. Wats. in Proc. Am. Acad. xvii. (1881-82) 364.-Calif.

hastatus, S. Wats. in Bot. King, Exped. 28. t. 3.Am. bor. occ.

inflatus, S. Wats. in Proc. Am. Acad. xvii. (1881-82) 364.-Calif.

pilosus, S. Wats. in Bot. King, Exped. 27.-Calif. procerus, S. Wats. l. c.-Calif.

CAULARTHRON, Rafin. Fl. Tellur. ii. $40(1836)=$ Fpidendrum, Linn. (Orchid.).

bicornutum, Rafin. 1. c. $41=$ Diacrium bicornutum. umbellatum, Rafin. 1. c. = E. umbellatum.

CAULINIA, DC. F1. Fr. iii. 156 (1805)=Posidonia Koen. (Naiad.).

antarctica, R. Br. Prod. $339=$ Cymodocea antarctica. australiana, F. Muell. Fragm. vi. 198.-Austral. oceanica, R. Br. Prod. $339=$ Posidonia australis. oceanica, DC. Bot. Gall. iii. $156=$ Posidonia Caulini. ovalis, R. Br. 1. c. $339=$ Halophila ovata. provepens, F. Mnell. Fragm. vii. 225. - Austral. serrulata, R. Br. Prod. $339=$ Cymodocea serrulata. spinulosa, R. Br. 1. c. = Halophila spinulosa.

CAULINIA, Moench, Meth. Suppl. 47 (1802) = Kennedya, Vent, (Legumin.).

Beckxiana, F. Muell. Fragm. xi. $98=$ K. Beckxiana. rubicunda, Moench, Meth. Suppl. $47=\mathrm{K}$. rubicunda.

CAULINIA, Willd. in Mém. Acad. Berl. (1798) $87=$ Najas, Linn.

alagnensis, Pollini, F1. Veron. iii. $49=\mathrm{N}$. alagnensis. alternifolia, Willd. ex Cham. in Linnaea, iv. (1829) $501=\mathrm{N}$. indica.

composita, Buch.-Ham in Wall. Cat. n.5184.-Ind. or flexilis, Willd. in Mém. Acad. Berl. (1798) 89. t. i. f. $\mathbf{1}=\mathrm{N}$. flexilis.

fragitis, Willd. 1 . c. $87=\mathrm{N}$. fragilis

guadalupensis, Spreng. Syst. i. $20=N$. tenuifolia.

indica, Willd. in Mém. Acad. Berl. (1798) $89=\mathrm{N}$. indica.

intermedia, Balb. \& Nocca, Fl. Tic. $11.163=\mathrm{N}$. alagnensis.

microphylla, Balb. \& Nocca, 1. c. $=$ N. graminea.

minor, Coss. \& Germ. Fl. Paris, $575=\mathrm{N}$. muricata

pectinata, Parl. Fl. Ital iii. 665.--Ttalia.

tenella, Nees, in Neuwied, Reise Bras, ii. $345=\mathrm{N}$. tenera.

CAULlinIA, Rafin. in Med. Repos. N. York, v. (1808)

$352=$ Hippuris, Linn. (Halorag.)

hippuroides, Rafin. 1. c. $=H$. vulgaris.

CAULOBRYON, Klotzsch, ex C. DC. in DC. Prod. xvi I. $240(1869)=$ Piper, Linn. 
CAULOPHYLLUIM, Michx, F1, Bor. Am. i. 204. t 21 (1803). BERBERIDEAE, Benth. \& Hook. f. 43 .

Phtheirotheca, Maxim. ex Regel, in Bull. Phys. Math. Acad. Pétersb. xv. (1857) 228.

gracile, Dougl. ex Hook. Fl. Bor. Am. i. $30=$ Vancouveria hexandra.

robustum, Maxim. Prim. Fl.Amur. 33.-Manchuria. thalictroides, Michx. Fl. Bor. Am. i. 205.-Am. bor.

thalictroides, Regel, in Bull. Phys.-Math. Acad.

Pétersb. xv. (1857) $223=$ robustum.

CAULOPSIS, Fourr. in Ann, Soc. Linn. Lyon, N. S. xvi (1868) $332=$ Arabis, L nn. (Crucif.).

alpina, Fourr. 1. c. = A. brassicaeformis.

CAULOTRETUS, Rich. ex Spreng. Syst. iv. Cur. Post. $406(1827)$ = Bauhinia, Linn. (Legumin.).

cordifotius, Rich. ex DC. Prod. ii. $517=$ B. Richardiana eriophorus, Tenore, in Rendic. Soc. Borb. Neap. i. (1842) $410=$ B. eriophora.

smilacinus, Schott, ex Spreng. Syst. iv. Cur. Post. 406 $=$ B. smilacina

CAULOTULIS, Rafin. Fl. Tellux. iv. 76 (1836) = Ipomoea, Linn. (Convolv.)

CAUSONIA; Rafin. Sylva Tellur. $87(1838)=$ seq.

CAUSONIS, Rafin. Med. Fl. ii. 122 $(1830)=$ Vitis Linn. (Ampelid.)

japonica, Rafin. 1. $\mathrm{c}_{\mathrm{n}}=\mathrm{V}$. japonica.

trifolia, Rafin. 1. c. = $=\mathrm{V}$. trifolia

CAUSTIS, R. Br. Pro'. 239 (1810). CYPERACEAE Benth. \& Hook. fo rii. 1067.

Eurostorhiza, Steud. Syd. P1. Cyp. 265 (1855).

dioica, R. Br.l.c.-Austral.

flexuosa, $R . B r . l_{0} c_{0}-$ Anstral

hexandra, Nees, in Lehm. Pl. Preiss, ii. $88=$ dioica pentandra, R. Br. Prod. 239-Austral.

recurvata, Spreng. Syst. iv. Cur. Post. 26.-Austral

restiacea, F. Muell. ex Benth. Fl. Austral. vii. 421.Austral.

Sieberi, Kunth, Enum. Pl. ii. $307=$ Gahnia Sieberi.

CAUTLEA, Royle, Illustr. Bot. Himal. 361 (1839)= Roscoea, Sm. (Scitam.).

lutea, Royle, 1. c. = R. lutea.

CAVALAM, Adans. Fam. ii. $357(1763)=$ Sterculia Linn.

CAVALLIUM, Schott, Melet. $33(1832)=$ Sterculia, Linn. comosum, Schott \& Endl. 1. c. = S. comosa. urens, Schott \& Endl. 1. c. $=\mathrm{S}$. urens.

CAVANALIA, Griseb. Cat. PI. Cub. 76 (1864), sphalm. = Canavalia.

CAVANILLA, J. F. Gmel. Syst. 1037 (1791) = Dombeya, Cav. (Sterculiac.).

acerifolia, J. F. Gmel. 1. c $=$ Pterospermum acerifolinm. acutangul $a, \mathrm{~J}$. F. Gmel. 1, $\mathrm{c}_{0}=\mathrm{D}$. acutangula. angulata, J. F. Gmel. 1. c. = D. acutangula decanthera, J. F. Gmel. 1. c. = Trochetia decanthera. ferruginea, J. F. Gmel. 1. c. $1088=$ D. ferruginea. ovata, J. F. Gmel. 1. c. $=$ D. ovata

palmata, J. F. Gmel. I. c. $1037=$ D. acutangula. phoenicea, J. F. Gmel. 1. c. $1038=$ Pentapetes phoenicea. punctata, J. F. Gmel. 1. c. $1037=$ D. punctata. tiliaefolia, J. F. Gmel. 1. c. =D. acutangula. tomentosa, J. F. Gmel. 1. c. = D. tomentosa. umbellata, J. F. Gmel. 1. $\mathrm{c}=\mathrm{D}=\mathrm{D}$. umbellata.

CAVANILLA, Salisb. Prod. 385 (1796) = Stuartia Linn. (Ternstroem.)

florida, Salisb. 1. c. $=$ S. Malachodendron.

CAVANILLA, Thunb. Nov, Gen, $105(1795)=$ Pyrenacantha, Hook. (Olacin.)

scandens, Thun b. 1. $\mathrm{c}_{\mathrm{s}}=\mathrm{P}$. scandens

CAVANILLA, Vell. F1. Flum. 226 (1825); v. t. 102 (1827) = Caperonia, St. Hil. (Enphorbiac.).

spinosa, Vell. 11. cc, = Caper. Velloziana.
CAVANTLLEA, Desr. in Lam. Encyc. iii. 663 (1789) = Diospyros, Linn. (Ebenac.)

philippinensis, Desr. 1. c. = D. Embryopteris

Mabolo, Hiern, Ebenac. $260=$ D. discolor.

CAVANILLEA, Medic. Malv. 19 (1787)=Anoda, Cav, (Malvac.)

hastata, Medic. 1. c. = A, hastata.

CAVANILLESIA, Ruiz \& Pav. Prod. 97, t. 20 (1794) MALVACEAE, Benth. \& Hook. f. i. 211 PourReTIA, Willd. Sp. Pl. iii. 844 (1801) cordata, Spreng. Syst. iii. 125.-Peruv.

platanifolia, H. B. E K. Nov. Gen. et Sp. v. 306.Panama.

tuberculata, Kostel. Allg. Med. Pharm, Fl. v. $1872=$ platanifolia?

umbellata, Ruiz E Pav. Syst. Veg. 166.-Peruv.

CAVARIA, Steud. Nom. ed. I. 169 (1821), sphalm. ?= Tovaria, Ruiz \& Pav. (Capparid.)

CAVENDISHIA, Lindl, Bot, Reg sub t, 1791 (1836). VACCINIACEAE, Benth. \& Hook. fo ii 570 .

Polybaea, Klotzsch, in Linnaea, xxiv. (1851) 30

Proelesia, Klotzsch, 1. c. 32.

Socratesia, Klotzsch, 1. c. 22

acuminata, Benth. ex Hemsl. Biol. Centr. Am. Bot. ii. 272.-Mexic

complectens, Hemsl. l. c.-Costa Rica.

crassifolia, Hemsl. l. c. 273.--Mexic.

Endresii, Hemsl. l. c.-Costa Rica.

latifolia, Hemsl. l. c.-Mexic.

laurifolia, Benth. E Hook. f. Gen. ii. 570.-Guatemala.

melastomoides, Bènth. E Hook. f. ex Hemsl. Biol. Centr. Am. Bot. ii. 273.-Costa Rica.

nobilis, Lindl. Bot. Reg. sub t. 1791.-Am. austr.

pubescens, Hemsl. Biol. Centr. Am. Bot. ii. 273.Panama.

Querema, Benth. Eo Hook. f. Gen, ii. 570.N. Granat. tarapotana, Benth. Eo Hook.f. l. c.-Bras.

veraguensis, Hemsl. Biol. Centr. Am. Bot. ii. 273,Panama.

Warscewiczii, Hemsl.l.c.274.-Guatemala.

CAVINIUM, Thou. Gen. Nov, Madag. $11(1806)=$ Vaccinium, Linn.

madagascariense, Thou, ex Poir, in Dict. Sc. Nat, vii. $310=$ Agapetes madagascariensis

CAVOLINIA, Rafin. in Am. Monthly Mag. (1818) $175=$ CAULINIA, Willd.= Najas, Linn

CAYAPONIA, Silva Manso, Enum. Subst. Brazil. 31 (1836). CUCURBITACEAE.

Allagosperma, M. Roem. Syn. Pepon. 15 (1846)

AnTAgonIA, Griseb. Pl. Lorentz. 144 (1874).

Alternasemina, Silva Manso, Cathart. Bras (1836).

Cionandra, Griseb. Fl. Brit. W. Ind. 286 (1860)

Dermophylda, Silva Manso, Enum. Subst. Brazil. $30(1836)$.

Druparia, Silva Manso, 1. c. 35 (1836)

Perianthopodus, Silya Manso, 1. c. 28 (1836)

Trianosperma, Mart. Syst. Mat. Med, Brazil. 79 (1843).

alata, $\operatorname{Cog} n$. in DC. Monog. Phan. iii. 746.-Yucatan. amazonica, $\operatorname{Cog} n$. . . c. 797.-Bras.

americana, $\operatorname{Cogn}$. l. c. 785,-Am. cent.

Andreana, Cogn. in Bull. Acad. Belg. Sér. II. xlix. (1880) 195.-Ecuador.

angustiloba, $\operatorname{Cogn}$. in DC. Monog. Phan. iii. 771.Bras.

attenuata, Cogn.l. c. 769.-Mexic.

Bonplandii, $\operatorname{Cog} n$. l. c. 796 .-Bras.

Boykinii, $\operatorname{Cog} n$. l. c. 766.-Am. bor.

Buraeavi, Cogn. L c. 790.-N. Granat.

Cabocla, Mart. Syst. Mat. Med. Veg. Bras. $81=$ globosa.

calycina, Cogn. in Mart. Fl. Bras. vi. 1v. 78.-Bras. citrulliolin, $\operatorname{Cogn}$. ex Griseb. in Goett. $A b b_{2}$ xxiv.

(1879) 135.-Reg. Argent.

coccinea, André, ex Cogn, in Bull. Acad. Belg. Sér. II. xlix. (1850) $196=$ micrantha.

cordifolia, Cogn. in Mart. Fl. Bras. vi. Iv. 77. t. 21.Bras.

coriacea, $\operatorname{Cog} n$. b.c. 79. t. 22,-Bras

\section{CAXAPONIA}

Crugeri, Cogn. in DC. Monog. Phan. iii. 778.-Ins, Trinit.

diffusa, Silva Manso, Enum. Subst. Brazil. 32.Bras.

diversifolia, Cogn. in DC. Monog, Phan. iii. 787.Bras.

elliptica, Silva Manso, Enum. Subst. Brazil. 32.Bras.

Espelina, Cogn. in DC. Monog. Phan. iii. 792.Bras.

excisa, Cogn.l.c. 747.-Cuba.

ficifolia, $\operatorname{Cog} n . l_{0} c_{0} 782$.-Bras.

floribunda, $\operatorname{Cog} n$. i. c. 779.-Bras.

fluminensis, Cogn. in Mart. Fl. Bras. vi. IV. 76.Bras.

glandulosa, Cogn. in DC. Monog. Phan. iii. 755.Peruy.

Glaziovii, Cogn in Mart. Fl. Bras, vi. Iv, 74 -Bras.

globosa, Silva Manso, Enum. Subst. Brazil. 32.Bras.

gracillima, Cogn. in DC. Monog. Phan. iii. 784.Bras.

granatensis, Cogn. l. c. 794.-N. Granat.

grandiflora, Cogn. l. c. 779.-Xucatan

heterophylla, Cogn. l. c. 758.-N. Granat.

hirsuta, Cogn. in Mart. Fl. Bras. vi. IV. 76.-Bras.

latebrosa, Cogn. in DC. Monog. Phan. iii. 776.-Ins. Canar.

latifolia, $\operatorname{Cogn}$. l. c. 752.-Paraguay.

Lhotzkyana, Cogn. l. c. 765.-Bras.

longifolia, Cogn. L. c. 796.-Bras.

Martiana, Cogn.l. c. 777.-Bras

Maximowiczii, $\operatorname{Cog} n$.2. c. 745.-Mexic.

micrantha, Cogn. in Bull. Acad. Belg. Sér. II. xlix. (1880) 196.-N Granat.

Ottoniana, Cogn. in DC. Monog. Phan. iii. 755.

Venezuela.

ovata, Cogn. l. c. 754.--N. Granat.

palmata, Cogn. in Bull. Soc. Bot. Belg. xvii. (1878 295.-Bras.

pedata, Cogn. in Mart. Fl. Bras. vi. Iv. 80, t. 23.Bras.

pentaphylla, Cogn. in DC. Monog. Phan. iii. 760.Bras.

peruviana, Cogn.l.c. 795.-Peruv.

petiolulata, Cogn. in Bull. Soc. Bot. Belg. xvii. (16:95.-Bras.

piauhiensis, Cogn. in DC. Monog. Phan. iii. 750.Bras.

pilosa, Cogn. in Mart. Fl. Bras. vi. IV. $75=$ diffusa.

podantha, Cogn. in DC. Monog. Phan. iii. 753.-

Paraguay.

Poeppigii, $\operatorname{Cogn}$. l.c. 756.-Peruy.

racemosa, Cogn. l. c. 768.-Porto Rico.

rigida, $\operatorname{Cog}$ n. l. c. 790.-Guiana.

Ruizii, $\operatorname{Cog} n$. l. c. 794.-Peruy.

Sandia, $\operatorname{Cog} n$. ex Griseb. in Goett. Abh. xxiv. (1879 135.- - Reg. Argent.

setulosa, Cogn, in DC. Monog. Phan, iii. 767.-Bras.

simplicifolia, $\operatorname{Cog} n$. . . c. $774 .-\mathrm{N}$. Granat.

Tayuya, Cogn.l. c. $772 .-$ Bras.

terata, $\operatorname{Cog} n$ in Mart. Fl. Bras. vi. IV. 79.-Bras

Tibiricae, Cogn. in DC. Monog. Phan. iii. 784.Bras.

tomentosa, Cogn.l. c. 747-Peruy.

triangularis, Cogn.l.c. 774 -Guiana.

trifoliolata, Cogn. l. c. 789.-Bras.

trilobata, Cognel. c. 7s0.-Bras.

tubulosa, Cogn. in Mart. Fl. Bras. vi. Iv. $78 .-$ Bras

villosissima, $\operatorname{Cog} n$. l. c. 81. t. 2t.-Bm.

Weddellii, Cogn. in DC. Moneg. Phan. iii. 798.Iras.

CAYLUSEA, A. St. Hil. 2mo Mém. Resed. 29 is $18{ }^{-}$ RESEDACEAE. Benth. \& IIook. f. i. 111 STYLEX1A, Ratio, Fl. Tellur, iv, 1.21 (1530) Sritrophe, G. Ehrenb. ex Mucll. Arg. in Sicue Denks. Schw, Ges. Zuerich, xiv, 1 1 -5s 2.2.

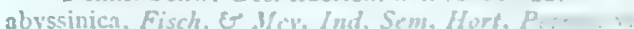
(1840) $\$ 3$ - Abrss.

canescens. A. S\%. Hill 2an Mím. Resed. 29.-Afr. bor. Arabia.

Monuiniann, Webb, Frasm. Fl. Actiaks. DS,-Afr bor.

CAIRATIA. Juse ex Cuill, in Dict. Class llist. Nat. it \$f6 (1S:S)-Vitis, Linn. (Ampelid,' (V. pedata. 
CसANOTHUS, Linn. in Act. Soc. Sc. Upsal. 77 (1741). RHAMNEAE, Benth. \& Hook. f. i. 378 Forrestia, Rafin. in Med. Repos. N. York, II. iii. (1806) 422.

africanus, Linn. Sp. Pl. $196=$ Noltea africana

Alamani, DC. Prod. ii. $31=$ Colubrina Alamani.

americanus, Linn. Sp. Pl. 195-Am. bor.

americanus, Mill. Ic. t. $86=$ Milleri.

arborescens, Mill. Gard. Dict. ed. VIII. n. $3=$ Colu brina ferruginosa?

asiaticus, Linn. Sp. Pl. $196=$ Colubrina asiatica. atropurpureus, Rafin. New Fl. Am. iii. $56=$ Nolteae sp. axillaris, Carr. in Rev. Hortic. (1876) $87=$ azureus? azurens, Desf. Tabl. ed. II. 232.-Mexic.

azureus, Kellogg, in Proc. Calif. Acad. i. (1855) $55=$ hirsutus.

Baumannianus, Spach, Hist. Vég. Phan. ii. $460=$ ovatus.

Bertini, Carr. in Rev. Hortic. (1872) $440=$ azureus bicolor, Willd. in Schult. f. Syst, vii. $65=$ hirsutus. Burmannianus, Steud. Nom. ed. II. i. 313, sphalm.= Baumannianus

buxifolius, Willd. ex Schult. f. Syst. vii. 62,-Mexic. caeruleus, Lag. Gen et Sp. Nov. 11.-Mexic.

californicus, Kellogg, in Proc. Calif. Acad. i. (1855 $55=$ integerrimus.

capensis, DC. Prod. ii. $30=$ Scutia Commersonii. capsularis, Forst. f. Prod. $18=$ Colubrina asiatica. celtidifolius, Cham. \& Schlecht. in Linnaea, v. (1830) $602=$ Colubrina celtidifolia .

Chloroxylon, Nees, Syst. Laurin. 660.-Jamaica.

circumscissus, Gaertn. Fruct. ii. 110. t. $106=$ Scutia Commersonii.

collinus, Dougl. ex Knight \& West. Fl. Cab. i. t. $13=$ sorediatus?

colubrinus, Lam. Tabl. Encyc. ii. $90=$ Colubrina ferruginosa.

cordulatus, Kellogg, in Proc. Calif. Acad. ii. (1863) 124. f. 39.-Calif.

crassifolius, Torr. in Pacif. Rail. Rep. iv. 75.Calif.

cubensis, Lam. Tabl. Encyc. ii. 90.-Ind. occ.

cuneatus, A. Gray, in Ives, Rep. Color. Riv. $9=$ Greggii

cuneatus, Nutt. in Torr. E Gray, Fl. N. Am. i. 267.Calif.

decumbens, Hort. ex Steud. Nom. ed. II. i. $313=$ americanus.

decumbens, S. Wats. in Proc. Am. Acad. x. (1875) 335 -Calif.

Delilianus, Spach, Hist. Vég. Phan. ii. 459.-Hab. ? dentatus, Torr. E Gray, Fl N.Am. i. 268.-Calif. depressus, Benth. Pl. Hartw. 8.-Mexic.

Dillenianus, Hort. ex C. Koch, Dendrol. i. $620=$ americanus.

discolor, Vent. Jard. Malm. 58=Pomaderris elliptica. divaricatus, Boland. Cat. Pl. Calif. $8=$ cordulatus. divaricatus, Nutt. in Torr. E Gray, Fl. N. Am. i. 266 -Calif.

diversifolius, Kellogg, in Proc. Calif. Aead. i. (1855) $57=$ decumbens.

elegans, Lem. Illustr. Hortic. vii. (1860) t. $268=$ thyrsiflorus.

ellipticus, Rafin. New Fl. Am. iii. 56.-Am. bor.

elongatus, Salisb. Prod. $140=$ Noltea africana

Fendleri, A. Gray, Pl. Fendl. 29.-Am. bor. occ.

ferreus, DC. Prod. ii. $30=$ Scutia ferrea.

ferrugineus, Wendl. ex Steud. Nom. ed. II. i. $313=$ Pomaderris lanigera.

floribundus, Hook. Bot. Mag. t. 4806.-Calif

Fontanesianus; Spach, Hist. Vég. Phan. ii. $460=$ ovatus.

glaber, Spach, l. c. 459.-Am. bor

glandulosus, Rafin. New Fl. Am. iii. $57=$ ovatus.

glandulosus, Schlecht. in Linnaea, xv. (1841) 474. Mexic.

globulosus, Labill. Nov. Holl P1. i.61. t. $85=$ Spyridium globulosum.

glomeratus, Rafin. New Fl. Am. iii. $55=$ americanus.

grandis, Dougl. ex Hook. F1. Bor. Am. i. $125=$ velutinus.

granulosus, Ruiz E Pav. Fl. Per. iii. 5. t. 228.-Peruy Greggii, A. Gray, Pl. Wright. ii. 28.-Arizona.

Guadalupae, Steud. Nom. ed. II. i. $313=$ laevigatus.

guineensis, DC. Prod. ii. $30=$ Chailletia toxicaria?

Hartwegii, Hook. ex Heynh. Nom. ii. 128, nomen. Mexic.

herbaceus, Rafin. in Med. Repos. N. York, v. (1808) $360=$ americanus

\section{CEANOTHUS :}

hirsutus, Nutt. in Torr. E Gray, Fl. N.Am. i. 266.Calif.

hybridus, Hort. ex C. Koch, Dendrol. i. $620=$ ameri cantus.

hypericoides, L'Hérit. ex DC. Prod. ii. $32=$ microphyllus.

incanus, Torr. \& Gray, F1. N. Am. i. 265.-Calif

infestus, H. B. \& K. Nov. Gen. et Sp. vii. 61 = Adol phia infesta.

integerrimus, Hook. Eo Arn. Bot. Beech. Voy. 329.Am. bor. occ.

intermedius, Hook. Fl. Bor. Am. i. $124=$ ovatus. intermedius, Pursh, F1. Am. Sept. i. $167=$ americanus. laevigatus, $D C$. Prod. ii. $30 .-$ Ind. occ.

laevigatus, Hook. FI. Bor. Am. i. $125=$ velutinus lancifolius, Moench, Meth. $651=$ Noltea africana. laniger, Andr. Bot. Rep. t. $569=$ Pomaderris lanigera.

latifolius, Rafin. New F\%. Am. iii. 55.-Am. bor.

Leschenaultii, DC. Prod. ii. 31.-Zeylan.

levigatus, Rafin. New Fl. Am. iii. $55=$ americanus.

Lobbianus, Hook. Bot. Mag. t. $4810=$ dentatus.

macrocarpus, Cav. Ic. iii. 38, t. 270.-Mexic

macrocarpus, Hort. ex Steud. Nom. ed. II. i. $313=$ americanus.

macrocarpus, Moc. \& Sesse, ex DC. Prod. ii. 32, $33=$ Mocinianus.

macrocarpus, Nutt. in Torr. \& Gray, F1. N. Am. i. $267=$ cuneatus.

macrophyllus, Desf. Tabl. ed. JI. $232=$ americanus. megacarpus, Nutt Sylv, Am. ii, $46=$ cuneatus. microphyllus, Michx. Fl. Bor. Am. i. 154.-Am. bor. Milleri, Tausch, in Flora, xxi. (1838) I. Beibl.79.Am. bor.

Mocinianus, DC. Prod. ii. 32.--Mexic.

mystacinus, DC. 1. c. $31=$ Helinus scandens.

napalensis, Wall in Roxb, F1. Ind ed, Carey, ii. 375 = Rhamnus nipalensis.

Neumanni, Tausch, in Flora, xxi. (1838) 738.-Am, bor.

nevadensis, Kellogg, in Proc. Calif. Acad. ii. (1863) 152 = integerrimus.

nitidus, Torr in Pacif. Rail. Rep. iv. $75=$ sorediatus. officinalis, Rafin. Med. Fl. ii. $205=$ americanus.

oliganthus, Nutt. in Tort. \& Gray, Fl. N. Am. i. 266 $=$ hirsutus.

oreganus, Nutt. 1. c. $265=$ sangnineus.

ovalifolius, Wender, in Schr. Naturf. Ges. Marb. ii. (1830) 247.-Am. bor.

ovalis, Bigel. Fl. Bost. ed. II. $92=$ ovatus

ovatus, Desf. Arb. ii. 381.-Am. bor.

ovatus, Hort. ex Lindl. Bot. Reg. (1840) t. $20=\mathrm{seg}$

pallidus, Lindl. l. c.-Hab?

paniculatus, Roth, Nov. Pl. Sp. $154=$ Celastrus paniculata.

papillosus, Torr. E' Gray, Fl. N. Am. i. 268.-Calif.

pauciflorus, Mo६. E Sesse, ex DC. Prod. ii. 33. Mexic.

perennis, Pursh, Fl Am. Sept. i. 167=americanus.

Pitcheri, Pickering, ex Torr. \& Gray, Fl. N. Am. i. 264 =americanus.

procumbens, Hort. ex C. Koch, Dendrol. i. $619=$ americanus.

prostratus, Benth. Pl. Hartw. 302.-Calif

pubescens, Ruiz E Pav. Fl. Per, iii. 6. t. 228.-Peruv. pubiflorus, DC Prod ii. $30=$ Zizyphus pubiflorus.

pulchellus, Delile, ex Spach, Hist. Vég. Phan. ii. $459=$

Delilianus.

reclinatus, Bosc, ex Steud. Nom. ed. II. i. $313=$ americanus.

reclinatus, L'Hérit. Sert. Angl. 6.-Ind. occ.

rigidus, Nutt. in Torr. हु Gray, Fl. N. Am. i. 268.Calif.

sanguineus, Pursh, Fl. Am. Sept. i. 167.-Am. bor. occ.

sanguineus, Nutt. Gen. Am. i. $153=$ americanus.

Sarcomphalus, DC. Prod. ii. $30=$ Sarcomphalus lau. rinus.

scandens, D. Dietr. Syn. Pl, i. $812=$ Noltea africana. serpyllifolius, Nutt. Gen. Am. i. 154.-Florida. sorediatus, Hook. E" Arn. Bot. Beech. Voy. 328. Calif.

spathulatus, Tabill. Nov. Holl. P1. i. 60. t. $84=$ Trymalium Billardieri.

sphaerocarpus, DC. Prod, ii. $30=$ Rhamnus sphaerospermus.

spinosus, Nutt. in Torr. E Gray, Fl. N. Am. i. 267.Calif.

\section{CWANOTHUS}

tardiflorus, Hornem. Hort. Hafn. i. $230=$ americanus. thyrsiflorus, Eschw. in Mém. Acad. Pétersb. Sér. VI x. (1826) 285.-Calif.

triflorus, Steud. Nom. ed.II. i. $313=$ Colubrina triflora trinerous, Moench, Meth, $651=$ americanus.

triqueter, Wall, in Roxb. Fl. Ind, ed. Carey, ii. $376=$

Rhamnus triqueter

Veitchianus, Hook. Bot. Mag. t. 5127.-Calif

velutinus, Dougl. in Hook. Fl. Bor. Am. i. 125. t. 45 -Am. bor. occ.

verrucosus, Nutt, in Torr. \& Gray, F1. N. Am. i. 267 cuneatus.

virgatus, Rafin. New Fl. Am. iii. 56=americanus,

Wendlandianus, Roem. \& Schult. Syst.v. $299=$ Poma derris ferruginea.

Wightianus, Wall. Cat. n. $4264=$ Rhamnus Wightii.

zeylanicus, Heyne, in Roth, Nov. Pl. Sp. $153=$ Scutia Commersonii.

CEARIA, Dum. Comm. Bot. 65 in adnot. (1822)= Eurycles, Salisb. (Amaryllid.).

amboinensis, Dum. 1. c. $=\mathbf{E}$. sylvestris

CEBATHA, Forsk. Fl. Aegypt. Arab. $171(1775)=$ Cocculus, DC. (Menisperm.) (C. Cebatha).

CECICODAPHNE, Nees, in Wall. Pl. As. Rar. ii. 70 (1831) = Cinnamomum, Blume (Laurin.).

glaucescens, Nees, $1 . \mathrm{c} .=$ Cinnam. Cecicodaphne.

CECROPIA, Linn. in Loefl. It. 272 (1758). URTICA $C E A E$, Benth. \& Hook. f. iii. 378

Ambaiba, Adans. Fam. ii. 377 (1763)

acutifolia, Tréc. in Ann. Sc. Nat. Sér. III. viii. (1847)

81.-Peruv.

adenopus, Mart. ex Miq. in Mart. Fl. Bras. iv. I. 147 -Am. trop.

albicans, Tréc. in Ann. Sc. Nat. Sér. III. viii. (1847) 82.- Peruy.

angustifolia, Tréc. l. c. 83.-Peruw.

argentea, Visiani, Ort. Bot. Padov. 135.-Hab.

bicolor, Klotzsch, in Linnaea, xx. (1847) 531.Peruv.

carbonaria, Mart. ex Mig. in Mart. Fl. Bras. iv. I. 144.-Am. trop.

cinerea, Miq. l.c. 142.-Am. trop.

commutata, Schott, ex Miq. l. c. 148.-Am. trop.

concolor, Hort. Schoenbr. ex Miq. 1. c. = Schiedeana

concolor, Willd. Sp. Pl. iv. 652.-Bras.

cyrtostachya, Miq. in Mart. Fl. Bras. iv. I. 145.-Am trop.

dentata, Klotzsch, in Linnaea, xx. (1847) 533.Peruv.

digitata, Tenore, ex Miq. in Mart. Fl. Bras. iv, I. 149 -Bras.

digitata, Klotzsch, in Linnaea, xx. (1847) $534=$ angus tifolia.

flagellifera, Tréc. in Ann. Sc. Nat. Sér. III. viii. (1847) 81 = bicolor.

frigida, Dufresne, in Illustr. Hortic. xx. (1873) 70.Hab. ?

Goudotiana, Tréc. in Ann. Sc. Nat. Sér. III. viii. (1847) 83.-N. Granat.

hololenca, Miq. in Mart. Fl. Bras. iv. I. 148.-Am. trop.

Humboldtiana, Klotzsch, in Linnaea, xx. (1847) 530 -Am. trop.

insignis, Lieb̆m. in Vidensk. Selsk. Skr. V. ii. (1851) 318.-Nicaragua.

Klotzschiana, Miq. in Mart. Fl. Bras. iv. I. 151.-Am. trop.

latiloba, Miq. l. c. 147.-Am. trop

leucocoma, Miq. l. c. 142.-Am. trop

leucophaea, Poepp. ex Miq. l. c. 151-Am. trop.

lyratiloba, Miq. l. c. 144.-Am, tтop.

membranacea, Tréc. in Ann. Sc. Nat. Sér. III. viii. (1847) 83.-Ind. occ.

mexicana, Hemsl. Biol. Centr. Am. Bot. iii. 151.Mexic.

nivea, Poepp. ex Klotzsch, in Linnaea, xx. (1847) 532 -Peruy.

obtusa, Tréc. in Ann. Sc. Nat. Sér. III. viii. (1847) 79.-Bras.

obtusifolia, Bertol. Fl. Guatimal. 39.-Guatemala pachystachya, Tréc. in Ann. Sc. Nat. Sér. III. viii (1847) 80.-Bras.

palmata, Willd. Sp. Pl. iv. 652.-Bras, 
CECROPIA :-

panamensis, Hemsl. Biol. Centr. Am. Bot. iii. 151.Panama.

peltata, Linn. Pugill. Pl. Famaic. 28 (Amoen. Acad. v. 410).-Am, trop

peltata, G. F. W. Mey. Prim. Fl. Esseq. $280=$ surinamensis.

peltata, Ruiz, ex Klotzsch, in Linnaea, xx. (1847) 532 $=$ Ruiziana.

peltata, Schreb. ex Miq. in Mart. Fl. Bras. iv。 I. $150=$ Schreberiana.

peltata, Vell. Fl. Flum.x. t. 101=adenopus.

peltata, Willd. ex Klotzsch, in Linnaea, xx. (1847) $530=$ Humboldtiana.

pinnatiloba, Klotzsch, in Linnaea, xx. (1847) 533.Peruv.

polystachya, Tréc. in Ann. Sc. Nat. Sér. III. viii. (1847) $80=$ pinnatiloba.

propinqua, Miq. in Mart. Fl. Bras. iv. I. 149.-Am.

trop.
Ruiziana, Klotzsch, in Linnaea, xx. (1847) 532.Peruy,

scabra, Mart. in Flora, xxiv. (1841) II. Beibl.95,-Bras. scabra, Ruiz, ex Klotzsch, in Linnaea, xx. (1847) 531 $=$ Klotzschiana

Schiedeana, Klotzsch, l. c.-Mexic.

Schreberiana, Miq. in Mart. Fl. Bras. iv. I. 150.-Am. trop.

sciadophylla, Mart. in Flora, xxiv. (1841) II. Beibl. 93.- Bras.

strigosa, Tréc. in Ann. Sc. Nat. Sér. III. viii. (1847) 82.-Peruv

surinamensis, Miq. in Mart. Fl. Bras. iv. I. 143.-Am. trop.

tubulosa, Ruiz, ex Klotzsch, in Linnaea, xx. (1847) 534.-Pernv.

CEDRET,A, P. Br. Hist. Jamaic. 158 (1756), MELIACEAE, Benth. \& Hook. fo i. 339.

Cedrus, Mill, Gard. Dict. ed. VII (1759).

CuveracA, Jones, in As. Res. iv. (1795) 281.

Johnsonia, Adans. Fam. ii. 343 (1763)

Pterosiphon, Turcz. in Bull. Soc. Nat. Mosc. (1868) I. 589.

TOoNA, M. Roem. Syn. Hesper. 131 (1846).

adenophylla, Mart. ex C. DC. in DC. Monog. Phan。 i.

$738=$ paraguaiensis

alternifolia, Steud. Nom. ed, I. 170.-Honduras.

angustifolia, Mof. Eo Sesse, ex DC. Prod. i. 624.Mexic.

australis, F. Muell. Fragm. i. 4=C. Toona

bogotensis, Triana E Planch, in Ann. Sc. Nat. Sér.

V. xv, (1872) 377-N. Granat.

brasiliensis, Juss. in St. Hil. Fl. Bras. Mer. ii. $86=$ fissilis.

Cedro, Loefl. It. $183=$ odorata.

Dugesii, S. Wats, in Proc. Am. Acad. xviii. (1882-83 190.-Mexic.

febrifuga, Forsten, Diss. Cedrel. $16=$ C. Toona.

fissilis, Vell. Fl. Flum. 75 ; ii. t. 68 .- Bras,

glabra, C. DC. in DC. Monog. Phan. i. $742=$ C. Toona.

Glaziovii, C. DC. in Mart. Fl. Bras, xi. I, 224. t. 65 . 2.-Am. trop.

guianensis, A. Fuss. in Mém. Mus. Par. xix. (1830)

255.-Guiana.

hexandra, Wall. in Roxb. Fl. Ind. ed. Carey, ii. $425=$ C. Toona.

inodora, Hassk. Hort. Bogor. i. 131.-Java.

Kotschyi, Schweinf, Reliq. Kotsch. 36, t. 35.-Afr. trop.

longifolia, Wall. Cat. n. $1273=\mathrm{C}$. Toona.

Mahagoni, Linn. Syst. ed. X. $940=$ Swietenia Maha goni.

mexicana, M. Roem. Syn. Hesper, 187=Swietenia hamilis.

microcarpa, C. DC. in DC. Monog. Phan, i, $745=$ C. Toona.

montana, Turcz. in Bull. Soc. Nat. Mosc. (1858) 415. -Venezuela.

multijuga, Kurz, in Journ. As. Soc. Beng. xli. (1872) II. $297=\mathrm{C}$. Toona.

odorata, Bianco, Fl. Filip. cd. I. 184=C. Toona.

odorata, Cham. \& Schlecht. in Linnaea, vi. (1831) 422 $=$ Swietenia humilis.

odorata, Griseb. in Mem. Am. Acad. N. S. viii, (1860) $169=$ Glaziovii.

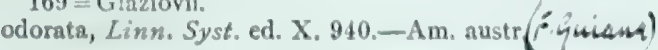

\section{CEDRELA}

odorata, Ruiz \& Pav, F1. Per, iii, $9=$ angastifolia. odorata, Vell. Fl. Flum. 74; ii. t. $67==$ Velloziana, paraguaiensis, Mart. in Flora, xx. (1837) Beibl. 93.Paraguay.

Rosmarinus, Lour. Fl. Cochinch, $160=$ Baeckia cochinchinensis.

serrata, Royle, Illustr. Bot. Himal. 144. t. $25=\mathrm{C}$ Toona.

serrulata, Miq. Fl. Ind. Bat: Supplo i. 508,-Sumatra. sinensis, fusso in Mém. Mus. Par, xix. (1830) 255. China

Teysmanni, Hassk. Hort. Bogor. i. 131.-Java

Toona, Roxb. ex Rottl. in Ges. Naturf. Fr. Neue Schr ii. (1803) 198.-Malaya; Austral.

Velloziana, M. Roem. Syn. Hesper. 137.-Am. trop.

velutina, DC. Prod, i. $625=$ Chickrassia taluularis.

villosa, Roxb. Hort. Beng. $18=$ Chickrassia tabularis

CEDRELLA, Scop. Introd. $324(1777)=$ Cedrela R. $\mathrm{Br}$.

CEDRONELLA, Riv. ex Rupp. Fl。 Jen, ed. Hall 225 (1745): Moench, Meth, 411 (1794). LABIATAE Benth. \& Hook. fo ii. 1200.

breviflora, A. Gray, in Proc. Am. Acad. xx. (1885) 309. - Arizona.

cana, Hook. Bot.Mag. t. 4618.-Mexic.

canariensis, Webb Es Berth. Phyt. Canar. iii. 87.-Ins. Canar.

cordata, Benth. Lab. Gen. et Sp. 502.-Am. bor. hastifolia, Regel, Ind. Sem. Hort. Petrop. (1868) $85=$ cana.

japonica, Hassk. in Verh. Natuurk.Ver. Ned. Ind. i. (1856) 36.-Japon.

mexicana, Benth. Lab. Gen. et Sp. 502,-Mexic

micrantha, A. Gray, in Proc. Am. Acad. viii. (1870) 369.-Am. bor. occ.

pallida, Lindl. Bot. Reg. (1846) t. 29.-Am. bor.

triphylla, Moench, Meth. 411.-Ins. Canar.

CEDROTA, Schreb. Gen. i. 259 (1789)=Ocotea, Anbl. (Laurin.).

guianensis, Blanco, Fl。Filip. ed. II. $213=$ Pisonia umbellifera.

guianensis, Raeusch. Nom. ed. III. $111=0$. commutata.

longifolia, Willd. Sp. Pl. ii. $338=$ O. commutata

CEDRUS, Mill. Gard, Dict. ed. VII $(1759)=$ Cedrela, Linn. (Meliac.)

alternifolia, Mill. 1. c. ed. VIII. no $3=$ Cedrela alternifolia.

Mahogani, Mill. 1. c. n. $2=$ Swietenia Mahagoni.

odorata, Mill. 1. c. n. $1=$ Cedrela odorata.

CEDRUS, [Tourn.] Mill. Gard. Dict. ed. III (1737) Loud. Arb. Brit. iv. 2402 (1838). CONIFERAE, Benth. \& Hook. f. iii. 439 .

africana, Gord, ex Knight, Syn. Conif, $42=$ Libani argentea, Hort. ex Carr. Conif. ed. I. $286=$ Libani. atlantica, Manetti, Cat. Hort. Madoet. Suppl. $8=$ Libani.

Deodara, Lond. Arbor. Brit. iv, $2428=$ Libani.

elegans, Knight, Syn. Conif. $42=$ Libani.

indica, Chambr. Trait. Prat. Arbr. Résin. Conif. 341 Libani.

Libani, Barrel. Ic. 499.-As. Min.; Syria; Affghan. Reg. Himal.; Alger

patula, C. Koch, Dendrol, ii. II. 268=Libani.

CEIBA, Medic Malv, 15 (1787); Gnertn. Fruct. ji. 244 t. $183(1791)=$ Eriodendron, DC. (Malvac,

Casearia, Medic. 1. c. $16=$ E. orientale.

pentandra, Gaertn. Fruct. ii. 244 . to $138=\mathrm{E}$ anfractuosum.

CELAENA, Wedd. Chlor. And. i. $230(1855)=$ Oligandra, Less, (Compos.).

pachymorpha, Wedd. 1. $\mathrm{c}=\mathrm{O}$. pachymorpha.

CELASINE, Pritz. Ic. Ind. 2st, sphalm, (1855)= Gelasine, Herb. (Irid.).
CELASTRUS, Linn. Gen. ed. I. 59 (1737). CELASTRINEAE, Bènth. \& Hook, f. i. 364 [365].

Catha, G. Don, Gen. Syst, ii. 11 (1832).

Guevinia, Hort. Par, ex Decoe, in Rev, Hortic. Sér. II. iv. (1845-46) 425

OrIXA, Thunb. Nov. Gen. 56 (1783); Fl。 Jap. 3 (1784)

Semarilla, Rafin. Sylva Tellur. 146 (1838).

acuminatus, Linn.f. Suppl. 154.-Afr. austr.

acuminatus, Rafin. New. Fl. Am. iii. 14.-Am. bor.

acuminatus, Wall. Cat. n. $4342=$ Chailletia gelo nioides

adenophylla, Miq. Ann. Mus. Bot. Lugd. Bat. ii. $85=$ Ilex crenata.

alatus, Thunb. Fl. Jap. $98=$ Evonymus Thanbergianus.

alnifolius, D. Don, Prod. Fl. Nep. $190=$ paniculatus. alpestris, Blume, Bijdr. 1145.-Java.

andongensis, Oliver, Fl。 Trop. Afr。 i. 361.-Afr trop.

angularis, Sond. in Harv. E Sond. Fl. Cap. i. 460.Afr. austr.

angulata, Maxim. in Bull. Acad. Pétersb. xxvii. (1881) 455.-China

aphyllus, Schlecht. in Linnaea, xv. (1841) 458.Mexic.

aquifolius, Regel, Ind.Sem. Hort. Petrop. (1856) 36.Hab. ?

arbutifolius, Hochst. ex A. Rich. Tent. Fl. Abyss. 133.-Abyss.

articulatus, Thunb. Fl. Fap. 97.-Japon.

Atkaio, A. Rich. Tent. Fl. Abyss. i. 132-Abyssin.

attenuatus, Wall, Cat. D. $4319=$ Gymnosporia neglecta.

auriculatus, Vitm. Summa, ii. 31, in syn.=articulatus.

australis, Harv. E F. Muell. in Trans. Phil. Soc. Vict. i. (1855) 41.-Austral.

barbarus, Linn. Mant. ii. 211, in obs. = Cassine barbara.

bilocularis, F. Muell, in Trans. Phil. Inst. Vict. iii (1859) 31.-Austral.

bivalvis, Jack, in Malay Misc, i. (1820) n. v. $19=$ Microtropis bivalvis.

Boaria, Baill. Hist. Pl. vi. $26=$ Maytenus chilensis.

bullatus, Hort. ex Steud. Nom. ed. II. i. $314=$

pyracanthus.

bullatus, Linn. Sp, Pl, $196=$ scandens.

buxifolia, Drège, ex Walp. Ann, i. 189 = Catha patens buxifolius, Linn. Sp.Pl. 197.-Afr, anstr.

buxifolius, Roxb. Hort. Beng. 18, nomen = Gymnosporia Wallichiana.

campestris, Eckl. \& Zeyh. Enum. $119=$ pyracanthus.

cantonensis, Hance, in Fourn. Bot. xxiii. (1885) 323 .

China.

capensis, Thunb. ex Steud. Nom. ed. II. i. $314=$ excisus.

capitatus, E. Mey. ex Sond. in Harv. E Sond. Fl. Cap. i. 458.-Afr, austr.

cassinifolius, Salisb. Prod. $141=$ lucidus.

cassinoides, L'Hérit. Sert. Angl. 6. t. $10=$ Gymnosporia cassinoide.

cernuus, Thunb. Prod. Pl. Cap. 42.-Afr. austr. Championi, Benth. in Hook. Kew Gourn. iii. (1551

334.-Ins, Hongkong.

ciliidens, Miq. Ann. Mus. Bot, Lugd, Bat。 ii. $85=$ flagellaris

collinus, Eckl. \& Zeyh. Enum. $119=$ undatus. Colpoon, Hort. ex Steud. Nom. ed. II. i. $315=$ pyracanthus.

concavus, Lam. Tabl. Encyc. ii, $98=$ lucidus.

confertus, Ruis Es Pav FT Per iii, T-Peruy.

cordatus, E. Mey. ex Sond. in Hart. E Sond. Fl. Cap 454.-Afr. austr.

coriacens, Guill. \& Perr. Fl. Seneg. Tent. i. 112= Grmnosporia montana, senegalensis.

corniculatus, L'Hirit. Sert. Angl. 8.-Afs. austr.

crassifolius, Salisb. Prod. 14] [assinoides

crenalus, Forst. f. Prod, 19-Ins. Marchion.

crenatus, Roth, Nov, PI. Sp. 150 = Gymnosporia montana

crenulatus, Wall. Car. n. 4303.-Siam.

crispulus, Regel, Gartrnff. (1S00() 107.-China.

crispus, Thunb, in IIoflm. Playtugz. Blacter, i. (ISin 3 23 - liviclea ovala

Cunninghamii, F. Murell, in Trans. Phil. Inst. l"ics. iii. (1:59) S0.-Austral.

gymaludes, Spreng. Syst. i. 775 - andatus. 


\section{CELASTRUS :}

cymosus, Eckl. \& Zeyh. Enum. 121 =heterophyllus. cymosus, Soland. in Bot. Mag. t. $2070=$ buxifolius. decolor, Delile, Voy. Méroë, 100.t. 64. f. $6=$ Gymno sporia montana, senegalensis.

dependens, Wall. Cat. 4302; et in Roxb. Fl. Ind. ed. Carey, i. $389=$ paniculatus.

diffusus, G. Don, Gen. Syst. ii. $6=$ Ventilago leiocarpa

dilatatus, Thunb. in Trans. Linn. Soc. ii. (1794) 332. -Japon.

dispermus, F. Muell. in Trans. Phil. Inst. Vict. ii. (1859) 31--Austral

dubius, Spreng. Syst. i. 774.-Ind. occ.

dumetorum, Eckl. \& Zeyh. Enum. $119=$ undatus.

edulis, Hochst. ex A. Rich. Tent. F1. Abyss. 1. 131 serratus.

edulis, Vahl, Symb. Bot. 1. $21=$ Catha edulis.

ellipticus, Thunb. in Hoffm. Phytogr. Blaetter, i. (1803)

22.-Afr. austr

emarginatus, Ruiz \& Pav. FI. Per. iii. $6=$ retusus.

emarginatus, Willd. Sp. Pl. i. $1128=$ Gymnosporia emarginata.

empleurifolius, Eckl. \& Zeyh. Enum. 121=buxifolins.

enonymifolius, Burm. f. Fl. Cap. Prod. 6.-Afr. austr.

enonymoides, Welw.ex Oliver, Fl. Trop. Afr. i. 362.Afr. trop.

europaeus, Boiss. Elench. $29=$ Gymnosporia montana excisus, Thunb. Fl. Cap. ii, 119.-Afr, austr.

filiformis, Linn. f. Suppl. 153 (=Mystroxylon filiforme).-Afr. austr.

Finlaysonianus, Wall. Cat. n. 4324.-Siam; China.

flagellaris, Rupr. in Bull. Phys.-Math. Acad. Pétersb. Xv. (1857) 357.-Reg. Amur.

flexuosus, Thunb. Fl. Cap. ii. 124.-Afr. austr.

floribundus, Span. in Linnaea, xv. (1841) 186.-

Hab. ?

Fournieri, Panch. E Sebert, Not. Bois Nouv. Caléd. 234.-N. Caled.

glaucus, R. Br. in Salt, Voy. Abyss. App. 64 Gymnosporia montana.

glaucus, Vahl, Symb. Bot. ii. $42=$ Elaeodendron glaucum.

glomeratus, E. Mey. ex Sond. in Harv. \& Sond. F1 Cap. i. $458=$ heterophyllus.

glomeratus, E. Mey. ex Walp. Rep. v. $401=$ patens goniocaulis, EckI. \& Zeyh. Enum. $120=$ buxifolins. gracilipes, Welw. ex Oliver, Fl. Trop. Afr. i. 361.Afr. trop.

Haenkea, Spreng. Syst. iv. Cur. Post. $88=$ Schoepfia flexuosa.

Hamelii, Spreng. Syst. i. $774=$ Rhamnus racemosus ?

heterophyllus, Eckl. E" Zeyh. Enum. 120.-Afr. austr

heterophyllus, E. Mey. ex Sond. in Harv. \& Sond. F1.

Cap. i. $467=$ Cassine latifolia

heterophyllus, Savi, in Mem. Torino, xxxviii. (1835) 173.-Hab. ?

Heyneana, Roth, in Roem. \& Schult. Syst. v. $421=$ Gymnosporia Heyneana.

Hindsii, Benth, in Hook. Kew Fourn. iii. (1851) $334=$ monospermus.

hispanicus, Hort. ex DC. Prod. ii. $8=$ multiflorus.

huillensis, Welw. ex Oliver, Fl. Trop. Afr. i. 364.Afr. trop.

humilis, Eckl. \& Zeyh. Enum. $120=$ buxifolius

ilicifolius, Schrad. in Goett. Gel. Anz. i. (1821) $716=$ Maytenus truncatus.

ilicinus, Burch. ex Loud. Hort. Brit. 83, nomen.Afr. austr.

ilicinus, Krauss. ex Sond. in Harv. \& Sond. F1. Cap. i. $457=$ procumbens.

inflexus, Zeyh. ex Sond. 1. c. $455=$ polyacanthus.

integer, Thunb. F1. Cap. ii. $123=$ pyracanthus.

integrifolius, Linn. f. Suppl. 153.-Afr. austr.

fackianus, Steud. Nom. ed. II. i. $314=$ lucidus.

japonicus, C. Koch, Dendrot. i. 625.-Japon.

Fodina, Steud. Nom. ed. II. i. $314=$ Iodina rhombifolia.

kiusiana, Franch. E Sav. Enum. Pl. Fap. ii. 314.Japon.

lanceolatus, E. Mey. ex Sond. in Harv. E Sond. Fl. Cap. i. 456.-Afr. austr.

lanceolatus, Spreng. Syst. i. 775.-Ins. Mascar.

lancifolius, Thonn, in Schum. E Thonn. Beskr. Guin. $P l .132 .-A$ - Ar. trop.

laurifolius, A. Rich. Tent. Fl. Abyss. i. 130.Abyssin.

\section{CELASTRUS}

laurinus, Thunb. Prod. Pl. Cap. 42-Afr. austr.

leptopus, Bernh. ex Walp. Rep. v. 401 = buxifolius,

linearis, Eckl. \& Zeyh. Enum. 121 = polyacanthus.

linearis, Linn. f. Suppl. 153.-Afr. austr

lineatus, D. Dietr. Syn. i. $815=$ linearis.

lucidus, Linn. Mant. i. 49-Afr ansir.

lucidus, Wall. in Roxb. Fl. Ind. ed. Carey, ii. 400.Ind or.

luteolus, Delile, in Ann. Sc. Nat. Sér. II. xx. (1843 90 . Afr. trop.

lycioides, Brouss. ex Willd. in Roem. E' Schult. Syst. v. 427. -Ins, Canar.

macrocarpus, Ruiz E Pav. Fl. Per. iii. 8. t. 230. f. 16 -Peruy.

macrophyllus, Welw. ex Oliver, F1. Trop. Afr. i. $364=$ lancifolius

magellanicus, DC. Prod. ii. $8=$ Maytenus magellanicus. mantitianus, Stadtm. ex Willem. in Ust. Ann. Bot. xviii. (1796) 2\%,-Ins. Maurit.

Maytenus, Willd. Sp. Pl. i. 1127 = Maytenus Boaria

Metzianus, Turcz, in Bull. Soc. Nat. Mosc. xxxi. (1858) I. 448 = paniculatus.

mexicanus, Moç. Eั Sesse, ex DC. Prod. ii. 8.Mexic.

micrantha, Roxb. Hort. Beng, 86; Fl. Ind. i, 625.Ins. Molucc.

microcarpus, D. Don, Prod. Fl. Nep. 191.--Reg. Himal.

microphyllus, Eckl. \& Zeyh. Enum. $119=$ acuminatus microphyllus, Linn. f. Suppl. 154.-Afr, austr.

mollis, Decne, in Rev. Hortic. Sér. II. iv, (1845-46) 425. - Hab. ?

monospermus, Roxb. Hort. Beng. 18 ; Fl: Ind. i. 625 -Ind. or. ; China

montanus, Roth, Nov. P1. Sp. $154=$ Gymnospori montana.

mossambicensis, Klotzsch, in Peters, Reise Mossamb. Bot. i. 112.-Afr, trop.

mucronatus, Eckl. \& Zeyh. Enum. $119=$ acuminatus.

Muelleri, Benth. Fl. Austrat. i. 399.-Austral. multiflorus, Eckl. \& Zeyh. Enum. 121=buxifolius.

multiflorus, Lam. Encyc. i. 661.-Afr. austr.

multiflorus, Roxb. Hort. Beng. 18; Fl. Ind, $622=$ paniculatus.

myrtifolius, Linn. Sp. Pl. 196.--Jamaica.

neglecta, Wall. Cat. n. $4341=$ Gymnosporia neglecta nemorosus, Eckl. E Zeyh. Enum. 120-Afr, austr.

nepalensis, Steud. Nom. ed. II. i. $315=$ Pittosporum floribundum.

nossibaeus, $O$. Hoffm. Sert. Madag. 12 (=Alsodeia).Madag.

nutans, Roxb. Hort. Beng. 18; Fl. Ind. i. $623=$ paniculatus.

obovatus, Hochst. ex Oliver, Fl. Trop. Afr. i. $362=$ Gymnosporia montana.

obscurus, A. Rich. Tent. Fl. Abyss. i. $131=$ serratus.

obtusatus, Presl, Bot. Bemerk. $34=$ Simmondsia californica.

obtusifolius, Roxb. Hort. Beng. 86 ; F1. Ind. i. $625=$ Gymnosporia trigyna

obtusus, Thunb. in Hoffm. Phytogr. Blaetter, i. (1803) 22 = pyracanthus

octogonus, L'Hérit. Sert. Angl. $6=$ Maytenus octogonus. octogonus, Hort. ex Steud. Nom. ed. II. i. $315=$ pyra canthus.

oleifolius, Pers. Syn, i, $327=$ oleoides

oleoides, Lam. Tabl. Encyc. ii. 93.-Afr. austr.

oppositus, Wall, in Roxb. Fl. Ind. ed. Carey, ii. $398=$ Pleurostylia Wightii

orbicularis, Humb. \& Bonpl. ex Roem. \& Schult. Syst.

v. $423=$ Maytenus uliginosus,

orbiculatus, Lam. Tabl. Encyc. ii. $94=$ articulatus.

Orixa, Sieb. E Zucc. in Abh. Akad. Muench. iv. II. (1846) 150.-Japon.

ovalifolius, Steud. Nom. ed. II. i. $315=$ Gymnosporia ovata.

ovatus, Hill, Veg.Syst. xiii. 62; Hort.Kew. 437.t. 16. -Ins. Bahama.

ovatus, Wall. Cat. n. $4308=$ Gymnosporia ovata.

oxyphyllus, Wall. Cat. n. $4312=$ Gymnosporia acuminata.

pallidus, Wall. Cat. n. $4307=$ Gymnosporia montana. paniculatus, Willd. Sp. Pl. i. 1125.-As. trop.; Malaya parvifolius, A. Rich. Ess. Fl. Cub. 349.-Cuba. parvifolius, Eckl. \& Zeyh. Enum. $121=$ heterophyllus. parviflorus, Vahl, wymb. Bot. i. 21.-Arabia patens, Eckl. E Zeyh. l. c. 120.-Afr. austr.

\section{CELASTRUS}

pauciflorus, Wall, in Roxb. Fl. Ind.ed. Carey, ii. 400 . -Ind. or.

peduncularis, Sond. in Harv. E Sond. Fl. Cap. i. 454. -Afr. austr.

pentagynus, Zipp. ex Span. in Linnaea, xv. (1841) 186. -Malaya?

peruvianus, F. G. Dietr, Vollst. Lexik. Gaertn, ii. $111=$ retusus.

phyllacanthis, L'Hérit. Sert. Angl. 6 = Gymnosporia montana.

Plectronia, DC. Prod. ii. $9=$ acuminatus.

polyacanthus, Sond. in Harv. E̋ Sond. Fl. Cap. i. 455. - Afr. austr.

polyanthemos, Eckl. Ev Zeyh. Enum. 121.-Afr. austr. polybotrys, Turcz. in Bull. Soc. Nat. Mosc. xxxi. (1858) I. 449--Ins. Philipp

populifolius, Lam. Tabl. Encyc. ii. $94=$ acuminatus.

procumbens, Linn. f. Suppl. 153.-Afr. austr.

pterocarpus, DC. Prod. ii. $5=$ Pterocelastrus tricuspidatus.

pubescens, Wall. Cat. n. 4303.-Ind. or.

punctatus, Thunb. F1. Jap. $97=$ articulatus.

punctulatus, Sieb. E Zucc. in Abh. Akad. Muench. iv.

II. (1846) 150.-Japon.

pyracanthifolius, Salisb. Prod. $\mathbf{1 4 1}=$ pyracanthus.

pyracanthus, Linn. Sp. Pl. 197.-Afr, austr.

pyrifolia, Herb. Franq. ex Oliver, F1. Trop. Afr. i. 362 - serratus.

pyrius, Willem. in Ust. Ann. Bot. xviii. (1796) $21=$ Gymnosporia trigyna.

quadrangulatus, Schrad, in Goett. Gel. Ans. i. (1821) 716.-Bras.

racemosus, Turcz. in Bull. Soc. Nat. Mosc. xxxvi. (1863) I. 599.-Japon

racemosus, Wall. Cat. n. $4320=$ Parastemon urophyllum racemulosus, Hassk. Hort. Bogor. i. 155.-Tava.

refractus, E. Mey, ex Sond. \& Harv. Fl. Cap. i. $467=$ Cassine scandens.

repandus, Blume, Bijdr. 1145.-Java.

retusus, Poir. Encyc. Suppl.ii. 146.--Peruv.

rhamnoides, Poir. l.c. 145.-Afr, austr.

rhombifolius, Eckl. E゙ Zeyh. Enum. 120.-Afr. austr.

rhombifolius, Hook \& Arn, in Hook. Bot. Misc. iii (1833) $170=$ Iodina rhombifolia.

Richii, A.Gray, Bot. U. St. Expl. Exped. i. 289.-Ins Fiji.

rigidus, Eckl. \& Zeyh. Enum, 121 = capitatus.

rigidus, Thunb. Fl Cap ii 124-Afr austr.

rigidus, Wall in Roxb. F1. Ind. ed. Carey, ii. $396=$ Gymnosporia Wallichiana.

robustus, Roxb. Hort. Beng. 18; Fl. Ind. i. $626=$ Kurrimia pulcherrima.

rostratus, Thunb. Prod. Pl. Cap. $42=$ Pterocelastrus rostratus.

Rothianus, Roem. \& Schult. Syst. v. $423=$ paniculatus.

Rothianus, Wight \& Arn. Prod. i. 159=Gymnosporia Rothiana.

rotundifolius, Thunb. Prod. PI. Cap. $42=$ Dovyalis celastroides,

Royleanus, Wall. Cat. n. $4317=$ Gymnosporia Royleana.

nuber, Gerrard, ex Oliver, Fl. Trop. Afr. i. $363=$ mossambicensis.

ruber, Harv. in Harv. E Sond. Fl. Cap. ii. 592,-Afr. austr.

rufus, Wall. Cat. n. $4309=$ Gymnosporia rufa.

rupestris, Eckl. \& Zeyh. Enum. $119=$ acuminatus.

saxatilis, Burch. Trav. ii. 264.-Afr. austr.

scandens, Linn. Sp.Pl. 196.-Am. bor.

Schimperi, Hochst. ex A. Rich. Tent. Fl. Abyss. i. 132 = serratus.

semiarillatus, Turcz, in Bull. Soc. Nat. Mosc, xxxvi. (1863) I. 599,-Java.

senegalensis, Lam. Encyc. i. $661=$ Gymnosporia montana.

sepiarius, Dennst. Schluess. Hort. Malab.31.-Ind. or serratus, Hochst. ex A. Rich. Tent. Fl. Abyss. i. 131.Abyssin.

serrulatus, R. Br. in Salt, Abyss. App. $64=$ serratus. serrulatus, Roth, Nov. P1. Sp. $155=$ Gymnosporia Heyneana.

Sieberi, Bernh. ex Harv. \& Sond. Fl. Cap. i. $473=$ Ilex capensis.

sinuato-dentatus, Hochst. ex A. Rich. Tent. Fl. Abyss.

i. $130=$ luteolus

spathephyllus, Eckl. \& Zeyh. Enum. 121=buxifolius 
CELASTRUS :-

spicatus, Vell. Fl. Flum. 92 ; ii. t. $138=$ Gouania corylifolia.

spinosus, Royle, Illustr. Bot. Himal. $167=$ Gymno sporia Royleana.

stenophyllus, Eckl. \& Zeyh. Enum. 122=linearis. striatus, Thunb. Fl. Jap. $98=$ Enonymus Thunbergianus.

stylosus, Wall. in Roxb. Fl. Ind.ed. Carey, ii. 401.Reg. Himal.

subspicatus, Hook. Ic. Pl. t. 482.-Hab.?

Tatarinowii, Rupr. in Bull. Phys.-Math. Acad. Pétersb. $\mathrm{xv} .(1857) 357=$ articulatus.

tenuispinus, Sond.in Harv. E' Sond. Fl. Cap. i. 456.-

Afr. austr.

tetragonus, Thunb. Prod. PI. Cap. $42=$ Cassine scandens.

tricuspidatus, Lam. Tabl. Encyc. ii. $93=$ Pterocelastrus tricuspidatus.

trigynus, Lam, 1. c. $94=$ Gymnosporia trigyna.

Tsaad, Ferr. E" Gal. ex Walp. Ann. iii. 841.-Abyssin.

umbellatus, Vell. Fl. Flum. 92 ; ii. t. $137=$ Reissekia cordifolia.

uncinatus, Ruiz \& Pav. Fl. Per. iii. $7=$ Maytents chilensis.

undatus, Thunb. Prod. Pl. Cap. 42.-Afr. austr.

undulatus, Lam. Encyc. 1. $662=$ Pittosporum Senacia venenatus, Eckl. \& Zeyh. Enum, 121 =buxifolius, venulosus, Wall. Cat. n. 4321.-Reg. Himal.

verrucosus, E. Mey. ex Harv. E Sond. Fl. Cap. i. 453. -Afr. austr.

verticillatus, Roxb. Hort. Beng. 18; Fl. Ind. i. $624=$

Pittosporum floribundum.

verticillatus, Ruiz \& Pav, Fl. Per, iii. $6=$ Maytenus verticillatus.

Wallichianus, Spreng. Syst. v. Index, $150=$ Gymnosporia Wallichiana.

Wallichianus, Wall. in Roxb. Fl. Ind. ed. Carey, ii.

$400=$ Gymnosporia Heyneana.

Wightianus, Wall. Cat. n. $4322=$ Pleurostylia Wightii.

Zeyheri, Sond. in Harv. E Sond. Fl. Cap. i. 456.Afr. austr.

geylanicus, Roth, ex Roem. \& Schult. Syst. v. $427=$ Scutia Commersonii.

CELEBNIA, Noronha, in Verh. Batav. Gen. v. (1790) ed. I. Art. IV. 2 (Quid?).

CELMISIA, Cass. in Dict. Sc. Nat. vii. $356(1817)=$ Alciope, DC. (Compos.)

rotundifolia, Cass. 1. c. $357=\mathrm{A}$. tabularis,

CELMISIA, Cass. in Dict. Sc. Nat. xxxvii. 259 (1825). COMPOSITAE, Benth. \& Hook. f. ii. 278. asteliaefolia, Hook. f. F1. Antarct. $35=$ longifolia. bellidioides, Hook. f. Handb. New Zeal. Fl. 135.-N. Zel.

cordatifolia, F. Buch, in Trans. N. Z. Inst. xi. (1879) 427. t. 18. - N. Zel.

coriacea, Raoul, in Ann. Sc. Nat. Sér. III. ii. (1844) 119.-N. Zul.

Dalli, f. Buch. in Trans. N. Z. Inst. xiv. (1882) 355. t. 35.-N. Zel.

densiflora, Hook. f. Handb. New Zeal. Fl. 130.-N. Zel.

discolor, Hook. f. Fl. N. Zel. i. 123.-N. Zel

glandulosa, Hook.f.l. c. 124.-N. Zel.

gracilenta, Hook. f. Fl. Antarct. 35.-N. Zel

graminifolia, Hook. f. l. c.- - N. Zel

Haastii, Hook. f. Handb. New Zeal. Fl. 131.-N. Zel.

Hectori, Hook. f. l. c. 135.-N. Zel.

hieracifolia, Hook. f. Fl. N. Zel. 124. t. 34.-N. Zel.

holosericea, Hook. f. Fl. Antarct. 36. - N Zel.

incana, Hook. f. Fl. N.Zel. 123. t. 34-N. Zel.

laricifolia, Hook. f. l. c. 331 - N. Zel.

lateralis, F. Buch. in Trans. N. Z. Inst. iv. (1872) 226. - N. Zel.

Lindsayi, Hook. f. Handb. New Zeal. Fl. 131.-N, Zel.

linearis, Armst. in Trans. N. Z. Inst. xiii. (1881) 337 - N. Zel.

longiolia, Cass. in Dict. Sc. Nat. xxxvii. 259.Anstral.

Lyallii, Hook. f. Handb. N.Zcal. Fl. 189.-N. Zel.

Mackaui, Raoul, Choix Pl. Nouv. Zel. 19, t, $14-\mathrm{N}$. Zcl.

\section{CELMISIA :}

Munroi, Hook. f. Handb. New Zeal. Fl. 133.-N. Zel.

petiolata, Hook.f.l. c. 135.-N. Zel.

ramulosa, Hook f. l. c. $733-\mathrm{N} . \mathrm{Zel}$

rupestris, Cheesem. in Trans. N.Z. Inst. xvi. (1884) $409 .-N$. Zel.

Lechleri, Sch. Bip. in Bonplandia, iv. (1856) 54, nomen.-Peruy

sessiliflora, Hook. f. Handb. New Zeal. Fl. 135.-N. Zel.

Sinclairii, Hook. f. l. c. 132,-N. Zel

spathulata, A. Cunn. in DC. Prod. v. $209=$ Trichocline scapigera.

spectabilis, Hook.f. Fl. Antarct. 35.-N. Zel.

Traversii, Hook. f. Handb. New Zeal. Fi. 134.-N. Zel.

verbascifolia, Hook. f. Fl. N.Zel. 121.-N. Zel

vernicosa, Hook. f. Fl. Antarct. 34. t. 26, 27.-Ins. Auckland.

viscosa, Hook. f. Handb. New Zeal. Fl. 133.-N. Zel.

Walkeri, T. Kirk, in Trans. N.Z. Inst. ix. (1877) 549 N. Zel.

CELOSIA, Linn. Gen, ed. I. 34 (1737). AMARANTACEAE, Benth. \& Hook, f. iii. 24.

Amaranthus, Adans. Fam. ii. 269 (1763).

Gonufas, Rafin. Sylva Tellur, 124 (1838).

Kokera, Adans. Fam. ii. 269 (1763).

LAgrezia, Moq. in DC. P'rod. xiii. ii. 252 (1849)

Lestibudesia, Thou. Hist. Vég. Iles Afr. 53. t. 16 (1806).

Lophoxera, Rafin. F1. Tellur. iii. $42(1836)$

Sukana, Adans. Fam, ii. 269 (1763)

acroporoides, Hochst. ex Benth. E Hook. f. Gen. iii. 25.-Abyss.

acroprosoides, Hochst. ex Oliver, in Trans. Linn. Soc. xxix. (1875) $140=$ trigyna.

adoënsis, Hochst. ex A. Rich. Tent. Fl. Abyss, ii. 211 = trigyna.

albida, Willd. Sp. P1. i. $1197=$ Allmania albida

allmanoides, Moq. in DC. Prod, xiii. II. 243 .Burma.

altissima, Salzm. ex Moq. 1. c. $381=$ Telarthera ramosissima.

amaranthoides, Medic. Malv. $92=$ trigyna.

amphibia, Salzm. ex Moq. in DC. Prod. xiii. II. $363=$ Telanthera philoxeroides.

anthelminthica, Aschers, in Schweinf. Beitr. Fl. Aethiop. 176.-Afr. trop.

arborescens, Spreng. Syst. i. $815=$ Deeringia altissima. arenaria, Salzm. ex Seub. in Mart. Fl. Bras. v. I. 170

$=$ Telanthera maritima.

argentea, Linn. Sp. Pl. 205.-Cosmop. trop.

aspera, Roth, Nov. P1. Sp. $173=$ Allmania nodiflora

aurea, T. Moore, Flor. Mag. i. (1861) t. $47=$ cristata.

axillaris, Mart. Hort. Erlang. $70=$ Altemanthera spinosa.

baccata, Retz. Obs. fasc. v. $23=$ Deeringia celosioides. bicolor, Blanco, Fl. Filip. ed. I, 191=philippica.

Boivini, Hook. f. in Benth. E Hook. f. Gen. iii. 25,Madag.

brasiliensis, Moq. in DC. Prod. xiii. II. 239.-Bras.

castrensis, Linn. Sp. Pl. ed. II. $297=$ cristata.

caudata, Vahl, Symb. Bot. i. 21.-Arabia.

cernua, Andr. Bot.Rep.x, t. 635--Ind, or.

cernua, Mairet, ex Moq. in DC. Prod. xiii. I1. $351=$

Alternanthcra canescens.

cernua, Roxb. Hort. Beng. 19; Fl. Ind. i. $680=$ cristata.

coccinea, Linn. Sp. P1. ed. II. $297=$ cristata.

comosa, Retz. Obs, fasc. vi. $26=$ cristata.

corymbifera, Didr. Ind. Sem. Hort. Havn. (1849) 18. -Hab.?

corymbosa, Retz. Obs. fasc. i. 13 = Polycarpaea corymbosa.

cristata, Linn. Sp. Pl. 205.-Cosmop. trop.

cymosa, Seub. in Mart. M. Bras. V. I. 245.-Bras.

decumbens, Hort. ex. Moq. in DC. Prod, xiii. II. 410

Gomphrena decumbens.

dichotoma, Heyne, in Roth, Nov. Pl. Sp. $172=$ Allmania nodiflora.

diffusa, Hofimgg. ex Seub. in Mart. Fl. Bras. v. 1. 17 : = Telanthera ramosissima.

echinata, Humb. \&c Bonpl, ex Roem. \& Schult. Syst. $531=$ Altemanthera Achyrantha.

elongata, Spreng. in Schrad. Journ. (1800) II. $196^{\circ}$

Telanthera porrigens.

eriantha, Vahl, ex Moq. in DC. Prod. xiij, II. $386=$ Gomphrena criantha.
CELOSIA :-

exstipulata, Hornem. ex Schrank, in Syll. Ratisb. i. (1824) 202.-Nepal.

floribunda, A. Gray, in Proc. Am. Acad. v. (1861) 167 -Calif.

glauca, Rottl. in Ges. Naturf. Fr. Nene Schr. iv. (1803) $\mathbf{1 9 8}=$ patula

glauca, Wendl. Beobacht. 43; Hort. Herrenh. 4. $2=$ Hermbstaedtia glauca

gnaphalioides, Linn. f. Suppl. $161=$ Gomphrena gnaphalioides.

grandifolia, Moq. in DC. Prod. xiii. II. 238.-Bras.

humifusa, Willd. ex Roem. \&c Schult. Syst. v. $531=$

Telanthera caracasana.

Huttoni, Mast. in Gard. Chron. (1872) 215.-Java.

intermedia. Hochst. ex. Oliver, in Trans. Linn. Soc.

xxix. (1875) $140=$ trigyna.

interrupta, Seub. in Mart. Fl. Bras. v. 1. $165=$ Froelichia interrupta.

japonica, Mart. Hort. Erlang. 70.-Japon. ?

lactea, Hort. ex Moq. in DC. Prod. xiii. II. $300=$

Aerva sanguinolenta.

lanata, Blanco, F1. Filip. ed. II. 134= Aerva lanata

lanata, Linn. Sp. P1, $205=$ Aerva tomentosa.

lanata, Poir. ex Steud. Nom. ed. II. i. $315=$ Gom phrena gnaphalioides.

lappacea, Medic. Beobacht. (1783) 147 = Pupalia atropurpurea.

latifolia, Steud. Nom. ed. II. i. 315.-Java.

laxa, Schur \& Thonn. Beskr. Guin. Pl. 141.-Afr. trop.

leptostachya, Benth. in Hook. Niger Fl. 491,-Afr trop.

linearis, Sweet, ex Hook. f. F1. Brit. Ind. iv. 714 argentea.

longifolia, Mart. Nov. Gen. et Sp. ii. 63. t. 157, 158 f. 2.-Bras.

madagascariensis, Poir. Encyc. v. 89.-Madao.

major, Griseb. in Goett. Abh. xix. (1874) 79.-Reg. Argent.

margaritacea, Linn. Sp. P1. ed. II. $297=$ argentea marylandica, Retz. Obs. fasc. iii. $27=$ argentea. maritima, Salzm. ex Moq. in DC. Prod. xiii. II. 341 Ihiloxerus vermicularis.

melanocarpos, Poir. Encyc. Suppl. iv. $318=$ trigyna. missionis, Wall. Cat. n. $6915=$ Banalin thyrsiflor.

Monsonia, Retz. Ubs. fasc. ii. 13 = Aerva Monsonia

Moquini, Guill. ex DC. Prod. xili. I1. 239.-Mexic.

mucronata, Herb. ex Moq. in DC. 1. c. $218=$ Allmania albida.

muricata, Spreng. Syst. iv. Cur. Post. $102=$ Cladostacbys muricata.

nana, Blanco, Fl. Filip. ed. I. 192=Ammania baccifera.

nitida, Vahl, Symb. Bot. iii. $44=$ paniculata.

nodiflora, Linn. Sp. Pl. $205=$ Allmania nodiflora.

nodiflora, Salzm. ex Mog. in DC. Prod. xiii. II. 36t=

Telanthera volygnnoides.

nodiflora, Wall. Cat. n. $6890=$ Allmania albida.

nudiflora, Pav, ex Moq. in DC. Prod. xiii, II. 941

Philoxerus vermicularis.

odorata, Burch. ex Moq. l. c. 244.-Afr. austr.

pallida, Hort. Vindob. ex Moq. 1. c. $248=$ Allmania albida.

pallida, Salisb. Prod. $145=$ argentea

Palmeri, S. Wats. in Proc. Am. Acad. xviii. (1S\&2 \$3 143.-Calif

paniculata, Linn. Sp. Pl. 206.-Florida; Ind. occ,

parviflora, Vahl, ex Moq. in DC. Prod. xiii. $11 . \$ 46=$ Iresine gracilis.

patula, Willd. in Ges. Natrurf. Fr. Wrue Schr. iv. (1803) 198.-Ind. or.

peruviana, Van Spand. ex Moq. in DC. Prod. xiii. II. $365=$ Telanthera fruteseens

peruviana, Zuccagni, in Rocm. Collect. $133=$ Telan. thera porrigens.

philippica, Sieud. Nom. ed. II. i. \$16.-Ins. Philipp.

phytolaccaefolia, Juss, ex Moq. in DC. I'rod. xiii. \$t. $258=$ maclayascariensis.

piloselloides, Poit. ex Moq. I. c. $99 \%=$ Guilleminca lanuginosa.

polygonoides, Rets. Obs. fasc, ii. 19.-Iad. or.

polygonvides, IV all. Cat. n. 6918 - pulchella.

polysperma, Ruxb. Hort. Heng. 84; Fl. Ind. i. 681 i)ecringia pulysperma.

propulifolia, Jling. in DC. Proul. xiij. 11. 299.-Abrse

prosumbens. Hort. ex Moq. I. c $110=$ Gomphrena decumbens.

302 


\section{CELOSIA}

procumbens, Jacq. Misc. ii. $344=$ Froelichia interrupta. prostrata, Hort. ex Moq. in DC. Prod, xiii. II, 410= Gomphrena decumbens.

pulchella, Moq. l. c. 238.-Ind. or.

purpurea, St. Hil. ex Steud. Nom. ed. II. i. 315, $316=$ cristata.

pyramidalis, Burm. f. Fl. Ind. $62=$ cristata, Allmania albida.

recurva, Burch. Trav. ii. $226=$ Hermbstaedtia elegans. sanguinea, Hoffmgg. Verz. Pf. ii. 85. - Ind. or.

sinuata, Mart. ex Steud. Nom. ed. I. 171.-Hab.?

sparsa, Forsyth, ex Moq. in DC. Prod. xiii. II. $250=$ Chamissoa altissima.

spathulata, Boj. Hort. Maurit. 267.-Madag.

spathulata, Saint-Elme, ex Moq. in DC. Prod. xiii. II. $253=$ madagascariensis

spicata, André, ex Moq. 1. c. $143=$ Anthochlamys polygaloides.

spicata, Spreng. Syst. i. 815.-Madag.

spinescens, Russ. ex Wall. Cat. sub n. $6932=$ Achyranthes aquatica.

splendens, Schum. Er Thonn. Beskr. Guin. Pl. 140.Afr. trop.

stolonifera, Leprieur, ex Moq. in DC. Prod, xiii. II. 365 $=$ Telanthera maritima.

stricta, Fisch. ex Fisch. Mey. \& Avé-Lall. Ind. Sem.

Hort. Petrop. ix. $65=$ brasiliensis.

stricta, Hornem. Hort. Hafn. Suppl. 28.-Bras,

tetragyna, Roxb. ex Moq. in DC. Prod. xiii. II. $237=$ Deeringia tetragyna.

texana, Scheele, in Linnaea, xxii. (1849) 148.Texas.

thyrsiflora, Wall. Cat. n. $6914=$ Banalia thyrsiflora.

tomentosa, Willd, in Roem. \& Schult. Syst. y, $531=$

Chamissoa macrocarpa.

trigyna, Linn. Mant. 212,-Afr. trop.

trigyna, Wight, ex Steud. Nom. ed. II. i. $316=$ Banalia thyrsiflora.

trigyna, Willd. ex Wall. Cat. n. $6915=$ polygonoides. triloba, E. Mey. ex Meissn. in Hook. Lond. Fourn. Bot. ii. (1843) 448, - Afr, austr.

tumida, Hort. Hall. ex Moq. in DC. Prod. xiii. II. 245. -Hab.?

virgata, Facq. Coll. ii. 279,-Am. trop.

CELSA, Vell. Fl. Flum. 173 (1825); iv. t. 93. ZYGOPHYLLEAE

frutescens, Vell. $l l . c c .174 .-$ Bras.

CELSIA., Heist. Syst. 5, $20(1748)=$ Ornithogalum, Tourn. (Liliac.)

CELSIA, Linn. Syst, ed. I (1735). SCROPHULARINEAE, Benth. \& Hook. f. ii. 928.

Dítoxia, Rafin. ex Desv. Journ. Bot. iv. (1814) 270.

Janthe, Griseb. Spicil. Fl. Rumel. ii. 40 (1844).

NeffleA, Spach, Hist. Vég. Phan. ix. 266 (1840).

THAPSANDRA, Griseb. Spicil. Fl. Rumel, ii. 40 (1844).

acaulis, Bory E Chaub. Expéd. Mor. Bot. 177. t. 18.Graecia.

affinis, A. Rich. Tent. Fl. Abyss. ii. 110--Abyssin.

agrimonifolia, C. Koch, in Linnaea, xxii. (1849) $732=$ heterophylla.

alpina, Boiss. \& Kotschy, Diagn. Ser. II. iii. 150.Syria.

arbuscula, A. Rich. Tent. Fl. Abyss. ii. 110.-Abyssin. arcturis, St. Lag. in Ann. Soc. Bot. Lyon, vii. (1880) $122=$ C. Arcturus.

Arcturus, Facq. Hort. Vindob. ii. 53. t. 117.-Creta.

armeniaca, Boiss. F1, Orient. iv. $361=$ aurea.

Aucheri, Boiss. Diagn. Ser. I. xii. 29.-Persia.

aurea, C. Koch, in Linnaea, xxii. (1849) 731.Armenia.

australis, Hort. Bonn. ex Flora, xvi. (1833) $125=$ cretica.

Bernadesii, G. Don, Gen. Syst. iv. 499,-Hispan.; Marocco.

betonicaefolia, Desf. Fl. Atlant. ii. 58.-Afr. bor.

Boissieri, Heldr. E' Sart. ex Boiss. Fl. Orient. iv. 353. -Graecia.

brachysepala, Fisch. \& Trautv. in Ind. Sem. Hort. Petrop. iv. 33.-As. Min.

bugulifolia, Faub. \& Spach, Illustr. v. 7. t. 407.-

Rumelia; As. Min.

caduca, Moench, Meth. $447=$ orientalis.

\section{CELSIA :}

Cavanillesii, Kunze, in Flora, xxix. (1846) $698=$ cretica.

chrysurus, Fenzl, ex Boiss. F1. Orient. iv. $359=$ heterophylla.

cilicia, Boiss. E Heldr. Diagn. Ser. I. xii. 30.Cilicia.

collina, Benth. in DC. Prod. x. $247=$ Suwarowiana.

coromandelina, Vahl, Symb. Bot. iii. 79.-Ind. or.

Afghanist.

coronopifolia, Boiss. E' Bal. Diagn. Ser. II. vi. 126.-

Phrygia.

cretica, Linn.f. Suppl. 281.-Reg. Mediterr.

cyllenea, Boiss. E Heldr. Diagn. Ser. II. iii. 151.Graecia.

Daenzeri, Fauché E Chaub. in Expéd. Mor. Bot. 342.Graecia.

densiflora, Hook. f. in Fourn. Linn. Soc. vii. (1864) 208.-Afr. trop.

dentata, Moench, Meth. Suppl. $156=$ coromandelina.

Doniana, Walp. Rep. iii. 150.-Hab.?

elata, Fisch. ex Steud. Nom. ed. I. 172.-Hab. ?

erecta, 'Fisch. Hort. Gorenk.' ex Steud. Nom, ed. II i. 316. - Hab. ?

floccosa, Benth. in DC..Prod. x. 245.-Abyssin.

glabrata, Roth, ex Steud. Nom. ed. II. i. 316. Hab.?

glandulosa, Bouché, in Verh. Ges. Naturf. Fr. Berl. i (1829) 395.-As. Min.

grandiflora, Hort. ex Steud. Nom. ed. II. i. 316.Asia.

heterophylla, Desf. ex Pers. Syn. ii. 161.-Persia ; As Min.; Ind. or.

horizontalis, Moench, Meth. $448=\mathrm{C}$. Arcturus.

incana, Benth, in DC. Prod. x. $247=$ lanceolata.

incarnatax, Reichb. ex Heynh. Nom. ii. 129, nomen.

interrupta, Fresen. in Flora, xvi. (1838) 605.-Abyssin intricata, Benth.in DC. Prod. x. 247.-Persia.

laciniata, Coss. ex Ball, in Journ. Linn. Soc. xvi (1878) $585=$ cretica.

laciniata, Poir. Encyc. Stppl. ii. $147=$ Bernadesii.

lanata, Spreng. Syst, ii. 810, err. typ. = sublanata.

lanceolata, Vent. Fard. Cels, t. 27.-Mesopot.; Persia.

lepturus, Schott \& Kotschy, in Oestr. Bot. Wochenbl. 1854) $186=$ brachysepala

linearis, Jacq. Coll. ii. $270=$ Alonsoa linearis.

Luciliae, Boiss. Diagn. Ser. I. iv. 65.-As. Min.

lycia, Boiss. Fl. Orient. iv. 357.-Lycia.

lyrata, G. Don, Gen. Syst. iv. $499=$ cretica.

maroccana, Ball, in Fourn. Bot. xiii. (1875) 172.Marocco.

orientalis, Linn.Sp.Pl. 621.-Graecia; As. Min.; Persia.

parviflora, Decne. in Ann. Sc. Nat. Sér. II. v. (1836) 254.-Arabia.

parviflora, G. Don, Gen. Syst. iv. $499=$ Doniana

pedunculosa, Hochst. Er Steud. ex Benth. in DC. Prod. x. 245.-Abyssin.

persica, C. A. Mey. Verz. Pfl. Cauc. 111.-Reg. Cauc, Persia.

pinetorum, Boiss. Diagn. Ser. I. xii. 30.-Cilicia.

pinnatifida, Boiss. \& Reut. Diagn. Pl. Nov. Hisp. 22 $=$ Bernadesii

pontica, Boiss. in Tchihat. Asie Min. Bot. ii. 11.-As. Min. purpurea, Fanka, in Termész. Füzetek, iv. (1880)
296.-Hungar.

pyroliformis, Boiss. E Heldr. Diagn. Ser. I. xii. 28.Lycaonia.

ramosissima, Benth. in DC. Prod. x. 244.-Marocco

scrophulariaefolia, Hochst. in A. Rich. Tent. Fl. Abyss. ii. 112.-Abyssin.

simuata, Cav. in Anal. Cienc. Nat. iii. (1801) $68=$ cretica.

sinuata, Colla, Hort. Ripul. App. ii. 344 ; iii. 30.$\mathrm{Hab}$ ?

speciosa, Fenzl, in Friedric. Reise, 280.-Graecia.

striatiflora, Hort. ex Steud. Nom. ed. II. i. 316.-Hab. sublanata, Jacq. Fragm. 79.t. $126=$ C. Arcturus

Suwarowiana, C. Koch, in Linnaea, xvii. (1844) 284. - Armenia : Persia.

tomentosa, Hochst. ex Benth. in DC. Prod. x. 245. Abysin.

tomentosa, Zucc. PI. Nov. Fasc. ii. $22=$ Verbascum graecum.

trapaefolia, Stapf, in Denkschr. Acad. Wien, I. (1885) 88. - Lycia.

\section{CELSIA}

urticaefolia, Sims, Bot. Mag. t. $417=$ Alonsoa incisifolia.

valerianaefolia, A. Rich. Tent. Fl. Abyss. ii. 112.Abysin.

viscosa, Roth, Catalect. ii. $69=$ coromandeliana

viscosa, Wight, ex Benth. in DC. Prod. x. $229=$ Verbascum virgatum.

CELTIS, Tourn. ex Linn. Gen. ed. I. 337

(1737).

UR TICACEAE, Benth. \& Hook. f. iii. 354

Mertensia, H. B. \& K. Nov. Gen. et Sp. ii. 30 (1817)

Momisia, F. G. Dietr. Vollst. Lexik. Gaertn. Nachtr. y. 122 (1819)

Saurobroma, Rafin. Sylva Tellur. 32 (1838)

Solenostigma, Endl. Prod. F1. Norf. 41 (1833)

Acata, Buch.-Ham. in Trans. Linn. Soc. xvii. (1837) $211=$ anstralis

aculeata, Sw. Prod. Veg. Ind. Occ. 53.-Ind. occ. Am. trop.

africana, Burm. f. Fl. Cap. Prod. 31.-Afr, austr

alba, Rafin. Fl. Ludov. 25.-Am. bor.

albicans, Willd. ex Steud. Nom. ed. II. i. $316=$ Trema micrantha.

alnifolia, Miq. in Mart. Fl. Bras. iv. I. 176.-Am, trop, amblyphylla, F. Muell. Fragm. ix. 76.-Austral.

amboinensis, Buch.-Ham. ex Wall. Cat. sub n. $3693=$ Trema politoria.

amboinensis, Willd. Sp. Pl. iv. $997=$ Trema amboinensis.

americana, Hort. ex Planch, in DC. Prod. xvii. $176=$ mississipiensis.

americana, Mill. Gard. Dict. ed. VIII. n. 4.-Ind. occ. amplifolia, Noronha, in Verh. Bataw. Gen, v. (1790) ed. I. Art. IV. 11.-Malaya.

anfractuosa, Liebm. in Vidensk. Selsk. Skr. V.ii. (1851) 338.-Mexic.

angustifolia, Lindl, in Wall. Cat. n, 3691=Trema angustifolia.

angustifolia, Planch. in DC. Prod. xvii. 186.-Sumatra appendiculata, E. Mey. ex Planch. in Ann. Sc. Nat. Sér. III. x. (1848) 341 = Chaetachme aristata.

arcata, Buch.-Ham. ex Wall. Cat. sub n. $3695=$ australis.

aristata, E. Mey, ex Planch. in Ann. Sc. Nat. Sér. III. $\mathrm{x} .(1848) 341=$ Chaetachme aristata.

aspera, Brongn, in Duperr. Bot. Voy. Coq. 213. t. 48 = Trema aspera.

aspera, Lodd. ex G. Don, in Loud. Hort. Brit. $413=$ australis.

asperula, Miq. in Mart. Fl. Bras. iv. I. 176.-Am. trop. Audibertiana, Spach, in Ann. Sc. Nat. Sér. II. xvi. (1841) 41 = occidentalis.

australis, Linn. Sp. Pl. 1043.-Europ.; As. temp.; Ind. or.

australis, A. Rich. Tent. Fl. Abyss, $257=$ Kraussiana. azcurrensis, Parodi, in Anal. Soc. Cient. Argent. v. (1878) 152.-Reg. Argent.

Balansae, Planch in DC. Prod. xvii. 183.-N. Caled.

Berlandieri, Klotzsch, in Linnaea, xx. (1847) 541.Mexic.

biflora, Ruiz, ex Miq. in Mart. F1. Bras. iv. 1. $182=$ dichotoma.

boliviensis, Planch. in Ann. Sc. Nat. Sér. III, x. (1848) 311.-Bolivia.

Bonplandiana, Planch. in DC. Prod. xvii. 190.-Am. austr.

brasiliensis, Planch. in Ann. Sc. Nat. Sér. III. x. (1848) 310.-Bras.

brevifolia, Miq. in Mart. Fl. Bras. iv. I. 180.-Am. trop. brevinervis, Blume, Mus. Bot. Lugd. Bat. ii. $67=$ paniculata.

brevipes, S. Wats. in Proc. Am. Acad. xiv. (1879) 297. -Arizona.

Bungeana, Blume, Mus. Bot. Lugd. Bat. ii. 71.China.

Burmannii, Planch, in Anz. Sc. Nat. Sér. III. x (1848) $296=$ Kraussiana.

canescens, H, B. \& K. Nov. Gen. et Sp. ii. $28=$ Trema micrantha.

canina, Rafin. in Am. Monthly Mag. ii. (1817) 43.Am. bor.

caucasica, Hohen. ex Planch. in Ann. Sc. Nat. Sér. III. x. (1848) $285=$ australis.

cancasica, Willd. Sp. Pl. iv. $994=$ australis.

caudata, Hance, in Ann. Sc. Nat. Sér. V. v. (1866) $241=$ Prunus pogonostyla. 


\section{CELTIS :-}

caudata, Planch. in Ann. Sc. Nat. Sér. III. x. (1848) 294.-Mexic

caudata, Wall. ex Planch, in DC. Prod, xvii. $199=$ Trema amboinensis.

Chichilea, Ruiz \& Pav. ex Planch. in Ann. Sc. Nat. Sér. III. $x .(1848) 335=$ Trema micrantha.

Chicope, Miq. in Mart. Fl. Bras. iv. I. $181=$ C. Tala.

chinensis, Bunge, Enum. Pl. Chin. Bor. $61=$ Bungeana. cinerea, Torr. Bot. Mex. Bound. t. $50=\mathrm{C}$. Tala.

cinnamomea, Lindl. in Wall. Cat. n. 3696.-Ind. or." Malaya.

Clausseniana, Miq. in Mart. Fl. Bras. iv. I. 178.-Am. trop.

Commersonii, A. Brongn. in Duperr. Voy. Coq. Bot. $215=$ Trema orientalis

conferta, Planch, in DC. Prod. xvii. 183.-Madag.

cordata, Pers. Syn. i. $292=$ occidentalis

cordifolia, L'Hérit. ex Duham. Arb. ed. Nov. ii. $37=$ occidentalis.

crassifolia, Lam. Encyc. iv. $138=$ occidentalis. crenata, Miq. in Mart. Fl. Bras, iv, 1, $181=$ C. Tala. crenata, Planch. in DC. Prod. xvii. 191.-Bolivia.

Curiandiuba, Gomez, ex Planch. 1. c. 204=Trema micrantha.

Davidiana, Carr. in Rev. Hortic. (1868) 300.-China. dichotoma, Ruiz, ex Miq. in Mart. Fl. Bras. iv. I. 18\%.-Peruv.

diffusa, Planch. in Ann. Sc. Nat. Sér. III. x. (1848) 314.-Bras.

discolor, A. Brongn. in Duperr. Voy. Coq. Bot. i. 215. t. $47 . \mathrm{f} . \mathrm{B}=$ Trema discolor.

disticha, Parodi, in Anal. Soc. Cient. Argent. v. (1878) 96 (Contrib. 44).-Paraguay.

Djungiel, Planch. in DC. Prod. xvii. 185.-Java.

Douglasii, Planch. in Ann. Sc. Nat. Sér. III. x. (1848) 293 = reticulata.

dumosa, Casar. ex Planch, in DC. Prod. xvii. $188=$ ferruginea.

dysodoxylon, Thw. Enum. Pl. Zeyl. $267=$ cinnamomea

Ehrenbergiana, Liebm. in Dansk. Vidensk. Selsk. Skrift. V. ii. (1851) $339=$ aculeata.

elongata, Wall. Cat. n. $3692 \mathrm{C}=$ Villebrunea integrifolia.

epiphylladena, Orteg. Hort. Matr. $79=$ aculeata.

eriantha, E. Mey.ex Planch. in Ann. Sc. Nat. Sér. III x. (1848) 296.-Afr. austr.

eriocarpa, Decne. in Jacquem. Voy. Bot. $150=$ australis. excelsa, Salisb. Prod. $175=$ australis.

ferruginea, Planch. in DC. Prod. xvii. 188.-Bras.

ferruginea, Walp. in Nov. Act. Nat. Cur. xix. Suppl. i. (1843) $424=$ Zizyphus exserta.

flagellaris, Casar, ex Planch. in DC. Prod. xvii. $189=$ brasiliensis.

flexnosa, Miq. in Mart. Fl. Bras. iv. I. (1852-62) 181. -Am. trop.

flexuosa, Planch, in DC. Prod. xvii. $192=$ boliviensis

foridana, Rafin. New F1. Am. iit. $37=$ occidentalis?

fuscata, Rafin. 1. c. $33=$ mississipiensis ?

Gardneri, Planch. in Ann. Sc. Nat. Sér. III. x. (1848) 311.-Bras.

glabra, Noronha, in Verh. Batav. Gen. v. (1790) ed, I. Art. IV. 12,-Malaya.

glabra. Planch. in Ann. Sc. Nat. Sér. III. x. (1848) $298=$ tetrandra.

glabrata, Spreng. Syst. v. $150=$ aculeata.

glabrata, Stev. ex Planch. in Ann. Sc. Nat. Sér. III. x. (1848) $285=$ anstralis.

glomerata, Hochst. in Flora, xxviii. (1845) 87 (= Sponia guineensis).-Afr. trop.

glycycarpa, Mart. ex Miq. in Mart. Fl. Bras. iv. I. 174.-Am. trop.

Goudotri, Planch. in Ann.Sc. Nat. Sér. III. x. (1848) 312. - N. Granat.

grandidentata, Tenore, Ind. Sem. Hort. Neap. (1833) $\mathbf{1 5}=$ mississipiensis?

guinecnsis, Schum. E Thonn. Beskr. Guin. Pl. 160.Afr. trop.

hamatn, Blume, Mus. Bot. Lugd. Bat. ii. 72.-Malaya.

Hamiltonii, Planch. in Ann. Sc. Nat. Sér. III x. (1848) $301=$ tetrandra.

Harperi, Horne, ex Baker, in fourn. Linn. Soc. $x x$. (1883) 371.-Ins, Fiji.

Hasselti, Planch, in DC. Prod. xvii. 185.-Java.

heterophyla, Rafin. New Fl. Am, iii. $87=$ occidentalis ?

Hilariana, Planch. in DC. Prod. xvii. 189.-Bras.

hypoleuca, Planch.l.c. 183,-N. Caled.

ingens, F. Muell. Fragm, iv, $88=$ paniculata.

\section{CELTIS :}

integrifolia, Lam. Encyc. iv. $140=$ mississipiensis. jamaicensis, Planch. in Ann. Sc. Nat. Sér. III. (1848) 290.-Jamaica.

japonica, Planch. in DC. Prod. xvï. 172.-Japon Kotschyana, Stev, in Bull. Soc. Nat. Mosc. xxx. (1857) I. $392=$ australis.

Kraussiana, Bernh. in Flora, xxviii. (1845) 87.-Afr. trop. et austr.

laeta, Salisb. Prod. $175=$ orientalis.

laevigata, Spreng. Syst. i. $932=$ aculeata.

laevigata, Willd. Enum. Hort. Berol. Suppl. 67 mississipiensis.

Lamarckiana, Roem. \& Schult. Syst. vi. $311=$ Trema Lamarckiana.

lanceolata, Parodi, in Anal. Soc. Cient. Argent. v. (1878) 152 (Contrib. 45).-Paraguay.

lancifolia, Miq. in Mart. Fl. Bras. iv. 1. 175.-Bras.

lancifolia, Planch. in DC. Prod. xvii. 192.-Bras.

latifolia, Planch. l. c. 186.-N. Guinea.

laurifolia Planch. l. c. 185-Java

Lima, Blanco, Fl. Filip, ed. I. $197=$ Trema Blancoi

Lima, Lam. Encyc. iv, $40=$ Trema Lamarckiana.

Lima, Sw. Prod. Veg. Ind. Occ. $53=$ Trema Lima.

Lindheimeri, Engelm. ex C. Koch, Dendrol. ii. II. 434 - Am. bor.

littoralis, Liebm. in Vidensk. Selsk. Skr. V. ii. (1851) $337=$ caudata.

longifolia, Rafin. Atl. Journ. $177=$ mississipiensis ?

lutea, Pers. Syn. i. $292=$ australis.

macrophylla, H. B. \& K. Nov. Gen. et Sp. ii. $24=$ Trema macrophylla.

madagascariensis, Boj. Hort. Maurit. $296=$ Trema orientalis.

maritima, Rafin. in Am. Monthly Mag. ii. (1817) 44 -Am. bor.

mauritiana, Planch. in Ann. Sc. Nat. Sér. III. x (1848) 307 .- Ins. Maurit.

membranacea, Miq. in Mart. Fl. Bras. iv. 1. 175.Bras.

micrantha, Sw. Prod. Veg. Ind. Occ. $53=$ Trema micrantha.

microcarpa, Salzm. ex Planch. in Ann. Sc. Nat. Sér III. $x .(1848) 333=$ Trema micrantha.

microphylla, Zipp. ex Blume, Mus. Bot. Lugd. Bat. ii. $59=$ Trema timorensis.

mississippiensis, Bosc, Encyc. Agric. vii. 577.-Am. Jor.

mollis, Humb. \& Bonpl. ex Willd. Sp. P1. iv. $996=$ Trema micrantha.

mollis, Wall. Cat. n. $7203=$ tetrandra

monoica, Hemsl. Biol. Centr. Am. Bot. iii. 139.Mexic.

montana, Jungh. ex Planch. in DC. Prod. xvii, $193=$ Parasponia parviflora.

morifolia, Planch. in Ann.Sc. Nat. Sér. III. x. (1848) 311.-Bras.

morifolia, Rafin. New F1. Am. iii. $34=$ occidentalis.

Mukii, Sieb. E Zucc. in Abh. Akad. Muench. iv. III. (1846) 223.-Japon.

napalensis, Planch. in Ann. Sc. Nat. Sér. III. x. (1848) $298=$ tetrandra.

obliqua, Moench, Meth. $344=$ occidentalis.

occidentalis, Linn. Sp. Pl. 1044.-Am. bor

opaca, C. Moore, ex Benth. Fl. Austral. vi. $157=$

paniculata.
Opegrapha, Planch. in Ann. Sc. Nat. Sér. III. x. (1848) $294=$ Kraussiana.

orientalis, Hort. ex Steud. Nom. ed. II. i. $316=$ occidentalis.

orientalis, Lam. Encyc。 iv. $188=$ Trema Commersonii orientalis, Linn. Sp. Pl. $1044=$ Trema orientalis. orientalis, Mill. Gard. Dict. ed. VIII. B. $3=$ australis.

orientalis, Thunb. Fl. Jap. $114=$ japonica.

orthacanthos, Planch. in Ann. Sc. Nat. Sér. III.

(1848) $309=$ aculeata

pacifica, Planch. l. c. 308.-Ins. Marquesas.

pallida, Torr. in Bot. Mex. Bound. $203=\mathrm{C}$. Tala

paniculata, Planch. in Ann. Sc. Nat. Sér. III. $x$

(1848) 305.-Austral.; Ins. Pacific.

parvifolia, Rafin. New F1. Am iii. $\$ 6=0 c c i d e n t a l i s$.

parvifolia, A. Rich. Fl. Cub. Fanerog. ii. 219.-Cuba.

patula, Rafin. New F1. Am. iii. $37=$ reticulata?

Pavonit, Planch. in Ann. Sc. Nat Ser. III. x. (IStS $313=$ dichotoma

philippinensis, Blanco, F\%. Filip. ed. I. 197.-Ins.

Philipp, ; Austral.

\section{CELTIS}

politoria, Wall. Cat. n, 3693=Trema politoria

procera, Salisb. Prod. $175=$ occidentalis.

pubescens, H. B. $\Xi^{\circ} K . N o v$. Gen. et Sp. ii. $32,-\mathrm{N}$ Granat.

pumila, Pursh, F1. Am. Sept. i. $200=$ occidentalis

reticulata, Hook. f. \& Thoms. ex Planch. in DC. Prod. xvii, $209=$ Gironniera reticulata.

reticulata, Torr. in Ann. Lyc. N. York, i. (1824) 247.Am. bor, occ

reticulosa, Miq. Pl. Jungh. $69=$ cinnamomea.

rhamnoides, DC. ex Planch. in DC. Prod. xvii. $189=$ brasiliensis.

rhamnoides, Willd. Sp. Pl. iv. $998=$ aculeata.

rigescens, Planch. in DC. Prod. xvii. 182.-Sumatra.

rigida, Blume, Bijdr. $486=$ Trema rigida.

rigida, Parodi, in Anal. Soc. Cient. Argent. v. (1878) 153 (Contrib. 45).-Paraguay.

riparia, H. B. \& K. Nov. Gen. et Sp. ii. $28=$ Trema riparia.

riparia, Liebm, in Vidensk. Selsk. Skr. V. ii. (1851 337 = caudata.

rostrata, Zipp. ex Span, in Linnaea, xv. (1841) 34 ? $(=$ Sponia rostrata). - Hab.

Roxburghii, Planch, in Ann. Sc. Nat. Sér. III. 1848) $302=$ tetrandra

rufescens, Banks, ex Planch. 1. c. $334=$ Trema micrantha.

rugosa, Willd. Sp. Pl. iv, $996=$ Trema rugosa

salicifolia, Rafin. New Fl. Am. iii. $34=$ mississipiensis?

scabra, Casar. ex Planch. in DC. Prod, xvii. $204=$ Trema carinata.

Schiedeana, Schlecht, in Linnaea, vii. (1832) $140=$ Trema micrantha.

Selloviana, Miq. in Mart. Fl. Bras. iv. 1. 179.-Bras. serotina, Planch. in Ana. Sc. Nat. Sér. III. x. (16t8 $301=$ tetrandra.

Shortii, Planch. l. c. 292.-Am. bor.

sinensis, Planch. 1. c. $286=$ Bungeana

sinensis, Pers. Syn. i. 292.-China.

sinensis, Willd. Enum. Hort. Berol. Suppl. 67 japonica.

spinosa, Ruiz, ex Miq. in Mart. Fl. Bras. iv. I. $182=$ dichotoma.

spinosa, Spreng. Syst. i. 932 (sp, dub.).-Bras.

spinosissima, Miq. in Mart. Fl. Bras, iv. 1. 176.-Bras.

strychnoides, Planch. in Ann. Sc. Nat. Sér. III. (1848) $306=$ philippinensis.

subdentata, E. Mey. ex Planch. 1. c. $341=$ Chaetachme aristata.

sumatrana, Planch, in DC. Prod xvii. 181,-Sumatra.

Swartzii, Planch. in Ann. Sc. Nat. Sér. III. x. (1819

304.-Ins. S. Doming.

Tala, Gill. ex Planch. l. c. 310.-Am. austr.

tenuifolia, Nutt. Gen. Am. i. $202=$ pumila?

tenuifolia, Rafin. New Fl. Am, iii. $36=$ occidentalis

tetrandra, Roxb. Hort. Beng. 21 ; Fl. Ind. ii. 63.-Ind.

or.; Malaya.

tetrandra, Wall. Cat. $\mathrm{n}, 3695 \mathrm{~F}=$ Villcbrunea integrifolia.

texana, Scheele, in Linnaea, xxii. (1849) $1 \sharp 6=$ Berlandieri.

timorensis, Span. l. c. xv. (1841) 343.-Ins. Timor.

tomentosa, Koxb. Hort. Beng. 86; Fl. Ind ii. $60^{\circ}$

Trema amboinensis.

Tournefortii, Lam. Encyc. iv. 138 = australis.

triflora, Ruiz, ex Miq. in Mart. Fo. Bras. iv. I. 181.Peruv.

trinervia, Lam. Encyc. iv, 140 (=Sponia trinemeia)-

Ins. S. Doming.

trinervia, Roxb. Hort. Beng. 86,; Fl. Ind. ii. 65 tetrandra

urticifolia, Rafin. New F1. Am. iii. 32 =ocidentalis. velutina. Plarch. in Anrs. Sco. Vat. Ser. III. x. Isis 313.-Perny.

gesiculosa, Hochst, ex Planch. 1. c. 2:05 = Kraussiana

virgata, Roxb, in Wiall. Cat. a. S69t = Trems timorensis.

Haitsii, Blume, Mus. Bot. Lugrt. Rat. ii. $i 1$ = cinna momica.

Wallichis. Steud, Nom. ed. II. i. $\$ 10$ = tcerandm.

Wightii. Planch, in dnm. Se Mat. Sér. III. $x$ lsts S07.-Ind. or.; Malaya; Austral.

llilldenoriana, Rocm. Schult. Sist. vi. Sinto |ajponica.

Zipprelii, Planch, in DC. Provl. xvii. 185.-\$. Guinca. zizyphoides, Spreng. Syrs. i. y3:2. - X. Grange. 
CEMBRA, Opiz, Seznam, $27(1852)=$ Pinus, Tourn (Conif.).

montana, Opiz, 1. c. = P. Cembra.

CENARIUM, Linn. Amoen. Acad. iv. 121, in nota $(1759)=$ Canarium, Rumph. (Burser.).

CENARRHENES, Labill. Nov. Holl. P1. i. 36. t. 50 (1804). PROTEACEAE, Benth. \& Hook. fo iii. 176. nitida, Labill. l. c.-Austral.

paniculata, Brongn. E" Gris, in Bull. Soc. Bot. Fr. xii. (1865) 41.-N. Caled.

spathulaefolia, Brongn. Eo Gris, l.c.-N. Caled.

spathulata, Panch. \& Sebert, Not. Bois Nouv. Caléd.

$180=$ spathulaefolia.

CENCHRUS, Linn. Coroll. Gen. 20 (1737), GRA-

MINEAE, Benth. \& Hook. f. iii. 1105.

ECHisachys, Neck. Elem. iii. 228 (1790).

RARAM, Adans. Fam. ii. 35 (1763).

aegyptius, Beauv. Agrost. $157=$ Eleusine aegyptiaca.

agrimonoides, Trin. Diss. Gram. Panic. 72.-Ins. Societ.

alopecuroides, F. E C. Presl, Rel. Haenk. i. 317.Am. austr.

alopecuroides, Thunb. Prod. Pl. Cap. $24=$ Pennisetum Linnaei.

annularis, Anderss. in Peters, Reise Mossamb. Bot. 553.-Afr. trop.

anomoplexis, Labill. Sert. Austr. Caled. 14. t. $19=$ caly culatus.

asperifolius, Desf: Fl. Atlant. ii. $388=$ Pennisetum asperifolium.

australis, R. Br. Prod i. 196.-Austral.

barbatus, Schum. in Schum. E Thonn. Beskr. Guin. Pl. 43.-Afr. trop.

biflorus, Roxb. Hort. Beng. [81] ; Fl. Ind. i. 233.Ind, or.

brevisetus, Fourn. Mex. Pl. Enum. Gram. 50; ex Hemsl. Biol. Centr. Am. Bot. iii. 506.-Mexic.

Brownei, Roem. \& Schult. Syst. ii. $258=$ inflexus.

bulbifer, Hochst. ex Boiss. F1. Orient. v. 448 montanus.

bulbosus, Fresen. ex Steud. Nom. ed. II. i. $317=$ pennisetiformis.

calyculatus, Cav. Ic. v. 39. t. 463.-Polynes.

capitatus, Linn. Sp. Pl. $1049=$ Echinaria capitata

carolinianus, Walt. F1. Carol. $79=$ tribuloides.

catharticus, Delile, Cat. Hort. Monsp. (1838).-Cf

Linnaea, xiii. (1839) Litt. 103.-As. et Afr. trop.

Cavanillesi, Tausch, in Flora, xx. (1837) 97.-Bras

ciliaris, Fig. E De Not. in Mem. Acc. Torin. (1854) 383.-Nubia?

ciliaris, Linn. Mant. $302=$ Pennisetum cenchroides.

dactylolepis, Steud. Syn. P1. Gram. $109=$ viridis.

digynus, Ehrenb. ex Boiss. F1. Orient. v. $449=$

Pennisetum cenchroides.

distichophyllus, Griseb. Cat. Pl. Cub. 234.-Cuba.

echinatus, Cav. Ic. v. 39. t. $462=$ Cavanillesii.

echinatus, Linn. Sp. Pl. 1050.-Cosmop. trop.

echinatus, A. Rich. Tent. F1. Abyss. ii. $389=$ catharticus.

echinatus, Steud. ex Doell, in Mart. Fl. Bras. ii. II. $309=$ viridis.

echinatus, Torr. F1. N. Am. i. $68=$ tribuloides

echinoides, Wight, ex Steud. Nom. ed. II. i. $317=$ Pennisetum cenchroides.

Elliotii, Kunth, Rer. Gram. i. 51.-Am. bor.

elymoides, F. Muell. Fragm. viii. 107.-Austral

frutescens, Linn. Sp. Pl. 1050.-'Am.

frutescens, Sieber, ex Steud. Nom. ed. II. i. 317, nomen - Armenia.

fusiformis, Nees, in Nov. Act. Nat. Cur. xix. Suppl. i. (1843) $170=$ agrimonoides.

geniculatus, Thunb. Prod. Pl. Cap. $24=$ Pennisetum Thunbergii.

gracilis, Beauv. Agrost. 157, nomen,-Hab.?

granularis, Anderss. Enum. Pl. Ins. Galap. 140.-Ins Galapag.

granularis, Linn. Mant. ii. App. $575=$ Manisuris granularis.

heterochaetus, Steud.Syn. Pl. Gram. 110.-Hab.?

hexaflorus, Blanco, Fl. Filip. ed. I. $36=$ Pennisetum nigricans.

hirsutus, Spreng. Neue Entdeck, iii. $\mathbf{1 5}=$ Scleria hirtella.

hordeiformis, Rottl. ex Steud. Syn. Pl. Gram. $102=$ Pennisetum Alopecuros.

\section{CENCHRUS :}

hordeiformis, Thunb. Prod. PI. Cap. $24=$ Pennisetum compressum.

Hystrix, Fig. E De Not. in Mem. Acc. Torin. (1854) 382.-Nubia.

incertus, $M$. A. Curt. in Bost. Fourn. Nat. Hist. i. (1837) 135.-Am. bor.

inflexus, Poir. Encyc. vi. $50=$ Echinolaena hirta.

inflexus, R. Br. Prod.i. 195.-Austral.

laevigatus, Trin. Fund. Agrost. $172=$ Anthephora elegans.

laniflorus, Steud. Syn. Pl. Gram. 110.-Ins, Tahiti

lappaceus, Linn. Sp. P1. ed. II. 1488=Centotheca lappacea.

lappaceus, Tausch, in Flora, xx. (1837) 97.-Hab. ?

Lechleri, Steud. in Lechl. Berb. Am. Austr. 56.Peruv.

limensis, Meyen, Reise, ii. 71.--Peruv.

linearis, Lam. F1. Fr. iii. $631=$ Tragus racemosus.

longifolius, Hochst. ex Steud. Syn. Pl. Gram. 109.Nubia.

macrocarpus, Ledeb. ex Steud. Nom. ed. II. i. $317=$ echinatus.

macrostachyus, Hochst. ex Steud. Syn. Pl. Gram. 109. -Abyssin.

marginalis, Rudge, P1. Guian. 19. t. 25=Echinolaena hirta.

mitis, Anderss. in Peters, Reise Mossamb. Bot. 553. Afr. trop.

montanus, Nees, in Royle, Illustr. Bot. Himal. 416.As. et Afr. trop.

mucronatus, Pers. ex Steud. Nom. ed. I, $172=$ muricatus.

multiflorus, F. E C. Presl, Rel. Haenk. i. 318.-Mexic muricatus, Linn. Mant. $302=$ Trachys mucronata muricatus, Phil. Sert. Mend. Alt. 44.-Chili.

myosuroides, $H . B$. E K. Nov. Gen, et Sp. i. 115. t. 35 -Am. trop.

niloticus, Fig. \& De Not. in Mem. Acc. Torin. (1854) $380=$ catharticus

orientalis, Willd ex Kunth, Enum. Pl i. $162=$ Pennisetum orientale.

ovatus, Lam. ex Poir. Encyc. vi. 51.-Afr, austr.

pallidus, Fourn. Mex. Pl. Enum. Gram. 50 ; ex Hemsl. Biol. Centr. Am. Bot. iii. 509.-Mexic.

parviflorus, Poir. Encyc, vi. $52=$ Panicum Ventenatii pauciflorus, Benth. Bot. Voy. Sulph. $56=$ tribuloides.

pennisetiformis, Hochst. EO Steud. ex Steud. Nom. ed. II. i. 317.-Arabia.

pilosus, H. B. E K. Nov. Gen. et Sp. i. 116. t. 36.Am. austr.

platyacanthus, Anderss. Enum. Pl. Ins. Galap. 139.Ins. Galapag.

pubescens, Steud. Nom. ed. II. i. 317.-Afr. austr.

pungens, H. B. E K. Nov. Gen. et Sp. i. 115.Mexic.

purpurascens, Thunb. in Trans. Linn. Soc. ii. (1794) $329=$ Gynothrix japonica

pycnostachyus, Steud. Syn. Pl. Gram. 109.-Afr. trop. racemosus, Linn. Sp. Pl. 1049= Tragus racemosus.

ramosissimus, Poir. Encyc. vi. $51=$ Pennisetum dicho tomum.

rigidifolius, Fig. De Dot. in Mem. Acc. Torin. (1854) 386.-Nubia.

rigidus, Willd. ex Doell, in Mart. Fl. Bras. ii. rr. 310, in obs.-Bras.

roseus, Fourn. Mex. Pl. Enum. Gram. 50; ex Hemsl Biol. Centr. Am. Bot. iii. 507.-Mexic.

rufescens, Desf. F1. Atlant. ii. $388=$ Pennisetum cenchroides.

Schimperi, Hochst. \& Steud. ex Steud. Nom. ed. II. i. $317=$ montanus

setigerus, Steud. 1. c. = Pennisetum Vahlii.

setigerus, Vahl, Enum. ii. $395=$ agrimonoides.

setosus, Sw. Prod. Veg. Ind. Occ, $26=$ Pennisetum setosum.

spicatus, Cav. Desc. 304, $614=$ Pennisetum typhoideum.

spinifex, Cav. Ic. v. 38. t. $461=$ tribuloides.

strictus, Chapm. in Coult. Bot. Gaz. iii. (1878) $20=$ incertus.

taitensis, Steud. Syn. Pl. Gram. 419.-Ins. Tahiti.

tomentosus, Poir. Encyc. vi. 51.-Afr. austr.

tribuloides, Linn. Sp. Pl. 1050.-Am. bor.

tripsaceus, Herb. Linn. ex Munro, in Journ. Linn. Soc. vi. (1862) $55=$ Trachys mucronata.

tripsacoides, R. Br. in Salt, Abyss. App. $62=$ montanus.

\section{CENCHRUS :-}

uniflorus, Ehrenb. ex Boiss. Fl. Orient. v. 448 montanus.

vaginatus, Steud. Syn. Pl. Gram 110-Hab. villosus, Spreng. Syst. i. $301=$ Anthephora elegans viridis, Spreng. l. c.-Am. trop.

ČEŇ̌KIA, Opiz, Seznam, 36 (1852) = Campanula Tourn.

rapunculoides, Opiz, 1. c. =Camp. rapunculoides simplex, Opiz, l. c.=Camp. bononiensis.

CENIA, Comm. ex Juss. Gen. 183 (1789). COM. POSITAE, Benth. \& Hook. f. ii. 429.

Lancisia, Gaertn. Fruct. ii. $422(1791)$

anthemoidea, DC. Prod vi. $83=$ turbinata.

barbata, Benth. Ev Hook. f. Gen. ii. 430.-Afr. austr.

debilis, DC. Prod. vi. 83 = turbinata.

discoidea, Less. Syn. Comp. $261=$ Cotula nudicaulis.

discolor, DC. Prod. vi. $82=$ sericea.

flosculosa, DC. 1. c. $83=$ microglossa.

geminata, Kunze, Del.Sem. Hort. Lips. (1846) 1.-Afr. austr.

hispida, Benth. E Hook.f. Gen. ii. 430.-Afr. austr.

microcephala, E. Mey. ex DC. Prod. vi. 79.-Afr austr.

microglossa, $D C$. l.c. 83,-Afr. anstr.

nudicaulis, E. Mey. ex Heynh. Nom, ii. 130 = Cotula nudicaulis.

pectinata, $D C$. Prod. vi. 83.-Afr, austr,

pruinosa, DC. 1. c. $82=$ turbinata.

sericea, $D C$. l. c.-Afr. austr.

subheterocarpa, Less. Syn. Comp. $261=$ turbinata.

Thunbergii, Benth. E Hook. f. Gen. ii. 430.-Afr. austr.

turbinata, Pers. Syn. ii. 465.-Afr. austr.

villosa, Heynh. Nom. ii. $130=$ Cotula villosa.

CENOCLINE, C. Koch, in Bot. Zeit. i. (1843) $41=$ Cotula, Tourn. (Compos).

acutiloba, C. Koch, 1. c. = Matricaria acutiloba,

albida, C. Koch, 1. c. = Matricaria albida.

aurea, C. Koch, 1. c. = Matricaria aurea

chamaemelifolia, C. Koch, 1. c. = Cotula chamaemeli folia.

cinerea, C. Koch, 1. c. = Cotula cinerea.

globifera, C. Koch, 1. c. = Matricaria globifera

grandiflora, C. Koch, 1. c. = Matricaria grandiflora,

pauciflora, C. Koch, 1. c. = Matricaria discoidea.

CENOLOPHIUM, Koch, Gen. Umbell. $103(1824)=$ Selinum, Linn. (Umbellif.)

divaricatum, Bess. in Flora, xv. (1832) II. Beibl. $27=$ Fischeri.

Fischeri, Koch, Gen. Umbell. 103.-Rossia; Reg. Caucas.; As. bor.

lapponicum, Nyl. ex Nyl. \& Sael. Herb. Mus. Fenn. $33=$ Fischeri.

CENOLOPHON, Blume, Enum. P1. Jav. $60(1830)=$ Alpinia, Linn. (Scitamin.).

rubrum, Blume, $\mathrm{I}_{\mathrm{c}} \mathrm{c}=\mathrm{A}$, rubra.

vitellinum, Horan. Prod. Scitam. $\mathbf{3 6}=$ Amomum vitellinum.

CENOSTIGMA, Tul. in Ann. Sc. Nat. Sér. II. xx. 140. t. 3 (1843), LEGUMINOSAE, Benth. \& Hook. f i. $56^{2} 4$.

angustifolium, Tul. 1. c. $141=$ Gardnerianum.

Gardnerianum, Tul.l.c.-Bras.

macrophyllum, Tul.l. c.-Bras.

CENTAUREA, Linn. Gen. ed. I. 263 (1737) (Centauria). COMPOSITAE, Benth. \& Hook. f. ii. 477.

Acrocentron, Cass, in Dict. Sc. Nat. xliv. 37 (1826).

ACrolophus, Cass. 1. c. 1.253 (1827)

Acroptilon, Cass. 1. c. 464 (1827).

Aegialophila, Boiss. \& Heldr. Diagn. Ser. I, x. $105(1849)$.

Aethecpappus, Cass. in Dict. Sc. Nat. 1. 250 (1827).

Alophium, Cass. 1. c. liv. 493 (1828)

Amblyopogon, Fisch. \& Mey. ex DC. Prod. vi. 561 (1837).

Avtaurea, Neck. Elem, i. 70 (1790)

Bielzia, Schur, Enum. Pl. Transs. 409 (1866). 


\section{CENTAUREA :}

Calcrtrapa, Hall. Enum. Stirp. Helv. ii. 689 (1742).

Callicephalus, C. A. Mey。 Verz. Pf. Cauc. 66 (1831).

Centaurium, Tourn. ex Linn. Syst. ed. I (1735).

Cestrinus, Cass. Bull. Soc. Philom. 33 (1817); et in Dict. Sc. Nat. viii. 24 (1817).

Chartolepis, Cass. Dict. Sc. Nat. xliv, 36 (1826).

Cheirolepis, Boíss. Diagn. Ser. I, x. 106 (1849).

Cheirolophus, Cass, in Dict. Sc. Nat. 1. 250 (1827).

Chryseis, Cass. I. c. ix. 154 (1817).

Colymbada, Hill, Veg. Syst, iv, 31 (1762).

Crepula, Hill. 1. c. 9 (1762).

Crocodilium, [Vaill.] Juss. Gen。 173 (1789).

Cyanus, [Tourn.] Linn. Syst. ed. I (1735); Juss.

Gen. $174(1789)$.

ERIOPHA, Hill, Hort. Kew. 69 (1769).

Fornicium, Cass. in Bull. Soc. Philom. 93 (1819); et in Dict. Sc. Nat. xvii. $249(1820)$

Halocharis, Bíeb. ex DC. Prod. vi. 665 (1837)

Heracle., Hill, Veg. Syst. iv. 37 (1762).

Heterolophus, Cass. in Dict. Sc. Nat. 1. 250 (1827).

Hippophaestum, S. F. Gray, Nat. Arr. Brit. P1. ii. 443 (1821).

HOOKIA, Neck. Elem. i. 70 (1790).

Hyalea, Jaub. \& Spach, Illustr, iii. 19, t. 214, 217 $292(1847)$.

Hymenocentron, Cass. in Dict. Sc. Nat. xliv. 37 (1826).

Hymenocephalus, Jaub. \& Spach, Illustr. iii. 12.t. 209 (1847).

JACEA, [Tourn.] Linn. Syst. ed. I (1735) ; Juss. Gen. $173(1789)$

LEPTERANTHUS, Neck. Elem. i. 73 (1790).

Leucantha, S. F. Gray, Nat. Arro Brit. Pl. ii. 443 (1821).

Lopholoma, Cass. in Dict. Sc. Nat. xliv, 37 $(1826)$

Malacocephalus, Tansch, in Flora, xi. (1828) II. 481.

Mantisalca, Cass. in Bull. Soc. Philom. (1818) 142.

Melanoloma, Cass. in Dict. Sc. Nat. xxix. 472 (1823).

Menomphalus, Pomel, Nouv. Mat. Fl. Atl. 32 (1874).

Mesocentron, Cass, in Dict. Sc. Nat. xliv. 38 (1826).

Microlonchus, Cass. 1. c. (1826); 1. 247 (182

Microlophus, Cass, 1. c. xliv. 37 (1826).

ODONTOLOPHuS, Cass, l. c. 1.252 (1827)

Pachycentron, Pomel, Nouv. Mat. Fl. Atl. 32 (1874).

Pectinastrum, Cass. in Dict. Sc. Nat. xliv. 38 (1826).

Phaeopappus, Boiss. Diagn. Ser. I. vi. 122 (1845).

Phalolepis, Cass. in Dict. Sc. Nat. 1. 248 (1827).

Philostizus, Cass. 1. c. xxxix. 498 (1826).

Ping gia, S. F. Gray, Nat. Arr. Brit. Pl. ii. 441 (1821).

Piptoceras, Cass. in Dict. Sc. Nat. 1. 469 (182 $\bar{i}$ ).

Platylophus, Cass. I. c. xliv, $36(1826)$.

Plectocephalus, D. Don, in Sweet, Brit. Fl. Gard. Ser, II. t. 51 (1838)

PSORA, Hill, Veg. Syst. iv. 30 (1762).

PolyaCantha, S. F. Gray, Nat. Arr. Brit. Pl. ii. 443 (181).

PTERolophus, Cass. in Dict. Sc. Nat. xliv. 34 (1826).

Ptosimopappus, Boiss. Voy. Bot. Espagne, 739 $(1839-45)$

Psephellus, Cass。 in Dict. Sc. Nat. xliii. 488 (1826.

Poon, Neck. Elem, i. 72 (1790)

Pycnocomus, Hill, Syst. Veg, iv, 38 (1762)

RhAPONTICA, Hill. 1. c. 47 (1762).

RHAPONTICUM, [Vaill.] Adans. Fam. ii. 117 (1763); Juss. Gen. 174 (1789).

SF:RII)IA, Juss, Gen. 173 (1789).

SetachNa, Dulac, Fl. Hautes-Pyr. 518 (1867).

SAGMEN, Hill, Ver. Syst, iv, 351762 .

Spilacron, Cass, in Dict. Sc. Nat. 1. 238 (1827).

Solstitiaria, Hill, Veg. Syst. iv, 21 (1762).

Sphaerocerhala, Hill, l. c. 48 (1762)

Stenolophus, Cass. in Diet. Sc. Nat. 1. 499

(1827).

\section{CENTAUREA}

Stizolophus, Cass. in Dict. Sc. Nat. xliv. 35

(1826), nomen; li. 49 (1827)

Staebe, Hill, Veg. Syst. iv. 33 (1762).

TetramorpHaEA, DC in Guill, Arch, Bot, ii (1833) 331.

TOManTHEA, DC. Prod. vi. 564 (1837)

Triplocentron, Cass. in Dict. Sc. Nat. xliv. 38 (1826)

VELTIS, Adans, Fam ii, 116 (1763)

Verutina, Cass. in Dict. Sc. Nat, xliv, 38 (1826).

Xanthopsis, C. Koch, in Linnaea, xxiv. (1851) 42 ? abrotanifolia, Lam. Encyc. i. $670=$ paniculata.

abyssinica, Sch. Bip. ex Boiss. Diagn. Ser. II. iii. 62. -Abysin.

acanthodes, Spreng. Syst, iii. 403,-Hab.

acaulis, Cav. ex Willk. \& Lange, Prod, Fl. Hisp it

$150=$ Cavanillesiana.

acaulis, Forsk. Fl. Aegypt. Arab. $52=$ glomerata.

acaulis, Haensel. ex Willk. \& Lange, Prod. Fl. Hisp.

ii. $151=$ Haenseleri.

acautis, Lag. 1. c. = Graelsii.

acaulis, Linn. Sp. Pl. 914.-Afr. bor.

achaia, Boiss. E Heldr. Diagn. Ser. II. iii. 79.Giraecia.

acicularis, Sibth. E Sm. Fl. Graec. t. 911.-Archip Graec.

acmophylla, Boiss. Diagn. Ser. II. iii. $68=$ axillaris.

acrolepis, Hoffmgg. ex Heynh. Nom. ii. 131, nomen.-

Hab.?

acromaura, Hoffmgg. ex Heynh. l.c. nomen.-Hab.?

acuta, Lam. FI. Fr. ii. $49=$ Crupina vulgaris.

acuta, Vahl, ex Bieb. Casp. $82=$ C. Behen.

acutangula, Boiss. Er Reut. Pugill. Pl. Nov. (1852) 68.

$$
\text { -Hispan. }
$$

acutifolia, Jord. Pugill. 105 = pectinata.

acutifolia, Schur, Enum. Pl. Transs. 899, Index = plumosa.

acutiloba, DC. Prod. vi, $581=$ cristata.

Adami, Willd. Sp. Pl, iii. $2310=$ solstitialis.

adonidifolia. Reichb, in Moessl. Handb, ed. II. ii.

$1545=$ rupestris.

adpressa, Ledeb. ex Steud. Nom. ed. II. i. $316=$ stereophylla.

adulterina, Moretti, ex DC. Prod. vi. 596=C. Calcitrapa.

aegialophila, Boiss. \& Heldr. ex Boiss. Fl. Orient. iii. $704=$ cretica.

aegyptiaca, Linn.Mant. i. 118.-Aegypt.; Arab. aegyptiaca, Sibth. \& Sm. Fl. Graec. t. $907=$ iberica. aeolica, Guss. ex DC. Prod, ví. $584=$ aplolepis.

affinis, Frivald, in Flora, xix. (1836) $435=$ dissecta.

africana, $L a m$. Encyc, is 664.-Afr, bor

aggregata, Fisch. E Mey. in DC. Prod. vi. 585.-As.

Min.; Persia.

Aichingeriana, Welw. ex Reichb. Fl. Germ. Excur $848=$ variegata.

ainetensis, Boiss. Diagn, Ser. I, x. $117=$ =ryngioides.

alata, Lam. Encyc, i. $665=$ C. Behen.

alba, Bieb. Fl. Taur. Cauc. ii. $353=$ sterilis

alba, Herb. Calc. ex C. B. Clarke, Comp. Ind. $239=$ Tricholepis elongata.

alba, Linn.Sp. Pl. 914.-Eur. austr.; Reg. Caucas.

alba, Suter, Fl. Helv. ii. 204 = amara.

albida, C. Koch, in Linnaea, xxiv. (1851) $433=$ aggregata.

albiflora, C. Koch, 1. c. $430=$ carduiformis,

alexandrina, Delile, Fl. Egypte, 280, t. 49. f. 3.Aegypt.

algeriensis, Dur. E Coss. Notes Pl. Crit. 136.-Algeria

Alophium, DC. Prod. vi. 601.-Hispan

alpestris, Hegetschw. F1. Schw. $854=$ C. Scabiosa.

alpina, Linn. Sp. Pl. 910-Europ.

altaica, Fisch. ex Spreng. Pugill. i. $59=$ Leuzea salina.

amaena, Boiss. \& Bal. Diagn. Ser. II. vi. $112=$ amoena.

amara, Habl. Taur. $155=$ trinervia.

amara, Linn. Sp. Pl. ed. II. 1292.-Europ. austr.; As. Min.

Amberboi, Mill. Gard. Dict. ed. VIII. n. $9=$ mos. chata.

ambigua, Guss. Ind. Sem. Hort. Boccad. (1826) 8 ; ex DC. Prod. vi. 582.-Italia.

ambigua, Thom. $\mathrm{ex}$ 1)C. 1. c. $573=$ nervosa.

amblensis, Graclls, in Mem. Acad. Cicnc. Madr. ii (1859) $462,-$ Hispan

amblyolepis, Ledeb. Fi. Ross, ii. 703.-Reg. Caucas.

\section{CENTAUREA :-}

ambracea, Schkuhr, Handb. t. $261=$ moschata. americana, Nutt. in Fourn. Acad. Philad. (1821) 117. -Am. bor.

americana, Spreng. Syst. iii. $407=$ melitensis

ammocyanus, Boiss. Diagn. Ser. I. x. 109.-Arab. Palaest.

ammophila, Bess. ex DC. Prod. vi. 586=diffusa.

amoena, Boiss. \& Bal. Diagn. Ser. II. vi. 112.Cappadoc.

Amoi, Campo, ex Campo \& Amo, in Revista, v. (1855 $56=$ Buissieri.

amourensis, Pomel, Nouv. Nat. Fl. Atl. 30.Algeria.

amplexicaulis, S. G. Gmel. It. i. 136. t. $24=$ Jurinea polyclonos.

amplifolia, Boiss. E Heldr. Diagn. Ser. II. iii. 68.Graecia.

anatolica, Griseb. Spicil. Fl. Rumel. ii. $231=$ depressa.

angulosa, Pomel, Nouv. Mat. Fl. Atl. 26.-Algeria.

angustifolia, Mill. Gard. Dict. ed. VIII. ․ $7=$ montana.

angustifolia, Schrank, Baier. Fl. ii. $376=$ amara

antennata, Dufour, in Ann. Sc. Nat. Sér. I. xxiii. (1831) 158.-Hispan.

antiochia, Boiss. Diagn. Ser. I. x. 115.-Syria.

aphrodisea, Boiss. l. c. iv. 17.-Caria.

apiculata, Ledeb. Ind. Hort. Dorp. Suppl. (1824) 3

C. Scabiosa.

aplolepis, Moretti, in Brugnat. Giorn. Fis. II. 1826) 154.-I talia.

appendicigera, C. Koch, in Linnaea, xxiv. (1851) 425

$=$ Balansae.

Apula, Lam. Encyc. i. $674=$ melitensis

arachnoidea, Viv. Ann. Bot. i. 11. $185=$ rupestris.

arancosa, Boiss. Diagn. Ser. I. x. 121.-Syria.

arborea, Webb E Berth. Phyt. Canar. ii. 356.-Ins. Canar.

arenaria, Bieb. Fl. Taur. Cauc, ii. 347.-Europ. or. Reg. Caucas.

arenaria, Reichb. P1, Crit, v, 26. t. 443. f, $634=$ Reichenbachii.

arenaria, Urv. in Mém. Soc. Linn. Par. i. (1522) 371 = polyclada.

argentea, Frivald. ex Nym. Consp. $429=$ rupestris, argentea, Linn. Sp. Pl. 912.-Ins. Creta et Istria. argophylla, Steud. Nom. ed. I. $173=$ argyrophylla. arguta, Nees, Hor. Phys. Berol. 116. t 25.-Ins. Canar.

argyrophylla, Willd. Enum. Hort. Berol. Suppl. 61.Hab. ?

arifolia, Boiss, Diagn. Ser. I x 112.-Syria.

aristata, Benth. E Hook. f. Gen. ii. 480.-Cappadoc.

aristata, Hoffmgg. \& Link, Fl. Port. ii. $226=$ caeru. lescens.

Armena, Boiss. Fl. Orient. iii. 676.-As. Min.

armoracifolia, Sibth. \& Sm. Fl. Graec. Prod. ii 205.Graccia.

arrectispina, Bertol. Fl. Ital, ix $487=\mathrm{C}$. Calcitraps.

aspera, Linn. Sp. Pl. 916.-Europ. austr.

astrachanica, Spreng. Syst. iii. $39 \overline{7}=$ stereophylla.

athoa, DC. Prod. vi. $588=$ rupestris.

atlantica, Pomel, Nowv. Mat. F\%. Atl. 283.-Algeria.

atrata, Willd. Sp. Pl. iii. $2290=$ axillaris.

atropurpurea, Griseb. Spicil. F1. Rumel. ii. $287=$ C. Scabiosa.

atropurpurea, Olivier, Voy. i. 818 = Olivieriana.

alropurpurea, Waldst. E Kit. Pl. Rar. Hung. ii. 12]. -Hungar.

atropurpurea, St. Lag, in An. Soc. Bot. Lyon, vii. (1580 65, $122=\mathrm{C}$. Centaurium.

attica, Nym. Syll. $38=$ graeca

Aucheriana, $D C$. Prod. vi. 5i6.-Assvr.

augustara, Reichb. f. Ic Fl. Germ. xv. \$i. C. : $: 5$. maculusa.

aurea, [Dryand, int] Ait. Hort. KNos. cd. I. iii. 205.Europ. austr.

aurea. Hort, ex Sicud. Nom, ed. II. j. $318=$ nicacensis auriculasa, Ralt. ex Pers. Sin. ii. $180^{\circ}=$ C. Seridis. auriculata, Spreng. Pugill. i. 59 - stereuphylla. australis, Bernth. E Hook. f. Gens. ii. 1;y.-Aussral. australis, Panc. Elcm. $1 t=$ sublanata. australis, Puepp. ex IXC. I'rud. vi. $575=$ chilensis. austriaca, C. A. Mey. Vicre 1'A. Cauc, 6t-ericho cephlialn.

ausfriacn, Kcichb. Ic. Fl. Cicrm. xv. \$i. e. is5, 3-1 = pbrygia. 


\section{CENTA UREA}

austriaca, Rochel, P1, Banat. Rar, 76, t. 36, f. $5=$ nervosa.

austriaca, Willd. Sp. Pl. iii. 2283.-Europ.; Reg Caucas. ; As. bor.

axillaris, Willd.l.c. 2290.-Europ.; Oriens.

babylonica, Bieb. Casp. $82=$ C. Behen.

babylonica, Linn. Mant. ii. 460_-As. Min.; Syria. badensis, Tratt. Arch. Gew. i. $28=$ C. Scabiosa.

Balansae, Boiss. E Reut Diagn. Ser. II. iii. 82.Afr. bor.

baldensis, Pers. Syn. ii. $481=$ alpina

balearica, Rodrig. in Bull. Soc. Bot. Fr. xvi. (1869) 237. -Ins. Minorca.

Balsamita, D. Don, in Sweet, Brit. Fl. Gard. Ser. II.t $355=$ Phaeopappus spectabilis.

Balsamita, Lam. Encyc. i. 667.-As. Min.; Persia. banatica, Kern. ex Nym. Consp. 427 =arenaria. barbara, Pomel, Nouv. Mat. Fl. Atl. 27.-Algeria. Barrelieri, Dufour, in Ann. Gén. Sc. Phys. vii. (1820) 301 = Serratula pinnatifida.

Barrelieri, Spreng. Syst. iii. 403.-Hungar

Behen, DC. Prod, vi. $567=$ Szovitsiana

Behen, Lam. Encyc. i. $665=$ cerinthifolia.

Behen, Linn. Sp. Pl. 914.-As. Min.; Syria; Persia.

Belangeriana, Stapf, in Denkschr. Acad. Wien, I

(1885) $66=$ phyllocephala.

bella, Trautv. in Bull. Acad. St. Pétersb. x. (1866) 394.-Reg, Cancas.

benedicta, Linn. Sp. P1. ed. II. $1296=$ Carbenia bene dicta.

Berini, Sieber, ex Steud. Nom. ed. II. i. $319=$ nervosa.

Besseriana, DC. Prod. vi. 585.-Europ. or.

Besseriana, Janka, ex Nym. Consp. $427=$ tenuifora.

bicolor, C. Koch, in Linnaea, xxiv. (1851) 428.-Reg. Caucas.

Biebersteinii, DC. Prod. vi. $583=$ maculosa

Biebersteini, Schur, Verh. Siebenb. Ver. Naturf 1859) $75=$ Reichenbachii.

biflora, Kalen. in Bull. Soc. Nat. Mosc. xviii. (1845) I. 237.-Astrakhan

bimorpha, Viv. Fl. Lib. Spec. 58.t. $24=$ sonchifolia.

Boissieri, DC. Prod. vii. 303.-Hispan.

Boissieri, Walp. Rep. vi, $298=$ graeca.

bombycina, Boiss. in DC. Prod. vii. 302.-Hispan.

borealis, Salisb. Prod. $208=$ C. Scabiosa.

borysthenica, Gruner, in Bull. Soc. Nat. Mosc. xli. 1868) II. 426. - Tauria.

Bourgaei, Boiss. Fl. Orient. iii. 637.-Lycia.

Bourgaei, Schult. ex Nym. Consp. $426=$ Langei.

Brachtii, Reichb. f. Ic. Fl. Germ. xv. 35. t. $786=$ mact losa.

brachyptera, DC. Prod. vi. $567=$ C. Behen

bracteata, Balb. ex Steud. Nom. ed. II. i. $319=$ nigrescens.

bracteata, Benth. E' Hook. f. Gen. ii. 481.-Syria.

bracteata, Scop. Delic. Insub. ii. $17=$ amara.

brevicaulis, Boiss. Diagn. Ser, I. x. $120=$ pallescens.

brevipappa, Boiss. \& Reut. 1. c. Ser. II. iii. $71=$ nigtescens.

Brosseana x, Bonnet, in Bull. Soc. Bot. Fr. xxvii. (1880) p. xi.-Gallia.

Bubanii, Timb. in Mém. Acad. Sc. Toul. Sér. VIII i. II. (1879) $187=$ caerulescens

budziackca, Tardent, Ess. Hist. Nat. Bessar. 61, nomen.--Bessarab.

bulbosa, Hook. Es Arn, in Hook. Comb. Bot. Mag. i. (1835) 111-Chili.

busambarensis, Guss. Fl. Sic. Syn. ii. 873.-Sicilia.

cachinalensis, Phil. Fl. Atac. 34.-Chili.

cadmea, Boiss. Diagn. Ser. I. iv. 16.-Caria

caerulescens, Willd.Sp.Pl. iii. 2319.-Europ. austr.

caespitosa, Cyrill. P1. Neap. Nov. Fasc. i. $24=$ sphaero cephala.

calalepis, Boiss. in Tchihat. Asie Min. Bot. t. 31.As. Min.

calcaria, Jord. Obs. Pl. Crit. vii. (1849) $32=$ C. Scabiosa.

Calcitrapa, Bieb. F1. Taur. Cauc. iii. $594=$ iberica

Calcitrapa, Linn.Sp.Pl. 917.-Europ. ; Afr. bor.; As. temp.

calcitrapoides, DC. Prod, vi. $597=$ iberica.

calcitrapoides, Gouan, Fl. Monsp. $461=$ Pouzini.

calcitrapoides, Linn. Cent. i. 29 ; Amoen. Acad. iv. 291,-Reg. Caucas.; As. Min.

calcitrapoides, Thuill F1. Par, $446=$ C. Calcitrapa

calendulacea, Lam. Encyc. i. $668=$ Zoegea leptaurea

\section{CENTAUREA}

alliacantha, Fisch. \& Mey, in Ann. Sc. Nat. Sér. IV. (1854) $32=$ patula

calocephala, Willd. Enum. Hort. Berol. $928=$ atropur purea.

calolepis, Boiss. Diagn. Ser. I. vi. $129=$ diffusa. calophylla, Steud. Nom. ed. I. 173=atropurpurea.

calva, Ledeb. ex DC. Prod. vi. 583.-Mont. Altai.

calva, Reut. ex Nym. Consp. $420=$ alba

cana, C. A. Mey. ex Steud. Nom. ed. II. i. $320=$ Lede bourii

cana, Sibth. \& Sm. Fl. Graec. Prod. ii. 198=axillaris canadensis, Hort. Huber, ex Regel, Ind. Sem. Hort. Petrop. (1866) 90.-Am. bor.

Canariensis, Willd Enum. Hort. Berol. 928-..Ins. Teneriff.

cancellata, Sieber, ex Spreng. Syst. iv. 406=aegyptiaca.

candidissima, Lam. Encyc. i. $669=\mathrm{C}$. Cineraria Candolleana, Boiss. Diagn. Ser. I. vi. 127.--Persia.

Candollei, C. Koch, in Linnaea, xxiv. (1851) 424.Reg. Caucas.

capillata, Linn. Sp. Pl. 910 (sp. dub.).-Sibir.; Hispan cappadocica, DC. Prod. vi. 595.-As. Min.

caprina, Stev. in Bull. Soc. Nat. Mosc. xxix. (1856) II. $394=$ ovina.

carduifolia, Salisb. Prod. $208=$ C. Calcitrapa

carduiformis, DC. Prod. vi. 590.-As. Min.; Persia.

carduncella, DC. I. c. $591=$ raphanina

Cardunculus, Boiss. Diagn. Ser. I. vi. 135.-Assyria

Cardunculus, Pall. Reise, i. 500 - Serratula glauca.

Carduus, Forsk. Fl. Aegypt. Arab. 152=Atractylis flava.

Carelli, Ucria, in Roem. Arch. i. 70.-Sicilia. cariensis, Boiss. Diagn. Ser. I. iv. 19.-As. Min. carneola, Boiss. l. c. Ser. II. iii. 83, -Cilicia.

carniolica, Host, F1. Austr. ii. $517=$ montan

caroliniana, Walt. F1. Carol. 214=americana

carpathica, Geners. Elem. n. $824=$ montana

carpatica, Floriaño, in Magyar Növént. Lapok, ix. 1885) 128.-Hungar.

carpetana, Boiss. \& Reut. Pugill. Pl. Nov. (1852) 65 = nigra.

carratracensis, Langé, in Kjoeb. Vidensk. Meddel. (1881) 94.-Hispan.

carthamoides, Benth. E Hook. f. Gen. ii. 479.-Sibir.

cassia, Boiss. Diagn. Ser. I. x. 108. - Syria.

Castellana, Boiss. l. c. vi. 129.-Hispan

cataonica, Boiss. E Haussk. ex Boiss. Fl. Orient. iii. 669.-Cataonia.

caucasica, Bieb. ex DC. Prod. vi. $579=$ montana

Cavanillesiana, Graells, in Mem. Acad. Cienc. Madr. ii. (1859) 464--Hispan.

Ceccariniana, Boiss. E Heldr. Diagn. Ser. II. ii.. 81.Macedon.

Centaurium, Host, ex Nym. Consp. $417=$ Serratula coronata.

Centaurium, Linn. Sp. Pl. 910.-Italia.

centauroides, Bieb. Fl. Taur. Cauc. ii. $359=$ saloni tana.

centauroides, Linn. Sp. Pl. 918.-Europ.

cephalariaefolia, Willk. in Flora, xxxiv, (1851) 762.-

Hispan.

ceratophylla, Moris, Elench. i. $55=$ filiformis

ceratophylla, Tenore, Cat. Hort. Neap. (1819) $72=$ rupestris.

cerinthifolia, Sibth. \& Sm. F1. Graec. Prod. ii. 197.Graecia.

chamaerhaponticum, Ball, in Fourn. Linn. Soc. xvi. (1878) 526.-Marocco.

Chaubardi, Reichb. f. Ic. F1. Germ. xv. 34. t. $781=$ maculosa.

cheiracantha, Fenzl, ex Boiss. Fl. Orient, iii. 693.-As. Min.; Syria.

cheiranthifolia, Willd. Phytog. 12 = axillaris.

chilensis, Bert. ex Bull. Férussac (1830), 109, nomen et ex Hook. EN Arn. in Bot. Beech. Voy. i. 33.Chili.

chlorantha, Adams, ex Ledeb. Fl. Ross. ii. $699=$ mon. tana.

Choulettiana, Pomel, Nouv. Mat. Fl. Atl. 31.Algeria.

chrysanthemifolia, Tausch, in Flora, xii. (1829) I. Erg. 43.-Hab. ?

chrysoleuca, Boiss. Diagn. Ser. I. iv. 21, in textu ; Fl. Orient. iii. 678.-As. Min.

chrysolepis, Vis. in Mem. Ist. Venet. ix. (1860) $172=$ orientalis.
CENTAUREA :-

chrysolopha, Boiss. \& Kotschy, Diagn. Ser. II. iii. $75=$ aggregata.

chthonocephala, Boiss. F1. Orient. iii. $677=$ ustulata.

cichoracea, Linn. Syst. ed. V. $1231=$ Serratula cichoracea.

ichoracea, Stev. in Mém. Soc. Nat. Mosc. iv. (1813) $66=$ Serratula caucasica

cicutaefolia, Hornem. Hort. Hafn. ii. $849=$ collina

ciliata, Frivald, in Flora, xviii. (1835) $334=$ pallida

cilicica, Boiss. है Bal. Diagn. Ser. II. v. 113.-Cilicia. Cineraria, Jacq. ex Nym. Consp. $425=$ cinerea.

Cineraria, Linn. Sp. Pl. 912.-Europ.; Afr. bor.

Cineraria, Pall. Tabl. Taur, $58=$ declinata,

Cineraria, Urv, in Mém. Soc. Linn. i. (1822) $371=$ rutifolia.

cinerascens, Bubani, in Nuov. Giorn. Bot. Ital. v (1873) 319.-Hispan

cinerea, Griseb. Spicil. Fl. Rumel. ii. $236=$ dissecta.

cinerea, Lam. Encyc. i. 669.-Italia.

cirrata, Reichb. Fl. Germ. Excurs. 214.-Europ. austr.

Clementei, Boiss. in DC. Prod. vii. 303.-Hispan. coarctata, Spreng. Syst. iii. $407=$ glomerata.

cochinchinensis, DC. Prod. vi. 601.-Cochinch.

coelolepis, Fisch. E Mey. ex Heynh. Nom. ii. 130, nomen.-Rossia.

collina, Asso, Syn. $127=$ ornata.

collina, Linn. Sp. Pl. 918.-Reg. Mediterr.

collina, Schur, Enum. Pl. Transs. $408=$ psendo-collina.

collina, Scop, ex Nym. Consp. $429=$ rupestris.

collina, Sibth. \& Sm. Fl. Graec. t. $914=$ salonitana

comata, Jord, Pugill. $106=$ pectinata.

commutata, Timb. ex Nym. Consp. $421=$ nigra.

Comperiana, Stev. in Bull. Soc. Nat. Mosc. xxix (1856) II. $393=$ diffusa.

concinna, Trautv. in Act. Hort. Petrop. ii. (1873) 553. -Armenia.

concinna, Willd. ex Steud. Nom. ed. II. i. $319=$ pul cherrima.

congesta, Willd. ex DC. Prod. vi. $593=$ melitensis

conglomerata, C. A. Mey. in Beitr. Pf. Russl. v. 44. -Rossia.

conifera, Linn. Sp. Pl. 915.--Reg. Mediterr.

conocephala, C. Bolle, in Bonplandia, viii. (1860) 134. - Ins. Canar

consanguinea, DC. Prod. vi. 585.-As. Min

consimilis, Por. F1. Cent. Fr. ed. III. ii. $351=$ C. Jacea contracta, Viv. Fl. Lib. Spec. 58.t. 24. f. 1, $2=$ Delilei. Cordonis, Boiss. \& Orph. ex Boiss. Fl. Orient. iii. 663 $=$ Ceccariniana

coriacea, Waldst. \& Kit. P1. Rar. Hung. ii. $214=$ C. Scabiosa.

corinthiaca, Boiss. \& Heldr. Diagn. Ser. II. vi. $113=$ achaia.

Conuti, Reichb. Hort. t. $146=$ alpina.

coronopifolia, Lam. Encyc. i. 667.-Iberia.

corymbosa, Pourr. in Mém. Acad. Sc. Toul. iii. (1788 $310=$ maculosa

Cossoniana, Ball, in Fourn. Bot. xi. (1873) 369.Marocco.

Costae, Willk. in Linnaea, xxx. (1859-60) 115.Hispan.

crassifolia, Bertol. in Ann. Stor. Nat. ii. (1829) 359. -Ins. Melita

cretica, Nym. Syll. 34.-Ins. Creta.

cretica, Spreng. Syst. iii. $408=$ Carthamus creticus.

crinita, Willd ex Spreng. l. c. 400.-Hab.

cristata, Bartl. in Wendl. Beitr. ii. 119.-Austria

crithmifolia, Vis. Fl. Dalmat. ii. 40.-Dalmatia.

crocodylioides, Boiss. Diagn. Ser. I. x. $118=$ C. Crocodylium.

Crocodylium, Linn. Sp. Pl. 919.-Syria.

cruenta, Willd. Enum. Hort. Berol 929,-Hab. ?

Crupina, Bory \& Chaub. Nouv. F1. Pélop. $59=$ Crupina pseudocrupina.

Crupina, Desf. Fl. Atlant. ii. $292=$ Crupina intermedia. Crupina, Linn. Sp. Pl. $909=$ Crupina vulgaris.

Crupina, Sibth. \& Sm. Fl. Graec. t. y00-Crupina Crupinastrum.

Crupinastrum, Moris, Ind. Sem. Hort. Taur. (1852) 12 ; et in Bot. Zeit. i. (1843) $168=$ Crupina Crupinastrum.

crupinoides, Desf. F1. Atlant. ii. $293=$ Volutarella bicolor

Csatoi, Borbas, in Ertek. Koré Magyar Tudom. Akad. ix. (1879) 29.-Hungar.

cucullata, Spreng. ex Steud. Nom. ed. I. 174.-Hab.? 


\section{CENTAUREA :}

cuneifolia, Orphan. ex Boiss. F1. Orient. iii. $645=$ sublanata.

cuneifolia, Sibth. E'Sm. Fl. Graec. t. 901.-Macedon. cuspidata, Aucher, ex DC. Prod. vi. $577=$ Aucheriana. cuspidata, Vis. in Flora, xii. (1829) I. Erg. 22.Dalmatia.

cyaneum, St. Lag. in Ann. Soc. Bot. Lyon, vii. (1880) $122=$ C. Cyanus.

cyanifolia, C. Koch, in Linnaea, xxiv. (1851) 436.Reg. Caucas.

cyanifolia, Poir. Encycl. Suppl. ii. 158=solstitialis cyanoides, Bergo. E Wahlenb. in Isis, V. xxi. (1828)

971.-Syria.

cyanoides, DC. Prod, vi. $578=$ axillaris.

cyanoides, C. Sm. in Buch, Beschr. Canar. Ins. 147.Ins. Canar.

Cyanus, Linn. Sp. Pl. 911.-Europ. ; Reg. Cancas.

cylindrocarpa, Reichb. f. Ic. Fl. Germ. xv 34. t. 781 = cuneifolia et sublanata.

cynaroides, C. Sm. ex Buch, in Berl. Acad. Abh. 1816-17 (1819) $369=$ Serratula canariensis.

cynaroides, Link, in Buch, Beschr. Canar. Ins. 147.-

Ins. Canar.

cyrtolepis, Ledeb. Fl. Ross. ii. 709. - As. Min.

damascena, Boiss. Diagn. Ser. I. x, 112,-Syria.

dealbata, Moris, ex Nym. Consp. $425=\mathrm{C}$. Cineraria,

dealbata, Willd. Sp. Pl. iii. 2295-As. Min.; Reg

Caucas.; Persia.

Debeauxii, Godr. \& Gren. Fl. Fr. ii. $243=$ nigra.

decipiens, Thuill. F1. Par, ed. II, $445=$ C. Jacea.

declinata, Aucher, ex DC. Prod, vi. $579=$ lanigera

declinata, Bieb. F1. Taur. Cauc. iii. $590=$ leucophylla.

decumbens, Boiss. ex DC. Prod, vii. $303=$ Boissieri

decumbens, DC. Prod. vi. $576=$ lencophylla.

decumbens, Dubois, Fl. Orl. ex Pers. Syn. $485=\mathrm{C}$. Jacea.

decurrens, DC. Prod. vi. 596.-Hab.?

deflexa, Tatarinow, in Beitr. Kenntn. Russ. Reich. xx. 252.-Soongaria.

deinacantha, Boiss. EF Haussk. in Fl. Orient. iii. 665 . - Kurdistan.

Delilei, Godr. in Mém. Acad. Montp. (Sect. Médic.) i (1853) 435 - - Gallia?

denticulata, Lejeune, Rev. Fl. Spa, $183=$ nigrescens.

depressa, Bieb. Fl. Taur. Cauc. ii. 346.-Reg. Caucas.; Iber.

dertosensis, Costa, F1. Catal. (1864) $141=$ podospermifolia.

derventana, Janka, in Oestr. Bot. Zeitschr. xxi. (1871) 287 - Kerneriana.

derventana, Vis. E Panč. in Mem. Ist. Venet. xii. (1864.) 472.-Oriens.

desmicephala, Fenzl, Ind. Hort. Vind. (1855) = aggregata.

deusta, Tenore, Prod. F1. Nap. p. $1 \mathrm{i}=$ alba

Devauxii, Bor. ex Nym. Consp. 431 = C. Calcitrapa.

dianthoides, Remy, in C. Gay, Fl. Chil. iv. 312. Chili.

dichroa, Boiss. E Heldr. Diagn. Ser. I. x. 111.Syria.

dichroantha, Kern. in Oestr. Bot. Zeitschr, xxiv. (1874) $104=$ sordida.

diffusa, Lam. Encyc. i. 675.-Europ. austr. or. ; As. Min.

diluta, [Dryand. in] Ait. Hort. Kew. ed. I. iii, 261.-

Afr. bor.

dimorpha, Viv. Fl. Lib. Spec. 58. t. 24. f. 3.-Afr. bor.

diomedea, Gasp. Descr. Trem. 19, 23.-Ital.; Ins. Trem.

discoidea, Balb. ex DC. Prod, vi. $573=$ flosculosa.

dissecta, Hill, Veg. Syst. iv, 33.-Germ.

dissecta, Tenore, Prod. Fl. Nap. p. Ii-Italia; Graecia.

divaricata, Wall. Cat. n. $2894=$ Volntarella divari cata.

divergens, Lange, in Kjoeb. Vidensk. Meddel. (1861) $87=$ Langei.

divergens, Vis. Fl. Dalmat. ii. 37. t. 12 b.-Europ. austr.

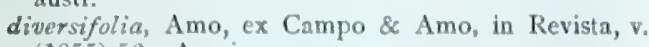
(1855) $56=$ Amoi.

diversifolia, Lag. ex Boiss. Voy. Bot. Espagne, ii. 354 = aspera.

Dornacina, Amo, Descr. Pl. Nuev. ex Willk. \&c Lange, Prod. F1. Hisp. ii. $178=$ Serratula nudicaulis.

\section{CENTAUREA :}

doryphora, Fenzl, ex Boiss. F1. Orient. iii. $665=$ Urville

drabaefolia, Anct. $=$ seq

drabifolia, Sibth. Es Sm. Prod. ii. 202 ; Fl. Graec. t. 910.-Bithynia.

dracunculifolia, Dufour, in Ann. Sc. Nat. xxiii. Sér. I (1831) 157.-Hispan.

druentica $x$, Rouy, in Bull. Soc. Bot. Fr. xxix. (1882 342, 348.-Gallia.

dubia, S. G. Gmel. ex Steud. Nom. ed. I. $174=$

Xeranthemum annuum.

dubia, Krock. Fl. Sil. Suppl. ii. $331=$ humilis?

dubia, Suter, F1. Helv, ii. $202=$ nigrescens.

Duboisii, Bor. Fl. Centr. Fr. ed. III. ii. $350=\mathrm{C}$ Jacea.

Dumortieri, Thys, in Bull. Soc. Bot. Belg. vili. (1869 464.-Belg.

dumulosa, Boiss. Diagn. Ser. I. x. 111-Syria.

dutosensis, Costa, ex Nym. Consp. $429=$ podospermi folin

ebenoides, Heldr. ex S. Moore, in Fourn. Bot. xvi (1878) 133.-Griaecia

elata, Poir. Encyc. Suppl. ii. 150.-Mauritan,

elbrusensis, Boiss. Es Buhse, in Nouv. Mém. Soc. N'at.

Mosc. xii. (1860) 131-Persia.

elegans, All. F1. Pedem. i. $163=$ Galactites tomentosa

elegans, Salisb. Prod. $207=\mathrm{C}$. Cineraria.

elongata, Desf. ex DC. Prod. vi. 604 (Quid

elongata, Schousb. Vextr. Marokko, $199=$ diluta.

elongata, Webb E Berth. Phyt. Canar. ii. 360.--Ins.

Canar

emigrantis, Bubani, in Nuov. Giorn. Bot. Ital. v. (1873) 318.- Hispan.

Endresii, Hochst. \& Stend. ex Steud. Nom. ed. II. $320=$ nigra.

eriocephala, Boiss. \& Reut. Diagn. Ser. II. iii. $86=$ dimorpha.

eriophora, Forsk. Fl. Aegypt. Arab. 74. n. $465=$ aegyptiaca.

eriophora, Linn.Sp.Pl.916.-Gall.; Lusit

eriophylla, Boiss. \& Bal. ex Boiss. Fi. Orient. iii. $678=$

chrysoleuca.

eriophylla, Spreng. Syst. iii. 404-Hab.?

erucifolia, Linn. Sp. Pl. $909=$ Volutarella erucifolia.

eryngioides, Lam. Encyc. 1. 675.-Arab. ; Syria.

eryngioides, Sibth. \& Sm. Fl. Graec. t. 913=achaia

Escobilla, Coss. ex Nym. Consp. $426=$ castellana.

euphratica, Boiss. Diagn. Ser. I. vi. $125=$ polypodi

folia.

exaltata, Adam, in Weber \& Mohr, Beitr. i. $74=$

coronopifolia.

exarata, Boiss. ex Coss. Notes Pl. Crit. 116.-Afr. bor

exscapa, Urv. in Mém. Soc. Linn. Par. i. (1822) 37 $=$ acicularis.

Fabrei x, Bonnet, ex Rouy, in Bull. Soc. Bot. Fr. xxix. (1882) 349,-Gallia.

Fenzlii, Reichardt, in Verh. Zool. Bot. Ges. Wien, xiii (1863) 1039.-As. temp.

Ferdinandi, Gren. Cat. Sem. Hort. Bot. Grat. (1847)

Collect. $20=$ nervosa.

ferox, Desf. Fl. Atlant. ji. 297. t. 242,-Numidia.

fliformis, Bieb, ex DC. Prod, vi. $566=$ pulchella

filiformis, Viv. Fl. Cors. App. 6.-Corsic.; Sardin.

Fischeri, Willd. Enum. Hort. Berol. Suppl. 61 axillaris.

fistulosa, Wender. ex Steud. Nom. ed. II. i. 320.Hab.

flavicans, Vukot. in Rad Jugos. Akad, Zagreb. lviii, (1881) $149=$ C. Jacea.

floccosa, Hook. \& Arn. in Hook. Comp. Bot. Mag. (1835) 110.-Chili.

floccosa, Schloss. ex Vukot. in Rad Jugos. Akad. Zagreb. Iviii. (1881) $149=$ montana

floccosa, Schloss, \& Vukot. Syll. Croat. $46=$ axillaris.

flosculosa, Balb. ex Nym. Consp. $422=$ nervosa.

flosculosa, Willd. Sp. Pl. iii. 2285. - Europ. austr.

foliosa, Boiss. E Kotschy, ex Boiss. Fl. Orient. iii. 672 -Syria.

Fontanesii, Spach, ex Dur. in Duch. Rev. Bot. ii. (1847) 429.-Algeria.

Forardi, Hornem. Hort. Hafn. Suppl. Add. 159.Italia.

Fraasii, Noé \& Bal. ex Boiss. Fl. Orient. iii. 6\$1 = monacantha.

Fraasii, Sch. Rip. ex Nym. Consp, $429=\mathrm{seq}$.

Fraatii, Sch. Bip. ex T'cbihat. Asie Min. Kor. ii. $\$ 23=$ Sproneri.

\section{CENTAUREA}

fragilis, Dur. in Duch. Rev. Bot. ii. (1847) 429. Afr. sept.

iraylensis, Sch. Bip.ex Nym. Consp. 420.-Hispan.

Friderici, Vis. Fi. Dalmat. ii. 40. t. 12 C.-Dalmat.

fruticosa, Linn. Syst. ed. X, $1229=$ Staehelina fruticosa.

fuliginosa, Dollin. ex Nym. Consp. $424=$ C. Scabiosa. fulva, Huet, in Aan. Sc. Nat. Sér. III. xix. (1853, 254 =nigra.

Funkii, Boiss. \& Reut. Diagn. Ser. II. iii. $83=$ macrorrhiza.

Funkii, Sch. Bip. ex Willk, in Linnaea, xxv. (1852) 37 $=$ Boissieri.

furfuracea, Coss. E Dur. in Bull. Soc. Bot. Fr. iv. 1857) 363.-Algeria.

fuscata, Desí. Fl. Atlant. ii. 302. t. $244=$ nicaeènsis.

fuscata, Jord. Pugill. 105 = pectinata .

fuscescens, Pomel. Nouv. Mat. Fl. Atl. 28.-Algeria.

Galactites, Linn. Sp. Pl. $919=$ Galactites tomentosa

garganica, Sch. Bip. ex Nym. Consp. $425=$ subtilis.

Gaudini, Boiss. \& Reut. Diagn. Ser. II. ii. $70=$ amara.

Gayana, Remy, in C. Gay, Fl. Chil. iv. 310.-Chili.

geluensis, Boiss. E Haussk. ex Boiss. Fl. Orient. iii. 674.- Persia.

geocephala, Boiss. Fl. Orient, iii. $677=$ ustulata.

Gerberi, Stev. in Bull. Soc. Nat. Mose. xxix. (1856) Ir. 391 , in textu.-Ross. austr.

Germaniciae, Haussk. ex Boiss. Fl. Orient. ili. $682=$ C. Behen.

gigantea, Sch.Bip. ex Boiss. l. c. 672.-Persia.

glaberrima, Tousch, in Flora, $x$ (1827) IP. 249.Dalmatia.

glandulifera, Vukot.-Cf. Oestr. Bot. Zeitschr. xxx. (1880) 163.-Europ.

glastifoliz, Linn.Sp. Pl.915.-As. Min. ; Reg. Cauc. Sibir.

glauca, Desf, ex DC. Prod. vi. 587=calocephala,

glauca, Puschk. ex Willd. Sp. Pl. iii. $2278=$ moschata.

glaucescens, Fisch. E Mey. in Ann. Sc. Nat. Sér. IV. i. (1854) 31.-Galatia.

Glehni, Trautv. in Act. Hort. Petrop. iv. (1876) 382. Rossia.

globosa, Hort. ex DC. Prod. vi. 569=alba,

glomerata, Vahl, Symb. Bot. ii. 94.-Aegypt

glomerata, Webb \& Berth. Phyt. Canar. ii. $\$ 60=$ melitensis.

Gmelini, Steud. Nom, ed. II. i. 320,-Sibir.

goniocanla, Boiss. Fl. Orient. iii. 647.-Lydia

gracilior, Reut. ex Nym. Consp. 421=amara.

gracilis, Bor. ex Nym. 1, c. = C. Jacea.

graeca, Boiss. E Sprun. Diagn. Ser. I. vi. 128.Graecia.

graeca, Griseb. Spicil. Fl. Rumel. ii. $242=$ Cecca . riniana.

Graëlsii, Nym. Consp. 429.-Hispan.

Grafiana, DC. Prod. vi. $587=$ sordida

graminifolia, Pours. ex Willk. \& Lange, Prod. Fl. Hisp, ii. $159=$ montana.

granatensis, Boiss. ex DC. Prod. vii. 303.-Hispan.

grandiflora, Moç. \& Sesse, ex DC. Prod. vi. $575=$ americani.

grandiflora, Pall. Reise, iii. $237=$ monanthos.

grinensis, Reut. Ind. Sem. Hort. Genev. (185i) 4.-Cf.

Linnaea, xxix. $(1857-58) 722=$ C. Scabiosa.

Grisebachii, Nym. Consp. $427=$ graeca,

gadrunensis, Boiss. E Haussk, ex Boiss, Fl. Orient, iii. 673.-Kurdist.

Guicciardii, Boiss. l. c. 661.-Baeotia.

gymnocarpa, Moris E De Not. Fl. Jnsul. Caprar. i6. t. 2.-Ins. Caprar.

gymnoclada, Benth. E Hook, f. Gen. ii. 4s:? Mesopot.

Haenseleri, Boiss. I'oy, Bot. Espagne, ii, 3t2.Hispan.

Hanrii, Jord. Obs, Pl. Crit. v. (1Sti) $70=$ coerulescens, limbata.

Hausiknechtii, Boiss. Fl. Orient. iii. dit0.-Syria.

Haynaldi, Borb. ex Vukot. in Kad Jugus Akad, Zagreb. Iviii. (1+81) 14! - C. Jacen

helenioides, Boiss. G Hausst. ex Busss. F7. Oriens. iii. 638.- Tontus

bellenica, Boiss. G Sprun. Diagw. Ser. I. Vi. 191.Linceia.

hemiptera $x$, Borb. in Oestr. Bob. Zeitschr. Ixviui. (15i8) $99 \%$ - Europ. austr. 


\section{CENTAUREA :-}

Herbichii, Fanka, in Flora, xli. (1858) 441.Transsylv.

Hermonis, Boiss. Diagn. Ser. I. x. $122=$ iberica.

heterocarpa, Boiss. E Gaill. ex Boiss. Fl. Orient. iii. 680.- Syria

heterophylla, Sprun. ex Boiss. 1. c. $663=$ Spruneri

heterophylla, Willd. Sp. P1. iii. $2314=$ aspera.

Heerffelii, Reichb. f. Ic. Fl. Germ. xv. 27. t. $801=$ Kotschyana.

hierapolitana, Boiss. Diagn. Ser. I. iv. 15.-Caria.

hispida, DC. Prod, vi. $589=$ reflexa.

Hladnickiana, Fisch. ex Heynh. Nom. ii. 130, nomen. -Europ. austr.

Hochstetteri, Oliver E Hiern, in Oliver, Fl. Trop. Afr. iii. 438.-Afr. trop.

Hoefftiana, C. A. Mey. in Mém. Acad. Pétersb. Sér.

VI. Sc. Nat. vii. (1855) 7.-Reg. Casp.

Hohenackeri, Stev, in Bull. Soc. Nat. Mosc. xxix (1856) Ir. $395=$ ovina.

Hohenackeriana, Trautv, in Act. Hort. Petrop. viii (1883) $493=$ praec.

hololenca, Boiss. Fl. Orient. iii. 694.-Syria.

horrida, Badaro, in Brugnat. Giorn. Fis. (1824) 363.-

Liguria: Sardin

horrida, Tenore, Ind. Sem. Hort. Neap. (1829) 15

Syll. $449=$ C. Calcitrapa

Huetii, Boiss. Diagn. Ser. II, iii. 69.-Armenia.

humifusa, Gueldenst. ex Ledeb. F1. Ross. ii. $696=$ decumbens.

humilis, Schrank, Baier. F1. ii. $376=$ pullata?

hyalina, L'Hérit. ex DC. Prod. vi. 566=pulchella.

hyalolepis, Boiss. Diagn. Ser. I. vi. $133=$ pallescens.

hybrida, All. Fl. Pedem. i. 161= corymbosa.

hybrida, Chaix, in Vill. Hist. Pl. Dauph, iil. $54=\mathrm{C}$ Calcitrapa.

hymenolepis, Trautv. in Act. Hort. Petrop. iii. (1874) 272.-Reg. Caucas.

hypericifolia, Brouss. ex Sch. Bip. in Webb \& Berth Phyt. Canar. ii. $355=$ canariensis.

hypoleuca, $D C$. Prod. vi. 575.-As. Min.

hyssopifolia, Georgi, Beschr. Russ. Reich. iii. IV. 1263 = trichocephala.

hyssopifolia, Vahl, Symb. Bot. i. 75.-Hispan.

Hystrix, Boiss. Voy. Bot. Espagne, ii. $351=$ polyacantha.

iberica, Trevir. ex Spreng. Syst. iii. 406.-Iber. Armen.; Caucas.

idaea, Boiss. E Heldr. Diagn. Ser. I. x. 119.-Creta.

incana, Burm. f. Fl. Cap. Prod. $28=$ Arctotis argentea.

incana, Desf. Fl. Atlant. ii. 301.-Marocco.

incana, Lag. Gen. et Sp. Nov. $32=$ Lagascae.

incana, Losc. \& Pardo, Ser. Inconf. $59=$ tenuifolia.

incana, Tenore, Prod. Fl. Nap. p. li.-Italia

incompta, Vis. Fl. Dalmat. 38. t. 13 ${ }^{\mathrm{b}}$. fig. 1.Dalmat.

indica, Less. in Linnaea, vi. (1831) 84 = Goniocaulon glabrum.

indurata, Janka, in Flora, xli. (1858) $444=$ nigra

infestans, Dur.in Duch. Rev. Bot. ii. (1847) 430.-Afr. bor.

intacta, Ledeb. Fl. Ross. ii. 705.-Reg. Caucas.

integrifolia, C. A. Mey. Ver\%. Pfl. Cauc. 64.-Reg. Caucas.

integrifolia, Tausch, in Flora, xi. (1828) II. $485=$ nigra.

integrifolia, Vukot. in Rad Jugos. Akad. Zagreb. Iviii. (1881) $153=$ C. Scabiosa.

integrisquama, Vukot. l. c. $152=$ C. Scabiosa

intermedia, Cariot, Etud. Fl. ed. V. $317=$ axillaris.

Intermedia, Mutel, in Duch. Rev. Bot. i. (1845-46) 400-Algeria.

interrupta, Hoffmgg. \& Link, Fl. Port. ii. 227.Lusitan.

intricata, Boiss. Diagn. Ser. I. vi. 130-Persia.

intybacea, Lam. Encyc. i. 671.-Gallia; Hispan.

inuloides, Fisch. ex Nym. Consp. $418=$ trinervia.

inusta, Hoffmgg. ex Heynh. Nom. ii. 131, nomen.Hob.?

involucrata, Desf. Fl. Atlant. ii. 295.-Alger.

iserniana, Graells, ex Willk. \& Lange, Prod. F1. Hisp. ii. $162=$ Janerii

Isernii, Willk. in Willk. \& Lange, l. c. 155.Hispan.

Isnardi, Linn. Sp. Pl. $916=$ aspera

ispahanica, Boiss. Diagn. Ser. I. vi. 133.-Persia.

italia, Steud. Nom ed. II i. $320=$ seq.

italica, Pers. Syn. ii. $484=$ C. Scabiosa.

\section{CENTAURFA}

ixodes, Pomel, Nouv. Mat. Fl. Atl. 284,-Algeria.

Jacea, Linn. Sp. Pl. 914.-Europ.; As. med.

jacobaeaefolia, Lam. Encyc. i. 675.-Hab. ?

jacobaeaefolia, Spreng. Syst. iii. $404=$ argyrophylla.

Facobi, Dufour, in Ball. Soc. Bot. Fr. vii. (1860) 348 = sonchifolia.

Janerii, Graells, in Mem. Acad. Cienc. Madr. ii. (1859) 466 (Ramill. 8).-Hispan

Jankeana, Simk. in Termész. Füzetek, i. (1817) 168.Europ. austr.

Jordaniana, Gren. Er Godr. Fl. Fr. ii. 245.-Gallia.

jurineaefolia, Boiss. Diagn. Ser. II. iii. $73=$ rutifolia.

juvenalis x, Detile, ex Godr. in Mém. Acad. Mont

(Sect. Médic.) i. (1853) 433.-Gallia.

karduchorum, Boiss. Fl. Orient, iii. 633.-Armenia

karlowensis, Frivald. ex Hampe, in Flora, xx. (1837) I. $228=$ napulifera.

Karschiana, Auersw. ex Nym. Consp. $426=$ cristata.

Karstiana, Griseb. Spicil. Fl. Rumel, ii. $240=$ pallida

Kartschiana, Scop. Carn. ed. II. ii. 140. t. 55.Carniol.

Kemeriana, Fanka, in Oestr. Bot. Zeitschr. xxii. (1872) 178.-Thracia.

kestanica, Franch. in Ann. Sc. Nat. Sér. VI xvi. 1883) 325.-Turkest.

kilaea, Boiss. Fl. Orient. iii. 643.- Byzant.

Kochii, F. Schultz, ex Nym. Consp. $421=$ nigrescens.

Kolczygini, Kalen. in Bull. Soc. Nat. Mosc. xviii. 1845 I. 236, - Reg. Caucas.

Kotschyana, Heuff. in Koch, Syn. F1. Germ. 437 = C. Scabiosa.

Kralikii, Boiss. Diagn. Ser. II. iii. $84=$ dimorpha.

kurdica, Reichardt, in Verh. Zool.-Bot. Ges. Wien, xiii. (1863) 1042,-Kurdist.

laciniata, Guss. in DC. Prod. vi. $582=$ ambigua,

laconica, Boiss. Fl. Orient. iii. 660.-Laconia.

lactucaefolia, Boiss. l. c. 622.-Ins. Rhodus.

Lagascae, Nym. Syll. 33.-Hispan.

Lagascana, Graells, in Mem. Acad. Cienc. Madr. ii. (1859) 465 (Ind. Pl. Nov. 7) = Graëlsii.

lanata, DC. Prod. vi. $610=$ Carthamus lanatus.

lanata, Roxb. Hort. Beng. 62; Fl. Ind. iii. $444=$ C. Cyanus.

lancifolia, Sieber, ex Spreng. Syst. iii. 406.-Creta.

Langeana, Willk. in Willk. \& Lange, Prod. Fl. Hisp. ii. $157=$ Langei.

Langei, Nym. Suppl. Syll.6.-Hispan.

lanigera, DC. Prod. vi. 579.-Cappadoc.

lappacea, Tenore, Ind. Sem. Hort. Neap. (1829) $15=$ solstitialis.

lasiorhiza, DC. Prod. vi. 600.-Persia.

latifolia, Pers. Syn. ii. $487=$ centauroides

latisquama, DC. Prod. vi. $589=$ salonitana

laxa, Boiss. E Haussk. ex Boiss. Fl. Orient. iii. 640.Mesopot.

Ledebourii, Steud. Nom. ed. II. i. $320=$ cana

leptocephala, Boiss. Diagn. Ser. I. x. 110.-Syria.

leptoloma, Pane. ex Nym. Consp. 426=maculosa.

leptophylla, C. Koch, in Linnaea, xxiv. (1851) 419.

- Lazistan.

leucantha, Pourr. in Mém. Acad. Toul. iii. (1788) 310 =intybacea.

leucantha, Web. \& Mohr, Beitr. i. 74. n. $49=$ montana.

leucocephala, Schur, Enum. P1. Transs. $403=$ phrygia.

leucolepis, DC. Prod. vi. 568=alba.

leucolepis, Ledeb. ex Nym. Consp. $420=$ sterilis.

leucolepis, Tenore, ex Nym. 1. c. = splendens.

lencophaea, ford. Obs. Pl. Crit. v. (1847) 64.Gallia.

leucophylla, Bieb. Fl. Taur. Cauc. iii. 591.-Reg. Caucas.

leuzeoides, Walp. Ann. i. 447.-Media.

ligerina x, Franch. in Bull. Soc. Bot. Fr. xxvii. (1880) p. xxii.-Gallia.

limbata, Hoffmgg. E Link, Fl. Port. ii. 221.Lusitan.

linarifolia, Steud. Nom. ed. II. i. $321=$ linifolia.

linearifolia, Lam. Encyc. i. $667=$ linifolia.

lingulata, Lag. Gen. et Sp. Nov. 32 =variegata.

linifolia, Lam. Encyc. i. $667=$ hyssopifolia.

linifolia, Linn. Mant. 1. 117 ; Vahl, Symb. Bot. i. 75. - Hispan.; Italia.

Linnaeana, Walp. Ann. i. $450=$ Fontanesii.

Lippii, Linn. Sp. Pl. $910=$ Volutarella Lippii

livoniana, Weinm, ex Ledeb. Hort. Dorp. $38=\mathrm{C}$. Jacea

longepedunculata, Sch. Bip. ex Boiss. Fl. Orient. iii. 668.-Persia.
CENTAUREA

lugdunensis, Jord. Obs. P1. Crit. v. (1847) $49=$ montana.

Luschaniana, Heimerl, ex Stapf, in Denkschr. Acad. Wien, 1. (1885) 113.-Lycia.

lusitanica, Boiss. \&c Reut. Diagn. Ser. II. iii. $85=$ sphaerocephala.

lutea, Gueldenst. It. ii. 43, ex Ledeb. Fl. Ross. ii. 712 -Ross. austr.

lycaonica, Boiss. E Heldr. Diagn. Ser. II. จ. 111.As. Min.

lycia, Boiss. Diagn. Ser. I. x. 109.-Lycia.

lycopifolia, Boiss. E Kotschy, ex Boiss. Fl. Orient, iii. 693.-Syria.

lydia, Boiss. Diagn. Ser. I. iv. 20.-Bithynia.

lyraefolia, Salisb. Prod. $208=$ salmantica.

lyrata, Bell. App. Fl. Pedem. $40=$ rhapontica.

lyrata, Pers. Syn. ii. 486.-Uruguay.

lyrata, [Soland.in] Russ. Aleppo, ed. II. ii. 270.Syria.

lyrophylla, Griseb. Spicil. Fl. Rumel. ii. 238.--Europ. austr.

macedonica, Boiss. Diagn. Ser. I. vi. 130.-Graecia. macracantha, Heldr. ex Boiss. Fl. Orient. iii. $690=$ iberica.

macroacantha, Guss. F1. Sic. Syn. ii. $518=$ calci trapoides.

macrocarpa, Boiss. Fl. Orient. iii. 677.-Persia.

macrocephala, Puschk. ex Willd. Sp. Pl. iii. 2299.Armen.

macrolopha, Fenzl, ex Boiss. Fl. Orient. iii. 595,Oriens.

macrorrhiza, Willk. in Linnaea, xxv. (1852) 38.Hispan.

maculata, Andrz. Rys Botan. i. (1823) $12=$ maculosa. maculosa, Eichw. Skizze, $146=$ Biebersteinii

maculosa, Guss. P1. Rar. $359=$ cinerea.

maculosa, Lam. Encyc. i. 669.-Gallia; Hispan. Italia.

maculosa, Noé, ex Nym. Consp. $425=$ cuneifolia

malacitana, Boiss. Diagn. Ser. II. iii. $85=$ sonchifolia.

margaritacea, Tenore, Syll. Add. iii. A. $628=$ splendens.

marginata, Tenore, Prod. F1. Nap. p. lii = nicaeënsis mariana, Nym. Suppl. Syll. $6=$ macrorrhiza

mariolensis, Rouy, in Bull. Soc. Bot. Fr. xxix. (1882 110.-Gallia.

maritima, Dufour, in Ann. Sc. Nat. Sér. I. xxiii. (1831) $165=$ sonchifolia

maroccana, Ball, in Fourn. Bot. xi. (1873) 370.Marocco.

Marschalliana, Spreng. Syst. iii. 398.-Podol.; Caucas.

Massoniana, Lowe, in Hook. Kew Fourn. viii. (1856)

297.-Ins. Madera.

mathiolifolia, Boiss. Diagn. Ser. I. iv. $19=$ axillaris.

maxima, Forsk. Fl. Aegypt. Arab. $152=$ verbascifolia.

melitensis, Linn. Sp. Pl. 917.-Europ.; Am. austr.

membranacea, Jacquem. Voy. Bot. $97=$ Saussurea denticulata.

membranacea, Lam. Encyc, i. 666=monanthos.

menteyerica, Vill. Hist. P1. Dauph. i. 365 ; iil. $48=$ C. Scabiosa.

Meryonis, DC. Prod. vi. $598=$ iberica.

mexicana, DC. 1. c. $575=$ americana

micracantha, Dufour, in Ann. Sc. Nat. Sér. I. xxiii (1831) 164.--Hispan.

micrantha, Hoffmgg. \& Link, Fl. Port. ii. $220=$ castellana.

micranthos, S. G. Gmel. It. i. t. 23. f. 1=maculosa. microcephala, Benth. E Hook. f. Gen. ii. 480,Cappadoc.

microlepis, Boiss. Fl. Orient. iii. 651.-Lycia.

microlonchoides, Boiss. Diagn. Ser. I. vi. 127.Persia.

microptilon, Godr. \& Gren. F1. Fr. ii. $242=$ nigra.

Mierghii, Jord. in Cat. Grain. Grenob. (1850) 15; et Pugill. $110=$ paniculata.

Minoa, Heldr. ex Boiss. Fl. Orient, iii. $662=$ Guicciardii.

minor, Willd. ex Spreng. Syst. iii. $403=$ polymorpha. mixta, DC. Prod. vi. $594=$ hellenica.

mollis, Bess. [F1. Galic. ii. 207 ?] = axillaris.

mollis, Schleich. Cat. Pl. Helv, ed. IV. $12=$ C. Jacea. mollis, Waldst. \& Kit. PI. Rar. Hung, iii. 243 t. $219=$ montana.

monacantha, Boiss. Fl. Orient. iii. 681.-Thracia. 


\section{CENTAUREA :-}

monacantha, Clark, Trav. ii. 354.-Cyprus.

monantha, Georgi, Bemerk. Reise Russ. Reich. i. 231. -Rossia.

monocephala, Remy, in C. Gay, Fl. Chil. iv. 311.Chili.

montana, Auct. ex Willk. \& Lange, Prod. Fl. Hisp. ii. $159=$ variegata, axillaris

montana, Burm. f. Prod. Fl. Cap. $28=$ sempervirens

montana, Costa, F1. Catal. $139=$ semiclecurrens, lugdunensis.

montana, Linn.Sp. Pl. 911.-Europ.

monticola, Boiss. ex DC. Prod. vii. 302.-Hispan.

Moritziana, Hegetschw. Fl. Schw. $851=$ phrygia

Moschata, Linn.Sp. Pl. 909.-Oriens.

Moschus, Habl. in S. G. Gmel. It. iv, $176=$ Jurinea depressa.

Motelli, Blanchet, in Bull. Soc. Bot. Fr. xxvili. (1880) 21.-Gallia

mucronata, Forsk. Fl. Aegypt. Arab. 151=pumila.

mucronifera, DC. Prod. vi. 569.-Cappadoc.

multifida, Pers. Syn. ii. 487.-Afr. bor.

multiflora, Pers. 1. c. $486=$ sicula

Mureti, Jord. Pugill. $108=$ coerulescens.

muricata, Linn. Sp. Pl. 918 = Volutarella muricata.

muricata, Spreng. Syst. iii. $402=$ Volntarella Lippii

musarum, Boiss. E' Orph. Diagn. Ser. II. v. 112.Graecia.

mutabilis, St. Amans, in Mém. Mus. Par. i. (1815) 477. - Mont. Pyren.

myacantha, DC. Fl. Fr. iv. $101=$ C. Calcitrapa.

myconia, Boiss. \& Sart. Diagn. Ser. II. vi. $113=$ Urvillei.

myriocephala, Clark, Tray. i. 23=diffusa.

myriocephala, Sch. Bip. ex Boiss, Fl. Orient. iii. 682. -Syria.

myriostigma, Lem. in Illustr. Hortic. (1856) Misc. 88. -Hab.?

myriostoma, Vis. E Fanč. in Mem. Ist. Venet. xii. (1864) 470.-Orient.

nana, Chesn. ex Steud. Nom. ed. II. i. $320,318=$ amara.

nana, Desf. Fl. Atlant. ii. 296. t. 241.-Mont. Atl.

nana, Sieber, ex Boiss. Fl. Orient. iii. $675=$ raphanina.

napifolia, Linn. Sp. Pl. 916.-Italia; Graecia; Afr. bor.

napulifera, Rochel, in 'Act. Hungar. Evhony.' (1834) t. 3.-Europ.

neapolitana, Boiss. Diagn. Ser. II. iii. $72=$ nigrescens neglecta, Bess. Enum. Pl. Volh. $35=$ centauroides. neglecta, Martr. ex Nym. Consp. $431=$ sonchifolia. neglecta, Schott, ex Spreng. Syst. iii. $400=$ orientalis. nemophila, Jord. ex Nym. Consp. $421=$ C. Jacea. nemoralis, Jord. Pngill. P1. Nov, $104=$ nigra.

nervosa, Griseb. Spicil. Fl. Rumel. ii. $233=$ Kerneriana.

nervosa, Reichb. ex Steud. Nom. ed. II. i. $321=$ phrygia.

nervosa, Willd. Enum. Hort. Berol. 925.-Europ. anstr.

nevadensis, Boiss. E Reut. Diagn. Ser. II. iii. 71.Hispan

nicaeensis, All. Fl. Pedem. i. 162. t. 74. f. 1.-Gall.; Ital.

nidulans, Pomel, Nouv. Mat. Fl. Atl. 280.-Algeria.

Niederi, Heldr, in Ann. Sc. Nat. Sér. IV. xiii. (1860) 880.-Graecia.

nigra, Frivald. ex Boiss. F1. Orient. ii. $630=$ Kerneriana

nigra, Lam. Encyc, i. $666=$ pratensis.

nigra, Linn. Sp. Pl. 911.-Europ.

nigrescens, DC. Prod. vi. $571=$ nigta.

nigrescens, Gren. \& Godr. Fl. Fr. ii. $241=\mathrm{C}$. Jacea.

nigrescens, Willd. Sp. Pl. iii. 2288.-Europ. med, austr

nigricans, DC. ex Steud. Nom. ed. II. i. $321=$ Endressii.

nigricans, Link, ex Spreng. Syst. iii. $401=$ nigra.

Nimrodis, Boiss. E Haussk. ex Boiss. Fl. Orient, iii. 664.-Mesopot.

nitens, Bicb. ex Willd. Sp. Pl. iii. 2305.-Tauria; Reg. Cauc.

nitida, Lam. Fl. Fr. zi. $49=$ alba.

nitida, Naldi, ex DC. Prod, vi, $601=$ crassifolia.

Noüana, Boiss, Diagn. Sér. II iii. 84 = iberica.

Noveliix, Franch, in Bull. Soco Bot. Fro xxvii. (18:0) p. xxi,-Gallia.

nudicaulis, Linn. Syst. ed. X. 1292-Serratula nudicanlis.

\section{CENTAUREA}

Nuttallii, Spreng. Syst. iv. Cur. Post. $298=$ americana, obscura, Jord. in F. Schultz, Arch. Fl. Fr. et Allem. $320=$ nigra

ochrolepis, Vukot. in Rad Jugos, Akad. Zagreb. Iviii. 1881) $149=$ axillaris

ochroleuca, Pushk. ex Willd. Sp. Pl. iii. $2289=$ axillaris.

ochrolopha, Costa, F1. Catal. $140=$ leucophaea.

odorata, Burm. f. Fl. Cap. Prod. 28.-Afr, austr

odorata, C. Koch, in Linnaea, xxiv, (1851) 417. Reg. Caucas.

Olivieri, Pomel, Nouv. Mat. Fl. Atl. 282.-Algeria

Olivieriana, DC. Prod. vi. 590.-Ins. Naxos.

olympica, Boiss. Diagn. Ser. II. iii. 77.-Bithynia.

omphalodes, Coss. E Dur, in Bull. Soc Bot. Fr.

1857) 397 , nomen.-Algeria

onopordifolia, Boiss, Diagn. Ser. I. x. 114.-Syria.

orientalis, Baumg. ex Schur, Enum. Pl. Transs. $408=$ pseudo-collina.

orientalis, Linn. Sp. Pl. 918.-Taur.; Sibir.

ornata, Willd Sp, Pl iii 2320-Hispan.

Orphanidea, Heldr. E Sart. ex Boiss, Diagn. Ser. II. iii. 73.-Graecia.

orthoacantha, Tausch, in Flora, xii. (1829) 1. Erg. 44. $-\mathrm{Hab}$. ?

ossica, C. Koch, in Linnaea, xvii. (1843) 40.-Reg. Caucas.

ovina, Hort, ex Steud. Nom. ed. II. i, $321=$ pterolopha.

ovina, Pall. ex Steud. 1. c. = diffusa

ovina, Pall. ex Willd.Sp. Pl. iii. 2292.-Taur. ; Sibir. pallescens, Bové, ex DC. Prod.vi. 597=alexandrina. pallescens, Delile, Fl. Egypte, 278. t. 49.-Aegypt.

pallida, Frivald, in Flora, xviii. (1835) 333,-Europ. pallida, Wall. Cat. n. $2983=$ Serratula pallida.

pamphylica, Boiss. E Heldr. Diagn. Ser. I. x. 120.Pamphylia.

paniculata, Auct. Hisp. ex Willk. \& Lange, Prod. Fl.

Hisp. ii. $157=$ castellana

paniculata, Bieb. F1. Taur. Cauc, ii. $346=$ maculosa paniculata, Lag. ex DC. Prod. vi. $583=$ caerulescens

paniculata, Linn. Sp. Pl. 912.-Europ, austr.

paniculata, Pett. ex Nym. Consp. 426, $427=$ cristata, divergens.

paniculata, Sibth, \& Sm. F1. Graec, Prod, ii. $199=$ graeca.

paniculata, Vill. Hist. P1. Dauph. iii. $58=$ leucophaea. pannosa, DC. Prod. vi. 582.-Mons Athos.

Parlatorii, Heldr. in Flora, xxvii. (1844) I. $68=\mathrm{seq}$. ?

Parlatoris, Heldr. in Ann. Acc. Asp. Nat. i. (1843) $287=$ dissecta.

Parolinii, DC. Prod. vi. 592.-Mons Ida; As. Min parviflora, Bieb. Fl. Taur. Cauc. iii. $594=$ diffusa. parviflora, Desf. Fl. Atlant. ii. 301.-Pers.; Afr. bor. parviflora, Kar. \& Kir. in Bull. Soc. Nat. Mosc. 1841) $450=$ squarrosa

parviflora, Lam. Fl. Fr. ii. $32=$ aspera, parviflora, Sm, Fl. Graec. x. 9, t. $912=$ diffusa patibilcensis, DC. Prod. vi. $593=$ melitensis.

patula, DC. l. c. 583.--Persia; Cappadoc.

pauciflora, C. Koch, in Linnaea, xxiv. (1851) 433 aggregata.

pauciloba, Trautv. in Act. Hort. Petrop. ii. (1873) 474--Daghestania.

pectinata, Auct. Ross. ex Boiss. Fl. Orient, iii. 632 trichocephala.

pectinata, Linn. Sp. Pl. ed. II. 1287.-Gall. austr.

pectinata, Siev. in Pall. N. Nord. Beitr. vii. $323=$ calva.

Pelia, DC. Prod. vi. 586.-Graecia.

penicillata, Delile, Fl. Aeg. Illustr. $74=$ trichacantha.

peregrina, Linn. Sp. Pl. 918.-Europ. austr.

pergamacea, $D C$. Prod. vi. 569,-Cappadoc

Perrottettii, DC. l. c. 598. - Afr. trop.

persica, Boiss. Diagn. Ser. I. vi. 132.-Persia

Pestalotii, De Not. ex Cesati, in Bibl. Ital. xci. (183s) $348=$ alba.

Pestalozzae, Boiss. Diagn. Ser. I. x. 118.-Lycia.

petrocaula, Trautv. in Act. Hort. Petrop. ji. (1873) 55:-Armenia.

Petteri, Reichb. f. Ic. Fl. Germ. xv. 36. t. 783 divergens.

peucedanifolin, Boiss. E Orph. in Boiss. Fl. Orients. iii. $6+7$ - Macerton.

phacolepis, Coss. Notes Pl. Crit. 198.-Mnaritania.

phaocephala, Wallr. Beitr. Fl. Hercyn. 270.-Europ.

Tharaonis, Poncl, Nowv. Mal. Fl. All. 281.-Algeria.

\section{CENTAUREA}

phlomoides, Boiss. E Haussk. ex Boiss. Fl. Orient. iii. 673.-Persia.

phrygia, Jacq. Hort. Vindob, $167=$ austriaca.

phrygia, Lapeyr. ex Willk. \& Lange, Prod. Fl. Hisp. ii. $164=$ nigra

phrygia, Linn. Sp. Pl. 910.-Europ.

phrygia, Lour. Fl. Cochinch. ii. $681=$ cochinchinensis, phyllocephala, Boiss. Diagn. Ser. I, vi. 134,-Afghan.

Pichleri, Boiss. Fl. Orient. iif. 638. - Bithynia.

Pieris, Pall. Tabl. Taur. 58; Willd. Sp.Pl. iii. 2302. -Reg. Casp.

Pinardi, Boiss. Diagn. Ser. I. iv. 17.-Caria.

pindicola, Griseb. Reise Rumel. ii. 164.-Maced.

pinnatifida, Schur, Sert. Transs. $35=$ axillaris.

pinnatispina, Turra, Farset. Nov. Gen. 13.--Sicilia.

pitycephala, Brot. Fl. Lusit. i. $369=$ Leuzea conifera.

platylepis, Peterm. in Flora, xxvii. (1844) $475=\mathrm{C}$. Jacea.

plumosa, Hort. ex Vilm. Fl. PI. Terre, ed. III. $245=$ gymnocarpa.

plumosa, Kern, in Oestr. Bot. Zeitschr, xxii. (1872)

44.-Europ, austr.

podospermifolia, Losc. E Pard. Ser. Inconf. 58.Hispan.

polyacantha, Spreng. Syst. iii. $406=$ sonchifolia. polyacuntha, Willd. Sp. Pl. iii. 2312.-Hispan. polycephala, Jord. Obs. Pl. Crit. v. (1847) paniculata.

polyclada, DC. Prod. vi. 584.-Graecia.

polymorpha, Lag. Gen. et Sp. Nov. 32.-Hispan.

polyphylla, Ledeb. ex Nordm. in Ball. Sc. Acad. Pétersb. ii. (183i) $311=$ ossica.

polyphylla, Pomel, Nouv. Mat. Fl. Atl. 281.-Algeria.

polypodifolia, Boiss. Diagn. Ser. I. vi. 126.-Persia.

Postii, Boiss. Fl. Orient. iii. 688.-Syria.

Pottii, [Spreng.] Bot. Gart. Halle, $23=$ sicula. sul. phurea.

Pourretiana, Timb. E Theven. in Mim. Acad. Toul.

Sér. VII. vi. (1874) 645.-Gallia.

Pouzini, DC. Cat. Hort. Monsp. $91=$ C. Calcitrapa.

praealta, Boiss. \& Bal. Diagn. Ser. II. v. 112. Cilicia.

praecox, Oliver E Hiern, in Oliver, Fl. Trop. Afr. iii. 438.-Afr. trop.

praetermissa, Martr. in Soc. Sc. Tarn et Gar. (1852.

P1. Crit. Tarn, $382=$ aspera.

praetoria, Reichb. f. Ic. Fl. Germ, xy, \$4, t. $886=$

leucophaea.

pratensis, Hornem. Hort. Hafn. Suppl. 104.Hungaria.

pratensis, Salisb. Prod. $208=$ C. Jacea

pratensis, Thuill. Fl. Paris. ed. II. $444=$ nigrescens.

Preauxiana, Webb \& Berth. Phyt. Canar. ii. 350 $=$ Atractylis Preauxiana.

princeps, Boiss. \& Heldr. Diagn. Ser. II. vi. $111=$ alba.

procera, Heynh. Nom. ii. 131 lapsu = Cephalaria procera.

procumbens, Balb. Misc Alt 31. t. 1.-Pedemont.

procumbens, $\mathrm{Habl}$ in S. G. Gmel. It. iv, $167=$ dealbata.

procumbens, Jord. Obs. v. $57=$ Jordaniana.

procurrens, DC. Prod. vi. $595=$ sinaica.

procurrens, Sieber, ex Spreng. Syst. iii. 407.-Palaestin.; Arab.

prolifera, Delile, ex Godr. in Mém. Acad. Mcntp. (Sect. Médic.) i. (1853) $\$ 35=$ Delilei.

prolifera, Vint. Jard. Cels, $16=$ glomerata

Prolongi, Boiss. ex DC. Prod. vii. 303.-Hispan.

prostıata, Coss. Notes Pl. Crit. 115.-Hispan.

prostrata, Huet, ex Nym. Consp. $\$ 25=$ cinerea.

provincialis, Boiss. ex Lindem. in Kull. Soc. Nat.

Mosc. Iv. (1880) I. 181 = jurinezefolia !

pseudo-behen, Boiss. Diagn. Ser. I. vi. 120.Cappadoc.

pseudo-collina, Siriur, Enum. Pl. Transs. 108. Transsylv.

psetudo-crupina, Mufel, in Duch. Rer. Bos. i. (184316) $4(10$.-. Morea.

psendophilostisus, Gudr, in Mferm. Acad. Stanislas Sir. III. [xvii] 1853 (1354) f(15-diruorpha.

psendo-phersgia, C. A. Mey. in liull. Phys-Math. Aead. l'etersb. vi. (1sts) $13 t=$ phrvivia.

setudo-senbiosn, lkoiss. \& Buhse, in Nour. Mcm. Soc

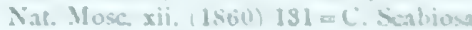

psendersoniforra, Schur, in Verh. Sicbenb. Ver. Nalurw.

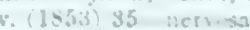

pailacantha, Beriss. E Heidlr. Diuen. Ser. II. iii. sqLirnecta. 


\section{CENTAUREA :-}

pterocaula, Trautv. in Act. Hort. Petrop. ii. (1873) 552.-Armenia.

pterocaulos, Pomel, Nouv. Mat. Fl. Atl. 29.-Algeria pterocephala, Hort. ex DC. Prod. vi. $597=$ trichacantha pterodonta, Pomel, Nouv. Mat. Fl. Atl. 28.-Algeria. pterolopha, DC. Prod. vi. 572.-Hab.?

pubescens, Willd. Sp. Pl. iii. $2322=$ incana.

pubigera, Pers. Syn. ii. $488=$ Volutarella muricata.

pulchella, Ledeb. Ic. Pl. Alt. 1.t. 93.-Persia; Cauca pulcherrima, Wight, ex DC. Prod, vi. $579=$ pulchra.

pulcherrima, Willd. Sp. Pl. iii. 2298-Armenia; Caucas.

pulchra, DC. Prod. vi. 578.-Ind. or.

pullata, Linn. Sp. Pl. 911.-Europ. austr.

pumila, Linn. Cent. i. 30 ; Amoen. Acad. iv. 292.Aegypt.; Graecia.

pumila, Sprun. ex Nym. Consp. $430=$ hellenica.

pumila, Urv. in Mem. Soc. Linn. Par. i. (1822) $374=$ raphanina.

Pumilio, Hill, Veg. Syst. iv. $26=$ pumila?

punctata, Dufour, in Ann. Sc. Nat. Sér. I. xxiii. (1831) $159=$ hyssopifolia.

punctata, Vis. in Flora, xix. (1829) $23=$ glaberrima.

pungens, Pomel, Nouv. Mat. Fl. Atl. 29.-Algeria.

pusilla, Thuill. ex Pers. Syn. ii. 482.-Aegypt.

pygmaea, Benth. E Hook. f. Gen. ii. 482.-Syria

pygmaea, Chesn. ex DC. Prod. vi. 571=amara.

pygmaea, Hoffm. Hort. Mosc. (1808) n. $783=$ depressa.

pyracantha, Boiss. Fl. Orient. iii. 685.-Tauria.

pyrenaica, Spreng. F1. Hal. Mant. $53=$ variegata.

pyrrhoblephara, Boiss. Diagn. Ser. II. iii. 66.-

Armenia.

Rabenhorstiana, Sch. Bip. ex Nym. Consp. $426=$ cristata.

Raddeana, Trautv. in Act. Hort. Petrop. ii. (1873) 475.-Armenia.

radiata, Linn. Syst. ed. XII. $656=$ Serratula xeranthemoides.

ragusina, Clem, ex Boiss. Voy. Bot. Espagne, ii. 346 Clementei.

ragusina, Linn. Sp. Pl. 912._Dalmat. ; Creta.

ragusina, Sm. F1. Graec. x. 2. t. $903=$ argentea

ramosa, Vukot.-Cf. Oestr. Bot. Zeitschr. xxx. (1880)

163.-Europ.

ramosissima, Tausch, in Flora, xii. (1829) Erg. $45=$ nitens.

raphanifolia, Salzm. ex DC. Prod. vi. $591=$ diluta.

raphanina, Sibth. E' Sm. Fl. Graec.t. 917.-Creta

raphanina, Sieber, ex Steud. Nom. ed. II. i. $322=$ nana.

raphanina, Sprun. ex Nym. Consp. $430=$ hellenica.

raphanina, Urv, in Mem. Soc. Linn. Par, i. (1822) $372=$ Urvillei.

recta, Krock. Fl. Sil. Suppl. ii. 383.-Europ.

recurvata, C. Koch, in Linnaea, xxiv. (1851) $428=$

carduiformis.

reflexa, Lam.Encyc. i. 675.-Armenia; Caucas.

regia, Boiss. Diagn. Ser. I. vi. 135.-Assyria.

Reichenbachii, DC. Prod. vi. 583.-Europ.?

reichenbachioides, Schur, Enum. Pl. Transs. $409=$ Reichenbachii.

repens, $L i n n$. Sp. Pl. ed. II. 1233.-Oriens.

resupinata, Coss. Notes Pl. Crit. 114.-Hispan.

reticulata, Bieb. ex Willd. Sp. Pl. iii. $2287=$ coronopifolia.

Reuteri, Reichb. f. Ic. Fl. Germ. xv. 33. t. $780=$ paniculata.

Reuteriana, Boiss. Diagn. Ser. I. iv. 18.-Graecia.

rhaetica, Moritz. in Denkschr. Ally. Schw. Ges. Natur.

iii. (Pf. Graub. 81. t. 3) = phrygia.

rhapontica, Wulf, in Jacq. Coll. i. $223=$ rhaponticum.

rhaponticoides, Benth. E Hook. f. Gen. ii. 479.Hispan.

Rhaponticum, Linn. Sp. Pl. 915.--Europ.

rhenana, Bor, ex Nym. Consp, $426=$ maculosa

rhizantha, C. A. Mey. Verz. Pf. Cauc. 64=sessilis.

thizantha, Tchihat. Asie Min. Bot. ii. $320=$ armena

rhizocalathitm, C. Koch, in Linnaea, xxiv. (1851) 417.

-Armenia.

rhizocephala, Oliver E Hiern, in Oliver, Fl. Trop. Afr. iii. 438.-Afr. trop.

rhizocephala, Trautv. in Act. Hort. Petrop. ii. (1873)

476. - Armenia.

rhutenica, Baumg. Enum. Stirp. Transs. iii. $70=$

Serratula coronata.

rigens, Lag. Gen. et Sp. Nov. 32.-Hispan.

\section{CENTAUREA :-}

rigescens, Hornem. Hort. Hafn. ji. 852.-Hab. ? rigida, [Soland.in] Russell, Aleppo, ed. II. ii. 263.Syria

rigida, Willd. Enum. Hort. Berol. Suppl. $61=$ rigescens.

rigidifolia, Bess. ex DC. Prod. vi. 587= orientalis, rigidula, Jord. Obs. P1. Crit. v. (1847) $69=$ paniculata riparia, $A$. Cunn. ex DC. Prod. vi. 602.-N. Cambria. rivularis, Brot. Fl. Lusit. i, $367=$ nigra.

romana, Linn.Sp.Pl.916.-Campania

Ropalon, Pomel, Nouv. Mat. Fl. Atl. 25.-Algeria.

rosea, Steud. Nom. ed. I. $175=$ trinervia.

rubescens, Bess. ex DC. Prod. vi. 587.-Tauria.

rufescens, Jord. Pugill. $107=$ pectinata.

rufescens, Noul. ex Nym. Consp. 422, partim = nigra.

rumelica, Boiss. Diagn. Ser. II. iii. 78.-Rumelia.

rupestris, Kit. ex Steud. Nom. ed. II. i. 322=dissecta.

rupestris, Linn. Sp. Pl. ed. II. 1298.-Austr.; Ital.

rupicola, Bad. ex Nym. Consp. $426=$ aplolepis.

rupicola, Pomel, Nouv. Mat. Fl. Atl. 31.-Algeria.

ruscinonensis, Boiss. Diagn. Ser. II. nii. $70=\mathrm{C}$.

Jacea?

ruthenica, Baumg. ex Nym. Consp. $417=$ rhutenica.

ruthenica, Lam. Encyc. i. 663.-Transsylv.; Caucas. Sibir.

rutifolia, Boiss. Fl. Orient, iii. $642=$ pannosa

rutifolia, Sibth. E' Sm. Prod. Fl. Graec, ii. 205. t, 916. -Byzant.

sabulosa, Ledeb. ex Spreng. Syst. iii. $405=$ diffusa.

Sadleriana, Fanka, in Termész. Füizetek, ii. (1878) 142 -Europ

Saharae, Pomel, Nouv. Mat. Fl. Atl. 30.-Afr. bor. salicifolia, Bess. ex Nym. Consp. $422=$ austriaca. salicifolia, Bieb, ex Willd. Sp. Pl iii, $2283=$ nigra salina, Benth. E' Hook. f. Gen. ii. 479.-Sibir

Salisiana x, Bruegg. in fahresb. Naturf. Ges. Graub. II. xxiii-xxiv. (1880) 110.-Europ.

salmantica, Linn. Sp. Pl. 918.--Europ.; Afr. bor.

salonitana, Vis. in Flora, xii. (1829) I. Erg, 23.-

Europ. or.

sanguinea, Spreng. Pugill. i. 60.-Hab.

saxatilis, Bertol. ex Nym. Consp. $429=$ rupestris

saxatilis, C. Koch, in Linnaea, xxiv. (1851) 419.Creta.

saxicola, Lag. Gen. et Sp. Nov. 32.-Hispan

Scabiosa, Asso, Syn. $126=$ cephalariaefolia

Scabiosa, Linn. Sp. Pl. 918.--Europ

Scabiosa, Sadl. F1. Pesth. ed. II. $409=$ Sadleriana.

scabiosaeformis, St. Lag. in Ann. Soc. Bot. Lyon, vii

(1880) $122=$ C. Scabiosa

scabiosifolia, St. Lag. 1. c. viii. (1881) $203=$ praec.

scabra, Presl, F1. Sicul. p. xxx = sicula.

schemnitzensis, Hort. ex Steud. Nom. ed. II. i. $322=$ nigrescens

Schimperi, DC. Prod. vi. 596.-Arab.

schizolepis, Trautv. in Act. Hort. Petrop. ii. (1873)

553.-Armenia.

Schmidtiana, Tausch, in Flora. xii. (1829) I. Erg. 44 - Hab. ?

Schousboei, Lange, in Kjoeb. Vidensk. Meddel. (1861) 85 (Pugill. 135).-Hispan.

Schouwii, DC. Prod. vi. $593=$ sicula.

Schwarzenbergiana, Schur, in Verh. Siebenb. Ver

Naturw. vi. (1855) 4 =ruthenica.

sciaphila, Vukot. in Rad Jugos. Akad. Zagreb. Iviii. (1881) $150=$ nigrescens.

sclerolepis, Boiss.Diagn. Ser. I. vi. 136.-Mesopot.

scoparia, Sieber, ex DC. Prod. vi. 596.-Palaest. Aegypt.

Scopolii, Vest, in Flora, xii. (1829) I. Erg. $31=$ cristata.

scopulorum, Boiss. E Heldr. Diagn. Ser. I. x. 115.Graecia.

scorpiurifolia, Dufour, in Ann. Sc. Nat. xxiii. (1831) $163=$ aspera

segetalis, Salisb. Prod. $207=$ C. Cyanus.

semidecurrens, Jord. Obs. Pl. Crit. v. (1847) $52=$ axillaris.

sempervirens, Linn. Sp. Pl. 913.-Lusit. ; Ital

senegalensis, $D C$. Prod. vi. 598.-Afr. trop.

Seridis, Linn. Sp. Pl. 915.-Europ. austr.

Seridis, Loisel. Fl. Gall. ed. II. ii. $212=$ aspera.

serotina, Bor. Fl. Cent. Fr. ed. III. ii. $350=$ nigrescens.

serrata, Kitt. Taschenb. ed. II. $563=$ montana.

serratuloides, Benth. E Hook. f. Gen. ii. 479.-As, Min.

\section{CENTAUREA}

serratuloides, Georgi, Bemerk. Reise Russ. Reich. i.

$231=$ salina.

serratuloides, Krock, FI Sil ii II 484 (delenda).Silesia.

sessiliflora, Lam. Fl. Fr. ii. $35=$ melitensis

sessitiflora, Linn. Sp. Pl. $912=$ nigra.

sessilifolia, Hill, Veg. Syst. iv. $32=$ praec. ?

sessilis, Willd. Sp.Pl. iii. 2300.-Armenia

setifera, Lag. Gen. et Sp. Nov, $32=$ nitens,

setosa, Cav. in Anal. Ciencias Nat. iv. (1801) 96.Marocco.

seusana, Benth. Cat. P1. Pyr. $68=$ montana

seusana, Chaix, in Vill. Hist. Pl. Dauph. iii. $52=$ variegata, axillaris.

sibirica, Bieb. F1. Taur. Cauc. ii. $348=$ Marschalliana. sibirica, Linn.Sp. Pl. 913.-Sibiria

sibirica Willd ex Ledeb Fl Ross, ii $695=$ declinata.

sicula, Lam. ex Willk. \& Lange, Prod. Fl. Hisp. ii. 145 $=$ nicaeënsis.

sicula, Leyss. ex DC. Prod. vi. $594=$ solstitialis

sicula, Linn. Sp. Pl. 918 -Sicilia.

simplex, Cav. in Anal. Ciencias Nat. iv. (1801) 95.Afr, bor.

simplex, Murr. ex Steud. Nom. ed. II. i. $322=$ C. Jacea.

simplicicaulis, Boiss. E" Huet, Diagn. Ser. II. iii. 67.-Armenia.

sinaica, DC. Prod, vi. 592.-Arab.

singarensis, Boiss. E Haussk ex Boiss. Fl. Orient. iii. $654 .-$ Assyria.

Smyrneae, Boiss. Diagn. Ser. I, iv, 20, in textu $=$ Urvillei.

solstitialis, Asso, Syn. $127=$ melitensis

solstitialis, Linn. Sp. Pl. 917.-Europ.

somalensis, Oliver E Hiern, in Oliver, Fl. Trop. Afr. iii. 438.-Afr. trop.

sonchifolia, Boiss. Voy. Bot. Espagne, ii. 352 = malacitana.

sonchifolia, Linn. Sp. Pl. 915.-Europ. austr.

sonchifolia, Welw. ex Nym. Consp. 432 = sphaerocephala.

sordida, Graf, ex DC. Prod. vi. 587= Grafiana.

sordida, Salisb. Prod, $207=$ sempervirens.

sordida, Willd. Sp. Pl. iii. 2323.-Austria.

Spachii, Sch. Bip. ex Willk. E Lange, Prod. Fl. Hisp. ii. 154 - Hispan.

Sparmanni, DC. Prod. vi. 598.-Africa.

spathulata, Tenore, Prod. Fl. Nap. p. li=nigra? spathulata, Zeraph. Fl. Melit. i. $11=$ crassifolia speciosa, Boiss. Diagn. Ser. I. x. 116.-Palaestina. speciosa, Mor. ex Nym. Consp. 428.=filiformis.

sphaerocephala, J. Gay, ex Dur. in Duch. Rev. Bot. ii. $(1846-47) 429=$ Fontanesii

sphaerocephala, Linn. Sp. Pl. 916.-Europ. med.

sphaerocephala, Schousb. ex Ball, in Journ. Linn. Soc. xvi. (1878) $531=$ fragilis.

spicata, Boiss. Diagn. Ser, I. x. 113.-Syria.

Spina-badia, Bubani, ex Timb. in Mém. Acad. Tou-

louse, Sér. VIII. i. II. (1879) 187= coerulescens.

spinosa, Griseb. Spicil. Fl. Rumel. ii. 241=diffusa

spinosa, Linn. Sp. Pl. 912.-Creta; Oriens.

spinulosa, Rochel, Pl. Ban. Rar. 76. t. $36=$ C. Scabiosa

splendens, Linn. Sp. Pl. 914.-Hispan.; Ital.

splendens, Tenore, Syll. Add. iii. $628=$ alba.

Spruneri, Boiss, E Heldr. Diagn. Ser. I. vi. 132.Graecia.

Spruneri, Boiss. \& Orph. ex Boiss. F1. Orient. iii. $662=$ Guícciardii.

spuria x, Kern, in Oestr. Bot. Zeitschr. xxii. (1872)

51.-Austria.

squarrosa, Roth, Catalecta, fasc. ii. $118=$ virgata.

stenolepis, Kern. in Oestr. Bot. Zeitschr. xxii. (1872) $45=$ austriaca

stenophylla, Dufour, in Ann. Sc. Nat. Sér. I. xxiii. (1831) $162=$ aspera

stenophylla, Walp. Ann. i. 448.-Persia.

stereophylla, Bess. Enum. Pl. Volh. 35.-Podol.

stereophylla, Griseb. Spicil. F1. Rumel. ii. $237=$ C. Scabiosa

sterilis, Stev. in Bull. Soc. Nat. Mosc. xxix. (1856) II 390,-Tauria.

Steveni, Bieb. Fl. Taur. Cauc. ii. 356.-Reg, Caucas.

Steveni, Kotschy, ex Boiss. Fl. Orient. ii. $693=$ cheira cantha.

Stoebe, I.edeb. FI. Alt. iv. $49=$ calva

Stoebe, Linn. Sp. Pl. 913.-Austria; Gallia. 


\section{CENTAUREA :}

Stoebe, Tausch, in Flora, xii. (1829) I. Frg. 42 =diffusa Stoebe, Tenore, F1. Nap. ii. $264=$ subtilis

stolensis, Panc. ex Nym. Consp. $428=$ orientalis straminea, Willd. Sp. P1. iii. $2312=$ glomerata. strepens, Hoffmgg. \& Link, Fl. Port. ii. $236=$ splendens?

stricta, Waldst. \& Kit. Pl. Rar. Hung, ii. $194=$ axillaris.

strictissima, Boiss. \& Buhse, in Nouv. Mém. Soc. Nat. Mosc. xii. $(1860) 130=$ Serratula coriacea.

strobilacea, Scop. Delic. Insub. i. $38=$ alba.

suaveolens, Willd. Sp. Pl. iii. $2279=$ moschata.

subacaulis, Ledeb, Fl. Ross, ii. $709=$ Urvillei.

subalbida, Jord. Pugill. $109=$ maculosa.

subalpina, Schur, lnum. P1. Transs. $407=$ atropurpurea.

subciliaris, Boiss. Eo Heldr. ex Boiss. Fl. Orient. iii. 627.-Cephalon.

sublanata, Boiss. l. c. 645.-Graecia.

sublanuginosa, Schur, Enum. Pl. Transs, 899, Index= nervosa.

subspinosa, Steud. Nom, ed. IT. i. $322=$ diluta.

subtilis, Bertol. Fl. Ital. ix. 451.-Ital.

sulphurea, Lag. Gen. et Sp. Nov. $32=$ dissecta, orientalis.

sulphurea, Willd. Enum. Hort. Berol. 930,-Sicilia.

sumensis, Kalen. in Bull. Acad. Soc. Nat. Mosc, xvii. (1845) I. 238.--Reg. Caucas.

supina, Jord. Pugill. $108=$ pectinata.

sylvatica, Pourr. in Mém. Acad. Toul. iii. (1788) $310=$ C. Scabiosa.

Szovitsiana, Boiss. Fl. Orient. iii. 683.-Armenia; Anatol.

tagana, Brot. Fl. Lusit. i. 369.-Lusit. ;. Afr. bor.

taraxacifolia, Boiss, in l'chihat. Asie Mis. Bot. ii. $321=$ rhizocalathium.

taraxacifolia, D. Don, Prod. F1. Nep. $167=$ Saussurea eriostemon.

tatarica, Linn. f. Suppl 383=orientalis.

tatarica, Pall. Ind. Taur. $58=$ centauroides

tauromenitana, Guss. Fl. Sicil. Syn. ii. 512.-Sicil.

Tauscheri, Kern. in Oestr. Bot. Zeitschr. xxii. (1872) $119=$ arenaria.

Tchihatcheffi, Fisch. E Mey. in Ann. Sc.Nat. Sér. IV. (1854) i. 31.-Lycaonia.

Teidis, Steud. Nom. ed. II. i. $323=$ arguta.

tenella, Hort, ex Spreng. Syst. iii. $401=$ salmantica.

Tenoreana, Willk. ex Nym. Consp. $420=$ incana.

tenuiflora, DC. Prod. vi. 584.-Tauria.

tenuiflora, Fisch. Hort. Gorenk. ed. II. (1812) $36=$ salmantica.

tenuifolia, Dufour, in Ann. Sc. Gén. Phys, ii. (1820) 303.--1lician.

tenuifolia, Hort. ex Stend. Nom. ed. II. i. $323=$ salmantica.

tenuifolia, Schleich. ex Stend. 1. c. = C. Scabiosa.

tenuifolia, Salisb. Prod, $207=$ Crupina vulgaris.

tenuiramea, Delile, ex Herd. in Ind. Sem. Hort. Petrop. (1860) 37 .- Hab. ?

tenuisecta, Jord. Pugill. $110=$ maculosa.

Teydis, C. Sm. ex Buch, in Berl. Acad. Abh. 1816-17 (1819) $369=$ arguta

theiantha, [Spreng.] Bot, Gart. Halle, $24=$ orientalis.

Thirkei, Sch. Bip. in Linnaea, xix. (1847) 314. Phrygia.

Thomasiana, Dalla Torre, Atl. Alpenfl. 141.-Europ.

thrinciaefolia, $D C$. Prod. vi. 590.-Cappadoc.

rimbali, Martr. Pl. Crit, Tarn, $982=$ amara.

tinctoria, [Clairv.] Man. Herb. $253=$ Serratula tinc-

$$
\text { toria. }
$$

tingitana, Linn. Sp. Pl. ed. II. $1300=$ Cardunoellus caeruleus.

tolutana, Boiss. E Reut. Diagn. Pl. Nov. Hisp. 18.Hispan.

tomentosa, Salisb. Prod. $207=$ ragusina.

Torreana, Tenore, Ind. Sem. Hort. Neap. (1829) $15=$ C. Calcitrapa.

tougourensis, Boiss. \& Reut. Diagn. Ser. II. iii. 76.Algeria.

Tournefortii, Walp. Ann. i. 448.-Armenia.

transalpina, Subleich. Cat. PI, IIelv, ed. III. $11=$ nigrescens.

trapezuntina, Boiss. F1. Orient. $630=$ nigrescens,

trichacantha, Willd. ex Spreng. Syst. iii. $404=$ C. Calcitrapa.

trichocephala, Bicb. ex Willd. Sp. Pl. iii, 2286.Tauria

\section{CENTAUREA :}

trifurcata, Pomel, Nouv. Mat. Fl. Atl. 27.-Afr, bor. trinervia, Stev, ex Willd. Sp. Pl. iii. 2301.-Tauria Cauc.

triniaefolia, Heuff, in Oestr. Bol. Zeitschr. viii. (1858) $27=$ maculosa

Triumfetti, All. F1. Pedem. i. 158=variegata

tuberosa, Vis. Fl. Dalmat. ii. 33. t. 12. f. $2=$ napu lifera.

tubulosa, Chab. ex Nym. Consp. $421=$ nigrescens,

turkestanica, Franch. in Ann. Sc. Nat. Sér. VI. xyt (1883) 325.-Turkestan

Tweedieii, Hook. E Arn. in Hook. Comp. Bot. Mag. i (1835) 110.-Bonaria.

ucrainica, Andrz. ex Trautv. in Act. Hort. Petrop, viii. (1883) 497, nomen.-Ross. aust

uliginosa, Brot. Fl. Lusit. i, 368.-Lusitan.

umbrosa, Huet, ex Reut. Ind. Sem. Hort. Genev. (1856

4.-Cf. Linnaea, xxix. (1857-58) 719.-Sicilia.

uniflora, Linn. Mant. i. 118.-Europ. austr.

uniflora, Pall. Reise, iii. 252 = Serratula glauca.

Urvillei, DC. Prod. vi. 592.-Ins. Samos.

ustulata, Bess. Enum. Pl. Volh. $108=$ Biebersteinii.

ustulata, DC. Prod. vi. 576.-Persia.

vallesiaca, Jord. Pugill. 111 = paniculata

vallesiaca, Reichb. f. Ic. Fl. Germ. xv. 33. t. 783.-

Europ.

variabilis, Bartl. ex Steud. Nom. ed. II. i, $323=$

rupestris.

varians, A. Rich. Tent. Fl. Abyss. i. 453.-Abyss.

variegata, Lam. Encyc. i. 668.-Europ. austr.

varifolia, Loisel. Not. $130=$ C. Scabiosa.

venetum, J. F. Gmel. Syst. 1267, sphalm. = C. Verutum

verbascifolia, Vahl, Symb. Bot. i..75.-Arab.

Verutum, Linn. Cent. i. 30; Amoen. Acad. iv. 292.-

As. Min.

vesceritensis, Boiss. Diagn. Ser. II. iii. 76.-Algeria.

Villarsii, Mutel, Fi. Dauph. ii. 254.-Gallia

viminea, Less. in Linnaea, vi. (1831) $83=$ pulchella.

viretorum, Jord, ex Nym. Consp. 421=C. Jacea

virgata, Bess. Enum. Pl. Volh. $35=$ Besseriana

virgata, Cav. Ic. iii. $16=$ caerulescens.

virgata, Lam. Encyc。 i. 670.-Armenia.

virgata, Portenschl. ex Nym. Consp. $426=$ glaberrima

vochinensis, Bernh, ex Reichb. Ic. F1. Germ. xy, $15=$ nigrescens.

vulgaris, Pers. Syn. ii. $488=$ Crupina vulgaris

vulnerariaefolia, Pomel, Nouv. Mat. Fl. Atl. 26.-Air. bor.

Wallichiana, Less, in Linnaea vi. (1831) 84.-Ind, or

Webbiana, Sch. Bip. in Webb o Berth. Phyt. Canar. ii. 353.-Ins, Canar.

Weldeniana, Reichb. Ic. Fl. Germ. xv, 12. t. 753:= amara.

Wiedemanniana, Fisch. E Mey. Ind.Sem. Hort. Petrop ii. (1835) 32. Anatolia.

Willkommii, Sch. Bip. ex Willk. in Linnaca, xxy. (1852) 36.-Hispan.

(1850ns, DC. Prod vi. $581=$ arenaria

xanthina, Boiss. \& Heldr, in Boiss. Fl. Orient, iii. 650 =Pelia.

xanthina, Spreng. Syst. iii. $407=$ fuscata.

xanthocephalus, Benth. E Hook. f. Gen. ii. 480.Armen.

Zanonii, Sebast. \& Maur. Fl. Rom. 298=romana.

Zuccariniana, DC. Prod.vi. 574.-Graecia.

CENTAURELLA, Delarb. Fl. Auv. ed. II. $28(1800)=$ Erythraea, Borckh. (Gentian.)

dichotoma, Delarb. 1. c. $29=\mathrm{E}$. Centaurium.

CENTAURElla, Michx. Fl. Bor. Am. i. 97. t. 12 $(1803)=$ Bartonia, Muhl. (Uentian.)

aestivalis, Pursh, Fl. Am. Sept. i. $100=$ B. verna. autumnalis, Pursh, $\mathrm{l}_{\mathrm{c}} \mathrm{c}=\mathrm{B}$, tenella.

Koseri, Steud. \& Hochst, in Griseb. Gen. et Sp. Gentian. $308=$ B. tenells.

paniculata, Michx. Fl. Bor. Am. i. 98. t. $12 . \mathrm{f} .1=13$. tenclla.

verna, Michx. 1. c. $98=$ B. verna.

vernalis, Pursh, Fl. Am. Sept. i. $99=$ B. verna.

CENTAUREUM, Rupp. Fl. Jen. ed. IIall, 22 (17 Erythraea, Borckh. (Gentian.).

CLNTAURIA, Lim, Gen. ed. 1. $2063(1797)=$ Cen. taurea, Linn. (Compos.).
CENTTAURIDIUM, Torr, \& Gray, Fl. N. Am, ii. 246 (1841) = Xanthisma, DC. (Compos.

Drummondii, Torr. \& Gray. 1. c。=X. texanum.

CENTAURIUM, Borckh. in Roem. Arch. i. (1796) 29 Canscora, Lam. (Gentian.)

malabaricum, Borckb. 1. c. =C. sessiliflora.

CENTAURIUM, Gilib, Fl, Lituan i 35 (1781) Moench, Meth. 449 (1794) = Erythraea, Borkh. (Gentian.)

Erythraea, Rafn, Danm. og Holst. F1, ii. $75=\mathrm{E}$. Centaurium.

inapertum, Rafn, 1. c. 77.-Europ.

minus, Moench, Meth. $449=\mathrm{E}$. Centaurium.

umbellatum, Gilib. Fl. Lituan. i. $35=\mathrm{E}$. Centaurium.

vulgare, Rafn, Danm. og Holst. F1. ii. $73=\mathrm{E}$. Centaurium.

CENTAURIUM, Pers, Syn。 i. $137(1805)=$ CEN TAURELLA, Michx。= Bartonia, Mihl. (Gentian. autumnale, Pers. $1 . \mathrm{c} .=\mathrm{B}$. tenella.

vernum, Pers. $\mathrm{l}_{\mathrm{c}} \mathrm{c}_{\mathrm{v}}=\mathrm{B}$. verna.

CENTAURIUM, Tourn, ex Linn. Syst. ed. I (1735 = Centaurea, Linn. (Compos.)

africanum, Cass, in Dict. Sc. Nat. 1viii. $10=$ Centaurea africana.

alpina, Pomel, Nouv, Mat. Fl. Atl. 32,-Algeria.

moschatum, Cass, in Dict. Sc. Nat, vii. $378=$ Centaurea moschata.

officinale, Cass. 1. c. = Centaurea Centaurium.

ruthenicum, Cass. 1. c. Iviii. $10=$ Centatrea rhutenica. suaveolens, Cass. 1. c. vii. 379 - Centaurea moschata. taganum, Pomel, Nouv. Mat. Fl. Atl. 32.-Algeria. tatarica, Pomel, l. c.-Algeria.

CENTAUROPSIS, Boj. ex DC. Prod. v. 93 (1836 COMPOSITAE, Benth. \& Hook. f. ii. 231.

fruticosa, Boj. l. c.-Madag.

lanuginosa, Boj. l. c. -Madag.

Rutenbergiana, Vatke, in Bremen Abh. ix. (1855) $11 y$ -Madag.

CENTELLA, Linn. Pl. Rar. Afr, 28 (1760); Amocn. Acad. vi. $112(1764)=$ Hydrocotyle, Lin. (Umbellif.).

asiatica, Urban, in Mart. Fl. Bras. xi. I. $25 \pi=H$. asiatica:

cuneifolia, F. Muell. in Hook. Kew Joura, vii. (1855 379. t. 12 = Azorella cuneifolia.

glabra, DC. Prod. iv. 69, sphalm. $=$ seq

glabrata, Linn. Pl. Rar. Afr. 28; Amoen. Acad. vi.

$112=\mathrm{H}$. Centella.

renifolia, Urban, in Mart. Fl. Bras, xi. 1. 2\$6, in obs. = Aicropleura renifolia.

villosa, Linn. Pl. Rar. Afr. 28; Amoen. Acad. vi. $112=$ H. villosa.

CENTEMA, Hook. f. in Benth. \& Hook. f. Gen. iii. 31 (1880), AMARANTACEAE, Benth. \& Hook. f. l. c. angolensis, Hook. f. l. c.-Afr. trop.

Kirkii, Hook. f. l. c.-Air. trop.

CENTHRISCUS, Spreng. ex Steud. Nom. ed. I. 170, 55 (1821) = Anthriscus, Bernb. (Umbellif.). fumarioides, Spreng. l. $\mathrm{c}=\mathrm{A}$. fumarioides. nemorosa, Spreng. l. $\mathrm{c} .=$ A. nemorosi.

CENTINODIA, Reichb. Handb. $236\left(183^{\circ}\right)=$ Poly gonum, Tourn.

agrestima, Fourr. in Ann. Soc. Linn. Lyon, N. S. xvij. (1869) $1 \pm 0=P$. aviculare.

arenaria, Fours. 1. $c=$. arearium.

avicularis, Fourr. 1. c. $=$ P. aviculare.

Bellardi, Four 1, $c_{1}=$ P. Bellardi.

Pumifusa, lourr. 1. c. $=$ P. aviculare.

maritima, Fourt. l. c. $\sim$ P. maritimum.

microsperma, Fourr. 1. c = P. aviculare.

rurizago, Fourr. 1. $c_{0}=l^{2}$. aviculare.

CENTIPEDA, Lour. K1. Coobinch. 492 (1790 C(O)BPOSIT.AE. Henth. \& Ilook, I, ii. ISU.

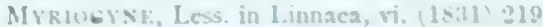

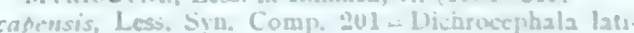
folus.

Cunninghami, A. Br. Ce Aschors. Ind. Srm. Bord. Rre.

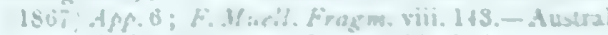
minima, A. Br. S Asthers. 1. C.-orbiculasis. 


\section{CENTIPEDA :-}

minuta, C. B. Clarke, Compos. Ind. 151 =orbicularis orbicularis, C. B. Clarke, 1. c. = Sphaeromorphaea Russeliana.

orbicularis, Lour. Fl. Cochinch. ii. 493.-As. et Austral. trop.; Ins. Pacif

racemosa, F. Muell. Census, 84.-Austral.

thespidioides, F. Muell. Fragm. viii. 143.-Austral,

CENTOPODIUM, Burch. Trav. i. $340(\mathbf{1 8 2 4})=$ Emex, Neck. (Polygon.).

spinosum, Burch. 1. c. $=$ E. spinosa.

CENTOTHECA, Desv. in Nouv. Bull. Soc. Philom. ii. (1810) 189 (Centosteca). GRAMINEAE, Benth. \& Hook, f. iii. 1190.

lappacea, Desv. l. c. -Geront. trop.

latifolia, Trin. Fund. Agrost. 141=lappacea.

parviflora, Anderss. in Peters, Reise Mossamb. Bot. 559.-Afr. trop.

CENTRACHAENA, Less. Syn. Comp. $255(1833)=$ seq.

CENTRACHENA, Schott, Cat. Ind. Sem. Hort. Vindob. (1823); ex Reichb. Ic. PI. Crit. iv. $47(1827)=$ Chrysanthemum, Tourn. (Compos.).

viscida, Schott, 1. c. ; ex Reichb. 1. c, = Chrys. viscosum.

CENTRADENIA, G. Don, Gen. Syst. ii. 755 (1832) MELASTOMACEAE, Benth. \& Hook. f. i. 739.

Doncklaeria, Hort. ex Loud. Encyc. Pl. Suppl. ii. $1350(1855)$.

Plagiophyllum, Schlecht. in Linnaea, xiii. (1839) 429.

divaricata, Klotzsch, in Otto \& Dietr. Allg. Gartenz. xix. (1851) 354.-Am. centr.

floribunda, Planch. in Fl. des Serres, Sér. I. v. (1849) t. 453.-Mexic.

grandifolia, Endl. ex Walp. Rep. ii. 119.-Mexic.

inaequilateralis, G. Don, Gen. Syst. ii. 765.-Mexic

Oerstediana, Klotzsch, in Otto छ Dietr. Allg. Gartenz. xix. (1851) 354.-Am. centr.

ovata, Klotzsch, l. c.-Am. centr.

rosea, Lindl. Bot. Reg. (1843) t. $20=$ inaequilateralis.

CENTRANDRA, Karst. in Linnaea, xxviii. (1856) 440 ; Julocroton, Mart. (Euphorbiac.)

hondensis, Karst. 1. c. = J. hondensis.

CENTRANTHERA, Scheidw. in Otto \& Dietr. Allg. Gartenz. x. (1842) $293=$ Pleurothallis, R. Br. (Orchid.).

punctata, Scheidw. 1. c. = P. Centranthera.

CENTRANTHERA, R. Br. Prod. 438 (1810) SCROPHULARINEAE, Benth. \& Hook. f. ii. 969. Gumételis, Buch.-Ham. ex D. Don, Prod. Fl. Nep. $87(1825)$.

Purshia, Dennst. Schluess. Hort. Malab. 35 (1818), Razumovia, Spreng. Syst. ii. 682 (1825).

Brunoniana, Thw. Enum. Pl. Zeyl. $220=$ procumbens.

Brunoniana, Wall. Cat.n. $38 \$ 2$; Benth. Scroph. Ind. 50.-Reg. Himal. ; Burma.

grandiflora, Benth.in Wall. Cat.n. 3880 ; Scroph. Ind. 50.-Reg. Himal.

hispida, Benth. F1. Hongk, $254=$ Brunoniana.

hispida, $R . B r$. Prod. 438.-Austral.; Afghan

humifusa, Wall. Cat. n. 3883.-Ind. or.

nepalensis, D. Don, Prod. F1. Nep. $88=$ hispida,

procumbens, Benth. in DC. Prod. X. 525.-Ind. or.

prostrata, Boj. Hort. Maurit. $246=$ Radamaea prostrata.

CENTRANTHUS, DC. Fl. Fr. iv. 238 (1805)

$V A L E R I A N E A E$, Benth.\& Hook f. ii. 155.

Hybidium, Fourr. in Ann. Soc. Linn. Lyon, N. S. xvi. (1868) 399

Kentranthus, Neck. Elem. i. 122 (1790), nomen prius.

angustifolius, Bieb. FI. Taur. Cauc. i. $67=$ longiflorus. angustifolius, Boiss. Voy. Bot. Espagne, 291=nevadensis.

angustifolius, $D C$. Fl. Fr. iv. 239.-Europ. austr.

Calcitrapa, Dufr. Hist. Valér. $39 ; D C$. l. c. v. 492.Europ.

Clausonis, Pomel, Nouv. Mat. Fl. Atl.73.-Afr. bor. dasycarpus, Kunze, Del. Sem. Hort. Lips. (1847); et Linnaea, xxiv. (1851) $176=$ macrosiphon.

elatus, Boiss. \& Heldr. Diagn. Ser. I. x. $73=$ longiflorus juncens; Boiss. Eे Heldr. l. c.-Graecia.

\section{CENTRANTHUS :-}

latifolius, Dufr. Hist. Valér. $38=$ ruber.

Lecoqii, Jord. Pugill. P1. Nov. $76=$ angustifolius,

longiflorus, Stev. Obs. Pl. Ross. 76.-As. Min.; Syria ; Reg. Caucas.

macrosiphon, Boiss. Diagn. Ser. I. iii. 57.-Hispan.

marinus, S. F. Gray, Nat. Arr. Brit. Pl. ii. $479=$ ruber maritimus, DC. Prod, iv, $632=$ ruber.

nervosus, Moris, Elench. Sard. ii. 4.-Corsic.; Sardin. nevadensis, Boiss, Diagn. Ser. II. ii. 120.-Hispan.

orbiculatus, Dufr. Hist, Valér. $39=\mathrm{C}$. Calcitrapa.

orbiculatus, Roem. E Schult. Syst. i. 35.-Cyprus.

pinnatifidus, St. Lag, in Ann. Soc. Bot. Lyon, vii.

(1880) $122=$ C. Calcitrapa.

ruber, $D C . F l$. Fr. iv. 239.-Europ.; Syria.

Sibthorpii, Heldr. E Sart. Diagn. Ser. II. ii. 119.Graecia.

CENTRAPALUS, Cass. in Dict. Sc. Nat. vii. 382 (1817) $=$ Vernonia, Schreb. $(\text { Compos. })_{\text {. }}$

galamensis, Cass. 1. c. $383=\mathrm{V}$. pauciflora.

CENTRATHERUM, Cass. in Bull. Soc. Philom.

(1817) 31. COMPOSITAE, Benth. \& Hook. f. ii. 225. Ampherephis, H. B. \& K. Nov. Gen. et Sp.iv. 31. t. $314,315(1820)$.

AMPHIBECIS, Schrank, in Syll. Ratisb, i. (1824) 86.

Crantzia, Vell. FI. Flum. Ic. viii. t. 153 (1827).

Decaneurum, DC. in Guill. Arch. Bot. ii. (1833) 516.

Phyllocephalum, Blume, Bijdr. 888 (1826).

RoLfinkia, Zenk. Pl. Ind. 13. t. 14 (1837).

SpIxiA, Schrank, Pl. Rar. Hort. Monac. t. 80 (1819)

Wightia, Spreng. ex DC. Prod. v. 67 (1836).

aristatum, Cass. in Dict. Sc. Nat. lvii. $342=$ punctatum.

brachylepis, Sch. Bip. ex Baker, in Mart. Fl. Bras. vi. II. 12.-Bras.

brevispinum, Cass, in Dict. Sc. Nat. lvii. $346=$ intermedium.

chinense, Less. in Linnaea, iv. (1829) $320=$ Vernonia chinensis.

courtallense, Benth. E Hook. f. Gen. ii, 225.-Ind, or. courtallense, C. B. Clarke, Comp. Ind. $3=$ Kitchiei.

Hookeri, C, B. Clarke, l. c.-Ind, or.

intermedium, Less. in Linnaea, iv. (1829) 320.-Bras. longispinum, Cass. in Dict. Se. Nat. lvii. $346=$ punctatum.

Metzianum, Hook. f. Fl. Brit. Ind. iii. 228.-Ind. or molle, Benth. E Hook. f. Gen. ii. 225.-Ind. or.

muticum, Less. in Linnaea, iv. (1829) 320.-Mexic.

phyllolaenum, Benth. ex Hook. f. Fl. Brit. Ind. iii. 228.-Ind. or.

pulchellum, Steud. Nom. ed. II. i. 324-N. Zel.

punctatum, Cass. in Dict. Sc. Nat. vii. 384.-Venezuela.

reticulatum, Benth. Ev Hook. f. Gen. ii. 225.-Ind. or.

Ritchiei, Hook. f. Fl. Brit. Ind. iii. 228.-Ind. or.

scariosum, C. B. Clarke, Comp. Ind. $4=$ Vernonia scariosa.

tenue, C.B. Clarke, l. c.-Ind. or.

CENTROCARPHA, D. Don, in Sweet, Hort. Brit. ed. II. 310 (1830) ; et in Brit. Fl. Gard. Ser. II. iv. t. 87 (1831) = Rudbeckia, Linn. (Compos.).

acutifolia, Sweet, Hort. Brit. ed. II. 310 , nomen $=$ R. Newmanni.

aristata, D. Don, in Sweet, Brit. F1. Gard. Ser. II. iv. sub t. $87=\mathrm{R}$. triloba.

chrysantha, Steud. Nom. ed. II. i. $321=$ R. Newmanni. chrysomela, D. Don, in Sweet, Brit. Fl. Gard. Ser. II iv. sub t. $87=\mathrm{R}$. fulgida.

discolor, D. Don, 1. c. = R. fulgida

fulgida, D. Don, 1. c. $=$ R. fulgida.

gracilis, D. Don, in Sweet, Hort. Brit. ed. II. 310 ; et 1. $\mathrm{c} .=\mathrm{R}$. hirta.

grandiflora, D. Don, in Sweet, Brit. F1. Gard. Ser. II. iv. t. $87=\mathrm{R}$. grandiflora.

hirta, D. Don, in Sweet, Hort. Brit. ed. II. 310 ; et 1. c. $=\mathrm{R}$. hirta.

moschata, J. Cree, ex Steud. Nom. ed. II. i. $321=$ R. moschata.

Radula, D. Don, in Sweet, Brit. F1. Gard. Ser. II. iv. sub t. $87=$ Helianthus Radula.

spathulata, D. Don, 1. c. = R. spathulata.

subtomentosa, Sweet, Hort. Brit. ed. I. 310 , nomen = R. subtomentosa.

triloba, D. Don, in Sweet, Brit. F1. Gard. Ser. II. iv, sub t. $87=\mathrm{R}$. subtomentosa.

triloba, Loud. Hort. Brit. Suppl, i. $584=$ R. triloba.
CENTROCHILUS, J. C. Schau. in Nov. Act. Nat. Cur. xix. Suppl. i. (Pl. Meyen.) 435. t. $113(1843)=$ Habenaria, Willd. (Orchid.).

gracilis, Schau. 1. c $=$ H. tipuloides.

CENTROCLINIUM, D. Don, in Trans. Linn. Soc, xvi. (1830) $254=$ Onoseris, DC. (Compos.) adpressum, Hook. Bot. Mag. t. $3115=0$. adpressa. albicans, D. Don, in Trans. Linn. Soc. xvi. (1830) 254 $=0$. integrifolia.

altissimum, Poepp. \& Endl. Nov. Gen. et Sp. iix. 52. $t$. 259.-Peruy.

hyssopifolium, D. Dietr. Syn. Pl. iv. $1565=$ O. hyssopifolia.

reflexum, Hook. Bot. Mag. t. $3115=$ O. reflexa.

salicifolium, D. Dietr. Syn. P1. iv. $1565=0$. salicifolia.

CENTRODISCUS, Muell. Arg. in Mart. Fl. Bras. xi. II. 325. t. $102(1874)=$ Caryodendron, Karst. (Euphorb.).

grandifolius, Muell. Arg. 1. c. 327.-Bras.

CENTROGLOSSA, Rodrig. Orch, Nov. ii, 234 (1881). ORCHIDEAE.

macroceras, Rodvig. l. c. 235.-Bras.

tripollinica, Rodrig. l. c.-Bras.

CENTROLEPIS, Labill. Nov. Holl. P1. i. 7. t. 1 (1804). CENTROLEPIDEAE, Benth. \& Hook. f. iii. 1026.

Alepyrum, R. Br. Prod. 253 (1810).

Centrosepis, R. Hedw. Gen. 51 (1806).

Devauxia, R. Br. Prod. 253 (1810) ed. Nees, 108 (1827).

aemula, Rudge, in Trans. Linn. Soc. x. (1811) $284=$ strigosa.

alepyroides, Walp. Ann. i. 897.-Austral.

aristata, Roem. E' Schult. Syst. i. 44.-Austral.

Banksii, Roem. E Schult. l. c.-Austral.

brevifolia, Walp. Ann. i. $896=$ Drummondii.

cambodiana, Hance, in fourn. Bot. xiv. (1876) 14.-

Cambodia.

cuspidigera, Rudge, in Trans. Linn. Soc. x. (1811) 283 $=$ fascicularis.

Drummondii, Walp. Ann. i. 896.-Austral.

exserta, Roem. E Schult. Syst. i. 44.-Austral

fascicularis, Labill. Nov. Holl. Pl. i. 7. t. 1.-Austral.

glabra, Hieron. in Abh. Naturf. Ges. Halle, xii. (1873) 209.-Austral.

humillima, F. Muell.ex Benth. Fl. Austral. vii. 203.Austral.

longifolia, Steud. Nom. ed. II. i. 324 ; et Kunth, Enum.Pl. iii. 489.-Austral.

monogyna, Benth. Fl. Austral. vii. 205.-Austral

muscoides, Hieron. in Abh. Naturf. Ges. Halle, xii. (1873) 209.-Tasmania.

mutica, Hieron. l. c. 211.-Austral.

Patersoni, Roem. \& Schult. Syst. i. $43=$ strigosa.

pilosa, Hieron. in Abh. Naturf. Ges. Halle, xii. (1873)

216. - Austral.

polygona, Hieron. Centrolep. $96=$ polygyna.

polygyna, Hieron. in Abh. Naturf. Ges. Halle, xii. (1873) 210.-A ustral.

pulchra, Hieron. 1. c. $213=$ Drummondi.

pulvinata, Roem. \& Schult. Syst. i. 43.-Tasmania.

pusilla, Roem. E' Schult. l. c. 44.-Austral.

strigosa, Roem. E Schult. l. c. 43.-Austral.

tenuior, Roem. \& Schult. l. c. = strigosa.

Urvillei, Hieron. in Abh. Naturf. Ges. Halle, xii. (1873)

$214=$ Drummondii

CENTROLOBIUM, Mart. ex Benth. in Ann. Wien. Mus. ii. (1838) 95. LEGUMINOSAE, Benth. \&

Hook. f. i. 546.

minus, Presl, Bot. Bemerk. $62=$ robustum

parä̈nse, Tul. in Arch. Mus. Par. iv. (1844) 87.-Am.

robustum, Mart. ex Benth. in Ann. Wien. Mus. ii. (1838) 95. - Bras.

tomentosum, Guill. ex Benth. in Hook. Fourn. Bot. ii. (1840) 66.-Bras.

CENTRONIA, Blume, Bijdr. $776(1826)=$ Aeginetia, Linn. (Orobanchac.).

mirabilis, Blume, 1. c. $=$ A. Centronia. 
CENTRONIA, D. Don, in Mem. Wern. Soc. iv. (1823) 314. MELASTOMACEAE, Benth. \& Hook f $-750$.

Brachycentrum, Meissn. Gen. 114 (1837)

Calyptraria, Naud。 in Ann. Sc. Nat. Sér. III. xviii. (1852) 132.

Stephanogastra, Karst. \& Triana, in Linnaea xxviii. (1856) 425 .

brachycera, Triana, in Trans. Linn. Soc. xxviii. (1871) 72.-N. Granat.

crassiramus, Triano, l. c.-Guiana.

excelsa, Triana, $l_{\text {. }} c_{0}-$ Peruv. ; Ecuador.

eximia, Triana, $l . c$. Ecuador.

haemantha, Triana, l. c. -N. Granat.

insignis, Triana, $l, c$-Ecuador.

laurifolia, D. Don, in Mem. Wern. Soc. iv. (1823) 315 -Peruv.

Mutisii, Triana, in Trans. Linn. Soc. xxviii. (1871) 72.-N. Granat.

phlomoides, Triana, $l$. c. -Costa Rica.

reticulata, Triana, l. c. 71.-Peruv.

CENTRONOTA, DC. in Meissn. Gen. 303 [213] (1840); et Prod. ix. $286(1813)=$ Aeginetia, Linn. (Orobanchac.).

mirabilis, DC. Prod, ix. $186=$ Ae. Centronia.

CENTROPAPPUS, Hook. f. in Hook. Lond. Journ. Bot. vi. (1847) $124=$ Senecio, Tourn. (Compos.).

Brunonis, Hook. f. l. c. $=$ S. Centropappus.

CENTROPETALUM, Lindl. Sert. Orch. sub t. 21 1839). ORCHIDEAE, Benth. \& Hook. f. iii. 570. Fernandezia, Ruiz \& Pav. Prod. Fl. Per. 123. 27 (1794).

NAsoNIA, Lindl, in Benth. Pl. Hartw. 150 (1844)

distichum, Lindl. l. c.-Peruv.

Myrtillus, Pfitser, Verg. Morph. Orch. 16.-Peruv.

Warszewiczii, Reichb. f. in Bot. Zeit. x. (1852) 706 .Peruv.

CENTROPHORUM, Trin. Fund. Agrost. 106. t. 5 (1820) =Chrysopogon, Trin. (Gramin.).

chinense, Trin. 1. c. = Chrys. aciculatus.

CENTROPHYLLUM, Dum. Anal. Fam, 32 (1829)= KENTROPHYLLUM, Neck.= Carthamus, Linn. (Compos.)

CENTROPHYTA, Reichb. Nom. 148 (1841)=KEN. TROPHYTA, Nutt.= Astragalus, Tourn. (Legum.).

CENTROPODIUM, Lindl. Introd. Nat. Syst. ed. II. 442 (1836), sphalm.= CEN'TOPODIUM, Burch. = Emex, Neck. (Polygon.).

CENTROPOGON, Presl, Prod. Monog. Lobel. 48 (1836). CAMPANULACEAE, Benth. \& Hook. f. ii. 547 .

affine, Mart \& Gal in Bull. Acad Brux ix. II. (1842) 40 - - Mexic.

amplifolius, Vatke, in Linnaea, xxxviii. (1874) 716.Peruv.

Andropogon, $D C$. Prod. vii. 345.-Ecuador.

argentinus, Griseb. in Goett. Abh. xxiv. (1879) 219.Reg. Argent.

Berterianus, DC. Prod. vii. 345.-Ins. Guadalup.

beslerioides, $D C$. . . c. $346 .-\mathrm{N}$. Granat.

Bonplandianus, Presl, Prod. Monog. Lobel. 48.-Am. austr.

calycinus, Benth. Pl. Hartw.212.-N. Granat.

Chamissonianus, Kanits, in Mart. Fl. Bras, vi. IV, 133. -Bras.

coccineus, Regel, Gartenfl. (1858) 374, in textu.-Bras. cordatus, Mart. \& Gal. in Bull. Acad, Brux, ix. II. (1842) $40=$ cordifolius

cordifolius, Benth. Pl. Hartw. 77.-Mexico.

costaricanus, Planch, \& Oerst, in Kjoeb. Vidensk. Meddel. (1857) 156.-Costa Rica.

cuspidatus, $D C$. Prod. vii. 346 .-Perav.

densiflorus, Benth. Pl. Hartw. 138.-Peruy

discolor, Kunth E Bouche, Ind. Sem. Hort. Berol.

(1847) 13.-Venezucla.

edulis, P'resl, Prod. Monog. Lobel. 48 = surinamensis.

exasperatus, Presl, $l_{0} c_{0}-$ Peruv.

fasciculatus, Regel, Cat. Pl. Hort. Aksakov. 29.IIab. ?

\section{CENTROPOGON :-}

fastuosus, Scheidw. in Otto E Dietr. Allg. Gartenz. ix (1841) 396.-Mexico.

floccosus, Planch, in Fl. des Serres, Sér. I. vi. (1850 51) 16.-N. Granat.

glandulosus, Decne, in Rev. Hortic. Sér. III. ii. (1848) 421.-N. Granat.

grandis, Presl, Prod. Monog. Lobel. 48.-N. Granat.

granulosus, Presl, l. c. 49.-Peruv.

hirtus, Presl, l. c. 48.-Ecuador.

laevigatus, DC. Prod. vii. 344.-Guiana.

longipes, Regel, Gartenfl. iii. (1854) 3. t. 75.-Am centr

nutans, Planch. E Oerst. in Kjoeb. Vidensk. Meddel.

1857 ) 156.-Costa Rica.

oblongus, Benth. Pl. Hartw. 214.-N. Granat.

prostratus, Benth. l. c. 212.-Peruy.

reflexus, Presl, Prod. Monog. Lobel. 49.-Peruv.

scandens, Planch. E Oerst. in Kjoeb. Vidensk. Meddel. (1857) 157.-Costa Rica.

solanifolius, Benth. Pl. Hartw. 139.-Peruy,

speciosus, Planch. in Fl. des Serres, Sér. I. vi. (185051) 16.-Venezuela

surinamensis, Presl, Prod. Monog. Lobel. 48.-Am. anstr

tovarensis, Planch. E Linden, in Fl. des Serres, Sér. I. viii. (1852-53) 145.-Venezuela.

virescens, Planch. \& Oerst, in Kjoeb. Vidensk. Meddel. (1857) $157=$ Burmeistera virescens

Warscewiczii, Van Houtte, ex Regel, Gartenf. (1858) 374 - $-\mathrm{Hab}$ ?

Warscewiczii, Vatke, in Linnaea, xxxviii. (1874) 716. - Costa Rica.

CENTROPSIS, Endl. Gen. Suppl, ii. $33(1842)=$ KEN. TROPSIS, Moq. = Sclerolaena, R. Br. (Chenop.)

CENTROSEMA, Benth. in Ann. Wien. Mus. ii. (1838) 117. LEGUMINOSAE, Benth. \& Hook. f. i. 527

Cruminium, Desv, in Ann. Sc. Nat. Sér. I. ix. (1826) 423

Pilanthus, Poit. ex Endl. Gen. 1289 (1841).

Platysema, Hoffmgg. ex Benth. in Ann. Wien. Mus. ii. (1838) 117.

Steganotropis, Lehm. Ind. Sem. Hort. Hamb. (1826).

Vexillaria, Hoffmgg. Verz. Pf. 119 (1824); Benth, in Ann. Wien. Mus, ii. (1838) 117

acutifolium, Benth. 1. c. $118=$ brasilianum.

angustifolium, Benth. l. c.-Venezuela.

arenarium, Benth. l. c. 119.-Bras.

bifidum, Benth. l. c. 118.-Bras.

biflorum, Mart. ex Benth. 1. c, $120=$ virginianum

brachypodum, Benth. in Ann. Nat. Hist. iii. (1839) 435 =brasilianum

bracteosum, Benth. in Ann. Wien. Mus. ii. 119.-Bras

brasilianum, Benth. l.c. 118.--Bras.

conjugatum, Steud. Nom. ed. II. i. 325.-Am, austr. coriaceum, Benth, in Ann. Wien. Mus. ii. (1838) 118 -Bras.

cuspidatum, Hassk. in Flora, li. (1868) 27.-Ind, or.

dasyanthum, Benth. in Ann. Nat. Hist. iii. (1839) 436.-Bras.

decumbens, Mart. ex Benth, in Ann. Wien. Mus. ii. 1838) $120=$ virginianum.

dubium, Hemsl. Biol. Centr. Am. Bot. i. $294=$ has tatum.

fasciculatum, Benth. in Ann. Wien. Mus. ii. (1838) 120.-Bras.

ferrugineum, A. Rich, Ess. Fl. Cub, 410.-Cnba.

glabrum, Benth. in Aon. Wien. Mus. ii. (1838) $119=$ coriaceum.

grandiforum, Benth. l. c.-Bras.

grandiforum, Walp. Rep. ₹. $529=$ Clitoria grandi flora.

hastatum, Benth. in Ann. Wien. Mus. ii. (1838) 120 . -Bras.

heptaphyllum, Moric. Pl. Nouv. Rar. Am. 26. t. 61.Calif.

insulanum, Steud. Nom. ed. II. i. $325=$ brasilianum. intermedium, A. Rich. Ess, F1. Cub. $410=$ pubescens. ongifolium, Bentb. in Ann. Wien. Mus. ii. (1898) 11 angustifolium.

macrocarpum, Bent/s. in Ann. Nat. Hist, iii. (1899) 436.-Guiana.

micranthum, Steud. Nom. ed. II. i. $\$ 86^{\circ}$ in sym. sphalm. = virginianum.

\section{CENTROSEMA :-}

molle, Mart. ex Benth. in Ann. Wien. Mus. il. (1838)

$119=$ pubescens.

oblongum, Benth. I. c. $118=$ coriaceum

pascuorum, Mart. ex Benth. l. c. 120-Bras.

perspicuum, Klotzsch, in Schomb. Faun. \& Fl. Gui. 12(13, nomen.-Guiana.

platycarpam, Benth. in Mart. Fl. Bras. xv. I. 126.Peruv.

Plomieri, Benth. in Ann. Wien. Mus, ii. (1838) 118.Am, austr.

pubescens, Benth. l. c. 119.-Bras.

rigidulum, Benth. in Hook. Journ. Bot. ii. (1846) 58 = arenarium.

rotundifolium, Mart. ex Benth. in Ann. Wien. Mus. ii. (1838) 119 - - Bras.

Salzmanni, Benth, in Ann. Nat. Hist. iii. (1839) 436 $=$ pubescens.

scabriusculum, Hassk. Pl. Jav, Rar. 377 = virginianum. sinuatum, Benth. in Ann. Wien. Mus. ii. (1838) 120 . - Bras.

sordidum, Klotzsch, in Schomb. Faun. \& Fl. Guy. 1203 , nomen.-Guiana.

venosum, Mart. ex Benth. in Mart. Fl. Bras. Xv. I. 133.-Bras.

verticillatum, Benth. in Hook. Fourn. Bot. ii. 1848 58.-Guiana.

vestitum, Klotzsch, in Schomb. Faun. Eo Fl. Guy. 1203 , nomen.-Guiana.

vetulum, Mart. ex Benth. in Ann. Wien. Mus, ii. (1838 119. - Bras.

vexillatum, Benth, in Ann. Nat. Hist. iii. (1839) 435 -Guiana.

virginianum, Benth. in Ann. Wien. Mus, ii. (1838) 120 . -Am. trop.

virginianum, Griseb. in Goett. Abh. vii. $(1857,204=$ pubescens.

CENTROSEPIS, R. Hedw, Gen. 51 (1806), sphalm. Centrolepis, Labill.

Centrosia, A. Rich. in Mém. Soc. Hist. Nat Par iv. (1828) $39=$ Calanthe, R. Br. (Orchid.)

Auberti, A. Rich. 1.c. $40=$ Cal, sylvatica.

CENTROSIS, Thou. Orch. Iles Afr. t. 35, 36 (1822) Calanthe, R. Br. (Orchid.)

corymbosa, Thou. 1. c. $1^{\text {or }} \mathrm{Tabl},=\mathrm{Cal}$. sylvatica plantaginea, Thou. 1. c. 1or Tabl. = Cal. sylvatica?

sylvatica, Thou. 1 . c. tt. $35,36=$ Cal, sylvatica.

CENTROSOLENIA, Benth. in Hook. Lond. Journ. Bot. v, (1846) $362=$ Episcia, Mart. (Gesnerac.). aenea Linden \& André, in Illustr. Hortic zxii. $(1875)$ t 222 - N. Granat.

bracteata, Planch. in Fl. des Serres, Sér. I. vi. (1850-51) 322.-N. Granat.

bractescens, Hook. Bot. Mrg. t. $4675=\mathrm{E}$. bractescens. bullata, Lem. Illustr. Hortic. xvi. (1869) \&. $607=\mathrm{E}$ tessellata.

glabra, Benth in Hook. Bot, Mag, t, $4552=\mathrm{E}$ glabra. glabra, Hook. Ic Pl. t. $873=$ E. Hookeri.

hirsuta, Benth. in Hook. Lond. Joum. Bot. v. (18t0) $362=$ E. hirsuta

hirtiflora, Sprace, ex Hanst. in Linnaea, xrriv. (1\$6566) $450=\mathrm{E}$, hirtiflora.

picta, Hook. Bot. Mag. t. $4611=$ E. picta.

CENTROSPERMUM, H. B. \& K. Nor. Gen. et Sp. ir. 270. t. $997(1820)=$ Acanthospermum, Schrank (Compos.)

Iumile, Less, Syn. Comp, $217=\mathrm{A}$, humile.

ranthioides, H. B. \& K. Nov. Gen. et Sp. ir. 2:0 = A. brasilum.

CENTROSIERMC'M, Spreng. Nor. Prov. 9 1818) : c Syst. iii. $588(18: 6)$ - Chrysanthemum, Linn. (Compos.).

Chrysanshemsm, Spreng. I. $c_{0}=$ C. riscosum.

EEVTROSTACIIYS, Wall. in Rusb. Fl. Int. ed. Caney, ii. 49\% 18:4)-Achyranthes, Linn. (Amarat, qupation, Wall, Cal, n. $6932=$ A. aqualica.

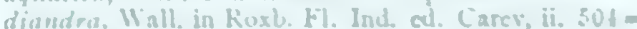
d. cliamelsa.

Pubrlligern, Fenal, ex Mog, in DC. Prod. xiii. 11. 321 - d. ayuatica 
CENTROSTEGIA, A. Gray, ex Benth. in DC. Prod. xiv. 27 (1856); et in Pacif. Rail. Rep, vii. 19 (1857) POLYGONACEAE, Benth. \& Hook. f. iii. 83.

leptoceras, A. Gray, in Proc. Am. Acad. viii. (1870) 192.-Calif.

Thurberi, A. Gray, ex Benth. in DC. Prod.xiv. 27 , et in Pacif. Rail. Rep. vii. 20.-Calif.

CENTROSTEMma, Decne. in Ann. Sc. Nat. Sér. II. ix. 1838) 271. t. $12=$ Hoya, R. Br. (Asclepiad.). coriaceum, Meissn. Gen. Comm. $177=\mathrm{H}$. coriacea Cyrtoceras, Meissn. 1. c. $=\mathrm{H}$. multiflora.

elegans, Blume, Mus. Bot. Lugd. Bat. i. 46 Cyrtoceras elegans).-Borneo.

laurifolium, Blume, 1. c. (=Cyrtoceras laurifolium).Java.

Lindleyanum, Decne. in DC. Prod. viii. $634=\mathrm{H}$. multiflora.

micranthum, Blume, Mus. Bot. Lugd. Bat. i. 46 (=Cyrtoceras micranthum).-Ins, Celebes.

multiflorum, Decne, in Ann. Sc. Nat. Sér. II. ix. (1838) $272=$ H. multiflora.

CENTROSTYLIS, Baill. Etud. Gén. Euph. 469 (1858) = Adenochlaena, Baill. (Euphorb.)

zeylanica, Baill. l. c. 470 . t. 2. f. $28-29=$ A. zeylanica.

CENTUNCULUS, Adans, Fam. ii. $256 \quad(1763)=$ Cerastium, Linn. (Caryophyll.)

alpinus, Scop. F1. Carn. ed. II. i. $321=$ Cerast. trigynum.

angustifolius, Scop. 1. c. $322=$ Cerast. strictum.

arvensis, Scop. 1. c. $321=$ Cerast. arvense.

rigidus, Scop. 1. c. $322=$ Cerast. strictum.

semidecandrus, Scop. 1. c. 331=Cerast, semidecandrum.

CENTUNCULUS, Dill. ex Linn. Syst. ed. I (1735)

PRIMULACEAE, Benth. \& Hook. f. ii. 637.

ANAGallidastrum, Mich, ex Adans. Fam. ii, 230

(1763).

Micropyxis, Duby, in DC. Prod. viii. 71 (1844).

erectus, Phil. Fl. Atac. 35.-Chili.

lanceolatus, Michx. Fl. Bor. Am. i. $94=$ minimus.

minimus, Linn. Sp. Pl. 116.-Europ.; Am. bor. et 'austr.

pentandrus, $R$. Br. Prod. 427.-Am. et Austral trop. simplex, Hornem, in Fl. Dan. ix. t. $1567=$ minimus. tenellus, Duby, in DC. Prod. viii. 72 = pentandrus.

CEODES, Forst. Char. Gen. 141. t. $71(1776)=$ Pisonia, Linn. (Nyctagin.).

umbellifera, F orst. i. c. $142=$ P. umbellifera

CEPA, [Tourn.] Linn. Syst. ed. I (1735); Gen. ed. I. 103 $(\mathbf{1 7 3 7})=$ Allium, Tourn. (Yiliac.)

alba, Renault, FI. Dep. Orne, $33=$ A. Cepa?

angulosa, Bernh. Syst. Verz. Erf, $202=$ A. angulosum.

ascalonica, Noronha, in Verh. Batav. Gen. v. (1790) ed. I. Art. IV. $11=\mathrm{A}$, ascalonicum.

carinata, S. F. Gray, Nat. Arr. Brit. Pl. ii. $185=$ A. carinatum.

cernua, Moench, Meth. Suppl. $80=$ A. cernuum.

esculenta, S. F. Gray, Nat. Arr. Brit. Pl. ii. $183=$ A. Cepa.

fistulosa, S. F. Gray, 1. c. $184=$ A. fistulosum.

flava, Moench, Meth. $243=$ A. flavum.

flexuosa, Moench, Meth. Suppl. $80=$ A. roseum.

Moly, Moench, Meth. $244=$ A. Moly.

obliqua, Moench, I. c. $243=$ A. obliquum

oleracea, Bernh. Syst. Verz. Erf. 202=A. oleraceum

pallens, Renault, Fl. Dép. Orne, $33=\mathrm{A}$. Cepa?

paniculata, Moench, Meth. $243=\mathrm{A}$. paniculatum.

prolifera, Moench, I. c. $244=$ A. Cepa.

rubra, Renault, Fl. Dép. Orne, $33=\mathrm{A}$. Cepa?

Schoenoprasa, Moench, Meth. $244=$ A. Schoenoprasum.

senescens, Moench, l. c. = A. semescens.

tenuifolia, S. F. Gray, Nat. Arr. Brit. Pl. ii. $114=$ A.

Schoenoprasum.

ursina, Bernh. Syst. Verz. Erf. $201=$ A. ursinum.

ventricosa, Moench, Meth: $244=\mathrm{A}$. fistulosum

Victorialis, Moench, 1. c. $243=$ A. Victorialis.

vulgaris, Renault, Fl. Dép. Orne, $33=$ A. Cepa.

CEPAEA, Caesalp. ex Fourr. in Ann. Sc. Linn. Lyon, N. S. xvi. (1868) $384=$ Sedum, Tourn. (Crassulac.).

Caesalpini, Fourr. 1. $c_{1}=\mathrm{S}$. Cepaea.
CEPALARIA, Rafin. F1. Tellur. iv. 95 (1836) = Cephalaria, Schrad. (Dipsac.).

CEPHAËLIS Sw. Prod. Veg. Ind. Occ. 45 (1788). RUBIACEAE, Benth. \& Hook. f. ii. 127.

CALlicocca, Schreb. Gen. i. 126 (1789)

CARAPICHEA, Aubl. Pl. Gui. 167. to 64 (1775).

Chesnea, Scop. Introd. 119 (1777).

EURHOTIA, Neck. Elem. i. 207 (1790).

EveA, Aubl. Pl. Gui. 103, t. 39 (1775).

IpecacuanHA, Arruda, Diss. 44 (1810), ex St. Hil Pl. Bras. t. 6 (1824)

NetTlera, Rafin. Sylva Tellur. 147 (1838)

Tapogomea, Aubl. Hl. Gui. i. 357.t. 60 ad 63 (1775) alba, Willd. Sp. Pl. i. 978.-Guiana.

ambigua, DC. Prod. iv. $534=$ Psychotria Salzmanniana attenuata, Miq. in Linnaea, xix. (1847) 444.-Bras. axillaris, Sw. Prod. Veg. Ind. Occ. 45.-Ind. occ.

Beeri, Teijsm. E Binn. Cat. Hort. Bog. 384, nomen. Hab.?

Beskeana, Schlecht. in Linnaea, xxviii. (1856) $533=$ Psychotria Beskeana,

bidentata, 'Benth. in Hook. Niger F1.421 = peduncularis. bidentata, Thunb. ex Roem. \& Schult. Syst. v. $214=$ Psychotria bidentata.

bracteocardia, DC. Prod. iv. 534= Psychotria bracteocardia.

brasiliensis, Cham. in Linnaea, ix. (1834) 237.-Bras.

bubalina, Pers. Syn. 1. $202=$ Burchellia capensis

calycina, Lindl. Collect. t. $21=$ Psychotria Lindleyana.

Carapichea, Raeusch. ex Steud. Nom. ed. II. i. $326=$ involucrata.

Chamissonis, Stend. 1. $c_{0}=$ Salmmannia nitida

clausa, Hiern, in Oliver, Fl. Trop. Afr. iii. 225.-Afr. trop.

colorata, Hoffmgg. ex Roem. E Schult. Syst. v. 213.Bras.

congensis, Hiern, in Oliver, Fl. Trop. Afr. iii. 226.--

Afr. trop.

coriacea, D. Dietr. Syn. Pl, i. $774=$ Psychotria xanthophylla.

coriacea, G. Don, Gen. Syst. iii. $606=$ peduncularis. cornuta, Hiern, in Oliver, Fl. Trop. Afr. iii. 224.

Afr. trop.

costaricensis, Schlecht. in Linnaea, xxviii. (1856) 546. -Costa Rica.

crocea, G. F. W. Mey. Prim. Fl. Esseq. 107.-Guiana. cuncata, Korth. in Nederl. Kruidk. Arch. ii. (1851) 248.-Malaya.

cyanocarpa, Moç. \& Sesse, ex DC. Prod. iv. 533= tomentosa.

cymosa, Spreng. Syst. i. $749=$ Psychotria maypurensis dichotoma, Rudge, Pl. Gui. i. 29.t. 44.-Guiana.

dichotoma, Willd. ex Roem. \& Schult. Syst. v. $214=$ Psychotria Hoffmannseggiana.

discolor,Polak. in Linnaea, xli. (1877)572.-Costa Rica. diversifolia, Blume, Bijdr. $1004=$ Geophila reniformis elata, Sw. Prod. Veg. Ind. Occ. 45,-Jamaica.

emetica, Pers. Syn. i. $203=$ Psychotria Ipecacuanha.

Evea, DC. Prod. iv. 535.-Guiana.

ferruginea, G. Don, Gen. Syst。 iii. $605=$ Sabicea ferruginea.

fragrans, Hook. \& Arn. Bot. Beech. Voy. 64. t. 13. -Ins. Societ.

furcata, Bartl. ex DC. Prod. iv. $513=$ Psychotria furcata.

fuscescens, Hiern, in Oliver, Fl. Trop. Afr. iii. 224.Afr. trop.

gemmiflora, Willd. ex Roem. E' Schult. Syst. v. 213.Hab. ?

glabra, Willd. Sp. Pl. i. 979.-Guiana

Griffithii, Hook. f. Fl. Brit. Ind. iii. 178.-Malacca.

herbacea, Kurz, in Journ. As. Soc. Beng. (18/7) Ir

$140=$ Geophila reniformis.

hirsuta, Mart. E Gal. in Bull. Acad. Brux. xi. I (1844) 135-Mexic.

hirta, Miq. in Linnaea, xvii. (1843) 71.-Guiana.

Hoffmannseggiana, Roem. \& Schult. Syst. v. $214=$ Psychotria Hoffmannseggiana.

Humboldtiana, Cham. \& Schlecht. in Linnaea, iv. (1829) $\mathbf{1 3 6}=$ Psychotria Humboldtiana. involucrata, Willd. Sp. Pl. i. 979 -Guiana

Ipecachuanha, Rich. in Bull. Fac. Med. iv. (1818) 92 = Psychotria Ipecacuanha.

justiciaefolia, Rudge, Pl. Gui. i. 28. t. 43.-Guiana,

latifolia, Hiern, in Oliver, Fl. Trop. Afr. iii. 226.

Afr. trop.

ligularis, Rich. ex DC. Prod. iv. 533.-Guiana.

\section{CEPHAËLIS:}

Mannii, Benth. E Hook. f. ex Hiern, in Oliver, Fl. Trop. Afr. iii. 225.-Afr. trop.

maranhaënsis, G. Don, Gen. Syst. iii. 605.-Bras,

microcephala, Humb. \& Bonpl. ex Roem. \& Schult. Syst. v. $214=$ Psychotria microcephala.

microcephala, Miq. in Linnaea, xviii. (1844) $748=$ Psychotria Hoffmannseggiana.

muscosa, Sw. Prod. Veg. Ind. Occ. 46.-Ins. Martinic. nuda, Cham. E Schlecht. in Linnaea, iv. (1829) 135. -Bras

oblonga, DC. Prod.iv. 535.-Guiana.

ornata, Spruce, ex Benth. Es Hook. f. Gen. ii. 128, nomen.--Bras.

Patabaea, Stend. Nom. ed. I. 177, 596 (=Patabea coocinea).-Bras.

Patrisii, D. Dietr. Syn. Pl. i. 773.-Guiana

peduncularis, Salisb. Parad. Lond. t. 99.-Afr. trop.

pedunculata, G. Don, Gen. Syst. iii. $605=$ peduncularis.

peruviana, Spreng. Syst. i. $749=$ Psychotria capitata

polycephala, Schlecht. in Linnaea, xxviii. (1856) 532. -Peruv.

prunifolia, H. B. \& K. Nov. Gen. et Sp. iii. $377=$ Psychotria microcephala.

psychotriaefolia, Seem. Bot. Voy. Herald. 138.Panama,

pubescens, Hoffmgg. ex Roem. \& Schult. Syst. v. 213 = Psychotria bracteocardia.

punicea, Vahl, Eclog. Am. i. $19=$ elata.

purpurea, Willd.Sp.Pl. i. 978.-Guiana.

reniformis, H. B. \& K. Nov. Gen. et Sp. iii. $377=$ Geophila reniformis.

rosea, Benth. in Hook. Journ. Bot. iii. (1841) $224=$ Psychotria rosea.

rubescens, Hiern, in Oliver, Fl. Trop. Afr. iii. 225.Afr. trop.

rubra, Huffmgg. ex Roem. \& Schult. Syst. v. $214=$

Psychotria rubra.

ruelliaefolia, Cham. \& Schlecht, in Linnaea, iv. (1829) $134=$ Psychotria ruelliaefolia.

salicifolia, H. B. E K. Nov. Gen. et Sp. iii. 376.-N. Granat.

sessiliflora, Willd. Sp. PI. i. 979 (=Patabea coccinea). -Bras.

spathacea, Hiern, in Oliver, Fl. Trop. Afr. iii. 225.Afr. trop.

speciosa, Spreng. Syst. i. $749=$ Psychotria speciosa.

stipulacea, Blume, Bijdr. 1005.-Java.

suaveolens, Schweinf. ex Hiern, in Oliver, Fl. Trop. Afr. iii. 224.-Afr. trop.

subconnata, Sagot, ex Benth. E' Hook. f. Gen. ii. 128. -Guiana.

subtomentosa, Spreng. Syst. i. $749=$ Psychotria subtomentosa.

Swartzii, DC. Prod. iv. 534.-Ind. occ.

tenuiflora, D. Dietr. Syn. Pl. i. 774 (=Patabea tenuiflora).-Guiana.

tenuis, D. Dietr. 1. c. = Psychotria tenerior

tetranda, Willd. Sp. PI. i. $979=$ C. Evea.

tomentosa, Vahl, Eclog. Am. i. 19= Psychotria tomentosa.

triplocephala, Bello, in Anal. Soc. Esp. Hist. Nat. x. (1881) 282.-Porto Rico

turbinata, Benth. E Hook. f. Gen. ii. 128, nomen,-Bras. vialacea, Sw. Prod. Veg. Ind. Occ. $45=$ Swartzii.

violacea, Willd. Sp. Pl. i. 977 .- Ind. occ.

violaefolia, H. B. \& K. Nov. Gen. et Sp. iii, $379=$ Geophila violaefolia.

CEPHALANDRA, Schrad. ex Eckl. \& Zeyh. Enum $280(1836)=$ Coccinia, Wight \& Arn. (Cucurb.).

decipiens, Hook. f. in Oliver, Fl. Trop. Afr. ii. $552=$ Cocc. decipiens.

diversifolia, Naud. in Ann. Sc. Nat. Sér. V. v. (1866) 18. t. $7=$ Cocc. Hartmanniana.

grandis, Kurz, in Journ. As. Soc. Beng. xlvi. (1877) II. $103=$ Cocc. indica.

indica, Naud. in Ann. Sc. Nat. Sér. V. v. (1866) $16=$ Cocc. indica.

McKennii, Naud. 1. c. $17=$ Cocc. Mac-Kennii

palmata, Sond. in Harv. \& Sond. Fl. Cap. ii. $493=$ Cocc. palmata.

pubescens, Sond. 1. c. $=$ Cocc. adoënsis.

quinqueloba, Schrad. ex Eckl. \& Zeyh. Enum. $280=$

Cocc. quinqueloba.

Schimperi, Naud. in Ann. Sc. Nat. Sér. V.v. (1866) 16 = Cocc. indica. 


\section{CEPHALANDRA :-}

senensis, Klotzsch, in Peters, Reise Mossamb. Bot. 151 = Coccinia senensis.

sessilifolia, Sond. in Harv. \& Sond. Fl. Cap. ii. $493=$ Cocc. sessilifolia.

Wightiana, Hook. f. Fl. Brit. Ind. ii. Index 757, sphalm, $=$ Cocc. indica.

CEPHALANOPHLOS, Neck. Elem. i. $68(1790)=$ Cnicus, Tourn. (Compos.).

CEPHALANTHERA, Rich. in Mém. Mus. Par. iv. (1818) 51. ORCHIDEAE, Benth. \& Hook. f, iii. 619. DORYCHEILE, Reichb. Nom. 56 (1841). acuminata, Ledeb. Fl. Ross. iv. $78=$ pallens. acuminata, Lindl. in Wall. Cat. $\mathrm{n} .7405=$ ensifolia. chloidophylla, Reichb. f. in Linnaea, xxv.(1852) 228. -Japon.

comosa, Tineo, in Guss, Fl. Sic. Syn. ii. $877=$ rubra.

cucullata, Boiss. \& Heldr. Diagn. Ser. 1. xiii. 12.Graecia; As. Min.; Persia.

ensifolia, Rich. in Mém. Mus. Par. iv. (1818) 60.Europ.; Afr. bor.; As. temp.

epipactoides, Fisch. \& Mey. in Ann. Sc. Nat. Sér. IV i. $(1854) 30=$ cucullata.

erecta, Blume, Orch. Archip. Ind. 188.-Japon.

falcata, Blume, l. c. 187.--Japon.

grandiflora, S. F. Gray, Nat. Arr. Brit. Pl. ii. 210 pallens.

japonica, A. Gray, in Perry, Exp. Jap. ii. $319=$ falcata lancifolia, Dum. Fl. Belg. 134; Tod. Orch Sic. 123. Sicilia.

lonchophylla, Reichb. f. Ic. F1. Germ. xiii. et xiv $136=$ pallens

longibracteata, Blume, Orch. Archip. Ind. 188.-Japon

Maravignae, Tineo, in Guss. Fl. Sic. Syn. ii. $877=$ ensifolia.

ochroleuca, Reichb. Fl. Germ. Excurs. $140^{20}=$ pallens.

oregana, Reichb. f. in Linnaea, xli. (1877) 53.-Am bor. occ.

pallens, Hohen, in Bull. Soc. Nat. Mosc. (1838) 257 =ensifolia.

pallens, Rich. in Mém. Mus. Par. iv. (1818) 60.Europ.; Reg. Caucas,

palustris, Rich. ex Pritz. Ic. Ind. ii. 71, sphalm.= Epipactis palustris.

platycheila, Reichb, f. in Bot. Zeit. iii. (1845) $335=$ falcata.

Royleano, Regel, in Act. Hort. Petrop. vi. (1879) 490 = Epipactis Royleana.

rubra, Rich. in Mém. Mus. Par. iv. (1818) 60.Europ.; As. Min.; Persia.

Thomsoni, Reichb. $f$. in Linnaea, xli. (1877) 54.-

Reg. Himal.

xiphophylla, Reichb. f. Ic. F1. Germ. xiii. et xiv. 135 =ensifolia.

CEPHALANTHUS, Linn. Gen. ed. I. 61 (1737) RUBIACEAE, Benth. \& Hook. f. ii. 30.

ACrodryon, Axolus, Eresimus, Gilipus, SilamNus, Rafin. Sylva Tellur. 60-61 (1838)

acuminatus, Rafin. New Fl. Am. iii. 25.-Am. bor.

africanus, Reichb. ex DC. Prod. iv. $345=$ Mitragyna africana.

angustifolius, Lour. Fl. Cochinch. i. 67.-China.

aralioides, Zoll. \& Moritzi, Syst. Verz. Zoll. 61= naucleoides.

chinensis, Lam. Encyc, i. $678=$ Nauclea purpurea. montanus, Lour. Fl. Cochinch. i. 67.-China. natalensis, Oliver, in Hook. Ic. Pl. t. 1331.-Natal. naucleoides, $D C$. Prod. iv. 539.-Reg. Himal.; Malaya; Chins.

obtusifolia, Rafin. Nerv Fl. Am. iii. 25.-Am. bor.

occidentalis, Linn. Sp. Pl. 95.-Am. bor.; Mexic.

Ind. occ.

occidentalis, Lour. Fl. Cochinch. i. $67=$ Nauclca orientalis.

oppositifolius, Moench, Meth. $487=$ occidentalis

orientalis, Blume, Cat. Gew. Buitenz, $88=$ Nauclea purpurea.

orientalis, Linn. Sp. P1. $85=$ Anthocephalus morindaefolius.

orientalis, Roem. E Schult. Syst. iii. 105.-China.

pilulifer, Lam. Encyc, i. 679 - Mitragyna parvifolia.

piluliflorus, Willd. ex Roem. E Schult. Syst. iii. 525

-Hab.?

procumbens, Lour. Fl. Cochinch. i. 7.-Cochinch.

pubescens, Rafin. New Fl. Am, iii. 5.Am. bor.

\section{CEPHALANTHUS :-} salicifolius, Humb. \& Bonpl. Pl. Aequin. ii. 63. t. $98=$
occidentalis,

Sarandi, Cham. Es Schlecht. in Linnaea, ii. (1827) 610. -Bras.

spathellifexus, Baker, in Fourn. Bot. xx. (1882) 187.-

Madag.

stellatus, Lour. Fl. Cochinch. i. 68.-China.

CEPHALARIA, Schrad, Cat. Sem. Hort. Gotting. (1814) ex Roem. \& Schult. Syst. iii. 1 (1818. DIPSACEAE, Benth. \& Hook, f, ii. 159 .

Cerionanthus, Schott, ex Roem, \& Schult. 1. c. 43 (1818).

Leprcephalus, Lag. Gen. et Sp. Nov. 7 (1816)

Levcopsora, Rafin. Fl. Tellur. iv. 95 (1836).

Picnocomum, DC. Prod. iv. 647 (1830) in syn.

Pterocephalus, Adans. Fam. ii. 152 (1763).

Pycnocomon, Wallr. Sched. Crit. 46 (1822) in syn. Succisa, Wallr. 1. c. (1822).

acaulis, Steud. ex A. Rich. Tent. Fl. Abyss. i. 368.Abyssin.

albescens, Roem. \& Schult. Syst. iii. $48=1$ eucantha.

alpina, Schrad. Cat. Sem. Hort. Gotting. (1814); ex

Roem. E Schult. Syst. iii. 43,-Europ.

ambrosioides, Roem. E Schult. l. c. 45.-Graecia

amplexicaulis, Steud. Nom, ed. II. i. 327.-Graecia Oriens?

appendiculata, Schrad. Cat. Sem. Hort. Gotting. 1814); ex Roem. \& Schult. Syst. iii. $42=$ Dipsacus pilosus.

aristata, C. Koch, in Linnaea, xxiv. (1851) 445.As. Min.

attenuata, Roem. E Schult. Syst. iii. 44.-Afr. austr.

balearica, Coss. ex Willk. in Linnaea, xl. (1876) 37 . Hispan.

bidens, Roem. \& Schult. Syst. iii. $45=$ Scabiosa biden boetica, Boiss. Voy. Bot. Espagne, $738=$ leucantha.

Boissieri, Reut. in Boiss. Diagn. Ser. II. ii. 122 syriaca.

cachemirica, Decne, in Jacquem. Voy. Bot, 86 . t. $94=$ Dipsacus inermis.

calva, Boiss. \& Bal. Diagn. Ser. II vi, $95=$ aristata.

centauroides, Roem. \& Schult. Syst. iii. $49=$ corn culata.

centauroides, Schur, Enum. P1. Transs. $294=$ laevigata,

cilicica, Boiss. E Kotschy, Diagn. Ser. II. v. 106.Cilicia.

coriacea, Stend. Nom. ed. II. i. 327 = corniculata.

corniculata, Roem. E Schult. Syst. iii. 49.-Bannatus.

cretacea, Roem. \& Schult. 1. c. $51=$ corniculata.

decurrens, Roem. \& Schult. 1. c. $50=$ attenuata

diandra, Roem. \& Schult. 1. c. $52=$ Scabiosa papposa.

dichaetophora, Boiss, Diagn. Ser. I. vi, 71.-Persia

dipsacoides, Boiss, E Bal. Diagn. Ser. II, v. 107. Cilicia ; Syria.

dipsacoides, Kar. \& Kir. in Bull. Soc. Nat. Mosc. (1841) $484=$ Dipsacus azureus.

elata, Schrad. in Cat. Sem. Hort. Gotting. (1814); ex

Roem. \& Schult. Syst. iii. $51=$ tatarica.

Fussiana, Heuff. ex Schur, Enum. Pl. Transs. $293=$ radiata.

graeca, Roem. E Schult. Syst. iii. 43.-Graecia.

hirsuta, Stapf, in Denkschr. Acad. Wien, 1. (1885) 55. - Persia.

humilis, Roem. \& Schult. Syst. iii. $50=$ attennata .

involucrata, Roem. E Schult. l.c. 53.-Creta; Cyprus.

joppensis, Coult. ex DC.Prod. iv, 648.-Italia ; Cilicia Syria.

juncea, Boiss. Diagn. Ser. I. vi. 72.-Persia

Kotschyi, Boiss. \& Hohen. 1. c. x. $76=$ procera. laevigata, Panc. ex Nym. Consp. 346 -alpina. laevigata, Schrad. Cat. Sem. Hort. Gotting. (1814)= corniculata.

lavandulacea, Sond. in Harv. E Sond. Fl. Cap. iii, 11 -Afr. austr.

leucantha, Baumg. ex Nym. Consp. $346=$ radiata. leucantha, Ledeb. Fl. Russ, i. $449=$ corniculats. leucantha, Schrad. in Cat. Sem. Hort. Gotting. (181) ex Roem. E Schult. Syst. iii. 47.-Hispan,; Gall leucanthema, Roem. \& Schult. 1. c. 48 =leocantha. linearifolia, Lange, in Kjoeb. Vidensk. Meddel. (1877 78) $220=$ leucantha.

longifolia, E. Mey. Zwei PA. Docum. 171 attenuata.

macrophylla, Griseb. Spicil. Fl. Rumel. ii. $174=$ ambrusioides.

\section{CEPHALARTA}

mauritanica, Pomel, Nouv. Mat. Fl. Atl. 66.-Af bor.

microcephala, Boiss. Diagn. Ser. II. ii. 123.-Persia. neglecta, Verlot, Ind. Sem. Hort, Gratianop. (1852)

10 ; et Linnaea, xxvi.(1853-55) 764.-Hab.

papposa, Roem. \& Schult. Syst. iii. $52=$ syriaca.

pilosa, Boiss. \& Huet, Diagn. Ser. II. ii. 122.Armenia.

pilosa, Gren, \& Godr. Fl. Fr. ii. 69=Dipsacts pilosns.

plumosa, Roem. \& Schult. Syst, iii. $53=$ =Scabios

lusitanica?

procera, Fisch. E Avé-Lall. Ind. Sem. Hort. Petrop. vii. 46.-As. Min.

procera, Pane. ex Nym. Consp. $346=$ alpina

radiata, Griseb. E Schenk, in Wiegm. Archiv, xviii (1852) I. 351.-Transsyly.

rigida, Eckl. \& Zeyh. Enum. $371=$ rigida.

rigida, Roem. E Schult. Syst. iii. 44.-Afr. austr.

rupestris, Griseb. ex Nym. Consp. $346=$ alpina.

scabra, Eckl. \&c Zeyh. Enum. 371 = rigida.

scabra, Roem. E Schult. Syst. iii. 44.-Afr. austr.

setosa, Boiss. E Hohen. Diagn. Ser. I. ii. 107.-Syria

setulifera, Boiss. \& Heldr. in Boiss. Fl. Orient. ii. $124=$ graeca

speciosa, Boiss. F Kotschy, in Boiss. l. c. 121 Armenia.

stellipilis, Boiss. Diagn. Ser. I. x. 76.-Syria

syriaca, Schrad. Cat. Sem. Hort. Gotting. (1814); ex

Roem. G Schult. Syst. iii. 45.-Reg. Mediterr. Oriens.

tatarica, Schrad. L c.; ex Roem. E Schult. l. c. 51 -Rossia; As. bor.; Oriens.

Tchihatchewi, Boiss, in Tchinat. Asie Min. Bot. ii. 220. t. 26.-Armenia.

transylvanica, Schrad. Cat. Sem. Hort. Gotting. (1814)

ex Roem. E Schult. Syst. iii. 45.-Europ. austr.; As. Min.; Reg. Caucas.

uralensis, Roem. \& Schult. Syst. iii. $50=$ corniculata. ustulata, E. Mey. Zwei PA. Docum, 171=attenuata. ustalata, Roem. EO Schult. Syst. iii. 43-Afr. austr.

Vaillantii, Schott, ex Roem, \& Schult. 1. c. $46=$ syriaca.

virginea, Janka, in Oestr. Bot. Zeitschr. xxii. (1872) $178=$ graeca

Willichii, Roem. \& Schult. Syst. iii. $53=$ Scabiosa plumosa.

CEPHALEIS, Vahl, Eclog. i. 19 (1796), sphalm. = Cephaëlis, Sw. (Rubiac.)

CEPHALIDIUM, A. Rich. in Mém. Soc. Hist. Nat. Far. v. $(1830)=$ Anthocephalus, A. Rich. (Rubiac.).

CEPHALINA, Thonn, in Schum. \& Thonn. Beskr. Guin. Pl. 105 (1827)= Sarcocephalus, Afzel. (Rubiac). esculenta, Schum. \& Thonn. 1. c. $=$ S. esculentus. scandens, DC. Prod. iv. 368 , in syn。 $=\mathrm{S}$. esculentus

CEPHALIPTERUM, A. Gray, in Hook. Kew Journ. iv. (1852) 271. COMPOSITAE, Benth. \& Hook. f. ii. 321.

Drammondii, A. Gray, L. c. 272.-Austral.

CEPHALOCARPUS, Nees, in Mart. Fl. Bras, ii, 162. t. 18 (1842). CYPERACEAE, Benth. \& Hook. f. iii. 1068 .

Dracaenula, Nees, b. c-Bras.

CEPHALOCEREUS, Pfeift. in Otto \& Dietr. Allg. Gartenz. vi. (1898) $142=$ Cereus, Haw. (Cacteae). senilis, $\mathrm{P}$ feiff, $1, c_{0}=\mathrm{C}$, senilis.

CEPHAlochloA, Coss. \& Dar. in Am. Sc. Nat. Sér. IV. i. (1854) $229=\mathbf{A m m o c h l o a , ~ B o i s s . ~}$ (Gramin.)

echinata, Coss. \& Dar. 1. c. = A. pungens.

CEPHALOCROTON. IJochst, in Flors xis (1841) 370. EUPHORBIACEAE, Benth. S Hook. iii. $90 \%$.

albicans, Muell. Arg. in DC. Prod. xy. 18. i00,Malaya.

cordofanus, Mruell. Arg. in Linnaca, xxxiv. (18005-66 155 . A fr. trop.

discolor, Muell. Arg. in DC. Prod. xv. 11. i61.Malaya. 


\section{CEPHALOCROTON :-}

indicus, Bedd. F1. Sylv. ii. t. 261 = Adenochlaena indica.

leucocephalus, Baill. Adansonia, v. (1864-65) 148.Madag.

mollis, Klotzsch, in Peters, Reise Mossamb. Bot. 99. t. 17.-Afr. trop.

orientalis, Miq. Ann. Mus. Bot. Lugd. Bat. iv. 120.Ins. Timor.

socotranus, Balf. in Proc. Roy. Soc. Edinb. xii. (1884) 95.-Ins. Socotra.

zeylanicus, Baill. Adansonia, v. (1864-65) $148=$ Adenochlaena zeylanica.

CEPHALODES, St. Lag. in Ann. Soc. Bot. Lyon, viii. (1881) $159=$ Cephalaria, Schrad. (Dipsac.)

CEPHALOMA, Neck. Elem. i. $314(1790)=$ Dracoce phalum, Linn. (Labiat.).

CEPHALOMAPPA, Baill. Adansonia, xi. 130 (1874). EUPHORBIACEAE, Benth. \& Hook. f. iii. 323.

Beccariana, Baill. l. c. 131.-Borneo.

CEPHALONOPLOS, Fourr. in Ann. Soc Linn. Lyon, N. S. xvii. (1869) $95=$ Cnicus, Tourn. (Compos.), arvensis, Fourr. 1. c. $=$ Cnicus arvensis.

CEPHALOPAPPUS, Nees \& Mart. in Nov. Act Nat. Cur. xii. (1824) 5.t. 1. COMPOSITAE, Benth. \& Hook. f. ii. 504.

sonchifolius, Nees \& Mart. l. c. 6.-Bras,

CEPHALOPHORA, Cav, Ic. vi. 79. t. 599 (1801) COMPOSITAE, Benth. \& Hook. f. ii. 413.

Actinea, A. Juss, in Ann. Mus. Par. ii. (1803) 425. t. 61.

ACTinella, Pers. Syn. ii. 469 (1807)

Graemia, Hook. Exot. Fl. t. 189 (1827).

Grahamia, Spreng. Syst. iv. Cur. Post. 297, 299 (1827).

Ptilepida, Rafin, in Am. Monthly Mag. (1818) 268.

acaulis, DC. Prod. v. $663=$ Actinella acaulis .

anthemoides, Less. in Linnaea, vi. (1831) $518=$ Actinella odorata.

aromatica, Schrad. Ind. Sem. Hort. Gotting. (1830), Less. Syn. Comp. 240,-Chili.

Berteroana, Phil. in Linnaea, xxix. (1857-58) 9.Chili.

collina, Phil. l. c. 8.-Chili.

decurrens, Less. I. c. vi. (1831) $517=$ Helenium puberulum.

Doniana, Hook. E Arn. in Hook. Fourn. Bot. iii (1841) 324.-Reg. Argent.

elongata, D. Don, ex DC. Prod. vii. 293, pro parte $=$ Gaillardia megapotamica.

elongata, D. Don, ex Hook. Journ. Bot. iii. (1841) 324 , pro parte $=$ Doniana

fasciculata, Pohl, ex J. A. Schmidt, in Mart. Fl. Bras. viii. $89=$ Hyptis caprariaefolia

foliosa, Phil. in Linnaea, xxix. (1857-58) 7.-Chili

glauca, Cav. Ic. vi. 80. t. 599.-Chili.

grandiflora, Walp. Ann. i. 416.-Am. bor. occ.

heterophylla, Less. Syn. Comp. 240.-Reg. Argent.

insularis, Phil. in Anal. Univ. Chil. (1873) 506.Chili.

integrifolia, Steud. Nom. ed. II. 1. $328=$ Helenium integrifolium.

litoralis, Phil. Fl. Atac. 34.-Chili.

plantaginea, DC. Prod. v. 662.-Chili.

punctata, Klatt, in Abh. Naturf. Ges. Halle, xv. (1882) 328.-Chili.

radiata, Less. in Linnaea, vi. (1831) $516=$ heterophylla

rigida, Phil. in Linnaea, xxxiii. (1864-65) 170.Chili.

scabiosoides, D. Don, ex DC. Prod. vii. $293=$ Gaillardia megapotamica.

scaposa, DC. Prod. v. $663=$ Actinella scaposa

setigera, Phil. in Anal. Univ. Chil. (1873) 505.Chili.

suffruticosa, D. Don, ex Hook. Journ. Bot. iii. (1841) $324=$ Doniana.

tenera, Cass. Opusc. iii. $93=$ aromatica.

Urmentae, Phil. in Anal. Univ. Chil. (1873) 505. Chili.
CEPHALOPHORUS, Lem. Cact. Aliq. Nov. Desc. p. xii $(1838)=$ Cereus, Haw. (Cacteae)

Columna-Trajani, Lem. 1. c. = Cereus ColumnaTrajani.

senilis, Lem. 1. c. $=$ Cereus senilis.

CEPHALOPHYTON, Hook. f, ex Baker, in Journ. Linn. Soc. $x x .(1883) 250$, nomen $=$ Thonningia, Vahl, (Balanoph.)

Parkeri, Hook. f. ex Baker, 1. c.-Madag

CEPHALORRHYNCHUS, Boiss. Diagn. Ser. I. iv. 28 $(1844)=$ Lactuca, Tourn. (Compos.)

Aucheri, Boiss, 1. c. vii. $11=\mathrm{L}$. microcephala.

Candolleanus, Boiss. Fl. Orient. iii. $820=\mathrm{L}$. hispida.

glandulosus, Boiss. Diagn. Ser. I. iv. 28.-As. Min.

hispidus, Boiss. F1. Orient. iii. $821=\mathrm{L}$. microcephala Kotschyi, Boiss. \& Reut. ex Boiss. 1. c. $816=\mathrm{L}$ seticuspis.

CEPHALOSCHOENUS, Nees, in Linnaea, ix. (1834) 295 = Rynchospora, Vahl (Cyperac.)

Armeria, Nees, 1. c. $296=\mathrm{R}$. globosa .

articulatus, Nees, in Edinb. N. Phil. 'Journ, xvii, (1834) $266=\mathrm{R}$. aurea

divergens, Nees, in Linnaea, ix. (1834) $296=\mathrm{R}$, aurea globosus, Nees, 1. c. = R. globosa

longisetis, Nees, 1. $\mathrm{c}_{\mathrm{r}}=\mathrm{R}$. longisetis.

marginatus, Liebm. in Vidensk. Selsk. Skr. V. ii, (1851) $250=\mathrm{R}$ globosa.

oligocephalus, Hochst. in Flora, xxviii. (1845) $759=\mathrm{R}$. cyperoides.

parvus, Nees, in Linnaea, ix. (1834) $296=\mathrm{R}$. Wallichiana.

Pohlianus, Nees, in Mart. F1. Bras. ii. I. $131=$ R. globosa.

polycephalus, Nees, in Linnaea, ix. (1834) $296=\mathrm{R}$. cyperoides.

pseudomariscus, Nees, I. c. = R. gigantea .

tenuirostris, Nees, $1_{\text {. }} \mathrm{c}_{\mathrm{o}}=\mathrm{R}$. cyperoides, tenuirostris.

zeylanicus, Nees, in Edinb. N. Phil. Journ. xvii. (1834) $265=\mathrm{R}$. triflora.

CEPHALOSCIRPUS, Kurz, in Journ. As. Soc. Beng. xxxviii. (1869) II. $83=$ Mapania, Aubl. (Cyperac.). macrocephalus, Kurz, 1. c. 84.-Ins. Molucc.

CEPHALOSERIS, Poepp. ex Reichb. Consp. 212 ${ }^{n}$ (1828) =Polyachyrus, Lag. (Compos.).

Poeppigii, Kunze, ex Steud. Nom. ed. II. i. $328=$ P. Poeppigii.

CEPHALOSORUS, A. Gray, in Hook. Kew Journ. iii. (1851) 152 = Angianthus, Wendl. (Compos.).

brevipapposus, F. Muell. Fragm。 iii $159=$ A. phyllocephalus.

gnephosoides, F. Muell. 1. c. ii. $158=$ Gnephosis cyathopappa.

gymnocephalus, A. Gray, in Hook. Kew Journ. iii. (1851) $153=$ Gnephosis macrocephala.

leptocladus, F. Muell. Fragm, iii. 158=Gnephosis leptoclada.

microcephalus, F. Muell, 1. c. = A. microcephalus.

phyllocephalus, A. Gray, in Hook. Kew Journ. iii. (1851) $152=\mathrm{A}$. phyllocephalus.

CEPHALOSTACHYUM, Munro, in Trans, Linn, Soc. xxvi. (1868) 138. GRAMINEAE, Benth. \& Hook. f. iii, 1213 .

capitatum, Munro, l. c. 139.-Reg. Himal.

Chapelieri, Munro, l. c. 140,-Madag.

flavescens, Kurz, in Fourn. As. Soc. Beng. xlii. (1873) 1I. 252,-Burma.

Griffithii, Kurz, For. Fl. Brit. Burma, ii. $566=$ Teinostachyum Griffithii.

latifolium, Munro, in Trans. Linn. Soc, xxvi. (1868) 140.-Reg. Himal.

pallidum, Munro, l. c. 139,-Reg. Himal.

pergracile, Munro, $l$. c. 141.-Burma.

schizostachyoides, Kurz, For. Fl. Brit. Burma, ii. 565 -Ins. Andaman.

virgatum, Kurz, l. c.-Burma.

CEPHAIOSTEMON, Rob. Schomb. Rap. \& SaxoFrid. 9 (1845). RAPATEACEAE, Benth. \& Hook. f. iii. 858 .

affinis, Koern. in Linnaea, xxxvii. (1871-73) 447.Venezuela.

\section{CEPHALOSTEMON}

gracilis, Rob. Schomb. Rap. E Saxo-Frid. 9.-Bras

Riedelianus, Koern. in Linnaea, xxxvii. (1871-73) 445 -Bras.

squarrosus, Koern. l. c. 450,-Venezuela.

CEPHALOSTIGMA, A. DC, Monog. Camp. 117 (1830). CAMPANULACEAE, Benth. \& Hook. f. ii 555 .

555.
anagalloides, Royle, Illustr. Bot. Himal. $253=$ hirsutum.

bahiense, A. DC. Prod. vii. $421=$ Perrottetii.

erectum, Vatke, in Linnaea, xxxviii. (1874) $699=$ Schimperi

flexuosum, Hook. f. E Thoms. in Fourn. Linn. Soc. ii. (1858) 9.-Ind. or

hirsutum, Edgew. in Trans. Linn. Soc.xx. (1851) 81.Reg. Himal.

hirsutum, Hook, f. \& Thoms. in Joum. Linn. Soc. ii (1858) $9=$ Schimperi

Hookeri, C. B. Clarke, in Hook. f. Fl. Brit. Ind. iii. 429.-Reg. Himal

paniculatum, A. DC. Monog. Camp. 117.-Burma.

paniculatum, Wall. Cat, n, $1295 \mathrm{C}=$ hirsutum.

Perrottetii, A.DC. Monog. Camp. 118.-Afr. trop.

Perrottetii, Hook. f. in Journ. Linn. Soc. vii. (1864) $204=$ ramosissimum

Prieurei, A. DC. Monog. Camp. 118.-Afr. trop.

ramosissimum, Hemsl. in Oliver, Fl. Trop. Afr. iii. 472 -Afr. trop.

Schimperi, Hochst, ex A. Rich. Tent. Fl. Abyss. ii. 2 -Ind. or.; Afr. trop.

spathulatum, Thw. Enum. Pl. Zeyl. 422 = Campanula canescens.

CEPHALOTAXUS, Sieb. \& Zucc. ex Endl. Gen. Suppl. II. 27 (1842). CONIFERAE, Benth. \& Hook. f. iii. 430 .

Buergeri, Miq. Ann. Mus. Bot. Lugd. Bat. iii. 169.-

Japon.
drupacea, Sieb. E Zucc. Fl. Fap. Fam. Nat. ii. 108.Japon.

Fortuni, Hook. Bot. Mag. t. $4499=$ drupacea.

Harringtonia, C. Koch, Dendrol. ii. II. $102=$ pedun. culata.

pedunculata, Sieb. E Zucc. Fl. Fap. Fam. Nat. ii. 108 -Japon.

sumatrana, Miq. Fl. Ind. Bat. ii. 1076.-Sumatra.

tardiva, Siebold, ex Endl. Syn. Conif. 239 = Taxus brevifolia.

umbraculifera, Siebold, ex Endl. 1. c. = Taxus brevifolia.

CEPHALOTOMANDRA, Karst. \& Triana, in Linnaea, xxviii. (1856) 429. NYCTAGINEAE, Benth. \& Hook, f, iii. 10.

fragrans, Karst. E' Triana, l. c. 430-N. Granat.

CEPHALOTROPHIS, Blume, Mus. Bot. Lugd. Bat. ii. 75. t. 27. $1852[1856]=$ Malaisia, Blanco (Urticac.).

javanica, Blume, 1. c. $76=\mathrm{M}$. tortuosa

puberula, Miq. Fl. Ind. Bat. Suppl. $416=$ M. puberula.

CEPHALOTUS, Labill. Nov. Holl. P1. ii. 6. t. 145 (1806). SAXIFRAGEAE, Benth. \& Hook. f. i. 655. follicularis, Labill. l. c. 7.-Austral.

CEPHALOXIS, Desv. Journ. Bot. i. (1808) t. $11=$ seq.

CEPHALOXYS, Desv. Journ. Bot. i. (1808) $321=$ Juncus, Tourn.

flabellata, Desv. 1.c. $324=\mathrm{J}$. repens

graminifolia, Nees, ex Kunth, Enum. P1. iii. $343=$ J. cyperoides.

CERADIA, Lindl. Bot. Reg. (1845) Misc. 12 = Othonna, Linn. (Compos.).

furcata, Lindl. 1. c. (=Doria Ceradia).-Afr. austr.

CERAIA, Lour. Fl. Cochinch. ii. $518(\mathbf{1 7 9 0})=$ Dendro bium, Sw. (Orchid.).

simplicissima, Lour. 1. c. =D. Ceraia.

CERAMANTHE, Dum. Not. Scroph. $7(1834)=$ Scrophularia, Linn.

vernalis, Dum. 1. $\mathrm{c}_{0}=\mathrm{S}$. vernalis. 
CERAMANTHUS, Hassk. Cat, Hort. Bogor. Alt. 240 (1844) $=$ Phyllanthus, Linn. (Euphorbiac.).

gracilis, Hassk. 1. c. $=$ P. gracilis

CERAMIA, D. Don, in Edinb. N. Phil. Journ. xvii. (1834) $153=$ Erica, Linn

auricularis, G. Don, Gen. Syst. iii. $806=$ E. urceolaris.

Blenna, G. Don, 1. c. $807=$ E. Vernix.

calathiflora, G. Don, l. c. $=$ E. bicolor.

cordata, G. Don, l. c. = E. cordata.

helianthemifolia, G. Don, 1. c. $806=$ E. mari folia.

humifusa, G. Don, 1. c. $807=$ E. humifusa.

latifolia, G. Don, l. c. = E. latifolia.

marifolia, G. Don, 1. c. $806=\mathrm{E}$. marifolia.

obliqua, G. Don, 1. c. $807=\mathrm{E}$. obliqua.

oxycoccifolia, G. Don, 1. c. = E. oxycoccifolia.

planifolia, G. Don, 1. c. $806=$ E. planifolia.

serpyllifolia, G. Don, 1. c. $807=\mathrm{E}$. hispidula.

teucriffolia, G. Don, 1. c. $=\mathbf{E}$, teucriifolia.

thymifolia, $\mathrm{G}_{v}$ Don, 1. $\mathrm{c}_{\mathrm{v}}=\mathrm{E}$. thymifolia.

urceolaris, D. Don, in Edinb. N. Phil. Journ. xvii. (1834) $153=\mathrm{E}$. urceolaris.

CERAMICALYX, Blume, Mus. Bot. Lugd. Bat. i. 50 $(1849)=$ Osbeckia, Linn. (Melastomac.).

calvus, Blume, $1 . \mathrm{c},=\mathrm{O}$. rostrata?

pulchellus, Blume, 1. c. $=$ O. rostrata.

stellatus, Blume, 1. c. $=0$. crinita.

ternifolius, Blume, 1. c. $=0$. rostrata.

CERAMIOCEPHALUM, Sch. Bip. in Bull. Soc. Bot. Fr. ix. (1862) $284=$ Crepis, Linn. (Compos.).

patulus, Sch. Bip. 1. c. 285 = Crep. patula.

CERAMIUM, Blume, Bijdr. 1134 (1826)=Bragantia Lour. (Aristolochiac.).

tomentosum, Blume, 1, c. $1135=\mathrm{B}$. tomentosa

CERAMOCARPIUM, Nees, ex Meissn, in DC. Prod. xy I. $111(1864)=$ Ocotea, Aubl. (Laurin.).

cubense, Nees, 1. c. $31=$ Phoebe cubensis.

lanatum, Nees, 1. c. $102(=$ Mespilodaphne lanata).Bras.

marginatum, Nees, 1. c. 106 (=Mespilodaphne marginata).-Madag.

Maximilianum, Nees, 1. c. 108 (= Mespilodaphne prolifera). - Bras.

obtusatum, Nees, I. c. 105 (=Mespilodaphne heteromorpha),-Ins. Maurit.

polyanthes, Nees, 1. c. $133=0$. polyantha.

psychotrioides, Nees, 1. c. $124=0$. psychotrioides.

semicompletum, Nees, 1. c. 133 (= Oreodaphne semi completa).-Bras.

umbrosum, Nees, 1. c. $129=$ O. umbrosa, $H$. B. E $K$.

CERAMOPHORA, Nees, ex Meissn. in DC. Prod. xv. I. 105, $111(1864)=$ Ocotea, Aubl. (Laurin.)

cymosa, Nees, 1. c. 105 (= Mespilodaphne cymosa).Madag.

CERANTHE, Opiz, Seznam, 27 (1852) = Cerinthe, Tourn. (Borag.),

CERANTHERA, Beauv. Fl. Ow. et Ben. ii. $10(1805)=$ Alsodeia, Thou. (Violar.).

dentata, Beauv, 1. c. 11. t. $65=\mathrm{A}$. guianensis

ilicifolia, Welw, in Trans. Linn. Soc. xxvii. (1869) 94 t. $2=$ A. ilicifolia.

subintegrifolia, Beauv, Fl. Ow, et Ben。 ii. 11, t. $66=$ A. owariensis.

CERANTHERA, Ell, Sketch, ii. 93 (1824), LABIATAE, Benth. \& Hook. f. ii. 1191.

DICERAndra, Benth。 in Bot. Reg. sub t. 1900 (1830).

densiflora, A. Gray, Syn. Fl. ii. II. 365.-Florida.

linearifolia, Ell. Sketch, ii. 94.-Am. bor.

CERANTHERA, Endl. Gen. Suppl. ii. 22, in syn $(1842)=$ CERATANTHERA, Homem. $=$ Cole brookia, Sm. (Labiat.).

CERANTHERA, Rafin。 in Am. Monthly Mag. (1818) $176=$ Solanum, Tourn.

hetcrandra Rafin. $1 . c_{2} \Rightarrow$ S. rostratum.
CERANTHUS, Schreb. Gen. i. 14 (1789)=Linociera, Sw. (Oleac.).

corniculatus, Schreb. ex Eichl. in Mart. Fl. Bras. yi. I. $307=$ L. compacta.

Schreberi, J. F. Gmel. Syst. 26=L. compacta.

CERASEIDOS, Sieb. \& Zacc. Abh. Akad. Muench. iii. (1843) 743. t. $5=$ Prunus, Linn. (Rosac.).

apetala, Sieb. \& Zucc. 1. c. 744.-Japon.

CERASIOCARPUM, Hook. $\mathrm{f}$, in Benth. \& Hook. $\mathrm{f}$. Gen. i. 832 (1867). CUCURBITACEAE, Benth。 \& Hook. f. l. c.

Bennettii, Cogn. in DC. Monog. Phan, iii. $729=$ zeylanicum.

Maingayi, C. B. Clarke, in Hook. f. Fl. Brit. Ind, ii. $629=$ Melothria Rumphiana.

penangense, C. B. Clarke, I. c. = Melothria Rumphiana.

zeylanicum, Hook. f. in Benth. E Hook. f. Gen. i. 832, -Zeylan.; Java.

CERASITES, Steud. Nom. ed. II. i. $528(1840)=$ CERA. STITES, S. F. Gray= Papaver, Tourn.

CERASOPHORA, Neck, Elem. ii. $71(1790)=$ Prunus, Linn. (Rosac.).

Cerastites, S. F. Gray, Nat. Arr. Brit. Pl. ii. 703 $(1821)=$ Papaver, Tourn

cambrica, S. F. Gray, 1. c. 704=Meconopsis cambrica. dubia, S. F. Gray, 1. c. = P. dubium.

hybrida, S. F. Gray, l. c. = P. hybridum

laciniata, S. F. Gray, 1. c. = P. dubium

macrocephala, S. F. Gray, 1. c. $705=$ P. Argemone.

CERASTIUM, [Dill.] Linn. Syst. ed. I (1735). CARYOPHYLLEAE, Benth. \& Hook. fo i. 148.

Centunculus, Adans. Fam. ii. 256 (1763).

Dichodon, Bartl. ex Reichb. Nom. 205 (1841)

DUFOUREA, Gren. in Act. Soc. Linn. Bord. ix. (1837) 25 .

ESMARChIA, Reichb. Fl. Germ. Excurs, 793 (1832)

Leucodonium, Opiz, Seznam, 59 (1852).

MoEnchia, Ehrh. Beitr. ii. 177 (1788).

Myosotis, Tourn. ex Moench, Meth. 224 (1794).

PENTAPle, Reichb. Ic. Fl. Germ. v, 37. t. 227 (1841).

Prevotia, Adans. Fam. ii. 256 (1763)

QUATERNELLA, Ehrh. Beitr。 iv. 149 (1789)

acutifolium, Schur, Enum. Pl. Transs。 $122=$ ovatum. adscendens, Wender.ex Steud. Nom。 ed. II. i. 328.Hab, ?

africanum, Oliver, Fl. Trop. Afr. i. 141.-Afr. trop.

aggregatum, Dur. ex Brignoli, in Flora, xxiii. (1840) $123=$ siculum

album, Presl, Fl. Sic. $167=$ fomentosum.

alpestre, Schur, in Verh. Naturf. Ver. Bruenn, Xv. II.

(1877) $151=$ triviale.

alpigenum, Schur, 1. c. $149=$ triviale.

alpinum, All. Fl. Pedem. ii. $116=$ arvense.

alpinum, Bieb. Fl. Taur. Cauc. i. $361=$ ovatum.

alpinum, Bunge, in Ledeb. Fl. Alt. ii. $180=$ glo-

meratum.

alpinum, Linn. Sp. Pl. 438.-Reg. bor. frigid.

alsinifolium, Tausch, in Syll, Ratisb. ii. (1828) $243=$ ovatum, arvense.

alsinoides, Pers. Syn. i. $521=$ glutinosum, Fries. ambiguum, Fisch. ex Ser. in DC. Prod。 i. $419=$ arvense.

amplexicaule, Sims, Bot. Mag, t. $1789=$ dahuricum andinum, Benth. Pl. Hartw. 162.-N. Granat.

andinum, Phil. in Anal. Univ. Chil. (1862) II. 818.Chili.

androsaceum, Ser. in DC. Prod, i. $416=$ illyricum. angustifolium, Vitm. Summa Pl, iii. 137 = arvense. anomalum, Waldst. Eo Kit. ex Willd. Sp. Pl. ii, 810 ;

et Pl. Rar. Hung. i. 21.-Europ.; Oriens.

apetalum, Dum. Comm. Bot. $47=$ glomeratum.

apricum, Schlecht. in Linnaea, xii. (1898) 20 S nutans.

apuanum, Parl, in Nuon. Giorn. Bot. vii. (1875) 69.Italia.

aquaticum, Linn. Sp. Pl. 49! = Stellaria aquatica.

arabicum, Fisch. \& Mcy. es Heynh. Nom. ii. 198, nomen.-Arab.

arabidis, E. Mey, ex Fensl, in Ann. Wiens. Mus.

1896) 340 . A Afr. nust:

\section{CERASTIUM}

araraticum, Rupr. Fl. Cauc. 234, in textu--Reg. Caucas.

arcticum, Lange, in Fl. Dan. t. 2963.-Groenland.

arenarioides, Crantz, Inst. ii. $402=$ Arenaria spathu lata.

arenarium, Tenore, FI. Nap. iv. $232=$ semidecandrum. arenosum, Kit. in Linnaea, sxxii. (1863) $518=$ glomeratum?

argaeum, Boiss. E Bal. Diagn. Ser. II. vi. 38.Cappadoc.

argenteum, Bieb. F1. Taur. Cauc. i. $361=$ grandi Horum.

armeniacum, Gren. Monog. Cerast. 19. t. 1.-Armenia. arvense, Cham. \& Schlecht. in Linnaea, v。(1830) 233 $=$ orithales.

arvense, Linn. Sp. Pl. 438.-Reg. temp. bor. et austr.

arvensiforme, Wedd. in Ann. Sc. Nat. Sér. V. i (1864) 296.-Bolivia.

atlanticam, Dur. in Duch. Rev. Bot. ii. (1840-47) 437. -Hispan.

atratum, Lapeyr. Hist. Abr. Pl. Pyr. $265=$ alpinum.

atrovirens, Bab, in Mag. Zool. \& Bot. ii. (1838) 317 t. $9=$ tetrandrum.

atticum, Boiss. \& Heldr. Diagn. Ser. II. i. 93 brachypetalum.

azoricum, Hochst. ex Seub. Fl. Azor. 45-Ins. Azoric.

banaticum, Kit. in Rochel, Banat. Rar., in ind.= grandiflorum.

barbulatum, Wahlenb. F1. Carp. 137 = brachype talum.

beeringianum, Cham. \& Schlecht, in Linnaea, (1826) 62 =alpinum.

Biebersteinii, DC. in Mém. Soc. Phys. Genèv. i. 1523, 436.-Tauria.

biflorum, Crantz, Inst. ii. $402=$ Stellaria biflora.

biflorum, Kit. in Linnaea, xxxii. (1863) 52j.Hungar.

blepharostemon, Fisch. \& Mey, in Bull. Soc. Nat. Mosc. (1838) $403=$ longifolium.

Boissieri, Gren. in Mém. Soc. Emul. Doubs, i. (1841) 67.-Hispan.

bombycinum, Schur, Enum. Pl. Transs. $128=$ alpinum.

brachycarpum, E. Mey. Zwei PA. Docum. 171= Dregeanum.

brachycarpum, Schur, Enum. P1. Transs. $121=$ arvense.

brachypetalum, Desp. in Pers. Syn. i. 520.-Europ.; Reg. Mediterr.

brachypterum, Steud. Nom. ed. II. i. 328, sphalm. praec. ?

bracteatum, Rafin. Préc. Découv. 36 =oblongifoliam?

breviflorum, Gilib. F1. Lituan. ii. $158=$ semide. candrum.

bulgaricum, Uechtrits, in Oestr. Bot. Zeitschr. xxvi. (1876) 221.-Bulgaria.

caeruleum, Boiss. Diagn. Ser. 1. i. 53.-As. Mia.

caespitosum, Gilib. Fl. Lituan, ii. $159=$ glomeratum.

caespitosum, Kit. ex Reichb. F1. Germ. Excurs. 799 $=$ arvense.

caespitosum, Malmgr. in Vet. Akad. Oefvers. xix. (1862) 242 =alpinum.

caespitosum, Triana E Planch. in Ann. Sc. Nat. Ser. IV. xvii. (1862) 152.-N. Granat

calycinum, Fenzl, Verbreit. Alsin. tab. ad p. 56 Arenaria calycina.

campanulatam, Viviani, in Ann. Bot. i. 11. 17I. t. 1. -Italia; Hung. ; Graecia.

camphoratacfolium, Stead. Nom. ed. I. $178,179=$ ariense.

candicans, Wedd. in Ann. Sc. Nat. Sèr. V. i. (1s6t) 295.-Ecuador.

canescens, Hornem. ex Ser, in DC. Prod. i tlic brachypetalum.

capense, Sond. in Hare. E Sond. Fl. Cap. i. 131. - Afr austr.

cardiopetalum, C. Gay, Fl. Chil. i. 27t-Commer. sontanum.

carinshiacum, Vest, in Hoppe, Newes Taschenb. (1S0s $2 \cdot 2 !)=0$ valum

carnusulum. Turce ex Ledeb. FI. Ross. i. 113 arrense.

concossitum. Fisich, ex Scr. in DC. Prual. i. H1t

nemurale

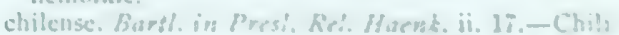




\section{CERASTIUM :}

chloraefolium, Fisch. E Mey. Ind. Sem. Hort. Petrop. iv. 34.-As. Min

ciliatum, Turcz, in Bull. Soc. Nat. Mosc. xv. (1842) $616=$ glomeratum.

ciliatum, Waldst, \& Kit. P1. Rar. Hung. iii. $250=$ arvense.

collinum, Hort. Dorpat. ex Flora, xvi. (1833) $122=$ purpurascens.

collinum, Salisb. Prod. $300=$ arvense.

Colsmanni, Lehm. ex Spreng. Syst. ii. 418.-Reg. Magell.

Columnae, Tenore, Prod. F1. Nap. p. xxvii=tomentosum.

Commersonianum, Ser, in DC. Prod. i. 417.-Reg. Argent.

Commersonii, Steud. Nom. ed. II. i. $329=$ praec.

connatum, Beck, N. et M. St. Bot. $55=$ viscosum.

connatum, S. G. Gmel. It. ii. 196; ex Ledeb. FI. Ross. i. $401=$ davuricum

consanguineum, Wedd. in Ann. Sc. Nat. Sér. V. i. 1864) 296 Peruv.

constantinopolitanum, Nym. Consp. $109=$ glomeratum.

cordatum, Crantz, Inst. ii. $400=$ Drymaria cordata

cordifolium, Roxb. Hort. Beng. 35; F1. Ind. ii. $458=$

Drymaria cordata.

corniculatum, Crantz, Inst. ii. $403=$ dichotomum.

coronense, Schur, in Verh. Naturf. Ver. Bruenn, xy, II

1877) $154=$ ovatum

corsicum, Soleir. ex Nym. Consp. $108=$ arvense.

crassipes, Bartl. in Presl, Rel. Haenk. ii. 18.Peruv.

cuspidatum, Hemsl. Diag. Pl, Nov, 21.-Mexic.

davuricum, Fisch. ex Spreng. Pugill. ii. 65.-As. occ. et bor.

dasyphyllum, Kit. in Linnaea, xxxi1. (1863) 521.Hungar.

decalvans, Schloss, ex Nym. Consp. $107=$ tomentosum deflexum, Ser. in DC. Prod. i. $417=$ Stellaria aquatica

densiflorum, Guss. Suppl. Fl. Sic. Prod. 136.Sicilia.

Diazi, Phil. in Anal. Univ. Chil. (1862) II. 391; et in Linnaea, xxxiii. (1864-65) 21.-Chifi.

dichotomum, Crantz, Inst. ii. 401=Stellaria dichotoma. dichotomum, Linn.Sp. Pl. 438.--Reg. Mediterr.; As. Min.

dichotomum, Schangin, in Pall. N. Nord, Beitr. vi. 93 $=$ davuricum

dicrotrichum, Fenzl, ex Rohrb. in Mart. Fl. Bras. xiv. II. 281.-Bras.

diffusum, Pers. Syn. i. 520=tetrandrum.

dioicum, [Soland. in] Ait. Hort. Kew. ed. I. ii. 120.Hispan.

divaricatum, Herbich, in Flora, vii. (1824) 184.Neapol.

divaricatum, Kit, in Rochel, Pl. Banat, Rar. in ind.= Kitaibelii.

Dregeanum, Fenzl, in Ann. Wien. Mus. i. (1836) 341 -Afr. austr.

echinulatum, Coss. Eo Dur. ex Debeaux, in Act. Linn. Soc. Bord. xxiii. (1860) 180, nomen.-China.

elatum, Huet, ex Nym. Consp. 107 = grandiflorum

elatum, Tenore, Fl. Nap. iv. $236=$ tomentosum.

elbrusense, Boiss. Fl. Orient. i. 729_-Persia

elegans, Fisch. ex Ser. in DC. Prod. i. $400=$ trigynum.

elongatum, Bieb. Fl. Taur. Cauc. iii. $316=$ nemorale.

elongatum, Pursh, F1. Am. Sept. i. 321=arvense

Endressianum, Prol. ex Willk. \& Lange, Prod. F1.

Hisp. iii. $63 \%=$ pyrenaicum.

eriophorum, Kit. ex Rochel, Pl. Banat. Rar. in ind.= alpinum.

erectum, Coss. \& Germ. Fl. Env. Paris (1845) $39=$ quaternellum.

falcatum, Bunge, Verz. Supp. Fl. Alt. 37.-Sibir altaic.

fallax, Guss. Suppl. F1. Sic. Prod. $139=$ semidecandrum.

fasciculatum, Bartl. in Presl, Rel. Haenk. ii. 16.Mexic.

filifolium, Vest, in Flora, iii. (1820) 353.-Styria.

filiforme, Schleich. ex Gaud. Fl. Helv. iii. 252, in syn. = latilolium.

filiforme, Ser. in DC. Prod. i. $420=$ filifolium.

fimbriatum, Ledeb. in Mém. Acad. Pétersb. v. (1815) $\mathbf{5 4 0}=$ Stellaria radians.

Fischeri, Gren. in Mém. Soc. Emul. Doubs, i. (1841) 3 = chloraerolium.

\section{CERASTIUM}

Fischerianum, Ser. in DC. Prod. i. $419=$ alpinum

flaccidum, Andrz. ex Trautv. in Act. Hort. Petrop. viii. (1883) 155, nomen-Rossia

flexuosum, Hegetschw. in Suter, Fl. Helvet. ed. II. App. $454=$ latifolium

floccosum, Benth. Pl. Hartw. 162.-N. Granat.

fontanum, Baumg. Enum. Stirp. Transs. i. $425=$ triviale.

fragillimum, Boiss. Diagn. Ser. I. i. 54.-As. Min. Syria.

frigidum, Bieb. F1. Taur. Cauc. i. $362=$ purpurascens. fulvum, Rafin. Préc. Déconv. $36=$ glomeratum furcatum, Cham. \& Schlecht. in Linnaea, i. (1826) 61 =alpinum.

Gayanum, Boiss. Diagn. Ser. II. i. 92.-Hispan.

gibraltaricum, Boiss. Elench. $24=$ Boissieri

glabellum, Turcz. ex Ledeb. Fl. Ross. i. $413=$ arvense.

glaberrimum, Lapeyr. Hist. Abr. P1. Pyr. $265=$ alpinum.

glabratum, Hartm. Handb. Skand. Fl. ed. I. $180=$ alpinum.

glaciale, Gaud. ex Ser. in DC. Prod. i. $419=$ latifolium.

glandulosum, Schur, in Oestr. Bot. Zeitschr. xix. 1869) 306.-Europ.

glaucum, Gren. in Mém. Soc. Emul. Doubs, i. (1841) $47=$ manticum, quaternellum.

glomeratum, Thuill. Fl. Par, ed. II. 226.-Reg. temp. et subtrop.

glutinosum, Fries, Novit. ed. II. 132.-Europ. ; As. bor

glutinosum, Hegetschw. Fl. Schweiz, $433=$ latifolium glutinosum, H. B. E K. Nov. Gen. et Sp. vi. 29.-N. Granat.

glutinosum, Nutt. Gen. Am. i. $291=$ nutans

gnaphalodes, Fenzl, in Russegg. Reis. i. $929=$ tomen tosum.

gracile, Dufour, in Ann. Gén. Sc. Phys. vii. (1820) 304 $=$ Riaei.

gracile, Wallr. Beitr. F1. Hercyn. $201=$ brachype. talum.

gramineum, Crantz, Inst. ii: $401=$ Stellaria graminea.

grandiflorum, D. Don, Prod. Fl. Nep. $216=$ glome ratum?

grandiflorum, Gilib. F1. Lituan. ii. $159=$ arvense.

grandiflorum, Waldst. \& Kit. Pl. Rar. Hung. ii. 168

-Europ. or. ; Reg. Caucas.

grandifiorum, Pourr. ex Willk, \& Lange, Prod. Fl. Hisp. iii. $636=$ Boissieri

Grenieri, F. Schultz, in Arch. F1. Fr. et Allem, 24= glutinosum.

Haussknechtii, Boiss.E Haussk. in Oestr. Bot. Zeitschr xxvi. (1876) 411.-Mesopot.

heterophyllum, Schur, Enum. P1. Transs, $121=$ ovatum

heterophyllum, Viviani, F1. Lib. Spec. 67 ; et Fl. Cors Sp. Nov, $17=$ illyricum

hirsutum, Crantz, Inst. ii. $400=$ Holosteum hirsutum.

hirsutum, Fisch. ex Ser. in DC. Prod. i. $419=$ alpinum.

hirsutum, Muhl. Cat. $46=$ glomeratum.

hirsutum, Tenore, Prod. F1. Nap. p. xxvii = arvense.

hirtellum, Pomel, Nouv. Mat. Fl. Atl. 206-Afr, bor

Hochstetterianum, Fenzl, Verbreit. Alsin. tab. ad p. 56, nomen.-Hispan,; Gall.

Holostea; Hornem. Hort. Hafn, $434=$ nemorale.

holosteiforme, Schur, Enum. PI. Transs, $119=$ semide candrum.

holosteoides, Fries, Novit. ed. II. $126 \doteq$ glomeratum.

holosteum, Crantz, Inst. ii. $401=$ Stellaria Holostea.

holosteum, Fisch. ex Ser in DC. Prod i. $415=$ dahuricum.

humifusum, Camb. in St. Hil. Fl. Bras. Mer. ii. 166.Bras.

hybridum, Schur, Enum. P1. Transs. $125=$ tomentosum.

illyricum, Ard.Animad. ii. 26.-Graecia; As. Min.

imbricatum, $H$. B. E K. Nov. Gen. et Sp. vi. 28.-Am austr.

incanum, Hoffm. Hort. Mosq. 1808. n. 805 ; ex Bieb. F1. Taur. Cauc. iii. $320=$ grandiflorum

incanum, Ledeb. in Mém. Acad. Pétersb. v. (1815) 540 $=$ arvense.

indicum, Wight E Arn. Prod. 43.-Ind. or.

intlatum, Link, ex Sweet, Hort. Brit. ed. II. 57 ; Boiss. F1. Orient. i $7: 31$. - As. Min.; Persia.

insubricum, Moretti, ex Reichb. Fl. Germ. Excurs. 799 Earvense.

\section{CERASTIUM :}

juvenale, Godr. in Mém. Acad. Stanislas, Sér. III [xvii.] 1853 (1854) 383.-Gallia?

Kablikianum, Wolfner, in Lotos, iv. (1854) $153=$ arvense.

Kasbek, Parrot, Reise Cauc. ii. t. 3. f. 3.-Reg. Caucas.

Kitaibelii, Steud. Nom. ed. II. i. 329.-Bannatus.

Kotschyi, Boiss. Fl. Orient. i. 715.-Syria.

Lamottei, Le Grand, ex Nym. Consp. $110=$ Riae

Lamyi, F. Schultz, in Arch. Fl. Fr. et Allem. $24=$ litigiosum.

lanatum, Lam. Encyc. i. $680=$ alpinum

laniferum, Schur, Enum. Pl. Transs. $123=$ alpinum.

lanigerum, Clem. in Atti Terza Riun. Scienz. Ital. 1841) $520=$ tomentosum

lanuginosum, Willd. ex Reichb. Fl. Germ. Excurs. 797 =alpinum.

lapponicum, Crantz, Inst. ii. $402=$ trigynum.

laricifolium, Vill. Hist. Pl. Dauph. iii. $644=$ arvense.

latifolium, Edmonst. in Phytolog. i. (1843) $498=$ alpinum.

latifolium, Hartm. Skand. Fl. ed. XI. $239=$ arcticum. latifolium, Lapeyr. Hist. Abr. Pl. Pyr. 265=pyre naicum.

latifolium, Linn. Sp. Pl. 439.-Europ.; Reg. Caucas,

laxiferum, Schur, Enum. Pl. Transs. 125.-Trans. sylvan.

laxum, Boiss. E Heldr. Diagn. Ser. I. vi. 25,Graecia.

Ledebourianum, Ser. in DC. Prod. i. $420=$ pilosum.

Lensii, F. Schultz, in Arch. Fl. Fr. et Allem. 24 litigiosum.

Lerchenfeldianum, Schur, Enum. Pl. Transs. $122=$ ovatum.

ligusticum, Viv. Cat. Hort. Dinegro, 15=campanu. latum.

lineare, All. Fl. Pedem. ii. $365=$ tomentosum

lithospermifolium, Bunge, in Ledeb. F1. Alt. ii. $179=$ falcatum.

lithospermifolium, Fisch, in Mém. Soc. Nat. Mosc. iii. (1812) 81.-Sibir.

litigiosum, De Lens, in Loisel. Fl. Gall. i. 323.Gallia.

Loeffingii, Crantz, Inst. ii. $403=$ pentandrum

longepedunculatum, Muhl. Cat. $47=$ nutans.

longifolium, S. G. Gmel. ex Ledeb. FI. Ross. i. $414=$ grandiflorum.

longifolium, Juss. ex Poir. Encyc. Suppl. ii, 164= Commersonianum.

longifolium, Tenore, Prod. Fl. Nap. p. xxvii=tomentosum.

longifolium, Willd. Sp. Pl. ii. 814.-Armenia.

longirostre, Wichura, in Jahresb. Schles. Ges. (1854) $75=$ triviale.

lucorum, Schur, in Verb. Naturf. Ver. Bruenn, xv. II. (1877) $150=$ triviale

luridum, Guss. Fl. Sic. Syn. i. $510=$ brachypetalum macilentum, Aspegr. Blek. F1 34=semidecandrum. macranthum, Boiss. Diagn. Ser. I. v. 85.-As. Min.

macranthum, Link, ex Steud. Nom. ed. II. i. 329 nomen.-Hab.?

macranthum, Schur, in Verh. Siebenb. Ver. Naturw iv. (1853) 14 = latifolium.

macrocarpum, Boiss. Eo Haussk, in Boiss. Fl. Orient. i. 716.-Mesopotam.

macrocarpum, Schur, Enum. P1. Transs. $120=$ trivial macrocarpum, Stev. ex Ledeb. Fl. Ross. i. $407=$ purpurascens.

magellanicum, Phil. in Anal. Univ. Chil. (1872) 678 -Chili.

malachiforme, Schur, in Verh. Naturf. Ver. Bruenn xv. II. (1877) $149=$ triviale.

manticum, Linn. Cent. Pl. ii. 18.-Europ, austr. matrense, Kit. ex Spreng. Pugill. i. $33=$ arvense. mauritanicum, Pomel, Nouv. Mat. Fl. Atl. 206.-Afr bor.

mauritianum, Bouton, ex Baker, Fl. Maurit. 14= glomeratum.

maximum, Gilib. F1. Lituan. ii. $\mathbf{1 5 8}=$ Stellaria aquatica maximum, Linn. Sp. Pl. 439.-Sibir.; Am. arct. medium, Crantz, Inst, ii. $401=$ Spergularia media. melanandrum, Maxim. in Bull. Acad. Pitersb. xxvi. (1880) 429.-China.

membranaceum, Jacquem. ex Hook. f. F1. Brit. Ind. $228=$ glomeratum?

Meralii, Fullien, in Mém. Soc. Acad. Maine-et-Loire, xii. (1862) 67.-Gallia. 


\section{CERASTIUM :}

Meyerianum, Rupr. Fl. Cauc. 221, in textu.-Reg Caucas.

micranthum, C. A. Mey. ex Heynh. Nom. ii. 133, nomen -Rossia.

microcarpum, Kit. ex Reichb. Fl Germ. Excurs. 799 -Croatia.

microphyllum, Schur, Enum. Pl. Transs. $123=$ alpinum. microspermum, C. A. Mey. Verz. Pfl. Cauc. 222.Reg. Caucas

minus, Schur, in Oestr. Bot. Zeitschr. xxi. (1871) $46=$ triviale

minutulum, Desmoul. ex Steud. Nom. ed. II. i. $329=$ glomeratum.

moesiacum, Frivald, in Flora, xix. (1836) $435=$ tomen tosum.

molle, Bartl. in Presl, Rel. Haenk. ii. 17.-Mexic.

molle, Vill. Hist. Pl. Dauph. iii. $644=$ arvense, tomen-

tosum.

mollissimum, Poir. Encyc. Suppl. ii. 164.-Peruv.

montanum, C. Gay, Fl. Chil. i. 275.-Chili.

montioides, C. Gay, l. c. 279.-Chili.

mosanum, Cloet, ex Steud. Nom. ed. II. i. 329.Belgitum.

mucronatum, Wedd. in Ann. Sa. Nat. Sér. V. i. (1864) 294.-Peruv.; Boliv.

multiforum, C. A. Mey. Verz. Pfl. Cauc, 222.-Reg. Caucas.

murale, Desp. in DC. Fl. Fr. vi, $609=$ triviale murale, Schur, Enum. Pl. Transs. $119=$ glutinosum. murale, Salisb. Prod. $300=$ Holosteum umbellatum. mutabile, Gren. in Mém. Soc. Emul. Doubs, i. (1841) $68=$ arvense.

mutabile,Spenn. Fl. Friburg. iii. $847=$ triviale, glomera tum, brachypetalum, semidecandrum

nemorale, Bieb. Fl. Taur.Cauc. iii. 317.-Reg. Cancas nemorum, Crantz, Inst. ii, $401=$ Stellaria nemorum. nepalense, Wall. Cat. n. $628=$ glomeratum? nervosum, C. Gay, Fl. Chil. i. 277.-Chili.

nigrescens, Edmondst. ex Syme, Engl. Bot. ed. III. ii nigrescens, Edm
$87=$ alpinum.

nitens, Stev. ex Ser. in DC. Prod. i. $415=$ nemorale. nivale, D. Don, ex Nym. Consp. $110=$ trigynum. nutans, Rafin. Préc. Découv. 36.-Am. bor.

oblongifolium, Anders. Cat. P1. Nevad. $118=$ nutans. oblongifolium, Torr. Pacif. Rail. Rep. iv. $70=$ pilosum. oblongifolium, Torr. Fl. U. St. 460.-A m. bor.

obscurum, Chaub. in St. Amans, Fl. Agen. $180=$ glutinosum, Fries.

obtusatum, Kit. in Linnaea, xxxii. (1863) 523.Hungar.

obtusifolium, Kar. E Kir. in Bull. Soc. Nat. Mosc. (1841) $343 .-$ Sibir. altaic.

obtusifolium, Lam. Fl. Fr。 jii. $58=$ glomeratum ? octandrum, Hochst. ex A. Rich. Tent. F1. Abyss. i. 45 = glomeratum.

Opisii, Scidl, in Opiz, Seznam, $28=$ glutinosum.

orithales, Schlecht. in Linnaea, xii. (1838) 209.Mexic.

orophyllum, Wedd. in Ann. Sc. Nat. Sér. V. i. (1864) 295.-Peruv.; Bolivia.

ovale, Bess. Prim. Fl. Galic. i. $294=$ glutinosum.

covale, Pers. Syn. i. $521=$ glomeratum?

ovatum, Hoppe, ex Willd. Enum. Hort. Berol. 493.Europ. ; Reg. Caucas.

Pallasii, Vest, in Flora, ii. (1820) $356=$ arvense

pallens, F. Schultz, Arch. Fl. 124=litigiosum.

pallidum, Schur, in Verh. Naturf. Ver. Bruenn, xv. Ir. 1877) $146=$ semidecandrum.

palustre, Moris, in Mem. Accad. Torino, xxxviii. (1835) p. xxviii = campanulatum.

pauciflorum, Bunge, in Ledeb. F1. Alt. ii. $176=1$ ithospermifolium.

pauciflorum, Stev. ex Ser, in DC. Prod. i. $414=$

pilosum.
pauciflorum, Turcz. ex Steud. Nom. ed. II. i. $390=$ alpinum.

pedunculare, Bory \& Chaub. Nouv. Fl. Pelop. 29. t. 13.-Graecia; As. Min.

pedunculatum, Gaud. ex Ser, in DC. Prod. i, $419=$ latifolium.

pedunculatum, Willd. ex Steud. Nom. ed. II. i, $330=$ nutans.

pellucidum, Chaub. in St. Amans, Fl. Agen. $181=$ semidecandrum.

pensylvanicum, Hook. Fl. Bor. Am. i. 10t=oblongifolium

pensylvanicum, Hornem. Hort. Hafn, i. $435=$ arvense.

\section{CERASTIUM :}

pentandrum, Bieb. F1. Taur. Cauc. i. $359=$ glutinosum.

pentandrum, Krock. F1. Siles, ii. I. $81=$ semidecan drum.

pentandrum, Linn. Sp. Pl. 438.-Europ.

pentandrum, Moris, Fl. Sard. i. 265-pumilum.

pentandrum, Tenore, Syll. $220=$ densiflorum

peplidifolium, Kotschy, ex Boiss. Fl. Orient. i. 725 fragillimum

perfoliatum, Falk, Beitr. ii. $182=$ davuricum.

perfoliatum, Linn. Sp. Pl. 437.-Reg. Mediterr.; As. Min.

persicum, Boiss. Diagn. Ser. I i. 54,-Persia.

petiolare, Hance, in Hook. Kew Journ. i. (1849) 143 Stellaria aquatica.

petraeum, F. Schultz, Arch. Fl. 124=glutinosum

petricola, Pant. Elem. Fl. Bulg. 20.-Bulgaria.

petrosum, Schur, Enum. Pl. Transs. $122=$ ovatum.

pilosissimum, Kit. in Linnaea, xxxii. (1863) 519

Hungar.

pilosum, Fisch. ex Ledeb. F1. Ross. i. $409=$ glomeratum. pilosum, Hornem. Hort. Hafn. ii. $965=$ grandiflorum? pilosum, Ledeb. in Mém. Acad. Pétersb. v. (1815) 539 -Sibir.; Am. bor. occ.

pilosum, Sibth. \& Sm, Fl. Graec. Prod i. $316=$ illyricum pilosum, Tenore, Prod. F1. Nap. p. xxvii=brachy

petalum.
Pohlianum, Fenzl, ex Rohrb. in Mart. Fl. Bras. xiv II. $282=$ dicrotrichum.

polymorphum, Rupr. Fl. Cauc. 237.-Reg. Cancas.

polyphyllum, Stev. ex Ledeb. Fl. Ross..i. $413=$ arvense.

praecox, Tenore, Prod. F1. Nap. p. xxvii= campanulatum.

procumbens, Forsk. Fl. Aegypt. Arab. 211.-Afr. bor

prostratum, Jan, Elench. 7, ex Bertol. Fl. Ital. iv. 756 = campanulatum.

pseudo-sylvaticum, Schur, in Oestr. Bot. Zeitschr. xxi. (1871) 46 - triviale.

pseudo-viscosum, Schur, 1. c. $99=$ glomeratum

pubescens, Goldie, in Edinb. Phil. Journ vi. (1822) $327=$ oblongifolium

pumilum, Bourg. ex Willk. \& Lange, Prod. Fl. Hisp. iii. $634=$ Gayanum

pumilum, Curt. Fl. Lond. fasc. vi. t. 30 -Europ.

pumilum, Griseb. Spicil. F1. Rumel. i. $208=$ glutinosum pumilum, Rafin. in Am. Monthly Mag. (1818) $266=$ glomeratum.

purpurascens, Adams, in Weber E' Mohr, Beitr. i. 60.As. Min.; Reg. Caucas.

purpurascens, Fenzl, Verbreit. Alsin. tab. ad p. $56=$ Arenaria purpurascens.

pusillum, Ser. in DC. Prod. i. $418=$ glomeratum.

pyrenaicum, F. Gay, in Ann. Sc. Nat. Sér. I. xxvi. 1832) 231.-Mont. Pyren.

quaternellum, Fenzl, Verbreit. Alsin. tab. ad p. 56.Europ.; Am. bor.

racemosum, Bartli in Presl, Rel. Haenk, ii, 18, - Chili. radians, Crantz, Inst. ii. $401=$ Stellaria radians.

ramigerum, Bartl. in Presl, Rel. Haenk. ii. 16.Mexic.

ramosissimum, Boiss. Elench. $23=$ Riaei

rectum, Frivald. in Flora, xix. (1836) 485,--Rumclia

refractum, All. Fl. Pedem. ii. $117=$ trigynum.

repens, Bertol. F1. Ital. iv, $757=$ sylvaticum.

repons, Bieb. Fl. Taur. Cauc. i. $360=$ Biebersteinii.

repens, Boiss, Voy. Bot. Espagne, $105=$ Boissieri.

repens, Linn. Sp. Pl. $439=$ tomentosum.

revolutum, Meinsh. in Baer \& Helm. Beitr. Kenntn. Russ. Reich. xxyi. 146.-Ins. Koraginsk.

Riaei, Des Moul. ex F. Gay, in Ann. Sc. Nat. Sér. II vi. (1836) 348. - Europ.; As. Min.

rigidum, Ledeb. in Mém. Acad. Pétersb. v. (1815) 538 =alpinum.

rigidum, Vitm. Summa Veg. iii. $137=$ arvense.

Ripartianum, $F$, Sclults, in Flora, xlv. (1862) 458 .

Mexic.

rivulare, Cambess. in St. Hil. Fl. Bras. Mer. ii. 166.Bras.

Roeseri, Boiss. \&c Heldr. Diagn. Ser. II. i. $9 \$=$ brachy petalum.

rotundatum, Schur, in Verh. Naturf. Ver, Bruenn, xy. II. $(187 \bar{i}) 146=$ semidecandrum

rotundifotium, Fisch. Cat. Hort. Goreak. (1812) 58. glomeratum.

rotundifolium, Schur, Enum.PI. Transs, $123=$ alpinum. ruderale, Bieb. F6. Taur. Cawc. i. 357 -Ross.; Keg. Caucas.

\section{CERASTIUM}

upestre, Fisch. ex Ser. in DC. Prod. i. $417=$ trigynum. salatavicum, Rupr. Fl. Cauc. 229.-Reg. Caucas. samnianum, Ser. in DC. Prod. i. 421 = grandiflorum, saxatile, Turcx. in Bull. Soc. Nat. Mosc. xv. (184) $616=$ alpinum

saxigenum, Schur, in Oestr. Bot. Zeitschr. xxi. (187. $100=$ glutinosum

scandens, Lejeune, Fl. Spa, i. 211.-Belgium

scaposum, Boiss. Eे Heldr. Diagn. Ser. I. viii. 104. Ins. Creta.

Scarani, Tenore, Prod. Fl. Nap. p. xxvii =arvense

Selloi, Schlecht, ex Rohrb. in Mart. Fl. Bras. xiv.

283.-Bras.

semidecandrum, Cham. \& Schlecht, is Linnaea, (1830) 233 = vulcanicum

semidecandrum, Chaub. Expéd. Sc. Moree, 129 brachypetalum.

semidecandrum, Linn. Sp. Pl. 438.-Europ.; As. Min.

semidecandrum, Sibth. \& Sm. Fl. Graec. Prod. i. 315 glutinosum.

sericeum, S. Wats, in Proc. Am. Acad. xx. (1885) 354 -Arizona.

sericenm, Pourr. in Mém. Acad. Toul. iii. (1788) 311. -Europ.

serpyllifolium, Bieb. ex Ser. in DC. Prod. i. 417 glomeratum.

serpyllifolium, Willd. Enum. Hort. Berol. Suppl. 26 arvense.

sibiricum, Stev. ex. Ledeb. FI. Ross, i. $407=$ alpinum. sibiricum, Turcz. ex Ledeb. 1.c. $410=$ glomeratum.

siculam, Guss. Suppl. Fl. Sic. Prod. 137.-Sicilia.

simense, Hochst. ex A. Rich. Tent. Fl. Abyss. i. 45 glomeratum.

Soleirolii, Ser. ex Duby, Bot. Gall. i. $87=$ arvense

soratense, Rohrb. in Linnaea, xxxvii. (1871-73) 291. -Bolivia.

spathulatum, Pers. Syn. i. 520,-Jamaica.

speciosum, Sprun, ex Boiss. Fl. Orient, i. $727=$ grandi.

florum.

Sprengelii, Ser. in DC. Prod. i. 421.-Hab. ?

squalidum, Ram. in Mím. Acad. Paris, vi. (1826) 156 =alpinum.

Stellaria, Tenore, ex Steud. Nom. ed. II. i. 330.Neapol.

stellarioides, Hartm, Handb. Skand, Fl, ed. I. 181

trigynum.

stellarioides, Moç. ex Ser. in DC. Prod. i. $415=$ pilosum.

stenopetalum, Fensl, ex Gren. E Godr. Fl. 1. 272.-Ins, Corsica.

strictum, Linn. Sp. Pl, $439=$ arvense.

strigosum, Fries, Fl. Halland. $78=$ brachypetalum.

subacaule, Hegetschw. in Suter, Fl. Helret. ed. II. App. $455=$ latifolium.

subspicatum, Wedd. in Ann. Sc. Nat. Sér. V. i. (186̆t 295.-Peruv.

succulentum, Crantz, Inst. ii. $400=$ A'renaria peploides. suffruticosum, Lam. Encyc. i. 681.-Gallop. ; As. Min. suffruticosum, Linn. Sp. Pl. $439=$ arvense.

sylvaticum, Opiz, Seanam, 28 = tririale.

sylvnticum, Stev, ex Ledeb. Fl. Ross. i. $410=$ glomeratum.

sylvaticum, Waldst. \& Kit. Pl. Rar. Hung. i. 100.Austria.

szalaberense, Kit. in Linnaea, xxxii. (1863) 524.Hungar.

Szowitsii, Boiss, Fl. Orient. i. 717.-Armenis.

tauricum, Spreng. ex Ser. in DC. Prod. i. $\$ 15=$ brachypetalum.

Tanschianum, Wolfner, in Lotos, iv. (1851) 57.Europ.

tenellum, Gaud. ex Ser, in DC. Prod. i. $116=$ glomeratum.

Tenoreanum, Ser. 1. c. $\$ 21$ abrachypetalum.

tenue, Viviani, Fl. Cors. Sp. Nov, 7 =quatemellum. tenvifolium, Pursh, Fl. Am. Sept. i. \$21 - arvense.

tenuifolism, Spreng. in Hornem. Hort. Haln. Suppl. 138 = Sprengelii

tenuifolism, Visiani, ex Reichb. F7. Germ. Excur. 799 - grandiflorum.

tetraponum, Baumg. Enum. Stirp. Transs, i. flt Sicllaria crnssifolia.

eetrandrum, Curt. Fl. Lowd. fasc. vi. t. 81.-Europ

Thomasii, Tenore, 17. Nrap. Prod. AAp. iv. 91.Europ.

Thumsonii. Hook. f. Fl. Brif. Ind, i. 228-Reg. Mimal tmolcwm, Boiss. Iliage. Ser. 1. ช. 86-\{ragllinum 


\section{CERASTIUM}

tomentosum, Boj. Hort. Maurit. $24=$ glomeratum.

tomentosum, Georgi, Beschr. Russ. Reich. iv. 988 Biebersteinii.

tomentosum, Haensel. ex Willk. \& Lange, Prod. FI Hisp. iii. $636=$ Boissieri.

tomentosum, Huds, Fl. Angl, ed. I. 176=alpinum.

tomentosum, Linn. Sp. Pl. 440.-Europ.; As. Min.

Tournefortii, Gren. in Mém. Soc. Emul. Doubs, i (1841) 11.t. 7.-Armenia.

transsilvanicum, Schur, in Verh. Siebenb. Ver. Naturw. iv. (1853) 14,-Transsyly.

trigynum, Vill. Prosp. 48 ; Hist. Pl. Dauph. iii. 645.Reg. bor. temp. et aret.

triviale, Link, Enum. Hort. Berol. 1. 433.--Europ.; As.; Afr. bor.

uliginosum, Hegetschw. Fl. Schweiz, $437=$ triviale? umbellatum, Crantz, Inst. ii. $401=$ Holosteum um bellatum.

umbellatum, C. Koch, in Linnaea, xy. (1841) 708.-

Armenia.

umbrosum, Kit. in Linnaea, xxxii. (1863) $515=$ triviale?

uniflorum, Thom, ex Reichb. F1. Germ. Excurs. $797=$ latifolium.

vagans, Lowe, in Trans. Camb. Phil. Soc. vi. (1838) reimp. 26.-Ins. Madera.

valachicum, Kit. in Linnaea, xxxii. (1863) 519.Hungar.

varians, Coss. \& Germ. Obs. P1. Crit. $26=$ glutinosum Fries, semidecandrum.

velutinum, Rafin. in Med. Repos. N. York, v. (1808) $359=$ vulgatum?

Vidali, Phil. in Anal. Univ. Chil. (1872) 677.Chili.

villosum, Baumg. Enum. Stirp. Transs. i. $424=$ alpinum.

villosum, Stev. in Bull. Soc. Nat. Mosc. xxix. (1856) I. $322=$ glomeratum

viscarium, Schur, Enum. P1. Transs. 118, in syn. glutinosum.

viscidum, Link, Enum. Hort. Berol. i. $433=$ semidecandrum.

viscosissimum, Schur, Enum. Pl. Transs, $123=$ alpinum.

viscosum, Linn. Sp. Pl. $437=$ glomeratum.

viscosum, Pollich, Hist. P1. Palat. i. $448=$ brachy petalum.

valcanicum, Schlecht. in Linnaea, xii. (1838) 208.Mexic.

vulgare, Hartm. Handb. Skand. Fl. ed. I. $182=$ triviale.

vulgatum, Linn. F1. Suec. ii. 158=glomeratum.

Wahlenbergii, Rupr. F1. Caucas. $237=$ latifolium

Willdenowii, $H . B$. \& K. Nov. Gen. et Sp. vi. 29.Ecuador.

CERASUS, [Tourn.] Linn. Syst. ed. I (1735); Gen. ed. I. $141(1737)=$ Prunus, Linn. (Rosac.). acida, Borck. in Roem. Arch. i. II. $38=$ P. Cerasus. acuminata, Wall. PI. As. Rar. ii. $78=\mathrm{P}$. acuminata. adenophylla, M. Roem. Syn. Rosifl. $81=$ P. undulata. affinis, Sweet, Hort. Brit. ed. III. 209.-Hab. ? americana, Hook. \& Arn. in Comp. Bot. Mag. i. (1835) $24=\mathrm{P}$. americana.

aspera, Loisel. in Duham. Arb. ed, nov. v. $33=$ $\mathrm{P}$. aspera.

asplenifolia, Hort. ex C. Koch, Dendrol. i. $106=$ P. Avium.

austera, Borck. in Roem. Arch. i. Ir, $38=$ P. Cerasus. avicularis, Dulac, Fl. Hautes-Pyr. $301=$ P. Avium. Avium, Moench, Meth. $672=$ P. Avium.

beroliensis, Nym. Consp. $213=\mathrm{P}$. Cerasus.

bigarella, Dum. F1. Belg. $91=$ P. Cerasus.

borealis, Michx. Fl. Bor. Am. i. $286=\mathrm{P}$. pensylvanica brachypetala, Boiss. Diagn. Ser. I. vi. $52=$ incisa . brasiliensis, Cham. \& Schlecht. in Linnaea, ii. (1827 $542=\mathrm{P}$. brasiliensis.

Bungei, Walp. Rep. ii. $9=$ P. Cerasus

campestris, Gueldenst. ex Ledeb. Fl. Ross. ii. $7=\mathbf{P}$. Chamaecerasus.

canadensis, Loisel. in Duham. Arb. ed. nov. v. $3=\mathrm{P}$. americana.

canadensis, Mill. Gard. Dict. ed. VIII. 12. $5=\mathrm{P}$.

Chamaecerasus.

Capollin, Ser. in DC. Prod. ii. $539=$ P. Capollin.

capricida, Wall. Cat. n. $718=\mathrm{P}$, undulata

Caproniana, DC. F1. Fr. iv. $482=$ P. Cerasus.
CERASUS :-

Capuli, Ser. in DC. Prod. ii. 541= Prunus Capollin

caroliniana, Michx. F1. Bor. Am. i. $285=$ P. caroliniana. cerasifera, Eaton \& Wright, N. Am. Bot. $189=\mathrm{P}$. maritima.

Chamaecerasus, Loisel. in Duham. Arb. ed. nov. v. 29 $=\mathrm{P}$. Chamaecerasus.

Chicasa, Ser, in DC . Prod ii. 538=P. Chicasa

chinensis, G. Don, Gen. Syst. ii. $514=$ P. japonica.

collina, Lej. \& Court. Comp. F1. Belg. ii. $130=$ P. Cerasus.

cornuta, Wall. Cat. n. $716=\mathrm{P}$. Padus.

corymbosa, St. Lag. in Ann. Soc. Bot. Lyon, vii. (1880) $122=\mathrm{P}$. Mahaleb.

cucullata, Hort. ex C. Koch, Dendrol. i. $111=\mathrm{P}$ Cerasus.

decumana, Mordant, ex DC. Prod. ii. $536=\mathrm{P}$. Avium.

demissa, Nutt. in Torr. \& Gray, Fl. N. Am. i. $411=$ P. demissa.

densiflora, Spach, Hist. Vég. Phan. i. $415=$ P. virginiana.

depressa, Ser. in DC. Prod. ii. $538=$ P. pumila.

diffusa, Boiss. \& Haussk. ex Boiss. F1. Orient. ii. 647.Persia.

domestica, Cat. Perck, ex Wesmael, in Bull. Congr. Bot. Brux. (1864) $255=\mathrm{P}$. Cerasus.

Duerinckii, Mart. Bull. Acad. Belg. viii. I. (1841) 68 $=\mathrm{P}$. virginiana.

dulcis, Borck. ex Steud. Nom. ed. II. i. $331=$ P. Avium, dulcis, Gaertn. Mey. \& Scherb. Fl. Wett. ii. $181=$ P. Cerasus.

duracina, DC. F1. Fr, iv, $483=\mathrm{P}$. Avium

ebroliensis, Lamotte, Prod. i. $238=\mathrm{P}$. Cerasus.

effusa, Host, F1. Austriac. ii. $6=\mathrm{P}$. Cerasus.

elliptica, LoiseI. in Duham. Arb. ed. nov. v. $4=\mathrm{P}$. elliptica.

emarginata, Dougl, ex Hook, F1. Bor. Am. i. $169=$ P. emarginata.

evecta, Presl, Epim. Bot. 194= P. emarginata

ferruginea, DC. Prod, ii. $540=$ P. ferruginea.

fimbriata, Spach, Hist. Vég. Phan. 1. $416=$ P. virginiana.

floribunda, Hort, ex C. Koch, Dendrol. i. $119=\mathrm{P}$. pumila.

Fontanesiana, Spach, Hist. Vég. Phan. i. $410=\mathrm{P}$. graeca.

fruticosa, Pall. Fl. Ross. t. $8^{\mathrm{b}} .=\mathrm{P}$. Chamaecerasus.

glandulosa, Kellogg, in Proc. Calif. Acad. i. 1855 (1873) $59=$ P. emarginata.

glandulosa, Loisel. in Duham. Arb. ed. nov. v. $33=\mathrm{P}$ japonica.

glauca, Moench, Meth. $672=$ P. pumila.

glaucifolia, Wall. Cat. n. $717=$ P. nepaulensis.

graeca, Hort. ex C. Koch, Dendrol. i. 705, Index $=$ P.

graeca.

Griffithii, Boiss. Fl. Orient. ii. 648.-Afghanist.

Heaumiana, M. Roem. Syn. Rosif. $69=$ P. Cerasus.

heterophylla, Hort. ex C. Koch, Dendrol. i. $106=$ P. Avium.

hirsuta, Spach, Hist. Vég. Phan. i. $417=$ P. virginiana.

Hixa, C. Sm. ex Spach, Hist. Nat. Veg. i. $419=$ P. Hixa hortensis, Mill. Gard. Dict. ed. VIII. n. $3=$ P. Cerasus. humilis, Host, Fl. Austr. ii. $7=\mathrm{P}$. Chamaecerasus.

humilis, Moris, Elench. Sard. $17=$ P. prostrata

hyemalis, Ser. in DC Prod ii. $538=\mathrm{P}$. americana.

ilicifolius, Nutt, ex Hook. \& Arn. Bot. Beech. Voy

$340 . t .83=\mathrm{P}$, ilicifolia

incana, Boiss. Fl. Orient. ii. $647=\mathrm{P}$. incana.

incana, Spach, in Ann. Sc. Nat. Sér. II. xix. (1843) $126=\mathrm{P}$. prostrata.

incisa, Boiss. Fl. Orient. ii. 648.-Persia.

incisa, Loisel in Duham. Arb. ed, nov, v, $33=\mathrm{P}$. incisa

integerrima, Wall. Cat. n. $722=\mathrm{P}$. acuminata

integrifolia, Presl, Epim. Bot. 194.-Peruv.

intermedia, Host, Fl. Austriac. ii. $7=$ P. Avium.

intermedia, Loisel. in Duham. Arb. ed. nov. v. $30=\mathrm{P}$. Chamaecerasus.

japonica, Ker-Gawl. ex Steud. Nom. ed. II. i. $331=$ P. Kerii.

japonica, Loisel. in Duham. Arb. ed. nov. v. $33=\mathbf{P}$. japonica.

javanica, Teijsm. \& Binn. in Nederl. Kruidk. Arch. iii. (1855) $412=P$. javanica

Fenkinsii, Hook. f. \& Thoms. ex Fl. Brit. Ind. ii. 317 $=\mathrm{P}$. Jenkinsii.

Fuliana, DC. Fl. Fr. iv. $482=$ P. Avium
CERASUS :-

Fuliana, Hort. ex Steud. Nom. ed. II. i. $331=$ Prunus Cerasus.

Launesiana, Carr. in Rev. Hortic. (1872) 198.-Japon. aurocerasus, Loisel. in Duham. Arb. ed. nov. v. $6=$ P. Lanrocerasus.

Lindleyana, Wall. Cat. n. $1008=$ P. nepaulensis.

littoralis, Eaton \& Wright, N. Am. Bot. $189=\mathrm{P}$ maritima.

Iusitanica, Loisel. in Duham. Arb, ed. nov. v. $5=$ P. Iusitanica.

macedonica, M. Roem. Syn. Rosif. $64=$ P. Chamaecerasus.

macrophylla, Sweet, Hort. Brit. ed. I. $485=$ P. Avium.

maeda, Hort. ex Lavall. Arbor. Segrez $119=$ P. paniculata.

Mahaleb, Mill. Gard. Dict. ed. VIII. п. $4=$ P. Mahaleb. Marasca, Host, Fl. Austriac. ii. $6=$ P. Cerasus.

martabanica, Wall. Cat. n. $4902=$ P. martabanica.

micrantha, Spach, Hist. Vég. Phan. i. $414=$ P. virginiana.

microcarpa, Boiss. F1. Orient. ii. $646=$ P. microcarpa.

minutiflora, A. Gray, P1. Wright. i, $68=\mathrm{P}$, minutiAlora.

mollis, Dougl, in Hook, F1, Bor, Am, i. $169=\mathrm{P}$. emarginata.

multicarpa, Hort, ex Rev. Hortic. (1875) $409=\mathrm{P}$. Cerasus.

napaulensis, Ser. in DC. Prod. ii. $540=$ P. nepaulensis.

nicotianaefolia, Hort. ex DC. Prod. ii. $536=$ P. Cerasus.

nigra, Loisel. in Duham. Arb. ed. nov. v. $32=\mathrm{P}$ americana

nigra, Mill. Gard. Dict. ed. VIII. n. $2=$ P. Avium.

nigricans, Borck, in Roem. Arch. i. II. $38=\mathrm{P}$ Avium.

obovata, Beck, N. et M. St. Bot. $37=$ P. virginiana.

occidentalis, Loisel. in Duham. Arb. ed. nov. v. $4=$ P. occidentalis.

opaca, Benth. Pl. Hartw. $172=$ P. opaca

orientalis, Spach, in Ann. Sc. Nat. Sér. II. xix. (1843)

$128=$ P. microcarpa.

oxypyrena, Spach, Hist. Vég. Phan. i. $413=$ P. Padus.

Padus, Delarb. F1. Auv. ed. II. 323; DC. F1. Fr. iv $480=$ P. Padus.

pallida, M. Roem. Syn. Rosifl. $69=$ P. Avium.

paniculata, Loisel. in Duham. Arb. ed. nov. v. $7=$ P. paniculata.

Pattoniana, Carr. in Rev. Hortic. (1872) $135=\mathrm{P}$ mollis.

pectinata, Spach, in Ann. Sc. Nat. Sér. II. xix. (1843) $127=\mathrm{P}$. pectinata

pendula, Sweet, Hort. Brit. ed. I. $485=$ P. fruticosa,

pensylwanica, Loisel, in Duham. Arb. ed. nov. v, 9

$\mathrm{P}$. pensylvanica.

persicifolia, Loisel. 1. c. = P. pensylvanica

Phoshia, Buch.-Ham, ex D. Don, Prod. F1. Nep. $239=$ P. Puddum.

polygyna, DC. ex Ser. in DC. Prod. ii. 537=P. Cerasus.

prostrata, Hort. ex C. Koch, Dendrol. i. $119=\mathrm{P}$ pumila.

prostrata, Ser. in DC. Prod. ii. 538=P. prostrata.

Pseudocerasus, G. Don, in Loud. Hort. Brit. $200=$ P. Puddum.

pubescens, Ser in DC. Prod ii. $538=\mathrm{P}$. maritima.

Puddum, Wall, Pl. As. Rar. ii. 37. t. $143=$ P. Puddum

pumila, Borck. in Roem. Arch. i. II. (1797) $38=$ P. Chamaecerasus.

pumila, Michx. Fl. Bor. Am. ii. 286=P. pumila. punctata, Hook. f. \& Thoms. ex Fl. Brit. Ind. ii. $317=$ P. punctata.

pygmaea, Loisel. in Duham. Arb. ed. nov. v. $32=$ P. maritima

racemosa, Gilib. Exercit. i. $349=$ P. Padus

reflexa, Gardn. in Hook. Lond. Journ. Bot. ii. (1843) $342=\mathrm{P}$. reflexa

Rhexii, Hort. Gall. ex Van Houtte, Fl. des Serres, Sér. II. vii. (1867-68) $159=\mathrm{P}$. Cerasus.

rosea, Hort. ex Steud. Nom. ed. II. i. $331=$ P. Cerasus. rubicunda, Bechst. Forstb. $160,355=\mathrm{P}$. Avium. rubra, Gilib. Fl. Lituan. ii. $229=$ P. Cerasus

rufa, Wall. Cat. n. $721=$ P. rufa.

salicifolia, Hort, ex C. Koch, Dendrol, i. $106=\mathrm{P}$. Avium.

salicifolia, Ser. in DC. Prod. ii. $540=$ P. salicifolia 
CERASUS :-

salicina, [G. Don, in] Loud. Hort. Brit. $480=$ Prunus saiicina.

samydoides, Walp. Rep. iv. Index, $311=$ P. samydoides.

semperflorens, Borckh. in Roem. Arch. i. II. $38=\mathbf{P}$. Cerasus.

serotina, Hook. Fl. Bor. Am. 1. 169= P. virginiana.

serotina, Loisel. in Duham. Arb. ed. nov, v. $3=\mathrm{P}$ serotina.

serrulatus, [G. Don, in] Loud. Hort. Brit. $480=$ P. paniculata.

sibirica, Hort. ex C. Koch, Dendrol. i. $114=\mathrm{P}$. fruticosa.

Sieboldii, Carr. in Rev. Hortic. (1866) 279. ; $370=\mathbf{P}$. paniculata.

sinensis, Spach, Hist. Vég. Phan. i. $425=\mathrm{P}$. sinensis.

sphaerocarpa, Loisel. in Duham. Arb. ed. nov. v. $4=$ P. sphaerocarpa.

Susquehannae, Sweet, Hort. Brit. ed. I. $485=$ P. pumila.

syivestris, S. G. Gmel. It. i. $102=$ P. Chamaecerasus. tomentosa, Wall. Cat. n. $715=\mathrm{P}$. tomentosa.

tortuosa, Boiss. \& Haussk. ex Boiss. Fl. Orient. ii. 647 -As. Min. ; Persia.

tridentina, M. Roem. Syn. Rosifl. $76=$ P. Cerasus. triftora, Wall. ex Steud. Nom. ed. II. i. $331=$ P. triflora.

umbellata, Torr. \& Gray, Fl. N. Am. i. $409=$ Prunus umbellata.

undulata, Ser. in DC. Prod. ii. $540=\mathrm{P}$. undulata.

varia, Borck. in Roem. Arch. i. II. $38=$ P. Avium.

virginiana, Michx, Fl. Bor. Am, i. $285=\mathrm{P}$, serotina.

virginica, Michx, ex Steud. Nom. ed. II. i. $331=$ P virginiana.

vulgaris, Mill. Gard. Dict. ed. VIII. n. $1=$ P. Cerasus.

Wallichii, M. Roem. Syn. Rosifl. $81=$ P. acuminata.

Wattererii, Hort. ex Lavall. Arbor. Segrez. $119=$ P.

Puddum.

CERATANDRA, Eckl. ex Bauer, Illustr. Gen. Orch. t. 16 (1837). ORCHIDEAE, Benth. \& Hook, f. iii. 634

affinis, Sond in Linnaea, xix (1847) 108.-Afr, austr. auriculata, Lindl. Gen. et Sp. Orch. $364=$ chloroleuca. bicolor, Sond. ex Drige, in Linnaea, xx. (1847) 220, nomen.-Afr. austr.

chloroleuca, Eckl. ex Bauer, Illustr. Gen. Orch.t. 16 -Afr. austr.

globosa, Lindl. Gen. et Sp. Orch. 364.-Afr. austr.

grandiflora, Lindl. l. c.-Afr. austr.

Harveyana, Lindl. l. c. 365 .-Afr. austr.

Harveyana, Sond. in Linnaea, xix. (1847) $108=$ bicolor.

ochroleuca, G. Don, in Sweet, Hort. Brit. ed. III. 651 =chlorolenca.

parviflora, Lindl. Gen. et Sp. Orch. 364.-Afr. austr.

CERAT ANTHERA, Hornem. Hort. Hafn. i. 2,5 (1813) Lestib, in Ann. Sc. Nat. Sér. II. xv. (1841) $335,341=$ Globba, Linn. (Scitamin.)

amomoides, Hornem. 1. c. i. $5=\mathrm{G}$. marantina.

pendula, Lestib. in Ann. Sc. Nat. Sér. II. xv. (1841) 335 $=\mathrm{G}$. pendula

CERATELLA, Hook. f. Fl. Antarct. i. 25. t. 18 (1845) - Abrotanella, Cass. (Compos.)

rosulata, Hook. f. 1. $\mathrm{c}_{\mathrm{o}}=\mathbf{A}$. rosulata.

CERATIA, Adans. Fam. ii. $319(1763)=$ Ceratonia Linn. (Legumin.).

CERATIOLA, Michx. Fl. Bor. Am. ii. 221 (1803) EMPETRACEAE, Benth. \& Hook. f. iii. 415. ericoides, Michx. l. c. 222.-Am. bor.

CERATIOSICYOS, Nees, in Eckl. \& Zeyb. Enum 281 (1836), PASSIFLOREAE, Benth. \& Hook. f. $281(1$
i. 814 .

Eckloni, Nees, l. c,-Afr. austr.

CERATOSYCIOS, Walp. Rep. ii. $222(1843)=$ praec.

CERATIUM, Blume, Bijdr. 341. t. $46(1825)=$ Eria, Lindl. (Orchid.).

compressum, Blume, 1 , c. $342-E$ compressa.
CERATOCALyX, Coss, in Ann. Sc, Nat. Sér. III. ix (1848) $145, \mathrm{t}, 10=$ Orobanche, Linn.

fimbriata, Lange, in Kjoeb. Vidensk. Meddel. (1863) 52.- Hispan.

macrolepis, Coss. in Ann. Sc. Nat. Sér. III. ix. (1848) 146. t. $10=0$. macrolepis

Reuteri, Lange, in Kjoeb. Vidensk. Meddel. (1863) 52, in obs. $=0$. gamosepala

CERATOCAPNOS, Dur. in Parlat. Giorn. Bot. Ital. I. (1844) $336=$ Corydalis, Vent. (Papaverac.). heterocarpa, Dur. I. c. $=$ C. heterocarpa.

palaestina, Boiss. Diagn. Ser. I. viii. 12.-Syria

umbrosa, Walp. Ann. ii. $30=$ Cor. heterocarpa.

CERATOCARPUS, Buxb. ex Linn. Diss. Dass. 28 (1747); Amoen. Acad. i. 412 (1749). CHENOPO DIACEAE, Benth. \& Hook. f. iii. 55.

arenarius, Linn. Sp. Pl. 969.-Sibir.

maritimus, Pall. Ind. Taur. ex Bicb. Fl. Taur, Cauc. ii $397=$ Atriplex pedunculata

salinus, Pall. Reise Statth. Russ. Reich. i. 268, $270=$ Atriplex pedunculata.

CERATOCARPUS, Dur. (lapsu) in Parlat. Giorn. Bot. Ital. i. I. (1844) $336=$ CERATOCAPNOS, Dur.= Corydalis, Vent.

CERATOCARYUM, Nees, in Lindl. Nat. Syst. ed. II 451 (1836). RESTIACEAE, Benth. \& Hook, f. iil. 1037.

argenteum, Nees, l. c. ; Kunth, Enum. Pl. iil. 483.Afr. austr.

fistulosum, Mart. in Fourn. Linn. Soc. x. (1869) 274 -Afr. austr.

speciosum, Nees, ex Mast. 1. c. $273=$ argenteum.

CERATOCAULOS, Reichb, Handb. 201 (1837) = Datura, Linn. (Solanac.)

daturoides, Spach, Hist. Vég. Phan. ix. $69=$ D. Ceratocaula.

CERATOCEPHALUS, Moench, Meth, 218 (1794)

(Ceratocephala) $=\mathbf{R}$ anunculus, Linn.

falcatus, Pers. Syn. i. $341=\mathrm{R}$, falcatus.

furfurascens, Pomel, Nouv, Mat. Fl. Atl. 248.Afr. bor.

incurvus, Stev. in Bull. Soc. Nat. Mosc. xxi. I1. (1848) 269 . t. $7=\mathrm{R}$. falcatus.

leiocarpus, Stev. 1. c. $=$ R. falcatus

orthoceras, DC. Syst. i. $231=\mathrm{R}$. falcatus.

platyceras, Stev. in Bull. Soc. Nat. Mosc. xxi. II (1848) $269=\mathrm{R}$. falcatus.

reflexus, Stev. 1. c. $268=$ R. falcatus.

spicatus, Moench, Meth. $218=\mathrm{R}$. falcatus

syriacus, Stev. in Bull. Soc. Nat. Mosc. xxi. II. (1848) $268=$ R. falcatus,

testiculatus, Roth, Enum. Pl. Phan. Germ. i. I. 101 $=\mathrm{R}$. falcatus.

CERATOCEPHALUS, Vaill, ex Cass in Dict. Sc. Nat. vii. $432(1817)=$ Bidens, Linn. (Compos.). pilosus, Rich. ex Cass. 1. c. = B. pilosa

CERATOCHILUS, Blume, Bijdr. 358, t, $25(1825)=$ Saccolabium, Blume (Orchid.)

biglandulosus, Blume, 1. c. $359=\mathrm{S}$. distichum?

micranthus, Lindl. Gen. et Sp. Orch. $282=$ S. micranthum.

orchideus, Lindl. l. c.-Ind. or.

CERATOCHILUS, Lindl. in Lodd. Bot. Cab. t. 1414 (1828) = Stanhopea, Frost (Orchid.)

grandiflorus, Lodd. 1. $c_{n}=$ S. eburnea.

insignis, Lindl. ex Stend. Nom. ed. II. i. $\$ 81=S$. insignis.

oculatus, Lodd. Bot. Cab. t. $1764=$ S. oculata.

CERATOCHLOA, Reauv. Agtost. 75. t. 15. f. 7 (1812)= Bromus, Dill. (Grrmin.)

australis, Spreng, ex Stcud. Nom. ed. II. i. $392 ; 229$

B. unioloides.

Boryana, Roem. \& Schult. Syst. ii. $597=$ B. strictus.

breviaristata, Hook. Fl. Bor. Am. ii. $258=\mathrm{B}$. breviari stintus.

brevis, Nees, ex Steud. Syn. 11. Gram. $\$ 26=$ B. brevis festucoides, Beauv. Agrust. $75=$ B. unioloides.
CERATOCHLOA :-

grandiflora, Hook. Fl, Bor. Am. ii. $253=$ Bromus virens.

Haenkeana, J. Presl, in Rel. Haenk. i. $285=$ B. unioloides.

marginata, Nees, ex Steud. Syn. P1. Gram. $322=$ B. ciliatus.

pendula, Schrad. Ind. Sem. Hort. Gotting. (1830)

Linnaea, vi. (1831) Litt. $72=\mathrm{B}$, unioloides.

secunda. J. Presl, in Rel. Haenk i. 285=B. Presli.

unioloides, DC. Cat. Hort. Monsp. $92=\mathrm{B}$, unioloides.

CERATOCNEMUM, Coss. \& Balansa, in Bull. Soc

Bot. Fr. xx. (1873) 239. CRUCIFERAE.

rapistroides, Coss. E Balansa, l. c.-Marocco

CERATOCOCCA, Willd ex Roem, \& Schult. Syst. vi. p. $\operatorname{lxx}(1820)=$ Microtea, Sw. (Phytolaccac.) maypurensis, Humb. \& Bonpl. ex Roem. \& Schult. 1. $800=$ M. maypurensis.

CERATOCOCCUS, Meissn. Gen. Comm. $369(1843)=$ Plukenetia, Linn. (Euphorbiac.)

CERATOGONON, Meissn, in Wall. Pl. As. Rar. iii. 63 (1832) = Oxygonum, Burch. (Polygonac.)

atriplicifolium, Meissn, 1. c.-Afr. trop.

cordofanum, Meissn. in DC. Prod. xiv. $39=$ atriplicifolium.

sinuatum, Hochst, \& Steud, ex A. Rich. Tent. F Abyss. ii. $231=$ atriplicifolium.

CERATOGYNE, Turcz, in Bull. Soc. Nat. Mosc. xxiv, (1851) II. 68, COMPOSITAE, Benth. \& Hook. f. ii. 431

Diotosperma, A. Gray, in Hook. Kew Journ. (1852) 275 .

obionoides, Turcz. L. c. 69 -Anstral

CERATOGYNUM, Wight, Ic, V. II. 26. t. $1900(1852)=$ Sauropus, Blume (Euphorbiac.)

concolor, Pritz. Ic。 Ind, 245, sphalm, = Ceratolobus concolor.

rhamnoides, Wight, Ic. พ. II. 26. t. $1900=$ S. quadrangularis.

CERATOLACIS, wedd. in DC. Prod, xvii. 66 (1879 PODOSTEMACEAE, Benth. \& Hook. f. iii. 118. erythrolichen, Wedd. l. c.-Bras.

CERATOLEPIS, Cass. in Bull. Soc. Philom. (1819) 111 = Pamphalea, DC. (Compos.)

CERATOLOBUS, Blume, in Schult. f. Syst. vii. p. Ixxx (1830). PALMAE, Benth. \& Hook. f. iii. 983.

concolor, Blume, ex Rumphia, ii. 165. t. 130. f. 1.Sumatra.

glaucescens, Blume, in Schult. f. Syst. vii. 1394.Java.

glaucescens, Blume, Rumphia, ii.t. $137=$ Korthalsiaesp. plicatus, Zipp. ex Blame, 1. c. $171=$ Korthalsia Zippelii. Zippelii, Blume, 1. $c_{0}=$ Korthaisia Zippelii.

CERATONIA, Linn. Gen, ed. I. 35 (1735). LEGL" MINOSAE, Benth. \& Hook. f. i. 5it. Ceratis, Adans. Fam. ii. 319 1763 chilensis, Molina, Sagg. Chil. 172= Prosopis julifora coriacea, Salisb. Prod. $323=$ C. Siliqua. incrmis, Stokes, Bot. Mat. Med. i $147=$ C. Siligea. Siliqua, Linn. Sp. Pl. 1026.-Europ. austr.; Uriens.

CERATONYCHIA, Edgew, in. Joum. As. Soc. Beng. xvi. (18+7) 1215 = Cometes, Linn. (A maraathac). Nidscs, Edgew. 1. $c=$ Com. surattensis.

CERATOPETALUM, Sm. Bot. N. Holl. 9. \&. S (1798). SAIPFRAGEAE, Benth. \& Houk. S. i. 651, npelalum, D. Don, in Edinb. N. Phil. Fuarn. ix. Isso 94.-Austral.

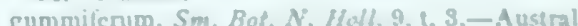

monoprialum, Calcy, ex D. Don, in Edonb. N. Phil, Journ. ix. (1830) 94 = apctalum.

monkanum, D. Don, 1. c - apcralurn.

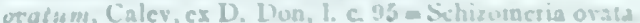


CERA TOPHORUS, Hassk. Retzia, i. 100 (1856) (= Keratophorus) = Payena, Linn. (Sapotac.).

Leerii, Hassk. 1. c. $101=$ P. Leerii.

longepetiolatus, Teijsm. \& Binn. Cat. Hort. Bog. 161 $=\mathrm{P}$. longepetiolata.

Wightii, Hassk. Retzia, i. 101=P. Incida?

Wightii, Maing. ex C. B. Clarke, in Hook. f. Fl. Brit. Ind. iii. $547=\mathrm{P}$. malaccensis.

CERATOPHORUS, Sond. in Linnaea, xxiii. (1850) 120 = Gelonium, Roxb. (Euphórbiac.).

africanus, Sond. 1. c. 121=G. africanum.

CERATOPHYLLUM, Linn. Syst. ed. I (1735) CERATOPHYLLEAE, Benth. \& Hook. f. iii. 415. Dichotophyluum, Dill. ex Moench, Meth. 345 (1794).

apiculatum, Cham. in Linnaea, iv. (1829) $504=$ demersum.

aquaticum, H. C. Wats. Topogr. Bot. i. $165=$ demersum?

asperum, Lam. Fl. Fr. ii. $196=$ demersum.

australe, Griseb. in Goett. Abh. xxiv. (1879) 14,--Reg. Argent.

chilense, Leyb. in Anal. Univ. Chil. (1859) 682,Chili.

cornutum, Rich. in Ann. Mus. Par. xvi. (1810) 299.demersum.

cristatum, Guill. E Perr. Fl. Seneg. Tent. 295.-Afr. trop.

demersum, Klein, ex Cham. in Linnaea, iv. (1829) 505 $=$ triberculatum.

demersum, Linn. Sp. Pl. 992.--Reg. temp. et trop.

demersum, Sieber, ex Cham. in Linnaea, iv. (1829) 504 $=$ muricatum.

echinatum, A. Gray, Man. Bot. U. St. 401.-Am. bor. gibbum, Laforet, ex Nym. Consp. 251 = demersum.

granulosum, Schur, Enum. PI. Transs. 218 = submersum.

Haynaldianum, Borb. in Magy. Növént. Lapok, viii. (1884) 20.-Hungar.

indicum, Willd. ex Cham. in Linnaea, iv. (1829) 504 $=$ tuberculatum.

inerme, Dum. Fl. Belg. 165 = submersum.

laeve, Lam. F1. Fr. ii. 197 = submersum.

missionis, Wall. Cat. sub n. 7007.-Ind, or.

muricatum, Cham。 in Linnaea, iv. (1829) 504.-As.

et Afr. trop.

muticum, Cham. 1, c. $505=$ submersum.

oxyacanthum, Cham. 1. c. $504=$ tuberculatum

oxyacanthum, Schur, Enum. PI. Transs. $218=$ muricatum.

pentacanthum, Haynald, in Magy. Nörént. Lapok, v. (1881) 109.-Hungar.

platyacanthum, Cham. in Linnaea, iv. (1829) $504=$ muricatum.

polyacanthum, Schur, Enum. Pl. Transs. $218=$ muricatum.

submersum, Linn. Sp. Pl. ed. II. 1409_-Europ.; As. trop.

triacanthum, Schur, Enum. P1. Transs. $218=$ muricatum.

tricorne, Dum. Fl. Belg. $165=$ demersum

tricuspidatum, Dum. l. c. = demersum.

tuberculatum, Cham. in Linnaea, iv. (1829) 504.-Ind. or.

unicorne, Dum. F1. Belg. $165=$ demersum.

verrucosum, S. F. Gray, Nat. Arr. Brit. Pl. ii. $554=$ submersum

verruculosum, Rich. in Ann. Mus. Par. xvi. (1810).299 $=$ submersum.

verticillatum, Roxb. Hort. Beng. 68 ; F1. Ind, iii. 624 $=$ demersum.

vulgare, Schleid. in Linnaea, xi. (1837) $540=$ muricatum, tuberculatum, submersum.

CERATOPSIS, Lindl. Gen. et Sp. Orch. $383(1840)=$ Epipogum, S. G. Gmel. (Orchid.).

rosea, Lindl. 1. c. $384=$ E. roseum.

CERATOPYXIS, Hook. f. Ic. Pl. t. 1125 (1872). RUBIACEAE, Benth. \& Hook. f. ii. 105. verbenacea, Hook. $f . l, c$. - Cuba.

CERATOSANTHES, Burm. ex Adans. Fam. ii. 139 (1763); Juss. Gen. 396 (1789). CUCURBITACEAE, Benth. \& Hook, f. i. 833.

\section{CERATOSANTHES}

corniculata, Cogn. in DC. Monog. Phan. iii. $724=$ tuberosa.

gracilis, Cogn. in Mém. Cour. Acad. Belg. 8vo. xxviii. (1878); Diagn. Cucurb. fasc. ii. 33.-N. Granat.

Hilariana, Cogn. l. c. 31.-Bras.

latiloba, $\operatorname{Cog} n . l$. c. 33.-Venezuela.

multiloba, Cogn.l.c. 29.-Bras

tomentosa, $\operatorname{Cogn}$. l. c.-Bras.

trifoliata, Cogn. l. c. 34.-Bras.

tuberosa, F. F. Gmel. Syst. 102.--Ind. occ

Warmingii, Cogn. in Mém. Cour. Acad. Belg. 8vo. xxviii. (1878); Diagn. Cucurb. fasc. ii. 30.-Bras.

CERATOSTANTHUS, Schur, in Verh. Sieb. Ver. Naturf. (1853) 46; et Enum. Pl. Transs. $30(1866)=$ Delphinium, Tourn. (Ranunculac.).

Ajacis, Schur, Enum. P1. Transs. $30=$ D. Ajacis.

Consolida, Schur, in Verh. Sieb. Ver. Naturf. (1853) $46=\mathrm{D}$. Consolida.

divaricatus, Schur, 1. c. = D. divaricatum.

paniculatus, Schur, 1. c. = D. paniculatum

CERATOSCHOENUS, Nees, in Linnaea, ix. (1831) $296=$ Rynchospora, Vahl (Cyperac.).

capitatus, Chapman, F1.S. U.St. $529=$ R. cyperoides. corniculatus, Nees, in Linnaea, ix. (1834) $296=\mathrm{R}$. laxa.

longirostris, Torr. in Ann. Lyc. N. York, iii. (1836) $369=$ R. laxa

macrophyllus, Tuckerm. in Am. Journ. Sc. Ser. II. vi. (1848) $232=\mathrm{R}$. laxa.

macrostachys, Torr. in Ann. Lyc. N. York; iii. (1836) $369=\mathrm{R}$. macrostachya

CERATOSEPALUM, Oerst. Rech. FI. Am. Centr. 18. t. $17(1863)=$ Passiflora, Linn.

micranthum, Oerst. 1. c. t. $17=\mathrm{P}$. ceratosepala.

parviflorum, Mast. in Mart. Fl. Bras. xiii. I. $555=\mathrm{P}$. ceratosepala.

CERATOSPERMUM, Pers, Syn, ii. $551(\mathbf{1 8 0 7})=$ Eurotia, Adans. (Chenop.).

papposum, Pers. 1. c. $552=$ E. ceratoides.

CERATOSTACHYS, Blume, Bijdr. 644 (1825) = Nyssa, Linn. (Cornac.)

arborea, Blume, 1. $c,=N$. sessiliflora.

CERATOSTEMA, Juss. Gen. P1. 163 (1789). VACCINIACEAE, Benth. \& Hook. f. ii. 570.

SipHoNandRA, Klotzsch, in Linnaea, xxiv. (1851) 24.

Siphonostema, Griseb. in Lechl. Berb. Am. Austr. $58(1857)$.

angulatum, Griff. Notul. iv. $302=$ Agapetes angulata. biforum, Poepp. \& Endl. Nov. Gen. et Sp. i. 6. t. $10=$ Eurygania biflora.

buxifolium, Gardn. E Field, Sert. Pl. t. 7.-Bras, calycinum, Benth. E Hook. f. Gen. ii. 570,-Ecnador cordifolium, Dun. in DC. Prod. vii. 553.-Peruy. costatum, Benth. E Hook. f. Gen. ii. 570.--Peruv. ellipticum, Benth. E Hook. f. l. c.-Am. austr. emarginatum, Ruiz \& Pav. Fl. Per. iv. t. 384.Peruv.

grandiflorum, Ruiz E Pav. l. c. 383.-Peruv

hirsutum, Ruiz \& Pav. l.c.-Peruv.

lanceolatum, Benth. Pl. Hartw. 142.-Peruv

longiflorum, Benth. E Hook. f. Gen. ii. 570.-Ecuador.

longiflorum, Lindl. ex Lem. in Fl. des Serres, Sér. I.

iv. $(1848) 346^{\mathrm{b}}=$ grandiflorum.

loranthiflorum, Benth. Pl. Hartw. 142.-Peruv.

miniatum, Griff. Notul. iv. $302=$ Agapetes miniata

myrtifolium, Griseb. ex Benth. E' Hook. f. Gen. ii. 570 , nomen.-Am. austr.

nanum, Griff. Notul. iv. $303=$ Agapetes nana.

oblongifolium, Dun. in DC. Prod. vi. 553.-Perav.

odoratissimum, Willd. ex Klotzsch, in Linnaea, xxiv. (1851) $31=$ Cavendishia Querema.

parvifolium, Benth. Pl. Hartw. $220=$ Eurygania parvifolia.

peruvianum, Pers. Syn. i. 480.-Peruv.

pubiflorum, Wedd. Chlor. And. ii. 181.-N. Granat.

rigidum, Benth. Pl. Hartw. 220.-N. Granat

Salapa,Benth. l. c. 141.-Peruv.

speciosum, André, Illustr. Hortic. xvii. (1870) t. 9.Ecuador.
CERATOSTEMA :-

vaccinaceum, Roxb. Hort. Beng. 33 ; Fl. Ind. ii. 412

Vaccinium serratum.

variegatum, D. Don, ex Steud. Nom. ed. II. i. $332=$ Agapetes variegata.

variegatum, Griff. Notul. iv. $302=$ Agapetes grandiflora.

variegatum, Roxb. Hort. Beng. 33 ; F1. Ind. ii. $413=$ Agapetes macrantha.

CERATOSTIGMA, Bunge, in Mém. Sav. Etr. Acacl Pétersb. ii. (1835) 129 (Enum. Pl. Chin. Bor. 55) PLUMBAGINEAE, Benth. \& Hook. f. ii. 628.

VALORADIA, Hochst. in Flora, xxv. (1842) 239

abyssinicum, Aschers, in Schweinf. Beitr. Fl. Aethiop. 288-Afr. trop.

Griffithii, C. B. Clarke, in Hook. f. Fl. Brit. Ind. iii. 481.-Reg. Himal.

plumbaginioides, Bunge, Enum. Pl. Chin. Bor. 55.China.

CERATOSTYLIS, Blume, Bijdr. 304.t. 56 (1825) $O R C H I D E A E$, Benth. \& Hook. f, iii. 517.

ACoridium, Nees \& Meyen, in Nov. Act. Nat. Cur xix. Suppl. i. (1843) 131.

anceps, Blume, Bijdr. 305.-Java.

braccata, Reichb. in Bonplandia, v. (1857) 53.Java.

capitata, Zoll. Eo Moritri, in Nat. en Geneesk. Arch. Neêrl. Indie, i. (1844) 404.-Java.

Cepula, Reichb. f. in Bonplandia, $\mathbf{v}$. (1857) 53.-Java. Gigas, Reichb. f. l. c.-Java.

gracilis, Blume, Bijdr.306.--Java.

graminea, Blume, l. c. 305.-Java.

latifolia, Blume, l. c.-Java.

retisquama, Reichb. f. in Bonplandia, v. (1857) 53.Ins. Philipp

senilis, Reichb. in Otia Bot. Hamb. 54,-Ins. Philipp. simplex, Blume, Bijdr. 305.-Java.

subulata, Blume, $l . c .306$.- Tava.

teres, Reichb. f. in Bonplandia, ii. (1854) 89.-Reg. Himal.

CERATOTHECA, Endl, in Linnaea, vii. (1832) 5. t. 1, 2. PEDALINEAE, Benth. \& Hook. f. ii 5. t. 1

SPORLEDERA, Bernh. in Linnaea, xvi. (1842) 41

Kraussiana, Bernh. in Linnaea, xvi. (1842) 32.-Afr. austr.

melanosperma, Hochst. ex Bernh. l. c-Afr. trop.

sesamoides, Endl. l. c. vii. (1832) 5. t. 1, 2--Afr trop.

triloba, E. Mey. ex Bernh.l.c. xvi. (1842) 29,-Afi austr.

CERATOzamia, Brongn. in Ann. Sc. Nat, Sér. III v. (1846) 7.t. 1, partim. CYCADACEAE, Benth. \& Hook. f. iii. 446 .

Dipsacozamia, Lehm. in Lindl. Veg. Kingd. 225 (1847).

angustifolia, Linden, in Illustr. Hortic. xxviii. (1881) 32 , nomen.-Mexic.

boliviana, Brongn. in Ann. Sc. Nat. Sér. III. v. (1846) 9.-Bolivia.

brevifrons, Miq. in Tijdschr. Wis- en Nat. Wetens, i. (1848) $41=$ mexicana

fusco-viridis, D. Moore, in Proc. Roy. Dubl. Soc (1878) $113=$ mexicana.

Ghiesbrechti, Hort, ex Regel, in Act. Hort. Petrop. iv (1876) $299=$ Miqueliana.

intermedia, Miq. in Tijdschr. Wis- en Nat. Wetens. i. (1848) $40=$ mexicana

Karsteniana, Hort. Kew. ex Dyer, in Hemsl. Biol. Centr. Am. Bot. iii. 192 = latifolia.

Katzeriana, Regel, Gartenfl. (1876) 261.-Hab. ?

Kuesteriana, Regel, in Bull. Soc. Nat. Mosc. xxx. (1857) I. 187.-Mexic.

latifolia, Hort. Belg. ex Miq. in Tijdschr. Wis-en Nat. Wetens, i. (1848) 206.-Mexic.

longifolia, Miq. 1. c. $40=$ mexicana.

mexicana, Brongn. in Ann. Sc. Nat. Sér. UII. v. (1846 8.-Mexic.

Miqueliana, $H$. Wendl. Ind. Palm.68.-Mexic. muricata, Miq. in Linden, Illustr. Hortic. xxviii. (1881) 32, nomen.-Mexic.

robusta, Miq. in Tijdschr. Wis- en Nat. Wetens. i. (1848) $42=$ mexicana 
CERAUNIA, Noronha, in Verh. Batav. Gen. y. (1790 ed. I. Art. IV. 2 (1827) (Quid?).

CERBERA, Linn. Gen. ed. I. 62 (1737). APOCYNA $C E A E$, Benth. \& Hook. f. ii. 699 .

CASCABela, Rafin. Sylva Tellur. 162 (1838).

Elcana, Blanco, Fl, Filip. ed. II. 584 (1845)

MangHAS, Burm. Thes. Zeyl. 150 (1737)

Neiosperma, Rafin. Sylva Tellut. 162 (1838).

Odollam, Adans. Fam. ii. 171 (1763).

Odollamia, Rafin. Sylva Tellur. 162 (1838).

Tanghinia, Thou, Gen. Nov. Madag. 10 (1806).

Ahouai, Linn. Sp. P1. $208=$ Thevetia Ahouai.

alliodora, Willd, ex Roem. \& Schult. Syst. iv. $798=$ Thevetia cuneifolia.

batjanica, Teijsm. E' Binn. Cat. Hort. Bog. 385, nomen. -Malaya.

borbonica, Spreng. Syst. i. $642=$ Ochrosia borbonica. chinensis, Spreng. 1. $\mathrm{c}_{\mathrm{n}}=$ Dissolaena verticillata.

cuneifolia, H. B. \& K. Nov, Gen. et Sp. iii. $224=$ Thevetia cuneifolia.

dichotoma, Lodd. Bot. Cab. t. 1516 - Tabernaemontana dichotoma.

Forsteri, Seem. F1. Vit. $157=$ C. Odollam.

fruticosa, Ker.Gawl. in Bot. Reg. t. $391=$ Kopsia fruticosa.

fruticosa, Roxb. Hort. Beng. 19; Fl. Ind. i. 691. Burma.

glomerata, Zipp. ex Blume, Mus. Bot. Lugd. Bat. i. 158 - Psendochrosia glomerata.

lactaria, Buch.-Ham. ex D. Dietr. Syn. Pl. i. $623=$ C. Odollam.

laurifolia, Lodd. Bot. Cab. t. $989=$ C. Odollam.

linearifolia, Stokes, Bot. Mat. Med. i. $490=$ Thevetia nereifolia.

Linnaei, Montr. in Mem. Acad. Lyon, x. (1860) 233. -N. Caled.

maculata, Willd. Sp. Pl. i. $1223=$ Ochrosia borbonica Manghas, Linn. Sp. Pl. $208=$ C. Odollam, et Tabernaemontana dichotoma.

musculiformis, Lam. Encyc. i. $62=$ Banksia musculiformis.

nereifolia, Zipp. in Bijdr. Nat. Wetensch. v. (1830) 178 = Porlocarpus Rumphia.

nitida, H. B. \& K. Nov. Gen. et Sp. iii. $225=$ Thevetia nitida.

obovata, Roem. E Schult. Syst. iv. 798.-Hab.?

obtusifolin, Heurck \& Muell. Arg. in Heurck, Obs. Bot. 203.-N. Caled.

Odollam, Gaertn. Fruct. ii. 193.-Ind. or. ; Malaya.

oppositifolia, Lam. Encyc. i. 62.-Ins. Molncc.

ovata, Cav. Ic. iii. 35 . t. $270=$ Thevetia ovata.

parviflora, Forst. f. Prod. $19=$ Ochrosia elliptica.

parviflora, Hook. \& Arn. Bot. Beech. Voy. $90=$ Ochrosia sandwicensis.

parviflora, Wall. Cat. n. $1584=$ Ochrosia borhonica.

peruviana, Pers. Syn. i. $267=$ Thevetia nereifolia.

platyspermos, Gaertn. Fruct. ii. 193. t. 124. f. $2=$ Ochrosia borbonica.

quatemifolia, Roxb. Hort. Beng. 19, nomen.-Sumatra.

salutaris, Blume, Bijdr. $1033=$ oppositifolia.

Tanghin, Hook. Bot. Mag. t. 2968.-Madag.

Tanquin, Steud. Nom. ed. II. i. $332=$ praec.

Thevetia, Linn. Sp. Pl. $209=$ Thevetia nereifolia.

thevetioides, H. B. \& K. Nov. Gen. et Sp. iii. $223=$ Thevetia Yccotli.

triphylla, Rudge, P1. Gui. 31.t. 48 = Couma guianensis. tubiflora, Zipp. ex Blume, Mns. Bot. Luyd. Bat. i. 156 = Neuburgia tubifora.

undulata, Andr. Bot. Rep. t. $130=$ Ochrosia borbonica. venenifera, Stcud. Nom. ed. II. i. $332=$ C. 'Tanghin.

CERBERA, Lour. Fl. Cochin. $196(1790)=$ Scaevola, Linn. (Goodeniac.)

ovata, Sieber, ex DC. Prod. vii. $507=$ S. Lobelia.

salutaris, Lour. Fl. Cochinch, $136=\mathrm{S}$. Koenigii ?

CERBERIOPSIS, Vieill, ex Panch. \& Sebert, Not. Bois Nouv. Caléd. 187 (1874). APUCYNACEAE. candelabra, Vieill. l. c.-N. Caled.

CERCESTIS, Schott, in Oestr. Bot. Wochenbl. vii. (1857) 414. AROIDEAE, Bentb. \& Hook. f, iii. 980. Afzelii, Schott, l. c.-Afr. trop.

CERCIDIPHYLLUM, Sieb. \& Zucc. in Abh. Math. Acad. Muench. iv. III. (1846) 238. MAGNOLIA. $C E A E$ ?

japonicam, Sicb. E Zucc. b.c.-Japon.
CERCIDIUM, Tul, in Arch. Mus, Par, iv, (1844)

133. LEGUMINOSAE, Benth. \& Hook. f. i. 570.

Hoopesia, Buckl. in Proc. Acad. Sc. Philad. '1861 (1862) 453, partim.

Rhetrnophloevm, Karst. Fl. Columb。 ii, 25. t. 113 (1862?).

andicolum, Griseb. in Goett. Abh. xxiv. (1879) 114.Reg. Argent.

floridum, Benth. ex A. Gray, Pl. Wright. i. 58.Mexic.

floridum, Torr. in Pacif. Rail. Rep. v. 360 . t. $3=$ Parkinsonia Torreyana.

spinosum, Tul. in Arch. Mus. Par. iv. (1844) 134.Bras.

texanum, A. Gray, Pl. Wright. i. 58.-Mexic

CERCIS, Linn. Sp. Pl. 374, ed. I (1753). LEGU MINOSAE, Benth. \& Hook, fo i. 576

Siliquastrum, Tourn. ex Adans. Fam. ii. 317 (1763).

californica, Torr. ex Benth. Pl. Hartw. 361, nomen = occidentalis

canadensis, Linn. Sp. Pl. 374.-Am. bor.

chinensis, Bunge, in Mém. Sav. Etr. Petersb. ii. (1835) 95.-China.

florida, Salisb. Prod. $327=$ C. Siliquastrum.

Griffithii, Boiss. Fl. Orient. ii. 633.-Afghan.

japonica, Siebold, ex Planch. in Fl. des Serres, Sér. I. viii. $(1852-53) 269=$ chinensis.

occidentalis, Torr.ex A. Gray, in Bost. Fourn. Nat. Hist. vi. (1850) 177.-Texas.

reniformis, Engelm. ex A. Gray, 1. c。 =occidentalis.

siliquosa, St. Lag. in Ann. Soc. Bot. Lyon, vii. (1880) $122=$ C. Siliquastrum.

Siliquastrum, Linn.Sp.Pl.374.-Europ.; Oriens.

Cercocarpus, H. B. \& K. Nov. Gen. et Sp. vi. 232. t. 559 (1823). ROSACEAE, Benth. \& Hook. f. i. 618 .

betulaefolius, Nutt. ex Hook. Ic. Pl. t. $322=$ parvifolius.

betuloides, Nutt. in Torr. \& Gray, Fl. N. Am. i. $427=$ parvifolius.

breviflorus, A. Gray, Pl. Wright. ii. 54.-N. Mexic

fothergilloides, $H . B$. $\mathcal{K} \mathrm{K}$. Nov. Gen. et Sp. vi. 233. Mexic.; Am. bor.

fothergilloides, Torr. in Ann. Lyc, N. York, ii. (1828) $198=$ parvifolius.

intricatus, S. Wats. in Proc. Am. Acad. x. (1875) 346. - Am. bor. occ.

ledifolius, Nutt. in Torr. E Gray, Fl. N. Am. i. 427. -Am. bor. occ.

montanus, Rafin. Atl. Fourn. 146-Am. bor.

parvifolius, Nutt. ex Hook. E Arn. Bot. Beech. Voy. 337.-Calif.

CERCOCOMA, Wall, Cat. n. $1623(1832)=$ Strophanthus, DC. (Apocynac.)

macrantha, Teijsm. \& Binn. Cat. Hort. Bog. 126. Hab.?

singaporiana, Wall. Cat. n. $1623=\mathrm{S}$. brevicaudatus.

CERCOCOMA, Miq. F1. Ind. Bat. ii. 445 (1856) Rhynchodia, Benth. (Apocynac.)

Wallichii, Miq. 1. c. = R. Wallichii.

CERCODEA, Soland. ex Lam. Encyc. i. $682(1783)=$ seq.

CERCODIA, Murr. in Comm. Gotting. iii. (1780) 3.t. I = Haloragis, Forst.

alternifolia, A. Cunn. in Ann. Nat. Hist. iii. (1839) 29 $=\mathrm{H}$. alata.

erecta, Murs, in Comm. Gotting. iii. (1780) 3. t. $1=\mathrm{H}$. alata.

incana, A. Cunn, in Ann. Nat. Hist. iii. (1839) $80=\mathrm{H}$. tetragryna.

racemosa, DC. Prod. iii. $67=\mathrm{H}$. racemosa.

CERCOPHORA. Miers, in Trans, Linn. Soc. xxx. 1874) 3U1. MYRTACEAE anomala, Miers, l. c. 302 - - Reg. Amazon.

CERCOSTXLOS, Less, Syn. Comp. 23y (189:)

Gaillardia, Fonger. (Compos.).

brasiliensis, Less, 1. c. $240=$ G. megnotamica.

scabiosoides, Arn. ex DC. Irod. vii. $298=\mathrm{G}$. megapotanicr.

sesrmoides, Stcud. Nom. ed. II. i. 393, sphalm. prace.
CERDANA, Ruiz \& Pay, Prod.37. $6(1794)=$ Cordia Linn. (Boragin.)

alliodora, Ruiz \& Pav, Fl, Per. ii. $47=$ Cordia Cerdana.

cujabensis, Manso, ex DC. Prod, ix. $473=$ Cordia cujabensis.

CERDIA, Moc. \& Sesse, ex DC. Prod, iii. 377 (1828) CARYOPHYLLEAE, Benth. \& Hook. f. i. 153 congestiflora, Hemsl. Diagn. Pl. Nov. 23.-Mexic. glauca, Hemsl. l. c. 22.-Mexic

purpurascens, Mof. E Sesse, ex DC. Prod. iii. 377.Mexic.

virescens, Mof. EO Sesse, l. c.-Mexic.

CEREFOLIUM, Riv, ex Rupp. Fl. Jen. ed. Hall. 283 $(1745)=$ Anthrigeus, Hoffm. (Umbellif).

nitidum, Celak. in Arch. Naturw. Landesd. Boehm. iii. $(1875) 586=\mathrm{A}$. nitida.

sativum, Bess. Prim. Fl. Galic. i. $219=$ A. Cerefolium. sylvestre, Bess. 1. c. $218=\mathrm{A}$. Cerefolium

trichospermum, Bess. Enum. Pl.Volh.44 = A. Cerefolium.

CEREOPSIS, Blanco, Fl. Filip. ed. II. Suppl. 591 (1845), sphalm. = Coreopsis, Linn. (Compos.)

CERESIA, Pers. Syn。 i. $85(1805)=$ Paspalum, Linn. (Gramin.).

aristata, Willd. ex Steud. Nom. ed. II. i, $333=$ Panicum Thrasya.

elegans, Pers. Syn. i. 85 = Pasp. membranaceum.

fluitans, Ell. Sketch, i. $109=$ Pasp. repens.

gracilis, Schlecht. in Linnaea, xxvi.(1853-55) $134=$ Pasp. gracile.

membranacea, Beauv, Agrost. 9.t. 5. f. 4= Pasp. membranaceum.

Wageneriana, Schlecht. in Linnaex, xxvi. (1853-55) $133=$ Pasp. Wagenerianum.

CEREUS, Mill. Gard. Dict. ed. VIII (1768); Haw. Syn. Pl. Suce. 178 (1812). CACTEAE, Benth \& Hook. f. i. 849

CEPHAlocereus, Pfeiff, in Otto \& Dietr. Allg. Gartenz. vi. (1838) 142.

Cephalophorus, Lem. Cact. Aliq. Nov. Desc. p. xii. (1838)

Cleistocactus, Lem. Mlust. Hortic, viii. (1861) Misc. 35.

Echinocereus, Engelm. in Wisliz. Tour North Mexico, 91 (1848).

Echinonyctanthus, Lem. Cact. Gen. Nor, et Sp. 10 (1839)

ECHINOPSIS, Zucc, in Abb. Akad. Muench, ii. (183\% 675

Pilocereus, Lem. Cact, Gen. Nov, et Sp, 6 (1839) abnormis, Sweet, Hort. Brit. ed. I. $171=$ peruvianus

acifer, Otto, ex Salm-Dyck, Cact. Hort. Dyck. ed. II 189.-Hab. ?

acinaciformis, Steud. Nom. ed. II. ¿. $393=$ cine rascens.

aciniformis, Hort. Berol. ex Pfeiff. Enum. Diagn. Cact. $101=$ cinerascens.

Ackermanni, Hort. Berol. ex Pfeiff. 1. c. $128=$ Phyllo. cactus Ackermanni.

acromelas, Hort. Berol. Index Cact. 1\$39, ex Pícift. Enum. Diagn. Cact. $84=$ crenulatus.

aculeatus, Hort. Berol. ex Foerst. Handb. Cact. ed. I. 433, nomen,-Hab, ?

acutangulus, Hort. Berol. ex Pfirtf. Ensm. Diagn. Cact. 107.-Mexic.

adustus, Engelm. in A. Gray, Pl. Ferdl. 50.N. Mexic.

Acthiops, Haw, in Pbil. Mag. 1\$30) 109 - caeru. lescens.

affris, Hort. ex Pfeiff. Faum. Diagr. Cact. 99, $100^{\circ}=$ variabilis, virens.

alacriportanus. Hort. Monac. ex Pfrift. Ename. Diaren. Cact. 8i.-Bras.

alatus, 1)C. Prod, iii. tio Khipsalis pachvpera.

albisctusus, Haw. Suspl. Pl. Surc. Ii.-Ins. S.

Doming.

albispinus, Salm-Dyck, Obs. Bot. (18\%?) 5.-Am. ausitr.

ambiguus, DC. Prat. iii. t6̆. - Mab.

amblyogonus, G. Dom, in Simres, Horf. Bril. ed. IIt

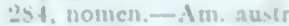

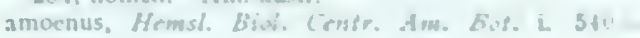
Mcxic 


\section{CEREUS :}

anisacanthus, DC. in Mém. Mus. Par. xvii. (1828) 116. -Mexic.

anizogonus, Hort. Angl. ex Salm-Dyck, Cact. Hort Dyck. ed. II. $52=$ triangularis.

Antoini, Hort. Vindob. ex Pfeiff. Enum. Diagn. Cact. $114=$ nycticalus.

aquicaulensis, Hort. ex Pfeiff. I. c. $90=$ geometrizans. arequipensis, Meyen, Reise, ii. $41=$ peruvianus. armatus, Otto, ex Pfeiff. Enum. Diagn. Cact. 81.-Ins. S. Thom.

Arrabidae, Steud. Nom, ed. II. i. 333.-Bras. articulatus, Pfeiff. Enum. Diagn. Cact. 103.-Chili. assurgens, Wright, ex Griseb. Cat. Pl. Cub. 116.Cuba.

atacamensis, Phil. Fl. Atac. 23.-Chili

auratus, Labour. in Rev. Hortic. Sér. IV. iv. (1855) 27. -Mexic.

qureus, Salm-Dyck, ex DC. Prod. iii, 465--Hab.?

azureus, Parm. ex Pfeiff. Enum. Diagn. Cact. 86.Bras.

bacciferus, HemsI. Biol. Centr. Am. Bot. i. $548=$ Rhipsalis Cassutha

barbatus, Wend1. ex Salm-Dyck, Cact. Hort. Dyck. ed. I. $29=$ floccosus.

Baumannii, Lem. in Hortic. Univ. (1844) 126, 315; ex Lem. Fard. Fleur. i. (1851) t. 48.-Peruv.?

baxaniensis, Karw. ex Pfeiff. Enum. Diagn. Cact. 109. -Mexic.

Beneckei, Ehrenb. in Bot. Zeit. ii. (1844) 835.Mexic.

Berlandieri, Engelm. Cact. Mex. Bound. 38. t. 58.Texas.

Bertini, E. Cels, ex Hérincq, L'Horticult. Franç. (1863) 251.-Chili.

biformis, Hort. ex Pfeiff. Enum. Diagn. Cact. $114=$ radicans.

biformis, Lindl. Bot. Reg. (1843) Misc. $51=$ Phyllocactus biformis.

bifrons, Haw. Suppl. P1. Succ. $76=$ coccineus

Bigelovii, Engelm. in Pacif. Rail. Rep. iv. t. 4. f. $8=$ mojavensis.

Blanckii, Poselg. in Otto \& Dietr. Allg. Gartenz. xxi. (1853) 134.--Mexic

Boeckmanni, Otto, ex Salm-Dyck, Cact. Hort. Dyck. ed. II. 217,-Mexic.

bonariensis, Sweet, Hort. Brit. ed. III. 283.-Reg. Argent.

bonariensis, Hort. Berol. ex Foerst. Handb. Cact. ed. I 388 = alacriportanus

Bonplandii, Parm. ex Pfeiff. Enum. Diagn. Cact. 108 -Bras.

brachiatus, Gal. ex Salm-Dyck, Cact. Hort. Dyck. ed, II. 195.-.Mexic.

bradypus, Steud. Nom. ed. II. i. $333=$ senilis

Brandii, Hort Angl, ex Salm-Dyck, Cact Hort. Dyck. ed. II. $49=$ variabilis.

brevispinulus, Salm-Dyck, Hort. Dyck. $339=$ nycticalus.

Bridgesii, Salm-Dyck, Cact. Hort. Dyck. ed. II. 208.Bolivia.

caerulescens, Salm-Dyck, Hort. Dyck. 335.-Bras.

caesius, Salm-Dyck, ex Pfeiff. Enum. Diagn. Cact 89.-Hab. ?

caespitosus, Engelm. E A. Gray, in Bost. Fourn. Nat. Hist. v. (1845) 247.-Texas

californicus, Torr. \& Gray, Fl. N. Am. i. 555= Opuntia serpentina?

callicoche, Gal. ex Scheidw. in Bull. Acad. Brux. vi. I. (1839) $88=$ Echinocactus myriostigma.

calvescens, DC. in Mém. Mus. Par. xvii. (1828) $116=$ peruvianus.

candelabrius, Hort. ex Pfeiff. Enum. Diagn. Cact. 109 $=$ tenellus.

candelaris, Meyen, Reise, i. $447=$ peruvianus.

candicans, Gill. ex Salm-Dyck, Hort. Dyck. 335.Chili.

caripensis, DC. Prod. iii. 467.-Mexic.

caudatus, Gill. ex Sweet, Hort. Brit. ed. III. $285=$ Mammillaria caudata.

Cavendishii, Monv. ex Salm-Dyck, Cact. Hort. Dyck. ed. II. 210 - -Hab. ?

chalibaeus, Hort. Berol. ex Salm-Dyck, l. c. 201.Hab.?

chalybaeus, Otto, ex Walp. Rep, ii. $340=$ polychaetus. chiloènsis, $D C$. Prod. iii. 465.-Ins. Chiloe

chloranthus, Engelm. Cact. Mex. Bound. 29.Texas.

\section{CERFUS :-}

chlorocarpus, DC. Prod. iii. 466.-Ecuador.

chrysomallus, Hemsl. Biol. Centr. Am. Bot. i. 541.Mexic.

cinerascens, DC. in Mém. Mus. Par. xvii. (1828) 11 -Mexic.

cirrhiferus, Labour. Cact. 311.-Mexic.

clavarioides, Hort. Berol. ex Pfeiff. Enum. Diagn. Cact. $173=$ Opuntia clavarioides.

clavatus, Otto E' Dietr. Allg. Gartenz. vi. (1838) 28. Venezuela.

claviformis, Regel E Klein, Ind. Sem. Hort. Petrop. 1860) 46.-Mexic.

coccineus, DC. Prod, iii, $469=$ setaceus.

coccineus, Engelm. in A. Gray, Pl. Fendl. $51=$ phoeniceus.

coccineus, Salm-Dyck, ex Pfeiff. \& Otto, Cact. i. t. 15.--Bras.

cognatus, Hort. ex Pfeiff. Enum. Diagn. Cact. $106=$ variabilis.

colicochus, Booth, Cat. ex Foerst. Handb. Cact. ed I. $336=$ Echinocactus myriostigma.

colubrinus, Otto, ex Foerst. l. c. 409 ; ex Salm-Dyck, Cact. Hort. Dyck. ed. II. 50, 215.-Hab. ?

Columna, Walp. Rep. v. $818=$ seq.

Columna-Trajani, Karw. ex Pfeiff. Enum. Diagn. Cact. 76.-Mexic.

columnaris, Lodd. ex Voigt, Hort. Suburb. Calc. 61 nomen.-Hab.

Colvillii x, Sweet, Hort. Brit. ed. II. 236, nomen, et p. 590.

cometes, Scheidw. in Otto E Dietr. Allg. Gartenz. viii. (1840) 339.-Mexic

compressus, Mill. Gard. Dict. ed. VIII. n. 10.Mexic.

concolor, Bigel. in Whipple, Exped. Add. p. $\mathrm{i}=$ caespitosus.

conformis, Hort. Berol. ex Salm-Dyck, Cact. Hort. Dyck. ed. II. 203.-Mexic.

conicus, Hort. Berol. ex Pfeiff. Enum. Diagn. Cact. 97.-Mexic.

conoideus, Engelm. \& Bigel. in Pacif. Rail. Rep. iv. 36.-Am. bor. occ.

coquimbanus, Hort. ex DC Prod iii $465=$ chiloensis. Coryne, Hort. Berol. ex Salm-Dyck, Cact. Hort. Dyck. ed. II. 205. $-\mathrm{Hab}$, ?

cossyrensis, Tin. ex Todaro, in Ind. Sem. Hort. Panorm. (1857) 39.-Hab.

crenatus, Lindl. Bot, Reg, (1844) t, $31=$ Phyllocactus crenatus.

crenoides, Engelm. Cact. Mex. Bound. 31. t. 42.Mexic.

crenulatus, Salm-Dyck, Obs. Bot. (1822) 6.-Am, austr. Crimsonii, Pritz. Ic. Ind. 246, sphalm.=Smithii. crispatus, Hort. Berol. ex Pfeiff. Enum. Diagn. Cact. $130=$ Rhipsalis crispata

cruciformis, Steud. Nom. ed. II. 1. 333.-Bras

cubensis, Zuccar, ex Pfeiff. Enum. Diagn. Cact. $94=$ eriophorus.

cupulatus, Hort. ex Pfeiff. 1. c. $97=$ marginatus.

Curtisi, Otto in Otto \& Dietr. Allg. Gartenz. i. (1833) $365,-N$. Granat

curvispinus, Pfeiff. Enum. Diagn. Cact. $89=$ peruviantus.

cylindricus, Haw. Syn. P1. Succ. $183=$ Opuntia cylindrica.

dasyacanthus, Engelm. in A. Gray, Pl. Fendl. 50.Texas.

decagonus, Hort. ex Pfeiff. Enum. Diagn. Cact. $85=$ albispinus.

Decandollii, Pfeiff. ex Foerst. Handb. Cact. ed. I. 389 -Hab.?

decorus, Lodd. ex Voigt, Hort. Suburb. Calc. 62 nomen.-Hab. ?

deficiens, Otto \&े Dietr. Allg. Gartenz. vi. (1838) 28 -Venezuela.

deflexispinus, Monv. Cat. (1846), ex Labour. Cact. $321=$ dasyacanthus.

denudatus, Hort. Berol. ex Pfeiff. Enum. Diagn. Cact. 73.-Bras.

Deppei, Hort. Berol. ex Pfeiff. 1. c. $101=$ cinerascens

dichroacanthus, Mart. ex Pfeiff. l. c. 76.-Mexic.

divaricatus, $D C$. Prod. iii. 466.-Ins. S. Doming.

divergens, Hort. Berol. ex Pfeiff. Enum. Diagn. Cact. 95.-Ins. S. Doming.

Donkelaarii, Salm-Dyck; in Otto \& Dietr. Allg. Gartenz. xiii. (1845) 355,-Bras.

dubius, Engelm. Cact. Mex. Bound. 36.-Texas.

\section{CEREUS :}

Duledevanti, Lem. Illustr. Hortic. v. (1858) Misc. 10. - Hab. ?

Dumortieri, Scheidw. in Bull. Acad. Brux. vi. I. (1839) 88.--Reg. Argent.

Dyckii, Mart, ex Pfeiff. Enum. Diagn. Cact. 87.Mexic.

eburneus, Salm-Dyck, Obs. Bot. (1822) 6.-Ins. Curaçao; Chili.

Ehrenbergii, Pfeiff. in Otto \& Dietr. Allg. Gartenz. viii. (1840) 282.-Mexic

elegans, Hort. ex Pfeiff. Enum. Diagn. Cact. 138= Rhipsalis Mittleri.

elegans, Lem. Illustr. Hortic. v. (1858) Misc. 10.Peruv.

Emoryi, Engelm. in Am. Fourn. Sc. Ser. II. xiv, 1852) 338.-Calif.

Engelmanni, Parry, ex Engelm. l.c.-Calif.

enneacanthus, Engelm. in A. Gray, Pl. Fendl. 50.Texas.

erectus, Karw. ex Pfeiff. Enum. Diagn. Cact. 95.Mexic.

ricomus, Hort. Berol. ex Salm-Dyck, Cact. Hort. Dyck, ed. II. $47=$ virens.

ericomus, Reichb. f. in Terscheck. Suppl. Cact. Verz. 3.-Bras.

erinaceus, Haw, ex Steud. Nom. ed. II. i. 334.-Ind. occ.

eriophorus, Hort. Berol. ex Pfeiff. Enum. Diagn. Cact. 94.-Cuba.

euphorbioides, Haw. Suppl. Pl. Succ. 75.-Am. austr.

exerens, Link, ex Pfeiff. Enum. Diagn. Cact. $99=$ virens.

extensus, Salm-Dyck, ex DC. Prod. iii. 469,-Am. austr.

Eyriesii, Hort. Berol. ex Pfeiff. Enum. Diagn. Cact. 72.-Reg. Argent.

farinosus, Haage, ex Salm-Dyck, in Otto \& Dietr. Allg. Gartenz. xiii. (1845) $355=$ Beneckei.

Fendleri, Engelm. in A. Gray, Pl. Fendl. 51.-N Mexic.

Ferchecki, Parm. ex Pfeiff. in Hort. Belg. v. (1838) 66.- Reg. Argent.

fernambucensis, Lem. sphalm. vide pernambucensis.

ferox, Haw. in Phil. Mag. (1830) 109.-Bras.

fimbriatus, DC. Prod. iii. $464=$ grandispinus.

fimbriatus, Hort. ex. Pfeiff. Enum. Diagn. Cact. $95=$ divaricatus.

flagelliformis, Mill. Gard. Dict. ed. VIII, n. 12.-Am. austr.

flagriformis, Zucc. ex Pfeiff. Enum. Diagn. Cact. 111. -Mexic.

flavescens, Otto, ex Pfeiff. l.c. 79 - Hab.?

flavicomus, Salm-Dyck, Cact. Hort. Dyck. ed. II. 202. $-\mathrm{Hab}_{\text {? }}$

flavispinus, Haw. ex Steud. Nom. ed. II. i. 334.-Am. austr.

flavispinus, Salm-Dyck, Obs. Bot. (1822) 5.-Am. calid.

floccosus, Hort. Berol. ex Pfeiff. Enum. Diagn. Cact. 81.-Ins. S. Thomas.

fluminensis, Miq. in Bull. Sc. Phys. Nat. Néerl. (1838) 48.-Bras.

Forbesii, Hort. Berol. ex Foerst. Handb. Cact. ed. I. 398; Salm-Dyck, Cact. Hort. Dyck. ed. II. 206.Hab. ?

formosus, Hort. ex Foerst. Handb. Cact. ed. I. 404.Reg. Argent.

formosus, Monv. Cat. $(1834)=$ Schrankii.

foveolatus, Haage, ex Pfeiff. Enum. Diagn. Cact. 77. - Hab.?

fulgidus, Hook. f. Bot. Mag. t. 5856.-Hab. ?

fulvibarbis, Otto \& Dietr. Allg. Gartenz. vi. (1838) $28=$ chiloënsis

fulvispinosus, Haw. Syn. Pl. Succ. 183=Royeni.

fulvispinus, Salm-Dyck, Cact. Hort. Dyck. ed. II. 46, sphalm. $=$ praec

Funkii x, Hort. Monac. ex Foerst. Handb. Cact. ed. I. 411 .

Garambello, Haage, ex Foerst. 1. c. $433=$ geometrizans. geminisetus, Reichb. in Terscheck. Suppl. Cact. Vers. 3.-Hab.?

gemmatus, Otto, ex Pfeiff. in Otto \& Dietr. Allg. Gartenz, iii. (1835) $314=$ turbinatus. gemmatus, Zucc. ex Pfeiff. Enum. Diagn. Cact. 96 -Mexic.

geometrizans, Mart. ex Pfeiff. l. c. 90.-Mexic. 


\section{CEREUS :-}

gibbosus, Sweet, Hort. Brit. ed. 1. 171.-Tamaica

giganteus, Engelm. in Emory, Notes Mil. Reconnoi 158.- - Texas.

gilvus, Salm-Dyck, in Otto E Dietr. Allg. Gartenz. xiii. (1845) 355 - - Hab?

Gladiator, Otto \& Dietr. 1. c. vi. (1838) $34=$ geometrizans.

gladiatus, Lem. Cact. Aliq. Nov. Desc. $28=$ candicans.

Gladiger, Cels, ex. Salm-Dyck, Cact. Hort. Dyck. ed. II. $47=$ resupinatus.

glaucescens, Trveedie, ex Sweet, Hort. Brit. ed. III. 284 , nomen.-Reg. Argent.

glaucus, Hort. ex Pfeiff. Enum. Diagn. Cact. $89=$ caesius, variabilis,

glaucus, Salm-Dyck, Hort. Dyck. 385.-Bras.

gloriosus, Hort. ex Pfeiff. Enum. Diagn. Cact. $80=$ Royeni.

gonacanthus, Engelm. E Bigel. in Pacif. Rail. Rep iv. 33. t. 5. f. 2. 3.-N. Mexic.

gracilis, Haw. in Phil. Mag. (1827) 125.-Hab.?

gracilis, Mill. Gard. Dict. ed. VIII. n. 8.-Ind occ.

gracilis, Salm-Dyck, ex DC. Prod. iii. $468=$ hu

milis.
grandiflorus, Mill. Gard. Dict. ed. VIII. n. 11.-Ind. occ.

grandis, Haw. Suppl. Pl. Succ, 76.-Bras.

grandispinus, Haw. in Phil. Mag. (1830) 109.-Ind.

Greggii, Engelm. in Wisliz. Rep. N. Mexico, 102.Texas.

griseus, Haw. Syn. Pl. Succ, $182=$ eburneus

Haageanus, Salm-Dyck, ex Foerst. Handb. Cact. ed. I. 381 , nomen.-Hab.

hamatus, [Scheidw.] Hort. Belg. ex Pfeiff. in Otto \& Dietr. Allg. Gartenz. v. (1837) $371=$ rostratus.

Hansii x, Baumann, in Rev. Hortic. Sér. II. i. (1842) 267.

Haworthii, DC. Prod. iii. 465.-Ind. occ.

heptagonus, Mill. Gard. Dict. ed. VIII. n. 6 ; Haw. Syn. Pl. Succ. 178.-Am. austr.

hermentianus, Monv, ex Lem. in Illustr. Hortic. vi. (1859) Misc. 90.-Hab. ?

heteracanthus, Tweedie, ex Sweet, Hort. Brit. ed. III 284.-Reg. Argent.

hexaedrus, Engelm. Eo Bigel. in Pacif. Rail. Rep. iv. 34. t. 5. f. 1. -N. Mexic.

hexagonus, Mill. Gard. Dict. ed. VIII. n. 1; Haw. Syn. Pl. Succ. 179.-Am. austr.

hexangularis, Hort, ex Pfeiff. Enum. Diagn. Cact. $106=$ varíabilis.

Histrix, Salm-Dyck, ex DC. Prod. iii. 464.-Cf. Hystrix.

Hoffmannseggii, Hort. ex Foerst. Handb. Cact. ed I. 292 - Echinocactus exsculptus.

Hookeri, Hort. Berol. ex Pfeiff. Enum. Dingn. Cact 125.-Bras.

horizontalis, Gill. ex Sweet, Hort. Brit. ed. III. 285. Chili.

horribarbis, Hort. Berol. ex Salm-Dyck, Cact. Hort Dyck. cd. II. 205.-Hab. ?

horridus, Otto, ex Pfeiff. in Otto \& Dietr. Allg. Gartens. v. (1837) 370.-Venezuela.

Humboldtii, DC. Prod. ii,. 467.-Ecuador

humilis, DC. l. c. 468.-Am. austr.

hybridus, Otto, in Otto \& Dietr. Allg. Gartenz. i. (1833) $72=$ speciosissimus

hypogaeus, Weber, ex Regel, Gartenfl. (1882) 165. t. 1085.- Hab.?

Hystrix, Sweet, Hort. Brit. ed. I. 171.-Ind. occ.

icosigonus, $D C$. Prod. iii. 467.-Ecuador.

imbricatus, Haw. Rev. Pl. Succ. $70=$ Opuntia imbricata.

imbricatus, Hort. ex Pfciff. Enum. Diagn. Cact. $93=$ = subrepandus.

incrustans, Steud. Nom. ed, II. i. $334=$ seq.

incrustatus, Hort. Berol. ex Pfeif. Elum. Diagn.

Cact. $97=$ marginatus.

incurvispinus, Hort. Darmst. ex Otto \& Dietr. Allg. Gartenz, iii. (1835) $244=$ leucanthus

inermis, Otto, ex Pfeiff. Enum. Diagn. Cact. 116.Venezuela.

inermis, Scheidw. in Bull. Acad. Brax. vi. (1839) $88=$ Echinocactus myriostigma.

insularis, Hemsl. Bot. Voy. Challenger, i. II. 16.Mons S. Mich.

\section{CEREUS :}

intricatus, Salm-Dyck, Cact. Hort. Dyck, ed. II. 194.Hab.?

inversus, Hort. Berol: ex Salm-Dyck, l. c. 219, nomen. -Hab.?

irradians, Lem. Illust. Hortic. xi. (1864) Misc. 74.Cuba.

Famacaru, Hort. Vindob. ex Salm-Dyck, Cact. Hort. Dyck. ed. I. $31=$ variabilis

Jamacaru, $D C$. Prod. iii. 467.-Bras.

janthothele, Monv, ex Salm-Dyck, Cact. Hort. Dyck. ed. I. $4 \mathrm{I}=$ Rhipsalis cereiformis.

jasmineus, Hort. Darmst. ex Pfeiff. Enum. Diagn. Cact. $72=$ turbinatus

Fenkinsonix, Sweet, Hort. Brit. ed. II. 237, nomen. jubatus, Salm-Dyck, ex Foerst. Handb. Cact. ed. I. $357=$ cometes.

Kageneckii, Gmel. ex Pfeiff. Enum. Diagn. Cact. $77=$ multangularis

Karstenii, Hort. Angl. ex Salm-Dyck, Cact. Hort. Dyck. ed. II. $207=$ lepidotus.

Karstenii, Salm-Dyck, Cact. Hort. Dyck. ed. II. 218.N. Granat.

Knightii, Parment. ex Pfeiff. Enum. Diagn. Cact. $139=$ Rhipsalis Knightii.

Kunthianus, Hort. Berol. ex Salm-Dyck, Cact. Hort. Dyck. ed. II, 217.-Hab.?

laetevirens, Hort. Berol. ex Pfeiff. Enum. Diagn. Cact. $99=$ lividus.

laetevirens, Salm-Dyck, Hort. Dyck. 336 = variabilis.

laetus, $D C$. Prod nii. 466-Ecuador.

laetus, Salm-Dyck, Hort. Dyck. $336=$ formosus

laevigatus, Salm-Dyck, Cact. Hort. Dyck. ed. II. 204.Hab.?

lagenaeformis, C. F. Foerst. in Hamb. Gartenz. xvii. (1861) 164.-Peruv.

lamprochlorus, Lem. Cact. Aliq. Nov. Desc. 30. Hab. ?

lanatus, DC. Prod. iii. 464-Ecuador.

Lanceanus, Hort. ex G. Don, in Sweet, Hort. Brit. ed, III. 285 , nomen.-Hab.?

Landbecki, Phil. ex Regel, Gartenfl. (1875) 162. t. 832.- Reg. Argent.

lanuginosus, Haw. Syn. PI. Succ. $182=$ repandus

lanuginosus, Mill. Gard. Dict. ed. VIII. n. 3.-Am. trop.

lateribarbatus, Hort. ex Lem. in Rev. Hortic. (1862) $427=$ C. Columna-Trajani.

latifrons, Zucc. in Denkschr. Akad. Muench. ii. 1837) $735=$ Phyllocactus latifrons

Lecchii, Pfeiff. Enum. Diagn. Cact. 78.-Hab. ?

Leeanus, Hook. Bot. Mag. t. 4417.-Mexic.

Lehmanni, Hort. ex Foerst. Handb. Cact. ed. I. $245=$ Mammillaria Lehmanni.

leiocarpus, Bello, in Anal. Soc. Esp. Hist. Nat. x. 1×81) 276.-Porto Rico.

Lemairii, Hook. Bot. Mag. t. 4814.-Hab. ?

lepidotus, Salm-Dyck, Cact. Hort. Dyck. ed. II. 207.Venezuela.

leptacanthus, DC. ex Pfeiff. Enum. Diagn. Cact. $101=$ pentalophus.

leptophis, DC. in Mém. Mus. Par. xvii. (1828) 117.Mexic

leucanthus, Pfeiff: Enum. Diagn. Cact.71.-Chili.

limensis, Lodd. ex Foerst. Handb. Cact. ed. I. 875 flavescens.

limensis, Salm-Dyck, in Otto E Dietr. Allg. Gartens. xiii. (1845) 353.-Bolivia.

Linkii, Pfeiff. Enum. Diagn. Cact. $48=$ Echinocactus Linkis.

Linnaei, C. F. Foerst. in Hamb. Gartens. xvii. (1861) 165.-Mexic.

lividus, Pfeiff. in Otto E Dietr. Allg. Gartens. (1835) 380.-Am. austr.

longifolius, Karw. ex Sweet, Hort. Brit. ed. III. 286, nomen.-Mexic.

longipedunculatus, Hort. Berol. ex Foerst. Handb. Cact. ed. I. 433 , nomen.-Hab. ?

longisetus, Engelm. Cact. Mex. Bound. 32. t. 45.Texas.

longispinus, Salm-Dvck, ex Otto G Dietr. Allg. Gartens. xiii. (1845) 954.-Bolivia.

lumbricoides, Lem. Cact. Ge'n. Nov. et Sp. 60.Bras.

lutescens, Salm-Dyck, ex Pfeiff. Enum. Diagn. Cach. 84.-Hab.

MacDonaldiac, Hook. Bot. Mag. 1. 4707.-Honduras,

\section{CEREUS}

macrogonus, Hort. Berol. ex Salm-Dyck, Cact. Hort Dyck. ed. Il. 203.-Hab.?

Maelenii, Pfeiff. in Otto \& Dietr. Allg. Gartenz. (1837) $379 .-$ Mexic

magnus, Haw. in Phil. Mag. (1830) 109.-Ins. S. Doming.

Mallisoni, Hort. ex Pfeiff. Enum. Diagn. Cact. 111 Smithii.

marginatus, DC. in Mém. Mus. Par. xvii. (1828) 116 -Mexic.

marginatus, Salm-Dyck, Hort. Dyck. $340=$ Hookeri.

Mariculi, Hort. ex Pfeiff. Enum. Diagn. Cact. $115=$ bumilis.

Martianus, Zucc. ex Pfeiff. l. c. 110.-Mexic

Mendory, Hort. ex Pfeiff. 1. c. $85=$ caerulescens.

meonacanthus, Link \&e Otto, ex Sterd. Nom. ed. II.

$334=$ Echinocactus meonacan thus.

mexicanus, Lem. ex Foerst. Handb. Cact. ed. I. 430.Mexic.

micracanthus, DC. in Mém. Mus. Par. xvii. (1828, 115.-Mexic

militaris, Audot, in Rev. Hortic. Sér. II. iv. (1845-46) 307.-Mexic.

Mirbelii, Hort. Belg. ex Pfeiff. Enum. Diaga. Cact. 97 = marginatus.

mohavensis, S. Wats. Bibliog. Ind. Fl. Am. Bor. 398 $=$ seq.

mojavensis, Engelm. E Bigel. in Pacif. Rail. Rep. iv 33.-Am. bor. occ

mollis, Hort. ex Pfeiff. Enum. Diagn. Cact. $83=$ strictus.

moniliformis, DC. in Mém. Mus. Par. xvii. (182S) 60

-Ins. S. Doming.

monoclonus, DC. Prod. iii. $464=$ peravianus,

monstrosus, Steud. Nom, ed. II. i. $\$ 34=$ peruvianus.

montevidensis, Hort. ex Pfeiff. Enum. Diagn. Cact. 65 $=$ Echinocactus exsculptus.

Monterumae, Hort. ex Pfeiff. 1. c. $91=$ candicans.

Moritzianus, Otto, ex Pfeiff. l. c. 84.-Bras

multangularis, Haw. Suppl. Pl. Succ. 75.-Am. austr. multiplex, Hort. Berol. ex Pfeiff. Enum. Diagn. Cact. 70.-Bras.

Myosurus, Salm-Dyck, in DC. Prod, iii. $469=$ Rhipsalis Myosnrus.

myriocaulon, Mart. ex Pfeiff. Enum. Diagn. Cact. 115 = humilis.

myriophyllus, Gill. ex Otto, in Otto \& Dictr. Allg. Gartenz. i. (1833) $365=$ strigosus.

nanus, $D C$. Prod. iii. 470,-Ecuador.

Napoleonis, R. Grah. in Bot. Mag. t. 3458.-Ind. occ.

niger, Salm-Dyck, Obs. Bot. (1822) 4.-Am. anstr. nigricans, Hort. ex Pfeiff. Enum. Diagn. Cact. $83=$ strictus.

nigricans, Lem. Cact. Gen. Nov, et Sp. 57.-Hab. ?

nigripilis, Phil. Fl. Atac. 23.-Chili.

nitens, Salm-Dyck, ex Otto \& Dietr. Allg. Garteng. xiii. (1845) 354.-Bolivia.

nitidus, Salm-Dyck, Cact. Hort. Dyck. ed. II. 211. Venezuela.

nobilis, Haw. Syn. Pl. Succ. $179=$ Haworthii.

nycticalus, Link, in Verh. Prenss. Ver. Garfenb. $x$.

(1834) 373.t. 4-Mexic.

nyriocaulon, Sweet, Hort. Brit. ed. III. 285 , sphalm. = myriocaulon.

obtusus, Haw. Rev. Pl, Succ. $\pi 0$ = variabilis

obtusus, Hort. ex Pfeiff. Enum. Diagn. Cact. 11t: nycticalus.

Ocamponis, Salm-Dyck, Cact. Hort. Dick, ed. II. 220. -Mexic.; N. Granat.

ochracanthus, Hort. ex Pfeift. Enum. Diaga. Cact is = multangularis.

octogonus, Hort. ex Otto, in Otto \& Dietr. Allg. Gartenz. i. (1893) $965=$ albispinus, Curtisii.

Olfersii, Salm-Dyck, Hort. Dyck. 335.-Brns.

olivaceus, Lem. in Rev. Horlic. Sir. IV. viii. (1559 its. - Ind. occ.

Oituris, I'feiff. Fnum. Diagn. Cact. 47, sphalm. = lichinocactus (Mttonis.

ovneus, G. Don, in Loud. Mort. Brif. 185 ; Pfeif. Ensm. Diugn. Cact. 102-C Chili.

oxygonus, Offo, in Ofto $G$ Diefr. Allg. Gardens. i (1593) $\$ 65 .-13$ ras.

orygonus, Salm-I Jyck, ex Foerst. Ilandb. Cact. ed. I. S!18 = euphorbioides. eryprialus, DC. Prod. iii. 1;0 - Phyllocactus lati. iruns. 


\section{CEREUS}

oxypetalus, Hort. ex Salm-Dyck, Cact. Hort. Dyck. ed. I. 37 , nomen $=$ Phyllocactus marginatus. paniculatus, $D C$. Prod. iii, 466.-Ins. S. Doming. panoplaeatus, Cels, ex Salm-Dyck, Cact. Hort. Dyck. ed. II. $44=$ pycnacanthus.

paradoxus, Hort. ex Steud. Nom. ed. II. i. $335=$ Opuntia brasiliensis.

parasiticus, Haw. ex Steud. 1. c.=Rhipsalis fasciculata.

parvisetus, Hort. Berol. ex Pfeiff. Enum. Diagn. Cact. 79.-Bras.

paucispinus, Engelm. E Bigel. in Pacif. Rail. Rep. iv. 34,36 ; et in Proc. Am. Acad. iii. (1857) 285 , Texas.

Paxtonianus, Monv.ex Salm-Dyck, Cact. Hort. Dyck. ed. II. 211. - Hab. ?

pectinatius, Engelm. in A. Gray, Pl. Fendl. $50=$ caespitosus.

pectiniferus, Labour. Monog. Cact. $320=$ caespitosus.

pellucidus, Hort. Berol. ex Pfeiff. Enum. Diagn. Cact.

108.-Cuba.

pentagonus, Hary. Syn. Pl. Succ. 180,-Am, austr.

pentagonus, Hort. ex Foerst. Handb. Cact. ed. I. 389 = peruvianus.

pentalophus, DC. in Mém. Mus. Par. xvii. (1828) 117 -Mexic.

pentapterus, Otto, ex Salm-Dyck, Cact. Hort. Dyck. ed. II. 220-N. Granat.

Pepinianus, Lem.ex Salm-Dyck, in Otto \& Dietr. Allg. Gartenz. xiii. (1845) 354--Bolivia

pernambucensis, Lem. Nov. Cact. Gen. et Sp. 58 (err typ. fernambucensis) = variabilis.

Perrotteti, Hort. ex Pfeiff. Enum. Diagn. Cact. $98=$ lividus.

peruvianus, Hort. ex Foerst. Handb. Cact, ed. I. $392=$ eburneus.

peruvianus, Mill. Gard. Dict. ed. VIII. n. 4 ; Haw Syn. Pl. Succ. 179.-Am, austr

Pfeifferi. Parm. ex Pfeiff. in Otto \& Dietr. Allo Gartenz. v. (1837) 370-Reg. Argent.

Philippi, Regel E Schmidt, Gartenfl. (1882) 98.Chili.

phoeniceus, Engelm. E Bigel. in Pacif. Rail. Rep. iv. 34. t. 4.-Am. bor. occ.

phyllanthoides, DC. Prod. iii. $469=$ Phyllocactus phyllanthoides.

Phllyanthus, DC. 1. c. = Phyllocactus Phyllanthus.

Pitajaya, DC. 1. c. $466=$ variabilis

platycarpus, Zucc. ex Foerst. Handb. Cact. ed. I. 452 - Rhipsalis platycarpa.

platygonus, Hort. Berol. ex Salm-Dyck, Cact. Hort. Dyck. ed. II. 199.-Hab. ?

polyacanthus, Engelm. in A. Gray, Pl. Fendl. 51.Texas.

polyachaetus, Reichb. in Tersch. Suppl. Cact. Verz. 4. -Hab.?

polygonatus, Hort. ex Pfeiff. Enum. Diagn. Cact. $91=$ eburneus.

polygonus, $D C$. Prod. iii. 466.-Ins. S. Doming.

polylophus, DC. in Mém. Mus. Par. xvii. (1828) 115. -Mexic.

polymorphus, G. Don, in Loud. Hort. Brit. 195.-Chili.

polymorphus, Hort. Monac. ex Foerst. Handb. Cact. ed. I. $472=$ articulatus.

polyptychus, Lem. Cact. Gen. Nov. et Sp. 56.Hab. ?

Pottsii, Salm-Dyck, Cact. Hort. Dyck. ed. II. $208=$ Greggii.

Princeps, Hort. Wuerzb. ex Pfeiff. Enum. Diagn. Cact. 108.-Am. bor. occ.

Pringlei, S. Wats. in Proc. Am. Acad.xx. (1885) 368. - Am. bor. occ.

prismaticus, Haw. ex Steud. Nom. ed. II. i. $335=$ pentagonus.

prismaticus, Salm-Dyck, in DC. Prod. iii. 469.-Am. austr.

prismatiformis, Hort. ex Pfeiff. Enum. Diagn. Cact $106=$ variabilis.

procumbens, Engelm. in A. Gray, Pl. Fendl. 50.Mexic

procumbens, A. Gray, in Bost. Fourn. Nat. Hist. vi. (1850) 203.-Texas.

propinquus, Salm-Dyck, ex Otto, in Otto \& Dietr. Allg. Gartenz. i. (1833) $366=$ pentalophus proteiformis, Steud. Nom. ed. II. i. 335.-Hab. ? pruinosus, Salm-Dyck, Cact. Hort. Dyck. ed. II. $47=$ Echinocactus pruinosus.

\section{CEREUS :-}

pterandrus, Hemsl. Biol. Centr. Am. Bot. i. 544, sphalm. = seg.

pteranthus, Link, ex Dietr. in Otto \& Dietr. Allg. Gartenz ii. (1834) $209=$ nycticalus.

pterocaulis, Hort. ex Pfeiff. Enum. Diagn. Cact. $140=$ Rhipsalis paradoxa.

pterogonus, Lem. Cact. Gen. Nov. et Sp. 59.-N. Granat.

pugioniferus, Lem. Cact. Aliq. Nov, Desc. $30=$ geometrizans, Gladiator.

pulchellus, Pfeiff. Enum. Diagn. Cact. 74-Mexic.

pycnacanthus, Salm-Dyck, in Otto \& Dietr. Allg. Gartenz. xiii. (1845) 355.-Bolivia

quadrangularis, Haw. Syn. Pl. Succ. 181 = caripensis.

quadrangularis, Hort. ex Pfeiff. Enum. Diagn. Cact. $106=$ variabilis

quadrangulispinus, Lem. ex Ehrenb. in Linnaea, xix. (1847) 363 .-Mexic.

quadricostatus, Bello, in Anal. Soc. Esp. Hist. Nat. x. (1881) 276. - Porto Rico.

Quintero, Hort. Gotting. ex Pfeiff. Enum. Diagn. Cact. $86=$ chilensis

Quisco, C. Gay, Fl. Chil. iii. 19-Chili.

radicans, $D C$. Prod. iii. 468.-Am. austr.

ramosus, Karw. in Pfeiff. Enum. Diagn. Cact. $108=$ baxaniensis.

ramulosus, Salm-Dyck, Hort. Dyck. $340=$ Rhipsalis ramulosa.

recurvus, Link \& Otto, ex Stend. Nom, ed. II. i. $335=$ Echinocactus recurvus.

reductus, DC. Prod. iii. $463=$ Echinocactus gibbosus reflexus, Hort. ex Stend. Nom. ed. II. i. $335=$ virens. regalis, Haw. ex Spreng. Syst. ii. 496-Am. austr.

Reichenbachianus, Labour. Monog. Cact. $318=$ caespitosus.

repandus, Haw. Syn. P1. Succ. $183=$ gracilis.

repandus, Mill. Gard. Dict. ed. VIII. n. 5.-Ind. occ

reptans, Haw. ex Steud. Nom. ed. II. i. $385=$ pentagonus.

reptans, Salm-Dyck, ex DC. Prod. iii. $468=$ radicans.

resupinatus, Salm-Dyck, in Otto E Dietr. Allg. Gartenz. viii. (1840) 10.-Hab. ?

retroflexus, Hort. ex Pfeiff. in Otto \& Dietr. 1. c. iii. (1835) $380=$ virens.

rhombeus, Salm-Dyck, Hort. Dyck. $341=$ Rhipsalis rhombea.

rigidispinus, Lem. Hort. Univ. (1840) 223. t. 1.Mexic.

rigidispinus, Muehlenp. in Otto E Dietr. Allg. Gartenz. xvi. (1848) 12.--Mexic.

rigidus, Lem. ex Salm-Dyck, Cat. Hort. Dyck. ed. I 34 ; ed. II. $52=$ humilis.

Roemeri, Engelm. in A. Gray, Pl. Fendl. 50.Texas.

Roemeri, Muehlenp. in Otto E Dietr. Allg. Gartenz. xvi. (1848) 19.-Hab.?

Roetteri, Engelm. Cact. Mex. Bound. 33. t. 41. f. 3-5. -Am. bor occ

roridus, Hort. Berol. ex Pfeiff. Enum. Diagn. Cact. 54. $=$ Echinocactus pruinosus.

rosaceus, Hort. ex Pfeiff. 1. c. 114=nycticalus.

rostratus, Lem. Cact. Aliq. Nov. Desc. 29.-Ins. Antigua.

Royeni, Haw. Syn. Pl. Succ. $182=$ lanuginosus.

Royeni, Hook. Bot. Mag. t. $3125=$ Curtisi.

Royeni, Mill. Gard. Dict. ed. VIII. n. 7.-Am austr.

rufispinus, Engelm. in A. Gray, Pl. Fendl. 50.-N. Mexic.

Russelianus, Forb. Hort. Tour Germ. 154, nomen.Guiana.

Russellianus, Gardn. ex Hook. Bot. Mag. t. $3717=$ Epiphyllum Russellianum.

Russellianus, Hort. Berol. ex Salm-Dyck, Cact. Hort. Dyck.ed. II. 201.-Laguayra.

Salm-Dyckianus, Hemsl. Biol. Centr. Am. Bot. i. 545. -Mexic.

Salm-Dyckianus, Hort. Vindob. ex Salm-Dyck, Cact. Hort. Dyck. ed. I. 31 ; ed, II. $49=$ variabilis. scandens, Salm-Dyck, $l$. c. ed. II. 219.-Guiana.

Scheerii, Salm-Dyck, l. c. 190_-Mexic

Schelhasii, Pfeiff. in Otto \& Dietr. Allg. Gartenz. iii. (1835) 314.- Hab.

Schomburgkii, Hort. Berol. ex Salm-Dyck, Cact. Hort. Dyck. ed. II. 219,-Guiana?

\section{CEREUS :-}

Schottii, Engelm. in Proc. Am. Acad. iii. (1857) 288. -Am. bor. occ.

Schrankii, Zucc. ex Pfeiff. Enum. Diagn. Cact. 122.Mexic.

Scopa, Salm-Dyck, ex DC. Prod. iii. $464=$ Echino cactus Scopa.

Siedelii, Lehm. ex Salm-Dyck, Cact. Hort. Dyck. ed. II. 200.- Hab.?

senilis, Salm-Dyck, in DC. Prod. iii. 464.-Am. austr.

sepium, $D C$. l. $c .467$.-Ecuador.

sericeus, Hort. ex Pfeiff. Enum. Diagn. Cact. $173=$ Opuntia clavarioides

serpens, DC. Prod. ili. 470.-Ecuador.

serpentinus, $D C$. l. c. 467.-Mexic.

serruliflorus, Haw. in Phil. Mag. (1830) 109.-Ind,

setaceus, Salm-Dyck, in DC. Prod. iii. 469.-Bras.

setiger, Haw. in Phil. Mag. (1830) 109.-Bras.

similis, Meinsh. in C. Koch \& Fint. Wochenschr. i (1858) 29.-Mexic.

Smithianus $\times$, Sweet, Hort. Brit, ed. II. 237, nomen =seq. ?

Smithii $\times$, Hort. Angl. ex Pfeiff. Enum. Diagn. Cact. 111.

Spachianus, Lem. Hort. Univ. i. 225.-Mexic.

speciosissimus, DC. Prod. iii. 468.-Mexic

speciosus, Sweet, Hort. Brit. ed. I. 172 =variabilis ?

spinibarbis, Hort. Berol. ex Pfeiff. Enum. Diagn. Cact. 86.-Chili.

spinosissimus, C. F. Foerst. in Hamb. Gartenz. xvii (1861) 165.-Peruv.

spinulosus, DC. in Mém. Mus. Par. xvii. (1828) 117. - Mexic.

splendens, Hort. Angl. ex Salm-Dyck, Cact. Hort. Dyck. ed. II. 214.-Hab.?

splendidus, Paxt. ex Steud. Nom.ed.II. i. 336 (=Epi phylli sp. ?).--Mexic.

squamulosus, Salm-Dyck, in DC. Prod. iii. $469=$ Rhi psalis Mittleri.

stellatus, Pfeiff. in Otto \& Dietr. Allg. Gartenz. iv. (1836) 258.-Mexic.

stramineus, Engelm. Cact. Mex. Bound. 35. t. 46.Texas.

strictus, $D C$. Prod. iii. 465.-Am. austr.

strigosus, Salm-Dyck, Hort. Dyck. 334.-Chili.

subinermis, Hemsl. Biol. Centr. Am. Bot. i. 546.Mexic.

sublanatus, Salm-Dyck, Hort. Dyck. 337.-Hab.?

subrepandus, Haw. Suppl. Pl. Succ. 78.--Ind. occ subrepandus, Hort. ex Pfeiff. Enum. Diagn. Cact. 86, $94=$ chilensis, eriophorus.

subsquamatus, Pfeiff. in Otto \& Dietr. Allg. Gartenz. iii. (1835) $380=$ extensus.

subtortuosus, Hort. ex Foerst. Handb. Cact. ed. I. 409 $=$ colubrinus

subuliferus, Salm-Dyck, in Otto $\xi$ Dietr. Allg. Gartenz, xiii. (1845) 354,-Mexic.

superbus, Ehrenb. in Bot. Zeit. iv. (1846) 324.Mexic.

Swartzii, Griseb. Fl. Brit. W. Ind. 301.-Ind. occ.

syringacanthus, Pfeiff. Enum. Diagn. Cact. 103.Chili.

tenellus, Salm-Dyck, ex Pfeiff. l. c. 109.-Bras.

tenuis, DC. Prod, iii. $469=$ Rhipsalis Myosurus.

tenuis, Pfeiff. in Otto E Dietr. Allg. Gartenz. viii 1840) 407.-Am. austr.

tenuispinus, Haw. in Phil. Mag. (1827) $125=$ Rhi psalis Myosurus.

tenuissimus, G. Don, in Sweet, Hort. Brit. ed. III 285 , nomen.-Hab.

tephracanthus, Link \& Otto, ex Steud. Nom. ed. II. i. 336.-Am. austr.

Terscheckii, Parm. ex Pfeiff. in Otto E Dietr. Allg. Gartenz. v. (1837) 370.-Reg. Argent.

tetracanthus, Labour. in Rev. Hortic. Sér. IV. iv, (1855) 25.-Bolivia.

tetragonus, Mill. Gard. Dict. ed. VIII. n. 2; Haw. Syn. Pl. Succ. 180.-Am. austr.

thalassinus, Otto E' Dietr. Allg. Gartenz. vi. (1838) 34. -Venezuela.

Thurberi, Engelm. in Am. Fourn. Sc. Ser. II. xvii. (1854) 234.-N. Mexic.

tilophorus, Pfeiff. in Otto \& Dietr. Allg. Gartenz. iii, (1835) $380=$ virens

Tinei, Todaro, Ind. Sem. Hort. Panorm. (1857) 39. -Cf. in Linnaea, xxix. (1857-58) 739.-Bras.? 


\section{CEREUS}

Tonelianus, Lem. Illustr. Hortic, ii. (1855) Misc, 63.Mexic.

tortuosus, Forbes, ex Otto Eั Dietr. Allg. Gartenz. vi (1838) 35.-Reg. Argent.

triangularis, Haw. Syn. Pl. Succ. $180=$ compressus. triangularis, Mill. Gard. Dict. ed. VIII. n. 9.-Hab. ? trichacanthus, Hort. Berol. ex Salm-Dyck, Cact. Hort Dyck. ed. II. $46=$ lutescens.

triglochidiatus, Engelm. in A. Gray, Pl. Fendl. 51.N. Mexic.

trigonus, Haw. Syn, Pl. Succ. 181.-Ind, occ

trigonus, Hort. ex Pfeiff. Enum. Diagn. Cact, $106=$ variabilis.

trinitatensis, Lem. E Herm. in Rev. Hortic. Sér. IV. viii. (1859) 642.- Ind, oec

tripteris, Salm-Dyck, in DC. Prod. iii. 468.-Am austr.

triqueter, Haw. Syn.Pl. Succ. 181.-Am, austr truncatus, Sweet, Hort. Brit. ed. I. $172=$ Epiphyllum Altensteinii.

tuberosus, Pfeiff. Enum. Diagn. Cact. 102.-Mexic.

tuberosns, Poselg. in Otto $F$ Dietr. Allg. Gartenz.xxi. (1853) 135. - Texas.

tubiflorus, Endl. in Harting. Parad. Vindob. t. 71 $(=$ Echinopsis Zuccarini).-Hab.

tubiflorus, Pfeiff. Enum. Diagn. Cact. $71=$ Echinocactus tubiflorus.

tunicatus, Pfeiff. 1. c. 173 in syn $=$ Opuntia tunicata. turbinatus, Pfeiff. in Otto E Dietr. Allg. Gartenz. ii (1835) 314.-Hab. ?

Tweediei, Hook. Bot. Mag. t. 4498.-Reg. Argent.

undatus, Haw in Phil. Mag. (1830) $110=$ Napoleonis.

undatus, Hort. Berol. ex Pfeiff. Enum. Diagn. Cact. 94.- Hab.

undiflorus, Wright, in Sauv. Fl. Cub. 59-Cuba.

undulatus, Hort. Berol. ex D. Dietr. Syn. Pl, iii. 104 $=$ undatus.

undulatus, Hort. Dresd. ex Pfeiff. Enum. Diagn. Cact. $107=$ acutangulus.

undulosus, DC. Prod. iii. $467=$ variabilis

ureacanthus, C. F. Foerst, in Hamb. Gartenz. xvii. 1861) 166.-Peruy.

validus, Haw. in Phil. Mag. x. (1831) 414.-Am. austr.

variabilis, Engelm. Cact. Mex. Bound, $40=$ Princeps.

variabilis, Pfeiff. Enum. Diagn. Cact. 105.-Am. austr.

Vasmerii, Young, Fl. Texas, $276=$ Princeps

violaceus, Lem. Cact. Gen. Nov, et Sp. 57.-Hab. ?

virens, DC. in Mém. Mus. Par. xvii. (1828) 116.Mexico.

viridiflorus, Engelm. in A. Gray, Pl. Fendl. 50.Texas.

xanthochaetus, Reichb. in Tersch. Suppl. Cact. Verz. 4.-Hab. ?

CERINTHE, [Tourn.] Linn. Syst. ed. I. (1\%35). $B O R A G I N E A E$, Benth. \& Hook. f. ii. 864.

Ceranthe, Opiz, Seznam, 27 (1852).

acuta, Moench, Meth. $520=$ major

alpina, Kit. ex Schult. Oestr. Fl. ed. II, i. 353.Europ.; As. Min.

alpina, Vis. Fl. Dalmat. Suppl. (1872) 94 ; fide Nym. Consp. $513=$ longiflora.

aperta, [Clairv.] Man. Herb. $53=$ major.

aspera, Roth, Catalect. i, $33=$ major:

atropurpurea, Vis. ex A. DC in DC. Prod. viii. $4=$ retorta.

auriculata, Tenore, Ind. Sem. Hort. Neap. (1830) 10 $=$ minor.

cilicica, Kotschy, ex Boiss. P1. Or. Nov. dec ii. $7=$ minor.

cleiostoma, Boiss. \& Sprun. Diagn. Ser. I. iv. $44=$ minor.

connivens, [Clairv.] Man. Herb. $54=$ minor.

echioides. Linn. Sp. Pl. 187 = Onosma echioides

glabra, Mill. Gard. Dict. ed. VIII. n. 2; DC. Fl. Fr

ii. $619=$ alpina

glabra, Scop. ex Nym. Consp. $513=$ minor.

glaucs, Moench, Meth. $520=$ major.

gymnandra. Gasp. in Rendic. Acc. Sc. Nap. i. (1त63) $72=$ major.

birsuta, Wettstein, ex Stapf, in Denkschr. Acad. Wien,

1. (1885) 85.-Lycia.

longiflora, Viv. App. Alt. ad Fl. Cors. (1830) 3.Italia.

\section{CERINTHE :-}

lurida, Salisb. Prod, $116=$ minor

macrophylla, Boiss, ex Boiss. PI. Or. Nov. dec. ii. 7. $=$ minor

maculata, All. F1. Pedem. i. $178=$ alpina

maculata, Linn. Sp. Pl. $137=$ minor.

major, Linn. l. c. 136.-Europ.; As. Min.

minor, Linn. l. c. 137.-Europ, As, Min. : Persia

orientalis, Linn. Cent. i. $7=$ Onosma orientalis.

pseudo aspera, Schur, Enum. PI. Transs. $470=$ minor

purpurea, Vis. in Flora, xii. (1829) Erg. $8=$ retorta.

quinquemaculata, Wahlenb. Fl. Carpat. 51=alpina.

retorta, Sibth. E Sm. Fl. Graec, ii. 60. 171

Graecia.

Smithiae, Kern. ex Nym. Consp. $513=$ longiflora

strigosa, Reichb. F1. Germ. Excurs. $340=$ major.

suevica, Martens, Reise Vened. i. 44 ; ex Reichb. Ic

Crit. v. 40, t. $658=$ alpina

tenuiflora, Bertol. Fl. Ital. ii. $325=$ longiflor

versicolor, Hall. ex Stend. Nom. ed. II. i. i. $336=$ major.

CERINTHOPSIS, Kotschy, ex Benth. \& Hook. f. Gen ii. $849(1876)=$ Solenanthus, Ledeb. (Boragin.) kurdica, Kotschy, ex Boiss. Fl. Orient. iv. $271=\$$ cerinthioides.

CERIONANTHUS, Schott, ex Roem. \& Schult. Syst. iii. $43(1818)=$ Cephalaria, Schrad, (Dipsac.) alpinus, Schott, ex Roem. \& Schult. 1. c. =Ceph.alpina corniculatus, Schott, ex Roem. \& Schult. 1. c, $49=$ Ceph. corniculata.

cretaceus, Schott, ex Roem. \& Schult. 1. c. $51=$ Ceph cornicuiata.

laevigatus, Schott, ex Roem. \& Schult. 1. c. $49=$ Ceph corniculata.

leucanthus, Schott, ex Roem. \& Schult. 1. c. $47=$ Cepl. leucantha.

syriacus, Schott, ex Roem. \& Schult. 1. c. $46=$ Ceph. syriaca.

tataricus, Schott, ex Roem. \& Schult. 1. c. $51=\mathrm{Ceph}$ tatarica.

Vaillantii, Schott, ex Roem. \& Schult. 1. c. $46=$ Ceph. syriaca.

CERIOPS, Arn. in Ann. Nat. Hist. i. (1838) 363. RHIZOPHOREAE, Benth. \& Hook. f. i. 679.

Boviniana, Tul. in Ann. Sc. Nat. Sér. IV. vi. (1856 112. - Madag.

Candolleana, Arn in Ann. Nat. Hist. i. (1838) 364.Reg. trop.

Candolleana, Naves, in Blanco, Fl. Filip. ed. III. t. 415 Roxburghiana.

Forsteniana, Blume, Mus. Bot.Lugd. Bat. i. 143.-Ins Moluce.

globulifera, Bor, ex Tul, in Ann. Sc. Nat. Sér. IV. vi (1856) $112=$ Boviniana

lucida, Miq. Fl. Ind. Bat. Suppl. i. 325.-Malaya mossambicensis, Klotzsch, in Peters, Reise Mossamb. Bot. i. $71=$ Candolleana.

pauciflora, Benth. in Hook. Lond. Fourn. Bot. il. (1843) 218.-Polynes.

Roxburghiana, Arn. in Ann. Nat. Hist. i. (1838:36. -Reg. trop.

Zippeliana, Blume, Mus. Bot. Lugd. Bat. i. 143.-N Guinea.

CERISCUS, Gaertn. Fruct, i. t. $28(1788)=$ Randia Linn. (Rubiac.).

malabaricus, Gaertn.1. $\mathrm{c}_{\circ}=\mathrm{R}$. dumetorum.

CERISCUS, Nees, in Flora, viii. (1825) 116 - Tarenna, Gaertn. (Rubiac.)

fragrans, Nees, 1. c. (=Webera fragrans) -Ind. or. ; Malaya.

CERIUM, Lour, FI. Cochinch, 135. INC. SED spicatum, Lour. b. c. 136.-China.

CEROCARPUS, Hassk. in Flora, xxv. (15\$2) Beibl, ii. 36 - Eugenia, Linn. (Myrtac.).

aquens, Hassk. 1. c. $=$ E. aquen.

bifaria, Colebr, in Wall. Cat. n. $\$ 606=\mathrm{E}$. Wallichii.

CEROCHILUS, Lindl. in Gard. Chron. (1854) 87 Hetreria, Blume (Orchid, ?

rubens, Lind1. $\mathrm{l}_{\mathrm{c}} \mathrm{c}_{\mathrm{s}}=\mathrm{H}$, rubens.
CEROPEGIA Linn. Gen. ed. I. $65(1737)$, ASCLE

PIADEAE, Benth. \& Hook. f. ii. 779.

APEGIA, Neck. Elem. i. 251 (1790).

Nrota, Adans. Fam. ii. 172 (1763)

SYSTEPHA, Burch. Trav. i. 546 (1822)

abyssinica, Decne. in DC. Prod. viii. 644.-Abyss,

acuminata, Dalz. \& Gibs. Romb. Fl. 117 = tuberosa

acuminata, Roxb. Pl. Corom i. 12, t. 8.-Ind, or.

affinis, Vatke, in Linnaea, xl. (1876) 218.-Abyss.

africana, $R_{0} B r$. in Bot. Reg. t. 626.-Afr. austr.

albiflora, Hook. f. Fl. Brit. Ind. iv. 75.-Ind. or

ampliata, E. Mey. Comm. Pl. Afr. Austr. 194.-Afr

austr.

angustifolia, Dalz. in Hook. Kew Journ. ii. (1850, 259 attenuata.

angustifolia, Vahl, ex Decne. in DC. Prod, viii. $503=$

Secamone saligna.

angustifolia, Wight, Contrib. 31.-Reg. Himal.

aphylla, Haw. Syn. Pl. Succ. $13=$ dichotoma.

arcta, Nimmo, in F. Grah. Cat. Bomb. Pl. 118, nomen. -Ind. or.

aristolochioides, Decne. in Ann. Sc. Nat. Sér. II. ix (1838) 263.-Afr. trop.

Amottiana, Wight, Contrib. 32.-Ind. or.; Burma.

attenuata, Hook. IC. Pl. t. 867.--Ind, or.; Burma.

australis, Lodd. Cat. ex Loud. Hort. Brit. 95, nomen. - Austral.

Barklyi, Hook.f. Bot. Mag. t. 6315.-Afr. austr.

Beudomei, Hook. f. Fl. Brit. Ind. iv. 75. -Ind. or

biflora, Linn. Sp. Pl. 211.-Zeylan.

Bowkeri, Harv. in Proc. Dubl. Zool. E Bot. Assoc.

(1859) 254. - Afr. austr.

brevicollis, Hook.f. Fl. Brit. Ind. iv. 74.-Ind. or

brevitubulata, Bedd. Ic. Pl. Ind. Or. i. $38=$ Brachy stelma Beddomei.

bulbosa, Roxb. Pl. Corom. i. 11. t. 7.-Ind. or.

campanulata, G. Don, Gen. Syst. iv. 112.-Air. trop.

candelabriformis, St. Lag. in Ann. Soc. Bot. Lyon, vii, 1880) $122=\mathrm{C}$. Candelabrum.

Candelabrum, Heyne, ex Decne, in DC. Prod. viii. $643=$ bulbosa

Candelabrum, Linn.Sp. Pl.211.-Ind. or.

Candelabrum, Lour. Fl. Cochinch. $114=$ Loureiri

Candelabrum, Roxb. Hort. Beng.21; Fl. Ind, if. $27=$ tuberosa.

Candelabrum, Thw. Enum. P1. Zeyl. 199=intermedia.

carnosa, E. Mey. Comm. Pl. Afr. Austr. 193.-Afr. austr.

ciliata, Wight, Ic. t. 1262,-Ind, or.

convolvnloides, $A$. Rich. Tent. Fl. Abyss. ii 4 t'

Abyssin.

cordata, Lour. Fl. Cochinch. 114.-Cochinch

Cumingiana, Decne in DC. Prod. viii. 648.-Ins Philipp.

curviflora, Hassk. in Flora, xl. (1857) 102.-Java.

Decaisneana, Wight, Ic. t. 1259.-Ind. or.

Decaisneana, Miq. ex Hook. f. Fl. Brit. Ind. iv. 42 Tylophora tenuis.

dichotoma, Haw. Syn. Pl. Succ. 13.-Ind. or.

edulis, Hort. ex Decne. in DC. Prod. riii. $649=$ bulbosa.

elegans, Wall. in Bot. Mag. t. 3015.-Ind, or.

Elliottii, Hook. f. F\%. Brit. Ind. iv. 70.-Ind. or.

cnsifolia, Bedd. in Madr. Fourn. Sc. Ser. III. i. $180^{\circ}$ 52.--Ind. or.

esculenta, Edgew, in Journ. Linn. Soc. vi. (1S62) $204=$ bulbosa.

fimbriata, E. Mey. Conm. Pl. Afr. Austr. 194.-Afr. austr.

fimbrifera, Bedd. in Madr. Gourn. Sc. Ser. III. (1564) 53.-Ind. or.

fusca, C. Bolle, in Bonplandia, ix. 1961) 51.-I. Canar.

Gardneri, Hook. Bot. Mag. t. 5306 ; Tks. Ensum. Pl Zeyl. 199.-Zeylan.

gracilis, Bedd. in Madr. Gourn. Se. Ser. III. L iscit 53.-Ind. or.

hirsuta. Hoibst. ex Deune. in DC. I'rod. viii. btt abysinica.

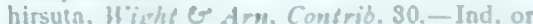

Houkeri, C. B. Clarke, es Hook. f. B\%. Brit. Ind. iv. is.

- Reg. Ilimal.

Horsficldinna, Mig. Fl. Ind. Bas. i. 52s.-Java.

infunclibuliformis, E. Mry. Comm. Pl. Afr. Austr. 101

- Mir. austr.

internedia, II'ight, /6. 1. 1268. -Ind. or. 


\section{CEROPEGIA :-}

Facquemontiana, Decne. in DC. Prod. viii. $641=$ hirsuta?

juncea, Roxb. Pl. Corom. i. 12,-Ind. or

lanceolata, Wight \& Arn. Contrib. $31=$ longifolia.

Lawii, Hook. f. Fl. Brit. Ind. iv. 67.-Ind. or.

linearis, E. Mey. Comm. Pl. Afr. Austr. 194.-Afr. austr longiflora, Poir. Encyc. ii. $177=$ bulbosa.

longifolia, Hook. f. \& Thoms. in FI. Brit. Ind. iv. $72=$ angustifolia.

longifolia, Wall. Pl. As. Rar, i. 56. t. 73.-Reg. Himal.

Loureirii, G. Don, Gen. Syst. iv. 112.-Cochinch.

lucida, Wall. Pl. As. Rar. ii. 33. t. 139.-Reg. Himal.; Burma.

Lushii, R. Grah. in Bot. Mag. t. $3300=$ bulbosa macrantha, Wight, Contrib. 31.-Reg. Himal

maculata, Bedd. in Madr. Fourn. Sc. Ser. III. i (1864) 52.-Ind. or.

madagascariensis, Decne - in DC.Prod. viii. 642.-Madag.

Metziana, Miq. Anal. Bot. Ind. iil. 11.-Ind. or.

Meyeri, Decne in DC. Prod. viii. 645.-Afr. austr

micans, Nimmo, in 7. Grah. Cat. Bomb. Pl. 118 nomen.-Ind, or.

mucronata, Roth, Nov. Pl. Sp. $179=$ tuberosa.

multiflora, Baker, in Saund. Refug. Bot. t. 10.-Afr. austr.

Munroi, Wight, Ic. t. $1254=$ fimbriifera?

mysorensis, Wight, l.c.t. 846.-Ind. or.

nilotica, Kotschy, in Sitzb. Acad. Wien. Math. Nat. li. (1865) 356.-Afr. trop.

nitida, Poir. Encyc. Suppl. ii. 178.-Ins. S. Doming.

obtusa, Lour. Cochinch 114.-Cochinch.

obtusiloba, Fawc. in Forbes, Nat. Wand. in East. Archip. 511.-Ins. Timor.

oculata, Hook. Bot. Mag, t. 4093.-Ind. or

odorata, Nimmo, in F. Grah. Cat. Bomb. Pl. 118.Ind, or.

ophiocephala, Dalz. in Hook. Kew Journ. ii. (1850) $259=$ hirsuta

palustris, Pursh, Fl. Am. Sept. i. 184=Vincetoxicum

palustre.
peltata, Regel, Cat. Pl. Hort. Aksakov. 31.-Hab.?

parasitica, Noronha, in Verh. Batav. Gen. v. (1790) ed. I. Art. IV. 12.-Malaya.

pubescens, E. Mey. Comm. Pl. Afr. Austr. 193.-Afr. austr.

pubescens, Wall. Pl. As. Rar. ii. 81, t. 187.--Reg. Himal.

pusilla, Wight ${ }^{\circ}$ Arn. in Wight, Contrib. 31.Ind. or.

ringens, A. Rich. Tent. Fl. Abyss. ii. 48.-Abyssin.

sagittata, Linn. Mant. $215=$ Microloma sagittatum.

Sandersoni, Decne. ex Hook. Bot. Mag. t. 5792.Natal.

sinuata, Decne.ex A. Rich. Tent. Fl. Abyss. ii. 47.Abysin.

sinuata, Poir. Encyc. Suppl. ii. $179=$ Microloma lineare.

Sororia, Harv. in Hook. Bot. Mag. t. 5578.-Afr. austr. sphenanantha, Wight \& Arn, in Wight, Contrib. $31=$ elegans.

sphenanthera, Decne. in DC. Prod. viii. $643=$ praec.

spiralis, Hook. f. \& Thoms. in Fl. Brit. Ind iv, $67=$

attenuata.

spiralis, Wight, Ic. t. 1267.--Ind. or.

squamulata, Decne. in Ann. Sc. Nat. Sér. II. ix. (1838) 263. t. 9.-Arabia.

stapeliaeformis, Haw. in Phil. Mag.(1827) 121.-Afr. austr.

stellata, Regel, Cat. Pl. Hort. Aksakov. 31-Hab?

Stephanotis, Poir. ex Decne. in DC. Prod. viii. $621=$ Stephanotis Isaura.

Stephanotis, Roem. \& Schult. Syst. vi. 4.-Madag.

Steudneri, Vatke, in Linnaea, xl. (1876) 217.Abysin.

Stocksii, Hook. f. Fl. Brit. Ind. iv, 74-Ind or tenuiflora, Willd. Sp. P1. i. $1276=$ Microloma lineare. tenuifolia, Linn. Mant. ii. $346=$ Microloma lineare.

Thwaitesii, Hook. Bot. Mag. t. 4758.-Zeylan.

torulosa, E. Mey. Comm. Pl. Afr. Austr. 194.-Afr. austr.

trichantha, Hemsl. in Fourn. Bot. xxiii. (1885) 286.China.

tuberosa, Roxb. Pl. Corom. i. 12. t. 9.-Ind. or.

tuberosa, Wall. Cat. $\mathrm{n} .8145 \mathrm{~A}=$ intermedia.

variegata, Decne. in Ann. Sc. Nat. Sér. II. ix. (1838)

\section{CEROPEGIA :}

Vignaldiana, A. Rich. Tent. Fl. Abyss. ii. 48.-Abyss. vincaefolia, Hook. Bot. Mag. t. $3740=$ hirsuta.

Walkeriae, Wight, Ic. t. 1266.-Zeylan.

Wallichii, Wight, Contrib. 32.-Reg. Himal

Wightii, R. Grah. in Bot. Mag. t. 3267.-Ind. or.

CEROPHORA, Rafin. Alsog. Am, 11 (1838)= Myrica, Tourn.

angustifolia, Rafin. 1. c. $=$ M. cerifera.

inodora, Rafin. 1. c. $=$ M. cerifera.

lanceolata, Rafin. 1. $\mathrm{c}_{\mathrm{v}}=\mathrm{M}$. cerifera

spicans, Rafin. 1. c. $12=$ M. cerifera.

CEROPHYLLUM, Spach, Hist. Vég. Phan. vi. 152 $(\mathbf{1 8 3 8})=$ Ribes, Limn. (Saxifrag.).

Douglasii, Spach, 1. c. $153=$ R. cereum.

inebrians, Spach, 1. c. $154=\mathrm{R}$. cereum.

CEROXYLON, Humb. \& Bonpl. Pl. Aequin. 1. t. 1, $1 \mathrm{~b}$ (1807). PALMAE, Benth. \& Hook. f. iii. 905.

BeEthovenia, Engelm. in Linnaea, xxxiii. (1864 65) 677.

Klopstockia, Karst. in Linnaea, xxviii. (1856) 251.

alpinum, Steud. Nom. ed. II, i. $337=$ seq.

a andicolym, Humb. E Bonpl. Pl. Aequin. 1. t. 1-N. Granat.

australe, Mart. Hist. Nat. Palm. iii. 314.-Juania australis.

coarctatum, H. Wendl. in Kerch. Palm. 238.-N. Granat.

ferrugineum, Regel, Gartenf. (1879) 163. t. 977.-N Granat.

interruptum, H. Wendl. in Bonplandia, viii. (1860) 70. -N. Granat

Klopstockia, Mart. Hist. Nat. Palm. iii. 314Venezuela.

niveum, Hort. Belg. ex H. Wendl. in Kerch. Palm. $239=$ Diplothemium caudescens.

parvifrons, $H$. Wendl. l. c.-N. Granat

pityrophyllum, Mart. ex H. Wendl. 1. c. $=$ Cocos pityrophylla.

quindiuense, $H$. Wendl. in Bonplandia, viii. (1860) 70.-N. Granat.

utile, $H$. Wendl. l. c.-N. Granat.

Vogelianum, H. Wendl. in Kerch. Palm. 239--N. Granat.

CERQUEIRIA, Berg, in Linnaea, xxvii. (1854) $5=$ Myrcia, DC. (Myrtac.)

Sellowiana, Berg, 1. c. 6.-Bras.

CERQUIERIA, Benth. \& Hook. f. Gen. i. 716 (1865) sphalm. = praec.

CERRARIA, Tausch, in Flora, xvii. (1834) I. 347, sphalm.=CERVARIA, Minuart = Peucedanum, Linn. (Umbellif.)

CERRIS, Rafin. Alsog. Am. 29 (1838)=Quercus, Linn.

australis, Rafin. 1. c. $=$ Q. Cerris.

austriaca, Rafin. 1. c. $=$ Q. Cerris.

crinita, Rafin. l. c. $=$ Q. Cerris

dulcis, Rafin. 1, c-Am, bor.

macrocarpa, Rafin. 1. c. = Q. macrocarpa.

microphyla, Rafin. 1. c. =Q. microphylla.

oliveformis, Rafin. 1. c. =Q. macrocarpa.

paliphleos, Rafin. 1. c.-Am. bor.

salicifolia, Rafin. 1. c. $=$ Q. salicifolia.

CERUANA, Forsk. Fl. Aegypt. Arab. 153 (1775). COMPOSITAE, Benth. \& Hook. f. i. 261.

fruticos $\alpha$, Less. Syn. Comp. $202=$ pratensis.

montana, Aucher, ex DC. Prod. vii. $287=$ Chrysophthalmum sternutatorium.

pratensis, Forsk. Fl. Aegypt. Arab. p. lxxiv.Aegypt.

rotundifolia, Cass. in Dict. Sc. Nat. xli. $123=$ pratensis.

Schimperi, Boiss. Diagn. Ser. I. xi. $4=$ Asteriscus Schimperi.

senegalensis, DC. Prod. v. 488.-Afr. trop.

CERUCHIS, Gaertn. ex Schreb. Gen. 543 (1791) = Spilanthes, Jacq.-(Compos.).
CERVANTESIA, Ruiz \& Pav. Prod. 39. t. 7 (1794). SANTALACEAE, Benth. \& Hook. f. iii. 222.

bicolor, Cav. Ic. 49. t. 475.-Peruv.

Kunthiana, Baill. Adansonia, ii. (1861-62) 373. t. 11.--Peruv.

tomentosa, A. DC. Prod. xiv. $692=$ bicolor

tomentosa, H. B. \& K. Nov. Gen. et Sp. vii. $139=$ Kunthiana.

tomentosa, Ruiz E Pav. Prod. Fl. Per. iii. 20. t. 7.Peruv.

CERVARIA, Minuart, ex Linn. Diss. Dass. 31 (1747) (Amoen. Acad. i. 142); Gaertn. Fruct. i. 90.t. $21=$ Peucedanum, Linn. (Umbellif.).

alsatica, Gaud. F1. Helv. ii. $327=$ P. alsaticum. angustifolia, Andrz. ex Trautv, in Act. Hort. Petrop. viii. (1883) $395=\mathrm{P}$. angustifolium ?

glauca, Gaud. Fl. Helv. ii. $326=$ P. Cervaria.

laevis, Gaud. 1. c. 327 , in obs. $=$ P. Cervaria?

latifolia, Andrz. ex Trautv. in Act. Hort. Petrop. viii. (1883) $395=$ P. latifolium.

nigra, Bernh. Syst. Verz. Erf. $171=$ P. Cervaria .

Oreoselinum, Gaud. Fl. Helv. ii. $324=\mathrm{P}$. Oreoselinum, rigida, Moench, Meth. $95=\mathrm{P}$. Cervaria

Rivini, Gaertn. Fruct. 91. t. $21=$ P. Cervaria.

CERVIA, Rodrig. ex Lag. Gen. et Sp. Nov. 7 (1816). CONVOLVULACEAE? (Cf. Benth. \& Hook. f. ii. 868 ).

saturejaefolia, Rodrig. ex Lag. l. c. - Hispan.

CERVICINA, Delile, Fl. Egypte,150 (1813) = Wahlenbergia, Schrad. (Campanulac.).

campanuloides, Delile, 1. c. t. 5.f. $2=$ W. Cervicina

tomentosa, Perr. ex Steud. Nom. ed. II. i. 337 ; ii. 740 $=$ Vahlia tomentosa.

CERVISPINA, [Dill.] Moench, Meth. 686 (1794)= Rhamnus, Tourn.

cathartica, Moench, I. c. $=$ R. cathartica.

infectoria, Fourr. in Ann. Soc. Linn. Lyon, N. S. xvi. (1868) $356=\mathrm{R}$. infectoria.

saxatilis, Fourr, $\mathrm{l}_{\mathrm{o}} \mathrm{c}_{\mathrm{o}}=\mathrm{R}$. saxatilis.

Villarsii, Fourr. I. $\mathrm{c}_{\mathrm{n}}=\mathrm{R}$. infectoria.

CESATIA, Endl. in Ann. Wien. Mus. ii. (1838) $200=$ Trachymene, Rudge (Umbellif.).

ornata, Endl. 1. c. $=$ T. eriocarpa

ovata, Steud. Nom, ed. II. i. 337, sphalm, = praec.

CESPEDESIA, Goudot, in Ann. Sc. Nat. Sér. III. ii. (1844) 368. OCHNACEAE, Benth. \& Hook. f. i. 320

Bomplandi, Goudot, l. c. 370.-N. Granat.

macrophylla, Seem. Bot. Voy. Herald, 97.-Panama

spathulata, Planch. in Hook. Lond. Fourn. Bot.' v. (1846) 647.-Peruv.

CESTICHIS, Thou. Orch. Afr. t. 90 (1822)=Liparis, Rich. (Orchid.).

CESTRINUS, Cass. in Dict. Sc. Nat. viii. $24(1817)=$ Centaurea, Linn. (Compos.).

carthamoides, Cass. 1. c. $=$ Cent. Chamaerhaponticum.

CESTRON, St. Lag. in Ann. Soc. Bot. Lyon, vii. (1880) $122=$ seq.

CESTRUM, Linn. Hort. Cliff. 491 (1737); Coroll. Gen. 3 (1737). SOLANACEAE, Benth. \& Hook. f. ii. 904 .

Habrothamnus, Endl. Gen. 667 (1836).

Lomeria, Rafin. Sylva Teliur. 56 (1838).

MEvenia, Schlecht, in Linnaea, viii. (1833) 251.

PARqui, Adans. Fam. ii. 219 (1763).

WadeA, Rafin. Sylva Tellur. 56 (1838).

acuminatissimum, Dun. in DC. Prod. xiii. 1. 627.Gniana.

acuminatum, Sweet, Hort. Brit. ed. II. 388.-Mexic.

affine, $H . B$. \& $K$. Nov. Gen. et Sp. iii. 60.-Ecuador.

affine, Pers. Syn. i. $230=$ auriculatum.

alaternoides, Desf. Tabl. ed. I. 70.-Ind. occ.

albo-punctatum, Dun. in DC. Prod. xiii. I. 635.Peruv.

album, Ferrero, ex Dun. l. c. 605.-Cuba.

Amelanchier, Dun. l. c. 662.-Hab.?

amictum, Schlecht. in Linnaea, vii. (1832) 64.-Bras. amygdalifolium, Dun. in DC. Prod. xiii. I. 653.Mexic. 


\section{CESTRUM :}

anagyridium, St. Lag, in Ann. Soc. Bot. Lyon, vii (1880) $122=\mathrm{seq}$

Anagyris, Dun. in DC. Prod, xiii. I. 608.-Mexic. angustifolium, Lodd. Bot. Cab. t. 618.-Ind. occ. aronioideum, St. Lag. in Ann. Soc. Bot. Lyon, vii. (1880) $122=$ C. Amelanchier.

arvense, Vell. Fl. Flum, 101 ; iii. t. 7.-Bras.

atrovirens, Dun. in DC. Prod. xiii, 1, 648=Sessea atrovirens.

aurantiacum, Lindl. Bot. Reg. (1844) Misc. 71.Guatimal.

aurantiacum, Mey. ex Steud. Nom. ed. II. i. 337= Freylinia cestroides.

auriculatum, L'Hérit. Stirp. Nov。 71. t. 35.-Am. austr.

auriculatum, Ruiz \& Pav. F1. Per. ii. 28. t. 155 f. $a=$ hediundinum.

axillare, Vell. Fl. Flum. 101 ; iii. t. $6=$ laevigatum.

Bella-Sombra, Dun. in DC. Prod. xiii. 1. 632.-Ins. Canar.

Benthami, Miers, in Hook. Lond. Fourn. Bot. v (1846) 151.-Mexic.

Billbergianum, Beurling, in Vet.Acad. Handl. (1854) 140.-Panama

bogotense, Willd. ex Roem. \& Schult. Syst. iv. $807=$ mariquitense.

bonariense, Dun. in DC. Prod. xiii. 1. 666.-Reg Argent.

bracteatum, $\operatorname{Link}$ \& Otto, Ic. Pl. Rar. i. 11. t. 6.Bras.

bupleurifolium, Dun. in DC. Prod. xiii. 1. 628.Bras.

buxifolium, H. B. E K. Nov. Gen. et Sp. iii. 57.-N. Granat.

calycinum, H. B. $\mathcal{F}^{\prime} K$. . . c. 58.--Peruv.

calycinum, Willd. ex Schlecht. in Linnaea, vii. (1832) $64=$ viridiflorum.

campanulatum, Lam. Encyc. i. $688=$ Acnistus aggregatus.

campestre, Griseb. in Goett. Abh. xxiv. (1879) 244.Reg. Argent.

cancellatum, Dun. in DC. Prod. xiii. I. 657.-Peruv.

candidum, Seem. E' Schmidt, in Flora, xxvii. (1844) 496.-Mexic

cauliflorum; Jacq. Hort. Schoenb. iii. 41. t. $325=$ Acnistus arborescens.

cauliflorum, Sieber, ex Bercht. \& Presl, Rostl. i. Solaneae. $52=$ Acnistus Plumieri.

chlamidatum, Dun. in DC. Prod. xiii. I. 645.-Bras.

chloranthum, Dun. l. c. 636. - Ins. Trinitat.

citrifolium, Rets. in Hoffm. Phyt. Blaetter, 1. (1803) 36.-Hab:?

Clausseni, Dun. in DC. Prod. xiii. I. 637.-Bras.

collinum, Miers, in Hook. Lond. Fourn. Bot. v. (1846) 160 - - Bras.

confertiflorum, Schlecht. in Linnaea, xix. (1847) 263.Mexic.

confertum, Mill. Gard. Dict. ed. VIII. n. 5=vespertinum.

confertum, Ruiz E Pav. Fl. Per. ii. 29. t। 153.Peruv.

conglomeratum, Ruiz \& Pav. l. c. 29. t. 156.Peruv.

corcovadense, Miers, in Hook. Lond. Fourn. Bot. v. (1846) $160 .-$ Bras.

cordatum, Schott, ex Sendt. in Mart. Fl. Bras. x. 224 -Bras.

coriaceum, Miers, in Hook. Lond. Fourn. Bot. v (1846) 161.-Brgs

corymbosum, Schlecht. in Linnaea, vii. (1832) 57.Bras.

cuspidatum, Sendt. in Mart. F. Bras. x. 223.-Bras.

cyaneum, Schlecht. ex Dun. in DC. Prod. xiii. 1, $673=$ Iochroma Schlechtendalianum.

daphnoides, Griseb. in Mem. Am. Acad. N. S. viii. (1863) 524.-Ind. occ

depauperatum, Dun. in DC. Prod. xiii. I. 660.-Ins. Guadalup.

discolor, Dun. l. c. 609--Peruv.

dizenum, Domb. ex Dun, in DC. 1. c. $667=$ lep tanthum.

diurnum, H. B. \& K. Nov. Gen, et Sp. iii. $61=$ Forsythi.

diurrum, Linn. Sp. Pl. 191.-Ind. occ

dubium, Steud. Nom. ed. II. i. 397.-Hab. ?

dumetorum, Schlecht. in Linnaca, vii. (1832) B1.Bras,

\section{CESTRUM:}

Ehrenbergi, Schlecht. ex Dun. in DC. Prod. xiii. I 613.-. Mexic.

elegans, Schlecht. in Linnaea, xix. (1847) 261.Mexic.

elongatum, Hort. ex Steud. Nom. ed. II. i. $337=$ can didum.

Endlicheri, Miors, in Hook. Lond. Fourn. Bot. v. (1846) 151.-Peruy

eriochiton, Sendt. in Mart. Fl. Bras, x. 217.-Bras. euanthes, Schlecht in Linnoea, vii. (1892) 60.Bras.
uanthes,

exstipulatum, Ledeb. in Schrad. N. Fourn. Bot iv. $(1810) 65 .-\mathrm{Am}$. austr.

fasciculare, Otto, ex Dun. in DC. Prod. xiii. I. $673=$ Toxicophlaea cestroides.

fasciculatum, Miers, in Hook. Lond. Fourn. Bot. v (1846) 151,-Mexic

fastigiatum, facq. Hort. Schoenb. iii. 44. t. 330.-Ind occ.

fastigiatum, Jan, Cat. Hort. Parm. 189, $10=$ diuruum. Fancheri, Dun in DC. Prod. xiii. x. 640,-Hab.?

ferrugineum, A. Rich. Fl. Cub. Fanerog. ii. 126.Cuba.

floribundum, Willd. ex Roem. \& Schult. Syst. iv. 807 $=$ tenuiflorum.

foetidissimum, Jacq. Hort. Schoenb. iii. 43. t. $329=$ nocturnum.

foetidum, Medic. in Act. Acad. Theod. Palat.iv. Phys. (1780) 192.-Hab.

foetidum, Salisb. Prod. $111=$ auriculatum.

Forsythi, Dun. in DC. Prod. xiii. 1.604.-Ind. occ.

frutescens, Aubl. Pl. Gui. i. 233.-Guiana.

Gardneri, Sendt. in Mart. Fl. Bras. x. 208.-Bras.

glaucescens, Sendt. l. c. 222,-Bras.

glomeratum, Schott, ex Sendt. l. c. 212,-Bras.

graciliflorum, Dun. in DC. Prod. xii. I. 669.-Mexic.

granadense, Willd. ex Roem. \& Schult. Syst. iv. $807=$

tomentosum.

grandiflorum, Hort. ex Steud. Nom. ed. II. i. $337=$

laurifolium.

grandistipulum, Sendt. in Mart. Fl. Bras. x. 214.Bras.

Hartwegi, Dun. in DC. Prod. xiii. I. 599.-Mexic

Hediunda, Lam. Encyc. i. $687=$ auriculatum.

Hediunda, Matr. ex Dun. in DC. Prod xili. I. $647=$ hodiundinum.

hediundinum, Dun. l. c.-Am. austr

heterofractum, Buek, in DC. Prod. Index, iii. 93, sphalm. = retrofractum

hirsutum, facq. Hoxt. Schoenb, iii, 41. t. 324.-Hab.?

hirtellum, Schlecht. in Linnaea, vii. (1832) 62.Mexic.

hirtum, Sieber, ex Sendt. in Mart. FI. Bras. x. $210=$ Poeppigii.

hirtum, Sw. Prod. Veg. Ind. Occ. 49.-Jamaic

intermedium, Sendt. in Mart. Fl. Bras. x. 221.--Bras

involucratum, Dun in DC. Prod. xiii. I. 610-Mexic.

jamaicense, Lam. Encyc. i. $687=$ C. Parqui, vespertinum.

jasminiflorum, Moric. ex Dun. in DC. Prod. xiii. 660.-Hab.

Kohauti, Bercht. \& Presl, Rostl. i. Solaneae, $52=$ cauliflorum.

laevigatum, Schlecht. in Linnaea, vii. (1882) 59.Bras.

Lamberti, Dum. in DC. Prod. xiii. I. 624.-Hab.?

lanatum, Mart. \& Gal. in Bull. Acad. Brux. xii. IL (1845) (reimpr. 18).-Mexic.

lanceolatum, Miers, in Hook. Lond. Fourn. Bot. v. (1846) 159.-Bras.

lanceolatum, Schott, ex Sendt. in Mart. Fl. Bros. $x$. 214.-Bras.

lancifolium, Schlecht. in Linnaca, xix. (1847) 267.Mexic.

lanuginosum, Ruis E Pav. Fl. Per. ii. 30. t. 157.Peruy.

lasianthum, Dun. in DC. Prod. xiii. 1. 649.-Peruv.

latifolium, Lam. Illustr. ii. 5.-Ios. Trinitat.

latifolium, Sieber, ex Dun. in DC. Prod. xiii. 1. $636=$ chloranthum

laurifoliam, L'Herit. Stirp. Nov. 69. t. 3t-Am, austr.

laxiflorum, Dun. in DC. Prod. xiii. 1. 655,-Venczucla.

laxum, Benth. Pl. Harta. 39. n. 207.-Mexic.

leptanthum, Dus, in DC. Prod. xiii, 1. 606,-Perav.

leucocarpum, Dun. l. c. 630.-Am. austr.

\section{CESTRUM:-}

Lindeni, Dun. in DC. Prod. xiii. I. 611.-Venezuela. longiflorum, Ruiz E Pav. Fl. Per. ii. 28. t. 154.Perny.

longifolium, Poepp.ex Dun. in DC. Prod. xiii. I. $657=$ unibracteatum.

Lorentzianum, Griseb. in Goett. Abh. xix. (1874) 217. -Am. austr.

lucidum, Pav, ex Dun. in DC. Prod. xiii. I. $665=$ servatum.

Lundianum, Dun. l. c. 658.-Bras,

luridum, Dun. l. c. 659.-Bras.

lycioides, Lichtst. ex Roem. \& Schult. Syst. iv. 558= Lycium cinereum

lycioides, Sendt. in Mart. Fl. Bras. x. 208.-Bras.

macrophyllum, Hort. Par. ex Dun. in DC. Prod, xiii. I. 626 = laurifolium.

macrophyllum, Salzm. ex Dun. 1. c. =Salzmanni.

macrophyllum, Vent. Choix 18.--Ind. occ.

mariquitense, H. B. E K Nov. Gen. et Sp. iii. 57.Granat.

Martii, Sendt. in Mart. Fl. Bras. x. 221.-Bras.

Mathewsii, Dun. in DC. Prod. xiii. I. 637.-Preruv.

megalophyllum, Dun. 1. c. $638=$ macrophyllum.

melanochloranthum, Dun. l. c. 622,-N. Granat

microphyllum, Linden, ex Dun. L. c. 623.-N. Granat.

Miersianum, Wedd. Chlor. And. ii. 97.-N. Granat.

Miersii, Dun. in DC. Prod. xili. 1.671.-Bras.

montanum, Miers, in Hook. Lond. Fourn. Bot. (1846) 161.-Am. austr.

Moquinianum, Dun. in DC. Prod. xiii. 1. 646.-Cuba

Moritzi, Dun. l. c. 619.-N. Granat.

mucronatum, Miers, in Hook. Lond. Fourn. Bot. v.

(1846) 160.-Bras.

multiflorum, Roem. छo Schult. Syst. iv. 553.-Am. austr.

multiflorum, Schlecht. in Linnaea, vii. (1832) 59 Schlechtendalii.

multiflorum, Schott, ex Sendt. in Mart. Fl. Bras. $x$ $216=$ laevigatum.

multinervium, Dun. in DC. Prod, xiii, I. $611=C$. Parqui ?

Mutisii, Willd. ex Roem. E Schult. Syst. iv, 807.Am. austr.

nemanthum, Dun. in DC. Prod. xiii. I. 637.-Bras.

nervosum, Mill. Gard. Dict. ed. VIII, n. $3=$ Tabernaemontana amygdalaefolia.

nitidum, Mart. E Gal. in Bull. Acad. Brux. xii. II. (1845) (reimpr. 19).-Mexic.

nocturnum, Lam. Encyc. i. 687 - leucocarpum.

nocturnum, Linn. Sp. Pl. 191.-Am, austr.

oblongifolium, Schlecht. in Linnaea, xix. (1847) 266. - Mexic.

obovatum, Sendt, in Mart. Fl. Bras, x. 209-Bras.

odontospermum, Facq. Hort. Schoenb. iii, 44. t. 331.Am. austr.

oliganthum, Dun, in DC.Prod. xiii. I. 684,-Guiana. oppositifolium, Lam. Mllustr. ii. t. 112. 6. 2. n. $2279=$ Acokanthera Lamarkii.

organense, Miers, in Hook. Lond. Journ. Bot. v. (1\& $\left.10^{\circ}\right)$ $158=$ amictum

ovatum, Willd. ex Roem. E Schult. Syst. iv. $807=$ tenuiforum.

pallidum, Lam. Encyc. i. 6\&8.-Jamaic.

paniculatum, H. B. E $K$. Noo. Gene et Sp. iij. 6s.-

Venezuela.

paniculatum, Schlecht. in Linnaea, xix. (1847) $262=$ sylvaticum.

Parqui, Benth. Pl. Hartw. $24=$ terminale.

Parqui, L'Herit. Stirs. Non, 73,-Am, trop.

parviflorum, Dun. in DC. Prod. xiii, I. 10.24.-['eruv.

parrifolium, Willd. ex Roem. E Schult Syst. ir. sos. - Hab?

pauciflorum, Nees Eo Mart. in N'vo. Act. Acusd. Caes. Leop. xi. (1823) 79.-Bras.

pauciftorum, Willd, ex Koem. \& Schult. Syst. iv, sos= Willdenowii.

pedicellatum, Sendt. in Mart. F\%. Bras. x. 221.-Brax. pedunculare, Pav. ex Dur. in DC. Prod. xiii. 1. 615.Mexic.

perululinum, Hort. Monsp. cx Dun. in DC. Prod. xiii. 1. 630 - untulatum.

pendulinum, farq. Hort. Scherenb. iii. 12. t. \$2:-N. Giranat.

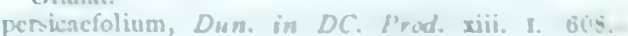
Mexic.

perusianum, Hort. Kutb. ex Duo. 1. c. $662=C$. Anclanchier. 


\section{CESTRUM:}

peruvianum, Willd.ex Roem. \& Schult. Syst. iv. $807=$ affine.

petiolare, H. B. \& K. Nov. Gen. et Sp. iii. $58=$ Sessea petiolaris.

Plukenetii, Tausch, in Flora, xix. (1836) 387.-Hab.?

Poeppigii, Schlecht. in Linnaea, xxvii. (1854) 510.Ins. Martinic.

Poeppigii, Sendt. in Mart. Fl. Bras. x. 210.-Bras.

polyanthum, Sendt. in Mart. l. c. vi. 216.-Bras.

polyanthum, Steud. Nom. ed. II. i. $337=$ Schlechtendalii.

porphyreum, Dun. in DC. Prod. xii. I. 602.-Hab.?

porphyroneuron, Schlecht. in Linnaea, xxv. (1852) 199 - Hab?

potaliaefolium, Dun. in DC. Prod. xiii. I. $638 .-\mathrm{N}$. Granat.

Prieurei, Dun.l.c. 635.-Guiana

propinquum, Mart. E Gal. in Bull. Acad.Brux. xii I. (1845) 147:-Mexic

Pseudo-Quina, Mart. in Flora, xxi. (1838) Beibl. 21 -Bras.

psychotrifolium, Schlecht. in Linnaea, xix. (1847) 265. -Mexic.

pubens, Griseb. in Goett. Abh.xix. (1874) 217.-Reg. Argent.

pubescens, Lichst. ex Roem. \& Schult. Syst. iv. $558=$ Acokanthera pubescens.

racemosum, Ruiz Er Pav. Fl. Per. ii. 29, t. 154.Peruv.

racemosum, Tausch, in Flora, xix. (1836) $387=$ dubium.

ramosissimum, Nocca, ex Dun. in DC. Prod. xiii. I. 673 , nomen.-Hab. ?

reflexum, Sendt. in Mart. Fl. Bras. x. 218.-Bras.

Regelii, Planch. in Fl. des Serres, Sér. I. ix. (1853-54) 229. t. 946.-Guatimal.

Requieni, Dun. in DC. Prod. xiii. I. 661.-Hab.?

reticulatum, Willd. ex Roem. \& Schult. Syst. iv. $808=$ conglomeratum.

retrofractum, Dun in DC. Prod, xiii. I, 655-Bras. roseum, Hort. ex Dun. 1. c. $602=$ porphyreum.

roseum, H. B. E K. Nov. Gen. et Sp. iii. 59. t. 197.Mexic.

rugulosum, Schott, ex Sendt. in Mart. F1. Bras. x. 215 $=$ lanceolatum.

salicifolium, Hort. Monsp. ex Dun. in DC. Prod, xiii I. $616=$ foetidissimum

salicifolium, Facq. Hort. Schoenb. iii. 421.-Veneznela. salicifolium, Kunth, ex Spreng. Syst: i. $673=\mathrm{C}$ Parqui.

Salzmanni, Dun. in DC. Prod. xiii. I. 626.-Bras

scandens, Thib. ex Dun. 1. c. $631=$ nocturnum.

scandens, Vahl, Eclog. Am, i. 24-Am, austr.

Schlechtendalii, G. Don, Gen. Syst. iv. 482.-Bras.

Schottii, Pohl, ex Sendt. in Mart. Fi. Bras. x. $218=$ amictum.

Schottii, Sendt. l. c. 213.-Bras

Sellowianum, Sendt. l. c. 219-Reg. Argent.

semivestitum, Dun. in DC. Prod. xiii, I. 651.-Mexic.

Sendtnerianum, Mart. ex Sendt. in Mart. Fl: Bras, $\mathrm{x}$ 215.-Bras.

servatum, Dun. in DC. Prod. xiii. I. 665.-Peruv.

sessiliflorum, Schott, ex Sendt, in Mart. Fl. Bras. x

213.-Bras.

spermacocifolium, Willd. ex Roem. \& Schult. Syst. iv.

$808=$ Bouvardia triflora

spicatum, Mill. Gard. Dict. ed. VIII. n. 4.-N. Granat.

spurium, Hort. Genev. ex Dun. in DC. Prod. xiii. I.

$617=$ C. Parqui.

stipulatum, Vell. FI. Flum. 101 ; ii, t. $5=$ bracteatum.

strictum, Schott, ex Sendt. in Mart. Fl. Bras. x. 208. -Bras.

strigillatum, Ruiz E Pav. Fl. Per. ii. 29. t. 156.Peruv.

suberosum, Facq. Hort. Schoenb, iv, 26, t. 452Hab.?

subpulverulentum, Mart. in Flora, xxi. (1838) II. Beibl. 65.-Bras.

subsessile, Vell. Fl. Flum. 102 ; iii. t. 8.-Bras.

subtriflorum, Dun. in DC. Prod. xiii. I. 623.-Ins, Trinitat.

subuniflorum, Dun, $l, c, 654$-Bras

sylvaticum, Dun. $l . c .603$ - Mexic.

tenuiflorum, H. B. E K. Nov. Gen. et Sp. iii. 61.Venezuela.

terminale, Dun. in DC. Prod, xiii. I. 608,--Mexic.

\section{CESTRUM :-}

thrysoideum, H. B. \& K. Nov. Gen. et Sp. iii. 63.Mexic.

tinctorium, facq. Hort. Schoenb. iii. 45. t. 332.-Am. austr.

Tinus, Dun in DC. Prod xiii. r. 614-Bras.

tomentosum, Linn.f. Suppl. 150.-Am. austr.

tomentosum, Moç. \& Sessé, ex Dun. in DC. Prod. xiii. I. $601=$ Benthami.

toxicarium, J. F. Gmel. Syst. 389, $1524=$ Antiaris toxicaria.

tubulosum, Sendt. in Mart. Fl. Bras. x. 207.-Bras.

umbellatum, E. Mey. ex Meissn. in DC. Prod. xiv. 528 - Peddiea Dregei.

umbellatum, Pauq. Diss. Bellad. 16.-Hab.?

undulatum, Ruiz \& Pav. Fl. Per. ii. 28, t. 155.Peruv.

unibracteatum, Dun. in DC. Prod. xiii. I. 656.Perny

velutinum, Hiern, in Kjoeb.Vidensk.Meddel.(1877-78) 63.-Am. trop.

venatorium, E. Mey. ex Sond. in Linnaea, xxiii. (1850) $79=$ Acokanthera venenata

venenatum, Burm. f. Fl. Cap. Prod. $5=$ Acokanthera venenata.

venenatum, Lam. Encyc. i. $688=$ laurifolium.

venenatum, Mill. Gard. Dict. ed. VIII. n. $6=$ pallidum.

renosum, Willd. ex Roem. \& Sclault. Syst. iv. $807=$ Sessea petiolaris.

vespertinum, Bertero, ex Dun. in DC. Prod. xiii. I. 660 = depauperatum.

vespertinum, Hort. Val. ex Roem. \& Schult. Syst, iv. $366=$ Vestia lycioides.

vespertinum, Linn. Mant. ii. 206.-Ind, occ.

vespertinu, Poepp. ex Sendt. in Mart. Fl. Bras. x. 218 $=$ Poeppigii.

vestioides, Schlecht, in Linnaea, vii. (1832) 65.-Bras. vestitum, Hook. Ic. Pl. t. $381=$ Sessea vestita. viminale, Sendt. in Mart. Fl. Bras. x. 220,-Bras. virgatum, Ruiz \& Pav, Fl, Per, ii. $27=\mathrm{C}$. Parqui. viride, Moric, ex Dun, in DC. Prod, xiii. I, 606.Mexic.

viridiflorum, Hook. Bot. Mag. t. 4022.-Bras.

Warscewiczii, Klotzsch, in Otto \& Dietr. Allg. Gartenz. xix. (1851) 362.-Am. austr.

Willdenowii, Steud. Nom. ed. II. i. 338.-Hab. ?

CETRA, Noronha, in Verh. Batav. Gen. v. (1790) ed. I. Art. IV. 2 (Quid ?).

CEVALLIA, Lag. in Varied. Cienc. ii. IV. (1805) 35. LOASEAE, Benth. \& Hook. f. i. 803.

Petalanthera, Nutt. in Journ. Acad. Philad. vii (1834) 107.

sinuata, Lag. l. c. 36.-N. Mexic.

CEYTOSIS, Munro, in Journ. Linn. Soc. vi. (1862) 54, err. typ $_{\mathrm{o}}=$ Crypsis, Ait. (Gramin.).

CHABoissaEA, Fourn. Gram. Mex. 112 ; ex Benth. \& Hook, f. Gen, iii. 1096 (1883). Gen. dub. GRAMIN. Bentb. \& Hook. f. 1. c.

ligulata, Fourn. l. c. ; ex Hemsl. Biol. Centr. Am. Bot. iii. 588.-Mexic

CHABRAEA, Adans. Fam. ii. $237(1763)=$ Peplis, Linn. (Lythrar.).

CHABRAEA, DC in Ann. Mus. Par. xix. (1812) 65.t. 5 =Leuceria, Lag. (Compos.).

abbreviata, Bert. 'Merc. Chil. (1829) 601,'-Cf, Bull. Férussac, xx. $(1830) 109=$ L. abbreviata.

Barrasiana, Remy, in C. Gay, Fl. Chil. iii. 399.Chili.

Berteroniana, Steud. Nom. ed. II..i. 338,-Chili. candidissima, DC. Prod, vii. $59=\mathrm{L}$ candidissima. canescens, Phil. in Linnaea, xxviii. (1856) 716.Chili.

cinerea, DC. Prod. vii. $60=$ L. cinerea

concinna, Phil. in Linnaea, xxxiii. (1864-65) 123.Chili.

coquimbana, Phil. in Anal. Univ. Chil. (1861) 50.Chili.

daucifolia, Wedd. Chlor. And. i. 35.-Peruy

elongata, Bert. 'Merc. Chil. (1829) 601'-Cf. Bull.

Ferussac, Xx. (1830) $109=\mathrm{L}$. senecioides.

fragrans, Phil. in Linnaea, xxix. (1857-58) 3.-Chili.
CHABRAEA :-

Gayana, Remy, in C. Gay, Fl. Chil. iii. 400.-Chili. glabra, DC. in Deless. Ic. Select. iv. t. 89.-Chili.

glabriuscula, Phil. in Linnaea, xxviii. (1856) 715.Chili.

glacialis, DC, in Deless, Ic. Select, iv, t. $91=\mathrm{L}$. pulchella.

glandulosa, DC. Prod. vii. $59=$ L. glandulosa, D. Don integrifolia, Phil, in Linnaea, xxviii. (1856) 716.Chili.

laciniata, Wedd. Chlor. And. i. 34. t. $10=\mathrm{I}$. laciniata.

Landbeckii, Phil, in Linnaea, xxxiii. (1864-65) 122 Chili.

lithospermifolia, DC. Prod. vii. 60.-Chili.

lyrata, Spreng. Syst. iii. $506=$ Gerbera Anandria.

modesta, Phil. Fl. Atac. 28.-Chili.

multifida, DC. Prod. vii. 60--Patagonia.

nutans, Bland. C. Gay, Fl. Chil. viii. 397.-Chili

nutans, Remy, in. Ann. Sc. Nat. Sér. III. xii. (1849) 182.-Chili.

oligocephala, Phil. in Anal. Univ. Chil. (1872) $745=$ L. oligocephala.

Poeppigit, Phil in Linnaea, xxix (1857-58) 3-Chili. polyclados, Remy, in C. Gay, Fl. Chil. iii. 399.-Chili. prenanthoides, Bert. in 'Merc. Chil. 1829.'-Cf. Bull Férussac, x.x. (1830) 109.-Chili.

pulchella, Phil. in Anal. Univ. Chil. (1872) $744=\mathrm{L}$ pulchella.

purpurea, DC. in Ann. Mus. Par, xix. (1812) 65, $71=$ L. purpurea.

rosea, DC in Deless. Ic. Select. iv, t. $90=$ L. runcinata. runcinata, Hook. Bot. Mag. t. $4116=$ L. runcinata. salina, Remy, in C. Gay, Fl. Chil. iii. 393. t. 41.Chili.

scrobiculata, DC, Prod, vii. 59= L, scrobiculata

suaveolens, DC. 1. c. = L. gossypina.

tenerifolia, Phil, in Linnaea, xxviii. (1856) 715:-Chili. tenuior, Bert. in 'Merc. Chil. 1829.'-Cf. Bull. Fé russac, xx. (1830) $109=$ Berteroniana.

tenuisecta, Sch. Bip. in Bonplandia, iv. (1856) 55, nomen.-Chili.

thermarum, Phil in Anal. Univ, Chil (1862) 380 Chili.

tomentosa, DC. Prod, vii. $60=$ L. Bridgesii,

viscida, Bert. in 'Merc. Chil. (1829) 601。'-Cf. Bull.

Férussac, xx. (1830) 109 -Chili

viscosa, Bert. ex DC. Prod. vii. $59=\mathrm{L}$. runcinata.

CHADARA, Forsk. Fl. Aegypt. Arab. 105 (1775)= Grewia, Linn. (Tiliac.)

arborea, Forsk. 1, c. $=\mathrm{G}_{\text {. }}$ excelsa.

tenax, Forsk. . $_{0}=\mathrm{G}$. populifolia.

velutina, Forsk, 1, c. =G, velutina.

CHADRA, T. Anders. in Journ. Linn. Soc. v. Suppl. i 1860) 11 , err. typ. $=$ praec

CHADSIA, Boj, in Ann. Sc. Nat Sér. II, xx, (1843) 104. LEGUMINOSAE, Benth. \& Hook. f. i, 497. andravinensis, Baill. in Bull. Soc. Linn. Par. i. (1883) 391. - Madag.

coluteifolia, Baill. l. c. 392.-Madag.

flammea, Boj. in Ann. Sc. Nat. Sér. II. xx. (1843) 106. -Madag.

Grandidieri, Baill. in Bull. Soc. Linn. Par. i. (1883) 391.-Madag.

granitica, Baill. l. c. 392,-Madag.

Lantziana, Baill. l. c. 391.-Madag

salicina, Baill. l. c. 392 -Madag.

versicolor, Boj. in Ann. Sc. Nat. Sér. II. xx. (1843) 106.--Madag.

CHAELANTHUS, Poir. in Dict. Sc. Nat. viii. 50 (1817) sphalm. $_{*}$ Chaetanthus, R. Br. (Restiac.).

CHAELOTHILUS, Neck. Elem. ii. $14(1790)=$ Gentiana, 'Tourn.

CHAENACTIS, DC. Prod. v. 659 (1836). COMPOSITAE, Benth. \& Hook. f. ii. 401

ACARphiaeA, Harv, \& A. Gray, Pl. Fendl. 98 (1849).

ACICARPHAEA, Walp. Ann. ii. 877 (1852)

Macrocarphus, Nutt. in Trans. Am. Phil. Soc Ser. II. vii. (1841) 376 .

achilleaefolia, Hook, \& Arn. Bot. Beech. Voy. $354=$ Douglasii. 
CHAENACTIS :-

artemisiaefolia, A. Gray, in Proc. Am. Acad. x. (1875) 74.-Calif.

attenuata, A. Gray, l. c. 73.--Arizona.

brachypappa, A. Gray, l. c. viii. (1872) 390.-Am. bor. occ.

carphoclinia, A. Gray, in Bot. Mex. Bound. 94.-Am. bor, occ.

Cusickii, A. Gray, Syn. Fl. N.Am. ii. II. 452.-Am. bor. occ.

denudata, Nutt, in Journ. Acad. Sc. Philad. Ser. II. i. (1847) 177 = glabriuscula.

Douglasii, Hook. E Arn. Bot. Beech. Voy. 354,-Am. bor, occ.

filifolia, Harv, in A. Gray, Pl. Fend1. $98=$ tenui-

Fremonti, A. Gray, in Proc. Am. Acad. xix. (1883) 30. -Calif.

glabriuscula, DC. Prod. v. 659.-Calif.

heterocarpha, A. Gray, Pl. Fendl. 98.-Calif.

lanosa, DC. Prod. v. 659.-Calif.

macrantha, Eaton, in Bot. King, Exp. 171. t. 18.Am. bor. occ.

nevadensis, A. Gray, in Bot. Calif. i. 391.-Calif.

Nevii, A. Gray, in Proc. Am. Acad. xix. (1883) 30.Am. bor. occ.

Parishii, A. Gray, l.c. xx. (1885) 299.-Calif.

santolinoides, Greene, in Bull. Torrey Club, ix. (1882) 17.-Calif.

stevioides, Hook. E Arn. Bot. Beech. Voy. 353.-Am. bor. occ.

suffrutescens, A. Gray, in Proc. Am. Acad. xvi. (1881) 100.-Calif.

tanacetifolia, A. Gray, 1. c. vi. (1864-65) $545=$ heterocarpha.

tenuifolia, Nutt. in Trans. Am. Phil. Soc. N. S. vii. (1841) $375 .-$ Calif.

thysanocarpha, A. Gray, in Proc. Am. Acad. xix. (1883) 30 - - Calif.

xantiana; A. Gray; l. c. vi. (1865) 545.-Calif.

CHAENANTHE, Lindl. Bot. Reg. (1838) Misc. $38=$ Diadenium, Poepp. \& Endl. (Orchid.).

Barkeri, Lindl. 1. $\mathrm{c}_{\mathrm{s}}=\mathrm{D}$. Barkeri.

CHAENANTHERA, Rich. ex DC. Prod. iii. 196 (1828) = Charianthus, D. Don (Melastomac.).

mucronata, Rich. 1. c. $197=$ Charianthus glaberrimus.

CHAENARRHINUM, Reichb. Consp. 123 (1828) = Linaria, Tourn. (Scrophul.).

crassifolium, Lange, in Willk. \& Lange, Prod. FI. Hisp. ii. $579=\mathrm{L}$ 。 origanifolia.

exile, Lange, in Kjoeb. Vidensk. Meddel. (1877-78) $232=\mathrm{L}$. exilis.

flexuosum, Lange, in Willk. \& Lange, Prod. Fl. Hisp. ii. $580=\mathrm{L}$. Langei.

macrocalyx, Pomel, Nouv. Mat. Fl. Atl. $98=\mathrm{L}$. macrocalyx.

macropodum, Lange, in Willk. \& Lange, Prod. Fl.

Hisp. ii. $579=\mathrm{L}$. macropoda.

minus, Lange, 1. c. $577=\mathbf{L}$. minor.

origanifolium, Fourr. in Ann. Soc. Linn. Lyon, N. S. xvii. (1869) $127=\mathrm{L}$. origanifolia.

praetermissum, Lange, in Willk. \& Lange, Prod. Fl.

Hisp. ii. $578=\mathrm{L}$. minor.

rubriflorem, Fourr. in Ann. Soc. Linn. Lyon, N. S. xvii. (1869) $127=$ L. rubrifolia.

rubrifolium, Lange, in Willk. \& Lange, Prod, Fl, Hisp. ii. $578=\mathrm{L}$. rubrifolia.

serpyllifolium, Lange, $1 . c_{-}=\mathbf{L}$. serpyllifolium.

tenellum, Lange, 1. c. $581=$ Anarrhinum tenellum.

thymiflorum, Losc. ex Lange, in Kjoeb. Vidensk. Meddel. $(1877-78) 232=\mathrm{L}$. exilis.

villosum, Lange, in Willk. \& Lange, Prod. Fl. Hisp. ii. $580=$ L. villosa.

CHAENESTHES, Miers, in Hook. Lond. Joum. Bot. iv (1845) $336=$ Iochroma, Benth. (Solanac.).

cornifolia, Miers, 1. c. $388=$ I. comifolia.

fuchsioides, Miers, 1. c. $937=I$. fuchsioides.

gesnerioides, Micrs, 1. c. $338=$ I. gesncrioides.

lanceolata, Miers, 1. c. = I. lanceolata.

longipes, Dun. in DC. Prod. xiii. I. $489=I$, longipes.

loxensis, Miers, in Hook. Lond. Journ. Bot. iv. (1848) $398=I$. loxensis.

umbrosa, Miers, 1. c. $837=$ I. umbrosa.
CHAENOCARPUS, Juss. in Dict. Sc. Nat. viii. 50 $(\mathbf{1 8 1 7})=$ CHENOCARPUS, Neck. = Spermacoce, Linn. (Rubiac.).

CHAENOCEPHALUS, Griseb. Fl. Brit. W. Ind. 374 (1861). COMPOSITAE, Benth. \& Hook. f. ii. 382.

heterophyllus, Griseb. in Goett. Abh. xxiv. (1879) 196. -Reg. Argent.

macrophyllus, Griseb. l. c.-Reg. Argent.

petrobioides, Griseb. Fl. Brit. W. Ind. 374.-Ind, occ. Suncho, Griseb. in Goett. Abh.xxiv. (1879) 196.-Reg. Argent.

CHAENOLOBIUM, Miq. F1. Ind. Bat. Suppl. i. 302 $(1860)=$ Ormosia, Jack (Legumin.)

decemjugum, Miq. 1. c. $=$ O. microsperma.

septemjugum, Miq. 1. c. $=$ O. microsperma.

CHAENOMELES, Lindl. Veg. Kingd. 560 (1847)= CHOENOMELES, Lindl, = Pyrus, Linn. (Rosac.).

CHAENOPHORA, Rich. ex Crueger, in Linnaea, $\mathbf{x x}$. (1847) 112 , err. typ. = seq.

CHAENOPLEURA, Rich. ex DC. Prod. iii. 197 (1828) = Miconia, Ruiz \& Pav. (Melastomac.).

densiflora, Gardn. in Hook. Lond. Journ. Bot. ii. (1843) $349=$ M. pusilliflora.

ferruginea, H. Crueger, in Linnaea, xx. (1847) $112=$ M. hypoleuca.

fulva, Griseb. in Goett. Abh. ix. (1861) $55=$ M. fulva. hypoleuca, Benth. in Hook. Journ. Bot. ii. (1840) 315

$=$ M. hypolenca

lanceolata, Gardn. in Hook. Lond. Journ. Bot. ii. (1843) $349=$ M. pusilliflora.

longifolia, Griseb. in Goett. Abh. ix. (1861) $55=\mathrm{M}$. longifolia.

parviflora, Gardn, in Hook. Lond. Journ. Bot. ii. (1843) $348=$ M. pusilliflora

quadrangularis, Macf. Fl. Jamaic. ii. $96=$ M. quadrangularis.

stelligera, Macf, 1. c. 97.-Jamaic.

stenobotrys, DC. Prod, iii. $197=$ M. quadrangularis.

CHAENORRHINUM, Lange, in Willk. \& Lange, Prod. Fl. Hisp. ii. $577(1870)$, err. typ $=$ CHAENAR RHINUM, Reichb. = Linaria, Tourn. (Scrophul.)

CHAENOSTOMA, Benth. in Hook. Comp. Bot. Mag. i. (1835) 374. SCROPHULARINEAE, Benth. \& Hook. f.ii. 945 .

Palmstruckia, Retz. f. Obs. Bot. Pugill. 15 (1810) Sutera, Roth, Bot. Bemerk. 172 (1878) aethiopicnm, Benth. l. c. 375.-Afr, austr.

affine, Bernh. in Flora, xxvii. (1814) 834.-Afr. austr calycinum, Benth. in Hook. Comp. Bot. Mag. i. (1835 374.-Afr. austr.

campanulatum, Benth. l. c.-Afr. austr.

cordatum, Benth. l. c. 377.-Afr. austr.

cuneatum, Benth. l. c. 376.-Afr. austr.

denudatum, Benth. l. c. 375.-Afr. austr.

fastigiatum, Benth. l. c. 376.-Afr. austr.

floribundum, Benth. l. c.-Afr. austr.

foetidum, Benth. l. c. 377.-Afr. austr.

glabratum, Benth. l, c. 375.-Afr. austr.

halimifolium, Benth. $l_{0} c_{0}-\mathrm{Afr}$. austr.

hispidum, Benth. l. c, 376.-Afr. austr.

integrifolium, Benth. l. c.-Afr. austr.

Kraussianum, Bernh, in Flora, xxvii. (1844) 835 . Lyperia Kraussiana.

laxiflorum, Benth. in Hook. Comp. Bot. Mag. i. (1835) 374 -Afr, austr.

linifolium, Benth. l. c. 375.-Afr. austr.

marifolium, Benth. l. c. 376.-Afr. austr.

natalensis, Bernh. in Flora, xxvii. (18t4) 835.-Afr. austr.

pauciflorum, Benth, in Hook. Comp. Bot. Mag. i. (1885) 374,-Afr. austr.

pedunculosum, Benth.l.c.377--Afr. austr.

polyanthum, Benth.l.c. 375.-Afr. austr.

procumbens, Benth.l. $c .374$ - - Afr. austr.

pumilum, Benth.l.c. 375.-Afr. austr.

racemosum, Benth.l.c. 377.-Afr. austr.

revolutum, Benth. 6 c. $\$ 75$ - Afr. austr.

rotundifolium, Benth. l. c. 374.-Afr. austr.

subspicatum, Benth. l. c. 376.-Afr. austr.

villosum, [G. Don, in] Sweet, Hort. Brit. ed. III. 520 = Polycarena capensis.
CHAERADOPLECTRON, Benth. \& Hook. f. Gen. iii. 626 (1883), err. typ. = CHOERADOPLECTRON Schau. = Habenaria, Willd. (Orchid.).

CHAEROPHYLLUM, Linn. Syst, ed. I (1735) UMBELLIFERAE, Benth. \& Hook, f. i. 898

Balansaea, Boiss. \& Reut. Pugill. Pl. Nov. 49 (1852).

Biasolettia, Bertol. Fl Ital. iii. 191 (1837).

Fiebera, Opiz, Seznam, 44 (1852).

FREYERA, Keichb. Handb. 291 (1837)

Grammosciadium, DC. Prod. iv. 232 (1830)

Physocaulis, Tausch, in Flora, xvii. (1834) 342

RhyNCHOSTYlis, Tausch, 1. c. 343 (1834)

acuminatum, Lindl. in Royle, Illustr. Bot. Himal. 232.--Reg. Himal.

affine, Steud. in A. Rich. Tent. Fl. Abyss. i. $332=$

Anthriscus sylvestris.

alpestre, Jord. Pngill. $75=$ Villarsii.

alpinum, Vill. Prosp. $26=$ Anthriscus sylvestris.

angelicaefolium, C. A. Mey. Verz. Pf. Cauc. $130=$ Meyeri.

angelicaefolium, Bieb. Fl. Taur. Cauc. iii. 240.Oriens; Iberia.

angelicaefolium, DC. Prod. iv. 227 = byzantinum.

angulatum, Kit. ex Spreng. in Comm. Gott. Rec. ii

(1813) Umbell. Animad. 7. t. 1. f. $6=$ Anthriscus sylvestris.

Anthriscus, Lam. Encyc. i. $685=$ Anthriscus vulgaris. arborescens, Linn. Sp. Pl. $259=$ Aralia spinosa?

aristatum, Thunb. Fl. Jap. $119=$ Osmorhiza Claytoni. aromaticum, Linn. Sp. Pl. 259.-Europ.

articulatum, Bosc, ex DC. Prod.iv. $225=$ procumbens. Astrantiae, Boiss. E Bal. ex Boiss. Fl. Orient. ii. 906. -As. Min.

aureum, Linn. Sp. Pl. ed. II. 370.-Europ. ; As. Min. aureum, Linn. Mant. ii. $356=$ temulum.

australe, Crantz, Cl. Umb. Emend. $76=$ Scandix australis.

Biebersteinii, Lag. ex Sweet, Hort. Brit. ed. I. 190.Reg. Caucas.

bifidum, Willd, ex DC. Prod, iv, $225=$ procumbens Boscii, Steud. Nom. ed. II. i. $339=$ procumbens.

brachycarpum, Bieb. ex Hoffm. Gen. Umb. i. 212 millefolium.

bulbosum, Linn. Sp. Pl. 258.-Europ.; As. Min.

byzantinum, Boiss. in Ann. Sc. Nat. Sér. III. ii. 1844) 65.-Byzant. ; As. Min.

cachemiricum, C. B. Clarke, in Hook. f. Fl. Brit. Ind. ii. 691.--Reg. Himal.

cadonense, Schult. ex Steud. Nom. ed. II. i. $339=$ Anthriscus sylvestris.

calabricum, Guss. ex DC. Prod. iv. 227.-Calabria.

californicum, Torr. in Pacif. Rail. Rep. iv. $93=$

Podosciadium californicum.

canadense, Pers. Syn. i. $320=$ Cryptotaenia canadensis

capense, Thunb. Prod. Pl. Cap. $51=$ Annesorbiza capensis.

capnoides, Benth. E Hook. f. Gen. i. 898--Reg. Himal.

Cerefolium, Crantz, Stirp. Austr. ed. I. fasc. iii. $70=$ Anthriscus Cerefolium.

chilense, Poir. Encyc. v. $145=$ Scandix chilensis.

Cicutaria, Vill. Prosp. $26=$ hirsatum.

ciliatum, Kit. ex Kanitg, Reliq. Kitaib. 108.Croatia.

Claytoni, Pers. Syn. i. $320=$ Osmorrhiza brevistylis.

coloratum, Linn. Mant. 57.-Dalmat.; Banat.

creticum, Boiss. E Heldr. Diagn. Ser. I. x. 51.-Ins. Creta.

crinitum, Boiss. in Ann. Sc. Nat. Sér. III. ¿i. (1飞t4 63.-Mesopot.; Persia.

Cyminum, Fisch. ex DC. Prod. iv. $290=$ Conopodium Cyminum.

dasycarpum, Nuti. ex Tor \& Gray, F!. N. Am. i.69S = Tainturieir.

daucifolium, Desf. Cat. Hort. Par. ed. III. 200, $\$ 05=$ Anthriscus alpestris.

daucophyllum, Nutt. ex Tort. \& Gray, Fl. N. Am. $698=$ Tainturieri.

dizaricatum, Poir. Encye. Suppl. iv. $\$ 4$ = Anthriscus fumarioides.

dulce, Fisch. ex Steud. Nom. ed. II. i. $\$ 99$ = Ostuorshiza Claytoni.

elegans, Gasud. Fl. Helv. ii. S64.-Helvet.

Friedrichsstahlii. Cesati, in Bibl. Ital. Ixxv. $\$ S 3=$ Anthriscus tenerrima.

geniculatum, Gilib. F1. Lituan, ii. $29=$ temulum. 


\section{CHAEROPHYLLUM :-}

glaberrimum, Pers. Syn. i. 320 (=Bunium glaberrimum).-Algeria.

gracile, Bess. Hort. Cremen. (1822) $=$ Conopodium Cyminum.

gracillimum, Klotzsch, in Bot. Ergeb. Waldem. Reise, $149=$ Vicatia coniifolia.

grandiflorum, Crantz, Cl. Umb. Emend. 77 ; Lam. Encyc. i. $686=$ Scandix grandifiora.

Heldreichii, Orph. in Boiss. Diagn. Ser. II. ii. 104.Graecia.

hirsutum, Linn. Sp. Pl. 258.-Europ. ; As. Min.

hirsutum, Pall. Tabl. Taur. $49=$ temulum.

hirsutum, Vill. ex Koch, Syn. Fl. Germ. ed. I. $317=$ Villarsii.

hispidum, Thunb. ex Miq. Ann. Mus. Bot. Lugd. Bat. iii. $64=$ Cancalis Anthriscus.

Hladnikianum, Reichb. ex Heynh. Nom. ii. $135=$ Anthriscas fumarioides.

humile, Bieb. Fl. Taur. Cauc. iii. 240.-Reg. Caucas. hybridum, Tenore, Fl. Neap. Prod. p. 1xvi=aureum. infestum, Salisb. Prod. $167=$ Anthriscus sylvestris.

Kotschyi, Fenzl, ex Boiss. Fl. Orient. ii. $913=$ Anthriscus Kotschyi.

lactescens, Rochel, ex Stend. Nom. ed. II. i. $339=$ Anthriscus sylvestris.

laevigatum, Vis. F1. Dalm. iii. $65=$ bulbosum.

lasiolaenum, Boiss. E Bal.ex Boiss. Fl. Orient. ii. 903. -As. Min.

leucolaenum, Boiss. l. c. 905.-Armenia

libanoticum, Boiss. E' Kotschy, Diagn. Ser. II. vi. 89. - Syria.

lucidum, Desf. Cat. Hort. Par. ed. III. $200=$ Anthriscus nemorosa.

macropodum, Boiss. in Ann. Sc. Nat. Sér. III. ii. (1844) 64.-Persia.

macrospermum, Fisch. E Mey. ex Hohen. in Bull. Soc Nat. Mosc. (1838) 327.-Reg. Caucas.

maculatum, Willd. Enum. Hort. Berol. Suppl. 15 aureum.

magellense, Tenore, Prod. Fl. Neap. App. iv. 15. Neapol.

Meyeri, Boiss. Ẽ Buhse, in Nouv. Mém. Soc. Nat. Mosc. xii. (1860) 103.-Persia.

millefolium, DC. Prod. iv. 226.-Reg. Caucas.

millefolium, Klotzsch, in Bot. Ergeb. Waldem. Reise,

$149=$ Vicatia millefolia

minimum, Vand. Fasc. Pl. 11.-Italia.

monogonum, Kit. ex Link, Enum. Hort. Berol. i. 281 = aureum.

neglectum, Zinger, in Bull. Soc. Nat. Mosc. 1vi. (1881) I. 313 - - Rossia.

nemorosum, Hoffm. Gen. Umb, $45=$ Anthrisctis nemorosa.

nemorosum, Lag. ex DC. Prod. iv. 224=Anthriscus Cerefolium.

nitens, Turcz. ex Bernh. in Linnaea, xii. (1838) Litt. $76=$ Anthriscus nitens.

nitidum, Wahlenb. Fl. Carp. $85=$ Anthriscus alpestris. nodosum, Crantz, $\mathrm{Cl}$. Umb. Emend. 76 ; Lam. Encyc. i. 685.-Europ.; As. Min.; Afr. bor.

odoratum, Crantz, 1. c. 75 ; Lam. 1. c. 683 ; Fl. Fr. iii. $439=$ Myrrhis odorata.

orientale, Willd. ex Boiss. FI. Orient. ii. $908=$ byzantinum.

orthostylum, Trautv. in Act. Hort. Petrop. iii. II. (1875) 273.--Reg. Caucas.

pallescens, Presl, ex DC. Prod. iv. 227 = hirsutum.

palustre, Lam. Encyc. i. $683=$ hirsutum.

Pecten-Veneris, Crantz, Stirp. Austr. ed. I. fasc. ii. 66 ; ed. II. $189=$ Scandix Pecten-Veneris.

pinnatifidum, Poir. Encyc. v. $144=$ Scandix pinnatifida.

polonicum, Fastrzebowski, ex Rostaf. Fl. Polon. Prod. 112,-Enrop.

Prescottii, DC. Prod. iv. $225=$ bulbosum.

procumbens, Crants, Cl. Umbell. Emend. 77.-Am. bor.

reflexum, Aitch. in Journ. Linn. Soc. xiii. (1882) 164 $=$ villosum.

reflexum, Lindl. in Royle, Illustr. Bot. Himal. 233.Reg. Himal.

rigidum, Huet, ex Nym. Consp. $300=$ Villarsii

roseum, Bieb. Fl. Taur. Cauc. i. 234.-Reg. Caucas.

rostratum, Lam. Encyc. i. $685=$ Scandix PectenVeneris.

sativum, Bieb. F1. Taur. Cauc. i. $232=$ Caucalis trichosperma.

sativum, Lam. Fl. Fr. iii. $438=$ Anthriscus Cerefolium.

\section{CHAEROPHYLLUM :-}

scabrum, Thunb. Fl. Jap. $119=$ Caucalis Anthriscus.

siculum, Guss. Fl. Sic. Prod. i. $352=$ Anthriscus sicula.

sphallerocarpus, Kar. E Kir. in Bull. Soc. Nat. Mosc. xv. (1842) 367. - Soongaria.

sylvestre, Bieb. Fl. Taur. Canc. i. $231=$ maculatum.

sylvestre, Linn. Sp. PI. $258=$ Anthriscus sylvestris.

syriacum, Hempr. E Ehrenb. ex Boiss. Fl. Orient. ii 904.-Syria.

Tainturieri, Hook. \& Arn. in Hook. Comp. Bot. Mag. i. (1835) 47.-Texas.

temulentum, Linn. Fl. Suec. $94=$ temulum.

temuloides, Boiss. in Ann. Sc. Nat. Sér. III. ii. (1844) 64.-Persia.

temulum, Linn.Sp. Pl. 258.-Europ.; Afr. bor.; Reg. Caucas.

tenuifolium, Poir. Encyc. Suppl. iv. 342.-Marocco.

tenuifolium, Stev, in Hoffm. Gen. Umbell. ed. II $212=$ millefolium.

tomentosum, Poir. ex Steud. Nom. ed. II. i. 339.Hab.?

torquatum, DC. F1. Fr. Suppl. $505=$ Anthriscus alpestris.

trapezuntinum, Boiss. F1. Orient. ii. $903=$ temuloides.

trichospermum, Lam. Encyc. i. $685=$ Cancalis trichosperma.

tuberculosum, Poir. Encyc. Suppl. iv. 342=Anthriscus fumarioides.

tuberosum, C. A. Mey, ex Regel, in Act. Hort. Petrop. v. $(\mathbf{1 8 7 7}) 587=$ Carum cylindricum.

tuberosum, Royle, Illustr. Bot. Himal. 231--Reg. Himal.

tumidum, Gilib. Fl, Lituan, if. $28=$ Anthriscus sylvestris.

umbrosum, Jord. Obs. Pl. Crit. vii. (1849) $30=$ hirsutum verticillatum, Pers. Syn, i. $320=$ bulbosum, Anthriscus vulgaris.

Villarsii, Koch, Syn. Fl. Germ. ed. I. 317.-Europ.

villosum, Wall. Cat. n. 558.- Reg. Himal.

villosum, Wall. 1. c. partim = reflexum

CHAETACANTHUS, Nees, in Lindl. Introd. Nat. Syst. ed. II. $444(1836)=$ Calophanes,D. Don (Acanthac.). Burchellii, Nees, in DC. Prod. xi. $462=$ Cal. Burkei. costatus, Nees, 1. c. $=$ Calophanes costatus.

glandulosus, Nees, 1. c. = Calophanes Persoonii.

Persoonii, Nees, in Linnaea, xv. (1841) $357=$ Calophanes Persoonii.

repandus, A. Gray, in Proc. Am. Acad. v. (1861-62) 349.-Ins. Fiji.

setigera, Nees, in Lindr. Introd. Nat. Syst. ed. II. 444 =Calophanes Persoonii.

CHAETACHLAENA, D. Don, in Trans. Linn. Soc. xvi. (1830) $256=$ Onoseris, DC. (Compos.). acerifolia, D. Dietr. Syn. P1. iv. $1565=0$. acerifolia. annua, D. Dietr. 1. c. =O. annua.

Cumingii, D. Dietr. I. c. $=$ O. Cumingii.

odorata, D. Don, in Trans. Linn. Soc. xvi. (1830) 256 $=\mathrm{O}$. odorata.

CHAETACHME, Planch. in Ann. Sc. Nat. Sér. 111. x. (1848) 340. URTICACEAE, Benth. \& Hook. f. iii. 356.

aristata, Planch. l. c. 341.-Afr. austr.

madagascariensis, Baker, in Fourn. Linn. Soc. xxi. (1885) 443.-Madag.

Meyeri, Harv. Thes. Cap. i. $16=$ aristata

nitida, Planch. \& Harv. in Harv. Thes. Cap. 16.-Afr, austr.

CHAETADELPHA, A. Gray, ex S. Wats. in Am. Natural. vii. (1873) 301; et in Proc. Am. Acad. ix. (1874) 218. COMPOSITAE, Benth. \& Hook. f. ii. 1238 .

Wheeleri, A. Gray, ll. cc.-Arizona.

CHAETAEA, Jacq. Enum. Pl. Carib. $2(1760)=$ Buettneria, Loefl. (Stercul.).

aculeata, Jacq. 1. c. $\mathbf{1 7}=\mathrm{B}$. carthaginensis.

CHAETAGASTRA, Crueg. in Linnaea, xx. (1849) 101 , sphalm.= CHAETOGASTRA, DC. = Tibouchina, Aubl. (Melast.).

CHAETANTERA, Less. Syn. Comp. 111 (1832) = Chaetanthera, Ruiz \& Pav. (Compos.)
CHAETANTHERA, Nutt. in Joum. Acad. Philad. vii. (1834) 111 = Chaetopappa, DC. (Compos.).

asteroides, Nutt. 1. c. = Chaetopappa asteroides,

CHAFTA NTHERA, Ruiz\& Pav, Prod. Fl, Per 106 . 23 (1794). COMPOSITAE, Benth. \& Hook. f. ii. 496. Aldunatea, Remy, in C. Gay, Fl. Chil. iii. 320 . t. 38 (1849).

Carmelita, C. Gay, in DC. Prod. vii. 14 (1838)

Cherina, Cass. in Dict. Sc. Nat. viii. 437 (1817)

CHONDRoChilus, Phil. in Linnaea, xxviii. (1856) 711.

Egania, Remy, in C. Gay, Fl. Chil. iii. 324 (1849)

Elachia, DC. Prod. vii. 256 (1838).

Euthrixia, D. Don, in Trans. Linn. Soc. xvi. (1830) 257.

Minythodes, Phil. ex Benth. \& Hook.f. Gen. ii. 496 (1873).

Oriastrum, Poepp. \& Endl. Nov. Gen. et Sp. iii. 50.t. $257(1847)$

Proselia, D. Don, in Trans. Linn. Soc. xvi. (1830) 234.

Tylloma, D. Don, 1. c. 238 (1830)

argentea, D. Don, in Phil. Mag. (1832) $392=$ chilensis. argentea, Phil. in Anal. Univ. Chil. (1872) 739.-Chili. Berteriana, Less. Syn. Comp. 111.-Chili.

Berteroana, Hook. \& Arn. in Comp. Bot. Mag. i. (1835) $104=$ praec.

Caput-Tringae, Less. ex DC. Prod. vii. $32=$ limbata. chilensis, DC. in Ann. Mus. Par.xix. (1812) 70,-Chili. chilensis, Hook \& Arn in Bot. Beech. Voy, $29=$ incana. ciliaris, Bert. ex Steud. Nom. ed. II. i. $340=$ spathulata. ciliata, Ruiz \& Pav. Syst. Veg. Per. et Chil. 190.-Chili. crenata, Remy, in C. Gay, Fl. Chil. iii. 302.-Chili. crispa, Phil. in Anal. Univ. Chil. (1872) 739.-Chili. dealbata, Hook. E Arn. in Comp. Bot. Mag. i. (1835) 104.-Chili.

debilis, Meyen \& Walp. in Nov. Act. Nat. Cur. xix. Suppl. i. (1843) 287.-Chili.

elegans, Phil. in Linnaea, xxviii. (1856) 712.-Chili. eryngioides, D. Don, in Phil. Mag. (1832) $391=$ tenuifolia.

flabellata, D. Don, 1. c. = multicaulis.

glandulosa, Remy, in C. Gay, Fl. Chil. iii.311.t. 35. f. 1.-Chili.

grandiflora, Steud. Nom. ed. II. i. 340.-Chili.

humilis, Phil. in Anal. Univ. Chil. (1872) 740.-Chili. incana, Poepp. ex Less. in Linnaea, v. (1830) 284 ... Chili.

Kunthiana, Less. Syn. Comp. $114=$ tenella.

limbata, Less. l. c. 116.-Chili.

linearifolia, Poepp. ex Stend. Nom. ed. II. i. $340=$ linearis.

linearis, Poepp. ex Less. Syn. Comp. 112.-Chili.

linifolia, Bert. ex Less. l. c.-Chili.

magellanica, Spreng. Syst. iii. $503=$ Perezia lactucoides. microphylla, Hook. \& Arn. in Comp. Bot. Mag. i. (1835) $104=$ linifolia

moenchioides, Less. Syn. Comp. 113.-Chili.

multicaulis, $D C$. Prod. vi. 31.-Chili.

multiflora, Humb. \& Bonpl. Pl. Aequin. ii. $168=$ Perezia multiflora

peruviana, A. Gray, in Proc. Am. Acad. v. (1861) 144. -Peruv.

pinnatifida, Humb. \& Bonpl. P1. Aequin. ii. $170=$ Perezia pinnatifida.

prostrata, D. Don, in Phil. Mag. (1832) $391=$ multicaulis.

pungens, Humb. \& Bonpl. Pl. Aequin. 146. t. $127=$ Perezia pungens.

pusilla, Hook. E' Arn. in Comp. Bot. Mag. i. (1835) 106.-Chili.

ramosissima, Hook. \& Arn. 1. c. 104=moenchioides, tenella.

recurvata, Spreng. Syst. iii. $503=$ Perezia recurvata. scariosa, D. Don, in Phil. Mag. (1832) 391=incana sericea, Lag. ex DC. Prod. vii. $30=$ chilensis.

serrata, Ruiz \& Pav. Syst. Veg. Per. et Chil. $191=$ chilensis.

spathulata, Poepp. ex Less. in Linnaea, v. (1830) 285. -Chili.

spinulosa, Cass, Opusc. ii. $103=$ tenuifolia.

tenella, Less. Syn. Comp. $114 ; D C$. in Deless. Ic. Sel. iv. t. 82.-Chili.

tenuifolia, D. Don, in Phil. Mag: (1832) 391.-Chili. valdiviana, Phil. in Linnaea, xxviii. (1856) 712.-Chili. villosa, D. Don, in Phil. Mag. (1832) 391.-Chili. Volkmanni, Phil. in Anal. Univ. Chil. (1872) 740.Chili. 
CHAETANTHUS, R. Br. Prod. 251 RESTIACEAE, Benth. \& Hook. f. iii. 1034. Prionosepalum, Steud. Syn. Pl. Cyp. 266 (1855). leptocarpoides, $R, B r . l$. c. -Austral.

CHAETARIA, Beauv. Agrost. 30.t. $8(1812)=$ Aristida, Linn. (Gramin.)

Adscensionis, Roem. \& Schult. Syst. ii. $390=$ A. Adscen sionis.

affinis, Roem. \& Schult. Syst. ii. Mant. $210=$ A. pur purascens.

Antillarum, Roem. \& Schult. Syst. ii. 395 = A. Antillarum.

Ascensionis, Beauv. Agrost. $\mathbf{3 0}=\mathrm{A}$. Adscensionis.

bipartita, Nees, F1. Afr. Austr. i. 187=A. bipartita. bromoides, Roem. \& Schult. Syst. ii. $396=$ A. setifolia.

caerulescens, Beauv. Agrost. $30=\mathrm{A}$. coerulescens calicina, Beauv. l. $\mathrm{c},=\mathrm{A}$. calycina.

canariensis, Beauv. 1. $c_{0}=\mathrm{A}$. coerulescens.

capensis, Beauv. 1. $c_{0}=$ A. capensis.

capillacea, Beauv. 1. c. = A. capillacea

capillaris, Nees, Agrost. Bras. $388=$ A. capillacea

coarctata, Roem. \& Schult. Syst. ii. $396=$ A. setifolin.

congesta, Nees, Fl. Afr. Austr. $189=$ A. congesta.

curvata, Nees, 1. c. $186^{\circ}=$ A. coerulescens.

cyanantha, Nees, ex Steud. Syn. P1. Gram. $141=$ A. cyanantha.

depressa, Beauv. Agrost. 30=A. Adscensionis. divaricata, Beauv. 1. $\mathrm{c}_{\mathrm{s}}=\mathrm{A}$. divaricata. divaricata, Nees, Agrost. Bras. 387 = A. longifolia. elatior, Beauv. 1. c. $=\mathrm{A}$. coerulescens,

elliptica, Nees, Agrost. Bras. $389=$ A. elliptica. fasciculata, Roem. \& Schult. Syst. ii. Mant. $578=$ A. fasciculata.

festucoides, Beauv. Agrost. $30=\mathrm{A}$. Adscensionis.

Forskolii, Nees, Fl. Afr. Austr. $188=$ A. paniculata.

furcata, Beauv. Agrost. 30 (=Eutriana juncifolia).Ind. oce.

gibbosa, Nees, Agrost. Bras. $383=$ A. gibbosa.

gigantea, Beauv, Agrost. $30=\mathrm{A}$. Adscensionis.

glauca, Nees, in Linnaea, xix. (1847) $688=\mathrm{A}$. longiramea.

gossypina, Beauv. Agrost. 30 ; Roem. \& Schult. Syst. ii $391=$ A. gossypina.

Histrix, Beauv. 1. c. = A. Hystrix.

humilis, Roem. \& Schult. Syst. ii. $396=$ A. humilis

Hystrix, Roem. \& Schult. 1. c. $390=$ A. Hystrix.

interrupta, Beauv. Agrost. $30=\mathrm{A}$. interrupta.

laevis, Nees, Agrost. Bras. ii. $384=$ A. laevis.

Lamarckii, Roem. \& Schult. Syst. ii. 393'= A. stipiformis.

Iuroniensis, Beauv. Agrost. $30=\mathrm{A}$. luzoniensis. mauritiana, Nees, Fl. Afr. Austr. $188=\mathrm{A}$. Adscensionis.

megapotamica, Roem. \& Schult. Syst. ii. Mant. $578=$ A. megapotamica.

murina, Nees, ex Trin. \& Rupr. in Mém. Acad. Pétersb.

Sér. VI. vii. (1849) $160=$ A. Royleana.

nana, Nees, ex Steud. Nom. ed. II. i. $340=$ A. nana

olygantha, Beauv. Agrost. $30=\mathrm{A}$. oligantha.

pallens, Benuv. 1. c. = A, oligantha

purpurascens, Beauv. 1. c. $=\mathrm{A}$. coerulescens.

racemosa, Beauv. 1. $c_{.}=\mathbf{A}$. racemosa

ramosa, Roem. \& Schult. Syst. ii. $397=$ A. ramosa.

recurvata, Roem. \& Schult. 1. c. = A, recurvata.

Royleana, Nees, ex Steud. Syo. PI. Gram. 143=A. Royleana.

setacea, Beauv. Agrost. $30=$ A. setacea

setifolia, Roem. \& Schult. Syst. ii. $396=$ A, setifolia.

Sieberiana, Roem. \& Schult. Syst. ii. Mant. $578=$

A. Hystrix

spadicea, Roem. \& Schult. Syst. ii. $397=$ A. spadicea.

spadicea, Nees, Agrost. Bras. $385=$ A. tincta.

squarrosa, Roem. \& Schult. Syst. ii. Mant. $577=$

A. squarrosa.

stipaeformis, Beauv. Agrost. $30=$ Avena stipneformis.

tormis.
stricta, Beauv, 1. $c_{0}=\mathrm{A}$, stricta

teneriffa, Beauv. 1. c. $=$ Panicum Teneriffac

torta, Nees, Agrost. Bras. $986=$ A. tincta.

trichodes, Nees, in Hook. Kew Journ. ii. (1850) 101 =

A. Cumingiana.

tuberculosa, Roem. \& Schult. Syst. ii. Mant. 211

A. tuberculosa.

vestita, Beauv. Agrost. $30=$ A. vestita.
CHAETHYMENIA, Hook, \& Arn. Bot. Beech. Voy. 298. t. 62 (1841) = Jaumea, Pers. (Compos.)

peduncularis, Hook. \& Am. 1. c. = J. peduncularis.

CHA ETIUM, Nees, Agrost. Bras. 269 (1829). GRA. MINEAE, Benth. \& Hook. f. iii. 1104.

Berchtoldia, Presl, Rel, Haenk. 323. t. 43 (1830)

bromoides, Benth, in Fourn. Linn. Soc. xix. (1881)

46.-Mexic.

festucoides, Nees, Agrost. Bras. 270.-Bras.

CHAETOBROMUS, Nees, in Lindl. Introd. Nat. Syst. ed. II. $449(1836)=$ Danthonia, DC. (Gıamin.) Dregeanus, Nees, FI. Afr. Austr. $343=$ D. Dregeana. fascicularis, Nees, 1. c. $341=\mathrm{D}$. fascicularis. interceptus, Nees, 1. c. $342=$ D. intercepta. involucratus, Nees, in Lindl. Introd. Nat. Syst. ed. II $449=\mathrm{D}$. involucrata.

CHAETOCALYX, DC. Mém. Lég. 262 (1825). LEGUMINOSAE, Benth. \& Hook. f. i. 513

BonnInghausia, Spreng. Syst. iii. 245 (1826).

Planarium, Desv. in Ann. Sc. Nat. Sér. I. ix。 (1826) 416.

RHadinocarpus, Vog. in Linnaea, xii. (1838) 108. acutiflora, Benth. in Mart. Fl. Bras. xv. I. 75.-Am. austr.

brasiliensis, Benth. l. co-Am. austr.

hebecarpa, Benth.l. c. 76.-Am, aust

latifolia, Benth. l. c. 75-Am, austr.

latisiliqua, Benth. Bot. Voy. Sulph. 81. t. 30.Panama.

longiflorus, Benth. ex A. Gray, Bot. U. St. Expl. Exped. i. 423 .-Bras.

parviflora, Benth. in Mart. Fl. Bras. xv. I. 74.-Am. austr.

polyphylla, Benth. l. c. 76.-Am. austr.

pubescens, $D C$. Prod. ii. 243.-Ins. S. Doming.

Schottii, Torr. in Bot. Mex. Bound. 56.-N. Mexic

vincentina, DC. Prod. ii. 243.-Ins. S. Vincent.

Wislizeni, A. Gray, Pl. Wright. i. 51.-Am. bor, occ.

CHAETOCAPNIA, Sweet, Hort. Brit, ed. III. 685 $(\mathbf{1 8 3 9})=$ COETOCAPNIA, Link \& Otto = Bravoa, Lex. (Amaryllid.),

geminiflora, Sweet, 1. c. $=$ B. geminiflora.

CHAETOCARPUS, Schreb. Gen. $75(1789)=$ Pouteria, Aubl. (Sapotac.)

Ponteria, J. F. Gmel. Syst. $248=$ P. guianensis.

CHAETOCARPUS, Thw. in Hook. Kew Journ, vi 1854) $300 . t$. 10 EUPHORBIACEAE, Benth, Hook. f. iii. 323 .

RegnaldiA, Baill. Adansonia, i. (1860-61) 187

Blanchetii, Muell. Arg. in Mart. Fl. Bras. xi. I1. 507 -Bras.

castanocarpus, Thw. Enum. Pl. Zeyl. 275.-Ind. or. Malaya.

coriaceus, Thw.l.c.-Zeylan.

myrsinites, Baill. Adansonia, xi. (1873) 95.-Bras,

Pohlii, Muell. Arg. in Mart.Fl. Bras, xi. s1. 508.-Bras.

pungens, Thw. in Hook. Kew Journ. vi. (1854) $301=$ castanocarpus, coriaceus.

CHAETOCEPHALA, Barb. Rodr. Orch. Nov. ii. 37 $(1881)=$ Pleurothallis, R. Br. (Orchid.).

lonchophylla, Barb. Rodr. 1. c. 39.-Bras.

punctata, Barb. Rodr. 1. c. 38.-Bras.

CHAETOCHILUS, Vahl, Enum. i. 101 (1805)

Schwenkia, Linn. (Solanac.)

lateriflorus, Vahl, 1. $\mathrm{c}_{0}=\mathrm{S}$. brasiliensis.

CHAETOCLADUS, Senilis [Nelson], Pinaceae, 161 $(1866)=$ Ephedra, Linn. (Gnetac.).

altissima, Senilis [Nelson], 1. c. $162=\mathrm{E}$. altissima

distachys, Senilis [Nelson], 1, c. $=\mathbf{E}$. vulgaris.

fragilis, Carr. Conif. ed. II. 860, Index = E. fragilis.

monostachys, Serilis [Nelson], Pinac. $162=E$. vul. garis.

CHAETOCRATER, Ruiz \& Pav. Prod. F1. Per. 61. t S6 (1799)= Casearia, Jacc. (Samydac.).

capitatus, Ruiz \&c Pav, Fl. Per. iv. 1. 396 ; Syst. 108 Casearia sylvestris.

fasciculatus, Ruiz \& Pav. 11. ce $\$ 96,107$ = Casearia punctata.
CHAETOCYPERUS, Nees, in Linnaea, ix. (1834) $28:$ Eleocharis, R. Br. (Cyperac.)

acicularis, Nees, in Mart. Fl. Bras, ii. I. $94=1$ acicularis.

albibracteatus, Nees \& Meyen, in Act. Nov. Nat. Cur. xix. Suppl.i. (1843) $95=$ E. albibracteata.

arenicola, Stead. Syn. Pl. Cyp. $73=\mathrm{E}$. Chaetaria.

Baldwinii, Torr. in Ann. Lyc. N. York, iii. (1836) $295=\mathrm{E}$. Baldwinii.

bonariensis, Nees, in Mart, Fl. Bras. ii. I. $96=\mathrm{L}$ bonariensis.

capillaceus, Nees, 1. c. $93=$ E. capillacea

costulatus, Nees \& Meyen, in Act. Nov. Nat. Cur. xix. Suppl. i. (1843) $96=\mathrm{E}$. acicularis.

depauperatus, Steud. Syn. Pl. Cyp. $73=$ E. Chaetaria. marginatus, Nees, in Mart. Fl. Bras, ii. I. 96.Bras.

Famesoni, Steud. Syn. Pl. Cyp. 74.-Ecuador.

Limnocharis, Nees, in Wight, Contrib. $96=\mathrm{E}$ Chaetaria.

membranaceus, Buckl. in Proc. Acad. Sc. Philad. '1862' 1863) $10=$ Scirpus nanus.

niveus, Liebm. in Vidensk. Selsk. Skr. V. ii. (1851.

$242=\mathrm{E}$. Chaetaria.

obtusatus, Nees, in Mart. F1. Bras, ii. I. $94=\mathrm{E}$ Chaetaria.

polymorphus, Nees, in Linnaea, ix. (1834) $289=\mathrm{E}$. acicularis, ochreata, Scirpus cernuus, nants. punctatus, Nees, in Mart. Fl. Bras. ii. 1. 93.-Bras. pusillus, Steud. Syn. Pl. Cyp. $74=$ Scirpos nanus. pygmaeus, Torr. ex A. Gray, Man. Bot. N. U. St. 524= Scirpus nanus.

radicans, Steud. Syn. PI. Cyp. $74=E$. acicularis. reptans, Boeck. in Flora, $\mathbf{x l}$. (1857) $34=\mathrm{E}$. minima rugulosus, Nees, in Bonplandia, 1ii. (1855) $86=\mathrm{E}$ Chaetaria.

setaceus, Nees, in Mart. Fl. Bras. ii. I. $94=\mathrm{E}$. Chac taria.

stoloniferus, Nees, in Linnaea, xix. (1847) $695=\mathrm{E}$. montana.

subarticulatus, Nees, in Mart. Fl. Bras. ii. 1. 96.Bras.

tenuiculus, Nees, 1. c. = E. Rothiana.

trichoides, Steud. Syn. Pl. Cyp. $73=$ E. acicularis, urceolatus, Liebm. in Vidensk. Selsk, Skr. V. ii. (1851) $243=$ E. minima.

viviparus, Nees, in Mart. Fl. Bras. ii. I. $93=\mathrm{E}$ tenuissima

CHAETODISCLS, Steud. Syn. Pl. Cyp. $261 ; 1=5$. Eriocaulon, Linn.

Gilberti, Steud. 1. c.-Anstral.

CHAETOGASTRA, DC. Prod. iii. 131 (1828); Naud. in Ann. Sc. Nat. Sér. III. xiv. (1850) $127=$ Tibouchina, Aubl. (Melast.)

alpestris, Mart. Nov. Gen. et Sp. iii. $101=$ Pterolepis alpestris.

asperior, Cham. in Linnaea, ix. (1894) $485=T$. asperior.

bicolor, Naud, in Ann. Sc. Nat. Sér. III. xiv. (1S50' 128 (= Pleroma bicolor).-Boliv.

Bonplandiana, Naud. 1. c. $137=$ Brachyolam ledifolium.

Callichacta, Benth. in Hook. Journ. Bot. ii. (1840) 241 = Pterolepis glomerata.

campanularis, Benth. P1. Hartw. $191=$ Brachyotum Benthamianum.

campanularis, Naud. in Ann. Sc. Nat. Serr. III. xiv. (1850) 180 = Brachyotum campanulare.

canescens, DC. Prod. iii. $194=$ Brachyotum canescens. cardinalis, DC. 1. c. $=$ T. cardinal is.

cataphracta, Cham, in Linnaea, ix (1591) $451=$ Pterolepis cataphracta.

cermua, DC. Prod. iii. $135=$ Brachyotum cemoum.

Chamaccistus, Griseb. Fl. Brit. W. Ind. $267 \mathrm{i}=$ Pleroma Chamaecistus).-Ind. oec.

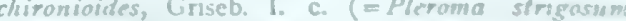
chironsimidess.--Ind oce.

ciliaris, DC, Prod iii. 132 (a Pleroma ciliorr) - N. Granat

ristoides, Griseb. Fl. Brit. W: Ind. $20 \%$ (= Pleromat cisterides). -Ins. S. Vincent.

clinopodifolia, DC. Prod. iii. 193 - T. clinopos: folia.

conficrsa, DC. 1. c. 185 - Brachyotum confertum.

cubersis, Griscb. Cal PI. Cub. 108-Chactoleris saturacivides. 


\section{CHAETOGASTRA :-}

debilis, Cham. in Linnaea, ix. (1834) $499=$ Tibouchina debilis.

debilis, Miq. in Linnaea, xxii. (1849) $540=\mathrm{T}$. ursina. depauperata, Naud. in Ann. Sc. Nat. Sér. III. xiv (1850) $129=\mathrm{T}$. longifolia.

divaricata, DC. Prod. iii. $132=$ Pterogastra divaricata echinata, DC. Prod. iii. 135 (=Pleroma echinatum) -Peruv.

ferruginea, Hook. \& Am. Bot. Beech. Voy. $423=\mathrm{T}$. longifolia.

floribunda, Griseb. in Lechl. Berb. Am. Austr. $59=$ Brachyotum floribundum.

fraterna, DC. Prod. iii. $133=$ T. gracilis.

Geitneriana, Schlecht. in Linnaea, xxvii. (1854) 523.N. Granat.

glomerata, Benth. in Hook. Journ. Bot. ii. (1840) 290 $=$ Pterolepis glomerata.

Goudotii, Naud. in Ann. Sc. Nat. Sér. III. xiv. (1850) $131=$ Brachyotum strigosum.

gracilis, DC. Prod. iii. $133=$ T. gracilis.

havanensis, DC. 1. c. $132=$ T. longifolia.

hermannioides, Naud. in Ann. Sc. Nat. Sér. III. xiv.

(1850) $183=$ Brachyotum hermannioides.

hieracioides, DC. Prod. iii. $133=\mathrm{T}$. hieracioides.

hirsuta, DC. 1. c. $=$ T. gracilis

hispida, DC. 1. c. $132=$ T. longifolia.

hypericoides, DC. 1. c. = Desmoscelis villosa.

ladanoides, Mart. Herb. F1. Bras. n. $500=$ Pterolepis trichotoma.

lanceolata, DC. Prod, iii. $131=\mathrm{T}$. longifolia.

lasiophylla, Benth. in Hook. Journ. Bot. ii. (1840) 291 $=\mathrm{T}$. lasiophylla.

lepidota, DC. Prod. iii. $134=$ T. lepidota.

Lhotskyana, Stend. in Flora, xxvii. (1844) $720=\mathrm{T}$ Lhotzkyana.

Lindeniana, Planch. in Fl. des Serres, Sér. I. (1854-55) 113. $\mathrm{t}$. $1011-12=\mathrm{T}$. grossa.

longifolia, DC. Prod. iii. $132=\mathrm{T}$. longifolia

lutescens, Griseb. ex Triana, in Trans. Linn. Soc xxviii. (1871) $48=$ Brachyotum lutescens.

lutescens, Naud. in Ann. Sc. Nat. Sér. III. xiv. (1850)

$134=$ Brachyotum Naudini.

lychnitoides, DC. Prod. iii. $132=$ Desmoscelis villosa

Martiana, Benth. in Hook. Journ. Bot. ii. (1840) $290=$ T. herbacea.

microdon, Naud. in Ann. Sc. Nat. Sér. III. xiv. (1850)

$134=$ Brachyotum microdon.

microphylla, Naud. 1. c. $136=$ Brachyotum microphyllum.

mollis, DC. Prod. iii. 134 (=Pleroma exappendicu. latum).-.-Peruv.

Moritziana, Klotzsch, ex Triana, in Trans. Linn. Soc xxviii. (1871) 46 (=Pleroma Naudinianum). $-\mathrm{N}$ Granat.

multiflora, Benth. PI. Hartw. 181=Monochaetum

Hartwegianum.

muricata, DC. Prod. iii. $134=$ T. grossa.

Naudiniana, Decne. in Rev. Hortic. Sér. III. i. (1847) 86 (=Pleroma Naudinianum).-Mexic.

nigritella, Naud. in Ann. Sc. Nat, Sér. III. xiv. (1850)

$137=$ Bucquetia nigritella

origanoides, Griseb. Cat. Pl. Cub. $103=$ Chatolepis cubensis.

panicularis, Naud. in Ann. Sc. Nat. Sér. III. xiv (1850) 129 (=Pleroma paniculare).-Bolivia.

Pentlandii, Naud. 1. c. $133=$ Brachyotum Pentlandi.

quinquenervis, Naud. I. c. $130=$ Brachyotum quin quenerve.

repanda, Mart. Nov. Gen. et Sp. iii. 100. t. $246=$ Pterolepis repanda.

reticulata, DC. Prod. iii. $131=$ T. reticulata

rhynchanthera, Benth. Pl, Hartw. $180=$ Monochaetum Bonplandii.

rosea, Regel, Cat. Pl. Hort. Aksakov, 31.-Hab.?

rosmarinifolia, Benth. Pl. Hartw. $131=$ Miconia ledi folia.

rosmarinifolia, Naud. in Ann. Sc. Nat. Sér. III. xiy.

(1850) 131 = Brachyotum rosmarinifolium.

rostrata, Naud. 1.c. $135=$ Brachyotum rostratum

rufipilis, Schlecht. in Linnaea, xiii. (1839) 430 (=Pleroma rufipile) - -Mexic.

sanguinolenta, Naud. in Ann. Sc. Nat. Sér. III. xiv. (1850) 131 - Brachyotum sanguinolentum.

sarmentosa, DC. Prod. iii. 134 (=Pleroma laxum).Peruv.

saturejoides, Griseb. Cat. P1. Cub. 103=Chaetolepis saturaeioides.

\section{CHAETOGASTRA :-}

scabriuscula, Schlecht. in Linnaea, xiii. (1839) 431 (=Pleroma scabriusculum).-Mexic.

Schiedeana, Cham. \& $c$ Schlecht. in Linnaea, v. (1830) 565 (=Pleroma rufipile).-Mexic.

sherardioides, DC. Prod. iii. $133=$ Pterolepis glomerata.

speciosa, DC. 1. c. 131= Meriania speciosa

stachyoides, DC. 1. c. $132=$ Desmoscelis villosa

stricta, Benth. Pl. Hartw. $180=$ Brachyotum cernuum

stricta, DC. Prod. iii. $134=$ Brachyotum strigosum.

strigillosa, DC. 1. c. $\mathbf{1 3 3}=\mathrm{T}$, gracilis

strigosa, DC. 1. c. iii. 134 (=Pleroma strigosum).Am. austr.

striphnocalyx, Mart. Nov. Gen. et Sp. iii. 101. t. $246=$ Pterolepis striphnocalyx.

sulphurea, Naud, in Ann. Sc. Nat. Sér. III. xiv. (1850) $135=$ Brachyotum ledifolium.

tortuosa, DC. Prod. iii. 132 (=Pleroma mexicanum) -Mexic.

Weddelliana, Naud. in Ann. Sc. Nat. Sér. III. xiv, (1850) 129 (=Pleroma paniculare).-Bolivia.

CHAETOLEPIS, Miq. Comm. Phyt. ii. 72 (1828) MELASTOMACEAE, Benth. \& Hook. f. i. 744.

Haplodesmium, Naud. in Ann. Sc. Nat. Sér. III xiv. $(1850)$ 154.t. 5

TrimeranthUS, Karst. in Linnaea, xxx. (1859-60) 159.

alpestris, Triana, in Trans. Linn. Soc. xxviii. (1871) 51.-Venezuela.

alpina, Naud. in Ann. Sc. Nat. Sér. III. xiv. (1850) 140.-Bras.

anisandra, Naud. l. c.-Bras.

cubensis, Triana, in Trans. Linn. Soc. xxviii. (1871) 51.-Cuba.

ericoides, Triana, 1. c. 51 . t. 3. f. $35 \mathrm{~g}=$ Marcetia ericoides.

heterophylla, Triana, l.c. 51.-Uruguay.

Lindeniana, Triana, l. c.-N. Granat.

loricarella, Triana, l. $c_{0}-\mathrm{N}$. Granat.

microphylla, Miq. Comm. Phyt. 72.-N. Granat.

saturaeioides, Triana, in Trans. Linn. Soc. xxviii. (1871) 51.-Cuba.

thymifolia, Triana, l.c. 50.-N. Granat.

CHAETONYCHIA, Sweet, Hort. Brit. ed. III. 263 1839) = Paronychia, Juss.

cymosa, Sweet, 1. c. $=$ P. cymosa.

CHAFTOPAPPA, DC. Prod. v. 301 (1836)。 COM POSITAE, Benth. \& Hook. f. ii. 268.

Chaetanthera, Nutt. in Journ. Acad. Sc. Philad. vii. (1834) 111

Chaetophora, Nutt. ex DC. Prod. v. 301 , in syn. (1836).

Diplostelma, Rafin. ex Torr. \& Gray, Fl. N. Am. ii. $187(1840)$.

Distasis, DC. Prod. v. 279 (1836).

asteroides, $D C$. l. c. 301. - Am. bor.

modesta, A. Gray, in Proc. Am. Acad. xvi. (1881) 82. -Mexic.

Parryi, A. Gray, $l$. c.-Texas.

CHAETOPHORA, Nutt. ex DC. Prod. v. 301, in syn. (1836) = Chaetopappa, DC. (Compos.).

asteroides, Nutt. ex DC. 1. $\mathrm{c} .=$ Chaetopappa asteroides,

CHAETOPTELEA, Liebm. in Kjoeb. Vidensk. Meddel. (1850) $76=$ Ulmus, Linn. (Urticac.).

mexicana, Liebm. 1. c. $77=\mathrm{U}$. mexicana.

CHAETOSCIADIUM, Boiss. Fl. Orient. ii. 1078 (1872) $=$ TORILIS, DC. = Caucalis, Linn. (Umbellif.). trichospermum, Boiss. 1. c. = Cauc. trichosperma.

CHAETOSPORA, H. B. \& K. Nov, Gen. et Sp. i. 229 (1815) = Rynchospora, Vahl (Cyperac.).

aurea, Cham. \& Schlecht. in Linnaea, vi. (1831) $28=$ $\mathrm{R}$, aristata.

aurea, H. B. \& K. Nov. Gen. et Sp. i. $231=$ R. aurea. capitata, H. B. \& K. 1. c. $229=$ R. capitata.

ferruginea, Cham. \& Schlecht. in Linnaea, vi. (1831) 28, partim $=$ R. eximia.

ferruginea, H. B. \& K. Nov. Gen. et Sp. ii. $85=$ R. glauca.

pterocarpa, H. B. \& K. Nov. Gen. et Sp. i. $230=$ R. pterocarpa.

\section{CHAETOSPORA : -}

triceps, Cham. \& Schlecht. in Linnaea, vi. (1831) $29=$ Rynchospora triceps.

vicozensis, Schrad. ex Roem. \& Schult. Syst. ii. Mant. $46=\mathrm{R}$. glauca .

CHAETOSPORA, R, Br. Prod. $232(1810)=$ Schoenus, Linn. (Cyperac.)

albescens, Franch. \& Sav. Enum. PI. Jap. ii. $548=$ S, apogon.

alpina, F. Muell. Fragm. ix. $39=$ Carpha alpina.

anceps, R. Br. Prod. $233=$ Mesomelaena anceps.

antarctica, Hook. f. FI. Antarct. ii. 361. t. 147,Chili.

arundinacea, A. Dietr. Sp. PI. ii. $31=$ Asterochaete arundinacea.

aurata, Nees, in Ann. Nat. Hist. Ser. I. vi. (1841) 49 $=\mathrm{S}$. curvifolius.

avenacea, F. Muell. Fragm. ix. $40=$ Cyathochaeta avenacea.

axillaris, R. Br. Prod. $233=\mathrm{S}$. axillaris.

brevisetis, R. Br. 1. c. $232=\mathrm{S}$. brevisetis.

brevisetis, F. Muell. Fragm. ix. $37=\mathrm{S}$. capitatus

Burmanni, Schrad. Anal. Cap. Cyp. 32.t. 3. f. 4.-Afr. austr.

calostachys, R. Br. Prod, $233=\mathrm{S}$. calostachyus

capillacea, Hook. f. Fl. Tasm. ii. 81. t. $141 \mathrm{~A}=$ Ely nanthus capillaceus.

capillacea, Nees, in Linnaea, ix. (1834) 299 ; x. (1836) $192=$ S. capillaceus

capillaris, F. Muell. Fragm. ix. $34=$ Elynanthus capillaceus.

Capitellum, A. Dietr. Sp. P1. ii. $27=$ Ficinia seti-

formis.
ciliata, Schrad. ex Nees, in Mart. F1. Bras. ii. I. $128=$ Rynchospora elatior.

circinalis, Schrad. in Goett. Gel. Anz. (1821) III $2070=\mathrm{S}$. circinalis.

clandestina, F. Muell. Fragm.ix. $40=$ Cyathochaeta clandestina.

compressa, S. F. Gray, Nat. Arr. Brit. PI. ii. 71 Nees, in Lehm. Pl. Preiss. ii. $85=$ Scirpus Caricis.

concava, Nees, in Ann. \& Mag. Nat. Hist. Ser. I. vi (1841) $47=$ Lepidospermum concavum.

concinna, Hook. f. Fl. N. Zeal, i. 274, t. $62 \mathrm{~B}=\mathrm{S}$, concinnus.

cruenta, Nees, in Lehm. Pl. Preiss. ii. $85=\mathrm{S}$. cruentus curvifolia, R. Br. Prod. $232=$ S. curvifolius.

cuspidata, Nees, in Linnaea, vii. (1832) $529=$ Elynan-

thus cuspidatus.
cygnea, Nees, in Ann. Nat. Hist. Ser. I. vi. (1841) 49 $=\mathrm{S}$. brevisetis

dactyloides, A. Dietr. Sp. Pl. ii. $32=$ Asterochaete glomerata.

deformis, $\mathrm{R}$. Br. Prod. $232=\mathrm{S}$. deformis

deusta, F. Muell. Fragm, ix, 39=Mesomelaena deusta diandra, F. Muell. 1. c. = Cyathochaeta diandra.

diodon, Schrad. ex Nees, in Mart. F1. Bras. ii. I. 148 $=$ Rynchospora lunata.

dispar, A. Dietr. Sp. PI. ii. $32=$ Ficinia secunda.

distachya, Nees, in Linnaea, x. (1836) 192.-Afr. austr.

distans, F. Muell. Fragm, ix, $35=\mathrm{S}$. calostachyus.

effusa, Schrad. ex Kunth, Enum. Pl. ii. $286=$ Plenrostachys sparsiflora

elongata, Nees, in Lehm. Pl. Preiss. ii. 275=Mesome laena anceps.

ferruginea, Reichb. Fl. Germ. Excurs. $74=$ S. ferrugineus.

fimbriolata, Nees, in Linnaea, x. (1836) 191.-Afr austr.

fimbristyloides, F. Muell. Fragm. ix. $34=$ Cladium undulatum.

flexuosa, Schrad. Anal. Cap. Cyp. 33. t. 3. f. 3=S. flexuosus.

globosa, H. B. \& K. Nov. Gen. et Sp. i. $135=$ Ryncbospora globosa

hexandra, Boeck. in Flora, 1xi. (1878) 37.-Afr. austr imberbis, R. Br. Prod. $233=\mathrm{S}$. apogon.

japonica, Franch. \& Sav. Enum. Pl. Jap. ii. $548=\mathrm{S}$ apogon.

laeta, Kunze, ex Steud. Nom. ed. II. i. $341=$ Fimbristylis aspera.

lanata, R. Br. Prod. $232=$ S. lanatus.

laxa, Hook. f. FI. Antarct. ii. 361. t. $146=$ Carpha paniculata.

Iucens, Poir. in Dict. Sc. Nat. viii. $58=\mathrm{S}$. nitens

madagascariensis, Stend. Syn. P1. Cyp. 161. Madag. 


\section{CHAETOSPORA :-}

Mauritii, Steud. Syn. P1. Cyp. 161=Rynchospora glauca.

microstachya, Nees, in Lehm. Pl. Preiss. ii. $84=$ Schoenus Drummondii.

microstachys, Schrad. Anal. Fl. Cap. i. 33, in obs. $=$ S. circinalis.

nana, Nees, in Lehm. P1. Preiss. ii. $85=$ S. nanus.

natans, F. Muell. Fragm. ix. $38=\mathrm{S}$. natans.

Neesii, Boeck. in Linnaea, xxxviii. (1874) $297=$ Tricostularia Neesii.

nigricans, Kunth, Enum. Pl. ii. $323=\mathrm{S}$. nigricans.

nitens, $\mathrm{R} . \mathrm{Br}$. Prod, $238=\mathrm{S}$, nitens.

oligostachya, Boeck. in Flora, xlii. (1859) $101=\mathrm{S}$. nigricans.

oligostachya, F. Muell. Fragm. ix. $38=$ S. bifidus. paludosa, R. Br. Prod. $233=$ Tricostularia paludosa paniculata, Steud. Syn. Pl. Cyp. 161.-Ins. Borbon. pedicellata, R, Br. Prod. $232=\mathrm{S}$. pedicellatus.

pterosperma, H. B. \& K. Nov. Gen. et Sp. i. $230=$ Haplostylis barbata.

punctoria, A. Dietr. Sp. P1. ii. $28=$ Bueckia punctoria. rhynchospermoides, Phil. f. PI. Vasc. Chil. $306=$ seq. rhynchosporoides, Stend. Syn. Pl. Cyp. 162.-Chili.

robusta, Kunth, Enum. Pl. ii. 325.-Afr. austr.

rufa, S. F. Gray, Nat. Arr. Brit. Pl. ii. $71=$ Scirpus rufus.

sphaerocephala, R. Br. Prod. $233=$ Mesomelaena sphaerocephala.

spicata, Boeck, in Linnaea, xxxviii. (1874) $297=$ Tri-

costularia compressa

striata, A. Dietr. Sp. Pl. ii. $27=$ Ficinia setiformis.

stygia, R. Br. Prod, $233=$ Mesomelaena stygia.

tenax, Hook. f. F1. N. Zel. i. $273=$ S. brevifolius.

Tendo, Hook. f. 1. c. = S. Tendo.

tenella, Rupr. Sert. Tiansch. 34.-Turkestan.

tenera, A. Dietr. Sp. P1. ii, $32=\mathrm{S}$. tener,

tenuissima, Hook. f. Fl. Tasm, ii. 81, t. $14=$ Lepidospora tenuissima

tenuissima, Steud. Syn. P1. Cyp. 319, 162=S. apogon. tetragona, R. Br. Prod. $233=$ Mesomelaena tetragona. turbinata, R. Br. 1. c. $232=\mathrm{S}$. turbinatus.

umbellulifera, Boeck. in Flora, lxv. (1882) $28=\mathrm{S}$. apogon.

villosa, Nees, ex Stend. Nom. ed. II. i. $34 \mathrm{I}=\mathrm{S}$. villosus.

CHAETOSTACHYS, Benth. in Wall. Pl. As. Rar. ii. 19 (1831) = Lavandula, Tourn. (Labiat.)

multifida, Benth. 1, c. = L. Burmanni.

CHAETOSTEMMA, Reichb. Consp. $176(1828)=$ seq.

CHAFTOSTOMA, DC. Prod. iii. 112 (1828). MELASTOMACEAE, Benth. \& Hook. f, i. 737.

acuminatum, Cogn. in Mart. Fl. Bras. xiv. III. 35.Bras.

armatum, Cogn. 1. c. $31=$ diosmoides.

castratum, $\operatorname{Cogn}$. l. c. $36 .-$ Bras.

diosmoides, Mart. Nov. Gen. et $S p$. iii. 130. t. 264.Bras.

ericoides, DC. Prod. iii. $112=$ Marcetia ericoides

fastigiatum, Naud. in Ann. Sc. Nat. Sér. III. iii. (1845) 191.-Bras.

Gardneri, Triana, in Trans. Linn. Soc. xxviii. (1871) 25. t. 1. f. 8. c.-Bras.

Glaziovii, Cogn. in Mart. Fl_Bras. xiv. III. 30.-Bras. inerme, Naud. in Ann. Sc. Nat. Sér. III. iii. (1845) 191.-Bras

longiflorum, Cogn. in Mart. Fl. Bras. xiv.. III. 32,Bras.

microlicioides, Cham, in Linnaea, ix. (1834) $382=$ Microlicia Chamissois.

oxyantherum, Triana, in Trans. Linn. Soc xxviii (1871) 25, pro parte.-Bras.

oxyantherum, Triana, 1. c. pro parte =acuminatum, castratum.

pungens, $D C$. Prod. iii. 112.-Bras.

Riedelianum, $\operatorname{Cogn}$. in Mart. Fl. Bras, xiv, I1x. 33.Bras.

tetrastichum, DC. Prod. iii. $112=$ Marcetia ericoides, tetrasticha.

CHAETOSUS, Benth, in Hook. Lond. Journ. Bot. ii. (1843) 226. APOCYNACEAE, Benth. \& Hook. f. ii. 695 .

Сиоетosus, Benth. in Joum. Linn. Soc, i. (1857) 87. volubilis, Benth. 6. c.-N. Guines.
CHAETOTHYLAX, Nees, in Mart. Fl. Bras, ix, 153 t. 6 (1847). ACANTHACEAE, Benth. \& Hook. t. $26(1847$.

Chaetothylopsis, Oerst. in Kjoeb. Vidensk. Med. del. (1854) 168

HeinzeliA, Nees, in Mart. FI. Bras. ix. 153 (1847) lythroides, Benth. E' Hook. f. Gen. ii. 1108.-Am. austr.

micranthus, Benth. Eo Hook. f. ex Hemsl. Biol. Centr. Am. Bot. ii. 515.-Nicaragua.

phyllostachyus, Nees, in DC. Prod. xi. 313.-Mexic tocantinus, Nees, in Mart. Fl. Bras. ix. 153.-Bras. umbrosus, Nees, in DC. Prod. xí. 313.-N. Granat.

CHAETOTHYLOPSIS, Oerst. in Kjoeb. Vidensk. Meddel (1854) $163=$ Chaetothylax, Nees (Acanthac.). micrantha, Oerst. 1. $\mathrm{c}_{\mathrm{v}}=$ Chaetothylax micranthus.

CHAETOTROPIS, Kunth, Rev. Gram, i. 72, 271 . $47(1830)$, GRAMINEAE, Benth. \&c Hook if ii 1151 .

andina, Ball, in Fourn. Linn. Soc. xxii. (1885) 58.Peruv.

chilensis, Kunth, Rev. Gram. i. 72, 271. t. 47.-Chili. latifolia, Phil. in Linnaea, xxx. (1859-60) $205=$ chilensis.

CHAETOTROPSIS, D. Dietr. Syn. Pl. i. 184 (1839) praec.

CHAFTURUS, Link, in Schrad, Journ, ii. (1799) 313 GRAMINEAE, Benth. \& Hook. f. iii. 1149

divaricatus, DC. Cat. Hort. Monsp. $93=$ fasciculatus. fasciculatus, Link, in Schrad. Fourn. ii. (1799) 313.Hispan.

prostratus, Hack. E Lange, in Kjoeb. Vidensk. Meddel. (1877-78) 223.-Lusitan.

spicatus, Schrad. Ind. Sem. Hort. Gotting. ex Steud. Nom. ed. II. i. $342=$ fasciculatus.

CHAILLetia, DC, in Ann. Mus. Par. xvii. (1811) 153. CHAILLETIACEAE, Benth. \& Hook. f. i 341 .

Dichapetalum, Thou. Gen. Madag. 23 (1806).

LeUcosta, Thou, 1. c. (1806)

Mestotes, Soland. ex Steud. Nom. ed. II. i. 342 (1842)

MoACurra, Roxb. Hort. Beng. 21 (1814); Fl. Ind. ii. 69 (1832)

Patrisia; Rohr, ex Stend, Nom, ed, II. i. 342 (1840).

PlaPperTia, Reichb. Consp. 146 (1828)

Quilesia, Blanco, Fl. Filip, ed. I. $176(1837)$

Symphyllanthus, Vahl, in Skriv. Nat, Hist: Selsk. vi. $86(1810)$.

WAHLENBERGLA, R, Br, in Wall. Cat. p. 250, sub n. $4342(1831)$

affnis, Planch. ex Benth. in Hook. Niger F1. $276=$ toxicaria.

Bangii, F. Didr. in Kjoeb. Vidensk. Meddel. (1854) 195.-Afr.trop.

Benthamiana, Thurce, in Bull Soc. Nat. Mosc. xxxyi. (1863) 1. 610.-Ins. Philipp.

Benthamii, F. Didr. in Kjoeb. Vidensk. Meddel. (1854) 196.-Afr, trop.

Bojeri, Tul. in Ann. Sc. Nat. Sér. IV. viii. (1857) 85. - Malacca.

Brunoniana, Wall. Cat. n. $4038=$ Helferiana.

chlorina, Tul. in Ann. Sc. Nat. Sér. IV. viii. (1857) 88.-Mađag.

cubensis, Poepp. E Endl. Nov. Gen. et Sp. iii, 41. t. 246. f. 3.-Cuba.

cymosa, Hook. Ic. Pl. t. 591.-Afr. austr.

cymulosa, Oliver, Fl. Trop. Afr. i. 340.-Afr, trop.

deflexa, Klotzsch, in Peters, Reise Mossanb. Bot. 109 -Afr. trop.

deflexifolia, Turcs. in Bull. Soc. Nat. Mosc. xxxvi. (1863) I. 611.-Malaya.

Dichapetalum, DC. Prod, ii. 57.-Madag.

discolor, Baker, in fourn. Linn. Soc. xx. (1889) 119.Madag.

edulis, Kurz, in Journ. As. Soc. Beng. xli. (1872) II. $298=$ Sarcostigma edule.

erecta, G. Don, in Edinb. Phil. Joum. xi. (1824) $\$ 18$ toxicaria.

fasciculata, Spreng. Syst. i. 991.-Madag.

flavicans, Klotesch, in Schomb. Faruna G Fl. Gui. 1184, nomen.-Guiana.

\section{CHAILLETIA}

flexuosa, Oliver, Fl. Trop. Afr。i. 340-Afr. trop floribunda, Planch. in Hook. IC. Pl. t. 792.-Afs. trop

gelonioides, Hook. f. Fi. Brit. Ind. i. 570.-Ind. or. Malaya.

Griffithii, Hook f. l. c. 571-Malacca

hainanensis, Hance, in fourn. Bot. xxiii. (1885) 322.China.

Helferiana, Kurz, in Fourn. As. Soc. Beng. xli. (1872) II. 297.-Burma.

Heudelotii, Planch. ex Oliver, Fl. Trop. Afr. i. 344.Afr. trop.

hirtella, Tul. in Ann. Sc. Nat. Sér. IV, viii, (1857) 88. -Ins. Mascar.

hispida, Oliver, Fl. Trop. Afr. i. 343.-Afr, trop. lanuginosa, Maing. ex Hook. f. F1. Brit. Ind. i. 572 Griffithii.

Lauro-cerasus, Planch. ex Hook. f. l. c. -Ins, Penang.

Leucosia, Spreng. Syst. i. 231.-Madag.

longipetala, Turcz. in Bull. Soc. Nat. Mosc. xxxy (1863) 1. 611.-Burma.

macrophylla, Oliver, Fl. Trop. Afr. i. 343.-Afr. trop. mossambicensis, Klotzsch, in Peters, Reise Mossamb. Bot. 108.-Afr. trop.

aigrescens, Tul. in Ann. Sc. Nat. Sér. IV, viii. (1857 85.-Madag.

oblonga, Hook. f. ex Benth. in Hook. Niger Fl. 277.Afr. trop.

Pachypus, Tul. in Ann. Sc. Nat. Sér. IV. viii. 1857 87.-Madag.

pallida, Oliver, Fl. Trop. Afr, i. 343, - Afr, trop.

paniculata, Benth. in Hook. Niger Fl. 279.-Afr trop.

papuana, Becc. Malesia, i. (1877) 176.-N. Guinea.

Parkerii, Planch. ex Triana E Planch. in Ann.

Nat. Sér. V. xv. (1872) 379.-Venezuela.

pedunculata, $D C$. in Ann. Mus. Par. xvii. (1811) 154 -Guiana.

reflexa, Klotzsch, in Peters, Reise Mossamb. Bot. $10 y$ t. 20.-Afr. trop.

rufa, Tul. in Ann.Sc. Nat. Sér. IV. viii. (1857) 86.Madag.

rufipilis, Turcz, in Bull. Soc. Nat. Mosc. xoxvi. (180'3 I. 611.-Afr. trop.

sessiliflora, DC. in Ann. Mus. Par. xvii. 1811) 15ّt

Tapura guianensis.

subauriculata, Oliver, Fl. Trop. Afr. i. 344.-Afr trop.

subcordata, Hook. fo ex Benth. in Hook. Niger Fl. 277. - Afr. trop.

sumatrana, Miq. Fl. Ind. Bat. Suppl. 328 = gelo nioides.

Thomsoni, Oliver, Fl. Trop. Afr. i. 342,-Afr. trop.

timoriensis, $D C$. Prod. ii. 57.- Ins. Timor.

toxicaria, G. Don, in Edinb. Phil. Fourn. xi. 1824

348.-Afr. trop.

vestita, Benth. in Hook. Kew Fourn. iii. (1851) 372.Bras.

Virchowii, O. Hoffm. E Hildeb. ex O. Hoffm. Sert. Madag. 11.-Madag.

vitiensis, Seem. Viti, 43t, nomen; Fl. Vit. 38.-In. Fiji.

CHAITAEA, Soland. ex. Seem. Fl. Vit. 102 (1865) Tacea, Forst.

Tacca, Soland. ex Seem. 1. c. =T. pinnatifidz

CHAITURUS, Willd. Prod. Fl, Berl. 200 (17:i)

Leonurus, Linn. (Labiat).

leonuroides. Willd. 1. c. $201=$ L. Marrubiastrum.

Marrubiastrum, Spenn. in T. Nees, Gen. Fl. Germ fasc. 18 t. $353=$ L. Marrubiastrum.

CHAIXIA, Lapeyr. Hist. Pl. Pyr. Suppl. 38 (1915 Ramondia, Kich. (Gesnerac).

Hyconi, Lapeyr. 1. c. $\$ 9=\mathbf{R}$. pyrenaica.

CHAKIATEILA, DC. Prod. $\times .563,1586^{\circ}=(\mathrm{CHAT1}$ KLLLA, Cass, - Wulftia, Nicet. (Compos.)

CIIALARIUM, Puis. ex DC. Prod. v. $540^{\circ}$, in syt. 159. (UGIliRA. Cass = Eloutheranthera Poir (Compes.)

CHALCANTILS, Roiss, Fl. Orient, 1. 211 is $30^{\circ}$ Hesperis, linn. (Cincifer).

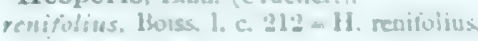


CHALCAS, Linn. Mant. 68 (1767)=Murraya, Koen (Rutac.).

Cammuneng, Burm. f. Fl. Ind. $104=$ M. exotica. crenulata, F. Muell. Phyt. N. Hebr. $7=$ M. crenulata. intermedia, Roem. Syn. Hesper. i. $48=$ M. exotica. jabanensis, Lour. Fl. Cochinch. $271=\mathrm{M}$. exotica. Koenigii, Kurz, in Journ. As. Soc. Beng. xliv。 (1875) II. $132=$ M. Koenigii.

paniculata, Linn. Mant. i. $68=$ M. exotica. sumatrana, Roem. Syn. Hesper. i. $49=$ M. exotica

CHALEPOA, Hook. f. Ic. Pl.t. 1082 (1871)= Tribeles, Phil, (Pittospor.)

magellanica, Hook. $\mathrm{f}_{\circ} \mathrm{1}_{\mathrm{c}} \mathrm{c}_{\star}=\mathrm{T}$ 。 australis ?

CHALEPOPHYLIUM, Hook. f. Ic. Pl. t. 1148 (1873). RUBIACEAE, Benth. \& Hook. f. ii. 50. guyanense, Hook. f. l. c.-Guiana.

CHALVBEA, Naud. in Ann. Sc. Nat. Sér. ITI. xvi (1851) 99 =Pachyanthus, A. Rich. (Melastomac.). corymbifera, Naud. 1. c. $100=$ P. corymbosus. corymbosa, Triana, in Trans. Linn. Soc. xxviii. (1871) $97=\mathrm{P}$. corymbosus.

CHAMABAINIA, Wight, Ic. vi. 11. t. 1981 (1853) URTICACEAE, Benth. \& Hook. fo iii. 387. cuspidata, Wight, l. c.-Ind. or.

squamigera, Wall. Cat. n. 4592; Wedd. in DC. Prod. xvi. I. $218=$ cuspidata.

CHAMAEBATIA, Benth. PI. Hartw。 308 (1850). ROSACEAE, Benth. \& Hook. f. i. 617 .

foliolosa, Benth.l.c.-Calif.

foliolosa, Newberry, in Pacif. Rail. Rep. vi. $73=$ Spiraea Millefolium.

CHAmaebatiaria, Maxim. in Act. Hort. Petrop. vi. (1879) $225=$ Spiraea, Linn. (Rosac.).

Millefolium, Maxim.1. $c_{0}=$ S. Millefolium.

CHAMAEbetUlA, Opiz, in Lotos, v. (1855) $258=$ Betula, Tourn. (Cupulif.).

acutifolia, Opiz, 1. c. 259.-Europ.

glandulosa, Opiz, 1. c. = B. glandulosa.

Gmelinii, Opiz, 1. c. $=$ B. fruticosa.

Hookeri, Opiz, 1. c. = B. glandulosa

humilis, Opiz, $\mathrm{I}_{\mathrm{c}} \mathrm{c}_{ }=\mathrm{B}$. humilis.

nana, Opiz, $1 . \mathrm{c}_{\mathrm{n}}=\mathrm{B}$. nana.

pumila, Opiz, l. c. = B. pumila.

rotundifolia, Opiz, $1 . \mathrm{c} .=\mathrm{B}$, glandulosa.

Chamaebuxus, [Tourn.] Spach, Hist. Vég. Phan. vii. $125(1839)=$ Polygala, Linn.

alpestris, Spach, 1. c. 127 = P. Chamaebuxus.

arillata, Hassk. in Miq. Ann. Mus. Bot. Lugd, Bat, i.

$153=\mathrm{P}$. arillata.

coriacea, Opiz, Seznam, $28=$ P. Chamaebuxus.

karensium, Kurz, For. F1. Brit. Burma, i. $79=$ P. karensium.

paniculata, Hassk. in Miq. Ann. Mus. Bot. Lugd. Bat. i. $154=$ P. arillata.

polygaleoides, Schur, in Verh. Siebenb. Ver. Naturw. iv. (1853) $11=$ P. Chamaebuxus.

pulchra, Hassk. P1. Jav. Rar. 294, in textu = P. pulchra. Vayredae, Willk. Illustr. PI. Hisp. 33. t. $23=\mathrm{P}$. Vayredae.

venenosa, Hassk. PI. Jav. Rar. 294.-Java.

vulgaris, Schur, Enum. Pl. Transs. $90=$ P. Chamaebuxas.

CHAMAECALAMUS, Meyen, Reise, i. $456(1834)=$ Deyeuxia, Clar. (Gramin.).

spectabilis, Meyen, l. c. ; et in Nov. Act. Nat. Cur, xix. Suppl. í. (1843) 156 (=Bromidium spectabile).Peruv.

CHAMAECASSIA, [Breyn] Link, Handb. ii. 139 (1831) Cassia, Tourn. (Legumin.).

grandiflora, Link, l. c. =Cassia laevigata.

laevigata, Link, 1. c. = Cassia laevigata.

CHAMAECERASUS, [Tourn.] Medic. Phil. Bot. i. 126 $(1789)=$ Lonicera, Linn, (Caprifol.).

alpigena, Medic. 1. $c_{\circ}=$ L. alpigena.

coerulea, Delarb. F1. Auv, ed. II. $131=$ L. coerulea

dumetorum, Delarb. 1. c. = L. Xylosteum.

fruticosa, Ser. in DC. Prod. ii. 537, sphalm. = Prunus Chamaecerasus.
CHAMAECERASUS :-

nigra, Medic. Phil. Bot. i. 126 ; Pf. Anat $390=\mathrm{L}$. nigra.

Standishii, Lescuyer, in L'Horticult. Franç. (1862) 138. to 10.-Hab.?

tatarica, Medic. Phil. Bot. i. 126 ; Pf. Anat. $390=$ Lonicera tatarica.

Xylosteum, Medic. Phil. Bot. i. $126=$ L. Xylosteum.

CHAMAECISTUS, S. F. Gray, Nat. Arr. Brit. Pl. ii. $401(1821)=$ Loiseleuria, Desv. (Ericac.).

serpyllifolius, S. F. Gray, 1. c. = L. procumbens.

CHAMAECISTUS, RegeI, Gartenfl. (1874) $60=$ Rhododendron, Linn. (Ericac.).

austriacus, Regel, l. e. $=$ R. Chamaecistus.

kamtschaticus, Regel, 1. c. = R. kamtschaticum.

CHAMAFCLADON, Miq. in Bot. Zeit. xiv, (1856) 564. AROIDEAE, Benth. \& Hook, f. iii. 983.

angustifolium, Schott, in Bonplandia, vi. (1858) 369 . -Ins. Penang.

consobrinum, Schott, in Ann. Mus. Bot. Lugd. Bat. i. 126.-Sumatra.

Griffthii, Schott, in Bonplandia, vi. (1858) 369.Malaya.

humile, Miq. Fl. Ind. Bat. iii. 213.--Ins. Penang.

lanceolatum, Miq. in Bot. Zeit. xiv. (1856) 564.-Java.

metallicum, N. E. Brown, in Illustr. Hortic. xxxi. (1884) t. 539.-Borneo.

nigrescens, Schott, in Ann. Mus. Bot. Lugd. Bat. i. 126.-Sumatra.

obliquatum, Schott, in Bonplandia, vi. (1858) 339.Ins. Penang.

ovalifolium, Schott, in Ann. Mus. Bot. Lugd. Bat. i. 281.-Borneo.

ovatum, Schott, in Bonplandia, vii. (1859) 30.Malaya.

purpurascens, Schott, 1.c. vi. (1858) $369=$ lanceolatum, pygmaeum, Engl。 in DC. Monog. Phan. ii. $345=$ lanceolatum.

rubescens, Schott, Gen. Aroid. sub t. 60, in obs.Hab? ?

sanguinolentum, Schott, Prod. Aroid. 316.--Malaya.

saxorum, Schott, in Ann. Mus. Bot. Lugd. Bat. i, 280. -Borneo.

subcordatum, Schott, l. c. 281,-Borneo.

truncatum, Schott, in Bonplandia, vi. (1858) 369,Burma.

CHAMAECLEMA, Moench, Meth. 393 (1794) = Nepeta, Tourn. (Labiat.)

hederacea, Moench, 1. c. $=$ N. Glechoma.

CHAMAECNIDE, Nees \& Mart. ex Miq. in Mart. Fl. Bras. iv. I. 203 (1853)= Pilea, Lindl. (Urticac.). microphylla, Nees, ex Miq. 1. c. $=$ P. muscosa.

CHAMAECRISTA, Moench, Meth. $272(1794)=$ Cassia, Tourn. (Legumin.)

Burmanni, Eckl. \& Zeyh. Enum. $260=$ Cassia capensis. capensis, E. Mey. in Linnaea, vii. (1832) $172=$ Cassia capensis.

comosa, E. Mey. Comm. Pl. Afr. Austr. $160=$ Cassia comosa.

nictitans, Moench, Meth. $272=$ Cassia nietitans.

plumosa, E. Mey. Comm. Pl. Afr. Austr. 159 = Cassia mimosoides.

stricta, E. Mey. 1. c. $=$ Cassia mimosoides.

CHAMAECYPARIS, Spach, Hist. Vég. Phan. xi. (1842) $329=$ Thuya, Tourn. (Conif.).

andelyensis, Hort. ex Gord. Pinet. ed. II. $365=$ leptoclada.

Boursieri, Carr. Conif, ed. II. 125 = Lawsoniana.

Boursieri, Decne, in Bull. Soc. Bot. Fr. i. (1854) $70=$ Juniperus occidentalis.

breviramea, Maxim. in Bull. Acad. Pétersb. x. (1866) $489=\mathrm{T}$, obtusa.

decussata, Hort. ex Carr. Conif. ed. II. $140=$ T. orientalis.

ericoides, Carr. 1. $\mathrm{c}_{\mathrm{0}}=\mathrm{T}$. orientalis, occidentalis. excelsa, Fisch. ex Carr. 1. c. $127=$ T. excelsa.

glauca, Hort. ex Carr. 1. c. ed. I. $141=$ T. orientalis,

Keteleri, Stand. ex Parl, in DC. Prod. xvi. II. $466=$ T . obtusa.

kewensis, Hort. ex Carr. Conif. ed. I. $133=$ T. sphaeroidalis.
CHAMAECYPARIS :-

Lazusoniana, Parl in Ann. Mas. Stor, Nat. Fir. i (1864) 181.-Am. bor. occ.

leptoclada, Henk. \& Hochst. Nadelhoelz. 257.--Japon. nana, Hort. ex Parl. in DC. Prod。 xvi. II. $464=$ Thuya sphaeroidalis.

nootkaënsis, Carr. Conif. ed. II. 127 = seq.

nutkaënsis, Jindl. \& Gord. in Journ. Hort. Soc. y. 1850) $207=\mathrm{T}$. excelsa.

nutkatensis, Spach, Hist. Vég. Phan. xi. $333=$ praec. obtusa, Sieb. \& Zucc. in Endl. Conif. 63=T. obtusa. pendula, Maxim. in Bull. Acad. Pétersb. x. (1866) $489=\mathrm{T}$. obtusa.

pisifera, Sieb. \& Zucc. in Endl. Conif. $64=$ T. pisifera. pseudo-squarrosa, Parl. in DC. Prod. xvi. II. $467=$ T. sphaeroidalis.

pumila, Hort. ex Carr. Conif. ed. II. $124=\mathrm{T}$. sphaeroidalis.

sphaeroidea, Spach, Hist. Vég. Phan. xi. $331=\mathrm{T}$. sphaeroidalis.

squarrosa, Hort. ex Carr, Conif. ed. I. $65=\mathrm{T}$. sphaeroidalis.

squarrosa, Sieb. \& Zucc. in Endl. Conif. $65=\mathrm{T}$, pisifera.

thujaeformis, R. Smith, ex Gord. Pinet. ed. II. 429.Hab. ?

thurifera, Endl. Synop. Conif. $62=$ Cupressus thurifera.

variegata, Hort. ex Carr. Conif. ed. I. $133=$ T. sphaeroidalis.

CHAMAECYTISUS, Link, Handb, ii. 154 (1831) Cytisus, Linn. (Legumin.).

austriacus, Link, 1. c. $155=$ Cytisus austriacus.

biflorus, Link, 1. c. $154=$ Cytisus biflorus. capitatus, Link, 1. c. $155=$ Cytisus capitatus. elongatus, Link, 1. $c_{0}=$ Cytisus biflorus.

hirsutus, Link, 1. c. = Cytisus hirsutus.

leucanthus, Link, 1. c. $154=$ Cytisus austriacus proliferus, Link, $1_{1} c_{0}=$ Cytisus proliferus. purpureus, Link, 1. c. $=$ Cytisus purpureus. supinus, Link, l. c. $155=$ Cytisus biflorus.

CHAMAECYTISUS, Vis. FI. Dalm. iii. $272(1852)=$ Argyrolobium, Eckl. \& Zeyh. (Legumin.).

dalmaticus, Vis. 1. c. = A. Linnaeanum.

CHAmaedactylis, T. Nees, Gen. Fl. Germ Monocot. i. n. $66(1840$ ?) = Aeluropus, Trin. (Gramin.)

maritima, Nees, $1 . \mathrm{c} .=\mathrm{A}$. littoralis.

CHAMAEDAPHNE, Mitchell, in Act. Phys. Med Acad. Nat. Cur. viii. (1748) 222, App. = Mitchellia, Linn. (Rubiac.)

CHAMAEDAPHNE, Moench, Meth. 457 (1794) = Cassandra, D. Don (Ericac.).

calyculata, Moench, 1. $\mathrm{c}$. = Cass. calyculata.

crispa, Spach, Hist. Vég. Phan. ix. 477 = Cass. calyculata.

CHAMAEDOREA, Willd. Sp. Pl. iv, 638 (1805) et in Mém. Acad. Berl. 1804 (1807) 40. PALMAE, Benth. \& Hook. f. iii. 910.

Dasystachys, Oerst. in Kjoeb. Vidensk. Meddel, (1858) 25.

Kunthia, Humb. \& Bonpl. Pl. Aequin. ii. 128. t. $122(1809)$.

Morenia, Ruiz \& Pav. Prod. 150 (1794).

NunNeZHaRIA, Ruiz \& Pav, 1. c. 147 (1794).

NunNezIA, Willd, Sp. Pl. iv, 1154 (1805).

Spathoscaphe, Oerst. in Kjoeb. Vidensk, Meddel. (1858) 29 .

STACHYOPHORBE, Liebm. in Overs. Dansk. Vidensk. Selsk. (1846) 8.

StePhanostachys, Klotzsch, ex Oerst. in Kjoeb.

Vidensk. Meddel. (1858) 26.

affinis, Liebm. in Mart. Hist. Nat. Palm. iii. 308.Mexic.

alternans, H. Wendl. in Regel, Gartenfl. (1880) 104. -Mexic.

amazonica, F. Linden, in Illustr. Hortic., xxviii. (1881) 16, nomen.-Bras.

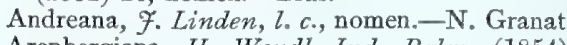

Arenbergiana, H. Wendl. Ind. Palm. (1854) 66.Guatemala? 
CHAMAEDOREA :-

atrovirens, Hort. ex H. Wendl. in Kerch. Palm. $239=$ Martiana.

atrovirens, Mart. in Flora, xxxv. (1852) 721.Mexic.

aurantiaca, A. Brongn. in Rev. Hortic. Sér. III. i.

(1847) 86.-Mexic.

Bartlingiana, H. Wendl. Ind. Palm. (1854) 80.-N. Granat.

biloba, H. Wendl. 1. c. 11=Bartlingiana.

hifurcata, Oerst. in Kjoeb. Vidensk. Meddel. (1858) 13.-Costa Rica.

brachyclada, H. Wendl. in Regel, Gartenfl. (1880) 101. -Panama.

bracteata, H. Wendl. in Bot. Zeit. xvii. (1859) 29.Am. centr.

brevifrons, H. Wendl. Ind. Palm. (1854) 61.-N. Granat.

Casperiana, Klotzsch, in Otto \& Dietr. Allg. Gartenz. xx. (1852) 363.-Guatemala.

cataractarum, Mart. Hist. Nat. Palm. iii. 309.Mexic.

concolor, Mart. l. c. 160.-Mexic.

conocarpa, Mart. Palmet. Orb. 6.-Bolivia.

costaricana, Oerst. in Kjoeb. Vidensk. Meddel. (1858)

19. - Costa Rica.

Deckeriana, Hemsl. Biol. Centr. Am. Bot. iii. 404.Guatemala.

Deppeana, Klotzsch, in Otto \& Dietr. Allg. Gartenz. xx. (1852) $362=$ elegans.

desmoncoides, H. Wendl. in Otto $E^{\circ}$ Dietr. $l$. c.

xxi. (1853) 177.--Mexic.

elatior, Mart. in Linnaea, v. (1830) 205.-Mexic.

elegans, Mart.l. c. 204.-Mexic.

elegantissima, Hort. ex H. Wendl. in Kerch. Palm. 239, nomen.-Hab.

Ernesti-Augusti, H. Wendl. in Otto E Dietr. Allo. Garteng. xx. (1852) 73.-Mexic.

fenestrata, Hort. ex H. Wendl. Ind. Palm. (1854) $28=$

Malortiea gracilis.

fenestrata, F. Linden, Illustr. Hortic. xxviii. (1881) 16 nomen.-Mexic.

fibrosa, H. Wendl. Ind. Palm. (1854) $57=$ Synechanthus

fibrosus.

flavo-virens, $H$. Wendl. $l$. c. $60,-\mathrm{Hab}$ ?

flexuosa, Hort. ex H Wendl. 1. c. 14=Martiana.

formosa, Hort.-Cf Gard. Chron. (1876) I. 724.Hab. ?

fragrans, Mart. Hist. Nat. Palm. ii. 4. t. 3. f. 1, 2.Peruv.

geonomaeformis, H. Wendl. in Otto \& Dietr. Allg. Gartenz. xx. (1852) 1.-Guatemala.

geonomoides, Drude, in Mart. Fl. Bras. iii. II.. 531.Peruv.

Ghiesbreghtii, Hort. ex H. Wendl. in Kerch. Palm. 239 , nomen.-Hab.?

glauca, Ұ. Linden, Illustr. Hortic. xxviii. (1881) 16 , nomen.-Venezuela.

glancifolia, H. Wendl. Ind. Palm. (1854) 64.Mexic.

gracilis, Willd. Sp. Pl. iv. 800.-Am. austr.

graminifolia, H. Wendl. Ind. Palm. (1854) 62.Guatemala.

Helleriana, Klotzsch, in Otto \& Dietr. Allg. Gartenz. xx. (1852) $362=$ elegans

humilis, Mart. Hist. Nat. Palm. iii. 308.-Mexic.

Karwinskyana, H. Wendl, in Otto \& Dietr. Allg Gartenz. xxi. (1853) $179=$ elatior

Klotzschiana, H. Wendl. Ind. Palm. (1854) 63.Mexic.

lanceolata, Kunth, Enum. Pl. iii. 172.-Peruv.

latifrons, H. Wendl. Ind. Palm. (1854) 11 -Aren bergiana.

lepidota, H. Wendl. in Otto E Dietr. Allg. Gartenz. xxi. (1853) 138-Mexic

Liebmanni, Mart. Hist. Nat. Palm, iii. $308-$ Mexic.

Lindeniana, $H$. Wendl. in Otto E Dietr. Allg. Gartenz xxi. (1853) 139.-N. Granat.

linearis, Mart. Hist. Nat. Palm. ii. 5.-Peruv.

lunata, Liebm. in Mart. 1. c. iii. $307=$ oblongata.

macrospadix, Oerst. in Kjoeb. Vidensk Meddel. (1858) 20. - Costa Rica

Martiana. H. Wendl. in Otto E Dietr. Allg. Gartens. xxi. 1858) 197.-Mexic.

membranacea, Oerst. in Kjoeb. Vidensk. Meddel. (1858)

22.-Nicaragua.
CHAMAEDOREA :-

mexicana, Hort. Belg. ex Heynh. Nom, ii. $135=$ Sartorii.

microphylla, H. Wendl. in Bot. Zeit. xvii. (1859) 102 - Panama.

montana, Liebm. in Mart. Hist. Nat, Palm. iii. 308. - Mexic.

oblongata, Mart. l. c. 160.-Bras.

obovoidea, $H$. Wendl, in Kerch. Palm, 239, nomen. Hab. ?

oreophila, Mart. Hist. Nat. Palm. iii. 309.-Mexic

Pacaya, Oerst. in Kjoeb. Vidensk. Meddel. (1858) 12 - Costa Rica.

paradoxa, H. Wendl. in Bot. Zeit. xvij. (1859) 29. Mexic.

panciflora, Mart. Hist. Nat. Palm. ii. 5. t. 3. f. 3.Bras.

pinnatifrons, Oerst. in Kjoeb. Vidensk. Meddel. (1858) $14=$ gracilis

pochutlensis, Liebm. in Mart. Hist. Nat. Palm. iii. 308.-Mexic.

pulchella, Linden, Cat. n. 117, p. 4.-Hab. ?

pygmaea, H. Wendl. in Otto E Dietr. Allg. Gartenz. xx. (1852) 217, 249.-N. Granat

radicalis, Mart. Hist. Nat. Palm. iii. 308.-Mexic.

regia, H. Wendl. Ind. Palm. (1854) $11=$ desmoncoides.

repens, $H$. Wendl. $1 . \mathrm{c}=$ desmoncoides

resinifera, H. Wendl. in Otto E Dietr. Allg. Gartenz. xxi. (1853) 179.-Mexic.

robusta, Hort. ex H. Wendl. in Kerch. Palm. 239 nomen.-Hab?

Sartorii, Liebm. in Mart. Hist. Nat. Palm. iii. 308.Mexic.

scandens, Liebm. in Mast. 1. c. = elatior

Schiedeana, Mart. in Linnaea, v. (1830) 204. Mexic.

simplicifrons, Hort. Belg. ex Heynh. Nom. ii. 135 Ernesti.Augusti.

speciosa, H. Wendl. Ind. Palm. (1854) $15=$ Schiedeana spectabilis, Hort. ex H. Wendl. in Kerch. Palm. 240, nomen.-Hab.

tenella, H. Wendl. in Regel, Gartenfl. (1880) 102.Mexic.

Tepejilote, Liebm. in Mart. Hist. Nat. Palm. iii. 308.-Mexic.

velutina, Hort ex $\mathbf{H}$. Wendl. Ind. Palm. (1854) 13 lepidota.

Verschaffelti, Hort. ex H. Wendl. in Kerch. Palm. 240, nomen.-Hab.

Wallisi, F. Linden, in Illustr. Hortic.. xxviii. (1881) 16, nomen.-Ecuador.

Warscewiczil, H. Wendl.in Bonplandia, x. (1862) 37. -Guatemala.

Wendlandi, H. Wendl. in Kerch. Palm. 240.Mexic.

Wendlandiana, Hemsl. Biol. Centr. Am. Bot. iii. 407 = praec.

Wobstiana, Linden, Cat. n. 117, p. 4.-Hab. ?

CHAMAEDRYS, Moench, Meth. $383(\mathbf{1 7 9 4})=$ Teucrium, Tourn. (Labiat.

Botrys, Moench, l. c. $=$ T. Chamaedrys capitata, Rafin. Fl. Tellur. iii. 85=T Polium.

cinerascens, Jord. \& Fourr. Brev. Pl. Nov. fasc. i. $47=$ T. flavum.

cretica, Rafin. Fl. Tellur, iii. $85=\mathrm{T}$. creticum.

flava, Moench, Meth. $383=\mathrm{T}$. flavum.

glauca, Jord, \& Fourr, Brev. Pl. Nov, fasc. i. $48=$ T. flavum.

laciniata, S. F. Gray, Nat. Arr. Brit. Pl. ii. $369=$ T. Botrys.

latifolia, Rafin. Fl. Tellur, iii. $85=\mathrm{T}$. fruticans

lucida, Moench, Meth. $383=$ T. lucidum.

Marum, Moench, l. c. $384=$ T. Marum.

montana, Rafin. Fl. Tellur, jii. $85=\mathrm{T}$, montanum.

Nissoliana, Rafin. 1. c. - T. Pseudochamaepitys.

officinalis, Moench, Meth. $383=\mathrm{T}$. Chamaedrys.

ovalifolia, Jord. \& Fourr. Brev. Pl. Nov, fasc. i. $48=$ T. flavum.

palustris, S. F. Gray, Nat. Arr. Brit. Pl. ii. $369=$ T Scordium.

Polium, Rafin. Fl. Tellur, iii. $85=$ T. Polium.

pulverulenta, Jord. \& Fours. Brev. Pl. Nor. fasc. i. 4 $=$ T. flavum.

pumila, Rafin. F1. Tellur. iii. $85=\mathrm{T}$. pumilum.

quadrula, Rafin. 1. c. - T. quadralulum ?

Scordium, Muench, Meth. $384=$ T. Scordium.
CHAMAEDRYS :-

tetonicifolia, Rafin. F1. Tellur. iii. $85=$ Teucriun betonicum.

virescens, Jord. \& Fourr. Brev. PI. Nov. fasc. i, $47=\mathrm{T}$ flavum.

CHAMAEFISTULA, G. Don, Gen. Syst. ii. 451 (1832 Cassia, Tourn. (Legumin

astroites, G. Don, 1. c. = Cass. villosa,

bacillaris, G. Don, 1. c. = Cass. Sophera.

chinensis, G. Don. 1. c. $452=$ Cass. Sophera.

contorta, G. Don, l. c. = Cass. Tora

coromandelina, $\mathrm{G}$. Don, 1. c. $=$ Cass, Suphera

corymbosa, G. Don, 1. c. $451=$ Cass. corymbosa

crotalarioides, G. Don, 1. c, $452=$ Cass, crotalarioides.

elegans, G. Don, 1. c. $451=$ Cass. obliqua.

excelsa, G. Don, 1.c. $452=$ Cass, excelsa.

foribunda, G. Don, 1. c.=Cass. laevigata.

gigantea, $\mathrm{G}$. Don, $\mathrm{l}$. $\mathrm{c}_{0}=\mathrm{Cass}_{\text {. siamea. }}$

Herbertiana, G. Don, 1. c. = Cass. laevigata.

inaequilatera, G. Don, 1. c. $451=$ Cass, inaequilater

indecora, G. Don, I. c. 452 = Cass, bicapsularis

inflata, G. Don, 1. c. 451 = Cass. bicapsularis.

laevigata, G. Don, 1. c. $452=$ Cass. lnevigata.

macrophylla, G. Don, 1. c. 451=Cass. macrophylla.

melanocarpa, G. Don, i. c. = Cass. viminea,

obliqua, G. Don, l. c., = Cass. obliqua.

oxyphylla, G. Don, 1.c. = Cass. oxyphylla.

pendula, G. Don, 1. c. $452=$ Cass. bicapsularis.

prominens, G. Don, 1. c. $451=$ Cass, macranthera.

puberula, G. Don, 1. c. = Cass, bacillaris.

Ruiziana, G. Don, 1.c. = Cass. Ruiziana.

Sophera, G. Don, 1. c. 452 = Cass. Sophera.

speriosa, G. Don, 1. c. $451=$ Cass, speciosa.

torosa, G. Don, 1. c. $452=$ Cass. Sophera

CHAMAEGERON, Schreak in Bull. Phys.-Math Acad. Pétersb. iii. (1845) 107.. COMPOSITAE. oligocephalum, Schrenk.l. c.-Soongaria.

CHAMAEIRIS, Medic. in Act. Acad. Theod. Palat vi Phys. $(1790) 417=$ Iris, Toum.

angustifolia, Medic. 1. c. $418=\mathrm{I}$. pumila desertorum, Medic. 1. c. = I. Gneldenstacdtiana. foetida, Medic. 1. $c_{\mathrm{s}}=1$. foetida.

graminea, Medic. 1. c. = I. graminea.

spuria, Medic. 1. c. =I. spuria.

CHAMAELAUCIUM, Desf, in Mém. Mus. Par. v. (1819) 39. t. 3. MYRTACEAE, Benth. \& Hook. i. 698

Decalophium, Turcz in Bull. Soc. Nat. Mose $x x$. (1847) I. 153 .

afine, Meissn. in Joum. Linn. Soc. i. (1857) $45=$ uncinatum.

axillare, F.. Muell. ex Benth. Fl. Austral. iii. 38.Austral.

brevifolium, Benth.l.c. 37.-Austral.

Brownii, Desf. in Mém. Mus, Par. v, (1819) 271. 19

=Verticordia Brownii.

ciliatum, Desf. l. c. 40.-Austral.

Drammondii, Meissn. in Fourn. Linn. Soc. i. 185;

44.-Austral.

gracile, F. Muell. Fragm. iv. 62.-A ustral.

heterandrum, Benth. Fl. Austral. iii. 36. Austml

megalopetalum, $F$. Muell.ex Benth. l. c. \$8.-Austral. pauciforum, Benth. l.c.-Austral.

plumosum, Desf. in Mim. Mus. Par. v. (1519) t2. t. f $=$ Verticordia Fontanesii.

Thomasii, F. Muell. Fragm, iv. 13i. co 90 I'arsinia Thomasii.

uncinatum, Schaus. in Lehm. Pl. Preiss. i. 9\%.-Austral verticordinum, F. Muell. Fragm. iv. $57=$ Darwinia verticordina.

virgatum, Endl. in Ann. Wien. Mus. ii. (1540) 199.Austral.

CHAMAELE. Miq. Ann. Mus. Bor. Lugd. Bac. iii. 59 1867). UMBELL/FER.AE.

Tanskae, Franch. \&. Sisv. Enuro. Pl. Jap. i. $185=$ C smum Tanakac.

tenera, Miq. Arw. Mus. Bot. Lagd. Bat. iii. 60,Japon.

CHAMAELEA, [Toum.] Adans. Fam. ii. $\$ 4501733$. Cneorum, I.un. Simarub.

fricosces, I am. 17. Fr. ji, 6s?-Cneorum iricoscum. 
CHAMAELEDON, Link, Enum. Hort. Berol. i. 210 $(1821)=$ Loiseleuria, Desv. (Ericac.).

procumbens, Link, 1. c. $211=\mathrm{L}$. procumbens.

CHAMAELEON, Cass. in Dict. Sc. Nat. xlvii. 509 (1827) = Atractylis, Linn. (Compos.)

caulescens, Cass. 1, c. 1. $60=$ A. macrophylla

gummifer, Cass. 1. c. xlvii. $509=$ A. gummifera.

megacephalus, Cass. 1. c. 1. $59=$ A. macrocephala.

CHAMAELINUM, Host, FI. Austr. ii. 224 (1831)= Camelina, Crantz (Crucif.)

austriacum, Host, 1. c. $225=$ Nasturtium austriacum paniculatum, Host, 1. c. $224=$ Neslia paniculata. sativum, Host, 1. c. $225=$ Cam. sativa.

CHAMApLIRIUM, Willd. in Ges. Nat. Fr. Berl Mag. ii. (1808) 18. LILIACEAE, Benth. \& Hook f. iii. 826 .

Dasurus, Salisb. Gen. P1. Fragm. 51 (1865)

Diclinotrys, Rafin. Neogen. 3 (1825).

Ophiostachys, [Delile] in Red. Lil. t. 464 (1816).

Siraitos, Rafin. Fl. Tellur, iv. 26 (1836).

carolinianum, Willd. l. c. 19.-Am. bor.

luteum, A. Gray, Man. Bot. N. U. States, ed. V. $527=$ carolinianum.

luteum, Miq. Ann. Mus. Bot. Lugd. Bat. $144=$ Chionographis japonica.

CHAMAELUM, Baker, in Journ. Linn. Soc. xvi. (1877) 120, sphalm. = Chamelum, Phil. (Irid.).

CHAMAEMELES, Lindl. in Trans. Linn, Soc. xiii (1822) 104. t. 11. ROSACEAE, Benth. \& Hook. i. 628 .

coriacea, Lindl. l. c.-Ins. Madera

mexicana, Baill. Adansonia, ix. (1869) $148=$ Photinia mexicana.

CHAMAEMEIUM, Tourn. ex Adans. Fam. ii. 128 (1763); Cass. in Dict.Sc. Nat. xxix. 179, 185 (1823) =Anthemis, Linn. (Compos.)

alpinum, All. F1. Pedem. i. 186=Achillea oxyloba. arvense, Schreb. Spicil. $18=$ A. arvensis.

austriacum, J. \& C. Presl, F1. Cech, $173=$ A. austriaca.

Cota, All. Fl. Pedem. i. $184=$ A. Cota

Cota, C. A. Mey. Verz. Pf. Cauc. $75=$ A. altissima.

Cotula, All. Fl. Pedem. i. $186=$ A. Cotula

discoideum, All. 1. c. 188=A. tinctoria.

foetidum, Baumg. Enum. Stirp. Transs. iii. $144=$ A Cotula.

incrassatum, Hoffmgg. Fl. Port. ii. 348, ex DC. Prod vi. $616=$ Anacyclus clavatus

maritimum, All. Fl. Pedem, i. $184=$ A. maritima.

Marschallianum, C. A. Mey. Verz. Pfl. Cauc. $75=$ A.

Biebersteiniana.

mixtum, All. F1. Pedem, i. $185=$ A. mixta

montanum, All. 1. c. $187=$ A. montana.

nobile, All, 1. c. $185=$ A, nobilis.

orientale, Schult. ex Steud. Nom. ed. II. i. $343=$ A montana.

pinnatifidum, Moench, Meth. $605=$ A. mixta.

proliferum, Moench, 1. c. Suppl. $257=$ Cladanthus proliferus.

tinctorium, Schreb. Spicil. $145=$ A. tinctoria.

tomentosum, All. F1. Pedem. i. 184=Anacyclus clavatus.

Triumfetti, All. 1. c. $187=$ A. austriaca

valentinum, All, 1. c. = Anacyclus valentinus.

CHAMAEMELUM, Vis. Osserv. Matric. 12 (1845); F1. Dalm. ii. $84(1847)=$ Matricaria, Linn. (Compos.) ambiguum, Boiss. Diagn. Ser. I. xi. 20 (=Pyrethrum ambiguum).--Oriens.

arvense, Reichb. f. ex Willk. in Bot. Zeit. xxii, (1864) $251=$ M. glabra.

auriculatum, Boiss. Diagn. Ser. I. xi. 23.-Arabia.

callosum, Boiss. \& Heldr. 1. c. 22.-As. Min.

caucasicum, Boiss, 1, c. $20=$ M. grandiflora.

conoclinium, Boiss. \& Bal. 1. c. Ser. II. vi. $98=$ M. conoclinia.

daghestanicum, Baiss. Fl. Orient. iii. 334.-Daghestan.

decipiens, Boiss. Diagn. Ser. I. xi. $22=$ M. decipiens. disciforme, Vis. Fl. Dalm. ii. $85=\mathrm{M}$. corymbifera. elongatum, Boiss. Diagn. Ser. I. xi. 20 (=Pyrethrum elongatum).-Oriens.

\section{CHAMAEMELUM :-}

grandiflorum, Boiss. \& Haussk, in Boiss. Fl. Orient. iii. 331.-Mesopotam.

heterocarpum, Boiss. 1. c. $329=$ Matricaria heterocarpa.

inodorum, Vis. Osserv. Matric. 13 ; F1. Dalm. ii. $85=$ M. inodora.

Kochii, Boiss. F1. Orient. iii, $329=$ M. microcephala.

Kotschyi, Boiss. Diagn. Ser. II iii. $27=$ M. Oreades.

lamellatum, Boiss. F1. Orient. iii. $326=\mathrm{M}$. lamellata.

limosum, Maxim. Prim. Fl. Amur. $156=\mathrm{M}$. inodora.

maritimum, Boiss. Diagn. Ser. I. xi. $21=$ M. maritima.

melanolepis, Boiss. \& Buhse, in Nouv. Mém. Soc. Nat

Mosc. xii. (1860) $118=$ M. Oreades.

microcephalum, Boiss. Diagn. Ser. I. xi. $23=$ M. microcepbala.

monticolum, Boiss. \& Huet, 1. c. Ser. II. iii. 27.Armenia.

nanum, Rupr. in Bull. Phys.-Math. Acad. Pétersb. xiv. 1856) 231 .-Kurdistan.

olympicum, Boiss. ex Tchihat. Asie Min. Bot. ii. 258 , nomen.-As. Min.

Oreades, Boiss Diagn. Ser. I. xi. $21=$ M. Oreades.

Pichleri, Boiss. F1. Orient. iii. 332,-Bithynia.

praecox, Vis. Osserv. Matric. 13; Fl. Dalm. ii. $86=$ M. praecox.

Reuterianum, Boiss. ex Tchihat. Asie Min. Bot. ii. 258, nomen.-As. Min.

rosellum, Boiss. \& Orph. in Boiss. F1. Orient. iii. $334=$ M. rosella.

Szovitsii, Boiss. 1. c. 332.-Reg. Caucas,

Tchihatchewi, Boiss. in Tchihat, Asie Min. Bot. ii. 256.-As. Min.

tetragonospermum, F. Schmïdt, Reisen Amur. 148.Reg. Amur.

trichophyllum, Boiss. Diagn. Ser. I. xi. $21=$ M. trichophylla.

uniglandulosum, Vis. Osserv. Matric. 13; Fl. Dalm. ii. $85=$ M. trichophylla.

CHAMAEMESPILUS, Medic. Phil. Bot. i. 138, 155 (1789) = Pyrus, Lina. (Rosac.)

ambigua, Gren. ex Nym. Consp. $242=$ P. Chamaemespilus.

Aria, M. Roem. Syn. Rosifl. $132=$ P. Aria

humilis, M. Roem. 1. c. $131=$ P. Chamaemespilus.

Pseudaria, M. Roem. 1. c. $132=$ P. Aria,

sudetica, M. Roem. 1, c. $131=\mathrm{P}$. sudetica.

CHAMAEMYRRHIS, Endl. ex Heynh. Nom. ii. 136 $(1846)$ = Caldasia, Lag. (Umbellif.)

eriopoda, Endl. 1. cs= Cald. eriopoda

CHAMAENERION, [Tourn.] Adans. Fam. ii. 85 (1763) = Epilobium, Linn. (Onagrar.)

americanum, Sweet, Hort. Brit, ed. II $198=$ E. palustre.

angustifolium, Schur, Enum. Pl. Transs. 213=E. angustifolium.

angustifolium, Scop. F1. Carn. ed. II. i. $271=$ E. Dodonaei.

denticulatum, Schur, Enum. Pl. Transs. $214=\mathrm{E}$. angustifolium.

Dodonaei, Schur, ex Fuss. Fl. Transs, $214=\mathrm{E}$. Dodonaei.

grandiflorum, Moench, Meth. $677=\mathrm{E}$. hirsutum

halimifolium, Salisb. Parad. Lond. t. $58=\mathrm{E}$. latifolium.

Halleri, Sweet, Hort. Brit ed. II. $198=$ E. Dodonaei.

hirsutum, Scop. F1. Carn. ed. II. i. $270=$ E. hirsutum.

latifolium, Sweet, Hort. Brit. ed. II. 198=E. latifolium.

montanum, Scop. Fl. Carn. ed. II. i. $270=$ E. montanum.

obscurum, Schreb. Spicil, $147=$ E. tetragonum.

palustre, Schreb. 1. c. $22=$ E. palustre

parviflorum, Schreb. 1. c. $146=\mathrm{E}$. parviflorum.

pubescens, Moench, Meth. $677=\mathrm{E}$. parviflorum.

ramosissimum, Moench, J. c. $678=\mathbf{E}$. tetragonum.

roseum, Schreb. Spicil. $147=\mathrm{E}$, roseum

rosmarinifolium, Moench, Meth. Suppl. $288=\mathbb{E}$.

Dodonaei.

speciosum, Lodd. ex Steud. Nom. ed. II. i. $343=\mathrm{E}$. angustifolium

spicatum, S. F. Gray. Nat. Arr. Brit. PI. ii. $559=$ E. angustifolium.

tetragonum, Scop. F1. Carn. ed. II, i. $271=\mathrm{E}$. tetragonum.
CHAMAENERIUM, Spach, Hist. Vég. Phan. iv. 396 $(1835)=$ praec

CHAMAEORCHIS, Koch, Syn, Fl. Germ. 092 (1837) = CHAMORCHIS, Rich. = Herminium, Willd. (Orchid.).

CHAMAEPEUCE, DC. Prod. vi. 657 (1837)=Cnicus Tourn. (Compos.)

afra, DC, 1. c. $659=\mathrm{Cn}$. afer.

Alpini, Jaub, \& Spach, Illustr. v. 26. t. $425=\mathrm{Cn}$. Chamaepeuce.

atropurpurea, Boiss. \& Heldr. Diagn. Ser. II. iii, $47=$ Cn. strictus.

Casabonae, DC. Prod. vi. $658=\mathrm{Cn}$. Casabonae.

cynaroides, DC. I. c. $659=\mathrm{Cn}$. cynaroides.

diacantha, DC. 1. $\mathrm{c}_{\mathrm{s}}=\mathrm{Cn}$. diacanthus.

echinocephala, DC. 1, c. $660=\mathrm{Cn}$, echinocephalus

firma, DC. 1. c. $659=\mathrm{Cn}$. firmus.

fruticosa, DC. 1. c. $658=\mathrm{Cn}$, fruticosus.

gnaphalodes, DC. 1. c. $=$ Cn. gnaphalodes

hispanica, DC. 1. $\mathrm{c}_{*}=\mathrm{Cn}$. hispanicus.

horrida, DC. 1. c. $660=\mathrm{Cn}$. horridus.

imbricata, Rafin. Fl. Tellur. iv. $118=\mathrm{Cn}$. Chamaepeuce.

macrantha, Schrank, in Bull. Sc. Acad. Pétersb. 1842) $354=$ Cousinia Hablizii

macrostachya, Trautv. in Bull. Phys.-Math. Acad Pétersb. xvi. (1858) 326.--Reg. Caucas.

mutica, DC. Prod. vi. $657=\mathrm{Cn}$. Chamaepeuce.

nivea, DC. Prod, vi. $659=\mathrm{Cn}$. niveus

polyacantha, St. Lag. in Ann. Soc. Bot. Lyon, vii. 1880) $144=$ Cn. Casabonae.

polycephala, DC. Prod. vi. $658=\mathrm{Cn}$. Chamaepeuce.

sinuata, Trautv. in Act. Hort. Petrop. ii. (1873) $477=$ Cn. cynaroides.

stellata, DC. Prod. vi. $658=\mathrm{Cn}$. stellatus

stricta, DC. 1. c. $659=\mathrm{Cn}$. strictus.

CHAMAEPEUCE, Zucc. in End1. Enchir. 139 (1841)= Thuya, Tourn. (Conif.)

obtusa, Zucc. ex Gord. Pinet. Suppl. $93=$ T. obtusa.

CHAMAEPHYTON, Fourr, in Ann. Soc. Linn. Lyon, N. S. xvi. (1868) $371=$ Potentilla, Linn. (Rosac.). supinum, Fourr. 1. c. $=$ P. supina.

CHAMAEPITYS, Tourn. ex Rupp. F1. Jen. ed. Hall $220(1745)=$ Ajuga, Toum. (Labiat.).

arvensis, Schur, in Verh. Siebenb. Ver. Naturw. iv (1853) $60=$ A. Chamaepitys.

Iva, Fourr, in Ann. Soc. Linn. Lyon, N. S. xvii. (1869) $138=$ A. Iva.

pseudoiva, Fourr. 1. c. = A. Iva.

trifida, Dum. Fl. Belg. $42=$ A. Chamaepitys.

vulgaris, Link, Handb. i. $453=$ A. Chamaepitys.

CHAMAEPLIUM, Wallr. Sched. Crit. i. $376(\mathbf{1 8 2 2})=$ Sisymbrium, Tourn. (Cracifer.)

officinale, Wallr. 1. c. $377=\mathrm{S}$. officinale.

polyceratium, Wallr. 1. c. $=\mathrm{S}$, polyceratium.

supinum, Wallr. 1. $\mathrm{c}_{*}=\mathrm{S}$. supinum.

CHAMAERANTHEMUM, Nees, in Lindl, Nat Syst. ed. II. 445 (1836). ACANTHACEAE, Benth. \& Hook, f. ii. 1095.

Beyrichii, Nees, l. c. 445.-Bras.

Gaudichaudii, Nees, in Mart. Fl. Bras. ix. 155.Bras.

igneum, Regel, Gartenfl. (1868) 353.-Peruv.

pictum, Mast. in Gard. Chron. (1878) 1. 527.Bras.

CHAMA FR PPHS, R. Br. Prod. 193 (1810) GRAMINEAE, Benth. \& Hook. f. iii. 1107.

abortiva, Poir. Encyc. Suppl. ii. $189=$ spinescens. aspera, Nees, in Wall. Cat. n. $8679=$ spinescens. compressa, Poir. ex Steud. Nom. ed. I. $183=$ Pennisetum compressum.

depauperata, Nees, ex Steud. Syn. Pl. Gram. $49=$ Panicum asperum, Wight.

gracilis, Hack. in Engl. Bot. Fahrb. vi. (1885) 236.Malaya.

hordeacea, R. Br. Prod. i. 194.-Austral.

paradoxa, Poir. Encyc. Suppl. ii. 189.-Austral.

parvigluma, Munro, ex Wright, in Sauv. Fl. Cub. 200, nomen.-Cuba. 


\section{CHAMAFRAPHIS}

spinescens, Poir. Encyc. Suppl. ii. 189.-As. trop. Austral.

spinosa, Beauv. ex Roem. \& Schult. Mant. ii. $253=$ spinescens.

CHAMAEREPES, Spreng. Syst, iii. 702 (1826) = Herminium, Willd, (Orchid.)

alpina, Spreng. 1. c. $=$ H. alpinum

CHAMAERHODODENDROS, Tourn. ex Hall. in Rupp. F1. Jen. ed. Hall. $249(1745)=$ Rhododendron, Linn. (Ericac.).

CHAMAERHODOS, Bunge, in Ledeb. Fl. Alt. i 429 (1829). ROSACEAE, Benth. \& Hook. f. i. 621. altaica, Bunge, $l$. c.-Sibir. alt. occ.

erecta, Bunge, l. c. 430.-Sibir.; Am. bor. occ.

grandiflora, Ledeb. l. c. 431, in nota.-Sibir.

mongholica, Bunge, in Ann. Sc. Nat. Sér. II, xix. (1843) 177.-Mongolia

polygyna, G. Don, Gen. Syst. ii. $563=$ erecta.

sabulosa, Bunge, in Ledeb. Fl. Alt. i. 431.-Sibir.

trifida, Ledeb. Fl. Ross. ii. 34.-Sibir.

CHAMAERIPHES, Ponted, ex Gaertn. Fruct. i. 25 1789) $=$ seq

CHAMAEROPS, Linn. Mus. Cliff. 10 ; Gen. ed. I 354 (1737). PALMAE, Benth. \& Hook. f. iii. 924. Chamaeriphes, Ponted. ex Gaertn. Fruct. i. 25 (1789).

acaulis, Michx. Fl. Bor. Am, ii. 207:=Sabal Adansoni. Antillarum, Desc. Antill. i. t. 28 (Thrinacis sp. ?).Ind. occ.

arborescens, Steud. Nom. ed. I. $183=$ humilis.

arundinacea, Sm. in Rees, Cycl. vii. n. $3=$ Rhapidophyllum Hystrix.

Biroo, Siebold, in Mart, Hist. Nat. Palm. 252= Livistona rotundifolia.

cochinchinensis, Lour. Fl. Cochinch. ii. $657=$ Rhapi cochinchinensis.

conduplicata, Kickx, in Bull. Acad. Brux. v. (1838) 61 = humilis.

excelsa, Thunb. F1. Jap. $139=$ Trachycarpus excelsus. excelsior, Boj. Hort. Maurit. 307.-Ins. Maurit.

Fortune, Hook, Bot. Mag, t. $5221=$ Trachycarpu Fortunei.

Ghiesbreghti, Hort. ex H. Wendl. in Kerch. Palm. 240 (=Sabal sp.) - - Hab. ?

slabra, Mill. Gard. Dict. ed. VIII. n. 2=Sabal Adansoni.

gracilis, Lodd. Cat. (1823) ex Schult. f. Syst. vii 1489, nomen.-Am. austr.

Griffithiana, Wall. ex Voigt, Hort. Suburb. Calc. 641, nomen $=$ seq.

Griffithi, Lodd. Cat. (1841) ex Verlot, in Rey. Hortic. $(1870)$ t. $276=$ Trachycarpus khasyanus.

guianensis, Lodd. Cat. ex Loud. Hort. Brit. 413 nomen.-Guiana,

humilis, Linn. Sp. Pl. 1187.--Reg. Mediterr, occ.

Histrix, Desf. ex Steud. Nom. ed. I. 183=Corypha Hystrix.

Hystrix, Fras. ex Pursh, Fl. Am. Sept. i, $240=$ Rhapidophyllum Hystrix.

khasyana, Grift. in Calc. Journ. Nat. Hist. v. (1845 $\$ 41=$ Trachycarpus khasyanus.

Kwanwartsik, Siebold, ex H. Wendl. Ind. Palm. (1854) $34=$ Rhapis flabelliformis

louisiana, Rafin. Fl. Ludov. $159=$ Rhapidophyllum Hystrix?

macrocarpa, Linden, Cat. n. 87 (1871).-Hab. ?

macrocarpa, Tin. in Guss. Fl. Sic. Syn. ii. $883=$ humilis.

Martiana, Wall, P1. As, Rar. iii. 5. t. $211=$ Trachy carpus Martianus

mitis, F. Mey. in Mim. Acad. Berl. (1769) 29.Hab. ?

Mocini, H. B. \& K. Nov, Gen, et Sp. i. $300=$ Acan thorhiza Mocinni.

nepalensis, Lodd. Cat. (1823) ex Schult. f. Syst. vii. 1489 = Trachycarpus Martianus.

Palmetto, Michx. Fl, Bor. Am. i. $206=$ Sabal Palmetto. reclinata, Fuss. ex Schult. f. Syst. vii. 1489, nomen.II ab. ?

Ritchiana, Griff. in Calc. Journ. Nat. Hist. v. (1845) $312=$ Nannorrhops Ritchicana.

serrulata, Michx. F1. Bor. Am. i. $239=$ Brahea serrulata.

\section{CHAMAEROPS}

Sirotsik, Hort, ex H. Wendl. Ind. Palm. (1854) 17 Rhapis humilis.

stauracantha, Hort. Belg. ex Heynh. Nom. ii. $136=$ Acanthorhiza aculeata.

tomentosa, Fulchiron, ex Schult. f. Syst. vii. 1489 nomen,-Hab.

tomentosa, Ch. Morr. in Ann. Gand, i. (1845) 488.Hab.?

CHAMAESARACHA, A. Gray, ex Franch. \& Sav. Enum. Pl. Jap. ii. 454 (1876). SOLANACEAE, Benth. \& Hook. f. ii. 891

conoides, Benth. E Hook. f. Gen. ii, 891.-Mexic

Coronopus, A. Gray, in Bot. Calif i. 540.-Calif

japonica, Franch. E Sav. Enum. Pl. Fap. ii. 454.Japon.

nana, A. Gray, in Bot. Calif. i. 540.-Calif.

physaloides, Greene, in Bull. Torrey Club, ix. (1882) $122=$ Physalis lobata

ordida, A. Gray, Synop. Fl. N. Am. ii. 1. 232,--Texas Mexic.

CHAMAESARACHIA, Franch. \& Sav. Enum. Pl. Jap. ii. $454(1876)=$ praec.

CHAivaEsciadium, C. A. Mey, Verz, Pf. Came 122 (1831). UMBELLIFERAE, Benth. \& Hook, f i. 895 .

acaule, C. A. Mey. l. c.-As. Min.; Reg. Caucas. albiflorum, Kar. E Kir. in Bull. Soc. Nat. Mosc. xy. 1842) 360.-Sibir

flavescens, C. A. Mey, Verz. Pf. Cauc, $122=$ acaule. gracile, Boiss. \& Heldr, in Boiss. Diagn. Ser. II. ii. 79 - Carum rupestre.

Heldreichii, Boiss. i. c. $78=$ Carnm Heldreichii.

CHAMAESCILIA, F. Muell. Fragm. vii. 68 (1870) LILIACEAE, Benth. \& Hook. f. iii. 791.

corymbosa, $F$. Muell. l. c.-Austral.

spiralis, F. Muell. l. c.-Austral.

CHAMAESPARTIUM, Adans. Fars. ii. 321 (1763)= Cytisus, Linn. et Genista, Linn. (Legamin.).

CHAMAESPARTON, Fourr, in Ann. Soc. Linn. Lyon, N. S. xvi. (1868) $357=$ Genista, Linn. (Legamin.). pilosum, Fourr. 1. c。=G. pilosa.

CHAMAESPHACOS, Schrenk, Enum. Pl. Nov. i. 27 (1841). LABIATAE, Benth. \& Hook. f. ii. 1207.

ilicifolius, Schrenk, l. c.-Sibir.

CHAMAESPHAERION, A. Gray, in Hook, Kew Journ. iii. (1851) $176=$ Chthonocephalus, Steetz (Compos.).

pygmaeum, A. Gray, 1. c. $177=$ Chthonocephalns pygmaens.

CHAMAESPILUS, Fourr. in Ann. Soc. Linn. Lyon, N.S. xvi. (1868) $378=$ Pyrus, Linn. (Rosac.) sudetica, Fourr. 1. c, $=$ P. sudetica.

CHAMAESTEPHANUM, Willd, in Ges. Nat. Fr. Ber Mag. i. (1807) $140=$ Schkuhria, Roth (Compos.)

CHAMAESYCE, S. F. Gray, Nat. Arr. Brit. Pl. ii. 260 (1821) = Euphorbia, Linn maritima, S. F. Gray, 1. c. $=$ E. Peplis.

CHAMAEZELUM, Link, Handb. i. 719 (1829) = Antennaria, R. Br. (Compos.)

alpinum, Link, 1. c. = A. alpina.

carpaticum, Link, 1. $\mathrm{c}_{\mathrm{s}}=\mathrm{A}$. carpathica.

dioicum, Link, 1. c. = A. dioica.

margaritaceum, Link. 1. c。=Anaphalis margaritacen,

CHAMAEXEROS, Benth. Fl. Austral, vii. 110 (1878). GUNCACEAE, Benth. \& Hook. fo iii. 864 .

fimbriata, Benth. l. c. 111-Austral.

Serra, Benth. l. c. 110.-Austral.

CHAMAEXIPIIUM, Hochst, in Flora, xviii. (184t $102=$ Ficinia, Schrad. (Cyperac.).

clandestinum, Hochst. 1. co $=F$, clandcstina

Dregeanum, Stend. Sya. Pl. Cyp. $59=$ F. lacvis.
CHAMAGROSTIS, Borkh, ex Wibel, Prim, F1, Werth. $126(\mathbf{1 7 9 9})=$ Mibora, Adans. (Gramin.)

minima, Borkh. I. $\mathrm{c}_{s}=$ M. verna

CHAMALIUM, Juss. in Ann. Mns, Par. vi. (1805) $324=$ Cardopatium, Juss. (Compos.).

CHAMALIUM, Cass, in Dict. Sc, Nat xlvii. (1827) 498 $509=\mathrm{CHAMAELEON}$, Cass $=$ Atractylis, Linn (Compos.).

CHAMAREA, Eckl. \& Zeyh. Enum. 346 (1837) = Carum, Linn. (Umbellif.)

caffra, Erkl. \& Zeyh. 1. c. -Afr. austr.

capensis, Eckl. \& Zeyh. 1. c. = Caram capense.

CHAMBEYRONIA, Vieill. in Bull. Soc. Linn Normand. Sér. II. vi. 1872 (1873) 229. PALMAE Brébissonii, Vieill. l. c. 230 , nomen.-N. Caled. macrocarpa, Vieill. l. c. nomen.-N. Caled. Morieri, Vieill. l. c. nomen.-N. Caled.

CHAMEDRYS, Rafin. F1. Tellur. iii. 85 (1838) = CHAMAEDRYS, Tourn. = Teucrium, Tourn. (Scrophul.).

CHAMELUM, Phil, in Linnaea, xxxiil. (1864-65) 250 IRIDEAE, Benth. \& Hook. f. iii. 700 .

Chamaelum, Baker, in Journ. Lina. Soc. xvi (1877) 120, sphalm.

andinum, Benth. E Hook, f. Gen. iii. 700.-Chili.

uteum, Phil, in Linnaea, xxxiii. (1864 65) 250.Chíli.

CHAMIRA, Thunb. Nov, Gen。 ii. 48 (1782), CRU CIFERAE, Benth. \& Hook. f. i. 81

cornuta, Thunb. l. c. 49-Afr, austr.

CHAMISME, Rafin, ex Stend, Nom, ed, II i 776 (in syn.) $(1840)=$ Houstonia, Gron. (Rubiac.).

CHAMrssoA, H. B. \& K. Nov, Gen, et Sp, ii. 158 t. 125 (1817). AMARANTACEAE, Benth. \& Hook f. iii. 27

KokerA, Adans. Fam. ii. 269 (1763)

acuminata, Mart. in Nov. Act. Nat. Cur. xiii. (1826) 286.-Bras.

albida, Mart. 1. c. $287=$ Allmania albida

altissima, H. B. E K. Nov. Gen. et Sp. 197. t. 125.Am. austr.

altissima, Nces \& Mart. in Nov. Act. Nat. Cor. xi. (1823) $32=$ Maximiliani.

angustifolia, Buch.-Ham. ex Hook. f. Fl, Brit. Ind. in $717=$ Allmania nodiflora.

arabica, Spreng. Syst. i. $815=$ Digera arvensis.

aspera, Wight, Ic, $\dot{\mathbf{v}}, t .1772=$ Allmania nodiflora.

Blanchetii, Moq. in DC. Prod. xiii. II. 251.-Bras.

Brownii, Steud. Nom. ed. II. i. $344=$ Allmania nodiflora.

celosioides, Griseb. in Goett. Abl. xix. 1S71) 79.Reg. Argent.

ciliata, Spreng. Syst. i. $815=$ Digera arvensis

commutata, Spreng. 1. c. = Digera arvensis.

dichotoma, Moq. in DC. Prod. xiii. 11. 249= Allmania nodiflora.

esculenta, Moq. 1. c. = Allmania nodifora.

jaranica, Hassk. Pl. Jar. Rar. $484=$ Allmania nodiflora. macrocarpa, $H . B . \xi^{\circ} K$. Now. Gene ef Sp ii. 197. Am, austr.

Martii, Moq. in DC. Prod. xiii. 11. $252=$ altissima.

Maximiliani, Mart. ex Mog. l. c. 251.-Bras.

muricata, Spreng. Syst. i. $815=$ Digera arvensis.

nodiflora, Mart. in Nov. Act. Nat. Cur. xiii. (1526) as:

Allmania nodifo:a.

orata, Fndl. cx Moq. in DC. Prod, xiij. 14. \$2:- C'bay. pentiera ovata.

paniculasa, Moq. ex Moq. l. c. $299-$ Cclosia Mo quini.

populifulia, Ilochst. ex Mọ. I. a Celosia populi.

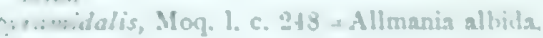

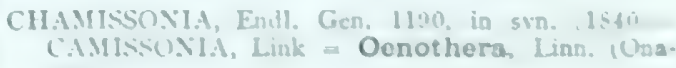
grar. 
CHAMITEA, Kern. in Verh. Zool,-Bot. Ges. Wien, x. (1860) 275 = Salix, Tourn.

reticulata, Kern. I. c. $277=$ S. reticulata.

CHAMITIS, Banks, ex Gaertn. Fruct. i. 94. t. 22 (1788) =Azorella, Lam. (Umbell.).

complicata, Banks \& Soland. ex Hook. f. Fl. Antarct. ii. $285=$ A. caespitosa.

integrifolia, Gaertn. Fruct. i. 94. t. 22. f. $4=$ A. filamentosa.

tricuspidata, Gaertn. 1. c. t. $22=$ A. trifurcata.

trifurcata, Banks \& Soland. ex Hook. f. Fl. Antarct. ii. $283=\mathrm{A}$. trifurcata.

trifurcata, Gaertn. Fruct. i. $95=$ A. caespitosa.

CHAMOLETTA, Adans. Fam. ii. $60(1763)=$ Iris, Linn.

CHAMOMILLA, [Hall.] S. F. Gray, Nat. Arr. Brit. Pl. ii. 454 (1821); C. Koch, in Linnaea, xvii. (1843) $45=$ Matricaria, Linn. (Compos.).

brachyglossa, J. Gay, ex Benth. \& Hook. f. Gen. ii. $428=$ M. brachyglossa.

Courrantiana, C. Koch, in Linnaea, xxiv. (1851) 338, in obs. = M. Chamomilla.

discoidea, J. Gay, ex A. Br. in Bot. Zeit. x. (1852) 650 $=$ M. discoidea.

glabrata, Sch.-Bip. Ueber Tanacet. $21=$ M. glabrata. inodora, C. Koch, in Linnaea, xvii. (1843) $45=$ M. inodora.

meridionalis, C. Koch, 1. c. = M. Chamomilla.

officinalis, C. Koch, 1. c. = M. Chamomilla,

patens, Gilib. Fl. Lituan. iii. $220=\mathrm{M}$. Chamomilla

praecox, C. Koch, in Linnaea, xvii. (1843) $46=$ M. inodora.

unilateralis, C. Koch, 1. c. xxiv. (1851) 338.--Reg. Caucas.

vulgaris, S. F. Gray, Nat. Arr. Brit. Pl. ii. $454=$ M. Chamomilla.

CHAMOMILLA, Godr. Fl. Lorr. if. $19(1843)=$ Anthemis, Linn. (Compos.).

aurea, J. Gay, in Bull, Soc. Bot. Fr. iv. (1857) $278=$ Cotula aurea.

fuscata, Gren. \& Godr. FI. Fr. ii. 151=A. fuscata.

mixta, Gren. \& Godr. 1. c. = A. mixta.

nobilis, Godr. Fl. Lorr. ii. $19=$ A. nobilis.

CHAMORCHIS, Rich. in Mém. Mus. Par. iv. (1818) 49 $=$ Herminium, Linn. (Orchid.).

albida, Dum. Fl. Belg. 133= Habenaria albida.

alpina, Rich. in Mém. Mus. Par. iv. (1818) $57=$ Herminium alpinum.

viridis, Dum. F1. Belg. $133=$ Habenaria viridis.

CHAMPACA, Adans. Fam. ii. 365 (1763)= Michelia, Linn. (Magnoliac.).

fasciculata, Noronha, in Verh. Batav. Gen. v. (1790) ed. I. Art. IV. 13.-Malaya.

Michelia, Noronha, 1. c. 11=M. Champaca.

turbinata, Noronha, 1. c. 12.-Malaya.

CHAMPEREIA, Griff. in Calc. Journ. Nat. Hist. iv. (1843) 237. SANTALACEAE, Benth. \& Hook.f, iii. 231.

Malulucban, Blanco, Fl. Filip. ed. I. 188 (1837) gnetocarpa, Kurz, in Fourn. Bot. xiii. (1875) 325.-
Ins. Nicobar. Ins. Nicobar.

Griffithiana, Planch. ex Kurz, in Fourn. As. Soc. Beng. xliv. (1875) II. 154.-Burma; Malaya.

Perrottetiana, Baill. Adansonia, iii. (1862-63) $125=$ Scleropyrum Wallichianum.

CHAMPIONIA, C. B. Clarke, Comm. et Cyrt. Beng. 98. t. $68(1874)=$ Leptobaea, Benth. (Gesnerac.).

multiflora, C. B. Clarke, $1_{\text {. c }}=\mathrm{L}$. multiflora.

CHAMPIONIA, Gardn. in Calc. Journ. Nat. Hist. vi. (1846) 485. GESNERACEAE, Benth. \& Hook. f. ii. 1024.

reticulata, Gardn. l.c.-Zeylan.

CHAMULA, Noronha, in Verh. Batav. Gen. v. (1790) ed. I. Art. IV. 2 (Quid?).

CHAPELIERA, Meissn. Gen. 162; Comm. $116(1838)=$ seq.
CHAPEIIERIA, A. Rich. in Mém. Soc. Hist. Nat. Par. v. (1830) 252. RUBIACEAE, Benth. \& Hook. f. ii. 96.

madagascariensis, A. Rich. l. c. 253.-Madag.

CHAPELLIERA, Nees, in Linnaea, ix. (1834) $298=$ Cladium, P. Br. (Cyperac.).

arthrophylla, Nees, in Lehm. P1. Preiss. ii. $77=\mathrm{Clad}$. arthrophyllum.

articulata, Nees, 1 . c. 76 , in adnot. $=$ Clad. articulatum. glomerata, Nees, $1 . \mathrm{c} .=$ Clad. glomeratum.

iridifolia, Nees, in Linnaea, ix. (1834) $298=\mathrm{Clad}$. flexuosum.

juncea, Nees, in Lehm. Pl. Preiss. ii. 76, in adnot. = Clad. junceum.

laxa, Nees, 1. c. $76=$ Clad. laxum.

pauciflora, Nees, l. c. 76 , in adnot $=$ Tricostularia pauciflora.

riparia, Nees, 1. c. $76=$ Clad. riparium.

teretifolia, Nees, 1. c. 76 , in adnot. $=$ Clad, teretifolium.

CHAPMANNIA, Torr. \& Gray, Fl. N. Am. i. 355 (1839). LEGUMINOSAE, Benth. \& Hook. f. i. 517. floridana, Torr. E Gray, l. c. -Florida.

CHAPTAliA, Royle, Illustr. Bot. Himal. t. 59. f. 2 $(1839)=$ Gerbera, Gronov. (Compos.).

gossypina, Royle, 1. c. $251=\mathrm{G}$. lanuginosa.

maxima, D. Don, Prod. Fl. Nep. $166=$ G. macrophylla.

CHAPTALIA, Vent. Jard. Cels, t. 61 (1800)。 COMPOSITAE, Benth. \& Hook. f. ii. 498.

Leria, DC. in Ann. Mus. Par. xix. (1812) 68.

Lieberkuhna, Cass, in Dict. Sc. Nat. xxvi. 286 (1823).

Loxodon, Cass. 1. c. xxvii. 253 (1823).

Oxydon, Less. in Linnaea, v. (1830) 357.

Thyrsanthema, Neck. Elem. i. 6 (1790)

albicans, Vent.ex Steud. Nom. ed. II. i. 344.-Ind. occ.

Anandria, Spreng. Syst. iii. $504=$ Gerbera Anandria.

araneosa, Casar. in Atti $3^{a}$ Riun. Sc. Ital. iii. (1841) 514.-Bras.

dentata, Cass. in Dict. Sc. Nat. xxvi. 104.-Ind. occ.

denticulata, Spreng. ex Baker, in Mart. Fl. Bras. vi III. $310=$ Senecio pulcher.

Ehrenbergii, Hemsl. Biol. Centr. Am. Bot. ii. 255.Mexic.

exscapa, Poepp. ex DC. Prod. vii. 44, in syn.-Chili.

heterophylla, D. Don, in Trans. Linn. Soc. xvi. (1830) $244=$ Trichocline heterophylla.

integrifolia, Baker, in Mart. Fl. Bras. vi. III. 377.Am. trop.

integrifolia, Vent. ex Spreng. Syst. iii. $504=$ tomentosa. lyrata, D. Don, in Trans. Linn. Soc. xvi. (1830) 243.Mexic.

lyrata, Spreng. Syst. iii. 504= Gerbera Anandria. nutans, Hemsl. Biol. Centr. Am. Bot. ii. 255.-Mexic. oblonga, D. Don, in Trans. Linn. Soc, xvi. (1830) 240.-Peruv.

obovata, Wright, in Sauv. Fl. Cub. 83.-Ins. Cuba. ovalis, D. Don, in Trans. Linn. Soc. xvi. (1830) 241 -Peruv.

piloselloides, Baker, in Mart. Fl. Bras. vi. III. 378.Bras.

piloselloides, Vent. ex Steud. Nom. ed. II. i. 344 Baker, in Mart. Fl. Bras. vi. III. 378.-Reg. Argent. rotundifolia, D. Don, in Trans. Linn. Soc. xvi. (1830) 242.-Peruv.

runcinata, $H . B . \&$ K. Nov. Gen. et $S p$. iv. 6.-N. Granat.

sarmentosa, Vent. ex Steud. Nom. ed. II. i. $344=$ Chevreulia stolonifera.

Seemannii, Hemsl. Biol. Centr. Am. Bot. ii. 255.Mexic.

sinuata, Baker, in Mart. Fl. Bras. vi. III. 378.Reg. Uruguay ; Argent.

sinuata, Vent. ex Steud. Nom. ed. II. i. 344.-Ins. Jamaic. spathulata, Hemsl. Biol. Centr. Am. Bot. ii. 255.-
Mexic.

tomentosa, Vent. Fard. Cels, t. 61.-Am. bor.

CHAQUEPIRIA, Endl. Gen. 562, in syn. (1838) sphalm. =CAQUEPIRIA, J. F. Gmel,=Gardenia, Linn. (Rubiac.).

CHARACHERA, Forsk. Fl. Aegypt. Arab. 115 (1775). ACANTHACEAE?, Benth. \& Hook, f. ii.1071 Xeralis, Rafin. Sylva Tellur. 82 (1838).

\section{CHARACHERA}

spicata, Lam. Encyc. i. $695=$ viburnoides.

viburnoides, Forsk. Fl. Aegypt. Arab. 116.-Arabia.

CHARACIAS, S. F. Gray, Nat. Arr. Brit. Pl. ii. 259 (1821) = Euphorbia, Linn

amygdaloides, S. F. Gray, 1. c. $260=\mathrm{E}$. amygdaloides purpurea, S. F. Gray, 1. c. $259=$ E. Characias.

CHARADRA, Scop. Introd. $270(\mathbf{1 7 7 7})=$ CHADARA, Forsk.$=$ Grewia, Linn.

CHARDINIA, Desf. in Mém. Mus. Par. iii. (1817) 455. t. 21. COMPOSITAE, Benth. \& Hook. f. ii. 464.

cylindrica, Desv. Fl. Anj. 216=Xeranthemum cylindraceum.

macrocarpa, C. Koch, in Linnaea, xxiv. (1851) $382=$ xeranthemoides.

xeranthemoides, Desf. in Mém. Mus. Par. iii. (1817) 456.-As. Min.; Persia.

CHARIANTHUS, D. Don, in Mem. Wern. Soc. iv. (1823) 327. MELASTOMACEAE, Benth. \& Hook. f. i. 762 .

Chatenanthera, Rich. ex DC. Prod. iii. 196 (1828). Tetrazygos, Rich. ex DC. I. c. 197 (1828).

Berteroanus, Ser. ex DC. 1. c. 197 = glaberrimus.

brasiliensis, Cham. ex Triana, in Trans. Linn. Soc. xxviii. (1871) $118=$ Miconia brasiliensis.

caeruleus, D. Dietr. Syn. P1. ii. 1277= Memecylon Spathandra.

ciliatus, DC. Prod. iii. 197.-Ins. Trinitat.

coccineus, D. Don, in Mem. Wern. Soc. iv. (1823) 328. -Am. austr.

crinitus, Naud. in Ann. Sc. Nat. Sér. III. xviii. (1852) 112.-Ind. occ.

Fadyeni, Griseb. in Goett. Abh. ix. (1861) 56.-Jamaic. glaberrimus, DC. Prod. iii. 196.-Ind. occ.

nodosus, Triana, in Trans. Linn. Soc. xxviii. (1871) 99 = ciliatus.

obliquus, Griseb, in Mem. Am. Acad. N. S. viii. (1861) $186=$ Miconia obtusa.

obtusus, Triana, in Trans, Linn. Soc. xxviii. (1871) $103=$ Miconia obtusa

purpureus, D. Don, in Mem. Wern. Soc. iv. (1823) 329. -Ins. Montserrat.

tinifolius, D. Don, l. c.-Ind. occ.

CHARIDIA, Baill. Etud. Gén. Euph. 572. t. 22 (1858) =Savia, Willd. (Euphorb.)

mimosoides, Baill. 1. c. $573=\mathrm{S}$. mimosoides.

pulchella, Baill. 1. $\mathrm{c}_{\mathrm{s}}=\mathrm{S}$. pulchella.

CHARIEIS, Cass. in Bull. Soc. Philom. (1817) 68 ; et in Dict. Sc. Nat, viii. 191; xxiv. 369 (1817). COMPOSITAE, Benth. \& Hook. f. ii. 266.

Kaulfussia, Nees, Hor. Phys. Berol. 53. t. 11 (1820). caerulea, Cass. in Dict. Sc. Nat. xxiv. $372=$ hetero. phylla.

heterophylla, Cass. in Bull. Soc. Philom. (1817) 68.Afr. austr.

Neesii, Cass. 1. c. (1821) 13, ex eod. in Dict. Sc. Nat. xxiv. $370,372=$ heterophylla.

pilosella, Baill. Hist. Pl. viii. $139=$ heterophylla.

CHARIESSA, Miq. F1. Ind. Bat. i. I. 794 (1855)=Vil. laresia, Ruiz \& Pav. (Olacin.).

Smythii, Becc. Malesia, i. (1877) 118.-Malaya.

suaveolens, Miq. Fl. Ind. Bat. i. 1. 794.-Malaya.

CHARIOMMA, Miers, Apocyñ. S. Am. 110 (1878)= Echites, Linn. (Apocyn.).

domingensis, Miers, 1. c. $112=$ Echites domingensis.

flaxa, Miers, 1. c. $113=$ Dipladenia flava.

mucronulata, Miers, 1. c. 112.-Ins. S. Thom

nobilis, Miers, 1. c. $113=$ Dipladenia nobilis.

scandens, Miers, 1. c. 114.-Ind. occ.

surrecta, Miers, 1. c. $111=$ Echites Andrewsii.

verticillata, Miers, 1. c. 113.-Jamaic.

CHARLWOODIA, Sweet, F1. Austral. t. 18 (1827)= Cordyline, Comm. (Liliac.).

angustifolia, Goepp. Beitr. Kenn. Dracaen. $17=$ Cord. Pumilio.

australis, G. Don, in Loud. Hort. Brit. $130=$ Cord. australis.

congesta, Sweet, Fl. Austral. t. $18=$ Cord. Pumilio.

ensata, Goepp. Beitr. Kenn. Dracaen. $17=$ Dianella ensifolia? 
CHARLWOODIA :-

fragrantissima, Lem. Jard. Fleur. iv. (1854) t. 399 Misc. $57=$ Cordyline dracaenoides.

indivisa, G. Don, in Loud. Hort. Brit. $130=$ Cord. indivisa.

longifolia, Goepp. Beitr. Kenn, Dracaen. 17.-Hab. ? rigidifolia, Koch \& Bouché, Ind. Sem. Hort. Berol (1855) $11=$ Cord. Pumilio.

rubra, Planch. in Fl. des Serres, vi. (1850-51) $138=$ Cord. rubra.

Sellowiana, Planch. 1. c. $137=$ Cord. Sellowiana.

spectabilis, Planch. 1.c. $136=$ Cord. dracaenoides.

stricta, Sweet, Fl. Austral. sub t. $18=$ Cord. Pumilio.

CHARPENTIERA, Gaudich. in Freyc. Voy. Bot 444. to 47,48 (1826). AMARANTACEAE, Benth. \& Hook. f. iii. 26.

obovata, Gaudich. l.c. t. 48.-Ins, Sandvic.

ovata, Gaudich. l. c. t. 47.-Ins. Sandvic.

CHARPENTIERA, Vieill. in Bull. Soc. Linn. Normand. ix. (1865) $346=$ Pavetta, Linn. (Rubiac.).

bracteata, Vieill. 1. c. 347.-N. Caled.

CHARTACALYX, Maing. ex Mast. in Hook, f. F1. Brit. Ind. i. 382 (1874). TILIACEAE accrescens, Mast. l. c.-Malacca.

CHARTOCALYX, Regel, in Act. Hort. Petrop. vi. (1879) 367. LABIATAE.

Olgae, Regel, $i$.c. 368.-Turkestan.

CHARTOLEPIS, Cass. in Dict. Sc. Nat. xliv, 36 (1826) Centaurea, Linn. (Compos.).

Biebersteinii, Jaub. \& Spach, Illustr. iii. $11=$ Cent. glastifolia (ex parte)

cappadocica, Fenzl, in Tchihat. Asie Min. Bot. ii. 328 $=$ Cent. cappadocica.

cappadocica, Jaub. \& Spach, Illustr, iii. 137. t. $291=$ Cent. macrolopha.

Cassiniana, Jaub. \& Spach, 1. c. $9=$ Cent. glastifolia.

cheirolopha, Fenzl, in Tchihat. Asie Min. Bot. ii. $324=$

Cent. cheiracantha.

drabaefolia, Jaub. \& Spach, Illustr. iii. $136=$ Cent. drabifolia.

glastifolia, Cass. in Dict. Sc. Nat. xliv, $36=$ Cent. glastifolia.

intermedia, Boiss. Diagn. Ser. II. iii. 64.-Ross. mer. ; Sibir.; Soongar.

Kotschyi, Fenzl, in Tchihat. Asie Min. Bot. ii. $328=$ Cent. macrolopha.

lancifolia, Fenzl, 1. c. $327=$ Cent. lancifolia

libanotica, Jaub. \& Spach, Illustr, iiii. 136.-Syria

lyrata, Boiss. \& Haussk. ex Boiss. Fl. Orient. iii. 696. -Persia.

saligna, C. Koch, in Linnaea, xxiv, (1851) 421 (= Phaeopappus salignus) --Armenia.

schizolepis, Boiss. ex Boiss. Fl. Orient. iii. 596 (= Phreopappus salignus).-Kurdist.

Tournefortii, Jaub, \& Spach, Illustr. iii. $9=$ Cent. glastifolia.

CHARTOLOMA, Bunge, in Bot. Zeit. ii. (1844) $249=$ Isatis, Tourn. (Crucif.)

platycarpum, Bunge, l. c. $250=$ I. platycarpa.

CHASAliA, Comm. ex DC. Prod. iv. 531 (1830). RUBIACEAE, Benth. \& Hook. f. ii. 126.

Pozyozus, Blume, Bijdr. 947 (1826).

amicorum, A. Gray, in Proc. Am. Acad. iv. (1860) 43 -Ins. Fiji.

Borboniae, Comm. ex DC. Prod. iv. $532=$ divaricata

Boryana, DC. l. $c_{0}-$ Ins. Mascar.

capitata, DC. l. c. 531.-Ins. Maurit.

chondrophylla, Miq. Ann. Mus. Bot. Lugd. Bat. iv. 203.-. Sumatra.

clusiaefolia, DC. Prod, iv, 532,-Ins. Maurit.

coffeoides, DC. 1. c. 581 = divaricata ?

Commersonii, Juss. ex Steud. Nom. ed. II. i. $345=$ capitata.

curviflora, Thw. Enum. Pl. Zeyl. 150,-Ind, or

Malnya.

divaricata, $D C$. Prod. iv, 582,-Ins. Maurit.

expansa, Mig. Fl. Ind. Bat. ii. $280=$ Psychotria

malayana.

Fontanesii, $D C$. Prod. iv. 531.-Ins. Mascar.

randifolia, DC. l. C. 582.-Ins. Maurit

\section{CHASALIA :-}

Hasseltiana, Miq. Ann. Mus. Bot. Lugd. Bat. iv. 204. -Java.

laxiflora, Benth. in Hook. Niger F1. 416 = Psychotria Ansellii.

leucocarpa, Miq. Fl. Ind. Bat. ii. 281=Psychotria leucocarpa.

lurida, Miq. 1. c. 282 = curviflora

montana, Miq. 1. c. $281=$ Psychotria montana.

Mooniae, Baker, Fl. Maurit. 155.-Ins. Mascax.

oxylepis, Miq. Fl. Ind. Bat, ii. 283.-Java.

parviflora, Benth, in Hook. Niger Fl. 417. - Afr. trop. perforata, Miq. Fl. Ind. Bat. Suppl. $546=$ Psychotria angulata.

psychotrioides, DC. Prod. iv, $531=$ Gaertnera psychotrioides.

pyriformis, A. Gray, in Proc. Am. Acad.iv. (1860) 44 -Ins. Samor

robusta, Miq. Fl. Ind. Bat, ii, $280=$ Psychotria robusta.

rostrata, Miq.l.c. 281.-Malaya.

sangiana, Miq. Fl. Ind. Bat. Suppl. $546=$ curviflora.

stipulacea, DC. Prod. iv. $532=$ divaricata.

tetrandra, Miq. Fl. Ind. Bat. ii. $282=$ curviflora.

umbraticola, Vatke, in Oestr. Bot. Zeitschr. xxy. (1875) 230.-Afr. trop.

CHASAllia, Comm. ex Poir. in Dict. Sc. Nat. viii. 198 (1817); et Juss. in Mém. Mus. Par. ví. (1820) 379 $=$ praec.

Chascanum, E. Mey. Comm. Pl. Afr. Austr. 275 $(1837)=$ Bouchea, Cham. (Verbenac.).

cernum, E. Mey. 1. c. $276=$ B. cernta.

cuneifolium, E. Mey, 1, c, = B, cuneifolia

garipense, E. Mey. 1, c. $277=$ B. garepensis

laetum, Fenzl, ex Schan, in DC. Prod. xi. $559=\mathrm{B}$. pterygocarpa.

marrubiifolium, Fenzl, ex Schan. 1. c. $558=$ B. marrubiifolia.

pinnatifidum, E. Mey. Comm. Pl. Afr. Austr. 277 = B. pinnatifida

pumilum, E. Mey. 1. c. $=$ B. pumila

CHASCOLYTRUM, Desv, in Nouv, Bull. Soc. Philom. ii. (1810) $190=$ Briza, Linn. (Gramin.)

barbatum, Kunth, Enum. Pl, i. $373=$ B. barbata.

coarctatum, Phil, in Linnaea, xxxiii. (1864-65) 293.Chili.

elegans, Beauv. Agrost. $86=$ B. elegans.

erectum, Desv. in Nouv. Bull. Soc. Philom. ii. (1810) $190=$ B. erecta.

nutans, Lind1. ex Heynh. Nom. ii. 137, nomen.Chili.

rotundatum, Kunth, Rev. Gram. i. $121=$ B. rotundata. rufum, J. \& C. Presl, Rel. Haenk. i. $258=$ B. rufa. spicigerum, J. \& C. Presl, 1. c. $282=$ B. spicigera. strictum, E. Desv. in C. Gay, Fl. Chil. vi. $384=$ B. stricta.

subaristatum, Desv, in Nouv. Bull. Soc, Philom. ii. (1810) $190=$ B. rotundata.

trilobum, E. Desv。 in C. Gay, Fl. Chil. vi. $384=$ B. triloba.

CHASMANTHERA, Hochsto in Flora, xxvii. (1844) 21. MENISPERMACEAE, Benth. \& Hook. f. i. 34 .

RHigrocarya, Miers, in Ann. Nat. Hist. Ser. III xiv. (1864) 100 .

dependens, Hockst. l. c.-Abyssin

nervosa, Miers, Contrib. Bot. iii. 39.-Afr. trop.

uviformis, Baill. in Bull. Soc. Linn. Par. i. (1885) 459.-Madag

CHASMANTHIUM, Link, Hort. Berol. i. 159 (182 $\tilde{i})=$ Uniola, Linn. (Gramin.)

gracile, Link, $1 . c_{c}=\mathrm{U}$, gracilis.

ornithoryncha, Nees, ex Steud. Syn. Pl. Gram. $280=U$. ornithoryncha,

CHASME, Salisb. Parad. Lond. sub t. 67 (1807); et in Knight, Prot. $16(1809)$ = Leucadendron, $\mathrm{R}$. Br (Protenc.).

comosa, Salisb. 1. c.; Knight, 1. c, $17=\mathrm{L}$. comosum.

pinifolia, Knight, l. c-A - Ars, austr.

ramentacea, Knicht, 1. c. $=$ I. acmulum.

spiralis, Knight, i. c. 16.-Afr. nustr.

teretifolia, Knight, 1. $c_{0}=$ L. abictioum
CHASMIA, Schott, ex Spreng. Syst. iv, Cur. Post. 409 $(1827)=$ Axrabidaea, DC. (Bignoniac.)

ochroleuca, Schott, 1. $c_{0}=$ A. Agnus-castus, vel A Salzmanni.

CHASMONE, E. Mey. Comm. Pl. Afr. Austr. 71 (1835) Argyrolobium, Eckl. \&c Zeyh. (Legum.). Andrewsiana, E. Mey. I. c. $74=\mathrm{A}$. Andrewsianm. angustissima, E. Mey. 1. c. $75=$ A. filiforme. apiculata, E. Mcy. 1. c. 73=A, collinum. argentea, E. Mey. 1. c. $74=\mathrm{A}=\mathrm{A}$. Linnaeanum. ascendens, E. Mey. 1. c. $73=\mathrm{A}$. ascendens. baptisioides, E. Mey. 1. c. $71=$ A. baptisioides. barbata, Meissn, in Hook, Lond. Journ. Boto ii. (1843) $77=\mathrm{A}$, barbatum.

calycina, E. Mey. Comm. Pl. Afr. Austr. 74, adnot. A. calycinum.

crassifolia, E. Mey, 1. c. $72=\mathrm{A}$. crassifoliam

crinita, E. Mey. 1. c. $71=\mathrm{A}$, crinitum.

cuneifolia, E. Mey. 1. c. = A. polyphyllum.

diversifolia, E. Mey, 1. c。=A. speciosum.

goodioides, Meissn. in Hook. Lond. Joum. Bot. ii.

(1843) $75=\mathrm{A}$, goodioides

holosericea, E. Mey. Comm. Pl. Afr, Austr. $72=\mathrm{A}$ sericenm.

lanceolata, E. Mey. 1. c. $75=\mathrm{A}$. lanceolatum.

longifolia, Meissn. in Hook. Lond. Journ. Bot, ii.

1843) $74=\mathrm{A}$. longifolium.

obcordata, E. Mey. Comm. Pl. Afr. Austr. $72=$ A. obcordatum.

petiolaris, E. Mey. 1. c. $75=$ A. petiolare.

pumila, Meissn. in Hook. Lond. Journ. Bot. ii. (1843) $77=$ A. pumilum

rupestris, E. Mey. Comm. Pl. Afr. Austr. $74=$ A. rupestre.

sessiliflorum, E. Mey, I. c. $72=$ A. candicans

splendens, Meissn, in Hook. Lond. Jourm. Bot. ii (18 13$) 78=\mathrm{A}$. splendens.

stricta, E. Mey. Comm. Pl. Afr. Austr. $75=\mathrm{A}$ strictum.

tenuis, E. Mey. 1. c. 75 , adnot. = A. angustifolium.

tuberosa, Meissn. in Hook. Lond. Journ. Bot. ii. (1843)

$73=\mathrm{A}$. tuberosum

venosa, E. Mey. Comm. Pl. Afr. Austr. $73=$ A. molle. verticillata, E. Mey. 1. c. $72=$ A. stipulaceum.

CHASMONIA, Presl, Fl. Sic. Praef. po xxxrii $(1826)=$ Moluceella, Linn. (Labiat.)

incisa, Presl, 1. c. = M. spinosa.

CHASSALIA, Comm, ex Poir. in Dict. Sc. Nat. viii. 198 (1817) $=$ Chasalia, Comm. (Rubiac.)

CHASSELOUPIA, Vieill, in Bull. Soc. Linn. Normand. x. (1866) $101=$ Symplocos, Linn. (Styrac.)

arborea, Vieill. 1. c. $102=\mathrm{S}$. arborea

caerulescens, Vieill. 1. c. 10\$ $=\mathrm{S}$. caerulescens, Vieil. lardi.

gracilis, Vieill. ex Miers, in Journ. Linn. Soc, xvii (1879) $305=\mathrm{S}$. gracilis.

Zucida, Vieill. in Bull. Soc. Lion. Normand, x. (1866) $102=$ S. glaucescens, lucida

microphylla, Vicill. 1. c. 104.-N. Caled.

montana, Vicill. 1. c. $=$ S. montana.

neo-caledonica, Vieill. 1. c. $103=$ S. stravadioides, Lenormandiana.

nitide, Vieill. ex Micrs, in Journ. Linn. Soc. svii. (1879) $305=$ S. rotundifolia.

tinctoria, Vieill. in Bull. Soc. Linn. Normand. x. (1\$60), $104=$ S. baptica.

CHASTENAEA, DC. Prod, iii. 102 1828)= A xinaea, Ruiz \& Pav, (Melastomad.'.

affinis, Nand, in Ann. Sc Nat. Sér. III. xviii. 1852 120 $=\mathrm{A}$. macropbylla.

coriacea, Naud, 1. c. iv. (18t5) 55 - A. Iepidota.

foribunda, Naud. L. c xviii, (185: 12:2=A. floribunda.

glandulosa, Naud. 1. c. $128=$ A. glandulusa. grandifulio. Naud. 1. c. 12:2 = A. grandifolia. Uancrolata. Naud. 1. c. $123=$ A lanceulata. lepidola, Benth. Pl. Hartw. 18? = A. lepidola longifolia, Naud, in Ann. Sc Nat. Ser. III. iv. 1815 55. Meriania Karsteris.

macrophylla, Naud. 1. c = A. macropbylla.

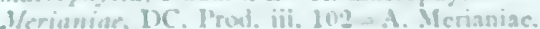

rigida, Naud. in Ann. Sc Nal Ser. III. xviii. (1552) $1: 2 y$ - Mcriania rigida. 
CHASTOLOMA, Lindl. Veg. Kingd. 355 (1847), sphalm.$=$ CHARTOLOMA, Bunge = Isatis, Linn.

CHATAEA, Soland. ex Seem. Pl. Vit. $102(1865)=$ CHAITAEA, Soland $=$ Tacea, Forst .

Tacca, Soland. I. $c_{0}=\mathrm{T}$. pinnatifida.

CHATELANIA, Neck. Elem. i. $53(1790)=$ Tolpis Adans. (Compos.).

CHATIAKELLA Cass, in Dict. Sc. Nat. xxix。 491 $(1823)=$ Wulffia, Neck. $($ Compos. $)$. platyglossa, Cass. 1. c. xlvi. $402=$ W. stenoglossa. stenoglossa, Cass. 1. c. $403=\mathrm{W}$. stenoglossa.

CHAUBARDIA, Reichb, f. in Bot. Zeit. x. (1852) 671= Zygopetalum, Hook. (Orchid.) surinamensis, Reichb. f. 1. c. 672.-Guiana.

CHAUlmoOGRA, Roxb. Hort. Beng. 105 (1814) ; F1 Ind. iii. 835 (1832)=Gynocardia, R. Br. (Bixin.). odorata, Roxb. 11. cc. 105, $836=\mathrm{G}$. odorata.

CHAUNOCHITON, Benth. in Benth. \& Hook. f Gen. i. 996 (1867). OLACINEAE, Benth. \& Hook. f. l. $\mathrm{c}$.

loranthoides, Benth. in Hook. Ic. Pl. t. 1005.-Bras.

CHAUVINIA, Stend. Syn. P1. Gram. $362(1855)=$ Spartina, Schreb. (Gramin.). chilensis, Steud. 1. $\mathrm{c}$. $=\mathrm{S}$. densiflora.

CHAVANnESIA, A. DC. in DC. Prod. viii. 444 (1844) $=$ Urceola, Roxb. (Apocyn.). esculenta, A. DC. 1. c.=U. esculenta. javanica, Miq. Fl. Ind. Bat. ii. 458.-Tava. lucida, A. DC. in DC. Prod. viii. $444=\mathrm{U}$. lucida.

CHAVICA, Miq. Syst. Pip. 222 (1843)= Piper, Linn. amboinensis, Miq. in Ann. Mus. Bot. Lugd. Bat. i. $134=\mathrm{P}$. amboinensis.

Arnottiana, Miq. Syst. Pip. 268 =P. Hapnium.

auriculata, Miq. 1. c. $269=\mathrm{P}$. Betle.

Benthamiana, Miq. 1. c. $233=$ P. Barclayanum.

Betle, Miq. l. c. $228=$ P. Betle.

Blumei, Miq. 1. c. $246=$ P. Malamiri.

boehmeriaefolia, Miq. 1. c. $265=$ P. boehmeriaefolium. canaliculata, Presl, Epim. Bot. $224=$ P. canaliculatum.

celebica, Miq. Syst. Pip. $276=$ P. celebicum.

celtidiformis, Miq. 1. $c_{0}=$ P. parvifolium, celtidiforme.

ceramica, Miq. in Ann. Mus. Bot. Lugd. Bat. i. $135=$ P. ceramicum.

Chaba, Miq. Syst. Pip. 251=P. Chaba, Blume.

chaerostachya, Pritz. Ic. Ind. ii. 75 , sphalm.= sphaerostachya.

Chawya, C. DC. in DC. Prod. xvi. I. $351=$ seq.

Chuvya, Miq. Syst. Pip. $267=$ P. Betle.

consanguinea, Miq. l. c. $282=$ P. Labillardieri.

corylistachya, Miq. 1. c. $281=\mathrm{P}$. corylistachyon

densa, Miq. 1. c. $252=\mathrm{P}$. Betle

diffusa, Miq. in Zoll. Syst. Verz. Ind. Archip. $84=$ P. attenuatum.

exasperata, Miq. Syst. Pip. $275=$ P. exasperatum.

frustrata, Miq. Pl. Jungh. 16.--Tava.

glandulosa, PresI, Epim. Bot, $223=$ P. miniatum.

grandis, Presl, 1. c. $224=$ P. grande.

Guigual, Miq. Syst. Pip. $280=$ P. brachystachyum, Wall.

Haenkeana, Presl, Epim. Bot. $224=$ P. Haenkeanum.

Huegeliana, Miq. in Linnaea, xxvi. (1853) $218=\mathrm{P}$

Novae-Hollandiae vel P. Hugelianum.

imperialis, Miq. in Ann. Mus. Bot. Lugd. Bat. i. $134=$ P. Forstenii.

Labillardieri, Miq. Syst. Pip. $263=$ P. Chaba, Hunter. lanceolata, Miq. 1. c. $264=$ P. miniatum.

leptostachya, Hance, in Journ. Bot. vi. (1868) 301.China.

Lessertiana, Miq. Syst. Pip. $270=$ P. Pseudo-chavica. macrostachya, Miq. 1. c. $236=\mathrm{P}$. miniatum maculata, Miq. 1. c. $256=$ P. maculatum. madagascariensis, Miq. 1. c. $277=\mathrm{P}$. madagascariense majuscula, Miq. 1. c. $271=$ P. majusculum

maritima, Miq. 1. c. $262=$ P. Chaba, Hunter.

Melamiris, Miq. 1. c, $245=$ P. Sirium.

microstigma, Miq. in Ann. Mus. Bot. Lugd. Bat. i. 138 $=\mathbf{P}$. microstigma.

miniata, Miq. Syst. Pip. $234=$ P. miniatum.
CHAVICA :-

Mullesua, Miq. Syst. Pip. $280=$ Piper brachystachyum, Wall.

multinervia, Miq. Fl. Ind. Bat. Suppl. $473=$ P. prianamense.

Neesiana, Miq. Syst. Pip. $249=$ P. peepuloides. officinarum, Miq. 1. c. $256=\mathrm{P}$. Chaba, Hunter. parvifolia, Hassk. in Flora, xlvii. (1864) $59=\mathrm{P}$. parvifolium.

peepuloides, Miq. Syst. Pip. $237=$ P. peepuloides. peepuloides, Wight, Ic, t. $1927=$ P. Chaba, Hunter. penangensis, Miq. in Hook. Lond. Journ. Bot. iv. (1845) $433=\mathrm{P}$. Lonchites

penangensis, Miq. Syst. Pip. $279=$ P. penangense. petiolata, C. DC. in DC. Prod, xvi. I. 389.-Ind, or. populifolia, Miq. Syst. Pip. 248.-Ins. Philipp. pothoides, Miq. 1. c. $266=\mathrm{P}$. pothoides,

pseudomelamiris, Miq. 1. c. $244=$ P. Sirium.

puberula, Benth. Fl. Hongk. 335.-China.

pyrifolia, Miq. Syst. Pip. $275=$ P. pyrifolium

radicans, Presl, Epim. Bot. $224=$ P. radicans

Rafflesii, Miq. Syst. Pip. $273=$ P. Rafflesii

Reinwardtiana, Miq. in Ann. Mus. Bot. Lugd. Bat. i,

$13 \hat{0}=$ P. Reinwardtianum.

retrofracta, Miq. Syst. Pip. $275=$ P. retrofractum.

Roxburghii, Miq. 1. c. $239=\mathrm{P}$, longum.

rufinervis, Presl, Epim. Bot. $224=$ P. rufinerve.

Rumphii, Miq. in Ann. Mus. Bot. Lugd. Bat. i. $141=\mathbf{P}$. Rumphii.

salicina, Presl, Epim. Bot. $224=$ P. salicinum.

sarmentosa, Miq. in Hook. Lond. Journ. Bot. iv. (1845)

$433=\mathrm{P}$. longum.

sarmentosa, Miq. Syst. Pip. $242=$ P. sarmentosum.

sinensis, Champ. ex Benth. in Hook. Kew Journ. v

(1854) $116=\mathrm{P}$, sinense.

Siriboa, Miq. Syst. Pip. $224=$ P. Betle.

sphaerostachya, Miq. 1. c. $278=$ P. brachystachyum, Wall.

subcordata, Miq. in Ann. Mus. Bot. Lugd. Bat. i. 138 $=$ P. subcordatum.

subseptemnervia, Miq. Fl. Ind. Bat. Suppl. $473=$ P. subseptemnervium.

Suipigua, Miq. Syst. Pip. $275=$ P. Snipigua.

sundaica, Miq. 1. c. $274=\mathrm{P}$. sundaicum.

sylvatica, Miq. 1. c. $248=$ P. sylvaticum.

syringaefolia, Miq. l. c. $275=$ P. syringaefolium.

Teysmanni, Miq. in Ann. Mus. Bot. Lugd. Bat. i. 141

$$
=\mathrm{P} \text {. Teysmanii. }
$$

thermalis, Miq. Syst. Pip. $276=$ P. thermale.

Thomsonii, C. DC in DC. Prod xvi. I. 389.-Ind, or viminalis, Miq. in Linnaea, $\mathrm{xx}_{\circ}(1847) 131=\mathrm{P}$. viminale. Wallichii, Miq. Syst. Pip. $254=$ P, aurantiacum.

CHAYoTA, Jacq. Am. Select. ed. pict. t. 245 (1780) Sechium, P. Br. (Cucurbitac.) edulis, Jacq. 1. c. $=$ S. edule.

CHEilanthos, St. Lag. in Ann. Soc. Bot. Lyon, vii. (1880) 56 (genus indesc. LABIATARUM).

CHEILOCLINIUM, Miers, in Trans. Linn. Soc. xxviii. (1872) 420. HIPPOCRATEACEAE. anomalum, Miers, l. c.-Bras.

CHEILOCOCCA, Salisb. ex Sm. Spec. Bot. N. Holl. 17 (1793), cum cit falsa = Platylobium, Sm. $\left(\mathrm{Le}^{-}\right.$ gumin.).

apocynifolia, Salisb. ex Sm. 1. c. = P. formosum.

CHEILODISCUS, Triana, in Ann. Sc. Nat. Sér. IV. ix. (1858) $36=$ Peetis, Linn. (Compos.).

littoralis, Triana, 1. c.-N. Granat.

CHEILOPSIS, Moq. in Ann. Sc. Nat. Sér. I. xxvii. (1832) $230=$ Acanthus, Tourn.

arborea, Nees, in DC. Prod. xi. $272=$ A. arboreus.

montana, Nees, l. c. = A. montanus.

polystachya, Moq. in Ann. Sc. Nat. Sér. I. xxvii. (1832)

$230=\hat{A}$. arboreus.

CHILOSA, Blume, Bijdr. 613 (1825). EUPHORBI$A C E A E$, Benth. \& Hook. f. iii. 322 .

montana, Blume, 1. c. 614.-Java.

CHEILOSANDRA, Griff. ex Lindl. Veg. Kingd, 672 $(1847)=$ Rhynchotechum, Blume (Gesnerac.). leptopus, Griff. ex Benth. \& Hook. f. Gen. ii. 1025= Leptobaea glabra.
CHEILOTHECA, Hook, f. in Benth. \& Hook. f Gen. ii. 607 (1876). MONOTROPEAE, Benth. \& Hook. f. 1. c.

khasiana, Hook. l. c. 608.-Reg. Himal.

CHEILYCTIS, Benth. Lab. Gen. et Sp. 726 (1836)= Monarda, Linn. (Labiat.)

CHEIRADENIA,Lindl. Fol. Orch. Cheirad. (1853) 1. $O R C H I D E A E$, Benth. \& Hook. f. iii. 544 cuspidata, Lindl. l. c,-Guiana.

CHEIRANTHERA, End1. Enchir. $515(1841)=$ Cheiro stemon, Humb. \& Bonpl. (Sterculiac.).

CHEIRANTHERA, Brongn. Voy, Cog. Bot, t. 77 (1826) ; et A. Cunn. in Bot. Reg. sub t 1719 (1834). PITTOSPOREAE, Benth. \& Hook. f. i. 133. brevifolia, F. Muell. Fragm. i. $97=$ filifolia. cyanea, Brongn. Voy. Coq. Bot. t. 77 =linearis filifolia, Turcz. in Bull. Soc. Nat. Mosc. xxvii (1854) II. 364.-Austral.

linearis, A. Cunn. in Bot. Reg. sub t. 1719.-Austral. parviflora, Benth. Fl. Austral. i. 128.-Austral.

Preissiana, Putterl. in Lehm. Pl. Preiss. i. 201 (sp dub.).-Austral.

tortilis, F. Muell. Fragm. ii. $79=$ filifolia.

volubilis, Benth. Fl. Austral. i. 128.-Austral.

CHEIRANTHODENDRON, Benth. \& Hook, f. 'Gen. $212(1862)=$ CHIRANTHODENDRON, Cerv. $=$ Cheirostemon, Humb. \& Bonpl. (Sterculiac.).

CHEIRAN'THODENDRUM, Steud. Nom. ed. I. 186 $(1821)=$ praec.

CHEIRANTHUS, Linn. Gen. ed. I. 195 (1737). CRUCIFERAE, Benth. \& Hook, f. i. 68.

Cheiri, Adans. Fam. ii. 418 (1763); [Clairv.] Man. Herb. 221 (1811).

Dichroanthus, Webb \& Berth. Phytog. Canar, i. 65. t. 5, 6 (1836).

Phoenicaulis, Nutt. ex Torr. \& Gray, Fl. N. Am. i. 89 (1838).

Schelhameria, Heist. Syst. 9 (1748).

acaulis, Balb. ex Spreng. Nov. Prov. $10^{\circ}=$ Matthiola acaulis.

africanus, Linn. P1. Afr. 13 (Amoen. Acad. vi. 90) = Heliophila pilosa.

albiflorus, T. Anders. in Hook. f. Fl. Brit. Ind. i. 133. -Tibet. occ.

albus, Mill. Gard. Dict. ed. VIII. n. $8=$ Matthiola incana.

alpinus, All. Fl. Pedem. iii. t. $20=$ Erysimum lanceolatum.

alpinus, Falk, Beitr. ii, $216=$ Erysimum altaicum

alpinus, Jacq. F1. Austr. i. 48 . t. $75=$ Erysimum canescens.

alpinus, Lam. Encyc. ii. $716=$ Erysimum ochroleucum alpinus, Linn. Mant. 93 (excl. syn.).-Scandinav. angulatus, Schult, Obs, $129=$ Syrenia sessiliflora. angustifolius, Gilib. Fl. Lituan. ii. $61=$ Erysimum hieracifolium.

angustifolius, Mill. Gard. Dict. ed. VIII. n. $4=$ Erysimum lanceolatum.

annuns, Georgi, Reise, i. $225=$ Hesperis aprica.

annuus, Linn. Sp. Pl.662.-Davuria.

apricus, Steph. ex Willd. Sp. Pl. iii. $518=$ Hesperis aprica.

aquaticus, Lejeune, F1. Spa, ii. $68=$ Erysimum cheiranthoides.

arborescens, Sieber, ex Link, Enum. Hort. Berol, ii. 166 nomen $=$ Matthiola arborescens.

arboreus, Sweet, ex Steud. Nom, ed. II. i. 345.Aegypt.

arbuscula, Lowe, in Hook. Kew Fourn. viii. (1856) 289 -Ins. Canar.

arenarius, Suffren, ex DC. Syst. ii. $171=$ Matthiola varia.

armeniacus, Sims, Bot. Mag, t. $835=$ Erysimun ibericum.

arvensis, Bernh. Syst. Verz. Erf. $196=$ Erysimum hieracifolium.

asper, Cham. Eshlecht. in Linnaea, i. (1826) 14. -Am. bor, occ.

asper, Nutt. Gen. Am. ii. $436=$ Erysimum asperum. aurantiacus, Bunge, Enum. Pl. Chin. Bor. 5.-China. aureus, Willd. ex DC. Syst. ii. $581=$ Sterigma elychrysifolium. 


\section{CHEIRANTHUS :}

auriculatus, Lapeyr. Hist. Abr. P1. Pyr. $362=$ Cochlearia auriculata.

axillaris, Brouss. ex Webb \& Berth. Phyt. Canar. i. $67=$ scoparius

bicolor, Hornem. Hort. Hafn, ii. $613=$ Erysimum bicolor.

bicornis, Sibth. \& Sm. Fl. Graec. Prod. ii. 26= Matthiola bicornis.

bicuspidatus, Willd. Sp. Pl. iii. $519=$ Hesperis bicts pidata.

bithynicus, Pers. Syn. ii. $200=$ Erysimum cuspidatum Bocconi, All. Fl. Pedem, i. $272=$ Erysimum canescens. callosus, Linn. f. Suppl. $296=$ Heliophila callosa.

canus, Piller \& Mitterp. Iter Poseg. 146. t. $15=$ Erysi mum angustifolium.

capitatus, Dougl. in Hook. Fl. Bor. Am. i. $38=$ asper.

carnosus, Thunb. Prod. Pl. Cap. $108=$ Heliophila platysiliqua.

caspicus, Lam. in Pall. Voy. $8^{\circ}$ App. 348=Sterigma tomentosum

Cheiri, Linn. Sp. Pl. 661.-Europ.

chius, Linn, 1. $\mathrm{c}_{*}=$ Malcolmia chia.

chius, Pall. Reise, i. $497=$ Chorispora tenella.

cinereus, Webb ह Berth. Phyt. Canar. i. t. 5-Ins. Canar.

coccineus, Mill. Gard. Dict. ed. VIII. n. $7=$ Matthiol incana.

collinus, Bieb. Fl. Taur. Cauc, ii. $119=$ Erysimum collinum:

contortuplicatus, Steph. in Willd. Sp. Pl. iii. $521=$ Sisymbrium contortuplicatum.

corinthius, Boiss. Diagn. Ser. II. i. 18.-Graecia.

cornutus, Lam. Encyc. ii. $717=$ Syrenia sessiliflora.

coronopifolius, Sibth. \& Sm. Fl. Graec. Prod. ii. 25 $=$ Matthiola tristis.

crassicaulis, Boiss. in Ann. Sc. Nat. Sér. II. xxii. (1842)

$45=$ Erysimum crassicaule.

Cumbrae, Link, in Buch, Beschr. Canar. Ins. $152=$ scoparius.

cuspidatus, Bieb. Fl. Taur. Cauc. ii. $120=$ Erysimum cuspidatum.

decumbens, Schleich. ex Willd. Enum. Hort. Berol. $680=$ ochroleucus

Delilianus, A. Gouault, in Rev. Hortic. Sér. IV. i. (1852) 401 - - Hab. ?

denticulatus, Willd. ex Steud. Nom. ed. II. i. $346=$ Pallasii.

dubius, Homem. Hort. Hafn. Suppl. 73 = Erysimum dubium.

dubius, Suter, F1. Helv. ii. $65=$ ochroleucus.

elongatus, Thunb. Prod. Pl. Cap. $108=$ Heliophil linearifolia

erucaefolius, Pourr. ex Willk. \& Lange, Prod. Fl. Hisp. iii. $793=$ Malcolmia lacera .

erysimoides, Gueldenst. ex Ledeb. F1. Ross, i. $188=$ Erysimum leptostylum.

erysimoides, Huds. FI. Angl. ed. II. 287 = Erysimum cheiranthoides.

erysimoides, Linn. Sp. Pl. $661=$ Erysimum lanceo. latum.

erysimoides, Pall. Reise, i. $192=$ Erysimum Andreioskianum.

erysimoides, Vill. ex Willk. \& Lange, Prod. Fl. Hisp. ii. $808=$ Erysimum ochroleucam.

Farsetia, Buch.-Ham. in Wall. Cat. n. $4801=$ Farsetia

Hamiltonii.

Farsetia, Linn. Mant. i. $94=$ Farsetia aegyptiaca.

fenestralis, Linn. Sp. Pl. $1198=$ Matthiola fenestralis.

firmus, Schleich. ex Willd. Enum. Hort. Berol. $45=$ Erysimum lanceolatum?

firmus, Willd. Enam. Hort. Berol. Suppl. $45=$ Erysimum virgatum.

flexuosus, Sibth. E Sm. Fl. Graec, Prod. ii. 24 ; Fl. Graec. t. 634.-Ins. Cyprus.

fragrans, Fisch. Hort. Gorenk. (1812) $51=$ Matthiola fragrans.

frutescens, Vent. ex Pers. Syn. ii. $201=$ semperflorens, fruticosus, L'Hérit, ex DC. Prod. i. 197 = C Cheiri.

fruticulosus, Georgi, Beschr. Russ. Reich. iii. IV. 1134 Sterigma tomentosum.

fruticulosus, L'Hérit. ex DC. Syst. ii. $495=$ Erysimum suffiuticosum.

fruticulosus, Linn. Mant. $94=$ C. Cheiri

fruticulosus, Linn. Sp, Pl. 662 = Matthioln tristis,

fruticulosus, Sibth. \& Sm, Fl. Graec. Prod. ii. $23=$

Lrysimum Boryanum.

\section{CHEIRANTHUS:-}

glaber, Mill. Gard. Dict. ed, VIII. ถ. $9=$ Matthiola glabra.

glaberrimus, Colla, Antol. Bot. v. $861=$ Matthiola glabra.

graecus, [Juss.] Pers. Syn. ji. 201= Matthiola incana.

gramineus, Thunb. Prod. Pl. Cap, $108=$ Heliophila graminea

Griffithii, Hook. f. \& Thoms, in Journ. Linn. Soc. v. 1861) $137=$ Erysimum Hookeri.

helveticus, Jacę. Hort. Vindob. iii. $9=$ Erysimum murale.

hesperidioides, Torr. E Gray, E\%. N.Am, i. 72,-Am. bor.

hieracifolius, Lam. Encyc, ii. $717=$ Erysimum hieracifolium

hilaris, Willd. ex Steud. Nom. ed. II. i. $346=$ Matthiola tristis.

himalaicus, Hook. f. \& Thoms. in Journ. Linn. Soc. v. 1861) $137=$ himalayensis

himalayensis, Cambess. in Facquem. Voy. Bot. 14.-Reg. Himal

hirtus, Schlecht. fide Stev. ex DC. Prod.- i. $189=$ Hesperis aprica.

hispidus, Adams, in Nouv. Mém. Soc. Nat. Mosc. iii. (1834) $250=$ Hesperis aprica.

hortensis, Lam. Fl. Fr, ii, $506=$ Matthiola incana

humitis, Clarke, Trav. iii. 42= Matthiola humilis

ibericus, Adams, in Weber \& Mohr, Beitr. i. $61=$ Erysimum ibericum.

ibericus, Willd. Enum. Hort. Berol. $681=$ Barbarea arcuata.

incanus, Linn. Sp. PI, 662 = Matthiola incana

incrassatus, Bory, ex Steud. Nom. ed. II. i. $846=$ Malcolmia flexuosa.

integrifolius, Mill. Gard. Dict. ed. VIII. n. $2=$ Erysimum canescens.

integerrimus, Steud. Nom, ed. II. i. $346=$ Erysimum canescens.

intermedius, Schleieh. Cat. Pl. Helv. ed. IV. $12=$ C. Cheiri?

Facomellii, Clem. Sert. Olymp.9. t. 4. f. $2=$ Erysimum Kotschyanum

junceus, Kit. Pl. Rar. Hung. iii, $259=$ Sisymbrium junceum.

Keiri, Neck. Delic. Gallo-Belg. i. $283=$ C. Cheiri

Knowleanus, D. Dietr. Syn. P1. iii. $683=$ ochroleucus.

Knowlesii, Walp. Rep. i. $125=$ ochrolencus.

lacerifolius, Pall. Reise Statth. Russ. Reich. i. $124=$ Matthiola tatarica.

lacerus, Gouan, Illustr. $44=$ Malcolmia parviflora

lacerus, Linn. Sp. Pl. $662=$ Malcolmia lacera.

laciniatus, Poir. Encyc. Suppl. ii. $780=$ Hesperis laciniata.

laevigatus, Willd. ex DC. Prod. i. $141=$ Barbarea arcuats.

lanatus, Gmel. ex DC. Syst. ii. 581 = Sterigma elychrysifolium.

lanceolatus, Willd. Sp. P1. iii. $515=$ Hesperis tristis.

leptophyllus, Bieb. Fl. Taur. Cauc. ii. $119=$ Erysimum leptophyllum

leptophyllus, Willd. ex. DC. Syst. ii. $464=$ Sisymbrium junceum.

leucanthemous, Steph. ex. Willd. Sp. PI. iii. $521=$ Erysimum versicolor.

linariaefolits, Vis. in Nuov. Sagg. Acc. Pad.v. (1840) 267.-Afr, bor.

linearis, Forsk. F1. Aegypt. Arab. 119 = Farsetia aegyptiaca.

linearis, Thunb. Prod. Pl. Cap. $108=$ Hcliophila linearis

linearis, Vent: Jard. Malm, t. $83=$ semperflorens,

linifolius, Pers. Syn, ii. $201=$ Erysimum linifolium.

littoreus, All. Fl. Pedem, i, 278=Malcolmia maritima.

littoress, Linn. Sp. P1. ed. II. 925= Malcolmia littoren. littoreus, Pall. Reise, ii. 741 = Sterigma tomentosum. lividus, Delile, F1. Aeg. Illustr. 67 a Matthiola livida.

lividus, Sieber, ex Stead. Nom. ed. II. i. $846=\mathrm{Mal}$ colmia aegyptiaca.

longifolius, Vent. Jard. Malm. t. $83=$ mutnbilis

longipetalus, Vent. Jard. Cels, t. 93 - Matthiola oxy ceras.

longisiliqurs, Steud, Nom. cd. II. i. $346=$ Erysimum longisiliquosum.

luteis, Dulac, FL Hautes Pyr, $199=$ C. Cbeiri.

\section{CHEIRANTHUS :-}

lyratus, Sibth. \& Sm. Fl. Graec. Prod, ii 24

Malcolmia lyrata.

maritimus, Linn. Cent. Pl. i. 19 (Amoen. Acad. iv. 280) $=$ Malcolmia maritima.

Marshallii, Stark, ex Moore, Gard. Mag. Bot. i. (1850 $289=$ ochroleucus.

Menziesii, Benth. E Hook. f. Gen. i. 68.-Am. bot.

mollis, Hornem. Hort. Hafn. ii. $615=$ Arabis albida. montanus, Pall. Reise, i. $496=$ Syrenia siliculosa. muralis, Salisb. Prod. $271=\mathrm{C}$. Cheir.

muricatus, Lam. Fl, Kr. ii. $507=$ Matthiola sinuata muricatus, Weinm. Cat. Hort Dorpat. (1810) $41=$

Dontostemon integrifolius.

mutabilis, Brouss. ex Spreng. Syst. ii $896=$ semper. florens.

mutabilis, L'Hérit. Stirp. Now. 92.-Ins. Mader et Canar.

nanus, Merk. ex DC. Syst. ii. $486=$ Matthiola nana.

nitrarius, Pall. Reise Statth. Russ, Reich. i. 105, 124

141.- Rossia.

nodosus, Lam. F1. Fr. ii. $508=$ Malcolmia littorea

ochroleucus, DC. Syst. ii. $181=$ Erysimum ochro. leucum.

ochroleucus, Hall. fo ex Schleich. Cat. 16.-Europ.

odoratissimus, Bieb. Casp. $116=$ Matthiola odora tissima.

odoratus, Pall. ex Spreng. Syst. ii. 896.-Persia.

olympicus, Sibth.ex DC. Syst. ii. 494.-Graecia.

Pallasii, Pursh, Fl. Am. Sept. ii. $436=$ pygmaens.

pallens, Hall. f. ex DC. Syst. ii. $501=$ Erysimum ochroleucum.

pallidus, Pall. Reise, iii. $230=$ Erysimum canescens.

paniculatus, Cav. Desc. $430=$ Erysinum Kanzeanum. paniculatus, Lam. Encyc. ii. $717=$ Esysimam repandum.

paniculatus, Stev, ex DC. Syst, ii, $210=$ Arabis incarnata.

Parnassii, Boiss. Diagn. Ser. II. i. $18=$ Erysimum Boryanum.

parryoides, Kurz, ex Hook. f. Fl. Brit. Ind. i. 132. Tibet.

parviflorus, Schousb. Vextr. Marokko, $195=$ Matthiola parviflora.

parviflorus, Thib. ex DC. Prod. i. 134=Matthiola coronopifolia.

persicus, Pall. ex DC. 1. c. $132=$ Anchonium Toumefortii.

persicus, Willd. ex Ledeb. Fl. Ross. i. $109=$ Matthiola tatarica.

pinmatifidus, Willd. Sp. Pl. iii. 528=Dontostemon pectinatus.

planifolius, Waldst. \& Kit. ex Bieb. Fl. Taur. Cauc. iii. $443=$ Erysimum cuspidatum.

pulchellus, Willd. Sp. Pl, iii. $523=$ Erysimum rupestre. Pumilio, Sibth. \& Sm. Fl. Graec. Prod ii. $26=$ Matubiols bicornis.

pumilus, Hornem. Hort. Hafn. ii. $613=$ Erysimum pumilum.

pygmaeus, Adams, in Mim. Soc. Nat. Mosc. v. (1817

114.-Sibir.; Am. bor. occ.

guadrangularis, Stend. Nom. ed. II. i. $346=\mathrm{seq}$

quadrangulus, L'Hérit. Stirp. Nov. 91 . t. $14=$ Svrenia sessilifiora.

ramosissimus, Lam. Encyc. ii. $717=$ Erysimum re pandum.

ramosissimus, Bory \& Chawb. Nouv. Fl. P'lop. 13.Graecia.

rhaeticus, Schlcich, Cat. PI. Helv, ed. III. 12 Erysimum ochroleucum.

ruderalis, Pall. ex DC. Syst. ii 5s0-Sterisn. tomentosum.

mupestris, Sibth. \& Stn. Fl. Grace. Prod. ü. 29; Fl.

Graec t. $683=$ Erysimum rupestre.

salinus, Lings. Nand y3_-Sibir.; T ur.

salinus, Pall, ex DC. Syst. ii. $580=$ Sterigma tamen. tusum.

salimus, Willd. ex DC. 1. c. $210=$ Aralis incamata.

scaber, Moench. Meth. 254 = Malculnia africana.

scaber, $13^{\circ} \mathrm{eb}$ \& Berth. Phy. Canar. i. 63.-Ins and.

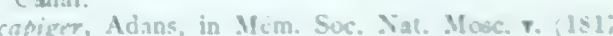

112 - Parrya macrocarma.

scopigerus, Willd. Proxl. Fl. Rerol. 211. ใ. 5. f. 10 erysimum chcirarthoides.

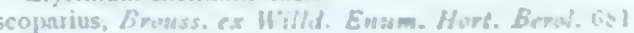

-Ins. Canar. 


\section{CHEIRANTHUS :-}

semperforens, Coss. \& Dur, in Bull. Soc. Bot. Fr. iv. (1857) $395=$ Erysimum longifolium.

semperflorens, Schousb. Vextr. Marokko, 195. Marocco,

Senoneri, Heldr. छ Sart. Cat. Hort. Athen. (1862) ex Reut. Cat. Gram. Genève (1865), 4.-Archip. Graec.

sibiricus, Juss. ex DC. Syst. ii. $492=$ Erysimum angustifolium

silenifolius, Willd. Enum. Hort. Berol. Suppl. $45=$ Erysimum murale.

siliculosus, Bieb. Fl. Taur. Cauc, ii $121=$ Syrenia siliculosa.

sinuatus, Linn. Sp. Pl. ed. II. 926 = Matthiola sinuata.

sinuatus, Pall. Reise, ii. $329=$ Sterigma tomentosum.

Stewartii, T. Anders. in Hook. f. Fl. Brit. Ind. i. 132 -Reg. Himal.

Stocksianus, Boiss. Diagn. Ser. II. i. 19=Erysimum Stocksianum.

strictus, Linn. f. Suppl. $296=$ Heliophila callosa.

strictus, Poir. Encyc. Suppl. ii. $781=$ Heliophila scoparia.

strigosus, Ledeb. in Mém. Acad. Pétersb. v. (1812) $589=$ Erysimum strigosum.

subulatus, Moench, Meth. $254=$ Malcolmia chia

sulphureus, [Soland. in] Russ. Aleppo, ed. II. ii. $257=$ Sterigma sulphureum.

ylvestris, Bernh. ex Steud. Nom. ed. II. i. $346=$

Erysimum hieracifolium.

syluestris, Crantz, Stirp. Austr. ed. I. i. 48 ; Lam.

Encyc. ii. $716=$ Erysimum lanceolatum.

syriacus, DC. Syst. ii. $185=$ Conringia orientalis

syriacus, Willd. ex Steud. Nom. ed. II. i, $346=$

Matthiola oxyceras.

taraxacifolius, Balb. Cat. Hort. Taur. App. (1814) 10 Malcolmia taraxacifolia.

taraxacifolius, Biasol. ex Reichb. F1. Germ. Excurs $687=$ Erysimum strictum.

taraxacifolius, Schrank, in Denkschr. Bot. Ges.

Regensb. ii. (1818) $164=$ Chorispora tenella

taraxacifolius, Steph. ex Willd. Sp. Pl. iii. 525.Sibir.

tataricus, Pall. ex DC. Syst. ii. $170=$ Matthiola tatarica

tauricus, Lepech. in Nov. Act. Petrop. xiii. (1802) 336 t. $9=$ Matthiola odoratissima.

tenuifolius, L'Hérit. Stirp. Nov, 92.--Ins. Madera.

tomentosus, Willd. Sp. Pl. iii. $523=$ Sterigma tomentosum.

torulosus, Bieb. Fl. Taur. Cauc. ii. 121=Sterigma torulosum.

torulosus, Thunb. Prod. P1. Cap. $108=$ Matthiola torulosi

tricuspidatus, Huds. Fl. Angl, ed. I. 250=Matthiola sinuata.

tricuspidatus, Linn. Sp. P1. 663 = Matthiola tricuspidata.

trilobus, Linn. 1. c. $662=$ Malcolmia littorea

tristis, Curt. Bot. Mag. t. $729=$ Matthiola varia

tristis, Forsk. F1. Aegypt Arab, $119=$ Matthiola livida.

tristis, Linn. Syst. Nat. ed. X, 1134= Matthiola tristis

turritoides, Lam. Encyc. ii. $716=$ Erysimum cheiranthoides.

unguiculatus, Willd. ex Steud. Nom. ed. II. i. $347=$

Malcolmia littorea.

vallesiacus, J. Gay, ex DC. Prod. i. 134= Matthiola varia.

varius, Sibth. \& Sm. Fl. Graec. Prod. ii. 25 ; F1. Graec. t. $636=$ Matthiola varia

versicolor, Bieb. Fl. Taur. Cauc. ii. $119=$ Erysimum versicolor.

versicolor, Pall. ex Steud. Nom. ed. II. i. $347=$ Hesperis hyrcanica.

villosus, Forsk. Fl. Aegypt. Arab. 120=Matthiola tricuspidata.

villosus, Spreng. ex DC. Prod. i. 188=Hesperis laciniata.

virgatus, Patr. ex DC. Syst. ii. $462=$ Sisymbrium junceum.

virgatus, Poir. Encyc. Suppl. ii. $781=$ Erysimum angustifolium.

viridifolius, Stend. Nom. ed. II. i. $347=$ Matthiola glabra.

viridis, Ehrh. Beitr, vii. $158=$ Matthiola incana.
CHEIRI, Adans. Fam ii, $418(1763)=$ Cheiranthus,

Linn. (Crucif.)

hieracifolium, [Clairv.] Man. Herb. 221=Erysimum hieracifolium

montanum, [Clairv.] l, c. = Cheiranthus Cheiri

vulgare, [Clairv.] 1. $\mathrm{c}_{\mathrm{\sigma}}=$ Cheiranthus Cheiri.

CHEIRINIA, Link, Enum. Hort. Berol, ii, 170 (1822)= Erysimum, Toum. (Crucif.)

altissima, Link, 1. c. $171=\mathrm{E}$. hieracifolium

Andrzejoreskiana, Hort. Berol, ex Steud. Nom. ed. II. i. $347=\mathrm{E}$. canescens.

angustifolia, Link, Enum. Hort. Berol. ii. $170=\mathrm{E}$ angustifolium.

canescens, Link, 1. c. $171=\mathrm{E}$. canescens.

cheiranthoides, Link, l. c. $170=\mathrm{E}$. cheiranthoides.

crepidifolia, A. Dietr, F1. Boruss, vii. $446=\mathrm{E}$. crepidifolium.

cuspidata, Link, Enum. Hort. Berol. ii. $170=$ E. cuspidatum.

erysimoides, Dum. Fl. Belg. $123=$ E. lanceolatum.

firma, Link, Enum. Hort. Berol. ii. $171=$ E. virgatum.

helvetica, Link, 1. c. = E. ochrolencum.

hieracifolia, Link, 1. c. $170=\mathrm{E}$. hieracifolium.

juncea, Link, 1. c. $172=$ Sisymbrium junceum.

lanceolata, Link 1 c $171=\mathrm{E}$ lanceolatum.

leptostyla, Link, Handb. ii. $315=\mathrm{E}$. leptostylum.

longifolia, Link, Enum. Hort. Berol. ii. $171=$ E. longifolium.

longisiliqua, Link, Handb. ii. $315=\mathrm{E}$. virgatum.

longisiliquosa, Link, Enum. Hort. Berol. ii. $170=\mathrm{E}$ longisiliquosum.

odorata, Link, Handb. ii. $315=\mathrm{E}$. odoratum

repanda, Link, Enum. Hort. Berol. ii. $171=\mathrm{E}$. repandum.

sessiliflora, Link, 1. c. $170=$ Syrenia sessiliflora

stricta, Link, 1, $\mathrm{c}=\mathrm{E}$. hieracifolium.

strictissima, Link, I c. $171=$ Sisymbrium strictissimum. suffruticosa, Link, 1. c. $170=\mathrm{E}$, murale.

virgata, Link, 1. c. = E. virgatum.

CHEIRISANTHERA, Hort. ex Regel, Gartenfl. ii. (1853) $353=$ Heppiella, Regel (Gesnerac.) atrosanguinea, Hort. ex Regel, l. $_{\mathrm{v}}=\mathrm{H}$, atrosanguinea coccinea, Hort. ex Regel, 1. $\mathrm{c}_{\mathrm{s}}=\mathrm{H}$. atrosanguinea.

CHEIRODENDRON, Nutt. ex Seem. in Journ. Bot. v. (1867) $236=$ Panax, Linn. (Araliac.).

Gaudichaudii, Seem. 1. c. =P. Gaudichaudii.

laeterirens, Seem. 1. c-Chili.

platyphylla, Seem. I. $c_{s}=$ P. platyphyllum.

samoënse, Seem. 1. c. 237.-Samoa.

valdiviense, Seem. 1. c. 236.-Chili.

CHEIROLAENA, Benth. in Benth. \& Hook. f. Gen. i. 222 (1862). STERCULIACEAE, Benth. \& Hook f. 1 . c.

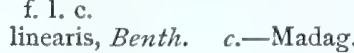

CHEIROLEPIS, Boiss. Diagn. Ser. I. x, $106(1849)=$ Centaurea, Linn. (Compos.).

cappadocica, Boiss. 1. c. $107=$ Cent. cappadocica drabifolia, Boiss. 1. c. = Cent. drabifolia.

Kotschyi, Boiss. \& Heldr. 1. c.=Cent. macrolopha.

libanotica, Boiss. 1. c. (=Phaeopappus libanoticus).Syria.

persica, Boiss. 1. c. $108=$ Cent. macrolopha.

CHEIROLOMA, F. Muell. in Linnaea, xxv. (1852) 401 = Calotis, R. Br. (Compos.)

hispidulum, F. Muell. 1. c. = Cal. hispidula

CHEIROLOPHUS, Cass. in Dict. Sc. Nat. 1. $250(1827)$ $=$ Centaurea, Linn. (Compos.).

lanceolatus, Cass. 1. c. li. $56=$ Cent. sempervirens.

pinnatifidus, Cass. 1. c. = Cent. intybacea.

sempervirens, Pomel, Nonv. Mat. F1. Atl. $32=$ Cent sempervirens.

CHEIROPETALUM, E. Fries, Ind. Sem. Hort. Upsal. (1857) ex Urban, Addit. Ind. Sem. Hort. Berol (1881) 11 = Silene, Linn. (Caryoph.).

radians, E. Fries, 1. c. $=\mathrm{S}$. odoratissima.

CHEIROPSIS, Bercht. \& Presl, Rostl. i. Ranunculac, 11 $(1823)=$ Clematis, Tourn. (Ranunculac.). balearica, Bercht. \& Presl, 1. c. = Clem. balearica cirrhosa, Bercht. \& Presl, l. c. = Clem. cirrhosa.
CHEIROPSIS :-

elegans, Spach, Hist. Vég. Phan. vii. 261=Clematis

semitriloba, Bercht. \& Presi, Rostl, i. Ranunculac. 11 $=$ Clem. semitriloba.

CHEIROPTEROCEPHALUS, Rodrig. Orch. Nov i. $28(1877)$ ORCHIDEAE sertuliferus, Rodrig. l. c. 29.-Bras.

CHFirostemoN, Humb. \& Bonpl. PI. Aequin. 81.t. 24 (1808). STERCULIACEAE, Benth. \& Hook f. i. 212,982 .

Chiranthodendron, Cerv. ex Cay in Anal. Cienc. Nat. vi. (1803) 303, adnot.

apetalum, Cerv, in Roem. Collect. Bot. $97=$ plata noides.

platanoides, Humb. \& Bonpl. Pl. Aequin. 82. t. 24.Mexic.

CHEIRostyLIS, Blume, Bijdr. 413. t. 16 (1825) ORCHIDEAE, Benth. \& Hook, f. iii. 600 .

cochinchinensis, Blume, Orch. Archip. Ind. t. 39. f. 2.-Cochinch

flabellata, Wight, Ic. v. 16. (t. 1727, Monochilus).Ind, or.

grantiflora, Blume, Orch. Archip. Ind. $55 .-\mathrm{N}$ Guinea.

Griffithii, Lindl. in Fourn. Linn. Soc. i. (1857) 188.Reg. Himal.; Burma.

gymnochiloides, Reichb. f. in Flora, lxviii. (1885) 537. -Madag.

heterosepala, Reichb. f. Otia Bot. Hamb. 110.-Afr. trop.

Humblotii, Reichb. f. in Flora, lxviii. (1885) 537.Ins. Comoro.

malleifera, Par. E Reichh. f. in Trans. Linn. Soc. xxx. (1874) 141.-Burma.

marmorata, Lindl. ex Lem, in Fl. des Serres, Sér. I. iv. (1848) t. $370=$ Dossinia marmorata.

montana, Blume, Bijdr. 413.-Java.

parvifolia, Lindl. Bot. Reg. (1839) Misc. 19.-Zeylan. pubescens, Par. E Reichb. f. in Trans. Linn. Sor. xxx. (1874) 141-Burma.

pusilla, Lindl. Gen. et Sp. Orch. 489.-Reg. Himal.

CHELIDONIUM, Tourn, ex Linn. Syst. ed. I (1735) PAPAVERACEAE, Benth. \& Hook. f. i. 53.

aurantiacum, Salisb. Prod. 377=-Glaucium corniculatum.

corniculatum, Donn, Hort. Cant. $100=$ Glaucium flavum.

corniculatum, Linn. Sp. Pl. 506=Glaucium cornica latum.

dahuricum, Hort, ex DC. Prod. i. $123=$ majus.

diphyllum, Michx. Fl. Bor. Am. i. 309=Stylophorum diphyllum.

dodecandrum, Forsk. Fl. Aegypt. Arab. 100=Roemeria orientalis.

fulvum, Poir. Encyc. Suppl. v. $606=$ Glaucium flavum.

glabrum, Mill. Gard. Dict. ed. VIII. n. 5 = Glaucium corniculatum.

Glaucium, Linn. Sp. Pl. $506=$ Glaucium flavum. glaucum, Hill, Veg. Syst. xi. 16=Glaucium flavum.

grandiflorum, DC. Prod. i. $123=$ majus.

haematodes, Moench, Meth. $249=$ majus.

hybridum, Linn. Sp, Pl. $506=$ Roemeria hybrida

japonicum, Thunb. FI. Jap. $221=$ Stylophorum japoni-

laciniatum, Mill. Gard. Dict. ed. VIII. n. $2=$ majus. littorale, Salisb. Prod. 377 = Glaucium flavum.

luteum, Gilib. Fl. Lituan: ii. $211=$ majus.

majus, Linn. Sp.Pl. 505.-Europ.; As. Min majus, Lour. Fi. Cochinch. i. $330=$ sinense. multifidum, Moç. \& Sesse, ex DC. Prod. iii. $344=$ Eschscholzia californica.

murale, Ren. Fl. Orne, $180=$ majus.

petiolatum, Spreng. ex Steud. Nom. ed. II. i. $347=$ Stylophorum diphyllum.

phoeniceum, Lam. F1. Fr, iii, $169=$ Glaucium phoeniceum

quercifolium, Willemet, Phyt. Encyc. ii. $613=$ majus. rubrum, Poir. Encyc. Suppl. v. $606=$ Glaucium corniculatum.

ruderale, Salisb. Prod. $377=$ majus.

sinense, DC. Syst. ii. 100 (sp. dub.).-China.

umbelliferum, Stokes, Bot. Mat. Med. ii. $180=$ majus 


\section{CHELIDONIUM :}

uniflorum, Sieb. \& Zucc in Abh. Akad. Muench. iv. II. (1846) $169=$ Stylophorum japonicum. violaceum, Lam. Fl. Fr. iii. $169=$ Roemeria hybrida vitellinum, C. Muell. in Walp. Ann. vii. $87=$ Glaucium vitellinum.

CHELIDOSPERMUM, Zipp. ex Blume, Mus. Bot Lugd. Bat. i. 162, in syn. (1850)= Pittosporum Banks.

verticillatum, Zipp. ex Blume, 1. c. $=$ P. Chelidospermum.

CHELIDURUS, Willd. in Cothen. Disp. Meth. 4 (1790) (Gen. ignot.)

ignotus, J. F. Gmel, Syst. 105.-Hab.?

CHELIUSIA, Sch. Bip. in Flora, xxiv. (1841) I. Intell. 26, nomen; A. Rich. Tent. Fl. Abyss. i. $380=$ Vernonia, Schreb. (Compos.).

abyssinica, Sch. Bip. HI. cc. $=$ V. amygdalina.

CHELONANTHERA, Blume, Bijdr. 384. t. 51 (1825)= Coelogyne, Lindl. (Orchid.).

gibbosa, Blume, 1. c. $383=$ Pholidota gibbosa.

incrassata, Blume, 1. c. $384=$ Coel. incrassata.

longifolia, Blume, l. c. $385=$ Coel. longifolia,

miniata, Blume, 1. $\mathrm{c}_{\mathrm{s}}=$ Coel. miniata.

speciosa, Blume, 1. c. $384 .=$ Coel. speciosa.

sulphurea, Blume, 1. c. $383=$ Coel. sulphurea.

ventricosa, Blume, $1 . \mathrm{c} .=$ Pholidota ventricosa.

CHELONE, Linn. Syst. ed. I (1735). SCROPHU.

LARINEAE, Benth. \& Hook. f. ii. 939.
CHLONANTHU, Rafin. Princ. Somiol. 26 (1814).

alba, Moench, Meth. $442=$ glabra.

albida, Spreng. Syst. ii. $813=$ Pentstemon albidus.

alpina, Spreng. 1. c. iv. Cur. Post. $235=$ Pentstemon glaber.

angustifolia, H, B. \& K. Nov. Gen. et Sp. ii. 365. t 173 =Pentstemon campanulatus.

angustifolia, Steud. Nom, ed. I. 186=Pentstemon caeruleus.

atropurpurea, Sweet, Brit. Flow. Gard. Ser. I. t. $235=$

Pentstemon campanulatus.

barbata, Cav. Ic. iii, 22. t. $242=$ Pentstemon barbatus.

Bradburii, Steud. Nom. ed. I. $186=$ Pentstemon grandiflorus.

caerulea, Spreng. Syst. ii. $813=$ Pentstemon caeruleus.

campanulata, Cav. Ic. i. 18. t. $29=$ Pentstemon campanulatus.

campanuloides, Andr. Bot. Rep. t. $40=$ Pentstemon campanulatus.

capitata, Rafin. Med. Fl. ii. $118=$ glabra.

centranthifolia, Benth. in Trans. Hort. Soc. Lond. N.

S. i. (1835) $481=$ Pentstemon centranthifolius.

cheilanthifolia, Paxt. Mag. Bot. ii. t. $50=$ praec.

cristata, Spreng. Syst. ii. $813=$ Pentstemon cristatus.

Digitalis, Sweet, Brit. Flow. Gard. Ser. I. t. $120=$

Pentstemon laevigatus.

elatior, Rafin. Med. F1. ii. $118=$ glabra.

elegans, H. B. \& K. Nov, Gen. et Sp. ii. $364=$

Pentstemon campanulatus.

erianthera, Steud. Nom. ed. I. $186=$ Pentstemon cristatus.

filiformis, Buch.-Ham. ex C. B. Clarke, in DC. Monog Phan, v. $134=$ Boeica filiformis.

formosa, Wendl. Beobacht. $51=$ Pentstemon barbatus.

frutescens, Steud. Nom. ed. I. $186=$ Pentstemon frutescens.

gentianoides, H. B. \& K. Nov. Gen. et Sp. ii. 364. t. $172=$ Pentstemon gentianoides

glabra, Linn. Sp. Pl. 611.-Am. bor.

gracilis, Spreng. Syst. ii. $813=$ Pentstemon gracilis.

grandiflora, Spreng. 1. $\mathrm{c}=$ = Pentstemon grandiflorus

hirsuta, Linn. Sp. Y. $611=$ Pentstemon pubescens.

imberbis, H. B. \& K. Nov. Gen. et Sp. ii. $363=$ Pent stemon imberbis.

inermis, Poir. in Dict. Sc. Nat. xxxviii. (1825) $985=$ Pentstemon imberbis.

laevigata, Pers. Syn, ii. $169=$ Pentstemon laevigatus.

lanceolata, Rafin. Med. Fl, ii. $117=$ glabra.

latifolia, Buch.-Ham. ex C. B. Clarke, in Hook, f. Fl. Brit. Ind. iv. $374=$ Rhynchotechum latifolium.

latifolia. Muhl. Cat. ex Ell. Sketch, ii. $127=$ obliqua.

Lyoni, Pursh, Fl. Am. Sept. ii. 787.-Am, bor.

maculata, Rafin. Med. Fl. ii. $117=$ glabra.

major, Sims, Bot. Mag. t. $1864=$ Lyoni.

\section{CHELONE :-}

nemorosa, Dougt. in Lindl. Bot. Reg. t. 1211.-Am. bor. occ.

obliqua, Linn. Syst. ed. XII. 408.-Am. bor, occ.

Penstemon, Linn. Mant. $415=$ Pentstemon pubescens.

Pentstemon, Linn. Sp. P1. 612, pro parte $=$ Pentstemon laevigatus.

pubescens, Sweet, Hort. Brit. ed. I. $305=$ Pentstemon pubescens.

purpurea, Mill. Gard. Dict. ed, VIII. n. $2=$ obliqua, purpurea, Rafin. Med. Fl, ii. $118=$ glabra.

rosea, Cerv. ex Sweet, Brit. Flow. Gard, Ser. I. t. 230 Pentstemon campanulatus.

rubicunda, Buch.-Ham, ex C. B. Clarke, in DC. Monog. Phan, y, $135=$ Boeica Griffithii.

ruelloides, Andr. Bot. Rep. t. $34=$ Pentstemon barbatus.

melloides, Linn, f. SuppI. $271=$ Ourisia magellanica.

CHELONOPSIS, Miq. in Ann. Mus. Lugd. Bat. in. 111 (1865). LABIATAE, Benth. \& Hook. fo ii. 1204 .

moschata, Miq. l. c.-Japon.

CHELROSTYLIS, Pritz. Ic. Ind. 255 (1855), sphalm.= Cheirostylis, Blume.

CHEMNICIA, Scop. Introd. 139 (1777)= Strychnos, Linn. (Loganiac.).

CHEMNIZIA, Steud. Nom. ed. II. i. $347(1840)=$ Strychnos, Linn. (Loganiac.).

CHENOCARPUS, Neck. Elem. i. $202(1790)=$ Sper macoce, Linn. (Rubiac.)

CHENOLEA, Thunb. Nov, Gen. 10 (1781). CHENO

PODIACEAE, Benth. \& Hook, f. iii. 59.

Bassia, All. Misc. Taur. iii. (1766) 177.t. 4.

ECHINOPSILon, Moq. in Ann. Sc. Nat. Sér. II. ii 1834) 1.27

Eriochiton, F. Muell. 2nd Gen. Report, 15 (1854), nomen.

Londesia, Fisch. \& Mey. Ind. Sem. Hort. Petrop..ii. 40 (1835).

Willemetia, Maerkl, in Schrad. Journ. Bot, iii. (1800) I. 329.

arabica, Boiss. Diagn. Ser. I. xii. 97.-Syria ; Arabia. asphaltica, Boiss. 1. c. xiii. $84=$ Suaeda asphaltica. astrocarpa, F. Muell. Fragm.xii. 12.-Austral.

biflora, F. Muell. $l$. c, x. 91.-Austral.

canariensis, Moq. Chenop. Enum. 96.--Marocco; Ins, Canar.

camosa, Benth. Fl. Austral. v. 190.-Austral.

Dallachyana, Benth. l. c. 191.-Austral.

diacantha, F. Muell. Fragm. x. 91,-Austral,

diffusa, Thunb. Nov. Gen. 10.-Afr, austr.

echinopsila, F. Muell. Fragm.x. 92;-A ustral.

enchylaenoides, F. Muell. l. c.-Austral.

eurotioides, F. Muell. ex Benth. Fl. Austral. v. 191.Austral.

Forrestiana, F. Muell. Fragm, xii. 12.-Austral,

hirsuta, Archang. Comp. Fl. Ital. 595.-Italia.

incana, $7 \mathrm{acg}$. Fragm. 76.-Afr. austr.

lanata, Jacq. ex Moq. in DC. Prod. xiii. II. $132=$ Kochia prostrata.

lanata, Moq. 1. c. $129=$ canariensis.

Muelleri, Benth. Fl. Austral. v. 191.-Austral.

paradoxa, F. Muell. Fragm. x. 91.-Austral.

quinquecuspis, $F$. Muell. $l$. c.-Austral.

sclerolaenoides, F. Muell. ex Benth. Fr. Austral.v. 192.-Austral.

salsuginosa, F. Muell. Fragm. x.92.-Austral.

tricornis, Benth. Fl. Austral. v. 191.-Austral

tricuspis, F. Muell. Fragm. x. 92.-Austral.

tridens, F. Muell. l. co xii. 12.-Austral.

CHENOPODINA, Moq. in DC. Prod. xiii. 11. 159 $(18 \pm 9)=$ Suaeda, Forsk. (Chenopod.)

acuminata, Moq. 1. c. $161=$ S. acuminats.

aestuaria, Dum, in Bull. Soc. Bot. Belg, vii. (1868)

$329=$ S. maritima.

altissima, Mog. in DC. Prod, xiii. 11, $162=\mathrm{S}$. altis. sima.

anonyma, Moq. 1. c. 164.-Acgypt.

asphaltica, Boiss Dingn. Ser. I. xii. $98=$ S. asphaltics. australis, Mog in DC. Prod, xiii. II. $163=\mathrm{S}$, aus tralis.
CHENOPODINA :-

baccifera, Moq. in DC. Prod. xiii. II. $160=$ Suaeda baccifera.

bacciformis, Dum. in Bull. Soc. Bot. Belg. vii (1868) $328=$ S. maritima

Biebersteiniana, Moq. in DC. Prod. xiii. II. $163=\mathrm{S}$. microphylla.

dendroides, Moq. 1. c. $164=\mathrm{S}$. dendroides.

depressa, Moq. 1. $\mathrm{c} .=\mathrm{S}$. plattensis.

filiformis, Moq. 1. $c_{0}=S$. marilima.

fruticulosa, Moq. 1. c. $165=$ S. fruticulosa.

glauca, Moq. 1. c. $162=$ S. glauca.

Hostii, Moq. 1. c. 165.-Dalmat.

indica, Wight, Ic. v. t. 1793 = S. maritima.

leiosperma, Moq. in DC. Prod. xiii. Ir. $162=\mathrm{S}$. altissima.

linearis, Moq. 1. c. $164=\mathrm{S}$, lineari

linearis, Torr. in Stansbury, Rep. $394=$ S. Torreyana. maritima, Coss. ex Willk. \& Lange, Prod. Fl. Hisp. $261=$ S. setigera.

maritima, Moq. in DC. Prod. xuii. II. $161=$ S. maritima.

microphylla, Moq. 1. c: =S. microphylla.

microsperma, Moq. 1. c. $165=\mathrm{S}$. microsperma.

minima, Moq. 1. c. $162=$ S. minima.

Moquini, Torr. in Pacif. Rail. Rep. vii. $18=\mathrm{S}$. Tor reyana.

parviflora, Moq. in DC. Prod. xiii. II. $165=\mathrm{S}$. microsperma?

physophora, Moq. 1. c. $164=\mathrm{S}$. physophora.

prostrata, Moq. 1. c. $162=$ S. microsperma.

pycnantha, C. Koch, in Linnaea, xxiv. (1851) $90=$ Seidlitzia florida.

pygmaea, Moq. in DC. Prod. xiii. I1. $161=\mathrm{S}$. microsperma?

salsa, Moq. 1. c. $160=\mathrm{S}$. salsa

sativa, Moq. 1. c. $165=$ S. maritima.

setigera, Moq. 1. c. $160=$ S. setigera.

spicata, Mog. 1, c. $165=$ S. maritima.

splendens, Gren, in Gren. \& Godr. Fl. Fr. iii. $30=\mathrm{S}$ setigera.

tortuosa, Moq. in DC. Prod. xiij. 11. $162=\mathrm{S}$, maritima?

vera, Moq. 1. c. $163=\mathrm{S}$. vera.

CHENOPODIUM, [Tourn.] Linn. Syst. ed. I (1735); Gen. ed. I. 67 (1737). CHENOPODIA.

$C E A E$, Benth. \& Hook. f. iii. 51 .

Agathophytum, Moq, in Ann. Se. Nat, Sér. II. i. (1834) 291. t. 10

AMbrina, Spach, Hist. Vég. Phan. v. 295 (1836)

ANSERINA, Dum.Fl. Belg. 21 (1827)

BLITUM, [Tourn.] Linn. Gen, ed. I. 20 (1737)

Botrydium Spach, Hist. Vég. Phan. v. 298 (1896)

Lipandra, Mog. Chenop. Enum. 19 (1840).

Morocarpus, Adans. Fam. ii. 261 (1768).

OLIGANDRA, Less. in Linnaea, ix. (iS34) 193

Origanthera, End1. Gen. Suppl, i. 1377 (1841).

OrthosperuuM, Opiz, Sernam, $70(1852)$; Schur, in

Verh. Siebenb. Ver. Naturw, iv. (1\$53) 69

Orthosporum, T. Nees, Gen. Fl. Germ. Monoch!. n. $58(1835)$

OxyBasis, Kar, \& Kir. in Bull. Soc Nat. Mose. (18\$1) 798 .

Teloxys, Moq. in Ann. Sc Nat Sér. II. i. (153t

289. t. 10

acerifolium, Andrs. ex Trauts. in Act. Hort. Petrop.

ix. (18s4) 124, nomen.-Rossia.

acuminatum, Schur, Enum. Pl. Transs. 902=rubrum acuminatum, Willd. in Ges. Nat. Fr. Neue Schr. it.

(17)9) 124.t. 5. . 2. - Soongaria.

acutifolium, Hook. \& Arn. Bot. Beech. Voy. 20\% =

acuminatum.

acutifolium, Kit. in Schult. Oestr. F. ed. U. i. 458 ;

Sm. Comp. Fl. Brit. 12 = polyspermum.

regyptiacum, Hasselg. 16. Palaest. 160 - Sunerla baceata.

album, Bosc, ex Mog, in DC. I'rod. xiii. 11. 61

Boscianum.

album, Linn. So. Pl. 219-Keg, temp, ef trop.

alerandrinum, Desf. ex Moq. in DC. Prod. xiii. II.

$155=$ Suaeda vermiculata.

allissimann, Linn. Sp, Pl. 221 = Suneda alrissima

ambigunm, K. Br. Proul. i. 40;-glaucum.

ambrasivides, Bert. ex sicad. Xusa. ed. II. i. SIS sitrivalurum.

ambrasicrifes. IIance, in Joum. Linn. Soc xiii. IS: Su - acummuntum.

ambrosivides, Limn. Sp. Pl. 219, - Keg. lemp. ef ..

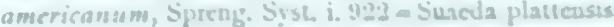




\section{CHENOPODIUM :}

angulatum, Curt. ex Steud. Nom. ed. I. 187 = hybridum angulosum, Lam. F1. Fr. iii. $249=$ hybridum. angustifolium, Gilib. Exercit. ii. 437 = polyspermum angustifolium, Pav. ex Moq. in DC. Prod. xiii. II. 114 $=$ Atriplex linifolia.

antarcticum, Benth. E Hook. f. Gen. iii. 52.-Reg Magellan.

anthelminticum, Bert. ex Steud. Nom. ed. II. i. $348=$ chilense.

anthelminticum, Linn. Sp. P1. $220=$ ambrosioides.

arcticum, Hort. ex Moq. in DC. Prod. xili. II. $86=$ Monolepis chenopodioides.

arenarium, Gaertn. Meyer \& Scherb. Fl. Wett. i. 356 $=$ Kochia arenaria.

aristatum, Linn. Sp. Pl. 221.-Sibir

arrectum, Desmaz. Cat. P1. Belg. $60=$ polyspermum

asphalticum, Boiss. Diagn. Ser. I. xii. $98=$ Suaeda asphaltica.

astracanium, Ledeb. Cat. Hort. Dorpat. (1819) =

rubrum.

atriplicinum, F. Muell. Fragm. vii. 11.-Austral

Atriplicis, Linn. f. Suppl. 171=purpurascens.

augustanum, All. Fl. Pedem. ii. 108. t. $38=$ Kochia prostrata.

augustanum, Hort, Par. ex Moq. in DC. Prod. xiii. II. $135=$ Kochia hyssopifolia

auricomum, Lindl. in Mitch. Fourn. Trop. Austral. 94. - Austral.

australasicum, Moq. Chenop. Enum. 20=Rhagodia linifolia.

australe, R. Br. Prod. $407=$ Suaeda australis.

baccatum, Labill. Nov. Holl. PI. i. 71 . t. $96=$ Rhagodia Billardieri.

baryosmum, Roem. \& Schult. Syst, vi. $269=$ Salsola foetida.

benghalense, Spielm. ex Steud. Nom. ed. II. i. $348=$ Atriplex hortensis?

Berlandieri, Moq. Chenop. Enum. 23.-Am. centr.

betaceum, Andrz, ex Trautv. in Act. Hort. Petrop. ix (1884) 125, nomen.-Rossia.

bicolor, Boj. ex Moq. in DC. Prod. xiii. II. $71=$ album.

Biebersteinianum, Roem. \& Schult. Syst. xi. 267= Suaeda microphylla.

biforme, Nees, in Lehm. P1. Preiss, i. 636=album.

bipinnatifidum, Moric. ex Moq. in DC. Prod. xiii. II. 76. -Mexic.

bisaeriale, Menyh. Kalocsa Vidék. Növény. $157=$ polyspermum.

blitoides, Lejeune, F1. Spa, 126 = rubrum.

Blitum, F. Muell. Sel. Pl. Indust. Cult. $49=$ capitatum.

bonariense, Hort. Par. ex Moq. in DC. Prod, xiii. II.

$67=$ purpurascens.

bonariense, Tenore, Ind. Sem. Hort. Neap. (1833) $13=$ bircinum.

Bonus-Henricus, Linn. Sp. Pl. 218.-Europ

Boscianum, Moq. Chenop. Enum. 21,-Texas

botrydium, St. Lag. in Ann. Soc. Bot. Lyon, vii. (1880) $122=$ C. Botrys.

botryoides, Rafin. ex Moq. in DC. Prod. xiii. II. $75=$ C. Botrys.

botryodes, Sm. Engl. Bot. t. $2247=$ rubrum.

Botrys, Linn. Sp. Pl. 219.-Reg. bor.

Browneanum, Roem. \& Schult. Syst. vi. $275=$ album.

bryoniaefolium, Bunge, Del. Sem. Hort. Petrop. (1876) 10 ; ex Trautv. in Act. Hort. Petrop. ix. (1884) 398 -Sibiria.

calceoliforme, Hook. F1. Bor. Am. ii. $120^{\circ}=$ Suaeda calceoliformis.

californicum, S, Wats, in Bot. Calif. ii. 48.-Calif.

camphorataefolium, Pourr. in Mém. Acad. Toul. iii (1788) $311=$ Kochia prostrata.

camphorosmoides, Hort. ex Moq. in DC. Prod. xiii. II. $132=$ praec

candicans, Lam. Fl. Fr. iii. $248=$ album.

cantabricum, Lag. Hort. Matrit. (1815) 15, nomen.-

Hispan.

capitatum, Aschers. Fl. Brandenb. 572.-Reg. bor. et austr.

carinatum, R. Br. Prod. 407.-Austral.; N. Zel.

carnosulum, Moq. in DC. Prod. xiii. II. 64.-Calif.

Caroxylon, D'Urban, in Journ. Linn. Soc. viii. (1865) $272=$ Salsola Caroxylon.

carthagenense, Zuccagni, in Roem. Collect. $133=$ murale.

catenulatum, Schleich. ex Stend. Nom. ed. II. i. $348=$ album.

\section{CHENOPODIUM :-}

caudatum, Jacq. Coll. ii. 325 ; Ic. Pl. Rar. ii. 12. t. $344=$ Amarantus viridis

Chamrium, Buch.-Ham, in Wall. Cat, n. $6953=$ murale.

Chaudana, Buch.Ham. in Wall. Cat. n. 6957.Ind. or.

chilense, Pers. Syn. i. $294=$ C. Quinoa

chilense, Schrad. Ind. Sem. Hort. Gott. (1832) 2.Chili.

chysomelanospermum, Zuccagni, in Roem. Collect. $134=$ urbicum

cinereum, Moq. Chenop. Enum. $27=$ Atriplex peruviana.

citriodorum, Steud. Nom. ed. II. i. 348.-Ins. Juan Fernand.

Clemente, Spreng. Syst, i. $922=$ Suaeda setigera

concatenatum, Hort. ex Willd. Enum. Hort. Berol 291 = lanceolatum.

concatenatum, Thuill. F1. Paris, ed. II. $125=$ album.

congestum, Hook. f, in Lond. Journ. Bot. vi. (1847) $280=$ Rhagodia Billardieri.

corispermifolium, Hort. Amstel. (1814) 14, nomen.Hab. ?

cornutum, Benth. Eo Hook. f. ex S. Wats. in Bot. Calif. ii. 482,-Mexic.

coronopodum, St. Lag. in Ann. Soc. Bot. Lyon, vii. (1880) $122=$ seq

Coronopus, Moq. in DC. Prod. xiii. II. 76.-Ins. Teneriff.

crassifolium, Bieb. F1. Taur. Canc. iii. $176=$ Suaeda microphylla.

crassifolium, Desf. Tabl. ed. II. 51 = Sueda maritima

crassifolium, Hornem. Hort. Hafn. $254=$ rubrum.

cristatum, F. Muell. Fragm. vii. 11.-Austral.

cuneifolium, Vahl, in West, Fl. S. Cruc. 278.-Santa Crux.

cuneifolium, Vent. ex Moq. in DC. Prod, xiii. II. $73=$ spathulatum.

deltoideum, Lam. Fl. Fr, iii. $249=$ urbicum,

detestans, T. Kirk, in Trans. N. Z. Inst. ix. (1877) 550.-N. Zel.

divaricatum, Fisch. Cat. Hort. Gorenk. (1808) 24, nomen.-Rossia?

effusum, Mart. \& Gal. in Bull, Acad. Brux, x. II. (1843) $346=$ foetidum

elatum, Shuttl. ex Moq. in DC. Prod. xiii. II. $71=$ album.

erosum, Bast. in Desv. Journ. Bot. iii. (1814) $20=$ opulifolium.

erosum, R. Br. Prod. $407=$ murale.

esculentum, Salisb. Prod, $151=\mathrm{C}$. Bonus-Henricus.

exocarpum, Griseb. in Goett. Abh. xxiv. (1879) 37.Reg. Argent

ficifolium, $S m$. Fl. Brit. i. 276.-Europ

filifolium, Krock. Fl. Sil. Suppl. i. 302=praec.

fliforme, Dum. Fl. Belg. $22=$ Suaeda maritima

filiforme, Moench, Meth, $330=$ Suaeda altissima

flavescens, Roem. \& Schult. Syst. vi. $269=$ Salsola vermiculata.

flavum, Forsk. Fl. Aegypt. Arab. Suppl. 205= murale.

foetidum, Lam. F1. Fr. iii. $244=$ C. Vulvaria

foetidum, Schrad, in Ges. Naturf. Fr. Berl. Mag. ii 1808) 79.-Reg. trop.

foliosum, Aschers. Fl. Brandenb. $572=$ capitatum.

Fremonti, S. Wats. in Bot. King, Exp. 287.-Am. bor. acc.

frigidum, Phil. Fl. Atac. 47.-Chili.

frutescens, C. A. Mey in Ledeb. Fl. Alt. i. 408.Sibir, altaic.

fruticosum, Bieb. F1. Taur. Cauc. i. $181=$ Suaeda dendroides.

fruticosum, Linn. Sp. P1. $221=$ Suaeda fruticosa.

furfuraceum, Moq. in DC. Prod. xiii. II. $64=$ auricomum.

Gandhium, Buch.*Ham. in Wall. Cat. n. $6953=$ murale.

giganteum, D. Don, Prod. Fl. Nep. 75=album glandulosum, F. Muell. Fragm. vii. $11=$ carinatum. glaucum, Linn. Sp. Pl. 220.-Reg, bor. et austr.

glochidatum, Gill. ex Moq, in DC. Prod, xiii. II. $61=$ papulosum.

glomerulosum, Reichb. F1. Germ. Excurs. $579=$ album.

graveolens, Lag. \& Rodr. in Anal. Cienc. Nat. v. 1802) $70=$ foetidum

\section{CHENOPODIUM :-}

graveolens, Willd. Enum. Hort. Berol. i. 290,Mexic.

guineense, Jacq. Coll. ii. 346 ; Ic. Pl. Rar. ii. 12. t $345=$ murale.

Guinoa, Krock. Fl. Sil. Suppl. 1. $301=$ C. Quinoa. Halimus, Thunb. Prod. Pl. Cap. $48=$ Atriplex Halimus.

halophilum, Phil. in Anal. Univ. Chil. (1861) 1. 67.Chili.

hastatum, Dum. in Bull. Soc. Bot. Belg. iv. (1865) 339 = Atriplex hastata.

hastatum, Phil. Fl. Atac. 47.-Chili.

hircinum, Schrad. Ind. Sem. Hort. Gott. (1833) 2.Bras.

hirsutum, Linn. Sp. Pl. $221=$ Kochia hirsuta

Hookerianum, Moq. in DC. Prod. xiii. II. $68=$ murale.

hortense, Raddi, ex Moq. 1. c. $161=$ Suaeda maritima.

hortense, Roem. \& Schult. Syst. vi. $268=$ Suaeda hortensis.

Hostii, Ledeb, Fl Ross, iii. $788=$ Suaeda maritima.

humifusum, Kitt. Taschenb. ed. II. $264=$ crassifolium.

humifusum, Zuccagni, in Roem. Collect. 134.Europ.

humile, Hook. F1. Bor. Am. ii. $127=$ rubrum.

hybridum, Linn. Sp. Pl. 219.--Reg. temp. bor.

hybridum, Lour. Fl. Cochinch. $174=$ Loureirei.

ilicifolium, Griff. Notul. iv. $337=$ C. Botrys.

incisum, Poir. Encyc. Suppl. i. 392.-Am. centr.

intermedium, Mert. \& Koch, in Roehl. Deutschl. F1 ed. III.ii. $297=$ urbicum.

Facquini, Tenore, Fl. Nap. iii. $258=$ Suaeda mari tima.

lacerum, Krock. Fl. Sil. Suppl. i. 304.-Silesia.

laciniatum, Roxb. Hort. Beng. 21; F1. Ind. ii. $59=$ album.

laciniatum, Thunb. Prod. P1. Cap. $48=$ Atriplex laciniata.

lanceolatum, R. Br. Prod. $407=$ album.

lanceolatum, Muhl. ex Willd, Enum. Hort. Berol. $291=$ album.

lanuginosum, Moench, Meth. $330=$ Kochia hyssopi folia.

laterale, [Soland. in] Ait. Hort. Kew. ed. I. i. $313=$ murale.

latifolium, Pall. Reise Statth. Russ. Reich. i. 280.Rossia.

leiospermum, DC. Fl. Fr. iii. $390=$ album

leptophyllum, Nutt. ex Moq. in DC. Prod. xiii. II. 71. -Am. bor.

leucospermum, Schrad. Ind. Sem. Hort. Gott. (1834) 2 = purpurascens.

lineare, Hort. ex Steud. Nom, ed. II. i. $348=$ Kochia prostrata.

linifolium, Roem. \& Schult. Syst. vi. $271=$ Suaeda linifolin.

littorale, Moq. Chenop. Enum. 24.-Austral

littorale, Thunb, in Act. Soc. Sc. Upsal. vii. (1815) 142 $=$ Atriplex littoralis.

Loureirei, Steud. Nom. ed. II. i. 348.-China.

lucidum, Gilib. Exercit. ii. $440=$ murale.

macrocarpum, Desv, Journ. Bot. i. (1813) $48=$ Suaeda maritima.

macrospermum, Hook. f. $\mathrm{Fl}$. Antarct. ii. 341.-Ins Falkland.

macrospermum, Hort. Ant. ex Moq. in DC. Prod. xiii. II. $84=$ rubrum.

marginatum, Spreng. ex Hornem. Hort. Hafn. i. $256=$ polyspermum.

maritimum, Friwald. ex Ledeb. Fl. Ross. iii. $783=$ Suaeda altissima.

maritimum, Linn. Sp. P1. $221=$ Suaeda maritima maritimum, Torr. in Ann. Lyc. N. York, ii. (1828) 239 = Snaeda diffusa.

Matthioli, Bertol. ex Moq. in DC. Prod. xiii, II. $84=$ rubrum.

melanospermum, Wallr. Sched. Crit. $112=$ urbicum, mexicanum, Moq. in DC. Prod. xiii. II. 70.-Mexic. micranthum, Trautv. in Bull. Soc. Nat. Mosc. xli (1868) I. 464.-Rossia.

microphyllum, Bieb. Fl. Taur. Cauc. ii., $175=$ Suaeda dendroides.

microphyllum, F. Muell. in Trans. Phil. Inst. Vict. ii. (1858) 74.-Austral.

microphyllum, Thunb. Prod. Pl. Cap. 48.-Afr. austr microspermum, Wallr. Sched, Crit. $112=$ urbicum. 


\section{CHENOPODIUM}

mucronatum, Thunb. Prod. Pl. Cap. 48.-A fr. austr. multifidum, Linn. Sp. Pl. $220=$ Roubieva multifida. multiflorum, Moq. in DC. Prod. xiii. II. $75=$ C. Botrys. murale, Linn. Sp. Pl. 219.-Reg. bor. et austr. neglectum, Dum, in Bull. Soc. Bot. Belg. iv. (1865) 339.-Belgium

nepalense, Hort. Monsp. ex Moq. in DC. Prod. xiii. II $74=$ C. Botrys.

nigrum, Rafin. Atl. Fourn, 146.-Am, bor. nitidum, Spreng. Syst, i, $921=$ Salsola nitida. nitrariaceum, F. Muell. ex Benth. Fl. Austral. v. 158. Austral.

obovatum, Moq. in DC. Prod. xiii. II. 73.-Am austr.

oleraceum, Schur, Enum. Pl. Transs. 573.-Transsylv. olidum, Curt. Fl. Lond. fasc. v. t. $20=$ C. Vulvaria. olidum, S. Wats, in Proc. Am. Acad. ix. (1874) 95. Am. bor.

oppositifolium, Linn. f. Suppl.172= Halogeton oppositi florns.

oppositifolium, Willd. Sp. Pl. i. 1307=Girgensohnia oppositiflora.

opulaceum, Neck. Delic. Gallo-Belg. i. 130=album opulifolium, Schrad. in DC. Fl. Fr.v. 372.-Reg. bor paganum, Reichb. F1. Germ. Excurs. $579=$ album. Pallasianum, Roem. \& Schult. Syst. vi. $271=$ Kochia hirsuta.

pallidum, Moq. Chenop. Enum. $30=$ glaucum ? paniculatum, Hook. Bot. Misc, ii. (1831) 237.-Peruy. paniculatum, Salzm. ex Moq. in DC. Prod. xiii. II. 18 $=$ Microtea paziculata

papulosum, Moq. l.c. $61 .-$ Bras

parvifolium, Roem. \& Schult. Syst. vi. $266=$ Suaeda denclroides.

patulum, Mérat, Nouv. Fl. Par. 96= rubrum.

patulum, Roth, Nov. Pl. Sp. 180.-Ind. or.

pauciflorum, Herb. Vind, ex Moq. in DC. Prod. xiii. II. $89=$ Exomis axyrioides.

pauciflorum, Mart. Hort. Monac. (1829) 56, nomen.-

Hab.?

Payco, Molina, Sagg. Chile, ed. II. 118=Roubieva multifida.

pedunculare, Bertol. FI. Ital. iii. $32=$ album.

petiolare, $H . B$. E $K$. Nov. Gen, et Sp. ii. 191, Ecuador.

petiolare, Mart. \& Gal. in Bull. Acad. Brux. x. II (1843) $345=$ Cryptocarpus globosus

physophora, Moq. ex Boiss. Fl. Orient. iv. $939=$ Suaeda physophora.

pinnatum, Hort. ex Moq. in DC. Prod. xiii. I1, $93=$ Atriplex laciniata.

polispermum, Neck. Delic. Gallo-Belg. i. $128=$ polyspermum.

polyspermum, Linn. Sp. Pl. 220.-Europ.; As. bor.

populifolium, Hort. ex Moq. in DC. Prod. xiii. Ir, 66 = ficifolium.

portulacoides, Thunb. Fl. Cap. ii. $178=$ Atriplex portulacoides.

precatorium, Dum. in Bull. Soc. Bot. Belg. iv. (1865) 340.-German.

proceram, Hochst. ex Moq. in DC. Prod. xiii. II. 75. Abysin.

prostratum, Hort. ex Moq. 1. c. $132=$ Kochia prostrata.

prostratum, Jacquem. ex Moq. 1. c. $72=$ glaucum?

prostratum, Roem. \& Schult. Syst, vi. $272=$ Suaeda prostrata.

pseudo-botrys, Hort. ex Heynh. Nom. ii. 138, nomen. -Hab.?

Pumilio, R. Br. Prod. i. 407.-Austral.

punctulatum, Scop. Delic. Insub. i. 26. t. $11=$ purpurascens.

purpurascens, Buch.-Ham. in Wall. Cat. n. $6956=$ album.

purpurascens, Jacq. Hort. Vindob. iii. 43. t. $80=$ album?

pusillum, Hook. f. Handb. New Zeal. Fl. 281.-N. Zel.

pusillum, Bertol. in Nov. Comm. Bonon. iv. (1842) 413.-Fl. Euphrat.

pygmacum, Menyb. Kalocsa Vidék. Növény. $154=$ rubrum.

guercifolium, Hort. Monsp. ex Moq. in DC. Prod. xiii. II. $74=$ graveolens.

Quinon, Willd. Sp. Pl. i. 1901.-Am. austr.

radiatum, Schrad. Neues Journ. iii. III. (1809) $85=$ Cycloloma platyphyllum.

\section{CHENOPODIUM :}

retusum, Fuss. ex Moq. in DC. Prod. xiii. II. 73.-Bras.

rhadinostachyum, F. Muell. in Wing, South Sc. Record, ii. (1882) 98.-Anstral.

rhombifolium, Muhl. ex Willd. Enum. Hort. Berol. 288 -urbicum.

riparium, Boeningh. ex Moq. in DC. Prod. xiii. II. 71 =album.

rubricaule, Schrad. ex Moq. 1. c. $67=$ purpurascens. rubrum, Forsk. ex Steud. Nom, ed. I. 188=murale. rubrum, Linn. Sp. Pl. 218.-Europ.; As. bor. ruderale, Kit. ex Moq. in DC. Prod. xii. II. 77.Hungaria.

ruderale, St. Lag. in Ann. Soc. Bot. Lyon, vii. (1880) $69=$ C. Bonus-Henricus.

sagittatum, Lam. Fl. Fr ii, $244-\mathrm{C}$. Bonus-Henricus. salsum, Guss. F1. Sic. Prod. i. $299=$ Suaeda maritima salsum, Hohen. ex Ledeb. F1. Ross. iii. $782=$ Suaeda altissima.

salsum, Linn. Sp. Pl. $221=$ Suaeda salsa.

Sancta-Maria, Vell. Fl. Flum. 126; iii, t. $104=$ ambrosioides.

sandwicheum, Moq. Chenop. Enum. 28.-Ins. Sandvic.

Schraderianum, Roem. \& Schult. Syst. vi. 260 foetidum.

scoparia, Linn. Sp. Pl. $221=$ Kochia scoparia

secundiflorum, Viv. F1. Lib. Spec. $67=$ aristatum.

sepium, Mey. in Abh. Boehm. Ges. Wiss. (1787) 320

-Bohemia.

sericeum, Spreng. Syst. i. $921=$ Kochia sericea.

sericeum, Vitm. Summa Veg. ii. $98=$ Kochia prostrata.

serotinum, Forsk. Fl. Aegypt. Arab. 205.-Arab.

serotinum, Ledeb. F1. Alt. i. $405=$ album.

serotinum, Linn. Cent. Pl. ii. 12 = ficifolium.

serotinum, Suter, Fl. Helv. i. $148=$ hybridum.

setigerum, DC. Cat. Hort. Monsp. $94=$ Suaeda setigera.

simplex, Rafin. Atl. Fourn. 146.-Am. bor

sinense, Hort. ex Moq. in DC. Prod. xiii. II. $60=$ aristatum

sinense, Willem. Ess. Med. iii. $233=$ Kochia sericea

sinuatum, Thunb. Fl. Cap. ii. $178=$ Atriplex laciniata.

spathulatum, Sieber, ex Moq. in DC. Prod. xiii. II. 73. -Bras.

spicatum, Lavy, Veg. Orig. 10.-Hab.?

spicatum, Roem. \& Schult. Syst. vi. $271=$ Sureda maritima.

spinacifolium, Stokes, Bot. Mat. Med. ii. $14=\mathrm{C}$. Bonus-Henricus.

spinosum, Hook. Fl. Bor. Am. ii. 127=Grayia poly galoides.

stellatum, S. Wats, in Proc. Am. Acad. xviii. (1882-83) 146.-Mexic.

stramoniifolium, Cheval. F1. Par. ii. 383 =hybridum. strictum, Roth, Nov. Pl. Sp. 180.-Ind. or.

subspicatum, Nutt. Gen. Am. i. 199=Atriplex hastata suffruticosum, Willd. Enum. Hort. Berol. $290=$ ambrosioides.

tenerrimum, Krock. Fl. Sil. Suppl. i. 305.-German.

tenue, Colla, in Mem. Acc. Torin. xxxix. (1836) 9. $50=$ Roubieva multifida.

tomentosum, Thou. Fl. Tristan. 38.-Ins. Tristan d'Acugn.

Tournefortianum, Hort. ex Moq. in DC. Prod. xiii. Ir. $158=$ Suaeda altissima.

Tournefortii, Hort. ex Moq. I. c. = praec.

triandrum, Forst.f. Prod. 21.-N. Zel.

triangulare, R. Br. Prod. 407.-Austral

triangulare, Dulac, Fl. Hantes-Pys. $171=$ C. Bonus

Henricus.

triangulare, Forsk. Fl. Aegypt. Arab. Suppl. $205=$ murale.

triangularifolia, Gilib. Exercit. ii. $437=$ C. Bonus Henricus.

trifid $u m$, Trev. Ind, Sem. Vratisl. $(1829)=$ Monplepi: chenopodioides.

trigonon, Roem. \& Schult. Syst. vi. $275=$ triangulare.

trigynum, Roem. \& Schult. 1. c. $268=$ Suacd altissima.

trilobatum, Hort. ex Moq. in DC. Prod. xiii. $11.76=$ foetidum.

trilobum, Hort. ex Mog. I. $\mathrm{c}_{2}=$ foetidum.

trilobum, Schuit. ex Moq, l. c. 66 - ficifolium.

tripteris, Dum. Fl. Belg. $22=$ Kochin tripteris.

tumidum, Kit. Cat. Kroem. (181t) Suppl. S, nomen. - Hab. ?

\section{CHENOPODIUM:}

Tweedii, Moq. in DC. Prod. xiii.II. 63.-Bras.

urbicum, Linn. Sp. Pl. 218.-Europ.; As, bor.

Vachellii, Hook. \& Am. Bot. Beech. Voy. $269=$ acuminatum.

variegatum, Gouan, in Cat. Hort. Taur. (1810)= ambrosioides.

vestitum, Thunb. Prod. P1. Cap. $48=$ Atriplex glanca. villosum, Hort, ex Moq, in DC. Prod. xiii. 11. $132=$ Kochia prostrata.

villosum, Lam. Encyc, i. $196=$ Kochia hyssopifolia

villosum, Spreng. Syst. i. $924=$ Suaeda microphylla.

virens, Wender. Sem. Marb. (1836), nomen.-Hab.?

virgatum, Thunb. in Nov. Act. Soc. Sc. Ups. vil

(1815) 143.-Japon.

virginicum, Linn. Sp. PI. 222 = aristata.

viride, Curt. F1. Lond, fasc. ii. t. 16 = ficifolium.

viride, Linn. Sp. Pl $219=$ album

viride, Loisel. Fl. Gall. 1. $145=$ opulifolium.

vulgare, Gueldenst. ex Ledeb. Fl. Ross. iii. $700=$ album.

vulpinum, Bach.-Ham. in Wall. Cat. n. $6954=\mathrm{albom}$, ambrosivides.

Vulvaria, Linn. Sp. Pl. 220.-Europ.: As. bor.

Wolffi, Simk. in Termés. Füzetek, iii. (1879) 164. Hangar.

Ziegleri, Perrot, ex Moq. in DC. Prod. xiii. II. $24=$ Limeum linifolium

zosteraefolium, Hook. Fl. Bor. Am. ii. 127 = Atriplex Gmelini.

CHEOBULA, Vell. FL Flum, iv, to 146 (1827) Cleobula, Vell. (Inc. sed.)

CHERINA, Cass, in Dict. Sc. Nat. viii. 437 (1817) Chaetanthera, Ruiz \& Pav. (Compos.)

microphylla, Cass. 1. c. $438=$ Chaet. linifolia.

CHERLERIA, Hall. It. Helv, ii. .. 79, t. 1 (1740); ex Linn. Gen. ed. II. $196(1742)=$ Arenaria, Rupp. (Caryophyll.)

bipartita, Fisch. ex Steud. Nom, ed. II. i. 349 , nomen. - Sibir. baical.

bisulca, Bartl. in Presl, Rel. Haenk. ii. 12.-Peruy

caespitosa, Lam. Fl. Fr. iii. $46=$ A. Cherleria.

dicranoides, Cham, in Linnaea, i. (1826) $63=$ Stellaria dicranoides.

grandiflora, D. Don, Prod. Fl. Nep. $214=$ A. globi. flora.

imbricata, Ser. in DC. Prod. i. $421=$ A, aretioides,

juniperina, D. Don, Prod. Fl. Nep. $214=$ A. densissima.

laevis, Bartl. in Presl, Rel. Haenk. ii. 12.-Peruv.

nitida, Bartl. 1. c.-Perur.

octandra, Sieber, ex Spreng. Syst. ii. $416=$ A, aretioides.

peduncularis, Bunge, ex Steud. Nom. ed. II. i. $\$ \$ 9=$ bipartita.

sedoides, Forsk. Fl. Aegypt. Arab. p. lxvi $=$ A geniculata.

sedoides, Linn. Sp. PI. $425=$ A. Cherleria

sedoides, Sibth. \& Sm. Fl. Graec. Prod. i. $306=$ A. trichocalycina.

sedoides, Turcz, in Bull. Soc. Nat. Mosc. xv. (1842 $608=$ Stellaria petraea .

sibirice, Regel \& Tiling - in Nonv. Mém. Soc. Nat. Mosc. xi. (1859) 72.-Sibir. or

stellata, Clarke, Trav. iv. 211 (=Alsine parnassica), -Graecia.

CHEROPHILUM, Nocca, in Usteri, Ann. Bot, $\vee$. (1799)

51 -Chaerophyllum, Lins. (Umbellif.

CHERSYDRIUM, Scholt, in Oestr. J3ot. Zcitschr. It: (1865) 72 = Dracontium, Linn. (Aroid.)

Fararaca, Schott, 1. c. $73=$ D. asperum.

CHFSNEA, Scop. Introd. $119(17 \% 7)=$ Cephaēlis, Sw. (Rubiac.).

CHISNEYA, Bertol. in Nov. Comm. Bonon, r. ilst? 127 (Misc. Bot. i. 17. t. 2)=-Pimpinella, Lina. Umbellif.

daucoides, Bertol. I. c. $=$ P. criocarpa.

CHISNEYA, Lindl, in EndL Ger. $19 ; 5(1840)=$ Calophaca, Fisch. Lecumin.'

astrogaling, Jaub. \& Spach. Illustr. i. 9A-Persia

ruphrabensis. [1 indll. ia] Cihesn. Niarat. Euph. (1805) t. ad p. 139 ryeiduspermu. 


\section{CHESNEYA :-}

Kotschyii, Boiss. Diagn. Ser. I. vi. 34.-Persia. microphylla, Jaub. \& Spach, Illustr. i. $94=$ rytido sperma.

mongolica, Maxim. in Bull. Acad. Pétersb. xxvii. (1881) 462.-Mongolia.

Oliverii, Jaub. \& Spach, Illustr. i. 94.-Mesopotam. parviflora, Jaub. \& Spach, 1. c. 95.-Persia. rytidosperma, Jaub. \& Spach, 1. c. 93.-Armenia. turkestanica, Franch. in Ann. Sc. Nat. Sér. VI. xv (1883) 253.-Turkestan.

vaginalis, Jaub. \& Spach, Illustr. i.96. t. 48. Mesopotam.

velutina, Jaub. \& Spach, 1. c. 94=rytidosperma.

CHESNYA, Reichb. Nom. 148 (1841) = praec.

CHETARIA, Steud. Nom. ed. II. ii. 521 (1841) = seq.

CHETASTRUM, Neck. Elem. i. $108(\mathbf{1 7 9 0})=$ Seabiosa Tourn. (Dipsac.).

CHETOCRATER, Rafin. Sylva Tellur. 149 (1838)= Casearia, Jacq. (Samydac.)

hirta, Rafin. 1. c. = Cas. hirta.

javitensis, Rafin. 1. c. = Cas. javitensis.

tinifolia, Rafin. 1. c. = Cas, tinifolia.

CHETROPIS, Rafin. Fl. Tellur. iii. 80 (1836)=Arenaria, Rupp. (Caryophyll.)

setacea, Rafin. 1. c. = A. rostrata

CHEVALIERIA, Gaudich, Voy, Bonite Bot, t. 61,62 $(1852$ ? $)$ Aechmea, Ruiz \& Pav. (Bromel.). crocophylla, E. Morr. in Belg. Hortic. (1885) 81.-Bras. Germinyana, Carr, in Rev. Hortic. (1881) 230.-N Granat.

grandiceps, Griseb. in Goett. Abh. xxiv. (1879) $329=$ Ae. brasiliensis.

lingulata, Griseb. F1. Brit. W. Ind. $591=$ Ae. lingulata ornata, Gaudich. Voy. Bonite Bot. t. $62=$ Ae. ornata. sphaerocephala, Gaudich. 1. c. t. $61=\mathrm{Ae}$. sphaerocephala.

Veitchii, E. Morr. in Belg. Hortic. xxviii. (1878) 177. t. $9=$ Ae. Veitchii.

CHEvallierA, Carr. in Rev. Hortic. (1881) $230=$ praec.

CHEVREULIA, Cass. in Bull. Soc. Philom. (1817) $69{ }^{\circ}$ et Dict. Sc, Nat. viii. $516^{\circ}$ (1817), COMPO SITAE, Benth. \& Hook。 fo ii. 303

Leucopodum, Gardn, in Hook. Lond. Journ. Bot iv. (1845) 124.

acuminata, Less. in Linnaea, v. (1830) 261.-Am. anstr. filiformis, Hook. \& Arn. in Hook. Comp. Bot. Mag. i. (1835) $102=$ acuminata.

gnaphalioides, D. Don, ex Hook. E Arn. in Hook. l. c -Chili.

lanceolata, Remy, in C. Gay, Fr. Chil. iii. 333.-Chili. longipes, Wedd. Chlor. And. i. $157=$ acuminata. lycopodioides, $D C$. Prod. vii. $4 \xi_{\text {c }}$-Ins. Falkland. nivea, Phil. in Anal. Univ. Chil. ii. (1862) 380 Chili.

pusilla, DC. Prod. vii, $45=$ stolonifera

stolonifera, Cass. in Bull. Soc. Philom. (1817) 69.Am. austr.

Thouarsii, Remy, in C. Gay, Fl. Chil. iii. 332. t. 37. f $2=$ stolonifera.

xeranthemoides, D. Don, ex Hook. Comp. Bot. Mag. i. (1835) 102.-Chili.

CHEYNIA, J. Drumm. ex Harv. in Hook. Kew Journ. vii. (1855) $56=$ Balaustion, Hook. (Myrtac.)

pulchella, J. Drumm. 1. c. $=$ B. pulcherrimum.

CHIAZOSPERMUM, Bernh. in Linnaea, viii. (1833) 465 - Hуреcoum, Linn. (Fumariac.)

erectum, Bernh. I. c. xii. (1838) $662=\mathrm{H}$. erectum.

lactiflorum, Kar. \& Kir. in Bull. Soc. Nat. Mose. xv. (1842) 142,-Soongaria.

pendulum, Bernh, ex Edgew. in Journ. Linn. Soc. vi. (1862) $183=\mathrm{H}$. procumbens.

CHIBACA, Bertol. fo in Mem. Acc. Bolog. iv. (1853) 545 , nomen (=Gen. dub. LAURIN.) Benth. \& Hook f. iii. 150 .

salutaris, Bertol. f. l. c. ; et in Rosenth. Syn. Pl. Diaphor. i. 238.-Afr. austr.
CHICHAEA, Presl, Rel. Haenk. ii. $140(1836)=$ Sterculia, Linn.

acerifolia, Presl, 1. c. $141=$ S. acerifolia.

CHICHARRONIA, A. Rich. Ess. Fl. Cub. 529. t. 43 $(1845)=$ Terminalia, Linn. (Combretac.).

intermedia, A. Rich. 1. c.-Ins. Cuba.

CHICkRAssia, A. Juss. in Mém. Mus. Par, xix 1830) 251. t. 22 (Chukrasia). MELIACEAE, Benth \& Hook. f. i. 339

PlagiotaXIs, Wall. Cat. (nomina) nn. 1269, 1270. Nimmonii, R. Grah. in Wight, Illustr. $148=$ tabularis. tabularis, A. Fuss, in Mém. Mus. Par. xix. (1830) 251. -Ind. or.; Malaya.

trilocularis, M. Roem. Syn. Hesper, i. $135=$ tabularis velutina, Wight \& Arn. Prod. $123=$ tabularis.

CHICoINAEA, Comm. ex DC. Prod. iv. $462(1830)=$ Psathura, Comm. (Rubiac.).

CHILECHIUM, Pfeiff. Nom. i. I. 713 (18 73$)=$ CHILOCHIUM, Rafin。 =Echiochilon, Desf. (Boragin.)

CHILERANTHEMUM, Oerst, in Kjoeb. Vidensk Meddel (1854) 166. ACANTHACEAE, Benth. \& Hook, f. ii. 1119

trifidum, Oerst. l. c. 167. t. 3. f. 30-33.-Mexic.

CHILIADENUS, Cass. in Dict. Sc. Nat. xxxiv. 34 (1825) =Jasonia, Cass. (Compos.).

camphoratus, Cass. 1. c. $35=$ J. glutinosa.

glutinosus, Fourr. in Ann. Soc. Linn. Lyon, N.S. xvii. (1869) $93=$ J. glntinosa.

CHILIANDRA, Griff. Notul. iv. $150 \quad(\mathbf{1 8 5 4})=\mathbf{R}$ yyn chotechum, Blume (Gesnerac.). obovata, Griff, l. c. = R, latifolium.

CHILIANTHUS, Burch. Trav. i. 94 (1822). LOGANIACEAE, Benth. \& Hook. fo ii. 793.

Semnos, Rafin. Sylva Tellur. 161 (1838).

arboreus, Benth. in DC. Prod. x. $435=$ oleaceus.

corrugatus, Benth. l. c. 436.-Afr. austr.

dysophyllus, Benth. l. c.-Afr. austr.

lobulatus, Benth. l. c.-Afr. austr.

oleaceus, Burch. Trav. i. 94.-Afr. anstr.

triphyllus, E。 Mey. Zwei Pfl. Docum. 172=Nuxia floribunda.

CHILIOCEPHAIUM, Benth, in Hook, Ic. Pl, t 1137 (1873). COMPOSITAE, Benth.\& Hook. f. ii.300. Kralikia, Sch. Bip. in Schweinf. Beitr. Fl. Aethiop. $151(1867)$

myriocephalum, Baill. Hist. Pl. viii. $173=$ Schimperi. Schimperi, Benth. in Hook. Ic. Pl. t. 1137.-Afr. trop. Schultzii, Buching. ex Baill. Hist. Pl. viii. $173=$ Schimperi.

CHILIOPHYLLUM, DC. Prod. v. $554(1836)=$ Zaluzania, Pers. (Compos.)

globosum, DC. 1. c. $=$ Z. globosa.

CHILIOPHYILUM, Phil. in Linnaea, xxxiii (1864-65) 132. COMPOSITAE, Benth. \& Hook. f. ii. 258

densifolium, Phil. l.c. 133.-Chili.

CHILIOTRICHUM, Cass. in Dict. Sc. Nat. viii. 576 (1817). COMPOSITAE, Benth. \& Hook, f. ii. 276. Tropidolepis, Tausch, in Flora, xii. (1829) 68. amelloides, DC. Prod. v. $216=$ seq.

amelloideum, Cass. in Dict. Sc. Nat, viii. 577.-Reg. Magellan.

Darwinii, Hook. f. Fl. Antarct. 305 $=$ Nardophyllum Darwini.

Feliciae, Hombr. \& Jacquin. ex Decne. Bot. Voy. Astrol. et Zél. 52=amelloidum.

humile, Hook. f. Fl. Antarct. $304=$ Nardophyllum humile.

Kingii, Hook. f. l. c. $305=$ Nardophyllum Kingii.

ovatifolium, Hombr. E Facquin. ex Decne. Bot. Voy. Astrol. et Zél. Dicot. Phan t. 28.-Hab.?

rosmarinifolium, Less. in Linnaea, vi. (1831) 109,-Chili. virgatum, Phil.in Anal.Univ. Chil. (1873) 485,-Chili.

CHILMORIA, Buch.-Ham. in Trans. Linn. Soc. xiii. (1822) $500=$ Gynocardia, R. Br. (Bixin.). dodecandra, Buch.-Ham. 1. c.-G. odorata.

pentandra, Buch.-Ham. 1. c. $501=$ Hydnocarpus inebrians.
CHILOCALYX, Klotzsch, in Peterg, Reise Mossamb. Bot. $154(1861)=$ Cleome, Linn. (Capparid.). macrophyllus, Klotzsch, 1. c. $155=$ Cleome Chilocalyx. tenuifolius, Klotzsch, 1. c. = Cleome Chilocalyx.

CHILOCALYX, Turcz, in Bull. Soc. Nat. Mosc. xxxyi (1863) I. 588=Atalantia, Correa (Rutac.).

elliptica, Turez. 1. c. =A. missionis.

CHILOCARPUS, Blume, Cat. Gew. Buitenz. 2: (1823); et Bijdr. 1025 (1826). APOCYNACEAE Benth. \& Hook. f. ii. 691

atroviridis, Blume, Mus. Bot. Lugd. Bat. i. 153.Burma; Malaya.

australis, F. Muell. Fragm. ii. 90-Austral.

ceylanicus, Wight, Ic.t. $1288=$ Willughbeia ceylanica compositus, Blume, Mus. Bot. Lugd. Bat. i. 152.Java

costatus, Miq. Fl. Ind. Bat. ii. 393.-Sumatra.

cuspidatus, Benth. \& Hook. f. Gen. ii. 698, in nota sub Hunteria $=$ Melodinus orientalis

decipiens, Hook. f. Fl. Brit. Ind. iii. 627.-Malacca

densiflorus, Blume, Mus. Bot. Lugd. Bat. i. 152.Sumatra.

denudatus, Blume, Bijdr. 1025 = atroviridis.

Diepenhorsti,, Miq. Fl. Ind. Bat. Suppl. 552.Sumatra.

enervis, Hook. f. Fl. Brit. Ind. iii. 626.-Malacca.

flavescens, Kew Gard. Report (1880) 47, ex Fl. Brit. Ind. iii. $625=$ Willughbeia flavescens.

globuliferus, Blume, Mus. Bot. Lugd. Bat. i. 152.Borneo.

Maingayi, Dyer, ex Hook. f. Fl. Brit. Ind. iii. 627.Malacca.

malabaricus, Bedd. Ic. Pl. Ind. Or. i. $33=$ atroviridis

suaveolens, Blume, Cat. Gew. Buitenz. 23 ; et Bijdr. 1025. - Java.

vernicosus, Blume, Mus. Bot. Lugd. Bat. i. 152.Borneo.

CHILOCHIUM, Rafin. in Ann. Gén. Sc. Phys. viii (1821) $269=$ Echiochilon, Desf. (Boragin.).

CHILOCHLoA, Beauv, Agrost. 37. t. 7. f. 2 (1812)= Phleum, Linn. (Gramin.)

annua, Roem. \& Schult. Syst. ii. $410=$ P. asperum.

arenaria, Beauv. Agrost. $37=\mathrm{P}$. arenarium.

aspera, Beauv. 1, c. = P. asperum.

Boëmerii, Beauv. 1. c. $=$ P. Boehmeri.

collina, Schur, Enum. P1. Transs. $729=$ P. phalaroides cuspidata, Beauv, Agrost. $37=\mathrm{P}$. Michelii.

cuspidata, Schur, Enum. P1. Transs. $729=$ P. phalaroides.

dentata, Trin. Gram. Unifl. $168=$ Phalaris dentata.

explicata, Roem. \& Schult. Syst. ii. $410=$ Heleochloa alopecuroides.

Gerardi, Bess. ex Schult. Mant. ii. 206=Alopecurus Gerardi.

hirsuta, S. F. Gray, Nat. Arr. Brit. Pl. ii. $139=\mathrm{P}$ Michelii.

hispida, Beauv. Agrost. 158, nomen = Arthraxon ciliaris.

Michelii, Trin. Gram. Unifl. $167=$ P. Michelii.

paniculata, Beauv. Agrost. $37=\mathrm{P}$. asperum.

ventricosa, Beauv. ex Stead. Nom. ed. II. i. $350=$ Gastridium australe?

CHILODIA, R. Br. Prod. 507 (1810)= Prostanthera Labill. (Labiat.).

australis, Loud. Hort. Brit. Suppl. i. 585.-Austral.

scutellarioides, R. Br. Prod. $507=\mathrm{P}$. empetrifolia.

CHILOGLOSSA, Oerst. in Kjoeb. Vidensk. Meddel. (1854) 160 = Dianthera, Linn. (Acanthac.).

glabra, Oerst. 1. c. $161=$ D. glabra.

secunda, Pritz. Ic. Ind. ii. $77=$ praec.

CHILOGLOTTIS, R. Br. Prod. 322 (1810), OR CHIDEAE, Benth. \& Hook. f. iii. 614

cornuta, Hook. f. Fl. Antarct. 69.-N. Zel

diphylla, R. Br. Prod. 323.-Austral.

formicifera, Fitzgerald, Austral. Orchids, i. III. (1877), -Austral.

Gunnii, Lindl. Gen, et Sp. Orch. 387.-Austral.

trapeziformis, Fitzgerald, Austral. Orchids, i. III. 1877. -Austral.

trilabra, Fitzgerald, in Fourn. Bot. xxi. (1883) 204.Austral.

Traversii, F. Mnell. Veg. Chath.-Isl, $51=$ Caladenia 
CHILOPORUS, Naud in Ann Sc. Nat. Sér. III. iv. (1843) $57=$ IMiconia, Ruiz \& Pav. (Melastomac.). andinus, Naud. 1. $\mathrm{c}_{0}=\mathrm{M}$. andina.

CHILOPSIS, D. Don, in Edinb. Phil. Journ. ix. (1823) 261. BIGNONIACEAE, Benth. \& Hook. f. ii. 1041. glutinosa, Engelm. in Bot. Wislizen. Mexic. Exped. 94-Mexic bor

linearis, Sweet, Hort. Brit. ed. I. $283=$ saligna.

saligna, D. Don, in Edinb. Phil. Fourn, ix. (1823) 261 -Mexic.

CHILOSCHISTA, Lind1. Bot. Reg. subt. 1522 (1832)= Sarcochilus, R. Br. (Orchid.)

usneoides, Lindl. 1. $\mathrm{c}_{2}=\mathrm{S}$. usneoides

CHILOSTIGMA, Hochst. in Flora, xxiv. (1841) $372=$ Aptosimum, Burch. (Scrophularin.) pumilum, Hochst. 1. c. = A. pumilum.

CHIMANTHUS, Rafin. Fl. Ludov. 26 (1817)= Prunus, Tourn. (Rosac.).

amygdalina, Rafin. 1. c. = P. caroliniana.

CHIMAPHILA, Pursh, Fl. Am. Sept. i. 279 (1814). ERICACEAE, Benth. \& Hook. f, ii. 603. ChIMAZA, R. Br, ex DC. Prod, vii. 775 (1839).

Pseva, Rafin. in Jonra. Phys. Sc. Ixxxix. (1819) 261 in obs.

astyla, Maxim. in Bull. Acad. Pétersb. xi. (1867) 434. -Japon.

corymbosa, Pursh, F1. Am. Sept. i. $\mathbf{3 0 0}=$ umbellata.

cymosa, J. \& C. Presl, Fl. Cech. $89=$ umbellata.

Durandi, Rafin. Atl. Fourn. 119.-Am. bor.

japonica, Miq.Ann. Mus. Bot. Lugd. Bat. ii. 165.Japon.

maculata, Pursh, Fl. Am. Sept. i. 300-Am. bor.

Menziesii, Spreng. Syst. ii. 317.-Am, bor. occ.

umbellata, Nutt. Gen. Am. i. 274.-Europ.; As. bor, ; Am. bor.

CHIMARHIS, Rafin. in Ann. Gén. Sc. Phys. vi. (1820) $84=$ seq.

CHIMARRHIS, Jacg. Stirp. Am. 61 (1763). RUBIA$C E A E$, Benth. \& Hook. f. 1i. 45.

cymosa, $7 a c g$. C.-Ins. Martinic.

Goudotii, Baill. Adansonia, xii. (1879) $307 .-\mathrm{N}$. Granat.

paraënsis, Baill. l. c. 308.-Bras.

turbinata, $D C$. Prod. iv. 404.-Guiana.

CHIMAZA, R. Br. ex DC. Prod. vii. 775 (1839)= Chimaphila, Pursh (Ericac.).

CHIMOCARPUS, Baill. Dict. i. $784(1879)=$ CHYMOCARPUS, D. Don= Tropaeolum, Linn. (Geraniac.).

CHIMONANTHUS, Lindl. Bot. Reg. sub t. 404 (1819); et t. 451 (1820). CALYCANTHACEAE, Benth. \& Hook. f. i. 16.

Meratia, Loisel. Herb. Gén. Amat. iii. t. 179 1819)

fragrans, Lindl. l. c.t. 451-Japon.

grandiflorus, Stend. Nom. ed. II. i. $350=$ fragrans.

iuteus, Hort. ex Bielawski, in Ann. Soc. Linn. Maine-

et-Loire, ix. (1867) $96=$ fragrans.

parviflorus, Rafin. Alsog. Am, $6=$ fragrans.

precex, Lindl. Bot. Reg, subt. $404=$ fragrans.

milacifolius, Steud. Nom, ed. II. i. 350 , sphalm.-

Myropyrum smilacifolium

verus, Hort, ex Bielawski, in Ann. Soc. Linn. Maineet-Loire, ix. (1867) 96 = fragrans.

CHIMOPHILA, Radius, Diss. Pyrol. 7, 83 (1821)= Chimaphila, Pursh (Ericac.).

CHINCHARRONIA, A. Rich. Fl. Cub. Fanerog. ii. $328(1853)=$ CHICHARRONIA, A. Rich. $=$ Ter minalia, Linn. (Combretac.).

CHINCHONA, Howard, in Rep. Bot. Congt. London, (1866) 221 = Cinchona, Linn. (Rubiac.).

CHIOCOCCA, P. Br, ex Linn. Syst. ed, X, 917 (1759). RUBIACEAE, lienth. \& Hook, f, ii. 105 . Siphonandra, Turcz. in Bull. Soc. Nat. Mose, xxi. (1848) I. 581 .

alternifolia, Linn. Syst. ed. XII. $165=$ Cestrum vespertinum.

\section{CHIOCOCCA}

anguifuga, Mart. Reise Bras. i. 306, 554; Mat. Med. Bras. 17. t. 5 = brachiata.

axillaris, Moç. ex DC. Prod. iv. 483 (= Margaris nudiflora).-Mexic.

barbata, Forst. f. Prod. 16.-Ins, Pacif

barbigera, D. Dietr. Syn. Pl. i. $777 \rightleftharpoons$ Symphoricarpos microphyllus.

brachiata, Ruiz E" Pav. Fl. Per. ii. 67.-Am. trop.

coriacea, Mart. E Gal. in Bull. Acad. Brux. xi. I. 1844) 231.--Mexic.

densifolia, Mart. Reise Bras. i. 544; Spec. Mat. Med.

Bras, 17. t. $6=$ brachiata.

floridana, Rafin. Alsog. Am. $75=$ racemosa

javanica, Blume, Bijdr. 968.--Java.

latifolia, Rafin. Alsog. Am. $75=$ racemosa.

macrocarpa, Mart. E Gal. in Bull. Acad. Brux. xi. I. 1844) 230.-Mexic.

malabarica, Dennst. Schluess. Hort. Malab. 37.-Ind or nitida, Benth. in Hook. Fourn. Bot. iii. (1841) 236.Guiana.

nocturna, Jacq. Enum. P1. Carib. 16:=Cestrum noc turnum.

nudiflora, D. Dietr. Syn. Pl. i. 777 (=Margaris nudiflora).-Mexic.

odorata, Hook. E Arn, Bot. Beech. Voy. 65.-Ins Societ.

opulina, Spreng. Syst. i. $756=$ Pavetta opulina.

paniculata, Hoffm. ex Roem. \& Schult. Syst. v. $202=$ brachiata.

paniculata, Linn. f. Suppl. 145= Psychotria paniculata parviflora, Humb. \& Bonpl, ex Roem. \& Schult. Syst. v. $202=$ brachiata

parvifolia, Wullschl. ex Griseb. F1. Brit. W. Ind. 337 $=$ racemosa.

phaenostemon, Schlecht. in Linnaea, ix. (1834) 594.Mexic.

pubescens, Humb. \& Bonpl. ex Roem. \& Schult. Syst. v. 202 = brachiata

racemosa, H. B. \& K. Nov. Gen. et Sp. iii. $352=$ brachiata.

racemosa, Linn. Syst. ed. X. 917 ; Facq. Select. Am 68.-Ind. oce.

racemosa, Schlecht. \& Cham. in Linnaea, v. (1830) 166 $=$ phaenostemon

sambucina, Spreng. Syst. i. $756=$ Pavetta sambucina

spicata, Blume, Bijdr. 958 = Xanthophytum spicatum

staminea, Mart. E' Gal. Bull. Acad. Brux. xi. I. (1844)

231.-Mexic

triflora, Spreng. Syst. i. $756=$ Payetta triflora.

trisperma, Hook. f. in Trans. Linn. Soc. xx. (1851) 219.-Ins. Galapag.

CHIOGENES, Salisb. in Trans. Hort. Soc. ii. (1817) 94. VACCINIACEAE, Benth. \& Hook. f. ii. 577 .

GLYCIPHYLla, Rafin. in Am. Monthly Mag. (1819) 192

LASIERPA, Torr. in Geol. Rep. N. York (1839), 152. Phalerocarpus, G. Don, Gen. Syst. iii.641 (1834) hispidula, Torr. \& Gray, ex Torr. Fl. N. York, 1. 450. $68=$ serpyllifolia

japonica, A. Gray, Syn. Fl. N. Am. ii. 1. 26.-Japon. serpyllifolia, Salisb. in Trans. Hort. Soc. ii. (1817) 94 -Am. bor.; Japon.

CHIONACHNE, R. Br. in Benn. Pl. Jav, Rar. 15 (1838). GRAMINEAE, Benth. \& Hook. f. iii. 1118 barbata, $R, B r$. l. c. 18,-Ind, or.

cyathopoda, F. Muell. ex Benth. Fl. Austral. vii. 516. -Austral.

Koenigii, Thw. Enum. Pl. Zeyl. 357 = barbatn

Wightii, Munro, ex Benth. E Hook. f. Gen. iii. 1113, nomen.--Ind. or.

CHIONANTHUS, Gaertn. Fruct. i. 189 , t. $39(1788)=$ Linociera, Sw. (Oleac.)

acuminata, Wall. ex DC. Prod, viii. $298=\mathrm{L}$. actminata. acuminigera, F. Muell. Fragm. viii. 42.-Austral. albidifora, Thw. Enum. Pl. Zeyl. $189=$ L. albidiflom. axillaris, $\mathrm{R}$. Br. Prod, $528=\mathrm{L}$, albidillora? axillaris, Roxb. ex Wall. Cat. sub n. $2824=$ I. macrophylla.

callophylla, Blume, Mus. Bot. Lugd. Bat. i. 919. Mralaya.

caribaea, Jacq. Coll. ii. $110=\mathrm{L}$. compacta.

compacta, Sw. Prod. Veg. Ind. Occ. 13 - L. compacta. cotinifolia, Willd. Sp, Yl. i. $47=\mathrm{L}$ cotinifolia.
CHIONANTHUS:-

courtallensis, Bedd. For. Man. Bot. $155=$ Linociera leprocarpa.

cuspidata, Blume, Mus. Bot. Lugd. Bat. i. 319.-Ins. Celebes.

densiflora, Zoll. \& Morr. in Nat. en Geneesk. Arch. Neêrl. Indie, ii. (1845) $4=\mathrm{L}$, densiflora.

dichotoma, Roxb. Hort. Beng. 8; Fl. Ind. i. 108= L. purpurea.

diversifolia, Miq. Fl. Ind. Bat. Suppl. 559.-Sumatra. domingensis, Lam. Tabl. Encyc. i. $30=$ L. latifolia.

effusiftora, F. Muell. Fragm. iv. $83=\mathrm{L}$. macrophylla.

elliptica, Blume, Mus. Bot. Lugd. Bat. i. 319.-Malaya.

Ghaeri, Gaertn. Fruct, i. $190=\mathrm{L}$ cotinifolia.

glomerata, Jlume, Mus, Bot. Lugd. Bat. i. 318.Sumatra.

guianensis, Pers. Syn. i. 9.-Guiana

incrassata, Sw. Prod. Veg. Ind. Occ. 13; Willd. Sp.

Pl. i. $47=\mathrm{L}$. tetrandra

insignis, Miq. F1. Ind. Bat. Suppl. $559=$ L. insignis,

intermedia, Bedd. Fl. Sylv. t. $239=$ L. intermedia.

laxiftora, Blume, Mus. Bot. Lugd. Bat. i. 319.-Bomeo.

leprocarpa, Thw. Enum. Pl. Zeyl. $189=$ L. leprocarpa

ligustrina, Pers. Syn. 1. $9=$ L. ligustrina.

littorea, Miq. Fl. Ind. Bat. Suppl. 559.-Sumatra.

Luronica, Blume, Mus, Bot. Lugd. Bat. i. 319

L. luzonica.

macrocarpa, Blume, $1_{0} \mathrm{c}_{\mathrm{o}}=\mathrm{L}$. insignis,

macrophylla, Blume, 1. c. 317 ; Kurz, in Journ. As. Soc.

Beng. xlv. (1876) II. $139=$ L. macrophylla.

malabarica, Heyne, ex Wall. Cat. sub n. $2828=$

L. malabarica.

Mayepea, Vahl, Symb. Bot. ii. $1=$ L. tetrandra.

minutiflorus, Kurz, For. Fl. Brit. Burna, ii. $159=$

L. minutiflora.

montana, Blume, Bijdr. $681=\mathrm{L}$. montana.

montana, Kurz, For. Fl. Brit. Burma, ii. $159=$

L. insignis.

monticola, Blume, Mus. Bot. Lugd. Bat. i. $317=$

L. montana.

palembanica, Miq. Fl. Ind. Bat. Sappl. $558=$ L. pauci

flora.

picrophloia, F. Muell. Fragm. iii, 139. t. $24=\mathrm{L}$. inter media.

pubescens, H. B. \& K. Nov. Gen. et Sp. iii. $235-$

N. Granat.

purpurea, Lam. Tabl. Encyc. i. $30=$ L. purpurea. quadristaminea, F. Muell. Fragn. viii. 41.-Austral. ramiflora, Roxb. Hort. Beng. 3; Fl. Ind. i. $107=$ L. macrophylla.

rostrata, Miq. F1. Ind. Bat, ii, $553=\mathrm{L}$, rostmata. rostrata, Thw. Enum. Pl. Zeyl. $189=$ L. albidiflora,

smilacifolia, Wall. in Roxb. Fl. Ind. ed. Carey, i. $108=$ Myxopyrum smilacifolium.

spicata, Blume, Mus. Bot. Lugd. Bat. i. 318.-Malays sumatrana, Blume, 1. c.-Sumatra.

tenuiflora, Wall. ex DC. Prod. viii. $298=$ L. macrophylla.

terniflora, Griff. Notul. iv, $740=$ L. temiflora. tetrandra, Vahl, Enum. i. $45=$ L. tetrandra. timorersis, Blume, Mus. Bot. Lugd. Bat. i. 31S.Timor.

zcylanica, Heyne, ex Wall. Cat. sub n. $2828=$ L. malabarica.

ceylanica, Lam. Tabl. Encyc i. $30=$ L. cotinifolia.

seylanica, Linn. Sp. P1. $8=$ L. parpurea.

CHIONANTHUS, Royen, ex Linn. Gen. ed. I. $\$ 3$ (1737). OLEACEAE. Benth. \& Hook. fo ii. 67-

chinensis, Maxim, in Bull. Acad, Petersb. xx (15;5) $430=$ retusa

angustifolia, Rafin. New Fl. Am. iii. $\$ 8=$ virginica. fraxinifolia, Kellogg, in Proc. Calif. Aad. $=$ Fraxinus dipetala

fragrans, Edwarks, ex Steud. Nom. ed. II. i. $\$ 51=$ virginico.

heterophyla, Rafin. New Fl. Am. iii. 87 = vinginica,

latifolia, Ait. ex Steud. Num. ed. II. \$. $950=$ virginic longifo!io, Katin. New Fl. Am. iii. 88 - virginica. maritima, Sweet. Hort. Brit. eł. II. $351=$ ringinica, montana, Ratin. New Fl. Am. ii. si = vimiaica.

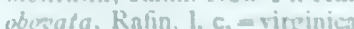

retusa, Part. Flens. Gard, jii. (1Sa2 53) 8s.-China.

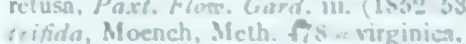

chlora, Stokes, Mor. Mat. Met. i. 19 virginica.

rernalis, Salish Prul. It $=$ virginica.

Eerna, Iknill. H list. I'l. i. 295 - virzinica.

virginica, Linn. Sp. Pl. \$.-Am. bor. 
CHIONE, DC. Prod. iv. 461 (1830). RUBIACEAE,

Benth. \& Hook. f. ii. 107.

Crusea, A. Rich. in Mém. Soc. Hist. Nat. Par. y.

(1830) 204. t. 19. f. 1

Sacconia, Endl. Gen. Pl. 541 (1838).

cubensis, A. Rich. Fl. Cub. Fanerog. ii. 22.-Ins. Cuba.

elliptica, Griseb. Pl. Wright. Cub. 507.--Ind. occ.

glabra, DC. Prod. iv. 461.-Ind. occ.

lucida, Griseb. Pl. Wright. Cub. 507.-Ind, occ.

myrtifolia, Griseb. l. c.-Ind. occ.

vaccinifolia, Griseb. Cat. Pl. Cub. $133=$ Erithalis vacciniifolia.

CHIONE, Salisb. Gen. Pl. Fragm. $100(1866)=$ Narcissus, Tourn. (Amaryllid.).

italica, Salisb. 1. $\mathrm{c}_{\mathrm{o}}=\mathrm{N}$. italicus.

papyracea, Salisb. 1. $\mathrm{c}_{\mathrm{s}}=\mathrm{N}$. papyraceus.

CHIONICE, Bunge, ex Ledeb. Fl. Ross. ii. $33(1844)=$ Potentilla, Tourn. (Rosac.)

dioica, Bunge, $1, c_{=}=\mathrm{P}$, tetrandra

CHIONODOXA, Boiss, Diagn. Ser. I. v. 61 (1844) LILIACEAE, Benth. \& Hook. f. iii. 813. cretica, Boiss. E Heldr. l. c. xiii. 24.-Ins. Creta. cretica, Jaub. \& Spach, Illustr. v. 46 t. $443=$ nana. Forbesii, Baker, in Journ. Linn. Soc. xi. (1871) $436=$ Luciliae.

Luciliae, Boiss. Diagn. Ser. i. v. 61.-As. Min

nana, Boiss. E Heldr, l. c. xiii. 24,--Ins. Creta.

CHIONOGRAPHIS, Maxim. in Bull. Acad. Pétersb. xi. (1867) 435. LILIACEAE, Benth. \& Hook, f. iii. 826 .

japonica, Maxim.l.c.436.-Japon.

CHIONOLAENA, DC. Prod. v. 397 (1836). COM-

POSITAE, Benth. \& Hook. f. ii. 302

arbuscula, $D C . l . c$ - Bras.

corymbosa, Hemsl. Diagn. Pl. Nov. 32.-Mexic

Glaziovii, Baker, in Mart. Fl. Bras. vî. III. 130.Bras.

glomerata, Baker, l. c.-Bras.

Isabellae, Baker, l. c.-Bras.

latifolia, Baker, 1. c. $132=$ Leucopholis latifolia

lavandulaceum, Hemsl. Biol. Centr. Am. Bot. ii. 134 $=$ seq.

lavandulifolium, Benth. E Hook. f. Gen. ii. 302.Mexic.

longifolia, Baker, in Mart. Fl. Bras. vi. III. 131.Bras.

lychnophorioides, Sch. Bip, in Pollichia, xx-xxi. 1863) 391.-Bras

phylicoides, Baker, in Mart. F1. Bras. vi. III. $131=$ Leucopholis phylicoides.

Wittigiana, Baker, l.c. 129.--Bras.

CHIONOPAPPUS, Benth. in Benth. \& Hook. f. Gen. ii. 485 (1873). COMPOSITAE, Benth. \& Hook. f 1. c.

CHIONOPHILA, Benth. in DC. Prod. x. 331 (1846) SCROPHULARINEAE, Benth. \& Hook. f. ii. 942. Jamesii, Benth. l. c.-Am. bor. occ.

CHIONOPHILA, Miers, ex Lindl. Veg. Kingd, 701 $(1847)=$ Boopis, Juss. (Calycer.)

CHIONOPTERA, DC. Prod. vii. 14 (1838). COMPOSITAE, Benth. \& Hook. f. ii. 495.

Gayophyta, $D C$. l. c.-Chili.

CHIONOTHRIX, Hook. f. in Benth. \& Hook, f Gen. iii. $33(1880)$. AMARANTACEAE, Benth. \& Hook. f. l. c.

somalensis, Hook. f. l. c.-Afr. trop.

CHIONOTRIA, Jack, in Malay. Misc. ii. (1822) vII. 53 = Glycosmis, Correa (Rutac.).

monogyna, Walp. Rep. i. $382=$ seq

rigida, Jack, in Malay. Misc. ii. (1822) vII. $54=\mathrm{G}$. pentaphylla.

CHIOPHILA, Rafin. Fl. Tellur. iii. $23(1836)=$ Gentiana, Linn.

nivalis, Rafin, 1. $c_{1}=\mathrm{G}$. nivalis.
CHIRANTHODENDRON, Cerv. ex Cav. in Anal. Cienc, Nat. vi. (1803) 303, adnot.= Cheirostemon, Humb. \& Bonpl. (Sterculiac).

californicum, Baill. Hist. Pl. iv. $70=$ Fremontia californica

pentadactylon, Larréat, Desc. Chiranth. ed. Lesc. $17=$ Cheirostemon platanoides.

CHIRATA, G. Don, Gen. Syst. iv, 659 (1837)= Chirita, Buch.-Ham.

CHIRA TIA, Montr. in Mém. Acad. Lyon, x. (1860) 202 = Sonneratia, Linn. f. (Lythrar.)

leucantha, Montr. 1. c. 203.-N. Caled.

CHIRITA, Buch.-Ham. in D. Don, Prod. Fl. Nep. 89 (1825). GESNERACEAE, Benth. \& Hook. f. i. 1022

Babactes, DC. Prod. ix. 260 (1845).

Calosacme, Wall. Cat. nn. 800 ad 806 (1829).

Chirata, G. Don, Gen. Syst. iv. 659 (1837).

Gonatostemon, Regel, Gartenfl. xv. (1866) 353.

Hypopteron, Hassk. Cat. Hort. Bog. Alt. i5 (1844).

Liebigia, Endl. Gen. 1407 (1841)

MorstdorfFia, Steud. Nom. ed. II, ii. 161 (1841)

TromsDorfFia, Blume, Bijdr. 762 (1826).

acuminata, R. Br. in Benn. Pl. Fav. Rar. 117.--Reg. Himal.

acuminata, A. DC. Prod. ix. 269=Didymocarpus acuminata.

amplectens, Steud. Nom. ed. II. i. $351=$ bifolia.

anachoretica, Hance, in Ann. Sc. Nat. Sér. V.v. (1866) 231.-China.

bifolia, D. Don, Prod. Fl. Nep. 90.-Reg. Himal.

Bilabium, C. B. Clarke, in A. DC. Monog. Phan. v. 127.-Sumatra.

Blumei, C. B. Clarke, l.c. 122.-Tava

bracteosa, Miq. Fl. Ind. Bat. ii. $728=$ Horsfieldii.

brevipes, C. B. Clarke, in A. DC. Monog. Phan. v. 120.-Ind. or.

caerulea, R. Br. in Benn. Pl. Fav. Rar. 117.Java.

caliginosa, C. B. Clarke, in A. DC. Monog: Phan. v. 122.-Malacca.

calva, C. B. Clarke, l. c. 116.--Reg. Himal.

Clarkei, Hook. f. Fl. Brit. Ind. iv. 359--Reg. Himal.

communis, Gardn. in Calc. Journ. Nat. Hist. iv. (1846) 481 = zeylanica.

cortusifolia, Hance, in Fourn. Bot. xxi. (1883) 324.China.

diaphana, Royle, Illustr. Bot. Himal. $294=$ pumila.

dimidiata, R. Br. in Benn. Pl. Fav. Rar. 117.-Reg. Himal.

eburnea, Hance, in Fourn. Bot. xxi. (1883) 168.China

Edgeworthii, A. DC. in Prod. ix. 269=pumila.

Fauriei, Franch. in Bull. Soc. Linn. Par. 1. (1885) 450.-China.

flava, R. Br. in Benn, Pl. Jav. Rar, $117=$ pumila.

fusca, C. B. Clarke, in A. DC. Monog. Phan. v. 129.Borneo.

glabra, C. B. Clarke, Comm. et Cyrt. Beng. t. $73=$ calva.

glabra, Miq. Fl. Ind. Bat. ii. 729.-Malaya.

grandiflora, Wall. Pl. As. Rar, i. $43=$ urticaefolia

Griffithii, Hook. f, \& Thoms. ex C. B. Clarke, in A. DC. Monog. Phan. v. $60=$ Loxostigma Griffithii. hamosa, R. Br. in Benn. Pl. Fav. Rar. 117.Ind. or.

Hookeri, C. B. Clarke, Comm. E Cyrt. Beng. t. 70.Reg. Himal.

Horsfieldii, R. Br. in Benn. Pl. fav. Rar. 117.Java.

Horsfieldii, De Vriese, Pl. Ind. Bat. Reinw. 11= Blumei.

humilis, Miq.Fl. Ind. Bat.ii. 729.-Sumatra.

insignis, C. B. Clarke, in A. DC. Monog. Phan. v. 121. -Assam.

Juliae, Hance, in Fourn. Bot. xxi. (1883) 168.China.

Kurzii, C. B. Clarke, in fourn. Linn. Soc. xv. (1876) 145.-Reg. Himal.

lachenensis, C. B. Clarke, in A. DC. Monog. Phan. v. 118.-Reg. Himal.

lilacina, Lem. Illustr. Hortic. (1869) t. 608.-Ind, or.

\section{CHIRITA :-}

macrophylla, Wall. Pl. As. Rar. i. 56. t. 72-Reg. Himal.

macrosiphon, Hance, in Ann.Sc. Nat. Sér. V. v. (1866) 231.-China.

mollis, Miq. Fl. Ind. Bat. ii. 728.-Sumatra.

monophylla, C. B. Clarke, in Hook. f. Fl. Brit. Ind. iv. 360.-Reg. Himal.

Moonii, Gardn. in Calc. Fourn. Nat. Hist. vi. (1846 479.-Zeylan.

obtusa, C. B. Clarke, in A. DC. Monog. Phan. v. 114. -China.

polycarpa, Steud. Nom. ed. II. i. 351.--Ind. or. polyneura, Miq. F1. Ind. Bat. ii. $728=$ Horsfieldii.

primulacea, C. B. Clarke, Comm. et Cyrt. Beng. t. 82 .

-Reg. Himal.

pumila, D. Don, Prod. Fl. Nep. 90.-Reg. Himal.

scaberrima, R. Br. in Benn. Pl. Fav. Rar. 117.Java.

scabra, Royle, ex C. B. Clarke, in A. DC. Monog. Phan. v. $113=$ bifolia

sinensis, Lindl. Bot. Reg. (1844) t. 59.-Hongkong.

speciosa, Kurz, in fourn. Bot. xi. (1873) 195.China.

spectabilis, Miq. Fl. Ind. Bat. Suppl. 564.-Sumatra.

ternifolia, Buch.-Ham. ex D. Don, Prod. Fl. Nep. 121 Lysionotus serrata.

urticaefolia, Buch.-Ham. ex D. Don, l. c. 90.-Reg. Himal.

vulgaris, Hort. ex Belg. Hortic. iii. (1853) t. [36].Cf. p. 238 = zeylanica.

Walkeri, Gardn. in Calc. Fourn. Nat. Hist. vi. (1846) 480. -Zeylan.

Walkeriae, Hook. Bot. Mag. t. $4327=$ Walkeri

zeylanica, Hook: $l$. c. t. 4182.-Zeylan.

Zollingeri, C. B. Clarke, in A. DC. Monog. Phan. v. 125. - Java.

CHIROCALYX, Meissn. in Hook. Lond. Journ. Bot. ii. (1843) $97=$ Erythrina, Linn. (Legumin.).

abyssinicus, Hochst. in Flora, xxix. (1846) $600=\mathrm{E}$. abyssinica.

Candolleanus, Walp. in FIora, xxxvi. (1853) $148=\mathrm{E}$, spathacea.

divaricatus, Walp. 1. c. $=$ E. divaricata

indicus, Walp. 1. c. = E. indica.

latifolius, Walp. I. c. $=\mathrm{E}$. senegalensis

mollissimus, Meissn. in Hook. Lond. Journ. Bot. ii. (1843) $98=\mathrm{E}$. tomentosa.

pictus, Walp, in Flora, xxxvi. (1853) $148=\mathrm{E}$. indica

pubescens, Walp. in Linnaea, xxiii. $(1850) 741=\mathrm{E}$. fissa.

rubrinervius, Walp. in Flora, xxxvi. (1853) $148=\mathbf{E}$. rubrinervis.

tomentosus, Hochst. in Flora, xxix. (1846) $600=\mathrm{E}$. tomentosa.

umbrosus, Walp. in Flora, xxxvi. (1853) $148=\mathrm{E}$. umbrosa.

velutinus, Walp. 1. $\mathrm{c}_{\text {. }}=\mathrm{E}$, velutina

CHIRONIA, Linn, Coroll. Gen.5 (1737). GENTIANEAE, Benth. \& Hook. f. ii. 805 .

Eu podia, Rafin. Fl. Tellur. iii. 29 (1836).

Evalthe, Rafin. 1. c. 77 (1836).

ONEFERA, Rafin. $l_{0}$ c. 30 (1836)

Plocandra, E. Mey. Comm. Pl. Afr. Austr. 181 (1837).

Roeslinia, Moench, Meth. Suppl. 211 (1802)

Roslinia, G. Don, Gen. Syst. iv. 203 (1837).

amoena, Rafin. in Med. Repos. N. York, v. (1808) $359=$ Sabbatia gracilis ?

amoena, Salisb. Prod, $137=$ linoides.

angularis, Linn. Sp. Pl, $190=$ Sabbatia angularis. angustifolia, Sims, Bot. Mag. t. $818=$ frutescens.

arenaria, E. Mey. Comm. Pl. Afr. Austr. ii. 180.-Afr. austr.

baccata, Hoffmgg. Verz. Pf. Nachtr. i. $211=$ seq. ?

baccifera, Linn. Sp. Pl. 190.-Afr. austr.

baccifera, Zeyb. ex Griseb. in DC. Prod. ix. $41=$ linoides.

Barclayana, Hort. Berol. ex Griseb. Gen. et Sp. Gent. $100=$ peduncularis.

brachiata, Willd. ex Griseb. 1. c. $145=$ Erythraea Roxburghii.

calycosa, Michx. F1. Bor. Am. i. $147=$ Sabbatia calycosa.

campanulata, Linn. Sp. Pl. $190=$ Sabbatia gracilis ? 


\section{CHIRONIA :-}

capsularis, Blanco, FI. Filip.ed. I. $102=$ Ipomoea peltata. caryophylloides, Linn. Cent. ii. 12; Amoen. Acad. iv $308=$ frutescens.

Centaurium, Schmidt, Fl. Bohem. ii. 31=Erythraea Centaurium.

centauroides, Roxb. Hort. Beng. 16; F1. Ind. i. $584=$ Erythraea Roxburghii.

chilensis, Willd. Sp. P1. i. $1067=$ Erythraea chilensis.

chloroides, Michx. Fl. Bor. Am. i. 147 = Sabbatia chloroides.

cymosa, Burm.f. Fl. Cap. Prod. 5.-Afr. austr.

cymosa, Lam. Encyc. i. $479=$ Sabbatia lanceolata.

decandra, Walt. Fl. Carol. 95 = Sabbatia chloroides.

decussata, Vent. Jard. Cels, $31=$ frutescens.

dichotoma, Walt. Fl. Carol. $95=$ Sabbatia calycosa.

dodecandra, Linn. Sp. Pl. $190=$ Sabbatia chloroides

dubia, Willd. ex Griseb. Gen. et Sp. Gent. $146=$

Erythraea Muehlenbergii.

emarginata, Jarosz, PI. Nov, Cap. 11=lychnoides.

Erythraea, Schousb. Vextr. Marok. $95=$ Erythraea ramosissima.

exigua, Oliver, in Hook. Ic. Pl. to 1229.-Afr. austr.

filiformis, Desf. Tabl. ed. I. 77 , nomen= Microcala filiformis.

Fischeri, Hort. ex Paxt. Mag. Bot. xi. (1844) $237=$ floribunda.

floribunda, Paxt. l. c. 223,-Afr. austr.

frutescens, Linn. Sp. Pl. 190 ; Berg. Desc. Pl. Cap. 45 -Afr, austr.

Gerardi, Schmidt, F1. Bohem. ii. $33=$ Erythraea pulchella.

glutinosa, Paxt. Mag..Bot.xv. (1849) 245,-Austral. ? gracilis, Michx. Fl. Bor. Am. i. $146=$ Sabbatia gracilis. grandiflora, Salisb. Prod, $137=$ frutescens.

helodea, St. Lag. in Ann. Soc. Bot. Lyon, vii. (1880

$125=$ Erythraea elodes

inaperta, Willd. Sp. Pl. i. 1069 = Erythraea ramosisisima.

intermedia, Mérat, E1. Paris, $91=$ Erythraea ramo sissima.

jasminoides, [Ker-Gawl. in] Bot. Reg. t. $197=$ tetragona.

jasminoides, Lam. Illustr. i. 479. t. 108. f. $2=$ nudicaulis.

jasminoides, Linn: Pl. Rar. Afro. 9. (Amoen。 Acad. vi 84). - Afr austr.

Krebsii, Griseb. Gen. et Sp. Gent. 98.-Afr. austr.

lanceolata, Walt. Fl. Carol. $95=$ Sabbatia lanceolata.

lanosanthera, Blanco, Fl. Filip. ed. II. $71=$ Ipomoe peltata.

latifolia, E. Mey. Comm. Pl. Afr. Austr. ii. 178.Afr. austr.

linarifolia, Loisel. Notes, $155=$ Erythraea linarifolia.

linearifolia, Steud. Nom. ed. II. i. 352 , in syn. sphalm.

$=$ praec.
linifolia,
Stend. 1, c. $351=$ Erythraea linarifolia.

linifolia, Stend. 1, c, $351=$ Erythraea lin
linoides, Linn. Sp. Pl. 189. -Afr.. austr.

littoralis, Tum. in Turn. \& Dillw. Bot: Guide, ii. 469 $=$ Erythraea linarifolia.

lutea, Bertol. Rar. It. Pl. dec. ii. $32=$ Erythraea maritima.

lychnoides, Berg. Desc. Pl. Cap. 45.-Afr. austr.

madagascariensis, Baker, in fourn. Linn. Socn xviii. (1881) 273.-Madag.

maritima, Eckl. in So Afr. Quart. Fourn. ii. (1830); ex Griseb. Gen, et Sp. Gent. 100.-Afr. austr.

maritima, Georgi, Beschr. Russ, Reich. iii. IV. 791 =Erythraea ramosissima.

maritima, Willd. Sp. Pl. i. $1069=$ Erythraea maritima melampyrifolia, Lam. Illustr. ii. 479.-Afr, austr. minima, Thuill, Fl. Par, ii. 116 = Cicendia pusilla. minor, Desf. Cat. Hort. Par. ed. III, $126=$ Erythraea ramosissima.

nana, Bast. ex Griseb. in DC. Prod. ix. $57=$ Erythraea ramosissima.

nadicaulis, Linn. f. Suppl. 151.-Afr. austr.

nummularifolia, Willd, ex Griseb. Gen. et Sp. Gent. $144=$ Erythraea diffusa.

occidentalis, DC. Fl. Fr. Suppl. $2782=$ Erythraea maritima.

orthostylis, Reichb. Exot. t. $245=$ fratescens.

ovata, Spreng. ex Griseb. in DC. Prod. ix. $41=$ serpyllifolia.

palustris, Burch. Trav. ii. (1821) 220.-Afr. austr.

paniculata, Michx. Fl. Bor. Am. i. $146=$ Sabbatia paniculata.

parviflora, Salisb. Prod. 136 = baccifera.

\section{CHIRONIA :}

parvifolia, E. Mey. Comm: Pl. Afr. Austr. 180,-Afr. austr.

peduncularis, Lindl. Bot. Reg.t. 1803.-Afr. anstr.

perfoliata, Eckl. in S. Afr. Quart. Fourn. ii. (1830), ex Griseb. Gen. et Sp. Gent.104.-Afr. austr. perfoliata, Salisb. Prod. $137=$ Chlora perfoliata pubescens, Baker, in Fourn. Bot. xx. (1882) 172. Madag.

pulchella, Willd. Sp.Pl. i. $1067=$ Erythraea ramosissima pusilla, Steud. Nom. ed. II. i. $351=$ Microcala filiformis.

ramosissima, Ehrh. ex Griseb. Gen. et Sp. Gent: $137=$ Erythraea ramosissima.

scabrida, Griseb. l. c. 103.-Afr. anstr.

scabriuscula, Willd. ex Griseb. 1. c. $143=$ Erythraea linarifolia

serpyllifolia, Lehm. Ind. Sem. Hort. Hamb. (1828).Afr. austr.

speciosa, E. Mey. Comm. Pl. Afr. Austr. 178.-Afr. austr.

spicata, Willd. Sp. Pl. i. $1069=$ Erythraea spicata.

stellata, Mubl. Cat. ex A. Gray, Syn. Fl. N. Am. ii. $115=$ Sabbatia stellaris

suffruticosa, Salzm. ex Griseb. Gen. et Sp. Gent. 141 = Erythraea Centaurinm.

tabularis, Page, ex Steud. Noma: ed. II. is 352,-Afr. austr.

tenuiflora, Link, ex Steud. l. c.-Hab. ?

tetragona, Linn.f. Suppl. 151.-Afr. austr.

trinervia, Linn. Sp. Pl. $189=$ Exacum zeylanicum.

trinervis, Hort. ex Loud. Encyc. Pl, Suppl. ii. $1306=$ = peduncularis.

uliginosa, Lapeyr. Hist. Abr. Pl. Pyr. Suppl. $39=$ Erythraea elodes.

uliginosa, Waldst. \& Kit. P1. Rar, Hung. iii. 287. t. 259 = Erythraea linarifolia

uniflora, Eckl. ex Griseb. in DC. Prod. ix. $41=$ linoides.

uniflora, Lam. Encyc. i. 737.-Afr. austr.

Vaillantii, F. W. Schmidt, Fl. Bohem. ii. $34=$ Erythraea ramosissima.

virescens, Willd, ex Steud. Nom. ed. II. i. $352=$ Erythraea maritima.

viscosa, Zeyher, ex Griseb. Gen. et Sp. Gent. $105=$ tetragona.

vulgaris, Cham. in Linnaea, vi. (1831) $343=$ linoides, lychnoides, melampyrifolia.

CHiropetalum, A. Juss, in Ann. Sc. Nat. Sér. I. xxv. (1832) 21 =Argithamnia, Sw. (Euphorbiac.) Berterianum, Schlecht. in Linnaea, xxvi. (1853-55) $687=\mathrm{A}$. Berteroana.

canescens, Phil, Fl. Atac. $49=\mathrm{A}$. canescens

griseum, Griseb in Goett. Abh. xxiץ. (1879) 57.-Reg. Argent.

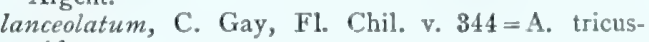
pidata.

lanceolatum, A. Juss. in Ann. Sc. Nat. Sér. I. xxv. (1832) $21=$ A. Berteroana

lineatum, Klotzsch, in Wiegm. Archiv, vii. (1841) 199 $=\mathrm{A}$. lineata.

molle, Klotzsch, 1. c. $=$ A. mollis.

ovatum, Phil. in Linnaea, xxix. (1857-58) 42=A tricuspidata.

peruvianum, A. Juss, in Ann. Sc, Nat. Sér. I. xxy. (1832) $2 \mathrm{z}=\mathrm{A}$. quinquecuspidata.

triandrum, Griseb, in Goett. Abh. xxiv, (1879) 56, Reg. Argent.

tricuspidatum, A. Juss. in Ann. Sc. Nat. Sér. I. xxy. (1832) $22^{\circ}=$ A. tricuspidata.

ChirostemuM, Cerv. in Anal. Cienc. Nat. vi. (1809) $\$ 03=$ Cheirostemon, Humb. \& Bonpl. (Sterculiac.)

CHISOCHETON, Blume, Bijdr. 168 (1825). MELIA $C E A E$, Benth. \& Hook, f. i. 399.

Schizochiton, Spreng. Syst. iv. Cur. Post. 25 (1827).

amabilis, Mig. in Ann. Mus. Bot. Lugd. Bat.iv. 27.As. or.

barbatus, C. DC. in A. DC. Monog. Phan. i. 586.As. or.

canalensis, Baill. Adansonia, xi. (1873-76) $260=$ Dysoxylum camalease.

ceramicus, Miq. in Ann. Mus. Bot. Lugd. Bat. ix. 29. -Ins. Ceram.

\section{CHISOCHETON}

costatus, Hierm in Hook of Fl. Brit. Ind i 552.-

Ind. or.

divergens, Blume, Bijdr. 169.-Java.

diversifolius, Miq. Fl. Ind. Bat. Suppl. i. 504.Sumatra.

dysoxylifolius, Kurz, in Fourn. As. Soc. Beng. xl.

(1871) 11. 49.-Burma.

erythrocarpus, Hiern, in Hook. f. Fl. Brit. Ind. i. 550 - Malacca.

fragrans, Hiern, l. c. 551.-Malacca.

glomeratus, Hiern, $l$. c.-Ins. Penang.

grandiflorus, Kurz, in Fourn. As. Soc. xli. (1872) I1.

296.-Burma.

holocalyx, Hiern, in Hook. f. Fl. Brit. Ind. i. 551.-

Malaya.

Junghubni, Miq. in Ann. Mus. Bot Lugd. Bat. iv. 30 -As. or.

paniculatus, Hiern, in Hook. f. Fl. Brit. Ind. i. 552 .Ind, or. : Burma.

patens, Blume, Bijdr. 169,-Java.

paucijugum, Miq. Ann. Mus. Bot. Lugd. Bat. iv. 30Sumatra.

penduliflorus, Planch. ex Hiern, in Hook: $f$. Fl. Brit Ind. i. 550.-Malaya.

spectabilis, Miq. Ann. Mus. Bot. Lugd. Bat. iv. 28 -As. or.

spicatus, Hiern, in Hook. f. Fl. Brit. Ind. i. 550,Malacca.

tetrapetalus, Turcz. in Bull. Soc. Nat. Mosc. (1858) I. 411. - Java.

Vrieseanus, C. DC. in A.DC. Monog. Phan. i. 532 .As. or.

CHITHONANTHUS, Lehm. in Ind. Sem. Hort. Ham. burg. (1842) 4; et Pl. Preiss. ii. 368 (1847 Acacia, Willd. (Legumin.

restiaceus, Lehm. Il. $\mathrm{cc} .=\mathrm{A}$, restiacea.

CHIToniA, D. Don, in Mem. Wem. Soc. iv. (1823 $317=$ Miconia, Ruiz \& Pav. (Melastomac.).

albicans, D. Don, ex Naud. in Ann. Sc. Nat. Sér. III. Xv. (1851) $339=$ Tetrazygia albicans.

aurea, D. Don, in Mem. Wem. Soc iv. (1823) $319=$ M. aurea

bubalina, D. Don, 1. c. = M, bubalina.

caudata, D. Don, 1. c. $=$ M. Donaeana.

Fothergilla, 1). Don, 1. c. $318=\mathrm{M}$. Fothergilla macrophylla, D. Don, 1. c. $319=$ M. macrophylla.

pyramidalis, G. Don, in Lond. Hort. Brit. $174=\mathrm{M}$. laevigata.

rubiginosa, Stead. Nom. ed. II. i. $352=$ M. Fothergilla.

Tamonia, G. Don, in Loud. Hort، Brit. $174=M$ Fothergilla.

CHITONIA, Moç. \& Sesse, ex DC. Prod. i. ît (1824). ZYGOPHYLLEAE, Benth. \& Hook. I. 268.

mexicana, Moc. E Sesse, l.c.-Mexic

CHITONIA, Salisb. Gen. Pl. Fragm. 51 (1860") Zygadenus, Michx. (Liliac.).

CHIZOCHETON, A. Juss, in Orb. Diet. Se, viii. So $(1849)=$ Chisocheton, Blume (Melisc.)

CHLAENANDRA, Miq. Ann. Mus, Bok Lugd. Bar. iv. $83(1868-09)$. MENISPER.MACE.AE ovata, Mig.l. c. $84 .-\mathrm{N}$. Guinen!

CHLAENOBOJ.US, Cass in Dict. Se Nat. xlix. S3: (1827) $=$ Pterocaulon, Ell. (Compos.) alopecuroides, Cass. 1. c. $399=\mathrm{P}$. virgatum, pycrostachyus, Crss, 1. c. $\$ 38=\mathrm{P}$. pycnostachrum. rugasus, Cass. 1. c. $341=$ ?'. virgmenm. spicatus, Cass. li, $c_{2}=\mathbf{P}$, virgatom. virgatus, Cass. L. c. $340=\mathrm{P}$. vingatum.

CHLAMYDANTHLS, C. A. Mey, in Bull. Phys.-Math, Acad. l'ctersb. j. (1843) $955,858-T h y m e l$ sea. Findl.

argenteus, C. A Ney, l. c $858-$ T. Tartonaira. raneserns, C. A. Mey. I. C. $=$ T. canescens ellipticus, C. A. Mcy. I. c. $35:-$ T. ellyptica. hirswiss, Griseb. Spicil. Fl. Kumcl. ii. 34 l'asserine hirsuta. 


\section{CHLAMYDANTHUS:}

nitidus, C. A. Mey。 in Bull. Phys,-Math. Acad.

Pétersb. i. (1843) $358=$ Thymelaea nitida.

Tartonraira, C. A. Mey. 1. c. = T. Tartonraira

thesioides, C. A. Mey. 1. c. 359=T. thesioides

Thymelaea, C. A. Mey. 1. $\mathrm{c}_{\mathrm{s}}=$ T. Sanamunda.

tinctorius, C. A. Mey. 1. c. $358=$ T. tinctoria.

villosus, C. A. Mey. 1. c. $=$ T. villosa

virgatus, C. A. Mey. 1. c. $359=$ T. virgata.

CHLAMYDIA, Banks, ex Gaertn. Fruct. i. 71. t. 18 $(1$ 158) $=$ Phormium, Forst. (Liliac.).

tenacissima, Gaertn. 1. $\mathrm{c}_{\mathrm{o}}=\mathbf{P}$. tenax.

\section{CHLAMYDOCARYA, Baill. Adansonia, $\mathrm{x}$} 276. OLACINEAE

capitata, Baill. l. c. 277.-Afr, trop.

Thomsoniana, Baill.l. co 276.-Afr, trop.

CHLAMYDOPHORA, Ehrenb. ex Less. Syn. Comp. 265 $448(1832)=$ Cotula, Linn. (Compos.)

pubescens, Coss. \& Dur. in Bull. Soc. Bot. Fr. iv. (1857) $279=$ Cot. pubescens.

tridentata, Ehrenb. ex Less. Syn. Comp. 266= Cot. tridentata.

CHLAMYdosperma, A. Rich. Ess. F1. Cub. 631 $(1845)=$ Stegnosperma, Benth. (Phytolacc.).

CHLAMYDOSTYLUS, Baker, in Journ. Bot. xiv. (1876) $185=$ Nemastylis, Nutt. (Irid.).

bracteolatus, Baker, in Journ. Linn. Soc. xvi. (1877) 107.-Boliv.

cernuus, Baker, in Journ. Bot. xiv. (1876) $186=\mathrm{N}$ triflora.

Medusa, Baker, l. c.-Bras.

multiflorus, Baker, 1, e $=\mathrm{N}$. multiflora.

spathaceus, Griseb, in Goett. Abh. xxiv. (1879) $324=$ N. spathacea.

tenuis, Baker, in Journ. Bot. xiv. (1876) $185=\mathrm{N}$ tentiis.

triflorus, Baker, in Journ. Linn. Soc. xvi. (1877) $107=$ N. triflora.

CHLAMYSPERMA, Less. Syn. Comp. $256(1832)=$ Villanova, Lag. (Compos).

arenaroides, Hook. \& Arn. Bot. Beech. Voy, 300, t. 64 $=\mathrm{V}$. pratensis.

polygama, Triana, in Ann. Sc. Nat. Sér. IV. ix. (1858) $40 .-\mathrm{N}$. Granat

pratense, Less. Syn. Comp. $256=$ V. pratensis.

CHLAMYSPORUM, Salisb. Parad. Lond. t. 103 (1808) = Thysanotus, R. Br. (1810) (Liliac.).

dichotomum, Salisb. 1. c. in nota sub t. $103=$ T. dichotomus.

hispidulum, Salisb. ex Steud. Nom. ed. II. i. $352=$ T. hispidulus.

juncifolium, Salisb. Parad. Lond. t. $103=$ T. junceus.

multiflorum, Salisb. ex Steud. Nom. ed, II. i. 352=T multiflorus.

pauciflorum, Salisb. ex Steud. 1. c. $=$ T. pauciflorus.

triandrum, Salisb. ex Steud. 1. $c_{.}=$T, triandrus.

CHLANIS, Klotzsch, in Peters, Reise Mossamb. Bot. $144(1861)=$ Oncoba, Forsk. (Bixin. $)$

macrophylla, Klotzsch, I. c. $145=$ O. macrophylla

tettensis, Klotzsch, 1. c. $=\mathrm{O}$. tettensis.

CHLAOTRACHELUS, Hook. f. Fl. Brit. Ind. iii. 234 1881), sphalm $=$ CLAOTRACHELUS, Zoll Vernonia, Schreb. (Compos.).

CHLETERUS, Rafin. Princ. Somiol. 25 (1814)=Boea, Comm. (Gesnerac.).

CHLIDANTHUS, Herb.App. 46 (1821). AMARYLLIDEAE, Benth. \& Hook. f. iii. 723

Coleophyllum, Klotzsch, in Otto \& Dietr. Allg. Gartenz, viii. (1840) 185.

Cumingii, Presl, Bot. Bemerk. $115=$ Hippeastrum advenum.

Ehrenbergii, Kunth, Enum. Pl. v. 654.-Mexic.

fragxans, Herb. App. 46.-Peruv.

luteus, D. Dietr. Syn. Pl. ii. $1175=$ Stenomesson luteum.

CHLOAMNIA, Rafin. Neogenyt. 4 (1825)=Festuca, Tourn, (Gramin.).
CHLOANTHES, R. Br. Prod. 513 (1810), VERBENACEAE, Benth. \& Hook, f. ii. 1140.

Hemistemon, F. Muell. Fragm. x. $73(1876)$

atriplicina, F. Muell. Fragm. i. $235=$ Pityrodia atriplicina.

Bartlingii, Lehm. Ind. Sem. Hort. Hamb. (1844), ex Bartl. in Lehm. Pl. Preiss. i. $352=$ Pityrodia Bartlingii.

Bonneyana, F. Muell. Fragm.x. 73.-Austral.

bullata, F. Muell. 1. c. vi. $156=$ Pityrodia nncinata

coccinea, Bartl. in Lehm. Pl. Preiss. i. 352.-Austral.

cuneata, F. Muell. Census, $103=$ Pityrodia cuneata.

dilatata, F. Muell. Fragm. vi. $157=$ Pityrodia dilatata.

Elderi, F. Muell. 1. c. x. 13=Hemiphora Elderi.

glandulosa, R. Br. Prod. 514.-Austral.

halganiacea, F. Muell. Fragm. x. 14.-Anstral.

hemigenioides, F. Muell. 1. c. vi. $156=$ Pityrodia hemigenioides.

lavandulaefolia, Sieber, ex Spreng. Syst. ii. $756=$ Stoechadis.

lepidota, F. Muell. in Wing, South. Sc. Record, iii. (1883) 3.-Austral.

Lewellini, F. Muell. Fragm. viii. 50.-Austral.

loricata, F. Muell. l. c. x. 14.-Austral.

loxocarpa, F. Muell. 1. c. ii. $22=$ Pityrodia Drummondii.

Oldfieldii, F. Muell, 1. c, i, $234=$ Pityrodia Oldfieldii.

paniculata, F. Muell, 1. c. iv. $80=$ Pityrodia paniculata.

parviflora, Walp. Rep. iv. 58.-Austral.

rosmarinifolia, A.Cunn. ex Steud. Nom. ed. II. i. 352. -Austral.

salvifolia, F. Muell. Census, $103=$ Pityrodia salvifolia, stachyodes, F. Muell. Fragm. v. 50 ; vi. $158=$ Pityrodia racemosa.

Stoechadis, $R$. Br. Prod. 514.-Austral

uncinata, Turcz. in Bull. Soc. Nat. Mosc. xxxvi. (1863) II. $194=$ Pityrodia uncinata.

verbascina, F. Muell. Fragm. i. $233=$ Pityrodia verbascina.

CHLOERUM, Willd. ex Spreng. Jabrb. i. III. 74 (1833) =Abolboda, Humb. \& Bonpl. (Xyrid.).

gramineum, Willd. ex Kunth, Enum. PL iv. $27=$ A. Poeppigii.

imberbe, Willd. ex Steud. Nom. ed. II. i. $352=$ A. imberbis.

CHLOIDIA, Lindl. Gen. et Sp. Orch. $484(1840)=$ Corymbis, Thou. (Orchid.).

decumbens, Lindl. 1. c.-Bras.

flava, Reichb, f. in Walp. Ann. vi. $644=$ Cor. flava polystachya, Reichb. f. l. c. = vernalis.

vernalis, Lindl. Gen. et Sp. Orch. 484.-Jamaica.

CHLONANTHES, Rafin. New Fl. Am, ii. $20(1836)=$ Chelone, Linn. (Scrophul.).

tomentosa, Rafin. 1. e.-Am. bor.

CHLONANTHUS, Rafin. Princ. Somiol. $26(1814)=$ praec.

CHLOOPSIS, Blnme, Enum. Pl. Jav. $14(1827)=$ Ophiopogon, Ker-Gawl. (Haemodorac.). acautis, Blume, l. c. =O. japonicus. caulescens, Blume, $1 . \mathrm{c}_{\mathrm{s}}=\mathrm{O}$. japonicus.

CHLoOTHAmnus, Buese, in Miq. PI. Jungh. 386 (1851-55) = Schizostachyum, Nees (Gramin.). chilianthus, Buese, 1. c. 387.-Sumatra.

CHLORA, Ren. ex Adans, Fam, ii. 503 (1763) GENTIANEAE, Benth. \& Hook. f. ii. 809

BLACKstonia, Huds. Fl. Angl. ed. I. 146 (1762), nomen prius.

Chlorostis, Rafin. Princ. Somiol. 26 (1814)

DISINSTYLis, Rafin. Fl. Tellur. iii. 31 (1836)

PLeUrimaria, Rafin. l. c. (1836).

acuminata, Koch \& Ziz, Cat. Fl. Palat. $20=$ serotina affinis, Willk. in Bot. Zeit. v. (1847) $874=$ imperfoliata. citrina, Boiss. E Reut. Pugill. Pl. Nov. 77.-Hispan. crenulata, Salzm. ex Griseb. Gen. et Sp. Gent. $118=$ imperfoliata.

dodecandra, Linn. Syst. ed. XII. $267=$ Sabbatia chloroides.

dubia, Lam. Tabl. Encyc. ii. $434=$ imperfoliata.

exaltata, Griseb. Gen. et Sp. Gent. $118=$ Eustoma silenifolium.

grandiflora, Viv. Cors. App. Alt. 4=perfoliata.

\section{CHLORA:-}

hybrida, Tratt. Arch t. 229 -Europ.

imperfoliata, Linn.f. Suppl. 218.-Europ.

intermedia, Tenore, Syll. $565=$ perfoliata.

lanceolata, Koch \& Ziz, Cat. Pl. Palat. $20=$ imperfoliata.

longifolia, Lam. Tabl. Encyc. ii. 434.-Hab?

mascariensis, Desf. ex Steud. Nom. ed. I. 190 ; ed. II. i $352=$ perfoliata

perfoliata, Gorter, ex Steud. Nom. ed. II. i. $352=$ Saponaria Vaccaria.

perfoliata, Linn. Syst. ed. XII. 267.-Europ.; As. Min quadrifolia, Linn. l. c.-Europ. austr.

quadrifoliata, F. W. Schmidt, in Roem. Arch. i. I. 13 =quadrifolia.

serotina, Koch, in Reichb. Pl. Crit. iii. 6. t 351.Europ.; As. Min.

sessilifolia, Desv. in Trav. Soc. Amat. i. (1807) 74, t. 3. f. 2 =imperfoliata

sessilis, Willd. Sp. Pl. ii. 341 (= Plantaginea?),-Reg. Argent.

sicula, Tineo, in Guss. Fl. Sic. Syn. ii, $819=$ perfoliata triphylla, Badaro, in Brugnat. Giorn. Fis. II. ix. (1826) 166.-Italia.

CHIORADENIA, Baill. Etud. Gén. Euph. 471, t 19 (1858). EUPHORBIACEAE, Benth. \& Hook. f iii. 312 .

Adenogynum, Zoll. in Linnaea, xxviii. (1856) 325. discolor, Baill. l. c. 472.-Java.

CHLORAFA, Lindl. in Brand. Quart. Journ. Roy. Instit. N. S. 1. (1827) 47. ORCHIDEAE, Benth. \& Hook. f. iii. 618 .

AsARCA, Lindl. in Quart. Journ. Roy. Instit. i. (1827) 52

BIENERIA, Reichb. f. in Bot. Zeit. xi. (1853) 3. t. 1. Gavillea, Poepp. \& Endl. ex Steud. Nom, ed. II. i. $666(1840)$.

Ulantha, Hook. Bot. Mag. 1vii. sub t. 2990 (1830).

affinis, Lindl. in Hook. Fourn. Bot. i. (1834) 4.-Chili. alaris, Lindl. in Brand. Quart. Fourn. Roy. Instit. N. S. i. (1827) 50.-Chili.

alpina, Poepp. Fragm. Syn. Pl. Chil. 17.-Chili.

aurantiaca, Lindl. Gen. et Sp. Orch. 403.-Chili.

aurea, Phil. in Linnaea, xxix. (1857-58) 48.-Chili

Austinae, A. Gray, in Proc. Am. Acad. xii. (1877) 83 = Cephalanthera Oregana.

barbata, Lindl. in Hook. Fourn. Bot. i. (1834) 5.Chili.

Pesseri, Reichb. f. in Linnaea, xxii. (1849) 862.Chili.

biserialis, Griseb. in Goett. Abh. xxiv. (1879) 339.Reg. Argent.

Bergii, Hieron. in Bol. Acad. Nac. Cordova, iii. (1879) 380-Reg. Argent.

bletioides, Lindl. in Brand. Quart. Journ. Roy. Instit. N.S. i. (1827) $50=$ ulanthoides.

calopogon, Phil. in Linnaea, xxix. (1857-58) 47.Chili.

campestris, Poepp. Fragm. Syn. Pl. Chil. 15.-Chili.

chlorosticta, Phil. in Linnaea, xxix. (1857-58) 52.Chili.

chrysantha, Poepp. Fragm. Syn. Pl. Chil. 15.-Chili.

chrysochlora, Phil. in Linnaea, xxix. (1857-58) 50.Chili.

collina, Phil. l. c. 54.-Chili.

Commersonii, Brongn. in Duperr. Voy. Bot. 189.Reg. Magell.

crispa, Lindl. Gen. et Sp. Orch. 401.-Chili.

cristata, Lindl. in Hook. Fourn. Bot. i. (1834) 4.Chili.

crocata, Phil. in Linnaea, xxix. (1857-58) 51:-Chili.

cuneata, Lindl. Gen. et Sp. Orch. 400,-Chili.

cygnaea, Phil. in Linnaea, xxxiii. (1864-65) 241.Chili.

cylindrostachya, Poepp. Fragm. Syn. Pl. Chil. 15.Chili.

dasypogon, Phil. in Linnaea, xxxiii. (1864-65) 243.Chili.

decipiens, Poepp. Fragm. Syn. Pl. Chil. $17=$ cristata, multiflora, Poeppigiana.

densa, A. Rich. in C. Gay, Fl. Chil. v. 454.-Chili.

disoides, Lindl. in Brand. Quart. Fourn. Roy. Instit

N. S. i. (1827) 47 .-Chili.

fimbriata, Phil. in Linnaea, xxix. (1857-58) 49. Chili. 


\section{CHIORAFA:}

fimbriata, Poepp. Fragm. Syn. Pl. Chil. 15=Bipinnula mystacina.

Fonkii, Phil. in Linnaea, xxix. (1857-58) 55.-Chili. galeata, Lindl. in Brand. Quart. Fourn. Roy. Instit. N. S. i. (1827) 48.-Chili.

Gaudichaudii, Brongn. in Duperr. Voy. Bot. 189.Reg. Magell.

Gavilu, Lindl. in Brand. Quart. Fourn. Roy. Instit N. S. i. (1827) 48.-Chili.

Gayana, A. Rich. in C. Gay, Fl. Chil. v. 439.Chili.

grandiflora, Poepp. Fragm. Syn. Pl. Chil. 14.-Chili. gymnoglossa, Phil. in Linnaea, xxix. (1857-58) 54. Chili.

heteroglossa, Reichb. f.l. c. xxii. (1849) 863.-Chili.

homopetala, Phil. l. c. xxix. (1857-58) 48.-Chili

incisa, Poepp. Fragm. Syn. Pl. Chil. 17.-Chili.

inconspicua, Phil. in Anal. Univ. Chil. (1865) II. 321. -Chili.

lamellata, Lindl. in Brand. Quart. Fourn. Roy. Instit. N. S. i. (1827) 49 -Chili.

Lechleri, Lindl. in Lechl. Berb. Am. Austr. 53.Chili.

Lindleyi, Poepp. Fragm. Syn. Pl. Chil. 16.-Chili

litoralis, Phil, in Linnaea, xxxiii. (1864-65) 244.Chili.

longebracteata, Lindl. in Brand. Quart. Fourn. Roy Instit. N. S. i. (1827) 48.--Peruv.

longipetala, Lindl. Gen. et Sp. Orch. 400.-Chili. magellanica, Hook. f. Fl. Antarct. ii. 350.-Reg. Magellan.

membranacea, Lindl. Gen. et Sp. Orch. 401.-Reg. Argent.

multiflora, Lindl, in Brand. Quart. Fourn. Roy. Instit. i. (1827) 49.-Chili.

nudilabia, Poepp. Fragm. Syn. Pl. Chil. 16.-Chili. obovata, Phil. in Linnaea, xxix. (1857-58) 49.Chili.

odontoglossa, A. Rich. in C. Gay, Fl. Chil. v. 455.Chili.

papillosa, Phil. in Linnaea, xxix. (1857-58) $50=$ cylindrostachys.

patagonica, Phil. h. c. xxxiii. (1864-65) 245.-Chili

Paronii, Lindl. Gen. et Sp. Orch. 404.-Chili.

Pearcei, Phil. in Linnaea, xxxiii. (1864-65) 243.Chili.

penicillata, Reichb. f. Otia Bot. Hamb. 51.-Patagon.

Philippi, Reichb. f. in Linnaea, xxii. (1849) 863.Chili.

Piquichen, Lindl. Gen. et Sp: Orch. 400.-Chili

Poeppigiana, A. Rich. in C. Gay, Fl. Chil. v. 443.Chili:

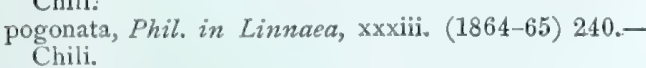

prodigiosa, Reichb. f. l. c. xxii. (1849) 863.-Chili, retlexa, Phil.l. c. xxix. (1857-58) 51,-Chili.

rypaloglossa, A. Rich. in C. Gay, Fl. Chil. v. 457.Chili.

Sceptrum, Reichb. f. in Linnaea, xxii. (1849) 862.Chili.

secunda, Phil. l. co xxix. (1857-58) 52.-Chili. semibarbata, Lindl. Gen. et Sp.Orch. 403.-Chili. speciosa, Poepp. Fragm. Syn. Pl. Chil. 14.-Chili. spectabilis, Phil. in Linnaea, xxxiii. (1864-65) 240.Chili.

suaveolens, Phil. l. c. xxix. (1857-58) 46.-Chili. ulanthoides, Lindl. Gen, et Sp. Orch. 404.-Chili.

Unguiscati, Reichb. f. in Linnaea, xxii. (1849) 864.Chili.

venosa, Reichb. f. l. c.-Chili.

verrucosa, Phil. l. c. xxix. (1857-58) 53.-Chili.

virescens, Lindl. in Brand. Quart. Fourn. Roy. Instit. i. (1827) 51.-Chili.

viridiflora, Poepp. Fragm. Syn. Pl. Chil. 14.-Chili.

volucris, Lindl. in Hook. Fourn. Bot. i. (1834) 4.Chili.

CHI,ORANTHUS, Sw, in Phil. Trans, lxxvii. (1787) 359. CHLORANTHACEAE, Benth. \& Hook. f. iii. 134 .

Creodus, Lour. F1. Cochinch. 88 (1790),

Cryphaea, Ham. in Brewst. Lidinb. Joum. Sc. ii (1825) 11

Nigrina, Thunb. Nov. Gen. 58 (1783).

PEPERIDIA, Reichb, Consp. $212^{\mathrm{n}}$ (1828)

Saintlegeria, Cordem. in Baill. Adansonia, iii (1862-63) 300 .

\section{CHLORANTHUS :}

ARCANDRA, Gardn, in Calc. Journ. Nat. Hist. vi (1846) 348 .

Stropha, Noronha, in Verh. Batav. Gen. v. (1790) ed. I. Art. IV. 4 ; ed. II. 66 (1827)

Tricercandra, A. Gray, in Perry, Jap. Exped. ii. $318(1857)$

Blumeanus, Cordem, in Baill. Adansonia, iii. (1862 63.) $296=$ serratus.

brachystachys, Blume, Fl. Fav. Chloranth. 13. t. 2.Ind. or.; Malaya; China.

ceylanicus, Miq. F1. Ind. Bat. i. I. $802=$ brachystachyus.

denticulatus, Cordem, in Baill. Adansonia, iii. (1862 63) $296=$ brachystachys.

elatior, R. Br. in Bot. Mag. sub t. $2190=$ officinalis. erectus, Sweet, Hort. Suburb. Lond. 28 - officinalis. Fortunei, Solms, in DC. Prod. xvi. I. 476.-China. grandifolius, Miq. Fl. Ind. Bat. 1. I. 802 , -Ind, or. ilicifolius, Blume, ex Miq. Ann. Mus. Bot. Lugd. Bat. iii. $129=$ brachystachyus

inconspicuus, Blanco, F1. Filip. ed. II. $54=$ officinalis. inconspicuus, Sw. in Phil. Trans. Ixxviri. (1787) 359. t. 15.-China; Japon.

indicus, Wight, Ic. t. $1945=$ inconspicuus.

insignis, Kurz, in fourn. As. Soc. Beng. xlii. (1873) II. 108.-Burma.

integrifolius, Schult. f. ex Miq. Ann. Mus. Bot. Lugd. Bat. iii. $130=$ Cornus suecica.

japonicus, Siebold, in Nov. Act. Nat. Cur. xiv. II. 1829) 681.-China ; Japon.

macranthera, Schult. f. ex Miq. Ann. Mus. Bot. Lugd. Bat. iii. 130,-Japon.

mandshuricus, Rupr. Dec. Pl. Amur. t. $2=$ japonicus. monander, R. Br. in Bot. Mag. sub t. $2190=$ brachy stachyus.

monostachyus, R. Br. l..c. t. 2190.-China.

montanus, Siehold, ex Miq. Ann. Mus. Bot. Lugd,

Bat. iii. 129 = brachystachyus.

obtusifolius, Miq. F1. Ind. Bat.i. I. $802=$ inconspicuus? officinalis, Blume, Enum: Pl. Fav. 79.-Ind. or.; Malaya.

Oldhami, Solms, in DC. Prod xvi. 1. 476.-Japon.

Pernyanus, Solms, l. c. 474.-China.

quadrifolius, A. Gray, in Miq. Ann. Mus. Bot. Lugd.

Bat. iii. $129=$ serratus.

salicifolius, Presl, Epim. Bot. $231=$ officinalis.

serratus, Roem. E' Schult. Syst. iii. 461.-Japon

sumatranus, Miq. F1. Ind. Bat. Suppl. $343=$ officinalis.

CHLORASTER, Haw, in Phil. Mag. Ixiii. 103 (1824)= Narcissus, Tourn. (Amaryllid.)

fissus, Haw. Monog. Narciss, $7=\mathbf{N}$. viridiflorus.

integer, Haw. 1. $\mathrm{c}_{0}=\mathrm{N}$, viridiflorus.

oblitteratus, M. Roem. Syn. Ensat. $214=$ N. Brous-

sonetii.

viridiflorus, M. Roem. 1. c. $213=\mathrm{N}$. viridiflorus,

CHLORIS, Sw. Prod. Veg. Ind. Occ, 25 (1788)

GRAMINEAE, Benth. \& Hook. f. iii. 1165.

Chlorordes, Fisch. ex Regel, in Ind. Sem. Hort. Petrop. (1863) 28.

Eustachys, Desv, in Nouv. Bull. Soc. Philom, ii. (1800) 188.

Heterolepis, Ehrenb. ex Boiss. Fl. Orient. v. 554 (1881)

Macrostachya, Hochst. ex A. Rich. Tent. Fl Abyss, ii. 408 , in nota (1851)

Phiceldaria, Willd ex Steud. Nom, ed. II i. 353 , in syn. $(1840)$; ii. 313 (1841).

Schultesia, Spreng. Pugill. ii. 17 (1815).

abyssinica, Hochst. ex A. Rich. Tent. Fl. Abyss. ii 406.-Abyssin.

acicularis, Lindl. in Mitch. Fourn. Trop. Austral. 91 -Austral.

acuminata, Trin. Sp. Gram. iii. t. $305=$ distichophylla.

alba, J. \& C. Presl, Rel, Haenk, i. $289=$ elegans.

Alberti, Regel, in Act. Hort. Petrop. vii. (1880) 650.Mongolia.

amethystea, Hoclsst, in Flora, xxxviii. (1855) 205.Abyssin.

andropogonoides, Fonm. Mex. Pl. Enum.Gram.149; ex Hemsl. Biol. Centr. An. Bot. iii. 558.-Mexic anoplia, Fourn. l. c.; ex Hemsl.l. c.-Mexic.

Aristida, Salzm. ex Stcud. Syn. Pl. Gram. 218 Gymnopogon foliosus.

arundiracea, Nees, cx Steud. 1. c. 207 polydactyla.

\section{CHLORIS :}

bahiensis, Steud. Syn. Pl. Gram. 208.-Bras. barbata, Sw. Fl. Ind. Occ. i. 200-Reg. trop. Beyreichiana, Steud. Nom. ed. II. i. $353=$ seq Beyrichana, Kunth, Rev. Gram. i. 89, 289. t. $56=$ radiata.

brachystachys, Anderss. in Peters, Reise Mossamb. Bot. 556.-Afr. trop.

brevigluma, Wright, in Sauv. Fl. Cub. 191.-Ins. Cuba.

breviseta, Benth. in Hook. Niger Fl. 566.-Afr. trop. campulodes, Trin. ex Steud. Nom. ed. II. i.353, nomen. -Hab.

caribaea, Spreng. Syst. i. $295=$ barbata.

candata, Trin. ex Bunge, Enum. Pl. Chin. Box. 70.China

ciliata, Sw. Prod. Veg. Ind. Occ. 25.-Am. trop.

compressa, DC. Cat. Pl. Hort. Monsp. (1813) 94.Am. austr.

confertifolia, Trin, in Spreng. Nene Entdeck. ii. $74=$ distichophylla.

consanguinea, Kunth, Rev. Gram. i. $89=$ poly dactyla.

crinita, Lag. Varied. Cienc. ii. IV. (1805) 143.-Ins. Philipp.

crinita, Salzm, ex Doell, in Mart. Fl, Bras, ii, III. 64 radiata.

crnciata, Sw. Prod. Veg. Ind. Occ. 25.-Ind. occ.

cryptostachya, Steud. ex F. A. Schmidt, Beitr. Fl. Cap. Verd. Ins. 148.-Ins. Cap. Verd.

ctenioides, Steud. Syn. Pl. Gram. 423.-Madag.

cucullata, Bisch. in Ann. Sc. Nat. Sér. III. xix.

(1853) 357.-Mexic

curtipendula, Michx. El. Bor. Am. i. 59 = Bouteloua

Cynodon, Trin. Gram. Unif. $229=$ Cynodon Dactylon.

cynodontoides, Balansa, in Bull. Soc. Bot. Fr. xix. (1872) 318.-N. Caled.

decora, Nees, ex Steud. Syn. P1. Gram. $205=$ barbata.

Digitaria, H. B. \& K. Nov. Gen. et Sp. i. $168=$ Leptochloa Digitaria.

digitata, Steud. Syn. Pl. Gram. 207.-Ind. or.

distachya, Kunth, Rev. Gram. i. 291. t. 57 = mono. stachya.

distichophylla, Lag. Gen. et Sp. Nov. 4.-Am. austr. divaricata, $R$. Br. Prod. i. 186.-Austral. dolichostachya, Lag. Gen, et Sp. Nov, $5=$ truncata dubia, H. B. \& K. Nov. Gen. et Sp. i. $169=$ Diplachne dubia.

Durandiana, Sehnlt. Mant. ii. $341=$ virgata.

elata, Desv. Opusc. 73.-Bras.

elegans, H. B. \& K. Nov. Gen. et Sp. i. 160.Mexic.

eleusinoides, Griseb. Fl. Brit. W. Ind. 539,-Ind, oce. elongata, Poir. Encyc. Suppl. ii. $2 \$ 6=$ trancata. emarginata, Beauv. Agrost. 158, nomen.-Hab. equitans, Trin. Sp. Gram. iii. t. 309.-Hab. ? falcata, Sw. in Ges. Naturf. Freunde, Neue Schr. (1801) 160 (=Campulosus falcatus). - Afr. austr. fasciculata, Schrad. in Schult. Mant. ii, 3\$9-disticho phylla.

filiformis, Hort. Par, ex Poir. Encyc. Sappl. ii. 23i, n. $8=$ Bouteloua tenuis.

filiformis, Poir. l. c. 238, n. 12.-Hab. ?

floccifolia, Poir. 1. c. = Eleusine floccifolia

floridana, Vasey, Cat. Gram. Un. St.61.-Florida

foliosa, Willd. Sp. Pl. iv. 92t = Gymnopogun Coliosns.

Gayana, Kunth, Rev. Gram. i. 89, 298. t 58.Afr. trop.

geminata, Hochst. in Flora, xxxviii. (1555) 205.Abysin.

glabmta, Anderss. in Peters, Reise Massamb. Bu: 557.-Afr. trop.

glaucn, Vasey, Cat. Grom. Un. St. 61.-Filorida

glaucescens, Sterud. Sym. Pl. Gram. 201.-Perar.

gracilis, I'. Durand, Chlor. 10 = virgata.

gracilis, H. B. \& K. Nov. Ges. el Sp. i. $168=$ Lepio chlon gracilis

Gryllus, Honck. Syn. Pl. Germ. i. 43i Chrysapogi-y Grvllus.

guincensis, Scham. E Thiren. Bestr. Gasin. Pl. 55. Afr. trop.

hispida, P. Durand, Chior. 1\%.-Ins. IMilip

Humixsldiana, Serud. Syrn. Pl. Grum. - I I ciubs. 


\section{CHLORIS :-}

humilis, Kunth, Rev. Gram. i. 89 ; ii. 531.t. $180=$ radiata.

imberbis, Desf. Cat. Hort. Par. ed. III. 15 = submutica.

incompleta, Roth, Nov. Pl.Sp.60.-Ind. or

inermis, Trin. Gram. Unifl. 232.-Mexic.

inflata, Link, Enum. Hort. Berol. i. 105.-Calif.; Ins Philipp.

intermedia, A. Rich. Tent. Fl. Abyss. ii. 407.Abyssin.

leptostachya, Hochst. ex A. Rich. l.c.-Abyssin.

longibarba, Michx. ex Beauv. Agrost. 158, nomen.Am. bor.

longifolia, Steud. Syn. Pl. Gram, 205,-Ins, Philipp, macrantha, Desv. Opusc. 73.-Arabia.

macrantha, Jaub. \& Spach, Illustr. iv, $42(=$ Tetra pogonis sp.).-Arabia.

macrostachya, Hochst. ex A. Rich. Tent. Fl. Abyss. ij 408 = Enteropogon macrostachya.

madagascariensis, Steud. Syn. Pl. Gram. 206.Madag.

maritima, Trin. Gram. Unif. $: 236=$ Cynodon Dac tylon.

meccana, Hochst. ex Steud. Syn. Pl. Gram. 205.Aegypt.; Arabia; Beluchist.

megastachya, Schrad. ex Schult. Mant. ii. $340=$ truncata.

mendocina, Phit. Sert. Mend. Alt. 50.-Chili.

monostachya, Michx. Fl. Bor. Am. i, $59=$ Ctenium carolinianum.

monostachya, Pair. Encyc. Suppl. ii. 238.-Ind. or. Ins. Mascar.

montana, Roxb. Hort. Beng. 82; Fl. Ind. i. 329.Ind. or.

Moorei, F. Muell. in Linnaea, xxy (1852) $444=$ acicularis.

mucronata, Michx. Fl. Bor. Am. i. $59=$ Eleusin aegyptiaca.

multiradiata, Hochst. in Flora, xxxviii. (1855) 204. Abyssin.

myriostachya, Hochst. l. c.-Afr. trop.

notocoma, Hochst. l. c.-Abysin.

obtusifolia, Desv. Opusc. 73.-Bras.

obtusifolia, Trin. Gram. Unifl.233.-Ins. Philipp.

orthonoton, Doell, in Mart. Fl. Bras. ii. III. 64.Bras.

pallida, Hack. in Engl. Bot. Fahrb. vi. (1885) 244.Austral.

pallida, Willd. Sp. P1. iv. $926=$ radiata

panicea, Willd. l. c. 923.-Ind. or.

paraguaiensis, Steud. Syn. Pl: Gram. $204=$ barbata. paspaloides, Hochst. in Flora, xxxviii. (1855) 206. Abyssin.

paytensis, Steud. Syn. Pl. Gram. 207.-Peruv.

pectinata, Benth.Fl. Austral. vii. 612.-Austral

pendula, Salzm. ex Steud. Syn. Pl. Gram, $208=$ bahiensis.

penicillata, Jan, ex Trin. Gram. Unif. $231=$ compressa.

penicillata, Pers. Syn. i. 87.--Ind. or.

penicillata, Willd. ex Steud. Nom. ed. II. i. $353=$ elegans.

peregrina, $P$. Durand, Chlor, 11.-Ins. Philipp.

petraea, Sw. Prod. Veg. Ind. Occ. 25-Reg. trop.

pilosa, Schum. E Thonn. Beskr. Guin. Pl. 55.-Afr.

trop.

piperita, Michx. ex Steud. Nom. ed. II. i. $353=$ Ctenium carolinianum.

poaeformis, H. B. \& K. Nov, Gen. et Sp. i. 169= Leptochloa virgata.

polydactyla, P. Durand, Chlor. 14, 22 =virgata.

polydactyla, Sw. Prod. Veg. Ind. Occ. 26.-Am austr.

polystachya, Lag. Gen. et Sp. Nov. $4=$ inermis, Leptochloa virgata.

polystachya, Roxb. Hort. Beng. 82 ; Fl. Ind. i. 330.Ind. or.

Prieurii, Kunth, Rew.Gram. i. 89 ; ii. 441. t. 134.Afr. trop.

procumbens, P. Durand, Chlor, $16=$ Bouteloua tenuis. propinqua, Steud. Syn. Pl. Gram. 204,-Guadaloupe. prostrata, Poir. Encyc. Suppl, ii. $239=$ Eleusine aegyptiaca.

pubescens, Lag. Varied. Cienc. ii. IV. (1805) 143.-

pubescens, Peyr. in Sitzb. Acad. Wien, Math. Nat. xxxviii. (1860) 585.-Am. austr.

\section{CHLORIS :-}

pulchra, Schum. E' Thonn. Beskr. Guin. Pl. 56.Afr. trop.

Pumilio, R. Br. Prod. 186.-Austral.

punctulata, Hochst. ex Steud. Syn. Pl. Gram. 205.Afr. trop.

pycnothrix, Trin. Gram. Unifl. $234=$ radiata.

radiata, Heyne, -ex Roth, Nov. Pl. Sp. $61=$ incompleta.

radiata, Sw. Prod. Veg. Ind. Occ. 26.-Am. trop.

repens, Auct. ex Steud. Nom. ed. II. i. $353=$ Eleusine indica.

repens, Hochst. in Flora, xxxviii. (1855) 204.Abysin.

retusa, Lag. Gen. et Sp. Nov. 5.-Reg. Argent.

Thachitricha, Steud. Syn. Pl. Gram. 205.-Ins. Philipp

Roxburghii, Edgew, in Joum. As. Soc. Beng, xxi. (1853) $183=$ digitata

Roxburghiana, Schult. Mant. ii. 239= polystachya rufescens, Lag. Varied. Cienc. ii. IV. (1805) 143.-Ins. Philipp.

mfescens, Steud. Syn. Pl. Gram. 206.-Ins. Maurit

Sagraeana, A. Rich. Fl. Cub. Fanerog. ii. 315.-Ins. Cuba.

Salzmanni, Steud. Syn. Pl. Gram. $206=$ radiata.

scariosa, Beauv. Agrost. 158, nomen.-Hab.?

scariosa, F. Muell. Fragm, vi. 85-Austral

sclerantha, Lindl. in Mitch. Journ. Trop. Austral. 31 = ventricosa

scoparia, Desf. Tabl. ed. I. $14=$ radiata

simplex, Schum. E Thonn. Beskr. Guin. Pl.54.-Afr. trop.

spathacea, Hochst. ex Steud. Syn. Pl. Gram. 204.Abysin.

subbiflora, Steud. l. c. 206.-Am. bor

subdolichostachya, C. Muell. in Bot. Zeit. xix. (1861) 341. - Am. bor.

submutica, H. B. E K. Nov. Gen. et Sp. i. 167. t. 50. -Mexic.

subtriflora, Steud. Syn. Pl. Gram. 208.-Afr. trop.

Swartziana, Doell, in Mart. Fl. Bras. ii. III. 68. Bras.

Swartzii, C. Muell. in Bot. Zeit. xix. (1861) $341=$ petraea.

tacnensis, Steud. in Lechl. Berb. Am. Austr. 56.Peruv.

tenella, Koen. ex Roxb. Hort. Beng. 82; Fl. Ind. i. 329.-Ind, or.

tenuior, Poir. ex Schult. Mant. ii. $321=$ Leptochloa cynosuroides.

tenuis, Poir. Encyc. Suppl. v. $614=$ Bouteloua tenuis. tetrameris, Trin. Gram. Unif. $235=$ Cynodon elongatus.

Tetrapogon, Beauv. Agrost. $158=$ Tetrapogon villosus. triangulata, Hochst. ex A. Rich. Tent. Fl. Abyss, ii. 40.9.-Abysin.

truncata, $R$. Br. Prod. 186.-Malaya; Austral.

unispicea, $F$. Muell. Fragm. vii. 118.-Austral.

ventricosa, $\dot{R}$. Br. Prod. 186.-Austral.

villosa, Pers. Syn. i. $87=$ Tetrapogon villosus.

virgata, P. Durand, Chlor. $10=$ radiata.

virgata, Sw. Fl. Ind. Occ. i. 203.-Am. trop.

Wightiana, Nees, ex Steud. Syn. Pl. Gram. $206=$ incompleta.

CHLORIZA, Salisb. Gen. P1. Fragm. 21 (1866)= Lachenalia, Jacq. (Liliac.)

fragrans, Salisb. 1. c.=L. versicolor.

lucida, Salisb. 1. c. = L. Incida.

mediana, Salisb. 1. c. =L. mediana.

pallida, Salisb. 1. c. = L. pallida.

pustulata, Salisb. 1. c. = L. pustulata.

unicolor, Salisb. 1. c. $=\mathrm{L}$. versicolor.

CHLOROCAULON, Klotzsch, in Endl. Gen. Suppl. iv. III. $89(1850)=$ Argithammia, Sw. (Euphorbiac.).

CHLorochlamys, Miq. Ann. Mus. Bot. Lugd. Bat. iv. $142(1868-69)=$ Marsdenia, R. Br. (Asclepiad.). celebica, Miq. 1. c.-Ins. Celebes.

CHLOROCODON, Fourr. in Ann. Soc. Linn. Lyon, N. S. xvii. (1869) $113=$ Erica, Tourn

scoparium, Fourr. l. c. $=$ E. scoparia.

CHLOROCODON, Hook. f. Bot. Mag.t. 5898 (1871). ASCLEPIADEAE, Benth. \& Hook, f, ii. 745

Whiteil, Hook.f.l. c.-Afr, austr.
CHLOROCREPIS, Griseb. in Goett. Abh. v. (1852) 155 = Hieracium, Linn. (Compos.)

staticifolia, Griseb. 1. c. $=\mathbf{H}$. staticefolinm.

CHIOROGALUM, Kunth, Enum. PI. iv. 681 (1843). LILIACEAE, Benth. \& Hook. f. iii. 785. LAOTHOË, Rafin. F1. Tellur. iii. 53 (1836), nomen prius.

angustifolium, Kellogg, in Proc. Calif. Acad. ii. (1863) 104, t, 30 -Calif

divaricatum, Kunth, Enum. PI. iv. $682=$ pomeri dianum.

Leichtlinit, Baker, in Gard. Chron. (1874) I. 689.Am. bor. occ.

parviflorum, S. Wats. in Proc. Am. Acad. xiv. (1879) 243.-Calif.

pomeridianum, Kunth, Enum. Pl. iv. 682.-Calif.

CHLOROWES, Fisch. ex Regel, Ind. Sem. Hort. Petrop (1863) $28=$ Chloris, Sw. (Gramin.)

petraeum, Fisch. 1. c. $=$ Chloris petraea.

CHLOROMYRON, Pers. Syn. ii. 73 (1807)= Rheedia, Linn. (Guttifer.).

verticillatum, Pers. $1 . c_{0}=\mathrm{R}$. acuminata.

CHLOROPHORA, Gaudich, in Freyc. Voy, Bot 508 , in nota (1826). URTICACEAE, Benth. \& Hook. f. iii. 363 .

tinctoria, Gaudich. l. c.-Mexic.

CHLOROPHYTUM, [Ker-Gawl] in Bot. Mag. t. 1071 (1808). LILIACEAE, Benth. \& Hook, fiii. 788 Asphodelopsis, Steud. ex Baker, in Journ. Linn. Soc. $\mathrm{xv} \cdot(\mathbf{1 8 7 6 )} 321$

Hartwegia, Nees, in Nov. Act. Nat. Cur. xv. II (1831) 372 .

Hollia, Heynh. Nom. ii. 303 (1846).

Schidospermum, Griseb, in Lechl. Berb. Am. Austr. $56(1857)$.

abyssinicum, Kotschy \& Peyr. PI. Tinn. 46 = laxiflorum.

acaule, Baker, in Fourn. Linn. Soc. xv. (1876) 327 . Ind. or.

affine, Baker, in Trans. Linn. Soc. xxix. (1875) 160. t. 104.-Afr, trop.

Afzelii, Baker, in Fourn. Linn. Soc. xv. (1876) 323.Afr. trop.

alismaefolium, Baker, l. c. 324.-Afr. trop.

alpinum, Benth. ex Baker, l.c. 328.-Ins. Tasman.

amplexicaule, Baker, l.c. 325.-Afr. trop.

andongense, Baker, in Trans. Linn. Soc. Ser. II. i (1878) 260 .-Afr. trop.

anthericoideum, Dalz. in Hook. Kew Journ. ii. (1850) $141=$ tuberosum

arundinaceum, Baker, in Fourn. Linn. Soc. xv. (1876) 323. - Ind, or.

attenuatum, Baker, l. c. 332.-mInd. or

blepharophyllum, Schweinf. ex Baker, l. c. 327.Abyssin.

Bowkeri, Baker, in Saund. Refug. Bot. t. 352.-Afr. anstr.

bracteosum, Welw. ex Baker, in Trans. Linn. Soc. Ser. II. i. (1878) $260=$ stenopetalum.

Brehmeanum, Schult. f. Syst. vii. 454.-Afr. austr.

breviscapum, Dalz. in Hook. Kew Fourn. ii. (1850) 141.- Ind. or.

Burchelli, Baker, in fourn. Linn. Soc. xv. (1876) 330. -Afr. austr.

ciliatum, Baker, in Fourn. Bot. xvi. (1878) 325.-Afr. trop.

comosum, Baker, in Gard. Chron. (1873) $75=$ Stern bergianum.

crispum, Baker, in fourn. Linn. Soc. xv. (1876) 331.Afr. austr.

debile, Baker, in Trans. Linn. Soc. Ser. II. i. (1878) 260.-Afr. trop.

decipiens, Baker, in Fourn. Linn. Soc. xx. (1883) 275. -Madag.

dubium, Schult. f. Syst. vii. $455=$ Anthericum Schultesii.

elatum, R. Br. Prod. 277.-Afr, austr

falcatum, Baker, in Saund. Refug. Bot. t. $333=$ laxiflorum.

filipendulum, Baker, in Trans, Linn. Soc. Ser. II. i. (1878) 260.-Afr. trop.

Finlaysonianum, Wall. Cat. n. 5061 (Dracaenae sp.). -Siam. 


\section{CHLOROPHYTUM :}

gallabatense, Schweinf. ex Baker, in Joarn. Linn. Soc xv. $(1876) 325=$ Orchidastrum.

glaucum, Dal., in Hook. Kew fourn. ii. (1850) 143.Ind. or.

graminifolium, Kunth, Enum. Pl. iv. $606=$ Anthericum undulatum.

Hartmannianum, Schweinf. Beitr. Fl. Aethiop. 294 nomen.-Afr. trop.

Heyneanum, Wall. Cat. n. 5060.-Ind. or.

Heynei, Baker, in Journ. Linn. Soc. xv. (1876) $322=$ praec.

inornatum, Ker-Gawl. in Bot. Mag. t. 1071.-Afr. trop. juncifolium, Baker, in fourn. Linn. Soc. xv. (1876) 333.-Bras.

Kirkii, Baker, in Gard. Chron. (1882) r. 108.-Afr. trop. lancifolium, Welw. ex Baker, in Trans. Linn. Soc Ser. II. i. (1878) 260.-Afr. trop.

laxiflorum, Baker, in Journ. Linn. Soc. xv. (1876) 328 $=$ laxum.

laxum, R. Br. Prod. 277.-Trop. As. ; Afr.; Austral.

leucolepis, Welw. ex Baker, in Trans. Linn. Soc. Ser. II. i. (1878) $259=$ macrophyllum.

longifolium, Schweinf. Beitr. Fl. Aethiop. 294, nomen.-Abyssin.

longipes, Baker, in Fourn. Bot, xvi. (1878) 325.-Afr. trop.

macrophyllum, Aschers. in Schweinf. Beitr. Fl. Aethiop. 294.-Abysin.

macrosporum, Baker, in fourn. Linn. Sac. xv. (1876) 330.-Afr. austr.

madagascariense, Baker, in Fourn. Bot. xvi. (1878) 326. - Afr. trop

malabaricum, Baker, in Fourn. Linn. Soc. xv. (1876) 331.-Ind. or

micranthum, Baker, in Fourn. Bot. xvi. (1878) 325.Afr. trop.

modestum, Baker, in Fonrn. Linn. Soc. xv. (1876) 329 - Afr. austr.

nepalense, Baker, l. c. 330.--Reg. Himal.

Nimmonii, Dalz. in Hook. Kew Journ. ii. (1850) 142 $=$ Orchidastrum.

Orchidastrum, Lindl.Bot.Reg.t.813.-Ind. or.; Afr.trop parviflorum, Dalz. in Hook. Kew Journ. ii. (1850) 141 =laxum.

petiolatum, Baker, in Fourn. Linn. Soc. xv. (1876) 326.-Afr. trop,

polyrhizon, Baker, in Gard. Chron. (1878) II. 396.Afr. trop.

polystachys, Baker, in Fourn. Bot. xvi. (1878) 326.Afr. trop.

pubiflorum, Baker, in fourn. Linn. Soc. xv. (1876) 329. -Afr. trop.

pulchellum, Kunth, Enum. P1. iv. $605=$ Anthericum pulchellum.

pusillum, Schweinf. ex Baker, in fourn. Bot. xvi. (1878) 325.-Afr. trop.

rhizomatosum, Baker, in Gard. Chron. (1885) II. 230. -Afr. trop.

rigidum, Kunth, Enum. Pl. iv. 604=Anthericum rigidum.

Rutenbergianum, Vatke, in Bremen Abh. ix. (1885)

138. - Ins. Nossibé.

schidospermum, Baker, in fourn. Linn. Soc. xv. (1876) 326.--Peruv.

sparsiflorum, Baker, l. c. 325 -Afr. trop.

stenopetalum, Baker, $l$. c. 331.-Afr, trop.

Sterabergianum, Steud. Nom. ed. II. i. 354.-Afr. austr. suffruticosum, Baker, in Fourn. Bot. xvi. (1878) 326.Afric.

tetraphyllum, Baker, in Fourn. Linn. Soc. xv. (1876) 328.-Abysin.

Tianeae, Baker, $l$. c. 383.-Afr, trop.

triflorum, Kunth, Enum. P1. iv. $606=$ Anthericum triflorum.

tuberosum, Baker, in Fourn. Linn. Soc. xv. (1876) 392 -Ind. or.; Abyss.

undulatum, Wall. Cat. ‥ $5059=$ nepalense,

vestitum, Baker, in fourn. Linn. Soc. xv. (1876) 326 -Afr. trop.

viscosum, Kunth, Enum. Pl. iv, $605=$ Anthericum viscosum.

xerotinum, F. Muell. Fragm, i. $63=\operatorname{laxum}$.

CHLOROPHYTUM, Pohl, ex DC. Prod, iv. 540 (1830) Spermacoce, Dill. (Rubiac.).

neroosum, Pohl, 1. c. $548=\mathrm{S}$. Ponya

pratense, Pohl, $1 . c=$ S. Poaya.
CHLOROPyRON, Behr, in Proc Calif. Acad. i. (1855) $61=$ Cordylanthus, Nutt. (Scrophul.)

palustre, Behr, 1. c。=Cordylanthus maritimus.

CHLorosa, Blume, Bijdr. 420. t. 31 (1825), ORCHIDEAE, Benth. \& Hook. f. iii. 616

gracilis, Blume, l.c.--Java.

latifolia, Blume, $\downarrow$. c.-Java.

CHLOROSPATHA, Engl. in Regel, Gartenfl. (1878) 97. t. 983. AROIDEAE, Benth. \& Hook. f. iii. 977

Kolbii, Engl. l. c.-N. Granat.

CHLOROSTEMmA, Fourr. in Ann. Soc. Linn. Lyon, N.S. xvi. (1868) $398=$ Asperula, Linn. (Rubiac.). odoratum, Fourr. l. c. $=$ A. odorata

CHLOROSTIS, Rafin. Princ, Somiol, 26 (1814)= Chlora, Ren. (Gentian.)

CHLOROXYLON, Rumph. ex Scop. Introd. 208 (1777); DC. Prod. i. 625 (1824). MELIACEAE, Benth. \& Hook. f. i. 340 .

Dupada, Buch.-Ham. Journ. Mysore, i. $184=$ Boswellia serrata.

Swietenia, DC. Prod. i. 625.-Ind. or.

CHLOROXYLUM, P. Br. Hist. Jamaic. 187. t. 7. f. 1 (1756); Adans. Fam. 1i. 303 (1763) (Quid?)

CHLORYLlis, E. Mey. Comm. Pl. Afr. Austr. 149 (1835) = Dolichos, Linn. (Legumin.)

pratensis, E. Mey. I. $\mathrm{c}_{\mathrm{o}}=\mathrm{D}$. Chloryllis.

CHNOANTHUS, Phil, in Anal. Univ. Chili (1862) II. $405=$ Gomphrena, Linn. (Amarantac.)

mendocinus, Phil. 1. c. ; et in Linnaea, xxxiii. (1864-65) 223.-Chili.

ovatus, Phil. Sert. Mend. Alt. 41.--Chili.

CHOCHO, Adans. Fam. ii. 500 (1763) = Sechium, P Br. (Cucurbit.).

CHODONDENDRON, Bosc, Encycl. Agric. vii, 296 (1822), sphalm. $=$ Chondodendron, Ruiz \& Pav. (Menispermac.)

CHOENOMELES, Lindl. in Trans. Linn. Soc. xii (1822) 97 = Pyrus, Linn. (Rosac.). alba, Carr. in Rev. Hortic. (1876) $410=$ P. japonica. cancellata, Pritz. Ic. Ind. i. 250, sphalm. = P. sinensis Poir.

japonica, Lindl. in Trans. Linn. Soc. xüi. (1822) $97=$ P. japonica.

CHOERADODIA, Herb. Amaryli. 87 (1837)=Stru maria, Jacq. (Amaryllid.)

chilensis, Herb. 1, c. $=$ S. chilensis.

CHOERADOPLECTRON, Schau. in Nov, Act. Nat, Cur. xix. Suppl, i. (1843) $436=$ Habenaria, Willd. (Orchid.).

Spiranthes, Schau, 1. c。 = H. lacertifera.

CHOEROPHILLUM, Neck. Delic. Gallo-Belg. i. 147 $(1768)=$ Chaerophyllum, Hoffm. (Umbell.).

CHOEROSERIS, Link, Handb. i. 798 (1829)= Picris, Linn, (Compos.)

heterosperma, Link, 1. c. $799=$ Crepis Dioscoridis. rhagadioloides, Link, 1. c. $=$ P. Sprengeriana.

Sprengeriana, Link, 1. c. $=$ P. Sprengeriana

CHOETOPHORA, Franch. \& Sav, Enum. Pl. Jap. ii. 548 (1879), sphalm. = CHAETOSPORA, R. Br. Schoenus, Linn. (Cyperac.).

CHOISY் A, H. B. \& K. Nov. Gen. et Sp. vi. 4. t. 519 (1823). RUTACEAE, Benth. \& Hnok. f. i. 297

Juliania, La Llave, in La J dave \& Lex. Nov. Veg. Desc. fasc ii. 4 (1825)

Plenckia, Mof. \& Sesse, ex DC. Prod, i. 724 (1824).

grandiflora, Regel, Gartenfl. (1876) $25 \%$; in Act. Hort Petrop. iv. $(1876) 396=$ ternata.

ternata, H. B. G K. Nov. Gen. et Sp. vi. 6. t. 619.Mexic.
CHOMELIA, Jacq. Enum. PI. Carib. I (1760), RU.

BIACEAE, Benth, \& Hook, f ii. 103.

ANisomeris, Presi, Symb. Bot. ii. 5. t. 54 (1833)

angustifolia, Benth. in Hook. Fourn. Bot. iii. (1841) 235. - Guiana

anisomeris, Muell. Arg. in Flora, lviii. (1875) 451.Bras.

barbinervis, Moric. ex Benth. in Linnaen, xxii. (1850) 446.-Bras.

brasiliana, A. Rich. in Mém. Soc. Hist. Nat. Par. v. (1834) 183, partim.-Bras.

brasiliana, A. Rich. 1, c. partim = Vauthieri.

estrellana, Muell. Arg, in Flora, lviii. (1875) 452.Bras.

fasciculata, Sw. Fl. Ind. Occ. i. 238. - Jamaica.

flipes, Benth. ex Oerst. in Kjoeb. Vidensk. Meddel. (1852) 41.-Nicaragua.

hirsuta, Gardn. in Hook. Lond. Fourn. Bot. iv. (1845) 107.-Bras.

intercedens, Muell. Arg, in Flora, lviii. (1875) 451.Bras.

malancoides, Muell. Arg. l. c. 452.-Bras.

Martiana, Muell. Arg. l. c. 451.-Bras.

obtusa, Cham. E Schlecht. in Linnaea, iv. (1829) 185 -Bras.

obtusa, Mart, in Flora, xxiv, (1841) 11. Beibl. 71

Martiana.

occidentalis, Muell. Arg. in Flora, 1viii. (1875) 45̌2.Bras.

odoratissima, Teijsm. E Binn. Cat. Hort. Bog. 384 , nomen.-Hab.

oligantha, Muell. Arg. in Flora, lviii. (1875) 452.Eras.

parviflora, Muell. Arg. in Mart. Fl. Bras. vi. v. 41.Bras.

pedunculosa, Benth. in Linnaea, xxiii. (1850;445Bras.

Pobliana, Muell. Arg。 in Flora, 1viii.(1875) 452.Bras.

pubescens, Cham. E Schlecht. in Linnaea, iv. (182y) 187.-Bras.

ribesioides, Benth. ex A. Gray, in Proc. Am. Acad. iv. (1860) 38. - Bras

sandvicensis, A. Gray, l. c.-Ins. Sandvis

sericea, Muell. Arg in Flora, 1viii. (1875) 451-Bras. sessilis, Muell. Arg. l. c-Bras,

spinosa, facq. Enum. Pl. Carib. 12.-Venezuela.

tenuiflora, Benth. in Hook. Fourn. BQt. iii. (1841) 285. -Guiana.

transiens, Muell. Arg. in Mart. Fl. Bras. vi. v. 457.Bras.

triacantha, Griseb. Cat. Pl. Cub. 193.-Cuba.

tristis, Muell. Arg. in Flora, Iviii. (1875, 452.Bras.

Vauthieri, Muell. Arg. l. c.-Bras.

versicolor, Spreng. Syst. i. $410=$ Scolosanthas versicolor

valpina, Muell. Arg. in Flora, lviii. (1875) 452.Bras.

CHOMELIA, Linn. Gen. ed. I. 55 (173\%) ; cf. Richter, Codex Linn. $183=$ Tarenna, Gaertn. (Rubiac.).

CHOMELIA, Vell. Fl. Flum. i. t. $107(1827)=$ Ilex, Tourr amara, Vell. 1. c.-Bras.

CHONA, D. Don, in Edinb. N. Phil. Journ. xvii. (18\$4) $155=$ Erica, Linn.

sangrimea, D. Don, l $\mathrm{C}=\mathrm{E}$. Nivenis.

CHON AIS, Salisb. Gen. P1. Fragm. $195150^{\circ}=$ Hip. peastrum, Herb. (Amarllid.) erittata, Salisb, l, $c_{0}=\mathbf{H}$, viltatum.

CHONDODENIDRON, Penth. \& Hook. f. Gen. i. St $\left(186^{\circ}\right)$, sphalm. = Odontocarya, Miers (Nenisperm.)

CHONDODENDRON, Ruiz \& Pav. Prod. 19: (1794). MEN/SPERHACE.tE, Berath. \& Hook f. i. 968 .

Butriopsis, Miers, in Ann. \& Mag. Nat. Hist. Ser. II. vii. $(1851)$ t3.

aemulum, Miers, L. c. Ser. 111. xix. (156", 192 mplaty. phyllam.

cinerascens, Mien, 1. c. = platyphyllarto.

consolvalacrum, Poepp. \& Endl. Nor. Gen. et Sp. ih OS - lomentosum. 


\section{CHONDODENDRON :}

cretosum, Miers, in Ann. E" Mag. Nat. Hist. Ser. III. xix. (1867) 192.-Peruv

hederifolium, Miers, I. c. Ser. II. vii. (1851) $44=$ tomentosum.

nemophilum, Miers, Contrib. iii. 319.-Bras.

obscurum, Miers, l.c. 314.--Bras.

ovatum, Miers, in Ann。 \& Mag. Nat. Hist. Ser. III. xix. (1867) 192.-Bras.

platyphyllum, Miers, l. c.-Bras.

scabrum, Miers, I. c. Ser. II. vii. (1851) $44=$ tomentosum. tamoides, Miers, l.c.-Guiana

tomentosum, Ruiz E Pav. Syst. Veg، 261.-Peruv.

CHONDRACHNE, R. Br. Prod, 220 (1810)= Lepironia, Rich. (Cyperac.)

articulata, R. Br. 1. c. = L. mucronata.

CHONDRACHYRUM, Nees, in Lindl. Introd. Nat. Syst. ed. II. $449(1836)=$ Melica, Linn. (Gramin.). scabrum, Nees, 1. c. 450.-Bras.

CHONDRILLA, [Tourn.] Linn. Syst. ed. I (1735); Gen. ed. I. 241 (1737). COMPOSITAE, Benth. \& Hook. f. ii. 524.

Calycocorsus, F. W. Schmidt, Samml. Phys. Aufs. i. $271(1795)$

Peltidium, Zollikof. Nat. Anz. (1820); Bartl. Ord. 145 (1830)

WIBELIA, Roehl. Deutschl. Flora, ii. 426 (1813)

WiLlemeTiA, Neck. Elem. i. 50 (1790).

Zollikoferia, Nees, in Bluff \& Fingerh. Comp. Fl. Germ. ii. 305 (1825)

acanthifolia, Poir. Encyc. Suppl. ii. $330=$ Lactuca acanthifolia.

acantholepis, Boiss. Diagn. Ser. I. xi. $48=$ juncea.

acanthophylla, Borckh. ex Reichb. Fl. Germ. Excurs. $271=$ juncea .

alba, Lam. Encyc, ii. $79=$ Prenanthes alba.

altissima, Lam. 1. c. $78=$ Prenanthes altissima.

ambigua, Fisch. ex Kar. \& Kir. in Bull. Soc. Nat. Mosc. xv. (1842) 398 = pauciflora.

angustissima, Hegetschw. Fl. Schw. $762=$ juncea.

aspera, Poir. Encyc. Suppl. ii. 329.-Hab.

asplenifolia, Poir. 1. c. $330=$ Launaea aspleniifolia auriculata, Wall. Cat. n. $3269=$ Lactuca dissecta. brevirostris, Fisch. Eo Mey. Ind. Sem. Hort. Petrop. iii. 32.--Sibir. altaic.

canescens, Kar. E' Kir. in Bull. Soc. Nat. Mosc. xv.

1842) 397.-Soongar.

capitata, Sieber, ex DC. Prod. vii, $180=$ Launaea glomerata.

chinensis, Poir. Encyc. Suppl. ii. $331=$ Lactuca versicolor.

crepidinea, Poir. 1. c. $331=$ Prenanthes crepidinea

crepoides, Lapeyr. Hist. Abr. P1. Pyr. $462=$ Lactuca saligna.

crepoides, Murr. Syst. Veg. ed. XIII. 595. - -Mont. Pyren.

crepoides, Reich. Fl. Moeno-Francof. $59=$ juncea.

cymosa, Poir. Encyc. Suppl. ii。 $330=$ Prenanthes cymosa.

debilis, Poir 1 . c. $332=$ Lactuca debilis

Decandollei, Spreng. ex DC. Prod. vi. $158=$ Crepis foetida.

dentata, Poir. Encyc. Suppl. ii. $328=$ Lactuca denticulata.

erysimifolia, Poir. 1. c. 331 = Lactuca muralis.

fontinalis, Wall. Cat. n. $3268=$ Lactuca polycephala

Gaudini, Hegetschw. in Suter, Fl. Helv. ed. II. ii. $162=$ juncea.

glomerata, C. Koch, in Linnaea, xxiii. (1850) $673=$ juncea.

gracilis, Wall. Cat. n. $3267=$ Lactuca gracilis.

graminea, Bieb. Fl. Taur. Cauc. ii. 244.-Reg. Caucas. et Himal. ; Sibiria.

graminea, Ledeb. Fl. Alt. iv. $148=$ piptocoma

graminifolia, Fisch. Cat. Hort. Gorenk. (1812) $33=$ graminea.

hastata, Poir. Encyc. Suppl. ii. 332=Lactuca denticulata.

hastata, Wall. Cat. n. $3271=$ Lactuca hastata.

hieracioides, Roth, in Usteri, Ann. Bot. x. $50=$ Tolpis coronopifolia.

hispida, Desf. Cat. Hort. Par. ed. III. $144=$ juncea.

hispida, Poir. Encyc. Suppl. ii. 328 = Lactuca microcephala.

illinoiënsis, Poir. 1. c. $331=$ Prenanthes aspera.

\section{CHONDRILLA :-}

indica, Steud. Nom。ed. I. 191 = Lactuca Heyneana intybacea, Frivald. in Flora, xviii. (1835) $335=$ junces intybacea, Ledeb. Fl. Ross. ii. $809=$ pauciflora. japonica, Lam. Encyc. ii. $79=$ Crepis japonica juncea, Ledeb. Fl. Alt. iv. 147 =brevirostris. juncea, Linn. Sp. Pl. 796._Europ.; As. med. laciniata, Stev, in Bull. Soc. Nat. Mosc. xxix. (1856) II. $\mathbf{4 1 0}=$ juncea

laevigata, Pursh, FI. Am. Sept. ii. $497=$ Pyrrhopappus carolinianus.

lanceolata, Poir. Encyc. Suppl. ii. $329=$ Crepis integra.

latifolia, Bieb. Fl. Taur. Cauc. ii. $244=$ juncea.

lejosperma, Kar. Eo Kir. in Bull. Soc. Nat. Mosc. (1841) 456.- Sibir. altaic

longifolia, Buch.-Ham. in Wall. Cat. sub n. $3274=$ Lactuca polycephala.

longifolia, Wall. Cat. n. $3273=$ Lactuca longifolia.

lutea, Dulac, Fl. Hantes-Pyr. $495=$ juncea.

lyrata, Poir. Encyc. Suppl. ii. $332=$ Crepis japonica.

maracandica, Bunge, in Mém. Sav. Etr. Pétersb. vii

(1851) 380 . - Turkestan

multiflora, Poir. Encyc. Suppl. ii. $332=$ Crepis japonica.

muralis, Lam. Fl. Fr. ii. 105 = Lactuca muralis. nudicaulis, Linn. Mant. $278=$ Launaea nudicaulis. paniculata, Lam. Encyc. ii. $78=$ prenanthoides. pauciflora, D. Don, in Trans. Linn. Soc. xvi. (1833) $180=$ Pyrrhopappus pauciflorus

pauciflora, Ledeb. Fl. Alt. iv. 148.-Rossia; Sibiria

Peltidium, Moritz, Fl. Schw. 361.-Europ.

phaeocephala, Rupr. Sert. Tiansch. 59.-As. centr. piestocarpa, Boiss. Fl. Orient. iii. 793.-Persia. pinnata, Lam. Encyc. ii. 79 = Sonchus leptocephalus. pinnatifida, Poir. Encyc. Suppl. ii. $330=$ Prenanthe cymosa.

piptocoma, Fisch. Mey. E Avè-Lall. Ind. Sem. Hort. Petrop, viii, 54, - Sibir, altaic.

Prenanthes, Steud. Nom. ed. I. $191=$ seq.

prenanthoides, Vill. Voy. (1812) 16. - Europ.

pulchra, Lam. Fl. Fr. ii. 106 = Phaecasium lampsanoides.

purpurea, Lam. 1. c. $105=$ Prenanthes purpurea.

pusilla, Boiss. Diagn. Ser. I. vii. 11.-Persia ; Turkestan.

racemosa, Poir. Encyc. Suppl. ii. $331=$ Lactuca Heyneana.

ramosissima, Sibth. E Sm. Fl. Graec. Prod. ii. 128. Graecia.

ramosissima Zeyher, ex DC. Prod. vii. 176=Lactuca viminea.

Rauillieri, Walp. Rep. ii. 694, sphalm. = Rouillieri.

repens, Lam. Encyc. ii. $79=$ Lactuca repens.

rhombifolia, Humb. ex Willd. Sp. Pl. iii. 1535-36=

Prenanthes rhombifolia.

rigens, Reichb. F1. Germ. Excurs, $271=$ juncea.

Rouillieri, Kar. E Kir. in Bull. Soc. Nat. Mosc. (1841) 456.-Sibir. altaic.

rubicunda, Poir. Encyc. Suppl. ii. $329=$ Prenanthes alba.

ruderalis, Gaertn. ex Steud. Nom. ed. I. 191, $655=$ Lactuca muralis.

runcinata, Wall. Cat. n. $3272=$ Crepis japonica

sagittata, Wall.'1. c. n. $3270=$ Lactuca sagittarioides.

sarmentosa, Poir. Encyc. Suppl. ii. $529=$ Launaea pinnatifida.

Schraderi, Steud. Nom. ed. II. ii. 393, in syn.= aspera.

secunda, Royle, ex C. B. Clarke, Comp. Ind. $276=$ Launaea secunda.

Sessaeana, D. Don, in Trans. Linn. Soc. xvi. (1833) $180=$ Pyrrhopappus Sessaeanus.

sessiliflora, Lam. Fl. Fr. ii. 104=Lactuca viminea

setulosa, C. B. Clarke, ex Hook. f. Fl. Brit. Ind. iii 402.- Himal. bor. occ.

sonchifolia, Poir. Encyc. Suppl. ii. $330=$ Lactuca Heyneana.

soongarica, Stschegl. in Bull. Soc. Nat. Mosc. xxvii.

(1854) 1. 179.-Soongar.

squarrosa, Poir. Encyc. Suppl, ii. $332=$ Lactuca brevirostris.

stipitata, Sch. Bip. in Linnaea, xv. (1841) 553.Europ.

stricta, Ledeb. Fl. Alt. iv. 146.-Sibir. altaic.

tenuifolia, Lam. Encyc. ii. $78=$ Prenanthes purpurea.

tenuis, Buch.-Ham. in Wall. Cat. n. $3274=$ Lactuca polycephala.

\section{CHONDRILLA:}

triquetra, Steud. Nom. ed. I. 191 ; ed. II. i. $354=$ Lactuca triquetra.

versicolor, Sch. Bip. in Mus. Senckenb. iii. (1845) 49, in obs. 2 = Lactuca Fischeriana.

viminea, Lam. Encyc. ii. $27=$ Lactuca viminea.

virgata, Poir. Encyc. Suppl。ii. $328=$ Prenanthes virgata.

virgata, J. \& C. Presl, Delic. Prag. $116=$ juncea.

viscosa, Gilib. Fl. Lituan. i. $232=$ juncea.

CHONDROCARPUS, Nutt. Gen. Am. ii. in corrigend.

(1818) = Hydrocotyle, Linn. (Umbellif.).

asiaticus, Nutt. 1. c.-Cf, i. $177=\mathrm{H}$, asiatica

erectus, Wats. Bibliog. Ind. N. Am. Bot. 425, sphalm. $=\mathrm{H}$. repanda.

repandus, Nutt. Gen. Am. ii. in corrigend.-Cf. i. 177 $=\mathrm{H}$. repanda.

sibthorpioides, Sweet, Hort. Brit. ed. I. $185=\mathrm{H}$. rotundifolia.

triflorus, Nutt. Gen. Am. ii. in corrigend.-Cf. i. 177 $=\mathrm{H}$. asiatica.

CHONDROCARPUS, Stev, in Bull. Soc. Nat. Mosc. iv. (1832) 268 = Astragalus, Tourn. (Legumin.).

brachycarpos, Stev. 1. c. $=$ A. brachycarpus.

clavatus, Stev. I. c. xxix. (1856) II. $149=$ A. clavatus.

elongatus, Stev. 1. c. iv. (1832) 268=A. elongatus.

incurvus, Stev. 1. c. $=$ A. incurvus.

macrorhizus, Stev, l. c. =A. macrorrhizus.

nummularioides, Stev. 1. c. xxix. (1856) II. $149=\mathrm{A}$.

nummularioides.

platyphyllus, Stev。 1, c.=A. platyphyllus.

CHONDROCHILUS, Phil. in Linnaea, xxviii. (1856)

$711=$ Chaetanthera, Ruiz \& Pav. (Compos.).

crenatus, Phil. 1. c.-Chili.

involucratus, Phil. Fl. Atac. 27.-Chili.

parvifolius, Phil. in Linnaea, xxxiii. (1864-65) 114.Chili.

CHONDROLAENA, Nees, Fl. Afr. Austr. Gram. 133 $(1841)=$ Prionachne, Nees (Gramin.)

dentata, Stend. Nom. ed. II. i. 355, sphalm. = seq. phalaroides, Nees, F1. Afr. Austr. Gram. $134=$ P. Ecklonii.

CHONDRODENDRON, Spreng. Syst. ii. 155, in syn.

$(1825)=$ Chondodendron, Ruiz \& Pav. (Menisp.).

CHONDROLOMIA, Nees, in Mart. F1. Bras. ii. I. 173 $(1842)=$ Scleria, Berg. (Cyperac.)

Selloviana, Nees, 1. c. $174=$ S. Sellowiana.

CHONDROPETALUM, Rottb. Progr. 12 (1772) ; Desc. 10. t. $3(1773)=$ Elegia, Linn. (Restiac. $)$.

deustum, Rottb. 11. cc. $=$ E. deusta.

nudum, Rottb. 11. cc. $12,11=\mathrm{E}$. nuda.

tectorum, Rafin. Fl. Tellur. iv. $33=$ E. deusta.

CHONDROPIS, Rafin. Fl. Tellur. iii. $29(1836)=$ Exacum, Linn. (Gentian.).

trinervis, Rafin. 1. c. = E. zeylanicum.

CHONDRORHYNCHA, Lindl. Orch. Linden. 12 (1846). ORCHIDEAE, Benth. \& Hook. f. iii. 548. Chestertoni, Reichb. f. in Gard. Chron. (1879),II. 648. -N. Granat.

fimbriata, Reichb. f. in Saund. Refug. Bot. t. 107.N. Granat.

rosea, Lindl. Orch. Linden. 13.-Venezuela.

CHONDROSEA, Haw. Saxifr. Enum. 10 (1821) = Saxifraga, Tourn.

Aizoon, Haw. 1. c. $11=$ S. Aizoon.

aizoopsis, Jord. \& Fourr. Ic. Pl. Eur. ii. $5=$ S. Aizoon. alpicola, Jord. \& Fourr. Brev. Pl. Nov, fasc. i. $34=$ S. Aizoon.

aretioides, Haw, Saxifr. Enum. $14=$ S. aretioides. beugesiaca, Jord. \& Fourr. Brev. Pl. Nov. fasc. i. $33=$ S. Aizoon.

brevicaulis, Jord. \& Fourr. Ic. Pl. Eur. ii. 3S. Aizoon.

Burseriana, Haw. Saxifr. Enum. 15=S. Burseriana. caesia, Haw, 1, c. $14=$ S. caesia.

calcarea, Jord. \& Fourr. Ic. Pl. Eur. ii. $3=$ S. Aizoon. calyciflora, Haw. Saxifr. Enum, $13=\mathrm{S}$. media. 
CHONDROSEA :-

carthusiana, Jord. \& Fourr. Ic. Pl. Eur. ii. $3=$ Saxifraga Aizoon.

cartilaginea, Haw. Saxifr. Enum. $12=$ S. cartilaginea diapensoides, Haw. $1_{\text {c c. }} 13=\mathrm{S}$, diapensoides. flexipes, Jord. \& Fourr. Ic. Pl. Eur. ii. $3=$ S. Aizoon. glabrata, Jord. \& Fourr. Brev. Pl. Nov. fasc. i. $34=$ S. Aizoon.

glareosa, Jord. \& Fourr. Ic. Pl. Eur. ii. $4=$ S. Aizoon. gracilescens, Jord. \& Fourr. Brev. P1. Nov。 fasc. i. $35=$ S. Aizoon.

intermedia, Haw. Saxifr. Enum. $11=$ S. intermedia.

juniperina, Haw. 1. c. $15=$ S. juniperifolia.

laevigata, Jord. \& Fourr. Ic. Pl. Eur. ii. $5=$ S. Aizoon.

leptopetala, Jord. \& Fourr. Brev. Pl, Nov, fasc. i. $34=$ S. Aizoon.

longifolia, Haw. Saxifr. Enum. $11=\mathrm{S}$. longifolia. luteo-purpurea, Haw. 1. c. $13=$ S. luteopurpurea.

mutata, Haw. 1. c. $=$ S. mutata.

nitida, Haw. l. c. $16=\mathrm{S}$, nitida.

orophila, Jord. \& Fourr. Brev, Pl. Nov, fasc. i. $33=$ S. Aizoon.

patens, Haw. Saxifr. Enum. $14=$ S. caesia

patulipes, Jord. \& Fourr. Ic. Pl. Eur. ii. $4=$ S. Aizoon. petrophila, Jord, \& Fourr. Brev. Pl. Nov. fasc. i. $34=$

S. Aizoon.

punctillata, Jord. \& Fourr. 1. c. $33=$ S. Aizoon.

pusilla, Jord. \& Fourr. Ic. Pl. Eur. ii. $3=$ S. Aizoon.

pyramidalis, Haw. Saxifr. Enum. $10=\mathrm{S}$. Aizoon.

refracta, Jord. \& Fourr. Ic. Pl. Eur. ii. $4=$ S. Aizoon.

rosella, Jord. \& Fourr. 1. c. $=$ S. Aizoon.

rosularis, Haw. Saxifr. Enum, $12=$ S. Aizoon.

tenella, Haw. 1. c. $15=\mathrm{S}$. tenella.

valida, Jord. \& Fourr. Brev. P1. Nov. fasc. i. $32=$ S. Aizoon.

Vandellii, Haw. Saxifr. Enum. 15=S. Vandelli.

virgata, Jord. \& Fourr. Ic. Pl. Eur. ii. $4=$ S. Aizoon.

viridula, Jord. \& Fourr. Brev. Pl. Nov, fasc. i. $33=$

S. Aizoon.

CHONDROSIA, Bentk, in Journ. Linn. Soc. xix. 1881) 104 , err. typ. $=$ seq.

CHONDROSIUM, Desv。 Journ. Bot. iii. (1813) $68=$ seq.

CHONDROSUM, Desv. in Nonv. Bull. Soc. Philom. ii. (1810) 188 = Bouteloua, Lag. (Gramin.)

Aschenbornianum, Nees, in Linnaea, xix. (1847) $692=$ B. oligostachya.

ciliatum, Beauv. Agrost. 41, nomen = Chloris ciliata

eriopodum, Torr. in Emory, Notes Mil. Reconnois. 153 $=$ B. eriopoda.

exile, Fourn. Mex. Pl. Enum. Gram. 137, ex Hemsl. Biol. Centr. Am. Bot. iii. 564.-Mexic.

foeneum, Torr. in Emory, Notes Mil. Reconnois. 153. t. $12=$ B. hirsuta .

gracile, H. B. \& K. Nov. Gen. et. Sp. i. 176. t. $58=$ B. oligostachya.

hirsutım, Sweet, Hort. Brit. ed. I. 455 , nomen $=$ seq. ? hirtum, H. B. \& K. Nov. Gen. et Sp. i. 176, t. $59=$

B. hirsuta.

Humboldtianum, Kunth, Rev. Gram. i. $93=$ B. ovata.

humile, Beauv. Agrost. $41=$ B. prostrata.

Karvvinskii, Fourn. Mex. Pl. Enum. Gram. 137, ex Hemsl. Biol. Centr. Am. Bot. iii. 564.-Mexic

microstachyum, Fourn, 1. c. 198, ex Hemsl. 1. c. $562=$ B. polystachya.

oligostachyum, Torr. in Marcy, Rep. $300=$ B. oligostachya.

Parryi, Fourn. Mex. P1. Enum. Gram. 150, ex Hems1. Biol. Centr. Am. Bot, iii. $562=$ B. polystachya.

polystachyum, Benth. Bot. Voy. Sulph. $56=$ B. polystachya.

procumbens, Desv. in Nouv. Bull. Soc. Philom.ii. (1810 $188=$ B. tenuis.

prostratum, Sweet, Hort. Brit. ed. I. $455=$ B. prostrata.

scorpioides, Kunth, Rev. Gram. i. $94=$ B. scorpioides. simplex, Kunth, 1. c. $=$ B. prostrata.

subscorpioides, C. Muell. in Bot. Zeit. xiv. (1856) 347 -Calif.

tenue, Beauv. Agrost. $41=$ B. tenuis.

I'irletii, Fourn. Mex. Pl. Enum. Gram. 196, ex Hemsl Biol. Centr. Am. Bot. iii. 564.-Mexic.
CHONDROSPERMUM, Wall. Cat. n. $2837(1832)=$

Myxopyrum, Blume (Oleac.)

coriaceum, Wall. 1. c. n. $2838=$ M. smilacifolium

laurifolium, Voigt, Hort. Suburb. Calc. $548=$ M. smilacifolium

smilacifotium, Wall. Cat. n. $2837=$ M. smilacifolium.

CHONEMIORPHA, G. Don, Gen. Syst, iv, 76 (1836) $A P O C Y N A C E A E$, Benth. \& Hook. f. ii. 720

Epichysianthus, Voigt, Hort. Suburb. Calc. 523 (1845)

antidysenterica, G. Don, 1. c. = Holarrhena antidysenterica.

bantamensis, G. Don, 1, c. = Echites bantamensis

convolvuloides, $G$. Don, $l$. $c_{0}$-Ins. S. Thomas.

coriacea, G. Don, 1. c。= Echites coriacea.

cristata, G. Don, 1. c. = Aganosma marginata

densiflora, G. Don, 1. c. = Echites densiflora.

dichotoma, G. Don, 1. c. = Aganosma caryophyllata.

grandiflora, G. Don, 1. c. = macrophylla.

Griffithi, Hook. f. Fl. Brit. Ind. ii. 662.-Reg. Himal.

inflata, G. Don, Gen. Syst. iv. $76=$ Echites inflata.

macrophylla, G. Don, l. c.-Ind. or.; Malaya.

malabarica, $G$. Don, l. $c_{\text {. }}$-Ind, or.

mollis, Miq. F1. Ind. Bat. ii. $444=$ macrophylla

pubescens, G. Don, in Sweet, Hort. Brit. ed. III. $458=$

Holarrhena antidysenterica.

reticulata, G. Don, Gen. Syst. iv. $76=$ Cryptolepis

Buchanani.

vestita, G. Don, 1. c. $=$ Wrightia tomentosa?

CHORETIS, Herb. Amaryll. 219, f. 35 (1837)= تHymenocallis, Salisb. (Amaryllid.)

galvestonensis, Herb. 1. c. 221 . t. 41 . f. $34,35=\mathrm{H}$. galvestonensis.

glauca, Herb. 1. c. 220, t. 35. f. $1=\mathrm{H}$, glauca.

CHORETRUM, R. Br. Prod. 354 (1810). SAN.

TALACEAE, Benth. \& Hook. f. ini. 228.

Candollei, F. Muell. ex Benth. Fl. Austral. vi. 219.Austral.

chrysanthum, F. Muell. in Trans. Phil. Soc. Vict. i. (1855) $23=$ glomeratum.

glomeratum, R. Br. Prod.354.-Austral.

lateriflorum, A. DC. in DC. Prod. xiv. $675=$ Candollei.

lateriflorum, $R$, Br. Prod. 354,-Austral.

oxycladum, F. Muell. Fragm. i. 21.-Austral.

pauciflorum, A. DC. in DC. Prod. xiv. $676=$ lateriflorum.

Preissianum, Miq. in Lehm. PI. Preiss. i. $608=$ Leptomeria Preissiana.

spicatum, F. Muell. Fragm. i. 21.-Austral

spinosum, Miq. in Lehm. P1. Preiss. i. $609=$ Leptomeria spinosa.

CHORIBENA, Steud. Nom. ed. II. i. 355 (1840), sphalm. Chorilaena, Endl. (Rutac.).

CHORICARPHA, Boeck. in Flora, xli. (1858) $19=$ Lepironia, Rich. (Cyperac.)

aphylla, Boeck. 1. c. $20=$ L. mucronata.

CHORICERAS, Baill. Adansonia, xi. (1873) $119=$ Dissiliaria, F. Mnell. (Enphorbiac.).

australiana, Baill. 1. c. $120=$ D. tricomis ?

CHORIIAENA, Endl. Enum. Pl. Hueg. 17 (1837) RUTACEAE, Benth. \& Hook. f. i. 295. angustifolia, F. Muell. in Trans. Phil. Soc. Vict. (1855) $10=$ Phebalium diosmeum.

hirsuta, Benth. Fl. Austral. 1. 357.-Austral.

myoporoides, Endl. ex Heynh. Nom, ii. 140.-Austral. quercifolia, Endl. Enum. Pl. Hueg. 17.-Austral.

CHORIOPHYLLUM, Benth. in Hook. Ic. Pl.t. 1280 (1829). EUPHORBIACEAE, Benth. \& Hook. f, iii. 280.

malayanum, Benth. l. c.-Malaya.

CHORIOZANDRA, Steud. Nom. ed. II. i. $\$ 55(1840$ sphalm $=$ Chorizandra, R. Br. (Cyperac.).

CHORIPETALUM, A. DC in Trans. Linn. Soc. xvii. (1884) 131 = Embelia, Burm. f. (Myrsin.) aurantiacum, A. DC. 1. C. $=\mathrm{E}$. viridiflora.
CHORIPETALUM:-

australianum, F. Maell. Fragm, iii. 36 (=Samara australiana).-Austral.

Benthamii, Hance, in Walp. Ann. iii. $10=$ obovatum. obovatum, Benth. in Hook. Lond. Joum. Bot. i. (1842) 490.--Ins. Hongkong.

Reevesianum, Wall. ex Voigt, Hort. Suburb. Calc 338 , nomen $=$ obovatum?

undulatum, A. DC. in Trans, Linn. Soc. xvii. (1837) $132=$ E. Nagushía.

viridiflorum, A. DC. in DC. Prod. viii. $88=\mathrm{E}$. viridi flora.

CHORISANDRA, Benth. \& Hook, f Gen, iii. 1057 (1883) err. typ. = Chorizandra, R. Br. (Cyperac.).

CHORISANDRA, Wight, Ic. vi. 13. t. 1994 (1853)= Fluggea, Willd. (Euphorbiac.)

pinnata, Wight, 1. c. = F. microcarpa.

CHORISANTHERA, Oerst. in Vidensk. Selsk. Skr. V. 1861) $109=$ Pentarhaphia, Lindl. (Gesnerac.). tenera, Oerst. 1. c. $=$ P. tenera.

CHORISEMA, Fisch. Ind. Sem. Hort. Petrop. viii. 5 1841) err, typ, = Chorizema, Labill. (Legumin.)

CHORIsia, H. B. \&c K. Nov. Gen. et Sp. .295. 485 (1821). MALVACEAE, Bentb. \& Hook. f. i 210.

crispiffora, $H . B . \&$ E. l. c. 297.-Bras.

insignis, H. B. E K. l. c. t. 485. f. 1.-Peruy.

rosea, Seem. Bot. Voy. Herald, 84.- N. Granat.

speciosa, St. Hil. Pl. Us. Bras. t. 63.-Bras.

ventricosa, Nees \& Mart. in Nov. Act. Nat. Cur. xi.

(1823) 102. t. $9=$ crispiflora

CHORISIS, DC. Prod. vii. $177(1838)=$ Lactuca Tourn. (Compos.)

repens, DC. 1. c. $178=\mathrm{L}$. repens.

CHORISMA, D. Don, in Edin, N. Phil. Journ. (1828-29) $308=$ CHORISIS, DC. = Lactuca, Linn. (Compos.) repens, D. Don, 1. c. $=$ L. repens.

CHORISMA, Lindl, in Sweet, Geran. sub t. $79(1820)=$ Pelargonium, L'Hérit. (Geraniac.)

fiavescens, Eckl. \& Zeyb. Enum. $71=$ P. tetragonum.

tetragona, Lindl. in Sweet, Geran. sub t. $79=\mathrm{P}$. tetra gonum.

CHORISPERMUM, R. Br. in Ait. Hort, Kew, ed, II. iv, $129(1812)=$ Chorispora, R. Br. (Crucifer.)

arcuatum, Andrz. ex DC. Syst. ii. $436=$ Chorispora tenella.

ibericum, Andrz. ex DC. 1. c. $437=$ Chorispora iberica.

sibiricum, Andrz, ex DC. 1. c. = Chorispora sibirica

strictum, Andrz. ex DC. 1. c. $436=$ Diptychocarpus strictus.

tenellum, R. Br. in Ait. Hort, Kew, ed. II. iv. $129=$ Chorispora tenella.

CHORISPORA, R. Br. ex DC. Syst. it. $\$ 85$ (18:2) CRUCIFERAE, Benth. \& Hook. f. i. $10 \%$.

CHORISPERMUM, R. Br. in Ait. Hort. Kew. ed. II. iv. $129(1812)$

Bungeana, Fisch. \& Mey. in Enum. Pl. Nov. Schrenk, $96=$ exscapa.

compressa, Boiss, in Ann. Sc. Nat. Sér. II. xvii. $18: 2$ 385 -iberica?

elegars, Cambess. in Jacquem. Voy. Bot. 15. \&. $14=$ sabulosa.

exscapa, Bunge, in Ledeb. Fl. Ross. i. 169.-Sibir. altaic.

Greigi, Regel, Gartenf. (18;9) 257. t. y84.-As.

hispida, Regel, in Bull. Soc. Nat. Mase. xliii. (18;0) I. 266. - As. temp.

iberica, DC. Syst. ii. 48:- As Min. : Persia.

macropoda, Traute in Bull. Soc. Nal. dVosc xxxiii. (1560) I. 109. Socnuraria.

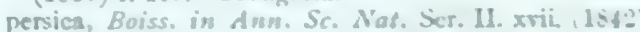
Sit.-Persia.

sabulosa, Cambrss. in Gargurm. Boy. But. 15. 2. 15.Keg. Himal. : Af chan.

sibirica, $D C$. Syst, ii. 197 . - Sibir, altaic; "litc: 


\section{CHORISPORA :-}

sibirica, Regel \& Herd. in Bull. Soc. Nat, Mosc. xliii (1870) I. $266=$ macropoda.

songarica, Fisch. E Mey. Enum. Pl. Nov. Schrenk, ii. 57.--Soongar.

stenopetala, Regel Es Schmalh. in Act. Hort. Petrop.v.

1877) 239.-Taschkent.

stricta, DC. Syst. ii, $436=$ Diptychocarpus strictus.

syriaca, Boiss. in Ann. Sc. Nat. Sér. II. xvii. (1842) 384.-Syria.

tenella, DC. Syst. ii. 435.-Reg. Caucas. et Himal.; Persia; Afghanist.

CHORISTEA, Thunb. Prod. Pl. Cap. 163 (1800); Nov. Gen. $179(1801)=$ Didelta, L'Hérit. $($ Compos. $)$. carnosa, Thunb. 11. cc. $163,180=\mathrm{D}$. camosa. glabra, Soland. ex Poir. Encyc: v. $507=$ D. spinosa spinosa, Thunb. Prod. P1. Cap. 163; Nov. Gen. $180=$ D. spinosa

CHORTSTES, Benth. PI. Hartw, $63(1840)=$ Deppea Cham. \& Schlecht. (Rubiac.).

cornifolia, Benth. 1. c. $64=\mathrm{D}$. cornifolia.

excelsa, Benth. 1. $c_{0}=$ Psychotria excelsa.

obtusiflora, Benth. 1. c. $63=\mathrm{D}$. obtusiflora.

CHORISTYLIS, Harv. in Hook. Lond. Joum. Bot. i. (1842) 19. SAXIFRAGEAE, Benth. \& Hook. f. i 647 . rhamnoides, Havv. l. c.-Afr. austr.

CHORITAFNIA, Benth. in Benth. \& Hook. f. Gen. i. 907 (1867). UMBELLIFERAE, Benth. \& Hook. f. 1. c. PAPPEA, Sond. \& Harv. F1. Cap. ii. 562 (1862).

CHORIZANDRA, Benth. \& Hook. f. Gen. iii. 275, in textu $(1880)=$ CHORISANDRA, Wight $=$ Fluggea Willd. (Euphorb.).

CHORIZANDRA, R. Br. Prod. 221 (1810), $C Y$ PERACEAE, Benth. \& Hook. f. iii. 1057.

cymbaria, $R$. Br. l. c.-Austral.

enodis, Nees, in Lehm. Pl. Preiss. ii. 73.-Austral multiarticulata, Nees, in Ann. Nat. Hist. Ser. I. vi. (1841) 48. -Austral.

sphaerocephala, R. Br. Prod.221.-Austral.

CHORIZANTHE, R. Br. ex Benth. in Trans. Linn Soc. xvii. (1836) 416. t. 19. POEYGONACEAE, Benth. \& Hook. f. iii. 93.

ACAnthogonum, Torr, in Pacif. Rail. Rep. iv. 132 (1856).

MUCRoneA, Benth. in Trans. Linn. Soc. xvii. (1836) 419. t. 20.

Trigonocarpus, Bert. ex Steud. Nom. ed. II. ii. $710(1841)$.

angustifolia, Nutt. in Fourn. Acad. Philad. N. S. i. (1847) 167.-Calif.

brevicornu, Torr. in Bot. Mex. Bound. 177.-Am. bor. occ.

Breweri, S. Wats. in Proc. Am. Acad. xii. (1877) 270 -Calif.

californica, A. Gray, in Proc. Bost. Soc. Nat. Hist. vii. (1861) 149.-Calif

Clevelandi, Parry, in Proc. Davenp. Acad. iv. (1884) 62.-Am. bor. occ.

commisuralis, Remy, in C. Gay, Fl. Chil. v. 287.Chili.

corrugata, Torr. E Gray, in Proc. Am. Acad. viii. (1870) 198.-Calif

dasyantha, Phil. in Linnaea, xxxiii. (1864-65) 227.Chili.

diffusa, Benth. Pl. Hartw. 333.-Calif

discolor, Nutt. in Fourn. Acad. Philad. N. S. i (1847) 167.-Calif.

Douglasii, Benth. in Trans. Linn. Soc. xvii. (1836) 418.-Calif

fernandina, S. Wats. Bot. Calif. ii. 481.-Calif.

fimbriata, Nutt. in Fourn. Acad. Philad. N. S. i. (1847) 168.-Calif.

flavescens, Phil. in Linnaea, xxxiii. (1864-65) 226.Chili.

frankenioides, Remy, in C. Gay, Fl. Chil. v. 288.Chili.

glabrescens, Benth. in Trans. Linn. Soc. xvii. (1836) 418.-Chili.

Kingii, Phil. in Anal. Univ. Chil. (1873) 536.-Chili.

\section{CHORIZANTHE:-}

laciniata, Torr. in Pacif. Rail. Rep. vii. 19.-Calif.

Lastarriaea, Parry, in Proc. Davenp. Acad. iv. (1884)

63.-Am. bor, occ.

leptoceras, S. Wats. in Proc. Am. Acad. xii. (1877) 269.-Calif.

Macraei, Benth. in Trans. Linn. Soc. xvii. (1836) 417. - Chili.

membranacea, Benth, l. c. 419-Chili.

nudicaule, Benth. Pl. Hartw. $332=$ Douglasii

nudicaule, Nutt. in Fourn. Acad. Philad. N. S. i. (1847) 166.-Calif.

Orcuttiana, Parry, in Proc. Davenp. Acad. iv. (1884 54.-Am bor occ

Palmeri, S. Wats. in Proc. Am. Acad. xii. (1877) 271 -Calif.

paniculata, Benth. in Trans. Linn. Soc. xvii. (1836) 417.-Chili.

Parryi, S. Wats. in Proc. Am. Acad. xii. (1877) 271.Calif.

peduncularis, Benth. in Trans. Linn. Soc. xvii. (1836) 416.-Chili.

perfoliata, A. Gray, in Proc. Bost. Soc. Nat. Hist. vii (1861) 148.-Calif.

polygonoides, A. Gray, in Proc. Am. Acad. viii. (1870) 197.-Calif.

procumbens, A. Gray, in Proc. Bost. Soc. Nat. Hist. vii. (1861) $148=$ Xanti.

procumbens, Nutt. in Fourn. Acad. Philad. N. S. (1847) 167.-Calif.

pungens, Benth. in Trans. Linn. Soc. xvii. (1836) 419 -Calif.

ramosissima, Benth. l. c. 417.-Chili.

rigida, Torr. E Gray, in Proc. Am. Acad. viii. (1870) 198.-Am. bor. occ.

rosea, Phil. in Linnaea, xxxiii. (1864-65) 225. Chili.

spinosa, S. Wats. Bot. Calif, i.. 481.-Calif.

staticoides, Benth. in Trans. Linn. Soc. xvii. (1836) 418.-Calif.

stellulata, Benth. Pl. Hartw. 333.-Calif

tenuis, Phil. in Linnaea, xxxiii. (1864-65) 227 . Chili.

Thurberi, S. Wats. in Proc. Am. Acad. xii. (1877) 269 -Am. bor occ.

umbellata, Phil. in Linnaea, xxxiii. (1864-65) 225.Chili.

uncinata, Nutt. in Fourn. Acad. Philad. N. S. i. (1847) 167.-Calif.

uniaristata, Torr. E Gray, in Proc. Am. Acad. viii (1870) 195.-Calif.

vaginata, Benth. in Trans. Linn. Soc. xvii. (1836) 417 -Chili.

valida, S. Wats. in Proc. Am. Acad. xî. (1877) 271.Calif.

virgata, Benth. in Trans. Linn. Soc. xvii. (1836) 416 t. 19. f. 1.-Chili.

Watsoni, A. Gray, in Proc. Am. Acad. viii. (1870) 199 -..Calif.

Wheeleri, S. Wats. l. c. xii. (1877) 272.-Calif.

Xanti, S. Wats. l. c.-Calif.

CHORIZEMA, Labill. Voy, i. 403, t, 21 (1799) LEGUMINOSAE, Benth. \& Hook. f. i. 467 Orthotropis, Benth. in Lindl, Swan River App. 16 (1839).

angustifolium, Benth. Enum. Pl. Hueg. 28.-Austral.

Baueri, Benth. in Ann. Wien. Mus. ii. (1838) $71=$

Mirbelia pungens.

Baueri, Meissn. in Lehm. Pl. Preiss. i. 34 ; ii. 209 Henchmanni.

Baxteri, R. Grah, in Edinb. Phil. Journ. (Apr.-June 1831) $187=$ Oxylobium scandens.

callistachys, F. Muell. Fragm. iv. 18= Oxylobium callistachys.

capillipes, Turcz. in Bull. Soc. Nat. Mosc. xxvi. (1853) I. 255 = angustifolium

Chandleri, Hort. ex Nichols. Dict. Gard. i. $318=$ varium.

cordatum, Lindl. Bot. Reg. (1838) t. 10.-Austral.

cordifolium, F. Muell. Fragm. iv. $17=$ Oxylobium cordifolium.

coriaceum, Sm. in Trans. Linn. Soc. ix. (1808) $254=$ Oxylobium retusum

costatum, Meissn, in Lehm. P1. Preiss. i. $33=$ Dicksoni.

cytisoides, Turcz. in Bull. Soc. Nat. Mose. xxvi. (1853) I. 256.-Austral.

\section{CHORIZEMA :-}

daviesioides, Meissn. in Lehm. Pl. Preiss, i. $34=$ Mirbelia daviesioides.

denticulatum, Turcz. in Bull. Soc. Nat. Mosc. xxvi. (1853) I. 252 = angustifolium.

Dicksoni, R. Grah. in Maund, Botanist, iii. t. 106.Austral.

diversifolium, A. DC. Pl. Rar. Fard. Genèv. $7^{\circ} \mathrm{Not}$. (1836) 44. t. 8.-Austral.

ellipticum, F. Muell. Pl. Vict. ii. $39=$ Oxylobium ellipticum.

ericifolium, Meissn. in Lehm. Pl. Preiss. ii. 209.Austral.

ericoides, Hort. Belg. ex Heynh. Nom. ii. $141=$ praec.?

flavum, Henfrey, in Moore \& Ayres, Gard. Mag. Bot. i, 73. $t .7=$ cordatum

gomphocarpum, Benth. ex A. Gray, in Bot. U. St. Expl. Exped. i. 380.-Austral.

Henchmanni, R. Br. in Bot. Reg. t. 986.-Austral.

heterophyllum, Turcz. in Bull, Soc. Nat. Mosc. xxvi. (1853) I. 255=Oxylobium heterophyllum.

humile, Turcz. l. c. 254.-Austral.

ilicifolium, Labill. Voy. i. 405.-Austral.

ilicifolium, Steud. Nom. ed. II. i. 356 , sphalm. = Oxylobium trilobatum.

Leichhardtii, F. Muell. Fragm. iv. $20=$ Isotropis filicaulis.

lineare, F. Muell. Fragm. iv. $17=$ Oxylobium lineare. magnifolium, F. Muell. 1. c. $18=$ Mirbelia racemosa. nanum, Sims, Bot. Mag. t. $1032=$ ilicifolium.

nervosum, T. Moore, in Gard. Comp. (1852) 122 Austral.

ovatum, Lindl. Bot. Reg. t. $1528=$ rhombeum

parviflorum, Benth. in Ann. Wien. Mus, ii. (1838) 71 . -Austral.

parvifolium, Turcz. in Bull. Soc. Nat. Mose xxvi. (1853) I. $253=$ nervosum.

platylobioides, DC. Prod. ii. 103=Mirbelia grandiflora.

pubescens, Turcz. in Bull. Soc. Nat. Mosc. xxvi. (1853) I. $256=$ Oxylobium carinatum.

Pultenaeae, F. Muell. Fragm. iv. 19 = parvifiorum.

reticulatum, Meissn. in Lehm. Pl. Preiss. i. 34.Austral.

rhombeum, R. Br. in Ait. Hort. Kew. ed. II. iii.9.Austral.

rhombeum, Lodd. Bot. Cab. t. $1619=$ diversifolium.

rhynchotropis, Meissn. in Lehm. Pl. Preiss. ii. $209=$ Henchmanni.

scandens, Sm. in Trans. Linn. Soc. ix. (1808) $253=$ Oxylobium scandens.

sericeum, Sm. 1. c. = Brachysema undulatum.

spartioides, Lodd. Bot. Cab. t. 1953=Isotropis striata. spectabile, Lindl. Bot. Reg. (1841) t. $45=$ diversifolium.

superbum, Lem. Illustr. Hortic. i... (1854) t. $29=$ cordatum.

triangulare, Lindl. Bot. Reg. t. $1513=$ ilicifolium.

trigonum, Turcz. in Bull. Soc. Nat. Mosc. xxvi. (1853) I. 254.-Austral.

trilobatum, DC. Prod. ii. 103, sphalm. = seq.

trilobum, Sm. in Trans. Linn. Soc. ix. (1808) $253=$ Oxylobium trilobatum.

varium, Benth.ex Lindl. Bot. Reg. (1839) t. 49; Misc. 45.-Austral.

CHORIZOTHECA, Muell. Arg. in Linnaea, xxxii. (1863) $76=$ Pseudanthus, Sieber (Euphorbiac.). micrantheoides, Muell. Arg. 1. c. $=$ P. virgatus.

CHOROBANCHE, Presl, Bot. Bemerk. 91 (1845) (Chorobane) $=$ Orobanche, Linn .

indica, Presl, 1. c. $=$ O. indica.

CHOROSEMA, Brongn. Enum. Gen. 126 (1843)= Chorizema, Labill. (Legumin.),

CHOROZEMA, Sm. in Trans. Linn. Soc. ix. (1808) 251, sphalm.= Chorizema, Labill. (Legumin.)

CHORYZEMUM, Bosc, Encyc. Agric. vii. 297 (1822) $=$ praec.

CHOTECKIA, Steud. Nom. ed. II i. 356 (1840), sphalm. = seq. 
CHOTEKIA, Opiz \& Corda; in Flora, xiii. (1830) I. 33 = Dysophylla, Blume (Labiat.).

sericea, Opiz \& Corda, 1. c. $35=\mathrm{D}$. quadrifolia.

CHOUleTTIA, Pomel, Nouv. Mat. Fl. Atl. 81 (1874) Gaillonia, A. Rich. (Rubiac.).

Reboudiana, Pomel, 1. c. $=$ G. Reboudiana.

CHRESTA, Vell. F1. Flum. viii. t. 150, $151(1827)=$ Eremanthus, Linn. (Compos.).

alpestris, Gardn. in Hook. Lond. Journ. Bot. i. (1842) $239=$ Vemonia alpestris.

angustifolia, Gardn. 1. c. $240=\mathrm{E}$. angustifolius.

cordata, Vell. Fl. Flum. viii. t. $150=$ E. sphaero. cephalus.

exsucca, DC. Prod v, $85=\mathrm{E}$. exsuccus.

intermedia, Gardn. in Hook. Lond. Journ. Bot. v, (1846) $236=\mathrm{E}$. sphaerocephalus.

lanceolata, Vell. Fl. Flum. viii. t. $151=$ Vanillosmopsis erythropappa.

plantaginifolium, Gardn. in Hook. Lond: Journ. Bot.

i. $(1842) 241=\mathrm{E}$. plantaginifolius

pycnocephala, DC. Prod. v. $85=\mathrm{E}$. pycnocephalus.

scapigera, Gardn. in Hook. Lond. Journ. Bot. i. (1842 $\mathbf{2} 4 \mathbf{1}=\mathrm{E}$. scapigerus.

speciosa, Gardn. 1. c. $240=$ E. speciosus.

sphaerocephala, DC. in Deless. Ic. Sel. iv. 2. t. $6=\mathrm{E}$.

sphaerocephalus.
spathulaefolia, Gardn. in Hook. Lond. Journ. Bot. i. (1842) $241=\mathrm{E}$. plantaginifolius.

CHRISANTHEMUM, Neck. Delic. Gallo-Belg. ii. 358 $(\mathbf{1 7 6 8 )}=$ Chrysanthemum, Tourn. (Compos.).

CHRISOSPLENIUM, Neck. Delic. Gallo-Belg. i. 190 $(1768)=$ Chrysosplenium, Tourn. (Saxifrag.).

CHRISTANNIA, Presl, Rel. Haenk. ii. 91, t. 67 (1831) = Banara, Aubl. (Samydac.).

salicifolia, Presl, 1. c $:=$ B. incana.

CHRISTANNIA, Walp. Rep. i. 360 (1842), sphalm. = Christiana, DC. (Tiliac.).

CHRISTIA, Moench, Meth. Suppl. $39(1802)=$ Lourea, Neck. (Legumin.).

lunata, Moench, 1. c. $40=\mathrm{L}$. vespertilionis.

CHRIstianA, DC. Prod. i. 516 (1824). TILIACEAE, Benth, \& Hook, fo i. 232.

africana, $D C$. l. c.-Afr. trop

cordifolia, Hook, f. in Niger F1. 238=africana.

madagascariensis, Baill. in Bull. Soc. Linn. Par. i. (1885) 542.-Madag.

CHRISTISONIA, Gardn. in Calc. Journ. Nat. Hist. viii. (1847) 153. OROBANCHACEAE, Benth. \& Hook. f. ii. 982 .

CAMPBEllia, Wight; Ic. iv. 5. t. 1424,1425 (1850).

OLIGOPHOLIS, Wight, 1. c. t: $1422(1850)$

albida, Thw. ex Hook. f. Fl. Brit. Ind. iv. 323.Zeylan.

aurantiaca, Wight, Ic. iv. t. $1486=$ bicolor

bicolor, Gardn. in Calc. Fourn. Nat. Hist. viii. (1847) 160.-Ind. or.

calcarata, Wight, Ic. iv. t. 1426.-Ind. or.

grandiftora, Gardn. in Calc. Joum. Nat. Hist. viii, (1847) $155=$ tricolor.

Hookeri, C. B. Clarke, ex Hook. fo Fl. Brit. Ind. iv. 321.-Reg. Himal.

Lawii, Wight, Ic. iv..t. 1427.-Ind. or.

neilgherrica, Gardn. in Calc. Fourn. Nat. Hist. viii. (1847) 157.-Ind. or.

pallida, Gardn. 1. c. $159=$ bicolor.

Stocksii, Hook. Ic. Pl. t. $836=$ calcarata.

subacaulis, Gardn. in Calc. Fourn. Nat. Hist. viii. (1847) 162.-Ind, or.

Thwaitesii, Trim. in Fourn. Bot. xxiii. (1885) 240.Zeylan.

tricolor, Gardn. in Calc. Fourn. Nat, Hist, viii. (1847) 156.-Zeylan.

tubulosa, Benth. ex Hook. f. Fl. Brit: Ind. iv. 321.Ind. or.

unicolor, Gardn. in Calc. Journ. Nat. Hist. viii.. (1847) $161=$ neilgherrica.
CHRISTMANNIA, Dennst. Schluess. Hort. Malab. 30 (1818). 'Genus delendum,' Benth. \& Hook. f. iii. 150. Curondia, Rafin. Sylva Tellur. 154 (1838\%

Courondi, Dennst. 1. c.--Ind, or

CHRISTOLEA, Cambess. in Jacquem. Voy. Bot. 17 t. 17 (1837). CRUCIFERAE, Benth. \& Hook. f. i. 80.

crassifolia, Cambess. l. c.-Tibet. oec.

CHRISTOPHORIANA, Tourn. ex Rupp. Fl. Jen, ed. Hall. $94(1745)=$ Actaea, Linn. (Ranunculac.).

spicata, Moench, Meth. $276=$ A. spicata.

vulgaris, Rupr. F1. Caucas. $44=\mathrm{A}$. spicata.

CHRISTY-A, Ward \& Harv, in Hook. Journ. Bot: iv. (1842) 134. t. $21=$ Strophanthus, DC. (Apocynac.)

speciosa, Ward \& Harv. 1, c. $=\mathrm{S}$. capensis.

CHRITMUM, Brot. F1. Lusit: i. 436 (1804), sphalm.= Crithmum, Linn. (Umbell.).

CHROILEMA, Bernh. Del. Sem. Hort. Erf. (1840); et in Linnaea, xv. (1841) Litt. 90=Aplopappus, Cass? (Compos.)

subcanescens, Bermh. 1I: cc.-Chili. CHROMANTHUS, Phil. Sert. Mend. Alt. 14 (1871)
PORTULACEAE?

CHROMATOLEPIS, Dulac, F1. Hautes-Pyr. 526 (1867) = Carlina, Linn. (Compos.)

acaulis, Dulac, 1. c. $527=$ Carl. acaulis.

lanata, Dulac, I. c. = Carl. lanata.

magna, Dulac, 1. c. = Carl. acanthifolia.

vulgaris, Dulac, 1. c. = Carl. vulgaris.

CHROMATOPOGON, F. W. Schmidt; Samml. Phys. Aufs, i. 275 (1795)= Scorzonera, Linn. (Compos.). Facquini, F. W. Schmidt, 1. $\mathrm{c}:=\mathrm{S}$. hirsuta.

CHROMOCHITON, Cass. in Dict. St. Nat. 1vi. 220 (1828)= Cassinia, R. Br. (Compos.). aculeata, Cass. 1. c. = Cassinia aculeata affinis, Cass. 1. c. = Cassinia aculeata aurea, Cass. 1. c. = Cassinia aurea.

CHROMOLAENA, DC. Prod. v. $133(1836)=$ Eupa torium, Linn. (Compos.).

alternifolia, Gardn. in Hook. Lond. Journ. Bot. v (1846) $465=\mathbf{E}$. stachyophyllum.

Candolleana, Gardn. 1. c. $464=\mathrm{E}$. horminoides. decumbens, Gardn. 1. c. $466=\mathrm{E}$. decumbens. epaleacea, Gardn. 1. c. vi. (1847) $436=\mathrm{E}$. lupulinum. horminoides, DC. Prod. v. $133=\mathrm{E}$. horminoides. leucocephala, Gardn. in Hook. Lond. Journ. Bot. (1846) $465=\mathrm{E}$. horminoides.

pratensis, Gardn. 1. c. i. (1842) $176=$ E. macrocephalum.

CHROMOIEPIS, Benth. Pl. Hartw. 40 (1840) COMPOSITAE, Benth. \& Hook, fo ii. 366: heterophylla, Benth.l. c.-Mexic.

CHRONE, Dulac, Fl. Hautes-Pyr. $512(1867)=$ Eupa torium, Linn. (Compos.).

heterophylla, Dulac, 1. $\mathrm{c}_{0}=\mathrm{E}$. cannabinum.

CHRONOBASIS, DC. ex Benth. \& Hook. fo Gen. ii. $457(1873)=$ Ursinia, Gaertn. (Compos.).

CHRONOPAPPUS, DC. Prod. v. 84 (1836) COMPOSITAE, Benth. \& Hook: f, ii. 286 : bifrons, $D C$. l. c. - -Bras.

CHROSPERMA, Rafin. Neogenyt. $3 \cdot(1825)=$ Zyga denus, Michx. (Liliac.).

laetum, Rafin. 1. c. $=$ Z. muscretoxicum,

CHROZOPHORA, Neck. Elem. ii: $397 \quad(1790)$ EUPHORBIACEAE, Benth. \& Hook. f. iii. 305.

Crozophora, A. Juss. Tent. Euph. 27 (18:24).

Lepidocruton, Presl, Epim. Bot. 219 (1850).

Ricrnoldes, Tourn. ex Moench, Meth. 256 (1794)

TOU RNESOLiA, Nissol, ex Scop. Introd. 243 (176).

Brocchiana, Schweinf. Pl. Nilot, 9.-Afr. trop.

Burmanni, Spreng. Syst. iii. $851=$ plicata.

\section{CHROZOPHORA:-}

gracilis, Fisch. \& Mey. ex Kar. in Bull. Soc. Nat.

Mosc. (1839) 171, nomen; Boiss. Fl. Orient. iv. 1140. - As. centr.

hierosolymitana, Spreng. Syst. iii. $850=$ verbascifolia . integrifolia, Bunge, in Mém. Sav. Etr. P'étersb. vit (1851) $490=$ verbascifolia.

mollissima, A. Juss. Tent. Euph. $28=$ Mallotus visci noides.

obliqua, A. Fuss. l. c.-Afr. bor.; As. occ.; Ind, or.

obliqua, Suhweinf. J1. Nilot. 13=- plicata.

oblongifolia, A. Juss. Tent. Luph. $2 x=$ ot,liqua.

farvifolia, Klotzsch, ex Schweinf. I'1. Nilet. 11 = plicata.

peltata, Labill. Sert. Austr.-Caled.74. t. $75=$ Codiaeur inophyllum.

plicata, A. Fuss. Tent: Euph. 28.-Europ. austr.; Afr. bor.; A6. occ. ; Ind. or.

prestrata, Dale. \& Gibs. Bomb. F1. $288=$ plicata.

Rottleri, A. Juss, Tent. Euph. $28=$ plicata.

sabulosa, Kar. \& Kir. in Bull. Soc. Nat. Mose. (1842) $446=$ gracilis

senegalensis, A. Fuss. Tent. Euph. 28.-Afr. trop.

Sieberi, Presl, Bot. Bemerk. $109=$ verbascifulia

tinctoria, A. Fuss. Tunt. Euph. 28. t. 7.-Europ. austr.

Oriens; Ind. or.; Afr. bor.

tinctoria, Muell. Arg. in DC. Prod. xv. II. $719=$ obliqua.

verbascifolia, A. Fuss. Tent. Euph. 28.-Reg. Meditert. Oriens.

CHROZORRHIZA, Ehrh. Beitr. iv, 147 (1789) =

Asperula, Linn. (Rubiac. A. tinctoria).

CHRYSA, Rafin. in Med. Repos. N: York, II. V. 'Isw:" $350=$ Coptis, Salisb. (Ranunculac.).

CHRYSACTINIA, A. Gray, in Mem. Am. Ac. N. iv. (1849) (Pl, Fendl.) 93. COMPOSITAE, Bench. \&e Hook, f. ii. 412

mexicana, A. Gray, l. c.-Mexic.

CHRYSACTINIUM, Wedd. Chlor. And. i. 212. t. 39 (1856) = Liabum, Adans. (Compos.)

acaule, Wedd, $1 . c_{0}=$ L. acaule.

CHRYSALIDOCARPUS, H. Wend?, in Bo: \%, it xxxvi. (1878) 171. PALMAE, Benth. \& Hook. f. iii. 882.

lutescens, H. Wendl. l. c.-Madag.

CHRTSANGIA; Link, IIandt, i, 132 '12:2: = Mus schia, Dum. (Campanul.).

aurea, Link, 1. c. = M: anrea.

CHRYSANTHELLINA, Cass, in Dict. Sc. Nat. xx\% 391 (1822) = Chrysanthellum, Rich. (Compos.) fasciculata, Cass. 1. c. = Chrysanthellum procumbens gracilis, Cass. 1. c. $392=$ Chrysanthellum procumbens. Swartsii, Cass. 1. c. = Chrysanthellum procumbens.

CHRYSANTHELLUM, Rich. in Pers. Syn, ii. 47 1807). COMPOSITAE, Benth. \& Hook. f. ii. 38\%. Adenospermum; Hook. \& Am. in Hook. Joum Bot. iii. (18t1) 318.

Chrysanthellina, Cass, in Dict. Se Nat. xury. $391(1028)$

Collaea, Spreng. Syst. iii. 622 (1826)

Hin'terhuzera, Sch. Bip. ex Benth. \& Hook. f. Gien. ii. 389 (1879)

Neuractis, Cass, in Dict. Sc. Nar, xxiv. $196(18: 25$ Sebastiania, Bertol. Lucubr. (1822 97.

Ucacou, Adans. Fam. ii. 191 (1768

abyssinicum, Sch. Bip. in Flora, xxv. (ISt? Ifl) Microlecane aby sisioicn,

americanum, Vatke, in Bremen Abh. ix. (1Ss5) 122.Am. trop.

boliviense, Sch. Bip. in Bull. Soc. Fr. xii. (1S65) \$3. nomen. - Boliv.

erectum, Anderss. in Vet. Akad. Handl. Sitrth. $153 y$ (1855) 188. - Ins. Galapag.

indicum, DC. Prod. v. 6is1.- As et Afr. trop.

intenrifolium, Sperta, in Serw. Bot. Voy. Herald, 160. -Panama.

procumbeas, A. Rich. in Pers. Sym. ii. ti1.-Am. trol pusillum, Hewk. f. in Trans. Lin . Sor. xx, 1851! 214. -Ins. Galapag.

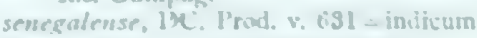

Sivariaii, LC: L c $c_{0}=$ procuubens. 
CHRYSANTHEMOIDES, Tourn. ex Medic. Phil. Bot. i. $159(1789)=$ Osteospermum, Linn. (Compos.). caerulea, Moench, Meth. 584=0. caeruleum. pisiformis, Medic. Phil. Bot. i. $159=$ O. moniliferum.

CHRYSANTHEMUM, [Toum.] Linn. Syst. ed. I (1735). COMPOSITAE, Benth. \& Hook. f. ii. 424.

Ammanthus, Boiss. \& Heldr. Diagn. Ser. I. xi. 18 (1849).

Argyranthemum, Webb, ex Sch. Bip, in Webb \& Berth. Phyt. Canar. ii. 258. t. 90 ad $96(1836-50)$. Balsamtta, Desf. in Act. Soc. Hist. Nat. Par. i. (1792) t. 1.

Brachanthemum, DC. Prod. vi. 44 (1837).

Centrachaens, Schott, Ind. Sem. Hort. Vindob. 1823), ex Reicht. Ic. Pl. Crit. iv. 47 (1827)

Centrospermum, Spreng. Nov. Prov. 19 (1818); Syst iii. 362 (1826),

Coleostephus, Cass. in Dict. Sc. Nat. xli. 43 (1826).

DeCaneurum, Sch. Bip. Tanacet. 44 (1844).

Dendranthema, Des Moul. in Act. Soc, Linn. Bord. xx. (1855) 561

ENDOpappus, Sch. Bip. in Bonplandia, viii. (1860) 369.

Glebionis, Cass. Dict. Sc. Nat. xli. 41 (1826).

Glossopappus, Kunze, in Flora, xxix. (1846) 748.

Gymnocine, Cass. in Bull. Soc. Philom. (1816) 199 ; et in Dict. Sc. Nat. xx. 119 (1821).

Heterant Hemis, Schott, in Oken, Isis, (1818) 821.

Heteromera, Pomel, Nouv. Mat. Fl. Atl. 60 (1874).

Hymenostemma, Kunze, in Flora, xxix. (1846) 699.

Ismelia, Cass. in Dict. Sc. Nat. xli. 40 (1826).

Kremeria, Dur. in Duch. Rev. Bot. i. (1846) 364.

Leucanthemum, [Tourn.] DC. Prod. vi. 45 (1837).

Matricaria, Hall. ex Scop. Fl. Carn. ed. II. ii. 147

(1772).
Monoptera, Sch. Bip. in Webb \& Berth. Phyt. Canar. ii. $253(1836-50)$

Myconia, Neck, Elem. i. 22 (1790)

OTospermum, Willk. in Bot. Zeit. xxii. (1864) 251.

PHaI ACrocarPuM, Willk. I. c. 252 (1864)

Phalacroniscus, Less. Syn. Comp 253 (1832)

Phalacroglossum, Sch. Bip. in Webb \& Berth. Phyt. Canar. ii. 276 (1855-60).

Pinardia, Cass. in Dict. Sc. Nat. xli. 38 (1826).

Plagius, L'Hérit. Diss. ex DC. Prod. vi. 135 (1837).

Pontra, Bubani, in Nuov. Giorn. Bot. Ital. v. (1873) 318.

Preauxia, Sch. Bip. in Webb \& Berth. Phyt. Canar. ii. $250(1836-50)$.

ProlongoA, Boiss. Voy. Bot. Espagne, 230. t. 29 a (1840).

Pyrethrum, Hall. Enum. Stirp. Helv, ii. 720 (1742).

Richteria, Kar. \& Kir, in Bull. Soc. Nat. Mosc. (1842) 126

Stigmatotheca, Sch. Bip. in Webb \& Berth. Phyt. Canar. ii. $255(1836-50)$

TridactYlina, Sch. Bip. Tanacet. $48(1844)$

XanthophthalmuM, Sch. Bip. 1. c. 17 (1844).

absinthifolium, Fisch. ex DC. Prod. vi. $46=$ sinuatum

Achilleae, Linn. Syst. ed. XII. 262.-Italia.

achilleaefolium, DC. Prod. vi. 68.-Reg. Caucas. ; Sibiria.

adustum, Fisch. ex Herd. in Bull. Soc. Nat. Mosc. xxxviii. $(1865)$ I. $415=$ arcticum.

alpestre, DC. Prod. vi. $68=$ coronopifolium

alpinum, Bieb. Casp. $211=$ caucasicum

alpinum, Linn. Sp. Pl. 889.-Europ.

anethifolium, Brouss. ex Willd. Enum. Hort. Berol.

904, in nota.-Ins. Canar.

angustifolium, Rafin. Herb. 25; Atl. Fourn. 178.-

Am. bor.

anomalum, Lag. Varied. Cienc. ii. Iv. (1805) 40.Hispan.

apetalum, Hort. ex Steud. Nom. ed. II. i. 356.Europ.

aragonense, Asso, Syn. 123, t. 9. f. $1=$ pulverulentum arcticum, Linn. Sp. Pl. 889.-Reg. arct.

argenteum, Willd. Sp. Pl. iii. 2146.-Armenia.

artemisiaefolium, Klatt, in Sitz. Akad. Muench. (1878)

$88=$ C. Richteria

\section{CHRYSANTHEMUM}

arvense, Herb. Mex. ex DC. Prod. v. 311=Xanthocephalum humile.

asteroides, Desf. Tabl. ed. II. 118, nomen.-Hab. ?

Atkinsoni, C. B. Clarke, Comp. Ind. 147.-Reg. Himal.

atlanticum, Ball, in Fourn. Bot. xi. (1873) 366.Marocco.

atratum, Georgi, Beschr. Russ. Reich. iii. IV. $1252=$ maximum?

atratum, Linn. Sp. Pl. ed. II. 1252.-Europ.

Balsamita, Baill. Hist. PI. viii. $311=$ Tanacetum Balsamita.

Balsamita, Linn. Sp. Pl. ed. II. 1252.-As. occ.

Barrelieri, DC. Prod. vi. $68=$ coronopifolium.

Bauhini, Tausch, in Syll. Ratisb. ii. (1828) 251= atratum.

bellidiflorum, Willd, ex Steud. Nom. ed. II. i. $356=$ Bellis dubia.

Biebersteinianum, Adam, in Weber \& Mohr, Beitr. i. $70=$ Anthemis Biebersteiniana.

bipinnatum, Linn. Sp. Pl. 890.-Reg. arct.

Bocconi, Pourr. ex DC. Prod. vi. 61.-Híspan

breviradiatum, Hort. ex DC. Prod. vi. $64=$ coronarium.

Broussonetii, Balb. ex Pers. Syn. ii. 461.-Ins. Canar. caespitosum, Weinm. Cat. Hort. Dorp. 43,-Hab. carinatum, Schousb. Vextr. Marokko, 198, t. 6.Marocco.

carneum, Steud. Nom ed. I. $192=$ coccineum.

carnosulum, DC. Prod. vi. $65=$ Phymaspermum carnosulum.

carnosum, Pers. Syn. ii. $460=$ glabrum.

carolinianum, Walt. Fl. Carol. $204=$ Boltonia asteroides.

Catananche, Ball, in Fourn. Bot. xi. (1873) 366.Marocco.

caucasicum, Pers. Syn. ii. 462.-Reg. Caucas.

cebennense, DC. ex Stend. Nom. ed. I. 192, $193=$ monspeliense.

centrospermum, Bernh. ex Reichb. Ic. PI. Crit. iv. $47=$ viscosum.

ceratophylloides, All. Fl. Pedem. i. 190=atratum

Chamomilla, Bernh. Syst. Verz. Erf. $145=$ Matricari Chamomilla.

cinerariaefolium, Vis. $F l$. Dalmat. ii. 88, t. 8.Dalmatia.

cinerarium, Steph. in Ledeb. F1. Ross. ii. $542=$ sinuatum.

coccineum, Sims, Bot. Mag. t. $1080=$ coronopifolium.

coccineum, Willd. Sp. Pl. iii. 2144.-Reg. Caucas.; Persia.

coronarium, Linn. Sp. Pl. 890,-Reg. Mediterr.

coronopifolium, Masf. in Anal. Soc. Esp. Hist. Nat. x. 1881) 208.-Ins. Canar.

coronopifolium, Steud. Nom. ed. II. i. $356=$ grandiflorum

coronopifolinm, Vill. Fl. Delphin. 98; Hist. Pl. Dauph. iii. 202.-Corsica.

coronopifolium, Willd. Herb. ex Boiss. FI. Orient. iii. $40=$ coccineum

corsicum, Sieber, ex DC. Prod. vi. $47=$ coronopifolium, Vill.

corymbiferum, Linn. Sp. Pl. ed. II. 1251.-Helv.; Austr.; Germ.

corymbiferum, Pall: Reise, i. $196=$ corymbosum.

corymbosum, Linn. Sp. Pl. 890.-Europ.; Afr. bor. Reg. Caucas.

crithmifolium, Brouss. ex Willd. Enum. Hort. Berol. 904, in syn. : Buch, in Berl. Acad. Abh. 1816-17 (1819) $375=$ anethifolium.

cuneatum, Roxb. Hort. Beng. [101] ; Fl. Ind. iii. 436 $=$ Boltonia indica

daucifolium, Pers. Syn. ii. 462.-Hab. ?

densum, Steud. Nom. ed. I. 192.-Syria.

dentatum, Gilib. F1. Lituan. i. $219=$ C. Leucan themum.

diffusum, Vell. Fl. Flum. viii. t. 128.-Bras.

disciforme, C. A. Mey. Verz. Pfl. Cauc. $75=$ Matricaria disciformis.

discoideum, All. Fl. Pedem. i. 190,-Italia.

dissectum, Lowe, in Trans. Camb. Phil. Soc. vi. (1838) reimpr. 17.-Ins. Canar.

elegans, Steud. Nom. ed. I. $192=$ maritimum

ericaefolium, Burm. $f . F l$. Cap. Prod. 27.-Afr. austr.

floridum, Salisb. Prod. $202=$ frutescens

flosculosum, Linn. Sp. Pl. 890.-Reg. Mediterr.

\section{CHRYSANTHEMUM:-}

foeniculaceum, Steud. Nom. ed. I. 192 ; DC. Prod. vi $66=$ anethifolium.

foliosum, Brouss. Hort. Monsp. (1804); ex DC. Prod. vi. $66=$ grandiflorum.

frutescens, Linn. Sp.Pl. 887.--Ins. Canar.

frutescens, Thunb. Prod. Pl. Cap. $161=$ Thunbergii fruticosum, Buch, in Abh. Berl. Acad. 1816-17 (1819) $375=$ frutescens?

fruticosum, Vell. Fl. Flum, viii, t. 130.-Bras,

fruticulosum, Ledeb. Fl. Alt. iv. 117.-Sibir. altaic

fuscatum, Desf. Fl. Atlant. ii. $283=$ Matricaria fuscata.

Gayanum, Ball, in Journ. Linn. Soc. xvi. (1878). 509 $=$ Mawii.

glabratum, Thunb. Prod. P1. Cap. 161=Matricaria glabrata.

glabrum, DC. Prod. vi. 49 , in syn. = paludosum.

glaucum, Pers. Syn. ii. $461=$ multifidum.

Gmelini, Turcz. in Bull. Soc. Nat. Mosc. (1838) $94=$ arcticum.

gracile, Masf. in Anal.Soc. Esp. Hist. Nat. x. (1881) 207.-Ins. Canar

gracilicaule, Dufour, in Ann. Gén. Sc. Phys. vii. (1820) $306=$ montanum

graminifolium, Linn. Sp. Pl. 889.-Europ.

grandiflorum, Brouss. Elench. PI. Hort. Monsp. (1804) $15=$ coronopifolium.

grandiflorum, Hook, in Parry, App. Second Voy. 398 - Matricaria inodora.

grandiflorum, Hort. Par. (1819) ex. DC. Prod. vi. 47= lacustre.

grandiflorum, Lapeyr. Hist. Abr. P1. Pyr. $527=$ maximum.

grandiflorum, Willd. Enum. Hort. Berol. 904.-Ins Canar.

Griffithii, C. B. Clarke, Compos. Ind. $148=$ Stoliczkai haematomma, Lowe, in Hook. Kew Fourn. viii. (1856) 296.-Ins. Madera.

Halleri, Suter, Fl. Helv. ii. $193=$ coronopifolium, Vill. Herminii, Hoffmgg. \& Link, Fl. Port. ii. t. $102=$ oppositifolium.

heterophyllum, Willd. Sp. Pl. iii. 2142,-Europ.

hirtum, Hort. ex Reichb. Ic. Pl. Crit. iv. $47=$ viscidum.

hirtum, Thunb. Prod. PI. Cap. 161 = Matricaria hirta hispidum, Rich. ex DC. Prod. vi. $47=\mathrm{L}$. pallens.

humile, Spreng. Syst iii. $584=$ Xanthocephalum humile hybridum, Guss. Adnot. Cat. Pl. Bocc. $3=\mathrm{C}$. Myconis. incanum, Thunb. Prod. Pl. Cap. $161=$ Pentzia virgata indicum, Linn.Sp. Pl. 889.-China; Japon.

indicum, Thunb. Fl. Jap. $320=$ sinense

inodorum, Linn. Sp. Pl. ed. II. $1253=$ Matricaria inodora.

integrifolium, Richards. in Frankl. 1st fourn. App. ed. II. 33.-Reg. arct.

intermedium, Hort. Monsp. ex DC. Prod. vi. $66=$ grandiflorum.

ircutianum, Turcz. in Bull. Soc. Nat. Mosc. xix. (1846) II. 177.-Sibiria

italicum, Linn. Mant. i. 116.-Italia

japonicum, Thunb. F1. Jap. $321=$ indicum

lacerum, Auct. ex Desv. in Lam. Encyc. iii. 729, in syn. = pinnatifidum.

laciniatum, Gilib. Fl. Lituan. i. $218=$ segetum.

lacustre, Brot. Fl. Lusit. i. 379.-Europ.

lanceolatum, Pers. Syn. ii. 460.--Europ.

lanceolatum, Vest, in Flora, iii. (1820) $4=$ C. Leucan themum.

lanuginosum, Geners. ex DC. Prod. vi. $57=$ corymbosum.

larvatum, Griseb. ex Pant. in Oestr. Bot. Zeitschr. xxiii. (1873) 266.-Montenegro.

latifolium, DC. Prod, vi. $69=$ grandiflorum.

leptophyllum, DC. 1. c. $65=$ nodosum.

Leucanthemum, Linn. Sp. Pl. 888.-Europ.; As. bor.

lidbeckioides, Less. Syn. Comp. 253.-Afr. austr

macrocephalum, Viv. F1. Lib. Spec. 56. t. 10. f. $4=$ trifurcatum

macrophyllum, Waldst. E Kit. Pl. Rar. Hung. i. 97 -Europ. or. ; Reg. Caucas.

macrotum, Ball, in Fourn. Linn. Soc. xvi. (1878) 509. -Hispan.; Marocco.

majus, Aschers. Fl. Brandenb. $329=$ C. Leucanthemum Maresii, Ball, in Fourn. Bot. xi. (1873) 366 (Maressii) -Marocco.

maritimum, Pers. Syn. ii. 462.-Europ. occ. 


\section{CHRYSANTHEMUM}

Mawii, Hook. f. Bot. Mag. t. 5997.-Marocco

maximum, Ramond, in Bull. Soc. Philom. ii. (1800) 140.--Mont. Pyren.

mexicana, H. B. E $K$. Nov. Gen. et Sp. iv. 299.Mexic.

millefoliatum, Linn. Syst. ed. XII.563.-Reg. Caucas.; As. Min.

minimum, Brot. Fl. Lusit. i. $379=$ pulverulentum? minimum, Vill. Hist. Pl. Dauph. iii. $202=$ alpinum. monspeliense, Linn. Sp. Pl. 889.-Europ.

monspeliense, Schkuhr, Handb. iii. 131. t. $253=$ arcticum.

montanum, Linn.Sp. Pl. 888.-Europ.

montanum, Willd. Sp. Pl. ii. $2143=$ C. Leucanthemum.

moschatum, Willd. ex Steud. Nom. ed. I. 192, nomen; ed. II. i. 357.-Hab. ?

multicaule, Desf. Fl. Atlant. ii.282,-Afr. bor

multifidum, Desf. Cat. Hort. Par. ed. III. 170,Oriens.

Myconis, Linn. Sp. Pl. ed. II. 1254.--Reg. Mediterr.

nanum, Hook. Fi. Bor. Am. i. $320=$ Blennosperma californicum.

nodosum, $D C$. Prod, vi. 65.-Afr. austr.

ochroleucum, Masf. in Anal. Soc. Esp. Hist. Nat. x. (1881) 208.-Ins. Canar.

odoratum, Lowe, Man. Fl. Mad. i, 462 = pinnatifidum. oppositifolium, Brot. Fl. Lusit. i. 381.-Lusit.

orcastrum, Hance, in fourn. Bot. xi. (1878) 108.-

China.

orientale, Pers. Syn, ii. $462=$ Anthemis Biebersteiniana osmitoides, Harv. Thes. Cap. ii. 33. t. 152.-Natal.

pallens, F. Gay, ex Perreym. in Guill. Arch. Bot. ii. (1833) 545.-Europ.

pallens, Pers. Syn. ii. 461, in syn.= pulverulentum.

pallidum, Mill. Gard. Dict. ed. VIII. n. 12=pulveru-

lentum.

palmatum, Ledeb. F1. Ross. ii. 552, sphalm. = parthenifolium.

paludosum, Poir. Voy. Barb. ii. 241.-Afr, bor

palustre, Pers. Syn. ii. 461.-Armenia.

parthenifolium, Pers. 1. c. $462=$ praealtum.

Parthenium, Bernh. Syst. Verz. Erf. 145.-Europ.

parviflorum, Pers. Syn. ii. $462=$ Matricaria praecox.

pectinatum, Linn. Sp. Pl. ed. II. 1255.-Hispan.

perpusillum, Loisel. in Desv. Journ. Bot. ii. (1809)

$369=$ Nananthea perpusilla.

pinnatifidum, Linn.f. Suppl. 377.-Ins. Madera.

praealtum, Vent. Fard. Cels, t. 43.-Reg. Caucas.; As.

Min.; Persia.

praecox, DC. Prod. vi. $69=$ Matricaria praecox.

pratense, Salisb. Prod, $203=$ C. Leucanthemum

procumbens, Lour. Fl, Cochinch. ii. $499=$ indicum.

prostratum, Pers. Syn. ii. $460=$ Egletis domingensis.

ptarmicaefolium, Puschk. ex Willd. Sp. Pl. iii. 2151;

Pers. Syn. ii. $460=$ Achillea Ptarmica.

pubescens, Hort. ex Reichb. Ic. Pl. Crit. iv. $47=$ viscidum.

pulverulentum, Lag. ex Pers. Syn. ii. 461.-Hispan

pumilum, Willd. Enum. Hort. Berol. 903,-Hab.?

punctatum, Pers. Syn. ii. 461, in syn.=palustre

purpureum, Pers. 1. c. = indicam.

pusillum, Viv. Fl. Lib. Spec. 56.-Afr. bor.

radicans, Pers. Syn. ii. 462.-Hispan.

ramosum, F. W. Schmidt, Samml. Phys. Aufs. i. (1795) 231, nomen,-Europ.

Richteria, Benth. ex Hook. f. Fl. Brit. Ind. iii. 315.Soongaria : Tibet, occ

rigidum, Vis. Del. Sem. Hort. Patav. $(1825)=$ cinerariaefolium.

roseum, Adam, in Weber \& Mohr, Beitr. i. $70=$ coccineum.

rotundifolium, Waldst. $*$ Kit. Pl. Rar. Hung. iii, 262. t. 236.-Hungar.

Roxhurghii, Desf. Cat. Hort. Par, ed. III. $170=$ coronarium.

scandens, Vell. Fl. Flum. viii. t. 129,-Bras.

segetale, Salisb. Prod. $203=$ segetum.

segetum, Forsk. ex DC. Prod. vi. $64=$ coronarium

segetum, Linn. Sp. Pl. 889.-Europ.; Afr. bor. ; As. occ.

senecioides, Dun, ex DC. Prod, vi. $64=$ coronarium

sericeum, Adam, in Weber \& Mohr, Beitr. i. $69=$ argenteum.

sericeum, Hoffmgg, \& Link, Fl. Port. นi. 1. $101=$ oppositifolium.

serotinum, Linn, Sp. Pl. 888,-Hungar.

\section{CHRYSANTHEMUM}

setabense, Dufour, ex DC. Prod. vi. $49=$ glabrum.

sibiricum, Turcz, ex DC. 1. c. $46=$ arcticum

sinense, Sabine, in Trans. Linn. Soc. xiv. (1825) 145. - Japon.

sinuatum, Ledeb. Fl. Alt. iv. 116.-Sibir. altaic

spathulatum, F. W. Schmidt, Samml. Phys. Aufs. i.

1795) 231.--Europ

speciosum, Brouss. ex Pers. Syn . ii. $463=$ coronarium.

speciosum, Steud. Nom. ed. II. i. $357=$ grandiflorum.

Stoliczkai, C. B. Clarke, Comp. Ind. 147.-Tibet. occ

suaveolens, Aschers. Fl. Brandenb. 332.-Europ.

subcorymbosum, Schur, in Verh. Siebenb. Ver.

Naturw. x. (1859) 146.-Transsylv.

sylvaticum, Hoffmgg. \& Link, ex Link, Handb. i.

$755=\mathrm{C}$. Leucanthemum?

sylvaticum, Jauvy, ex DC. Prod. vi. $47=$ pallens

sylvestre, Brot. ex Steud. Nom. ed. I. 193 ; ed. II. i.

357, nomen.-Lusit.

sylvestre, Willd. Enum. Hort. Berol. Suppl. $60=\mathrm{C}$

Leucanthemum.

tanacetifolium, Desf. Cat. Hort. Par. (1821); ex DC.

Prod. vi. $66=$ grandiflorum.

tanacetifolium, Willd. Sp. Pl. iii. 2145.-Oriens.

Tanacetum, Vis. F1. Dalmat. ii. $89=$ Tanacetum vulgare.

tenuifolium, Kit. in Schult, Oester. Fl. ed. II. ii. 498 - Hungaria.

tenuifolium, Tenore, ex Steud. Nom. ed. II. i. 357 C. Achilleae.

tenuissimum, [Soland. in] Russell, Aleppo, ed. II. ii. 263.-Syria.

Thunbergii, Harv. in Harv. E Sond. Fl. Cap. iii. 162 -Afr. austr.

tibeticum, C. B. Clarke, Comp. Ind. 147.-Tibet. occ.

tingitanum, Bernh. in Linnaea, x. (1835) Litt. 74.Marocc.

tomentosum, Loisel. Fl. Gall. 580, t. 18.-Corsica. trichophyllum, Boiss. Diagn. Ser. I. iv, 10-As. Min. trichotomum, Walp. Ann. ii. 891 = trichophyllum. tricolor, Andr. Bot. Rep. t. $109=$ carinatum.

trifurcatum, Desf. Fl. Atlant. ii. 281.-Afr. bor.

tripartitum, Sweet, Brit. Flow. Gard. Ser. I. t. $193=$

indicum.
Turreanum, Vis. Stirp. Dalm. Spec. $19=$ cinerariaefolium.

uliginosum. Pers. Syn. ii. 460,-Hungar.

umbellatum, Vell. Fl. Flum. viii. t. 127.-Bras.

umbrosum, Willd. Sp. Pl. iii, 2149-Graecin.

variabile, Rochel, Pl. Banat. Rar. Ind. Spec. $=$ atratum.

viscosum, Desf. Cat. Hort. Par. ed. III. 170.-Reg. Mediterr.

Webbianum, Ball. in Fourn. Linn. Soc. xvi. (1878) 509.-Maroce

Webbii, Masf. in Anal. Soc. Esp. Hist. Nat. x. (1881) 207.-Ins. Canar.

Welwitschii, Sch. Bip. ex Nym. Consp. $370=$ segetum.

Zawadskii, Herbich, Add. Fl. Galic. 48.-Galicia.

CHRYSEIS, Cass. in Dict. Sc. Nat. vii. 377 ; ix. 154 (1817) = Centaurea, Linn. (Compos.)

Centaurium, Kostel. Allg. Med. Pharm. F1. ii. $606=$ Cent. Centaurium

glauca, Cass. in Dict. Sc. Nat. xliv. $39=$ Cent. mos. chata.

moschata, Cass, 1. $\mathrm{c}=$ Cent. moschata.

odorata, Cass. 1. c. ix. $154=$ Cent. moschata.

suaveolens, Cass. 1. c. xliv. $89=$ Cent. moschata.

CHRYSEIS, Lindl. Bot. Reg. t. 1948 (1835) = Eschscholzia, Cham. (Papaverac.)

caespitosa, Torr. \& Gray, Fl. N. Am. i. $68=\mathrm{E}$. californica.

californica, Hook. \& Arn. Bot. Beech. Voy. $319=\mathrm{E}$. californica.

compacta, Lindl. Bot. Reg. t. $1948=$ E. californica

crocea, Lindl. 1. co $=\mathbf{E}$, californics.

Douglasii, Hook. \& Arn. Bot. Beecb. Voy. $320=E$. californica.

hypecoides, Torr. \& Gray, FI. N. Am. 1. $64=\mathrm{E}$ californica

tenuifolia, Torr. \& Gray, 1. c. = E. califomica.

CHRYSION, Spach, Hist. Vég. Phan, v. 509 (1896) Viola, Liun.

biflorm, Spacb, 1. c. $510=$ V. biflora.
CHRYSIPHIALA, [Ker-Gawl. in] Bot. Reg, t. 778 $(1824)=$ Stenomesson, Herb. (Amaryllid.)

aurantiaca, Schult. f. Syst. vii. $904=\mathrm{S}$. aurantiacum coccinea, [Ker-Gawl. in] Bot. Reg. sub t. $778=\mathrm{S}$ coccineum.

curvidentata, Herb. ex Stend. Nom, ed. II, i. $358=\mathrm{S}$. flavum.

fava, [Ker-Gawl, in] Bot. Reg, t. $778=\mathrm{S}$. flavnm. incarnata, Schult. f. Syst. vii. $908=\mathrm{S}$. incarnatum. latifolia, [Ker-Gawl. in] Bot. Reg. sub t. $778=$ Urceolina latifolia.

pauciflora, Hook. Exot. FI.t. 132 = S. flavum

recurvata, [Ker-Gawl. in] Bot. Keg. sub t. $778=\mathrm{S}$ recurvatum.

trichroma, Schult. f. Syst. vii. $907=$ Pancratium trichromum.

variegata, Schult. f. 1. $\mathrm{c}_{0}=$ Pancratium variegatum

viridiflora, Schult. f. 1. c. $908=\mathrm{S}$. viridiforum,

CHRYSIS, Renealm. ex DC. Prod. v. 585 (1836) Helianthus, Linn. (Compos.).

CHRYSITRIX, Linn. Mant, ii. 165 (1771)

PERACEAE, Benth. \& Hook. f. iii 1057

capensis, Linn. Mant. ii. 304; Linn. f. Gram. 27.

1, 2.-Afr. austr

junciformis, Nees, in Linnaea, x. (1836) 144.-Aft. austr.

CHRYSOBACTRON, Hook \&. Fl. Antarct, i. $72, \mathrm{t}$. is $1845)$ = Bulbinella, Kunth (Liliac)

Hookeri, Colenso, in Hook. Ic. Pl. t. 817.-N. Zel.

Rossi, Hook. f. Fl. Antarct. i. 72. t. 44-45.-Ins Anckland.

CHRYSOBALANUS, Linn.. Gen. ed. I. 365 (1737

ROSACEAE, Benth. \& Hook. f. i. 606

ICACo, Adans. Fam. ii. 305 (1763).

cuspidatus, Griseb. Fl. Brit. W. Ind. 711.-Ind.

ellipticus, Soland. ex Sabine, in Trans. Hort. Soc. 1824) 453.-Afr. trop.

guianensis, Klotzsch, in Schomb. Fauna et Fl. Brit. Guian. $1024=$ ellipticus.

Icaco, Linn. Sp. Pl. 513.-Afr. et Am. trop.

incanus, Rafun. New Fl. Am, iii. 26 = oblongifolius.

luteus, Sabine, in Trans. Hort. Soc. v. (1824) $453=\mathrm{C}$. Icaco?

macrophyllus, Schott, in Spreng. Syst. iv. App. 407.Bras.

oblongifolius, Michx. Fl. Bor. Am. i. 289.-Am. bor.

orbicularis, Schum. in Schnm. \& Thonn. Beskr. Guin. Pl. $232=$ C. Icaco.

ovalifolias, Schott, in Spreng. Syst. iv. App. 406. Bras.

pellocarpus, G. F. W. Mey. Prim. Fl. Esseq. $199=$ Icaco.

prunifolius, Rafin. New Fl. Am. iii, $26=$ oblongi folius.

purpureus, Mill. Gard. Dict. ed. VIII. ฉ. $2=\mathrm{C}$. Icaco.

racemosus, Roxb. Hort. Beng. [92]; Fl. Ind. ii. $5100^{\circ}$ -Ins. Molucc.

retusus, Rafin. New Fl. Am. iij. $26=$ oblongifolius

subundulatus, Brign. in Mem. Soc. Ital. Mod. Ser. II. i. $(1962) 71$. - Bras.

CHRYSOBAPHUS, Wall. Tent. Fl. Nep. 37. t. 2\% $(1826)=$ Anoectochilus, Blome (Orchid.) Roxburghii, Wall. I. c. $=$ A. Koxborghii.

CHRYSOBOTRYA, Spach, in Ann. Sc. Nat. Ser II. iv. (1885) $18=$ Ribes, Linn. (Saxifrag.) intermedin, Spach, 1. c. $19=\mathbb{R}$. aureum. Lindleyans, Spach, 1. c. $20=\mathbb{R}$, anreum. revoluia, Spach, I. c. $19=$ R. aurcum.

CHRYSOCALYX, Guill. Se Pert. Fl. Seneg. Tene 15: 48. Is $\$ .3$ Crotalaria, Lina. Legumin.

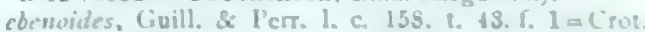
elenvides.

gracilis, Guill. \& Perr. 1. c 159 = Crot. gracilis.

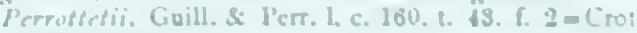
Ferrolfetii.

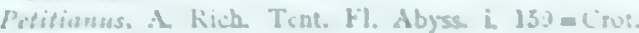
macrocalyx. 
CHRYSOCALYX :-

platycaly $x$, Steud. ex A. Rich. Tent. Fl. Abyss. 160 - Crotalaria platycalyx

Quartinianus, A. Rich. 1. c. $159=$ Crot. Dilloniana.

rubiginosa, Guill. \& Perr. Fl. Seneg. Tent. $158=$ Crot. atrorubens.

Schimperi, Hochst, ex A. Rich. Tent. Fl. Abyss. i. 151 $=$ Crot. incana.

CHRYSOCEPHALUM, Walp. in Linnaea, xiv. (1840) $503=$ Helichrysum, Vaill. (Compos.).

apiculatum, Steetz, in Lehm. Pl. Preiss. i. $474=\mathrm{H}$. apicalatum.

asperum, Steetz, 1. c. $473=\mathrm{H}$. semipapposum.

Behrianum, Sond. in Iinnaea, xxv。(1852) $517=\mathrm{H}$. Baxteri.

brevicilium, Walp. Rep. vi. $238=\mathrm{H}$. semipapposum. canescens, Turcz. in Bull. Soc. Nat. Mosc. xxiv. (1851) I. $\mathbf{1 9 6}=\mathrm{H}$. apiculatum.

ciliatum, Steetz, in Lehm. Pl. Preiss. i. $474=$ H. semipapposum.

Aavispinum, Walp. Rep. i. 237, sphalm. = seq

flavissimum, Steetz, in Lehm. Pl. Preiss. i. $472=\mathrm{H}$ apiculatum.

glabratum, Turcz, in Bull, Soc. Nat. Mosc. xxiv. (1851) I $197=\mathrm{H}$, apiculatum

helichrysoides, Walp. in Linnaea, xiv. $(1840) 503=\mathrm{H}$. apiculatum.

odorum, Walp. Rep. vi. $238=\mathrm{H}$. apiculatum.

pterochaetum, F. Muell. in Linnaea, xxv. (1852) $416=$ H. pterochaetum.

semipapposum, Steetz, in Lehm. P1. Preiss. i. $474=\mathrm{H}$ semipapposum.

squarrulosum, Sond. in Linnaea, xxi. (1852) $515=\mathrm{H}$. semipapposum.

quarrulosum, Steetz, in Lehm. P1. Preiss. i. $472=\mathrm{H}$ apiculatum.

vitellinum, Sond. \& F. Muell. in Linnaea, xxv. (1852)

$514=$ H. apiculatum.

CHRYSOCHAMELA, Boiss. F1. Orient. i. 313 (1867)= Cochlearia, Tourn. (Crucifer.)

elliptica, Boiss. 1. c. 314.-As. Min.

Noëana, Boiss. 1. c-Armenia.

velutina, Boiss. 1. c. $313=$ Coch. velntina

CHRYSOCHIAMYS, Poepp. \& Endl. Nov. Gen et Sp. iii. 13. t. 211 (1842). GUTTYFERAE, Benth. \& Hook. f. 172

Bertolonia, Spreng. Neue Entdeck, ii. 110.t. 1. f. 1 (1821).

Commirhoea, Miers, in Trans, Linn. Soc. xxi. (1855) 252. t. 26

Poecrlostemon, Planch. \& Triana, in Ann. Soc. Nat. Sér. IV. xiv. (1860) 256

Tovomitopsis, Planch. \& Triana, 1. c. 261 (1860). clusioides, Griseb. Cat. Pl. Cub. 37.-Cuba.

costa-ricana, Hemsl. Biol. Centr. Am. Bot. i. 87.Costa Rica.

dependens, Planch. E Triana, in Ann. Sc. Nat. Sér IV. xiv. (1860) 259.-Am. trop.

glauca, Hemsl. Biol. Centr. Am. Bot. i. 87.-Costa Rica. Goudotii, Planch. E Triana, in Ann. Sc. Nat. Sér IV. xiv. (1860) 259.-N. Granat.

laxa, Planch. E Triana, l. c. 258.-N. Granat.

membranacea, Planch. \% Triana, l. c. 260.-N. Granat.

multiflora, Poepp. E Endl. Nov. Gen. et $S p$. iii. 13. t. 211 -.-Peruv.

myrcioides, Planch. E Triana, in Ann. Sc. Nat. Sér. IV. xiv. (1860) 260.-N. Granat.

nicaraguensis, Hemsl. Biol. Centr. Am. Bot. i. 87.Nicaragua.

pachypoda, Planch. E Triana, in Ann. Sc. Nat. Sér. IV. xiv. (1860) 257.-Peruv.

Pavonii, Planch. E Triana, l. c. 258.-Peruv.

psychotriaefolia, Hemsl. Biol. Centr. Am. Bot. i. 87.-Costa Rica.

CHRYSOCOMA, Linn. Gen.ed.I. 248 (1737), partim. COMPOSITAE, Benth. \& Hook. f. ii. 286.

acaulis, Walt. Fl. Carol. 196=Vernonia oligophylla adpressa, Vell. F1. Flum. 332 ; viii. t. $35=$ Vernonia monticola.

Aitoni, Spreng. Fl. Hal. Mant. 50.-Hab. ?

alata, Vell. Fl. Flum. 335 ; vii. t. 48 (Eupatorii sp.?). -Bras.

albida, Vell. l.c. 333 ; vini. t. 42.-Bras

\section{CHRYSOCOMA :-}

alterna, Vell. Fl. Flum. 333 ; viii.t. 40 (Vernoniae sp.?) -Bras

amara, Schum, \& Thonn. Beskr. Guin. Pl. $383=$ Vernonia senegalensis.

angustifolia, Steud. Nom. ed. II. i. $358=$ Vernonia angnstifolia.

aphylla, Vell. F1. Flum. 324 ; viii. t. $1=$ Baccharis aphylla.

arb̌rea, Vell, 1. c. 326 ; viii t. $11=$ Vernonia Tweedieana.

artemisifolia, Poepp. ex Steud, Nom. ed. II. i. $358=$ Eupatorium coronopifolium.

aspera, F. G. Dietr. Vollst. Lexik. Gaertn. Nachtr. ii $239=$ Inula germanica

aurea, Boj. ex DC. Prod. vi. $322=$ Nidorella Chrysocoma.

aurea, Salisb. Prod. 118=C. Coma-aurea

biflora, Linn. Sp. P1. $841=$ Aster dracunculoides.

camphorata, Rob. \& Cass, in Dict. Sc. Nat. xxxiv. 35 = Jasonia glutinosa.

candicans, Delile, F1. Egypte, 271. t. $46(=$ Varthemia candicans).-Aegypt.

capillacea, Michx. Fl. Bor. Am, ii. 101 = Eupatorium foeniculaceum.

cernua, Linn. Sp. Pl. $840=$ C. Coma-aurea.

cernua, Thunb. Prod, Pl. Cap. 142, partim = tenuifolia.

ciliaris, Link, Enum. Hort. Berol. ii. $311=$ Aster Ecklonis.

ciliaris, Willd. Sp. P1. iii. $1789=$ ciliata.

ciliata, Linn. Sp. Pl. 841.-Afr. austr.

ciliata, E. Mey. ex DC. Prod. v. 354=oblongifolia.

cinerea, Labill. Nov, Holl, Pl, ii. 39.t. 182=Helichrysum cinereum.

Coma-aurea, Linn. Sp. Pl. 840.-Afr. austr.

coronopifolia, Michx. Fl. Bor. Am. ii. $102=$ Eupatorium coronopifolium.

crassa, Vell. Fl. Flum. 326 ; viii. t. 8.-Bras.

cruciata, Vell.l. c. 326 ; viii. t. 10 (Baccharidis sp. ?). -Bras.

cuneifolia, Facq. Coll. iii. 280.-Reg. Magell

cymosa, Vell. Fl. Flum. 327 ; viii. t. $16=$ Vernonia missionis

decurrens, DC. Prod. v. 354.-Afr. austr.

decurrens, Harv. in Harv. \& Sond. Fl. Cap. iii. $95=$ Heteromma decurrens.

decussata, Vell. Fl. Flum. 326 ; viii. t. $9=$ Baccharis camporum.

dentata, Vell. 1. c. 334 ; viii. t. $47=$ Baccharis orgyalis. denticulata, Jacq. Hort. Schoenb. iii. $62=$ Chrysanthemum flosculosum.

dichotoma, Jacq. Ic. Pl. Rar. i. 17. t. $\mathbf{I 7 1}=$ Allagopappus dichotomus.

divaricata, Fisch. Hort. Gorenk. ed. II. (1812) $37=$ Aster divaricatus.

dracunculoides, Lam. Encyc. ii. $192=$ Aster dracunculoides.

dracunculoides, Pursh, F1. Am. Sept. ii. $517=$ Bigelowia dracunculoides.

ferruginea, Spreng. Syst. iii. $424=$ Helichrysum ferrugineum.

florida, Vell. Fl. Flum. 334; viii. t. 44.-Bras,

foetida, Lam. Encyc. ii. 193= Nidorella foliosa

fruticosa, J. F. Gmel. Syst. 1203= cuneifolia

fruticosa, Steud. Nom. ed. II. i. 358 = Vernonia. rigida gigantea, Walt. F1. Carol. 196=Vernonia altissima.

gnaphaloides, Burm. f. Fl. Cap. Prod. 23.-Afr. austr.

graminifolia, Boeber, in Pall. N. Nord. Beitr. vi. 261 $=$ Aster Linosyris.

graminifolia, Linn. Sp. Pl. $841=$ Solidago lanceolata . graminifolia, Walt. Fl. Carol. 196 = Vernonia angustifolia.

grandis, Lepech. It. iii. 38.-Sibir. ural.

graveolens, Nutt. Gen. Am. ii. 136=Bigelowia dracunculoides.

graveolens, Torr. in Ann. Lyc. N. York, ii. (1828) 211 $=$ Bigelowia pluriflora.

herbacea, Vell. Fl. Flum. 330 ; viii. t. $29=$ Vernonia obovata.

heterophylla, Rafin. Fl. Ludov. 64 (=Baccharidis sp. ?).-Am. bor

hirsuta, Vell. Fl. Flum. 333 ; viii. t. 41.-Bras.

horizontalis, Vell. F1. Flum. 330 ; viii. t. $28=\mathrm{Ver}$ nonia obscura.

humilis, DC. Prod. vii. $280=$ Aster angustus .

imberbis, Vell. Fl. Flum. 331 ; viii. t. 34.-Bras.

incana, Burm. f. Fl. Cap. Prod. $23=$ Pteronia incana.

\section{CHRYSOCOMA :-}

incana Léveillé, in Demid. Voy. Russ. Mér. ii. 237 ; iv. 496 (=Linosyris villosa).-Rossia

indivisa, Vell. Fl. Flum. 326 ; viii. t. $12=$ Baccharis brachylaenoides.

integerrima, Vell.l. c. 328 ; viii. t. 19.-Bras.

juncea, Desf. Tabl. ed. II. 115, nomen.-Hab.?

lappulina, Boj. ex DC. Prod, v. 323 = Nidorella mucronata.

lateralis, Vell. F1. Flum. 329 ; viii. t. $21=$ Baccharis cassinaefolia

liburnica, Spreng. Syst. iii. $425=$ Aster Linosyris.

linearis, Vell. Fl. Flum. 330 ; viii. t. 27 .-Bras.

linifolia, Steud. Nom. ed. II. i. $358=$ Aster subulatus?

Linosyris, Linn. Sp..Pl. 841=Aster.Linosyris.

longifolia, DC. Prod. v. 354.-Afr, austr

maculata, Vell. Fl. Flum. 325 ; viii. t. $6=$ Eupatorium conyzoides.

maritima, Vell. 1. c. 329 ; viii. t. $22=$ Baccharis orgyalis.

medioserrata, Vell. l. c. 327 ; viii. t. 15.-Bras,

megapotamica, Spreng. Syst. iii. $424=$ Eupatorium ericoides.

microcephala, DC. Prod. v. $353=$ tenuifolia.

microphylla, Thunb. Prod. Pl. Cap. $142=$ tenuifolia

monantha, Vell. Fl. Flum. 331 ; viii. t. 33.-Bras.

montana, Vahl. Symb. Bot. i. $70(=$ Varthemia mon$\tan a$ - Arabia.

mucronata, Forsk. Fl. Aegypt. Arab. $147=$ Iphiona juniperifolia.

nauseosa, Pursh, F1. Am. Sept. ii. $517=$ Bigelowia dracunculoides.

nivea, Willd. Sp. Pl. iii. 1790.-Afr, austr.

noveboracensis, Desf. Tabl. ed. I. $98=$ Vernonia noveboracensis.

nuda, Vell. Fl. Flum. 335 ; viii. t. $50=$ Baccharis aphylla.

nudata, Michx. Fl. Bor. Am. ii. 101= Bigelowia nudata nupera, S. F. Gray, Nat. Arr. Brit. Pl. i1. $467=$ Aster Linosyris.

oblongifolia, DC. Prod. 354.-Afr. austr.

obscura, Vell. Fl. Flum. 330 ; viii. t. $30 .-$ Bras.

odoratissima, Raeusch. Nom. ed. III. $235=$ Trilisia odoratissima.

oligophylla, Vell. Fl. Flum. 324 ; viii. t. 2.= Vernonia Cephalotes.

opposita, Vell. l. c. 334 ; viii.t. 46.-Bras.

oppositifolia, Linn. Pl. Rar. Afr. $18=$ Pteronia divaricata.

oppositifolia, Vell. Fl. Flum. 328 ; viii. t. 18.-Bras.

ovata, Forsk. Fl. Aegypt. Arab. 147.-Arabia.

palustris, Savi, Pugill. 12 ; ex Bertol. Fl. Ital. ix. 91=

Aster Linosyris.

paniculata, J. F. Gmel. Syst. 1204=Trilisia pani culata.

paniculata, Vell. F1. Flum. 327 ; viii. t. $14=$ Vernonia geminata.

patula, Berg. Desc. Pl. Cap. $234=$ C. Coma-aurea.

pauciflora, Vell. Fl. Flum. 325 ; viii. t. $5=$ Ageratum melissaefolium.

peduncularis, $D C$. Prod. v. 353.-Afr. austr.

pedunculata, Vell. Fl. Flum. 332 ; viii. t. $37=$ Vernonia ammophila.

phosphorica, Vell, 1. c. 325 ; viii. t. $4=$ Vernonia polyanthes.

pilosa, J. F. Gmel. Syst. $1203=$ Liatris pycnostachya

pilosa, Vell. l.c. 328 ; viii. t. 17.-Bras.

pinifolia, Burm. f. Fl. Cap. Prod. 23.-Afr. austr.

pinifolia, Spreng. Syst. iii. 424 (=Ozothamnus pini-

folius). - N. Zel

pinnatifida, DC. Prod. v. 354.-Afr, austr.

praeacoa, Stend. Nom. ed. II. i. $358=$ C. Preacaa.

praealta, Desf. Tabl. ed. I. $98=$ Vernonia altissima

Preacaa, Vell. Fl. Flum. 333 ; viii. t. $39 .-$ Bras.

pterocaula, DC. Prod. v. 354.-Afr. austr.

pumila, Vell. Fl. Flum. 331 ; viii. t. $32=$ Vernonia grandiflora.

punctata, Steud. Nom. ed. II. i. $358=$ seq.

punctulata, Vell. Fl. Flum. 335 ; viii. t. $49=$ Enpa torium laevigatum

purpurascens, Vell. l. c. 331 ; viii. t. 31 .-Bras

purpurea, Forst. f. Prod. 54.-N. Hebrid.

purpurea, Rafin. Fl. Ludov. 64 (=Liatridis sp.).Am. bor.

purpurea, Vell. 1. c. 334 ; viii. t. $45=$ Baccharis cassinaefolia.

quadrangularis, Vell. Fl. Flum. 329 ; viii. t. $25=$

Piptocarpha quadrangularis. 


\section{CHRYSOCOMA}

radiata, Fisch. ex Steud. Nom, ed. II. i. 359.Hab. ?

ramosa, Raeusch. Nom, ed. III. 235, nomen.-Carolin. repanda, Vell. Fl. Flum. 327 ; viii. t. $13=$ Vernonia scorpioides.

reticulata, Labill. Nov. Holl. Pl, ii. 40, t. $183=$ Helichrysum reticulatum.

rosmarinifolia, Spreng. Syst. iii. $424=$ Helichrysum rosmarinifolium.

sancta, Vell. Fl. Flum. 324 ; viii. t. $3=$ Baccharis Lundii.

saxatilis, DC. Fl. Fr. Suppl. $468=$ Jasonia saxatilis. scabra, Ledeb. in Mém. Acad. Pétersb. v. (1812) 563 Inula germanica

scabra, Linn. Sp. Pl, ed. II. $1177=$ Felicia reflexa

scoparia, Linn. Pl. Jam. Pug. 21 ; Amoen. Acad. v. 381 = Baccharis scoparia.

sericea, Linn. f. Suppl. 360 (=Schizogyne sericea).Ins. Canar.

sernua, Hill, Veg. Syst. iii. 128, sphalm. = C. Comaaurea.

serrata, Vell. Fl. Flum. 329 ; viii. t. 23.-Bras

sessilis, Vell. 1. c. 328 ; viii. t. $20=$ Vernonia macrophylla.

ingularis, Vell. 1. c. 325 ; viii. t. $7=$ Vernonia nitidula et Baccharis cassinefolia.

spathulata, Forsk. Fl. Aegypt. Arab. $147=$ Vernonia atriplicifolia.

sphacelata, Moench, Meth. 577 = Senecio paniculatus.

spicata, Forsk, Fl. Aegypt, Arab. p. lxxiii=Ifloga Fontanesii.

spinosa, Delile, F1. Aegypt. 128. t. $46=$ Iphiona juniperifolia.

squamata, Labill. Nov. Holl. P1. ii. 40. t. $184=$ Leptorhynchus squamatus.

tatarica, Less. in Linnaea, ix. (1834) 186.-Reg. - Casp.

tenuifolia, Berg. Desc. Pl. Cap. 235.-Afr. austr.

tenuifolia, Salisb. Prod. $188=$ Aster Linosyris.

tomentosa, Vell. Fl. Flum. 332 ; viii. t. 38.-Bras.

tomentosa, Linn. Syst. ed. XII. 539.-Afr. austr.

tomentosa, Walt. Fl. Carol. $196=$ Vernonia noveboracensis.

tridentata, DC. Prod. v. 354-Afr. austr.

trinervis, Vell. Fl. Flum. 333 ; viii. t. $43 .-$-Bras.

truncifolia, J. Shaw, in Journ. Linn. Soc. xiv. (1874) 206 , sphalm. = tenuifolia.

tuberosa, Vell. Fl. Flum. 332 ; viii. t. $36 .-$ Bras.

undulata, Thunb. Prod. P1. Cap. 142=Nidorella amplexicaulis.

uniflora, Raeusch. Nom. ed. III. 235, nomen.Am. bor.

uniflora, Spreng. Nov. Prov. (1818) 11 (=Varthemia candicans).-Aegypt.

verticalis, Lag. Gen, et Sp. Nov. $25=$ Jasonia saxatilis.

verticillata, Vell. Fl. Flum. 330 ; viii. t. $26=$ Piptocarpha oxyphylla.

villosa, Linn. Sp. P1. 841 (=Linosyris villosa).Europ.; Cauc.; Sibir.

violacea, Schum. \& Thonn. Beskr. Guin. Pl. 384= Vernonia cinerea.

virgata, Nutt. Gen. Am. ii. 137 = Bigelowia nudata

virginiana, Hort. ex DC. Prod. v. $341=$ Solidago lanceolata.

volubilis, Vell. Fl. Flum. 329 ; viii. t. 24.-Bras.

vulgaris, Gueldenst. ex Ledeb. Fl. Ross. ii. $495=$ Aster Linosyris.

CHRYSOCOPTIS, Nutt. in Journ. Acad. Philad, vii. (1834) 8. t. 1 =Coptis, Salisb. (Ranunculac.). asplenifolia, Nutt. 1. c. 9 , in obs. = Coptis asplenifolia occidentalis, Nutt. 1. c. $8=$ Coptis occidentalis,

CHRYSOCORYNE, Endl, in Bot. Zeit. i. (1843) $457=$ Angianthus, Wendl. (Compos.).

angianthoides, F. Muell. in Linnaea, xxy. (1852) 404, $488=$ A. pusillus.

Drummondii, A. Gray, in Hook. Kew Journ. iii. (1851) $152=\mathrm{A}$. tenellus

Huegelii, A. Gray, 1, c. $151=$ A. tencllus.

myosuroides, A. Gray, 1. c. $152=\mathbf{A}$. myosuroides.

pusilla, Endi. in Bot. Zeit. i. (1843) $458=$ A. pusillus.

tenella, F. Muell. in Trans. Vict. Inst. (1855) $190=\mathrm{A}$. tenellus.

uniflora, Turcz, in Bull. Soc. Nat. Mosc, xxiv. (1851)

1. $188=$ A. myosuroides.
CHRYSOCY ATHUS, Falc. in Proc. Linn. Soc. i. (1839) 17 = Calathodes, Hook. f. \& Thoms. (Ranunculac.)

CHRYSOCYCNIS, Linden \& Reichb. fo in Bonplandia, ii. (1854) 280. ORCHIDEAE, Benth. \& Hook. f. iii. 553.

Schlimii, Linden Eै Reichb. f. l. c.-N. Granat.

CHRYSODENDRON, Vaill. ex Meissn. in DC. Prod. xiv. $230(1856-57)=$ Protea, Linn.

CHRYSODISCUS, Steetz, in Lehm. P1. Preiss. i, 460 (1845) = Athrixia, Ker-Gawl. (Compos.)

niveus, Steetz, l. c. = A. stricta.

CHRYSOGLOSSUM, Blume, Bijdr. 337. t. 7 (1825) ORCHIDEAE, Benth. \&c Hook. f. iii. 507.

Diglyphis, Blume, Fl. Jav. Praef. p. vii. (1828)

Diglyphosa, Blume, Bijdr. 336. t. 60 (1825).

latifolium, Benth. E Hook. f. Gen. iii. 508.-Java. ornatum, Blume, Bijdr. 338.--Java.

vesicatum, Reichb. f. in Seem. Fl. Vit. 304.-Ins. Fiji. villosum, Blume, Bijdr. 338.- Java.

CHRYSOGONUM, Linn. Hort. Cliff. 424 (1737) Coroll. Gen. 17 (1737). COMPOSITAE, Benth. \& Hook. f. ii. 350

CARgilla, Adans. Fam. ii. 130 (1763

Diotostephus, Cass. in Dict. Sc. Nat, xlviii. 543 (1827).

Moonia, Arn, in Nov. Act. Nat. Cur. xviii. (1836) 348.

Pentalepis, F. Muell. in Trans. Bot. Soc. Edinb. vii. (1863) 496.

Arnottianum, C. B. Clarke, Compos. Ind. 132.Ind. or.

dichotomum, Vahl, in West, Bidr. Ste. Croix, 303 ; DC. Prod. v. 510.-Ins, S. Crucis.

Diotostephus, DC. 1. c. = virginianum.

ecliptoides, Benth. E Hook. f.ex F. Muell. Census, 83 - Austral.

heterophyllum, C. B. Clarke, Comp. Ind. 132.-Ird or peruvianum, Linn. Sp. Pl. $920=$ Zinnia multiflora.

procumbens, Benth. \& Hook. f. ex F. Muell. Census, 83.-Austral.

trichodesmoides, Benth. Er Hook.f.l. c.-Austral.

virginianum, Linn. Sp. Pl.920.-Am, bor.

CHRYSOLIGA,Willd. ex DC. Prod. iii. 89, in syn. (1828) =Nesaea, Comm. (Lythrar.)

CHRYSOLINUM, Fourr. in Ann. Soc. Linn. Lyon, N. S. xvi. (1868) $349=$ Linum, Tourn.

gallicum, Fourr. 1. $c_{\mathrm{s}}=\mathrm{L}$. gallicum.

strictum, Fourr. 1. $\mathrm{c} .=\mathrm{L}$, strictum.

CHRYSOLYGA, Willd. ex Stend. Nom. ed. II. i. 359 $(1840)=$ Nesaea, Comm. (Lythrar.)

salicifolia, Willd, ex Steud. 1. c. =N. salicifolia

CHRYSOMA, Nutt. in Journ. Acad. Philad, vii. (1834) $67=$ Solidago, Vaill. (Compos.).

pumila, Nutt. in Trans. Am. Phil. Soc. N. S. vii. (1841) $325=$ S. pumila.

solidaginoides, Nutt, in Journ. Acad. Philad, vii. (1834) $67=\mathrm{S}$. pauciflosculosa

uniligulata, Nutt. in Trans. Am. Phil. Soc. N. S. vii. (1841) $325=\mathrm{S}$. neglecta

CHRYSOMALLUM, Thou. Gen. Nov. Madag. 8 (1806) = Vitex, Linn. (Verbenac.)

madagascariense, Thou. ex Steud. Nom. ed. I. 194=V. Chrysomallum.

CHRYSOMELEA, Tausch, Hort Canal, fasc, i-CF DC. Prod. v. 569 (1836) = Coreopsis, Linn. (Compos.). auriculata, Tausch, 1. c.; ex DC. 1. c. $571=$ Cor. pabescens.

lanceolata, Tausch, 1. c. ; ex DC. 1. c. $570=$ Cor. lanceolata.

CURYSOMELON, Forst, ex A. Gruy, Bot. U. St. Expl. Exped, i. 374, in syn. $(1854)=$ Spondias, Lino. (Anacard.).

poniferum, Forst, ex A. Gray, 1. c $=\mathrm{S}$. dulcis.

CHRXSONIAS, Benth. ex Steud. Nom. ed. II. i. 259 (1840) err. typ. = Chryaoscias, E. Mcy.
CHRYSOPHANIA, Kunth, ex Less. Syn. Comp. 224 1832) = Zaluzania, Pers. (Compos.

fastigiata, Kunth, 1. c. $=\mathrm{Z}$. angusta.

CHRYSOPHORA, Cham, ex Triana, in Trans. Linn. Soc. xxviii. (1871) $94,95.147=$ Oxymeris, DC (Melastomac.)

cinnamomifolia, Cham.ex Triana, 1. c. $147=0$ ssaca cinnamomifolia.

cordigera, Cham. ex Triana, 1. c. $94=$ Oxym. cordigera. hirsutior, Cham. ex Triana, 1. c. 95=Oxym. deflexa. secundifolia, Cham. ex Triana, 1. $\mathrm{c}_{\diamond}=$ Oxym. secundiflora.

CHRYSOPHTHALMUM, Phil, in Linnaea, xxix. (1857) $9=$ Grindelia, Willd. (Compos.) andinum, Phil. 1. c. $=\mathrm{G}$. andina.

CHYSOPHTHALMUM, Sch. Bip, in Walp. Rep. ii 955 (1843) (Chrysophtalmum). COMPOSITAE Benth. \& Hook. f ii. 341 .

dichotomum, Boiss. E Heldr. Diagn. Sér. I. xi. 5.As. Min.

montanum, Boiss. 1. c. $4=$ sternutatorium.

sternutatorium, Sch. Bip. in Walp. Rep. ii. 955.-As, Min.

CHRYSOPHYLLUM, Linn. Gen. ed. I. 361 (1737

SAPOTACEAE, Benth. \& Hook, f. ii. 653 .

Cainito, Plum, ex Adans, Fam. ii. 166 (1763)

Tuss. Fl. Antill. iii. 41. t. 9 (1824)

Dactimala, Rafin. Sylva Tellur. 153 (1838)

GUeRSENTIA, Rafin. 1. c. (1838).

Niemeyera, F. Muell. Fragm. vii. 114 (1869-71)

Nycterisition, Ruiz \& Pav. Prod. 30.t. 5 (1794)

Scleroxylon, Bertol, in Mem. Acc. Sc. Bolog.

viii. (1857) 237 (Misc. Bot. xiii. 15)

acuminatum, Boj. Hort. Maurit, $197=$ Sideroxylon ferrugineum.

acuminatum, Lam. Tabl. Encyc. ii. $44=$ monopy renum.

acuminatum, Poir. Encyc. Suppl. ii. 15=Sideroxylon guyanense.

acuminatum, Roxb. Hort. Beng. 17 ; FI. Ind. i. $599=$ Roxburghii.

acuminatum, Willd. ex Roem. \& Schult. Syst. iv, 813 $=$ Humboldtianum.

africanum, A. DC. in DC. Prod. viii. 163.-Afr. trop,

albidum, G. Don, Gen. Syst. iv. 32.-Afr. trop.

alnifolium, Baker, in Oliver, Fl. Trop. Afr. iii. 499.Afr. trop.

amplifolium, A. DC. in DC. Prod. viii. 159.-Bras. angustifolium, Lam. Tabl. Encyc, ii. 44.-Ins. S. Doming aquaticum, H. B. \& K. Nov. Gen. et Sp. iii. $286=$ C Cainito.

argenteum, Facq. Enum. Pl. Carib. 15.-Ins. Martinic. auratum, Miq. in Mart. Fl. Bras. vii. 97.-Bras.

bancanum, Mig. Fl. Ind. Bat. Suppl. 579-Ins. Banca.

Barbasco, Loefl. ex DC. Prod. viii. $1 \pm 9=$ Jacquinia armillaris.

bicolor, Poir. Encyc. Suppl. ii. 15.-Ins. Porto Rico. Bonplandii, Klotzsch, ex Miq. in Mart. Fl. Bras, vii. $94=$ C. Cainito.

bmsiliense, A. DC in DC. Prod, viii. 156-Bms.

bumelioides, Mart. in Flora, xxii. (1839) 1. Bcibl. 1. -Bras.

Buranhem, Riedel, in Taunay, Man. Agric. Bras. ed. II. $318=$ Lucuma glycyphloen.

cacruleum, Jacq. Stirp. Select, Am, $52=$ C. Cainito.

Cainito, Linn. Sp. Pl. 192.-Ind. oco

carolinense, Jacq. Obs. Bot. iii. $\$=$ Bumelis tengx.

cayennense, $A . D C$. in DC. Prod. viii. 100.-Guiana.

cuneifolium, A.DC. l. c.-Guiana.

decandram, Montr. in Mém. Acad. Lyon, x. (150̈i 228.-N. Caled.

dnbiom, Steud. Nom, ed. II i 359 -Ins S. Doming.

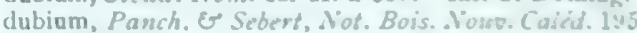

-N. Caled.

ebenaceam, Mart. in Flora, xxi. (15\$5) 11. Beibl. 96.Bras.

emarginalum, Rlotasch, in Schomb. Fanne of Fl. Gu 108 i.-Ciuiana.

ferrugineum, Gaertn. Fruct. iji. $133=$ manopyrenum. ferrugineum, Sicad. Nom. ed. 1I. i. \$59.-Peruv.

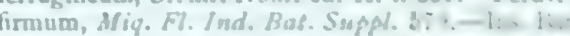

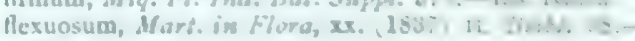
Hras.

fuscum, Fisch. ex Sirud. Piom. ed. II. i. 35:, - Ind, or. 


\section{CHRYSOPHYLLUM:-}

Gardneri, Mart. E Eichl. ex Miq. in Mart. Fl. Bras. vii. 102,-Bras.

glabrum, Facq. Enum. Pl. Carib. 15.-Ins. Martinic. glabrum, Juss. ex Lam. Encyc. í. $245=$ Bumelia tenax. glycyphloeum, Casar, in Atti 3zia Riun. Sc. Ital. Firenze (1841) 514; Dec. Stirp. Bras. $12=$ Lucuma glycyphloea.

granatense, Spreng. Syst. i. 667.-N. Granat.

grandifolium, Steud. Nom. ed. II. i. 359.-Ins. Philipp. guyanense, Klotzsch, ex Miq. in Mart. Fl. Bras. vii. 98 = sericeum.

Guilleminianum, A. DC. in DC. Prod. viii. $161=$ ebenaceum.

Hostmannianum, Klotzsch, ex Mig. in Mart. Fl. Bras. vii. $98=$ sericeum

Humboldtianum, Roem. E Schult. Syst. iv. 813.-Am. anstr.

Inophyllum, Mart. ex Miq. in Mart. F1. Bras. vii. 105 Iucuma Inophyllum.

inornatum, Mart. in Flora, xxi. (1838) II. Beibl. 96:Bras.

jamaicense, Jacq. Stirp. Select. Am. $52=$ C. Cainito.

januariense, Eichl. in Kjoeb. Vidensk. Meddel. (1870) 206.-Bras.

javanicum, Steud. Nom. ed. II. i. 359.-Java.

lanceolatum, Casar. Stirp. Bras. Dec. $64=$ inornatum

lanceolatum, $A . D C$. in DC. Prod. viii. 162.-Java.

leptocarpum, Spruce, ex Miq. in Mart. F1. Bras. vii. 106 $=$ Lucuma leptocarpa.

longifolium, Mart. E Eichl. ex Miq. l. c. 97.-Bras,

lucumifolium, Griseb, in Goett. Abh. xxiv. (1879) 223. -Reg. Argent

ludovicianum, Rafin. Fl. Ludov. 53.-Louisiana.

Macoucou, Aubl. Pl. Gui. i. 233. t. 92.-Guiana

macrophyllum, Desf. Cat. Hort. Par. ed. III. $132=$ grandifolium.

macrophyllum, Gaertn. f. Fruct. iii. 122. t. 202. f. $1=$ dubium.

macrophyllum, Lam. Tabl. Encyc. ii. $44=$ Lucuma Rivicoa.

macrophyllum, Mart. in Flora, xxi. (1838) II. Beibl. 95 $=$ brasiliense.

macrophyllum, Sabine, in Trans, Hort. Soc. v. (1824) 458 = africanum

magalis-montana, Sond. in Linnaea, xxiii. (1850) 72.Afr. austr.

maliforme, Linn. Syst. ed. X. $937=$ C. Cainito

Manglillo, Lam. Tabl. Encyc. ii. $45=$ Myrsine Manglilla.

Martianum, A. DC. in DC. Prod. viii. $161=$ ebenaceum maytenoides, Mart. in Flora, xxii. (1839) I. Beibl. 1.Bras.

melanophleum, Lam. Tabl. Encyc. ii. $45=$ Myrsine mitis.

Michino, H. B. E K. Nov. Gen. et Sp. iii. 236.-N Granat.

microcarpum, Sw. Prod. Veg. Ind. Occ. 49.-Ins. S. Doming.

microphyllum, A. DC. in DC. Prod. viii. $158=$ mono pyrenum.

microphyllum, Jacq. Stirp. Select. Am. 53. t. 37. f. $2=$ C. Cainito.

Millerianum, Lam. Tabl. Fncyc. ii. $45=$ Myrsine mitis molle, Wall. Cat. n. 4161 = Payena Maingayi. monopyrenum, Spreng. Syst. i. $666=\mathrm{C}$. Cainito

monopyrenum, Sw. Prod. Veg. Ind. Occ. 49.-Ind. occ myrsinodendron, F. Muell. Fragm. vi. 178=Sideroxy lon Brownii.

myrtifolium, Mart. in Flora, xxii. (1839) I. Beibl. 1= maytenoides.

natalense, Sond. in Linnaea, xxiii. (1850) 72.-Afr austr.

nitidissimum, Klotzsch, ex Miq. in Mart. F1. Bras. vii. $98=$ auratum

nitidum, G. F. W. Mey. Prim. Fl. Esseq. 116.Guiana.

obovatum, Sabine, in Trans. Hort. Soc. v. (1824) 458. -Afr. trop.

obovatum, Wall. ex A. DC. in DC. Prod. viii. $178=$ Sideroxylon ferrugineum.

obtusatum, Willd. ex Roem. \& Schult. Syst. iv. $813=$ C. Cainito.

oleaefolium, Spruce, ex Mig. in Mart. Fl. Bras. vii 101.--Bras.

Olfersii, Klotzsch, ex Miq. 1. c. $91=$ splendens. oliviforme, Lam. Encyc. i. $552=$ monopyrenum oliviforme, Linn. Syst. ed. X. $937=$ C. Cainito.

\section{CHRYSOPHYLLUM:-}

Ottonis, Klotzsch, ex Miq. in Mart. Fl. Bras. vii. $94=$ C. Cainito.

parviflorum, Casar. Stirp. Bras, Dec. 63.-Bras. pauciflorum, Lam. Tabl. Encyc. ii. $44=$ glabrum. pentagonum, Hance, in fourn. Bot. xx. (1882) 78. China.

Persicastrum, Eichl. in Kjoeb. Vidensk. Meddel. (1870) 208.-Bras.

pomiforme, Bert. ex Spreng. Syst. i. 667.-Jamaic.

Prieurei, A. DC. in DC. Prod. viii. 161.-Guiana

pruniferum, F. Muell. Fragm. vi. 26.-Austral.

prunifolium, Baker, in Oliver, Fl. Trop. Afr. iii. 499 -Afr. trop.

psilophyllum, A. $D C$. in DC. Prod. viii. 160.Guiana.

pulcherrimum, Mart. E Eichl. ex Miq. in Mart. Fl. Bras. vii. 92,-Bras.

pyriforme, Willd. Sp. Pl. i. $1084=$ C. Macoucou.

ramiflorum, A. DC. in DC. Prod. viii. $158=$ Ecclintusa ramiflora.

revolutum, Mart. E Eichl. ex Miq. in Mart. Fl. Bras. vii. 104.-Bras.

rhodoneurum, Hassk. in Flora, xxxvili. (1855) 579.Java.

Richardii, Klotzsch, ex Miq. in Mart. Fl. Bras. vii. 97 = auratum.

Roxburghii, G. Don, Gen. Syst. iv. 33.-As. trop

rufum, Mart. in Flora, xxi. (1838) II. Beibl. 94. Bras.

rugosum, Sw. Prod. Veg. Ind. Occ. 49=Sideroxylon rugosum.

Schomburgkianum, A. DC. in DC. Prod. viii. 157.Guiana.

Sebertii, Panch. in Panch. E Sebert, Not. Bois Nouv. Caléd. 194.- - N. Caled.

sericeum, A.DC. in DC. Prod. viii. 158.-Guiana,

sericeum, Salisb. Prod. $138=$ C. Cainito.

sessiliflorum, Poir. Encyc. Suppl. ii. 16-Guiana.

sessilifolium, Panch. E Sebert, Not. Bois Nouv. Caléd. 195.-N. Caled.

sparsiflorum, Klotzsch, ex Miq. in Mart. Fl. Bras. vii. 90.-Guiana.

splendens, Spreng. Syst. i. 666.-Bras. ; Peruv.

subnudum, Baker, in Oliver, Fl. Trop. Afr, iii, 499.Afr. trop.

sumatranum, Miq. Fl. Ind. Bat. Suppl. $579=$ Roxburghii.

sundaicum, Miq. l. c. 578.-Ins. Sunda.

viride, Mart. E Eichl. ex Miq. in Mart. Fl. Bras, vii. 102.-Bras.

Wakere, Panch. E Sebert, Not. Bois Nouv. Caléd. 193. -N. Caled.

CHRYSOPIA, Noronha, ex Thou. Gen. Nov. Madag. $14(1806)=$ Symphonia, Linn. (Guttif.).

fasciculata, Thou. 1 , c. n, $48=\mathrm{S}$, fasciculata

gymnoclada, Planch. \& Triana, in Ann. Sc. Nat. Sér. IV. xiv. (1860) 291.-Madag.

macrophylla, Cambess. Mém. Tern. et Gutt. 55. t. 4.Madag.

microphylla, Cambess. \& Boj. ex Cambess. in Mém. Mus. Par. xvi. (1828) 423. t. 4.-Madag.

urophylla, Decne. ex Planch. \& Triana, in Ann. Sc. Nat. Sér. IV. xiv. (1860) 291.-Madag.

verrucosa, Hilsenb. \& Boj. ex Planch. \& Triana, l. c. 290.-Madag.

CHRYSOPOGON, Trin. Fund. Agrost. 187 (1820). GRAMINEAE, Benth. \& Hook. f. iii. 1135. Centrophorum, Trin. 1. c. 106. t. 5 (1820). Poranthera, Rafin. in Ser. Bull. Bot. i. 221.

RapHIS, Beauv, Agrost. 120 (1812).

RHAPHIS, Loux. Fl. Cochinch. 552 (1790)

Trianthium, Desv. Opusc. 69, obs. (1831).

aciculatus, Trin. Fund. Agrost. 188.-Reg. trop.

alternans, Trin. ex Steud. Nom. ed. II. i. $359=$ violascens?

argutus, Trin. ex Steud. l. c. 360.-Austral.

Arnottianus, Nees, ex Steud. Syn. Pl. Gram. 396Ind. or.

avenaceus, Benth. in Fourn. Linn. Soc. xix. (1881) 73. -Am. calid.

ciliolatus, Boiss. Fl. Orient. v. $458=$ serrulatus.

filiformis, Voigt, Hort. Suburb. Calc. $704=$ Dimeria

ornithopoda.

elongatus, Benth. Fl. Austral. vii. 538.-Austral.

\section{CHRYSOPOGON .}

Esenbeckii, Arn. ex Steud. Syn. Pl. Gram, $395=$ serrulatus.

Francavillanus, Hemsl. Biol. Centr. Am. Bot. iii. 530 = avenaceus.

fuscus, Trin. ex Stend. Nom. ed. II. i. $360=$ Andropogon serratus.

glabratus, Trin. in Mém. Acad. Pétersb. Sér. VI ii. (1833) $318=$ C. Gryllus.

Gryllus, Trin. Fund. Agrost. 188.-Reg. trop. et subtrop.; Europ. austr.; Afr.

increscens, Nees, ex Steud. Syn. Pl. Gram. $396=$ serrulatus.

Minarum, Benth. in Journ. Linn. Soc. xix. (1881) $73=$ stipoides.

montanus, Trin. in Spreng. Neue Entdeck. ii. 93.Ind. or.

nutans, Benth. in Fourn. Linn. Soc. xix. (1881) 73.Am. calid.

pallidus, Trin. ex Steud. Nom. ed. II. i. 360.Austral.

parviflorus, Benth. in Hook. Lond. Journ. Bot, ii. (1843) $411=$ violascens

pauciflorus, Benth. ex Vasey, Gram, U. St. $20=$ Sorghum pauciflorum.

pictus, Hance, in Ann. Sc. Nat. Sér. V. v. (1866) 252. -As. trop.

quinqueplumis, A. Rich. Tent. Fl. Abyss. ii. 450.Abyssin.

secundum, Benth. ex Vasey, Gram. U. St. $20=$ Sorghum secundum.

serrulatus, Trin. in Mém. Acad. Pétersb. Sér. VI. ii. 1833) 318.-Ind. or.; Afr. trop.

stipoides, Benth. in Journ. Linn. Soc. xix. (1881) $73=$ avenaceus.

stipoides, Trin. in Bull. Sc. Acad. Pétersb. i. (1836) 71.-Bras.

strictus, Nees, in Hook. Kew Journ. ii. (1850) $95=$ Andropogon intermedius.

subtilis, Miq. Fl. Ind. Bat. iii. 492.-Java.

subulatus, Trin. ex Steud. Nom. ed. II. i. $360=$ aciculatus.

tener, Nees, ex Steud. Syn. Pl. Gram. 397.-'Andor.' trivialis, Am. \& Nees, in Nov. Act. Nat. Cur. xix. Suppl. i. (1843) $171=$ aciculatus.

verticillatus, Trin. ex Steud. Nom. ed. II. i. 360. Ind. or.

violascens, Trin. in Mém. Acad. Pétersb. Sér. VI. ii. (1833) 319.-As. trop.; Abyssin. ; Austral.

Wightianus, Thw. Enum. Pl. Zeyl. 366.-Zeylan.

Wrightii, Munro, ex Vasey, Cat. Gram. U. St. $29=$ Sorghum panciflorum.

zeylanicus, Thw. Enum. P1. Zeyl. $366=$ Arnottianus.

CHRYSOPSIS, Ell. Sketch, ii. 333 (1824). COMPOSITAE, Benth. \& Hook. f. ii. 252

Ammodra, Nutt, in Trans. Am. Phil. Soc. Ser. II vii. (1841) 321 .

Diplogon, Rafin. in Am. Monthly Mag. (1818) 268.

HeCtorea, DC. Prod. v. 95 (1836)

HEYFELDERA, Sch. Bip. in Flora, xxxvi. (1853) 35.

Macronema, Nutt, in Trans. Am. Phil. Soc. Ser. II. vii. (1841) 322 .

PitYOPSIS, Nutt. 1. c. (1841) 317.

acaulis, Nutt. in Journ. Acad. Philad, vii. (1834) $33=$ Aplopappus acaulis.

alba, DC. Prod. v. 264, in syn. $=$ Aster ptarmicoides

alpina, Nutt. in Journ. Acad. Philad, vii. (1834) 34 . 3. f. $2=$ Aster scopulorum.

amygdalina, DC. Prod. v. 272, in syn. $=$ Aster umbellatus.

andicola, Phil. in Anal. Univ. Chil. (1862) ii. 398; et in Linnaea, xxxiii. (1864-65) 131.-Chili.

argentea, Ell. Sketch, ii. $334=$ graminifolia

Bolanderi, A. Gray, in Proc. Am. Acad. vi. (1864-65) $543=$ villosa.

Breweri, A. Gray, l. c. 542.-Calif.

caespitosa, Nutt. in Journ. Acad. Philad. vii. (1834) 33 = Aplopappus acaulis.

canescens, DC. Prod. v. $328=$ Erigeron filifolius.

canescens, Torr. \& Gray, F1. N. Am. ii. $256=$ villosa.

coronopifolia, Nutt. in Journ. Acad. Philad. vii. (1834)

$34=$ Aster tanacetifolius.

decumbens, Chapm. Fl. S. U. St. $217=$ gossypina.

dentata, Ell. Sketch, ii. $337=$ gossypina.

divaricata, Ell. 1. c. $338=$ Aster divaricatus. 


\section{CHRYSOPSIS :}

echioides, Benth. Bot. Voy. Sulph. $25=$ villosa.

ericoides, Torr. \& James, ex Eaton, N. Am. Bot. ed. VIII. $195=$ Aster ericaefolius.

falcata, Ell. Sketch, ii. $336=$ villosa.

foliosa, Nutt. in Trans. Am. Phil. Soc. Ser. II. vii. (1841) $316=$ villosa.

gossypina, Ell. Sketch, ii. 237.-Am. bor.

graminifolia, Ell. l. c. 334.-Am. bor.

hirtella, DC. Prod. v. $327=$ Erigeron chrysopsidis.

hispida, DC. 1. c. vii. $279=$ villosa.

humilis, DC. 1. c. v. 273 , in syn. = Aster infirmus

hyssopifolia, Nutt. in fourn. Acad. Philad. vii. (1834)

67.-Am. bor.

Lamarckii, Nutt. in Trans. Am. Phil. Soc. Ser. II. vii. (1841) $315=$ Aplopappus spinulosus.

linariifolia, DC. Prod. v. $277=$ Aster linariifolius

linifolia, DC. 1. c. 255 , in syn. $=$ Aster acris

Mariana, Ell. Sketch, ii. 385,-Am. bor.

mollis, Nutt, in Trans. Am. Phil. Soc. Ser. II. vii. (1841) $316=$ villosa

abovata, Nutt. Gen. Am. ii. $152=$ Aster reticulatus.

oligantha, Chapm. ex Torr. \& Gray, Fl. N. Am. i

$253=$ graminifolia

oregana, A. Gray, in Proc. Am. Acad. vi. (1864-65)

543.-Am, bor. occ

pilosa, Nutt. in Gourn. Acad. Philad. vii. (1834) 66 . - Texas.

pinifolia, Ell. Sketch, ii. 335.-Am. bor

scabra, Ell. 1. c. $339=$ Heterotheca Lamarckii.

scabra, Hook. \& Arn. Bot. Beech. Voy。 $434=$ Oxy-

pappus scaber.

scabrella, Torr. \& Gray, Fl. N. Am. ii. 255.-Am. bor sessiliflora, Nutt. in Trans. Am. Phil. Soc. Ser. II vii. (1841) $317=$ villosa.

trichophylla, Ell. Sketch, ii. 336.-Am. bor.

villosa, DC. Prod. v. 327 ; vii. 279 . - Am. bor.

Wrightii, A. Gray, Syn. Fl. N.Am. i. II. 445.Calif.

CHRYSORHOË, Lindl. in Hook. Comp. Bot. Mag. ii. (1836) $357=$ Verticordia, DC. (Myrtac.).

nitens, Lindl. 1. c. $=\mathrm{V}$. nitens.

serrata, Lindl. Swan River App. $6=$ V. serrata.

CHRYSOSCIAS, E. Mey. Comm. Pl. Afr. Austr. 139 (1835) = Rhynchosia, Lour. (Legumin.).

calycina, E. Mey. 1. c. $140=$ R. leucoscias.

floribunda, Lem. in Illustr. Hortic. i. (1854) Misc. 56 ; ii. $(1855)$ t. 47 . - Afr. anstr.

grandiflora, E. Mey. Comm. PI. Afr. Austr. i. $139=$ R. Chrysoscias.

media, E. Mey. 1. c.-Afr. austr.

parviflora, E. Mey. 1. c. $=$ R. microscias.

CHRYSOSPERMUM, Reichb. Consp. 166 (1828), nomen Anthospermum, Linn. (Rrbiac.)

repens, Pritz. Ind. Ic. 263 , sphalm. $=$ Cryphiospermum repens, Beauv. = Enhydra fluctnans, Lour. (Compos.).

CHRYSOSPLENIUM, Tourn. ex Linn. Syst. i. (1735), SAXIFRAGEAE, Benth. \& Hook. f. i 638

adoxoides, Hook. f. \& Thoms. ex Maxim. in Bull. Acad. Pétersb. xxiii. (1877) 342 = lanuginosum album, Maxim. l. c. xvii. (1872) 420.-Japon.

alpinum, Schor, in Verh. Siebenb. Ver. Naturw, v. (1852) $86=$ oppositifolium.

alternans, Thunb. Fl. Jap. $182=$ alternifolium.

alternifolium, Linn. Sp. Pl. 398.-Europ.; As. bor.; Am. bor.

americanum, Schwein. ex Hook. Fl. Bor. Am. i. 242,Am. bor.

aulacocarpum, Ernst, in Flora, Ivii. (1874) 214.Venezucla.

auriculatum, Crantz, Inst. i. 133 -oppositifolium.

axillarè, Maxim. in Bull. Acad. Pétersb. xxiii. (1877) 341.-China.

baicalense, Maxim. in Bull. Soc. Nat. Mosc. liv. (1879)

I. 21.-Sibir.

carnosulum, Maxim. in Bull. Acad. Pétersb، xxiii。(1877) $340=$ carnosum.

carnosum, Hook. fo \& Thoms. in Gourn. Linn. Soc, ii, (1858) $73 .-$ Keg. Himal.

Davidianum, Decne. ex Maxim.in Bull. Acad. Pitersb. xxiii. (1877) 343.-Tibet. or.

Delavayi, Franch, in Bull. Soc. Bot. Fr, xxxii. (1885) 7.-As. or.

\section{CHRYSOSPLENIUM}

Dickinsii, Franch. E Sav. Enum. Pl. Fap. ii. 357.Japon.

dubium, J. Gay, ex DC. Prod. iv. $48=$ macrocarpum echinulatum, Franch. E Sav. Enum. Pl. Fap. ii. 358.Japon.

Echinus, Maxim. in Bull. Acad. Pétersb. xxiii. (1877) 347.-Japon.

elevatum, Banks \& Soland. ex. Hook, f. Fl. Antarct. ii. $281=$ macranthum.

Fauriae, Franch. in Bull. Soc. Bot. Fr. xxyi. (1879) 85.-Japon.

flagelliferum, F. Schmidt, Reisen Amurl. 134.As. or.

flagelliforme, Franch. \& Sav. Enum. PI. Jap. ii. 355, lapsu $=$ praec

geoides, Fisch. ex Ledeb。Fl. Ross。 ii. $227=$ alternifolium.

glaciale, Fuss, F1. Transs. $247=$ oppositi folium

glechomaefolium, Nutt. ex Torr. E Gray, Fl. N. Am.

i. 589.-Am. bor. occ.

Grayanum, Maxim. in Bull. Acad. Pétersb. xxiii. 1877) 348.--Japon.

Griffithii, Hook. f. E Thoms. in Fourn. Linn. Soc. ii. (1858) 74.-Reg. Himal.

kamtschaticum, Fisch. ex DC. Prod. iv。 48,-Kamtschat.

kamtschaticum, A. Gray, Bot. Jap. $389=$ ramosum.

lanuginosum, Hook. f. E Thoms, in Fourn. Linn. So ii. (1858) 74.-Reg. Himal.

macranthum, Hook. Lond. Fourn. Bot. i. (1842) 458. t. 16.-Patagon.

macrocarpum, Cham. in Linnaea, vi. (1831) 558. Am. arct.

macrostemon, Maxim. ex Franch. E Sav. Enum. Pl. Fap. ii. 358.-Japon.

Maximowiczii, Franch. \& Sav. l. c.-Japon.

multicaule, Franch. E' Sav. L. c. 361-Japon.

nepalense, D. Don, Prod. Fl. Nep. 210 - Reg. Himal.

nepalense, Maxim. Prim. Fl. Amur. 121, in nota = sul catum.

nipponicum, Franch. E Sav. Enum. Pl. Fap. ii. 356Japon.

nivale, Schur, in Verh. Siebenb. Ver. Naturw. iv. (1853) 28 =alternifolium.

nudicaule, Bunge, in Ledeb. Fl. Alt. ii. 114,-Sibir.

octandrum, Caqué, ex Steud. Nom. ed. II. 1. $360=$ oppositifolium.

oppositifolium, Cham. in Linnaea, vi. (1831) $557=$

kamtschaticum.

oppositifolium, Linn. Sp. Pl. 398.-Europ.; As. bor.; Ind. or.

oppositifolium, Trantv, \& Mey, in Middend. Reise (Fl Ochot). $42=$ ramosum

oppositifolizm, Walt. Fl. Carol, 140=americanum.

ovalifolium, Bertol. Fl. Ital, iv, $449=$ macrocarpum

ovalifolium, Bieb. ex Ledeb. Fl. Alt, ii, 115.-Sibir altaic.

ovalifolium, Miq. Ann. Mus. Lugd. Bat. iii. $97=$ macro stemon.

papillosum, Franch. \& Sav. Enum. Pl. Jap. ii. $355=$ alternifolium.

peltatum, Turcz. in Bull. Soc. Nat. Mosc, xvii. (1844) 273.-Sibir.

pilosum, Maxim. Prim. Fl. Amur. 122.-Manchur.

ramosum, Maxim. l.c. 121.-Manchur.

repens, Link, ex Steud. Nom. ed. II. i. $360=$ oppositifolium.

rhabdospermum, Maxim. in Bull. Acad. Pétersb, xxiii. (1877) 347 - -As. or.

rosulare, Schott, ex Maxim. 1. c. $345=$ oppositifoliam. rotundifolium, Schlecht. ex Ledeb. Fl. Ross, ii. $227=$ alternifolium.

Sedakowii, Turcs. in Bull. Soc. Nat. Mosc, xvii. (1844) 273.-Sibir.

sibiricum, Steph. ex DC. Prod. iv, $48=$ alternifolium

sinicum, Maxim. in Bull. Acad. Petersb. xxiii. (1877) 348.-China.

sphaerospermum, Maxim. l. c. 349,-Japon.

sulcatum, Maxim. 1. c. $947=$ ncpalense.

tenellum, Hook, of Thones. in Gourn. Linn, Soc, ii (1858) 73.-Reg. Himal.

tetrandrum, Fries, in Bot. Notiser (1858), $198=$ alternifolium.

trachyspermum, Maxim, in Bull. Acad. Pétersb. xxvii. (1881) 474 . - China.

transsilvanicum, Schur, in Verh. Siebenb. Ver. Natura. iv. (1859) 28.-Transsylian.
CHRYSOSPIENIUM

trichospermum, Edgew. ex Hook.f. ET Thoms. in Fourn Linn. Soc. ii. (1858) 73.-Reg. Himal

uniforum, Maxim. in Bull. Acad. Petersb. xxvii. (1881) 472.-China.

valdivicum, Hook. Lond. Fourn. Bot. i. (1842) 459 17.-Chili.

Vidalii, Franch. E Sav. Enum. Pl. Fap. ii. 360.Japon.

Wrightii, Franch. \& Sav. l.c. 356.-Sibir. or yesoënse, Franch. Oo Sav. l. c. 355 .-Japon. yunnanense, Franch in Bull. Soc. Bot. Fr. xxxii. (1885) 7.-China.

CHRYSOSTACHYS, Pohl, PL Bras. ii. 65. t, 143 (1831 Combretum, Linn

ovatifolia, Pohl, 1. c. 66.-Bras.

CHRYSOSTEMMA, Less, Syn. Comp. 227 ' 183 ') Coreopsis, Linn. (Compos.)

calendulacea, E. Mey, ex DC. Prod. vi, $501=$ Gorteria calendulacea.

senifolium, Shuttl. ex Walp. Ann. ii. $857=$ Cor. senifolia.

Tripteris, Less. Syn. Comp. $227=$ Cor. Tripteris.

CHRYSOSTEMON, Klotzsch, in Lebm. Pl. Preiss. $232(1847)=$ Pseudanthus, Sieber (Compos.) virgatus, Klotzsch, 1. $\mathrm{c}_{0}=\mathrm{P}$. virgatus.

CHRYSOSTOMA, Lilja, Fl. Suppl. i. 33 (1840); et in Linnaea, xv. (1841) $263=$ Mentzelia, Linn. (Loas.) aurea, Lilja, 11. cc. $33,264=$ M. oligosperma.

CHRYSOTHAMNUS, Nutt. in Trans. Am. Phil. Soc N. S. vii. (1841) $323=$ Bigelowia, DC. (Compos.). depressus, Nntt. in Journ. Acad. Philad. N. S. i. (181? $171=\mathrm{B}$. depressa

dracunculoides, Natt, in Trans, Am. Phil. Soc. N.S. vii. (1841) $324=\mathrm{B}$. dracunculoides.

lanceolatus, Nutt, $\mathrm{l}, \mathrm{c}=\mathrm{B}$, viscidifora.

pumilus, Nutt. 1. c. $323=$ B. viscidiflora.

speciosus, Nutt. 1. c. = B. viscidiflora.

viscidiflorus, Nutt. 1. c. $324=$ B. viscidiflora.

CHRYSOTHEMIS, Decne. in Rev. Hortic, Sér. III. iii (1849) 242 = Tussacia, Reichb. (Gesnerac.). aurantiaca, Decne. 1.c. iv. (1850) 381.-Ind. occ melissaefolia, G. Don, ex Loud. Encyc. PI. Suppl. it. $1402=\mathrm{T}$. pulchella.

mellitifolia, G. Don, ex Lond. 1. c. = praec

ovata, Klotzsch, in Schomb. Fauna et Fl. Gui. 108 Guiana.

pulchella, Decne. in Rev. Hortic. Sér. III. iii. 1849) $242=\mathrm{T}$. pulchella

venosa, Decne. 1. $\mathrm{c} .=$ Episcia melittifolia

CHRYSOTHRIX, Roem, \& Schult. Mant ii, 6, 14s (1824) = Chrysithrix, Linn. (Cyperac.).

CHRYSOXYLON, Casar. Nov. Stirp. Bras. Dec. 59 (1843) = Plathymenia, Benth. (Legumin.).

Vinhatico, Cacar. 1. $c=$ P. reticulata.

CHRYSOXYLON, Wedd. Hist. Nat. Quinqquin. 100 (1849) = Pogonopus, Klotzsch (Rubiac.

febrifugum, Wedd. 1. c.-Bolivia.

CHRYSURUS, Pers. Syz. i. $80(1505)=$ Lamarckia Moench (Gramin.)

aureus, Bcauv. Agrost. 123 = L. aurea. cynosuroides, Pers. Syn. i. $80=\mathrm{L}$ aurea echinalus, Beauv. Agrost. $128=$ Cynosuras cchinalus. Cffusus, Beauv, l. $c_{1}=$ Cynosarus clegans. clegans, Beauy, l, $\mathrm{c}=\mathrm{C}$ - nosurus polybractomes. giganteus, Tenore, Fl. Nap. iv. 19. c. $210-$ Cimosturus echinatus.

gracilis, Moris, Stirp. Sard. Elench. i. 50 Cymosurus gracilis.

CrrlvTOTHFCA, G, Don, Gen, Sis?, ii, 706 (1532) CRYPTOTHECA Blume - Ammannia Huns (Lytbrar.).

CHKYZA, Rafis, in Med. Repos N. lork, V. (150s 35') - Coptis, Linn. (Kanunculac).

boreulis, Kafin. 1. c. $=$ C'oplis trifolia. 
CHTHAMALIA, Decne. in DC. Prod. viii. 605 (1844) = Gonolobus, Michx. (Asclepiad.).

bifiora, Decne. 1. c. $=\mathrm{G}$. biflorus.

humifusa, Fourn. in Mart. Fl. Bras. vi. IV. 313.-Bras. major, Fourn. 1. c. 314,-Bras.

nummularia, Decne. in DC. Prod. viii. $605=\mathrm{G}$. nummalarius.

pedunculata, Decne. 1. c. $=\mathrm{G}$. pedunculatus.

pubiflora, Decne. 1. c. $=\mathrm{G}$. pubiflorus.

purpurea, Decne. 1. c.-Bras.

CHTHONIA, Cass. in Dict. Sc. Nat. ix. 173 (1817) $=$ Pectis, Linn. (Compos.).

Bonplandiana, Cass. 1. c. xxvii. $206=$ P. Bonplandiana. canescens, Cass. 1. c. $=\mathbf{P}$. canescens.

ciliaris, Cass. 1 . $\mathrm{c} .=\mathrm{P}$. ciliaris.

elongata, Cass. 1. $c_{0}=\mathrm{P}$. elongata.

glaucescens, Cass. 1. c. ix. $173=\mathrm{P}$. ciliaris.

humifusa, Cass. 1. c: $=$ P. humifusa.

leptocephala, Cass. 1. c. xxvii. $206=$ P. Swartziana.

prostrata, Cass. 1. c. ix. $173=\mathrm{P}$. prostrata.

pygmaea, Cass, 1. c. xxvii, $206=\mathrm{P}$. pygmaea.

repens, Cass. 1. c. $=$ P. serpyllifolia.

CHTHONOCEPHALUS, Steetz, in Lehm. Pl, Preiss. i. 444 (1845). COMPOSITAE, Benth. \& Hook. f. ii. 322.

Chamaesphaerion, A. Gray, in Hook. Kew Journ. iii. (1851) 176

Gyrostephium, Turcz. in Bull. Soc. Nat. Mosc. xxiv. (1851) II. 76.

Lachnothalamus, F. Muell. Fragm. iiî. 156 (1863).

Drummondi, A. Gray, in Hook. Kew Fourn. iii. (1851) 178. - Austral.

pseudevax, Steetz, in Lehm. Pl. Preiss. i. 445.Austral.

pygmaeus, Benth. Fl. Austral. iii. 582.-Austral

tomentellus, Benth.l. c. 581.-Austral.

CHUKRASIA, A. Juss. in Mém. Mus. Par, xix. (1830) 251. t. 22, vide Chickrassia, A. Juss. (Meliac.).

CHULUSIUM, Rafin. Ann. Nat. $12(1820)=$ Poly gonum, Tourn.

acuminatum, Rafin. F1. Tellur. iii. $14=$ P. acuminatum.

amphibium, Rafin. 1. c. =P. amphibium.

filiforme, Rafin. 1. $\mathrm{c}_{\mathrm{v}}=\mathrm{P}$. tenue

fluitans, Rafin. 1. c. = P. amphibium

natans, Rafin. 1. $\mathrm{c}_{\mathrm{s}}=\mathrm{P}$. amphibium?

CHUNCHOA, Pers. Syn. i. 486 (1805) =seq.

CHUNCOA, Pav, ex Juss. Gen. 76 (1789) = Terminalia

Linn. (Combretac.).

actinophylla, Griseb. in Goett. Abh, xxiv. (1879) $133=$ T. actinophylla.

amazonia, J. F. Gmel. Syst. 702.-Bras.

arbuscula, Griseb. Fl. Brit. W. Ind. $275=$ T. arba scula.

brasiliensis, Cambess. in St. Hil. F1. Bras. Mer. ii $244=$ T. brasiliensis, Eichl.

Chicharronia, Griseb. Cat. P1. Cub. $109=$ T. Chicharronia.

diptera, F. G. Dietr. Vollst. Lex. Gaertn. Nachtr. ii

$244=\mathrm{T}$. oblonga

eriostachya, Griseb. Cat. Pl. Cub. $109=$ T, erio stachya.

flavescens, Presl, Epim. Bot. 215.-Bras.

glabra, Buch.-Ham. ex Wall. Cat. sub n. $3979=\mathrm{T}$ Arjuna.

lactiflua, F. Muell. Fragm. ii. 149=T. bursarina.

oblonga, Pers. Syn. i. $486=$ T. oblonga.

obovata, Pers. 1. c. = T. obovata.

tomentosa, Buch.-Ham. ex Wall. Cat. sub n. $3978=\mathrm{T}$ tomentosa.

triflora, Griseb. in Goett. Abh. xxiv. (1879) 132.-Reg. Argent.

CHUPALON, Adans. Fam. ii. 164 (1763)= Thibaudia, Pav. (Vacciniac.)

CHUPALONES, Nieremb. ex Stend. Nom. ed. II. i. 361 $(1840)=$ praec
CHUQUIRAGA, Juss. Gen. 178 (1789). COM-

POSITAE, Benth, \& Hook. f. ii. 488 .

Dasyphyluum, H. B. \& K. Nov. Gen. et Sp. iv. 17. t. $308(1820)$

Diacantha, Lag. Amen. Nat. i. 40 (1811).

Flotovia, Spreng. Syst. iii. 359 (1826)

JoAnnesia, Pers. Syn. ii. 383 (1807).

TOHANNIA, Willd. Sp. Pl. iii.. 1705 (1801).

Piptocarpa, Hook. \& Arn. in Comp. Bot. Mag. (1835) 110.

acanthophylla, Wedd. Chlor. And. i. 5.-Bolivia

acicularis, D. Don, in Phil. Mag. (1832) 392.-Chili. alpina, Poepp. ex Less. Syn. Comp. $96=$ oppositifolia. anomala D. Don, in Phil. Mag. (1832) 392 -Chili

Avellanedae, Lorentz, in Roca, Exped. Rio-Negro, ii. 245.-Patagon.

Candolleana, Baker, in Mart. Fl. Bras. vi. III. 358.Bras.

chrysantha, Field. E Gardn. Sert. Pl. t. 42,-Chili.

cryptocephala, Baker, in Mart. Fl. Bras. vi. III. 355 -Bras.

Doniana, Baker, . c. 358.-Bras.

Echegarayi, Hieron. in Bol. Acad. Nac. Cordova, iv (1881) 47.--Reg. Argent.

erinacea, D. Don, in Phil. Mag. (1832) 392.-Chili ;

Patagon.

excelsa, D. Don, $l$. $c$.-Chili.

floribunda,"Baker, in Mart. Fl. Bras, vi. III. 362.Bras.

fodinarum, Baker, l. c. 356.-Bras.

fruticosa, Juss. ex Steud. Nom. ed. II. 1. $361=$ insignis glabra, Baker, in Mart. Fl. Bras. vi. III. 363,-Bras.

Grisebachii, Hieron. in Bol. Acad. Nac. Cordova, iv. (1881) 359.-Reg. Argent.

hispida, D. Don, in Trans. Linn. Soc. xvi. (1830) 287. -Bras.

Hystrix, D. Don, in Phil. Mag. (1832) 392.-Chili Patagon

incana, D. Don, 1. c. $=$ ulicina

infundibularis, Baker, in Mart. Fl. Bras. vi. III. 357. -Bras.

insignis, Humb. \& Bonpl. Pl. Aequin. i. 153= Jussieui. juniperina, Decne, in Orbign. Voy. Bot.t. 11.-Am. austr.

Jussieui, F. F. Gmel. Syst. 1205.-Peruv. ; Ecuador

Kingii, Ball, in Fourn. Linn. Soc. xxi. (1884) 224.Patagon.

lancifolia, Humb. E Bonpl. Pl. Aequin. i. 153.Peruv.; Ecuador.

latifolia, Baker, in Mart. Fl. Bras. vi. IIr. 357.Bras.

latifolia, D. Don, in Trans. Linn. Soc. xvi. (1830) $288=$ glabra

leptacantha, Baker, in Mart. Fl. Bras. vi. III. 360.Bras.

leucoxylon, Poepp. ex Less. Syn. Comp. 95, in syn.Chili.

linearis, Turcz. in Bull. Soc. Nat. Mosc. xxiv. (1851) II. 94.-Chili

macrocephala, Baker, in Mart. Fl. Bras. vi. III. 359. -Bras.

microphylla, Humb. \& Bonpl. Pl. Aequin. i. 151. t. 43 $=$ Jussieui.

oppositifolia, D. Don, in Phil. Mag. (1832) 392.Chili.

orthacantha, Baker, in Mart. Fl. Bras. vi. III. 360.Bras.

paniculata, D. Don, in Trans. Linn. Soc. xvi. (1830) 289.-Bras

patagonica, Phil. in Linnaea, xxxiii. (1864-65) 111.Patagon.

peruviana, Jaume St. Hil. Fam. Nat. i. $394=$ Jussieui

racemosa, Baker, in Mart. Fl. Bras. vi. III. 363.-Bras.

Regnellii, Baker, l. c. 359.-Bras.

reticulata, $D C$. Prod vii. 9.-Bras.

revoluta, Field. E Gardn. Sert. Pl. sub t. 43.-Chili.

rotundifolia, Wedd. Chlor. And. 1. 4. t. 4.-Peruv.

ruscifolia, D. Don, in Phil. Mag. (1832) 392..Chili.

spinescens, Baker, in Mart. Fl. Bras. vi. III. 362.Bras.

spinosa, D. Don, in Trans. Linn. Soc. xvi. (1830) 285. -Peruv.

Sprengeliana, Baker, in Mart. Fl. Bras. vi. III. 357.Bras.

synacantha, Baker, l. c. 361.-Bras

tomentosa, Baker, 1. c. $360=$ paniculata

trichophylla, Baker, l. c. 356.-Bras.

ulicina, Hook. Comp. Bot. Mag. i. (1835) 110.-Chili.

\section{CHUQUIRAGA :-}

Unguis-cati, Ces. in Atti Soc. Sc. Nap.v. (1873) 11 n. 7.-Hab. ?

vagans, Baker, in Mart. Fl. Bras. vi. III. 361.-Bras. velutina, Baker, $l . c .358$.-Bras.

vepreculata, D. Don, in Trans. Linn. Soc. xyi. (1830) 290.-Venezuela.

CHURUMAYA, Rafin. Sylva Tellur. $85(1838)=$ Piper, Linn.

arborea, Rafin. 1. c. = P. Churumaya.

CHUSQUEA, Kunth, Syn. P1. Aequin. i. 254 (1822). GRAMINEAE, Benth. \& Hook. f. iii. 1209.

DENDRAgrostis, Nees, in Linnaea, ix. (1834) 487

Mustelia, Cav. ex Steud. Nom. ed. II. i. 361 , in syn. $(1840)$; ii. 168.

Rettbergia, Raddi, Agrost. Bras. 17 (1823).

abietifolia, Griseb. Fl. Brit. W. Ind. 529.-Ind. occ.

acuminata, Doell, in Mart. Fl. Bras. ii. III. 204.Bras.

amplopaniculata, Steud. Syn. Pl. Gram. 337=Dinochloa Tjankorreh

andina, Phil. in Linnaea, xxix. (1857-58) 103.-Chili. anelythra, Nees, in Linnaea, ix. (1834) 491.-Bras.

anelytroides, Rupr. ex Doell, in Mart. Fl. Bras. Hi. III. 206 -Bras.

aristata, Munro, in Trans. Linn. Soc. xxvi. (1868) 61.-Ecuador.

Bilimeki, Fourn. ex Hemsl. Biol. Centr. Am. Bot. iii. 587.--Mexic.

breviglumis, Phil. in Linnaea, xxix. (1857-58) $103=$ C. Culeou.

capitata, Nees, in Linnaea, ix. (1834) 489.-Bras.

capituliflora, Trin. in Mém. Acad. Pétersb. Sér. VI. iii. (1835) 613.-Bras.

carinata, Fourn. ex Hemsl. Biol. Centr. Am. Bot. iii 587.-Mexic.

ciliata, Phil. in Linnaea, xxxiii. (1864-65) $299=$ tenuiflora.

Culeou, E. Desv. in C. Gay, Fl. Chil. vi. 450.-Chili.

Cumingii, Nees, in Linnaea, ix. (1834) 487.-Chiil.

Dombeyana, Kunth, Rev. Gram. ii. 553. t. 191.Peruv.

fasciculata, Doell, in Mart. Fl. Bras. ii. III. 202,Bras.

Fendleri, Munro, in Trans. Linn. Soc. xxvi. (1868) 61. -Venezuela.

Fernandeziana, Phil. in Anal. Univ. Chil. (1873) 577 -Chili.

fimbriata, Stend. Syn. Pl. Gram. 338=Merostachys capitata.

Galeottiana, Rupr. in Bull. Acad. Brux. ix. II. (1842) 246.-Mexic.

Gaudichaudii, Kunth, Rev.Gram. i. 138, 331. t. 78.Bras.

glomerata, Munro, in Trans. Linn. Soc. xxvi. (1868) $50=$ Merostachys capitata.

heterophylla, Nees, in Linnaea, ix. (1834) 488.Bras.

humilis, Lechl. ex Munro, in Trans. Linn. Soc. xxvi. (1868) $60=$ spicata.

intermedia, Steud. in Leshl. Berb. Am. Austr. 52, nomen $=$ C. Quila

Famesoni, Steud. Syn. P1. Gram. $337=$ scandens.

leptophylla, Nees, in Linnaea, ix. (1834) $489=$ Arthrostylidium leptophyllum, Trinii.

Liebmanni, Fourn. ex Hemsl. Biol. Centr. Am. Bot. iii. 587.-Mexic

ligulata, Munro, in Trans. Linn. Soc. xxvi. (1868) $62=$ Fernandeziana.

Lorentziana, Griseb. in Goett. Abh. xix. (1874) 249.Reg. Argent.

Meyeriana, Rupr. ex Doell, in Mart. Fl. Bras. ii. III. 203.-Bras.

montana, Phil. in Linnaea, xxxiii. (1864-65) 298Chili.

Mulleri, Munro, in Trans. Linn. Soc. xxvi. (1868) 65. -Mexic.

oligophylla, Rupr. in Mém. Acad. Pétersb. Sér. VI. v. (1839) 124.-Bras.

nigricans, Phil. in Anal. Univ. Chil. (1865) II. 323.Chili.

pallida, Munro, in Trans. Linn. Soc. xxvi. (1868) 65 . -N. Granat.

parvifolia, Phil. in Linnaea, xxxiii. (1864-65) $299=$

Cumingii.

pinifolia, Nees, l. c. ix. (1834) 490.-Bras. 


\section{CHUSQUTA :}

pubescens, Steud. Syn. Pl. Gram. $337=$ C. Quila Purdieana, Munro, in Trans. Linn. Soc. xxvi. (1868) 56.-N. Granat.

Quila, E. Desv。 in C. Gay, F1. Chil. vi. $447=$ tenui flora.

Quila, Kunth, Rev.Gram. i. 138, 329. t. 77.-Chili scandens, Kunth, Syn. Pl. Aequin. i. 254.-Am. austr sclerophylla, Doell, in Mart. Fl. Bras. ii. III. 200.Bras.

Sellowii, Rupr. in Mém. Acad. Pétersb. Sér. VI. y. (1839) 125.-Bras.

simplicifora, Munro, in Trans. Linn. Soc. xxvi. (1868) 54.-Panama

simplicifolia, Hemsl. Biol. Centr. Am. Bot. iii. 587, sphalm. = simpliciflora.

Spencei, Ernst, in fourn. Bot. x。 (1872) 262.-Venezuela.

spicata, Munro, in Trans. Linn. Soc, xxvi. (1868) 60. -Peruv.

spinosa, Fourn. ex Hemsl. Biol. Centr. Am. Bot, iii 587.--Mexic.

tenella, Nees, in Linnaea, ix. (1834) 492.-Bras.

tenuiflora, Phil. in Linnaea, xxx. (1859-60) 206.Chili.

tenuiglumis, Doell, in Mart. Fl. Bras. ii, III. 199.Bras.

tessellata, Munro, in Trans. Linn. Soc. xxvi. (1868) 60.-N. Granat.

uliginosa, Phil. in Linnaea, xxx. (1859-60) 207.Chili.

uniflora, Steud. Syn. Pl. Gram. 337.-Ins. Cuba.

valdiviensis, E. Desv, in C. Gay, Fl. Chil. vi. $446=$ C. Quila.

Venezuelae, Steud. Syn. Pl. Gram. 337.-Venezuela.

Wilkesii, Munro, in Trans. Linn. Soc. xxvi. (1868) 63.-Bras.

CHYDENANTHUS, Miers, in Trans. Linn. Soc. Ser. II i. (1875) $111=$ Barringtonia, Forst. (Myrtac.) excelsus, Miers, 1. c. $112=$ B. excelsa.

CHYLOCALYX, Hassk. in Flora, xxv. (1842) II. Beibl. $20=$ Polygonum, Tourn

perfoliatus, Hassk. 1, c. $=\mathrm{P}$. perfoliatum.

senticosus, Meissn, in Miq. Ann. Mus, Bot. Lugd. Bat. ii. $65=\mathrm{P}$. senticosum.

CHYLODIA, Rich. ex Cass, in Dict. Sc. Nat. xxix. 491 (1823) = Wulffia, Neck. (Compos.) sarmentosa, Rich. 1. c. $492=$ W. stenoglossa

CHYLOGALA, Fourr. in Ann. Soc. Linn. Lyon, N. S xvii. (1869) $150=$ Euphorbia, Linn. serrata, Fourr. 1. c. = E. serrata.

CHYMOCARPUS. G. Don, in Trans. Linn. Soc. xvii. 13 $(1834)=$ Tropaeolum, Linn. (Geraniac.). brachyceras, Heynh. Nom, i. $195=$ T. brachyceras. Farattii, Heysh. 1. c. $=$ T. Jarattii.

pentaphyllus, D. Don, in Trans. Linn. Soc. xvii. (1834) $14=\mathrm{T}$. pentaphyllum.

polyphylius, Heynh. Nom. i. $195=$ T. polyphyllum. speciosus, Walp. Ann. i. $142=$ T. speciosum. tricolor, Heynh. Nom. i. $195=$ T. tricolorum. tuberosus, Heynh, 1, c. $=$ T. tuberosum.

CHYMOCOCCA, Meissn. in DC, Prod, xiv, 565 (1857). THYMELAEACEAE, Benth. \& Hook. f. iii. 194

empetroides, Meissn. l.c.-Afr. austr.

CHYMOCORMUS, Harv, in Hook. Lond. Journ. Bot. i. (1842) $28=$ Fockea, Endl. (Asclepiad.) edulis, Harv, 1. c. 24,-Afr. austr.

CHYSJ.S, Lindl. Bot. Reg. xxiii. t. 1937 (1837)。 ORCHIDEAE, Benth. \& Hook. fo iii. 514.

aurea, Lindl. l. c,-Chili.

bractescens, Lindl. l. c. (1840) Misc. 61.-Mexic.

Bruennowiana, Reichb. $f$. E Warsc, in Bot, Zeit, xy, (1857) 157.-Peruy.

Chelsoni $x$, Reichb. fo in Gard. Chron. (1874) I. 535 (c.) p. 385).

laevis, Lindl. Bot. Reg. (1840) Misc. 61.-Mexic

Limminghii, Linden E Reichb. f. in C. Koch, Allg. Gartens. xxvi. (1858) 380-Mexic.

Makoyi, Heynh. Nom. ii. 143,-Mcxic.

Scdenix, Reichb. f, in Gard. Chron. (1880) 1. 616.
CHYTRA, Gaertn. f Fruct iii, 184, t $214(1805)=$ Buchnera, Linn.? (Scrophularin.).

Buchnera, Linn.? (Scrophula
anomala, Gaertn。 fol. c.-Hab.?

CHYTRACULIA, P. Br. Hist. Jamaic. 239. t. 37 (1756) Calyptranthes, Sw. (Myrtac.).

CHYTRALIA, Adans。Fam. ii.80 (1763)=Calyptranthes, Sw. (Myrtac.)

CHYTRANTHUS, Hook. fo in Benth. \& Hook f. Gen。 i. 403 (1863). SAPINDACEAE, Benth. \& Hook. f. 1. c.

Mannii, Hook. f.l. c.-Afr. trop

Prieurianus, Baill. Adansonia, xi. (1873-76) 241.Guiana.

CHYTROGLOSSA, Reichb. f. in Hamb. Gartenz. xix. (1863) 546. ORCHIDEAE, Benth. \& Hook. f。 iii. 569 .

aurata, Reichb. f. l. c.- - Hab.

Marileoniae, Reichb. f. l. $c$.-Bras.

CHYTROMA, Miers, in Trans. Linn. Soc, xxx. (1874) $229=$ Leeythis, Loefl. (Myrtac.) amara, Miers, 1. c. $231=$ L. amara. apiculata, Miers, 1. c. 245.-Bras.

basilaris, Miers, 1. c. 239.-Guiana.

chartacea, Miers, l. c. $231=\mathrm{L}$. chartacea.

cincturata, Miers, 1. c. 237.-Bras.

cistella, Miers, 1. c. 233.-Bras.

grandifolia, Miers, 1. c. $237=\mathrm{L}$. grandiflora.

Ibiriba, Miers, 1. c. 236.-Bras

Idatimon, Miers, 1. c. $239=\mathrm{L}$. Idatimon.

incarcerata, Miers, l. c. 232.-Bras.

marawynensis, Miers, 1. c. $245=\mathrm{L}$. marawynensis.

monosperma, Miers, 1. c. $239=$ L. monosperma.

ovalifolia, Miers, 1. c. $244=$ L. ovalifolia.

perspicua, Miers, 1. c. 246.-Guiana.

pilocarpa, Miers, 1. c. 238.-Bras.

retusa, Miers, 1. c. $243=\mathrm{L}$. retusa

rorida, Miers, l. c. = I. rorida.

rosea, Miers, 1. c. $242=\mathrm{L}$, rosea

nubriftora, Miers, 1. c. 241.-Guiana.

salebrosa, Miers, 1. c. $240=$ L. salebrosa.

Schomburgkiana, Miers, 1. c. $230=$ L. Schomburgkii.

Spruceana, Miers, 1. c. $235=$ L. Spruceana.

turbinata, Miers, I. c. $234=$ L. turbinata.

urceolata, Miers, 1. c. 237.-Bras.

valida, Miers, I. c. $241 .-\mathrm{N}$. Granat.

CIANITIS, Reinw. in Syll. Ratisb. ii. (1828) $10=$ CYANITIS, Reinw.= Dichroa, Lour. (Saxifrag.).

CICCA, Linn. Mant, i. 124 (1767)= Phyllanthus, Linn。 (Euphorbiac:).

acidissima, Blanco, Fl. Filip. ed. I. $700=\mathrm{P}$. acidissimus.

albizzioides, Kurz, in Journ. As. Soc. Beng. xlii. (1873) II. 239.-Burma.

anomala, Baill. Etud. Gén. Euph. $619=$ P. indicus,

antillana, A. Juss. Tent. Euph. 108. $t_{6}$ 4. fo 13 B= P. nobilis.

arborea, Wright, ex Griseb. in Goett. Nachr. (1865) $166=\mathrm{P}$. nobilis

brasiliensis, Baill. Etud. Gén. Euph. 618, nomen = P nobilis.

chinensis, Baill. 1. c.; Atlas, $45=P$. nobilis,

decandra, Blanco, Fl, Filip ed. I. $701=\mathrm{P}$. reticulatus.

discoidea, Baill. in Adansonia, i. (1860-61) $85=\mathrm{P}$. discoideus.

disticha, Linn. Mant, i. $124=\mathrm{P}$. distichus.

Emblica, Kurz, For. Fl. Brit. Burma, ii, $352=\mathrm{P}$. Emblica.

flexuosa, Sieb. \& Zucc. Fl. Jap. Fam. Nat. i. $85=$ P. japonicus.

Gaertneriana, Muell. Argo in DC. Prod, xv。 11. 416, in $\mathrm{syn}_{\mathrm{*}}=\mathrm{P}$. cyanospermus

Leucopymus, Kurz, For. Fl. Brit. Burma, ii. $358=$ Fluggia Leucopyrus.

macrocarpa, Kurz, in Journ. As. Soc. Beng。 xlii. (1873) II. 289.-Burma.

macrostachya, Benth. Bot. Voy. Sulph. $166=$ Ficramnia Antidesma.

microcarpa, Penth. Fl. Hongk. $812=$ P. reticulatus.

nodiffora, Lam. Encyc, ii. $1=P$, distichus.

obovata, Kurz, For. F1. Brit. Burma, ii. $854=$ Fluggin microcarpa.
CICCA :-

Pavoniana, Baill. Etud. Gén. Euph. $618=$ Phyllanthus nobilis.

pentandra, Blanco, Fl. Filip. ed. I. $701=$ Fluggia microcarpa.

racemosa, Lour, Fl, Cochinch, $5556=\mathrm{P}$, acidissimus? reticulata, Kurz, For. Fl, Brit. Burma, ii. $354=\mathrm{P}$. reticulatus.

rhomboidalis, Baill. Adansonia, ii. $(1861-62) 51=\mathrm{I}$ rhomboidalis.

scandens, Griseb. in Goett. Nachr. (1865) $165=1$ scandens.

sinica, Baill. Etud. Gén. Euph. 618, 4. 24=P. nobilis. surinamensis, Miq. in Linnaea, xxi. (1848) $479=\mathrm{P}$ nobilis.

virens, Wright, ex Griseb. in Goett. Nachr. (1865) 166 $=\mathrm{P}$. virens.

CICENDIA, Adans, Fam. ii. 503 (1763), GENTIA NEAE, Benth. \& Hook. f. ji. 810

campestris, Rafin. Fl. Tellur, iii. $26=$ Gentiana campestris.

Candollei, Griseb. Gen. et Sp. Gent. $158=$ pusilla. exaltata, Griseb. I. c. $159=$ Erytbraea Douglasii. fastigiata, Griseb. 1. c. $158=$ Hoppea fastigiata. filiformis, Delarb. Fl. Auy. i. 20 ; ed. II. $20=$ Micro cala filiformis.

glacialis, Rafin. Fl. Tellur, iii. $28=$ Gentiana tenella hyssopifolia, Wight \& Am. in Hook. Comp. Bct Mag. if. (1836) $249=$ Enicostema littorale. microphylla, Edgew. in Trans. Linn. Soc. xx. (18j1 83 = Sebaea khasiana.

Poeppigii, Griseb. in DC. Prod, ix, 62 (Microcalae sp)

pulchella, Griseb. Gen. et Sp. Gent. $159=$ Erythraea ramosissima.

pusilla, Griseb. l.c. 157.-Europ.

quadrangularis, Griseb. 1. c.=Microcala quadrangularis.

quitensis, Griseb, in Linnaea, xxii. (1819) $33=$ Erythraea quitensis.

Roxburghii, Griseb. Gen. et Sp. Gent. 160=Hoppea dichotoma.

stricta, Griseb. in Fourn. Linn. Soc. vi. (1862) 143.Griatemala.

tenella, Rafin. F1. Tellar, iii, 26=Gentiana tepella

CICER, [Toum.] Limn. Syst, ed. I (1735), LEGLMI. $\operatorname{NOSAE}$, Benth. \& Hook. f. i. 524

NochotTA, S. G. Gmel. Reise, iii. 23. t. 3 (17\%4).

Adonis, Orph. ex Nym. Consp. $200=$ ervoides.

anatolicum, Alef. in Bomplandia, ix. (1861) 349.-As. Min.

arietinum, Linn. Sp. Pl. 738.-Europ.; Oriens; Ind.

muneatum, Hochst, ex A. Rich. Tent. Fl, Abyss, i $195=$ arietinum.

ervoides, Brign. Fasc. Pl. Forojul. $27=$ Lens Lenticula.

ervoides, Fengl, in Russegg. Reise, i. 894, in obs.Graccia: As. Mfin.; Syria.

floribundum, Fensl, l. c. 892. t. 9.-Cilicia.

glutinosum, Alef. in Bonplandia, ix. (1861) $\$ 49=$ anatolicum.

graecam, Orph. ex Boiss. Diagn. Ser. II. ii 43. Graecia.

grossum, Salisb. Prod $\$ 40=$ ariefinam.

Facquemontii, Jaub. \& Spach, in Ann. Sc. Nat. Ser. II. xviii. $(1842) 231=$ soongaricum.

judaicum, Boiss. Diagn. Ser. I. ix. $190=$ pinnati. fidum.

Lens, Willd. Sp. Pl. iii. $1114=$ Lons esculents.

microphyllsm, Royle, Illustr. Bot. Hianal. 200 : soongaricum.

minutum, Boiss. E Hohen. Diagn. Ser. I. ix. 190.Persia.

Montbretii, Gasub. G Spach, in Ann. Sc. Nas. Sèr. II. xviii. (1S42) 2.y.-As. Min.

nigrum, Hort. ex Stead. Nom. ed. II. is $\$ 81=$ Lens csiulenta.

numulariacfolium, Lam. Encve ii. $\%$ - Crolalaria billura.

oxyoulon, Boiss. \& Mohrn. Diagn. Ser. I. ix, 199.l'ersia.

physodes, Reichb. Fl, Germo. Excurs $58 ?$ ? aricl..... pimpimallifolium, Jaub. \& Spach, in Ann. Sc. Nat Ser. 1I. xviii. (1st? $228=$ esvoides. 


\section{CICER :-}

pinnatifidum, Faub. Es Spach, in Ann. Sc. Nat. Sér. II. xviii. (1842) 227.-As. Min.; Mesopotam.

punctatum, Hort. ex Steud. Nom. ed. II. i. $361=$ Lens Lenticula.

punctulatum, Hort. ex Ser. in DC. Prod. ii. $366=$ Lens esculenta.

pungens, Boiss. Diagn. Ser. II. ii. 44.-Afghanist. sativum, Schkuhr, Handb. ii. 367. t. $202=$ arietinum

soloniense, Schrank, ex G. Don, Gen. Syst. ii. $312=$

Lens Lenticula.

songaricum, Jaub. \& Spach, Illustr, i. 84, t. 43 B = anatolicum

songaricum, Steph. ex DC. Mém. Lég. viii. 349.Soongar, ; Himal. bor. occ.

spiroceras, fawb. E Spach, in Ann. Sc. Nat. Sér. II xviii. (1842) 233.-Persia.

subaphyllum, Boiss. Diagn. Ser. I. vi. 44.-Persia.

tragacanthoides, Faub. E Spach, in Ann. Sc. Nat Sér. II. xviii. (1842) 234.-- Persia; Turkestan.

CICERBITA, Wallr. Sched. Crit. 433 (1822)=Lac tuca, Tourn. (Compos.)

acuminata, Wallr. 1. c. $434=$ L. acuminata

alpina, Wallr. 1. c. = L. leucophaea.

borealis, Wallr. 1. c. = L. leucophaea.

canadensis, Wallr. 1. c. = L. canadensis

corymbosa, Wall. 1. c. = L. quercina,

elongata, Wallr. . $_{\mathrm{c}}=\mathrm{L}$. canadensis

floridana, Wallr. 1. c。=L. floridana.

intybacea, Wallr. 1. c. = Brachyramphus intybaceus

leucophaea, Wallr. 1. c. = L. leucophaea.

macrophylla, Wallr. 1. c. =L. macrophylla

muralis, Wallr. 1. c. $436=\mathrm{L}$. muralis.

Plumieri, Kirschl. in Mém. Soc. Hist. Nat. Strassb. iv

(1855) [n. Xv.] t. $1=$ L. Plumieri.

quercina, Walls. Sched. Crit. $435=\mathrm{L}$. quercina

CICERCULA, Medic. in Vorles. Churpf. Phys. Ges. i. (1787) $358=$ Irathyrus, Toum. (Legumin.).

alata, Moench, Meth. $163=\mathrm{L}$. sativus.

alba, Medic. in Vorles. Churpf. Phys. Ges. ii. (1787)

$358=\mathrm{L}$. sativus.

anceps, Moench, Meth. $163=\mathrm{L}$. Cicera.

caerulea, Medic in Vorles. Churpf. Phys. Ges. ii.

(1787) $358=\mathrm{L}$. sativus.

Cicera, Alef. in Bonplandia, ix. (1861) $147=\mathrm{L}$.

Cicera.

sativa, Medic. Phil. Bot. i. $203=$ L. sativus

CICERELLA, DC. Prod. ii. 369 (1825)=praec

CICHORIUM, [Toum.] Linn. Syst. ed.

COMPOSITAE, Benth. \& Hook. f. ii. 506.

Acanthophyton, Less. Syn. Comp. 128 (1832)

alatum, Hochst. \& Steud. ex DC. Prod. vii. $75=$

Geigeria alata.

ambiguum, Schult. Obs. $170=$ pumilum.

byzantinum, Clem. in Mem. Acc. Sc. Torin. Ser. II xvi. $(1857) 285=$ C. Intybus.

caeruleum, Gilib. F1. Lituan. i. $224=$ C. Intybus.

callosum, Pomel, Nouv. Mat. Fl. Atl. 17.-Afr bor.

calvum, Sch. Bip. in Ind. Sem. Hort. Berol. (1859)

7, nomen; Schweinf. Beitr. Fl. Aethiop. 143.-Afr. trop.

Casnia, C. B. Clarke, Comp. Ind. $250=$ C. Intybus.

Cicorea, Dum. Fl. Belg. Prod. $64=$ C. Intybus.

commune, Pall. Reise, iii. $655=\mathrm{C}$. Intybus.

Cosnia, Buch.-Ham, in Wall. Cat. n. $3241=$ C. Intybus.

crispum, Mill. Gard. Dict. ed. VIII. n. $4=\mathrm{C}$. Endivia.

dichotomum, Link, Handb. i. 811, sphalm. = pumilum.

divaricatum, Heldr. ex Nym. Consp. $472=\mathrm{C}$ Intybus.

divaricatum, Schousb. Vextr. Marok, 197=pumilum.

Endivia, Linn. Sp. Pl. 813.-Europ.; Oriens.

esculentum, Salisb. Prod. $183=\mathrm{C}$. Endivia.

glabratum, Presl, FI. Sic. i. $32=$ C. Intybus

glandulosum, Boiss. \& Huet, Diagn. Ser. II. iii. 87.-

As. Min.; Mesopotam.

glaucum, Hoffmgg. E Link, Fl. Port. ii. 178.Hispan.

hirsutum, Gren, in Acad. Sc. Besanç. Séanc. Publ. (1838) $137=\mathrm{C}$. Intybus

Intybus, Linn. Sp. Pl.813.-Europ.; Oriens.

\section{CICHORIUM :-}

minimum, Portenschl. Enum. Pl. Dalm. 16.-Dalmatia.

nanum, Portenschl. ex Nym. Consp. 472=pumilum. Noëanum, Boiss. Fl. Orient, iii. 717-Mesopot. officinale, Gueldenst. ex Ledeb. Fl. Ross. ii. $774=\mathrm{C}$. Intybus.

perenne, Stokes, Bot. Mat. Med. $133=\mathrm{C}$. Intybus.

polystachyum, Pomel, Nouv. Mat. Fl. Atl. 18.-Afr. bor.

pumilum, Facq. Obs. iv. 3.t. 80.-Reg. Mediterr. rigidum, Salisb. Prod. $183=$ C. Intybus.

spinosum, Linn. Sp. Pl. 813.--Italia; Graecia.

sylvestre, Lam. Fl. Fr. ii. $120=$ C. Intybus.

CICLOSPERMUM, Lag. Amen. Acad. Madr, ii. (1821) $101=$ Apium, Linn. (Umbellif.)

Ammi, Lag. 1. c. $=$ A. Ammi.

CICONIUM, Sweet, Geran. i. p. ix $(1822)=$ Pelar gonium, L'Hérit. (Geraniac.)

acetosellum, Hoffingg. Verz. Pf. $48=\mathrm{P}$. acetosellum. acetosum, Hoffungg. 1. $\mathrm{c} .=\mathrm{P}$. acetosum.

aequaliflorum, Sweet, ex Stend. Nom. ed. II. i. $362=$ P. aequaliflorum.

albidum, Sweet, 1. c. = P. albidum.

amabile, Hoffmgg. Verz. Pfl. $48=\mathrm{P}$. amabile.

Bentinckianum, Sweet, Hort. Brit. ed. I. $85=$ P Bentinkianum.

Bluecherianum, Hoffmgg. Verz. Pf. $48=$ P. Blue cherianum

bracteosum, Sweet, Hort. Brit. ed. I. $85=$ P. bracteosum.

cerinum, Sweet, Geran. ii. t. $176=\mathrm{P}$. inquinans

clarum, Hoffmgg. Verz. Pfl, $48=$ P. zonale.

coccineum, Hoffmgg. 1. c. $=\mathrm{P}$. hybridum.

cocciniflorum, Hoffmgg. 1. c. $=$ P. zonale

crenatum, Hoffmgg. 1. $\mathrm{c}_{\mathrm{s}}=\mathrm{P}$. zonale

crenatum, Hoffmgg. 1.c. ; Sweet, Hort. Brit. ed. I. 85 $=\mathrm{P}$. crenatum

densiflorum, Eckl. \& Zeyh. Enum. $75=\mathrm{P}$. zonale

Fothergillii, Sweet, Geran. iii. to $226=\mathrm{P}$. Fother gillii.

fulgens, Hoffmgg. Verz. Pfl. $48=\mathrm{P}$. formosissimum. fulgens, Sweet, Hort. Brit. ed. I. Add. $471=$ P. fulgens glabrifolium, Sweet, Geran. iv. t. $363=$ P. glabrifolium. heterogamum, Sweet, Hort. Brit. ed. I. $84=$ P. heterogamum.

hilare, Hoffmgg. Verz. Pf. $49=$ P. hilare.

homogamum, Hoffmgg. 1. c. = P. heterogamum.

humile, Sweet, Hort. Brit. ed. I. $84=$ P. scandens.

hybridum, Sweet, Geran. i. Ind. $=\mathrm{P}$. hybridum.

inquinans, Hoffmgg. Verz. Pf. $49=\mathrm{P}$. inquinans.

lanuginosum, Hoffmgg. 1. c. = P. lanuginosum

lateritium, Hoffmgg. 1. c. $=$ P. malvaefolium.

lavateraefolium, Eckl. \& Zeyh. Enum. $75=$ P. lavateraefolium.

leptopetalum, Sweet, Hort. Brit. ed. I. $84=$ P. leptopetalum.

leucanthum, Hoffmgg. Verz. Pf. $49 \Rightarrow$ P. zonale.

lucidum, Hoffmgg. 1. c. = P. Iucidum.

malvaefolium, Sweet, Hort. Brit. ed. I. $84=$ P. mal. vaefolium.

marginatum, Hoffmgg. Verz. Pf. $49=$ P. marginatum micranthum, Sweet, Geran. iii. t. $195=\mathrm{P}$ micranthum.

monstrum, Sweet, Geran. i. Ind. $=$ P. monstrum.

multiflorum, Hoffmgg. Verz. Pfl. $49=$ P. multifloram.

orbiculare, Hoffmgg. 1. c. = P. obtusifolium.

oxyphyllum, Sweet, Hort. Brit. ed. III. $120=$ P. hybridum.

placidum, Hoffmgg. Verz. Pf. $49=$ P. amoenum.

Porphyrio, Hoffmgg. 1. c. $50=\mathrm{P}$. Porphyrio.

propugnatum, Hoffmgg. 1. $\mathrm{c}_{\mathrm{o}}=\mathrm{P}$. fulminans.

pumilum, Hoffmgg. 1. c. = P. scandens.

puniceum, Hoffmgg. 1, $\mathrm{c}=\mathrm{P}$. puniceum.

purpuriflorum, Hoffmgg. 1. c. $=$ P. purpureum

reticulatum, Sweet, Geran. ii. t. $143=\mathrm{P}$. retinervium

Rosula, Hoffmgg. Verz. Pf. $50=\mathrm{P}$. zonale.

scandens, Hoffmgg. 1. c. $=$ P. scandens.

siccifolium, Hoffmgg. 1. $\mathrm{c}_{0}=\mathrm{P}$. siccifolium.

Skelii, Hoffmgg. 1. c. = P. Skelii.

stenopetalum, Hoffmgg. 1. c. = P. zonale.

umbellatum, Hoffmgg. 1. c. = P. umbellatum.

urenaefolium, Eckl. \& Zeyh. Enum. $75=$ P. urenaefolium.

velutinum, Hoffmgg. Verz. Pfl. $50=\mathrm{P}$. ovale.

zonale, Hoffmgg. 1. $\mathrm{c}_{\mathrm{v}}=\mathrm{P}$. zonale.
CICUTA, [Tourn.] Linn. Syst. ed. I (1735). UM BELLIFERAE, Benth. \& Hook. fo i. 889.

Keraskomion, Rafin. New Fl. Am. iv, 21 (1836).

africana, Lam. Encyc. ii. 4 = Capnophyllum africanum.

Amomum, Crantz, Cl. Umb. Emend. $96=$ Sison Amomum.

angustifolia, Kit. in Schult. Oester. Fl. ed. II. i. 515 = virosa.

Bolanderi, A. Gray, in Proc. Am. Acad. xi. (1876) 139. -Am. bor. occ.

bulbifera, Linn. Sp. Pl. 255.-Am. bor.

californica, A. Gray, in Proc. Am. Acad. vii. (1868) 344.-Calif.

capillacea, Nutt. ex DC. Prod. iv. $107=$ Discopleura Nuttallii.

cynapicum, Crantż, Cl. Umb. Emend. 98=Aethusa Cynapium.

Cynapium, Targ. Ist. Bot. ii. $227=$ Aethusa Cyna pium.

cellulosa, Gilib. Fl. Lituan. ii, $36=$ virosa.

dahurica, Fisch. Hort. Gorenk. ed. II. (1812) 45, nomen = Apium lineare

dichotoma, Poir. Encyc. Suppl. ii. 261=Capnophyllum dichotomum.

latifolia, Crantz, Cl. Umb. Emend. $97=$ Sium latifolium.

maculata, Hook. \& Arn. Bot. Beech. Voy. $142=$ californica?

maculata, Lam. Fl. Fr. iii. $104=$ Conium maculatum.

maculata, Linn. Sp. Pl. 256.-Am. bor.

major, Lam. Fl. Fr. iii. $456=$ Conium maculatum.

Ninci, Crantz, Cl. Umb. Emend. $97=$ Sium Ninsi.

nipponica, Franch. in Bull. Soc. Bot. Fr. xxvi. (1879) 85.-Japon.

nodiflora, Crantz, Cl. Umb. Emend. $97=$ Apium nodiflorum.

occidentalis, Dougl. ex Heynh. Nom. ii. 144, nomen.Am. bor.

officinalis, Crantz, Cl. Umb. Emend. $98=$ Conium maculatum.

perennans, Walt. Fl. Carol, $116=$ Cryptotaenia canadensis?

rigens, Lam. Encyc. ii. 4 (=Bunium rigens).-Afr. austr.

sicula, Crantz, Cl. Umb. Emend. $97=$ Kundmannia sicula.

sinensis, Zuccagni, in Roem. Collect. $135=$ Selinum Monnieri.

suffruticosa, Poir. Encyc. Suppl. ii. 261 = Capnophyllum Jacquini.

tenuifolia, Schrank, in Denkschr. Akad. Muench. vii. (1818? 56. t. 4. f. 1 = virosa.

trachypleura, S. Wats. Bibliog. Ind. N. Am. Bot. 417. -Am. bor. occ.

venenata, Nutt. ex Steud. Nom. ed. II. i. $362=$ Archangelica hirsuta.

venenosa, Greenw. in Trans. Am. Phil. Soc. iii. (1793) $234=$ Archangelica hirsuta

virosa, Linn. Sp. Pl. 255.-Europ.; As. bor.; Am. bor.

CICUTARIA, Moench, Meth. Suppl. 32 (1802) (Umbellif.)

dioica, Moench, 1. c. $=$ Trinia vulgaris.

verticillata, Moench, 1. c. = Molopospermum cicutarium.

CICUTARIA, [Tourn.] Lam. Fl. Fr. iii. 445 (1778)= Cicuta, Tourn. (Umbellif.).

aquatica, Lam. Fl. Fr, iii. $445=$ Cicuta virosa. bulbifera, Lam. Encyc. ii, 3=Cicuta bulbifera. maculata, Lam. 1. c. $2=$ Cicnta maculata. virosa, Delarb. F1. Auv. ed. II. $415=$ Cicuta virosa.

CIECA, Adans. Fam. ii. $355(1763)=$ Julocroton Mart. (Euphorb.) (J.argenteus).

CIECA, Medic. Malv. 97 (1787)= Passiflora, Linn. angustifolia, M. Roem. Syn. Pepon. $143=\mathrm{P}$, suberosa appendiculata, M. Roem. 1. c. $145=\mathrm{P}$, auriculata. auriculata, M. Roem. 1. c. $143=\mathrm{P}$, auriculata bauhinaefolia, M. Roem. 1. c. $145=$ P. bauhinifolia. Berteriana, M. Roem. 1. c. $=$ P. Berteriana. bilobata, M. Roem. 1. c. $146=$ P. bilobata. Cavanillesii, M. Roem. 1. c. $140=$ P. cuprea cinerea, M. Roem. 1. c. $148=\mathrm{P}$. cinerea 
CIECA :-

colubrina, M. Roem. Syn. Pepon. $143=$ Passiflora tri- loba.

coriacea, M. Roem. 1. c. $148=\mathrm{P}$. coriacea.

cuprea, M. Roem. 1. c. $139=$ P. cuprea

Dictamo, M. Roem. 1. c. $146=$ P. Dictamo.

difformis, M. Roem. 1. c. $140=\mathrm{P}$. coriacea

discolor, M. Roem. 1. c. $=$ P. Maximiliana.

flexuosa, M. Roem. 1. c. $148=$ P. suberosa.

glabrata, M. Roem. 1. c. $143=$ P. lunata.

globosa, M. Roem. 1, c. $144=$ P. suberosa.

gracilis, M. Roem. 1. c. $141=\mathrm{P}$. gracilis.

guyanensis, Klotzsch, in Schomb. Fauna et Fl. Gui

986, nomen.-Guian.

hederacea, Kilotzsch, 1. c. 1090, nomen.-Guian.

hederacea, M. Roem. Syn. Pepon. $141=$ P. suberosa.

heterophylla, Moench, Meth. Suppl.101=P. angustifolia

limbata, M. Roem. Syn. Pepon. $148=$ P. limbata.

littoralis, M. Roem. 1. c. $145=\mathrm{P}$, suberosa

maculata, M. Roem. 1. c. = P. maculata.

membranacea, M. Roem. 1. c. $140=$ P. membranacea.

mexicana, M. Roem. 1. c. $146=$ P. mexicana.

minima, Moench, Meth. Suppl. $102=$ P. minima.

misera, M. Roem. Syn. Pepon, $140=$ P. misera.

multiflora, M. Roem. 1. c. $148=$ P. multiflora.

nigra, Medic. Malv. $97=\mathrm{P}$. suberosa.

normalis, M. Roem. Syn. Pepon. $144=$ P. perfoliata.

olivaeformis, M. Roem. 1. c. $=$ P. suberosa.

pallida, M. Roem. 1. c. $142=\mathrm{P}$, suberosa.

pannosa, M. Roem. 1. c. $148=$ P. pannosa

peltata, M. Roem. 1. c. $141=$ P. suberosa.

porophylla, M. Roem. 1. c. $147=\mathrm{P}$. porophylla.

pseudo-suberosa, M. Roem. 1. c. $146=\mathrm{P}$. suberosa

pubscens, M. Roem. 1. c. $141=\mathrm{P}$. capsularis.

suberosa, Moench, Meth. Suppl. $102=$ P. suberosa.

Sururuca, M. Roem. Syn. Pepon. $141=$ P. setacea.

trisetosa, M. Roem. 1. c. $147=$ P. fuscinata.

variolata, M. Roem. I. c. $140=$ P. variolata.

Vellozii, M. Roem. I. c. $142=$ P. Vellozii.

viridis, Medic. Malv. $97=\mathrm{P}$. minima.

Warei, M. Roem. Syn. Pepon. $146=$ P. Warei.

CIENFUEGIA, Willd. Sp. P1. iii. $723(1800)=$ seq.

CIENFUEGOSIA, Cav, Diss. 174. t. 72. f. $2(1787)=$ Fugosia, Juss. (Malvac.).

digitata, Cav, 1. c, = F. digitata,

heterophylla, Garcke, in Bonplandia, viii. (1860) $150=$

F. heterophylla.

Hildebrandti, Garcke, in Eichl. Jahrb.Bot. Gard. Berl. ii. (1883) 397.-Afr. trop.

phlomidifolia, Garcke, in Bonplandia, viii. (1860) 150 = F . phlomidifolia.

sulphurea, Garcke, 1. c. $=$ F. sulfurea.

Welshii, Garcke, in Eichl. Jahrb. Bot. Gard. Berl. ii. (1883) 337.-Arabia.

CIENFUGOSIA, DC. Prod. i. 457 (1824)=praec.

CIENKOWSKIA, Regel \& Rach, in Ind. Sem. Hort. Petrop. (1858) 48. 'Gen. dub.' Benth. \& Hook. f. i. 997.

nitida, Regel \& Rach, 1. c.-Hab. ?

CIENKOWSKIA, Solms, in Schweinf. Beitr. Fl. Aethiop. t. 1. $(1867)=$ seq.

CIENKOWSKYA, Solms, in Schweinf. Beitr. Fl. Aethiop. 197 (1867) = Kaempferia, Linn. (Scitamin.).

aethiopica, Solms, 1. c.-Afr. trop.

Kirki, Hook. f. Bot. Mag, t. 5994.-Afr, trop.

CILIARIA, Haw.Saxifr. Enam. 41 (1821)= Saxifraga, Toum.

aspera, Haw, 1. c. $42=\mathrm{S}$. aspera.

bronchialis, Haw. 1. c. $43=\mathrm{S}$. bronchialis.

bryoides, Haw. 1. c. $42=\mathrm{S}$, aspera.

CIMBARIA, Hill, Veg. Syst. xx. $43(1772)=$ Cym baria, Linn. (Scrophul.).

CIMICIFUGA, Linn. PI. Rar. Camsch, 21 (1750), RANUNCULACEAE, Bentb. \& Hook, f, i. 9 Actinuspora, Turcz in Fisch, \& Mey. Ind, Sem. Hort. Petrop. i. 21 (1885)

Botrophrs, Rafin. Med, Fl, i. 85 (1828).

\section{CIMICIFUGA :}

Macrotrys, Rafin. in Med. Repos. N. York. II. v. (1808) 352.

MACrotys, DC, Syst。i. 383 (1818)

Megotrys, Rafin. in Am. Monthly Mag. (1818) 267.

Picyrosperma, Sieb. \& Zucc, in Abh. Acad. Muench. iii. (1846) 734 .

americana, Michx. Fl. Bor. Am. i. 316.-Am. bor

americana, Muhl. Cat. ed. II. $54=$ cordifolia.

arizonica, S. Wats, in Proc. Am. Acad. xx. (1885) 352. -Arizona.

biternata, Miq. Ann. Mus. Bot. Lugd. Bat. iii. 9.Japon.

cordifolia, Pursh, Fl. Am. Sept. ì. 373.-Am. bor. elata, Nutt. in Torr. \& Gray, Fl. N. Am. i. 36.-Am. bor. occ.

foetida, Linn. Syst. ed. XII. 659.-Europ.; Sibir.

foetida, Pursh, Fl. Am. Sept. ii. $373=$ elata.

frigida, Royle, Illustr. Bot. Himal. 57. t. $14=$ foetida.

japonica, Spreng. Syst. ii. 628.-Japon.

laciniata, S. Wats. in Proc. Am. Acad. xx. (1885) 352. -Am. bor. occ.

obtusiloba, Miq. Ann. Mus. Bot. Lugd. Bat. iii. 9.Japon.

palmata, Michx. Fl. Bor. Am. i. $316=$ Trautvetteria palmata.

podocarpa, Ell. Sketch, ii. 16 = americana

racemosa, Nutt. Gen. Am. ii. 15.-Am. bor.

Serpentaria, Pursh, Fl. Am. Sept. ii. $372=$ racemosa.

simplex, Wormsk. ex DC. Prod, i. $64=$ foetida.

CIMINALIS, Adans. Fam. ii. 504 (1763)= Gentiana,

Tourn

acaulis, Borckh. in Roem. Arch. i. 1. $26=$ G. acaulis.

algida, Bercht. \& Presl, Rostl. i. Gentian. 10 G. frigida.

decumbens, Bercht. \& Presl, 1. c. $=\mathrm{G}$. decumbens.

frigida, Bercht. \& Presl, 1. c. =G. frigida.

glauca, Bercht. \& Presl, l. c. $11=G$. glauca.

grandiflora, Mayrh. in Schrank, F1. Monac. t. $37=$ G. acaulis.

linearis, Bercht. \& Presl, Rostl. i. Gentian. $11=$ $\mathrm{G}$. linearis.

longiflora, Moench, Meth. $514=\mathrm{G}$. acaulis.

ochroleuca, Bercht, \& Presl, Rost. i. Gentian. 11 G. ochroleuca.

Pneumonanthe, Borckh. in Roem. Arch. i. I. $26=$ G. Pneumonanthe.

pseudopneumonanthe, Bercht. \& Presl, Rostl. i. Gentian. $11=G$. Pneumonanthe.

saponaria, Bercht. \& Presl, l. c.=G. saponaria

saxosa, Bercht. \& Presl, 1. c. = G. montana.

septemfida, Bercht. \& Presl, 1. c. $10=\mathrm{G}$. septemfida.

vulgaris, Bercht. \& Presl, 1. c. =G. Pneumonanthe.

CIMINALIS, Rafin. Fl. Tellur. iii. $19(1836)=$ Voyria Aubl. (Gentian.).

alpina, angustifolia, grandiflora, Rafin. 1. c. = V. aphylla.

CINARA, [Tourn.] Linn. Syst. ed. I. (1735)= Cynara Linn. (Compos.).

CINCHONA, Linn. Gen. ed. II. 526 (1742). RUBIA$C E A E$, Benth. \& Hook. f. ii. 22.

Calisaya, Hort. ex Pav. Nuev, Quinol. sub t. 5. p. 6 (1862).

Cascarell 4 , Ruiz, ex Steud, Nom. ed. II. i. 165 (1840).

KINKINA, Adans. Fam, ii. 147 (1768)

QUINQuina, Condam, in "Act. Acad. Par. (1738) 226.

academica, Guibourt, Drogues Simples, iii. $98=$ ofticinalis.

acuminata, Poir. Encyc. Suppl. iv. $640=$ Cosmibuena acuminata

acutifolia, Ruiz \& Pav, Fl. Per. iii. 1. t. $225=$ Cascarilla acutifolia.

affinis, Wedd, in Ann. Se. Nat. Sér. III. x. (1848) 8. Peruy,

afroinda, Willem. in Usteri, Ann. Bot. xviii. (17)6) 16 $=$ Danais fragrans.

amygdalifolia, Wedd. in Ann. Sc. Nat. Sér. III. x. (1848) 6.-Bolivin

angustifolia, Ruiz, Quin. Suppl. 14, a. $17=$ lancifolia. angustifolia, Sw. Prod. Veg. Ind. Occ. $41=$ Exostemma ancustifolium.

asperifolia, Wedd. in. Ann. Sc. Nat. Sér. III. x. (1848) 7.-Bulivia.

\section{CINCHONA:-}

australis, Brign. in Mem. Soc. Ital. Mod. Ser. II. 1862) $63=$ Exostemma australe.

australis, Wedd. in Ann. Sc. Nat. Sér. III. x. (1848 7.-Bolivia.

barbacoënsis, Karst.in C. Koch EN Fint. Wochensch, ii. 1859) 31.-N, Granat.

Bergeniana, A. Braun, ex Mart. Reise Bras. iii. $1286=$ Remijia Bergeniana.

bicolor, Brign, in Mem. Soc. Ital. Mod. Ser. II. i. (1862) $63=$ Exostemma bicolor.

bogotensis, Karst. in C. Koch E Fint. Wochenschr. ii. (1859) $30 .-\mathrm{N}$. Granat.

boliviana, Wedd, in Ann. Sc. Nat. Sér. III. x. (1848 $7=\mathrm{C}$. Calisaya.

Jonplandiana, Klotzsch, in Hayne, Arzneigew. vii.t. 37.-Peruv.

brachycarpa, Sw. Prod. Veg. Ind. Occ. $41=$ Exostemma brachycarpum.

brasiliensis, Hoffmgg. ex Humb. in Ges. Naturf. Fr. Berl. Mag. i. (1807) $119=$ Machaonia brasiliensis.

caduciflora, Humb. \& Bonpl. P1. Aequin. i. 168, in obs. = Cascarilla caduciflora.

Calisaya, Wedd. in Ann. Sc. Nat.Sér. III. x. (1848) -Bolivia.

caloptera, Miq. Ann. Mus. Bot. Lugd. Bat. iv. (186s69) 273 - F'eruv

Candollii, G. Don, Gen. Syst. jii. $478=$ Remijia pani. culata.

canescens, Brign. in Mem. Soc. Ital. Mod, Ser. II. (1862) $63=$ Exostemma canescens.

capensis, Burm. ex DC. Prod. iv, $369=$ Burchellia capensis.

capitata, Brign. in Mem. Soc. Ital. Mod. Ser. II. (1862) 63 - Exostemma capitatum

carabayensis, Wedd. in Ann. Sc.Nat.Sér. III. x. (1848) 9.-Perav.

caribaea, Jacq. Enum. Pl. Carib. $16=$ Exostemma caribaeum.

caribbeana, W. Wright, in Phil. Trans. 1xvii. (1778, $506=$ pracc

caroliniana, Poir. Encyc. vi. $40=$ Pinckneya pabens.

Carua, Miq. Ann. Mus. Bot. Lugd. Bat. iv. 275.Bolivia.

Cattukambar, Koen, ex Retz, in Vet. Acad. Handl. Stockh. (1814) 32. t. $3=$ Uncaria acida.

cava, Pav. ex Lamb. Illustr. Cinch. $8=$ Cascarilla Pavonii.

Chahuarguera, Pav, ex DC. Prod, iv, $352=$ officinalis.

China, DC. Prod .iv. 356, sphalm. = Cosmibuena obtusi. folia.

chlorrhisa, Bory, ex DC. 1. c. $361=$ Danais rotundi. folia.

Chomeliana, Wedd. in Ann. Sc. Nat. Sér. III. x. (1Sts 9.-Bolivia.

cladorrhisa, Bory, ex Wedd. Hist. Nat. Quing. $\tau^{2}$ Danais rotundifolio.

coccinea, Pav. ex DC. Prod. iv. $353=$ macrocalyx.

colorata, Laubert, in 'Bull. de Pharm. (1810) 294'= officinalis.

Condaminea, Humb. \& Bonpl. P1. Aequin, i. $38=$ officinalis.

conglomerata, Pav. Nuev. Quinol. t. 15.--Ecuador,

cordifolia, Mutis, ex Humb. in Ges. Naturf. Fr. Berl. Mag. i. (1807) 117.-N. Granat.; Perus.

coriacea, Poir. Encyc. vi. $38=$ Exostemma coriaceum. coronulata, Miq. in fourn. Bot. Neerl. i. (1861) 140.Peruv.

corymbifera, Forst. in Act. Nov. Soc. Sc. Ups, iii. (1;SU $176=$ Exostemma corymbiferam.

corymbosa, Brign. in Mem. Soc. Ital. Mod. Ser. II. (1S62) 68 = Exostemma corymbosum.

corymbosa, Karst. Fl. Columb i. 19. \& $10=$ pitayensis.

crassifolia, Pav, ex DC, Bibl. Univ, xli, (18:09) 150 Cascarilla calyptrata.

crispa, Tafalla, ex Howard, in Pav. Nuer. Coinol. ?. =oficinalis.

cucumarfolia, Pav. ex Lamb. Illustr. Cinch. a lancijulin.

crojabensis, Manso, ex Klotrscb, in Hayne, Armeijew.

xiv. sub t. 15 - Kendiia clialensis ruspidafa, Krign. in Mem. Soc. Ital. Al decurrenfifolia, Pav. Nact. Cuinol. t. 29 = purper siens,

Delernedriama. Weht. in Aan. Sc. Xat. Sir. 111, x. Is ts 7 - scruliculas. 


\section{CINCHONA:-}

densiflora, Brign. in Mem. Soc. Ital. Mod. Ser. II. i. 1862) $63=$ Remijia densiflora.

dichotoma, Ruiz \& Pav. Fl. Per, ii. 53. t. $197=$ Ladenbergia dichotoma.

discolor, Klotzsch, in Hayne, Arzneigew. xiv. sub t. 14 = pubescens.

dissimiliflora, Mutis, ex Humb. in Ges. Naturf. Fr. Berl. Mag. i. (1807) $120=$ Exostemma dissimiliflorum.

elliptica, Wedd. in Ann. Sc. Nat. Sér. V. xii. (1869) 60.-Peruv

erythrantha, Pav. Nuev. Quinol. t. 12.-Ecuador.

erythroderma, Wedd. in Ann. Sc. Nat. Sér. V. xi. (1869) 362.-Peruv.

euneura, Miq. Ann. Mus. Bot. Lugd. Bat. iv. 265.Bras.

excelsa, Roxb. Pl. Corom. ii. 3. t. $106=$ Hymenodictyon excelsum.

ferruginea, St. Hil. in Mém. Mus. Par. ix. (1822) $314=$ Remijia ferruginea.

firmula, Mart. ex Klotzsch, in Hayne, Arzneigew. xiv. sub t. $15=$ Remijia firmula.

flaccida, Spreng. Syst. iv. Cur. Post. $78=$ Hymenodictyon flaccidum.

floribunda, Sw. Prod. Veg. Ind. Occ. $41=$ Exostemma floribundum.

Forbesiana, Howard, Quinol. E. Ind. Plant. $37^{*}=$ lancifolia.

formosa, Brign. in Mem. Soc. Ital. Mod. Ser. II. i. (1862) $63=$ Exostemma formosum.

fusca, Ruiz, ex Vitm. Summa, Suppl. i. 262 (=Lasionema roseum).-Am. trop.

glabra, Ruiz, Quinol, 64=lancifolia.

glandulifera, Ruiz \& Pav. Fl. Per. iii. 1. t. 224Peruv.

globifera, Pav. ex DC. Prod. iv. $345=$ Nauclea Cinchonae.

govana, Miq. in Fourn. Bot. Néerl. i. (1861) 142.Peruv.

grandiflora, Ruiz \& Pav. F1. Per. ii. 54=Cosmibuena obtusifolia.

grandifolia, Poir. Encyc. vi. $36=$ Cascarilla magnifolia.

gratissima, Wall. in Raxb. Fl. Ind. ed. Carey, ii. 154 $=$ Luculia gratissima.

Haenkeana, Bartl ex DC Prod iv 530=Palicourea

Haenkeana.

Hasskarliana, Miq. Ann. Mus. Bot. Lugd. Bat.iv. 266. -Peruv.

Henleana, Karst. in C. Koch E Fint. Wochenschr. ii. (1859) 31.-Venezuela.

herbacea, Linn. Mant. ii. $338=$ Exostemma caribaeum?

heterocarpa, Karst. Fl. Columb. i. 11. t. 6.N. Granat.

heterophylla, Pav. ex DC. Prod. iv. $353=$ cordifolia.

heterophylla, Pav. Nuev. Quinol. t. $18=$ macro calyx.

hexandra, G. Don, Gen. Syst. iii. $478=$ Cascarilla hexandra.

hirsuta, Ruiz \& Pav. Fl. Per. ii. 51. t. 192.Peruv.

Howardiana, O. Kuntze, Monog. Cinch. (1878). 30.Peruv.

Humboldtiana, Lamb. Illustr. Cinch, 7-Peruv.

Humboldtiana, Roem. \& Schult. Syst. v. 13. (=Lasio nema Humboldtianum).-Peruv.

Humboldtiana, Wedd. Hist. Nat. Quinq. $67=$ villosa.

jamaicensis, W. Wright, in Phil. Trans. Ixvii. (1778) $506=$ Exostemma caribaeum.

Josephiana, Wedd. in Ann. Sc. Nat. Sér. V. xii. (1869) 58.-Bolivia.

Kattukambar, Koen. ex DC. Prod. iv. $347=$ Uncaria acida.

laccifera, Ruiz \& Pav, ex Fée, Ess. Crypt. Ecorces Exot. Off. 8; Tafalla, ex Wedd. Hist. Nat. Quing. $72=$ Condaminea tinctoria?

Lambertiana, A. Braun, ex Mart. Reise Bras. iii. 1286 $=$ Cascarilla Lambertiana.

lanceolata, Ruiz \& Pav, Fl. Per. ii. 51=officinalis.

lancifolia, Mutis, in Periodico de Santa Fé (1793) 465, nomen,--Peruv, N. Granat.

Lechleriana, Schlecht. in Linnaea, xxvi. (1853-55) 728. -Perur.

Ledgeriana, Moens, ex Trimen, in Fourn. Bot. xix. (1881) 323.-Bolivia.

legitima, Ruiz, ex Laubert, in Bull. de Pharm. (1810) 293.-Peruv.

\section{CINCHONA :-}

leucocalyx, Brign. in Mem. Soc. Ital. Mod. Ser. II. i. (1862) 64.-Bras.

lineata, Vahl, in Skriv, Naturh-Selsk. i. (1790) $22=$ Exostemma lineatum.

longiflora, Lamb. Desc. Cinch. 38. t. $12=$ Exostemma longiflorum.

longiflora, Mutis, ex Steud. Nom. ed. I. $196=$ Cosmi buena obtusifolia.

longifolia, Mutis, ex Brign. in Mem. Soc. Ital. Mod. Ser. II. i. (1862) $62=$ praec. ?

Luciana, Vitm. Summa, Suppl. 1. $264=$ Exostemma floribundum.

lucumaefolia, Pav. ex Lindl. Fl. Med. 416=macrocalyx.

lutea, Pav, Nuev, Ouinol. t. $14=$ cordifolia

lutescens, Ruiz, ex Vitm. Summa, Suppl.i. $262=$ Cascarilla magnifolia.

macrocalyx, Pav. ex DC. in Bibl. Univ. Sc. et Arts, xli. (1829) 150.-Am. austr.

macrocarpa, Vahl, in Skriv. Naturh.-Selsk. i. (1790) 20 $=$ Cascarilla macrocarpa.

Macrocnemia, A. Braun, ex Mart. Reise Bras. iii. 1286 = Remijia Macrocnemia.

macrophylla, Karst. in Linnaea, xxx. (1859-60) 151.N. Granat.

magniflora, Pav. ex DC. Prod. iv. 354=Cascarilla macrocarpa.

magnifolia, Humb. \& Bonpl. PI. Aequin. i. $136=$ Cascarilla caduciflora.

magnifolia, Ruiz \& Pav. Fl. Per. ii. 53. t. $196=$ Cascarilla magnifolia.

maynensis, Brign. in Mem. Soc. Ital. Mod. Ser. II. i. 1862) $63=$ Exostemma maynense.

micrantha, Ruiz \&o Pav. Fl. Per. ii. 52, t. 194.Peruv.

microphylla, Mutis, ex Lamb. Illustr. Cinch. $9=$ Mutisii microphylla, Pav. Nuev. Quinol. t. 17.-Peruv.

montana, Badier, in Journ. Phys. (1789) $129=$ Exostemma floribundum.

Morado, Ruiz, Quinol. 67.n. $5=$ purpurea.

Moritziana, Karst. ex Miq. Ann. Mus. Bot. Lugd. Bat. iv. 275 .-Peruv.

Mutisii, Lamb. Illustr. Cinch. 9.-Peruv.

muzonensis, Goudot, in Phil. Mag. (1828) $182=$

Cascarilla muzonensis.

myrtifolia, Stokes, Bot. Mat. Med. i. $359=$ Exostemma caribaeum

nitida, Benth. Pl. Hartw. $109=$ Cascarilla nitida

nitida, Ruiz \& Pav. Fl. Per. ii. 50.-Peruv.

oblongifolia, Lamb. Illustr. Cinch. $12=$ Buena Riveroana.

oblongifolia, Mutis, in Periodico de Santa Fé (1793) 465 , nomen; Humb. in Ges. Naturf. Fr. Berl. Mag i. $(1807) 118=$ Cascarilla oblongifolia.

obovata, Pav. Nuev. Quinol. sub t. 18. et t. $24=$ pubescens.

obovata, Spreng. Syst. iv. Cur. Post. $73=$ Hymenodictyon obovatum.

obtusifolia, D. Dietr. Syn. Pl. i. $721=$ Cosmibuena obtusifolia.

obtusifolia, Pav. ex DC. Prod. iv. $353=$ macrocalyx.

officinalis, Linn. Mant. ii. $338=$ cordifolia.

officinalis, Linn Syst. ed. X. 929--Peruy.

ovalifolia, Humb. \& Bonpl. Pl. Aequin. i. 65 (=Lasionema Humboldtianum).-Peruv.

valifolia, Mutis, ex Humb. in Ges. Naturf. Fr. Berl Mag. i. (1807) $118=$ Cascarilla macrocarpa

ovata, Ruiz \& Pav. Fl. Per. ii. 52. t. 195.-Peruv.

Pahudiana, Howard, in Pav. Nuev. Quinol. t. 21.Am. anstr.

pallescens, Ruiz, ex DC. Prod. iv. $353=$ ovata.

Palton, Pav. Nuev. Quinol. t. $13=$ macrocalyx.

paniculata, D. Dietr. Syn. P1. i. $721=$ Remijia panicalata.

parabolica, Pav. Nuev. Quinol. t. 16.-Peruv.

parviflora, Brign. in Mem. Soc. Ital. Mod. Ser. II. i (1862) $63=$ Exostemma parviflorum.

parviflora, Poir. Encyc. vi. $38=$ micrantha.

pauciflora, Tafalla, ex Steud. Nom. ed. II. i. 363.Am anstr.

Pavoniana, O. Kuntze, Monog. Cinch. (1878) 29,Peruv.; Bolivia.

Pavonii, Lamb. Illustr. Cinch. $8=$ Cascarilla Pavonii.

pedunculata, Karst. in C. Koch E' Fint. Wochenschr. ii. (1859) $30 .-\mathrm{N}$. Granat.

Pelalba, Pav. ex DC. Bibl. Univ. xli. (1829) 152.-Am. austr.

\section{CINCHONA :}

Pelletieriana, Wedd, in Ann. Sc. Nat. Sér. III. x. (1848) $8=$ pubescens.

peruviana, Howard, in Pav. Nuev. Quinol. t. 27.Andes.

peruviana, Poir. Encyc. Suppl. iv. $640=$ Exostemma peruvianum.

philippica, Cav. Ic. iv. $15=$ Exostemma philippicum.

pitayensis, Wedd. in Ann. Sc. Nat. Sér. III. xi. (1849)

269 ; et V. xii. (1862) 37.-N. Granat.

platyphylla, Wedd. l. c. Sér. V. xi. (1869) 362 ; xii. (1869) 73.-N. Granat

prismatostylis, Karst. Fl. Columb. i. 13. t. 7.-N. Granat.

pubescens, Hort. Mack. ex Walp. Rep. ii. $943=$ Rhyssocarpus pubescens.

pubescens, Lamb. Illustr. Cinch. $6=$ ovata.

pubescens, Vahl, in Skriv. Naturh.-Selsk. i. (1790) 19 = cordifolia.

purpurascens, Wedd. in Ann. Sc. Nat. Sér. III. x (1848) 8--Bolivia.

purpurea, Ruiz Es Pav, Fl Per, ii. 52 t 193--Peruy. quercifolia, Pav. ex Lamb. Illustr. Cinch. 9= Mutisii.

Quina, Ruiz, in Ruiz \& Pav. Fl. Per, iii. $4=$ Cosmi buena obtusifolia.

racemosa, Schrank, ex Steud. Nom. ed. II. i. $363=$ Exostemma caribaeum.

Reicheliana, Howard, in Pav. Nuev, Quinol. t. $5=$ micrantha.

Remijiana, St. Hil. Pl. Us. Bras. sub t. $2=$ Remijia Hilarii.

Riedeliana, Casar. in Atti 3zia Riun. Scienz. Ital. (1841) $513=$ Cascarilla Riedeliana

robusta, Howard, in Fourn. Linn. Soc. xx. (1884) 327 , nomen-Hab?

Roraimae, Benth. in Hook. Journ. Bot. iii. (1841) 214 $=$ Cascarilla Roraimae.

rosea, Ruiz \& Pav. Fl. Per. ii. 54. t. 199 (=Lasionema roseum).-Peruv.

rosulenta, Howard, ex Wedd. in Ann. Sc. Nat. Sér. V. xi. (1869) 362.-N. Granat.

rotundifolia, Pav. ex Lamb. Illustr. Cinch. $5=$ cordifolia.

rubicunda, Auct. ex Steud. Nom. ed. II. i. 363.-Am. austr.

rubicunda, Tafalla, ex Wedd. in Ann. Sc. Nat. Sér. V. xi. (1869) $362=$ ovata.

rufinervis, Wedd. in Ann. Sc. Nat. Sér. III. x. (1848) 8.--Peruv.

rugosa, Pav, ex DC. Prod. iv. $353=$ cordifolia.

Sanctae-Luciae, Davids, ex Roem. \& Schult. Syst. v. 19 $=$ Exostemma floribundum.

scrobiculata, Humb. छ Bonpl. Pl. Aequin. i. 165. t. 47.--Peruv.

sourana, Brign. in Mem. Soc. Ital. Mod. Ser. II. i. (1862) 63 - Exostemma souzanum.

spinosa, Vavass. in Journ. Phys. (Oct. 1790) $273=$ Exostemma Vavassorii.

stenocarpa, Lamb. Illustr. Cinch. 13 = Cascarilla stenocarpa.

stupea, Pav. ex Lindl. Fl. Med. $416=$ lucumaefolia subcordata, Pav. Nuev. Quinol. ed. Howard, ad calcem = cordifolia.

suberosa, Pav. 1. c. $=$ macrocalyx.

subsessilis, Miq. Ann. Mus. Bot. Lugd. Bat. iv. 272.Peruv.

succirubra, Pav. ex Klotzsch, in Abh. Akad. Berl. 1857 (1858) 60.-Perav.

Tarontaron, Pav. Nuev. Quinol. ed. Howard, ad calcem.-Peruv.

tenuiflora, Brign. in Mem. Soc. Ital. Mod. Ser. II. i. (1862) $63=$ Remijia tenuiflora.

tenuis, Ruiz, ex DC. Prod. iv. $353=$ cordifolia.

thyrsiflora, Roxb. Hort. Beng. 15; Fl. Ind. i. $530=$ Hymenodictyon excelsum.

timorana, Span. in Linnaea, xv. (1841) $315=$ Hymenodictyon timoriense.

timorensis, Walp. Rep. ii. $509=$ praec.

Trianae, Karst. in C. Koch \& Fint. Wochenschr, ii. (1859) $31=$ pitayensis.

triflora, W. Wright, in Lond. Med. Journ. viii. (1787) $240=$ Exostemma triflorum.

tucujensis, Karst. Fl. Columb. i. 17. t. 9.-N. Granat. umbellulifera, Pav. Nuev. Quinol.t. 22.-Peruv. undata, Karst. ex Wedd. in Journ. Linn. Soc. xi (1869) $187=$ Cascarilla undata.

undulata, Pav. Nuev. Quinol. 2. t. 6. = glandulifera.

Uritusinga, Pav, ex DC. Prod. iv. $353=$ macrocalyx 


\section{CINCHONA :-}

Uritusing $\alpha$, Pav. ex Howard, Nuev. Quinol. t. $19=$ officinalis.

vanilliodora, Auct.ex Steud. Nom. ed. II. i. 363.-Am. austr.

Vellozii, St. Hil. Pl. Us. Bras, sub t. $2=$ Remijia Vellozii.

villosa, Pav, ex Lamb. Illustr. Cinch. $7=$ Humbold tiana.

violacea, Pav. Nuev. Quinol. ed. Howard, ad calcem. -Ecuador.

viridiflora, Pav. l. c. $=$ pubescens.

Vritusino, Pav. ex DC. Prod. iv. $352=$ C. Condaminea. Weddelliana, O. Kuntze, Monog. Cinch. (1878) 29.Bolivia.

CINCLIA, Hoffmgg. Preisverz. (1841).—Cf. Linnaea, xvi (1842) Litt. 267 = Ceropegia, Linn. (Asclepiad.).

CINCLIDOCARPUS, Zoll. \& Mor. in Nat. en Geneesk. Arch. Neerl. Indie, iii. (1846) 81 =Caesalpinia, Linn, (Legumin.).

nitidus, Zoll. \& Mor. 1. c. $82=$ Caesalpinia Cinclidocarpa.

CINERARIA, Linn. Sp. P1. ed. II. 1242 (1763). COMPOSITAE, Benth. \& Hook. f. ii. 445.

Xenocarpus, Cass. in Dict. Sc. Nat. lix. 108 (1829). abrotanifolia, Berg. Desc. Pl. Cap. 292.-Afr. austr. abyssinica, Sch. Bip. ex A. Rich. Tent. Fl. Abyss. i 433.-Afr. trop.

acanthifolia, Reichb. Hort. Bot. t. $24=$ Senecio Cineraria.

acutangula, Bertol. Fl. Guatimal. $35=$ Senecio acutangulus.

Aitoniana, Spreng. F1. Hal. Mant. $51=$ canescens

alata, Linn. f. Suppl. $374=$ Othonna alata.

alchemilloides, DC. Prod. vi. 307.-Afr. austr.

alliarifolia, Desf. Cat. Hort. Par. ed. III. 403.Hab.?

alpestris, Hoppe, Taschenb. (1806) $130=$ Senecio alpestris.

alpestris, Pall. Reise, ii. $28=$ Senecio campestris.

alpestris, Willk, in Willk. \& Lange, Prod. Fl. Hisp. ii. 111 = Senecio brachychaetus.

alpina, All. Fl. Pedem, i. 203. t. $38=$ Senecio aurantiacus.

alpina, Huds. Fl. Angl. ed. II. $370=$ Senecio campestris.

alpina, Linn. Sp. Pl, ed. II. 1243= Senecio alpinus.

altaica, C. A. Mey. ex DC. Prod. vi. $315=$ Senecio altaicus.

ambigua, Bivona, Manip. iii. $5=$ Senecio ambiguus.

ambracea, Hornem. Hort. Hafn. Add. $972=$ Senecio ambraceus.

amelloides, Linn. Sp. PI. ed. II. $1245=$ Aster rotundifolius.

americana, Linn. f. Suppl. $373=$ Senecio denticulatus. amoena, Salisb. Prod. $200=$ Aster rotundifolius.

angulata, Alam. ex DC. Prod. vi, 431. n. $544=$ Senecio sublobatus.

angulata, Mair, ex DC. 1. c. n。 $547=$ Senecio angulifolius.

angulosa, Lam. Encyc. ii. $6=$ humifusa, geifolia.

angulosa, E. Mey。 ex DC. Prod. vi. $337=$ Senecio longiflorus.

angristata, Schur, Enum. Pl. Transs. $346=$ transsilvanica.

angustifolia, H. B. \& K. Nov。 Gen, et Sp. iv. $189=$ Senecio salimus.

anomala, Sibth. \& Sm, Fl. Graec. Prod. ii. 179; Fl. Graec. ix. 56 - Senecio Othonnae.

anthemoides, Lam. Encyc. ii. $9=$ Senecio gallicus.

anthemoides, Spreng. ex DC. Prod。 vi. $365=$ Senecio ramosus.

appendiculata, Poir. Encyc. Suppl. ii. 263=Senecio appendiculatus.

appendiculata, Steud. Nom。 ed. II. i. $363=$ Senecio populifolins.

arachnoidea, Reichb. in Moessl. Handb. ed. II. ii. $1501=$ - Senecio lanatus.

arachroidea, Turcz, ex Ledeb, Fl. Ross. ii. $632=$ senecio frigidus.

arctotidea, DC. Prod. vi. 306,-Afr. anstr.

urctotidea, Drège, ex Harv. \& Sond. Fl. Cap. iii. $309=$ mollis.

arvernensis, Rouy, in Bull. Soc. Bot. Fr. xxviii. (1880) $68=$ Sentcio campestris.

\section{CTNERARIA :}

aspera, Thunb. Prod. Pl. Cap.155-Afro austr.

atriplicifolia, $D C$. Prod. vi. 308--Afr. austr.

atropurpurea, Ledeb. in Mém. Acad. Pétersb. v. (1814) $574=$ Senecio frigidus.

Aucheri, C. Koch, in Linnaea, xxiv. (1851) 358 . Oriens.

aurantiaca, Bess. Enum. Pl. Volh. $33=$ Senecio campestris.

aurantiaca, Hoppe, ex Willd. Sp. Pl. iii. $2081=$ Senecio aurantiacus.

aurea, Linn. Sp. Pl. ed. II. 1244= Senecio auratus,

auriculata, Ledeb. Fl. Alt. iv, $105=$ Senecio race mosus.

aurita, Andr. Bot, Rep. i. 24. t. 24=Doronicum cruentum.

aurita, L'Hérit. Sert. Angl. $26=$ Senecio maderensis.

Balbisiana, Bertol. Fl. Ital. ix 290 -Italia

Balsamita, Lam. Encyc. ii. $7=$ Senecio aureus.

belbeisia, Spreng. Syst. iii. $552=$ Senecio belbeysius.

Bergeriana, Spreng. 1. c. $551=$ Aster Bergerianus.

bicolor, Willd. Sp. Pl. iii. $2085=$ Senecio bicolor.

bipinnata, Willd. l. c. $2075=$ Senecio pinnatifidus,

bracteata, Chr. Sm. ex Link, in Buch, Beschr. Canar Ins. 148 = Senecio malvaefolius.

brasiliensis, Spreng. Neue Entdeck. ii. $142=$ Senecio brasiliensis.

cacaliformis, Lam. Fl. Fr, ii, $124=$ Senecio Ligularia.

cacalioides, Linn. f. Suppl. $374=$ Othonna carnosa.

Caledoniae, Spreng. Fl. Hal, Mant. $50=$ Brachyglotti Caledoniae.

calvescens, Nym. Syll. Suppl, $1=$ Senecio Cineraria.

campestris, DC. Fl. Fr. iv. 164= Senecio campestris.

campestris, Fellm. ex Ledeb. Fl. Ross, ii. $647=$ Senecio aurantiacus.

campestris, Zett. ex Willk, \& Lange, Prod, Fl. Hisp. ii. $110=$ Senecio pyrenaicus.

canadensis, Linn. Sp. Pl. ed. II. $1244=$ Senecio Cineraria.

canadensis, Walt. Fl. Carol. $207=$ Erechtites hieracifolia?

candida, J. \& C. Presl, Delic. Prag. (1822) 95= Senecio candidus.

canescens, Spreng. Syst. iii. $549=$ Erigeron canescens.

canescens, Wendl. Obs, ex Link, Enum. Hort. Berol.

ii. 332.-Afr. austr.

cantabrica, Nym. Syll. $2=$ Senecio brachychaetus.

capillacea, Linn. f. Suppl. $375=$ Steirodiscus capillaceus.

capitata, Ledeb. Fl. Alt. iv. 104=Senecio campestris.

capitata, Wahlenb. Fl. Carp. 271 = Senecio auran tiacus.

carolinensis, Walt. Fl. Carol. 207 (sp. indeterminab.).Am. bor.

caspica, Pers. Syn. ii. $439=$ Senecio racemosus.

cancasica, Bieb. F1. Taur. Cauc. ii. $313=$ Senecio caucasicns.

caucasica, Hoffm. Hort. Mosq. (1808) n. $598=$ Senecio platyphyllus.

caucasica, Schlecht, ex Ledeb, Fl. Ross, ii. 858

Senecio renifolius, Sch. Bip.

ceratophylla, Tenore, Ind. Sem. Hort. Neap. $1825=$ Senecio Cineraria.

cernua, Thore, Chl. Land, $344=$ Arnica montana.

cernua, Wall. ex DC. Prod。 vi. $314=$ Senecio arnicoides.

chamaedrifoliz, Lam. Encyc, ii. 9-Afr. austr

chinensis, Spreng. Syst. iii. $549=$ Senecio scandens.

Cinia, Webb, in Webb \& Berth. Phyt. Canar. ii. $339=$

Doronicum papyraceum.

Clusiana, Host, Fl. Austr. ii. $482=$ Senecio alpestris.

Coderi, Nym. Consp. $352=$ Senecio brachychaetus.

collina, Salisb. Prod, $200=$ Senecio campestris.

conformis, Rochel, P1. Banat. Rar. Ind。= Senecio aurnnticus, brachychaetus.

congesta, R. Br. in Parry, 1st Voy. A pp. $279=$ Senecio palustris.

cordata, Jacq. FI. Austr. ii. t. $176=\mathrm{scQ}$

cordifolia, Gouan, Illustr. $69=$ Senecio alpinus,

cordifolia, Jacq. Fl. Austr. t. $17 \overline{7}=$ Senecio subalpinus.

cordifolia, Lapeyr. ex Willk. \& Lange, Prod. Fl. Hisp.

ii. $115=$ Senecio Doronicum

coronata, Thunb. Prod. Pl. Cap. $154=$ Senecio lasio rhizus,

coronata, Zcyh. ex DC. Prod. vi. $18 S$ a Scnecio junceus.

corymbosa, Moench, Meth. $588=$ Erigeron annuus.

\section{CINERARIA}

crassiflora, Poir. Encyc. Suppl. ii. $267=$ Senecio crassiflorus.

crassifolia, Host, [F1. Austr. ii. 482?] ex DC. Prod. vi. 360.-Europ.

crassifolia, Kit. in Schult. Oestr. Fl. ed. II. ii. $514=$ Senecio alpestris.

crenata, Spreng. ex DC. Prod, vi. 388 = Senecio erosus. crispa, Jacq. Fl. Austr. ii. 48 = Senecio crispatus.

crocea, Tratt. Arch. i. $26=$ Senecio crispatus.

cruenta, Mass. ex L'Hérit. Sert. Angl, 26 = Doronícum cruentum.

cuneata, E. Mey. ex DC. Prod. vi. $439=$ Senecio diversifolius, Harv.

cymbalarifolia, Linn. Amoen. Acad. vi. $106=$ Senecio cymbalarifolius,

dealbata, Spreng. ex DC. Prod, vi. $369=$ Senecio Kunthianus.

decipiens, Harv. in Harv. E Sond. Fl. Cap, iii. 312,Afr. austr.

decipiens, Spreng. ex DC. Prod. vi. $366=$ Senecia chrysanthemoides.

degenerans, Kit. ex Kanitz, in Verh. Zool.-Bot. Ges. Wien, xiii. (1863) $523=$ Senecio alpestris?

deltoidea, Sond. in Linnaea, xxiii. (1850) 68,-Afr. austr.

denticulata, DC. Prod. vi. 416, in syn.= Senecio denticulatus.

denticulata, Linn. f. Suppl. 375 (=Brachyrhynchos eupatorioides).-Afr. austr.

difformis, Rochel, P1. Banat, Rar. Ind. = Senecio alpinus.

discoidea, Kit. in Linnaea, xoxii. (1863) 389,-Europ.

discolor, Sw. Prod. Veg. Ind. Occ. $114=$ Senecio discolor.

distans, Kunze, in Linnaea, xvii. (1843) $571=$ Senecio geifolius.

divaricata, Spreng. ex DC. Prod. vi. $370=$ Senecio scandens.

Doria, Spreng. ex DC. 1. c. $364=$ Senecio Wallichii

dracunculoides, Mos, \& Sesse, ex DC. 1. c. 430 Senecio salignus.

Dregeana, $D C$. Prod. vi. 305 ,-Afr. austr.

dubia, Spreng. Syst. iii. $550=$ Senecio tomentosus

elata, Steud. Nom, ed. II. i. $364=$ Senecio Ligularia

elatior, Bouché, in Link, Enum. Hort. Berol. ii. 333 Senecio multiflorus.

elodes, Nym. Syll. $2=$ Senecio elodes

elongata, Linn. f. Suppl. $374=$ Senecio diversifolium, Harv.

erodioides, $D C$. Prod. vi. 307.-Afr. anstr.

erosa, Harv. in Harv. \&e Sond. Fl. Cap. iii. 309 oxyodonta.

erosa, Willd. Sp. Pl. iii. 2073.-Afr. anstr.

exilis, DC. Prod. vi. 305.-Afr. austr.

Farfara, Bemb. Syst. Verz. Erf. $146=$ Tussilago Farfara.

flifolia, Thunb. Prod. Pl. Cap. $154=$ Senecio longi. folius.

Fischeri, Ledeb. Ind. Sem. Hort. Dorpat. (1820) 17 Senecio Ligularia.

flammea, Turcz. ex DC. Prod. vi. $362=$ Senecio flammeus.

Forsteri, Spreng. Pugill. i. $58=$ Brachyglottis Forsteri fragrans, Hofimgg. ex Steud. Nom. ed. II. i. $964=$ Erigeron fragrans.

frigida, Richards. in Frankl. Narr. 1st Journ. App. its Senecio frigidus.

fulva, Ster, in Mém. Soc. Nat. Mosc. iv. (1816; 64 Senecio aurantiacus.

Fussii, Griseb. \& Schenk, in Wiegm. Arch. xviiz. (1852) $342=$ Senecio campestris

geifolia, Linn. Sp. Pl. ed. II. 1242 -Afr. anstr.

geifolia, C. A. Mey. ex Steud. Nom, ed. II. i. 361 Senecio geifolius.

gerviculata, Wendl. ex Steud. Nom. ed. II. 1. Sot Senecio geniculatus.

geraniifolia, DC. Prod. vi. 308. - Afr. anstr.

gibbosa, Guss. Adnot. Cat. Pl. Hort. Hocc 15:1 : Senecio gibbosus.

gigunbea, Sm. Exot. Bot. ii. 11 = Sceecio Smithii.

glabella, Turcz. ex DC. Prod. ri. 360 - Sencel campestris.

glaberrima, spreng. ex DC. I. co Y. $25=1 \mathrm{cmol}$

glaberea.

glabra, Sw. Prod. Veg. Ind. Ooc $113=$ Senesilu

Siwartzil

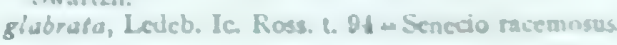

32 


\section{CINERARIA}

glabrata Sw. Fl. Ind Occ. iii. $1354=$ Senecio Swartzii. glandulifera, Vukot. in Rad Jugos. Akad. Zagreb. li. (1880) $34=$ Senecio crispatus.

glastifolia, Banks \& Soland. ex Hook. f. Fl. N. Zel. $148=$ Senecio glastifolius.

glauca, Linn. Sp. Pl. ed. II. 1242 (=Senecillis glauca)

-Ross, austr.

gnaphalodes, Nym. Consp. 351.-Europ.

grandiflora, Spreng, ex DC. Prod, vi. $314=$ Senecio arnicoides.

grandiflora, Vatke, in Linnaea, xxxix. (1875) $503=$ abyssinica.

Gualtata, Gill. ex Hook. \& Arn. in Hook. Journ. Bot iii. (1841) $340=$ Senecro Hualtata

hastifolia, Linn. f. Suppl. 376=Senecio cymbalarifolins.

Heldreichii, Nym. Syll. $2=$ Senecio Heldreichii

Helenitis, Georgi, Beschr. Kuss. Reich. iii. IV. $1246=$

Senecio campestris.

Helenitis, Steud. Nom. ed. II. i. $364=$ Senecio brachy chaetus.

heterophylla, Fisch. in Mém. Soc. Nat. Mosc. iii (1812) $75=$ Senecio resedifolius.

heterophylla, Orteg. Hort. Matr. $71=$ Senecio minutus. heterophylla, Pursh, Fl. Am. Sept. ii. 528=Seneci tomentosus.

Heuffelii, Hoppe, ex Nym. Consp. 351 = Senecio lugens.

Hinniculus ×, Hort. ex Marnock, Floric. Mag.iv. (1839) t. 39 .

hirsuta, Vent. Jard. Malm. $95=$ Aster hirsutus.

hirta, Vahl, ex DC. Prod. v. 226= Aster elongatus.

Hualtata, Walp. Rep, ii. $658=$ Senecio Hualtata.

humifusa, L'Hérit. Sert. Angl. 25.-Afr. austr.

humilis, Poepp. ex DC. Prod. vi. $417=$ Senecio glaber.

hybrida, Bernh. Syst. Verz. Erf. $146=$ Petasites officinalis.

hybrida, Willd. Enum. Hort. Berol. 893 = Doronicum cruentum.

hypoleuca, Reichb. ex DC. Prod. vi. 389.-Afr. austr.

hypoleuca, Sieber, ex Harv. \& Sond. F1. Cap. iii. $381=$ Senecio verbascifolius.

hypolenca, Spreng. ex DC. 1. c. $369=$ Senecio rufinervis.

incana, Sw. Fl. Ind, Occ, iii, $1356=$ Seneciojamaicensis.

incisa, Houtt. ex DC. Prod. vi. $438^{\circ}=$ Senecio incertus.

incisa, Thunb. Prod. Pl. Cap. $156=$ Senecio incisus

incisa, Willd. Sp. P1. iii. $2074=$ Senecio erosus.

integrifolia, Benth. ex Willk. \& Lange, Prod, F1.

Hisp. ii. $110=$ Senecio pyrenaicus.

integrifolia, Hook. \& Arn, in Bot. Beech. Voy. $126=$ Senecio lugens.

integrifolia, Jacq. ex Willd. Sp. Pl. iii. $2082=$ Senecio alpestris.

integrifolia, Pursh, F1. Am. Sept. ii. $528=$ Senecio tomentosus.

integrifolia, Richards, in Frankl. Narr. 1st Journ. ed. II. 31 = Senecio Hookeri.

integrifolia, Schkuhr, Handb. t. $246=$ Seneciocrispatus. integrifolia, Vill. ex Steud. Nom, ed. II. i. $364=$ Senecio aurantiacus.

integrifolia, Wallr. Sched. Crit. $474=$ Senecio spathulaefolius.

integrifolia, With. Bot. Arr. ed. II. 920 ; Sm. Eng. Bot. t. $152=$ Senecio campestris.

japonica, Thunb. F1. Jap. $317=$ Senecio japonicus

laciniata, Sw. F1. Ind. Occ. iii. $1352=$ Senecio Swartzianus.

lactea, Jacq. f. Eclog. t. $105=$ Senecio cruentus.

lactea, Willd. Enum. Hort. Berol. Suppl. 59=Senecio appendiculatus.

laevis, Spreng. ex DC. Prod, vi. $404=$ Senecio angulatus.

lanata, Jacq. Coll. iii. $177=$ lanosa

lanata, Lam. Encyc. ii. 7 = Senecio Heritieri

lanata, Link, Enum. Hort. Berol. ii. $333=$ Doronicum cruentum.

lanceolata, Lam. Fl. Fr. ii. 125 = Senecio campestris.

lanosa, DC. Prod, vi, 309-Afr, austr

laricifolia, Lam. Encyc. ii. $8=$ Senecio pinifolius.

leucanthema, Banks \& Soland. ex Hook. f. Fl. Antarct. ii. $316=$ Senecio Smithii, acanthifolius.

Lewisii, Richards. in Frankl. Narr. 1st Journ. App. $748=$ Erigeron compositus.

\section{CINERARIA :-}

lineata, Linn. f. Suppl. $375=$ Senecio lineatus.

lineata, Vahl, ex DC. Prod. vi. $395=$ Senecio tripli nervius.

linifolia, Linn. Amoen. Acad. vi. 106 = Euryops lini olius.

linifolia, Zeyh. ex DC. Prod. v. 224=Aster linifolius.

littoralis, Vest, in Flora, iii. (1820) 2 = Senecio gibbosus.

lobata, L'Hérit. Sert. Angl. 26.-Afr. austr.

lobata, Mair. ex DC. Prod. vi. $431=$ Senecio sublo batus.

longifolia, All. Fl. Pedem. i. $203=$-Senecio Balbisianus.

longifolia, Bess. Enum. P1. Volh. 33 = Senecio alpestris.

longifolia, Eichw. Casp. Cauc. $22=$ Senecio cladobotrys.

longifolia, Jacq. FI. Austr. ii. 49. t. $181=$ Senecio brachychaetus.

longifolia, Lapeyr. Hist. Abr. Pl. Pyr. $521=$ Senecio pyrenaicus.

lucida, Sw, Fl. Ind. Occ, iii, $1360=$ Senecio lucidus.

lyrata, $D C$. Prod. vi. 308.-Afr. austr.

lyrata, Ledeb. in Mém. Acad. Pétersb. v. (1818) $576=$ Senecio resedifolius.

lyratifolia, Bluff \& Fing. Comp. ii. $377=$ Senecio alpinus.

macrophylla, Ledeb. Fl. Alt. iv, $108=$ Senecio Ledebourii

malvaefolia, L'Hérit. Sert. Angl. $26=$ Senecio malvaefolius.

maritima, Linn. Sp. Pl. ed. II. 925 = Senecio Cineraria.

maritima, Wulf, ex Steud. Nom. ed. II. i. $364=$ Senecio gibbosus.

megapotamica, Spreng. Syst, iii. $547=$ Senecio pinnatus microglossa, DC. Prod. vi. 305.-Afr, austr.

microphylla, Vahl, ex DC. I. c. v。 $225=$ Aster aethiopicns.

microrhiza, Schur, in Verh. Siebenb. Naturw. Ver. (1859) $147=$ Senecio campestris

minuta, Cav. Ic. i. 21. t. 33. f. 3-Senecio minutus. mitellaefolia, L'Hérit. Sert. Angl. 25.-Afr, austr. mollis, E. Mey. ex DC. Prod. vi. 306.-Afr. austr. monrolica, Turcz in Bull. Soc. Nat. Mosc. v. (1832) $199=$ Senecio mongolicus.

montevidensis, Spreng. Syst. iii. $548=$ Senecio chilensis multiflora, L'Hérit. Sert. Angl. 26 = Senecio multi florus.

nebrodensis, Guss. Adnot. Cat. P1. Bocc. (1821) $4=$ Senecio candidus.

nivea, Willd. Sp. Pl. iii. $1974=$ Senecio niveus.

nuda, Kit. in Linnaea, xxxii. (1863) $389=$ Senecio alpestris.

oppositifolia, Moench, Meth. 588 = Aster rotundifolius.

Othonnitis, Linn. Sp. Pl. ed. II. $1244=$ Othonna frutescens.

othonnoides, Harv. in Harv. E" Sond. Fl. Cap. iii 314.-Afr. austr.

ovata, Spreng. ex DC. Prod. v. $344=$ Aster asperulus.

ovirensis, Koch, in Flora, vi. (1823) $507 \simeq$ Senecio alpestris.

oxyodonta, $D C$. Prod. vi. 306.-Afr, austr.

palmensis, Nees, Hort. Phys. Berol. 115. t. $24=$ Senecio palmensis.

palustris, Linn. Sp. Pl. ed. II. $1243=$ Senecio palustris.

pandurata, Thunb. Prod. Pl. Cap. $155=$ Senecio panduratus.

papposa, Reichb. in Moessl. Handb. ed. II. ii. $1500=$ Senecio papposus.

Parnassi, Nym. Consp. 352= Senecio Parnassi.

parviflora, Bieb. Fl. Taur. Cauc. ii. $316=$ Senecio lampsanoides.

parviflora, [R. Br. in] Ait. Hort. Kew. ed. II. v. $72=$ canescens.

pauciflora, Spreng. ex DC. Prod. vi. $367=$ Senecio nudicaulis.

pedunculosa, $D C . l$. c. 305 - Afr. austr.

perfoliata, Linn. f. Suppl, $375=$ Othonna perfoliata. Petasitis, Sims, Bot. Mag. t. $1536=$ Senecio Pe tasitis.

phylicaefolia, Poepp. ex DC. Prod. vi. $415=$ Senecio phylicaefolius.

innata, La Llave, in La Llave \& Lex. Nov. Veg. Desc. i. $29=$ Senecio pinnatisectus.
CINERARIA :-

pinnatifida, Willd. Sp. Pl. iii. $2074=$ Senecio incertus.

platanifolia, Schrank, P1. Rar. Hort. Monac. t. $95=$ Senecio Petasites.

platycarpa, DC. Prod. vi. 305.-Afr. austr.

polycephala, $D C$. l. c. 307.-Afr. austr.

polyglossa, DC. 1. c. $306=$ mollis.

populifolia, Lam. Encyc, ii. 8 = Senecio appendiculatus.

populifolia, L'Hérit. Sert. Angl. 25 = Senecio populifolius.

praecox, Cav, Ic. iii. 23. t. $244=$ Senecio praecox.

pratensis, Herder, in Bull. Soc. Nat. Mosc. xl. (1867) 1. 400 , partim $=$ Senecio lugens.

pratensis, Hoppe, ex Reichb. FI. Germ, Excurs. ii. 241 $=$ Senecio campestris.

procera, Griseb. Spicil. Fl. Rumel. ii. 219.-Rumel.

pulchella, E. Mey. ex DC. Prod. vi. $438=$ Senecio cymbalariaefolius.

pulchella, Sweet, Hort. Brit. ed. I. 232.-Ins. Canar.

pumila, Thunb. Prod. Pl. Cap. $155=$ Senecio repandus.

purpurascens, Banks \& Soland. ex Hook. f. Fl. Antarct. ii. $318=$ Senecio acanthifolius.

purpurata, Linn. Mant. 285.-Afr. austr.

pyrenaica, Nym. Syll. 2 =Senecio pyrenaicus.

racemosa, Bieb. Fl. Taur. Cauc. ii. $314=$ Senecio racemosus.

ramentosa, L'Hérit. Sert. Angl. 26 = Senecio echinatus.

ramosa, Vukot. in Rad Jugos. Akad. Zagreb. li. (1880) 35.-Europ.

renifolia, C. A. Mey. Verz. Pfl. Cauc. $82=$ Senecio renifolius.

reniformis, Spreng. ex DC. Prod, vi. $315=$ Cremanthodium reniforme.

répanda, Lour. Fl. Cochinch. ii. $501=$ Senecio scandens.

repanda, Willd. Sp. Pl. iii. $2076=$ Senecio Forsteri.

retusa, Wall. ex C. B. Clarke, Comp. Ind. $206=$ Senecio retusus.

rivularis, Waldst. \& Kit. Pl. Rar. Hung. iii. $265=$ Senecio crispatus.

robusta, Ledeb. Fl. Alt. iv. $106=$ Senecio robustus.

rotundifolia, J. F. Ginel. Syst. 1240 ; Willd. Sp. Pl. iii. $2076=$ Senecio rotundifolius.

rupicola, Nym. Consp. $351=$ transsilvanica.

salicifolia, H. B. \& K. Nov. Gen. et Sp. iv. $188=$ Senecio salignus.

samnitum, Huet, ex Nym. Consp. $352=$ Senecio alpinus.

sarmentosa, Lesch. ex DC. Prod. vi. $369=$ Senecio candicans.

Saxifraga, DC. l. c. 306.-Afr. austr.

scapiflora, L'Hérit. Sert. Angl. 25 = Senecio diversifolius, Harv.

scapigera, Banks, ex DC. Prod. vi. $439=$ Senecio diversifolius, Harv.

Schimperi, Sch. Bip. ex A. Rich. Tent. Fl. Abyss. i. 439.-Abyssin.

Schkuhrii, Reichb. in Moessl. Handb. ed. II. ii. $1499=$ Senecio crispatus.

scirpina, E. Mey. ex DC. Prod. vi. $438=$ Senecio junceus.

scordifolia, Link, ex DC. 1. c. $439=$ Senecio diversifolius, Harv.

Selloi, Spreng. Syst, iii, $541=$ Senecio Selloi.

senecifolia, Poir. Encyc. Suppl. ii. $265=$ Senecio alpinus.

Senecionis, L'Hérit. Sert. Angl. 26.-Hab.?

serrata, Willd. Sp. Pl. iii. $2073=$ Senecio Leontodontis.

serratifotia, S. F. Gray, Nat. Arr. Brit. P1. ii. $469=$ Senecio paludosus.

sessilifolia, Jacquem. Voy. Bot. $91=$ Werneria

nana.
sibirica, Linn. Sp. Pl. ed. II. 1242=Senecio Ligularia.

solidaginifolia, Fisch. ex Ledeb. FI. Ross. ii. $858=$ Senecio racemosus.

sonchifolia, Linn. Sp. Pl. ed. II. 1243.-Afr. austr.

spathulaefolia, C. C. Gmel. F1. Bad. iii. $454=$ Senecio spathulaefolius.

spathulata, Lam. Encyc. ii. $8=$ Othonna alata.

speciosa, Fisch. ex Turcz. in Bull. Soc. Nat. Mosc. xx.

(1847) II, 11 (=Ligularia speciosa).--Sibiria. 


\section{CINERARIA}

speciosa, Schrad. ex Link, Enum. Hort. Berol. ii. 334 $=$ Senecio Ligularia.

spinulosa, Lam. Encyc ii. 9-Afr. austr.

subdentata, Bunge, Enum. Pl. Chin. Bor, $39=$ Senecio campestris.

sudetica, Koch, in Flora, vi. (1823) $505=$ Senecio crispatus.

taraxacifolia, Bieb. Fl. Taur. Cauc. ii. $313=$ Senecio taraxacifolius.

taygetea, Nym. Syll. 2 = Senecio candidus.

tenella, Link, Enum. Hort. Berol. ii. 334 = Aster tenellus.

tenuifolia, Gaudin, F1. Helv. v. $306=$ Senecio brachy chaetus.

thapsoides, Nym. Syll. $2=$ Senecio thapsoides

thyrsoidea, Host, Fl Austr, ii. 481--Austria.

thyrsoidea, Ledeb. Fl. Alt. iv. $107=$ Senecio sibiricus.

tillandsiaefolia, Poepp. ex DC. Prod. vi. $415=$ Senecio argenteus.

tomentosa, Less. Syn. Comp. 391.-Afr. austr.

tomentosa, Mill. Gard. Dict. ed. VIII. n. 5 = Senecio canadensis.

trachyphylla, Spreng. Neue Entdeck. iii. $43=$ Aster Ecklonis.

transsilvanica, Schur, Enum. Pl. Transs. $345=$ Senecio lugens.

trifurcata, Spreng. Syst. iii. $551=$ Senecio trifurcatus.

tuberosa, E. Mey. ex DC. Prod. vi. 438 = Senecio incertus.

tussilaginea, Thunb. F1. Cap. $671=$ Senecio verbascifolius.

Tussilaginis, L'Hérit. Sert. Angl. $26=$ Senecio Tussilaginis.

tussilaginoides, Webb, ex Loud. Hort. Brit. Suppl. ii. 621 , nomen $=$ Senecio Tussilaginis

uliginosa, Ledeb. in Spreng. Nov. Prov. (1818) $11=$ Senecio gallicus.

uncinata, Spreng. ex DC. Prod. vi. $369=$ Senecio densiflorus.

unctuosa, Gilib. F1. Lituan. i. $211=$ Senecio palustris. undulata, Willd. Sp. Pl. iii. $2071=$ Senecio petiolaris. verna, Mair. ex DC. Prod, vi. $430=$ Senecio salignus. verticillata, Mair. ex DC. 1. c。= Senecio Andrieuxii.

vestita, Haw. in Phil. Mag. (1828) $187=$ Othonna vestita.

vestita, Spreng. Syst. iii. $550=$ Senecio crassitlorus. viscosa, L'Herit. Sert. Angl. 25.-Afr. austr.

Visianiana, Nym. Consp. $351=$ Senecio thapsoides.

vulneraria, Alam. ex DC. Prod. vi. $428=$ Senecio volnerarius.

Waterhousiana, Paxt. Mag. Bot. iv. (1838) t. $219=$ Senecro Tussilaginis?

Webberiana, Paxt. 1. c. ix, (1842) t. 125.-Hab. ?

Wolffi, Schur, ex Nym. Consp. $352=$ Senecio cam-

7.ahlbruckneri, Host, F1. Austr. ii. $479=$ Senecio lyratifolius.

CINGA, Noronha, in Verh. Batav. Gen. v. (1790) ed. I. Art. IV. 2 (Quid?)

CINHONA, Linn, Gen, ed. VI. 91 (1764), lapsu= Cinchona, Linn. (Rubiac.).

CINNA, Linn. Sp. Pl. 5 (1753). GRAMINEAE Benth. \& Hook. f. iii. 1151

Abola, Adans. Fam. ii. $\$ 1$ (1763)

Buytria, Fries, Nov. FI. Suec. Mant. ii. 2 (1839).

agrostidea, Beauv. ex Steud. Nom. ed. I. 20, $198=$ arundinacea.

alba, Nees, ex Steud Syn. Pl. Gram, 182,Chili

arachnoidea, Kunth, Rev. Gram. 1. $67=$ arundinacea.

arundinacea, Hook. Fl. Bor. Am. ii. 238=Colpodium latifolium.

arundinacea, $\operatorname{Lin} n$. Sp. Pl. 5.-Reg. bor.

arundinacea, Retz. ex Steud. Nom. ed. II. i. $365=$

Muehlenbergia mexicana.

Brownii, Rupr. Beitr. PA. Russ, Reich. ii. $66 \approx$ Colpodium latifolium.

crinita, Trin. Fund. Agrost, $118 \Rightarrow$ Dichelachne crinita.

decipiens, Kunth, Rev. Grmm。 i. $67=$ Deycuxia

scabra.
expansa, Link, Hort. Berol. ii. $236=$ arundinacea.

fliformis, Link, Lnum. Hort. Berol, i. $70=$ Muehlenbergia mexicana.

\section{CINNA}

glomerata, Link, Hort. Berol. ii. 237 $=$ Muehlenbergia glomerata.

glomerata, Walt. F1. Carol. $59=$ Andropogon ma crourus.

japonica, Steud. Syn. Pl. Gram. $182=$ Sporobolns indicus.

lanata, Kunth, ex Steud. Nom. ed. II. i. $365=$ Epicampes lanata.

lateralis, Walt. F1. Carol. $59=$ Andropogon virginicus.

lateriflora, Kunth, Rev. Gram. i. $67=$ Muehlenbergia mexicana.

latifolia, Griseb. in Ledeb. Fl. Ross. iv. $435=$ arun dinacea.

macroura, Kunth, Rev. Gram. i. $67=$ Epicampes macroura.

macroura, Thurb. in S. Wats. Bot, Calif ii, $276=$ Epicampes rigens.

mexicana, Beauv. Agrost. $32=$ Muehlenbergia mexi cana.

ovata, Kunth, Rev. Gram. i. $67=$ Echinopogon ovatus.

pendula, Trin. in Mém. Acad. Péters̄b. Sér. VI. vi (1845) II. $280=$ arundinacea

phleoides, Kunth, Rev. Gram. i. 67.-Venezuela.

pubescens, Kunth, 1. c. = Epicampes pubescens.

Purshii, Kunth, 1. c. = Calamagrostis canadensis.

racemosa, Kunth, 1. c. = Muehlenbergia glomerata

setifolia, Kunth, 1. c. 64; et Enum, Pl i. 208 =Epicampes macroura.

sobolifera, Link, Enum. Hort. Berol. i, $71=$ Muehlenbergia sobolifera.

stricta, Kunth, Rev. Gram. i. $67=$ Epicampes ma croura.

suaveolens, Rupr. ex Ledeb. F1. Ross, iv, $435=$ arundinacea.

tenuiflora, Link, Enum. Hort. Berol. i. $71=$ Muehlen bergia Willdenowii.

valdiviana, Phil. in Anal. Univ. Chil. 1873) 563.Chili.

CINNAGROSTIS, Griseb. in Goett. Abb. xix. (1874) 256. GRAMINEAE, Benth. \& Hook, f. iii. 1152. polygama, Griseb. l. c. 257.-Reg. Argent.

\section{CINNAMODENDRON, Endl. Gen. 1029 (1840}

CANELLACEAE, Benth. \& Hook. f. i. 121.

axillare, Endl. ex Walp. Rep. i. 398.-Bras.

corticosum, Miers, in Ann. E Mag. Nat. Hist. Ser. III i. (1858) 351.-Ind. occ.

macranthum, Baill. in Bull. Soc. Linn. Par. i. (1882) 317.--Porto Rico.

rubrum, Griseb. F1. Brit. W. Ind. $109=$ corticosum.

CINNAMOMUM, [Tourn.] Linn. Syst. ed. I. (1735, Blume, Bijdr. 568 (1825). LAURINEAE, Benth. \& Hook. f. iii. 155.

CAMphora, [Bauh.] Linn. Syst. ed, I (1735); Nees, in Wall. Pl. As. Rar. ii, 61 (1831) ; Syst. Laurin. 87 (1836).

Cecicodaphne, Nees, Syst. Laurin. 202 (1836)

Parthenoxylon, Blume, Mus. Bot. Lugd. Bat. 322 (1851).

albiflorum, Hook. f. \& Thoms, ex Meissn. in DC. Prod. xv. I. 21 = impressinervium

albiforum, Nees, in Wall. Pl. As. Rar. ii. $75=\mathrm{C}$. Tamala.

angustifolium, Rafin. Sylva Tellur. 195=Acrodiclidium salicifolium

aromaticum, J. Grah. Cat. Bomb. Pl. $173=$ zeyla nicum.

aromaticum, Nees, in Wall. Pl. As. Rar, ii. $74=$ C. Cassia.

aromaticum, Zoll. Syst. Verz. Ind. Arch. $112=$ iners.

Bagania, Nees, in Wall. Pl. As. Rar. ii. $78=$ obtusi folium.

Bejolghota, Sweet, Hort. Brit. ed. I. $\$ 44=$ obtusifolium.

bormeense, Miq. Ann. Mus. Bot. Lugd. Bat. i. 260 Meissn. in DC. Prod. xv. 1. 19.-Borneo.

brevifolium, Miq. in Verh. Nederl. Inst. III. (1852) v 14.-Japon.

Burmanni, Blume, Bijdr. 589.-Jave.

calophyllum, Nces, Syst. Laurin. 10 - camphomtum.

calyculatum, Mig. Fl. Ind. Bat. Suppl. 36y. - Sumatm.

\section{CINNAMOMUM:-}

Camphora, T. Nees E Eberm. Handb. Med.-Pharm. Bot. ii. 430.-China; Japon.

camphoratum, Blume, Bijdr.571.-Java

camphoriferum, St. Lag. in Ann. Soc. Bot. Lyon, vi (1880) $122=\mathrm{C}$. Camphora.

Cappara-Coronde, Blume, Rumphia, i. 34. t. 9. f. 2 , $=$ incrs.

Cassia, Blume, Bijdr. 570,-Burma; China.

Cassia, D. Don, Prod. Fl. Nep. $67=$ C. Tamala

Cassia, Siebold, in Verh. Batay, Gen, xii. (1830) $23=$ Burmanni.

Cathia, D. Don, Prod. Fl. Nep. 66= Phoebe pani culata.

caudatum, Nees, in Wall. Pl. As. Rar. ii. 76.-Reg Himal.; Burma.

Cecidodaphne, Meissn. in DC. Prod. xv. I. 25.-Keg. Irimal.

celebicum, Miq. Ann. Mus. Bot. Lugd. Bat. i. 264. Ins. Celebes.

chinense, Blume, Bijdr. $569=$ Burmanni.

Chloroxylon, J. S. Presl, Rostl. ii. $37=$ Ceanothus Chloroxylon.

citriodorum, Thw. Enum. Pl. Zeyl. 253.-Zeylan.

crassinervium, Miq. Ann. Mus. Bot. Lugd. Bat. i. 264 -Malaya.

Culiban, Rafin. Sylva Tellur, $135=$ seq. ?

Culilawan, Blume, Bijdr. 571.-Malaya; China.

Culitlawan, Nees, in Wall. Pl. As. Rar. ii. $75=$ praec.

curvifolium, Nees, Syst. Laurin. 80.-China.

cuspidatum, Miq. Ann. Mus. Bot. Lugd. Bat. i. 262 -Sumatra.

cyrtopodum, Miq. Fl. Ind. Bat. i. 1. 897.-Sumatra. daphnoides, Sieb. \& Zucc, in Abh. Acad. Muench. iv III. (1846) 202,-Japon.

dasyanthum, Miq. Ann. Mus, Bot. Lugd. Bat. i. 2j9.-

Doederleinii, Engl. in Engl. Bot. Fahrb. vi. (1885' 57 -Archip. Loo-Choo.

dubium, Nees, in Wall. Pl. As. Rar, ii. $73=$ iners.

dulce, Nees, 1. c. $75=$ Burmanni.

eucalyptoides, Nees, 1. c. $73=$ iners.

glabrescens, Miq. Ann. Mus. Bot.Lugd. Bat. i. 264.Malaya.

glanduliferum, Meissn. in DC. Prod. xY. I. 25.-Reg. Himal.

glaucum, J. S. Presl, Rostl. ii. 37; G. Don, ex Lond, Hort. Brit, $160=$ Litsaea glauca.

gracile, Hort. ex Sweet, Hort, Brit. ed. I. 34 , nomen $=$ C. Camphora.

gracile, Miq. Ann. Mus. Bot. Lagd. Bat, i. 259 iners.

Griffthii, Meissn. in DC. Prod. XV. I. 19=iners.

Heyneanum, Nees, in Wall. Pl. As. Rar ii. 76.Ind. or.

impressinervium, Meissn. in DC. Prod. xv. 1. 21.-Reg. Himal.; China.

iners, Reinw. ex Blume, Bijdr. 570._Burma; Malaya. iners, Wall, Cat. D. $2583 \mathrm{E}=$ nitidum.

iners, Wight, Ic, t. 122 , bis = zeylanicum.

inodorum, Meissn. in DC. Prod. xv, 1. 26.-Malaya.

inunctum, Meissn. L. c. 24.-Burma.

japonicum, Siebold, in Verb. Gen. Batav. xii. (1680 23 = pedunculatum.

javanicum, Blume, Bijdr. 570,-Mfalaya.

Kiamis, Hassk. Cat. Hort. Bogor. Alt. 87 = peduncu. latum.

Kiamis, Nees, in Wall. Pl. As. Rar. ii. $75=$ Burmanni.

lampongum, Mig. Fl. Ind. Bat. Suspl. i. 358.Sumatra.

Laubatii, F Muell. Fragm, v, $165=$ C. Tamala

laxiflorum, Mcissps, in DC: Prod xv, \&. 21. - Java.

litsaeaefolium, Thw. Enum. Pl. Zevl. 259.-Zeylan.

Loureirii, Nees, Syst. Las rins. 65.-Cochinch.

lucens, Miq. Aan. Mus. Bot. Lugd. Bar i. 2081 tavoyanum.

macrophyllum, Mig. I. 6. 20\% - Java.

Malabashrum, Ratka, in Nor. Ace. Sat. Cur. xri. (1885) $11.618=$ ines:

Malababhraw, Miq. Pl. Jungh. i. 1it me subletra pierum.

malaciense. Mcisen in DC, Prot. xv, I. 87 Parthenoxylon.

Maruba, Mrissn. in DC. I. c. 15.-Malasa.

monforoum, J. S. I'resil, Koarl. ii. 38 ; Nees. Sivse. Lurio. 81-1'bucle montama. 


\section{CINNAMOMUM :-}

multiflorum, Wight, Ic. t. 131.-Zeylan.

Neesianum, Meissn. in DC. Prod. xv, I. $26=\mathrm{C}$ Parthenoxylon.

neglectum, Blume, Rumphia, i. 38 , in nota, t. 11. f. 2 = javanicum.

nitidum, Blume, l. c. 35 . t. 13. f. $2 ;$ t. 16 . f. 1,2 -

Burma : Malaya.

nitidum, Hook. Exot. Fl. iii. t. $176=$ iners.

obscurum, Meissn. in DC. Prod. xv. I. 26. -Sumatra.

obtusifolium, Nees, in Wall. Pl. As. Rar. ii. 73.-Reg.

Himal. ; Burma.

ochraceum, Blume, Rumphia, i. $37=$ iners.

officinarum, Nees, ex Steud. Nom, ed. II. i. $366=$ C Cassia?

ovalifolium, Gardn. ex Meissn. in DC. Prod. xv, I. 11 =Wightii.

ovalifolium, Wight, Ic. t. 125.-Zeylan.

paraneuron, Miq. Fl. Ind. Bat. i. I. 895.-Sumatra.

Parthenoxylon, Meissn. in DC. Prod. xv. I. 26.Burma; Malaya; China.

pauciflorum, Nees, in Wall. Pl. As. Rar. ii. 75.-Reg. Himal.

pedatinervium, Meissn. in DC. Prod. xv. I. 15.Ins. Fiji.

pedunculatum, F. S. Presl, Rostl. ii. 37; Nees, Syst. Laurin. 79.-Japon

Perrottetii, Meissn. in DC. Prod. xv. I. 22,-Ind. or.

politum, Miq. Ann. Mus. Bot. Lugd. Bat. i. 265.Malaya.

pseudo-sassafras, Meissn. in DC. Prod. xv. I. $27=$ C. Parthenoxylon.

pseudo-sintok, Miq. Fl. Ind, Bat, i. I, $902=$ iners.

pyrifolium, D. Don, Prod. Fl. Nep. 66 (sp. dubia). Nepal.

Rauwolfi, Blume, Rumphia, i. 36. t. 9. f. 4, 5 =iners.

recurvatum, Wight, Ic. $\mathrm{t} .133=$ pauciflorum.

Reinwardti, Miq. Fl. Ind. Bat. i. I. $900=$ iners

Reinwardti, Nees, Syst, Iaurin $70=\mathrm{C}$. Tamala

rhynchophyllum, Miq. Fl. Ind. Bat. i. I. 895.Sumatra.

rubrum, Blume, in Hoev. \& De Vriese, Tijdschr. i. 1834) $62 \Rightarrow$ C. Culilawan.

sericans, Hance, in Fourn. Bot. xv. (1877) 336.China.

sericeum, Siebold, in Batav. Gen. Verh. xii. (1830) 24 = Laurus sericea.

Sieboldii, Meissn. in DC. Prod. xv. I. $18=$ Burmanni.

Sintok, Blume, Bijdr. 571.-Malaya.

subavenium, $\mathrm{Miq}$. Fl. Ind. Bat. i. I. 902.-Sumatra.

subcuneatum, Miq. l. c. 895.-Sumatra.

subtetrapterum, $M i q$. l. c. 902,-Sumatra

sulphuratum, Kurz, For. Fl. Brit. Burm. ii. $288=$ tavoyanum

sulphuratum, Nees, in Wall. Pl. As. Rar. ii. 74.Ind. or.

sumatranum, Meissn. in DC. Prod. xv. I. 25.Sumatra.

Tamala, T. Nees E Eberm. Handb. Med.-Pharm. Bot. ii. 426.- Reg. Himal.

tavoyanum, Meissn. in DC. Prod.xv. i. 20.-Burma.

tomentosum, D. Don, Prod. F1. Nep. $66=$ Phoebe paniculata.

validinerve, Hance, in Fourn. Bot. xx, (1882) 80.China.

verum, J. S. Presl, Rostl. ii. 36; Sweet, Hort. Brit. ed. I. $344=$ zeylanicum.

villosum, Wight, ex Meissn. in DC. Prod. xv. I. $15=$ multiflorum.

villosum, Wight, Ic. t. $127=$ iners.

vimineum, Nees, in Wall. Pl. As. Rar. ii. 76.-Ins. Penang.

Wightii, Meissn. in DC. Prod. xv. I. 11.-Ind. or,

xanthoneurum, Blume, in Hoev. E' De Vriese, Tijdschr.

i. (1834) 63.-N, Guinea.

zeylanicum, Nees, in Wall. Pl. As. Rar. ii. 74 ; iii. 32 -Ind. or.; Malaya.

CINNAMOSMA, Baill. Adansonia, vii. (1866-67) 219. CANELLACEAE, Benth. \& Hook. f. i. 970.

fragrans, Baill. l. c.--Malaya.

CINNASTRUM, Fourn. Gram. Mex. 90, ex Benth. \& Hook. f。 Gen. iii. $1153(1883)=$ Deyeuxia, Clar. (Gramin.).

C.INOGASUM, Neck. Elem. ii. $336(1790)=$ Croton, Linn. (Euphorbiac.).
CIONANDRA, Griseb. FI. Brit. W. Ind. $286(1860)=$ Cayaponia, Silva Manso (Cucurbitac.).

angustiloba, Bello, in Anal. Soc. Esp. Hist. Nat. x (1881) 274.-Porto Rico.

cuspidata, Griseb. F1. Brit. W. Ind. $287=$ Cay. ameri

graciliflora, Griseb. 1. c.=Cay. americana.

racemosa, Griseb. 1. c. $286=$ Cay. racemosa.

CIONISACCUS, Breda, Orch. Kuhl et Hass. (1827) [t. 8] $=$ Goodyera, R. Br. (Orchid.)

lanceolatus, Breda, 1. c. $=\mathrm{G}$. procera.

CIONOSICYOS, Benth. \& Hook. f. Gen. i. 826 (1867) $=$ seq.

CIONOSICYS, Griseb, F1. Brit. W. Ind. $288(1860)$ CUCURBITACEAE, Benth. \& Hook, f. i. 826 . pomiformis, Griseb. l. c.-Ind. occ.

CIONURA, Griseb. Spicil. Fl. Rumel. ii. 69 (1844)= Marsdenia, R. Br. (Asclepiad.)

erecta, Griseb. 1. c. = M. erecta.

CIPADESSA, Blume, Bijdr, 162 (1825). MELIA $C E A E$ [Benth. \& Hook, f. i. 332 ]

Mallea, A. Juss, in Mém. Mus. Par. xix. (1830) 221.

baccifera, Miq. Ann. Mus, Bot. Lugd. Bat. iv. $6=$ fruticosa.

Boiviniana, Baill. Adansonia, xi. (1874) 255 Madag.

borneensis, Miq. Ann. Mus. Bot. Lugd. Bat. iv. 6.Borneo.

depauperata, Baill. Adansonia, xi. (1874) 256.-Ins. Comor.

fruticosa, Blume, Bijdr. 162.-Tava

subscandens, Miq. Ann. Mus. Bot. Lugd. Bat. iv. $7=$ fruticosa.

CIPONIMA, Aubl. Pl. Gui. i. 566. t. $266(1775)=$ Sym plocos, Linn. (Styrac.)

guianensis, Aubl. 1. c. $567=\mathrm{S}$. Ciponima

scabridula, Miers, in Journ. Linn. Soc. xvii. (1879) $288=$ S. Ciponima

CIPURA, Aubl. Pl. Gui. i. 38. t. 13 (1775), IRI$D E A E$, Benth. \& Hook. f. iii. 694.

MARICA, Schreb. Gen.Pl. 37 (1789) (non Ker-Gawl) asurea, Griseb. \& Klatt, in Abh. Naturf. Ges. Halle, xii. (1882) $387=$ Calydorea azurea.

caerulea, Heynh. Nom. i. $197=$ Marica caerulea.

coelestis, Heynh. 1. c. = Nemastylis coelestinus.

cubensis, Griseb. Cat. Pl. Cub. 251.-Ins. Cuba

gracilis, Heynh. Nom. i. $197=$ Marica gracilis.

graminea, H. B. \& K. Nov。 Gen。 et Sp. i. $320=$ paludosa.

humilis, H. B. \& K. 1. c. = palndosa

linearis, Klotzsch \& Klatt, in Abh. Naturf. Ges. Halle, xii. (1882) $387=$ Calydorea cipuroides.

longifolia, Heynh. Nom. i. $197=$ Marica longifolia.

martinicensis, H. B. \& K. Nov. Gen. et Sp. i. $320=$ Trimezia lurida.

Northiana, Endl. in Harting. Parad. Vindob. t. 6.Bras.

paludosa, Aubl. Pl. Gui. i. 38. t. 13.-Am. trop.

plicata, Griseb. Fl. Brit. W. Ind. $589=$ Eleutherine plicata.

Sabini, Heynh. Nom. i. $197=$ Northiana.

Sabiniana, Voigt, Hort. Suburb. Calc. $602=$ Marica Sabini.

semiaperta, Heynh. 1. c. = Trimezia lurida.

CIPURA, Klotzsch, ex Klatt, in Abh. Naturf. Ges Halle, xii. (1882) $362=$ Herbertia, Sweet (Yrid.).

CIRCAEA, Tourn. ex Linn. Syst. ed. I (1735); Gen. ed. I. 3 (1737). ONAGRARIEAE, Benth. \& Hook. f. i. 793 .

Regmus, Dulac, Fl. Hautes-Pyr, 328 (1867). alpestris, Schur, Enum. Pl. Transs. $214=$ C. Iutetiana. alpestris, Wallr. Beitr. Fl. Hercyn. $167=$ alpina alpina, Linn. Sp. Pl. 9.-Europ.; As. bor. ; Am. bor. canadensis, Muhl. Cat. $2=$ C. lutetiana.

cordata, Royle, Illustr. Bot. Himal. 211. t. 43. f. 1.Reg. Himal.

cordifolia, Stokes, Bot. Mat. Med, i. $26=$ alpina.

decumbens, Gilib. Fl. Lituan, ii. $127=$ alpina.

erecta, Gilib. 1. c. $126=$ C. Jutetiana.

\section{CIRCAEA :-}

ericetorum, Martr. Pl. Crit. Tarn. 29-Gallia. erubescens, Franch. E Sav. Enum. Pl. Fap. ii. 370.Japon.

intermedia, Ehrh. Beitr. iv. 42.-Europ

intermedia, Wall. Cat. n. $6342=$ alpina

lutetiana, Georgi, It. i. 195=alpina.

lutetiana, Linn. Sp. Pl. 9.--Reg. bor.

major, Lam. Fl. Fr. iii. $473=$ C. lutetiana.

minima, Lam. I. c. $=$ C, alpina.

mollis, Sieb. E Zucc. in Abh. Akad. Muench. iv. (1847) 134.-Japon.

nemoralis, Salisb. Prod. $276=\mathrm{C}$. Iutetiana.

ovatifolia, Stokes, Bot. Mat. Med. i. $26=$ C. lutetiana. pacifica, Aschers. E\% Magnus, in Bot. Zeit. xxix. (1871) 392-Am bor occ

pubescens, Pohl, ex Steud. Nom. ed. II. i, $366=\mathrm{C}$ lutetiana.

quadrisulcata, Maxim. in Franch. E Sav. Enum. Pl. Fap. i. 169.-Japon.

repens, Wall. Cat. n. $6341=\mathrm{C}$. lutetiana.

vulgaris, Moench, Meth. $279=$ C. lutetiana.

Circafaster, Maxim. in Bull. Acad. Pétersb. xxvii. (1881) 556. CHLORANTHACEAE?, Benth. \& Hook. f. iii. 1220 .

agrestis, Maxim. l. c. 557.-Reg. Himal.; As. centr.

CIRCINNUS, Medic. in Vorles. Churpf. Phys. Ges. ii. (1787) $384=$ Hymenocarpus, Savi [1798] (Legumin.).

oulnerarioides, Medic. 1. c. $=\mathrm{H}$. circinnata.

CIRCINUS, Medic. Phil. Bot. i. 208 (1789)=praec.

CIRCIS, Chapm. F1. S. U. St. 114 (1860), lapsu = Cercis, Linn. (Legumin.).

CIRINOSUM, Neck. Elem. ii. $84(\mathbf{1 7 9 0})=$ Cereus, Haw. (Cactac.).

CIRIPEDIUM, Zumag. Fl. Pedem. i. 18 (1829) = Cypripedium, Linn. (Orchid.).

CIRRHAFA, Lindl. Bot. Reg. sub t. 930 (1825) ORCHIDEAE, Benth. \& Hook. f. iii. 585.

SArCoglossum, Beer, Prakt. Orch. 306 (1854). SCLEROPTERIS, Scheidw. in Allg. Gartenz. (1839) 407 adspersa, Hoffm.ex Heynh. Nom. ii. 145, nomen.-Bras. dependens, Loud. Hort. Brit. $370=$ Loddigesii. dependens, Reichb. fo in Walp. Ann. vi. 496 = viridipurpurea.

fuscolutea, Hook. Bot. Mag. t. 3726=saccata.

fuscolutea, Lindl. Bot. Reg. sub t. 1538.-Bras.

Hoffmanseggii, Heynh. ex Reichb. f. in Walp. Ann.

vi. $496=$ viridipurpurea

Loddigesii, Lindl. Bot. Reg. t. 1538.-China?

obtusata, Lindl. l. c. xxiii. (1837) 2005.-Bras.

pallida, Lindl. $l$. c. sub t. 2005, nomen.-Hab.

saccata, Lindl. l. c. (1839) Misc. 72.-Bras.

tristis, Lindl. l. c. t. 1889.-Mexic.

violaceo-virens, Hoffmgg. Verz. Orch.-Cf. Bot. Zeit. i. (1843) 831. - Hab?

violascens, Hoffmgg. $l l$. cc.-Hab. ?

viridipurpurea, Lindl. Bot. Reg. t. 1538.-Bras

viridi-purpurea, Lodd. Bot. Cab. t. 1967 = Loddigesii

Warreana, Lindl. ex Reichb. f. in Walp. Ann. vi. 497 , -Bras.

CIRRHOPETAIUM, Lindl. Bot, Reg. sub. t. 832

1824). ORCHIDEAE, Benth. \& Hook. f. iii. 504.

EPHippium, Blume, Bijdr. 309 . t. 65 (1825).

BOLBOPHYLLOPSIS, Reichb, f. in Bot. Zeit. x. (1852 933.

Hippoglossum, Breda, Orch. Kahl et Hass. (1827)

[t. 14].
ZyGogLossum, Reinw. in Syll. Ratisb. ii. (1828) 4.

abbreviatum, Reichb. f. in Gard. Chron. (1881) II. 70 -Hab. ?

albidum, Wight, Ic. t. 1653.-Ind. or.

Andersonif, Kurz, Rep. Veg. Andaman. 51.-Ins.

Andaman.

antenniferum, Lindl. Bot. Reg. (1843) sub t. 49.-Ins. Philipp.

auratum, Lindl. l. c. (1840) Misc. 50.-Ins. Philipp.

Blumii, Lindl. Gen. et Sp. Orch. 59.-Java.

botanensis, Griff. Notul. iii. $296=$ maculosum.

caespitosum, Wall. ex Lindl. Bot. Reg. (1838) Misc.

35.-Reg. Himal. 


\section{CIRRHOPETATUM}

capitatum, Lindl. Bot. Reg. (1843) sub t. 49.Java.

carinatum, Teijsm. E Binn. in Nederl. Kruidk. Arch. iii. (1855) 397.-Java.

caudatum, Wight, Ic. t. $1658=$ vaginatum.

chinense, Lindl. Bot. Reg. (1842) Misc. 37.China.

clavigerum, Fitzgerald, in Fourn. Bot. xxi. (1883) 204.-Austral.

compressum, Lindl. Bot. Reg. xxix. (1843) sub t. 49. -Java.

cornutum, Lindl. l.c. (1838) Misc. 75.-Reg. Himal

Cumingii, Lindl. $l$. c c sub t. 49.-Ins. Phílipp.

delitescens, Rolfe, in Gard. Chron. (1882) II. 461. Hongkong.

elegans, Teijsm. E Binn. in Tijdschr. Nederl. Ind. xxiv. (1862) 310.-Malaya.

Elisae, F. Muell. Fragm, vi. 120, t, $57=$ Bulbophyllum

Elisae.
elongatum, Lindl. Bot. Reg. (1843) sub t. 49.-Reg. Himal.

fimbriatum, Lindl. l. c. (1839) Misc. 72.-Ind, or.

fagelliforme, Teijsm. \& Binn. ex Reichb. in Walp. Ann. vi. $264=$ Pahudi.

gamosepalum, Griff. Notul. iii. 296.-Burma.

grandiflorum, Wight, Ic. v. t. 1658.-Zeylan

lasiochilum, Par. E Reichb. f. in Trans. Linn Soc. xxx. (1874) 153 (Bulbophylli §).-Burma.

leopardinum, Teijsm. E Binn. in Tijdschr. Nederl. Ind. xxiv. (1862) 309,-Java.

lineatum, Teijsm. E Binn. l. c. 311.-Malaya

longiscapum, Teijsm. \& Binn. l. c. 310.-Malaya.

Macraei, Lindl. Gen. et Sp. Orch. 59.-Zeylan.

Macraei, Wight, Ic, t. $1652=$ Wightii.

maculosum, Lindl. Bot. Reg. (1841) Misc. 81.-Reg. Himal.

Makoyanum, Reichb. f. in Gard. Chron. (1879) I. 234 = Bulbophyllum Makoyanum.

maxillare, Lindl. Bot. Reg. (1843) sub t. 49--Ins. Philipp.

Medusae, Lindl. l. c. (1842) t. 12.-Malaya.

neilgherrense, Wight, Ic. vi, t. 1654,-Ind. or

nutans, Lindl. Bot. Reg. (1839) Misc. 71.-Manilla.

ornatissimum, Reichb. f. in Gard. Chron. (1882) II. 424.--Reg. Himal.

Pahudi, De Vriese, Epim. Lugd.-Bat. (1863) 2.Java.

picturatum, Lodd. in Bot. Reg. (1840) Misc. 49.Burma.

Pumilio, Par. E Reichb. f. in Trans. Linn. Soc. xxx. (1874) 153 (Bulbophylli §).-Burma.

putidum, Teijsm. E Binn. in Tijdschr. Nederl. Ind. xxiv. (1862) 311.-Java.

refractum, Zoll. in Flora, xxx. (1847) 456.-Reg,

Himal, Malaya.

retusiusculum, Reichb. f. in Gard. Chron. (1869) 1182. -Burma.

Roxburghii, Lindl. Gen. et Sp. Orch. 58,--Ind, or.

simillimum, Reichb. f. Otia Hamburg. 48.-Burma

stramineum, Teijsm. \& Binn. in Tijdschr. Nederl. Ind. xxiv. (1862) 310.-Java.

Thouarsii, Lindl. Bot. Reg. sub t. 832, in textu,-Ins. Mascar.

trigonopus, Reichb. f. in Gard.Chron. (1881) 11. 71.Hab.? tripudians, Par. E Reichb. f. l. c. (1876) 1. $816 .-$
Burma.

umbellatum, Linden, Illustr. Hortic. xxviii. (1881) 80 . $=$ maculosum?

vaginatum, Lindl. in Wall. Cat. n. 1979-Malaya.

Walkerianum, Wight, Ic. v. t. $1657=$ Macraei.

Wallichii, J. Grah. Cat. Pl. Bomb. $205=$ fimbria. tum?

Wallichii, Lindl. in Wall. Cat. D. $1980=$ refractum

Wallichii, Lindl, in Wall. Pl. As. Rar. i. 53. t. 67.Reg. Himal.

Wighti, Thw. Enum. Pl. Zeyl. 299,-Zeylan.

CIRSELIUM, Brot. F1. Lusit. i. $346(1804)=$ seq.

CIRSELLIUM, Gaertn. Fruct. ii. 454, t. $169(1791)=$ Atractylis, Linn. (Compos.),

cancellatum, Gaerti. 1. c. = A, cancellata.

humile, Gaertn. 1. c. $455=\mathrm{A}$. humilis,

gummiferum, Brot. Fl, Lusit, i. $346=$ A. gummifera.
CIRSIUM, [Tourn.] Adans. Fam. ii. 116 (1763); DC. Fl Fr. iv. $110(1805)=$ Cnicus, Tourn. (Compos.). abyssinicum, Sch. Bip. ex A. Rich. Tent. Fl. Abyss. $456=\mathrm{Cn}$. lanceolatus.

acanthifolium, Arv. in Bull. Soc. Dauph. iii. (1876 73.-Gallia.

Acarna, Moench, Meth. Suppl. $226=$ Cn. Acarna.

acaule, [Weber, ex] Wigg. Prim. Fl. Hols. $59=\mathrm{Cn}$. acaulis.

acaulos, Scop. Fl. Cam, ed. II, ii. $131=\mathrm{Cn}$. acaulis. aciculaxe, Tausch, in Flora, xii. (1829) I. Erg. 40. Hab.

aduncum, Fisch. \& Mey. ex DC. Prod, vi. $636=$ falla affine, Tausch, in Flora, xvi. (1833) 228.-Bohem. afrum, DC. Cat. Hort. Monsp. $96=\mathrm{Cn}$, afer aggregatum, Ledeb F1. Ross. ii. 737. - Reg. Caucas. Alberti, Regel \& Schmalh. in Act. Hort. Petrop. (1879) 318.-Turkestan.

albicans, Willk. in Linnaea, xxx. (1859-60) 109.Hispan.

Allionii, Spenn. Fl. Friburg. iii. $1079=\mathrm{Cn}$. acaulis.

Allionii, Thurm. ex Arduin. Fl. Alpes-Marit. $198=\mathrm{Cn}$ pyrenaicus.

alpestre, Naegeli, Cirs. Schw. $84=\mathrm{Cn}$. acaulis

alpestre $\mathrm{x}$, Treuinf. in Zeitschr. Ferdinand. Tirol. III xix. (1875) 228.-Tyrol.

alpinum, All. F1. Pedem. i. 153=Saussurea alpina, discolor

altissimum, Hill, Hort. Kew. $63=\mathrm{Cn}$. altissimus. ambiguum, All. Auct. Pedem. $10=\mathrm{Cn}$. heterophyllus. anglicum, DC. F1. Fr, iv, $118=\mathrm{Cn}$. pratensis,

angulosum, Tausch, in Flora, xix. (1836) 402.Hab. ?

angustifolium, DC. Prod. vi. $648=$ Carduus angustifolius. angustifolium, Tausch, in Flora, xii. (1829) I. Erg.
$39=$ Tauschii.

angustissimum, DC. Prod. vi. $652=$ Tricholepis strictophyllum.

apiculatum, DC. 1, c. $642=$ libanoticum

appendiculatum, Griseb. Spicil. F1. Rumel. ii. 250.Rumel.; Herceg.

arachnoideum, Bieb, Fl, Taur. Cauc. iii. $557=\mathrm{Cn}$. arachnoideus.

araneosum, Steud. Nom. ed. II. i, $367=$ Cn. areneosus. arctioides, Scop. Fl. Carn.ed. II. ii. $124=$ Carduus arctioides.

arctotidifolium, Sch. Bip. in Schweinf. Beitr. Fl. Aethiop. $144=$ Cn. Schimperi.

argentum, Peyer, ex Vest, in Flora, xii. (1829) I. Erg. $57=\mathrm{Cn}$. arvensis

argunense, DC. Prod. vi. 644,-Sibiria.

argyracanthum, DC. 1. c. $640=\mathrm{Cn}$. argyracanthus.

aristatum, DC. 1. c.-Armenia.

armenum, DC. 1. c. $647=$ simplex.

arvense, Scop. Fl. Carn. ed. II. ji. $126=\mathrm{Cn}$. arvensis

Aschersoniix, Celak. in Arch. Naturfw. Landesd. Boelim. ii. (1873) 263.-Bohem.

atriplicifolium, Fisch. ex Steud. Nom. ed. II. i. $367=$ Serratula atriplicifolia.

atticum, Sch. Bip. ex Nym. Consp. $406=$ crinitum.

Ausserdorferi $x$, Hausm. ex Treuinf, in Zeitschr. Ferdin. Tirol. III xix. (1875) $223=$ Cn. ochroleucus autareticum, Mutel, Fl. Dauph. ii. $262=\mathrm{C}$. heterophyllus.

baeticum, Spreng. Syst. iii. 377 .-Hispan

benacense, Treuinf, in Oestr. Bot. Zeitschr, xxiv. (1874) 172. - Tyrol.

Bertolonii, Spreng. Syst, iii. $377=\mathrm{Cn}$. Bertolonii.

Bigelowii, DC. Prod. vi. $652=\mathrm{Cn}$. muticus

bipontinum, F. Schultz, in Arch. Fl. Fr. et Allem. 9 $=$ Cn. acaulis.

Boujarti, Sch. Bip, in Oestr. Bot. Wochenbl. vi. (1856) $299=$ Cn. ciliatus

Bourgaeanum, Willk, in Willk. \& Lange, Prod. Ft. Hisp. ii. 191.-Hispan.

brachycephahum, Juratzka, in Verh. Zool. Bot. Ver. Wien, vii. (1857) $99=$ Chailleti, Koch.

bracteatum, Link, in Linnaea, ix. (1834) $580=\mathrm{Cn}$. syriacus.

bracteosum, DC. Prod. vi. $641=\mathrm{Cn}$. strigosus.

Braunii, F. Schultz, ex Nym. Censy, $409=$ Cn, olemocus. brevicaule, A. Gray, in Mcm. Am. Acad. N. S yid. $(1858-59) 396=\mathrm{Cn}$. japunicus.

brevifolium, Nutt. in Trans. Am. Phil. Soc. N. S. vi. (1841) $421=\mathrm{Cn}$. undulatus.

brevispinum, Sch. Bip. ex Nym. Consp. $410=C$. pungens.

\section{CIRSIUM :-}

britannicum, Scop. Ann. It. Hist. Nat. (1769) $60=\mathrm{Cn}$. pratensis

Brueggerix, Kill. ex Bruegg. in Jahresb. Naturf. Ges. Graub. II, xxiii.-xxiv. (1880) 108.- Helvet

Brunneri, A. Braun, ex Nym. Consp. $407=\mathrm{C}$. tuberosus.

Buchingeri, Sch. Bip. ex Schweinf. Beitr. Fl. Aethiop. 284, nomen.-Abyss.

Buergeri, Miq. Ann. Mus. Bot. Lugd. Bat. ii. $185=\mathrm{Cn}$. Buergeri.

bulbosum, DC. Fl. Fr. iv. $118=$ Cn, tuberosus.

bulbosum, Lam. Fl. Fr. ii. $22=\mathrm{Cn}$. monspessulanus.

bulbosum, Willk in Flora, xxxiv, (1851) $760=$ filipendulum, Lange.

bulgaricum, DC. Prod, vi. $639=\mathrm{C}$. giganters.

byzantinum, Steud. Nom. ed. II. i. 367.-Rumel.

californicum, A. Gray, in Pacif, Rail, Rep. iv. 112 Cn. californicus.

Candelabrum, Griseb. Spicil. Fl. Rumel. ii. 251. Graecia ; Rumel.

Candolleanum, Naeg. Cir. Schweiz. $98=\mathrm{Cn}$. ochro. leucus?

canescens, A. Gray, Pl. Fendl. $110=\mathrm{Cn}$. neo-mexi. canus.

canescens, Nutt in Trans. Am. Phil. Soc. N. S vii (1841) $420=\mathrm{Cn}$. undulatus.

canum, All. Fl. Pedem. i. $151=\mathrm{Cn}$. pratensis ?

canum, Bieb. Fl. Taur. Canc. ii. $274=\mathrm{C}$. canus.

Caput-Medusae, Schmr, ex Nym. Consp. $408=\mathrm{Cn}$ spinosissimus.

carlinoides, Fisch. in DC. Prod. vi. $661=\mathrm{Cn}$. carl. noides.

carminans, Dum. Fl. Belg. 74.-Belgium.

carniolicum, All. Fl. Pedem. i. $149=\mathrm{Cn}$. rivularis.

carniolicum, Scop. Fl. Carn. ed. II. ii. $128=C_{n}$. rufescens.

Carolorumx, C. Jenner, ex Nym. Consp. $407-\mathrm{Cn}$. heterophyllus.

carthamoides, Link, Enum. Hort. Berol. ii. $3(13$ Centaurea carthamoides.

Casabonae, DC. Fl. Fr. iv, $121=\mathrm{Cn}$. Casabonae

castellanum, Willk. in Linnaea, xxx. (1859-60) $109=$ Cn. flavispinus.

cataonicum, Boiss, \& Hanssk in Boiss. Fl. Orient, iii 535.-_Syria.

Celakorskianum x, Knaf, in Oestr. Bot. Zeitschr. xxii. 1872) $309=\mathrm{Cn}$. arvensis.

Cephalotes, Boiss. Diagn. Ser. I. vi. $102=\mathrm{Cn}$. horridus. cernuum, Lag. Gen. et Sp. Nov, $24=$ Cn. niralis.

Cervini, Koch, Syn. FI. Germ. ed. I. $399=\mathrm{Cr}$. spinosissimus.

Chailleti, Gaudin, F1. Helv. v. $182=$ Cn. palustris. Chaillet, Koch, Syn. Fl. Germ. ed. 1. 393.-Enrop.

Chamaepence, Tenore, Fl. Nap. $\nabla .211=$ CD. graphalodes.

chelmeum, Orph. in Boiss. Diagn. Ser. II. iii. 41 Candelabrum.

chinense, Gardn. \& Champ. in Hook. Kew Joum. $(18 \pm 9) 323=$ Cn. chinensis.

chium, DC. Prod. vi. $646=$ Cardaus chius.

chynysicum, Boiss. Fl. Orient. iii. 536. - Armenia.

cichuraceum, Spreng. Syst. iii. $370=$ Serratula cichomcen.

ciliato-afine, Bess. Enum. PI. Volb. $32=\mathrm{Cn}$, serrularus.

ciliatum, Bieb. Fl. Taur. Cauc. iii. $550=\mathrm{Ca}$. ciliatus

ciliatum, Moench, Mcth. Sappl. 227.-Hab.

cilliacum, Tardent, Ess. Hist. Nat. Bessar. $62=\mathrm{C}_{\mathrm{a}}$. cilintus.

compactum, Lam. Fl. Fr. ii. $24=\mathrm{CD}$. monspesculanus.

congestum, Fisch, \& Mey, ex DC Prod, vi. itl. Persia.

consanguineum, DC. 1. c. = congestum.

conspicurum, Sch. Bip, in Scem. Bot. Voy. Mcrald, 912 Cn. conspicuus.

controversum, DC. Prod, vi, $65 t=\mathrm{C}_{0}$, sninosiscimui

Cosmelii, Fisch. \& Mcy. cx Hohen. in J3ull. Juc. Nai Mosc. vi. (1588) $251=\mathrm{Ca}$. Iappaceus.

Coulteri, Harv. \& Gray, Pl. Fendl. $110=\mathrm{Cn}$. mestien talis.

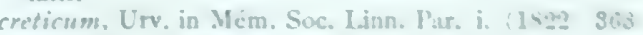
-Archip. Giraec.

crinstum, Boiss. ex DC. Prod. vii. S05._llispan.

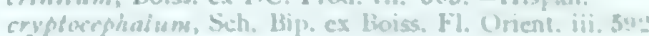
Centaurea pyigmaca.

sepeliense, Borb. in Oestr. Bot. Zcitschr. xuviii. (15:9 \$::2.-Eurup.

cyanoides, Hill, Hort. Ker. $63=$ Turinea cranoiles

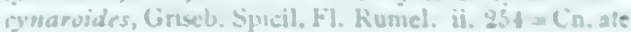




\section{IRSIUM :-}

cynaroides, Spreng. Syst. iii. $372=$ Cnicus cynaroides. dealbatum, Bieb. F1. Taur. Cauc. iii. 560.-Reg. Caucas. decipiens, Nym. Syll. Suppl. $4=$ Cn. acaulis.

decoloratum, Koch, Syn. F1. Germ. ed. I. $398=\mathrm{Cn}$ acaulis, oleraceus.

decussatum, Janka, in Linnaea, xxx. (1859-60) $582=$

Cn. ferox, Sibth. E Sm

defloratum, Scop. F1. Carn. ed. II. ii. $127=$ Carduus defloratus.

dentatum, DC.Prod. vi.654 = Kentrophyllum dentatum depilatum, Boiss. \& Bal. in Boiss. Fl. Orient. iii. 543. -As. Min.

desertorum, Fisch. ex Link, Enum. Hort. Berol. ii. 300. - Sibiria.

desertorum, Janka, ex Nym. Consp. $405=\mathrm{Cn}$. ciliatus. Diacantha, DC. Cat. Hort. Monsp. $96=$ Cn. Diacantha dioicum, Cass. in Dict. Sc. Nat. xxvii. $190=$ Cn. arven Sis.

discolor, Hort. ex Steud. Nom. ed. II. i. $368=\mathrm{Cn}$. ciliatus.

discolor, Spreng. Syst. iii. $373=\mathrm{Cn}$. altissimus dissectum, Hill, Hort. Kew. $63=\mathrm{Cn}$. dissectus. diversifolium, DC. Prod. vi. $649=\mathrm{Cn}$. altissimus. Dollinerii, Sch. Bip. ex Hausm. in Verh. Zool.-Bot. Ges. Wien, viii. $(1858) 373=\mathrm{Cn}$. pannonicus.

Douglasii, DC. Prod. vi. $643=\mathrm{Cn}$. undulatus.

Drejeri, Reichb. f. Ic. Fl. Germ. xv, $60=\mathrm{Cn}$. lanceo latus.

Drummondii, Torr. \& Gray, Fl. N. Am. ii. $459=\mathrm{Cn}$. Drummondii.

duriusculum, C. Koch, in Linnaea, xxiv. (1851) $410=$ elodes, Cn. palustris.

echinatum, DC. Fl. Fr. Suppl. $465=$ Cn. echinatus.

echinocephalum, Bieb. F1. Taur. Cauc. iii. $559=\mathrm{Cn}$ echinocephalus.

echinopifolium, Boiss, ex Tchihat. Asie Min. Bot, ii. 343.-As. Min.

edule, Nutt. in Trans. Am. Phil. Soc. N. S. vii. (1841) $420=\mathrm{Cn}$. edulis.

elatius, Link, Enum. Hort. Bernl. ii. $299=\mathrm{Cn}$. polyanthemus.

elatum, Sauter, in Flora, xxviii. (1845) 130.-Europ.

elatum, Tod. Ind. Sem. Hort. Panorm. (1858) 25 ; et in Ann. Sc. Nat. Sér. IV. xi. (1859) 378,-Sicilia.

elegans, Willd. ex Spreng. Syst. iii. $375=$ igniarium.

elodes, Bieb. Fl. Taur. Canc. iii. 555.-Rossia; Reg

Caucas.; Persia.

Empedocleanum, Lojac. in NaturaI. Sicil. iii. (1884) 284 -Sicil.

eriocephalum, A. Gray, in Proc. Acad. Sc. Philad ' 1863 ' (1864) $69=\mathrm{Cn}$. eriocephalus.

eriocephalum, Wallr. Beitr. Fl. Hercyn. $262=\mathrm{Cn}$. eriophorus.

eviophorum, Scop. Fl. Carn. ed. II. ii. $130=$ Cn. eriophorus.

Erisithales, Scop. Ann. II. Hist. Nat. $62=$ Cn. ochro leucus?

erisithaloides $\times$, Huter, ex Treuinf, in Zeitschr. Ferdin Tirol. III. xix. (1875) 271.-Tyrol.

erucagineum, DC. Fl. Fr. iv. $115=\mathrm{Cn}$. rivularis.

erythrolepis, C. Koch, in Linnaea, xvii. (1843) 41.-

Reg. Caucas.

esculentum, C. A. Mey. in Beitr. Pf. Russ. Reich. iv 43 ; et in Flora, xxxii. (1849) $747=\mathrm{Cn}$. esculentus.

xaltatum $\times$, Bruegg. in Jahresb. Naturf. Ges. Graub.

II. xxiii-xxiv. (1880) 109.-Helvet.

exscapum, Fisch. Hort. Gorenk. ed. II. (1812) 35, nomen.-Hab. ?

falcatum, Turcz, ex DC. Prod. vi. $650=\mathrm{Cn}$. pendulus.

fallax, Fisch. \& Mey. ex Hohen. in Bull. Soc. Nat. Mosc. (1838) 280.-Reg. Caucas.

fallax, Franch. in Billot, Annot. $109=\mathrm{Cn}$. acaulis.

ferox, DC. F1. Fr. iv, $120=\mathrm{Cn}$. ferox

ferox, Schur, ex Nym. Consp. $405=\mathrm{Cn}$. ciliatus

ficifolium, Fisch. in Mém. Soc. Nat. Mosc. iii. (1812) $69=$ Serratula atriplicifolia.

filipendulum, Engelm. in A. Gray, Man. Bot. N. U. St. ed. V. $273=\mathrm{Cn}$, altissimus.

flipendulum, Lange, in Kjoeb. Vidensk. Meddel. (1861) 92.-Hispan.

fimbriatum, Spreng. Syst. iii. $373=\mathrm{Cn}$. fimbriatus.

Fischerianum, Andrz. ex Trautv. in Act. Hort. Petrop. viii. (1883) 501, nomen.-Rossia.

fissum $x$, Ausserd. ex Treuinf. in Zeitschr. Ferdin. Tirol. III, xix. (1875) 262,-Tyrol.

flavescens, Koch, Taschenb. $292=\mathrm{Cn}$. ochroleucus.

flavescens Lam. Fl. Fr. ii. $28=$ Cn. parviflorus.
CIRSIUM :-

flavispinum, Boiss. in DC. Prod. vii. $305=$ Cnicus flavispinus.

foliosum, DC. 1. c. vi. $654=\mathrm{Cn}$. foliosus

Forsteri, Loud. Hort. Brit. Suppl. i. $585=$ Cn. palustris.

fraternum, DC. Prod. vi. $636=\mathrm{Cn}$. strigosus,

Freyerianum, Koch, Taschenb. 288 ; Syn. Fl. Germ. ed. II. 454-Dalmat.

Frickii, Fisch. \& Mey. in Mém. Acad. Pétersb. Sér. VI. Sc. Nat. vi. (1849) $47=$ rhizocephalum.

fulvispinum, Walp. Rep. ii. 676 , sphalm. $=\mathrm{Cn}$. flavispinus.

furiens, Griseb. \& Schenk, in Wiegm. Archiv, xviii. (1852) I. $348=\mathrm{Cn}$. ciliatus

Gaillardoti, Boiss. Diagn. Ser. II. iii. 42.-Syria

Galactites, Hill, Hort. Kew. $64=$ Galactites tomentosa.

Ganderi $\times$, Huter, ex Treuinf. in Zeitschr. Ferdin. Tirol. III. xix. (1875) 274.-Tyrol.

Gerhardti, Sch. Bip. in Flora, xxxii. (1849) $547=\mathrm{Cn}$. lanceolatus.

giganteum, Spreng. Syst. iii. $375=$ Cn. giganteus.

glabrum, DC. F1. Fr. Suppl. $463=$ Cn. spinosissimus

glaucescens $\times$, Treuinf, in Zeitschr. Ferdin. Tirol. III. xix. (1875) 227.-Tyrol.

glutinosum, Lam. F1. Fr. ii. $27=\mathrm{Cn}$. ochroleucus.

Gmelini, Tausch, in Flora, xi. (1828) $482=$ Cn. acaulis. gnaphalodes, Spreng. Syst. iii. $375=\mathrm{Cn}$. gnaphalodes.

Godroni, Sch. Bip. ex Nym. Consp. $406=\mathrm{Cn}$. lanceolatus.

gracile, Rostr. ex Nym. 1. c. = Cn. lanceolatus.

gracile, Schur, Enum. PI. Transs. $422=\mathrm{Cn}$. rivularis

Grahami, A. Gray, Pl. Wright. ii. $102=$ Cn. Grahami.

grandiflorum $\times$, Kitt. Taschenb. ed. II. 551.-Europ.

gregarium, Willk. in Willk. \& Lange, Prod. F1. Hisp. ii. 189.-Hispan.

Gremblichiix, Treuinf. in Zeitschr. Ferdin. Tirol. III. xix. (1875) 213.-Tyrol.

Griffithii, Boiss. FI. Orient, iii. 540-Afghanist.

grumosum, Fisch. \& Mey. in Mém. Acad. Pétersb. Sér. VI. Sc. Nat. vi. (1849) $48=$ rhizocephalum. grumosum, Willk. \& Lange, Prod. Fl. Hisp. ii. $199=$ Cn. grumosas.

Gutnickianum $\times$, Loehr, Enum. Fl. Deutsch. 365.Europ.

Halleri, Tausch, in Flora, xix. (1836) 401.-Helvet.

Hallerianum, Gaudin, F1. Helv. v. $188=\mathrm{Cn}$. spinosissimus.

Hallerianum, Hill, Veg. Syst. iv. 27.- Helvet.

halophilum, Turcz. ex Herd. in Bull. Soc. Nat. Mosc. xliii. $(1870)$ I. $83=\mathrm{Cn}$. arvensis.

Haussknechtii, Boiss. Fl. Orient iii. 535-Kurdistan.

helenioides, All. Fl. Pedem. 1. $152=\mathrm{Cn}$. heterophyllus

helenioides, Hill, Hort. Kew. $64=\mathrm{Cn}$. helenioides.

hellenicum, Boiss. \& Orph. ex Boiss. Fl. Orient. iii $530=\mathrm{Cn}$. ferox

Hermonis, Boiss. Diagn. Ser. II. iii. $40=\mathrm{Cn}$. lappaceus heterolepis, Benth. P1. Hartw. $87=\mathrm{Cn}$. subcoriaceus,

heteromallum, Spreng. Syst. iii. 472 ; Sweet, Hort. Brit. ed. I. $214=$ Saussurea candicans.

heterophylloides $x$, Treuinf. in Zeitschr. Ferdin.

Tirol. III. xix. (1875) 245.-Austr.

heterophyllum, Hill, Hort. Kew. 64; All. Fl. Pedem. i. $152=\mathrm{Cn}$. heterophyllus.

heterotrichum, Pane. Elem. F!. Bulg. 42.-Europ.

Hippolyti, Link, ex Steud. Nom. ed. II. i. $368=\mathrm{Cn}$. pungens.

Hookerianum, Nutt. in Trans. Am. Phil. Soc. N. S. vii. (1841) $418=$ Cn. Hookerianus

horridulum, Michx. F1. Bor. Am. ii. $90=$ Cn. horridulus.

horridum, Fisch. Hort. Gorenk. ed. II. (1812) $35=\mathrm{Cn}$. horridus.

horridum, Lag, ex DC. Prod. vi. 660-Hispan.

Hugueninix, Buegg, in Jahresb. Naturf. Ges. Graub. II. xxiii-xxiy. (1880) 109.-Europ.

Huterix, Hausm. ex Treuinf. in Zeitschr. Ferdin. Tirol. III. xix. (1875) 221.-Europ.

hybridum, Koch, in DC. F1. Fr. Suppl. $463=$ Cn. ochroleucus.

hygrophilum, Boiss. Diagn. Ser. I. x. 89.-Persia. hypoleucum, DC. Prod. vi. 645.-Balkan; As. Min. hypopsilum, Boiss. \& Heldr. Diagn. Ser. I. vi. 101 = Cn. ferox.

igniarium, Spreng. Syst. iii. 373.-Sibir. altaic imereticum, Boiss. Fl. Orient. iii. 537.-Reg. Caucas. incanum, Bieb. F1. Taur. Cauc. iii. $561=\mathrm{Cn}$. arvensis inclinatum, Lam. F1. Fr. ii. $22=$ Carduus medius.
CIRSIUM :-

inerme, G. Don, in Loud. Hort. Brit. 330 ; Reichb. F1 Germ. Excurs. $287=$ Cnicus tuberosus.

inerme, Link, Enum. Hort. Berol. ii. $301=$ Cn. cyna roides.

insubricum, Moretti, ex Bertol. Fl. Ital. ix. $25=\mathrm{Cn}$. eriophorus.

involucratum, DC. Prod. vi. $639=\mathrm{Cn}$. involucratus.

italicum, DC. Cat. Hort. Monsp. $96=\mathrm{Cn}$. italicus

Faegeri $x, F$. Schultz, in Flora, xxxii. (1849) 228.Europ.

japonicum, DC. Prod. vi. $640=\mathrm{Cn}$. japonicus

jorullense, Spreng. Syst. iii. $376=\mathrm{Cn}$, jorullensis

Faschii, Pacher, in Jahrb. Landesm. Kaernt. xv. (1882)

136.-Europ.

Furatzkae $\times$, Reichardt, in Verh. Zool.-Bot. Ges. Wien, xi. (1861) 380.-Austr.

kantschaticum, Ledeb. ex DC. Prod. vi. $644=\mathrm{Cn}$ kamtschaticus.

Kernerix, Ausserd, ex Treuinf, in Zeitschr. Ferdin. Tirol. III. xix. (1875) 260.-Europ.

Killiasii, Bruegg. in Jahresb. Naturf. Ges. Graub. II. xxiii-xxiv. (1880) 108.-Helvet.

kirbense, Pomel, Nouv. Mat. Fl. Atl. 274.-Afr. bor. Kochianum, Loehr, in Flora, xxv. (1842) $111=\mathrm{Cn}$ palustris.

Kosmelii, Boiss. Fl. Orient. iii. 531, in syn。 $=\mathrm{Cn}$. lappaceus.

Kotschyanum, Boiss. Diagn. Ser. I. vi. $103=$ libanoticum.

Lachenalii, DC. Prod. vi. 648 , in syn. $=$ Cn. rigens

Lachenalii, Koch, Syn. F1. Germ. ed. I. $397=\mathrm{Cn}$ acaulis, oleraceus.

laciniatum, Doell, ex Nym. Consp. $409=\mathrm{Cn}$. palustris lacteum x, Ruhm. in Eichl. Jahrb. Bot. Gart. Berl i. (1881) 241.-Europ.

lacteum, Schleich. Cat. (1821), ex Koch, Syn. Fl. Germ. ed. I. $394=$ palustris.

laeve, Moench, Meth. Suppl. $227=\mathrm{Cn}$. tataricus

laevigatum, Tausch, in Flora, xi. (1828) $483=\mathrm{Cn}$. arvensis.

lamprophyllum, Herbich, Stirp. Rar. Bucov. 54.Bukovina.

lanatum, Spreng. Syst. iii. $373=\mathrm{Cn}$. arvensis.

lanceolatum, Hill, Herb. Brit. i. 80 ; Scop. FI. Carn. ed. II. ii. $130=$ Cn. lanceolatus.

laniflorum, Bieb. Fl. Taur. Cauc. iii. $557=\mathrm{Cn}$. laniflorus.

lanigerum, Naegeli, Cirs. Schweiz.-114. t. $3=\mathrm{Cn}$. lanceolatus.

lappaceum, Fisch. Hort. Gorenk. ed. II. (1812) $35=\mathrm{Cn}$ lappaceus.

lappaceum, Lam. FI. Fr. ï. 24=Carduus Personata.

lappoides, Sch. Bip. in Seem. Bot. Voy. Herald, $312=$ Cn. lappoides.

latifolium, Lowe, in Trans. Camb. Phil. Soc. iv. (1831) 28.-Ins. Madera.

Lecontei, Torr. \& Gray, Fl. N. Am. ii. $458=\mathrm{Cn}$ Lecontei.

Ledebourii, Steud. Nom. ed. II. i. 368.-Sibiria.

leucanicum, Lojac. in Natural. Sicil. iii. (1884) 283.Sicilia.

leucocephalum, C. Koch, in Linnaea, xxiv. (1851) 401 =chynysicum.

leucocephalum, Spreng. Syst. iii. $377=\mathrm{Cn}$. leucocephalus euconeurum, Boiss. \& Heldr. in Boiss. F1. Orient. iii 534.-Cataonia.

leucophanum, Schur, Enum. Pl. Transs. $418=\mathrm{Cn}$. laniflorus.

leucopsis, DC. Prod. vi. 644.-As. Min,

leucostylum, Moench, Meth. $556=$ Carduus defloratus.

libanoticum, DC. Prod. vi. 647-As. Min.; Syria.

ligulare, Boiss. Fl. Orient. iii. 529.-Thracia.

Linkii, Nym. Syll. 23.-Lusitan

lineare, Sch. Bip. in Linnaea, xix. (1847) $335=\mathrm{Cn}$. linearis.

litorale, Maxim. Prim. Fl. Amur. $173=\mathrm{Cn}$. japonicus. Linkianum $\times$, Loehr, Enum. Fl. Deutsch. 364.-Europ Lobelii, Tenore, F1. Nap. v. 211. t. $189=$ Cn. ferox.

longespinosum, Tod. ex Nym. Consp. $406=\mathrm{Cn}$. lanceo latus.

longifolium, Boiss. F1. Orient. iii. 553, sphalm. (= Epitrachys longifolia).-Reg. Caucas.

lucidum, DC. Prod. vi. 654.-Hab. ?

lutescens, Rafin. in Med. Repos. N. York, II. v. (1808) 354, nomen.-Hab. ?

lycaonicum, Boiss. \& Heldr. Diagn. Ser. I. x. $90=$ libanoticum. 
CIRSIUM :-

lyratum, Bunge, Enum. Pl. Chin. Bor. $36=$ Saussurea affinis.

Maackii, Maxim. Prim. Fl. Amux. $172=$ Cn. japonicus. macracanthum, Sch. Bip. in Flora, xxxv. (1852) $135=$ Cn. Wallichii.

macrobotrys, Boiss. Fl. Orient, iii. 532-Armenia. macrocephalum, C. A. Mey. Verz. Pfl. Cauc. $70=\mathrm{Cn}$ munitus.

macrochaetum, Tausch, in Flora, xix. (1836) 397.Hab. ?

macrostachyum, Boiss, F1. Orient. iii. 550,-Reg. Caucas.

macrostylon, Reichb. F1. Germ. Excurs. $856=\mathrm{Cn}$. arvensis.

maculatum, Lam. Fl. Fr。 ii, 22=Tyrimnus leucographus.

maculatum, Moench, Meth. $557=\mathrm{Cn}$. syriacus, maculatum, Scop. Fl. Carn. ed. II. ii. $130=$ Silybum Marianum.

mareoticum, Spreng. Syst. iii. $377=$ Carthamus mareo ticus.

matritense, Lag. ex Cut. Fl. Comp. Madrid, $409=\mathrm{Cn}$ flavispinus.

maximum, Benth. Pl. Hartw. $289=\mathrm{Cn}$. subcoriaceus. medium, All. Fl. Pedem, i. $149=\mathrm{Cn}$. tuberosum.

megacanthum, Nutt. in Trans. Am. Phil. Soc. N. S. vii. (1841) $421=$ Cn. horridulus.

mexicanum, DC. Prod. vi. $636=\mathrm{Cn}$. mexicanus.

micranthum $\times$, Treuinf. in Zeitschr. Ferdin. Tirol. III xix. (1875) 218.-Europ.

microcephalum, Lange, Ind. Sem. Hort. Havn. (1854) 22.-Hispan.

microcephalum, Moris, Fl. Sard, ii. $466=$ Cn. micro cephalus.

microcephalum, Sch. Bip. in Oestr. Bot. Zeitschr, viii. (1858) $246=\mathrm{Cn}$. siculus

Mielichhoferi, Sauter, in Flora, xxviii. (1845) $130=\mathrm{Cn}$ heterophyllus.

misilmerense, Ces. Passer. \& Gib. Comp. Fl. Ital. 483 $=\mathrm{Cn}$. misilmerensis.

mite, Fisch. in Spreng. Nov. Prov. $13=\mathrm{Cn}$. mitis.

molle, Scop, F1. Carn. ed. II. ii. $126=$ Jurinea mollis. monspessulanum, Hill. Hort. Kew. 63 ; All. Fl. Pedem. i. $152=\mathrm{Cn}$. monspessulanus.

montanum, Hill, Herb. Brit. i. $80=$ Cn. montanus.

Morettianum, Nym. Syll. $24=\mathrm{C}$. spathulatus.

morinaefolium, Boiss. \& Heldr. ex Boiss. Fl. Orient. iii. 530.-Ins. Creta.

Morisianum, Reichb. f. Ic. Fl. Germ, xv, 59.-Europ munitum, Fisch. Hort. Gorenk, ed. II. (1812) $35=\mathrm{Cn}$ munitus

mutatum, Menyb. Kalocsa Vidék. Növény. $102=\mathrm{Cn}$ arvensis.

muticum, Michx, Fl. Bor, Am. ii, $89=\mathrm{Cn}$, muticus.

Naegelianum x, Loehr, Enum. Fl. Dentsch. 362.-

Europ.

neglectum, Fisch. ex Spreng. Syst. iii. $370=$ Cn. arvensis. nemorale, Reichb. Fl. Germ. Excurs. $286=\mathrm{Cn}$. lanceo latus.

neo-mexicanum, A. Gray, Pl. Wright, ii. $101=\mathrm{Cn}$ neo-mexicanus.

nepalense, DC. Prod. vi. $642=\mathrm{Cn}$. Wallichii.

nevadense, Willk. in Linnaea, xxx. $(1859-60) 111$. Hispan.

nidulans, Regel, in Bull, Soc. Nat. Mosc. xl. (1867)

II. 160.-As. centr.

nivale, Sch. Bip. in Seem. Bot. Voy. Herald, $312=\mathrm{Cn}$ nivalis.

niveum, Spreng. Syst. iii. $373=\mathrm{Cn}$. niveus.

numidicum, Spreng. 1. c. 377 .-Afr. bor.

Nuttali, DC. Prod. vi. $651=\mathrm{Cn}$. Nuttalli.

oblongifolium, C. Koch, in Linnaea, xvii. (1843) 41.-

Reg. Cancas.

obscurumx, Kern. ex Treuinf. in Zeitschr. Ferdin. Tirol. III. xix. (1875) 264-Europ.

obvallatum, Bieb. Fl. Taur. Cauc, iii. $559=\mathrm{Cn}$. obval. latus.

ochro-centrum, A. Gray, P1. Fend1. $110=\mathrm{CD}$. ochrocentrus.

ochroleucum, All. F1. Pedem, i. $150=$ Cn, ochroleucns. odontolepis, Boiss. ex DC. Prod. vii. 305.-Hispan.;

Balkan.

oenanum $\times$, Treuinf. in Zeitschr. Ferdin. Tirol. III

xix. (1875) 215 . - Europ.

oenipontanum $\times$, Treuinf. 1. c. 280.-Enrop.

oleraceum, Scop. Fl. Cam. ed. II. ii. $124=\mathrm{C}$ oleraceus.

\section{CIRSIUM :-}

onopordioides, Kotschy, ex Boiss. Fl. Orient. iii. $564=$ Onopordum polycephalum.

oreithales, Hance, ex Walp. Ann. ii. $944=$ Cnicus chinensis.

orgyale, Hort. ex Tausch, in Flora, xii. (1829) I. Erg. $41=$ aciculare?

orgyale, Link, Enum. Hort. Berol. ii. $302=\mathrm{Cn}$ orgyalis.

orientale, Spreng. Syst, iii. $373=$ Galactites tomentosa

palatinum, Sch. Bip. ex Nym. Consp. $409=\mathrm{Cn}$ palustris.

pallens, DC. Prod. vi. $647=\mathrm{Cn}$. oleracens.

paludosum, G. Don, in Loud. Hort. Brit. $331=\mathrm{Cn}$ paludosus.

palustre, Coss. ex Willk. \& Lange, Prod. ii. $191=$ Bourgeanum.

palustre, Scop. Fl. Carn. ed. II. ii. $128=\mathrm{Cn}$. palustris. paniculatum, Boiss. \& Haussk. ex Boiss. Fl. Orient. ii $535=$ cataonicum?

paniculatum, Lam. Fl. Fr. ii. $25=$ Carduus carlinoides paniculatum, Spreng. Syst. iii. 371.--Mont. Pyren. paniculatum, Vahl, ex Willk. \&c Lange, Prod. Fl. Hisp ii. $186=\mathrm{Cn}$. flavispinus.

pannonicum, Link, Enum. Hort. Berol. ii. $301=\mathrm{Cn}$ pannonicus.

paradoxum x, Wallr. Beitr. Fl. Hercyn. 264.-Europ. parviflorum, DC. Prod. vi. $647=\mathrm{Cn}$. oleraceus. parviflorum, Lange, ex Nym. Consp, $409=\mathrm{Cn}$ palustris.

parviflorum, Schleich. ex Steud. Nom. ed. II. i. $369=$ Cn. ochroleucus.

pauciflorum, Koch, Syn. F1. Germ. ed. I. $395=\mathrm{Cn}$ heterophyllus.

pauciflorum, Lam. Fl. Fr. ii. 22 = Carduus defloratus pauciflorum, Spreng. Syst. iii. $375=\mathrm{Cn}$. pauciflorus

pazcuarense, Spreng. 1. c. $372=\mathrm{Cn}$. pazcuarensis.

pectinellum, A. Gray, in Mem. Am. Acad. N. S. vi. $(1858-59) \quad 395=\mathrm{Cn}$, pectinellus

pendulum, Fisch. ex DC. Prod. vi. $650=\mathrm{Cn}$. pen dulus.

penicillatum, C. Koch, in Linnaea, xvii. (1843) $41=$ Cn. lappaceus.

persicum, Boiss. Diagn. Ser. I. vi. $103=$ Cn. strigosus,

phyllocephalum, Boiss. \& Blanche, in Boiss. 1. c. Ser. II iii. 39.-Syria.

pinnatifidum, Spreng. Syst. iii. $395=$ Serratula pinnatifida.

Pitcheri, Torr. \& Gray, Fl. N. Am. ii. $456=\mathrm{Cn}$ Pitcheri.

platycephalum, Benth. ex Oerst. in Kjoeb. Vidensk Meddel. $(1852) 110=\mathrm{Cn}$. subcoriaceus.

polyacanthum, Hochst. ex A. Rich. Tent. Fl. Abyss. $456=\mathrm{Cn}$. polyacanthus.

polyacanthum, Kar. \& Kir. in Bull. Soc. Nat. Mosc. (1841) 450 - -Sibir. altaic.

polyanthemon, Spreng. Syst. iii. $371=\mathrm{Cn}$. poly anthemus.

polyanthos, Urv. in Mém. Soc. Linn. Par. i. (1822) 363 $=\mathrm{Cn}$. pungens.

polycephalum, IC. Prod. vi. $639=$ byzantinum

polycephalum, Willd. ex Spreng. Syst, iii. 371.Hab.?

polymorphum, Doll. ex Hausm. in Verh. Zool.-Bot. Ges. Wien, viii. (1858) $375=$ Linkianum

ponticum, C. A. Mey. Ind. Sem. Hort. Petrop. ix. $67=$ polycephalum.

Portae, Hausm. in Verh. Zool.-Bot. Ges. Wien, viii (1858) $373=$ Linkianum

praealtum, Cass, in Dict. Sc. Nat. xli. $\$ 83=\mathrm{Cn}$ arvensis.

praemorsum, Koch, Syn. Fl., Germ. ed. 1. $397=\mathrm{Cn}$. ochroleucus?

pratense, DC. Fl. Fr. iv. $113=\mathrm{Cn}$. monspessulanus,

proponticum, Griseb. Spicil. Fl. Rumel. ii. $254=\mathrm{C}$. eriophorus.

pseudo-canum, Schur, Enum. Pl. Transs. $421=\mathrm{Cn}$. pannonicus.

pseudo-lanceolatum, Schur, I. c. $418=\mathrm{Cn}$. lanceolatus. pseudo-oleraceum, Schur, 1. c. $428=\mathrm{Cn}$. pannonicus. pseudo-palustre, Schur, 1. c. $420=$ Chailleti, Koch. pseudo-pannonicum, Schur, $1 . \mathrm{C}_{\mathrm{n}}=\mathrm{Cn}_{\mathrm{n}}$ canus. pseudo-personata, Boiss. \&c Bal. ex Boiss. Fl. Orient. ii 545.-As. Min.

pubigerum, DC. Prod. vi. $650=\mathrm{Cn}$. pubigerus,

Pumilio, Tausch, in Syll. Ratisb. ii. (1828) 249.Austria.

pumilum, Spreng. Syst. iii. $975=\mathrm{Cn}$. pumilus.
CIRSIUM:

pungens, Schur, Enum. Pl. Transs. 420.-Europ pungens, Spreng. Syst. iii. $370=$ Cnicus polyanthemus purpureum, All. Fl. F'edem. i. $150=\mathrm{Cn}$. spinosissimus. Pustariacum $x$, Ausserd. ex Treninf. in Zeitschr. Ferdin. Tirol. III. xix. (1875) 258.-Europ.

pygmaeum, Scop. Fl. Carn. ed. II. ii. $123=$ Saussurea pygmaea.

pyrenaicum, All. F1. Pedem, i. $151=$ Cn. montanus.

pyrenaicum, DC. Fl. Fr. iv, $112=\mathrm{C}$. pyrenaicus,

racemosum, Boiss. in Tchihat. Asie Min. Bot. ii. $338=$

tenuilobum.

radians, Benth. $\mathrm{Pl}$. Hartw. $77=\mathrm{C}$, radians,

Reichardtiix, Jurotzka, in Verh. Zool.Bot.

Wien, ix. (1859) 317.-Europ.

Reichenbachianum x, Loehr, Enum. F1. Deutsch. 3154 $=\mathrm{Cn}$. arvensis.

remotifolium, DC. Prod, vi. $655=\mathrm{Cn}$. remotifolius

repandum, Michx. Fl. Bor. Am. jii. $28=\mathrm{Cn}$. repand

replicatum, DC. Prod. vi. $655=\mathrm{Cn}$. replicatus.

rheginum, Spreng. Pugill. ii. $77=$ Cn. strictus,

rhizocephalum, C. A. Mey. Verz. Pff. Cauc. 70.-A

Min.; Persia; Afghan.

rhodo-leucanthum, Walp. Ann, i. $453=\mathrm{Cn}$, esculentu

Richterianum, Gillot, in Bull. Soc. Bot. Fr. xxvii. 1880) p. li -Europ.

rigens, Spreng. Neue Entdeck. iii. $38=\mathrm{Cn}$. oleraceus.

rigens, Wallr. Sched. Crit. $446=\mathrm{Cn}$. acaulis .

rigidum, DC. Prod. vi. $640=\mathrm{Cn}$. arachnoideus.

rivulare, All. Auct. Pedem, $10=\mathrm{C}$. montanns.

rivulare, Link, Ennm. Hort. Berol, ii. $301=$ rivularis.

Rosani, Tenore, Ind. Sem. Hort. Neap. (1830) 15; ex Syll. $414=\mathrm{C} n$. lanceolatus.

Rosenii, Vill. Hist. P1. Dauph. iii. 14, t. $21=\mathrm{Cr}$. acauli rufescens, Ramond, ex DC. Fl. Fr. iv. $114=\mathrm{C} n$. rufescens.

ruthenicum, Fisch. Hort. Gurenk, ed. II. 1812) 35

Cn. arvensis.

sabaudum x, Loehr, Enum. F1. Deutsch. 362.-Earop. sabaudum X, Ruhm. in Eichl. Jahrb. Bot. Gard. Berl. 1. (1881) 240 .-Europ.

salamanticum, Hill, Hort. Kew. $64=$ Centaurea salmantica.

salinum, Bieb. ex Stend. Nom. ed. II. i. $370=$ Centaurea salina.

salisburgense, G. Don, in Loud. Hort. Brit. $331=\mathrm{C}$. rivalaris.

samniticum, Steud. Nom. ed. II. i. $370=\mathrm{Cn}$. italicus. scariosum, Nutt, in Trans. Am. Phil, Soc. N. S. ví. 184] ) $420=\mathrm{Cn}$. scariosus.

schantarense, Trautv. \& Mey. in Middend. Reise (Fl. Ochot. 58).- Sibir. or.

Schultgianum $\times$, Loehr, Enum. Fl. Deutsch. 365.

scleranthum, Bieb. F1. Taur. Cauc. iii. 559.-As. Mir.; Persia.

Scopolianum, Sch. Bip. ex Nym. Consp. $408=C$ D. Eristhales.

segetum, Bunge, Enum. Pl. Chin. Bor. $36=\mathrm{Cn}$ segetum.

Semenowi, Regel, in Ball. Soc. Nat. Mosc. xl. ( $1 \leq 6 \%$ I1. 161.-As. centr.

semidecurrens, DC Prod. vi. 646. - Hat.

semidecurrens, Richt. Fl. Lips. $673=\mathrm{Cn}$. palustris

semipectinatum, Ledeb. ex Steud. Nom. ed. II. i. Sil $=$ Ledebourii.

semipectinatum, Reichb. Fl. Germ. Excurs. 237 $=\mathrm{C}$. rivularis.

semipectinatum, Spreng. Syst. iii. $3-s=C n$, serm: pectinatus

serratuloides, Hill, Hort. Kew. $6 t=C n$. sermatuloides. serratuloides, Scop. F1. Carn, ed. II. ii. $12 \%=\mathrm{Cn}$. pannonicus.

serratum, Tausch, in Florn, xii. 1820: I, I $\mathrm{r}=\mathrm{a}$ Europ.

serrulatum, Bieb, Fl. Taur, Cauc iii. $\left[\because 5-\mathrm{C}^{-}\right.$ serrulatus.

serrulatum. Schar, Enum. Pl. Transa $419=\mathrm{Cn}$ fimbriatus.

sessiliflorum, Herbich, Stirp. Rar. Bucov. 5f.-Turcia setigerum, Ledeb. lc. Pl. Fl. liuss. i. . - . altaic.

setasum. Bieb. Fl. Taur. Cauc. iii. $560=\mathrm{Cn}$. arvensis siculuw, Spreng. Neue lintdeck, iii. $\$ 6-\mathrm{Cn}$. pungens. Sirboldi, Miq. Ana. Mus Bot. Lugd. Bat. ii. $181=\mathrm{C}$. sieboldii.

Siegerti, Sch, Bip, ex Iym. Consp, fos $=$ C $\mathrm{n}$. rivularis. 


\section{CIRSIUM :-}

silesiacum, Sch. Bip. ex Nym. Consp. $409=$ Cnicus palustris.

silvaticum, Tausch, in Flora, xii. (1829) I. Erg. $38=$ Cn. lanceolatus.

simplex, Hornem. Hort. Hafn. Suppl. 93=Centaurea salina.

simplex, C. A. Mey. Verz. Pfl. Cauc. 70.-Reg. Caucas.

sinense, C. B. Clarke, Comp. Ind. $219=\mathrm{Cn}$. chinensis. sinuatum, Boiss. Fl. Orient. iii. $546=\mathrm{Cn}$. cynaroides. sinuatum, Boiss. \& Kotschy, ex Boiss. 1. c. $542=$ rhizocephalum.

sordidum, Wallr. Beitr. Fl. Hercyn. $266=$ Cn. arkensis. sorocephalum, DC. Prod, vi. $636=$ fallax, Fisch. \& Mey sorocephalum, Fisch. \& Mey. Ind. Sem. Hort. Petrop. ii. 33.-Reg. Caucas.

spathulatum, Gaudin, F1. Helv. v. $202=\mathrm{Cn}$. exiophorus.

spectabile, DC. Prod. vi. 641.-Persia.

spinifolium $\times$, Beck, in Oestr. Bot. Zeitschr. $x x x$ (1881) 312.-Europ.

spinosissimoides $\times$, Ausserd, ex Treuinf, in Zeitschr

Ferdin. Tirol. III. xix. (1875) 250.-Europ.

spinosissimum, Scop. Fl. Carn. ed. II. ii. $129=$

Cn. spinosissimus.

Spitzelii, Sch. Bip. ex Nym. Consp. $408=\mathrm{Cn}$. spinosissimns.

spurium, Delastre, in Ann. Sc. Nat. Sér. II. xviii 1842) $149=\mathrm{Cn}$. pratensis.

squarrosum, Fisch. ex Spreng. Syst. iii. $376=\mathrm{Cn}$ squarrosus.

stellatum, All. F1. Pedem. i. $153=$ Cn. stellatus.

stenolepidum, Nutt. in Trans. Am. Phil. Soc. N. S. vii (1841) $419=$ Cn. remotifolins.

stenophyllum, Boiss. F1. Orient. iii. $534=$ tenuilobum.

Stocksi, Boiss. Diagn. Ser. II. iii. $40=\mathrm{Cn}$. arvensis.

strictum, Moris, Stirp. Sard. Elench. i. $27=\mathrm{Cn}$. microcephalus

strictum, Spreng. Syst. iii. $370=$ Cn. strictus.

strigosum, Bieb. Fl. Taur. Cauc. iii. $558=\mathrm{Cn}$ strigosus.

subalatum, Gaudin, Fl. Helv. v. $180=\mathrm{Cn}$. oleraceus.

subalpinum, Gaudin, 1. c. $182=\mathrm{Cn}$. palustris.

subalpinum, Schleich. ex Reichb. Ic. Fl. Germ. xv. 73 - Helvetia.

subcoriaceum, Sch. Bip. ex Seem. Bot. Voy. Herald, $312=\mathrm{Cn}$. subcoriaceus

ubinerme, Fisch. \& Mey. in Mém. Acad. Pétersb. Sér.

VI. Sc. Nat vi. $(1849) \mathbf{5 5}=$ elodes.

subsagittatum, Schur, Enum. Pl. Transs. $421=\mathrm{Cn}$ pannonicus.

succinctum, Ledeb. Fl. Ross. ii. $732=$ Cn. lappaceus.

supertextum, Tausch, in Flora, xix. (1836) 397.

Hab. ?

sylvaticum, DC. Prod vi, $656=\mathrm{Cn}$. lanceolatus

syriacum, Gaertn. Fruct. ii. 383. t. 163. f. $2=\mathrm{Cn}$ syriacus.

Szovitsii, Boiss. Fl. Orient. iii. 527.-Reg. Caucas. tartaricum, All, Fl. Pedem. i. $151=\mathrm{Cn}$. tataricus.

tataricum, DC. F1, Fr. iv. $114=$ Cn. rigens.

tauricolum, Boiss. \& Bal, ex Boiss. Fl. Orient. iii. 551.

- Cataonia.

Tauschii, DC. Prod. vi. 656.-Hab. ?

tchefouënse, Debeaux, Fl. Tchef. $86=\mathrm{Cn}$. tche fotiënsis.

tenuilobum, Boiss. Fl. Orient. iii, 534.-Armenia.

texanum, Buckl, in Proc. Acad. Sc. Philad. '1861 (1862) $460=\mathrm{Cn}$. virginianus.

Thamasii, Naeg. Cirs. Schweiz. $93=\mathrm{Cn}$. oleraceum.

tirolense $x$, Treuinf. in Zeitschr. Ferdin. Tirol. III. xix. (1875) 243.-Europ

tomentosum, C. A. Mey. Verz. Pfl, Cauc. $69=\mathrm{Cn}$. munitus.

tomentosum, Moench, Metb. Suppl, 227=Jurinea cynaroides.

trachylepis, Boiss. Fl. Orient. iii. 528.-Armenia.

transsilvanicum, Schur, Enum. Pl. Transs. 419

$\mathrm{Cn}$. transsilvanicus.

tricephalodes, DC. Fl. Fr. iv. $116=\mathrm{Cn}$. rivularis.

tricephalum, St. Lag. in Ann. Soc. Bot. Lyon, vii. (1880) $122=$ praec.

tricholoma, Fisch. \& Mey. in Bull. Soc. Nat. Mosc (1838) 251.-Reg. Caucas.

trispinosum, Moench, Meth. $556=\mathrm{Cn}$. Casabonae.

tryphilinumx, Treuinf. in Zeitschr. Ferdin. Tirol.

III. xix. (1875) 276.-Europ.

tuberosum, All. F1. Pedem. i. $151=\mathrm{Cn}$. tuberosus.
CIRSIUM :-

ukranicum, Bess. ex DC. Prod. vi. $635=$ Cnicus serrulatus.

uliginosum, Bieb. F1. Taur. Cauc. iii. $555=\mathrm{Cn}$. uliginosus.

uliginosum, Heldr. ex Boiss. Diagn. Ser. I. x. $90=$ libanoticum.

undulatum, Spreng. Syst. iii. $374=\mathrm{Cn}$. undulatus.

Vallis-Demonii, Lojac. in Natural, Sicil. iii. (1884) 267. -Sicilia.

variabile, Moench, Meth. $558=\mathrm{Cn}$. oleraceus.

Verutum, Spreng. Syst. iii. $370=$ Cn. argyracanthus.

virens, Timb. \& Jeanb. ex Nym. Consp. $406=\mathrm{Cn}$. lanceolatus.

virgatum, Tausch, in Flora, xix. (1836) 402.-Tauria. virginianum, Hook. Comp. Bot. Mag. i. (1835) $48=$ Cn. Lecontei.

virginianum, Michx. Fl. Bor. Am. ii. $90=\mathrm{Cn}$. virginianus.

Vlassovianum, Fisch. ex DC. Prod. vi. $653=\mathrm{Cn}$. Vlassovianus.

Wallichii, DC. 1. c. $643=\mathrm{Cn}$. Wallichii.

Wankeliix, Reichardt, in Verh. Zool.-Bot. Ges. Wien, xi. (1861) 381.-Europ.

Welwitschii, Coss. Notes Crit. 118,-Hispania.

Weyrichii, Maxim. Prim. Fl. Amur. $174=\mathrm{Cn}$. Weyrichii.

Wiedemanni, Fisch. Mey. \& Avé-Lall. Ind. Sem. Hort. Petrop. vi. 48 =hypoleucum.

Willdenowii, Steud. Nom. ed. II. i. $370=\mathrm{Cn}$. Willdenowii.

Wimmeri, Čelak. in Arch. Naturfw. Landesd. Boehm ii. (1873) 263. - Bohemia

Winklerianum $\times$, Celak. 1. c. 262.-Europ.

Wirtgenii x, Loehr, Enum. F1. Deutsch. 362.-Europ.

Woodwardii, H. C. Wats. ex Nym. Consp. $407=\mathrm{Cn}$. tuberosus.

Wrightii, A. Gray, Pl. Wright. ii. $101=\mathrm{Cn}$. Wrightii. Zizianum, Koch, Syn. Fl. Germ. ed. I. $398=$ Cn. tuberosus.

CISSAMPELOPSIS, Miq. Fl. Ind. Bat. ii. $102(1856)=$ Senecio, Tourn. (Compos.).

volubilis, Miq. 1. $\mathrm{c}_{\mathrm{o}}=\mathrm{S}$. araneosus.

CISSAMPFLOS, Linn. Gen. ed. I. 368 (1737). $M E N I S P E R M A C E A E$, Benth. \& Hook. f. i. 37 Antizoma, Miers, in Ann. \& Mag. Nat. Hist. Ser. II. vii. (1851) 41.

CAAPEBA, Plum. ex Adans, Fam. ii. 357 (1763)

Dissopetalum, Miers, in Ann. \& Mag. Nat. Hist. Ser. III. xvii. (1866) 267.

Abutua, Vell. F1. Flum. x. t. $140=$ Chondodendron platyphyllum

acuminata, Benth. Pl. Hartw. $58=$ C. Pareira.

acuminata, $D C$. Syst, i. 538.-Ind, or

acuta, Triana $E^{\prime}$ Planch. in Ann. Sc. Nat. Sér. IV xvii. (1862) 43.-N. Granat.

amazonica, Miers, ex Benth. in Hook. Kew Journ. iii. (1851) $114=$ ovalifolia

andromorpha, DC. Syst. i. 539.-Guiana.

angustifolia, Burch. Trav, i. 389.-Afr, austr.

angustifolia, Drège, ex Harv. \& Sond. F1. Cap. i. 13 (=Antizama Miersiana).-Afr, austr.

apiculata, Hochst, in Flora, xxviii. (1845) 93=C. Pareira.

argentea, H. B. \& K. Nov, Gen. et Sp. v. $67=\mathrm{C}$. Pareira.

aristolochiaefolia, Fenzl, in Flora, xxvii. (1844) $312=$ C. Pareira.

assimilis, Miers, ex Benth. in Hook. Kew Journ. iii. (1851) $114=$ ovalifolia.

auriculata, Miers, Contrib. iii. 158.-Reg. Argent. australis, St. Hil. Fl. Bras, Mer i, $54=$ C. Pareira barbata, Wall. Cat. n. $4978=$ Cyclea peltata.

Benthamiana, Miers, Contrib. iii. 144.-Mexic.

Boivini, Baill. in Bull. Soc. Linn. Par. i. (1885) 460. -Madag.

Bojeriana, Miers, Contrib. iii. 182,-Ins. Maurit. Caapeba, Linn. Sp. P1. $1032=$ C. Pareira.

Caapeba, Vell. F1. Flum. x. t. 139=fasciculata?

calcarifera, Burch. Trav. ii. $266=$ fruticosa.

canescens, Miq. Sert. Exot. i. 7. t. 4=C. Pareira.

capensis, Thunb. Prod.Pl. Cap. 110.-Afr. austr

capitata, Griff. Notul. iv. 309.-Ind. or.

clematidea, Presl, Bot. Bemerk. $7=\mathrm{C}$. Pareira

Cocculus, Buch.-Ham. ex Steud. Nom. ed. II. i. $371=$ C. Pareira.

\section{CISSA MPEIOS :-}

Cocculus, Poir. Encyc. v. 9.-Ind. or.

Cocculus, Steud. Nom. ed. I. $198=$ Anamirta paniculata.

comata, Miers, in Hook. Niger Flora, $215=\mathrm{C}$. Pareira.

communis, St. Hil. Fl. Bras. Mer, i. 52 =ovalifolia.

consociata, Miers, Contrib. iii.167.--Ind. occ.

convexa, Vell. Fl. Flum. x. t. $142=$ Abuta rufescens.

convolvulacea, Willd. Sp. Pl. iv. $863=$ C. Pareira.

cordifolia, Boj. Ann. Sc. Nat. Sér. II. xx. (1843) 54.-

Afr. austr.

crenata, DC. Syst. i. $537=$ ovalifolia

Cumingiana, Turcz, in Bull. Soc. Nat. Mosc. xxvii.

(1854) II. 283.-Ins. Philipp.

delicatula, Miers, Contrib. iii. $197=$ C. Pareira.

denudata, Miers, ex Benth. in Hook. Kew Journ. iil.

(1851) $115=$ fasciculata.

diffusa, Miers, Contrib, iii. 168.-Ind. occ.

discolor, DC. Syst. i. $534=$ Stephania hernandifolia.

discolor, A. Gray, Bot. U. St. Expl. Exped. i. $38=$ C. Pareira.

discolor, Wall. Cat. n. $4982=$ Cyclea peltata

diversa, Miers, Contrib. iii. $187=$ C. Pareira.

ebracteata, St. Hil. Pl. Us. Bras. t. $35=$ ovalifolia.

elata, Miers, Contrib, iii. $187=$ C. Pareira.

eriantha, Miers, 1. c. $192=$ C. Pareira.

eviocarpa, Triana \& Planch. in Ann. Sc. Nat. Sér. IV xvii. (1862) $41=$ C. Pareira.

errabunda, Miers, Contrib. iii. 138.-Bras.

fasciculata, Benth. in Hook. Lond. Fourn. Bot. ii (1843) 361.-Bras

floribunda, Miers, Contrib. iii. 164.--Peruv.

fluminensis, Eichl. in Flora, xlvii. (1864) 392 [err.typ “ 382 ' ;] et in Mart. Fl. Bras. xii. 1. 191.-Bras.

fruticosa, Thunb. Prod. Pl. Cap. $110=$ capensis.

glaberrima, St. Hil. Fl. Bras. Mer. i. 57--Bras.

glabra, Buch.-Ham. ex Wight \& Arn. Prod. i. $14=$

Clypea hernandifolia et Cocculus Roxburghianus.

glabra, Roxb. Hort. Beng. 74; Fl. Ind. iii. $840=$ Stephania rotunda.

glaucescens, Triana \& Planch. in Ann. Sc. Nat. Sér,

IV. xvii. $(1862) 41=$ C. Pareira.

gracilis, St. Hil. F1. Bras. Mer, i. $56=$ C. Pareira.

grallatoria, Miers, Contrib. iii. $189=$ C. Pareira.

grandifolia, Triana \& Planch. in Ann. Sc. Nat. Sér. IV xvii. (1862) $44=$ C. Pareira:

guayaquilensis, H. B. \& K. Nov. Gen. et Sp. v. $67=$ C. Pareira.

Haenkeana, Presl, Rel. Haenk. ii. $80=$ ovalifolia.

hederacea, Miers, Contrib. iii. 159.-Reg. Argent.

Hernandia, Vell. Fl. Flum. x. t. 136.-Bras.

hernandifolia, Wall. Cat. 4977 , partim $=$ C. Parcira.

hernandifolia, Willd. Sp. PI. iv. $861=$ Stephania hernandifolia.

heterophylla, DC. Syst. i. $534=$ C. Pareira

hexandra, Roxb. Hort. Beng. 74 ; Fl. Ind, iii. $841=$ Stephania hernandifolia.

hirsuta, Buch.-Ham. in DC. Syst. i. $535=$ C. Pareira.

hirsutissima, Presl, Rel. Haenk. ii. $80=$ ovalifolia.

hirta, Klotzsch, in Peters, Reise Mossamb. Bot. 174= C. Pareira.

humilis, Poir. Encyc. v. $11=$ capensis.

hypoglauca, Schau. in Nov. Act. Acad. Nat. Cur. xix Suppl.i. (1843) 479.-China.

insolita, Miers, Contrib. iii. 179.-Afr. trop.

kohautiana, Presl, Rel. Haenk. ii. $81=$ C. Pareira.

laurifolia, Poir. Encyc. v. 11.--Ind. occ.

limbata, Miers, Contrib. iii. 143-Am. trop.

littoralis, St. Hil. Fl. Bras. Mer, i. $54=$ C. Pareira.

longipes, Miers, Contrib. iii. 138.-Ind. occ.

macrostachya, Klotzsch, in Peters, Reise Mossamb.

Bot. $172=$ C. Pareira.

madagascariensis, Miers, Contrib. iii. 181.-Madag. Ins. Borb.

mallophylla, Miers, l. c. 169.-Am. trop.

mauritiana, Thou. in Desv. Journ. Bot. ii. (1809) 67

t. $3,4=\mathrm{C}$. Pareira.

mauritiana, Wall. Cat. n. $4980=$ Pericampylus incanus.

microcarpa, DC. Syst, i. $534=$ C. Pareira.

monoica, St. Hil. F1. Bras. Mer. i. $55=$ C. Pareira

mucronata, A. Rich. in Guill, \& Perr. Fl. Seneg. Tent.

i. $11=$ C. Pareira.

myriocarpa, Triana \& Planch. in Ann. Sc. Nat. Sér.

IV, xvii. (1862) $42=$ C. Pareira.

nephrophylla, Boj. 1. c. Sér. II. xx. (1843) $55=$ C. Pareira. 


\section{CISSAMPELOS :-}

nympheaefolia, R. Br. in Salt, Abyss. App. $65=$ Stephania abyssinica.

obtecta, Wall. Cat. n. $4981=$ C. Pareira.

oleracea, Wall, l. c. n. $4984=$ Parabaena sagittata.

orbiculata, DC. Syst. i. $537=$ C. Pareira

orinocensis, H. B. \& K. Nov. Gen. et Sp. v. $68=$ C Pareira.

ovalifolia, DC. Syst. i. 537.-Bras.

ovata, Poir. Encyc. v, $10=$ Pachygone ovata.

ovata, Vell. Fl. Flum. x.t. $141=$ Abuta Selloana?

owariensis, Beauv. ex DC. Prod. i. $100=$ C. Pareira

pannosa, Turcz. in Bull. Soc. Nat. Mosc. xxvîi. (1854)

II. 283.-Cuba.

Pareira, Linn. Sp. Pl. 1031.-Reg. trop.

pareiroides, DC. Ess. Med. Pl. Comp. ed. II. $78=$ C. Pareira.

Parriera, Vell. Fl. Flum. x. t. $138=$ glaberrima.

Pata, Roxb. ex Wight \& Arn. Prod. i. $15=$ C, Pareira.

pauciflora, Nutt. in Journ. Acad. Philad. vii. (1834) 114 = Croomia pauciflora.

peltata, Ruiz, ex Eichl. in Mart. F1. Bras. xiii. 1. $191=$ tropaeolifolia.

psilophylla, Presl, Rel. Haenk. ii. 80,-Ins, Luzon.

ramiflora, Miers, Contrib. iii. 163.-Bras.

rotundata, Pohl, ex Eichl. in Mart. F1. Bras, xiii. I. 187 = ovalifolia.

sagittata, Buch.-Ham. ex Wall. Cat. n. $4983=$ Parabaena sagittata.

Salzmanni, Turcs. in Bull. Soc. Nat. Mosc. xxvii. 1854) II. 284.--Bras.

scutigera, Triana \& Planch. in Ann. Sc. Nat. Sér. 1V. xvii. (1862) $42=$ C. Pareira.

senensis, Klotzsch, in Peters, Reise Mossamb. Bot. i $173=$ C. Pareira.

smilacina, Linn. Sp. Pl. $1082=$ Menispermum canadense.

subcrenata, Klotzsch, in Schomb. Fauna, Fl. Gui. 1162, nomen.-Guiana.

suborbicularis, St. Hil. Fl. Bras. Mer. i. $53=$ ovalifolia.

subpeltata, Thw. Enum. Pl. Zeyl. 13, $399=\mathrm{C}$. Pareira.

subreniformis, Triana \& Planch, in Ann. Sc. Nat. Sér. IV. xvii. (1862) $41=$ C. Pareira.

subtriangularis, St. Hil. Fl. Bras. Mer. i. 51=ovalifolia.

sympodiales, Eichl. in Flora, xlvii. (1864) 382 [err. typ. 392]. - Bras.

tamnifolia, Miers, Contrib. iii. 185.-Afr. austr.

tamoides, Sagot, ex Eichl. in Mart. Fl. Bras. xiii. I. 194 - fasciculata.

tamoides, Willd. ex DC. Syst. i. 536.-Bras.

testudinaria, Miers, in Ann. \& Mag. Nat. Hist. Ser III. $x$ vii. $(1866) 134$, nomen $=$ seq. ?

testudinum, Miers, Contrib. iii. 143.--Ins. Galapag

tetrandra, Roxb. Hort. Beng. [105]; Fl. Ind. iii. 842 =C. Pareira.

tomentosa, DC. Syst. i. $535=$ C. Pareira.

tomentosa, Vell. Fl. Flum. x. t. $143=$ Abuta rufescens.

torulosa, E. Mey. ex Harv. E Sond. Fl. Cap. 1. 11.Afr. austr.

triloba, Spreng. Neue Entdeck. ii. 152.-Bras.

tropaeolifolia, DC. Syst. i. 532.-Am. austr.

umbellata, E. Mey. ex Harv, \& Sond. Fl. Cap. i. 10 = Stephania hernandifolia.

velutina, St. Hil. F1. Bras. Mer. i. $52=$ ovalifolia.

vestita, Triana \& Planch. in Ann. Sc. Nat. Sér. IV, xvii. (1862) $44=$ ovalifolia.

Vitis, Vell. Fl. Flum. x.t. 137,-Bras.

Vogelii, Miers, in Hook. Niger H1. 214=C. Pareira.

zairensis, Miers, Contrib. iii. 180.-Afr. trop.

CISSABRYON, Meissn. Gen. 58; Comm. $42(1837)=$ seq. ?

CISSAROBRYON, Poepp. Fragm. Syn. Fil. Chil. 29 $(1893)=$ Viviania, Cav. (Geraniac.).

elegans, Kunze, 1. c, 30.-Chili.

macrophyllum, Phil. in Linnaea, xxxiii. (1864-65) 32 -Chili.

parvifolium, Phil. 1. c. 33.-Chili.

CISSOIDENDRON, F. Muell. Census, 61 (1882) = KIS. SODLNDRON, Seem, - Hedera, Tourn. (Araliac.)
CISSUS, Linn. Diss. Dass. 6 (1747) : Amoen. Acad. i $389(1749)=$ Vitis, Toum. (Ampelid.).

acetosa, F. Muell. in Trans. Phil. Inst. Vict. iii. (1859) $24=V$. acetosa.

acida, Linn. Sp. Pl. ed. II. $170=$ V. acida.

acida, Roxb. ex Wight \& Arn. Prod. $127=$ V. trifolia. acida, Wall. Cat. n. $6009 \mathrm{~B}=\mathrm{V}$, setosa.

aconitifolia, Walp. Rep. i. $441=$ V. serjaniaefolia. aculeata, Span. in Linnaea, xv. (1841) $184=\mathrm{V}$. aculeata. acuminata, A. Gray, Bot. U. St. Expl. Exped, i. $273=$ V. acuminata.

acuminata, Thw. Enum. Pl. Zeyl. $62=\mathrm{V}$. repanda acutifolia, Poir. Encyc. Suppl. i. $106=$ V. trilolia. adenantha, Fresen. in Mus. Senckenb. ii. (1837) $283=$ $\mathrm{V}$. adenantha. adenocaulis, Steud. ex A. Rich. Tent. Fl. Abyss. i. 111
$=$ V. adenocaulis.

adnata, Roxb. Hort. Beng. 11; Fl. Ind. i. $405=$ V. adnata.

adnata, Wight, ex Wall. Cat. sub n. $5988=\mathrm{V}$. Hey neana.

aegirophylla, Bunge, in Arb. Naturf. Ver. Riga, i. (1847) $193=\mathrm{V}$. aegirophylla.

alata, Blanco, Fl. Filip. ed. II. $51=\mathrm{V}$. geniculata.

alata, Jacq. Select. Am. $23=V$, sulcicaulis ?

albida, Cambess. in St. Hil. Fl. Bras. Mer. i. $344=$ V. albida.

altissima, Zipp. ex Miq. Ann. Mus. Bot. Lugd. Bat. i $74=\mathrm{V}$. papuana

amazonica, Linden, in Belg. Hortic, xv. (1865) 99.Bras.

amboinensis, Zipp. ex Miq. Ann. Mus. Bot. Lugd. Bat i. $76=\mathrm{V}$. amboinensis.

Ampelopsis, Pers. Sym. i. $142=$ V. indivisa

anaimalaiensis, Bedd. in Madr. Journ. Sc. Ser. III. i

1864) $41=\mathrm{V}$. anamallayana

anemonifolia, Zipp. ex Miq. Ann. Mus. Bot. Lugd. Bat i. $80=\mathrm{V}$. anemonifolia.

angulata, Lam. Tabl. Encyc. i. $331=$ V. Linnaei

angustifolia, Roxb. Hort. Beng. 11 ; F1. Ind. 1. $408=$ $\mathrm{V}$. angustifolia.

antarctica, Vent. Choix, 21. t, $21=\mathrm{V}$, antarctica aquosa, Buch.-Ham, ex Wall. Cat, n. $6000=\mathrm{V}$, repanda.

arachnoidea, Hassk. Cat. Hort. Bog. Alt. $166=$ $\mathrm{V}$. indica.

araneosa, Miq. Fl. Ind. Bat. Suppl. i. $517=$ V. araneosa.

arborea, Blanco, Fl. Filip. ed. II. $51=$ Evodia Roxburghiana.

arborea, Desmoul. in Durand, Monog. Vit. $60=$ V. arborea.

arborea, Forsk. Fl. Aegypt. Arab. 32 = Salvadora persica.

arborea, Willd. ex Roem. \&c Schult. Syst. iii. Mant. $248=$ Cybianthus Humboldtii.

argenteus, Linden, in Belg. Hortic. xvii. (1867) 103.Bras.

arguta, Hook. f. in Hook. Niger Fl. 261 V. arguta.

aristata, Blume, Bijdr. $183=\mathrm{V}$. adnata.

articulata, Guill. \& Perr. Fl. Seneg. T'ent. i, 135, in obs.-Afr. trop.

assimilis, Kurz, ex Laws. in Hook. f. Fl, Brit. Ind. i $660=$ V. lanceolaria.

auriculata, DC. Prod, i. $682=$ V. auriculata

auriculata, Roxb. Hort. Beng. 11; F1. Ind. i. $411=$ V. trifolia.

australasica, F. Muell, in Trans. Phil. Soc. Vict, i (1855) $8=\mathrm{V}$, hypoglanca

Baudiniana, Brouss. ex DC. Prod. i. $629=$ V. antarctica.

bifida, Schum. \& Thonn. Beskr. Guin. Pl. $80=$ V. quadrangularis.

bigemina, Harv, in Harv. \& Sond, F1. Cap. i. $253=\mathrm{V}$. gracilis.

biglandulosa, Zipp. ex Miq. Ann. Mus. Bot. Lugd. Bat. i. $75=$ V. pubiflora.

bipinnata, Nutt. Gen. Am. i. $144=$ V. arborea.

Blumeana, Hassk. in Flora, xxy. (1842) II. Beibl. $3 y=$ $\mathrm{V}$. indica.

Blumeana, Span, in Linnaca, xv. (1811) 184.-Java.

Blumeana, Steud. Now. ed. 11. i. 371 - V. pallida.

bonariensis. Hook. \& Arn. in Hook. Bot. Misc ii 1833) $159=\mathrm{V}$. striats.

bororensis, Klotzsch, in Peters, Keise Mussamb. Buc $179-\mathrm{V}$, bururensis.

brevipedurculata, Maxim. l'rim. Il. Anur. is s V. heterophyllix.
CISSUS :-

bryonifolia, Regel, Fl. Ussur. t. 3. f. $3=$ Vitis hetero phylla.

caesia, Afzel. Rem. Guin. $55=\mathrm{V}$. caesia.

canescens, Lam. Tabl. Eacyc. i. 331.-Peruv.

cantoniensis, Hook. \& Arn. Bot. Beech. Voy. $175=$ $\mathrm{V}$. cantoniensis

capensis, Willd. Sp. Pl. i. $655=$ V. capensis.

capreolata, Walp. Rep. i. $439=\mathrm{V}$. capreolata

carnosa, Lam. Encyc. i., $31=$ V. trifolia.

caustica, Tussac, Fl. Ant. i. 116. t. $16=$ V. trifoliata, Baker.

cerifera, Teijsm. \& Binn. in Tijdschr. Nederl. Ind. xxv. (1863) $418=\mathrm{V}$. cerifera

cinerea, Lam. Tabl. Encyc. i. $332=$ V. trifolia

cirrhiflora, Eckl. \& Zeyh. Enum. 56 = pauciftora.

cirrhosa, Willd. Sp. Pl. i. $657=$ V. cirrhosa.

clematidifolia, Zipp. ex Span. in Linnaea, xv. (1841)

$\mathrm{I} 84=\mathrm{V}$, aculeata

clematifolia, Walp. Rep. i. $439=$ V. aculeata.

cochinchinensis, Spreng. Syst. i. 450.-Cochinchin.

compressa, Blume, Bijdr. $182=\mathrm{V}$. adnata.

compressicaulis, Ruiz \& Pav. F1. Per. i. 64. t. 100.-

Perny.

connivens, Lam. Tabl. Encyc, i. 332.-Madag

cordata, Roxb. Hort. Beng. 11; Fl. Ind. i. $407=$

V. glauca, repens.

cordata, Wall. Cat. n. $6001=$ V. adnata.

cordifolia, Linn. Sp. Pl. ed. II. 170,-Am. austr

coriacea, DC. Prod, i. $632=\mathrm{V}$. coriacea.

crenata, Blume, Bijdr. $186=$ Blumeand

crenata, Vahl, Symb. Bot. iii. $19=\mathrm{V}$, trifolia.

cuneifolia, Eckl. \& Zeyh. Enum. 56,-Afr. austr

Currori, Hook, fo in Hook. Niger F1. $265=\mathrm{V}$. Cur

rori.

cyanocarpa, Miq. Fl. Ind. Bat. 1. II. $603=\mathrm{V}$. japonica.

cymosa Schum \& Thonn. Beskr. Guin. Pl. $82=$

V. Thonningii.

cymosa, Steud. Nom. ed. II. i. $372=$ V. tenuifolia.

cyphopetala, Fresen. in Mus. Senckenb. ii. (1837) $282=$

V. cyphoperala.

Darik, Miq. Fl. Ind. Bat. Suppl. i. 515.-Sumatra.

Davidiana, Carr in Rev. Horlic (1868) 29

China.

dealbata, Bedd. in Madr. Journ. Sc. Ser. II. xxii. (1861) 74 .--Ind. or.

deficiens, Hook. \& Am. in Hook. Bot. Misc. iii. (1833

$160=V$. striata.

dendroides, Roem. \& Schult. Syst. iii. Mant. $248=$ Ardisia acuminata.

denticulata, Turcz. in Bull. Soc. Nat. Mosc, xxxvi. (1863) 1. $591=$ V. Afzelii ?

dichotoma, Blume, Bijdr. $186=\mathrm{V}$. dichotoma.

dichrothrix, Miq. Fl. Ind. Bat. Suppl. i. 514.Sumatra.

Diepenhorstii, Mig, 1. c. $515=\mathrm{V}$. Diepenhorstii.

digitata, Lam. Tabl. Encyc. i. 392.-Arabiz.

dimidiata, Eckl. \& Zeyh. Enum. 57.-Afr. austr.

dioica, Roxb. ex DC. Prod. i. $632=$ V. lanceolaria

discolor, Blume, Bijdr. $181=\mathrm{V}$. discolor.

diversifolia, DC. Prod. i. 631 (=heterophylla. Link) - Hab?

diversifolia, Walp. in Nov. Act. Nat. Cur. xis.

Suppl. i. (1843) $\$ 14=$ V. cantoniensi.

Dregeana, Bernh. in Flora, xurvi. (1844) 297 V. capensis.

Duarteana, Cambess. in St. Hil. Fl. Bras. Mer. i. \$ł $=\mathrm{V}$. Duarteana.

dubia, Steud. Nom. ed. II. i. $3 \pi^{2}$-China.

edulis, Dalz in Houk. Kew Joum. ix. 1957. 21s = V. quadrangularis.

elegans, Hort. ex C. Koch, Dendrol. i. $555=1$. betero phylla.

elliptica, Chnm. \& Schlecht. in Lianaca, $1 .(1 \leqslant 30) 2: 1$ V. elliptica.

elongata, Mliq. in Nat. Verh. Wet. Haarl, vii. (1551 $110=V$. Miqueliana.

elongata, Koxb. Hort. Beng. 11 ; F1. Ind. i. \$11 a V. clongat?.

emarginella, Sw, in Vet. Akad. Handl. Stowkl. 18:5 $+2 i=V$. crenata.

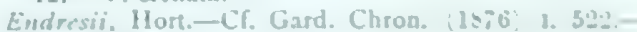
Custa Kica.

enncuphylla, Vell. Fl. Flum. to ; l. L $103=$ V. ennea. phivila.

cpidendrica, Vell. I. c. 39 ; L. \&. $99=$ V. trifoliata. Epidendron, Lithl. in Mart. Fl. liras xir. 11. 21:

pracc. 


\section{CISSUS :-}

erosa, Rich. in Act. Soc. Hist. Nat. Par. i. (1792) 106 $=$ Vitis erosa.

erythrodes, Hochst. ex Miq. Ann. Mus. Bot. Lugd. Bat. i. $79=$ V. erythrodes.

feminea, Roxb. Hort. Beng. 11; F1. Ind. i. $410=$ $\mathrm{V}$. lanceolaria.

ferruginea, E. Mey. Zwei Pfl. Docum. $173=$ Thunbergii.

ferruginea, Willd. ex Roem. \& Schult. Syst. nii. Mant. $248=$ Ardisia ferruginea.

Figariana, Webb, Fragm. F1. Aethiop. $58=$ V. Figariana.

flexuosa, Turcz. in Bull. Soc. Nat. Mosc. xxxi. (1858) I. 415.-Ins. Luzon.

foemina, Steud. Nom. ed. II. i. $372=$ V. lanceolaria.

fragariaefolia, Boj. Hort. Maurit. 60.-Zanzibar.

fragilis, E. Mey. Zwei Pf. Docum. 173, nomen; Harv. $\&$ Sond. Fl. Cap. i. 249.-Afr. austr.

frutescens, Blanco, F1. Filip. ed. I. $70=$ Evodia Roxburghiana.

fuliginea, H. B. \& K. Nov. Gen. et Sp. v. 224.-Am. austr.

Gardneri, Thw. Enum. Pl. Zeyl. $63=$ V. Gardneri.

geniculata, Blume, Bijdr. $184=\mathrm{V}$. geniculata.

gigantea, Bedd. in Madr. Journ. Sc. xxii. Ser. II. (1861) 75 . - Ind or.

glaberrima, Steud. Nom. ed. II. i. $3 \zeta_{2}=$ V. glaberrima.

glabra, Herb. Madr. ex Wall. Cat. sub n, $5988=$ V. Heyneana.

glabra, E. Mey. Zwei Pfl. Docum. $173=\mathrm{V}$. orientalis

glabrata, Blume, Bijdr. $189=\mathrm{V}$. serrulata.

glandulosa, J. F. Gmel. Syst. 256.-Arabia.

glandulosa, Poir. Encyc. Suppl. i. $105=$ V. antarctica.

glandulosa, Roxb. Hort. Beng. 11, nomen.-Ind. or. glauca, Roxb. 1. c. 11 ; Fl. Ind. i. $406=$ V. glauca

glauca, Thw. Enum. Pl. Zeyl. $62=$ V. pallida?

glaucophylla, Hook. f. in Hook. Niger Fl. $263=$ V. glaucophylla.

glyptocarpa, Thw. Enum. Pl. Zeyl. $62=$ V. glyptocarpa gongylodes, Burch. ex Baker, in Mart. F1. Bras. xiv. II. $209=\mathrm{V}$. gongylodes.

gracilis, Guill. \& Perr. Fl. Seneg. Tent, i. $134=$ V. gracilis, Baker.

granulosa, Ruiz \& Pav. Fl. Per. i. $62=$ V. striata

haematantha, Miq. in Linnaea, xxvi. (1853) 220. Guiana.

Hahniana, Ernst, in Journ. Bot. xiv. (1876) 179.Venezuela.

hastata, Miq. F1. Ind. Bat. Suppl. i. $517=$ V. hastata

hederacea, Pers. Syn, i. $143=V$, hederacea.

hederacea, Royle, ex Walp. Rep. i. $439=\mathrm{V}$. capreolata.

helleborifolia, Zipp. ex Span. in Linnaea, xv. (1841) $184=\mathrm{V}$. auriculata

heptaphylla, Retz. Obs. v. $22=\mathrm{V}$. pedata.

heteroma, Turcz. in Bull. Soc. Nat. Mosc. xxxvi. (1863) I. 591.-Java.

heterophylla, Herb. Madr. ex Wall. Cat. n. $6036=$ V. Rheedei.

heterophylla, Link, Enum. Hort. Berol. i. $143=$ diversifolia, DC.

heterophylla, Poir. Encyc. Suppl, i. 107.-Java

heterophylla, Walp. Rep. i. $441=\mathrm{V}$. Landuk.

heterotoma, Tuxcz. in Bull. Soc. Nat. Mosc. xxxvi (1863) I. 591.- - Java

Heyneana, Steud. Nom. ed. II. i. $372=$ V. Heyneana.

himalayana, Walp. Rep. i. $441=\mathrm{V}$. himalayana

hirsuta, Steud. Nom. ed. 1. $199=$ V. hederacea.

hirtella, Blume, Bijdr. $185=\mathrm{V}$. geniculata,

humulifolia, Regel, Tent. Fl. Ussur. $36=\mathrm{V}$. heterophylla.

hydrophora, Gaud. Bot. Voy. Bonite, t. 131.-Hab.?

hypoglanca A. Gray, Bot. U. St. Expl. Exped. i. $272=$ V. hypoglauca.

hypoleuca, Harv. in Harv. \& Sond. F1. Cap. i. 252.Afr. austr.

ibuensis, Hook. f. in Hook. Niger Fl. $2,65=$ V. ibuensis. inaequalis, Heyne, ex Wall. Cat. n. $6010=\mathrm{V}$. inaequalis.

incarnata, Teijsm. \& Binn. in Tijdschr. Nederl. Ind. xxv. (1863) $417=\mathrm{V}$. incarnata.

incisa, Desmoul. in Durand, Monog. Vit. 59, ex S. Wats. Bibliog. Ind. N. Am, Bot. $173=$ V. incisa.

indica, Koen, ex Steud. Nom, ed. II. i. $371,372=\mathrm{V}$ Linnaei.
CISSUS:-

indica, Rottl. in Ges. Naturf. Freunde, Nene Schr. iv 1803) $183=$ Vitis repanda.

indica, Walp. Rep. i. $441=\mathrm{V}$. indica.

indivisa, Desmoul. in Durand, Monug. Vit. 59, ex S. Wats. Bibliog. Ind. N. Am. Bot. $173=$ V. indivisa.

intermedia, A. Rich. Ess. Fl. Cub. $311=$ V. trifoliata Baker.

involucrata, Spreng. Syst. iv. Car. Post. $44=$ Pterisanthes cissoides.

ipomaeifolia, Webb, Fragm. F1. Aethiop. $57=$ V. ipomoeifolia.

fackii, Korth. ex Miq. in Ann. Mus. Bot. Lugd. Bat. i.

$81=\mathrm{V}$. geniculata.

japonica, Willd. Sp. Pl. i. $659=\mathrm{V}$. japonica.

javana, DC. Prod. i. 628.- Java.

juncea, Webb, Fragm. F1. Aethiop. $57=$ V. juncea

Kleinii, Laws. in Hook. f. F1. Brit. Ind. i. 619, in syn $=\mathrm{V}$. adnata.

laciniata, Linn. Syst. ed. X. $897=$ Sicyos laciniata

laevigata, Blume, Bijdr. $191=\mathrm{V}$. auriculata.

Lamarckiana, Roem. \& Schult. Syst. iii. Mant. $239=$ V. sicyoides.

lanceolaria, Roxb. Hort. Beng. 11; F1. Ind. i. $412=$ $\mathrm{V}$. lanceolaria.

Landuk, Hassk. in Flora, xxv. (1842) II. Beibl. $39=$ V. Landuk.

lanigera, Harv. in Harv. \& Sond. Fl. Cap. 1. 252.Afr. austr.

latifolia, Descourt. Fl. Med. Ant. v. 29. t. $11=\mathrm{V}$. sicyoides.

latifolia, Lam. Encyc. i. $30=\mathrm{V}$. glauca.

latifolia, Vahl, Symb. Bot. iii. $18=$ V. adnata.

latifolia, Walp. Rep. i. $441=\mathrm{V}$. latifolia.

leonensis, Hook. f. in Hook. Niger Fl, 264=V. leonensis.

leucocarpa, Blume, Bijdr. $189=\mathrm{V}$. japonica.

leucostaphyla, Steud. Nom. ed. II. i. $372=$ V. lanceolaria.

Lindeni, André, Illustr. Hortic. xvii. (1870) 12, t. 2.N. Granat.

Livingstoniana, Welw. in Joum. Linn. Soc. viii (1865) 76.-Afr. trop.

lonchiphylla, Thw. Enum. Pl. Zeyl. $62=$ V. lonchiphylla.

longepedunculata, Teijsm. \& Binn. in Tijdschr. Nederl. Ind. xxv, (1863) $417=\mathrm{V}$. longepedun culata.

lucida, Poir. Encyc. Suppl. i. 106=V. erosa

macrobotrys, Turcz. in Bull. Soc. Nat. Mosc. xxxii (1859) I. 269.-Sumatra.

macrophylla, Jungh, in Hoev. \& De Vriese, Tijdschr. vii. (1840) 306.- -Java.

macropus, Welw. in Journ. Linn. Soc. viii. (1865) 77 $=\mathrm{V}$. macropus.

Mappia, Lam. Tabl. Fncyc. i. $332=$ V. Mappia,

membranacea, Hook. fo in Hook. Niger F1.266 = V. gracilis.

mexicana, Moç. \& Sesse, ex DC. Prod. i. $631=\mathrm{V}$. mexicana.

micrantha, Poir. Encye. Suppl. i. 105.-Ins. S. Doming.

micrantha, Willd, ex Roem. \& Schult. Syst. iii. Mant $248=$ parviflora

microcarpa, Vahl,Eclog. Am. i. 16=V.trifoliata,Baker. microphylla, Turcz, in Bull. Soc. Nat. Mosc. xxxi. (1858) I. 416.-Afr. austr.

mollis, Steud. ex Baker, in Oliver, F1. Trop. Afr. i.

$413=\mathrm{V}$. serpens.

mucronata, Hook. \& Arn. ex Stend. Nom. ed. II. i. $372=\mathrm{V}$. lanceolaria

multibracteata, Zipp. ex Miq. Ann. Mus. Bot. Lugd. Bat. i. $75=\mathrm{V}$. pubiflora.

multiflora, Willd. ex Roem. \& Schult. Syst. iii. Mant. 249.-Am. austr.

muricata, Dalz. \& Gibs. Bomb. Fl. 40 ; Thw. Enum

Pl. Zeyl. $63=$ V. lanceolaria

mutabilis, Blume, Bijdr. $190=\mathrm{V}$. mutabilis.

napaulensis, DC. Prod. i. $632=$ V. capreolata

natalensis, Bernh. ex Krauss, in Flora, xxvii. (1844)

$349=$ Rhus natalensis.

neilgherrensis, Wight, Spicil. Neilgh. i. 32. t. $36=\mathrm{V}$. himalayana.

nepalensis, Steud. Nom. ed. II. i. 372, vide napaulensis.

nilagivica, Miq. in Linnaea, xxvi. (1853) 221.Ind. or.

nitida, Vell. Fl. Flum. 39 ; i. t. $100=$ V. sicyoides.
CISSUS :-

nivea, Hochst. ex Schweinf. Beitr. Fl. Aethiop. 83.Abysin

nodosa, Blume, Bijdr. $182=$ Vitis nodosa

obliqua, Ruiz \& Pav. Fl. Per. i. 65.--Peruv.

obovata, Vahl, Symb. Bot. iii. $19=$ V. trifoliata, Baker. obscura, DC. Prod.i. $629=$ V. sicyoides.

obtusata, Benth, Bot. Voy. Sulph. 77.-Panama.

obtusifolia, Lam. Encyc. i. $31=$ V. trifolia.

ochracea, Teijsm. \& Binn. in Tijdschr. Nederl. Ind. xxvii. (1864) $35=\mathrm{V}$, ochracea.

officinalis, Klotzsch, in Bot. Zeit. iv. (1846) $110 .-\mathrm{N}$ Granat.

opaca, F. Muell. in Trans. Phil. Inst. Vict. iii. (1859) $23=\mathrm{V}$. opaca

orientalis, Lam. Tabl. Encyc. 1. 332. t. 84. f. $2=$ V orientalis.

ovata, Lam. 1. c. $331=\mathrm{V}$. sicyoides

ovata, Rich. in Act. Soc. Hist. Nat. Par. i. (1792) 106. - Guiana.

oxyodon, Planch, in CataI. Pl. Hort. Donat. 5.-Hab.? pallida, Salisb. Prod. $66=\mathrm{V}$. sicyoides,

pallida, Steud. Nom. ed. II. i. $372=$ V. pallida.

palmata, Poir. Encyc. Suppl. i. $107=$ V. Commersoni

paniculata, Heyne, in Wall. Cat. n. $6022=\mathrm{V}$. tenuifolia.

papillosa, Blume, Bijdr. $183=V$. pubiflora

parviflora, Roem. \& Schult. Syst. iii. Mant. 248.Ind. or.

parvifolia, Salisb. Prod. $66=$ V. acida

paucidentata, Ernst, in Journ. Bot. viii. (1870) 37. -Venezuela.

paucidentata, Klotzsch, in Peters, Reise Mossamb. Bot. i. $179=V$. paucidentata.

pauciflora, DC. Prod. i. 630.-Afr. austr.

Pauli-Guilielmi, Schweinf. Rel. Kotsch. 46.-Afr. trop.

paullinifolia, Vell. Fl. Flum. 40 ; i. t. $102=\mathrm{V}$ ternata?

pedata, Lam. Encyc, i. $31=\mathrm{V}$. pedata

pedatà, Naves, ex Villar, in Blanco, Fl. Philipp. ed. III Nov. App. $50=$ V. lanceolaria.

peltata, Turcz. in Bull. Soc. Nat. Mosc. xxxvi. (1863) I. 590.-Java.

pentagona, Roxb. Hort. Beng. 11 ; Fl. Ind. i. $408=\mathrm{V}$. pentagona.

pentandra, Willd. ex Roem. \& Schult. Syst. iii. Mant. 248 .-Am. austr.

pentaphylla, Buch.-Ham. ex Wall. Cat. sub n. 6016 $=\mathrm{V}$. elongata.

pentaphylla, Herb. Madr. ex Wall, 1. c. sub n. $6022-$ $\mathrm{V}$. tenuifolia.

pentaphylla, Willd. Sp. Pl. i. $659=$ V. pentaphylla pergamacea, Blume, Bijdr. $183=\mathrm{V}$. pergamacea.

petiolata, Hook. fo in Hook. Niger F1. $262=\mathrm{V}$. pallida.

pinnata, [Soland. in] Russell, Aleppo, ed. II. ii. 267. -Cilicia.

pisocarpa, Zipp. ex Miq. Ann. Mus. Bot. Lugd. Bat. i. $79=\mathrm{V}$. pisicarpa

platanifolia, Carr. in Rev. Hortic. (1868) 39.China.

populnea, Guill. \& Perr. Fl. Seneg. Tent. i. $134=$ V. pallida.

porphyrophylla, Lindl. in Proc. Hort. Soc. i. (1861) $225=$ Piper porphyrophyllum.

producta, Afzel. Rem. Guin. $63=$ V. producta.

pruinata, Weinm. in Syll. Ratisb. i. (1824) 224.Bras.

pruinosa, Desf. Cat. Hort. Par, ed. III. 238.-Hab. ?

pubescens, H. B. \& K. Nov. Gen. et Sp. v. 226.-Am anstr.

pubescens, Walp. Rep. i. $441=\mathrm{V}$. pubescens.

pubiflora, Miq. Fl. Ind. Bat. Suppl. i. $516=$ V. pubiflora.

pubinervis, Blume, Bijdr. 185.-Tava.

pulcherrima, Vell. Fl. Flum. 40 ; i. t. $101=$ V. pulcherrima.

puncticulosa, Rich. in Act. Soc. Hist. Nat. Par. i. 1792) $106=\mathrm{V}$. sicyoides

purpurea, Roxb. ex Steud. Nom. ed. II. i. $373=$ V. glauca.

purpurascens, Zipp. ex Miq. Ann. Mus. Bot. Lugd. Bat. i. $85=\mathrm{V}$. rostrata.

pyrrhodasys, Miq. Fl. Ind. Bat. Suppl. i. 517.-Sumatra quadrangula, Salisb. Prod. $66=$ V. quadrangularis. quadrangularis, Linn. Mant, i. $39=V$. quadrangularis. 
CISSUS :-

quadrialata, H. B. \& K. Nov. Gen. et Sp. พ. $225=$ Vitis erosa.

quinata, [Dryand, in] Ait. Hort. Kew. ed. II. i. $260=$

V. cirrhosa.

quinquefolia, Desf. "Cat. Hort. Par. ed. III. $238=\mathrm{V}$. hederacea.

quinquefolia, Soland. in Sims, Bot. Mag. t. $2443=\mathrm{V}$. Simsiana.

repanda, Vahl, Symb. Bot. iii. $18=$ V. repanda

repens, Lam. Encyc. i. $31=V$. repens.

repens, Thw. Enum. Pl. Zeyl. $62=$ V. repanda.

reticulata, Willd. ex Roem. \& Schult. Syst. iii. Mant. $248=$ canescens.

reticulata, Thw. Enam. Pl. Zeyl. $63=$ V. reticulata.

rhodocarpa, Blume, Bijdr. $185=\mathrm{V}$. geniculata.

rhombifolia, Vahl, Eclog. Am. ii. $10=$ V. rhombifolia.

rhomboidea, E. Mey. Zwei Pfl. Docum. 173, nomen;

Harv. \& Sond. F1. Cap. i. 252,-Afr. austr.

riparia, Laws. in Hook. f. F1. Brit. Ind. i. 649, in syn. $=\mathrm{V}$. repanda.

Rocheana, Planch. in Comptes-rendus, xciii. (1881) 369.-Afr. trop.

rosea, Walp. Rep. i. $437=$ V. repanda

rotundata, Heyne, ex Wall. Cat, sub n, $5988=\mathrm{V}$ Heyneana.

rotundifolia, Blume, Bijdr. $480=\mathrm{V}$. pallida.

rotundifolia, Vahl, Symb. Bot, iii. 19.-Arabia.

rubescens, Blanco, Fl. Filip. ed. I. $71=\mathrm{V}$. geniculata.

rubricaulis, Carr. in Rev. Hortic. (1868) 39.-China.

rufescens, Guill. \& Perr. Fl. Seneg. Tent. i. $133=\mathrm{V}$. rufescens.

rugosa, DC. Prod, i. 629.-Ins. Jamaic

salutaris, H. B. \& K. Nov. Gen. et Sp. v. $225=$ V salutaris.

Sandersoni, Harv, in Harv, \& Sond. Fl. Cap. i. 253.Afr. austr.

scariosa, Blume, Bijdr. $191=\mathrm{V}$. coriacea.

Schimperi, Hochst. ex A. Rich. Tent. Fl. Abyss. i. $114=\mathrm{V}$. oxyphylla.

semicordata, Wall. in Roxb. F1. Ind. ed. Carey, ii. 481 $=\mathrm{V}$. himalayana.

semiglabra, Harv. in Harv. \&c Sond. Fl. Cap. i. $250=$ V. semiglabia.

sericea, Eckl. \& Zeyh. Enum. 57.-Afr. austr.

serjaniaefolia, Walp. Rep. i. $441=$ V. serjaniaefolia,

serpens, Hochst. ex A. Rich. Tent. Fl. Abyss. i. $111=$

V. serpens.

serratifolia, Rottl. ex Wight, in Hook. Bot. Misc. ii.

(1831) $104=\mathrm{V}$. pedata

serrulata, Roxb. Hort. Beng. 11; F1. Ind. i. 414 $=\mathrm{V}$. eapreolata.

setosa, Roxb. 11. cc. $83 ; 410=\mathrm{V}$. setosa.

sexangularis, Ernst, in Journ. Bot. viii. (1870) 374 .Venezuela.

sicyoides, Klein, ex Stend. Nom. ed. II. i. $372,373=$ V. discolor.

sicyoides, Linn. Syst. ed. X. $897=$ V. sicyoides.

simplex, Blanco, Fl. Filip, ed. I. $72=\mathrm{V}$. adnata.

Simsirna, Roem. \& Schult. Syst. iii. $246=$ V. Simsiana.

smilacina, H. B. \& K. Nov. Gen. et Sp. v. $224=\mathrm{V}$. sicyoides.

spicifera, Griff. Notul. iv. $693=$ V. macrostachys.

spinosa, Cambess. in St. Hil. F1. Bras. Mer. i. $345=$ $\mathrm{V}$. spinosa.

stans, Pers, Syn i, $143=\mathrm{V}$, arborea.

stipulata, Vell. F1. Flum. 39 ; i.t. $99=\mathrm{V}$. sulcicaulis? striata, Kuiz \& Pav, Fl. Per. i. 64. t. $100=$ V. striata.

stricta, Bert. ex Steud. Nom, ed. II. i. 372 , in syn.= V. striata.

subdiaphana, Steud, in A. Rich. Tent. Fl. Abyss, i.

$110=V$. gracilis.

suberecta, Bedd. in Madr. Journ. Sc. Ser. II. xxii. (1861)

75. - Ind. or.

vylvatica, Cambess. in St. Hil. Fl. Bras. Mer, i. $345=$ V. erosa

tamoides, Cambess, 1. c. $842=$ V. sicyoides.

tenuicaulis, Hook. \&. in Hook. Niger Fl. $266=\mathrm{V}$. tenuicaulis.

tenuifolia, Heyne, in Wall. Cat, n. $6022 \mathrm{~A}=\mathrm{V}$. tenuifolia.

ternati. J. F. Gmel. Syst. 250.-Arabia.

tetragona, Harv, in Harv. \& Sond. Fl. Cap. i. 249.-

Afr. austr.

tetraptera, Hook. f, in Hook. Niger Fl, $269=\mathrm{V}$. quad. 1angularis.
CISSUS :-

Teysmanni, Miq. Fl. Ind. Bat. Suppl. i. 516. - Sumatra Thunbergii, Eckl. \& Zeyh. Enum. 56.-Afr. austr. Thunbergii, Sieb. \& Zucc. in Abh. Akad. Muench. iv. II. (1846) $195=$ Vitis inconstans.

thyrsiflora, Blume, Bijdr. $187=\mathrm{V}$. thyrsiflora,

tiliacea, H. B. \& K. Nov. Gen. et Sp. v. $222=$ V. tiliacea.

timoriensis, DC. Prod. i. 630.-Ins. Timor.

tinctoria, Arrucla, in Koster, Trav. Braz. 496.-Bras.

tinctoria, Mart. in Spix \& Mart. Reise Bras. $368=\mathrm{V}$ sicyoides.

tomentosa Lam. Tabl. Encyc i. $330=\mathrm{V}$. capensis

triandra, Schum. \& Thonn. Beskr. Guin. Pl. $81=\mathrm{V}$ quadrangularis.

tricuspidata, Sieb. \& Zucc, in Abh. Akad. Muench. iv. II. (1846) 196. - Japon.

tricuspis, Burch. ex Baker, in Mart. Fl. Bras. xiv. II. $209=V$. tricuspis

tridentata, Eckl. \& Zeyh. Enum. $56=$ pauciflora.

trifoliata, Buch.-Ham. in Wall. Cat. D. 6013? K=V. angustifolia.

trifoliata, Linn. Sp. Pl. ed. II. $170=$ V. trifoliata Baker.

trifoliata, Lour. $\mathrm{FI}$. Cochinch. $83=d u b i \alpha$

trigona, Willd. ex Roem. \& Schult. Syst. iii. Mant. 248. - Bras.

trilobata, Lam. Encyc. i. $31=$ V. Rheedei.

triternata, Miq. F1. Ind. Bat. Suppl. i. 516.-Sumatra.

truncata, Laws. in Hook. f. F1. Brit. Ind, i. $660=\mathrm{V}$ tenuifolia.

tuberculata, Blume, Bijdr. $189=\mathrm{V}$, tuberculata.

tuberculata, Jacq. Hort. Schoenb. i. 14.-Am. austr

tuberosa, Moç. \& Sesse, ex DC. Prod. i. $629=$ V tuberosa.

umbellata, Lour. Fl. Cochinch. 84.-China.

umbrosa, H. B. \& K. Nov. Gen. et Sp, v. 223.-Am. austr.

unifoliatc, Harv. in Harv. \& Sond. Fl. Cap. i. 250.Afr. austr.

uvifer, Afzel. Rem. Guin. $69=$ V. uvifer

vagans, Carr. in Rev. Hortic. (1875) $60=\mathrm{V}$. japonica?

Veitchii, Carr. 1. c. (1877) 176.-Hab. ?

velutinus, Linden, ex Hook. Bot. Mag, t. 5207. Hab?

venatorum, Descourt. Fl. Méd. Ant. v. 21. t. $309=\mathrm{V}$ sicyoides.

verrucosa, Stend. Nom. ed. II. i. $373=$ V. tubercu lata.

vesicatoria, Blanco, Fl. Filip. ed. II. $50=$ V. repens

villosa, Roxb. Hort. Beng. 11, nomen.-Hab. ?

violacea, Meyen, Reise, i. 300.-Chili.

viticifolia, Sieb. \& Zucc. in Abh. Akad. Mrench. iv. II (1846) $196=\mathrm{V}$, serianaefolia.

vitiensis, A. Gray, Bot. U. St. Expl. Exped. 1. $272=$ V. vitiensis.

vitifolia, Boiss. Diagn. Ser. I. vi. $31=$ V. persica.

vitifolia, Salisb. Prod. $66=$ V. repanda.

vitiginea, Linn. Sp. Pl. $117=$ V. repanda.

vitiginea, Roxb. F1. Ind. i. $406=\mathrm{V}$. lanata

Vogelii, Hook. f. in Hook. Niger Fl. $267=$ V. Vogelii.

Wallichiane, Turcz, in Bull. Soc. Nat, Mosc. xxxi.

(1¿58) 1. $416=$ Hedera Helix

Zollingeri, Turcz. 1. c. xxxvi. (1863) I. 591.-Java.

C.ISTANCHE, Hoffmgg. \& Link, F1. Port. i. 318. 63 (1806). OROBANCHACEAE, Benth. \& Hook. f. ii. 983 .

HAEMODORON, Reichb. Consp. 212 ${ }^{\mathrm{b}}$ (1828)

Iutea, Hoffmgg. E Link, l. c. 319.-Reg. Mediterr. Arabia.

lutea, Wight, Illustr, ii, 180 , t 158 , b. f, $4=$ tubulosa tubulosa, Wight, Ic. t. 1420 bis.-Ind, bor. occ.

CISTANTHE, Spach, Hist. Vég. Phan, v. $229\left(1836^{\circ}\right)=$ Calandrinia, H. B. \& K. (Portulac.)

anceps, Spach, 1. c. $230=\mathrm{Cal}$, grandithora.

discolor, Spach, 1. c. $231=$ Cal. discolor

glauca, Spach, ex Heynb. Nom. ii. $146^{\circ}=$ Cal. grandi. flora,

speciosa, Lilja, ex Heynh. 1. c。 $=$ Cal. discolor.

CISTELA, Blume, Fil. Jav. pracf. p. vi $\left(1828^{\prime}=\operatorname{seq}^{\prime}\right.$

CISTELLA, Blume, Bijicr. 293. t. 55 (1525)-Geodorum, Jack . Orchich.

cernes, Blume, $1 . c_{0}=G$. dilataturn.
CISTICAPNOS, Adans, Fam, ii. $431(1763)=$ CYSTI. CAPNOS, Boerh.=Corydalis, Vent. (Papaverac.).

CISTOCARPIUM, Spach, Hist. Vég. Phan. vi. 471 (1838) = Vesicaria, Tourn. (Crucifer.). utriculatum, Spach, 1. c。 $472=\mathrm{V}$. utriculata.

CISTOCARPUM, Pfeiff. Nom. i. $766(1874)=$ seq.

CISTOCARPUS, Kanth, in Mém. Soc. Nat. Hist. Pa iii. (1827) $389=$ Balbisia, Cav. (Geraniac.)

CISTOMORPHA, Caley, ex DC. Syst. i. 427, in syn. $(1818)=$ Hibbertia, Andr. (Dilleniac.)

lanceolata, Caley, 1. c $=$ H. saligna

CISTRUM, Hill, Veg. Syst. iv. $36(1762)=$ Centaurea Linn. (Compos.)

asperum, Hill, l. $\mathrm{c},=$ Cent, aspera.

$J_{\text {snardi, Hill, l. } \mathrm{c}_{0}=\text { Cent. aspera }}$

napifolium, Hill, 1. c. = Cent. napifolia.

CISTULA, Noronba, in Verh. Batav, Gen. v. (1790) ed I. Art. IV. 2 (Quid ?).

CISTUS, [Toum.] Linn. Syst. ed. I (1735). CIS TINEAE, Benth. \& Hook. f. i. 113

Halimium, Spach, in Ann. Sc. Nat. Sér. II. vi (1836) 365 .

LADANIUM, Spach, 1. c. 367 (1836)

LEUONIA, Spach, i c. 369 (1836)

Libanotrs, Rafin. Sylva Tellur. 132 (1838).

RHodocis'tus, Spach, in Ann. Sc. Nat. Sér. II. (1836) 367

STEPHANOCARPUS, Spach, 1. c. 368 (1836).

Strobon, Rafin. Sylva Tellur. 132 (1838).

acuminatus, Viv, Ann. Hot. i. II. (1804) $172=$

Helianthemum variabile.

acutifolius, Sweet, Cist. t. 78.-Europ.

aegypticus, Linn. Sp. Pl. $527=$ Helianthemum aegyp tiacum.

aegyptius, Pall, ex Bieb. Fl. Taur. Cauc. ii. $8=$

Helianthemum salicifolium.

affnis, Bertol. ex Guss, Fl. Sic. Prod. ii. $12=$ monspeliensis.

albidus, Linn. Sp. Pl. 524.-Reg. Mediterr.

albissimus, Noronha, in Verh. Batav. Gen. v. (1790) ed. I. Art IV. 10.-Malaya.

algarvensis, Sims, Bot. Mag. t. $627=$ Helianthemum ocymoides.

alpestris, Crantz, Stirp. Austr. ed. I. fasc ii. 73 ; ed.

II. $103=$ Helianthemum' cinereum.

alternifolius, Vahl, Symb. Bot. i. $38=$ Helianthemum brasiliense.

alyssoides, Lam. Encyco ii. $20=$ Helianthemum alyssoides.

anglicus, Linn. Mant. ii. $245=$ Helianthemum cine reum.

angustifolius, Jaç. Hort. Vindob. iii. $29=$ Helian themum variabile.

angustifolius, Lag. ex W'illk. \&c Lange, Prod. Fl. Hisp. iii. $734=$ Helianthemum leptophyllum.

angustifolizs, Salisb. Prod. $368=$ Helianthemum umbellatum.

annuses, Lamb. ex Dun. in DC. Prod, i. $272=$ Helian. themum villosum.

anthurus, Link, in Schrad. Neues Journ. i. (1805) 112 - Helianthemum umbellatum.

appeninus, Linn, Sp. Pl. $559=$ Helianthemum mria bile.

arabicus, Linn. Cent. i. $14=$ Helianthemum arabicum. a-perifolius, Pomel, Nouv. Mat. Fl. At!. \$55.-Afr bor.

asperifolius, Swect, Cist, t. 87 m lon:vifulius.

atriplicifolius, Lam. Encyc. ii. $19=$ Helianthenum atriplicifolium.

barbatus, Lam. I. c. $24=$ Helianthemum volpare

Barrelieri. Steud. Nom. ed. 1. 19y-IIclianthemum glutinosum.

Rourgaennus, Coss. dietes Crit. id. $30,-$ Hisman.

brasiliensis, Lam. Encyc. ii. $22=$ Helianthemum brasiliense.

brevifulius, I/sll. Gord. Dict, el. VIII. n. 3.-1lah. I

bupleurifolius, Lan. kncyc. ii. 22 - IIclianthemum guttalum.

Givinus. Linn. Mant. ii. $565=$ Mclianchemum Fumsns.

canudensis, Linn. SY. II. $520=$ Helianthemum cana donse. 


\section{CISTUS :-}

canariensis, Jacq. Misc. ii, $389=$ Helianthemum

candidissimus, Dun. ex DC. Prod. i. $264=$ vaginatus. canescens, Sweet, Cist. $t .45=$ polymorphus.

canus, Georgi, Beschr. Russ, Reich. iii. IV. $1047=$ Helianthemum oelandicum.

canus, Jacq. F1. Austr. iii. 42. t. $277=$ Helianthemum montanum.

canus, Linn. Sp. Pl. 525= Helianthemum vineale.

capensis, Linn. $l$. $c$. ed. II. 736.-Afr. anstr.

carolinianus, Walt. F1. Carol. $152=$ Helianthemum carolinianum.

cheiranthoides, Lam. Encyc, ii. $19=$ Helianthemum lasianthum.

ciliatus, Desf. Fl. Atlant. i.421.t. $109=$ Helianthemum virgatum.

ciliatus, Rostung, ex Dun. in DC. Prod. i. $281=$ Helianthemum obtusifolinm.

cinereus, Cav. Ic, ii, 33, t, $141=$ Helianthemum cinereum.

cistifolius, Steud. Nom. ed. I. $200=$ Helianthemum variabile.

Clusii, Dun. in DC. Prod. i. 266.-Hispan. ; Afr. bor.

collinus, Salisb. Prod. 368=monspeliensis. complicatus, Lam. Encyc. ii. $14=$ parviflorus. complicatus, Sprun. ex Nym. Consp. $70=$ villosus corbariensis, Pourr. in Mém. Acad. Toul. iii. (1788) $312=$ salvifolius.

cordifolius, Mill. Gard. Dict. ed. VIII. n. 12.Hab?

cordifolius, Moench, Meth. $245=$ populifolius

coriaceus, Poir. Encyc. Suppl. ii. 278 (= Hemistemma Aubertii, Commersonii).-Madag.

corsicus, Loisel. Nouv. Not. $24=$ villosus.

corymbosus, Poir. Encyc. Suppl. ii. $272=$ Helianthemum corymbosum.

crassifolius, Poir. 1. c. $277=$ Helianthemum cinereum creticus, Linn. Sp. P1. ed. II. $738=$ polymorphus. creticus, Sibth. \& Sm. F1. Graec. Prod. i. $364=$ parvi florus.

crispus, Linn. Sp. Pl. 524.-Reg. Mediterr.

croceus, Desf. FI. Atlant. i. 422 . t. $110=$ Helianthemum glaucum.

Cupanianus, Presl, F1. Sic. i. $117=$ polymorphus

cymosus, Dun. in DC. Prod. i. $265=$ parviflorus.

cyprius, Lam. Encyc。 ii. 16.-Ins. Cyprus.

denticulatus, Kit. ex Kanitz, in Verh. Zool.-Bot. Ges.

Wien, xiii. (1863) 529.-Hungar.

denticulatus, Poir. Encyc. Suppl. ii. $278=$ Helianthemum salicifolium.

dichotomus, Cav. Ic. îi. $32=$ Helianthemum origanifolium.

distachyus, Roth, Catalecta, i. $62=$ Helianthemum distachyum.

dubius, Pourr. in Mém. Acad. Toul. iii. (1788) 312.Mont. Pyren.

Dunalianus, Steud. Nom. ed. II. i. $374=$ polymorphus.

echioides, Lam. Encyc. i. $21=$ Helianthemum variabile.

ellipticus, Desf. Fl. Atlant. i. 418. t. 107=Helianthemum Lippii.

elongatus, Vahl, Symb. Bot. i. $38=$ Helianthemum lasiantham

ericoides, Cav. Ic. ii. 56. t. $172=$ Helianthemum Fumana.

eriocephalus, Viv. Fl. Cors. Sp. Nov. $8=$ polymorphtis.

fasciculatus, Steud. Nom. ed. I. $200=$ Helianthemum fasciculatum.

fastigiatus, Guss. Fl. Sic. Prod, ii. $13=$ Clusii.

feredjensis $\times$, Battand. in Bull. Soc. Bot. Fr. xxx. 1883) 263.-Afr. bor.

ferrugineus, Lam. Encyc. ii. $25=$ Helianthemum arabicum.

forentinus, Lam. 1. c. $17=$ monspeliensis

floribundus, Tausch, in Flora, xix. (1836) 417.Gallia.

foetidus, Jacq. Misc. ii. $341=$ Helianthemum variabile.

formosissimus, Schneev. Ic. Pl. Rar. t. 47.-Lusitan.

formosus, Curt. Bot. Mag. t. $264=$ Helianthemum lasianthum.

Fumana, Linn. Sp. PI. $525=$ Helianthemum procumbens.

Fumana, Schousb. ex Ball, in Journ. Linn. Soc. xvi. (1877) $348=$ Helianthemum glutinosum.

\section{CISTUS :}

galactites, Schmidel, Ic. Pl. ed. II. 250, t. $65=$ Helianthemum vulgare?

garganicus, Tenore, Ind. Sem. Hort. Neap. (1829) 15 ex Syll. ed. fol. $74:=$ villosus.

glaucophyllus, Lam. F1. Fr. iii, $162=$ Helianthemum laevipes.

glaucus, Cav. Ic. iii. 31. t. $261=$ Helianthemum glaueum.

glaucus, Desf. F1. Atlant. i. $418=$ Helianthemum crassifolium.

glaucus, Pourr. in Mém. Acad. Toul. iii. (1788) 311. - Gallia.

glaucus, Salisb. Prod. $368=$ Helianthemum laevipes.

globularifolius, Lam. Encyc. ii. $22=$ Helianthemum Tuberaria.

glomeratus, Lag. Gen. et Sp. Nov. $16=$ Helianthemum glomeratum.

glutinosus, Linn. Mant. ii. $246=$ Helianthemum glutinosum.

grandiflorus, Pourr. ex Willk. \& Lange, Prod. F1. Hisp. iii. $712=$ ladaniferus.

grandiflorus, Scop. F1. Carn. ed. II. i. $377=$ Helianthemum vulgare.

guttatus, Linn. Sp. P1. $526=$ Helianthemum guttatum. halimifolizs, Linn. 1. c. $524=$ Helianthemum halimifolium.

helianthemoides, Crantz, Stirp. Austr. ed. I. i. 69 ; ed. II. $101=$ Helianthemum variabile.

helianthemoides, Desf. Fl. Atlant. i. 422,-Afr. bor.

Helianthemum, Linn. Sp. P1, $528=$ Helianthemum vulgare.

heterophyllus, Desf. FI. Atlant. i. 411. t. $104=$ polymorphus.

hirsutus, Lam. Fl. Fr. iii. 157.-Hispan. ; Lusitan.

hirsutus, Lapeyr. Hist. Abr. Pl. Pyr. $303=$ Helian themum polymorphum.

hirtus, Chaub, ex Nym. Consp. $74=$ Helianthemum glaucum.

hirtus, Gilib. FI. Lituan. v. $225=$ Helianthemum vulgare.

hirtus, Linn. Sp. P1. $528=$ Helianthemum hirtum

hirtus, Sibth. \& Sm. Fl. Graec. vi. 1. t. $501=$ Helianthemum obtusifolium.

hirtus, Thib, ex Dun, in DC. Prod..i. $283=$ Helian themum asperum.

hispanicus, Mill. Gard. Dict. ed. VIII. n. 5.Hispan.

hispidus, Lam. Encyc. ii. $26=$ Helianthemum hirtum.

horridus, Lag, in Varied. Cienc. ii. IV. (1805) 214 sphalm. (=Cirsium horridum)

humilis, Salisb. Prod. $368=$ Helianthemum vulgare.

hybridus, Pourr. in Mém. Acad. Toul. iii. (1788) $312=$ salvifolius.

hybridus, Vahl, Symb. Bot. i. 37.-Hispan.

imbricatus, Poir. Encyc. Suppl. ii. $278=$ Helianthemum ledifolium.

immaculatum, Steud. Nom. ed. I. $200=$ Helianthemum guttatum.

incanus, Linn. Sp. P1. 524= polymorphus.

incanus, Sibth. \& Sm. Fl. Graec. v. 76. t. $494=$ parviflorus.

inconspicuus, Poir. Encyc. Suppl. ii. $278=$ Helianthemum guttatum.

indicus, Linn. Syst. ed. XII. 36\%, sphalm. vide italicus.

intermedius, Poir. Encyc. Suppl: ii. $278=$ Helianthemam intermedium.

involucratus, Lam. Encyc, ii. $20=$ Helianthemum lasianthum.

italicus, Linn. Syst. ed. X. $1078=$ Helianthemum montanum.

italicus, Pall. ex Bieb. Fl, Taur. Cauc. ii. $8=$ Helianthemum oelandicum.

japonicus, Fortune, in Fourn. Agri.-Hort. Soc. Ind. ix. (1855) 96.-Japon

kahiricus, Steud. Nom. ed. I. $200=$ Helianthemum kahiricum.

ladaniferus, Curt. Bot. Mag. t. $112=$ cyprius.

ladaniferus, Gouan, ex Steud. Nom. ed. II. i. $374=$ C. Ledon.

ladaniferus, Linn. Sp. Pl. 523.--Reg. Mediterr. occ.

ladaniferus, Stokes, Bot. Mat. Med. iii. $209=$ poly morphus.

ladanosma, Hoffmgg. Verz. 51=ladaniferus.

laevipes, Linn. Cent. i, $14=$ Helianthemum laevipes.

laevis, Cav. Ic. ii. 35 . t. 145. f. $1=$ Helianthemum thymifolium

\section{CISTUS:-}

lanceolatus, Vahl, Symb. Bot. ii. $62=$ Helianthemum guttatum.

lanuginosus, Viv. F1. Lib. Spec. 28. t. 14, f. $3=$ Helianthemum lanuginosum.

lasianthus, Lam. Encyc. ii. $19=$ Helianthemum lasianthum.

latifolius, Sweet, Cist. t. $15=$ populifolius

laurifolius, Linn. Sp. Pl. 523.-Europ. austr. occ. As. Min.

lavandulaefolius, Lam. Encyc. ii. 25=Helianthemum lavandulaefolium.

laxus, [Dryand, in] Ait. Hort. Kew. ed. II. iii. $305=$ longifolius, Lam.

laxus, Brot. ex Nym. Consp. $71=$ hirsutus.

ledifolius, Georgi, Beschr. Russ. Reich. Nachtr. $276=$ Helianthemum salicifolium.

ledifolius, Linn. Sp. P1. $527=$ Helianthemum ledi folium.

ledonius, St. Lag. in Ann. Soc. Bot. Lyon, vii. (1880) $122=$ glaucus

Ledon, Lam. Encyc. ii. $17=$ glaucus

lepidotus, Amo, F1. Iber. vi. $357=$ Helianthemum halimifolium.

Libanotis, Desf. F1. Atlant. i. $412=$ Clusii.

Libanotis, Linn. Syst. ed. X. 1077 = Helianthemum Libanotis.

lilacinus, Hoffmgg. ex Steud. Nom. ed. II. i. $374=$ parviflorus.

linearis, Cav. Ic. iii. 8. t. $216=$ Helianthemum variabile.

Lippi, Linn. Mant. ii. $245=$ Helianthemum Lippii.

longifolius, Hort, ex Steud. Nom. ed. II. i. $374=$ grandiflorus.

longifolius, Lam. Encyc. ii. 16.-Hispan.; Gallia.

longifolius, Mill. Gard. Dict. ed. VIII. n. 18. Hab. ?

Iunulatus, All. Auct. Pedem. 30. t. 2. fo $3=$ Helianthemum lunulatum.

lusitanicus, Mill. Gard. Dict, ed. VIII. n. $4=$ = Helianthemum variabile.

luteus, Gilib. F1. Lituan. ii. $225=$ Helianthemum variabile.

majoranifolius, Gouan, Herbor. $36=$ Helianthemum hirtum.

marifolius, Bieb. F1. Taur. Cauc. ii. $8=$ Helianthemum oelandicum

marifolius, Linn. Sp. Pl. $526=$ Helianthemum vineale.

mauritanicus, Thib. ex Dun. in DC. Prod. i, $276=$ Helianthemum glutinosum

medius, F. F. Gmel. Syst. 822.-Italia.

micranthus, Viv. Fl. Lib. Spec. $27=$ Helianthemum micranthum.

mollis, Cav. Ic. iii. 32. t. 262. f. $2=$ Helianthemum origanifolium.

monspeliensis, Linn. Sp. Pl. 524.-Reg. Mediterr. ()cc.

multiflorus, Amo, FI. Iber. vi. $359=$ Helianthemum halimifolium,

Munbyi, Pomel, Nouv. Mat. Fl. Atl. 215.-Afr. bor

mutabilis, Jacq. Misc. ii. $340=$ Helianthemum variabile.

myrthifolius, Lam. Fl. Fr. iii. $161=$ Helianthemum cinereum.

nervosus, Lam. 1. c. $164=$ Helianthemum Tuberaria. nigricans, Pourr. in Mém. Acad. Toul. iii. (1788) 311 $=$ longifolius.

niloticus, Linn. Mant. ii, $246=$ Helianthemum ledifolium.

nudifolius, Lam. Fl. Fr. iii. $163=$ Helianthemum Fumana.

nummularius, Cav. Ic. ii. 34. t. $142=$ Helianthemum rubellum.

nummularius, Linn. Sp. P1. $527=$ Helianthemum vulgare.

oblongifolius, Sweet, Cist. t. $67=$ longifolius.

obscurus, Steud. Nom. ed. I. $201=$ Helianthemum variabile.

obtusifolius, Sweet, Cist. t. $42=$ longifolius

occidentalis, Amo, Fl. Iber. vi. $352=$ Helianthemum alyssoides.

ochreatus, Chr. Sm. ex Buch, in Berl. Acad. Abh 1816-17 (1819) 380.--Ins. Canar.

ocymoides, Brot.-Cf. Nym. Consp. 72 = Helianthemum ocymoides.

ocymoides, Lam. Encyc. ii. $18=$ polymorphus, 


\section{CISTUS}

oelandicus, Lam. Encyc. ii. $20=$ Helianthemum montanum.

oelandicus, Linn. Sp. Pl. $526=$ Helianthemum italicum.

olbiensis, Huet \& Hanry, in Bull. Soc. Bot. Fr, vii. (1860) $346^{\circ}=$ monspeliensis.

oleaefolius, Mill. Gard. Dict. ed. VIII. n. $10=$ monspeliensis.

oligophyllus, Clark, Trav. ii. $452=$ Helianthemum oligophyllum.

origanifolius, Lam. Encyc. ii. $21=$ Helianthemum origanifolium.

ovatus, Viv. F1. Ital. Fragm. i. $6=$ Helianthemum variabile.

parasiticus, Noronha, in Verh. Batav. Gen. v. (1790) ed. I. Art. IV. 10.-Malaya.

parviflorus, Lam. Encyc. ii. 14.-Reg. Mediterr. or.

Pechii, Pourr. ex Timb. in Bull. Soc. Sc. Phys. et Nat. Toul. ii. (1874) 90.-Gallia.

petiolatus, Martr. Herbor. Midi Fr.-Cf. Bull. Soc. Bot. Fr. ii. (1855) 122.-Gallia.

petiolatus, Poir. Encyc. Suppl. ii. $278=$ Helianthemum petiolatum.

piliferus, Gmel, ex Willk, \& Lange, Prod. F1. Hisp. iii. $729=$ Helianthemum pulverulentum.

piloselloides, Lapeyr. Hist. Abr. Pl. Pyr. $301=$ Helianthemum montanum.

pilosus, All. Fl. Pedem. ii. $104=$ Helianthemum polifolium.

pilosus, Linn. Sp. PI. $528=$ Helianthemum variabile.

piluliferus, Thib. ex Drn. in DC. Prod. i. $282=$ Helianthemum variabile.

piperifolius, Noronha, in Verh. Batav. Gen. v. (1790) ed. I. Art. IV. 10.-Malaya.

plantagineus, Willd. Sp. Pl. ii. $1197=$ Helianthemum

guttatum.
plantaginifolius, Salisb. Prod. $368=$ Helianthemum Tuberaria.

platysepalus, Sweet, Cist. t. 47.-Ins. Creta.

polifolius, Linn. Sp. Pl. ed. II. $745=$ Helianthemum pulverulentum.

polufolius, Huds. Fl. Angl, ed. I. $205=$ praec.

polyanthos, Desf. Fl. Atlant. i. $420=$ Helianthemum polyanthum.

polymorphus, Willk. Ic. Pl. Hisp. ii. 19 (sp. aggregat.). - Reg. Mediterr.

populifolius, Linn. Sp. Pl. i. 523.-Reg. Mediterr. occ porquerollensis, Hanry \& Huet, in Bull. Soc. Bot. Fr. vii. (1860) $345=$ monspeliensis.

Pousolzii, Delile, Suppl. Cat. Hort. Monsp. (1839); ex Gren, \& Godr. F1. Fr, i. $163=$ albidus.

psilosepalus, Sweet, Cist. t. $33=$ hirsutus.

pulverulentus, Pourr. in Mém. Acad. Toul. iii. (1788) $312=$ albidus

punctatus, Willd. Sp. Pl. ii. $1199=$ Helianthemum salicifolium.

purpureus, Lam. Encyc. ii. 14.-Oriens.

quinquenervis, Noronha, in Verh. Batav. Gen. v, (1790) ed. I. Art. Iv. 10.-Malaya

quinquevulnerus, Vis. in Act. Ist. Ven. Sc. Ser. III iv. (1858-59) 138.-Hab. ?

racemosus, Cav. Ic. ii. 81 . t. $140=$ Helianthemum lavandulaefolium.

racemosus, Lam. Encyc. ii. $25=$ Helianthemum virga tum.

racemosus, Linn. Mant. i. $76=$ Helianthemum variabile.

ramuliflorus, Poir. Encyc. Suppl. ii. $274=$ Helianthemum canadense.

retrofractus, Poir. 1. c. $278=$ Helianthemum retrofractum.

rorismarinifolius, Pourr. ex Timb. in Bull. Soc. Se Phys, \& Nat. Toul, ii. (1874) $101=$ Clusii

roseus, All. Fl. Pedem, ii. $105=$ Helianthemum vulgare.

reseus, Jacq. Hort. Vindob. iii. $87=$ Helianthemum variabile.

rosmarinifolius, All. F1. Pedem. ii. 105=Helianthemum rosmarinifolium.

rosmarinifolius, Pourr. in Mém. Acad. Toul. iii. (1788) $313=$ Clusii.

rosmarinifolius, Salisb. Prod. $368=$ Helianthemum Libanotis.

rotundifolius, Swect, Cist. t. $75=$ vulgaris.

ruficomus, Viv. Fl. Cors. Sp. Nov. $8=$ Helianthemum ruficomum.

salicifolius, Cav. Ic. ii. 35 . t. 144-Helianthemum intermedium.

\section{CISTUS:-}

salicifolius, Huds. F1. Angl.ed. II. $233=$ Helianthemum ledifolium.

salicifolius, Linn. Sp. Pl. $527=$ Helianthemum salicifolium.

salviaefolius, Boiss, F1, Orient. iii. $438=$ seq.

salvifolius, Linn. Sp. Pl. 524.-Reg. Mediterr

salvifotius, Pall. ex Bieb. Fl. Taur. Cauc. ii. $7=$ poly morphus.

sampsucifolius, Cav. Ic. i. $65=$ Helianthemum ocy moides.

sampsucifolius, Sims, Bot. Mag. xliii. (1816) t. $1803=$ Helianthemum variabile.

sanguineus, Lag. in Varied. Cienc. ii. IV. (1805) 40.Austr.

Savi, Bertol, ex Dun. in DC. Prod. i。 275=Helian themum arabicum.

scabrosus, [Soland. in] Ait. Hort. Kew. ed. I. ii. $236=$ Helianthemum lasianthum.

scorpioides, Desf. ex Steud. Nom. ed. II. i. $375=$ Helianthemum glaucum.

sedjera, Pomel, Nouv. Mat. Fl. Atl. 216.-Afr. bor. Seguieri, Crantz, Stirp. Austr. ed. I. fasc. ii. 74, ed. II $104=$ Helianthemum cinereum

Seguieri, Pourr. ex Dun. in DC. Prod. i. $277=$ Helian themum italicum.

sericeus, Munby, Fl. Algér. 53.-Algeria.

sericeus, Vahl, Symb. Bot. i. 37.-Hispan.

serpillifolius, Balb. ex Dun. in DC. Prod. i. $280=$

Helianthemum variabile.

serpillifolius, Linn. Sp. Pl. $527=$ Helianthemum vul gare.

serratifolius, Lamb. ex Dun. in DC. Prod, i. $271=$

Helianthemum guttatum.

serratus, Cav. Ic. ii. 57. t. $175=$ Helianthemum gutta tum.

sessiliflorus, Desf. Fl. Atlant. i. $417=$ Helianthemum Lippii.

Sideritis, Presl, Fl. Sic. i. 116.-Sicilia.

Skanbergi, Lojac. in Natural. Sicil. iv. (1885) 95.Sicilia.

splendens, Lam. Fl. Fr. iii. $156=$ Helianthemum variabile.

squamatus, Linn. Sp. Pl. $1196=$ Helianthemum squamatum.

stellulatus, Steud. Nom. ed. I. 201=Helianthemum stellulatum.

stenophyllus, Link, Enum. Hort. Berol. ii. $74=$ Clusii cyprius.

stipulatus, Forsk. F1. Aegypt. Arab. $100=$ Helian themum kahiricum.

stoechadifolius, Brot. Fl. Lusit. ii. $270=$ Helianthemum glaticum.

toechadifolius, Hort. ex Dun. in DC. Prod. i. $280=$ Helianthemum leptophyllum.

strictus, Cav. Ic. iii. 32. t. 263. f. $2=$ Helianthemum virgatum.

strigosus, Fisch. ex Steud. Nom. ed. II. i. $375=$ Helian themum cineream.

sulphureus, Steud. 1. c. ed. I. $201=$ Helianthemum variabile.

surrejanus, Linn. Sp. P1. 527 = Helianthemum Chamaecistus.

symphytifolius, Lam. Encyc. ii. $15=$ vaginatns

syriacus, Jacq. Ic. PI. Rar. i. 10.t. $96=$ Helianthemum lavandulaefolium.

syrticus, Viv, Fl. Lib. Spec, $27=$ Helianthemum syrticum.

tauricus, F. E C. Presl, Delic. Prag. 24.-Tauria.

telephioides, Noronha, in Verh. Batav. Gen. v. (1790) ed. I. Art. IV. 10.-Malaya.

teretifolius, Poir. Encyc. Suppl. ii. $279=$ Helianthemum hirtum.

teretifolius, Thib. ex Dun. in DC. Prod. i: $281=$

Helianthemum variabile.

Thibaudi, Poir, Encyc. Suppl, ii. $277=$ Helianthemum lavandnlaefolium.

thimifolius, Gouan, ex Vill. Prosp. $49=$ Helianthemum thymifolium.

thymifolius, Falk, Beitr. ii. $197=$ Helianthemum soon-

goricum.
thymifolius, Linn. Sp. Pl. $528=$ Helianthemum gluti nosum.

thymifolius, Sibtb. \& Sm. Fl. Graec. v. 81. t. $500=$ Helianthemoan thymifolium.

tomentosus, Lam. Fl. Fr. iii. $168=$ polymorphus, tomentosis, Scop. Ann. II. II Ist. Nat. $(1 ; 69) 58 ; I^{\circ}$.

Carn. ed. II. i, $370=$ Helianthemum Channecistus.

\section{CISTUS:-}

ricuspis, Darwin, Variation Pl. \& Anim. Domest. 377 , err. typ. $=$ Hibiscus tricuspis.

Tuberaria, Linn. Sp. Pl. $526=$ Helianthemum Tuberaria.

umbellatus, Linn. 1. c. $525=$ Helianthemum umbellatum. undulatus, Moench, Meth. $245=$ polymorphus.

vaginatus, [Dryand. in] Ait. Hort. Kew. ed. II. ii.. 304.-Teneriffa

valentinus, Pourr, ex Nym. Consp. $71=$ monspeliensis. varius, Pourr. in Mém. Acad. Toul. iii. (1788) $312=$ albidus.

verticiliflorus, Steud. Nom. ed. II. i, $375=\mathrm{Helian-}$ themum anthurum

verticillatus, Brot. Fl. Lnsit, ii. $262=$ Helianthemum umbellatarn.

villosus, Linn. Gen. ed. VI. pag, ult. (nomen incertum) - Hispan.

vinealis, Willd. Sp. Pl. ii.1195= Helianthemum vineale. violaceus, Cav, Ic. ii. 38, t $147=$ Helianthemurn variabile.

virgatus, Desf. Fl. Atlant. i. $422=$ Helianthemum virgatum.

virgatus, Thib. ex Dun, in DC. Prod. i, $269=$ Hclian themum canadense.

viscosissimus, Tausch, in Flora, xix. (1836) 418.Hab.

viscosus, Stokes, Bot. Mat. Med. iii. $209=$ ladaniferus.

vulgaris, Spach, in Ann. Sc. Nat. Sét. II. vi. 18:36 $368=$ polymorphus.

CITHARELLA, Noronha, in Verh. Batav. Gen. v. (1790 ed. I. Art. IV. 2 = (Quid ?).

CITHARELOMA, Bunge, in Cat. Hort. Dorp. (1843) 6 ; et in Linnaca, xviii. (1844) 149. CRUCIFERAE, Benth. \& Hook. f. i. 67.

canescens, Bunge, in Linnaea, xviii. (1844) 150, in nota $=$ vernum.

Lebmanni, Bunge, Cat. Hort. Dorp. (1843) 6; et iu Linnaea, xviii. (1844) 149.-As. med.

vernum, Bunge, in Linnaea, xviii. (18\$4) 150, nota.-As. med.

CITHAREXYLUM, Mill. Gard. Dict. ed. VI. 175 (1752); Linn. Sp. Pl. ed. I. 625 (1753). VERBE. V. $C E A E$, Benth. \& Hook. f. ii. 1149.

Poeppigia, Bert. in Bull. Férussac, xxiii. (Oct. 183 u 109.

Rauwolfia, Ruiz \& Pav, Fl. Per, ii, 26. t. 15\% (1799).

affine, D. Don, in Edinb. N. Phil. Fourn. (Jan.-March 1831) 238 - Mexic.

affine, Mart. \& Gal. in Bull. Acad. Brux, xi. 11. 184t 328 = reticulatum.

albicaule, Turcz. in Bull. Soc. Nat. Mose. xxixi. (1863) II. 208.-Cuba.

album, Mill. Gard. Dict. ed. VIII. n. $2=$ caudatum, alpinum, Poepp. ex Schau. in DC. Prod. xi. $5 \pm 5$

Verbena cinerascens.

barbinerve, Chan, in Linnaea, vii. (1832) 116.-Bras.

Burterii, Spreng. Syst. ii. 763 --Ins. Jamaica.

caudatum, Hort. ex Walp. Rep. vi. $6 \pm 6=$ Buddleia melliodora.

candatum, Linn. Sp. Pl. ed. II. S72.-Ins. Jamaic

caudatum, Sw. Obs. Bot. $234=$ quadrangularc.

Chamissonis, Walp. Rep. iv. $75=$ candatum.

cinereum, Linn. Sp. Pl. ed. II. \$72.-Am. trop.

cinereum, Moç. \& Sesse, ex D. Don, in Edinb. D. Phil Journ. Uan.-March, $1881: 238$ = lucidum. cinereum, Spreng. Syst. ii. 764 , partim = myrianthum. coriaceum, Desf. Cat. Hort. Par. ed. 1II. Suld = nund. rangulare.

cranocarpum, C. Gay, Fl, Chil, v, $S f=$ Rhaphithamnus parvifolius.

cyanocarpum, Hook. \& Am. Bot. Becch. Voy. 58. $11=$ Kbaphithamnus cyanocarpus.

dentatum, D. Don, in Edinb. N. Phil. Fororn. 'Tan Varch, 1881) $28 \%$ - - I'eruv.

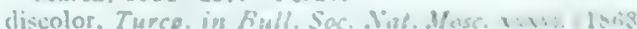
11. 209) - - (uba

elegans, Phil. ex Mirs, in Trans. Linn. Soc xrun 1870) 98 - Rhaphithamnas longiflorus,

ellipticum, Mor. of Sesse ex D. Don, in Edines. Phil. Gourn, Jan Jarch, 18\$1 28s - Merio. erectum Sw. l'rod. Veg. Ind. Oce. 21 caudatusm

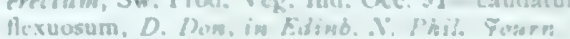

March is3il 230 - Pcruv. 


\section{CITHAREXYLUM:}

fruticosum, Linn. Syst. ed. X. $1115=$ cinereum. ilicifolium, H. B. E $K$. Nov. Gen. et Sp. ii. 256.Ecuador.

incanum, Moc. \& Sesse, ex D. Don, in Edinb. N. Phil. Fourn. (Jan.-March, 1831) 238.-Mexic.

laetum, Hiern, in Kjoeb. Vidensk. Meddel. (1877-78) 104.-Am. centr

laevigatum, Hostm. ex Griseb. Fl. Brit. W. Ind. $497=$ lucidum.

Lindenii, Turcz. in Bull. Soc. Nat. Mosc. xxxvi. (1863) II. 208.-Cuba.

longiflorum, Turcz. l. c. 207.-Cuba.

lucidum, Cham. \& Schlecht. in Linnaea, v. (1830) $97=$ caudatum.

lucidum, D. Don, in Edinb. N. Phil. Fourn. (Jan. March, 1831) 238.-Mexic.

lycioides, D. Don, $l$. c. 237.-Mexic.

macrophyllum, Poir. Encyc. Suppl. ii. 367.-Guiana. melanocardium, Sw. Prod. Veg. Ind. Occ. $91=$ Petitia domingensis.

mendocinum, Phil. Sert. Mend. Alt. 35.-Chili.

Mocinni, D. Don, in Edinb. N. Phil. Fourn. (Jan.March, 1831) 238.--Mexic.

molle, H. B. \& K. Nov. Gen. et Sp. ii. $257=$ quitense.

molle, Facq. ex Spreng. Syst. ii. 764.-Am. anstr.

molle, Salisb. Prod. $108=$ villosum.

myrianthum, Cham. in Linnaea, vii. (1832) 117.Bras.

ovatum, Turcz. in Bull. Soc, Nat. Mosc. xxxvi. (1863) II. 207.-Chili.

paniculatum, Gaertn. Fruct. i. 270.t. 56.-Jamaica. paniculatum, Poir. in Lam. Tabl. Encyc. iii. $95=$

Premna integrifolia.

pentandrum, Vent. Fard. Cels, t. 47.-Porto Rico.

perforatum, Forst. f. Prod. $44=$ Myoporum laetum

Poeppigii, Walp. Rep. iv. 76.-Bras.

polystachyum, Turcz. in Bull. Soc. Nat. Mosc. xxxvi.

(1863) II. 209.-Cuba.

psilacanthum, Turcz. l. c. 207.-Hab.?

pulverulentum, Pers. Syn. ii. 142.-Am. austr.

quadrangulare, Hort. Madr. ex Steud. Nom. ed. II. i. $375=$ pulverulentum.

quadrangulare, Facq. Enum. Pl. Carib. 26.-Ind. occ. quadrangulare, Moc. \& Sesse, ex D. Don, in Edinb.

N. Phil. Journ. (Jan.-March, 1831) $238=$ Sessaei quitense, Spreng. Syst. ii. 763.-Ecuador.

reticulatum, $H$. B. E K. Nov. Gen. et Sp. ii. 257.Peruv.

retusum, D. Don, in Edinb. N. Phil. Fourn. (Jan.March, 1831) 237.-Peruv.

Rugendasii, Cham. in Linnaea, vii. (1832) 120.Bras.

scabrum, Moc. Fourn. (Jan.-March, 1831) 238.-Mexic.

scabrum, Willd. ex Cham。 in Linnaea, vii. (1832) 117 = myrianthum.

scariosum, Moc. \& Sesse, ex D. Don, in Edinb. N

Phil. Journ. (Jan.-March, 1831) $238=$ reticulatum.

Sessaei, D. Don, l. c.-Mexic.

solanaceum, Cham, in Linnaea, vii. (1832) 119. Bras.

spinosam, H. B. E K. Nov. Gen. et Sp. ii. 256.Peruv.

spinosum, Linn. Sp, Pl. 625.--Ins. Barbad.

subserratum, Sw. Prod. Veg. Ind. Occ. 91.-Ins. S. Doming.

surrectum, Griseb. Fl. Brit. W. Ind.497.-Ind. occ.

tenuifolium, Forst. f. Prod. $44=$ Myoporum tenuifolium.

teres, Jacq. Enum. P1. Carib. $46=$ cinereum

tomentosum, H. B. E K. Nov. Gen. et Sp. ii. 258.Am. anstr.

tomentosum, Moç. \& Sesse, ex D. Don, in Edinb. N. Phil. Journ. (Jan.-March, 1831) 238=Mocinni.

tomentosum, Poir. Encyc. Suppl. ii. $368=$ pentan drum.

tristachyum, Turcz. in Bull. Soc. Nat. Mosc. xxxvi. (1863) II. 209.-Cuba.

venustum, Phil. in Bot.Zeit. xiv. (1856) $646=$ Rhaphithamnus Iongiflorus.

verticillatum, Klotzsch, ex Walp. Rep. iv. $73=$ cyanocarpom

villosum, facq. Ic. Pl. Rar. i. 12. t. 118 ; Coll. i. 72. -Ins. S. Doming.

CITINUS, All. Fl. Pedem. ii. $214(1785)=$ Cytinus, Tourn.
CITREUM, Toum. ex Rupp. Fl. Jen. ed. Hall. 141 1745); Mill. Gard. Dict. ed. VI. $(1752)=$ Citrus, Linn.

CITRIOBATHUS, A. Juss, in Orb. Dict. x. 228 (1849) $=$ seq

CITRIOBATUS, A. Cunn, in Loud. Hort. Brit. Suppl. i. 585 (1832). PITTOSPOREAE, Benth. \& Hook. f. i. 132

Ixiosporum, F. Muell. Fragm. ii. 76 (1860). megacarpus, F. Muell. Fragm. î. 76.-Austral. multiflorus, A. Cunn. in Loud. Hort. Brit. Suppl. i. 585.-Austral.

pauciflora, A.Cunn. l.c.-Austral.

CITRonella, D. Don, in Edinb. N, Phil. Joum [xiii.] (Oct. 1832) $243=$ Villaresia, Ruiz \& $\mathrm{Pav}$ (Olacin.).

mucronata, D. Don, $1 . \mathrm{c}_{\mathrm{s}}=\mathrm{V}$. mucronata.

CITROSENA, Bosc, ex Steud. Nom. ed. II. i. 375 (1840) $=$ seq.

CITROSMA, Ruiz \& Pav. Fl. Per. et Chil. Prod. 134. t. $29(1794)=$ Siparuna, Aubl. (Monimiac.).

alternifolia, Spreng. Neue Entdeck. ii. $112=$ S. alternifolia.

amazonum, Tul. in Areh. Mus. Par. viii. (1855-56) $332=\mathrm{S}$. asperula.

andina, Tul. in Ann. Sc. Nat. Sér. IV. ii. (1855) $36=$ S. andina.

apicifera, Tul. 1. c. $38=\mathrm{S}$. apicifera.

Apiosyce, Mart. ex Tul. 1, c. $34=\mathrm{S}$. Apiosyce.

aspera, Tul. in Arch. Mus. Par. viii. (1855-56) $324=$ S. aspera.

asperula, Tul. in Ann. Sc. Nat. Sér. IV. iii. (1855) 35 $=\mathrm{S}$. asperula.

bifida, Poepp. \& Endl. Nov. Gen. et Sp. ii. $48=\mathrm{S}$. bifida.

brasiliensis, Spreng. Nene Entdeck. ii. $113=$ S. brasiliensis.

buddleiaefolia, Benth. P1. Hartw. $250=$ S. budleiae folia.

camporum, Tul. in Ann. Sc. Nat. Sér. IV. iii. (1855) 39 $=\mathrm{S}$. camporum.

chividota, Tul. 1. c. $37=\mathrm{S}$. chiridota

cristata, Poepp. \& Endl. Nov. Gen. et Sp. ii. 47. t $164=\mathrm{S}$. cristata

cujabana, Mart. ex Tul. in Ann. Sc. Nat. Sér. IV. iii. 1855) $33=\mathrm{S}$. cujabana

cuspidata, Tul. 1. c. $40=\mathrm{S}$. cuspidata

decipiens, TuI. in Arch. Mus. Par, viii. (1855-56) 368 $=\mathrm{S}$. decipiens.

dentata, Poepp. ex A. DC. Prod. xvi. II. $653=\mathrm{S}$. mollicoma.

dentata, Ruiz \& Pav, Syst. Veg. 1. $264=$ S. limoniodora.

dimidiata, Sello, ex A. DC. Prod. xvi. II. $656=\mathrm{S}$. paniculata.

discolor, Poepp. \& Endl. Nov. Gen. et Sp. ii. $47=\mathrm{S}$. discolor.

dubia, H. B. \& K. Nov, Gen, et Sp. ii. $174=\mathrm{S}$. mollis.

echinata, H. B. \& K. 1. c. $173=$ S. echinata.

eriocalyx, Tul. in Ann. Sc. Nat. Sér. IV. iii. (1855) 35 $=$ S. eriocalyx.

erythrocarpa, Mart. ex A. 1DC. Prod. xvi. II. $645=$ S. estrellensis.

erythrocarpa, Tul. in Ann. Sc. Nat. Sér. IV. iii. (1855) $32=\mathrm{S}$. erythrocarpa.

estrellensis, Tul. 1. c. $33=$ S. estrellensis

foliosa, Tul. 1. c. $38=\mathrm{S}$. foliosa.

gesnerioides, H. B. \& K. Nov. Gen. et Sp. ii. $172=\mathrm{S}$. gesnerioides.

glabra, Spreng. Syst, ii. $545=$ S. glabra

glabrescens, Presl, Bot. Bemerk. $110=$ S. glabrescens

grandiflora, H. B. \& K. Nov. Gen. et Sp. ii. $172=\mathrm{S}$ Kunthii.

Gudotiana, Tul. in Ann. Sc. Nat. Sér. IV. iii. (1855) $38=\mathrm{S}$. Goudotiana.

guianensis, Tul, in Arch. Mus. Par. viii. (1855-56) 361 $=\mathrm{S}$. guianensis.

Kunthii, Tul. in Ann. Sc. Nat. Sér. IV. iii. (1855) 37 $=\mathrm{S}$. Kunthii.

Lagopus, Tul. 1. c. =S. Lagopus.

lanceolata, Tul, 1. c. $33=\mathrm{S}$. lanceolata.
CITROSMA :-

laurifolia, H. B. \& K. Nov. Gen. et Sp. ii. $171=$ Siparuna laurifolia.

lepidota, H. B. \& K. 1. c. $170=$ S. lepidota.

limoniodora, Pav. ex Tul. in Ann. Sc. Nat. Sér. IV. iii (1855) $35=\mathrm{S}$. limoniodora.

Lindeni, Seem. Journ. Bot. ii. (1864) $343=\mathrm{S}$. Lindeni. macrophylla, H. B. \& K. Nov. Gen. et Sp. ii. $172=\mathrm{S}$. macrophylla.

macrophylla, Mart. ex A. DC. Prod. xvi. Ix. $655=\mathrm{S}$. cristata.

mollicoma, Mart. ex Tul. in Ann. Sc. Nat. Sér. IV. iii. (1855) $38=\mathrm{S}$. mollicoma.

mollis, H. B. \& K. Nov. Gen. et Sp. ii. $173=$ S. mollis. muricata, Raiz \& Pav. Syst. Veg. $265=$ S. muricata.

Mutisii,H. B. \& K. Nov. Gen, et Sp. ii. $170=$ S. Mutisii myristicoidea, Spruce, in Journ. Linn. Soc. v. (1861) 5.-Bras.

neglecta, Tul. in Ann. Sc. Nat. Sér. IV. iii. (1855) $36=$ S. neglecta.

oblongifolia, Ruiz \& Pav. Syst. Veg. i. $266=$ S. laurifolia, oblongifolia.

obovata, Gardn. in Hook. Lond. Journ. Bot. ii. (1843) $343=\mathrm{S}$. obovata

oligandra, Tul. in Ann. Sc. Nat. Sér. IV. iii. (1855) $32=\mathrm{S}$. obovata.

oligocarpa, Mart. ex A. DC. in DC. Prod. xvi. II. 654 $=\mathrm{S}$. guianensis.

ovalis, Ruiz \& Pav. Syst. Veg. i. $266=$ S, ovalis.

paniculata, Spreng. Syst. ii. $545=\mathrm{S}$. paniculata

pauciflora, Beurling, in Vet. Akad. Handl. Stockh. $1854(1856) 144=\mathrm{S}$. pauciflora.

pellita, Tul. in Ann. Sc. Nat. Sér. IV. iii. (1855) $34=$ S. pellita.

petiolaris, H. B. \& K. Nov. Gen. et Sp. ii. $171=\mathrm{S}$. petiolaris.

plebeia, Tul. in Ann. Sc. Nat. Sér. IV. iii. (1855) $33=$ S. cujabana.

Poeppigii, Tul. 1. c. $39=\mathrm{S}$. Poeppigii.

polyantha, Tul. 1. c. $31=\mathrm{S}$, polyantha.

pyricarpa, Ruiz \& Pav. Syst. Veg. i. $264=$ S. macro phylla.

pyricarpa, Willd. ex Tul, in Arch. Mus. Par. viii $(1855-56) 358=\mathrm{S}$. mollis.

radiata, Poepp. \& Endl. Nov. Gen. et Sp. ii. $48=\mathrm{S}$ radiata.

reginae, Tul. in Ann. Sc. Nat. Sér. IV. iii. (1855) $39=$ S. reginae.

riparia, Tul. 1. c. $36=\mathrm{S}$. riparia

ruficeps, Tul. 1. c. $34=\mathrm{S}$. ruficeps.

Schottiana, Spreng. Syst. iv. Cur. Fost. $407=$ Mollinedia brasiliensis.

Selloi, Spreng. Syst. ii. $545=$ Mollinedia cinerea

sessiliflora, H. B. \& K. Nov. Gen. et Sp. ii. $174=$ S. sessiliflora.

suaveolens, Tul, in Ann. Sc. Nat. Sér. IV. iii. (1855) 36 $=\mathrm{S}$. suaveolens.

subinodora, Ruiz \& Pav. Syst. Veg. i. $265=\mathrm{S}$. subinodora.

Thea, Seem. Journ. Bot. ii. (1864) $343=\mathrm{S}$. Thea.

thecaphora, Poepp. \& Endl. Nov. Gen, et Sp. ii. $48=$ S. thecaphora

tomentosa, Ruiz \& Pav. Syst. Veg. i. 265=S. aspera, tomentosa.

tomentosa, Willd, ex Tul, in Ann. Sc. Nat. Sér. IV. iii. (1855) $36=\mathrm{S}$. neglecta.

triftora, Spreng. Syst. ii. $544=$ Mollinedia triflora. umbellata, Spreng. 1. c. $545=$ Mollinedia umbellata.

CITRUILUS, Forsk. FI. Aegypt. Arab. 167 (1775) Neck. Elem. i. 240 (1790). CUCURBITACEAE, Benth. \& Hook. f. i. 826

amarus, Schrad. in Eckl. \& Zeyh. Enum. $279=$ vulgaris aquosus, Schur, Enum. Pl. Transs. 221 - vulgaris.

Battich, Forsk. Fl. Aegypt. Arab. 167.-Arabia.

caffer, Schrad. Ind Sem. Hort. Gotting. (1834); ex Eckl. \& Zeyh. Enum, $279=$ vulgaris.

caffrorum, Schrad. in Linnaea, xii. (1838) $413=$ vulgaris.

chodospermus, Fal. \& Dun. in Ball. Soc. Agr. Hérault (1836), $264=$ vulgaris

Colocynthis, Schrad. in Linnaea, xii. (1838) 414.Afr. calid.

edulis, Spach, Hist. Vég. Phan. vi. $214=$ vulgaris.

fistulosus, Stocks, in Hook. Kew Journ. iii. (1851) 74. t. $3=$ vulgaris.

Naudinianus, Hook. f. in Oliver, Fl. Trop. Afr. ii. 549. -Afr. trop. 
CITRULLUS:-

Pasteca, Sageret, in Ann. Sc. Nat. Sér. 1. viii. (1826) $312=$ vulgaris

Pseudo-Colocynthis, M. Roem. Syn. Pepon. $50=$ C, Colocynthis.

variegatus, Schrad. ex M. Roem. 1. c. $51=$ Cuctrbita, Pepo.

vulgaris, Schrad. ex Eckl. E० Zeyh. Enum. 279.-Afr. trop.

CITRUS, Linn. Syst. ed. I (1735). RUTACEAE, Benth. \& Hook. f. i. 305.

Citreum, Toum. ex Rupp. F1. Jen. ed. Hall. 141 (1745); Mill. Gard. Dict. ed. VI (1752).

CITrophorum, Neck. Elem. ii. 401 (1790).

Limon, Tourn. ex Mill. Gard. Dict. ed. VI (1752).

Oxanthera, Montrous. in Mém. Acad, Lyon, x. (1860) 186.

PAPEDA, Hassk. in Flora, xxv. (1842) Ir. Beibl. 42.

PONCIRUS, Rafin. Sylva Tellur. 143 (1838).

Pseudatgle, Miq. Ann. Mus. Lugd. Bat. ii. 83 (1865-66).

Sarcodactilis, Gaertn。 f. Fruct. iii. 39. t. 185 (1805).

acida, Pers. Syn, ii. $73=$ C. Medica.

albida, Boj. Hort. Maurit. 49.-Ins. Maurit.

amara, Hassk, in Flora, xxy. (1812) Beibl. II. 43.Java.

amara, Link, Handb. ii. $346=$ C. Aurantium. angulata, Willd. Sp. Pl. iii. 1426.-Ins. Amboin. articulata, Willd. ex Spreng. Syst. iii. 334.-Afr. trop. Aurantium, Linn. Sp. Pl. 783--As. trop.

aurata, Risso, Hist. Nat. Or. Europ. Mérid. i. $409=\mathrm{C}$. Aurantium.

australasica, F. Muell. Fragm. i. 26.-Austral.

australis, Planch. in Hort. Donat. 18.-Austral.

Bergamia, Risso, Hist. Nat. Or. Europ. Mérid. t. 53$56=$ C. Aurantium

Bergamota, Rafin. Sylva Tellur. $141=$ praec.

Bigaradia, Loisel. in Duham. Arb, ed. nov. vii. $99=$ C. Aurantium.

buxifolia, Hort. ex Ten. Atti $3^{\mathrm{a}}$ Reun. Sc. Ital. (1841) $503=$ Atalantia buxifolia

buxifolia, Poir. in Lam. Encyc. iv. $580=$ C. Aurantium.

Calot, Lag. Gen. et Sp. Nov. $17=$ C. Aurantium.

cedra, Link, Handb. ii. $\$ 46=$ C. Medica.

cedrata, Rafin. Sylva Tellur. $141=$ C. Medica.

chilensis, Molina, Sagg. Chile, $171=$ Villaresia mucronata.

Combara, Rafin. Sylva Tellur. 142.-Malaya.

costata, Rafin. 1. $\mathrm{c}_{\mathrm{f}}=$ decumana?

crassa, Hassk. Cat. Pl. Hort. Bog. Alt. 217.--Java.

Daidai, Bieb. ex Van Houtte, Cat. n. 126 (1869).Japon.

decumana, Murr. Syst. ed. XIII. 508.-As. trop.

deliciosa, Tenore, Sull Arancio Mandarino, $11=\mathrm{C}$. Aurantium.

dulcimedulla, Pritz. Ic. Bot. Ind. $275=$ C. Aurantium? dulcis, Pers. Syn, ii. $74=$ C. Aurantium.

echinata, St. Lag, in Ann. Soc. Bot. Lyon, vii. (1880) $122=\mathrm{C}$. Hystrix.

emarginata, Desf. Cat. Hort. Par. ed. III. 406.Hab.?

florida, Salisb. Prod. $378=$ C. Aurantium.

fragrans, Salisb. 1. $c_{0}=$ C. Medica.

fusca, Lour. Fl. Cochinch, $467=\dot{C}$. Aurantium

fusiformis, Rafin. Sylva Tellur. 142.-Hab.?

Gongra, Rafin. 1. c. = C. Medica?

grandis, Hassk. in Flora, xxv. (1842) Beibl. II. 44.Java.

granulata, Rafin. Sylva Tellur. 143.-Hab.

heterophyla, Rafin. 1. c, 141.-Hab.?

Hillii, F. Muell. i. 26.-Austral.

humilis, Poir. in Lam. Encyc. iv. 580.-Ind. or.

Hystrix, DC. Cat. Hort. Monsp. 97.- Ind. or.; Malaya.

inermis, Roxb. Hort. Beng. 59 ; Fl. Ind. iii. $393=$ japonica.

japonica, Thunb. Fl. $¥ a p .292 .-J a p o n ;$ China.

javasica, Blume, Bijdr. 140.-Java.

Karna, Rafin. Sylva Tellur. 142,-Hab.

latipes, Hook. f. \& Thoms. ex Hook, f. 11. Brit. Ind, i $515=$ C. Hystrix.

Lima, Macfad, in Hook. Bot. Misc, i. (1830) $300=$ C. Medica.

Limetta, Risso, in Ann. Mus. Par. xx. (1813) 195. t. 2. s. $1=\mathrm{C}$. Medica.

\section{CITRUS :}

imonellus, Buch.-Ham. ex Wall. Cat. n. $6386=$ C. Medica.

Limonum, Risso, in Ann. Mus. Par. xx. (1813) $201=$

C. Medica.

lumia, Risso, Hist. Nat. Or. Europ. Mérid. i. $414=$

C. Medica.

macracantha, Hassk. Cat. Pl. Hort. Bog. Alt. 218. Java?

macroptera, Montrous. in Mém. Acad. Lyon, x. (1860)

187.-N. Caled.

madurensis, Lour. Fl. Cochinch. 467 = japonica.

Margarita, Lour. 1. $\mathrm{c}_{\mathrm{s}}=$ japonica

marginata, Steud. Nom. ed. II. i. $376=$ japonica.

Medica, Linn. Sp. Pl. 782.-As. trop.

microcarpa, Bunge, in Mém. Sav. Etr. Pétersb.ii. (1835)

$84=$ japonica

mitis, Blanco, Fl. Filip. ed. I. $610=$ C. Medica.

myrtifolia, Rafin. Sylva Tellur, 141.-Hab, ?

nobilis, Lour. Fl. Cochinch. $466=\mathrm{C}$. Aurantium

notissima, Blanco, F1. Filip. ed. I. $607=$ C. Medica

obovata, Rafin. Sylva Tellur. 142.-Hab.

obversa, Hassk. Cat. Pl. Hort. Bog. Alt. 218.-Java.

ovata, Hassk, in Flora, xxy, (1842 Beibl. 11. 42.-Java.

paniculata, Schum. E Thonn. in Dan. Vid. Selsk. Ath.

iv. (1828) 152.-Afr. trop

Papaya, Hassk. in Cat. Pl. Hort. Bog. Alt. 218.

Papedia, Miq. FI. Ind. Bat. i. II. $530=$ C. Hystrix.

papillaris, Blanco, Fl. Filip.ed. I. $610=$ C. Aurantium

Paradisi, Macfad. Fl. Jamaic i. $131=$ C Aurantium.

Planchoni, F, Muell. Sel. Pl. Indust. Cult. 34.-

Austral.

pyriformis, Hassk. in Flora, xxv. (1842) Beibl. I1. 44. - Java.

reticulata, Blanco, Fl. Filip. ed. I. $610=$ C. Aurantium rotundifolia, Rafin. Sylva Tellur. 141.- - Hab.

salicifolia, Rafin. 1. c. - Hab. ?

scandens, Griff. Notul. iv. $495=$ Paramignya Griffithii. sinensis, Pers. Syn. ii. $74=\mathrm{C}$. Aurantium.

spinosa, S. G. Gmel. Reise Russl. iii. 278. t. 22.Persia.

spinosissima, G. F. W. Mey. Prim. Fl. Esseq. $247=$

C. Medica.

torosa, Blanco, Fl. Filip. ed. I. 609.-Ins. Philipp.

trifolia, Thunb. Fl. Jap. $294=$ trifoliata.

trifoliata, Hort. ex M. Roem. Syn. Hesper. $39=$

Glycosmis pentaphylla.

trifoliata, Linn. Sp. Pl. ed. II. 1101.-Japon.

triptera, Desf. Cat. Hort. Par. ed. III. $406^{\circ}=$ trifoliata.

tuberosa Mill Gard. Dict ed VIII n $2=\mathrm{C}$ Medica

Vangasay, Boj. Hort. Maurit. 49.-Hab.?

Volkameriana, Pasq. Cat. Orto Bot. Nap. 29. $\mathrm{Hab}$.?

ulgaris, Risso, in Ann. Mus. Par. xx. (1813) $190=$ C.

Aurantium.

CITTA, Lour. F1. Cochinch. $456(1790)=$ Mucuna Adans. (Legumin.).

nigricans, Lour. 1. c.= M. nigricans.

CITTARONIUM, Reichb. Nom, $186(1841)=$ Viola Tourn.

CITTORHINCHUS, Willd, ex H. B. \& K. Nov, Gen et Sp. vi. 14 (1823)= Gomphia, Schreb. (Ochnac.) javitensis, Willd. 1. c. $=\mathrm{G}$. aquatica.

CLADANTHUS, Cass, in Bull. Soc. Philom. (1816) COMPOSJTAE, Benth. \& Hook. f. ii. 421

axabicus, Cass.l.c. ; et in Dict.Sc. Nat. ix. 342.t. 87.Arab. (Quid?)

canescens, Sweet, Hort. Brit. ed. III. 366.-Ins. Canar. Geslini, Coss. \& Dur. in Bull. Soc. Bot. Fr. iv. (1857) 397 - Mecomischus Geslini.

halimifolius, Coss. \& Dur. I. c. = Mecomischus Geslini.

peduncularis, Benth. \& Hook. f. Gen. ii. 422, err. typ.

$\quad=$ seq.
pedunculatus, Dur. in Bull. Soc. Bot. Fr. iv. (1957)

$14=$ Anthemis peduncularis.

proliferus, DC. Prod. vi. 18.-Afr. bor.

CLADERIA, Rafin. Sylva Tellur. 12 (1S35)= Molia Linn.?

parviflora, Rafin, 1, c.-IIab. ?

CLADIUM, P. Br. Hist. Jamaic. 114 (1758), CIPERA. CEAE, Benth. \& Hook. To iii. 1005

\section{CI.ADTUM :-}

Agylla, Phil. in Anal. Univ. Chil. (1865) 1. 643.

BAumeA, Gaudich. in Freyc. Voy. Bot. 416. t. 29 1826

Chapelliera, Nees, in Linnaea, ix. (1834) 298

MACHAERINA, Vahl, Enum. ii. 228 (1806)

Schoenopsis, Beauv. in Lestib. Essai Fam. Cyp. 341 (1819)

Terorera, Steud. Syn. Pl. Cyp. 164 (1855)

Trasi, Beauv, in Lestib. Essai Fam. Cyp. 32 1819)

Trachyrhynchium, Nees, in Nov. Act. Nat. Cur. xix. Suppl. i. (1843) 113.

Trachyrhyngium, Nees, ex Kunth, Enum. Pl, ji. 314 (1837)

Vincentia, Gaudich. in Freyc. Voy. Bot. 417 1826)

ucutum, Poir. in Dict. Sc. Nat. ix. $344=$ schoenoides.

anceps, Hook, f. Handb. New Zeal. Fl. 305, in obs. iridifolium.

ancistrophyllum, F. Muell. ex Benth. F1. Austral. vii. 415 = Crahnia ancistrophylla

aristatum, F. Muell, ex Benth. 1. c. $416=$ Gahnia aristata.

articulatum, R. Br. Prod. 237.-Austral.

asperum, F. Muell. Fragm, ix. 12 = Gahnia aspera

athrophyllum, F. Muell. l. c. 49.-Austral.

bahiense, Nees, in Linnaea, ix (1834) $301=$

germanicum.

chinense, Nces, 1. c, ; et in Nov. Act. Nat. Car. xix. Suppl, i. (1843) $116=$ germanicum.

complanatum, Bergg. in Minneskr. Fisiog. Sallks. Lund, (1877) n. 8. p. 23.-N. Zel.

decompositum, R. Br. Prod. $237=$ Gahnia decom posita.

deustum, R. Br. 1. c. = Gahnia deusta.

dubium, Spreng. Syst. iv. Cur. Post. $21=$ glomeratum

effusum, Torr. in Ann. Lyc. N. York, iii. (1836, 37 $=$ germanicum.

elynanthoides, F. Muell. Fragm. ix. 31.-Austral.

ensifolium, Benth. E Hook. f. Gen. iii. 1066.-Bras.

ensigerum, Hance, in Fourn. Bot. xxiii. (1885) 80.China.

ficticum, Hemsl. Bot. Challenger, Voy, iii. 59, in obs.

t. 60 . f. 5-7. Am. austr.

filifolium, Benth. E Hook.f. Gen. iki. 1065.-Cuba.

Filum, R. Br. Prod. 237, partim = Gahnia trifida

floribundum, Presl, in Oken, Isis, xxi. (1828) 270

germanicum.

gahnoides, Colenso, in Trans. N. Z. Inst, xvi. (1m) $340=$ Sinclairi.

germanicum, Schrad. Fl. Germ. i. 75. t. 5. f. 7.-Reg. temp. et subtrop.

giganteum, Willk, in Willk. \& Lange, Prod. Fl. Hisp i. $136=$ germanicum.

glomeratum, R. Br. Prod. 287.-As. or.; Australas.

Gunnii, Hook.f. Fl. Tasm. ii. 95. t. 148 B. -Austral ; N. Zeland.

Huttoni, T. Kirk. in Trans. N. Z. Inst. ix. (157T: 55]. - N. Zeland.

insulare, Benth. Fl. Austral. vii. 403.-Austral.

iridifolium, Baker, Fl. Maurit. 42t-Ins. Mascar.

Bras.

jamaicense, Crantz, Inst. i. $30^{\circ} 2=$ germanicum

japonicum, Steud. Syn. Pl. Cyp. 152 = germanicnn.

juncenm, R. Br. Prod. 237. - Austral.

lanigerum, R. Br. l. c. = Gahnia lanigera.

latissimum, $F$ Muell. Fragm ix 15- Anstm?

laxiflorum, Hook. f. Fl. Tosm, ii. 95. 2 148 A

Gunnii.

laxum. Berth. Fl. Austral. vii. 105.-Austral.

leptostachyum, [Necs, in] Meyen, Reise, ii. 119 ; el in Nov. Act. Nat. Cur. xix. Suppl. i. $1 \$ 43,115$ germanicum.

mariscoides, Torr, in Ann, Lyc. N. Jork, iii. Isso $372=$ triglomemtum.

mariscoides, F. l'illar, in Blanco, Fl. Philima. ed. II] Now. App. 809. - Ins. Philipp.

Mariscus, R. Br. Prod. $290^{\circ}$ eerm …....

medisum, R. Br. l. c. "2S" = Ciahnia langs.

melanocarasum, F. Muell. krasm. ix. Is n imelanocarpa.

Melleri, Bater, in Gomrn. Linm. Sor. xxi. ISS5 131 Matng.

microsbachyom, F. Mucll. Census, 129 a Gahnia mier stachy?

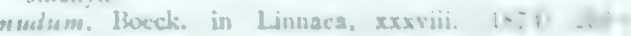
(ivngii. 


\section{CLADIUM}

accidentale, Schrad. F1. Germ. i. $76=$ germanicum palustre, Poir. in Dict. Sc. Nat. ix. $344=$ ger manicum.

pantopodum, Baker, in Fourn. Linn. Soc. xxi. (1885) 451.-Madag.

pauciflorum, R. Br. Prod. 237 = Tricostularia pauciflora.

polyphyllum, F. Muell. Census, 129 = Gahnia polyphylla.

Preissii, F. Muell. ex Benth. Fl. Austral. vii. $405=$ latissimum.

psittacorum, F. Muell. Fragm。 ix. $13=$ Gahnia psittacorum.

quadrangulare, Nees, in Linnaea, ix. (1834) $301=$

Lampocarya Gaudichaudii.

Radula, R. Br. Prod. $237=$ Gahnia Radula.

rigidifolium, Presl, in Oken, Isis, wxi. (1828) $270=$ teretifolium.

riparium, Benth. Fl. Austral, vii. 405.-Austral

schoenoides, R. Br. Prod. 237.-Austral.

scirpoideum, Benth. \& Hook. f. ex Hemsl. Bot. Challenger Voy. ii. 59. t. 60 . f. 1-4.-Ins. Juan Fernand.

scleroides, F. Muell. Fragm. ix. 12 = Exocarya scleroides.

Sieberi, F. Muell. 1. c. 14=Gahnia Sieberi

Sinclairii, Hook. f. Handb. N, Zeal. Fl. $304-\mathrm{N}$. Zel.

teretifolium, R.Br.Prod. 237.-Austral

tetragonocarpum, F. Muell. Census, $129=$ Gahnia tetragonocarpa.

tetraquetrum, Hook. f. Fl. Tasm. ii. 95. t. 149.Tasmania.

trifidum, F. Muell. in Papers Roy. Soc. Tasm. (1878) $117=$ Gahnia trifida

triglomeratum, Nees, in Linnaea, ix. (1834) 301Am. bor.

undulatum, Thw. Enum. Pl. Zeyl. 353.-Malaya Austral.

vaginale, Benth. Fl. Austral. vii. 408.-Anstral.

xanthocarpum, F. Muell. Fragm. ix. $13=$ Gahnia xanthocarpa.

xipholepis, Baker, Fl Maurit. $424=$ Schoenus elongatus.

CLADOBIUM, Lindl. Introd. Nat. Syst. ed. II. 446 $(1836)=$ Scaphyglottis, Poepp. (Orchid.).

violaceum, $\mathrm{Lindl}$. $1 . \mathrm{c}_{\mathrm{s}}=\mathrm{S}$, violacea.

CLADOCAULON, Gardn, in Hook. Ic. Pl. t. 528 $(1843)=$ Paepalanthus, Mart. (Eriocauleae).

brasiliense, Gardn. 1. c. = P. Gardnerianus.

CLADOCHAETA, DC. Prod. vi. 245 $(1887)=$ Heli chrysum, Vaill. (Compos.).

candidissima, DC. $1 . \mathrm{c},=\mathrm{H}$. candidissimum

CLADODA et CLADODEA, Poir. in Dict. Sc. Nat. ix. $345(1817)=$ seq.

CLADODES, Lour. F1. Cochinch. ii. $574(1790)=$ Alchornea, Sw. (Euphorbiac.).

ilicifolia, Baill. Adansonia, vi. (1866) $1=$ A. ilici folia.

rugrosa, Lour. F1. Cochinch. ii. 574=A. rugosa.

Thozetiana, Baill. Adansonia, vi. (1866) $321=$ A Thozetiana.

CLADOGYNOS, Zipp, ex Span, in Linnaea, $x \mathrm{v}$. 1841) 349. EUPHORBIACEAE, Benth. \& Hook. f. iii. 323 .

orientalis, $Z i p p$. l. c.-Malaya

CLADOLEPIS, Moq. in DC. Prod. xiv. II. 203, in syn. $(1849)$ Ofaiston, Rafin. (Chenopod.)

CLADOMISCHUS, Klotzsch, ex A. DC, in DC. Prod. xv. I. $278(1864)=$ Begonia, Linn

CLADOPOGON, Sch. Bip, in Ind. Sem. Hort. Hamb. (1852) 8, ex Lehm. in Ann. Sc. Nat. Sér. III. xix (1853) 359 = Senecio, Tourn. (Compos.). aurantiacum, Lehm. 11. cc. 8 ; 360.-Mexic.

CLADOSERIS, Spach, Hist. Vég. Phan. x. $35(1841)=$ Onoseris, DC. (Compos.).
CLADOSICYOS, Hook, $f$, in Oliver, Fl. Trop. Afr. ii $534(1871)=$ Cucumeropsis, Naud. (Cucurbitac.) edulis, Hook, f. $1 . \mathrm{c}=$ Cucum. edulis.

CLADOsTACHYS, D. Don, Prod. F1. Nep. 76 (1825)= Deeringîa, R. Br. (Amarantac.)

alternifolia, Sweet, Hort. Brit. ed. I. $336=$ Digera arvensis.

arborescens, D. Dietr. Syn. P1. i. $861=$ Digera arvensis. frutescens, D. Don, Prod. Fl. Nep. $76=$ Deeringia celosioides.

muricata, Moq. in DC. Prod. xiii, II. $235=$ Digera arvensis.

CLADOSTEMON, A. Br. \& Vatke, in Monatsb. Acad. Berl. (1876) 866. CAPPARIDEAE paradoxus, $A . B r$. E Vatke, l.c.-Afr. trop.

CLADOSTIGMA, Radlk. in Bremen Abh. viii. (1883) 412. CONVOLVULACEAE.

dioicum, Radlk. l. c.-Abyssin.

CLADOSTYLES, Humb. \& Bonpl. P1. Aequin. i. 202. t. $57(1808)=$ Evolvulus, Linn. (Convolvulac.) ericoides, Nees, ex Steud. Nom. ed. II. i. $377=$ E. glomeratus.

paniculata, H. B. \& K. Pl. Aequin. i. $202=$ E. paniculatus.

CLADOTHAMNUS, Bong. Veg. Sitcha, 37. t. 1, in Mém Acad Pétersb. Sér. VI ii. (1833). ERICA$C E A E$, Benth. \& Hook, f. ii. 598.

TolmieA, Hook. Fl. Bor. Am. ii. 44 (1834) pyroliflorus, Bong. $l l$. $c c$.-Am. bor. occ.

CLADOTHECA, Steud. Syn. Pl. Cyp. $178(1855)=$ Cryptangium, Schrad. (Cyperac.). vaginans, Steud. 1. c. = Crypt. Ieptocladum.

CLADothrix, Nutt. ex Moq. in DC. Prod. xiii. Ir. 359 (1849). AMARANTACEAE, Benth. \& Hook. f $359(184$.
iii. 37 .

lanuginosa, Nutt. ex Moq. l. c. 360.-Calif.

oblongifolia, S. Wats. in Proc. Am. Acad. xvii (1881-82) 376.-Am. bor. occ.

CLADOTRICHIUM, Vog. in Linnaea, xi. (1837) $401=$ Caesalpinia, Linn. (Legumin.)

epunctatum, Vog. 1. c. $403=$ Caes, epunctata.

pilosum, Vog. 1. c. = Caes. pilosa

rubicundum, Vog. 1. c. $401=$ Caes. rubicunda.

stipulare, Vog. 1. c. $403=$ Caes, stipularis.

CLADRASTIS, Rafin. Neogenyt. 1 (1825). LEGU MINOSAE, Benth. \& Hook. f, i. 554.

Buergeria, Miq. Ann. Mus. Bot. Lugd. Bat. iii. 53 (1867).

MaAckia, Rupr in Bull. Phys.-Math. Acad. Pétersb. xv. (1856) 128, 143 .

albiflora, Rafin. New Fl. Am. iii. 83.-Am. bor. amurensis, Benth. ex Maxim. in Bull. Acad. Pétersb. xviii. (1873) 400.-Reg. Amur.

kentuckensis, Rafin. Neogenyt. (1825) 1 = tinctoria?

lutea, Rafin. 1. c. = tinctoria.

secundiflora, Rafin. 1. c. = Sophora secundiflora

tinctoria, Rafin. l. c., New Fl. Am. iii. 83.-Am. bor.

CIAIRISIA, Abat, ex Benth. \& Hook. f. Gen. iii. 78 $(1873)=$ CLARISIA, Abat $=$ Anredera, Juss. (Chenopodiac.)

CLAIRvillEA, DC. Prod.v. 636 (1836) = Cacosmia, H. B. \& K. (Compos.).

quinquenervia, DC. 1. c. = Cacosmia rugosa

CLAMBUS, Miers, in Ann. \& Mag. Nat. Hist. Ser. III. xviii. (1866) 16. MENISPERMACEAE, Benth. \& Hook. f. i. 962

araneosus, Miers, $l$. c. 17.-Mexic.

CLAMYDANTHUS, Fourr. in Ann. Soc. Linn. Lyon, N. S. xvii. (1869) $147=$ CHLAMYDANTHUS, C. A Mey.=Thymelaea, Linn.
CLANDESTINA, Tourn. ex Adans, Fam. ii. 207 (1763) =Lathraea, Linn. (Orobanch.)

japonica, Miq. in Versl, en Med. Kon. Akad. Wetensch. II. ii. (1868) $85=\mathrm{L}$. Miqueliana. penduliflora, Lam. Fl. Fr. ii. $329=$ L. Clandestina rectiflora, Lam. 1. c. $328=$ L. Squamaria.

CLANDESTINARIA, Spach, Hist. Vég. Phan. vi. 427 (1838) = Nasturtium, R. Br. (Crucif.) indica, Spach, 1. c. $429=$ N. indicum.

CLAOTRACHELUS, Zoll. in Nat. en Geneesk. Arch Neêrl. Indie, ii. (1845) 565=Vernonia, Schreb. (Compos.).

rupestris, Zoll. \& Mor. 1. c.-Java

CLAOXYLON, A. Juss. Euph. Tent. 43. t. 1 (1824). EUPHORBIACEAE, Benth. \& Hook. f. iii. 309.

ERythrochilus, Reinw. ex Flora, viii. (1825) I. 103.

affine, Baill. Adansonia, ii. (1861-62) $227=$ insulanum affine, Zoll. E Mor. in Nat. en Geneesk. Arch. Neêrl. Indie, ii. (1845) 582,-Java.

africanum, Muell. Arg. in DC. Prod. xv. II. $777=$ Barteri.

angolense, Muell. Arg. in Fourn. Bot. ii. (1864) 333 -Afr. occ.

angustifolium, Muell. Arg, in Linnaea, xxxiv (1865-66) 165.-Austral

australe, Baill. Etud. Gén. Euph. 493.-Austral.

Barteri, Hook. f. in Fourn. Linn. Soc. vi. (1862) 21.Afr. occ.

capense, Baill. Etud. Gén. Euph. 493.-Afr. austr.

columnare, Muell. Arg, in Flora, xlvii. (1864) 437.Afr. trop.

cordifolium, Benth. in Hook. Niger Fl. 506=Mallotus oppositifolits.

coriaceum, Baill. Etud. Gén. Euph. $493=$ erythrophyllum.

crassifolium, Baill. Adansonia, i. (1860-61) 279.Afr. trop.

digynum, Wight, Ic. t. $1884=$ Macaranga digyna

echinospermum, Muell. Arg. in DC.Prod.xv. I1. 787 -Ins. Pacif.

erythrophyllum, Miq. Fl. Ind. Bat. i. 11. 387.-Java

fallax, Muell. Arg. in DC. Prod. xv. II. 780.--Ins. Pacif.

glabrifolium, Miq. Fl. Ind. Bat. i, II. 387.--Java.

glandulosum, Baill. Adansonia, i. (1860-61) 281.Ins. Mascar.

graciliflorum, Miq. Fl. Ind. Bat. i. II. 386=affine.

grandidentatum, Boiv. ex Baill. in Adansonia, i. (1860-61) 283 = racemiflorum.

grandifolium, Muell. Arg. in Linnaea, xxxiv. (1865-66) $163=$ crassifolium.

hexandrum, Muell. Arg, in Flora, xlvii. (1864) 438.Afr. oce.

Hillii, Benth. Fl. Austral. vi. 131.-Austral.

hirtellum, Baill. Adansonia, i. (1860-61) 284.Madag.

indicum, Hassk. Cat. Hort. Bogor. Alt. 235.-As. trop.

insulanum, Muell. Arg. in Linnaea, xxxiv. (1865-66) 164.-N. Caled

Kirkii, Muell. Arg. in Flora, xlvii. (1864) 436.Afr. occ.

leucocarpum, Kurz, in fourn. As. Soc. Beng. xlii. (1873) II. 244.-Burma.

linostachys, Baill. Adansonia, i. (1860-61) 281.Ins. Maurit.

longifolium, Baill. Etud. Gén. Euph. 493, pro parte $=$ oligandrum.

longifolium, Muell. Arg. in DC. Prod. xv. II. 781.Malaya.

longipetiolatum, Kurs, in fourn. As. Soc. Beng. xlii (1873) II. 244.-Burma

macranthum, Muell. Arg. in Linnaea, xxxiv. (1865-66) 164.--Ins. Madag.

macrophyllum, Boj. Hort. Maurit. $284=$ indicum.

Mannii, Hook. f. in Fourn. Linn. Soc. vi. (1862) 20.Afr. trop.

marianum, Muell. Arg. in DC. Prod. xv. II. 783.Ins. Marian.

medullosum, Baill. Adansonia, i. (1860-61) 283.Madag.

membranaceum, Muell. Arg. in Flora, xlvii. (1864) 437.-Afr. trop. 


\section{CLAOXYLON :}

Mercurialis, Thw. Enum. Pl. Zeyl. 271.-As, trop. Afr. trop.

Metzierii, Bouton, ex Boj. Hort. Maurit. 285.-Ins. Maurit.

minus, Hassk. Pl. Jav. Rar, $251=$ indicum.

molle, Miq. Fl. Ind. Bat. i. $\mathrm{xr} .386=$ indicum.

monoicum, Baill. Adansonia, i. (1860-61) 283.Madag.

muricatum, Wight, Ic. t. $1886=$ Mallotus muricatus

Neraudianum, Baill. Adansonia, i. (1860-61) 280.Afr. trop.

occidentale, Muell. Arg. in Flora, xlvii. (1864) 438.-

Afr. trop.

oligandrum, Muell. Arg。 in Linnaea, xxxiv. (1865-66) 164.-Afr, trop.

parviflorum, Hook. \& Arn. Bot. Beech. Voy. $212=$ indicum.

parviflorum, A. Fuss. Tent. Euph. 114. t. 14. fo 48.-

Ins. Mascar.

parviflorum, Seem. in Bonplandia, ix. (1861) $258=$ fallax.

pauciflorum, Muell. Arg. in Fourn. Bot. ii. (1864) 383. -Afr. trop.

pedicellare, Muell. Arg. in Flora, xlvii. (1864) 437.Afr. trop.

racemiflorum, Baill. Etud. Gén. Euph. 493.-Ins. Borbon.

reticulatum, Boj. Hort. Maurit. 285.--Ins. Maurit.

rivulare, Muell. Arg. in Flora, xlvii, (1864) 518.Afr. trop.

rubescens, Miq. Fl. Ind. Bat, i. YI 387.-Ins. Pacif.

rubrinerve, Baill. Etud. Gén. Euph. 493, nomen = rubescens

sandwicense, Muell.Arg. in Linnaea, xxxiv. (1865-66) 165.-Ins. Sandvic

scabrum, Boj. Hort. Maurit. 285, nomen $=$ linostachys spiciforum, Baill. in Adansonia, i. (1860-61) $285=$ indicum.

spiciflorum, A. Juss. Tent. Euph. $43=$ Acalypha spiciflora.

stipulosum, Reichb. [f.] ex Zoll. in Verh. Naturk. Ver. Nederl. Indie, i. (1856) 20 ; et in Linnaea, xxviii. (1856') $323=$ Mallotus stipulosus.

taitense, Muell. Arg. in Linnaea, xxxiv. (1865-66) 165.-Ins. Tahiti.

tencrifolium, $F_{0}$. Muell. ex Baill. Adansonia, vi. (1866) 323. -Austral.

trichogyne, Muell. Arg. in Fourn. Bot. ii. (1864) 334. -Afr. trop.

triste, Muell. Arg. l. c.-Afr. trop.

Wallichianum, Muell. Arg. in DC. Prod. xv, II. 781.Malaya.

Welwitschianum, Muell.Arg. in Fourn. Bot. ii. (1864) 333.-Afr. trop.

CLAPPERTONIA, Meissn. Gen. Pl. 36 [28] (1837)= Honckenya, Willd. (Tíliac.)

ficifolia, Decne. in Deless. Ic. Select. Pl. v. 1. t. $1=\mathrm{H}$. ficifolia.

CLAPPIA A. Gray, in Torr. Bot. Mex. Bound. 93. (1858). COMPOSITAE, Benth. \& Hook. f. ii. 413. aurantiaca, Benth. in Hook. Ic. P1. t. 1104 (=Dysodicae sp.).-Mexic.

suacdaefolia, A. Gray, in Torr. Bot. Mex. Bound. 93 - Mexic.

CLARA, Kunth, in Abh. Akad. Berl. (1848) $44=$ Herreria, Ruiz \& Pav. (Liliac.)

ophiopogonoides, Kunth, Enum. PI. v. 296.-Bras.

CLARCKIA, Pursh, Fl. Am. Sept. i. $260(1814)=$ Clarkia, Pursh (Onagrar.

CLARIONA, Spreng. Syst, iii. $504(1826)=$ seq.

ClARIONEA, Lag. ex DC. in Ano. Mus. Par. xix. (1812) 65 = Perezia, Lag. (Compos.).

acanthoides, D. Don, ex Hook. \& Arn, in Comp. Bot. Mag, i. (1855) $34=$ P. multiflora.

afinis, Phil. in Anal. Univ, Chil. (1879) 479。-Chili. carthamoides, D. Don, in Pbil. Mag. (1832) $328=\mathrm{P}$ diversifolin

ciliaris, D. Don, ex Hook. \& Arn. in Comp. Bot. Mag i. (1835) $34=\mathrm{P}$, cilinris,

dicephala, DC. Prod, vii. $62=\mathrm{P}$ dicephals

clegans, Phil, in Linnaen, xxviii. 1856) 717 -Chili. Fonki, Phil, 1. c. 718,-Chili.

\section{CLARIONEA :-}

glaberrima, Cass. Opusc, ii. $165=$ Perezia lactucoides humilis, Phil, in Linnaea, xxviii. (1856) 717. Chili.

laciniata, Phil. in Anal. Univ. Chil. (1873) 479.Chili.

lactucoides, D. Don, in Trans. Linn. Soc. xvi. (1833) $206=$ P. lactucoides.

Lechleri, Sch. Bip. in Flora, xxxviii. (1855) 122.Peruy.

macrocephala, Sch. Bip. in Lechl. Berb. Am. Austr. 57.-Peruv

magellanica, DC, in Ann. Mus. Par, xix. (1812) 66. t $3=$ P. magellanica.

multicapitata, Remy, in C. Gay, Fl. Chil. ii. $410=$ P. multicapitata

parvifolia, Phil, in Anal, Univ. Chil. (1873) 480.Chill

pedicularifolia, DC. Prod, vii. $61=$ P. pedicularidi folia.

pilifera, D. Don, in Phil. Mag. (1832) $388=\mathrm{P}$. pilífera.

pinnata, Phil. in Linnaea, xxviii. (1856) 718, - Chili.

pinnatifida, DC. Prod. vii. $62=$ P. pinnatifida.

polycephala, Cass. Opusc. ii. $167=P^{2}$. multiflora.

pungens, DC. Prod. vii. $62=\mathrm{P}$. pungens,

recurvata, D. Don, in Trans. Linn. Soc. xyi. (1830) $206=$ P. Doniana

runcinata, Lag, ex D. Don, 1. c. $207=$ P. runcinata spathulata, Lag. ex D. Don, 1, c. $205=\mathrm{P}$. viscosa. variabilis, Phil. in Linnaea, xxxiii. (1864-65) 125. Chili.

virens, D. Don, in Trans. Linn. Soc. xvi. (1833) 208 P. Poeppigii.

Volckmanni, Phil. in Anal. Univ. Chil. (1873) 480.Chili.

CLARIONELlA, DC. ex Stend. Nom. ed. II. i. 377 $(1840)=$ CLARIONEA, Lag. = Perezia, Lag. (Compos.

magellanica, Hombr. \& Jaçuin. ex Decne. Bot. Voy. Astrol. \& Zél. $45=$ P. magellanica.

CLARIONEMA, Phil. in Linnaea, xxviii. (1856) 717 praec.

Clarionia, D. Don, in Trans, Linn. Soc. xvi. (1830) $204=$ praec

CLARISIA, Abat, in Mem. Soc. Med. Sev. x. (1792) 418. - Cf. Spreng. Gen. $202(1830)=$ Anredera, Juss (Chenopod.)

volubilis, Abat, l. c.; ex Moq. in DC. Prod. xiii. II $230=$ A. spicata

CLARISIA, Ruiz \& Pav, Prod. FI. Per. \& Chil, 158 t. 28 (1794), URTICACEAE, Benth, \& Hook, fo iii 377

SoAresia, Fr. Allem. in Palestr. Scient. Rio Jan. (1858) 142

biflora, Ruiz Es Pav. Syst. Veg. 256.,-Peruv.

racemosa, Ruiz \& Pav. lo c. 255.-Peruv.

CLARKELLA, Hook. f. Fl. Brit. Ind。 iii。 46 (1880 RUBIACEAE.

nana, Hook. f. l. c.-Reg. Himal.

CLARKIA, Pursh, Fl. Am. Sept. i. t. 11 (1814) ONAGRARIEAE, Benth. \& Hook, f. i. 789

Guaropsis, Presl, Epim. Bot. 219 (184y).

OPSiANTHES, Lilja, Fl. Sverig. Suppl. 25 (1840).

Phaeostoma, Spach, Hist. Vég. Pban. iv. 392 (1835).

Eiseneana, Kellogg, in Proc. Calif. Acad. vii. (1577) 1). - Calif.

elegans, Dougl. in Lindl. Bot. Reg. t. 1575.-Am. bor occ.

elegans, Poir. in Dict. Sc. Nat. ix. $255=$ pulchella. gauroides, Dougl. ex Sweet, Brit. Flow. Gard, Ser. It. t. $\mathbf{3 7 9}=$ rhomboidea.

pulchella, Pursh, 17. Am. Sept. i. t. 11.-Am. bor

pulcherrima, Hort. ex L'Horticul. Franç. (1861) 7 . pulchella.

rhomboidea, Dougt. in Hook. F\%. Bor. An, i. 214.-

Am. bor. Occ.

ungusiculata, Lindl. Bot, Keg. t. 1981 = clegrans.

diantiana, A. Gray, in Proc. Bast. Sox. Nat. Hisp, vii. (1859-61) 145 -Calif
CLASTA, Comm. ex Vent. Choix, sub to 47 (1803)

Casearia, Jacq. (Samydac.)

fragilis, Comm. ex Vent. 1. $\mathrm{c}_{0}=$ Cas, fragilis,

CLASTILIX, Rafin. Sylva Tellur. 99 (1838)=Miconia Ruiz \& Pav. (Melast.).

mexicana, Rafin. $1 . \mathrm{c} .=\mathrm{M}$. mexicana

tunicata, Rafin. l. $_{\text {. }}=$ M. tunicata,

CLASTOPUS, Bunge, ex Boiss. Fl. Orient. i. 261 (1867)

= Vesicaria, Tourn. (Crucif.

purpureus, Bunge, l. c--Persia.

vestitus, Boiss. l. c--Persia.

CLATHROSPERMUM, Planch, ex Benth. \&c Hook. f. Gen. i. 29 (1862), ANONACEAE, Benth. \& Hook. f. l. c.

biovulatum, S. Moore, in Fourn. Bot. xv. (1877) 65.Afr. trop.

Mannii, Oliver, Fl. Trop. Afr. i. 25.-Afr. trop.

Vogelii, Planch. ex Benth. in Trans. Linn. Soc. xxii. (1862) 479,-Afr. trop.

CLAUCENA, Burm. f. Fl. Ind. 87 (1768) $=$ Clausena Burm. f. (Rutac.).

CLAUdiA, Opiz, ex Panz, in Denkschr, Bot. Ges. (18018 I1, $177=$ Melica, Linn. (Gramin.)

ciliata, Opiz, 1, $c_{0}=\mathrm{M}$. ciliata.

CLAUSENA, Burm. f. Fl, Ind. 243 (1768)。 RUTA CEAE, Benth. \& Hook. f. i. 304.

AUlaCia, Lour. Fl. Cochinch. 273 (1790) Cook1A, Sonner. Voy. ii. 130, t. 131 (1782), Fagarastruyi, G. Don, Gen. Syst. ii. 87 (183\%). Gallesioa, M. Roem, Syn. Hesper. 45 (1846). GLAuCENA, Vitm. Summa, ii. 441 (1789, Myaris, Presi, Bot. Bemerk. 40 (1849). QUINARIA, Lour. Fl. Cochinch. $272(1790)$

Piptostylis, Dalz. in Hook. Kew Journ, iii, (1851 33. t. 2.

Polycyema, Voigt, Hort. Suburb. Calc. 141 (1845). anisata, Hook. f. in Hook. Niger Fl. 256.-Afr. trop. brevistyla, Oliver, in Fourn. Linn. Soc. v. Suppl. it. (1861) 31.-Austral.

chrysogyne, Miq. Fl. Ind.Bat. Suppl, i. 502 _-Malava. corymbiflora, Linden, Cat. n. 98 (1878) 3. - Ins Loyalt crenulata, F. Muell. Phyt. New Hebr. $7=$ Murraya crenulata.

dentata, M. Roem. Syn. Hesper. $44=$ Willdenowii.

excavata, Burm. f. Fl. Ind. 89, t 29,-Ind. or Malaya.

Halmaheirae, Miq. Ann. Mus. Bot. Lugd. Bat. 211.-Malaya.

heptaphylla, Wight \& Arn. Prod. 95, in nota-Iod. or. ; Burma.

inequalis, Benth. in Hook. Niger Fl. 257.-Afr. trop. indica, Oliver, in Fourn. Linn. Soc. v. Suppl. ii. (1S6) 36.-Ind. or.

javanensis, Raeusch, ex DC. Prod. i. $588=$ excavata

javanica, M. Roem. Syn. Hesper. 45.-Java.

javensis, J. F. Gmel. Syst. $610=$ excavata ? macrophylla, Hook. f. Fl. Brit. Ind. i. 504.-Burma nana, Wight \& Am. Prod. $96=1$ lilldenowii. pentaphylla, DC. Prod. i. 588. - Reg. Himal. pubescens, Wight \& Am. Prod. 96 - Willdenowii punctata, Wight \& Am. l. c. $95=$ excavata.

simplicifolia, Dalz. in Hook. Kew Joum. iii. 185 $180=$ Acronychia laurifolia.

sufiruticosa, Wight \& Arn. Prod.96, in nota_Reg. Himal.

sumatrana, Wight \& Am. I c. $95=$ excavata

timorensis, M. Roens. Syr. Hesper. tt.-Ins. Timon

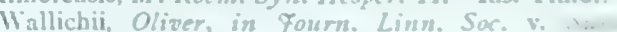
ii. (1861) 35.-Burma.

Wampi, Oliver, l. c. 34.-Chins ?

IIightio, M. Roem. Sym. Hesper. If = Willderowii!

Willdenowii, Wight \& A Am. Prod. 96-Ind. or. Malaya.

CLAUSIA. Trolzkr, Ind. Scrn. Hort. Casan. (1Ss: Hesperis, Linn. Crucif. aprica, Trotzky, 1. c. = H. aprica

CLAUs(IN1A, Pomel, Mat. Fl. All. \& 1860'= Aspho delus, Toum. Liline.

acaulis, b'omel, I. ㄷ․ A. acsulse

CLAVAKIA, Stcurl, Nom, ed. I. 204 (IS:21), sphalm Calvaria, Gacren. (Gica. dub. 
CLAVENA, DC. Prod. vi. 633 (1837)=Carduus, baeocephala, Sch. Bip. in Webb \& Berth. Phyt. Canar. baeocephala, Sch. Bip. in Webb
ii. $373=$ Card. baeocephalus. canariensis, DC. Prod, vi. $633=$ Card, clavulatus. squarrosa, DC. 1. c. $=$ Card. squarrosus.

CLAVENNA, Neck. Elem. ii. $145(1790)=$ Ammannia, Houst.? (Lythrar.)

CLAvigerA, DC. Prod. v. $127(1836)=$ Brickellia,

Ell. (Compos.).
brachyphylla, A. Gray, Pl. FendI. $63=$ B. brachyphylla. corymbosa, DC. Prod. v. $128=$ B. corymbosa.

dentata, DC. 1. $\mathrm{c} .=\mathrm{B}$. Riddellii.

pinifolia, Gardn. in Hook. Lond. Journ. Bot. v. (1846) $461=B$. pinifolia

Riddellii, Torr. \& Gray, Fl. N. Am. ii. $77=$ B. Riddellii.

scabra, Benth. Pl. Hartw. $19=$ B. corymbosa.

scoparia, DC. Prod. v. $128=$ B. scoparia.

spinulosa, A. Gray, Pl. Fendl. $63=\mathrm{B}$, spinulosa.

CLAviJA, Ruiz \& Pav. Prod. 142. t. 30 (1794). MYRSINEAE, Benth. \& Hook. f. ii. 649. HORTA, Vell. Fl. Flum. 48 (1825); i. t. 124

TheopHrasta, Linn. Gen, ed. I. 45 (1737)

Zacin'rha, Vell. Fl. Flum. 276 (1825); viii. t. 9.

biborrana, Oerst. in Kjoeb. Vidensk. Meddel. (1861) 117.-Costa Rica.

caloneura, Mart. ex Miq. in Mart. Fl. Bras. x. 277.Bras.

clavata, Decne, in Ann. Sc. Nat. Sér. VI. ủi. (1876) 144.-Hab. ?

grandis, Decne. l. c.-Hab. ?

fulgens, Hook. f. Bot. Mag. t. 5626.-Peruv.

Hookeri, DC. Prod. viii. 148.-Peruv.

integrifolia, Mart. ex Miq. in Mart. Fl. Bras. x. 277. - Bras.

lancifolia, Desf. in Nouv. Ann. Mus. Par. i. (1832) 402. t. 14.-Guiana.

iatifolia, C. Koch, in C. Koch \& Fint. Wochenschr (1859) 108.-Ind. occ

longifolia, Ruiz E Pav. Syst. Veg. i. 284.-Peruv. macrocarpa, Ruiz E Pav. l.c.-Am. austr. macrophylla, Miq. in Mart. Fl. Bras. x. 275,-Bras. onata, D. Don, in Edinb. Phil. Fourn. (Jan. 1831) 236.-Am. austr.

pendula, Ruiz E' Pav. Syst. Veg, i. 285.-Am. austr. Riedeliana, Regel, Gartenfl. (1859) 245.-Bras.

Rodekiana, Linden E André, Illustr. Hortic. xxi. (1874) t. 188.-N. Granat.

sparsifolia, Miq. in Mart. Fl. Bras. x. $278=$ Leonia glycycarpa.

spathulata, Hook. Ic. Pl. t. 140= Hookeri.

spathulata, Ruiz Eo Pav. Syst. Veg. i. 285.-Am. austr.

speciosa, C. Koch E Linden, Ind. Sem. Hort. Berol. (1867) App. i. 8.-Am. trop.

umbrosa, Regel, Ind. Sem. Hort. Petrop. (1868) 86.Bras.

undulata, D. Don, in Edinb. Phil. Fourn. (Jan. 1831 ) 234.-Am, austr.

CLAvimyrtus, Blume, Mus. Bot. Lugd. Bat. i. 113. t. $49(1849)=$ Fugenia, Linn. (Myrtac.).

claviflora, Blume, 1. c. 114 , in obs. $=\mathrm{E}$. claviflora

cylindrica, Blume, 1. c. $115=\mathrm{E}$. cylindrica.

firma, Blume, 1. c. 116.-Java.

glabrata, Blume, 1. c. 114.-Java.

latifolia, Blume, 1. c. 117.-Borneo

lineata, Blume, 1. c. $116=$ E. lineata, Duthie. marginata, Blume, 1. c. 115.-Java,

panciflora, Blume, 1. c. 114, in obs. = E. laeta. ramosissima, Blume, 1. c. $115=$ E. ramosissima symphytocarpa, Blume, 1. c. 117.-Sumatra.

virens, Blume, 1. c. 114.-Java

CLAvUlA, Dum. F1. Belg. $143(1827)=$ Eleocharis, R. B3r. \& Scirpus, Linn. (Cyperac.). acicularis, Dum. 1. c. $=\mathrm{E}$. acicularis. Boeotryon, Dum. 1. c. $=$ S. pauciflorus. caespitosa, Dum. 1. $\mathrm{c}_{\mathrm{s}}=\mathrm{S}$. caespitosus comosa, Dum. 1. $\mathrm{c} .=\mathrm{S}$. nanus? fluitans, Dum. 1. c. $=$ S. fluitans. multiculmis, Dum. 1. c. = E. multicaulis. ovata, Dum. J. c. = E. ovata.

palustris, Dum. 1. $\mathrm{c}_{\mathrm{r}}=\mathrm{E}$. palustris. uniglumis, Dum. $1_{0} \mathrm{c}_{0}=\mathrm{E}$. palustris.
CLAVUliUM, Desv, in Ann. Sc. Nat. Sér. I. ix. (1826) $407=$ Crotalaria, Dill. (Legumin.).

mucronatum, G. Don, Gen. Syst. ii. $142=$ Crot. mucronata.

pedunculatum, Steud. Nom. ed. II. i. $378=$ seq.

pedunculosum, Desv. in Ann. Sc. Nat. Sér. I. ix. (1826) $407=$ Crot. laburnifolia

Clavulum, G. Dỏn, Gen. Syst. ii. 96, $142(1832)=$ praec.

\section{CLAYTONA, Linn. Hort. Ups. $52(1748)=$ seq.}

CiAYTONIA, Gronov. ex Linn. Gen. ed. I. 339 (1737). PORTULACEAE, Benth. \& Hook. f. i. 158

Belia, Steller, ex S. G. Gmel. Fl. Sibir. iv. 88 (1769).

acutifolia, Ledeb. Fl. Alt. i. 253; Ic.'t. $272=$ arctica.

acutifolia, Pall.ex Willd. in Roem. E Schult. Syst. v. 436.--Sibir. or.

cautiflora, Sweet, Hort. Brit. ed. II. $220=$ virginica. alsinoides, Sims, Bot. Mag. t. $1309=$ sibirica

ambi ua, S. Wats, in Proc. Am. Acad. xvii. (1881-82) 365.-Am. bor. occ.

aquatica, Nutt. in Torr. \& Gray, F1. N. Am. i. $201=$ Chamissonis.

arctica, Adam, in Mém. Soc. Nat. Mosc. v. (1817) 94. -As, et Am. arct.

assarifolia, Bong. Veg. Sitcha, $136=$ sibirica?

australasica, Hook. f. in Hook. Ic. Pl. t. 293.-Austral

balonnensis, F. Muell. Census, $27=$ Calandrinia balonnensis.

bifida, Willd. ex Roem. \& Schult. Syst. v. $434=$ sibirica.

brevipedata, F. Muell. Census, $27=$ Calandrinia brevipedata.

bulbifera, A. Gray, in Proc. Am. Acad. xii. (1877) 54. -Am. bor. occ.

californica, Herb. Petrop. ex Loud. Hort. Brit. Suppl. ii. 621.-Calif.

calyptrata, F. Muell. Fragm. iii. $89=$ Calandrinia calyptrata.

caroliniana, Michx. Fl. Bor. Am. i. 160-Am. bor

Chamissoi, Ledeb. ex Spreng. Syst. i. $790=$ sarmentosa.

Chamissonis, Eschscholtz, ex Cham. in Linnaea, vi. 1831) 562.-Am. bor, occ

composita, F. Muell. Census, $27=$ Calandrinia composita.

cordifolia, S. Wats. in Proc. Am. Acad. xvii. (1881-82) 365.-Am. bor. occ.

corrigioloides, F. Muell. Census, $27=$ Calandrinia corrigioloides.

cubensis, Bonpl. in Ann. Mus. Par. vii. (1806) 82, t. 6 $=$ perfoliata.

dichotoma, Nutt. ex Torr. E Gray, Fl. N. Am. i. 202. -Am. bor. occ.

diffusa, Nutt. l. c.-Calif.

Eschscholtzii, Cham. in Linnaea, vi. (1831) 561.-Am arct.

exigua, Torr. E Gray, Fl. N. Am. i. 200.-Calif

filicaulis, Dongl, in Hook. FI. Bor. Am. i. 224. t. $72=$ parvifolia.

flagellaris, Bong. Veg. Sitcha, $136=$ Chamissonis. gracilis, F. Muell. Census, $27=$ Calandrinia gracilis. grandiflora, Sweet, Brit. Flow. Gard. t. $216=$ virginica. granulifera, F. Muell. Census, $27=$ Calandrinia granulifera.

gypsophiloides, Fisch. \& Mey. Ind. Sem. Hort. Petrop. ii. $33=$ perfoliata.

Foanneana, Roem. \& Schult. Syst. v. $434=$ arctica. lanceolata, Hook. \& Arn. Bot. Beech. Voy, 123, $344=$ sarmentosa.

lanceolata, Pursh, F1. Am. Sept. i. 175. t. $3=$ caroliniana.

Lehmanni, F. Mneil. Census, $27=$ Calandrinia Lehmanni.

linearis, Dougl. in Hook. Fl. Bor. Am. i. 224, t. 71.Am. bor. occ

liniflora, F. Muell, Census, $27=$ Calandrinia liniflora media, Link, Handb. ii. $44=$ virginica.

megarrhiza, Parry, ex S. Wats. Bibliog. Ind. N. Am Bot. i. 118.-Am, bor. occ.

nemo"osa, Willd. ex Roem. \& Schult. Syst. v. 436 (= Irlbachia Bonplandiana),-N. Granat. nevadensis, S. Wats. Bot. Calif. i. 77.-Calif

\section{CLAYTONIA :-}

parviflora, Dougl. ex Hook. Fl. Bor. Am. i. 225. t. 73 - perfoliata.

parvifolia, Moç. ex DC. Prod. iii. 361.-Am. bor, occ. perfoliata, Donn, Ind. Hort. Cant. 25, ex Willd. Sp. Pl. i. 1186.-Am. bor.

Pickeringi, F. Muell. Census, $27=$ Calandrinia Pickeringii.

pleiopetala, F. Muell. 1. c. = Calandrinia pleiopetala. pogonophora, F. Muell. I. $\mathrm{c}=$ = Calandrinia pogonophora.

polyandra, F. Muell. 1. c.=Calandrinia polyandra. polypetala, F. Muell. 1. c. = Calandrinia polypetala. Portulacaria, Linn. Mant. ii. $211=$ Portulacaria afra. ptychosperma, F. Muell. Census, $27=$ Calandrinia ptychosperma.

pumila, F. Muell. 1. c. = Calandrinia pumila.

quadrivalvis, F. Muell. 1. c.= Calaudrinia quadrivalvis.

sarmentosa, C. A. Mey. in Nouv. Mém. Soc. Nat. Mosc. vii. (1829) 137. t. 3.-As. et Am, arct.

sibirica, Linn. Sp. Pl. 204.-As. bor.; Am. bor. occ. sibirica, Pall. ex Steud. Nom. ed. II. i, $378=$ arctica. Simsii, Sweet, Brit. Flow. Gard. sub t. $216=$ virginica.

spathulaefolia, Salisb. Parad. Lond. t. $71=$ caroliniana.

spathulata, Dougl. in Hook. F1. Bor. Am. i. 226. t. 74 $=$ perfoliata

spathulata, Hook. \& Arn. Bot. Beech. Voy. $344=$ exigua.

spatulata, Eaton, Man. ed. IV. 263=caroliniana.

spergularina, F. Muell. Census, $27=$ Calandrinia spergularina.

stolonifera, C. A. Mey. in Nouv. Mém. Soc. Nat. Mosc. vii. (1829) $139=$ Chamissonis,

strophiolata, F. Mnell. Fragm. xi. $82=$ Calandrinia strophiolata.

tenuifolia, Torr. \& Gray, F1. N. Am. i. $201=$ exigna.

triphylla, S. Wats. in Proc. Am. Acad. x. (1875) 345 -Am. bor. occ.

tuberosa, Moç. \& Sesse, ex DC. Prod. iii. 357 - Talinum napiforme.

tuberosa, Pall. ex Willd. in Roem. E Schult. Syst. v. 436. - Sibir. or.

umbellata, S. Wats. in Bot. King, Exp. 43.t. 6.-Am. bor. occ.

unalaschkensis, Fisch. Hort. Gorenk. ed. II. (1812) 62; et in Roem. \& Schult. Syst. v. $434=$ sibirica.

uniflora, F. Muell. Census, 27 = Calandrinia uniflora.

Vancouverii, A. Murr. Oreg. Circ. 1.-Am. bor, occ.

Vestiana, Fisch. ex G. Don, Gen. Syst. iii. $82=$ sarmentosa.

virginica, Linn.Sp.Pl. 204.-Am. bor.

volubilis, F. Muell. Census, $27=$ Calandrinia volubilis.

CLEACHNE, Roland. ex Steud. Nom. ed. II. i. 378 $(1840)=$ Paspalum, Linn. (Gramin.).

CLFANTHE, Salisb. in Trans. Hort. Soc, i.

312. IRIDEAE, Benth. \& Hook. f, iii. 701.

bicolor, Salisb. l. c.-Afr, austr.

melaleuca, Baker, in Journ. Linn. Soc. xvi. (1877) 112 $=$ bicolor.

CLEANTHES, D. Don, in Trans. Linn. Soc. xvi. (1830) $194=$ Trixis, P. Br. (Compos.).

brasiliensis, D. Don, l. c. $195=$ T. brasiliensis hieracioides, D. Don, 1. c. $197=$ T. ochrolenca. othonnoides, Griseb. in Goett. Abh. xxiv. (1879) $217=$ $\mathrm{T}$. brasiliensis.

CLEGHORNIA, Wight, Ic. tt. 1310, $1312(\mathbf{1 8 5 0})=$ Baissea, DC. (Apocyn.).

acuminata, Wight, 1. c. t. $1310=$ B. acuminata. cymosa, Wight, 1. c. t. $1312=\mathrm{B}$. acuminata.

CLEIDION, Blume, Bijdr. 612 (1825). EUPHOR BIACEAE, Benth. \& Hook. f. iii. 320. Lasiostyles, Presl, Bot. Bemerk. 149 (1844).

Psilostachys, Turcz, in Bull. Soc. Nat. Mosc, xvi. (1843) 58 .

Redia, Casar. Noy. Stirp. Bras. Dec. 51 (1842).

Tetraglossa, Bedd, in Madr. Journ. Sc. Ser. II. xxii. (1861) 70

castaneaefolium, Muell. Arg. in Linnaca, xxxiv. (186166) 184.-Peruv.

claoxyloides, Muell, Arg. l. c.-N. Caled. 


\section{CLEIDION :}

coriaceum, Baill. Adansonia, ii. (1861-62) $218=$ Macaranga coriacea.

gabonicum, Baill. l. c. xi. (1874) 129.-Afr. trop. javanicum, Blume, Bijdr. 613.-Ind. or. ; Malaya. macrophyllum, Baill. Adansonia, i. (1861-62) $219=$ Vieillardii.

nicaraguense, Hemsl. Biol. Centr. Am. Bot. iii. 130.Nicaragua.

nitidum, Thw. ex Kurg, in Fourn. As. Soc. Beng. xlii. (1873) II. 245.-Ins, Andaman.

populifolium, Zipp. ex Span. in Linnaea, xv. (1841) 349, nomen.-Malaya.

spathulatum, Baill. Adansonia, ii. (1861-62) 221.N. Caled.

tricoccum, Baill. l.c. iv. (1863-64) 370.-Bras

ulmifolium, Muell. Arg. in Flora, xlvii. (1864) 481.-

Ins. Loo-Choo,

verticillatum, Baill. Adansonia, ii. (1861-62) 221.N. Caled.

Vieillardii, Baill. l. c. 220.-N. Caled.

CLEIEMERA, Rafin, F1. Tellur, iv. $77(1836) \doteq$ Ipomoea, Linn. (Convolvulac.).

cuspidata, Rafin. 1. c. $78=$ Convolvulus Meyeri.

guinensis, Rafin. 1. c. = I. capitata

hederacea, Rafin. 1. c. $77=\mathrm{I}$. Nil.

hirsuta, Rafin. 1. c. $78=$ I. hederacea.

indica, Rafin, 1. c. (=Pharbitis violacea).-As. trop.?

peruviana, Rafin. 1. c. = I. longicuspis.

CLEISOCRATERA, Korth. Verh. Nat, Geschied. 256. t. 62 (1842). RUBIACEAE, Benth. \& Hook, f. ii. 123 .

elegans, Korth. 1. c. 257. t. 62.-Borneo.

CIEISOSTOMA, Blume, Bijdr. 362 (1825). ORCHI$D E A E$, Benth. \& Hook, f. iii. 580.

Echinoglossum, Reichb. Nom. 54 (1841)

Echioglossum, Blume, Bijdr. 364. t. 28 (1825)

Pomatocalpa, Breda, Orch. Kuhl \& Hass. (1827).

Synptera, Llanos, Fragm. Pl. Filip. 98 (1851).

acaule, Lindl. Gen. el Sp. Orch. 227 (= Saccolabii sp.). -Zeylan.

amabile, Teijsm. E Binn. in Nat. Tijdschr. Ned. Ind. v. (1853) 493.-Malaya.

appendiculatum, Benth. \& Hook. f. Gen. iii. 577.Ind. or.

Armitii, F. Muell. Fragm. ix. 49 = Sarcochilus Armitli.

Beckleri, F. Muell. ex Benth. Fl. Austral. vi. 296.Austral.

bicolor, Lindl. \& Paxt. Flow. Gard. ii. (1851-52) 99. - Manilla.

bifidum, Teijsm. EN Binn. Cat. Hort. Bog. 49, nomen. - Java.

brevilabre, F. Muell. Fragm. xi. 87.-Austral.

callosum, Blume, Bijdr. 364.-Java.

carinum, Hance, in Fourn. Bot. xx. (1882) 359.China.

complanatum, Lindl. (Cf. Gen. et Sp. Orch.227. n. 8); Steud. Nom. ed. II. i. 378.-Ind. or.

crassifolium, Lindl. E Paxt. Flow. Gard.iii. (1852-53) t. 99, 126.-Burma?

cryptochilum, F. Muell. in Wing, South Sc. Record, N. S. i. $(1885) \cdot-\mathrm{N}$. Gtuinea.

Cumingii, Reichb. f. in Otto \& Dietr. Allg. Gartenz. xxiv. (1856) 218.-Hab. ?

Dawsonianum, Reichb. f. in Gard. Chron. (1868) 815 = Trichoglottis Dawsoniana.

dealbatum, Lindl. Bot. Reg. (1843) Misc, 5.-Manilla.

decipiens, Lindl. l. c. (1844) Misc. 11.-Zeylan.

discolor, Lindl. l. c. (1845) Misc. 59.-Ind, or.

emarginatum, Blume, ex Teijsm. E Bimn. Cat. Hort.

Bog. 49, nomen.-Java.

erectum, Fitey. Austral. Orch. i. IV-Austral.

expansum, Reichb. f. Otia Bot. Hamb. 52.-Ins.

Mindanao.

Fordii, Hance, in Gourn. Bot. xiv. (1876) 45.-Ins. Hongkong.

formosanum, Hance, l. c. xxii. (1884) S64.-China.

fuscum, Lindl. in Journ. Hort. Soc. v. $(1550) 80=$

latifolium.

galcatum, Thw. Enum. PI. Zeyl. $905=$ maculosum, Lindl.

\section{CLEISOSTOMA}

Guiberti, Linden \& Reichb. in Bot. Zeit. xx. (1862) 375 ; in Hamb. Gartenz. xviii. (1862) 529.-Hab.? onosmum, Lindl. Bot. Reg. (1847) t. 41.-Manilla.

Keffordii, F. M. Bailey, in Rep.Queensl. Acclim. Soc (Apr. 1884) 9.-Austral.

lanatum, Lindl. in Fourn. Hort. Soc. iv. (1849) 164.Burma.

latifolium, Lindl. Bot. Reg. (1840) Misc. 60.Malaya.

longifolium, Teijsm. E Binn. in Nat. Tijdschr. Nederl. Ind. v. (1853) 494.-Java.

loratum, Reichb. f. in Flora, 1v. (1872) 273.-Reg. Himal.

Macphersoni, F. Muell. ex Benth. Fl. Austral. vi. 297 -Austral.

macrostachyum, Teijsm. E Binn. Cat. Hort. Bog. 49. -Java.

maculosum, Blume, ex Teijsm. E Binn. Cat. Hort. Bog. 49, nomen.-Java.

maculosum, Lindl. Gen. ot Sp. Orch. 227.-Zeylan.

maculosum, Thw. Enum. Pl. Zeyl. $304=$ decipiens.

Mannii, Reichb. f. in Flora, Iv. (1872) 274.-Reg.

Himal.

roseum, Lindl. Bot. Reg. (1838) Misc. 80.

Manilla.

sagittatum, Blume, Bijdr. 363.-Java.

spathulatum, Blume, l. c. 364.- Java.

spicatum, Lindl. Bot. Reg. (1847) sub to 32.-

Malaya.

suaveolens, Blume, Bijdr. 368.-Java.

subulatum, Blume, l. c.-Java.

subviolaceum, Reichb. f. in Bonplandia, x. (1862) 335 -Ins. Philipp.

teretifolium, Teijsm. E Binn. in Tijdschr. Nederl. Ind. xxvii. (1864) 20,-Sumatra.

Thwaitesianum, Trim. in Journ. Bot. xxiii. (1885) 244 $=$ decipiens.

tridentatum, Lindl. Bot. Reg. (1838) Misc. 33.Austral.

undulatum, Reichb. f. in Flora, Iv. (1872) 274.-Reg.

Himal.

virginale, Hance, in Fourn. Bot. xv. (1877) 38.-Ins. Hongkong.

vitellinum, Reichb. f. in Linnaea, xli. (1877) 76.-Ins. Philipp.

Wendlandorum, Reichb. fo in Otto \& Dietr. Allg.

Gartenz. xxiv. (1856) 219.-Reg. Himal.; Burma.

CLEISOSTOMA, Rafin. Fl. Tellur. iv. $80(1836)=$ Convolvulus, Tourn

villosum, Rafin. 1. c. = Conv。 aggregatus,

CLEISSOCRATERA, Miq. F1. Ind. Bat. ii. 383 (1856)= Cleisocratera, Korth. (Rubiac.).

CLEISTACHNE, Benth. in Journ. Linn. Soc. xix. (1881) 61. GRAMINEAE, Benth. \& Hook. f. ii 1120.

sorghoides, Benth. in Hook. Ic. Pl. t. 1379.-Afr. trop. Ind. or.

CLEISTANTHIUM, Kunze, in Bot.Zeit. ix. (1851) 350 = Gerbera, Gronov. (Compos.)

nepalense, Kunze, $\mathrm{I}, \mathrm{c}=\mathrm{G}$. Kunzeana

CLEISTANTHUS, Hook. fox Planch, in Hook. Ic Pl. t. 779 (1848). EUPHORBIACEAE, Benth, \& Hook. f. iii. 268

Lebidiera, Baill. Etud. Gén. Euph. Atlas, 50. t. 27 (1858).

LEbIdierorsis, Muell. Arg. in Linnaea, xxxii. (1863) 79

Lelopyxis, Miq. Fl. Ind. Bat. Suppl. 445 (1860).

Nanopetalum, Hassk. in Versl. Kon. Akad. Wetensch iv. (1855) 140 .

acuminatus, Muell. Arg. in DC. Prod. xv. I1. 508.Zeylan.

angolensis, Welw. ex Muell. Arg. in Gourn. Bot. ii. 1864) 389.-Afr. occ.

apodus, Benth. Fl. Austral. vi. 122.-Austral.

Blancoi, Rolfe, in Fourn. Linn. Soc. xxi. (1884) 315. Ins. Philipp.

Boivinianus, Muell. Arg. in DC. Prod. xv. 11. 505.Madag.

chartaceus, Muell. Arg. b. c. 507.-Reg. Himal. Malaya.

collinus, Benth. E Hook. f. Gen. iii. 268.-Ind. or.

\section{CLEISTANTHUS :-}

Cunninghamii, Muell. Arg. in DC. Prod. xv. 11. 506.Austral.

Dallachyanus, Baill. ex Benth. Fl. Austral. vi. 122.Austral.

diversifolius, Muell. Arg. in DC. Prod.xv. II. 509.Madag.

ferrugineus, Muell. Arg. in DC. Prod. xv. II. 507.Zeylan.

ferrugineus, F. Vill. in Blanco, F1. Philipp. ed. III. Nov. App. 187. t. $353=$ Blancoi

lanceolatus, Muell. Arg. l. c.-Java.

malabaricus, Muell. Arg. l. c. 508.-Ind. or.

monoicus, Muell. Arg.l. C.-China.

myrianthus, Kurz, fior. Fl. Br. Burm. ii. 370.Burma; Malaya.

oblongifolius, Muell. Arg, in DC. Prod, xy, II, 506, pro parte $=$ chartaceus

pallidus, Muell. Arg. l. c.508.-Zeylan.

patulus, Muell. Arg. l. c. 505.-Ind. or.

polystachyus, Hook. f. ex Planch. in Hook. Ic. Pl. t. 779.-Afr. trop.

robustus, Muell. Arg in DC Prod. xv. II. 504.Zeylan.

semiopacus, F. Muell. ex Benth. Fl. Austral. vi. 12u. -Austral.

stenophyllus, Kurz, in fourn. As. Soc. Beng. xlii. 1873) 11. 242. - Burma.

stipitatus, Muell. Arg, in DC. Prod. xv. 11. 50b,-D. Caled.

stipularis, Muell. Arg. L. c. 509.-Ind. or

subglaucus, Thw. ex Trimen, Cat. Pl. Ceyl, 78 pallidus.

sumatranus, Muell. Arg. in DC. Prod. xv. It. 504. Sumatra.

tomentosus, Hance, in Fourn. Bot. xv. (1877) 337.China.

CLEISTES, Rich, in Mém, Mus. Par. iv. (1818) 31 Pogonia, Juss. (Orchid.)

Liliastrum, keichb. $f$, in Linnaea, xxii. (1849) $\$ 16=P$. Liliasturum.

lutea, Lindl. Gen. et Sp. Orch. 409.-Guiana.

Miersii, Gardn。 in Hook. Ic. Pl. sub t. $473-474$ P. Miersii.

montana, Gardn. 1. c. = P. montana

paludosa, Reichb. f. in Linnaea, xxii. (18\$9) $816=1$. paludosa.

parviflora, Lindl. Gen. et Sp. Orch. 410.-Guiana.

rosea, Lindl. 1. c. $=$ P. rosea.

speciosa, Gardn. in Hook. Ic. Pl. t. $473-47 t=1$ speciosa.

CLEISTOCACTUS, Lem. Illustr. Hortic. viii. (1ह6] Misc. $35=$ Cereus, Mill. (Cact.).

Baumannii, Lem. 1. c. = Cereus Bamannii.

colubrinus, Lem. 1. c. = Cereus colubrinus.

rhodacanthus, Lem. 1. c. = Echinopsis rhodacantha.

CLEISTOCALYX, Blume, Mus, Bot. Lagd. Bat. i. 84. $56(1849)=$ Eugenia, Linn. (Mytac.). nervosus, Blume, 1. c. $85=\mathrm{E}$. nervosa. nitidus, Blume, 1. c. 84--Java.

CLEISTOCALYX, Steud. Sym. Pl. Cyp. 151 (1555)= Rynchospora, Vahl (Cyperac.)

junciformis, Steud. $\mathrm{I}_{0} \mathrm{c}_{\mathrm{c}}=\mathrm{K}$. uligantha.

CLEISTOCHLAMYS, Oliver, in Journ, Linn. So ix. (1867) 175. ANONACEAE, Benth. \& Hook. f.

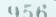

Kirkii, Oliver, l. c.-Afr. trop.

CLEITHRIA, Steud. Nom. ed. II. ii. $\left.710^{\circ}(18 t 1)=\operatorname{ser}\right]$

CLEITRIA, Schand, Ind Sem. Hor Gotring, issI ex Linnnea, viii. (153:2) Litt. 29 - Veaidium, Les: Compos.)

hirta, Schrad. 11. $\mathrm{cc}_{0}=\mathrm{V}$. Suhraderi.

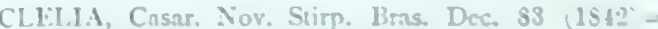
Calliandra, Berth. Lcrunin.).

ormata. Casar. L. c. sid = Call. IArrisii.

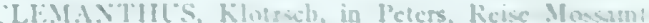
live. I\$3 Isbil)-Modocea. I am. Tavitlor." senensis, Klutivech, I. c - Ml. sencisis. 
CLEMATIS, Dill, ex Linn. Gen, ed. I. 163 (1737) RANUNCULACEAE, Benth. \& Hook. f. i. 3. Atragena, Linn. Syst. ed. I (1735); et Diss. Dass. 21 (1747); in Amoen. Acad. i. 132 (1749) (Atragene).

Cheiropsis, Spach, Hist. Vég. Phan. vii. 260 (1839).

Clematitis, [Tourn.] Linn. Syst. ed. I (1735).

Meclatis, Spach, Hist. Vég. Phan. vii. 272 (1839).

Muralta, Adans. Fam. ii. 460 (1763)

Sieboldia, Hoffmgg. ex Heynh. Nom. ii. 665 (1846).

Trigula, Noronha, in Verh. Batav. Gen. v. (1790) ed. I. Art. IV. 4 ; ed. II. 67 (1827)

VIORNA, Reichb. Handb. 277 (1837).

Viticella, Dill. ex Moench, Meth. 296 (1794)

acapulcensis, Hook. E Arn. Bot. Beech. Voy. 410.Mexic.

acerifolia, Maxim. in Bull. Soc. Nat. Mosc. liv. (1879) I. 2.-China.

acuminata, DC. Syst. i. 148.-Reg. Himal.

acutangula, Hook. f. E Thoms. Fl. Ind. 5.-Reg Himal.

aethusiaefolia, Turcz. in Bull. Soc. Nat. Mosc. v. (1832) 181.-Mongolia.

affinis, St. Hil. Fl. Bras. Mer. i. 3.-Bras.

affinis, Wight, Illustr. i. 5.-Ind. or. afoliata, F. Buch. in Trans. N. Z. Inst. iii. (1871) 211.

ajanensis, O. Kuntze, in Verh. Bot. Ver. Brand. xxvi. (1885) 176.-As. bor.

albida, Klotzsch, in Bot. Ergeb. Waldem, Reise $131=$ orientalis.

alpina, Mill. Gard. Dict. ed. VIII. n. 9.-Europ. Am. bor.

americana, Mill, l, c. n. $14=$ dioica.

amplexicaulis, Edgew. in Trans. Linn. Soc. xx. (1851) $24=$ connata

anemonifiora, D. Don, Prod. F1. Nep. $192=$ montana. anemonoides, O. Kuntze, in Verh. Bot. Ver. Brand. xxvi. (1885) $149=$ florida

anethifolia, Hook. Ic. Pl. t. 78.-Madag.

angustifolia, Jacq. Enum. Vindob. $310=$ C. Flammula.

aphylla, O. Kuntze, in Verh. Bot. Ver. Brand. xxyi. (1885) $146 .-$ N. Zel.

apiculata, Hook. f. E Thoms. in Fl. Brit. Ind. i. 4.Reg. Himal.

apiifolia, DC. Syst. i. 149.-Tapon.

aquifolia, Steud. Nom. ed. II. i. 378, sphalm.=apiifolia.

aristata, R. Br. in Bot. Reg. t. 238.-Austral

Armandi, Franch. in Nouv. Arch. Mus. Par. Sér. II. viii. (1885) 184.-As. or.

aromatica, Lenné Eo C. Koch, in App. Ind. Sem. Hort. Berol. (1855) 15 ; ex Walp. Ann. iv. 4,-Hab.?

asplenifolia, Schrenk, Enum. Pl. Nov. Alt. 68,Soongaria; Afghanist.

azurea, Hort. ex Turcz. in Bull. Soc. Nat. Mosc. xxvii. (1854) II. 272 [bis].-Tauria (cult.)

azurea, Siebold, ex Stend. Nom. ed. II. i. $378=$ florida.

baccata, Pers. Syn. ii. $99=$ C. Viticella.

Baldwini, Torr. E Gray, Fl. N. Am. i. 8.-Am. bor.

balearica, Rich. in Journ. Phys. (Févr. 1779) $127=$ cirrhosa.

bannatica, Schur, in Verh. Siebenb. Ver. Naturw. iv. (1853) 7.-Europ.

barbellata, Edgew. in Trans. Linn. Soc. xx. (1851) 25 -Reg. Himal.

Bergeroni, A. Lavall. Clemat. 35. t. 10.-Hab. ?

bicolor, Steud. Nom. ed. II. i. $378=$ florida.

Bigelovi, Torr. in Pacif. Rail. Rep. iv. 61.-Am. bor.

biloba, Stend. Nom. ed. II. i. 379, vide triloba, St. Hil.

biternata, DC. Syst. i. 149.-Japon.; China.

blanda, Hook. Joum. Bot. i. (1834) $241=$ aristata.

Bojeri, Hook. Ic. Pl. t. 10.-Madag.

bonariensis, Fuss. ex DC. Syst. i. 145.-Reg. Argent.

brachiata, Ker-Gawl. in Bot. Reg. t. $97=$ Kerrii.

brachiata, Thunb. Prod. Pl. Cap. 94.-Afr, austr.

brachyura, Maxim. in Bull. Acad. Pétersb. xxii. (1877) 221.-Corea

bracteata, DC. Syst. i. $142=$ virginiana.

bracteata, Kurz, in Fourn. As. Soc. Beng. xliii. (1874) II. 43.-Ind, or.

bracteosa, Banks, ex Stend. Nom. ed. 1. 204, $205=$ recta.

brasiliana, DC. Syst. i. 143.-Bras.

brevicaudata, $D C$. l. c. 138.-China.

\section{CLEMATIS}

Bucamara, Buch.-Ham. ex DC. Syst. i. $140=$ Buchaniana.

Buchanani, D. Don, Prod. Fl. Nep. $191=$ seq.

Buchananiana, Wall. Cat. n. $4677=$ seq.

Buchaniana, DC. Syst. i. 140.-Reg. Himal.

Cadmia, Buch.-Ham. ex Wall. Cat. n. 4669.-Reg.

Himal.; Burma.

caerulea, Lindl. Bot. Reg. t. $1955=$ patens.

caesariata, Hance, in Fourn. Bot. viii. (1870) 71.China.

caespitosa, Scop. F1. Carn. ed. II. i. $389=$ C. Flam. mula.

calycina, [Soland. in] Ait. Hort. Kew. ed. I. ii. $259=$

cirrhosa.

campaniflora, Brot. Fl. Lusit. ii. 359.-Lusitan.

campaniflora, Lodd. ex Steud. Nom. ed. II. i. $379=$ parviflora.

campestris, St. Hil. Fl. Bras. Mer. i. 4.-Bras.

cana, Wall. Cat. n. $4672=$ Gouriana.

canadensis, Mill. Gard. Dict. ed. VIII. n. $5=$ virginiana.

canaliculata, Lag. Gen. et Sp. Nov, $17=$ C. Flammula

capensis, Poir. Encyc. Suppl. ii. $296=$ Anemone

capensis.

caracassana, H. B. \& K. ex DC. Syst. i. $141=$

caripensis.

caripensis, H. B. E K. Nov. Gen. et Sp. v. 36.-Mexic

Catesbyana, Pursh, Fl. Am. Sept. ii. 736.-Am. bor.

caudata, Hook, ex Hemsl. Biol. Centr. Am. Bot. i. $2=$

Drummondii.

Chandleri, Hort, ex Lavall. Clemat, $40=$ eriostemon.

chinensis, Osb. Iter, ed. Angl. i. $393=$ recta.

chinensis, Retz. Obs. ii. 18. t. 2.-China.

chlorantha, Lindl. Bot. Reg. t. $1234=$ grandiflora.

chrysocarpa, Welw. ex Oliver, Fl. Trop. Afr. i. 5.-

Afr, trop.

cirrhosa, Linn. Sp. Pl. 544.-Reg. Mediterr.

clitorioides, DC. Syst. i. $158=$ aristata.

coccinea, Engelm. ex A. Gray, Pl. Wright. ii. $7=$ C. Viorna.

cocculifolia, A. Cunn. in Ann. Nat. Hist. Ser. I. iv.

(1840) 260 -N. Zel.

cognata, Steud in Lehm. Pl. Preiss, i, $263=$ aristata.

Colensoi, Hook. f. Fl. N. Zeland. i. 6.-N. Zel.

coloradoènsis, Buck1. in Proc. Açad. Sc. Philad. '1861 1862) $448=$ Pitcheri.

columbiana, Torr. \& Gray, F1. N. Am. i. $11=v e r-$ ticillaris.

commutata, O. Kuntze, in Verh. Bot. Ver. Brand.

xxvi. (1885) 128.-Afr. trop.

comosa, DC. Syst. i. $157=$ triloba?

connata, DC. Prod. i. 4.-Reg. Himal.

contorta $\times$, Carr. in Rev. Hortic. (1879) 380

cordata, Pursh, F1. Am. Sept. ii. 384=virginiana

cordata, Royle, Illustr. Bot. Himal. 51-Ind. or,

cordata, Sims, Bot. Mag. t. $1816=$ crispa.

cordifolia, DC. Syst. i. 142=virginiana.

coriacea, DC. 1. c. $146=$ aristata

coriacea, Korth. in Nederl. Kruidk. Arch. i. (1848)

208.- Java.

corymbosa, Poir. Encyc. Suppl. ii. $297=$ recta

crassifolia, Benth. Fl. Hon g $\vec{k}$. 7.-China.

crenata, Jord. in Billot, Annot. F1. Fr. Allem. $12=$ C. Vitalba.

crispa, Lam. Encyc. ii. $44=$ cylindrica.

crispa, Linn. Sp. Pl. 543,-Am. bor.

crispa, Thunb. Fl. Jap, $239=$ paniculata.

cylindrica, Sims, Bot. Mag. t. $1160=$ crispa.

dahurica, DC. Prod. i. $7=$ daurica.

dasyoneura, O. Kuntze, in Verh. Bot. Ver. Brand. xxvi (1885) 123.--Borneo.

daurica, Pers. Syn. ii. 99.-As. temp.

Davidiana, Decne. ex Verlot, in Rev. Hortic. (1867) $90=$ heracleaefolia

davurica, Ledeb. F1. Ross. i. $4=$ daurica.

denticulata, Vell. Fl. Flum. 240 ; v. t. $134=$ Hilarii.

depauperata, Colenso, in Trans. N. Z. Inst. i. (1868)

248, nomen.-N. Zel.

dioíca, Linn. Syst. ed. X. 1084.-Tamaica.

dioica, Lour. FI. Cochinch. $344=$ Loureiriana.

dioica, Sieber, ex Presl, in Oken, Isis, xxi. (1828) $273=$ caripensis.

discolor, Gardn. in Hook. Lond. Fourn. Bot. ii. (1843) 330 - Bras.

discolor, Steud. in Lehm. P1. Preiss. i. 262=aristata

dissecta, Baker, in Tourn. Linn. Soc. xx. (1883) 87.Madag.

\section{CLEMATIS :}

distorta, Lavall. Clemat. 37. t. 11,-Hab.

divaricata, Jacq. Eclog. Pl. i. 51. t. $33=$ crispa.

diversifolia, DC. Syst. i. 155.-Hab. ?

diversifolia, Gilib. Exercit. i. $383=$ C. Flammula

dominica, Lam. Encyc, ii. 45.-Ind. occ.

Douglasii, Hook. Fl. Bor. Am. i. 1. t. 1.-Am. bor, occ.

Drummondii, Torr. E Gray, Fl. N. Am. i. 9.-Am bor.

dumosa, Salisb. Prod. $371=$ C. Vitalba.

edentata, Baker, in fourn. Linn. Soc. xxi. (1884) 318 - Madag.

elliptica, Endl. in Enum. Pl. Hueg. 1 =aristata.

elongata, Tratt. Archiv, t. $149=$ integrifolia.

erecta, Linn. Syst. ed. XII. 377 ; All. F1. Pedem. i. $296=$ recta.

eriopoda, Maxim. in Bull. Acad. Pétersb. xxii. (1877) 223. - Japon.

eriostemon, Decne. in Rev. Hortic. Sér. IV. i. (1852)

341.-Hab. ?

excelsior $x$, Van Houtte, in F1. des Serres, Sér. II. x. (1874) 24. t. 2054-55.

Fawcettii, F. Muell. Fragm.x. 1.--Austral.

filifera, Benth. Pl. Hartw. $285=$ reticulata.

Flammula, Linn. Sp. Pl. 544.-Reg. Mediterr

Flammulastrum, Griseb in Mem. Am. Acad. N. S, viii (1861) 153.-Cuba

fava, DC. Syst. i. $135=$ orientalis.

flavescens, Rafin. Fl. Ludov. 81.-Am. bor.

floribunda, Kurz, in Fourn. Bot. v. (1867) 240.-Ind.

foribunda, Planch. Es Triana, in Ann. Sc. Nat. Sér.

IV. xvii. (1862) 9.-N. Granat.

florida, Thunb. Fl. Fap. 240.-Japon.

fluminensis, Vell. Fl. Flum. 240 ; v. t. 133.-Bras

foetida, Raoul, Choix Pl. Nouv.Zél. 23.-N. Zel.

Forsteri, J. F. Gmel. Syst. $873=$ hexasepala

Fortunei, T. Moore, in Gard. Chron. (1863) 460, $676=$ Williamsii.

fragrans, Salisb. Prod. $371=$ virginiana

fragrans, Tenore, Prod. Fl. Nap. p. xxxii=C. Flammula.

francofurtensis, Rinz. ex C. Koch, Dendrol. i. $431=$ C. Viticella.

Fremonti, S. Wats. in Proc. Am. Acad. x. (1875) 339 -Am. bor, occ

fruticosa, Turcz. in Bull. Soc. Nat. Mosc. v. (1832) 180.-China,

fulva, Zoll. \& Moritzi, Syst. Verz. Zoll. 35.-Java.

fusca, Turcz. in Bull. Soc. Nat. Mosc. (1840) 60.China; Japon.

Gebleriana, Bong. in Bull. Sc. Acad. Pétersb. viii. 1841) $338=$ soongarica.

gentianoides, DC. Syst. i. 159.-Austral.

Gilbertiana, Turez. in Bull. Soc. Nat. Mosc. xxvii. (1854) II. 273 [bis] = aristata.

glabra, DC. Syst. 1. 143.-Ins. S. Doming.

glandulosa, Blume, Bijdr. 1 = smilacifolia.

glauca, Claus, in Goebel, Reise, ii. $247=$ orientalis.

glauca, Willd. Berl. Baumz. $65=$ orientalis.

glaucescens, Presl, in Mus. Senckenb. ii. (1837) 268 $=$ Thunbergii.

globosa, Royle, Illustr. Bot. Himal. $51=$ orientalis.

glycinoides, DC. Syst. i. 145.-Austral.

Goudotiana, Planch. E' Triana, in Ann. Sc. Nat. Sér.

IV. xvii. (1862) 10.-N. Granat.

Gouriana, Roxb. Hort. Beng. 43 ; Fl. Ind. ii. 670 Ind. or. : Malaya.

gracilis, Edgew. in Trans. Linn. Soc. xx. (1851) $24=$ connata.

Grahami, Benth. Pl. Hartw. 3.-Mexic.

grandiflora, DC. Syst, i, 151-Afr, trop.

grata, O. Hoffm. ex Baker, in Journ. Linn. Soc. xx. 1883) $88=W$ ightiana

grata, Wall. Pl. As. Rar. i. 83. t. 98.--Reg. Himal.; China; Afr. trop.

graveolens, Hook. Bot. Mag. t. $4495=$ orientalis.

graveolens, Lindl. in Fourn. Hort. Soc. i. (1846) 307.

-Reg. Himal

grewiaeflora, DC. Syst. i. 140,-Reg. Himal

grossa, Benth. Pl. Hartw. 33.-Mexic.

grossa, Wall. Cat. n. 4671.-Burma.

Guadeloupae, Pers. Syn. ii. $99=$ americana.

Guascoi $\times$, Lem. \& Versch. in Illustr. Hortic. iv.

(1857) 117.

Haenkeana, Presl, Rel. Haenk. ii. 69.-Peruv.

hakonensis, Franch. E' Sav. Enum. Pl. Fap. ii. 263.Japon. 
CLEMATIS :-

Hancockiana, Maxim. in Bull. Soc. Nat. Mosc. liv, (1879) I. 1.-China.

Hartwegi, Hort. ex C. Koch, Dendrol. i. $434=$ reticulata.

havanensis, H.B. E K. ex DC. Syst. i. 152,-Cuba.

hedysarifolia, $D C$. l. c. 148,-Ind. or.

Hendersonii, Hort. ex Steud. Nom. ed. II. i. $379=$ reticulata.

Henryi, Hort.-Cf.Gard. Chron. (1878) Ir. 439.-Hab.?

heracleaefolia, DC. Syst. i. 138.-China.

hexapetala, Linn, f. Suppl. $271=$ hexasepala.

hexapetala, Pall, Reise, iii. $735=$ C. Flammula.

hexasepala, DC. Syst. i. 146.-N. Zel.

Hilarii, Spreng. Syst. v. 177.-Bras.

hirsuta, Gaill. \& Perr. Fl. Seneg. Tent. i. $1==$ Thunbergii.

hirsutissima, Pursh, Fl. Am. Sept. ii. 385= Anemone patens.

hispanica, Mill. Gard. Dict. ed. VIII. n. $3=$ recta.

holosericea, Pursh, Fl. Am. Sept. ii. 384.-Am. bor.

Hookeri, Decne. in Fl. des Serres, Sér. II. xiii. (1880) 282 = heracleacfolia.

Hothae, Kurz, For. Fl. Brit. Burma, i. 17.-Burma. hysudrica, Munro, ex Hook, f. \& Thoms. Fl. Ind. $9=$ orientalis.

ibarensis, Baker, in Fourn. Linn. Soc. xviii. (1881) 264.-Madag.

incisodentata, A. Rich. Tent. Fl. Abyss. i. $2=$ grata. inclinata, Scop. Fl. Carn. ed. II. i. $389=$ integrifolia. indica, Heyne, ex Roth, Nov. Pl. Sp. $252=$ Gouriana. indivisa, Stend. in Lehm. Pl. Preiss. i. $262=$ aristata. indivisa, Willd. Sp. Pl. ii. 1291.-N. Zel.

insidiosa, Baill. in Bull. Soc. Linn. Par. i. (1882) 331.-Madag.

insulensis, Hort. ex C. Koch, Dendrol. i. $433=$ crispa.

integra, Vell. Fl. Flum. 241 ; v. t. 135.-Bras.

integrifolia, Forst. f. Prod. $42=$ indivisa.

integrifolia, Linn. Sp. Pl. 544.-Eur. austr. ; As. bor.

intermedia, Carr. in Rev. Hortic. (1866) 339.-Hab,

intricata, Bunge, in Mém. Sav. Etr. Acad. Pétersb. vi. (1835) 75 - China.

inversa, Griff. Notul. iv. 700.-Ind. or

ispahanica, Boiss. Diagn. Ser. I. vi. $3=$ orientalis.

italica, Schnizl. Icon. iii. Ind. 2.-Europ. Fackmanni x, Van Houtte, in F1. des Serres, xvi. (1865)

japonica, Thunb. Fl. Fap. 240.-Japon.

javana, DC. Syst. i. 152= Gouriana.

javanica, Steud. Nom. ed. II. i. $379=$ praec.

jubata, Bisch. Del. Sem. Hort. Heidelb. (1849) 4 ; ex Walp: Ann, ii. 4.-Hab. ?

Junghuhniana, De Vriese, in Miq. Pl. Fungh. 75.Java.

kamtschatica, Bong. Ver.. Saisang-Nor Pfl. $10=$ Kamtchatka.

Keriii, Steud. Nom. ed, II. i. 379.-Afr. austr.

Kirilowi, Maxim. in Bull. Acad. Pétersb. xxil. (1877) 210.-China.

Kirkii, Oliver, Fl. Trop. Afr. i. 5.-Afr. trop.

Kousabotan, Decne. in Fl. des Serres, xxiii. (1880) 284.-Japon.

lacta, Salisb. Prod. $370=$ cirrhosa

lanuginosa, Lindl. \& Paxt. Flow. Gard. iii. (1852-53) 107.-China.

lasiandra, Maxim. in Bull. Acad. Pétersb. xxii. (1877) 213.-Japon.

lasiantha, Fisch. Hort. Gorenk. ed. II. (1812) $47=$ C. Flammula

lasiantha, Nutt. ex Torr. Eo Gray, Fl. N. Am. i. 9.Am. bor. occ.

lathyrifolia, Bess. ex Reichb. Fl. Germ. Excurs. $734=$

Lavallei, Decne. in Fl. des Serres, xxiii. (1880) 284.Japon.

laxillora, Baker, in fourn. Linn. Soc. xxi. (1884) 317 -Madag.

Lechenatiliana, $D C$. Syst. i. 151.-Java ; Ind. or.

leptomera, Hance, in Fourn. Bot. xviii. (1880) 257.China.

ligusticifolia, Nutt. ex Torr. E Gray, Fl. N.Am. i. 9 . -Am. bor.

linearifolia, Steud. in Lehm. P1. Preiss, i. $262=$ microphylla.

lineariloba, DC. Syst, i. $155=$ crispa.

loasacfolia, DC. 1. c. $140=$ grewiactlora?

loasifolia, D. Don, Prod. Fl. Ncp, 191 - Buchaniana?

\section{CIEMATIS :}

longecaudata, Ledeb. Fl. Ross, i. 3 = orientalis

longicauda, Steud. ex A. Rich. Tent. Fl. Abyss. i. 2.Abysin.

longiloba, DC. Syst. i, 136.-Chili.

longipes, Freyn, in Bremen Abh. viii. (1880) 5. Madag.

Loureiriana, DC. Syst. i. 144.-China.

lugubris, Salisb. Prod. $371=\mathrm{C}$. Viticella

Luloni, Hort. ex C. Koch, Dendrol. i. $435=$ patens.

macropetala, Ledeb. Ic. Pl. Fl. Ross, i. 5. t. 11

Sibiria.

magniflora, Hoffmgg. Verz. Pf. Nachtr. i. 167.-Hab.?

mandschurensis, Hort. ex. C. Koch, Dendrol. i. $429=$ fusca.

mandschurica, Rupr. in Bull. Phys.-Math. Acad.

Pétersb. xv, $(1857) 258=$ recta.

marata, Armst. in Trans. N. Z. Inst. xiii. (1881) 335 - N. Zel.

maritima, Lam. Encyc. ii. $174=$ C. Flammula

maritima, Linn. Sp. Pl. $767=$ recta.

Massoniana, DC. Syst. i. $135=$ brachiata.

Massoniana, Maxim. Ind. Fl. Pekin. in Prim. Fl.

Amur, $468=$ Kirilowi.

mauritiana, Lam. Encyc. ii. 42.-Ins. Maurit.; Madag.

Maximowicziana, Franch. E Sav. Enum. Pl. Fap. il. 261.-Japon.

Mechowiana, O. Kuntze, in Verh. Bot. Ver. Brand. xxvi. (1885) 171.-Afr. trop.

medusaea, Planch. E Linden, in Ann. Sc. Nat. Sér. IV. xvii. (1862) 11.-N. Granat.

mendocina, Phil. in Anal. Univ. Chil. (1862) I1. 389.Chili.

Meyeniana, Walp. in Nov. Act. Nat. Cur. xix. Suppl I. (1843) 297.-China.

microcuspis, Bakex, in fourn. Linn. Soc. xxi. (1884) 317.-Madag.

microphylla, DC. Syst. i. 147.-Austral.

millefoliata, Eichl. in Mart. Fl. Bras. xiii. I. 150.Peruv.

minor, Lour. Fl. Cochinch. i. 345.-China.

Mociniana, G. Don, Gen. Syst. i. 5.-Mexic

monstrosa, Hort. ex C. Koch, Dendrol. i. $436=$ patens.

montana, Buch.-Ham. ex DC.Syst. i. 164.-Reg. Himal montana, D. Don, Prod. FI. Nep. $192=$ napaulensis montevidensis, Spreng. Syst. ii. 667.-Reg. Argent.

Munroiana, Wight, Illustr. Ind. Bot. i. 5. t. $1=$ smilacifolia.

nannophylla, Maxim. in Bull. Acad. Pétersb. xxiii. (1877) 305.-China.

napaulensis, DC. Syst. i. 164.-Nepal.

naravelioides, O. Kuntze, in Verh. Bot. Ver. Brand.

xxvi. (1885) 119.-Ind. or.

nepalensis, Royle, Illustr. Bot. Himal, 51 =barbellata nervata, Benth. P1. Hartw. $5=$ Drummondii.

Noronhiana, DC. Syst. i. 151.-Java.

nutans, Crantz, Stirp. Austr. ed. I. fasc. ii. 110 ; ed. II. $127=$ integrifolia.

nutans, Royle, Illustr. Bot. Himal. 51.-Reg. Himal. occidentalis, A. Cunn. ex Honk. in Mitch. Journ.

Trop. Austral. $368=$ microphylla.

occidentalis, DC. Prod. i. 10.-Hab.

ochotensis, Poir. Encyc. Suppl. ii. 298.-Sibir. or

ochroleuca, [Soland. in] Ait. Hort. Kew.ed. I. ii. 260. -Am bor.

odora, Wender. 'Ind. Sem. Hort. Marb. App. n. 4iCf. Steud. Nom。ed II. i. 380 - Hab.

odorata, Wall. ex Stend. Nom. ed. II. i. 380.-Ind. or oligophylla, Hook. Ic. Pl. t. 80,-Maclag.

Oliveri, O. Kuntse, in Verh. Bot. Ver. Brand. xxy (1885) 165-Abyssin.

oreophila, Hance, in Walp. Ann. ii. $3=$ Meyeniana. orientalis, Linn. Sp. Pl. 543_-Reg. Himal. Oriens, orientalis, Secm. ex Steud. Nom. ed. II. i. 3s0 C. Flammula

ovata, Pursh, Fl. Ant. Sept. ii. 736.-Am. bor. Orvenine, Harv. in Harv. E Sond. Fl. Cap. i. 2.-

Air. trop.

Pallasii, J. F. Gmel. Syst. $878=$ C. Flammula pallida, A. Rich. Ess. F\%. Creb. 10,-Cuba.

panduana, Steud. Nom. ed. II. i. 380 , sphalm. montana.

paniculata, J. F. Gmel. Syst. $879=$ indivisa. paniculata, Thunb. in Trans. Linn. Soc, ii. (17!4) 937 . -Japon.

Parkinsoniann, Colenso, in Trans. N.Z. Insto xii. (Issi) 359.-N. Zel.

\section{CLEMATIS}

parviflora, A. Cunn. in Ann. Nat. Hist. Ser. I. (1840) $259 .-\mathrm{N}$. Zel.

parviflora, DC. in Mém. Soc. Phys. Genèv. 1. (1823)

433.-Hab.?

parviflora, Nutt. ex Torr. EN Gray, Ft. N. Am. i 9, Am. bor.

parvifolia, Edgew. in Trans, Linn. Soc: xx. (1846) 25 orientalis

parvifolia, Hook. f. \& Thoms. Fl. Ind. $9=$ graveolen parviloba, Gardn. EF Champ. in Hook. Kew Founn. i. (1849) 241 ,-China.

patens, Morr. EN Decne. in Bull. Acad. Brux. iii. (1836) 173.-Japon.

pauciflora, Nutt. ex Torr. E Gray, Fl. N. Am. i. 9.Calif.

pedicellata, Sweet, Hort. Brit. ed. 1. 2 ; Loud. Hort. I3rit. $1=$ cirrhosa.

pensylvanica, Donn, Hort. Cantab. ed.IV. 129 ; Hort. ex Turcz. in Bull. Soc. Nat. Mose. xxvii. (1854) 273 [bis].-Am. bor.

perulata, O. Kuntze, in Verh. Bot. Ver. Brand. xxu (1885) 153.-Bras.

peruviana, $D C$. Syst. i. 141.-Peruv

Petersiana, Klotzsch, in Peters, Keise Mossamb. But i. $170=$ grata.

Pickeringii, A. Gray, Bot. U. St. Expl. Exped. i. 1.Ins. Fiji.

Pierotii, Miq. Ann. Mus. Bot. Lugd. Bat. iii. 1.Japon.

pilosa, Dulac, Fl. Hautes-Pyr. $211=$ C. Vitalba. pimpinellifolia, Hook. Ic. Pl.t. 77.-Madag. pinnata, Maxim. in Bull. Acad. Pétersb. xxii. (187) 216.-China.

Pitcheri, Sarg. ex Lavall. Clemat. $60=$ Sargenti.

Pitcheri, Torr. E Gray, Fl. N.Am. i. 10,-Am. bor.

Plukenetii, DC. Syst. i. $153=$ Catesbyana.

Poisati, Hort. ex Lavall. Clemat. $40=$ eriostemon. polycephala, Bertol. Fl. Guat. 23.-Guatemala. polygama, facq. Enum. Pl. Carib. 24,-Ind. occ. polymorpha, Viv. Fl. Cors. Sp. Nov. $y=$ cirrhosa. polypetala DC. Syst. i. $167=$ Anemone japonica. polypetala, Poir. Encyc. Suppl. ii. 296. - Japon.

populifolia, Turcs. in Bull. Soc. Nat. Mosc. 1854) II. 272.-Venezuela.

pseudoatragene, O. Kuntse, in Verh. Bot. Ver. Brand.

xxvi. (18ð5) 160.-Am. bor.

pseudograndiflora, O. Kuntge, l. c. 128.-Afr. trop.

pseudo-orientalis, $O$. Kuntze, l. c. 171.-Persia.

puberula, Hook. f. E Thoms. in Fl. Brit. Ind. i. 4.Reg. Himal.

pubescens, Benth. Pl. Hartw. 5.-Mexic.

pubescens, Hueg. Enum. Pl. Hueg. 1 =aristata.

pulchella, Pers. Syn. ii. $99=\mathrm{C}$. Viticella.

punduana, Wiall. Cat. n. $4682=$ montana

Purshii, D. Dietr. Syn. Pl, iii. $345=$ virginiana.

quadribracteolata, Colenso, in Trans. N. Z. Inst.

(1882) 329.-N. Zel.

recta, Linn. Sp. Pl. 544.-Europ. austr.

reticulata, Walt. Fl. Carol. 156 -Am, bor.

revoluta, Hort. Par. ex Steud. Nom. ed, II. i. 380

parviflora.

Robertsiana, Aitch. E Hemsl. in Fourn. Linn. Soc.

xviii. (1880) 29. - Afghan.

rosea, Hort. ex Lavall. Clemat. $35=$ Bergeroni.

rosea, Sm. in Abbot, Nat. Hist. Lepidopt. 201. 1. 101 - reticulata.

rubella, Pers. Syn. ii. $100=$ C. Flammula.

rubro-violacen $x$, Van Houtte, in Fl. des Serres, xvi (1865) 37 = lanuginosa.

Sargenti, Lavall. Clemat. 630. t. 18.-Am. bor.

Savatieri, Decne. in Fl. des Serres, xxiii. 15su' $250^{\circ}$

Japon.

saxicola, Hils, E Goj, ex Boill, Bull. Sai, Limn. i. (188:) \$31, nomen.-Madng.

scabiosaefolia, $D C$. Syst. i. 154.-Ind. or.

scamdens. Borkls. Iland b. Forstb. ii. $11 ! n !=$ C. Vira!l

Sithillingri, C. Koch, in App. Ind. Sem. Hort. Berol 1\$55) 16 = cylindrice.

Scottii, Porter, Syr. Fl. Colurialo, 1.-Am. I ocivi

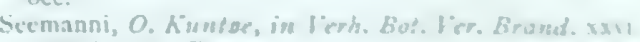
lass 140 , - Perus.

smisriluba. Lag. Gen. el Sp. Nov, $1 \%=$ cirrhesen.

sepisum, I.am: Fl. Fr. iii. Sub - C. Vitalha.

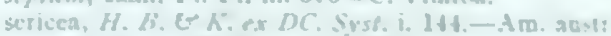

sericea, Michx. Fl. Ihor. Am. i. $\$ 19$ = ochmleuca. 


\section{CLEM ATIS}

sibirica, Mill. Gard. Dict. ed. VIII. n. 12 = angusti folia.

Sieboldii, D. Don, ex Steud. Nom. ed. II. i. $380=$ florida.

simensis, Fresen. in Mus. Senckenb. ii. (1837) 267.Abyssin.

sinensis, Lour. Fl. Cochinch. $344=$ chinensis.

Simsii, Sweet, Hort. Brit. ed. I. $1=$ crispa.

smilacifolia, Wall. in As. Res. xiii. (1820) 402. -Ind. or. ; Malaya.

smilacina, Blume, Bijdr, 1= smilacifolia

songarica, Siev, ex Steud. Nom. ed. II. i. $380=$ glauca.

songorica, Bunge, Del. Sem. Hort. Dorp. (1839) 8.Cf. Linnaea, xiv. (1840) Litt. 119.-Sibiria.

Sonnerati, Pers. Syn. ii. $99=$ mauritiana.

Standishi, Van Houtte, in F1. des Serres, xvi. (1865) $39=$ patens.

Stanleyi, Hook. Ic. Pl. t. 589.-Afr. austr.

stans, Sieb. E Zucc. in Abh. Akad. Muench. iv. (1846) II. 177.- Japon.

stenopetala, R. Br。ex DC. Syst。 i. $147=$ glycinoides

stenophylla, Fraser, ex Hook, in Mitch. Trop. Austr. $368=$ microphylla

stenosepala, DC. Syst. i. $147=$ glycinoides

stipulata, O.Kuntze, in Verh. Bot. Ver. Brand. xxvi. (1885) 154.-Mexic.

striata, Rafin. Fl. Ludov. 82.-Am. bor.

stricta, Wender, in Ind. Sem. Marb. (1836).-Cf. Linnaea, xii (1898) Litt. 85 . Hab. ?

strigillosa, Baker, in Fourn. Linn. Soc. xviii. (1881) 265. - Madag.

Strobeliana, Ces. in Atti Soc. Acc. Sc. Nap. v. (1873) 3. 1. 7.-Europ.

Stronachii, Hance, in fourn. Bot. xvi. (1878) 103.China.

suaveolens, Salisb. Prod. $371=$ C. Flammula

subpeltata, Wall. P1. As. Rar. i. 19. t. $20=$ smilacifolia.

substipulata, O. Kuntze, in Verh. Bot. Ver. Brand. xxvi. (1885) 147.--Ind. or

subtriflora, Walp. Rep. 1. 8, sphalm. $=$ seq.

subtriloba, Nees, ex G.Don, Gen. Syst. i. 7.-Mexic.

subumbellata, Kurz, For. Fl. Brit. Burma, i. 16.Burma.

sulcata, Wall. Cat. n. $4667=$ C. Cadmia.

Tatarinowii, Maxim. in Bull. Acad. Pétersb. xxii. (1877) 214.-China.

taurica, Bess. ex Nym. Consp. $1=$ C. Vitalba.

tenuiflora, DC. Prod. i. $3=$ recta.

tenuifolia, Poir. Encyc. Suppl. ii. 298=Anemone tenuifolia.

tenuifolia, Royle, Mllustr. Bot. Himal. $51=$ orientalis.

terniflora, DC. Syst. i. $138=$ recta.

Tessen, Hassk. Cat. Hort. Bog. Alt. $179=$ Noronhiana

texensis, Buckl. in Proc. Acad. Sc. Philad. ' 1861 (1862) $448=\mathrm{C}$. Viorna.

thalictroides, Stend. in Flora, xxxix. (1856) 407.Peruv.

Thunbergii, Steud. Nom. ed. II. i. 380.-Afr, austr.

tibetana, O. Kuntze, in Verh. Bot. Ver Brand. xxvi. (1885) 172.-Tibet.

tortuosa, Wall. Cat. n. $4675=$ Buchaniana

Tournefortii, DC. Syst. i. 167.-Oriens.

trifida, Hook. Ic. Pl. t. 79.-Madag.

triflora, Vahl, Symb. Bot. iii. $74=$ mauritiana.

trifoliata, Thunb. in Trans. Linn. Soc. ii. (1794) 337 -Japon.

triloba, Heyne, ex Roth, Nov. Pl.Sp.251.-Ind. or

triloba, St. Hil. F1. Bras. Mer. i. $3=$ montevidensis.

triloba, Thunb. Prod. Pl. Cap. $94=$ Thunbergii.

trinervis, Buch.-Ham. ex DC. Syst. 1. $148=$ acuminata. triternata, $D C$. l. c. 150,-Hab.

tubulosa, Hook. Bot. Mag. t. $6801=$ heracleaefolia.

tubulosa, Turcz. in Bull. Soc. Nat. Mosc. (1837) n. VII. $148=$ heracleaefolia

tunbridgensis $\times$, Hort. ex Lavall. Clemat. 13.

umbraticola, Schur, in Verh. Naturf. Ver. Bruenn,

xv. II. (1877) $8=$ recta.

uncinata, Champ. ex Benth. in Hook. Kew Fourn. iii. (1851) 255.-Hongkong.

uniflora, Balb. Cat. Hort. Taur. (1810) $21=$ ochroleuca.

urophylla, Franch. in Bull. Soc. Linn. Par. i. (1884) 433.-China.

velutina, Edgew. in Trans. Linn. Soc. xx. (1859) $24=$ connata.

\section{CLEMATIS}

venosa, Royle, 1llustr. Bot. Himal. $51=$ connata.

verticillaris, $D C$. Syst. i. 166.-Am, bor.

villosa, $D C$. l. c. 154.-Ind, or.

violacea, A. DC. in Mém. Soc. Phys. Genèv. xi. (1845) 67.-Hab. ?

Viorna, Andr. Bot. Rep. i. t. $71=$ crispa.

Viorna, Linn. Sp. Pl. 543.-Am. bor.

viornoides, Schrad.ex Steud. Nom. ed. II. i. 380.-Am. bor.

virginiana, Linn. Cent. i. 15; Amoen. Acad. iv. 275.

-Am. bor.

wirginiana, Lour. F1. Cochinch. $345=$ apiifolia

virginica, Thunb. F1. Jap. $240=$ biternata.

viridiflora, Bert. Misc. Bot. xix. 7.t. $3=$ grata.

virosa, Sterl. Hort. Nymph. ex Steud. Nom. ed. II. i, 380.-Hab. ?

Vitalba, Buch.-Ham. ex Steud. 1.c. $379,380=$ grewiaefolia.

Vitalba, Linn.Sp.Pl. 544.-Europ.; Afr. bor.; Reg. Caucas.

Viticella, Linn.l.c. 543.-Europ. or.; As. Min.; Persia. vitifolia, Wall. Cat. n. $4676=$ Buchaniana.

Walteri, Pursh, Fl. Am. Sept. ii. 384=crispa

Welwitschii, Hiern, ex O.Kuntze, in Verh. Bot. Ver.

Brand. xxvi. (1885) 171.-Afr. trop.

Wenderothii, Steud. Nom. ed. II. i. 380.-Europ

Wightiana, Wall. Cat. n. 4674.-Ind. or.

Williamsii, A. Gray, ex Perry, Fap. Exp. ii. 306.-

Japon.

Wyethii, Nutt. ex Torr. \& Gray, Fl. N. Am. i. $8=$ Douglasii.

zanzebarica, Sweet, Hort. Brit. ed. II. 1 -seq.

zanzibarensis, Boj. ex Loud. Hort. Brit. 228.-Ins

Zanzibar.

zeylanica, Poir. Encyc. Suppl. ii. $296=$ Naravelia

zeylanica

Zollingeri, Turcz. in Bull. Soc. Nat. Mosc. xxvii. (1854) II. 274 [bis].-Java.

CLEMATITARIA, Bur. Monog. Bign. $44(1864)=$ Bignonia, Linn.

CLEMATITIS, [Toum.] Linn. Syst. ed. I (1735) = Clematis, Dill. (Ranunculac.)

bracteata, Moench, Meth. Suppl. $103=$ Clematis virginiana.

cordifolia, Moench, 1. c. $104=$ Clematis virginiana.

crispa, Moench, Meth. $296=$ Clematis crispa.

erecta, Steud. Nom. ed. I. $206=$ Clematis erecta.

flava, Moench, Meth. $296=$ Clematis orientalis.

integrifolia, Moench, 1. c. = Clematis integrifolia.

Vitalba, Moench, l. c. = Clematis Vitalba.

CLEMATOPSIS, Boj. ex Hook. Ic. Pl. i. t. 10 (1837) Clematis, Dill. (Ranunculac.)

suaveolens, Boj. $1 . c_{.}=$Clematis Bojeri.

CLEMENTEA, Cav. in Anal. Cienc. Nat. vii. (1804) 63 = Canavalia, Adans. (Legumin.).

nitida, Cav. 1. c. t. $47=$ Can. ensiformis.

CLEOBUIA, Vell. FI. Flum. 187 (1825). INC. SED. Cheobula, Vell. Fl. Flum. iv.t. 146 (1827)

pinnata, Vell. l. c.-Bras.

CLFOBUIIA, Mart. ex Benth. in Ann. Wien. Mus. ii. (1838) 131. LEGUMINOSAE, Benth. \& Hook. f. i. 537.

diocleoides, Benth. in Mart. Fl. Bras. xv. I. 168.-

Am. trop.

leiantha, Benth. l. c.-Bras

multiflora, Mart, ex Benth. in Ann. Wien. Mus. ii. (1838) 131.-Bras.

CLEOCHROMA, Miers, in Hook. Lond. Journ. Bot. vii. (1848) $349=$ Iochroma, Benth. (Solanac.).

calycina, Miers, 1. c. $350=\mathrm{I}$. calycina.

grandiflora, Miers, 1. c. $351=$ I. grandiflora.

macrocalyx, Miers, 1. c. $350=\mathrm{I}$. macrocalyx.

CLEODORA, Klotzsch, in Wiegm. Archiv, vii. (1841)

$196=$ Croton, Linn. (Euphorbiac.)

Sellowiana, Klotzsch, 1. c. $197=$ Croton sphaerogynus.
CLEOME, Linn. Syst. ed. I (1735). CAPPARI-

$D E A E$, Benth. \& Hook. f. i. 105

Aleome, Neck. Elem. iii. 68 (1790).

Anomalostemon, Klotzsch, in Peters, Reise Mossamb. Bot. 162 (1861)

Arivela, Rafin. Sylva Tellur. 110 (1838).

Atalanta, Nutt. Gen. Am. ii. 73 (1818)

Aubion, Rafin. Sylva Tellur. 110 (1838).

Buhsia, Bunge, Del. Sem. Hort. Dorpat. (1859) 4.

Chilocalyx, Klotzsch, in Peters, Reise Mossamb.

Bot. 154 (1861)

Coatisia, Rafin. Sylva Tellur. 114 (1838)

Corynandra, Schrad. Cat. Sem. Hort. Gotting. (1846).

Decastemon, Klotzsch, in Peters, Reise Mossamb Bot. 157 (1861)

Dianthera, Klotzsch, 1. c. 160. t. 27 (1861),

Diorimasperma, Rafin. Sylva Tellur, 111 (1838)

Hemiscola, Rafin. 1. c. (1838).

IsEXINA, Rafin. 1. c. 112 (1838)

Lagansa, Rumpf, ex Rafin. 1. c. 110 (1838).

MELIDiscus, Rafin. 1. c. (1838).

Micambe, Adans. Fam. ii. 407 (1763).

Mitostylis, Rafin. Sylva Tellur. 114 (1838).

Mozambe, Rafin. 1. c. 112 (1838).

Oncufis, Rafin. 1. c. 114 (1838).

Pericla, Rafin. 1. c. 112 (1838)

Peritoma, DC. Prod. i. 237 (1824)

Physostemon, Mart. Nov. Gen, et Sp. i. 73. t. 45 (1824).

Podogyne, Hoffmgg. Verz. Pf, 185 (1840)

Polanisia, Rafin. in Am. Monthly Mag. (1818) 267 ;

Journ. Phys. (Août 1819) 98.

Rorida, J. F. Gmel. Syst. 260 (1791).

RoRIDUla, Forsk. Fl. Aegypt. Arab. 35 (1775).

Scolosperma, Rafin. Sylva Tellur. 111 (1838).

Sieruela, Rafin. 1, c. 112 (1838)

Siliquaria, Forsk. Fl. Aegypt. Arab. 78 (1775).

Sinapistrum, Tourn. ex Hall. in Rupp. Fl. Jen. 269 (1745).

Strlista, Rafin. Sylva Tellur. 112 (1838).

Symphyostemon, Klotzsch, in Peters, Reise Mossamb. Bot. 159 (1861)

TARENAYA, Rafin. Sylva Tellur. 111 (1838)

Tetrateleia, Sond. in Harv. \& Sond. Fl. Cap. i. $58(1859)$

aculeata, Linn. Syst. ed. XII. iii. 232.-Am. trop. acuta, Schum. \& Thonn. in Dansk. Vidensk. Selsk Afh. iv. (1828) $67=$ Gynandropsis pentaphylla. affinis, $D C$. Prod. i. 241,-Bras.

affinis, Spreng. Syst. iv. Cur. Post. $138=$ Blumeana albescens, Franch. in Revoil, Comali, 11.-Afr. trop. alliacea, Blanco, F1. Filip. ed. I. 522=Gynandropsis pentaphylla.

alliodora, Blanco, 1. c。 ed. II. $363=$ Gynandropsis pentaphylla.

angulata, Schult. f. Syst. vii. 45.-Java.

angustifolia, Forsk. Fl. Aegypt. Arab. $120=$ tenella anomala, H. B. E $K$. Nov. Gen. et Sp. v. 85.-

N. Granat.

aphylla, Thunb. Prod. Pl. Cap. $109=$ Schepperia juncea.

arabica, Linn. Cent. Pl. i. 20.-Afr. bor. ; Arab.

arborea, H. B. धण K. Nov. Gen. et Sp. v. 86. Venezuela

arborea, Schrad. in Goett. Gel. Anz. i. (1821) $707=$

Crataeva Tapia.

arborea, Weinm. in Syll. Ratisb. i. (1824) $227=$ den droides.

armata, Thunb. Prod. Pl. Cap. 109.-Afr. austr.

Aschersoniana, Pfund, in Flora, 1vii. (1874) $413=$ trinervia.

aspera, Koen in DC. Prod i 241 - Ind or.

atropurpurea, Schott, in Schreib. Nachr. Oestr. Naturf. i. $129=$ dendroides.

aurea, Celak. in Oestr. Bot. Zeitschr. xxxiv. (1884) 113 -Graecia.

aurea, Nutt. ex Torr. \& Gray, Fl. N. Am. i. $122=$ lutea.

bicclor, Gardn. in Hook. Lond. Fourn. Bot. ii. (1843) 330. -Bras.

Blumeana, D. Dietr. Syn. Pl. ii. 1065-Java.

bororensis, Oliver, Fl. Trop. Afr. i. 81,-Afr. trop brachycarpa, Vahl, ex DC. Prod. i. 240.-Afr. bor.

Arab. : Ind bor occ.

brasiliensis, Weinm. in Syll. Ratisb. i. (1824) 122.Bras.

brevisiliqua, Schult. f. Syst. vii. 40.-Arab. 


\section{CLEOME:}

Bungei, Steud. Nom. ed. II. i. 381.-China

Burmanni, Wight E Arn. Prod.22.-Ind, or.

canadensis, Hort. ex Schult. f. Syst. vii. $38=$ cardaminoides.

Candelabrum, Sims, Bot. Mag, t. 2656.-Hab.?

canescens, Stev. in DC. Prod. i. $241=$ ornithopodioides.

capensis, Linn. Sp. Pl. ed. II. $940=$ Heliophila callosa.

capparoides, Willd. ex Eichl. in Mart. Fl. Bras. xiii. I. $247=$ anomala

cardaminoides, Hoffmgg. Verz. Pfl. 93.-Afr. austr.

cardinalis, $D C$. Prod. i. 238. - Mexic.

Chelidonii, Boj. in Ann. Sc. Nat. Sér. II. xx. (1843) 56 =strigosa.

Chelidoni, Linn. f. Suppl. 300.-Ind. or. ; Java.

chilensis, DC. Prod. i. 238.-Chili.

chilocalyx, Oliver, Fl. Trop. Afr. i. 81.-Afr. trop.

chrysantha, Decne in Ann. Sc. Nat. Sér. II. iii. 1835) 274 -Arab.; Nubia.

ciliata, Schum. E Thonn. in Dan. Vid. Selsk. Afh. iv.

(1828) 67.-Afr. trop.

coluteoides, Boiss, Diagn. Ser, I, i. 3,-Persia

cordata, Burch. ex DC. Prod. i. $239=$ monophylla

cordata, Ehrenb. ex Schweinf. Beitr. Fl. Aethiop. $68=$ Ehrenbergiana.

cordobensis, Eichl. ex Griseb. in Goett. Abh. xix. (1874) 73.-Am. austr.

cremoloba, Turcz. in Bull. Soc. Nat. Mosc, xxvii. (1854)

II. 318.-Mexic.

crenopetala, DC. in Mém. Soc. Phys. Genev. vi. (1836) 220. t. 2.-Am. austr.

cubensis, A. Rich. Ess. Fl. Cub. $74=$ Houstoni.

cuneifolia. Muhl. ex Nutt. Gen. Am. ii. 73.-Georgia.

cypria, Celak. in Oestr. Bot. Zeitschr. xxxiv. (1884)

114,-Ins. Cyprus.

decipiens, Triana \& Planch. in Ann. Sc. Nat. Sér. IV. xvii. (1862) 74.-N. Granat.

deflexa, Ruiz E Pav. ex DC. Prod. i. 240.-Peruv.

clendroided, Schult. f. Syst. vii. 28.-Bras.

denticulata, Schult. f. l. c. 26.-Afr. trop.

diandra, Burch. Trav. i. 548.-Afr. austr.

dichotoma, Turcz. in Bull. Soc. Nat. Mosc. xxvii. 1854) II. 318.-Bras.

didynama, Hochst. ex Oliver, Fl. Trop. Afr. i. 79.Abysin.

diffusa, Banks, ex DC. Prod. i. 241.-Bras.

diffusa, Roxb. Hort. Beng. [96]; FI. Ind. iii. $129=$ aspera.

digitata, Forsk. Fl. Aegypt. Arab, 120.-Arabia.

Dilleniana, DC. Prod. i. $240=$ ornithopodioides.

diversifolia, Hochst. \& Steud. ex T. Anders. in Journ.

Linn. Soc. v. Suppl, i. (1860) $5=$ brachycarpa.

dodecandra, Banks, ex Wight \& Arn. Prod. 22, partim - Burmanni.

dodecandra, Linn. Sp. Pl. ed. II. $939=$ graveolens.

dodecaphylla, Vell. Fl. Flum. 271; vi. t. 110.-Bras

droserifolia, Delile, Fl. Egypt. 250,-Aegypt.; Arab.

Eckloniana, Schrad. in Linnaea, x. (1836) Litt. $109=$ Gynandropsis pentaphylla.

edulis, Rafin. Fl. Ludov. 86.-Am. bor

Ehrenbergiana, Schweinf. Beitr. Fl. Aethiop. i. 68.Nubia.

epilabioides, Jan, Elench. fide Schult. f. Syst. vii. $47=$ graveolens.

Erucago, Mill. Gard. Dict. ed. VIII.n. $6=$ heptaphylla, spino:a.

felina, Linn.f. Suppl. 300.-Ind. or.

filifolia, Vahi, Symb. Bot. i. $48=$ tenella.

timbriata, Vicary, in Ann. Nat. Hist. Ser. II. i. (1848) 425. - Scinde.

flawa, Banks, ex DC. Prod. i: $241=$ graveolens.

Rexuosa, F. G. Dietr. Vollst. Lexik. Gaertn. Nachtr. ii. 296 ; ex Schult. f. Syst. vii. $27=$ Gynandropsis pentaphylla.

Alexuosa, Griseb. in Goett. Abh. xix. (1874) 73.-Am. austr.

foliolosa, DC. Prod. i. 240.-Persia.

foliosa, Hook. $f$. in Hook. Niger Fl. 219.-Afr. trop.

frutescens, Aubl.Pl. Gui. ii. 677.-Guiana.

fruticosa, Linn. Sp. Pl. $671=$ Cadaba indica.

fugax, Schrad. Ind. Sem. Hort. Gotting. (1890), -Cf. Linnaen, vi. (1831) Litt. 72-Hab. ?

gigantea, Blanco, Fl. Filip. ed. II. 364=Gynandropsis speciosa.

gigantea, Linn. Mant. 430.-Am. sustr.

glandulosa, Ruis \& Pav. cx DC. Prod. i. 238.-Perav.

\section{CLEOME:}

glauca, DC. Prod. i. 239.-Mesopotam.

glaucescens, $D C$. l. c.-Mesopotam, : Persia,

gracilis, Edgew. in Joum. As. Soc. Beng. xvi. (1847) II

$1212=$ papillosa

gracilis, Planch. Eo Triana, in Ann. Sc. Nat. Sér. IV. xvii. (1862) 74.-N. Granat.

Grandidieri, Baill. in Bull. Soc. Linn. Par. i. (1885) 462.-Madag.

grandiflora, Ehrenb. ex Schweinf. Beitr. Fl. Aethiop. 71.-Afr. trop.

graveolens, Rafin. in Fourn. Phys. (Août 1819) 98.Am. bor.

guianensis, Aubl. Pl. Gui, ii, 675--Guiana.

guineensis, Hook. fo in Hook. Niger Fl. $218=$ ciliata.

gynandra, Linn. Sp. Pl. $671=$ pentaphylla.

heptaphylla, Linn. l. c. ed. II. 987.-Am. trop.

heptaphylla, G. F. W. Mey. Prim. FI. Esseq. $222=$ Houstoni.

heptaphylla, Sw. Obs. $252=$ pungens.

heratensis, Bunge E० Bien. ex Boiss. Fl. Orient. i. 412 -Afghanist.

heterotricha, Burch. Trav, i. $537=$ Gynandropsis heterotricha.

hexandra, Poir. ex Steud. Nom, ed. I. $206=$ arabica. hirsuta, Ruiz E* Pav. ex DC. Prod. i. 238.-Peruy.

hirta, Oliver, Fl. Trop. Afr. i. 81.-Afrotrop.

horrida, Mart. in Schult. f. Syst. vii. $32=$ spinosa

Hostmanni, Miq. in Linnaea, xxii. (1819) $470=$ latifolia.

Houstoni, R. Br. in Ait. Hort. Kew. iv. 131.-Jamaica. Houstoni, Miq. 1. c. xix. (1847) $433=$ diffusa.

Houtteana, Schlecht. in Linnaea, xxiv. (1851) 669.Am. austr.

Humboldtii, DC. Prod. i. 241.-Am. trop.

iberica, DC. 1. c. $240=$ ornithopodioides.

iberidella, Welw. in Oliver, Fl. Trop. Afr. i. 79.-Afr trop.

icosandra, Linn. Sp. Pl. $672=$ graveolens.

indecora, Hornem. Ind. Sem. Hort. Hafn. (1846); ex Walp. Ann. i. 60,-Mexic.

integrifolia, Torr. E Gray, Fl. N. Am. i. 122,Am. bor.

juncea, Berg. Desc. Pl. Cap. 164=Heliophila callosa, juncea, Sparm. in Nov. Act. Soc. Sc. Upsal. iii. (1780 192 - Schepperia juncea.

khorassanica, Bunge E Bien. ex Boiss. Fl. Orient. i. 412.--Persia.

Kotschyana, Boiss. l. c. 413.-Assyria

laevigata, Soland. ex DC. Prod. i. $200=$ Stanleya gracilis.

lateralis, Planch. E Triana, in Ann. Sc. Nat. Sér. IV. xvii. (1862) 73.-N. Granat.

latifolia, Vahl, ex DC. Prod. i. 239-Guiana.

laxa, Thunb. Prod. Pl. Cap. 109.-Afr. austr.

Lechleri, Eichl. in Mart. Fl. Bras. xiii. I. 250.Peruv.

Leschenaultii, Schult. f. Syst. vii. $49=$ Chelidonii.

linearis, Stocks, ex T. Anders. in Journ. Linn. Soc.

Suppl. i. (1860) $3=$ papillosa.

longifolia, Presl, Rel. Haenk. ii. 84.-Perur.

longifolia, Vahl, ex DC. Prod. i. $240=$ Wormskioldia heterophylla.

longifolia, Willả. ex Schult. f. Syst. vii. 1617 = speciosa. longipes, $D C$. Prod. i. 239.-Ecuador.

lusitanica, Mill, Gard. Dict. ed. VIII. n, $3=$ graveolens.

lutea, Hook. Fl. Bor. Am. i. 70. t. 25.-Am. bor. occ.

lutea, E. Mey. Zwei PR. Docum. 173.-Afr. austr. macrantha, Turca. in Bull. Soc. Nat. Mosc. xxvii. (1854) II. 319.-Mexic.

macrophylla, Roxb. Hort. Beng. [96], nomen (quid): -Ind or.

macrorhiza, Sauv. Fl, Cub. 4.-Cuba.

macrothyrsas, Planch. E Triana, in Ann. Sc. Nat.

Sér. IV, xvii. (1862) 72, - N, Granat.

malhadensis, Mart. ex Schult. f. Syst. vii. $48=$ aculeata.

melilotoides, Turcs. in Bull. Soc, Nat. Mosc. xxii (1854) II. 320 - Persia.

mexicana, D. Dictr. Syn. Pl. ii. 1068,-Mexic.

mexicana, fiemsl. Diag. Pl. Noro. 20-Mexic.

micrantha, Desv, in Ham. Prod. F\%. Jnd. Occ. 18.Guiana.

micrantha, Schrad. ex Schult. f. Syst. vii. $30=$ Dactylaena micrantha.

\section{CLEOME}

monandra, DC. Pl, Rar. Hort. Genèv. 54, t, $15=$

Dactylaena micrantha.

monophylla, Law, in J. Grah. Cat. Bomb. Pl. 7= simplicifolia.

monophylla, Linn. Sp. Pl. 672.-Ind. or.; Afr. trop.

Moritziana, Klotzsch, ex Eichl. in Mart. Fl. Bras. xii. 1. 250.-Venezuela.

moschata, Stocks, ex T. Anders. in Journ. Linn. Soc. v Suppl. i. (1860) 4 =brachycarpa.

multicaulis, Mo६. E Sesse, ex DC. Prod. i. 240.Mexic.

muricata, Edgew. in Fourn. As. Soc. Beng. xvi. (1847) II. $1212=$ paradoxa

muricata, Schult. f. Syst. vii. 25.-Ind. or

nivalis, Vahi, ex DC. Syst. ii. $245=$ Macropodium nivale.

Noëana, Boiss, Diagn. Ser. II. i. $48=$ quinquenervia.

nummularia, DC. Prod. i. $239=$ rosea

ofidocarpa, Balb. Hort. Lugd. Alob. (1826); ex Schult. f. Syst. vii. $51=$ Gynandropsis muricata.

oleracea, Welw. A pont. $586=$ pentaphylla

ornithopodioides, Forsk. Fl. Aegypt. Arab. n. $402=$

brevisiliqua.

ornithopodioides, Linn. SP. Pl. 672-As, Min.; Persia.

oxalidea, F. Muell. Fragm. i. 69.-Austral.

oxypetala, Boiss. Diagn. Ser. I. vi. 20.-Persia; Arab.

oxyphylla, Burch. Trav. i1. 226.-Air. anstr.

pallida, Kotschy, in Sitzb. Acad. Wien. Math. Nat. liv. Abth. I. (1866) 262.-Aratia.

palmipes, Spreng. Syst. ii. 122.-Guiana.

paludosa, Willd. ex Eichl. in Mart. Fl. Bras. xiii. 255 . Bras.

palustris, Salzm. ex Turcz. in Bull. Soc. Nat. Mose.

xxvii. (1854) 1I. 317.-Bras.

papillosa, Steud.Nom. ed. II. i. 362,-Aesrpt.; Arab.

Ind. bor. occ.

paradoxa, R. Br. in Salt, Abyss. App. 65.-Abyssin.

parviflora, R. Br. in Salt, Abyss. App. $65=$ brachy carpa.

parviflora, H. B. \& K. Nov. Gen. et Sp. v. $83=$ psoraleaefolia.

pedunculata, Vell. Fl. Flum. 272; vi. t. $112=$ gigantea.

pentaphylla, Blanco, Fl. Filip. ed. I. $323=$ Gynandropsis speciosa.

pentaphylla, Hort. Van Houtte, ex Eichl. in Mart. Fl. Bras, xiii. I. $251=$ Houtteana.

pentaphylla, Linn. Sp. Pl. ed. II. 938=Gynandropsis pentaphylla

pentaphylla, Vell. Fl. Flum. $2 \pi 2$; vi. t. $111=$ rosea

pilosa, Benth. Bot. Voy. Sulph. 65.-Am. austr.

pinnata, Pursh, Fl. Am. Sept. ii. $739=$ Stanleya pinnatifida.

platycarpa, Torr. in Bot. U. St. Expl. Exped. ii. $23 \%$ t. 2.-Am. bor. occ.

Poiteauana, Pacquet, in Fourn. Hort. Prat. i. '18 43 349.-Hab. ?

polygama, Linn. Sp. Pl. ed. II. 939 ; DC. Prod. i. 211 serrata.

porphyrantha, Planch. E Trizna, in Ann. Sc. Nat.

Sér. IV. xvii. (1862) 71.-N. Granat.

procumbens, facq. Enum. Pl. Carib. 261 ; Linn. Syst. ed. XII. 448.-Ind. occ.

prostrata, Hort. ex DC. Prod, ii. $3 \leq 2=$ Rotivia

trilolinta.

prostrata, Koen. ex Steud. Nom. ed. II. i $8 \& 2$ aspera.

pruinosa, T. Anders, in fourn. Linn. Soc. V. Snppl. (1860) 3.-Arabia,

pruriens, Planch, \& Triana, in Ann. Sc dot. Sir. Il. xvii. (1862) 68, -N. Granat.

psoraleacfolia, DC. Prod, i. 230 - - Bras.

puberula, Planch. E Triana, in atnn. Sc. Siat. Ser. $1 \mathrm{~V}$ xvii. (1862) 71.-N. Granal.

pubescens, Sieber, ex Steud. Nom. ed. II. i. $992=$ Gynandropsis pentaphylla,

pubescens, Sims, Bot. Mag. L. 1857.-Panama.

pulchella, Schulle. f. Sist. vii. 161\%.-Bras.

prongens, Willd. Enum. Hort. Herol. cis9 = spinesa.

purpurea, DC. Prod. i. 239.-Perus.

yuinquenervia, DC. I. c.-Persia; Alghauist, Ind, bor

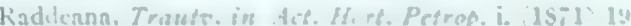
- Turcom:an.

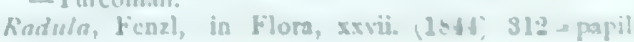
lusa. 


\section{CLEOME :}

ramosissima, Parl. ex Webb, Fragm. Fl. Aethiop. 22 -Afr. trop.

raphanoides, DC. Syst. ii. $662=$ Wormskioldia heterophylla.

recta, Facquem. Voy, Bot. 19.-Ind, or.

Regnelli,, Eichl. in Kjoeb. Vidensk. Meddel. (1870) 190.-Am. austr.

Richii, A. Gray, in Bot. U. St. Expl. Exped. i. 67.Bras.

roridula, R. Br. in Salt, Abyss. App. 65=droserifolia.

rosea, Eckl. ex Steud. Nom. ed. II. i. $382=$ Gynandropsis pentaphylla.

rosea, Poit. in Rev. Hortic. Sér. II. i. (1841-43) 69.Texas.

rosea, Vahl, ex DC. Prod. i. 239.-Bras.

rubella, Burch. Trav. i. 543.-Afr. austr.

rubiginosa, Planch. E' Triana, in Ann. Sc. Nat. Sér. IV xvii. (1862) 69,-N. Granat

rupestris, Sond. in Linnaea, xxiii. (1850) 6.-Afr. austr.

rupicola, Vicary, in Ann. Nat. Hist. Ser. II. i. (1848) 425.-Scinde.

Ruta, Cambess. in Jacquem. Voy. Bot. 19. t. $19=$ brachycarpa.

rutidosperma, $D C$. Prod. i. 241.-Ind. occ.?

sandwicensis, A. Gray, Bot. U. St. Expl. Exped. i. 65 -Ins. Sandvic.

scabrella, Eichl. in Kjoeb. Vidensk. Meddel. (1870) 188.-Am. trop.

scandens, Ruiz, ex Eichl. in Mart. F1. Bras. xiii. I. 251 = longipes.

scaposa, DC. Prod. i. $239=$ papillosa.

Schraderi, Schult. f. Syst. vii. $48=$ Chelidonii

secundiflora, Schrad. in Schult. f. t. c. 37.-Hab.?

Selloana, Klotzsch, ex Eichl. in Mart. Fl. Bras, xiii. I. 252.-Bras.

semibetandra, Sond. in Linnaea, xxiii. (1850) 5.-Afr. austr.

serrata, Facq. Enum. Pl. Carib. 26.-Ind. oce servulata, Pursh, Fl. Bor. Am. ii, 441 = integrifolia. sessilifolia, Schult. f. Syst. vii. 23.-Ind. or. occ.

siliculifera, Eichl. in Mart. Fl. Bras, xiii. I, 260.Bras.

siliquaria, R. Br. in Salt, Abyss. App. $65=$ arabica.

simplicifolia, Hook. $f$. E Thoms. in Fl. Brit. Ind. i 169.-Ind. or

socotrana, Balf. f. in Proc. Roy. Soc. Edinb. xi. (1882 501.-Ins. Socotra.

Sonorae, A. Gray, Pl, Wright. ii. 16.-N. Mexic.

sparsifolia, S. Wats. in Bot. King, Exp. 32 . t. 5.Am. bor. occ.

speciosa, H. B. \& K. Nov. Gen. et Sp. v. 84.st. $436=$

Gynandropsis speciosa.

speciosa, Rafin. Fl. Ludov. 86.-Am. bor.

speciosissima, Deppe, ex Lindl. Bot. Reg.-t. 1312.Mexic.

spinosa, Facq. Enum. Pl. Carib. 26 ; Linn. Sp. Pl. ed. II. 939.-Am. austr

spinosa, Sw. Obs. 252 = pungens.

stenophylla, Klotzsch, in Rich. Schomb. Reise, iii. $1164=$ Physostemon lanceolatum.

Stevensiana, Schnlt. f. Syst. vii. $40=$ ornithopodioides

Stocksiana, Boiss. Diagn. Ser. II. i. 47.-Belnchistan

strigosa, Oliver, Fl. Trop. Afr. i. 80.-Afr. trop.

stylosa, Eichl. in Mart. Fl. Bras, xiiii. I. 250. Venezuela.

subcordata, Steud. ex Oliver, in Trans. Linn. Soc.xxix. (1872) $28=$ monophylla.

surinamensis, Miq. in Linnaea, xviii. (1844) 239.Guiana.

tenella, Linn. f. Suppl. 300.-Ind. or. ; Afr. trop.

tenuifolia, Le Conte, ex Torr. E Gray, Fl. N. Am. 123.-Am. bor

ternata, Willd. ex Eichl. in Mart. Fl. Bras. xiii. I. 257 $=$ polygama.

tetrandra, Banks, ex DC. Prod. i. 240.-Austral.

tetraphylla, Willd, ex Eichl. in Mart. Fl. Bras. xiii. I. $257=$ psoraleaefolia.

titubans, Speg. in Anal. Soc. Cient. Argent. xv. (1883) 97.-Reg. Argent.

trachycarpa, Klatzsch, ex Eichl. in Mart. Fl. Bras. xiii. I. 252.-Bras.

trinervia, Fresen. in Mus. Senckenb. i. (1834) 177.Aegypt. : Arabia

triphylla, Descourt. F1. Med. Ant. i. t. $44=$ polygama.

\section{CLFOME :}

triphylla, James, in Long, Exped, ii. $239=$ integrifolia. triphylla, Linn. Sp. Pl. ed. II. $938=$ serrata. triphylla, Vell. Fl. Flum. 272 ; vi. t. $113=$ affinis uniglandulosa, Cav. Ic, iv. 3.-Mexic.

urens, Brot. ex Heynh. Nom. ii. 149, nomen.-Hab.?

Vahliana, Fresen. in Mus. Senckenb. ii. (1837) 110 brachycarpa.

venusta, Fenzl, in Flora, xxvii. (1844) $312=$ paradoxa.

villosa, Gardn. in Hook. Lond. Fourn. Bot. i. (1842) 166.-Bras.

viminea, Schrad. in Linnaea, \%. (1836) Litt. 109.Hab. ?

violacea, Linn. Sp. PI. $672=$ graveolens

vingata, Stev. in DC. Prod. i. $240=$ ornithopodioides.

virgata, Thunb. Prod. Pl. Cap. 109.-Afr. austr.

viridiflora, Schreb. in Nov. Act. Nat. Cur. iv. (1770)

136. $\mathrm{t} .3$ = gigantea.

viscosa, Linn. Sp. Pl. 672.-Geront, trop.

CLEOMELLA, DC. Prod. i. 237 (1824). CAPPARI$D E A E$, Benth. \& Hook. f. i. 105.

IsoparA, Rafin. Atl. Journ. 144 (1832)

angustifolia, Torr. in Hook. Kew Fourn. ii. (1850) 255. -Mexic.

brevipes, S. Wats. in Proc. Am. Acad. xvii. (1881-82) 365.-Calif.

Coulteri, Harv. ex A. Gray, Pl. Wright, i. 12, $129=$ Wislizenia refracta.

Fremontii, Torr. in Smithson, Contrib. iii. (1852) 12, in nota.-Am. bor.

longipes, Torr. in Hook. Kew Fourn. ii. (1850) 255.Mexic.

medicaginea, Turcz. in Bull. Soc. Nat. Mosc. xxvii. (1854) II. 313,-Mexic

mexicana, Moç. E Sesse, ex DC. Prod. i. 237.-Mexic. mexicana, Torr. in Ann. Lyc. N. York, ii. (1828) 167 $=$ angustifolia

obtusifolia, Torr. Ë Frém. in Frém. Second Report, 311.-Am. bor. occ.

oocarpa, A. Gray, in Proc. Am. Acad. xi. (1876) 72.Am. bor. occ.

parviflora, A. Gray, l.c. vi. (1864-65) 520--Calif

plocasperma, S. Wats. in Bot. King, Exp. 33.-Am. bor. occ.

CLEOMENA, Roem. \& Schult. Syst. ii. 18, 383 (1817) = Muehlenbergia, Schreb. (Gramin.).

CLEONIA, Linn. Sp. Pl. ed. II. 837 (1762). LABI$A T A E$, Benth. \& Hook. f. ii. 1203.

lusitanica, Linn. l. c.-Europ. austr.

CLEOPHORA, Gaertn. Fruct. ii. 185. t. $120(\mathbf{1 7 9 1})=$ Latania, Comm. (Palm.).

dendriformis, Lodd. ex Baker, F1. Maurit. $381=\mathrm{L}$. Loddigesii.

lontaroides, Gaertn. Fruct. ii. 185. t. $120=$ L. Commersonii.

CLERCIA, Vell. Fl. Flum. 29 ; i. t. $73,74(1825)=$ Salacia, Linn. (Celastr.

clusiaefolia, Miers, in Trans. Linn. Soc. xxviii. (1872) $381=\mathrm{S}$. sylvestris

dispansa, Miers, 1. c. 379.-Bras.

guianensis, Miers, 1. c. 378.-Guiana.

lanceolata, Miers, 1. c. 377.-Bras.

micrantha, Miers, 1. c. $379=\mathrm{S}$. Miersii.

ovata, Vell. F1. Flum. 30 ; i. t. $73=\mathrm{S}$. arborea

Passiflora, Vell. 1. c. t. 74.--Bras.

retusa, Miers, in Trans. Linn. Soc. xxviii. (1872) $380=$ S. sylvestris.

Tweediana, Miers, 1. c.-Bras.

CLERKIA, Neck. Elem. i. $251(1790)=$ Tabernae montana, Plum. (Apocyn.)

CLERMONTIA, Gaudich. in Freyc. Voy. Bot. 459. t. 71 ad 73 (1826). CAMPANULACEAE, Benth \& Hook. f. ii. 546.

grandiflora, Gaudich. l. c. t. 73.-Ins. Sandvic. Kakeana, Meyen, Reise, ii. 139.-Ins. Sandvic macrocarpa, Gaudich. Bot. Voy. Bonite, t. $49=$ Kakeana

macrophylla, Nutt. Trans, Am. Phil. Soc. N. S. viii. 1843) 251 = Kakeana

oblongifolia, Gaudich. in Freyc. Voy. Bot. 459. t. 71. -Ins. Sandvic.

\section{CIFRMONTIA}

parviflora, Gaudich. ex A. Gray, in Proc. Am. Acad. v. (1861) 150.-Ins. Sandvic.

persicifolia, Gaudich. in Freyc. Voy. Bot. 459. t. 72.Ins. Sandvic.

CLERODENDRON, Linn. Gen. ed. I. 186 (1737) $V E R B E N A C E A E$, Benth. \& Hook. f, ii. 1155. AgricolaeA, Schrank, in Denkschr. Akad. Muench. (1808) 98.

Cornacchinia, Savi, in Mem. Soc. Ital. Mod. xxi. (1837) 184.t. 7 .

Cyclonema, Hochst. in Flora, xxy. (1842) 225.

Cyrtostemma, Kunze, in Bot. Zeit. i. (1843) 272

Douglassia, Adans. Fam. ii. 200 (1763)

EGENA, Rafin. F1. Tellur. ii. 85 (1836).

OviEDA, Linn. Gen. ed. I. 59 (1737).

RothecA, Rafin. Fl. Tellur. iv. 69 (1836).

Siphonanthus, Linn. Gen, ed. II. 526 (1742)

SPIRONEMA, Hochst. in Flora, xxy. (1842) 226.

TorreyA, Spreng. Neue Entdeck, ii. 221 (1821)

Valdia, Plum. ex Adans. Fam. ii. 157 (1763).

VolKameria, Linn. Syst. ed. I (1735); Gen. ed. I. $347(1737)$.

VolkmanNia, Jacq. Hort. Schoenbr. iii. 48. t. 338 (1798).

Acerbiana, Benth. E Hook. f. Gen. ii. 1156.-Nubia. aculeatum, Griseb. Fl. Brit. W. Ind. 500,-Jamaic. acuminatum, Wall. Cat. n. $1792=$ disparifolium.

affine, Griff. Notul. iv. 170.-Burma.

amicorum, Seem. in Bonplandia, x. (1862) 249.-Ins. Pacif.

amplizs, Hance, in Ann. Sc. Nat. Sér. V. v. (1866) $233=$ cyrtophyllum.

angustifolium, Salisb. Prod. $108=$ fortunatum.

angustifolium, Spreng. Syst. ii. 758.-Jamaic.

attenuatum, R, Br. Prod. $511=$ floribundum.

aurantium, G. Don, in Edinb. Phil. Fourn. xi. (Oct. 1824) 349.-Afr. trop.

Arthur-Gordoni, Horne, ex Baker, in Journ. Linn. Soc. xx. (1883) $370=$ Gordoni.

Balfouri, Hort. ex Flor. Mag. viii. (1869) sub t. $432=$ Thomsonae.

Bethuneanum, Low, Sarawak, 378; et in Bot. Mag. t. 4485.-Borneo.

Blancoanum, Villar, in Blanco, Fl. Philipp. ed. III Nov. App. $161=$ Navesianum

Blancoi, Naves, ex Villar, l. c.-Ins. Philipp.

Blumeanum, Schau. in DC. Prod. xi. 669.-Java.

brachyanthum, Schau. l. c. 668.-Ins. Philipp.

bracteatum, Wall. Cat. n. 1800.-Reg. Himal

brunsvigioides, Baker, in fourn. Linn. Soc xxi. (1885) 435.-Madag.

Buchananii, Herb. Roxb. ex Wall. Cat. 2653 (sp. dub.). - Ind. or.

Bungei, Steud. Nom. ed. II. i. $382=$ foetidum

buruanum, Miq. Ann. Mus. Bot. Lugd. Bat. iii. 252 - Malaya.

buxifolium, Spreng. Syst. ii, 758.-Hab.?

calamistratum, Hort. Belg. ex Lem. Jard. Fleur. iv. (1854) Misc. $48=$ elegans.

calamitosum, Linn. Mant. i. 90,-Malaya

calycinum, Turcz. in Bull. Soc. Nat. Mosc. xxxvi. (1863) Ir. $222=$ infortunatum.

canescens, Wall. Cat. n. 1800.-China.

capense, D.Don, ex Steud. Nom. ed. II. i. 382.-Afr austr.

capense, Eckl. \& Zeyh. ex Schau. in DC. Prod. xi. 661 $=$ glabrum.

capitatum, Hook. Bot. Mag. t. $4355=$ Whitfieldii

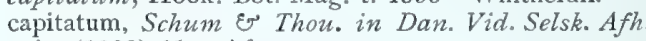

iv. (1828) 61.-Afr. trop.

capsulare, Blanco, F1. Filip. ed. I. $509=$ inerme

cardiophyllum, F. Muell. Fragm. iii. $144=$ flori bundum.

castaneaefotium, Klotzsch, in Bot. Ergeb. Waldem Reise, $\mathbf{1 0 2}=$ infortunatum.

castaneifolium, Hook. \& Arn. Bot. Beech. Voy. $205=$ fortunatum.

cauliflorum, Vatke, in Linnaea, xliii. (1880-82) 538. -Ins. Nossibé.

cernuum, Wall. ex Steud. Nom. ed. II. i. 382.Ind. or.

coccineum, D. Dietr. Syn. P1. iii. $616=$ squamatum. Colebrookianum, Walp. Rep. iv. 114.-Ind. or.; Malaya.

Commersonii, Spreng. Syst. ii. 758.-Ins. Philipp. condensatum, Miq. Fl. Ind. Bat. ii. 874.-Malaya. 


\section{CLERODENDRON :-}

cordatum, D. Don, Prod. F1. Nep. 103=infortunatum.

cordifolium, A. Rich. Tent. Fl. Abyss, ii. 170.Abyssin.

coriaceum, R. Br. Prod, $511=$ floribundum.

coriaceum, Poir. Encyc. Suppl. iv. $353=$ javanicum.

coromandelianum, Spreng. Syst. ii. $758=$ ovatum.

costatum, R. Br. Prod. 511.-Austral.

cruentum, Lindl. in Gard. Chron. (1860) 456.-As. trop.

cubensis, Schau, in DC. Prod xi, 658.-Cuba.

Cumingianum, Schau. l. c. 666.-Ins. Philipp.

cuneatum, Turcz. in Bull. Soc. Nat. Mosc. xxxvi. (1863) II. $221=$ serratum

Cunninghamii, Benth. Fl. Austral, v. 64.-Austral.

cuspidatum, Turcz. in Bull. Soc. Nat. Mosc. xxxvi.

(1863) II. 221. - N. Granat.

cyrtophyllum, Turcz. l.c. 222, - China.

deflexum, Wall. Pl. As. Rar. ii. 10. t. 215.Malaya.

densiflorum, Griff. Notul. iv. 170.-Burma.

dentatum, Wall. Cat. n. $1799=$ squamatum

depauperatum, Wall. ex Steud. Nom. ed. II. i. $382=$ infortunatum.

Diepenhorstii, Miq. Fl. Ind. Bat. Suppl. 568.Malaya.

discolor, Vatke, in Linnaea, xliii. (1880-82) 536.Afr. trop.

disparifolium, Blume, Bijdr. 809.-Malaya.

divaricatum, Jack, in Malay. Misc. i. (1820) n. v, p. 48 = serratum.

divaricatum, Sieb. \& Zucc. in Abh. Akad. Muench. iv. III. (1846) $1.54=$ Caryopteris divaricata.

diversifolium, Vahl, Symb. Bot. ii. $75=$ emirnense?

elegans, Manetti, ex Lem. Fard. Fleur. iv. (1854)

Misc. 47.-Hab.?

ellipticum, Zipp. ex Span. in Linnaea, xv. (1841) 329 =laevifolium.

emirnense, Boj. ex Hook. Bot. Mag. t. 2925.Madag.

eriosiphon, Schau, in DC. Prod, xi. 662.-Java.

fallax, Lindl. Bot. Reg. (1844) sub t. 19.-Java.

farinosum, Wall. Cat. n. $1810=$ serratum.

ferrugineum, Turcz. in Bull. Soc. Nat. Mosc. xxxvi. (1863) II. $221=$ villosum.

fistulosum, Becc. Malesia, ii. (1884) 48.-Malaya.

floribundum, R. Br. Prod. 511-Austral.

floribundum, Hort. Angl. ex Walp. Rep. iv. $111=$ emirnense.

foetidum, Bunge, Enum. Pl. Chin. Bor. 52,-China.

foetidum, D. Don, Prod. Fl. Nep. $103=$ Caryopteris grata.

foetidum, Hort. Par. ex Planch, in Fl, des Serres, Sér. I. ix. $(1853-54) 17$ = fragrans, Vent.

fortunatum, Buch,-Ham, ex Wall. Cat. n, 2652 (sp. dub.).-Assam.

fortunatum, Linn. Cent. Pl. ii. 23.-China.

fragrans, Vent. Fard. Malm. t. 70._China; Sumatra;

Java.

fragrans, Willd. Enum. Hort. Berol. 659.-Am. trop.

galeatum, Balf. $f$. in Proc. Roy. Soc. Edinb. xii. (1884) 91.-Ins. Socotra.

glabrum, E. Mey. Comm. Pl. Afr. Austr. i 273.-Afr. anstr.

glandulosum, Colebr. ex Wall. Cat. n. $1806=$ Colebrookianum.

glandulosum, Lindl. Bot. Reg. (1844) sub t. $19=$ praec.?

glaucum, Wall. ex Steud. Nom. ed. II. i. 383.-

Ind. or.

Gordoni, Baker, in Gourn. Linn. Soc. xx. (1883) 370 . -Ins. Fiji.

grandiflorum, Schau, in DC. Prod. xi. 659.-Hab.

grandifolium, Salisb. Prod. $108=$ serrata.

gratum, Kurz, For. Fl. Brit. Burma, ii. 268=Caryopteris paniculata.

gratum, Wall. Cat, n. 1813 = Caryopteris grata.

Griffithianum, C. B. Clarke, in Hook. f. Fi. Brit. Ind. iv. 590.-Assam; Burma.

haematocalyx, Hance, in Walp. Ann. iii. $238=$ canescens.

Harnierianum, Schweinf. Beitr. F\%. Acthiop. 110.Afr. trop.

hastatum, Lindl. Bot. Reg.t. 1907.-Reg. Himal

helianthemifolium, Wall. ex Steud. Nom. ed. II. i. 389, sphalm, = Caryopteris Wallichiana.

\section{CLERODENDRON :}

hemiderma, F. Muell. ex Benth. Fl. Austral. v, 61,Austral.

herbaceum, Wall. Cat. $\mathrm{n}, 1815=$ serratum.

heterophyllum, [R. Br. in $]$ Ait. Hort. Kew, ed. II. iv, 64.-Ins. Mascar.

Hildebrandtii, Vatke, in Linnaea, xliii. (1880-82) 536.-Afr. trop.

hircinum, Schau. in DC. Prod. xi. 661.-Madag.

hirsutum, G. Don, in Edinb. Phil. Journ. xi. (1824) $349=$ umbellatum.

Horsfieldii, Miq. Fl. Ind. Bat. ii. 880.-Java.

Huegelii, Hort. ex Regel, Gartenfl. (1861) 51.Austral.

illustre, N. E. Br. in Gard. Chron. (1884) II. 424, Ins. Celebes.

imperialis, Carr. in Rev. Hortic. (1874) 110,-Hab.? incisum, Klotzsch, in Peters, Reise Mossamb. Bot. 257 -Afr. trop.

inerme, R. Br. Prod. $511=$ neriifolium.

inerme, Gaertn. Fruct. i. 271.-Ind. or.

infortunatum, Gaertn. l. c.-Ind. or.; Malaya.

infortunatum, Dennst. Schluess. Hort. Malab. $27=$ villosum.

intermedium, Cham, in Linnaea, vii. (1832) 150.-Ins. Luzon.

involucratum, Vatke, in Linnaea, xliii. (1880-82) 537 -Afr. trop.

ixoraeflorum, Hassk. in Retria, 60.--Singapore.

Fackianum, Wall, in Hook. Bot. Misc. i. (1830) 284

Cat. n. $1794=$ disparifolium.

japonicum, Sweet, Hort. Brit. ed. I. 322.-Japon.

javanicum, Spreng. Syst. ii. 759.-Java.

javanicum, Walf. Rep. iv. $113=$ serratum.

Kaempferi, Fisch. ex Morr. Ann. Soc. Gand, i. (1845

17 , in syn.$=$ squamatum.

laciniatum, Balf. $f$. in Fourn. Linn. Soc. xvi. (1877) 19.--Ins. Mascar.

laevifolium, Blume, Bijdr. 808.-Malaya.

lanceolatum, F. Muell. Fragm. iii. 145.-Austral.

lanuginosum, Blume, Bijdr. 810.-Ins. Molucc.

lasiocephalum, C. B. Clarke, in Hook. f. Fl. Brit. Ind. iv. 594.-Reg. Himal.

laxiflorum, Baker, in fourn. Linn. Soc. xx. (1883) 229. -Ins. Fiji.

Lehuntei, Horne, ex Baker, l. c. 369.-Ins. Fiji.

leucophloeum, Balf. $f$. in Proc. Roy. Soc. Edinb. xii. (1884) 91.-Ins, Socotra.

Leucosceptrum, D. Don, Prod. Fl. Nep. $103=$ Leucosceptrum canum.

ligustrinum, $[R . B r . i n]$ Ait. Hort. Kew. ed. II. iv. 64. -Mexic.

Lindemuthianum, Vatke, in Linnaea, xliii. (1880-82) 537 -Afr, trop.

Lindenianum, $A$. Rich. Fl. Cub.Fanerog. ii. 147.-Cuba.

Lindleyi, Decne. ex Planch. in Fl, des Serres, Sér. I. ix. (1853-54) $17=$ fragrans, Vent.

Linnaei, F. Muell. Fragm. vi. $151=$ hemiderma.

Linnaei, Thw. Enum. Pl. Zeyl. 243 = Glossocarya Linnaei.

lividum, Lind1. Bot. Reg. t. $945=$ fortunatum.

Lobbii, C. B. Clarke, in Hook. f. Fl. Brit. Ind. iv. 590. -Ins. Penang.

longicolle, G. F. W. Mey. Prim. Fl. Esseq. 217.Guiana.

longiflorum, Decne, in Nov. Ann. Mus. Par, iii 1834) 400.-Ins. Timor.

macradenium, Miq. Fl. Ind. Bat. ii. 874,-Java.

macrocalycinum, Baker, in Fourn. Linn. Soc. xviii. (1881) 275.-Madag.

macrophyllum, Blume, Bijdr. 808.-Java.

macrophyllum, Sims, Bot. Mag, t. $2536=$ serratum.

macrosiphon, Hook. f. Bot. Mag. t. 6695.-Afr, trop.

macrostachyum, Turcz. in Bull. Soc. Nat. Mosc. xxxyi

1863) r. 220.- -Reg. Himal. ; Burma.

macrostegium, Schau. in DC. Prod. xi. 666.-Ins. Philipp.

Madacera, Voigt, Hort. Suburb. Calc. 467.-Ind. or.? magnoliaefolium, Baker, in Gourn. Bot. xx. (1882) 243. -Madag.

Manctt, Vis. Sem. Hort. Patav. (1848-49) n. 2.Ilab.?

medium, R. Br. Prod. $510=$ floribundum.

Minahassae, Terijsm. E Binn. in Tijdsehr. Nederl. Ind. xxy. (1868) 409. - Ins. Celebes.

mite, Vatke, in Linnaea, xliii. (1850-82) 59\%.-Afr. trop.

molle, H. B. E K. Nov. Gen. et Sp. ii. 244.-Ecuador.

\section{CLERODENDRON}

molle, Jack, in Malay. Misc. i. (1820) D. I. $15=$ villosam. mossambicense, Klotzsch, in Peters, Reise Mossamb. Bot. 259-Afr. trop.

multiflorum, G. Don, in Edinb. Phil. Joum, xi. (1821) $350=$ volubile

myricoides, R. Br. in Salt, Abyss. App. p. 1xv, nomen -Abysin.

Navesianum, Vidal, Cat. Prov. Manila, n. 398.-Ins. Philipp.

nereifolium, Wall. Cat. n. 1789,-Malaya.

Neumayeri, Vatke, in Linnaea, xlii. (1880-82) 585. Afr, trop.

mutans, Jack, in Malay. Misc. i. (1820) D. I. 17 Jackianam.

nutans, Wall. Cat. n. 1793.-Reg. Himal.; Burma. obovatum, Walp. Rep. iv. 112.-Ins. Molucc.

obtusidens, Miq.Fl. Ind. Bat. ii. 870.-Malaya.

odoratum, D. Don, Prod. Fl. Nep. 102 = Caryopteris Wallichiana.

ornatum, Wall, Cat. $n .1811=$ serratum.

ovale, Klotzsch, in Peters, Reise Mossamb. Bot. 257. Afr. trop.

ovalifolium, A. Gray, in Proc. Am. Acad. vi. (1862) 50.-Ins. Fiji

ovatum, Poir. Encyc. Suppl. iv. $352=$ coromandelinum ovatum, R. Br. Prod. $511=$ floribundum.

oxysepalum, Miq. in Fourn. Bot. Neerl. i. (1861) 114 -China.

paniculatum, Linn. Mant. i. 90-Borma; Malaya;

China.

papunnum, Scheff. in Ann. Fard. Buitenz. i. (1876) 41 -N. Guin.

penduliflorum, Wall. Cat. n. 1795.-Burma.

pentagonum, Hance, in Walp. Ann. iii. $238=$ fortunatum.

petunioides, Baker, in fourn. Linn. Soc. 2x. (1883 230.-Madag.

philippinum, Schau. in DC. Prod. xi. 667.-Malaya.

phlomoides, Hort. Ital. ex DC. 1. c. $\mathbf{v}, 613=$ Montano

arborescens.

phlomoides, Linn.f. Suppl. 292.-Ind. or.

phyllomega, Steud. Nom. ed. II. i. $383=$ macrophyllum pubescens, Lindl. in Bot. Reg. t. 1035.-Ind. or. pubescens, Walp. in Nov. Act. Nat. Cur. xix. Sappl. (1843) 380 , lapsu $=$ canescens.

pulchrum, Fawc. in O. Forbes, Nat. Wand. East. Archip. 514.-Ins. Timor.

pumilum, Spreng. Syst. ii. 759.-China

putre, Schau. in DC. Prod. xi. 661.-Madag.

pyramidale, Andr. Bot. Rep. t. $628=$ paniculatum

pyrifolium, Baker, in Fourn. Linn. Soc. xx. (1883

228.-Madag.

ramosissimum, Baker, l. c.-Madag.

Riedelii, Oliver, in fourn. Linn. Soc. xv. (1876) 100 -Ins. Celebes.

robustam, Klotasch, in Peters, Reise Mossamb. Bot 259.-Afr. trop.

roseum, Poit. in Rev. Hortic. (1876) 80,-Hab.

rotundifolium, Oliver, in Trans. Linn. Soc. xuxix. (1575

132. - Afr. trop.

rubellum, Baker, in Fourn. Linn. Soc. xx. (1583) 229 - Madag.

Rumphianum, De Vriese, in Mig. Ann. Mus. Bot. Lugd. Bat. iii. 252.-Ins. Amboina.

sagittatum, Wall. Cat, n. 1786= hastatum.

Sagraei, Schare. in DC. Prod. xi. 6591.-Ins. Cuba.

scanders, Beauv. Fl. Owar. i. 52. t. 32 = umbellatum.

scopiferum, Miq. Fl.Ind. Bat. ì. \&\$1.-Malaya

semiserratum, Wall. Cat. n. 1785.-Burma.

sericeum, Wall. l. c. a. $181 t=$ Hiptage scricea

serotinum, Carr. in Rev. Hortic. (156\%) $351=$ tricho tomum.

serratum, Spreng. Syst. ii. 758.-Ind. or.; Burma

simplex, G. Don, in Edinb. Phil. Gourn. xi. (182t 84 : Afr. trop.

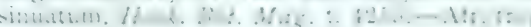

Siphonanthus, [R. Br. in j dit. Hort. Antr. ed, II. iv. is

Ind. or.; Malave.

speciosissimum, Hort. Angl. ex Selrau. in DC. Prod. xi $6 \% 2$ - glandulosum.

speciusissimum, Paxt. Mag. Bor iii. (1S3i) $217 \mathrm{et} 2=$ sỵuamatum.

specriusum x, Teijsm. \& Binn. Cat. Hort. Bog. S50 ;

L.en. Illustr. Hortic xvi. (1569) 1.393.

spicatum, T7umb. F\%. Goran. 202.-Java.

spidusum, Sperng. Sy sh. ii. 760 . - Ins. Dominic 


\section{CLERODENDRON :-}

splendens, G. Don, in Edinb. Phil. Fourn. xi. (1824) 349.-Afr. trop.

splendidum, Wall. Cat. n. $1803=$ paniculatum.

squamatum, Vahl, Symb. Bot. ii. 74.-Reg. Himal.;

Burma ; China.

stenanthum, Klotzsch, in Peters, Reise Mossamb. Bot. 258.-Afr. trop.

ternifolium, Baker, in Fourn. Linn. Soc. xx. (1883) 229.-Madag.

ternifolium, D. Don, Prod. Fl. Nep. $103=$ serratum. ternifolium, $H . B . \&$ E Kov. Gen. et Sp. ii. 244.-Fl Orinoco.

Thomsonae, Balf. in Edinb. New Phil. Fourn. N. S. xv. (Jan.-Apr. 1862) 233.-Afr. trop.

tomentosum, R. Br. Prod. 510.-Austral

Tracyanum, F. Muell. ex Benth. Fl. Austri.v.62.Austral.

trichotomum, Thunb. Fl. Fap. 256.-Japon.

trichotomum, Wall. Cat. n. $6315 \mathrm{~B}=$ villosum.

triflorum, Vis. Illustr. Piante Nov. Ort Padov. 19. -Nubia.

trifoliatum, Steud. Nom. ed. II. i. 383.-Ind. or. tuberculatum, A. Rich. Fl. Cub. Fanerog.ii.147.-Cuba umbellatum, Poir. Encyc. v. 166.-Afr. trop.

urticifolium, Wall. Cat. n. $1801=$ squamatum.

velutinum, Wall. 1. c. n. $1797=$ villostm.

venosum, Wall.l.c. n. 1807.-Reg. Himal.

verrucosum, Splitg. ex De Vriese, in Nederl. Kruidk. Arch i. (1848) 351.-Guiana.

verticillatum, D. Don, Prod. F1. Nep. $102=$ C. Siphonanthus.

vestitum, Wall. ex Steud. Nom. ed. II. i. $383=$ infortunatum.

villosum, Blume, Bijdr. 811.-Malaya.

viscosum, Vent. Jard. Malm. t. 25 = infortunatum.

volubile, Beauv. Fl. Orvar. i. 52. t. 32.-Afr. trop.

Whitfieldi, Seem. in Bonplandia, x. (1862) 250.-Afr. trop.

\section{CLERODENDRUM, Linn. = praec}

CLETHRA, Bert. ex Steud. Nom. ed. II. i. $384(1840)=$ Viviania, Cav.

mollis, Bert. ex Steud. I. c。=V. parvifolia.

CLETHRA, Gronov. ex Linn. Syst, ed. I (1735). ERICACEAE, Benth. \& Hook f ii. 603.

Crossophrys, Klotzsch, in Linnaea, xxiv. (1851) 3.

Cuellaria, Ruiz \& Pay. Prod.59. t. 10 (1794); Syst. Veg. 103 (1798).

Gillena, Adans. Fam. ii. 166 (1763).

JunIA, Adans. 1. c. 165 (1763)

Kowalewskia, Turcz, in Bull. Soc. Nat. Mosc. (1859) I. 263

Tinus, Linn. Syst. ed. X. 1010 (1759).

VolkAMERIA, P. Br. Hist. Jamaic. 214. t. 21. f. 1 (1756).

acuminata, Michx. Fl. Bor. Am. i. 260.-Am. bor.

Alexandri, Griseb. Fl. Brit. W. Ind. 142.--Ind. occ.

alnifotia, Blanco, F1. Filip, ed. II. $259=$ canescens

alnifolia, Linn. Sp. Pl. 396.-Am. bor.

angustifolia, DC. Prod. vii. 589.-Chili

arborea, [Soland. in] Ait. Hort. Kew. ed. I. ii. 73.Ins. Madera.

arborea, Vent. Jard. Malm, t. $40=$ secundiflora.

barbinervis, Sieb. E Zucc, in Abh. Akad. Muench. iv. III. (1846) 128. - Japon.

bicolor, H. B. ध K. Nov. Gen. et Sp. iii, 289.-N. Granat. bracteata, Griseb. Fl. Brit. W. Ind. 141.-Ind. occ. brasiliensis, Cham. E Schlecht. in Linnaea, viii. (1833) 510.-Bras.

brevifolia, Benth. Pl. Hartwe 143.-N. Granat. byrsonimoides, Griseb. Pl. Wrioht. Cub. 170,-Cuba canescens, Herb. Reinw. ex Blume, Bijdr. 863.-Java. castaneaefolia, Meissn. in Mart. Fl. Bras. vii. 169.Peruv.

confertifolia, Ernst, in Flora, Ivii. (1874) 213.Venezuela.

cubensis, A. Rich. Fl. Cub. Fanerog, i1. 75.-Cuba,

dentata, [Soland. in] Ait. Hort. Kew. ed. I. ii. $73=$ alnifolia.

divaricata, Loisel. in Duham. Arb. ed. Nov. v. 134.-

Am. austr.

Fabri, Hance, in Fourn. Bot. xxi. (1883) 130.-Chin

fagifolia, $H . B$. है $K$. Nov. Gen et Sp. iii. 289 . Am. austr.

ferruginea, Link, Enum. Hort. Berol. i. 396, nomen.Hab.?

\section{CLETHRA.}

ferruginea, Ruiz E Pav. Fl. Per. iv. t. 380.-Peruv. fimbriata, H. B. E K. Nov. Gen. et Sp. iii. 290. t. 264 -N. Granat.

Gardneri, Turcz. in Bull. Soc. Nat. Mosc. xxxvi. (1863) II. 233.-Bras.

glauca, Hort. ex Steud. Nom. ed. II. i. $383=$ pubescens. glauca, Pers. Syn. i. 483 = acuminata.

guianensis, Klotzsch, ex Meissn. in Mart. Fl. Bras. vii 170.-Guiana.

incana, Pers. Syn. i. $483=$ pubescens.

integrifolia, Moç. \& Sesse, ex DC. Prod. vii. $590=$ mexicana.

japonica, Thunb. ex Steud. Nom. ed. II. i. $383=$ barbinervis.

javanica, Turcz. in Bull. Soc. Nat. Mosc. xxxvi. (1863) II. 232.-Java.

Kowalewskii, Turcz. 1, c. $233=$ mexicana.

laevigata, Meissn. in Mart. Fl. Bras, vii. 168.-Bras.

lanata, Mart. \& Gal. in Bull. Acad. Brux. ix. (1842) 538.-Mexic.

lancifolia, Turcz. in Bull. Soc. Nat. Mosc. xxxvi. (1863) II. 231.-Singapore.

macrophylla, Mart. E Gal. in Bull. Acad. Brux. ix. 1842) 539.-Mexic

macrostachya, Loisel. in Duham. Arb.ed. Nov. v. 155.Hab. ?

Mathewsii, Turcz. in Bull. Soc. Nat. Mosc. xxxvi (1863) II. 232.-Peruv.

mexicana, $D C$. Prod. vii. 590.-Mexic

Michauxi, R. Court. in Mag.Hortic. i. (1833) 249,Am. bor.

micrantha, Remy, in Ann.Sc. Nat. Sér. III. viii. (1847) 233.-N. Granat.

montana, Fras. ex Loisel. in Duham. Arb. ed. Nov, v. $130=$ acuminata

nervosa, Loisel. in Duham. l. c. 133.-Peruv.

obovata, Hook. \& Arn. Bot. Beech. Voy. $302=$ querci folia.

obovata, Ruiz E Pav. Fl. Per. iv.t. 381.-Peruv.

ocanensis, Turcz. in Bull. Soc. Nat. Mosc. xxxvi. (1863) II. 231.-N. Granat.

occidentalis, Auct. ex Steud. Nom. ed. II. i. $383=$ tinifolia.

ovalifotia, Moç. \& Sesse, ex DC. Prod. vii. $590=$ mexicana.

ovalifolia, Turcz. in Bull. Soc. Nat. Mosc. xxxvi. (1863) II. 232-Reg. Andin.

paniculata, [Soland, in] Ait. Hort. Kew. ed. I, ii. 73 =alnifolia.

pedicellaris, Turcz. in Bull. Soc. Nat. Mosc, xxxvi. (1863) II. 234.-Peruv.

pubescens, Willd. Enum. Hort. Berol. 455=alnifolia.

punctata, Turcz, in Bull. Soc. Nat. Mosc. xxxvi. (1863) II. 235.-N. Granat.

quercifolia, Schlecht. in Linnaea, viii. (1833) 524 Lindl. Bot. Reg. (1842) t. 23.-Mexic.

repanda, Turcz. in Bull. Soc. Nat. Mosc. xxxvi. (1863) Ix. 231-Venezuela.

revoluta, Ruiz E ${ }^{\circ}$ Pav. Fl. Per, iv, t. 380.-Peruv,

scabra, Loisel in Duham. Arb ed. Nov, y, $132=$ brasiliensis.

scabra, Pers. Syn, i. $482=$ alnifolia

secundifora, Decne. in Fl. des Serres, Sér. II. xii

1877) 171 , in nota.-Hab. ?

serrulata, Turcz. in Bull. Soc. Nat. Mosc. xxxvi. (1863)

II. $233=$ mexicana

spicigera, Meissn. in Mart. Fl. Bras. vii. 168.-Bras.

Spracei, Turca. in Bull. Soc. Nat. Mosc. xxxvi. (1863 II. 232.-Peruv.

suaveolens, Turcz. l. c. 230.-Mexic

tinifolia, Schlecht. in Linnaea, viii. (1833) $524=$ quercifolia.

tinifolia, Sw. Prod. Veg. Ind. Occ. 74.-Jamaic.

tomentosa, Lam. Encyc. ii. $46=$ alnifolia.

virgata, Ruiz E Pav. Fl. Per. iv. t. 381.-Peruv.

CLETHROPSIS, Spach, in Ann. Sc. Nat. Sér. II. xv.

(1841) 201 = Alnus, Tourn. (Cupulif.).

nepalensis, Spach, I. c. $202=$ A. nepalensis.

nitida, Spach, 1. c. = A. nitida.

CLETHROSPERUM, Planch, in Hook. Ic. Pl. sub t. 767 (1848), sphalm. = Clathrospermum, Planch (Anonac.).

CLEYERA, Adans. Fam.ii. $224(1763)=$ Polypremum Linn. (Loganiac.)
CIEYERA, DC. in Mém. Soc. Phys. Genèv. i. (1822) 412 ; Prod. i. 524. (1824). TERNSTROEMIACEAE, Benth. \& Hook. f. i. 183

Mokof, Adans. Fam. ii. 50 (1763)

Tristylium, Turcz. in Bull. Soc. Nat, Mosc. xxxi. (1858) I. 247.

elegans, Choisy, in Mém. Soc. Phys. Genèv. xiv. (1855) 112.-Ins. Guadelup

grandiflora, Hook. f. E' Thoms. in Fil. Brit. Ind. i. 284. -Reg. Himal.

grandifiora, Wall. Cat. n. 1461=ochnacea.

integrifolia, Choisy, in Mém. Soc. Phys. Genèv, xiv. (1855) 112.-Mexic.

japonica, Sieb. \& Zucc. Fl. Jap. i. 153. t. $81=$ ochnacea.

Lushia, G. Don, Gen. Syst: i. $566=$ ochnacea

Mertensiana, Sieb. E Zucc. Fl. Fap. i. 154.-Japon.

mexicana, Planch ex Hemsl. Biol. Centr. Am. Bot. i. 93. - Mexic.

ochnacea, DC. in Mém. Soc. Phys. Genèv. i. (1822) 413.-Reg. Himal.

ochnoides, Wall, ex G. Don, Gen. Syst. i. $566=$ ochnacea.

serrulata, Choisy, in Mém. Soc.Phys. Genèv. xiv. (1855) 112.-Mexic.

siphilitica, Choisy, l. c.-Mexic.

theoides, Choisy, l. c.-Ind. occ.

Wallichiana, Sieb. \& Zucc. F1. Jap. i. 154=ochnacea.

CLEYERA, Thunb. Nov. Gen. 68 (1783)=Ternstroemia, Linn. f.

dubia, Champ. ex Benth. in Hook. Kew Journ, iii. 1851) $308=\mathrm{T}$, japonica.

emarginata, Gardn. in Calc. Journ. Nat. Hist. vii.

(1847) $447=\mathrm{T}$, emarginata

fragrans, Champ. ex Benth. in Hook. Kew Journ. iii. (1851) $307=\mathrm{T}$. japonica

gymnanthera, Wight \& Arn. Prod. $87=$ T. japonica. japonica, Thunb. Nov. Gen. $69=$ T. japonica,

lasiopetala, Wight, Illustr. i. $99=$ Adinandra lasiopetala.

Milletti, Hook. \& Am, Bot. Beech. Voy, $171=$

Adinandra Millettii.

pentapetala, Spreng. Syst. ii. 596=Saurauja tristyla. rubiginosa, Spreng. 1. c.- Sumatra.

CLEYRIA, Neck. Elem. ii. $183(\mathbf{1 7 9 0})=$ Dialium, Linn. (Legumin.).

CLIANTHUS, Banks \& Soland. ex G. Don, Syst. ii. 468 (1832). LEGUMINOSAE, Benth. \& Hook. f. i. 503.

Donia, D. \& G. Don, Gen. Syst. ïi. 467 (1832). Eremocharis, R. Br. in Sturt, Exped. Centr. Austral. ii. App. 73 (1849)

Binnendyckianus, Kurz, in Fourn. As. Soc. Beng.xl. (1871) 51.-Ins. Ceram.

carneus, Lindl. Bot. Reg. (1841) Misc. $2=$ Streblorrhiza speciosa.

Dampieri, A. Cunn ex Lindl. in Trans. Hort. Soc. Ser. II. i. (1835) 522.-Austral

Dampieri, R. Br. in Sturt, Exped. Centr. Austral. ii. 71 $=$ Oxleyi.

Oxleyi, A. Cunn. ex Lindl. in Trans. Hort. Soc. Ser. II. i. (1835) 522.-Austral.

pictus, Endl. in Ann. Wien. Mus. i. (1836) $185=$ Streblorrhiza speciosa.

puniceus, Banks Eo Soland. ex Lindl. in Trans. Hort. Soc. Ser. II. i. (1835) 521.-N. Zel.

speciosus, Stend. Nom. ed. II. i. $381=$ Streblorrhiza speciosa.

CLIBADIUM, Linn. Mant. ii. 161 (1771), COMPOSTTAE, Benth. \& Hook. f. ii. 345.

Bailitieria, Aubl. Pl. Gui. ii. 804. t. 317 (1775) OrsinIA, DC. Prod. v. 104 (1836).

Oswalda, Cass, in Dict. Sc. Nat. lix. 322 (1829).

Trixis, Sw. Prod. Veg. Ind. Occ. 115 (1788)

acuminatum, Benth. Bot. Voy. Sulph. 114.-Ins. Cocos.

agreste, Mart. ex Baker, in Mart. F1. Bras, vi, III, 15 ? $=$ Ichthyothera agrestis

Alexandri, Griseb. Fl. Brit. W. Ind. 368.--Tamaic. angustifolium, Mart, ex Baker, in Mart. Fl. Bras, vi. III. $154=$ lineare.

Armani, Sch. Bip. ex Baker, l. c. $152=$ rotundifolium. asperum, DC. Prod. v. $506=$ surinamense.

Badieri, Griseb. Fl, Brit. W. Ind, $367=$ surinamense. 


\section{CLIBADIUM :-}

Barbasco, DC. Prod. v. 507.--Venezuela.

caracasanum, DC. l. c. 506.-Venezuela.

commelinoides, DC. 1. c. = Icthyothera Cunabi

erosum, $D C . l$. $c_{0}$-Ind. occ.

foetidum, Alemand, ex Linn. Mant. ii. 294=surinamense.

fragiferum, Griseb. Fl. Brit. W.Ind. 368.-Ind. occ.

havanense, DC. Prod. v. 506.-Cuba.

leiocarpum, Steetz, in Seem. Bot. Voy. Herald, 152.Panama.

neriifolium, DC. Prod. v. 507.-Venezuela.

pedunculosum, $D C$. l. c.-Guiana.

peruvianum, Poepp, ex DC. 1. c. $505=$ surinamense.

rotundifolium, DC.l. c.-Bras.

Schomburgkii, Sch. Bip. in Schomb. Fauna \& Fl. Guian nomen, 940.-Guiana.

surinamense, Linn. Mant. ii. 294.-Am. austr.

sylvestre, Baill. Hist. P1. viii, $307=$ surinamense

terebinthinaceum, DC. Prod. v. 506.-Ind. occ.

Trinitatis, DC. 1. c. $505=$ surinamense.

Vargassi, $D C$. l. c. 506.-Venezuela.

villosum, Benth. Pl. Hartw. $205=$ surinamense.

CLIDANTHERA, R. Br. in Sturt, Exped. Centr. Austral. ii. App, $73(1849)=$ Glycyrrhiza, Linn. (Legumin.). psoralioides, R. Br. 1. c. $74=\mathrm{G}$. psoraloides.

CLIDEMIA, D. Don, in Mem. Wern. Soc. iv. (1823) 306. MELASTOMACEAE, Benth. \&E Hook. f. i 766.

DANCERA, Rafin. Sylva Tellur. 93 (1838).

Staphidium, Naud. in Ann. Sc. Nat. Sér. III. xvii. (1852) 306.

Stephanotrichum, Nand, 1. c. iv. (1845) 54.

acutiflora, Naud. 1. c. xvii. (1852) $371=$ Oxymeris acutiflora.

aggregata, D. Don, in Mem. Wern. Soc. iv. (1823 $309=$ Henriettella aggregata

arrestis, $\mathrm{D}$. Don, 1. $\mathrm{c}_{\mathrm{c}}=$ Oxymeris agrestis

alata, G. Don, ex Loud. Hort. Brit. 174= Miconia alata.

alpestris, Gardn. in Hook. Lond. Journ. Bot. iv. (1845) $101=$ Oxymeris alpestris

althaeoides, Naud, in Ann. Sc. Nat. Sér. III. xvii. 1852) $363=$ Octopleura confertiflora.

amblyandra, Naud. 1. c. $353=$ Oxymeris subseriata.

amygdaloides, DC. Prod. iii. $156=$ Ossaea amygda loides.

angustifolia, Naud. in Ann. Sc. Nat. Sér. III. xvii (1852) $358=$ Oxymeris angustifolia.

anisophylla, DC. Prod, iii. $161=$ Oxymeris anisophylla.

anisotrichum, Schlecht. in Linnaea, xiii. (1839) $427=$ Miconia Berghesiana.

apbanantha, Sagot, in Ann. Sc. Nat. Sér. VI. xv. (1883) 327.-Guiano.

aptera, DC. Prod. iii, $161=$ Oxymeris aptera

aristigera, Naud, in Ann. Sc. Nat. Sér. III, xvii

(1852) $366=$ Oxymeris aristigera

asperifolia, Naud. 1. c. $342=$ Oxymeris asperifolia, Ossaea asperifolia.

astrotricha, DC. Prod. iii. $161=$ Miconia astrotricha atrata, Spreng. in Flora, xx, (1837) Beibl. ii. $78=$ Miconia atrata.

aurea, Cham. in Linnaea, $\mathrm{x} .(1836) 47=$ Oxymeris aurea.

auricoma, Nand. in Ann. Sc. Nat. Sér. III. xvii. (1852) $975=$ Leandra aurea

arstralis, Cham. in Linnaea, x. (1836) $44=$ Oxymeris australis.

barbata, Triana, in Trans. Linn. Soc. xxviii. (1871) 136.-N. Granat.

barbinervis, Benth. Bot. Voy. Sulph. $95=$ Miconia barbinervis.

Benthamiana, Miq. in Linnaes, xviii. (1844) $276=$ hirts.

berbiceana, DC. Prod, iii. $160=$ Miconia erionoda.

Berterii, Griseb. in Goett. Abh. ix. (1861) $47=$ Sagraea plumosa.

bifaria, Rich, ex Naud, in Ann. Sc. Nat. Sér. III. xvii. 1852) $374=$ Oxymeris heterobnsis.

biseptena, DC. Prod. iii. $164=$ Oxymeris dichotoma.

biscptena, Gardn, in Hook. Lond. Journ. Bot. i. (1842)

$171=$ Oxymeris Nianga.

biserrata, DC. Prod. iii. 158.-Bras.

hlepharodes, DC. l. c.-Bras.

\section{CLIDEMIA}

botryophora, Naud. in Ann. Sc. Nat. Sér. III. xvii. (1852) $350=$ Oxymeris Nianga.

brachystachya, DC. Prod. iii. 156 = Ossaea brachystachya.

brachystephana, Triana, in Trans. Linn. Soc. xxviii. (1871) 185.-N. Granat.

Brackenridgei, A. Gray, Bot. U. St. Expl. Exped. i. $591=$ Oxymeris Brackenridgei.

bracteata, DC. Prod. iii. $162=$ Miconia bracteata

bullosa, DC. l. c. 158--Bras.

calvescens, $\mathrm{O}$. Berg, ex Triana, in Trans, Linn. Soc. xxviii. (1871) $91=$ Oxymeris calvescens.

campestris, Benth. in Hook. Journ. But. ii. (1840) 308 $=$ Miconia campestris.

capillaris, D. Don, in Mem. Wern. Soc. iv. (1823) 309 $=$ Octopleura leptopus.

capillaris, Griseb in $\mathrm{Mcm}$. Am. Acad, N S viii (1861) $184=$ Sagraea capillaris.

capitata, Benth. in Hook. Journ. Bot. ii. (1840) $307=$

Sagraea capitata.

capitellata, D. Don, in Mem. Wern. Soc. iv. (1823 $310=$ dependens,

carassana, DC. Prod. iii. $162=$ Oxymeris carassana.

carassana, DC. ex Triana, in Trans. Limn. Soc. xxviji. (1871) $111=$ Miconia spondylantha

cephalophora, Steud. ex Triana, 1. c. = Miconia bracteata.

ceranicarpa, DC. Prod. iii. $160=$ Miconia spondy lanthe.

cernua, D. Don, in Loud. Hort. Brit. 174.-Peruv.

chaetocalyx, A. Gray, Bor. U. S. Expl. Exped, i. 589 t. $74=$ Oxymeris chaetocalyx.

Chaetodon, Naud. in Ann. Sc. Nat. Sér. III. xvii. 1852) $360=$ Oxymeris Chaetodon.

Chamissois, Naud. 1. c. $375=$ Miconia ibaguensis

chinatlana, Triana, in Trans. Linn. Soc. xxviii. (1871) 135.-Mexic.

chrysopogon, Bearl. in Vet. Akad. Handl. Stockh. 1854 (1856) $127=$ Miconia barbinervis.

ciliata, D. Don, in Mem. Wern. Soc. iv. (1824) $309=$ Calophysa ciliata.

cinerea, Griseb. Cat. P1. Cub. $97=$ Oxymeris cinerea.

cinnamomifolia, Naud. in Ann. Sc. Nat. Sér. III, xvii. (1852) $369=$ Ossaea cinnamomifolia

Claussenii, Naud. 1. c. $357=$ Oxymeris purpurascens.

coccinea, DC. Prod. iii. $162=$ Miconia spondylantha.

cognata, Steud. ex Naud. in Ann. Sc. Nat. Sér. III. xvii. (1852) $308=$ hirta.

confertiflora, DC. Prod. iii. $156=$ Ossaea confert flora.

congestiflora, Naud. in Ann. Sc, Nat, Sér. III xvii 1852) $344=$ Oxymeris congestiflora.

conglomerata, DC. Prod. iii. 156.-Guiana.

cordifolia, Naud. in Ann. Sc. Nat. Sér. III. xvii. (1852) $361=$ Oxymeris cordifolia

cordigera, O. Berg, ex Triana, in Trans. Linn. Soc xxviii. (1871) $94=$ Oxymeris cordigera.

coriacea, Naud, in Ann. Sc. Nat. Sér. III, xvii. (1852) $368=$ Ossaea coriacea

cornoides, Griseb. in Goett. Abh. ix. (1861) 50.-Reg Argent.

crenata, DC. Prod. iii. $157=$ hirts.

crenata, D. Don, in Mem. Wern. Soc. iv. (1823) $308=$ Oxymeris crenata.

crossosepala, Griseb. F1. Brit. W. Ind. $248=$ Sagtaea heteroneura, crossopetala.

Cruegeriana, Griseb. 1. c. $249=$ Sagraea salicifolia cuneata, Naud. in Ann. Sc. Nat. Sér. III. xvii. (1852 $375=$ Oxymeris cuneata.

cyanocarpa, Benth. Bot. Voy. Sulph. $94=$ Octopleur quinquenervia.

dasytricha, A. Gray, Bot. U. S. Expl. Exped. i. 58S

Oxymeris carassana.

debilis, Crueg. in Linnaea, xx. (1847) $104=$ Sagraca

rebilis, Naud, in Ann. Sc. Nat. Sér. III. xvil. (1852 $361=$ Oxymeris debilis.

decurrens, Beurl. in Vet. Akad. Handl. Stockb. 185 (1856) 127 = Octopleura quinquenervia.

deflexa, $\mathrm{O}$. Berg, ex Triana, in Trans. Linn. Soc. xxvii. (1871) $94=$ Oxymeris deflexa.

deflexn, Bumb, in Proce Linnt. Sor, i. (18+1) 10 s. Bras.

deredroides, Naud, in Ann. Sc. Nat. Sér. III. xvii. (1852) $367=$ Oxymeris dendroides.

\section{CLIDEMIA :-}

dentata, D. Don, in Mem. Wern. Soc. iv. (1823) 308,Peruv.

depauperata, DC. Prod, iii. $161=$ Oxymeris agrestis.

dependens, D. Don, in Mem. Wern. Soc iv (1823 $307 .-$ Peruy

Deppeana, Steud. Nom. ed. II. i. 384.-Mexic

desmantha, Benth. in Hook. Joum. Bot. ii. (1840) 30 = Miconia rhytidophylla.

dichotoma, D. Don, in Mem. Wern. Soc. iv, (1893 $307=$ Oxymeris dichotoma.

dispar, Gardn. in Hook. Lond, Journ. Bot, ii. (1843; $345=$ Oxymeris dispar.

divaricata, Naud, in Ann. Sc. Nat. Sér. III. xvis 1852) $373=$ - Oxymeris secundifora.

diversifolia, DC. Prod. iii. $159=$ Octopleura diversi. folia.

dolichantha, Naud, in Ann. Sc. Nat. Sér. III xvii (1852) $351=$ Oxymeris dolichantha.

dolichostachya, Naud. 1. c. $359=$ Oxymeris dolicho stachya.

Drosera, Sagot, I. c. Sér. VI. xv. (1883) $328=$ aphanantha.

elegans, DC. Prod. iii. 157.-Am. trop

elegans, D. Don, in Mem. Wern. Soc. iv. (1823) $309=$ hirta.

Epibaterium, DC. Prod. iii. $157=$ Octopleura Epila terium.

erostrata, DC. 1. c. $160=$ Oxymeris erostrata.

erythropogon, DC. l. c. 157.-Jamaica.

euphorbioides, Naud, in Ann. Sc. Nat. Sér. III. xvii. (1852) $370=$ Ossaea euphorbioides.

fallax, Cham, in Linnaea, x. (1836) $41=$ Oxymerifallax.

fallax, Gardn. in Hook, Lond. Journ. Bot. ii. (18t3; $344=$ Oxymeris xantholasia.

fenestrata, Benth. Bot. Voy. Sulph. $94=$ umbonata. fenestrata, Seem. Bot. Voy. Herald, $124=$ neglecta.

foribunda, Naud, in Ann. Sc. Nat. Sér. III. xvi.

1852) $349=$ Oxymeris foribunda.

foveolata, DC. Prod. iii. $163=$ Oxymeris foveolata.

glabrata, Bunb. in Proc. Linn. Soc. i. (1841) 108.Bras.

glabrata, Stend. in Flora, xxvil. (1844) II. 721 Miconia auriculata.

glabriflora, Presl, Bot. Bemerk. $70=$ Miconia decussata.

glomerata, DC. Prod. iii. $163=$ Oxymeris Nianga.

guadaloupensis, Griseb. in Goett. Abh. vii. $\{1857,21$ = Sagraea guadalupensis.

hematostemon, Nand. in Ann. Sc. Nat. Sér. III. rvi. (1852) $348=$ Oxymeris aurea.

herbacea, Steud. ex Cogn. in Mart. Fl. Bras. xiv, It $468=$ Aciotis herbacea.

hetcrobasis, DC. Prod. iii. $164=$ Oxymeris hetero. basis.

heteroclita, Naud. in Ann. Sc. Nat. Sér. III. xvii. 1852) $365=$ japurensis.

heteromalla, D. Don, in Mem. Wern. Soc. iv. (1 1223 $\$ 10=$ Sagraes rubra.

heterophylla, Steud. in Florg, xxvii. (1844) II. T? I,Bras.

heterotricha, Griseb. Cat. Pl. Cab. $96=$ Calycogonium heterotrichum,

hirsuta, Griseb. in Mem. Am. Acad. N.S. viii. 156 185. -Ind. occ.

lirsuta Griseb. Fl. Brit WV. Ind 24s Ussaca hissuta.

hirsuta, Macf. Fl. Jamaic. ii. $45=$ Ossaen asperifolia.

hirta, D. Don, in Mem. Wern. Soc. iv. (1s:3) \$ug.Jamaica.

hirtella, Griseb. in Goett. Abh. ix. (186 ' $50=0$ sstea hirtella, llrightii.

humilis, Miq. in Linnaea, xxii. (1849) $542=$ Oxymeri Nianga.

holusericer, D. Don, cx Losd. Howh. Bris. 1it.liras.

inaequalifolia, DC. Prod, iii. $16 f=0 x y m c r i s$ insc. qualifulia,

inopogon, Mart. in Flora, xxiv. (15+1' Bcibl. ii. 37 Uxymeris inoprogon.

intermetia, DC. Frod. iii. lof , Oxumeris inte: mexlia.

iuferrupto, Poepp. ex Triana, in Trans, linn Sos.

vxviii. $13 i 1) 111$ = Miconia bractcala.

invulucrata, $D C$. Privd iii. 163.-Guiana

japurensis, $D C$. I. c. 15\%, - Mras.

lacere. DC: I. c. Itit Micunia lacera. 


\section{CLIDEMIA :}

laevigata, O. Berg, ex Triana, in Trans. Linn. Soc. xxviii. (1871) $94=$ Oxymeris laevigata.

Lambertiana, DC. Prod. iii. $164=$ Oxymeris crenata.

lanata, DC. 1. c, $\mathbf{1 6 3}=$ Miconia lanata.

lanata, Griseb. in Mem. Am. Acad. N. S. viii. (1861) $184=$ Ossaea lanata.

lappacea, DC. Prod. iii. 160= Miconia lappacea.

latifolia, DC. 1. c. $159=$ Sagraea latifolia.

latifolia, Griseb. FI. Brit. W. Ind. $247=$ Sagraea umbrosa.

laxiflora, Schlecht. in Linnaea, xiii. (1839) 426.Mexic.

leandroides, Naud. in Ann. Sc. Nat. Sér. III. xvií. 1852) $355=$ Oxymeris purpurascens,

leptoclades, H. Crueg. in Linnaea, xx. (1847) $103=$ hirta.

leptopus, Mart. ex Triana, in Trans. Linn. Soc. xxviii. (1871) $147=$ Ossaea leptopus.

leptostachya, Gardn. in Hook. Lond. Journ. Bot. i. (1842) $172=$ Ossaea brachystachya.

leucandra, Wright, ex Griseb. Cat. PI. Cub. $96=$ Sagraea domingensis

Lima, DC. Prod. 1ii. $161=$ Ossaea Lima.

lineata, Naud. in Ann. Sc. Nat. Sér. III. xvii. (1852) $356=$ Oxymeris purpurascens.

longibarbis, DC. Prod. iii. $163=$ Oxymeris longibarbis.

lugubris, Beurl, in Vet. Akad. Handl. Stockh. 1854 (1856) $127=$ Oxymeris heterobasis

lutescens, Naud. in Ann. Sc. Nat. Sér. III. xvii. (1852) $347=$ Oxymeris crenata

macrophylla, Naud. l. c. 375.-Ins. Cocos.

macrophylla, Seem. Bot. Voy. Herald, $124=$ Miconia simplex.

macropora, O. Berg, ex Triana, in Trans. Linn. Soc. xxviii. (1871) $94=$ Oxymeris macropora .

maculata, Benth. in Hook. Journ. Bot. ii. (1840) $310=$ Miconia auriculata.

marginata, DC. Prod. iii. 156=Ossaea marginata .

Martiana, Naud. in Ann. Sc. Nat. Sér. III. xvii. (1852) $340=$ Oxymeris cuneata.

Martii, Naud. 1. c. $375=$ Oxymeris ciliata.

melanodesma, Naud. 1. c. $353=$ Oxymeris melanodesma.

melanotricha, Triana, in Trans. Linn. Soc. xxviii. (1871) 136.-Costa Rica

Miconiastrum, Naud. in Ann. Sc. Nat. Sér. III. xvii.

1852) $352=$ Oxymeris Miconiastrum

miconioides, Benth. in Hook. Journ. Bot. ii. (1840) 310 $=$ Miconia auriculata

micrantha, Sagot, in Ann. Sc. Nat. Sér. VI. xv. (1883) 327.-Guiana.

micropetala, Naud, in Ann. Sc. Nat. Sér. III. xvii. 1852) $367=$ Oxymeris micropetala.

microphylla, D. Don, in Loud. Hort. Brit. 174.Am. austr.

microphylla, Griseb. F1. Brit. W. Ind. $248=$ Ossaea microphylla.

microstachya, Naud, in Ann. Sc. Nat. Sér. III. xvii.

(1852) $357=$ Oxymeris purpurascens

monticola, Naud. 1. c. $341=$ Miconia erythrantha

multiplinervis, Naud. 1. c. $358=$ Oxymeris multiplinervis.

mutabilis, DC. Prod. iii. $162=$ Miconia mutabilis.

naevula, Triana, in Trans. Linn. Soc. xxviii. (1871) 137.-Guiana.

neglecta, D. Don, in Mem. Wern. Soc iv. (1823) 307. -Peruv.

nervosa, Naud. in Ann. Sc. Nat. Sér. III. xvii. (1852) $341=$ Oxymeris nervosa.

Nianga, DC. Prod. iii. $163=$ Oxymeris Nianga

Nianga, Gardn. in Hook. Lond. Journ. Bot. ii. (1843) $344=$ Oxymeris xantholasia.

nivea, D. Don, in Loud. Hort. Brit. 174.-Am. austr. novemnervia, Triana, in Trans. Linn. Soc. xxviii. (1871) 136.-Am. trop.

oaxacensis, Steud. ex Triana, 1. c. $92=$ Oxymeris subseriata.

obscura, DC. Prod. iii. $162=$ Miconia obscura

octona, Griseb. in Goett. Abh. ix. (1861) 50.-Reg. Argent.

oligochaeta, Cham. in Linnaea, x. (1836) $45=$ Oxymeris foveolata.

oocarpa, A. Gray, Bot. U. S. Expl. Exped. 1. $590=$ Oxymeris oocarpa.

ossaeoides, Naud. in Ann. Sc. Nat. Sér. III. xvii. (1852) $360=$ Oxymeris ossaeoides.

\section{CLIDEMIA :}

oxyura, Triana, in Trans. Linn. Soc. xxviii. (1871) 135.-Guiana.

paraguayensis, Steud. in Flora, xxvii. (1844) II. $721=$ Oxymeris paraguayensis

parasitica, O. Berg, ex Triana, in Trans. Linn. Soc. xxviii. (1871) 135.-Bras.

pauciflora, DC. Prod. iii. $157=$ hirta.

penduliflora, Naud. in Ann. Sc. Nat. Sér. III. xvii. (1852) $369=$ Oxymeris penduliflora

penninervis, Griseb. in Mem. Am. Acad. N. S. viii. (1861) $\mathbf{1 8 5}=$ Sagraea penninervis.

pennipilis, O. Berg, ex Triana, in Trans. Linn. Soc. xxviii. (1871) $92=$ Oxymeris pennipilis.

petiolaris, Triana, 1. c. $135=$ Deppeana.

petiolata, DC. Prod. iii. $157=$ Sagraea petiolata

phaeostaphis, Naud. in Ann. Sc. Nat. Sér. III. xvii. (1852) $343=$ Oxymeris dichotoma.

phaeotricha, Naud. 1. c. $35=$ Oxymeris australis.

Pickeringii, A. Gray, Bot. U. S. Expl. Exped. i. $592=$ Oxymeris Pickeringii.

pilosa, D. Don, in Mem. Wern. Soc. iv. (1823) $308=$ Calophysa pilosa.

plumosa, DC. Prod. iii. 159 =-Sagraea plumosa,

polyandra, Benth. Bot. Voy. Sulph. $95=$ Miconia Benthamiana.

polystachya, Naud. in Ann. Sc. Nat. Sér. III. xvii. (1852) $347=$ Oxymeris polystachya

pulchra, A. Gray, Bot. U. St. Expl. Exped. i. $591=$ Oxymeris pulchra.

purpurascens, DC. Prod. iii. 161 = Oxymeris purpurascens.

purpurea, DC. 1. c. $158=$ dentata.

purpurea, D. Don, in Mem. Wern. Soc. iv. (1823) 308 Peruv.

pustulata, DC. Prod, iii. $159=$ umbonata.

quadrisulca, Nand. in Ann. Sc. Nat. Sér. III. xvii (1852) $364=$ Oxymeris secundiflora.

quinquedentata, Naud. 1. c. $375=$ Oxymeris quinquedentata.

quinquenodis, Naud.1. c. $370=$ Oxymeris quinquenodis quintuplinervia, Steud. ex Triana, in Trans. Linn. Soc. xxviii. (1871) 137 = involucrata.

radulaefolia, Benth. in Hook. Journ. Bot. ii. (1840) $309=$ Miconia radulaefolia .

rariflora, Benth. l. c. 3(8.-Guiana.

reclinata, Beurl. in Vet. Akad. Handl. Stockh. 185 (1856) $\mathbf{1 2 5}=$ petiolaris.

Regnellii, O. Berg, ex Triana, in Trans. Linn. Soc. xxviii. (1871) $91=$ Oxymeris Regnellii

Renggeri, Stend. in Flora, xxvii. (1844) $721=$ Oxy meris inopogon.

repens, Triana, in Trans. Linn. Soc. xxviii. (1871) 136.-N. Granat.

retropila, DC. Prod. iii. $\mathbf{1 5 6}=$ Ossaea retropila

reziersa, DC. 1.c. $161=$ Oxymeris reversa

rhamnifolia, Naud, in Ann. Sc. Nat. Sér. III. xvii. (1852) $373=$ Oxymeris secundiflora.

phodolasia, Beurl. in Vet. Akad. Handl. Stockh. 185 1856) $126=$ Miconia lacera.

rhodopogon, DC. Prod. iii. $163=$ Oxymeris rhodopogon.

ribesifflora, Cham. in Linnaea, $\mathrm{x}$. (1836) $38=$ Oxymeris ribesiaeflora.

Riedeliana, O. Berg, ex Triana, in Trans. Linn. Soc xxviii. (1871) $92=$ Oxymeris Riedeliana.

rubra, Mart. Nov. Gen. et Sp. iii. 152. t. 281.-Am. austr.

rubrinervis, Griseb. in Mem. Am. Acad. N. S. viii. (1861) 185.-Cuba.

rufescens, Griseb. Cat. P1. Cub. $97=$ Ossaea rufescens. sagittata, Naud. in Ann. Sc. Nat. Sér. III. xvii. (1852) $359=$ Oxymeris subseriata.

salicifolia, Naud. 1. c. $364=$ Ossaea brachystachya

scabrosa, Griseb. in Mem. Am. Acad. N. S. viii. (1861) 184.-Ind. occ.

scandens, Gardn. in Hook. Lond. Joum. Bot. ii. (1843) $346=$ blepharodes.

secunda, D. Don, in Mem. Wern. Soc. iv. (1823) 308 $=$ Oxymeris secunda.

secundiflora, DC. Prod. iii. $164=$ Oxymeris secundiflora.

sericea, D. Don, in Mem. Wern. Soc. iv. (1823) $309=$ Sagraea rubra.

serrulata, Schlecht. in Linnaea, xiii. (1839) 425.Mexic.

silvestris, C. Muell. in Walp. Ann. iv. 760=Oxymeris sylvestris.

\section{CLIDEMIA}

simplicicaulis, Naud. in Ann. Sc. Nat. Sér. III. xvii. (1852) $346=$ Oxymeris simplicicaulis.

solearis, Naud. 1. c. $339=$ Octopleura macrophylla.

sparsiflora, Griseb. in Goett. Abh. vii. (1857) 218.-

Reg. Argent.

spicaeformis, DC. Prod. iii. $160=$ Miconia spondylantha.

spicata, DC. 1. c. $159=$ dependens.

spicata, D. Don, in Mem. Wern. Soc. iv. (1823) $308=$ Miconia spondylantha.

spicata, Griseb. Cat. P1. Cub. $96=$ neglecta, Heterotrichum octonum.

spondylantha, Mart. ex Triana, in Trans. Linn. Soc. xxviii. (1871) $111=$ Miconia spondylantha.

staphidioides, Naud. in Ann. Sc. Nat. Sér. III. xvii. (1852) $344=$ Miconia staphidioides

stenopetala, DC. Prod. iii. $163=$ Oxymeris dichotoma strigilliflora, Naud. in Ann. Sc. Nat. Sér. III. xvii. 1852) $372=$ Oxymeris strigillifiora.

strigillosa, DC. Prod. iii. 159.-Am. trop.

subseriata, Nand. in Ann. Sc. Nat. Sér. III. xvii. (1852) $354=$ Oxymeris subseriata.

subspicata, Beurl. in Vet. Akad. Hand1. Stockh. 1854 1856) $126=$ dependens.

suffruticosa, O. Berg, ex Triana, in Trans. Linn. Soc. xxviii. (1871) 135.-Bras.

sulcicaulis, Poepp. ex Naud. in Ann. Sc. Nat. Sér. III. xvii. (1852) $342=$ Oxymeris dichotoma.

sulphurea, Naud. 1. c. $371=$ Oxymeris velutina.

surinamensis, Miq. Comm. Phytog. ii. $82=$ umbonata.

Swartzii, Griseb. F1. Brit. W. Ind. 248, pro parte= Sagraea pilosa.

sylvestris, Naud. in Ann. Sc. Nat. Sér. III. xvii. (1852)

$356=$ Oxymeris sylvestris

tetraquetra, Cham. in Linnaea, x. (1836) $42=$ Oxymeris tetraquetra.

tiliaefolia, DC. Prod. iii. 158.-Bras.

trichodes, DC. 1. c. 161 = Miconia trichodes

trichotoma, Wright, ex Griseb. Cat. Pl. Cub. $96=$ Sagraea trichotoma.

triflora, Scheele, in Linnaea, xvii. (1843) $338=\mathrm{Ti}^{-}$ bouchina viminea.

trinitensis, Griseb. Fl. Brit. W. Ind. $249=$ Sagraea trinitensis.

tristis, D. Don, in Mem. Wern. Soc. iv. (1823) $307=$ strigillosa.

umbonata, $D C$. Prod. iii. 158.-Bras.

urceolata, DC. 1. c. = neglecta.

urticaefolia, Naud. in Ann. Sc. Nat. Sér. III. xvii. (1852) $354=$ Miconia Berghesiana.

Valenzuelana, A. Rich. Ess. F1. Cub. $552=$ Heterotrichum octonum.

velutina, D. Don, in Loud. Hort. Brit. 174.-Ind. occ. verticillata, DC. Prod, iii. $160=$ Ossaea verticillata.

violacea, DC. 1. c. $162=$ Miconia spondylantha

vittata, Linden E' André, Illustr. Hortic. xxii. (1875) 152. t. 219.-Peruy.

Weddellii, Naud. in Ann. Sc. Nat. Sér. III. xvii. (1852) $346=$ Oxymeris erostrata.

Wrightii, Griseb. in Mem. Am. Acad, N. S. viii. (1861) 185 = Sagraea Wrightii.

xanthocoma, Naud, in Ann. Sc. Nat. Sér. III, xvii (1852) $352=$ Oxymeris xanthocoma

xantholasia, DC. Prod. iii. $163=$ Oxymeris xantholasia.

xantholasia, Gardn. in Hook. Lond. Journ. Bot. ii. (1843) $344=$ Oxymeris carassana.

xanthopogon, Naud. in Ann. Sc. Nat. Sér. III. xvii. (1852) $349=$ Oxymeris xanthopogon.

CLIDEMIASTRUM, Naud. in Ann. Sc. Nat. Sér. III. xvii. (1852) $87=$ Oxymeris, DC. (Melast.)。 biseptum, Naud. 1. c. $88=$ Leandra reversa. mexicanum, Naud. 1. c. $87=0$. heterobasis.

CIIFFORTIA, Linn. Gen. ed. I. 311 (1737). ROSA $C E A E$, Benth. \& Hook. f. i. 624 .

Monographidium, Presl, Epim. Bot. 202 (1850).

Moril.andia, Neck. Elem. ii. 99 (1790).

acerosa, Banks, ex Gaertn. Fruct. i. $165=$ Nenax acerosa.

arachnoidea, Lodd. Bot. Cab. t. $260=$ ruscifolia

baccans, Harv. in Harv. E Sond. Fl. Cap. ii. 303.Afr. austr.

berberidifolia, Lam. Encyc. ii. $48=$ ferruginea

cinerea, Thunb. Prod. Pl. Cap. 93 (=Ambraria hirta). -Afr. austr. 


\section{CLIFFORTIA :}

complanata, E. Mey. ex Harv. \& Sond. Fl, Cap. ii. $301=$ serpyllifolia.

concavifolia, Eckl. E Zeyh. Enum. 268.-Afr. austr.

cordifolia, Lam. Encyc. ii. $47=$ ilicifolia.

cordifolia, E. Mey. ex Harv. E Sond. Fl. Cap. ii. 295. ordifolia, $E$.

crenata, Linn. f. Suppl. 430.-Afr. austr.

cuneata, [Dryand. in] Ait. Hort. Kew. ed. I. iii, 413. Afr. austr.

dentata, Eck1. \& Zeyh. Enum. $268=$ triloba.

dentata, E. Mey. ex Harv. \& Sond. Fl. Cap. ii. $299=$ gracilis.

dentata, Willd. Sp. Pl. iv. 842.-Afr. austr.

Dregeana, Presl, Bot. Bemerk. 141.-Afr, austr.

drepanoides, Eckl. E Zeyh. Enum. 269.-Afr. austr.

ericaefolia, Linn.f. Suppl. 430.-Afr. austr.

eriocephalina, Cham. in Linnaea, vi. (1831) 349.Afr. austr.

falcata, Linn. f. Suppl. 431.-Afr. anstr.

falcata, Spreng. ex Eckl. \& Zeyh. Enum. $269=$ drepanoides.

ferruginea, Linn.f. Suppl.429.-Afr. austr.

flicaulis, E. Mey. ex Harv. \& Sond. Fl. Cap. ii. $299=$ tricuspidata.

filicaulis, Schlecht. in Linnaea, ii. (1827) 33.-Afr. austr.

filifolia, Linn.f. Suppl. 430.-Afr. austr.

flabellifolia, Sond. ex Harv. \& Sond. F1. Cap. ii. $597=$ Myrothamus flabellifolia.

flexuosa, E. Mey, ex Harv. \& Sond. 1. c. ii. $296=$ ferruginea.

gracilis, Harv. l. c. 299.-Afr. austr,

graminea, Linn. f. Suppl. 429.-Afr. austr.

grandifolia, Eckl. E Zeyh. Enum. 265.-Afr. austr.

hirsuta, Eckl. \& Zeyh. 1. c. = odorata.

hirta, Burm. f. Fl. Cap. Prod. 31 (err. typ. 27).-Afr. austr.

ilicifolia, Linn. Sp. Pl. 1038.-Afr. ausir.

intermedia, Eckl. E Zeyh. Enum. 266.-Afr. austr.

juniperina, Linn. f. Suppl. 430,-Afr. austr.

laricina, E. Mey. ex Meissn. in Hook. Lond. Journ Bot. ii. (1843) $528=$ juniperina.

leptophylla, Eckl. \& Zeyh. Enum. $271=$ tilifolia.

linearifolia, Eckl. E Zeyh. l. c. 270.-Afr. austr.

marginata, Eckl. E Zeyh.l. c. 269.-Afr. austr.

Meyeriana, Presl, Epim. Bot. 202.-Afr. austr.

obcordata, Linn.f. Suppl. 429.-Afr, austr.

obliqua, Spreng. Neue Entdeck. ii. $174=$ obcordata.

obovata, E. Mey. ex Harv. E Sond. Fl. Cap. ii. 297.-

Afr, austr.

octandra, Cham. in Linnasa, vi. (1831) 350.-Afr. austr.

odorata, Linn.f. Suppl. 431.-Afr. austr.

phylicoides, Eckl. \& Zeyh. Enum. $269=$ eriocephalina.

polycephala, E. Mey. ex Harv. EN Sond. Fl. Cap. ii, 302-Afr, austr.

polygonifolia, Linn. Sp. Pl. 1038.-Afr. austr.

polyphylla, Eck1. \& Zeyh. Enum. $268=$ serpyllifolin.

propinqua, Eckl. \& Zeyh. 1. c. = serpyllifolia.

pulchella, Linn. f. Suppl. 430.-Afr. austr.

pungens, Presl, Epim. Bot. 202.-Afr. austr.

reticulata, Eckl. \& Zeyh. Enum. $266=$ odorata.

rubricaulis, Presl, Bot. Bemerk. $141=$ ilicifolia

ruscifolia, Linn. Sp. Pl. 1038.-Afr, austr.

sarmentosa, Linn. Mant. ii. 299.-Afr. austr.

sericen, Eckl. E Zeyh. Enum. 269.-Afr. austr.

serpyllifolia, Cham. E Schlecht. in Linnaea, ii. (1827)

34.-Afr, austr.

serpyllifolia, E, Mey. ex Harv. \& Sond. Fl. Cap. ii. $299=$ octandra.

serrata, Reichb. ex Spreng. Syst. iv. Cur. Post. 209.Afr. austr.

serrata, Thunb, Prod. PI, Cap, $98=$ ferruginea,

spicata, Reichb, ex Spreng. Syst. iv. Cur. Post. 209.Afr. austr.

strobilifera, Murr. Syst. ed. XIII. 749.-Afr. austr.

teretifolia, Linn. f. Suppl. 430.-Afr. austr.

ternata, Linn, f. 1. co= polygonifolia.

tricuspidata, Harv. in Harv. E Sond. Fl. Cap. ii. 299.

- Afr. austr.

tridentata, Willd. Sp. PI. iv. $898=$ ruscifolia

trifoliata, Linn. Sp. Pl. $1038=$ polygonifolia.

\section{CLIFFORTIA :-}

triloba, Harv. in Harv. E Sond. Fl. Cap. ii. 298.Afr. austr.

CLIFFORTIOIDES, Dryand. ex Hook. Ic. Pl. t. 639 (1844) = Fagus, Toum. (Cupulif.).

oblongata, Dryand. 1. c. $639,673=\mathrm{F}$. Solandri.

CLIFTONIA, Banks, ex Gaertn. f. Fruct. iii. 246.t. 225 (1805). CYRYLLEAE, Benth. \& Hook. fo ii. 1226.

Mylocaryum, Willd. Enum. Hort. Berol. 454 (1809).

Walteriana, Fras. ex Endl, Gen, 1413 (1841).

ligustrina, Sims, ex Spreng. Syst, ii. $316=$ nitida.

nitida, Gaertn. f. l. c. 247 . - Am. bor.

CLIMACANDRA, Miq. Pl. Jungh. 199 (1851-55)= Ardisia, Sw. (Myrsin)

littoralis, Kurz, in Joum. As. Soc. Beng. xl. (1871) II. $68=\mathrm{A}$. humilis.

multiflora, Miq. Pl. Jungh. $200=$ A. humilis.

obovata, Miq. 1. c. $199=$ A. humilis.

pergamacea, Miq. Fl. Ind. Bat. Suppl. 578=Embelia pergamacea.

salicifolia, Miq. P1. Jungh. $200=$ A. humilis.

CLIMEDIA, Rafarin, in Rev. Hortic. (1877) 38, sphalm. Clidemia, D. Don (Melast.)

CLINACANTHUS, Nees, in DC. Prod, xi. 511 (1847). ACANTHACEAE, Benth. \& Hook. f. il $(1847)$.
1105.

angustus, Nees, 1. c.=Isoglossa angusta.

Burmanni, Nees, l. c.-Java.

CLINANTHUS, Heib. App. $40(1821)=$ Stenomesson, Herb. (Amaryll.).

luteus, Herb. 1. c, $40=\mathrm{S}$. luteum.

CLINHYMENIA, A. Rich. \& Gal. in Comptes-Rendus, Acad. Sc. Par. xviii. (1844) 512=Cryptarrhena R. Br. (Orchid.).

pallidiflora, A. Rich. \& Gal. 1. c $_{*}=$ Crypt. pallidiflora.

CIINOGYNE, Salisb. in Trans. Hort. Soc. i. (1812) 276. SCITAMINEAE, Benth. \& Hook. fo iii 651.

Donax, Lour. F1. Cochinch. 11 (1790)

dichotoma, Salisb. l. c.-Ind. or.; Malaya.

filipes, Benth. E Hook.f. Gen. iii. 651. -Afr. trop

grandis, Benth. E' Hook. f. l. c. - Burma; Malaya.

virgata, Benth. E Hook.f.l. c.-Ind, or.

CLINOPODIUM, Linn. Syst. ed. I $(1735)=$ Cala mintha, Tourn. (Labiat.)

aegyptiacum, Mill. Gard. Dict. ed. VIII. n. $6=$ Cala. mintha Clinopodium.

albidum, Vell. Fl. Flum. 242; vi. t. $6=$ Hyptis paludosa.

angustifolium, Roxb. Hort. Beng. 44, nomen (quid ?) -Hab?

arundanum, Nym. Syll. $101=$ Calamintha Clino podium.

arvense, Vell. Fl. Flum. 243 ; vi. t. 9.-Bras.

asiaticum, Lour. F1. Cochinch. ii. 374 (=Melissa asiatica) (=Anisochili sp.).-Cochinch.

atropurpureum, Hort. Hafn. ex Steud. Nom, ed. II. i. $386=$ Calamintha Clinopodium.

brasilicum, Vell. F1. Flum. 241; vi. t. 9.-Bras

capitatum, Sw. Prod. Veg. Ind. Occ. $88=$ Hyptis capitata.

carolinianum, Mill. Gard. Dict. ed. VIII. n. 5=Cala. mintha caroliniana.

Chamaedrys, Vahl, Symb. Bot. iii. $77=$ Marsypianthes hyptoides.

cordatum, Vell. Fl. Flum. 248 ; vi. t. 8,-Brns.

fruticostm, Forsk. Fl. Aegypt. Arab. $107=$ Otostegia scariosa.

glabrescens, Pomel, Nouv. Mat. Fl. Atl. 122.Algeria.

grandiforum, Gueldenst, ex Bieb, Fl, Tnur. Cnuc, iii. $3 ! 9=$ Stachys grandiflora,

humile, Mill. Gard. Dict. ed, VIII. n. 4. Am. bor.
CLINOPODIUM :-

imbricatum, Vell. F1. Flum. 242 ; vi.t. $5=$ Hyptis pectinata.

incanum, Linn. Sp. P1. 588= Pycnanthemum incanum

longicaule, Benth. in Wall. PI. As. Rar. i. $66=$ Calamintha longicaulis

martinicense, Jacq. Enum. P1. Carib. 25 = Leucas martinicensis.

origanifacie, Gilib. F1. Lituan, i. $76=$ Calamintha Clinopodium.

origanifolium, Labill. Ic. Pl. Syr, dec. iv. 14. t. $9=$ Calamintha origanifolia.

plumosum, Sieber, in Flora, $v \cdot(1822) 242=$ Cala mintha Clinopodium.

repens, Roxb. Hort. Beng. 44; Fl. Ind. iii. $18=$ Calamintha umbrosa.

repens, Vell. Fl. Flum. 242; vi. t. $7=$ Peltodon radicans.

rugosum, Linn. Sp. P1. $588=$ Hyptis radiata.

variegatum, Hort. ex Steud. Nom. ed. II. i. $386=$ Calamintha Clinopodiam.

verticillatum, Vell. Fl. Flum. 242; vi. t. 4.Bras.

villosum, Noé, in Bull. Soc. Bot. Fr. ii. (1855) 580

Calamintha Clinopodium.

vulgare, Linn. Sp. P1. $587=$ Calamintha Clinopodium.

CLINOSTIGMA, $\mathrm{H}$. Wendl. in Bonplandia,

(1862) 196. PALMAE, Benth. \& Hook. f. iii. 894.

Billardierii, Becc. Malesia, i. (1877) 41 =Microkentia Billardierii.

bractealis, Becc. 1. c. $40=$ Cyphokentia bractealis. Deplanchei, Becc. 1. c. $41=$ Microkentia Deplanchei. eriostachys, Becc. 1. $\mathrm{c}_{\mathrm{o}}=$ Microkentia $€$ riostachys.

Humboldtiana, Becc. 1. c. $40=$ Cyphokentia Humboldtiana.

macrostachya, Becc. 1. co = Cyphokentia macrostachya.

Moorianum, F. Muell. Fragm. viii. 235.-Austral,

Pancheri, Becc. Malesia, i. (1877) $40=$ Microkentia Pancheri.

robusta, Becc. 1. $c_{.}=$Cyphokentia robasta

samoënse, H. Wendl. in Bonplandia, x. (1862) 196.Ins. Samoa.

surculosa, Becc. Malesia, i. (1877) 41 = Microkentia surculosa.

vaginata, Becc. $1 . \mathrm{c}_{\mathrm{s}}=$ Cyphokentia vaginata.

CLINOSTXLIS, Hochst. in Flora, xxvii. (1841) $26^{\circ}=$ Gloriosa, Linn. (Liliac.)

speciosa, Hochst. 1. $\mathrm{c}_{0}=\mathrm{G}$. abyssinica.

CLINTONIA, Dougl. ex Lind1. Bot. Reg. t. 1241 '18: = Downingia, Torr. (Campantac).

Bergiana, Cham. in Linaaea, vii. (1832) $217=$ Lobelia Bergiana.

corymbosa, DC. Prod, vii, $347=\mathrm{D}$. elegans.

elegans, Dougl. ex Lindl. Bot. Reg. t. 1211 I'. clegans.

pulchella, Lindl. 1, c, t, $1909=$ D. pulchella

pusilla, G. Don, Gen. Syst. iii. 718.-Chili.

CLINTONIA, Rafin。 in Am. Monthly Mag. (181s 266 ; Joum. Phys. lxxxix. (1819) 102. LILIACEA Benth. \& Hook. f. iii. \$32.

Hylocharis, Tiling, ex Regel \& Tiling, in Nour. Múm. Soc. Nat. Mosc. xi. (185! 123 .

Xeniatrum, Salisb. Gen. Pl. Fragm. 58 (1860). Aitoni, Rafin. Atl. Journ. $120=$ borealis. alpinn, Kunth, Enum. Pl. ₹. 159.-Reg. II Iimal. Andrewsinna, Tory. in Pacif. Raib. Rep. iv. 150.

Calif.

Andrecusii. llood, in Proc. Acad. Mhilad. (Sis) 1it $=$ Andrewsiana.

angustifolia, Rafin. Ver Fl. Am. ii. 79.-Am. bor. biflor, Kafin. 1. c. 78.-Am. bor.

biumerlla, Rrfin. L, c. $\mathrm{SL}=$ borealis.

boreslis, Rafin. Afl Gourn, 120 - Am, bor.

cilinta, Ratin. is Am. Montbly Mag. 1512) 85:

ciliata, Rafn.
borealis.

decantha, Rafin. All. Fusurn. 120._Am. bor.

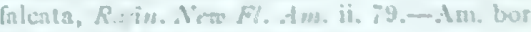

fulva, Rasin. I. e. S: Am. hor.

lomeraia, Ro ... s. l. c. \$\$.-Am. ber.

Iatifolia, Rot: n. l. $6 ., 1 .-$ Am. Lor.

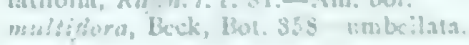




\section{CLINTONIA :-}

multiflora, Ráfin. Atl. Fourn. 120.-Am. bor mutans, Rafin. Ann. Nat. $16=$ borealis. nutans, Rafin. Med. Fl. ii. $85=$ praec.

odorata, Rafin. Ann. Nat. $16=$ umbellata.

ophioglossoides, Rafin. New Fl. Am. ii. 80,-Am. bor.

parviflora, Rafin. Ann. Nat. 16.-Am. bor.

podanisia, Rafin. l. c.-Am. bor.

triflora, Rafin. New Fl. Am. ii. 79.-Am. bor.

udensis, Trautv. E Mey. in Middend. Reise (Fl.

Ochot. 92).--Sibiria; Japon.

umbellata, Torr. Fl. N. York, ii, 301.-Am. bor.

undulata, Rafin. New Fl. Am. ii. 81 = borealis.

uniflora, Kunth, Enum. Pl. v. 159.-Am. bor. occ.

CLIOCARPUS, Miers, in Ann. Nat. Hist. Ser. II. iv (1849) 141 = Solanum, Tourn.

didymus, Miers, 1. c. xv. (1855) $204=\mathrm{S}$. didymum

eviocalyx, Miers, 1. c. = S. trichocalyx.

Gardneri, Miers, 1. c. iv. (1849) 141.-Bras.

megalochiton, Miers, 1. c. xv. (1855) $203=\mathrm{S}$. megalochiton.

CLIOCOCCA, Bab. in Proc. Linn. Soc. i. (1841) 90; et Trans, Linn. Soc, xix. (1842) 33. t. $3=$ Linum, Tourn.

tenuifolia, Bab. in Trans. Linn. Soc. xix. (1845) 33, 34 $=\mathbf{L}$. selaginoides

CLIPTERIA, Rafin. New F1. Am. ii. 44 (1836) = Eclipta?, Linn. (Compos.).

dichotoma, Rafin. 1. c.-Am. bor.

CLISTANTHUS, Muell. Arg. in DC. Prod. xv. II. 1025 $(1866)=$ CLISTRANTHUS, Poit. = Pera, Mutis (Euphorb.).

CLISTAX, Mart. Nov. Gen. et Sp. iii. 26 (1829). $A C A N T H A C E A E$, Benth. \& Hook. f. ii. 1120.

Corythacanthus, Nees, in Lindl. Introd. Nat. Syst. ed. II. 444 (1836)

brasiliensis, Mart. l. c.-Bras.

speciosus, Nees, in Mart. Fl. Bras. ix. 14.-Bras.

CLISTRANTHUS, Poit. ex Baill. Etud. Gén. Euph. $434(1858)=$ Pera, Matis (Enphorb.).

CLITANDRA, Benth. in Hook. Niger F1. 445 (1849) APOCYNACEAE, Benth. \& Hook. f. ii. 692. cirrhosa, Radlk. in Bremen Abh. viii. (1883) 400.Afr. trop.

cymulosa, Benth. in Hook. Niger Fl. 445.-Afr. trop.

CLITANTHES, Herb. in Bot. Reg. (1839) Misc. $87=$ Chlidanthus, Herb. \& Stenomesson, Herb. (Amaryll.).

humilis, Herb. 1. $c_{.}=$Stenomesson humile

lutea, Herb. 1. c. = Chlidanthus fragrans.

Macleanica, Herb. 1. c.-Peruv.

CLITANTHUM, Benth. \& Hook. f. Gen. iii. 733 (188083) = Chlidanthus, Herb. (Amaryll.).

CLITOCYAMOS, St. Lag. in Ann. Soc. Bot. Lyon, vii. (1880) $128,133=$ Ipomoea, Linn. (Convolvulac.) pinnatifidus, St. Lag. 11. cc. =I. Quamoclit.

CLITORIA, Linn. Gen. Pl. ed. I. 216 LEGUMINOSAE, Benth. \& Hook. f. i. 527

MARTIA, Leandr. Sacr, in Denkschr. Akad. Muench. vii. (1821) 233, t. 12 .

Martiusia, Schult. Mant. i. 69 (1822).

Nauchea, Descourt. in Mém. Soc. Linn. Par. iv. (1825) 7.t. 1.

Neurocarpum, Desv. Journ. Bot. i. (1813) 119 ; iii. (18.14) 75 .

Ríombifolxum, Rich, ex DC. Prod. ii. 235 (1825).

Ternatea, Tourn. ex Linn. Syst. ed. I. (1735); H B. \& K. Nov. Gen. et Sp. vi. $415(1823)$

Vexillaria, Rafin, in Am. Monthly Mag. (1818) 268.

acuminata, Benth. in Ann. Wien. Mus. i. (1838) 115 =amazonum.

\section{CLITORIA :-}

acuminata, R. Grah. in Wall. Cat, n. $5346=$ Mariana.

alabamensis, Bertol, Misc. Bot. ix. $12=$ virginiana.

alba, G. Don, Gen. Syst. ii. 215.--Ins, S. Thomas.

amazonum, Mart. in Ann. Wien. Mus. ii. (1838) 115.

-Bras.

amoena, Miq. in Nat. Verh. Wet. Haarl. vii. (1851) 24 $=$ arborescens.

amoena, Roth, in Roem. Arch. i. IIr. 42 = Centrosema virginianum.

angustifolia, H. B. \& K. Nov, Gen. et Sp. vi. $417=$ Centrosema angustifolium.

angustifolia, Nees \& Mart. in Nov. Act. Nat. Cur. xii. (1824) 29= Galactis Martii

aquilupiensis, Raeusch. Nom. ed. III. $210=$ quadalupensis.

arborea, Benth. in Ann. Wien. Mus. ii. (1838) $115=$ Hoffmanseggii

arborescens, [R. Br. in] Ait. Hort. Kew. ed. II. iv. 302.-Ins. Trinitat.

australis, Benth. Fl. Austral. ii. 242.-Austral

Berteriana, DC. Mém. Lég. vi. $239=$ Periandra Berteriana.

biflora, Dalz. in Hook. Kew Fourn. ii. (1850) 35.Ind. or.

brachystegia, Benth. Bot. Voy. Sulph. 84.-Ecuador. bracteata, Poir. Encyc. Suppl. ii. $301=$ C. Ternatea brasiliana, Linn. Sp. P1. $753=$ Centrosema brasilianum. brasiliana, Vell. F1. Flum. 312 ; vii. t. $129=$ Canavalia ensiformis.

Broussonetii, Balb. Cat. Taur. (1813) $26=$ Cologania Broussonetii.

cajanifolia, Benth. in Mart. Fl. Bras. xv. 1. 121.-Reg. trop.

calcarata, L'Hérit. ex DC. Prod. ii. $235=$ Centrosema Plumieri.

calcarigera, Salisb. Parad. Lond. t. 51=Centrosema virginianum.

capitata, Rich. in Act. Soc. Hist. Nat. Par. i. (1792) 111.-Ind. occ

coccinea, Schrad, in Goett. Gel. Anz. i. (1821) $717=$ Periandra coccinea.

densiflora, Benth. in fourn. Linn. Soc. ii. (1858) 41 -Am. trop.

erecta, Roxb. Hort. Beng. 56.-Am. trop.

falcata, Lam. Encyc. ii. 51 = glycinoides.

falcata, Nees, in Flora, iv. (1821) $329=$ Periandra coccinea.

flagellaris, Benth. in Fourn. Linn. Soc. ii. (1858) 39. -Am. trop.

fuminensis, Vell. Fl. Flum. 312; vii. t. $128=$ Centrosema Plumieri.

formosa, H. B. \& K. Nov. Gen. et Sp. vi. $417=$ Centrosema brasilianum.

fulgens, Paxt. Mag. Bot. xi. (1844) 121 (=Collaea scarlatina).-Bras.

Galactia, Linn. Sp. Pl. ed. II. 1026=Galactia pendula. gemina, Vell. Fl. Flum. 313 ; vii. t. $130=$ Centrosema virginianum.

glabella, Desf. Tabl ed. I. $192=$ Galactia glabella

gladiata, Schrank, in Syll. Ratisb. i. (1824) $229=$

Centrosema virginianum.

glomerata, Griseb. Cat. Pl. Cub. 74.-Cuba.

glycinoides, DC. Prod. ii. 234.-Bras.

Grahami, Steud. Nom. ed. II. i. 386=Mariana.

grandiflora, Mart. E Gal, in Bull. Acad. Brux. (1843) II. 189-Mexic

guadelupensis, vide quadelupensis.

guianensis, Benth. in Fourn. Linn. Soc. ii. (1858) 40.

Am. trop.

heterophylla, Lam. Encyc. ii. 51.-Ind. or.

Hoffmanseggii, Benth. in Fourn. Linn. Soc. ii. (1858) 43.-Am. trop.

insulana, Vell. F1. Flum. 313 ; vii. t. 131 =Centrosema brasilianum.

javanica, Miq. F1. Ind. Bat. i. I. $226=$ macrophylla

javitensis, Benth. in Fourn. Linn. Soc. ii. (1858) 42.Mexic.

lactescens, Linn. Syst. ed. X. 1172= Galactia pendula. lasciva, Boj. Hort. Maurit.92, nomen; Benth. in Ann Wien. Mus. ii. (1838) 114.-Madag.

laurifolia, Desv. in Ann. Sc. Nat. Sér. I. ix. (1826) 411 = Centrosema vexillatum.

laurifolia, Poir. Encyc. Suppl. ii. $301=$ cajanifolia.

leptostachya, Benth. in fourn. Linn. Soc. ii. (1858) 43.-Am. trop.

macrophylla, Wall. Cat. n. 5345.--Burma.

\section{CLITORIA :}

Mariana, Linn. Sp. Pl. 753.-Ind. or.; Burma; Am bor.

Mariana, Moç. \& Sesse, ex LC. Prod. ii. 238=Galacti radicata.

mexicana, Link, Enum. Hort. Berol. ii. 235= Mariana micrantha, Guill. E' Perr. Fl. Seneg. Tent. i. 190.Afr, trop.

micrantha, Scop. Delic. Insub. ii. 1 = Galactia longifolia micrantha, Sm. ex Steud. Nom. ed. II. i. $386=$ Centrosema virginianum.

mucronulata, Benth. in Ann. Nat. Hist. iii. (1839) 435 -Bras.

multiflora, Mart. E Gal. in Bull. Acad. Brux. x II. (1843) 188.-Mexic.

multiflora, Sw. Prod. Veg. Ind. Occ. $106=$ Vilmorinia multiflora.

nana, Benth. in Fourn. Linn. Soc. ii. (1858) 40.-Am. trop.

oblonga, Hassk. in Flora, xxv. (1842) II. Beibl. $48=$ Centrosema virginianum

occidentalis, Sweet, Hort. Brit. ed. II. 140.--Ind. occ

parviflora, Rafin. Atl. Fourn. 147.-Am. bor.

pedunculata, Boj. ex Benth. in Ann. Wien. Mus, ii 1838) 114.--Madag.

pedunculata, Micheli, in Kjoeb. Vidensk. Meddel. (1875) 77.-Bras.

Phyrne, Steud. Nom. ed. I. 208, 349=Galactia sericea pilosula, Wall. Cat. n. $5347=$ C. Ternatea.

Plumieri, Turp. in Pers. Syn. ii. $303=$ Centrosem Plumieri.

Poitaei, Benth. in Ann. Nat. Hist. iii. (1839) $434=$ arborescens.

Poiteaui, DC. Prod. ii. $234=$ arborescens.

polyphylla, Poir. Encyc. Suppl. ii. $300=$ Barbieria poly phylla.

polystachya, Benth. Pl. Hartw. 60.-Mexic.

portobellensis, Beurl. in Vet. Akad. Handl. Stockh. 1854 (1856) 119.-Panama.

pudica, Steud. Nom. ed. II. i. 386.-Cuba.

quadalupensis, Scop. Delic. Insub.ii. 4.-Ins. Guadalup. racemosa, G. Don, Gen. Syst. ii. 215 ; Benth. in Ann. Wien. Mus ii. (1838) 115-Bras.

rubiginosa, Juss. ex Pers. Syn. ii. $312=$ glycinoides.

rubiginosa, Nees \& Mart. in Nov. Act. Nat. Cur. xii. (1824) $29=$ Galactia Neesi

rufescens, Benth. in Fourn. Linn. Soc. ii. (1858) 39.Bras.

Schiedeana, Schlecht. in Linnaea, xii. (1838) $284=$ Centrosema pubescens.

Selloi, Benth. in Fourn. Linn. Soc. ii. (1858) 42.Am. trop.

simplicifolia, Benth. l. c. 40.-Am. trop.

sinuata, Desv. in Ann. Sc. Nat. Sér. I. ix. (1826) 120 = Centrosema sinuatum.

speciosa, Cav. Desc. 182.-Mexic.

spectabilis, Salisb. Prod. $336=\mathrm{C}$. Ternatea.

stipularis, Benth. in Fourn. Linn. Soc. ii. (1858) 41 - Am. trop.

Ternatea, Linn. Sp. Pl. 753.--Reg. trop.

ternatensium, Crantz, Inst. ii. $59=\mathrm{C}$. Ternatea.

tetragona, Poir, ex DC. Prod, ii. $236=$ glycinoides.

tomentosa, Mart. in Nov. Act. Nat. Cur. xii. (1824 $30=$ Galactia tomentosa.

tristis, Tenore, Cat. Hort. Neap. (1845) 82.-Hab. ?

vicioides, Nees \& Mart. in Nov. Act. Nat. Cur, xii. (1824) $28=$ Coursetia vicioides.

virginiana, Linn. Sp. P1. 753=Centrosema virginianum.

viridiflor $a$, Bouton, ex Hook. Ic. Pl. t. $152=$ Dolichos axillaris.

zanzibarensis, Vatke, in Oestr. Bot. Zeitschr. xxviii. (1878) 261.-Afr. trop.

roophthalmum, Linn. Syst. ed. X. $1172=$ Dolichosurens?

CLITORIASTRU.M, Heist. Syst. $9(1748)=$ Clitoria, Linn.? (Legumin.).

CLI.VIA, Lindl. Bot. Reg. t. 1182 (1828). AMARYLLIDEAE, Benth. \& Hook. f. iii. 729.

IMATOPHyLlum, Hook. Bot. Mag. t. 2856 (1828)

Gardeni, Hook. Bot. Mag. t. 4895.-Afr. austr. miniata, Regel, Gartenfl. (1864) 131.-Afr. austr. nobilis, Lindl. Bot. Reg. t. 1182.-Afr。 austr.

CLOANTHE, Nees, in R. Br. Verm. Schr. i. 78 (1825) Chloanthes, R. Br. (Verbenac.) 
CLOËzIA, Brongn. \& Gris, in Bull. Soc. Bot. Fr. x. (1863) 576. MYRTACEAE, Benth. \& Hook. f. i. 709. BAIIARDiA, Montr. in Mém. Acad. Lyon, x. (1860) 204.

MOORIA, Montr. 1. c. (1860) 207

buxifolia, Brongn. E' Gris, l. c. 577.-N. Caled. canescens, Brongn. E Gris, l. c.-N. Caled. Deplanchei, Brongn. E Gris, l. c.-N. Caled. floribunda, Brongn. E Gris, l. c.-N. Caled. ligustrina, Brongn. Eris, l. c. -N. Caled. sessilifolia, Brongn. E Gris, l. c.-N. Caled.

CLOMENA, Beauy, Agrost. 28. t. 7. f. $10(1812)=$ Muehlenbergia, Schreb. (Gramin.).

peruviana, Beauv. 1. $\mathrm{c}$. =M. Clomena.

CLOMENOCOMA, Cass. in Dict. Sc. Nat. ix. 416 (1817) = Dysodia, Cav. (Compos.). aurantia, Cass. 1. c. $=$ D. appendiculata. montana, Benth. P1. Hartw. $86=\mathrm{D}$. grandifora sinnata, DC. Prod. v. $641=\mathrm{D}$. pubescens.

CLOMENOLEPIS, Cass, in Dict. Sc. Nat. iii. Suppl. 64 (1816), nomen (Compos.)

CLOMIUM, Adans. Fam. ii. $116(1763)=$ Carduus, Tourn. (Compos.).

CLOMOPANUS, Steud. Nom. ed. II. i. $386(1840)=$ seq

CLOMPANUS, Aubl. Pl. Gui. ii. $773(1775)=$ Lonchocarpus, Humb. \& Bonpl. (Legumin.). paniculata, Aubl. 1. c.-Guiana.

CLOMPANUS, Rafin. Sylva Tellur. 73 (1838)=Ster culia, Linn.

molucanus, Rafin. 1. c.-Ins. Molucc.

CLONODIA, Griseb. in Mart. F1. Bras, xii. I. 26 (1858). MALPIGHIACEAE, Benth. \& Hook. f. i. 253.

verrucosa, Griseb. l. c.-Bras.

CLONOSTACHYS, Klotzsch, in Wiegm. Archiv, vii. (1841) 185 = Sebastiania, Spreng. (Euphorbiac.).

CLOSASCHIMA, Korth. Verh. Nat. Gesch. Bot. 139 $(1842)=$ Laplacea, H. B. \& K. (Ternstroemiac.). marginata, Korth. 1. c. $141=\mathrm{L}$. marginata. ovalis, Korth. I, c. $140=$ L. ovalis.

CLOSIA, Remy, in C. Gay, F1. Chil. iv. 119. t. 46. f. 2 (1849). COMPOSITAE, Benth. \& Hook. fo ii. 404. anthemoides, Phil. Fl. Atac. 31.-Chili.

catula, Remy, in C. Gay, Fl. Chil. iv. 120.-Chili.

chilensis, Regel Eo Koern. Ind. Sem. Hort. Petrop. (1857) 39.-Chili

discoidea, Phil. Fl. Atac. 31.-Chili

elata, Phil. l. c.-Chili.

pusilla, Phil. l. $c_{2}$-Chili.

CLOSIROSPERMUM，Neck. Elem. i. $54(1790)=$ Crepis, Linn. (Compos.).

CLOSTERANDRA, Boiv. ex Belang. Voy. Indes Or. t. absque num. $(1839)$ = Papaver, Tourn.

minor, Boiv, 1. c. $=$ P. Belangeri.

CLOSTERANTHERA, Walp. Rep. i. $115(1842)=$ praec.

CLOWESIA, Lindl, Bot. Reg. xxix. (1843) Misc. 25. t. $39=$ Catasetum, Rich. (Orchid.)

rosea, Lind1. 1. c. = Catasetum roseum, Reichb. f.

CLUACENA, Rafin. Sylva Tellur. 104 (1838)= Myrtus, Tourn.

myrsinoides, Rafin. 1. $\mathrm{c}_{2}=\mathrm{M}$, myrsinoides.

vaccinioides, Rafin. 1. c. = M. vaccinioides, $H . B . \& K$.

CLUERIA, Rafin. FI. Tellur. iii. 87 (1836)= Eremostachys, Bunge (Labiat.).

laciniata, Rafin. 1. c. $=$ E. laciniata.

CLUGNIA, Comm。ex DC. Syst. i. 493 (1818)= Wormia, Rottb. (Dilleniac.)

volubilis, Comm. ex Stead. Nom. ed. I. $208=W$ unadagascaricnsis.

volupis, Comm. ex DC. Syst. i. $493=W$, madngascariensis.
CLUSIA, Linn. Gen. ed. I. 344 (1737). GUTTIFERAE, Benth. \& Hook. f. 1. 170 .

Androstyluum, Miq. in Nat. Verh. Wet. Haarl. vii. (1851) 93.

ARrudeA, St. Hil, Fl. Bras, Mer。 i. 318. t. 66 (1827)

AsthothecA, Miers, ex Planch. \& Triana, in Ann. Sc. Nat. Sér. IV. xiv. (1860) 254

Birolia, Rafin. Sylva Tellur. 163 (1838)

CAHotia, Karst. in Linnaea, xxviii. (1856) 448.

Cochlanthera, Choisy, Gutt. Ind. 46. t. 3 (1823).

Elwertia, Rafin. Sylva Tellur. 163 (1838).

Firkea, Rafin. 1. c. (1838)

Havetia, H. B. \& K. Nov. Gen. et Sp. v. 203 (1821).

ICostegra, Rafin. Sylva Tellur. 163 (1838)

Lipophylud, Miers, in Trans, Linn. Soc, xxi. (1855) $251, \mathrm{t}, 26^{\circ}$

Oxystemon, Planch. \& Triana, in Ann. Sc. Nat. Sér. IV. xiii. (1860) 314

Polythecandra, Planch. \& Triana, 1. c. (1860).

Quapoya, Aubl. Pl. Gui. ii. 897 (1775)

Smithia, Scop. Introd, 322 (1777

Triplandron, Benth. Bot. Voy. Sulph. 73. t. 38 (1844)

XANTHE, Schreb. Gen. 710 (1791).

acuminata, Planch. EN Triana, in Ann. Sc. Nat. Sér.

IV. xiii. (1860) 358.-Panama.

acuminata, Spreng. Syst. ii. 599.-Porto Rico.

alata, Planch. Eo Triana, in Ann. Sc. Nat. Sér. IV. xiii. (1860) 361.-N. Granat.

alba, Choisy, in Planch. \& Triana, 1. c. $326=$ palmicida.

alba, Facq. Enum. Pl. Carib. 34.-Ind. occ

alba, Kunth, ex Griseb. F1. Brit. W. Ind. $107=$ rosea.

amazonica, Planch E Triana, in Ann. Sc. Nat.

Sér. IV xiii. (1860) 358,-Bras.

bicolor, Mart. Nov. Gen. et Sp. iii. 164.-Bras.

Brongniartiana, Planch. E Triana, in Ann. Sc. Nat.

Sér. IV. xiii. (1860) 355.-Ind. oce.

Cambessedii, Planch. E Triana, l. c. 360.-Bras.

Candelabrum, Planch. EN Triana, l. c. 348.-Am.trop.

cassinioides, Planch. E Triana, l. c. 369.-Peruv

Couleti, Duchass. ex Planch. \& Triana, 1. c. $333=$ minor.

crassifolia, Planch. E Triana, l. c. 351.-Am. trop.

Cruiva, Cambess. in St. Hil. Fl. Bras. Mer. i. 317 . Bras.

cuneata, Benth. in Hook. Lond. Fourn. Bot. ii. (1843) 368.-Guiana.

decussata, Ruiz \& Pav. ex Planch. E Triana, in Ann. Sc. Nat. Sér. IV. xiii. (1860) 320, 345.Peruv.

Dueu, Benth. Pl. Hartw, 126.-Peruv.

elliptica, H. B. \& K. Nov. Gen et Sp, y, 199Peruv.

eugenioides, Planch. E Linden, ex Planch. E Triana, in Ann. Sc. Nat. Sér. IV. xiii. (1860) 319, 328.-N. Granat.

flava, Facq. Enum. Pl. Carib, 34.-Jamaica.

flava, Willd. ex Steud. Nom. ed. I. 1. $387=$ Hoffmanseggiana

fluminensis, Planch. E Triana, in Ann. Sc. Nat. Sér. IV. xii. (1860) 349.-Bras.

Fockeana, Mig. in Hoev. Es De Vriese, Tijdschr. (1843) 82.-Guiana.

fragrans, Gardn, in Hook, Lond. Fourn. Bot, ii. (18t9) 334.-Bias.

ganabarica, Casar. Nov. Stirp. Bras. Decad. $60=$ Sellowiana.

Gardnerii, Planch. Es Triana, in Ann. Sc. Nat. Sér.

IV xiii. (1860) 319, 328,-Bras.

Gaudichaudii, Cambess, in St. Hil. Fl. Bras. Mer. 318.-Bras.

Gaudichaudii, Choisy, ex Planch. \& Triana, in Ann. Sc. Nat. Sér. IV. xiii. (1860) $359=$ Sellowiana.

grandifora, Splitg, in Hoev. E De Vriese, Tijdschr. ix. (18.2) 101.-Guiana.

guntemalensis, Henrsl. Diag. Pl, Nor 2-Arm, centr.

Gundlachi, Stahl, Estud. F\%. Puerto-Rico, foll. ii. 122 . -Ind. occ.

havetioides, Planch. E Triana, in Ann. Sc. Nat. Seir. IV. xiii. (1860) \$68. - Ind. occ.

Hilariana, Schlecht. in Linnaea, viù. (1\$33) 181.-

Bras.
Hoffmannseggiana, Schlecht. l. c. 185.-Bras.

Hofmannseggiana, Schlector. I. c. 185.-Bras,

Sc. Nat. Ser. IV. xiii. (1860! 859 - Sellowians.

\section{CLUSIA :}

insignis, Mart. Nov. Gen. et Sp. iii. 164.-Bras.

lanceolata, Cambess. in St. Hil. Pl. Bras. Mer. i. 318. -Bras.

latipes, Planch. E Triana, in Ann. Sc. Nat. Sér. IV. xiii. $(1860) 365 .-\mathrm{N}$. Granat.

laurifolia, Planch. E Triana, l. c. 344.-N. Granat.

laxiflora, D. Dietr. Syn. Pl. iv. 866.-Peruv.

leprantha, Mart. Nov. Gen. et Sp. iii. 165.-Bras.

leprata, Mart. l. c.-Bras.

lencantha, Schlecht. in Linnaea, viii. (1833) 186.Bras.

Lhotzkyana, Schlecht. in Linnaea, viii. (1833) 184. Bras.

Lhotzskyana, Choisy, ex Planch. \& Triana, in Ann. Su Nat. Sér. IV. xiri. (1860) 319, pro parte=Hila

lineata, Planch. E Triana, in Ann. Sc. Nat. Sér. IV. xiii. $(1860) 345 .-N$. Granat.

longifolia, Rich. in Act. Soc. Hist. Nat. Par. i. (1792, $113=$ Micranthera clusioides.

oranthacea, Planch. \& Triana, in Ann. Sc. Nat. Sér.

IV. xiii. (1860) 346.-N. Granat.

macrocarpa, Spreng. Syst. ii. 599.-Guiana.

major, Linn. Sp. P1. $509=$ alba.

mammosa, Casar. Nov. Stirp. Bras. Decad. 60.-Bras.

Mangle, Rich. ex Planch. E Triana, in Ann. Sc. Nat. Sér. IV. xiii. (1860) 369.-Ins. Guadelup.

maxima, Rich. ex Planch. \& Triana, 1. c. $325=$ grandiflora.

micrantha, Choisy, ex Planch. \& Triana, 1. c. $259=$ Sellowiana.

microcarpa, Spreng. Syst. ii. 598.-Guiana

microstemon, Planch. E Triana, in Ann. Sc. Nat. Sér.

IV. xiii. (1860) 331.-Bras.

minor, Linn. Sp. Pl.510.-Guatemala.

multiflora, H. B. E K. Nov. Gen. et Sp, v. 200.N.

Granat.

myriandra, Planch. E Triana, in Ann. Sc. Nat. Sér. IV. xiii. (1860) 332.-Guiana.

nemorosa, G. F. W. Mey. Prim. Fl. Esseq. 203.Guiana.

nutans, Planch. E Triana, in Ann. Sc. Nat. Sér. IV. xiii. (1860) 373.-N. Granat.

odorata, Seem. Bot. Voy. Herald, 89.-Am. centr. organensis, Planch. E Triana, in Ann. Sc. Nat. Sér. IV. xiii. (1860) 349.-Bras.

Orizabae, Hems?. Diag, Pl. Noy 3.-Mexic.

ovigera, Planch. E Triana, in Ann. Sc. Nat. Sér. IV. xiii. (1860) 354.-Mexic.

palmicida, Rich. ex Planch. E Triana, l. c. $326 .-$ Guian.

Panapanari, Choisy, in DC. Prod. i. $559=$ macro. carpa.

parviflora, Humb. E Bonpl. ex Willd. Sp. Pl. iv. 970. -Ins. Margarita.

Pavonii, Planch. E Triana, in Ann. Sc. Nab. Sir. IV xiii. (1860) 363. - Peruv.

pedicellata, Forst. f. Prod. 74. n. 390,-N. Caled.

pentarhyncha, Planch. E Triana, ins Ann. Sc. Nat.

Sér. IV. xiii. $(1860) 365 .-N$. Granat.

petiolaris, Planch. E Triana, l.c. 378.-N. Granat

Plumerii, Planch. \& Triana, l. c. 340. -Ins. Doming.

popayenensis, Planch. E Triana, ל. c. $968 .-\mathrm{N}$ Granat.

pratensis, Secm. Bot. Voy, Herald, $s g=$ minor.

pseudochina, Poepp. E Endl. Non. Gen. et Sp. iii. 1? -l'eruy.

pseudo-havetia, Planch. E Triana, in Ann. Sc. Va: Sér. IV. xiii. (1s60) $\$ 0^{\circ} 0^{\circ}-$ Peruv.

pseud!o-mangle, Planch. E Triana, l.c. $\$ 70$ - Pezm:

I'unt, Wontr. in Méns. Acad. Lyon, x. Iscio 1ss.-.. Caled.

¿uapoya, Choisy, in DC. Prod. i. 559 = microcarpa.

malicans, Pav. ex Planch. E Triana, ina Ann. Sc. Ais: Ser. IV. xiii. (1S6i) 37t.-l'erav. rengserioides, Planch. \& Triana, l. c. $950,-13$ ras.

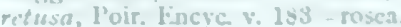

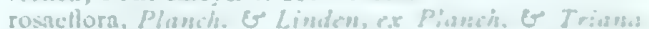
in Ann Sc. Ser. IV. xiii. Iseiu sts. Venczucla.

rosen, Facq. Enum. Pl. Carrib. 9t.-Ins. S. Doming. rusca. Camless. in St. Ilil. Fl. Iirss. Mcr. i. \$16 Hilarians.

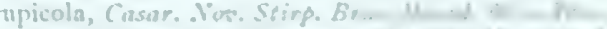

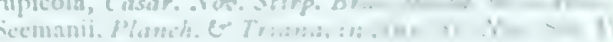

xiii. (1s60) Sti.-I'anama. 


\section{CIUSIA}

Sellowiana, Schlecht. in Linnaea, viii. (1833) 183.Bras.

sessiliflora, Poir. Encyc。 v. 183.-Madag.

sessilis, Forst. f. Prod. 74. n. 391.-Ins. Amicor

Sieboldii, Regel, Cat. Pl. Hort. Aksakov. 38.-Hab.?

sphaerocarpa, Planch. E Triana, in Ann. Sc. Nat.

Sér. IV. xiii. (1860) 362.-Peruv.

Spruceana, Planch. E Triana, l.c. 346-Peruv.

subsessilis, Benth. Bot. Voy. Sulph. 72.-N. Granat.

sulpharea, D. Dietr. Syn. Pl. iv. 866.-Peruv.

tetrandra, Humb. E Bonpl. ex Willd. Sp. Pl. iv. 978. -Ecuador.

thurifera, Planch. E Triana, in Ann. Sc. Nat. Sér. IV. xiii. (1860) 364.-Peruv.

venosa, facq. Enum. Pl. Carib. 34.-Ind occ.

venosa, Linn. Sp. Pl. ed. II. $1495=$ minor.

volubilis, $H . B . \& K$. Nov. Gen. et Sp. v. 200 . N. Granat.

Weddelliana, Planch. E Triana, in Ann. Sc. Nat. Sér. IV. xiv. (1860) 233.-Bras.

CLUSIANTHEMUM, Vieill. in Bull. Soc. Linn. Normand. ix. (1865) $338=$ Garcinia, Linn. (Guttifer.)

coriaceum, Vieill. 1. c. $339=$ pedicellatum.

densiflorum, Vieill. ex Pierre, Fl. For. Cochinch. fasc. v. $25=\mathrm{G}$. densiflora.

pedicellatum, Vieill. in Bull. Soc. Linn. Normand. ix. (1865) $339 .-$ N. Caled.

CLUSIELLA, Planch. \& Triana, in Ann. Sc. Nat. Sér. IV. xiv. (1860) 253. GUTTIFERAE, Benth. \& Hook. f. i. 172.

elegans, Planch. E Triana, l. c.-N. Granat.

CLUSIOPHYLLEA, Baill. Adansonia, xii. (1878) $197=$ Plectronia, Linn. (Rubiac.)

Pervilleana, Baill. 1. c. (=Canthium Pervilleanum). -Madag.

CLUSIOPHYLLUM, Muell. Arg. in Flora, xlvii. (1864) $518=$ Cunuria, Baill. (Euphorb.).

Sprucei, Muell. 1. c. $519=$ Cun. Spruceana.

CIUYTIA, Boerh. ex Linn. Syst. ed. I (1735) (Clntia). EUPHORBIACEAE, Benth. \& Hook. f. iii. 302 .

Altora, Adans. Fam. ii. 356 (1763)

Cratochwilia, Neck. Elem. ii. 339 (1790).

abyssinica, Faub. \& Spach, Illustr. v. 77. t. 468.Abyssin.

acuminata, E. Mey. ex Sond. in Linnaea, xxiii. (1850) $125=$ polifolia .

acuminata, Linn. f. Suppl. 432.-Afr. austr.

acuminata, Thunb. Prod. Pl. Cap. $53=$ Lachnostylis hirta.

affinis, Sond. in Linnaea, xxiii. (1850) 126.-Afr. austr.

africana, Poir. Encyc. Supp1. ii. $302=$ daphnoides. alaternoides, Linn. S.. Pl. 1042.-Afr. austr.

androgyna, Linn. Mant. i. $128=$ Sauropus albicans.

benguelensis, Muell. Arg. in Fourn. Bot. ii. (1864) 337.-Afr. trop.

brevifolia, Sond. in Linnaea, xxiii. (1850) $125=$ polifolia.

Cascarilla, Linn. Sp. P1. $1042=$ Croton Cascarilla.

collina, Roxb. Pl. Corom. ii. $37=$ Cleistanthus collinus.

cordata, Bernh. in Flora, xxviii. (1845) 81.-Afr. anstr.

cotinifolia, Salisb. Prod. $390=$ pulchella.

curvata, C. Mey. ex Sond. in Linnaea, xxiii. (1850) 121 = polygonoides.

daphnoides, Eckl. \& Zeyh. ex Muell. Arg. in DC. Prod. xv. II. $1054=$ polygonoides.

daphnoides, Lam. Encyc. ii. 54.-Afr. austr.

decandra, Crantz, Inst. i. $201=$ Croton Eluteria.

diosmoides, Sond. in Linnaea, xxiii. (1850) 122.-Afr. austr.

diversifolia, Roxb. Hort. Beng. 104 ; Fl. Ind. iii. 731 $=$ Cleistanthus diversifolius.

Dregeana, Scheele, in Linnaea, xxv. (1852) 583.-Afr. austr

Eckloniana, Muell. Arg, in DC. Prod. xv. II. 1054.Afr. austr.

Eluteria, Linn. Sp. P1. $1042=$ Croton Eluteria.

\section{CLUYTIA :}

ericoides, Krebs, in Flora, xxriii. (1845) $82=$ poly gonoides.

ericoides, Thunb. Prod. Pl. Cap. 53.-Afr. austr.

floribunda, Baill. Etud. Gén. Euph. Atlas, 30.t. 16. f $1-5=$ alaternoides.

gracilis, Baill. Adansonia, iii. (1862-63) $151=$ tenui folia.

heterophylla, Sond. in Linnaea, xxiii. (1850) $128=$ Sonderiana.

heterophylla, Thunb. Prod. Pl. Cap. 53.-Afr, austr.

hirsuta, Eckl. \& Zeyh. ex Sond. in Linnaea, xxiii. (1850) $126=$ daphnoides

hirsuta, Muell. Arg. in DC. Prod. xv, II. 1046.-Afr. austr

hirta, Linn. f. Suppl. $432=$ Lachnostylis hirta.

hirta, Vahl, Symb. Bot. ii. 101.-Afr. austr.

humilis, Bernh. in Flora, xxviii. (1845) $81=$ pubescens.

Jaubertiana, Muell. Arg. in DC. Prod. xv. II. 1044.Arabia.

lanceolata, Forsk. Fl. Aegypt. Arab. 170.-Arabia.

lanceolata, Jaub. \& Spach, Illustr. Pl. Or. v. t. $467=$ Jaubertiana.

marginata, E. Mey. ex Sond. in Linnaea, xxiii. (1850) $130=$ tomentosa

Meyeriana, Muell. Arg. in DC. Prod. xv. II. 1055. Afr. austr.

monoica, Lour. F1. Cochinch. ii. $638=$ Cleistanthus monoicus.

montana, Roxb. PI. Corom. iii. 38. t. $171=$ Brie delia montana.

myricoides, Faub. E Spach, Illustr. Pl. Or. v. 73.t 456, 466.-Arabia

natalensis, Bernh. in Flora, xxviii. (1845) 81.-Afr. austr.

oblongifolia, Roxb. Hort. Beng. 70 ; Fl. Ind. iii. 730 $=$ Cleistanthus chartaceus.

oblongifolia, Wall. Cat. n. $7886=$ Trigonostemon semperflorens.

ovalis, Scheele, in Linnaea, xxv. (1852) 583=An. drachne ovalis.

ovalis, Sond. in Linnaea, xxiii. (1850) 129.-Afr austr.

patula, Herb. Roxb. ex Wall. Cat. n. 7877 = Cleistanthus collinus.

patula, Roxb. Pl. Corom. ii. 37. t. $170=$ Cleistanthus patulus.

phyllanthifolia, Baill. Adansonia, iii. (1862-63) $153=$ affinis.

polifolia, Facq. Hort. Schoenb. ii. 67. t. 250,-Afr austr.

polifolia, Sond, in Linnaea, xxiii. (1850) $124=$ pterogona.

polygalaefolia, Salisb. Prod, $390=$ alaternoides.

polygonoides, Burm. f. Fl. Cap. Prod. 31 (err. typ. 27) -Afr. austr.

polygonoides, Linn. Sp. Pl. ed. II. 1475.-Afr. austr. polygonoides, Thunb. Prod. PI. Cap. $53=$ daphnoides.

polygonoides, Willd. Hort. Berol. t. $51=$ alaternoides. pterogona, Muell. Arg. in DC. Prod. xv. II. 1048.Afr, austr.

pubescens, Eckl. \& Zeyh. ex Sond. in Linnaea, xxiii. (1850) 126 = affinis.

pubescens, Thunb. Prod. Pl. Cap. 53.-Afr. austr. pubescens, Willd. Sp. Pl. iv. $881=$ daphnoides. pulchella, Linn. Sp. Pl. 1042.-Afr. austr.

pulchella, Sparm. ex Sond. in Linnaea, xxiii. (1850) $126=$ daphnoides.

retusa, Herb. Wight, ex Wall. Cat. n. $7877=$ Cleistanthus collinus.

retusa, Linn. Sp. P1. $1475=$ Bridelia retusa

retusa, Moon, Cat. Pl. Ceyl, $71=$ Bridelia Moonii.

Richardiana, Muell. Arg, in DC. Prod. xv. I1. 1044.Afr. trop.

rubricaulis, Eck1, ex Sond. in Linnaea, xxiii. (1850) $128=$ alaternoides

scandens, Roxb. Pl. Corom. ii. 39. t. $173=$ Bridelia stipularis.

semperflorens, Roxb. Hort. Beng. 104; Fl. Ind. iii $730=$ Trigonostemon semperflorens.

semperflorens, Wall. Cat. n. $7852 \mathrm{~B}$, ex Baill. Etud. Gén. Euph. $474=$ Symphyllia silhetiana.

sempervirens, Muell. Arg. in DC. Prod. xv. II. 764=

Symphyllia silhetiana, Trigonostemon Hookerianus,

sericea, Muell. Arg. l. c. 1053.-Afr. austr.

similis, Muell. Arg. $l_{0} c$. 1046.-Afr. austr.

Sonderiana, Muell. Arg. l. c. 1051.-Afr. austr.

\section{CLUYTIA}

spinosa, Roxb. Pl. Corom. ii. 38. t. $172=$ Briedelia retusa.

squarrosa, Lam. Encyc. ii. $54=$ Briedelia retusa.

stipularis, Linn. Mant. 127 = Briedelia stipularis.

tabularis, Eckl. \& Zeyh. ex Sond. in Linnaea, xxiii. (1850) $122=$ polygonoides.

tenuifolia, Willd. Sp. Pl. iv. 880 .-Afr. austr.

teretifolia, Sond. in Linnaea, xxiii. (1850) $124=$ polifolia.

Thunbergii, Sond. 1. c. $130=$ daphnoides.

tomentosa, Linn. Mant.299.-Afr. austr.

tomentosa, Thunb. Fl. Cap. ed. Schult. $271=$ daphnoides.

CLUYTIA, Roxb. ex Steud. Nom. ed. II. i. $225(1840)=$ Bridelia, Willd. (Euphorb.).

CLUYTIANDRA, Muell. Arg, in Journ. Bot. ii. (1864) 328. EUPHORBIACEAE, Benth. \& Hook. f. iii. 272 .

trichopoda, Muell. Arg. l. c.-Afr. trop.

CLYBATIS, Phil. in Anal. Univ. Chil. (1872) 742. COMPOSITAE, Benth. \& Hook. f. ii. 1237.

Volckmanni, Phil. l. c. 7.43.-Chili.

CLYMENUM, [Tourn.] Linn. Syst. ed. I $(1735)=$ Lathyrus, Tourn. (Legumin.)

alatum, Link, Handb. ii. $188=\mathrm{L}$. alatus.

articulatum, Medic. Phil. Bot. i. $204=\mathrm{L}$. articulatus.

bicolor, Moench, Meth. $150=\mathrm{L}$. articulatus.

dolichoides, Medic. in Vorles. Churpf. Phys. Ges. ii. (1787) $358=\mathrm{L}$. articulatus.

Ochrus, Link, Handb. ii. 188; Alef. in Bonplandia, ix. (1861) $127=$ L. Ochrus.

tenuifolium, Link, 1. c. 494 ; Alef. 1. c. $128=$ L. tenui. folius.

tingitanum, Medic. in Vorles. Churpf. Phys. Ges. ii. (1787) $358=\mathrm{L}$. tingitanus

uncinatum, Moench, Meth. $150=\mathrm{L}$. Clymenum.

CLYNHYmENIA, A. Rich. \& Gal. in Ann. Sc. Nat. Sér. III. iii. (1845) 24, in syn = CLINHYMENIA, A. Rich. \& Gal.= Cryptarrhena, R. Br. (Orchid.).

CLYPEA, Blume, Bijdr. 26 (1825)= Stephania, Lour. (Menispermac.).

abyssinica, Dillon \& A. Rich. in Ann. Sc. Nat. Sér. II. xiv. (1840) $263=\mathrm{S}$. abysinica.

acuminatissima, Blume, Bijdr. $28=\mathrm{S}$. acuminata

Burmanni, Wight \& Arn. Prod. $14=$ Cyclea Burmanni.

capitata, Blume, Bijdr. $28=\mathrm{S}$. capitata

consummata, Miers, Contrib. iii. 209.-Japon.

corymbosa, Blume, Bijdr. $27=\mathrm{S}$. rotunda.

discolor, Blume, l, c. $26=\mathrm{S}$. discolor.

effusa, Miers, Contrib. iii. 207.-Malabar.

Forsteri, Miers, in Ann. \& Mag. Nat. Hist. Ser. III. xvii. (1866) $270=\mathrm{S}$. Forsteri.

glaucescens, Decne. in Nouv. Ann. Mus. Par. iii. (1834) 423 t. $18=\mathrm{S}$. glaucescens.

hernandifolia, Wight \& Arn. Prod. $14=\mathrm{S}$. hernandifolia.

longa, G. Don, Gen. Syst. i. $113=$ S. hernandifolia. oxyphylla, Miers, Contrib. iii. 206.-Nepal. rotund $a$, Steud. Nom. ed. II. i. $387=\mathrm{S}$. rotunda. subovata, Miers, Contrib. iii. 209.-Japon. tomentosa, Blume, Bijdr. $27=\mathrm{S}$. tomentosa venosa, Blume, $1 . \mathrm{c}_{\mathrm{o}}=\mathrm{S}$, venosa.

CLYPEOLA, Burm. ex DC. Prod. ii. 420 (1825)= Pterocarpus, Linn. (Legamin.).

CLYPEOLA, Linn. Gen. ed. I. 193 (1737). CRUCIFERAE, Benth. \& Hook. f. i. 93.

Bergeretia, Desv. Journ. Bot. iii. (1813) 161.

Fosselinia, Scop. Introd. 318 (1777).

IONTHLASPI, Adans. Fam. ii. 423 (1763)

OrIUM, Desv. Joum. Bot. iii. (1813) 161. t. 35. f. 10.

alliacea, Lam. Tabl. Encyc. iii. 113= Peltaria alliacea altaica, Schangin, ex Ledeb. F1. Ross, i. $135=$ Alyssum spathulatum.

alyssoides, Linn. Sp. Pl. $652=$ Alyssum calycinum

ambigua, Jord. \& Fourr. Brev, Pl. Nov, ii. $15=$ microcarpa. 


\section{CLYPEOLA :-}

auriculata, Crantz, Class. Crucif. $93=$ Biscutella auri culata.

Bruhnsii, Gruner, in Bull. Soc. Nat. Mosc. xl. (1867) II. 396.-Reg. Casp.

calycina, All. ex Steud. Nom. ed. II. i. 387=Alyssum calycinum.

capensis, Burm. ex DC. Prod. ii. $420=$ Wiborgia fusca capensis, Poir. Encyc. Suppl. ii. $304=$ Heliophila diffusa.

caroliniana, Walt. F1. Carol. $173=$ Lepidium virginicum.

chaetocarpa, Jaub: \& Spach, Illustr. iii. 8. t. $206=$ echinata.

ciliata, Boiss. Fl. Orient. i. 309.-Lycia.

edentula, Link, Handb. ii. $296=$ Alyssum gemonense. cyclodontea, Delile, in Bull. Soc. Agr. Hérault, (1830) 258.-Gallia.

dichotoma, Boiss, in Ann. Sc. Nat. Sér. II. xvii 1842) 175.-Persia ; Armen.

didyma, Crantz, Stirp. Austr. ed. I. fasc. i. 20 ; ed. II $22=$ Biscutella laevigata.

echinata, Boiss. Fl. Orient. i. $310=$ lappacea

echinata, DC. Syst, ii. 328,-Syria ; Persia ; Afghan.

elegans, Boiss. \& Huet, Diagn. Ser. II. v. 38.Armenia.

eriocarpa, Cav. Desc. 401.--Hispan.

eriophora, DC. Syst. ii. $327=$ eriocarpa.

Gaudini, Trachsel, in Flora, xiv. (1831) $743=$ microcarpa.

glabra, Boiss, in Ann. Sc. Nat. Sér. II. xvii. (1842) 173 = microcarpa.

gracilis, Planch. in Bull. Soc. Bot. Fr. v. (1858) 494 = microcarpa

halimifolia, Link, Handb. ii. $295=$ Alyssum halimifolium.

hispida, Presl, Bot. Bemerk. 9-Arabia.

hispidula, Jord. \& Fourr. Brev. Pl. Nov. fasc. ii. $15=$ microcarpa.

indica, Poir. Encyc. Suppl. ii. 304=Fortuynia Garcini Jonthlaspi, Linn. Sp. Pl. 652.--Reg. Mediterr. ; Oriens, laevigata, Jord. Brev. Pl. Nov, fasc ii. $16=$ microcarpa. lapidicola, Jord. \& Fourr. 1. c. $14=$ C. Jonthlaspi.

lappacea, Boiss. in Ann. Sc. Nat. Sér. II. xvii. (1842) 174.--Mesopotam.; Persia.

lasiocarpa, Jaub. \& Spach, Illustr. iii. 6. t. $205=$ lappacea.

lasiocarpa, Juss. ex Pers. Syn. ii. $193=$ echinata,

lomatotricha, Jord. \& Fourr. in Ann. Soc. Linn.

Lyon, N. S. xvii. (1869) $194=$ microcarpa.

macrocarpa, Link, Handb. ii. $295=$ Alyssum macrocarpum.

maritima, Georgi, Beschr. Russ. Reich. iii. IV. 1126 = Alyssum canescens.

maritima, Linn. Sp. Pl. $652=$ Alyssum maritimum.

microcarpa, Boiss. Diagn. Ser. I. i. 74.-Graecia; As. occ.

monosperma, Lam. Fl. Fr. ii. $462 ; 484=$ C. Jonthlaspi montana, Crantz, Stirp. Austr. ed. I. fasc. i. 19; ed.

II. $19=$ Alyssum montanum.

perennis, Ard. Animad. Spec. 16. t. $6=$ Peltaria alliacea.

petraea, Jord. \& Fourr. Brev. Pl. Nov. fasc. ii. $14=$ C. Jonthlaspi.

psilocarpa, Jord. \& Fourr. 1. c. = C. Jonthlaspi.

pyrenaica, Bordere, ex Dur, in Act. Soc. Linn. Bord. xxvi. (1866) $87=\mathrm{C}$. Jonthlaspi

pyrenaica, Link, Handb. ii. $295=$ Alyssum pyrenaicum. rupestris, Link, I. c. = Alyssum rupestre.

Schangini, Sievers, in Pall. N. Nord. Beitr. vi. $274=$ Alyssum spathulatum.

semiglabra, Jord. \& Fourr. in Ann. Soc. Linn. Lyon, N. S. xvii. (1869) $194=$ C. Jonthlaspi.

spathulaefolia, Jord. \& Four. Brev. PI. Nov, fasc. ii. $15=$ microcarpa.

spinosa, Link, Handb. ii. $295=$ Alyssum spinosnm.

tomentosa, Linn. Mant. $92=$ Alyssum orientale.

CLYTIA, Stokes, Bot. Mat. Med. iv. 543 (1812)= Cluytia, Boerh. (Euphorb.)

CLYTORIA, J. S. Presl, Rostl, iii, 196 (1835) = Clitoria, Linn. (Legumin.).

Cly TOSTOMA, Miers, ex Bur. in Adansonia, viii. (1868) $\$ 53$ - Pithecoctenium, Mart. (Bignoniac.). calystegioides, Bur.-Cf. Adansonia, viii. (1868) 359.Am. austr.
CNEMIDIA, Lindl. Bot. Reg. sub t. 1618 (1833) Tropidia, Lindl. (Orchid.) angulosa, Lindl. 1. c. $=$ T. angulosa

bambusifolia, Thw. Enum. Pl. Zeyl. 314.-Zeylan. ctenophora, Reichb. f. Otia Bot. Hamb. 51.-Ins. Fiji.

semilibera, Lindl. Bot. Reg. sub t. $1618=$ T. angulosa.

CNEMIDOSTACHVS, Mart. Nov. Gen. et Sp. i. 66. $t$ 40-44 (1824) = Sebastiana, Spreng. (Euphorb.). acalyphoides, Mart. 1. c. $71=\mathrm{S}$. corniculata.

bidentata, Mart. 1. c. $69=\mathrm{S}$. virgata

campestris, Mart. ex Baill. Etud. Gén. Euph. 516= S. corniculata.

Chamaelaea, Spreng. Syst. iii, $835=\mathrm{S}$. Chamaelea

coriacea, Mart. Nov. Gen. et Sp. i. $68=$ S. marginata.

crotonoides, Mart. 1. c. $71=\mathrm{S}$. corniculata.

daphnoides, Mart. I. c. =S. daphnoides.

ditassoides, F. Didr. in Kjoeb. Vidensk. Meddel. (1853) $88=\mathrm{S}$. ditassoides

dubia, Wawra, in Oestr. Bot. Zeitschr. xii. (1862) 241 $=\mathrm{S}$. corniculata.

glabra, Mart. ex Baill. in Adansonia, v。(1864-65) 325 $=\mathrm{S}$. multiramea.

glabrata, Mart. Nov. Gen. et Sp. i. $70=$ S. comiculata glandulosa, Mart. 1. c. $71=\mathrm{S}$. corniculata.

hispida, Mart. $1 . \mathrm{c}_{\mathrm{o}}=\mathrm{S}$. corniculata.

linearifolia, Miq. Fl. Ind. Bat. Suppl. $460=\mathrm{S}$. Chamaelea.

longifolia, Mart. Nov, Gen. et Sp. i. $71=\mathrm{S}$. cornicu lata.

madagascariensis, Boj. Hort. Maurit. 284=Excoecaria

melanosticta.

marginata, Mart. Nov, Gen, et Sp. i. 68. t. $41=\mathrm{S}$. marginata.

myrtilloides, Mart: 1. c. 67. t. $40=\mathrm{S}$. daphnoides,

oleoides, Mart. 1. c. $71=\mathrm{S}$. oleoides.

patula, Mart. in Flora, xxiv. (1841) II. Beibl. $8=\mathrm{S}$. corniculata.

prostrata, Mart. Noy, Gen et Sp. i. $70=$ S. corniculata salicifolia, Mart. I. c. $=\mathrm{S}$. corniculata.

scoparia, Mart. 1. $\mathrm{c}_{。}=\mathrm{S}$. virgata.

Sellowiana, Klotzsch, ex Baill. Etud. Gén. Euph. 516 $=\mathrm{S}$. corniculata

serrulata, Mart. Nov. Gen. et Sp. i. $68=$ S. serrulata. stipulacea, Klotzsch, ex Baill. Etud. Gén. Euph. $516=$ S. stipulacea.

tragioides, Mart. Nov. Gen. et Sp. i. $70=$ S. corniculata Pahlii, Spreng. Syst. iii. $834=\mathrm{S}$. corniculata.

velutina, Klotzsch, ex Baill. Etud. Gén. Euph. $516=$ S. corniculata.

CNENAMUM, Tausch, in Flora, xi. (1828) I. Erg. $80=$ CRENAMUM, Adans.=Crepis, Linn. (Compos.).

CNEORIDIUM, Hook. f. in Benth. \& Hook. f. Gen i. 312 (1862). SIMARUBEAE, Benth. \& Hook. 1. c.

Pitavia, Nutt. ex Torr. \& Gray, Fl. N. Am. 215 (1840)

dumosum, Hook. f. l. c.-Am. bor. occ.

CNEORUM, Linn. Syst. ed. I (1735). SIMARU. $B E A E$, Benth, \& Hook, f. i. 811

pulverulentum, Vent. Fard. Cels, t. 77.-Ins. Canar.

tricoccon, Gueld. ex Bieb. Fl. Taur. Cauc. iii. 160 Evonymus nanus.

tricoccon, Linn. Sp. Pl. 34.-Europ. austr.

CNESMOCARPUS, Zipp. ex Blume, Rumphia, iii. 115 $(\mathbf{1 8} 47)=$ Pometia, Forst. (Sapind.)

excelsus, Zipp.ex Blume, 1. c. (=Irina Diplocardia). N. Guinea.

CNESMONE, Blume, Bijdr. '690 (1825) (Cnesmosa) Fl. Jav. Praef. p. vi (1828), EUPHORBIACEAE, Benth. \& Hook. f, iii. 330

glabrata, Kurs, in Flora, lviii. (1875) 81.-Singapore. javanica, Blume, Bijdr. 680.-Java.

CNESTIDIUM, Planch, in Linnaea, xxiii. (1850) 499 CONNARACEAE, Benth. \& Hook. f. i. 493.

lasiocarpum, Baker, in Mart. F\%. Bras, xiv. 11. 195.Bras.

rufescens, Planch. in Linnaea, xxiii. (1850) $\$ 40,-$ Mexic.; Panama.
CNESTIS, Juss. Gen. 374 (1789). CONNARACEAE, Benth. \& Hook. f. i. 433.

SPONDIOIDES, Smeathm. ex Lam. Encyc. iii. 23 (1789)

acuminata, Wall. Cat. $\mathrm{n} .8533=$ Rourea acuminata

borboniensis, Raeusch. Nom. ed. III. $132=$ glabra.

corniculata, Blanco, Fl. Filip. ed. I. $386=$ Connarus ferrugineus.

corniculata, Lam. Encyc. iii. 23.-Afr. trop.

diffusa, Blanco, F1. Filip. ed. I. $386=$ Rourea rugosa.

emarginata, Fack, in Malay. Misc. ii. (1822) vi. 42.-Malaya.

ferruginea, $D C$. Prod. ii. 87.-Afr. trop.

flaminea, Griff. Notul. iv. 433 = ramifora.

flammea, Kurz, in Journ. As. Soc. Beng. xxxix. (1870)

I1. $76=$ praec.

forida, Fack, in Malay. Misc. ii. (1822) v11. 43.Sumatra.

foliosa, Planch. ex Kurz, in Journ. As. Soc. Beng. xlv. (1876) II. $216=$ ramiflora.

fraterna, Planch. in Linnaea, xxiit. (1850) 440.-Afr. trop.

glabra, Blanco, F1. Filip. cd. I. $387=$ Connarus paniculatus.

glabra, Lam. Encyc. iii. 23.-Ins. Mascar.

glabra, Naves, in Blanco, Fl. Philipp. ed. III. t. 140 Rourea multiflora.

grisea, Baker, in Oliver, Fl. Trop. Afr. i. 461.-Afr. trop.

ignea, Planch. ex Kurz, in Journ. As. Soc. Beng. xly. (1876) II. $216=$ ramifora

lasiocarpa, Mart. ex Baker, in Mart. Fl. Bras, xiv. II. 195 = Cnestidium lasiocarpum.

Iurida, Baill. Adansonia, vii. (1866-67) 244. - Ins. Nossibé.

macrantha, Baill. l. c. 242.-Afr. trop.

madagascariensis, Raeusch. Nom. ed. III. $132=$ polyphylla.

mimosoides, fack, in Malay. Misc. ii. (1822, vir. 44.- Malaya.

monadelpha, Roxb. Hort. Beng. 34 ; Fl. Ind. ii. $454=$ Rourea commutata.

natalensis, Planch. E Sond. ex Harv. E Sond. Fl. Cap. i. 528.-Afr. austr.

obliqua, Beauv. Fl. Orwar. i. 97. t. 59.-Afr. trop

obliqua, Boj. Hort. Maurit. $84=$ Agelaea Lamarcki

oblongifolia, Baker, in Oliver, Fl. Trop. Afr. i. 462.Afr. trop.

pentaphylla, Span. in Linnaea, xr. (1841) 189-Ins. Timor.

pinnata, Beauv. Fl. Owar. i. 98. t. $60=$ Rourea Palisotii.

platantha, Griff. Notul. iv, $481=$ ramiflor

polyphylla, Blanco, Fl. Filip. ed. II. $270=$ Rourea rugosa.

polyphylla, Lam. Encyc. iii. 23.-Marit.; Madag. racemosa, G. Don, Gen. Syst. ii. 91.-Afr. trop. ramiflora, Griff. Notal. iv. 432.-Ind. or. scandens, J. F. Gmel. Syst. $729=$ glabra stenopetala, Griff. Notul. iv. $433=$ Rourea stenopetala trifolia, Lam. Encyc. iii. $24=$ Arelaea villosa

vestita, Wall. ex Hook, I. Fl. Brit. Ind. is. $47=$ Agelaca vestita.

volubilis, Blanco, Fl. Filip. ed. I. $385=$ Rourea beterophylla.

CNICOTHAMNUS, Griseb, in Goett. Abh, xix. 1874) 196. COMPOSITAE, Benth. \& Hook. fo ii. 1237

Lorentzii, Griseb. l. c. 197.-Reg. Argent.

CNICUS, Linn, Syst, ed. I (1735), COMPOSITAE, Benth. \& Hook. f. ii. 168

ACARNA, Hill. Veg. Syst. iv. $19\left(170^{\circ}\right.$.

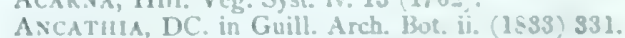

BREEA, Less. Sin. Comp, 9 (1582).

Cephasavorlos, Neck. Elem. i. 69 1;90)

CHAMAFPEUCF. DC' l'rod. vi. 65i, 153i).

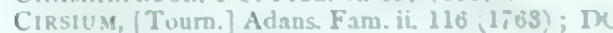

[il. Fr, iv, 110 (18 $(15)$.

Crovery adans fam li. 116 (1-69).

lichesats. Cass in Bull. So: Philom. 1 151533.

Evitrachys, C. Koch, in Lirnaca, xxiv. $\mid 1 \leqslant 5)$ 3 U.

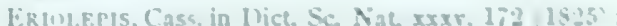
xli. $99118 \pm$ (t)

Frovthrotarya, Swect, Brit. Flow. Gard. Ser. I. R. 181 (15:33). 


\section{CNICUS :-}

IXINE, Hill, Veg. Syst. iv. 17 (1762).

LAMYRA, Cass. in Dict. Sc. Nat. xxv. 218 (1822),

Lophiolepis, Cass. 1. c. xli. 313 (1826)

Noto Basis, Cass. 1. c. xxxv. $170(1825)$.

ONOTROPHE, Cass. 1. c. xxxvi. 145 (1825)

Orthocentron, Cass. 1. c. 480 (1825)

PICNOMON, Adans. Fam. ii. 116 (1763).

Platyraphium, Cass。 in Dict. Sc. Nat. xxxv. 173 (1825).

Polyacantha, Hill, Veg. Syst. iv. 12 (1762).

Ptilostemon, Cass. in Dict. Sc. Nat. xxxv。 173 (1825).

Pycnocomon, St. Lag. in Ann. Soc. Bot. Lyon, vii. (1880) 78,84

Spanioptilon, Less. Syn. Comp. 10 (1832)

Tetralix, Hill, Veg. Syst. iv. 18 (1762).

Xylanthema, Neck. Elem. i. 67 (1790).

acantholepis, Hemsl. Biol. Centr. Am. Bot. ii. 251.Mexic.

Acarna, Linn. Syst. ed. X. 1201.-Europ.

acaulis, Willd. Prod. Fl. Berl. 260.-Europ.

afer, Sibth. E' Sm. Fl. Graec. ix. 20. t. 829.-Graecia;

As. Min.

afer, Tenore, Prod. p. lxiii $=$ nivens.

afer, Willd. Sp. Pl. iii. $1682=$ Cn. Diacantha

alpinus, Loisel. Fl. Gall. $542=$ Saussurea alpina.

alsophilus, Pollini, Fl. Veron. ii. 620. t. 5.-Italia.

altaicus, Steph. ex DC. Prod. vi. $538=$ Saussurea Frolowii.

altissimus, Willd. Sp. Pl. iii. 1671-- Am o bor.

ambiguns, Loisel. Fl. Gall. $540=$ heterophyllus.

americanus, A. Gray, in Proc. Am. Acad. xix. (1884)

56.-Am, bor. occ

Andersonii, A. Gray, l. c. x. (1874) 44.-Am. bor. occ.

Andrewsii, A. Gray, l. c. 45,-Calif.

anglicus, C. C. Gmel. Fl. Bad. iii. $372=$ pratensis. anoustifolius, Buch.-Ham. in Wall. Cat. n. $2915=$ Tricholepis Stictophyllum.

arabicus, Roth, in Usteri, Ann. Bot. viii. 8.-Arabia.

arachnoides, Hort. Par. ex DC. Prod. vi. $635=$ fimbriatus.

arachnoides, Wall. Cat. n. $2891=$ Wallichii

arachnoideus, Bieb. Fl. Taur. Cauc. ii. 277.-Reg. Cancas.

araneosus, Desf. ex DC. Prod. vi. 635.-Reg. Caucas.

arenarius, Willd. Sp. Pl. iii. $1663=$ Carduus arenarits,

Argemone, Lapeyr. Hist. Abr. Pl. Pyr. ii. $493=$ medius.

argentatus, Roth, Catalect. i. $111=$ Carduus argentatus.

argyracanthus, C. B. Clarke, Comp. Ind. 218.-Reg. Himal.

arizonicus, A. Gray, in Proc. Am. Acad. x. (1874) 44. -Arizona.

armatus, [Soland. in] Russ. Aleppo, ed. II. ii. 262,Syria.

arvensis, Hoffm. Deutschl. Fl. ed. II. i. II. 130.Europ.; As. temp.

arvensis, Hook. Comp. Bot. Mag. i. (1835) $48=$ virginianus.

asiaticus, Sievers, in Pall: N. Nord. Beitr. vii. 350 Sibir, altaic

auriculatus, Wall. Cat. n. $3289=$ Saussurea hypoleuca, autareticus, Chaix, in Vill. Hist. PI. Dauph. i. 381 Willd. Sp. Pl. iii. $1676=$ heterophyllus.

autareticus, Loisel. Fl. Gall. $541=$ rivularis,

Bertolonii, Bertol. Fl. Ital. ix. 23.-Italia.

Boujarti, DC. Prod. vi. $635=$ fimbriatus vel arachnoideus.

bracteatus, Gilib. Fl. Lituan. i. $184=$ oleraceus.

Breweri, A. Gray, in Proc. Am. Acad. x. (1874) 48,Calif.

Buergeri, Maxim. in Bull. Acad. Pétersb. xix. (1874) 502.- - Japon

californicus, A. Gray, in Proc. Am. Acad. x. (1874) 46.-Calif.

callosus, Roth, Catalect. iii. $76=$ Carduus callosus.

candicans, Wall. Cat. n. $2893=$ arvensis.

canus, Roth, Tent. Fl. Germ. i. 345.-Furop.

capitatus, Krock. Fl. Sil. Suppl. ii. 290.-Europ.

carlinoides, Fisch. ex Schrank, Pl. Rar. Hort. Monac. t. 11. - Reg. Caucas

carniolicus, Willd. Sp. Pl. iii. 1677.-Europ.

carthamoides, Wall. Cat, n, $2896=$ Saussurea affinis.

carthamoides, Willd. Sp. Pl. iii. $1686=$ Centaurea carthamoides.

\section{CNICUS}

Casabonae, Roth, in Usteri, Ann. Bot. viii. 9.-Ins. Ital.; Marocco.

centauroides, Linn. Sp. Pl. 826.-Mont. Pyren.

centauroides, Willd. ex Ledeb. Fl. Ross. ii. $753=$ Leuzea salina.

cernuus, A. Gray, in Proc. Am. Acad. x. (1874) $44=$ subcoriaceus.

cernuus, Linn. Sp. P1. 826= Cardnus cernuus.

cernuus, Wall. Cat. n. $2892=$ Wallichii.

chamaecephalus, Vatke, in Linnaea, xxxix. (1875) 511. -Abyssin.

Chamaepeuce, Desf. Arb. i. 280-Graecia; As. Min.

Chamaepeuce, Tenore, Prod. p. xlviii = gnaphalodes.

chinensis, Benth. ex Maxim. in Bull. Acad. Pétersb. xix. (1874) 509.-China.

chrysacanthus, Ball, in Fourn. Bot. xi. (1873) 369.Marocco.

ciliatus, Roth, Catalect. ii. 104.-Europ.

ciliatus, Vitm. Summa, iv. $447=$ ochroleucus

collinus, Hornem. Hort. Hafn. Suppl. $92=$ Carduus collinus

communis, Lam. Fl. Fr. ii. 15 = Cynara Cardunculus. comosus, Franch. E Sav. Enum. Pl. Fap. ii. 409. Japon.

conspicuus, Hemsl. Biol. Centr. Am. Bot. ii. 251.Mexic.

costaricensis, Polak. in Linnaea, xli. (1879) 581.Costa Rica

cyanoides, Roth, in Usteri, Ann. Bot. viii. 9.-Europ Cynara, Lam. F1. Fr. ii. $14=$ Centaurea cynaroides.

cynaroides, Bieb. Fl. Taur. Cauc. ii. $280(=$ Cirsium sinuatum).-Reg. Caucas.

cynaroides, Sibth. \& Sm. Fl. Graec. ix. 20. t. $828=$ eriophorus.

cynaroides, Willd. Sp. Pl. iii. 1670.-Ins. Creta.

deltoideus, Wall. ex DC. Prod. vi. 541 = Saussurea deltoidea.

dentatus, Forsk. Fl. Aegypt. Arab. $217=$ Ken-

trophyllum dentatum.

dentatus, Willd. Sp. Pl. iii. $1672=$ pratensis.

Diacantha, Desf. Cat. Hort. Par. ed. III. 152.-As

Min.; Syria.

dipsacolepis, Maxim. in Bull. Acad. Pétersb. xix (1874) 497.- Japon.

discolor, Muhl. ex Willd. Sp. Pl. iii. 1670.-Am. bor.

discolor, Roth, ex Steud. Nom. ed. II. i. 283, $388=$ Carduus callosus.

dissectus, Willd.Sp. Pl. iui. 1665.-Europ.

Drummondii, A. Gray, in Proc. Am. Acad.x. (1874) 40.-Am. bor. occ.

dubius, Willd. Prod. Fl. Berl. $260=$ acaulis

Eatoni, A. Gray, in Proc. Am. Acad. xix. (1883) 56.Am. bor. occ.

echinatus, Willd. Sp. Pl. iii.: 1668.-Reg. Mediterr. occ.

echinocephalus, Willd. l. c. 1685.-Reg. Caucas.

edulis, A. Gray, in Proc. Am. Acad. X. (1874) 47.Am. bor. occ.

effusus, Maxim. in Bull. Acad. Pétersb. xix. (1874) 500.-Japon.

longatus, Wall. ex C. B. Clarke, Comp. Ind. $239=$ Tricholepis elongata.

eriocephalus, A. Gray, in Proc. Am. Acad. x. (1874) 46.-Am. bor. occ.

eriophoroides, Hook. f. Fl. Brit. Ind. iii. 363.-Re Himal.

eriophorus, C. B. Clarke, Comp. Ind. $217=$ eriophoroides.

eriophorus, Juss. ex DC. Prod. vi. $635=$ spathulatus.

eriophorus, Roth, Tent. Fl. Germ. i. 345.-Europ.; As Min.

Erisithales, Linn. Sp. Pl, ed. II. $1157=$ ochroleucus?

esculentus, Sievers, in Pall. N. Nord. Beitr. vii. 362.Rossia.

Falconeri, Hook. f. Fl. Brit. Ind. iii. 363.-Reg. Himal.

ferox, Linn. Mant. i. 109 ; Sibth. E Sm. Fl. Graec

Prod. ii. 152.-Europ. or, ; As. Min.

fumbriatus, Bieb. Fl. Taur. Cauc. ii. 276.-Reg. Caucas.

firmus, F. E C. Presl, Delic. Prag. 107.-Europ.

flavescens, Willd. Sp. Pl. iii. $1683=$ Serratula fla vescens.

flavispinus, Ball, in Fourn. Linn. Soc. xvi. (1878) 522.-Hispan, ; Marocco.

foliosus, A. Gray, in Proc. Am. Acad. x. (1874) 40,Am. bor. occ.

\section{CNTCUS :-}

fruticosus, Desf. Arö. i. 280.-Graecia.

Galactites, Loisel. F1. Gall. ed. I. $538=$ Galactites tomentosa.

giganteus, Willd. Sp. Pl. iii. 1671.-Reg. Mediterr.

glaber, Ell. Sketch, ii. $270=$ Nuttallii.

glaber, Nutt. Gen. Am. ii. $129=$ muticus?

glutinosus, Bigel. Fl. Bost. ed. II. $291=$ muticus.

glutinosus, Gilib. Fl. Lituan. i. 185=ochroleucus

Gmelini, Spreng. Hist. Rei Herb. ii. $270=$ acaulis

gnaphalodes, Willd. ex Spreng. Syst. iii. 375.-Italia.

gossypinus, Wall. ex DC. Prod. vi. 541, $542=$ Saussurea gossypiphora.

Gouani, Willd. Sp. Pl. iii. $1665=$ Carduus medius

Grahami, A. Gray, in Proc. Am. Acad. xix, (1883) 57.-Árizona.

Griffithii, Hook. f. Fl. Brit. Ind. iii. 363.-Reg. Himal.

grumosus, Hoffmgg. Eo Link, Fl. Port. ii. 196.Lusitan.

Hallii, A. Gray, in Proc. Am. Acad. xix. (1883) 56.Am. bor. occ.

helenioides, Willd. Sp. Pl. iii. $1674=$ heterophyllus.

heterolepis, A. Gray, in Proc. Am. Acad. x. (1874) 44 = subcoriaceus.

heteromallus, Steud. Nom. ed. II. i. $388=$ Saussurea candicans.

heterophyllus, Roth, Catalect. i. 114.-Europ.

Hilgendorfi, Franch. E Sav. Enum. Pl. Fap. ii. 410 -Japon.

hispanicus, Ball, in fourn. Linn. Soc. xvi. (1878) 523. -Hispan.

Hookerianus, A. Gray, in Proc. Am. Acad. x. (1874) 46.-Am. bor. occ.

horridulus, Pursh, Fl. Am. Sept. ii. 507-Am. bor.

horridus, Bertol. Amoen. Ital. $40=$ Bertolonii.

horridus, Bieb. Fl. Taur. Cauc. ii. 278.-Reg. Cancas.

horridus, C. B. Clarke, Comp. Ind. $220=\mathrm{F}$ alconeri.

horridus, Forsk. Fl. Aegypt. Arab. $217=$ Cardopatium corymbosum.

hybridus, Schleich. Cat. P1. Helv. ed. III. $12=$ ochroleucus.

igniarius, Benth. E" Hook. f. Gen. ii. 469.-Sibir, altaic incomptus, Franch. E Sav. Enum. Pl. Fap. ii. 410.Japon.

inermis, Willd. Sp. Pl. iii. $1672=$ centauroides.

intermedius, Heller, Fl. Wirc. ii. 256.-Europ.

involucratus, Wall. ex DC. Prod. vi. 639.-Reg. Himal.

italicus, Seb. E Mauri, Fl. Rom. Prodr. ii. 282Italia.

japonicus, Maxim. in Bull. Acad. Pétersb. xix. (1874) 503.-Japon.

jorullensis, $H . B$. E K. Nov. Gen. et $S p$. iv. 22,Mexic.

kamtschaticus, Maxim. in Bull. Acad. Pétersb. xix. (1874) 495.-Japon.; Alaska.

Kosmelii, Willd. ex Ledeb. Fl. Ross. ii. $729=$ lappaceus.

Kotschyi, Sch. Bip. in Ind. Sem. Hort. Berol. (1857) App. $24=$ Carbenia benedicta.

Lachenalii, C.C. Gmel. Fl. Bad. iii. 380.-Europ.

lacteus, Schleich. Cat. P1. Helv. ed. IV. $13=$ palustris,

lanatus, Willd. Sp. P1. iii. $1671=$ arvensis.

lanceolatus, Willd. Prod. Fl. Berl. 259.-Europ.

laniflorus, Bieb. Fl. Taur. Cauc. ii. 276.-Reg. Caucas.

lappaceus, Bieb. l. c. 277.-Reg. Caucas

lappaceus, Hort. Par. ex DC. Prod. vi. $639=$ nivalis.

appoides, Hemsl. Biol. Centr. Am. Bot. ii. 251.Mexic.

Lecontei, A. Gray, in Proc. Am. Acad. x. (1874) 39.Am. bor.

leucocephalus, Willd. Sp. Pl. iii. 1668,-Creta; As. $\mathrm{Min}$

leucographus, Roth, in Usteri, Ann. Bot. viii. $8=$ Tyrimnus leucographus.

leucophanus, Baumg. ex Schur, Enum. Pl. Transs, 418 $=$ lanceolatus.

linearis, Benth. E Hook. f. ex Franch. E Sav. Enum. Pl. $\mathscr{F} a p$. i. 261.-Japon.

lomatolepis, Hemsl. Biol. Centr. Am. Bot. ii. 251.Mexic.

longifolius, Lam. F1. Fr. ii. 13=Carduncellus monso peliensis.

lucidus, Wall. ex DC. Prod. vi. $622=$ Carduus nutans. macrostylus, Moretti, in Brugnat. Giorn. Fis. II. (1824) 102.-Italia. 


\section{CNICUS}

medius, Krock. Fl. Sil. Suppl. ii. 278.-Silesia. mexicanus, Hemsl. Biol. Centr. Am. Bot. ii. 251.Mexic.

microcephalus, Bertol. Fl. Ital. ix 36--Ital, S Sardinia.

microcephalus, Boiss. Fl. Orient. iii. $705=$ Carbenia benedicta.

misilmerensis, Tineo, ex Ces. Passer. E Gib. Comp. Fl. Ital. 483.-Ital

mitis, Hornem. Hort. Hafn. Suppl. 93.-Sibir.

mitissimus, Lam. F1. Fr. ii. $13=$ Carduncellus mitissimus.

mollis, DC. Prod. vi. 652, sphalm.=acaulis

mollis, Roth, Tent. Fl. Germ. i. $346=$ Jurinea mollis.

monspessulanus, Roth, in Usteri, Ann. Bot. viii. 9.-

Gallia.

montanus, Waldst. E Kit. ex Willd.Sp. Pl. ii. 1676.Europ.

multicaulis, Wall. ex DC. Prod. vi. $540=$ Saussurea affinis.

munitus, Bieb. Fl. Taur. Cauc. ii. 279.-Reg. Caucas, muticus, Ell. Sketch, ii. 268 -Am. bor

neo-mexicanus, A. Gray, in Proc. Am. Acad. x. (1874) 45.-Am. bor. occ.

nipponicus, Maxim. in Bull. Acad. Pétersb. xix. (1874) 496.- Japon.

nivalis, $H . B . E$. $K$. Nov. Gen, et $S p$. iv. 23.-Mexic. niveus, F. E C. Presl, Delic. Prag. 108.-Europ. nivens, Wall. Cat. n. $2898=$ Saussurea deltoidea. nudiflorus, Schleich. Cat. Pl. Helv. ed. IV. 14, nomen. -Helvet.

Nuttallii, A. Gray, in Proc. Am. Acad. x. (1874) 41.Am. bor.

obvallatus, Bieb. Fl. Taur.Cauc, ii. 279,-Rer. Caucas.

obvallatus, Salzm. ex DC. Prod. vi, $660=$ Notobasis syriaca.

occidentalis, A. Gray, in Proc. Am. Acad. x. (1874) 45.-Am. bor occ.

ochrocentrus, A. Gray, l. c. xix. (1883) 57.-Am. bor. occ.

ochroleucus, Spreng. Nachr. i. Bot. Gart. Halle, 19.Europ.

odoratus, Muhl. ex Stend. Nom. ed. II. i. $388=$ pumilus.

oleraceus, Linn. Sp. Pl. 826-Europ.

oligophyllus, Franch. E Sav. Enum. Pl. Fap. ii. 412. -Japon.

orgyalis, Willd. Enum. Hort. Berol. Suppl. 56.-Hab. ?

orientalis, Willd. Sp. Pl. iii. $1670=$ Galactites tomentosa.

ornatus, Ball, in fourn. Bot. xi. (1873) 368.-Marocco. ovalifolius, Franch. E Sav. Enum. Pl. Fap. ii. 412.Japon.

paludosus, Loisel. Fl. Gall. 542.--Europ.

palustris, Sibth. \& Sm. F1. Graec. Prod. ii. $151=$ pungens.

palustris, Willd. Prod. Fl. Berl, 260.-Europ.; As. bor.

pannonicus, Host, Fl. Austriac. ii. 444.-Europ

Parryi, A. Gray, in Proc. Am. Acad. x. (1874) 47.Am. bor. occ.

parviflorus, Heller, Fl. Wirc. Suppl.76.-Europ.

panciflorus, Waldst. E Kit. Pl. Rar. Hung, ii. 175.-

Europ. or.

pazcuarensis, H.B. $\mathcal{F}^{\circ}$. Nov. Gen. et $S p$. iv. 22 . t. 310.-Mexic.

pectinelks, Maxim. in Bull. Acad. Pétersb. xix. (1874) 494.- Japon.

pedemontanus, Willd. Sp.Pl. iii. 1675.-Europ.

pendulus, Maxim, in Bull. Acad. Pétersb, xix. (1874) 510.-Sibir. or

pexus, Franch. E Sav. Enum. Pl. Fap, ii. 4l0.Japon.

pinnatifidus, Willd, Sp. Pl. iii. $1684=$ Serratula pinna-

Pitcheri, Torr, in Eaton, Man. ed, V, 180-Am. bor.

polyacanthus, Vatke, in Linnaea, xxxix. (1875) 510... Afr. trop.

polyanthemus, Bertol. Amoen. Ital. 41.-Italia.

Pontederae, Pollini, in Brugnat. Giom. Fis, ix. (1816) $98=$ rivularis.

praemorsus, Michl, in Flora, iii. (1820) $317=$ ochroleucus ?

pratensis, Lam. Fl. Fr. ii, $14=$ oleraceus.

pratensis, Willd.Sp. Pl. iii. 1672.-Lurop.

\section{CNICUS:-}

seudo-benedictus, Hort. Dorpat, ex Aschers. Ind. Sem. Hort. Berol. (1861) $5=$ Carbenia benedicta

pubigerus, Desf. Cat. Hort. Par. ed. III. 399-As. Min.

pumilus, Torr. Compend. 282.-Am. bor

pungens, Bivona, Sic. Pl. Cent, i. $26=$ siculus.

pungens, Sebast. P1. Rom. fasc. i. 9. to $2=$ polyanthemus.

pungens, Willd. Sp. Pl. iii. 1663.-Europ. or.; As. Min.

purpuratus, Maxim. in Bull. Acad. Pétersb. xix. (1879) 491.- Japon.

purpureus, Bertol. F1. Ital. ix. $21=$ spinosissimus.

pycnocephalus, Roth, in Usteri, Ann. Bot. viii. $8=$

Carduus pycnocephalus ?

pygmaeus, Linn. Sp. Pl. ed. II. $1156=$ Saussurea pyg. maea.

pyrenaicus, Willd.Sp.Pl. iii. 1664.-Europ.

quercetorum, A. Gray, in Proc. Am. Acad. x. (1874) 40.-Calif.

radians, Hemsl. Biol. Centr. Am. Bot. ii. 252.-Guatemala.

rhaphilepis, Hemsl.l.c.-Mexic

rectus, Hort. Par. ex DC. Prod. vi. $659=$ strictus.

Reinii, Franch. E Sav. Enum. Pl. Fap. ii. 413.Japon.

remotifolius, A. Gray, in Proc. Am. Acad. x. (1874) 47.-Am. bor. occ

repandus, Ell. Sketch, ii. 269.-Am. bor

replicatus, Hornem. Hort. Hafn. Suppl. 93.-Hungaria.

rigens, Willd. Sp. Pl. iii. 1675.-Europ.

rivularis, Willd. l.c. 1676 .-Europ.

Rothrockii, A. Gray, in Proc. Am. Acad. xvii. (1881 82) 220 . - Arizona

rufescens, Loisel. Fl. Gall. 541.-Gallia.

ruthenicus, Henning, in Mém. Soc. Nat. Mosc. vi 1823) $78=$ arvensis.

saanensis, Schlecht. ex DC. Prod. vi. $648=$ ochroleucus.

salinus, Willd. ex Ledeb. F1. Ross. ii. $752=$ Lenzea serratuloides.

salisburgensis, Willd. Sp. PI. iii. $1675=$ rivularis

samniticus, Tenore, ex Steud. Nom. ed. II. i. $389=$ italicus.

scariosus, A. Gray, Syn. Fl. N. Am. i. II. 402-Am bor. occ.

Schimperi, Vatke, in Linnaea, xxxix. (1875) 511. Afr, trop.

segetum, Maxim. in Bull. Acad. Pétersb. xix. (1874) 511.-China.

seminudus, Schleich, ex DC. Prod, vi. $650=$ rivularis semipectinatus, Desf. Cat. Hort. Par. ed. III. 151.As. centr.

semipectinatus, Hornem. E Ledeb. ex DC. Prod. vi 647.-Hab.

semipectinatus, Thom. ex Steud. Nom. ed. II. i. 389 (=Cirsium subalpinum).-Europ.

serratuloides, Roth, Tent. Fl. Germ. i. 346.-Sibiria.

serrulatus, Bieb. Fl. Taur.-Cauc. ii. 275.-Reg. Caucas. setosus, Bess. Prim. Fl. Galic. ii. $172=$ arvensis? siculus, Guss. Fl. Sic. Syn, ii. $442=$ pungens.

Sieboldii, Maxim. in Bull. Acad. Petersb.xix. (1874) 503.-Japon.

sinensis, C. B. Clarke, Comp. Ind. $219=$ chinensi

spathulatus, Moretti, in Brugnat. Giorn. Fis. II. v. (1822) 111.-Italia.

spicatus, Maxim. in Bull. Acad. Pétersb. xix. (1874) 501.-Japon.

spinosissimus, Darling. Fl. Cestr. ed. II. $438=$ horri dulus.

spinosissimus, Habl. Taur. 158, ex Bieb. Pl. Taur. Cauc. ii. 281 = echinocephalus.

spinosissimus, Lapcyr. Hist. Abr. Pl. Pyr。 ii. $496=$ seq. ?

spinosissimus, Linn. Sp. Pl. 826.-Europ.

spurius, Hoffm. Deutschl. Fl. ed. II. ii. 128 pratensis.

squarrosus, Hornem. Hort. Hafn. ii. 782.-Sibiria. stellatus, Roth, in Usteri, Ann. Bot. viii. 90-Europ. strictus, Tenore, Prod. po xlviii.-Italia.

strigosus, Bieb. Fl. Taur.-Cauc. ii. 277.-Reg. Caucas, Persia.

subcoriaceus, Hemsl. Biol. Centr. Am. Bot. ii. 252. Mexic.

sufiultus, Maxim. in Bull. Acad. Petersb. xix. (1szd) 498.-Jаров.

\section{CNICUS :}

syriacus, Roth, in Usteri, Ann. Bot. viii. 10.-Reg. Mediterr.

Tanakae, Franch. \& Sav. Enum. Pl. Fap. ii. 411.Japon.

tartaricus, Willd. Sp.Pl. iii. 1677.-As. temp.

tchefouensis, Franch. in Mém Soc. Sc. Nat. Cherbourg, xxiv. (1884) 229.-China.

ranssylvanicus, Schur, in Oestr. Bot. Zeitschr. (1860) 179.-Transsylyan.

tuberosus, Roth, Tent. Fl. Germ. i. 345.-Europ.

uliginosus, Bieb. Fl. Taur.-Cauc. ii. 274.-Reg. Caucas.

undulatus, A. Gray, in Proc. Am. Acad. x. (1874) 42 . -Am. bor.

uniflorus, Linn. Mant. ii. 572 =Centaurea monanthos. uniflorus, Sievers, in Pall. N. Nord. Beitr. vii. $346=$

Leuzea carthamoides.

Verutus, D. Don, Prod. Fl. Nep. 167 =argyracanthus.

virginianus, Hook. Comp. Bot. Mag. i. (1835) $48=$ Lecontei.

virginianus, Pursh, Fl. Am. Sept. ii. 506.-Am. bor.

Vlassovianus, Maxim in Bull. Acad. Petersb. xix. (1874) 509.-As. temp.

Wallichii, Hook. f. Fl. Brit. Ind. iii. 363.-Reg. Himal.

Weyrichii, Maxim. in Bull. Acad. Petersb. xix. (1874 495. - Ins. Sachalin.

Wheeleri, A. Gray, in Proc. Am. Acad. xix. (1883 56.--Arizona.

Willdenowii, F. G. Dietr. Vollst. Lexik. Gaertn. Nachtr ii. 331 - Hab. ?

Wrightii, A. Gray, in Proc. Am. Acad. x. (1874) 41. -Texas; Arizona.

yezoënsis, Maxim. in Bull. Acad. Pétersb.xix. (1874) 508.- Japon.

CNICUS, [Vaill.] Gaertn. Fruct. ii. 385.t. 162 (179] = Carbenia, Adans. (Compos.)

benedictus, Linn. Sp. Pl. 826; Gaertn. 1. c.=Carb benedicta.

CNIDIUM, Cusson, in Mém. Soc. Méd. Paris (1752 280 = Selinum, Linn. (Umbell.)

affine, C. A. Mey. in Beitr. Pfi. Kuss. Reich, vi. 38.Reg. Caucas.

alatum, Spreng. ex Link, Handb. i. $929=$ Ligusticun alatum.

alsaticum, Spreng. P1. Umbellif. Prod. $40=$ Peucedanani alsaticum.

anomalum, Ledeb. Fl. Alt. i. 380 ; Ic. Fl. Ross. t. 311. -Sibir. altaic.

apioides, Spreng, Pl. Umbellif. Prod. $40=$ Carum rio dulum.

argenteum, Cesati, in Linnaea, xi. (1537) $324=$ Peucu danum involucratum?

athoum, Griseb. Spicil. Fl. Rumel. i. $963=$ Carum rigidulum.

atropurpureum, Spreng, in Roem, \& Schalt. Syst. vi. $418=$ Thaspium trifoliatum.

conadense, Spreng. 1. c. $415=\mathrm{S}$. canadense.

carvifolium, Bieb. Fl. Taur.-Cauc. iii. $212=$ Carum caucasicum.

cenolophioides, Benth. \& Hook. f. Gen. i. $914=5$ sylvestre.

chinense, Spreng. ex Steud. Nom. ed. II. i. $\$ S 9=S$. canadense.

confertum, Moench, Meth. $98=$ S. Monnieri.

coniifolium, Boiss, in Ann. Sc. Nat. Sér. 111. i. (18tt 299.-As. Min.

cuneatum, Ledeb. Fl. Alt. i. $\$ 91$; et Ic. FL Ross. 312.-Sibir. altaic

cuneifolium, Griseb. Spicil. Fl. Rumel. i. $\$ 6 \$$, in obs = Ligusticum cuncifolium.

dahuricum, Fisch. \& Mey, in Ann. Sc. Ną Ser. II. y. (1s36) 183,-Dahuria.

diffusum, DC. Prod. iv. 158 = Seseli indicum.

divaricaḱm, Ledeb. Fl. Alc. i. 824 -Silaus lonf't folius.

Fischeri, Spreng. Nov, Prov. 12 - Silaus langifolius.

fonfanesii, Spreng. Sp. Umbellif. Prod. 11.-Nu. midia.

intermentium, Tchibat. Asic Min. Bot. i $130,-$ As Min.

japonicum, Miq̨. Aan. Mus. Bor. Lugd. Bal uii. 60. Japron.

Kromssianum, Sond, in Hary. \& Sond. Fl. Cap. in 552 - Pimpunclla callra. 


\section{CNIDIUM}

meifolium, Bieb. F1. Taur. Cauc. iii. $213=$ Carum armenum.

microcarpum, Turcz. ex Steud. Nom. ed. II. i. 389.Sibir. baical.

Monnieri, Cusson, in Mém. Soc. Méd. Par. (1782) 280 = Selinum Monnieri.

multicaule, Ledeb. Fl. Ross. ii. 284.-Sibiria.

myrrhidifolium, Bieb. Fl. Taur. Cauc. iii. $212=$ Ligusticum alatum.

orientale, Boiss. in Ann. Sc. Nat. Sér. III. i. (1844) $299=\mathrm{S}$, orientale

palustre, Reichb. Fl. Germ. Excurs. $469=\mathrm{S}$, sylvestre, Petroselinum, DC. Prod, iv, 152= Carum Petroselinum peucedanoides, H. B. \& K. Nov. Gen. et Sp. v. $15=$ Eulophus peucedanoides.

pyrenaeum, Spreng. in Roem. \& Schult. Syst. vi. $416=$ Ligusticum pyrenaeum.

salinum, Turcz. in Bull. Soc. Nat. Mosc. xvii. (1844) 733.-Dahuria.

Silaus, Bieb. F1. Taur. Cauc. iii. $212=$ Silaus Besseri.

Silaus, Spreng. P1. Umbellif. Prod. $40=$ Silaus pratensis.

striatum, Turcz. ex Fisch. \& Mey. in Ann. Sc. Nat. Sér II. v. (1836) $188=$ dahuricum.

suffruticosum, Cham. \& Schlecht. in Linnaea, i. (1826) $387=\mathrm{S}$. suffruticosum

tenuifolium, Moench, Meth. $98=$ A pium leptophyllum tolucense, Spreng. Syst. i. $888=$ Arracacia tolucensis. venosum, Koch, Umbellif. $109=\mathrm{S}$. sylvestre.

CNIDONE, E. Mey. ex Endl. Gen. Suppl. ii. 76 (1842)= Kissenia, R. Br. (Loasac.).

mentzelioides, E. Mey. ex Pres1, Bot. Bemerk. $73=$ K. spathulata.

CNIDOSCOLUS, Pohl, P1. Bras. Ic. i. 56. t. 49 (1827)= Jatropha, Linn. (Euphorbiac.).

angustidens, Torr. Bot. Mex. Bound. 198=J. augustidens.

cnicodendron, Griseb. in Goett. Abh. xxiv. (1879) 53. -Reg. Argent.

fragrans, Pohl, Pl. Bras. i. $63=$ J. fragrans.

hamosus, Pohl, 1. c. $57=\mathrm{J}$. hamosa

lobatus, Pohl, 1. c. $62=\mathrm{J}$. phyllacantha.

Marcgravii, Pohl, l. c. 58. t. $50=$ J. urens.

Michauxii, Pohl, 1. c. $58=\mathrm{J}$. urens.

napaefolius, Pohl, 1. c. $63=\mathrm{J}$. aconitifolia

neglectus, Pohl, 1. c. 60 . t. $51=\mathrm{J}$. urens.

obtusifolius, Pohl, ex Baill. in Adansonia, iv. (1863-64) $275=$ J. obtusifolia.

osteocarpus, Pohl, Pl. Bras, i. $63=\mathrm{J}$. osteocarpa.

palmatus, Pohl, l. c. $=$ J. palmata.

pubescens, Pohl, 1. c. $62=\mathrm{J}$. obtusifolia.

quercifolius, Pohl, ex Baill. in Adansonia, iv. (1863-64.) $275=\mathrm{J}$. phyllacantha.

quinquelobus, Pohl, Pl. Bras. 1. $63=\mathrm{J}$, arens.

repandus, Pohl, 1. c. $62=\mathrm{J}$. phyllacantha

stimulosus, Engelm. \& A. Gray, in Bost. Journ. Nat.

Hist. v. $(1845) 234=J$. texana.

stimulosus, A. Gray, Man. Bot. $389=$ J. urens.

surinamensis, Miq. in Linnaea, xviii. (1844) $749=$

Croton lobatus.

vitifolius, Pohl, Pl. Bras, i. $61=$ J. vitifolia.

CNOPOS, Rafin. F1. Tellur. iii. 13 (1836)= Polygonum, Tourn.

ramosissimum, Rafin. 1. c. $=$ P. ramosissimum.

COA, Adans. Fam. ii. $445(1763)=$ Hippocratea, Linn. (Celastr.).

COALISIA, Rafin. Sylva Tellur. $114(1838)=$ Cleome, Linn. (Capparid.).

angustifolia, Rafin. 1. $\mathrm{c}_{\mathrm{v}}=$ Cleome angustifolia.

COATESIA, F. Muell. Fragm. iii. $26(1862)=$ Geijera, Schott (Rutac.).

paniculata, F. Muell. I, c. = G. Muelleri.

COBAEA, Cav. Ic. i. 11. t. 16, 17 (1791), POLEMONIACEAE, Benth. \& Hook. f. ii. 824 .

Rosenbergia, Oerst. in Kjoeb. Vidensk. Meddel. (1856) 30.

gracilis, Hemsl. in The Garden, xvii. (1880) 352.Costa Rica.

\section{COBAFA:}

lutea, D. Don, in Edinb. Phil. Journ. x. (1824) $4=$ macrostemma.

macrostemma, Pav. ex D. Don, l. c. 112,-Guatemala.

minor, Mart. Eo Gal. in Bull. Acad. Brux. xi1. (1845) II. 276.-Mexic.

penduliflora, Hook. f. Bot. Mag. t. 5757.-Venezuela

scandens, Cav. Ic. i. 11. tt. 16, 17.-Mexic

stipularis, Benth. Pl. Hartw. 45.-Mexic.

COBAEA, Neck. Elem. i. $129(\mathbf{1 7 9 0})=$ Lonicera, Linn (Caprifol.).

COBAMBA, Blanco, Fl. Filip. ed. I. $510(1837)=\mathbf{C a n}$ scora, Lam. (Gentian.)

Blancoi, Blanco, 1. c. ed. II. Suppl. $591=$ Cans. decus. sata.

dichotoma, Blanco, 1. c. ed. I. $510=$ Cans. diffusa.

COBRESIA, Pers. Syn. ii. $534(\mathbf{1 8 0 7})=$ Kobresia, Willd. (Cyperac.).

COBURGIA, Sweet, Brit. Flow. Gard. Ser. II. t. 17 (1838) = Stenomesson, Herb. (Amaryllid.).

acuta, Herb. in Bot. Mag. t. $3865=\mathrm{S}$. incarnatum. angusta, Herb. in Bot. Keg. (1842) Misc. $55=\mathrm{S}$, recurvatum.

Belladonna, Herb. in Bot. Mag. sub tt. 2113, $2114=$ Amaryllis Belladonna.

blanda, Herb. 1. c. = Amaryllis Belladonna.

chachapoyensis, Herb. in Bot. Reg. (1842) Misc. $53=$ $\mathrm{S}$. incarnatum.

ciliaris, Herb. in Trans. Hort. Soc. iv. (1822) $181=$ Buphane disticha.

coccinea, Herb. in Bot. Reg. (1842) Misc. $54=$ - S. coccineum

discolor, Herb. Amaryll. $197=\mathrm{S}$. recurvatum

flava, Hort. Belg, ex Heynh. Nom, ii. $151=$ seq.

fulva, Herb. in Bot. Reg. t. $1497=\mathrm{S}$. incarnatum.

humilis, Herb. 1. c. (1842) Misc. $55=\mathrm{S}$. humile.

incarnata, Sweet, Brit. Flow. Gard. Ser. II. t. $17=$

S. incarnatum.

Fosephinae, Herb. in Trans. Hort. Soc. iv. (1822) 181 = Brunsvigia Josephinae.

laeta, Herb. in Bot. Reg. (1842) Misc. $53=\mathrm{S}$. incarnatum.

langensis, Herb. 1. c. $=\mathrm{S}$. incarnatum.

lutea, Herb. 1. c. $55=\mathrm{S}$. recurvatum.

Macleanica, Herb. 1. c. $=$ S. recurvatum

miniata, Lindl. Bot. Reg. (1844) Misc. 13.Peruv.

multiflora, Herb. in Bot. Mag. sub tt. 2113, $2114=$ Brunswigia multiflora.

obragillensis, Herb. in Bot. Reg. (1842) Misc. $54=$ S. recurvatum.

pallida, Herb, in Trans. Hort. Soc. iv. (1822) $181=$

Amaryllis Belladonna.

praecipitata, Herb. in Bot. Reg. (1842) Misc. $54=$ S. coccineum.

pudica, Herb. in Bot. Mag. sub tt. 2113, $2114=$ Amaryllis Belladonna.

quitensis, M. Roem. Syn. Ensat. 165-Ecuador.

Radula, Herb. ex Stend. Nom. ed. II. i. $390=$ Bruns vigia Radula.

recurvata, Herb. in Bot. Reg. (1842) Misc. $54=$ S. recurvatum.

reticulata, Herb. App. $34=$ Hippeastrum reticulatum.

splendens, Herb. Amaryll. 400. t. 47. fo $5=\mathrm{S}$. in-

carnatum.

striatifolia, Herb. App. $34=$ Hippeastrum reticulatum.

stylosa, Lindl. in Journ. Hort. Soc. ii. (1847) 310.Peruv.

taenisphylla, Salisb. Gen. Pl. Fragm. 134-Hab.

trichroma, Herb. Amaryll, $196=\mathrm{S}$. incamatum.

variegata, Herb. 1. c. $=\mathrm{S}$, incarnatum.

venusta, Herb. in Bot. Reg. (1842) Misc. $54=\mathrm{S}$. coccineum.

versicolor, Herb. 1. c. 53. $\mathrm{t} .66=\mathrm{S}$. incarnatum.

COCCANTHERA, C. Koch \& Hanst. Ind. Sem. Hort. Berol. (1855) $17=$ Codonanthe, Hanst. (Gesnerac.). Devosiana, C. Koch \& Hanst. 1. c. =Cod. Devosiana.

Hookeriana, C. Koch \& Hanst. 1. c. $=$ Cod. Hookerii,
COCCINIA, Wight \& Arn. Prod, 847 (1834).

CUCURBITACEAE, Benth. \& Hook. f. i. 827.

CEPHALANDRA, Schrad. in Eckl. \& Zeyh. Enum. ii $280(1836)$

abyssinica, Cogn. in DC. Monog, Phan. iii. 536.Abyssin.

adoënsis, Coon. l. c. 538.-Afr. trop. et austr.

cordifolia, Cogn. 1. c. $529=$ indica

decipiens, $\operatorname{Cog} n$. l. c. 539.-Afr. trop..

diversifolia, Cogn. 1. c. $536=\mathrm{C}$. Hartmanniana.

grandis, Voigt, Hort. Suburb. Calc. $59=$ indica.

Hartmanniana, Schweinf. Reliq. Kotschy. 42. t. 27.Abysin.

indica, Wight \& Arn. Prod. 347.-As. trop.

jatrophaefolia, $\operatorname{Cogn}$. in DC. Monog. Phan. iii. 538.Abysin.

Loureiriana, M. Roem. Syn. Pepon. $93=$ indica.

Mac-Kennii, $\operatorname{Cog} n$. in DC. Monog. Phan. iii. 541.Afr. austr.

Moghadd, Aschers. in Schweinf. Beitr. F1. Aethiop. $267=$ C. Moimoi.

Moimoi, M. Roem.Syn. Pepon. 93.-Afr.trop.; Arabia.

Monteroi, Hort.-Cf. Cat. Gr. Fard. Bot. Bordeaux (1866).-Afr. trop. ?

palmata, Cogn. in DC. Monog. Phan. iii. 540.-Afr. austr.

palmata, M. Roem. Syn. Pepon. $93=$ Bryonopsis laciniosa.

palmatisecta, Kotschy, in Sitzb. Acad. Wien, Math. Nat. li. (1865) 360. t. 4.-Abyssin.

quinqueloba, $\operatorname{Cogn}$. in DC. Monog. Phan. iii. 533.Afr. austr.

Schimperi, Naud. in Ann. Sc. Nat. Sér. IV. viii. (1857) $366=$ C. Moinoi.

senensis, Cogn. in DC. Monog. Phan. iii. 535.-Afr trop.

sessilifolia, Cogn . l. c. 534,-Afr, austr.

Wightiana, M. Roem. Syn. Pepon. $93=$ indica.

COCCOBRYON, Klotzsch, in Miq. Syst. Pip. $343(1843)$ $=$ Piper, Linn

capense, Klotzsch, 1. c. $=\mathbf{P}$. capensis, radicans.

COCCOCERAS, Miq Fl Ind Bat Suppl 455 (1860). EUPHORBIACEAE, Benth, \& Hook, f iii. 318.

muticum, Muell. Arg. in Flora, xlvii. (1864) 470.Malaya.

plicatum, Muell. Arg, l. c. 539.-Burma

sumatranum, Miq. Fl. Ind. Bat. Suppl. 456.Sumatra.

COCCOCYPSELUM, P. Br. Hist. Jamaic. 144 (1756)

(Coccocipsilum). RUBIACEAE, Benth. \& Hook. f

ii. 73 .

Bellardia, Schreb. Gen. i. 790 (1789)

Condalia, Ruiz \& Pav. Prod. 11. t. 2 (1794).

Lipostoma, D. Don, in Edinb. Phil. Journ. (1830) i. 168.

SiCELIUM, P. Br. Hist. Jamaic. 144 (1756).

Tontanea, Aubl. Pl. Gui. i. 108. t. $42(1775)$

aureum, Cham. E Schlecht. in Linnaea, iv. (1829) 139. -Bras.

biflorum, Willd. Sp. Pl. i. 618= Manettia Lygistum. buxifolium, Spreng. Syst. i. $416=$ Fernelia buxifolia.

campanuliflorum, Cham. E Schlecht. in Linnaea, iv. (1829) 140 - Bras

canescens, Willd. ex Roem. E Schult. Syst. iii. Mant. 130.-Am, austr.

capitatum, Willd. ex DC. Prod. iv. $396=$ umbellatum ciliatum, Cham. \& Schlecht. in Linnaea, vi. (1831) 414.--Mexic.

Condalia, Pers. Syn. i. $132=$ umbellatum

cordifolium, Nees E Mart. in Nov. Act. Nat. Cur. xii (1824) 14,-Bras.

dichroolasium, Mart. in Flora, xxiv. (1841) II. Beibl. 76. - Bras.

discolor, Van Houtte, ex Kunze, in Linnaea, xxiv. (1851) 192.-Bras.?

erythrocephalum, Cham. \& Schlecht. in Linnaea, iv. (1829) 144.--Bras.

geophiloides, Wawra, in Oestr. Bot. Zeitschr. xxxi. (1881) 70.-Bras

glabrum, Bartl. ex DC. Prod. iv. 397.-Panama.

herbaceum, Aubl. Pl. Gui. i. $68=$ repens.

hirsutum, Bartl. ex DC. Prod. iv. 396.-Hab. ?

lanceolatum, Pers. Syn. i. 132.-Peruv. 


\section{COCCOCYPSFLUM}

metallicum, Linden, in Belg. Hortic. xv. (1865) 99.Guiana

microphyllum, Willd. ex Roem. Es Schult. Syst. iii. Mant. 130.-Ins. Maurit

montanum, Mart. in Flora, xxiv. (1841) 11. Beibl. 76.Bras.

nummularifolium, Cham. E Schlecht. in Linnaea, iv. (1829) 145.-Bras.; Ind. occ.; Mexic.

obovatum, Pers. Syn. i. 182.-Peruv.

ovatum, Cham. E Schlecht. in Linnaea, iv. (1829) 141.-Bras.

pedunculare, Cham. Es Schlecht. l. c. 142,-Bras.

Pseudo-Tontanea, Griseb. Fl. Brit. W. Ind. 322.-Ind.

oce.

pulchellum, Cham. in Linnaea, ix. (1834) 238.-Bras. repens, H. B. \& K. Nov. Gen, et Sp. iii. $403=$ canescens.

repens, Sw. Prod. Veg. Ind. Occ. 31.-Ind. occ. sessile, Pers. Syn. i. 132.-Peruv.

spicatum, H. B. \& K. Nov. Gen. et Sp. iii. 406 = Gonzalea spicata.

Tontanea, H. B. \& $K . l$. c.-Am. austr

umbellatum, Poir. Encyc, Suppl. ii. 307.-Peruv.

uniflorum, Willd. Sp. Pl. i. $618=$ Fernelia obovata

veronicoides, Presl, Bot. Bemerk. 87.-Am. trop.

virgatum, Lam. Illustr. i. 270. n. $1457=$ Manettia picta.

violaceum, Desf. Cat. Hort. Par. ed. III. $404=$ capituliftorum.

COCCODERMA, Miers, in Lindl. Veg. Kingd. 309 b (1847), nomen (Menisperm.).

COCCOLOBA, Linn. Syst. ed. X. 1007 (1759). POLYGONACEAE, Benth. \& Hook. f. iii. 102

LyPerodendRON, Willd. ex Meissn, in DC. Prod. xiv. 168 , in syn. (1857).

Naucorephes, Rafin. Fl. Tellur. ii. 34 (1836).

Schlosseria, Mill. ex Steud. Nom. ed. II. ii. 531 (1841).

acrostichoides, Cham. in Linnaea, viii. (1833) 132.Bras.

acuminata, $H . B$. \& $K$. Nov. Gen. et Sp. ii. 176,-N. Granat.

alagoënsis, Wedd. in Ann. Sc. Nat. Sér. III. xiii. (1849) 260.-Bras.

alnifolia, Casar. Nov. Stirp. Bras. Dec. viii. $71=$ populifolia.

appressa, Meissn. ex Stend. Nom, ed. II. i. $390=$

Polygonum adpressum.

armata, Wright, ex' Griseb. Cat. Pl. Cub. 283.-Cuba.

asiatica, Lour. Fl. Cochinch. $289=$ Polygonum asia ticum.

australis, Forst. f. Prod. 29. n. $176=$ Muehlenbeckia anstralis.

barbadensis, facq. Enum. Pl. Carib. 37 ; Linn. Syst. ed. XII. 277.-Am. trop.

barbadensis, Willd. Sp. Pl. ii. $459=$ caracasana

Blanchetiana, Wedd. in Ann. Sc. Nat. Sér. III. xiii. 1849) 257 = ochreolata.

bracteolosa, Meissn. in Mart. Fl. Bras. v. 1. 30.-Bras, brasiliensis, Nees E Mart. in Now. Act. Nat. Cur. xi. 1823) I. 30.-Bras.

brasiliensis, Spreng. Syst. ii. 252 (=Hedyosmi sp.).Bras.

bullata, Hort. ex Meissn. in DC. Prod. xiv. $152=$ rugosa.

calobotrys, Meissn. 1. c. $157=$ coriacea.

Candolleana, Meissn. in Mart. Fl. Bras. v. I. 41.Bras.

caracasana, Meissn. in DC. Prod. xiv. 157.-Venezuela.

carinata, Ruiz, ex Meissn. 1. c. $150=$ Muehlenbeckia leptobotrys

cordata, Cham. in Linnaea, viii. (1833) 183.-Bras. cordifolia, Meissn. in Mart. FI. Bras. Y. I. $37=$ laevis. coriacea, A. Rich. Fl. Cub. Fanerog. ii. 184.-Cuba.

coriacea, Willd. ex Meissn. in DC. Prod. xiv. $155=$ obovata.

coronata, Facq. Enum. Pl. Carib. 19.-Ind, occ.

costata, Mart. ex Meissn. in DC. Prod. xiv. $158=$ populifolia.

costata, Wright, in Sauv. Fl. Cub. 139.-Cuba.

crescentiaefolia, Cham. in Linnaea, viii. (1833) 184.Bras.

crispata, Buch.-Ham. in Roxb. Fl. Ind, ii, $292=$ l'olygonum chinense.

\section{COCCOLOBA}

Cruegerii, Griseb. Fl. Brit. W. Ind. 710.-Ind. occ cubensis, Meissn. in DC. Prod. xiv. 162.-Cuba. cujabensis, Wedd. in Ann. Sc. Nat. Sér. III. xi 1849) 259.-Bras.

cymosa, Lour. F1. Cochinch. $240=$ Polygonum cymosum

declinata, Mart. ex Meissn. in Mart. Fl. Bras. v. I. 30.-Bras.

densifrons, Mart. ex Meissn. I. c. 26.-Bras.

dioica, Steud. Nom. ed. II. i. 390=Muehlenbeckia sagittifolia.

diversifolia, facq. Enum. Pl. Carib, 19,-Ins. S. Doming.

emarginata, Facq. l. c. 37 (sp. dub.).-Am. austr.

excelsa, Benth. in Hook. Lond. Fourn. Bot. iv. (1845) 624. -Am. trop.

excoriata, Linn. Syst. ed. X.1007. - Ind, occ.

fagifolia, facq. Hort. Schoenb. iii. 55. t. 352.-Am. austr.

fasciculata, Meissn. in Kjoeb. Vidensk. Meddel. (1870) $128=$ longependula

fasciculata, Wedd. in Ann. Sc. Nat. Sér. III. xiii. (1849 $258=$ crescentizefolia

fastigiata, Meissn. in Mart. Fl. Bras, v. I. 34.-Bras. ferruginea, Endl. Cat. i. $274=$ excoriata.

flavescens, facq. Enum. Pl. Carib. 19.-Ins. S Doming

floridana, Meissn. in DC. Prod. xiv. 165= laurifolia,

Gardneri, Meissn. in Mart. Fl. Bras, v. I. 36 crescentiaefolia.

Goudotiana, Meissn, 1. c. $35=$ fastigiata.

Goudotiana, Wedd. in Ann. Sc. Nat. Sér. III. xiii (1849) $260=$ obovata.

gracilis, H. B. E K. Nov. Gen. et Sp, ii. 176.-Peruy. grandifolia, Facq. Enum. Pl. Carib. 19.-Am, trop.

grandis, Benth. in Hook. Lond. Journ. Bot. iv. (1845) $624=$ latifolia

guatemalensis, Teijsm. \& Binn. Cat. Hort. Bog. 383 , nomen.-Hab. ?

guianensis, Meissn. in Linnaea, xxi. (1848) 254.Guiana.

Humboldtii, Meissn. in DC. Prod. xiv, 163.-Bras,

ilheensis, Wedd. in Ann. Sc. Nat. Sér. III. xiii. (1849) 258.-Bras.

indica, Wight, ex Meissn. in DC. Prod. xiv. $131=$ Polygonum chinense.

japurana, Meissn. in Mart. Fl. Bras, v. I. $25=$ (Alsodeiae sp.).-Bras.

Klotzschiana, Meissn. in DC. Prod.xiv, 155.-Ins. S. Thomas.

Kunthiana, Meissa. 1. c. $166=$ pyrifolia.

laevis, Casar. Noo. Stirp. Bras. Dec, viii. 71.Bras.

latifolia, Lam. Encyc. vi. 61.-Am, anstr.

latifolia, Poepp. ex Meissn. in DC. Prod, xiv, $151=$ polystachya.

laurifolia, Facq. Hort. Schoenbr. iii. 9. t. 267.-Am trop.

leoganensis, Jacq. Enum. Pl. Carib, $19=$ uvifera

leptostachya, Benth. Bot. Voy. Sulph. 159.-Am. austr.

longependula, Mart. ex Meissn. in Mart. Fl. Bras. v. I. 27.-Bras.

longifolia, Fisch. Hort. Gorenk. 25.-Ind. occ.

lucidula, Benth. in Hook. Lond. Fourn. Bot. iv

(1845) 627.-Guiana.

macrantha, Hook. Bot. Mag, sub t. $4536=$ seq

macrophylla, Desf. Tabl. ed. I. $38=$ rugosa

magnifolia, Hort. ex Meissn. in DC. Prod. xiv. $152=$ rugosa.

manzinellensis, Beurl. in Vet. Akad. Handl. Stockl. 1854 (1856) 142.-Panama.

marginata, Benth, in Hook. Lond. Fourn. Bot, iv, (1845) 626.-Bras.

Martii, Meissn。 in Mart. Fl. Bras, v. I. $37=$ nitida

membranacea, Klotzsch, in Linnaea, xiv. (1 181 ) 289 , nomen $=$ ilheensis.

microneura, Meissn. in DC. Prod. xiv. 163.Demerara.

microphylla, Griseb. Cat. Pl. Cub. 62.-Cuba. microstachya, Willd. Sp. Pl. ii. 459.-Ind. oce

mollis, Casar. Nov. Stirp. Bras. Dec. viii. $72=$ poly stachya.

monoica, Ruiz, ex Meissn. in DC. Prod. xiv. $149=$ = Muchlenbeckin tamsifolin.

Morituii, Klotzsch, ex Meissn, in Mart. Fl. Bras. V. \&. $28=$ ovata

\section{COCCOLOBA}

nitida, Desf. Tabl. ed. II. $46=$ fagifolia.

nitida, H. B. \& $K$. Nov. Gen. et Sp. ii. 176 . N. Granat.

nitida, Mart. ex Meissn. in DC. Prod. xiv. $164=$

ovata.

nivea, Jacq. Enum. Pl, Carib, $19=$ excoriata

nutans, H. B. \& K. Nov. Gen. E Sp. ii. 176.Perny.

nymphaeifolia, Linden, Cat. n. $13(1858)=$ peltata.

obovata, H. B. E K. Nov。 Gen. et Sp. ii. 175,-N Granat.

obtusifolia, Jacq. Enum. Pl. Carib. $19=$ microstachya. . (1849) 259.-Am, austr.

orbicularis, Lodd. Cat. ex Loud. Hort. Brit. $159=$ Muchlenbeckia orbicularis

ovata, Benth. in Hook. Lond. Fourn. Bot. iv. (1845 627.-Guiana.

padiformis, Meissn. in DC. Prod xiv, 166.-Venezuela.

pallida, Wright, ex Griseb. Cat. Pl. Cub. 61.Cuba.

paniculata, Meissn. in Mart. Fl. Bras, v. 1. 43=poly. stachya.

paraènsis, Meissn. l. c. 38-Bras.

parimensis, Benth, in Hook. Lond. Journ. Bot. it (1845) $626=$ excelsa

parvifolia, Nutt. N. Am. Sylv. iii. 25. t. 89 (sp. dub.). -Am. bor.

parvifolia, Poir. Encyc vi. $64=$ microstachya.

peltata, Schott, in Spreng. Syst. iv. Cur. Post. 405.-

Bras.

peltigera, Meissn. in Mart. Fl. Bras. v. I. 39 peltata.

pendula, Salzm. ex Meissn. in DC. Prod. xiv. $159=$ nitida.

Persicaria, Wedd. in Ann. Sc. Nat. Sér. III. xiii. (1849) 256.-Bolivia.

peruviana, Willd. ex Meissn. in DC. Prod. xiv. $163=$ gracilis.

pipericarpa, Mart. ex Meissn. l. c. 161.-Bras.

plantaginea, Wedd. in Ann. Sc. Nat. Sér. III. xiii (1849) 257.-Bras.

platyclada, F. Muell. ex Hook. Lot. Mag. t. $5392=$

Muehlenbeckia platyclada.

Plumieri, Griseb. Fl. Brit. W. Ind. 162.-Ind. occ

polystachya, Wedd. in Ann. Sc. Nat. Sér. III. xiii. 1849) 261.-Bras.

populifolia, Wedd.l. c. 257.-Bras.

pubescens, Linn. Syst. ed. X, $1007=$ grandifolia

punctata, Linn. Sp. Pl. ed. II. 523 = coronata.

pyrifolia, Desf. Tabl. ed. II. 46.-Ind, occ.

racemulosa, Meissn. in Mart. Fl. Bras. v. I. 30.Bras.

ramosisissima, Wedd. in Ann. Sc. Nat. Sér. III. xiii. (1849) 258.-Bras.

retusa, Griseb. Cat. Pl. Cub. 61.-Ind. occ.

rheifolia, Desf. Tabl. ed. II. 46 = latifolia.

rigida, Meissn. in Mart. Fl. Bras. v. 1. $29=$ perri folia.

rigida, Willd. ex Meissn. in DC. Prod, xiv. 163= Humboldti.

rosea, Meissn. in Mart. Fl. Bras. v. 1. 33.-Bras.

rotundifolia, Meissn. in DC. Prod. xiv. 154.-Ins. Doming.

rubescens, Linn. Sp. Pl. ed. II. 523= grandifolia

nubiginosa, Mart. ex Meissn. in DC. Prod. xiv. $160=$ acrostichoides.

rufescens, Wright, in Sauv. Fl. Cub. 19S.-Cuba.

rugosa, Desf. Cat. Hort. Par. ed. III. 389. - Ind. occ.

sagitiata, Poir. Encyc. vi. $64=$ Muchlenbeckia sagiti. folia.

sagitlifolia, Ortega, Hort. Matr. Y. 80 = Mreblenbeckia sagittifolia.

salicifolia, Wedd. in Ann. Sc. Nat. Ser. III. xiis (1849) 259.-Bras

scaudens, Casar. Nov. Stirp. Bras. Dec viii. $70=$ sticticaulis.

seandens Forsyth, ex Bensh. in Hool. Lond. Fourn. Bot. iv. (15 i5) 625. - Ind, ocv.

scandens, Poepp. ex Mcissn. in DC. Prud. xiv. 154 pellats.

Schomburgkiana, Brwsh. in Howk. Lond. Gourn. Bist iv. $18+5$ : 025 . - (iviars.

Sihomburgki, Mcissn. in Limnana, wi. ist5) 205.Civiana. 


\section{COCCOLOBA :}

sticticaulis, Wedd. in Ann. Sc. Nat. Sér. III. xiii. 1849) 261.-Bras.

striata, Benth. in. Hook. Lond. Fourn. Bot. iv. (1845) 626. - Bras.

stricta, Klotzsch, in Schomb. Faun. et Fl. Guian. 934 $=$ lucidula.

strobilulifera, Meissn. in Mart. Fl. Bras. v. I. 25.-N. Granat.

Swartzii, Meissn. in DC. Prod. xiv. 159.-Ind. occ. tenuifolia, Griseb. Fl. Brit. W. Ind. $162=$ retusa. tenuifolia, Linn. Syst. ed. X. 1007; Amoen. Acad. v. 397 (sp, dub.).-Jamaic.

Totnea, Buch.-Ham. ex D. Don, Prod. Fl. Nep. 74 = Polygonum molle.

uvifera, Linn. Syst. ed. X. 1007.-Am. trop.

Vellosiana, Casar. Nov. Stirp. Bras. Dec. viii. $70=$ crescentiaefolia.

venosa, Linn. Syst. ed. X. $1007=$ coronata.

virens, Lindl. Bot. Reg. t. $1816=$ coronata

Warmingii, Meissn. in Kjoeb. Vidensk.Meddel.(1870) 128. - Bras

Zebra, Griseb. Fl. Brit. W. Ind. 162.-Jamaic.

COCCOLOBIS, P. Br. Hist. Jamaic. $209 \quad(1756)=$ Coccoloba, Linn.

COCCOMELIA, Reinw. Cat. Gew. Buitenz, 110 (1823); et in Syll. Ratisb. ii. (1828) $5=$ Baccaurea, Lour. (Euphorbiac.).

racemosa, Reinw. 1l. ce. $110,6=\mathrm{B}$. racemosa

COCCONERION, Baill. Adansonia, xi. (1873) 8\%. EUPHORBIACEAE, Benth. \& Hook. f. nii. 323. Balansae, Baill. l. c. 88.-N. Caled.

minus, Baill. l. $c_{0}-\mathrm{N}$. Caled.

CocCOS, Gaertn. Fruct. i. $15(1788)=$ Cocos, Linn. (Palm.).

COCCOSIPSILUM, Sw. Prod. Veg. Ind. Occ. 31 (1788) = Coceocypselum, P. Br. (Rubiac.).

COCCOSPERMA, Klotzsch, in Linnaea, xii. (1838) 215 = Salaxis, Salisb. (Enicac.).

Forbesianum, Klotzsch, l. $c_{s}=\mathrm{S}$. hexandra.

rugosum, Klotzsch, 1. c. $=$ S. rugosa.

COCCULIDIUM, Spach, Hist. Vég. Phan. viii. 16 $(1839)=$ Cocculus, DC. (Menisp.)

bopulifolium, Spach, 1. c. $17=$ Cocculus carolinus.

COCCULUS, DC. Syst. i. 515 (1818). MENISPERMACEAE, Benth. \& Hook. f. i. 36.

Adenocheton, Fenzl, in Flora, xxv. (1842) 312

ANDROPHYLAX, Wendl. Beobacht. 38 (1798)

Baumgartia, Moench, Meth. 650 (1794)

Cebatha, Forsk. Fl. Aegypt. Arab. 171 (1775).

Cocculidiu M, Spach, Hist. Vég. Phan. viii. $16(1839$

Columbra, Comm. ex Endl. Gen. 826 (1840).

Diploclisia, Miers, in Ann. \& Mag. Nat. Hist. Ser. II. vii. (1851) 42

EPIbATERIUM, Forst. Char. Gen. 107. t. 54 (1776),

EPibiastrum, Scop. Introd. 253 (1777).

Ferrandia, Gaudich. Freyc. Voy. Bot. 477 (1826)。

GalloA, Hassk. Cat. Hort. Bog. Alt. 172 (1844).

Holopeira, Miers, in Ann. \& Mag. Nat. Hist. Ser. II. vii. (1851) 42 .

LEAEBA, Forsk. Fl. Aegypt. Arab. 172 (1775).

LEGNePHORA, Miers, in Ann. \& Mag. Nat. Hist.

Ser. III. xix. (1867) 88 .

NEPHROIA, Lour. Fl. Cochinch. $565(1790)$.

Quinio, Schlecht. in Linnaea, xxvi. (1854) 732.

Selwynia, F. Muell. Fragm. iv. 153 (1864).

WENDLANDIA, Willd. Sp. Pl. ii. 275 (1799).

Abuta, Kostel. Allg. Med.-Pharm. F1. ii. 501=Abuta rufescens.

acuminatus, DC. Syst. i. $527=$ Tiliacora racemosa

amazonum, Mart. ex Herberger, in Buchn. Rep. Pharm. xxxvi. (1830) 353.-Bras.

angustifolius, Hassk. Cat. Pl. Hort. Bog. Alt. $172=$ laurifolius.

Aristolochiae, DC. Syst. 1. $520=$ villosus.

Bakis, A. Rich. in Guill. \& Perr. Fl. Seneg. Tent. i. 12. t. $4=$ Tinospora Bakis.

\section{COCCULUS :-}

Balfourii, Schweinf ex Balf, $f$ in Proc. Roy. Soc Edinb. xi. (1882) 500.-Ins. Socotra.

banisteriaefolius, A. Rich. ex St. Hil. \& Tul. in Ann. Sc. Nat. Sér. II. xvii. (1842) $136=$ Pachygone oblongifolia.

bantamensis, Blume, Bijdr. 26.-Java.

Blumeanus, Wall. Cat. n. 4971 , partim $=$ Coscinium fenestratum.

brachystachyus, $D C$. Syst. i. 528.-Ins. Timor.

Burmanni, DC. 1. c. $517=$ Cyclea Burmanni.

calophyllus, Wall. ex Voigt, Hort. Suburb. Calc. 331, nomen; et ex Mast. in Hook. f. Fl. Brit. Ind. i. $578=$ Erythropalum scandens.

carolinus, DC. Syst. i. 524.-Am. bor.

Cebatha, DC. l. c. 526--Arabia.

Chondodendrum, DC l. c. 522.-Am. austr.

cinerascens, St. Hil. Fl. Bras. Mer, i. $59=$ Chondodendron platyphyllum.

cinereus, Zoll. E Moritzi, Syst. Verz. Zoll. 38.-Java. canvolvulaceus, DC. Syst. i. $518=$ Tinospora cordifolia convolvulaceus, Endl. ex Walt, Rep, i. 95.-Peruv. cardifolius, DC. Syst. i. $517=$ Tinospora cordifolia。 coriaceus, Blume, Bijdr. 25.-Java.

corymbosus, Blume, l. c. 24,-Java.

Cotoneaster, DC. Syst. i. 525.-Am。 austr.

crispus, DC. 1. c. $521=$ Tinospora crispa.

cuneatus, Benth. in Fourn. Linn. Soc. v. Suppl. ii. (1861) 50.-China.

cuspidatus, Wall. Cat. n. $4960=$ Limacia cuspidata. cynanchoides, Presl, Rel. Haenk. ii. 79.-Zeylan.

diantherus, Hook. \& Arn. Bot. Beech. Voy. 167 = Thunbergii.

dichopetalus, Turcz. in Bull. Soc. Nat. Mosc. xxvii (1854) II. 280.-Japon.

dichrous, Mart. in Flora, xxiv. (1841) II. Beibl. 46.Bras.

diversifolins, DC. Syst. i. 523.-Mexic.

domingensis, DC. 1. c. $528=$ Pachygone domingensis. ellipticus, DC. 1. c. $526=$ C. Leaeba

enneandra, Eichl. in Flora, xlvii. (1864) 391.Peruv.

Epibaterium, DC. Syst. i. 530.-Ins. Pacif.

Ferrandianus, Gaudich. in Freyc. Voy. Bot. 477.Ins. Sandvic.

Fibraurea, DC Syst. i. $525=$ Fibraurea tinctoria

filipendula, Mart. in Flora, xxiv. (1841) II. Beibl. 43. -Bras.

Finlaysonianus, Wall. Cat. n. $4974=$ Stephania rotunda.

flavescens, $D C$. Syst. i. 520.-Ins. Molucc.

flavicans, Wall. Cat. n. 4976.-Ins. Penang.

Forsteri, DC. Syst. i. 517.-Hab. ?

glaber, Wight \& Arn. Prod. i. $13=$ C. Leaeba.

glaucescens, Blume, Bijdr. 25.-Burma; Java.

glaucus, DC. Syst. i. 521.-Ins. Molucc.

gomphioides, DC. . . c. 530.-Madag.

hastatus, DC. 1. c. $522=$ villosus,

hexagynus, Colebr. in Trans. Linn. Soc, xiii. (1822) 63 . -China.

Hookerianus, F. Muell. ex Benth. in fourn. Linn. Soc. v. Suppl. ii. (1861) 52.-Austral.

Imene, Mart. in Flora, xxiv. (1841) II. Beibl. $44=$ Anomospermum japurense.

incanus, Colebr. in Trans. Linn. Soc. xiii. (1822) 57. t. $17=$ Pericampylus incanus.

japonicus, $D C$. Syst. i. 516.-Japon.

japurensis, Mart. in Flora, xxiv. (1841) II. Beibl. $44=$ Anomospermum japurense.

lacunosus, DC. Syst. i. 519=Anamirta Cocculus

laevigatus, Mart. in Flora, xxiv. (1841) II. Beibl. $45=$ Abuta concolor.

laevis, Wall. Cat. n. $4975=$ C. Leaeba.

lanuginosus, Blume, Bijdr. 24.-Java.

laurifolius, DC. Syst. i. 520--Reg. Himal. : Japon.

Leaeba, $D C$. l. c. i. 529.-As. trop. occ.; Afr. trop.

leptostachyus, DC. L. C. 528.-Ins. Timor.

Limacia, DC. l. c. 526.-Cochinch.

Linnaeanus, Kurz, in fourn. As. Soc. Beng. xliii. 1874) II. 62 (err. typ. 61)-Burma.

lobata, Mart. ex Eichl. in Mart. Fl. Bras, xiii. I. $169=$ Disciphania lobata.

longifolius, Decne. in Miq. Ann. Mus. Bot. Lugd. Bat. iv. 84. - Ins. Timor

lucidus, Teijsm. \& Binn. in Nat. Tijdschr. Nederl. Ind. iv. (1853) $397=$ Antitaxis fasciculata.

macranthus, Hook. fo in Hook. Ic. PI. t. $759=$ Jateorhiza strigosa.

\section{COCCULUS:-}

macrocarpus, Wight $\xi^{\prime}$ Arn. Prod. 13.-Ind. or.; Burma: China.

macrophyllus, St. Hil. E Tul. in Ann.Sc. Nat. Sér. II. xvii. (1842) 134.-Bras.

malabaricus, DC. Syst. i. 518=Tinospora malabarica.

Martii, St. Hil. E Tul. in Ann. Sc. Nat. Sér. II. xvii. (1842) 135.-Bras.

megaspermus, Voigt, Hort. Suburb. Calc. 331.Silhet.

membranaceus, Wall. Cat. n. $4967=$ Cissampelos Pareira.

milleflorus, DC. Syst. i. 530-Madag.

mollis, Wall Cat n. 4973.-Reg. Himal

Moorei, F. Muell. Fragm. i. $162=$ Pericampylus incanus.

Nephroia, DC. Syst. i. 531.-Cochinch.

nudiflorus, Griff. Notul. iv. 307.-Burma.

oblongifolius, DC. Syst. i. 529.-Am. bor. occ.

oblongifolius, Mart. in Flora, xxiv. (1841) II. Beibl. 43 $=$ Pachygone oblongifolia.

oblongus, Wall. Cat. n. $4963=$ Limacia oblonga. orbiculatus, DC. Syst. i. $523=$ Cissampelos Pareira ovalifolius, Blume, Bijdr. $25=$ umbellatus. ovalifolius, DC. Syst, i. 526= Thunbergii

Pahni, Mart. in Flora, xxiv. (1841) II. Beibl. $45=$ Anomospermum japurense.

palmatus, DC. Syst. i. $522=$ Jateorhiza Columba.

palmatus, Hook. Bot. Mag. tt. 2970-71 = Jateorhiza Miersii.

paniculiger, Mart. in Flora, xxiv. (1841) II. Beibl. 43 $=$ Pachygone domingensis.

pauper, Griseb. in Goett. Abh. vii. (1856-57) 162.Am. trop.

peltatus, DC. Syst. i. $516=$ Cyclea peltata

petiolaris, Wall. Cat. n. $4964=$ Tinomiscium petiolare planiflorus, Wall. 1. c. n. $4961=$ Pycnarrhena planiAlora.

platyphyllus, St. Hil. Fl. Bras. Mer. i. $59=$ Chondodendron platyphyllum.

Plukenetii, DC. Syst. i. $520=$ Pachygone ovata.

polycarpus, Wall. Cat. n. $4958=$ Tiliacora racemosa

populifolius, DC. Syst. i. $519=$ Anamirta Cocculus.

radiatus, DC. 1. c. $527=$ Tiliacora racemosa.

recisus, Miers, 'Contrib. iii. $258=$ C. Leaeba.

reticulatus, Mart. in Flora, xxiv. (1841) II. Beibl. $44=$ Anomospermum reticulatum.

rimosus, Blume, Bijdr. 24.-Java.

rotundifolius, $D C$. Syst. i. 517.- Hab?

Roxburghianus, DC. 1. c. $516=$ Stephania rotunda

sagittaefolius, Miers, Contrib. iii. 255-Am. bor

Selwynii, F. Muell. Fragm. iv. 153=Selwynia laurina

sepium, Colebr. in Trans. Linn. Soc. xiii. (1822) 58. t. $6=$ villosus.

smilacinus, F. Muell. ex Benth. in Journ. Linn. Soc. v. Suppl ii. (1861) $52=$ Tinospora smilacina .

suberosus, DC. Syst. i. $519=$ Anamirta paniculata.

tamoides, DC. 1. c. $521=$ Chondodendron tamoides.

tetrandrus, Zipp. ex Span. in Linnaea, xv. (1841) 164, nomen.-Malaya.

Thunbergii, DC. Syst. i. 524.-Japon.

tomentosus, Colebr. in Trans. Linn. Soc. xiii. (1822) $59=$ Tinospora tomentosa

tomentosus, Mart. ex Eichl. in Mart. F1. Bras. xiii. I. $175=$ Abuta rufescens.

triandrus, Colebr. in Trans. Linn. Soc. xiii. (1822) 64 $=$ Limacia triandra.

triangularis, Zipp.ex Span. in Linnaea, xv. (1841) 164 , nomen.-Malaya.

triflorus, DC. Syst. i. 529.-Java.

trilobus, DC. $l$. c. 522.- Japon.

umbellatus, Steud. Nom. ed. II. i. 392.--Java

urophyllus, Mart. in Flora, xxiv. (1841) II. Beibl. 45.

-Bras.

velutinus, Wall. Cat. n. $4970=$ Limacia velutina.

verrucosus, Wall. 1. c. n. 4966 A, B=Tinospora crispa.

verrucosus, Wall. 1. c. n. 4966 C, D, E = Tinospora cordifolia.

villosus, $D C$. Syst, i. 525.-Ind, or.; Afr. trop.

villosus, Wall. Cat. n. 4957 , partim $=$ Cissampelos Pareira.

Wightianus, Wall. 1. c. n. $4959 \mathrm{~A}=$ Pachygone ovata.

COCCUS, Linn. Mus. Cliff. 11 (1736); Gen. ed. I. 355 $(1737)=$ Cocos, Linn. (Palm.). 
COCCYGANTHE, Reichb. Fl. Germ. Excurs. xvi. 55 (1844) = Lyehnis, Linn. (Caryophyll.). Flos-cuculi, Reichb. 1. c. =L. Flos-cuculi

pratensis, Schur, Enum. Pl. Transs. $107=$ L. Floscuculi.

COCHLANTHERA, Choisy, in Mém. Soc. Phys. Genèv. xii. (1851) $426=$ Clusia, Linn. (Guttifer.).

lanceolata, Choisy, 1. c.-Venezuela.

COChlantrhus, Balf. f. in Proc. Roy, Soc. Edinb. xii. (1884) 78. ASCLEPIADACEAE. socotranus, Balf. f. l. c. 79.-Ins. Socotra.

COCHLEANTHES, Rafin. Fl. Tellur. $45(1836)=$ Zygopetalum, Hook. (Orchid.).

fragrans, $\mathrm{Rafin} . \mathrm{l}$. $\mathrm{c}=\mathrm{Z}$. cochleare.

COCHLEARIA, Tourn. ex Linn. Syst. ed. I (1735). CRUCIFERAE, Benth. \& Hook. f. i. 75.

Armoracia, Riv. ex Gaertn. Mey. \& Scherb. Fl, Wett. ii. $426(1800)$

Chrysochamela, Boiss, Fl. Orient. i. 313 (1867).

Gonyclisia, Dulac, Fl. Hautes-Pyr, 191 (1867).

Ionopsidium, DC. ex Steud. Nom. ed. II. i. 392 (1840).

Kernera, Medic. Pflanzeng. 71 (1792).

Raphanis, Dod. ex Moench, Meth. 267 (1794).

Rhizonotrya, Tausch, in Flora, xix. (1836) 33.

TAPHRospermum, C. A. Mey, in Ledeb. Fl. Alt. iii. $172(1831)$.

TROPHOSPERMUM, Walp. Rep. i. 171 (1842),

acaulis, Desf. Fl. Attant. ii. 69.-Lusitan. ; Afr. bor. alpina, Sweet, Hort. Brit. ed. I. $22=$ officinalis. altaica, Schlecht, ex DC. Prod. i. 173=microcarpa. alyssoides, DC. 1. c. 172 = flava.

amphibia, Ledeb. Fl. Ross. i. 160,-Soongaria. anglica, Linn. Syst. ed. X. 1128.- Reg. bor. et arct. aphragmodes, Boiss. Diagn. Ser. I. vi. 15.-Persia. aquatica, Eaton, Man. ed. V. $181=$ Nasturtium lacustre?

aquatica, C. A. Mey, in Ledeb. Fl. Alt. iii. 88.As. bor.

arctica, Schlecht. in DC. Syst. ii. $\mathbf{3 6 7}=$ anglica.

Armoracia, Linn. Sp. Pl. t. 648.-Europ.

Armoracia, Pall. ex DC. Syst. ii. $\mathbf{3 6 2}=$ microcarpa

Aucheri, Boiss. in Ann. Sc. Nat. Sér. II, xvii. (1842)

168.-Armenia.

auriculata, Lam. Encyc. ii. 165.-Europ.

austriaca, Ledeb. Fl. Ross. i. 160.-Rossia.

austriaca, Vis. Fl. Dalm. iii. $122=$ Nasturtium austriacum.

batava, Dum. Fl. Belg. Prod. 120.-Batavia.

brevicaulis, Facch. in Zeitschr. Ferdin. Tirol. III. 1854) 79 , - Tyrol.

Caisia, Wall. Cat. n. $4802=$ flava.

Camelinae, Boiss, in Ann. Sc.Nat. Sér. II. xvii. (18t2) 172.-Persia.

Camelinae, Ledeb. Fl. Ross. i. 160, in nota-Manchuria.

campylocarpa, Boiss, in Ann. Sc. Nat. Sér. II, xvii. (1842) 171.-Persia.

cordifolia, Turcs. ex Bunge, in Mém. Sav. Etr. Acad. Petersb. ii. (1885) 579.-Sibir. baical.

Coronopzes, Linn. Sp. P1, $648=$ Senebiera Coronopus.

Crantzii, Crantz, Class. Crucif. Emend. 100,-Europ.

crassifolia, Willd. ex DC. Prod. i. $173=$ macrocarpa.

danica, Gunn. Fl. Norv, 72.n. $197=$ officinalis.

danica, Linn.Sp. Pl. 647.- Reg. bor, et arct.

decipiens, Willk. Sert. Fl. Hispan. 12,-Mont. Pyren.

Draba, Linn. Syst. ed. X. $1129=$ Lepidium Draba.

drabaecarpa, Boiss. in Ann. Sc. Nat. Sér. II. xvii. (1842) 169-Persia.

fenestrata, R. Br. in App. Voy. Ross, (1819) p. cxliii $=$ officinalis.

fugrans, Gilib. Fl. Lituan. ii. $51=$ officinalis.

flava, Buch.Ham.ex Roxb. Hort. Beng. 48, nomen.Ind. or.

foetida, Schkuhr, Baier. Fl. ii, 185 = Camelina foetida glastifolia, Falk, Beitr. ii. $215=$ Hymenophysa pubescens.

glastifolia, Linn.Sp. Pl. 648,-Europ.

glastifolia, Pall. ex DC. Syst. ii. $369=$ Draba salsa.

glaucophylla, Boiss. in Ann. Sc. Nat. Sér. II. xvii. (1842) 169.-Persia.

globosa, Ledeb. Fl. Ross, it. 159,-Dahuria.

grandiflora, DC. Syst. ii. $363 .-$ Sibiria.

groenlandica, Gunn. Fl. Norv, 7\%, B, $196=$ anglica.

\section{COCHLEARIA}

groenlandica, Linn. Sp. Pl. $647=$ officinalis, groenlandica, Willd. ex DC. Prod. i. $173=$ lenensis, hastata, Moench, Meth. Suppl. 87 =danica. hederacea, S. F. Gray, Nat. Arr. Brit. P1. ii. 696 danica.

heterophylla, Cav. Desc. $405=$ Camelina dentata.

heterophylla, Fisch. Hort. Gorenk, ed. II. (1812) 50 nomen $=$ seq.

heterophylla, Schlecht. in DC. Syst. ii. 372 sisymbrioides.

himalaica, Hook. f. E Thoms, in Fourn. Linn. Soc, v. (1861) 154.-Keg. Himal.

humifusa, Michx. Fl. Bor。Am。 ii, $27=$ Senebier didyma.

integrifolia, DC. Syst. ii. 368 = Eutrema alpestre.

kamtschatica, Schlecht. ex DC. Prod, i. $173=$ offi cinalis.

lancifolia, Stokes, Bot. Mat. Med. iii. $437=$ C. Armoracia.

lapathifolia, Gilib. F1. Lituan. iv. $53=$ C. Armoracia

lenensis, Adams, ex Fisch. in DC. Syst. if. 367.Sibiria.

Linnaei, Griewank, ex Aschers. in Fl. Prov. Brandenb. $\mathbf{5 4}=$ officinalis.

longifolia, Medic. in Usteri, Neu. Ann。 ii. 41.Europ.

lyrata, Sibth. E Sm. Fl. Graec. Prod. ii. 8 ; Fl. Graec . 619.--Sicilia.

macrocarpa, Waldst. Eo Kit. Pl. Rar. Hung, ii. 101 t. 184.-Hungar. ; Transsylv.

mexicana, S. Wats. in Proc. Am. Acad. xvii. (1881 82) 320 .-Mexic.

microcarpa, DC. Syst, ii. 362,-Sibir.

minima, Steud. Nom. ed. II. i. $392=$ danica.

natans, C. A. Mcy。 in Ledeb. Fl. Alt. iii. $90=$ amphibia.

nilotica, Delile, Fl. Egypte, $245=$ Senebiera nilotica.

oblongifolia, DC. Syst. ii. $363=$ officinalis

officinalis, Lapeyr. Hist. Abr. Pl. Pyr. $368=$ pyrenaica,

officinalis, Linn. Sp. Pl. 647.-Reg. bor. et arct.

olyssiponensis, Brot. Fl. Lnsit. i. $571=$ acaulis.

ovalifolia, Stokes, Bot. Mat. Med, iii, 436 = anglica.

planisiliqua, Boiss. in Ann. Sc. Nat. Sér. II. xvii. (1842) 169.-Persia.

polysperma, Costa, ex Willk. in Linnaea, xxx. (1859-60) $86=$ Kernera polysperma.

Pseud-Armoracia, Czern. ex Trantv. in Act. Hort.

Petrop. viii. (1883) $93=$ macrocarpa ?

pusilla, Brot. Phyt. $100=$ acaulis

pyrenaica, DC. Syst. ii. $365=$ officinalis.

renifolia, Stokes, Bot. Mat. Med. iii. $435=$ officinalis.

repanda, Medic. in Usteri. Neu. Ann. ii. 42.-Europ.

repens, Lam. Fl. Fr. ii. 473 =Senebiera Coronopus,

rhizobotrya, Walp. Rep.i. 153.-Austria.

rotundifolia, S. F. Gray, Nat. Arr. Brit. Pl. ii. $695=$ officinalis.

rusticana, Lam, Fl. Fr. ii. $471=$ C. Armoracia.

sagittaefolia, Desv. Fourn. Bot. iii. (1812) 182.-

Hab. ?

sagittata, Crantz, Class. Crucif. Emend. $99=$ Neslia paniculata.

salsa, Schlecht. ex DC. Syst. ii. 369.-Sibiria?

sativa, Cav. Desc. $405=$ Camelina sativa

saxatilis, Linn. Sp.Pl. 648.-Europ.

saxifragaefolia, DC. Syst. id, $370=$ Graellsia saxifragaefolia.

scapiflora, Hook. f. \& Thoms. in Foum. Linn. Soc. v. (1861) 154.--Reg. Himal.

Sempervivum, Boiss. \& Bal. Diagn. Ser. II. v. 28.As. Min.

septentrionalis, DC. Prod. i. $174=$ Draba hyperborea septentrionalis, Schlecht, in DC, Syst. ii. $355=$ officinalis.

sibirica, Willd. Sp. Pl. iii. $450=$ Sobolewskia lithophila.

siliquosa, Schlecht. in DC. Syst, ii. $369=$ Draba hyperborea.

sisymbroides, $D C$. l. c. 368.- Sibir. arct.

spathulata, Schlecht. in DC. l. c. $369=$ Draba hyperborea.

Szovitzii, Boiss. Fl. Orient. i. 248.-Persia.

tenuifolia, Salisb. Prod. $267=$ Senebicra Coronopus,

tridactylites, Banks, ex DC. Syst, ii. 367 -Am. artt.

variifolia, Salisb. Prod, $267=\mathrm{C}$. Armoracia,

velutina, DC. Syst. ii. 870.-Mesopos.

violacea, Boisso in Ann. Sc. Nat. Sir. II. xvii. (18t2 171.-Persia.

\section{COCHLEARIA}

Wahlenbergii, Rupr. Beitr. PA, Russ. Reich. ii. $21=$ anglica.

Wunderlichii, C. A. Mey. ex Claus, in Beitr. PR. Russ. Reich. viii, 203.-Rossia.

COCHLEATA, Riv, ex Rupp. Fl. Jen. ed, Hall, 261 $(\mathbf{1 7 4 5})=$ Medicago, Linn. (Legum.

intertexta, Medic. in Vorles. Churf. Ges, ii. (1787) 385 $=\mathrm{M}$. intertexta.

scutellata, Medic. Phil. Bot. i. $210=$ M. scutellata.

COCHLIA, Blume, Bijdr. 320.t. $59(1825)=$ Bulbo phyllum, Thou. (Orchid.

violacea, Blume, $1 . c_{n}=\mathrm{B}$. violaceum.

COCHLIANTHUS, Benth. in Miq. PI. Jungh, i. 234, in nota (1851?). LEGUMINOSAE, Benth. \& Hook. f. i. 533.

gracilis, Benth. l. c.-Reg. Himal.

COCHLIDIOSPERMUM, Reichb. Consp. 121 (1826)= Veronica, Tourn. (Scrophularin.).

agreste, Opiz, Seznam, $31=V$, agrestis.

Buxbaumii, Opiz, 1. $c_{n}=$ V. Toumefortil.

digitatum, Opiz, 1. $\mathrm{c}_{\mathrm{s}}=\mathrm{V}$, triphyllos.

Frieseanum, Opiz, 1. c. =V. opaca.

hederaefolium, Opiz, $\mathrm{l}_{\text {. }} \mathrm{c}_{\mathrm{v}}=\mathrm{V}$, hederacfolia

Lappago, Opiz, in Lotos, iv. (18j4) $158=\mathrm{V}$. hederae rolia.

opacum, Opiz, Seznam, $31=$ V. opaca.

praecox, Opiz, 1. c. $=$ V. praecox.

COCHLIODA, Lindl. Fol. Orchid. (1853). ORCHI$D E A E$, Benth. \& Hook. f. iii. 560. densiflora, Lindl. $l$. c.-Reg. Andin.

COCHLIOPETALUM, Beer, in Flora, xxxvi. (1854 347; Bromel. 68 (1857) = Pitcaimia, L'Hérit. (Bromeliac.)

albiflos, Beer, Bromel. $68=\mathrm{P}$. albiflos

flavescens, Bcer, 1. c. $69=\mathrm{P}$. xanthocalyx

odoratum, Hemsl. Biol. Centr. Am. Bot. iii. $317=$ P. odorata.

Schuechii, Beer, Bromel, $69=\mathrm{P}$ albiflos.

stamineum, Beer, in Flora, xxxvii. (1854) $347=0$. staminea.

COCHLIOSPERMUM, Lag. Mem. P1. Barill. 58 (1817 $=$ Suaeda, Forsk. (Cheaopod.)

altissimum, Lag. 1. c. $57=\mathrm{S}$. altis:ima.

Cavanillesii, Lag. 1. c. $60=$ S. maritima

Clementei, Lag. 1. c. $62=\mathrm{S}$. splendens.

fruticosum, Lag. 1. c. $59=\mathrm{S}$. fruticosa

hispanicum, Lag. 1. c. $58=$ S. altissima.

salsum, Lag. 1. C. $55=\mathrm{S}$. maritima.

COCHLIOSTEMA, Lem. Illustr. Hortic. vi. (185: Misc. 70 et t. 217. COMMELINACEAE, Benth. Hook. f, iii. 850 .

Jacobianum, C. Koch E Linden, in C. Koch E Fint. Wochenschr. x. (186i) 322.-Ecuador.

odoratissimum, Lem. Illustr. Hortic. vi. (18.59) Misc. 70. t. 217.-Ecuador.

odoratum, C. Koch, in C. Koch \& Fint. Wochenschr. ii. (1859) $340=$ odoratissimum.

COCHLOSPERMUM, Kunth, Malv, 6 (182) BJYINEAE Benth. \& Hook f i 1.24.

Azfredia, Arruda, ex Allem. Desenb. $(1+46)$

Maximliaxa. Mart. in Flora, ii. 1519 4. 1.

Wittelsbachia, Mart. Nov, Gen. et Sp. i. E0. t. 35 (1824)

angolense, Welvo. Apont. 566; Oliser, Fl. Trop. Afr. i. 113. - Afr. trop.

Cadinae, Eichl. in Mart. Fl. Bras. xiii. 1. 431.Bras.

Fraseri, Planch. in Hook. Lond. Gourm. Bof. vi. 15+i) $30 \overline{0}$ - Austral.

Gilliwraei, Benth. Fl Alsstral. i. 106.-Auspral.

Gossypium, DC. Pred. i. 52i--Ind. or.

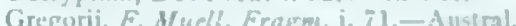

beteronemum, $F$. Muell, in Hook. Rres Gourn. ix $(1 \leq 5 i) 15$ ( = seq. 1).-Austral.

heleroneurum, fo. If well. ex Bensh. Fl. Asusfral. i. 10hi. Auviral.

hiliscoides, Aunth, Sym. Pl. Ang, iii. 211. Mexic.

insigze, S6. Hil. Pl. Us. Pras. R. 37. - Mras

ailaticum, Oliser, Fl. Trop. Afr. i 113. - Afr. trop. 


\section{COCHLOSPERMUM :-}

orinoccense, Steud. Nom. ed, II. i. 393.-Venezuela.

Parkeri, Planch. in Hook. Lond. Fourn. Bot. vi.

(1847) 310.-Guiana.

parkiaefolium, Planch. l. c. 311_-Guiana.

Planchoni, Hook. f. ex Planch. l. c. 309.-Afr. trop.

serratifolium, DC. Prod. i. 537= hibiscoides.

tinctorium, Perr. in Ann. de la Marine et des Colonies

(1830); ex A. Rich. in Guill. E" Perr. Fl. Seneg.

Tent. i. 99.-Afr. trop.

vitifolium, Spreng. Syst. ii. $596=$ serratifolium

vitifolium, Spreng. l. c. iv. Cur. Post. 206.-Mexic.

COCHRANEA, Miers, Trav. Chile, ii. 529 (1826) nomen; et in Ann. \& Mag. Nat. Hist. Ser. IV. ii (1868) 125. BORAGINEAE, Benth. \& Hook. fo ii. 845 .

chenopodiacea, Miers, in Ann. E Mag. Nat. Hist. Ser. JV. ii. (1868) 132.-Chili.

conferta, Miers, Trav. Chile, ii. 529, nomen; et l. c. 125 -Chili.

corymbosa, Miers, in Ann. E Mag. Nat. Hist. Ser. IV. ii. (1868). 126,-Chili.

ericoidea, Miers, l. c. 130.-Chili.

filifolia, Miers, l. c. 131.-Chili.

florida, Miers, l. c. 129.-Chili.

hebecula, Miers, l. c. 130.-Chili.

hispidula Miers, l. c. 132-Chili

myosotifolia, Miers, $l$. $c$. 128-Chili.

sinuata, Miers, l. c. 127.-Chili

stenophylla, Miers, $l$. c. 128.-Chili.

COCKBURNIA, Balf, f. in Proc. Roy. Soc. Edinb. xii (1884) 90. SELAGINEAE.

socotrana, Balf.f.l. c.-Ins. Socotra.

COCOCIPSILUM, Jaume St. Hil. Expos. i. $434(1805)$ =Coccocypselum, P. Br. (Rubiac.).

COCOLOBA, Rafin. Fl. Tellur. ii. $34(1836)=$ Cocco loba, Linn. (Polygal.).

COCOS, Linn. Sp. Pl. ed. I, 1188 (1753). PALMAE, Benth. \& Hook. f. iii. 945.

Glaziova, Mart. ex H. Wendl, in Flor, et Pom. (1871) 116.

LANGSDorffiA, Raddi, in Mem. Soc. Ital. Mod. xviii. (1820) 347. t. 1 .

Lithocarpus, Targ. Tozz. ex Steud. Nom. ed. II. i. 173 , in sym. (1840).

Platenia, Karst. in Linnaea, xxviii. (1856) 250.

Syagrus, Mart. Hist. Nat. Palm ii. 129 (1824)

acaulis, Drude, in Mart. Fl. Bras. iii. II. 426.-Bras.

acicularis, Sw. Prod. Veg. Ind. Occ. $58=$ Bactris minor.

acrocomioides, Drude, in Mart. Fl. Bras. iii. Ir. 409. -Bras.

aculeata, Jacq. Select. Am. 278 = Acrocomia sclerocarpa.

aequatorialis, Drude, in Mart. Fl. Bras. iii. II. 407, sphalm. $=$ C. Inajai.

amara, facq. Select. Am. 277.-Ind. occ.

arenaria, Gomez, in Mem. Ac. Lisboa, iii. (1812)

Mem. dos Corresp. $61=$ Diplothemium littorale.

argentea, Engel, in Linnaea, xxxiii. (1864-65) 690.N. Granat.

Aricui, Neuwied, Reise Bras. i. 272=schizophylla.

australis, Mart. Palmet. Orbign. 95.-Paraguay.

Bonneti, Hort. ex H. Wendl. in Kerch. Palm. 240 nomen.-Hab.?

botryophora, Mart. Hist. Nat. Palm. ii. 118. t. 83, 84 . - Bras.

butyracea, Linn. f. Suppl. 454.-Am. austr.

butyracea, Mart. ex H. Wendl, in Kerch. Palm. $140=$ Scheelea butyracea.

butyrosa, H. Wendl. 1. c. = Attalea humilis

campestris, Mart. Hist. Nat. Palm. ii. 121.-Bras.

capitata, Mart. l. c. 114.-Bras.

chilensis, Molina, ex H. B. \& K. Nov. Gen. et Sp. i. 309 , in obs. $=$ Jubaea spectabilis.

comosa, Mart. Hist. Nat. Palm. ii, 121. t. 88. f. 1-2.Bras.

coronata, Mart. l.c. 115. tt. 80,81 .-Bras.

crispa, H. B. E. K. Nov. Gen. et Sp. i. 302.-Cuba.

Datil, Drude E' Griseb. in Goett. Abh. xxiv. (1879) 283.--Reg. Argent.

elegantissima, Hort. ex $\mathrm{H}$. Wendl. in Kerch. Palm. $241=$ Weddelliana.

\section{Cocos:}

equatorialis, Barb.-Rodr. Enum. Palm. Nov. 38=C,

Inajai.

eriospatha, Mart. ex Drude, in Mart. Fl. Bras. iii. II. 424.-Bras.

flexnosa, Mart. Hist. Nat. Palm. ii. 120.-Bras

frigida, Linden, in Illustr. Hortic. xxviii. (1881) 16 , nomen.-Bras.

fusiformis, Sw. Fl. Ind. Occ. i. $616=$ Acrocomia sclerocarpa.

Geriba, Barb.-Rodr. Prot. App. $43=$ botryophora

graminifolia, Drude, in Mart. Fl. Bras. iii. II. 415.Bras.

Guacruyle, Liebm. ex Mart. Hist. Nat. Palm. iii. 323. -Mexic.

guineensis, Linn. Mant. i. $137=$ Bactris minor.

Inajai, Spruce, ex Trail, in Fourn. Bot. xv. (1877) 79. -Bras.

insignis, Mart. ex H. Wendl. in Kerch. Palm. 241.Bras.

Kotchoubeyi, Linden, Illustr. Hortic. xxviii. (1881) 16 , nomen.-Bras.

lapidea, Gaertn. Fruct. i. 16. t. 6. f. 1.-Bras.

leiospatha, Barb.-Rodr. Prot. App. 44.-Bras.

maldioica, J. F. Gmel. Syst. $569=$ Lodoicea sechel. larum.

mamillaris, Blanco, Fl. Filip. ed. I. 722.--Ins. Philipp. maritima, Comm. ex H. Wendl, in Kerch. Palm. $241=$ Lodoiceae sp.

Martiana, Drude \& Glaz. ex Drude, in Mart. Fl. Bras. iii. II. 418.-Bras.

melanococca, Hort. Belg. ex Heynh. Nom. ii. 152, nomen.-Hab.?

Mikaniana, Mart. Hist. Nat. Palm. iii. 128-Bras.

Naja, Arruda, ex Kunth, Enum. Pl. iii. 288.Am. trop.

nana, Griff. Notul. iii. $166=$ nucifera.

Nolaia-assu, Neuried, Reise Bras. i. 271--Bras.

Normanbyi, W. Hill, Rep, Brisb, Bot. (1876) 6; ex F. Muell. Fragm. viii. $235=$ Areca Normanbyi. nucifera, Linn. Sp. Pl. 1188.--Reg. trop.

Nypa, Lour. F1. Cochinch. $567=$ Nipa fruticans.

oleracea, Mart. Hist. Nat. Palm. ii. 117. t. 82.-Bras.

orinocensis, Spruce, in fourn. Linn. Soc. xi. (1871) 161.-Am. trop.

ovata, Hort. Belg. ex Heynh. Nom. ii. 152, nomen.Hab.?

petraea, Mart. Palmet. Orbign. 100.-Bolivia

pityrophylla, Mart. l. c. 99.-Bolivia.

plumosa, Hook. Bot. Mag. t. 5180.--Bras.

plumosa, Lodd ex Loud. Hort. Brit. $381=$ comosa

Procopiana, Glaz. ex Drude, in Mart. Fl. Bras, iii. II 412. - Bras.

regia, Liebm. in Mart. Hist. Nat. Palm. iii. 323.Mexic.

Romanzoffiana, Cham, in Choris, Voy. Pittor. (Chili) 5. t. 6 \& 6 [bis].-Bras.

rupestris, Barb.-Rodr. Prot. App. $45=$ petraea

schizophylla, Mart. Hist. Nat. Palm. ii. 119. tt. 84, 85 -Bras.

speciosa, Barb.-Rodr.Enum. Palm. Nov. 38.-Bras.

simplicifolia, Hort. Belg. ex Heynh. Nom. ii. 152.Hab. ?

Syagrus, Drude, in Mart. Fl. Bras. iii. II. 406.-Bras.

sylvestris, Hort. ex H. Wendl. in Kerch. Palm. 241, nomen.-Hab. ?

Urucuru, Linden, in Illustr. Hortic. xxviii. (1881) 16 , nomen.-Bras.

ventricosa, Arruda, in Koster, Trav. Braz. 485.-Bras. venatorum, Poepp. ex H. Wendl, in Kerch. Palm. 241 = Maximiliana venatorum.

vinifera, Mart. Hist. Nat. Palm. iii. $324=$ Gaussia vinifera.

Weddelliana, H. Wendl. in Flor. et Pom. (1871) 114.

Weddellii, Drude, in Mart. Fl. Bras, iii. II. 411.Bras.

Yatay, Mart. Palmet. Orb. 93.-Reg. Argent.

Yurumaguas, Hort. ex H. Wendl. in Kerch. Palm. 241. -Peruy.

CODANTHERA, Rafin. Fl. Tellur. iii. $90(1836)=$ Salvia, Tourn. (Labiat.)

biflora, Rafin. 1. c. = S. hebiflora.

glabra, Rafin. I. c. $=$ S, strictiflora

CODARIA, Linn. ex Benn. Pl. Jav. Rar. 99 (1838)= Lerchea, Kalm. (Rubiac.).
CODARIOCALYX, Hassk. in Flora, xxv. (1842) II. Beibl. 48 = Desmodium, Desv. (Legumin.)

capitatus, Hassk. 1. c. $49=$ D. capitatum.

conicus, Hassk. 1. c. $49,62=\mathrm{D}$. gyroides

gyrans, Hassk. 1. c. $=\mathrm{D}$, gyrans.

gyroides, Hassk. 1. c. $49=\mathrm{D}$. gyroides,

CODARIUM, Soland. ex Vahl, Enum. i. $302(1806)=$ Dialium, Linn. (Legumin.)

acutifolium, Afzel. in Schrad. N. Journ. ii. (1807) 233 $=$ D. guineense,

discolor, DC. Prod. ii. $520=\mathrm{D}$. guineense.

nitidum, Vahl, Enum. i. 302 ; ii. $400=$ D. guineense. obtusifolium, Afzel. in Schrad. N. Journ. ii. (1807) 233 $=\mathrm{D}$. guineense.

Solandri, Vahl, Enum. i. $302=$ D. guineense.

CODAZZIA, Karst. \& Triana, in Linnaea, xxviii. (1856) $426=$ Delostoma, D. Don (Bignoniac.).

dentata, Karst. Fl. Columb. ii. 37. t. $119=$ D, rosea. rosea, Karst. in Linnaea, xxviii. (1856) $427=$ D. rosea speciosa, Karst. 1. c.-N. Granat.

CODDAMPULI, Adans. Fam.ii. 445 (1763)= Garcinia Linn. (Guttif.).

CODDA-PANA, Adans. Fam. ii. $25(1763)=$ Ben tinckia, Berry (Palm.)

CODIA, Forst. Char. Gen. 59. t. 30 (1776). SAXIFRAGEAE, Benth. \& Hook. f. i. 648.

ferruginea, Bronon. Eo Gris, in Bull. Soc. Bot. Fr. ix. 1862) 77.-N. Caled.

florihunda, Brongn. E Gris, l. c.-N. Caled.

montana, Forst. Char. Gen. 68.-N. Caled

montana, Labill. ex D. Don, in Edinb. N. Phil. Journ (Apr.-June 1830) 94=Callicoma Billardieri.

obcordata, Brongn. EN Gris, in Bull. Soc. Bot. Fr. ix. (1862) 77.-N. Caled.

serratifolia, Ser. ex DC. Prod. iv, $7=$ Callicoma serratifolia.

spathulata, Brongn. E Gris, in Bull. Soc. Bot. Fr. ix. (1862) 77 . - N. Caled

CODIAEUM, Rumph. ex A. Juss. Euph. Tent. 33. t. 9 1824). EUPHORBIACEAE, Benth. \& Hook, f. iii. 299.

Crozophyla, Rafin. Sylva Tellur. 64 (1838).

Junghuhnia, Miq. F1. Ind. Bat. i. II. 412 (1855).

Phyllaurea, Lour. F1. Cochinch. 575 (1790)

SYNASPISMA, Endl. Gen. 1110 (1840).

alternifolium, Muell. Arg. in DC. Prod. xv. II. 1117. -N. Caled.

andamanicum, Kurz, in Journ. As. Soc. Beng. xlii. (1873) I1. 246 (= Blachiae sp.).-Ins. Andaman. aurantiacum, Muell. Arg. in DC. Prod. xv. II. 1118.Ins. Banca.

Balansae, Baill. Adansonia, xi. (1873-76) 77.-N. Caled.

Brongniartii, Baill. l. c. 76.-N. Caled.

Bureavi, Baill. l. c. 74.-N. Caled.

carunculatum, Muell. Arg. in DC. Prod. xv. II. 1117.N. Caled.

chrysosticton, Spreng. Syst. iii. $866=$ variegatum. cuneifolium, Zipp. ex Span. in Linnaea, xv. (1841) $348=$ variegatum.

Deplanchei, Baill. Adansonia, xi. (1873-76) $75 .-\mathrm{N}$. Caled.

drimiflorum, Baill, l. c-N. Caled.

inophyllum, Muell. Arg, in DC. Prod. xv. II. 1120.N. Caled,

lutescens, Kurz, in Journ. As. Soc. Beng. xlii. (1873) II. $246=$ Sphyranthera capitellata.

medium, Baill. Adansonia, i. (1860-61) $251=$ variegatum.

moluccanum, Decne, in Nouv. Ann. Mas. Par. iii. (1834) 485 = variegatum,

obovatum, Zoll. \& Morr. in Nat. en Geneesk. Arch. Neêrl. Indie, ii. (1845) $582=$ variegatum.

Pancheri, Muell. Arg. in DC. Prod. xv. II. $1117=$ Baloghia Pancheri.

Pentzii, Muell. Arg. 1. c. $1118=$ Blachia Pentzii.

pictum, Hook. Bot. Mag. t. 3051 = variegatum.

roseo-pictum, André, Illustr. Hortic. xxvi. (1879) 170. t. 364 .-Hab.?

timorense, A. Juss. Tent. Euph. 34, nomen = variegatum. umbellatum, Muell. Arg. in DC. Prod. xv. II. $1118=$ Blachia umbellata.

variegatum, Blume, Bijdr.606.-Malaya. 
CODIAMINUM, Rafin. F1. Tellur. iv. 21 (1836)= Narcissus, Tourn. (Amaryllid.) (N. Bulbocodium).

CODIPHUS, Rafin. Fl. Tellur. ii. $77(1836)=$ Prismatocarpus, L'Hérit. (Campanulac.).

nitidus, Rafin. $1 . c_{.}=\mathrm{P}$. nitidus.

CODIVALIA, Rafin. F1. Tellur. iii. 40 (1836) Pupalia, Juss. (Amarant.). lappacea, Rafin. 1. c。= P. lappacea. patula, Rafin. 1. c.=P. lappacea.

CODOCHONIA, Dun. in DC. Prod. xíii. I. 482 (1852) =Acnistus, Schott (Solanac.). solanoides, Dun. $1 . \mathrm{c}_{0}=\mathrm{A}$. umbellatus,

CODON, Linn, Syst ed. XII. 292 (1767), HYDROPHYLLACEAE, Benth. \& Hook. f. ii. 830 . aculeatum, Gaertn. Fruct. ii. $88=$ Royeni. Dregei, E. Mey. Zwei Pfl. Docum. 174, nomen.-Afr. austr.

Royeni, Linn. Syst. ed. XII. 292.-Afr, austr.

CODONACANTHUS, Nees, in DC. Prod, xi. 103 (1847). ACANTHACEAE, Benth. \& Hook. f. ii. 1098 .

acuminatus, Nees, 1. c. = pauciflorus

pauciflorus, Nees, l. c.-Hongkong.

CODONACHNE, Wight \& Arn. ex Stend. Nom. ed. II. i. $393(1840)=$ Chloris, Sw. (Gramin.).

Neesiana, Wight \& Arn. 1, c. = Chloris tenella.

CODONANDRA, Karst. F1. Columb, ii, 43, t. 122 $(1862$ ?)= Calliandra, Benth. (Legumin.). coroënsis, C. Muell. in Walp. Ann. vii. 841 , sphalm. $=$ Call, purpurea,

purpurea, Karst. Fl. Columb, ii. 43. t. $122=$ Call Codonandra.

CODONANTHE, Hanst, in Linnaea, xxvi. (1853) 209. GESNERACEAE, Benth, \& Hook. f. ii. 1011 Coccanthera, C. Koch \& Hanst. Ind. Sem. Hort. Berol. (1855) 17

aggregata, Hanst. in Linnaea, xxvi. (1853-55) 209.Bras.

calcarata, Hanst. l. c. xxxiv. (1865-66) 416.-Am. trop. carnosa, Hanst. in Mart. Fl. Bras. viii. 418.-Bras.

ciliosa, Lem. in Illustr. Hortic. ii. (1855) sub t. 56.Bras.

Devosiana, Lem. l.c. t. 56.-Bras.

gracilis, Hanst. in Linnaea, xxvi. (1853-55) 209.Bras.

Hookerii, Lem. in Illustr. Hortic. ii. (1855) sub t. 56 - Bras.

picta, Lem. 1. c. iv. (1857) t. $144=$ Devosiana.

CODONANTHE, Mart. ex Steud. Nom. ed. II. i. 791, in syn. $(1840)=$ Hypocyrta, Mart. (Gesnerac.)

CODONANTHEMUM, Klotzsch, in Linnaea, xii. (1838) $240=$ Simocheilus, Klotzsch (Ericac。). discolor, Benth. in DC, Prod. vii. 708.-Afr, austr. parviflorum, Klotesch, in Linnaea, xii. (1838) 240.Afr. austr.

pubcrulum, Klotzsch, 1. c.-Afr. atstr.

tenue, Benth. in DC. Prod. vii. 708.-Afr. austr.

CODONANTHES, Rafin. Fl. Tellur. iv. 24 (1836)= Pitcairnia, L'Hérit. (Bromeliac.).

albiflos, Rafin. I. c. = P. albiflos.

CODONANTHUS, G. Don, Gen. Syst. iv. $166(\mathbf{1 8 3 6})=$ Breweria, R. Br. (Convolvulac.).

africana, G. Don, 1. C。= B. africana

alternifolia, Planch. in Hook. Ic. PI. t. 796.-Afr. trop.

CODONANTHUS, Hassk. in Flora, xxv, (1842) II. Beibl. $24=$ Physostelma, Wight (Asclepiad.) campanulatus, Hassk. 1. c. = P. Wallichii.

CODONEMMA, Miers, Apoeyn. S. Am. 72 (1878)= Tabernaemontana, Plum. (A pocynac.) calycinum, Miers, 1. c. $78=$ T. Muclleriana. macrocaly $x$, Miers, $1 . c_{1}=$ T. macrocalyx.

CODONIUM, Vahl, in Skriv. Naturh. Selsk. ii. (1793) 206 ; Symb. Bot, ii. $36(1794)=$ Schoepfia, Schreb. (Olacin.).

arborescens, Vahl, 11. cc. $207 ; 96=$ S. arborescens.

fexuosum, M. Roem. Syn. Hesper. $21=\mathrm{S}$. flexuosa.
CODONOCALYX, Klotzsch, ex Baill. Etud. Gén. Euph 369 (1858) = Croton, Linn. (Euphorb.).

divaricatus, Klotasch, 1. c. $370=$ Crot. nitrariaefolius lanatus, Klotzsch, 1. c. = Crot. lanuginosus.

longifolius, Klotzsch, 1. c. = Crot. montevidensis,

montevidensis, Klotzsch, 1. c. = Crot. montevidensis

polymorphus, Klotzsch, 1. c. = Crot, nitrariaefolius.

velleriflorus, Klotzsch, 1. $\mathrm{c}_{\mathrm{s}}=$ Crot. nitrariaefolius.

CODONOCALYX, Miers, in Lindl. Veg. Kingd. 764 (1847) = Suteria, DC. (Rubiac.)

CODONOCARPUS, A. Cunn, ex Hook, Bot. Misc, i (1830) 244, in syn. PHYTOLACCACEAE, Benth. \& Hook, f iii. 86 .

HymenothecA, F. Muell. Fragm. i. 201 (1859).

australis, A.Cunn. l. c.-Austral.

colinifolia, F. Muell. Pl. Vict. i. 200--Austral.

pyramidalis, F. Muell. l. c. 201.-Austral.

CODONOCEPHALUM, Fenzl, in Flora, xxyi. (1843) 397. COMPOSITAE, Benth. \& Hook. f. ii. 330. Sprunnera, Sch. Bip. in Walp. Rep. ii. 954 (1843). inuloides, Fenzl, l. c.-Kurdistan.

CODONOCRINUM, Willd. ex Schult. f. Syst. vii. 718 $(1829)=$ Yucca, Dill. (Liliac.).

agavoides, Willd. ex Schult. f, 1. c. = Y. acaulis.

CODONOPHORA, Lindl. Bot. Reg, sub t. 1110 (1827) = Paliavana, Vand. (Gesnerac.)

grandiflora, Lindl. 1, c。=P. prasinata.

lanceolata, Lindl. 1. c. = Rytidophyllum tomentosum.

prasinata, Lindl. 1. c. $=$ P. sericiflora.

Selloana, Hanst. in Mart. F1. Bras. viii. $396=$ P. prasinata.

CODONOPRASUM, Reichb. Consp. 66 (1828) = Allium, Tourn. (Liliac.)

alpicolum, Jord. \& Fourr. Brev. Pl. Nov. fasc. ii. $127=$ A. oleracenm.

carinatum, Reichb, Fl. Germ. Excurs. $114=$ A. carina tum.

complanatum, Fourr. in Ann. Soc. Linn. Lyon, N.S xvii. (1869) $159=\mathrm{A}$. oleraceum.

consimile, Fourr. 1. c. $=$ A, carinatum.

flavum, Reichb. F1. Germ. Excurs. $115=$ A. flavum.

flexifolium, Fourr, in Ann. Soc. Linn. Lyon, N. S. xyi (1869) $159=\mathrm{A}$. carinatum.

flexum, Reichb. F1. Germ. Excurs. $114=$ A. flavum.

fuscum, Reichb. 1. c. $115=$ A. paniculatum.

intermedium, Reichb. 1. c. $114=\mathrm{A}$, oleraceum.

longispathum, Reichb. 1. c. $115=$ A. paniculatum

oleraceum, Reichb. 1. c. $114=\mathrm{A}$, oleraceum

pallens, Reichb. 1. c. $115=$ A. flavum.

paniculatum, Reichb. 1. c. =A. pulchellum.

pulchellum, Fourr. in Ann. Soc. Linn. Lyon, N. S. xvi

(1869) $159=$ A. pulchellum.

viridiflorum, Schur, Enum. PI. Transs. $671=$ A. oleraceum.

CODONOPSIS, Wall. in Roxb. F1. Ind ed. Carey, 103 (1824). CAMPANULACEAE, Benth. \& Hook f. ii. 557 .

Glosocomia, D. Don, Prod. Fl. Nep. 158 (1824)

affinis, Hook. $f$. E Thoms. in Fourn. Linn. Soc. (1858) 12. - Reg. Himal.

albiflura, Griff. Notul. iv. $279=$ Campanumoea celc bica.

Benthamii, Hook. f. E Thoms. in Fourn. Linn. Soc. i (1858) 14.-Reg. Himal.

celebica, Miq. Fl. Ind. Bat. ii. 566=Campanumoca celebica.

clematidea, C. B. Clarke, in Hook, f. Fl. Brit. Ind. ii $433=$ ovata

convolvulacea, Kurs, in fourn. Bot. xi. (1873) 195. Burma.

cordata, Hassk. in Retzia, i. $9=$ Campanumoea java nica.

foctens, Hook. f. E Thoms. in Gourn. Linn. Soc. it (1858) 16.-Reg. Himal.

gracilis, Hook. fo \& Thoms, in Illustr. Himal. Pl, t. $16 \mathrm{~A}=$ Leptocodon gracilis.

Griffithii, C. B. Clarke, in Hook. f. Fl. Brit. Ind. iii 431.-Reg. Himal.

inflata, Hook. f. \& Thoms. in Journ, Linn. Soc. it. (1858) $18=$ Campanumoea inthta.

japonica, Miq. Ann. Mus. Bot. Lugd. Bat. ii. 192.. Japon.

\section{CODONOPSIS :-}

javanica, Hook. f. E Thoms. in Illustr. Himal. Pl. $16 \mathrm{~B}=$ Campanumoea javanica.

lanceolata, Benth. E Hook. f. Gen. ii. 558; Trautv. in Act. Hort. Petrop. vi. (1879) 46.-As. temp.

leucocarpa, Mí. Il. Ind. Bat, ii. $565=$ Campanumoea celebica.

lurida, Lindl. Bot. Reg. (1839) Misc. $82=$ rotundifolia ovata, Benth. in Royle, Illustr. Bot. Himal. 253. t. 69 f. 3.-Reg. Himal.

parviflora, Wall. Cat. ת. $1300=$ Campanumoea parvi flora.

purpuren, Wall, in Roxb. Fl. Ind.ed. Carey, ii. 105.Reg. Himal.

rotundifolia, Royle, Illustr. Bot. Himal. 254. t. 62.Reg. Himal.

subsimplex, Hook. f. E Thoms. in Fourn. Linn. Soc if. (1858) 16.-Reg. Himal.

thalictrifolia, Wall. in Roxb. Fl. Ind.ed. Carey, ii, 10f. - Reg. Himal.

truncata, Wall. Cat. n. 1301= Campanumoea celebica. viridifora, Maxim. in Bull. Acad. Pétersb. xxvii. (188 $496,-$ As. or.

viridis, Wall. in Roxb. Fl. Ind. ed. Carey, ii, 103. Reg. Himal.

CODONORAPHIA, Oerst. in Vidensk. Selsk. Skr. Y v. (1859) 82; (Gesn. Centr. Am. 8) = Penta rhaphia, Lindl. (Gesnerac.

CODONORCHIS, Lindl. Gen. et Sp. Orch. 410 (1840 $=$ Pogonia, Juss. (Orchid.).

Lessonit, Lindl. 1. c. $411=\mathbb{P}$, tetraphylla.

Poeppigii, Lindl. 1. c. $410=$ P. tetraphylla.

CODONOSTIGMA, Klotzsch, ex Benth. in DC. Prod. vii. $709(1839)=$ Seyphogyne, Brongn. (Ericac.).

Erinus, Klotzsch, ex Benth. 1. c.-Afr. austr.

CODORIOCALYX, Hassk -Cf Linnaea, XY (1841) Lit. $80,81=$ CODAKIOCALYX, Hassk. $=$ Desmodium, Desv. (Legumin.).

CODVLIS, Rafin. in Am. Monthly Mag. (1819) $191=$ Nicotiana, Linn. (Solanac.)

COELACHNE, R. Br. Prod, 187 (1810). GRAM/. NEAE, Benth. \& Hook. fo iii, 1156.

brachiata, Munro, ex Benth. Fl. Austral. vii, 626, in obs.-Zeylan.; China.

infirma, Buese, in Mig. Pl. Fungh. 350.-Java perpusilla, Thw. Enum. Pl. Zeyl. 373.-Zeylan. pulchella, R. Br. Prod. 187-Burma; Ausiml. simpliciuscula, Munro, ex Benth. in Journ. Linn. xix. (1881) $93=$ brachiata.

subulifolia, F. Muell. Fragm. v. $208=$ Micraira subul folia.

COELACHYRUM, Nees, in Linnaea, xvi. (1542, 221 Eragrostis, Beauv, Gramio

brevifolium, Nees, $l_{0} \mathrm{c}_{\mathrm{o}}=\mathrm{E}$. Coeiachyrumo.

COELANDRIA, Fitzg. Austral. Orch. i. pt vil. 2. 2 $(1882)=$ Dendrobium, Sw. (Orchid.

Smilliae, Fitzg. 1. c. = D. Smilliae.

COELANTHE, Griseb. Gen. et Sp. Gent, 297, in $5 \mathrm{ym}$. $(1839)=$ COILANTHA, Borckb.= Gentiana, Linn.

COELANTHIUM, Sond, in Har". \& Sond. Fl. Can, i. $147(1859)=\mathrm{seq}$.

COELANTHUM. E. Mey. ex Fenzl, in Ann. Wien. MIus, i. (1\$96) 959 ; ii. (1S38) $200^{\circ}$. F/COIDE.tE Benth. \&e Hook. f. i. S5i. grandiflorum, E. Mey. ex Fersl, 6. 6. - Afr. austr. parviflorum, Fenst, 1. c. 268.-Arr. austr.

COELANTHUS, Willd. $c x$ Schult. to Syst. vii. p. xlr $1390)=$ Luchenalia. Jacy. I Liliac. complicalus, Willd. l. c. in adnot. $=$ L. reflexa.

COLLAS, Dulac, FI. Hautes-1'yt. Sus $150 \%$ - Poten. tilla. Toum liusac.)

grocumberis, Dulac, $1 . c=1$. Siblatdi.

COELEROGYYE. J. Sin. in Iroc Linn. Soc i. 1s\$4 11: Trans. Linn. Suc. xvii. 1st1: 311 . 2 S6 Alchornea, Sw. tuphorb.

ilicifolia, J. Sw. 1. C. 512 . 1. 30 -A. ilicifolia 
COELESTINA, Cass, in Bull. Soc. Philom. (Jan. 1817) 10 = CAELESTINA, Cass. = Ageratum, Linn. (Compos.).

COELESTINA, Hill, Hort. Kew. 8 (1769); Veg. Syst. ii. $60^{* *}=$ Aster, Tourn. (Compos.).

COELESTINIA, Endl. Gen. $366(1838)=$ CAELES TINA, Cass. = Ageratum, Linn. (Compos.).

COEIIA, Lindl. Gen. et Sp. Orch. 36 (1830). ORCHI$D E A E$, Benth. \& Hook. f. iii. 508.

Botrir Iochinus, Lem. Illustr. Hortic. iii. (1856) Misc. 30 .

Baueriana, Lindl. Gen. et Sp. Orch. 36.-Mexic.

bella, Reichb. f. in Walp. Ann. vi. 218.-Guatemala.

Galeottiana, Van Houtte, ex Heynh. Nom. ii. 152, nomen.-Mexic.

glacialis, Van Houtte, $l$. $c_{\text {. }}$, nomen.-Am. austr.

guatemalensis, Reichb. $f$. in Walp. Ann. vi. 219.Guatemala.

macrostachya, Lindl. in Benth. Pl. Hartw. 92.Mexic.

triptera, G. Don, ex Steud. Nom. ed. II. i. $394=$ Baneriana.

COFLIDIUM, Vog, ex Walp. in Linnaea, xiii. (1839) 472. LEGUMINOSAE, Benth. \& Hook. f. i. 473.

Bowei, Benth. in Hook. Lond. Fourn. Bot. ii. (1843) 454,-Afr. austr.

bullatum, Benth. l.c. 453.-Afr. austr

ciliare, Vog. ex Walp. in Linnaea, xiii. (1839) 472.Afr, austr.

muraltioides, Benth. in Hook. Lond. Fourn. Bot. ii, (1843) 455.-- Afr, austr.

roseum, Benth. l. c. 454.-Afr. austr.

'Thunbergii, Harv. in Harv. E' Sond. Fl. Cap. ii. 24. -Afr. austr.

Vogelii, Walp.in Linnaea, xiii. (1839) 472.-Afr. austr.

COELINA, Noronha, in Verh. Batav. Gen. v. (1790) ed. I. Art. IV. 2 (Quid?).

COELIOPSIS, Reichb. f. in Gard. Chron. (1872) 9 ORCHIDEAE, Benth. \& Hook. f. iii. 477.

hyacinthosma, Reichb.f. l. c.-Panama.

COELOCARPUM, Balf. f. in Proc. Roy. Soc. Edinb. xii. (1884) 90. VERBENACEAE.

socotranum, Balf. f. l. c. 91.-Ins. Socotra.

COELOCHLOA, Hochst. ex Steud. Nom. ed. II. i. 394 $(1840)=$ COELACHYRUM, Nees = Eragrostis Beauv. (Gramin.)

brevifolia, Hochst. 1. c. = E. Coelachyrum.

COELOCLINE, A. DC in Mém. Soc. Phys. Genèv. v. (1832) $208=$ Xylopia, Linn. (Anonac.).

acutiflora, A. DC. 1. c. $=\mathrm{X}$, acutiflora.

lucida, A. DC. 1. c. $209=\mathrm{X}$. longifolia.

oxypetala, A. DC. 1. c. $=\mathrm{X}$. acutiflora?

parviflora, A. DC. 1. c. =X. parviflora.

polycarpa, A. DC. l. c. =X. polycarpa.

COELOCOCCUS, H. Wendl. in Bonplandia, x. (1862) 199 - Metroxylon, Rottb. (Palm.). vitiensis, $\mathrm{H}$. Wendl. $1 . \mathrm{c}_{\mathrm{o}}=\mathrm{M}$. vitiense.

COELODEPAS, Hassk. in Flora, xl. (1857) 531. EUPHORBIACEAE, Benth. \& Hook. f. iii. 313.

KoILodePas, Hassk. in Versl. en Med. Kon. Akad. Wetensch. iv. (1855) 139.

bantamense, Hassk. in Versl. en Med. Kon. Acad. Wetensch.iv. (1855) 140 (Koilodepas).-Ins, Bantam. calycinum, Bedd. Forest. Man. Bot. 207.--Ind. or.

Wallichianum, Benth. in Hook. Ic. Pl. t. 1288.--Ins. Penang.

COELODISCUS, Baill. Etud. Gén. Euph. 293 (1858). EUPHORBIACEAE, Benth. \& Hook. f. iii. 317.

dispar, Kurz, in fourn. As. Soc. Beng. xlii. (1873) II 244.- - Ind. or.

eriocarpoides, Kurz, 1. c. = Mallotus decipiens.

eriocarpus, $K u r z, l$. $c$-Ind. or.

glabriusculus, Kurz, For. Fl. Brit. Burma, ii. 393 .Burma.

\section{COELODISCUS:-}

hirsutulus, Kurz, in Fourn. As. Soc. Beng. xlii. (1873)

II. 243.-Burma.

lappaceus, Kurz, l. c. 244 ; et For. Fl. Brit. Burma, ii 392.-Burma.

longipes, Kurz, $l l . c c .244,393$.-Burma.

montanus, Muell. Arg. in DC. Prod. xv. II. 759.Ins. Penang.

speciosus, Muell. Arg. in Linnaea, xxxiv. (1865-66) 154.-Ind. or.

Thunbergianus, Muell. Arg. in DC. Prod. xv. II. 758. -Zeylan.

COELOGLOSSUM, Hartm. Handb. Skand. Fl. ed. I. $329(1820)=$ Habenaria, Willd. (Orchid.)

acuminatum, Lindl. Gen. et Sp. Orch. $302=\mathrm{H}$ lacertifera.

albidum, Hartm. Handb. Skand. Fl, ed. I. $329=$ H. albida.

alpinum, Schur, in Verh. Siebenb. Ver. Naturw. ii (1851) 169 ; iv. (1853) $72=$ H. cucullata.

bracteatum, Parl. Fl. Ital. iii. $409=\mathrm{H}$. viridis.

brevifolium, Lindl. Gen. et Sp. Orch. $302=$ H. cubitalis.

cernum, Reichb, f. in Bonplandia, iii. (1855) $250=\mathrm{H}$. stenostachya.

cordatum, Nym. Syll. $359=$ H. cordata

densiflorum, Hartm. ex Willk. \& Lange, Prod. Fl.

Hisp. i. $164=\mathrm{H}$. intacta

densum, Lindl. Gen. et Sp. Orch. $302=$ H. stenostachya.

Erdingeri, Kerner, in Oestr. Bot. Zeitschr. xiv. (1864 $140=\mathrm{H}$. viridis.

lacertiferum, Lindl. Gen. et Sp. Orch. $302=\mathbf{H}$. lacertifera.

luteum, Dalz. in Hook. Kew Journ. ii. (1850) 263.Ind. or.

Mannii, Reichb. f. in Linnaea, xli. (1877) 54,-Reg. Himal.

peristyloides, Reichb. f. in Bonplandia, iv. (1856) 321 $=$ H. stenostachya.

purpureum, Schur, Enum. Pl. Transs, $646=\mathbf{H}$, cucullata.

satyrioides, Nym. Syll. 359.-Tauria.

secundum, Lindl. Bot. Reg. sub t. 1701.-Ind, or

tenue, Lindl. 1. $c_{\circ}=$ H. stenostachya,

Vaillantii, Schur, Enum. Pl. Transs. $645=\mathrm{H}$. viridis. viride, Hartm. Handb. skand. Fl. ed. I. $329=\mathrm{H}$ iride,
viridis.

COELOGYNE, Lindl. Collect. sub t. 33 (1825), ORCHIDEAE, Benth. \& Hook. f. iii. 518.

Acanthoglossum, Blume, Bijdr. 381 (1825). Bolborchis, Zoll. \&c Mor. Verz. Pfl. 89 (1846)

Gomphostylis, Wall. ex Lindl. Gen. et Sp. Orch. $43(1830)$.

NEOGYNA, Reichb. f. in Bot. Zeit. x. (1852) 931.

Pleione, D. Don, Prod. Fl. Nep. 36 (1825).

advena, Par. E Reichb. f. Otia Bot. Hamb. 47.Burma.

alba, Reichb. fo in Walp. Ann. vi. $236=$ Otochilus alba. angustifolia, A. Rich. in Ann. Sc. Nat. Sér. II. Xv. (1841) $16 . t, 6=$ odoratissima

angustifolia, Wight, Ic. t. $1641=$ breviscapa

apiculata, Reichb. f. in Walp. Ann. vi. $225=$ Panisea apiculata.

Arthuriana, Reichb, f. in Gard. Chron. (1881) t. $40=$ maculata

articulata, Reichb. f. in Walp. Ann. vi. $238=$ Pholidota articulata.

asperata, Lindl. in Fourn. Hort. Soc. iv. (1849) 221.Malaya.

assamica, Linden \& Reichb. f. in C. Koch, Allg. Gartenz. xxv. (1857) $403=$ fuscescens.

barbata, Lindl. ex Griff. Itin. Not. 72.-Reg. Himal.

bifora, Parish, ex Reichb. f. in Gard. Chron. (1865) 1035.-Burma.

bilamellata, Lindl. Fol. Orchid, Coelog. 14.-Ins. Philipp.

birmanica, Reichb. f. in Gard. Chron. (1882) II. 840. -Burma.

brachyptera, Reichb.f. l.c. (1881) II. 6.-Burma.

brevifolia, Lindl. Fol. Orchid. Coelog. 7.-Reg. Himal. breviscapa, Lindl. l. c. 4.-Ind. or.

brunnea, Lindl. in Gard. Chron. (1848) $71=$ fuscescens.

calceata, Reichb. f. in Walp. Ann. vi. 238 = Pholidota calceata.

\section{COELOGYNE :-}

camelostalix, Reichb. f. in Walp. Ann. vi. $238=$ Pholidota camelostalix.

carnea, Reichb. f. 1. c. $237=$ Pholidota carnea.

caulescens, Griff. Notul. iii. 282.-Malacca.

chinensis, Reichb. f, in Walp. Ann, vi. $237=$ Pholidota chinensis.

chloroptera, Reichb. f. in Gard. Chron. (1883) I. 466. -Ins. Philipp.

ciliata, Boxall, ex Naves, in Blanco, Fl. Philipp. ed. III. Nov. App. 237.--Ins. Philipp.

clypeata, Reichb. f. in Walp. Ann. vi. $237=$ Pholidota clypeata.

conchoidea, Reichb. f. 1. c. = Pholidota conchoidea.

conferta, Hort.-Cf. Gard. Chron. (1875) I. 314.Ind. or.

Convallariae, Par. E' Reichb. f. in Flora, lv. (1872) 277.-Reg. Himal. ; Burma.

corniculata, Reichb. f. in Gard. Chron. (1865) 746.Assam?

coronaria, Lindl. Bot. Reg. (1841) Misc. $83=$ Trichosma suavis.

corrugata, Wight, Ic. t. 1639.-Ind. or.

corymbosa, Lindl. Fol. Orchid. Coelog, 7.-Reg. Himal.

cristata, Lindl. Collect. Bot. sub t. 33.-Reg. Himal.

Croockewitii, Teijsm. E Binn. in Tijdschr. Nederl. Ind. v. (1853) 488.--Java.

crotalina, Reichb. f. in Walp. Ann. vi. $238=$ Pholidota crotalina

Cumingii, Lindl. Bot. Reg. (1843) Misc. 76.-Malaya.

Cycnoches, Par. E' Reichb. f. in Trans. Linn. Soc. xxx. (1874) 147.-Burma.

cymbidioides, Reichb. f. in Walp. Ann. vi. 239.-Ins. Molucc.

Dayana, Reichb. f. in Gard. Chron. (1884) I. 826.Borneo.

decora, Wall. ex Voigt, Hort. Suburb. Calc. 621, nomen.-Hab. ?

diphylla, Lindl. Fol. Orchid. Coelog. 15.-Ind. or.

elata, Lindl. in Wall. Cat. n. 1959--Reg. Himal.

fimbriata, Lindl. Bot. Reg. t. 868.-Reg. Himal

flaccida, Lindl. in Wall. Cat. n. 1961.-Reg. Himal.

flavida, Hook. f. ex Lindl. Fol. Orchid. Coelog. 10.Reg. Himal.

fuliginosa, Lodd. ex Hook. Bot. Mag. t. 4440.-Reg. Himal.

fusca, Reichb. f. in Walp. Ann. vi. $236=$ Otochilus fusca.

fuscescens, Lindl. in Wall. Cat. n. 1962.-Malaya.

fusco-lutea, Teijsm. E Binn. Cat. Hort. Bog. 378 nomen.-Hab.?

Gardneriana, Lindl. in Wall. Pl. As. Rar. i. 33. t. 38. - Reg. Himal

gibbosa, Reichb. f. in Walp. Ann. vi. $237=$ Pholidota gibbosa.

glandulosa, Lindl. Fol. Orchid. Coelog. 6.-Ind. or

globosa, Reichb. f. in Walp. Ann. vi. $236=$ Pholidota globosa.

Goweri, Reichb. f. in Gard. Chron. (1869) 443Reg. Himal.

graminifolia, Par. E Reichb. f. in Trans. Linn. Soc. xxx. (1874) 146.-Burma.

Hookeriana, Lindl. Fol. Orchid. Coelog. 14.-Reg. Himal.

Huettneriana, Reichb. f. in Flora, lv. (1872) 277.Burma.

humilis, Lindl. Collect. Bot. sub t. 37.-Reg. Himal.

imbricata, Reichb. f. in Walp. Ann. vi. $238=$ Pholidota imbricata.

incrassata, Lindl. Gen, et Sp. Orch. 40.-Java.

interrupta, Lindl. ex Heynh. Nom. ii. 153, nomen.Ind. or.

javanica, Lindl. Fol. Orchid. Coelog: 17.-Java.

khasyana, Reichb. f. in Walp. Ann. vi. $238=$ Pholidota articulata.

lactea, Reichb. f. in Gard. Chron. (1885) I. 692.Burma.

Lagenaria, Lindl. Fol. Orchid. Coelog. 15.-Reg. Himal.

lentiginosa, Lindl. l. c. 3.-Burma

ligulata, Teijsm. E Binn. Cat. Hort. Bog. 46.Java.

longeciliata, Teijsm. xxvii. (1864) 16.- - Ind. or.

longifolia, Lindl. Gen. et Sp. Orch. 42.-Java.

longipes, Lindl. Fol. Orchid. Coelog. 10-Reg Himal 
COELOGYNE :-

loricata, Reichb. f. in Walp. Ann. vi. $238=$ Pholidota

loricata.
Lourii, Paxt. Mag. Bot. xvi. (1849) $225=$ asperata.

macrophylla, Teijsm. E Binn. in Tijdschr. Nederl. Ind. xxix. (1867) 241.--Sumatra.

maculata, Lindl. Gen. et Sp. Orch. 43.-Reg. Himal. marmorata, Reichb. $f$. in Linnaea, xli. (1877) 116. Ins. Philipp.

Massangeana, Reichb. f. in Gard. Chron. (1878) II. 684.-Malay.

Mayeriana, Reichb. f.l.c. (1877) II. 134.-Hab.?

media, Wall. ex Voigt, Hort. Suburb. Calc. 621, nomen.-Ind. or.

micrantha, Lindl. in Gard. Chron. (1855) 173.-Reg.

Himal.; Burma.

miniata, Lindl. Gen. et Sp. Orch. 42,-Java.

nervillosa, Reichb. f. in Walp. Ann. vi. $236=$ Pholidota nervosa.

nervosa, A. Rich. in Ann. Sc. Nat. Sér. II. xv. (1841) $16=$ corrugata

nervosa, Wight, Ic. t. $1638=$ glandulosa.

nigrescens, $P$. Don, ex Loud. Hort. Brit. Suppl. iii 520 , nomen. - Ind. or.

nitida, Lindl. in Wall. Cat. n. 1954.-Reg. Himal.

ocellata, Lindl. Gen. et Sp. Orch. 40.-Ind. or.

ocellata, Lindl. in Wall. Cat. n. $1953=$ nitida, ochracea, cristata.

ochracea, Lindl. Bot. Reg. (1846) t. 69,-Reg. Himal.

odoratissima, Lindl. in Wall. Cat. n. 1960.-Ind. or.

ovalis, Lindl. Bot. Reg. (1838) Misc. 91... Reg. Himal.

pallida, Reichb. f. in Walp. Ann. vi. 238 = Pholidota imbricata.

pandurata, Lindl. in Gard. Chron. (1853) 791.Malaya.

Papagena, Reichb. f. in Bot. Zeit. xx. (1862) $214=$ micrantha.

Parishii, Hook.f. in Bot. Mag. t. 5323.-Burma.

parviflora, Lindl. Gen. et Sp. Orch. $44=$ Panisea parviflora.

peltastes, Reichb. f. in Gard. Chron. (1880) Il. 296.Borneo.

Pholas, Reichb. f. in Walp. Ann. vi. $237=$ Pholidota Pholas.

pholosissima, Planch. Hort. Donat. $144=$ ovalis.
plas.

plantaginea, Lindl. in Gard. Chron. (1855) 20.Ind. or.

porrecta, Reichb. f. in Walp. Anu. vi. $236=$ Otochilus porrecta.

praecox, Lindl. Collect. Bot. sub t, 37.-Reg. Himal.

prolifera, Lindl. in Wall. Cat. n. 1956.-Reg. prolifera, Lindl. in Wall. Cat. n. 1956.-Reg.
Himal. psittacina, Reichb. f. Xenia Orch. ii. 141.-Ins.
Moluec.

pulverula, Teijsm. E Binn. in Tijdschr. Nederl. Ind. xxiv. (1862) 306.-Sumatra.

pumila, Reichb. f. in Walp. Ann. vi. $236=$ Dendrochilum pumilum.

punctulata, Lindl. Collect. Bot. sub t. $83=$ nitida.

recurva, Reichb. fo in Walp. Ann. vi. 237 - Pholidota recurva.

Reichenbachiana, T. Moore, in Gard. Chron. (1868) 1210. - Buruma.

Rhodeana, Reichb. f. 1. c. (1867) $901=$ Rossiana.

rhombophora, Reichb. f. in Linnaea, xli. (1877) 116. -Ins. Manilla.

rigida, Par. E Reichb. f. in Trans. Linn. Soc. xxx, (1874) 146.-Burma.

Rochusseni, De Vriese, Illustr. Orch. [t. 2. et t. 11. f. 6].

Rossiana, Reichb.f. in Gard. Chron. (1984) I1. 808.Burma.

rubra, Reichb. f. in Walp. Ann. vi. $238=$ Pholiclota rubra.

Rumphii, Lindl. Fol. Orchid. Coelog. 14.-Malaya.

salmonicolor, Reichb. $f$. in Gard. Chron. (1888) II 328.-Ins. Sundaic.

Schilleriana, Reichb. f. in C. Koch, Allg. Gartens. xxvi. (1858) 189.-Burma.

simplex, Lindl. Fol. Orchid. Coclog. 18.-Ind. or. sparsa, Reichb. f. in Gard. Chron. (1883) 1. 306.-Ins. Philipp.

speciosa, Lindl. Gen. et Sp. Orch. 39.-Malaya.

sulphuren, Reichb. $f$. in Bonplandia, v. (1857) 43.Malaya.

\section{COELOGYNE:-}

testacea, Lindl. Bot. Reg. (1842) Misc. 38.-Malaya.

Thuniana, Reichb. f. in Otto E Dietr. Allg. Gartens.

xxiii. (1855) 145.-Nepal

tomentosa, Lindl. Fol. Orchid. Coelog. 3.-Malaya.

trifida, Reichb. fo in Hamb. Gartenz. xix. (1863) 546 = odoratissima.

trinervis, Lindl. in Wall. Cat. n. 1955.-Burma.

triotos, Reichb. f. in Hamb. Gartenz. xviii. (1862) 34.-Ins. Philipp.

triplicatula, Reichb. f. in Bot. Zeit. xxii. (1864) $415=$ fuliginosum?

triptera, A. Brongn. in Duperr. Voy. Coq. Bot. $201=$ Epidendrum caespitosum, Poepp. E Endl.

trisaccata, Griff. Notul. iii, $400=$ Gardneriana,

undulata, Reichb. f. in Walp. Ann. vi. $238=$ Pholidota rubra.

undulata, Wall. ex Voigt, Hort. Suburb. Calc. 621 , nomen.-Ind, or.

uniflora, Lindl. in Wall. Cat. n. 1966.-Reg. Himal. Burma.

ustulata, Par, E Reichb. f. in Trans. Linn. Soc, xxx (1874) 146.-Burma.

ventricosa, Reichb. f. in Walp. Ann. vi. $237=$ Pholidota ventricosa.

viscosa, Reichb. f. in Otto E Dietr. Allg. Gartenz. xxiv. (1856) 218.-Reg. Himal.

Wallichiana, Lindl. Gen. et Sp. Orch. $43=$ praecox.

COELONEMA, Maxim, in Bull. Acad. Pétersb. xxvi (1880) 423. CRUCIFERAE.

draboides, Maxim.l. c. 424.-China.

COELOPLEURUM, Ledeb. Fl. Ross. ii. 361 (1844)= Archangelica, Hoffm. (Umbellif.)

Gmelini, Ledeb. 1. c. = A. Gmelini.

COELOPYRUM, Jack, in Malay. Misc. ii. (1822) VII. 65. INC. SED coriaceum, fack, l. c.-Malaya.

COELORACHIS, Brongn.in Duperr. Voy. Coq. Bot. 64 t. $14(1829)=$ Rottboellia, Linn. (Gramin.) hirsuta, Brongn. 1. c. 65 , in obs. $=\mathrm{R}$. hirsuta, muricata, Brongn, 1. c. 65. t. $14=\mathrm{R}$. glandulosa.

COELOSPERMUM, Blume, Bijdr. 994 (1826 (Caelospermum). RUBIACEAE, Benth. \& Hook. 1 . ii. 119.

Pogonolobus, F. Muell. Fragm. i. 55 (1858).

Balansaeanum, Baill. Adansonia, xii. (1876-79) 236 . N. Caled.

barbatum, Span. in Linnaea, xv. (1841) 318.-Ins Timor.

corymbosum, Blume, ex DC. Prod. iv, 468.-Java. decipiens, Baill. in Bull. Soc. Linn. Par. i. (1879) 218 - Austral.

Gmelini, Miq. Ann, Mus. Bot. Ingd. Bat. iii. 62 sphalm. = Archangelica Gmelini.

paniculatum, F. Muell. Fragm. v. 19.-Austral.

reticulatum, Benth. Fl. Austral. iii. 425. - Austral.

scandens, Blume, Bijdr. 994.-Malaya.

COELOSTEGIA, Benth. in Benth. \& Hook. f, Gen, 213 (1862). MALVACEAE, Benth. \& Hook. f. I. Griffithii, Benth. l, c.-Malacea.

COELOSTemina, Fonrn. in Mart. Fl, Bras, vi. 1V. 320 (1885). ASCLEPIADEAE refractum, Fourn. $l$. c.-Bras.

COELOSTYLIS, Torr. \& Gray, ex Endl. Nov. Stirp. Dec. $93(1839)=$ Spigelia, Linn. (Loganiac.). loganioides, Torr. \& Gray, 1. c. - S. loganioides.

texana, Torr. \& Gray, FI. N. Am. ii. $44=$ S. texana.

COEMANSIA, March。 in Bull. Acad. Belg. Sér. II xlvii. (1879) 94, ARALIACEAE.

Coudenbergis, March. 1. c. 514 (1879)

Warmingiana, March.l. c. 95.-Am. nustr.

COENOLOPHIUM, Reichb. Consp. 148 (1828) CENOLOPHIUM, Koch = Selinum, Linn. (Un. bell.).

COENOTUS, Benth. \& Hook. f. Gen. ii. 281 (18\%3), lapsu = CALNOTUS, Ratin. - Erigeron, Linn. (Compos.).
COERULINIA, Fourr. in Ann. Soc. Linn. Lyon, N. S. xvii. (1869) 128 = Veronica, Toum. (Scrophular.). montana, Fourr. 1. c. $=$ V. montana.

COETOCAPNIA, Link \& Otto, Ic. Pl. Rar, 35. t. 18 $(1828)=$ Bravoa, La Llav. (Amaryllid.)

geminiflora, Link \& Otto, 1. c.= B. geminifora.

COFFEA, Linn. Syst, ed. I (1735). RUBIACEAE, Benth. \& Hook. f. ii. 114.

Hexepta, Rafin. Sylva Tellur. 164 (1838)

Lachnastoma, Korth. in Ned. Arch. Kruidk. ii. II. (1£51) 201.

acuminata, Ruiz \& Pav. Fl. Per. ii, 64.-Peruv.

Afrelii, Hiern, in Trans. Linn. Soc. Ser. II. i. (1876) 174.-Afr. trop.

alpestris, Wight, Ic. t. $1040=$ Webera lucens.

angustifolia, Roxb. Hort. Beng. 86; Fl. Ind. i. 541.Malaya.

arabica, Benth, in Hook. Niger Fl. 413 = liberica, stenophylla.

arabica, Linn. Sp. Pl. 172.-Arabia; Afr. trop.

australis, Vell. Fl. Flum. 62; it. to $13=$ Faramea australis.

bengalensis, Roxb. Hort. Beng. 15 ; Fl. Ind. i. 540.Ind. or.; Malaya.

bidentata, D. Dietr. Syn. Pl. i. $776=$ microcarpa

biflora, Vell. Fl. Flum, 63 ; ii. t. $16=$ Coussarea biflora.

Boryana, D. Dietr. Syn. Pl. i. $777=$ Chasalia Boryana. brachyphylla, Radlk, in Bremen Abh. viii. (1883) 390. -Ins. Nossibé.

brasiliensis, Walp. Rep. ii. $477=$ Rudgea lanceolata. brevipes, Hiern, in Trans. Linn. Soc. Ser. II. i. (1876) 172.-Afr. trop.

calycina, Benth. in Hook. Fourn. Bot. iii. (1841) 232. -Guiana.

capitata, D. Dietr. Syn. Pl. i. $777=$ Chasalia capitata. capitata, Sicber, ex DC. Prod. iv. $531=$ Chasalia divaricata?

Chamissonis, Hook. \& Arn. Bot. Beecb. Voy. $86=$

Stralıssia kaduana.

chasalioides, D. Dietr. Syn. Pl. i. $777=$ Chasalia divaricata?

ciliata, Ruiz E Pav. Fl. Per. ii. 65. t. 216.-Peruy

clusiaefolia, D. Dietr. Syn. Pl. i. 777 = Chasalia clusiac folia.

coriacea, Humb. \& Bonpl. ex Roem. \& Schult. Syst. v. $201=$ laurifolia

corymbulosa, Bertol. Fl. Guatimal. 10.-Guatemala.

crassiloba, Benth. in Hook. Journ. Hot. iii. (18\$1) 233 $=$ Rudgea Schombargkiana.

cymosa, Wilid, ex Roem. \& Schalt. Syst. พ. $201=$

Chasalia Fontanesii.

densifora, Blume, Bijdr. 965.-Java.

Deppeana, Steud. Nom. ed. II. i. 394.-Mexic

didymocarpa, Bartl. ex DC. Prod. iv. $481=$ Declieuxia psychotroides.

divaricata, Tausch, ex DC. 1. c. $532=$ Chasalia divaricala.

elliptica, Thw. Enum. Pl. Zcyl. 154=Byrsopbyllum ellipticum.

elongati, Korth. in Nederl. Kruidk. Arch. ii. II. (1851) 25 t.-Sumatra.

criantha, Gardn. in Hook. Lond. Journ. Bot. i. ( $18 f$ ] 534 - Rudger eriantha.

favicans, Humb. \& Bonpl. ex Roem. \& Schult. Syst. ₹. $201=$ Faramea jasminoides.

foribunda, Mart. in Flora, xxiv. (1541) 11. Beibl. 85 Ixora densillora.

foribunda, Mfiq. in Linnaca, xxii. (1S4?) 804.-Bras

Fontaresio, D. Dielr. Syn. Pl. i. $777=$ Chasalia Fontanesii.

foveolata. Ruiz E Pav. Fl. Per. ii. 65. t. 210.-Peruv.

fragrans, W'all. ex Hook. f. F\%. Brif. Ind. iii. 15 t. Ind, or.: Burma

gardenioides, Cham. in Linnaca, ix, (1891) 280 K'udgea garclenioides.

glabra, Korth. in Niderl. Kruidk. Arch. ii. II. (ISs]

glabra, Korth. im
254.-Bornco.

grasdifoija, Boj. ex Raker, Fl. Maurit. 152-macro carpla.

grandifolia, D. Dictr. Syn. PI. i. $778=$ Chasalia gramd. folia.

grumelioides, Wighe, Ic. R. 1041 Webera lucens

guianensis, Arubl. Pl. Gri. i. 15u. L 57.-Cuiana. hirsufa, G. Don, Gicn. Sist. iij. 591 -Cremaspura
africina. 


\section{COFFEA :}

Horsfieldiana, Miq. Fl. Ind. Bat. ii. $308=$ bengalensis.

Humblotiana Baill in Bull Sac Linn Par. (1885) 514.- - Ins. Comor.

hypoglauca, Welw.ex Hiern, in Trans. Linn. Soc Ser. II. i. (1876) 173.-Afr. trop.

indica, Poir. Encyc. Suppl. ii. 14.-Java.

jasminoides, Cham. in Linnaea, ix. (1834) $222=$ Rudgea jasminoides.

jasminoides, Welry. ex Hiern, in Trans. Linn. Soc Ser. II. i. (1876) 175.-Afr. trop.

Savanica, Blume, Cat. Gew. Buitenz. 46=Chiococca javanica.

Jenkinsii, Hook. f. Fl. Brit. Ind. iii. 155.-Reg. Himal

kaduana, Cham. \& Schlecht. in Linnaea, iv. (1829) $33=$ Straussia kaduana.

khasiana, Hook. f. Fl. Brit. Ind.iii. 154.-Reg. Himal.

Kraussiana, Hochst. in Flora, xxv. (1842) $237=$ Kraussia floribunda.

lanceolata, Cham. in Linnaea, ix. (1834) $232=$ Rudgea lanceolata.

lanceolata, Cham. \& Schlecht. 1. c. vi. (1831) $412=$ Deppeana.

lautrifolia, H. B. E K. Nov. Gen. et Sp. iii. 372.Venezuela.

laurifolia, Salisb. Prod. $62=$ arabica.

laurina, Poir. in Lam. Encyc. Suppl. ii. $14=$ Craterispermum laurinum

laurina, Smeathm.ex DC. Prod. iv. 499.-Afr. trop.

lepidophloia, Miq. Fl. Ind. Bat. Suppl. 548.-Ins. Banca.

liberica, Hiern, in Trans. Linn. Soc. Ser. II. i. (1876) 171. t. 24.-Afr. trop.

longifolia, Ruiz E Pav. Fl. Per. ii. 66. t. 218.-Peruv. luçoniensis, Cham. \& Schlecht. in Linnaea, iv. (1829) $32=$ Psychotria luzoniensis.

macrocarpa, A. Rich. in Mém. Soc. Hist. Nat. Par. v. (1834) 168.-Ins. Mascar.

macrophylla, F. G. Dietr. Vollst. Lexik. Gaertn. Nachtr. ii. $344=$ subsessilis

madurensis, Teijsm. E Binn. Cat. Hort. Bog. 112.Ins. Madur.

magnoliaefolia, Cham. in Linnaea, ix. (1834) $225=$ Rudgea magnoliaefolia.

major, Cham. 1. c. $226=$ Rudgea major.

marginata, Benth. Pl. Hartw. 193.-N. Granat

Mariniana, Cham. \& Schlecht, in Linnaea, iv. (1829) $35=$ Straussia Mariniana.

mauritiana, Lam. Encyc. i. 550.-Ins. Mascar.

melanocarpa, Welw. ex Hiern, in Trans. Linn. Soc. Ser.

II. i. (1876) 173.-Afr. trop.

meridionalis, Vell. F1. Flum, 62; ii. t. 14=Conssarea meridionalis.

mexicana, DC. Prod. iv. 501.-Mexic

microcarpa, DC. 1. c. $499=$ Perrottetii.

microcarpa, Ruiz Es Pav. Fl. Per. ii. 66. t. 218.-Peruv. minor, Cham. in Linnaea, ix. (1834) $227=$ Rudgea Clausseniana.

Moka, Hort. ex Heynh. Nom. ii. $\mathbf{1 5 3}=$ arabica

mozambicana, DC. Prod. iv. $500=$ racemosa, Lour.

myrtifolia, Roxb. Hort. Beng. 15, nomen.-Ins. Maurit.

neurophylla, Miq. Fl. Ind. Bat. ii. 1079.-Java.

nitida, Ruiz E Pav. Fl.Per, ii. 65. t. 217.-Peruv.

nodosa, Cham. in Linnaea, ix. (1834) $233=$ Rudgea nodosa.

novoguineensis, Miq. in Ann. Mus. Bot. Lugd. Bat. iv. 259.-N. Guinea.

obovata, Cham. E Schlecht. in Linnaea, vii. (1832) 412.-Mexic.

bovata, D. Dietr. Syn. Pl. i. $777=$ Chasalia divaricata

occidentalis, Jacq. Enum. Pl. Carib. 16=Faramea odoratissima.

occidentalis, Vell. F1. Flum. 62 ; ii. t. $12=$ Faramea occidentalis.

odorata, Forst. f. Prod. 16.-Ins. Amicor

oleifolia, H. B. E K. Nov. Gen. et Sp. iii. 372.-N. Granat.

opulina, Forst. f. Prod. $16=$ Pavetta opulina

paniculata, Aubl. Pl. Gui. i. 152. t. 58.-Guiana.

parquioides, Cham. in Linnaea, ix. (1834) $224=$ Rudgea parquioides.

parvifolia, Cham. 1. c. 231 = Rudgea parvifolia.

pedunculata, Roxb. Hort. Beng. 86 ; Fl. Ind. i. 541.Ins. Moluce.

Perrottetii, Steud. ex Buek, DC. Prod. Index, i. praef. p. ix.-Afr. trop.

porophylla, Vell. Fl. Flum. 62 ; ii. t. $11=$ Coussarea porophylla.

\section{COF'EA:}

psychotrioides, D. Dietr. Syn. Pl i. $777=$ Gaertnera psychotrioides.

racemosa, Lour. Fl. Cochinch. 145.-Afr. trop.

racemosa, Ruiz \& Pav. Fl. Per. i1. 64. t. 214.-Peruv rachiformis, Baill. in Bull. Soc. Linn. Par. i. (1885)

514.-Ins. Comor.

ramosa, Roem. \& Schult. Syst. v. $198=$ racemosa, Lour rosea, Mof. E' Sesse, ex DC. Prod. iv. 499.-Mexic.

rupestris, Hiern, in Trans. Linn. Soc. Ser. II. i. (1876) 174. - Afr. trop.

salicifolia, Miq. Fl. Ind. Bat. ii. 307.-Java

sambucina, Forst. f. Prod. $16=$ Pavetta sambucina

semiexserta, Colebr. ex Wall. in Roxb. Fl. Ind. ed Carey, ii. 195.-Ind. or.

sessilis, Vell. Fl. Flum. 64 ; ii. t. $20=$ Psychotria axil laris.

spicata, H. B. E K. Nov. Gen. et Sp. iii. 371. t. 286.N. Granat

stenophylla, G. Don, Gen. Syst. iii. 581.-Abyssin

stipulacea, DC. Prod. iv. 499.-Guiana.

stipulacea, Steud. Nom. ed. II. i. $395=\mathrm{seq}$.

stipulata, Vell. Fl. Flum. 63 ; ii. t. $17=$ Bathysa stipulata.

subcordata, Hiern, in Trans. Linn. Soc. Ser. II. i.

(1876) 174.-Afr. trop.

subsessilis, Benth. in Hook. Journ. Bot. iii. (1841) 239 $=$ Mapouria subsessilis.

subsessilis, Ruiz E Pav.Fl. Per. ii. 64. t. 215.-Peruv.

sundana, Miq. Fl. Ind. Bat. ii. 306.-Java.

sylvestris, Willd. ex Roem. \& Schult. Syst. v. $201=$ mauritiana.

tenuiflora, Benth. in Hook. Fourn. Bot. iii. (1841) 232 -Guiana.

tetrandra, Roxb. Hort. Beng. 85; Fl. Ind. i. $538=$ Prismatomeris albidiflora.

travancorensis, Wight E० Arn. Prod. 435.-Ind. or.

triflora, Forst. f. Prod. $16=$ Pavetta triflora.

triflora, Moon, Cat. $\mathbf{1 5}=$ travancorensis.

truncata, Vell. Fl. Flum. 63 ; ii. t. $\mathbf{1 5}=$ Faramea truncata.

nmbellata, Ruiz E" Pav. Fl. Per. ii. 64. t. 215.-Peruv.

umbellata, Vell. Fl. Flum. 63 ; ii. t. $19=$ Farame salicifolia.

verticillata, Ruiz \& Pav. Fl.Per, ii. 66. t. 217.-Peruv verticillata, Vell. F1. Flum. 63 ; ii, t. $18=$ Ixora verti cillata.

viburnoides, Cham. in Linnaea, ix. (1834) $228=$ Rudgea viburnoides.

volubilis, Blanco, F1. Filip. ed. I. $157=$ Morinda tinctoria.

vulgaris, Moench, Meth. 504=arabica

Wightiana, Wall. Cat. n. 6246; Wight E Arn. Prod. 436.-Ind. or.

Zanguebariae, Lour. Fl. Cochinch. i. 145.-Afr. trop.

COGNIAUXELLA, Baill. in Bull. Soc. Linn. Par. (1884) $424=$ Cogniauxia, Baill. (Cucurb.).

COGNIAUXIA, Baill. in Bull. Soc. Linn. Par. (1884) 423. CUCURBITACEAE.

CogNiauxella, Baill. l. c. 424

podolaena, Baill. l. c. 424,-Madag.?

COGSWELLIA, Schult. in Roem. \& Schult. Syst. vi. p. xlviii $(1820)=$ Peucedanum, Tourn. (Umbellif.). villosa, Schult. 1. c. $588=\mathrm{P}$, foeniculaceum.

COGYLIA, Molina, Sagg. Chil. ed. II. $300(\mathbf{1 8 1 0})=$ Lardizabala, Ruiz \& Pav. (Berberid.).

biternata, Molina, 1. c. = L. biternata.

ternata, Molina, l. $\mathrm{c}_{\mathrm{.}}=\mathrm{L}$. trifoliata.

triternata, Molina, $1 . \mathrm{c}_{\infty}=\mathrm{L}$. triternata

COHAUTIA, Endl. Ench. 273 (1841)=KOHAUTIA Cham. \& Schlecht.=Oldenlandia, Linn. (Rubiac.).

COHIBA, Rafin. Fl. Tellur. iii. 75 (1836)=Wigandia, H. B. \& K. (Hydrophyllac.). urens, Rafin. 1. c. =W. pruritiva

COHNIA, Kunth, Enum. PI. v. $35(1850)=$ Cordỳline, Comm. (Liliac.)

floribunda, Kunth, 1. c. $36=$ Cord. floribunda, macrophylla, Kunth, 1. c. $37=$ Cord. macrophylla. mauritiana, Baker, in Journ. Linn. Soc. xiv. (1875) 546 $=$ Cord. macrophylla.

neocaledonica, Baker, 1. c. = Cord, neocaledonica.

parviflora, Kunth, Enum. PI. v. $37=$ Cord. floribunda.
COHNIA, Reichb. f. in Bot. Zeit. x. (1852) 928. $O R C H I D E A E$, Benth. \& Hook, f, iii. 477. quekettioides, Reichb. $f . l$. c.-Nicaragua.

COILADENA, Rafin. FI. Tellur. ii. 12 (1836) = Ipomoea, Linn. (Convolvulac.).

hyemalis, Rafin. 1. c. $=$ I. Horsfalliae.

COILANTHA, Borckb, in Roem. Arch. i. I. (1796) $25=$ Gentiana, Tourn.

asclepiadea, G. Don, Gen. Syst. iv. $186=$ G. asclepiadea.

biloba, Bercht. \& Presl, Rostl. i. Gentian. $6=$ G. lutea.

Burseri, Bercht. \& Presl, 1. c. $=\mathrm{G}$. Burseri.

campanulata, G. Don, Gen. Syst. iv. $185=\mathrm{G}$. punctata. glauca, G. Don, 1. c. = G. glauca.

Mocinni, D. Don, ex G. Don, 1. c.=G. calyculata.

pannonica, G. Don, l. c. =G. pannonica.

punctata, G. Don, 1, $\mathrm{c}_{r}=\mathrm{G}$. punctata.

purpurea, Borckh. in Roem. Arch. i. I. (1796) $25=$ G. purpurea.

Sessaei, D. Don, ex G. Don, Gen. Syst. iv. $185=$ G. Sessaei.

COILAN'THERA, Rafin. Sylva Tellur. 38 (1838)= Cordia, Linn. (Boragin.).

rotundifolia, Rafin. 1. c. = Cordia rotundifolia.

COILMEROA, Endl. Gen. Suppl. iii. $99(1843)=$ COLMEIROA, Reut. = Securinega, Juss. (Euphorbiac.).

COILONOX, Rafin. Fl. Tellur. ii. $28(1836)=$ Ornithogalum, Toum. (Liliac.).

albucoides, Rafin. l. c. $=$ O. suaveolens.

COILOSPERMA, Rafin. F1. Tellur. iii. 43 (1836) = Deeringia, R. Br. (Amarantac.)

cordata, Rafin. 1. c。=D. baccata.

COILOSTIGMA, Klotzsch, in Linnaea, xii. (1838) $234=$ Seyphogyne, Brongn. (Ericac.).

Dregeanum, Klotzsch, 1. c. 235.-Afr. austr.

glabrum, Benth. in DC. Prod. vii. 708.-Afr. austr. puberulum, Benth. 1. $\mathrm{c}_{\mathrm{s}}=\mathrm{S}$. puberula.

tenuifolium, Klotzsch, in Linnaea, xii. (1838) 234 .Afr. austr.

Zeyherianum, Klotzsch, 1, c.-Afr. austr.

COILOSTYLIS, Rafin. F1. Tellur. iv. 37 (1836) = Epidendrum, Linn. (Orchid.).

emarginata, Rafin. $1 . \mathbf{c} .=\mathrm{E}$. ciliare.

obtusifolia, Rafin. l. c. =E. lineare?

COILOTAPALUS, P. Br. Hist. Jamaic. 111 (1756)= Cecropia, Loeff. (Urticac.).

COINOCHIAMYS, T. Anders. ex Benth. \& Hook. f. Gen. ii. 1091 (1876). ACANTHACEAE, Benth. \& Hook, f. 1. c.

angolana, S. Moore, in Fourn. Bot. xiv. (1876) 322.Afr. trop.

hirsuta, T. Anders. ex Benth. E Hook. f. Gen. ii. 1091. -Afr. trop.

COINOGYNE, Less. in Linnaea, vi. (1831) $520=\mathrm{Jau}$ mea, Pers. (Compos.)

carnosa, Less. 1. c. $521=\mathrm{J}$. carnosa

COIX, Linn. Gen, ed. I. 280 (1737). GRAMINEAE, Benth. \& Hook. f. iii. 1112.

Lacryma, Medic. Phil. Bot. i. 177 (1789).

LACrXMA-Job, Tourn. ex Linn. Gen. ed. I 280 (1737).

LACHRYMARIA, Heist. Syst. 12 (1748)

Lithagrostis, Gaertn. Fruct. i. 7. t. 1 (1788),

SpHaErium, Linn. Syst. ed. I (1735)

agrestis, Lour. Fl. Cochinch. 551.-Amboina; China. angulata, Mill. Gard. Dict. ed. VIII. n. $2=$ Tripsacum dactyloides.

aquatica, Roxb. Hort. Beng. 66 ; Fl. Ind. iii. 571.Ind. or.

arundinacea, Koen. ex Willd. Sp. Pl. iv. $203=$ Chionachne barbata.

arundinacea, Lam. Encyc. iii. $422=$ C. Lacryma-Jobi. barbata, Roxb. Hort. Beng. 66 ; Fl. Ind. iii. $569=$ Chionachne barbata. 
COIX :

crypsoides, C. Muell. in Bot. Zeit. xix. (1861) 334.Ind. or.

dactyloides, Linn. Sp. Pl. $972=$ Tripsacum dactyloides exaltata, Jacq. ex Spreng. Syst. i. $228=$ C. Lachryma Jobi.

gigantea, Koen. ex Roxb. Hort. Beng. 66 ; Fl, Ind. iii. $570=$ C. Lachryma-Jobi.

heteroclita, Roxb. 1l, cc. $66 ; 572=$ Polytoca bracteata Koenigii, Spreng. Syst. i. $228=$ Chionachne barbata. Lacryma, Linn. Syst. ed. X. $1261=$ C. Lachyydma-Jobi. Lacryma-Jobi, Linn. Sp. Pl.972-As. trop.

Ma-Yúên, Romanet, in Bull. Soc. Acclimat. Sér. II viii. (1881) 442.-Cochinch.; China ; Burma. avata, Stokes, Bot. Mat. Med. iv. $342=$ C. Lachryma Jobi

pendula, Salisb. Prod. $28=$ C. Lachryma-Jobi

pumila, Roxb. Hort. Beng. 66; Fl. Ind. iii. 572,-Ins. Maurit.

stigmatosa, C. Koch É Bouché, Ind. Sem. Hort. Berol. (1855) 9.- Hab. ?

COLA, Schott \& Endl. Meletem, 33 (1832). STERCULIACEAE, Benth. \& Hook. f. i. 218

BicheA, Stokes, Bot. Mat. Med. ii. 564 (1812).

Colaria, Rafin. Sylva Tellur. 73 (1838).

Courtenia, R. Br. in Benn. Pl. Jav. Rar. 236 (1844).

EDWARDIA, Rafin. Specch. i. 158 (1824); ex DC Prod. ii. 92 (1825)

Lunanea, DC. Prod. ii. 92 (1825).

Siphoniopsis, Karst. Fl. Columb. i. 139, t. 69 (1858).

acuminata, Schott E Endl. Meletem, 33.-Afr. trop.

Afzelii, Mast. in Oliver, Fl. Trop. Afr. i. 223.-Afr. trop.

argentea, Mast. l. c. 224.-Afr. trop

cauliflora, Mast. l. c. 221.-Afr, trop.

clavata, Mast. l. c. 222.-Afr. trop.

cordifolia, [R. Br. in] Benn. Pl. Fav. Rar. 237.-Java. digitata, Mast. in Oliver, Fl. Trop. Afr, i. 224.-Afr trop.

ficifolia, Mast. l.c. 223.-Afr. trop.

gabonensis, Mast.l. c. 222.-Afr. trop.

grandiflora, Schott E Endl. Meletem. 33.-Hab. ?

heterophylla, Schott E Endl. l.c.; Mast. in Oliver, Fl. Trop. Afr. i, 223-Afr. trop.

laurifolia, Mast. in Oliver, l. c. 222.-Afr. trop.

macrocarpa, Schott 8 Endl. Meletem. $33=$ acuminata.

natalensis, Oliver, in Hook. Ic. Pl. t. 1390.-Afr austr.

nitida, Schott \& Endl. Meletem. $33=$ acuminata.

quinqueloba, Garcke, in Peters, Reise Mossamb. Bot. 130.-Afr. trop.

tomentosa, Schott \& Endl. Meletem. 33=Sterculia tomentosa.

COLARIA, Rafin. Sylva Tellur. $73(1838)=$ Cola Schott \& Endl. (Stercal.)

acuminata, Rafin. 1. c。=Cola acuminata.

heterophyla, Rafin. 1. $\mathrm{c}_{\mathrm{s}}=$ Cola heterophylla

COLAX, Lindl, ex Spreng. Syst. iii. 727 (1826); et Bot Reg. (1843) Misc. $50=$ Lycaste, Lindl. (Orchid.).

aromaticus, Spreng. Syst. iv, Cur. Post. $307=\mathrm{L}$ aromatica.

Barringtoniae, Lind]. ex Spreng. Syst. iii. $727=\mathrm{L}$. Barringtoniae.

grandiflorus, Rafin. F1. Tellur. ii. $85=$ Bifrenaria Harrisoniae.

Harrisoniae, Lindl. ex Spreng. Syst. iii. $727=$ Bifrenaria Harrisoniae.

jugosus, Lindl, Bot. Reg. (1843) Misc. 51.-Bras.

modestior, Reicbb. f. in Hamb. Gartenz. xvi. (1860

14.-Bras.

pallidiflorus, Spreng. f. Tent, $29=$ Maxillaria pallidiflora.

palmifolius, Lind1. ex Spreng. Syst. iii. $727=$ Maxillaria palmifolia.

Parkeri, Spreng. f. Tent. 28 = Maxillaria Parkeri

parvulus, Spreng. Syst. iv. Cur. Post. $307=$ Bifrenaria parvula.

placantherus, LindI. Bot. Reg. (1843) Misc. 50.Bras.

Puydtii, Linden \& André, in Illustr. Hortic xxvii. (1880) t. 869. -Bras

racemosus, Spreng. f. Tent. $29=$ Bifrenaria racemosa viridis, Lind1. Bot. Reg. (1843) Misc. $50=$ L. viridis.
COLBERTIA, Salisb. Parad. Lond. sub t. 73 (1807) Dillenia, Linn.

augusta, Wall. Cat. n. $948=$ D. pentagyna

coromandelina, DC. Syst. i. $435=\mathrm{D}$. pentagyna.

floribunda, Wall. Cat. n. $950=$ D. Horibunda.

minor, Zoll. \& Mor. in Nat. en Geneesk. Arch. Neêrl.

Indie, ii. (1845) 579.-Java.

obovata, Blume, Bijdr, $6=\mathrm{D}$, aurea.

scabrella, D. Don, Prod. F1. Nep. $226=$ D. scabrella

COLCHICUM, Linn. Syst. ed. I (1735); Gen. ed. I. 107 (1737). LILIACEAE, Benth. \& Hook. f. iii. 821.

Fouha, Pomel, Mat. Fl. Atl. 2 (1860)

Hermodactylos, Reichb. Consp. 64 (1828)

Monocaryum, R. Br. in App. Voy. Denh. et Clapp. $243(1826)$.

Paludaria, Salisb. Gen. Pl. Fragm. 53 (1865)

SynsiphoN, Regel, in Act. Hort. Petrop. vi. (1879) 490.

aegyptiacum, Boiss. Diagn. Ser. I. y, $66=$ montanum. aestivale, Bor. Fl. Centr. Fr. ed. III. ii. $612=$ byzantinum aetnense, Tineo, in Guss. F1. Sic. Syn. ii. $818=$ neapo litanum.

agrippinum, Baker, in Fourn. Linn. Soc. xvii. (1879) 425.-Hab. ?

Alberti, Regel, in Act. Hort. Petrop. viii. (1884) 647 -As. centr.

alpinum, $D C$. $F l$. Fr. iii. 195-Europ.

alpinum, Schimp. ex Nym. Consp. $742=$ montanum.

amabile, Heldr. in Atti Congr. Bot. Firenze, 1874 (1876) 227.-Graecia.

arenarium, Koch, Syn. F1. Germ. ed. I. $836=$ neapoli. tanum.

arenarium, Waldst. E Kit. Pl. Rar. Hung. ii. 195, t. 179.-1tal.; Hungar.

atticum, Sprun. ex Tommas. in Flora, xxiii. (1840) 730 Merendera attica.

autumnale, Linn. Sp. Pl. 341.-Europ.

Balansae, Planch, in Ann. Sc. Nat, Sér. IV iv. (1855) $\mathbf{1 4 5}=$ laetum.

Bertolonii, Stev. in Nouv. Mém. Soc. Nat. Mosc. vii (1829) $268=$ montanum.

Bisignani, Tenore, fide Janka, ex Baker, in Journ. Linn. Soc. xvii. (1879) $427=$ Tenorii.

Bivonae, Guss. Adnot. Cat. Pl. Bocc. (1821) 4.-Europ. austr.

Bivonae, Tenore, F1. Nap. Prod. App. v. $11=$ Tenorii.

Bivonae, Willk. \& Lange, Prod. Fl. Hisp. 1. 194, ex parte $=$ lusitanum

Boissieri, Orph. in Atti Cong. Bot. Firenze, 1874 (1876) 31.-Graecia.

brachyphyllum, Boiss. E Haussk. ex Boiss. Fl. Orient. v. 164.-Syria.

bulbocodioides, Bieb. F1. Taur. Cauc. i. 293 ; iii. $281=$ montanum.

bulbocodioides, Brot. Fl. Lusit. i. $597=$ Merender Bulbocodium

Bulbocodium, Ker-Gawl. in Bot. Mag. sub t. $1028=$ Bulbocodium vernum.

byzantinum, Ker-Gawl. l. c.-Graccia; As. Min byzantinum, Tenore, F1. Nap. iii. $397=$ Tenorii. castrense, Laramb. in Bull. Soc. Bot. Fr. ii. (1855) 688 =neapolitanum.

candidum, Schott \& Kotschy, ex Baker, in Journ. Liar.

Soc. xvii. (1879) $429=$ laetum

catacuzenium, Heldr. ex Boiss. Fl. Orient. v. 165 montanum.

caucasicum, Spreng. Syst. i. $148=$ Merendera caucasica chionense, Haw. ex Kunth, Enum. Pl. iv. 189=variegatum?

Clementei, Graells, in Mem. Acad. Cienc. Madr. ii [1854] $483=$ bulbocodioides.

commune, Neck. Delic. Gallo-Belg. i. $176=$ autumnale. corsicum, Baker, in Fourn. Linn. Soc. xvii. (1879) 431 .

-Ins. Corsica.

crociflorum, Sims, Bot. Mag, t. 2673.-Europ snstr.

crociflorum, Regel, in Act. Hort. Petrop. vii. (1880) $385 .-$ Kokan.

crociflorum, Schott \& Kotschy, in Oestr. Bot. Wochenbl, iv. (1854) $97=$ montanum.

crocifolium, Boiss. Diagn. Ser. I. v. $67=$ montanum.

Cupani, Guss, FL. Sic. Prod i. $452=$ montanum

Decaisnei, Boiss. Fl. Orient. v. 157.-Syria.

euboeum, Orph. in Atti Cong. Bot. Firenze, 187 $\$(1876$ 28 - Bivonae.

fasciculare, Boiss. Fl. Orient, v. 163.-Syriß

fasciculare, R. Br. in Denh. \& Clapp. Trav. 249 montanum.

\section{COLCHICUM}

alcifolium, Stapf, in Denkschr. Acad. Wien, 1. (1885) 19.-P'ersia.

floribundum, Lawson, Cat. 6; ex Salisb. in Trans. Hort. Soc. i. (1812) $329=$ byzantinum.

Haussknechtii, Boiss. Fl. Orient. v. 157.-Persia

Haynaldi, Heuff. in Verh. Zool.-Bot. Ges. Wien, viii. (1858) 213 = antumnale.

hexapetalum, Pourr. ex Schult. f. Syst. vii. $1521=$ Merendera Bulbocodium

hololophum, Coss. \& Dur. in Buil. Sac. Bot. Fr. iv 1857) $489=$ montanum.

illyricum, Frivald. ex Kunth, Enum. Pl. iv. 140speciosum.

illyricum, Stokes, Bot. Mat. Med. ii. 331.-As. Min.

Fankae, Freyn, in Oestr. Bot. Zeitschr. xxvii. (1877) 361 = neapolitanum

Kochii, Parl. Fl. Ital, iii. 188 = Deapolitanum.

Kotschyi, Boiss. Diagn. Ser. I. xiii, 38 = laetum.

laetum, Stev in Nouv. Mém. Soc. Nat. Mosc vii. (1829) 202. t. 13.-Oriens.

latifolium, Griseb. Spicil. Fl. Rumel. ii. 378 speciosum.

latifolium, Sibth. \& Sm. Fl. Graec. iv. 43. t. $350=$ Sibthorpii, byzantinum.

Levieri, fanka, in Oestr. Bot. Zeitschr. xxv. (1875) 82. -Italia.

libanoticum, Ehrenb. ex Boiss. Fl. Orient iii. 166. Syria.

lingulatum, Boiss. E Sprun. Diagn. Ser. I. v. 66.Europ.

longifolium, Castag. Cat. PI. Marseille, $135=$ neapolitanum.

lusitanum, Brot. Phyt. Lusit. ii. 211. t. 173, 174.Lusitania.

luteum, Baker, in Gard..Chron. (1874) 39.-Reg. Himal.

Merendera, Ker-Gawl. in But. Reg. sub to $541=$ $=$ Mcrendera Bulbocodium.

micranthum, Boiss. Fl. Orient. v. 162.-Byzant.

minimum, Elwes, ex Baker, in Journ. Lina. Soc. xvii. 1879) $439=$ montanum.

monogynum, Bieb, ex Schult. f. Syst. vii. $796=$ Stern bergia caucasica.

montanum, All. Fl. Pedem, i, 117 = alpinum.

montanum, Linn. Sp. Pl. 342,-Europ austr.

montanum, Linn. 1. c, partim = Merendera Bulbocodium.

montanum, Schousb. Vextr. Marok. $185=$ autumnale. multiflorum, Brot. Fl. Lusit. i. $597=$ autumnale.

neapolitanum, Orph. ex Nym. Consp. $743=$ parmassicum.

neapolitanum, Tenore, Fl. Neap. Prod. App. v. 11.Italia.

nivale, Boiss. \& Huet, ex Baker, in Journ. Linn. Soc. xvii. $(1879) 433=$ montamum.

orientale, Frivald, ex Kunth, Enum. Pl. iv. $113=$ neapolitanum.

pannonicum, Griseb. \& Schenk, in Wiegm. Archiv, xviii. $(1852)$ I. $359=$ autumnale.

Parkinsoni, Hook. f. Bot. Mag. t. $6090=$ variegatum.

Parlatoris, Orph. in Atti Congr. Bot. Firense, 1s-t

(1876) 32.-Graecia.

parnassicum, Sart. Orph. E Heldr. in Boiss, Dingn. Ser. II. iv. 122.-Graecia.

parviflorum, Bivona, ex Parl. Fl. Ital. iii. 191 montanum.

parvulum, Janks, in Oestr. Bot. Zeitschr. xxiii. (1s;s $243=$ micranthum.

parvulum, Tenore, Viag. in Basilic. $120=$ alpinam. patess, Schultz, in Flora, ix. (1826) $182=$ autumnale.

persicum. Baker, in fourn. Linn. Soc. xvii. $(187 y, 480$. - Persia.

polyanthon, Ker-Ganl. in Bot. Mag. sab to 1025 autumnale.

polymorpham, Orph. in Atti Congr. Bot. Firenze, $15 i t$ $18 ; 6) 29=$ neapolit.rnum.

polyphyllum, Boiss. \& IIeldr. Diagn. Ser. I1. iv. 121 = sieveni.

praccox, Spenn. Fl. Fribung. i. 215 - aurumnale.

prosinciale, H. Loret, in Hull. Soe, Bot. F's. vi. (155\%) +59 a neapclienum.

pulchrum, Herb. pr Baker, in Gunrm. Lime. Sor. xvii. (15i9) 125. - Graccia.

pusillum, Sicber, in klora, v. 1522) 215 mon tanuแu.

Pyrennicum, Puurr. in Mcm. Acad. Toul, iii. lis \$10 - Merendicra liulbucudiuro. 


\section{COLCHICUM :-}

Ritchii, R. Br. in App. Denh. \& Clapp. Trav. $241=$ montanum.

Sibthorpii, Baker, in Fourn. Linn. Soc. xvii. (1879) 427.-Graecia.

speciosum, Stev, in Nouv. Mém. Soc. Nat. Mosc. vii. 1829) 265. t. 15.-Reg. Cancas.

Steveni, Kunth, Enum. Pl. iv, 144.-Syria; Arab.

Szovitsii, Fisch. E Mey. Ind. Sem. Hort. Petrop. i. 24 -Reg. Caucas.

Tenorii, Parl. Fl. Ital. iii. 176.-Italia.

tessellatum, Hort. ex Baker, in Journ. Linn. Soc. xvii (1879) $425=$ agrippinum.

tesselatum, Link. - Cf. Kunth, Enum. Pl. iv. $139=$ Bivonae.

tessellatum, Salisb. Prod. 236 = variegatum.

tessulatum, Mill. Gard. Dict. ed. VIII. n. $4=$ variegatum.

Todarii, Parl. Fl. Ital. iii. $178=$ lusitanum.

trapezunticum, Boiss. ex Baker, in Journ. Linn. Soc. xvii. (1879) $430=$ polyphyllum.

transsilvanicum, Schur, Enum. Pl. Transs. $679=$ byzantinum.

triphyllum, Kunze, in Flora, xxix. (1846) $755=$ montanum.

Troodi, Kotschy, in Unger E Kotschy, Cyprus, 190.Ins, Cyprus.

turcicum, Fanka, in Oestr. Bot. Zeitschr. xxiii. (1873) 242. - Europ. or.

umbrosum, Stev. in Nouv. Mém. Soc. Nat. Mosc. vii (1829) 268. t. 14.-Tauria.

Valery, Tineo, in Guss, Fl. Sic. Syn. ii. $818=$ montanum variegratum, Bivona, Sic. PI. Cent. i. $27=$ Bivonae. variegatum, Linn. Sp. Pl. 342,-Europ, austr. variegatum, Sieber, ex Baker, in Journ. Linn. Soc. xvii (1879) $427=$ Sibthorpii.

variopictum, Janka, in Oestr. Bot. Zeitschr. xxv. (1875) 83 = amabile.

vernale, Hoffm. Deutsch1. FI. ed. II. i. $174=$ autum nale.

vernum, Kunth, Enum. P1. iv. 141 = autumnale.

vernum, Kunth, 1. c. $146=$ Bulbocodium vernum.

vernum, Pall. ex Bieb. F1. Taur. Cauc. i. $293=$ montanum.

versicolor, Ker-Gawl. in Bot. Reg.t. $571=$ Bulbocodium versicolor.

Visianii, Parl. F1. Ital. iii. $175=$ Bivonae.

COLDENIA, Linn. Diss. Dass. 9 (1747); Amoen Acad. i. 393 (1749). BORAGINEAE, Benth. \& Hook. f. ii. 841.

EDDyA, Torr. \& A. Gray, in Pacif. Rail. Rep. ii. 170 (1855).

GalapagoA, Hook. f. in Trans. Linn. Soc. xx. (1847) 196

GoldeniA, Raeusch. Nom. ed. III. 43 (1797)

Lobophyllum, F. Muell, in Hook. Kew Journ. ix. (1857) 21.

Monomesia, Rafin. Fl. Tellur. iv. 87 (1836).

Ptilocalyx, Torr. \& A. Gray, in Pacif. Rail. Rep. ii. 170 . t. 8 (1855).

STEgNoCARPUS, Torr. 1. c. 169 (1855).

Trouilia, Pers. Syn. i. 157 (1805)

angolensis, Welw. Apont. 591.-Afr. trop.

atacamensis, Phil. Fl. Atac. 37.-Chili.

canescens, DC. Prod. ix. 559.-Am. bor, occ

dichotoma, Lehm. Asperifol. 9.-Peruy.

Dombeyana, Buek, Ind. DC. Prod. iii. $108=$ dicho

toma.

Greggii, A. Gray, Syn. Fl. N.Am. ii. I. 182.-Am. bor occ.

hispidissima, A. Gray, in Proc. Am. Acad. v. (1862) 340.-Am. bor. occ

litoralis, Phil. Fl. Atac. 37.-Chili.

mexicana, S. Wats. in Proc. Am. Acad. xviii. (1882-83) 119.-Mexic.

Nuttallii, Hook. in Hook. Kew Fourn. iii. (1851) 296. Am. bor. occ.

Palmeri, A. Gray, in Proc. Am. Acad. viii. (1870) 292. - Am bor occ.

pentandra, Juss. ex Steud. Nom. ed. II. i. $396=$ dichotoma.

procumbens, Linn. Sp. Pl. 125.-Ind. or.

tomentosa, S. Wats. in Proc Am. Acad. xviii. (1882-83) 120.-Am. bor. occ.

COLEA, Boj. Hort. Maurit, 220 (1837). BIGNONIA$C E A E$, Benth. \& Hook. f. ii. 1051
COLFA :-

TRIPINNA, Lour. Fl. Cochinch. 391 (1790)

Tripinnaria, Pers. Syn. ii. 173 (1807).

Uloma, Rafin. F1. Tellur. ii. 62 (1836)

cauliflora, DC. Prod. ix. $241=$ floribunda.

Chapelieri, DC. 1. c. $242=$ decora.

Commersonii, DC. 1. c. = floribunda

decora, Boj. Hort. Maurit. 220, nomen; DC. l. c. 241. - Madag.

discolor, Seem. in Trans. Linn. Soc. xxiii. (1860) 8.Madag.

floribunda, Boj. Hort. Maurit. 220, nomen; Lindl. Bot. Reg. (1841) t. 19.-Madag.

hispidissima, Seem. in Trans. Linn. Soc. xxiii. (1860) 9.-Madag.

involucrata, Boj. Hort. Maurit. 221, nomen; DC.Prod. ix. 242,-Madag.

mauritiana, Boj. l. c. 220.-Ins. Mascar

nitida, DC. Prod. ix. $242=$ decora.

obtusifolia, DC. 1. c. $241=$ mauritiana.

parviflora, Baker, in fourn. Linn. Soc. xxi. (1885) 428. -Madag.

pedunculata, Baker, Fl. Maurit. 244.-Ins. Seychelles.

purpurascens, Seem. in Trans. Linn. Soc, xxiri. (1860) 8.-Madag.

ramiflora, DC. Prod. ix, $241=$ mauritiana

Seychellarum, Seem. in Trans. Linn. Soc. xxiii. (1860) 8.--Ins. Seychelles.

Sieberi, A. DC. in DC. Prod. ix. 240, in notaHab.?

Telfairii, Boj. Hort. Maurit. 220,-Madag.

tetragona, DC. Prod. ix. 242.-Madag.

tripinnata, Seem. in Bonplandia, iv. (1856) 128.Cochinch.

undulata, Regel, Gartenf. (1870) 322.-Madag.?

COLEACHYRoN, J. Gay, ex Boiss. Fl. Orient. v. 408 (1881) = Carex, Dill. (Cyperac.)

oliverianum, J. Gay, 1. c.=Carex illegitima.

COLEANTHERA, Stschegl. in Bull. Soc. Nat. Mosc. xxxii. (1859) 1. 4. EPACRIDEAE, Benth. \& Hook. f. ii. 611 .

MichieA, F. Muell. Fragm. iv. 95.t. 27 (1864). caelophylla, Benth. Fl. Austral. iv. 150.-Austral. myrtioides, Stschegl. in Bull. Soc. Nat. Mosc. xxxii. (1859) I. 4.-Austral

virgata, Stschegl. l. c. 5.-Austral.

COLFANTHUS, Seid. in Roem. \& Schult. Syst. ii 11, 276 (1817). GRAMINEAE, Benth. \& Hook. f. iii. 1147

Schmidtia, Tratt. F1. Austr. i. 12, t. 451 (1811)

WIIIBALdA, Sternb. in Flora, ii. (1819) 6.

subtilis, Seid. in Roem. E Schult. Syst. ii. 276.-Europ.

COLEATAENIA, Griseb. in Goett. Abh. xxiv. (1879) 308 = Panicum, Linn. (Gramin.).

gynerioides, Griseb. 1. c.-Reg. Argent.

COLEBROOKEA, Sm. Exot. Bot. ii. 111. t. 115 (1806). LABIATAE, Benth. \& Hook. fo ii. 1180 oppositifolia, Lodd. Bot. Cab. t. $487=$ Elsholtzia polystachya.

oppositifolia, Sm. Exot. Bot. ii. 111. t. 115.-Ind. or.; Burma.

ternifolia, Roxb. Hort. Beng. 45 ; Fl. Ind. iii. $25=$ oppositifolia.

COLEBROOKIA, Donn, Cat. Hort. Cantab. i. $(\mathbf{1 7 9 6 )}=$ Globba, Linn. (Zingib.).

bulbifera, Donn, 1. c. = G. marantina.

COLEBROOKIA, Spreng. Syst. ii. $713=$ Colebrookea, Sm. (Labiat.)

COLEMA, Rafin. New Fl. Am. iii. $49(1836)=$ Corema, D. Don (Empetrac.).

arenaria, Rafin. $1 . \mathrm{c} .=$ Cor. Conradii.

COLENSOA, Hook. f. Fl. N. Zel. i. $156(1853)=$ Pratia, Gaudich. (Campanulac.)

physaloides, Hook. f. 1. c. 157.-N. Zel.

COLEOCOMA, F. Muell, in Hook. Kew Journ. ix. (185\%) 19. COMPOSITAE, Benth. \& Hook. f. ii. 293.

Centaurea, F. Muell. l. c.-Austral.
COLEOGYNE, Torr. in Smithson. Contrib. vi. (Plant Frémont.) 8. 't. iv. (1854), ROSACEAE, Benth. \& Hook. f. i. 617

ramosissima, Torr. $l$. c.-Calif.

COLEONEMA, Bartl. \& Wendl. f. Diosm. 55. t. A (1824). RUTACEAE, Benth. \& Hook. f. i. 289 album, Bartl. \& Wendl. f. l.c. 56.-Afr. austr. album, E. Mey, Zwei Pfl, Docum. 174=Diosma vulgaris

aspalathoides, A. Fuss. in Mém. Mus. Par. xii. (1825) 471. - Afr. austr.

Dregeanum, Presl, Bot. Bemerk. 31=pulchrum.

filiforme, A. Juss. in Mém. Mus. Par. xii. (1825) 471 = pulchrum.

gracile, Eckl. \& Zeyh. Enum. 106=pulchrum.

juniperifolium, Eckl. E Zeyh. l. c.-Afr. austr.

juniperinum, Sond. in Harv. \& Sond. Fl. Cap. i. 379 = juniperifolium.

pulchrum, Hook. Bot. Mag. t. 3340,-Afr. austr.

virgatum, Eckl, \& Zeyh. Enum, 106= pulchrum.

virginianum, Eckl. \& Zeyh.1. c。=juniperifolium.

COLEOPHORA, Miers, in Ann. Nat. Hist. Ser. II. vii. (1851) $197=$ Daphnopsis, Mart. (Thymel.).

gemmiflora, Miers, 1. c. - D. Martii.

COLEOPHYLLUM, Klotzsch, in Otto \& Dietr. Allg. Gartenz, viii. (1840) $185=$ Chlidanthus, Herb (Amaryll.)

Ehrenbergii, Klotzsch, 1. c. = Chlidanthus Ehrenbergii.

COLEOSANTHUS, Cass. in Bull. Soc. Philom. (1817) 67 ; et Dict. Sc. Nat. x. (1818) $36=$ Brickellia, Ell. (Compos.),

Cavanillesii, Cass. in Dict. Sc. Nat. $x .37=B$. Cavanillesii.

tiliaefolius, Cass. 1. c. xxiv. $519=$ Eupatorium macrophyllum.

COLFOSPADIX, Becc. in Ann. Jard. Buitenz. ii. (1885) 90. PALMAE.

litigiosa, Becc. $l . c,-\mathrm{N}$. Guinea.

oninensis, Becc. l. c.-N. Guinea.

COLFOSTACHYS, A. Juss, in Ann. Sc. Nat. Sér II. xiii. (1840) 329. MALPIGHIACEAE, Benth. \& Hook. f. i. 253 .

genipaefolia, $A$. Fuss. $l$. c.-Bras.

hypoleuca, Benth. in Hook. Lond. Journ. Bot, vii (1848) $125=$ Blepharandra hypoleuca.

spicata, Juss. in Arch. Mus. Par, iii. (1843) t. $5=$ genipaefolia.

vestita, Benth. in Hook. Lond. Journ. Bot. vii. (1848) $124=$ Diacidia vestita

COLEOSTEPHUS, Cass. in Dict. Sc. Nat. xli. 43 (1826) Chrysanthemum, Linn. (Compos.).

Clausonis, Pomel, Nouv. Mat. Fl. Atl, 59.-Algeria. hybridus, Lange, in Kjoeb. Vidensk. Meddel. (1861) 77 (Pugill. 127) $=$ Chrys. Myconis

macrotus, Dur. in Duch. Rev. Bot. i. (1845-40) $363=$ Chrys, macrotum

multicaulis, Dur. 1. c. $364=0$ Chrys. multicaule.

Myconis, Cass. in Dict. Sc. Nat. xli. $43=$ Chrys. Myconis.

COLEOSTYLES, Benth. \& Hook. f, Gen. ii. 535 [bis] $(1873)=$ seq.

COLEOSTYLIS, Sond, in Lehm. PI. Preiss. i. 391 $(1845)=$ Levenhookia, R. Br. (Stylid.)

Preissii, Sond. 1. $c_{\mathrm{s}}=\mathrm{L}$. Preissii

Sonderi, F. Muell. in Trans. Phil. Soc. Vict. i. (1855) $46=\mathrm{L}$. Sonderi.

umbellulata, Sond, in Lehm. Pl. Preiss. i. 391=L stipitata.

COLEOTRYPE, C. B. Clarke, in DC. Monog. Phan ii. 238, t. 8 (1881), COMMELINACEAE, Benth. \& Hook. f. iii. 851 .

Goudotii, C. B. Clarke, l. c. 240.-Madag madagascarica, C. B. Clarke, l. c. 239.-Madag. natalensis, $C . B$. Clarke, $l$. c.-Afr. austr.

COLETIA, Vell. Fl. Flum. 32 (1825)= Mayaca, Aubl madida, Vell. 1. c. 33 ; i. t. $79=$ M. Sellowiana. 
COLEUS, Lour. Fl. Cochinch, ii. $372(1790)$ LA BIATAE, Benth. \& Hook. f. ii. 1176

Mitsa, Chap. ex Benth. Lab. Gen. et Sp. 52 (1832) acuminatus, Benth. in Linnaea, vi. (1831) 81.-Ins. Philipp.

africanus, Benth. Lab. Gen, et Sp, 54,-Afr, trop. albidus, Vatke, in Linnaea, xxxvii. (1871-73) 321.Abyss.

alpinus, Vatke, l. c. 322.-Abyss

amboinicus, Lour. F1. Cochinch. ii. $372=$ aromaticus anamallayensis, Bedd. in Madr. Fourn. Sc. Ser. II xxii. (1861) 73. - Ind. or

arabicus, Benth. in DC. Prod. xii. 79.-Arab. aromaticus, Benth. in Wall. Pl. As. Rar. ii. 16.Ind. or.

atropurpureus, Benth.l. c.-Malaya; Pacific.

barbatus, Benth. l. c. 15. -Ind. or. ; Afr. trop

Benthamianus, Arn. in Nov. Act. Nat, Cur. xviii. (1836) $354=$ inflatus.

bicolor, Benth. Lab. Gen. et Sp. 55.-Java.

Blancoi, Benth. in DC. Prod. xii. 79.-Ins. Philipp.

Blumei, Benth. Lab. Gen. et Sp. 56.-Java.

Bojeri, Benth. l. c. 52.-Madag.

caninus, Vatke, in Linnaea, xxxvii. (1871-73) 318.Abyss.

carnosus, Hassk in Flora, xxy. (1842) II. Beibl. 25.Java.

comosus, Hochst. ex A. Rich. Tent. Fl. Abyss. ii. $183=$ spicatus.

crassifolius, Benth. in Wall. Pl. As, Rar. ii. $15=$ aromaticus.

edulis, Vatke, in Linnaea, xxxvii. (1871-73) 319.Abyss.

flaccidus, Vatke, in Linnaea, xliii. (1880-82) 90.Afr. trop.

fruticosus, Benth, in DC. Prod. xii. $78=$ Plectranthus fruticosus.

fruticosus, Wight, ex Benth. in DC. Prod. xii. 78.Ind. or.

galeatus, Benth. Lab. Gen. et Sp. 56.-Java.

Garckeanus, Vatke, in Linnaea, xxxvii. (1871-73) 323.-Abyss.

Gibsonii, Verlot, in Rev. Hortic. (1866) 279.-Hab.? glabratus, Benth. Lab. Gen. et Sp. $58=$ Plectranthus colcoides.

glandulosus, Hook. f. in Fourn. Linn. Soc. vii. (1864) 211.-Afr, trop.

grandifolius, Benth. Lab. Gen. et Sp. 53.-Ins. Timor. grandifolius, Blanco, Fl. Filip. ed. I. $482=$ Blancoi.

Heynei, Benth. Lab. Gen. et Sp. $50=$ spicatus.

Huberi, Regel, in Act. Hort. Petrop. vii. (1880) 543.Abyss.

igniarius, Schweinf. Beitr. Fl. Aethiop. 121.-Afr. trop.

inflatus, Benth. Lab. Gen. et Sp. 58.-Zeylan.

ingratus, Benth.l. c. 53,-Java,

laciniatus, Benth.l.c. 56.-Java.

lactiflorus, Vatke, in Linnaea, xliii. (1880-82) 89.Afr. trop.

lanuginosus, Hochst. ex Benth. in DC. Prod. xii. 79. Abyss.

latifolius, Hochst. ex Benth. l. c. 74.-Abyss.

leptostachys, Benth. l.c.77.-Zeylan.

Macraci, Benth. Lab. Gen, et Sp, $58=$ malabaricus

macrophyllus, Benth. l. c. 55.-Java.

macropus, Miq. Fi. Ind. Bat. ii, 956.-Java

macrostachys, Benth. Lab. Gen. et Sp. 57.-Java.

malabaricus, Benth. in Wall. Pl. As. Rar. ii. 16. Ind. or.

Mannii, Hook. f. in Fourn. Linn. Soc. vii. (1864) 211. -Afr. trop.

micranthus, Maxim. in Act. Hort. Petrop. iii. (1875) 108.-Abyss.

mollis, Benth. in DC. Prod. xii. $77=$ malabaricus. multiflorus, Benth. Lab. Gen. et Sp. 55. - Ins. Philipp, ovatus, Benth. 1. c, $57=$ malabaricus.

palustris, Vatke, in Linnaea, xxxvii. (1871-73) 319.Abyss.

paniculatus, Benth. in Wall. Pl. As, Rar. ii. $16=$ Plectranthus colcoides.

parviflorus, Benth, in DC. Prod. xii. 72.-Ind, or.

Persoonii, Benth. Lab. Gen. et Sp. 55.-Madag.

Petersianus, Vatke, in Linneca, xl. (1876) 180,-Afr. trop.

puberulus, Miq. Fl. Ind. Bat. ii. 955.-Malnya. pumilius, I3lanco, F1. Filip. ed. I. $482=$ acuminatus, remotiflorus, Miq. Fl. Ind. Bat. ii. 954 .-Java. rivularis, Vatke, in Linnaea, xxxvii. (1871-73) 320 -

Abyss.

\section{COLEUS :}

rugosus, Benth. in Wall. Pl. As. Rar, ii. 15=Plectranthus rotundifolius.

Schimperi, Vatke, in Linnaea, xxxvii. (1871-73) $320=$ barbatus.

Schweinfurthii, Vatke, l. c. 323, in textu.-Afr. trop scutellarioides, Benth. in Wall. Pl. As. Rar. ii. 16. Malaya: Austral.

secundiforus, Benth. Lab. Gen. et Sp. 55.-Ins. Timor spectabilis, Miq. Fl. Ind. Bat. ii. 955.-Java.

spicatus, Benth. in Wall. Pl. As. Rar. ii. 15.-Ind or.

suborbicularis, Zoll. E $M$ oritzi, Syst. Verz. Zoll.4.Java.

subspicatus, Walp. Rep. vi. 658 = Plectranthus spi-

Suganda, Blanco, Fl. Filip. ed. I. $483=$ aromaticus. tenuicaulis, Hook. fo in fourn. Linn. Soc. vii. (1864) 211.-Afr. trop.

enuiflorus, Vatke, in Linnaea, xliii. (1880-82) 92.Afr. trop.

Tryoni $x$, Hort. ex Flor. Mag. N. S. i. (1872) t. 34

tuberosus, Benth. Lab. Gen. et Sp. $59=$ parviflorus.

tuberosus, A. Rich. Tent. Fl. Abyss. ii. 185.-Abyss. umbrosus, Vatke, in Linnaea, xliii. (1880-82) 91.

Afr. trop.

urticifolius, Benth. in DC. Prod. xii. $78=$ Plectranthns urticifolius.

Verschaffeltii, Lem. Illustr. Hortic. viii. (1861) t. 293 - Java.

Walkeri, Benth. in DC. Prod. xii. $77=$ malabaricus.

Wightii, Benth. Lab. Gen, et Sp. $58=$ Plectranthus coleoides.

Zatarhendi, Benth. 1. c. $50=$ spicatus ?

COLICODENDRON, Mart. in Flora, xxii. (1839)

Beibl. 25 - Capparis, Linn.

anceps, Shuttl. ex Chapm. Fl. S. U. St. $32=$ Capp. jamaicensis.

avicenniaefolium, Seem. Bot. Voy. Herald, $78=$ Capp avicennifolia.

Breynia, Endl. ex Heynh. Nom. ii. 154=Capp. Breynia.

lepidotum, Turcz in Bull. Soc. Nat. Mosc. xxvii. (1854) II. 327.-Venezuela.

longifolium, Mart. in Flora, xxii. (1839) 1. Beibl. 26 - Bras.

obliquifolium, Turcz. in Bull. Soc. Nat. Mosc. xxvii 1854) II. 328.-N. Granat.

obovatum, Turcz. 1. c. 327.-Venezuela.

pulchellum, Seem. Bot. Voy. Herald, $78=$ Capp. pulcherrima.

scabridum, Seem. 1. c. = Capp. scabrida.

subbilobum, Seem. 1. c. = Capp. subbiloba

Yco, Mart. in Flora, xxii. (1839) I. Beibl. 25=Capp Yco.

COLIGNONIA, End1. Gen. 311 (1837). NYCTAGINEAE, Benth. \& Hook. f. iii. 8.

Collignonia, Endl. Ench. 193 (1841)

biumbellata, Ball, in fourn.Linn. Soc. xxii. (1885) 54. -Peruv.

glomerata, Griseb. in Goett. Abh.xix. (1874) 87.-Reg. Argent.

parvifora, Endl. Gen. 311; Choisy, in DC. Prod. xii. II. 489,-Peruv

scandens, Benth. Pl. Hartw. 148.-Peruv.

COLIOUEA, Steud. ex Bibra, in Denkschr. Wien. Acad. v. (1853) $115=$ Chusquea, Kunth (Gramin.) Quila, Steud. ex Bibra, 1. c. =Chus, Cumingii.

COLLABJUM, Blume, Bijdr. 357 (1825). ORCHI $D E A E$, Benth. \& Hook. f. iii. 508.

Debulosum, Blume, l. c. 358,-Java

simplex, Reichb. f. in Gard. Chron. (1881) x. 462.Eorneo.

COLLADEA, Pers. Syn, i. $107(1805)=$ seq .

COLLADOA, Cav, Ic. v. $37 . t .460(1799)=$ Ischaomum Linn. (Gramin.)

distachia, Cav. I. $\mathrm{c}_{2}=\mathrm{I}$. rugosum.

monostachya, Pers. Syn, i. $107 \Rightarrow$ Anthephora elegans.

COLLADONIA, Spreng. Syst. i. $516(18 \pm 5)=$ Pali courea, Aubl. (kubiac.)

tinifolia, Spreng. 1. c. $757=$ P. tinifolia.
COLLADONIA, DC. Prod. iv. 240 (1830)=Prangos, Lindl. (Umbellif.).

alata, Boiss. Fl. Orient. ii. 945.-Syria

anatolica, Boiss. 1. C.-As. Min.

angustifolia, Bertol. Fl. Ital. iii. $408=$ P. angustifolia.

anisoptera, Boiss. Fl. Orient, ii. 946.-Syria.

cilicica, Boiss. 1. c. 947.-Cilicia.

crenata, Boiss. 1. c. 946-Syria.

heptaptera, Boiss. 1. c. $945=\mathrm{P}$. colladonioides

microcarpa, Boiss. 1. c. $946=$ P. microcarpa

syriaca, Boiss. in Ann. Sc. Nat. Sér. III. ii. (1844) $86=$

Smyrniopsis cachroides.

triquetra, DC. Prod. iv. $240=$ P. triquetra.

COLlAEA, DC. Mém. Leg. vi. 244 (1825); et in Ann, Sc. Nat. Sér. I. iv. (1825) $96=$ Galactia, P. Br. (Legumin.).

angustifolia, Benth. in Ann. Wien. Mus. ii. (1838) 129 G. angustifolia

argentina, Griseb. in Goett. Abh. xix. (1874) 125.

Reg. Argent.

bullata, Benth in Mart. Fl. Bras. XY. I. 149.Bras.

cinerascens, R. Grab. in Wall. Cat. n. $5575=$ Atylosia mollis.

crassifolia, Benth. in Ann. Wien. Mus. ii. (1838) 128. - Bras.

decumbens, Benth. in Linnaca, xxii. (1849) 515.Bras.

diversifolia, Benth. in Mart. FI. Bras, xv, 1. 147.-Am. trop.

formosa, Griseb. in Goett. Abh. xix. (1874) 126.-Reg. Argent.

gibba, R. Grab. in Wall. Cat. 10. $5572=$ Dunbaria Hieynei, ferruginea.

glaucescens, Benth. in Ans. Wien. Mus, ii. (1838) 128 $=\mathrm{G}$. glaucescens.

grewiaefolia, Benth. 1. c. 128.-Bras.

guianensis, Klotzsch, ex Schomb, Faun. \& Fl. Gui. 1203.-Guiana.

lancifolia, Benth. in Mart. Fl. Bras. xv. I. 150.liras.

latisiliqua, Benth. in Ann. Wien. Mus. ii. (1838) 120

$\mathrm{G}$. latisiliqua.

longiflora, Benth. 1. c. 128.-Ins. Trinit

longifolia, Benth. in Mart. F1. Bras. xv. 1. 151.-Am. trop.

macrophylla, Benth. in Ann. Wien. Mus, ii. (1838) 128.-Bras.

Martii, Benth. l. c. $129=\mathrm{G}$. Martii.

mollis, R. Grah. in Wall. Cat. n. $5574=$ Atylosia mollis.

Neesii, Benth, in Ann. Wien. Mus. ii. (1838) $129=$ G. Neesii.

obtusa, Benth. 1. c. 128-Bras.

pascuorum, Mart. ex Benth. 1. c.-Bras.

pedicellatum, Benth. in Hook. Journ. Bot. ii. (18 10 60.-Bras.

peduncularis, Benth. in Ann. Wien. Mus. ii. 153n 128.-Bras.

pendula, Benth. 1. $c_{\mathrm{s}}=\mathrm{G}$. pendula.

rosea, Benth, in Ann. Nat. Hist, iii. (1839) 43 G. Jussiaeana.

rotundifolia, Benth. in Mart. Fl. Bros. xv. 1. 11y.Bras.

rugosa, Benth. in Ann. Wien. Mas. ii. (1\$38) 128.Bras.

scarlating, Mart, ex Benth. 1, c 1.29 -Bms.

speciosa, DC in Mém. Leg. vi. 2\$5.-Peruy.

stenophylla, Benth. in Mart. Fl. Bras. xv. 1. $116=\mathrm{C}$ stemophylla.

trinervia, DC. Mim. Lig. vi. $247=$ Atylusia Candollei.

tomentosa, Benth, in Mart. Fl. Bras. xy. I. $\mid f !=$ (f. iomentosis.

velustina, Benth. in Ann. Wien. Mus, ii. $1 \sin 8129$ G. velulina.

venosa. R. Grah. in Wall. Cat. D. 55;9-1 Iunbaria ferruginea.

virgata, Benth. in Mart. Fl. Bras xv. I. 140.-Brase

COLLAFA, Endl. Gen, Suppl, ii. 20 1842 : $\cdots$.

COLLLA, Lindl. Pelexia, Lindl. Urch:

COLIAEA, Spreng. Syst iii. 622 $1520^{\circ}$ Chryman. thellum, kich. (Compos.)

procumbens, spreag. I. $c=\mathrm{Chnz}$ procumbens 
COLLANDRA, Lem. in F1. des Serres, iii. (1847) sub t $223=$ Columnea, Linn. (Gesnerac.)

atronitens, G. Don, ex Loud. Encyc. Pl. Suppl. ii. 1402 $=$ Columnea aureo-nitens.

aureo-nitens, Hanst. in Linnaea, xxvi. (1853) $209=$ Columnea aureo-nitens.

petiolaris, Griseb. Fl. Brit. W. Ind. 463.-Ind. occ.

phoenicea, G. Don, ex Loud. Encyc. Pl. Suppl. ii.

1402 -N. Granat.

picta, Lem. Jard. Fleur. ii. (1852) t. $214=$ Columnea picta.

pilosa, Lem. in Fl. des Serres, iii. (1847) sub t. $223=$ Columnea aureo-nitens.

sanguinea, Griseb. in Mem. Am. Acad. N. S. viii (1863) $526=$ Columnea sanguinea.

COLLANIA, Herb. Amaryll. 103. t. 8 (1837) = Bomarea, Mirb. (Amaryllid.)

andimarcana, Herb. 1. c, $105=\mathrm{B}$. andimarcana.

dulcis, Herb. 1. c. $104=$ B. glaucescens.

glaucescens, Herb. 1. c. = B. glaucescens.

involucrosa, Herb. 1. c. 103. t. $9=$ B. glaucescens.

puberula, Herb. 1. c. 105 . t. 11 . f. $1=$ B. glaucescens.

COLLANIA, Schult. f. Syst. vii. II. p. 1iii, 893 (1830)= Urceolina, Reichb. (Amaryllid.).

dubia, Schult. f. 1. c.-Ecuador

fulva, M. Roem. Syn. Ensat. $55=\mathrm{U}$. fulva.

urceolata. Schult. f. Syst. vii. $893=$ U. pendula.

COLLEA, Lindl. Bot. Reg. sub t. $760(\mathbf{1 8 2 3})=$ Pelexia,

Lindl. (Orchid.).

adnata, Lindl. 1. c. $=$ P. spiranthoides.

calcarata, Lindl. $\mathrm{I}_{\text {. }} \mathrm{c}_{\mathrm{s}}=\mathrm{P}$, setacea.

CollemA, Anders. ex DC. Prod. vii. 512 (1839)= Goodenia, Sm.

COLLFTIA, Comm. ex Juss. Gen. 380 (1789) RHAMNEAE, Benth. \& Hook. f. i. 383.

Scypharia, Miers, in Ann. \& Mag. Nat. Hist. Ser. III. vi. (1860) 8 .

aciculata, Miers, in Ann. Mag. Nat. Hist. Ser. III v. (1860) 214.--Peruy.

armata, Miers, 1, c. $211=$ spinosa

articulata, Phil. in Linnaea, xxviii. (1856) 679.Chili.

atrox, Miers, in Ann. E Mag. Nat. Hist. Ser. III. v. (1860) 206.-Reg. Argent.

bictonensis, Lindl. in Journ. Hort. Soc. v. (1850) $31=$ cruciata.

brevispina, Phil. in Anal. Univ. Chil. (1872) 690.Chili.

cataphracta, Miers, in Ann. E' Mag. Mat. Hist. Ser.

III. v. (1860) 210.-Chili.

Chacaye, G. Don, Gen. Syst, ii. $35=$ Discaria serratifolia. crenata, Clos, in C. Gay, Fl. Chil. ii. 35.-Chili.

crenata, Regel, Ind. Sem. Hort. Petrop. (1856) $37=$ Discaria crenata.

cruciata, Gill. E' Hook. in Hook. Bot. Misc. i. (1830) 152. t. 43 .-Chili.

Cruzerillo, Bert. in 'Merc. Chil. 1829'.-Cf. Bull. Férussac, xx. (1830) 109, nomen.-Chili.

Cunninghami, Fenzl, in Enum. Pl. Hueg. $23=$ Discaria australis.

discolor, Hook. Ic. Pl. t. 538.-Patagon.

disperma, Moç. E Sesse, ex DC. Prod. ii. 29.-Mexic.

Doniana, Clos, in C. Gay, Fl. Chil. ii. 36.-Chili.

dumosa, Miers, in Ann. E Mag. Nat. Hist. Ser. III v. $(1860) 212$-Chili.

Ephedra, Bert. ex Steud. Nom. ed. II. i. $397=$ Trevoa Trutilla.

Ephedra, Vent. Choix, 16. t. 16.-Peruv.

exserta, Klotzsch, ex Reiss. in Mart. Fl. Bras. xi. I. 100.-Bras.

ferox, Gill. E Hook. in Hook. Bot. Misc. i. (1830) 154. -Chili.

horrida, Brongn. ex Drap. Encyc. \& Fl. des Serres Angl. iii. (Juill. 1835) f. $6=$ ferox.

horrida, Willd. Sp. PI. i. $1113=$ spinosa

Hystrix, Clos, in C. Gay, Fl. Chil. ii. 32.-Chili.

infesta, Brongn. in Ann. Sc. Nat. Sér. I. x. (1827) 366 $=$ Adolphia infesta.

insidiosa, Reiss. in Mart. Fl. Bras. xi. I, 100.-Bras.

intricata, Miers, in Ann. E Mag. Nat. Hist. Ser. III.

จ. (1860) 204.-Chili.

invicta, Miers, $l, c .205$-Chili

Kunthiana, Miers, l. c. 208.-Peruv.

\section{COLLETIA :}

longispina, Hook. Eo Arn. in Hook. Bot. Misc. iii. (1833) 173.-Chili

longissima, Steud. Nom. ed. II. i. $397=$ praec.

maytenoides, Griseb. in Goett. Abh. vi. (1854) 117.Reg. Argent.

montana, Phil. in Linnaea, xxxiii. (1864-65) 37.Chili.

multiflora, Moç. \& Sesse, ex DC. Prod. ii. $29=$ Cela strus aphyllus.

nana, Clos, in C. Gay, Fl. Chil. ii. 37.-Chili.

obcordata, Vent. Fard. Cels, t. 92.-Peruv.

polyacantha, Humb. \& Bonpl. ex Roem. \& Schult. Syst, v. $513=$ obcordata, spinosa

pubescens, Brongn. in Ann. Sc. Nat. Sér. I. x. (1827) $366=$ Discaria australis.

pungens, Miers, in Ann. $\mathrm{E}$ Mag. Nat. Hist. Ser. III. v. (1860) 209. - Chili

serratifolia, Vent. Choix, 15. t. $15=$ Discaria serratifolia.

spartioides, Bert.ex Colla, in Mem. Acc. Torin. xxxvii. (1834) 52.-Ins. J. Fernand.

spicata, Humb. E Bonpl. ex Roem. E Schult. Syst. v. 513.-Am. austr.

spinosa, Lam. Tabl. Encyc. ii. 91. t. 129.-Am. austr. spinosissima, J. F. Gmel. Syst. $408=$ praec.

stipellacea, Phil. in Linnaea, xxxiii. (1864-65) 36. Chili.

tenuicola, Miers, in Ann. E Mag. Nat. Hist. Ser. III. v. (1860) 209.-Reg. Argent.?

tetragona, Brongn. in Ann. Sc. Nat. Sér. I. x. (1827) 366.--Peruv.

tetrandra, Clos, in C.Gay, Fl. Chil. ii. 31-Chili

tomentosa, Phil. in Linnaea, xxviii. (1856) 618.Chili.

Tralhuen, Bert. ex Colla, in Mem. Acc. Torin. xxxvii. 1834) $53=$ Trevoa quinquenervia.

Treba, Bert. ex Colla, 1. c. = Trevoa trinervia.

ulicina, Gill. E Hook. in Hook. Bot. Misc. i. (1830) 155.-Chili.

valdiviana, Phil. in Linnaea, xxxiii. (1864-65) 35.Chili.

Valenzuela, Bert. ex Steud. Nom. ed. II. 1. $397=$ ulicina.

velutina, Spreng. Syst. i. 771.-Bras.

veprecula, Miers, in Ann. \& Mag. Nat. Hist. Ser. III. v. (1860) 213.-Chili.

Weddelliana, Miers, l. c. 207.-Bolivia.

COLLETIA, Seop. Introd. $207(1777)=$ Celtis, Linn. (Urticac.).

COLLIGNONIA, Endl. Ench. $193(1841)=$ Colignonia, Endl. (Nyctag.).

COLIIGUAJA, Molina, Sagg. Chil. 158, 354 (1782) EUPHORBIACEAE, Benth. \& Hook, f, iii. 338. brasiliensis, Klotzsch, ex Baill. Etud. Gén. Euph. 535.

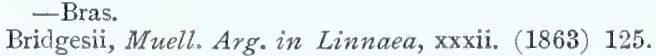
Chili.

Dombeyana, C. Gay, F1. Chil. $342=$ salicifolia.

Dombeyana, A. Fuss. in Ann. Sc. Nat. Sér. I. xxv, (1832) 23.-Chili.

integerrima, Gill. Eo Hook in Hook. Bot. Misc. i. (1830) 140.-Chili.

obtusa, Regel, Ind. Sem. Hort. Petrop. (1855) 18.Chili.

odorifera, Molina, Sagg. Chil. 158, 354.-Chili. salicifolia, Gill. EN Hook. in Hook. Bot. Misc. 1. (1830)
141.-Chili.

triquetra, Gill. \& Hook. .. c. 142.-Chili.

COLLINARIA, Ehrh. Beitr. iv. (1780) $147=$ Koeleria, Pers. (Gramin.).

COLLINIA, Liebm. in Oefers. Danske Vid. Selsk. 1845 (1846) 8=Chamaedorea, Willd. (Palm.).

elatior, Liebm. 1. c. = Cham. Liebmanni.

elegans, Liebm. 1. c. = Cham. elegans.

fibrosa, Oerst. in Kjoeb. Vidensk. Meddel. (1858) 5 = Synechanthus fibrosus.

humilis, Liebm. in Oefers. Danske Vid. Selsk. 1845 (1846) $8=$ Cham. humilis.

COLLINIA, \& COLLINIANA, Rafin. in Am. Montbly Mag. (1819) $194=$ seq.
COLLINSIA, Nutt. in Journ. Acad. Philad. i. (1817 190. t. 9. SCROPHULARINEAE, Benth. \& Hook. f. ii. 941 .

barbata, Bosse, in Verh. Berl. Gartenb. Ver. N. Reihe, i. (1853) $399=$ tinctoria.

bartsiaefolia, Benth. in DC. Prod. x. 318-Calif

bicolor, Benth. in Trans. Hort. Soc. N. S. i. (1831-35) 480.-Calif.

Childii, Parry, ex A. Gray, Syn. Fl. N. Am. ij. I. 257 -Calif.

corymbosa, Herder, Ind. Sem. Hort. Petrop. (1857) 32 ; Regel, Gartenf. (1868) 33. t. 568.-Calif.

divaricata, Kellogg, in Proc. Calif. Acad. iii. (1863) 36.-Calif.

grandiflora, Dougl. ex Lindl. Bot. Reg. sub t. $1166 \mathrm{et}$ t. 1107.-Am. bor. occ.

Greenii, A. Gray, in Proc. Am. Acad. x. (1874) 75. Calif.

heterophylla, R. Grah. in Hook. Bot. Mag. t. $3695=$ bicolor.

hirsuta, Kellogg, in Proc. Calif. Acad. ii. (1863) 110 t. $33=$ bartsiaefolia

linearis, A. Gray, in Proc. Am. Acad.xv. (1880) 50.Am. bor. occ.

minima, Nutt. in Journ. Acad. Philad. vii. (1834) $47=$ parviflora.

multicolor, Lindl. E Paxt. Flow. Gard. ii. (1851-52 89. t. 55.-Calif

Parryi, A. Gray, Syn. Fl. N. Am. ii. I. 257.-Calif. parviflora, Lindl. Bot. Reg. t. 1082.-Am. bor.

pauciflora, Hook. Fl. Bor. Am. ii. 94, sphalm. = parvi flora.

purpurea, Rafin. Atl. Fourn. 149.-Am, bor.

Rattani, A. Gray, in Proc. Am. Acad. xv. (1880) 50.Am. bor. occ.

septemnervia, Kellogg, in Proc. Calif. Acad. ii. (1863) $224=$ tinctoria.

solitaria, Kellogg, 1. c. $10=$ sparsiflora.

sparsiflora, Fisch. E Mey. Ind. Sem. Hort. Petrop. ii (1836) 33.-Calif.

tenella, Benth. in DC. Prod. x. $593=$ Tonella collin sioides.

tinctoria, Hartw. ex Benth. Pl. Hartw. 328.-Calif,

Torreyi, A. Gray, in Proc. Am. Acad. vii. (1868) 378. -Caiif.

tricolor, Rafin. Cat. $13=$ verna

verna, Nutt. in Fourn. Acad. Philad. i. (1817) 190.t 9.-Am. bor.

violacea, Nutt. in Trans. Am. Phil. Soc. v. (1837) 179 -Am. bor.

COLLINSONIA, Linn. Gen. ed. I, 334 (1737)

LABIATAE, Benth. \& Hook. f. ii. 1181.

Diallosterra, Rafin. Neogenyt. 2 (1825)

HyPogon, Rafin. F1. Ludov. 148 (1817)

Pleuradenia, Rafin. Neogenyt. 2 (1825)

anisata, Sims, Bot. Mag. t. 1213.-Am. bor.

canadensis, Linn. Sp. Pl. 28.-Am. bor.

cuneata, Wender. in Schr. Nat. Ges. Marb. ? ex Benth.

in DC. Prod. xii. $253=$ canadensis.

decussata, Moench, Meth. $379=$ canadensis.

ovalis, Pursh, Fl. Am. Sept. i. $21=$ scabriuscula.

praecox, Walt. Fl. Carol. $65=$ scabriuscula.

punctata, E1l. Sketch, i. $36=$ canadensis.

scabra, Pers. Syn. i. $29=$ scabriuscula.

scabriuscula, Ait. Hort. Kew, ed. I. i. 47.-Am. bor.

serotina, Walt. FI. Carol. $65=$ canadensis

tuberosa, Michx. 11. Bor. Am. i. 17=scabriuscula.

urticifolia, Salisb. Prod. $75=$ canadensis.

verticillaris, Rafin. F1. Ludov. $41=$ seq. ?

verticillata, Baldw. ex Ell. Sketch, i. 36.-Am. bor.

COLLoCoccus, P. Br. Hist. Jamaic, 167 (1756) (Gen.dub.).

COLLOMIA, Nutt. Gen. Am. i. 126 (1818). POLEMONIACEAE, Benth. \& Hook. f. ii. 822 .

Courtoisia, Reichb. Ic. Exot. iii. 4. t. 208 (1827). aggregata, T. C. Porter, ex A. Gray, Syn. Fl. N. Am. ii. I. $394=$ Gilia aggregata.

Cavanillesiana, G. Don, Gen. Syst. iv. 247.-Mexic. Texas.

Cavanillesii, Hook. \& Arn. Bot. Beech. Voy. $34=$ coccinea.

coccinea, Lehm. ex Benth. in Bot. Reg. t. 1622.-Chili. eritrichoides, Griseb. in Goett. Abh. vi. (1853-55) 130 . -Chili.

erythraeoides, Griseb. l. c.-Chili. 


\section{COLLOMIA :-}

gilioides, Benth. in Bot. Reg. sub t. 1622.-Calif. glutinosa, Benth. 1. c. = gilioides.

gracilis, Dougl. ex Benth. l. c.-Am. bor, oce. grandiflora, Dougl. in Lindl. Bot. Reg.t. 1174,-Am. bor. occ.

heterophylla, Hook. Bot. Mag. t. 2895-Am. bor. occ lateritia, D. Don, in Sweet, Brit. Flow. Gard. Ser. II iii. t. $206=$ coccinea.

leptalea, A. Gray, in Proc. Am. Acad. viii. (1870) 261 - Calif.

linearis, Nutt. Gen. Am。 i. 126--Am. bor. occ.

linoides, Nutt, in Journ. Acad. Philad. N. S. i. (1847) $159=$ Gilia minutiflora.

longiflora, A. Gray, in Proc. Am. Acad. viii. (1870 261.-Am. bor. occ.

micrantha, Kellogg, in Proc. Calif. Acad. iii. (1863)

18. f. $3=$ gracilis.

myotien, Griseb. in Goett. Abh. vi. (1853-55) 129.Chili.

Navarretia, G. Don, Gen. Syst. iv. $247=$ Gilia Navarettia.

nudicaulis, Hook. En Arn. Bot. Beech. Voy. 368.-Am. bor. occ.

stenosiphon, Kunze, in Linnaea, xxiv. (1851) 228.Chili.

tenella, A. Gray, in Proc. Am. Acad. viii. (1870) 259 -Am. bor. occ.

Thurberi, A. Gray, l.c. 261.-N. Mexic.

tinctoria, Kellogg, in Proc. Calif. Acad. iii. (1863) 17 f. $2=$ linearis.

COLLOMIA, Sieber, ex Steud. Nom. ed. II. i. 398 (1840) $=$ Felicia, Cass. (Compos.)

setosa, Sieber, ex Steud, $1, \mathrm{c}_{\mathrm{c}}=\mathrm{F}$. reflexa.

COLLOPHORA; Mart. in Buchn. Rep. Pharm. (1828).- Cf. Bull. Férussac (Jan, 1831) $64=$ Couma, Aubl (A pocyn.).

utilis, Mart. 1, c. = Couma utilis.

COLLYRIS, Vahl, in Skrift. Nat. Selsk. Kiobenh. vi. (1810) $110=$ Dischidia, R. Br. (Asclepiad.). major, Vahl, 1. $c_{0}=\mathrm{D}$. Rafflesiana, D. Collyris. minor, Vahl, 1. c. $111=$ D. nummularia.

COLMFIROA, F. Muell, Fragm. vii. 149 (1871). SAXIFRAGEAE

carpodetoides, F. Muell. l. c.-Ins. D. Howe.

COLMErroA, Reut. in Mém. Soc. Phys. Genèv. x (1843) 240 . t. $6=$ Securinega, Comm. (Euphorb.). buxifolia, Reut. 1. c. =S. buxifolia.

COLOBACHNE, Beauv. Agrost. 22. t. 6. f. $9(1812)=$ Alopecurus, Linn. (Gramin.).

brachystachys, Nym. in Bot. Notiser (1851) $69=\mathrm{A}$. brachystachys.

Gerardi, Link, Hort. Berol, j. 74=Phleum Gerardi. pontica, Nym. in Bot. Notiser (1851) $69=\mathrm{A}$. glacialis, vaginata, Beauv. Agrost. $22=\mathrm{A}$, vaginatus.

COLOBANDRA, Bartl. in Lehm. Pl. Preiss, i, 357 $(1845\rangle=$ Hemigenia, R. Br. (Labiat.). canescens, Bartl. 1. c. $358=\mathrm{H}$. canescens. lanata, Bart1. 1. c. $359=\mathrm{H}$. canescens? mollis, Bartl, 1. c. $358=\mathrm{H}$. canescens. platyphylla, Bartl, 1. c. $=$ H. platyphylla. robusta, Bartl. 1. c. $357=\mathrm{H}$. polystachya subvillosa, Bartl. 1. c. $359=\mathrm{H}$. platyphylla ?

COLOBANTHUS, Bartl. in Presl, Reliq. Haenk. ii. 13. t. 49 (1830) CARYOPHYLLEAE, Benth. \& Hook. f. i. 151.

acicularis, Hook. f. Handb. New Zeal. Fl. 25.-N. Zel.

affinis, Hook. f. in Hook. Journ. Bot. ii. (1840) $410=$ Billardievi.

aretioides, Gill.ex Hook. Bot. Misc. iii. (1833) 336.Chili.

Benthamianus, Fenzl, in Ann. Wien. Mus. i. (1830) $49=$ subulatus.

Billardieri, Fenel, l, e.-Austral.

cherlerioides, Hook. f. Fl. Antarct. 249,-Patagon.

crassifulius, Hook. f. l. c. 248,-Chili ; Patagon

diffusus, Hook. f. l. c. 249.-Ins. Amsterdam.

kergnclensis, Hook f. l. c.-Ins, Kergucl.

Lechleri, Phibo in Linuaea, xxviii, (1856) 689,-Chil

\section{COLOBANTHUS}

ycopodoides, Griseb. in Goett. Abh. vi. (1853-55) 116.--Reg. Magellan

muscoides, Hook. f. Fl. Antarct. 14.-Ins. Antarct.

polycnemoides, Hieron. in Bol. Acad. Nac. Córdova, iii. (1879) 384.--Reg. Arge t.

pulvinatus, F. Mucll. in Trans, Pliil. Soc. Vict. (1855) $101=$ subulatus,

quitensis, Bartl. in Presl, Reliq. Haenk. ii. 13. t. 49. \&. 2.-Ecuador.

saginoides, Bartl. lo c.-Chili.

subulatus, Hook. f. Fl. Antarct. 13.-Ins. Antarct.

COLOBANTHUS, Trin in Mém, Acad. Pétersb. Sér. VI i. (1831) $66=$ Avellinia, Parl. (Gramin.)

COLOBATUS, Walp. in Linnaea, xiii. (1839) 478 . COLOBOTUS, E. Mey。=Buchenroedera, Eckl. Zeyh. (Legumin.)

COLOBIUM, Roth, in Roem. Archiv, i. (1796) x. 36 Leontodon, Linn. (Compos.)

hirtum, Roth, l. c. = L. hirtum.

hispidum, Roth, 1. c. $37=$ L. Rothii.

COLOBOGYNIUM, Schott, in Oestr. Bot. Zeitschr, xy. (1865) 34 -Schismatoglottis, Zoll. (Aroid.) tecturatum, Schott, 1. c. =S. variegata.

COLobotus, E. Mey. Comm. Pl. Afr. Austr. 156 $(1835)=$ Buchenroedera, Eckl. \& Zeyh. (Legumin.). ochreatus, E. Mey, 1, c-Afr, austr.

COLOCASIA, Link, Diss. Bot. Suerin (1795) 77; et Handb. i. $267=$ Richardia, Kunth (Aroid.). aethiopica, Link, ll. $\mathrm{cc} .=\mathrm{R}$. aethiopica.

COLOCASIA, Neck. Elem. iii. 289 (1790) (Gen. dub. Aroidearum\}.

COLOCASIA, Schott, Meletem. i. 18 (1832). AROI$D E A E$, Benth. \& Hook. fo iii. 974

Leucocasia, Schott, in Oestr. Bot. Wochenbl, vii. 1857) 34 .

acris, Schott, Meletem, i. 18 = antiouorum.

affinis, Schott, in Bonplandia, vii. (1859) 28,-Rea. Himal.

alba, Hort. ex Engl. in DC. Monog. Phan, ii. $501=$ Alocasia alba.

argyroneura, Hort.-Cf. Gard. Chron. (1875) x. 589 Caladium Schomburgkii.

antiquorum, Schott, Meletem. i. 18-As, trop.

Boryi, Kunth, Enum. P1. iii. $41=$ Alocasia indica

cochleata, Miq. Epim. Sem. Hort. Amstelod. (1853)= Alocasia cucullata.

cucullata, Schott, Meletem. i. 18 = Alocasia cucullata esculenta, Schott, $\mathrm{l}_{\mathrm{c}} \mathrm{c}_{\mathrm{s}}=$ antiquorum.

euchlora, C. Koch \& I.inden, in App. Sem. Hort. Bot. Berol. (1854) 4 =antiquorum.

fallax, Schott, in Bonplandia, vii. (1859) 28.-Ind, or Fontanesiz, Schott, in Oestr. Bot. Wochenbl. iv. (185t) $409=$ antiquorum.

fornicata, Kunth, Enum. Pl, iii, $41=$ Alocasin fornicat gracilis, Engl. Bot. Fahrb. i. (1881) 185,-Sumatra

heterophylla, Kunth, Enum. Pl. iii. 40.-Ins. Philip humilis, Hassk. Cat. Hort. Bogor. Alt. 56.-Java. indica, Hassk. in Hoev. E De Vriese, Tijdschr. ix

1842) 160.- Java.

indica, Kunth, Enum. Pl. iii, $39=$ Alocasia indica . macrorrhiza, Schott, Meletem. i. 18=Alocasia macrorhiza.

Marchalii, Engl. in DC. Monog. Phan. ii. 494.-Hab. montana, Kunth, Enum. Pl. iii. $40=$ Alocasia montana mucronata, Kunth, l. c. = Alocasia macrorhiza.

mavicularis, C. Koch \& Bouché, Ind. Sem. Hort.

Berol. (1853) $18=$ Alocasia navicularis.

neo-gnineensis, André, in Illustr. Hortic. xxvii. (18s0 68.-N. Guinea.

nitida, Walp. Aun. i. 1041, sphalın. • Coprosma nitida. nymphaeifolia, Kunth, Enum. Pl. iii. $37=$ antiquoram. obtusiloba, Kunth, l, c, 41-Hab,?

odora, Brongn, in Nouy, Ann. Mlus, Par, iii. (1834) 1.15. 5. $7=$ Alocasia udora

peregrina, Rafin. Fl. Tellur. iii, 65.-Hab. ?

prunipes, C. Koch \& Bouché, Ind. Sem. Hort. Berol. (1854) $4=$ indica.

pubera, Hassk. Cat, Ilort. Bugor. Alt. 302 = Alucasia pubera.
COLOCASIA :-

pumila, Kunth, Enum. Pl. iii. $40=$ Gonatanthus sarmen tosus.

ramosa, Schott, ex Heynh. Nom. ii. 154=Arum ramosum.

rapiformis, Kunth, Enum. Pl. iii. 40-Burma.

rugosa, Kunth, 1. c. $41=$ Alocasia cucullata

virosa, Kunth, l. c.-Ind. or.

vivipara, Thw. Enum. Pl. Zeyl. 336.-Zeylan.

vulgaris, Rafin. F1. Tellur. iii. $65=$ antiquorum.

COLOCOCCA, Rafin. Sylva Tellur. $40(1838)=$ Cordis Linn. (Boragin.).

macrophyla, Rafin. 1. c. = Cordia macrophylla.

COLOCYNTHIS, [Tourn.] Linn. Syst. ed. I (1735 Schrad. Ind. Sem. Hort. Got'ing. (1833) 2; Linnaea, x. (1886) Lit. $70=$ Citrullus, Neck. (Cucurbit.). amarissima, Schrad. 11. $\mathrm{cc}=$ Cit. vulgaris,

officinalis, Schrad. in Linnaea, xii. (1838) $421=$ Cit Colocynthis.

officinarum, Cogn. in DC. Monog. Phan. iii. 511 sphalm, = praec

vulgaris, Schrad. Ind. Sem. Hort. Gotting. (1833) $2=$ Cit. Colocynthis.

COLOGANIA, Kunth, Mim. 205. t. 57 (1823). LEGU MINOSAE, Benth. \& Hook. f i. 529 .

affinis, Mart. \& Gal. in Bull. Acad. Brux. x. (1843 II. 188.-Mexic.

angustifolia, Kunth, Mim. 209.t. 58.-Am. bor. occ australis, Griseb. in Goett. Abh. xix. (1874) 124. Reg. Argent.

biloba, Nichols. Dict. Gard. i. 363.-Mexic.

Bronssonetii, DC Prod. ii. 237-Mexic

heterophylla, Gill. ex Hook. Bot. Misc. iii. (1833) 181 Galactia marginalis.

humifusa, Hemsl. Diagn. Pl. Nov. 4h.-Mexic.

intermedia, H. B. \& K. Nov. Gen. et Sp. vi. 414.Mexic.

Lemmoni, A. Gray, in Proc. Am. Acad xix. (185: 74.-Arizona.

longifolia, A. Gray, Pl. Wright. ii. 35.-Am. bor. occ. Martia, S. Wats. in Proc. Am. Acad. xvii. (1881-8? 345.-Mexic.

obovata, Schlecht in Linnaea, xii. (1838) 287-Mexic. ovalifolia, H. B. \& K. Nov. Gen. et Sp. vi. $412=$ pulchella.

procumbens, Kunth, Mim. 205. t. 57.-N. Granat.

pulchella, H. B. E K. Nov. Gen. et Sp. vi. 413 . -Am. bor. occ.

COLOGYNE, Grifi. Notul. iii. 280 (1851) err. typ. $\Rightarrow$ Coelogyne, Lindl. (Orchid.).

COLOMANDRA, Neck. Elem. ii. $142(1790)=$ Aiouea Aubl. (Laurin.).

COLONA, Cay. Ic, iv. 47. t. $370(1797)=$ Columbia Pers. (Tiliac).

serratifolia, Cav. 1. c. = Columbia americana

COLONNA, Jaume St. Hil. Expos, ii. 95 (1805) praec.

COLONNEA, Endl. Gen. 421, in syn $(1589)=\mathrm{CA}$ LONNEA, Buchoz=Grillardia, Foug. (Compos.).

COLOPHONIA, Comm, ex Kunth, in Ann. Sc. Nat, Sct. I. ii. (1824) $352=$ Canarium, Linn. Burserac.). mauritiona, DC. Prod. ii. $79=$ Canarium mauritianum. tetramera, Boiv ex Engl. in DC Munog. I'han. iv. 2\% =Commiphora tetmora.

COLPIAS, E. Mey. ex Benth. in Hook. Comp. Bo Mag. ii. (1836) 53. SCROPBLLARI.VEAE, BCorb. \& Hook. . ii. 931 .

mollis, E. M/cy, l. c.-Afr. austs.

COLPODIUM. Trin. Fund. Agrost. 119 ; 1 sgit

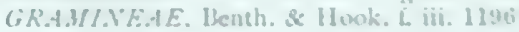
altaicum, Trins in Ledeb. 17. All, i. 100,-Sibir. alt aquasicum, Trio. Fund. Agrust. 1300 = Carabrosa aqua. rics.

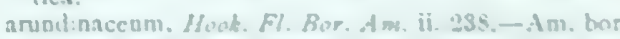

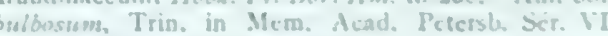
1831) 394-C atahrusa humalis.

Calverti, Hoiss. Diagn. Ser. II. iv. $199=$ Calabrons bumilis. 


\section{COLPODIUM:-}

compressum, Trin, in Spreng, Nene Entdeck. ii. 58 = Sporobolus compressus.

fibrosum, Trautv. in Act. Hort. Petrop. ii. (1873) 486 $=$ Catabrosa fibrosa.

filifolium, Trin. in Bull. Sc. Acad. Pétersb. i. (1836) 69 $=$ Catabrosa humilis.

fulvum, Griseb, in Ledeb. F1. Ross. iv. $385=$ Poa fulva. trumile, Griseb. 1. c. $384=$ Catabrosa humilis.

junceum, Trin. in Spreng. Neue Entdeck. ii. $37=$ Sporobolus junceus.

latifolium, R. Br. in Parry, 1st Voy. Suppl. p. clxxxvi. -Reg. arct.

Malmgrenii, Anderss. in Ofvers. Vet. Akad. Stockh. xxiii. (1866) 121.--Ins. Spitzberg.

minutum, Steud.Syn. Pl. Gram. 177.-Hispan.

monandrum, Trin. Fund. Agrost. $119=$ Phippsia algida. parviflorum, Boiss. \& Buhse, Diagn. Ser. II. iv. $133=$ Catabrosa parviflora.

pauciflorum, Hook. Fl. Bor. Am. ii. 238.-Am, bor. pendulinum, Griseb. in Ledeb. Fl. Ross. iv. $386=$ Poa Laestadii.

pusillum, Nees, Fl. Afr. Austr. 149.--Afr, austr.

Steveni, Hohen. in Bull. Soc. Nat. Mosc. vi. (1833) $213=$ Catabrosa humilis.

Steveni, Trin. Fund. Agrost. 119. t. 7.-Reg. Caucas.

Tilesii, Griseb. in Ledeb. Fl. Ross, iv, 385-Sibir, or.

variegatum, Boiss, ex Griseb.l. c. 384, in textu.-As. Min.

violaceum, Griseb. l. c.-Persia.

COLPOON, Berg. Desc. Pl. Cap. 38. t. I

SANTALACEAE, Benth. \& Hook. f. iii. 225 .

Fusanus, Murr. Syst. ed. XIII 765 (1774).

Hamiltonia, Harv. Gen. Pl. Cap. ed. I. 298 (1838)

Rhoicarpos, A. DC. Prod. xiv. 634 (1857).

compressum, Berg. Desc. Pl. Cap. 38-Afr. austr.

COLPOTHRINAX Griseb \& H. Wendl in Bot. Zeit. xxxvii. (1879) 147. PALMAE, Benth. \& Hook.

f. iii. 927.

COLQUHOUNIA, Wall. in Trans. Linn. Soc. xiii. (1822) 608. LABIATAE, Benth. \& Hook. f. ii. 1208 , coccinea, Wall. l. c. 608.-Reg. Himal.

elegans, Wall. Pl. As. Rar. i. 65.-Burma.

mollis, Schlecht. in Linnaea, xxiv. (1851) 681,-Reg. Himal.?

tenuiflora, Hook. f. Fl. Brit. Ind. iv. 674.-Burma.

tomentosa, Houll. in Rev. Hortic. (1873) $131=$ coccinea vestita, Wall. Tent. Fl. Nep.i. 14.-Reg. Himal.

COLSMANNIA, Lehm. in Ges. Nat. Fr. Berl, Mag. viii. (1814) 92. t. $4=$ =nosma, Linn. (Boragin.).

flava, Lehm. 1. c: = O. flavum.

COLUBRINA, Rich. ex Brongn. in Ann. Sc. Nat. Sér. I. x. (1827) 368. t. 15. f. 3. RHAMNEAE, Benth. \& Hook. f. i. 379

DrPliscA, Rafin. Sylva Tellur. 31 (1838).

MARCoRElla, Neck. Elem. iii. $122(1790)$

Tubanthera, Comm. ex DC. Prod. ii. 30 (1825).

acuminata, Griseb. Cat. Pl. Cub. 34.-Cuba.

Alamani, G. Don, Gen. Syst. ii. 37.-Mexic.

americana, Nutt. Sylva, ii. $58=$ ferruginosa.

asiatica, Brongn. in Ann. Sc. Nat. Sér. I. x. (1827) 369.-As. et Afr. trop.

buxifolia, Schlecht, in Linnaea, xv. (1841) $469=$ Ceanothus buxifolius.

celtidifolia, Schlecht. l. c. 471.-Mexic.

cordifolia, Reiss. in Mart. Fl. Bras. xi. I. 98.-Bras.

cubensis, Brongn. in Ann. Sc. Nat. Sér. I. x. (1827) $369=$ Ceanothus cubensis.

Ehrenbergii, Schlecht. in Linnaea, xv. (1841) 469.Mexic.

excelsa, Fenzl, in Enum. P1. Hueg. 20=Alphitonia excelsa.

fermenta, Rich, ex Brongn. in Ann. Sc. Nat. Sér. I. x. (1827) 369.-Guiana.

ferruginosa, Brongn. l. c.-Am. bor.

glomerata, Hemsl. Biol. Centr. Am. Bot. i. 200-Mexic

granulosa, Brongn. in Ann. Sc. Nat. Sér. I. x. (1827) 369.-Mexic

Greggii, S. Wats. in Proc. Am. Acad. xvii. (1881-82) 336.-Am. bor. occ.

guineensis, G. 'Don, Gen. Syst. ii. $37=$ Chailletia toxicaria?

\section{COLUBRINA :-}

infesta, Schlecht. in Linnaea, xv. (1841) $468=$ Adolphia infesta.

javanica, Miq. FI. Ind. Bat. i. I. $648=$ asiatica

Leschenaultii, G. Don, Gen. Syst. ii. $37=$ asiatica ?

macrocarpa, G. Don, 1. c. $36=$ Ceanothus macrocarpus.

Mociniana, G. Don, 1. c. = Ceanothus Mocinianus.

mystacina, G. Don, 1. c. $37=$ Helinus scandens.

nepaulensis, G. Don, l. c, $36=$ Rhamnus nepaulensis.

oppositifolia, Brongn. ex H. Mann, in Proc. Am. Acad. vii. (1867) 161.-Ins. Sandvic

pubescens, G. Don, Gen. Syst. i. $36=$ Ceanothus pubes cens.

pubescens, Kurz, in Fourn. As. Soc. Beng. xli. (1872) II. 301.-Burma.

pubiflora, G. Don, Gen. Syst. ii. $37=$ Zizyphus pubiflorus.

rectinata, Brongn. in Ann. Sc. Nat. Sér. I. x. (1827 $369=$ Ceanothus reclinatus

rufa, Reiss. in Mart. Fl. Bras. xi. I. 98.-Bras.

texensis, A. Gray, in Bost. Fourn. Nat. Hist. vi. (1850) 169.-Texas.

travancorica, Bedd. Ic. Pl. Ind. Or. i. 43.-Ind. or

triflora, Brongn. in Ann. Sc. Nat. Sér. I. x. (182\%) 369.-Mexic.

triquetra, G. Don, Gen. Syst. ii, $37=$ Rhamnus triquetra.

vitiensis, Seem. Syst. List Vit. Pl, $4=$ Rhamnus vitiensis.

COLUMbaria, J. \& C. Presl, F1. Čech. $32(1819)=$ Scabiosa, Tourn. (Dipsac.)

canescens, J. \& C. Presl, 1. c. = S. suaveolens.

crenata, Presl, ex Steud. Nom. ed. II. i. $398=$ S crenata.

glabrescens, Fourr. in Ann. Soc. Linn. Lyon, N. S. xvi. (1868) $401=\mathrm{S}$. Iucida

gramuntea, Fourr. 1. c. $=\mathrm{S}$. gramuntea.

minor, S. F. Gray, Nat. Arr. Brit. Pl. ii. $476=$ S. Columbaria.

norica, J. \& C. Presl, Fl. Cech. $32=\mathrm{S}$. lucida.

ochroleuca, J. \& C. Pres1, 1. c. =S. ochroleuca

patens, Fourr. in Ann. Soc. Linn. Lyon, N. S. xvi. (1868) $401=$ S. Columbaria.

pratensis, Fourr. $1 . \mathrm{c}=$ Knautia arvensis

rubella, Opiz, ex Steud. Nom. ed. II. i. $398=$ S. Columbaria.

suaveolens, Fourr. in Ann. Soc. Linn. Lyon, N. S. xvi.

(1868) $401=\mathrm{S}$. suaveolens.

tenuisecta, Fourr. 1. $\mathrm{c}_{\mathrm{c}}=\mathrm{S}$. gramuntia

vulgaris, J. \& C. PresI, FI. Cech. $32=$ S. Columbaria.

COLUMBEA, Salisb, in Trans. Linn. Soc. viii. (1807) $317=$ Araucaria, Juss. (Conifer.).

angustifolia, Bertol. in Bologn. Opusc. Sc. iii. (1819) $411=$ excelsa.

angustifolia, Raddi, ex Steud. Nom. ed. II. i. $398=\mathrm{A}$ brasiliana.

Bidwilli, Carr. Conif. ed. II. 601=A. Bidwillii.

brasiliensis, Carr. 1. c. $596=$ A. brasiliana.

excelsa, Spreng. Syst. iv. Cur. Post. $215=$ A. excelsa

imbricata, Carr. Conif. ed. II. $598=\mathrm{A}$. imbricata.

quadrifaria, Salisb. in Trans. Linn. Soc. viii. (1807

$317=$ A. imbricata.

COLUMBIA, Pers. Syn. ii. 66 (1807). TILIACEAE, Benth. \& Hook, f, i. 233.

Colona, Cav. Ic. iv. 47. t. $370(1797)$.

americana, Pers. Syn ii. 66.--Ins. Philipp.

Anilao, Blanco, Fl. Filip. ed. I. 654.-Ins. Philipp.

Blancoi, Rolfe, in Fourn. Linn. Soc. xxi. (1884) 308 -Ins. Philipp.

celebica, Blume, Bijdr. 117.--Ins. Celebes.

floribunda, Naves, in Blanco, Fl. Philipp. ed. III. t. $312=$ Blancoi.

floribunda, Kurz, in fourn. As. Soc. Beng. xlii. (1873) II. 63.-Burma.

gamosepala, Turcz. in Bull. Soc. Nat. Mosc. xxxvi (1863) I. 575.-Hab.?

inaequilatera, Turez. 1. c. xxxi. (1858) I. $233=$ serratifolia.

javanica, Blume, Bijdr. 117.-Java.

merguensis, Planch. ex Mast. in Hook. f. Fl. Brit. Ind. i. 394 --Burma.

serratifolia, Blanco, Fl. Filip. ed. II. $427=$ Grewia

columnaris.

serratifolia, DC. Prod. i. 512.-Ins. Philipp.
COLUMella, Comm. ex DC. Prod. i. 443, in syn. (1824) = Pavonia, Cav. (Malvac.)

Malvinda, Comm, ex DC. 1. c. = P. Colnmella.

COLUMELLA, Lour. F1. Cochinch. i. $85(1790)=$ Vitis, Linn. (Ampelid.).

pedata, Lour. 1. c. $86=\mathrm{V}$. cochinchinensis.

COLUMELLA, Vahl, Enum. i. $300(1805)=$ Colu. mellia, Ruiz \& Pav.

COLUMELLA, Vell. Fl. Flum. 155 (1825); iv. t. $17=$ Pisonia, Linn. (Nyctagin.).

rustica, Vell. 1. $c_{s}=\mathrm{P}$. subcordata.

COLUMELLEA, Jacq. Hort. Schoenbr, iii. 28, t. 301 1798) = Nestlera, Spreng. (Compos.).

biennis, Jacq. 1. c. $29=\mathrm{N}$. biennis.

COLUMFLLIA, Ruiz \& Pav. Prod. 3.t. 1 (1794). COLUMELLIACEAE, Benth. \& Hook. f. ii. 989.

UluxiA, Juss, in Dict. Sc. Nat. x. 103 (1818).

arborescens, Pers. Syn. i. $13=$ oblonga.

frutescens, Pers. 1. $\mathrm{c}_{\mathrm{c}}=$ oblonga.

oblonga, Ruiz E Pav. Fl. Per. 1. 28.-Peruv.

obovata, Ruiz E Pav. l. c.-Peruv

sericea, H. B. E K. Nov. Gen. et Sp. ii. 388.Ecuador.

COLUMNEA, Plum. ex Linn. Gen. ed. I. 373 (1737), GESNERACEAE, Benth. \& Hook. f. ii. 1009

APONOA, Rafin. Sylva Tellur. 84 (1838)

Collandra, Lem. in Fl. des Serres, iii. (1847) sub t. 223 .

Dalbergaria，Tussac, FI. Antill. i. 141. t. 19 (1808).

Eusynetra, Rafin. FI. Tellur. ii. 57 (1836)

Glycanthes, Rafin. Sylva Tellur. $83(1838)$

ORTHOLOMA, Hanst. in Linnaea, xxvi. (1853) 209.

Pentadenia, Hanst. 1. c. 211 (1853)

Stenanthus, Oerst. ex Hanst. 1. c. 209 (1853).

STYGNANTHE, Hanst. 1. c. (1853).

acuminata, Benth. Pl. Hartw. 231.-N. Granat.

anisophylla, DC. Prod. vii. 542.-Am. austr.

argentea, Griseb. Fl. Brit. W. Ind. 465.-Ind. occ.

aurantiaca, Decne, ex Planch, in Fl. des Serres, vi

(1850-51) 45.-Reg. Andin.

aurea, Warcz. in Otto $\sigma^{\circ}$ Dietr. Allg. Gartenz. xiii. (1845) $253 .-\mathrm{N}$. Granat.?

aureonitens, Hook. Bot. Mag. t. 4294--N. Granat.

balsamea, Roxb. Hort. Beng. 47 ; Fl. Ind. iii. $97=$

Limnophila gratioloides.

bilabiata, Seem. Bot. Voy. Herald, 186.-Panama.

Billbergiana, Beurl. in Vet. Akad. Handl. Stockh. 1854 (1856) 135.-Panama.

campanulata, Benth. Pl. Hartw. 232.-N. Granat.

capitata, Walp. Rep. vi. 405, sphalm. = Besleria capitata.

coccinea, Hort. ex Hanst. in Linnaea, xxxiซ. (1865-66) $405=$ rotundifolia.

cochinchinensis, Poir. Encyc. Suppl. ii. 315 (=Diceros cochinchinensis).--Cochinch.

consanguinea, Hanst. in Linnaea, xxxiv. (1865-66) 383.-Costa Rica

crassifolia, Hook. Bot. Mag. t. 4330.-Mexic.

divaricata, Walp. Rep. vi. 405 , sphalm.= Besleria divaricata.

diffusa, Roxb. ex Hook, f. FI. Brit. Ind. iv. $277=$ Torenia vagans.

erecta, Lam. Encyc, ii, $66=$ Achimenes coccinea

eriantha, Hanst. in Linnaea, xxxiv. (1865-66) 391.Ecuador.

erythrocalyx, Oerst. in Vidensk. Selsk. Skr. V. v. 1861) $133=$ querceti.

erythrophaea, Decne. ex Houll. in Rev. Hortic. (1867) 172.--Mexic。

erythrophylla, Hanst. in Linnaea, xxxiv. (1865-66) 389.-N. Granat.

flaccida, Seem. Bot. Voy. Herald, 186.-Panama.

flava, Mart. E Gal. in Bull. Acad. Brux. ix. (1842) II. 39.--Mexic.

glabra, Oerst, in Vidensk. Selsk. Skr. V. v. (1861) 136. - Costa Rica.

grandiflora, Hort. ex Hanst. in Mart. Fl. Bras. viii. $414=$ Nematanthus longipes.

guttata, Poepp. E Endl. Nov. Gen. et Sp. iii. 1.Peruv.

henkelioides, Spreng. ex Heynh. Nom. ii. $154=$ Streptocarpus Rexii. 


\section{COLUMNEA :-}

heterophylla, Hanst. in Linnaea, xxxiv. (1865-66) 390.-Costa Rica.

heterophylla, Roxb. Hort. Beng. 47 ; Fl. Ind. iii. $97=$ Limnophila heterophylla.

hirsuta, Klotzsch, ex Oerst. in Vidensk. Selsk. Skr. V. v. $(1861) 135=$ hirta.

hirsuta, Sw. Prod. Veg. Ind. Occ. 94.-Jamaica.

hirta, Klotzsch $\Xi^{\circ}$ Hanst. in Linnaea, xxxiv. (1865-66) 403.-Costa Rica.

hispida, Sw. Prod. Veg. Ind. Occ. 94.-Jamaica.

humilis, Lam. ex Stend. Nom. ed. I. 213; ed. II. i. 399.-Hab. ?

inaequilatera, Poepp. E Endl. Nov. Gen. et Sp. iii. 1.Peruv.

Kalbreyeri, Hook. f. Bot. Mag. t. $6633=$ Kalbreyeriana.

Kalbreyeriana, Mast. in Gard. Chron. (1882) I. 44 217.-N. Granat.

Kienastiana, Regel, in Act. Hort. Petrop. viii. (1883) 274 . - N. Granat.

labellosa, Karst. Fl. Columb, ii. 105. t. 154.-N. Granat.

lepidocaula, Hanst. in Linnaea, xxxiv. (1865-66) 411. - Costa Rica.

Lindleyana, Pasq. Cat. Orto Bot. Nap. 31.-Hab. ?

linearis, Oerst. in Vidensk. Selsk. Skr. V. v. (1861)

133. - Costa Rica

longepedunculata, Hort. ex Hanst. in Mart. Fl. Bras. viii. $414=$ Nematanthus longipes.

longifolia, Linn. Mant. $90=$ Artanema sesamoides.

lucida, Walp. Rep. vi. 405, sphalm.= Besleria lucida. macrantha, Benth. Pl. Hartw. 232.-Ecuador.

magnifica, Klotrsch \& Hanst. ex Oerst. in Vidensk. Selsk. Skr. V. v. (1861) 184. - Costa Rica.

major, Hanst. in Linnaea, xxxiv. (1865-66) 388.N. Granat.

microcalyx, Hanst. l. c. 408.-Costa Rica.

microphylla, Klotrsch E Hanst. ex Oerst. in Vidensk.

Selsk. Skr. V. v. (1861) 137.-Costa Kica.

minor, Hanst. in Linnaea, xxxiv. (1865-66) 387.-N Granat.

minuta, Roxb. Hort. Beng. 47 ; Fl. Ind. iii. $98=$ Vandellia scabra.

moesta, Poepp. E Endl. Nov. Gen. et Sp. iii. 1. t. 206. -Peruy.

nervosa, Klotasch E Hanst. in Linnaea, xxxiv. (186566) 400 . - Costa Rica.

nicaraguensis, Oerst. in Vidensk. Selsk. Skr. V. v, 1861) 136. - Nicaragua.

ochroleuca, Klotssch \& Hanst. in Linnaea, xxxiv. (1865-66) 393.-Costa Rica.

Oerstediana, Klotosch, ex Oerst. in Vidensk. Selsk. Skr. V. v. (1861) 135.-Costa Rica.

ovata, Cav. Ic. iv. 62.t. 391 .-Ins. Chiloe.

oxyphylla, Hanst. in Linnaea, xxxiv. (1865-66) 405 . Costa Rica.

pendula, Klotrsch \& Hanst. l. c. 397.-Costa Rica.

pichinchensis, Hanst. l. c. 398.-Ecuador.

picta, Karst. Fl. Columb. ii, 105. t. 154.-N. Granat.

pilosa, Lem. in Fl. des Serres, iii. $(1847)$ t. $223=$ aurconitens.

praetexta, Hanst. in Linnaea, xxxiv. (1865-66) 394.Costa Rica.

purpurata, Hanst. l. c. 386.-Costa Rica.

querceti, Oerst. in Vidensk. Selsk. Skr. V. v. (1861) 133. - Costa Rica.

repens, Hanst. in Linnaea, xxxiv. (1865-66) 396.Costa Kica.

repens, Rafin. Sylva Tellar. $84=$ scandens

ringens, Regel, in Act. Hort. Petrop. viii. (1883) 273.N. Grenat.

rotundifolia, Salisb. Parad. Lond. t. 29.-Ins. Trinit. rutilans, Sw. Prod.Veg. Ind. Occ. 94.-Jamaica.

sanguinea, Hanst. in Linnaea, xxxiv. (1865-66) 384. Ins, S. Doming.

sanguinolenta, Hanst. l. c. 389 -Costa Rica

scabrosa, Soland. ex DC. Prod. ix. $277=$ Rhabdo. thamnus scabrosus.

scandens, Billb. ex Beurl, in Vet. Akad. Handl. Stockb. $1854\left(1856^{\circ}\right) 136=$ Billbergiana.

scandens, Linn. Sp. Pl. 938.-Am, austr.

scandens-hirsuta, Schott, ex Hanst. in Mart. Fl. Bras. viii. $\mathbf{4 1 7}=$ Codonanthe Hookerii.

Schiedeana, Schlecht. in Linnaea, viii. (1893) 249.Mexic.

serratr, Hanst. in Linnaca, xxxiv. (1865-66) 390. Costa Rica.

\section{COLUMNEA :-}

speciosa, Presl, Bot. Bemerk. $145=$ rotundifolia.

speciosa, Wendl. ex Steud. Nom. ed. II. i. $399=$

Rytidophyllum prasinatum.

splendens, Paxt. Mag. Bot. x. (1843) 5=Nematanthus longipes.

stellata, Lour. Fl. Cochinch. 384.-Cochinch.

strigosa, Benth. Pl. Hartw. 232.-N. Granat.

tenuis, Klotzsch, ex Oerst. in Vidensk. Selsk. Skr. V. v. (1861) 137.-Costa Rica

tincta, Griseb. in Mem. Am. Acad. N. S. viii. (1863) 526.-Ins. Cuba.

tomentosa, Oerst. in Vidensk. Selsk. Skr. V. v. (1861) 138.--Nicaragua.

tomentosa, Roxb. Hort. Beng. 47 ; F1. Ind. ii. $98=$

Mazus rugosus.

trifoliata, Link, Enum. Hort. Berol. ii. $145=$ Stemodia trifoliata.

umbellata, Bertol. Fl. Guatim. 26.-Guatemala

vestita, Hanst. in Linnaea, xxxvi. (1865-66) $392=$

Warszewicziana

villosa, Willd. Enum. Hort. Berol. Suppl. $43=$ scandens.

violacea, Jaeq. f. ex Steud. Nom. ed. II. i. $399=$ Stemodia trifoliata.

Warscewicziana, Klotrsch $\sigma^{\circ}$ Hanst. in Linnaea,

xxxiv. (1865-66) 392.-Costa Rica.

Wendlandiana, Hanst. l. c. 402,-Costa Rica

Wullschlaegeliana, Hanst, l. c. 414--Jamaica.

aebrina, Hort. ex Loud. Encyc. Pl. Suppl. ii. $1402=$ Alloplectus dichrous.

COLUPPA, Adans. Fam. ii. 268 (1763)=Gomphrena Linn. (Amarantac.).

COLURIA, R. Br. in Parry, Voy. App. 276 (1823) ROSACEAE, Benth. \& Hook. f. i. 619. LAXMannia, Fisch. ex Ledeb. F1. Alt, ii. 262 (1830).

geoides, Ledeb. F1. Alt. ii. $263=$ potentilloides,

mongolica, Maxim. in Bull. Acad. Pétersb. xxvii. (1881) 466.-As. or.

potentilloides, R. Br. in Parry, 1st Voy. Suppl. p. cclxxvi.-Sibir.

COLUS, Raeusch. Nom. ed. III. $171(1797)=$ Coleus, Lour. (Labiat.).

COLUTEA, [Tourn.] Linn. Syst, ed. I (1735) LEGUMINOSAE, Benth, \& Hook, f. i. 505.

aeschinomenoides, Scop. Delic. Insub. iii, 22, t. 12,Ins. Baham.

alpina, Lam. Encyc. i. $354=$ Astragalus alpinus, membranaceus.

americana, Mill. Gard. Dict. ed. VIII. n. 5.-Mexic. annua, Murr. in Nov. Cornm. Gotting. 1774 (1775) 40 $=$ halepica.

aperta, Moench, Verz. $24=$ orientalis.

arborescens, Linn. Sp. Pl. 723.-Europ.; Oriens.

arenaria, Poir. Encyc. Suppl. i. 562=Astragalu chorinensis.

armena, Boiss. E Huet. Diagn. Sér. II. v. 83.Armenia.

astragalina, Poir. Encyc. Suppl. i. 561=Astragalus alpinus.

australis, Lam. Encyco. i. $854=$ - Astragalus anstralis.

batica, Poir. Encyc. Suppl. i. $561=$ Astragalus lusitanicus.

brevialata, Lange, Ind. Sem. Hort. Haun. (1861) 30.Hab.?

caspica, Bieb. Fl. Taur. Cauc. ii. $169=$ Sphaerophysa salsula.

cilicica, Boiss. E Bal. Diagn. Sér. II. v. 83.Cilicia.

cruenta, [Dryand. in] Ait. Hort. Kew. ed. I. iii. 55.Reg. Caucas.

davurica, Spreng. Syst. iii. $242=$ Sphacrophysa salsula.

excisa, Thunb. Prod. Pl. Cap. $194=$ Lessertia excisa.

fistulosa, Retz, Obs, iii, $40=$ Lessertia perennans,

floribunda, Poir. Encyc, Suppl. i. $562=$ Sesbunia vesicaria

forida, Salisb. Prod. $397=$ arborescens.

frigida, Poir. Encyc. Suppl. i. $501=$ Astragalus frigidus.
COLUTEA :-

frutescens, Linn. Sp. P1. $723=$ Sutherlandia frutescens galegifolia, Sims, Bot, Mag. t. $792=$ Swainsona galegifolia.

glabra, Poir. Encyc. Suppl. i. 561 = Astragalus australis

grandiflora, Salisb. Prod. 338 = Sutherlandia fratescens.

halepica, Lam. Encyc. i. 353.-Arab.; Abyssin

halicacaba, Poir. Encyc. Suppl. i. 562=Astragalus Vulneraria.

herbacea, Linn. Sp. Pl. $723=$ Lessertia linearis.

hirsuta, Roth, Tent. F1. Germ. 1. $305=$ arborescens.

humilis, Scop. Delic. Insub. ii. $23=$ orientalis.

incana, Poir. Encyc. Suppl. i. $562=$ Astragalus anthylloides.

istria, Mill. Gard. Dict. ed. VIII. n. 2 = halepica.

linearis, Thunb. Prod. Pl. Cap. $135=$ Lessertia linearis.

media, Willd. Enum. Hort. Berol. 771.-Hab.

melanocalyx, Boiss. \& Heldr. Diagn. Ser. I. ix. $35=$ arborescens.

microphylla, Delile, Ind. Sem. Hort. Monsp. (1847) 7 $=$ halepica.

nepalensis, Sims, Bot. Mag. t. 2622 =arborescens

Novae-Hollandiae, Walp. Ann. ii. $368=$ Clianthus Dampieri.

obtusata, Thunb. Prod. Pl. Cap. $134=$ Lessertia obtusata.

orientalis, Lam. Encyc. i. $353=$ cruenta.

pallida, Salisb. Prod. $337=$ halepica.

perennans, Jacq. Enum. Vindob. App. $311=$ Lessertia perennans.

persica, Boiss. Diagn. Ser. I. vi. 33.-Persia.

Pocockii, [Dryand. in] Ait. Hort. Kew, ed. I. iii. $55=$ halepica.

procumbens, Mill. Gard. Dict. ed. VIII. n. $7=$ Lessertia procumbens.

prostrata, Thunb. Prod. Pl. Cap. $184=$ Lessertia prostrata.

prubescens, Thunb. 1. c. = Lessertia pubescens.

rigida, Thunb. 1. c. = Lessertia fruticosa,

rubra, Medic. Beobacht. (1782) $359=$ arborescens

salsola, Poir. Encyc. Suppl. i. $562=$ Sphaerophysa salsula.

sanguinea, Pall. Fl. Ross. ii. $88=$ cruenta.

spinosa, Forsk. F1. Aegypt. Arab. 131=Astragalus Russellii.

tomentosa, Thunb. Prod. P1. Cap. 135=Lessertia tomentosa.

triflora, Poir. Encyc. Suppl. i. 562=Astragalus triflorus.

trifoliata, Poir. 1. c. (=Phaca trifoliata) -China.

triphylla, Bunge, ex Boiss. Fl. Orient. ii. 196.Persia.

vesicaria, Thunb. Prod. P1. Cap. $135=$ Lessertia vesicaria.

versicolor, Salisb. Prod. $897=$ cruenta.

Wightiana, Wall. ex Stend. Nom. ed. II. i. $399=$

Sutherlandia frutescens.

wolgarica, Lam. Encyc. i. $353=$ Calophnea wolgarica.

COLUTEOCARPUS, Boiss, in Ann. Sc. Vist. Seir. II. xxii. (1842) 162. CRUCIFERAE, Benth. \& Hook. if i. 73 .

LAcowskia, Trantv, in Bull. Phys.-Math. Acad. Pétersb. xvi. (1858) 321 .

reticulatus, Boiss. l. c.-As. Min.

COLUTIA, Medic. in Vorles. Charpf. Phys. Ges. ii. (1787) $966^{\circ}=$ Sutherlandia, R. Br. (1s12: (Le gumin.)

amoersa, Medic. 1. c. = S. frutescens.

frutescens, Medic. Phil. Bot. i. $210=$ S. frutescens. rubra, Mocach, Mcth. $160-$ S. frutescens.

COLVILIEA. Boj. ex Hook. Bot. Mag. 11. $\$ 325$,

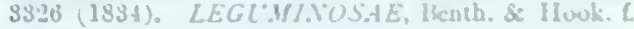
i. $56 ! 3$

racemusa, Boj. l. c.-Madag.

COI.MBADA, Hill, leg. Suse iv. $31\left(170^{\circ} ?=\right.$ Cen taurea, Iinn. Compos.' Kew. 63 - Ceat. Kaspan consansondes
ticum.

sicula, Ilill, I. c. $=$ Cent, sicula. 
COLYMBEA, Steud. Nom. Bot. ed. II. i. 399 (1840) $=$ COLUMBEA, Salisb. = Araucaria, Juss. (Conif。)

COLYRIS, Endl. Gen. $596(1838)=$ COLLYRIS, Vahl = Dischidia, R. Br. (Asclepiad.).

COLYTHRUM, Schott, Rutac. 13.t. $7(1834)=$ Esen beckia, Kunth (Rutac.).

febrifugum, Schott, 1. c. 14=E. febrifuga.

grandiflorum, Steud. Nom, ed. II. i. $399=$ E. grandiflora.

latifolium, Schott, Rutac. $14=\mathbf{E}$. pumila.

maurioides, Schott, $1_{\mathrm{n}} \mathrm{c}_{\mathrm{n}}=\mathrm{E}$. maurioides.

puberulum, Schott, 1. c. 13. t. 7.-Bras.

pumilum, Schott, 1. c. $14=$ E. pumila.

COMACEPHALUS, Klotzsch, in Linnaea, xii. (1838) $224=$ Grisebachia. Klotzsch (Ericac.).

incurous, Klotzsch, 1, c.-Afr. austr.

COMACLINIUM, Scheidw. \& Planch. in Fl. des Serres, viii. (1852) 19. t. $756=$ Dysodia, Cav. (Compos.). aurantiacum, Scheidw. \& Planch. 1. c. $=$ D. grandiflora.

COMACUM, Adans. Fam. ii. 345 (1763) = Myristica Linn.

COMANDRA, Nutt. Gen. Am. i. 157 (1818). SANTALACEAE, Benth. \& Hook. f. iii. 224. Hamiltonia, Spreng. Syst. i. 831 (1825), pro parte. cuneifolia, Rafin. New F1. Am. ii. $33=$ umbellata. Darbya, A. DC. in DC. Prod. xiv. 637.-Am. bor. elegans, Reichb.f. Ic. Fl. Germ. xi. 11. t. 547. f. 1162 -Europ. or. austr.

elliptica, Rafin. New Fl. Am. ii. $33=$ umbellata.

livida, Richards. in Frankl. Narr. 1st Fourn. App. 734. -Am. bor.

media, Rafin. New Fl. Am. ii. $33=$ umbellata.

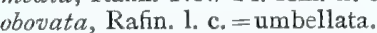

obtusifolia, Rafin. 1. c. =umbellata.

pallida, A. DC. in DC. Prod. xiv. 636.-Am. bor.

rigida, Steud. Nom. ed. II. i, $399=$ livida.

umbellata, Nutt. Gen. Am. i. 157.-Am, bor.

umbellulata, Rafin. New F1. Am. ii. $33=$ praec.

COMANTHOSPEACE, S. Moore, in Journ. Bot xv. (1877) 293. LABIATAE.

barbinervis, S. Moore, l. c.-Japon.

japonica, S. Moore, l. c.-Japon.

stellipila, S. Moore, $l$. c--Japon.

sublanceolata, S. Moore, l. c.-Japon.

COMAROPSIS, Rich. in Nestl. Monog. Potent. 16. t. 1 $(1816)=$ Waldsteinia, Will. (Rosac.).

Doniana, Ser. in DC. Prod. ii. 555=W. fragarioides.

fragarioides, Ser. 1. c. $=$ W. fragarioides.

pedata, Ser. 1. c. = Rubus pedatus.

radicans, Ser. 1. c. = Rubus radicans.

sibirica, Ser. 1. c. $=$ W. sibirica.

COMAROSTAPHYLIS, Zucc, in Abh. Akad, Muench ii. (1837) $331=$ Arctostaphylos, Adans. (Ericac.) angustifolia, Klotzsch, in Linnaea, xxiv. (1851) $74=$ A. angustifolia.

arbutoides, Lindl. Bot. Reg. (1843) t. $30=$ A. arbutoides.

arguta, Zucc. in Linnaea, xii. (1838) Litt. $86^{\circ}=\mathrm{A}$. arguta.

attenuata, Klotzsch, 1. c. xxiv. (1851) $75=$ A. attenuata.

bicolor, Klotzsch, 1. c. $78=\mathrm{A}$. bicolor.

formosa, Lem. in Illustr. Hortic. v. (1858) sub t. 162 $=$ Pieris formosa.

glauca, Buckl. in Proc. Acad. Sc. Philad. "1861' (1862) $461=$ Arbutus Menziesii

glaucescens, Zucc. ex Klotzsch, in Linnaea, xxiv. (1851) $76=$ A. glaucescens.

Hartwegiana, Klotzsch, in Linnaea, xxiv. (1851) $77=$ A. Hartwegiana.

latifolia, Klotzsch, 1. c. 76,-Mexic

longifolia, Klotzsch, 1. c. $75=$ A. longifolia.

mucronata, Klotzsch, 1. c. $77=$ A. mucronata

mucronifera, Klotzsch, l. c. $76=$ A. mucronifera

oaxacana, Klotzsch, 1. c. $77=$ A. oaxacana.

polifolia, Zucc. ex Klotzsch, 1. c. = A. polifolia.

rubescens, Klotzsch, I. $\mathrm{c}_{\mathrm{r}}=\mathrm{A}$. rubescens.
COMAROUNA, Carr, in Rev. Hortic. (1873) $232=$ COUMAROUNA, Aubl. = Dipteryx, Schreb. (Legumin.).

COMARUM, Linn. Syst. ed. I $(1735)=$ Potentilla, Linn. (Rosac.)

anoustifolium, Rafin. F1. Tellur. ii. $56=$ P. Comarum. digitatum, Rafin. 1. $c .=P$. Comarum.

flavum, Buch.-Ham. ex Roxb. Hort. Beng. 39 ; Fl. Ind. ii. $521=\mathrm{P}$. supina

fragarioides, Roth, Tent. F1. Germ. ii. 577 = P. Fragariastrum.

palustre, Linn. Sp. P1. 502=P. Comarum.

rubrum, Gilib, Fl, Lituan. ii. $255=$ P. Comarum.

Salessowiz, Bunge, Del. Sem. Dorp. (1839) 8.-Cf.

Linnaea, xiv. (1840) Lit. $119=$ P. Salessoviana.

supinum, Alef. in Bot. Zeit. xxiv. (1866) $262=\mathrm{P}$. supina?

COMASPERMUM, Pers, Syn, ii. $275(1807)=$ Come sperma, Labill. (Polygal.).

COMATOCROTON, Karst. in C. Koch \& Fint. Wochenschr. (1859) 6=Croton, Linn. (Euphorbiac.) ovalifolia, Karst. 1. c. = C. ovalifolius.

COMATOGLOSSUM, Karst. \& Triana, in Linnaea, xxviii. (1856) $436=$ Talisia, Aubl.? (Sapindac.). strictum, Karst. \& Triana, 1. c. 437.-N. Granat.

COMBESIA, A. Rich. Tent. Fl. Abyss, i. $307(\mathbf{1 8 4 7})=$ Tillaea, Linn. (Crassulac.) abyssinica, A. Rich. 1. c. = T. pharnaceoides.

Schimperi, Sihweinf. in Beitr. F1. Aethiop. $80=\mathrm{T}$. pentandra.

COMBRETOCARPUS, Hook. f. in Benth. \& Hook. f. Gen. i. 683 (1865). RHIZOPHOREAE, Benth. \& Hook. f. l. c.

Motleyi, Hook. f.l. c.-Borneo.

COMBRETUM, Linn. Gen. ed. I. App. 308 (1737). COMBRETACEAE, Benth. \& Hook. f. i. 688.

AETIA, Adans. Fam. ii. 84 (1763)

BUREAVA, Baill. Adansonia, i, 71 (1860)

CAlopyxis, Tul. in Ann. Sc. Nat. Sér. IV. vi. (1856) 86.

Chrysostachys, Pohl, Pl. Bras, ii. 65. t. 143 (1831).

Cristaria, Sonner. Voy. Ind. iii. 284 (1782)

Embryogonia, Blume, Mus. Bot. Lugd. Bat. ii, 122 (1854).

Forsgardia, Vell. Fl. Flum. 152 (1825); iv. t. 13 (1827)

Gonocarpus, Ham. Prod, Fl. Ind. Occ, 39 (1825)

Pevraea, Comm. ex Juss. Gen. 320 (1789).

PoIvrea, Comm。 ex Thou, Obs. Pl. Afr. Austr. 28 (1806).

Seguiera, Reichb. ex Oliver, Fl. Trop. Afr. ii. 424 (1871).

Scheadendron, Bertol. $f$. in Mem. Acc. Sc. Bolorn. ii. (1850) 572 .

Sheadenuron, Bertol. f. l. c. t. 40 (1850)

THulo a Eichl in Flora, xlix. (1866) 149 .

accedens, Heurck \& Muell. Arg. in Heurck, Obs. Bot. 234.-Guiana.

aculeatum, Vent. Choix, 58.-Afr. trop.

acuminatum, Roxb. Hort. Beng. [28] ; Fl. Ind. ii. 228.

-Ind. or.; Malaya.

acutum, Laws. in Oliver, Fl. Trop. Afr. ii. 424.-Afr. trop.

adenogonium, Steud. ex A. Rich. Tent. FI. Abyss. i. $266=$ reticulatum.

adenophyllum, Mart. in Flora, xxiv. (1841) II. Beibl. 1 $=$ Jacquini.

Afzelii, G. Don, in Trans, Linn. Soc. xv. (1827) $437=$ grandiflorum.

Afzelii, Hort. ex A. Juss. in Walp. Rep. v. $338=$ Hiraea Wiedeana.

albidum, G. Don, in Trans. Linn. Soc. xv. (1827) 429 $=$ ovalifolium.

album, Pers. Syn. i. $411=$ decandrum

Alfredi, Hance, in Fourn. Bot. ix. (1871) 131.China.

alternifotium, Herb. Madr. ex Wight \& Arn. Prod.

$317=$ Lumnitzera racemosa.

alternifolium, Pers. Syn. ii. 412,-Panama.

alternifolium, Spreng. Syst. ii. $331=$ aculeatum.

\section{COMBRETUM:-}

altum, Guill. E" Perr. ex DC. Prod. iii. 20.-Afr trop.

anfractuosum, Mart. in Flora, xxiv. (1841) II. Beibl. 3. -Bras.

angolense, Welw. ex Laws. in Oliver, Fl. Trop. Afr. ii. 428.-Afr. trop.

anisopterum, Welw. ex Laws. l. c. 429-Afr. trop.

apetalum, Wall. Cat. n. 3990.-Burma.

apiculatum, Sond. in Linnaea, xxiii. (1850) 45.-Afr austr.

arboreum, Miq. Ann. Mus. Bot. Lugd. Bat. iv. 115.Malaya.

argenteum, Bertol. Fl. Guatimal. 12 =erianthum argyrotrichum, Welw. ex Laws. in Oliver, Fl. Trop. Afr. ii. 432.-Afr. trop.

assimile, Eichl. in Mart. Fl. Bras. xiv. Ir. 109.Bras.

attenuatum, Wall. Cat. n. $3989=$ quadrangulare.

Aubletii, DC. Prod. i. 19.-Guiana.

aurantiacum, Benth, in Hook. Fourn. Bot. ii. (1840) 222.-Guiana.

auratum, Steud. Nom. ed. II. 1. $400=\mathrm{seq}$.

aureum, Wall. Cat. n. 3988.-Burma

barbatum, Newm. ex G. Don, in Loud. Hort. Brit. 157 -Bras.

bellum, Steud. Nom. ed. II. i。 $400=$ trifoliatum.

Benthamianum, Heurck \& Muell. Arg. in Heurck, Obs Bot. $220 .-\mathrm{N}$. Granat.

Binderianum, Kotschy, in Sitzb. Wien. Akad. li. Abth II. (1865) 363.-Afr. trop.

Blanchetii, Eichl. in Mart. Fl. Bras. xiv. II. 114.Bras.

bracteatum, Herb. Madr. ex Wall. Cat. n. $4009=$ decandrum.

brevistylum, Eichl, in Mart. Fl. Bras. xiv. Ii. 118.Bras.

Bugi, Cambess. in St. Hil. Fl. Bras. Mer. ii. 247. t. $130=$ Jacquini

butyrosum, Tul, in Ann. Sc. Nat. Sér. IV. vi. (1856) 87 , in nota. - Afr. trop.

capituliflorum, Fenzl, ex Schweinf. in Reliq. Kotsch. 33.-Afr, trop.

celastroides, Welw. ex Laws. in Oliver, Fl. Trop. Afr. ii. 422,-Afr. trop.

chinense, Roxb. Hort. Beng. [28]; Fl. Ind. ii. 230.As. trop.

chrysophyllum, Guill. \& Perr. F1. Seneg. Tent. i. $289=$ tomentosum.

coccineum, Lam. Encyc. i. 734.-Madag. ; Ins. Maurit. collinum, Fresen, in Mus. Senckenb. ii. (1837) 153.Abyssin.

comosum, G. Don, in Edinb. Phil. Fourn. (1824) 344. - Afr. trop.

confertum, Laws. in Oliver, Fl. Trop. Afr. ii. 422.Afr. trop.

constrictum, Lawws. $l$. c. 423.-Afr. trop.

cordatum, G. Don, in Trans. Linn. Soc. xv. (1827) 440.- - Ins. S. Doming.

corylifolium, Griseb. Fl. Brit. W. Ind. 711.-Ind. occ corymbosum, Schum. in Schum. \& Thonn. Beskr. Guin Pl. $185=$ racemosum.

costatum, Roxb. Hort. Beng. [28] ; F1. Ind. ii. $227=$ acuminatum.

cuspidatum, Planch. ex Benth. in Hook. Niger Fl. 340.-Afr. trop.

cyclophyllum, Steud. Nom. ed. II. i. $400=$ extensum. dasystachyum, Kurg, in fourn. As. Soc. Beng. xliii. (1874) II. 187.-Reg. Himal.; Burma.

decandrum, Jacq. Enum. Pl. Carib. $19=$ alternifolium decandrum, Ruiz \& Pav. ex G. Don, Gen. Syst. ii. 665 $=$ Pavonii.

decandrum, Roxb. Pl. Corom. i. 43. t. 59.-Ind. or.; Burma.

dipterum, Welw. ex Laws. in Oliver, Fl. Trop. Afr. ii 429.-Afr. trop.

distillatorium, Blanco, Fl. Filip. ed. I. $295=$ ovalifolium.

Duarteanum, Cambess. in St. Hil. Fl. Bras. Mer. ii. 248.-Bras.

elaeagnifolium, Planch. in App. Speke, Journ. Disc. Nile, $634=$ collinum.

elaeagnoides, Klotzsch, in Peters, Reise Mossamb. Bot. 73.-Afr. trop.

elegans, Cambess. in St. Hil. Fl. Bras. Mer. ii. 247.Bras.

elegans, H. B. \& K. Nov. Gen. et Sp. vi. 109. t. $538=$ Aubletii. 


\section{COMBRETUM :-}

elegans, Wall. Cat. n. $4003=$ trifoliatum

erianthum, Benth. Pl. Hartw. 73.-Guatemala,

eriopetalum, G. Don, Gen. Syst. ii.665.-Ins. S. Doming. erythrophyllum, Sond. in Linnaea, xxiii. (1850) 43.Afr. austr.

extensum, Roxb. Hort. Beng. [28]; Fl. Ind. ii. 229.Ind. or.; Malaya.

farinosum, H. B. E K. Nov. Gen. et Sp. vi. 110.Mexic.

ferrugineum, G. Don, in Trans. Linn. Soc. xv. (1827) 440.-Am. austr.

ferrugineum, Hoffmgg. ex Walp. Rep, ii. $65=$ Jacquini.

ferrugineum, A. Rich. Tent. F1. Abyss, i. $267=$ trichan thum.

flagrocarpum, Herb. Calc. ex C. B. Clarke, in Hook. f. Fl. Brit. Ind. ii. 455. -Ind, or.; Burma.

floccosum, Eichl. in Mart. Fl. Bras, xiv. II. 119.Bras.

formosum, G. Don, in Trans. Linn. Soc. xv. (1827) 420.-Bras

formosum, Griff. Notul. iv, $682=$ extensum

frangulaefolium, H. B. E K. Nov. Gen. et $S p$. vi. 109 -Venezuela.

fuscum, Planch. ex Benth. in Hook. Niger Fl. 339.Afr. trop.

gallabatense, Schweinf. in Verh. Zool.-Bot. Ges. Wien, xviii. (1868) 664.-Afr. trop.

Geheebii, Heurck Es Muell. Arg. in Heurck, Obs. Bot. 223.-Bras.

glabrum, DC. Prod, iii. 19.-Guiana

glaucocarpum, Mart. in Flora, xxiv. (1841) II. Beibl. 3. - Bras.

glomeruliflorum, Sond. in Linnaea, xxiii. (1850) 42.Afr. austr.

glutinosum, Guill. E Perr. Fl. Seneg. Tent.288. t. 68. -Afr. trop.

glutinosum, Hochst. ex A. Rich. Tent. Fl. Abyss. i. 268 = lepidotum.

Goldieanum, F. Muell. Desc. Papuan Pl. iv. 66.N. Guinea.

gracile, Schott, in Spreng. Syst. iv. App. 406.-Bras. grandiforum, G. Don, in Edinb. Phil. Fourn. (182t) 346.-Afr, trop.

Griffithii, Heurck \& Muell. Arg. in Heurck, Obs. Bot. 231 = chinense

Gueinzii, Sond. in Linnaea, xxiii. (1850) 43.-Afr. austr.

guianense, Miq. in Ann. Mag. Nat. Hist. xi. (18t3) $12=$ Aubletii

Hartmannianum, Schweinf. Beitr. Fl. Aethiop. 24.t. 3. -Afr. trop.

herbaceum, G. Don, in Edinb. Phil. Fourn. xi. (1824) 347.-Afr. trop.

Heyneanum, Wall. Cat. n. $4001=$ ovalifolium.

Hilariana, D. Dietr. Syn. Pl. ii. 1303.-Bras.

hispidum, Laws. in Oliver, Fl. Trop. Afr. ii. 421.Afr. trop.

holosericeum, Sond. in Linnaea, xxiii. (1850) 44.Afr. austr.

Horsfieldii, Miq. F1. Ind. Bat. i. 1. $609=$ extensum.

imberbe, Wawra, in Sitzb. Acad. Wien, Math.-Nat. xxxviii. (1860) 556.-Afr. trop.

insigne, Heurck \& Muell. Arg. in Heurck, Obs. Bot. $247=$ pilosum.

intermedium, G. Don, in Edinb. Phil. Journ. xi. (1824) $345=$ comosum.

Jacquini, Griseb. Fl. Brit. W. Ind. 275,-Ind. occ

Kirkii, Laws. in Oliver, Fl. Trop. Afr. ii. 429.-Afr. trop.

Klotzschii, Welw.ex Laws. l. c. 422.-Afr. trop.

Kraussii, Hochst. in Flora, xxvii. (1844) II. 424.-Afr. austr.

laetum, Wall. Cat. n, 4004= pilosum.

lanceolatum, Pohl, ex Eichl, in Mart. Fl. Bras, xiv, I1, 110.-Bras

lanuginosum, G. Don, in Trans. Linn. Soc. xv. (1827) 422.-Abyss.

latifolium, Blume, Bijdr. $641=$ extensum.

datifolium, G. Don, in Trans. Linn. Soc, xv. (1827) 432. -Ind. or.

laurifolium, Mart. in Flora, xxii. (1839) I. Beibl. 64 -Bras.

laxiflorum, Welw. ex Laws, in Oliver, Fl. Trop. Afr. ii. 428. - Afr. trop.

laxum, Aubl. 1). Gni. 951 = Aubletii.

baxum, Jacq. Luum. Pl. Carib. $19=$ Jacquini

\section{COMBRETUM}

laxum, Loef. It. $248,308=$ Ioeflingii.

laxum, Roxb. Hort. Beng. [88]; Fl. Ind. ii. $231=$ ovalifolium.

lepidotum, Presl, Bot. Bemerk, $142=$ squamosum

lepidotum, A. Rich. Tent. Fl. Abyss. i, 268,-Abyss.

leprosum, Mart, in Flora, xxiv, (1841) 11, Beibl. 1. Bras.

leptostachyum, Mart.l. c. 2.-Bras.

leucanthum, Heurck \& Mucll. Arg. in Heurck, Obs. Bot. $240=$ extensum.

leucophyllum, G. Don, in Edinb. Phil. Journ. xi. (1824) $346=$ racemosum.

Loeflingii, Eichl. in Mart. Fl. Bras. xiv. 11. 110.-Am trop

lucidum, Blume, Bijdr. 641 = trifoliatum.

macrocarpum, Beauv. Fl. Owar. ii. 90. t. $118=$ race mostum.

macrophyllum, Roxb. Hort. Beng. [88]; FI. Ind. ii 231 = latifolium.

macrostachyum, Wall. Cat. n. $3997=$ extensum.

Madolata, Buch.-Ham. ex Wall. Cat. n. $4009=$ decal drum.

magnificum, Mart. in Flora, xxiv. (1841) II. Beibl. 4.Bras.

Malulaea, Wall. Cat. n. 3991=squamosum

Mechowianum, O. Hoffm. in Linnaea, xliii. (1880-82 131.-A fr. trop.

mellifuum, Eichl. in Mart. Fl. Bras. xiv. II. 113.Bras.

mexicanum, Humb. Es Bonpl. Pl. Aequin. ii. 159. 132.-Mexic.

micranthum, G. Don, in Edinb. Phil, Journ. xi. (1824) $347=$ altum

micropetalum, DC. Prod, iii. 19 = Loeflingii.

micropetalum, Llanos, in Mem. Acad. Cienc. Madr. iv. (1856) $502=$ extenstm.

microphyllum, Klotzsch, in Peters, Reise Mossamb. Bot. 74:-Afr. trop

molle, $R$. Br..ex G. Don, in Trans. Linn. Soc. xy. (1827) 431.-Abyss

Monetaria, Mart. in Flora, xxiv. (1841) II. Beibl. 2.Bras.

mucronatum, Schum. E Thonn.Beskr. Guin. Pl. 184 -Afr. trop.

myrtifolium, Laws. in Oliver, Fl. Trop. Afr. ii. 431.Afr. trop.

nanum, Buch.-Ham. in D. Don, Prod. Fl. Nep. 219.-

Reg. Himal.

neurophyllum, Miq. FI. Ind. Bat. i. 1. $608=$ acumina tum.

nigricans, Leprieur, ex Guill. E Perr. Fl. Seneg. Tent i. 290.-Afr. trop.

nitidum, Spruce, ex Eichl. in Mart. Fl. Bras. xiv, II

118.-Bras.

obscurum, Tul. in Ann. Sc. Nat. Sér. IV. vi. (1856) 83 -Madag.

obtusifolium, Rich. in Act. Soc. Hist. Nat. Par. (1792) 108.-Guian

obtusum, Walp. Rep. ii. $67=$ praec.

occidentalis, Linn. Syst. ed. X.999.-Am. austr.

odoratum, Pav ex G. Don, in Trans. Linn. Soc. xv. (182i) 430.-Ecuador

ovale, R. Br. ex G. Don, i. c. $434=$ aculeatum

ovalifolium, Roxb. Hort. Beng. [28]; Fl. Ind. ii. 226 -Ind. or.

oxypetalum, G. Don, in Trans. Linn. Soc. xv. (1827) $420=$ Loeflingii.

oxystachyum, Welw.ex Laws, in Oliver, Fl. Trop. Afr. ii. 422.-Afr. trop.

pachycladum, Baker, in Fourn. Lirn. Soc. xviï. (1881) 270 -Madag.

paniculitum, Vent. Choix, t. 58,-Afr. trop.

paradoxum, Welw.ex Laws. in Oliver, Fl. Trop. Afr. ii. 430.-Afr.trop.

parviflorum, Eichl. in Mart. Fl. Bras. xiv. I1. 114.Bras.

parviflorum, Reichb. ex DC. Prod. iii. $21=$ altum.

Pavonii, G. Don, in Trans. Linn. Soc. xv. (18:27) 496 - Icuador.

pedicellare, DC. Prod. iii. 20.-Bras

pentagonum, Laws. in Oliver, Fl. Trop. Afr. ii. 424. Afr. trop.

Petitianum, A. Rich. Tent. Fl. Abys. i. 268.-Abyss. phneocnryum, Mart. in Flora, xxiv. (1811) 11. Beibl. 1. - Bras.

pilosum, Roxb. Hort. Beng. [28]; Fl. Ind. ii. 231. Ind. or. ; Burma.

\section{COMBRETUM :}

Pincianum, Hook. Bot. Mag. (1846) sub t. 4262.-Afr trop.

pisoniaeflorum, Klotzsch, in Peters, Reise Mossamb. Bot. t. 14.-Afr. trop.

platypetalum, Welw. ex Laws. in Oliver, Fl. Trop. Afr. ii. 433.-Afr. trop

platyphyllum, Heurck \& Muell. Arg. in Henrck, Obs. Bot. $242=$ extenstm

polyandrum, Hoffmgg. ex Walp. Rop. ii. $6=$ Moquilia paraensis.

Porterianum, Wall. Cat, n, $4000=$ chinense.

puberum, Rich. in Act. Soc. Hist. Nat. Par. i. (1792) 108.-Guiana.

pulchellum, Mart. in Flora, xxii. (1839) 1. Beibl. 64 . Jacquini.

punctatum, A. Rich. Tent. Fl. Abyss, i. $266=$ lepidotum.

punctatum, Blume, Bijdr. 640 . - Java.

punctatum, Steud. in Flora, xxvi. (1843) I1. 761 Aubletii.

purpureum, Vahl, Symb. Bot. iii. $51=$ coccineum

pyramidatum, Desw. in Ham. Prod. Fl. Ind. Occ. 35. - Guiana.

pyrifolium, Kurz, in Fourn. As. Soc. Beng. xliii. (1874) II. 188.-Burma.

quadrangulare, Kurz, $l_{\text {. }} c_{0}-$ Burma.

Quartinianum, A. Rich. Tent. Fl. Abyss. i. $266=$ lepidotum.

racemosum, Beauv. Fl. Owar. 87.t. 118.-Afr. trop.

reticulatum, Fresen, in Mus. Senckenb. ii. (1837) 154 -Abyss.

rcticulatum, Presl, Reliq. Haenk. ii. 25.-Mexic.

Kichardianum, Heurck \& Muell. Arg. in Heurck, Obs. Bot. 234.-Abyss.

riparium, Sond in Linnaea, xxiii. (1850) 47.-Afr. austr.

Rochelianum, A. Rich. ex A. Fuss, in Ann. Sc. Nat. Sér. III. xv. (1851) 369.-A byss.

rotundifolium, Rich. in Act. Soc. Hist. Nat. Par. (1792) $108=$ Anbletii.

rotundifolium, Roxb. Hort. Beng. [88]; Fl. Ind. ii, $226=$ extensum

Roxburghii, G. Don, in Trans, Linn. Soc. xv, (1827 $429=$ ovalifolium.

Roxburghii, Spreng. Syst. ii. $331=$ decandrum.

rubiginosum, Welw. ex Laws. in Oliver, Fl. Trop. Afr.

ii. 428.-Afr. trop.

Rueppellianum, A. Rich. Tent. Fl. Abyss. i. 267.Abyss.

salicifolium, E. Mey. ex Hook. Ic. Pl. t. 592,-Afr. austr.

sarcopterum, Thw. Enum. Pl. Zeyl. $\$ 15=$ acuminatum. Schimperianum, A. Rich. Tent. Fl. Abyss. i. 265.Abyss.

secundum, G. Don, in Trans. Linn. Soc, xv. 1627 $419=$ Aubletii.

secundum, Jacq. Enum. Pl. Carib. $19=$ Jacquini.

semiadnatum, Heurck \& Muell. Arg. in Heurck, Ob. Bot. 244.-Ind. or.

sericeum, G. Don, in Edinb. Phil. Fourn. xi. 18:4 347.-Afr. trop.

sericent, Wall, ex C. B. Clarke, in Hook, f. Fl. Brit. Ind. ii. $450=$ Calycopteris floribuada.

Smeathmanni, G. Don, in Trans. Linn. Soc. xv. (1827) $425=$ inveronatum.

Sonderi, Gerr. ex Sond. in Harv. Es Sond. Fl. Cap. ii. 511.-Afr austr.

spinescens, Wall, Cat. $\mathrm{n}, 4006=$ nilosum.

spinosum, G. Don, in Edinb. Phil. Journ, xi. 1s24) $\$ 45=$ paniculatum.

spinosum, Humb. \& Bonpl. Pl. Acquio. ii. $161=$ alternifolium,

Sprucei, Fichl. in Mart. Fl, Bras. xiv. II. 115. - Brens. squamosum, Roxb. Hort. Berg. [8s]; Fl lnd ii "2S1. -Ind. or. ; Malayn.

stelligerum, Presl, Esim. Bo\&. 215.-Ind, or.

stenopetalum, Heurck \& Muell. Arg. in Ilucrek, Obs. Bot. $2: 5=$ scurninat um.

stigmarium, Mart. in Flora, xxiv. (1St1'11. Bribl. \$ -lBriss.

subalternans, Wall. Cat, n. toos = frifoliaturu.

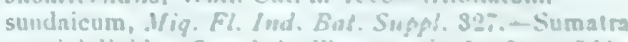

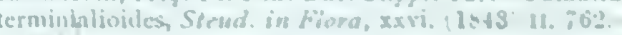
Giunma.

Ceruatum, Wall. Cat. n. fCos = chinenso.

tetragonocarpun, Aura, in Fomrn. As. Sor. Brug. xls. (15.2) 11. $300^{\circ}$ - Burtua. 


\section{COMBRETUM}

tetragonum, Laws, in Oliver, Fl. Trop. Afr. ii. 430.Afr. trop.

tetragonum, Presl, ex Steud. Nom. ed. II. i. 400.Mexic.

tetralophum, C. B. Clarke, in Hook. f. Fl. Brit. Ind. ii. 454.-Malaya.

Thenschii, O. Hoffm. in Linnaea, xliii. (1880-82) 132 -Afr. trop.

Thwaitesianum, Heurck \& Mnell. Arg. in Heurck, Obs. Bot. $238=$ ovalifolium.

tinctorum, Welw. ex Laws. in Oliver, Fl. Trop. Afr. ii. $430=$ Kirkii.

tomentosum, G. Don, in Edinb. Phil. Fourn. xi. (1824) 346.-Afr. trop.

tomentosum, Willd. ex Eichl. in Mart. Fl. Bras. xiv. II. 111 = frangulaefolium.

trichanthum, Fresen. in Mus. Senckenb. ii. (1837) 155. -Abyssin.

trifoliatum, Vent. Choix, t. 58.-Hab.?

trigonoides, Perr, ex DC. Prod. iii. $20=$ racemosum.

truncatum, Welw. ex Laws. in Oliver, Fl. Trop. Afr. ii. 427.--Afr. trop.

undulatum, Wall. Cat. n. $3993=$ trifoliatum

Vanheurckii, Muell. Arg. in Heurck, Obs. Bot. 227. -Ind. or.

variabile, Mart. in Flora; xxii. (1839) I. Beibl. 62.Bras.

velutinum, DC. Prod. iii. 20.-Bras

vernicosum, Fenzl, in Flora, xxvii. (1844) $312=$ lepidotum.

villosum, Boj. ex Tul. in Ann. Sc. Nat. Sér. IV. vi (1856) 80 , in syn.-Madag.

violaceum, Boj. ex Tul.l.c.79.-Madag.

virgatum, Wall. Cat. n, $3992=$ apetalum.

virgatum, Welw. ex Laws. in Oliver, Fl. Trop. Afr. ii. 425.-Afr. trop.

viscidum, Griseb. Cat. Pl. Cub. 109.-Cuba

Wallichii, $D C$. Prod. iil 21-Reg. Himal

Wallichii, Kurz, For. F]. Burm. i. $465=$ flagrocarpum

Wightianum, Thw. Enum. P1. Zeyl. 103, partim= ovalifolium.

Wightianum, Wall. Cat. n. $4007=$ extensum.

Zeyheri, Sond. in Linnaea, xxiii. (1850) 46.-Afr. austr.

COMESPERMA, Labill. Nov. Holl. P1. ii. 21. t. 159 -163 (1806). POLYGALEAE, Benth. \& Hook. f. i. 138 .

acerosum, Steetz, in Lehm. Pl. Preiss. ii. 299.Austral.

acutifolium, Steetz, 1. c. $296=$ ericinum.

aemulum, Steud. 1. c. i. $208=$ virgatum.

anthocarpum, Walp. Rep. v. 66, sphalm.= xanthocarpum.

aphyllum, R. Br. ex Benth. Fl. Austral. i. 143.Austral.

calymega, Labill. Nov. Holl. Pl. ii. 23.--Austral.

ciliatum, Steetz, in Lehm. Pl. Preiss. ii. 304.Austral.

compactum, Sieber, ex Steud. Nom. ed. II. i. $400=$ retusum.

confertum, Labill. Nov. Holl. Pl. ii. 23. t. 161.-Austral. contractum, Steud. in Lehm. Pl. Preiss. i. 208= virgatum.

coridifolium, A. Cunn. in Field, N. S. Wales, $337=$ ericinum.

corniculatum, Stend. in Lehm. P1. Preiss. i. $206=$ virgatum.

defoliatum, F. Muell. Vict. Pl. i. 189.-Austral.

Drummondi, Steetr, in Lehm. Pl. Preiss. ii. 301.Austral.

ericinum, $D C$. Prod. i. 334.-Austral.

flavum, $D C$. $l_{\text {. }} c_{n}$-Austral.

floribundum, St. Hil. F1. Bras, Mer, ii. 55. t. $91=$. Bredemeyera floribunda.

gracile, Paxt. Mag. Bot. v. (1838) $145=$ volubile.

herbaceum, Steud. in Lehm. Pl. Preiss. i. $211=$ calymega.

hirtulum, Steud. 1. c. $209=$ confertum.

integerrimum, Endl. in Enum. Pl. Hueg. 7.-Austral. isocaly $x$, Spreng. Syst. iii. $172=$ calymega

Kunthianum, St. Hil. Fl. Bras. Mer, ii. 54. t. $90=$ Bredemeyera Kunthiana.

lanceolatum, R. Br. ex Benth. Fl. Austral. i. 148.Austral.

latifolium, Steetz, in Lehm. Pl. Preiss. ii. $295=$ ericinum.

\section{COMESPERMA}

laurifolium, St. Hil. F1. Bras. Mer. ii. $56=$ Bredemeyera lanififolia.

laxiusculum, Steud. in Lehm. Pl. Preiss. i. $210=$ virgatum.

Lhotzkyanum, Manso, ex Klotzsch, in Peters, Reise Mossamb. Bot. 117, nomen (=Bredemeyerae sp.).Afr. trop.

linariaefolium, A. Cunn. ex Steetz, in Lehm. P1. Preiss. ii. $297=$ ericinum.

longebracteatum, Steud. 1. c. 1. $207=$ virgatum. longifolium, Steud. 1. c. $206=$ confertum.

lucidum, Baill. Hist. Pl. v. $82=$ Bredemeyera lucida.

Mansonii, Lhotsky, ex Klotzsch, in Peters, Reise Mossamb. Bot. $117=$ Bredemeyera lucida.

megapteryga, Steud. in Lehm. Pl. Preiss. i. $207=$ nudiusculum.

nudiusculum, $D C$. Prod. i. 334-Austral

nudiusculum, Steetz, in Lehm. Pl. Preiss. ii. $308=$ defoliatum.

parviflorum, Steud. 1. c. i. $210=$ calymega

patentifolium, F. Muell. Fragm. i. $48=$ ericinum.

paucifolium, Turcz. in Bull. Soc. Nat. Mosc. xxvii. (1854) II. $352=$ volubile.

planifolium, Hassk. in Miq. Ann. Mus. Bot. Lugd. Bat. i. 185.-Austral.

polygaloides, F. Muell. in Trans, Phil. Soc. Vict. i. (1855) 7.-Austral

praecelsum, F. Muell. Fragm. xi. 2,-Austral.

pubescens, Gardn. ex A. W. Benn. in Mart. Fl. Bras. xiii. III. $49=$ Bredemeyera brevifolia.

ramosissimum, Steud, in Lehm. Pl. Preiss. i. $209=$ nudiusculum.

retusum, Labill. Nov. Holl. Pl. ii. 22. t. 160.Austral.

rhadinocarpun, F. Muell. Fragm. xi. 1.-Austral. roseum, Steud. in Lehm. Pl. Preiss. i. $207=$ virgatum. scandens, Steud. 1. c. $211=$ integerrimum.

scoparium, Drum in Hook. Fourn. Bot. ii. (1840) 369; Steetz, in Lehm. Pl. Preiss. ii. 309.-Austral. secundum, Banks, ex DC. Prod. i. 334.-Austral.

selaginoides, Turcz. in Bull. Soc. Nat. Mosc. xxvii. (1854) II. 352 = virgatum.

silvestre, F. Muell. Fragm. i. $49=$ sylvestre

simplex, Endl in Enum. Pl. Hueg. 7 =virgatum.

spathulatum, Turcz. in Bull. Soc. Nat. Mosc. xxvii. (1854) II. 352 = calymega

sphaerocarpum, Steetz, in Lehm. Pl. Preiss. ii. 314.Austral.

spinosum, F. Muell. Fragm. i. 144.-Austral.

strictum, Endl in Enum. Pl. Hueg, $7=$ calymega.

subherbaceum, Walp. Ann. ii. 84, sphaim. = calymega.

sylvestre, Lindl. in Mitch. Fourn. Trop. Austral. 342. -Austral.

tenue, Steud. in Lehm. P1. Preiss. i. 208=calymega.

tortuosum, Steetz, 1. c. ii. $303=$ volubile.

variabile, Mart. ex Steud. Nom. ed. II. i, 400 (=Bredemeyerae sp.).-Bras.

varians, Steud. in Lehm. Pl. Preiss, i. $210=$ calymega.

virgatum, Labill. Nov. Holl. Pl. ii. 21. t. 159.Austral.

viscidulum, F. Muell. Fraom. x. 4.-Austral.

volubile, Labill. Nov. Holl. Pl. ii. 24.-Austral.

xanthocarpum, Stend. in Lehm. Pl. Preiss. i. $209=$ flavum.

COMETPS, Linn. Mant. i. 4 (1767)

ILLECEBRA

$C E A E$, Benth. \& Hook. f. iii. 18.

Ceratonychia, Edgew. in Journ. As. Soc. Beng. xvi. (1847) 1215

Saltia, R. Br. in Salt, Abyss. App. 64 (1814), nomen, abyssinica, R. Br. in Wall. Pl. As. Rar. i, 18.-Abyssin. alternifolia, Linn. Syst. ed. XII. $127=$ surattensis.

apiculata, Decne. in Ann. Sc. Nat. Sér. II. ii. (1834) $244=$ surattensis

surattensis, Linn. Mant.i. 39 ; Burm.f. Fl. Ind.39.t. 15.--Ind. bor. occ. ; Arab.

COMETIA, Thou. ex Baill. Etud. Gén. Euph. 642 (1858). EUPHORBIACEAE, Benth. \& Hook. f. iii. 283 .

lucida, Baill. Adansonia, ii. (1861) 55.-Madag.

Thouarsii, Baill. Etud. Gén. Euph. 643.-Madag.

COMEURYA, Baill. Adansonia, x. (1872) $329=$ Dra contomelon, Blume (Anacard.)

Cumingiana, Baill. 1. c. $330=\mathrm{D}$. Cumingianum.
COMMARUM, Schrank, Prim. Fl. Salisb. 132 (1792)= COMARUM, Linn. = Potentilla, Linn. $($ Rosac.).

COMMELINA, Plum. ex Linn. Syst. ed. I. (1735) COMMELINACEAE, Benth. \& Hook. f. iii. 847 .

ANanthopus, Rafin. Fl. Ludov. 20 (1817)

Disecocarpus, Hassk, in Flora, xlix. (1866) 211.

Erxlebia, Medic. in Act. Acad. Theod. Palat. vi. Phys. (1790) 494.

Hedwigia, Medic. 1. c. 495 (1790).

HeterocarPus, Wight, Ic. vi. 29. t. 2067 (1853)

LeCHEA, Lour. Fl. Cochinch. 60 (1790).

OmphalothecA, Hassk. in Bull. Congr. Bot. Amst. (1865) 103.

Spathodithyros, Hassk. in Flora, xlix. (1866) 211

Trithyrocarpus, Hassk. l. c. (1866).

Allosperma, Allotria, Ditelesia, Dirtea, Eudipetala, Larnalles, Nephraeles, et Ovidia, Rafin, Fl, Tellur, iii. 68-70, 122 (1836) acuminata, $H . B$. $\sigma^{\circ} K$. Nov, Gen, et Sp. i 258Mexic.

acuminata, Poir. Encyc. Suppl. ii. 324=Aneilema acuminatum

acuminata, R. Br. in Salt, Abyss. App. $62=$ pyrrhoblepharis.

aequinoctialis, Roem. \& Schult. Syst. i. $538=$ Aneilema aequinoctiale.

aequinoxialis, Beauv. Fl. Owar. i. t. $38=$ praec.

aethiopica, C. B. Clarke, in DC. Monog. Phan. iii. 189 -Afr. trop.

affinis, Poir. Encyc. Suppl. ii. 324=Aneilema gramineum.

africana, $\operatorname{Linn}$. Sp. Pl. 41.-Afr. austr.

africana, Mirb. in Ann. Mus. Par. xvi. (1810) $456=$ communis.

agraria, Kunth, Enum. Pl. iv. $38=$ nudiflora.

agrostophylla, F. Muell. Fragm. viii. 59.-Austral.

alba, Buch.-Ham. ex C. B. Clarke, in DC. Monog. Phan iii. $186=$ appendiculata.

albescens, Hassk. in Schrveinf. Beitr. Fl. Aethiop. 210 -Afr. trop.

ambigua, Beauv. Fl. Owar. i. 26. t. $\mathbf{1 5}=$ Palisota ambigua.

amplexicaulis, Hassk. in Schweinf. Beitr. Fl. Aethiop. 208.-Afr. trop.

angolensis, C. B. Clarke, in DC. Monog. Phan. iii 167.-Afr. trop.

angustifolia, Hassk. in Peters, Reise Mossamb. Bot $528=$ Gerrardi.

angustifolia, Hort. Berol. (1841) ex Kanth, Enum. Pl. iv. $659=$ graminifolia.

angustifolia, Michx. Fl. Bor. Am. i. $24=$ virginica.

angustifolia, Reichb. Ic. Bot. Exot. ii. 17. t. $143=$ graminifolia.

anthericoides, Poir. Encyc. Suppl. ii. 324=Aneilema gramineum.

appendiculata, C. B. Clarke, Commel. et Cyrt. Beng. t. 13.-Ind. or.

aspera, G. Don, ex Benth. in Hook. Niger Fl. 542. Afr. trop.

attenuata, Heyne, ex Steud. Nom. ed. II. i. $401=$ subulata.

attenuata, Koen. ex Vahl, Enum. ii. 168.-Ind. or. auriculata, Blume, Enum. Pl. Fav. 1. 2.-Sumatra. auriculata, E. Mey. in Presl, Rel. Haenk. i. $137=$ virginica.

avenaefolia, 7. Grah. Cat. Pl. Bombay, 224.-Ind. or. axillaris, Linn. Sp. P1. $42=$ Cyanotis axillaris.

bahiensis, Hoffmgg. ex Spreng. Jahrb. i. III. $73=$ virginica.

Bainesii, C. B. Clarke, in DC. Monog: Phan. iii. 184. -Afr. austr.

barbata, Boj. Hort. Maurit. $359=$ communis

barbata, Lam. Tabl. Encyc. i. 129.-Am. austr.

barbata, Sieber, ex C. B. Clarke, in DC. Monog. Phan iii. $247=$ Cyanotis cristata

benghalensis, Forsk. F1. Aegypt. Arab. 12 =divaricata benghalensis, Linn. Sp. Pl. 41.-Geront. trop. benohalensis, Wall. Cat. n. $8980=$ persicariaefolia.

beniniensis, Beauv. Fl. Owar. ii. 49. t. $87=$ Aneilema beninense.

bicolor, Poepp. ex Kunth, Enum. P1. iv. 89=Tradescantia gracilis.

biflora, Poir. Encyc. Suppl, ii. $324=$ Aneilema biflorum. Blumii, A. Dietr. Sp. Pl. ii. $400=$ auriculata.

Boissieriana, C. B. Clarke, in DC. Monog. Phan. iii. 161.-Afr. trop.

bracteolata, Lam. Encyc. ii. $69=$ Aneilema spiratum. 
COMMELINA :-

bracteosa, Hassk. in Flora, xlvi. (1863) 386 -Afr. trop. Brownii, A. Dietr. Sp. P1. ii. $415=$ Aneilema acuminatum.

bulbosa, Heyne, ex Steud. Nom. ed. II. i. $401=$ Aneilema dimorphum.

caerulea, Salisb. Prod. $216=$ virginica

caespitosa, Roxb. Hort. Beng. 5; F1. Ind. i. $174=$ nudiflora.

cajannensis, Sieber, ex Steud. Nom. ed. II. i. 401.Ins, Martinic.

cajennensis, Kunth, Enum. P1. iv. 38, in syn.=nadiflora.

Callisia, Steud. Nom. ed. II. i. $401=$ Aneilema Hamiltonianum.

canariensis, Ch.Sm.in Buch, Canar. Ins. $140=$ nudiflora. canescens, Vahl, Enum, ii. $173=$ benghalensis.

capitata, Benth, in Hook. Niger Fl. 541.-Afr. trop.

capitata, Klotzsch, éx C. B. Clarke, in DC. Monog. Phan. iii. $178=$ obliqua

cardiocephala, Kunze, ex C. B. Clarke, 1. c. $157=$ quitensis.

cardiosepala, Kunze, in Linnaea, xx. (1847) $9=$ quitensis.

caripensis, H. B. \& K. Nov, Gen, et Sp. i, 260= virginica.

carnea, Schlecht. Ind. Sem. Hort. Halens. (1839) adn. $9=$ scabra.

caroliniana, Hort. Berol. (1841) ex Kunth, Enum. Pl. iv. $659=$ stricta

caroliniana, Walt. F1. Carol. $68=$ nudiflora.

caroliniana, Willd. ex Kunth, Enum. Pl. iv. $54=$ angustifolia.

cayennensis, Rich, in Act. Soc. Hist. Nat. Par. i. (1792) $105=$ nudiflora.

Chamissonis, Klotzsch, ex C. B. Clarke, in DC. Monog. Phan. iii. 186.-Austral.

Chantransia, Roem. \& Schult. Mant. i. Add. I. $376=$ Floscopa africana.

clandestina, Hort. Berol. (1832) ex Kunth, Enum. Pl. iv. $46=$ graminifolia.

clandestina, Mart. ex Stend. Nom. ed. II. i. 401.-Bras, clayata, C. B. Clarke, Commel. et Cyrt. Beng. t. 5.Ind. or.; Malaya.

coelestis, Willd. Enum. Hort. Berol. 69.-Mexic.

conmelinoides, Forsk. Fl. Aegypt. Arab. 12.-Arab.

communis, Engelm. ex Kunth, Enum. Pl. iv. 38 agraria.

communis, F. Muell. Fragm. viii. 59=cyanea

communis, Linn. Sp. Pl. 40 - China

communis, Roxb. Hort. Beng. 5; F1. Ind. i. $171=$ obliqua.

communis, Wall. Cat. n. $8978=$ salicifolia, Hasskarlii.

communis, Walt. Fl. Carol. $68=$ nudiflora.

comosa, E. Mey. Zwei Pfl. Docum. 174=Aneilema Dregcanum.

condensata, C. B. Clarke, in DC. Monog. Phan. iii. 190.-Afr. trop.

congesta, C. B. Clarke, l. c. 160--Afr. trop

conspicua, Blume, Enum. Pl. Jav. i. $4=$ Aneilema conspicuum.

conspicua, Zoll. Syst. Verz. Ind. Arch. $64=$ Aneilema monadelphum.

cordifolia, A. Rich. Tent. Fl. Abyss. ii. 341.-Abyss.

crassicaulis, C. B. Clarke, in DC. Monog. Phan. iil. 149.-Afr. trop.

crispata, Poir. Encyc. Suppl. ii. $324=$ Pollia crispata.

cristata, Linn. Sp. $\mathrm{Pl} .42=$ Cyanotis cristata.

cucullata, Linn. Mant. ii. $176=$ benghalensis.

cyanea, R. Br. Prod. 269,-Austral.

cymosa, Blume, Enum. Pl. Jav. i. $4=$ Floseopa scandens,

debilis, Hort. Berol. (1841) ex Kunth, Enum. Pl. iv. $659=$ graminifolia

debilis, Ledeb. in Roem. \& Schult. Mant. i. $342=$ virginica.

decumbens, E. Mey. in Presl, Rel. Haenk. i. $136=$ pallida.

deficiens, Herb. ex Steud. Nom. ed. II. i. 401.-Bras.

deficiens, Hook. Bot. Mng. t. $2644=$ virginica.

deficiens, Van Houtte, Fl. des Serres, xviii. (1869) t. $1824=$ nudiflor

delicatula, Schlecht, in Garten A. (1854) 349, t. 104= benghalensis.

densiflora, Blume, Enum. Pl. Jav, i. $4=$ Floscopa scandens.

diandra, Steud. Nom. ed. II. i. $401=$ Ancilema nudiflorum.

dianthifolia, [Delile, in] Red. Lil, vii. t. 390,-Mexic.
COMMELINA:

didyma, Steud. Nom. ed. II. i. $401=$ Pollia sorzogo nensis.

diffusa, Burm. f. Fl. Ind. 18. t. 7. f. $2=$ nudiflora.

diffusa, Willd. ex Kunth, Enum. Pl. iv. 39, $40=$ salicifolia, barbata.

diffusa, Zoll. ex C. B. Clarke, in DC. Monog. Phan iii. $171=$ clavata

divaricata, Vahl, Enum. ii. 169.-Arab.

Donii, A. Dietr. Sp. Pl. ii. $395=$ obliqua

dubia, [Delile, in] Red. Lil. t. 359.-Mexic.

dubia, Hort. Berol. (1841) ex Kunth, Enum. P1. iv $659=$ coelestis.

dubia, Jacq. Obs. Bot. iii. $9=$ Heteranthera graminea. ebracteata, Ehrenb. ex Schweinf. Beitr. Fl. Aethiop. $210=$ Aneilema Ehrenbergii.

Eckloniana, Kunth, Enum, Pl. iv. 57.-Austral.

edulis, A. Rich. Tent. Fl. Abyss. ii. 341.-Abyss.

cdulis, Stokes, Bot. Mat. Med. i. 184 = tuberosa.

Ehrenbergiana, Link, Klotasch \& Otto, Ic. Pl. Rar. 75 t. $30=$ scabra.

elata, Vahl, Enum. ii. $178=$ Aneilema herbaceum.

elegans, H. B. \& K. Nov. Gen. et Sp. i. $259=$ virginica.

elliptica, $H . B . \xi^{\circ} K$. l. c.-Am. trop.

ensifolia, F. Muell. Fragm. viii. $60=$ undulata.

ensifolia, R. Br. Prod. 269.-Austral.

equinoctialis, Beauv. Fl. Owar。 i. $65=$ Aneilema aequinoctiale.

erecta, Chapm. F1. S. U. St. $497=$ hirtella

erecta, Hort. Berol. (1841) ex Kunth, Enum. Pl. iv, $659=$ coelestis

erecta, Linn.Sp. Pl. 41.-Am. bor.

esculenta, Herb. Madr. ex Wall. Cat. sub n. $5208=$ Aneilema esculentum.

exilis, Steud. Nom. ed. II. i. $401=$ Aneilema nudiflorum. falcata, Hassk. in Flora, xlvi. (1863) $387=$ Forskalaei. fasciculata, Ruiz E Pav. Fl. Per. i, 44. t. 72. f, 6.Peruv.

filiformis, Steud. Nom. ed. II. i. $401=$ Aneilema vagi natum.

firma, Welw. ex C. B. Clarke, in DC. Monog. Phan. iii. $180=$ aspera

flava, Salisb. Prod. $215=$ africana.

Rexuosa, Welw. ex C. B. Clarke, in DC. Monog. Phan iii. $258=$ Cyanotis nodiflora.

floribunda, H. B. \& K. Nov. Gen. et Sp. i. $260=$ Tradescantia cumanensis.

foecunda, Hochst. ex C. B. Clarke, in DC. Monog.

Phan. iii. $255=$ Cyanotis foecunda.

formosa, R. Grah. in Edinb. N. Phil. Journ. (July Sept. 1830) $366^{\circ}=$ nudiflora.

Forskaili, Hochst. ex C. B. Clarke, in DC. Monog. Phan. iii, $173=$ Kotschyi.

Forskålaei, Vahl, Enum. ii.172.-Geront. trop.

Gambiae, C. B. Clarke, in DC. Monog. Phan. iij. $1 \pm 6$. -Afr, trop.

gelatinosa, Edgew. in fourn. As. Soc. Beng. xxi. (1853) 177.-Ind. or.

geniculata, Ham. Prod. Fl. Ind. Occ. 4.-Ins. S Doming.

Gerrardi, C. B. Clarke, in DC. Monog. Phan. iii. 183 -Afr. austr.

gigantea, Vahl, Enum. ii. $177=$ Aneilema giganteum.

glabra, Baker, in Saund. Refug. Bot. ii. t. $166=$ fasciculata.

glabra, C. B. Clarke, in DC. Monog. Phan. iii. 163.Ind, or.

glabra, G. F. W. Mey. Prim. F1. Esseq. $22=$ nudiflora gracilis, Hook. Bot. Mag. t. $3047=$ fasciculata.

gracilis, Ruiz \& Pav. Fl. Per. 1. 44. t. 72. fo a =nudiflora.

graminea, Poir. Encyc. Suppl. ii. $\$ 24=$ Aneilema gramineum.

graminifolia, H. B. E K. Nov. Gen.et Sp. i. 258.-Mexio. graminifolia, Pav. ex C. B. Clarke, in DC. Monog Phan, iii. $151=$ dianthifolia.

grandiflom, Tenore, Cat. Hort. Bot. Nap. (1845) 22. Hab. ?

guianensis, Klotzsch, in Schomb. Faun. et Fl. Guian. $1064=$ Phacospherion persicariacfolium.

Hamiltonii, Spreng. Syst. v. $186=$ Floscopa scandens.

hamipila, Wright, in Sasv. Fl. Cub. 157.-Cubs.

Harcocuskii, Hort. Pillnits. ex Tenore, Cat. Ort. Bot. Nap. $(1845) 100 .-11 \mathrm{ab}$.

Hasskarlii, C. R. Clarke, Commel. ef Cyrt. Bergg. t. 5. - Ind. or.

herbacea, Roxb. Hort. Beng. [5]; FI. Ind. i. 1;5 Ancilema herbaccum.

\section{COMMELINA :-}

Heudelotii, C. B. Clarke, in DC. Monog. Phan. ili. 184.-Afr. trop.

hexandra, Aubl. Pl. Gui. i. 35. t. 12=Dichorisandra Aubletiana.

hirsuta, R. Br. in Salt, Abyss. App. $62=$ benghalensis. hirsuta, C. B. Clarke, in DC. Monog. Phan. iil. 163.Ind. or.

hirsuta, Hochst. ex A. Rich. Tent. Fl. Abyss, ii. $344=$ Cyanotis hirsuta.

hirsuta, Hort. Berol. (1841) ex Kunth, Enum. Pl, iv. $660=$ elliptica.

hirsuta, Willd. in Spreng. \& Link, Jahrb. i. IIx. 73= virginica.

hirtella, Vahl, Enum, ii. 166.-Am. bor.

hispida, Haw. ex Spreng. Syst. iv. Cur. Post. $25=$ Floscopa scandens.

hispida, Ruiz E Pav. Fl. Per, i. 43, t. 73. f, a-Perny Hookeri, A. Dietr. Sp. Pl. ii. $404=$ Ancilema giganteura. Hookeriana, Spreng. Syst. v. 186 = Aneilema giganteum. huillensis, Welw. ex C. B. Clarke, in DC. Monog Phan. iii. 175.-Afr. trop.

humilis, Klotzsch, ex C. B. Clarke, 1. c. $154=$ C elliptica.

ignorata, Kunth, Enum. Pl.iv, B0.-Am, bor.

imberbis, Ehrenb. ex Hassk. in Scbweinf. Beitr. Fl. Aethiop. $209=$ latifolia.

intermedia, Schlecht. in Linnaea, xxiv. (1851) $655=$ coelestis.

involucrosa, A. Rich. Tent. Fl. Abyss, ii. 342.-Abyss,

Jamesoni, C. B. Clarke, in DC. Monog. Phan. jii.155. - Iicuador.

japonica, Hort. Berol. (1811) ex Kunth, Enum. iv. 659 $=$ coelestis.

japonica, Thunb. in Trans. Linn. Soc. ii. (1791) $332=$ Ancilema japonicum.

karooica, C. B. Clarke, in DC. Monog. Phan. iii. 168 -Afr. austr.

Karwinskiana, Hort. Berol. (18\1) ex Kunth, Enum. Pl. iv, $660=$ seq

Karwinskii, Mart. ex Kunth, 1. c. = elliptica.

Kirkii, C. B. Clarke, in DC. Monog. Phan. iii. 167.Afr. trop.

Koenigii, Steud. Nom. ed. II. i. $401=$ Aneilema herbaceum, Koenigii.

Kotschyi, Hassk. in Schweinf. Beitr. Fl. Acthiop. 207. -Aegypt.

Krebsiana, Kunth, Enum. Pl. iv. $40=$ africana.

Kurzii, C. B. Clarke, in Fourn. Linn. Soc. xi. (1871) 444.- -Ind. or.

lanceolata, Benth. FI. Anstral. vii. 84 =agrostophylla. lanceolata, R. Br. Prod. 269.-Austral.

lanuginosa, Heyne, ex Wall. Cat. n. 5221=Aneilema lanuginosum.

latifolia, Hochst. ex A. Rich. Tent. Fl. Abyss. ii. 340 . -Abyss.

latifolia, Hochst. ex C. B. Clarke, in DC. Monog. Phan. iii. 160,169 = benghalensis, uncata.

laxa, Poir. Encyc. Suppl. ii. $32 t=$ Aneilema laxum.

leiandra, C. B. Clarke, in DC. Monog. Phan. iii. 150.Mexic.

leiocarpa, Benth. in Bot. Voy. Sulph. $176=$ Athyrocarpus lciocarpus.

linearifolia, Kunth, Enum. Pl. iv. 48 = subulata.

linearis, Benth. Pl. Hartw. $27=$ dianthifolia.

lineolata, Blume, Enum. Pl. Jav. i. $8=$ Areilema herbaceum.

Livingstoni, C. B. Clarke, irs DC. Monog. Phan. iii. 190. -Afr. austr.

Loddigesii, Steud. Nom. ed. II. i. $401=$ tuberos?

longicapsa, C. B. Clarke, in DC. Monog. Phan. iii. 1;6. - Afr. occ.

longicaulis, Hort. Berol. (1Et1) ex Kunth, Enum. Pl.iv. ti5 9 = cuelestis.

longicaulis, Jacr. Coll. iii, $294=$ nudiftora.

longifolia, Lams. Tabl. Encyc. i. 129,-Java.

longrifolia, Michx. Fl. Am. Bor. i. 29-birtella.

lonsy ifolia, Spreng. Syst. iv. Cur. Pust. 25 -Ancilena grgnnteum.

longifolia, Thw. Enum. Pl. Zcyl. 322 o Kurzii.

Lourciri, Kunsh, Enom. Pl. ir. 80 ._C Chins

loudens, Miq. in Joura. Hot Nicerl. i. Jsol) ss

cันแาแ

In muka, Heyne, ex C. 13. Clarkic, in MC. Murog. Thaniii. Iss ensifulia

Insen. Moench, Me:h, as; - africana

mocruphyllaz, l'oir. Fincye. Suppl ii. Silt a Pollia unacry.

playlla. 


\section{COMMFITINA:}

maculata, Edgew, in Trans. Linn. Soc. xx. (1851) 89 =obliqua.

madagascarica, C. B. Clarke, in DC. Monog. Phan. iii. 174.- Madag.

Mannii, C. B. Clarke, l. c. 167.-Afr. trop.

Martiana, Seub. in Mart. F1. Bras. iii. I. 265. t. 37. f. $1=$ virginica.

mascarenica, C. B. Clarke, in DC. Monog. Phan. iii. 174. - Ins. Maurit

medica, Lour. F1. Cochinch. $40=$ Aneilema medicum. mexicana, E. Mey, in Presl, Rel. Haenk. i. $137=$

Tradescantia elongata.

micrantha, Vahl, Enum, ii. 178=Aneilema micran thum.

minuta, Blume, Cat. Gew. Buitenz. $34=$ Aneilema nudiflorum

mollis, Jacq. Coll. iii. $235=$ benghalensis

moluccana, Roxb. Hort. Beng. [81]; F1. Ind. 1. $172=$ Cyanotis uniflora.

monadelpha, Blume, Enum. Pl. Jav. i. 4='Aneilema monadelphum.

montana, Steud. Nom. ed. II. i. $401=$ Aneilema montanum

monticola, Seub. in Mart. Fl. Bras, iii. I. 264.--Bras, multicaulis, Hochst. ex C. B. Clarke, in DC. Monog

Phan. iii. $184=$ albescens.

multiflora, Martens \& Gal, in Bull. Acad. Brux. ix. (1842) Ir. 374=Callisia Martensiana

nana, Roxb. Hort. Beng. 5; Fl. Ind. i. $173=$ Aneilema spiratum.

nervosa, Burm. f. FI. Ind. $18=$ benghalensis

nervosa, Rniz \& Pay. F1. Per, i. $44=$ fasciculata.

nigritana, Baker, in Trans. Linn. Soc. xxix. (1875) 163 = subulata.

nigritana, Benth. in Hook. Niger F1. $541=$ umbellata.

nilagirica, Steud, ex C. B. Clarke, in DC. Monog

Phan, iii. 163, $171=$ hirsuta, clavata

Nimmoniana, f. Grah. Cat. Pl. Bombay, 224.Ind. or.

nitens, Hort. Pillnits. ex Tenore, Cat. Ort. Bot. Nap. (1845) 100 - - Hab, ?

nudicaulis, Burm. f. F1. Ind. 17. t. 8.f. 1=Aneilema nudiflorum.

mudiflora, Linn, Mant. ii. $177=$ Aneilema nudiflorum

nudiflora, Linn. $S p . P l$. 4.-Reg. trop.

obliqua, Buch.-Ham ex D. Don, Prod. Fl. Nep. 45.-Ind. or. ; Malaya.

obliqua, Vahl, Enum. ii. $173=$ erecta

oblongifolia, Hassk. Commel. Ind. $27=$ auriculata.

obtusifolia, Vahl, Enum. ii. 168=nudiflora.

ochreata, Schau. in Nov. Act. Nat. Cur. xix. Suppl. i. (1843) $447=$ nudiflora.

oligotricha, Miq. Fl. Ind. Bat. iii. 532.-Malaya.

orchioides, Booth, ex Lindl. Bot. Reg. (1838) Misc. $53=$ elliptica.

orchioides, Roth, ex Steud. Nom. ed. II. i. 402.Mexic.

vvata, Steud. 1, c. = Aneilema ovatum.

ovato-oblonga, Roem. \& Schult. Mant. i. Add. I. 376 = Aneilema ovato-oblongum.

pacifica, Vahl, Enum. ii. $168=$ nudiflora.

paleata, Hassk. in Miq. Pl. Fungh. 139.-Ind. or. Malaya.

Palisoti, A. Dietr. Sp. P1. ii. $414=$ Aneílema ovatooblongum.

pallida, Willd. Hort. Berol. ii. 87. t. 87.-Mexic.

ballida, Schlecht in Linnaea, xxvi。(1853-55) $454=$

Athyrocarpus leiocarpus.

paludosa, Blume, Enum. Pl. Jav. i. $2=$ obliqua

paludosa, Steud. Nom. ed. II. i. $402=$ persicariaefolia.

paniculata, Hill, Veg. Syst. xxiii. 4.-Ind. or.

paniculata, Hort. Berol. (1841) ex Kunth, Enum. Pl. iv, $659=$ coelestis.

paniculata, Soland. ex C. B. Clarke, in DC. Monog.

Phan. iii. $223=$ Aneilema laxum.

paniculata, Vahl, Enum. ii. $179=$ Aneilema Forskalei

papilionacea, Burm. f. Fl. Ind. $17=$ Cyanotis papilic nacea.

parviflora, Link, Enum. Hort. Berol. i. $61=$ graminifolia.

parviflora, Reichb. F1. Exot. ii. 17. t. $142=$ tuberosa.

pedunculosa, Spreng. \& Link, Jahrb. i. III. $74=$ salicifolia.

persicariaefolia, [Delile, in] Red. Lil. t. $472=$ Athyrocarpus persicariaefolius,

persicariaefolia, Wight, in Wall. Cat. n. 8984--Burma,

Petersii, Hassk. in Flora, xlvi. (1863) 385.-Afr. trop.

\section{COMMELINA.}

phalangoides, Crantz, Inst. i. 459-Hab.?

pilosa, Pers.' Syn. i. 55 = nudiflora.

pilosa, Steud. Nom. ed. II. i. $402=$ Aneilema ochraceum. pilosula, Rich. in Act. Soc. Hist. Nat. Par. i. (1792) $106=$ nudiflora

platyphylla, Klotzsch, in Schomb. Faun.et Fl. Guiana, 8y7.-Guiana.

Pohliana, Seub. in Mart. F1. Bras, iui. 1. 265. t. 37. f. 1 $=$ erecta

poligama, Blanco, F1. Filip. ed. Naves (Ic. sine num. = benghalensis.

polyclada, Welw. ex C. B. Clarke, in DC. Monog. Phan. iii. $165=$ africana.

polygama, Roth, in Roem. \& Ust. Mag. iv. x. (1790) $14=$ communis

polyspatha, Wight, Ic. t. $2066=$ obliqua.

procurrens, Schlecht. in Linnaea, xxv. (1852) $183=$

benghalensis.

prostrata, H. B. \& K. Nov. Gen. et Sp. i. $259=$ nudiflora.

prostrata, Poepp. ex Kunth, Enum. Pl. iv. $38=$ nudiflora. prostrata, Regel, Gartenfl. (1868) 289. t. 592. f. $1=$ benghalensis.

protensa, Steud. Nom. ed. II. i. $402=$ Aneilema protensum.

puberula, Hort. Berol. (1841) ex Kunth, Enum. PI. iv 659 ; et in Linnaea, xxiv. (1851) $197=$ dianthifolia.

pubescens, Klotzsch, ex C. B. Clarke, in DC. Monog. Phan. iii. 152 = acuminata.

pubinervis, Hassk. in Flora, xxv. (1842) II. Beibl. 4.Java.

pumila, Royle, ex C. B. Clarke, in DC. Monog. Phan. iii. $207=$ Aneilema spiratum.

pyrrho-blepharis, Hassk. in Schweinf. Beitr. Fl. Aethiop. 209.-Abyssin.

quitensis, Benth. Pl. Hartw. 258.-Ecuador.

radicans, Spreng. Syst. iv. Cur. Post. $25=$ Aneilema nudiflorum.

radiciflora, $\mathrm{R}$. Br. ex C. B. Clarke, in DC. Monog Phan. iii. $159=$ benghalensis.

Rafinesquei, Kunth, Enum. Pl. iv, 60.-Am. bor.

rajmahlensis, C. B. Clarke, in Journ. Linn. Soc. xi. (1871) $444=$ attenuata.

rara, Roxb. ex Steud. Nom, ed. II. i. 402,-Ind. or reniformis, Steud. 1. c. - Pollia subumbellata.

repens, Roxb. \& Heyne, ex C. B. Clarke, in DC. Monog. Phan. iii. $172=$ attenuata.

rhizocarpa, Afzel. ex C. B. Clarke, 1. c. $159=$ benghalensis.

robusta, Kunth, Enum. Pl. iv. 52.-Bras.

rorigera, Fisch. ex Tenore, Cat. Ort. Bot. Nap. (1845) $100 .-\mathrm{Hab}_{*}$ ?

rosea, Schlecht. Ind. Sem. Hort. Hal. (1838) 7.Mexic.

rubens, Hort. Berol. (1841) ex Kunth, Enum. Pl. iv. $659=$ graminifolia.

rubens, [Delile, in] Red. Lil. vii. t. $367=$ pallida

rufipes, Seub. in Mart. F1. Bras. iii. I. $265=$ Phaeaspherion persicariaefolium

rugulosa, C. B. Clarke, in Journ, Linn. Soc. xi. (1871) $446=$ suffruticosa.

Rumphii, Kostel. Allg. Med.-Pharm. Fl. i. 126.-As. trop.

Sabatieri, C. B. Clarke, in DC. Monog. Phan. ini. 146. -Afr. trop.

sagittifolia, Hassk. in Schweinf. Beitr. Fl. Aethiop. $206=$ latifolia

salicifolia, Boj. Hort. Maurit, $360=$ communis

salicifolia, Roxb. Hort. Beng. 5 ; Fl. Ind. i. 172,-Ind,

salicifolia, Thw. Enum. P1. Zeyl. $321=$ clavata

Saltiana, Steud. Nom.ed. II. i. $402=$ pyrrho-blepharis.

scaberrima, Blume, Enum. Pl. Jav. 1. $4=$ Aneilema protensum.

scabra, Benth. Pl. Hartw. 26.-Mexic.

scabrata, Seub. in Mart. Fl. Bras. iii. I. $266=$ Phaeospherion persicariaefolium.

scandens, Welw. ex C. B. Clarke, in DC. Monog. Phan, iii. 146.-Afr. trop

scapiflora, Roxb. Hort. Beng. [5]; Fl. Ind. i. $175=$ Aneilema scapiforum.

scapigera, Hort. Berol. (1832) ex Kunth, Enum. Pl. iv. $46=$ elliptica.

Schimperiana, Hochst. ex C. B. Clarke, in DC. Monog.

Phan, iii. $184=$ albescens.

Schomburgkiana, Klotzsch, in Schomb. Faun. et Fl. Guiana, 1064 = nudiflora.

\section{COMMELINA:-}

Schoubertii, Zucc ex Tenore, Cat. Hort. Bot. Nap. (1845) $22=$ hispida.

Schweinfurthii, C. B. Clarke, in DC. Monog. Phan. iii. 158.-Afr. trop.

secundiflora, Blume, Enum. Pl. Jav. i. $3=$ Pollia sorzugonensis.

Sellowiana, Kunth, Enum. Pl. iv, $44=$ nudiflora.

Sellowii, Schlecht. Ind. Sem. Hort. Hal. (1850) $7=$ nudiflora.

semi-ovata, Buch.-Ham. in Wall, Cat. n. 8985 obliqua, suffruticosa

senegalensis, Tenore, Cat. Ort. Bot. Nap. (1845) $22=$ benghalensis.

serrulata, Vahl, Eclog. Am. ii. 4.-Guiana.

setosa, Wight, in Wall. Cat. n. $8981=$ undulata,

sikkimensis, C. B. Clarke, Commel. \& Cyrt. Beng. t. 6 -Reg. Himal.

siliculosa, Poir. Encyc. Suppl. ii. $324=$ Aneilema siliculosum.

simplex, Vahl, Enum, ii. $177=$ Aneilema sinicum

Simsoni, C. B. Clarke, in Journ. Lim. Soc. xi. (1871 $446=$ suffruticosa

singularis, Vell. Fl. Flum. 31 ; i. t. 76.-Bras.

sinica, Roem. \& Schult. Mant. i. App. I. $376=$ Aneilema sinicum.

speciosa, Thunb. Prod. Pl. Cap. 58=Cyanotis nodi flora

spectabilis, C. B. Clarke, in DC. Monog. Phan. iii 175.-Afr. trop.

spicata,Steud. Nom. ed. II. 1. $402=$ Aneilema Loureirii spirata, Koen. ex Steud. I. c. = Aneilema herbaceum.

shirata, Linn. Mant. ii. 176= Aneilema spiratum.

striata, Edgew. in Trans. Linn. Soc. xx. (1851) $89=$ obliqua.

striata, Hochst. ex A. Rich. Tent. F1. Abyss. ii. $340=$ subulata.

striata, Wall. Cat. n. $8981=$ albescens, Kurzii, ensifolia stricta, Desf. Cat. Hort. Par. ed. III. $388=$ graminifolia.

subamplectens, Hassk. Commel. Ind. $27=$ africana.

subaurantiaca, Hochst. in Kunth, Enum. Pl. iv. $658=$ subulata.

subulata, Roth, Nov. Pl. Sp. 23.-Geront. trop.

suffruticosa, Blume, Enum, Pl. Fav, i. 3.-Java.

sulcata, Benth. in Hook. Niger F1. $541=$ Vogelii.

sulcata, Hoffmgg. in Spreng. \& Link, Jahrb. i. IIr. 74 = virginica.

tenuis, Roth, Nov. P1. Sp. $22=$ Aneilema acuminatum.

tinctoria, Nees, in Linnaea, xix. (1847) $699=$ dianthifolia.

triquetra, Steud. Nom. ed. II. i. $-402=$ Aneilema triquetrum.

truncata, Willd. Enum. Hort. Berol. Suppl. $4=$ virginica.

tuberosa, Billb. ex Beurl. in Vet. Akad. Handl. Stockh. $1854(1856) 110=$ virginica.

tuberosa, Burm. ex Steud, Nom. ed. II. i. $402=$ salicifolia.

tuberosa, [DC. in] Red. Lil. ii. t. 108=coelestis.

tuberosa, Forsk. FI. Aegypt. Arab, $12=$ Aneilema Forskalei.

tuberosa, $\operatorname{Linn}$. Sp. Pl. 41.-Mexic.

tuberosa, Lour. F1. Cochinch, $40=$ Aneilema Loureirii turbinata, Vahl, Enum. ii. 171 = benghalensis.

umbellata, Schum. E Thonn. Beskr. Guin. Pl. 21.Afr. trop.

umbrosa, Vahl, Enum. ii. $179=$ Aneilema ovatooblongum.

uncata, C. B. Clarke, in DC. Monog. Phan. iii. 169.Abyssin.

undulata, Benth. Fl. Austral. vii. $83=$ Chamissonis. undulata, Lodd. Bot. Cab. t. $1553=$ tuberosa.

undulata, R. Br. Prod. 270 -Austral.

vaginata, Heyne, ex Stend. Nom ed. II. i. $402=$ Aneilema esculentum.

vaginata, Linn. Mant. $177=$ Aneilema vaginatum. vaginata, Sonn. ex C. B. Clarke, in DC. Monog. Phan. iii. $188=$ ensifolia.

variabilis, Schlecht. Ind. Sem. Hort. Hal. (1838) $7=$ elliptica.

vestita, Seub. in Mart. F1. Bras. iii. I. $264=$ monticola. villosiuscula, Soland. ex C. B. Clarke, in DC. Monog. Phan. iii. 159 = benghalensis.

virginica, Forst. f. Prod. $6=$ nudiflora.

virginica, Linn. Sp. Pl. ed. II. 61.-Am, bor

Vogelii, C. B. Clarke, in DC. Monog. Phin. iii. 189.Afr. trop. 
CONMELINA :-

vulgaris, [DC. in] Red. Lil. iv. t. $206=$ communis. Wallichiana, Steud. Nom. ed. II. i. $402=$ Aneilema divergens.

Welwitschii, C. B. Clarke, in DC. Monog. Phan. iii. 175.-Afr. trop.

Werneana, Hassk. in Schweinf. Beitr. Fl. Aethiop. 206 = nudiflora.

Willdenowii, Kunth, Enum. Pl. iv. $37=$ communis.

zambesica, C. B. Clarke, in DC. Monog. Phan. iii. 161.-Afr. trop.

Zanonia Linn Sp. Pl, 41=Campelia Zanonia.

Zebrina, Hort, ex C. B. Clarke, in DC. Monog. Phan. iii. $318=$ Zebrina pendula.

zeylanica, Falkenberg, in Fust, Fahresb. iv. (1876) 406.-Zeylan.

COMMELYNA, Hoffmgg. ex Endl. Gen. 125 (1837)= Commelina, Linn.

COMMERÇONIA, F. Muell. Census, $16(1882)=$ Com mersonia, Forst. (Stercul.).

COMMERSONA, Sonner. Voy. t. $89(1782)=$ Barring. tonia, Forst. (Myrtac.).

speciosa, Salisb. Prod. $355=$ B. Butonica.

COMmersoniA, Comm. ex DC. Prod. ii. 10, in syn. $(1825)=$ Polycardia, Juss. (Celastrin.).

COMMERSONIA, Forst. Char, Gen, 43. t, 22 (1776). STERCULIACEAE, Benth. \& Hook. f. 226.

aspera, G. Don, Gen. Syst. i. $523=$ Buettneria aspera. cinerea, Steud, in Lehm. P1. Preiss, i. $238=$ Rulingia grandiflora.

craurophylla, F. Muell. Fragm. ix. $59=$ Rulingia craurophylla.

crispa, Turcz. in Bull. Soc. Nat. Mosc. xix. (1846) I. 501.-Austral.

cuneata, F. Muell. Census, $16=$ Rulingia cuneata.

cygnorum, Steud. in Lehm. Pl. Preiss. i. $237=$ Rulingia malvaefolia.

dasyphylla, Andr. Bot. Rep. t. $603=$ Rulingia pannosa.

dasyphylla, Hort. ex Steud. Nom. ed. II. i. $402=$ Rulingia pannosa.

densiflora, F. Muell. Fragm. x. $21=$ Rulingia densiflora.

diphylla,Andr. Bot. Rep. t. $603=$ Rulingia pannosa.

echinata, Blume, Bijdr. $86=$ platyphylla.

echinata, Forst. Char. Gen. 43, t. 22.-Malaya.

Fraseri,F. Gay, in Mím. Mus. Par. x. (1823) 215. t. 15.-Austral.

Fraseri, Sieber, ex Steetz, in Lehm. Pl. Preiss. ii. $352=$ Rulingia pannosa

Gaudichaudii, f. Gay, in Mém. Mus. Par. x. (1823) 213. t. 14.-Austral.

herbacea, G. Don, Gen. Syst, i. $523=$ Buettneria herbacea.

hermanniaefolia, F. Gay, in H. B. \& K. Nov. Gen. et Sp. v. 311 , in nota.-Hab. ?

hermanniaefolia, F. Muell. Census, $16=$ Rulingia hermanniaefolia.

Fackiana, G. Don, Gen. Syst. i. 523 = Buettneria Jackiana.

javensis, G. Don, l. c. = platyphylla

Kempeana, F. Muell. Fragm, xi. $113=$ Rulingia Kempeana.

laxophylla, F. Muell. 1. c. x. $22=$ Rulingia laxophylla

Leichardtii, Benth. Fl. Austr. i. 242.-Austral.

magnifora, F. Muell. Fragm. viii. $223=$ Rulingia magnifora.

melanopetaln, F. Muell. l. c. x. 21.-Anstral.

microphylla, Benth. Fl. Austral. i. 244.-Austral.

parviflora, F. Muell. Census, $16=$ Rulingia parviflora.

pilosa, G. Don, Gen. Syst. ii. $524=$ Buettneria pilosa.

platycalyx, F. Muell. Census, $16=$ Rulingia platycalyx.

platyphylla, Andr. Bot. Rep.t. 603 adn. et t. $519 .-$

Malaya.

Preissi, Steud. in Lehm. Pl. Preiss. i. $298=$ Rulingia corylifolia.

pulchella, Turcs. in Bull. Soc. Nat. Mosc. xix. (1846) I. 502.-Austral.

rotundifolia, F. Muell. Census, $16=$ Rulingia rotundifolia.

rugosa, F. Mucll. l. c. = Rulingia rugosa.

salvifolia, F. Muell. 1. c.= Rulingia salvifolia.
COMMIA, Lour. Fl. Cochin. $605(1790)=$ Excoecaria Linn. (Euphorb.).

cochinchinensis, Lour. 1. c, $606=$ E. Agallocha.

COMMIANTHUS, Benth. in Hook. Journ. Bot. iii. (1841) 223 = Retiniphyllum, Humb. \& Bonpl (Rubiac.).

concolor, Spruce, ex Benth. in Hook. Kew Journ. v. (1853) $235=R$. concolor.

discolor, Spruce, ex Benth. 1. c. $234=$ R. discolor.

pilosus, Spruce, ex Benth. 1. c. $233=$ R. pilosum.

Schomburgkii, Benth, in Hook, Journ. Bot. iii. (1841) $223=\mathrm{R}$. Schomburgkii.

speciosus, Spruce, ex Benth. in Hook. Kew Joura. v. (1853) $234=\mathrm{R}$. speciosum.

COMMIDENDRON, Lem. in Orb. Dict. iv. 147 (1849) =seq.

COMMIDENDRUM, Burch. ex DC. in Guill. Archiv, Bot, ii. (1833) 334. COMPOSITAE, Benth. 8c Hook. ii. 277.

Burchellii, Benth. E Hook. f. ex Hemsl. Bot. Chall. Voy. i. II. 71.-Ins. S. Helena.

gummiferum, DC. Prod, v. $344=$ robustum.

robustum, $D C$. $l$. c. - Ins. S. Helena.

rotundifolium, DC. I. $\mathrm{c}_{\mathrm{r}}=$ Psiadia rotundifolia.

rugosum, $D C$. l. c. 345.-Ins. S. Helena.

spurium, $D C . l . c .344 .-$ Ins, S. Helena.

COMMILOBIUM, Benth. in Ann. Wien. Mus. ii. (1838) $110=$ Pterodon, Vog. (Legumin.)

abruptum, Moric. Pl. Rar. Nouv. Am, 98. t. $62=$ P abruptus.

polygalaeflorum, Benth. in Ann. Wien. Mus. ii. (1838 $111=\mathrm{P}$. polygalaeflorus.

pubescens, Benth. l. c. = P. pubescens.

COMMIPHORA, Jacq. Hort. Schoenb. ii. 66 (1797) BURSERACEAE.

Bad.SAMEA, Gled, in Berl. Ges. Naturf. Fr. Schr, iii. (1782) 127 .

Balsamodendron, Kunth, in Ann. Sc. Nat. Sér. I. ii. (1824) 348 .

Balsamophloeos, O. Berg, in Bot. Zeit. xx. (1862) 163.

Balsamus, Stackh. De Liban. 11 (1814).

Hemprichia, Ehrenb. in Linnaea, iv. (1829) 396.

Heudelotia, A. Rich. in Guill. \& Perr. Fl. Seneg. Tent. 150. t. $39(1832)$.

HitzerIA, Klotzsch, in Peters, Reise Mossamb. Bot. 89 (186 L).

Niotoutr, Adans. Voy. 162 (1759).

Protionopsis, Blume, Mus. Bot. Lugd. Bat. i. 229 (1850).

Protium, Wight \& Arn. Prod. 176 (1834).

abyssinica, Engl. in DC. Monog. Phan. iv. 10.-Abyss,

africanum, Endl.l. c. 14.-Abyss.

Agallocha, Engl. l. c. 11.-Ind. or.

angolensis, Engl. l. c. 24.-Afr, trop.

Berryi, Engl. l. c. 17.-Ind. or.

Boiviniana, Engl. l. c. 21.-Afr, trop.

capensis, Engl. l. c. 18.-Afr. austr.

caudata, Engl. l. c. 27.-Ind. or.

edulis, Engl. l. c. 22.-Afr. trop.

erythraea, Engl.l. c. 20.-Afr. trop.

grandifolia, Engl. l. c. 25.-Madag.

Harveyi, Engl. $l . c$. -Afr. austr.

Hildebrandtii, Engl. l.c. 15.-Afr, trop.

Kataf, Engl.l. c. 19.-Arab.

longebracteata, Engl. l. c.-Afr. trop.

madagascariensis, facq. Hort. Schoenb. ii. 66.-Madag.

Marchandi, Engl. in DC. Monog. Phan. iv. 26.

Madag.

mollis, Engl.l. c. 33.-Afr. trop.

mossambicensis, Engl. l. c. 26.-Afr. trop.

Mukul, Engl. l. c. 12. -Ind, or.

Myrrha, Engl. l. c. 10.-Arab.

Olivieri, Engl. l. c. 24.-Afr. trop.

Opobalsamum, Engl.l.c. 15.-Arab.

orbicularis, Engl. l. c. 18.-Madag.

parvifolia, Engl. l. c. 536.-Ins. Socotra.

pedunculata, Engl. l. c. 23.-Africa.

Pervilleana, Engl. l. c. 29.-Madag

pilosa, Engl. l. c. 12.-Afr. trop.

planifrons, Engl. l.c. 536.-Ins, Socotra

pubescens, Engl. l. c. 21.-Ind. or.

Kehmanni, Engl. l. c. 15.-Afr. austr.

Schimperi, Engl. l. c. 13.-Abyssin.

\section{COMMIPHORA:-}

serrata, Engl. in DC. Monog. Phan. iv. 24.-Afr. trop.

socotrana, Engl. l. c. 536.-Ins. Socotra

Stocksiana, Engl. l. c. 17.-Beluchist

tetramera, Engl. l. c. 27.-Madag.

Welwitschii, Engl. l. c. 22.-Afr. trop.

zanzibarica, Engl. l. c. 28.-Afr. trop.

COMMIRHOEA, Miers, in Trans. Linn. Soc. xxi. (1855 $252=$ Chrysochlamys, Poepp.? (Guttif.)

mecocarpa, Miers, 1. c. 258.-Hab.

COMOCLADIA, P. Br. Hist. Jamaic 124 (1756 ANACARDIACEAE, Benth. \& Hook. f. i. 419. Dodonaea, Plum, ex Adans. Fam. ii. 342 (1763). acuminata, Moc. E Sesse, ex DC. Prod. ii. 65.Mexic.

angulosa, Willd. Sp. Pl, i. $188=$ ilicifolia.

Brasiliastrum, Poir. Encyc. Suppl. ii. 325,-Am, austr. dentata, facq. Enum. Pl. Carib. 12. -Ind. occ.

Ehrenbergii, Engl. in Bot. Fahrb. i. (1881) 420.-Ins. S. Doming.

glabra, Spreng. Syst. i. 176.-Cuba.

ilicifolia, Sw. Prod. Veg. Ind. Occ. 17.-Ind. occ.

integrifolia, Facq. Enum. Pl. Carib. 12.-Am. trop.

intermedia, Wright, ex Engl. in DC. Monog. Phan.

366.-Cuba.

loxensis, H. B. E K. Nov. Gen. et $S p$. vii. 16.-N, Granat.

mollissima, $H . B . E$. K. ᄂ.c. 16. t. 607.-Mexic.

pinnatifida, Linn. Syst. ed. X. $861=$ integrifolia.

platyphylla, A. Rich. ex Griseb. Cat. Pl. Cub. 68.Cuba.

propinqua, H. B. E K. Nov. Gen. et Sp. vii. 16.Cuba.

pubescens, Engl. in Bot. Fahrb. i. (1881) 420.Jamaic

serrata, Blanco, F1. Filip. ed. I. $30=$ Salacia oblonga. Tapaculo, H. B. \& K. Nov. Gen, et Sp. vii. $16=$ Tapiria guianensis.

tomentosa, Willd. ex Schult. Mant. i. $350=\mathrm{mol}$ lissima.

tricuspidata, Lam. in Mém. Acad. Sc. Par. 1784 1787) $347=$ ilicifolia

COMOLIA, DC. Prod. iii. 114 (1828). MELASTO. MACEAE, Benth. \& Hook. f. i. 741.

Hostmannia, Steud, ex Nand, in Ann. Sc. Nat. Sér. III. xiii. (1849) 25

Leiostegia, Benth. in Hook. Journ. Bot. ii. (1840) 294.

PaChyloma, DC. Prod. iii. 120 (1828)

Tetrameris, Naud. in Ann. Sc. Nat. Sér. III. xir. (1850) 120.t. 4.

TRICENTRUM, DC. Prod, iii, 123 (1828).

amazonica, Cogn. in Mart. Fl. Bras. xiv. 111. 422.Bras.

Aubletii, Triana, in Trans. Linn. Soc. xxviii. (1Si] 37. -Guiana.

berberifolia, $D C$. Prod. iii. 115.-Bras.

denudata, Naud, ins Ann. Sc. Nat. Sér. III xiii (1850) 25.-Bras.

birtella, Naud. l. c. $26=$ microphylla

lanceaefora, Triana, in Trans. Linn. Soc. xxviii. (1871) 37.-Bras.

latifolia, Cogn. in Mart. Fl. 13ms, xiv. III. $439=$ Aubletii.

leptophylla, Naud. in Anr. Sc. Nat. Sur. 111. .... (1850) 27 .-Guina.

lytbrarioides, Naud. l. c.-Guiana.

microphylla, Benth. in Hook. Gourn. Bot. ii. (1St0 295.-Guiana.

neglecta, Cogn. in Mart. Fl. Bras, xis. \$1. t23. Guiana.

numnularioides. Acaucl. in atnn. Sc, Vas. Scr. III. xii. (1850) 27.-Bras.

ovalifolia, Triann, in Trans. ILinn. Soc xxviii. \{18:1 si. t. 2- denulata.

purpurea, Miq. in Linnaca, xviii. 1:tfl 617 veroni. cicfolia.

Scrtularia, Triana, in Trans. Linns. Sox, xxviii, : : : Si. t. 2. i. 27 f. [Bras.

sessilis, Trianta, d. \& f. 2\% c. - Bros

stenudon, Triana, l. c. \$i,-Bris.

surinamensis, Mie. Sirp, Surito. 55 - Irthrarivides

ectraptem, Coys. in Mars. F\%. Bras. xir. III. 196.Bras. 


\section{COMOLIA :-}

vernicosa, Triana, in Trans. Linn. Soc, xxviii. (1871) 37. t. 2. f. $27 \mathrm{~g}$. - Bras

veronicaefolia, Benth. in Hook. Fourn. Bot. ii. (1840) 295.-Guiana.

veronicaefolia, Triana, in Trans. Linn. Soc. xxviii. 1871) $36=$ purpurea.

villosa, Triana, l. c. 37.-Guiana.

violacea, Triana, l. c. -Bras,

COMOMYRSINE, Hook, $f$. in Benth. \& Hook, f Gen. ii. 643 (1876), MYRSINEAE, Benth. \& Hook. f. 1. c.

Schlimii, Hook. f. l. c. 644.-Am. austr.

simplex, Hook. f. l. c.-Am. austr.

Sprucei, Hook.f.l.c.-Am. austr.

COMOSPERMA, Poir. in Dict. Sc. Nat. x. (1818) $128=$ Comesperma, Labill. (Polygal.).

COMostemUM, Nees, in Linnaea, ix. (1834) $283=$ Androtrichum, Brongn. (Cyperac.).

globuliferum, Nees, in Mart. Fl. Bras. ii. I. $5=\mathrm{A}$. polycephalum.

impolitum, Nees, in Hook. Journ. Bot. ii. $(\mathbf{1 8 4 0}) 397=$ Cyperus impolitus.

laetum, Nees, 1. $\mathrm{c}_{\mathrm{o}}=$ Cyperus laetus, Prest .

montevidense, Nees, in Linnaea, ix. (1834) $283=\mathrm{A}$ polycephalum.

prolixum, Nees, in Hook. Journ. Bot. ii. (1840) $397=$ Cyperus prolixus.

Schottii, Nees, in Linnaea, ix. 1834) $283=$ Cyperus prolixus.

COMPARETTIA, Poepp, \& Endl. Nov, Gen. et Sp. i. 42 . t. $73(1835)$, ORCHIDEAE, Benth. \& Hook. f i. $42 . \mathrm{t}$.

iii. 558. Wetensch. i. (1848) 212.

coccinea, Lindl. Bot. Reg. xxiv. (1838) t. 68.Bras.

cryptocera, Morr. in Belg. Hortic. ii. (1852) 310 . Hab.?

falcata, Poepp. Ev Endl. Nov. Gen.et Sp. i. 42. t. 73.Peruv.

macroplectron, Reichb. $f$. E Triana, in Gard. Chron. (1878) II. 524 ; (1879) I. 398 -N. Granat.

rosea, Lindl. Bot. Reg. (1840) Misc. $78=$ falcata

saccata, Poepp. E" Endl. Nov. Gen. et Sp. i. 42. t. 72.Peruv.

speciosa, Reichb. f. in Gard. Chron. (1878) II. 524.Ecuador.

COMPERIA, C. Koch, in Linnaea, xxii. (1849) $287=$ Orchis, Linn.

taurica, C. Koch, 1. c. $288=$ O. Comperiana.

COMPHOROPSIS, Moq: in DC. Prod. xiii. II. 200, in syn. (1849)=CAMPHOROPSIS, Moq. = Nanophytum, Less. (Chenopod.).

COMPHRENA, Aubl. Pl. Gui. i. 280 (1775), sphalm. = Gomphrena, Linn. (Amarant.).

COMPSANTHUS, Spreng. Syst. iv. Cur. Post. 127 (1827) = Tricyrtis, Wall. (Liliac.).

maculatus, Spreng. 1. c. = T. pilosa,

COMPSOA, D. Don, Prod. Fl. Nep. $50 \quad(\mathbf{1 8 2 5})=$ Tricyrtis, Wall. (1826) (Liliac.).

maculata, D. Don, 1. c. $51=$ T. pilosa.

COMPTONIA, Banks, ex Gaertn. Fruct. ii. 58, t. 90 $(1791)=$ Myrica, Linn

asplenifolia, Banks, 1. c. = M. asplenifolia

Ceterach, Mirb. in Duham. Arb. ed. nov. ii. t. $11=\mathrm{M}$ asplenifolia.

COMUS, Salisb. Gen. Pl. Fragm. 24 (1866)= Muscari Tourn. (Liliac.)

carnosus, Salisb. 1. c. $25=$ M. comosum.

CONAMI, Aubl. Pl. Gui. ii. 926. t. 354 (1775)= Phyll anthus, Linn. (Euphorb.)

brasiliensis, Aubl. 1. c. $927=\mathbf{P}$. Conami.
CONANDRON, Sieb. \& Zucc. in Abh. Akad. Wiss Muench, iii. 1843$) 729$, 3 GESNERACEAE, Benth. \& Hook. f. ii. 1024

ramondioides, Sieb. \&" Zucc. l. c.-Japon.

CONANTHERA, Ruiz \& Pav, Fl. Per, iii. 68, t. 301 (1802) HAEMODORACEAE, Benth. \& Hook. f. iii. 679 .

Cummingia, D. Don, in Sweet, Brit. Flow. Gard Ser. I. iii. t. $257(1828)$.

albiflora, Cham. \& Schlecht. in Linnaea, vi. (1831) 50 $=$ Echeandia terniflora.

bifolia, Ruiz E Pav. Fl. Per. iii. 68, t. 301.-Chili

bifolia, Sims, in Bot. Mag. t. $2496=$ Simsii.

campanulata, Lindl. in Trans. Hort. Soc. vi. (1826) $283=$ Simsii.

Echeandia, Pers. Syn. i. $370=$ Echeandia terniflora.

Forsteri, Spreng. Syst. ii. 91.-N. Caled.

Simsii, Sweet, Hort. Brit. ed. I. 423,-Chili.

CONANTHODIUM, A. Gray, in Hook. Kew Journ. iv (1852) $272=$ Helichrysum, Vaill. (Compos.).

Drummondii, A. Gray, l. c. $=\mathbf{H}$. argyroglottis.

CONANTHUS, S. Wats. Bot. King's Exped. 256 (1871), HYDROPHYLLACEAE, Benth. \& Hook. f. ii. 828 .

aretioides, S. Wats. l. $c_{\text {o }}-\mathrm{Am}$. bor. occ

CONCEVEIBA, Aubl. PI. Gui. ii. 923. t. 353 (1775) EUPHORBIACEAE, Benth. \& Hook. f. iii. 316 africana, Muell. Arg. in Flora, xxxiii. (1864-65) 530 -Afr. trop.

cordata, A. Juss. Tent. Euph. 43. t. 13=Alchornea cordata.

guianensis, $A u b l$. Pl. Gui. ii. 924. t. 353.-Guiana

Hostmani, Benth. in Hook. Kew Ұourn. vi. (1854)

332. - Guiana.

javanensis, Blume, Bijdr. $614=$ Alchornea rugosa.

latifolia, Zipp. ex Span. in Linnaea, xv. (1841) $349=$

Alchornea rugosa.

latifolia, Benth. in Hook. Kew fourn. vi. (1854) 332 -Bras.

macrophylla, Klotzsch, ex Benth. 1. c. $333=$ Alchomea cordata.

Martiana, Baill. in Adansonia, v. (1864-65) 221.Bras.

megalophylla, Muell. Arg. in Linnaea, xxxiv. (1865-66) 167 = Alchornea Martiana.

ovata, Rich. ex A. Juss. Tent. Euph. 43 = guyanensis. rhytidocarpa, Muell. Arg. in Mart. Fl. Bras. xi. II. 372.--Peruv.

terminalis, Muell. Arg. in Linnaea, xxxiv.(1865-66) 167.-Bras.

tomentosa, Span. 1. c. xv. (1841) $349=$ Cladogynos orientalis.

trigonocarpa, Muell. Arg. in Mart. Fl. Bras, xi. II. 372.-Bras.

CONCEVEIBUM, Rich. ex A. Juss. Tent. Euph. 42 $(1824)=$ praec.

CONCHIDIUM, Griff. Notul, iii. 321. t. $310(1851)=$ Eria, Lindl. (Orchid.)

pusillum, Griff. 1. c. = E. pusilla.

sinicum, Lindl. ex Benth. in Hook. Kew Journ. vii. (1855) $34=\mathrm{E}$. sinica.

CONCHIUM, Sm. in Trans. Linn. Soc. iv. (1798) $215=$ Hakea, Schrad. (Proteac.).

aciculare, Sm. ex Vent. Jard. Malm. t. $111=$ H. acicularis.

ceratophyllum, Sm. in Trans. Linn. Soc. ix. (1808) 124 $=\mathrm{H}$. ceratophylla.

clavatum, Willd. Enum. Hort. Berol. $141=$ H clavata.

compressum, Sm. in Trans. Linn. Soc. ix. (1808) $121=$ H. acicularis.

corniculatum, Sm. ex Willd. Enum. Hort. Berol. $141=$ H. pugioniformis.

cornutum, Gaertn. f. Fruct. iii. 216. t. $219=$ H. gibbosa.

dactyloides, Vent. Jard. Malm. t. $110=\mathrm{H}$. dactyloides. drupaceum, Gaertn f Fruct iii 217 t $219=\mathrm{H}$. leucoptera.

ellipticum, Sm. in Trans. Linn. Soc. ix. (1808) $123=$ H. elliptica.
CONCHIUM :-

epiglottis, Willd. Enum. Hort. Berol. $141=$ H. epiglottis.

gibbosum, Sm. in Trans. Linn. Soc, ix. (1808) $119=$ H. gibbosa.

longifolium, Sm. 1. c. $121=$ H. pugioniformis.

mucronatum, Cels, ex Spreng. Syst. i. $480=$ H. varia.

nervosum, Sm, ex Willd. Enum. Hort. Berol 141= H. dactyloides.

oleifolium, Sm. in Trans. Linn. Soc. ix. (1808) $124=$ H. oleifolia.

puhescens, Willd. Enum. Hort. Berol, $141=$ H. gibbosa pugioniforme, Sm. in Trans. Linn. Soc. ix. (1808) 122 $=\mathrm{H}$. pugioniformis.

pyriforme, Willd. Enum. Hort. Berol. $141=\mathrm{Xylomelum}$ pyriforme.

ruscifolium, Willd. 1. c. $=$ H. ruscifolia

salicifolium, Gaertn. f. Fruct. iii. $217=\mathrm{H}$. saligna .

salignum, Sm. in Trans. Linn. Soc. ix. (1808) $124=$ H. saligna.

sphaeroideum, Sm. 1. c. $120=$ H. gibbosa,

teretifolium, Gaertn. f. Fruct. iii. 217. t. $219=\mathrm{E}$. epiglottis.

trifurcatum, Sm. in Trans. Linn. Soc. ix. (1808) $122=$ H. trifurcata.

CONCHOCARPUS, Mikan, Delect. fasc. i. t. $2(1820)=$ Cusparia, Humb. (Rutac.).

cuneifolius, Nees \& Mart. in Nov, Act. Nat. Cur. xi (1823) $162=$ Cusp. cuneifolia.

macrophyllus, Mikan, Delect. fasc. i. t. $2=$ Cusp. macrophylla.

CONCHOCHILUS, Hassk. in Hoev. \& De Vriese, Tijdschr. ix. (1842) $146=$ Appendicula, . Blume, (Orchid.)

distichus, Hassk. 1. c. = A. pendula.

oppositiflorus, Hassk. 1. c. $147=$ A. cristata.

CONCHOPHYLLUM, Blume, Bijdr. 1060 (1826) = Dis chidia, R. Br. (Asclepiad.)

imbricatum, Blume, 1. e. $1061=\mathrm{D}$. Collyris.

CONCILIUM, Rafin. Fl. Tellur, ii. 78 (1836)= Light footia, L'Hérit. (Campan.) pedunculare, Rafin. 1. c. = L. subulata.

CONDAEA, Steud. Nom. ed.II. i. $403(1840)=$ CONDEA, Adans. = Hyptis, Jacq. (Labiat.).

CONDALIA, Cav. in Anal. Cienc. Nat. i. (1799) 39, t. 4. RHAMNEAE, Benth. \& Hook. f. i. 376 .

buxifolia, Reiss. in Mart. Fl. Bras. xi. I. 89.-Bras. coriacea, Reichb. in Flora, xiii. (1830) I. $130=$ Rham nus integrifolius.

ferrea, Griseb. F1. Brit. W. Ind, $100=$ Scutia ferrea infectoria, Reiss. in Mart. Fl. Bras, xi, I. 90.-Bras.

lineata, A. Gray, Bot. U. St. Expl. Exped. i. 275.Patagon.

maytenoides, Miers, in Ann. E Mag. Nat. Hist. Ser. III. vi. (1860) 14.-Chili.

mexicana, Schlecht. in Linnaea, xv. (1841) 471.Mexic.

microphylla, Cav. in Anal, Cienc. Nat, i. (1799) 40.Chili.

obovata, Hook. Ic. Pl. t. 287.-Texas.

paradoxa, Spreng. Syst. i. $825=$ Colletia cruciata

spathulata, A. Gray, Pl. Wright. i. 32.-Am. bor. occ spinosa, Spreng. Syst. iv, Cur. Post. 108.-Bras.

CONDALIA, Ruiz \& Pav. Prod. 11. t. $2(1794)=$ Coccocypselum, P. Br. (Rubiac.).

lanceolata, Ruiz \& Pav. Fl. Per. i. $54=$ Cocc. lanceolatum.

obovata, Ruiz \& Pav, 1. c. = Cocc, obovatum.

repens, Ruiz \& Pav. 1. c. = Cocc. umbellatum.

sessilis, Ruiz \& Pav. 1. c. $=$ Cocc. sessile.

CONDAMINEA, DC. Prod. iv. $402(1830)$, RUBI$A C E A E$, Benth. \& Hook. f. ii. 42

corymbosa, $D C$. l. c.-Am, austr.

glabrata, DC. l. c.-Peruv.

macrophylla, Poepp. E Endl. Nov. Gen. et Sp. iii. 30. -Bras.

microcarpa, DC. Prod. iv. 402.-Pernv.

tinctoria, $D C . l$. c.-Venezuela.

utilis, Goudot, in Comptes Rendus, xviii. (1844) 260 .N. Granat.

venosa, $D C$. Prod. iv. 402.-Peruv. 
CONDEA, Adans. Fam. ii. $504(1763)=$ Hyptis, Jacq. (Labiat.).

CONDYLICARPUS, Steud. Nom. ed. II. ii. 691 (1841) err. typ. $=$ CONDVLOCARPUS, Hoffm. $=$ Tordy lium, Tourn. (Umbellif.).

CONDYLOCARPON, Desf. in Mém. Mus. Par. viii. (1822) 119. t. 11. APOCYNACEAE, Benth. \& Hook. f. ii. 701.

Hortsmania, Miq. in Nat. Verh. Wet. Haarl. vii $167(1850)$

MAYCockiA, A. DC Prod viii. 324 (1844)

brasiliense, Mart. ex Muell. Arg. in Mart. Fl. Bras. vi. I $64=$ Rauwolfiae.

breviarticulatum, Muell. Arg. l. c. 65.-Bras.

ciliatum, Muell. Arg. l. c. 66.-Bras.

gracile, Miers, Apocyn. S. Am. 28.-Am. austr.

guyanense, Desf. in Mém. Mus. Par. viii. (1822) 120.t. 8.-Guiana.

intermedium, Muell. Arg. in Mart. Fl. Bras. vi. 1.65.Bras.

isthmicum, A. DC. Prod. viii. 381.-Bras.

laxum, Muell. Arg. in Mart. Fl. Bras. vi. 1. 66.-Bras. myrtifolium, Muell. Arg. l.c.65, in obs.-Guiana.

obtusiusculum, Muell. Arg, l. c.-Bras.

pubiflorum, Muell. Arg. l. c. 67.-Bras

Rauwolfiae, Muell. Arg. l. c. 64.-Bras.

CONDYLOCARPUS, Hoffm. Gen Umb, ed. II. 202 (1816) = Tordylium, Tourn. (Umbellif.)

apulus, Hoffm. 1. c. $203=$ T. apulum.

humilis, Koch, in Nov. Act. Nat. Cur. xii. 1. (1824) $87=\mathrm{T}$. apulum

officinalis, Koch, l. c. $=\mathrm{T}$. officinale.

CONDYLOCARPUS, Salisb. ex Lamb. Pinus, ed. 8vo 120, sub t. 64 (1832)=Sequoia, EndI. (Conif.). sempervirens, Salisb. ex Carx. Conif. ed. I. $163=S$ sempervirens.

CONFORATA, Caesalp. ex Fourr. in Ann. Soc. Linn Lyon, N. S. xvii. (1869) $91=$ Achillea, Linn (Compos.)

Ageratum, Fourr. 1. c. $=$ A. Ageratum

CONGDONIA, Muell. Arg. in Flora, lix. (1876) 437 RUBIACEAE.

caerulea, Muell. Arg. l. c.-Bras.

CONGEA, Roxb. PI. Corom. iii. 90. t. 293 (1819) VERBENACEAE, Benth. \& Hook. f. ii. 1159 Calochlamys, Presl, Bot. Bemerk. 148 (1844) asurea, Wall. Cat, n. 1733=Sphenodesma pentandra. barbata, Wall. 1. c, n. $1738=$ Sphenodesma barbata.

ferruginea, Wall. 1. c. n. $1737=$ Sphenodesma unguiculata.

involucratum, Wall. 1. c. n. $1740=$ Symphorema poly andrum.

Fackiana, Wall. 1. c. n. $1735=$ Sphenodesma pentandra, triflora.

paniculata, Wall, 1. c. n. $1739=$ Symphorema involucratum, Sphenodesma paniculata.

pentandra, Wall. 1. c. n. $1734=$ Sphenodesma pent andra.

tomentosa, Roxb. Pl. Corom. ìi. 90.-Burma.

unguiculata, Wall. Cat. n. $1736=$ Sphenodesm onguiculata.

velutina, Wight, Ic. t. 1479/9.-Ind. or

vestita, Griff. Notul. iv. 174.-Burma

villosa, Wight, Ic. t. 1479 B.-Burma

CONGHAS, Wall Cat, $\mathrm{n}, 8080$; ex Hiern, in Hook. Fl. brit. Ind. i. 681 (1875) = Schleichera, Willd (Sapindac.).

seylonensis, Wall. 1. $\mathrm{c}_{\mathrm{n}}=\mathrm{S}$. trijuga

CONIANDRA, Schrad. in Eckl. \& Zeyh. Enum. 275 $(1836)=$ Kedrostis, Medic. (Cucurb.)

africana, Sond. in Harv. \& Sond. Fl. Cap. ii. $483=$ K. africana.

corallina, Fenzl, ex Naud, in Ann. Sc. Nat. Sér. IV xvi. $(1862) 180=$ Corallocarpus Fenzlii.

digitata, Sond, in Harv. \& Sond. Fl. Cap. ii. $483=\mathrm{K}$ digitata.

dissecta, Schrad. in Eckl. \& Zeyh. Enum. $276=\mathrm{K}$ africana.

glanca, Schrad. 1. c. $275=\mathrm{K}$. grossulariaefolia

\section{CONIANDRA :-}

grossulariaefolia, Arn. in Hook. Journ. Bot. iii. (1841) $273=$ Kedrostis grossulariaefolia

mollis, Sond. in Harv. \& Sond. Fl. Cap. 11. $485=\mathrm{K}$ mollis.

pinnatisecta, Schrad. in Eckl, \& Zeyh. Enum. $276=\mathrm{K}$. africana.

punctulata, Sond, in Harv, \& Sond. Fl. Cap. ii. $484=$ K. punctulata.

Thunbergi, Sond. 1. c. =K. nana.

Zeyheri, Schrad. in Eckl. \& Zeyh. Enum. $275=\mathrm{K}$ Zeyheri.

CONIOGETON, Blume, Bijdr. $1156(1826)=$ Bucha nania, Roxb. (Anacard.)

arborescens, Blume, 1. $\mathrm{c} .=\mathrm{B}$. florida.

CONIOSELINUM, Fisch, ex Hoffm, Gen. Umb, ed. I. p. 180 et xxviii. $(1814)$; ed. II. $185(1816)=$ Ligusti cum, Linn. (Umbellif.)

altaicum, Rupr. in Beitr. Pf. Russ. Reich. xi. 22.Sibir.

canadense, Torr. \& Gray, Fl. N. Am. i. $619=$ Selinum canadense.

cenolophioides, Turcz, in Bull. Soc Nat. Mosc, xvii. (1844) $736=$ Selin um cenolophioides

Czernaevia, Fisch. \& Mey. Ind. Sem. Hort. Petrop. ii $33=$ Peucedanum latifolium.

Fischeri, Wimm. \& Grab. Fl. Siles, (1827) i, $266=$ Selinum Benthami.

gayoides, Less. in Linnaea, ix. (1834) 178.-Sibi

Gmelini, Steud. Nom. ed. II. i. $403=$ Ligusticum Gmelini.

humile, Turcz. ex Ledeb. F1. Ross. ii. $313=$ Peuce danum salinum.

ingricum, Fisch. Ind. Sem. Hort. Petrop. (1824) ex Ledeb, 1. c. $290=$ Selinum Benthami.

kamtschaticum, Rupr, in Beitr. Pf. Russ, Reich. xi. 22.-Kamtsch.

latifolium, Rupr. Sert. Tiansch. 48.-Am. centr.

iongifolium, Turcz. in Bull. Soc. Nat. Mosc. xvil. 1844) 736.-Sibir.

neglectum, Fisch, ex Steud. Nom, ed. II i. 403, $404=$ Selinum Benthami.

tataricum, Hofim. Gen. Umb. ed. II. 185=Selinum Benthami.

nivittatum, Turcz. ex Kar. \& Kir. in Bull. Soc. Nat. Mosc. xv. (1842) $363=$ Selinum Benthami.

CONIOTHELE, DC. Prod. v. $531(1836)=$ Blennosperma, Less. (Compos.)

californica, DC. 1. c. = B, californicum.

CONIROSTRUM, Dulac, Fl. Hautes-Pyr. 195 (1867)= Brassica, Tourn. (Crucif.)

obtusangulum, Dulac, 1. c. =B. Erucastrum.

CONISA, Desf. ex Steud. Nom. ed. II. i. $404(1840)=$ Conyza, Linn. (Compos.).

CONIUM, Linn. Syst, ed. I (1735)

UMBELLI-

FERAE, Benth. \& Hook. f. i. 888

africanum, Hort. ex DC. Prod. iv. $108=$ Carum copticum.

africanum, Jacq. Hort. Vind. ii. 91. t. 194 = Capnophyllum Jacquini.

africanum, Linn. Sp. Pl. 249 = Capnophyllum africanum. Arracacia, Hook. Exot. Bot. t. $152=$ Arracacia xanthorrhiza.

chaerophylloides, Eckl. \& Zeyh. Enum. $355=$ Seseli chaerophylloides.

Cicuta, Neck. Delic. Gallo-Belg. i. $142=$ maculatum.

croaticum. Waldst \& Kit. ex Willd. Enum. Hort. Berol, $305=$ maculatum

dichotomum, Desf. Fl. Atlant. i. 246. t. $66=$ Capnophyllum dichotomum

divaricatum, Boiss. \& Orph. Diagn. Ser. II. v. $103=$ maculatum.

filifolium, Vahl, Symb. Bot. iii. $49=$ Oenanthe filiformis.

Facquini, D. Dietr. Syo. Pl. ii. $988=$ Capnophyllum Jacquini.

maculatum, Lirn. Sp. Pl. 243.-Europ.; Oriens.

maculostm, Pall. Reis, Statth. Kuss, Reich, i. 478 .

maculatum.

Monieri, Hort. ex Opis, Natural. x. (1825) 200, notwen. -Europ.

\section{CONIUM}

moschatum, H. B. \& K. Nov. Gen, et Sp. v. 14. t. 420 = Arracacia moschata.

nepalense, D. Dietr. Syn. Pl. ii. $988=$ Vicatia coniifolia nodosum, Fisch. ex Steud. Nom. ed. I. $215=$ maculatum.

rigens, Linn. Mant. ii. $352,512=$ Bunium rigens.

rigidum, Mert. ex DC. Prod. iv. $140(=$ Sclerosciadium humile .-Marocco.

Royeni, Linn. Sp. P1. $243=$ Caucalis daucoides.

rugosum, Thunb. Prod. Pl. Cap. $50=$ Capnopliyllum Jacquini.

siricum, Hort. ex Steud. Nom. ed. II. i. $404=$ maculatum.

strictum, Tratt. Arch. Gew. i. t. $21=$ maculatum

suffruticosum, Berg. Desc. Pl. Cap. $77=$ Selinum suffruticosum.

tenuifolium, Mill. Gard. Dict. ed. VIII. n. $2=$ maculatum.

tenuifolium, Vahl, Symb. Bot. iii. $49=$ Oenanthe fliformis.

verrucosum, Hochst. ex A. Rich. Tent. Fl. Abyss. $324=$ Pimpinella simensis.

CONIZA, Neck. Delic Gallo-Belg. ii, 348 (1768) =

Conyza, Linn. (Compos.)

CONNAROPSIS, Planch, ex Hook. f. in Trans, Linn Soc. xxili. (1860) 166. GERANIACEAE, Benth. \& Hook. f. i. 277

diversifolia, Kurz, in Journ. As. Soc. Beng. zxxix. (1870) II. $69=$ Griffithii.

glauca, Hook. f. in Linn. Soc. Trans. xxiii. (1860) $166^{\circ}$ -Borneo.

Griffithi, Planch. l. c. et ex Hook. f. Fl. Brit. Ind. 440.-Malaya.

monophylla, Planch. Il.cc-Malacca.

philippica, Villar, in Blanco, Fl. Philipp. ed. III. Nov App. 33.--Ins. Philipp.

CONNARUS, Linn. Diss. Dass. 23 (1747); in Amoen Acad. i. 406 (1749), CONNARACEAE, Benth. \&

Hook. f. i. 432 .

Anisostemon, Turcz in Bull Soc Nat. Mose ax (1847) I. 152

CANicidia, Vell. Fl. Flum. 184 (1825); iv. t. 134 (1827).

Castanola, Llanos, in Mem. Acad. Cienc. Madr. ii (1859) 503.

ERYTHROSTIGMA, Hask, in Flom, xxy (1842) II. Beibl. 45.

Kalawael, Adans. Fam, ii. $344(1763)$

Mathrancia, Steud. Nom. ed. II. i. 404, in sym (1840)

OMPHALOBIUM, Gaertn. Fruct, i. 217. t. $46(1788$.

TAlI, Adans. Fam, ii, $319(1763)$

TAPGMana, Adans. Fam, ii. 343 (1763.

africanus, Lam. Encyc. ii. 95.-Afr. trop.

africanus, G. F. W. Mey. Prim Fl. Esseg. 228guianensis.

Afselii, R. Br. ex Planch. in Linnaea, xxiii. (1850)

$418=$ Rourea santaloides.

asiaticus, Willd. Sp. Pl. iii. $692=$ monocarpus

Beyrichii, Planch. in Linnaea, xxiii. (1550; 430. Bras.

Blanchetii, Planch. l.c. 481.-Bras.

Championii, Thry. Enum. Pl. Zeyl. S0-Zeylan.

conchacarpus, F. Muell. Fragm y, 105. - Ausernl

confurtiflorus, Baker, in Jart. Fo. Bras. xiv. 11. 193.

Guiana.

crassifolizus, Benth. ex Baker, 1. c. $186^{\circ}=$ farosus.

cuneifolius, Baker, l. c. 194 .-Bras.

cymosus, Planch. in Linnaca, xxiii. 1:50) $₫ 34$ Bras.

decumbens, Thumb in Rorm Arch i i 1996" 1

Afr. austr.

detersus. Planch. in Linnmea, xxiii. (1850) 435. - Bras.

Diepenhorstii, Mig. Fl. Ind. Bas. Sugp?. i. 529. Sumatra.

Duparquetianus, Baill. Ad -Afr. trop.

erianthus. Benth. ex Baher, ine .16arf. F. Bross. xir. II. 191.-Bras.

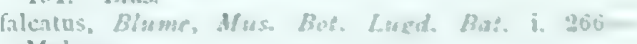
Malaya.

fasciculalus, Planch in Litmaza, Ixiii. 1850 19? crianthus.

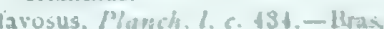




\section{CONNARUS:-}

fecundus, Baker, in Mart. Fl Bras, xiv. II. 185.-Bras. ferrugineus, Fack, in Malay. Misc. ii. (1822) n. viI. 37. -Malaya.

floribundus, Planch. in Linnaea, xxiii. (1850) $435=$ Perrottetii.

floribundus, Schum. E Thonn. Beskr. Guin. Pl. 299.Afr. trop.

floribundus, Wall. ex Hook. f. F1. Brit. Ind. ii. $52=$ semidecandrus.

florulentus, Thonn. ex DC. Prod. ii. $86=$ floribundus. fuminensis, Gardn. in Hook. Lond. Journ. Bot. (1842) $529=$ Bernardinia fluminensis.

foetens, Blanco, Fl. Filip, ed. I. 525= Murraya exotica fol.slosus, Jack, in Wall. Cat. n. $8529=$ Cnestis ramiflora.

fulgens, Wall. Cat. n. $8524=$ Rourea fulgens.

fulvus, Planch. in Linnaea, xxiii. (1850) 434.-Bras. furfuraceus, Blume, Mus. Bot. Lugd. Bat. i. 268.Sumatra.

Gaudichandii, Planch. in Linnaea, xxiii. (1850) 429 Ins. Molucc.

gibbosus, Wall. Cat. n. 8541, ex Planch. l. c. 436.Burma; Malaya.

glaber, DC. Prod. ii. 85 = Rourea glabra.

grandifolius, Planch. in Linnaea, xxiii. (1850) 432.-

Ins. S. Doming.

grandis, Fack, in Malay. Misc. ii. (1822) n. vII. 40. - Burma; Malaya.

Griffithii, Hook. f. Fl. Brit. Ind. ii. 52.-Burma.

Griffonianus, Baill. Adansonia, vii. (1866-67) 235.Afr. trop.

guianensis, Lamb. ex DC. Prod ii. 85-Am trop.

haemorrhaeus, Karst. Fl. Columb. ii, 73. t. 137. N. Granat.

Hasseltii, Blume, Mus. Bot. Lugd. Bat. i. 266.-Java. igneus, Wall. Cat. n. $8528=$ Cnestis ramiflora.

incomptus, Planch. in Linnaea, xxiii. (1850) 433.Griana.

Fackianus, Wall. Cat. n. 8552=Cupania Jackiana

javanicus, Blume, Bijdr. 1166.-Java.

juglandifolius, Hook. \& Arn. Bot. Beech. Voy. $179=$ Rhus succedanea.

kavaiensis, H. Mann, in Proc. Am. Acad. vii. (1867) 162.-Ins. Sandvic.

latifolius, Wall. Cat. n. 5837.-Burma.

laurifolius, Baker, in Mart. Fl. Bras. xiv. II. 186.Bras.

lucidus, Hassk. in Hoev. \& De Vriese, Tijdschr. x. (1843) 144.-Malaya

lucidus, Fack, in Malay. Misc. ii. (1822) n. viI. 41. - Malaya.

macrophyllus, Poepp. \& Endl. Nov. Gen. et Sp. iii. 76 = Rourea macrophylla.

Maingayi, Hook. f. Fl. Brit. Ind. ii. 53.-Malaya.

Manni, Baker, in Oliver, Fl. Trop. Afr. i. 459.-Afr. trop.

marginatus, Planch. in Linnaea, xxiii. (1850) 429 . Bras.

microphyllus, Hook. \& Am. Bot. Beech. Voy. $179=$ Rourea microphylla.

mimosoides, Jack, in Malay. Misc, ii. (1822) n. viI. $44=$ Rourea concolor

mimosoides, Vahl, Symb. Bot. iii. 87 (sp. dubia),-Ins. Nicobar.

mimosoides, Wall. Cat. n. $8526=$ Rourea Wallichiana, similis.

moluccanus, Zipp. ex Blume, Mus. Bot. Lugd. Bat. i. $266=$ Gaudichaudii.

monadelphus, Wall. Cat.n. 8547 B--Ind or

monocarpus, Linn. Sp. Pl. 675.-Ind. or

monocarpus, Wight \& Arn. Prod. $143=$ Rourea santaloides.

monophyllus, Wall. Cat. n. 8551=Ellipanthus tomentosus.

mutabilis, Blume, Mus. Bot. Lugd. Bat. i. 269.Malaya.

nemorosus, Vahl, ex Schum. E Thonn. Beskr. Guin: Pl. 299.-Afr. trop.?

neurocalyx, Planch. in Linnaea, xxiii. (1850) 248.Ins. Philipp.

nitidus, Hassk. in Flora, xxvii. (1844) II. 616.-Java. nitidus, Roxb. Hort. Beng. 49 ; Wall. Cat. n. 8540 C. -Ind. or.

nodosus, Baker, in Mart. Fl. Bras. xiv. II. 190.-Bras. obliquus, Presl, in Walp. Ann. iii. 844.--Ins, Luzon. oblongifolius, Mart. Herb. Fl. Bras. n. $1267=$ Rourea glabra.

\section{CONNARUS :}

obtusifolius, Planch. in Linnaea, xxiii. (1850) 428 Ins. Luzon.

odoratus, Hook. f. in Trans. Linn. Soc. xxiii. (1862) 172.-Borneo.

oligophyllus, Planch. in Linnaea, xxiii. (1850) 427.Penang.

panamensis, Griseb. in Bonplandia, vi. (1858) 6.Panama.

panamensis, Turcz. in Bull. Soc. Nat. Mosc. xxxii (1859) $1.277=$ Turczaninowii.

paniculatus, Roxb. Hort. Beng. 49 ; Fl. Ind. iii. 139.Ind. or.

Patrisii, Planch. in Linnaea, xxiii. (1850) 432.Guiana.

pentagynus, Lam. Encyc. ii. 95=Agelaea Lamarckii.

pentandrus, Roxb. Hort. Beng. 49 ; Fl. Ind. iii. $140=$ paniculatus.

Perrottetii, Planch. in Linnaea, xxiii. (1850) 432.Guiana.

Pickeringii, A. Gray, Bot. U. St. Expl. Exped. i. 375. -Ins. Fiji.

pinnatus, Hasselt, ex Blume, Mus. Bot. Lugd. Bat. i. $266=$ Hasseltii

pinnatus, Lam. Encyc. ii. $95=$ monocarpus.

polyanthus, Planch. in Linnaea, xxiii. (1850) 428.Ins. Iuzon.

polyphyllus, Miq. Fl. Ind. Bat. Suppl. 529.Sumatra.

pubescens, Baker, in Oliver, Fl. Trop. Afr. i. 458.Afr. trop.

pubescens, DC. Prod. ii. $85=$ Rourea revoluta.

punctatus, Planch. in Linnaea, xxiii. (1850) 432.Guiana.

pyrrhocarpus, Miq. Fl. Ind. Bat. Suppl. i. 530.Sumatra.

reticulatus, Griseb. Cat. $\mathrm{Pl}$. Cub, 84,-Cuba.

Ritchiei, Hook. f. Fl. Brit. Ind. ii. 51.-Ind. or.

Rolfei, Vidal, Phan. Cuming. Philipp. 23, 106.-Ins Philipp.

Roxburghii, Hook. \& Am. Bot. Beech. Voy. $179=$ Rourea Millettii.

ruber,Planch. in Linnaea, xxiii. (1850) 436.-Am. austr. rugosus, Wall. Cat. n. $8527=$ Rourea rugosa.

santaloides, Blanco, Fl. Filip. ed. II. $366=$ Murraya exotica.

santaloides, Vahl, Sym. Bot. iii. $87=$ Rourea santaloides. Schomburgkii, Planch. in Linnaea, xxiii. (1850) 431 - Guiana.

semidecandrus, fack, in Malay. Misc. ii. (1822) n. vir. 39 - Burma : Malaya.

Smeathmanni, Planch. in Linnaea, xxili. (1850) 436 Baker, in Oliver, Fl. Trop. Afr. i. 458.-Afr. trop.

Spanoghei, Blume, Mus. Bot. Lugd. Bat. i. 267.-Ins Timor.

Sprucei, Baker, in Mart. Fl. Bras. xiv. II. 187-Bras, stictophyllus, Kurz, For. Fl. Brit. Burma, i. 548.Burma.

suberosus, Planch. in Linnaea, xxiii. (1850) 433.Bras.

Thomsoni, Baker, in Oliver, Fl. Trop. Afr. i. 458.Afr. trop.

Turczaninowii, Triana E Planch, in Ann. Sc. Nat. Sér. V. xvi. (1872) 364.-Panama.

turgidus, Wall. Cat. n. 8545 , ex Planch. in Linnaea xxiii. (1850) 436. -Ind, or.

unifoliolatus, Thw. Enum. Pl. Zeyl. $80=$ Ellipanthus Thwaitesii.

velutinus, Wall. Cat, n. $8536=$ Ellipanthus tomentosus venezuelanus, Baill. Adansonia, ix. (1868-70) 151.Venezuela.

venosus, Smeathm. ex DC. Prod. ii. $85=$ africanus

villosus, Fack, in Malay. Misc. ii. (1822) n. VII. 38 -Sumatra.

villosus, Planch. in Linnaea, xxiii. (1850) $429=$ grandis Wallichii, Planch. 1. c. $426=$ grandis.

Wightii, Hook. f. Fl. Brit. Ind. ii. 51.-Ind. or.

CONOBAEA, Bert. ex Steud. Nom. ed. II. i. 404 (1840) = Muehlenbeckia, Meissn. (Polygon.). sagittaefolia, Bert. ex Steud. 1. c. = M. sagittifolia.

CONOBEA, Aubl. Pl. Gui. ii. 639. t. 258 (1775) SCROPHULARINEAE, Benth, \& Hook. f. ii, 951. Blanckia, Neck. Elem. j. 347 (1790).

Leucospora, Nutt, in Journ. Acad. Philad, vii. (1834) 87

\section{CONOBEA :-}

ScHistophragma, Benth. in Endl. Gen, 679 (1838) Sphakrotheca, Cham. \& Schlecht. in Linnaea, ii. (1827) 605

alata, R. Grah. in Edinb. N. Phil. Journ. (1830) $3=$ Leucocarpus alatus.

aquatica, $\mathrm{Aubl}$. $\mathrm{Pl}$. Gui. ii. 639. t. 258.-Guiana.

aquatica, Billb. ex Beurl. in Vet. Akad. Handl. Stockh.

1854 (1856) $141=$ Herpestis lanigera.

borealis, Spreng. Neue Entdeck. iii. $26=$ Gratiola virginiana.

indica, Spreng. Syst. ii. $771=$ Limnophila polystachya intermedia, A. Gray, in Torr. Bot. Mex. Bound. 117 -Mexic.

multifida, Benth in DC. Prod. x. 391-Am. bor

ovata, Spreng. ex Schrank, in Syll. Ratisb. ii. (1828) $62=$ Stemodia parviflora?

pumila, Spreng. Nov. Prov. $13=$ Stemodia parviflora. punctata, Nees E Mart. in Nov. Act. Nat. Cur, xi. (1823) 143.-Bras.

pusilla, Benth. E'Hook. f. Gen. ii. 951.-Mexic.

scoparioides, Benth. in DC. Prod. x. 391.-Mexic.

vandellioides, Benth. l. c.-Bras.

verticillaris, Hort. Berol. ex Spreng. Nov. Prov. $13=$ Stemodia durantifolia.

viscosa, Schrank, in Syll. Ratisb. ii. (1828) $61=$ Stemodia durantifolia

viscosa, Spreng. Neue Entdeck. i. 263.-Bras.

CONOCALPIS, Boj. ex Decne. in DC. Prod. viii. 621 (1844) = Gymnema, R. Br. (Asclepiad.).

umbellata, Boj. ex Decne. 1. c. $=$ G. rufescens

CONOCARPUS, Adans. Fam. ii. $284(1763)=$ Leuca dendron, R. Br. (Proteac.).

CONOCARPUS, Linn. Gen. ed. I. 376 (1737); Gaertn. Fruct. ii. 470, t. 177 (1791), COMBRETA$C E A E$, Benth. \& Hook. f. i. 686

Rhizaeris, Rafin. Sylva Tellur. 90 (1838) RUDBECKIA, Adans. Fam. ii. 80 (1763).

acuminatus, Buch.-Ham. ex Wall. Cat. n. 4014, $4015=$ Anogeissus latifolia.

acuminatus, Roxb. Hort. Beng. 34 ; Fl. Ind. ii. $443=$ Anogeissus acuminata.

acutifolius, Willd, in Roem. \& Schnlt. Syst. v. 574= erectus.

erectus, Linn. Sp. Pl. 147 ; Facq. Select. Am. 78. t. 52. -Ind. occ.

hirtus, Buch.-Ham. ex Wall. Cat. n. 4016=Anogeissus acuminata.

lanceolatus, Heyne, ex Wall. 1. c. n. $4014=$ Anogeissus acuminata.

latifolius, Roxb. Hort. Beng. 34; F1. Ind. ii. $442=$ Anogeissus latifolia.

leiocarpus, DC. Prod, iii. $16=$ Anogeissus leiocarpa. monocarpus, Steud. Nom. ed. I. $216=$ Rhus Rhadaeli javel.

myrtifolius, Buch.-Ham, ex Wall. Cat. n. $4017=$ Anogeissus pendula.

niloticus, Delile, ex Steud. Nom. ed. II. i. 404.Aegypt.

Novae-Zeylandiae, Cels, ex Tenore, Cat. Hort. Neap. (1845) 82.-N. Zel.

parvifolius, Hochst. ex A. Rich. Tent. Fl. Abyss. i. $269=$ Anogeissus leiocarpa.

procumbens, Linn. Sp. P1. $148=$ erectus.

pubescens, Schum. E Thonn. Beskr. Guin. Pl. 115.Afr. trop.

racemosus, Linn. Syst. ed. X. 930 ; Jacq. Select. Am. $80=$ Laguncularia racemosa.

Schimperi, Hochst. ex A. Rich. Tent. Fl. Abyss. i. 269 $=$ Anogeissus leiocarpa.

sericea, Forst. ex G. Don, Gen. Syst. ii. $662=$ erectus. supina, Crantz, Inst. i. $355=$ erectus.

CONOCEPHALUS, Blume, Bijdr. 483 (1825). URTICACEAE, Benth. \& Hook. f. iii. 380.

acuminatus, Tréc. in Ann. Sc. Nat. Sér. III. viii. (1847) 91.-Ins. Philipp.

azureus, Teijsm. E Binn. in Tijdschr. Nederl. Ind. xxvi. (1864) 26.-Java; Sumatra.

Blumei, Gaudich. Bot. Voy. Bonite, t. 96.-Malaya

borneensis, Miq. Ann. Mus. Bot. Lugd. Bat. iii, 210. -Borneo.

concolor, Dalz. in Dalz. E Gib̆s. Bomb. Fl. 239.Ind. or

ellipticus, Tréc. in Ann. Sc. Nat. Sér. III. viii. (1847) 91.-Penang. 
CONOCEPHALUS :-

erectus, Villar, in Blanco, Fl. Philipp. ed. III. Nov. App. 203.--Ins. Philipp.

gratus, Miq. Pl. Jungh. i. $43=$ suaveolens.

Ianceolatus, Tréc. in Ann. Sc. Nat. Sér. III. viii. (1847) 88, - Ind, or.

micranthus, Miq. Ann. Mus. Bot. Lugd. Bat. iii. 210. -Borneo.

microphyllus, Tréc. in Ann. Sc. Nat. Sér. III, viii. (1847) 92.-Ins. Philipp.

naucleiformis, Lindl. Bot. Reg, t. $1203=$ suaveolens. nivens, Wight, Ic. vi.7. t. $1959=$ Debregeasia veluniveus,

ovatus, Tréc. in Ann. Sc. Nat. Sér. III. viii. (1847) 88 $=$ suaveolens.

pubescens, Tréc. 1. c. $90=$ suaveolens.

Roxburghii, Tréc. 1. c. $88=$ suaveolens.

suaveolens, Blume, Bijdr. 483.-Ind. or.; Malaya.

subtrinervius, Miq. Fl. Ind. Bat. Suppl. 417.Malaya.

CONOCLINIUM, DC. Prod. v. $135(1836)=$ Eupa

torium, Tourn. (Compos.)

acuminatum, Sch, Bip. ex Baker, in Mart. Fl. Bras, vi. II. $361=\mathrm{E}$, organense.

adenolepis, Sch. Bip. ex Baker, 1. $\mathrm{c}_{\mathrm{v}}=\mathrm{E}$. Selloi

affine, Gardn. in Hook. Lond. Journ. Bot. v. (1846) $466=\mathrm{E}$. betonicaeforme.

album, Mart. Del. Sem. Hort. Monac. (1848) 4.Mexic.

ballotaefolium, Sch. Bip. ex Baker, in Mart. Fl. Bras. vi. Ir. $360=$ E. ballotaefolium.

betonicaeforme, DC. Prod. v, $185=\mathrm{E}$. betonicae forme.

betonicum, DC. Prod, v, $135=$ E. betonicum

cerasifolium, Scb. Bip, ex Baker, in Mart. Fl. Bras, vi. II. $308=\mathrm{E}$. cerasifolium

coelestinum, DC. Prod. v. $135=\mathrm{E}$. coelestinum.

dichotomum, Chapm. in Coult. Bot. Gaz. iii. (1878) 5 $=\mathrm{E}$. coelestinum.

dissectum, A. Gray, Pl. Wright, i. $88=$ E. Greggii.

hirsutissimum, Sch. Bip. ex Baker, in Mart. Fl. Bras, vi. II. $311=\mathrm{E}$. hirsutissimum.

humile, Benth. P1. Hartw. 199.-N. Granat.

ianthinum, Morr. in Ann. Soc. Gand, v. (1849) 173 $=\mathrm{E}$. ianthinum.

Lasseauxii, Dur. Ind. Sem. Hort. Burdig. (1872) 15.Uruguay.

maritimum, Sch. Bip. ex Baker, in Mart. Fl. Bras. vi. II. $362=\mathrm{E}$. apiculatum.

microcephalum, Sch. Bip. ex Baker, 1. c. $364=\mathrm{E}$, Candolleanum

microphyllum, DC. Prod, v. $135=$ E. microphyllum. mikanioides, Sch. Bip. ex Baker, in Mart. Fl, Bras, vi II. $306=$ E. sordescens.

oligolepis, Kunze, Del. Sem. Hort. Lips. (1840) iv. $2=$ E. oligolepis.

organense, Sch. Bip. ex Baker, in Mart. Fl. Bras, vi. 11. $361=\mathrm{E}$. organense.

palustre, Sch. Bip. ex Baker, 1. c, $363=\mathrm{E}$. palustre

platylepis, Sch. Bip. ex Baker, 1. e. $355=$ E. platylepis.

prasiffolium, DC. in Deless. Ic. Sel. iv. t. $15=\mathrm{E}$. nepetoides.

resinosum, Sch, Bip, ex Baker, in Mart. Fl. Bras. vi, Ir. $306=\mathrm{E}$, sordescens.

rigidum, Chapm, in Coult. Bot. Gaz, iii. (1878) $6=$ E. heteroclinum.

rugosum, Turcz. in Bull. Soc. Nat. Mosc. xxiv. (1851) I. 168, - Ecuador.

scandens, Gardn. in Hook. Lond. Journ. Bot. vi. (1847) 437-Bras.

semistriatum, Sch. Bip, ex Baker, in Mart. Fl. Bras. vi. II. $318=\mathrm{E}$. semistriatum.

subglutinosum, A. Gray, in Proc. Am. Acad. v. (1861) 115 ; Sch. Bip. ex Baker, 1. c. $362=$ E. apicu latum.

subviscosum, Baker, l. c., sphalm. =E. apiculatum.

Vindex, Sch. Bip. ex Baker, in Mart. Fl. Bras. vi. II $312=\mathrm{E}$. Vindex.

CONOHORIA, Aubl. Pl. Gui. i. 239. t. $95(1775)=$ Alsodeia, Thou. (Violar.)

alternifolia. Spreng. Neue Eintdeck, ii. $151=\mathrm{A}$ intecrifolia.

Aubletii, D. Dietr. Syn. Pl. i. $831=$ Casearia dentata.

castaneaefolia, St. Hil. in Mém. Mus. Par. xi. (1824) $495=$ A. guianensis
CONOHORTA :-

Cuspa, H. B. \& K. Nov. Gen. et Sp. vii. $242=$ Alsodeia Cuspa.

dentata, D. Dietr. Syn. Pl. i. $831=$ A. guianensis.

flavescens, Aubl. P1. Gui. i. $239=$ A. flavescens.

Loboloba, St. Hil, in Mém. Mus. Par. xi. (1824) $494=$

A. physiphora

megapotamica, G. Don, Gen. Syst. i. $341=$ A. megapo tamica.

owariensis, D. Dietr. Syn. PI. i. $831=$ A. owariensis.

Passoura, DC. Prod. i. $312=$ A. flayescens.

Perrini, D. Dietr. Syn. Pl. i. $832=$ A. Perrini.

Regnellii, Miq. in Linnaea, xxii. (1849) 555.-Bras.

Riana, DC. Prod. i. $312=$ A. prunifolia

Rinorea, St. Hil. Pl. Rem. $321=$ A. paniculata

ulmifolia, H. B. \& K. Nov. Gen. et Sp. v. 387 . t. 491

$=$ A. ulmifolia.

CONOMITRA, Fenzl, in Endl. Nov. Stirp. Dec. 65 $(1839)=$ Glossonema, Decne. (Asclepiad.).

linearis, Fenzl, 1. $\mathrm{c}_{\mathrm{o}}=\mathrm{G}$. lineare.

CONOMORPHA, A. DC in Trans. Linn. Soc, xvii (1834) 102. MYRSINEAE Benth \& Hook f ii. 644.

Conostylus, Pohl, ex A. DC. 1. c. (1834).

bumelioides, Griseb. Cat. Pl. Cub. 163.-Cuba.

guianensis, A. DC, in Ann. Sc. Nat. Sér. II. xvi.

(1841) $92=$ Cybianthus guyanensis.

heterantha, Benth. ex Miq. in Mart. Fl. Bras. x. 304 -Bras.

jacquinioides, Griseb. Cat. Pl. Cub. 163.-Cuba

laxiflora, DC. in Trans. Linn. Soc. xvii. (1837) 103:Bras.

macrophylla, Mart. Herb. Fl. Bras. n. 260.-Bras. multipunctata, Miq. Stirp. Surin. Sel. 111. t. 34.Guiana.

nemoralis, Mart. E Miq. in Mart. Fl. Bras. x. 304.Bras.

oblongifolia, A. DC. in Trans. Linn. Soc. xvii. (1837) 103.-Bras.

peruviana, A. DC. in Ann. Sc. Nat. Sér. II. xvi. (1841) 92.-Perav.

reticulata, Benth. ex Miq. in Mart. Fl. Bras. x. 303.Bras.

robusta, Klotzsch, in Faun. \& Fl. Gui. 974.Guiana.

CONOPHALLUS, Schott, Syn. Aroid. 34 (1856) = Amorphophallus, Blume (Aroid.)

Blumei, Schott, in Ann. Mus. Bot. Lugd. Bat. i. 124.Java.

bulbifer, Schott, Syn. Aroid, $34=\mathrm{A}$ : bulbifer.

commutatus, Schott, in Bonplandia, vii. (1859) $28=$

A. commutatus

giganteus, Schott, ex Miq. Fl. Ind. Bat. iii. $198=$ A giganteus.

Gigas, Miq. Ann. Mus. Bot. Lugd. Bat. i. $285=$ A. Gigas

Konjak, Schott, Syn. Aroid, $34=$ A. Rivieri

Zyratus, Schott, 1. c. $85=$ A. lyratus

Muelleri, Miq. Ann. Mus. Bot. Lugd. Bat. 286, in obs. A. Mulleri.

planus, Miq. 1. c. $286=\mathrm{A}$. planus.

punctulatus, Schott, Prod. Aroid. $35=$ A. punctulatus.

sativus, Schott, 1. $c_{0}=$ A. sativus,

spectabilis, Miq. Fl. Ind. Bat. iii. $199=$ A; spectabilis.

Titanum, Becc. in Bull. Soc. Tosc. Ortic. iii. (1878) $271,291=$ A. Titanum

tuberculiger, Scbott, in Bonplandia, vii, (1859) $28=A$ tuberculiger.

CONOPHARYNGIA, G. Don, Gen. Syst. iv. 94 (1837 Plumeria, Tourn. (Apocyn.)

longifolia, G. Don, 1. c. $95=$ P. longifolia.

retusa, $\mathrm{G}$. Don, $\mathrm{l} . \mathrm{c}_{\mathrm{r}}=\mathrm{P}$. retusa.

CONOPHOLIS, Wallr. Orob, Diask, 78 (1825) OROBANCHACEAE, Benth. \& Hook. fo ii. 985. americana, Wallr. l. c.-Am. bor. americana, Endl. Iconogg. t. 81 - mexicana. mexicana, A. Gray, ex S. Wals. in Proc. Am. Acad. xviii. (1882-98) 181.-N. Mexic.

CONOPHYTA, Schnm. ex Hook. fo in Trans. Linn. Sos xxii. (1856) 42 -Thonningia, Vahl (Balanoph.).
CONOPODIUM, Koch, in Noy, Act. Nat, Cur, xii. (1824) 118. UMBELLIFERAE, Benth. \& Hook. f. i. 896 .

Bulbocastanum, Lag. Amen. Acad. Madr. 99 (1821)

Butinia, Boiss. Elench. 53 (1838)

Finaesticta, Fenzl, in Flora, xxyi, (1843) 458.

Heterotaenia, Boiss. Voy. Bot. Estogne, 267. $80 \mathrm{~A}(1840)$

SCAligeria, DC. Prod. iv. 248 (1830)

Sphallerocarpus, Bess. in DC. Prod. iv. 230 (1830)

allioides, Regel EO Schmalh. in Act. Hort. Petrop. $\mathrm{y}$ (1877) 588. - Turkestan.

boetica, Boiss. Voy. Bot. Espagne, ii. 738.-Hispan.

Bourgaei, Coss. Notes Crit. 110.-Hispan.

brachycarpum, Boiss: ex Lange, in Kjoeb. Vidensk. Meddel. (1865) 44.--Hispan.

butinoides, Boiss. E Reut. ex Boiss. Voy. Bot. Espagne, ii. 736.-Hispan.

canadense, Koch, in Nov. Act. Nat. Cur: xii. (1824) $119=$ Cryptotaenia canadensis.

capillifolinm, Boiss. Voy. Bot. Espagne, ii. 736.Lusitan.

Cyminum, Benth. E Hook. f. Gen. i. 896.-Dahuria ; Volh.

denudatum, Koch, in Nov. Act. Nat. Cur. xii. (1824 118.-Europ.

hirtulum, Regel \& Schmalh. in Pl. Nov. Fedsch. 28.As. centr.

Marianum, Lange, in Kjoeb. Vidensk. Meddel. (187778) 232.-Hispan.

mutabile, Miégev, in Bull Soc Bot Fr xxi. (1875) p. $x x x i i=$ denudatum.

pumilum, Nym. Consp. $303=$ Bourgaei

pyrenaicum, Miégev, in Bull. Soc. Bot. Fr. xxi. (1874) p. $x \times x i i=$ denudatum

ramosum, Costa, Fl. Catal. 105.-Hispan.

subcarneum, Boiss. E" Reut. ex Boiss. Voy. Bot Espagne, ii. 736.-Hispan.

subcarneum, Bourg. in Bull. Soc. Bot. Fr. ii. (1855 643 = Bourgaei.

CONOPSIDIUM, Wallr, in Limnaea, xiv. (1810) $14 \tilde{\tau}=$

Habenaria, Willd. (Orchid.

platantherum, Wallr, I, $\mathrm{c}_{-}=\mathrm{H}$, bifolia.

sthenantherum, Wallr. 1. $c=\mathrm{H}$. bifolia.

CONORIA, Juss. Gen. $287(1789)=$ Alsodeia, Thou. (Violar.).

CONOSAPIUM, Muell. Arg. in Linnaea, xxxii. (1863; 87 = Sapium, P. Br. (Euphorb.).

madagascariensis, Muell. Arg. 1. c.-Madag.

CONOSILENE, Fourr. in Ann. Soc. Linn. Lyon, N. S. xvi. (1868) 344 = Silene, Linn. (Caryophyll.)

conica, Fours. 1: c. $=\mathrm{S}$, conica.

conoidea, Fourr. I. c. $=$ S, conoidea.

CONOSIPHON, Poepp, \& Endl. Nor. Gen et Sp, iii $27(1842)$; Endl. Gen. Pl. Suppl, ii. $54\left(1 \times 4^{\circ}=\right.$ Sphinctanthus, Benth. (Rubiac.)

aureus, Poepp. \& Endl. 1. c. =S. rupestris.

polycarpus, Karst. in Linnaea, rex. (1859-60) 155.N. Granat.

strifflorus, Walp. Rep. ii, 520=S. rupestris.

CONOSPERMUM, Sm, in Tians, Linn. Soc, iv. (1798) 213. PROTEACEAE, Benth \& Hook. r. iii. 174 .

acerosum, Lindl. Swan River App. S0, -A Astral. acinacifolium, R. Grah. in Edinb. N. Phil. Gourn. Apr.July, 1826) 171.-Austral.

affine, Roent \&o Schult. Sust, iii. Bfane 2att-Austral. amoenum, Meissn. in Lchm. Pl. Priss. i. 522.Austral.

brachyphyllum, Lirdl. Swan River Aps. \$1.-Austral. bracteosum. Meissn. in Lehm. Pl. Proiss. i. 31S; ij. 248.-Austral.

Browiii, Meissm. I c ii. 248. Austral.

conaliculatum. Meissn. I. c. $250-$ Sincchadis

capitatum, R. Br. in Trons. Linn. Sor, x。 (1sil) 155. -Austrin.

coerulescens, F. Mfucll. Fragm. i. 15i amoenum. cocruleum, R. Br. in Trans. Livn. Sor. x. 1811 15t. Auseral.

commutatum, Roem. G Sohmll. Syst. iii. Mand. 273. Austral. 


\section{CONOSPERMUM .}

rassinervium, Meissn. in Hook, Kew Fourn. iv 1852) 184.-Austral.

Dallachyi, F. Muell. Ann. Rep. (1858) fide Benth. F1 Austral. v. $371=$ Mitchellii.

debile, Kipp. ex Meissn. in Hook. Kew Fourn. vii. (1855) 70.-Austral.

densiflorum, Lindl. Swan River App. 32.-Austral.

diffusum, Benth. Fl. Austral. v. 367.-Anstral.

distichum, Meissn. in Lehm. Pl. Preiss. i. $522=$ floribundum.

distichum, R. Br. in Trans. Linn. Soc. x. (1811) 155. -Austral.

ellipticum, Sm. in Rees, Cycl. ix. n. 2.-Austral.

ephedroides, Kipp. ex Meissn. in Hook. Kew Fourn. vii. (1855) 70.-Austral.

erectum, Hort. ex R. Grah. in Edinb. N. Phil. Journ. (Apr.-June 1828) $172=$ ericifolium.

ericifolium, $S m$. in Rees, Cycl. ix. 0. 4.-Austral

falcifolium, [Salisb. in] Knight, Prot, $95=$ taxifolium.

filifolium, Meissn. in Lehm. P1. Preiss, i. $523=$ brachyphyllum.

flexuosum, R. Br. Prod. Suppl. 11.-Austral

floribundum, Benth. Fl. Austral. v. 373.-Austral

glumaceum, Lindl. Swan River App. 30.-Austral

Huegelii, R. Br, ex Endl. Nov. Stirp. Dec. 58.Austral.

imbricatum, Sieber, ex Spreng. Syst. iv. Cur. Post. 46. -Austral.

incurvum, Lindl. Swan River App. 30.-Austral.

intricatum, Lindl. ex Meissn. in DC. Prod. xiv. $323=$ Huegelii.

lanceolatum, R.Br. Prod. Suppl. 10.-Austral

laniflorum, Endl. in Ann. Wien. Mus. ii. (1838) 208 -Austral.

lavandulaefolium, A. Cunn. ex Meissn. in DC. Prod. xiv. 319 ,-Austral

linifolium, A. Cunn.l.c. 320.-Austral.

longifolium, Sm. Exot. Bot. ii. 45. t. 82.-Austral

lupulinum, Endl. ex Meissn, in Lehm. Pl. Preiss. ii. 249 = glumaceum

marginatum, Meissn. l. c. 248.-Austral.

Mitchellii, Meissn. in DC. Prod. xiv. 320.-Austral.

nervosum, Meissn. in Hook. Kew fourn. vii. (1855) 71.-Austral.

patens, Schlecht. in Linnaea, xx. (1847) 587.-Austral petiolare, R. Br. Prod. Suppl. 11.-Austral.

polycephalum, Meissn. in Lehm. Pl. Preiss. ii. 249.Austral.

procerum, F. Muell. Fragm. i. 157=distichum. propinquum, R. Br. Prod. Suppl. $10=$ taxifolium.

repens, Sieber, ex Roem. \& Schult. Syst. iii. Mant. 276 = tenuifolium.

reticulatum, S.m. in Rees, Cycl. ix. n. $5=$ Synaphea petiolaris.

rigidum, [Salisb. in] Knight, Prot. $95=$ ellipticum

scaposum, Benth. Fl. Austral. y. 369.-Austral.

sclerophyllum, Lindl. Swan River App. 30.-Austral.

Smithii, Pers. Syn. i. $113=$ longifolium.

sphacelatum, Hook. in Mitch. Trop. Austral. 342. -Austral.

spicatum, R. Br. Prod. Suppl. $10=$ taxifolium.

Stoechadis, Endl. in Ann. Wien. Mus, ii. (1838) 208 -Anstral.

taxifolium, Sieber, ex Roem. \& Schult. Syst. iii. Mant. $274=$ affine

taxifolium, Sm. in Rees, Cycl. ix. n. 3.-Austral.

tenuifolium, R. Br. in Trans. Linn. Soc. x. (1811) 154 - Austral.

tenuifolium, Sieber, ex Roem. \& Schult Syst. iii Mant. $275=$ commutatum

teretifolium, R. Br. in Trans. Linn. Soc. x. (1811) 155. -Austral.

Toddii, F. Muell. Fragm. x. 20.-Austral

triplinervium, R. Br. Prod. Suppl. 11-Austral.

undulatum, Lindl. Swan River App. 31.-Austral.

CONOSTEGIA, D. Don, in Mem. Wern. Soc. iv. (1823) 316. MELASTOMACEAE, Benth. \& Hook. f. i. 763 .

Bruguiera, Rich. ex DC. Prod. iii, 173, in syn. (1828)

Calycotomus, Rich. ex DC. 1. c. (1828).

Synodon, Rafin. Sylva Tellur. 95 (1838).

acuminata, Steud. in Flora, xxvii. (1844) $722=$

Miconia axilliflora.

acutidentata, A. Rich. Ess. Fl. Cub. $558=$ xalapensis.

alpina, Macf. Fl. Jamaic. ii. $72=$ montana.

\section{CONOSTEGIA}

alternifolia, Macf. Fl. Jamaic, ii. $\mathbf{7 1}$ = superba.

arborea, Steud. Nom. ed. II. i. 405 ; Schau. in Linnaea, xx. (1847) 733.-Mexic.

attenuata, Triana, in Trans. Linn. Soc. xxviii. (1871 98.- N. Granat.

Balbisiana, Ser. ex DC. Prod. iii. 174=procera

bracteala, Triana, in fourn. Bot, v. (1867) 209.-

Nicaragua.

calyptrata, D. Don, in Mem. Wern. Soc. iv. (1823) 317. -Ind. occ.

clidemioides, Wright, ex Griseb. Cat. Pl. Cub. 98.Cuba.

cornifolia, Ser. ex DC. Prod. iii. $175=$ Miconia cinnamomifolia.

cucullata, D. Don, in Mem. Wern. Soc. iv. (1823) 317 = Calyptrella cucullata.

dentata, Triana, in Trans. Linn. Soc, xxviii. (1871) 99. -N. Granat.

discolor, DC. Prod. iii. $174=$ Charianthus coccineus.

extinctoria, D. Don, in Mem. Wern. Soc. iv. (1823) 317.-N. Granat.

formosa, Macf. F1. Jamaic. ii. $70=$ rufescens

Galeottii, Naud. in Ann. Sc. Nat. Sér. III. xvi. (1851) $107=$ arborea

glabra, D. Don, in Mem. Wern. Soc. iv, (1823) $317=$ Astronia Forsteri.

gloriosa, Macf. Fl. Jamaic. ii. $68=$ procera.

holosericea, D. Don, in Mem. Wern. Soc. iv。 (1823) $317=$ xalapensis

lasiopoda, Benth. Bot. Voy. Sulph. 96.-N. Granat.

lutescens, Ser. ex DC. Prod. iii. $175=$ Miconia cinnamomifolia.

macrantha, O. Berg, ex Triana, in Trans. Linn. Soc xxviii. (1871) 97.-Costa Rica.

macrophylla, Naud. in Ann. Sc. Nat. Sér. III. xvi. (1851) 112 = superba.

mexicana, Ser. ex DC. Prod. iii. $175=$ Miconia mexicana.

montana, D. Don, in Mem. Wern. Soc. iv. (1823) 317 - Jamaic.

Mutisii, Ser. ex DC. Prod. iii. $174=$ Centronia Mutisii.

myriasporoides, Triana, in Trans. Linn. Soc. xxviii. (1871) $99 .-\mathrm{N}$. Granat.

Oerstediana, O. Berg, ex Triana, l. c. 98.-Costa Rica.

parviflora, $D C$. Prod. iii. 175.-Ins. S. Doming.

polyandra, Benth. Bot. Voy. Sulph. 96. t. 35.-N.

Granat.

procera, D. Don, in Mem. Wern. Soc. iv. (1823) 317. -Jamaic.

pulverulenta, Naud. in Ann. Sc. Nat. Sér. III. xvi. (1851) $110=$ extinctoria

purpurea, Griseb. in Bonplandia, vi. (1858) 6.Panama.

quadrangularis, Schlecht. ex Steud. Nom. ed. II. i. 405.-Mexic.

rufescens, Naud. in Ann. Sc. Nat. Sér. III. xvi. (1851) 107.-Ind, occ.

semicrenata, Ser. ex DC. Prod. iii. $175=$ Miconia semicrenata.

setosa, Triana, in Trans. Linn. Soc, xxviii. (1871) 99 -N. Granat.

speciosa, Naud. in Ann. Sc. Nat. Sér. III. xvi. (1851) 109.-Panama.

sphaerica, Triana, in Trans. Linn. Soc. xxviii. (1871)

98.-Mexic.

subcrustulata, Triana, $1 . c_{.}=$purpurea.

subhirsuta, $D C$. Prod. iii. 174.-Cuba.

superba, D. Don, in Mem. Wern. Soc.iv. (1823) 317.Am. austr.

tunicata, Ser. ex DC. Prod. iii. $175=$ Miconia tunicata.

xalapensis, D. Don, in Mem. Wern. Soc. iv. (1823) 317.-Mexic.

CONOSTEMUM, Kunth, Enum. Pl. ii. 557 (1837) sphalm. = COMOSTEMUM, Nees = Androtri chum, Brongn. (Cyperac.).

CONOSTEPHIOPSIS, Stschegl. in Bull. Soc. Nat. Mosc. xxxii. (1859) r. $5=$ Conostephium, Benth. (Epacrid.).

Drummondi, Stschegl. 1. c. $6=$ Conostephium plani folium.

minor, Stschegl. 1. c. = Conostephium minus.

Preissii, Stschegl. 1. c. = Conostephium Preissii
CONOSTEPHIUM, Benth in Enum. Pl. Hueg. 76

(1837). EPACRIDEAE, Benth. \& Hook, f. ii. 611

ConosTePHIOPSIS, Stschegl. in Bull. Soc. Nat. Mosc.
Col. xxxii. (1859) I. 5.

minus, Lindl. Swan River App. 25.-Austral.

nitens, Lindl. ex Sond. in Lehm. Pl. Preiss. 1. 303.Austral.

pendulum, Benth. in Enum. Pl. Hueg. 76.-Austral

pendulum, Deless. Ic. Sel. $\nabla . t .23=$ minus.

planifolium, F. Muell. Fragm. vi. 30.-Austral.

Preissii, Sond. in Lehm. Pl. Preiss. i. 304.-Austral.

Roei, Benth. Fil. Austral. iv. 160.-Austral.

CONOSTYLIS, R. Br. Prod. 300 (1810).

DORACEAE, Benth. \& Hook. f. iii. 676.

ANDROSTEMMA, Lindl. Swan River

aemula, Lindl. Swan River App. $45=$ setigera

albicans, A. Cunn. ex Benth. Fl. Austral. vi. $436=$ candicans.

americana, Pursh, Fl. Am. Sept. i. 224. t. $6=$ Lophiola aurea.

androstemma, F. Muell. Fragm. viii, 19.-Austral

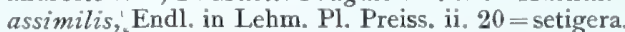

aurea, Lindl. Swan River App. 44.-Austral

Bealiana, F. Muell. Fragm. ix. 50.-Austral

bracteata, Endl. in Lehm. Pl. Preiss. ii. 16.Austral.

bracteata, Lindl. Swan River App. $45=$ dealbata

breviscapa, R. Br. Prod. 301.-Austral.

bromelioides, Endl. in Lehm. Pl. Preiss. ii. 18.Austral.

candicans, Endl. Nov. Stirp. Dec. 20.-Austral.

canescens, F. Muell. Fragm. viii. $19 \equiv$ Blancoa canescens.

caricina, Lindl. Swan River App. 45.-Austral.

cymosa, F. Muell. ex Benth. Fl. Austral. vi. 439.Austral.

dealbata, Lindl. Swan River App. 45.-Anstral.

discolor, Endl. in Lehm. Pl. Preiss. ii. $20=$ setigera.

Drummondi, Benth. Fl. Austral. vi. 433-Austral.

ensifolia, Endl, in Lehm. Pl. Preiss. ii. $21=$ serrulata

festucacea, Endl. 1. c. $18=$ Preissii.

filifolia, F. Muell. Fragm. viii. 18.-Austral.

gladiata, Benth. Fl. Austral. vi. 434.-Austral.

graminea, Endl. in Lehm. Pl. Preiss. ii. 19= caricina.

involucrata, Endl. l. c. ii. 23.-Austral.

juncea, Endl. Nov. Stirp. Dec. 19.-Austral.

juncea, Lindl. Bot. Reg. (1839) Misc. 54.-Austral.

laxiflora, Benth. Fl. Austral. vi. 439.-Austral.

longifolia, Endl. in Lehm. P1. Preiss. ii. $22=$ serrulata.

melanopogon, Endl. l. c. ii. 18.--Austral

minima, End1. 1. c. ii. $21=$ C. Psyllium.

misera, Endl. 1. c. $22=$ serrulata

occulta, Endl. 1. c. = serrulata.

petrophiloides, F. Muell. ex Benth. Fl. Austral. vi 431. - Austral.

Preissii, Endl. in Lehm. Pl. Preiss, ii. 18.-Austral prolifera, Benth. Fl. Austral. vi. 436.-Austral, propinqua, Endl. in Lehm. Pl. Preiss. ii. $17=\mathrm{can}$ dicans.

Psyllium, Endl. l. c. 21.-Austral.

pusilla, Endl. 1. c. $20=$ psyllium.

racemosa, Benth. Fl. Austral. vi. 436.-Austral.

scorsiflora, F. Muell. Fragm. i. 158.-Austral.

serrulata, R. Br. Prod. 300.-Austral.

setigera, R. Br. l.c.-Austral.

setosa, Lindl. Swan River App. 44. t. 6 A-Austral.

spathacea, Endl. in Lehm. Pl. Preiss. ii. $22=$ serrulata.

spinuligera, $F$. Muell. ex Benth. Fl. Austral. vi. 438.Austral.

stylidioides, F. Muell. Fragm. viii. 17.-Austral.

sulphurea, Endl. in Lehm. Pl. Preiss. ii. $17=$ aurea.

teretiuscula, F. Muell. Fragm. viii. 18.-Austral.

vaginata, Endl. in Lehm. Pl. Preiss, ii. 23.-Austral

villosa, Benth. Fl. Austral. vi. 433.-Austral.

CONOSTyLUS, Pohl, ex A. DC. in Trans. Linn. Soc. xvii. (1834) $102=$ Conomorpha, A. DC (Myrsin.). oblongifolius, Pohl, ex A. DC. 1. c. $103=$ Conom. ob longifolia.

CONOTHAMNUS, Lindl. Swan River App. 9 (1839). MYRTACEAE, Benth. \& Hook. f. i. 705. divaricatus, Benth. Fl. Austral. iii. 164.-Anstral. trinervis, Lindl. Swan River App.9.-Austral. 
CONOTRICHIA, A Rich in Mém. Soc Hist. Nat. Par. (1830) 277.t. 24. f. $1=$ Manettia, Mutis (Rubiac.). alba, A. Rich. I. c. = M. picta.

CONRADIA, Mart. Nov. Gen. et Sp. iii. $38(1829)=$ Pentarhaphia, Lindl. (Gesnerac.)

calycina, Mart. 1. c. $38=$ P. calycina.

calycina, Mart. . c. $38=\mathrm{P}$. calycina.
calycosa, Hook. Ic. Pl, t. $689-690=\mathrm{P}$. calycosa

cassioides, Benth. in DC. Prod. x. 511, lapsu, in syn. Seymeria tenuifolia.

celsoides, Griseb. Cat. Pl. Cub. 200.-Cuba.

clandestina, Griseb. F1. Brit. W. Ind. 461.--Jamaica.

corrugata, Griseb. in Mem. Am. Acad. N. S. viii. (1863) 526.-Cuba.

Craniolaria, Mart. Nov. Gen. et Sp. iii. $38=$ P. Craniolaria.

cuneifolia, DC. Prod. vii. $526=$ P. cuneifolia.

depressa, Griseb. Cat. Pl. Cub. 200,-Cuba.

exserta, Mart. Nov. Gen. et Sp. iii. $38=$ P. exserta

floribunda, Paxt. Mag. Bot. xv. (1849) $99=$ P. libanensis.

gloxinioides, Griseb. Cat. P1. Cub. 200.-Cuba.

hispida, Benth. Pl. Hartw. $264=$ P. hispida

humilis, Mart. Nov. Gen. et Sp. iii, $38=$ P. humilis.

libanensis, Griseb. F1. Brit. W. Ind. $462=\mathrm{P}$. libanensis.

mimuloides, Griseb. 1. c. 461.-Jamaica.

neglecta, Hook. Ic. Pl. t. $874=$ P. neglecta.

pedunculosa, DC. Prod. vii. $525=\mathrm{P}$. pedunculosa

pumila, Mart. Nov. Gen. et Sp. iii. $38=$ P. pumila

reticulata, Griseb. Cat. Pl. Cub. 201.-Cuba.

scabra, Mart. Nov. Gen. et Sp. iii, $38=$ P. scabra.

Sloanei, DC. Prod. vii. $526=$ P. Sloanei.

ventricosa, Mart. Nov. Gen. et Sp. iii. $38=$ P. longiflora.

verrucosa, Scheidw, in Otto \& Dietr. Allg. Gartenz. $\mathrm{xv} .(1847) 226=\mathrm{P}$. verrucosa.

CONRADIA, Nutt. in Joum. Acad. Philad. vii. (1834) 88. t. $12=$ Macranthera, Torr. (Scrophul.). fuchsioides, Nutt. 1. $\mathrm{c}_{\mathrm{r}}=\mathrm{M}$. fuchsioides.

CONRADIA, Rafin. Neog. 3 (1825) = Tofieldia, Huds (Liliac.).

ConRadina, A. Gray, in Proc. Am. Acad, viii. (1870) 294. LABIATAE, Benth. \& Hook. f. ii. 1191 .

canescens, A. Gray, l. c. 295.-Am. bor.

CONRINGIA, Heist. ex Linn. Syst. ed. I (1735) Link, Enum. Hort. Berol. ii. 172 (1822). CRUCIFERAE, Benth. and Hook. f. i. 78.

Gorinkia, J. \& C. Presl, Fl. Čech, 140 (1819).

alpina, Link, Enum. Hort. Berol. ii. 172.-Europ.

austriaca, Sweet, Hort. Brit. ed. I, 25.-Austria ; Reg. Caucas.

clavata, Boiss. in Ann. Sc. Nat. Sér. II. xvii. (1842) 84.-As. Min.; Syria.

grandifora, Boiss, \& Heldr. Diagn. Ser. I. viii. 25.-As. Min.

nana, Boiss, 1. c. Ser. II. vo $25=$ Malcolmia conringioides.

orientalis, Dum. Fl. Belg. 123.-Europ.; Oriens.

perfoliata, Link, Enum. Hort. Berol. ii. $172=$ orientalis. persica, Boiss. Diagn. Ser. I. vi. 12.-Persia.

planisiliqua, Fisch. E Mey. Ind. Sem. Hort. Petrop. iii. 32. - As. occ.

Thaliana, Reichb. Ic. Fl. Germ. ii, t, 60, fig. 4380 = Sisymbrium Thalianum.

CONSANA, Adans. Fam. ii. $420(1763)=$ Draba, Linn. (Crucif.).

CONSOLEA, Lem. Rev. Hortic. (1862) $174=$ Opuntia Tourn. (Cacteac).

catacantha, Lem. 1. $c_{1}=\mathrm{O}$. catocantha

ferox, Lem. 1. c. $=$ O. ferox.

leucacantha, Lem. 1. c. $=0$. leucacintha

rubescens, Lem. 1. $c_{0}=0$. rubescens.

spinosissima, Lem. 1. c. = O. spinosissima.

CONSOL.IDA, S. F. Gray, Nat. Arr. Brit, Pl. ii, 711 $(1821)=$ Delphinium, Tourn. (Ranunculac.).

Aconiti, Lindl. in Journ. Hort. Soc. vi. (1851) $55=\mathrm{D}$ Aconiti.

Ajacei, Schur, in Verh. Siebenb. Ver. Naturw, iv. (1858) $47=\mathrm{D}$. A jacis.

amensis, Opiz, Seznam, $32=$ D. Consolida.

\section{CONSOLIDA :-}

paniculata, Schur, in Verh. Siebenb. Ver. Naturw. iv. 1853) 47 = Delphinium paniculatum

regalis, S. F. Gray, Nat. Arr. Brit. Pl. ii. $711=0$ Consolida.

segetum, Schur, in Verh. Siebenb. Ver. Naturw, iv

(1853) $47=\mathrm{D}$. Consolida.

CONSOLIDA, Riv. ex Rupp. Fl. Jen. ed. Hall. 8 (1745 =Symphytum, Tourn. (Boragin.)

major, Gilib. Fl. Lituan. i. $24=\mathrm{S}$. officinale.

CONSTANTIA, Rodrig. Orch. Nov. i. 78 (1877) ORCHIDEAE.

rupestris, Rodrig. l.c. 79.-Bras.

CONSUEGRA, Spreng. Neue Entdeck. ii. $303(1821)=$ seq

CONSUEGRIA, Mutis, ex Caldas, in Nuev, Seman. Gran. III. (1810) 22 (Quid?).

CONTARENA, Adans. Fam. ii. $120(1763)=$ Coryma bium, Linn. (Compos.).

CONTARENIA, Vand. Fl. Lusit. et Bras. Spec. 42.t. 8. f 20 (1788) (Gen. delend.). Benth. \& Hook, f. ii. 1137. trinervia, Vand. ex Roem. \& Schult. Syst. iii. 294. Bras.

CONTORTUPLICATA, Medic. in Vorles. Churpf. Phys Ges.ii. (1787) $378=$ Astragalus, Tourn. (Legumin.) astragaloides, Medic. 1. c. $=$ A. contortuplicatus.

CONTRARENIA, Jaume St. Hil. Expos، ii. 346 (1805)= CONTARENIA, Vand.

CONULfUM, A. Rich. in Mém. Soc. Hist. Par. i (1823) 391. t. 25. MONIMIACEAE, Benth. \& Hook. f. iii. 143.

guianensis, A. Rich. l. c.-Guiana.

CONVALLARIA, Linn. Syst, ed. I (1735); Gen ed. I. 96 (1737). LILIACEAE, Benth. \& Hook. f. ii 770 .

Axillaria, Rafin. in Journ. Phys. Ixxxix. (1819) $102,261$.

GLoberia, Rafin. Med. Fl. ii. 84 (1880)

Lilium-Convallium, Tourn. ex Moench, Meth. 636 (1794).

ambigua, Schrank, Baier. Fl. i. $606=$ Polygonatum multiflorum.

angulosa, Lam. F1. Fr. iii. 268=Polygonatum off cinale.

angustifolia, Poir. Encyc. Suppl. v. $737=$ Polygonatum biflorum.

biflora, Walt. Fl. Carol. $122=$ Polygonatum biflorum. bifolia, Linn. Sp. Pl. $316=$ Smilacina bifolia

borealis, Poir. Encyc. Suppl.v. $737=$ Clintonia borealis bracteata, Dulac, Fl. Hautes-Pyr. $135=$ majalis.

bracteata, Thomas, in Gaud. F1. Helv. ii. $531=$ Pol gonatum multiflorum.

Broteri, Guss. Fl. Sic. Syn. i. $416=$ Polygonatum Gussonii.

canadensis, Poir. Encyc. Suppl. iv. $30=$ Smilacina bifolia.

canaliculata, Willd. Enum. Hort. Berol. $45=$ Poly gonatum biflorum.

ciliata, Poir. Encyc. Suppl. iv. $30=$ Smilacina race-

cirrhifolia, Wall. in As. Res. xiii. (1820) $382=$ Poly. gonatum sibiricum.

commutata, Schuit. f. Syst. vii. $1671=$ Polygonatum latifolium.

compressa, Steud. Nom. ed. II. i. 406 Polygonatum japonicum.

cordifolia, Stokes, Bot. Mat. Med. ii. $265=$ Smilacina bifolia.

dichotoma, Thib. ex Pers. Syn. i. $\$ 79=$ Streptopus dis tortus.

diffusa, Vell. F1. Flum. 143 ; iii. ใ. $160=$ Dichorisandra pubescens.

frograns, Salisb. Prod, $254=$ majalis

fruticosa, Linn. Syst. Nat. ed. X. $984=$ Cordyline terminalis.

sigantea, Hort. ex Kunth, Fnam. PI. v. $196=$ Polygonatum latifolium.

glabra, Kit. in Liwnoea, xxxii. (1863) 347 . Lurop.

Govaniana, Wall. Cat. B. 5187 Polygonatum multi. florum.

\section{CONV AITARTA}

graminifolia, Salisb. Prod. $254=$ Ophiopogon ponicus.

hirta, Bosc, ex Poir. Encyc. iv. 369=Polygonatum latifolium.

hybrida, March, in Van Hall, Bijdr. iv. $343=$ Smila. cina stellata.

japonica, Linn. f. Suppl. $204=$ Ophiopogon japonicus Keiskei, Miq. Ann. Mus. Bot. Lugd. Bat. iii. 148. -Japon.

latifolia, Jacq. F1. Austr, iii. 18. t. $232=$ Polygonatuna

latifolia, Lam. ex Steud. Nom. ed. II. i. $406=$ Poly gonatum multiflorum.

latifolia, Mill. Gard. Dict. ed. VIII. n. $2=$ majalis.

latifolia, Savi, Bot. Etrusc. ii. 222 = Polygonatum officinale.

leptophylla, D. Don, Prod. F1. Nep. $47=$ Polygonatum verticillatum.

majalis, Linn. Sp. Pl. 314.-Reg. bor, temp.

Mappii, C. C. Gmel. F1. Bad. ii. $52=$ majalis.

monophylla, Oed. in F1. Dan. t. 291 = Smilacina bifolia multiflora, Linn. Sp.Pl. $315=$ Polygonatum multiflorum obtusifolia, Guenth. ex Steud. Nom. ed. II. i. $406=$ Polygonum officinale.

odorata, Mill. Gard. Dict. ed. VIII. n. 4= Polygonaturn officinale.

oppositifolia, Wall. in As. Res. xiii. (1820) $380=$ Polygonatum oppositifolium.

orientalis, Poir. Encyc. Suppl. iv. $90=$ Polygonatum polyanthemum.

parviflora, Poir. 1. c. $22=$ Polygonatum officinale.

polyanthema, Bieb. Fl. Taur. Cauc. iii. $272=$ Poly gonatum polyanthemum.

Polygonatum, Linn. Sp. PI. 315= Polygonatum off cinale.

Polygonatum, Muhl. Cat. $35=$ Polygonatum latifolium. Polygonatum, Thunb. F1. Jap. 142 = Polygonatum japonicum.

pubescens, Willd. Hort. Berol. i. $45=$ Polygonatum billorum.

pulchella, Salisb. Prod, $255=$ Smilacina bifolia.

punctata, Wall. Cat. D. $5133=$ Polygonatum panc tatum.

quadrifida, Lam. Fl. Fr. iii. $269=$ Smilacina bifolia

racemosa, Forsk. Fl. Aegypt. Arab. $73=$ Smilacina Forskaliana.

racemosa, Linn. Sp. Pl. $315=$ Smilacina racemosa

racemosa, Vell. Fl. Flum. 142; iii. t. $159=$ Dichori sandra Gaudichaudiana.

rosea, Ledeb. Fl. Alt. ii. $41=$ Polygonatum roseum.

rupestris, Salisb. Prod. $254=$ Polygonatum officinale

scaposa, Gilib. Exercit. ii. $460=$ majalis

scepusiensis, Kit. in Linnaea, xxxii. (1863) $347=$ glabra

sibirica, Schult. f. Syst. vii. 1, $297=$ Polygonatom sibiricam.

spicata, Thunb. Fl. Jap. $141=$ Liriope graminifolia.

stellata, Linn. Sp. P1. $316=$ Smilacina stellata

stellifolia, Peterm. in Flora, xxvii. (1844) $\$ 63=$ Polygonatum verticillatum.

tetrapetala, Gilib. Exercit. ii. $461=$ Smilacina bifolia

Thunbergii, Steud. Nom. ed. II. i. $\$ 06=$ Yolygonatum latifolium.

trifolic, Linn. Sp. P1. $316=$ Smilacina trifolia

umbellata, Bunge. ex Baker, in Joarn. Linn. Soc. xiv. (1875) 553 = Polygonatum umbellatum.

umbellulata, Michx. F1. Bor. Am. i. $202=$ Clintonia umbellata.

verticillata, Linn. Sp. Pl. $\$ 15$ Polygonatum rertici? latum.

CONVOLVuloInEs. Monch, Meth. 451 (17:4)

Ipomoea, Linn. (Convolv,

elongata, Moench, 1. c. $152=\mathrm{I}$. sibirica

leucosperma, Moench, $1 . c$. $=$ I. purpurea.

palmata, Moench, 1. c. = I. Pes-tigridis.

pilosa, Moench, I. c = I. pubescens.

purpurea, Moench, I. c. - I. purvurea.

triloba, Moench, 1. $c=\mathrm{I}$, hederacea.

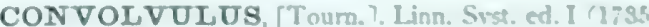

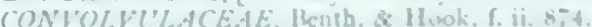

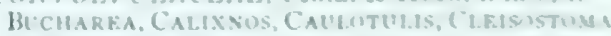

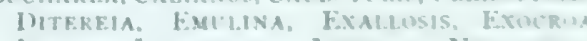

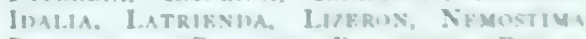

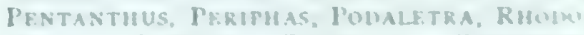

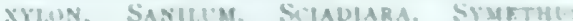
Turetiu, Ratio. Fl. Tellur. 70-si 1596 


\section{CONVOLVULUS:-}

Merremia, Dennst. Schluess. Hort. Malab. 34 (1818).

Pantečsekta, Griseb。 in Oestr. Bot. Zeitschr. (1873) 267 .

RHODORHIZA, Webb, in Bot. Reg. (1841) Misc. 69. StevogTia, Neck. Elem. ii. 23 (1790).

abruptus, Spreng. Syst. i, $596=$ Ipomoea abrupta.

abutiloides, H. B. \& K. Nov. Gen. et Sp. iii. $106=$

Ipomoea abutiloides.

acanthocladus, Boiss.' Kotschy, Diagn. Ser. I. vii. 27. -Persia.

acaulis, Choisy, in . DC. Prod, ix, $406=$ erubescens.

acetosaefolius, Steud. Nom. ed. II. i. $400=$ Ipomoea martinicensis.

acetosaefolius, Turcz. in Bull. Soc. Nat. Mosc。(1840) $73=$ Calystegia hederacea

acetosaefolius, Vahl, Eclog. Am. i. 18=Ipomoea carnosa.

acetosellaefolius, Desr. in Lam. Encyc. iii. $564=$ Ipomoea acetosellaefolia.

acicularis, Vatke, in Linnaea, xliii. (1880-82) 518.Afr. trop.

aculeatus, D. Dietr. Syn. Pl. i. $667=$ Ipomoea Bonanox.

aculeatus, Hill, Veg. Syst. vii. $10(=$ seq. ?), $-\mathrm{Am}$. merid.

culeatus, Linn. Sp. Pl. 155.-Am. trop.

acuminatus, Salzm. ex Meissn. in Mart. Fl. Bras. vii. $267=$ Ipomoea fastigiata.

acuminatus, Vahl, Symb. Bot. iii. $26=$ Ipomoea acuminata.

acutangulus, Spreng. Syst. 1. $605=$ Ipomoea coccinea.

Adansonit, Desr. in Lam. Encyc. iii. $560=$ Ipomoea aquatica.

adpressus, Wall. Cat. n. 1424= Lettsomia adpressa.

adscendens, De Vriese, in Lehm. Pl. Preiss. i. $346=$ erubescens.

adsrendens, Steud. ex Boiss. Fl. Orient. iv. $100=$ reticulatus.

aegyptius, Linn. Syst. ed. X. 923.-Aegypt.

affghanus, Vatke, in Oestr. Bot. Zeitschr. xxy. (1875) 168.-Afghan.

affinis, Scheele, in Linnaea, xxi. (1848) 749.-

Texas.
affinis, C. Sm. ex Steud. Nom. ed. II. i. $407=$ Tuckeyanus.

affinis, Wall. Cat. n. $1385=$ Ipomoea polyantha.

africanus, Nickols, Hort. St. Doming. $260=$ Ipomoea cathartica.

aggregatus, Lour. Fl. Cochinch. 109=Ipomoea aggregata.

aggregatus, Steud. Nom. ed. II. i. $407=$ Lettsomia aggregata.

agrestis, Mart. ex Choisy, in DC. Prod. ix. $405=$ Jacqnemontia agrestis.

agrophilus, C. Koch, in Linnaea, xxii. (1849) $745=$ galaticus.

agrostopolis, Vell. Fl. Flum. 71; ii. t. 51=Breweria Burchellii.

Aitchisoni, C. B. Clarke, in fourn. Linn. Soc. xix. (1882) 179,-Afghan

alatus, Ham. Prod. Fl. Ind. Occ. $24=$ Ipomoea Turpethum.

alatus, Spreng. Syst. i. $596=$ Ipomoea alata.

albicans, Wall. Cat. n. $1401=\mathrm{I}$ pomoea pilosa.

albiflorus, West, Bidr. Ste Croix, $271=$ nodiflorus.

albivenius, Lindl. Bot. Reg. t. $1116=$ Ipomoea albivemia.

albus, [Nocca $]$ Onom. Hort. Ticin. (1813) 19.-Hab. ? alceaefolius, Bory \& Chaub. Fl. Pélop. $14=$ althaeoides. alceaefolius, Lam. Tabl. Encyc, i. 461.-Afr, austr. alsinoides, Linn. Sp. PI. $157=$ Evolvulus alsinoides. althaeoides, Linn. l. c. 156.-Reg. Mediterx.

althaeoides, Tenore, Syll. Fl. Neap. $92=$ tenuissimus.

althaeoides, Thunb, Fl. Cap. ii. $18=$ Thunbergii.

altissimus, Spreng. Syst, i. $613=$ Ipomoea staphylina

amblyocalyx, Steud. Nom. ed. II. i., $407=$ fatmensis.

Ammanniî, Desr. in Lam. Encyc, iii. 549.-Sibir.

ammocharis, Boiss. E Haussk. Pl. Or. Nov. Dec. i. 6. -Persia.

ammophilus, St. Lag. in Ann. Soc. Bot. Lyon, vii (1880) 123 -ammocharis.

amoenus, D. Dietr. Syn. Pl. i. $670=$ Ipomoea amoena.

amoenus, C. Koch, in Linnaea, xix. (1846) $19=$ hirsutus.

ampelopsifolius, Cham. \& Schlecht. 1. c. v. (1830) $118=$ Ipomoea quinquefolia.

\section{CONVOLVULUS :-}

ampliatus, Herb. Brit. Mus. ex Choisy, in DC. Prod. ix. $361=$ Ipomoea ampliata.

amplus, Wall. Cat. n. 1420=Argyreia Roxburghii. ampullaceus, Vahl, ex Choisy, Conv. Or. $61=$ Lepi stemon Wallichii

anceps, Linn. Mant. i. $43=$ Tpomoea Turpethom. andinus, Phil. in Linnaea, xxxiii. (1864-65) 184.Chili.

angularis, Burm. f. F1. Ind. $46=$ Ipomoea vitifolia angulatus, Buch.-Ham. ex Choisy, Conv. Or. $52=$ Ipomoea coccinea

angulatus, Salzm. ex Choisy, in Mém. Soc. Phys. Genèv. ix. (1837) 137 = Ipomoea bahiensis.

angulatus, Spreng. Syst. i. $594=$ Ipomoea angulata.

angustifolius, Desr. in Lam. Encyc. iii. $547=$ Ipomoea angustifolia.

angustissimus, R. Br. Prod. 482=erubescens.

aphyllus, Viv. Ann. Bot. i. $95=$ Ipomoea pentaphylla.

apocynoides, Cham. \& Schlecht. in Linnaea, v. (1830)

$117=$ Jacquemontia hirsuta.

aquaticus, Walt. Fl Carol: $94=$ Breweria aquatica.

arborescens, Humb. \& Bonpl. ex Willd. Enum. Hort.

Berol. 204 = Ipomoea arborescens.

arboreus, Balb. ex Steud. Nom. ed. II. i. $407=$ praec.

arcuatus, Presl, Fl. Sic. p. xxxiii = pentapetaloides.

arenarius, Vahl, Symb. Bot. i. $18=$ Ipomoea carnosa

argenteus, Heyne, ex Wall. Cat. n. 1394=Argyreia fulgens.

argenteus, Lam. Fl. Fr. ii. 266 ; Desr. in Lam. Encyc. iii. $552=$ C. Cneornm

argenteus, Pourr. in Mém. Acad. Toul. iii. (1788) 316 $=$ lanuginosus.

argenteus, Wall. Cat. n. 1364= Argyreia argentea argyraeus, DC. Fl. Fr. Suppl. $423=$ althaeoides. argyrophyllus, Hoffmgg. Verz. Pfl. $53=$ althaeoides argyrophyllus, Wall. Cat. n. $1395=$ Argyreia lanceolata.

aristolochiaefolius, H. B. \& K. Nov。 Gen. et Sp. iii. $102=$ Ipomoea aristolochiaefolia

aristolochiaefolius, Mill. Gard. Dict. ed. VIII. n. $9=$ Ipomoea umbellata.

aristolochiaefolius, Willd, ex Roem. \& Schult. Syst. iv. $302=$ Humboldtianus

armatus, Delile, Fl. Egypte, 189. t. $18=$ C. Hystrix . armenus, Boiss. E' Kotschy, ex Boiss. Fl. Orient. iv, 105. -Armenia; Syria.

arvensis, Linn. Sp. Pl. 153.-Geront. temp.

asarifolius, Desr. in Lam. Encyc. iii. $562=$ Ipomoea asarifolia.

asarifolius, Salisb. Prod, $125=$ Calystegia Soldanella ascendens, Steud, ex Choisy, in DC. Prod. ix. 400 reticulatus.

ascendens, Walp. Rep. vi. $540=$ erubescens.

asclepiadeus, Wall. Cat. n. $1396=$ parviflorus.

asper, Wall. 1. c. n. 1388 = Ipomoea grandiflora.

assyricus, Griseb. Spicil. Fl. Rumel. ii. 75, in nota.-

As. Min. ; Mesopotam.

asyrensis, Kotschy, in Sitzb. Acad. Wien, Math. Nat. lii. Abth. I. (1866) 260 -Oriens.

atriplicifolius, Poir. Encyc. Suppl. 1ii. $467=$ hirsutus.

atropurpureus, Wall. in Roxb. Fl. Ind. ed. Carey, ii. $54=$ Lettsomia atropurpurea.

attenuatus, Mart. \& Gal. in Bull. Acad. Brux, xii. IL. (1845) 261.--Mexic

aturensis, H. B. \& K. Nov. Gen. et Sp. iii. $96=$ Ipomoea aturensis.

Aucheri, Choisy, in DC. Prod. ix. 402.-Syria.

aureus, D. Dietr. Syn. PI. i. $672=$ Jacquemontia hirsuta. aureus, Thunb. Mus. Nat. Ups. 168,-Hab.?

auriculatus, Desr. in Lam. Encyc. iii. $540=$ arvensis. auritus, Willd. ex Roem. E' Schult. Syst. iv. 301.Ins. Porto Rico.

agureus, Desr. in Lam. Encyc. iii. 554 ; Rich. in Act. Soc. Hist. Nat. Par。 i. (1792) $107=$ Jacquemontia hirsuta.

babylonicus, Tenore, Ind, Sem. Hort. Nap. (1829) 16. -'Afr.'

bahiensis, Spreng. Syst. i. $598=$ Ipomoea bahiensis. barbarus, Pomel, Nouv. Mat. Fl. Att. 294.-Afr. bor. barbatus, Wall. Cat. n. 1391 ; Pl. As. Rar. ii. 45. $155=$ Let tsomia barbata.

barbiger, Wall. Cat. n. $1404=$ Lettsomia barbigera. barlerioides, Buch.-Ham. ex Wall. 1. c. n. $2256=$ Ipomoea barlerioides.

Batata, Vell. Fl. Flum. 73 ; ii, t. $59(=$ seq. ?).-Bras.

Batatas, Linn. Sp. P1. 154; Amoen. Acad. vi. $121=$ Ipomoea Batatas.

\section{CONVOLVULUS:-}

batataefolius, Boiss. \& Haussk. ex Boíss. Fl. Orient. iv. $106=$ armenus.

Batatilla, H. B. \& K. Nov. Gen. et Sp. iii. $106=$ Ipomoea Batatilla.

bauhiniaefolius, Salisb. Prod. 125=Ipomoea Pescaprae.

Beladambu, Spreng. Syst. i. $608=$ Ipomoea Beladamboe, bellus, Spreng. 1. c. $590=$ Ipomoea palmata

benehoavensis, C. Bolle, in Bonplandia, ix. (1861) 54. -Ins. Canar.

Benthami, Wall. Cat. n. $1393=$ Ipomoea linifolia.

Bentira, Buch.-Ham. ex Wall. 1. c. sub n. $1358=$ Ipomoea martinicensis.

Besseri, Spreng. Syst. i. $610=$ lineatus.

betonicaefolius, Mill. Gard. Dict. ed. VIII. n. $20=$ hirsutus.

bibracteatus, Poepp. ex Meissn. in Mart. Fl. Bras. vii $270=$ Ipomoea luxurians.

bicolor, Desr. in Lam. Encyc. iii. $564=$ Ipomoea pilosa. bicolor, Vahl, Symb. Bot. iii. $25=$ Hewittia bicolor

bicuspidatus, Fisch. ex Link, Enım. Hort. Berol. i. $201=$ arvensis

bidentatus, Bernh. in Flora, xxvii. (1844) II. 829.Afr. austr.

bifidus, Vahl, Symb. Bot. iii. $30=$ Ipomoea cymosa.

bifidus, Vell. F1. Flum. 71 ; ii. t. 52 (=Aniseia Velloziana).-Bras.

biflorus, Forsk. F1. Aegypt. Arab. $203=$ Ipomoea acetosaefolia

biflorus, Georgi, Beschr. Russ. Reich. Nachtr. 261 (quid ?).-Tauria.

biflorus, Linn. Sp. Pl. ed. II. $1668=$ Ipomoea biflora

biglandulosus, Stokes, Bot. Mat. Med. i. $326=$ Ipomoea biloba.

bignonioides, Spreng. Syst. iv. Cur. Post. $60=$ Ipomoea bignonioides.

bilobatus, Roxb. Hort. Beng. 14; Fl. Ind. i. $485=$ Ipomoea biloba.

binectariferus, Wall. in Roxb. Fl. Ind, ed. Carey, ii $47=$ Lepistemon Wallichii.

Blanchetii, Steud. Nom. ed. II. i, $407=$ Jacquemontia Blanchetii.

blandus, Roxb. Hort. Beng. [13]; Fl. Ind, i. $470=$ Ipomoea cymosa.

Blumii, D. Dietr. Syn. Pl. i. $675=$ Ipomoea angustifolia.

Boerhavia, [Spreng.] Böt. Gart. Halle, 28.--Hab.

boerhavioides, Blanco, Fl. Filip. ed. II. $67=$ Breweria valerianoides.

bogotensis, Humb. \& Bonpl. ex Willd. Enum. Hort. Berol. $203=$ Ipomoea bogotensis

Boissieri, Steud. Nom. ed. II. i. $407=$ nitidus,

Bona-nox, Spreng. Syst. i. $600=$ Ipomoea Bona-nox.

bonariensis, Cav. Ic. v. 54. t. $480=$ incanus.

Bonplandianus, Roem. \& Schult. Syst. iv. $884=$ Ipomoea sidaefolia.

Bonplandii, Meissn. in Mart. Fl. Bras. vii. $825=$ praec Bourgaei, C. Bolle, in Bonplandia, ix. (1861) 54.Ins. Teneriffa.

brachyphyllus, Boiss. Diagn. Ser. II. iii. $122=$ scindicus, bracteatus, Bert. \& Balb. ex Choisy, in DC. Prod. ix. $359=$ Ipomoea setifera.

bracteatus, Vahl, Symb. Bot, iii. $25=$ Hewittia bicolor.

brasiliensis, Linn. Sp. Pl. $159=$ Ipomoea Pes-caprae breviacuminatus, Mart. \& Choisy, in DC. Prod, ix $409=$ Jacquemontia racemosa.

breviflorus, Spreng. Syst. i, $606=$ Ipomoea setifera.

brevipes, Pomel, Nouv. Mat. Fl. Att. 86.-Afr. bor.

brevispinus, Jaub. \& Spach, Illustr. iv, 106. t. $369=$ fruticosus.

Brownii, Spreng. Syst. i. $590=$ Ipomoea quinata.

Brownii, Spreng. 1. c. $612=$ Ipomoea heterophylla.

bryoniaefolizs, Reichb. Fl. Germ. Excurs. $348=$ althaeoides.

bryoniaefolius, Salisb. Prod. 125 = Ipomoea Pestigridis.

bryoniaefolius, Sims, Bot. Mag. t. 943.-Reg. Mediterr.

bufalinus, Lour. Fl. Cochinch. $109=$ Ipomoea bufalina.

Burmanni, Choisy, in DC. Prod. ix. 405.-Afr. austr. caddoënsis, Buckl. in Proc. Acad. Sc. Philad. 1862 (1863) 6= Jpomoea leptophylla.

caeruleus, Anct. vide coeruleus.

caespitosus, Roxb. Hort. Beng. 14 ; Fl. Ind. i. $483=$ Hewittia linifolia.

cairicus, Linn. Syst. ed. X, 922 = Ipomoea palmata. 
CONVOLVULUS :-

californicus, Benth. Pl. Hartw. $326=1$ lnteolus. californicus, Choisy, in DC. Prod. ix, 405,-Am. bor. oec.

caliginosus, Koen. ex Choisy, in Mém. Soc. Phys. Genèv. ví. (1833) $461=$ I pomoea cymosa

Calverti, Boiss. Diagn. Ser. II. iii. 124.-Tauria ; As. Min.

calycinus, Drige, ex Choisy, in DC. Prod. ix. 408.Afr. austr.

calycinus, H. B. \& IK. Nov. Gen. et Sp. iii. $109=$ Ipomoea cissoides.

calycinus, Roxb. Hort. Beng. [13] ; F1. Ind. i. $471=$ Ipomoea calycina.

calyculatus, Noronha, in Verh. Batav. Gen. v. (1790) ed. I. Art. IV. 10.-Malaya.

calystegioides, Choisy, Conv. Or.98.-China.

campanulatus, Spreng. Syst. i. $608=$ Ipomoea campanulata.

campestris, Vell. F1. Flum. 74 ; ii. t. $66=$ Ipomoea polymorpha.

canariensis, Linn. Sp. Pl. 155.-Ins. Canar.

candicans, Roem. \& Schult. Syst. iv. $302=$ Rivea hypocrateriformis

candicans, Roth, Nov. Pl. Sp. $106=$ Rivea ornata.

candicans, Soland. ex Sims, in Bot. Mag. t. $1603=$ Ipomoea fastigiata.

canescens, H. B. \& K. Nov. Gen. et Sp. iii. $99=$ Jacquemontia violacea.

canescens, Phil. in Linnaea, xxxiii. (1864-65) 182.Chili.

canescens, Roth, Nov. Pl. Sp. $107=$ Lettsomia aggregata.

cantaber, Pall. Phys. Topogr. Gem. Taur. $99=$ C. Cantabrica?

Cantabrica, Linn. Sp. Pl. 158.-Europ.; Oriens.

capensis, Burm. f. Fl. Cap. Prod. 5.-Afr. austr

capensis, Willd. Sp.Pl. i. $877=$ hastatus.

capillaceus, H. B. \& K. Nov. Gen. et Sp. iv. $260=$

Ipomoen muricata.

capitatus, Cav. Ic. ii. 72. t. $189=$ lanuginosus,

capitatus, Desv, in Lam. Encyc. iii, $554=$ Jacquemontia tamnifolia.

capitatus, Schimp. ex T. Anders. in Journ. Linn. Soc. v.

Suppl, i. $(1860) 25=$ glomeratus.

capitatus, Vahl, Symb. Bot. 1ii. $28=$ Lettsomia strigosa

capitellatus, Buch.-Ham. ex Wall. Cat. n. $2250=$

Ipomoea Pes-tigridis.

capitiformis, Poir. Encyc. Suppl. iii. $469=$ Lettsomia strigosa.

capituliferus, Franch. in Révoil, Comali, 41.--Afr, or trop.

capripes, Stokes, Bot. Mat. Med. i. 327=Ipomoea Pes-caprne.

Caput-Medusae, Lowe, in Ann.' \& Mag. Nat. Hist.

Ser. III. vi. (1860) 155.-Ins. Madera.

caracasanus, Willd. ex Roem. \& Schult. Syst. iv. 301

$=$ Ipomoea umbellata.

cardiosepalus, Boiss. Fl. Orient. iv. 96-Cilicia

carneus, Spreng. Syst. i. $602=$ Ipomoea cainea

carnosus, Spreng. 1. c. $609=$ Ipomoea carnosa

carolinus, Linn. Sp. Pl. $154=$ I pomoea commutata.

cataonicus, Boiss. E Haussk. ex Boiss. Pl. Or. Nov.

dec, i. 5-As. Min.

Catesbaei, Spreng. Syst. i. $603=$ Calystegia sepium .

catharticus, Blanco, Fl. Filip. ed. I. $94=1$ pomoea grandiflora.

catharticus, Crantø, Inst. ii. 338.-Am. trop.?

Cavanillesii, Spreng. Syst. i. $590=$ Ipomoea Cavanillesii.

cephalanthus, Wall. Cat. n. $1402=$ Lepistemon Wallichii.

cephalophorus, Boiss. Diagn. Ser. I. vii. 22.-Persia

cephalopodus, Boiss. I. c. $24=$ sericeus.

cespitosus, Ehrenb. ex Buiss. Fl. Orient, iv. $97=$ libanoticus.

chenopodioides, Desr. in Lam. Encyc. iii. 544.Hab.?

Cherleri, Agardh, ex Roem. \& Scbult. Syst. iv, $261=$ arvensis.

chilensis, Pers. Syn. i. $180=$ dissectus.

chinensis, Ker-Gawl, in Bot, Reg, t. 822 marvensis.

Choisyanus, Wall. Cat. 0. 2259=Argyreia Lesche naultii.

cholulensis, Spreng. Syst. i. $599=$ I pomoea coccinea

chondrilloides, Boiss. Diarn, Scr, I. xi, 83.-I'ersia.

Choysianus, Stcud. Nom. ed. II. i. 408, lapsu $=$

Choisyanus.

\section{CONVOLVULUS :-}

chryseides, Spreng. Syst. i. $598=$ Ipomoea chryseides. chrysorrhizus, S.hrad. (vel Soland.) ex Steud. Nom. ed.

II. i. 108, 109-Ipomoea manmosa?

ciliatus, Roth, Catalect. fasc. i. $39=$ undulatus

ciliatus, Vahl, Eclog. Am. ii. 13=Jacquemontia tamnifolia.

ciliolatus, Michx. Fl. Bor. Am. i. $137=$ Ipomoea pandurata.

cinerascens, Spreng. Syst. i. $609=$ Ipomoea incisa.

circinnatus, Willd. ex Roem. \& Schult. Syst. iv. $302=$ Ipomoea parasitica.

cirrhosus, R. Br. in Salt, Abyss. App. p. lxiv ; ed. Germ. 475.-Abyss.

cissoides, Lam. Tabl. Encyc, i. 462 ; Vahl, Eclos. Am. ii. $15=$ Ipomoea cissoides.

cladotrichus, Mart. Del. Sem. Hort. Monac. (1846) 4. -Mexic.

Clappertoniz, Spreng. Syst. iv. $62=$ Ipomoea Clappertonii.

clavatus, Pav, ex Choisy, in DC. Prod, ix. 46 (=Calonyction clavatum).-Bras.

Cneorum, Horsk. F1. Aegypt. Arab. p. 1xiii-lanatus.

Cneorum, Habl. Taur. 147, ex Bieb. F1. Taur. Cauc i. $146=$ Calverti.

Cneorum, Linn. Sp. Pl. 157.-Europ. austr.

Cneorum, Sprun, ex Nym. Consp. $505=$ oleaefolius.

coccineus, Salisb. Prod. $124=$ Ipomoea coccinea

cochlearis, Griseb. Spicil. Fl. Rumel. ii. 76, in nota.Graec, ; As. Min.

coelestis, Forst. f. Prod. $14=$ Ipomoea hederacea

coelesyriacus, Boiss. Diagn. Ser. I. xi. 85.-byria.

coeruleus, Mart, \& Gal, in Bull. Acad. Brux, xii. (1845) 259 = Jacquemontia pa:viflora

ceruleus, Schum. \& Thonn. Beskr. Guin. Pl. $101=$ Ipomoea ovalifolia

coeruleus, Spreng. Syst. i. $593=$ Ipomoea hederacea

coiubrinus, Blanco, Fl. Filip. ed. II. 66=Ipomoea muricata.

commatophyllus, Steud. ex Choisy, in DC. Prod, ix. $354=$ Ipomoea commatophylla.

Commersonii, Steud. Nom. ed. II. i. $408=$ Evolvulus incanus.

commutatus, Boiss, Diagn. Ser. I. xi. 81.-Mesopot

compactus, Boiss. l. c. iv, 40.-As, Min.

condensatus, Bertol. Misc. Bot. xv. $18=$ Jacquemontia tamnifolia.

confertus, Hort. Hamb. ex Steud. Nom. ed. II. i. $408=$ Argyreia setosa.

congestus, R. Br. in Salt, Abyss. App. p. Ixiv.Abyss.

congestus, Spreng. Syst. i. $601=$ Ipomoea congesta.

contortus, Vell. Fl. Flum. 70 ; ii. t. $48=$ Ipomoea glabra.

copticus, Linn. Mant. ii. 559=Ipomoen dissecta

cordatifolius, Vell. Fl. Flum. 73 ; ii. t. $60=$ Ipomoea Batatas.

cordifolius, Bacle, ex Choisy, in DC. Prod. ix, $381=$ Ipotnoea Baclii.

cordifolius, Juss. ex Choisy, 1. c. $412=$ farinosus.

cordifolius, Salzm. ex Meissn. in Mart. Fl. Bras. vi $267=$ I pomoea fastigiata.

cordifolius, Thunb. Prod. Pl. Cab, 35.-Afr. austr.

coriaceus, Herb. Brit. Mus, ex Choisy, in DC. Prod, ix.

$385=$ Ipomoea pentaphylla.

Correjuela, Steud. Nom. ed. II, i, 408.-Chili.

corsicus, Roem. \& Schult. Syst. iv. $256=$ arvensis

corymbosus, Forst. f. Prod. $14=$ parviforus,

corymbosus, Linn. Syst. ed. X. $923=1$ pomoea Bur manni.

costatus, Meyen, Reise, i. 264 (=Aniseia costata).Chili.

crassifolius, Scheele, in Linnaea, xxi. (1849) 752.-

Bras.

crassipes, Kunze, ex Choisy, in DC. Prod. ix. $433=$ Calystegia sepium.

crenatifolius, Ruis E Pav. Fl. Per.ii, 10,-Peruv.

crenatus, Jacq. Coll. ii. $277=$ Hermannine.

crenatus, Vahl, Symb. Bot, iii. $3 \mathrm{l}=\mathrm{Vablii}$.

crinitus, Desr. in Lam. Lncyc. iii. $568=$ Jacquemontia

tamnilolia.

crispatulus, Wall. Cat. n. $1403=I$ pomoca peta-

loidea.

crispifolius, F. Muell, in Linuaen, xxv. (1852) 423.-

Austral.

crispus, Thunb. Fl. Cap. ji. 15.-Afr, austr.

cumanensis, H. B. \& K. Nov. Gen. et Sp, iii. $99=$

Ipomoea ferruginea.

\section{CONVOLVULUS:-}

cuneatus, Willd. Sp. PI. i. 873=Argyreia coneata,

cuneiformis, Buch.-Ham. ex Wall. Cat. p. 84. n. 1366 Argyreia cuneata.

Cupanianus, Tod.in Ann. Sc. Nat. Sér. IV. xx. (1863 $304=$ tricolor.

Curtana, Buch.-Ham. ex Wall. Cat. p. 83, n. $1344=$ Ipomoea eriocarpa.

cuspidatus, Willd. ex Spreng. Syst. i. $697=$ Meyeri.

cymosus, Desr. in Lam. Encyc. iii. $556=$ Ipomoea cymosa.

cymosus, Herb. Madr. ex Wall. Cat. p. 84, מ. $1366=$ Argyreia cuncata.

cymosus, Roem. \&c Schult. Syst. iv, $303=$ Sence gaunbiae.

ymosus, Ruiz \& Pav, F1. Per. ii. $9=$ Ipomoea ramosissima.

cynanchifolius, Wall. Cat. n. 1399=Ipomoea cynan. chifolia.

cynanchifolizus, Willd. ex Roem. \& Schult. Syst. iv. 301 = mollis, Ipomoea Bona $-10 x$.

cyprius, Boiss. Fl. Orient. iv. 93.-Ins. Cyprus.

dahuricus, Herb. in Bot. Mag. t. $2609=$ Calystegia dahurica.

damascenus, Boiss. \& Gaill. Diagn. Ser. II. vi. $122=$ stachydifolius.

dasycephalus, Pail. ex Choisy, in DC. Prod ix, $401=$ lanuginosus.

dasyspermus, Spreng. Syst. i. $591=$ Ipomoea dasy sperma.

decumbens, Orteg. ex Steud. Nom. cd. II. i. $408=$ undulatus.

defloratus, Choisy, in Zoll. Syst. Vers. Ind. Archip. 130,132 -Malaya.

demissus, Choisy, in DC. Prod. ix, 404.-Chili.

densiflorus, Hook. \& Arn. Bot. Beech. Voy. 303 Ipomoca umbellata.

dentatus, Blanco, Fl. Filip. ed. I. $89=$ Ipomoea Blancoi.

dentatus, Vahl, Symb. Bot. iii. $25=$ Ipomoea chryseides.

denticulatus, Desr. in Lam. Encyc. iii. 540 -Ipomoea denticulata.

denticulatus, Spreng. Syst, i. $603=$ Ipomoea angustifolia.

denticulatus, Steud. Nom. ed. II. i. 408=Ipomoea chryseides.

deserti, Hochst. \& Steud. ex Steud, 1. c.=micro. phyllus.

dianthoides, Kar. \& Kir. in Bull. Soc. Nat. Mose. (1841) $708=$ C. Pseudo-Cantabrica.

Dianthus, J. F. Gmel. Syst. $343=$ Ipomoea littoralis.

dichrous, Roem. \& Schult. Syst. iv. 263=Ipomoca pilosa.

digitatus, Buch.-Ham. ex Wall. Cat. p. 85. n. $1423=$ Ipomoea cissoides.

digitatus, Roxb. Hort. Beng. 14; Fl. Ind. i. $479=$ Ipomoea palmata.

digitatus, Spreng. Syst. i. $592=$ Ipomoea digitata.

Dillenii, Desr. in Lam. Encyc. iii. $54 \$=$ Ipomoea hederacea.

discolor, H. B. \& K. Nov. Gen, et Sp, iii. $105=$ I pomoea discolor.

dissectus, Cav. Ic. v. $54=$ incannos.

dissectus, Herb. Madr. ex Wall. Cat. p. 84 , n. 1351 Ipomoea dissecta.

dissectus, Jacq. Obs, Bot. ii. 4 -Ipomoca sinuata.

distillatorius, Blanco, F1. Filip. ed. I. $95=I$ pomoca campanulata.

divaricatus, Regel Es Schmalh, in Act. Hort. Petros. vi. (1879) 357,385 . - Turkestan.

divaricatus. Wall Cat. D. $14: 22=$ arvensis

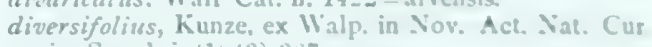
xix. Suppl. i. $(1843) 367=$ incunus.

diversifulius, Sihum. \& Thono. Beskr. Liuin. Pl. $94=$ Ipomoen sagittata.

diversifolius, Spreng. Syst i. $592=$ Ipomoca diversilolia.

ditisus, Vell. Fl. Flum, 71; ii. \&. 49 Jacỵuemantia menispermnides.

domingensis, Desr. in Lam. Encye. iii. 5it Ipomora tubata.

domingensis, Spreng. Neue kntuleck. iii. 99 -Ipomoes llispaniolac.

doryenioiles, Den. Rep. Lis. 2s\$._Ligur. : Ins. Palm 1)orycnium, Linn. Syss. ed. X. 92S - Graccia. Dorycnium, Pall. ex Sicud, Nors. ed. II. i 10 s. lanuginosus ? 


\section{CONVOLVULUS:-}

Dregeanus, Choisy, in DC. Prod. ix, 411.-Afr. austr.

Dryandri, Spreng. Syst. i. $597=$ Massoni

Dudia, Buch.-Ham. ex Wall. Cat. p. 83. n. $1328=$ Calystegia hederacea.

dumetorum, H. B. \& K. Nov. Gen. et Sp. iii. 101 = Ipomoea dumetorum.

Durandoi, Pomel, Nouv. Mat. Fl. Atl. 85-Afr. bor.

ebracteatus, Desr. in Lam. Encyc. iii. $541=$ Ipomoea ebracteata.

echioides, Hochst. ex Choísy, in DC. Prod. ix. $332=$ Argyreia abyssinica.

edulis, Thunb. Fl. Jap. $84=$ Ipomoea Batatas.

edulis, Vell. Fl. Flum. 72 ; ii. t. 55.-Bras.

Eichwaldi, Boiss. Diagn. Ser. I. vii. 27, in nota $=$ fruticosus.

elegans, Wall. Cat. n. 1392=Breweria elegans.

elegantissimus, Mill. Gard. Dict. ed. VIII. n. $22=$ althaeoides.

ellipticus, Spreng. Syst. i. $613=$ Lettsomia elliptica.

elongatus, Salisb. Prod. $123=\mathrm{C}$. Scammonia.

elongatus, Willd. Enum. Hort. Berol. 205.-Ins. Canar.

emarginatus, Link, Enum. Hort. Berol. i. 201.-Hab.? emarginatus, Vahl, Symb. Bot. iii. $23=$ Ipomoea martinicensis.

equitans, Benth. P1. Hartw. $16=$ incanus.

erectus, Spreng. Syst. i. $612=$ Ipomoea erecta

eremophilus, Boiss. E Buhse, in Nouv. Mim. Soc. Nat. Mose. xii. (1860) 148.-Persia.

erianthus, Willd. ex Spreng. Syst. 1. $610=$ Breweria aquatica.

erinaceus, Ledeb, in Eichw. Casp. Cauc. 11, t. 7.-Reg. Casp.

erinaceus, C. A. Mey. Verz. Pf. Cauc. $102=$ eremophilus.

eriocarpus, Spreng. Syst. i. $598=$ Ipomoea eriocarpa.

eriocaulos, Willd. ex Roem. \& Sehult. Syst. iv. 301

Ipomoea purpurea.

eriospermus, Desr. in Lam. Encye. iii. $567=$ Ipomoea Desrousseauxii

erosus, Desr. 1. c. $558=$ Hermanniae

erubescens, Sims, Bot. Mag.t. 1067.-Austral.

erythrocarpus, Wall. Cat.n. $1413=$ Argyreia lanceolata esculentus, Salisb. Prod. $123=$ Ipomoea Batatas.

esculentus, Vell. Fl. Flum. 73 ; ii. t. $58=$ septangu. laris.

essequebensis, Spreng. Syst. i. $600=$ Ipomoea fastigiata. evolvuloides, Boiss. Diagn. Ser. I. vii. 25.-Persia.

evolvuloides, Desf. Fl. Atlant. i. 176. t. $49=$ undulatus.

excisus, Zipp. ex Span. in Linnaea, xv. (1841) $338=$

Ipomoea reniformis.

Falckia, Thunb. Prod. Pl. Cap. $35=$ Falkia repens.

Falkia, Facq. Hort. Schoenb, ii. 38. t. 198.-Afr. austr.

farinosus, Linn. Mant. ii. 203.-Afr. trop.

fastigiatus, Herb: Roxb. ex Wall. Cat. n. 2258= Argyreia populifolia.

fastigiatus, Roxb. Hort. Beng. [13] ; F1. Ind. i. $468=$ Ipomoea fastigiata.

fatmensis, Kunze, in Flora, xxiii. (1810) I. 172.-Afr. bor.

ferrugineus, Steud. Nom. ed. II. i. $408=$ Jacquemontia ferruginea.

ferrugineus, Vahl, Eclog. Am. i. 17 = Ipomoea ferruginea.

festivus, Wall. Cat. n. $1414=$ Argyreia argentea, populifolia.

flicaulis, Vahl, Symb. Bot. iii. 24=Ipomoea angustifolia.

filifolius, Hook. \& Am. Bot. Beech. Voy. 35=Ipomoea Cruckshanksii.

fliformis, Desr, in Lam. Encyc. iii. $555=$ Ipomoea filiformis.

filiformis, Thunb. F1. Cap. ii. $16=$ Ipomoea angustifolia.

flipes, Balf. $f$. in Proc. Roy. Soc. Edinb. xii. (1884) 82.-Ins. Socotr.

Finlaysonianus, Wall. Cat. n. 6607 (Argyreiae sp.).Cochinch.

firmus, Spreng. Syst. i. $613=$ Ipomoea stans,

flagelliformis, Roxb. Hort. Beng. 14 ; Fl. Ind. i. 481 = Ipomoea Beladamboe

flavescens, D. Dietr. Syn. Pl. i. $680=$ Ipomoea flavescens.

flavus, Heyne, ex Wall. Cat. sub n. $1349=$ Ipomoea chryseides.

favus, Salisb. Prod. $124=$ Ipomoea umbellata.

\section{CONVOLVULUS}

flavus, Willd. $S p, P l . i .852$,-Ind. or.

flexuosus, Pomel, Nouv. Mat. Fl. Atl. 84-Algeria

flexuosus, Spreng. Syst. i. $612=$ Ipomoea erecta.

floribundus, H.B. E K. Nov. Gen. et Sp. iii. 96.-Am austr.

floridus, Linn.f. Suppl. 136.-Ins. Teneriff.

formosus, J. F. Gmel Syst, $343=$ Ipomoea sagittata

formosus, Roxb, ex Hook. f. Fl. Brit. Ind. iv. $214=$

Ipomoea kentrocaulos.

Forskalei, Delile, F1. Egypte, 190. t. 18. f. $3=$ sericeus Forskolei, Spreng. Syst. 1. $596=$ Ipomoea verticillata.

Frankeanus, Schlecht. in Linnaea, vi. (1831) $613=$

Jacquemontia menispermoides.

frondosus, Willd. ex Roem. \& Schult. Syst. iv. $303=$

havanensis.

frutescens, Mill. Gard. Dict. ed. VIII. n. 13=Ipomoea operculata?

frutescens, Pall. ex Ledeb. F1. Ross, iii. $88=$ fruticosus.

fruticans, Pall. Reise, ii. $474=$ seq.

fruticosus, Pall. $l$. $c_{\text {. }}$ ii. 734.-Oriens.

fruticulosus, Desr. in Lam. Encyc. iii. 541-Ins. Canar.

fugacissimus, Hochst. ex Choisy, in DC. Prod. ix. $449=$ Evolvulus alsinoides

fulcratus, Greene, in Bull. Calif. Acad, i. (1885) $208=$ villosus.

fulgens, Wall. Cat. n. 1394=Argyreia fulgens

galapagensis, Anderss. in Vet. Acad. Handl. Stockh. 1853 (1855) 213. - Ins. Galap.

galaticus, Rost. ex Choisy, in DC. Prod. ix. 408.-As. Min.

gangeticus, Linn. Cent. Pl. ii. 9 ; Amoen. Acad. iv. 306 =Evolvulus gangeticus.

gangeticus, Roxb. Hort. Beng. [13]; Fl. Ind. i. $467=$ Argyreia tiliaefolia.

gangeticus, Wall. Cat. n. $1340=$ Ipomoea staphylina.

Garberi, Chapm. in Coult. Bot. Gaz. iii. (1878) $11=$ havanensis.

Gaudichaudii, Choisy, Conv. Or. $68=$ Ipomoea Turpethum.

gemellus, Burm. f. F1. Ind. 46 ; Vahl, Symb. Bot. iii 27 = Ipomoea obscura.

geniculatus, Lehm. Sem. Hort. Hamb. (1826) $17=$ erubescens.

geniculatus, Munby, ex Pomel, Nouv. Mat. Fl. Atl. 85 - Afr. bor

genistoides, Jaub. \& Spach, Illustr. iv, 107. t. $370=$ spinosus.

geranioides, Phil. in Anal. Univ. Chil. (1884) reimp. 7.-Chili.

Gerardi, Roem. \& Schult. Syst. iv. $294=$ lineatus.

Germaniciae, Boiss. Eo Haussk. ex Boiss. Fl. Orient. iv 104.-As. Min.

giganteus, Silva Manso, Enum. Subst. Braz. $18=$ Calystegia palmato-pinnata.

glaber, Aubl. Pl. Gui. i. $138=$ Ipomoea glabra

glaber, Mill. Gard. Dict. ed. VIII. n. 11.-Ind. occ.

glandulifer, Spreng. Syst. i. $599=$ Ipomoea purpurea.

glandulosus, Herb. Buch.-Ham. ex Wall. Cat. n. 2252 $=$ Lettsomia rubens.

glaucescens, H. B. \& K. Nov. Gen. et Sp. iii. 101= Ipomoea dumetorum.

glaucifolius, Choisy, in DC. Prod. ix. $412=$ incanus.

glaucifolius, Spreng. Syst. i. $604=$ Ipomoea glauci folia.

glomeratus, Choisy, in DC. Prod. ix. 401.-Arab. glomeratus, Thunb. in Mus. Nat. Ups, 168,-Hab. ? glomeratus, Wall. Cat. n. $2257=$ Argyreia cymosa. gonatodes, Steud. ex A. Rich. Tent. F1. Abyss. ii. $69=$ Ipomoea obscura.

gonocladus, Boiss. Diagn. Ser. I. vii. $22=$ Hanssknechtii.

Gortschakovii, Schrenk, Enum. Pl. Nov. Song. 18.Soongaria.

gossypifolius, H. B. \& K. Nov. Gen. et Sp. iii. $107=$ Ipomoea taberosa

gossypinus, Wall. Cat. n. $1407=$ Ipomoea Wightii. gracilis, Salisb. Prod, $124=$ Argyreia mollis

rracilis, Spreng. Syst. i. $604=I$ pomoea gracilis gramineus, Spreng. 1. c. $607=$ Ipomeea graminea grandiflorus, Dest. in Lam. Encyc. iii. $543=$ Ipomoea Tuba.

grandiflorus, Hort. Brit. ex Steud. Nom. ed. II. i. 409 $=$ Argyreia tiliaefolia.

grandiflorus, Jacq. Hort. Vindob. iii. $39=$ Ipomoea latiflora.

\section{CONVOLVULUS :-}

grandiflorus,Linn. f. Suppl. $136=$ Ipomoea grandiflora grandiflorus, Wall. Cat. n. $1370=$ Ipomoea Bona-nox. griseus, Rafin. Atl. Fourn. 177.-Am. bor.

guadaloupensis, Steud. Nom. ed. II. i. 409.-Ins. Guadalup.

guianensis, Aubl. Pl. Gui. i. 136 = Jacquemontia guyanensis.

uineensis, Schum. \& Thonn. Beskr, Guin. Pl. $90=$ Ipomoea capitata.

guinensis, D. Dietr. Syn. P1. i. $673=$ Ipomoea pileata. Iamiltonii, Spreng. Syst. iv. Cur. Post. $61=$ Ipomoea Hamiltonii.

Hardwickii, Spreng. 1. c. $60=$ Ipomoea calycina

hastatus, Desr, in Lam. Encyc. iii. $542=$ Ipomoea angustifolia.

hastatus, Forsk. F1. Aegypt. Arab. $203=$ arvensis

hastatus, Heyne, ex Wall. Cat. n. 1384=Ipomoea sepiaria.

hastatus, Nutt. in Am. Phil. Trans. N. S. v. (1837) 194 = incanus.

hastatus, Sieber, ex Choisy, in DC. Prod. ix. $412=$ fatmensis

hastatus, Thunb. Prod. Pl. Cap. 35.-Afr. austr.

hastifolius, Poir. Encyc. Suppl. iii. $467=$ arvensis.

hastigerus, Spreng. Syst. i. $594=$ Ipomoea coccinea

Hanssknechtii, Boiss. Fl. Orient. iv. 102.--Persia.

havanensis, facq. Obs. Bot. ii. 25.-Ind. occ.

havanensis, Willd. ex Steud. Nom. ed. II. i. $409=$ Ipomoea umbellata.

hederaceus, Blanco, Fl. Filip. ed. I. $90=$ Hewittia bicolor.

hederaceus, Linn. Sp. Pl. 154=Ipomoea hederacea

hederaceus, Mill. Gard. Dict. ed. VIII, n. 17 Ipomoea commutata.

hederaefolius, Salisb. Prod. 123 = Ipomoea hederacea.

helianthemifolius, Poir. Encyc. Suppl. iii. 465.-Am. austr.

hepaticaefolius, Spreng. Syst. i. 594=Ipomoea Pestigridis.

hepaticaefotius, Willd ex Roem \& Schult. Syst. iv. $303=$ Ipomoea trifida

heptaphyllus, Rottl. in Ges. Naturf. Fr. Neue Schr. iv. 1803) $196=$ Ipomoea palmata

Hermanniae, Choisy, in DC. Prod. ix. $408=$ hermannioides.

Hermanniae, L'Hérit. Stirp. Nov. 67. t. 33.-Peruv.

hermannioides, A. Gray, Syn. Fl. N.Am. ii. I. 216.Texas.

heterophyllus, Ehrenb. ex Boiss. Fl. Orient. iv. $109=$ coelesyriacus

heterophyllus, Spreng. Syst. i. $592=$ Ipomoea heterophylla.

Heynii, Spreng. 1. c. $699=$ Lettsomia aggregata.

Heynii, Wall. Cat. n. $1387=$ Ipomoea sepiaria.

Hildebrandtii, Vatke, in Linnaea, xliii. (1880-82) 519.-Afr trop.

hirsutissimus, Wall. Cat. n. $1400=$ Lettsomia hirsu tissima.

hirsutus, Bieb. Fl. Taur. Cauc. i. 422.-Graecia; As. Min.

hirsutus, Roem. ex Choisy, in DC. Prod. ix. $344=$ Ipomoea hederacea.

hirsutus, Roxb. Hort. Beng. 14; Fl. Ind. i. $479=$ Ipomoea pentaphylla.

hirsutus, Tenore, Fl. Nap. i. 60. t. 15 =althaeoides.

hirtus, Herb. Madr. ex Wall. Cat. n. $2254=$ Ipomoea rumicifolia.

hirtus, Linn. Sp. Pl. 159.-Ind. or

hirtus, Wight, ex Steud. Nom. ed. II. i. $409=$ Ipomoea eriocarpa.

Hispaniolae, Spreng. Syst. i. $590=$ Ipomoea Hispaniolae.

hispidus, Vahl, Symb. Bot. iii. $29=$ Ipomoea eriocarpa. holosericeus, Bélang, ex Choisy, in DC. Prod. ix. $402=$ Aucheri.

holosericeus, Bieb. Fl. Taur. Cauc. i. 147.-As. Min.

Hookerianus, D. Dietr. Syn. Pl. i. $666=$ Ipomoea ficifolia.

Horsfalliae, D. Dietr. 1. c. $664=$ Ipomoea Horsfalliae. Houstoni, Stend. Nom. ed. II. i. 408, in syn.=glaber.

Huegelii, De Vriese, in Lehm. PI. Preiss. i. $346=$ erubescens.

Humboldtianus, Roem. E Schult.Syst. iv. 884.-Venezuela.

humilis, Jacq. Coll. iv. 209. t. $32=$ undulatus.

humilis, Salisb. Prod. $125=$ lineatus.

humistratus, Walt. Fl. Carol. $94=$ Breweria humistrata. 


\section{CONVOLVULUS :-}

hybridus, Zoll. E Morr. in Nat. Geneesk. Arch. Neêrl. Ind. ii. (1845) 6.-Malaya.

byoscyamoides, Vatke, in Linnaea, xliii. (1880-82) 520. -Afr. trop.

hypocrateriformis, Desr. in Lam. Encyc. iii. $561=$ Rivea hypocrateriformis.

hypoleucus, Roem. \& Schult. Syst. iv, $884=$ Rivea hypocrateriformis.

Hystrix, Vahl, Symb. Bot. i. 16.-Aegypt. ; Arab.

ianthinus, Hance, ex Walp. Ann. iii. $113=$ parviflorus. igneus, Schrad. in Goett. Gel. Anz. i. (1821) $716=$ Ipomoea flammea.

imbricatus, Spreng. Syst. i. $613=$ Lettsomia aggregata Imperati, Vahl, Symb. Bot. i. $17=$ Ipomoea littoralis. incanus, $\mathrm{Vahl}$, l. c. iii. 23.-Am. bor, et austr.

incarnatus, Vahl, Eclog. Am. ii. $12=$ Ipomoea incarnata.

incisus, Herb. Mus. Par. ex Choisy, in DC. Prod. ix. 409.-Peruv.?

incisus, Spreng. Syst. i. $609=$ Ipomoea incisa

incrassatus, Wall. Cat. n. $1386=$ Ipomoea sepiaria.

incurvus, Schum. \& Thonn. Beskr. Guin. Pl. $99=$ Ipomoea Clappertonii.

indicus, Mill. Gard. Dict. ed. VIII. n. 5=Ipomoea violacea.

indivisus, Vell. Fl. Flum. 71; ii. t. 50=Ipomoea coccinea.

inflatus, Desf. Tabl. ed. I. $74=$ Calystegia silvatica.

insignis, Spreng. Syst, i, $592=$ Ipomoea digitata.

insuavis, D. Dietr. Syn, Pl, i, $668=$ I pomoea obscura.

intermedius, Loisel. in Journ. Bot. ii. (1809) 264 (Not. $40)=$ lineatus.

intermedius, Roem. \& Schult. Syst. iv. 264=Ipomoea purpurea.

involucellatus, Klotzsch, in Peters, Reise Mossamb. Bot. 241.-Afr. trop.

involucratus, Ker-Gawl. in Bot. Reg. t. $318=$ Hewittia bicolor.

involucratus, Spreng. Syst. i. $690=$ Ipomoea pileata.

involucratus, Willd. Sp. Pl. i. $845=$ Ipomoea teretistigma.

Ipomoea, Vell. Fl. Flum. 72; ii. t. $56=$ Ipomoea triloba.

italicus, Roem. \& Schult. Syst. iv. $266=$ althaeoides.

jacobaeus, C. Sm. in Tuckey, Congo, 249, nomen.Ins. Cap. Verd.

Falapa, Linn, Mant. i. $42=$ Ipomoea Jalapa

jamaicensis, Jacq. Obs. iii. $6=$ havanensis?

jamaicensis, Spreng. Syst. i. $595=$ Ipomoea jamaicensis.

japonicus, Thunb. F1. Jap. $85=$ Ipomoea angustifolia.

Fatiauca, J, F. Gmel. Syst. $339=$ Ipomoea Jalapa.

javanensis, Burm. f. FI. Ind. $43=$ Ipomoea denticulata.

javanicus, Burm. f. 1. c. 50= Ipomoea sagittaefolia.

javanicus, Spreng. Syst. i. $605=$ Ipomoea hastata.

jemensis, Kotschy, in Sitzb. Wien. Acad. lii. (1866)

t. 2.-Arab.

kentrocaulos, Steud. ex Choisy, in DC. Prod. ix. $362=$

Ipomoea kentrocaulos.

Kleinii, Spreng. Syst. i. $606=$ Ipomoea staphylina

Kleinii, Wall. Cat. n. 1377 = Ipomoea sinuata.

Korolkowi, Regel E Schmalh. in Act. Hort. Petrop.

vi. (1879) 337, 398.-Turkestan.

Kotschyanus, Boiss. Diagn. Ser. I. vii. 23.-Persia.

Krauseanus, Regel E" Schmalh, in Act. Hort. Petrop. vi. (1879) 389.-Turkestan.

lachnaers, Spreng. Syst. i. $606=$ Ipomoea lachnaea.

lachnospermus, Hochst. in Ind. Sem. Hort. Monsp. (1847) $7=$ Ipomoea lachnosperma.

laciniatus, Desr, in Lam. Encyc, iii. 546.-Reg. Argent.

lactescens, Gronov, ex Choisy, in DC. Prod. ix. $433=$ Calystegia sepium.

lacteus, Wall. in J. Grah. Cat. Bomb. Pl. $133=$ Ipomoea lactea.

lacunosus, Spreng. Syst. i. $597=$ Ipomoea lacunosa

laetus, Salisb. Prod. 123 = Calystegia sepum.

laevicaulis, Willd. ex Roem. \&e Schult. Syst. iv. $803=$ Ipomoer siclaefolia.

laevigatus, Herb. Mus. Brit. ex Steud. Nom. ed. II. $409=$ Ipomoen laevigata.

lanatus, Vahl, Symb. Bot. i. $16=$ sericeus.

laniger, Willd. ex Spreng. Syst. i. 5!98. - Hab. ?

lanuginosus, Aitch. Cat. Punjal, PI. 98 - Aitchisoni.

lanuginosus, Desy. in Lam. Encyc。 iii. 551.- Hispan

\section{CONVOLVULUS:}

anuginosus, Heyne, ex Wall. Cat. n. 1407=Ipomoea Wightii.

lanuginosus, Ledeb. Fl. Ross. iii. $88=$ Calverti.

lanuginosus, Vahl, Symb. Bot iii. 23 - hirsutus

lapathifolius, Schlecht. in Linnaea, xix. (1847) 736. Mexic.

lapathifolius, Spreng. Syst. i. $604=\mathrm{I}$ pomoea acetosellaefolia.

lasianthus, Cav. Ic. v. 53. t. 479.-Chili.

lasiophloeus, Jaub. \& Spach, Illustr. iv. 105. t. $368=$ leiocalycinus.

lasiospermus, Vis. Pl. Aeg. Nub. 13. t. 1. f. 2 Ipomoea rumicifolia

latiflorus, Desr. in Lam. Encyc. iii. 561=Ipomoea Bona-nox.

laurifolius, Roxb. Hort. Beng. [13]; Fl. Ind. i. $470=$ Lettsomia elliptica.

laurifolius, Wight, ex C. B. Clarke, in Hook. fo Fl Brit. Ind. iv. $186=$ Argyreia obtecta

leiocalycinus, Boiss. Diagn. Ser. I. vii. 28.-Persia

leptocladus, Boiss. l. c. 25.-Persia.

leucanthus, Desr. in Lam. Encyc. iii. $541=$ Ipomoea leucantha.

leucanthus, Herb. Madr. ex Wall. Cat. p. 83, n. $1340=$ Argyreia tiliaefolia.

leucophyllus, Willd. ex Roem. \& Schult. Syst. iv. 301 $=$ Ipomoea discolor

leucotrichus, Pomel, Nouv. Mat. Fl. Atl. 87.-Afr. bor.

libanoticus, Boiss, Diagn. Ser. I. xi. 82.-Syria.

liberalis, Lhotsky, ex Choisy, in Mém. Soc. Phys Genèv. ix. (1837) $132=$ Ipomoea echioides.

lilacinus, D. Dietr. Syn. PI. i. $669=$ Ipomoea lilacina. limphaticus, Vell. Fl. Flum. $70=$ Ipomoea palmata?

Lindleyi, Steud. Nom. ed. II. i. $409=$ Ipomoea hederacea.

linearifolius, Mill. Gard, Dict. ed, VIII. n. $28=$ pilosellaefolius.

linearis, Curt. Bot. Mag. t. $289=$ oleaefolius

linearis, DC. Fl. Fr. Suppl. $424=$ lanugi osus.

linearis, Lam. Fl. Fr, ii. $267=$ cantabrica.

lineatus, Linn. Syst. ed. X. 923.-Europ. austr. ; As. temp.

lineatus, Sibth. \& Sm. Fl. Graec. ii. 81. t. $199=$ oleaefolius.

linifolius, D. Dietr. Syn. P1. i. $675=$ Ipomoea linifolia. linifolius, Linn. Cent. Pl. ii. $10=$ Evolvulus alsinoides.

linifolius, Wall. Cat. n. 1389=Ipomoea angustifolia

Linki, F. G. Dietr. Vollst. Lexik. Gaertr. Nachtr. II. iii. $94=$ emarginatus

ittoralis, D. Dietr. Syn. Pl. i. 680, in syn. =Ipomoea littoralis.

littoralis, I.inn. Syst. ed. X. $924=$ Ipomoea carnosa

littoralis, Vatke, in Linnaea, xliii. (1880-82) 519. Afr. trop.

lividus, Mog. ex Steud. Nom. ed. II. i. $409=$ Ipomoea Jalapa.

lobatus, Engelm. \& Gray, PI. Lindheim. i. $44=$ incanus.

longiflorus, Heyne, ex Steud. Nom, ed. II. i. $409=$ Ipomoea palmata.

longiflorus, Spreng. Syst. i, 595=Ipomoea grandiflora?

longipes, S. Wats. in Am. Natural. vii. (1873) 302.Am, bor. occ.

Lotnoha, Buch.-Ham. ex Wall. Cat. p. 83, n. 1342 Ipomoea cymosa.

Loureiri, G. Don, Gen. Syst. iv. $290=$ calystegioides

lucanus, Tenore, F1. Neap. Prod. App. v, $9=$ Caly stegia sepium.

lupulifolia, Griff. Notul, iv. $284=$ Ipomoea palmata.

Iuteolus, A. Gray, in Proc. Am. Acad. xi. (1876) 90.Calif.

luteolus, Spreng. Syst. i. $599=$ I pomoea coccinea

luteolus, Wight, ex Wall. Cat. p. 84 . n. $1349=$ I pomoen chryseides.

luteus, Mart. \& Gal. in Bull. Acad. Brux. xii. II. 1845) 260 - Mexic.

lycioides, Boiss. Diagn. Ser. I. vii. $28=$ leiocalycinus.

lycioides, Wall. Cat. n. $1990=$ Blinkworthia lycioides

lymphaticus, Vell, Fl, Flum, ii. t, $47=1$ pomoen palmata.

macranthus, H. B. \& K. Nov. Gen. et Sp. iii. 95 Ipomoes murucoides.

macrocalyx, Ruiz \& Pav. Fl. Per. ii. $10=I$ pomoca glabra

macrocarpus, Linn. Syst. ed. X. 123.-Ind. oco

\section{CONVOLVULUS}

macrocarpus, Spreng. Syst. i. $592=$ Ipomoea tuberosa macrorhizus, Ell. Sketch, i. $252=$ Ipomoea Jalapa macrorhizus, A. Gray, ex Choisy, in DC. Prod. ix. 38 Ipomoea fastigiata.

macrorhizus, Linn. Syst. ed. X. $923=$ Ipomoea Jalapa macrorrhiza.

macrorrhizus, Heyne, ex Wall. Cat. n. $1350=$ Ipomota paniculata.

macrosolen, Spreng. Syst. i. $603=$ Ipomoea Hona-nox macrospermus, Willd. Sp. Pl. i. $860=$ Maripa passifloroides.

macrostegins, Greene, in Bull. Calif. Acad. i. (1885 208.-Calif

Mahur, Buch.-Ham. ex Wall. Cat. p. 85, n. $1422=$ arvensis

major, Gilib, Fl Lituan, i, 43= Calystegia sepium

major, Hort. ex Nichols, Dict. Gard. 1. $370=$ Ipomota purpurea.

malabaricus, Linn. Sp. P1. $155=$ Argyreia malabarica

malabaricus, Roxb. Hort. Beng. [13]; Fl. Ind. i. 465 = Ipomoea staphylina.

malabaricus, Wall. Cat. n. 1414 B = Argyreia Hookeri.

Malcolmi, Roxb. Hort. Beng. [14]; Fl, Ind, i. 474 arvensis

malvaceus, Oliver, in Trans. Linn. Soc. xxix. (1874 117.-Afr. trop.

mammosus, Lour. F1. Cochinch. $108=$ Ipomoea manmosa.

marginalis, Buch.-Ham. ex Wall. Cat. p. 83, n. 1840

Argyreia tiliaefolia.

marginatus, Desr. in Lam. Encyc. iii. 558=Ipomoea sepiaria.

marginatus, Spreng. Syst. i. $603=$ Calystegia marginata.

maritimus, Desr. in Lam. Encyc. iii. 550 Ipomoe biloba.

maritimus, D. Dietr. Syn. Pl, i. $680=$ Ipomoea littoralis

maritimus, Gouan, Fl. Monsp. $27=$ Calystegia sepium maritimus, Lam. Fl. Fr. ii. $265=$ Calystegia Solda nella.

maritimus, Pall. ex Ledeb. Fl. Ross, iii. $89=$ C. Cantabrica.

Martii, Spreng. Syst, i. $598=$ Calystegia heterantha martinicensis, Jacq. Select. Am. $26=1$ pomoea martini. censis.

mascatensis, Boiss. Diagn. Ser. I. vii. 25 = virgatus.

Massoni, A. Dietr. Gaert. Nachr. ii. $97 \%$.-Ins. Canar.

mataxocarpus, Spreng. Syst. i. 606.-N. Granat.

matutinus, West, Bidrag. Ste-Croix, 271,-Iod. occ mauritanicus, Boiss. Voy. Esp. 418. t. 122.-Afr. bor.

Maximiliani, Nees, in $\mathrm{Pr}$. Nenwied, Reise, 17

Calystegia sepium.

maximus, Buch.-Ham. ex Wall. Cat. n. $1341=$ Ipomoea staphylina.

maximus, Linn. f. Suppl. 137 ; Vahl, Symb. Bot. iii. 26 =Ipomoea sepiaria.

Mechoacana, Vitm. Summa P1. i. $434=$ Ipomoea Jalapa.

Medium, Linn. Sp. P1. 156=Ipomoea denticulata.

Medium, Roxb. Hort, Reng. 14; Fl. Ind. i. $474=$ Ipomoea angustifolia.

megapotamicus, Spreng. ex Meissn. in Mart. FI. Bras. vii. $259=$ Ipomoea megapotamica

melanostictus, Schlecht. in Linnaen, vi. 1581' $73 \%=$

Argyreia tiliaefolia.

meonanthus, Huffmgg. \& Link, Fl. I'urt. i. 969 tricolor.

meslatanus, Thunb. Mus. Nat lips. 188.- Hab.

Meyeri, Spreng. Syst. i. 597.-Hab,

micranthus, Kiddell, Syn. Fl. W. St. $00-I$ pomoea

lacunosa.

micranthus, Roem. E Schulb. Syst. iv, 2ivi-Ind. occ. Mexic.

micranthus, Willd ex Spreng. Syst i. 601 Sprengelii. microcalyx, C. B. Clarke, in Howk. f. Fi. Brib. Inat. is $2 \cdot 20$-Asinm.

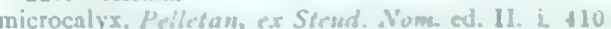

Mexis.

mierophyllus, Sicber. ex Sprenge. Syst. L 611. Acgyit.

Milleriurus, Rocm. \& Nichult. Sist. iv. ludex, \$21 Ipomoea umbellata.

minimus, duht. M. Livi. i. 1+1.-Liunasa.

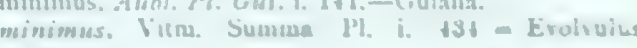
แncanus. 


\section{CONVOLVULUS:-}

minor, Gilib. Fl. Jituan. 1. $43=$ arvensis.

minor, Hort. ex Mill. Gard. Dict. ed. VIII. sub n. 24 $=$ tricolor

minutiflorus, Mart. E' Gal. in Bull. Acad. Brux. xii. II. (1845) 262 - Mexic

modestus, Boiss. Diagn. Ser. I. xi. $82=$ commutatus.

mollis, Burm. f. Fl. Ind. $44=$ Argyreia mollis.

mollis, H. B. \& K. Nov. Gen. et Sp. iii. $104=$ Ipomoea mollis.

mollis, Meissn. in Mart. Fl. Bras, vii. 314.,Bras.

mollissimus, Bertol. Misc. Bot. xx. 11. t. 3.-Guatemala.

mollissimus, Pall. ex Choisy, in DC. Prod. ix. $403=$ holosericeus.

monospermus, [Tin.] Elench. Pl. Hort. Parm. (1802) $1 .-\mathrm{H}$ ab?

montevidensis, Spreno. Syst. i. 604.--Reg. Argent. mucronatus, Benth. Pl. Hartw. $120=$ nodiflorus. mucronatus, Furst. f. Prod. $14=$ Ipomoea palmata. mucronifer, Choisy, in DC. Prod. ix. $414=$ Jacque montia guyanensis.

multibracteatus, Wall. Cat. n. 1408=Argyreia tomen tosa.

multifidus, Thunb. Prod. Pl. Cap. 35.-Afr. austr.

multiflorus, Banks, ex Steud. Nom. ed. II. i. $410=$ Ipomoea congesta.

multiflorus, Bess. ex Choisy, in DC. Prod.ix. $407=$ arvensis.

multiflorus, H. B. \& K. Nov. Gen. et Sp, iii. 100 Ipomoea tubata.

multiflorus, Mill. Gard. Dict. ed. VIII. n. 15 Ipomoea multiflora

multiflorus, Poit. ex Choisy, in DC. Prod. ix. $367=$ Ipomoea quinquepartita.

multivalvis, R. Br. Prod. $483=$ parviforus,

munitiflorus, Mart. \& Gal. in Bull. Acad. Brux, xii, II. (1815) 262, sphalm. = minutiflorus.

munitus, Wall. Cat. n. $1354=$ Ipomoea quinata, pentaphylla.

muricatus, Linn. Mant. i. $44=$ Ipomoea muricata.

mutabilis, Blanco, Fl. Filip. ed. I. $92=$ Ipomoea

Buna-nox.

mutabilis, Salisb. Prod. 123 = I pomoea purpurea.

mutabilis, Spreng. Syst. i. $593=$ Ipomoea acuminata.

muticus, Steud. Nom. ed. II. i. $410=$ Ipomoea grandiflora.

natalensis, Bernh. in Flora, xxyii. (1844) II. 829.Afr, austr.

Neei, Spreng. Syst. i. $593=$ Ipomoea peduncularis nemorosus, Willd. ex Roem. \& Schult. Syst. iv, $303=$ Ipomoea pentaphylla.

nervosus, Burm. f. F1. Ind. $48=$ Argyreia speciosa nervosus, Rafin. $\mathrm{Fl}$. Ludow, 46,-Am bor,

nevisiensis, Ham. Prod. Fl. Ind. Occ, $25=$ Jacquemontia hirsuta.

Nil, Linn. Sp. P1. ed. II. $219=$ Ipomoea hederacea. nitens, C. Koch, in Linnaea, xxii. (1849) $743=$ lineatus. nitidus, Boiss. Elench. 65.-Hispan.

nitidus, Desr in Lam. Encyc, iii $544=$ Argyreianitida. nodiflorus, Desr. l.c.557.-Mexic

nolanaeflorus, Zipp. ex Span. in Linnaea, xv. (1841) 341 = Ipomoea pumila.

nummularius, Linn. Sp. Pl. $157=$ Evolvulus alsinoides. nummularius, Vahl, Eclog. Am. ii. $13=$ Jacquemontia nummularia.

nymphaeaefolius, D. Dietr. Syn. P1. i, $670=$ Ipomoea peltata.

obdentatus, Steud. Nom. ed. II. i. $410=$ Ipomoea chryseides.

oblongus, Wall. Cat. n. $1382=$ Ipomoea barlerioides, obovatus, Wall. 1. c. n. $1381=\mathrm{L}$ ttsomia setosa

obscurus, Linn. Sp. Pl. ed. II. $220=$ Ipomoea obscura

obtectus, Wall. Cat. n. $1416=$ Argyreia obtecta.

obtusilobus, Michx. Fl. Bor, Am, i. 139=Ipomoea acetosaefolia.

obvallatus, Spreng. Syst. i. $595=$ Ipomoea bracteata.

occidentalis, A. Gray, in Proc. Am. Acad. xi. (1876)

89.-Am. bor occ.

occidentalis, S. Wats. I. c. $118=$ macrostegius.

ocellatus, Hook. Bot. Mag. t. 4 65. -Afr. austr.

ochraceus, Lindl. Bot. Reg. t. $1060=$ I pomoea ochracea,

ochraceus, Vahl, ex Choisy, in DC. Prod. ix. $380=$ Ipomoea afra.

Oenotherae, Vatke, in Linnaea, xliii. (1880-82) 520,Afr. trop.

oenotheroides, Linn. f. Suppl. 157 =Ipomoea argy-

\section{CONVOLVULUS:-}

fficinalis, Pelletan, ex Steud. Nom. ed. II. i. $410=$ Ipomoea Purga.

oleaefolius, Desr. in Lam. Encyc. iii. 552.-Graecia.

Olgae, Regel E' Schmalh, ex Regel, Pl. Nov. Fedsch. 55.-As. centr.

oligodontus, Baker, in Fourn. Linn. Soc. xx. (1883) 212.-Madag.

operculatus, Gomez, in Mem. Ac. Lisboa, iii. (1812)

Mem. Corresp. $27=$ Ipomoea operculata.

orinoccensis, Willd. ex Stend. Nom. ed. II. i. $410=$ Ipomoea cissoides.

orixensis, Wall. Cat. n. $1362=$ Lettsomia aggregata.

orizabensis, Pelletan, ex Steud. Nom. ed. II. i. $410=$ Ipcmoea orizabensis.

ornatus, Wall. Cat. n. $1369=$ Rivea ornata.

oronocensis, Willd. ex Roem. \& Schult. Syst. iv. 303, vide orinoccensis.

osyrensis, Roth, Nov. PI. Sp. $405=$ Lettsomia aggre-

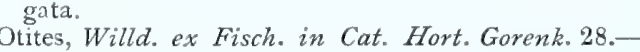
$\mathrm{Hab}$. ?

Ottonis, Meissn. in Mart. Fl. Bras. vii. 311.-Bras.

ovalifolius, Vahl, Eclog. Am. ii, 16 = Ipomoea ovalifolia.

ovalifolius, West, Bidrag. Ste-Croix, $271=$ Ipomoea quinquepartita.

ovatus, Moench, Meth. $450=$ siculns.

ovatus, Reinw. ex Choisy, in DC. Prod. ix. $332=$ Argyreia Guichenotii.

owariensis, Spreng. Syst, i. $594=I$ pomoea owariensis.

Owsjanianus, Smirnow, ex Trautv. in Act. Hort. Petrop. ix. (1884) 25, nomen-Rossia.

oxyphyllus, Boiss. Diagn. Ser. I. vii. 26.-Persia.

oxysepalus, Boiss. l. c. 23.-Persia.

palaestinus, Boiss. $l$. $c$. xi. 84.-Palaestin.

pallidus, Salisb. Prod. $123=$ canariensis.

pallidus, Wall. Cat. n. $1418=$ Argyreia pallida.

palmatus, Mill. Gard. Dict. ed. VIII. n. $8=$ Ipomoea quinquefolia.

palustris, Cav. Ic. vi. 80 , t. 600 . f. 2-Mexic

palustris, Herb. Ham. ex Wall. Cat. p. 85, n. $1422=$ arvensis.

panduratus, Linn. Sp. PI. $\mathbf{1 5 3}=$ Ipomoea fastigiata.

panduratus, Lour. F1. Cochinch. $107=$ Ipomoea panduraeformis.

paniculatus, Blanco, Fl. Filip. ed. I, $96=$ Ipomoea tuberosa.

paniculatus, Linn. Sp. PI. 156 = Ipomoea digitata.

paniculatus, Wall. Cat. n. $1350=$ Ipomoea kentrocanlos.

pannifolius, [Dryand. in] Ait. Hort. Kew. ed. II. i 328.-Ins, Canar

pannosus, Spreng. Syst. i. $612=$ Ipomoea erecta

Papiria, Spreng. 1. c. $592=$ I pomoea pubescens.

paradoxus, Poir. Encyc. Suppl. v. $720=$ sagittatus.

parasiticus, H. B. \& K. Nov. Gen. et $\mathrm{Sp}$. iii. $163=$ Ipomoea parasitica.

pareiraefolius, Bert. ex Spreng. Syst. 1. $613=$ Ipomoea pareiraefolia.

parnassicus, Boiss. \& Orph. Diagn. Ser. II. iii. $125=$ cochlearis.

parviflorus, Arn. ex Steud. Nom. ed. II. i. $410=$ C Retzia.

parviflorus, Desr. in Lam. Encyc. iii. $556=$ micranthus. parviflorus, Salisb. Prod. $125=$ siculus.

parviflorus, Vahl, Symb. Bot. iii. 29.-Geront. trop. parvifolius, Spreng. Syst. i. $611=$ pluricaulis.

patens, Clarke, Trav. i. ed. II. Add. p. xxii.-Oriens.

patens, Desr. in Lam. Encyc. iii. $547=$ Breweria humistrata.

pauciflorus, Willd. ex Roem. \& Schult. Syst. iv. $302=$ Ipomoea fastigiata.

paulistanus, Silva Manso, Enum. Subst. Braz. $17=$ Ipomoea echioides.

pedatus, Forsk. ex Choisy, in DC. Prod. ix. $410=$ althaeoides.

pedatus, Roxb. Hort. Beng. 14; Fl. Ind. i. $478=$ Ipomoea dasysperma.

peduncularis, Boiss. Diagn. Ser. I. xi. $84=$ hirsutus. peduncularis, Wall. Cat. n. $1417=$ Argyreia elliptica. pedunculatus, Walp. Ann. iii. 112, sphalm, = hirsutus. pellitus, Ledeb. Fl. Alt. i. $223=$ Calystegia pellita. peltatus, Linn. Sp. Pl. 1194=Ipomoea peltata

penangianus, Wall. Cat. n. $1425=$ Lettsomia penangiana.

pendulus, Silva Manso, Enum. Subst. Bras. $17=$ Ipomoea utilis.

\section{CONVOLVULUS:-}

pendulus, Spreng. Syst. i. $590=$ Ipomoea palmata penicillatus, A. Rich. Tent. Fl. Abyss. ii. 74.-Abyssin pennatifolius, Salisb. Prod, $124=$ Ipomoea Quamoclit. pennatus, Desr. in Lam. Encyc. iii. $567=$ praec.

pennifolius, Drapiez, Encycl. iii. $(1835)=$ praec

pensylvanicus, Schrank, in Syll. Ratisb. i. (18:24) $197=$ spithamaeus.

pentadactylis, Wall. Cat. n. $1367=$ Ipomoea quinata.

pentagonus, Roxb. Hort. Beng. 14 ; Fl. Ind. i. $485=$ Ipomoea cymosa.

pentanthus, Jacq. Coll. iv. $210=$ Jacquemontia violacea.

pentapetaloides, Linn. Syst. ed. XII. 229.-Europ. austr.; As. Min

pentaphylloides, Schrank, in Flora, vii. (1824) II Beil. 50-Bras

pentaphyllus, Linn. Sp. Pl. ed. II. $223=$ Ipomoea pentaphylla.

pentaphyllus, Salzm. ex Meissn. in Mart. F1. Bras. vii. $287=$ Ipomoea glabra

perfoliatus, Schum. \& Thonn. Beskr. Guin. P1. $89=$ Ipomoea involucrata.

persicus, Linn. Sp. Pl. 158.-As. Min.; Persia.

peruvianus, Spreng. Syst. i. $593=$ I pomoea cuspidata

Pes-caprae, Linn. Sp. P1. $159=1$ pomoea Pes-caprae.

Pes-tigridis, Spreng. Syst. i. $502=$ Ipomoea Pes tigridis.

petiolaris, Kunth, ex Spreng. 1. c. $598=$ Ipomoea Bona-nox.

petraeus, Lee, ex Choisy, in DC. Prod ix. 413.-Afr.

philomega, Vell. F1. Flum. 74; ii. t. $63=$ Ipomoea capparoides.

phoeniceus, Pav. ex Meissn. in Mart. F1. Bras. vii. 214 (=Operculina pteropus).-Bras.

phoeniceus, Spreng. Syst. i. $596=$ Ipomoea coccinea

physoides, Pomel, Nouv. Mat. Fl. Atl. 294.-Algeria

Pickeringii, M. A. Curt. in Bost. Journ. Nat. Hist. (1837) $130=$ Breweria Pickeringii.

pileatus, Spreng. Syst. iv. $61=$ Ipomoea pileata.

piliferus, Steud Nom. ed. II. i. 410 -Abyssin.

pilosella, Liebm. Ind. Sem. Hort. Haun. (1853) 22 ; in Ann. Sc. Nat. Sér. IV. i. (1854) 33.-Hab. ? pilosellaefolius, Desr. in Lam. Encyc. iii. 551.-As. Min.; Persia.

piloselloides, D. Dietr. Syn. Pl. i. $676=$ pilosellaefolius.

pilosus, R. Br. in Salt, Abyss. App. p. lxiv=piliferus.

pilosus, Rottl. in Ges. Naturf. Fr. Neue Schr. iv. (1803) 196.-Ind. or.

pilosus, Roxb. Hort. Beng. 14 ; F1. Ind. i. $473=$ Ipomoea pilosa.

pilosus, Wickstr. in Vet. Acad. Handb. Stockh. (1827) $60=$ Ipomoea cissoides.

pinnatifidus, H.B. E K. Nov. Gen. et Sp. iii. 168.Cuba.

pinnatus, Baker, Fl. Maurit. 212, sphalm. vide pennatus.

Pinto, Vand. Fasc. Pl. 9.-Bras.

plantagineus, Choisy, in DC. Prod. ix. $405=$ Ipomoea simplex.

platanifolius, Vahl, Sym. Bot. iii. $26=$ Ipomoea fastigiata.

platensis, Spreng. Syst. i. $591=$ Ipomoea digitata.

platycarpus, Cav. Ic. v. $\mathbf{5 5}=$ Phacelia platycarpa.

platypeltis, Zipp. ex Span. in Linnaea, xv. (1841) $338=$ Ipomoea campanulata.

platyphyllus, Juss. ex Steud. Nom, ed. II. i. 410; ii. $460=$ Rivea tiliaefolia.

plebejus, Spreng. Syst. i. $604=$ Ipomoea plebeia.

plicatus, Desr. in Lam. Encyc, iii. 558.-Afr, austr.

Plumerii, Spreng. Syst. i. 602.-Ins. S. Doming.

pluricaulis, Choisy, Conv. Or. 95.-Ind. or.

polyanthus, Cham. \& Schlecht. in Linnaea, v. (1830) $117=$ Jacquemontia violacea.

polyanthus, Wall. Cat. n. $1378=$ Ipomoea polyantha, staphylina.

polycarpus, H. B. \& K. Nov. Gen. et Sp. iii. $98=$ micranthus.

polyrhizos, Silva Manso, Enum. Subst. Braz. $18=$ Ipomoea polyrhizos.

pomaceus, Wall. Cat. n. 1419 = Argyreia pomacea, nellygheria.

portoricensis, Spreng. Syst. i. $595=$ Ipomoea cathartica.

pratensis, Buch.-Ham. ex Choisy, Conv. Or. $105=$ Ipomoea linifolia. 


\section{CONVOLVULUS:-}

Preissii, De Vriese, in Lehm. Pl. Preiss. i. $346=$ erubescens.

procumbens, Lund, ex Choisy, in DC. Prod. ix. $352=$ Ipomoea polymorpha.

procumbens, Pall. ex Roem. \& Schult. Syst. iv. $295=$ holosericeus.

proliferus, Vahl, Eclog. Am. i. 18.-Am. austr.

proliferus, Willd. ex Roem. \& Schult. Syst. iv. $302=$ Ipomoea tubata.

prostratus, Forsk. Fl. Aegypt. Arab, $203=$ pentapetaloides.

prostratus, F. W. Schmidt, Fl. Boëm. ii. $93=a r$ vensis.

pruinosus, Steud, Nom. ed. II. i. $411=$ Jacquemontia glancescens.

Pseudo-Cantabrica, Schrenk, Enum. Pl. Nov. i. $21=$ dianthoides.

Pseudo-Scammonia, C. Koch, in Linnaca, xxii. (1849) $746=$ C. Scammonia

Pseudo-siculus, Cav. Desc. $97=$ elongatus.

Pseudo-Soldanella, Mer. in A pp. Loisel. ex Bull.

Férussac (1828) 111 = Calystegia Soldanella.

Pseudo-tricolor, Viv. Ann. Bot. i. II. $164=$ tricolor.

pterocarpus, Bert. ex Coll. Hort. Ripul. $37=$ Ipomoea martinicensis.

pterygocaulos, Steud. ex Choisy, in DC. Prod. ix. 381 Ipomoea pterygocanlus.

pubescens, [Soland. in] Russ. Aleppo, ed. II. ii. $246=$ hirsulus.

pubescens, Willd. Enum. Hort. Berol. 203=Ipomoea pubescens.

pudibundus, Lind1. Bot. Reg. t. $999=$ Ipomoea cathartica.

puellaris, Thunb. Mus. Nat. Ups. 168,-Hab.?

pulchellus, H. B. \& K. Nov, Gen. et Sp. iii. $101=$ Ipomoea fastigiata.

pulcher, D. Dietr. Syn. Pl. i. $667=$ Argyreia Guichenotii.

pulcherrimus, Vell. Fl. Flum. 72 ; ii. t. $54=$ Ipomoea Bona-nox.

pungens, Kar. \& Kir. in Bull. Soc. Nat. Mosc. (1841) $709=$ Gortschakovii

puniceus, Silva Manso, Enum. Subst. Braz. $18=$ Ipomoea punicea.

Purga, Wender. in Pharm. Centralb. i. (1830) $457=$ Ipomoea Purga.

purpureus, Linn. Sp. Pl. ed. II. $219=$ Ipomoea

purpurea.
pusillus, Pall. ex Roem. \& Schult. Syst. iv. $295=$ Calverti.

pycnanthus, Hochst. ex Choisy, in DC. Prod. ix. 365 Ipomoea capitata.

pyrrhotrichus, Boiss. Diagn. Ser. II. iii. $122=$ Hausslinechtii.

quadriflorus, Hochst. in Lorent, Wanderungen, 335. As. Min.

Quamoclit, Spreng. Syst. i. $591=$ Ipomoea Quamoclit. quinatus, Spreng. 1. c. $590=$ Ipomuea quinata.

quinqueflorus, Vahl, Symb. Bot. iii. 31.-Ins. Mascar.

quinquefolizs, Linn. Syst. ed. X. $923=$ Ipomoea quinquefolia.

quinquelobus, Lindem, in Bull. Soc. Nat. Mosc. xxiii. (1850) II. $508=$ arvensis.

quinquelobus, Vahl, Symb. Bot. iii, $32=$ Ipomoea palmata.

quinquenervis, Buch.-Ham. ex Wall. Cat. p. 85, n. 1396 = parviflorus.

quinquepartitus, Vahl, Eclog. Am. ii. $14=$ Ipomoea quinquepartita.

racentosus, Roem. \& Schult. Syst. iv. $302=$ Ipomoea staphylina.

radicans, Thunb. Fl. Cap. ii. 15.-Afr, austr.

radicosus, Heldr. E Sart. in Boiss. Diagn. Ser. II. iii. 124.-Graecia.

ramosissimus, Poir. Encyc. Suppl, iii. $468=$ Ipomoea ramosissima.

Rampania, Buch.-Ham. ex Wall. Cat. D. $2251=$ Ipomoen eriocarpa.

refractus, Pomel, Nouv. Mat. Fl. Atl. 84.-Afr. bor.

Reinwardtianus, D. Dietr. Syo. PI, i. $675=$ Argyreia Guichenotii.

remotus, R. Br. Prod. $483=$ erubescens.

reniformis, Cat. Hort, Carlsr. (1811) 76 (Quid ?).

reniformis, Poir. Encyc. Suppl. iii. 475 -Calystegia Soldanella.

reniformis, Roxb, Hort. Beng, 14; Fl. Ind. i. $481=$ Ipomoea reniformis.

\section{CONVOLVUIUU: :-}

repandus, Desr. in Lam. Encyc. iii. $555=$ Ipomoea repanda.

repens, Linn. Sp. P1. $158=$ Calystegia sepium

repens, Sw. Obs. $64=$ I pomoea acetosaefolia.

repens, Vahl, Symb. Bot. i. 17 = Ipomora aquatica.

repens, Willd. Sp. Pl. i. $874=$ Ipomoea reptans.

reptans, Linn. Sp. PI. $158=$ Ipomoea aquatica.

reticulatus, Buch.-Ham. ex Steud. Nom. ed. II. i. 411

$=$ Ipomoea petaloidea.

reticulatus, Choisy, in DC. Prod. ix. 399.-Syria.

retusus, Colla, App. Hort. Ripul. iii. $31=$ Ipomoea biloba.

Retzia, Steud. Nom. ed. II. i. 410.-Ind. or.

Rheedii, Wall, in Roxb. Fl. Ind. ed. Carey, ii. $70=$ Ipomnea uniflora.

rhyniospermus, Hochst. ex Choisy, in DC. Prod. ix 405.-Afr. trop.

Riedlei, Choisy, Conv. Or. $68=$ Ipomoea Turpethum.

riparius, H. B \& K. Nov. Gen. et Sp, iii. $109=$ Ipomoea cissoides.

Robertianus, Spreng. Syst. v. $192=$ Ipomoea heterophylla.

roseus, H. B. \& K. Nov. Gen. Sp. iii. $108=$ Ipomoca digilata.

roseus, Mill. Gard. Dict. ed. VIII. n. 18=Ipomoea fastigiata.

roseus, Pall. Reise, iii. $317=$ lineatus.

rostratus, Zipp. ex Span. in Linnaea, xv. (1841) $339=$

Ipomoea aquatica

Rothii, Spreng. Syst, i. $600=$ Ipomaea cymosa.

Rottleri, Spreng. Syst. iv. Cur. Post. $61=$ Argyrei malabarica.

Rottlerianus, Choisy, Conv. Or. 95.-Ind. or

rotundifolius, Schum. \& Thonn, Fl. Beskr. Guin. Pl $102=$ Ipomoea biloba

Roxburghii, Wall. Cat. n. $1415=$ Argyreia Rox burghii.

Royeni, Steud. Nom. ed. II. i. 410 , in syn $=$ Ipomoea pentaphylla.

rubens, Wall. Cat. n. $1421=$ Lettsomia rubens.

ruber, Vahl, Liclog. Am. ii. 12 =Calystegia setifera.

rubescens, Poir. Encyc. Suppl. iii. $466=$ erubescens.

rubicundus, Wall. Cat. n. $1409=$ Lettsomia rubi cunda.

rubrocoeruleus, D. Dietr. Syn. Pl. i. $670=$ Ipomoea rubrocoerulea.

ruderarius, H. B. \& K. Nov. Gen. et Sp. iii. $96=$ havanensis.

rufescens, Choisy, Conv. Or. 97 = flavus.

rugosus, Rottl, in Ges. Naturf. Fr. Neue Schr. iv.

(1803) $196=$ Ipomoea Beladamboe.

Ruizii, Spreng. Syst. i. $5.94=$ Ipomoea villosa.

rupestris, Buch, Beschr. Canar. Ins. $193=$ Massoni

rupestris, Pall. Reise, iii, $723=$ I pomoea sibirica.

rupestris, Willd. Sp. Fl. i. 846,-sibit.

Ruprechti, Boiss. Fi. Orient. iv, 96.-Reg. Caucas

sabatius, Viv. Fi. Lib. Spec. $67=$ elongatus.

sagittaefolius, Salisb. Prod. $123=$ arvensis.

sagittatus, Dulac, F1. Hautes-Pyr. $439=$ arvensis.

sagittatus, A. Gray, in Syn. F1. N. Am. ii. 1. 434 $=$ hirsutus?

sagittatus, Thunb. Prod. Pl. Cap. 35.-Afr. austr.

sagittifer, H. H. \& K. Nov. Gen. et Sp. iii. $100=$

Ipomoea umbellata.

sagittifolizes, Fisch. ex Choisy, in DC. Prod. ix. $407=$

arvensis.

sagittifolius, Michx. Fl. Bor. Am. i. $138=$ Ipomoea sagittata.

sagittifolius, Schlecht. in Linnaea, xxi. (1848) 747.

Texas.

segittifolius, Sibth, \& Sm. Fl. Graec. Prod. i. 133

Fl. Grace. t. 193 = hirsutus.

salicifolius, Desr. in Lam. Encyc. iii. $543=$ Ipomoca martinicensis.

salicifolius, Roxb. ex Steud. Nom. ed. II. i. $411=$

Ipomoea salicifolia.

Saltii, Stered. $l_{\text {. }} c_{-}=$congestus.

salvifolius, Sieber, ex Link, Enum. Hort. Berol. i. $20 \$$ $=$ secundus.

sangriners, Spreng. Syst. i. $594=$ Ipomoea hederi. folia.

sanguincus, Willd, ex Roem. \& Schult. Syst. iv. 302 Ipomoea sup rba.

sarcocarpus, Silva Manso, Enum. Subst. Braz, 49

Ipomoea operculata.

sarmentosus, Balf. f. in Proc. Roy. Soc. Edinb. xii. (1884) 8i. - Ins. Socotra.

\section{CONVOLVULUS:-}

sarothrocladus, Boiss. E Haussk. ex Boiss. Fl. Orient. iv. 92.-Assyria.

saxatilis, Bieb. F1. Taur. Cauc. i. $146=$ Calverti.

saxatilis, Salisb. Prod. $124=$ Massoni.

saxatilis, Vahl, Symb. Bot. iii. $33=$ lanuginosus.

scamensis, Wall. ex Steud. Nom. ed. II. i. 411

siamensis.

Scammonia, Linn. Sp. Pl. 153. - As. Min.

Scammonia, Lour. Fl, Cochinch. $106=$ calystegioides.

scandens, Delile, Ind. Sem. Hort. Monsp. (1847) 7 Acgypt.

Schicdeanus, D. Dictr. Syn. Pl. i. $670=$ Ipomoea Schiedeana.

Schimperi, Boiss. Diagn. Ser. I. xi. 81.-Aravia.

schirazianus, Boiss. l. c. 82.-Persia.

Schottianus, Dehnh. Cat. Pl. Hort. Camald. ed. II 19

-Hab.?

Schultesii, Roem. \& Schult, ex Steud. Nom. ed. II. i $411=$ Ipomoea purpurea.

Schultesi, Weinw, ex Steud. 1. co = Hewittia bicolor.

scindicus, Boiss. Diagn. Ser. II. iii. $123=$ micro. phyllus.

scindicus, Stocks, in Hook. Kew fourn. iv. (1852) 173.

- Ind. bor. occ

scoparius, Linn. f. Suppl. 135.-Ins. Teneriff.

scrobiculatus, Lindl. Bot. Reg. t. 1076 = Iporaves scrobiculata.

secundus, Desr. in Lam. Encyc, iii. 553.-Aegypt. Syria.

secundus, Ruiz \& Pav. Fl. Per. il. $10=$ Jacquemontia secuncla.

Selloi, Meissn. in Mart. Fl. Bras. vii. 314.-Bras.

Semenovii, Herder, in Bull. Soc. Nat. Mosc. xli.

(1868) r. 74.-Sibir.

semidigynus, Roxb. Hort. Beng. [13] ; Fl. Ind. i. 468 = Breweria cordata.

Senegrmbiae, Spreng. Syst. i. $610=$ Ipomoea Senegambiae.

sepiarius, Wall. Cat. n. $1384=$ Ipomoea sepiaria,

sepincola, St. Lag in Ann. Śoc. Bot. Ljon, vii. (1880' $123=$ Calystegia sepium

sepium, Linn. Sp. Pl. $153=$ Calystegia sepium.

sepium, Pall. Reise, iii. $270=$ arvensis.

septangularis, Steud. Nom. ed. II. i. $411=$ Ipomoea Batalas.

septenatus, Spreng. Syst. i. $591=$ Ipomoea umbellifera. Ser, Sprenc, l, c. 598-Ipomoea sinensis.

sericeus, Burm.f. Fl. Ind. 49. t. 19. f. 3.-Persia

sericeus, Ghoisy, in DC. Prod. ix. $400=$ lanatus.

sericeus, Forsk. Fl. Aegypt. Arab. $203=$ tenuissimus.

sericeus, Linn. Mant. 43=Argyreia mollis.

sericophyllis, T. Anders. in fourn. Linn.

Suppl. i. (1860) 25. - Arab.

serotinus, DC. Cat. Hort, Monsp. 97 = Ipomoea serotina.

serpens, Linn. Syst. ed. X. $923=$ Ipomoea pentaphylla.

serpiculans, Noronha, in Verh. Batav, Ges. v. (1790) ed. I. Art IV. 10.-Malaya?

serpyllifolius, H. B. \& K. Nov. Gen. el Sp. iii. $95=$ Ipomoea serpyllifolia.

serpylloides, Griseb. Cat. Pl. Cub. 207.-Caba. sessiliftorus, Spreng. Syst. i. $599=$ I pomoea eriocarpa. setifer, Spreng. 1. c. $597=$ Calystegia setilera.

setosus, Spreng. I. c. 594= Argyreia seto-a.

setosus, Wall. Cat, n. 1412 = Letrsonia serosa.

Sherardi, Pursh, Fl. Am. Sept. ii. $30=$ micranthus.

Shumardianus, Torr. Bot. Expl. Red Riser (1852: 201 -Am. bor.

siamensis, Hall. Cat. n. bibs.-Simm.

sibiricus, Linm. Mant. ii. 2018 = Ipomuca sihirica.

Sibthorpii, Roem. \& Schult. Sist. jv. $235=$ hirsutus.

siculus, Linn. Sp. Pl.156.-Keg. Merliterr.

sidaefolius, H. B. \& K. Nor. Gen. st Sp. iii. 99 I pomoca tubata.

simplex, liuck. Ind. DC. Prod, jiil. 115 = plantagineus

simplex, Pers. Syn. i, 1;8 - I pomoca angustifulia.

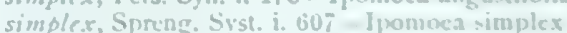

sine'ssis, Dest, in Lam. Lincye. iji. $53^{\circ}=$ Ipomuca

sincensis.

simuabus, Xices, ex G. Don, Gen. Syst. iv. 27001 promoca Dippeana.

sinmulus, Ietagna, ex Sicud. Niom. ed, II. i. \11 Ipomuea camusa.

sinualus, Srigccle, in Linmenen, xxi. 15ts -;

Texas.

Sloanei, Spreng. Syst. L 593 - Ipomuea trilutu. 


\section{CONVOLVUIUS:}

smilacifolius, Salisb. Prod, $124=$ Ipomoea muricata sogdianus, Bunge, Reliq. Lehm. Bot. $219=$ pilosellae folius.

solanifolius, Lowe, in Trans. Camb. Phil. Soc. iv. 1831) $22=$ Massoni.

solanifolius, Spreng. Syst. i. 596=Ipomoea solanifolia.

Soldanella, Despr. ex Choisy, in DC. Prod. ix. 345 (= Pharbitis Preauxii).-Ins. Canar.

Soldanella, Linn. Sp. PI. 159 = Calystegia Soldanella. somalensis, Franch. in Révoil, Comali, 43,-Afr. trop somalensis, Vatke, in Linnaea, xliii. (1880-82) 517.Afr. trop.

speciosus, Linn. f. Suppl. 137=Argyreia speciosa. speciosus, Walt. Fl. Carol. $93=$ Ipomoea sagittata spectabilis, Hort. Brit. ex Steud. Nom. ed. II. i. $411=$

Rivea tiliaefolia.

sphaerocephalus, Roxb. Hort. Beng. 14 ; F1. Ind. i. 472 = eriocarpa.

sphaerostigma, Cav. Ic. v. 54. t. 481= Jacquemontia hirsuta.

spicaefolius, Desr. in Lam. Encyc. iii. $549=$ lineatus. spicaefolius, Buch.-Ham. ex Wall. Cat. p. 83. n. 1316 $=$ pluricaulis.

spinosus, Burm.f. Fl. Ind. 47. t. 19. f. 4.-Persia.

spinosus, Desr. in Lam. Encyc. iii. $548=$ fruticosus. spinosus, Forsk. Fl. Aegypt. Arab. p. cvi = Hystrix. spiralis, Willd. ex Roem. \& Schult. Syst. iv. $302=$ nodiflorus.

spithamaeus, Linn. Sp. Pl. 158.-Am. bor.

splendens, Hornem. Hort. Hafn. Suppl. $123=$ Argyreia splendens.

Sprengelii, Choisy, in DC. Prod. ix. 416-- Hab. ? stachydifolius, Choisy, l. c. 408.-Syria; Mesopotam. stans, H. B. \& K. Nov. Gen. et Sp. iii. $96=$ Ipomoea

stans.
stans, Michx. Fl. Bor. Am. i. 136=spithamaeus. stans, Michx. Fl. Bor. Am. $1.136=$ spitha
stellaris, Salisb. Prod. $124=$ Hermanniae.

stellatus, Brot. ex Heynh. Nom. ii. 158, nomen.Hab.?

stenophyllus, Boiss. Fl. Orient. iv. 106.—Syria.

stipulaceus, Roxb. Hort. Beng. 14; Fl. Ind. i. $484=$

Ipomoea sepiaria,

stipulatus, Desr. in Lam. Encyc. iii. 546=Ipomoea dissecta.

Stocksii, Boiss. Fl. Orient. iv. 110.-Beluchist.

stoloniferus, Cyrilli, Pl. Rar. Neap. i. 14. t. $5=$ Ipomoea

carnosa.
striatus, Vahl, Symb. Bot. iii. $28=$ Ipomoea sepiaria.

strictus, Lehm. Ind. Sem. Hort. Hamb. (1823) $17=$ undulatus.

strictus, Willd. ex Steud. Nom. ed. II. i. $412=$ Ipomoea murucoides.

strigosus, Russell, ex Wall. Cat. n. $2259=$ Argyreia Leschenaultii.

strigosus, Spreng. Syst. i. $600=$ Lettsomia setosa. strigosus, Wall. Cat. n. 1365 = Lettsomia strigosa. strigulosus, Boiss. Diagn. Ser. I. xi. $83=$ assyricus. suaveolens, Mart. \& Gal. in Bull. Acad. Brux, xii. II. (1845) 261 = Ipomoea suaveolens.

subacaulis, Buch.-Ham. ex Wall Cat. sub n. $2256=$ Ipomoea barlerioides.

subangularis, Buch.-Ham. ex Steud. Nom. ed. II. i $412=$ Ipomoea obscura.

suberosus, Willd. Enum. Hort. Berol. Suppl. 10= Massoni.

subglobosus, G. Don, Gen. Syst. iv, 293.-Cochinch.

subhirsutus, Regel \& Schmalh. in Act. Hort. Petrop. vi. (1879) 338, 339.-Turkestan.

sublobatus, Linn. f. Suppl. $135=$ Hewittia bicolor.

subpinnatifidus, De Vriese, in Lehm. Pl. Preiss. i. 347 = erubescens.

subpubescens, Meyen, ex Walp. in Nov. Act. Nat. Cur. xix. Suppl.i. (1843) $367=$ incanus.

subsericeus, Schrenk, Enum. Pl. Nov. i. 19.-Sibir. altaic.

subsessilis, Steud. Nom. ed. II. i. $4 \mathbf{1 2}=$ Jacquemontia subsessilis.

subspathulatus, Vatke, in Linnaea, xliii. (1880-82) 520.-Afr. trop.

subulatifolius, Noronha, in Verh. Batav. Gen. v. (1790) ed. I. Art. IV. 10.-Malaya.

subviscidus, Steud. Nom. ed. II. i. 412.-Chili

subvolubilis, Ledeb. F1. Alt. i. 222, in nota =Caly stegia subvolubilis.

suffruticosus, [Dryand. in] Ait. Hort. Kew.ed.II. 1. 331 = Massoni.

\section{CONVOIVULUS:}

suffruticosus, Desf. Fl. Atlant. i. 175. t. 48.-Afr. bor suffultus, H. B. \& K. Nov. Gen. et Sp. iii. 102. t. 211 $=$ Ipomoea suffulta.

sulphureus, La Llave, in Nov. Veg. Desc. fasc. i. $17=$ Ipomoea corralinensis.

superbus, H. B. \& K. Nov. Gen. et Sp. iii. $103=$ Ipomoea superba.

supinus, Coss. E Kral. in Bull. Soc. Bot. Fr. iv. (1857) 397,487 , nomen.-Algeria.

sylvaticus, Spreng. Syst. i. $602=$ Calystegia sylvatica sylvestris, Waldst. \& Kit. Pl. Rar. Hung. iii. $290=$ Calystegia sylvatica.

tamnifolius, G. F. W. Mey. Prim. Fl. Esseq. $95=$ Jacquemontia tamnifolia.

tamnifolius, Willd. ex Roem. \& Schalt. Syst. iv. $301=$ Ipomoea eriocarpa.

Tarita, Buch.-Ham. ex Wall. Cat. n. $2253=$ Rivea ornata.

tenellus, Desr. in Lam. Encyc. iii. $559=$ Breweria humistrata.

tenellus, Stocks, in Hook. Kew Journ. iv. (1852) 1/2 $=$ Stocksii.

tenuiflorus, Steud. Nom. ed. II. i。 $412=$ Jacquemontia parviflora.

tenuifolius, Buch.-Ham. ex Wall. Cat. p. 84, n. 1354 $=$ Ipomoea pentaphylla.

tenuifolius, Heyne, ex Wall. 1. c. n. $1353=$ Ipomoea palmata.

tenuifolius, Mart. E Gal. in Bull. Acad. Brux. xii. II. 1845) 260.-Mexic

tenuifolius, Vahl, Symb. Bot. iii. $33=$ Ipomoea quinata.

tenuirostris, Steud. ex Choisy, in DC. Prod. ix. $380=$ Ipomoea tenuirostris.

tenuissimus, Sibth. E Sm. Fl. Graec. Prod. i. 134; Fl. Graec, t. 195.-Europ. austr.; Afr. bor.

terminalis, Salisb. Prod. $125=$ cantabrica.

ternatus, Spreng. Syst. i. $590=$ Ipomoea ternata.

ternifolius, Spreng. 1. c. $613=$ Ipomoea ternifolia.

terrestris, Linn. Sp. Pl. ed. II. 224 = cantabrica.

thalassicus, Stend. Nom. ed. II. i. $412=$ Ipomoea

littoralis.

Thonningii, Schum, \& Thonn. Beskr. Guin. P1. $98=$ Ipomoea dissecta.

Thunbergii, Roem. E Schult. Syst. iv. 268.-Afr, austr.

tiliaceus, Willd. Enum. Hort. Berol. $203=$ Ipomoea fastigiata.

tiliaefolius, Desr. in Lam. Encyc. iii. 544=Argyreia tiliaefolia.

timorensis, D. Dietr. Syn. Pl. i. $667=$ Hewittia bicolor.

tomentosus, Choisy, in DC. Prod. ix. $413=$ hirsutus.

tomentosus, Linn. Sp. Pl. 156--Jamaica.

tomentosus, Vell. Fl. Flum. 74 ; ii. t. $65=$ Ipomoea acuminata.

Tournefortii, Sieber, ex Spreng. Syst.' i. $611=$ oleae folius.

tragacanthoides, Turcz. in Bull. Soc. Nat. Mosc. v. 1832) 201.-Mongolia.

translucens, Seem. in Fourn. Bot. vii. (1869) 165.Mongolia.

trianthus, Spreng. Syst. i. $598=$ Ipomoea sepiaria ?

trichocalyx, Schum. \& Thonn. Beskr. Guin. P1. 91 =Ipomoea ochracea.

trichocalyx, Zoll. \& Mor, in Nat. en Geneesk. Arch. Nêerl. Indie, ii. (1845) $6=$ Ipomoea pileata.

trichocarpus, Spreng. Syst. i. $593=$ Ipomoea commutata.

trichophorus, Wall. Cat. n. 1423=Ipomoea cissoides. trichosanthes, Michx. Fl. Bor. Am. i. 137 $=$ Breweria humistrata.

trichotosus, D. Dietr. Syn. Pl. i. $670=$ Argyreia capitata.

tricolor, Linn. Sp. Pl. 158.-Europ. austr.

tricornutus, Noronha, in Verh. Batav. Gen. v. (1790) ed. I. Art. IV. 10,-Malaya.

tridentatus, Linn. Sp. Pl. 157 = Ipomoea tridentata

trifidus, H. B. \& K. Nov. Gen. et Sp. iii. $107=$ Ipomoea trifida.

triflorus, Pav. ex Choisy, in DC. Prod. ix. $340=$ Ipomoea quinquefolia.

triforus, Phit. in Linnaea, xxxiii. (1864-65) 183.Chili

triflorus, Vahl, Symb. Bot. iii. $30=$ Ipomoea sepiaria.

trigonus, Buch.-Ham. ex Wall. Cat. p. 84, n. 1383 =Ipomoea obscura.

\section{CONVOLVUIUS:-}

trilobus, Desr. in Lam. Encyc. iii. $564=$ Ipomoea triloba.

trilobus, Thunb. Prod. Pl. Cap. 35.-Afr, austr.

trinervis, Thunb. Fl. Fap. 85.-Japon.

triqueter, Rehm. ex Boiss. Fl. Orient. iv. $94=$ Calverti.

triqueter, Vahl, Symb. Bot. iii. $30=$ Ipomoea Turpe thum.

triquetrus, Vell. F1. Flum. 71; ii. t. $53=$ Ipomoea batatoides.

truncatus, Vell. $l . c, 74$; ii. t, 74,-Bras.

Tuba, Schlecht, in Linnaea, vi. (1831) $735=$ Ipomoea grandiflora.

tuberculatus, Desr. in Lam. Encyc. iii. 545=Ipomoea palmata.

tuberifer, Steud. Nom. ed. II. i. $412=$ Ipomoea Batatas.

tuberosus, Spreng. Syst. i. $591=$ Ipomoea tuberosa.

tuberosus, Vell. F1. Flum. 72 ; ii. t. $57=$ Ipomoea Batatas.

Tuckeyanus, Steud. Nom, ed. II. i.407.lin. 1.-Afr. trop tuguriorum, Forst. f. Prod. $14=$ Calystegia tuguriorum.

turbinifolius, Hort. Bonon. ex Pasq. Cat. Orto Bot. Nap. 81, nomen.-Hab.?

Turpethum, Linn. Sp. Pl. $155=$ Ipomoea Turpethum. uliuinus, Boiss. Diagn. Ser. I. vii. 26.-Arabia. umbellatus, Linn. Sp. Pl. $155=$ Ipomoea umbellata. umbellatus, Wall. Cat. n. $2329=$ I pomoea cymosa. undulatus, Cav. Ic iii. 39. t. 277. f. 1-Reg. Mediter uniflorus, Burm. f. Fl. Ind. $47=$ Ipomoea unifora.

unilateralis, Roem. \& Schuit. Syst. iv. $284=$ Jacque montia secunda.

urbicus, Salzm. ex Choisy, in DC. Prod. ix. $350=$ Ipomoea asarifolia.

urceolatus, Spreng. Syst. i. $601=I$ pomoea urceolata.

Vahlii, Roem. E Schult. Syst. iv, 280.-Bras.

Vahlii, Spreng. Syst. i. $611=$ Ipomoea chryseides.

valentinus, Cav. Ic. ii. 65. t. 180. f. 2.-Hispan.

valentinus, Hort. ex Steud. Nom. ed. II. i. $412=$ Ipomoea sagittata.

valenzuelanus, A. Rich. Fl. Cub. Fanerog. ii. $134=$ havanensis.

valerianoides, Blanco, Fl. Filip. ed. I. $90=$ Evolvulus alsinoides.

variabilis, Cham. \& Schlecht. in Linnaea, v. (1830 $116=$ Ipomoea variabilis.

variabilis, Weinm, ex Steud. Nom. ed. II. i. $412=$ dissectus.

variifolius, Steud. 1. c. =I Ipomoea hederacea.

varius, Vell. Fl. Flum. 73 ; i. t. $61=$ Ipomoes Batatas.

velutinus, Spreng. Syst. i. $601=$ Ipomoea velutina.

venenatus, West, Bidr. Ste-Croix, 271.-Ins. S. Crux.

venosus, Desr, in Lam, Encyc. iii. $566=$ Ipomoea venosa.

venosus, Herb. Madr. ex Wall. Cat. p. 84 , n. $1353=$ Ipomoea palmata.

ventricosus, Bert. ex Colla, Hort. Ripul. $37=$ Ipomoea ventricosa.

ventricosus, Silva Manso, Enum, Subst. Braz. 20 . Ipomoea silvana.

venulosus, Ehrenb. ex Boiss. Fl. Orient. iv. $10 \tau=$ stachydifolius.

venustus, Spreng. Syst. i. $600=$ Ipomoea tricolor. verrucipes, Tenore, Ind. Sem. Hort. Neap. $(\mathbf{1 8 4 0})$ Ipomoea verrucipes.

verrucosus, D. Dietr. Syn. Pl. i. $670=$ Ipomoes verrucosa.

versicolor, Salisb. Prod. $125=$ tricolor

verticillatus, Linn. Sp. Pl. ed. II. $220=$ Jacquemontia hirsuta.

vestitus, Wall. Cat. n. $1411=$ Lettsomia bella?

villosulus, D. Dietr. Syn. Pl. i. $667=$ Ipomoea villosula.

villosus, A. Gray, in Proc. Am. Acad. xi. (1876) 90.Calif.

villosus, Pers. Syn. i. 177 = Jacquemontia tamnifolia

violaceus, Spreng. Syst. i. $599=$ Ipomoea violacea.

violaceus, Vahl, Symb. Bot. iii. $29=$ Jacquemontia violacea.

virgatus, Boiss. Diagn. Ser. I. vii. 24.-Persia ; Arab. viscidus, Roxb. Hort. Beng. 14, nomen = Ipomoea tridentata.

vitifolius, Burm. f. Fl. Ind. $45=$ Ipomoea vitifolia.

vittatus, Zipp, ex Span. in Linnaea, xv. (1841) $340=$ Ipomoea palmata. 


\section{CONVOLVULUS}

volubilis, Brouss, ex Link, in Buch, Beschr. Canar. Ins. $145=$ Massoni.

Wallichianus, Spreng. Syst. iv. Cur. Post. $61=$ Calystegia hederacea.

waltherioides, Boiss. E Haussk. ex Boiss. Pl. Or. Nov. dec. i. 6.-Persia.

Wheleri, Vahl, Symb. Bot. ii. $36=$ Ipomoea sagittata.

Wightii, Wall. Pl. As. Rar. ii. 55. t. 171=Ipomoea Wightii.

Willdenowii, Steud. Nom. ed. II. i. $412=$ Ipomoea heterophylla.

seylanicus, Hook, ex Steud. 1. c. =Argyreia populifolin.

zeylanicus, Moon, ex Wall. Cat. n. $1379=\mathbf{I}$ pomoea sidaefolia

Zollingeri, Choisy, in Zoll. Syst. Verr. Ind. Archip. 130, 132. - Ins. Saraja.

CONYSA, Burm. f. Fl. Ind. $180(1768)=$ Conyza, Linn. (Compos.).

CONYSTYLUS, Pritz. Ic. Index, ii. $90(1866)=$ Gonystylus, Teijsm. \& Binn. (Thymel.)

CONYZA, Linn, Gen, ed. I. 251 (1737); Less, Syn, Comp. 203 (1832), COMPOSITAE, Benth. \& Hook. f. ii. 283.

Dimorphanthes, Cass. in Bull. Soc. Philom. (1818) 30 ; et in Dict. Sc. Nat. xiii. 254 (1819).

Edemias, Rafin. Fl. Tellur. ii. 49 (1836).

Eschenbachia, Moench, Meth. 573 (1794).

FxMBKILlakia, Cass. in Bull. Soc. Philom. (1818)

31 ; et in Dict. Sc. Nat. xvii. 54 (1820).

Fragmosa, Rafin. Fl. Tellur. ii. 50 (1836).

I.AENNECIA, Cass. in Dict. Sc. Nat, xxv. 91 (1822)

Marsed, Adans. Fam. ii. 122 (1763)

Musteron, Rafin. Fi. Tellur. ii. 50 (1836).

Pinardia, Neck, ex Steud. Nom, ed. II. i. 412 (1840).

TUBIFERA, DC. ex Steud. 1. c. (1840).

Webria, Sch. Bip. in Walp. Rep. ii. 970 (1843) abbreviata, Wall. Cat. n. $3048:=$ Vernonia cinerea. absinthifolia, DC. in Wight, Contrib. $16=$ stricta abyssinica, Sch. Bip. ex A. Rich. Tent. Fl. Abyss. i. 890.-Geront. trop.

acrocepbala, Miq. Fi. Ind. Bat. ii. 43.-Malaya. acuminata, Wall. Cat. n. $3034=$ Vernonia arborea acutata, Miq. Fl. Ind. Bat. ii. $48=$ Blumea laciniata. adenocarpa, Dals. E Gibs. Bomb. Fl. 125.-Ind. or. adnata, $H . B . \&$. Nov. Gen. et Sp. iv, 74.Mexic.

Mexic. 183.-Aegypt.

aegyptiaca, Hook. f. \& Thoms, ex Fl. Brit. Ind. iii. $254=$ Erigeron asteroides.

ageratoides, DC. Prod, v, 385,-Madag.

alata, Baumg. Enum. Transsyl. iii. $102=$ Inula bifrons alata, Roxb. Hort. Beng. 61 ; Fl. Ind. iii, $430=$ Laggera alata.

albicans, Wall. Cat, n. $\$ 072=$ Vernonia albicans.

albida, Willd. ex Spreng. Syst. iii. $514=$ Erigeron

bonariensis.

alopecuroides, Lam. Encyc. ii. 93 ; Sw. Fl. Ind. Occ. iii. $1344=$ Pterocaulon virgatum.

altaica, DC. Prod. v. $380=$ Aster angustus.

ambigua, DC. Fl. Fr. Suppl. $468=$ Erigeron unifolius. ambigua, Hook. \& Arn, in Bot. Beech. Voy. 57= chilensis.

amboinica, Crants, Inst. i. 272.-Amboina.

amoena, Link, Enum. Hort. Berol. ii. $822=$ Blumea lacera.

amorphoglossa, Boiss. Diagn. Ser. I. vi. $81=$ Erigeron amorphoulossus.

amplectens, Wall. Cat. n. $3096=$ Blumea amplectens. amplexicaulis, Lam. Encyc. ii. $84=$ Blumea an plectens.

amplexicaulis, Michx. Fl. Bor, Am. ii, 126 = Plachea bifrons.

amplexicaulis, Wall. Cat. n. $8104=$ Blumea bifoliata. amygdalina, Lam. Encyc, ii. 90.-Ins. Mascar.

amygdalina, Spreng. ex DC. Prod. vi. $446=$ Blume densiflora.

anagallidifolia, Wall. Cat. n. $3098=$ Blumea bifolinta.

anchusaefolia, Poir. Encyc. Suppl. ii. 399.-Ins.

Mascar.

andina, Remy, in C.Gay, Fl. Chil. iv, 72-Cbili.

\section{CONYZA :-}

andryaloides, DC. Prod, v. 377=Erigeron andrya loides.

angustifolia, Hort. Par, ex DC. 1. c. $420=\mathrm{Bac}$ charis Pingraea.

angustifolia, Nutt. in Journ. Acad. Philad. vii. (1834 $109=$ Pluchea bifrons?

angustifolia, Roxb. Hort. Beng. 61 ; Fl. Ind. iii. 429.Reg. Himal.

angustifolia, Steud. Nom.ed. I. $221=$ Monarrhenus salicifolius.

angustifolia, Thw. ex Hook. f. F1. Brit. Ind. iii. 254 $=$ Erigeron linifolius.

anthelmintica, Linn. Sp. Pl. ed. II. $1207=$ Vernonia anthelmintica.

appendiculata, Blume, Bijdr. $895=$ Blumea balsamifera appendiculata, Lam. Encyc. ii. $88=$ Senecio appendi culatus.

apurensis, H. B. \& K. Nov. Gen. et Sp. iv. $73=$

Erigeron apurensis.

arabica, Willd. Sp. Pl. iii, 1949-Arab.

arabidaefolia, Remy, in C. Gay, Fl. Chil. iv. 76.Chili.

arborea, Wall. Cat. n. $3074=$ Vernonia arborea.

arborescens, DC. Prod.v. 344, in syn. cum cit. falsa $=$ Commidendron spurium?

arborescens, Linn. Syst. ed. X. $1213=$ Vernonia ar borescens.

arbutifolia, Lam. Encyc. ii. 92 = Baccharis arbutifolia.

argentea, Lam. l. c. 87.-Ins. Mascar.

argentea, Yerr. \& Lepyr. ex DC. Prod.v. $449=$ Laggera aurita.

argentea, Wall. Cat. n. 3014=Inula Cappa

arguta, Less. in Linnaea, vi. (1831) 138,-Bras.

argutidens, $\mathrm{Miq}$. Fl. Ind. Bat. ii. 58.-Malaya.

aromatica, Wall. Cat. n. $3054=$ Blumea aromatica

artemisiaefolia, Meyen $\xi^{\circ}$ alp. in Nov. Act. Nat. Cur. xix. Suppl. i. (1843) 262.-Peruy.

artemisioides, Sch. Bip. ex Baker, in Mart. Fl. Bras, vi III. $63=$ Baccharis rufescens

articulata, Lam. Encyc. ii. $94=$ Baccharis articulata. arvensis, Phil. in Linnaea, xxxiii. (1864-65) 143. Chili.

aspera, Bory, Voy. iii. $174=$ melastomoides.

aspera, Wall, ex Steud. Nom. ed. II. i. $413=$ Vernonia Roxburghii.

asperifolia, Benth. Ev Hook. f. Gen. ii. 284.-Guatemala.

asperula, Phil. in Linnaea, xxviii. (1856) 736.-Chili asteroides, Desf. Tabl. ed. II. (1815) $114=$ Pluchea subdecurrens.

asteroides, Host, ex Beck, in Denkschr. Acad. Wien, Math. Nat. xliv. (1882) 332 = Inula bifrons. asteroides, Linn. Sp. Pl. $861=$ Sericocarpus conyzoide asteroides, Wall. Cat. n. $3052=$ aegyptiaca. asteroides, Wall. ex Steud. Nom. ed. II. i. $413=$ Chrysopsis gossypina.

attenuala, $D C$. Prod. v. 384.-Madag.

attenuata, Wall. Cat. n. $3020=$ Vernonia attenuata. Aucheri, DC. Prod. vii. $281=$ Erigeron Aucheri. aurea, Perr. ex DC. 1. c. . $68=$ Vernonia sene galensis.

auriculata, Moench, Meth. Suppl. 235=Phagnalon rupestre.

aurita, Heyne, ex DC. Prod. v. $441=$ Blumea lacera aurita, Linn.f. Suppl. 867.-Nubia.

axillaris, Hornem. ex Willd. Enum. Hort. Berol. 871. -Afr. occ.

axillaris, Lam. Encyc, ii. $84=$ Blumea lacera.

Baccharis, Mill. Gard. Dict, ed. VIII, 0, 16.-Hon duras.

baccharoides, Sch. Bip. ex A. Rich. Tent. Fl. Abyss. $390=$ Pluchea Dioscoridis

balsamica, Wall. ex DC. Prod, v. $319=$ Psiadia bal samica.

balsamifera, Linn. Sp. Pl. ed. II. $1208=$ Blumea bal samifera.

barbata, Wall, Cat. n. 3099 - Blumea barbata,

bellidifolia, Baker, in Gourn. Bot. xx. (1882) 169. Madng.

bellidifolia, Wall. Cat. n. 3048 Vernonia cinerea.

Berteruana, Phil. in Linncea, xxviii. (1856) 737. Chili.

bidentata, Stcud. Nom. ed. I. $222=$ calocephala.

bifoliata, Cham. \& Less, in Linnnea, vi. (1831) 195

Blumen Wighriona.

bifoliata, Linn. Sp. Pl. $862=$ Blumen bifoliala.

\section{CONYZA :}

bifoliata, Walt. Fl. Carol. 204=Sericocarpus torti. folius.

bifoliolata, DC. Prod, v. $435=$ Blumea Wightiana bifrons, Linn. Sp. Pl. 861; Gouan, Hort. Reg. $436=$ Inula bifrons.

bifrons, Pursh, FI. Am. Sept. ii. $524=$ Pluchea bifrons. Bilbaoana, Remy, in C. Gay, Fl. Chil. iv. $76=$ Erigeron canadensis.

Blanchetii, Baker, in Mart. Fl. Bras. vi. III. 36.Bras.

blanda, Wall. Cat. n. $3033=$ Vernonia blanda

Bojeri, DC. Prod.v. 384.-Madag.

Bovei, DC. in Ann. Sc. Nat. Sér. II i. (1834) 261. Erigeron Bovei.

bovina, Buch.-Ham, ex DC. Prod, vo $444=$ Blumea oxyodonta.

bracteolata, Rottl. ex DC. 1. c. $434=$ Blumea bifoliata. bracteolata, Wall. Cat. n. $3036=$ Vemonia subsessilis brasiliensis, Steetz, in Peters, Reise Mossamb. Bot. 455 = Epaltes brasiliensis.

britannica, Rupr. Fl. Ingric. $569=$ Inula britannica. bryoides, Lam. Encyc. ii. $91=$ Baccharis bryoides. burmeana, Miq. Fl. Ind. Bat. ii. 44.-Burma.

Bustilloziana, Remy, in C. Gay, Fl. Chil. iv. 72 Chili.

buxifolia, Lam. Encyc. ii. 92 = Baccharis buxifolia caffra, DC. Prod. v. $381=$ Blumea natalensis. calocephala, Bory, Voy. ii. 395.-Ins. Borbon. callosa, Klatt, in Decken, Reise Ost-Afr. iii. 76. Afr. trop.

calycina, Cav, in Anal. Cienc. Nat. iv. (1801) 87

Yhagnalon rupestre.

camphorata, Pursh, F1. Am. Sept. ii. $523=$ Pluchea camphorata

canariensis, Willd. Sp. Pl. iii. $1937=$ Inula candida

candicans, Wall. Cat. $\mathrm{n} .2999=$ Leucomeris spectabilis. candida, Linn. Sp. Pl. $80^{\circ} 2=$ Inula candida.

Candolleana, Boiss. Fl. Orient. jii. $21 \bar{i}=$ Pluchea W'allichiana.

canescens, Bory, ex DC. Prod. v. 473 (= Schisogyne sericea).-Ins. Canar.

canescens, Linn. f. Suppl, $367=$ Vernonia pinifolia.

canescens, Phil. in Linnaea, xxviii. (1856) 734.Chili.

canescens, Thunb. Fl. Cap. $655=$ Vernonia pinifoliz.

capitata, Spreng. Neue Entdeck. ii. $141=$ Vanillosmopsis capitata.

Cappa, Buch.-Ham. in D. Don, Prod. Fl. Nep. $176=$ Inula Cappa.

caprariaefolia, Willd. ex Steud. Nom. ed. II. i. 413. Hab. ?

cardaminaefolia, H. B. E K. Nov. Gen. et Sp. iv. 71.Ecuador.

carolinensis, Jacq. Ic. Rar, iii. t. $585=$ Pluchea odorata cataphracta, Willd. ex DC. Prod. v. $427=$ Baccharis cataphracta.

cayennensis, Spreng. Syst iii. 512.-Guian.

celebica, Sch. Bip. in Zoll. Syst. Vers. Ind. Archip. 122. - Ins. Celebes.

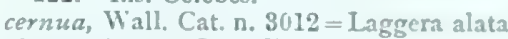

chenopodiifolia, Lam. Encyc. ii. 85 - Gynura mauritiana. chenopodivides, DC. Prod, $\vee .379=$ Erigeron bonariensis, chilensis, Spreng. Nor. Proos. 14.-Chili.

chinensis, Lam. Encyc. ii. $88=$ Vemunia chinensis

chinensis, Linn. Sp. Pl. $862=$ Blumea chinensis.

chinensis, Pers. Syn. ii. $426=$ Lourierii.

Chingoyo, H. B. \& K. Nov. Gcn. et Sp. iv. 70. 1. 928 = Pluchea Chingoyo.

chrysocuma, Vatke, in Brement Abl, is I...: Madag.

hrysocomoides, Desf. Fl. Atlant. ii. 209. ¿. 23: Nolletia chrysocomoides,

chrysocomoides, Desf. Hist. Arb. i. 292 Velicia angustifolia.

chrysocomoides, Tenore, ex Stcud. Num. ed. II. i. 119 = procumbens.

cichoriffolia, Miq. Fl. Ind. 13at. ii. ti - Blumea laciniata.

ciliaris, Spreng. . Vion. Prot. 1f.-Hab.

cinerarivides, Boj. ex IIC. Prod, v. $813=$ Kochonia cineraniobeles

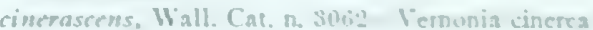
cinereo, Linn. Sp. Pl. Sien = lemonis cineres

clarenceana, Olisere \& Miem, in (Diser. Ei, Trwa of iii. $\$ 16 .-A l r$. troy.

clephrarfolia. Willd. ex Kaber, in Mar. Fl. Mras vi. II. 100 - Vernunt.i siabra 


\section{CONYZA}

collina, Phil. in Linnaea, xxxiii. (1864-65) 144.Chili.

communis, Wall. Cat, n. $3018=$ Blumea hieracifolia. concava, Spreng. ex Steud. Nom. ed. II. i. $413=$

Baccharis concava.

congesta, Spreng. ex DC. Prod. v. $383=$ japonica.

conica, Poir. Encyc. Suppl. ii. 341.-Hab.?

consanguinea, Phil. in Linnaea, xxxiii. (1864-65) 142. Chili.

conspicua, Wall. Cat. n. $3066=$ Microglossa albescens, coronipifolia, $H$. B. \& $K$. Nov. Gen. et Sp. iv. 70.Mexic.

Coronopus, Lam. Encyc. ii. $89=$ Psiadia Coronopus. Cortesii, H. B. E K. Nov. Gen. et Sp. iv. 75.-Mexic. corymbosa, Mill. Gard. Dict. ed. VIII. n. 7.-Mexic. corymbosa, Roxb. Hort. Beng. 61 ; Fl. Ind. iii. $426=$ Pluchea indica.

costata, Harv. in Harv. Eo Sond. Fl. Cap. iii. 114.Afr. austr.

Cotoneaster, Willd. ex Spreng. Syst. iii. $509=$ Vernonia Cotoneaster.

Coulteri, A. Gray, in Proc. Am. Acad. vii. (1868) 355. -Am. bor. occ.

Coulteri, Rothr. in Wheeler, Rep. $155=$ Erigeron subdecurrens.

crispa, Rupr. in Bull. Phys.-Math. Acad. Pétersb. xiv. (1856) $235=$ Erigeron linifolius.

crispata, Vahl, Symb. Bot. i. 71.-Arabia.

ctenoptera, Kunth, Ind. Sem. Hort. Berol. (1845) $12=$ Laggera pterodonta.

cuneata, Boj. ex DC. Prod. v. $345=$ Rochonia cuneata. cuneata, Buch.-Ham. ex DC. 1. c. 384 = absinthifolia cuneifolia, Lam. Encyc, ii. 91 = Baccharis cuneifolia. cuneifolia, Raeusch. Nom. ed. III. $240=$ Commidendrum spurium.

cuneifolia, Wall. Cat. n. 3101=Blnmea lacera.

cupressiformis, Lam. Enc)c. ii. 91; Illustr. t. $697=$ Lepidophyllum cupressiforme.

Dampieri, A. Cunn. ex DC. Prod. マ. 266=Olearia axillaris.

dasycoma, Miq. F1. Ind. Bat. ii. $56=$ Blumea densiflora.

decurrens, Linn. Sp. Pl. ed. II. 1206.-Ind. or.

densifiora, Heyne, in Wall. Cat. n. $2997=$ Blumea densiflora.

dentata, Blanco, Fl. Filip. ed. I. $629=$ Inula Cappa. dentata, Willd. Sp. Pl. iii. 1928.-Afr. trop.

dichotoma, Pers. Syn. ii. $428=$ Jasonia di hotoma diffusa, Poir. Encyc. Suppl. ii. 338= Gouani.

diffusa, Roxb. Hort. Beng. 61; F1. Ind. iii. $429=$ Blumea membranacea.

dilatata, Steud. Nom. ed. I. $222=$ laurifolia,

Dioscoridis, Desf. Tabl.ed. II.114= Pluchea Dioscoridis discolor, Bory, ex DC. Prod. vi. $376=$ Senecio appendiculatus.

disticha, Heyne, in Wall. Cat. n. $3024=$ viscidula.

disticha, Spreng. Syst. iii. 509.-Am. austr.

divaricata, Spreng. 1. c. $508=$ Vernonia diffusa.

divergens, Wall. Cat. n. $3027=$ Vernonia divergens

diversifolia, Weinm. in Flora, iii. (1820) $611=\mathrm{chi}$ lensis.

domingensis, Willd. ex DC. Prod.v. $389=$ lucens

dongolensis, Delile, Pl. Afr. Voy. Méroé, i. 43.-Nubia. dumetorum, Phil. in Linnaea, xxxiii. (1864-65) 144 -Chili.

echinoides, A. Rich. Tent. F1. Abyss. i. $388=$ aegyptiaca. elaeagnifolia, Wall. Cat. n. $3041=$ Vernonia elaeagnifolia.

elata, Kunth Eo Bouché, Ind. Sem. Hort. Berol. (1848) 14.-Bras.

elegantula, Wall. Cat, n. $3049=$ Vernonia cinerea. elongata, Wall. 1. c. n. $3078=$ Blumea elongata. ericoides, Lam. Encyc. ii. $92=$ Liabum ericoides. erigeroides, DC. Prod. จ. $378=$ Erigeron bonariensis. eriophora, Wall. Cat. n. $3013=$ Intla Cappa.

erosa, Blanco, Fl. Filip. ed. II. $439=$ Blumea manil lensis.

eucoma, $M i q . P l$. Fungh. 500.-Java.

eupatorioides, Wall. Cat. n. $2993=$ Inula eupatorioides. excisa, Wall. 1. c. n. $3011=$ Blumea densiflora.

extensa, Wall. 1. c. n. $3016=$ Vernonia extensa.

falcata, Buch-Ham. ex Spreng. Syst. ii. 513.-Reg. Himal.

falcigera, Wall. Cat, n. $2048=$ Blumea densiflora. fasciculata, Wall. 1. c. n. $3019=$ Laggera flava. fasciculata, Wall, 1. c, n。 3094 (ex steud.)=Blumea glomerata.

\section{CONYZA :-}

fastigiata, Willd. Enum. Hort. Berol. Suppl. 57.Afr. bor.

fistulosa, Roxb. Hort. Beng. [101]; Fl. Ind. iii. $429=$

Blumea glomerata.

flexilis, DC. Prod. v. 385.-Madag.

floresiana, Sch. Bip. in Zoll. Syst. Verz. Ind. Archip. 121.- Malaya.

floribunda, H. B. \& K. Nov. Gen. et Sp. iv. $73=$ Erigeron bonariensis.

foetida, Lam. Encyc ii. 85=Pluchea camphorata.

foetida, Willd. Sp. Pl, iii, $1952=$ Nidorella foliosa

foliolosa, Buch.-Ham. in Wall. Cat. n. 3281 = Pulicaria foliolosa.

foliolosa, Wall. ex DC. Prod, v. 451=Pluchea indica.

foliolosa, Wight, in Wall. Cat. n. $3092=$ Blume

bifuliata.

foliolosa, Willd. Sp. $P l$. iii. 1919.-Ind, or.

fruticosa, Linn. Sp. Pl. ed. II. $1209=$ Vernonia rigida. Garnieri, Klatt, in Linnaea, xxxvii. (1871-73) 509.Madag.

Gayana, Phil. l. c. xxviii. (1856) 737.-Chili

geminiflora, Tenore, Cat. Hort. Neap. (1819) $75=$

Phasnalon rupestre.

genistelloides, Lam. Encyc. ii. $93=$ Baccharis genistel loides.

glabra, Willd. Sp. Pl. iii. $1940=$ Vernonia Vahliana.

glabrata, Wall. ex Steud. Nom. ed. II. i. $414=$

Enpatosium glabrum.

glomerata, Link, Enum. Hort. Berol. ii. $322=$ decurrens.

glomerata, Wall. Cat. n. $3055=$ Blumea glomerata.

glutinosa, Lam. Encyc. ii. $89=$ Psiadia glutinosa.

gnaphalioides, Sch. Bip. ex A. Rich. Tent. Fl. Abyss

i. $389=$ Gouani

griaphalodes, H. B. E K. Nov. Gen, et Sp. iv. 73. t. 327.-Mexic

gnaphalodes, Sieber, Reise Kreta, i. 352 ; ii. $322=$ Senecio gnaphalodes.

Gouani, Blanco, F1. Filip. ed. I. $627=$ Blumea manillensis.

Gouani, Willd. Sp. Pl. iii. 1928.--Ins. Canar.

gracilis, Heyne, in Wall. Cat. n. $3064=$ Blumea membranacea.

gracilis, Hoffmgg. \& Link, Fl. Port. ii. $253=$ Pulicaria gracilis.

gracilis, Wall. Cat. n, $3064=$ Blumea glomerata.

graeca, Nym. Syll. $16=$ Phagnalon graecum.

graminifolia, Spreng. Syst. iii. 515= Aster divaricatus.

Grahami, DC. Prod. v. 380.-Reg. Argent.

grandis, Wall. Cat. n. $3051=$ blumea densiflora

graveolens, Steud. Nom. ed. I. $222=$ Inula graveolens.

graveolens, Wall. ex DC. Prod. v. $29 \%=$ Erigeron asteroides.

guineensis, Willd. Sp. Pl. iii. $1930=$ Laggera aurita

gummifera, Roxb. in Beats. St. Hel. Tracts, App. $304=$ Commidendrum robustum.

halimifolia, Desf. Tabl. ed. II. $114=$ Baccharis halimi folia.

Hamiltoni, Steud. Nom. ed. II. i. $414=$ Blumea hieracifolia.

heliotropifolia, Lam. Encyc. ii. $90=$ Monarrhenus rufescens.

heterophylla, Lam. Encyc. ii. $84=$ Vernonia cinerea.

heterotricha, Wall. Cat. $\mathrm{n} .3225=$ Inula eupatorioides.

Heudelotii, Oliver E Hiern, in Oliver, Fl. Trop. Afr. iii. $31 \%$.-Afr. trop

Heyneana, Wall, Cat. n. $3089=$ Blumea lacera.

hieracifolia, Spreng. Syst. iii. $514=$ Blumea hieracifolia.

hirsuta, Comm. ex DC. Prod. v. 458=Cylindrocline Commersonii.

hirsuta, Linn Sp. Pl. i. $863=$ Pluchea hirsuta.

hirsuta, Wall. ex DC. Prod. v. 292 ; et Cat. n. 3007 B, partim = aegyptiaca.

hirtella, $D C$. Prod. v. 385.-Madag.

hispida, H. B. E $K$. Nov. Gen. et Sp. iv. 71.-Mexic.

Hochstetterii, Sch. Bip. ex A. Rich. Tent. Fl. Abyss. i. 387.-Abysin

holosericea, Wall. Cat. n. $3103=$ Blumea glomerata.

Huberti, Boj. ex Sweet, Hort. Brit. ed. III. 349. Madag.

humifusa, Miq. Fl. Ind. Bat. ii. 41.-Java.

hymenophylla, Wall. Cat. n. $3038=$ Blumea membranacea.

hypoleuca, A. Rich. Tent. Fl. Abyss. i. 391.-Abyssin.

iliensis, Trautv. in Bull. Soc. Nat. Mosc. xxxix. (1866) II. 342.-As, centr.

\section{CONYZA :}

incana, Heyne, ex DC. Prod. v. $24=$ Vernonia cinerea ? incana, Wall. Cat. n. $3046=$ Vernonia cinerea.

incana, Willd. Sp. Pl. iii. 1937.-Arabia.

incisa, [Dryand. in] Ait. Hort. Kew.ed. I. iii. 184.Afr, austr.

indica, Blume, ex DC. Prod. v. $451=$ Pluchea indica.

indica, Wall. Cat. n. $3042=$ Vernonia indica.

intermedia, Lag. Gen. et Sp. Nov. $28=$ Phagnalon saxatile.

inuloides, [Dryand. in] Ait. Hort. Kew. ed. I. iii. 182 = Jasonia dichotoma.

ivaefolia, Burm. f. Fl. Ind. 180.-Ind. or.

ivaefolia, Less. in Linnaea, vi. (1831) 138.-Afr. austr.

japonica, Less. Syn. Comp. 204.-Reg. Himal.; China ; Japon.

javanica, Blume, Bijdr. $897=$ Blumea lacera

Ferdoni, C. B. Clarke, Comp. Ind. $62=$ Erigeron asteroides.

Junghuhniana, Miq. Fl. Ind. Bat. ii. 55.-Java.

Kotschyi, Boiss. Diagn. Ser. I. vi. $83=$ Erigeron Aucheri.

Kotschyi, Sch. Bip. ex Schweinf. Beitr. Fl. Aethiop. $307=$ Vicoa auriculata

Korthalsiana, Miq. Fl. Ind. Bat. ii. 51.-Malaya.

Krausseana, Regel Eo Schmalh. in Act. Hort. Petrop. v. (1877) 616.-Turkestan.

Kraussii, Sch. Bip.ex Walp.Rep. ii. 972.-Afr. austr.

Kunthiana, DC. Prod, v. 379.-Ecuador.

lacera, Burm. f. Fl. Ind. $180=$ Blumea lacera

laciniata, Roxb. Hort. Beng. 61; F1. Ind, iii. $427=$ Blumea laciniata.

lactucaefolia, Wall, Cat. n, $3088=$ Blumea Wightiana.

laeta, Hort. Calc. ex C. B. Clarke, Comp. Ind. $14=$ Vernonia saligna

lanceolaria, Roxb. Hort. Beng. 61 ; F1. Ind. iii. $432=$ Blumea myriocephala.

lanceolata, Wall. 1. c. n. $2991=$ Pluchea lanceolata.

lanceolata, Wall. Cat. n. $3059=$ Vernonia divergens.

lanuginosa, Wall. 1. c. n. $2922=$ Inula Cappa.

Larrainiana, Remy, in C. Gay, Fl. Chil. iv. 71 Chili.

laurifolia, Lam. Encyc, ii. 89.-Ins. Mascar.

laxa, Spreng. Syst. iii. 513.-Bras.

laxiflora, Desf. Cat. Hort. Par. ed. III. 400.-Hab.?

leucanthema, Buch.-Ham. ex Steud. Nom. ed. II. i. $414=$ Blumea leucanthema

leucodasys, Miq. in Fourn. Bot. Néerl. i. (1860) 103. - Malaya

leucophylla, Sch. Bip. ex A. Rich. Tent. F1. Abyss. i. $387=$ incana

limonifolia, Sibth. \& Sm. F1. Graec. Prod. ii. 174= Inula candida.

linearifolia, Lam. Encyc. ii. $92=$ Psiadia linearifolia.

lineariloba, DC. Prod. v. $385=$ aegyptiaca.

linearis, $D C$. $l . c .378$. - Chili

linifolia, Burm. f. Prod. Fl. Cap. 26.-Afr. austr

linifolia, Linn. Sp. P1. 861= Selicocarpus solidagineus

linitolia, Phil. in Linnaea, xxviii. (1856) 734-Chili.

linifolia, Wall. Cat. n. $3063=$ Vernonia cinerea.

lithospermifolia, Lam. Encyc. ii. 90.-Ins. Mascar.

lobata, Juss. ex Steud. Nom, ed. II. i. 414, $521=$ Verbesina diversifolia.

lobata, Linn. Sp. P1. $862=$ Neurolaena lobata

longicaulis, Wall. Cat. n. $3073=$ Eupatorium Reevesii longifolia, Desf. Cat. Hort. Par. ed. III. 164= chilensis.

longifolia, Heyne, in Wall. Cat. n. $3026=$ Blumea spectabilis.

longispina, Hook. f. Fl. Brit. Ind. iii. 268, sphalm.= seq.

longissima, Zoll. \& Moritzi, Syst. Verz. Zoll. $68=$ Blumea chinensis.

Lorentzii, Griseb. in Goett. Abh. xxiv. (1879) 176.Reg. Argent.

Loureirii, Poir. Encyc. Suppl. ii. 339.-China.

lucens, Poir. l. c. 341.-Ins. S. Doming.

lucida, Spreng. Neue Entdeck. ii. 142=Piptocarpha lucida.

lurida, F. A. Schmidt, Beitr. Fl. Cap. Verd. Ins. 186. -Ins. Madera.

lycopodioides, Lam. Encyc. ii. $91=$ Eriothrix juniperifolia.

lyrata, H. B. E K. Nov. Gen. et Sp. iv. 70.-Ecuador. macrophylla, Spreng. Syst. iii. 513.-Reg. Argent. macrorhiza, Sch. Bip. ex A. Rich. Tent. Fi. Abyss. i 387.-Abyssin. 


\section{CONYZA :-}

macrostachya, Wall. Cat. n. $3053=$ Blumea hieracifolia.

madagascariensis, Lam. Encyc. ii. $85=$ = Psiadia madagasicariensis.

magellanica, Lam. 1. c. 91=Baccharis magellanica. manillensis, Less. in Linnaea, vi. (1831) $135=$ Blumea manillensis.

marginata, Edgew, in Trans. Linn. Soc. xx. (1851) 67 $=$ rufa

marylandica, Michx. F1. Bor. Am. ii. 126=PIuchea camphorata.

mauritiana, Boj, ex Sweet, Hort. Brit. ed. III. 349.Ins. Mauit.

mauritiana, Mérat, ex Steud. Nom. ed. II. i. $414=$ Nidorella compressa.

mauritiana, Willd, ex Steud. 1. c.=Nolletia chrysocomoides.

maxima, Zoll. \& Mor. in Nat. en Geneesk. Arch Neêrl. Ind. ii. (1845) 236.-Java.

megapotamica, Spreng. Syst. iii. 516= Stenachaenium megapotamicum.

melastomoides, Lam. Encyc, ii. 90.-Ins. Mascar.

membranacea, Wall. ex DC. Prod. v. 441 ; Cat. n. 3019

= blumea memhranacea.

membranifolia, Klatt, in Leopoldina, xx. (1884) 94,Bras.

micrantha, Spreng. ex DC. Prod. v. $384=$ stricta.

microcephala, Hemsl. Biol. Centr. Am. Bot. 126.Mexic.

modatensis, Sch. Bip. ex Schweinf. Beitr. Fl. Aethiop. $144=$ Pluchea Dioscoridis.

modesta, Phil. in Linnaea, xxxiii. (1864-65) 142.Chili.

modesta, Kunth, Ind. Sem. Hort. Berol. (1845) 11.Hab. ?

mollis, Willd. Sp. Pl. iii. $1924=$ Vernonia cinerea.

moluccana, Gaudich. Bot. Voy. Bonite, 465.-Ins. Molucc.

monocephala, Sch. Bip. in Zoll. Syst. Verz. Ind. Archip. 122.-Malaya.

montana, Heyne, ex DC. Prod. v. $384=$ stricta.

montevidensis, Spreng. Syst. iii. 510.-Reg. Argent.

multicaulis, DC. Prod. v. $383=$ japonica.

multiflora, Wall. Cat. n. $3032=$ Vernonia divergens,

muralis, Buch.-Ham. in Wall. Cat. n. $3077=$ Blumea membranacea.

Mursa, Buch.-Ham. 1. c. n. $3095=$ Blumen lacera.

myosotifolia, H. B. E K. Nov. Gen. et Sp. iv. $69 .-\mathrm{N}$ Granat.

myriocephala, Remy, in C. Gay, Fl. Chil. iv. $76=$ Erigeron canadensis.

myrsinites, Lam. Encyc. ii. $92=$ Baccharis myrsinites,

nana, Sch. Bip. ex Oliver \& Hiern, in Oliver, Fl. Trop. Afr. iii. 315.-Abyss.

napifolia, Wall. Cat. n. $3075=$ Blumea Iacera

natalensis, Sch. Bip. ex Walp. Rep. ii. 971.-Afr. austr.

natans, Buch.-Ham, ex Hook. f. Fl. Brit. Ind, iii. 263 $=$ Blumea hieracifolia.

Naudini, Bonnet, in Bull. Soc. Bot. Fr. xxv. (1878) 208.-.Hab.?

necessaria, Buch,-Ham. ex DC. Prod. v. $439=$ Blumea hieracilolia.

nereifolia, L'Hérit. ex DC. 1. c. $430=$ Brachylaena nereifolin.

Neuri, Oliver $\sigma$ Hiern, in Oliver, Fl. Trop. Afr. iii. 317. - Afr. trop.

nitida, Miq. Fl. Ind. Bat. ii. $54=$ Blumea Wallichii.

nitida, Sch. Bip. in Zoll. Syst. Vers. Ind. Archip 121.-Malaya.

nivalis, Boiss. Diagn. Ser. I. vi. $82=$ Erigeron chionophilus.

notobellidiastrum, Griseb. in Goett. Abh. xxiv. (1879) 177.-Reg. Argent.

nutans, Blume, Bijdr. $896=$ Laggera alata

nutans, Buch.-Ham. ex DC. Prod. v. $436=$ Blumea cernuล.

nutans, Wall. Cat. n. $3080=$ Blumea hieracifolia

obliqua, Buch.-Ham. ex DC. Prod. v. $439=$ Blumea

obliqua,
Plava.

obliqua, Willd. Sp. Pl. iii. $1930=$ Blumer amplectens.

oblonga, Wall. ex DC. Prod. va $469=$ Inula Cappa.

oblongifolia, Spreng. Syst. iii. 512.-Bras.

abovata, Wall. Cat. n. 3022 = Blumea obovata

obscura, DC, Prod, v. 387.-Am. austr.

obtusa, H. B. \& K. Nov. Gen. et Sp. iv. 71.Mexic.
CONYZA:-

odontophylla, Boiss. Fl. Orient. iii. $217=$ Pluchea arguta.

odontoptera, Webb, in Hook. Niger Fl. 135.-Ins. Cap. Verd.

odora, Forsk. Fl. Aegypt. Arab. 148.-Aegypt

odorata, Linn. Sy st. ed. X. $1213=$ Pluchea odorata

odorata, Willd, ex Steud. Nom. ed. 1I. i. $414=$ Ver nonia chinensis.

oleaefolia, Lam. Encyc. ii. $86=$ Linosyris villosa. oligandra, Turcz. in Bull. Soc. Nat. Mosc (1851) I. 179.-Java.

oligocephala, Miq. Fl. Ind. Bat. ii. $41=13$ lumea bifoliata.

orientalis, Willd. Sp. Pl. iii. 1931.-Armen.

ovata, Wall. Cat n. $3097=$ Blumea cinerea

oxyodonta, Wall. ex DC. Prod. v. $444=$ Blumea oxyo donta.

pallida, Zipp. ex Span. in Linnaca, xv. (1841) 322 nomen.-Malaya.

panamensis, Willd. Sp. Pl. iii. 1942.-Panama. paniculata, Desf. Tabl. ed. II. $114=$ fastigiata. paniculata, Wall. Cat. n. $3090=$ Blumea Wightiana. paniculata, Willd. Sp. Pl. iii. $1920=$ Blumea mens branacea.

pannosa, Webb, in Hook. Niger Fl. 135.-Afr. trop. parvifolia, Wall. Cat. n. $3004=$ Blumea Wightiana. patula, [Dryand. in] Ait. Hort. Kew. ed. I. ii. $184=$ Vernonia chinensis.

pauciflora, Willd. Sp. P1. iii. 1927=Vernonia panciflora, paucifolia, Wall. Cat, n. $3037=$ Blumea membranacea. pectinata, Sch. Bip. ex Oliver E Hiern, in Oliver, Fl. Trop. Afr. iii. 315.-Afr. trop.

pedunculata, Mill. Gard. Dict. ed. VIII. n. 15. Hab.?

persica, Boiss. Diagn. Ser. I. vi. $81=$ Erigeron persicus. persicaefolia, Oliver \& Hiern, in Oliver, Fl. Trop. Afr. iii. 312.-Afr. trop.

petiolaris, Wall. Cat. 1..3282= japonica

pinifolia, Bory, Voy. ii. $395=$ Faujasia pinifolia pinifolia, Lam. Encyc. 1i. $86^{\circ}=$ Vernonia pinifolia. pinnatifida, Buch.-Ham. ex Roxb. Hort. Beng. 61 ;

Fl. Ind, iii. $430=$ stricta.

pinnatifida, Less. Syn. Comp. 204.-Afr. austr

pinnatilobata, DC. Prnd. v. 387.-Afr. austr.

platensis, spreig. Syst。 iii. $509=$ Vernonia platensis

platylepis, Spreug. ex DC. Prod. v. $31=$ Vernonia Koxburghir.

podocepuala, DC. l. c. 387.-Afr, austr.

polycephala, Edgew, in Trans. Linn. Soc. xx. (1851) $66=$ visciclula.

polygonata, Wall. Cat. n, 3010=Inula polygonata.

Ponae, Sitber, ex Tausch, in Flora, xii. (1029) I. Erg. $37=$ Cylindrocline Commersonii.

populifolia, Lam. Encyc. ii. 87 =Vernonia populifolia. portoricensis, Bert, ex DC, Prod, v. 52=Vernonia remotiflora?

pratensis, Phil. in Linnaea, xxviii. (1856) 736.Chili.

procera, Desf. Cat. Hort. Par. ed. III. 164=chilensis. procera, Wall. Cat. n. $3050=$ Blumea procera. procumbens, Balb. Cat. Hort. Taur. 28.-Ins. Creta. prolifera, Lam. Encyc. ii. $84=$ Vernonia cinerea. prostrata, Tenore, Cat. Hort. Neap. (1๖19) $75=$ pro. cumbens.

proteiformis, Perr. ex DC. Prod. v. $376=$ Pluchea lanceolata.

pterocaulon, C. Bolle, in Bonplandia, vii. (1859) 295. -Ins. Canar.

pubescens, DC. Prod. v. $381=$ Brachyactis robusta.

pubigera, Linn. Mant. i. 113.-Amboina.

pulchella, H. B. \& K. Nov. Gen. et Sp. iv, 78 sophiaefolia.

pulchra, Lam, ex Steud. Nom. ed. II. i. $415=$ amygdalina.

pumila, Lam. ex Pers. Syn. ii. 427.-Hab.

pumila, Sibth. \& Sm. Fl. Graec. Prod. ii. $178=$ Phag nalon pumilum.

punctata, Willd. Sp. Pl. iii. 1997 = Aplopappus Chamissonis.

punctulata, Wall. Cat. n. $2995=$ Vernonia chinensis.

punduana, Wall. 1. c. 1. $\$ 035=$ Vernonia volkameriae fulia.

pungens, Lam. Encyc. ii. $86=$ Iphiona juniperifolia. purpurascens, Sw. Yrod. Veg. Ind. Oce. $112=$ Pluchen purpurascens.

purpurea, Buch.-Ham, in Wall. Cat. n. $3076=$ Blumea purpurca, buch.
glomerata.
CONYZA :-

pusilla, Houtt. Handleid. x. 618. t. 69-Afr. austr.

pusilia, H. B. \& K. Nov. Gen. et Sp. iv. $69=$ Kunthiana.

pycnostachya, Michx. F1. Bor. Am. ii. $126=$ Pterocaulon pycnostachyum.

pygmaea, Sieber, Reise Krela, ii. 322 = Phagralon pumilum.

pyrifolia, Lam. Encyc, ii. $89=$ Microglossa volubilis.

pyrhopappa, Sch. Bip. ex A. Rich. Tent. Fl. Abyss. 389 - Abyss.

racemosa, Spreng. Syst. iii. $508=$ Baccharis avicenniaefolia.

racemosa, Wall. Cat. n. $3002=$ Blumea glomerata.

ramiflora, Spreng. Syst. iii. $509=$ Piptocarpha ramiflota.

redolens, Willd. Sp.'Pl. iii. 1951 (= Monenteles redolens). $-\mathrm{N}$. Caled.

repanda, Roxb. Hort. Beng. 61; F1. Ind. iii. 431 Blumea procera.

retusa, Lam. Encyc. ii. 90.-Ins. Mascar.

rigida, Sw. Prod. Veg. Ind. Occ. $113=$ Vernonia risida.

riparia, Blume, Bijdr, $899=$ Blumea chinensis,

riparia, H. B. \& K. Nov. Gen. et Sp. iv. $76=$ Tessaria integrifolia

ivularis, Gardn. in Hook. Lond. Fourn. Bot. iv. (1845) 124.-Bias.

robusta, Koxb. in Beats. St. Hel. Tracts, App. 304 Commidendrum robustum.

Roylei, DC. Pıod. v. $3 \succ 1=$ Brachyactis menthodora

rubra, Buch.Ham.ex DC. 1. c. $376=$ Pluchea lanceolata.

rudis, Willd. ex Steud. Nom. ed. II. i. $415=$ lyrata.

rufa, Wall. Cat. n. 3079.-Ind. or.

rufescens, Hoffmgg, \& Link, Fl. Port. ii. $253=$ l'ulicaria rufescens.

rufidula, Spreng. Neue Entdeck. ii. 141.-Bras.

rugosa, [Dryand. in] Ait. Hort. Kew. ed. 1. iii. $184=$ Commidendrum rugosum.

rugosa, Vabl, Symb. Bot. i. $71=$ Pterocaulon vir yatum.

runcinata, Wall. Cat, n. $3087=$ Blumea laciniata

rupestris, Linn. Mant. $113=$ Phagnalon rupestre.

rutilans, Poir. Encyc. Suppl. ii. $341=$ Vermonia senegalensis.

sagittalis, Lam. Encyc. ii. $94=$ Baccharis sagittalis

salicifolia, L.am. Encyc. ii. $\delta 9=$ Monarrhenus saljcifolius.

salicifolia, Mill. Gard. Dict. ed. VIII, D. 6.-Ind. occ.

salicina, Kellogg, in Proc. Calif. Acad. iii. (1063, 36. -Calif.

salicina, Rupr. Fl. Ingric. $568=$ Inula salicina.

saligna, $W_{2}$ ll. Cat. $\mathrm{n} .3061=$ Vernonia saligna.

salsoloides, Turcz, in Bull. Soc. Nat. Mosc. v. (1832

197 = Inula ammophila.

salvifolia, Bory, Voy, iii. $176=$ Blumea salvifolia

saxatilis, Linn. Sp. Pl. ed. II. 1206 = Ihagnalon saxatile.

saxatilis, Sibth. \& Sm. Fl. Graec t. $862=$ Phagnalon graecum.

saxatilis, Tenore, Fl. Neap. ii. $213=$ Phagnalon rupestre.

saxatilis, 'Loll. ex C. B. Clarke, Comp. Ind. $90=$ Blumea balsamifera.

cabiosaefolia, Remy, in C. Gay, Fl. Chil. iv. iaChili.

scabra, Linn. Mant. 119.-Ind, or.

scabrida, DC. Prod. v. 387.-A. Ar. austr.

scandens, Mill. Gard. Dict. ed. V1l1. n. 11.-Meric.

scandens, Wall. Cat a. $3060=$ Vernonia scandens.

Schimperi, Sch. Bip. ex A. Kich. Tent. Fl. Abyss i. $380^{\circ}=$ stricta

Schlechtendalii, C. Bolle, in Bonplandia, vii. \{1559) 2!4.-Ins. Canar.

scorpioides, Lam. Encyc. ii. 88 = Vernonia scorpsoides. semipinnatifida, W'all. Ca\&. n. 3155.,-Ind. or. semivestita. Wall, 1, c D, 2940 = Blumea prucera. seregalensis, Sieber, ex DC: Prod. $x^{\circ}+t y=1$ Lggera aurua

senegalensis, Wi!dd. Sp. Pl. iii. 19:8.-Afr. trop.

sericea, Bory, Voy. ii. \$i 6.-Ins. Kurbun.

sericea, [Soland. in] Al. Hort Kicw. cd. 1. uii. 159 Schisogyese sericea - Ins. Canar.

sericca, Wall. Cal. D. 3021 - Blumea glomerala.

serici-vestisa. Wall. 1. c. ฉ. 2096-13iumea chunencis scrpentaria, Griseb. in Goest. Abh. xxiv, 15:9) 176.

Keg. Argent. 
CONYZA :-

serrata, Bory, ex DC. Prod. vi. $376=$ Senecio salici folius.

serrulata, C. B. Clarke, Comp. Ind. 64.-Ind. or. serrulata, Lam. Encyc. ii. $85=$ Baccharis serrulata. serrulata, Wall. Cat. sub n. $3024=$ viscidula. sessifolia, Blume, Bijdr. $897=$ = Pluchea sessifolia. sessiliflora, Miq. Fl. Ind. Bat. ii. 48.-Ins. Timor. sessiliflora, Salisb. Prod. 195.-Ins. Bourbon. sessilifolia, Steud. Nom. ed. II. i. $415=$ Pluchea sessifolia.

sessilifolia, Wall. Cat. n. $3029=$ Pluchea Wallichiana.

sicula, Willd. Sp. PI. iii. $1931=$ Pulicaria sicula.

sinensis, J. F. Gmel. Syst. $1221=$ Blumea chinensis.

sinuata, Ell. Sketch, ii. $323=$ Erigeron linifolius. solidaginoides, Wall. Cat. n. $3066=$ Aster ignoratus.

sonchifolia, Buch.-Ham, in Wall. 1. c. n. $3085=$ Blumea laciniata.

sophiaefolia, H. B. E K.Nov. Gen, et Sp. iv. 73. t. 326.-Mexic

sordida, Linn. Mant. $466=$ Phagnalon sordidum. spathulata, Hornem. Hort. Hafn. ii. 805.-Hab.? spathulifolia, Maxim. ex Regel, in Act. Hort. Petrop. iii. (1874) $109=$ stricta.

spatulata, Link, Enum. Hort. Berol. ii. $322=$ Vernonia pauciflora.

spicata, Lam. Encyc. ii. $93=$ Pterocaulon virgatum spicata, Mill. Gard. Dict. ed. VIII. n. 14.-Hab.? spinellosa, $\mathrm{Miq}$. Fl. Ind. Bat. ii. 45.-Burma. spinidens, Miq. 1. c. $44=$ Blumea membranacea spinosa, Sch. Bip. ex Oliver \& Hiern, in Fl. Trop. Afr. iii. 312.-Afr. trop.

spinulosa, Spreng. Syst. iii. $510=$ Sommerfeldtia spinulosa.

splendens, Spreng. 1. c. $509=$ Piptocarpa lucida

Sprengelii, Sch. Bip. ex Walp. Rep. ii. 958.-Afr. austr.

squamata, Spreng. Syst. iii. $515=$ Aster divaricatus.

squamosa, Bory, Voy. iii. $110=$ Senecio squamosus.

squarrosa, Georgi, It. i. 229.-Sibir. baical.

squarrosa, Linn. Sp. Pl. 861 = Inula vulgaris.

squarrosa, Wall. Cat. n. $3025=$ Blumea myriocephala.

stachyoides, Spreng. ex DC. Prod, v. $442=\mathrm{blumea}$ glomerata.

Steetzii, Griseb. App. Ind. Sem. Hort. Gotting. (1878) 8.-Afr. austr.

stellata, Spreng. Neue Entdeck. ii. $142=$ Vernonia oppositifolia.

Steudelii, Sch.Bip, ex A. Rich. Tent. Fl. Abyss. i 388.-Abyssin

stipulacea, Desf. Cat. Hort. Par. ed. III, 164.-Hab.? stipulata, Vahl, ex DC. Prod. v. $97=$ Liabum Jussieui. striata, Wall. Cat. n, 3065=viscidula.

stricta, Wall. 1. c. n. $3044=$ japonica.

stricta, Willd. Sp. Pl iii. 1922,-Ind, or ; Afr. trop. subcapitata, Wall. Cat. n. $3056=$ Blumea subcapitata

subdecurrens, DC. Prod. v. $379=$ Erigeron subdecurrens.

subdecurrens, A. Gray, Pl. Fendl. 78 ; P1. Wright. i. $102=$ Coulteri

subracemosa, Miq. Fl. Ind. Bat. ii, 41.-Java.

subsessilis, Wall. Cat. n. $3000=$ Vernonia subsessilis.

subsimplex, Wall. 1. c. n. $3003=$ Vernonia cinerea.

subspicata, Phil. in Linnaea, xxviii. (1856) 735.Chili.

suffruticosa, Phil. l. c.-Chili.

sumbavensis, Miq. Fl. Ind. Bat. ii. 46.-Malaya.

sylvatica, Blume, Bijdr. $898=$ Blumea sylvatica.

symphytifolia, Mill. Gard. Dict. ed. VIII. n. 10.Hab.?

syringaefolia, Meyen E Walp. in Nov. Act. Nat. Cur. xix. Suppl. i. (1843) 263.-China.

tenella, Miq. Fl. Ind. Bat. ii. 40-Ins. Timor.

tenera, Wall. Cat. n. $3023=$ Blumea oxyodonts

Tenorii, Presl, ex Spreng. Pugill. i. 55=Phagnalon rupestre.

tenuifolia, Salisb. Prod. 194 (=Schizogyne sericea). - Ins. Canar.

ternatensis, Miq. Fl. Ind. Bat. ii. 49.-Ins. Ternate

tetraptera, Turcz. in Bull. Soc. Nat. Mosc, xxiv. (1851) x. $178=$ Blumea tetraptera.

thapsoides, Bieb. F1. Taur. Cauc. ii. $304=$ Inula thapsoides.

thermarum, Phil. in Anal. Univ. Chil. (1862) II. 381. -Chili.

thesiifolia, H. B. E K. Nov. Gen. et Sp. iv. 75.Mexic.

\section{CONYZA}

thuyoides, Lam. Encyc. ii. $90=$ Baccharis thyoides.

thyrsifera, C. B. Clarke, Comp. Ind. 76, sphalm. seq.

thyrsiflora, Wall. Cat. n. $3082=$ Blumea lacera.

thyrsoidea, Pers. Syn, ii. 426. n, $8=$ Blumea lacera

tigrensis, Oliver Es Hiern, in Oliver, Fl. Trop. Afr.

iii. 316.-Afr. trop.

timorensis, $\mathrm{Miq}$. Fl. Ind. Bat. ii. 47.-Ins. Timor.

tomentosa, Burm. f. Fl. Cap. Prod. $26=$ Alciope lanata.

tomentosa, Forsk. F1. Aegypt. Arab. 148 = Phagnalon rupestre.

tomentosa, Mill. Gard. Dict. ed. VIII. n. 5.-Mexic.

tomentosa, Wall. Cat. n. $3031=$ Pluchea tomentosa.

tortuosa, Linn. Sp. Pl. 862.-Am. austr.

travancorensis, Wall. Cat. n. $3067=$ viscidula

tricuneata, Willd. Sp. PI. iii. $1946=$ Baccharis conferta.

tridentata, Poir. Encyc. Suppl. ii. 342 = Baccharis tridentata?

triloba, Decne, in Ann. Sc. Nat. Sér. II. ii. (1834) 261 $=$ Erigeron trilobus.

trinervia, Mill. Gard. Dict. ed. VIII. n. 12.--Mexic.

trinervis, lam. Encyc, ii. $85=$ Baccharis trinervis.

triplinervia, Less, in Linnaea, vi. (1831) 137.-Bras.

trisulca, Buch.-Ham. ex D. Don, Prod. Fl. Nep. $172=$ stricta.

tuberosa, Lam. ex Steud. Nom. ed. II. i. $415=$ Jasonia radiata.

uliginosa, Pers. Syn. ii. $426=$ Pluchea bifrons.

umbrosa, Kar. Er Kir. in Bull. Soc. Nat. Mosc. xv. 1842) 379.-Sibiria

undulata, Poir. Encyc. Suppl. ii. 339.-Afr. trop. uniflora, Banks \& Soland. ex Hook. f. FI. N. Zel. i $140=$ Helichrysum filicaule.

uniflora, Mill. Gard. Dict. ed. VIII. n. 13,-Mexic.

vagans, Wall. Cat.- n. $3040=$ Vernonia vagans.

variegata, Sch. Bip. ex A. Rich. Tent. Fl. Abyss. 389.-Abyssin.

Vatkeana, Oliver $\mathrm{F}$ Hiern, in Oliver, Fl. Trop. Afr. iii. 314.-Afr. trop.

verbascifolia, Bieb. ex Georgi, Beschr. Russ. Reich. iv. 1239 = Inula thapsoides.

verbascifolia, Bory, Voy. ii. $377=$ anchusaefolia

verbascifolia, Frivald. ex Nym. Consp. 393=Inula Aschersoniana

verbascifolia, Willd. Sp. P1. iii. 1924=Inula candida

veronicaefolia, Wall. Cat. n. $3005=$ japonica

verrucosa, Hontt ex DC. Prod vii. $13=$ Printzi Bergii.

vestita, Wall. Cat. n. $2998=$ Blumea balsamifera.

villosa, Herb. Madr. ex Wall. I. c. n. $3105=$ Blumea amplectens.

villosa, Willd. Sp. Pl. iii. $1929=$ Laggera aurita

viminea, $\mathrm{Miq}$. Fl. Ind. Bat. ii. 49.-Malaya.

virens, Wall. Cat. $\mathrm{n} .3037=$ Blumea virens.

virgata, DC. Prod. v. 385.-Madag.

virgata, Linn. Sp. Pl. ed. II. $1206=$ Pterocaulon virgatum.

viscidula, Wall. Cat. n. 3006.-As. trop. A Austral.

viscosa, Boj. ex Sweet, Hort. Brit. ed. III. 349.-Ins. Maurit.

viscosa, Hort. ex Steud. Nom. ed. II. i. $415=$ Inula viscosa.

viscosa, Mill. Gard. Dict. ed. VIII. n. 8.-Mexic.

viscosula, Wall. ex DC. Prod. v. $441=$ Blumea membranacea.

volkameriaefolia, Wall. Cat. n. $3001=$ Vernonia volkameriaefolia.

volubilis, Wall. I. c. n. $3057=$ Microglossa volubilis.

vulgaris, Lam. Fl. Fr. ii. $78=$ Inula valgaris.

vulgaris, Phil. in Linnuea, xxviii. (1856) 735.-Chili

Wallichii, DC. Prod. v. $384=$ viscidula.

wangtuensis, C. B. Clarke, Comp. Ind. 61.-Reg Himal.

Wightiana, Wall. Cat. n. $3028=$ Vernonia arborea.

Wightiana, Wall. ex DC. Prod. v. $435=$ Blumea Wightiana.

Wulfeni, Host, ex Beck, in Denkschr. Akad. Wien, Math. Nat. xliv. $(1882) 332=$ Inula bifrons.

Zollingeriana, Turcz. in Bull. Soc. Nat. Mosc. xxiv (1851) I. 179. - Java.

CONYZELLA, Rupr. in Mém. Acad. Pétersb. Sér. VII. xiv. n. 4 (1869); Sert. Tiansch. $51=$ Erigeron, Linn (Compos.).

canadensis, Rupr. 1. c. = E. canadensis.
CONYZOIDES, Tourn. ex DC. Prod. vi. $281(1837)=$ Carpesium, Linn. (Compos.).

COOCKIA, Batsch, Tab. $53(1802)=$ COOKIA, Sonner.

COOKIA, J. F. Gmel. Syst. 24 (1791)= Pimelea, Ranks \&c Soland. (Thymel.)

Gnidia, J. F. Gmel. 1. c. = P. Gnidia.

pilosa, J. F. Gmel. 1. c. = P. pilosa.

prostrata, J. F. Gmel. 1. c. $=$ P. prostrata.

COOKIA, Sonner. Voy. Ind. iii. 258. t. 130 (1782) = Clausena, Burm. f. (Rutac.)

anisata, Desf. Cat. Hort. Par. ed. III. 415, 406.Hab.?

anisodora, Blanco, F1. Filip. ed. II. $253=$ Clausena excavata.

Anisum-olens, Blanco, 1. c. ed. I. $359=$ Clausena excavata.

australis, F. Muell. Fragm. i. $25=$ Pentaceras australis.

chlorosperma, Blume, Bijdr. 135=Glycosmis chlorosperma.

cyanocarpa, Blume, 1. c. $136=$ Glycosmis cyanocarpa.

dulcis, Bedd, in Madr. Journ. Sc. Ser. II. xxii. (1861) $73=$ Clausena Willdenowii

falcata, DC. Prod.1. 537.-China.

glabrescens, Miq. Fl. Ind. Bat. i. II. 524.-Ins. Philipp.

graveolens, Wight \& Arn. Prod. $95=$ Clausena excavata.

macrophylla, Lindl, in Wall. Cat. n. $6367=$ Clausena heptaphylla.

pentaphylla, Wight \& Arn. ex M. Roem. Syn. Hesper, $45=$ Clausena pentaphylla.

punctata, Hassk. Cat. Hort. Bog. Alt. $215=$ Micromelum pubescens.

punctata, Retz. Obs. vi. $29=$ Clansena excavata

punctata, Sonner. Voy. Ind. iii. 258. t. $130=$ Clausena Wampi.

Sonneratii, Montr. in Mém. Acad. Lyon, x. (1860) 184. -N. Caled. ?

Wampi, Blanco, Fl. Filip. ed. I. $358=$ Clausena Wampi

COOPERIA, Herb. in Bot. Reg. t. 1835 (1836).

AMARYLLIDEAE, Benth. \& Hook. f. iii. 722.

Sceptranthus, R. Grah. in Edinb. N. Phil. Journ. xx. (1838) 413

chlorosolen, Herb. in Bot. Reg. t. $1835=$ Drummondi

Drummondii, Herb. l. c.-Texas.

mexicana, Herb. Amaryll. $182=$ Drummondii

pedunculata, Herb. l. c. 179. t. 42. ff. 3-5.-Texas.

COPAIBA, Adans. Fam. ii. 341 (1763)=seq.

COPAIFERA, Linn. Sp. Pl. ed. II. 557

LEGUMINOSAE, Benth. \& Hook. f. i. 585

Coparba, Adans. Fam. ii. 341 (1763).

Copaiva, Jacq. Enum. Pl. Carib. 4 (1760).

Gorskia, Bolle, in Peters, Reise Mossamb. Bot. i 15. t. 3 (1861)

Guibourtia, J. J. Benn. in Journ. Linn. Soc. i. (1857) 149

Beyrichii, Hayne, Arzneig. x. t. 12.-Bras.

bijuga, Willd. ex Hayne, $l$. $c$. t. 16.-Bras.

bracteata, Benth. in Hook. Fourn. Bot. ii. (1840) 101. -Guiana.

coleosperma, Benth. in Trans. Linn. Soc. xxv. (1866) 316. f. 43.-Afr. trop.

confertiflora, Benth. in Mart. Fl. Bras. xv. Ir. 241.Am. trop.

copallina, Baill. Hist. P1 ii. 142, $163=$ Guibourtiana cordifolia, Hayne, Arzneig. x. t. 21.-Bras.

coriacea, Mart. Reise Bras. i. 285 ; et in Hayne, l.c t. 20.-Bras.

disperma, Willem. in Usteri, Ann. Bot. xviii. (1796) 34.-Ins, Maurit.

elliptica, Mart. in Flora, xx. (1837) II. Beibl. 127.Bras.

glabra, Vogel, in Linnaea, xi. (1837) 410.-Bras.

Gorskiana, Benth, in Trans. Linn. Soc. xxy. (1866) 317.-Afr. trop.

guyanensis, Desf. in Mém. Mus. Par. vii. (1821) 376.Guiana.

Guibourtiana, Benth. in Trans. Linn. Soc. xxv. (1866) 317.-Afr, trop. 


\section{COPAIF'ERA :-}

hymenaeifolia, Moric. in Mem. Soc. Phys. Genèv, vi. (1833) 529.-Cuba.

Facquini, Desf. in Mém. Mus. Par. vii. (1821) $376=$ officinalis.

Facquiniana, G. Don, Gen. Syst, ii. $455=$ officinalis.

Jussieui, Hayne, Arzneig, x. sub t. 17.-Peruv.

Lansdorfii, Desf. in Mèm. Mus. Par. vii. (1821) 377. -Bras.

laxa, Hayne, Arsneig. x. t. 18.-Bras

Mannii, Baill. Adansonia, vi. (1866) $202=$ Hardwickia Mannii.

marginata, Benth. in Mart. Fl. Bras. xv. II. 243.-

$$
\text { Bras. }
$$

Martii, Hayne, Arzneig. x. t. 15.-Bras

Mopane, J. Kirk, ex Benth. in Trans. Linn. Sos. xxy. (1866) 317.-Afr, trop.

multijuga, Hayne, Arrneig. x. sub t. 17.-Bras

nitida, Mart. ex Hayne, l. c. x. t. 17-Bras.

oblongifolia, Mart. ex Hayne, l. c. t. 23; et in Mart

Reise Bras. i. 545.-Bras.

officinalis, Linn. Sp. Pl. ed. II. 557.-Am. trop.

pubifora, Benth. in Hook. Fourn. Bot. ii. (1840) 101 -Guiana.

rigida, Benth. in Mart. Fl. Bras. xv. II. 243.-Bras

Sellowii, Hayne, Arzneig. x. t. 22.-Bras.

trapezifolia, Hayne, l. c. sub t. 23.-Bras.

COPAIVA, Jacq. Enum. P1. Carib. $4(1760)=$ Copai fera, Linn. (1762).

officinalis, Jacq. 1. c. $21=$ Copaifera officinalis.

COPERNICIA, Mart. Hist. Nat. Palm. ii. 151. t. 50 A iii. 242 (1837 ?). PALMAE, Benth. \& Hook, fo iii.927. Cryosophila, Blume, Rumphia. ii. 53, in nota (1836).

Crysophila, Benth. \& Hook. f. Gen. iii. 928 (1883) cerifera, Mart. Hist. Nat. Palm. iii, 242. t. 50 A.Am, trop.

hospita, Mart. l. c.-Cuba.

macroglossa, H. Wendl. in Kerch. Palm. 241, nomen. -Hab.?

maritima, Mart. Hist. Nat. Palm. iii. 243. t. 50 A -Cuba.

Miraguana, Mart. 1. c. = Thrinax Miraguana.

nana, Liebm. ex Hemsl. Biol. Centr. Am. Bot. iii. 411. -Mexic.

Pumos, Mart. Hist. Nat. Palm. iii. 243,-Cuba

robusta, Hort. ex Linden, Illustr. Hortic. xxviii. (1881) 16.-Cuba.

tectorum, Mart. Hist. Nat. Palm. iii. 243.-N. Granat

Wrightii, Griseb, Cat. Pl. Cub. 220.-Cuba.

COPIANTHUS, Hill, Decade t. 1 (1773). Amaranthac. ? monstr.

indica, Hill, 1. c.-Ind. or.

COPIOGLOSSA, Miers, in Proc. Roy. Hort. Soc, iii. (1863) 294 = Ruellia, Linn. (Acanthac.)

pilosa, Miers, 1. c. (=Dipteracanthus Neesianus).Bras.

COPISMA, E. Mey. Comm. Pl. Afr. Austr. 132 (1885)=

Rhynchosia, Lour. (Legumin.)

caribaeum, E. Mey, 1. c. $133=\mathrm{R}$, caribaea

diversifolium, E. Mey. 1. c. $185=$ R. hirsuta.

effusum, E. Mey. 1. c. $=\mathrm{R}$, adenodes.

falcatum, E. Mey, 1. c. $136=\mathrm{R}$. minima

gibbum, E. Mey. 1. c. $137=$ R. caribaea.

glabrum, E. Mey. 1. c. $184=$ R. glandulosa.

glandulosum, E. Mey. l. c. $139=$ R. glandulosa

grandifolium, E. Mey. 1. c. $138=$ R. grandifolia.

nitidum, E. Mey. 1. c. $136=\mathrm{R}$, nitida.

paniculatum, E. Mey. 1. c. $134=\mathrm{R}$. totta

pictum, E. Mey. 1. c. $185=\mathrm{R}$. caribaea.

pilosum, E. Mey, 1. c. $133=$ R. pilosum.

rotundifolium, E. Mey. 1. c. $197=$ R. rotundifolis

secundum, Walp. in Linnaea, xiii. (1899) $597=$ $R$. secunda.

simplicifolium, E. Mey. Comm. Pl. Afr. Austr. i. $188=$ R. singulifolia.

singulifolium, Steud. Nom. ed. II. ii. 454, sphalm. R. singulifolia.

subsericeum, Sond, in Linnaea, xxiii. (1850) $34=$ Galactia tenuiflora.

tenue, E. Mey. Comm. Pl. Afr. Austr. $186=$ R. minima

tothum, E. Mey. 1. c. $133=$ R. puberula.

trichodes, E. Mey, 1. c, $194=\mathrm{K}$. totta.

viscidulum, E. Mey, 1. c. . R. viscidula.
COPPENSIA, Dum. in Mém. Acad. Brux, ix. (1835) (Sur Maelen.) 10, in nota. = Oncidium, Sw. (Orchid.), bifolia, Dum. 1. c. = O. bifolium.

COPPOLERIA, Todaro, in Atti Acc. Sc. Palermo, N. S. i. (1845) 14 =Vicia, Toum. (Legumin。).

monantha, Todaro. 1. c. $=\mathrm{V}$. monantha.

COPROSMA, Forst. Char. Gen. 137. t. 69 (1776 RUBIACEAE, Benth. \& Hook. f ii. 139.

Euarthronia, Nutt. ex A. Gray, in Proc. Am. Acad. iv. (1860) 49 , in syn.

EURYNOME, DC. Prod. iv. 475 (1830)

Marquisia, A. Rich, in Mém. Soc. Hist. Nat. Par. v. (1830) 192

Pelaphia, Banks \&c Soland, ex A. Cunn. in Ann. Nat. Hist. ii. (1839) 206.

acerosa, A. Cunn. in Ann. Nat. Hist. ii. (1839) 207. -N. Zel.

acutifolia, Hook. $f$. in fourn. Linn. Soc. i. (1857) 128. -N. Zel.

acutifolia, F. Muell. ex Benth. Fl. Austral. iii. 429 Morinda acutifolia.

affinis, Hook, f. Fl. Antarct. i. 21. t. 14=foetidissima arborea, T. Kirk, in Trans. N.Z. Inst. x. (1878) 420 - N. Zel.

arcuata, Colenso, Excurs. North. Isl. 84-N. Zel.

Baueri, Endl. Iconog. t. 111.-Ins. Norfolc.; N. Zel.

Baueriana, Hook. f. Fl. N. Zel. i. $104=$ Baueri.

Billardieri, Hook. f. in Hook. Lond. Fourn. Bot. vi. 1847) 465 [bis]. - Austral.

calycina, A. Gray, in Proc. Am. Acad. iv. (1860) 306 =Leptostigma Arnottianum).-Chili

ciliata, Hook.f. Fl. Antarct. i. 22,--Ins. Auckland.

Colensoi, Hook. f. Handb. New Zeal. Fl. 117.-N. Zel.

concinna, Colenso, in Trans. N. Z. Inst. xvi. (1884) 330. -N. Zel

conferta, A. Cunn. in Ann. Nat. Hist. ii. (1839) $206=$ Cunninghamii.

crassifolia, Colenso, Excurs. North. Isl. 75.-N. Zel.

cuneata, Hook. f. Fl. Antarct. i. 21. t. 15.-N. Zel.

Cunninghamii, Hook. f. Handb. New Zeal. Fl. 113.N. Zel.

cuspidifolia, DC. Prod. iv. $578=$ hirtella.

depressa, Colenso, ex Hook. f. Fl. N. Zel. 110.N. Zel.

divaricata, A.Cunn. in Ann. Nat. Hist. ii. (1839) 207. N. Zel.

ernodeoides, A. Gray, in Proc. Am. Acad. iv. (1860) 49.-Ins. Pacif.

foetidissima, A. Cunn, in Ann. Nat. Hist. ii. (1839) 206 = Cunninghamii

foetidissima, Forst. Char. Gen. 138.-N. Zel.

foliosa, A. Gray, in Proc. Am. Acad. iv. (1860) 48.Ins. Sandvic.

gracilis, A. Cunn. in Ann. Nat, Hist. ii. (1839) $206=$ rhamnoides?

grandifolia, Hook. f. Fl. N. Zel. 104.-N. Zel.

hirtella, Labill. Nov. Holl. Pl. i. 70. t. 95.-Austral.

lanceolaris, F. Muell. Fragm. ix. 70.-Austral.

ligustrina, Kunth, Ind. Sem. Hort. Berol. (1846) 13. -Hab.?

linarifolia, Hook, f. Handb. Nerw Zeal. Fl. 118. N. Zel.

longifolia, A. Gray, in Proc. Am. Acad. iv. (1860) 48. Ins. Sandvic.

lucida, Forst. Char. Gen. 138.-N. Zel.

Menziesii, A. Gray, in Proc. Am. Acad. iv. (1860) 49.Ins. Pacific

microcarpa, Hook. f. Fl. N. Zel. 110.-N. Zel.

microphylla, A. Cunn. ex Hook. f. in Hook. Lond. Journ. Bot. vi. (1847) 465 [bis] = Billardieri

myrtifolia, Noronha, in Ver. Batav. Gen. v. 1790$)$ ed.

I. Art. IV. 10.-Java.

myrtillifolia, Hook. f. Fl. Antarct, i, $21=$ parviflora.

Nertera, F. Muell, Fragm. ix, $186=$ Nertera depressa

nitida, Hook. f. in Hook. Lond. Fourn. Bot. vi. (18t7) 465 [bis].-Austral.

parviflora, Hook. f. Fi. N. Zel. 106.-N. Zel.

persicaefolia, A. Gray, in Proc. Am. Acad. iv. (1860)

50.-Ins. Fiji.

petiolata, Hook. fo in Fourn. Linn. Soc i. (1857) 128 -Ins. Kurmadec.

pilosa, Endl. Fl. Ins. Norf. Prod. 60.-Ins. Norfolc.

propinqua, A. Cunn. in Ann. Nat. Hist. ii. (183!) 206. - N. Zel.

pubens, A. Gray, in Proc. Am. Acad. iv. (1860) 49.Ins. Sandvic.

\section{COPROSMA}

pumila, Hook. f. Fl. N. Zel. 111-Austral, N. Zel. pusilla, Forst. f. Prod. 90; A. Rich. Voy. Astrol. Bot i. 265 = foetidissima

putida, C. Moore E F. Muell. Fragm. vii. 45.-Ins. D. Howe.

repens, A. Rich. Voy. Astrol. Bot. i. $264=$ foetidissima. repens, Hook. f. Fl. Antarct. i. 22. t. 16,-N. Zel.

reptans, F. Muell. Fragm. ix. 186.-Austral.

etusa, Banks \& Soland. ex Hook. f. in Hook. Lond. Journ. Bot. iii. (1844) $415=$ Baueri.

rhamnoides, A. Cunn. in Ann. Nat. Hist. ii. (1839) 206.-N. Zel.

rhynchocarpa, A. Gray, in Proc. Am. Acad. iv. (1860) 48.- - Ins. Sandvic.

robusta, Raoul, in Ann. Sc. Nat. Sér. III. ii. (1844) 121. - N. Zel.

rotundifolia, A. Cunn. in Ann. Nat. Hist. ii. (1839) 206.-N. Zel.

rubra, Petrie, in Trans. N. Z. Inst. xvii. (1885) 269.N. Zel.

serrulata, Hook. f. ex F. Buch. l. c. iii. (1871) 212. N. Zel

pathulata, A. Cunn. in Ann. Nat. Hist. ii. (1839) 207.-N. Zel.

Stocki Hort. ex J. Barbier, in Rev. Hortic. Belg. iii 1877) t. $12=$ Baueri

sundana, Miq. Fl. Ind. Bat. ii. 327.-Malaya.

taitensis, A. Gray, in Proc. Am. Acad. iv. (1860) 49 -Ins. Tahiti.

tenuicaulis, Hook. f. Fl. N. Zel. 106--N. Zel.

triflora, Benth. E Hook. f. Gen. ii. 139.-Ins. Jua! Fernand.

venosa, A. Cunn. ex Hook. f. in Hook. Lond. Journ. Bot. vi. (1847) 465 [bis] = hirtella

virescens, Petrie, in Trans. N. Z. Inst. xi. (1879) $426^{\circ}$ -N. Zel.

Waimeae, Wawra, in Flora, lvii. (18\%ँ) 327.-Ins. Pacif.

COPROSMANTHUS, Kunth, in Abh. Akad. Berl. (1848 35 ; et Enum. Pl. v. $263(1850)=\mathbf{S m i l a x}$, Linn. (Liliac.)

consanguineus, Kunth, Enum. Pl. v. $268=\mathrm{S}$, berbacea.

herbaceus, Kunth, 1. c. $265=\mathrm{S}$. herbacea.

japonicus, Kunth, 1. c. $268=$ S. China.

lasioneuron, Kunth, 1. c. $265=$ S. herbacea.

peduncularis, Kunth, 1. c. $264=\mathrm{S}$. herbacea.

tamnifolius, Kunth, 1. c. $267=$ S. tamnifolia.

COPTIDIUM, Nym. Consp. 13 (1878)=Ranunculus, Tourn.

ranunculoides, Nym. 1. c $=$ R. lapponicus.

COPTIS, Salisb, in Trans Linn. Soc viii. (1807) 305 RANUNCULACEAE, Benth. \& Hook. f. i. 8 .

Chrysocoptis, Nutt. in Joum. Acad. Philad. vii. (1834) 9.t. 1 .

anemonaefolia, Sieb. E Zucc. in Abh. Math. Phys. Kl. Muench. iv. II. (1843) 180.-Japon.

asplenifolia, Salisb. in Trans. Linn. Soc. viii. (180 306. - Am. bor.

brachypetala, Sieb. E Zucc, in Abh. Math. Phys. K! Muench. iv. II. (1843) 180.-Japon.

occidentalis, Torr. E Gray, Fl. N. Am. i. 28.-Am bor. occ.

orientalis, Maxim. in Bull. Acad. Pitersb. xij, 1stis 60.-Japon.

quinquefolia, Miq. Anr. Mus. Bot. Lugd. Bas. iii. 7.-

Japon. Himal.

trifolin, Salisb, in Trans, Linn. Soc, viii. (1ะ07 905. Keg. bor, temp. et arct.

COPTOCHEILE, Huffmgr. Verz. PA. Nacher. $(19+1$ ex Linnaea, xvi. : 1s42) Lith. 278. GES.1ER.ACE.AE। macrorhiza, Holfmgg. Vl. cc.-Bras.]

COPTOPHYLUUM, Korth, in. Ned. Kruidl. Arch

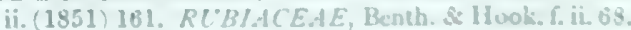
bracteatum, Korsh. l. c. 16 . - - Sumatra. capitatum, Mig. Fl. Ind. Bab. ii. 318. - Malaya.

pilosum, Miq. Ann. M/us. Bos. Lagul. Bart. ir. 290.Java.

COPTOSA PELT A, Korth, in Ninl, Kruill. Arch.ii.l1 (1551) 11\%. R('B).ACEAE, lenth. \& Hook. 6. ii. 33. Anvesceus, Lursho l. c. 11S-Malaya. Griftithii, Hoot. f. IG. Pl. R. 1059. - Malaya. 
COPTOSPERMA, Hook. f. in Benth. \& Hook. f. Gen. ii. 86 (1873). RUBIACEAE, Benth. \& Hook. f. $1 . \mathrm{c}$.

nigrescens, Hook.f.l. $c_{0} 87 .-$ Afr. trop.

COQUEBertia, Brongn. in Ann. Sc. Nat. Sér. I. xxx. (1833) $111=$ Zollernia, Maximil. \& Nees (Legumin.)

ilicifolia, Brongn. 1. c. - Z . ilicifolia.

CORALLIORRHIZA, Aschers. F1. Brandenb. 697 (1864) = Corallorrhiza, Hall. (Orchid.)

CORALLOBOTRYS, Hook. f, in Benth. \& Hook. $f$. Gen. ii. 575 (1876). VACCINIACEAE, Benth. \& Hook. f. 1. c.

acuminata, Hook. f. Fl. Brit. Ind. iii. 455.-Reg. Himal.

CORALLOCARPUS, Welw. ex Benth. \& Hook. f. Gen。 i. 831 (1867), CUCURBITACEAE, Benth. \& Hook. f. 1. c.

conocarpus, Benth. E Hook. f. l. c.-Ind. or.; Afr. trop.

corallinus, Cogn. in DC. Monog. Phan. iii. $647=$ Fenzlii.

Courb nii, Cong. 1. c. $655=$ velutinus.

Ehrenbergii, Hook. f. in Oliver, Fl. Trop. Afr. ii. 566. -Nubia.

epigaens, Benth. E' Hook. f. Gen. i. 831.--Ind. or.

erostris, Hook. f. in Oliver, Fl. Trop. Afr. ii. 567.Afr. trop.

etbaicus, Hook. f. 1. c. = velutinus.

Fenzlii, Hook. f.l. c. 565.-Air. trop.

Gijef, Hook. f. l. c. 566.-Nubia.

glomeratus, Cogn. in DC. Monog. Phan. iii. 658.-

Venezuela.

gracilipes, $\operatorname{Cog} n . l . c .650$.-Ind, or.

palmatus, $\operatorname{Cog} n . l$. c. 648.-Ind, or

parvifolius, $\operatorname{Cogn}$. l. c. 658.-Arabia.

pedunculosus, $\operatorname{Cog} n . \ell$. c. 654.-Abyssin

Poissonii, Cogn.l. c. 651.-Madag.

Schimperi, Hook. $f$. in Oliver, Fl. Trop. Afr. ii. 567.Abyssin.

velutinus, Benth. مو Hook. f. Gen. i. 831.-Ind. or.

Welwitschii, Benth. E Hook. f. l. c.-Afrotrop.

CORALLODENDRON, Tourn. ex Rupp. Fl. Jen. ed. Hall. 257 (1745) - Erythrina, Linn. (Legumin.). aculeatum, Medic. in Vorles. Churpf. Phys. Ges. ii. (1787) $341=\mathrm{E}$, Corallodendron.

CORAllophyllum, H. B. \& K. Nov. Gen. et Sp. vii. 275 . t. 660 bis $(1825)=$ Lennog, La Llave \& Lex.

caeruleum, H. B. \& K. 1. c. $276=$ L. caerulea.

CORAII,ORRHIZA, Hall. Enum. Stirp. Helv, i. 278 (1742) (Corallorhiza); R. Br. in Ait. Hort. Kew. ed. II. v. 209 (1813). ORCHIDEAE, Benth. \& Hook. f. iii. 497 .

Rhizocorallon, Hall. in Rupp. Fl. Jen. 301 (1745).

arizonica, S. Wats. in Proc. Am. Acad xvii. 1881-82) 379. - Arizona.

Bigelovii, Wats. l. c. xii. (1877) 275.-Calif.

bulbosa, A. Rich. \& Gal. in Ann. Sc. Nat. Sér. III. ii

(1845) $19=$ mexicana.

dentata, Host, $\mathrm{Fl}$. Austr. ii. 547 = innata

Ehrenbergii, Reichb. f. in Linnaea, xxii. (1849) 833.Mexic.

ericetorum, Drej. in F1. Dan. t. $2364=$ innata.

foliosa, Lindl. Gen. et Sp. Orch. 535.-Ind. or.

grandiflora, A. Rich. E Gal. in Ann. Sc. Nat. Sér. III, iii. (1845) 19-Mexic.

Halleri, Rich. in Mém. Mus. Par. iv. (1818) $61=$ innata.

hiemalis, Nutt. Gen. Am. ii. 198.-Am. bor.

indica, Lindi. in Fourn. Linn. Soc. iii. (1859) 26.Ind, or.

innata. R. Br. in Ait. Hort. Kew。 ed. II. v, 209.Europ.; Am. bor.

intacta, Cham. \& Schlecht. in Linnaea, iii. (1828) $35=$ innata.

Jacquemontii, Decne. in facquem. Voy. Bot. 165. t. 163.-Reg. Himal.

Macraei, A. Gray, Man. Bot. N. U. St. (1856) $453=$ stricta.

\section{CORALIORHIZA:}

Mertensiana, Bong. Veg. Ins. Sitcha, 165.-Alaska. mexicana, Lindl.Gen. et Sp. Orch. 534.-Mexic. micrantha, Chapm. Fl. S. U. St. 454.-Am. bor. multiflora, Nutt. in Fourn. Acad. Philad. iii. (1823) 138. t. 7.-Am. bor

nemoralis, Sw. ex Nym. Consp. $686=$ innata.

Neottia, Scop. Fl. Carn. ed. II, ii. $207=$ innata.

odontorhiza, Nutt. Gen. Am. ii. 197.-Am. bor.

patens, Lindl. Gen. et Sp. Orch. $535=$ Oreorchis patens.

squamata, Poir. in Dict. Sc. Nat. x. $375=$ Dipodium squamatum.

striata, Lindl. Gen. et Sp. Orch. 534.-Am. bor.

verna, Nutt. in Journ. Acad. Philad. iii. (1823) $136=$ innata.

virescens, Drej. ex Heynh. Nom. ii. 159, nomen $=$ innata.

Wisteriana, Conrad, in Journ. Acad. Philad. vi. (1829) $145=$ odontorhiza

CORALIOSPARTIUIM, Armst, in Trans, N. Z. Inst. xiii. (1881) 338 . LEGUMINOSAE. crassicaule, Armst. l. c.- -N. Zel.

CORALLUMA. Schrank, ex Haw. Syn. Pl. Succ. ed. II. $47(1819)=$ Caralluma, R. Br. (Asclep.).

CORBICHONIA, Scop. Introd. $264(1777)=$ Orygia, Forsk. (Ficoid.).

CORBULARIA, Salisb. in Trans. Hort. Soc. i. (1812) $349=$ Narcissus, Tourn. (Amaryllid.)

albicans, Haw. Revis. $122=\mathrm{N}$. Bulbocodium.

aurea, Haw. Monog. (in Sweet, Brit. Flow, Gard, iv.) 1. ก. $5=$ N. Bulbocodium

Bulbocodium, Haw. Revis. $123=\mathrm{N}$. Bulbocodium. cantabrica, Haw. Monog. 1. n. $1=$ N. Bulbocodium. conspicua, Haw. 1. c. n. $8=$ N. Bulbocodium

filifolia, M. Roem. Syn. Ensat. $190=$ N. Bulboco dium.

Gigas, Haw. Monog. 1. n. $10=$ N. Bulbocodium. Graëllsii, Wehb, ex Willk. \& Lange, Prod. Fl. Hisp. i. $150=\mathrm{N}$. Bulbocodium

hedraeantha, Webb \& Heldr. Cat. Pl. Hisp. $220=$ N. Bulbocodium.

lobulata, Haw. Revis. $122=$ N. Bulbocodinm. monophylla, Dur. in Duch. Rev. Bot. ii. $(1846-47) 425$ =N. Bulbocodium.

nivalis, Nym. Consp. $713=\mathrm{N}$. Bulbocodium

abesa, Salisb, in Trans. Hort. Soc. i. (1812) $350=\mathrm{N}$, Bulbocodium.

Schultesii, M. Roem. Syn. Ensat. 190=N. Bulbocodium.

serotina, Haw. Monog. 1. n. $9=$ N. Bulbocodium.

tenuifolia, Salisb. in Trans. Hort. Soc. i. (1812) $349=$ N. Bulbocodium

turgida, Salisb. 1. c. $351=$ N. Bulbocodium.

CORCHOROPSIS, Sieb. \& Zucc. in Abh. Akad Muench. iii. (1843) 737. t. 4. TILIACEAE, Benth. \& Hook. f. i. 235

crenata, Sieb. E Zucc. l. c.-Japon

CORCHORUS, [Tourn.] Linn. Syst. ed. I (1735). TILIACEAE, Benth. \& Hook. f. i. 235. ANTICHORUS, Linn. Mant. 9. n. 1257 (1767). CARICHERIA, Scop. Introd. 104 (1777) Ganja, Reichb. Handb. 303 (1837) Maerlensia, Vell. Fl. Flum. v. t. 112 (1827). Palladia, Lam. Illustr. t. 285 (1792). acutangulus, Lam. Encyc. ii. 104.-Cosmop. trop. aesticans, Hill, Veg. Syst. xiv, $23=$ aestuans. aestuans, Blanco, F1. Filip. ed. I. $441=$ acutangulus. aestuans, Forsk. F1. Aegypt. Arab. $101=$ trilocularis.

aestuans, Herb. Madr. ex Wall. Cat. p. 237. n. $1074=$ urticaefolius.

aestuans, Linn. Syst. ed. X. 1079.-Am. trop. alatus, G. Don, Gen. Syst. i. 542.-Afr. trop.

americanus, Schrank, ex Stend. Nom. ed. II. i. $416=$ Sida erubescens.

angustifolius. Schum. E Thonn. in Dan. Vid. Selsk. Afh. x. (1828) 18.-Afr. trop.

Antichorus, Raeusch. Nom. ed. III, 158.-Geront. trop.

arenarius, H. B. E K. Nov. Gen. et Sp. v. 339.Mexic.

\section{CORCHORUS :}

argutus, H. B. \& K. Nov. Gen. et Sp. v. 337.-N. Granat.

asplenifolius, Burch. Trav. i. 400.-Afr. austr.

asplenifolius, E. Mey. ex Harv, \& Sond. F1. Cap. i. $2 \cdot 29=$ trilocularis.

australis, A. Cunn. ex F. Muell. Fragm. iii. $8=$ Cunninghami.

bifurcatus, Mill. Gard. Dict. ed. VIII. n. 5.-Tamaic. brachycarpos, Rich. ex Steud. Nom. ed. II. i. 416.Afr. trop.

brachycarpus, Guill. \& Perr. FI. Seneg. Tent. i. $89=$ fascicularis.

bullatus, Jacq. Eclog. P1. t. 163=pilolobus.

Burmanni, DC. Prorl. i. $505=$ triủens.

campestris, Macfad. Fl Jamaic. i. 107-aestuans.

capstlaris, Linn. Sp. Pl. 529.-Cosmop. trop.

caryophylloides, Linn. Syst. ed. X. $1079=$ siliquosus?

catharticus, Blanco, Fl. Filip. ed. I, $442=$ olitorius.

cordifolius, Salisb. Prod. $366=$ capsularis.

Coreta, Linn. Pl Jam. Pugill. 14= siliquosus.

Cunninghami, F. Muell. Fragm, iii. 8.-Austral.

decemangularis, Roxb. Hort. Beng. 42; F1. Ind. ii. $582=$ olitorius

depressus, Stocks, in Proc. Linn. Soc. i. (1848) $367=$

C. Anti-horus.

echinatus, Benth. Fl. Austral. i. 276.-Austral.

elachocarpus, F. Muell. Fragm. viii. 6.-Austral.

erodioides, Balf. $f$. in Proc. Roy. Soc. Edinb. xi. (1882) 504--Ins. Socotra.

fascicularis, Lam. Encyc. ii. 104.- Geront. trop.

flexuosus, Thunb. in Trans, Linn. Soc. ii. (1794) 335. -Japon.

foliosus, Spreng. Syst ii. 583.-Cuba.

frutescens, Lam. Encyc. ii. $105=$ hirsutus.

fruticulosus, Vis. in Flora, xx. (1837) $443=$ trilocularis.

furcatus, G. Don, Gen. Syst. i. $544=$ seq.

fuscus, Roxb. Hort. Beng, 42; Fl, Ind. ii. $582=$ a:utangulus.

gracilis, R. Br. in Salt, Abyss. App. 65.-Abyssin.

grandiflorus, Spring, ex Mart. in Flora, xx. (1837) II. Beibl. $102=$ Tumera serrata.

Greveanus, Baill. in Bull. Soc. Linn. Par. i. (1885) 543. - Madag.

guadalupensis, Spreng. Syst. ii. 584.-Ins. Guadalup.

hirsutus, Linn. Sp. Pl. 530.-Ind. occ.

hirtus, Linn. l. c. er. II. 747.-Am. calid.

hirtus, Thunb. F1. Jap. $228=$ Zelkova acuminata.

humilis, Munro, ex Stocks, in Proc. Linn. Soc. i.

(1848) $367=$ C. Antichorus.

humilis, A. St. Hil. Fl. Bras. Mer. i. 280.-Bras.

hygrophilus, A. Cunn. ex Benth. Fl. Austral. i. 276. -Austral.

japonicus, Thunb. Fl. Jap. $227=$ Kerria japonica.

javanicus, Burm. f. Fl. Ind. 123. t. 36. f. 3.-Ind. or.

lanceolatus, G. Don, Gen. Syst. i. 543.-Guinea.

lanuginosus, Macfad. Fl. Jamaic, i. 108 = hirsutus.

lasiolobus, Spreng. Syst. ii. $5 £ 3=$ pilolobus.

leptocarpus, A. Cunn. ex Benth. Fl. Austral. i. 278.Ausiral.

linearis, Mill. Gard. Dict. ed. VIII. n. 5.-Mexic.

linearis, Wall. Cat. n. $1070=$ tridens.

longicarpus, G. Don, Gen. Syst. i. 543.-Guinea.

longipedunculatus, Mast. in Oliver, Fl. Trop. Afr. i 26z-Afr. trop.

Marua, Buch.-Ham. in Wall. Cat. n. $6311=$ capsularis. microphyllus, Fresen. in Mus. Senckenb. ii. (1837) 156 $=\mathrm{C}$. Antichorus.

mompoxensis, H. B. E K. Nov. Gen. et Sp. v. 338.N. Granat.

muricatus, Hochst. ex A. Rich. Tent. Fl. Abyss. i. 81. -Abyssin.

muricatus, Schum. EN Thonn. in Dan. Vid. Selsk. Afh. x. (1828) 20.-Afr. trop.

olitorius, Linn. Sp. Pl. 529.-Cosmop. trop

oppositiflorus, Hassk. in Hoev. \& De Vriese, Tijdschr. xii. (1845) $126=$ acutangulus.

orinocensis, H. B. E K. Nov. Gen. et Sp. v. 337.Venezuela.

patens, Lehm. Sem. Hort. Hamb. (1823) ex Linnaea, iii. (1820) Lit. $9=$ tridens.

pilolobus, Link, Enum. Hort. Berol. ii. 72.-Am calid.

pilosus, H. B. E K. Nov. Gen. et Sp. v. 338. t. 487.N. Granat.

polygonus Schum. E Thonn. in Dan. Vid. Selsk. Afh x. (1828) 20.-Afr. trop. 


\section{CORCHORUS:-}

prismatocarpus, St. Hil. Fl. Bras. Mer. i. 282, Lras.

procumbens, Boj. Hort. Maurit. 43.-Afr. trop.

psendocapsularis, Schweinf. in Verh. Zool.-Bot. Ges. Wien, xviii. (1868) 670-Afr. trop.

Pumilio, R. Br. ex Benth. Fl. Austral. i. 277.Austral.

pumilus, Buch.-Ham. ex Wall. Cat. n. 6310.-Ind. or. quadrangularis, F. A. Schmidt, Beitr. Fl. Cap. Verd. Ins. 293. - Ins. Cap. Verd.

quinquelocularis, Moench, Meth. 248 = olitorius.

quinquenervis, Hochst. ex A. Rich. Tent. Fl. Abyss. $\mathrm{i}$ $80-$ urticifolius.

scandens, Thunb. in Trans. Linn. Soc. ii. (1794) 335 - Japon.

secundiflorus, Moç. \& Sesse, ex DC. Prod. i. 504= siliquosts.

senegalensis, Juss. ex Stend. Nom. ed. II. i. $417=$ tridens.

serraefolius, Burch. Trav. i. 537.-Afr. austr. serraefolius, DC. Prorl. 1. $504=$ trilocularis. serratus, Thunb. in Trans. Linn. Soc. ii. (1794) 335.Japon.

sidoides, F. Muell. Fragm. iii. 9.-Austral.

siliquosus, Linn. Sp. Pl.529, - Am. calid.

siliquosus, Poepp. ex Steud. Nom. ed. II. i. $417=$ foliosus.

siliquosus, Torr. \& Gray, FI. N. Am. i. $239=$ pilolobus.

spinosus, Sieber, ex Steud. Nom. ed. II. i. $417=$ Pavonia spinifex.

subscandens, Wall. Cat, n. 1074=urticaefolins. tetragona, Mill. Gard. Dict. ed. VIII. n. 4.-Hab.? tetrangulus, Langsd. in Syll. Ratisb. ii. (1828) $168=$ pilololius.

tomentillus, F. Muell. Fragm. iii, 10.-Austral.

tomentosus, Thunb. Fl. Fap. 228.-Japon.

Torresianus, Gaudich. Bot. Voy. Bonite, 477.-Ins. Marian.

tortipes, A. St. Hil. Fl. Bras. Mer. i. $281=$ hirtus.

triclens, Linn. Mant. 566.-Cosmop. trop.

triflorus, Boj. Hort. Maurit, 43 = trilocularis.

trilocularis, Burm. f. F1. Ind. 123. t. 37. f. $2=$ tridens.

trilocularis, Linn. Mant. 77.-Geront. trop.

urticaefolius, Wight \& Arn. Prod. 73.-Ind. or.; Afr. trop.

vermicularis, F. Muell. Fragm. iii. 10.-Austral.

villosiscimus, A. St. Hil. Fl. Bras. Mer. i. 280.-Bras.

Walcottii, F. Muell. Fragm. iii. 9.-Austral.

CORDA, St. Lag, in Ann. Soc. Bot. Lyon, viii. (1881) 177 Cordia, Linn.

CORDAEA, Spreng. Gen. ii. 581 (1831)=Cyamopsis, DC. (Legumin.).

fabaeformis, Spreng. 1. c. =Cyamopsis psoralioides.

CORDEMOYA, Baill. Adansonia, i. $255(1861)=$ Mallotus, Lour. (Euphorb.)

acuminata, Baill. 1. $\mathrm{c}_{2}=$ M. Baillonianus.

integrifolia, Baill. 1. $\mathrm{c}_{\mathrm{.}}=\mathrm{M}$. integrifolius.

CORDIA, Linn. Gen. ed. I. 52 (1737). BORAGINEAE, Benth. \& Hook. f ii. 838.

Acnadena, Carpiphea, Collanthera, ColoCOCCA, Ectemis, Novella, Piloisa, Quarena, Topiaris, Tonuera, Rafin. Sylva Tellur. 39 $43(1838)$

BORELI.IA, Neck. Elem. i. 275, 276 (1790).

CORdiana, Vell. F1. Hum. 98 (1825); ii. t. 156.

Cerdana, Ruiz \& Pav. Prod. 37. t. 6 (1794).

FIRENSIA, Neck. Elem. i. 275, 276 (179(i).

Gerascanthus, P. Br. Hist. Jamaic. 170 , t. 29 f. 3 (1756).

Gynaion, A. DC. Prod. ix. 468 (1845)

Hemigymin, Griff, in Calc. Journ. Nat. Hist. iii. (1843) 363.

Macreula, Vand. Fl. Lnsit, et Bras, Spec, 14 (1788)

MACRIA, Tunore, in Mem. Soc. Ital. Moden xxiv. (1818) 966

Myxia, Cacsalp. ex Linn. Hort. Cliff. 63 (1797) in syn.

Pakanigan, Miers, in Trans. Linn. Soc. Ser. II. i. (1875) 30. t. 8.

Pavonia, Domb. ex Lam. Tabl. Encyc. i, 421 (1800).

\section{CORDIA :}

Plithostephia, Miers, in Trans. Linn. Soc. Ser. II, i. 1875$) 32 . \mathrm{t} .8$

RHABnoCALYX, Lindl. Veg. Kingd. 629 (1847)

Sebestena, [Dill.] Gaerin. Fruct. i. 364. t. 7o, f, 1 (1788:

VARRONIA, P. Br. Hist. Jamaic. $172(1756)$; I n. Syst, ed. X. $916(1759)$

abyssinica, R. Br. in Salt, Abyss. App. 65 ; ed. Germ. $473=\mathrm{C}$. Myxa

acuminata, Wall. Cat. n. 896 ; et in Roxb. F1. Ind.ed. Caley, ii. $339=$ Ehretia Wallichiana.

acutifolia, Fresen. in Mart. Fl. Bras. viii. 11.-Am. trop.

adnata, $D C$. Prod. ix 493-Cuba?

affinis, Fresen. in Mart. Fl. Bras, viii. 22.-Am. trop africana, Lam. Illu itr. n. $18.16=\mathrm{C}$. Myxa. alba, Roem. E Schult. Syst. iv. 466. -Ind, occ alliodora, Cham. in Linnaea, viii. (1833) 121.-Am. trop.

alnifolia, Hornem. Hort. Hafn. i. 227.-Hab. ?

alnifolia, Roem. \& hichult. Syst. iv. $801=$ serratifolia, ambirua, Cham. in Linnaea, v. (1830) 115.-Mexic. ambigua. Cham. 1. c. viii. (1833) $125=$ anabaptista. amplifolia, $A, D C$. in DC. Prod. ix. 481.-Matuit.? anabaptista, Cham, in Linnaea, viii. (1833) 512.-Bras. angiocarpa, A. Rich. Fl. Cub. Fanerog. ii. 110.Culıa

angustifolia, Roem. E Schult. Syst. iv. 460.-Ind. occ anyustifolia, Roxb. Hort. Beng. 17; Fl. Ind. i. 595= Kothii.

aspera, Forst. f. Prod. 18.n. 109.-Austral. ; Ins. Pacif. asperrima, DC. Prod. ix. 498.- Jamaic.

asperrima, Spreng. Syst. i. $649=\mathrm{Hyplis}$ membranacea. asterophora, Mart. ex Fresen. in Mart. Fl. Bras viii. 5.-Am. trop.

avicularis, Salisb. Prod. $111=$ nodosa

Aubletii, DC. Prod. iv 490.-Guiana.

bahiensis, DC. 1. c. ix, $489=$ cylindristachy

Banalo, Blanco, F1. Filip. ed. I. 124 = subcordata.

bantamensis, Blume, Bijdr. 843 . - Java.

Berteri, Spreng. ex Griseb. Fl. Brit. W. Ind. $480=$ salvifolia.

Beurreria, Willd. Sp. Pl. i. 1078, in syn.= Bourreria succulenta.

bi.olor, A. DC. ex DC. Prod. ix. 485.-Guiana.

bifurcata, Roem. Eo Schult. Syst. iv. 466.-Peruv

Blanche ii, $D C$. Prod. ix. 477.-Am. trop.

bogotensis, Benth. Pl. Hartw. 240.-N. Granat

Buis ieri, A. DC in DC. Prod ix. 478.-Mexio.

Bonplandiana, H. B. \& K. Nov. Gen et Sp. iii. $77=$

Ponplandii, Roem. E Schult. Syst. iv. 462.-Am. austı

Bourreria, Linn. Syst. ed. X. $936=$ Bourreria suc culenta.

brachypoda, DC Prod ix. 487-Am. trop.

brachytricha, Fresen. in Mart. Fl. Bras. viii. 18.-Am. trop.

bracleata, $D C$. Prod. ix. 472.-Cuba.

brevispicata, Mart. E Gal. in Bull. Acad. Brux. xi. It

(1ఠ44) 331.-Mexic.

Bromnii, DC. Prod ix, $499=$ C. Myxa.

bullata, Roem. \& Schult, Syst. iv, $462=$ globosa.

buxifolia, fuss. in Poir. Encyc. vii. 47.-Ind, occ

caffra, Sond. in Linnaea, xxiii. (1850) 81.-Afr. aust

Callococca $=$ Collococca

calocephala, Cham. in Linnaea, iv. (182.9) 488.-Bras

calocoma, Miq. Fl. Ind. Bat. ii. 916.-Java.

calophylla, Vahl, Eclog. Am。 iii. 5.-Guinns,

calyptrata, Bert. ex Spreng. Syst i. $649=$ alla

campanulata, Roxb. Hort. Beng. 17 ; Fl. Ind. i. 59 = subcordata.

campestris, Warm. in Kjoeb. Vidensk. Meddel. (1867)

12.-Bras.

cann, Mart E Gal, in Bull. Acad. Brux xi. II. (1844) 3:31-Mexic

candida, Vell. Fl. Flum. 98 ; ii. t. 155.-Bras.

canescens, H.B. $K^{\circ}$. Nov. Gen. et Sp. iii. 73.-N. Granat.

canescens, Willd. ex Roem. \& Schult. Syst, iv. $799=$ polystnchya.

caracasana, DC. Prod ix. $459-$ Venezuela.

Cerdana, Koem. \& Schult. Syst, iv. $467=$ alliodora.

chamaedrifolia, DC. Prod, ix. 499, in syn. = mirabili. flora.

chamaedryoides, Roem. E Schult.Syst. iv, S01.-Hab.

Chamissonians, Stered. Nons. ed. II. i. 117.-13ms.

cincrascens, DC. Prod. ix. $442=$ cylimlristachya.

\section{CORDIA:}

coffeoides, Warm, in Kjoeb. Vidensk. Meddel. (1867) 4.-Bras

Collococa, Aubl. Pl. Gui. i. $219=$ nodosa.

Collococca, Linn. Sp. Pl. ed. 1I. 274.-Tamaic.

Collococca, Sw. ex Griseb. F1. Brit. W. Ind. 479

niticla.

copulata, Poir. in Dict. Sc. Nat. x. 410.-Java.

corchorifolia, A. DC. in DC. Prod. ix. 496.-Am. trop. cordata, Stcud. Nom. ed. II. i. $417=$ grandis.

cordifolia, H. B. E K. Now. Gen. et Sp. iii. 70.-N. Granat.

cordifolia, Wall. Cat. n. $8.94=$ grandis.

coromandeliana, Retz. ex DC. Prod, ix. $509=$ Ehretia buxifolia.

corylifolia, Willd. ex Roem. \& Schuit. Syst. iv. $461=$ alta.

corymbosa, G. Don, Gen. Syst. iv. $3 \times 3=$ monosperma. corymbosa, Willd. ex Steud. Nom. ed. II. i. $417=$ alba. crenata, Delile, Fl. Egypte, 195. t. 20.-Aegypt. crenata, Roem. \& Schult. Syst. iv. $463=$ lanranoides. crenulata, A. DC. in DC. Prod. ix, 492.-Mexic. crispifora, $D C$. l. c. 476.-Mcxic。

cujabensis, Manso E Lhotzky, ex Cham. in Linnaea, viii. (1833) 12.-Bras.

Cumingiana, Vidal, Phan. Cuming. Philipp. 187.Ins. Philipp.

cuneata, Heyne, ex DC. Prod. ix. $480=$ Rothii.

cunciformis, $D C$. l. c. 492.-Vencztiela.

curassavica, Rocm. E Schult. Syst. iv, 460 - Am, austr. "cylindristachya, Roem. E Schult. l. c. 459.-Am. trop. dasycephala, H. B. E K. Nov. Gen. et Sp. iii. 76.Mexic.

decandra, Hook. E Arn. Bot. Beech. Voy. i. 38.-Chili. dentata, Vahl, Eclog. Am. iii. $5=$ = alba. dichotoma, Forst. f. Prod. $18 . n .110=$ C. Myxa. digynia, Vell. Fl. Flum. 97 ; ii. t. 153.-1iras.

Dillenii, Spreng. Syst. i. 649.-Ins. Jaham.

dioica, Boj. ex DC. Prod. ix. 481.-Madag.

dioica, Thonn. ex DC. 1. c. $480=$ guineensis.

diospyrifolia, Cham. in Linnaea, iv. $(182 y) 477$. - Bras. discolor, Cham. lo c. 482-Bras.

divaricata, H.B. E K.Nov. Gen. et Sp. iii. 74.-Am. austr.

diversa, "Thw. Enum. Pl. Zeyl. 21t=monoica.

diversifolia, Pav. ex DC. Prod. ix. 474.-Mexic.

clodecandra, DC. l. c. 478.-Mcxic.

domestica, Bouton, ex Boj. Hort. Maurit. $235=$ ampli. Colia.

domestica, Roth, Nov, Sp. Pl, 123 = C. Mrxa.

domingensis, Lam.Illustr. n. 1900.-Ins. S. Doming.

dubiosa, Blume, Bijdr. 844.-Java.

ecalyculata, Vell. Fl. Flum. 96 ; ii. t. $199 .-$ Bras.

egyp iaca, Rafin. Sylva Tellur. 37.-Aegypt.

ehretioides, Lam. Illustr. n. $1902=$ C. Collococca vel nilida.

elaengnoides, DC. Prod. ix. 474.-Mexic.

elliptica, Sieber, ex Griseb. Fl. Brit. W: Ind. $47^{9}=$ lnevigata.

elliptica, Sw. Prod. Veg. Ind. Occ. 47.-Ind. occ. erythrococca, Griseb. Cat. Pl. Cub. 208.-Cubs.

exalmta, Lam. Illustr. n. 1919.-Guiana.

excelsa, $A . D C$ in DC Prod ix 473-Am. trop.

ferruginea, Roem. E Schult. Syst. iv. $458 ; H$. B. E K Nov. Ger. et Sp. iii. 71.-Mexic. ; N. Granat. Finlaysoniana, Wall. Cat, n. F010.-Ind. or flavescens, Aubl. Pl. Gui. i. 226. 1. 89.-Guiana. Aoribunda, Spreng. Syst. i. 65\%.-Am. austr.

foridana, Nutt. Sylva, iii. $10 \tau=$ Buurrerin havanensis.

foliosa, Mart, \& Gal. in Bull. Acad. Brux, xi. 11 . 1844) 330. - Mexic

formicarum, Roem. \& Schult. Syst, iv. $S 00=$ nolosi.

fragrantisima, Kurs, For. Fl. Brit. Burma, ii. 207. Ind. or. : Burma.

Francisci, Tenore, Cat. Orto Xap. (I\$ 15 ) \$3.-Hab. frondosa, Scholt, in Spreng. Syst. iv. App. $403=$ allio. dora.

fulvosa, Wight, Ic. iv. t. 13:0.-Ind. of

Ginlcottiann, A. Rich. F\%. Cub. Famerog. ii. 109.-Cuba. Gerascanthus, H. B. Se K. Nov. Gen. el Sp, iii, ig tiuisolin.

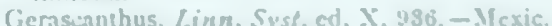

Gerascanthus, Sw. ex (iriseb. H1. Bric. Wi. Ind. 10 gerascheanthoides.

geraschanthuides, H. B. E R. .Vov. Gen. of Sp. iii. 69. Culas.

geraschanthoides, Kich. ex Griscb. Fl. Mrit. W: Inc. $178=$ A. Gicraicantlaus. 


\section{CORDIA :}

Geraschanthus, Jacq. Select. Am. 43. t. $175=$ A. Gerascanthus.

glabra, Cham. in Linnaea, viii. (1833) 124.-Bras.

glabra, Linn. Sp. Pl. $191=$ C. Collococca.

glabrata, A. DC. Prod. ix, 473.-Am, trop

glandulosa, Fresen. in Mart. Fl. Bras. viii. 19.-Am.

trop.

globosa, Andr. ex DC. Prod. ix. $497=$ oaxacana.

globosa, $H . B$. . E K. Nov. Gen. et Sp. ii. 76. -Ind. occ.; Am. centr.

glomerata, Lem. Fard. Fleur. iv. (1854) t. 326.-Bras.

grandiflora, H. B. E K. Nov. Gen. et Sp. iii. 77.-Am.

austr.

grandifolia, $D C$. Prod. ix. 475-Am. trop.

grandis, Cham. in Linnaea, iv. (1829) $473=$ grandifolia.

grandis, Roxb. Hort. Beng. 17; Fl. Ind. i. 593.Ind. or.

grandis, Wall. Cat. n. $892 \mathrm{~B}=$ obliqua.

graveolens, H. B. Eo K. Nov. Gen. et Sp. iii. 74.-Am.

austr.

Greggii, Torr. in Bot. Mex. Bound. 135.-Calif. Mexic

Griffithii, C. B. Clarke, in Hook. f. Fl. Brit. Ind. iv. 139.-Malaya.

guayaquilensis, $D C$. Prod. ix, 496.-Ecuador.

guazumaefolia, Roem. \& Schult. Syst. iv. $463=$ urti cifolia.

guianensis, Roem. Es Schult. l. c. 460.-Guiana

guineensis, Thonn. in Schum. Beskr. Guin. Pl. 128.Afr. trop.

Hartwissiana, Regel, Gartenf. (1857) 342.-Mexic.

hebecarpa, DC. Prod. ix. 488.-Am. trop.

hermanniaefolia, Cham. in Linnaea, iv. (1829) 484.Am. trop.

heterophylla, Poir. in Dict. Sc. Nat. x. 409; Roem. E' Schult. Syst. iv. 800.Guiana.

hexandra, Willd. ex Roem. \& Schult. 1. c. $799=$ sabcordata.

hirsuta, Willd. Sp. Pl. i. $1076=$ nodosa.

hispida, Benth. Bot. Voy. Sulph. 139.-Mexic.

hispidissima, $D C$. Prod. ix. 475.-Am. trop.

Humboldtii, Willd. ex Roem. \& Schult. Syst. iv. $801=$ floribunda.

hypoleuca, $D C$. Prod. ix. 472--Am, trop.

ignota, Blanco, Fl. Filip. ed. II. $88=$ subcordata

incana, Royle, Illustr. Bot. Himal. 306, nomen = vestita

indica, Lam. Encyc. vii. 49.; Illustr. n. $1913=$ C. Myxa.

insignis, Cham. in Linnaea, viii. (1833) 122.-Bras,

integrifolia, Roem. $\xi$ Schult. Syst. iv. 461.-Ins.

S. Doming.

intermedia, Fresen. in Mart. Fl. Bras. viii, 8.-Am trop.

interrupta, DC. Prod. ix. 491.-Guiana

intricata, Wright, in Sauv. Fl. Cub. 109.-Cuba

ipomoeaefolia, Hook. Bot. Mag. t. 5027.- Hab.

ixiocarpa, F. Muell. Fragm. i. $59=$ C. Myxa.

juglandifolia, Facq. Enum, Pl, Carib, 14.-Ins, S. Doming.

lacerata, F. Muell. Fragm. v. $193=$ aspera.

laevigata, Lam. Illustr. n. 1912.--Ind. occ.

laevis, Facq. Hort. Schoenb. 1. t. 40.-N. Granat.

lanata, H. B. \& K. Nov. Gen. et Sp. iii. $72=$ tomentosa.

lanceolata, H. B. \& K. l. c. 75.-N. Granat.

lantanoides, Spreng. Syst. i. 658.-Peruv.

lapensis, Warm. in Kjoeb. Vidensk. Meddel. (1867) 9 -Bras.

latifolia, Cham in Linnaea, viii. (1833) 126.-Bras.

iatifolia, Roxb. Hort. Beng. 17; Fl. Ind. i. $588=$ obliqua.

latifolia, Wall. Cat. n. $893=$ C. Myxa

Latora, Buch.-Ham.ex Royle, Illustr. Bot. Himal. 306. -Ind. or.

laxiflora, H. B. \& $K$. Nov. Gen. et $S p$. iii. $72,-\mathrm{N}$ Granat.

Leschenaultii, DC. Prod. ix. $482=$ oblongifolia

leucocalyx, Fresen. in Mart. Fl. Bras. viii. 22.-Am. trop.

leucocephala, Moric. Pl. Nouv. Am. 148. t. 88.-Bras,

leucocoma, Miq. Fl. Ind. Bat. ii. 916.-Malaya

leucophlyctis, Hook. f. in Trans. Linn. Soc. xx. (1851) 199.-Ins. Galap.

leucosebestera, Griseb. Cat. Pl. Cub. 208.-Cuba

Lima, Roem. Echult. Syst. iv. 475.-Ins. S. Doming

linearis, A. DC. in DC. Prod. ix. 493.-Mexic.

linearis, Hook. f. in Trans. Linn. Soc. xx. (1851) 199 -Ins. Galap.

\section{CORDIA :-}

lineata, Roem, \& Schult. Syst, iv, $464=$ ulmifolia.

longifolia, A. $D C$ in $D C$. Prod ix. 495.-Am. trop.

Loureiri, Roem Eo Schult. Syst iv, 465-China.

lutea, Lam. Tabl. Encyc. i. 421.-Peruv.

Macleodii, Hook. f. E Thoms. in Fourn. Linn. Soc. ii (1858) 128.-Ind. or.

macrocephala, H. B. E* K. Nov. Gen. et Sp. iii. 77.Peruy.

macrophylla, Linn. Sp. Pl. ed. II. 273.-Ind, occ.

macrophylla, Vahl, ex Griseb. F1. Brit. W. Ind. 480 sulcata.

macrostachya, Roem. E Schult. Syst. iv. 461.-N. Granat.

macrostachya, Spreng. Syst. i. $652=$ cylindristachya magnoliaefolia, Cham in Linnaea, iv (1829) 476 . Bras.

mariquitensis, H. B. E K. Nov. Gen. et Sp. ini. 75.-N Granat.

Martii, DC. Prod. ix. $471=$ insignis

martinicensis, Link, Enum. Hort. Berol. i. $162=$ curassavica.

martinicensis, Roem. छ Schult. Syst. iv, 461.-Ins Martinic.

martinicensis, Sieber, ex Griseb. F1. Brit. W. Ind. 480 $=$ cylindristachya.

McLeodii, vide Macleodii.

melanoneura, Klotzsch, in Schomb. Fauna et Fl. Gui. 960.-Guiana

membranacea, A.DC. ex DC. Prod. ix. 484.--Ecuador micrantha, Sw.Prod. Veg. Ind. Occ. 47.-Jamaica. micrantha, Sw. 1. c. pro parte, ex Griseb. Fl. Brit. W Ind. $479=\mathrm{C}$. Collococca.

microcephala, Willd. in Roem. Es Schult. Syst. iv. 801 -Venezuela.

microphylla, Roem. E Schult. l. c. 463.-Ins. S Doming.

mirabiliflora, A. DC. in DC. Prod. ix. 499.-Cuba. mirabiloides, Roem. \& Schult. Syst. iv. 465.-Ins. S. Doming

miranda, DC. Prod. ix. 475.-Am. trop.

moluccana, Roxb. Hort. Beng. 84; Fl. Ind. ii. 594.Ins. Molucc.

monoica, Boj. Hort. Maurit. $235=$ ovalis

monoica, Roxb. Pl. Corom. i. 43. t. 58.-Ind. or

monosperma, Roem. Es Schult. Syst. iv, 463.-Venezuela.

mucronata, Fresen. in Mart. Fl. Bras. viii. 9.-Am. trop. multispicata, Cham. in Linnaea, iv. (1829) 499.Bras.

Munneco, H. B. E K. Nov. Gen. et Sp, vii. 207.Venezuela.

Myxa, Forsk. Fl. Aegypt. Arab. p. 1xiii = crenata.

Myxa, Linn. Sp. Pl. 190.-As. trop.; Austral

Myxa, Thw. Enum. Pl. Zeyl. $213=$ obliqua.

Neowediana, A. DC. in DC. Prod. ix. 498.-Am. trop. nervosa, Lam. Illustr. n. 1906.-Guiana.

nitida, Vahl, in West, Bidrag Ste-Croix, 275.-Ind

nitida, Willd. in Roem. E Schult. Syst. iv. 800.Hab.

nivea, Fresen. in Mart. Fl. Bras. viii. 26.-Am. trop.

nodosa, Lam. Illustr. n. 1905.-Guiana.

oaxacana, $D C$. Prod, ix, 497--Mexic

obliqua, Heyne, ex DC. 1. c. $479=$ Wallichii.

obliqua, H. B. \& K. Nov. Gen, et Sp. iii. $74=$ peru viana.

obliqua, Vell. Fl. Flum. 97 ; ii. t. 150.-Bras.

obliqua, Willd. Sp. Pl. i. 1072.-Ind. or,

oblongifolia, Hochst. ex DC. Prod. ix 480, nota.Abyssin

oblongifolia, Thw. Enum. Pl. Zeyl. 214.-Zeylan.

obovata, Balf. f. in Proc. Roy. Soc. Edinb. xii. (1884) 80.-Ins. Socotra.

obscura, Cham. in Linnaea, xiii. (1839) 480,-Bras.

obtusa, Balf. f. in Proc. Roy. Soc. Edinb. xii. (1884) 80

-Ins. Socotra.

ochnacea, DC. Prod. ix. 477.-Am. trop.

octandra, A.DC. l. C.--Ind. or.

officinalis, Lam. Illustr. ii. $420=$ C. Myxa.

olitoria, Blanco, Fl. Filip. ed. I, 123.-Ins, Philipp.

oncocalyx, F. Allem. in Trab. Comm. Sc. Expl.

Bot. i. (1862) 11.-Bras.

orientalis, R. Br. Prod. $498=$ subcordata.

ovalis, R. Br. in Salt, Abyss. App. 65.-Abyssin.

oxyphylla, DC. Prod. ix. 492.-Guiana.

panicularis, Rudge, Pl. Guian. 30. t. 46.-Guiana.

paniculata, Roth, Nov. Pl. Sp. $125=$ C. Myxa.
CORDIA :-

paniculata, Sieber, ex Presl, in Oken, Isis, xxi. (1828) $273=$ Wilbrandia paniculata.

parviflora, Orteg. Hort. Matr. $85=$ serratifolia

parvifolia, A. DC. in DC. Prod. ix. 498.-Mexic.

parvifolia, Hemsl. Biol. Centr. Am. Bot. ii. 369, in syn. = serratifolia

Patagonula, Ait. Hort. Kew. i. $259=$ Patagonula americana.

patens, H. B. E K. Nov. Gen. et Sp. iii. 75.-Am austr.

patens, Miq. ex Griseb. Fl. Brit. W. Ind. $480=$ ulmifolia.

paucident ta, Fresen, in Mart. Fl. Bras. viii. 25.Bras.

pedunculosa, Griseb.Cat. $\mathrm{Pl}$. Cub. 209-Cuba.

Pelida, Perr. ex DC. Prod. ix. $480=$ senegalensis.

pellita, Willd. ex Roem. \& Schult. Syst. iv. $800=$ Tournefortia hirsutissima.

Perrottetii, A. DC. Prod. ix. 482.-Ind. or.

peruviana, Roem. E' Schult. Syst. iv. 459.-Peruv.

petiolata, Hort. ex Steud. Nom. ed. II. i. $418=$ Ehretia petiolaris.

Petta-pelioporet, Heyne, ex Roth, Nov. Pl. Sp. $125=$ paniculata.

piauhiensis, Fresen. in Mart. Fl. Bras. viii. 9.-Bras.

pilulifera, Willd. ex Roem. \& Schult. Syst. iv. $801=$ globosa.

platyphylla, Steud. Nom. ed. II. i. $418=$ latifolia.

podocephala, Torr. in Bot. Mex. Bound. 135.-Texas; Mexic.

Poeppigii, DC. Prod. ix, 492.-Am. austr.

poliophylla, Fresen. in Mart. Fl. Bras. viii. 26.-Am. trop.

polyantha, Benth. Pl. Hartw. 121.-Ecuador.

polygama, Roxb. Hort. Beng. 17; F1. Ind. i. $594=$ monoica.

polygama, Wall. Cat. n. 892, partim = fulvosa.

polystachya, H. B. E K. Nov. Gen. et Sp. iii. 73.Venezuela.

portoricensis, Spreng. Nene Entdeck. ii. 127 = cylindristachya.

prionodes, Voigt, Hort. Suburb. Calc. $441=$ octandra.

pubescens, Willd. ex Roem. E Schult. Syst. iv, 803.Venezuela.

pyrifolia, Willd. ex Roem. \& Schult. 1. c. $802=$ ferruginea.

quercifolia, Klotzsch, in Peters, Reise Mossamb. Bot. 247.-Afr, trop.

Radula, Spreng. Syst. i. $654=$ Lima,

rariflora, A. Rich. Fl. Cub. Fanerog, ii. 110.-Cuba

reflexa, Willd. ex Roem E Schult Syst. iv. 800 .-Ind or.

reticulata, Roth, Nov. P1. Sp. $124=$ Rothii

reticulata, Vahl, Eclog. Am, iii. 5.-Ins. Montserrat.

retusa, Vahl, Symb. Bot. ii. $42=$ Ehretia buxifolia

revoluta, Hook. f. in Trans. Linn. Soc. xx. (1851) 199.

-Ins. Galap.

riparia, H. B. E K. Nov. Gen. et Sp. iii. 71.--N. Granat.

rotata, Moc. ex DC. Prod. ix. 483.-Mexic

Rothii, Roem. E' Schult. Syst. iv. 798.-Ind, or.

rotundifolia, Heyne, ex C. B. Clarke, in Hook. f. Fl.

Brit. Ind. iv. $139=$ fragrantissima.

rotundifolia, Ruiz \& Pav. Fl. Per. ii. 24. t. 148.Panama.

Roxburghii, C. B. Clarke, in Hook. f. Fl. Brit. Ind. iv. 138.-Zeylan.

rubra, Hochst. ex A, Rich. Tent. Fl. Abyss, ii. $82=$ C. Myxa.

rufa, Klotzsch, in Schomb. Fauna et Fl. Gui.960.Guiana.

rufescens, $A . D C$. in $D C$. Prod. ix. 476.--Am, trop

rugosa, Willd, ex Roem. \& Schult. Syst. iv. $801=$ canescens.

Rumphii, Blume, Bijdr. $843=$ subcordata

salicifolia, Cham. in Linnaea, iv. (1829) 481.-Bras.

salicina, DC. Prod. ix. 492.-Am, trop.

salviaefolia, H. B. \& K. Nov. Gen. et Sp. iii. $72=$ cylindristachya.

salvifolia, Fuss. in Poir. Encyc. vii. 46.-Ins. Guadalup.

Salzmanni, [Benth. ex] Griseb. F1. Brit. W. Ind. 480 $=$ ulmifolia.

Salzmanni, DC. Prod. ix. 494.-Bras

sarmentosa, Lam. Illustr. n. $1907=$ flavescens

scaberrima, H. B. E $K$. Nov. Gen. et Sp. iii. 71.Peruy. 


\section{CORDIA :}

scabra, Desf. Tabl. ed. I. 71.-Ind, or.

scabrida, Mart. ex Fresen. in Mart. Fl. Bras. viii. 11. -Bras.

scabrifolia, [Benth. ex] Griseb. Fl. Brit. W. Ind. $479=$ paniculata.

scabrifolia, A. DC. in DC. Prod. ix. 485.-Guiana.

scandens, Martin, ex Poir. in Dict. Sc. Nat. x. 410.Guiana.

Schomburgkii, DC. Prod. ix. 490.-Guiana.

Schottiana, Fresen. in Mart. Fl. Bras. viii. 7.-Am. trop.

Scouleri, Hook. f. in Trans. Linn. Soc. xx. (1851) 200 -Ins. Galap.

Sebestena, Andr. Bot. Rep. iii.t. $157=$ scabra

Sebestena, Forsk. Fl. Aegypt. Arab. p. Ixiii =C. Myxa.

Sebestena, Forst. f. Prod. $18=$ subcordata

Sebestena, Linn. Sp. Pl. 190-Am. trop.

Sebestena, Willd. ex Spreng. Syst. i. $649=$ Dillenii.

Sellowiana, Cham. in Linnaea, iv. (1829) 479.-Bras.

senegalensis, Fuss. in Poir. Encyc, vii. 47.-Afr. occ.

sericicalyx, A. DC. in DC. Prod. ix. 485.-Guiana

serrata, Fuss. ex Poir. Encyc. vii. 41.-Ind. or.

serrata, Roxb. Hort. Beng. 17; Fl. Ind. i. $591=$ octandra.

serratifolia, H. B. E K. Nov. Gen. et Sp. iii. 76.Mexic.

sessilifolia, Cham. in Linnaea, iv. (1829) 488.--Bras.

sinensis, Lam. Illustr. n, 1914.--China.

speciosa, Salisb. Prod. $111=$ C. Sebestena.

spectabilis, Steud. Nom. ed. II. i. 419.-Ind. or.

sphaerocephala, Willd. ex Roem. \& Schult. Syst. iv. $801=$ dasycephala.

spicata, Willd. ex Roem. \& Schult. 1. c. $799=$ graveolens.

spinescens, Linn. Mant. 206.--Ind, or.

Sprengelii, DC. Prod. iv, 473, - Ins. Fiji.

striata, Fresen. in Mart. Fl. Bras. viii. 23.-Am. trop.

strigosa, Spreng. Neue Entdeck, iii. 30.-Ind. occ.

suaveolens, Blume, Bijdr. 843.-Java.

subcordata, Lam. Illustr. n. 1899.-As. et Austral. trop.

subdentata, Miq. Fl. Ind. Bat. Suppl. 571.-Sumatra. subopposita, DC. Prod. ix. $480=$ Rothii.

subpubescens, Decne. Herb. Timor. 67.-Ins. Timor.

sulcata, DC. Prod. ix. 488.-Ind. or.

superba, Cham. in Linnaea, iv. (1829) 474.-Bras.

taguahyensis, Vell. Fl. Flum. 98 ; ii. t. 154.-Bras.

tenuifolia, Bertol. Misc. Bot. xxi. 13. t. 1.-Guatemala.

tetrandra, Awbl. Pl. Gui, i. 222. t. 87.-Guiana.

tetraphylla, Aubl. l. c. 224. t. 88.-Guiana.

Thibandiana, DC. Prod. ix. 489.-Am. austr.

thyrsiflora, Sieb. \& Zucc. Fl. Jap. Fam. Nat. ii. $26=$ Ehretia acuminata

timorensis, Span. in Linnaea, xv. (1841) $334=$ sub-

pubescens.
tinifolia, Willd. ex Roem. E Schult. Syst. iv. 800.-Am. austr.

tomentosa, Cham. \& Schlecht. in Linnaea, iv. (1829) $472=$ Chamissoniana

tomentosa, Rocm。 \& Schult. Syst. iv, 459,-Am. austr.

tomentosa, Wall. in Roxb. Fl. Ind. ed Carey, ii. $339=$ obligua,

Toqueve, Aubl. Pl. Gui. i. 228. t. 90.-Am. trop

Toqueve, Sieber, ex Griseb. Fl. Brit. W. Ind. $480=$ sulcata.

trachyphylla, Mart. Herb. Fl. Bras. n. 412.-Bras, tremula, Griseb. Fl. Brit. W. Ind. 479.-Ind. occ.

trichoclada, DC. Prod. ix. 474.-Am, trop.

trichostemon, DC. l. c. 482.-Ins. Timor,

trichotoma, Vell. ex Steud. Nom. ed. II. i. 419.Bras.

truncata, Fresen. in Mart. Fl. Bras. viii. 25.-Am. trop.

ulmifolia, guss. in Dum.-Cours. Bot. Cult. ed. I. ii.

148.-Panama ; Ind. occ.

ulmifolia, Spreng. Syst. i. $653=$ monosperma.

umbraculifera, DC. Prod. ix. 484.-Am. trop.

urticifolia, Cham. in Linnaea, iv. (1829) 483.-Bras.

Valenzuelana, A. Rich. F\%. Cub. Fanerog. ii. 110.Cuba.

velutina, Mart. Herb. F1. Bras. n. $268=$ cujabensis.

verbenacea, $D C$. Prod. ix. 491.-Am, trop.

vestita, Hook, $f$, Thoms, in Fourn. Linn. Soc. ii. (1858) 128,-Reg. Himal.

viburnoides, Zipp. ex Span. in Linnaea, xv. (1841) 385, nomen.-Malaya.
CORDIA:

villicaulis, Fresen. in Mart. Fl. Bras. viii. 24.-Am trop.

villosa, Spreng. Neue Entdeck. iii. 31.-Ins. S. Doming.

Wallichii, G. Don, Gen. Syst. iv, $379=$ obliqua.

Wickstroemii, Steud. Nom. ed. II. i. 419.-Ins, Guadalup.

CORDIADA, Vell. Fl. Flum, 98 (1825); ii. t. $156=$ Cordia, Linn. (Boragin.

trichotoma, Vell. ll. cc. = Cordia trichotoma

CORDIERA, A. Rich, in Mém. Soc. Hist. Nat. Par, y 1830) 222. t. $20=$ Alibertia, A. Rich. (Rubiac.) acuminata, Benth, in Hook. Journ. Bot. iii. (1841) 221.-Guiana.

latifolia, Benth. 1. c.-Bras.

triflora, DC. Prod. iv. 445-Guiana

trifolia, Steud. Nom. ed. II. i. 419 , sphalm。= praec.

CORDIOPSIS, Desv, in Ham. Prod. Fl. Ind. Occ. 23 (1825) = Cordia, Linn. (Boragin.)

mirabiliflora, DC. Prod. ix. $499=$ Cordia mirabiliflora mirabiloides, Desv. in Ham. Prod. FI. Ind. Occ. $23=$ Cordia mirabiliflora.

monosperma, Ham. ex Heynh. Nom. ii. $160=$ Cordia monosperma.

CORDUlA, Rafin. Fl. Tellur. iv. $46(1836)=$ Cypripe dium, Linn. Orchid.

insignis, Rafin. 1. c. = Cyprip. insigne.

CORDYLA, Blume, Bijdr. 416 (1825)= Pogonia, Juss Orchid.)

concolor, Blume, 1. c. = P. concolor.

discolor, Blume, 1. c. $=\mathrm{P}$. discolor.

CORDYLA, Lour. F1. Cochinch. 411 (1790). LEGU. MINOSAE, Benth. \& Hook. f. i. 562

CalyCandra, Lepr. ex A. Rich. in Guill. \& Perr. Fl. Seneg. Tent. 30 ; et 232. t. 9 (1832).

africana, Lour. l. c. 412.-Afr. trop.

Richardi, Planch. in App. Speke, Journ. Disc. Nile, $632=$ africana

CORDYLANTHUS, Blume, Mus. Bot. Lugd. Bat. ii. 27 t. 3. $1852[1856]=$ Homalium, Jacq. (Samydac.). frutescens, Blume, 1. c. $28=\mathrm{H}$. Cordylanthus.

CORDYLANTHUS, Nutt. ex Benth. in DC. Prod x. 597 (1846), SCROPHULARINEAE, Benth. Hook. f. ii. 974.

Adenostegra, Benth, in Lindl. Nat. Syst, ed, II $445(1826)$.

Chloropyron, Behr, in Proc. Calif. Acad. i. (1855) 61 .

canescens, A. Gray, in Proc. Am. Acad.vii. (1868) 383. -Am. bor. occ.

capitatus, Nutt. ex Benth. in DC. Prod. x. 597.-Am. bor occ.

filifolius, Nutt. ex Benth. l. c.-Calif.

Kingii, S. Wats, in Bot. King's Exp. 233, 459. t. 22.Am. bor. occ.

laxiflorus, A. Gray, in Torr. Bot. Mex. Bound. 120.Arizona.

maritimus, Nutt. ex Benth. in DC. Prod. x. 598. Calif.

mollis, A. Gray, in Proc. Am. Acad. vii. (1868) 384.Calif.

Nevinii, A. Gray, l. c. xvii. (1881-82) 229,-Calif. Orcuttianns, A. Gray, L c. xix. (1883) 95-Calit. Parryi, S. Wats. in Am. Natural. ix. (1575) 946 cariescens.

pilosus, A. Gray, in Proc. Am. Acad. vii. (1868) 382 -Calif.

Pringlei, A. Gray, l.c. xix. (1883) 94,-Calif.

ramosus, Nutto ex Benth, in DC. Prod x. 597-Am. bor. occ.

tenuis, A. Gray, in Proc. Am. Acad. vii. (1868) 9ss.Am, bor. occ.

Wrightii, A. Gray, in Torr. Bot. Mex. Bound. 120.Texas; N. Mexic.

CORDY LESTY LIS, Falc. in Hook. Journ. Bot. iv. (1542) $74=$ Goodyera, R. Br. (Orchid.)

foliosa, lialc. 1. c. $75=\mathrm{G}$. procern.
CORDVLIA, Pers. Syn. ii. $260(1807)=$ Coryda, Lour. Legumin.).

CORDYLINE, Royen, ex Adans, Fam ii. 54 (1763) LILIACEAE, Benth. \& Hook, f. iii. 799.

Calodracon, Planch, in Flo des Serres, Sér. I. yi. $(1850-51) 137$

CHarlwoonia, Sweet, Fl. Austral, t. 18 (1\&27).

Cohnia, Kunth, Enum. P1. v. 35 (1850).

Dracaenupsis, Planch, in Fl. des Serres, Sér. I. vi. (1850-51) 110.

TAetsia, Medic. Theodora, 82 (1786)

angustifolia, Kunth, Ennm. Pl. v. $32=$ stricta

arborea, Goepp. in Nov. Act. Nat. Cur. xxv. (1855) 55. -Afr. trop.

atropurpurea, Planch, in Fl, des Serres, Sér. I vi

$(1850-51) 132=$ Dracaena clliptica.

australis, Endl. Prod. Fl. Ins, Norf, $29=$ Baueri.

australis, Hook. f. in Gard. Chron. (1860) 792 .

N. Zel

australis, Nadeaud \& Jouan, in Mém. Soc. Sc, Nat. Cherb. xi. (1865) $127=$ terminalis

Banksii, Hook. f. in Gard. Chron. (1860) 792. N. Zel.

Baueri, Hook.f.l. c.-Ins. Norfolc.

Betschleriana, Goepp. in Nov. Act. Nat. Cur. $x x y$ 1885) $55=$ Dracaena concinna.

Beuckelaerii, C. Koch, Wochenschr. viii. (1885; 91 Banksii

brasiliensis, Planch. in Fl. des Serres, Sér. I. vĩ. 1850 51) 136.-Bras.

calocoma, Hort. ex Baker, in Journ. Linn. Soc. xiv. 1875) $542=$ anstralis

cannaefolia, R. Br. Prod. $280=$ terminalis.

Casanovae, Linden, ex André, Illustr. Hortic. $x x i$. (1874) 137. t. 181. - N. Hebrid.

cernua, Planch. in Fl. des Serres, Sér. I. vi. (1850-51) $111=$ Dracaena reflexa.

coerulea, Goepp. in Wow. Act. Wat. Cur. xxw. Inji, 5. - Hab.?

congesta, Endl. Gen. 151 = stricta.

congesta, Steud. Nom. ed. II. i. 419-Austral.

Dennisoni, Hort. ex Andre, Illustr. Hortic. xix. (1872) $360 .-$ Hab.

densicoma, Linden \& André, l. c. (1874) 185. t. 190.Austral.

diffusa, Colenso, in Trans. N. Z. Inst. xv. (1883) 390. $-\mathrm{N}$. Zel.

dracaenoides, Kunth, in Abh. Acad. Berl. 1842) $30, \ldots$ Bras.

ensifolia, Planch. in Fl. des Serres, Sér. I. vi. (1850-51) $132=$ Dianella ensifolia

erythrorachis, Hort. ex Baker, in Journ. Linn. Soc xiy. 1875) $541=$ Banksii.

Eschscholziana, Mart, in Schult. f. Syst. vii. 347, 1677 $=$ terminalis.

ferrea, C. Koch, Wochenschr. xiv. (1871) 12 =terminalis.

flabelliformis, C. Koch, Allg. Garteng.(1558; 254.-Ins. Maurit.

Alexuosa, Miq. Fl. Ind. Bat. iii. 558.-Malaya.

floribunda, C. Koch, Allg. Garteng. (1858 254.Ins. Maurit.

Fontanesiana, Goepp, in Nov, Act. Nat. Cur. xuv. 1855) 54 t. $3=$ Dracaena Fontanesiana.

Forsteri, F. Muell. Sel. Pl. Indust. Cult. 58 ב australis.

fragrans, Planch.in Fl des Serres, Seir. I. vi. '1550-51' 111,136 . - Afr. trop.

fruticosi, Goepp. in Nov. Act. Nał. Cur. xxv. $185 j$ 53.- Java.

gloriosa, Linden \& Andri, 1lluser. Hortic. xx. 15:3 t. $1: 25-6=$ terminalis.

Guilforler, Hort. Linden, ex Lcm. Illustr. Hortic xvi. $(1 \leqslant 69)$ t. 600 - teiminalis.

Hangeana, C. Koch, Worhenschr. (150\%) 195.Austral.

heduchivides, F. Muell. Fragm, vo. $1960=$ terminalis

heliconiactolia. ()to \& Dicts, in Alle. Cestens. 1535 $3 !=$ ecrminnalis

hemichrysa, Comm. cos Lam. Encre. ii. 286.-Ios Mamrit.

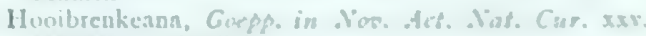
$1855) 55 .-\mathrm{N}$. Zel.

Huokeri, T. Ä̈k. in Trans. N. 2. Joss, ri. 1s:i $285 .-\mathrm{X}$. Zecl.

bumilis, Gerpp. in Non. Ads. Nas. Car. xrv. 1535: 35 $-11 \mathrm{ab}$. 


\section{CORDYLINE:-}

indivisa, Recel, Gartenf. (1859) 331 -australis indivisa, Steud. Nom. ed. II i. 419-N. Zel

Facquini, Kunth, in Abh. Acad. Berl. (1842) $30=$ terminalis.

javanica, Klotzsch, ex Kunth, Enum. Pl. v. $26=$ terminalis.

lentiuinosa, Linden \& André, Illustr. Hortic. xvii, $1870) \mathrm{t} .35=$ australis

linearifolia, Miq. Fl. Ind. Bat. Suppl. 610.Sumatra.

longifolia, Benth. P1. Hartw. $53=$ Nolina Hartwe. giana.

macrophylla, C. Koch, Allg. Gartenz. (1858) 254.Ins, Mascar.

maculata, Planch.in F1. des Serres, Sér. I。 vi. (1850-51) $132=$ Dracaen elliptica.

madagascariensis, Goepp. in Nov. Act. Nat. Cur. xxv, 1855) 53.-Madag

Manners-Suttoniae, F. Muell. Fragm, v. $195=$ terminalis.

marginata, Goepp. in Nov. Act. Nat. Cur. xxv. (1855) 55.-Madag. ; Ins. Borb.

metallica, Hort. Dalliere, in Belg. Hortic. xxii. (1872) 353. t. $26=$ terminalis.

micrantha, Baker, in Gard. Chron. (1880) II. $243=$ Brocchinia cordylinoides.

Murchisoniae, F. Muell. Fragm. v. 195= Haageana.

neo-caledonica, Linden, Cat. n. $97(1877) 4 .-\mathrm{N}$ Caled.

nobilis, C. Koch, Allg. Gartenz. (1858) $254=$ terminalis.

nutans, Hort, ex Goepp. in Nov. Act. Nat. Cur. xxy. (1855) 55, nomen.-Hab.?

obtecta, Baker, in Journ. Linn. Soc. xiv. (1875) $543=$ Baveri.

odorata, C. Koch, in C. Koch \& Fint. Wochenschr. 1858) $97=$ dracaenoides.

orjata, Planch. in Fl. des Serres, Sér. I. vi. $(1850-51)$ $111,136=$ Dracaena ovata

oxyphylla, Miq. Fl. Ind. Bat. Suppl. 609.-Sumatra.

parviflora, H. B. \& K. Nov. Gen. et Sp. i. $269=$ Nolina parviflora.

Pumilio, Hook. f. in Gard. Chron. (1860) 792.N. Zel.

Reali, Nichols. Dict. Gard. i. 374.-Hab,

reflexa, Planch. in Fl. des Serres, Sér. I. vi. (1850 51) 109.-Afr. trop.

Regelii, C. Koch, Wochenschr. viii. (1865) 90.Hab.?

Regina, Veitch, ex Regel, Gartenfl. (1871) $149=$ terminalis.

rigida, Miq. Fl. Ind. Bat. Suppl. 610.-Sumatra.

rigidifolia, C. Koch, in C. Koch \& Fint. Wochenschr (1858) $359=$ stricta.

rubra, Hueg. ex Kunth, Enum. Pl. v. 34。-N. Zel.

Rumphii, Hook. Bot. Mag. t. $4297=$ Dracaena angustifolia, Hookeriana.

Rumphii, F. Muell. Fragm. v. 194=Dracaena angustifolia.

salicifolia, Goepp. in Nov. Act. Nat. Cur. xxy. (1855) 53.- Java.

Sellowiana, Kunth, in Abh. Acad. Berl. (1842) $30=$ dracaenoides.

Sepiaria, Seem. Fl. Vit. 311 t. $94=$ terminalis,

Sieberi, Kunth, in Abh. Acad. Berl. (1842) $30=$ terminalis.

Sieboldii, Planch. in Fl. des Serres, Sér. I. vi. (1850-51) 109. sub t. $569=$ Dracaena elliptica.

spectabilis, Kunth \& Bouché, in Ind. Sem. Hort. Berol. 1848) = dracaenoides

spicata, Planch. in Fl. des Serres, Sér. I. vi. (1850-51) 132.- Hab.?

stricta, Endl. in Ann. Wien. Mus. i. (1836) 162. Austral.

stricta, Hook. f. in Fl, N. Zel. i. 257, t. $50=$ Pumilio.

Sturmii, Colenso, in Trans. N. Z. Inst. xv. (1883) 331 $-\mathrm{N}$. Zel.

superbiens, C. Koch, in C. Koch \& Fint. Wochenschr. (1859) $381=$ australis.

terminalis, Kunth, in Abh. Acad. Berl. (1820) 30.As. trop.; Austral

$T i$, Schott, in Flora, xi. (1828) $575=$ terminalis.

timorensis, Planch. in Fl. des Serres, Sér. I. vi. (1850-51) 132.--Ins. Timor

umbraculifera, Planch. 1, c. $111=$ Dracaena umbraculifera.

\section{CORDYLINE :-}

Voitchii. Kegel, Gartenf. (1871) $149=$ australis.

violascens, Regel, Ind. Sem. Hort. Petrop. 1858) 25 et Gartenf. (1859) $331=$ rubra.

vivipara, Hort. ex Steud. Nom. ed. II. i. $419=$ Chlorophytum Sternbergianum.

Wallichii, Planch, in Fl. des Serres, Sér. I. vi. (1850-51) 132 (Dracaenae sp.).-Ind. or

CORDYloblaste, Hensch. ex Moritzi, in Bot Zeit. vi. (1818) 604=Symplocos, Linn. (Styrac.). Henschelii, Moritzi, 1. c. $=\mathrm{S}$. Henscheli.

CORDYLOCARPUS, Desf. Fl. Allant. ii. 79. t. 152 $(\mathbf{1 8 0 0})=$ Rapistrum, Tourn. (Crucif.)

crassifolius, Steud. Nom. ed. I. $226=$ Erucaria crassifolia.

glaber, Dietr. ex Steud. 1. c. $=$ R. glabrum.

laevigatus, Willd. Sp. Pl. iii. 563-Erucaria aleppica muricatus, Desf. Fl. Atlant, ii. 79. t. 152,-Algeria. pubescens, Siltth. \& Sm. Fl. Graec. Prod. ii. $33=$ Brassica adpressa.

ramosissimus, Pomel, Nouv, Mat. F1. Atl. 357.Algcria.

tenuifolius, Sibth. \& Sm. Fl. Graec. Prod. i. $33=$ Erucaria tenuifolia.

CORDYLOGNE, Lindl. Veg. Kingd. 626 (1848), sphalm. $=$ seq.

CORDYLOGYNE, E. Mey. Comm. Pl. Afr. A ustr. 218 (1837). ASCLEPIADEAE, Benth.\& Hook, ii. 759 .

Perigiossum, Decne. in DC. Prod. viii. 520 (1844) globosa, E. Mey. Comm. Pl. Afr. Austr. 218.-Afr austr.

COREMA, D. Don, in Edinb. N. Phil. Journ. ii. (1826-27) 63. EMPETRACEAE, Benth. \& Hook f. iii. 414 .

Endammia, Rafin. New Fl. Am, iii. 49 (1836).

Euleucum, Rafin. Fl. Tellur, iii. $56(1836)$

OAKESIA, Tuckerm. in Hook. Lond. Journ. Bot. i. (1842) 445 .

Tuckermannia, Klotzsch, in Wiegm. Archiv, vii (1811) 248.

album, D. Don, in Edinb. N. Phil. Fourn. ii. (1827) 63.-Lusitan.

Conradi, Torr. ex Loud. Encyc. Trees, 1092.Am. bor.

febrifugum, Boiss. ex Willk. \& Lange, Prod. F1. Hisp iii. 512 = album

COREOCARPUS, Benth. Bot. Voy. Sulph. 28. t. 16 1844). COMPOSITAE, Benth. \& Hook. f. ii. 384.

Acoma, Benth. Bot. Voy. Sulph. 29, t. 17 (1844)

heterocarpus, A. Gray, in Proc. Am. Acad. v. (1861) 162.-Calif.

parthenioides, Benth. Bot. Voy. Sulph. 28. t. 16.-Calif.

COREOPIS, Gunn. F1. Norveg, ii. 87 (1772), spbalm.= seq.

COREOPSIS, Linn. Gen. ed. I. 263 (1737), COM-

POSITAE, Benth. \& Hook. f. ii. 385

ACISPERMUM, Neck. Elem. i. 34 (1790).

Agarista, DC Prod, v. 569 (1836)

ANACIS, Schrank, in Denkschr. Acad. Muench. v. (1817) 5 .

Calliopsis, Reichb. Ic. et Descr. Pl. t. 10 (1824).

Campilntheca, Cass. Dict. Sc. Nat. li. 476 (1827).

Chrisomelea, Tausch, Hort. Canal. fasc. i. (1823).

Chrysostemma, Less. Syn. Comp. 227 (1832)

Coreopsoines, Moench, Meth. 594 (1794)

Diatonta, Walp. Rep. ii. 614 (1843).

Diodonta, Nutt. in Trans. Am. Phil. Soc. Ser. II. vii. (1841) 360

Diplosastera, Tausch, Hort. Canal. fasc. i. t. 4 (1823)

Durichotheca, Cass. Dict. Sc. Nat. li. 476 (1827).

Ei ectra, DC Prod, v. 630 (1836).

EPILEPIS, Benth. P1. Hartw. 17 (1839).
COREOPSIS :-

Heterudonta, Nutt. in Trans, Am. Phil. Soc. Ser. I1. vii. (1841) 361 .

LeAChiA, Cass, in Dict. Sc. Nat. xxy. 388 (1822).

Lerchia, Reichb. Consp. 109 (1828).

Peramibus, Rafin. ex DC. Prod. v. 568 (1836)

Prestinaria, Sch. Bip. ex Steud. Nom. ed. II. ii. $393(1841)$

abyssinica, Sch. Bip. ex Walp. Rep. vi. 163.-Abyssin. acuta, Pursh, Fl. Am. Sept. ii. 569=Actinomeris squarrosa.

alata, Cav. Ic. iii. 30. t. $260=$ Actinomeris tetraptera.

alata, Pursh, F1. Am. Sept. ii. $567=$ Verbesina occiden. talis.

alba, Linn. Sp. Pl. $908=$ Bidens pilosa

alternifolia, Linn. 1. c. $909=$ Actinomeris squarrosa.

ambigua, Nutt. in Journ. Acad. Philad. vii. (1834) 75 = aurea.

amplexicaulis, Cav. Desc. $226=$ Encelia amplexicaulis.

angustifolia, [Dryand. in] Ait. Hort. Kew. ed. I. iii. 253 - Am. bor.

angustifolia, Linn. Sp. Pl. $908=$ Helianthus angustifolins.

angustifolia, Pav. ex DC. Prod. v. $603=$ Bidens provera.

anthemoides, DC Prod v. 573-Mexic.

arguta, Pursh, Fl. Am. Sept. ii. $517=$ aurea.

aristata, Willd. Sp. Pl. iii. $2253=$ aristosa.

aristosa, Michx. Fl. Bor. Am. ii. 140.-Am. hor.

artemisiaefolia, Jacq. Coll. Suppl. $155=$ Cosmus sulphureus.

aspera, Pursh, Fl. Am. Sept. ii. 570.-Am. bor.

Atkinsoniana, Dougl. in Lindl. Bot. Reg. t. 1376.$\mathrm{Am}$. bor. occ.

aurea, [Dryand. in] Ait. Hort. Kew. ed. I. iii. 252.Am. bor.

aurea, Lindl. Bot. Reg. t. $1228=$ trichosperma.

auriculata, Linn. Sp. Pl. 908.-Am. bor

auriculata, Schkuhr, Handb. t. $260=$ pubescens.

Bacana, Heyne, ex DC. Prod. v. $632=$ Glossogyne pinnatifida.

baccata, Linn. Pl. Surin. n. 111; Amoen. Acad. viii $262=$ Wulffia stenoglossa

baccata, Linn.f. Suppl. 380,-Guiana.

Barteri, Oliver E Hiern, in Oliver, Fl. Trop. Afr. iii 390.-Afr. tiop.

bicolor, Bosse, ex Buchenau, in Linnaea, xxv (1852) 630.-Hab. ?

Bidens, Linn. Sp. Pl. $908=$ Bidens cernua.

Bidens, Walt. F1. Carol. $215=$ Bidens chrysanthem oides.

bidentoides, Nutt. ex Torr. E Gray, Fl. N. Am. ii. 339.-Am. bor

biternata, Lour. Fl. Cochinch. 508.-China.

bituminosa, Noronha, in Verh. Batav. Gen. v. (1790) ed. I. Art. IV, 11-Malaya.

Borianiana, Sch. Bip. ex Schweinf. in Verh. Zool.-Bot Ges. Wien, xviii. (1868) 684.-Afr, trop.

Boykiniana, Nutt, in Trans. Am. Phil. Soc. Ser. II. vii 1841) $358=$ grandiflora.

calliopsidea, A. Gray, in Torr. Bot. Mex. Bound. $90=$ Leptosyne calliopsidea.

callosa, Bertol. Misc. Bot. vii. 42.-Am. bor.

capillacea, $H . B$. E K. Nov. Gen. et Sp. iv. 230.Peruy.

cardaminefolia, Torr. E Gray, Fl. N. Am. ii. 346.Am. bor. occ.

chrysantha, Linn. Sp. Pl. ed. II, $1282=$ Bidens chrysantha.

chrysantha, Spreng. Syst. iii. $614=$ Bidens rubifolia.

chrysantha, Vatke, in Linnaea, xxxix. (1875) 499. Afr. trop.

coronata, Bert. ex Steud. Nom. ed. II. i. $420=$ Cosmus caudatus.

coronata, Hook. Bot. Mag. t. 3460.-Texas.

coronata, Linn. Sp. Pl. ed. II. 1282 (ex syn. Plum.) = Bidens pilosa.

coronata, Walt. Fl. Carol, ii. $15=$ aurea.

corymbifolia, Buch.-Ham. ex DC. Prod.v. $602=$ Bidens pilosa.

cosmoides, A. Gray, in Proc. Am. Acad. v. (1861) 126. - Ins. Sandvic.

crassifolia, [Dryand. in] Ait. Hort. Kew. ed. I. iii $252=$ lanceolata.

cuspidata, Bertol. Misc. Bot. vii. 44.-Am. bor.

delphinifolia, Lam. Encyc ii. 108-Am bor.

dichotoma, Michx. Fl. Bor. Am. ii. $137=$ gladiata. 


\section{COREOPSIS :-}

discoidea, Torr. E Gray, Fl. N.Am. ii. 339.-Am. bor.

discolor, Link, Enum. Hort. Berol. ii. 353.-Am. bor. diversifolia, DC. Prod. v. 571. (exil. syn.) = auriculata. diversifolia, Hook. Bot. Mag. t. $3474=$ Drummondii. diversifolia, Jacq. Eclog. 80 . t. $54=$ Bidens grandiflora. Drummondii, Torr. E Gray, Fl. N.Am. ii. 345.Texas.

emarcida, Noronha, in Verh. Batav. Gen.v. (1790) ed. I. Art. rv, 11.-Malaya.

fasciculata, Wedd. Chlor. And i. 71.-Peruy.

ferulaefolia, Jacq. Hort. Sthoenb. iii. $65=$ Bidens ferulaefolia

filifolia, Hook. Bot. Mag. t. $3505=$ Thelesperma filifolium.

Flammula, Banks, ex Steud. Nom. ed. I. 226, $108=$ Bidens chrysanthemoides.

flexicaulis, Rafin. in Med. Repos. N. York, v. (1808) 361. -Am. bor

foeniculacea, Moç. \& Sesse, ex DC. Prod. v. $603=$ Bidens foeniculifolia.

foetida, Cav, Ic, i. $55=$ Encelia foetida.

foliosa, A. Gray, in Proc. Am. Acad. v. (1861) 125.Peruv.

formosa, Bonato, Memoria 2; ex Pritz.Ic.Ind. i. 301 - Hab. ?

formosa, Hort. ex Stend. Nom. ed. II. i. 420=Cosmos bipinnatus.

frulicosa, Forst f. Prod. 91- Ins. Sandvic.

fruticosa, Soland. ex Seem. Fl. Vit. 143.-Ins. Pacif,

fruticosa, Vest, in Flora, iii. (1820) 7 =Bidens fruti cosa.

Galeottii, Hemsl. Biol. Centr. Am. Bot. ii. 195.Mexic.

Georgina, Cass. in Dict. Sc. Nat. xvili. $441=$ Dahlia variabilis.

gladiata, Walt. Fl. Carol. 215.-Am. bor.

glaucescens, Oliver \& Hiern, in Oliver, Fl. Trop. Afr. iii. 389.-Afr. trop.

gracilis, Blanco, Fl. Filip. ed. II. Suppl. 591=Cosmos caudatus.

grandiflora, Nutt. ex Chapm. Fl. S. U. St. 335.-Am. bor.

Granti, Oliver, in Trans. Linn. Soc. xxix. (1874) 98. t. 65.-Afr. trop.

guineensis, Oliver \& Hiern, in Oliver, Fl. Trop. Afr. iii. 390.-Afr. trop.

Harveyana, A. Gray, Syn. Fl. N. Am. i. II. 292.-Am. bor. occ.

heteropliylla, Bertol. Misc. Bot. vii. 43.-Am. bor

heterophylla, Cav. Ic. iii. 34. t. $268=$ Iostephane heterophylla.

heterophylla, Nutt, in Trans. Am, Phil. Soc. Ser. II. vii. (1841) $358=$ grandiflora.

hirta, Rafin. Ann. Nat. 15.-Am. bor.

incisa, Ker-Gawl. in Bot. Reg. t. $7=$ Bidens mbifolia.

incurva, Moench, Meth. Suppl. $245=$ Bidens ferulae folia.

integrifolia, Poir. Encyc, Suppl. ii. 352 (1811).-Am. bor.

involucrata, Nutt. in fourn. Acad. Philad. vii. (1834) 74.-Am. bor

involucrata, Sch. Bip. ex Walp. Rep. vi. 163.-Abyss. jasminifolia, Bertol. Misc, Bot, vii, 44,-Am bor.

Kirkii, Oliver \& Hiern, in Oliver, Fl. Trop. Afr. iii. 390.-Afr. trop.

lanceolata, Linn. Sp. Pl. 908.-Am. bor,

latifolia, Michx. Fl. Bor. Am. ii. 137.-Am. bor.

Leavenworthii, Torr. E Gray, Fl. N. Am. ii. $346 .-$ Am. bor.

leucantha, Linn. Sp. Pl. ed. II. $1282=$ Bidens pilosa leucantheme, I.inn. Cent. Pl. i. $29=$ praec.

leucorrhisa, Lour. Fl. Cochinch. ii. $508=$ Bidens leucorrhiza.

Liebmannii, Sch. Bip. ex Hemsl. Biol. Centr. Am. Bot. ii. 196.-Mexic

limensis, Jacq. Coll. ii. $299=$ Encelia canescens.

linearifolia, $D C$ Prod y, 570-Mexic.

linearifolia, Oliver \& Hiern, in Oliver, Fl. Trop. Afr. iii. 390.-Afr. trop.

linifolia, Nutt. in Journ. Acad. Philad. vii. (1834) 75 = angustifolia.

longipes, Hook. Bot. Mag. t. $9586=$ grandiflora.

Iucida, Cav. Desc, 224 - Bideus heterophylla.

Macraei, A. Gray, in Proc. Am. Acad. v. (1861) 126. Ins. Sandvic.

macrantha, Sch. Bip. ex Walp. Rep. vi., 163,-Abyss.

\section{COREOPSIS :-}

macrocarpa, A. Gray, in Proc. Am. Acad. v. (1861)

126.-Ins. Sand vic.

major, Walt. Fl. Carol. $214=$ senifolia

maritima, Hook.f. Bot. Mag.t 6241-Calif

Menziesii, A. Gray, in Proc. Am. Acad.v. 1861) 127 -Ins. Sandvic.

mexicana, Hemsl. Biol. Centr, Am. Bot. ii. 196.Mexic.

micrantha, A. Gray, in Proc. Am. Acad. v. (1861) 127 -Ins. Sandvic.

minima, Hort. ex Steud. Nom. ed, II. i. 420.-Am. bor.

mitis, Michx. F1. Am. Bor, ii. 14:0=aure

monticola, Oliver Es Hiern, in Oliver, Fl. Trop. Afr iii. 390.-Afr. trop.

multifida, $D C$. Prod. v. 573.-Peruv.

mutica, $D C$. l. c. 571.-Mexic.

Neaei, DC. l. c. 579.-Am. austr

nudata, Nutt. Gen. Am. ii. 180.-Florida.

oblongifolia, Nutt. in Journ. Acad. Philad. vii. (1834 $76^{\circ}=$ lanceolata.

odorata, Lam. Illustr. t. 704. f. 1 = Birens odorata.

odoratissima, Cav. ex Pers. Syn. ii. $477=$ Cosmo tenellus.

Oemleri, Ell, Sketch, ii. $435=$ senifolia

Oerstediana, Benth. ex Oerst. in Kjoeb. Vidensk. Meddel. (1852) 93.-Bias.

ovata, Cav, Ic. iii. 41 . t. $280=$ Actinomeris ovata.

pachyloma, Oliver E Hiern, in Oliver, Fl. Trop. Afr iii. 391.-Afr. trop.

palmata, Nutt. Gen. Am. ii. 180.-Am. bor.

parviflora, Jacq. Hort. Schoenb. iii. $65=$ Cosmos parvi florus.

pauciflora, Lehm. Ind. Sem. Hort. Hamb. (1833)

Linnaea, x. (1836) Litt. $76=$ palmata.

perfoliata, Walt. F1. Carol. $214=$ Bidens chrysanthe moides?

Pickeringii, A. Gray, in Proc. Am. Acad.w. (1861) 124.-Peruv.

praecox, Fresen. in Linnaea, xiii. (1839) Litt. $93=$ pal mata.

Prestinaria, Sch.Bip. ex Walp. Rep. vi. 163.-Abyss. prestinariaeformis, Vatke, in Linnaca, xxxix. (1875) 499.-Afr. trop.

procera, [Dryand. in] Ait. Hort. Kew. ed. I. iii. $253=$ Actinomeris squarrosa.

pubescens, Ell. Sketch, ii. 441.-Am. bor

purpurea, Moc. \& Sesse, ex DC. Prod.v. $604=$ Cosmos purpureus.

quadricornis, Krock. Fl. Siles. ii. II. 481 = Bidens cernua.

radiata, Mill. Gard. Dict. ed. VIII. n. 5.-Am. bor,

reptans, Linn. Syst. ed. X. 1228; Amoen. Acad. v. 507 $=$ Bidens rubifolia

ridens, Gunn. Fl. Norveg. ii. 87.-Norvegia.

rigida, Nutt. Gen. Am. ii. $180=$ delphinifulia

rosea, Nutt.l. c. 179.-Am, bor.

rudis, Benth. E Hook. f. ex Hemsl. Biol. Centr. Am. Bot. ii. 196,-Mexic.

Rueppellii, Sch. Bip. ex Walp. Rep. vi. $163=$ chrysantha.

sambucifolia, Cav. Desc. $225=$ Bidens sambucifolia.

scabra, Rafin. Fl. Ludov. 72,-Louisiana.

Schafineri, A. Gray, in Proc. Am. Acad. xix. (1883) 15.-Mexic.

senifolia, Michx. Fl. Bor. Am. ii. 188 -Am. bor.

serrulata, Poir. Encyc. Suppl. iii. $352=$ Bidens grandi. flora.

setigera, Sch. Bip. ex Walp. Rep. vi. 163.-Abyss.

spectabilis, A. Gray, in Proc. Am. Acad. v. 1861

125.-Peruv.

stellata, Banks, ex DC. Prod, y. $572=$ senifolia

stellata, Nutt. in Fourn. Acad. Philad. vii. (1834) 76. -Am. bor.

Steppia, Steetz, in Peters, Reise Mossamb. Bot. 496. Afr. trop.

Tanna, Steud. Nom. ed. II. i. $420=$ Glossogyne tenuifolia.

tannensis, Spreng. Fl. Hal. Mant. 53=Glossogyne tenuifolia.

tenuifolia, Ehrh. Beitr. vii. 168 = verticillata.

tetraguna. Cerv, ex La Llave \& Lex. Nov. Veg. Desc. fasc. i. $81=$ Bidens tetragona.

tinctoria, Nutt, in Fourn. Acad. Philad, ii. (1821) 114.-Am, bor.

trichosperma, Michx. F\%. Bor. Am. ii. 139.-Am. bor.

trifida, Poir. Encyc. Suppl. ii. $\$ 5 \$$ - Thelesperma filifolium.

\section{COREOPSIS}

trifoliata, Bertol. Fl. Guatimal. 36.-Guatemala.

Triptelis, Linn. Sp. Pl. y08.-A m. bor.

varifolia, Salisb. Prod. $206=$ Bidens rubifolia

venusta, $H . B$. E $K$. Nov. Gen, et Sp, iv, 229. - Perr

verticillata, Ehrh. Beitr, vii. 168-de]phinifolia.

verticillata, Lam. Encyc. ii. 108 - tenuifolia.

verticillata, Linn. Sp. Pl. 907.-Am. bor.

Wrayi, Nutt. in Journ. Acad. Philad. vii. (1834) 76

seniolia.

COREOPSOIDES, Moench, Meth, 594 $(1794)=$ Core opsis, Linn. (Compos.).

lanceolata, Moench, 1. c = Coreopsis lanceolata.

COREOSMA, Spach, in Ann. Sc. Nat. Sér. II. iv. (1835 2 = Rikes, Lix.n. (vaxifrag.

affinis, Spach, 1. c. $24=\mathrm{R}$, campanulatum.

Dombeyana, Spach, l. c 25- K. viscosum.

florida, Spach. I, c. $22=$ R. floridum.

multiflora, Spach, 1, c, $24=\mathrm{K}$. Kunthii.

sanguinea, Spach, Hist. Vég. Phan. vi. $155=$ R. sangu'ncum.

viscosissima, Spach, in Ann. Sc. Nat. Sér. II. iv. (1835 $23=\mathrm{R}$, viscosissimum.

CORESANTIMA, Alef. in Bot. Zeit. xxi. (1863) 298

Iris, Tuurn.

alata, Klatt, in Linnaea, xxxiv, (1865-66) 575

I. stylosa.

caucasica, Klatt, 1. c. = I. caucasica.

persica, Alef. in Bot. Zeit. xxi. (1863) 298

I. persica.

CORESANTHE, Baker, in Journ. Linn. Soc. xvi. (1877, 122 = praec.

CORETHRODENDRON, Fisch. \& Basin. in Mím Sav. Etr. Péterst. vi. (1851) yo (Munogr. Hedy. 4F. t. 2). LEGUMINOSAE, Benth. \& Hook. f. 512 .

scoparium, Basin. l. c. 91.-Soongaria.

CORETHROGYNE, DC, Prod, $\nabla, 215$ (1836 COMPOSITAE, Benth. \& Hook. f, ii. 270.

californica, $D C$. l. c.-Calif.

detonsa, Greene, in Bull. Torrey Club, x. (1883) 41

Diplostephium canum.

Glaginifolia, Nutt, in Trans, Am. Phil. Soc Ser. II vii. (1841) 290.-Calif.

incana, Nutt. 1. c. = californica.

obovata, Benth. Bot. Voy. Sulph. 22.-Calif

spathulata, A. Gray, in Proc. Am. Acad. vii. (1868

$351=$ obovata.

tomentella, Torr. \& Gray, Fl. N. Am. ii. $99=$ filagini. folia.

virgata, Benth. Bot. Voy. Sulph. $23=$ filaginifolia.

CORETHROSTYLES, Benth. \& Hook. f. Gen. i. 22 (1862), spbalm. = seq.

CORETHROSTYLIS, Endl. Nov. Stirp. Dec. i. (1\$39) Lasiopetalum, sm. (Stercul.)

bracteata, Eindl. 1. c, = L. bractentum.

cordifolia, Steetz, in Lchm. Pl. Preiss. ii. $\$ 4 t=$ L. cordifolium.

coriacea, Steud. l. c. i. $236=$ L, bracteatum.

nembranacea, Steud. 1. c. = L membranactum.

micropluylla, Turcz, in Bull. Soc. Nize Mlose zxs

(185.2) 11. $148=\mathrm{L}$ cordifoliom.

oppositifolia, F. Muell. Frmgm. ii. $6=$ L. floribundum.

parvifiora, Turcz in Bull. Soc. Nat. Musc. xx. (1S17) $174=$ L. floribundum.

Schulsensi, r. Muell. in Trans. Phil. Soc, Vict i. 155 . $\$ 6^{\circ}=\mathbf{L}$. Schulzenii.

CORLTIRUM, Vahl, in Skr. Naturk. Solsk. Kiobenh. vi. (1510) $85=$ Bouteloua, Lag. Gramin.).

bromoides, lahl, I. $c_{0}=13$. bromuides.

CORIANDRUM, [Toum] [inn, Syst ed, I i I

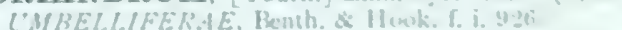

Keramocarpt's, Fenzl, in Kunagg. Keise ii. $96 \%$ (1543

americanans, Sult. ex DC. Prod, iv. 250 - Hifora ame nucama.

Cicufa, Cimate Stirp, Austr. ed. I. (asc. iii, 100; d. It 211 Conium mav viatum.

Cicrefa, Kuth, Tent. H. Germ. i. 130-Cicula virma. 


\section{CORIANDRUMT:}

Cynapium, Crantz, Stirp. Austr, ed. I. fasc. iii. 99 ; ed II. 211 = Aethusa Cynapium

didymum, Stokes, Bot. Mat. Med. ii. 121=Bifora testiculata.

diversifolium, Gilib. Fl. Lituan. ii, $26=$ sativum.

glöbosum, Salisb. Prod. $166=$ sativum

latifolium, Crantz, Stirp. Austr. ed. I. fasc. iii. 101 ; ed. II. 211 = Sium latifolium.

maculatum, Roth, Tent. Fl. Germ. i. $130=$ Conium maculatum.

majus, Goỉan, Hort. Monsp. $145=$ sativum.

melphitense, Tenore \& Guss. Ind. Sem. Hort. Neap.

(1837) 3.-Italia.

sativum, Linn.Sp.Pl. 256.-Europ. austr.; Oriens

seselifolium, DC. ex DC. I'rod. iv. $250=$ Astoma seselifolium.

tordylivides, Boiss. Fl. Orient. ii. 921.--Oriens.

testiculare, Salisb. Prod. $166=$ Bifora testiculata

testiculatum, Bieb. Fl. Taur. Canc. i. $228=$ Bifora radians.

testiculatum, Linn. Sp. P1. $256=$ Bifora testiculata

testiculatum, Lour. $\mathrm{H}$. Cochinch. $225=$ Bifora Loureiri.

CORIARIA, Niss. ex Linn. Gen. ed. I. 310 (1737). CORIARIEAE, Benth. \& Hook. f. i. 429 .

Heterocladus, Turcz. in Bull. Soc. Nat. Mosc. xx. (1847) I. 152

HeterophylletA, Turcz. l. c. (1848) I. 591.

angustissima, Hook. f. Handb. New Zeal. Fl. 47.-N. Zel.

arborea, Lindsay, Contrib. N. Z. Bot. 84.-N. Zel

atropurpurea, Moç. \& Sesse, ex DC. Prod. i. $740=$ thymifolia.

hermaphrodita, Turra, Farset. Nov. Gen. $13=$ myrtifolia japonica, A. Gray, in Mem. Acad. Am. N. S. vi. (185859) 383.--Japon.

microphylla, Poir. Encyc. vi. 87.-Peruv

myrtifolia, Linn. Sp. 1 . 1037.-Reg. Mediterr.

nepalensis, Wall. Pl. As. Rar. iii. 67.-Keg. Himal, China.

phylicifolia, Humb. E Bonpl. ex Willd. Sp. Pl. iv. 819. -Feruv.

procumbens, Whitl. ex Hoffmgg. Verz. Pf. Nachtr. iii. 9 , nomen.-Hab.?

ruscifolia, Linn. Sp. Pl. 1037.-Peruv.

sarmentosa, Forst. f. Prod. 71. n. 377.--N. Zel

sinica, Maxim. in Mém. Acad. Pétersb. Sér. VII. xxix. (1881) n. III. 9.-China.

thymifolia, Humb. Eo Bonpl.ex Willd. Sp. Pl. iv. 819. -Peruv.

tinctoria, Dulac, F1. Hautes-Pyr. $243=$ myrtifolia.

Tutu, Lindsay, Contrib. N. Z. Bot. 84.-N. Zel.

CORIDOCHLOA, Nees, in Edinb. N. Phil. Journ. xv. (1833) 381, in nota = Panicum, Liun. (Gramin.). cimicina, Nees, l. $_{\text {c. }}=$ P. cimicinum.

semialata, Nees, ex Benth. H1. Austral. vii. $473=$ P. semialatum.

CORIDOTHYMUS, Reichb. f, in Oestr. Bot. Wochenbl. vi. (1857) $160=$ Thymus, Tourn. (Labiat.). capitatus, Reichb. f. 1. c. $161=$ T. capitatus.

CORILUS, Nocca, in Usteri, Ann. But. ii. (1793) $50=$ Corylus, Tourn. (Cupul.).

CORINDUM, Adans. Fam. ii. $388(1763)=$ Paullinia, Linn. (Sapind.).

CORINDUM, Tourn. ex Medic. Malv. $110(\mathbf{1 7 8 7})=$ Cardiospermum, Linn. (Sapind.).

Halicacabum, Medic. 1. $\mathrm{c}_{\mathrm{s}}=$ Card. Halicacabum.

CORINGIA, J. \& C. Presl, 'Fl. Čech. 141'; FI. Sicula, $79(1 \diamond 26)=$ Conringia, Heist. (Crucif.)

CORINOCARPUS, Poir. in Dict. Sc. Nat. x. 441 (1818) = Corynocarpus, Forst. (Anacard.).

CORION, Hoffmgg. \& Link, FI. Port. ii. $457(1820)=$ Bifora, Hoffm. (Umbellif.)

esticulatum, Hoffmgg. \& Link, 1. c. = B. testiculata.

CORION, Mitch. in Act. Nat. Cur. viii. (1748) 208, App. = Spergularia, J. \& C. Presl (Caryophyll.).
CORIS, Tourn. ex Linn. Gen, ed. I. 338 (1737). PRIMULACEAE, Lenth. \& Hook. fo ii. 638.

hispanica, Lange, in Kjoeb. Vidensk. Meddel. (1863) 53 (Pugill. 219).-Hispan.

monspeliensis, Linn. Sp. Pl. 177.-Europ. austr.

CORISANTHERA, C. B. Clarke, in Hook. f. F1. Brit Ind. iv. $373(1884)=$ CORYSANTHERA, Wall. $=$ Rhynchotechum, Blume (Gesnerac.).

CORISANTHES, Stend. Nom, ed. II. i. 474, in syn 1840 $=$ CRIOSANTHES, Rafin $=$ Cypripedium, Linn. (Orchid.).

CORISPERMUM, B. Juss. ex Linn. Syst. ed. I (1735). CHENOPODIACEAE, Benth. \& Houk. f. iii. 57 .

apetalum, Hort. ex Steud. Nom. ed. II. i. 420.-Hab.? bolysthenium, Andrz.ex Trautv. in Act. Hort. Petrop. ix. (18 4) 129, nomen.-Rossia.

bracteatum, Viv. Lett. Corisp. $2=$ Marschallii.

canescens, Kit. ex Schult. Oestr. Fl. ed. II. i. 7.Europ. occ.

coloratum, Andrz. ex Trautv. in Act. Hort. Petrop. ix (18॰4) 129, nomen.-Rossia

confertum, Bunge, in Maxim. Prim. Fl. Amur.225.Reg. Amur.

crassifolium, Turcz. in Bull. Soc. Nat. Mosc. xxy. (1852) 428.-Sibiria.

declinatum, Steph. ex Stev. in Mém. Soc. Nat. Mosc. v. $(1 \circ 14) 334=$ hyssopifolium.

elatum, Host, Fl. Austr. i. $319=$ Marschallii.

elongatum, Bung', ex Maxim. Prim. Fl. Amur. 224 Manchur.

flifolium, Becker, in Bull. Soc. Nat. Mosc. xxxi (185ð) I. 13.-Kossia.

glomeratum, Lag. Gen. et Sp. Nov. 1.-Hab.?

Gimelini, Bunge, in Bull. Acad. Pétersb. xxv, (1879) 357 - Siliria.

heteracanthum, Ledeb. ex Heynh. Nom. ii. 161, nomen -Rosisia.

hybridum, Bess. ex Moq. in DC. Prod. xiii. II. $141=$ Marsihallii.

hyssopilolium, Linn.Sp.Pl.4.-Europ.; As. temp.; Am. bor.

hyssopifolium, Pall. Reise, i. 484 ; Fl. Ross. t. $98=$ oi icntale.

intermedium, Reichb. F1. Germ. Excurs. $584=$ Marschallii.

intermedium, Schweig, in Koenigsb. Arch. Naturw. i. (1812) 211.-Europ.

latifolium, Link, Handb. ii. $408=$ orientale.

laxiflorum, Schrenk, in Eull. Phys,-Math. Acad. Pétersb. i. (1843) 361-Marschallii.

Lehmannianum, Bunge, in Mèm. Sav. Etr. Pétersb. vii. (1851) 458.-Turkestan.

macrocarpum, Bunge, in Maxim. Prim. Pl. Amur. 226.-Manchur.

macrospermum, Trautv. in Act. Hort. Petrop. ix. (1884) $130=$ macrocar $u$ um

marginatum, Steph. ex Mog. in DC. Prod. xiii. II. $140=$ Marschallii.

Marschallii, Stev. in Mém. Soc. Nat. Mosc. v. (1814) 336 .-Europ.

microspermum, Host. F1. Austr. i. $319=$ nitidum.

nitidum, Kit. ex Schult, Oestr. Fi. ed. II. i. 7.-Europ. As, bor.

orientale, Lam. Encyc. ii. 111; Illustr. i. 15.-Rossia ; As, bor.; P'ersia.

Pallasii, Stev. in Mém. Soc. Nat. Mosc. v. (1814) 336 =orientale.

patens, Fisch. in Roem. \& Schult. Syst. i. $579=$ hysso pifolium

patens, Link, in Spreng. Jahrb. Gewaechsk, i. Ir. $28=$ Redowskii.

patens, Roem. Echult. Syst. i. 579.-Sibir.

pentandrum, Willd. ex Link, in Spreng. Jahrb. Gewaechsk. i, III. 28 = orientale.

pilosum, Rafin. New Fl. Am. iv, $46=$ hyssopifolium? polygaloides, Fisch. \& Mer. Ind. Sem. Hort. Petrop. i $24=$ Anthochlamus polygaloides.

pungens, Savi, sec. Uechtr. ex Steud. Nom. ed. II. i. 421 = squarrosum.

pungens, Vahl, Enum. i. $117=$ Agriophyllum arenairum, Bieb.

purpurascens, Host, FI. Austr. i. $318=$ nitidum.

Redofski, Fisch. \& Stev. in Mém. Soc. Nat. Mosc. v. (1814) $336=$ seq.

\section{CORISPERMUM}

Redowskii, [Fisch.] Hort. Gorenk. ed. I. (1808) 25.Siliir. baical.

sabulosum, Ledeb. ex Sweet, Hort. Brit. ed. III. 257.Sibir.

salsoloides, Hort. ex Steud. Nom. ed. II. i. $420=$ glomeratum.

spicatum, Willd. Enum. Hort. Berol. Suppl. $I=$ orientale.

squarrosum, Bieb. F1. Taur. Cauc. i. 3=Marschallii.

squarrosum, Link, Enum. Hort. Berol. i. $7=$ arientale. squarrosum, Linn. Sp. Pl. 4-hyssopifolium.

squarrosum, Pall. H 1. Ross. i. II. 113. t. $99=$ Agriophyllum arenarium, Bieb.

squarrosum, Vahl, Enum. i. 16.-Europ.; As. temp. squarrosum, Willd. Enum. Hort. Berol. $8=$ Marschallii.

Stauntonii, Moq. Chenop. Enum. 104.-China.

subpentandrum, Pall. 1l!ustr. t. $59=$ orientale.

tenue, Link, in Spreng. Jahrb. Gewaechsk, i. III. $9=$ nitidum.

tylocarpum, Hance, in Fourn. Bot. vi. (1868) 47.China.

ulopterum, Fenzl, ex Ledeb. Fl. Ross. iii. 765.-Sibir.

CORISTOSPERMUM, Bertol. F1. Ital. iii. $466(1837)=$

Ligusticum, Linn. (Umbellif.).

cuneifolium, Bertol. 1. c. $467=\mathrm{L}$. cuneifolium.

CORIZOSPERMUM, Zipp. ex Blume, Mus. Bot. Lugd. Bat. i. 255 (1850)=Casearia, Jacq. (Samyd.).

clutiaefolium, Zipp. ex Blume, 1. c.=Cas. clutiaefolia.

CORMIGONUS, Rafin. in Ann. Gén. Sc. Phys. vi. (1820) 83 = Bikkia, keinw. (Rubiac.).

CORMONEMA, Reissek, ex Endl. Gen. 1098 (1840). RHAMNEAE, Benth. \& Hook. f. i. 379.

CAEsIA, Vell. H1. Flum. iii. t. 23 (1827).

spinosum, Reissek, in Mart. Fl. Bras. xi. I. 96.-Bras.

CORMUS, Spach, Hist. Vég. Phan. ii. 96 (1834)= Pyrus, Linn. (Rosac).

domestica, Spach, 1. c. $97=$ P. Sorbus

CORNA, Noronba, in Verh. Batav. Gen. v. (1790) ed. I. Art. IV. 2 (quid?).

CORNACCHINIA, Savi, in Mem. Soc. Ital. Moden. xxi. 1837) 184.t. 7 =Clerodendron, Linn. (Verbenac.). fragiformis, Savi, 1. c. $\mathbf{1 8 5}=$ Clerod. Acerbiana.

CORNELIA, Ard. Spec, ii. $9(1764)=$ Ammannia, Houst. (Lythrar.)

verticillata, Ard. 1. c $=$ A. salicifolia

CORNICINA, Boiss. Voy. Bot. Espagne, ii. 162 (1840 ?) Anthyllis, Linn. (Legumin.).

circinata, Boiss. 1. c. $163=$ Hymenocarpus circinnatus hamosa, Boiss. 1. c. $162=\mathrm{A}$. hamosa

Loeflingii, Boiss. 1. c. = A. Cornicina

lotoides, Boiss. 1. $\mathrm{c}=$ A. lotoides.

nummularia, Boiss. 1. c. $163=$ Hymenocarpus nummularius.

psendocytisus, Boiss. Diagn. Ser. I. ii. $\mathbf{1 5}=$ Cytisopsis dorycniifolia.

CORNIDIA, Ruiz \& Pav. Prod. 63. t. $35(1794)=$ Hydrangea, Linn. (Saxifrag.)

integerrima, Hook \& Arn in Hook: Bot. Misc, iii. (1833) $344=\mathrm{H}$. scandens, Poepp.

radiata, Oerst. in Kjoeb. Vidensk. Meddel. (1856) 42 $=\mathbf{H}$. peruviana.

serratifolia, Hook. \& Arn. in Hook. Bot. Misc. iii.

(1 33 ) $344=\mathrm{H}$, serratifolia

umbellata, Ruiz \& Pav. Syst. Veg. 91.-Peruv.

CORNIOLA, Adans. Fam. ii. $321(1763)=$ Genista, Linn. (Legumin.)

anxanthica, Presl, Bot. Bemerk. $137=\mathrm{G}$. anxantica.

corsica, Presl, l. c. $136=\mathrm{G}$. corsica.

mantica, Presl, l, $\mathrm{c}=\mathrm{G}$ mantica.

microphylla, Presl, 1. c. $137=$ G. microphylla

ovata, Presl, l. c. $136=\mathrm{G}$. ovata.

scariosa, Presl, l. c. $=\mathrm{G}$. triangularis.

Scorpius, Pıesl, l. c. $137=$ G. Scorpius.

sibirica, Medic. in Vorles. Churpf. Phys. Ges. ii. (1787)

$342=\mathrm{G}$. sibirica.

tinctoria Medic l $\mathrm{c}=\mathrm{G}$ tinctoria

triangularis, Presl, Bot. Bemerk. $136=$ G. triangularis. virgata, Presl, 1. c. = G. virgata. 
CORNUCOPIAE, Linn. Gen. ed. I. 13 (1737). GRAMINEAE, Benth. \& Hook, f. iii. 1139. alopecuroides, Linn. Mant. i. $28=$ Alopecurus utricn. latus.

altissimum, Walt. Fl. Carol. $74=$ Agrostis elata? cucullatum, Linn. Sp. Pl. 54.-As. Min.; Mesopot. hyemale, Walt. Fl. Carol. $73=$ Agrostis scabra. perennans, Walt. 1. c. $74=$ Agrostis scabra.

CORNULACA, Delile, FI. Egypte, 206. t. 22. f. 3 (1813). CHENOPODIACEAE, Benth. \& Hook. f. iii. 69 .

amblyacantha, Bunge, Anabas. Rev. 88.-Persia

Aucheri, Moq. Chenop. Enum. 163.-Persia.

Ehrenbergii, Aschers. in Schweinf. Beitr. Fl. Aethiop. 184. - Afr. trop.

monacantha, Delile, Fl. Egypte, 206.-Aegypt.; Persia. muricata, Delile, Fl. Lgypte Illustr. $57=$ Kochia muricata.

setifera, Moq. in DC. Prod. xiii. $\mathrm{Xx} .218=$ tragacanthoides.

tragacantboides, Moq. Chenop. Enum. 163.-Syria; Mesopot.

CORNUS, [Tourn.] Linn. Syst. ed. I (1735). COR-

NACEAE, Benth. \& Hook. f, i. 950.

Benthamia, Lindl. Bot. Reg. t. 1579 (1833).

Cynoxylon, kiafin. Alsog. Am. 59 (18u8).

Eukrania, Rafin. 1. c. (1<38).

Svida, Opiz, Seznam, 94 (1852)

Telukrama, Ratin. Alsog. Am, 64 (1838).

alba, Hook. \& Arn. Bot. Beech. Voy. $142=$ californica.

alba, Lam. Encyc. ii. 115, partim (et auct. Amer.) = stolonifera.

alba. Linn. Mant. i. 40.-Sibir.

alba, Thunb. F1. Jap. $62=$ macrophylla,

alba, Walt. Fl. Carol. $88=\mathrm{C}$. Amomum.

albida, Ehrh. Beitr. iv. $16=$ candidissima.

alterna, Marsh. Arbust. 35 = alternifolia.

alternifolia, Linn. $f$. Suppl. 125.-A m. bor.

Amomum, Mill. Gard. Dict. ed. VIII. n. 5.-Am, bor.

asperifolia, Michx. Fl. Bor. Am. i. 93.-Am, bor.

atrata, Rafin. Alsog.Am.61.-Am. bor.

australis, C. A. Mey. in Bull. Phys.-Math. Acad.

Pétersb. iii. (1845) $372=$ sanguinea.

biramis, Stokes, Bot. Mat. Med. 1. $221=$ suecica.

borealis, Krasch. 1 l. Ingr. $24=$ suecica.

brachypoda, C. A. Mey. in Mém. Acad. Pétersb. vii. (1845) II. $223=$ macrophylla.

caerulea, Auct. vide coerulea.

californica, C. A. Mey. in Bull. Phys.-Math. Acad. Petersb. iii. (1845) 3:3.-Am, bor. occ.

canadensis, Cham. \& Schlecht. in Linnaea, iii. (1828) $139=$ unalaschkensis.

canadensis, Linn. Sp. Pl. 118.-Am. bor.

canadensis, Willd. ex Ledeb. F1. Ross. ii. $377=$ suecica.

candissima, Bisch. Ind. Sem. Hort. Heidelb. (1851)= stolonifera.

candirlissima, Mill. Gard. Dict. cd. VIII. n. 6.-Am, bor.

capitata, Wall. in Roxb. Fl. Ind.ed. Carey, i. 434.Reg. Himal.

caudata, Zoll. in Flora, xxx. (1847) $608=$ Polyosma integrifolia.

chilensis, Molina, Sagg. Chil. 173= Aristotelia Macqui. cinerea, Rafin. Alsog. Am. 59.-Am. bor.

circinata, L'Herit. Cornus, 7.-Am. bor.

circinnata, Cham. \& Schlecht. in Linnaea, iii. (1828) 139 = californica.

citrifolia, Hort. ex Lam. Encyc. ii. $116=$ candidissima.

citrifolia, Wablenb. in Isis, xxi. (1828) $982=$ sanguinca.

coerulea, Lam. Encyc. ii. $116=$ C. Amomum.

coerulea. Meerb. Pl. Sel. t. $3=$ stricta.

comosn, Rafin. Alsog. Am.63.-Am. bor.

crispula, Hance, in Journ. Bot. xix. (1881) 216 macrophylla.

cyananthus, Rafin. Atl. Gourn. 151.-Am. bor. cyanocarpus, J. F. Gmel. Syst. $257=$ stricta. cyanocarpus, Mocnch, Verz $27=\mathrm{C}$. Amomum. davurica, Laxm. ex Ledeb. Fl. Ross. ii. $386=$ Viburnum davuricum.

dichotoma, Rafin. Alsog. Am. 60.-Am. bor

disciflora, Mof. o Sesse, ex DC. Prod, iv 279Mexic.

Drummondi, C. A. Mey, in Bull. Phys.-Math. Acad. Pctersb. iii. (1845) 372.-Am. bor.

\section{CORNUS :-}

erythrocarpa, St. Lager, ex Bull. Soc. Bot. Fr. xxxi (1 83 ) Bibl. $201=$ C. Mas.

excelsa, H. B. E K. Nov. Gen. et Sp. iii. 430.Mexic.

fastigiata, Michx. Fl. Bor. Am. i. 92=stricta

femina, Auct. virle foemina.

ferruginea, Hort, ex Lam. Encyc. ii. $116=\mathrm{C}$ Amomum.

ferulacea, Jacq. ex Roem. \& Schult. Syst. iii. $325=$

ferulaefolia.

ferulaefolia, Nocca, Syn. Pl. 38,-Hab.

fava, Steud. Nom. ed. I. $227=$ C. Mas.

florentina, Decne. in Nouv. Arch. Mus. Par. Sér. I. x (1々74) 157.-IIab. ?

florida, Hook, H1. Bor. Am. i. 277, partim = Nuttallii. florirla, Linn. Sp. Pl. 117.-Am. bor.

foemina, Mill. Gard. Nict. ed. VIII. n. 4 = sanguinea. glabrata, Benth. Bot. Voy. Sulph. 18. - Calif.

grandis, Cham. E Schlecht. in Linnaea, v. (1\&30) 171 -Mexic.

herbacea, Steller, in Pall. N. Nord. Beitr. ii. $300=$ suecica,

ignorata, C. Koch, Ind. Sem. Hort. Berol. (1\&67) App.

i. 8.-Japon.

ilicifolia, Hassk. \& Zoll. ex Hassk. Cat. Hort. Bcg.

Alt. $168,311=$ Polyosma ilicifolia.

japoni.a, Thunb. Fl. Fap. 63.-Japon.

Konsa, Buerger, ex Miq. Ann. Mus. Bot. Lugd. Bat. ii. 159 , in syn.-Japon.

lancifolia, Rafin. Alsog. Am. $€$...-Am, bor

lanuginosa, Michx. Fl. Lor. Am. i $92=\mathrm{C}$. Amomum. latifolia, Bray, in Denkschr. But. Ges. kegensb. i. It (18]8) 35 - sanguinea.

longifolia, Medic, Beobacht. (1782) 308.-Hab, ?

macrophylla, Wall. in Roxb. Ft. Ind. ed Carey, i. 433. -Keg. Himal.; China; Japon.

Mas, Linn. Sp. Pl. 117.-Europ.; As. Min.

mascula, Lino. Syst. ed. X. $89^{7}=$ C. Mas.

mexicana, Carr. in Rev. Hortic. (1875) $460=\mathrm{C}$.

Amomum.

minor. Hort ex Stend. Nom. ed. II. i. $421=$ sericea.

nudiflora, Dum. Fl. Belg. $\prec 3=$ C. Mas.

Nuttallii, Audubon, Birds Am. t. 367; ex Torr. E

Gray, Fl. N. Am. i. 652.-Am. i.or.

obliqua, Rafin. Ann. Nat. (1820'13=C. Amomum.

oblunga, Wall. in Roxb. Fl. Ind.ed. Carey, i. 432.-

lieg. Himal.

oblongifolia, Rafin. ex DC. Prod. iv. $272=$ sericea

officinalis, Sieb. E Zucc. Fl. Fap. i. 100. t. 50.Japon.

paniculata, Buch.-Ham. ex D. Don, Prod. Fl. Nep

$140=$ oblonga.

paniculata, L'Hérit. Cornus, 9 . t. 5 = candidissima.

parvifolia, Rafin. Alsog. Am.61.-Am, bor

paucinervis, Hance, in Fourn. Bot. xix. (1881) 216.China.

plicata, Tausch, in Flora, xxi. (1838) $733=$ altemi folia.

polygama, Rafin. F1. Ludov. $78=$ C. Amomum? praecox, Stokes, Bot. Mat, Med. i. $222=$ C. Mas. pubescens, Nutt. Sylva, iii. $54=$ C. Amomum. pubescens, Torr. Bot. Mex. Bound. $71=$ californica. pubescens, Willd. ex Roem. \& Sibuit. Syst. iii. $252=$ excelsa.

punctata, Rafin.Alsog. Am.62.-Am. bor.

purpurea, Tausch, in Flora, xxi. (1838) $791=$ lartanca.

Purshii, G. Don, Gen. Syst. iii. $399=$ stolonifera racemosa, Lam. Encyc. ii. $116=$ candidissima. riparia, Rafin. Alsog. Am.62.-Am. bor.

rotundifolia, Rafin. \% c.-Am. bor.

rubiginosa, Etrh. Beitr. iv, $15=\mathrm{C}$. Amomum.

rugosa, Lam. Encyc. ii. $115=$ circinala.

sanguinea, Forsk. Fl. Aegypt. Arab. $33=$ Cordia Myxa.

sanguinea, Linn. Sp. Pl. 117.-Europ. : As, bor

sanguinea, Thunb. Fl. Jap. $68=$ macrophylla.

sanguinea, Walt. H1. Carol, 88 - stricta

sericea, Linn. Mant, ii, 199; LHérit. Cornus, 5. t. 2 -

C. Amomum.

serotina, Rafin. Alsog. Am. 60.-Am. bor.

serrulata, Hassk. \& Zoll. ex Hassk. Cat. Bog. Alt.

$168=$ Polyosma serrulata.

sessilis, Torr, ex Durand, in Gourn. Acad. Nat. So.

Philad. Ser. II iii. (1855) 89.-Am. bor, occ

sibirica, Lodd, in Loud. Hort. Brit. 50 -I Inrtarica.

stolonilira, Michx. F6. Bur. Am.1.92.-An. bor.

\section{CORNUS:}

striata, DC. Prod. iv, $272=$ foemina.

stricta, A. Gray, in Hall, Pl. Texas, 11, ex S. Wats

Libling. Ind, N. Am. Bot. i. $438=$ Drummondii

stricta, L'Hérit. Cornus, $8=$ foemina.

stricta, Lam. Encyc, ii, 116.-Am, bor.

stricta. Zull. \& Morr. in Nat. en (jencesk. Arch. Neêrl.

Inrlie, ii. $(18 \pm 5 ; 10=$ Polyosma integrifo:ia.

suecica, A. Gray, in Proc. Am. Acad. viii. (1873) 387 = canadcnsis.

suecica, Linn Sp. Pl. 118.--Reg, bor, et arct.

suffulicosa, Rafin. Atl. Fourn. 151.-Am. bor.

tartarica, Mill. Gard. Dict ed. VIII, s. 7.-Sibir.

tolucensis, H. B. \& K. Nov. Gen. et Sp. iii. 430.-

Mexic.

tomentosa, Steud. Nom. ed. II. i. $422=$ circinata.

tomentosula, I)C. Prod. iv. $272=$ circinata.

tomentulosa, Michx. Fl. Bor. An. i. $y 1=$ circinata

Torreyi, S. Wats. in Proc. Am. Acad. xi. (1876) 145 -Calif.

trilubata, Decne. in Nouv. Arch. Mus. Par. Sér. I. x.

(1<74) 15\%.-Hab.

unalaschkensis, Ledeb. Fl. Ross. ii. 378.-Alaska.

undulata, Rafin. Alsog. Am.61.-Am. bor.

wernatis, Salisb. Prod. $66=$ C. Mas

virginiana, Hort. ex Lam. Encyc. ii. $115=$ circinata.

CORNUTA, Linn. Gen. ed. VI. $316(1764)=$ Cornutia

Plum. (Verbenac.

CORNUTIA, Plum. ex Linn. Gen. ed. I. 366 (1737

VERBENACEAE, Benth. \& Hook. f. ii. 1153

AGNANTHUS, Vaill. ex Linn. Gen. ed. I. 366 (1737

CORNUTA, Linn. 1. c. ed. VI. 316 (1764)

Hosta, Jacq. Hort. Schoenb. i. 60. t. $114(1797)$

Hostava, Pers. Syn. i. $143(1805)$.

cayennensis, Schau, in DC. Prod. xi. 681.-Guiana.

corymbosa, Burm. f. Fl. Ind, 132 = Premna corymbosa

corymbosa, Lam. Encyc. i. 54=Callivarpa lanata

Yremna tomentosa.

crenata, Medic. Beobacht. (1783) $112=$ pyramidata.

grandiflora, Steud. Nom. ed. II. i. $422=\mathrm{seq}$

grandifolia, Schau. in DC. Prod. xi. 682.-Mícic.

longilulia, Spreng. Syst. i. 39.-Mexic.

odorata, Poepp. ex Schau. in DC. Prod. xi. 681.-Am. trop.

pubescens, Gaertn.f. Fruct. iii. 172.t. 213.-Guiana.

punctata, Willd. Sp. Pl. iii. 322.-Am. trop.

pyramidata, Ait. Hort. Kew. ii. 353 = punctata.

pyramiclata, Linn. Sp. Pl. 628.-Mexic.

quinata, Lour. F1. Cochinch. ii. $387=$ Vitex Loureirii.

CORNUTIOIDES, Linn. Fl. Zeyl. 195 (1747) (Gen. dub.).

COROCEPHALUS, D. Dietr. Syn. PL i. 424, 540 (1839), sphalm.= Conocephalus, Blume (Urtic.).

CORONA-IMPERIALIS, Tourn. ex Rupp. Fl. Jen. ed. Hall. $148(1745)=$ Fritillaria, Linn. (Liliac.).

COROKIA, A, Cunn, in Ann. Nat Hist, iii. (153y 219. CORIACEAE, Benth. \& Ilook. f. i. 949. buddleioides. A. Cunv, l. $C_{0}-\mathrm{N}$. Zel.

Cotoneaster, Raoul, Choix Pl. N. Zil. 22.-N. Zel.

CORONANT HERA, Vieill. ex C. B. Clarke, in DC. Munog. I'han. v. 170 (1833). GES.VERACEAE. aspera, C. B. Clarke, l. C. 172-N. Caled. barbata, C. B. Clarke, l. c.-N. Caled.

delioidlfuli.s, Vieill. ex C. B. Clarke, l. c. $1 ; 1-\mathrm{N}$ Caled.

glabra, C.B. Clarke, l c. 174.-N. Caled.

Pancheri, C. B. Clarke, l. c.-N. Caled.

pec'unculosa, C. B. Clarke, l. c. lis.-N. Caled.

pinguior, C. B. Clarke, 6. C. 171.-N. Caled.

pulchra, C. B. Clarke, 1. c. 17 \$. - N. Caled.

sericea, C. B. Clarke, I. C. 172.-N. Caled.

CORONARIA, Linn. Gen. ed. I. $295(173 i)$ - Lychnis. Linn. (Canophyll.)

Cocli-rosa, fries, ex lleynh. Nom. ii. 161 - L. Coch rusa

Elos-cuculi, A. Br. in Flore, xxvi. (15t3) $3605=1$. r. lusicusuli.

Fus-Guris, A. Br. I. c. L. Flos-Juris.

comerufusa, A. Bir. I. c. L Curonaria. 
CORONE, Hoffmgg ex Stend Nom, ed, II. i. 429 $(1840)=$ Silene, Linn. (Caryophyll.)

agrestina, Fourr. in Ann. Soc. Liun. Lyon, N. S, xvi. (1868) $344=\mathrm{S}$. sylvestris.

gallica, Fourr. l. c. = S. gallica.

nocturna, Fourr. 1. co = S. nocturna.

quinquevulnera, Hoffmgg. ex Steud. Nom. ed. II. i. $422=\mathrm{S}$. quinquevulnera.

vespertina, Hoffmgg. ex Steud. 1. $\mathrm{c}=\mathrm{S}$. vespertina.

CORONILIA, Tourn. ex Linn. Gen. ed. I, 227 (1737).

LEGUMINOSAE, Penth. \& Hook f. i. 509.

Aviunculus, Fourr. in Ann. Soc. Linn. Lyon, N. S. xvi. (1868) 367

Calintephana, Fourr. 1. c. (1868)

EMerUS, Tourn. ex Mill. Gard. Dict. ed. VI. (1752)

Scorpius, Medic. in Vorles. Churpf. Phys. Ges. ii. (1787) 369 .

aculeata, Willd. Sp. P1. iii. $1147=$ Sesbania aculeata

argentea, Burm. f. Cap. Prod. 22; Thunb. Prod. ii

$131=$ Lessertia argentea.

argentea, Linn. Sp. Pl. 743.-Ins. Creta.

atlantica, Boiss. E Reut. Pugill. Pl. Nov. (1852) 42, in syn.-Marocco.

Balansae, Boiss. \& Bal, in Boiss. F1. Orient. ii. $181=$ cappadocica.

buxifolia, Hance, in Ann. Sc. Nat. Sér. IV. xviii (1862) 219.-China.

cannabina, Willd. Sp. Pl. iii. 1147 = Sesbania aculeata cappadocica, Willd. l. c, 1152_-As, Min.

chia, Orph, ex Boiss. Fl. Orient. ii, 183=parviflora.

Clusii, Dufour, in Ann. Sc. Gén. Phys, vii. (1820)

$307=$ minima

coccinea, Willd. Sp. Pl. iii. $1145=$ Sesbania grandifora cocbinchinensis, Lour. Fl. Cochinch. ii. 452.-Cochinch coronata, DC. Prod. ii. $310=$ minima.

coronata, Jacq. Fl. Austr. i. 59. t. 95=montana.

coronata, Linn. Syst. ed. X. 1168.-Europ. austr.

cretica, Linn. Sp. Pl. 743.-Europ. or.; As. Min.

dura, Boiss. Diayn. Ser. II. ii. 34--Lusitan.

elegans, Panð. ex Nym. Consp $185=$ varia?

emera, St. Lag. in Ann. Soc. Bot. Lyon, vii. (1880) 123 C. Emerus.

emeroides, Boiss. E Sprun. Diagn. Ser. I. иi. 100.-

Graecia: As. Min.

Emerus, Linn. Sp. Pl. 742.-Europ. austr.

Emerus, Sibth. \& Sm. Fl. Graec. viii. 7. t. $710=$ emeroides.

eriocarpa, Boiss. Elench $37=$ Hippocrepis squamata,

extensa, Jord. Pugill. $61=$ minima

florida, Salisb. Prod. $341=$ C. Emerus.

fruticans, Ford. Pugill. 62.-- Europ.

gibraltarica, Brouss. ex Ball, in fourn. Linn. Soc. xvi.

(1) 78 4:8.-Hispan.; Afr, bor

glauca, Asso, ex Nym. Consp. $185=$ coronata

glauca, Linz. Cent. Pl. i. 23.-Reg. Mediterr.

globosa, Lam. Encyc. ii. 122.-Ins. Creta.

Glycyrrhiza, Spreng. Syst, iii. $324=$ Glycyrrhiza asper rima.

grandiflora, Boiss, Diagn. Ser. I. v. 88.-As. Min.

grandiflora, Willd. Sp. PI. iii. $1145=$ Sesbania grandi flora.

Haussknechtii, Reut. ex Boiss. FI. Orient. ii. $182=$

varia.

Heineri, Regel, Cat. Pl. Hort. Aksakov, 41.-As. temp.

hirsuta, $D C$. Prod, ii. 310.-Afr. austr.

hirsuta, Vell. Fl. Flum, 311; vii, t. $122=$ Isodesmia tomentosa.

hirta, Bunge, ex Boiss. Fl. Orient. î. 182 = varia.

hispanica, Mill. Gard. Dict. ed, VIII, n. $4=$ glauca

iberica, Bieb. Fl. Taur. Cauc, ii, 171 = cappadocica.

juncea, Linn. Sp. Pl.742.-Europ, austr

libanotica, Boiss. Diagn. Ser. I. ix. $104=$ varia.

lotoides, Koch, in Roehl. DeutschI. Fl. ed. Mert. \& Koch, v. $199=$ minima.

minima, Jacq. Fl. Austr. iii. 39. t. $271=$ virginalis.

minima, Linn. Cent. Pl. ii. 28.--Europ.

monilis, Linn. Pl. Surin. n. 102; Amoen. Acad. viii

261 = Muellera moniliformis?

montana, Scop. Pl. Carn. ed. II. ii. 72.-Reg. Caucas.; Persia.

multiflora, DC. Prod. ii. 310.-Hispan.

myrtifolia, Burm. f. F1. Cap. Prod. 22=Tephrosia myrtifolia.

occidentalis, Willd. Sp. Pl. iii. 1147 = Sesbania occidentalis.

orbiculata, Moench, Meth. Suppl. $40=$ valentina.

\section{CORONILLA:-}

orientalis, Mill. Gard. Dict. ed. VIII. n. 8.-Iberia; As. Min.

pallida, Salisb. Prod. $341=$ glauca

parviflora, Moench, Meth. $121=$ cretica.

parviflora, Willd.Sp. Pl. iii, 1155.-Graecia; As. Min. panciflora, Lam. Fl. Fr, ii. $661=$ C. Emerus.

pendula, Kit. in Linnaea, xxxii. (1863) 634.-Europ

pentaphylla, Desf. Fl. Atlant. ii. 171.-Afr. bor.

picta, Willd. Sp. PI. iii. $1148=$ Sesbania aegyptiaca

pubescens Schum. \& Thonn. in Kon. Dan. Vid. Sel.

Afh, iv. (1828) 128.-Afr. trop.

pulchra, Ball, in Journ. Bot, xi. (1873) $307=$ viminalis.

ramosissima, Ball, $l$. c. 306.-Marocco

repanda, Boiss. Diagn. Ser. II. ii. 35.-Hispan.

rostrata, Boiss. \& Sprun. Diagn. Ser. I. ii. $100=$ parviflora.

sanguinea, Roxb. Hort. Beng. 56, nomen.-Hab.

scandens, Linn. Sp. $P l$. 743.-Ind. occ.

scandens, Vell. Fl. Flum. 310 ; vii. t. $121=$ Chaeto calyx brasiliensis.

scorpioides, Koch, in Roehl. Deutschl. Fl. ed Mert. E Koch, v. 201.-Reg. Mediterr.; Persia.

Securidaca, Linn. Sp. Pl. $743=$ Securigera Coronilla.

Securigera, Salisb. Prod, $341=$ Securigera Securidaca

sericea, Willd. Enum. Hort. Berol. 773 - Sesbania

selicea.

Sesban, Moench, Meth. $120=$ Sesbania aegyptiaca.

squamata, Cav. Ic, ii. $43=$ Hippocrepis squamata.

stipularis, Lam. Encyc ii. $120=$ valentina.

stipulata, Buch.-Ham. ex D. Don, Prod. Fl. Nep. 246.

-Reg. Himal.

suaveolens, Salisb. Prod. $340=$ valentina.

surattensis, Garc. ex DC. Prod. ii. $323=$ Smithia sensitiva.

thymilolia, Burm.f. Fl. Cap. Prod. 22.-Afr. austr.

vaginalis, Lam. Encyc, ii. 121 .-Europ.

vaginalis, Ledeb. F1. Ross. i. $625=$ emeroides.

valentina, Lam. F1. Fr. ii. $663=$ coronata.

valentina, Linn. Sp. Pl. 742.-Europ. austr.

valentina, Pall. ex Bieb. Fl. Taur. Cauc. ii. $173=$ parviflora.

varia, Linn. Sp. Pl. 743.-Europ.

viminalis, Salisb. Parad. Lond. t. 13.-Afr. bor.

virgata, Willd. Sp. Pi. iii. $1148=$ Coursetia virgata.

CORONOCARPUS, Schum. \& Thonn. Beskr. Guin. Pl.

$393(1827)=$ Aspilia, Thou. (Compos.).

Gayanus, Benth. in Hook. Niger Fl. $434=$ A. helianthoides.

helianthoides, Benth. 1, $\mathrm{c}_{n}=$ A. latifolia

helianthoides, Schum. \& Thonn. Beskr. Guin. Pl. $393=$ A. helianthoides.

Kotschyi, Benth. in Hook. Niger F1. $433=$ A. Kotschyana.

Prieurianus, Benth. 1. c. =A. Kotschyana.

CORONOPUS, Reichb. Handb. 202 (1837)= Plantago,

Tourn.

ulgaris, Fourr. in Ann. Soc. Linn. Lyon, N. S. xvil. (1869) $140=\mathrm{P}$. Coronopus.

CORONOPUS, Rupp. ex Linn. Syst. ed. I (1735) Gaertn. Fruct. ii. $293(1791)=$ Senebiera, DC (1799) (Crucif.).

anomalus, Spreng. Syst. ii. $853=$ Brachycarpaea varians.

coadunatus, Stokes, Bot. Mat. Med. iii. $440=$ S. Coronopus.

cristatus, Clairv.] Man. Herb. $212=\mathrm{S}$. Coronopus.

depressus, Moench, Meth. $220=\mathrm{S}$. Coronopus.

didymus, Sm. Fl. Prit. ii. $691=\mathrm{S}$. didyma.

fungosus, $\mathrm{Sm}$. ex DC. Syst. ii. $522=\mathrm{S}$. integrifolia.

Helenae, Spreng. Syst. ii. $853=\mathrm{S}$. Heleniana.

incisus, Hornem. Hort. Hafn. $599=\mathrm{S}$. didyma.

integrifolius, Spreng. Syst. ii. $853=\mathrm{S}$. integrifolia.

linoides, Spreng. 1. c. $=S$. integrifolia.

myricaefolius, Sm. ex DC. Syst. ii. $526=$ S. serrata

niloticus, Spreng. Syst. ii. $853=\mathrm{S}$. nilotica

pinnatifidus, Dulac, Fl. Hautes-Pyr. $[186]=\mathrm{S}$. didyma.

pinnatus, Hornem. Hort. Hafn. $599=\mathrm{S}$. didyma.

procumbens, Gilib. Fl. Lituan. ii. $52=\mathrm{S}$. Coronopus.

Raddii, Savi, in Mem. G. Raddi, (1830) 33.-

Aegypt.

Ruellii, All. F1. Pedem. i. $256=\mathrm{S}$. Coronopus.

serratus, Desv. Journ. Bot. iii. (1814) $163=$ S. serrata.

squamatus, Aschers. Fl. Brandenb. $62=\mathrm{S}$. Coronopus

vulgaris, Desf. Tabl. ed. I. $132=\mathrm{S}$. Coronopus.
COROTHAMNUS, Presl (Bot Bemerk, 137) ; in Abh. Boehm. Ges. V. iii. (1844) $567=$ Genista, Linn (Legunin.).

decumbens, C. Koch, Dendrol. i. $44=$ Cytisus decumbens.

diffusus, Presl, Bot. Bemerk. $137=$ Cytisus decumbens. Halleri, Presl, $1 . \mathrm{c}_{\sigma}=$ Cytisus decumbens. myrtifolius, Presl, 1. c.-Hungar. procumbens, Presl, 1. c. $=$ G. procumbens, Waldst.

COROZO, Jacq. ex Giseke, Prael. $42(1792)=$ Elaeis Jacq. (Palm.).

CORPODETES, Reichb. Consp. 61 (1828) = CARPODETES, Herb. = Stenomesson, Herb. (Amaryll.).

CORRAEA, Sm. in Trans. Linn. Soc. iv. (1798) 219 = seq.

CORREA, Andr. Bot. Rep.t. 18 (1798). RUTACEAE, Benth, \& Hook, f, i. 294

Antommarchia, Colla, Hort. Ripul. App. ii. 345 $(1826)$.

Didimeria, Lindl. in Mitch. Three Exp. Austral.

ed. II. ii. 198 (1839)

Mazeutoxeron, Labill. Voy. ii. 11 (1798).

aemula, F. Muell. Fragm. i. 3.-Austral.

alba, Andr. Bot. Rep. t. 18.-Austral.

Backhousiana, Hook. Journ. Bot. i. (1834) $253=$ speciosa.

Bauerl nii, F. Muell. in Proc. Linn. Soc. N. S. W. ix. (1885) 960.-Austral.

bicolor, Paxt. Mag. Bot. ix (1842) $267=$ speciosa.

cardinalis, F. Muell. ex Hook. Bot. Mag. t. $4912=$ speciosa.

cordifolia, Lindl. in Mitch. Three Exp. Austral. ii. 233 = speciosa.

cotinifolia, Salisb. Parad. Lond, t. 100=alba.

decumbens, F. Muell. in Trans. Vict. Inst. i. (1855) 30.-Austral.

ferruginea, Hook. Comp. Bot. Mag. i. (1835) $276=$ Lawrenciana.

glabra, Lindl. in Mitch. Three Exp. Austral. ii. $48=$ speciosa.

Latroheana, F. Muell. in Dietr. F1. Univ. N. Ser. t. 11 = Lawrenciana,

Lawrenciana, Hook. Fourn. Bot. i. (1834) 254.Au-tral.

leucoclada, Lindl. in Mitch. Three Exp. Austral.ii. 39 = speciosa.

pulchella, Mackay, ex Sweet, F1. Austral. t. $1=$ speciosa.

reflexa, Vent. Jard. Malm. sub t. 13 - speciosa.

revoluta, Vent. 1. c. sub t. $13=$ speciosa.

rotundifolia, Lindl. in Mitch. Three Exp. Austral. ii. $219=$ alba

rubra, Sm. Exot. Bot. ii. $26=$ speciosa

rufa, Vent. Jard. Malm. t. 13 adnot. = alba.

Schlechtendalii, Behr, in Linnaea, xx. (1847) $630=$ speciosa.

speciosa, Ait. Epit. Hort. Kew. 366.-Austral virens, Hook. Fourn. Bot. i. (1834) 253.--Austral virens, $\mathrm{Sm}$. Exot. Bot. ii. 25. t. $72=$ speciosa. viridiflora, Aadr. Bot. Rep. t. $436=$ speciosa.

CORREAS, Hoffmgg. Verz Pf. Nachtr. i. 168 (1824)= Correa, Andr. (Rutac.).

CORREIA, Vell. in Roem. Script. 106. t. $6(1796)=$ Gomphia, Schreb. (Ochnac.)

CORRIGIOLA, Linn. Gen ed. I. 340 (1737). ILLE CEBRACEAE, Benth. \& Hook. f. iii. 17.

Polygonaria, Heist. Syst. 6 (1748).

Polygonifolia, Adans. Fam. ii. 272 (1763)

albella, Forsk. FI. Aegypt. Arab. $207=$ Paronychia arabica.

andina, Planch. E Triana, in Ann. Sc. Nat. Sér. IV xvii. (1862) 146.-N. Granat.

capensis, Willd. Sp. Pl. i. 1507.-Afr, austr.

deltoidea, Hook. \& Arn. Bot. Beech. Voy. $24=$ Mono cosmia corrigioloides.

glomeruliflora, Steud. Nom. ed. II. i. 423.-Chili.

imbricata, Lapeyr. FI. Pyr. i. 83 ; Abr. $169=$ littoralis

latifolia, C. Gay, $\mathrm{Fl}$. Chil. ii. 517.-Chili.

liltoralis, Linn. Sp. Pl. 271.-Europ.

littoralis, Thunb. Prod. P1. Cap. $55=$ capensis

propinqua, C. Gay, Fl. Chil. ii. 517.-Chili.

psammatrophoides, Baker, in Fourn. Linn. Soc. xx (1883) 238.-Madag. 
CORRIGIOLA :-

repens, Forsk. Fl. Aegypt. Arab. $207=$ Polycarpaea fragilis.

squamosa, Hook. Es Arn, in Hook. Bot. Misc, iii. (1833) 337.-Chili.

telephiifolia, Pourr. in Mém. Acad. Toul. iii. (1788) 316 ; (Chl. Narb. 20) = littoralis.

CORSIA, Becc, Malesia, i. 238. t. 9 (1878). BURMANNIACEAE, Benth. \& Hook. f. iii. 460. ornata, Becc. l. c. 239.-N. Gu.n.

CORTESIA, Cav. Ic. iv. 53. t. 377 (1797) - BORAGINEAE, Benth \& Hook. f. ii. 841.

cuneata, Micrs, in Ann. \& Mag. Nat. Hist. Ser. IV. ii. (1£68) $429=$ cuneifolia.

cuneifolia, Cav. Ic. iv. 53. t. 377,-Reg. Argent.

cuneiformis, Poir. in Dict. Sc. Nat. X. $668=$ cuneifolia.

microphylla, Miers, in Ann. \& Mag. Nat. Hist. Ser. IV. ii. (1868) 430.-Am. austr.

CORTHumia, Reichb. Nom. $201 \quad 1841)=$ Pelargonium, L'Hérit. (Geran.).

CORTHUSA, Reichb. Consp. 128 (1828)=Cortusa, Linn. (Primul.).

CORTIA, DC. Prod. iv. 186 (1830). UMBELLIFERAE, Benth. \& Hook. f. i. 915 Sche'ltzin, Wall. Cat. n. $589(1830)$.

elata, Edyew, in Trans. Linn. Soc. xx. (1851) $55=$ Ligusticum elatum.

Hookeri, C. B. Clarke, in Hook. f. Fl. Brit. Ind. ii. 702,- Keg. Himal.

Linclleyi, DC. Prod. iv. 187.- Reg. Himal.

vaginata Edgew。 in Trans. Linn. Soc. xx. (1851) $55=$ Selinum vaginatum.

CORTUSA, Linn. Gen. ed. I. 40 (1737). PRIMU. LACEAE, Penth. \& Hook. f. ii. 633.

Gmelini, Linn. Sp. Pl. 144= Androsace Gmelini. gradissima, Schur, Enum. PI. Transs. $556=$ Matthioli. Matthioli, Linn.Sp. Pl. 144.-Europ.; As. bor. pubens, Schott, Nyman E Kotschy, Analect. Bot. 17. -Transsylv.

Semenovii, Herd. in Bull. Soc. Nat. Mosc. xli. (1868) I. 63 - As centr.

sibirica, Andrz. ex Steud. Nom. ed. II. i. 423.-Sibir. baical.

CORTUSINA, Eckl. \& Zeyh. Enum. 77 (1835)= Pelar gonium, L'Hérit. (Geraniac.).

odoratissima, Eckl. \& Zeyb. 1. c. = P. odoratissimum. reniformis, Eckl. \& Zeyh. l. c. = P. reniforme. rubropurpurea, Eckl. \& Z Zeyh. l. $\mathrm{c}_{r}=\mathrm{P}$. echinatum. sidaefolia, Likl. \& Zeyh. 1. c. = P. sidoides, velutina, Eckl. \& Zeyh. 1. c $v=$ P. velutinum.

CORVINA, Stend. Nom. ed. II. i。 256 (1840) sphalm. = Muricaria, Desv. (Crncif.). prostrata, Stcud, 1. c = M. prostrata.

CORVINIA, Stadtm. ex Willem. in Usteri, Ann. Bot. xviii. $28(1796)=$ Nephelium, Linn. (Sapindac.). Litschi, Stadm. ex Willem. 1. c. =N. Litchi.

CORvisARTiA, Mérat, Fl. Par. ed. I. $328(1812)=$

Inula, Linn. (Compos.).
caucasica, G. Dus, ex Loud. Hort. Brit. $350=$ Buphthalmum speciosum.

Helenium, Merat, 1'1. Par, ed. I. $328=$ I. Helenium. indica, Lindl. Bot. Reg. (1842) Misc. $58=$ I. Royleana.

CORYANTHES, Hook, Bot. Mag, t. 3102 (1831) ORCHIDEAE, Benth. \& Hook. f. iii. 549.

CORYTHANTHES, Lem. in Orb. Dict. iv. 259 (1849). Panstrepis, Kafin. Fl. Tellar. iv. 41 (1836).

Meliclis, Rafin. I. c. ii. 99 (1836).

Albertinae, Karst. Ausw. Ncuer Gew. Venez. $5=$ maculata.

Barkerii, Becr, Prakt. Orch. 222, sphalm, = Parkeri.

biflora, Rodrig. Orch. Nov, i. 103.-Bras.

Bruchmuelleri, Reichb. fo in Linnaea, xli. (1877) 74. N. Granat.

elegantissima, Mart. in Gard. Chron. (1885) I. 144= elegantium.

elegantium, Linden \& Reichb. fo in Gard. Chron. (1068) 1114.-Bras.

\section{CORYANTHES}

Feildingii, Lindl。 in Fourn. Hort. Soc. iii. (1848) 15 . - Hab.?

macrantha, Hook. Bot. Mag. t. 3102, in textu.-Venezuela.

macrantha, [Mast. in] Gard. Chron. (1882) I. $592=$ elegantium.

maculata, Hook. Bot. Mag. t. 3102.-Am. austr

Parkeri, Endl. in Harting. Parad. Vindob. 19. t. 32. f. $1=$ speciosa.

picturata, Reichb. f. in Bot. Zoit. xxii. (1864) 332.Honluras.

punctata, Beer, Prakt. Orch. $222=$ maculata.

speciosa, Hook. Bot. Mag. t. 3102. in textu.-Bras.

splendens, Rodrig. Orch. Nov, i, 103.-Bras.

Sumneriana, Lindl. in Gard. Chron. (1856) 452.Hab. ?

CORYBAS, Salisb, Parad. Lond. t. $83(1805)=$ Cory santhes, R. Br. (1810) (Orchid.).

aconitifolius, Salisb. $\mathrm{l}_{\mathrm{c}} \mathrm{c}_{\mathrm{f}}=$ Corysanthes bicalcarata.

fimbriatus, Reichb. f. Beitr. Syst. Pf. $42=$ Corysanthes fimbriata.

fornicatus, Reichb, f. 1. c. $67=$ Corysanthes fornicata. macranthus, Reichb, $f, 1 . c=$ Corysanthes macrantha. mucronatus, Reichb. f. 1. $c=$ Corysanthes mucronata. oblongus, Reichb. f. 1. c. - Corysanthes oblonga.

pictus, Reichb. f. 1. $\mathrm{c}_{*}=$ Corysanthes picta.

pruinosus, Reichb. f. l. c. $43=$ Corysanthes fimbriata. vivularis, Reichb, f. 1. c. $67=$ Corysanthes rivularis

rotundifolius; Reichb, f, 1. c. = Corysanthes rotundifolia.

trilobus, Reichb. f. 1. c. $=$ Corysanthes triloba.

unguiculatus, Reichb. f. 1. c. $43=$ Corysanthes unguicula:a.

CORYCARPUS, Zea, ex Spreng. Syst. i. $123(1825)=$ Diarrhena, Rafin. (Gramin.)

arundinaceus, $\mathrm{Zea}_{\mathrm{e}}$ ex Spreng. $\mathrm{i}, \mathrm{c}=\mathrm{D}$. americana.

CORYCIUMI, Sw. in Vet. Acad. Nya Handl, Stockh. xxi. (1800) 220. ORCHIDEAE, Benth. \& Hook. to iii. 633 .

bicolorum, Srw. l.c. 222.-Afr, austr.

tifidum, Sond. in Linnaea, xix.. (1847) 111.-Afr. anstr.

crispum, Sw. in Vet. Acad. Nya Handl. Stockh. xxi. (1860) 222. - Afro austr.

excisum, Lindl. Genn. et Sp. Orch. 368.-Afr. austr.

ligulatum, Reichb. f. in Linnaea, xix. (1847) $375=$ bifidum.

microglossum, Lindl. Gen. et Sp. Orch. 369.-Afr. austr.

nigrescens, Sond. in Linnaea, xix. (1847) 110.-Afr. austr.

orobanchoides, Sw. in Vet. Acad. Nya Handl. Stockh. xxi. (1800) 222.-Afr. austr.

vestitum, Sw. $l$. c.-Afr. austr.

CORYDALIS, Vent. Choix, 19 (1803), in nota; DC. Fl. Fr. iv. 636 (1805). PAPAVERACEAE, Benth. \& Hook. f. i. 55.

Burckhausenia, Gaertn. Mey. \& Scherb. Fl. Wett. iii. 4 (18v1)

Bulbocapnos, Bernh. in Linnaea, viii. (1833) 469 . CAPNOIDES, Adans. Ham. ii. 431 (1763).

Ceratocapnos, Dur. in Parl. Giorn. Bot. Ital. i. 1. (1844) 336.

CrXptoceras, Schott \& Kotschy, in Oestr. Bot. Wochenbl. iv. (1854) 121.

Cysticapnos, Boerh. ex Adans. Fam. ii。 481 (1763). NECKERIA, Scop. Introd. 313 (1777).

PHacocapros. Bernh. in Linnaer, xii. (1838) 66. Pistolochia, Bernh. Syst. Verz Erf. 57 (1:00).

Psevdofumaria, Medic. Phil. Bot. i. 110 (17 5 b)

Sophorocapnos, Turcz. in Bull. Soc. Nat. Mose xxi. $(1848)$ I. 570

acaulis, Pers. Syn, ii. $270=$ ochroleuca.

adiantifolia, Hook. f. E Thoms. Fl. Ind. i. 271.-Re Himal.

adunca, Maxim. in Bull. Acad. Pitersb. xxiv. (18is) 29.-China.

albicaulis, Franch. Pl. David. i. (1884) 30 -As, or alliflora, Kit. in Linnsea, xxxii. (1863) 491 . Hungar.

alpestris, C. A. Mey, Verz. PH. Cauc, 176 = paucifloes alpina, J Gay, in Ann. Sc. Nat. Ser. I. xxvi. (1SJ? $252=$ labacea.

\section{CORYDALIS}

alpina, C. Knch, in Linnaea, xv. (1841) $252=$ rutae folia.

ambigua, Cham. E Schlecht. in Linnaea, i. (1826.

558. - Kamtschat.

angustifolia, DC. Syst. ii. 120.-Reg. Caucas.; Persia.

annua, Hioffmgg. ex Steud. Nom. ed. II. i. $423=$ slauca.

astragalina, Hook. f. \& Thoms. Fl. Ind. i. $270=$ stricta.

aurea, Willd. Enum. Hort. Berol, 740.-Am. bor.

biaurita, Hornem. Hort. Hafn, ii. $668=$ Dicentra furmosa.

bicalcarata, Haw. ex G. Don, in Loud. Hort. Brit. suppl, i, $585=$ rutaefolia.

Bidwelliae, S. Wats. in Bot. Calif, ii. 429,-Calif.

blanda, Schott, in Oestr. But. Wochenbl. vii. (1857 $149=$ tuberosa.

bracteata, Pers. Syn。 ii. 269.--Sibiria.

bracteosa, Spreng Syst. iii. 162 (= Diclytrabracteosa). -Am. bor.

Brandegei, S. Wats, in Bot. Calif, ii. 430,-Calif.

brevifluia, $D C$. Syst. ii. 127.-Kamtschat.

bulbosa, $D C$. Fl. Fr. iv. 63i.-Europ.

bulbosa, Ytrs. Syn, ii, $269=$ ut brrosa

bulbosa, Turcz. ex Steud. Nom. ed. II. j. $423=$

Tuıtschaninovii.

Rungeana, Turcz. in Bull. Soc. Nat. Mose. $(1840,62$ -Sibir.

Burmanni, Eckl. E Zeyh. Enum. 4-Afr, austr.

canadensis, Goldb. in Edinb. Phil. Journ, vi. (182.2

$329=$ Dicertitra canadensis.

capnoides, Pers. Syn. ii $-270=$ lutea.

Caseanà, A. Gray, in Proc. Am. Acad. x. (1874) 69.-

Calif.

cashmeriana, Royle, Illustr, Bot. Himal. 69. t. 16. f. 1 .

- Keg. Himal.

caucasica, Adams, ex Steud. Nom. ed. II. i. $423=$ angustifolia.

caucasica, DC. Syst. ii. 119.-Reg. Caucas.

caudata, Pers, Syn, ii. 269 = lung'fora.

cava, Schweigg. \& Kort. Fl. Erlang. ii. 44; Wableab.

Veg. Helv, 126 [bis] = tuberost

chaerophylla, DC. Prod. i. 128.-Reg. Himal.

chinensis, Franch. PI. David. i. 28 = edulis.

c'avicula, S. H. Gray, Nat. Arr, Brit. 1'. ii. $700=$ seq.

claviculata, DC. Fl. Fr. iv, 638,-Europ.

conorhiza, Ledeb. Fl. Ross. i. 99. - Reg. Caucas.

cornuta, Royle, Illustr. Bot. Himal. 69.-Reg. Himal.

Cracca, Cham. \& Schlecht. in Linnaca, i. . 1826) 567.

-Afr. austr.

crassifolia, Royle, Illustr. Bot. Himal. 68.-Reg Himal.

crassissima, Jacquem. Voy. Bot. 12. t. $11=$ crassifolia.

crithmifolia, Royle, Illustr. Bot. Himal. 68.-Reg. Himal.

crystallina, Engelm. ex A. Gray, Man. U. St. Bot. ed V. 62.-Am. vor.

Cucullaria, I'ers. Syn, ii. $269=$ = Dicentra Cucullaria curvisiliqua, Engelm. ex A. Gray, in Man. Bot. U. St.

ed. V. 62.-Am, bor. occ.

Cusickii, S. Wats. in Bot. Calif. ii, 430.-Calis.

dasyptera, Maxim. in Bull. Acad. Pétersb, xxiv. (1875 28.,-China,

debilis, Edgew. in Trans. Linn. Suc. xx. (1851) $90=$ cornuth.

decipiens, Schott, Nyman \& Kotschy, Analect. It i. $42=$ pumila

decumbens, Pers. Syns. ii. 269.-Japon.

dersiflora, J. \& C. Pre 1, Velic. Pras. $10=$ bulbosa

depauperata, Schur, in lerh. Siebenb. Ver. Naturw. iv 1853) 51 = bull:

dipitate, Pers, Syn, ii, $\left.26^{\circ}\right)=$ bubosa.

diphella, Winll. Tene. Fl. Nep, 5t-rutaefulia

edulis. Maxim, in Bull. Acud. Pitersb. xuv. 1sis si

legrans, Wall. Cat. n. 1485.-Keys. Ilimal.

Emanueli, C. A. Mey. Verz. $\left.\mathbb{P}^{\prime}\right\}$. Cauc. $1 ; 0=$ pauei thara.

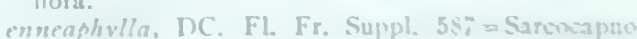

enneaphyilia. Walp. Rep. i. 12u, splusim. = criti. mulelia.

Erdelii. Zuec, in Abh. Ahad, Muench, iii. 1:43 251 rutac fulia.

crimia, Link, linum. Hort. Ierol, ii. 21s - Inicent:2 cximia

fabacea, Pers. Syn. ii. 269-1 Lurop 


\section{CORYDALIS:-}

Falconeri, Hook. f. E Thoms. in Fl. Brit. Ind. i. 124 - Keg. Himal.

Fedtichenkoana, Regel, Pl. Nov. Fedsch. 3.-As,

fibrosa, Maxim. in Bull. Phys.-Math. Acad. Pétersb. $\mathrm{xv} .(1<57) 227$, nomen.-Manchur.

filiformis, Royle, Illustr. Bot. Himal. $68=$ sibirica.

Habellata, Edgew. in Trans. Linn. Soc, xx. (1851) 30.Reg. Himnl.

flaccida, Hook. f. E Thoms. Fl. Ind. i. 260.-Reg. Himal.

flavidula, Chapm. Fl. S. U. St. Suppl. $604=$ flavula.

flavula, DC. Prod. i. 129.-Am. bor.

formosa, Pursh, Fl. Am. Sept. ii. $462=$ Dicentra canadensis eximia.

formosa, Spreng. Syst. iii. $162=$ Dicentra formosa

fumariaefolia, Maxim in Prim. Fl: Amur. 39.-Manchur.

fungosa, Vent. Choix, t. $19=$ Adlumia cirrbosa. gamosepa'a, Maxim. Irim. Fl. Amur. $38=$ bulbosa Geblevi, Ledeb. Ind. Hort. Dorpat. (1823) $3=$ capnoides geraniifolia, Hook. f. \& Thoms. Fl. Ind. i. $269=$ chaerophylla.

giganiea, Trautv. E Mey. in Middend. Reise (FI. Ochot. 13).-Manchur.

glauca, Pursh, Fl. Am. Sept. ii. 463.-Am. bor.

glaucescens, Regel, in Bull. Soc. Nat. Mosc. xliii. (1870) E. 253.-As, temp.

Gortschakorii, Srhrenk, Enum. Pl. Nov. i. ]00.-Reg. Himal.; Soongar.

Govaniana, Wall. Tent. Fl. Nep. 55,-Reg. Himal. gracilipes, S. Moore, in Jonrn. Bot. xii. (1875) $226=$ dicumiens.

gracilis, Ledeb. Fl. Ross. i. 101.-Reg. Caucas.

Griffithii, Boiss. Diagn. Ser. II. i. 15 (Griffithsii) = rutaefolia.

Halleri, Willd. Enum. Hort. Berol. $740=$ bulbosa.

Hamiltoniana, G. Don, Gen. Syst. i. $143=$ rutaefolia.

heterocarpa, Ball, in fourn. Linn. Soc. xvi. (1877)

314.-Air, bor, occ.

heterocarpa, Si b. \& Zucc. in Abh. Akad. Muench. iv. (1843) 1 I. $173=$ pallida.

Hoffmeisteri, Klotzsch, in Bot. Ergeb. Waldem. Reise, $129=$ meifolia.

Impatiens, Hisch. in DC. Syst, ii. $124=$ sibirica.

incisa, Pers. Syn. ii. 269.--Japon.

inconspicua, Bunge, ex Ledeb. Fl. Ross. ¿. 104,-Sibiria intermedia, Mérat, $\mathrm{F}$. Par.:272 = fabacea.

juncea, Wall. Tent. Fl. Nep.54. t. 42,-Reg. Himal.

Kareliniana, Pritz. ex Walp. Rep. ii. 750-As. centr.

kaschmiriana, Auct. = cachmeriana.

kashgarica, Rupr. Sert. Tiansch. 38.-As. centr.

Kolpakowskiana, Regel, in Act. Hort. Petrop. v (1877) 633 - Turkestan.

lachenaliaeflora, Fisch. ex DC. Syst. ii. $111=$ Dicentra lachenaliaeflora.

laevigata, E. Mey. ex Bernh. in. Linnaea, xii. (1838) $664=$ C. Cracca

latiflora, Hook. f. E Thoms. Fl. Ind. i. 270.-Reg, Himal.

laxa, Franch. E Sav. Enum. Pl. Fap. ii. 274.Japon.

laxa, Fries, Summa Veg. Scand. 145.-Fennia.

Ledebouriona, Ka*. E' Kir. in Bull. Soc. Nat. Mosc

(1841) 377.--Sibiria.

leptocarja, Hook. f. E Thoms. Fl. Ind. i. 260.-Reg Hima

libanotica, Hochst. in Lorent, Wanderungen, $339=$ rutaefolia.

linarioides, Maxim. in Bull. Acad. Pétersb̆. xxiv. (1078) 27 -China

lineariloba, Sieb. \& Zucc. in Abh. Akad. Muench. iv. II. (1843) $174=$ bulbosa.

Lobelie, Tausch, ex Hoppe, in Flora, xxii. (1839) $379=$ pumila.

longiflura, Pers Syn. ii, 269.-Reg. Casp.; Sibir.

longipes, DC. Prod, i. $128=$ sibirica.

longipes, D. Don, Prod. Fl. Nep. $198=$ rutaefolia.

lutea, $D C$. Fl. Fr. iv. 638.--Europ.

Maachii, Rupr. ex Trautv. in Act. Hort. Petrop. viii. (1£83) 71.-Manchur.

macrocentra, Regel, l. c. viii。(1884) 694.-As. centr. macrophylla, Nutt. in Torr. E Gray, Fl. N. Am. i. 69 - Am. bor. occ.

macrosepala, Ssred. ex Trautv. in Act. Hort. Petrop. viii. (1 83 ) 71.-Reg. Cancas.

Marschalliana, Pers. Syn. ii. 269.-Rossia; As. Min

\section{COR YDALIS}

neifolia, Wall. Tent. Fl. Nep. 55.-Reg. Himal. melanochlora, Maxim. in Bull. Acad. Petersb. xxiv (1<78) 26.-China.

micropoda, Franch. Pl. Davidian. i. (1884) 29.-As. or.

montana, Engelm. ex A. Gray, Man. U. St. Bot. ed. V. $62=$ atrea

Moorcroftiana, Wall. Cat. n. 1432.--Reg. Himal.

nana, Royle, Illustr. Bot. Himal. 68.-Reg. Himal.

nivalis, Boiss. \& Huet, in Diagn. Ser. II. v. $16=$ pauciflora.

nobilis, Pers. Syn ii, 269 -Sibir

nudicanlis. Regel, in Act. Hort. Petrop. viii. (1884) 695.-As. centr.

ochotensis, Turcz. in Bull. Soc. Nat. Mosc. (1840) 62 -Sibir.

ochroleuca, Koch, in Flora, xiv, (1831) 708,-Italia.

ophiocarpa, Hook. f. E' Thoms. Fl. Ind. i. 259.-Reg. Himal.

oppositifolia, DC. Syst. ii. $114=$ rutaefolia.

orthoceras, Sieb. E" Zucc. in Abh. Akad. Muench. iv (1843) II. 175.-Japon.

paeoniaefolia, Pers. Syn. ii, 269.-Sibir.; Am bor. occ. pallida, Pers. l. c. 270. - Chi.ı; Japon.

paniculigera, Regel $\xi^{\circ}$ Schmalh. ex Regel, Pl. Nov. Fedsch. 3.-As, centr.

parnassica, Orph. Er Heldr. in Boiss. Diagn. Ser. II. vi. 9.-Graecia.

pauciflora, Edgew. in Trans. Linn. Soc. xx. (1851) $30=$ rutaefolia.

pauciflora, Pers. Syn. ii. 269.-As. bor.; Am. bor. occ persica, Cham. E' Schlecht. in Linnaea, i. (1826) 567. -Persia.

physocarpa, Cambess. in Jacquem. Voy. Bot. 13. t. $12=$ crassifolia.

polygalina, Hook. f. E" Thoms. Fl. Ind. i. 263.-Reg Himal.

pruinosa, E. Mey. ex Bernh. in Linnaea, xii. (1838) $6 \mathrm{r} 4$, in syn. - Afr. austr

pseudo-cava, Pantoc, in Verh. Ver. Natur-u. Heilk. Presb. ii. (1871-72) $88=$ tuberosa

pseudo-pumila, Schur, Enum. Pl. Transs, $37=$ pumila

pulchella, Aitch. E Hemsl. in Fourn. Linn. Soc. xi (1882) 151.-Afghan.

pumila, Koch, Syn. Fl. Germ. ed. II. 34.-Europ.

racemosa, Bunge, Enum. Pl. Chin. Bor. $5=$ Bungeana

racemosa, Pers. Syn. ii. 270.-Japon.

Raddeana, Regel, in Bull. Soc Nat. Mosc. xxxiv. (1861) II. 143.-Manchur.

ramosa, Wall. Cat.n. 1434.-Reg. Himal.

remota, Fisch. ex Maxim. Prim. Fl. Amur. $37=$ bull osa.

rosea, Maxim. in Bull. Acad. Pétersb. xxiv. (187\&) 29. -China.

rosea, Zeyh. ex Steud. Nom, ed. II. 1. 424.-Afr. austr. rupestris, Kotschy, ex Boiss. Diagn. Ser. I. vi. 8.Persia.

rutacea, $T . M$. Fr. in Bot. Notiser (1854) 39.-Sibir.? rutaefolia, Boiss. \& Buhse, in Nonv. Mém. Soc. Nat. Mosc. xii. (1860) $13=$ persica.

rutaefolia, DC. Syst. ii. 115.-As. Min.; Persia; Reg. Himal.

scandens, Spreng. Syst. iv. Cur. Post. $265=$ Dicentra spectabilis.

Schelesnowiana, Regel \& Schmalh. ex Regel, Pl. Nov. Fedsch. 4.-As. centr.

Sconleri, Hook. Fl. Bor. Am. i. 36. t. 14.-Am. bor. oic.

Semenowii, Regel E Herd. in Bull. Soc. Nat. Mosc. xxxvii. (1864) I. 407.-Sibir.

sempervirens, Pers. Syn. ii. $269=$ glauca

senanensis, Franch. E Sav. Enum. Pl. Fap. ii. 273.Japon.

Sewerzowi, Regel, in Bull. Soc. Nat. Mose. xliii (1870) 1. 252.-As. centr.

Sheareri, S. Moore, in Fourn. Bot. xili. (1875) 225.China.

sibirica, Pers. Syn ii, 270.-Sibir. : Reg. Himal

solida. [Sw, in] Svensk Bot. viii. $531(1819)=$ bulbosa. speciosa, Maxim. Prim. Fl. Amur. $39=$ pallida. spectabilis, Pers. Syn. ii. $269=$ Dicentra spectabilis. streptocarpa, Maxim. in Bull. Acad. Pétersb. xxiv. (1878) 30 -China.

stricta, Steph. ex DC. Syst. ii. 123.-Sibir.; Reg. Himal.

Stummeri, Pantoč. in Magyar Növént. Lapok, v. (1881) 150.-Hungar.

\section{CORYDALIS:-}

suaveolens, Hance, in Fourn. Bot. xviii. (1880) 258.China.

tenella, Kar. E Kir. in Bull. Soc. Nat. Mosc. xv. (1842) 143.-As. centr.

tenella, Ledeb. ex Nordm. in Bull. Sc. Acad. Pétersb. ii. (1837) 313.-Keg. Cancas.

tenuifolia, Pursh, F1. Am. Sept. ii. $462=$ Dicentra lachenaliat flora.

tenuis, Schott, Nyman \& Kotschy, Analect. Bot. $43=$ bulbosa.

thalictrifolia, fameson, ex Regel, in Bull. Soc. Nat. Mosc. xxxiv. (1861) I1, 118.-China.

tibetica, Hook. f. E Thoms. Fl. Ind. 1. 265.-Reg. Himal.

trachycarpa, Maxim. in Bull. Acad. Pétersb. xxir. (1878) 27.-China.

triternata, Zucc, in Abh. Akad. Muench, iii. (1843) $251=$ bulbosa.

tuberosa, DC. Fl. Fr. iv. 637.-Europ.

Turtschaninovii, Bess. in Flora, xvii. (1834) 1. Beibl. 6. -Rossia.

uniftora, Nym. Syll. $185=$ rutaefolia.

uralensis, Fisch. ex DC. Syst. ii. 127.-Mont. Ural

vaginans, Royle, Illustr. Bot. Himal. 68.-Keg. Himal Vernyi, Franch. E' Sav. Enum. Pl. Fap. ii. 273.Japon.

verticillaris, DC. Syst. ii. $114=$ rutrefolia.

vesicaria, Pers. Syn. ii. 269.-Afr, austr.

Wilfordi, Regel, in Bull. Soc. Nat. Mosc. xxxiv. (1861) II. $148=$ pallida

CORYDALLIS, Aschers. F1. Brandenb. 28 (1864)= piaec

CORYDANDRA, Reichb. Nom. $53(1841)=$ Gale andra, Lindl. (Orchid.)

CORYIOPSIS, Sieb. \& Zucc. Fl. Jap. i. 45. tt. 19, 20 (1835). HAMAMELIDEAE, Benth. \& Hook. f. 'i. 667.

glahrescens, Franch。 E Sav. Enum. Pl. Fap. ii. 367.Japon.

himalayana, Griff. in Fourn. As. Soc. Beng. xxiii (1854) 641.-Reg. Himal

Kesakii, Sieb. \& Zucc. Fl. Fup. i. 49.-Japon.

multiflora, Hance, in Ann. Sc. Nat. Sér. IV.xv. (1861) 224 -China.

pauciflora, Sieb. E Zucc. Fl. Fap. i. 48. t. 20.-Japon spicata, Sieb. \& Zucc. l. c. 45. t. 19.-Japon.

CORYLUS, [Tourn.] Linn. Syst. ed. I (1735). CU. PULIFERAE, Benth. \& Hook. f. iii. 406 alba, Ait. ex Stend. Nom. ed. II. i. $421=$ C. Avellana americana, Siebold, in Verh. Bat, Gen. xii. (1830) $26=$ heterophylla.

americana, Walt. Fl. Carol. 236.-Am, bor.

americana, Willd. Sp. Pl iv. $471=$ humilis.

arborea, Hort. ex Steud. Nom. ed. II. i. $424=\mathrm{C}$. Avellana.

arborescens, Gaertn. Mey. \& Scherb. F1. Wett. iii. 376 $=$ tubulosa.

arborescens, Muench. Hausv. iii. 8?6-C. Columa. atropurpurea, Hort. ex A. DC. in DC. Prod, xvi. Ix. 132 = tubulosa.

Arellana, Linn. Sp. Pl. 998.-Europ.; As. Min.

Avellana, Thunb. Fl. Jap. $160=$ heterophylla.

bizantina, Desf. Tabl. ed. II. $245=$ C. Colurna.

californica, Hort. ex C. Koch, Desdrul. ii. II. $15=$ rostrata.

Colurna, Linn. Sp. Pl. 999.-Europ. or.; As. Min. Himal

cornuta, Duroi, ex Steud. Nom. ed. I. $229=$ rostrata.

Davidiana, Baill. Hist. Pl. vi. 224.-China.

ferox, Wall. Cat. n. 2797.-Reg. Himal.

filicifolia, Hort. ex A. DC. in DC. Prod. xvi. II. $131=$ C. Avellana,

grandis, [Dryand. in] Ait. Hort. Kew. ed. I. iii. $363=$ C. Avellana.

Hasibani, Siebold, Kruidk. Naaml.27.-Japon.

heterophylla, Fisch. ex Bess. in Flora, xvii. (1834) I.

Beibl. 24 = C. Avellana.

humilis, Willd. Enum. Hort. Berol. $983=$ americana. intermedia, Fingerh. in Linnaea, iv. (1829) $385-\mathrm{C}$ Colurna.

Facquemsntii, Decne. in Jacquem. Voy. Bot. 160. t. 169 -C. Colurna.

lacera, Wall. Cat. n. $2798=$ C. Colurna 


\section{CORYLUS :-}

laciniata, Hort. ex A. DC. in DC. Prod. xvi. II. $131=$ C. Avellana.

mandshurica, Maxim. in Bull. Phys.-Math. Acad. l'éte sb. xv. (1856) $137=$ rostrata.

maxima, Mill Gard. Dict erl, VIII, n, $2=\mathrm{C}$. Avellana mexicana, Hort. ex C. Koch, Dendrol. ii. 11. $15=$ rostrata.

mongolica, Hort. ex C. Koch, 1. c. $13=$ C. Avellana. ovata, Lam. ex Steud. Nom. ed. II. i. $424=$ C. Avellana pontica, Dochmahl, Fuehr. Obstkunde, iv. $38=\mathrm{C}$. Avellana.

pontica, C. Koch, in Linnaea, xxii. (1849) $329=\mathrm{C}$ Colurma.

pumila, Lodd. ex Loud. Hort. Brit. Suppl. iii. $523=$ C. Avellana.

purpurea, Hort. ex A. DC. in DC. Prod.xvi. II. $132=$ tubulosa.

quercifolia, Hort. ex A. DC. 1. c. $131=$ C. Avellana. rostrata, Ait. Hort. Kew. iii. 364.-Am. bor.

Serínyiana, Plusk, ir Uestr. Bot. Wochenbl. ii. (1852) $394=$ C. Avellana.

Sieboldiana, Blmme, Mus. Bot. Lugd. Bat. i. $310=$ heterophylla.

sylvestris, Salisl, Prod. 392 - C. Avellana.

tetraphylla, Ledeb. in Denkschr, Baier. Bot. Ges. iii. (1841: 11. 58, sphalm, = C. Avcllana.

Thunbergii, Hurt. ex C. Koch, Dendrol. ii. II. $18=$ heterophylla.

tiliacea, Jacquem. Voy. Bot. $160=$ C. Colurna,

tubulosa, Willd Sp.Pl. iv, 470 - Europ, austr.; As. Min

Turtschaninovii, Steud. Nom. ed. 11. i. 425 , sphalm. Corydalis Turtschaninovii.

CORYMBIS, Thou. Orch. Iles Afr. t. 3i, 38 (1822), ORCHIDEAE, Jienth. \& Hook. f. iii. 591.

Chlolvia, Lind1. Gen. et Sp. Orch. $48+$ (1840).

CORYMBORCHIS, Thou ex Blume, Orch. Aich. Ind. $125(1 \succ 55)$.

Hysteria, Reinw. in Blume, Cat. Gew. Buitenz. 99 (1823).

MAcrostylis, Beda Orch. Kuhl. et Hass. (1827 ?) Rhynchantiera, Blume, Bijdr. Tabell. 7ð (1826).

Tomotris, Rafin. Fl. 'Tellur. ii. 89 (1836).

angustufulia, Miq Fl. Ind. Bat. Suppl. 617.-Sumatra. coiymbosa, Thou. Orch. Iles Afr. it 37, 38.-Madag. disticha, Lindl. Hol. Orthid. Curymbis = corymbosa. flava, Hemsl. Biol. Centr. Am. Bot. iii. 2:77--Mexic. galipanensis, Reichb. f. in Fora, xlviit. (1865) 184.-Am. trop.

Thomarsii, Reichb. f. in Bot. Zeit. vii. (1849) $886=$ curj mbosa.

veratrilolia, Reichb. $f$. in Flora, xlviii. (1865) 184. Ind. or.; Millaya,

Weswitschii, Reichb.f. l.c. 183.-Afr. occ.

CORYMBIUM, Linn. Coroll. Gen, 14 (1737). COMPOSITAE, lienth. \& Hook, f. ii. 234.

Contrarena, Adans. Fam. ii. 120 (1763),

africanum, Linn. Sp. Pl. 928.-Afr, austr

congestum, E. Mey. ex Steud. Nom. ed. II. i. 425.Atr. austr.

cymosum, E. Mey. ex Steud. l. c.-Afr. austr.

filiforme, Linn. f. Suppl. 392 . - Afr. austr.

glabrum, Linn. Syst. eil. X1I. 582 - Afr, austr.

glabrum, Thunb. Prod. P1. Cap. $170=$ filiforme?

gramineum, Burn. f. F1. Cap. Prod. $2 y=$ filiforme

gramincum, Lam. Lncyc. ii, $129=$ filiforme, glabrum.

hirsutum, Lickl. ex DC. Prod. v. $89=$ villosum.

hirsutum, "Thunt. Fl. Cap. $724,730=\mathrm{seq}$.

hirtum, Thunb. Prod. Pl. Cap. 170.-Afr. austr.

latifulium, Harv. in Harv. E Sond. Fl. Cap. ii. 55. Alr. austr.

luteum, E. Mcy. ex Steud. Nom. ed. II. i. 725.-Afr. nustr.

nervosum, Thunb. Prod. Pl. Cap. 170.-Afr. austr. scabridum, Berg. Ies: Pl. Cup. $341=$ afi icaum.

scabrum, Linn. Mant. i. $120=$ praec.

villo:um, Linn.f. Suppl.3J2,-Afr, austr.

CORYMBORCHIS, Thou. ex 13lume, Orch. Ind. Arch $125(1855)=$ Corymbis, Thou. (Orchid.)

assamica, Blume, Oichid. Archip. Ind. 126, to $43=$ Corymbis veratrifulia.

Thouarsit, Blumc, 1. c. 126. t. 44. f. 1. a-c=Corymbis corymbosa.

veratrifolia, Bhume, 1. c. 125 . t. $42=$ Corymbis veratrifolia.
CORYMbUla, Rafrn. New Fl. Am. iv. 88 (1836)= Polygala, Linn.

CORYNAEA, Hook, f in Trans, Linn Soc xxii. (1856) 31. t. 1:, 14. BALANOPHOREAE, Benth. \& Hook. f. iii. 237.

crassa, Hovk. f. l. c. 31, 54. t. 13.-N. Granat

Purdici, Hook. f. l. c. 31, 55.-N. Granat.

sphaerica, Hook. f. l. c. 31, 54, t. 14.-N. Granat.

Sprucei, Eichl, in DC. Prod. xvii. 137.-N. Granat.

CORYNANDRA, Schrad. ex Spreng. Syst. iv. Cur. Post $201(1827)=$ Cleome, Linn. (Cappar.) pulchella, Schrad, ex Spreng. 1. c. $204=$ Cleome Chelidonii.

CORYNANTHE, Welw, in Trans. Linn. Soc. xxvii. (1869) 37. t. 14. RUBIACEAE, Benth. \& Hook. f. ii. 36 .

paniculata, Welw. l.c.-Afr. trop.

CORYNANTHFLIUM, Kunze, in Linnaea, xx. (184\%) $19=$ Mikania, Willd. (Compos.)

Moronoa, Kunze, 1, c-Bras.

CORYNANTHES, Schlecht. in Bot. Zeit. vi. (1848) $65=$ Coryanthes, Hook. (Orchid.).

CORYNELIA, Reichb. Nom. 148 (1841) =seq.

CORYNELLA, DC. in Ann. Sc. Nat. Sér. I. iv. (1825 93. LEGUMINOSAE, Benth. \& Hook. f, i. 500. Corynitis, Spieng. Syst, iv. Cur. Post, 263 (1827)

Toxotropis, Turez, in Bull. Soc, Nat. Mosc, xix. (1846) 506 .

gracilis, Griseb. Cat. $P l . C u b .71$-Cuba.

immarginata, Wright, in Sauv. Fl. Cub. 26.-Cuba, paucifolia, DC. in Ann. Sc. Nat. Sér. I. iv. (1825) 93 -Ins. S. Doming.

polyantha, $D C . l . c$.-Ind. occ

CORYNELOBOS, R. Roem. ex Willk. in Linnaea, xxy (1852) $7=$ Brassica, Linn. (Crucif.)

boeticus, R. Roem. ex Willk. 1. c.= Brassica coryne loba.

CORYNEPHORUS, Beanv. Agrost. 90, t. 18. f。

(1812). GRAMINEAE, Benth. \& Hook, f. iii. 1157

Weingaertneria, Bernh. Syst. Verz. Erf. 23, 51 (1810), nomen prius.

aetnensis, Schult. Mant. iii. $641=$ articulatus,

articulatus, Beauv. Agrost. 90.-Europ.; As. Min.

canescens, Beauv. $l$. c. t. 18. f. 2.-Europ, austr

fasciculatus, Bois.s. E' Reut. Pugill. Pl. Nov. 123.-

Algieria.

macrantherus, Boiss. \& Reut. 1. c. $124=$ fasciculatus.

CORYNITIS, Spreng. Syst. iv. Cur. Post. 263, 280 (1827) = Corynella, DC. (Legum.).

domingensis, Spreng. 1. c. $280=$ Corynella paucifolia. polyantha, Spreng. 1. c. = Corynella polyantha.

CORYNOCARPUS, Forst. Char. Gen. 31. t. 16 (1776). ANACARDIACEAE, Benth. \& Hook. fo i 425 .

laevigata, Forst. l. c. 32.-N. Zel.

CORY NOPHALLUS, Schott, in Oestr. Bot. Wochenbl (1857) $389=$ Amorphophallus, Blume (Aroid.).

Afrelii, Schott, 1. c. (= Hydrosme leononsis).-Afr. trop.

leonensis, Engl. in DC. Monog. Phan. ii. $326=$ A. leonensis.

CORYNOPHORUS, Kunth, in Mém. Mus. Par. ii. (1815) 72 =Corynephorus, \$eruv. (Gramin.)

CORYNOSICYOS, F. Muell. Sel. Pl. Indust. Cult. 59 $(1876)=$ Cucumeropsis, Naud. (Cucurbit.).

edulis, F. Muell. 1. c. = Cucum. edulis.

CORYNOSTIGMA, Presi, Epim. Bot. 218 (1849) Jussieua, Liın. (Onagrar.)

jussiacoides, Presi, 1. co = J. acrvosa.
CORYNOSTYLIS, Mart. Nov. Gen, et Sp i. 25. t. 17, 18 (1824). VIOLARIEAE, Benth. \& Hook. f. i. 116.

Calyptrion, Ging. in DC. Prod. i. 288 (1824).

albiflora, Linden, ex $\mathrm{I}$. Moose, in Flor.st (1872) 9.Bras.

Benthami, Walp. Rep. i. $223=$ C. Hubanthus

Berteri, Spreng. Syst i. 805-Mexic.

carthagenensis, Karst. Fl. Columb. ii. 53. t. 127. f. 9 $1 \pm=C$. Hybanthus.

diandra, Spreng. Syst. i, 805.-Am. austr.

guayanensis, Karst. Fl. Columb. î. 53. t. 127. f. 1-8

C. H banthus.

Hybanthus, Mart. E Zucc. Nov. Gen. et Sp. i. 26. 17.-Mexic

Loeflingii, Spreng. Syst. i. 805.-Am. austr.

CORYNOTHECA, F. Muell. Fragm. vii. 68. (1870 LILIACEAÉ, Bentb. \& Hook. f. iii, 792.

acalsthoclada, $F$. Mucll. l. c.-Austral.

diclustoma, F. Muell. l. c.-Austral.

lateriflora, F. Muell. l. co-Austral

CORYNULA, Hook. fo Ic. Pl. to 112

RUBIACEAE, Hersth. \& Hook f, ii. 138.

pilosa, Hook. f. l. co-Am, austr.

CORYPHA, Linn. Mus. Cliff. 11 (1736); Gen. ed. 354 (1737). PALMAE, Benth. \& Hook. f. iii. 922. Bessia, Rafin. Sylva Tcllur. $13: 1 \nvdash 38:$

Conda-PANA, Aclans, Fam, ii. 25 (1763)

DENDREMA, kiafin, Sylva Tellur. 14 (18ú8)

GEMBANGA, Hlume, in Flora, viii. (1c25) 580,678.

Talikra, Mart. Progr. Halm. Fam. et Gen. io (1. $3 t$,

africana, Lour. F1. Cochinch. $213=$ Hyphaene coriacea, australis, R. Br. Prod. $267=$ Livistuna astralis.

cerifora, Arruda, in Koster, I rav. Braz, 4y t: Mart. Hist. Nat. Palm ii. 56, t. $49=$ Copernicia cerifera.

dulcis, H. B. \& K. Nuv, Gen. et Sj. i. $300=$ Brahea dulcis.

ela1a, Roxb. Hort. Beng. 25 ; Fl. Ind. ii. 17ô..-Ind. or Gebang, Mart. Hist. Nat. Palm. iii. 233.-Bras.

Gebanga, Blume, Rumphia, ii. 59. \&. 97, 98, 105.Millaya.

glaucescens, Lodd. ex Loud. Hort. Brit. $125=\mathrm{Sabal}$ glaucescens?

guineensis, Linn. Mant. i. 137 = umbraculi?era

Hystrix, Desf. Tabl. ed. I. $19=$ Rhapidophyllum Hystrix.

Licuala, Lam. Encyc. ii. 131= Licuala Rumphii.

macropoda, Kurs, ex Linder, Cat. D. 87 (10\%1).-Ins. Andain.

maritima, H. B. \& K. Nov. Gen. et Sp. i. $298=$ Copernicia maritıma.

minor, Blanco, Fl. Filip. ed. I. 229.-Ins. Philipp.

minor, Jacq. Hort. Vindob. iii, 8 = Sabal Adansoni.

Miraguama, H. B. \& K. Nov. Gen. et Sp. i. $2: 8$ Thrinax Miraguama.

nana, H. B. \& K. 1. c. $299=$ Copernicia nana.

palmacea, Steud. Nom. ed. I. 224, $834=$ Thrinax parviflora.

Palmetto, Walt. Fl. Carol. $119=$ Salual Palmetto.

pilearia, Lour. F1. Cocninch. $213=\mathrm{Li}$ :uala pilearia.

pumila, Walt. Fi. Carol. $11 \mathrm{y}=\mathrm{Sabal}$ Adansoci

Pumos, H. B. \& K. Nov. Gea. et Sp. i. 2.18 Coper. nicia Pumos.

repens, Bertram, Trav, 61 = Rbapidophyllum Hystrix.

rotundifolia, Lam. lincyc. ii. 131 - Livistona rosundifulia.

Saribus, Lour. Fl. Cochinch. 21:2 Livistona cochin. chinensis.

sylvestris, Mart. Hist. Nat. Pa!m. iii. 29S. Ins. Moluce Talit ra, Roxb. Hort. Beng. 23 ; Fl. Ind. ii. 1it.Incl, or.

tectorum, H. B. \& K. Nov. Gen. et Sp. i. $299=$ Coper nicia tectorum.

thebaica, Linn. Sp. Pl. 11 : H H phaene cucifera. umbracralifera, Jacq. Fragm. bot. 12 sabal black burniann.

umbraculifera, Linn, Sp. Pl. 1178.-Afr. erop

Ind. or.

C'tan, Lam. Encyc. ii. 131 sylvestris.

CORlPHANTHA, Lem. Cact. \$2 (1ะos) Mammis. laria, Haw. (Cact).

acunthosiephes, Lcm. I. c. $\$ 5=\mathrm{M}$. acanthestepha.

ancistracouthol, Lem. I. c. $34=$ M. raphidecantha 


\section{CORYPHANTHA :-}

aulacothele, Lem. Cact. $34=$ Mammillaria aulacothele brevimamma, Lem. ex Foerst. Handb. Cact. ed. II. 394 $=$ M. brevimamma.

calcarata, Lem. Cact. $35=$ M. calcarata.

Clava, Lem. 1. c. $34=$ M. Clava.

conspicua, Lem. 1. c.-Hab. ?

cornifera, Lem. 1. c. $35=$ M. comifera

daimonoceras, Lem. 1. c. $=$ M. scolymoides

elephantidens, Lem. 1. c. =M. elephantidens.

Engelmanni, Lem. 1. c. 34.-Hab.?

erecta, Lem. 1. c. $=$ M. erecta

exsudans, Lem. ex Foerst. Hardb. Cact. ed. II. $395=$

M. exudans.

glandulifera, Lem. Cact. $34=$ M. glandulifera?

heterophylla, Lem. l. c.-Hab. ?

Hookeri, Lem. 1. c.-Hab.?

impexicoma, Lem. ex Foerst. Handb. Cact. ed. II. 414

$=\mathrm{M}$. comifera.

Lehmanni, Lem. Cact. $34=$ M. Lehmanni

Loricata, Lem. 1, c. $35=$ M. loricata.

macromeris, Lem. 1. c. - M. macromeris.

Nuttallii, Engelm. ex Foerst. Handb. Cact. ed. II. 407

$$
=\text { M. Nuttallii. }
$$

Ottonis, Lem. Cact. $34=\mathrm{M}$. Ottonis.

pycnacantha, Lem. 1. c. $35=$ M. pycnacantha.

raphidacantha, Lem. 1. c. $34=$ M. raphidacantha.

Scheerii, Lem 1. c. $35=$ M. Scheerii.

Schlechtendalii, Lem. 1. c. $34=$ M. Schlechtendalii.

sublanáta, Lem. 1. c. 35 - Hab.?

sulcolanata, Lem. 1. $\mathrm{c} .=$ M. suicolanata.

CORYsadenia, Griff. in Proc. Linn. Soc. i. (1846) 281 $=$ Illigera, Blume (Combret.).

CORYSANTHERA, Wall. Cat. n. $6411 \quad(1832)=$ Rhynchotechum, Blume (Gesnerac.)

elliptica, Wall. 1. c. $=\mathrm{R}$, ellipticum.

vestita, Giiff. Itin. Notes, $124=\mathrm{R}$. vestitum

CORYSANTHES, R. Br. Prod. 328 (1810). ORCHIDEAE, Benth, \& Hook. fo iii, 609

CALCEARIA, Blume, Bijdr. 417. t. 33 (1825).

CORYBAS, Salisb. Parad. Lond. t. 83 (1805), nomen prius.

Nematoceras, Hook, f. Fl. N. Zel. i. 249. t. 57 1853 .

Betchei, F. Muell. in Wing, South Sc. Record, i. 1881) 171. -Ins, Samoa.

bicalcarata. R. Br. Prod. 328.-Austral.

callosa, Blume, Orch. Archip. Ind. 173. t. 63.Malaya.

Cheesemanii, Hook. f. ex T. Kirk, in Trans. N. Z. Inst. iii. (1871) $180 .-\mathrm{N}$. Zel

diemenica, Lindl. Gen. et Sp. Orch. $393=$ fimbriata.

fimbriata, R. Br. Prod. 328. - Austral.

fornicata, Lindl. Gen. et Sp. Orch. 394.--Malaya

hypogea, Colenso, in Trans. N. Z. Inst. xvi. (1884) 336.-N. Zel.

limbata, Hook. f. Bot. Mag. t. 5357.-Java.

macrantha, Hook. f. Handb. N. Zeal. Fl. 266.-N. Zel maculata, Heynh. Nom. i. $\angle 22=$ Coryanthes maculata. mucronata, Blume, Orch. Archip. Ind. 175.-Malaya. oblonga, Hook.f. Handb. N. Zeal. Fl. 266.-N. Zel.

papiliosa, Colenso, in Trans. N. Z. Inst. xvi. (1884) 337.-N. Zel.

picta, Lindl. Gen. et Sp. Orch. 394-Malaya.

pruinosa, R. Cunn. in N. S. Wales Mag. (1833) a. $1=$ fimbriata.

tivularis, Hook. fo Handb. N. Zeal. Fl。 266, - N . Zel.

rotundifolia, Hook. f. l.c. $-\mathrm{N}$. Zel.

triloba, Hook. f. l. c. 265.-N. Zel.

undulata, $R$. Cunn. in N. S. Wales Mag. (1833), nomen.-Austral.

unguiculata, $R . B r$. Prod. 328.-Austral.

CORYTHACANTHUS, Nees in Lindl. Introd. Nat. Syst. ed II. 444 (1836) = Clistax, Mart. (Acanthac.). speciosus, Nees, 1. c--Bras.

CORYTHANTHES, Lem in Orb. Dict. iv. 259 (1849) = Coryanthes, Hook. (Orchid.).

CORYTHOLOBIUM, Mart. ex Benth. in Ann. Wien Mus. ii (1838) 93 = Securidaca, Linn. (Polygal.). macrophyllum, Benth. 1. c. $=$ S. Corytholobium.
CORYTHOLOMA, Decne, in Rev. Hortic. Sér. III. ii. (1848) $466=$ Gesneria, Mart.

aggregatum, Decne. l. c. $467=\mathrm{G}$. aggregata.

caracasanum, Decne. $\mathrm{L}$. $\mathrm{c}=\mathrm{G}$. caracasana.

chelonoides, Regel, Gartenfl. vii. (1858) $374=\mathrm{G}$.

chelonoides.

ellipticum, Decne. in Rev. Hortic. Sér. III. ii. (1848) $466=\mathrm{G}$, elliptica.

fragile, Decne. 1. c. $467=$ G. Sceptrum.

gracile, Brongn. ex Decne. 1. c. 466.--Hab. ?

igneum, Decne. 1. c. $467=$ G. Sceptrum.

Lindleyi, Decne. 1. c = G. Lindleyi.

Marchii, Decne, 1, $\mathrm{c}_{\mathrm{f}}=\mathrm{G}$. Marchii.

melittifolium, Brongn。 ex Decne. 1. c. $=$ G. melittifolia.

Merckii, Decne. ex Regel, Gartenfl. iv. (1855) $247=\mathrm{G}$. Merckii.

pendulinum, Decne. in Rev. Hortic. Sér. III. ii. (1848) $467=\mathrm{G}$. pendulina.

rupicolum, Decne. 1. c. $=\mathrm{G}$. rupicola.

rutilum, Decne. $\mathrm{l}_{\mathrm{c}} \mathrm{c}_{\mathrm{v}}=\mathrm{G}$. rutila.

Sceptrum, Decne. 1. c. = G. Sceptrum.

strictum, Decne. 1. c. $466=\mathrm{G}$ 。 stricta.

tubiflorum, Decne. 1. c. $467=$ Isoloma tubiflorum.

CORYTOPLECTUS, Oerst. in Vidensk. Selsk. Skr. V.v. (1E61) 119 = Alloplectus, Mart. (Gesnerac.)

capitatus, Oerst. 1. c. $120=$ A. capitatus?

CORYZADENIA, Griff, Notul. iv. $356(1854)=$ Illigera, Blume (Combretac.).

trifoliata, Griff. 1. c. = I. Coryzadenia.

COSARIA, J F. Gmel. Syst. 22, 71 (1791)= KOSARIA, Forsk, = Dorstenía, Linn. (Urticac.).

Forskăliz, J. F. Gmel. I. co =D, radiata.

COSBAEA, Lem. Illustr. Hortic. ii. (1855) Misc. $71=$ Schisandra, Michx. (Magnoliac.) coccinea, $\bar{L}$ em. 1. c. $=$ S. Hanceana.

COSCINIUM, Colebr. in Trans. Linn. Soc. xiii (1 22) 51. MENISPERMACEAE, Benth. \& Houk. f. i. 35

PEREIRIA, Lindl. Fl. Med. 370 (1838)

Blumeanum, Miers, in Ann. E Mag. Nat. Hist. Ser. II. vii. (1851) 37.-Ind. or.

fenestratum, Colebr. in Trans. Linn. Soc. xiii. (1822) 65.-Ind。 or.

Maingayi, Pierre, Fl. For. Cochin. sub t. 112 (err. Mangayi),-Malaya.

usitatum, Pierre, $l$. c. - Cambodia.

Wallichianum, Miers, in Ann. \& Mag. Nat. Hist. Ser. II. vii. (1£51) $37=$ fenestratum.

Wightianum, Miers, 1. c. = fenestratum.

COSM AnthUS, Nolte, ex A. DC. Prod. ix. 296 (1838) - Phacelia, Juss. (Hydrophyll.).

fimbriatus, Nolte. ex A. DC. 1. c. $297=$ P. fimbriata. grandiflorus, A. DC. 1. c. = P. grandiflora. mexicanus, A. DC. 1. c. = P. pimpinelloides. nemophiloides, Kunth, Ind. Sem. Hort. Berol. (1846) 12.-Texas.

parviflorus, A. DC. in DC. Prod. ix. $297=$ P. parviflora.

pectinatus, E. Mey. in Ann. Sc. Nat. Sér. III. v. (1846) ¿66.-Am. bor.

viscidus, A. DC. in DC. Prod. ix, $296=$ P. grandiflora.

COSMARIUM, Dulac, Fl. Hautes-Pyr。 215 (1867) [non Corda, quod Algar. gen.] = Adonis, Linn (Ranunc.).

aestivale, Dulac, $1 . \mathrm{c}_{\mathrm{.}}=\mathrm{A}$. aestivalis.

autumnale, Dulac, $\mathrm{l}_{\mathrm{c}} \mathrm{c}=\mathrm{A}$. autumnalis.

pyrenaicum, Dulac, 1. c. = A. pyrenaica.

COSMEA, Willd. Sp. Pl. iii. $2250(1803)=$ Cosmos, Cav. (Compos.).

bipinnata, Willd. l. c. $=$ Cosmos bipinnatus. caudata, Spreng. Syst. iii. $615=$ Cosmos caudatus. chrysanthemifolia, Spreng. 1. c. = Cosmos chrysanthemifolius.

crithmifolia, Spreng. 1. c. = Cosmos crithmifolius,

diversifolia, Heynh. Nom. ii. $163=$ Cosmos diversifolius.

lutea, Sims, Bot. Mag. to $1689=$ Bidens grandiflora.
COSMEA :-

parviftora, Willd. Sp. Pl. iii. $2250=$ Cosmos parviflorus.

pilosa, Spreng. Syst. iii. $615=$ Cosmos pilosus.

Scabiosae, Spreng. 1. c. $=$ Cosmos seabiosoides

sulphurea, Willd. Sp. Pl. iii. $2250=$ Cosmos sulphureus.

tenella, Spreng. Syst. iii. $615=$ Cosmos tenelius.

COSMELIA, R. Br. Prod. 553 (1810)。 EPACRI$D E A E$, Benth. \& Hook. f. ii. 617

angustifolia, DC. Prod. vii. $766=$ rubra.

rubra, $R$. Br. Prod. 553.-Austral.

COSMIA, Domb. ex Juss. Gen. $312(1789)=$ Calan drinia, H. B. \& K. (Portulac.).

caulescens, Domb. ex Spreng. Syst. ii. $453=$ = Calandrinia caulescens.

montana, Domb. ex DC. Prod. iii. $359=$ Calandrinia caulescens.

prostrata, Domb. 1. c. = Calandrinia acaulis.

COSIMIBUENA, Ruiz \&c Pav, Fl. Per. iii. 3. t. 226 1802). RUBIACEAE, Benth. \& Hook. f. ii. 40 Buena, Pohl, Pl. Bras. Ic. i. 8 , partim (1827). acuminata, Ruiz \& Pav. Fl. Per. iii. 3. t. ¿36. - P.eruv. dichotoma, G. Don, Gen. Syst. iüi. 479 = Ladenbergia dichotoma.

latifolia, Klotzsch, ex Walp. Rep. vi. 69.--N. Granat. macrocarpa, Klotzsch, ex Walp. L. c.-Ins. Gorgona.

obtnsifolia, Ruiz \& Pav. Fl. Per. iii. 3.-Peruv,

ochracea, Endl. Iconogr. t. 90.-Hab.?

quinqueflora, Klotzsch, in Hayne, Arzneig. xiv. sub t. 15.-Venezuela.

Skinneri, Hemsl. Biol. Centr. Am. Bo ii, 12-Nicaragua.

triflora, Klotzsch, in Hayne, Arzneig. xiv. sub t. 15.Guiana.

COSmibuena, Ruiz \& Pav. Prod. Fl. Per. 10. t. 2 $(1794)=$ Hirtella, Linn. (Rosac.)

COSMIDIUM, Nutt, in Trans. Am. Phil. Soc. Ser. II vii. (1841) $361=$ Thelesperma, Less. (Compos.).

Burridgeanum $\times$, Hort. ex Regel, Ind. Sem. Hort

Petrop. (1857) $40=\mathrm{T}$. filifolium.

flifolizm, Nutt. in Trans. Am. Phil. Soc. N. S. vii. (1841) $362=\mathrm{T}$, filifolium

gracile, Nutt. $1 . \mathrm{c}_{\mathrm{s}}=\mathrm{T}$. gracile.

simplicifolium, A. Gray, P1, Fendl. $86=$ T, subsimplicifolium.

COSMIUSA, Alef. in Bot. Zeit. xxiv. (1866) $146=$ Paro . chetus, Buch.-Ham. (Legumin.)

repens, Alef. 1. c. $=$ P. communis ?

COSMIZA, Rafin. Fl. Tellur. iv. $110(1836)=$ Polypompholyx, Lehm. (Lentibul.)

coccinea, Rafin. lo c. = P. multifida.

COSMOPHYLLUM, C. Koch, Ind. Sem. Hort. Berol. (1854) 12 =Podachaenium, Benth. (Compos.) cacaliaefolium, C. Koch, 1. c.-Guatemala.

COSMOS, Cav. Ic. i. 9. tt. 14, 79 (1791). СОMPOSITAE, Benth. \& Hook. f. ii. 387. ADENOLEPIS, Less. in Linnaea, vi. (1831) 510. Cosmea, Willd. Sp. Pl. iii. 2250 (1803).

Cosmus, Pers. Syn. ii. 477 (1807).

bipinnatus, Cav, Ic. i. 10. t. 14-Am. bor.; Mexic. carvifolius, Benth. Bot. Voy. Sulph. 117.-Mexic. caudatus, $H . B . \&$. K. Nov. Gen. et Sp. iv. 240.-Ind. occ.

chrysanthemifolius, $H . B$. \& $K$. l. c. 239 . t. 382 . Mexic.

crithmifolins, H. B. E K. l.c. 242.-Mexic

diversifolius, Otto, in Knowles \& Westc. Flor. Cab. ii. 3. t. 47.-Am. bor.

integrifolius, Wedd. Chlor. And. i. 70, nota.-Bolivia. linearifolius, Hemsl. Biol. Centr. Am. Bot. ii. 200.Mexic.

marginatus, Klatt, in Abh. Naturf. Ges. Halle, xv. (1882) 328,-Peruv.

parviflorus, Pers. Syn. iì. $477 ;$ H. B. E K. Nov. Gen. et $S p$. iv. 241.-N. Mexic,

peucedanifolius, Wedd.Chlor. And. i. 70,-Bolivia.

pilosus, $H . B$. \& $K$. Nov. Genn. et Sp. iv. 241.-Mexic. pinnatus, Jacq. ex Steud. Nom. ed. II. i. $426=$ Coreopsis coronata. 


\section{Cosmos}

pulcherrimus, Sch. Bip. in Bull. Soc, Bot. Fr. xii (1865) $79=$ diversifolius.

purpureus, Benth. E Hook, f. ex Hemsl. Biol. Centr. Am. Bot. ii, 200.-Mexic.

reptans, Benth. P1. Hartw. $40=$ diversifolius.

roseus, Mart. ex Steud. Nom. ed. II. i. 426. Bras.

scabiosoides, H. B. ש K. Nov. Gen. et Sp. iv, 242.Mexic.

subpubescens, Wedd. Chlor. And. i. 70.-Peruv.

sulphureus, Cav. Ic. i. 56. t. 79.-Mexic.

tenellus, H. B. \& $K$. Nov. Gen. et Sp. iv, 240.Mexic.

tenuifolius, Lindl. Bot. Reg. t. 2007.-Mexic.

Uhdeanus, Kunth, Ind. Sem. Hort. Berol. (1846) 12.Mexic.

COSMOSTIGMA, Wight, Contrib. Bot. Ind. 41 (1834) ASCLEPIADEAE, Benth. \& Hook. f. ii. 774 . acuminata, Wight, Ic. t. $1270=$ racemosa racemosa, Wight, Contrib. Bot.Ind.42.-Ind. or.

COSSIGNEA, Willd. Sp. Pl. ii. $226(1799)=$ seq. COSSIGNIA, Comm. ex Juss. Gen. 248 (17.89)=seq.

COSSIGNYA, Baker, F1. Maurit. 58 (1877) =seq,

COSSINIA, Comm. ex Lam. Encyc. ii. 132 (1786). SAPINDACEAE, Benth. \& Hook. f. i. 397. MeLiCopsidium, Baill. Adansonia, xi. (1874) 243 borbonica, DC. Prod. i. $614=$ pinnata.

Commersonii, Raeusch. Nom, ed. III. $103=$ pinnata. madagascariensis, Baill. Adansonia, xi. (1874) 247.Madag.

pinnata, Comm. ex Lam. Encyco ii. 132. t. 256.-Ins. Maurit.

splendens, Sieber, ex Steud. Nom. ed. II. i. $426=$ pinnata.

ternata, Baker, Fl. Manrit. $59=$ pinnata.

trifoliata, Radlk, in Sitzb. Math.-Phys. Acad. Muench viii. (1878) 272 , - N . Caled.

triphylla, Comm. ex Lam. Encyc. ii. $132=$ pinnata.

COSSONIA, Dur. in Ann. Sc. Nat. Sér. III. xx. (1853) 82. t. 6 =Raffenaldia, Godr. (Crucifer.).

africana, Dur. 1. c. $=$ R. primuloides.

COSTA, Vell. Fl. Flum. 19 (1825); i. t. $48(1827)=$ Gralipea, Aubl. (Rutac.)

aromatica, Vell. 1. c. 20 ; i. t. $48=$ Galipea Arrabidae.

COSTAEA, A. Rich. Fl. Cub. Fanerog. ii. 75 (1853 $=$ Purdiaea, Planch. (Cyrill.).

cubensis, A. Rich. 1. c. $76=$ P. monodynama

COSTEA, A. Rich. Fl. Cub, Fanerog. ii. 328 (1853)= praec.

COSTIA, Willk. in Bot. Zeit. xvi. (1858) $\mathbf{3 7 7}=$ Agropy ron, J. Gaertn. (Gramin.).

cristata, Willk. 1. c. = A. cristatum.

imbricata, Willk. 1. $\mathrm{c}_{\mathrm{s}}=\mathrm{A}$. imbricatum

orientalis, Willk. 1. $c_{0}=\mathrm{A}$. orientale.

squarrosa, Willk. 1. c. = A. patulum.

COSTIA, Willk, in Bot. Zeit. xviii. (1860) $131=$ Iris, Tourn.

caucasica, Willk. 1. c. $=$ I, caucasica.

persica, Willk. 1. c. $=$ I, persica.

scorpioides, Willk. I, c. $m$ I. alata.

COSTUS, Linn. Mus. Cliff. 2 (1736); Gen. ed I 331 (1737). SCITAMINEAE, Benth. \& Hook. f iii. 646 .

Acrnax, Rafin. Fl. Tellur, iv. 53 (1886).

BankseA, Koen. in Retz. Obs. iii. 75 (1783)

Gissanthe, Salisb, in Trans. Hort. Soc. i. (1812) 279.

Hellenia, Retz. Obs. vi. 18 (1791)

Tsiana, J. F. Gmel. Syst. 9 (1791).

JaCuANGA, Lestib. in Ann. Sc。 Nat. Sér. II. xv. (1841) 329,341 .

Planera, Giseke, Prael. 205 (1792).

afer, Ker-Gavul. in Bot. Reg.t. 683.-Afr. trop.

Anachiri, Jacq. Fragm. $55=$ spicatus.

angustifolius, Ker-Gawl, in Rot. Reg. t. $665=$ speciosus.

\section{Costus :-}

appendiculatus, Humb. E Bonpl. ex Roem. E Schult.

Mant. i. 32.-Am. austr.

arabicus, Aubl. Pl. Gui, i. 2 = spicatus.

arabicus, Linn. Sp. Pl. 2 = speciosus,

arabicus, Rosc. ex Spreng. Syst. i. $13=$ glabratus.

arabicus, Vell. Fl. Flum. 2 ; i. t. $5=$ Arrabidae.

argenteus, Ruiz \&s Pav. Fl. Per. i. 3. t. 4,-Peruv.

argyrophyllus, Wall, Cat. $\mathrm{n}, 6555 \mathrm{G}, \mathrm{H}=$ speciosus

Arrabidae, Steud. Nom. ed. II. i. 426 .-Bras.

cernuus, Sw. ex Roem. E Schult. Syst. i. 25.-Am.

trop.

ciliatus, Humb. Eo Bonpl. ex Roem. E Schult. Mant, 32.-Am. trop.

ciliatus, Miq. in Linnaea, xviii. (1844) 73.-Guian.

comosus, Rosc. in Trans. Linn. Soc, viii. (1807) 350,-

Am. austr.

conicus, Stokes, Bot. Mat. Med. i. $75=$ spicatus.

crispiflorus, Stokes, 1. e. $=$ speciosus.

cylindricus, Jacq. Fragm. $54=$ spiralis

cylindricus, Rosc. Scitam. t. 78.-Ins. Trinit.

discolor, Rosc. l. c. t. 81.-Bras.

echinatus, Pers. Syn, i. $3=$ Amomum echinatum.

foeniculaceus, Noronha, in Verh. Batav. Gen.

(1790) ed. I. Art. IV. 12.-Malaya.

glabratus, Reichb. in Moessl. Handb. ed. II. i. 8 speciosus.

glabratus, Sw. Prod. Veg. Ind. Occ. 11.-Ind. occ

globosus, Blume, Enum. Pl. Fav. 62,-Java.

hirsutus, Presl, Rel. Haenk. i. 112.-Mexic,

igneus, $N . E$. Br. in Illustr. Hortic, xxxi。(1884) 25. t. 511.-Bras.

laevis, Ruiz \& Pav. Fl. Per. i. 3.-Peruv.

linearis, Spreng. Syst. i. $13=$ Kaempferia secunda

Loureiri, Horan. Prod. Scitam. 38.- Sumatra.

luteus, Blanco, F1. Filip. ed. I. $4=$ Roscoea lutea.

maculatus, Rosc. Scitam. t. 82.-Afr. trop.

malaccensis, Retz. Obs. iii. $71=$ Alpinia malaccensis

Malortieanns, $H$. Wendl. in Hamb. Gartenz. xix. (1863)

30.-Am. centr.

nepalensis, Rosc. Scitam. t. $80=$ speciosus.

nigricans, Blanco, Fl, Fïlip. ed. II. $3=$ Roscoea nigro ciliata.

niveopurpureus, facq. Fragm. 55.-Ins. Martinic.

niveus, G. F. W. Mey. Prim. Fl, Esseq. 1.-Guian.

pictus, D. Don, ex Lindl. Bot. Reg. t. 1594.-Mexic

Pisonis, Lindl. 1. c. t. $899=$ spiralis.

Potierae, F. Muell. Fragm. iv. 164,-Austral.

pulverulentus, Presl, Rel. Haenk. i. 111.-Mexic.

pungens, Teijsm. \& Binn, in Tijdschr. Nederl. Ind

xxix. (1867) $244=$ Tapeinocheilos pungens.

quartus, Roem. \& Schult. Syst. i. $26=$ cylindricus.

quintus, Roem. \& Schult. l. c. = spicatus.

ruber, Wright, ex Griseb. Cat. Pl. Cub. 256.-Cuba.

sarmentosus, Boj. in Ann. Sc. Nat. Sér. II. iv, (1835)

262. t. 8.-Ins, Maurit.

scaber, Ruiz \& Pav. Fl. Per. i. 2, t. 3,-Peruv,

secundus, Roem. \& Schult. Syst. i. $22=$ Renealmi Pasco-Secora.

secundus, Spreng. Syst. i. $13=$ Kaempferia secunda. septimus, Roem. \& Schult. Syst. i. $26=$ villosissimus. sericeus, Blume, Enum. Pl, Jav. $62=$ speciosus. sextus, Roem. \& Schult. Syst. i. $26=$ niveo-purpureus. speciosus, Sm. in Trans. Linn. Soc. i. (1791) 249. Ind. or.; Malaya.

spicatus, Sw. Prod. Veg. Ind. Occ. 11.-Ind. occ.

spiralis, Rosc. in Trans. Linn. Soc. viii. (180\%) 350.-

Venezuela.

vaginalis, Salisb. in Trans. Hort. Soc. i. (1812) $277=$ speciosus.

Verschaffeltianus, Lem. in Fard. Fleur, iv. (1854) t 381.-Bras.

villosissimus, facq. Fragm. 55.-Ins. S. Vincent.

Zerumbet, Pers. Syn. i. $3=$ Alpinia nutans.

COTA, J. Gay, in Guss. Fl. Sic. Syn. ii. $866(1844)=$ Anthemis, Mich. (Compos.).

altissima, J. Gay, l. c. $867=\mathrm{A}$. Cota.

austriaca, Sch. Bip, in Oestr. Bot. Wochenbl. iv. (1854) $155=\mathrm{A}$, austriaca.

Bourgaei, Boiss. F1. Orient. iii. $284=$ A. coelopoda.

brachycentros, J. Gay, in Guss. FI. Sic. Syn, ii. $867=$ A. brachycentros.

Brachmanni, Boiss. Diagn. Ser. II. iii, $21=$ A. Brachmanni.

caelopoda, Boiss. 1. c. = A. coelopoda.

Cossoniana, Willk. \& Lange, Prod. Fl. Hisp. ii, $85=$ A. austriaca.
COTA :-

lyonnetioides, Boiss. \& Kotschy, Diagn. Ser. II. v. $109=$ A. lyonnetioides.

ormenioides, Boiss. 1. c. iii. $21=$ A. Wiedemanniana.

oxylepis, Boiss 1. c. $\nabla \cdot 109=$ A. oxylepis

palaestina, Reut. ex Unger \& Kotschy, Ins. Cyp. 240 $=\mathrm{A}$. palestina?

parnassica, Boiss. \& Heldr. Diagn. Ser, II, iii. $20=$ A. tinctoria.

Pestalozzae, Boiss. 1. c. $21=$ A. Pestalozzae

Thirkei, Sch. Bip. in Oestr. Bot. Wochenbl. iv. (1854) $163=\mathrm{A}$. brachycentros.

tinctoria, J. Gay, in Guss. Fl. Sic. Syn. ii. $867=$ A tinctoria.

Triumfetti, J. Gay, 1. c. = A, austriaca.

COTINUS, [Tourn.] Linn. Syst. ed. I $(1735)=$ Rhus, Linn. (Anacard.)

americanus, Nutt. Sylva, ii. t. $81=$ R. cotinoides coggygria, Scop. Fl. Cam. ed. II. i. $220=$ R. Cotinus. Coriaria, Duham. Arb. ed. I. i. $191=$ R. Cotinus.

COTONEASTER, Rupp. Fl. Jen. ed. Hall. 137 (1745); Medik. Phil. Bot. i, 155 (1789), ROSACEAE, Benth. \& Hook. f. i, 627.

GYMNOPYRENIUM, Dulac, Fl. Hautes-Pyr. 316 (1867),

Naegelia, Lindl. Veg. Kingd. 560 (1847)

acuminata, Lindl, in Trans. Linn. Soc. xiii. (1822) 101.-Reg. Himal.

acutifolia, Maxim. Prim. Fl. Amur. 171=integer rima.

acutifolia, Turcz. in Bull. Soc. Nat. Mosc. iv. (1882) 190.--Mongolia.

aestivalis, Wenzig, in Linnaea, zxxviii. (1874) 202 Crataegus aestivalis.

affinis, DC. Prod. ii. $632=$ buxifolia.

affinis, Hohen, ex Hook. f. Fl. Brit. Ind. ii. 385 frigida?

affinis, Lindl. in Trans. Linn. Soc. xiii. (1822) 101 Stranvaesia glaucescens.

arborescens, Wenzig, in Linnaea, xxxviii. (1874) 203 Crataegus arborescens.

bacillaris, Wall. ex Lindl. Bot. Reg. sub t. 1229.-Reg. Himal.

buxifolia, Baker, in Saund. Refug. Bot. i. t. $52=$ microphylla.

buxifolia, Wall. Cat. n. 661 ; et Lindl. Bot. Reg. sul t. 1229.-Reg. Himal.

californica, A. Murr. Oreg. Circ. 1, nomen.-Calif.

coccinea, Steud. Nom. ed. II. i. $426=$ tomentosa.

comptus, Lem. in Fl. des Serres, Sér. I. iv. (1848) 33: b.-Mexic.

congesta, Baker, in Saund. Refug. Bot. i. t. $51=$ microphylla.

crenulata, C. Koch, Dendrol, i. 175 = Crataegas crenulata.

Cuila, Lee, ex C. Koch, 1. c. 172=nummularia.

denticulata, H. B. E K. Nov. Gen. et Sp. vi. 214. t. 556. -Mexic.

disticha, Lange, in Bot. Tidssk- xiii. (1882) 19.Nepal ?

elliptica, Hort. ex Loud. Encyc. P1. 1208 = nummularia emarginata, Hort. ex C. Koch, Deodrol. i. 178 microphylla.

Fontanesii, Spach, Hist. Vkg. Phan, ii. 77.-Hab.

Fortunei, Wenzig, in Linnaes, xuxviii. (18it) $200=$ Photinia Fortuneana.

frigida, Wall. Cat. n. 657 ; et Lindl. Bot. Reg. t. 1229.-Reg. Himal.

Grammontii, Hort. ex C. Koch, Dendrol. i. 17.2 nummularia.

granatensis, Boiss. Elench. 41.-Hispran.

horizontalis, Decre. in Fl. des Serres, Ser. II. xii. 1877) 168.-China.

hymalaica, Carr. in Rev. Hortic. (15;3) 160.-Reg. Himal.

integerrima, Merdic. Gesch. 85.-Europ.; As. temp.

intermedia, Medic, ex Trautw, in Act. Hurt. Petrop, viii. (1883) 937 , sphalm. = pracu

lacris, Hort. ex Steud. Noun. ed. II. i. $\$ 20=$ nummu laria.

lanaba, Hort. ex Regel, Gartenf. ix 1stit) $5: 4$ buxifolia.

lariflor, Jacq. ex Lindl. Bol. Keg. I. $1905-$ integel

rima.

Lindloyi, Steud. Nom, ed. 11. i. $120^{-}$- nemmularia. 


\section{COTONEASTER :-}

lucida, Schlecht. in Linnaea, xxvii. (1854) $541=$ integerrima.

marginata, Hort. ex C. Koch, Dendrol. i. $177=$ buxifolia.

melanocarpa, Fisch. ex Loud. Hort. Brit. Suppl. ii. $624=$ integerrima

microphylla, Wall. ex Lindl. Bot. Reg. t. 1114 ; Cat.n. 662 A.-Reg. Himal.

microphylla, Wall. Cat. n. $662 \mathrm{~B}=$ thymifolia.

multiflora, Bunge, in Ledeb. Fl. Alt. ii. 220.-Sibir. alt.

multiflora, C. A. Mey. Verz. Pf. Cauc. $171=$ nummularia.

nebrodensis, Nym. Syll. 267.-Sicil.

nepalensis, Hort. ex C, Koch, Dendrol. i. $177=$ frigida.

nervosa, Decne, in Nouv. Arch. Mus. Par. Sér. I. x. (1874) 177.-Hab. ?

nigra, Wahlenb. Fl. Gothob. $53=$ integerrima.

nummularia, Fisch. Eo Mey. Ind. Sem. Hort. Petrop.

ii. 34.-Afr, bor.; Oriens.

obtusa, Wall. Cat. n. 659; et Lindl. Bot. Reg. sub t. 1229 = bacillaris.

orientalis, Kerner, in Oestr. Bot. Zeitschr. xix. (1869) 270.-Europ.

parnassica, Boiss. E Heldr. Diagn. Ser. II. ii. 48.Graecia.

peduncularis, Boiss. 1. c. Ser. I. iii. $8=$ integerrima.

polonica, Fastrz. ex Rostaf. Fl. Polon. Prod. 121.Polonia.

prostrata, Baker, in Saund. Refug. Bot. i. t. $53=$ rotundifolia.

Pyracantha, Spach, Hist. Vég. Phan。 ii. $73=$ Crataegus Pyracantha.

racemiflora, C. Koch, Dendrol. i. $170=$ nummularia.

reflexa, Carr. in Rev. Hortic. (1870-71) 520.-China. rosea, Edgew. in Trans. Linn. Soc。xx. (1851) $46=$ bacillaris.

rotundifolia, Wall. Cat. n. 663 ; et Lindl. Bot. Reo. sub t. 1229.-Reg. Himal.

Royleana, Hort. ex C. Koch, Dendrol. i. $171=$ acuminata.

Simonsii, Hort. ex Baker, in Saund. Refug. Bot. i. t. 55.-Reg. Himal.

spathulata, Wenzig, in Linnaea, xxxviii. (1874) 201 -Am. bor.

spicata, Hort. ex C. Koch, Dendrol. i. $166=$ tomen . tosa.

thymaefolia, Hort. ex Baker, in Saund. Refug. Bot. i. t. 50.-Reg. Himal.

thymifolia, Hort. ex Loud. Encyc. Pl. 1384=microphylla.

tomentosa, Lindl. in Trans. Linn. Soc. xiii. (1822) 101.-Europ.

tomentosa, C. A. Mey. Verz. Pfl. Cauc. $171=$ num mularia.

uniflora, Bunge, in Ledeb. Fl. Alt.ii. 220.-Sibir alt

Uva-ursi, G. Don, in Loud. Hort. Brit. $480=$ rotundifolia.

vulgaris, Lindl. in Trans. Linn. Soc. xiii. (1822) $101=$ integerrima.

COTTAEA, Endl. Gen. $92(1841)=$ seq.

COTTEA, Kunth, Rév. Gram. i. 84, 281。 t. 52 (1830) GRAMINEAE, Benth. \& Hook. f. iii. 1174. pappophoroides, Kunth, l. c.-Peruv.

sarmentosa, Nees, ex Steud. Syn. Pl. Gram. 201.-Ins. S. Vinc.

COTTENDOREIA, Schult. f. Syst, vii. 64, 1193 (1830). BROMELIACEAE [Benth. \& Hook, f. iii. $667]$.

albicans, Griseb. in Goett. Abh. xxiv. (1879) 330.Reg. Argent.

florida, Schult. f. Syst. vii. II, 1193,-Bras.

guianensis, Klotzsch, ex Beer, Bromel. 44.-Guiana.

COTPONIA, Wight, Ic. v. I. 21. t. 1755 (1852). ORCHIDEAE, Benth. \& Hook. f. iii. 572.

Championii, Lindl. ex Benth. in Hook. Kew Fourn. vii. (1855) 35.-Hong Kong.

macrostachya, Wight, Ic. t. 1755.-Ind or.

peduncularis, Thw. Enum. PI. Zeyl. $303=$ macrostachya.
COTULA, [Tourn.] Linn. Syst. ed. I (1735). COM.

POSITAE, Benth. \& Hook, f. ii. 428.

BALDINGERIA, Neck. Elem, i, 88? (1790)

BrocCHIA, Vis, Pl. Aeg, et Nub. 35 (1836)

Cenocline, C. Koch, in Bot. Zeit. i. (1843) 41

Chlamydophora, Ehrenb. ex Less. Syn. Comp. 265, 448 (1832).

Cotulina, Pomel, Nouv. Mat. F1. At1. 56 (1874).

Ctenosperma, Hook. f. in Hook. Lond. Journ. Bot. vi. (1847) 115 .

Gymnogyne, Steetz, in Lehm. Pl. Preiss. i. 431 (1845).

LANCISIA, Adans. Fam. ii. 126 (1763)

Leptinella, Cass. in Bull. Soc. Philom. (1822) 127.

LEPTOGYNE, Less, in Linnaea, vi. (1831) 151

Machlis, DC. Prod. vi. 140 (1837)

Otoglyeris, Pomel, Nouv. Mat, F1. Atl. 56 (1874)

Pleiogyne, C. Koch, in Bot. Zeit. i. (1843) 40.

Strongylosperma, Less. Syn. Comp. 261 (1832).

SYMPHYOMERA, Hook. f. in Hook. Lond. Journ.

Bot. vi. (1847) 116

abrotanifolia, Willd. Sp. PI. iii. $2167=$ Anacyclus creticus.

abyssinica, Sch. Bip. ex A. Rich. Tent. Fl. Abyss. i 419.-Afr. trop.

africana, Steud. Nom. ed. I. $230=$ Matricaria capensis. alba, Linn. Syst. ed. XII. ii. 564=Eclipta erecta

alpina, Hook. f. Fl. Tasm. i. 192. t. 51 A-Austral

anthemoides, Linn. Sp. Pl. 891.-Hisp.; Afr. bor. et austr. ; Ind. or.

anthemoides, Willd. Sp. Pl. iii. $2165=$ microcephala.

atrata, Hook. f. Handb. N. Zeal. Fl. 142.-N. Zel.

aurea, Loefl. Iter, 163.-Reg. Mediterr.; Oriens.

aurea, Sibth. \& Sm. Fl. Graec, ix. 61=Matricaria decipiens.

australis, Hook. f. Fl. Nov, Zel. 128.-Austral.; N Zel.

barbata, DC. Prod, vi. $79=$ Cenia barbata.

bicolor, Roth, Catalect. fasc. ii. $116=$ Dichrocephala latifolia.

bipinnata, Thunb. Prod. Pl. Cap. 162.-Afr. austr.

bracteolata, E. Mey. ex DC. Prod. vi. 78.-Afr. austr.

capensis, Linn. Mant. ii. $287=$ Matricaria capensis.

ceniaefolia, DC. Prod. vi. 79.-Afr. austr.

chamaemelifolia, Ehrenb. ex C. Koch, in Bot. Zeit. i. (1843) 41.-Africa?

chrysanthemifolia, Blume, Bijdr. 918=Dichrocephala chrysanthemifolia.

cinerea, Delile, Fl. Egypte, 275. t. 47. f. 4.-Afr. bor. Arab.

cinerea, Kotschy, ex Benth. \& Hook. f. Gen. ii. $420=$ Kotschyi.

complanata, Sibth. \& Sm. Fl. Graec. Prod. ii. $187=$ Anthemis pectinata.

conica, Wall. Cat. n. $3185=$ Spilanthes Acmella.

coronopifolia, Linn. Sp. Pl. 892.-Afr. austr. (Europ,

alien)

crinita, E. Mey. ex DC. Prod. vi. $144=$ Hippia gracilis

cryptocephala, Sch. Bip.ex A. Rich. Tent. Fl. Abyss. i. 420 -Abyss.

cuneifolia, Willd. Sp. Pl. iii. $2169=$ Centipeda orbicularis.

Cunninghami, F. Muell. Fragm. viii, $143=$ Centipeda Cunninghami

debilis, Balb. ex Spreng. Neue Entdeck. ii. $137=$ Eclipta pusilla.

decumbens, Pers. Syn. ii. $464=$ Centipeda orbicularis

dichotoma, Pers. 1. c. $=$ C. Pyrethraria.

dichrocephala, Sch. Bip. ex A. Rich. Tent. Fl. Abyss. i. $419=$ anthemoides.

dichrocephaloides, C. B. Clarke, Comp. Ind. $150=$ Dichrocephala Hamiltoni.

dioica, Hook. f. Handb. N. Zeal. Fl. 143.-N. Zel.

divaricata, Wall. ex DC. Prod. v. $375=$ Thespis divaricata.

Drummondii, Benth. Fl. Austral. iii. 550.-Austral

ebracteata, Walp. Rep. ii. $991=$ bracteolata.

ebracteolata, C. Koch, in Bot. Zeit. i. (1843) $39=$ bracteolata.

elongata, C. B. Vogel, in Trew, Pl. Rar. iii. 11. t. 26. -Java.

Featherstonei, F. Muell. ex F. Buch. in Trans. N. Z Inst. vii. (1875) 337.-Ins, Chatham.

Filicula, Hook. fo ex Benth. Fl. Austral. iii. 551.Austral.

filifolia, Thunb. Prod. Pl. Cap. 161.-Afr, austr.

filiformis, Hook. f. Handb. N. Zeal. Fl. 142.-N. Zel.
COTULA :-

fimbriata, Spreng. Neue Entdeck, iii. 41=Hippia gracilis.

foetida, Poepp. ex DC. Prod. vi. 139 (=Myriogyne elatinoides).-Chili.

globifera, Licht. ex Stend. Nom. ed. II. i. $427=$ Pentzia globosa.

globifera, Thunb. Prod. Pl. Cap. $162=$ Matricaria globifera.

grandis, Jacq. Obs. Bot. iv. 4. t. $81=$ Chrysanthemum flosculosum.

grandis, Linn. Sp. Pl. ed. II. 1257 (= Plagius grandiflorus).-Afr. bor.

gymnogyne, F. Muell. ex Benth. Fl. Austral. iii. 549. -Austral.

hemisphaerica, Wall. Cat. n. 3236.-Ind. or.

heterocarpa, DC Prod vi. 80.-Afr, austr.

hispida, Harv in Harv. \& Sond. Fl. Cap. iii. $183=$ Cenia hispida.

humifusa, Willd. ex Steud. Nom, ed, II, i. $427=$ Egletes humifusa.

integrifolia, Burch. Trav, i. $5 \mathrm{I}=$ bracteolata.

integrifolia, Hook. $f$. Fl. Tasm. i. 192. t. 50 B--Tas. mania.

Kotschyi, Benth. E Hook. f. Gen. ii. 429.-Afro trop. lanata, Hook. f. Handb. N. Zeal. Fl. 141.-N. Zel.

latifolia, Pers. Syn. ii. $464=$ Dichrocephala latifolia.

laxa, DC. Prod. vi. 78.-Afr. austr.

leptalea, $D C$. l. c. 80 . -Afr. austr.

linearifolia, Cheesem. in Trans. N. Z. Inst. xv. (1883) 299.-N. Zel.

linifolia, Burm. f. F1. Cap. Prod. $27=$ Felicia fragilis. lyrata, Boj. ex DC. Prod.v. 372=Dichrocephala lyrata. maderaspatana, Willd. Sp. Pl. iii. $2170=$ Grangea maderaspatana.

Maniotota, Petrie, in Trans. N. Z. Inst. xiv. (1882) 362.-N. Zel.

matricarioides, Bong. Veg. Ins. Sitcha, $29=$ Matricaria discoidea.

microcephala, DC. Prod. vi. 79.-Afr. austr.

minima, $D C$. l. c. $80 .-\mathrm{Hab}$ ?

minima, Willd. Sp. Pl. iii. $2170=$ Centipeda orbicularis.

minor, Caruel, ex Boiss. Fl. Orient. iii. $358=$ cinerea.

minor, Hook. f. Handb. N. Zeal. Fl. 142.-N. Zel.

minuta, Forst. f. Prod. $57=$ Centipeda orbicularis.

montevidensis; Spreng. Syst. iii. $497=$ coronopifolia.

Moseleyi, Hemsl. Bot. Voy. Challenger, i. II. 152.Tristan d'Acugna.

multifida, DC. Prod. vi. $80=$ villosa

myriophylloides, Hook. Ic. Pl. t. 335.-Afr. austr.

nudicaulis, Thunb. Prod. Pl. Cap. 162.-Afr, austr.

Oederi, Murr. Hort. Bot. Stirp. 228.-Hab. ?

oxydonta, DC. Prod. vi. $78=$ bipinnata.

pectinata, Hook.f. Handb. N. Zeal. Fl. 142,-N. Zel. perpusilla, Hook. f. l. c. 143.-N. Zel.

pilulifera, Linn. f. Suppl. $378=$ Matricaria globifera.

Piper, Vell. Fl. Flum. viii. t. 136.-Bras.

plumosa, Hook. f. Handb. N. Zeal. Fl. 141.-N. Zel.

poekilophylla, C. Koch, in Bot. Zeit. i. (1843) 39.Abyss.

prostrata, Linn. Syst. ed. XII. $564=$ Eclipta erecta.

pterocarpa, DC. Prod. vi. 80.-Afr. austr,

pubescens, Desf. Fl. Atlant. ii. 284.-Afr, bor,

pubescens, Viv. ex Coss, in Bull. Soc. Bot. Fr. xii (1865) $278=$ aurea.

pumila, Houtt. Handleid. x. $772=$ Cenia turbinata.

pusilla, Thunb. Prod. Pl. Cap. 162.-Afr, austr.

pygmaea, Benth. E Hook. f. ex Hemsl. Biol. Centr. Am. Bot. ii. 230.-Mexic.

pygmaea, Poir. Encyc. Suppl. ii. (1810) $371=$ Nananthea perpusilla.

Pyrethraria, Linn. Mant. i. 116-Am. austr.

pyrethrifolia, Hook. f. Handb. N. Zeal. Fl. 142.-N, Zel.

quinquefida, Thunb. Prod. Fl。Cap. $161=$ Pentzia quinquefida.

quinqueloba, Blanco, F1. Filip. ed. I. $626=$ Centipeda orbicularis.

quinqueloba, Linn. f. Suppl. $377=$ Lidbeckia lobata

reptans, Benth. Fl. Austral. iii. 551.-Austral.

reptans, Boj. ex DC. Prod. v。 $371=$ Sphaeranthus cotuloides.

rosea, Boj. ex Less. in Linnaea, vi. (1831) 152.Madag.

Russeliana, Wall. Cat. n. $3240=$ Sphaeromorphea Russeliana.

sericea, Linn. f. Suppl. $377=$ Cenia sericea 


\section{COTULA :-}

sinapifolia, Buch.-Ham. ex Roxb. Hort. Beng. 62 ; Fl Ind, iii. 437 = Dichrocephala latifolia.

sinapifolia, Wall, ex DC. Prod. v. $375=$ Thespi divaricata.

sonchifolia, Bieb. F1. Taur. Cauc. ii. 328=Dichrocephala latifolia.

sororia, DC. Prod. vi. 79.-Afr. austr.

Sphaeranthus, Link, Enum. Hort. Berol. ii. $344=$ Grangea maderaspatana.

Spilanthus, Linn. Mant. i. 116=Spilanthes urens.

squalida, Hook. f. Handb. N. Zeal. Fl. 143.-N. Zel

stenophylla, C. Koch, in Bot. Zeit. i. (1843) 40.-Afr. austr.

sternutatoria, Wall. Cat. n. $3259=$ Centipeda orbicularis.

stolonifera, Harv. in Harv. \& Sond. Fl. Cap. iii. $182=$ ceniaefolia.

stricta, Linn. Mant. $287=$ Lidbeckia pectinata.

tanacetifolia, Linn. Syst. ed. XII ; Murr. Syst. Veg. ed XIII, 644 n. $10=$ Matricaria multiflora.

Teesdaliae, $D C$. Prod. vi. 80 .-Afr. austr.

tenella, E. Mey. ex DC. l. c. 80 .-Afr. austr.

thespidioides, F. Muell. Fragm. viii. $143=$ Centipeda thespidioides.

Thunbergii, Harv, in Harv. \& Sond, F1. Cap. iii. 183 $=$ Cenia Thunbergii.

tridentata, Benth. E' Hook. f. Gen. ii. 420.-Aegypt.

tripinnata, Thunb. Prod. Pl. Cap. $162=$ Matricari grandiflora.

turbinata, Linn. Sp. Pl. $892=$ Cenia turbinata

umbellata, Linn. f. Suppl. $378=$ Peyronsea calycina.

valparadisea, Phil. in Anal. Univ. Chil. (1873) 503.Chili.

Verbesina, Linn. Amoen. Acad. v. $407=$ Adenostemma Swartzii.

villosa, DC. Prod. vi, 79.-Afr. austr.

viscosa, Linn. Sp. Pl. $892=$ Egletes viscosa.

Zeyheri, Fensl, ex Harv. E Sond. Fl. Cap. iii. 180. -Afr. austr.

COTULINA, Pomel, Nouv. Mat. Fl. At1. 56. (1874)= Cotula, Tourn. (Compos.).

aurea, Pomel, 1. c. = Cotula aurea.

COTYLANTHERA, Blume, Bijdr, 707 (1825)

GENTIANEAE, Benth. \& Hook, f, ii. 803.

EOPHYLON, A. Gray, in Journ. Linn. Soc. xi. (1871) 22.

pancisquama, C. B. Clarke, in Hook. f. Fl. Brit. Ind, iv. 94.-Reg. Himal.

tenuis, Blume, Bijdr. 708.-Java.

COTYLARIA, Rafin. Princ. Somiol. 25 (1814) = Cotyledon, Tourn. (Crassulac.).

COTYLEDON, Tourn. ex Linn. Syst. ed. I (1735),

CRASSULACEAE, Benth. \& Hook. f. i. 659.

Cotylaria, Rafin. Princ. Somiol. 25 (1814)

COTYLIPHYLLUM, Link, Handb. ii. 22 (1831).

Courantia, Lem. Jard. Fleur. i. (1851) Misc. 92.

Echeveria, DC. Prod. iii. 401 (1828).

Orostachys, [Fisch.] Hort. Gorenk. ed. I. 99 (1808).

ORThostachys, Spach, Hist. Vég. Phan, ix. 32 (1840).

PAchyphytum, Klotzsch, in Otto \& Dietr. Allg. Gartenz. ix. (1841) 9.

Pistorinia, DC. Prod. iii. 999 (1828).

Umbilicaria, Pers. Syn. i. 510 (1805).

Umbilicus, DC in Bull. Soc. Philom. (1801) 49.

acaulon, Walt. ex Steud. Nom. ed. I. $230=$ spuria

acutifolia, Baker, in Saund. Refug. Bot. i. sub t. 71 n. 34.-Mexic.

adunca, Baker, l. c. t. 60.-Mexic.

aegyptiaca, Lam. Lncyc. ii. $142=$ Kalanchoë crenata

africana, Burm. fo ex Steud. Nom, ed. I. $230=$ spuria

agavoides, Baker, in Saund. Refug. Bot. t. 67.Mexic.

albiflora, Hemsl, Diagn. Pl. Nov. 9-Mexic.

alternans, Haw. Suppl. Pl. Succ. $26=$ maculata.

alternans, Vahl, Symb. Bot。 ii. $51=$ Kalanchoë alternans.

ambigua, Salisb. Prod. $307=$ orbiculata.

amplexicaulis, Heyne, ex C. B. Clarke, in Hook. f. Fl.

Brit. Ind. ii. $415=\mathrm{K}$ alanchoe floribundn.

\section{COTYLEDON :-}

arborescens, Mill. Gard, Dict, ed. VIII. n, $7=$ Crassula arborescens.

aristata, Walp. Rep. ii. 258, sphalm, = cristata.

atropurpurea, Baker, in Saund. Refug. Bot. t. 198.Mexic.

Batesii, Hemsl. Diag. Pl. Nov.9-Mexic

bifida, Hemsl. Biol. Centr. Am. Bot i. 388.-Mexic.

bracteolata, Baker, in Saund. Refug. Bot. sub t. 62 -N. Granat.

brasilica, Vell. F1. Flum. 197; iv. t. $184=$ Kalanchué brasiliensis.

cacalioides, Eckl. \& Zeyh. Enum. 307 = Eckloniana

cacalioides, Linn. f. Suppl. 242.-Afr, anstr.

caespitosa, Haw. Syn. Pl. Succ. 107.-Am, bot occ.

californica, Baker, in Saund. Refug. Bot. 70,-Am bor. occ.

calycina, Roth, Nov. Pl. Sp. $217=$ Bryophyllum calycinum.

canaliculata, Baker, in Saund. Refug. Bot. i. sub t. 58.-Mexic

canaliculata, Haw. Suppl. P1. Succ. $22=$ ungulata

canalifolia, Haw. in Phil. Mag. (1825) 327 coruscans.

carnicolor, Baker, in Saund. Refug. Bot. iii. t. 199.Mexic.

caryophyllacea, Burm. f. Prod. Fl. Cap. 13.-Af austr.

cespitosa, Haw, Misc. $180=$ caespitosa.

chiclensis, Ball, in Fourn. Linn. Soc. xxii. (1885) 38.

-Peruy.

clavifolia, Haw. in Phil. Mag. (1827) 274.-Afr. austr.

coccinea, Cav. Ic. ii. 54. t. 170.-Mexic.

Cooperi, Baker, in Saund. Refug. Bot. t. 72.-Afr austr.

Corderoyi, Baker, in Gard. Chron. (1874) 599.Mexic.

coruscans, Haw. Suppl. Pl. Succ. 21.-Afr. austr.

corymbosa, Rottl. ex Wight \& Arn. Prod. 360 Kalanchoë floribunda

Cossoniana, Ball, in Fourn. Bot. xi. (1873) $332-$ Marocc.

crassifolia, Haw, in Phil. Mag. (1827) $273=$ or biculata?

crassifolia, Salisb. Prod. $307=$ hemisphaerica

crenata, Vent. Jard. Malm, $49=$ Kalanchoë crenata.

cristata, Haw. in Phil. Mag. (1827) 274.-Afr.

austr.

cuneata, E. Mey, ex Harv, \& Sond. Fl. Cap. ii. 372 $=$ Meyeri.

cuneata, Thunb. Prod. Pl. Cap. 83.-Afr, austr.

cuneiformis, Haw. in Phil. Mag. (1828) 185.-Afr. austr.

curviflora, Sims, Bot, Mag. t. 2044.-Afr. austr,

cymosa, Baker, in Saund. Refug. Bot. $\mathrm{t} .68$.

Mexic.

decipiens, Baker, l. c. 200.-Peruv

decussata, Sims, Bot. Mag. t. 2518.-Afr. austr

deficiens, Forsk. Fl. Aegypt. Arab. $89=$ Kalanchoè crenata.

deficiens, Hochst. \& Stend, ex A. Rich. Tent. Fl Abyss. i. $310=$ Kalanchoë Schimperiana.

Desmetiana, Hemsl. Biol. Centr. Am. Bot. i. 389.Mexic.

dichotoma, Haw. Suppl. Pl. Succ. 27.-Afr, austr.

Eckloniana, Harv. in Harv. E Sond. Fl. Cap. ii. 374 -Afr. austr.

edulis, Brewer, in Bot. Calif. i. 211.-Calif.

clata, Haw. Suppl. Pl. Sacc. $20=$ orbiculata, triflora.

erecta, D. Dietr. Syn. Pl. ii. $1626=$ lusitanica.

farinosa, Baker, in Saund. Refug. Bot. i. t. 71.Calif.

farinulenta, Hemsl. Biol. Centr. Am. Bot, i. 389Mexic.

fascicularis, [Soland. in] Ait. Hort, Kew. ed. I. ii. 106 ; Bot. Mag.t. 5602 -Afr. austr.

filicaulis, Eckl. \& Zeyb. Enum. $807=$ mamillaris fimbriata, Turcs. in Bull. Soc. Nat. Mosc. xvii. (1844) 241 -China: As, bor.

fulgens, Baker, in Saund. Refug. Bot. t. 64.Nlexic.

Galeottiana, Hemsl. Diag. Pl. Nov. i. 9.-Mexic.

gibuiflora, Mog. E Sesse, ex DC. Prod. iii. 401.Mexic

glauca, Baker, in Saund. Refug. Bot. t. 61.Mexic.

\section{COTYIFDON}

globulariaefolia, Baker, in Saund. Refug. Bot. t. 201 -Syría; As. Min.

gracilis, Harv. in Harv. E Sond. Fl. Cap. ii. 373.Afr. austr.

gracilis, Hav. Suppl. Pl. Succ. 26.-Afr. anstr.

grandiflora, Burm. f. Fl. Cap. Yrod. 13 =tuberculosa

Grayii, Baker, in Saund. Refug. Bot. sub t. 71, n. 33 - N. Mexic.

hemisphaerica, Linn. Sp. Pl. 429.-Afr. austr.

heterophylla, Roxb. Hort. Beng. 34; Fi. Ind. ii. $456=$ Kalanchoé floribunda.

hirsuta, Herb. Hevne, ex C. B. Clarke, in F1. Brit. Ind. $414=$ Kalanchoë glandulosa

hispanica, Linn. Sp.Pl. 1196.-Hispan.; Maroce.

hispida, Lam. Encyc. ii. $141=$ C. Mucizonia.

horizontalis, Guss. Ind. Sem. Hort. Boccad. (1826) $4=$ C. Umbilicus.

hybrida, Hort. Par. ex DC. Prod. iii. $395=$ Kalanchoe spathulata.

incarum, Ball, in fourn. Linn. Soc, xxii. (1885, 37 (err. typ. incanum).-Peruv.

integra, Medic. in Act. Acad. Theod. Palat. iii. Phys (1775) 200.t. $9=$ Kalanchoë crenata.

interjecta, Haw. in Phil. Mag. (1828) 185.-Afr. austr. japonica, Maxim in Bull. Acad. Pétersb xxix. (1883, 122.-Japon.

jasminiflora, Salm-Dyck, Obs. 5.-Afr. austr.

Jurgensenii, Hemsl. Diag. Pl. Nov. 9.-Mexic.

laciniata, Linn. Sp. P1. $430=$ Kalanchoë laciniata

lanceolata, Benth. E Hook. f. ex S. Wats. Bot. Calif i. 211.-Calif。

lanceolata, Blanco, Fl. Filip. ed. I. 382 =spathulata

lanceolata, Forsk. Fl. Aegypt. Arab. $89=$ Kalanchoi lanceolata.

laxa, Benth. \& Hook. f. ex Bot. Calif. i. $212=$ cali fornica.

leucantha, Ledeb. Fl. Alt. ii. 198.-As, bor.; Silir. altaic.

libanotica, Labill. Ic. Pl. Syr. Dec. iii. 3.-Kurdist. Syria.

Lievenii, Ledeb. Fl. Alt. ii. 197.-Persia ; Sibiria.

linguaefolia, Lem. Illustr. Hortic. x. (1863) Misc. 81, in syn.-Mexic.

linguaeformis, [R. Br. in] Ait. Hort. Kew. ed. II. iii. $109=$ caespitosa.

Lingula, S. Wats. in Proc. Am. Acad. xiv. (187s 293.-Am. bor. occ

Iurida, Baker, in Saund. Refug. Bot. t. 59.-Mexic.

lusitanica, Lam. Encyco ii. 140,-Europ.

lutea, Hort, ex Lam. 1. c. $172=$ Crassula portulacea.

lutea, Huds. F1. Angl. ed. II. 194=lusitanica.

maculata, Salm-Dyck, Obs. 5.-Afr. austr.

malacophylla, Pall. Reise, iii. 729.-Sibiria.

mamillaris, Linn. f. Suppl. 242.-Afr. austr.

marginatum, Rafin. Atl. Fourn. 79.-Hab.?

mexicana, Hemsl. Biol. Centr. Am. Bot. i. 390.Mexic.

Meyerii, Hary. in Harv. E Sond. Fl. Cap. ii. \$72.Afr. austr.

Mucizonia, Ortega, Mucis. (1772).-Hispan.; Marocc. mucronata, Baker, in Saund. Refug. Bot, sab L. 55. 4.-Mexic.

mucronata, Lam. Encye, ii. 142-Afr. austr.

nevadensis, S. Wats. Bot. Calif. i. $212 .-$ Am. bor. occ. nodulosa, Baker, in Saund. Refug. Bot. t 56.Mexic.

nuda, Baker, l. c. t. 57--Mexic

nudicaulis, Lam. Encyc. ii. 142; Vahl, Srmb. Bot. it $51=$ Kalanchoè crenata

oblonga, Haw. Syn. Pl. Succ $106=$ orbiculaia

ombilicus, Lam. Encyc. ii. $140=$ C. Limbilicus.

oppositifolia, Ledeb. ex Nordm. in Bull. Sc. Acad Pltersb, ii. (1897) 913.—Reg. Caucas.

orbiculata, Forsk. Fl. Aegypt. Arab. p. cril

Kialanchö̈ alternans.

orbiculata, Linn. Sp. Pl. 429.-Afr. austr.

Oreades, C. B. Clarke, in Hook. f. F\%. Bril. Ind. i 416. - Ind. or.

oreconensis, S. Wats. in Proc. Am. Acad. xvit 1881-\$2) 3:8.-Am, bor. occ.

mata, Haw. Syn. I'l. Succ, $105=$ orbiculats

prata. Mill. Gind. Dict. ed. Vill. o. $S=$ Crassula portulacea.

Pachyphytum, Baker, in Sasnd. Refug. Bus. i. sub 50. n. 12. - Mexic

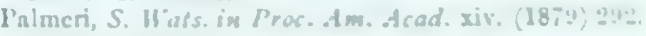
-Aar. bur. acc 


\section{COTYLEDON :-}

paniculata, Linn. f. Suppl. $242=$ orbiculata. paniculata, Rottl. ex Wight \& Arn. Prod. $360=$ Kalanchoë floribunda

paniculata, Thunb. Prod. Pl. Cap. $83=$ fascicularis pannosa, Baker, in Fourn. Linn. Soc. xviii. (1881) 269. -Madag.

papillaris, Haw. Suppl. PI. Succ. $21=$ decussata. papillaris, Linn. f. Suppl.242.-Afr. austr.

papillosa, Aitch. E Hemsl. in Fourn. Linn. Soc. xviii. (1880) 58.-Afghan.

parviflora, Desf. in Ann. Mus. Par. xi. (1808) 444; Sibth. Er Sm. Fl. Graec. Prod. i. 308.-Europ. parviflora, Hemsl. Diag. Pl. Nov. 9.-Mexic.

parvula, Burch. Trav. i.219.-Afr. austr.

Peacockii, Baker, in Gard. Chron. (1874) II. 258.Am. bor.

peltata, Wendl. Beobacht. $49=$ C. Umbilicus.

peruviana, Baker, in Saund. Refug. Bot. sub t. 58.Peruv.

Pestalozzae, Mast. in Gard. Chron. (1877) II. 456.Oriens.

pinnata, Lam. Encyc. ii. $141=$ Bryophyllum calycinum.

Pistorinia, Ortega, Muciz. (1772).-Hispan.

pubescens, Baker, in Saund. Refug. Bot. i. sub t. 55. -Mexic.

pubescens, C. A. Mey. Verz. Pfl. Cauc. $150=$ Sedum pilosum.

pulverulenta, Baker, in Saund. Refug. Bot. i. t. 66.Calif.

pumila, Baker, l.c. t. 62.-Mexic.

punctata, Hort. ex Lam. Encyc, ii. $173=$ Crassula arborescens.

purpurea, Haw. Suppl. Pl. Succ. $23=$ curviflora.

purpurea, Thunb. Prod. Pl. Cap. 83.-Afr, austr.

quitensis, Baker. in Saund. Refug. Bot. sub t. 55.

Ecuador.

racemosa, E. Mey. ex Harv. E Sond. Fl. Cap. ii. 375 -Afr. austr.

ramosa, Haw. Suppl. PI. Succ. $24=$ orbiculata.

ramosissima, Mill. Gard. Dict. ed. VIII, n. $6=$ orbiculata.

ramosissima, Salm-Dyck, ex Haw. l. c. 25.-Afr. austr.

reflexa, Willd. Enum. Hort. Berol. Suppl. $24=$ caespitosa.

reticulata, Thunb. Prod. Pl. Cap. 83.-Afr. austr

retusa, Baker, in Saund. Refug. Bot. sub t. 64. n. 22.--Mexic.

vhizophylla, Roxb. Hort. Beng. 34; Fl. Ind. ii. $456^{6}=$ Bryophyllum calycinum

rhombifolia, Eckl. \& Zeyh. Enum. $307=$ hemisphaerica.

rhombifolia, Haw. in Phil. Mag. (1825) 33.-Afr. austr.

rosea, Less. in Linnaea, ix. (1834) 177.-Sibiria.

roseata, Baker, in Saund. Refug. Bot. sub t. 55. n. 3. -Mexic.

rotundifolia, Eckl. \& Zeyh. Enum. $307=$ hemi. sphaerica.

rotundifolia, Haw. in Phil. Mag. (1827) $273=$ orbiculata.

mupestris, Salisb. Prod. $307=$ C. Umbilicus.

Rusbyi, Greene, in Bull. Torrey Club, x. (1883) 125 -Am. bor. occ

Salzmannii, Hook. f. Bot. Mag. t. $5801=$ hispanica

Samium, Urvo in Mém. Soc. Linn. Par. 1. (1822) 306. -As. Min.

Schaffneri, S. Wats. in Proc. Am. Acad. xvii. (1881-82) 354.-Am. bor. occ.

Scheerii, Baker, in Saund. Refug. Bot. sub t. 62. n.

19.-Mexic.

secunda, Baker, l. c. sub t. 60. n. 14.-Mexic

sediformis, Lapeyr. Hist. Abr. Pl. Pyr. $257=$ sedoides.

sedoides, DC. Rapp. Fard. Bot. Genèv. ii. 79.-Europ

Sempervivum, Bieb. Beschr. Casp. 176.-Reg. Casp.

serrata, Linn.Sp, Pl. 429.-As. Min.

simensis, Britten, in Oliver, Fl. Trop. Afr. ii. 399.-

Afr. trop.

spathulata, C. B. Clarke, in Hook. f. Fl. Brit. Ind. ii. 416.-Reg. Himal.

spathulata, Poir. Encyc. Suppl. ii. $373=$ Kalanchoë spathulata.

spinosa, C. B. Clarke, in Hook. f. Fl. Brit, Ind. ii. 416 = leucantha.

spinosa, Linn. Sp. Pl. 429.-As. bor.

Sprucei, Baker, in Saund. Refug. Bot. sub t. 71.Ecuador.

\section{COTYLEDON}

spuria, Linn. Sp. Pl. ed. II. 614.-Afr. austr.

stolonifera, Baker, in Saund. Refug. Bot. t. 63.Mexic.

strictiflora, Baker, l.c. sub t. 62. m. 17.-N. Mexic

subspicata, Baker, $l$. c sub t. 71-N. Granat.

subulata, C. A. Mey. Verz. Pfl. Cauc. $150=$ Sedum subulatum.

subulifolia, Baker, in Saund. Refug. Bot. sub t. 71. n. 32.-Mexic.

tardiflora, Bonpl. Pl. Rar. Malm. 93. t. $37=$ fascicularis.

tenuicaulis, Aitch. E Hemsl. in Fourn. Linn. Soc. xviii. (1880) 57.-Afghan.

teretifolia, Lam. Encyc. 1i. $139=$ spuria.

teretifolia, Thunb. Prod.Pl. Cap. 83.-Afr. austr.

thyrsiflora, D. Dietr. Syn. Pl. ii. 1627.-Sibir.

thyrsiflora, Maxim. in Bull. Acad. Pétersb. xxix. (1884)

123 = leucantha

tomentosa, Harv. in Harv. E Sond. Fl. Cap. ii. 373.Afr. austr.

tricuspidata, Harv. in Phil. Mag. (1825) $32=$ papillaris.

triflora, Thunb. Prod. Pl. Cap. 83.--Afr. austr.

trigyna, Burch. Trav. ii. 226.-Afr. austr.

tuberculosa, Lam. Encyc. iii. 139.-Afr. austr.

tuberosa, Hort. Par. ex Webb \& Berth. Phyt. Canar.

i. 177. - Ins. Canar.

umbilicata, Lam. F1. Fr. ii.. $59=$ C. Umbilicus.

umbilicifolia, Stokes, Bot. Mat. Med. ii. $545=\mathrm{C}$. Umbilicus.

Umbilicus, Linn. Sp. Pl. 429.-Europ.; As. Min.

undulata, Eckl. \& Zeyh. Enum. 306=cuneata.

undulata, Haw. Suppl. Pl. Succ. 20.-Afr. austr.

ungulata, Lam. Encyc. ii. 139.-Afr. austr.

velutina, Hook. f. Bot. Mag. t. 5602.-Afr. austr.

ventricosa, Burm. f. Fl. Cap. Prod. 13.-Afr. austr.

Verea, Jacq. Hort. Schoenb. iv. $17=$ Kalanchoë crenata.

viridis, Haw. in Phil. Mag. (1827) $273=$ orbiculata?

viscida, S. Wats. in Proc. Am. Acad. xvii. (1881-82)

372.-Am. bor. occ.

viscosa, Vahl, Symb. Bot. ii. $51=$ C. Mucizonia

Wallichii, Harv. in Harv. E Sond. Fl. Cap. ii. 374.Afr. austr.

Zeyheri, Harv. l. c. 377.-Afr. austr.

COTylePHORA, Meissn. Gen. Comm. 28 (1837)= Neesia, Blume (Malvac.)

altissima, Meissn. 1. $c_{0}=\mathbf{N}$. altissima

COTYLIPHYLLUM, Link, Handb. ii. 28 (1831)=

Cotyledon, Tourn. (Crassulac.).

erectum, Link, $1 . \mathrm{c}_{\mathrm{s}}=$ Cotyledon Umbilicus

horizontale, Link, 1. c. = Cotyledon Umbilicus

Mucizonia, Link, 1. c. = Cotyledon Mucizonia.

Umbilicus, Link, 1. c。 = Cotyledon Umbilicus.

COTYLISCUS, Desv. Journ. Bot. iii. (1813) $164,175=$ Senebiera, DC. (Crucif.)

niloticus, Desv. 1. $\mathrm{c}_{\mathrm{s}}=\mathrm{S}$, nilotica.

COTYLODISCUS, Radlk. in Sitzb. Math.-Phys. Acad. Muench. viii. (1878) 334. SAPINDACEAE. stelechanthus, Radlk. l. c.-Madag.

COTYLOPLECTA, Alef. in Oestr. Bot. Zeitschr. xiii. (1863) $\mathbf{1 4}$ = Hibiscus, Linn. (Malvac.). corymbosa, Alef. 1. c. $15=\mathrm{H}$. corymbosus.

dongolensis, Alef. $\mathrm{l}_{\text {. }} \mathrm{c}_{\mathrm{o}}=\mathrm{H}$. lunariifolius.

macrantha, Alef. 1. c. $=$ H. lunariifolius.

COUBLANDIA, Aubl. Pl. Gui. ii. 937.t. $356(1775)=$ Muellera, Linn. (Legumin.)

frutescens, Aubl. 1. c. $=$ M. moniliformis

mexicana, Baill. Adansonia, ix. (1870) 238.-Mexic.

COUDENBERGIA, March. in Bull. Acad. Belg. Sér. II. xlvii. (1879) $514=$ Coemansia, March. (Araliac.).

COUFrPIA, Aubl. Pl. Gui. i. 519. t. 221 (1775). ROSACEAE, Benth. \& Hook. f. i. 608.

Acra, Willd. Sp. Pl, iii. 717 (1800).

ACIOA, Aubl. Pl. Gui. ii.698. t. 280 (1775).

Dulacia, Neck. Elem. ii. $414(1790)$

bracteosa, Benth. in Hook. Fourn. Bot. ii. (1840) 215. -Guiana.
COUEPIA :-

canomensis, Benth. in Hook. Fourn. Bot. ii. (1840) 215. -Bras.

chrysocalyx, Benth. ex Hook. f. in Mart. Fl. Bras, xiv.

II. 42.-Bras.

comosa, Benth. in Hook. Fourn. Bot. ii. (1840) 215.Guiana.

eriantha, Spruce, ex Hook. f. in Mart. Fl. Bras. xiv. II. 45.-Bras.

glandulosa, Miq. Stirp. Surin. Sel. 28.-Guian.

glaucescens, Spruce, ex Hook. f. in Mart. Fl. Bras.

xiv, II. 49.-Bras

grandiflora, Benth. in Hook. Fourn. Bot. ii. (1840) 215.-Bras.

guianensis, Aubl. Pl. Gui. i. 519, 207.-Guiana.

hypoleuca, Miq. in Linnaea, xix. (1847) 438.Mexic.

Kunthiana, Benth. in Hook. Fourn. Bot. ii. (1840) 216.-Mexic

leptostachya, Benth. ex Hook. f. in Mart. Fl. Bras. xiv. II. 44.-Bras.

macrophylla, Spruce, ex Hook. f. l. c. 41.-Peruv.

magnoliaefolia, Benth. ex Hook. f. l. c. 43,-Bras.

Martiana, Hook.f. l. c. 47.-Bras.

multiflora, Benth. in Hook. Fourn. Bot. ii. (1840) 215. -Guiana.

myrtifolia, Benth. ex Hook. f. in Mart. Fl. Bras. xiv. II. 44.-Bras.

ovatifolia, Benth. in Hook. Fourn. Bot. ii. (1840) 216. -Bras.

paraënsis, Benth. l. c.-Bras.

Parillo, DC. Prod. ii. 526.-Guiana.

racemosa, Benth. ex Hook. f. in Mart. Fl. Bras, xiv. II. 43.-Bras,

Steudeliana, Miq. Stirp. Surin. Sel. 28.-Guiana.

subcordata, Benth. ex Hook. f. in Mart. Fl. Bras, xiv. II. 46.-Bras.

thyrsiflora, Hook.f.l. c. 45--Bras

vismioides, Klotzsch, ex Hook. f. in Mart. Fl. Bras xiv. II. $48=$ paraënsis.

Uiti, Benth. in Hook. Fourn. Bot. ii. (1840) 215.Bras.

COULA, Baill. Adansonia, iii. 61, 64. t. 3 (1862). OLACINEAE, Benth. \& Hook. f. i. 995.

edulis, Baill. l. c. 64.-Afr. trop.

COUIEJIA, Dennst. Schluess. Hort. Malab. 31 (1818)= Antidesma, Linn. (Euphorb.). amentacea, Dennst. 1. c.-Ind. or.

COUlTERIA, H. B. \& K. Nov. Gen. et Sp. vi. 328. t. 568 = Caesalpinia, Linn. (Legumin.)

africana, Guill. \& Perr. F1. Seneg. Tent. i. $256=$ Prosopis oblonga.

chilensis, DC. Prod. ii. 481 = Caesalp. tinctoria.

horrida, H. B. \& K. Nov. Gen. et Sp. vi. $330=$ Caesalp. horrida.

mexirana, DC. Prod. ii. $481=$ Caesalp. vesicaria mollis, H. B. \& K. Nov. Gen. et Sp. vi. $330=$ Caesalp mollis.

tinctoria, H. B. \& K. 1. c. $331=$ Caesalp. tinctoria.

COUMA, Aubl. P1. Gui. Suppl. 39. t. 392 (1775) APOCYNACEAE, Benth. \& Hook, f. ii. 693.

Collophora, Mart. in Buchn. Rep. Pharm. xxxy. (1830) 196, ex Bull. Férussac (Janv. 1831), 64. dulcis, Spruce, ex Muell. Arg. in Mart. Fl. Bras. vi. I. 19 $=$ utilis.

guianensis, Aubl. Pl. Gui. Suppl. 39. t. 392.Guiana.

rigida, Muell. Arg. in Mart. Fl. Bras. vi. 1. 20.-Bras. utilis, Muell. Arg. l. c. 19.-Bras.

COUMAROUNA, Aubl. Pl. Gui. ii. 740, t. $296(1775)=$ =Dipteryx, Schreb. (1791) (Legumin.) odora, Aubl. 1. c. t. $296=$ seq. odorata, Aubl. 1. c. $740=\mathrm{D}$. odorata.

COUPIA, G. Don, Gen. Syst. ii. 44 (1832) sphalm.= Goupia, Aubl, (Celastrin.).

COUPOUI, Aubl. Pl. Gui. Suppl. 16. t. 377 (1775) APOCYNACEAE [Benth. \& Hook. f. i. 696].

Cupirana, Miers, Apocyn. S. Am. 15 (1878)

Cupuia, Rafin. Princ. Somiol. 29 (1814). aquatica, $A u b l$. l. c.-Guiana. 
COURALIA, Splitg. in Hoev. \& De Vriese, Tijaschr. ix. (1842) 14. BIGNONIACEAE, Benth. \& Hbok。 f. ii. 1042.

fluviatilis, Splitg. l. c. 15.-Guiana.

COURANTIA, Lem. Jard. Fleur. i. (1851) Misc. $92=$ Cotyledon, 'Tourn. (Crassulac.).

cherverioides, Lem. 1. c. $=$ Cotyl. roseata.

rosea, Lem. 1. c. iii. (1853) 244, in nota =Cotyl, rosea.

COURATARI, Aubl. Pl. Gui. ii. 723. t. 290 (1775). MYRTACEAE, Benth. \& Hook. f. i. 722

AmpHORICARPUS, Spruce, ex Miers, in Trans. Linn. Soc. xxx. (1874) 288.

Cariniana, Casar. Nov. Stirp. Bras. 35 (1842).

aulacocarpa, Mart. ex Berg, in Mart. Fl. Bras. xiv. I. 509. - Bras.

coriacea, Mart. ex Berg, l. c. 510.-Bras.

dictyocarpa, Mart. ex Berg, l. c.-Bras.

domestica, Mart. in Flora, xx. (1837) II. Beibl. 127, in textu.-Bras.

estrellensis, Raddi, in Mem. Mod. xviii. Fis. (1820) 403.-Bras.

guianensis, $A u b l$. Pl. Gui. ii. 724. t. 290,-Amo trop.

Lecythopsis, Mart. in Flora, xx. (1887) II. Beibl. 89.Bras.

legalis, Mart.l.c. 88.-Bras.

lineata, Mart. ex Berg, in Mart. Fl. Bras. xiv. I. 508. -Bras.

macrocarpa, Mart. ex Berg, l. c. 509.-Bras.

Martiana, Miers, in Trans. Linn. Soc. xxx. (1874) 282 -Bras.

paraënsis, Mart. ex Berg, in Mart. Fl. Bras. xiv. I. 510.-Bras.

rubra, Gardn. ex Miers, in Trans. Linn. Soc. xxx. (1874) 288.-Bras.

Tauari, Berg, in Mart. Fl. Bras. xiv. I. 509.-Bras.

uaupensis, Spruce, ex Berg, l. c. 508.-Bras.

Vriesii, Miers, in Trans. Linn. Soc. xxx. (1874) 284.Guiana.

COURATARI, Cambess, in St. Hil. Fl, Bras. Mer. ii. 379 (1829) = Lecythopsis, Schrank (Myrtac.). glabra, Cambess. 1. c. = L. glabra.

rufescens, Cambess. 1. c. $380=\mathrm{L}$. rufescens.

COURBARI, Adans. Fam. ii. $317(1763)=$ Hymenaea, Linn. (Legumin.).

COURBARIL, Plum. ex Endl. Gen. 1317 (1841)=praec.

COURBONIA, Brongn. in Bull, Soc. Bot. Fr. vii.

(1860) 901. CAPPARIDEAE, Benth. \& Hook. f. i. 969.

Physanthemum, Klotzsch, in Peters, Reise Mossamb. Bot. 167. t. 29 (1861).

decumbens, Brongn. l. c.-Afr. trop.

virgata, Brongn. l. c.-Afr, trop.

COURIMARI, Aubl. Pl. Gui. Suppl. 27 (1775) (Gen. dub. affin.).

guianensis, Aubl.l.c.-Guiana.

COURINGIA, Adans. Fam. ii. 418 (1763)= Conringia Heist. (Crucif.).

COUROUPITA, Anbl. Pl. Gui. ii. 708, t. 282 (1775) MYRTACEAE, Benth. \& Hook. f. i. 722 . ElsholTZIA, Neck. Elem, ii. 256 (1790).

Pontopidana, Scop. Introd. 195 (1777).

antillana, Miers, in Trans. Linn. Soc。xxx. (1874) 191.

-Ind. occ.

crenulata, Miers, l. c. 195.-Bras.

guianensis, Aubl. Pl. Gui. ii. 708, t. 282.-Guian.

guianensis, Hook. Bot. Mag. t. $3158=$ antillana.

lentula, Miers, in Trans. Linn. Soc. xxx. (1874) 194.Bras.

membranacea, Miers, l.c.-N. Granat.

nicaraguarensis, DC. Prod. iii, 294.-Am. centr.

odoratissima, Seem. Bot. Voy. Herald, 126.-Panama. peruviana, Berg, in Linnaea, xxxi. (1861-62) 261.Peruv.

surinamensis, Mart.ex Berg, in Mart. Fl. Bras, xiv, I. 476.-Guian.

COURRANTIA, Sch. Bip. in Webb \& Berth. Phyt Canar, ii. 276. t. 89 (cir. 1845) $=$ Matricaria, Linn (Compos.).

chamomilloides, Sch. Bip. 1. c. $278=$ M. Courrantia.
COURSETIA, DC. in Ann. Sc. Nat. Sér. I. iv. (1825) 92. LEGUMINOSAE, Benth. \& Hook. f. i. 501.

Poissonia, Baill. Adansonia, ix. (1870) 295.

arborea, Griseb. Fl. Brit. W. Ind. 183.-Ins. Trinit

dubia, DC.Prod. ii. 264.-Am. austr.

eriantha, Benth. in Hook. Ic. Pl. sub t. 1065.-Peruv.

glandulosa, A. Gray, in Proc. Am. Acad. v. (1861) 156 -Calif.

grandiflora, Benth. ex Oerst. in Kjoeb. Vidensk. Meddel. (1853) 10.-Peruy.

microphylla, A. Gray, in Proc. Am. Acad. xvii. (1881 82) 201.-Arizona.

orbicularis, Benth. in Hook. Ic. Pl. t. 1065.-Peruv.

rostrata, Benth. in Mart. Fl. Bras. xv. 1. 44.-Am trop.

tomentosa, DC. in Ann. Sc. Nat. Sér. I. iv. (1825) 92 -Peruv

vicioides, Benth. in Mart. Fl. Bras. xv. I. 44.-Am. trop.

virgata, $D C$. in Ann. Sc. Nat. Sér. I. iv. (1825) 92.Mexic

COURTENIA, R. Br. in Benn. Pl. Jav. Rar. 236 (1844) Cola, Schott (Sterculiac.)

Afzelii, R. Br. 1. c. = Cola Afzelii.

heterophylla, R. Br. I. c. = Cola heterophylla.

triloba, R. Br. 1. c. $=$ Cola heterophylla.

COURTOISIA, Nees, in Linnaea, ix. (1834) 286. CYPERACEAE, Benth. \& Hook. f. iii. 1046. cyperoides, Nees, l. c. -Ind. or.

olivacea, Boeck. in Flora, xliv. (1861) 331.-Guiana.

COUSINIA, Cass. in Dict. Sc. Nat. xlvii. 503 (1827) COMPOSITAE, Benth. \& Hook, f. ii, 467.

Auchera, DC. Prod, vi. 557 (1837).

acicularis, Franch. in Ann. Sc. Nat. Sér. VI. xvi. (1883) 319.-Turkestan.

Actinia, Boiss. Diagn. Ser. II. iii. 55.-Afghan.

actinocephala, Jaub. \& Spach, Illustr. ii. 93.t. 175 xiphiolepis.

adnata, Bunge, Gatt. Cous. 50.-Persia.

affinis, Schrenk, Enum. Pl. Nov. i. 41.--Soongaria.

aggregata, DC. Prod. vi. 553.-Persia.

aintabensis, Boiss. E Haussk. ex Boiss. Fl. Orient. iii 503.-Syria.

alata, Schrenk, Enum. Pl. Nov. i. 40.-Reg. Casp. Soongaria.

Alberti, Regel E Schmalh. in Act. Hort. Petrop. vi. (1879) 315.-Turkestan.

albicaulis, Boiss. E' Buhse, in Nouv. Mém. Soc. Nat. Mosc. xii. (1860) 128.--Persia.

albida, DC. Prod. vi. 552.-Persia

Alepideae, Boiss. Diagn. Ser. II. iii. 53.-Beluchist.

aleppica, Boiss. l. c. Ser. I. x. 101.-Syria.

alpicola, Borszczow, ex Trauty. in Act. Hort. Petrop. viii. (1883) $484=$ seq.

alpina, Bunge, Del. Sem. Hort. Dorp. (1845) 3.Turkest.

amplissima, Boiss. Fl. Orient. iii. 462.-Persia.

enisoptera, Jaub. \& Spach, Illustr. ii. 88 . t. $170=$ calolepis.

enomala, Franch. in Ann.Sc.Nat. Sér. VI. xvi. (1883) 316.-Turkestan.

anthacantha, Regel, in Bull. Soc. Nat. Mosc. xl. (1867) II. 156 , sphalm. vide xanthacantha.

aptera, Aitch. E Hemsl. in fourn. Linn. Soc. xix. (1882) 170.-Afghan.

arachnoidea, Fisch. E Mey. ex DC. Prod. vi. 553.Soongar.

aralensis, Bunge, in Mém. Sav. Etr. Pétersb, vii. (1851) $854=$ minuta.

araneosa, $D C$. Prod. vi. 556.-Persia.

atctioides, Schrenk, in Bull. Phys.-Math. Acad. Pétersb. ii. (1844) 115. - Soongaria.

arctotidifolia, Bunge, Gatt. Cous, 42.-Persia.

arenaria, Bunge, l. c. 29.-Persia.

assyriaca, Jaub. \& Spach, Illustr. ii. 87. t. $179=$ leucochlora.

attopatana, Bunge, Gatt. Cous. 17.-Persia.

Aucheri, DC. Prod. vi. 555.-Cappadoc.

fulata, Boiss. Diagu. Ser. II. iii. 53.-Ind. bor.

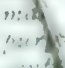

$\cdots ?$

?:ne of ?oiss. Dingn. Ser. II. iii. 58.-Afghan.

villus o: a Boiss, E Haussk, in Boiss. N\%. Orient. iii

an insia.

\section{COUSINIA :}

Belangeri, DC. Prod. vi. 553.-Persia.

Bienerti, Bunge, Gatt. Cous. 27.-Persia.

bipinnata, Boiss. Diagn. Ser. II. iii, 52.-Afghan.

Boissieri, Buhse, in Nouv. Mém. Soc. Nat. Mosc. xi. (1860) 127.--Persia.

Bonvaleti, Franch. in Ann. Sc. Nat. Sér. VI. xvi. (1883) 320.-Turkestan

brachyptera, DC. Prod. vi. 554.-Armenia.

Brandisii, C. B. Clarke, Comp. Ind, $214=$ Thomsoni

Buhsei, Bunge, Gatt. Cous. $22=$ hamosa.

bulgarica, C. Koch, in Linnaea, xxiv. (1851) 385.Europ. or

Bungeana, Regel Es Schmalh. in Act. Hort. Petrop. vi, (1879) 318.-Turkestan.

buphthalmoides, Regel, in Bull. Soc. Nat. Mosc. xl.

1867) Ir. 155.-Afghan, ; Ind. bor. occ.

caesarea, Boiss. E Bal. Diagn. Ser. II. vi. 116.Cappadoc.

calcitrapaeformis, Jaub. \& Spach, Illustr. ii. 76. t. 158 = rninuta.

Calcitrapa, Boiss. Fl. Orient. iii. 490.-Persia.

calocephala, Faub. E Spach, Illustr. ii. 96. t. 178.-

Persia.

calolepis, Boiss. Diagn. Ser. I. vi. 116.-Persia

calolepis, Boiss. Fl. Orient. iii. $480=$ commutata.

Candolleana, Faub. \& Spach, Illustr. ii. 74. t. 156.Persia.

canescens, $D C$. Prod. vi. 556.-Armenia

canescens, Franch. in Ann. Sc. Nat. Sér. VI. xvi. (18\&3)

323. - Turkestan.

Capusi, Franch. l. c. 317.-Turkestan.

carduiformis, Cass. in Dict. Sc. Nat. xlvii, 503.-Reg.

Caucas.

carduncelloidea, Regel E Schmalh, in Pl. Nov. Fedsch. 50. - As. centr.

carlinoides, Boìss. \& Buhse, in Nouv. Mém. Soc. Nat. Mosc. xii. (1860) $126=$ obovata.

carlinoides, DC. Prod. vi. 554.-Persia.

carthamoides, Aitch. E Hemsl. in Fourn. Linn. Soc.

xix. (1882) 171.-Afghan

cataonica, Boiss. E Haussk. Fl. Orient. iii. 483.-As. Min.

centanroides, Fisch. E Mey. in Bull. Soc. Nat. Mosc. 1839) 159.-Persia.

centauroides, Regel, in Bull. Soc. Nat. Mosc. xl. (1867) II. 152.-As, centr.

Chamaepence, Boiss. Diagn. Ser. I. vi. 120.-Persia

chlorocephala, C. A. Mey. ex DC. Prod. vi. 554 Armenia.

chrysacantha, Faub. E Spach, Illustr. ii. 78. t. 160.Persia.

cirsioides, Bariss. E Bal. Diagn. Ser. II. vi. 117.Cappadoc.

commutata, Bunge, Gatt. Cous. 24.-Persia.

concinna, Boiss. E' Haussk. in Boiss. Fl. Orient. iii. 513.-Persia.

concolor, Bunge, Gatt. Cous. 33.-Persia.

congesta, Bunge, l. c. 12.-Persia

coronata, Franch. in Ann. Sc. Nat. Sér. VI Xri. (185') 321.-Turkestan.

crispa, Faub. E Spach, Illustr. ii. 81. t. 163.-Persia.

cylindracea, Boiss. Diagn. Ser. I. vi. 115.-Persia.

cylindrocephala, Faub. E Spach, Illustr. ii. 34. t. $166^{\circ}$. -Persia.

cymbolepis, Boiss. Diagn. Ser. I. vi. 119.-Kurdist.

cynaroides, C. A. Mey. Vers. Pf. Cauc. $230-$ Kieg.

Caucas.

decipiens, Boiss. E Buhse, in .Von M/Em. Soc. Nat. Mosc. xii. (1860) 125.-Persia.

decurrens, Regel, in Bull. Soc. Nat. Mosc. Il, (156"

1I. 154.-Afghan.

deserti, Burge, Gatt. Cous. 29.-Persia.

dichotoma, Bunge, Del. Sema. Hort. Durpate. (1S45)

3.-Turkest.

discolor, Bunge, Gatt. Cous. 34.-Persia.

dissectn. Kar. \& K̈̈r. in Bull. Soc. Vat. Mose. xv.

(1842) 391 . - Turcoman.

dolicholepis, Schrenk, in Bull. Physo-Mospi. Acout.

Petersb. iii. (1845) 107.- Suone

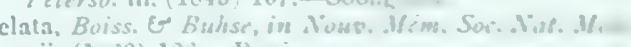

xii. $(1=60) 120,-$ l'ersia.

elemans, Airch. E Hemst. in Fourn. Limn. Sar. xix.

(18*2) 172 - Af

crinncen, Gaub. E Spach, Illaustr. ii. \$3. t. 185.-Persia.

eriobasis, Bunger, Gatf. Cons. 37. - I'ersia

eriocephala, Buiss. G Hasasot. a.r Borss. Fl. Oriente iii.

50t. - As. Mun. 


\section{COUSINTA :-}

eriophora, Regel ES Schmalh. in Act. Hort. Petrop. vi. (1879) 313.-Turkestan.

eryngioides, Boiss. Diagn. Ser. I. x. 101,--Persia.

Falconeri, Hook. f. Fl. Brit. Ind. iii. 360.-Res Himal.

flavispina, Franch. in Ann.Sc. Nat. Sér. VI, xvi. (1883) 315.-Turkestan.

foliosa, Boiss. E' Bal. Diagn. Ser. II. vi. 116.-Cappadoc.

gracilis, Boiss. l. c. Ser. I. vi. 117.-Persia.

grandiceps, Bunge, Gatt. Cous. 54.-Persia.

grandis, C. A. Mey ex DC. Prod. vi. 557.-Persia.

Griffithiana, Boiss. Diagn. Ser. II. iii. 55.-Afghan.

Gundelia, C. Koch, in Linnaea, xxiv. (1851) $387=$

brachyptera.

Hablitzii, C. A. Mey. ex DC. Prod. vi. 554,--Persia.

hamosa, C.A. Mey. l. c. 555--Persia

hamulosa, C. A. Mey. ex Boiss. Fl. Orient. vi. $483=$ hamosa

heliantha, Bunge, Gatt. Cous. 39.-Persia.

Hermonis, Boiss, Diagn. Ser. I. x. 102.-Syria

heterolepis, C. Koch, in Linnaea, xxiv. (1851) $386=$ brachyptera.

heterophylla, Boiss. Diagn. Ser. II. iii. 54.-Afghan

Hohenackeri, Fisch. E Mey. Ind.Sem. Hort. Petrop. ii. 34.-Persia.

hololeuca, Bunge, Gatt. Cous. 27.-Persia

humilis, Boiss. in Ann. Sc. Nat. Sér. IV. ii. (1854) 248. - Cappadoc.

hypolenca, Boiss. Diagn. Ser. I, x. 103; Fl. Orient. ii 464.-Persia.

Hystrix, C. B. Clarke, Comp. Ind. $214=$ microcarpa.

Hystrix, C. A. Mey. Ind. Sem.Hort. Petrop. ii. 34. Persia.

ilicifolia, Faub. Eo Spach, Illustr. ii. 82.t. 164.-Persia incompta, DC. Prod. vi. 553.-Persia

inflata, Boiss. \& Haussk. ex Boiss. Fl. Orient. iii. 512. -Kurdistan.

inteorifolia, Franch in Ann. Sc. Nat. Sér. VI. xyi. (1883) 322.-Turkestan

intermedia, C. A. Mey. ex DC. Prod. vi. 553.Armenia.

involucrata, Boiss. Diagn. Ser. I. vi. 114.-Persia.

karatavica, Regel E" Schmalh. in Act. Hort. Petrop. vi. (1879) 317.-Turkestan.

Karelini, Less. ex Kar. in Bull. Soc. Nat. Mosc. (1839) $159=$ onopordioides

kokanica, Regel EJ Schmalh. ex Regel, Pl. Nov.

Fedsch, 49.-As, centr.

Kornhuberi, Heimerl, in Denkschr. Acad. Wien, 1. (1885) 62.-Persia

Korolkowi, Regel E Schmalh. in Act. Hort. Petrop. vi. (1879) 315.-Turkestan.

Kotschyi, Boiss. Diagn. Ser. I. vi. 120.-Persia.

Krauseana, Regel Eे Schmalh. ex Regel, Pl. Nov. Fedsch. 48.-As, centr.

lachnosphaera, Bunge, Gatt. Cous. 36.-Persia.

lappacea, Schrenk, Enum. Pl. Nov. i. 42.-Soongaria

lasiandra, Bunge, Gatt. Cous, 40,-Persia.

lasiolepis, Boiss. Diagn. Ser. I. vi. 118.-Persia.

lepida, Bunge, Gatt. Cous. 26, in nota.-Persia.

leptocephala, Fisch. Er Mey. in Bull. Soc. Nat. Mosc. (1839) 159.-Turcoman.

leucochlora, Bunge, Gatt. Cous. 24, in nota-Persia.

libanotica, DC. Prod. vi. 556.-Syria.

lucida, $D C$. l. $C .553$. - Assyria.

lyrata, Bunge, Gatt. Cous. 53.-Persia.

macrocephala, C. A. Mey. Verz. Pf. Cauc. 231.-Reg. Caucas.

macrolepis, Boiss. E Haussk. ex Boiss. Fl. Orient. iii. 505.-Persia.

macroptera, C. A. Mey。 ex DC. Prod. vi. 555,Armenia.

microcarpa, Boiss. Diagn. Ser. II. iii. 59.-Persia Reg. Himal.

microcephala, C. A. Mey. ex DC. Prod. vi. 552.Persia

minuta, Boisș. Diagn. Ser. I. vi. 117.-Persia; Ind. bor. occ

mollis, Schrenk, in Bull. Phys.-Math. Acad. Pétersb. iii. (1845) 108.-Soongaria.

monocephala, Bunge, Gatt. Cous. 52.-Persia.

multiloba, $D C$. Prod. vi. 554.-Persia

neurocentra, Bunge, Gatt. Cous. 29.-Persia.

Noëana, Boiss. Diagn. Ser. II. iii. 57.-Persia

obovata, Boiss. Fl. Orient. iii. 491.-Persia.

odontolepis, DC. Prod. vi. 556.-Assyria.

\section{COUSINIA :-}

dontolepis, Sch. Bip. ex Boiss, 1. c. $512=$ cymbolepis

Olgae, Regel \& Schmalh. in Pl. Nov. Fedsch. 48. As. centr.

oligocephala, Boiss. Diagn. Ser. I. vi. 116.--Persia oligocephala, Haussk. ex Boiss. Fl. Orient, iii., 475 bachtiarica.

Olivieri, $D C$. Prod. vi. 552,-Persia?

Olivieri, Jaub. \& Spach, Illustr. t. $172=$ serratuloides. onopordioides, Ledeb. in Eichw. Pl. Casp. Cauc. 40. 37.- Turcoman.

orientalis, C. Koch, in Linnaea, xxiv. (1851) 386. Oriens.

outichaschensis, Franch. in Ann.Sc. Nat. Sér. VI. xvi 1883) 322,-Turkestan.

palmatiloba, Jaub. \& Spach, Illustr. ii. 80. t. 162= multiloba.

pauciflora, Bunge, Gatt, Cous. 12 =aggregata.

pentacantha, Regel E Schmalh. in Act. Hort. Petrop.

vi. (1879) 315.-As. centr.

pergamacea, Boiss. E Haussk, ex Boiss. Fl. Orient. iii. 513,-Persia.

Pestalozzae, Boiss. l. c. 471.-Syria

pinarocephala, Boiss. Diagn. Ser. I. vi. 121.-Persia

piptocephala, Bunge, Gatt. Cous. 26.-Persia.

platyacantha, Bunge, 1, c. $37=$ centauroides.

platylepis, Fisch. Mey. \&o Avé-Lall. Ind. Sem. Hort Petrop. ix. Suppl. 10.-Turkestan.

polycephala, Rupr. Sert. Tiansch. 54.-As. centr

prasina, Faub. E Spach, Illustr. ii. 86. t. 168.-Persi

Princeps, Franch. in Ann. Sc. Nat. Sér. VI. zv

1883) 324-Turkestan.

prolifera, Faub. E Spach, Illustr. ii. 74. t. 157.Persia

pterocarpa, Boiss. Fl. Orient. iii. 501.-Afghan

pugionifera, Faub. E Spach, Illustr. ii. 92. t. 17 Persia.

pulchella, Bunge, Del. Sem. Hort. Dorpat. (184

3.-As. cent

purpurea, C. A. Mey, ex DC. Prod. vi. 555.-Persia

pycnoloba, Boiss. Diagn. Ser. II. iii. $57=$ multiloba.

pyrrhocephala, Jaub. \& Spach, Illustr. ii. 85. t. 167 Olivieri.

racemosa, Boiss. Diagn. Ser. II. iii. 56,-Afghan

radians, Bunge, Del. Sem. Hort. Dorpat. (1845)

As. centr.

ramosissima, DC. Prod. vi. 552.-Cappadoc.

recurvata, $D C . l . c .555$.--Persia.

sakawensis, Boiss. \& Haussk. ex Boiss. Fl. Orient. Ai. 488. - Persia.

Scala, Aitch. E Hemsl. in Fourn. Linn. Soc. ix. (1882) 172.-Afghan.

scariosa, Regel, in Bull. Soc. Nat. Mosc. xl. (1867) I. 154.-Afghan.

Schtschurowskiana, Regel E" Schmalh. ex Regel, pl. Nov. Fedsch. 50.-As. centr.

Schultziana, Jaub. \& Spach, Illustr. ii. 95. t. 17: cymbolepis.

Seidlitzii, Bunge, Gatt. Cous. 20.-Persia.

Semenovii, Regel, in Bull. Soc. Nat. Mosc. xl. (187) II. 147.-As. centr.

serratuloides, Boiss. Diagn. Ser. I. vi. 118.-Persia

Sewerzowi, Regel, in Bull. Soc. Nat. Mosc. xl. (187) II. 151.-Turkestan.

silyboides, Jaub. \& Spach, Illustr. ii. 94. t. $17=$ Kotschyi.

Smirnowii, Trautv. in Act. Hort. Petrop. viii. (183) 488.-As centr.

sphatrocephala, Jaub, \& Spach, Illustr, ii. 79, t.61 C. Chamaepeuce

squarrosa, Boiss. Diagn. Ser. I. x. 102.-Persia.

squarrosa, C. Koch, in Linnaea, xxiv. (1851) brachyptera.

stenocephala, Boiss, Diagn, Ser I. vi, 115-Assyn. stenolepis, Regel \& Schmalh. in Pl. Nov. Fedsch 49 -As. centr.

submutica, Franch. in Ann. Sc. Nat. Sér. VI. vii. (1883) 314.-Turkestan.

sylvicola, Bunge, Del. Sem. Hort. Dorp. (145) $3=$ dichotoma.

tabrisiana, Bunge, Gatt. Cous. 16.-Persia

tenella, Fisch. E Mey. Ind. Sem. Hort. Petrop.

Armenia.
tenuifolia, C. A. Mey. ex DC. Prod. vi. 554.-P

thamnodes, Boiss. E Haussk. in Boiss. Fl. Or

471.-Persia.
Thomsoni, C. B. Clarke, Comp. Ind. 2(0) 215. Himal.

\section{COUSI]NIA :-}

trachylepis, Bunge, Gatt. Cous. 22.-Persia.

Trautvetteri, Regel, in Act. Hort. Petrop. v. (1877) 257.--Turkestan.

triflora, Schrenk, in Bull. Phys.-Math. Acad. Pétersb. iii. (1845) 108.-Sonngaria

umbrosa, Bunge, Gatt. Cous, 10,-Persia.

uncinata, Regel, in Bull. Soc. Nat. Mosc. xI. (1867) II 145. - Soongaria

verbascifolia, Bunge, Gatt. Cous. 52.-Persia

verticillaris, Bunge, in Mém. Sav. Etr. Pétersb. vi. 1851) 357.-As, centr.

Verutum, Bunge, Gatt. Cous. 31.-Persia.

wolgensis, C. A. Mey. ex DC. Prod. vi. 555.-Rossia. xanthacantha, Regel, in Bull. Soc. Nat. Mosc. xl (1867) Ir. 156 (sphalm. anthacantha).-Oriens. xeranthemoides, Bunge, ex Boíss. F1. Orient. ii. 497 =microcarpa.

xiphiolepis, Boiss. Diagn. Ser. I. vi. 121.-Persia.

COUSSAPOA, Aubl. P1. Gui. ii. 955, t, 362,363 (1775). URTICACEAE, Benth. \& Hook. f. iii. 379. acutifolia, Klotzsch, in Linnaea, xx. (1847) 529. Peruv.

angustifolia, Aubl. Pl. Gui. ii. 956. t. 363.-Guiana.

asperifolia, Tréc. in Ann. Sc. Nat. Sér. III. viii. (1847) 96.-Guiana.

cuneata, Miq. in Mart. Fl. Bras.iv. I. 138.-Guiana.

dealbata, André, Illustr. Hortic. xvii. (187.0) 16. Bras.

fagifolia, Klotzsch, in Linnaea, xx. (1847) 529.Guiana.

ferruginea, Tréc. in Ann. Sc. Nat. Sér. III, viii. (1847) 93.-Guiana.

Fontanesiana, A. Brongn. ex Tréc. l. c. 94.-Bras

hirsuta, Tréc. l. c. 97.-Peruv.

intermedia, Mart. ex Miq. in Mart. Fl. Bras. iv. I. 133.-Bras.

laevigata, Poepp. Es Endl. Gen. et Sp. ii. 33.-Bras latifolia, Aubl. Pl. Gui. ii. 955. t. 362.-Guiana. magnifolia, Tréc. in Ann. Sc. Nat. Sér. III. viii. (1847) 98.--Peruv

Martiana, Miq. in Mart. Fl. Bras. iv. I. 132.-Bras.

microcephala, Tréc. in Ann. Sc. Nat. Sér. III. viii (1847) 96.-Guiana.

nitida, Miq. in Mart. Fl. Bras. iv. I. 133.-Bras.

obovata, Miq. in Versl. en Medel. Kon. Nederl. Inst. 1842 (1843) 200.-Hab.

ovalifolia, Tréc. in Ann. Sc. Nat. Sér. III. viiii. (1847) 95.-Peruv.

puberula, Klotzsch, in Linnaea, xx。(1847) 529.Peruv.

Ruizii, Klotzsch, l. c. 529.-Peruv.

Schottii, Miq. in Mart. Fl. Bras. iv. 1. 137.-Bras.

setosa, Klotzsch, in Linnaea, xx. (1847) 528.-Peruy. subincana, Mart. ex Miq. in Mart. Fl. Bras. iv. I. 134 -Bras

vellerea, Klotzsch, in Linnaea, xx. (1847) 527.Peruv.

villosa, Poepp. E Endl. Nov. Gen. et Sp. ii. 33. t. 147 Peruv.

COUSSAREA, Aubl. Pl. Gui. i, 98, t. 38 (1775) RUBIACEAE, Benth. \& Hook, f. ii. 120

Billardieria, Vahl, Eclog. Am. i. 13. t. 10 (1796) Froelichia, Vahl, 1. c. Praef. 3 (1796).

PecheyA, Scop. Introd. 143 (1777).

accedens, Muell. Arg. in Flora, lviii. (1875) 467.Bras.

albescens, Muell. Arg. in Mart. Fl. Bras. vi. v. 87, in nota.-Guiana.

ampla, Muell. Arg. in Flora, 1viii. (1875) 466. Bras.

bahiensis, Muell. Arg. l.c. 467.-Bras.

biflora, Muell. Arg. L. c. 468-Bras.

capitata, Benth. E Hook. f. Gen. ii. 121.-Bras.

Catingana, Muell. Arg. in Flora, 1viii. (1875) 468. Bras.

coffeoides, Muell. Arg. in Mart. Fl. Bras. vi. v. 89.Bras.

congestiflora, Muell. Arg. in Flora, Iviii. (1875) 466. -Bras.

contracta, Benth. E Hook.f. Gen. ii. 121.-Bras. corcovadensis, Muell. Arg. in Flora, lviii. (1875) 468 -Bras.

cornifolia, Benth. E" Hook. f. Gen, ii. 121-Bras.

flava, Poepp. E Endl. Nov. Gen. et Sp. iii. 26. t. 231. -Peruv. 


\section{COUSSARFA:-}

Froelichia, A. Rich. in Mém. Soc. Hist. Nat, Par.v. 1834) 177. - Ins. Tribit

gracilifora, Benth. E Hook. f. Gen. ii. 121.-Bras.

grandis, Muell. Arg. in Mart. Fl. Bras. vi. v. 100.Brandis,

hydrangeaefolia, Benth, Eo Hook. f. Gen. ii. 121.Bras.

ilheotica, Muell. Arg. in Flora, lviii. (1875) 466.Bras.

lagoënsis, Muell. Arg. l.c.-Bras.

lanceolata, Muell. Arg. in Mart. Fl. Bras. vi. v, 104

leptoloba, Muell. Arg. in Flora, lviii. (1875) 468.Bras.

leptophragma, Muell. Ag. l. c. 466.-Bras.

leptopus, Muell. Arg. l.6. 465.-Bras.

longiflora, Muell. Arg. l.c. 468.-Bras.

longifolia, Muell. Arg. hic-Bras.

macrocarpa, A. Rich. in Mém. Soc. Hist. Nat. Par. v. (1834) 177.- Guiana.

macrophylla, Muell. Arg in Flora, lviii. (1875) 466. -Bras.

Martini, Benth. E Hook.f Gen. ii. 121.-Am. trop. meridionalis, Muell. Arg. in Mart. Fl. Bras. vi. v. 85 $=$ nemoralis

nemoralis, Benth. \& Hook f. Gen. ii. 121.-Bras.

nodosa, Benth. E' Hook. J. l. c.-Bras.

obscura, Muell. Arg. in Flora, 1viii. (1875) 467.Bras,

pentanera, Karst. Fl. Columb. ii. 13. t. 107.-Costa Rica.

platyphylla, Muell. Arg. An Flora, lvihi. (1875) 466.-

Bras.
porophylla, Muell. Arg. Mart. Fl. Bras. vi. v. 87. -Bras.

procumbens, Muell. Arg. Lc. 104.-Bras.
racemosa, A. Rich. in Mim. Soc. Hist. Nat. Par, v. (1834) 177.-Guiana.

Regnelliana, Muell. Arg. in Flora, 1viii. (1875) 466.Bras.

Schomburgkiana, Benth. Hook. f. Gen. ii. $121=$ violacea.

squamosa, Lam, Tabl. En c. i. 281-Ind, occ.

strigosipes, Muell. Arg. if Flora, lviii. (1875) 467.Bras.

triflora, Muell. Arg. l. c. 48.-Bras.

uniflora, Gardn. in Hook. Lond. Fourn. Bot. iv. (1845)

107.-Bras.

verticillata, Muell. Arg. in Flora, lviii. (1875) 467.Bras.

violacea, Aubl. Pl. Gui. i. 18. t. 38.-Guiana.

virens, Muell. Arg。 in Flow, lviii. (1875) 467.-Bras,

viridis, Muell. Arg. in Mrt. Fl. Bras, vi. v. 104.-

Bras.

COUTAREA, Aubl. P1. Gui. i. 314. t. 122 (1775). RUBIACEAE, Benth. \& Iook. f. ii. 42.

alba, Griseb. in Goett. Ab, xxiv. (1879) 153.-Reg. Argent.

Campanilla, DC. Prod. iv. 50 - Venezuela.

corymbosa, Brign. in Mem.Soc. Ital. Mod. Ser. II. i. (1862) 69.-Bras.

diervilloides, Planch. E Linlen, Cat. n. 9 (1854) 3.N. Granat.

flavescens, Moc. \& Sesse, is DC. Prod. iv. 350.Mexic.

latifolia, Mof. E Sesse, ex DC. l. c.-Mexic.

Lindeniana, Baill. Adansoni xii. (1879) 300 -Venezuela.

Lumaeana, Baill. l. c. 301.-juntemala.

mexicana, "zucc. \& Mart.en X. Prod iv. 350-_Mrexic mollis, Cham. in Linnaer, is (1834) 259.-Bras.

pubescens, Pohl, Pl. Bras.Desc. ii. 148. t. 200.Bras.

Scherffiana, André, in Illusth Hortic. xxv. (1878) 120. t. 321.-N. Granat.

speciosa, Aubl.Pl. Gui. i. 81 t. 122.-Guiana.

COUThOVIA, A. Gray, it Proc. Am. Acad. iv. (1858) $824 ; \quad$ \% (1861) 20. LOGAN/ACEAE Henth. \& Hook, f, ii. 797.

corynocarpa, A. Gray, bo c iv, (1858) 324.-Ins.

Secmanni, A. Gray, l. c. v. (181) 320.-Ins. kiji.

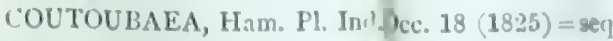

COUTOUBEA, Aubl Pl Gui. i. 72, t. 27, 28 (1775) GENTIANEAE, Benth. \& Hook. f. ii. 812.

LIMBORCHIA, Scop. Introd. 139 (1777)

PICRIUM, Schreb. Gen. 791 (1791).

alba, Lam. Encyc. ii. 162= spicata

arenaria, Willd. ex Griseb. Gen. et Sp. Gent. $132=$

racemosa.

densiflora, Mart. Nov. Gen. et Sp. ii. 111. t. $185=$ spicata.

lutea, Steud. in Flora, xxvi. (1843) 765 - spicata. minor, H. B. \& K. Nov. Gen. et Sp. iii. $179=$ spicata. purpurea, Lam. Encyc. ii. $162=$ ramosa.

racemosa, G. F. W. Mey. Prim. Fl. Esseq. 86.Guiana.

ramosa, Aubl. Pl. Gui.i. 74. t. 28.-Am. trop.

reflexa, Benth. in Ann. Nat. Hist. ii. (1839) 442.Guiana.

spicata, Aubl. Pl. Gui. 1. 72.-Am. trop.

spicata, Griseb. in Journ. Linn. Soc. vi. (1862) $141=$

sicatar

spicata, H. B. \& K. Nov, Gen. et Sp. rii. $179=$ densiflora. ternifolia, Cav. Ic. iv. $14=$ densiflora.

verticillata, G. Don, in Loud. Hort. Brit. $48=$ Enicostema littorale.

volubilis, Mart. Nov. Gen. et $S p$. ii. 112,-Ins, S Doming.

OUTUBEA, Steud. Nom. ed. II. i. $429(\mathbf{1 8 4 0})=$ Coutoubea, Aubl. (Gentian.).

OVALIA, Reichb. Consp. $94(1828)=$ COVOLIA Neck $=$ Spermacoce, Linn. (Rnbiac.)

OVELIA, Endl. Gen. 527, in syn. (1838)= praec.

OVElLIA, Gasp. Nov. Gen. Fic, $10(1844)=$ Ficus, Tourn. (Urticac.)

albipila, Miq. F1. Ind. Bat. Suppl. $434=$ F. mollis. assamica, Miq. in Hook. Lond. Journ. Bot. vii. (1848) $464=\mathrm{F}$. hispida.

aurata, Miq. Fl. Ind. Bat. Suppl. $433=$ F. chrysocarpa.

Barclayana, Miq. in Hook. Lond. Journ. Bot. vii. 1848) 461. t. $7 \mathrm{~B}=\mathrm{F}$. Barclayana

composita, Miq. Fl. Ind. Bat. i. II. $324=$ F. rapiformis congesta, Miq. in Hook. Lond. Journ. Bot. vií. (1848) $463=\mathrm{F}$. congesta.

conglomerata, Miq. I. c. $459=$ F. Cunia.

costata, Miq. 1. c. $468=\mathrm{F}$, costigera.

courtallensis, Miq. 1. c. $463=\mathrm{F}$. hispida.

suneata, Miq. 1. c. 466 . t. $8 \mathrm{~B}=\mathrm{F}$. cuneata

Zunia, Miq. 1. c. $459=\mathrm{F}$. Cunia.

yrtophylla, Miq. 1. c. $460=\mathrm{F}$. cyrtophylla.

laemonum, Miq. I. c. $462=\mathrm{F}$. hispida

lasycarpa, Miq. 1. c. $465=\mathrm{F}$. hispida.

lasycaula, Miq. 1. c. $460=\mathrm{F}$. obscura.

lidynama, Miq. Pl. Jungh. i, $65=\mathrm{F}$. lepicarpa

lomerata, Miq. in Hook. Lond. Joum. Bot. vii. (1848) $465=\mathrm{F}$. glomerata .

randifolia, Miq. Fl. Ind. Bat. Suppl. $434=$ F. rapiformis.

Frifrthii, Miq. in Hook. Lond. Journ. Bot. vii. (1818) $\$ 67=F$. heterophylla.

uttata, Wight, Ic. t. $1966=$ F. guttata.

ispida, Miq. in Hook. Lond. Journ. Bot. vii. (1848)

$462=\mathrm{F}$. hispida.

aequiloba, Miq. 1. c. $459=\mathrm{F}$. Cunia.

nceolata, Miq. 1. c. $465=\mathrm{F}$. lanceolata.

picarpa, Miq. Fl. Ind. Bat. i. 11. $828=$ F. lepicarpa.

ucopleura, Miq. I. c. $326=\mathrm{F}$. leucatoma

acrophylla, Miq. in Hook. Lond. Journ. Bot. vii (1848) $465=$ F. Roxburghii.

icrocarpa, Miq. 1. c. 466. t. $9 \mathrm{~A}=\mathrm{F}$. Ribes.

ollis, Miq. 1. co $466=\mathrm{F}$. glomerata.

positifolia, Gasp. Nov. Gen. Fic. $85=$ F. hispida,

iniculata, Miq. in Hook. Lond. Journ. Bot.

(1848) $\$ 67=\mathrm{F}$. Ribes.

ostrata, Miq. 1. c. $465=\mathrm{F}$. prostrata

cemifera, Miq. 1. $\mathrm{c}_{0}=\mathrm{F}$. variegala.

diata, Miq. Fi. Ind. Bat. i. 11. 928 = F. septica.

siformis, Miq. in Hook. Lond. Journ. Bot. vii

(s 48 ) $464=$ F. rapiformis.

bes, Miq. Fl. Ind. Bat. i. I1. $\$ 25=\mathrm{F}$. Ribes.

fescens, Kurz, ex Teijsm. G Binn. in Tijdschr.

Nederl. Ind. xxvii. $(1864) 38=\Gamma$. hotryacarps.

ulosa, Miq. in Hook. Lond. Journ. Bot. vii. 184 s

$10^{2} 2=\mathrm{F}$, hispida.

tocarpa, Miq. PI. Jungh. $65=\mathrm{F}$. lencantatoma.

\section{COVELLIA :-}

ubdenticulata, Miq. Fl. Ind. Bat. i. II. $324=$ Ficus subdenticulata.

subopposita, Miq. P1. Jungh. $66=$ F. fistulosa.

ternatana, Miq. Fl. Ind. Bat. 1. I1. $323=$ F. tematana. tuberculata, Miq. in Zoll. Syst. Verz. Ind. Archip. 94, $99=\mathrm{F}$. fistulosa.

umbonata, Miq. Fl. Ind. Bat. i. II. $323=$ F umbonata venosa, Miq. in Hook. Lond. Journ. Bot. vii. (1848) $468=\mathrm{F}$. leucatoma

volkameriaefolia, Miq. in Hook. 1. c. 464.t. $8 \mathrm{~A}=\mathrm{F}$. lepicarpa.

Webbiana, Miq. 1. c. $467=$ F. Webbiana

Wightiana, Miq. 1. c. $463=\mathrm{F}$. bispida.

Zollingeriana, Miq. 1. c. $460=\mathrm{F}$, coronata

COVILHAMIA, Korth. in Nederl. Kruidt. Arch. (1848) 307. STERCULIACEAE

ovata, Korth. l. c.-Borneo.

COVOLA, Medic. in Staatsw. Vorles. Churpf. Phys,-Oek. Ges. i. (1791) $227=$ Salvia, Tourn. (Labiat.). napifolia, Medic. Phil. Bot. ii. $67=$ S. napifolia. verticillata, Medic. $1 . \mathrm{c} .=$ S. verticillata

COVOLIA, Neck. Elem. i. $201(1790)=$ Spermacoce, Linn. (Rubiac.)

COW ANIA, D. Don, in Trans. Linn. Soc. xiv. (1825) 574. t. 22. ROSACEAE, Benth. \& Hook. f. i. 618.

GREGGIA, Engelm, in Bot. Wisliz. Exped, $30(1848)$. ericaefolia, Torr. ex A. Gray, Pl. Wright. ii. 1C6.Calif.

Havardia, S. Wats. in Proc. Am. Acad. xx. (18\$5) 364.-Texas.

mexicana, D. Don, in Trans. Linn. Soc xiv. (1825) 575. t. 22. f. 1-6.-Am, bor. occ.

plicata, D. Don, in Sweet, Brit. Flow. Gard. Ser. II t. 400.-Am. bor. occ

plicata, Torr. in Frém. Rep. $314=$ mexicana.

purpurea, Zucc. in Abh. Akad. Muench. iv. II. (1843)

7. t. 2 = plicata.

Stansburiana, Torr, in Stansb. Exped. Utab, $386=$ mexicana.

COXIA, Endl. Gen. 733 (1839)=Iysimachia, Linn. (Primulac.).

CRABBEA, Harv. Gen. S. Afr. P1. 276 (1835) = Barleria, Linn. (Acanthac.).

pungens, Harv. I. $\mathrm{c}_{0}=\mathrm{B}$. pungens.

CRABBEA, Harv, in Hook. Lond. Joum. Bot. i. 1842) 26. ACANTHACEAE, Benth. \& Hook. f. ii. 1092

angustifolia, Nees, in DC. Prod. xi. 163.-Afr. austr.

cirsioides, Nees, 1.c. $163=$ nana

hirsuta, Harv. in Hook. Lond. Fourn. Bot. i. (1812, 27 . -Afr. austr.

nana, Nees, in DC. Prod. xi. 162.-Afr. austr.

ovalifolia, Ficalho \& Hiern, in Trans. Linn. Soc. Ser. II. ii. (1881) 24.-Afr. trop.

CRABOWSKIA, G. Don, Gen. Syst. iv. 180 (1836), sphalm.= Grabowskia, Schlecht. Solan.

CRACCA. Benth. ex Oerst. in Kjocb. Vijlensk. Maldel. (1853) 8. LEGLMIINOSAE, Benth. \& Hook. f. i. 501

caribaea, Benth. ex Oerst. l. c. 9.-Ind. occ.

Edwardsii, A. Gray, Pl. Wright. ii. 35.-Mexic.

glabrescens, Benth. ex Oerst. in Kjoeb. Videnst. Weddel. (1853) 9.-Ecuador.

glandulifera, Bers/t. l. c. 8.-Ecuador.

mollis. Benth. l. c. 9.-Peruv.

ochroleuca, Bernth. lo c.-Peruv.

sericen, A. Gray, in Proc. Am. Acad vix. 1SES' it N. Mtexic.

CRACCA, Linn. Fl. Zeyl. 199 (17t = Tophrasia, Pers. (1:07) Le:umin.

maxima, Linn. Sp. Pl. al. I. 752 - T. purpurea

purpures, Linn. 1. c. - T. purpures.

senficosa, Lims. I. c. - I. senticusa.

finctoria, Linn. I. c. $=$ T. tincturia.

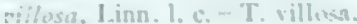

sirginiana, Lina. 1. c. = T. virgi .... 
CRACCA, [Riv.] Medic. in Vorles. Churpf. Phys. Ges. ii. (1787) $359=$ Vicia, Tourn. (Legum.)

acutifolia, Alef. in Bonplandia, ix. (1861) $118=$ Vicia acutifolia.

agrigentina, Alef. 1. c. $119=\mathrm{V}$, Bivonea.

albicans, Alef, 1. c. $120=\mathrm{V}$. atropurpurea.

atropurpurea, Gren. \& Godr. Fl. Fr. i. $471=\mathrm{V}$. atropurpurea.

benghalensis, Medic, in Vorles. Churpf. Phys. Ges. ii. (1787) $359=\mathrm{V}$. benghalensis.

Bertolonii, Gren. \& Godr. Fl. Fr. i. $470=$ V. Pseudocracca.

Bivonea, Alef, in Bonplandia, ix. (1861) $121=\mathrm{V}$. Bivonea.

Boissieri, Alef. 1, c. $=$ V. villosa.

Broteriana, Alef. 1. c. $120=$ V. atropurpurea.

calcarata, Gren. \& Godr. Fl. Fr. i. $472=$ V. calcarata.

caroliniana, Alef. in Bonplandia, ix. (1861) $124=\mathrm{V}$, caroliniana.

cassubica, Opiz, Seznam, $34=$ V. cassubica

ciceroidea, Alef. in Bonplandia, ix. (1861) $121=\mathrm{V}$ ciceroidea

cirrhosa, Alef. 1. c. $119=\mathrm{V}$. cirrhosa.

corsica, Gren. \& Godr. Fl. Fr。 i. 473 (=Ervum corsicum),-Corsica.

dasycarpa, Alef. in Bonplandia, ix. (1861) $121=\mathrm{V}$ varia.

disperma, Gren. \& Godr. Fl, Fr. i. $472=$ V. disperma dumetorum, Opiz, Seznam, $34=\mathrm{V}$, dumetorum.

elegans, Alef. in Bonplandia, ix。 (1861) $124=\mathrm{V}$. tenuifolia.

erotanthos, Alef. 1. c. $118=\mathrm{V}$. Leavenworthii

exigua, Alef. 1. c. $119=\mathrm{V}$. exigua.

Gerardi, Gren. \& Godr. Fl. Fr. i. $469=$ V. Gerardi.

Gerhardi, Medic. in Vorles. Churpf. Phys. Ges. ii

(1787) $359=$ V. Gerardi

hypoleuca, Alef. in Bonplandia, ix. (1861) $123=\mathrm{V}$. alpestris.

Kotschyana, Alef. 1. c. $119=$ V. Kotschyana

linifolia, Alef. 1. c. $118=$ V. atropurpurea

longifolia, Alef. 1. c. $123=\mathrm{V}$. Iongifolia.

Iudoviciana, Alef. 1. c. $119=\mathrm{V}$, ludoviciana

major, Alef, 1. c. $125=$ V. Cracca.

microphylla, Alef. 1. c. $121=\mathrm{V}$. microphylla.

minor, Gren. \& Godr. Fl. Fr. i. $473=$ V. hirsuta

monanthos, Gren. \& Godr. 1. c. $471=$ V. monanthos.

Monardi, Alef. in Bonplandia, ix. (1861) $119=\mathrm{V}$.

Monardi.

ochroleuca, Alef. 1. c. $123=\mathrm{V}$, ochroleuca

pauciflora, Genneri, in Nuov. Giom. Bot. ii. (1870) $136=$ V. pauciflora?

pineta, Alef. in Bonplandia, ix. (1861) $123=\mathrm{V}$. pinetorum.

pisiformis, Opiz, Seznam, $34=$ V. pisiformis.

plumosa, Timb. in Bull. Soc. Se. Phys. et Nat. Tou

louse, iii. $(1875-76) 143=\mathrm{V}$. Cracca.

polyphylla, Alef. in Bonplandia, ix. (1861) $124=\mathrm{V}$. tenuifolia?

Pseudocracca, Alef. 1. c. 121=V. Pseudocracea.

pulchella, Alef. 1. c. $119=$ V. .pulchella

Sibthorpii, Alef. 1.c. $120=$ V. Sibthorpii.

sylvatica, Opiz, Seznam, $34=$ V. sylvatica.

syriaca, Medic. in Vorles. Churpf. Phys. Ges. ii. (1787) 359.-Syria.

tenuifolia, Opiz, Seznam, 34; Gren. \& Godr. Fl. Fr. i. $469=$ V, tenuifolia.

tenuissima, Alef. in Bonplandia, ix. (1861) $120=\mathrm{V}$. gracilis.

Timbaliana, Debeaux.-Cf. Bull. Soc. Bot. Fr. xxviii. (1881) Bibl. $73=$ V. cuneata.

tridentata, Alef, in Bonplandia, ix. (1861) 119, $125=$ $\mathrm{V}$. Iudoviciana.

varia, Gren. \& Godr, Fl. Fr. i. $469=$ V varia.

villosa, Gren. \& Godr. 1. c. $470=$ V. villosa.

vulgaris, Opiz, Seznam, $34=$ V. Cracca.

CRACCINA, Stev. in Bull. Soc. Nat. Mosc. iv. (1832) $266=$ Astragalus, Tourn. (Legumin.)

austriaca, Stev. 1. c. = A. austriacus.

bifidus, Stev. 1. c. xxix. (1856) II. $145=$ A. multicaulis.

Cracca, Stev. 1. c. iv. (1832) $266=$ A. Cracca,

depressa, Stev. 1. c. $=$ A. depressus.

ervoides, Stev. 1. c. xxix. (1856) I. $145=$ A. ervaides.

falcata, Stev. 1. c. iv. (1832) $266=$ A. falcatus.

gracilis, Stev. 1. c. $=$ A. gracilis.

leptocaulis, Stev. 1. c. xxix. (1856) II. $145=$ A. leptocaulis.

\section{CRACCINA :-}

leptostachys, Stev. in Bull. Soc. Nat. Mosc. iv. (1832) $266=$ Astragalus sulcatus.

leucophaea, Stev. I. c. = A. leucophaeus.

longipes, Stev. I. c. xxix。 (1856) II. $145=$ A. macro-

pterus.
multicaulis, Stev. 1. c. $=$ A. multicaulis.

puberulus, Stev. 1. c. $=$ A. puberulus.

racemosa, Stev. l. c. iv. (1832) $266=$ A. racemosus.

reptans, Stev. I. c. $=$ A. reptans.

scopaeformis, Stev。 1. c. xxix. (1856) II. $145=$ A. tauricus.

sulcata, Stev. 1. c. iv. (1832) $266=$ A. sulcatus.

taurica, Stev, l. c. $=$ A, tauricus.

triangularis, Stev. 1. e. = A, triangularis.

tunetana, Stev, 1. $c_{1}=$ A. tunetanus.

vaginata, Stev. $1_{0} \mathrm{c}_{0}=\mathrm{A}$. vaginatus.

versicolor, Stev, $1, c_{1}=\mathrm{A}$, versicolor.

vicioides, Stev. 1. c. xxix (1856) II. $145=$ A. macro pterus.

CRAEPALIA, Schrank, Baier. F1.i. 102, 382 (1789)= Iolium, Linn. (Gramin.)

temulenta, Schrank, 1. c. $382=\mathrm{L}$. temulentum.

CRAEPALOPRUMNON, Karst. F1. Columb, i. 123 t. 61, 62 (1859 ? )= Xylosma, Forst. (Bixin.). heterophyllum, Karst. 1. c. 123. t. 61.-N. Granat. cordatum, Karst. 1. c. $124=$ Flacourtia cordata. obovatum, Karst. 1. c. 123. t. 61.-N. Granat. prunifolium, Karst. 1.c. $124=$ Flacourtia prunifolia. racemosum, Karst. 1. $c_{0}=$ Flacourtia racemosa. rubicundum, Karst. 1. c. 125. t. 62.-Venezuela.

CRAFORDIA, Rafin. Specch. i. $156 \quad(1814)=\mathbf{T}_{\epsilon}$ phrosia, Pers. ? (Legumin.).

bracteata, Rafin. 1. $c_{0}=$ T. spicata?

CRAMBE, Tourn. ex Linn. Syst. ed. I (1735 CRUCIFERAE, Benth. \& Hook. f. i. 98.

amplexicaulis, [Soland, in] Russell, Aleppo, ed. ii. 258 = Calepina Corvini.

aspera, Bieb. Fl. Taur. Cauc. ii. $90=$ tatarica.

Aucheri, Boiss. in Ann. Sc. Nat. Sér. II. xvii. (1842) $=$ orientalis.

Biebersteiniî, Fanka, in Termész. Fïzetek, viii. (18 36.--Еurop

bursaefolia, L'Hérit. ex DC. Syst. ii. $649=$ Calep Corvini.

Buxbaumii, Willd, ex Ledeb, Fl. Ross. i, 222 orientalis.

caspica, Raeusch. Nom. ed. III. $183=$ tatarica. chlorocarpa, Kit. in Linkaea, xxxii. (1863) 502

Austria.

cordata, Willd. Enum. H.ort. Berol. Suppl. 48 cordifolia.

cordifolia, Duf. in Ann. Gén. Sc. Phys. vii. (1820) 3 $=$ glabrata.

cordifolia, Stev. in Mém. Soc. Nat. Mosc. iii. (18) 267.--Reg. Caucas

Corvini, All. Fl. Pedem. i. $256=$ Calepina Corvini. edentula, Fisch. Eo Mey. ex Kar. in Bull. Soc. N Mosc. (1839) 145, nomen.-Turcoman.

filiformis, Boiss. Voy. Bot. Espagne, $43=$ hispanica filiformis, Facq. Coll. Suppl. 120.-Patagon。; Chili

fruticosa, Linn. f. Suppl. 299.-Ins. Madera.

gibberosa, Rupr. Fl. Cauc. 136, in textu.-R Caucas.

gigantea, Kit. ex Janka, in Oestr. Bot. Zeitschr. x

(1871) $65=$ maritima

glabrata, DC. Prod. i. 226-Hispan.

grandiflora, DC. Syst. ii. 652.-As. Min

hispanica, Linn. Sp. Pl. 671.-Reg. Mediterr.

juncea, Bieb. Fl. Taur. Cauc. iii. 421.-Reg. Cauc Himal.

Kotschyana, Boiss. Diagn. Ser. I. vi. $19=$ cordifolia.

Kralikii, Coss. in Bull. Soc. Bot. Fr. iv. (1857) nomen.-Afr, bor.

laciniata, Desf. ex Steud. Nom. ed. II. i. $429=$ pina fida

laciniata, Lam. Encyc. ii. 163 = tatarica.

laevis, Kit. in Linnaea, xxxii. (1863) $502=$ chlorsaze macrocarpa, Bieb. Fl. Taur. Cauc. ii. $90=$ Sobolew lithophila.

maritima, Linn. Sp. Pl. 671.-Europ.

orientalis, Jacq. Ic. Rar. i. t. $128=$ pinnatifida.

orientalis, Linn. Sp. Pl.671.-As. Min.; Persia.

orientalis, Reich. Syst. iii. $290=$ tatarica.

\section{RAMBE :}

palmatifida, Regel E Schmalh. in Act. Hort. Petrop. v. (1877) 243. - Turkestan.

paniculata, All. Fl. Pedem, i. 256=Neslia paniculata. pannonica, Hort. Par, ex Lam. Encyc. ii, $163=$ tatarica.

persica, Boiss. in Ann. Sc. Nat. Sér. II. xvii. (1842) 389.-Persia.

pinnatifida, [R. Br, in ] Ait. Hort. Kerv. ed. II. iv. 72 -Reg. Cancas.

pontica, Ster. ex Rupr. Fl. Cauc. 293.-Tauria.

Pritzelii, C. Bolle, Ind. Sem. Hort. Berol. (1861) 10.-

Ins. Canar.

quadricostata, Boiss. in Ann. Sc. Nat. Sér. II. xvii. 1842) $388=$ orientalis.

reniformis, Desf. Fl. Atlant. ii. 78. t. $151=$ hispanica. scabra, Lam. Encyc. ii. $\mathbf{1 6 3 =}$ strigosa.

Sewerzowi, Regel, in Bull. Soc. Nat. Mosc. xlii (1870) I. 282.-Turkestan

sinuato-dentata, Hochst. E Schimp. Beitr. Fl. Aethiop. 238.-Abyss.

Steveniana, Rupr. Fl. Cauc. 136, in textu.-Reg. Caucas.

strigosa, L'Hérit. Stivp. Nov. 151. t. 72,-Ins. Canas. suecia, Mill. Gard, Dict, ed. VIII, n. 2 = pinnatifida.

tatarica, facq. Misc. ii. 274.-Europ. or.; As. bor.

CRAMERIA, Murr, Syst. ed. XIII. $138(1774)=$ Kra meria, Linn. (Polygal.)

CRANICHIS, Sw. Prod. Veg. Ind. Occ. 120 (1788) ORCHIDEAE, Benth. \& Hook. f. iii. 593.

OCAMPOA, A. Rich. \& Gal. in Ann. Sc. Nat. Sér.

III. iii. (1845) 31 .

aphylla, Sw.l.c.-Jamaia.

apiculata, Lindl. in Berth. Pl. Hartw. 92-Guate mala.

ciliata, Kunth, Syn. Pl. Leq. i. 324.-Venezuela.

diphylla, Sw. Prod. Veg.Ind. Occ. 120.-Jamaica

Engelii, Reichb. f. in Linnaea, xli. (1877) 19.-

Venezuela.

foliosa, Lindl. Gen. et St. Orch. 451.-Peruv.

gibbosa, Lindl. in Ann. Vat. Hist. xv. (1845) 385.Jamaica.

glandulosa, A. Rich. E Fal. in Ann. Sc. Nat. Sér. III

iii. (1845) 30.-Mexic

Lehmanni, Reichb. f. Ota Bot. Hamb. 4.-Ecuador.

luteola, Sw. Fl. Ind. Occ.iii. $1433=$ Polystachya luteola

macroblepharis, Reichb. f. Otia Bot. Hamb. 4.Ecuador.

micrantha, Griseb. in Gett. Abh. xxiv. (1879) $337 .-$

Reg. Argent.

micrantha, Spreng. Syst iii. $700=$ Prescottia Myosurus monophylla, Lindl. Orchid. Linden, 27.-N. Granat.

multiflore, Ell. ex Nutt Gen. Am. ii. 191 - Ponthieva glandulosa.

muscosa, Sw. Prod. Veg. Ind. Occ, 120.-Jamaic

nudifolia, Pers. Syn. ii. 511.-China.

oligantha, Sw. Prod. Veg. Ind. Occ. $120=$ Prescottia Myosurus.

ovata, Wickstr. in Vet. Akad. Handl. Stockh. (1827) 73.-Ins. Guadalup.

parvilabris, Lindl. Orchid. Linden, 27.-N. Granat.

pauciflora, Swe. Fl. Ind. Occ. iii. 1431.-Jamaic.

picta, Reichb. f. in Linnaea, xli. (1877) 52.-Ecuador.

reticulata, Reichb. f. Beitr. Orch. Centr. Am. 62.-

Costa Rica.

Schaffneri, Reichb. f. in Bonplandia, iii. (1855) 238.Mexic.

Schlimii, Reichb. $f$. in Linnaea, xli. (1877) 19.-

Venezuela.

similis, Reichb. f. Otix Bot. Hamb, 83-Bras.

speciosa, La Llave E Lex. Nov. Veg. Desc. fasc. ii. (Orch. Opusc.) 5.-Mexic.

stachyoides, Sw. Prod Veg. Ind. Occ. $120=$ Ponthieva glandulosa.

subumbellata, A. Rick. E Gal. in Ann. Sc. Nat. Sér

III. iii. (1845) 30.-Mexic

sylvatica, A. Rich. E Gal. l. c.-Mexic

tenuiflora, Griseb. Cat. Pl. Cub. 268.-Cuba.

tenuis, Reichb. f. in Flora, xlviii. (1865) 274.-Ind. occ.

tubularis, La Llave is Lex Nov. Veg. Desc. fasc. ii. (Orch. Opusc.) b.-Mexic.

tubulosa, Lindl. Gen. et Sp Orch. 451.-Mexic

ventricosa, Griseb. Fl. Brit. W. Ind. 639.-Ind. occ.

Wageneri, Reichb. f. in Linnaea, xli. (1877) 19.Venezuela. 



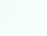





